\title{
AlIIOI 262532
}

NAT'L INST OF STANDARDS \& TECH R.IC.

\section{NSRDS-NBS 63}

Heller, Stephen A/E;M.W. 30-186 C.1 NSRDS

Oetroan of की

U.S. DEPARTMENT OF COMMERCE / National Bureau of Standards

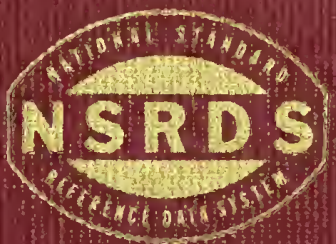

EPA/NIH Mass Spectral Data Base Volume 1 Molecular Weights 30-186 


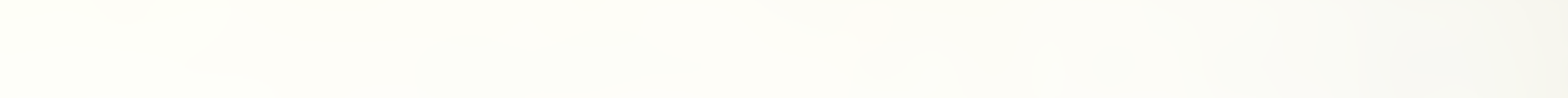






\title{
EPA/NIH Mass Spectral Data Base
}

\section{Volume 1}

Molecular Weights 30-186

\author{
S.R. Heller \\ Office of Planning and Management \\ Environmental Protection Agency \\ Washington, D.C. 20460 \\ and \\ G.W.A. Milne \\ National Heart, Lung, and Blood Institute \\ National Institutes of Health \\ Bethesda, Maryland 20014
}

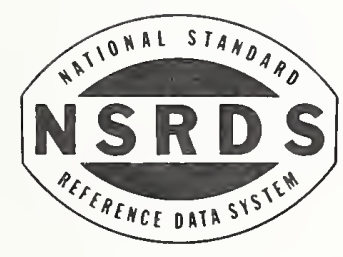

U.S. DEPARTMENT OF COMMERCE, Juanita M. Kreps, Secretary

Dr. Sidney Harman, Under Secretary

Jordan J. Baruch, Assistant Secretary for Science and Technology

NATIONAL BUREAU OF STANDARDS, Ernest Ambler, Director

Issued December 1978 
Library of Congress Cataloging in Publication Data

Heller, S.R.

EPA/NIH mass spectral data base.

(Nat. stand. ref. data ser. ; NSRDS-NBS 63)

"National Standard Reference Data System."

Supt. of Docs. no.: C 13.48:63.

CONTENTS: v. 1. Molecular weights 30-186. -v. 2.

Molecular weights 186-273. - v. 3. Molecular weights 273-

381. [etc.]

1. Organic compounds-Spectra-Indexes. 2. Mass spectrometryIndexes. 3. United States. Environmental Protection AgencyIndexes. 4. United States. National Institutes of HealthIndexes. 1. Milne, George W.A., 1937- joint author. II. Title. III. Series: United States. National Bureau of Standards. National Standard Reference Data Series; NSRDS-NBS 63. QC100.U573 no. 63 [QC462.85] 602'.1s [547'.308'7]

$78-606175$

\section{NSRDS-NBS 63}

Nat. Stand. Ref. Data Ser., Nat. Bur. Stand.(U.S.), 63, Vol. 3, 1001 pages (Dec. 1978) CODEN: NSRDAP

C(C1978 by the Secretary of Commerce on Behalf of the United States Government 


\section{Foreword}

The National Standard Reference Data System provides access to the quantitative data of physical science, critically evaluated and compiled for convenience and readily accessible through a variety of distribution channels. The System was established in 1963 by action of the President's Office of Science and Technology and the Federal Council for Science and Technology, and responsibility to administer it was assigned to the National Bureau of Standards.

NSRDS receives advice and planning assistance from a Review Committee of the National Research Council of the National Academy of Sciences-National Academy of Engineering. A number of Advisory Panels, each concerned with a single technical area, meet regularly to examine major portions of the program, assign relative priorities, and identify specific key problems in need of further attention. For selected specific topics, the Advisory Panels sponsor subpanels which make detailed studies of users' needs, the present state of knowledge, and existing data re. sources as a basis for recommending one or more data compilation activities. This assembly of advisory services contributes greatly to the guidance of NSRDS activities.

The System now includes a complex of data centers and other activities in academic institutions and other laboratories. Components of the NSRDS produce compilations of critically evaluated data, reviews of the state of quantitative knowledge in specialized areas, and computa. tions of useful functions derived from standard reference data. The centers and projects also establish criteria for evaluation and compilation of data and recommend improvements in ex. perimental techniques. They are normally associated with research in the relevant field.

The technical scope of NSRDS is indicated by the categories of projects active or being planned: nuclear properties, atomic and molecular properties, solid state properties, thermody. namic and transport properties, chemical kinetics, and colloid and surface properties.

Reliable data on the properties of matter and materials are a major foundation of scientific and technical progress. Such important activities as basic scientific research, industrial quality control, development of new materials for building and other technologies, measuring and correcting environmental pollution depend on quality reference data. In NSRDS, the Bureau's responsibility to support American science, industry, and commerce is vitally fulfilled.

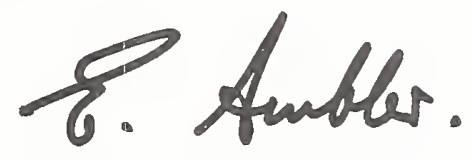

Ernest Ambler, Director 


\section{Preface}

In carrying out its mandate to provide reliable reference data needed by the U.S. technical community, the Office of Standard Reference Data works closely with other Agencies of the Federal Government which are concerned with data bases in support of their mission responsibilities. The present publication is an example of this collaboration. The collection of mass spectral data contained herein represents a major effort of the Environmental Protection Agency and the National Institutes of Health. The National Bureau of Standards is participating in this effort by helping to assure adequate quality control of the data and by providing suitable dissemination mechanisms.

This is a continuing program; both an expansion of the size of the mass spectral data base and an enhancement of the quality of the data are planned. Contributions of new or improved spectra, as well as general comments on the format and utility of the data, are strongly encouraged.

DAVID R. LIDE, JR., Chief

Office of Standard Reference Data

National Bureau of Standards 


\section{Contents}

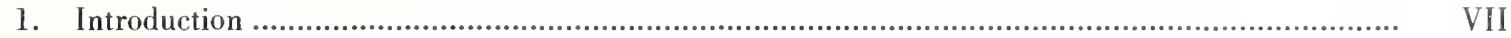

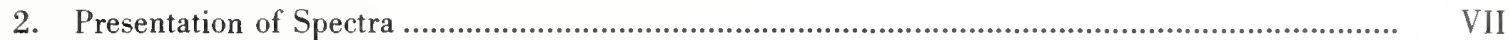

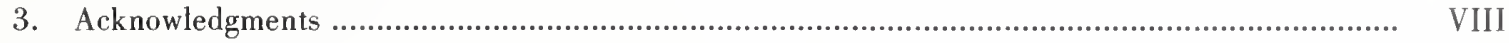

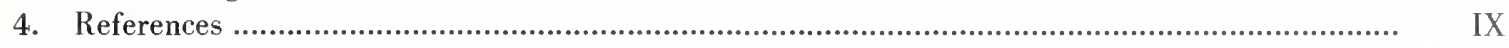

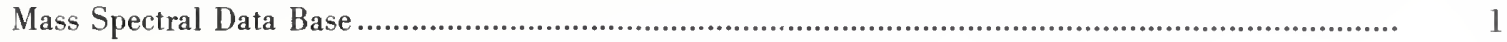





\title{
EPA/NIH Mass Spectral Data Base
}

\author{
S. R. Heller \\ Environmental Protection Agency, Washington, D.C. 20460 \\ and \\ G. W. A. Milne \\ National Institutes of Health, Bethesda, Maryland 20014
}

\begin{abstract}
This publication presents a collection of 25,556 verified mass spectra of individual substances compiled from the EPA/NIH mass spectral file. The spectra are given in bar graph format over the full mass range. Each spectrum is accompanied by a Chemical Abstracts Index substance name, molecular formula, molecular weight, structural formula, and Chemical Abstracts Service Registry Number.

Key words: Analytical data; mass spectra; organic substances; verified spectra.
\end{abstract}

\section{Introduction}

During the last seven years, two agencies of the United States Government, the Environmental Protection Agency (EPA) and the National Institutes of Health $(\mathrm{NIH})$, have developed a mass spectrometry data base together with computer software to search this data base. The Mass Spectrometry Data Centre (MSDC), supported by the United Kingdom Department of Industry, has collaborated in this project. A major objective of the project has been to provide a means of rapid identification of unknown chemical substances by matching their mass spectra against a comprehensive library of verified spectra.

The result of this international cooperative effort has been a machine-readable data base of mass spectra of 25,556 different compounds. This EPA/NlH Mass Spectral Data Base is available in two ways: through lease of a magnetic tape from the National Bureau of Standards (NBS) [1] and through interactive access via an international time-sharing computer network [2]. The magnetic tape contains the same data listed herein. They include the spectrum, and indexes listing name, formula, molecular weight, and the CAS Registry Number.

While many organizations and laboratories have been well served by one or the other of these mechanisms for the dissemination of mass spectral data, neither of the approaches was suitable for those lacking access to computers or computer terminals. Hence, at the suggestion of EPA's Industrial Environmental Research Laboratory (IERL) in Research Triangle Park, North Carolina, we undertook to prepare this book of mass spectra in bargraph format derived from the EPA/NIH Mass Spectral Data Base.

This publication, which has been produced by the Photocomposition System APS-IV [3] of the Chemical Abstracts Service (CAS) under contract to EPA (Contract 68-01-2731), differs in a number of significant ways from earlier published collections of mass spectral data such as the Eight Peak Index of Mass Spectra [4], the Registry of Mass Spectral Data [5], and the Compilation of Mass Spectral Data [6]. The 25,556 mass spectra herein are of different

\footnotetext{
'Figures in brackets indirate literature references.
}

substances; there are no duplicate spectra. Neither are there any spectra of substances labelled with less-abundant isotopes (e.g., deuterium, oxygen-18).

The current data base was derived from an initial file of about 48,000 mass spectra. This larger file was processed by CAS, which identified the CAS Registry Number for every substance. These CAS Registry Numbers are unique numerical identifiers assigned to chemical substances in the CAS Chemical Registry System [7]. The Chemical Registry System identifies a chemical substance on the basis of an unambiguous, computer-language description of its molecular structure. Currently, there are some 4 million chemical substances in the master file of the Registry System which was begun in 1965. Approximately 8,000 of these substances were first entered into the Registry System during the processing of the EPA/NIH Mass Spectral Data Base, i.e., these substances had not previously been reported in the open literature.

Once the Registry Numbers for all substances in the file of 48,000 spectra were identified, all the duplicate entries in the file were found using these Registry Numbers. Finally, the best spectrum from each group of duplicate spectra was selected and the resultant data base is presented in this book. The Quality Index of a mass spectrum is calculated using an algorithm devised by McLafferty [8] which detects common errors in mass spectra. This index takes account of 9 different parameters including such items as ionization conditions, impurity peaks, etc.

All the 25,556 substances whose spectra are given in this book are identified by their respective CAS Registry Numbers and the name under which the substances appear in the CAS 8th (19671971) or 9th (1972-1976) Collective Indexes-the "8CI" or "9CI" name. Synonyms from the CAS Registry System, as well as the Collective Index names, are used in the indexes. For further information regarding the Collective Index names, the reader is referred to the CAS Index Guide [9].

\section{Presentation of Spectra}

Spectra are presented as shown in figure 1. The conventional bar-graph format is used in "boxes" of width 150 mass units. 


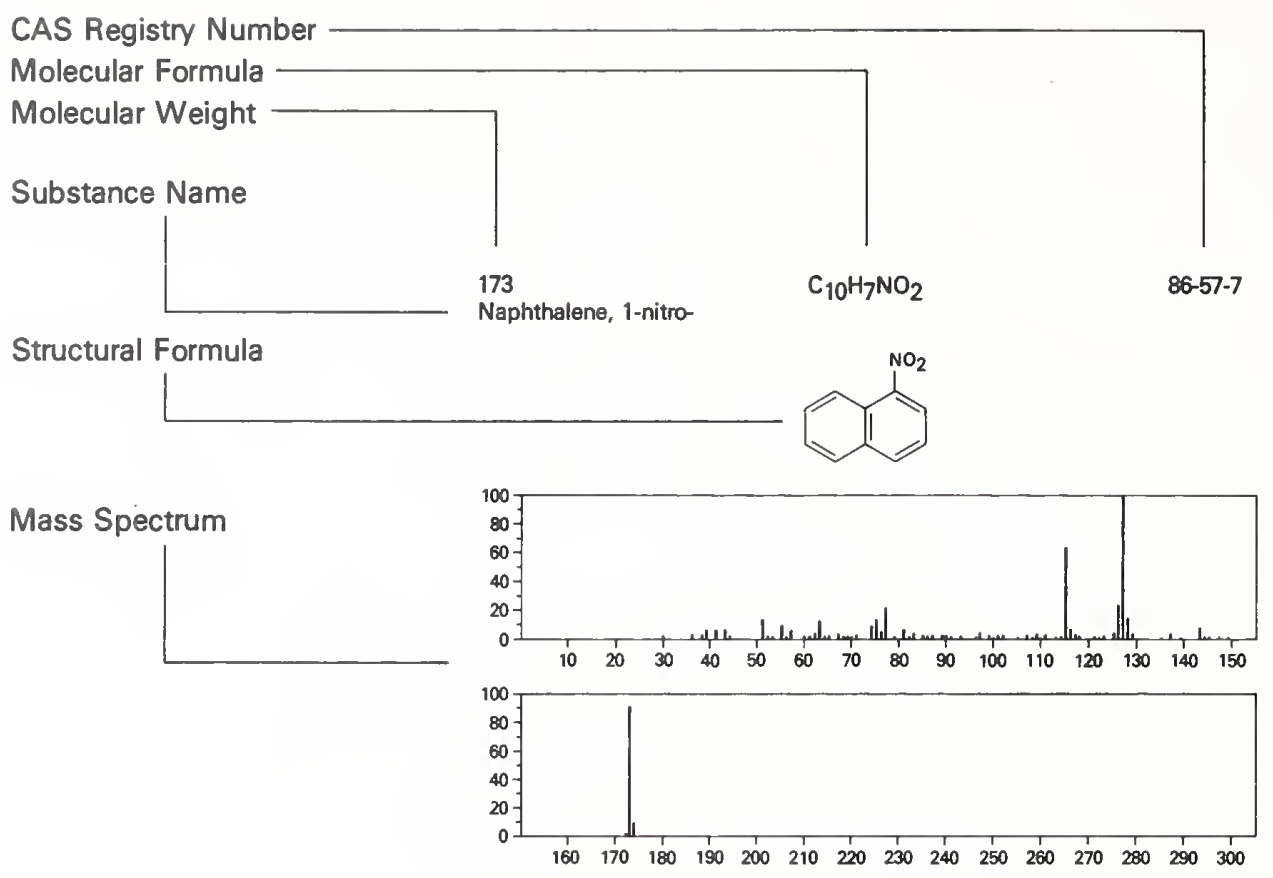

Figure 1. Typical mass spectrum.

Additional boxes are provided only if there are peaks in a broader mass range. Each spectrum is also accompanied by the molecular formula of the substance, the molecular weight, and the structure diagram. The molecular formulas are ordered by the Hill convention [10], and were derived by computer from the CAS-supplied connection table record. Molecular weights were derived by computer from the same records, using the integral atomic masses $\mathrm{C}=12, \mathrm{H}=1, \mathrm{O}=16$, and so on. The structure diagrams, a unique feature of this book, are also machine derived from the connection table record for each substance [11].

The spectra reported in this book do not contain any metastable or multiple-charge ions, and all $\mathrm{m} / \mathrm{e}$ and intensity data are rounded off to the nearest integer. Relative intensities between $0.1 \%$ and $2.0 \%$ are arbitrarily adjusted to $2 \%$ for the sake of clarity. It should be noted that the relative intensities of the peaks are sensitive to instrumental conditions and can only be taken as a rough guide. Spectra are presented in order of the molecular weights of the corresponding substances. In cases where substances have the same (integral) molecular weight, those spectra are further ordered according to molecular formula and, if necessary, further ordered by CAS Registry Number, in increasing order of the first set of digits.

The mass spectra themselves have been checked before entry into the file, and many further corrections have been made as a result of the registration processing by the CAS. In addition, a large number of changes have been made as a result of comments from the many users of the computerized Mass Spectral Search System and users of the tape copies of the data base supplied by NBS.

The four indexes provided in the final volume of this book may be used to find the spectrum of a specific substance, as opposed to finding the substance that might give a specific mass spectrum. The first of these gives the substance name in alphabetical order, the second is arranged by formula, the third is ordered by increasing molecular weight, and the fourth by CAS Registry Number. It is planned to produce further volumes of this compilation as the data base increases in size. When this is done, completely new indexes will be produced and may be used to replace the older versions. It is for this reason that the indexes are in a separate volume and paper bound rather than cloth bound. It is expected that this will facilitate additions and revisions to the data.

It is hoped that this book and the subsequent additions to it will be of value to the mass spectrometry community. Your comments, criticisms, and suggestions are most welcome and will certainly lead to further improvements in future volumes.

\section{Acknowledgments}

It is a pleasure to acknowledge, first, the large number of mass spectroscopists, too many by far to be identified individually, who labored to produce the mass spectra presented in these volumes.

The impetus to publish this book came from Joe McSorley and Gene Tucker of EPA-IERL, Research Triangle Park, North Carolina, who were responsible for providing the necessary funding to develop the software used in the production of the book, and also defrayed some of the production costs. The remainder of the production costs were provided by EPA-MIDSD, and in this connection, we thank Willis Greenstreet, Morris Yaguda, and Mike Springer for their support. The printing of the books was carried out by the Government Printing Office and the cost of printing was borne by NBS. Further EPA financial and technical support was provided by William Budde and John McGuire of EPA's Office of Research and Development. Computer support for the management of the data base has been provided by NIH-NHLBI. The master mass spectra file was assembled and is being maintained by Alvin Fein, Gary Marquart, and David Martinsen of Fein-Marquart Associates, Inc.

We are also very grateful to the many people responsible for technical improvements in the data base. Included among these are: Klaus Biemann, Alice Bridy, Henry Fales, Rachelle Heller, David Maxwell, Andrew McCormick, and Fred McLafferty. 


\section{References}

[1] For further information regarding the leasing of this magnetic tape, please contact:

Office of Standard Reference Data

National Bureau of Standards

A537 Administration Building

Washington, D.C. 20234

[2] For further information regarding access to the Mass Spectral Search System, please contact:

Dr. H. J. Bernstein

Department of Chemistry

Brookhaven National Laboratory

Upton, New York 11973
[3] Blake, J. E., Farmer, N., and Haines, R. C., J. Chem. Inf. Comput. Sci. 17, 223 (1977).

[4] Eight Peak Index of Mass Spectra, 2nd Edition, Her Majesty's Stationery Office, London (1975).

[5] Cornu, A., and Massot, R., Compilation of Mass Spectral Data, 2nd Edition, Heyden, London (1975).

[6] Stenhagen, E., Abrahamsson, S., and McLafferty, F. W., Registry of Mass Spectral Data, 1st Edition, Wiley, New York (1974).

[7] CA Volume 76-85 Cumulative Index Guide (1972-1976), Chemical Abstracts Service.

[8] Speck, D. D., Venkataraghavan, R., and McLafferty, F. W., J. Org. Mass Spectrom. 13, 209 (1978)

[9] CAS Index Guide, Chem. Abs. 76, (1972).

[10] Hill, E. A., J. Amer. Chem. Soc. 22, 478 (1900).

[11] Dittmar, P. G., et al., J. Chem. Inf. Comput. Sci. 17, 186 (1977). 

16

Methane

$\mathrm{CH}_{4}$

$\mathrm{CH}_{4}$

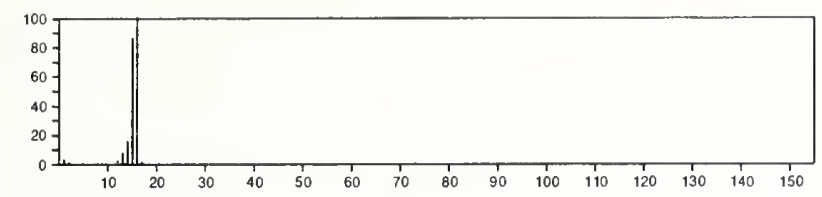

17

Ammonia

$\mathrm{H}_{3} \mathrm{~N}$

$\mathrm{NH}_{3}$
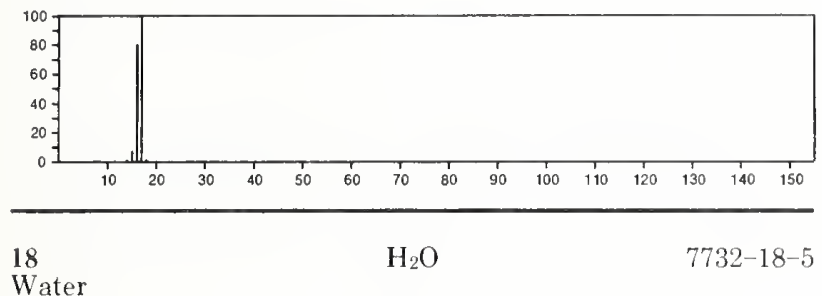

$\mathrm{OH}_{2}$

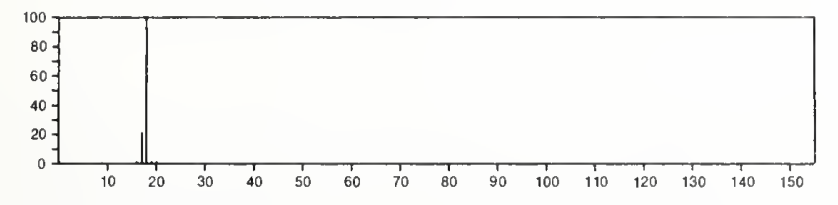

26

Ethyne

$\mathrm{C}_{2} \mathrm{H}_{2}$

$\mathrm{HC}: \mathrm{CH}$

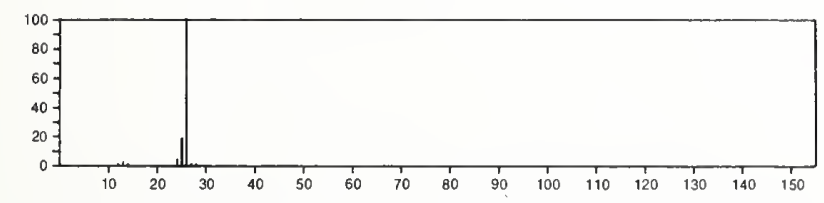

27

Hydrocyanic acid

$\mathrm{CHN}$

$H C \equiv N$
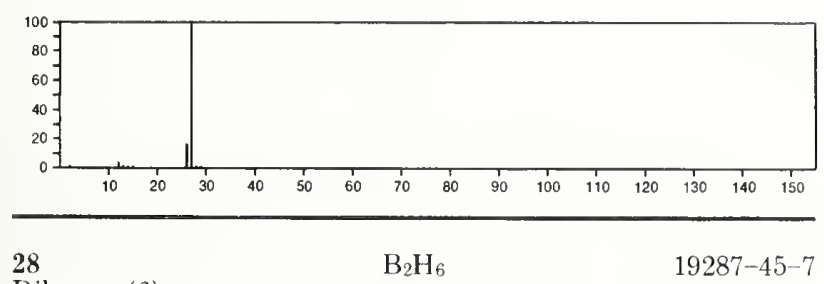

Diborane(6)
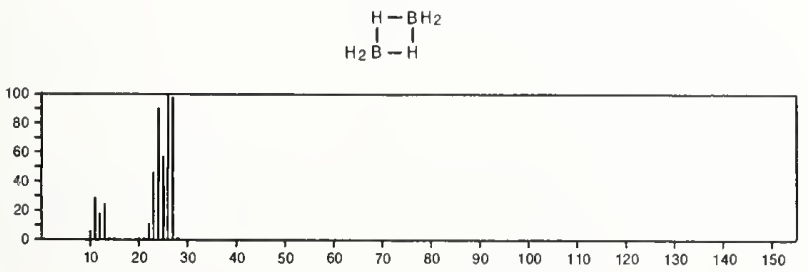

28

Carbon monoxide

$\mathrm{CO}$

$630-08-0$

$-c: 0^{+}$

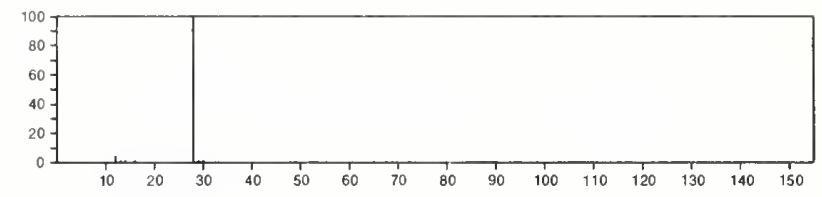

28

Ethene

$\mathrm{C}_{2} \mathrm{H}_{4}$

74-85-1

$\mathrm{H}_{2} \mathrm{C}: \mathrm{CH}_{2}$

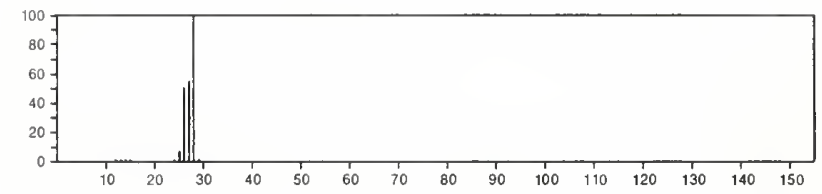

28

Nitrogen

$\mathrm{N}_{2}$

7727-37-9

$N \equiv N$

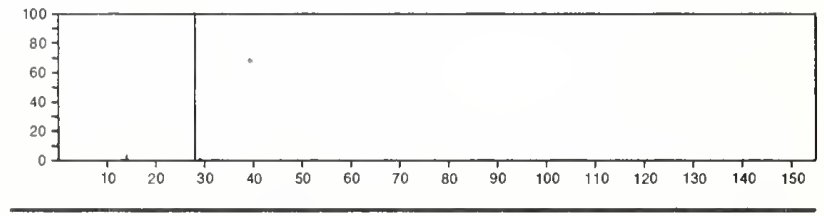

30

Formaldehyde

$\mathrm{CH}_{2} \mathrm{O}$

50-00-0

$\mathrm{H}_{2} \mathrm{C}=\mathrm{O}$

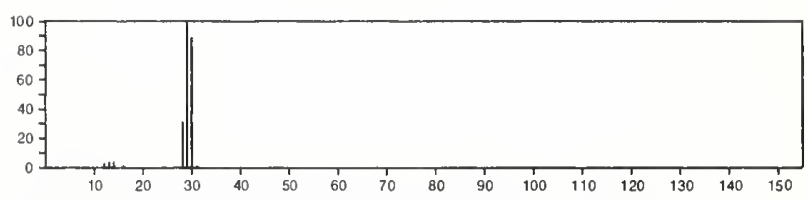

30

Ethane

$\mathrm{C}_{2} \mathrm{H}_{6}$

74-84-0

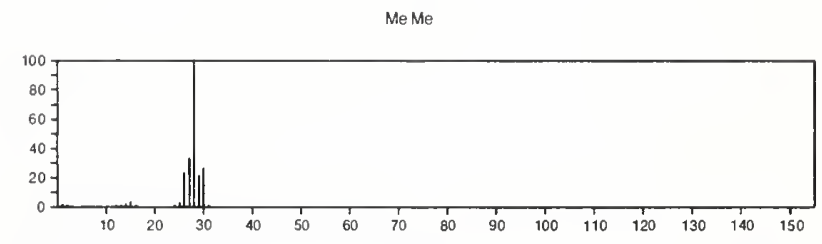

30

Nitrogen oxide (NO)

NO

10102-43-9

$N=0$

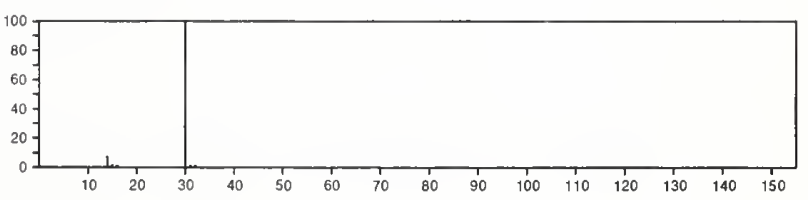


31

Methanamine

$\mathrm{CH}_{5} \mathrm{~N}$

$\mathrm{MeNH}$

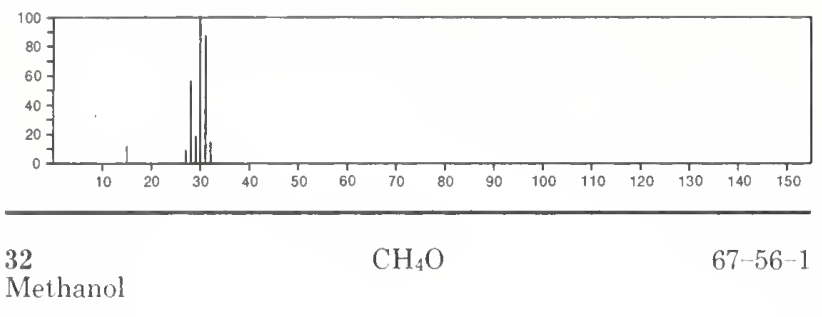

$\mathrm{Me} \mathrm{OH}$

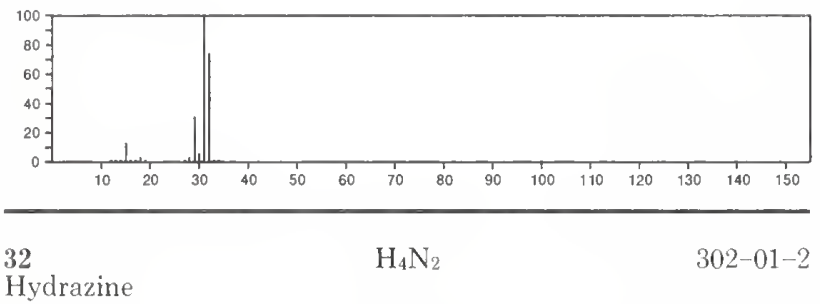

$\mathrm{H}_{2} \mathrm{NNH}_{2}$

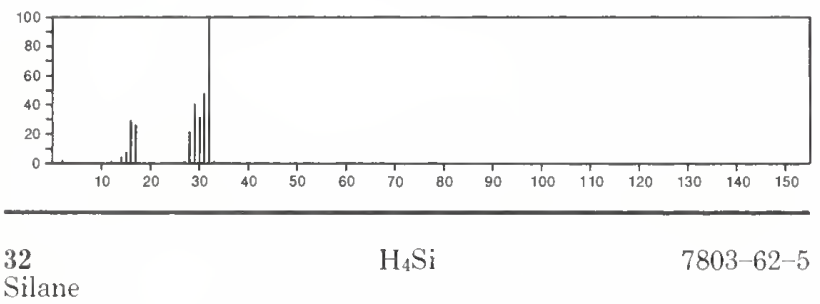

$\mathrm{SiH}_{4}$

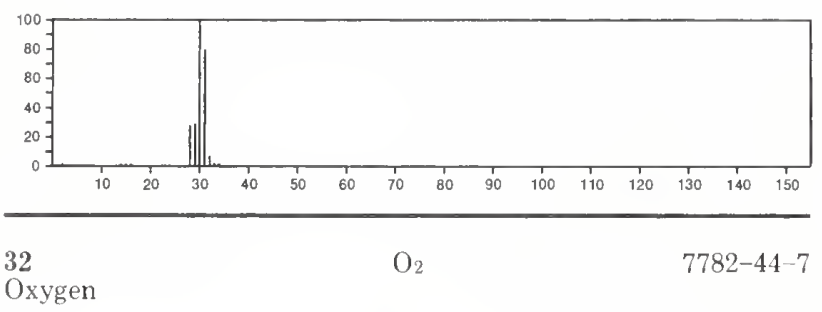

$0: 0$

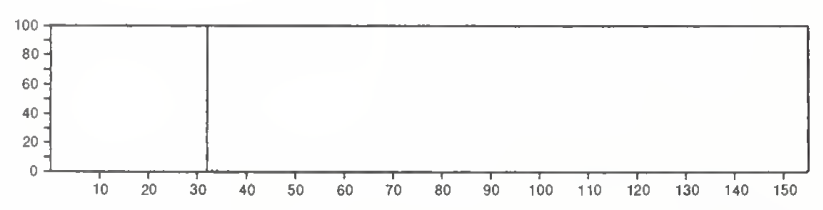

34

Methane, fluoro

$\mathrm{CH}_{3} \mathrm{~F}$

$593-53-3$

MeF

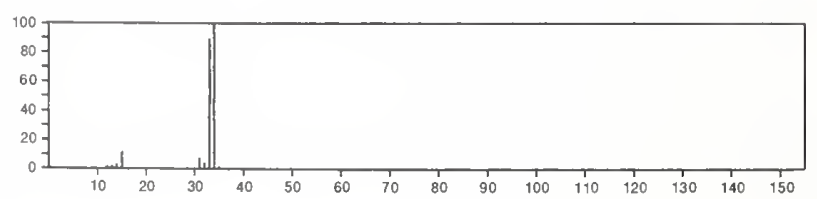

34

Hydrogen sulfide $\left(\mathrm{H}_{2} \mathrm{~S}\right)$

$\mathrm{H}_{2} \mathrm{~S}$

7783-06-4
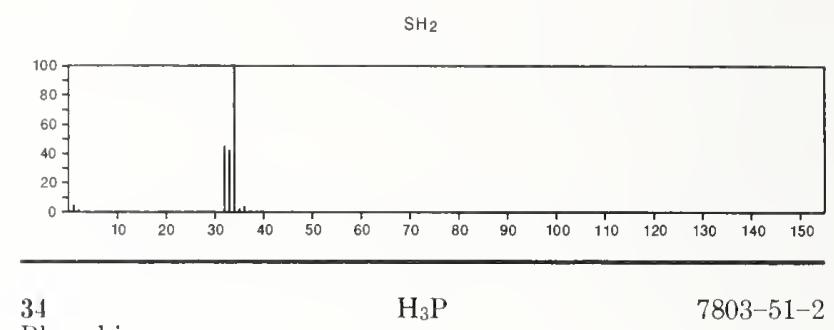

$7803-51-2$

Phosphine

$\mathrm{PH}_{3}$

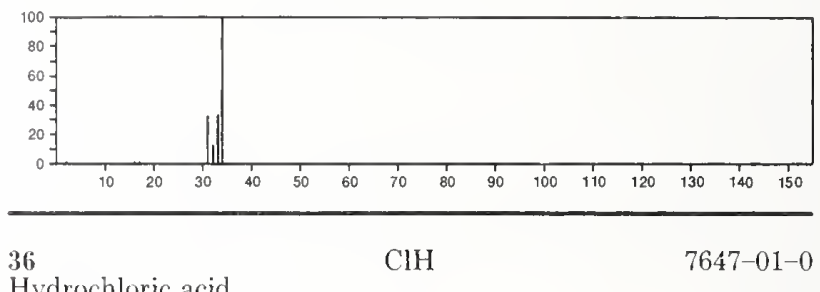

Hydrochloric acid

$\mathrm{ClH}$

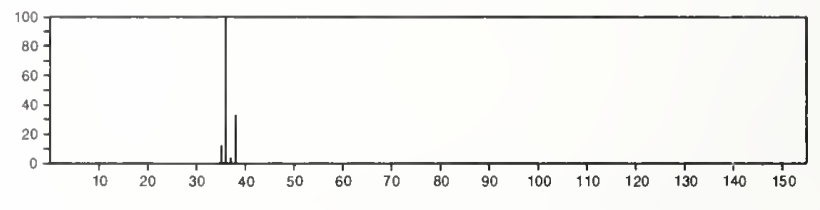

40

Ar

$7440-37-1$

Argon

Ar
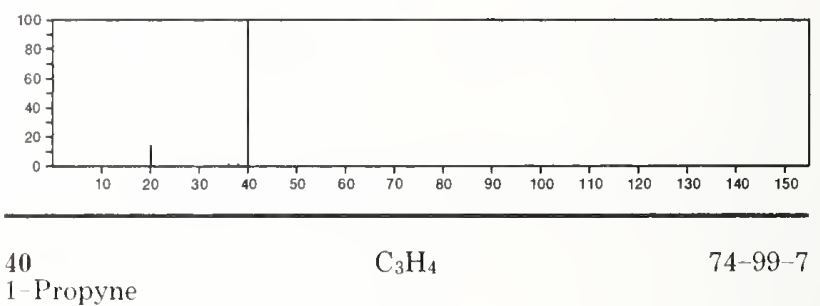

1 - Propyne

$\mathrm{MeC}: \mathrm{CH}$

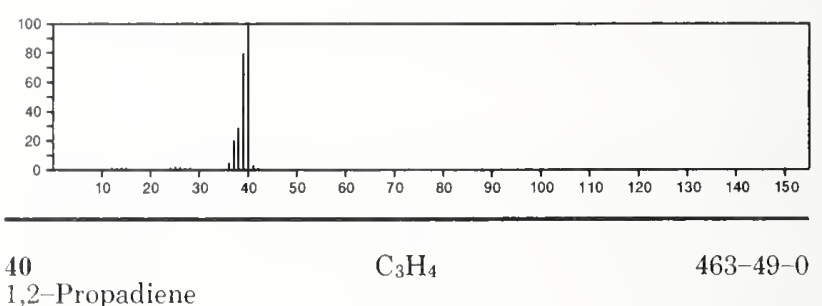

$\mathrm{H}_{2} \mathrm{C}: \mathrm{C}: \mathrm{CH}_{2}$

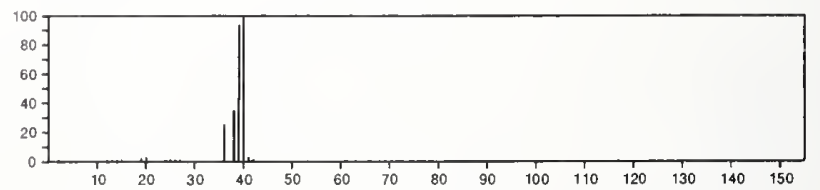


41

Acetonitrile

$\mathrm{C}_{2} \mathrm{H}_{3} \mathrm{~N}$

$\mathrm{NCME}$

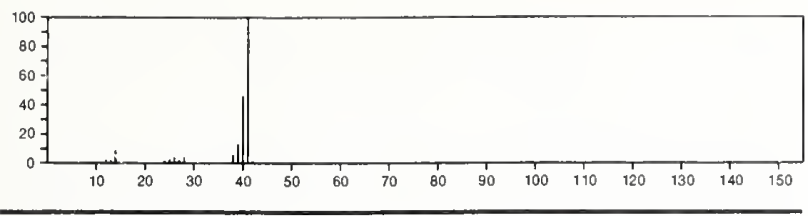

41

Methane, isocyano-

$\mathrm{C}_{2} \mathrm{H}_{3} \mathrm{~N}$

CNME

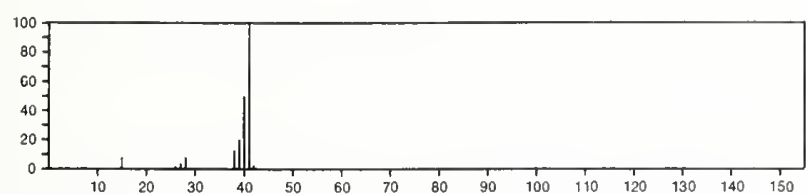

$\mathrm{CO} . \mathrm{BH}_{3}$

42

Borane, compd. with carbon monoxide (1:1)

$13205-44-2$
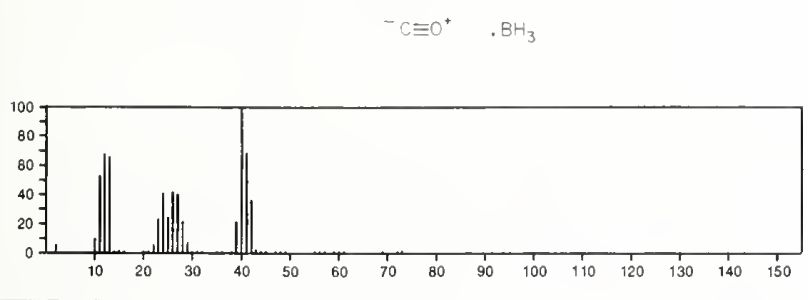

42

Cyclopropane

$\mathrm{C}_{3} \mathrm{H}_{6}$

75-19-4
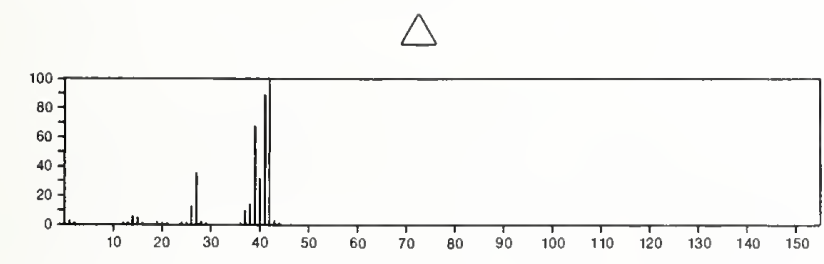

42

1-Propene

$\mathrm{C}_{3} \mathrm{H}_{6}$

115-07-1

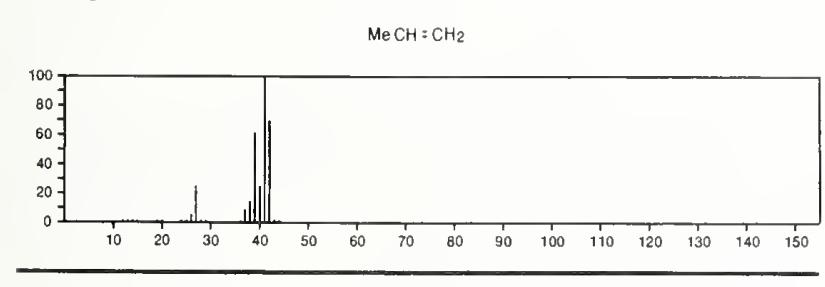

43

Aziridine

$\mathrm{C}_{2} \mathrm{H}_{5} \mathrm{~N}$

$\triangle_{\mathrm{NH}}$

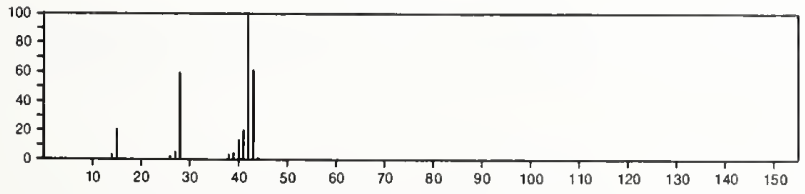

44

Carbon dioxide

$\mathrm{CO}_{2}$

$O=C: 0$

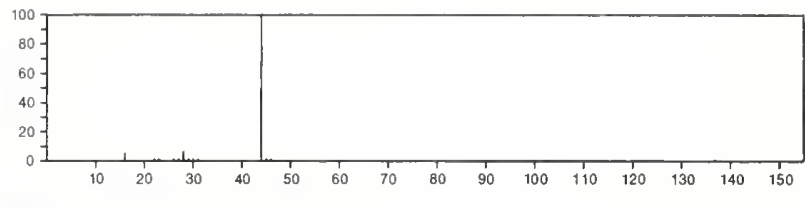

44

Ethyne, fluoro-

$\mathrm{C}_{2} \mathrm{HF}$

2713-09-9

$F C \equiv C H$

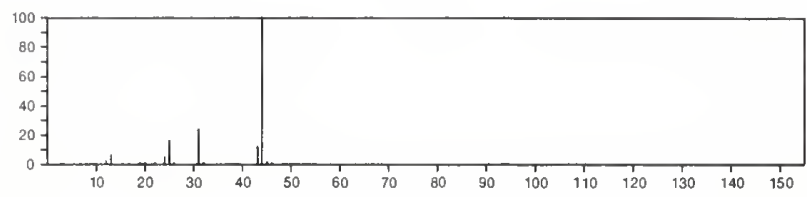

14

Acetaldehyde

$\mathrm{C}_{2} \mathrm{H}_{4} \mathrm{O}$

75-07-0

OCHME

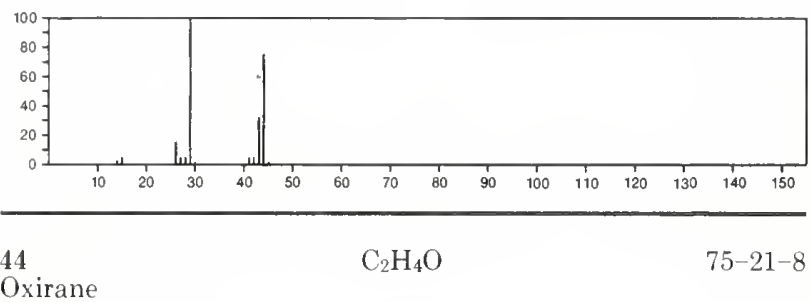

$\triangle_{\circ}$

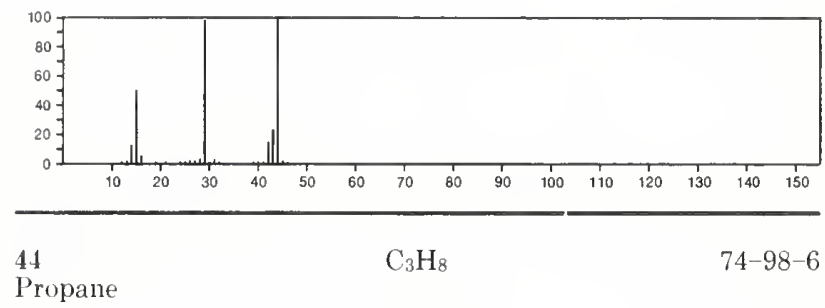

EtMe

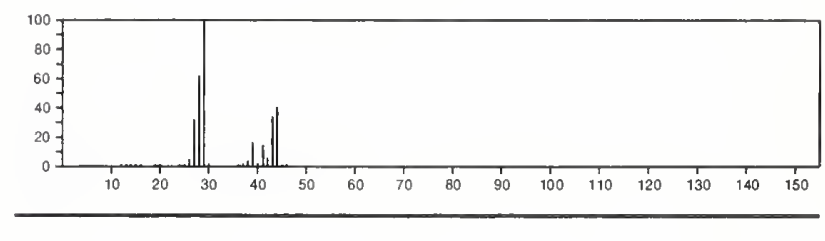

44

$\mathrm{N}_{2} \mathrm{O}$

10024-97-2

Nitrogen oxide $\left(\mathrm{N}_{2} \mathrm{O}\right)$

$\mathrm{N}_{2}=0$

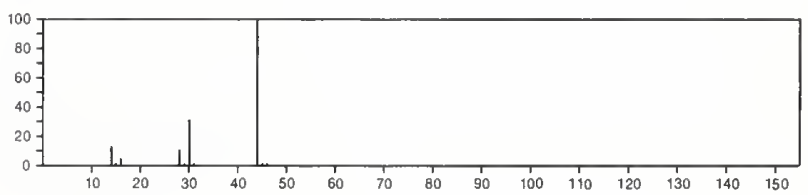


45

Formamide

$\mathrm{CH}_{3} \mathrm{NO}$

75-12-7

$\mathrm{H}_{2} \mathrm{NCH}=0$
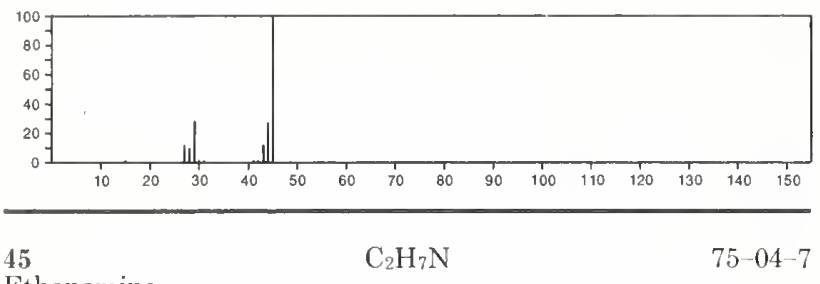

Ethanamine

$\mathrm{E}_{\mathrm{NH}} \mathrm{H}_{2}$

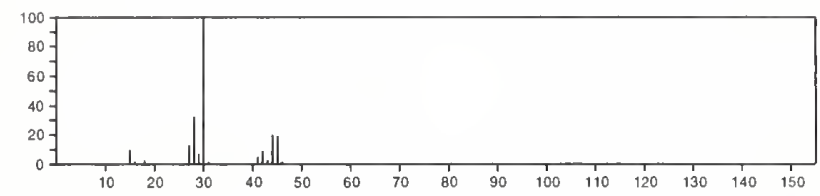

$45 \quad \mathrm{C}_{2} \mathrm{H}_{7} \mathrm{~N}$

Methanamine, $\mathrm{N}$-methyl-

NHMe 2

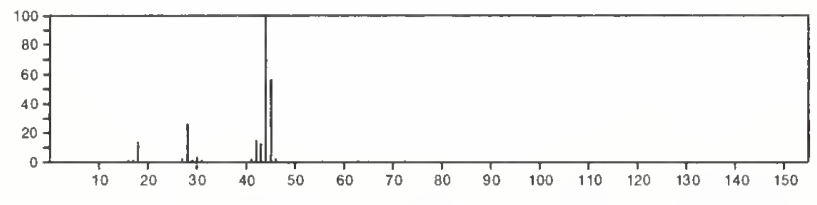

46

$\mathrm{CH}_{2} \mathrm{O}_{2}$

64-18-6

Formic acid

$\mathrm{HOCH}: \mathrm{O}$
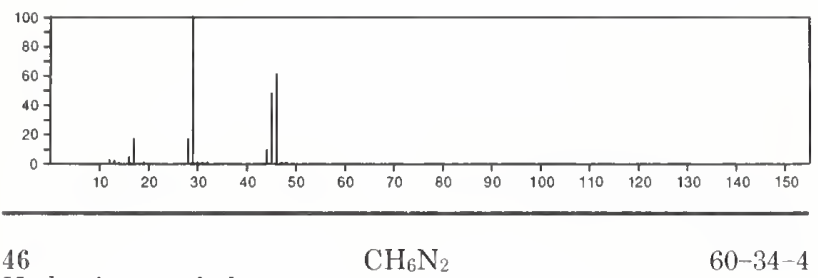

Hydrazine, methyl-

$\mathrm{CH}_{6} \mathrm{~N}_{2}$

MeNHNH2

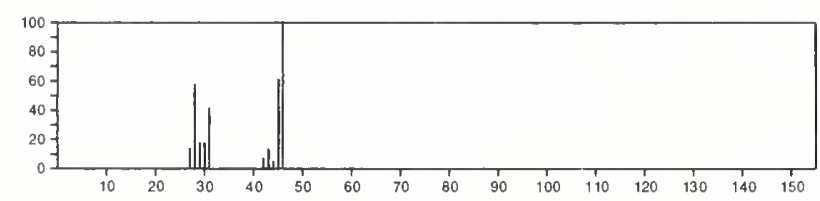

46

Silane, methyl

$\mathrm{CH}_{6} \mathrm{Si}$

$\mathrm{MeSiH}_{3}$

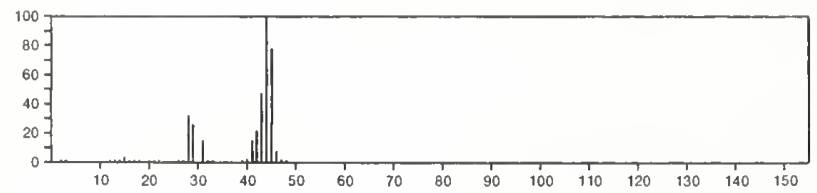

46

Ethene, fluoro

$\mathrm{C}_{2} \mathrm{H}_{3} \mathrm{~F}$

$75-02-5$

$\mathrm{FCH}=\mathrm{CH}_{2}$

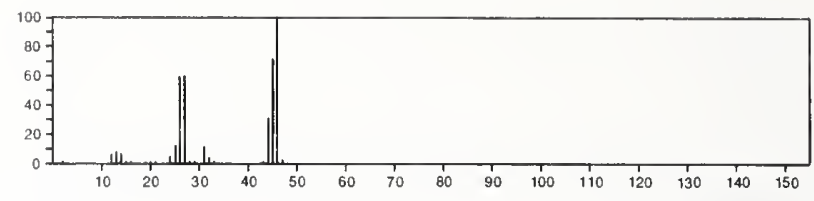

46

Ethanol

$\mathrm{C}_{2} \mathrm{H}_{6} \mathrm{O}$

64-17-5

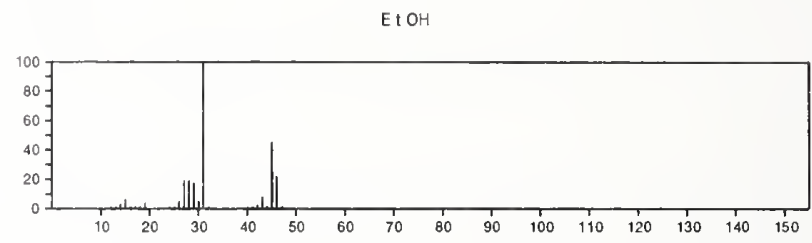

46

$\mathrm{C}_{2} \mathrm{H}_{6} \mathrm{O}$

$115-10-6$

Methane, oxybis

OMe 2

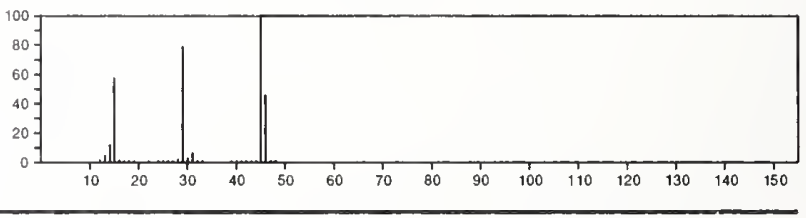

46

$\mathrm{NO}_{2}$

10102-44-0

Nitrogen oxide $\left(\mathrm{NO}_{2}\right)$

ONO

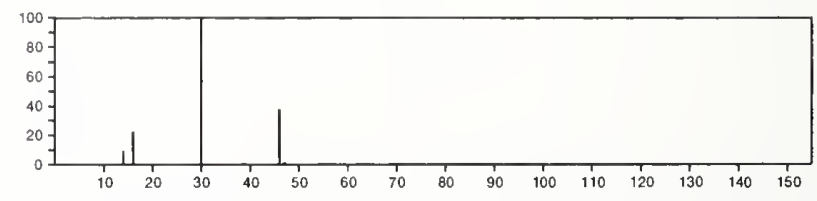

48

Methanethiol

$\mathrm{CH}_{4} \mathrm{~S}$

74-93-1

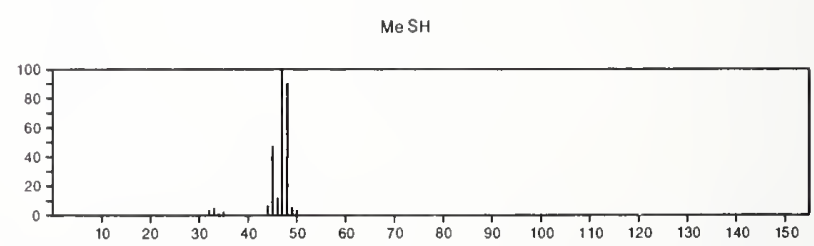

48

$\mathrm{CH}_{5} \mathrm{P}$

593-54-4

Phosphine, methyl-

$\mathrm{MePH}_{2}$

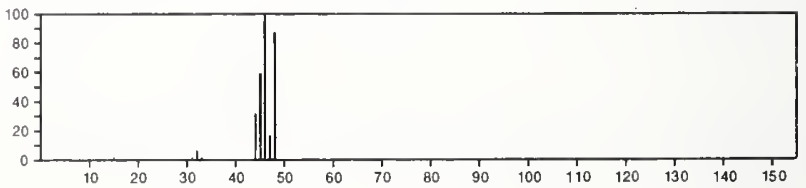


48

Ethane, fluoro-

$\mathrm{C}_{2} \mathrm{H}_{5} \mathrm{~F}$

EtF
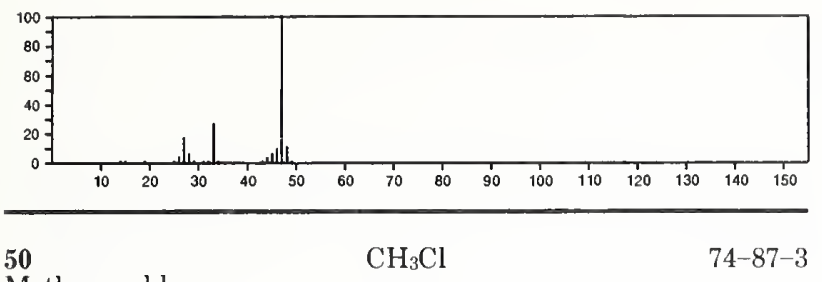

Methane, chloro-

$\mathrm{MeCl}$

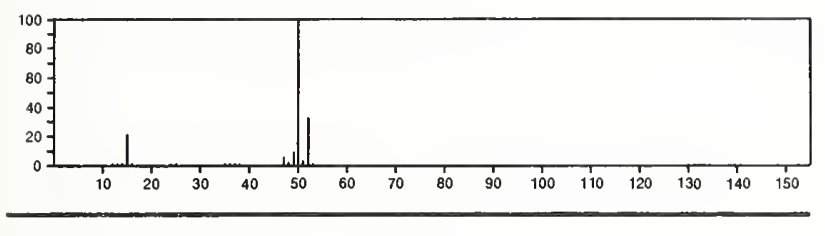

50

$\mathrm{C}_{4} \mathrm{H}_{2}$

$460-12-8$

1,3-Butadiyne

$\mathrm{HC} \equiv \mathrm{CC} \equiv \mathrm{CH}$

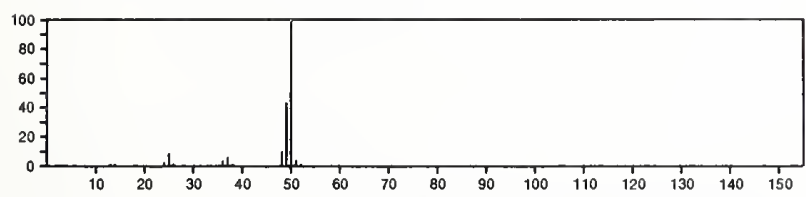

52

Methane, difluoro-

$\mathrm{CH}_{2} \mathrm{~F}_{2}$

75-10-5

$\mathrm{CH}_{2} \mathrm{~F}_{2}$
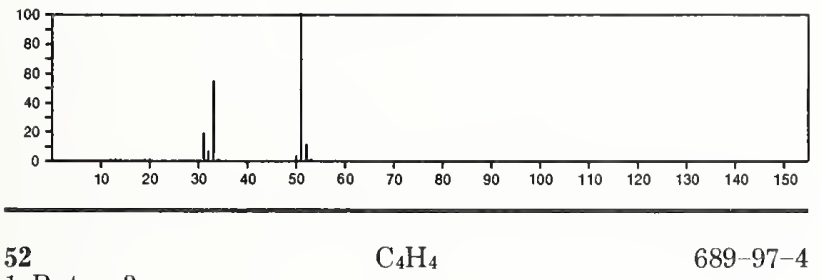

1-Buten-3-yne

$\mathrm{HC} \equiv \mathrm{CCH}=\mathrm{CH}_{2}$

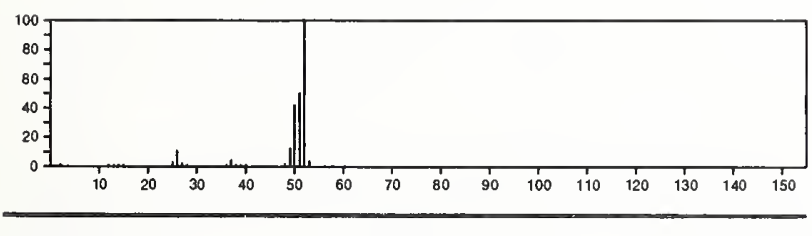

53

2-Propenenitrile

$\mathrm{C}_{3} \mathrm{H}_{3} \mathrm{~N}$

107-13-1

$\mathrm{NCCH}=\mathrm{CH}_{2}$

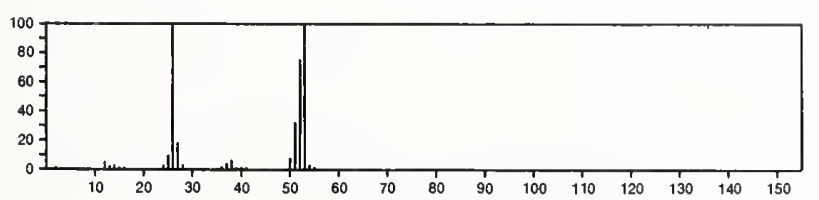

54

Tetraborane (10)

$\mathrm{B}_{4} \mathrm{H}_{10}$

18283-93-7
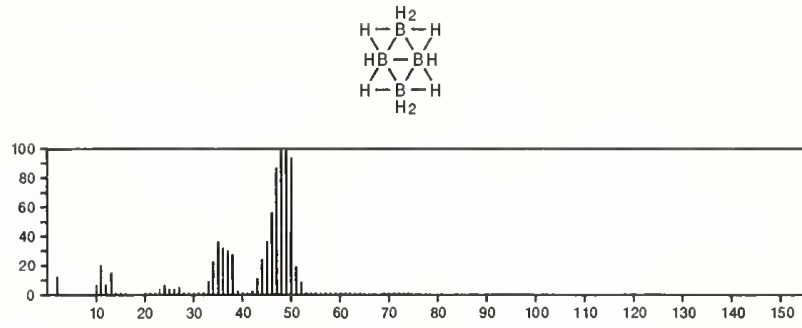

54

1,3-Butadiene

$\mathrm{C}_{4} \mathrm{H}_{6}$

106-99-0

$\mathrm{H}_{2} \mathrm{C}=\mathrm{CHCH} \equiv \mathrm{CH}_{2}$

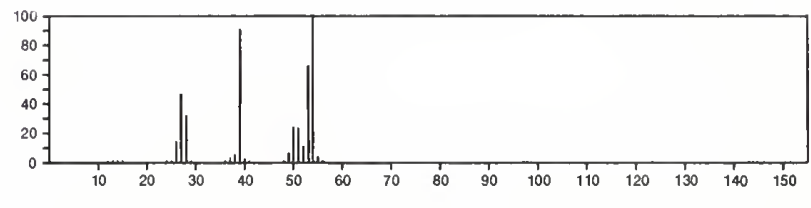

54

1-Butyne

$\mathrm{C}_{4} \mathrm{H}_{6}$

$107-00-6$

$\mathrm{E}: \mathrm{C} \equiv \mathrm{CH}$

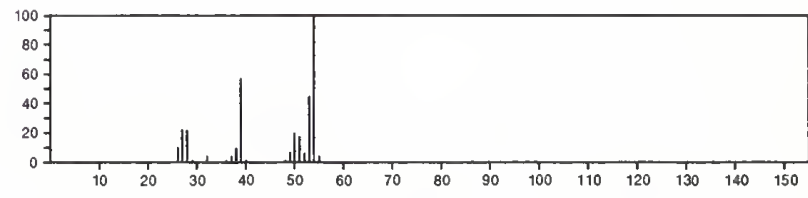

54

2-Butyne

$\mathrm{C}_{4} \mathrm{H}_{6}$

$503-17-3$

$\mathrm{MeC}=\mathrm{CMe}$

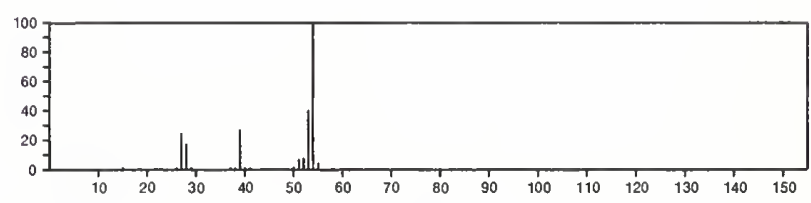

54

1,2-Butadiene

$\mathrm{C}_{4} \mathrm{H}_{6}$

$590-19-2$

$\mathrm{H}_{2} \mathrm{C}: \mathrm{C}=\mathrm{CHM}$
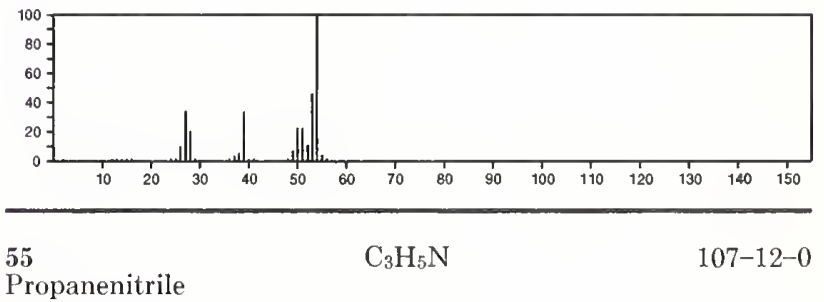

Propanenitrile

EICN

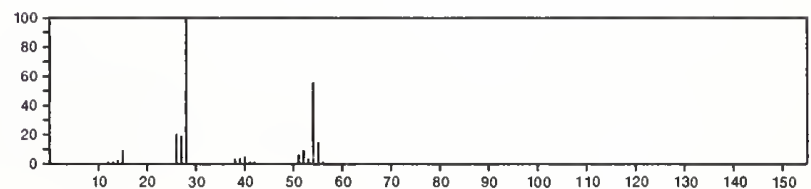


5.5

Ethane, isocyano-

$\mathrm{C}_{3} \mathrm{H}_{5} \mathrm{~N}$

EINC

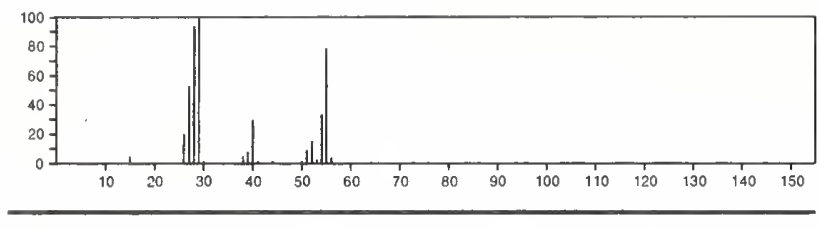

56

Ethane, diazo-

$\mathrm{C}_{2} \mathrm{H}_{4} \mathrm{~N}_{2}$

1117-96-0

$\mathrm{Me} \mathrm{CH}=\mathrm{N}$
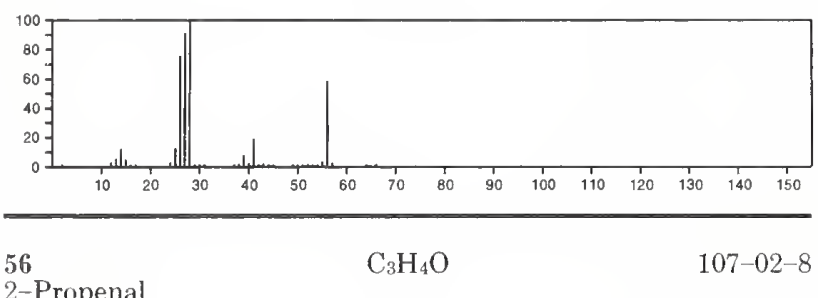

2-Propenal

$\mathrm{OCHCH}=\mathrm{CH}_{2}$

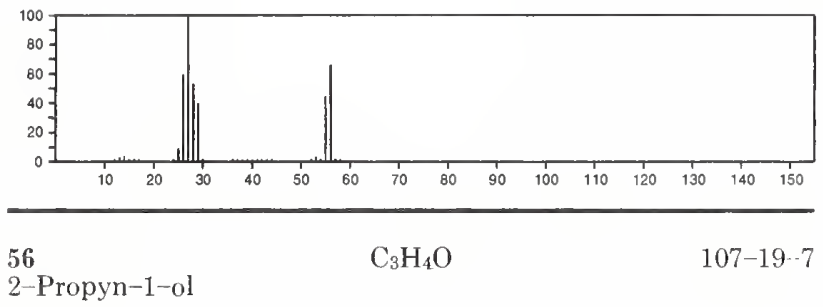

$\mathrm{HOCH}_{2} \mathrm{C}: \mathrm{CH}$

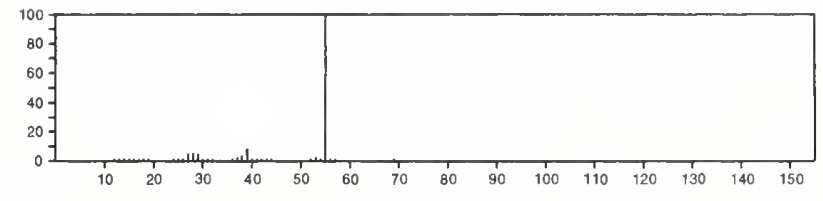

56

Borane, trimethyl-

$\mathrm{C}_{3} \mathrm{H}_{9} \mathrm{~B}$

593-90-8

BMe

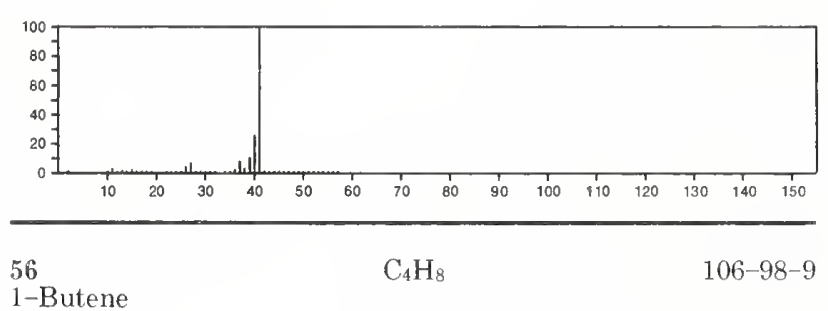

$\mathrm{Et} C \mathrm{CH}=\mathrm{CH}_{2}$

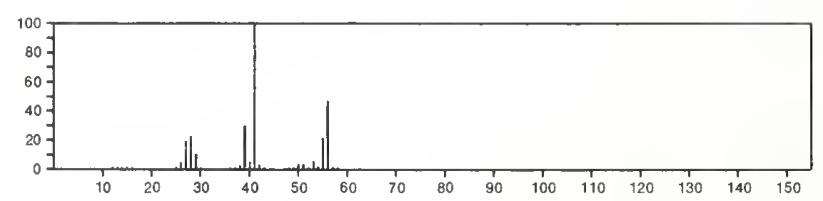

56

2-Butene

$\mathrm{C}_{4} \mathrm{H}_{8}$

107-01-7

$\mathrm{MeCH}=\mathrm{CHMe}$

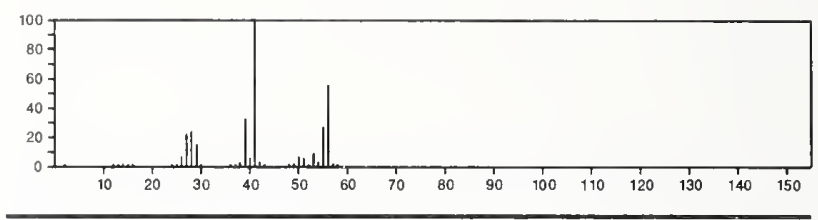

$\mathrm{C}_{4} \mathrm{H}_{8}$

115-11-7

1-Propene, 2-methyl

$\mathrm{Me}_{2} \mathrm{C}=\mathrm{CH}_{2}$

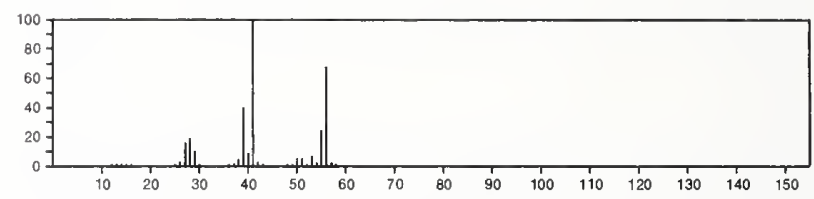

56

Cyclobutane

$\mathrm{C}_{4} \mathrm{H}_{8}$

$287-23-0$

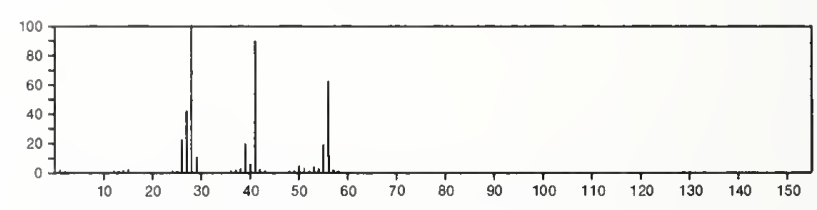

56

2-Butene, (Z)-

$\mathrm{C}_{4} \mathrm{H}_{8}$

590-18-1

$\mathrm{MeCH}=\mathrm{CHMe}$

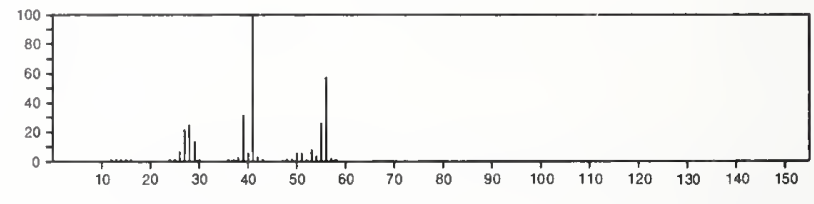

56

2-Butene, (E)

$\mathrm{C}_{4} \mathrm{H}_{8}$

624-64-6

$\mathrm{MeCH}=\mathrm{CHMe}$

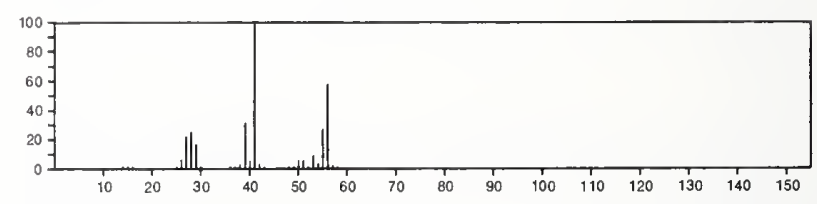

$57 \quad \mathrm{C}_{2} \mathrm{H}_{3} \mathrm{NO} \quad 107-16-4$

Acetonitrile, hydroxy-

$\mathrm{HOCH}_{2} \mathrm{CN}$

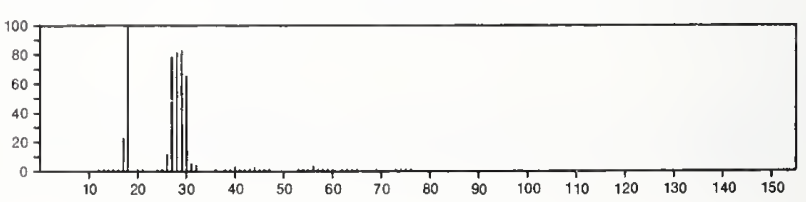


57

Boranamine, $N, N$-dimethyl-

$\mathrm{C}_{2} \mathrm{H}_{8} \mathrm{BN}$

$\mathrm{Me}_{2} \mathrm{NBH}_{2}$
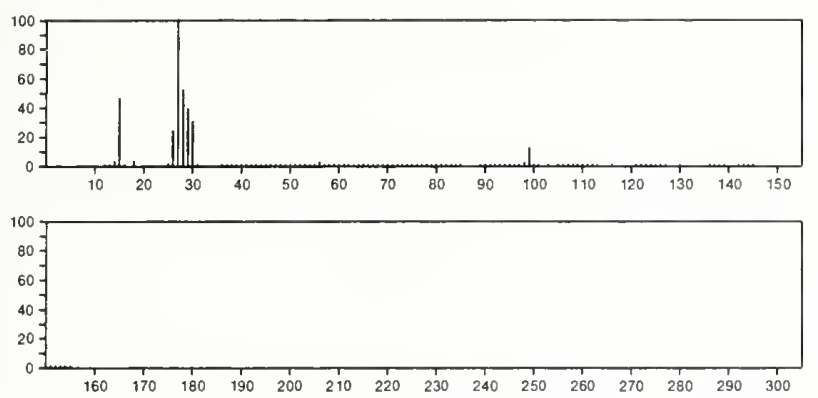

57

Aziridine, 2-methyl-

$\mathrm{C}_{3} \mathrm{H}_{7} \mathrm{~N}$

$75-55-8$

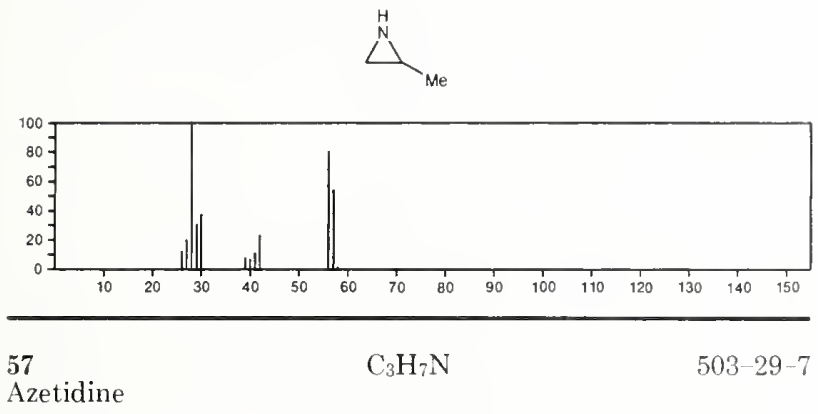

$\square^{N H}$

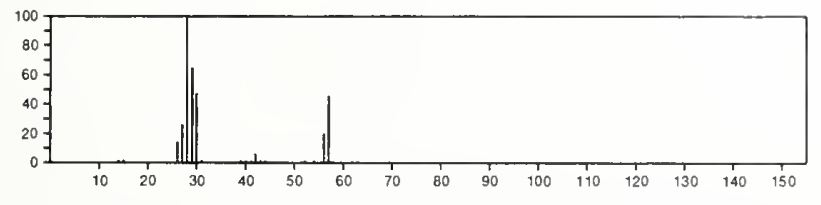

57

Aziridine, 1-methyl-

$\mathrm{C}_{3} \mathrm{H}_{7} \mathrm{~N}$

1072-44-2
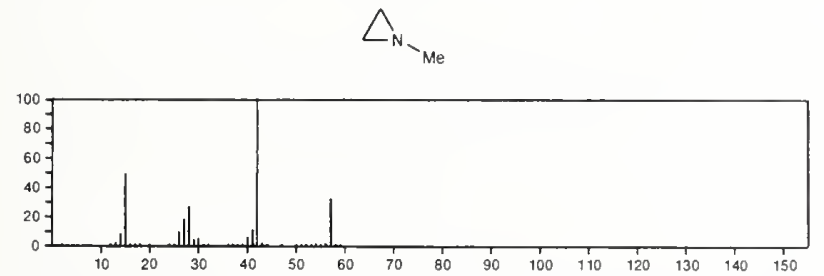

58

$\mathrm{C}_{2} \mathrm{H}_{2} \mathrm{O}_{2}$

$107-22-2$

Ethanedial

$\mathrm{OCHCHO}$

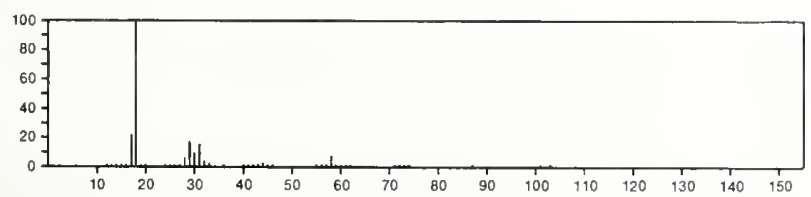

58

Diazene, dimethyl

$\mathrm{C}_{2} \mathrm{H}_{6} \mathrm{~N}_{2}$

$503-28-6$

MeN $=$ NMe
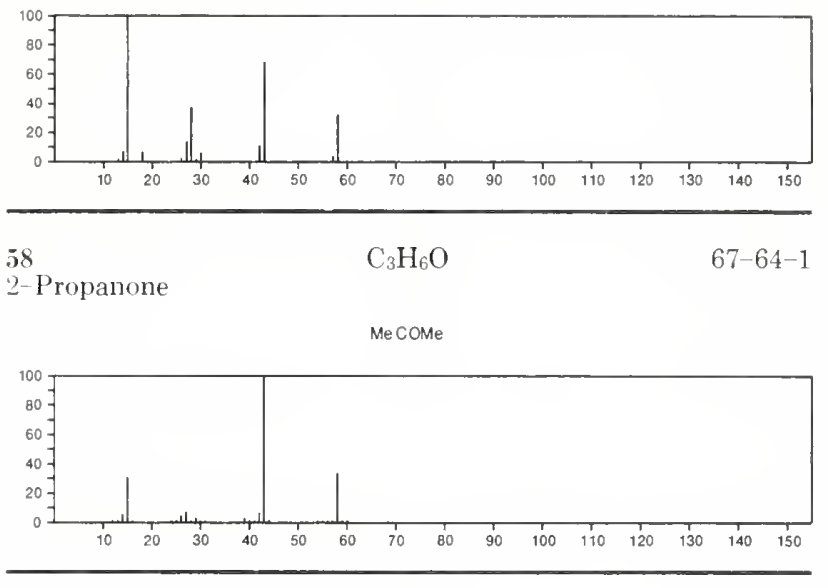

58

$\mathrm{C}_{3} \mathrm{H}_{6} \mathrm{O}$

$75-56-9$

Oxirane, methyl
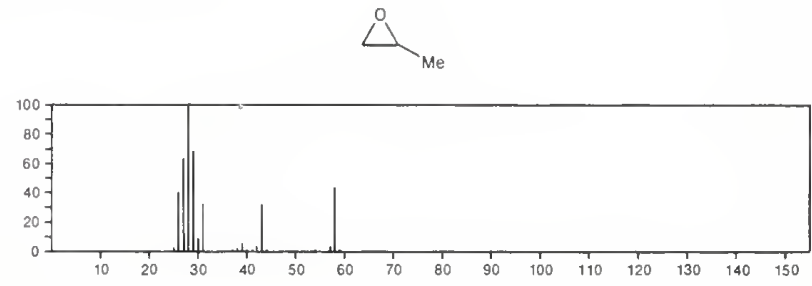

58

2 Propen-1-ol

$\mathrm{C}_{3} \mathrm{H}_{6} \mathrm{O}$

$107-18-6$

$\mathrm{HOCH}_{2} \mathrm{CH}=\mathrm{CH}_{2}$

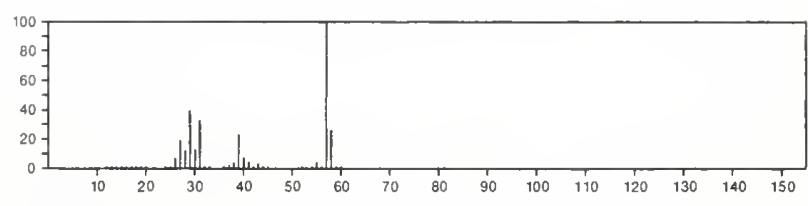

58

$\mathrm{C}_{3} \mathrm{H}_{6} \mathrm{O}$

$107-25-5$

Ethene, methoxy-

Me $\mathrm{OCH}=\mathrm{CH}_{2}$
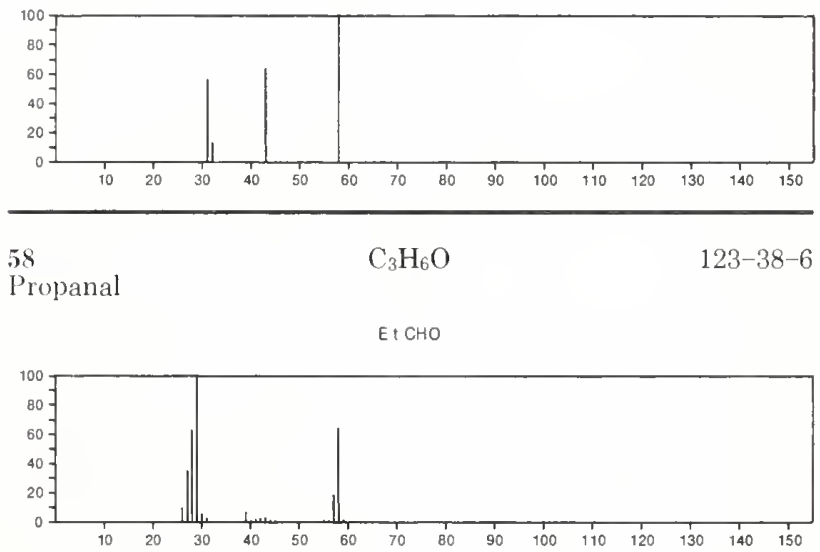
58 Oxetane

$\mathrm{C}_{3} \mathrm{H}_{6} \mathrm{O}$

$\square$

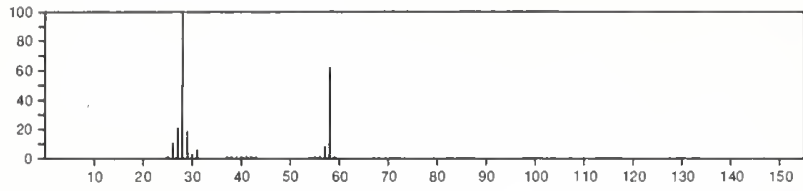

58

Propane, 2-methyl

$\mathrm{C}_{4} \mathrm{H}_{10}$

$75-28-5$

CHMes

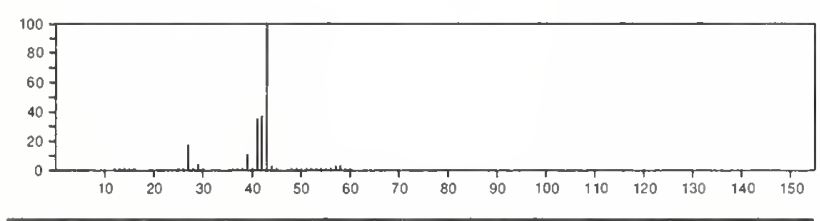

58

Butane

$\mathrm{C}_{4} \mathrm{H}_{10}$

$106-97-8$

PrMe

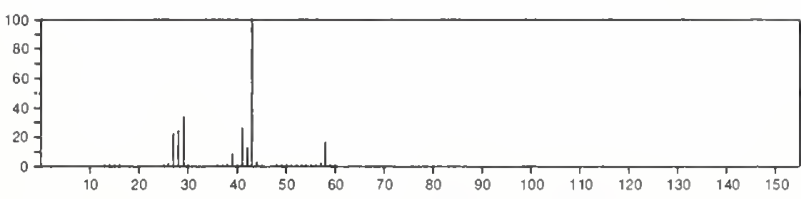

59

$\mathrm{C}_{2} \mathrm{H}_{5} \mathrm{NO}$

$60 \quad 35-5$

Acetamide

$\mathrm{ACNH}_{2}$

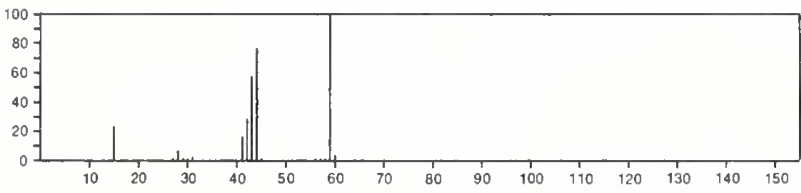

59

$\mathrm{C}_{2} \mathrm{H}_{5} \mathrm{NO}$

$123 \quad 39-7$

Formamide, $N$-methyl-

$\mathrm{MeNHCH}=0$

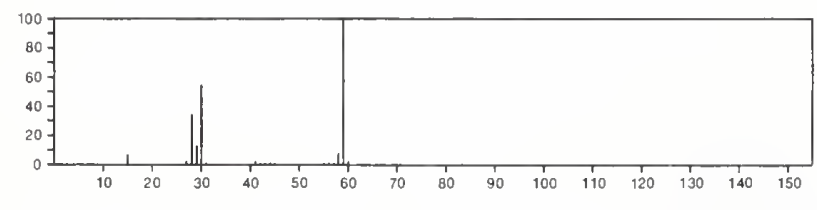

59

$\mathrm{C}_{2} \mathrm{H}_{7} \mathrm{~N} . \mathrm{BH}$

Methanamine, $N$-methyl-, compd. with burane $(1: 1)$

$74-94-2$

$$
\mathrm{NHMe}_{2} \cdot \mathrm{BH}_{3}
$$

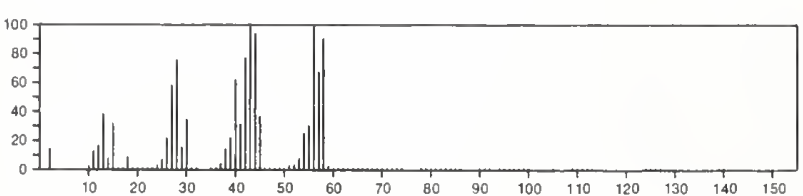

59

2-Propanamine

$\mathrm{C}_{3} \mathrm{H}_{9} \mathrm{~N}$

$75-31-0$

$\mathrm{i}-\mathrm{PrNH}$

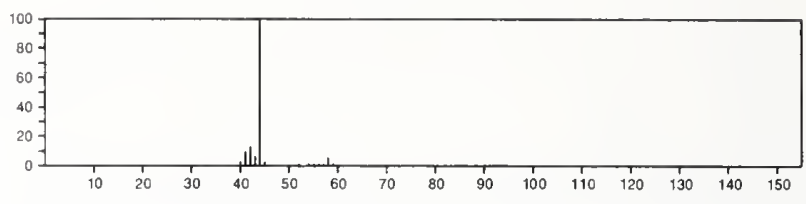

59
Methanamine, $N, N$-dimethyl-

$75-50-3$

NMe 3

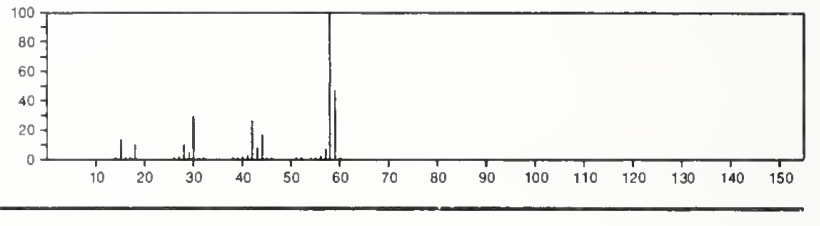

59

1 -Propanamine

$\mathrm{C}_{3} \mathrm{H}_{9} \mathrm{~N}$

$107-10-8$

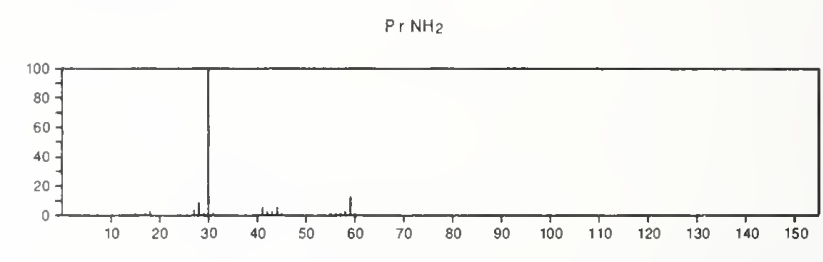

60

$\mathrm{B}_{2} \mathrm{H}_{6} \mathrm{~S}$

$22548-43-2$

Diborane(6), $\mu$-mercapto-
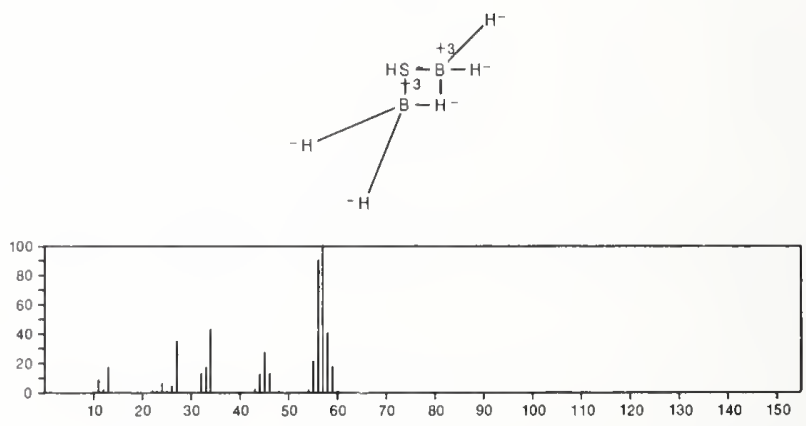

60

$\mathrm{CH}_{4} \mathrm{~N}_{2} \mathrm{O}$

$57-13-6$

Irea

$\mathrm{H}_{2} \mathrm{NCONH}_{2}$

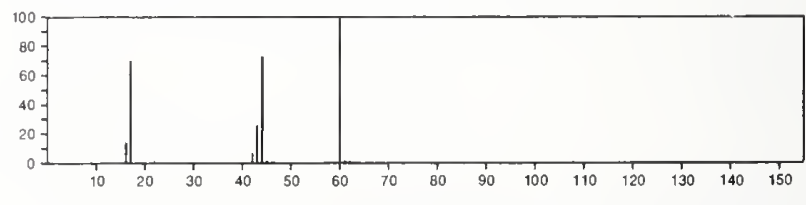

60

Carbon oxide sulfide (COS)

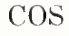

$463-58-1$

$0=C=S$

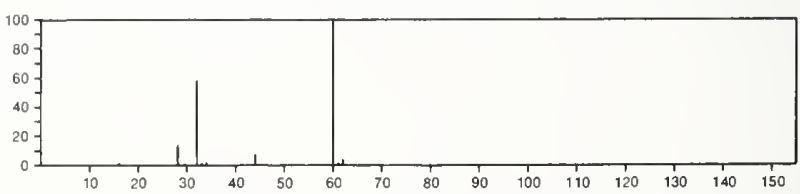


60 Ethyne, chloro-

$\mathrm{C}_{2} \mathrm{HCl}$

$\mathrm{CIC} \equiv \mathrm{CH}$

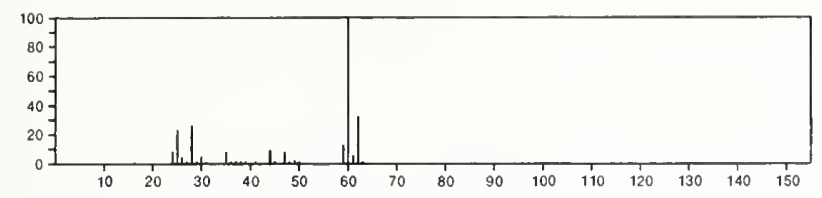

60

Acetic acid

$\mathrm{C}_{2} \mathrm{H}_{4} \mathrm{O}_{2}$

$\mathrm{HO}_{2} \mathrm{CMe}$

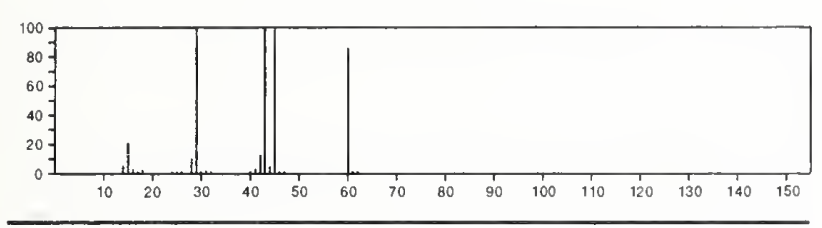

60

Formic acid, methyl ester

$\mathrm{C}_{2} \mathrm{H}_{4} \mathrm{O}_{2}$

$\mathrm{MeOCH}=\mathrm{O}$

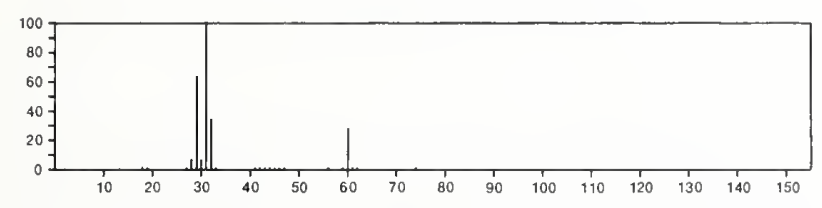

60

Acetaldehyde, hydroxy-

$\mathrm{C}_{2} \mathrm{H}_{4} \mathrm{O}_{2}$

$141-46 \quad 8$

$\mathrm{HOCH}_{2} \mathrm{CHO}$

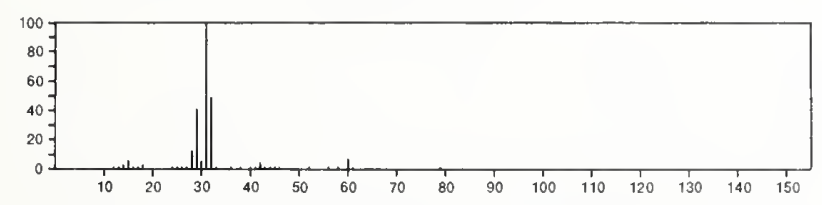

60

Thiirane

$\mathrm{C}_{2} \mathrm{H}_{4} \mathrm{~S}$

$\triangle_{s}$

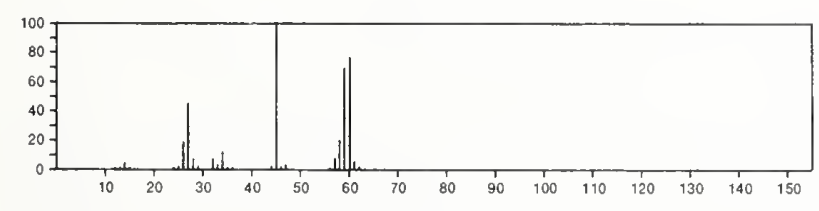

60

Hydrazine, 1,1-dimethyl-

$\mathrm{C}_{2} \mathrm{H}_{8} \mathrm{~N}_{2}$

$\mathrm{Me}_{2} \mathrm{NNH}_{2}$

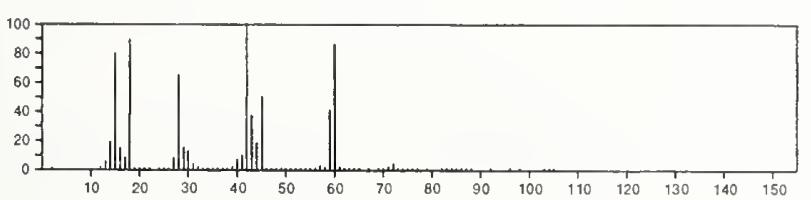

60

1,2-Ethanediamine

$\mathrm{C}_{2} \mathrm{H}_{8} \mathrm{~N}_{2}$

$107-15-3$

$\mathrm{H}_{2} \mathrm{NCH}_{2} \mathrm{CH}_{2} \mathrm{NH}_{2}$

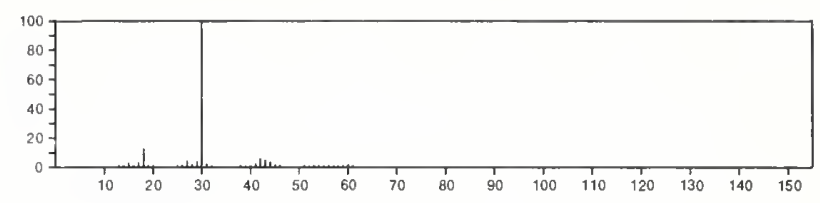

$60 \quad \mathrm{C}_{2} \mathrm{H}_{8} \mathrm{~N}_{2}$

Hydrazine, 1.2-dimethyl

$540-73-8$

MeNHNHMe

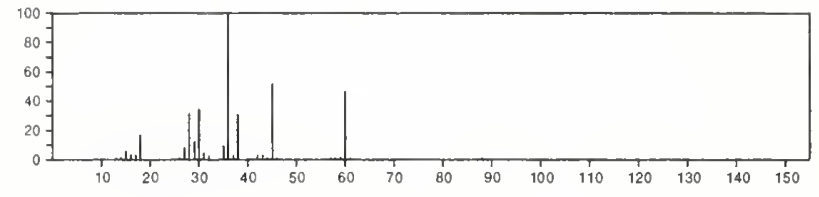

60)

Silane, dimethyl

$\mathrm{C}_{2} \mathrm{H}_{8} \mathrm{Si}$

1111-74-6

$\mathrm{Si} \mathrm{H}_{2} \mathrm{Me}_{2}$

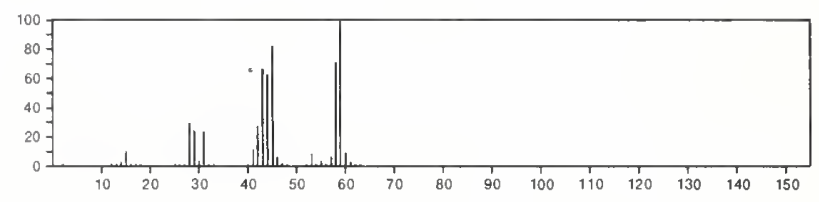

(i)

1 Propene, 3-fluoro

$\mathrm{C}_{3} \mathrm{H}_{5} \mathrm{~F}$

818-92-8

$\mathrm{FCH}_{2} \mathrm{CH}: \mathrm{CH}_{2}$

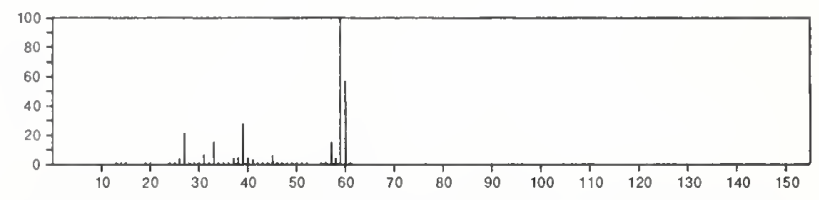

60)

1 Propene, 2-fluoro

$\mathrm{C}_{3} \mathrm{H}_{5} \mathrm{~F}$

1184-60-7

$\mathrm{Me} C \mathrm{CF}: \mathrm{CH}_{2}$

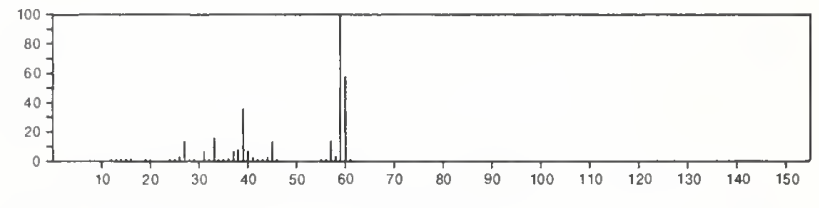

60) $\mathrm{C}_{3} \mathrm{H}_{8} \mathrm{O} \quad 67-63-0$

2 Propanol

$\mathrm{i}-\mathrm{PrOH}$

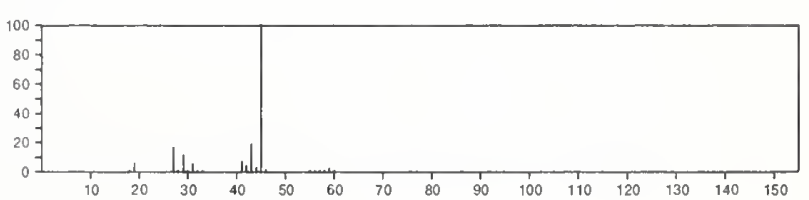


1-Propanol

$\mathrm{C}_{3} \mathrm{H}_{8} \mathrm{O}$

$\operatorname{PrOH}$
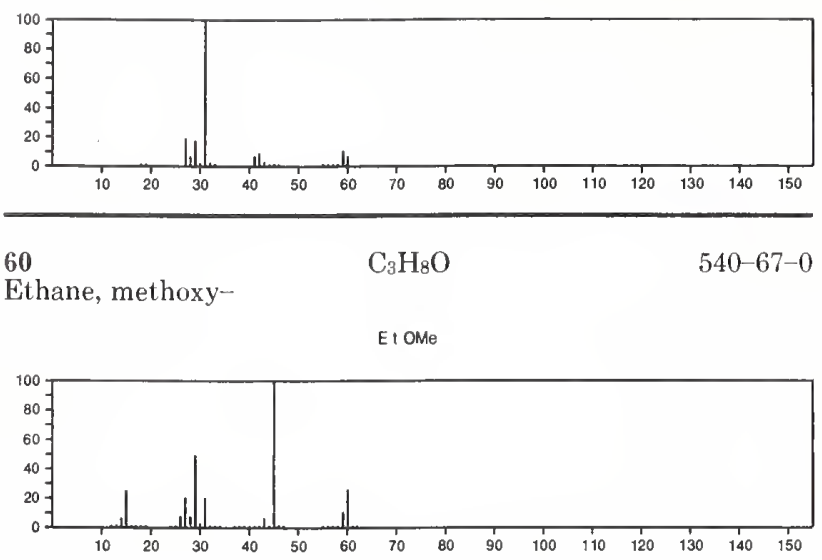

61

Cyanogen chloride

CClN

NCCl

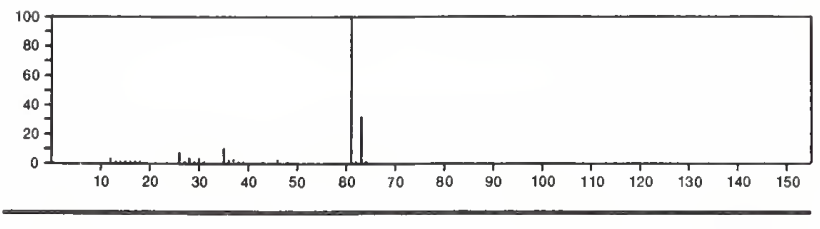

61

Methane, nitro-

$\mathrm{CH}_{3} \mathrm{NO}_{2}$

75-52-5

$\mathrm{O}_{2} \mathrm{NMe}$

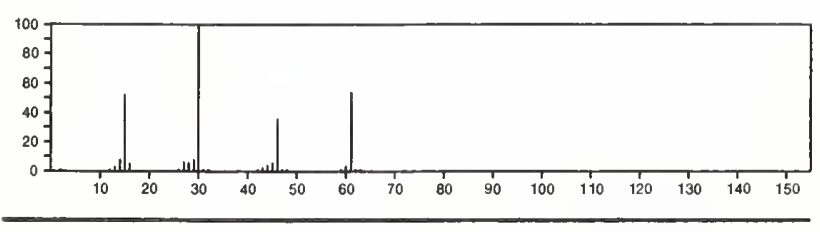

61

$\mathrm{CH}_{3} \mathrm{NO}_{2}$

624-91-9

MeONO

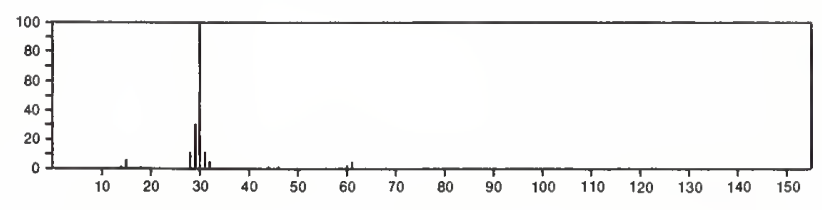

61

Ethanol, 2-amino-

$\mathrm{C}_{2} \mathrm{H}_{7} \mathrm{NO}$

$141-43-5$

$\mathrm{HOCH}_{2} \mathrm{CH}_{2} \mathrm{NH}_{2}$

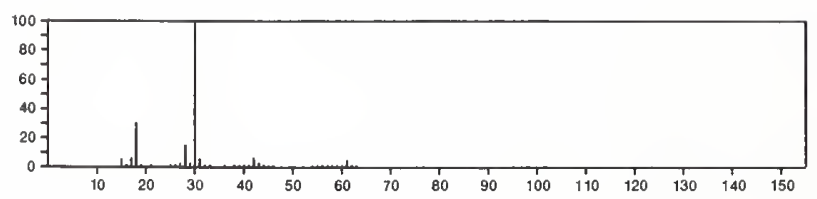

61

$1117-97-1$

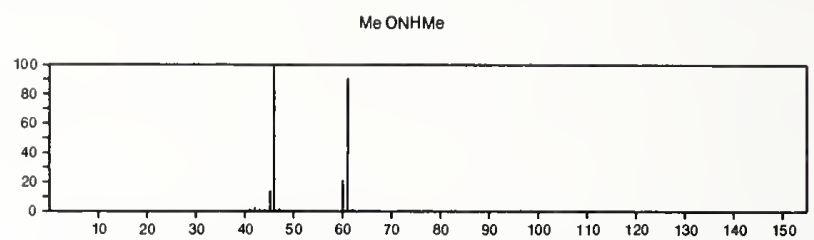

62

Ethene, chloro-

$\mathrm{C}_{2} \mathrm{H}_{3} \mathrm{Cl}$

75-01-4

$\mathrm{Cl} \mathrm{CH}=\mathrm{CH}_{2}$

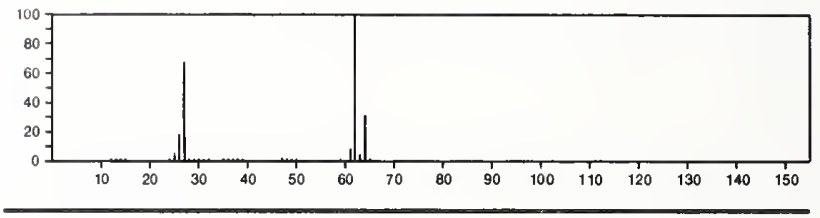

62

1,2-Ethanediol

$\mathrm{C}_{2} \mathrm{H}_{6} \mathrm{O}_{2}$

107-21-1

$\mathrm{HOCH}_{2} \mathrm{CH}_{2} \mathrm{OH}$

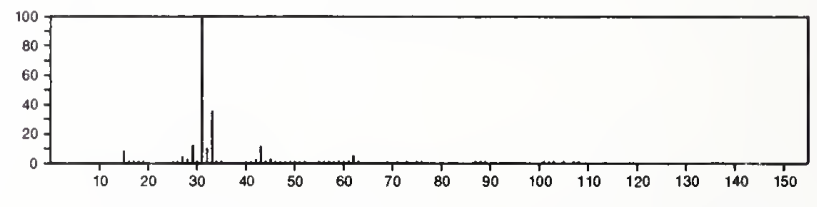

62

Peroxide, dimethyl

$\mathrm{C}_{2} \mathrm{H}_{6} \mathrm{O}_{2}$

690-02-8

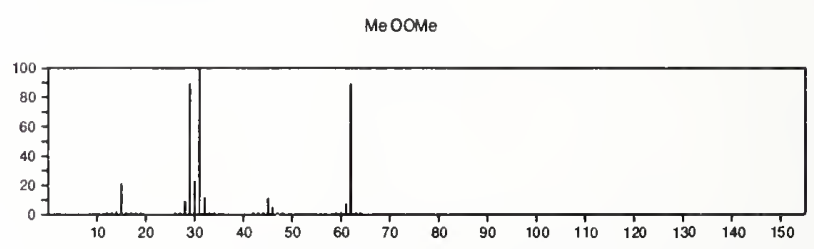

62

$\mathrm{C}_{2} \mathrm{H}_{6} \mathrm{~S}$

75-08-1

Ethanethiol

EISH

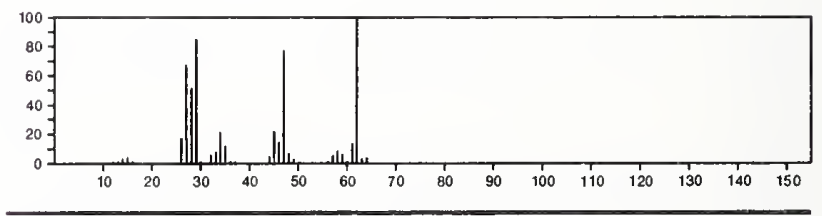

62

Methane, thiobis-

$\mathrm{C}_{2} \mathrm{H}_{6} \mathrm{~S}$

75-18-3

$\mathrm{SMe}_{2}$

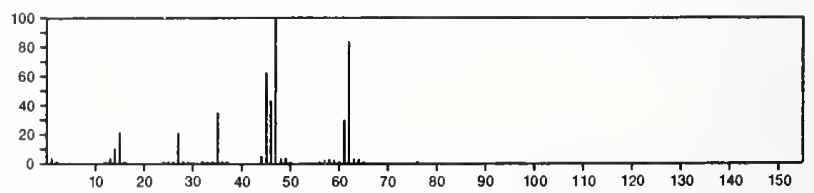


62

Phosphine, ethyl-

$\mathrm{C}_{2} \mathrm{H}_{7} \mathrm{P}$

- EtPHz

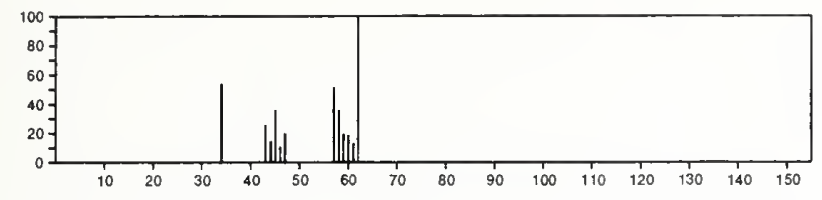

$62 \quad \mathrm{C}_{2} \mathrm{H}_{7} \mathrm{P}$

Phosphine, dimethyl-

PHMe 2

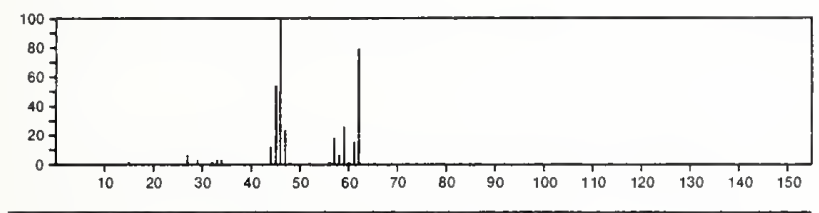

62

Propane, 2-fluoro-

$\mathrm{C}_{3} \mathrm{H}_{7} \mathrm{~F}$

420-26-8

i-PrF

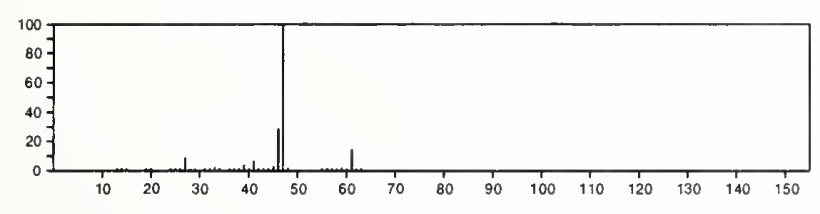

62

Propane, 1-fluoro-

$\mathrm{C}_{3} \mathrm{H}_{7} \mathrm{~F}$

460-13-9

PrF

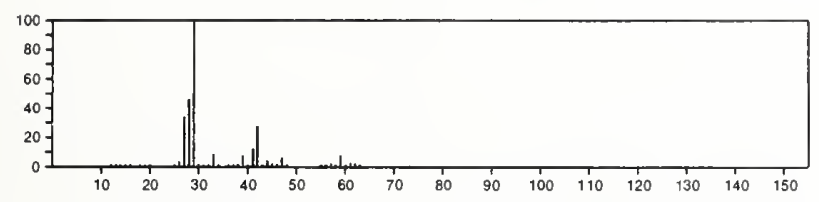

64

$\mathrm{B}_{5} \mathrm{H}_{9}$

19624-22-7

Pentaborane(9)
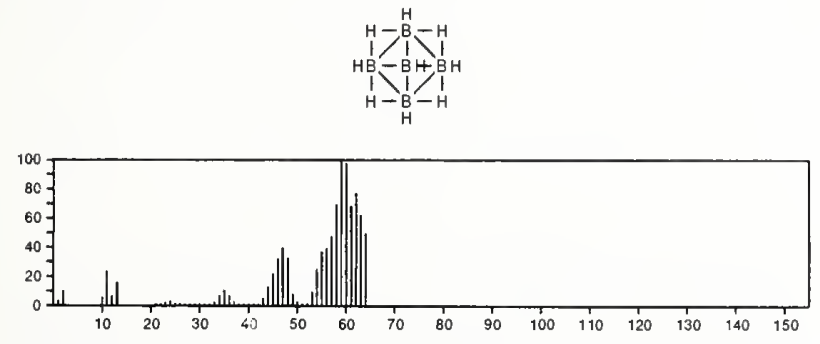

64

Ethene, 1,1-difluoro-

$\mathrm{C}_{2} \mathrm{H}_{2} \mathrm{~F}_{2}$

75-38-7

$\mathrm{F}_{2} \mathrm{C}=\mathrm{CH}_{2}$

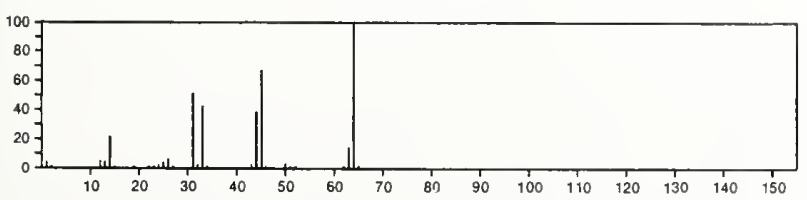

64

Ethene, 1,2-difluoro-

$\mathrm{C}_{2} \mathrm{H}_{2} \mathrm{~F}_{2}$

1691-13-0
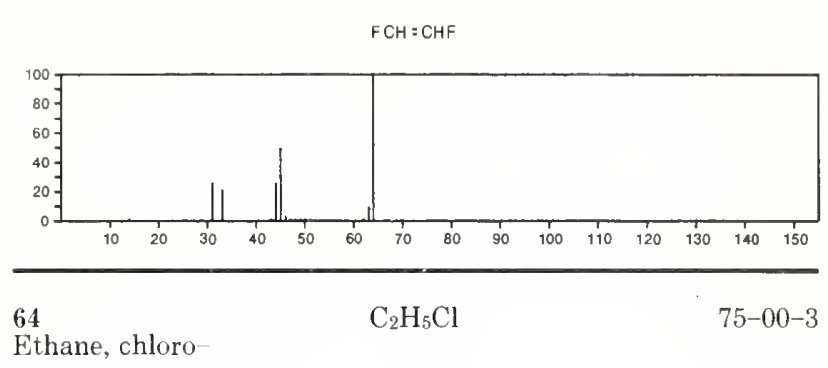

EtCl

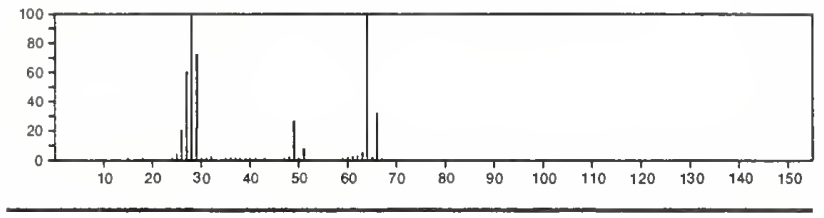

64

Ethanol, 2-fluoro-

$\mathrm{C}_{2} \mathrm{H}_{5} \mathrm{FO}$

371-62-0

$\mathrm{HOCH}_{2} \mathrm{CH}_{2} \mathrm{~F}$

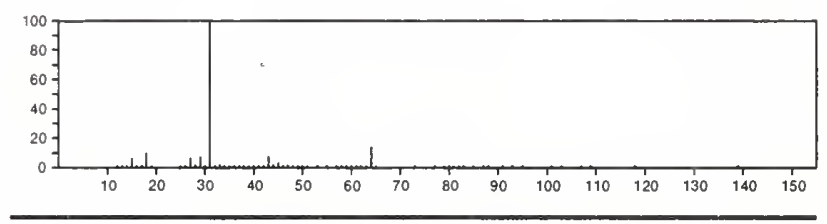

64

Sulfur dioxide

$\mathrm{O}_{2} \mathrm{~S}$

7446-09-5

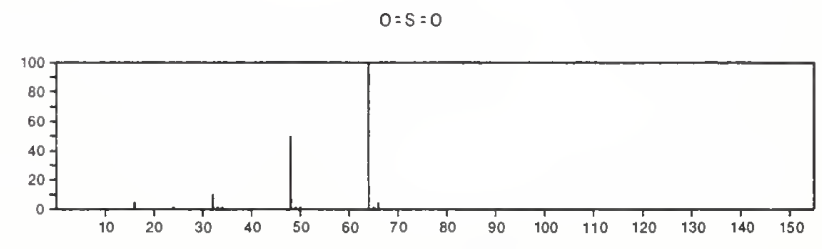

65

Nitrosyl chloride

CINO

2696-92-6

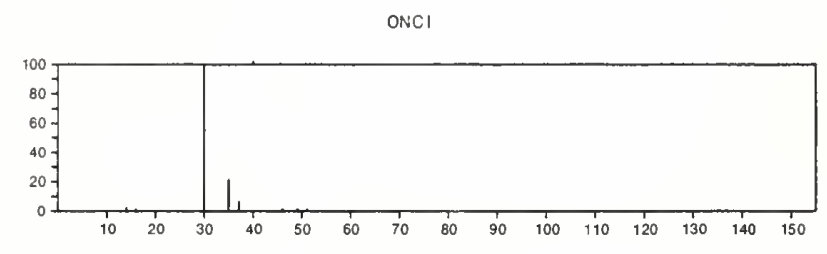

66

Pentaborane(11)

$\mathrm{B}_{5} \mathrm{H}_{11}$

18433-84-6
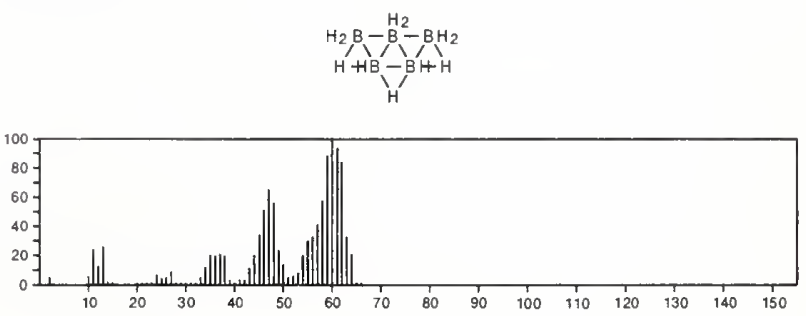
66

Carbonic difluoride

$\mathrm{CF}_{2} \mathrm{O}$

FCOF

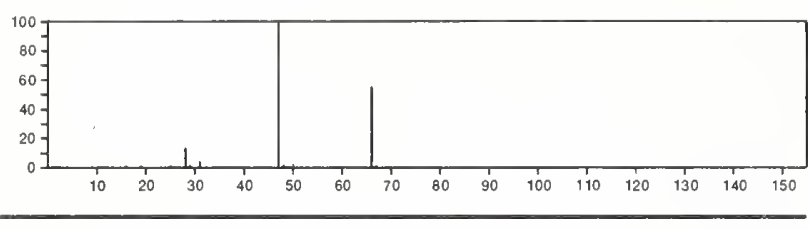

$66 \quad \mathrm{C}_{2} \mathrm{H}_{4} \mathrm{~F}_{2} \quad 75-37-6$

Ethane, 1,1-difluoro-

$\mathrm{F}_{2} \mathrm{CHMe}$

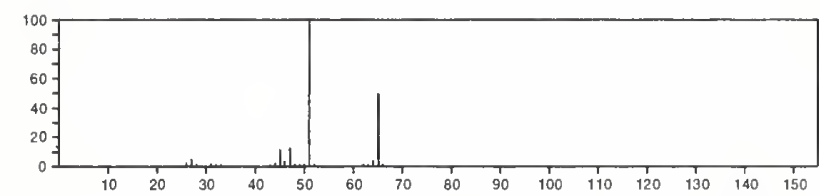

66

Propanedinitrile

$\mathrm{C}_{3} \mathrm{H}_{2} \mathrm{~N}_{2}$

$\mathrm{CH}_{2}(\mathrm{CN})_{2}$

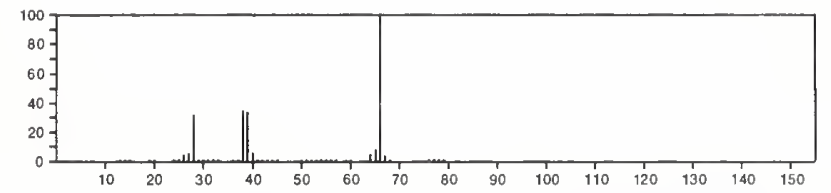

66

1-Buten-3-yne, 2-methyl-

$\mathrm{C}_{5} \mathrm{H}_{6}$

$\mathrm{HC}: \mathrm{CCMe}_{\mathrm{C}}: \mathrm{CH}_{2}$

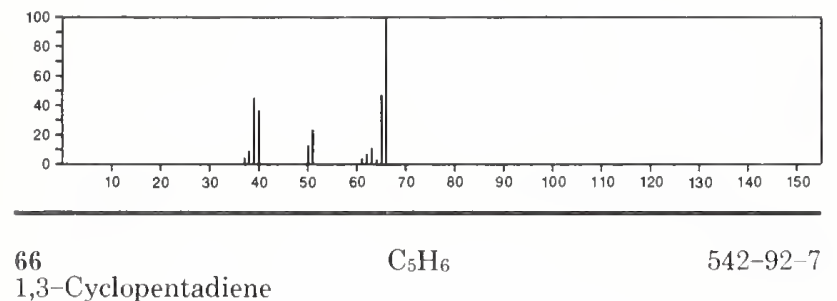

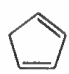

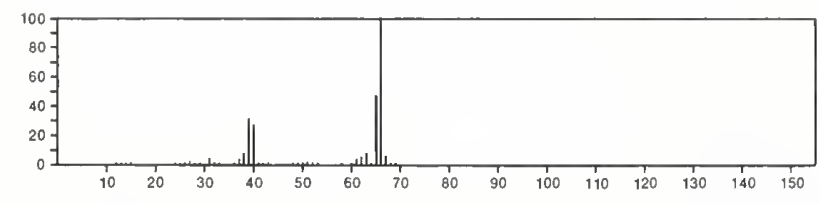

66

1-Penten-3-yne

$\mathrm{C}_{5} \mathrm{H}_{6}$

$646-05-9$

$\mathrm{H}_{2} \mathrm{C}=\mathrm{CHC} \equiv \mathrm{CMe}$

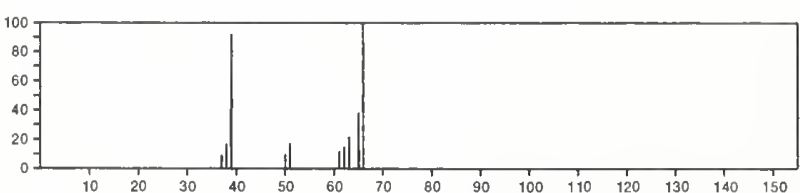

66

3-Penten-1-yne, $(E)$

$\mathrm{C}_{5} \mathrm{H}_{6}$

$2004-69-5$

$\mathrm{HC} \equiv \mathrm{CCH}: \mathrm{CHMe}$

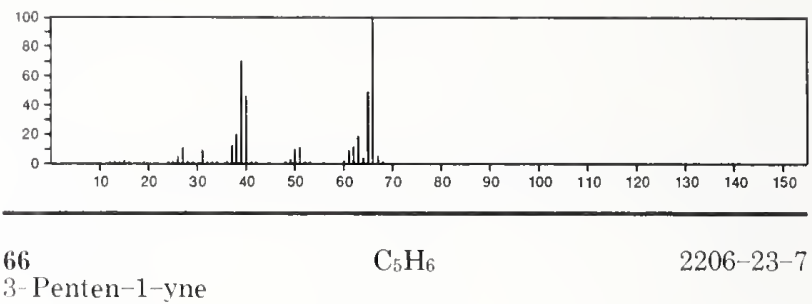

$\mathrm{HC}: \mathrm{CCH}=\mathrm{CHM}$

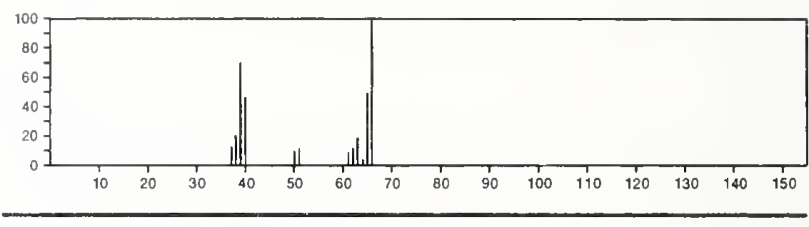

67

$\mathrm{CH}_{3} \mathrm{~F}_{2} \mathrm{~N}$

$753-58-2$

Methanamine, $N, N$-difluoro-

$\mathrm{F}_{2} \mathrm{NMe}$

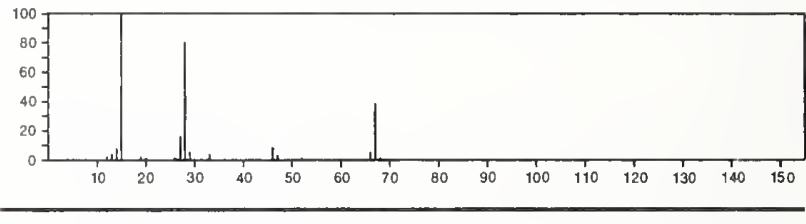

67

$\mathrm{CH}_{5} \mathrm{~N} . \mathrm{ClH}$

593-51-1

Methanamine, hydrochloride

$\mathrm{MeNH}_{2} \cdot \mathrm{HCl}$
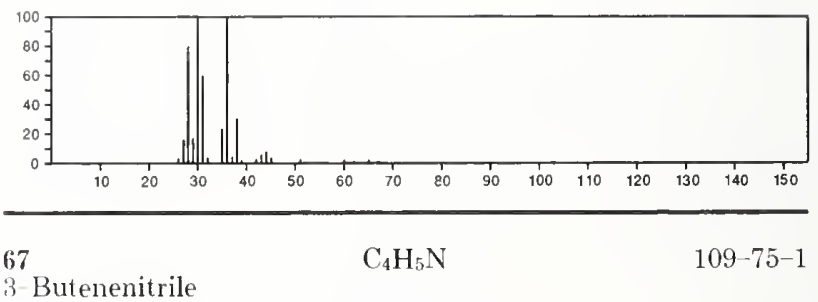

$\mathrm{H}_{2} \mathrm{C}=\mathrm{CHCH}_{2} \mathrm{CN}$

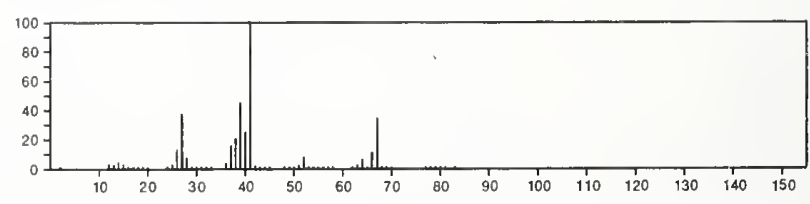

67

$1 H$-Pyrrole

$\mathrm{C}_{4} \mathrm{H}_{5} \mathrm{~N}$

$109-97-7$

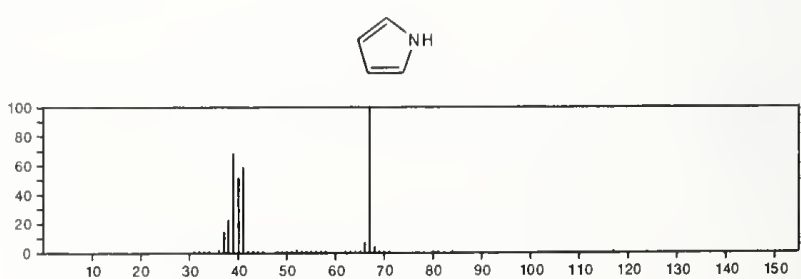


${ }_{2-\text { Propenenitrile, 2-methyl- }}^{67} \mathrm{C}_{4} \mathrm{H}_{5} \mathrm{~N}$

$\mathrm{NCCMe}: \mathrm{CH}_{2}$

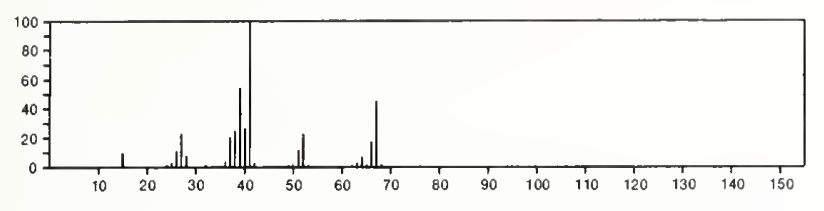

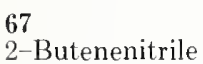

$\mathrm{C}_{4} \mathrm{H}_{5} \mathrm{~N}$

$\mathrm{Me} \mathrm{CH}: \mathrm{CHCN}$

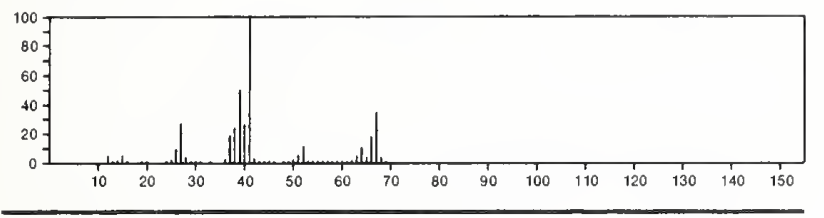

68

Borane, trifluoro-

$\mathrm{BF}_{3}$

$\mathrm{BF}_{3}$

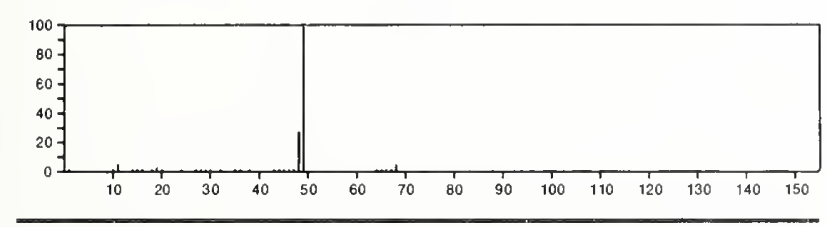

68

$\mathrm{CH}_{2} \mathrm{ClF}$

$593-70-4$

Methane, chlorofluoro-

$\mathrm{CH}_{2} \mathrm{ClF}$

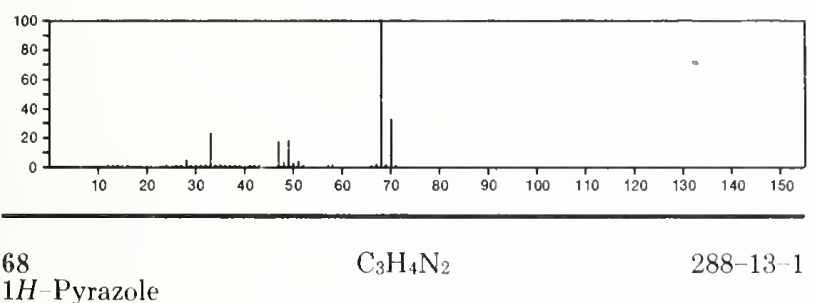

${ }^{\mathrm{N}}$
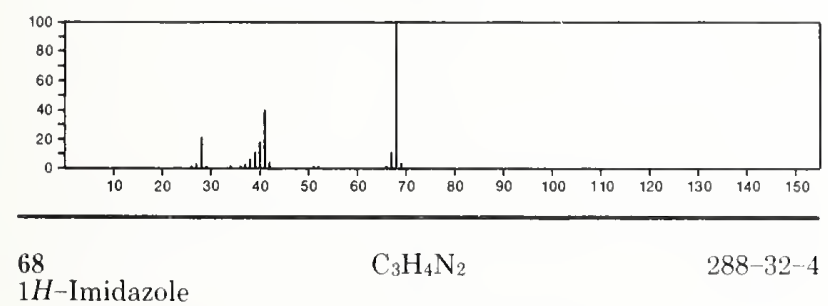

$1 H$-Imidazole

$\overbrace{N}^{N}$

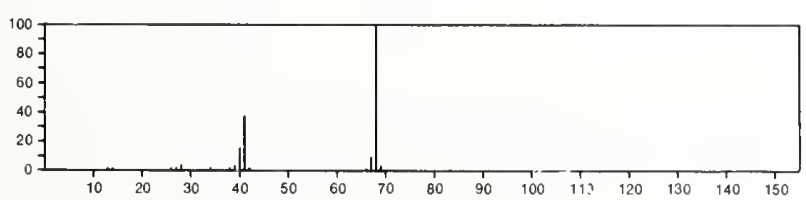

68

Furan

$\mathrm{C}_{4} \mathrm{H}_{4} \mathrm{O}$

110-00-9

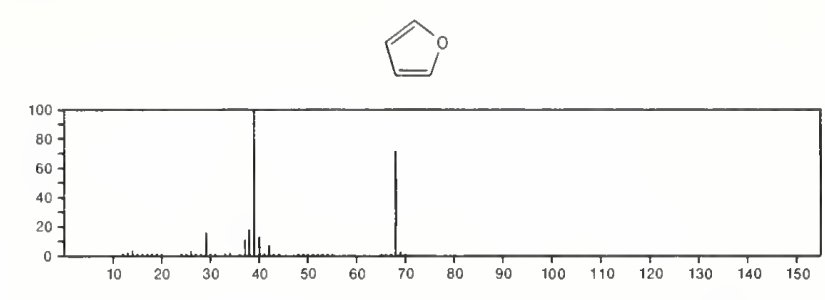

68

1.3 Butadiene, 2-methyl

$\mathrm{C}_{5} \mathrm{H}_{8}$

$78-79-5$

$\mathrm{H}_{2} \mathrm{C}=\mathrm{CHCMe}=\mathrm{CH}_{2}$

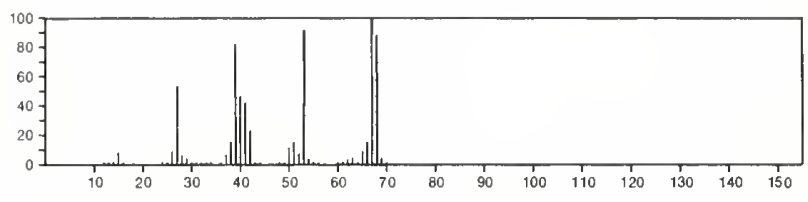

68

$\mathrm{C}_{5} \mathrm{H}_{8}$

$142-29-0$

Cyclopentene
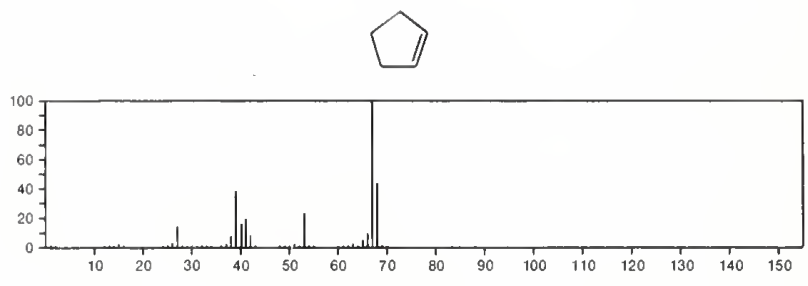

68

Spiropentane

$\mathrm{C}_{5} \mathrm{H}_{8}$

$157-40-4$

$\infty$

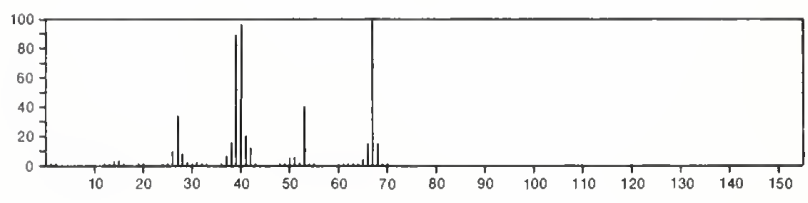

68

1,3 Pentadiene

$\mathrm{C}_{5} \mathrm{H}_{8}$

504-60-9

$\mathrm{H}_{2} \mathrm{C}=\mathrm{CHCH}=\mathrm{CHMe}$

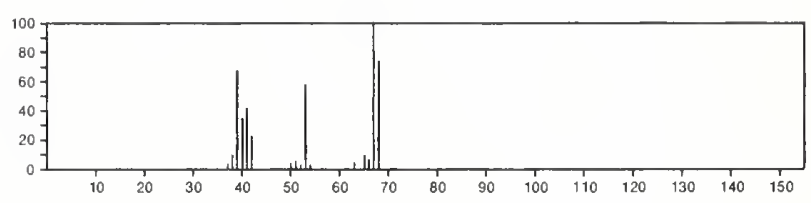

68

1,4 Pentadiene

$\mathrm{C}_{5} \mathrm{H}_{8}$

591-93-5

$\mathrm{H}_{2} \mathrm{C}=\mathrm{CHCH}_{2} \mathrm{CH}=\mathrm{CH}_{2}$

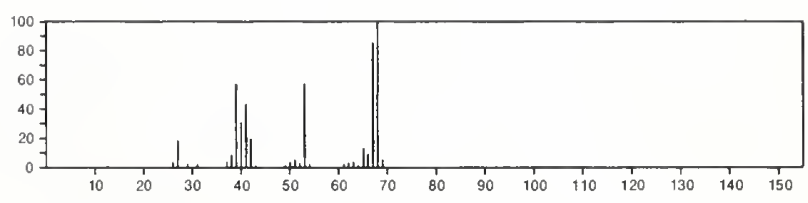


68

1,2-Pentadiene

$\mathrm{C}_{5} \mathrm{H}_{8}$

$\mathrm{H}_{2} \mathrm{C}=\mathrm{C}=\mathrm{CHE}$

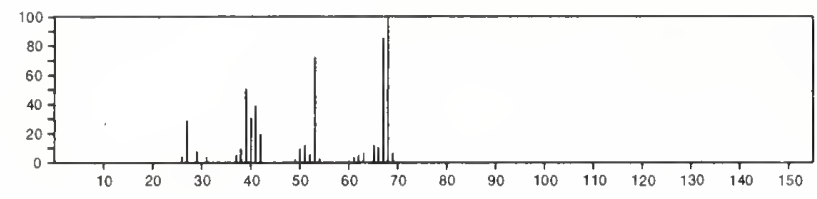

68

2,3-Pentadiene

$\mathrm{C}_{5} \mathrm{H}_{8}$

$591-96-8$

$\mathrm{Me} C \mathrm{CH}=\mathrm{C}=\mathrm{CHMe}$

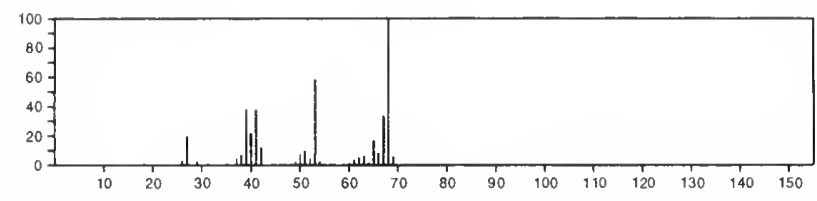

68

1-Butyne, 3-methyl-

$\mathrm{C}_{5} \mathrm{H}_{8}$

598-23-2

$\mathrm{Me} 2 \mathrm{CHC}: \mathrm{CH}$

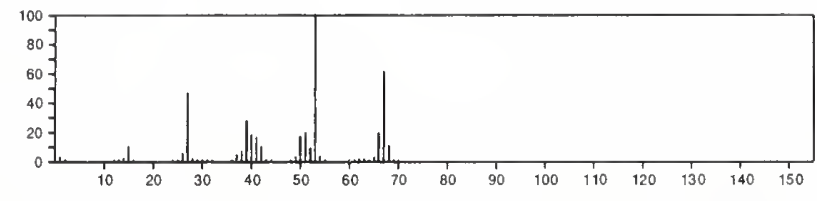

68

1,2-Butadiene, 3-methyl-

$\mathrm{C}_{5} \mathrm{H}_{8}$

$598-25-4$

$\mathrm{Me} 2 \mathrm{C}=\mathrm{C}=\mathrm{CH}_{2}$
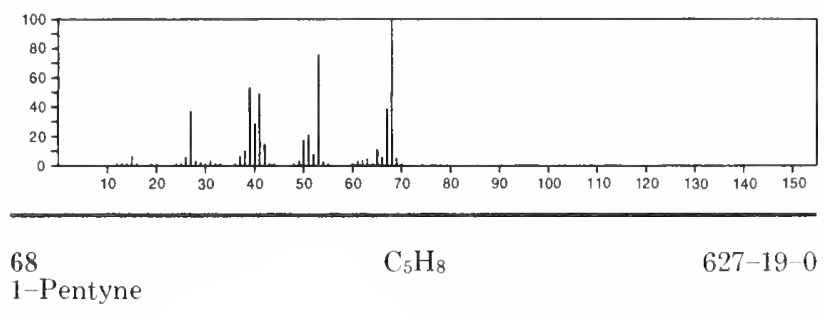

$\operatorname{PrC} \equiv \mathrm{CH}$

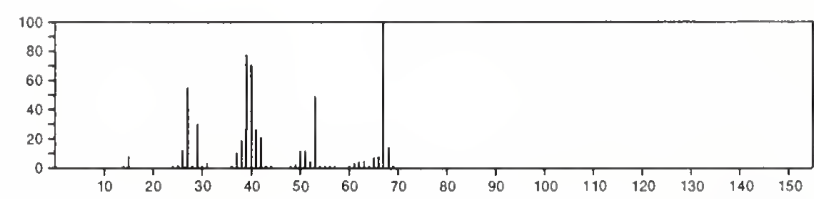

68

2-Pentyne

$\mathrm{C}_{5} \mathrm{H}_{8}$

$627-21-4$

MeC:CE t

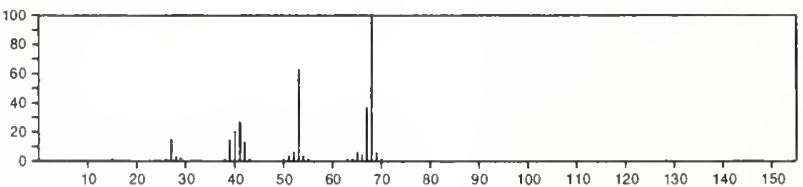

68

Cyclobutane, methylene-

$\mathrm{C}_{5} \mathrm{H}_{8}$

$1120-56-5$

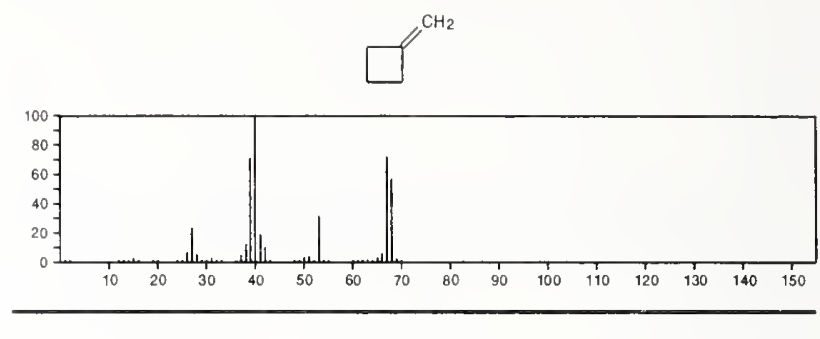

68

1.3-Pentadiene, $(Z)$

$\mathrm{C}_{5} \mathrm{H}_{8}$

1574-41-0

$\mathrm{H}_{2} \mathrm{C}=\mathrm{CHCH}=\mathrm{CHM}$

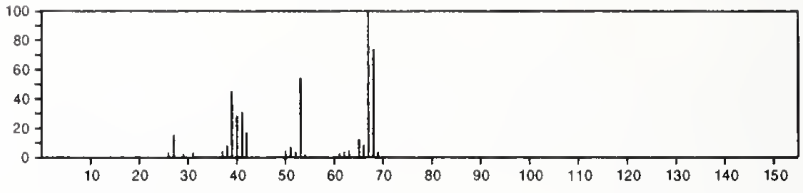

68

$\mathrm{C}_{5} \mathrm{H}_{8}$

$2004-70-8$

1,3-Pentadiene, (E)-

$\mathrm{H}_{2} \mathrm{C}=\mathrm{CHCH}=\mathrm{CHMe}$

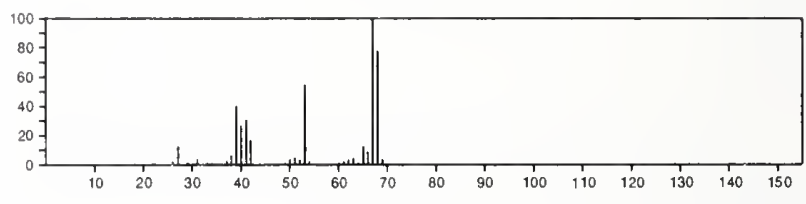

69

1H-1,2,3-Triazole

$\mathrm{C}_{2} \mathrm{H}_{3} \mathrm{~N}_{3}$

$288-36-8$
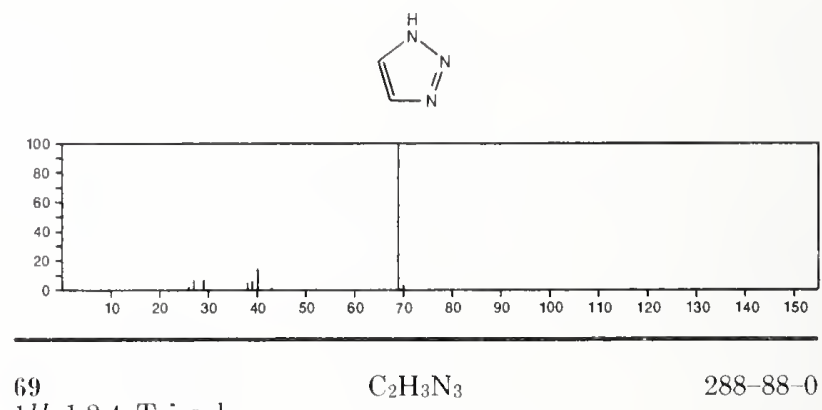

1H-1,2,4-Triazole<smiles>c1c[nH]cn1</smiles>

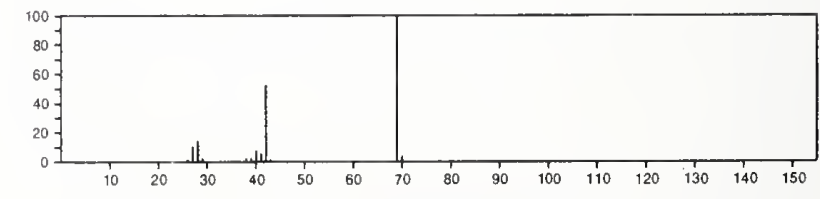

69

$\mathrm{C}_{3} \mathrm{H}_{3} \mathrm{NO}$

$631-57-2$

Propanenitrile, 2-oxo-

NCCOMe

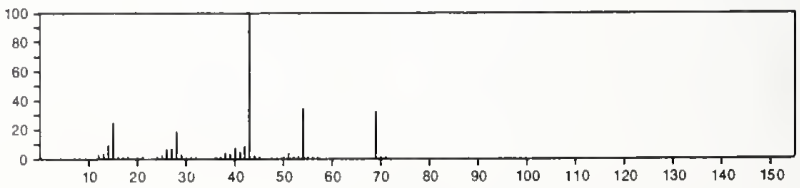


69
Propanenitrile, 2-methyl-
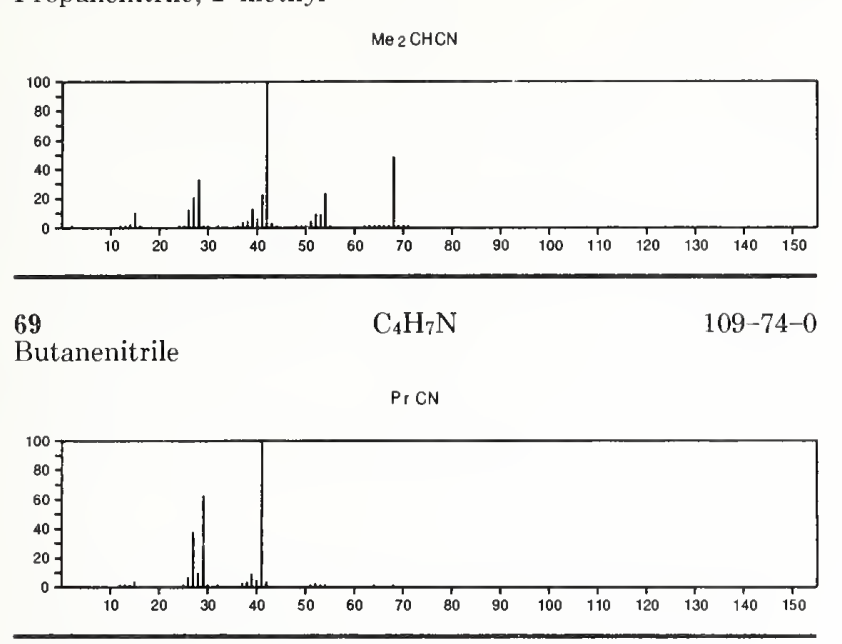

69

Propane, 1-isocyano-

$\mathrm{C}_{4} \mathrm{H}_{7} \mathrm{~N}$

PrNC

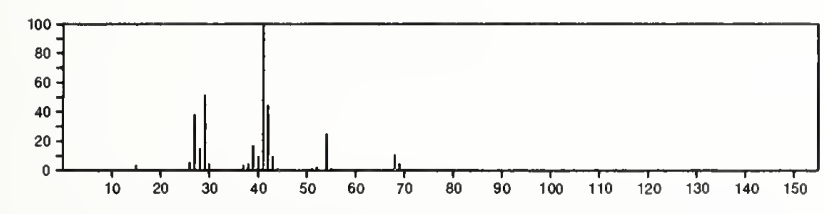

70

Methane, trifluoro-

$\mathrm{CHF}_{3}$

CHF $_{3}$
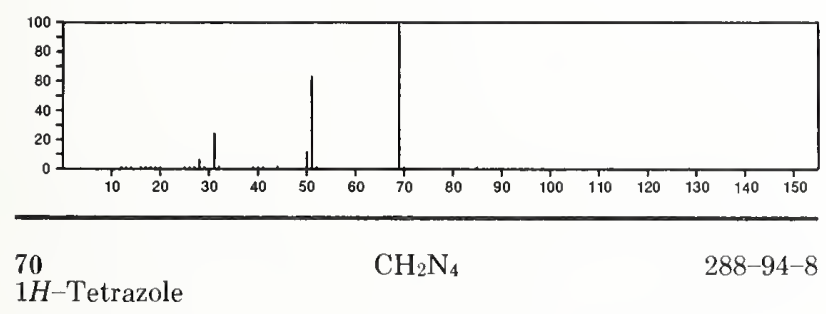

1H-Tetrazole
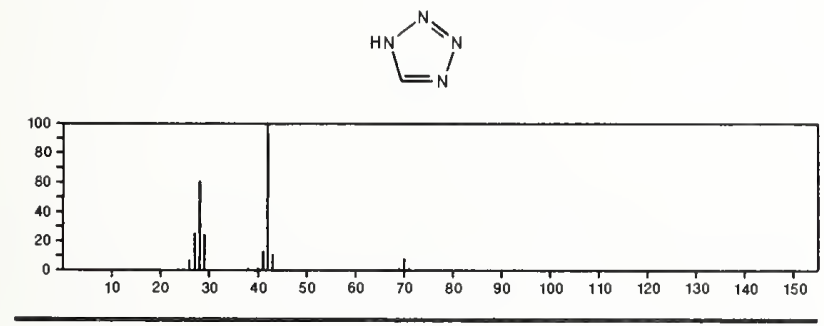

70

Cyanamide, dimethyl-

$\mathrm{C}_{3} \mathrm{H}_{6} \mathrm{~N}_{2}$

1467-79-4

Me 2 NCN

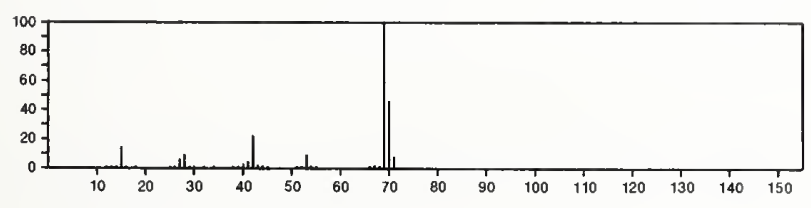

70

2-Propenal, 2-methyl-

$\mathrm{C}_{4} \mathrm{H}_{6} \mathrm{O}$

78-85-3

OCHCMe $=\mathrm{CH}_{2}$

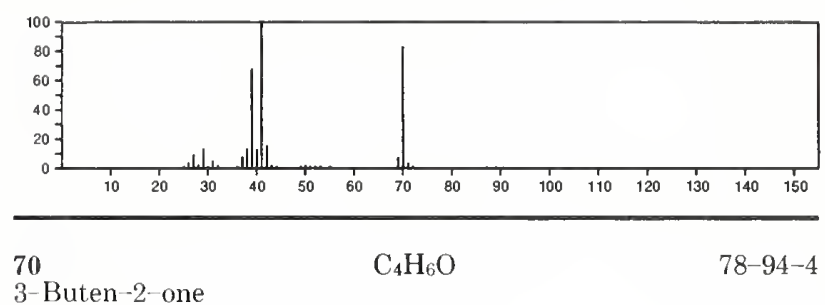

$\mathrm{H}_{2} \mathrm{C}=\mathrm{CHCOMe}_{\mathrm{C}}$

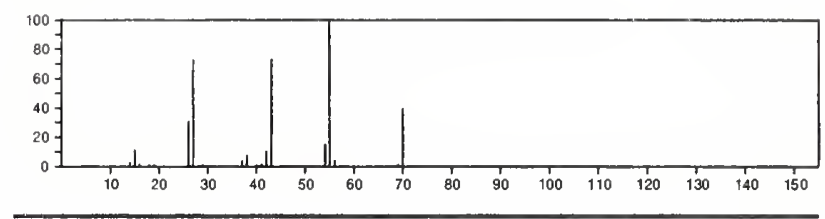

70

Ethene, 1,1'-oxybis-

$\mathrm{C}_{4} \mathrm{H}_{6} \mathrm{O}$

109-93-3

$\mathrm{H}_{2} \mathrm{C}=\mathrm{CHOCH}=\mathrm{CH}_{2}$

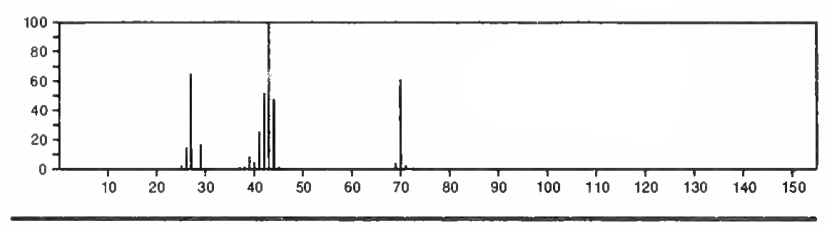

70

1-Propen-1-one, 2-methyl-

$\mathrm{C}_{4} \mathrm{H}_{6} \mathrm{O}$

598-26-5

$\mathrm{Me}_{2} \mathrm{C}=\mathrm{C}=0$

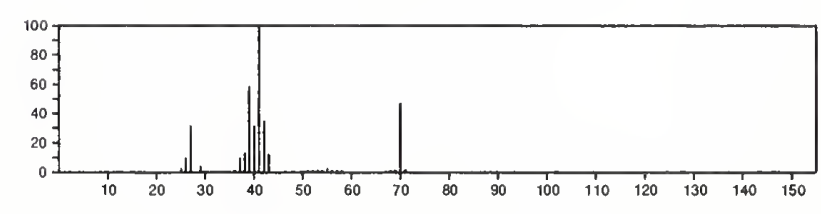

70
$2-B u t y n-1-o l$

$\mathrm{C}_{4} \mathrm{H}_{6} \mathrm{O}$

764-01-2

$\mathrm{MeC} \equiv \mathrm{CCH}_{2} \mathrm{OH}$

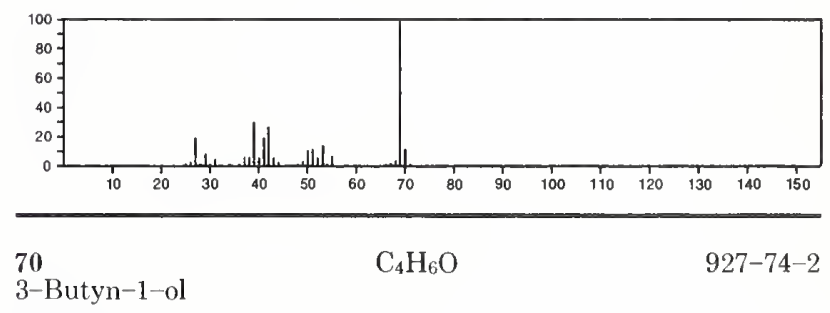

$\mathrm{HC} \equiv \mathrm{CCH}_{2} \mathrm{CH}_{2} \mathrm{OH}$

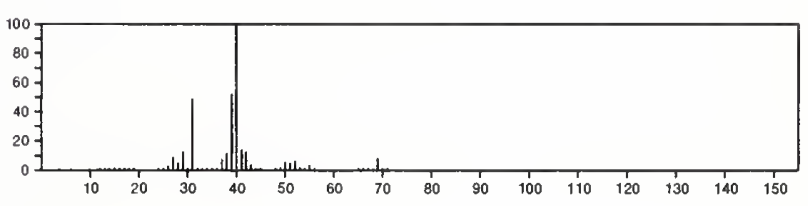


70

Oxirane, ethenyl-

$\mathrm{C}_{4} \mathrm{H}_{6} \mathrm{O}$
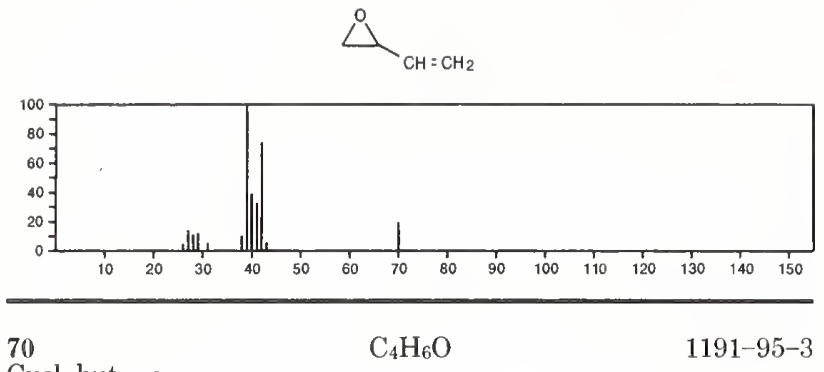

Cyclobutanone

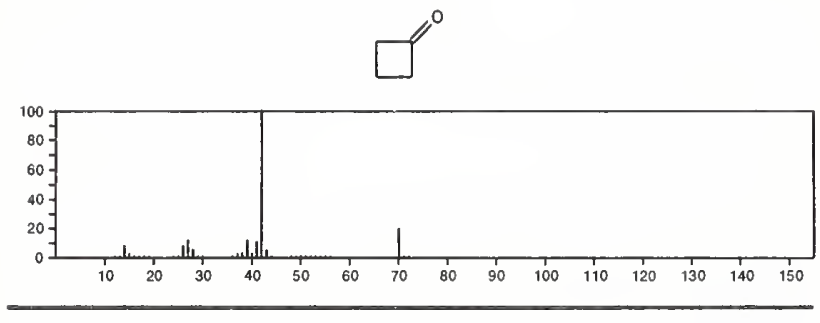

70

$\mathrm{C}_{4} \mathrm{H}_{6} \mathrm{O}$

$1708-29-8$

Furan, 2,5-dihydro-

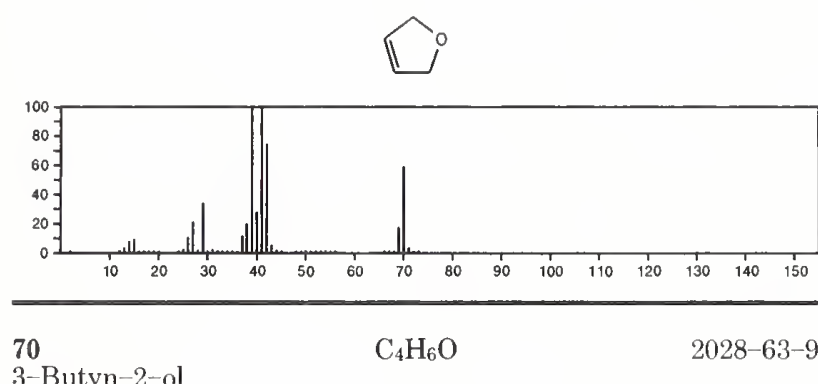

3-Butyn-2-ol
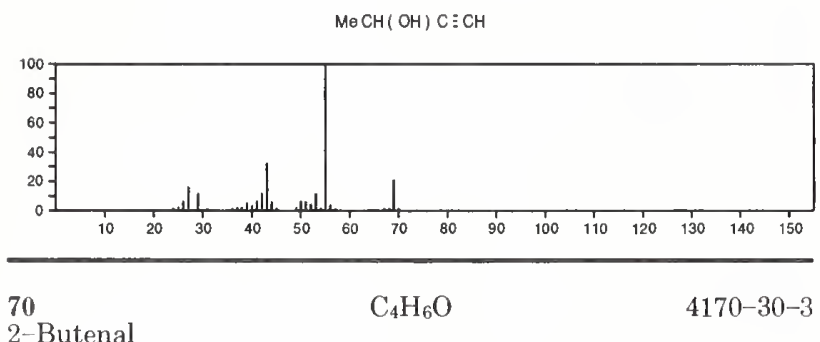

2-Butenal

$\mathrm{Me} \mathrm{CH}=\mathrm{CHCHO}$

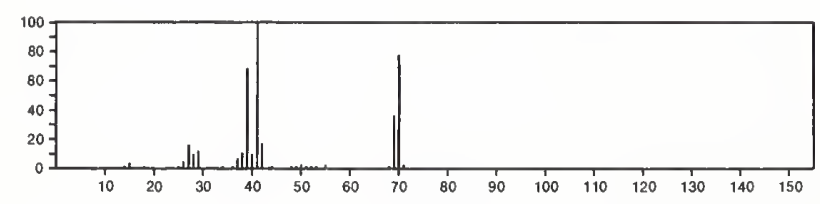

$70 \quad \mathrm{C}_{4} \mathrm{H}_{11} \mathrm{~B}$

$1113-22-0$

Borane, ethyldimethyl-

$\mathrm{Me}_{2} \mathrm{BE}_{\mathrm{t}}$

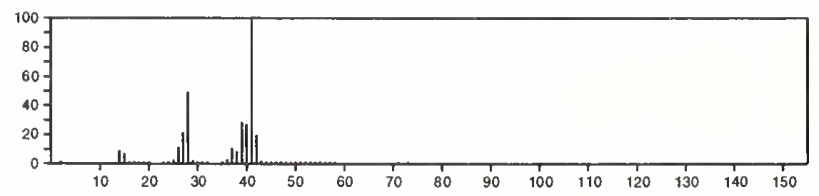

70

1-Pentene

$\mathrm{C}_{5} \mathrm{H}_{10}$

109-67-1

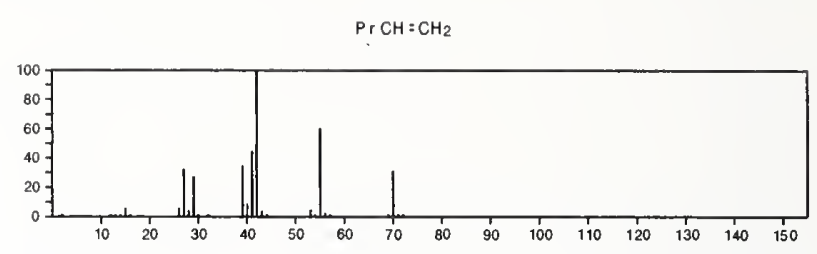

70

2-Pentene

$\mathrm{C}_{5} \mathrm{H}_{10}$

109-68-2

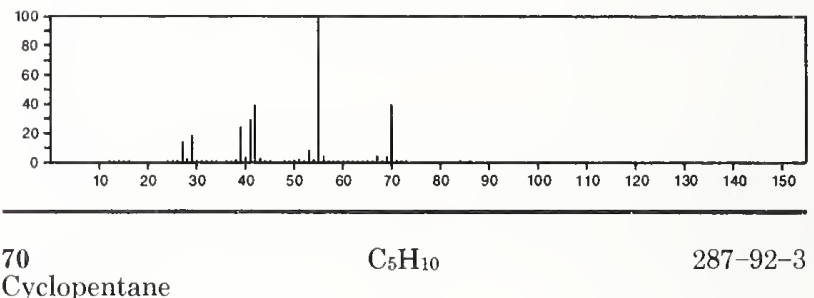

70
Cyclopentane

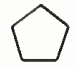

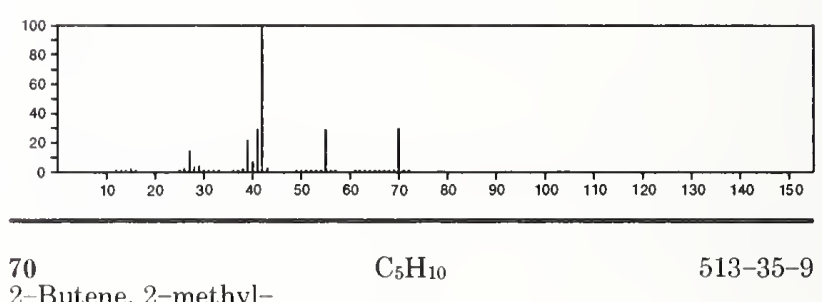

$\mathrm{MeCH}=\mathrm{CMe}_{2}$

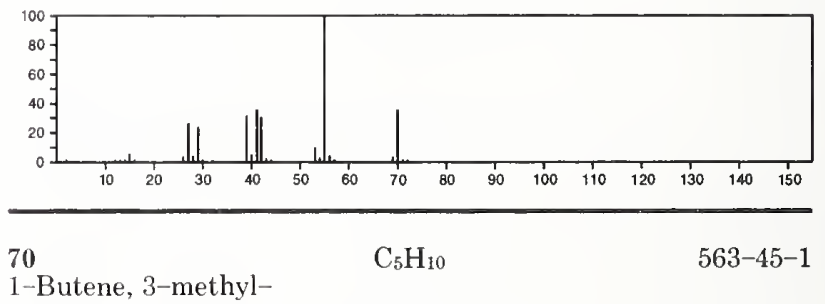

1-Butene, 3-methyl-

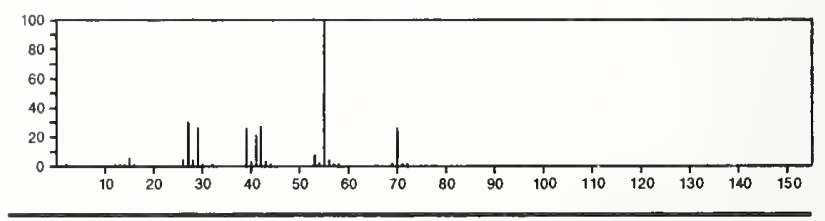

70

1-Butene, 2-methyl

$\mathrm{C}_{5} \mathrm{H}_{10}$

563-46-2

$\mathrm{E}_{1} \mathrm{CMe}=\mathrm{CH}_{2}$

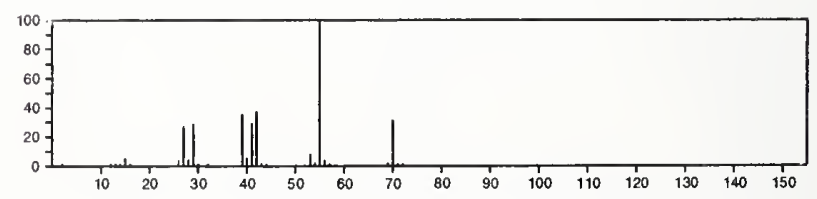


70

Cyclobutane, methyl-

$\mathrm{C}_{5} \mathrm{H}_{10}$
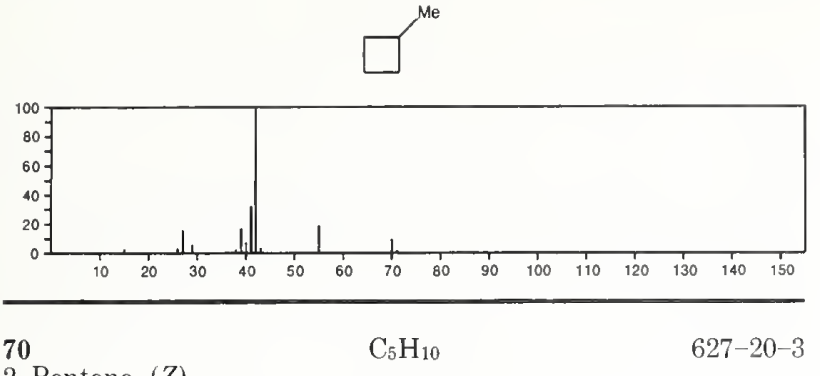

2-Pentene, $(Z)$

$\mathrm{Me} C \mathrm{CH}=\mathrm{CHEt}$

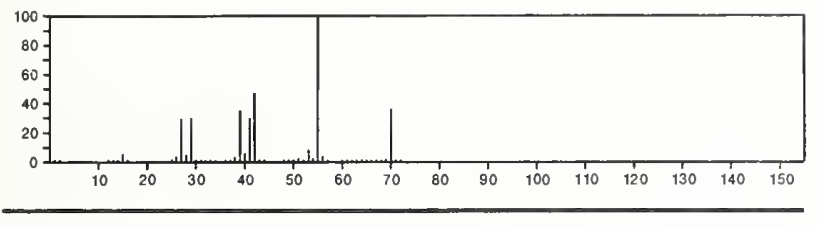

70

2-Pentene, $(E)-$

$\mathrm{C}_{5} \mathrm{H}_{10}$

646-04-8

$\mathrm{Me} C H=C H E$ t

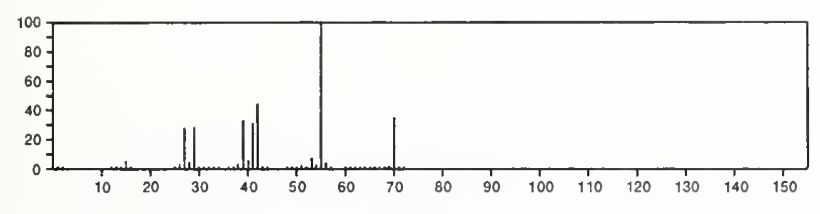

70

\section{$\mathrm{C}_{5} \mathrm{H}_{10}$}

$930-18-7$

Cyclopropane, 1,2-dimethyl-, cis-
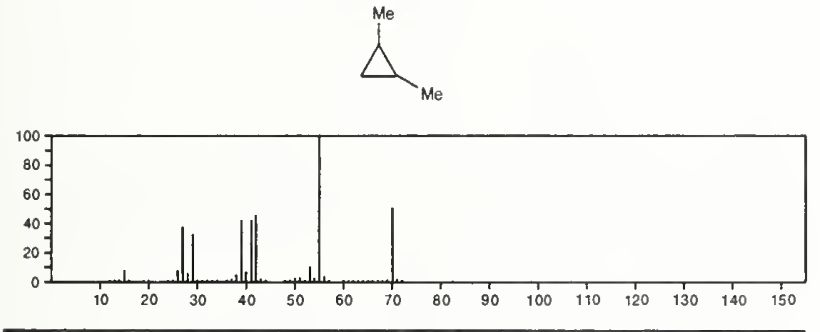

70

Cyclopropane, ethyl

$\mathrm{C}_{5} \mathrm{H}_{10}$

$1191-96-4$
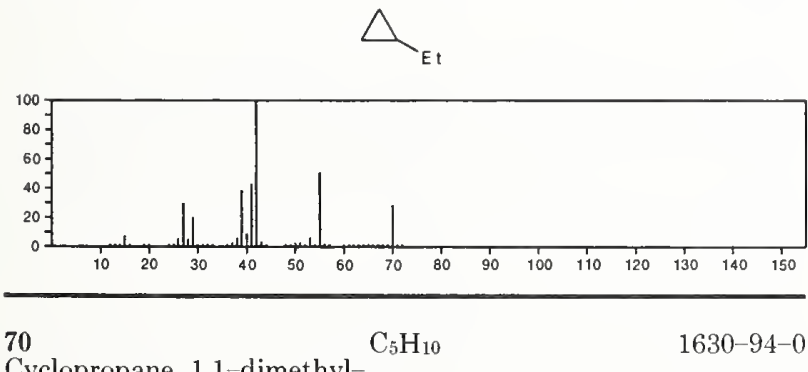

$1630-94-0$

Cyclopropane, 1,1-dimethyl-
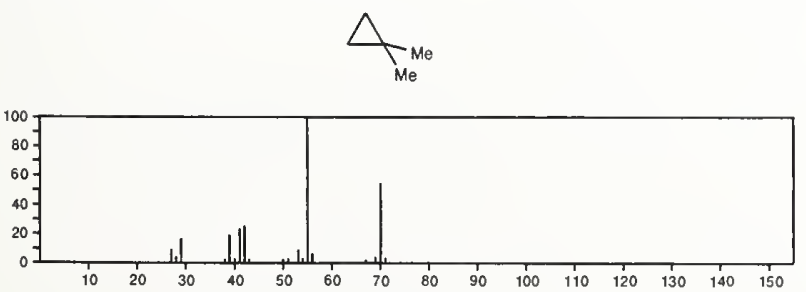

$70 \quad \mathrm{C}_{5} \mathrm{H}_{10}$

Cyclopropane, 1,2--dimethyl-, trans-

2402-06-4
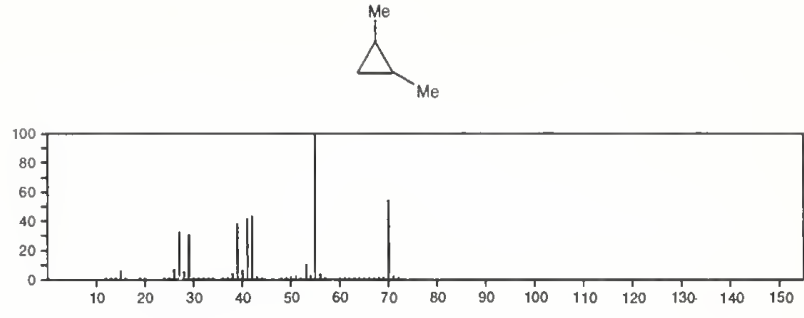

71

Propanenitrile, 2-hydroxy-

$\mathrm{C}_{3} \mathrm{H}_{5} \mathrm{NO}$

78-97-7

$\mathrm{MeCH}(\mathrm{OH}) \mathrm{CN}$

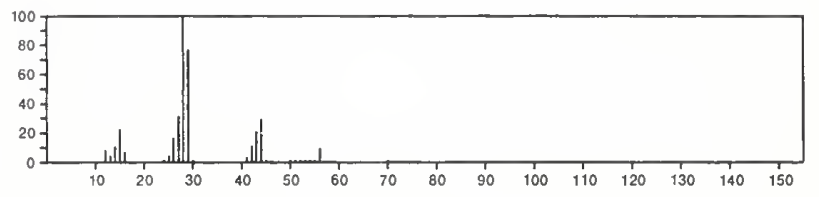

$71 \quad \mathrm{C}_{3} \mathrm{H}_{5} \mathrm{NO} \quad 79-06-1$

2-Propenamide

$\mathrm{H}_{2} \mathrm{C}=\mathrm{CHCONH}_{2}$

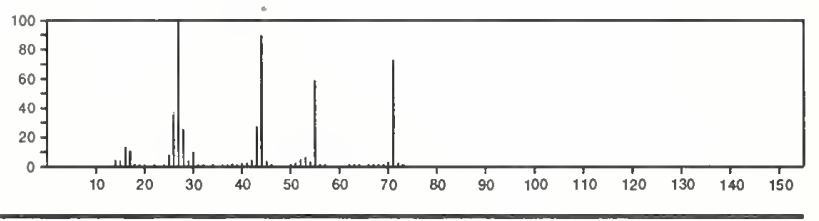

71

$\mathrm{C}_{3} \mathrm{H}_{5} \mathrm{NO}$

109-90-0

Ethane, isocyanato

OCNE:

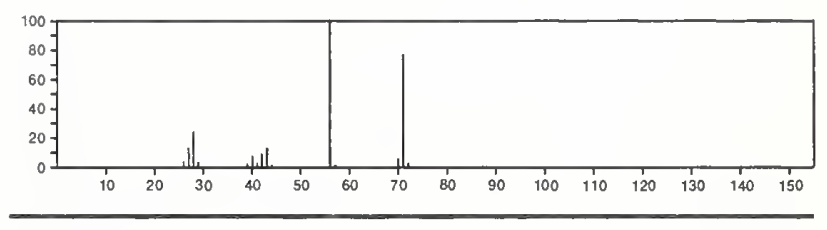

71

$\mathrm{C}_{3} \mathrm{H}_{5} \mathrm{NO}$

$627-48-5$

Cyanic acid, ethyl ester

Et OCN

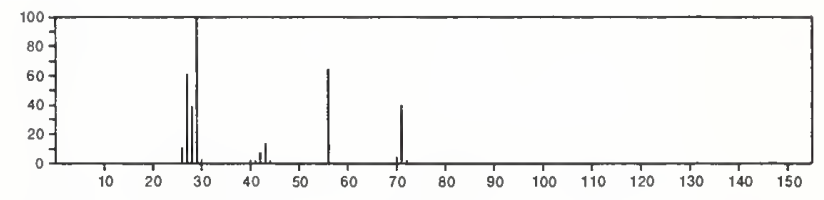

71

Pyrrolidine

$\mathrm{C}_{4} \mathrm{H}_{9} \mathrm{~N}$

123-75-1
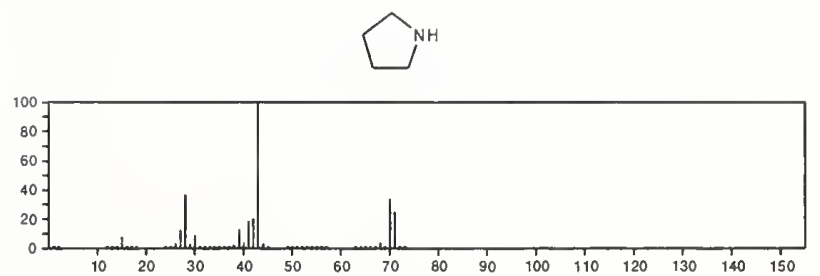
71

Aziridine, 2-ethyl-

$\mathrm{C}_{4} \mathrm{H}_{9} \mathrm{~N}$

$\stackrel{H}{\wedge}$

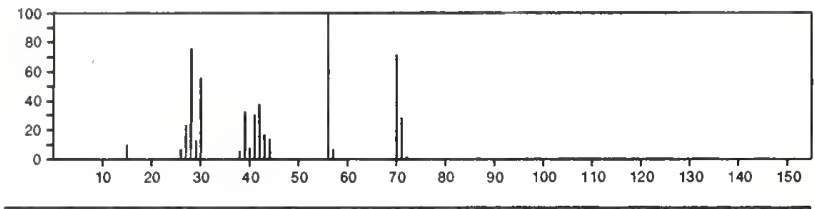

71

Aziridine, 2,2-dimethyl-

$\mathrm{C}_{4} \mathrm{H}_{9} \mathrm{~N}$

$2658-24-4$
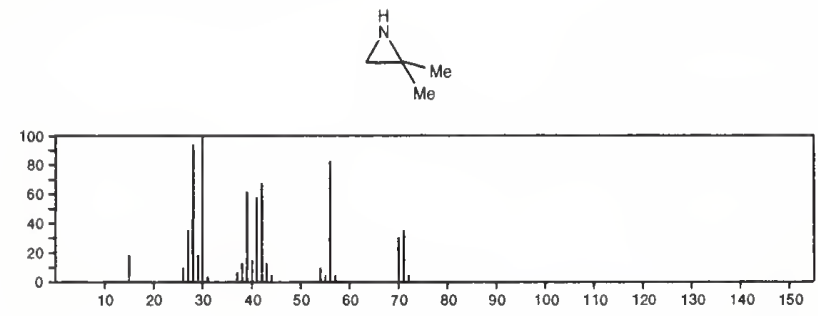

71

Azetidine, 2-methyl-

$\mathrm{C}_{4} \mathrm{H}_{9} \mathrm{~N}$

$19812-49-8$
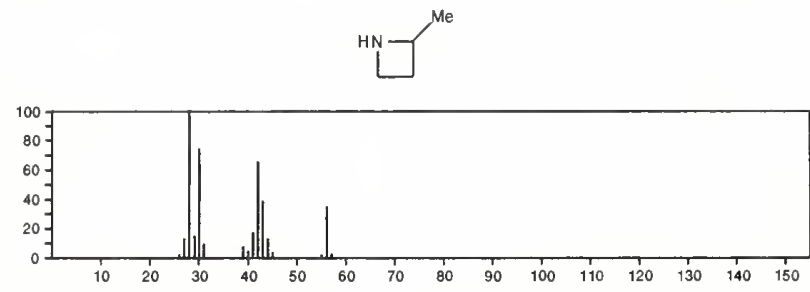

Nitrogen fluoride $\left(\mathrm{NF}_{3}\right)$

$\mathrm{F}_{3} \mathrm{~N}$

$\mathrm{NF}_{3}$

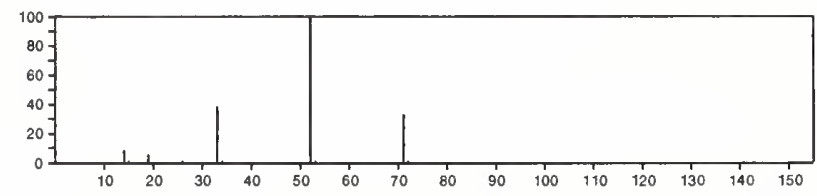

72

2-Oxetanone

$\mathrm{C}_{3} \mathrm{H}_{4} \mathrm{O}_{2}$

$57-57-8$
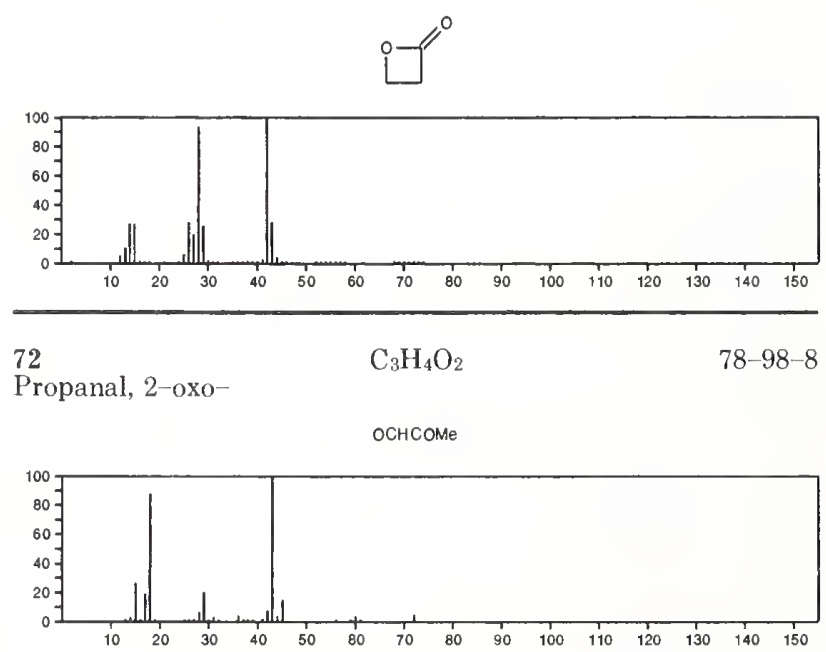

72

2-Propenoic acid

$\mathrm{C}_{3} \mathrm{H}_{4} \mathrm{O}_{2}$

79-10-7

$\mathrm{HO}_{2} \mathrm{CCH}=\mathrm{CH}_{2}$

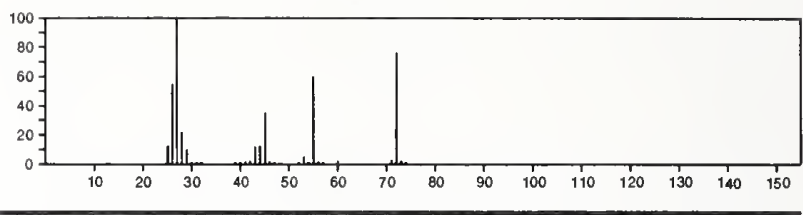

72

$\mathrm{C}_{3} \mathrm{H}_{8} \mathrm{~N}_{2}$

Formaldehyde, dimethylhydrazone

2035-89-4

$\mathrm{Me}_{2} \mathrm{NN}=\mathrm{CH}_{2}$

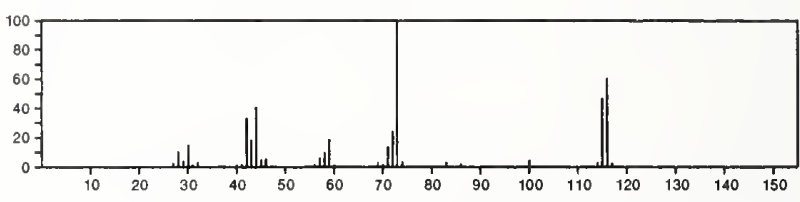

72

1,3-Butadiene, 2-fluoro-

$\mathrm{C}_{4} \mathrm{H}_{5} \mathrm{~F}$

381-61-3

$\mathrm{H}_{2} \mathrm{C}=\mathrm{CHCF}=\mathrm{CH}_{2}$

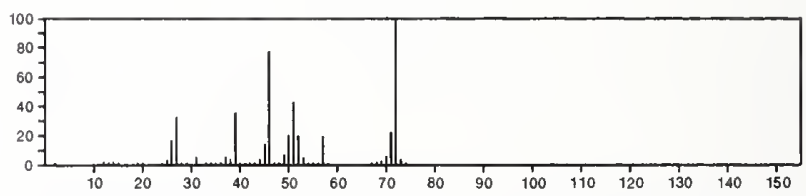

72

Propanal, 2-methyl-

$\mathrm{C}_{4} \mathrm{H}_{8} \mathrm{O}$

78-84-2

$\mathrm{Me}_{2} \mathrm{CHCHO}$

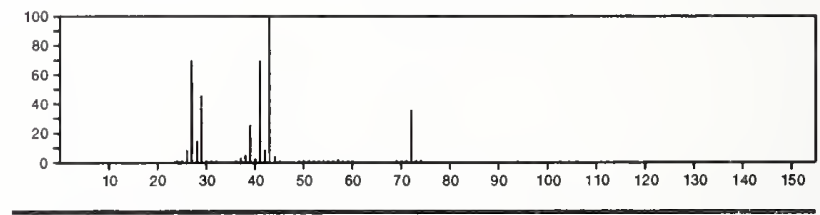

72

2-Butanone

$\mathrm{C}_{4} \mathrm{H}_{8} \mathrm{O}$

78-93-3

Et COME

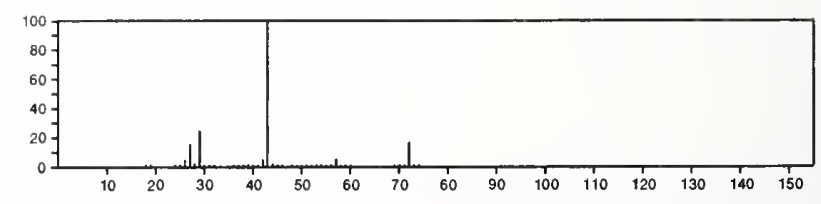

72

Oxirane, ethyl

$\mathrm{C}_{4} \mathrm{H}_{8} \mathrm{O}$

106-88-7
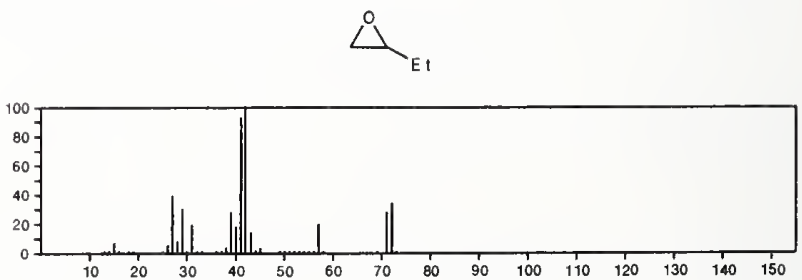
72

Ethene, ethoxy-

$\mathrm{C}_{4} \mathrm{H}_{8} \mathrm{O}$

$\mathrm{H}_{2} \mathrm{C}=\mathrm{CHOE}$ !

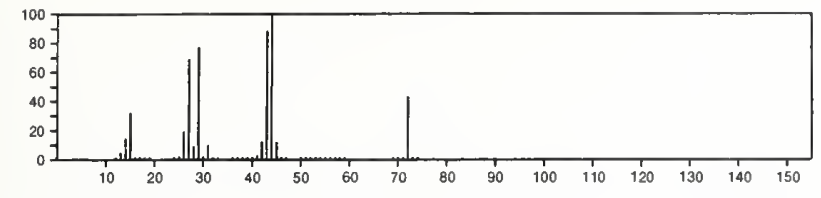

72

Furan, tetrahydro-

$\mathrm{C}_{4} \mathrm{H}_{8} \mathrm{O}$

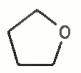

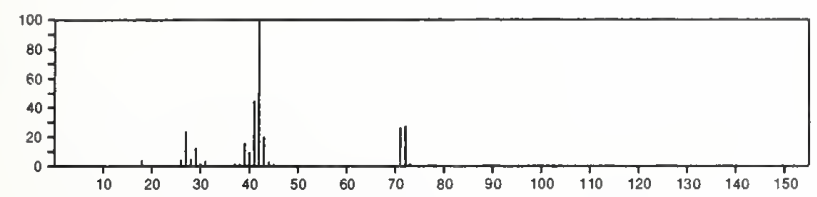

72

1-Propene, 2-methoxy-

$\mathrm{C}_{4} \mathrm{H}_{8} \mathrm{O}$

$\mathrm{MeC}(\mathrm{ONe})=\mathrm{CH}_{2}$

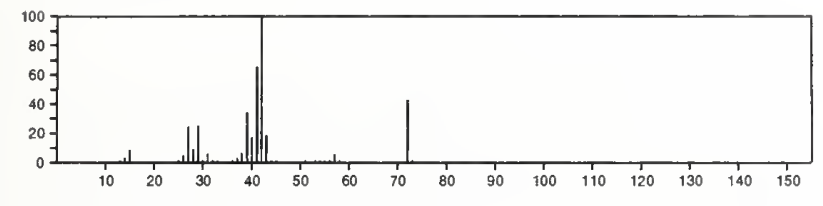

72

Butanal

$\mathrm{C}_{4} \mathrm{H}_{8} \mathrm{O}$

PrCHO

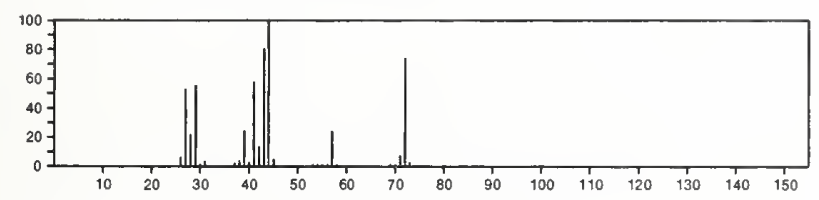

72

2-Propen-1-ol, 2-methyl-

$\mathrm{C}_{4} \mathrm{H}_{8} \mathrm{O}$

$513-42-8$

$\mathrm{HOCH}_{2} \mathrm{CMe}^{\mathrm{C}} \mathrm{CH}_{2}$

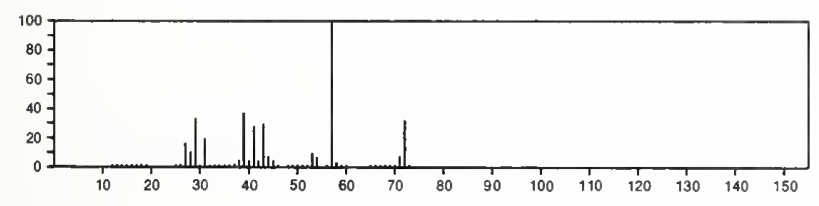

72

Oxirane, 2,2-dimethyl-

$\mathrm{C}_{4} \mathrm{H}_{8} \mathrm{O}$

$558-30-5$
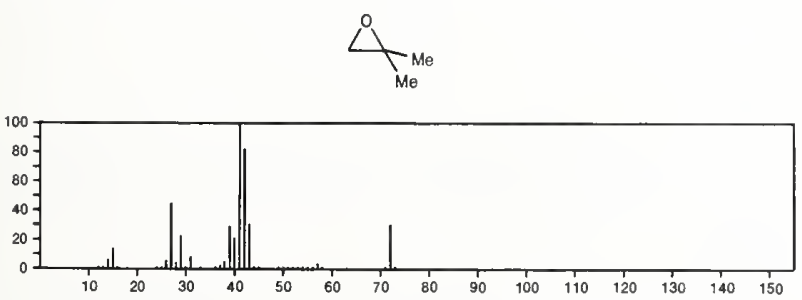

72

3-Buten-2-ol

$\mathrm{C}_{4} \mathrm{H}_{8} \mathrm{O}$

$598-32-3$

$\mathrm{MeCH}(\mathrm{OH}) \mathrm{CH}=\mathrm{CH}_{2}$

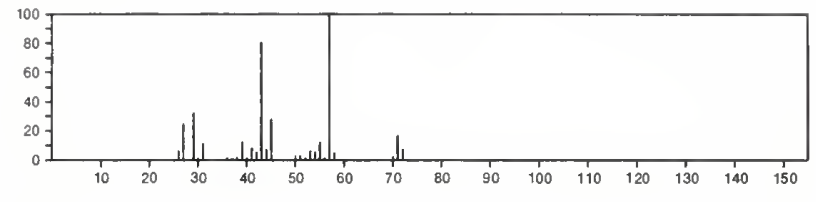

$\mathrm{C}_{4} \mathrm{H}_{8} \mathrm{O}$

$627-27-0$

3-Buten-1-ol

$\mathrm{H}_{2} \mathrm{C}=\mathrm{CHCH}_{2} \mathrm{CH}_{2} \mathrm{OH}$

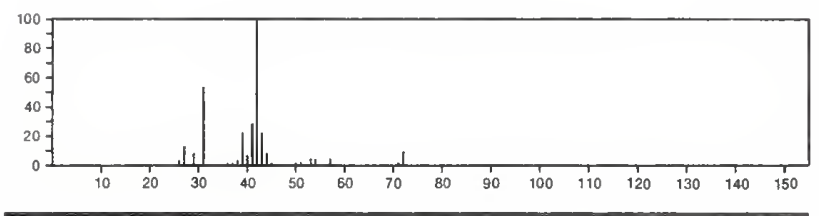

72

1-Propene, 3-methoxy-

$\mathrm{C}_{4} \mathrm{H}_{8} \mathrm{O}$

$627-40-7$

$\mathrm{H}_{2} \mathrm{C}=\mathrm{CHCH}_{2} \mathrm{OMe}$

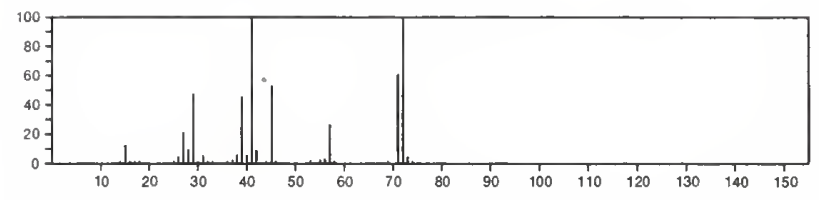

72

Oxirane, 2,3-dimethyl-, $\mathrm{C}_{4} \mathrm{H}_{8} \mathrm{O}$

$1758-33-4$
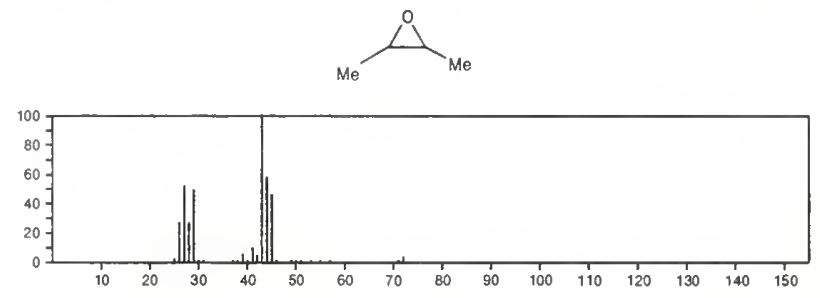

72

Cyclobutanol

$\mathrm{C}_{4} \mathrm{H}_{8} \mathrm{O}$

2919-23-5

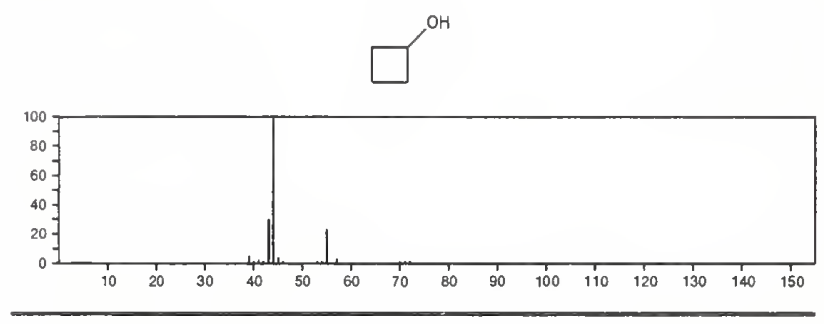

72

$\mathrm{C}_{4} \mathrm{H}_{8} \mathrm{O}$

$3266-23-7$

Oxirane, 2,3-dimethyl-
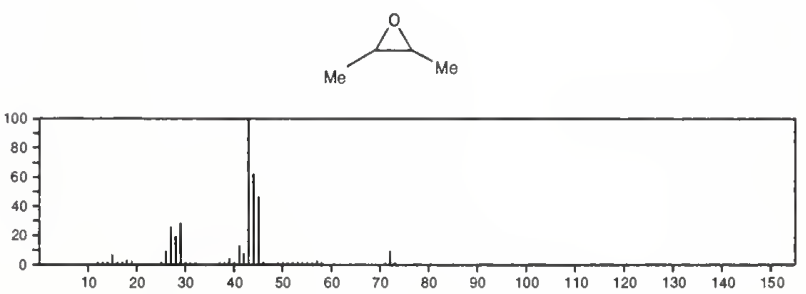
$\mathrm{MeCH}=\mathrm{CHCH}_{2} \mathrm{OH}$
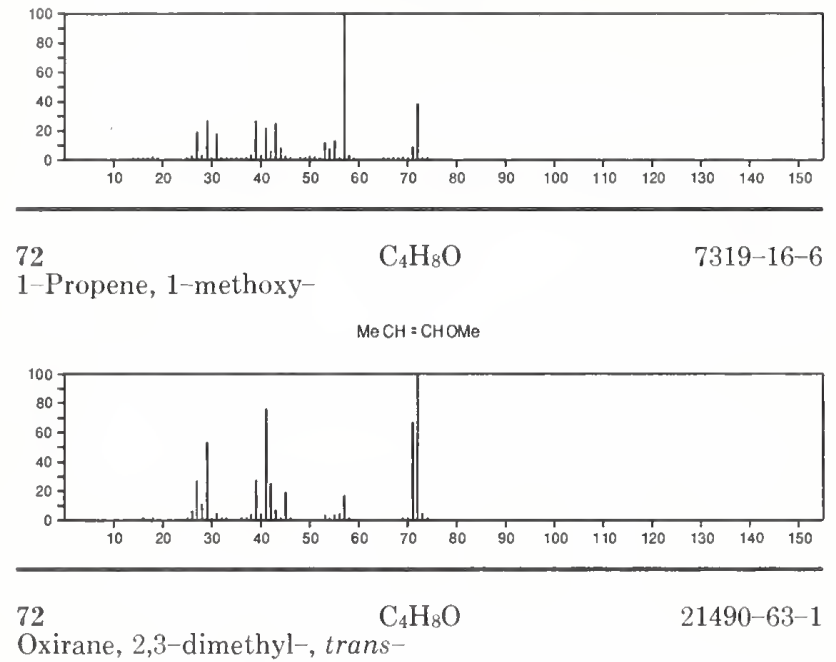

$\overbrace{M e}$

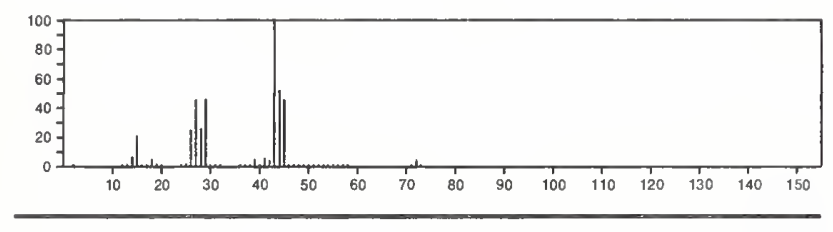

72

Butane, 2-methyl-

$\mathrm{C}_{5} \mathrm{H}_{12}$

$78-78-4$

$\mathrm{MeCH}_{2} \mathrm{CHMe}_{2}$

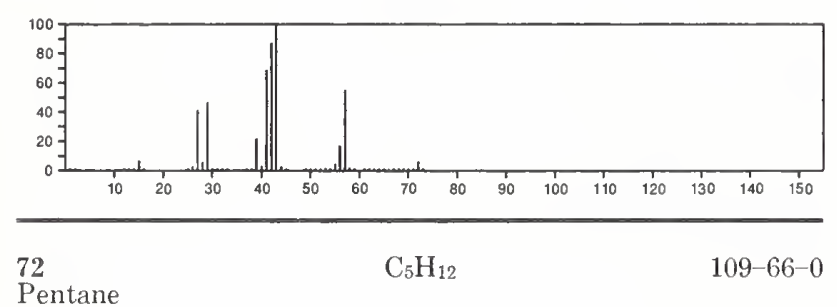

$\mathrm{Me}\left(\mathrm{CH}_{2}\right){ }_{3} \mathrm{Me}$

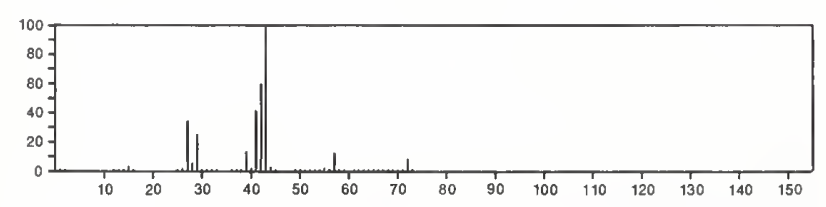

72

$\mathrm{C}_{5} \mathrm{H}_{12}$

$463-82-1$

Propane, 2,2-dimethyl-

$\mathrm{CMe}_{4}$

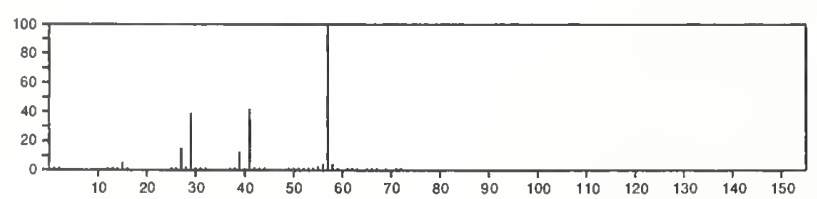

Methine, isothiocyanato

SCNME
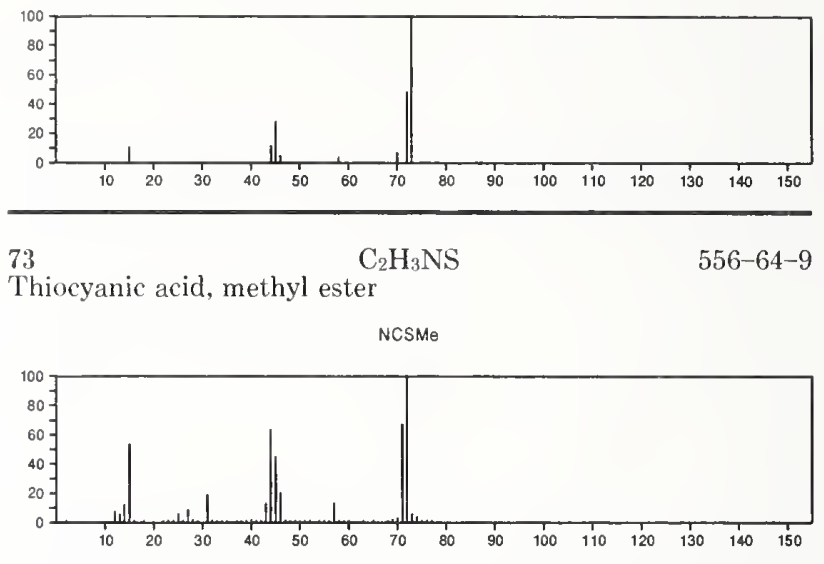

$73 \quad \mathrm{C}_{3} \mathrm{H}_{7} \mathrm{NO}$

$68-12-2$

Formamide, $N, N$-dimethyl-

$\mathrm{Me} 2 \mathrm{NCH}: 0$

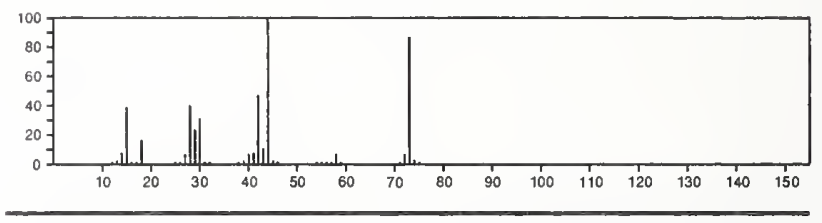

73

$\mathrm{C}_{3} \mathrm{H}_{7} \mathrm{NO}$

79-05-0

Propanamide

$\mathrm{E}+\mathrm{CONH}_{2}$
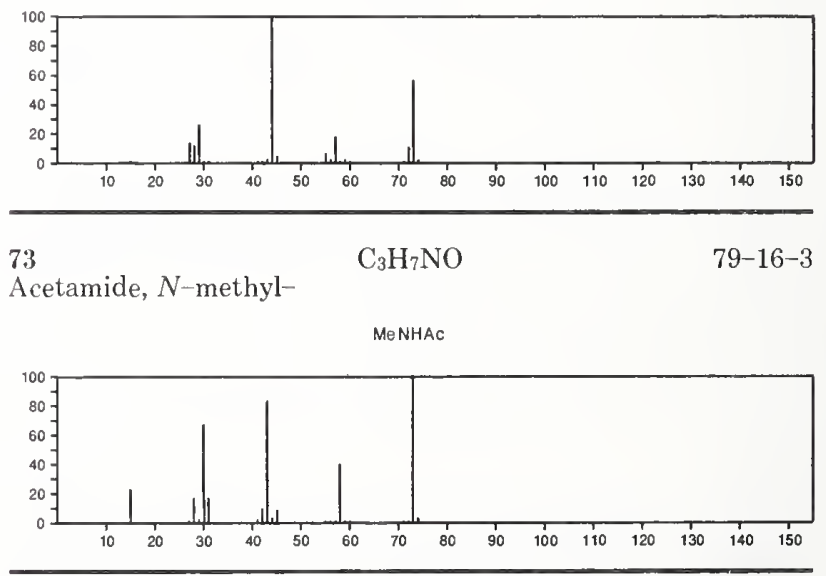

73

2-Propanone, oxime

$\mathrm{C}_{3} \mathrm{H}_{7} \mathrm{NO}$

127-06-0

$\mathrm{HON}=\mathrm{CMe}_{2}$

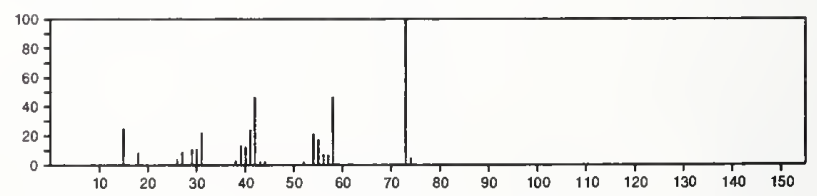


73

Isoxazolidine

$\mathrm{C}_{3} \mathrm{H}_{7} \mathrm{NO}$
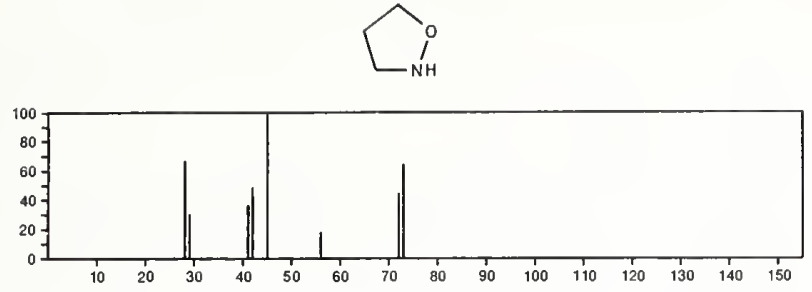

73

Acetaldehyde, $\mathrm{O}$-methyloxime

$\mathrm{C}_{3} \mathrm{H}_{7} \mathrm{NO}$

$33581-43-0$

$\mathrm{MeCH}=\mathrm{NOMe}$

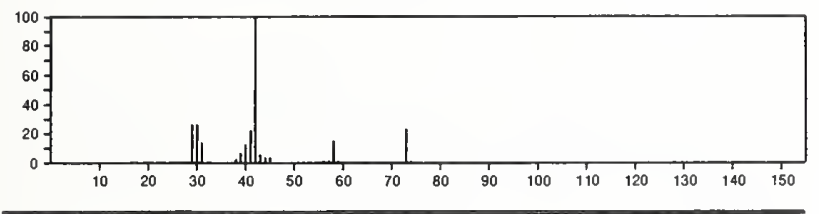

$73 \quad \mathrm{C}_{3} \mathrm{H}_{9} \mathrm{~N} . \mathrm{BH}_{3} \quad 75-22-9$

Methanamine, $N, N$-dimethyl-, compd. with borane (1:1)

$\mathrm{NMe}_{3} \cdot \mathrm{BH}_{3}$

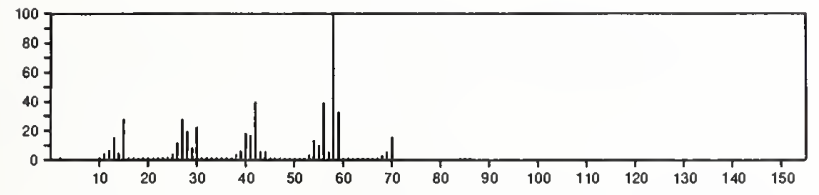

73

$\mathrm{C}_{4} \mathrm{H}_{11} \mathrm{~N}$

75-64-9

2-Propanamine, 2-methyl-

I-BuNH2

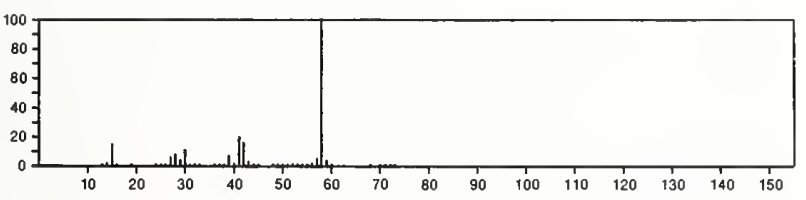

73

1-Propanamine, 2-methyl-

$\mathrm{C}_{4} \mathrm{H}_{11} \mathrm{~N}$

78-81-9

$\mathrm{i}-\mathrm{BuNH}$

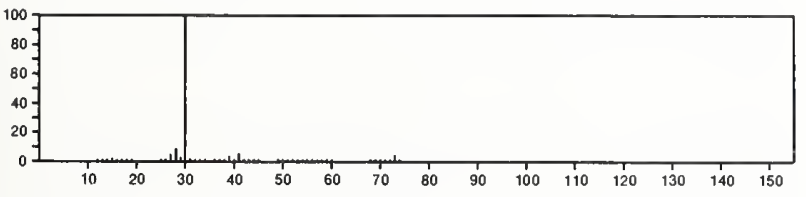

73

1-Butanamine

$\mathrm{C}_{4} \mathrm{H}_{11} \mathrm{~N}$

109-73-9

$\mathrm{Me}\left(\mathrm{CH}_{2}\right)_{3} \mathrm{NH}_{2}$

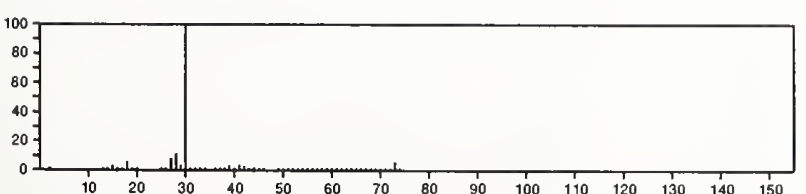

73

Ethanamine, $N$-ethyl-

$\mathrm{C}_{4} \mathrm{H}_{11} \mathrm{~N}$

109-89-7

NHE $: 2$

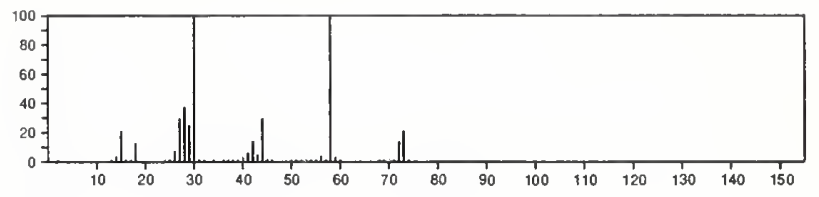

73

$\mathrm{C}_{4} \mathrm{H}_{11} \mathrm{~N}$

598-56-1

Ethanamine, $N, N$-dimethyl-

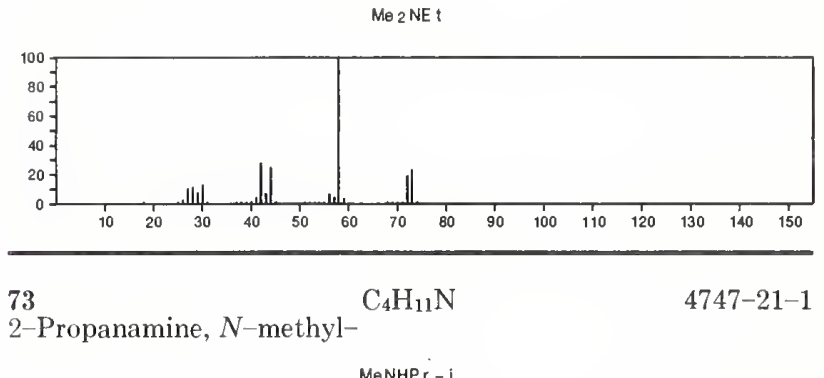

MeNHPr $-i$

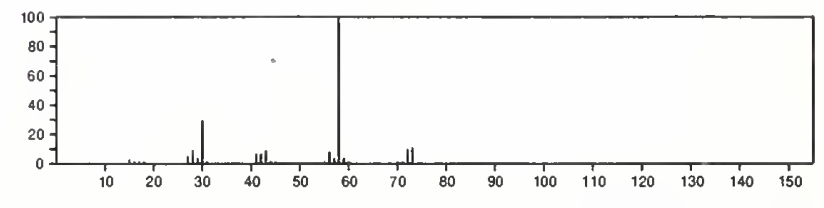

73

2-Butanamine

$\mathrm{C}_{4} \mathrm{H}_{11} \mathrm{~N}$

13952-84-6

s-BuNH2

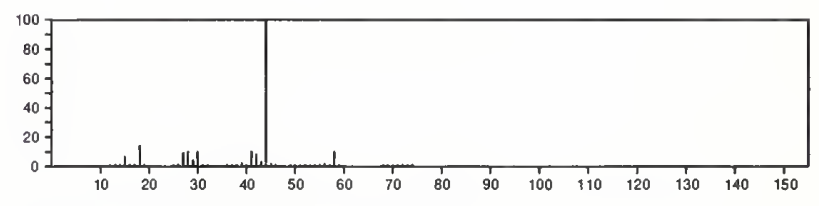

74

$\mathrm{CH}_{6} \mathrm{~N}_{4}$

79-17-4

Hydrazinecarboximidamide

$\mathrm{H}_{2} \mathrm{NNHC}\left(\mathrm{NH}_{2}\right)=\mathrm{NH}$

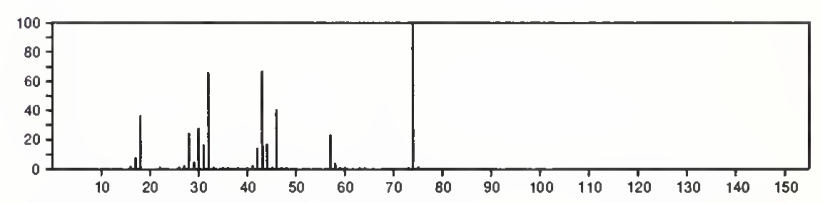

74

1-Carbahexaborane(7)

$\mathrm{CH}_{7} \mathrm{~B}_{5}$

25301-90-0
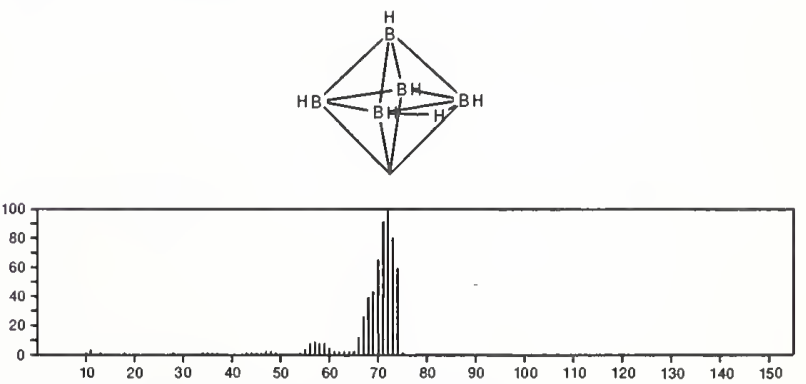
$74 \quad \mathrm{C}_{2} \mathrm{H}_{6} \mathrm{~N}_{2} \mathrm{O}$

Methanamine, $N$-methyl- $N$-nitroso

Me 2 NNO

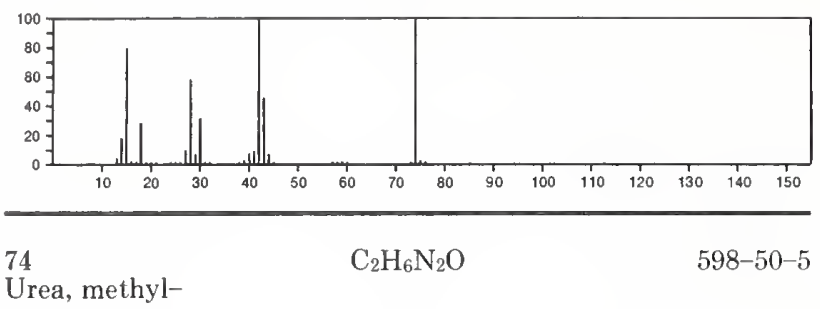

$\mathrm{MeNHCONH} 2$

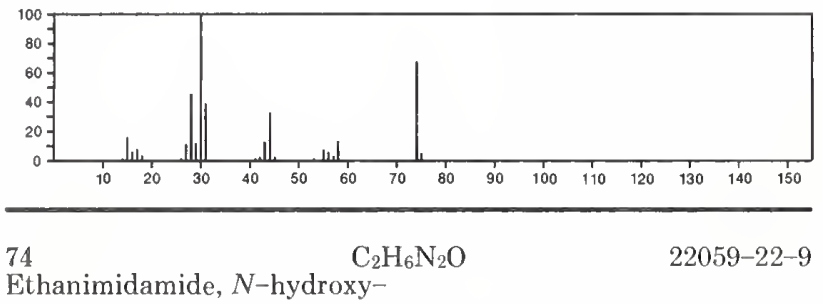

HONHCME $=\mathrm{NH}$
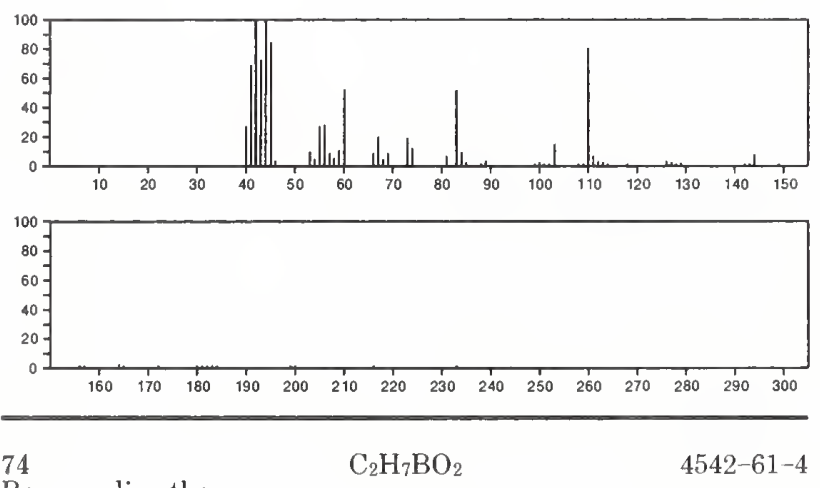

Borane, dimethoxy-

Me OBHOMe

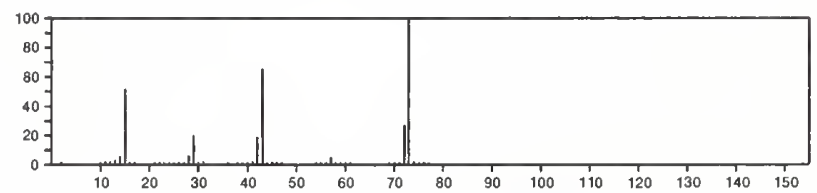

74

Propanoic acid

$\mathrm{C}_{3} \mathrm{H}_{6} \mathrm{O}_{2}$

$79-09-4$

$\mathrm{HO}_{2} \mathrm{CE} 1$

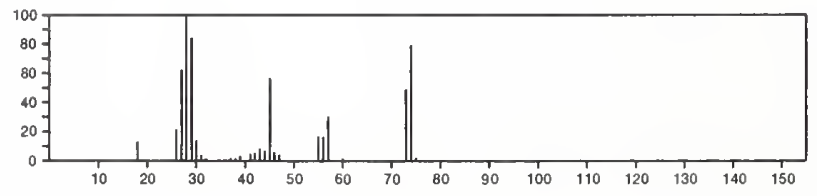

74

$\mathrm{C}_{3} \mathrm{H}_{6} \mathrm{O}_{2}$

79-20-9

Acetic acid, methyl ester

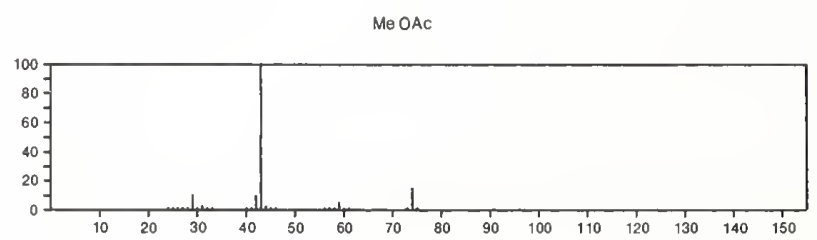

74

Formic acid, ethyl ester

$\mathrm{C}_{3} \mathrm{H}_{6} \mathrm{O}_{2}$

109-94-4

$0=$ CHOE

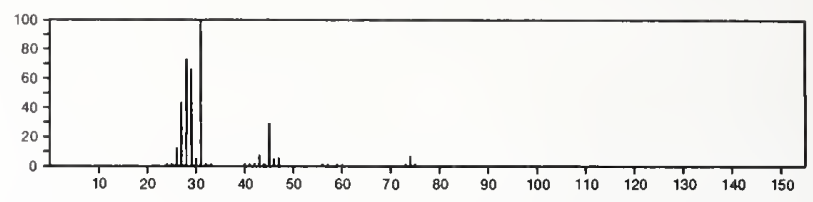

$74 \quad \mathrm{C}_{3} \mathrm{H}_{6} \mathrm{O}_{2}$

$116-09-6$

2-Propanone, 1-hydroxy-

$\mathrm{HOCH}_{2} \mathrm{COM}$

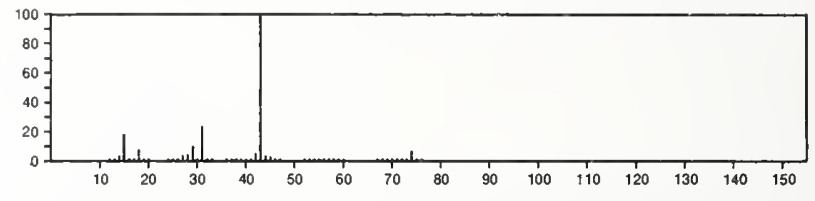

74

Oxiranemethanol

$\mathrm{C}_{3} \mathrm{H}_{6} \mathrm{O}_{2}$

$556-52-5$
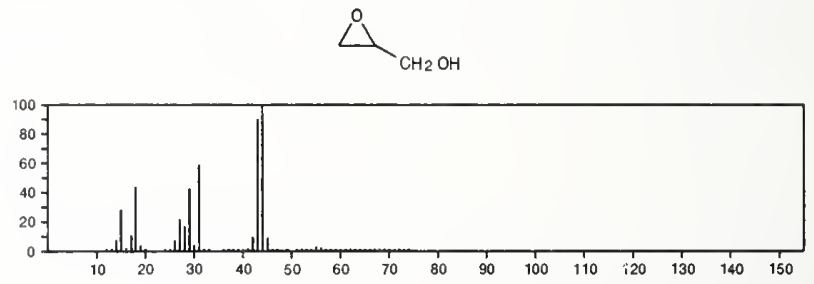

74

1,3-Dioxolane

$\mathrm{C}_{3} \mathrm{H}_{6} \mathrm{O}_{2}$

646-06-0
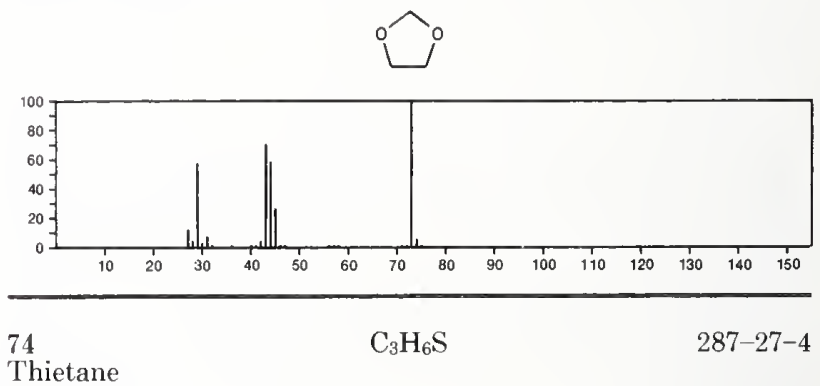

-
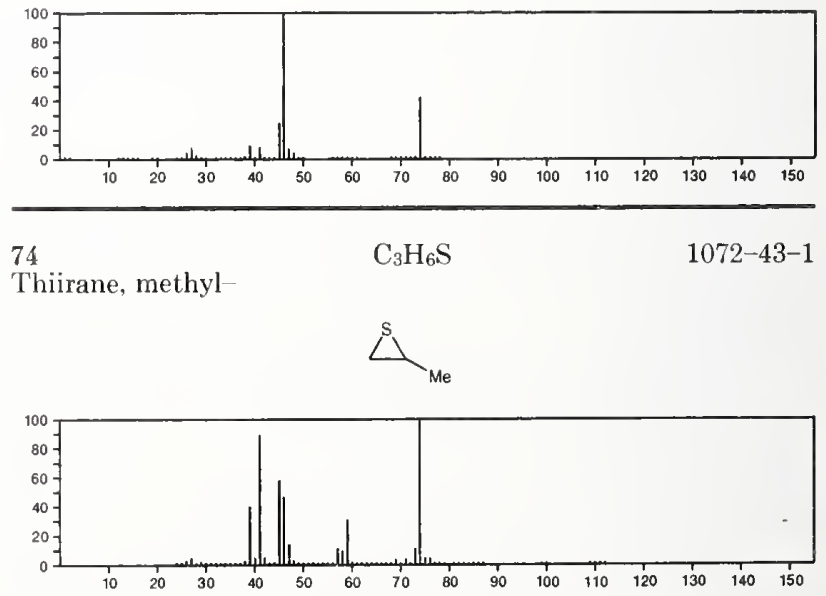
74

1,2-Propanediamine

$\mathrm{C}_{3} \mathrm{H}_{10} \mathrm{~N}_{2}$

$\mathrm{H}_{2} \mathrm{NCH}_{2} \mathrm{CH}\left(\mathrm{NH}_{2}\right) \mathrm{Me}$

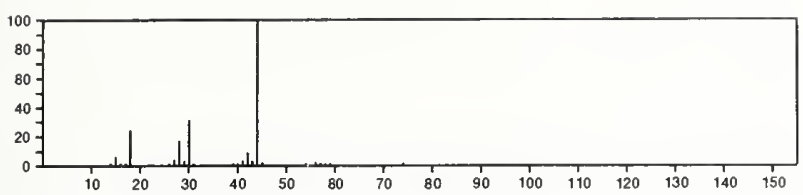

74

1,3-Propanediamine

$\mathrm{C}_{3} \mathrm{H}_{10} \mathrm{~N}_{2}$

$\mathrm{H}_{2} \mathrm{~N}\left(\mathrm{CH}_{2}\right)_{3} \mathrm{NH}_{2}$

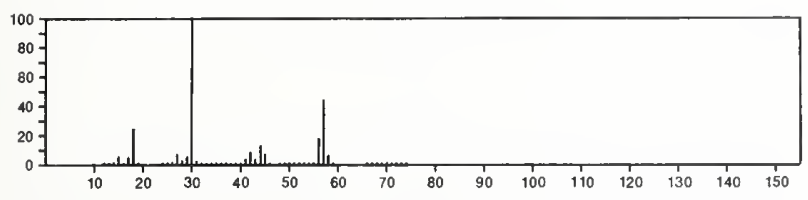

74

Silane, trimethyl-

$\mathrm{C}_{3} \mathrm{H}_{10} \mathrm{Si}$

$993-07-7$

SiHMe 3

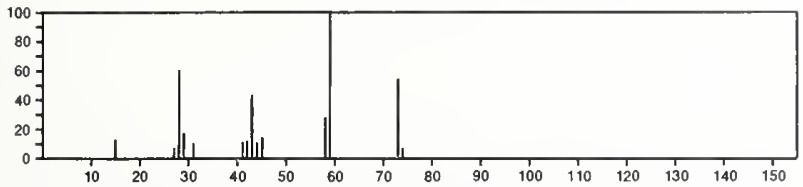

74

Ethane, 1,1'-oxybis-

$\mathrm{C}_{4} \mathrm{H}_{10} \mathrm{O}$

60-29-7

$\mathrm{OE}: 2$

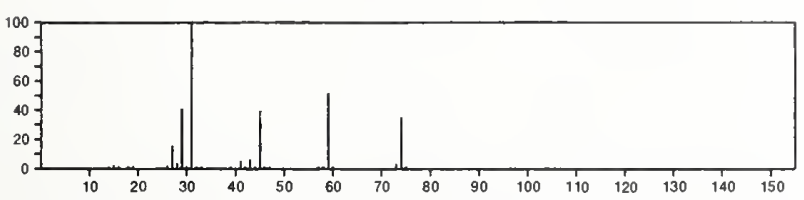

74

1-Butanol

$\mathrm{C}_{4} \mathrm{H}_{10} \mathrm{O}$

71-36-3

$\mathrm{Me}\left(\mathrm{CH}_{2}\right)_{3} \mathrm{OH}$

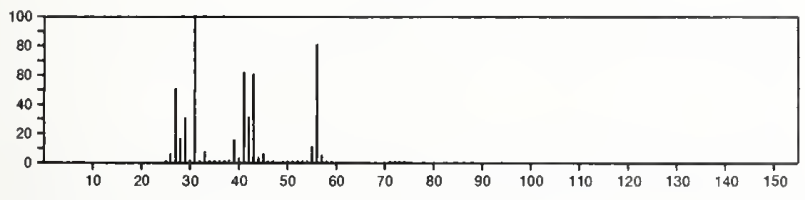

2-Propanol, 2-methyl-

$\mathrm{C}_{4} \mathrm{H}_{10} \mathrm{O}$

t-BuOH

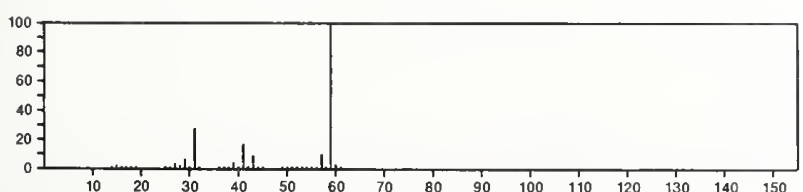

74

1-Propanol, 2-methyl-

$\mathrm{C}_{4} \mathrm{H}_{10} \mathrm{O}$

78-83-1
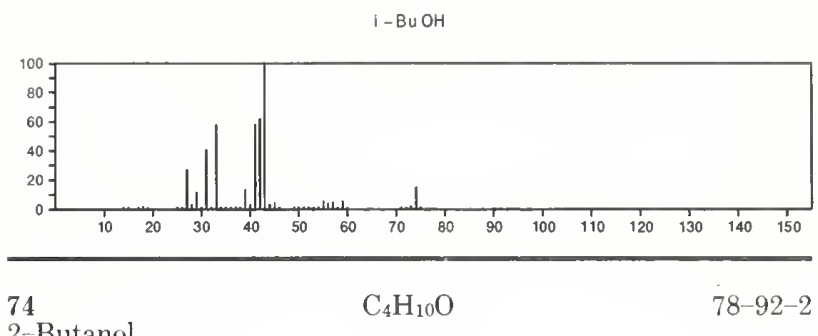

78-92-2

2-Butanol

$s-\mathrm{B} \cup \mathrm{OH}$

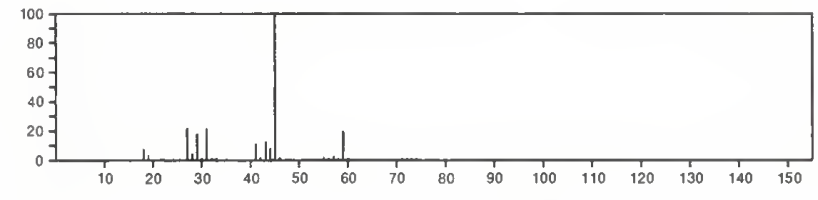

$74 \quad \mathrm{C}_{4} \mathrm{H}_{10} \mathrm{O}$

Propane, 1-methoxy-

557-17-5

PrOMe

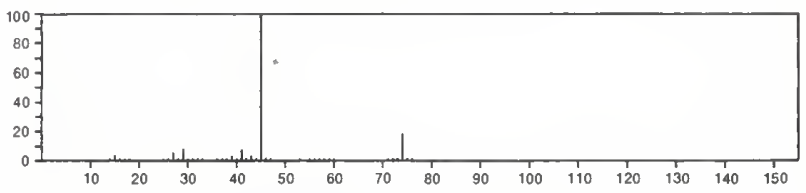

74

$\mathrm{C}_{4} \mathrm{H}_{10} \mathrm{O}$

598-53-8

Propane, 2-methoxy-

$\mathrm{MeOPr}-\mathrm{i}$

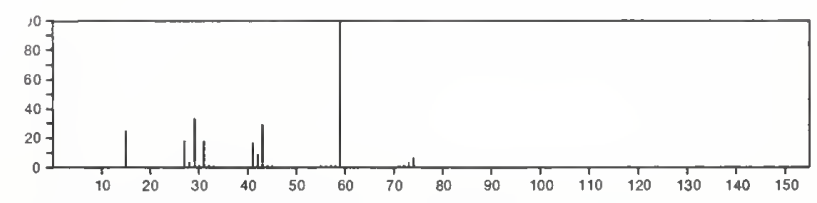

75

Acetonitrile, chloro-

$\mathrm{C}_{2} \mathrm{H}_{2} \mathrm{ClN}$

107-14-2

$\mathrm{Cl} \mathrm{CH}_{2} \mathrm{CN}$

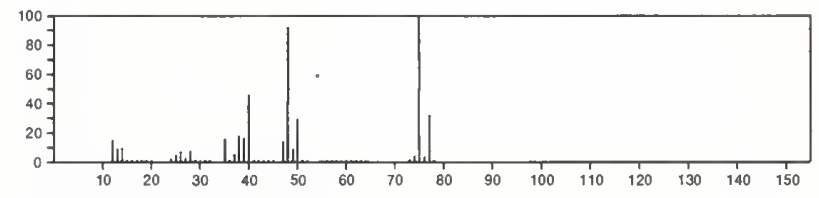

75

Glycine

$\mathrm{C}_{2} \mathrm{H}_{5} \mathrm{NO}_{2}$

56-40-6

$\mathrm{H}_{2} \mathrm{NCH}_{2} \mathrm{CO}_{2} \mathrm{H}$

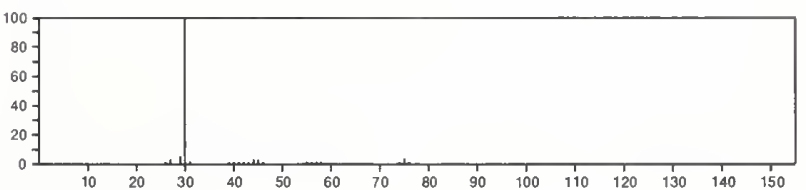


75

Ethane, nitro-

$\mathrm{C}_{2} \mathrm{H}_{5} \mathrm{NO}_{2}$

$\mathrm{O}_{2} \mathrm{NEt}$

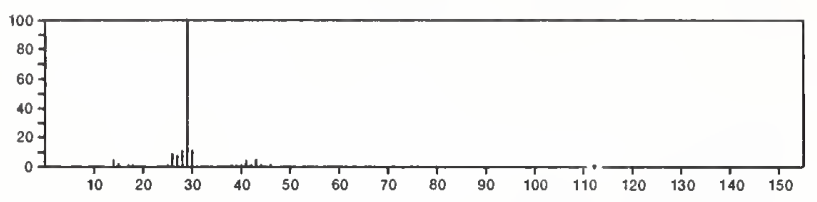

$75 \quad \mathrm{C}_{2} \mathrm{H}_{5} \mathrm{NO}_{2}$

$598-55-0$

Carbamic acid, methyl ester

$\mathrm{Me} O \mathrm{OC}(\mathrm{O}) \mathrm{NH}_{2}$

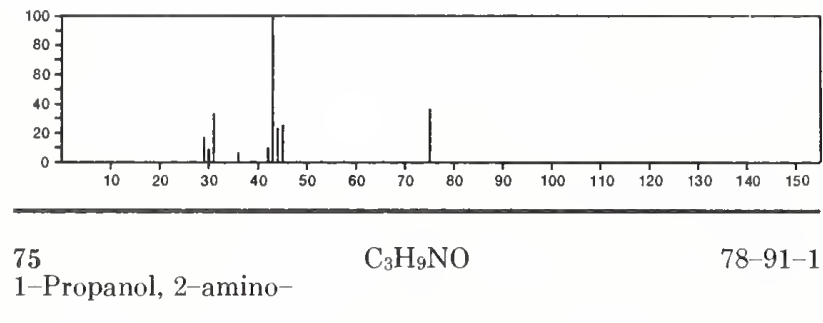

$\mathrm{HOCH}_{2} \mathrm{CH}\left(\mathrm{NH}_{2}\right) \mathrm{Me}$

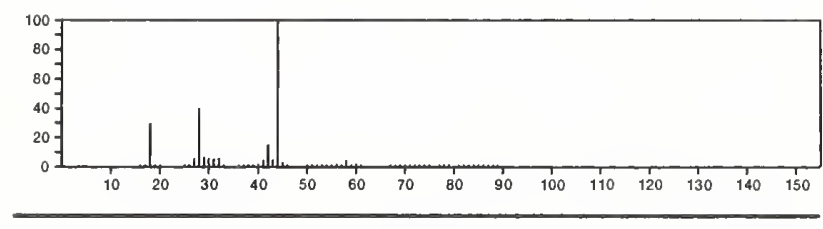

75

2-Propanol, 1-amino-

$\mathrm{C}_{3} \mathrm{H}_{9} \mathrm{NO}$

$\mathrm{H}_{2} \mathrm{NCH}_{2} \mathrm{CH}(\mathrm{OH}) \mathrm{Me}$

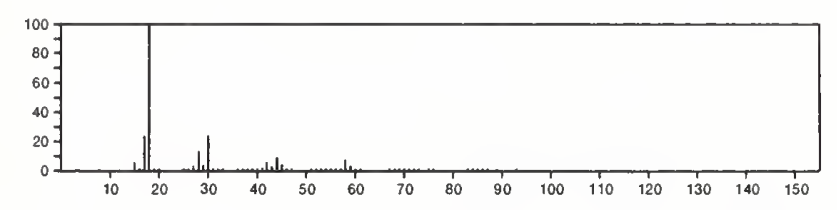

75

1-Propanol, 3-amino-

$\mathrm{C}_{3} \mathrm{H}_{9} \mathrm{NO}$

$\mathrm{H}_{2} \mathrm{~N}\left(\mathrm{CH}_{2}\right)_{3} \mathrm{OH}$
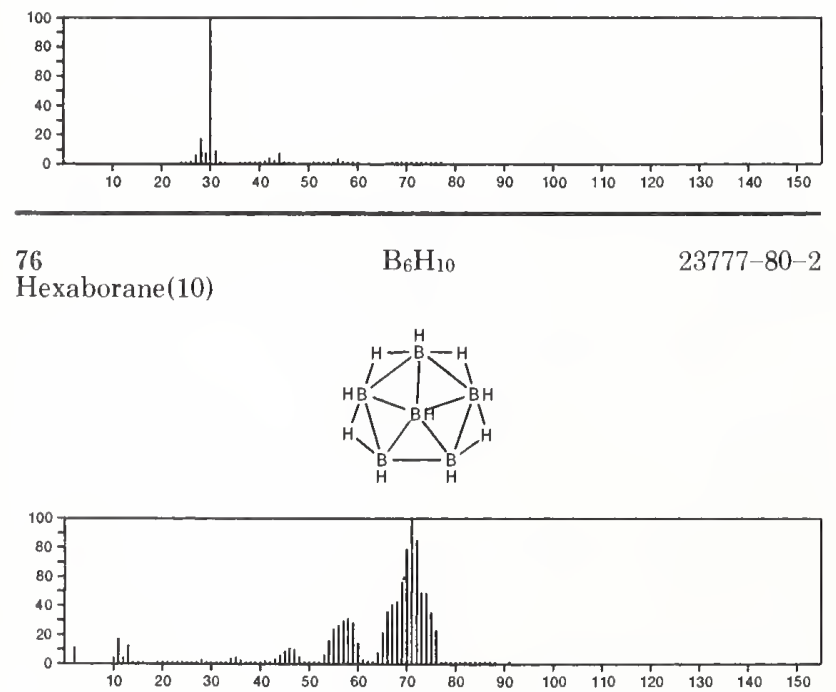

76

Thiourea

$\mathrm{CH}_{4} \mathrm{~N}_{2} \mathrm{~S}$

$62-56-6$

$\mathrm{H}_{2} \mathrm{NCSNH}_{2}$

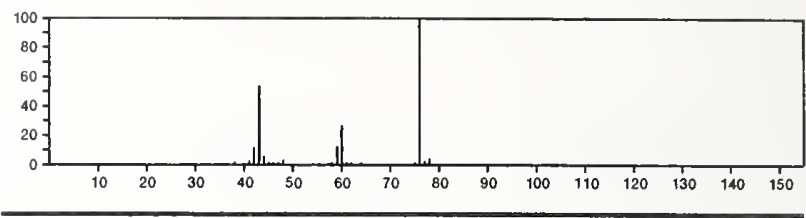

76

$\mathrm{CH}_{8} \mathrm{Si}_{2}$

Silane, methylenebis-

$\mathrm{CH}_{2}\left(\mathrm{SiH}_{3}\right)_{2}$
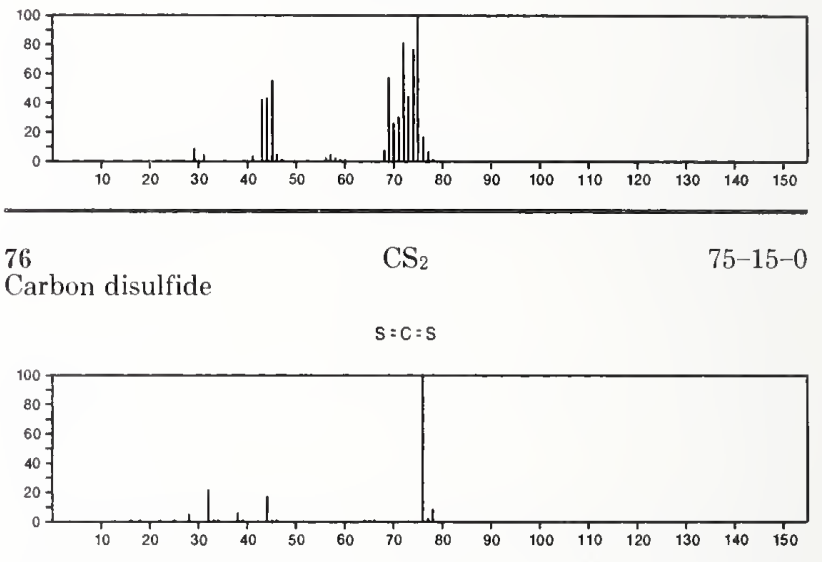

$76 \quad \mathrm{C}_{2} \mathrm{H}_{4} \mathrm{OS}$

507-09-5

Ethanethioic acid

HSOCMe

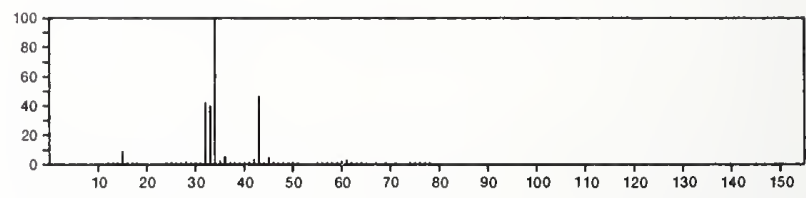

76

Acetic acid, hydroxy-

$\mathrm{C}_{2} \mathrm{H}_{4} \mathrm{O}_{3}$

79-14-1

$\mathrm{HOCH}_{2} \mathrm{CO}_{2} \mathrm{H}$

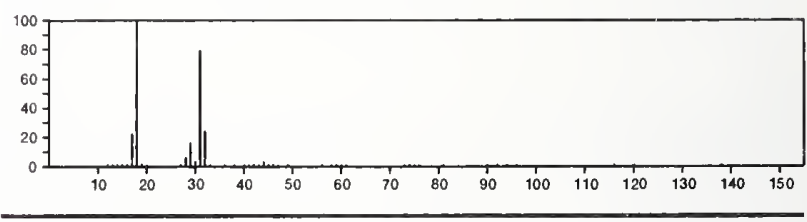

76

1-Propene, 3-chloro-

$\mathrm{C}_{3} \mathrm{H}_{5} \mathrm{Cl}$

107-05-1

$\mathrm{Cl} \mathrm{CH}_{2} \mathrm{CH}=\mathrm{CH}_{2}$

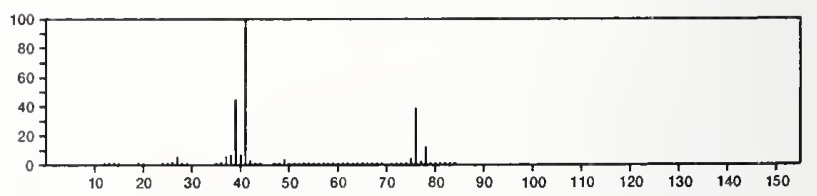


76

$\mathrm{C}_{3} \mathrm{H}_{5} \mathrm{Cl}$

$\mathrm{Me} \mathrm{CCl}=\mathrm{CH}_{2}$

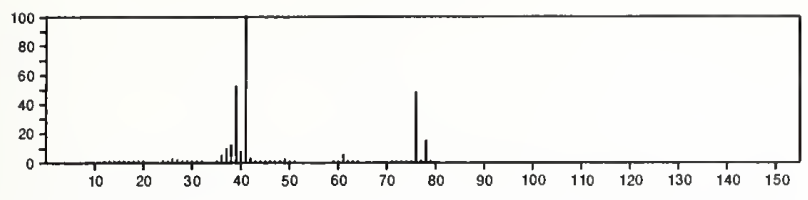

76

1-Propene, 1-chloro-

$\mathrm{C}_{3} \mathrm{H}_{5} \mathrm{Cl}$

$\mathrm{Cl} \mathrm{CH}=\mathrm{CHMO}$

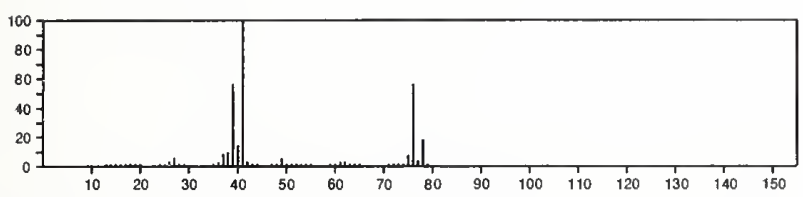

76

1-Propene, 1-chloro-, $(Z)$ -

$\mathrm{C}_{3} \mathrm{H}_{5} \mathrm{Cl}$

$\mathrm{Cl} \mathrm{CH}=\mathrm{CHMO}$

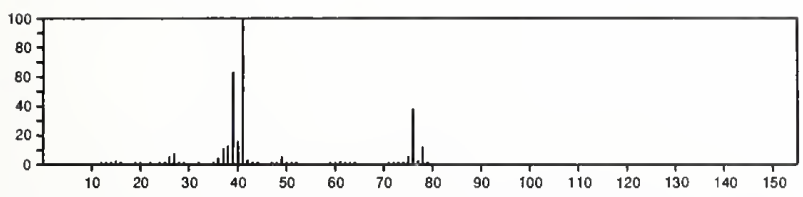

$76 \quad \mathrm{C}_{3} \mathrm{H}_{5} \mathrm{Cl}$

1-Propene, 1-chlorn-, $(E)$ -

$\mathrm{Cl} \mathrm{CH}=\mathrm{CHMO}$

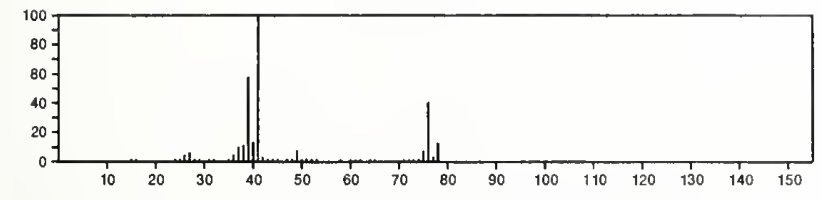

76

2-Propanone, 1-fluoro

$\mathrm{C}_{3} \mathrm{H}_{5} \mathrm{FO}$

$\mathrm{FCH}_{2} \mathrm{COM}$

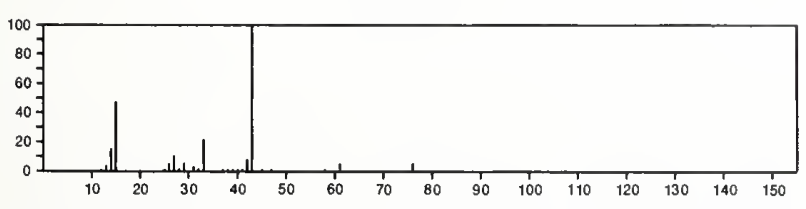

76

$\mathrm{C}_{3} \mathrm{H}_{8} \mathrm{O}_{2}$

57-55-6

1,2-Propanediol

$\mathrm{HOCH}_{2} \mathrm{CH}(\mathrm{OH}) \mathrm{Me}$

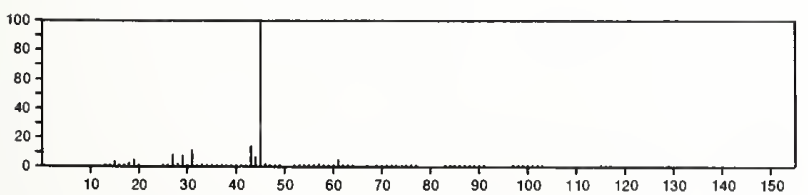

76

$\mathrm{C}_{3} \mathrm{H}_{8} \mathrm{O}_{2}$

$109-86-4$
$\mathrm{HOCH}_{2} \mathrm{CH}_{2} \mathrm{OMe}$

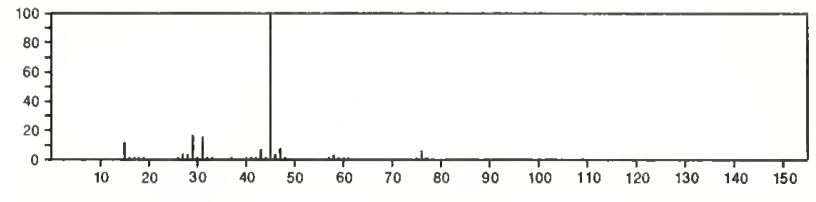

$\mathrm{C}_{3} \mathrm{H}_{8} \mathrm{O}_{2}$

$109-87-5$

Methane, dimethoxy-

$\mathrm{MeOCH} 2 \mathrm{OMe}$

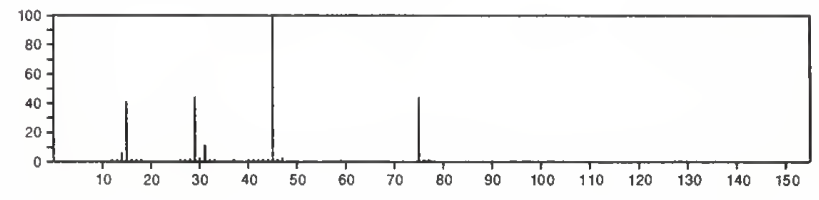

76

1,3-Propanediol

$\mathrm{C}_{3} \mathrm{H}_{8} \mathrm{O}_{2}$

$504-63-2$

$\mathrm{HO}\left(\mathrm{CH}_{2}\right)_{3} \mathrm{OH}$

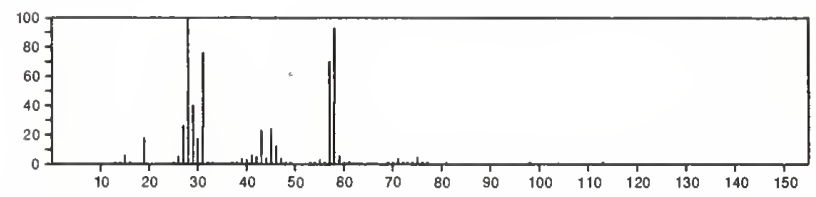

$76 \quad \mathrm{C}_{3} \mathrm{H}_{8} \mathrm{O}_{2}$

Hydroperoxide, 1-methylethyl

$3031-75-2$

HOOP $\mathrm{r}-\mathrm{i}$

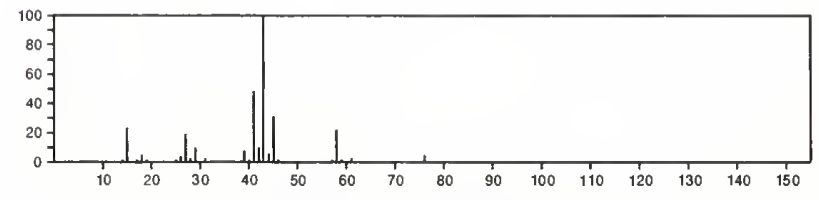

76

2-Propanethiol

$\mathrm{C}_{3} \mathrm{H}_{8} \mathrm{~S}$

$75-33-2$

$\mathrm{i}-\mathrm{Pr} \mathrm{SH}$

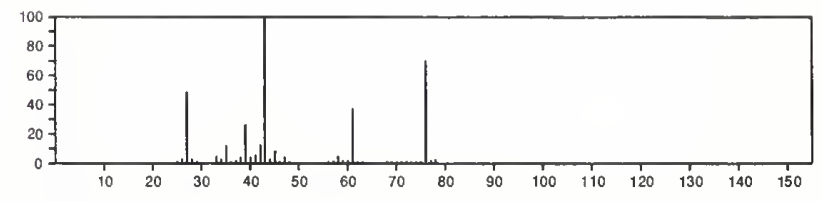

76

1-Propanethiol

$\mathrm{C}_{3} \mathrm{H}_{8} \mathrm{~S}$

$107-03-9$

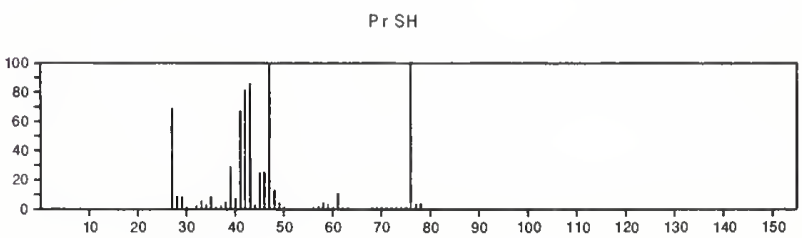


76

Ethane, (methylthio)-

$\mathrm{C}_{3} \mathrm{H}_{8} \mathrm{~S}$

EtSMe

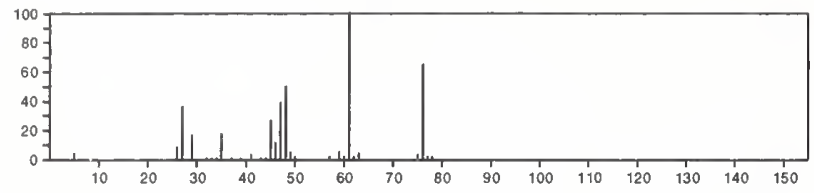

76

Phosphine, trimethyl-

$\mathrm{C}_{3} \mathrm{H}_{9} \mathrm{P}$

PMe

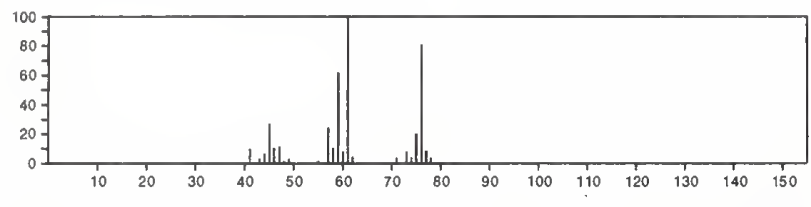

76

Propane, 2-fluoro-2-methyl-

$\mathrm{C}_{4} \mathrm{H}_{9} \mathrm{~F}$

$\mathrm{t}$-BuF

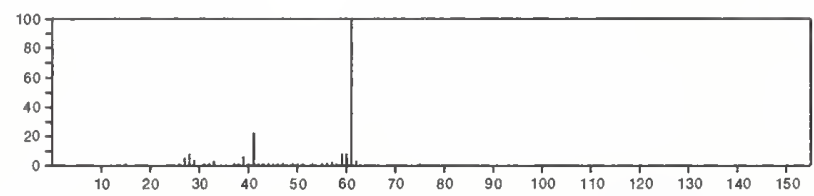

76

$\mathrm{C}_{4} \mathrm{H}_{9} \mathrm{~F}$

2366-52-1

$\mathrm{Me}\left(\mathrm{CH}_{2}\right)_{3} \mathrm{~F}$

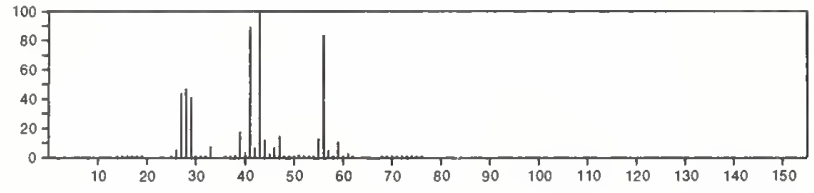

77

Nitric acid, methyl ester

$\mathrm{CH}_{3} \mathrm{NO}_{3}$

598-58-3

$\mathrm{MeONO}_{2}$

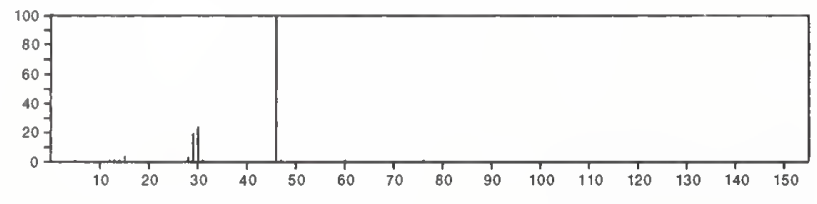

77

Silanamine, $N$-silyl-

$\mathrm{H}_{7} \mathrm{NSi}_{2}$

5702-11-4

$\mathrm{NH}\left(\mathrm{SiH}_{3}\right)_{2}$

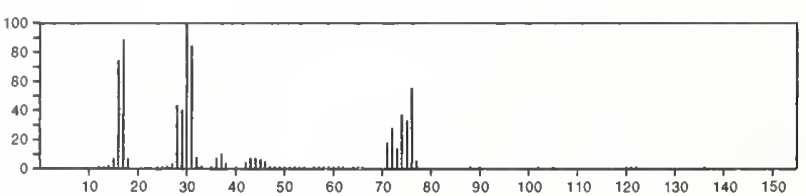

78

Arsine

$\mathrm{AsH}_{3}$

As $\mathrm{H}_{3}$

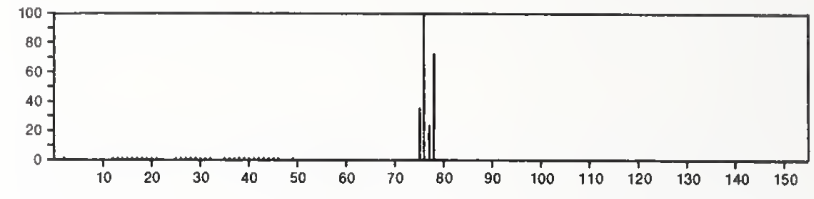

78

3H-Diazirine, 3,3-difluoro-

$\mathrm{CF}_{2} \mathrm{~N}_{2}$

693-85-6
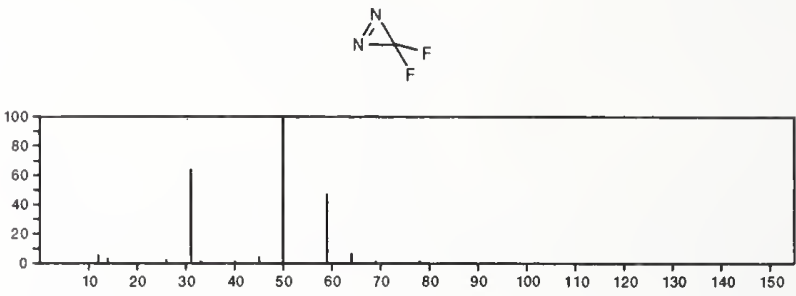

78

$\mathrm{C}_{2} \mathrm{H}_{3} \mathrm{ClO}$

75-36-5

Acetyl chloride

$\mathrm{ACCl}$

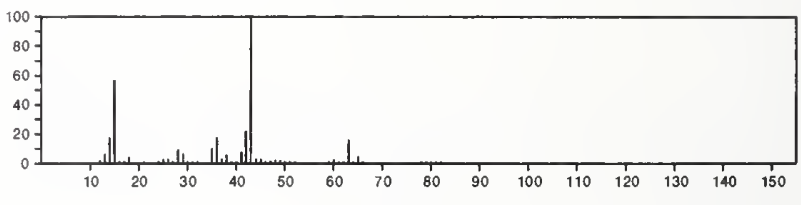

78

Acetaldehyde, chloro-

$\mathrm{C}_{2} \mathrm{H}_{3} \mathrm{ClO}$

107-20-0

$\mathrm{Cl} \mathrm{CH}_{2} \mathrm{CHO}$

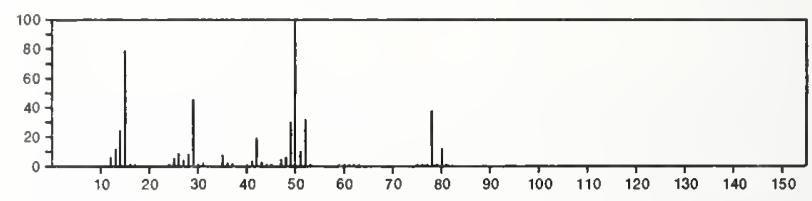

78

Acetic acid, fluoro-

$\mathrm{C}_{2} \mathrm{H}_{3} \mathrm{FO}_{2}$

144-49-0

$\mathrm{FCH}_{2} \mathrm{CO}_{2} \mathrm{H}$

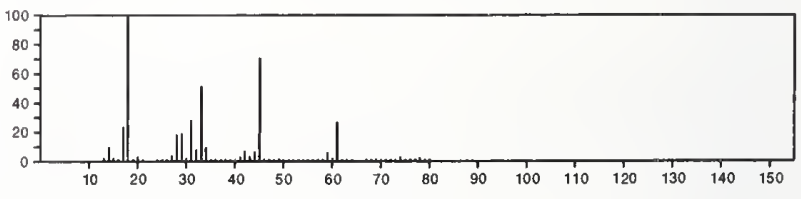

78

Ethanol, 2-mercapto-

$\mathrm{C}_{2} \mathrm{H}_{6} \mathrm{OS}$

60-24-2

$\mathrm{HSCH}_{2} \mathrm{CH}_{2} \mathrm{OH}$

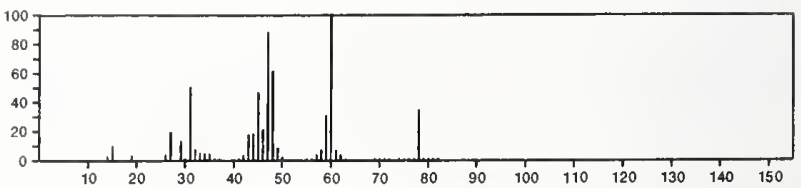


78

Methane, sulfinylbis-

$\mathrm{C}_{2} \mathrm{H}_{6} \mathrm{OS}$

$\mathrm{MeS}(0) \mathrm{Me}$

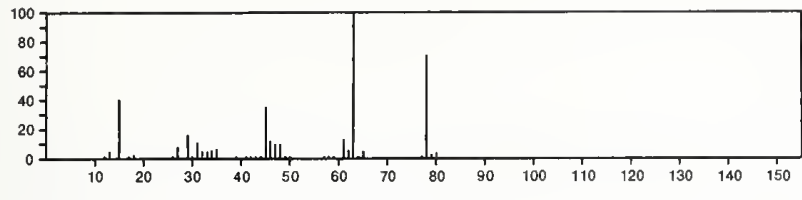

78

Propane, 2-chloro-

$\mathrm{C}_{3} \mathrm{H}_{7} \mathrm{Cl}$

75-29-6

$\mathrm{i}-\mathrm{PrCl}$

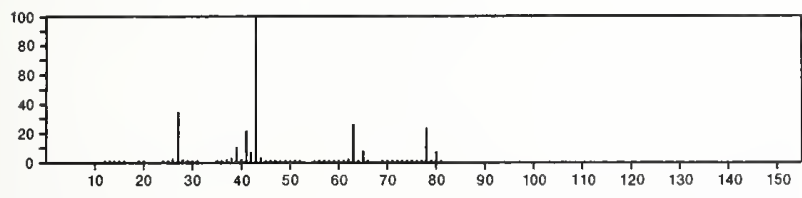

78

Propane, 1-chloro-

$\mathrm{C}_{3} \mathrm{H}_{7} \mathrm{Cl}$

$540-54-5$

$\mathrm{PrCl}$

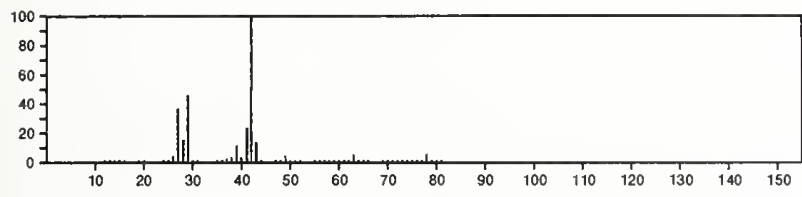

78

$78 \quad \mathrm{C}_{4} \mathrm{H}_{2} \mathrm{~N}_{2}$

2-Butenedinitrile, $(E)$

$\mathrm{NCCH}=\mathrm{CHCN}$

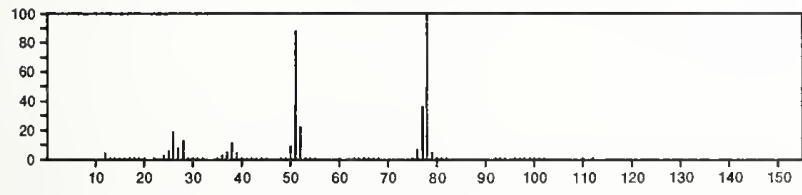

78

$\mathrm{C}_{4} \mathrm{H}_{2} \mathrm{~N}_{2}$

$922-64-5$

Propanedinitrile, methylene-

(NC) ${ }_{2} \mathrm{C}=\mathrm{CH}_{2}$

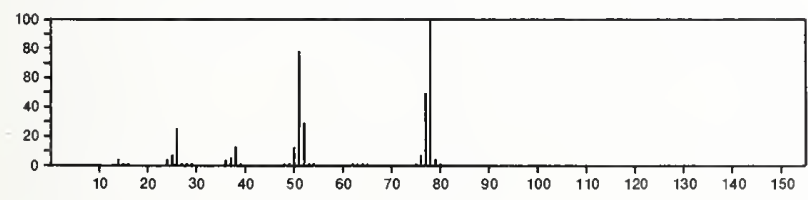

78

$\mathrm{C}_{6} \mathrm{H}_{6}$

71-43-2

Benzene
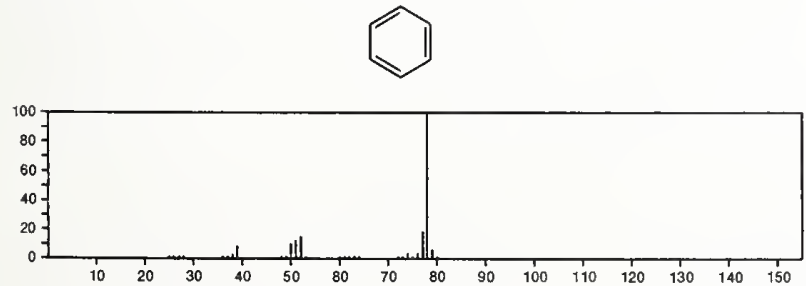

78

1,5-Hexadiyne

$\mathrm{C}_{6} \mathrm{H}_{6}$

628-16-0

$\mathrm{HC} \equiv \mathrm{CCH}_{2} \mathrm{CH}_{2} \mathrm{C} \equiv \mathrm{CH}$

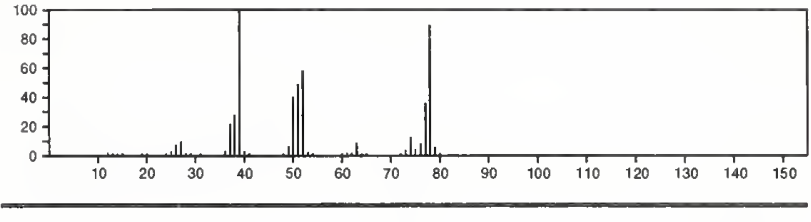

78

1,5-Hexadien-3-yne

$\mathrm{C}_{6} \mathrm{H}_{6}$

821-08-9

$\mathrm{H}_{2} \mathrm{C}=\mathrm{CHC} \equiv \mathrm{CCH}=\mathrm{CH}_{2}$
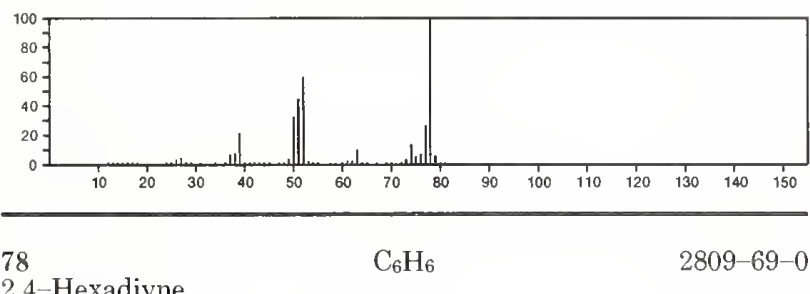

2,4-Hexadiyne

$\mathrm{MeC} \equiv \mathrm{CC} \equiv \mathrm{CM}$

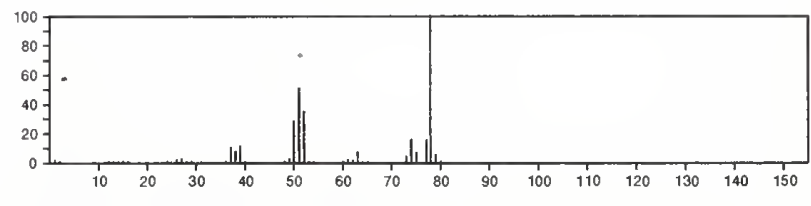

$\begin{array}{ll}79 & \mathrm{C}_{5} \mathrm{H}_{5} \mathrm{~N}\end{array}$

110-86-1
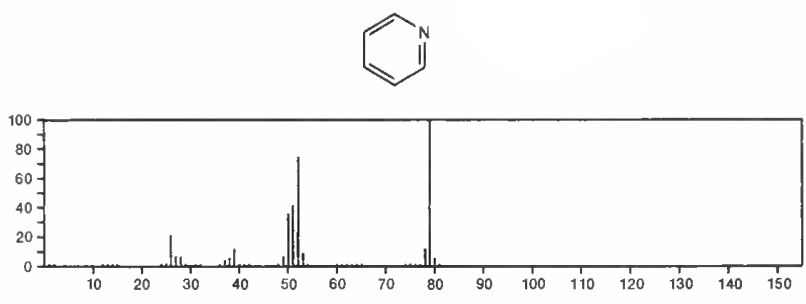

79

2,4-Pentadienenitrile

$\mathrm{C}_{5} \mathrm{H}_{5} \mathrm{~N}$

1615-70-9

$\mathrm{NCCH}=\mathrm{CHCH}=\mathrm{CH}_{2}$

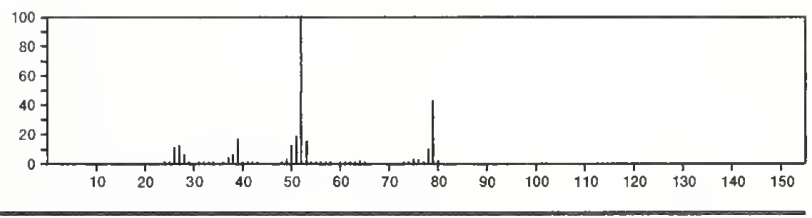

80

Hydrobromic acid

$\mathrm{BrH}$

10035-10-6

$\mathrm{BrH}$

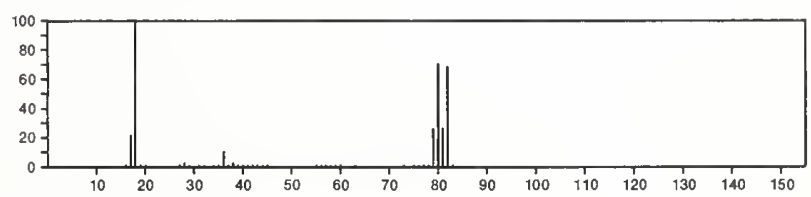


80

$\mathrm{CH}_{4} \mathrm{O}_{2} \mathrm{~S}$

$\mathrm{MeS}(\mathrm{O}) \mathrm{OH}$

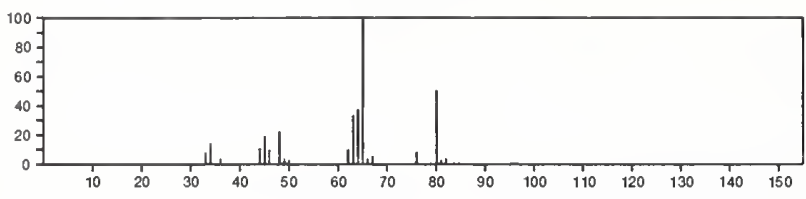

80

Ethene, 1-chloro-2-fluoro-

$\mathrm{C}_{2} \mathrm{H}_{2} \mathrm{ClF}$

$\mathrm{FCH}=\mathrm{CHCl}$

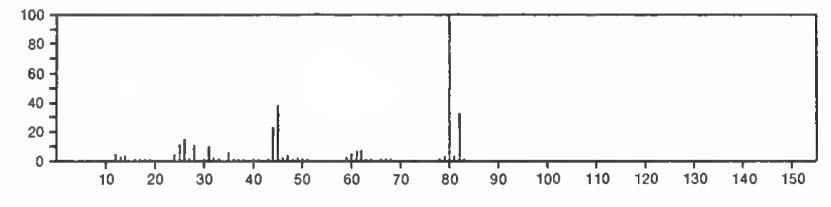

80

$\mathrm{C}_{2} \mathrm{H}_{2} \mathrm{ClF}$

2317-91-1

Ethene, 1-chloro-1-fluoro-

$\mathrm{Cl} \mathrm{CF}=\mathrm{CH}_{2}$

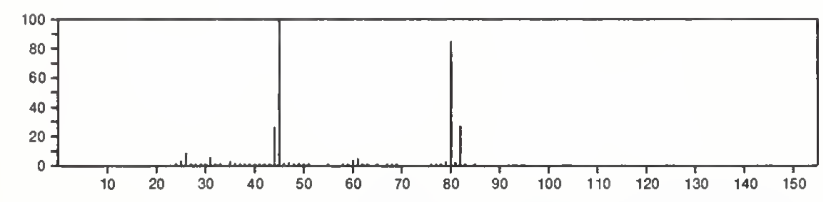

80

Ethanol, 2-chloro-

$\mathrm{C}_{2} \mathrm{H}_{5} \mathrm{ClO}$

$107-07-3$

$\mathrm{HOCH}_{2} \mathrm{CH}_{2} \mathrm{Cl}$

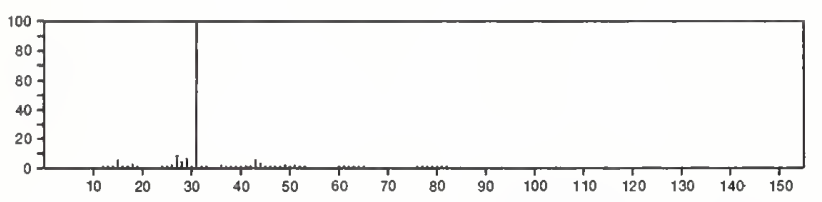

80

Methane, chloromethoxy-

\section{$\mathrm{C}_{2} \mathrm{H}_{5} \mathrm{ClO}$}

$107-30-2$

$\mathrm{Me} \mathrm{OCH}_{2} \mathrm{Cl}$

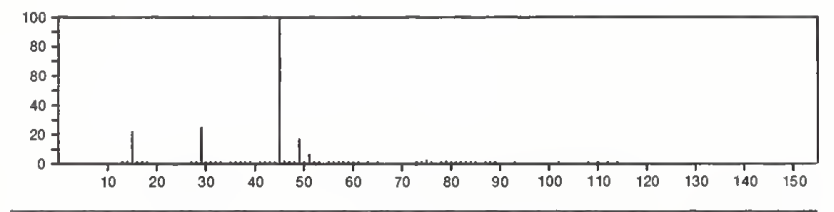

80

$\mathrm{C}_{3} \mathrm{H}_{6} \mathrm{~F}_{2}$

420-45-1

Propane, 2,2-difluoro-

$\mathrm{F}_{2} \mathrm{CMe}_{2}$

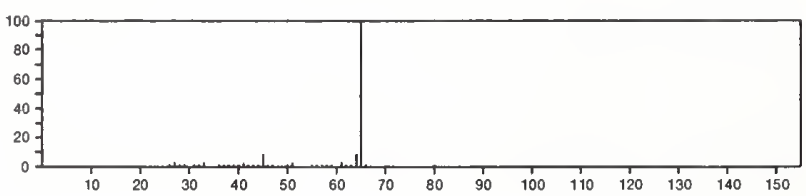

80

Butanedinitrile

$\mathrm{C}_{4} \mathrm{H}_{4} \mathrm{~N}_{2}$

$110-61-2$

$\mathrm{NCCH}_{2} \mathrm{CH}_{2} \mathrm{CN}$

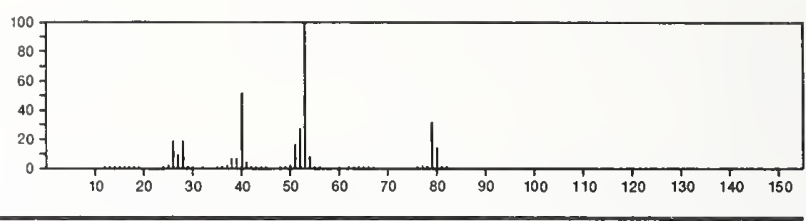

80

Pyridazine

$\mathrm{C}_{4} \mathrm{H}_{4} \mathrm{~N}_{2}$

$289-80-5$
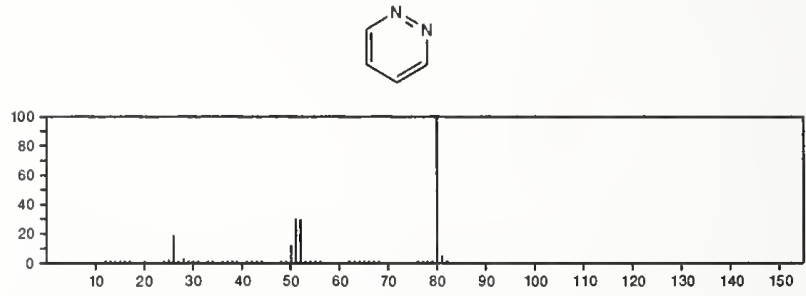

80

$\mathrm{C}_{4} \mathrm{H}_{4} \mathrm{~N}_{2}$

289-95-2

Pyrimidine
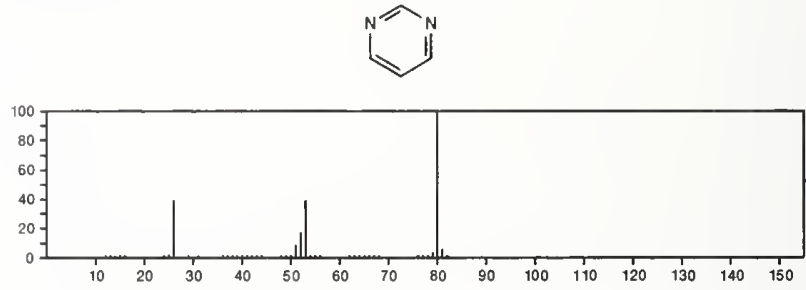

80

$\mathrm{C}_{4} \mathrm{H}_{4} \mathrm{~N}_{2}$

$290-37-9$

Pyrazine
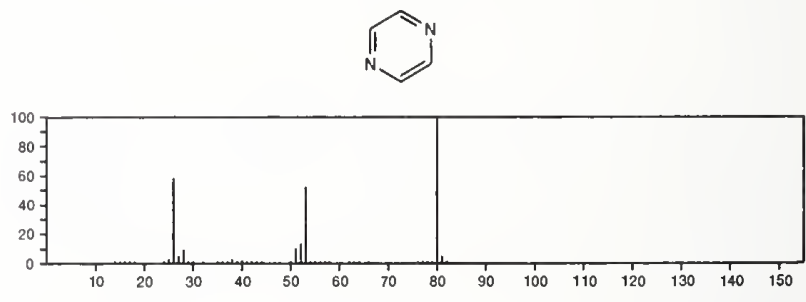

$80 \quad \mathrm{C}_{4} \mathrm{H}_{4} \mathrm{~N}_{2}$

Propanedinitrile, methyl-

$\mathrm{MeCH}(\mathrm{CN})_{2}$

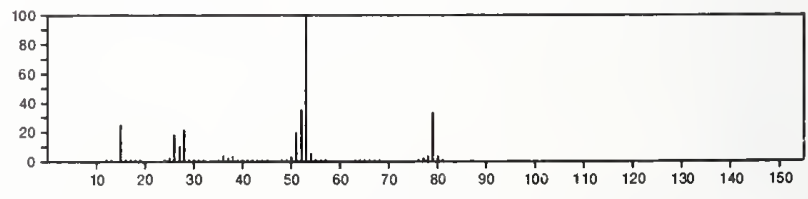

80

1,3-Cyclopentadiene, 5-methyl-

$96-38-8$
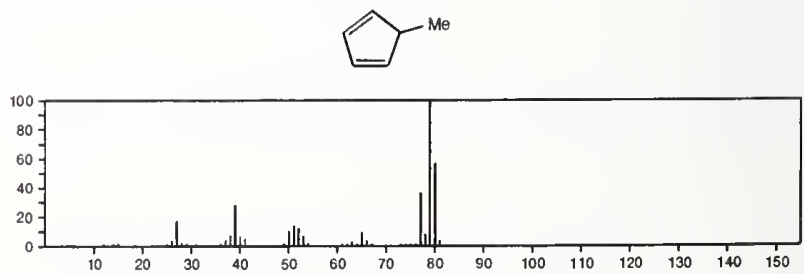
${ }_{1,3-\text { Cyclopentadiene, 1-methyl- }}^{\mathrm{C}_{6} \mathrm{H}_{8}}$
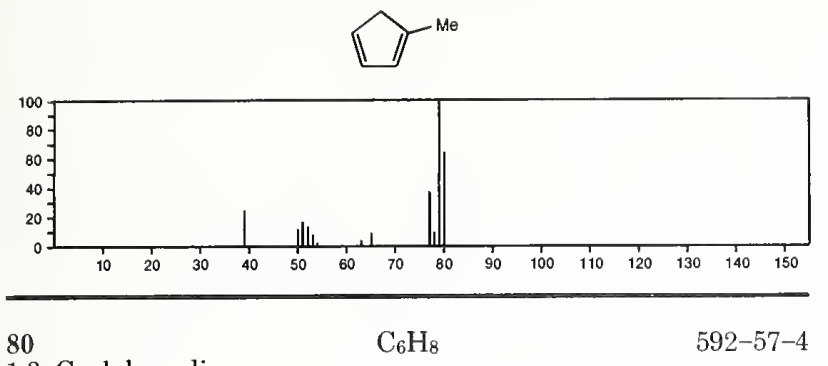

1,3-Cyclohexadiene
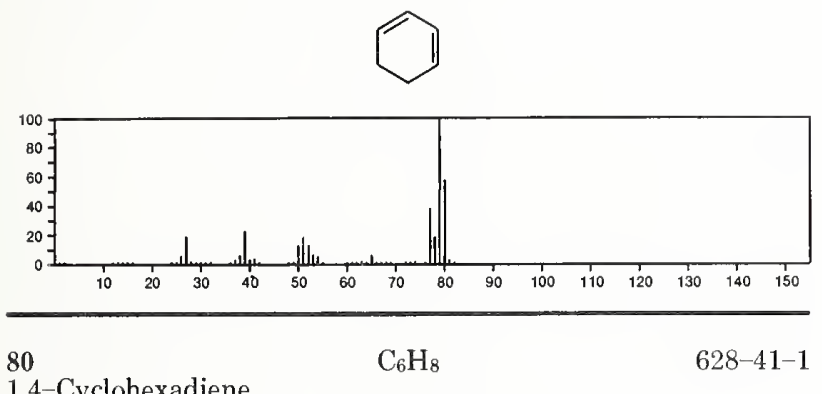

1,4-Cyclohexadiene
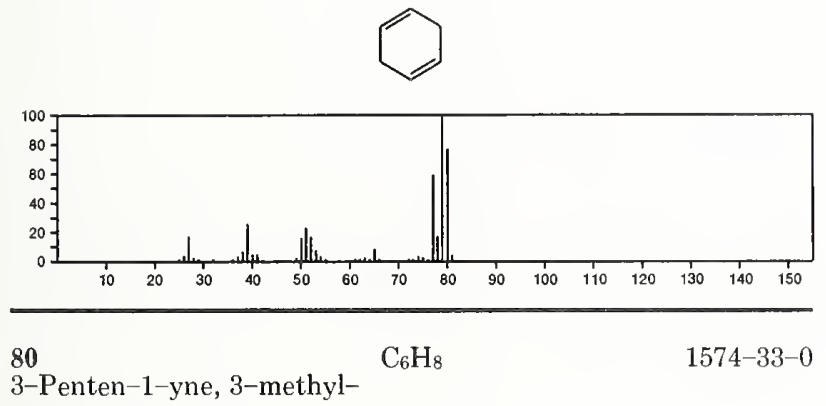

HCミ $\cong \mathrm{CMe}=\mathrm{CHMe}$
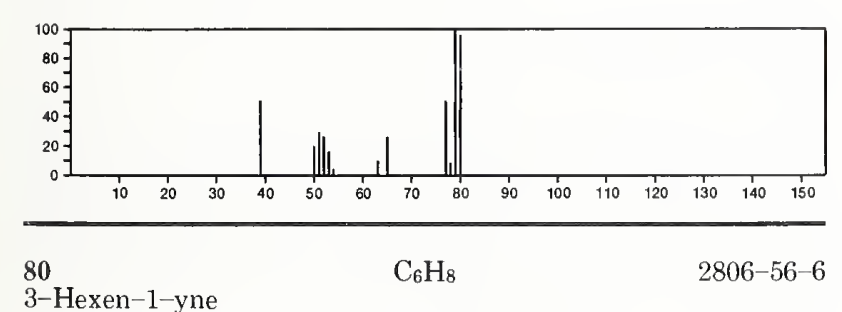

3-Hexen-1-yne

$\mathrm{EtCH}=\mathrm{CHC} \equiv \mathrm{CH}$

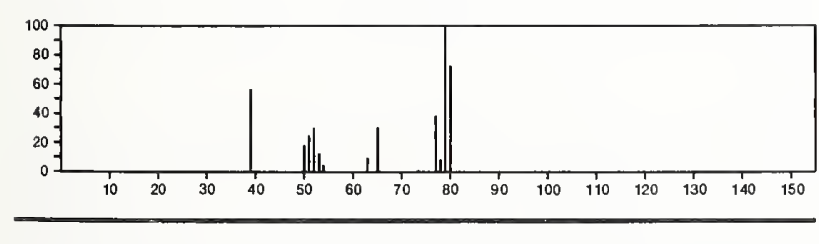

80

1-Hexen-3-yne

$\mathrm{C}_{6} \mathrm{H}_{8}$

$13721-54-5$

$\mathrm{E} T \mathrm{C} \equiv \mathrm{CCH}=\mathrm{CH}_{2}$

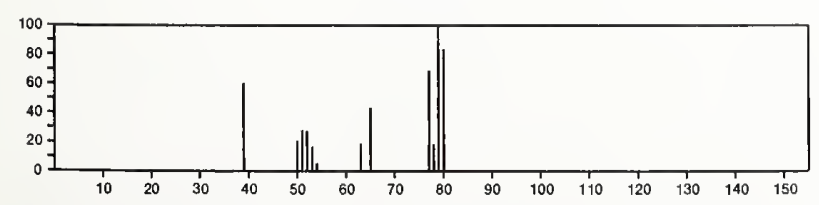

80

2-Hexen-4-yne

$\mathrm{C}_{6} \mathrm{H}_{8}$

14092-20-7

$\mathrm{Me} \mathrm{C} \equiv \mathrm{CCH}=\mathrm{CHMe}$

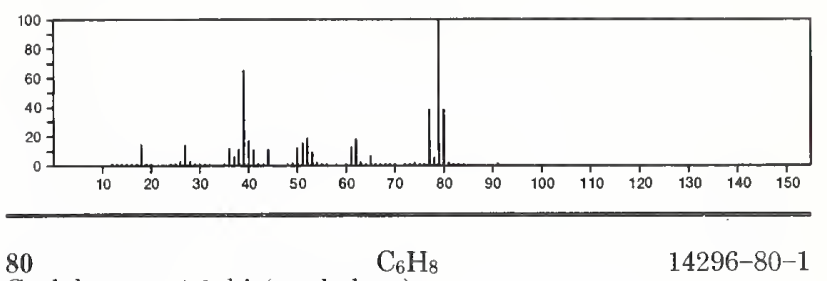

Cyclobutane, 1,2-bis(methylene)-
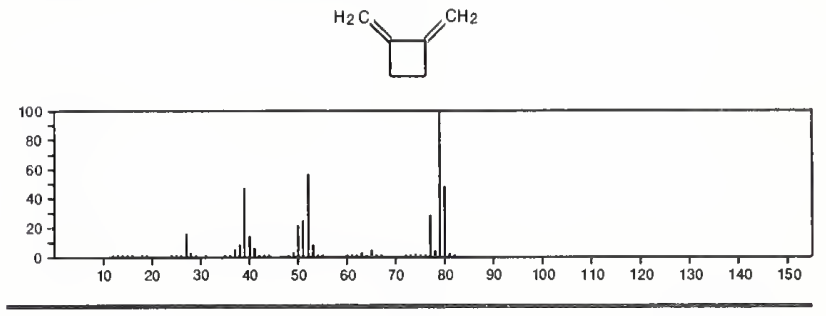

$80 \quad \mathrm{C}_{6} \mathrm{H}_{8}$

$26519-91-5$
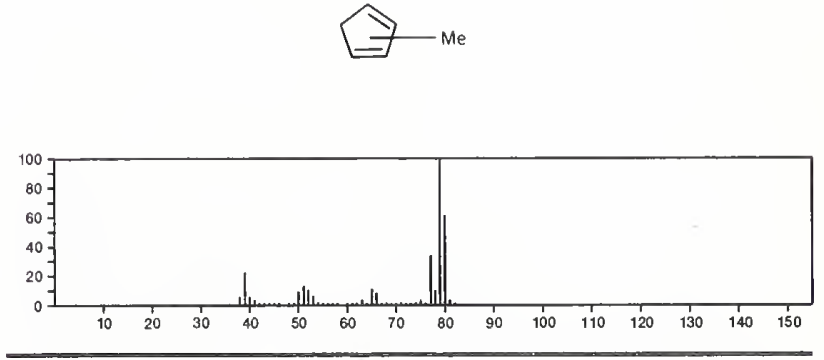

81

Borazine

$\mathrm{B}_{3} \mathrm{H}_{6} \mathrm{~N}_{3}$

$6569-51-3$

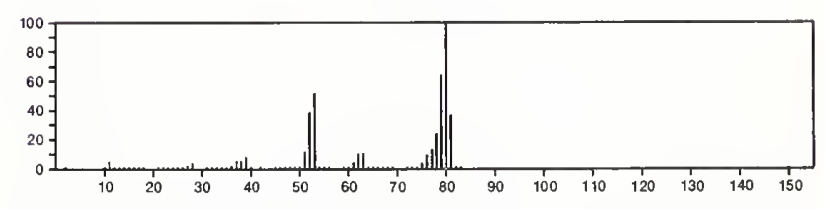

81

758-18-9

Ethylamine, $N, N$-difluoro-

$\mathrm{F}_{2} \mathrm{NE} t$

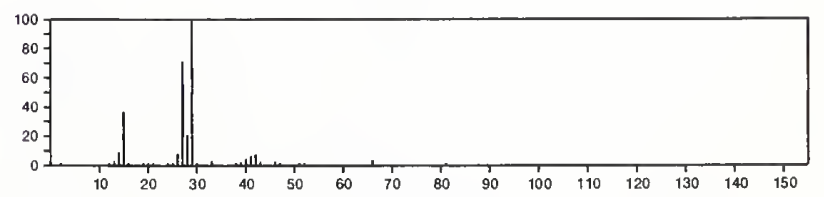


81

1,3,5-Triazine

$\mathrm{C}_{3} \mathrm{H}_{3} \mathrm{~N}_{3}$<smiles>c1ncncn1</smiles>

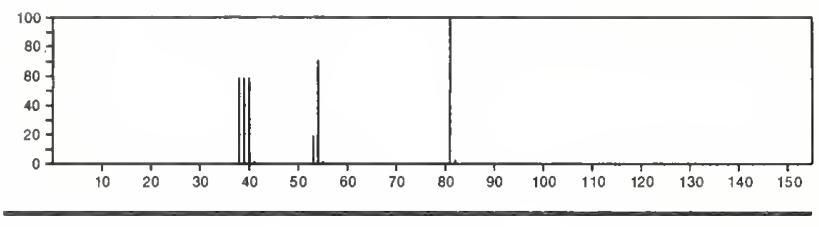

$81 \quad \mathrm{C}_{5} \mathrm{H}_{7} \mathrm{~N} \quad 96-54-8$ 1H-Pyrrole, 1-methyl-
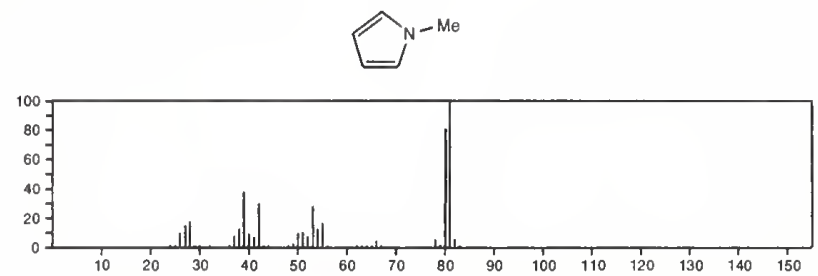

$81 \quad \mathrm{C}_{5} \mathrm{H}_{7} \mathrm{~N} \quad 636-41-9$ 1H-Pyrrole, 2-methyl-
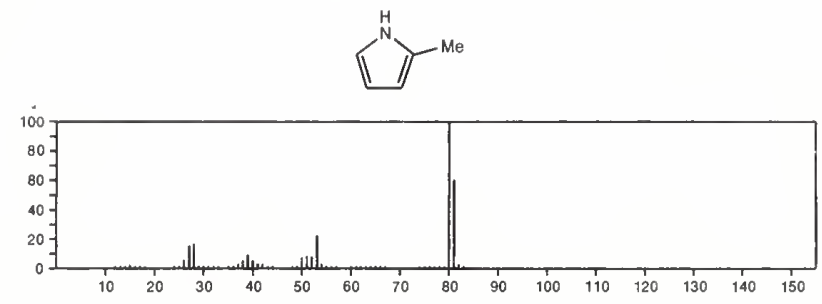

$81 \quad \mathrm{C}_{5} \mathrm{H}_{7} \mathrm{~N}$

$1647-11-6$

Butanenitrile, 2-methylene-

NCCE $\mathrm{t}=\mathrm{CH}_{2}$

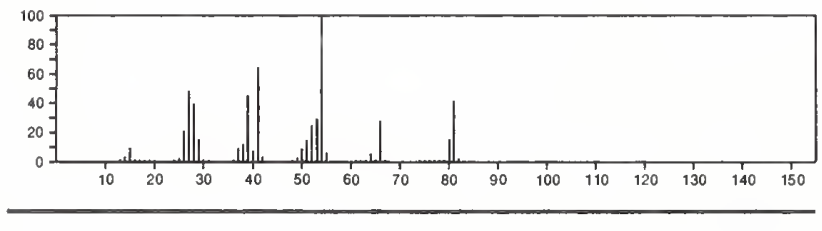

81

$\mathrm{C}_{5} \mathrm{H}_{7} \mathrm{~N}$

13284-42-9

$\mathrm{NCCH}=\mathrm{CHE}$ :

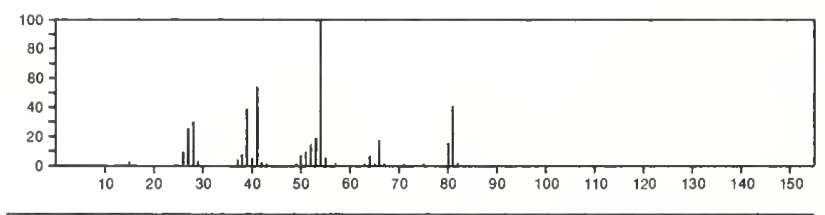

81

3-Butenenitrile, 2-methyl-

$\mathrm{C}_{5} \mathrm{H}_{7} \mathrm{~N}$

$16529-56-9$

NCCHMe $\mathrm{CH}=\mathrm{CH}_{2}$

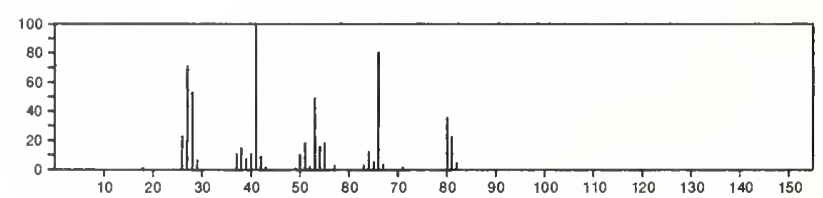

82

Carbonic chloride fluoride

$\mathrm{CClFO}$

$353-49-1$

CI COF

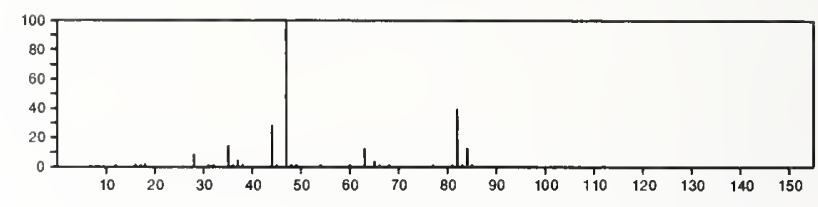

82

$\mathrm{CH}_{6} \mathrm{~N}_{2 .} \mathrm{ClH}$

Hydrazine, methyl-, monohydrochloride

$7339-53-9$

$\mathrm{MeNHNH} 2 \cdot \mathrm{HCl}$

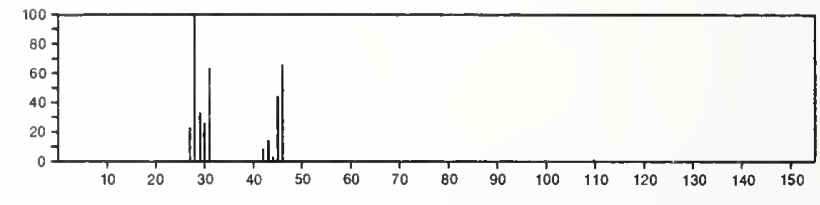

82

$\mathrm{C}_{2} \mathrm{HF}_{3}$

$359-11-5$

Ethene, trifluoro-

$\mathrm{FCH}=\mathrm{CF}_{2}$

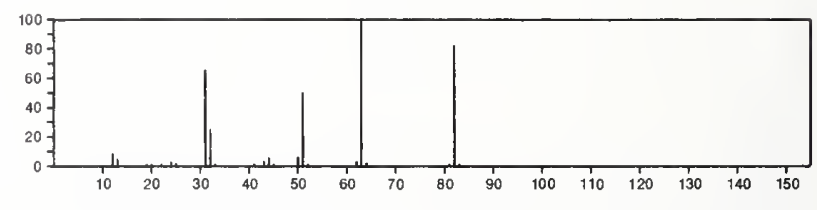

82

1,2,4,5-Tetrazine

$\mathrm{C}_{2} \mathrm{H}_{2} \mathrm{~N}_{4}$

$290-96-0$
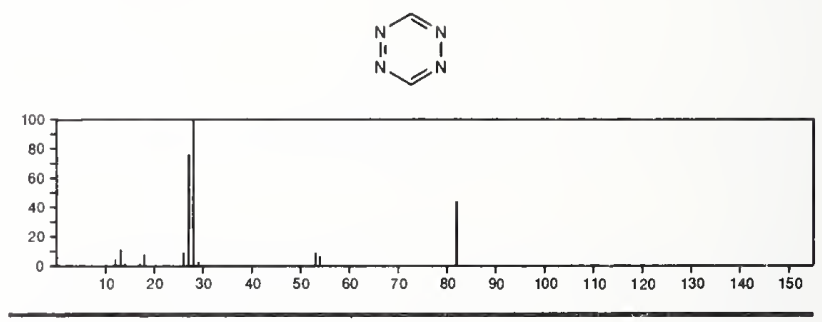

82

$\mathrm{C}_{2} \mathrm{H}_{4} \mathrm{ClF}$

$1615-75-4$

Ethane, 1-chloro-1-fluoro-

Me CHCl $\{\mathrm{Me}$

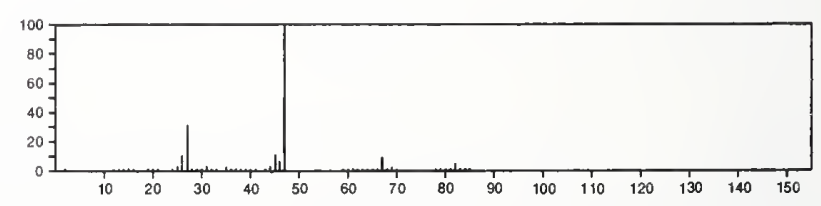

82
$1 H$-Imidazole, 1-methyl-

$\mathrm{C}_{4} \mathrm{H}_{6} \mathrm{~N}_{2}$

$616-47-7$
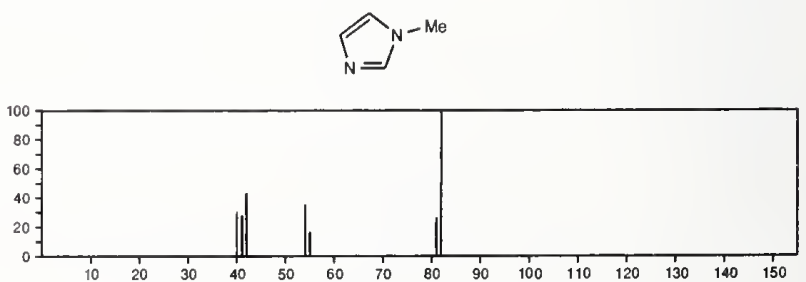
${ }_{1 H}^{82}$-Imidazole, 2-methyl-

$\mathrm{C}_{4} \mathrm{H}_{6} \mathrm{~N}_{2}$<smiles>[NH3+]c1ncc[nH]1</smiles>

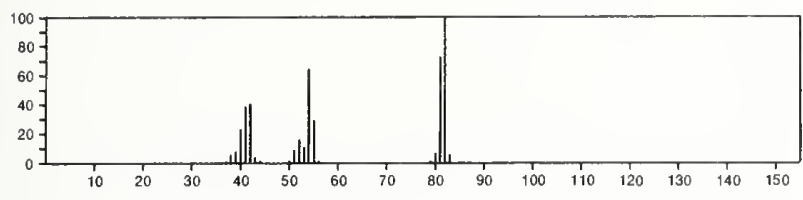

82

1H-Pyrazole, 1-methyl-

$\mathrm{C}_{4} \mathrm{H}_{6} \mathrm{~N}_{2}$

930-36-9<smiles>Cn1cccn1</smiles>

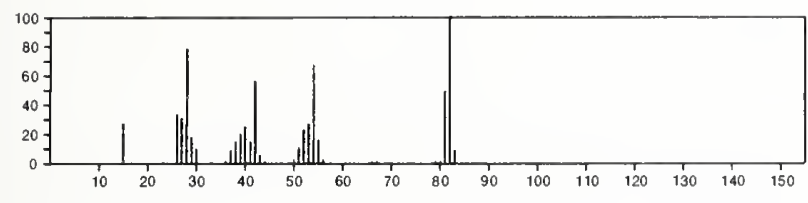

82

1H-Pyrazole, 3-methyl-

$\mathrm{C}_{4} \mathrm{H}_{6} \mathrm{~N}_{2}$
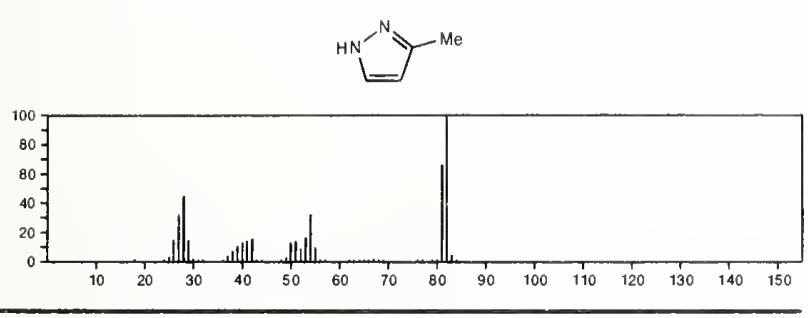

82

$\mathrm{C}_{5} \mathrm{H}_{6} \mathrm{O}$

$534-22-5$

Furan, 2-methyl-
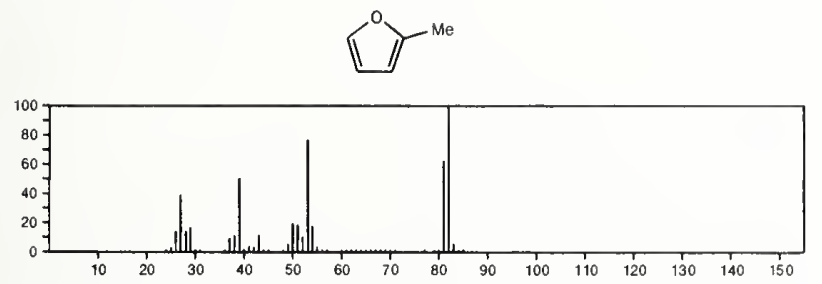

82

$\mathrm{C}_{5} \mathrm{H}_{6} \mathrm{O}$

$930-30-3$

2-Cyclopenten-1-one
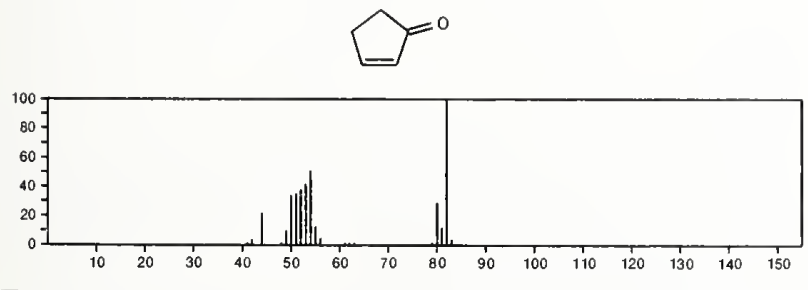

82

3,4-Pentadienal

$\mathrm{C}_{5} \mathrm{H}_{6} \mathrm{O}$

4009-55-6

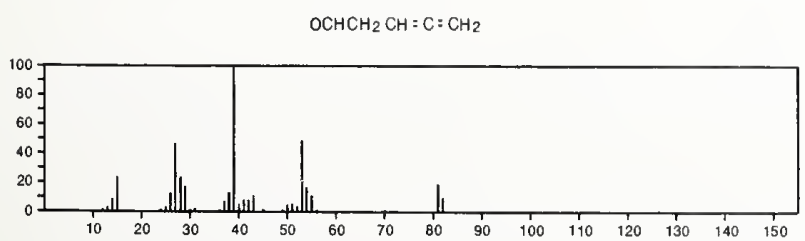

82

Cyclohexene

$\mathrm{C}_{6} \mathrm{H}_{10}$

110-83-8
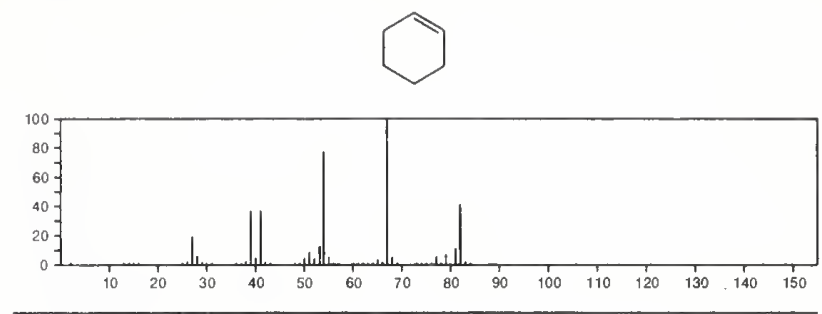

82

Bicyclo[3.1.0]hexane

$\mathrm{C}_{6} \mathrm{H}_{10}$

$285-58-5$
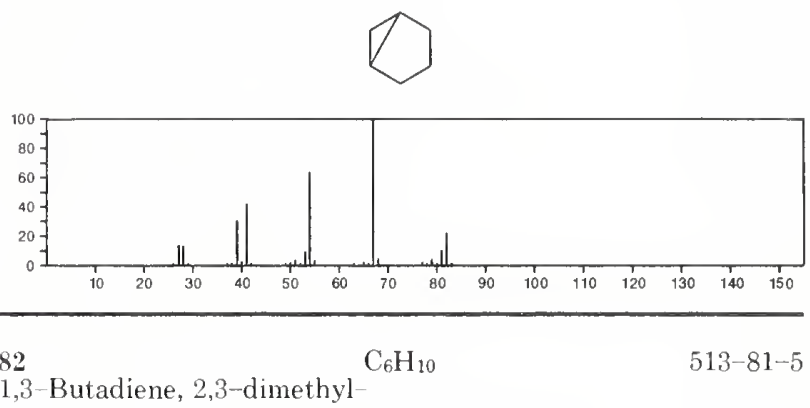

$\mathrm{H}_{2} \mathrm{C}=\mathrm{CMe} \mathrm{CMe}=\mathrm{CH}$

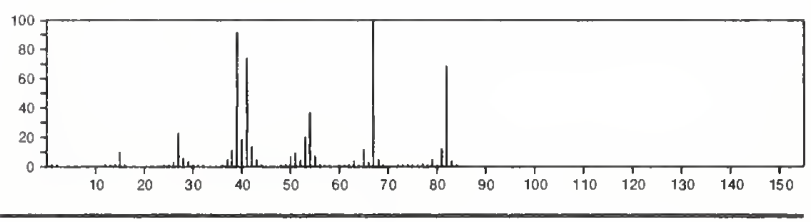

82

1,5-Hexadiene

$\mathrm{C}_{6} \mathrm{H}_{10}$

592-42-7

$\mathrm{H}_{2} \mathrm{C}=\mathrm{CHCH}_{2} \mathrm{CH}_{2} \mathrm{CH}=\mathrm{CH}_{2}$

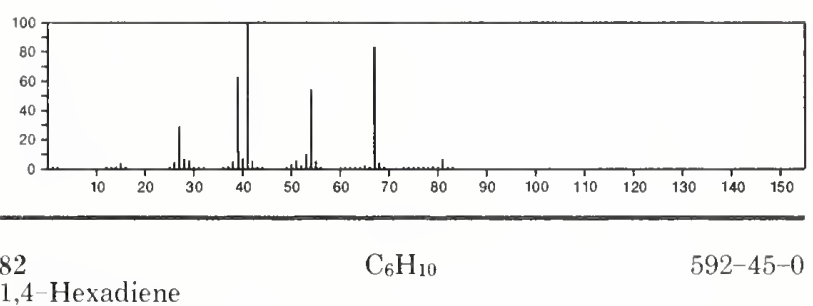

$\mathrm{Me} \mathrm{CH}=\mathrm{CHCH}_{2} \mathrm{CH}=\mathrm{CH}_{2}$

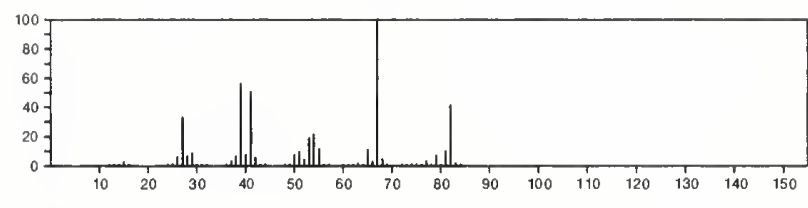

82

2,4-Hexadiene

$\mathrm{C}_{6} \mathrm{H}_{10}$

592-46-1

$\mathrm{MeCH}=\mathrm{CHCH}=\mathrm{CHMe}$

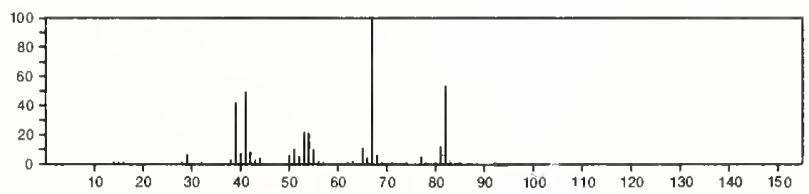


82

1-Hexyne

$\mathrm{C}_{6} \mathrm{H}_{10}$

$\mathrm{HC} \equiv \mathrm{C}\left(\mathrm{CH}_{2}\right)_{3} \mathrm{Me}$

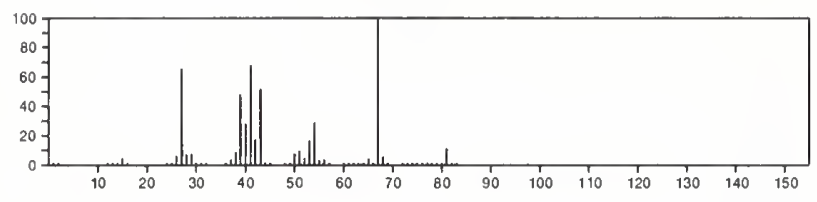

82

Cyclopentene, 1-methyl-

$\mathrm{C}_{6} \mathrm{H}_{10}$

693-89-0
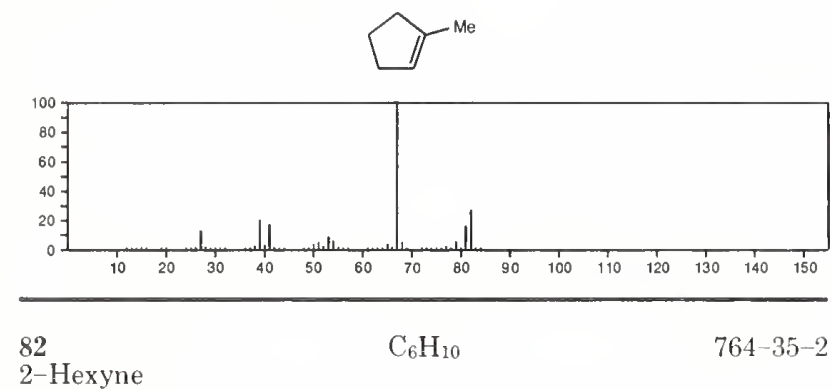

$\mathrm{Me} C \cong \mathrm{CP}$

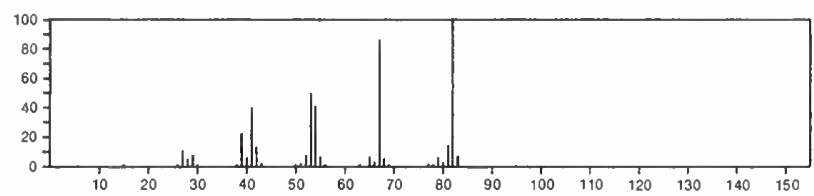

$82 \quad \mathrm{C}_{6} \mathrm{H}_{10}$

1-Butyne, 3,3-dimethyl-

$\mathrm{Me} 3 \mathrm{CC} \equiv \mathrm{CH}$

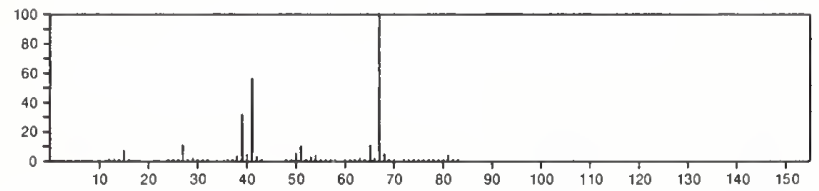

82

3-Hexyne

$\mathrm{C}_{6} \mathrm{H}_{10}$

928-49-4

$E t C \equiv C E t$

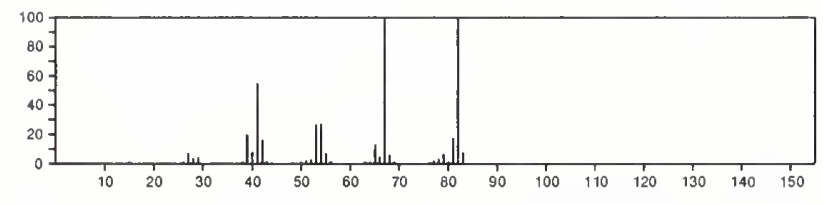

82

1,3-Pentadiene, 2-methyl-

$\mathrm{C}_{6} \mathrm{H}_{10}$

1118-58-7

$\mathrm{H}_{2} \mathrm{C}=\mathrm{CMe} \mathrm{CH}=\mathrm{CHM}$

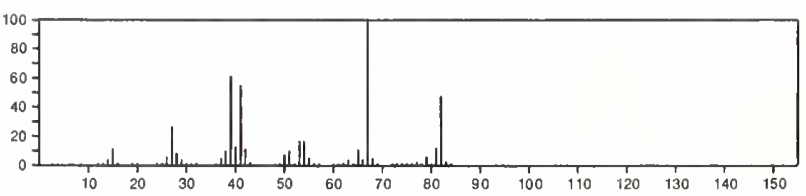

82

Cyclopentene, 3-methyl-

$\mathrm{C}_{6} \mathrm{H}_{10}$

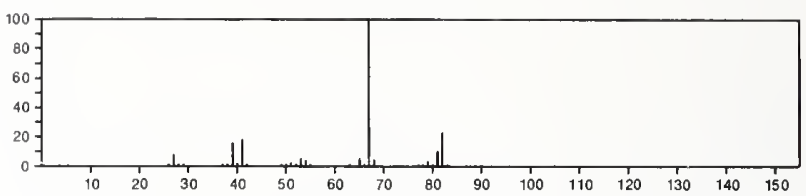

82

$\mathrm{C}_{6} \mathrm{H}_{10}$

1528-30-9

Cyclopentane, methylene
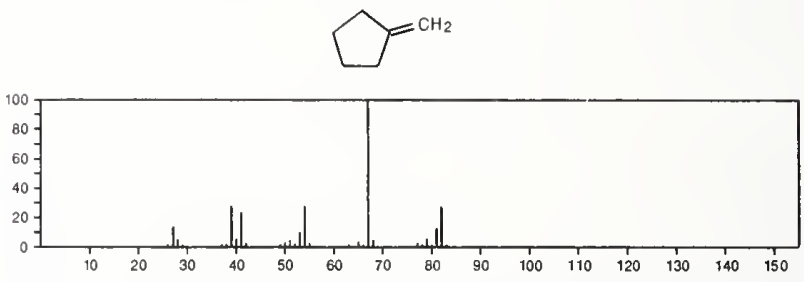

82

$\mathrm{C}_{6} \mathrm{H}_{10}$

1759-81-5

Cyclopentene, 4-methyl
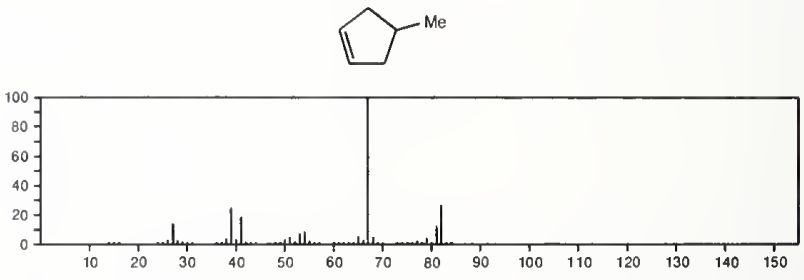

82

$\mathrm{C}_{6} \mathrm{H}_{10}$

4663-22-3

Cyclopropane, (1-methylethenyl)-

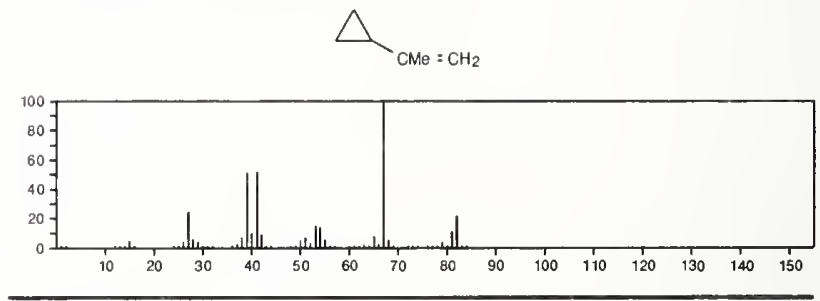

82

1,1'-Bicyclopropyl

$\mathrm{C}_{6} \mathrm{H}_{10}$

5685-46-1

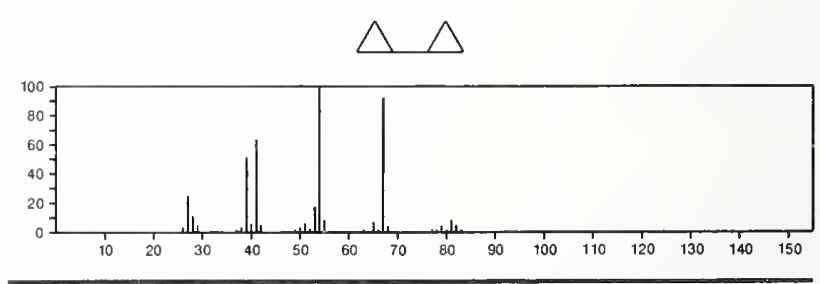

82

$\mathrm{C}_{6} \mathrm{H}_{10}$

$7154-75-8$

1-Pentyne, 4-methyl-

$\mathrm{HC} \equiv \mathrm{CCH}_{2} \mathrm{CHMe}_{2}$

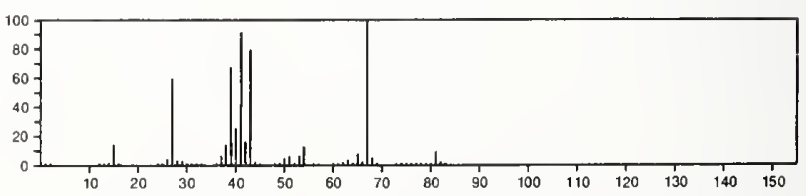


$83 \quad \mathrm{C}_{3} \mathrm{H}_{5} \mathrm{~N}_{3} \quad 6086-21-1$ 1H-1,2,4-Triazole, 1-methyl-
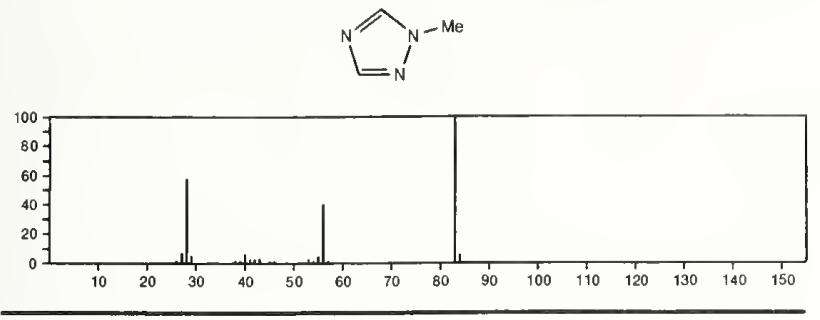

83

$1 H$-1,2,4-Triazole, 3-methyl-

$\mathrm{C}_{3} \mathrm{H}_{5} \mathrm{~N}_{3}$

$7170-01-6$
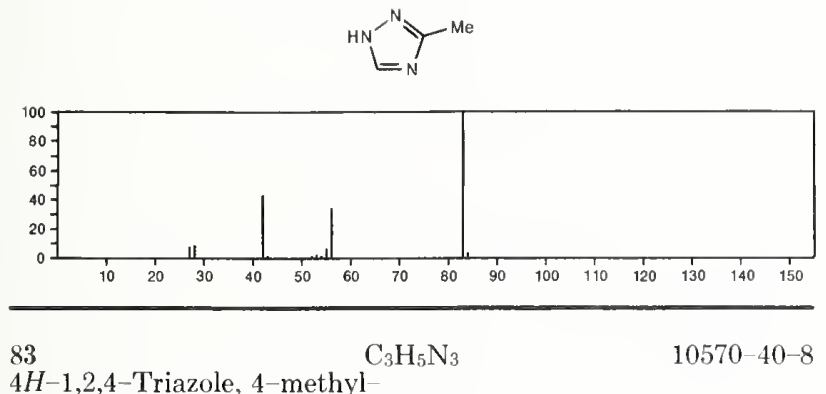

$4 H$-1,2,4-Triazole, 4-methyl
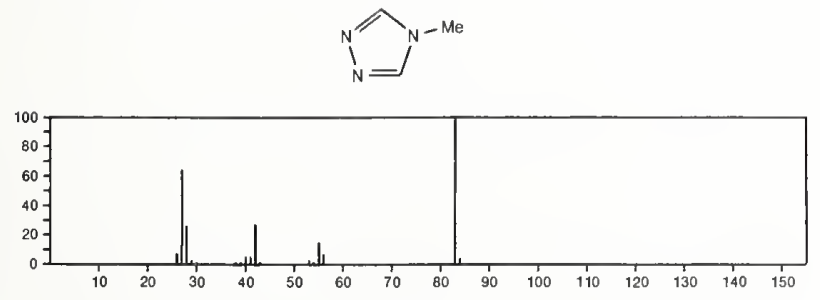

83

Isoxazole, 5-methyl

$\mathrm{C}_{4} \mathrm{H}_{5} \mathrm{NO}$
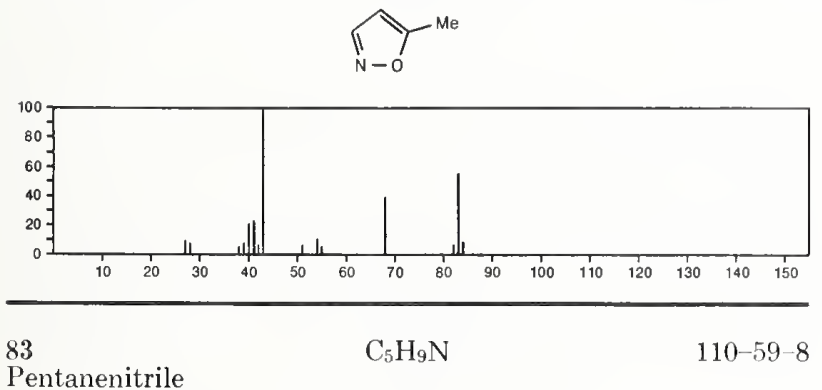

Pentanenitrile

$\mathrm{NC}\left(\mathrm{CH}_{2}\right)_{3} \mathrm{Me}$

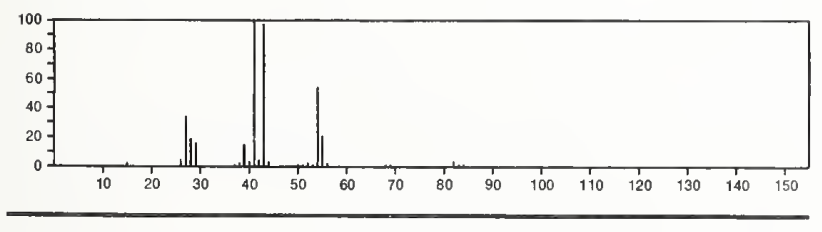

83

1-Azabicyclo[3.1.0]hexane

$\mathrm{C}_{5} \mathrm{H}_{9} \mathrm{~N}$

$285-76-7$
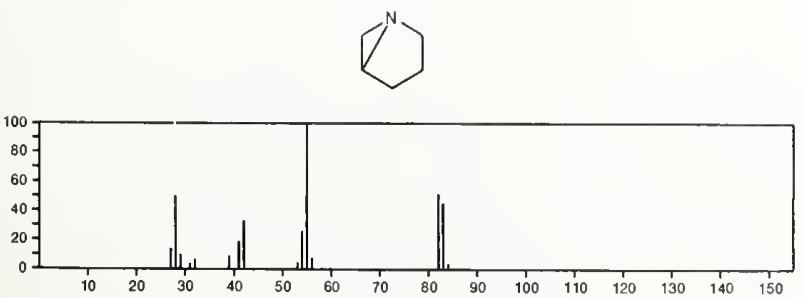

83

$\mathrm{C}_{5} \mathrm{H}_{9} \mathrm{~N}$

$505-18-0$

Pyridine, 2,3,4,5-tetrahydro-
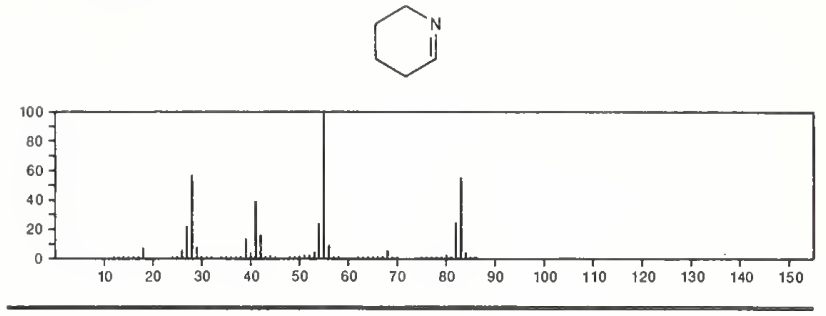

83

Propanenitrile, 2,2-dimethyl

$\mathrm{C}_{5} \mathrm{H}_{9} \mathrm{~N}$

$630-18-2$

$\mathrm{Me} 3 \mathrm{CCN}$

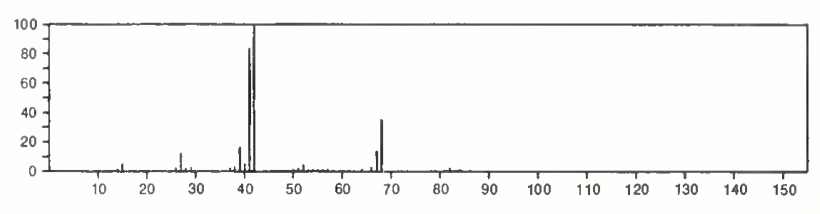

83

Pyridine, 1,2,3,6-tetrahydro-

$\mathrm{C}_{5} \mathrm{H}_{9} \mathrm{~N}$

$694-05-3$
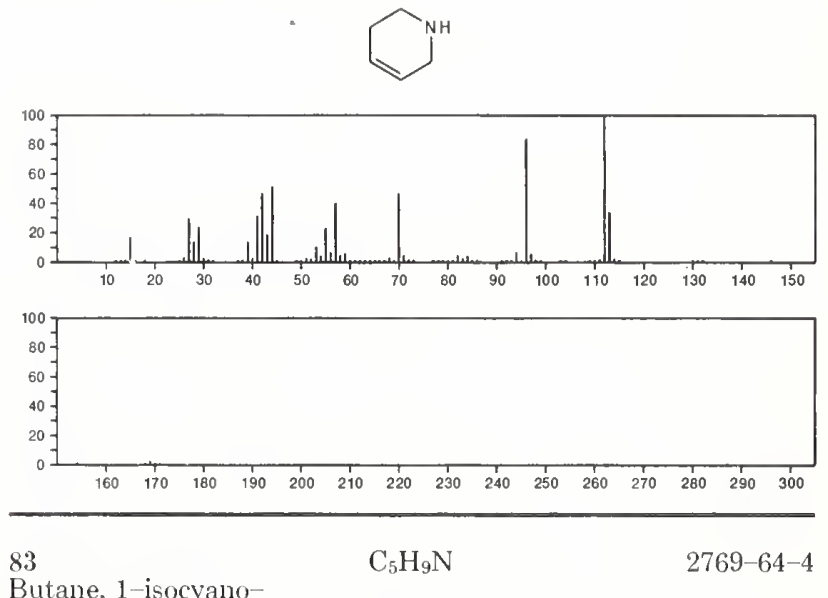

Butane, 1-isocyano-

$\mathrm{CN}\left(\mathrm{CH}_{2}\right)_{3} \mathrm{Me}$

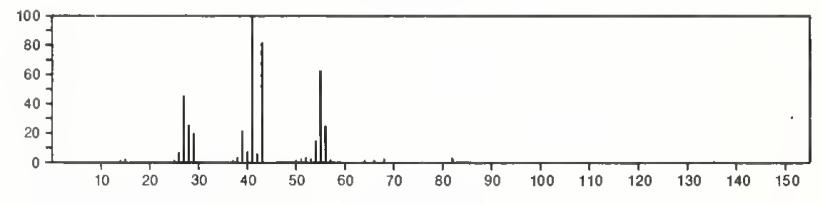

83

Propane, 2-isocyano-2-methyl-

$7188-38-7$

$t-B u N C$

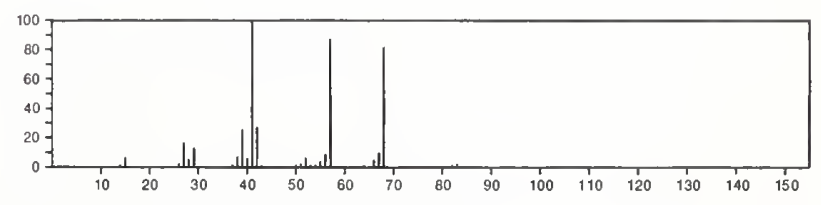

84

Methane, dichloro-

$\mathrm{CH}_{2} \mathrm{Cl}_{2}$

$75-09-2$

$\mathrm{CH}_{2} \mathrm{Cl}_{2}$

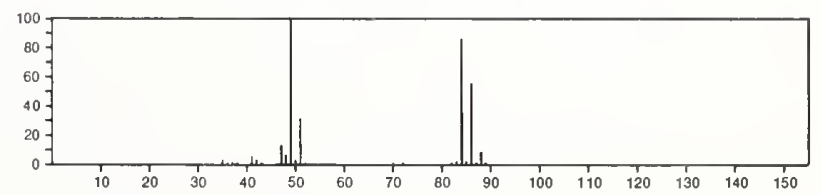


84 Ethane, 1,1,1-trifluoro-

$\mathrm{C}_{2} \mathrm{H}_{3} \mathrm{~F}_{3}$

$420-46-2$
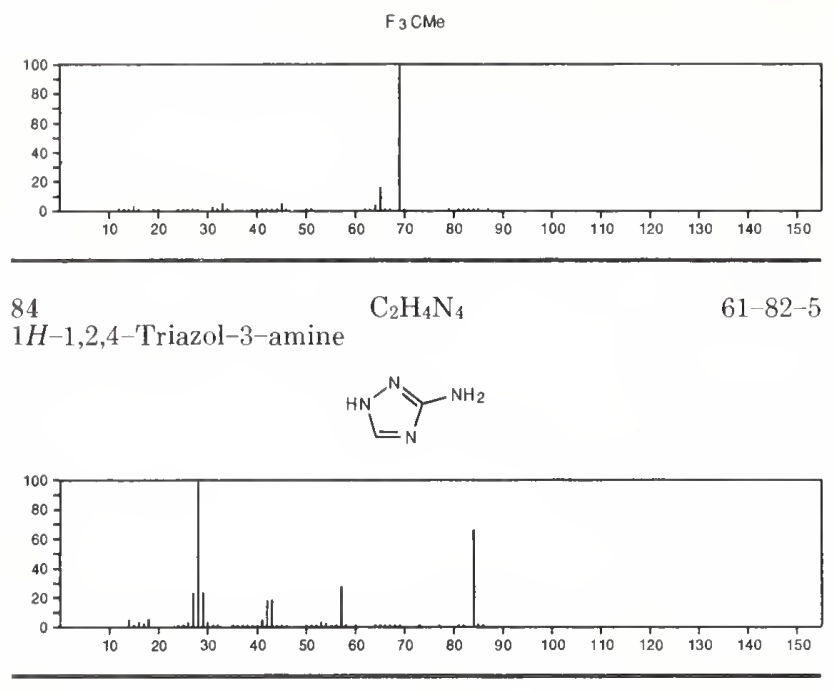

84

Guanidine, cyano

$\mathrm{C}_{2} \mathrm{H}_{4} \mathrm{~N}_{4}$

$461-58-5$

$H N=C\left(\mathrm{NH}_{2}\right) \mathrm{NHCN}$

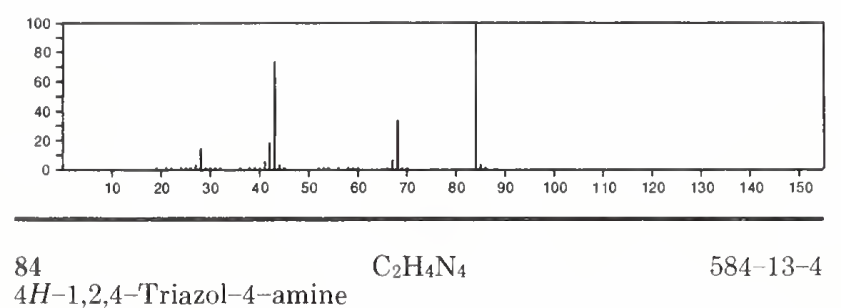

${ }_{N}^{N}=\int^{N-H_{2}}$
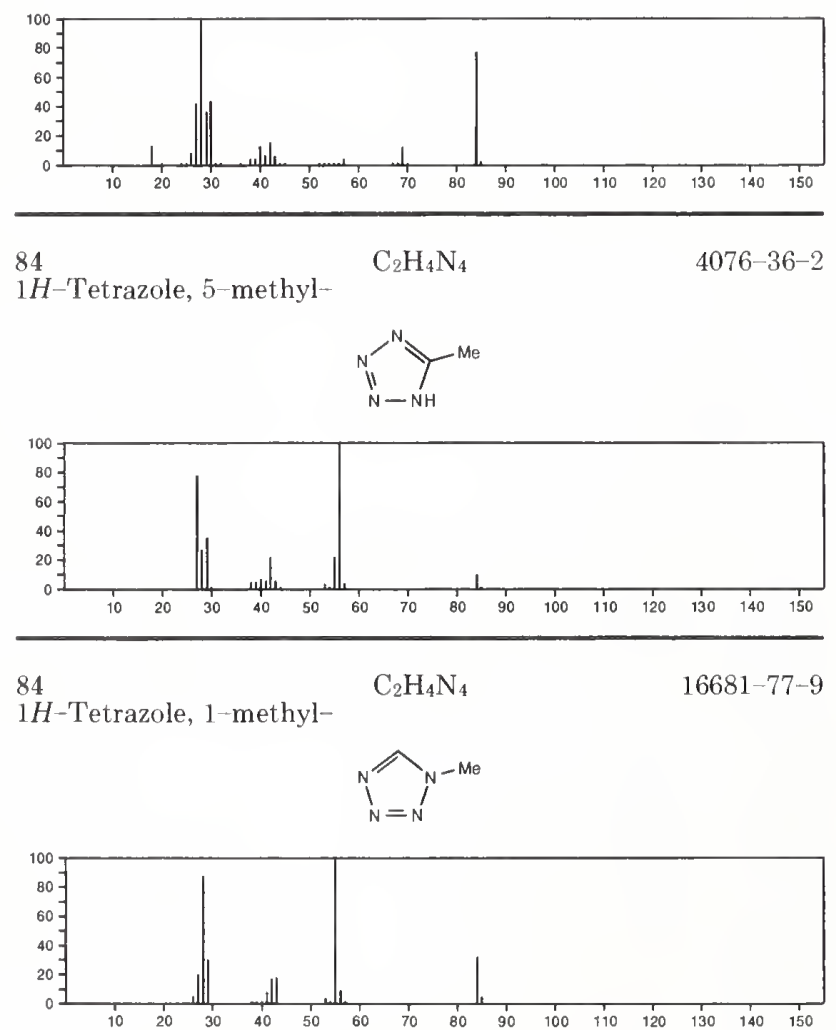

84

$\mathrm{C}_{2} \mathrm{H}_{4} \mathrm{~N}_{4}$

$16681-78-0$

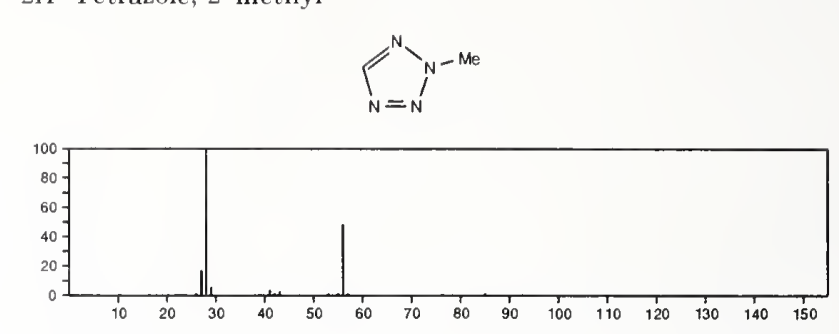

${ }_{24}^{84}$ Oxetanone, 4-methylene- ${ }^{-} \mathrm{C}_{4} \mathrm{H}_{4} \mathrm{O}_{2}$

$674-82-8$
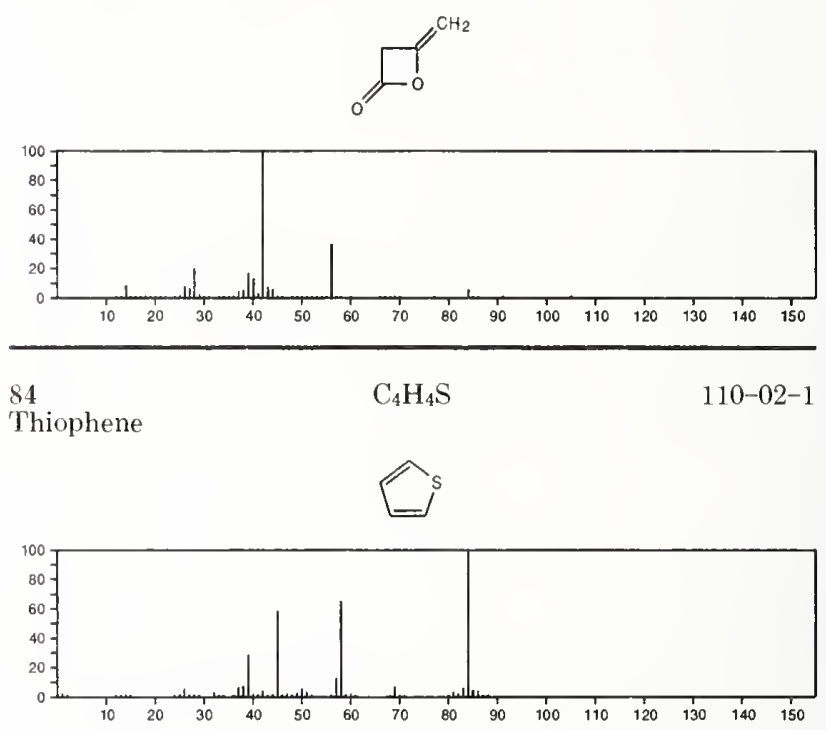

84

$\mathrm{C}_{4} \mathrm{H}_{8} \mathrm{~N}_{2}$

Acetaldehyde, ethylidenehydrazone

$592-56-3$

$\mathrm{Me} C H=\mathrm{NN}=\mathrm{CHMe}$

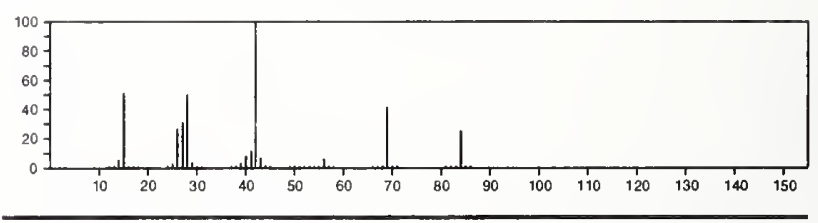

84

Acetonitrile, (dimethylamino)

$\mathrm{C}_{4} \mathrm{H}_{8} \mathrm{~N}_{2}$

926-64-7

$\mathrm{Me}_{2} \mathrm{NCH}_{2} \mathrm{CN}$

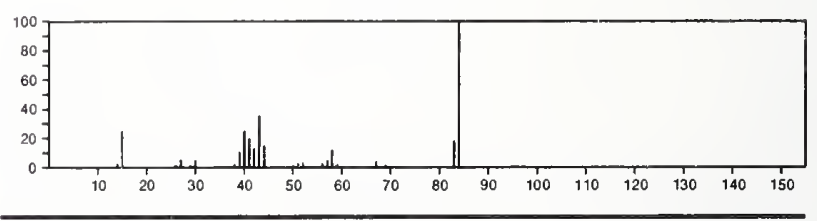

84

$\mathrm{C}_{5} \mathrm{H}_{8} \mathrm{O}$

$110-87-2$

2H-Pyran, 3,4-dihydro-
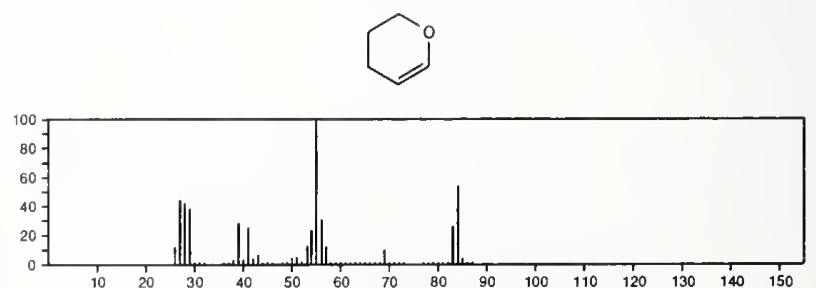
84

3-Butyn-2-ol, 2-methyl-

$\mathrm{C}_{5} \mathrm{H}_{8} \mathrm{O}$

$\mathrm{Me}_{2} \mathrm{COHC} \equiv \mathrm{CH}$

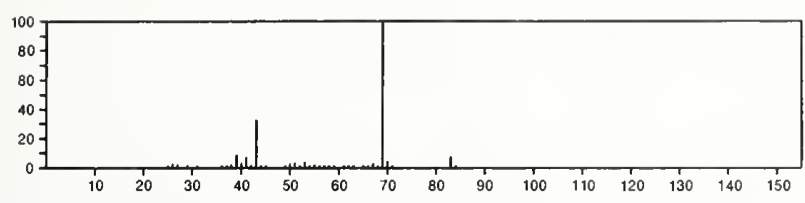

84

Cyclopentanone

$\mathrm{C}_{5} \mathrm{H}_{8} \mathrm{O}$
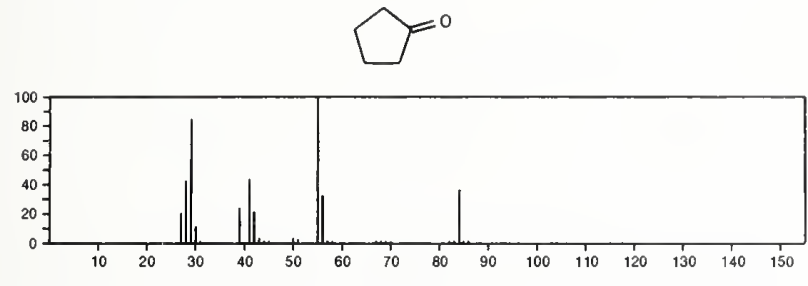

$84 \quad \mathrm{C}_{5} \mathrm{H}_{8} \mathrm{O}$

6-Oxabicyclo[3.1.0]hexane
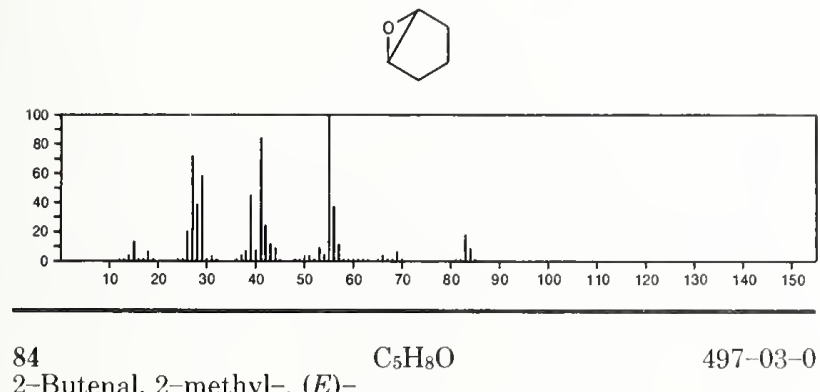

2-Butenal, 2-methyl-, (E)-

$\mathrm{MeCH}=\mathrm{CMeCHO}$

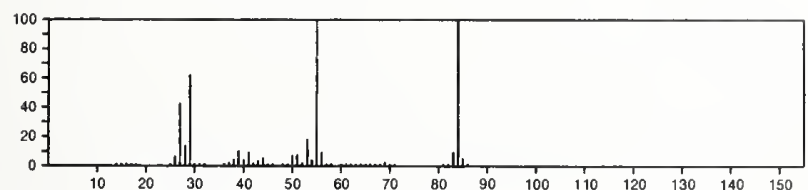

84

3-Penten-2-one

$\mathrm{C}_{5} \mathrm{H}_{8} \mathrm{O}$

$625-33-2$

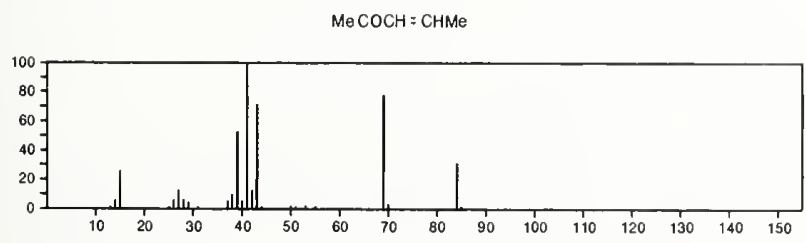

84

Ethanone, 1-cyclopropyl-

$\mathrm{C}_{5} \mathrm{H}_{8} \mathrm{O}$
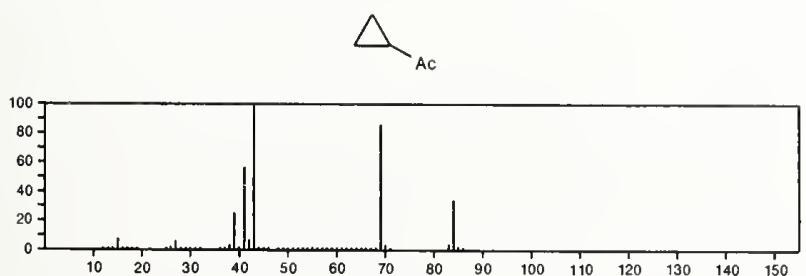

84

3-Buten-2-one, 3-methyl-

$\mathrm{C}_{5} \mathrm{H}_{8} \mathrm{O}$

$814-78-8$

$\mathrm{Me}$ COCMe $=\mathrm{CH}_{2}$

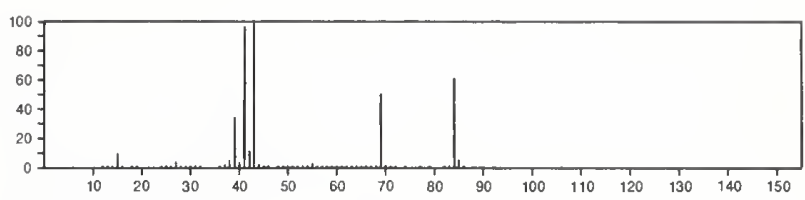

84

2-Butenal, 2-methyl-

$\mathrm{C}_{5} \mathrm{H}_{8} \mathrm{O}$

$1115-11-3$

$\mathrm{Me} \mathrm{CH} \equiv \mathrm{CMeCHO}$

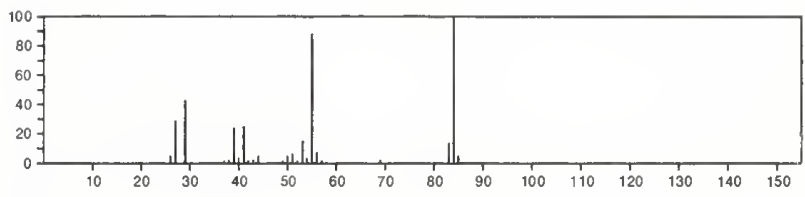

84

Furan 2,3-dihydro-5-methyl $\mathrm{C}_{5} \mathrm{H}_{8} \mathrm{O}$

$1487-15-6$

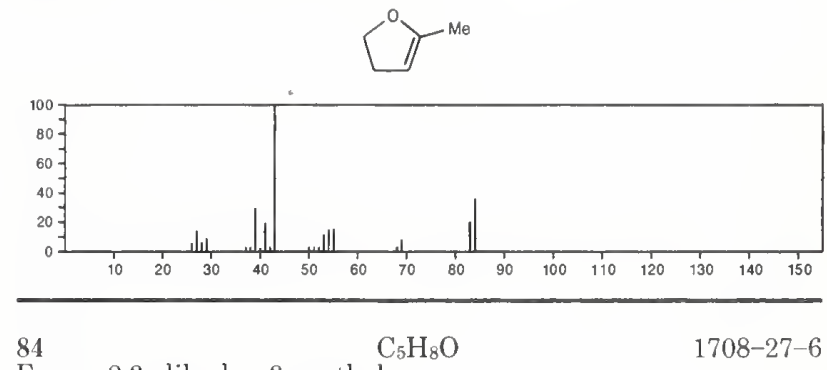

Furan, 2,3-dihydro-3-methyl-
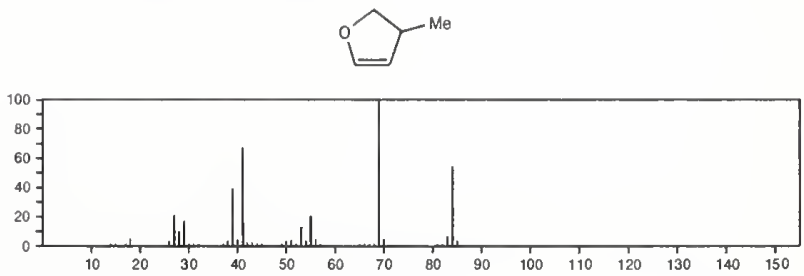

84

Furan, 2,5-dihydro-3-methyl-

$1708-31-2$

$\mathrm{C}_{5} \mathrm{H}_{8} \mathrm{O}$

$\overbrace{}^{\mathrm{Me}}$

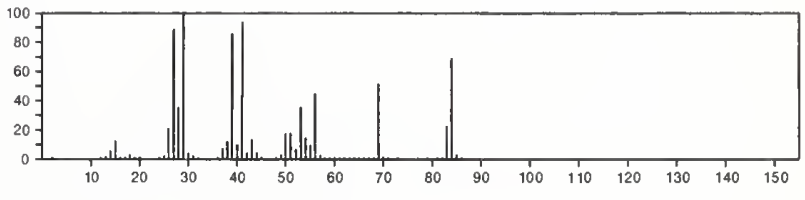

84

4-Pentenal

$\mathrm{C}_{5} \mathrm{H}_{8} \mathrm{O}$

$2100-17-6$

$\mathrm{OCHCH} \mathrm{CH}_{2} \mathrm{CH}=\mathrm{CH}_{2}$

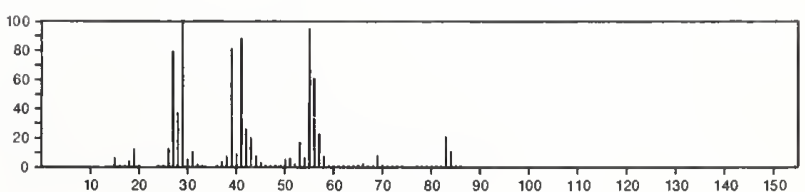


84

3-Penten-2-one, $(E)$ -

$\mathrm{C}_{5} \mathrm{H}_{8} \mathrm{O}$

$\mathrm{Me} \mathrm{COCH}=\mathrm{CHM}$

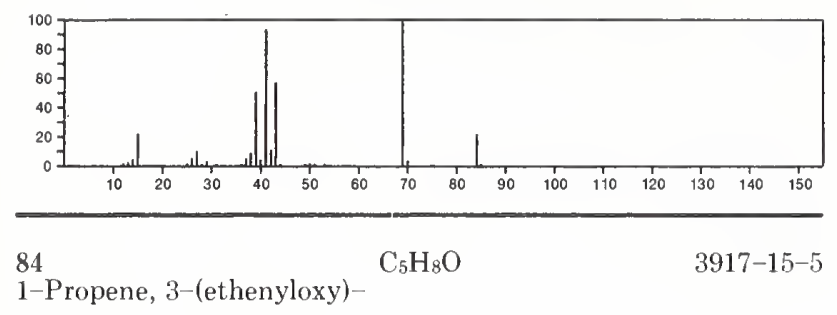

$\mathrm{H}_{2} \mathrm{C}=\mathrm{CHOCH}_{2} \mathrm{CH}=\mathrm{CH}_{2}$

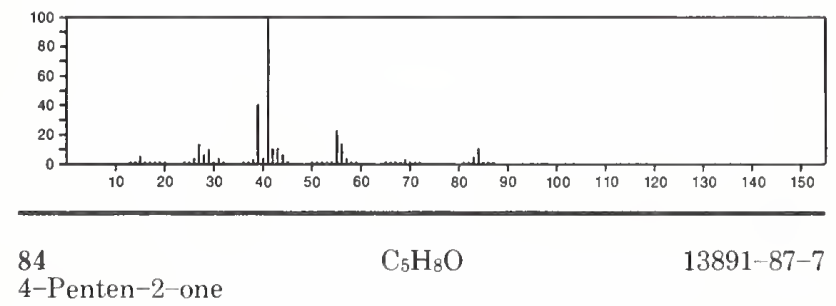

$\mathrm{MeCOCH} \mathrm{CH}_{2}=\mathrm{CH}_{2}$

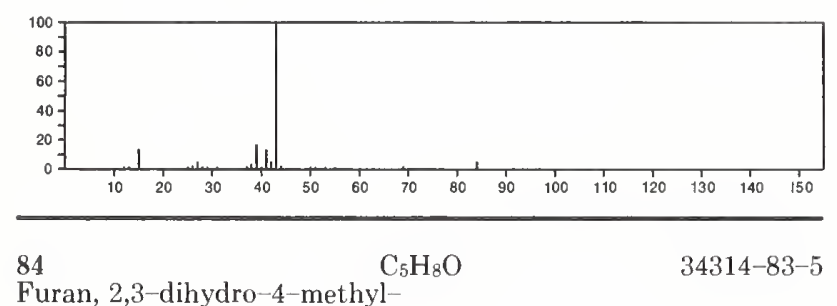

¿ye

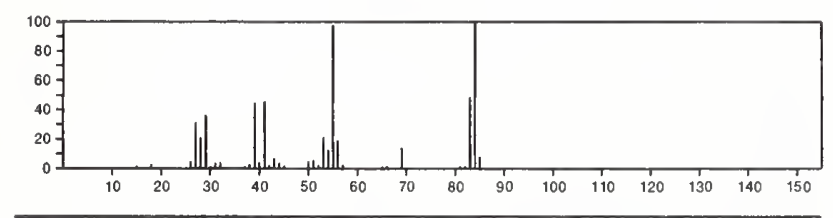

$84 \quad \mathrm{C}_{5} \mathrm{H}_{13} \mathrm{~B} \quad 1115-07-7$

Borane, diethylmethyl-

E ${ }_{2} B M e$

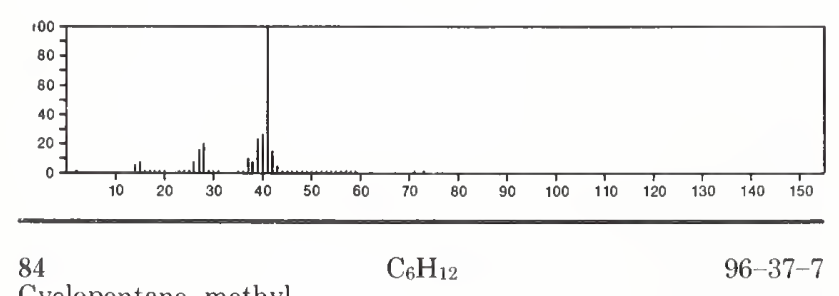

Cyclopentane, methyl-
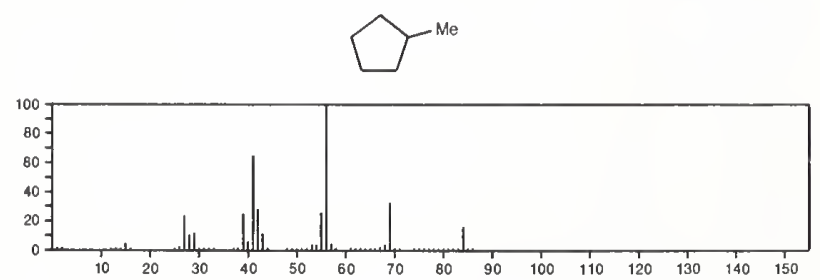

84

Cyclohexane

$\mathrm{C}_{6} \mathrm{H}_{12}$

$110-82-7$

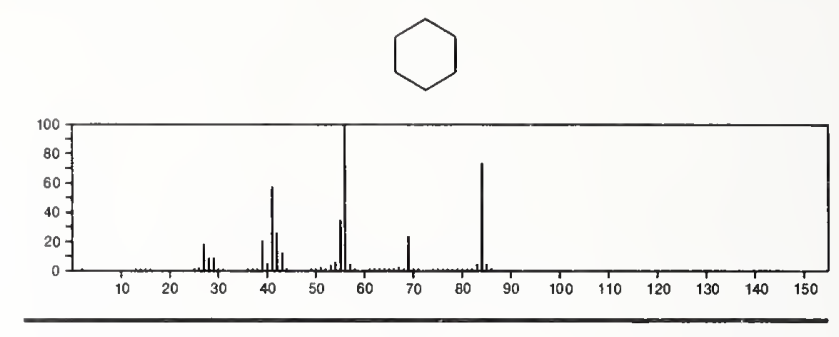

84

1-Butene, 3,3-dimethyl-

$\mathrm{C}_{6} \mathrm{H}_{12}$

558-37-2

$\mathrm{Me}{ }_{3} \mathrm{CCH}=\mathrm{CH}_{2}$
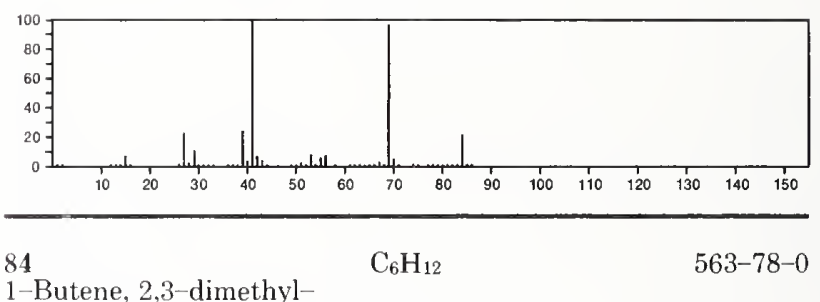

1-Butene, 2,3-dimethyl-

$\mathrm{Me}_{2} \mathrm{CHCMe}=\mathrm{CH}_{2}$

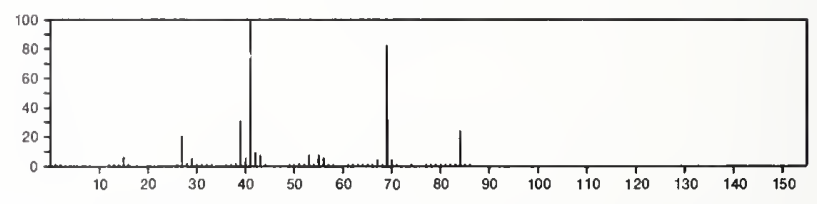

84

2-Butene, 2,3-dimethyl-

$\mathrm{C}_{6} \mathrm{H}_{12}$

563-79-1

$\mathrm{Me}_{2} \mathrm{C}=\mathrm{CMe}_{2}$

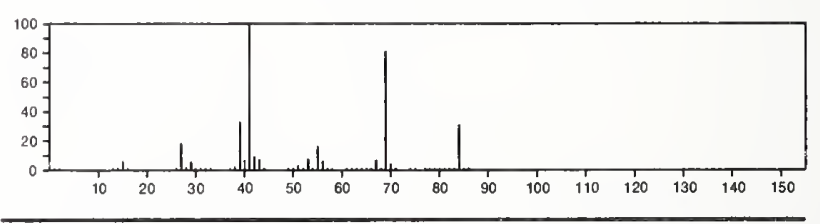

84

1-Hexene

$\mathrm{C}_{6} \mathrm{H}_{12}$

592-41-6

$\mathrm{H}_{2} \mathrm{C}=\mathrm{CH}\left(\mathrm{CH}_{2}\right){ }_{3} \mathrm{Me}$

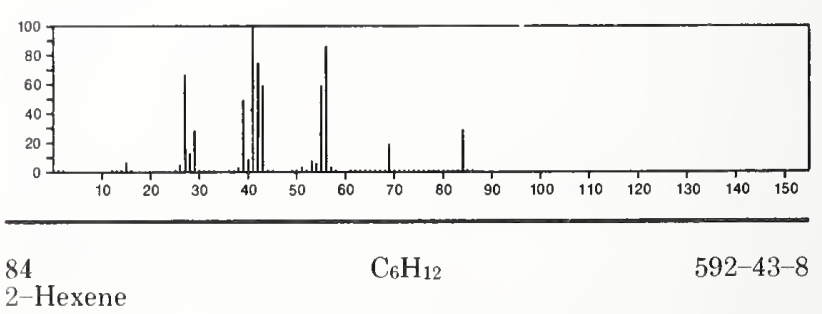

$\mathrm{Me} \mathrm{CH}=\mathrm{CHPr}$

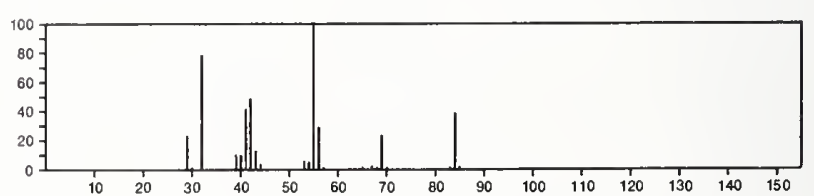


84

2-Pentene, 3-methyl-, (E)

$\mathrm{C}_{6} \mathrm{H}_{12}$

$\mathrm{MeCH}=\mathrm{CE}: \mathrm{Me}$

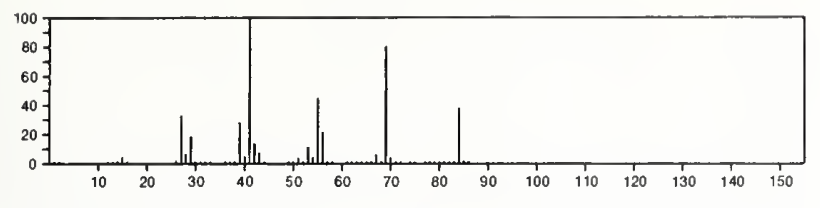

$84 \quad \mathrm{C}_{6} \mathrm{H}_{12}$

$625-27-4$

2-Pentene, 2-methyl-

$\mathrm{Me}_{2} \mathrm{C}=\mathrm{CHE}$

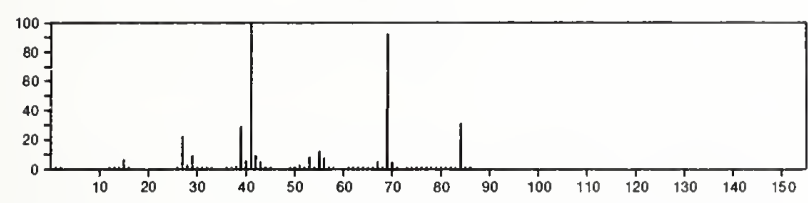

84

2-Pentene, 4-methyl-, $(E)$ -

$\mathrm{C}_{6} \mathrm{H}_{12}$

$\mathrm{MeCH}=\mathrm{CHCHMe}_{2}$

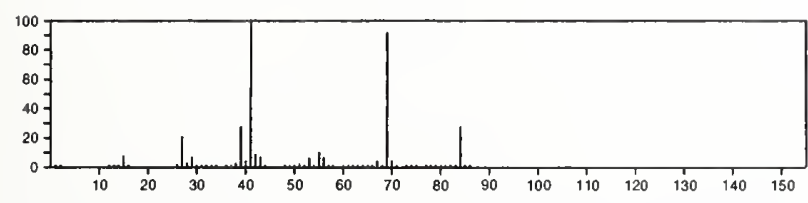

84

1-Pentene, 4-methyl

$\mathrm{C}_{6} \mathrm{H}_{12}$

$691-37-2$

$\mathrm{H}_{2} \mathrm{C}=\mathrm{CHCH}_{2} \mathrm{CHMe} 2$

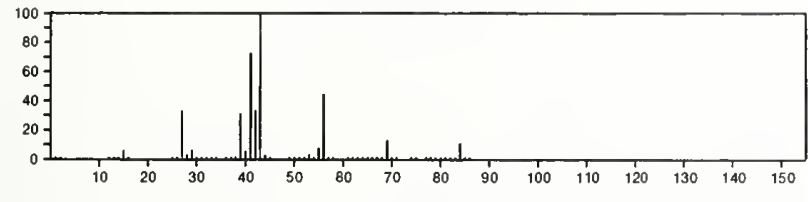

84

2-Pentene, 4-methyl-, (Z)-

$\mathrm{C}_{6} \mathrm{H}_{12}$

$691-38-3$

$\mathrm{MeCH}=\mathrm{CHCHMe}_{2}$

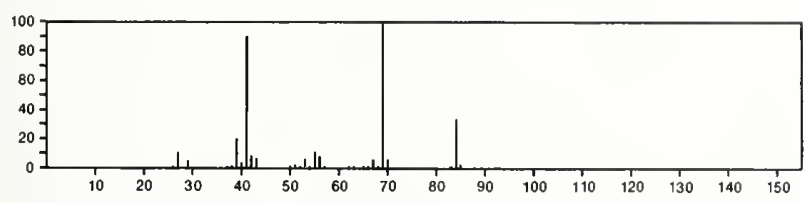

84

$\mathrm{C}_{6} \mathrm{H}_{12}$

$760-20-3$

1-Pentene, 3-methyl-

$\mathrm{Me} \mathrm{CH}_{2} \mathrm{CHM} \Theta \mathrm{CH}=\mathrm{CH}_{2}$

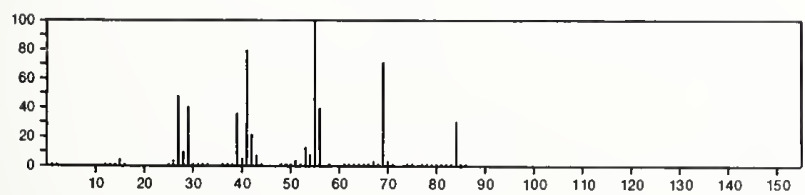

84

$\mathrm{C}_{6} \mathrm{H}_{12}$

$760-21-4$

Pentane, 3-methylene

$\mathrm{Et}_{2} \mathrm{C}: \mathrm{CH}_{2}$

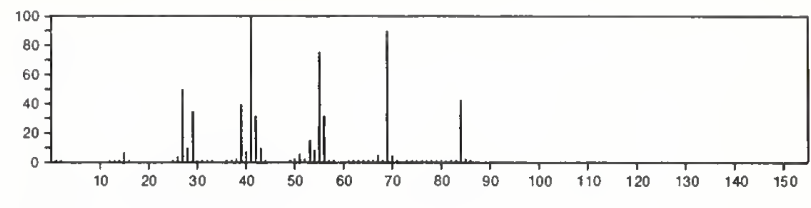

$84 \quad \mathrm{C}_{6} \mathrm{H}_{12}$

$763-29-1$

1-Pentene, 2-methyl-

$\mathrm{P}, \mathrm{CMe}_{\mathrm{e}}=\mathrm{CH}_{2}$

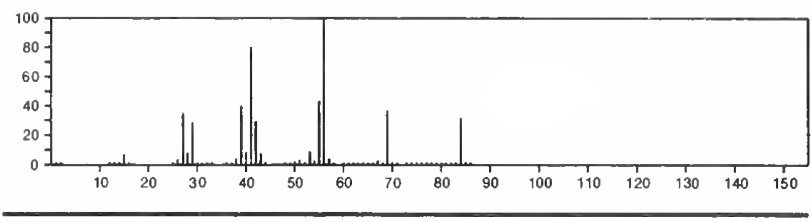

84

2-Pentene, 3-methyl-, (Z)-

$922-62-3$

$\mathrm{MeCH}=\mathrm{CE}+\mathrm{Me}$

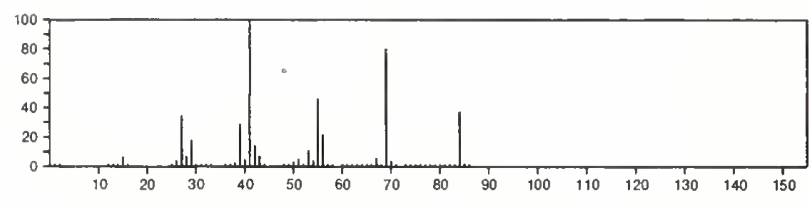

$84 \quad \mathrm{C}_{6} \mathrm{H}_{12}$

$3638-35-5$ Cyclopropane, (1-methylethyl)

$\Delta_{p r-i}$

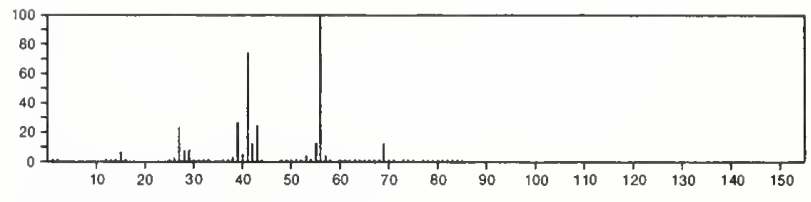

84

2-Hexene, $(E)$ -

$\mathrm{C}_{6} \mathrm{H}_{12}$

$4050-45-7$

$\mathrm{MeCH}=\mathrm{CHPr}$

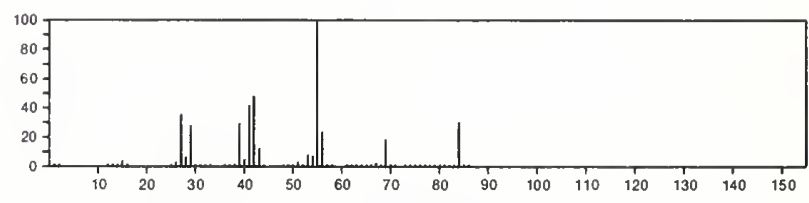

84

Cyclopropane, 1,1,2-trimethyl-

$\mathrm{C}_{6} \mathrm{H}_{12}$

$4127-45^{-1}$

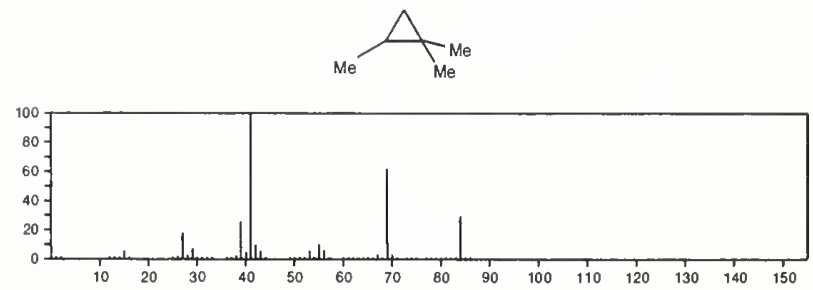


84

2-Pentene, 4-methyl-

$\mathrm{C}_{6} \mathrm{H}_{12}$

$\mathrm{Me} \mathrm{CH}=\mathrm{CHCHME} 2$
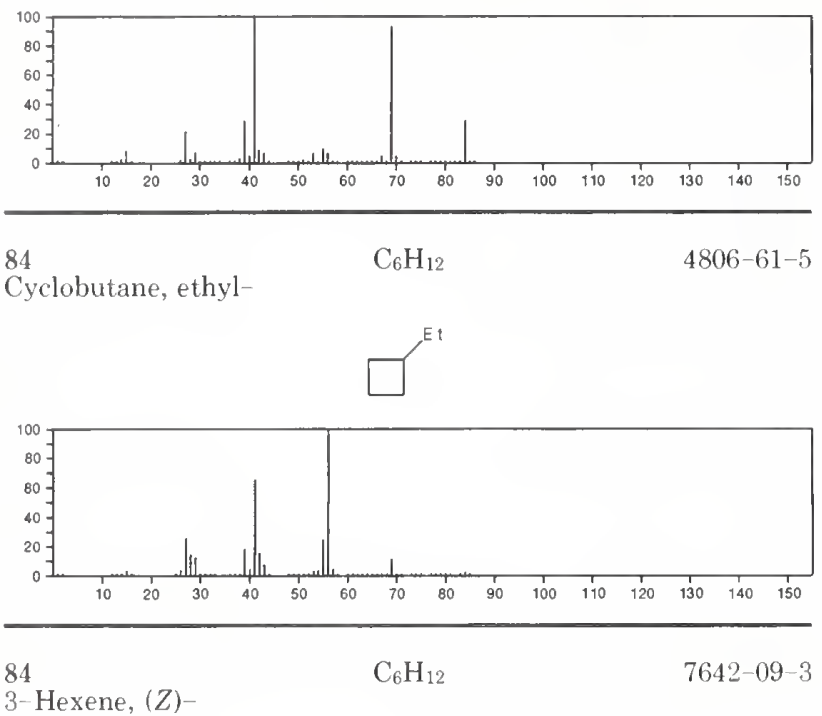

E I CH $=$ CHE I
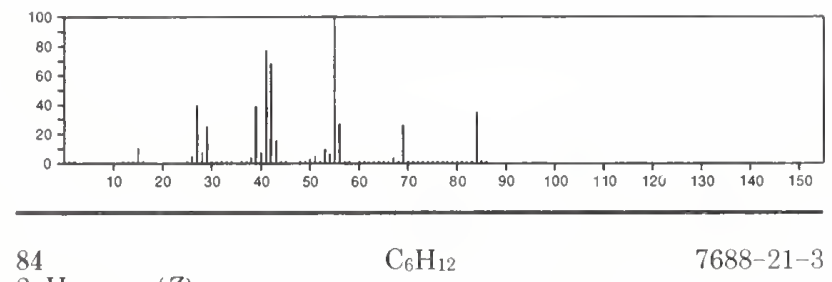

2-Hexene, (Z)-

$\mathrm{Me} C \mathrm{CH}=\mathrm{CHP}$ r

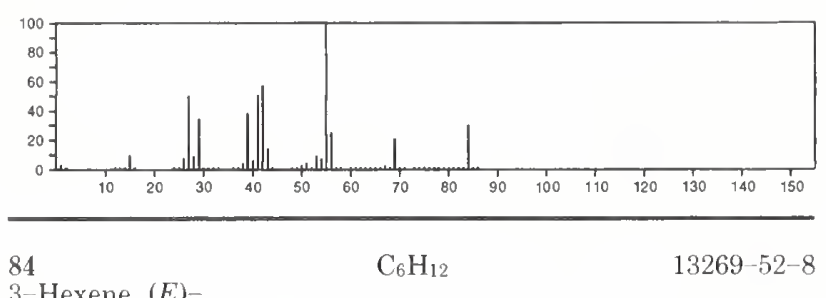

3-Hexene, $(E)$

$\mathrm{E} t \mathrm{CH}=\mathrm{CHE} \mathrm{t}$

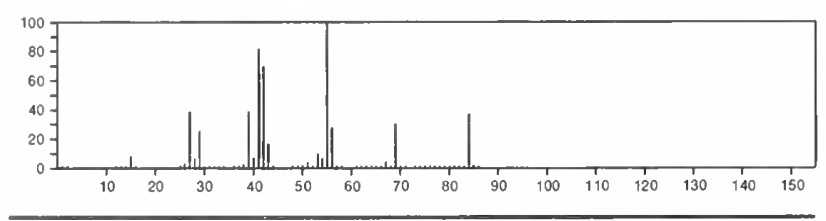

$84 \quad \mathrm{C}_{6} \mathrm{H}_{12}$

Cyclopropane, 1-ethyl-1-methyl-

$53778-43-1$

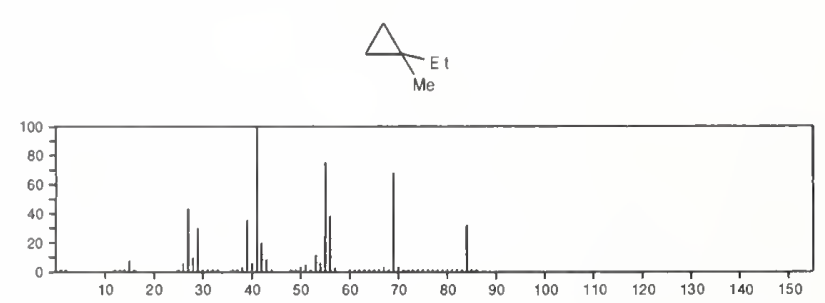

84

Krypton

$\mathrm{Kr}$

$7439-90-9$

$\mathrm{kr}$

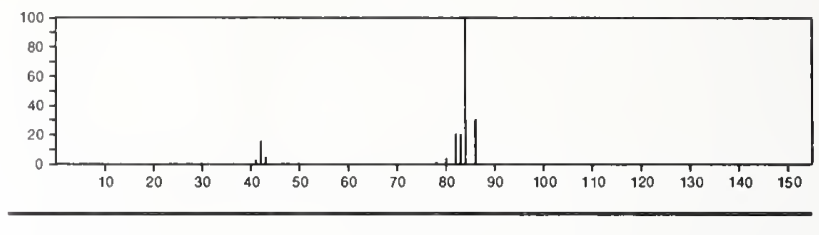

85

Acetic acid, cyano-

$\mathrm{C}_{3} \mathrm{H}_{3} \mathrm{NO}_{2}$

372-09-8

$\mathrm{CO}_{2} \mathrm{HCH}_{2} \mathrm{CN}$

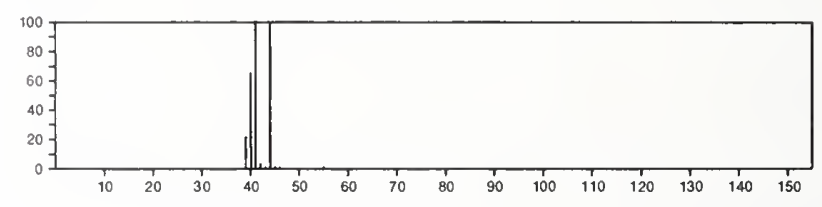

85

$\mathrm{C}_{3} \mathrm{H}_{3} \mathrm{NS}$

$288-16-4$

Isothiazole
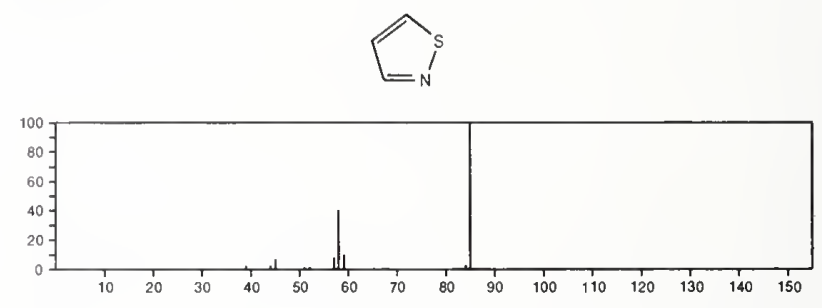

$85 \quad \mathrm{C}_{4} \mathrm{H}_{7} \mathrm{NO}$

Propanenitrile, 2-hydroxy-2-methyl

$75-86-5$

$\mathrm{Me}_{2} \mathrm{C}(\mathrm{OH}) \mathrm{CN}$

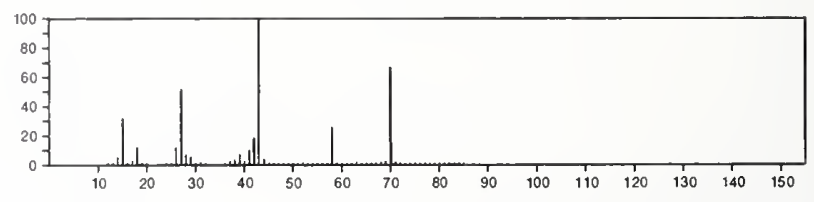

$85 \quad \mathrm{C}_{4} \mathrm{H}_{7} \mathrm{NO}$

$110-67-8$

Propanenitrile, 3-methoxy-

$\mathrm{NCCH}_{2} \mathrm{CH}_{2} \mathrm{OMe}$

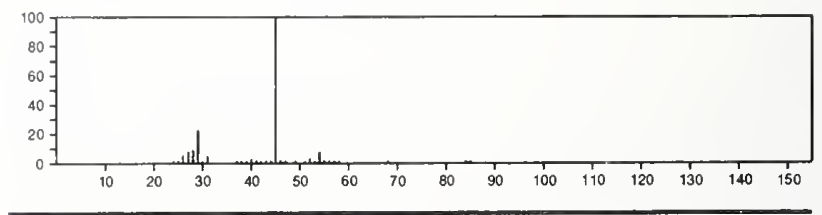

85

Propane, 1-isocyanato

$\mathrm{C}_{4} \mathrm{H}_{7} \mathrm{NO}$

110-78-1
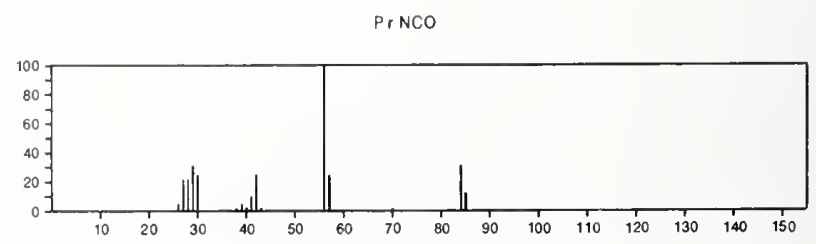
85 2-Pyrrolidinone

$\mathrm{C}_{4} \mathrm{H}_{7} \mathrm{NO}$
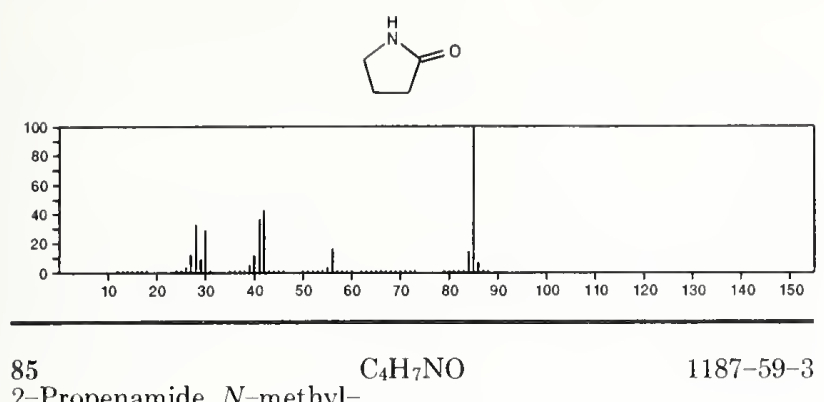

2-Propenamide, $N$-methyl-

$\mathrm{H}_{2} \mathrm{C}=\mathrm{CHCONHME}$

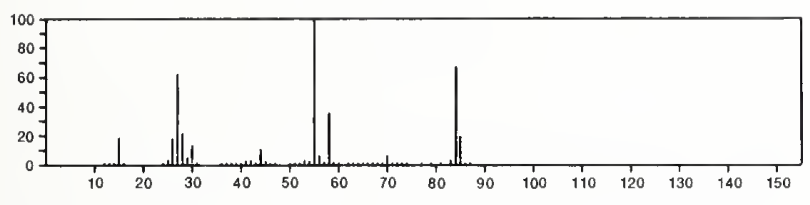

85

Cyanic acià, propyl ester

$\mathrm{C}_{4} \mathrm{H}_{7} \mathrm{NO}$

PrOCN

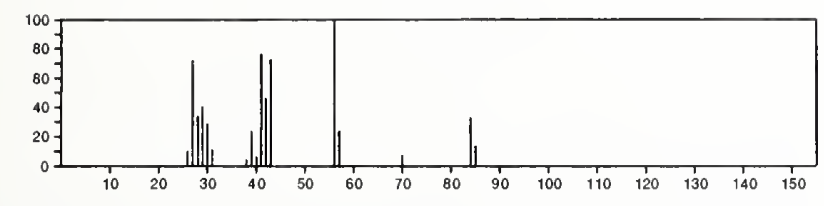

$85 \quad \mathrm{C}_{4} \mathrm{H}_{7} \mathrm{NO}$

$1768-37-2$

Cyanic acid, 1-methylethyl ester

I-PrOCN
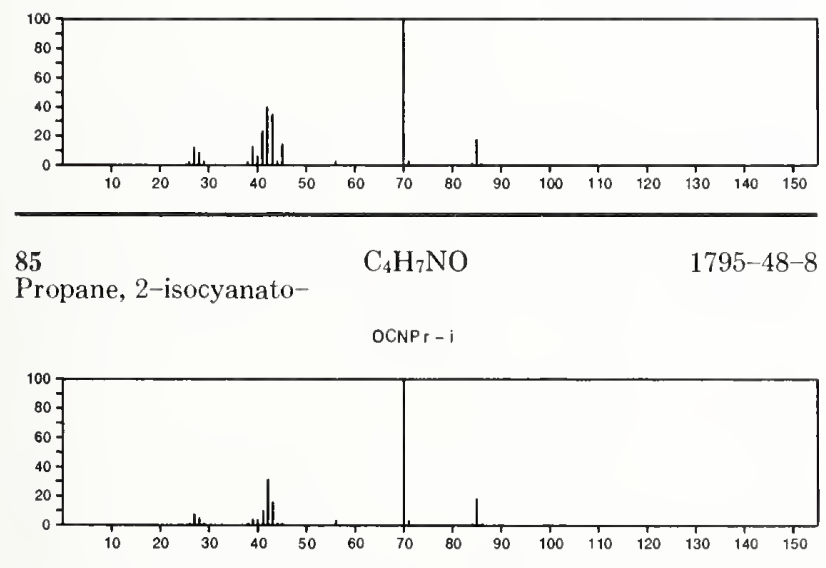

85

Cyclobutanone, oxime

$\mathrm{C}_{4} \mathrm{H}_{7} \mathrm{NO}$

$2972-05-6$
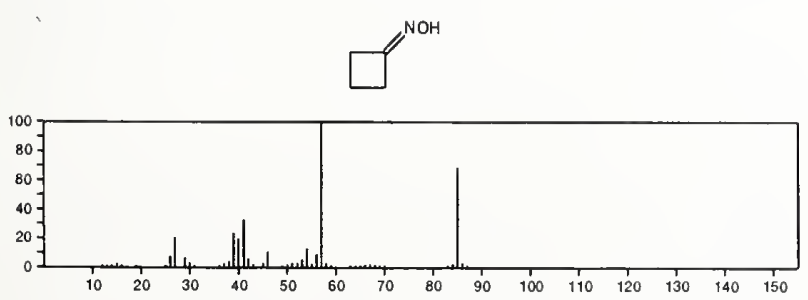

85

Piperidine

$\mathrm{C}_{5} \mathrm{H}_{11} \mathrm{~N}$

$110-89-4$

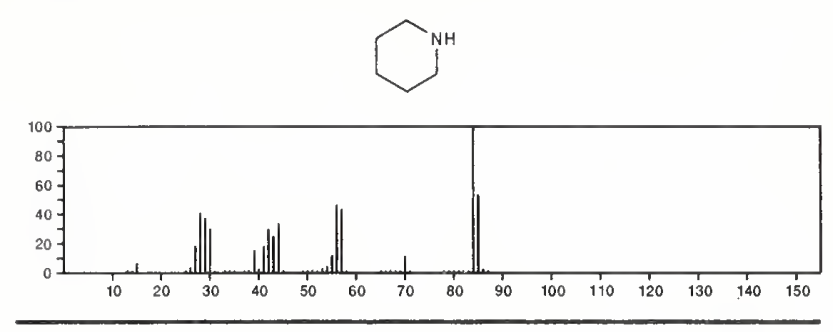

85

$\mathrm{C}_{5} \mathrm{H}_{11} \mathrm{~N}$

$120-94-5$

Pyrrolidine, 1-methyl-
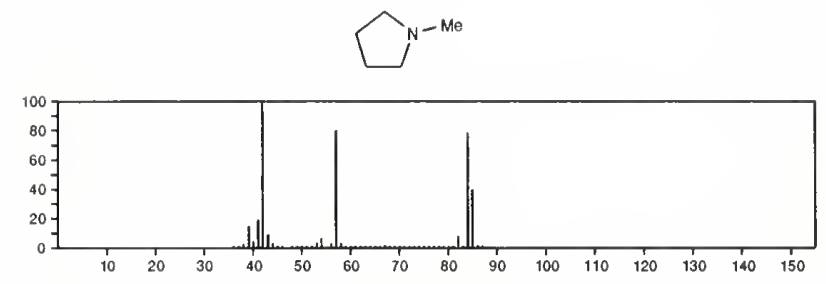

85
$\mathrm{C}_{5} \mathrm{H}_{11} \mathrm{~N}$ Aziridine, 1,2,3-trimethyl-, trans-<smiles>CC1C(C)N1[Na]</smiles>

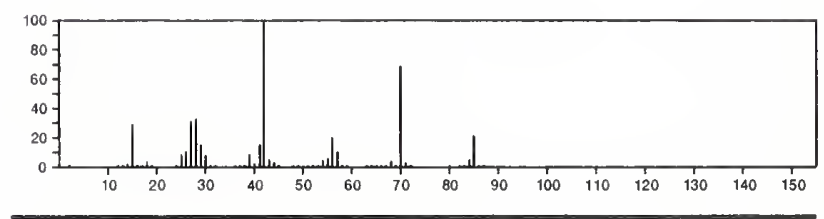

\begin{tabular}{lll}
\hline 85 & $\mathrm{C}_{5} \mathrm{H}_{11} \mathrm{~N}$ & $1003-03-8$
\end{tabular}
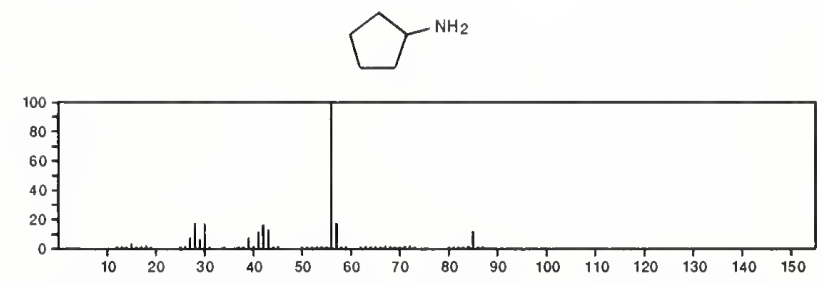

85

Aziridine, 1-propyl

$\mathrm{C}_{5} \mathrm{H}_{11} \mathrm{~N}$

$5536-98-1$

$\widehat{S N}_{\mathrm{Pr}_{\mathrm{r}}}$

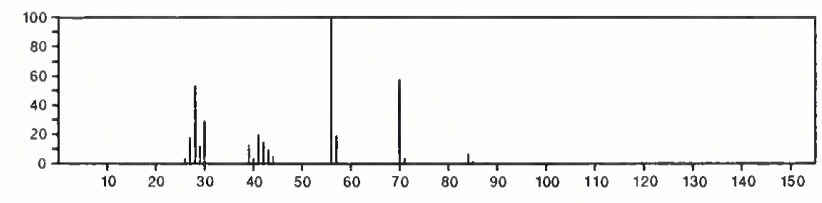

85

Methanamine, $N$-butylidene

$\mathrm{C}_{5} \mathrm{H}_{11} \mathrm{~N}$

6898-69-7

$\mathrm{MeN}=\mathrm{CHP} r$

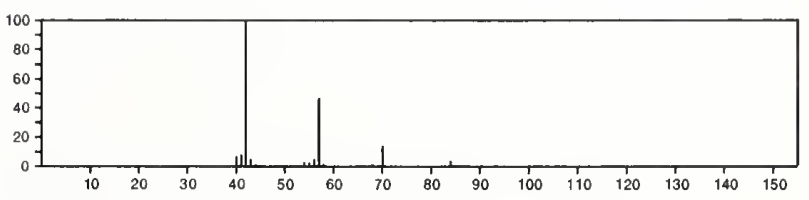


85

$\mathrm{C}_{5} \mathrm{H}_{11} \mathrm{~N}$
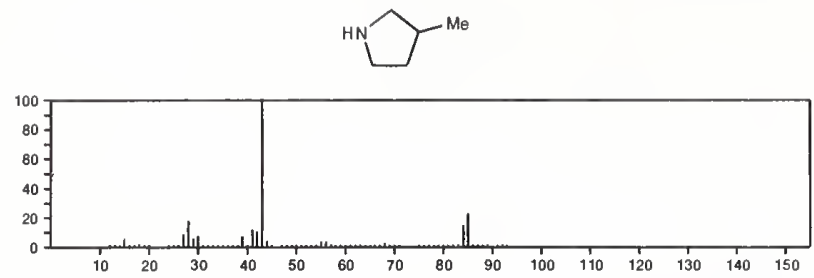

85

$\mathrm{C}_{5} \mathrm{H}_{11} \mathrm{~N}$

Azetidine, 1,2-dimethyl-
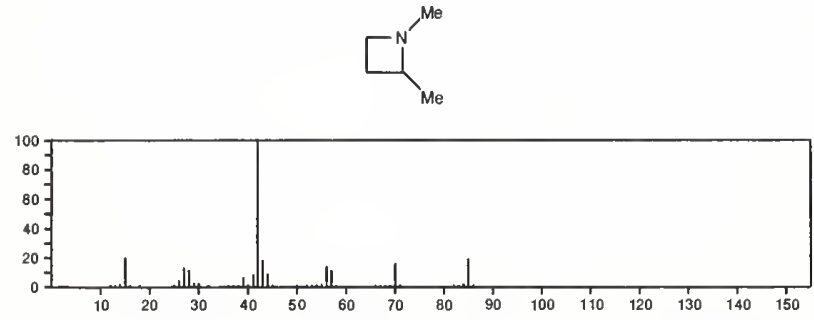

85

Azetidine, 1,3-dimethyl-

$\mathrm{C}_{5} \mathrm{H}_{11} \mathrm{~N}$
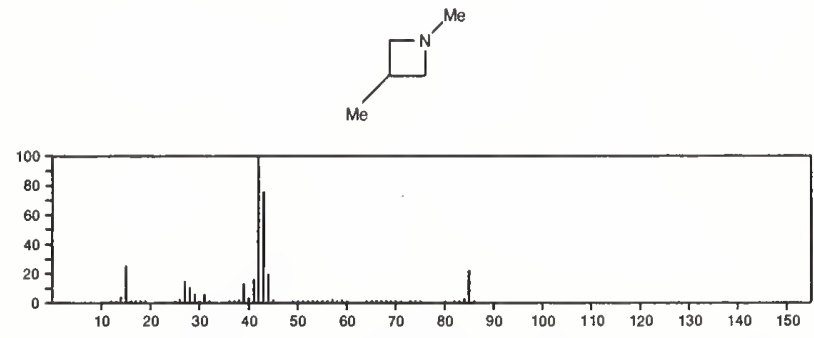

85

Phosphoramidous difluoride

$\mathrm{F}_{2} \mathrm{H}_{2} \mathrm{NP}$

$\mathrm{F}_{2} \mathrm{PNH}_{2}$

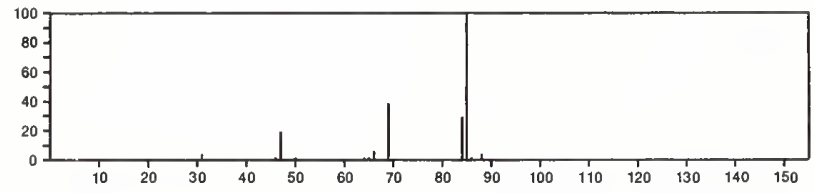

86

Methane, chlorodifluoro-

$\mathrm{CHClF}_{2}$

$75-45-6$

$\mathrm{ClCHF}_{2}$

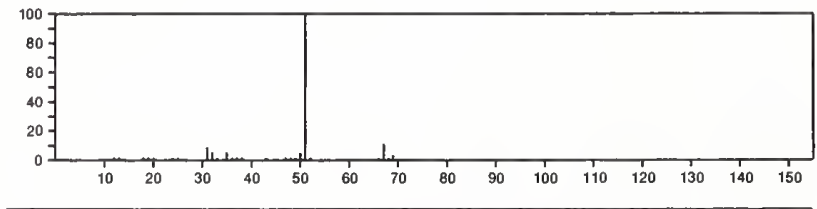

86

1,2,3-Thiadiazole

$\mathrm{C}_{2} \mathrm{H}_{2} \mathrm{~N}_{2} \mathrm{~S}$

$288-48-2$

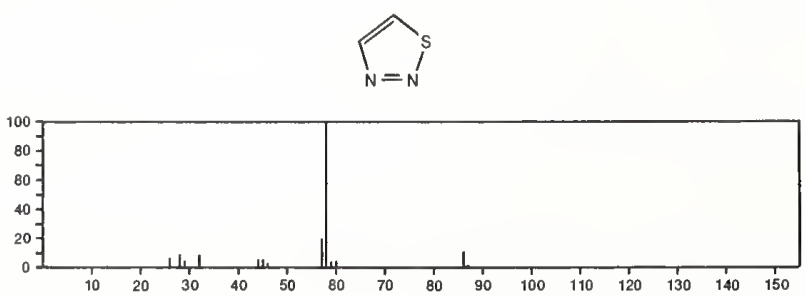

86

1,3-Dioxol-2-one

$\mathrm{C}_{3} \mathrm{H}_{2} \mathrm{O}_{3}$

$872-36-6$

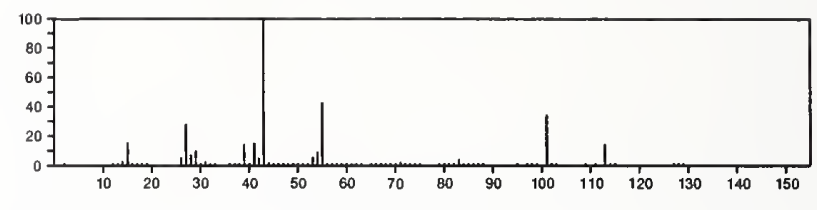

86

2-Imidazolidinone

$\mathrm{C}_{3} \mathrm{H}_{6} \mathrm{~N}_{2} \mathrm{O}$

$120-93-4$
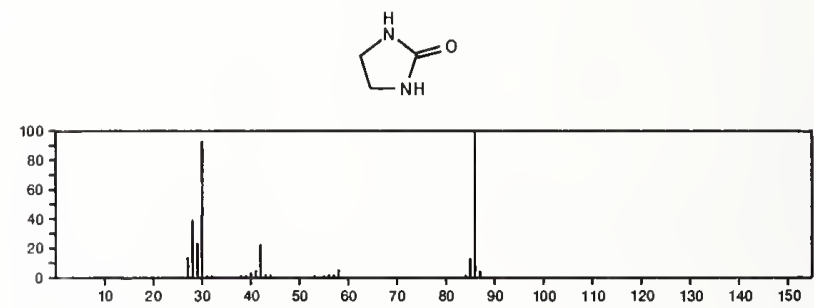

86

$\mathrm{C}_{3} \mathrm{H}_{6} \mathrm{~N}_{2} \mathrm{O}$

Ethenamine. $N$-methyl- $N$-nitroso-

$4549-40-0$

$\operatorname{MeN}(\mathrm{NO}) \mathrm{CH}=\mathrm{CH}_{2}$

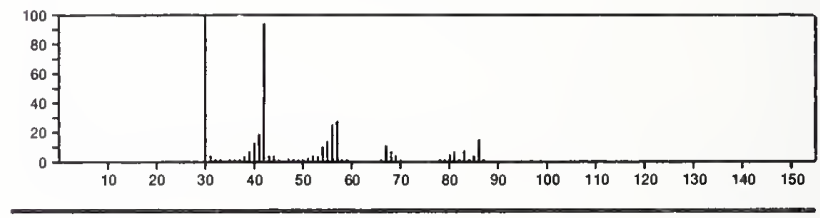

86

$\mathrm{C}_{3} \mathrm{H}_{6} \mathrm{~N}_{2} \mathrm{O}$

15216-10-1

Azetidine, 1-nitroso-
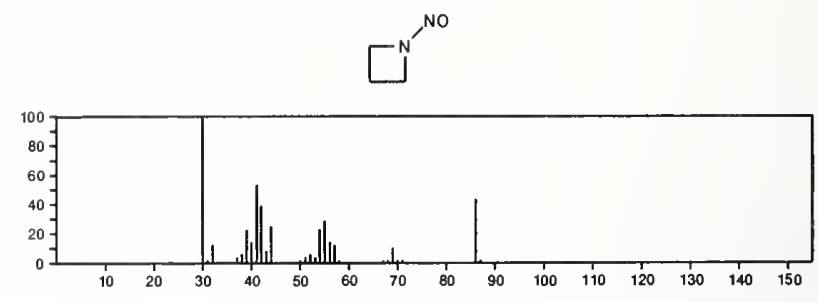

86

$\mathrm{C}_{4} \mathrm{HI}_{3} \mathrm{Cl}$

$17712-36-6$

$\mathrm{HC} \equiv \mathrm{CCCl}=\mathrm{CH}_{2}$

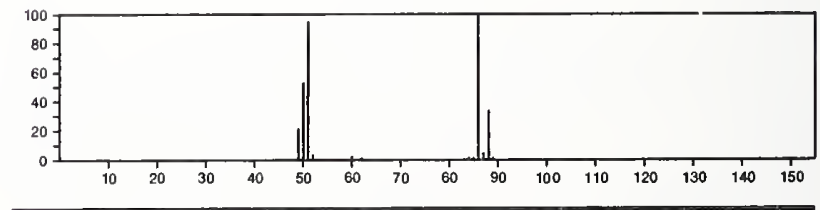

86

$\mathrm{C}_{4} \mathrm{H}_{3} \mathrm{Cl}$

20374-90-7

1-Buten-3-yne, 1-chloro-, (Z)-

$\mathrm{HC}: \mathrm{CCH}: \mathrm{CHCI}$

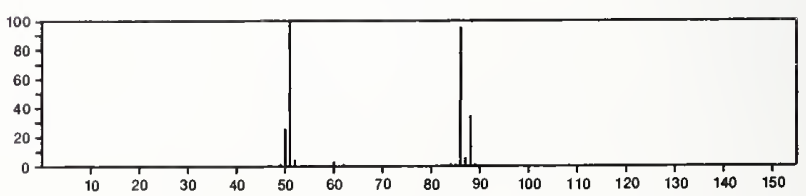


86

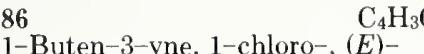

$20374-91-8$

$\mathrm{HC} \equiv \mathrm{CCH} \equiv \mathrm{CHCl}$

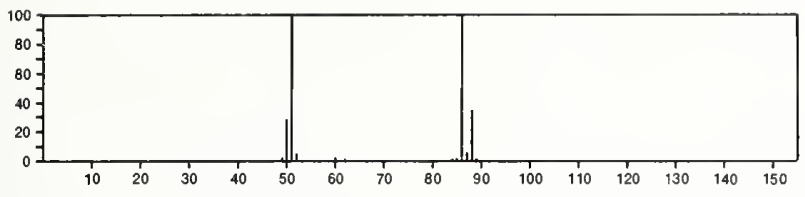

$86 \quad \mathrm{C}_{4} \mathrm{H}_{3} \mathrm{Cl}$

1,2,3-Butatriene, 1-chloro-

$\mathrm{H}_{2} \mathrm{C}=\mathrm{C}=\mathrm{C}=\mathrm{CHCl}$

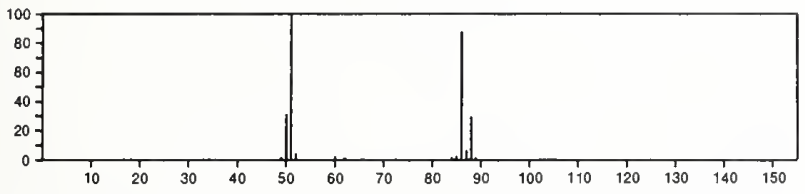

86

2-Propenoic acid, 2-methyl-

$\mathrm{C}_{4} \mathrm{H}_{6} \mathrm{O}_{2}$

$\mathrm{HO}_{2} \mathrm{CCMe}=\mathrm{CH}_{2}$

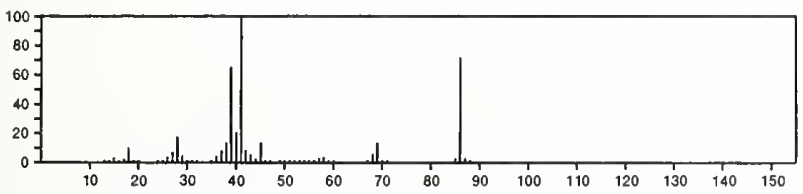

86

2-Propenoic acid, methyl ester

$\mathrm{C}_{4} \mathrm{H}_{6} \mathrm{O}_{2}$

$\mathrm{H}_{2} \mathrm{C}=\mathrm{CHC}(\mathrm{O}) \mathrm{OMe}$

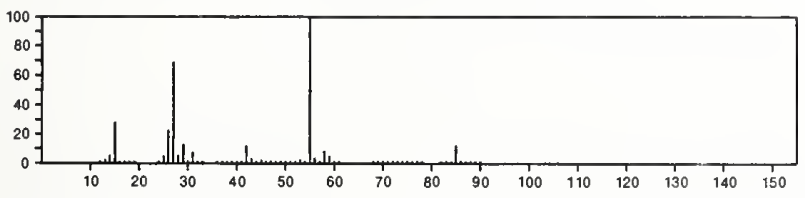

$86 \quad \mathrm{C}_{4} \mathrm{H}_{6} \mathrm{O}_{2}$

2(3H)-Furanone, dihydro-
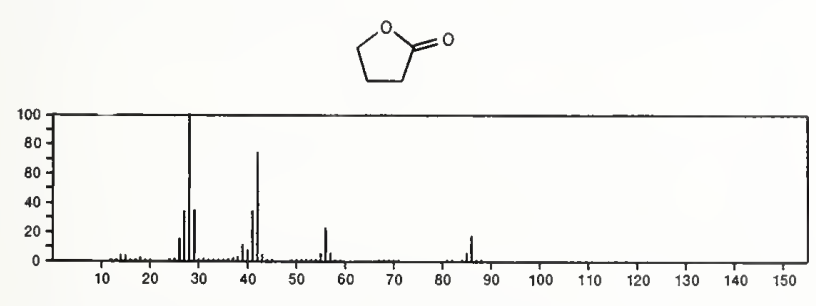

86

2-Butenoic acid, $(E)$

$\mathrm{C}_{4} \mathrm{H}_{6} \mathrm{O}_{2}$

$107-93-7$

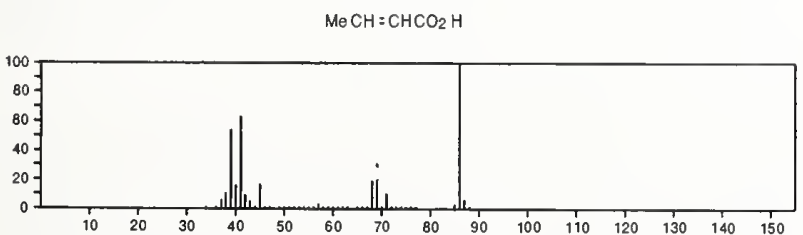

86

Acetic acid ethenyl ester

$\mathrm{C}_{4} \mathrm{H}_{6} \mathrm{O}_{2}$

$108-05-4$

$\mathrm{H}_{2} \mathrm{C}=\mathrm{CHOAC}$

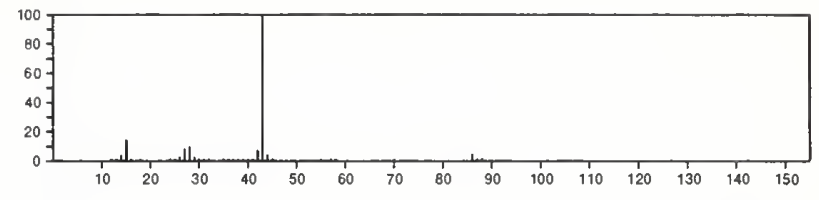

$\begin{aligned} & 86 \\ & 2-\text { Butyne-1,4-diol }\end{aligned} \mathrm{C}_{4} \mathrm{H}_{6} \mathrm{O}_{2} \quad 110-65-6$

$\mathrm{HOCH}_{2} \mathrm{C}: \mathrm{CCH}_{2} \mathrm{OH}$

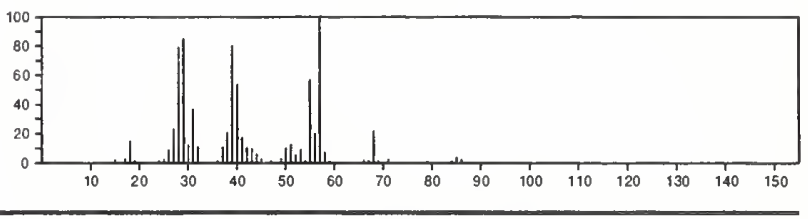

86

2,3-Butanedione

$\mathrm{C}_{4} \mathrm{H}_{6} \mathrm{O}_{2}$

431-03-8

Me COCOMe

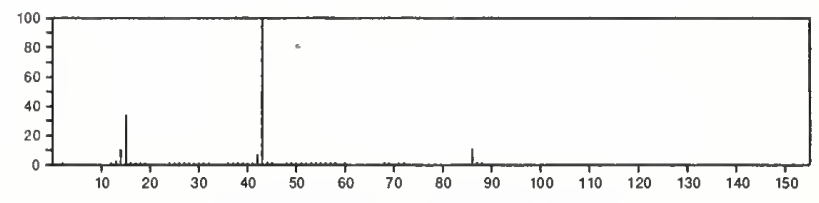

86

2-Butenoic acid, $(Z)-$

$\mathrm{C}_{4} \mathrm{H}_{6} \mathrm{O}_{2}$

$503-64-0$

$\mathrm{Me} \mathrm{CH}=\mathrm{CHCO}_{2} \mathrm{H}$

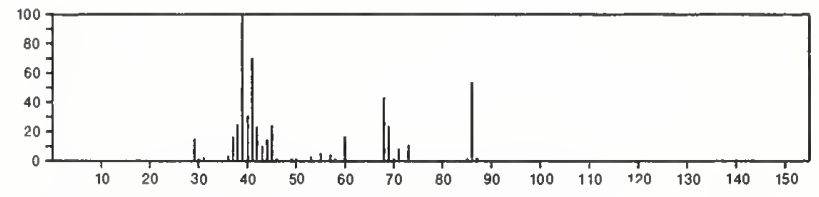

86

3-Butenoic acid

$\mathrm{C}_{4} \mathrm{H}_{6} \mathrm{O}_{2}$

625-38-7

$\mathrm{H}_{2} \mathrm{C}=\mathrm{CHCH}_{2} \mathrm{CO}_{2} \mathrm{H}$

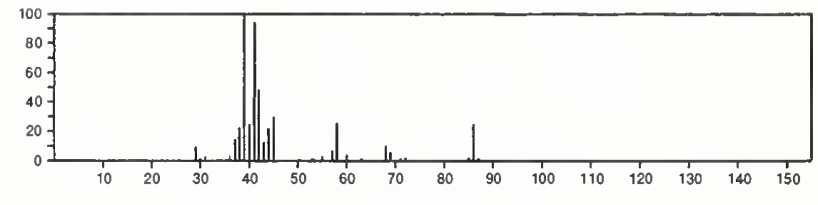

86

$\mathrm{C}_{4} \mathrm{H}_{6} \mathrm{O}_{2}$

638-37-9

Butanedial

$\mathrm{OCHCH}_{2} \mathrm{CH}_{2} \mathrm{CHO}$

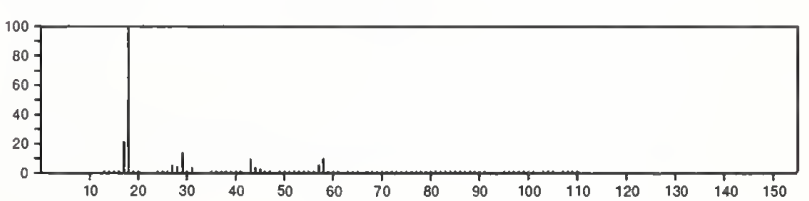


$1464-53-5$
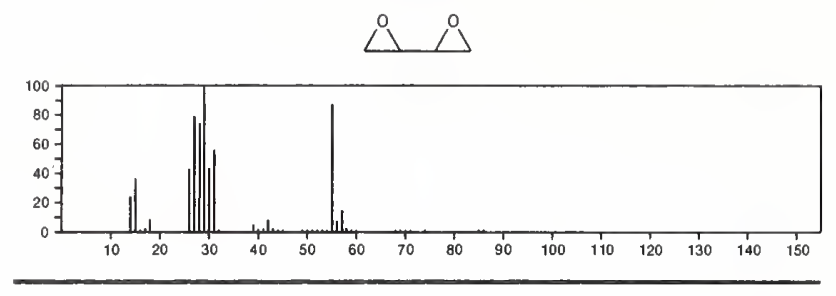

86
Cyclopropanecarboxylic acid $\mathrm{C}_{4} \mathrm{H}_{6} \mathrm{O}_{2}$

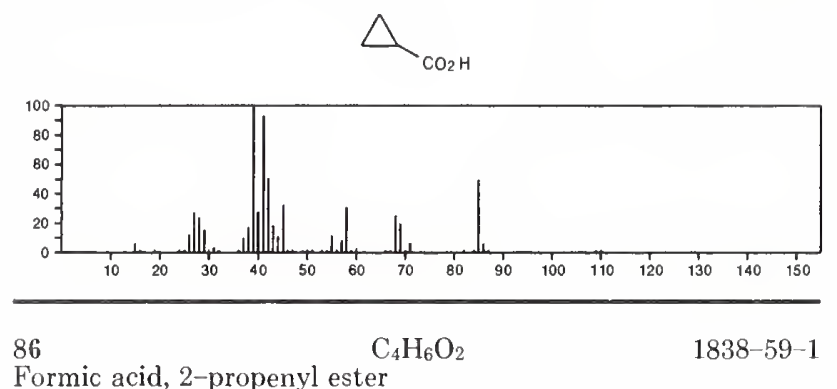

$\mathrm{O}=\mathrm{CHOCH}_{2} \mathrm{CH}=\mathrm{CH}_{2}$

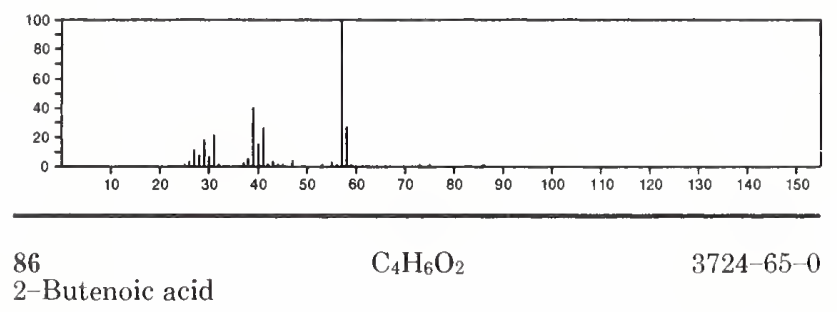

$\mathrm{Me} C \mathrm{H}=\mathrm{CHCO}_{2} \mathrm{H}$

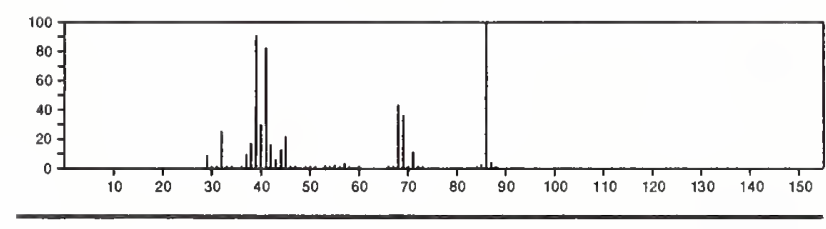

86

$\mathrm{C}_{4} \mathrm{H}_{6} \mathrm{O}_{2}$

4401-11-0

Ethanone, 1-oxiranyl-
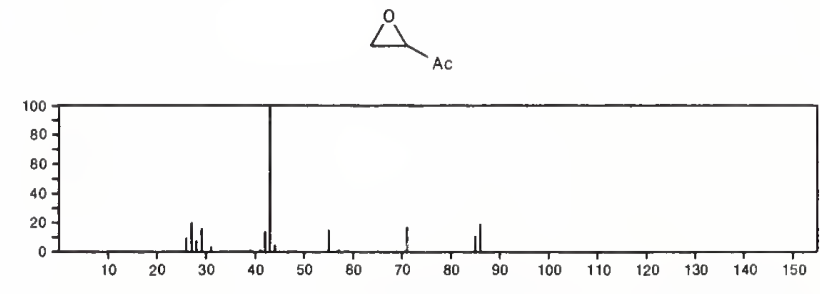

$86 . \quad \mathrm{C}_{4} \mathrm{H}_{6} \mathrm{~S}$

Thiophene, 2,3-dihydro-

1120-59-8

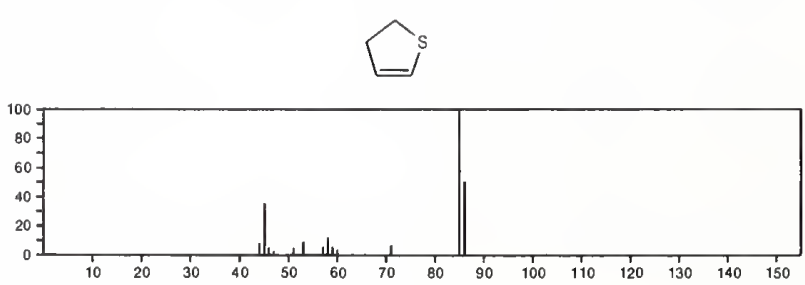

86

Thiophene, 2,5-dihydro-

$\mathrm{C}_{4} \mathrm{H}_{6} \mathrm{~S}$

$1708-32-3$

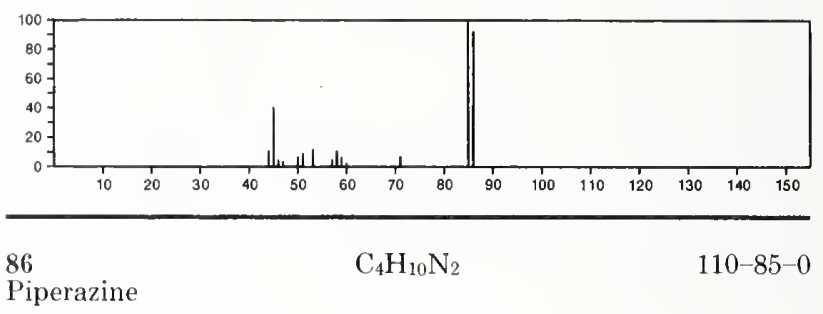

Piperazine
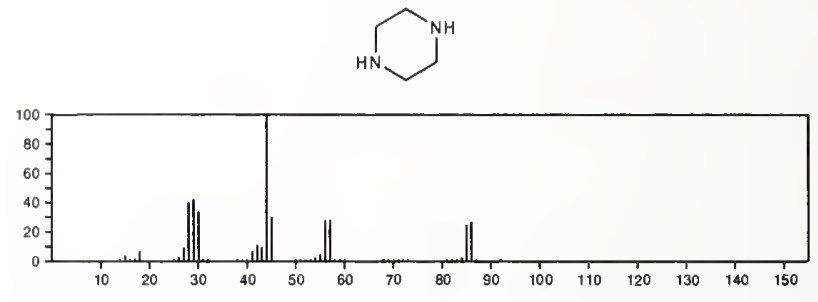

86

Silacyclopentane

$\mathrm{C}_{4} \mathrm{H}_{10} \mathrm{Si}$

288-06-2
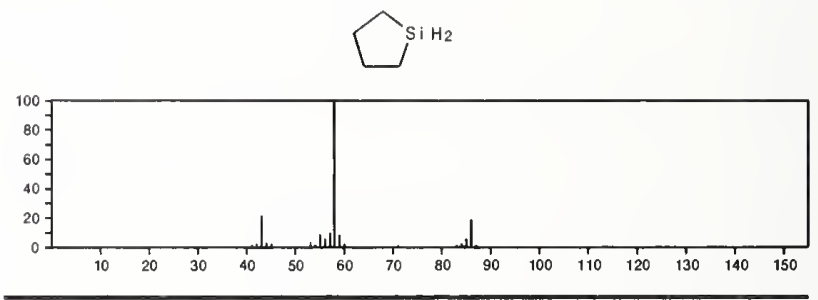

86

$\mathrm{C}_{5} \mathrm{H}_{10} \mathrm{O}$

96-17-3

Butanal, 2-methyl-

$\mathrm{Me} \mathrm{CH}_{2} \mathrm{CHMeCHO}$

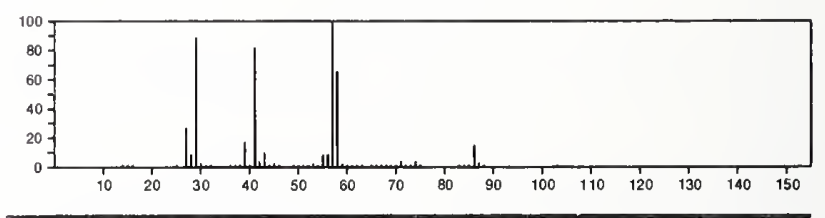

86

$\mathrm{C}_{5} \mathrm{H}_{10} \mathrm{O}$

$96-22-0$

3-Pentanone

E 1 COE t
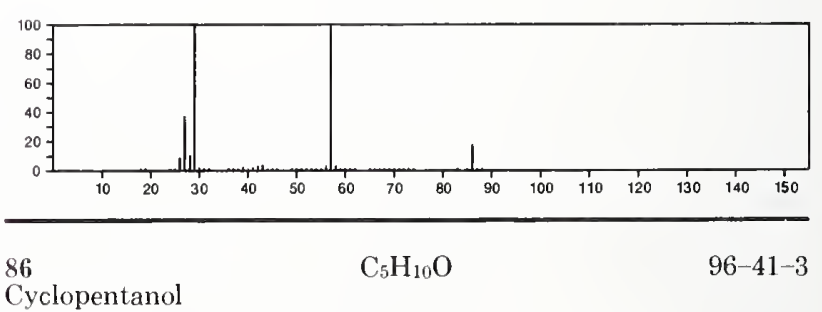

Cyclopentanol
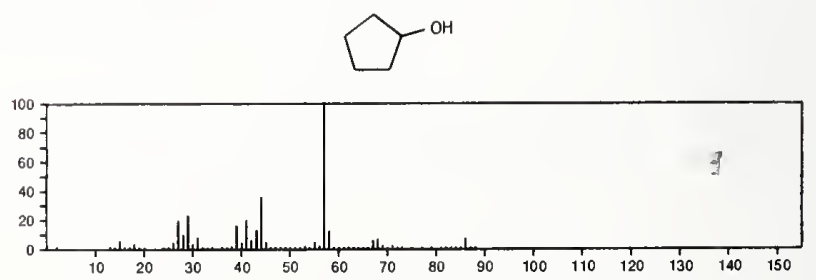
86

Furan, tetrahydro-2-methyl-
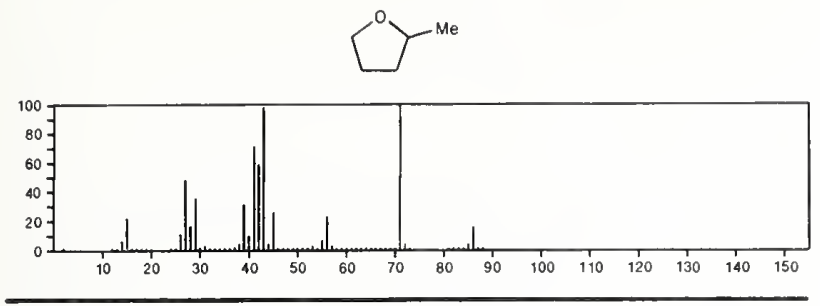

86

2-Pentanone

$\mathrm{C}_{5} \mathrm{H}_{10} \mathrm{O}$

$107-87-9$

Prcome

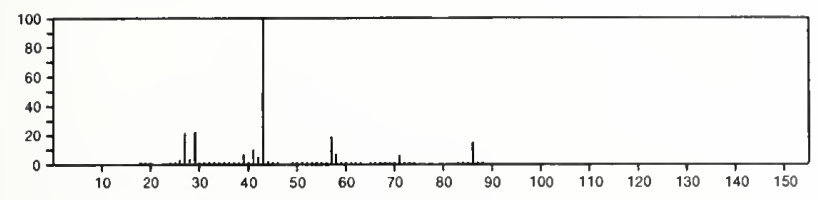

86

Pentanal

$\mathrm{C}_{5} \mathrm{H}_{10} \mathrm{O}$

$110-62-3$

$\mathrm{OCH}\left(\mathrm{CH}_{2}\right)_{3} \mathrm{Me}$

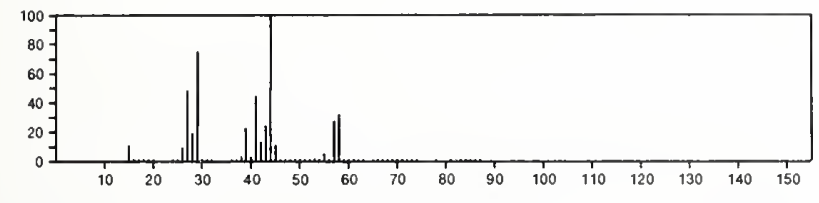

86

3-Buten-2-ol, 2-methyl-

$\mathrm{C}_{5} \mathrm{H}_{10} \mathrm{O}$

115 -18-4

$\mathrm{Me} 2 \mathrm{COHCH}=\mathrm{CH}_{2}$

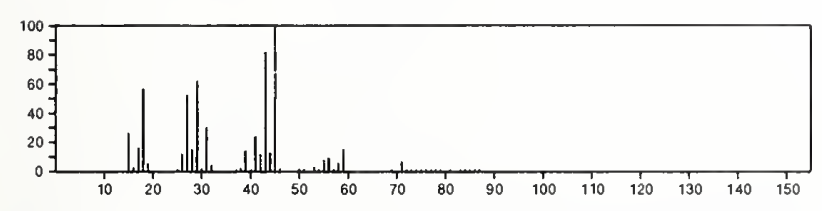

86

$2 H$-Pyran, tetrahydro-

$\mathrm{C}_{5} \mathrm{H}_{10} \mathrm{O}$

$142-68-7$
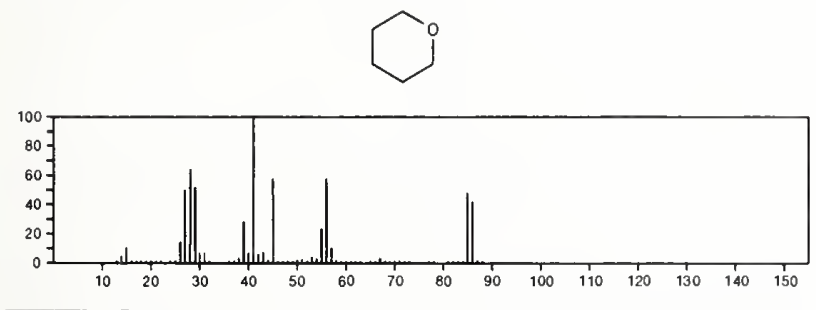

86

$\mathrm{C}_{5} \mathrm{H}_{10} \mathrm{O}$

556-82-1

2-Buten-1-ol, 3-methyl-

$\mathrm{HOCH}_{2} \mathrm{CH}=\mathrm{CMe}_{2}$

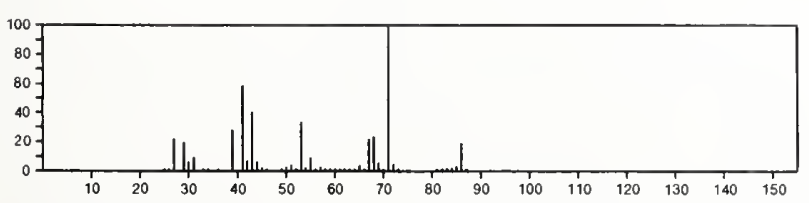

1-Propene, 3-ethoxy

$\mathrm{C}_{5} \mathrm{H}_{10} \mathrm{O}$

$557-31-3$

$\mathrm{E}+\mathrm{OCH}_{2} \mathrm{CH}=\mathrm{CH}_{2}$

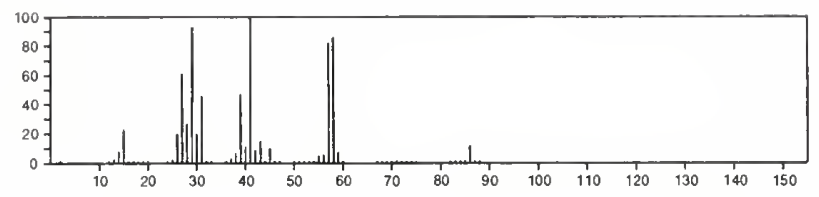

86

2-Butanone, 3-methyl-

$\mathrm{C}_{5} \mathrm{H}_{10} \mathrm{O}$

563-80-4

$\mathrm{Me}_{2} \mathrm{CHCOM}_{\mathrm{O}}$

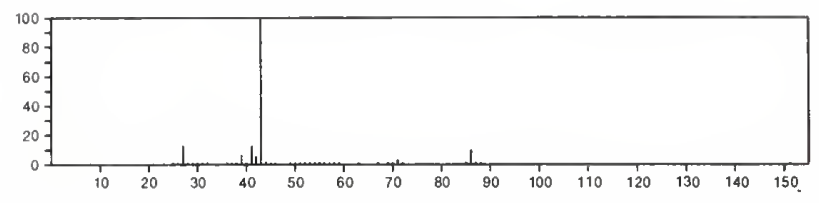

86

Butanal, 3-methyl-

$\mathrm{C}_{5} \mathrm{H}_{10} \mathrm{O}$

$590-86-3$

$\mathrm{Me}_{2} \mathrm{CHCH}_{2} \mathrm{CHO}$

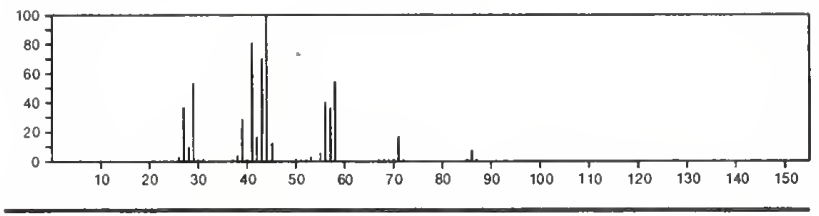

86

4-Penten-2-ol

$\mathrm{C}_{5} \mathrm{H}_{10} \mathrm{O}$

$625-31-0$

$\mathrm{H}_{2} \mathrm{C}=\mathrm{CHCH}_{2} \mathrm{CH}(\mathrm{OH}) \mathrm{Me}$

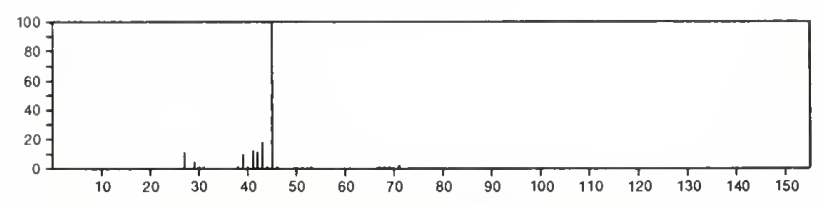

86

4-Penten-1-ol

$\mathrm{C}_{5} \mathrm{H}_{10} \mathrm{O}$

821-09-0

$\mathrm{HO}\left(\mathrm{CH}_{2}\right)_{3} \mathrm{CH}=\mathrm{CH}_{2}$

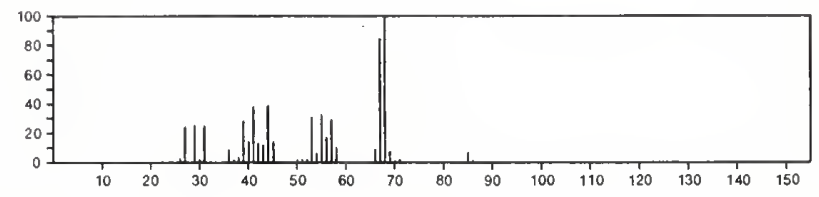

86
Propane, 2-(ethenyloxy)-

$926-65-8$

$\mathrm{H}_{2} \mathrm{C}=\mathrm{CHOP}_{\mathrm{r}}-\mathrm{i}$

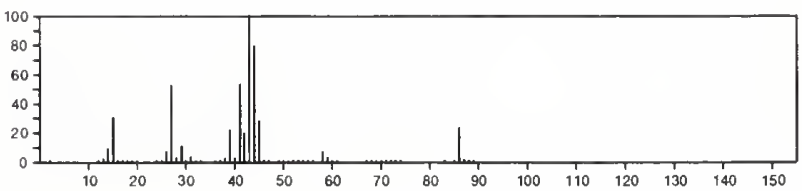


86

$\mathrm{C}_{5} \mathrm{H}_{10} \mathrm{O}$

$\sum_{p r}$

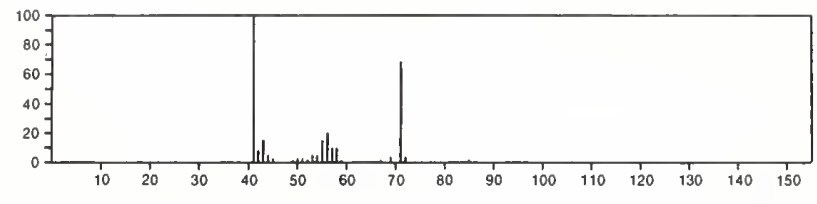

86

Oxirane, (1-methylethyl)-

$\mathrm{C}_{5} \mathrm{H}_{10} \mathrm{O}$

1438-14-8
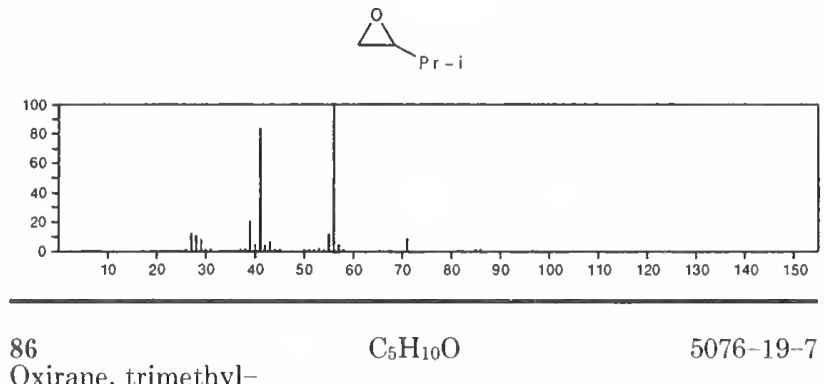

Oxirane, trimethyl-
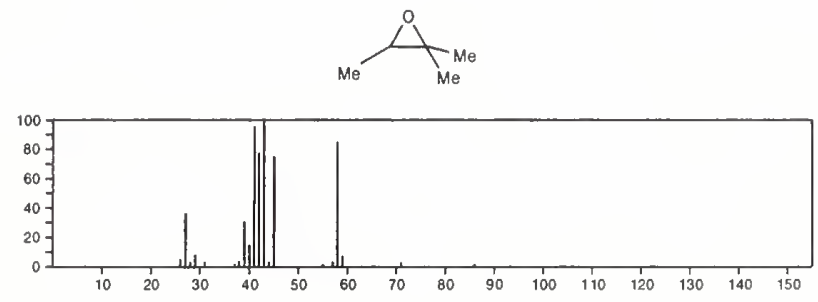

86

Oxetane, 3,3-dimethyl-

$\mathrm{C}_{5} \mathrm{H}_{10} \mathrm{O}$

$6921-35-3$

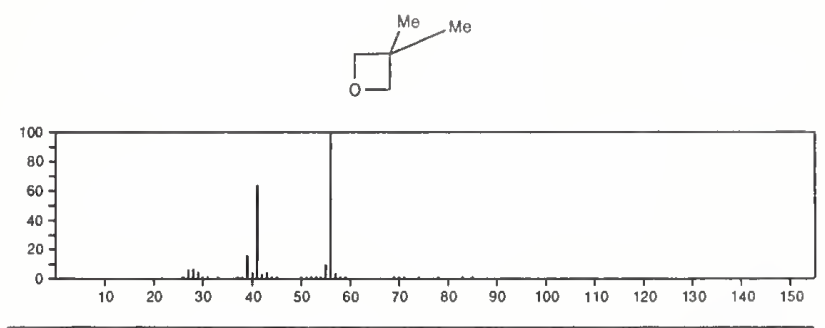

86

$\mathrm{C}_{5} \mathrm{H}_{10} \mathrm{O}$

10034-14-7

2-Butene, 1-methoxy-, (E)-

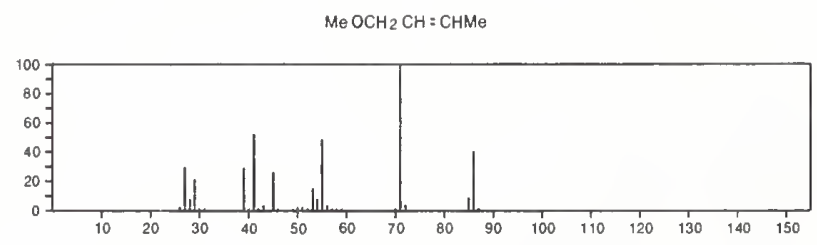

86
Furan, tetrahydro-3-methyl-

13423-15-9
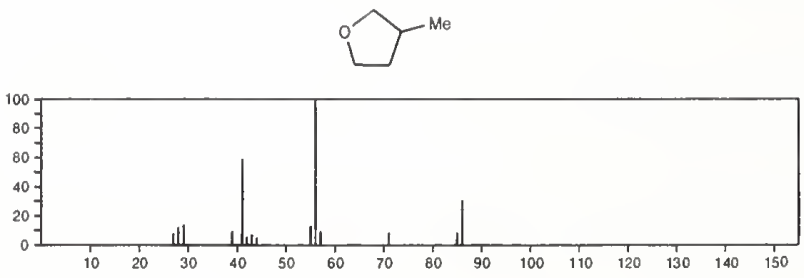

86
1 -Propene, 1-methoxy-2-methyl-

$17574-84-4$

$\mathrm{Me} \mathrm{OCH}=\mathrm{CMe}_{2}$

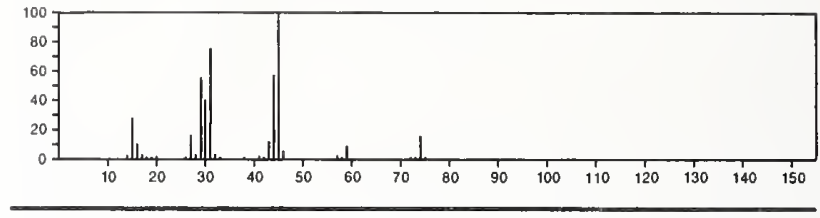

86

1-Propene, 3-methoxy-2-methyl-

22418-49-1

$\mathrm{H}_{2} \mathrm{C}=\mathrm{CMeCH}_{2} \mathrm{OM}$

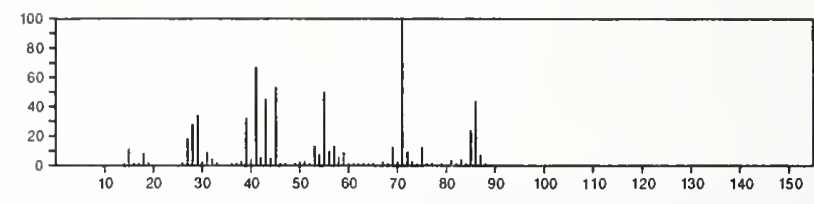

86

$\mathrm{C}_{5} \mathrm{H}_{10} \mathrm{O}$

Oxetane, 2,4-dimethyl-, trans-

29424-94-0
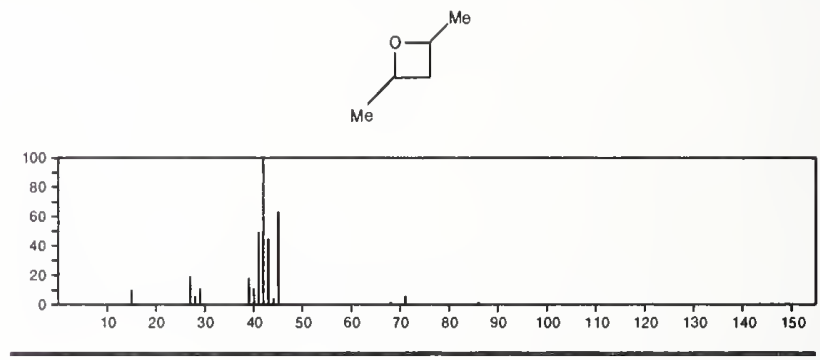

86

1-Butene, 1-methoxy-

$\mathrm{C}_{5} \mathrm{H}_{10} \mathrm{O}$

$29512-02-5$

$E+\mathrm{CH}: \mathrm{CHOMe}$

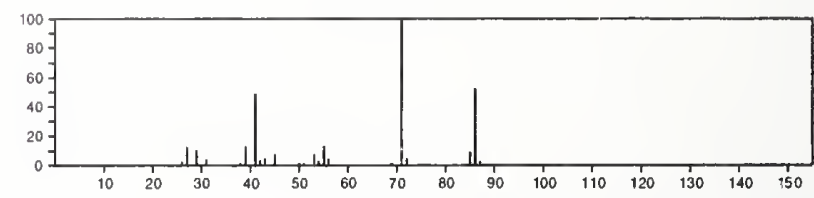

86
Oxirane, 2-ethyl-2-methyl--

$30095-63-7$
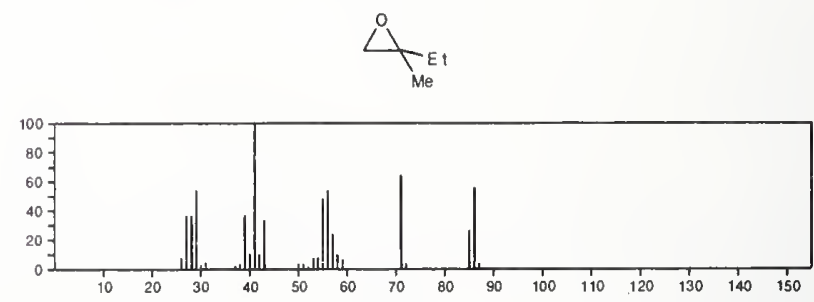

86

$\mathrm{C}_{6} \mathrm{H}_{14}$

$75-83-2$

Butane, 2,2-dimethyl-

Mes ${ }_{3}$ I

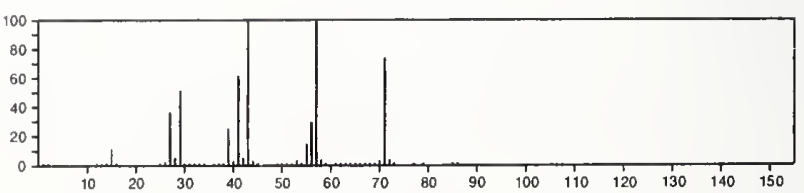


86

Butane, 2,3-dimethyl-

$\mathrm{C}_{6} \mathrm{H}_{14}$

79-29-8

$\mathrm{Me}_{2} \mathrm{CHCHM}_{2}$

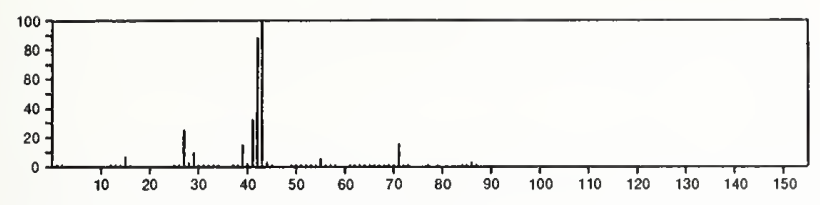

86

Pentane, 3-methyl-

$\mathrm{C}_{6} \mathrm{H}_{14}$

$\mathrm{MeCH}_{2} \mathrm{CHE}$ t Me

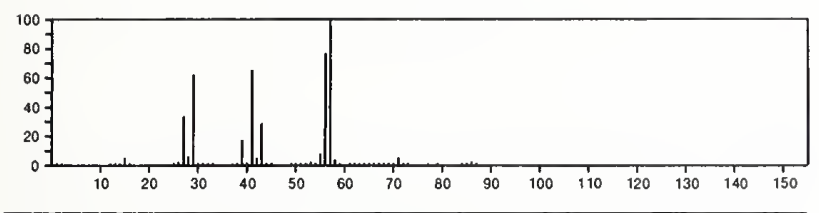

86

Pentane, 2-methyl-

$\mathrm{C}_{6} \mathrm{H}_{14}$

$107-83-5$

$\mathrm{Me}_{2} \mathrm{CHPr}$

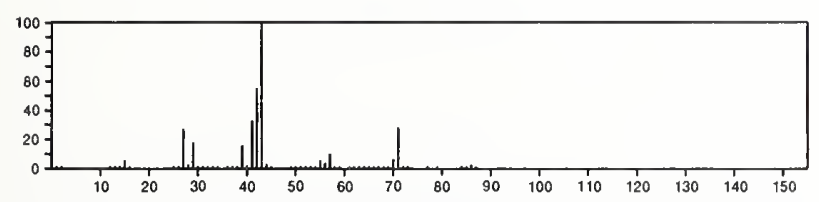

86

Hexane

$\mathrm{C}_{6} \mathrm{H}_{14}$

$110-54-3$

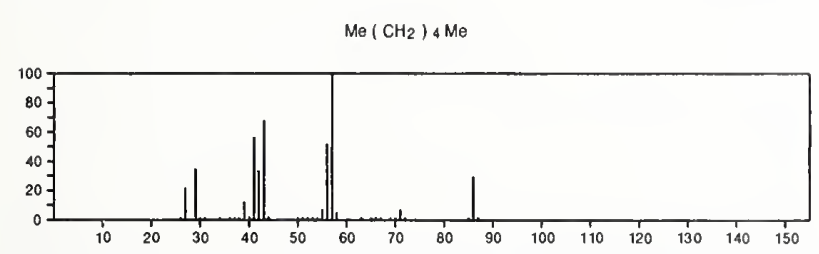

\section{6}

Chlorine oxide $\left(\mathrm{Cl}_{2} \mathrm{O}\right)$

$\mathrm{Cl}_{2} \mathrm{O}$

$\mathrm{OCl}_{2}$

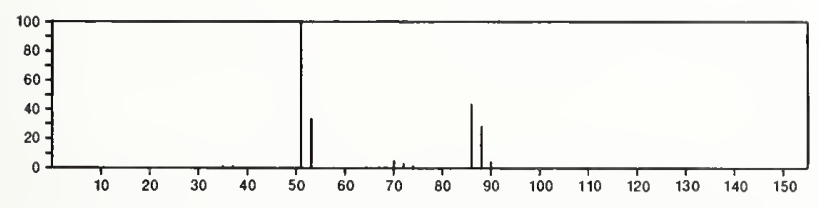

86

Phosphonic difluoride

$\mathrm{F}_{2} \mathrm{HOP}$

$\mathrm{F}_{2} \mathrm{PH}=0$

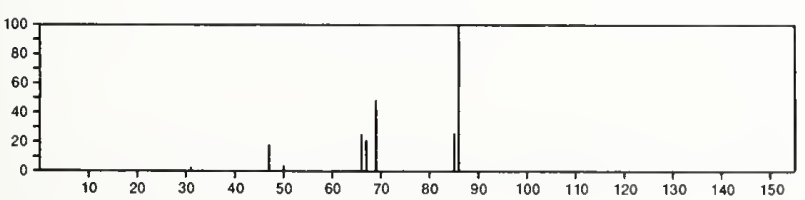

86

Thionyl fluoride

$\mathrm{F}_{2} \mathrm{OS}$

$7783-42-8$

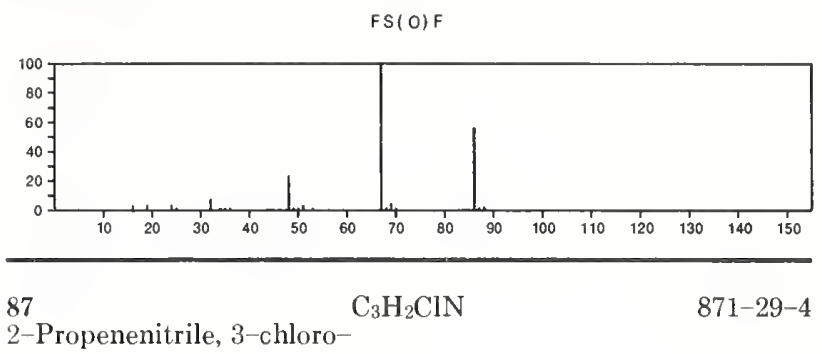

$\mathrm{Cl} \mathrm{CH}=\mathrm{CHCN}$

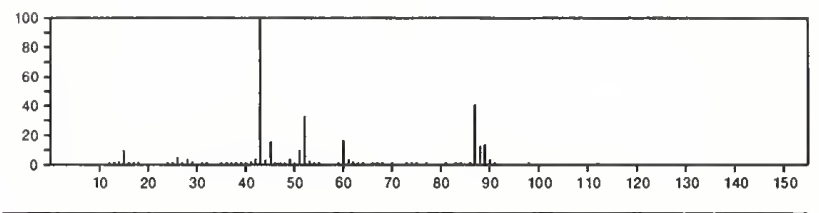

87

Ethane, isothiocyanato-

$\mathrm{C}_{3} \mathrm{H}_{5} \mathrm{NS}$

542-85-8

SCNE I

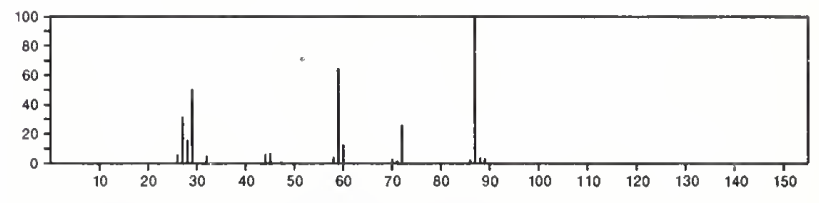

87

Thiocyanic asid, ethyl ester

$\mathrm{C}_{3} \mathrm{H}_{5} \mathrm{NS}$

$542-90-5$

NCSE

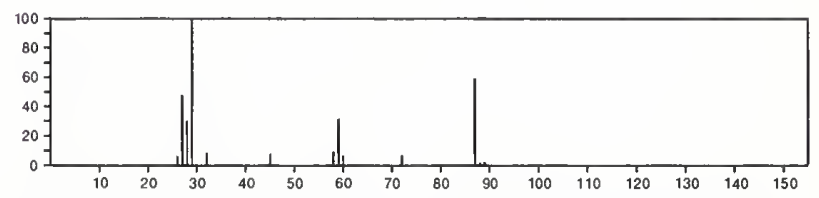

87

Butanal, oxime

$\mathrm{C}_{4} \mathrm{H}_{9} \mathrm{NO}$

110-69-0

$H O N=C H P r$

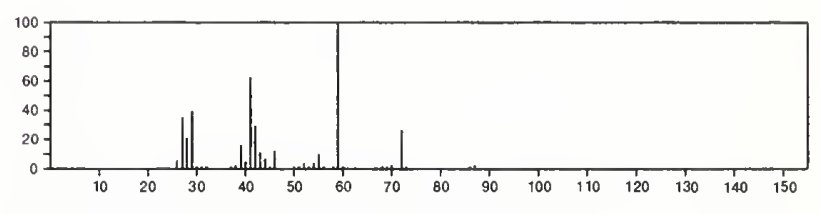

87

Morpholine

$\mathrm{C}_{4} \mathrm{H}_{9} \mathrm{NO}$

110-91-8<smiles>C1COCCN1</smiles>

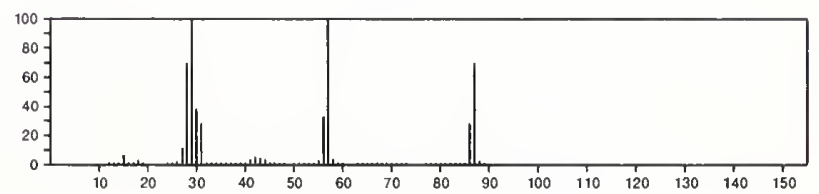


87

Acetamide, $N, N$-dimethy

Me 2 NAC
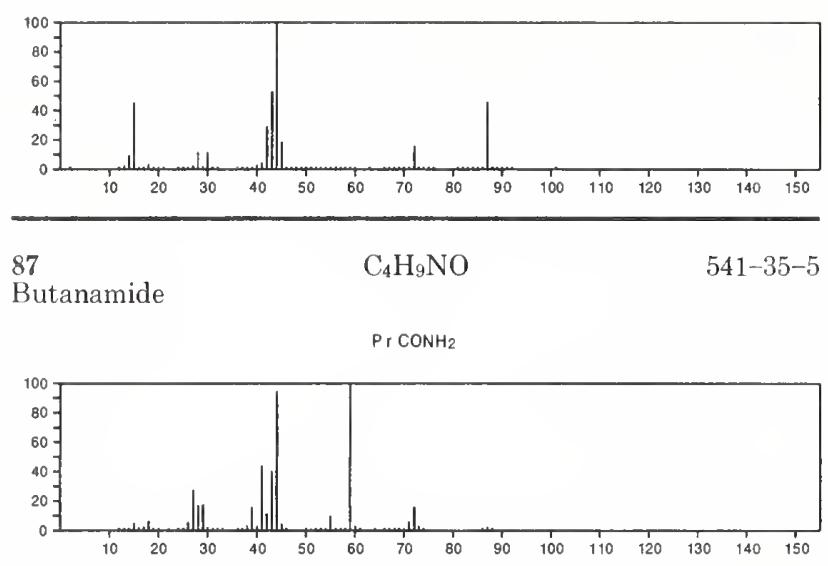

$87 \quad \mathrm{C}_{4} \mathrm{H}_{9} \mathrm{NO}$

Propanamide, 2-methyl-

$\mathrm{Me}_{2} \mathrm{CHCONH}_{2}$
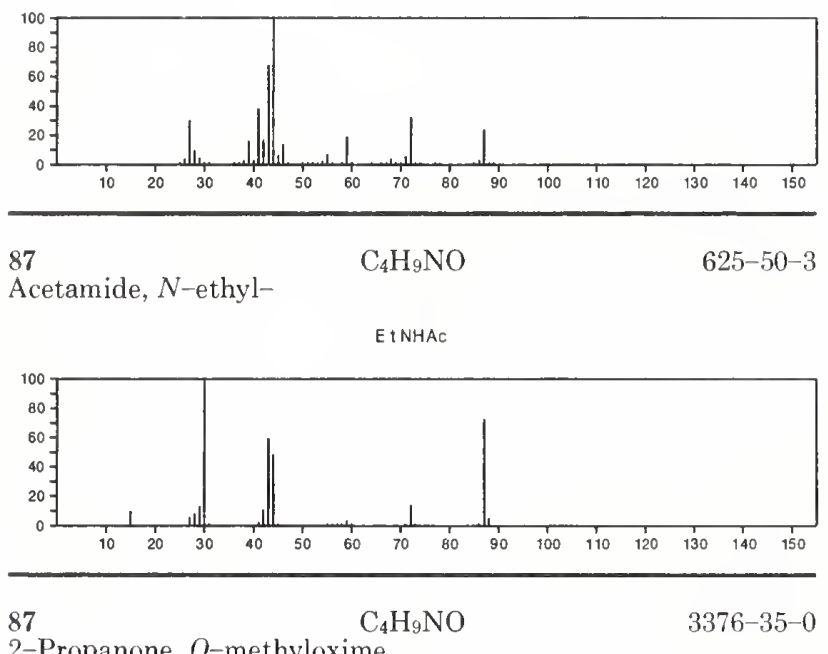

$\mathrm{Me} \mathrm{ON}=\mathrm{CMe}_{2}$

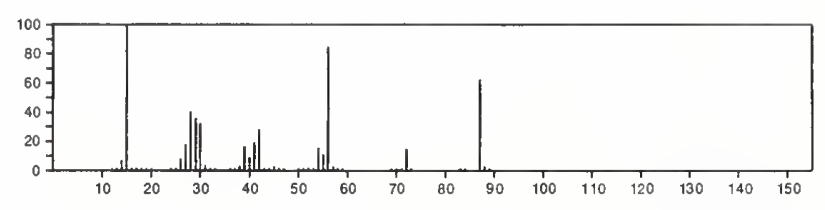

$87 \quad \mathrm{C}_{5} \mathrm{H}_{13} \mathrm{~N}$

$107-85-7$

1-Butanamine, 3-methyl-

$\mathrm{H}_{2} \mathrm{NCH}_{2} \mathrm{CH}_{2} \mathrm{CHMe}_{2}$

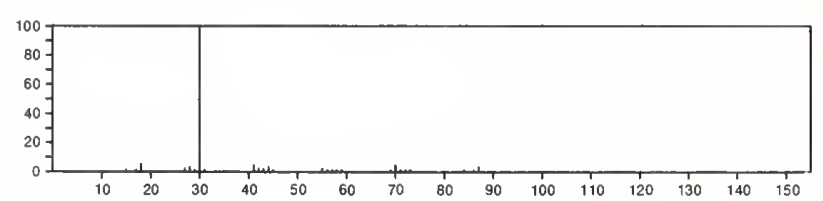

87

1-Pentanamine

$\mathrm{C}_{5} \mathrm{H}_{13} \mathrm{~N}$

$110-58-7$

$\mathrm{Me}\left(\mathrm{CH}_{2}\right)_{4} \mathrm{NH}_{2}$

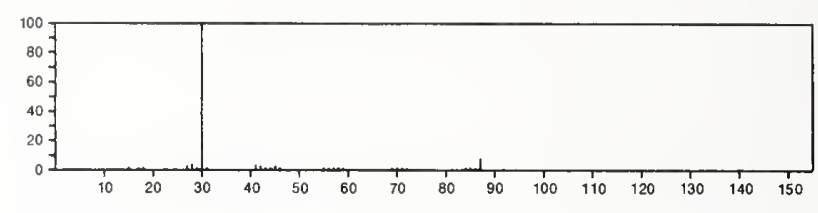

87

1-Butanamine, $N$-methyl-

$\mathrm{C}_{5} \mathrm{H}_{13} \mathrm{~N}$

$110-68-9$

$\mathrm{MeNH}\left(\mathrm{CH}_{2}\right)_{3} \mathrm{Me}$

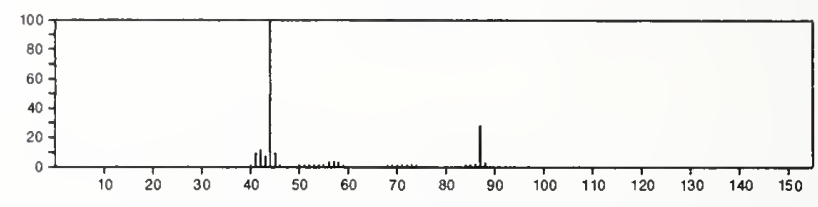

87

2-Butanamine, 2-methyl-

$\mathrm{C}_{5} \mathrm{H}_{13} \mathrm{~N}$

$594-39-8$

$\mathrm{E} t \mathrm{CMe} 2\left(\mathrm{NH}_{2}\right)$

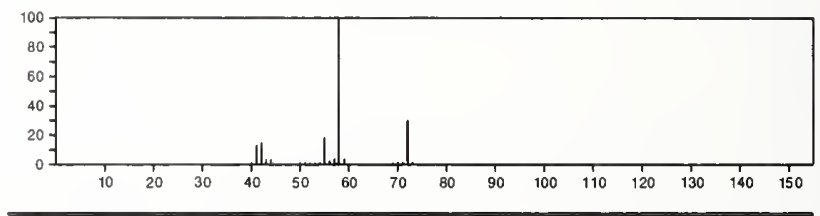

87

2-Butanamine, 3-methyl-

$\mathrm{C}_{5} \mathrm{H}_{13} \mathrm{~N}$

$598-74-3$

$\mathrm{MeCH}\left(\mathrm{NH}_{2}\right) \mathrm{CHMe} 2$

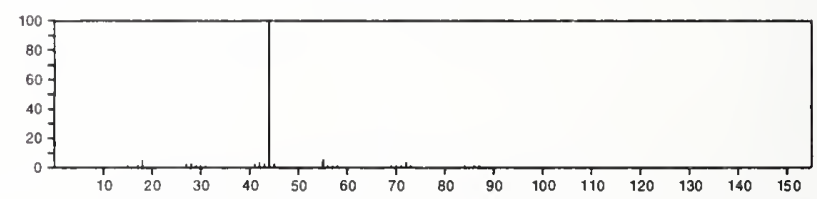

87

3-Pentanamine

$\mathrm{C}_{5} \mathrm{H}_{13} \mathrm{~N}$

$616-24-0$

$\mathrm{E}_{2} \mathrm{CHNH}_{2}$

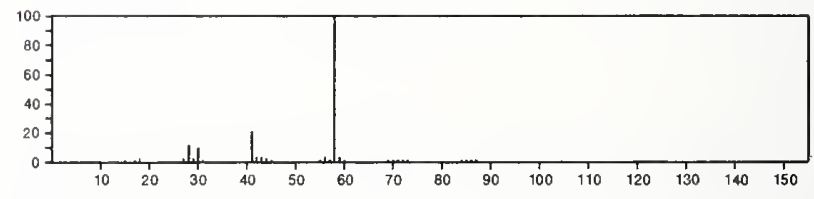

87

Ethanamine, $N$-ethyl-N-methyl

$616-39-7$

$\mathrm{E} \mathrm{I}_{2} \mathrm{NMe}$

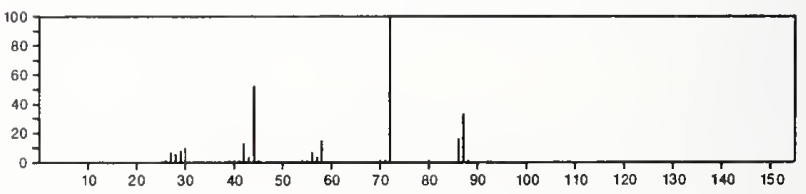


87

2-Pentanamine

$\mathrm{C}_{5} \mathrm{H}_{13} \mathrm{~N}$

$\operatorname{PrCHMe}\left(\mathrm{NH}_{2}\right)$

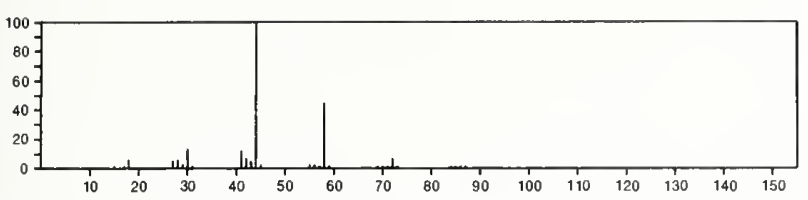

87

1-Propanamine, $N, 2$-dimethyl

$\mathrm{C}_{5} \mathrm{H}_{13} \mathrm{~N}$

MeNHBU - i

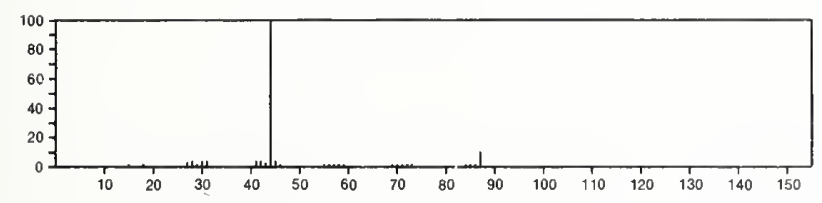

$87 \quad \mathrm{C}_{5} \mathrm{H}_{13} \mathrm{~N}$

2-Butanamine, $N$-methyl

MeNHBu-s

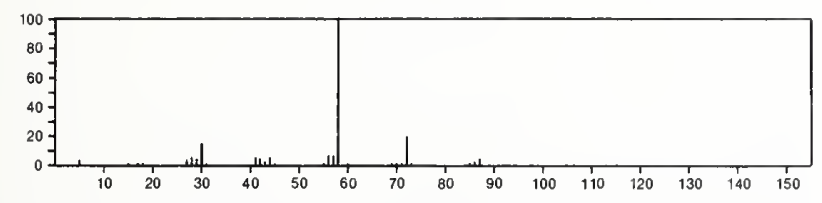

87

1-Propanamine, $N$-ethyl-

$\mathrm{C}_{5} \mathrm{H}_{13} \mathrm{~N}$

20193-20-8

PrNHE t

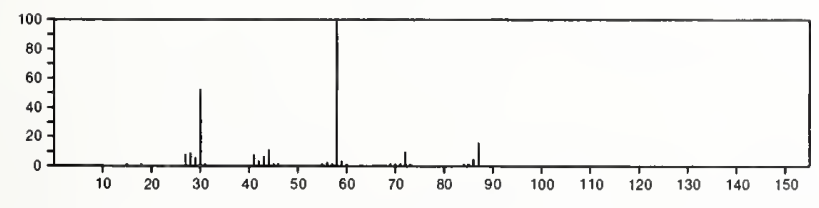

87

Nitrogen fluoride oxide $\left(\mathrm{NF}_{3} \mathrm{O}\right)$

$\mathrm{F}_{3} \mathrm{NO}$

$13847-65-9$

$F_{3} N=0$

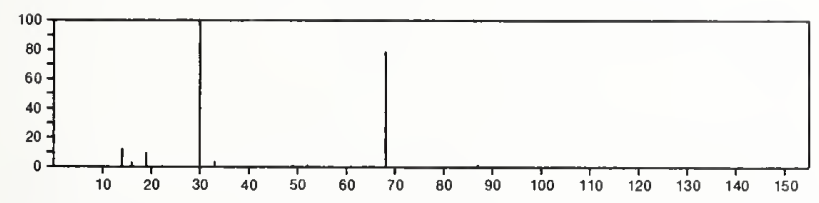

88

Methane, tetrafluoro-

$\mathrm{CF}_{4}$

$\mathrm{CF}_{4}$

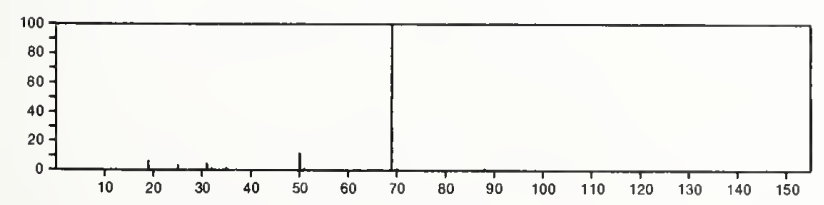

$88 \quad \mathrm{C}_{2} \mathrm{H}_{4} \mathrm{~N}_{2} \mathrm{O}_{2}$

1,2-Hydrazinedicarboxaldehyde

$628-36-4$

$\mathrm{O}=\mathrm{CHNHNHCH}=\mathrm{O}$

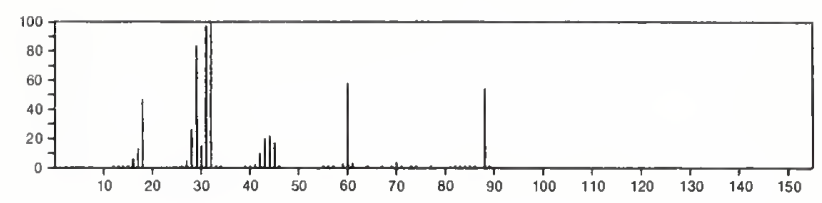

88

1,3-Dioxolan-2-one

$\mathrm{C}_{3} \mathrm{H}_{4} \mathrm{O}_{3}$

96-49-1
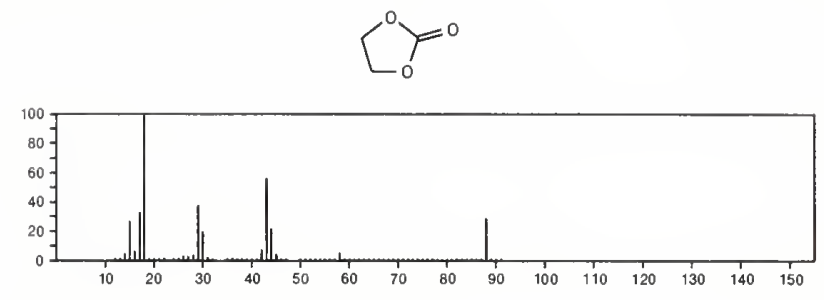

88

$\mathrm{C}_{3} \mathrm{H}_{4} \mathrm{O}_{3}$

127-17-3

Propanoic acid, 2-oxo-

$\mathrm{HO}_{2}$ CCOMe

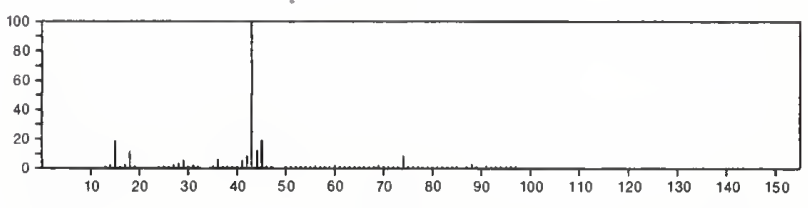

88

Urea, $N, N^{\prime}$-dimethyl-

$\mathrm{C}_{3} \mathrm{H}_{8} \mathrm{~N}_{2} \mathrm{O}$

96-31-1

MeNHCONHME

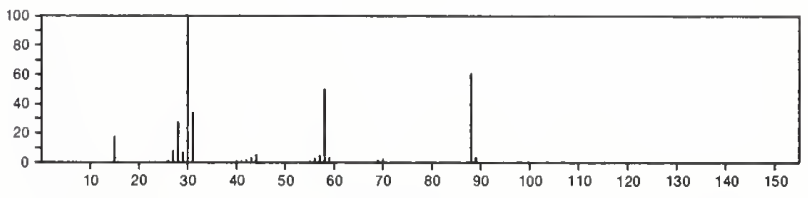

88

$\mathrm{C}_{3} \mathrm{H}_{8} \mathrm{~N}_{2} \mathrm{O}$

598-94-7

Urea, $N, N$-dimethyl-

$\mathrm{Me} 2 \mathrm{NCONH}_{2}$

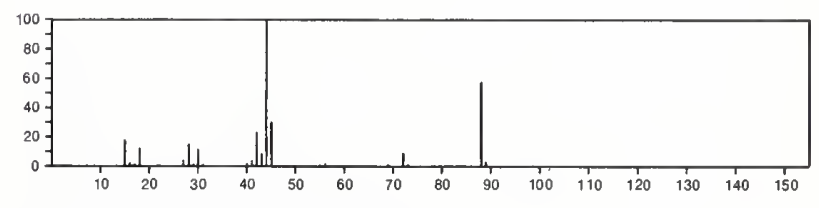

88

$\mathrm{C}_{3} \mathrm{H}_{8} \mathrm{~N}_{2} \mathrm{O}$

Ethanamine, $N$-methyl- $N$-nitroso-

10595-95-6

EINME (NO)

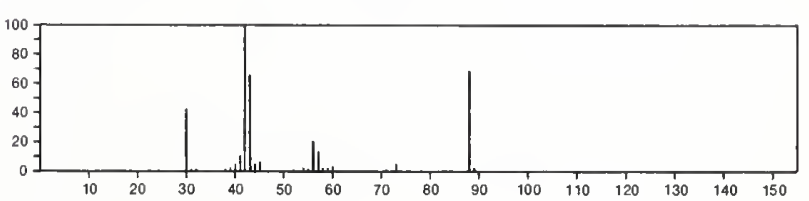


88

1,3-Butadiene, 2-chloro-

$\mathrm{C}_{4} \mathrm{H}_{5} \mathrm{Cl}$

$\mathrm{H}_{2} \mathrm{C}=\mathrm{CHCCl}=\mathrm{CH}_{2}$

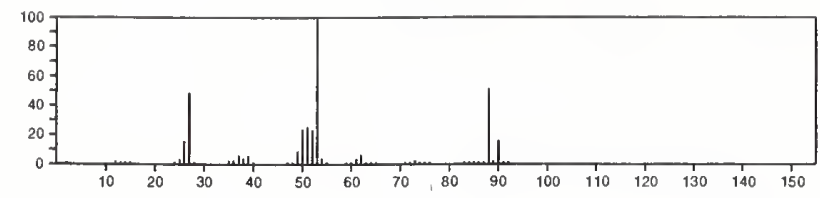

$88 \quad \mathrm{C}_{4} \mathrm{H}_{8} \mathrm{O}_{2}$

79-31-2

Propanoic acid, 2-methyl-

$\mathrm{Me} 2 \mathrm{CHCO}_{2} \mathrm{H}$

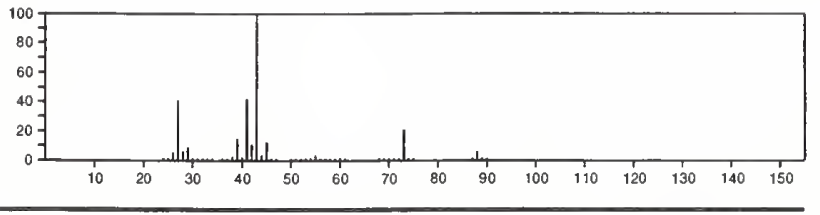

88

Butanal, 3-hydroxy-

$\mathrm{C}_{4} \mathrm{H}_{8} \mathrm{O}_{2}$

107-89-1

$\mathrm{MeCH}(\mathrm{OH}) \mathrm{CH}_{2} \mathrm{CHO}$

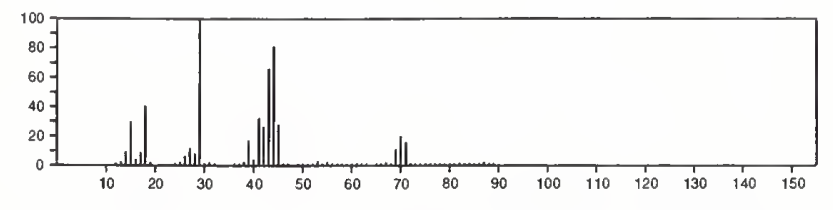

88

Butanoic acid

$\mathrm{C}_{4} \mathrm{H}_{8} \mathrm{O}_{2}$

$107-92-6$

$\mathrm{PrCO}_{2} \mathrm{H}$

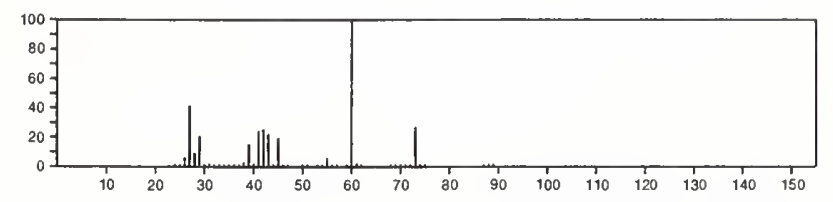

88

2-Butene-1,4-diol

$\mathrm{C}_{4} \mathrm{H}_{8} \mathrm{O}_{2}$

110-64-5

$\mathrm{HOCH}_{2} \mathrm{CH}=\mathrm{CHCH}_{2} \mathrm{OH}$

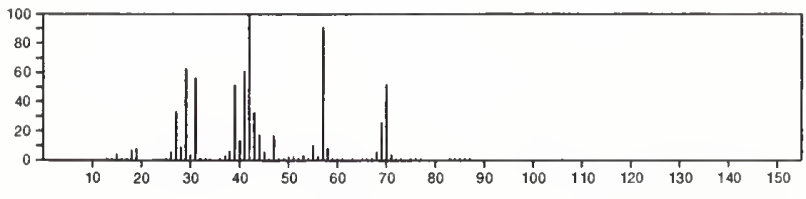

88

$\mathrm{C}_{4} \mathrm{H}_{8} \mathrm{O}_{2}$

110-74-7

Formic acid, propyl ester

$\mathrm{O}=\mathrm{CHOP}$

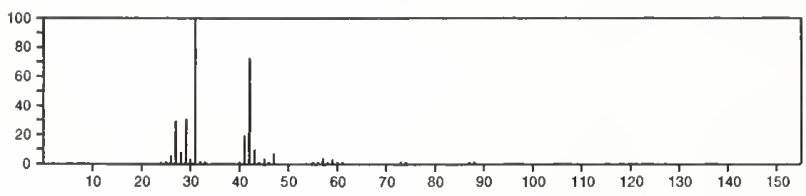

88

1,4-Dioxane

$\mathrm{C}_{4} \mathrm{H}_{8} \mathrm{O}_{2}$

123-91-1
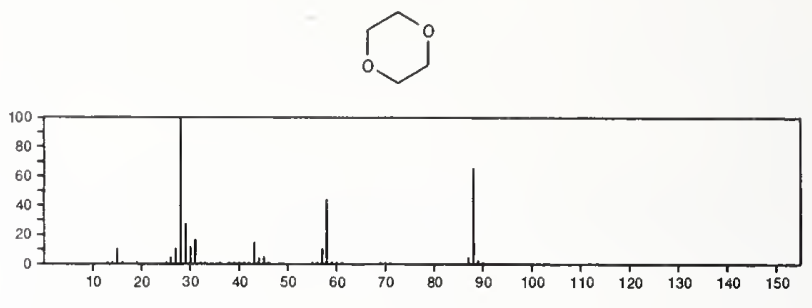

88

Acetic acid ethyl ester

$\mathrm{C}_{4} \mathrm{H}_{8} \mathrm{O}_{2}$

$141-78-6$

EtOA

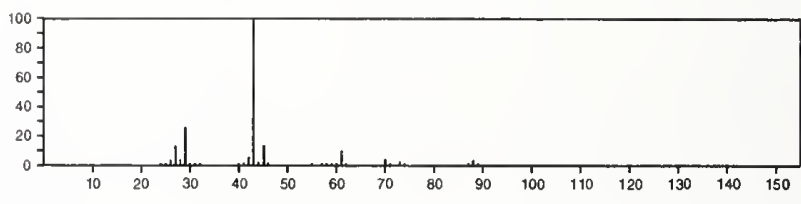

88

3-Butene-1,2-diol

$\mathrm{C}_{4} \mathrm{H}_{8} \mathrm{O}_{2}$

497-06-3

$\mathrm{H}_{2} \mathrm{C}=\mathrm{CHCH}(\mathrm{OH}) \mathrm{CH}_{2} \mathrm{OH}$

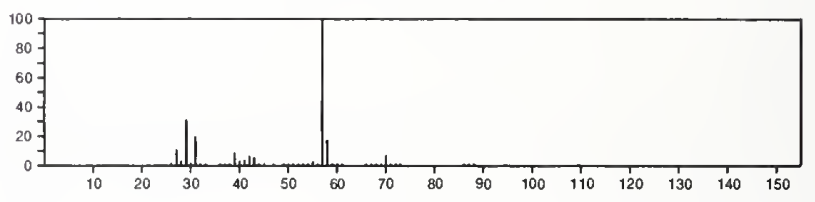

88

1,3-Dioxolane, 2-methyl-

$\mathrm{C}_{4} \mathrm{H}_{8} \mathrm{O}_{2}$

497-26-7
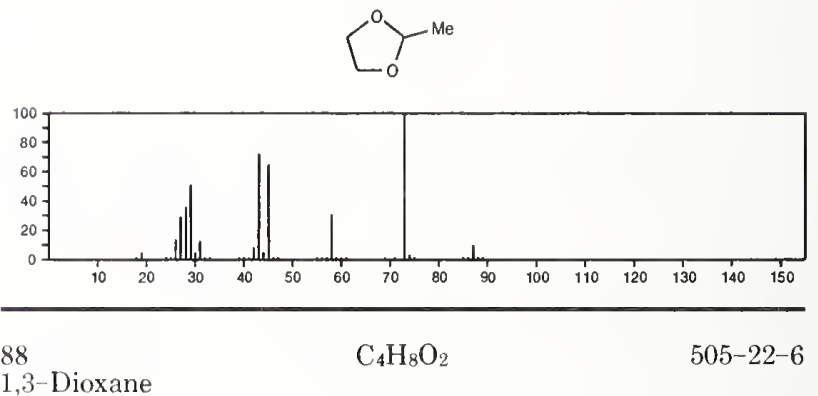

ij

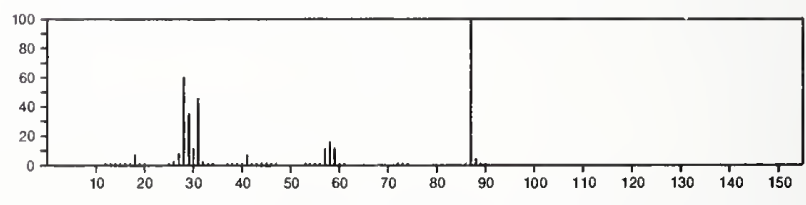

88

2-Butanone, 3-hydroxy-

$\mathrm{C}_{4} \mathrm{H}_{8} \mathrm{O}_{2}$

513-86-0

$\mathrm{Me} \mathrm{CH}(\mathrm{OH}) \mathrm{COM}$

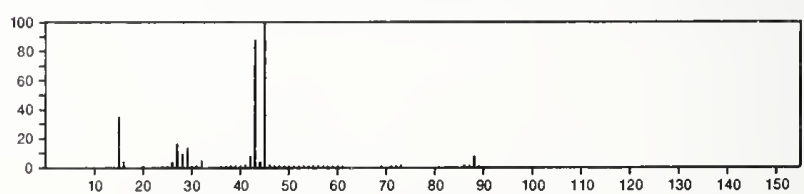


88

Propanoic acid, methyl ester

$\mathrm{C}_{4} \mathrm{H}_{8} \mathrm{O}_{2}$

MeOC(O)Et

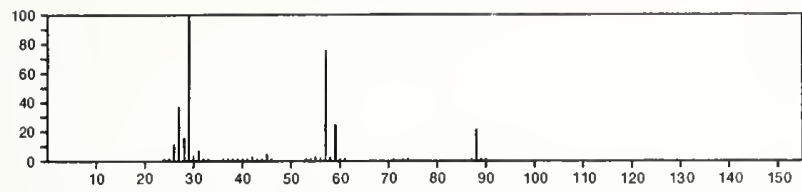

88

Formic acid, 1-methylethyl ester

$\mathrm{O}=\mathrm{CHOPr}-\mathrm{i}$

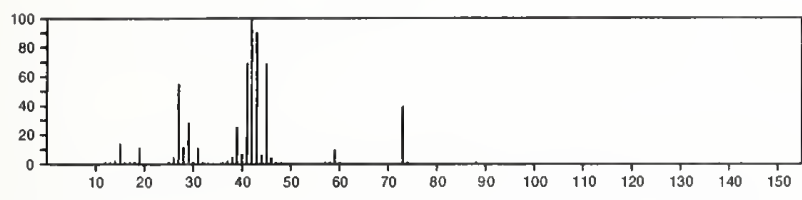

88

Ethanol, 2-(ethenyloxy)-

$\mathrm{C}_{4} \mathrm{H}_{8} \mathrm{O}_{2}$

$764-48-7$

$\mathrm{H}_{2} \mathrm{C}=\mathrm{CHOCH}_{2} \mathrm{CH}_{2} \mathrm{OH}$

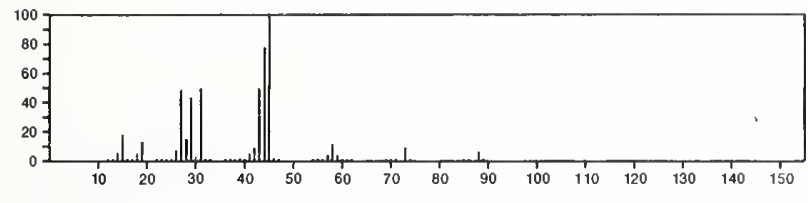

88

Oxirane, (methoxymethyl)-

\section{$\mathrm{C}_{4} \mathrm{H}_{8} \mathrm{O}_{2}$}

$930-37-0$
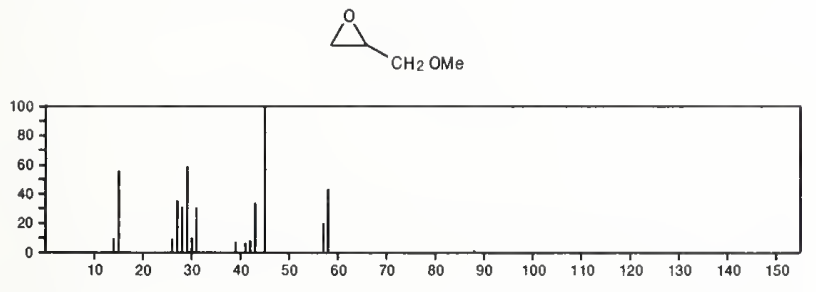

88

1,3-Dioxolane, 4-methyl-

$\mathrm{C}_{4} \mathrm{H}_{8} \mathrm{O}_{2}$

$1072-47-5$
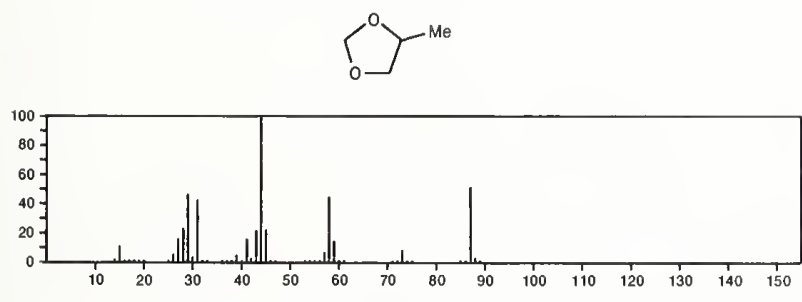

88

2-Butene-1,4-diol, (Z)-

$\mathrm{C}_{4} \mathrm{H}_{8} \mathrm{O}_{2}$

$6117-80-2$

$\mathrm{HOCH}_{2} \mathrm{CH}=\mathrm{CHCH}_{2} \mathrm{OH}$
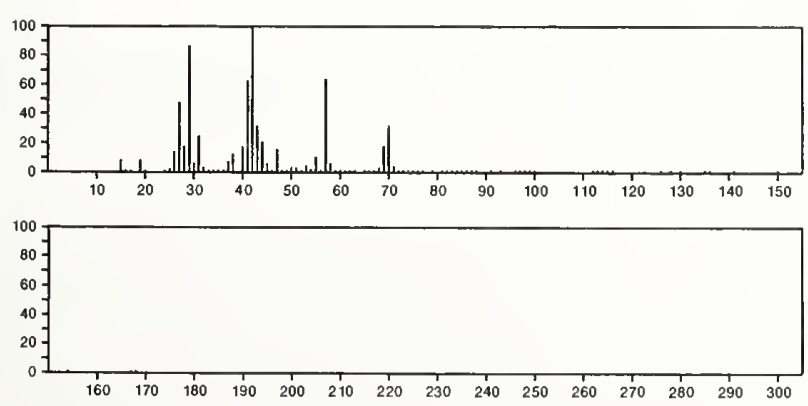

88

Thiophene, tetrahydro-

$\mathrm{C}_{4} \mathrm{H}_{8} \mathrm{~S}$

$110-01-0$
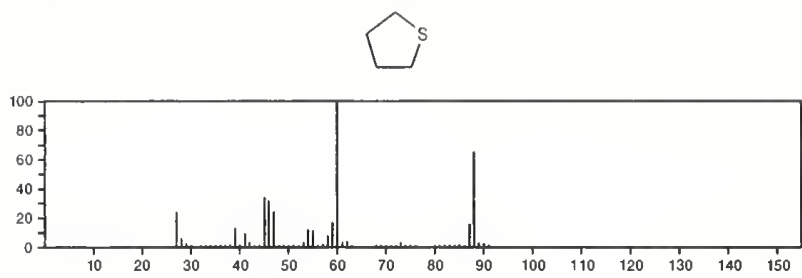

88

Cyclobutanethiol

$\mathrm{C}_{4} \mathrm{H}_{8} \mathrm{~S}$

6861-61-6

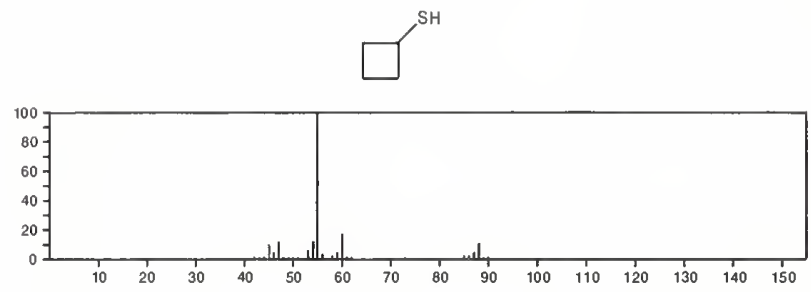

88

1-Propene, 3-(methylthio)-

$\mathrm{C}_{4} \mathrm{H}_{8} \mathrm{~S}$

10152-76-8

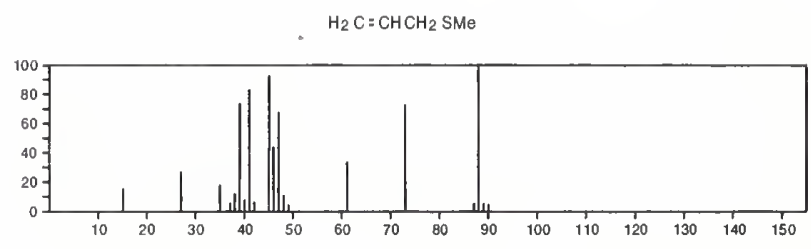

88

Thietane, 2-methyl-

$\mathrm{C}_{4} \mathrm{H}_{8} \mathrm{~S}$

$17837-41-1$

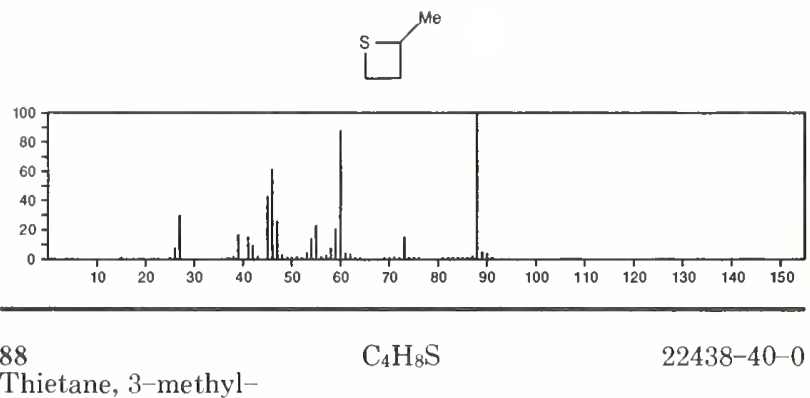

Thietane, 3-methyl-
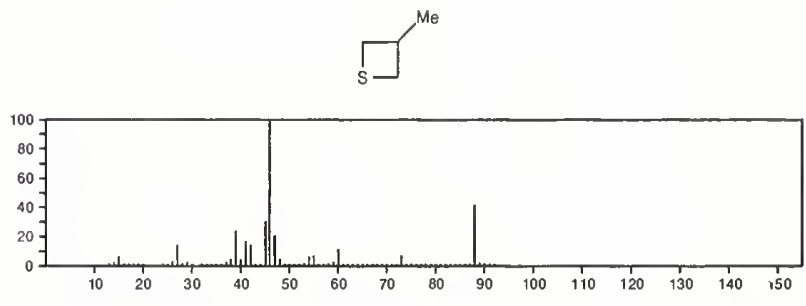

88

1-Propene, 1-(methylthio)-,$(E)-$

$42848-06-6$

$\mathrm{Me} \mathrm{CH}=\mathrm{CHSMe}$

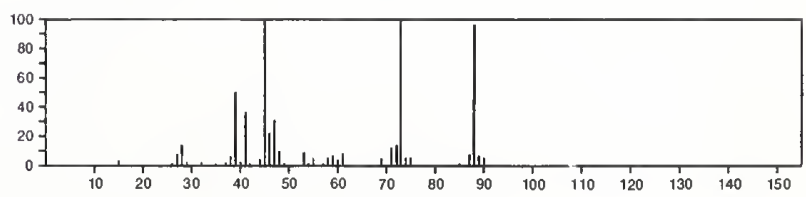


$\begin{array}{ll}88 & \mathrm{C}_{4} \mathrm{H}_{8} \mathrm{~S} \\ 1 \text {-Propene, 1-(methylthio)-, } & (Z)-\end{array}$

$52195-40-1$

$\mathrm{Me} \mathrm{CH}=\mathrm{CHSMe}$

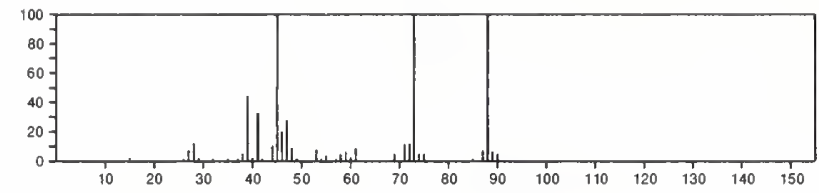

88

Phospholane

$\mathrm{C}_{4} \mathrm{H}_{9} \mathrm{P}$

$3466-00-0$
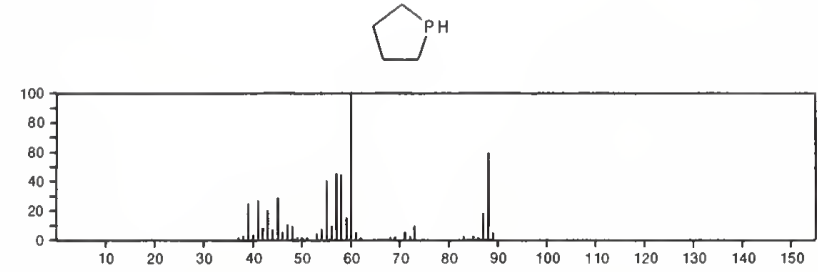

88

1,4-Butanediamine

$\mathrm{C}_{4} \mathrm{H}_{12} \mathrm{~N}_{2}$

$110-60-1$

$\mathrm{H}_{2} \mathrm{~N}\left(\mathrm{CH}_{2}\right){ }_{4} \mathrm{NH}_{2}$

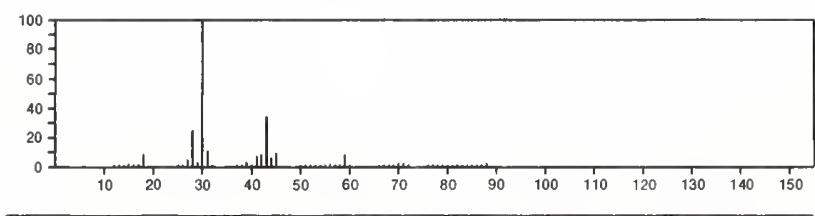

88

Hydrazine, butyl-

$\mathrm{C}_{4} \mathrm{H}_{12} \mathrm{~N}_{2}$

$3530-11-8$

$\mathrm{H}_{2} \mathrm{NNH}\left(\mathrm{CH}_{2}\right)_{3} \mathrm{Me}$

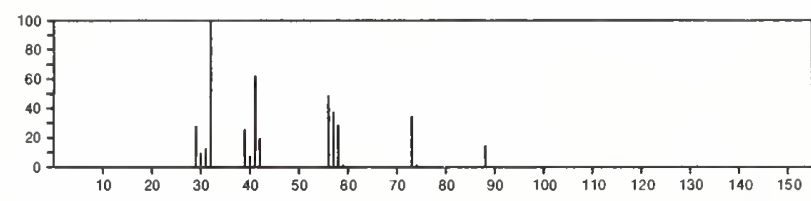

$88 \quad \mathrm{C}_{4} \mathrm{H}_{12} \mathrm{Si}$

Silane, tetramethyl-

$\mathrm{SiMe}_{4}$

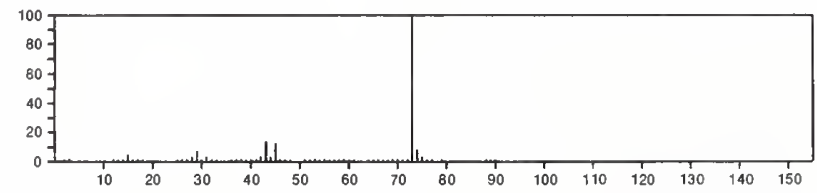

88

1-Pentanol

$\mathrm{C}_{5} \mathrm{H}_{12} \mathrm{O}$

$71-41-0$

$\mathrm{Me}\left(\mathrm{CH}_{2}\right){ }_{4} \mathrm{OH}$

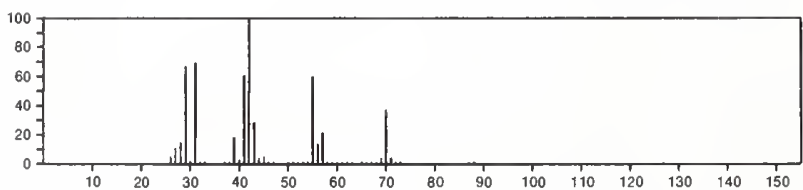

$88 \quad \mathrm{C}_{5} \mathrm{H}_{12} \mathrm{O}$

$75-84-3$

1-Propsanol, 2,2-dimethyl-

$\mathrm{HOCH}_{2} \mathrm{CMe}_{3}$

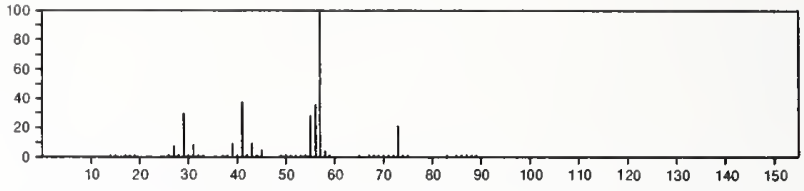

88

2-Butanol, 2-methyl-

$\mathrm{C}_{5} \mathrm{H}_{12} \mathrm{O}$

$75-85-4$

$\mathrm{EtCMe} 2(\mathrm{OH})$

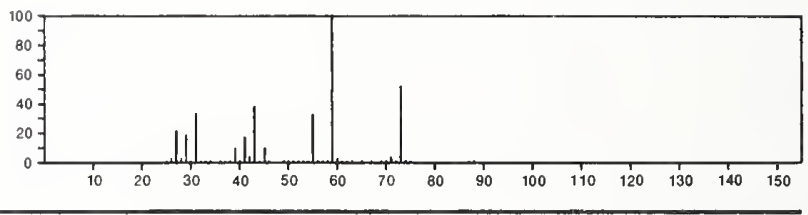

88

$\mathrm{C}_{5} \mathrm{H}_{12} \mathrm{O}$

$123-51-3$

1-Butanol, 3-methyl-

$\mathrm{HOCH}_{2} \mathrm{CH}_{2} \mathrm{CHMe}_{2}$

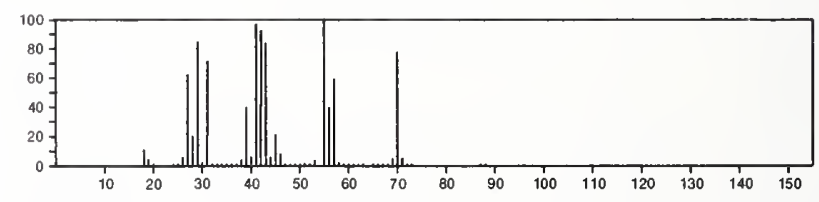

$88 \quad \mathrm{C}_{5} \mathrm{H}_{12} \mathrm{O}$

1-Butanol, 2-methyl-

$137-32-6$

$\mathrm{MeCH}_{2} \mathrm{CHMe} \mathrm{CH}_{2} \mathrm{OH}$

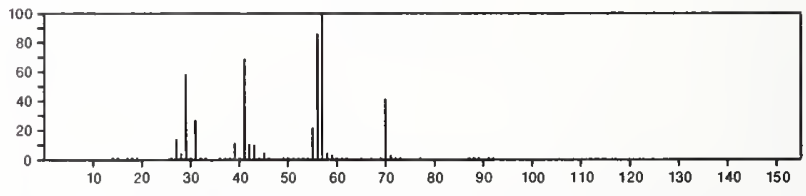

88

$\mathrm{C}_{5} \mathrm{H}_{12} \mathrm{O}$

584-02-1

3-Pentanol

$\mathrm{Et}_{2} \mathrm{CHOH}$

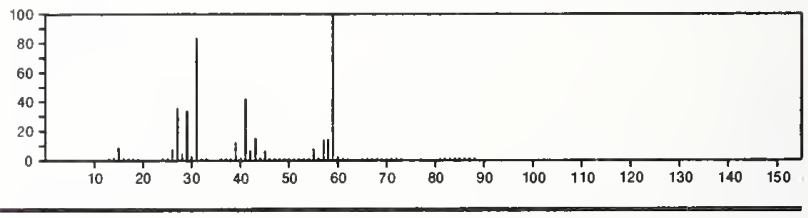

88

$\mathrm{C}_{5} \mathrm{H}_{12} \mathrm{O}$

$598-75-4$

-Butanol, 3-methyl-

$\mathrm{MeCH}(\mathrm{OH}) \mathrm{CHMe}$

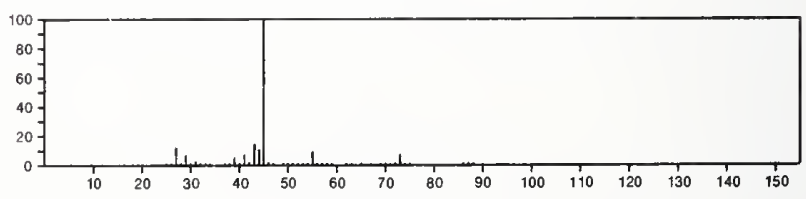


$88 \quad \mathrm{C}_{5} \mathrm{H}_{12} \mathrm{O}$

Propane, 1-methoxy-2-methyl-

$\mathrm{MeOBu}-\mathrm{i}$
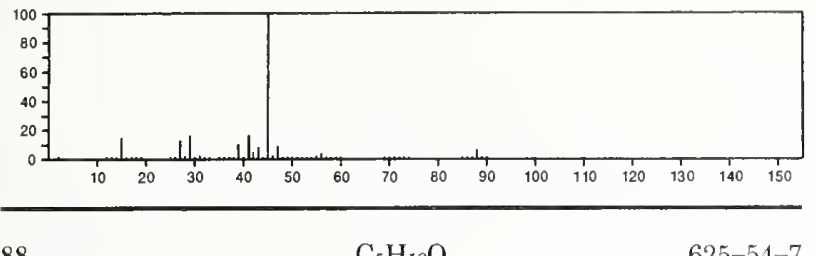

88

$\mathrm{C}_{5} \mathrm{H}_{12} \mathrm{O}$

EtoPr-i

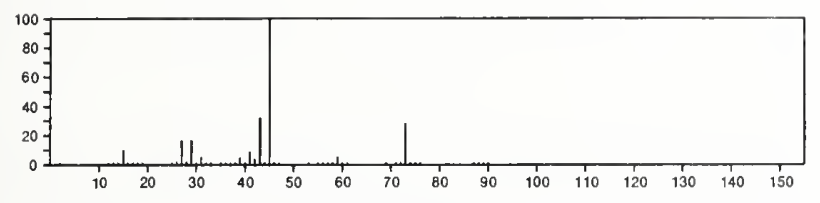

88

$\mathrm{C}_{5} \mathrm{H}_{12} \mathrm{O}$

$628-28-4$

Butane, 1-methoxy-

$\mathrm{MeO}\left(\mathrm{CH}_{2}\right)_{3} \mathrm{Me}$
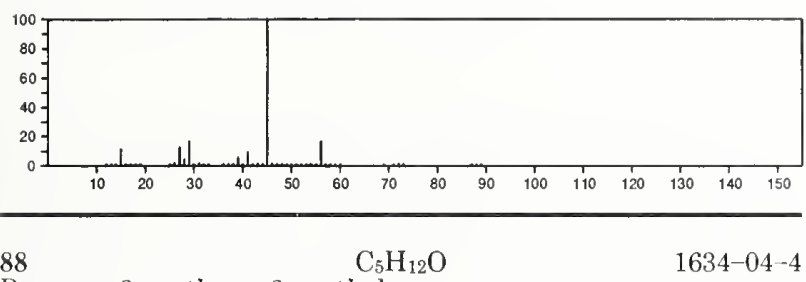

1634-04-4

Propane, 2-methoxy-2-methyl-

$\mathrm{MeOBu}-1$

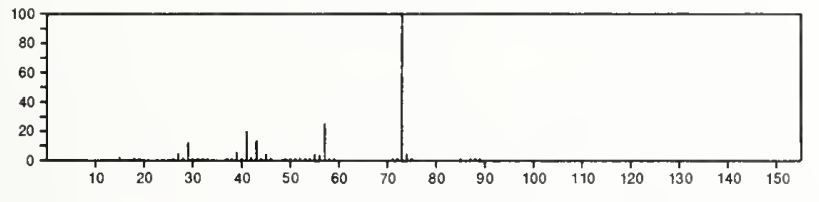

88

2-Pentanol

\section{$\mathrm{C}_{5} \mathrm{H}_{12} \mathrm{O}$}

$\operatorname{PrCHMe}(\mathrm{OH})$

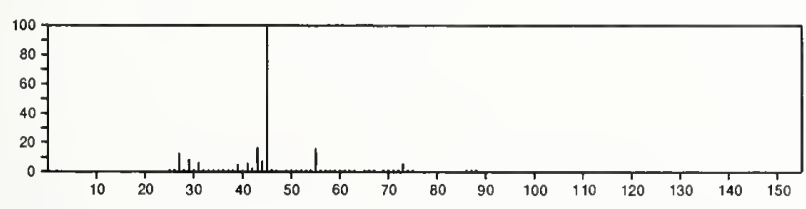

88

Butane, 2-methoxy-

$\mathrm{C}_{5} \mathrm{H}_{12} \mathrm{O}$

$6795-87-5$

Me OBu-s

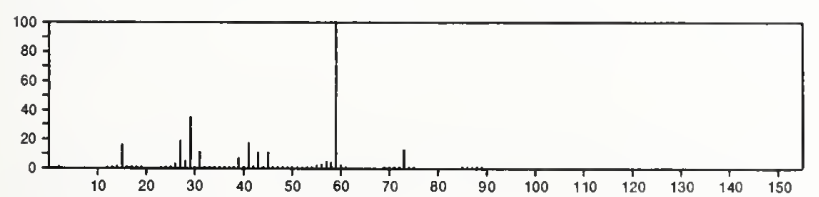

89

Propanenitrile, 3-chloro-

$\mathrm{C}_{3} \mathrm{H}_{4} \mathrm{ClN}$

$542-76-7$

$\mathrm{Cl} \mathrm{CH}_{2} \mathrm{CH}_{2} \mathrm{CN}$

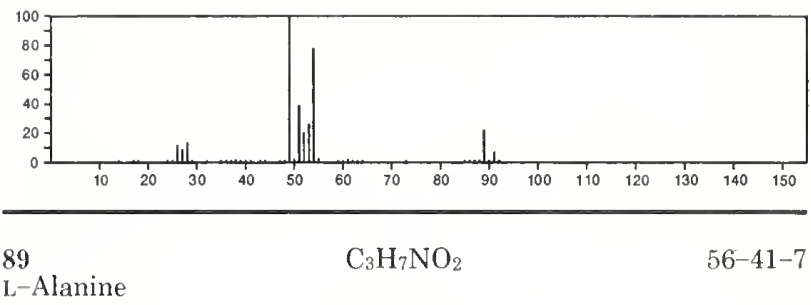

$\mathrm{Me} \mathrm{CH}\left(\mathrm{NH}_{2}\right) \mathrm{CO}_{2} \mathrm{H}$

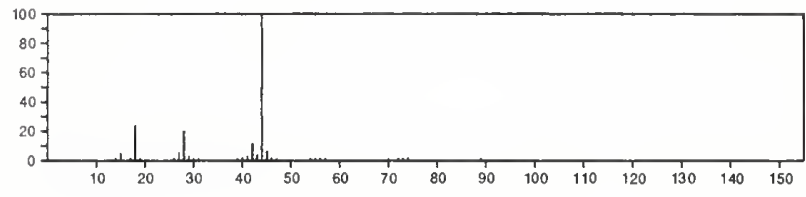

89

Propane, 2-nitro-

$\mathrm{C}_{3} \mathrm{H}_{7} \mathrm{NO}_{2}$

$79-46-9$

$\mathrm{i}-\mathrm{PrNO}$

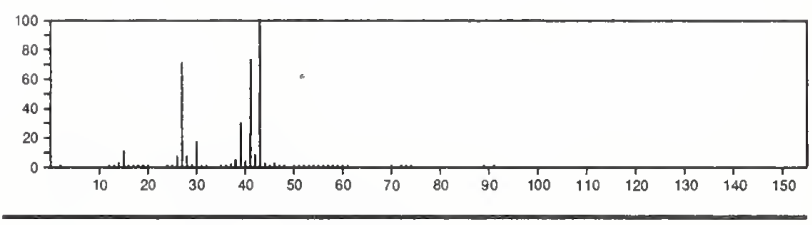

89

$\mathrm{C}_{3} \mathrm{H}_{7} \mathrm{NO}_{2}$

108-03-2

Propane, 1-nitro-

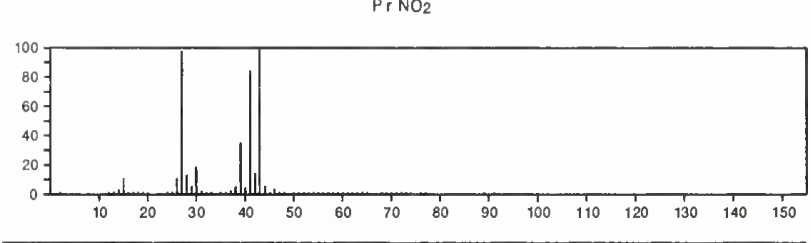

89

1-Butanol, 2-amino-

$\mathrm{C}_{4} \mathrm{H}_{11} \mathrm{NO}$

$96-20-8$

$\left.\mathrm{HOCH} \mathrm{CH}_{2} \mathrm{CH} \mathrm{NH}_{2}\right) \mathrm{E}$

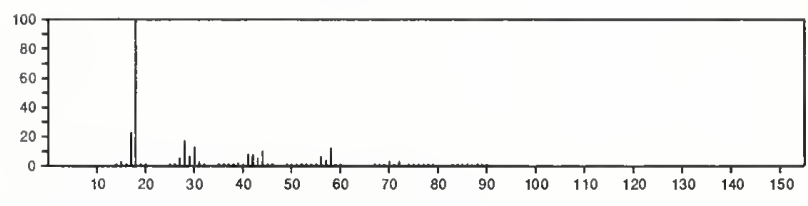

89

Ethanol, 2-(dimethylamino)

$\mathrm{C}_{4} \mathrm{H}_{11} \mathrm{NO}$

108-01-0

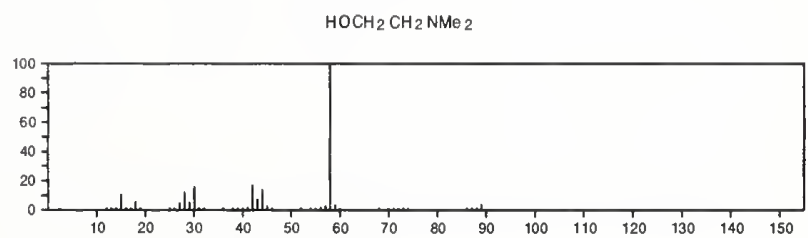


89

1-Propanol, 2-amino-2-methyl-

$\mathrm{C}_{4} \mathrm{H}_{11} \mathrm{NO}$

$\mathrm{HOCH}_{2} \mathrm{CMe}_{2} \mathrm{NH}_{2}$

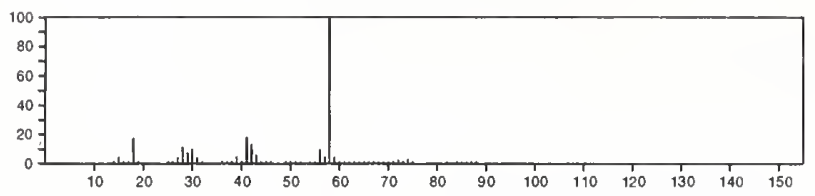

$89 \quad \mathrm{C}_{4} \mathrm{H}_{11} \mathrm{NO}$

1-Propanamine, 3 -methoxy-

$\mathrm{MeO}\left(\mathrm{CH}_{2}\right)_{3} \mathrm{NH}_{2}$

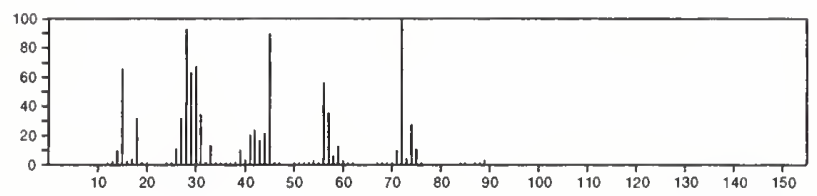

89

$\mathrm{C}_{4} \mathrm{H}_{11} \mathrm{NO}$

Hydroxylamine, $\mathrm{O}-(2-$ methylpropyl)-

$\mathrm{H}_{2} \mathrm{NOBu}-\mathrm{i}$

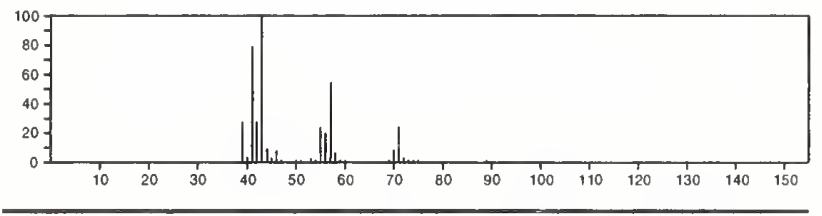

90

Carbonic dihydrazide

$\mathrm{CH}_{6} \mathrm{~N}_{4} \mathrm{O}$

$497-18-7$

$\mathrm{H}_{2} \mathrm{NNHCONHNH}_{2}$

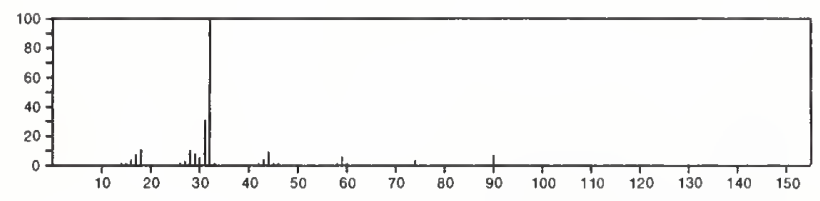

$90 \quad \mathrm{C}_{2} \mathrm{H}_{2} \mathrm{O}_{4}$

$144-62-7$

Ethanedioic acid

$\mathrm{HO}_{2} \mathrm{CCO}_{2} \mathrm{H}$

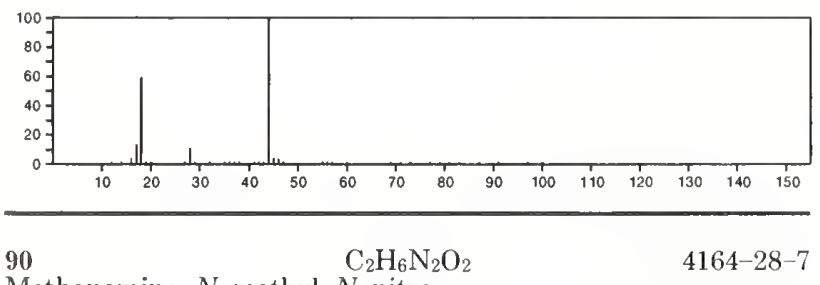

Methanamine, $\mathrm{N}$-methyl- $\mathrm{N}$-nitro-

$\mathrm{Me}_{2} \mathrm{NNO}_{2}$

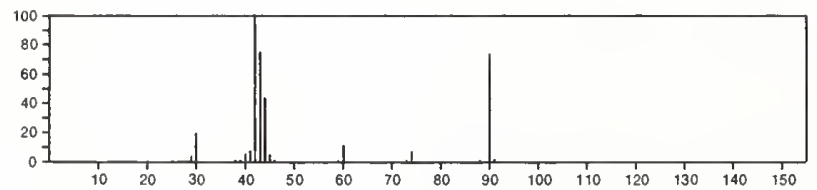

$90 \quad \mathrm{C}_{2} \mathrm{H}_{6} \mathrm{~N}_{2} \mathrm{O}_{2}$

Hydrazinecarboxylic acid, methyl ester

6294-89-9

$\mathrm{H}_{2} \mathrm{NNHC}(\mathrm{O}) \mathrm{OMe}$

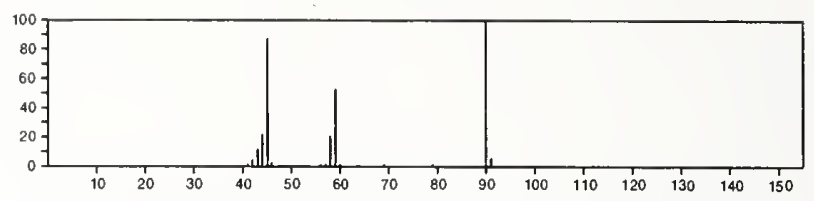

$90 \quad \mathrm{C}_{2} \mathrm{H}_{6} \mathrm{~N}_{2} \mathrm{O}_{2}$

Methanamine, $N$-methoxy-N-nitroso-

16339-12-1

$\mathrm{MeON}(\mathrm{NO}) \mathrm{Me}$

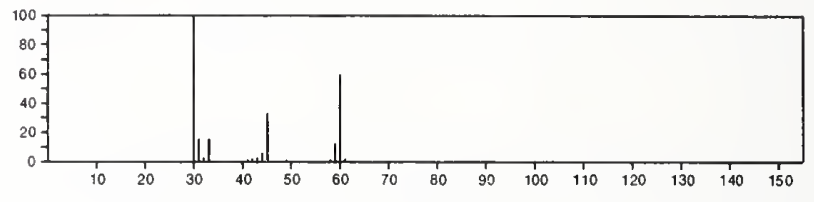

90

$\mathrm{C}_{2} \mathrm{H}_{6} \mathrm{~N}_{2} \mathrm{~S}$

$598-52-7$

Thiourea, methyl-

MeNHCSNH 2

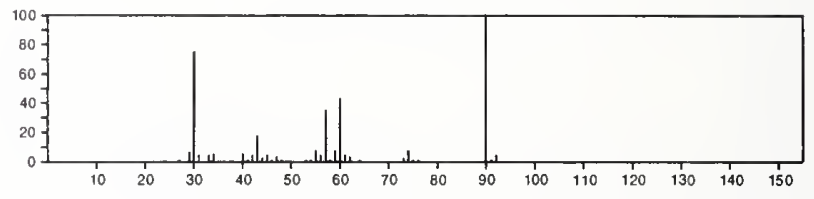

90

$\mathrm{C}_{2} \mathrm{H}_{6} \mathrm{~N}_{2} \mathrm{~S}$

13849-02-0

Sulfur diimide, dimethyl-

MeN $=\mathrm{S}: \mathrm{NME}$

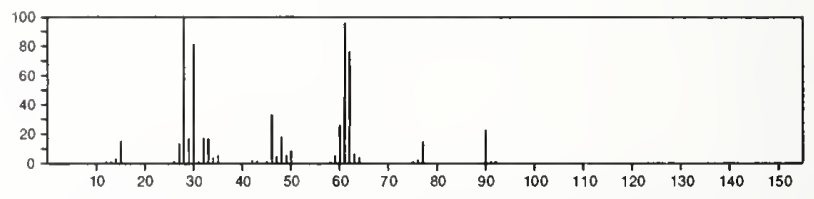

90 $\quad \mathrm{C}_{3} \mathrm{H}_{3} \mathrm{ClO}$

$814-68-6$

2-Propenoyl chloride

$\mathrm{H}_{2} \mathrm{C}=\mathrm{CHCOCI}$

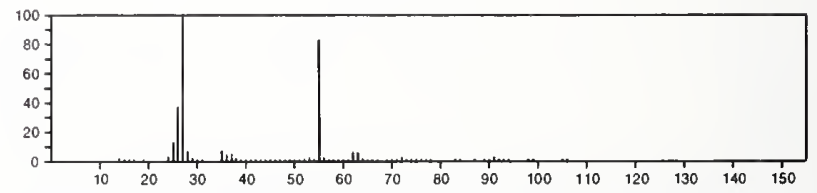

90

$\mathrm{C}_{3} \mathrm{H}_{6} \mathrm{OS}$

1534-08-3

Ethanethioic acid, $S$-methyl ester

MeSAC

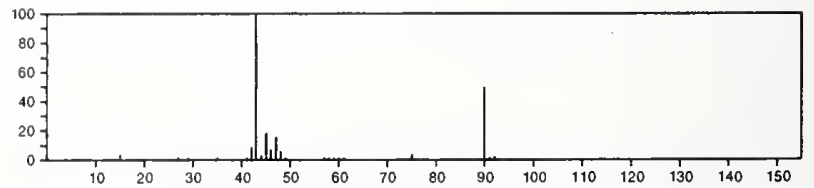


90

1,3-Oxathiolane

$\mathrm{C}_{3} \mathrm{H}_{6} \mathrm{OS}$
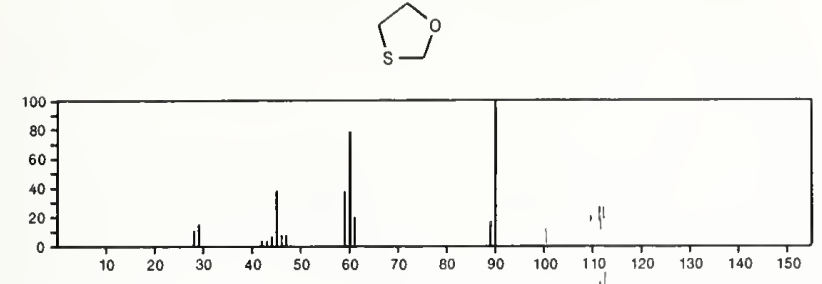

$90 \quad \mathrm{C}_{3} \mathrm{H}_{6} \mathrm{OS}$

10258-86-3

Ethene, (methylsulfinyl)-

$\mathrm{H}_{2} \mathrm{C}=\mathrm{CHS}(\mathrm{O}) \mathrm{Me}$

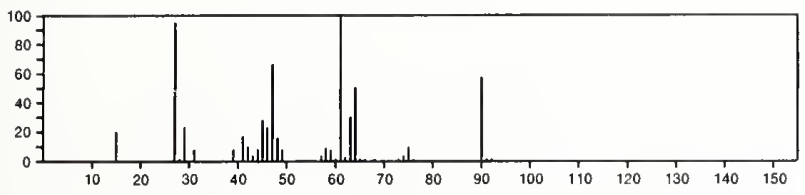

90

$\mathrm{C}_{3} \mathrm{H}_{6} \mathrm{OS}$

$13153-11-2$

Thietane, 1-oxide
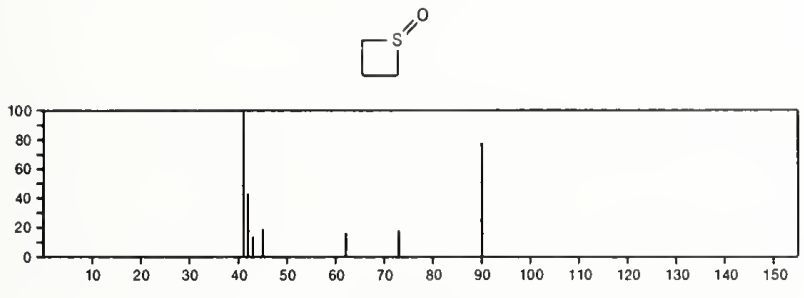

90

$\mathrm{C}_{3} \mathrm{H}_{6} \mathrm{O}_{3}$

96-26-4

2-Propanone, 1,3-dihydroxy-

$\mathrm{HOCH}_{2} \mathrm{COCH}_{2} \mathrm{OH}$

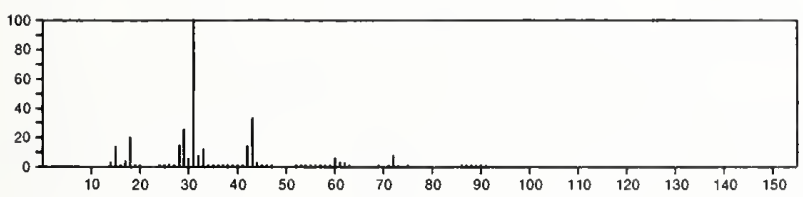

$\mathrm{C}_{3} \mathrm{H}_{6} \mathrm{O}_{3}$

90

hyl ester

96-35-5

Acetic acid, hydroxy-, methyl ester
\[ \mathrm{HOCH}_{2} \mathrm{C}(\mathrm{O}) \mathrm{OM}^{\circ} \]

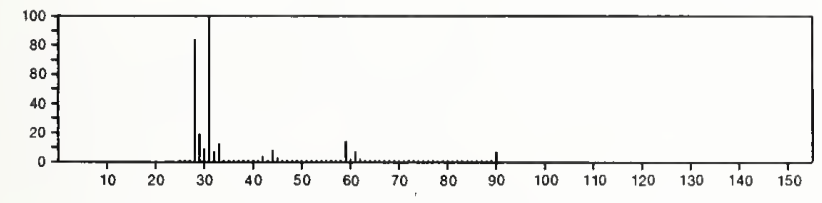

90

$\mathrm{C}_{3} \mathrm{H}_{6} \mathrm{O}_{3}$

110-88-3

1,3,5-Trioxane<smiles>C1OCOCO1</smiles>

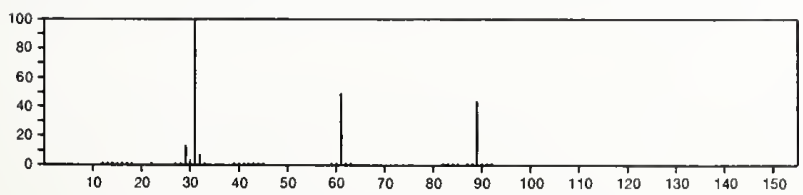

90

$\mathrm{C}_{3} \mathrm{H}_{6} \mathrm{O}_{3}$

$367-47-5$

Propanal, 2,3-dihydroxy-

$\mathrm{HOCH}_{2} \mathrm{CH}(\mathrm{OH}) \mathrm{CHO}$

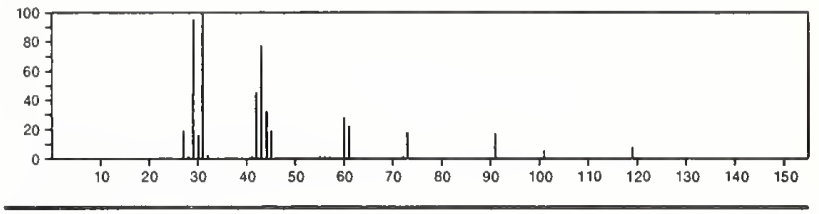

90

Carbonic acid, dimethyl ester

$\mathrm{C}_{3} \mathrm{H}_{6} \mathrm{O}_{3}$

616-38-6

$\mathrm{MeOC}(\mathrm{O}) \mathrm{OMe}$

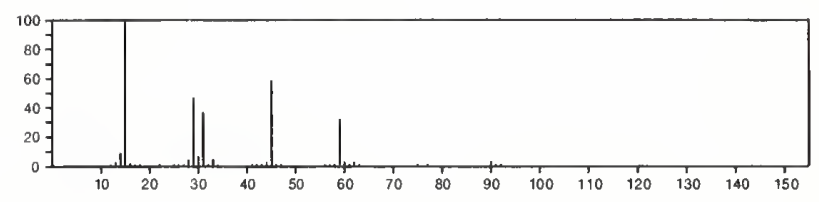

90

$\mathrm{C}_{3} \mathrm{H}_{6} \mathrm{O}_{3}$

625-45-6

Acetic acid, methoxy-

$\mathrm{MeOCH} \mathrm{CO}_{2} \mathrm{H}$

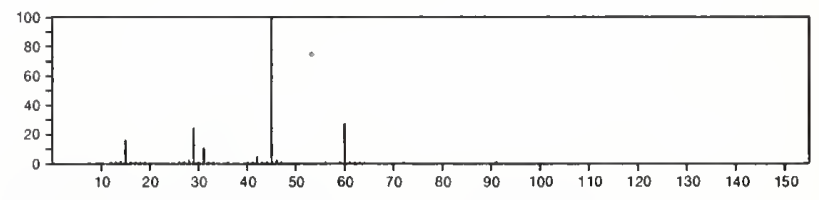

90

1,2-Ethanediol, monoformate

$\mathrm{C}_{3} \mathrm{H}_{6} \mathrm{O}_{3}$

628-35-3

$\mathrm{O}=\mathrm{CHOCH}_{2} \mathrm{CH}_{2} \mathrm{OH}$

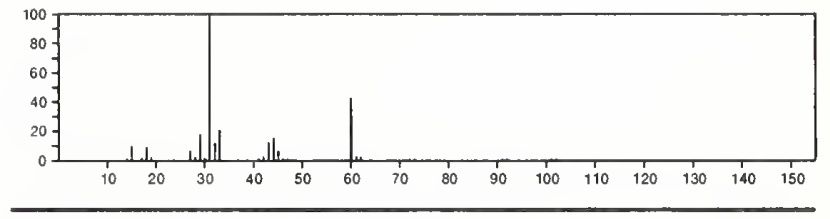

90

$\mathrm{C}_{4} \mathrm{H}_{7} \mathrm{Cl}$

1-Propene, 3-chloro-2-methyl-

$563-47-3$

$\mathrm{Cl} \mathrm{CH_{2 }} \mathrm{CMe}=\mathrm{CH}_{2}$

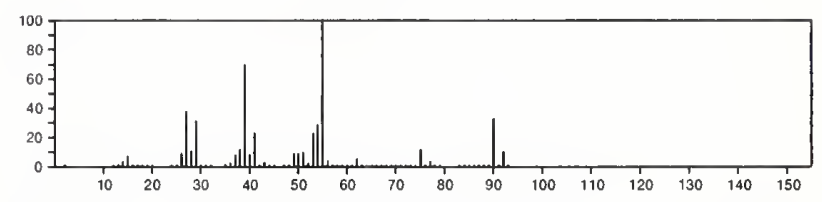

90

$\mathrm{C}_{4} \mathrm{H}_{7} \mathrm{Cl}$

$563-52-0$

1-Butene, 3-chloro-

$\mathrm{MeCHCl} \mathrm{CH}=\mathrm{CH}_{2}$

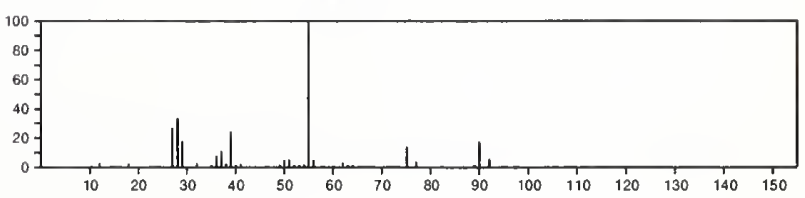


90

2-Butene, 1-chloro-

$\mathrm{C}_{4} \mathrm{H}_{7} \mathrm{Cl}$

$591-97-9$

$\mathrm{Me} \mathrm{CH}=\mathrm{CHCH}_{2} \mathrm{Cl}$

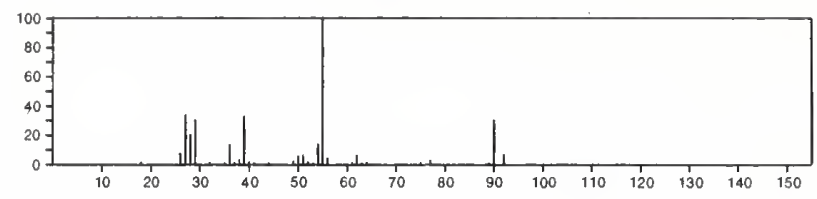

$90 \quad \mathrm{C}_{4} \mathrm{H}_{7} \mathrm{Cl}$

2-Butene, 2-chloro-

$\mathrm{MeCH}=\mathrm{CCI} \mathrm{Me}$

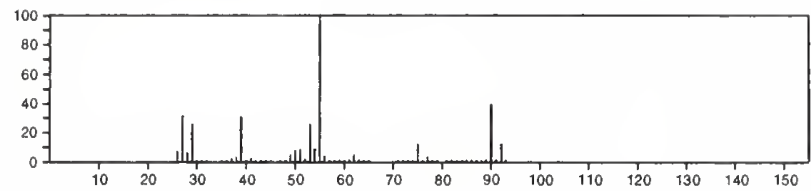

90

1,3-Butanediol

$\mathrm{C}_{4} \mathrm{H}_{10} \mathrm{O}_{2}$

$107-88-0$

$\mathrm{HOCH}_{2} \mathrm{CH}_{2} \mathrm{CH}(\mathrm{OH}) \mathrm{Me}$

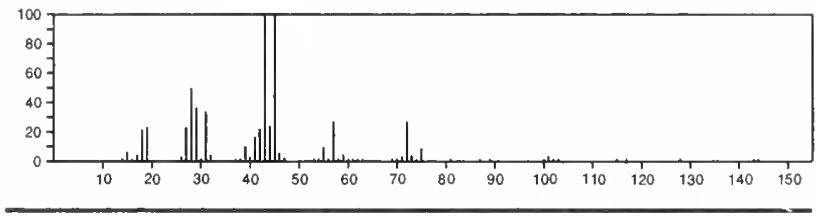

90

2-Propanol, 1-methoxy

$\mathrm{C}_{4} \mathrm{H}_{10} \mathrm{O}_{2}$

107-98-2

$\mathrm{MeOCH}_{2} \mathrm{CH}(\mathrm{OH}) \mathrm{Me}$

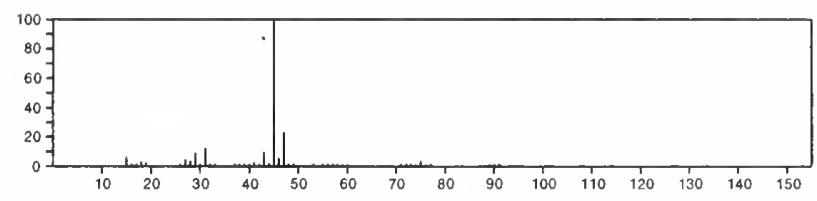

90

1,4-Butanediol

$\mathrm{C}_{4} \mathrm{H}_{10} \mathrm{O}_{2}$

$\mathrm{HO}\left(\mathrm{CH}_{2}\right) 4 \mathrm{OH}$

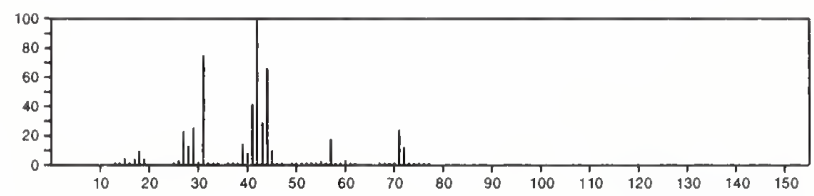

90

Ethane, 1,2-dimethoxy-

$\mathrm{C}_{4} \mathrm{H}_{10} \mathrm{O}_{2}$

$\mathrm{MeOCH} \mathrm{CH}_{2} \mathrm{OMe}$

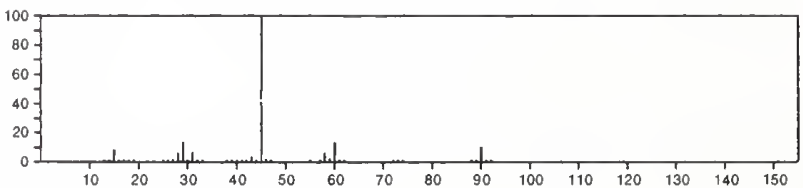

90

Ethanol, 2-ethoxy

$\mathrm{C}_{4} \mathrm{H}_{10} \mathrm{O}_{2}$

$110-80-5$

$\mathrm{E}_{1} \mathrm{OCH}_{2} \mathrm{CH}_{2} \mathrm{OH}$

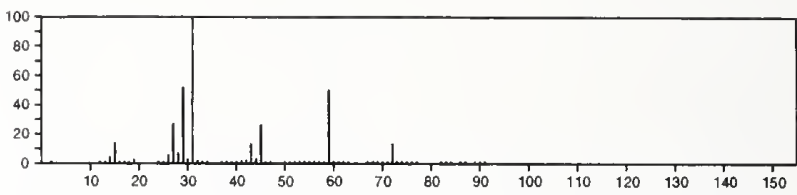

90

2,3-Butanediol

$\mathrm{C}_{4} \mathrm{H}_{10} \mathrm{O}_{2}$

513-85-9

$\mathrm{MeCH}(\mathrm{OH}) \mathrm{CH}(\mathrm{OH}) \mathrm{Me}$

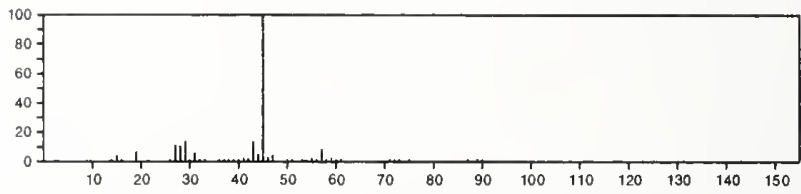

90

$\mathrm{C}_{4} \mathrm{H}_{10} \mathrm{O}_{2}$

Ethane, 1,1-dimethoxy-

$\mathrm{MeCH}$ ( OMe $)_{2}$

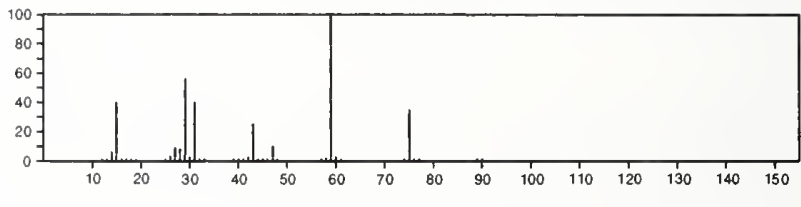

90

1,2-Butanediol

$\mathrm{C}_{4} \mathrm{H}_{10} \mathrm{O}_{2}$

584-03-2

$\mathrm{HOCH}_{2} \mathrm{CH}(\mathrm{OH}) \mathrm{E}$

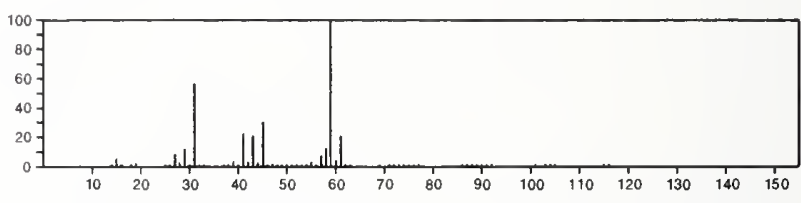

$90 \quad \mathrm{C}_{4} \mathrm{H}_{10} \mathrm{O}_{2}$

$628-37-5$

Peroxide, diethyl

E T OOE I

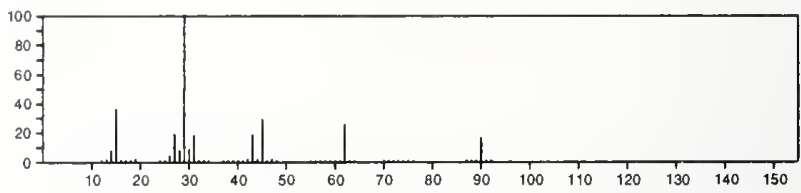

90

$\mathrm{C}_{4} \mathrm{H}_{10} \mathrm{O}_{2}$

1589-47-5

1-Propanol, 2-methoxy-

$\mathrm{HOCH}_{2} \mathrm{CH}$ ( OMe) Me

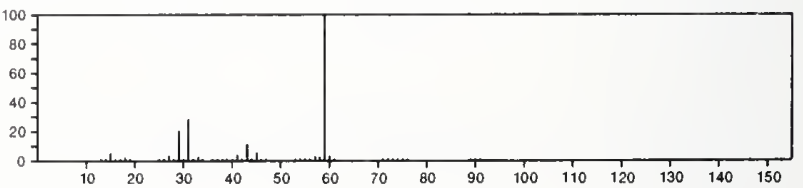



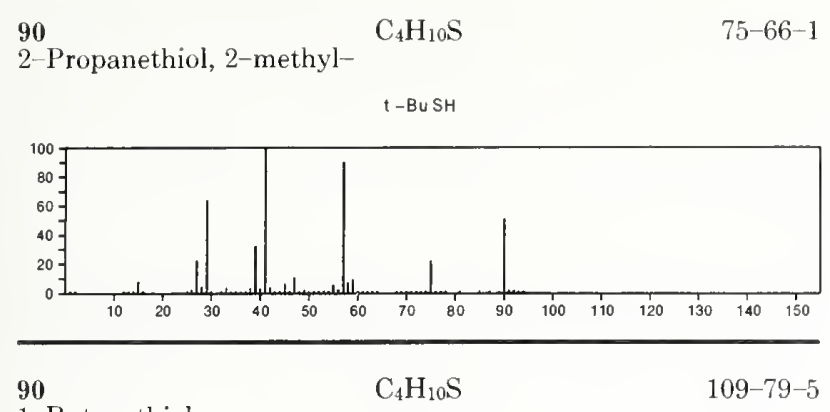

1-Butanethiol

$\mathrm{Me}\left(\mathrm{CH}_{2}\right)_{3} \mathrm{SH}$

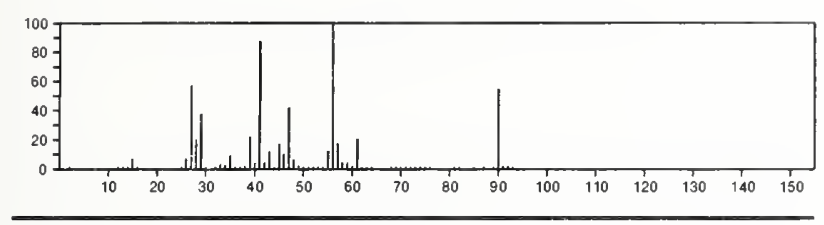

90

Ethane, 1, $1^{\dagger}$-thiobis-

\section{$\mathrm{C}_{4} \mathrm{H}_{10} \mathrm{~S}$}

$352-93-2$

SE 12
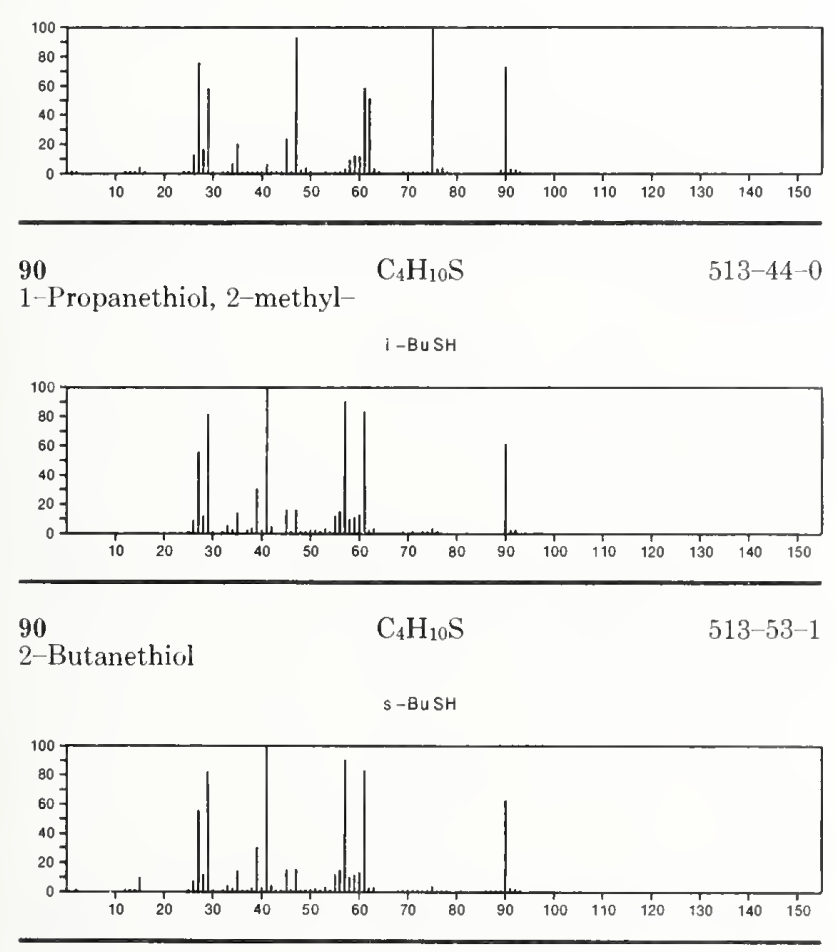

90

$\mathrm{C}_{4} \mathrm{H}_{10} \mathrm{~S}$

$1551-21-9$

Propane, 2-(methylthio)-

MeSPr-i

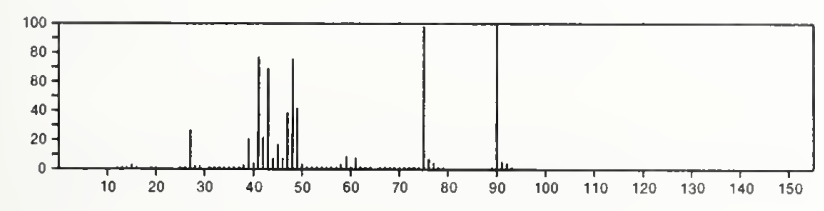

90

Propane, 1-(methylthio)-

$\mathrm{C}_{4} \mathrm{H}_{10 \mathrm{~S}}$

$3877-15-4$

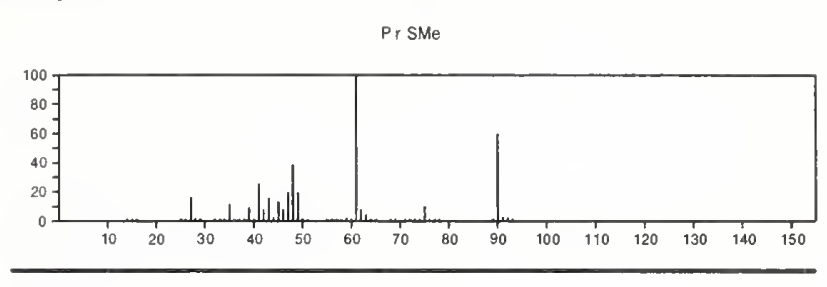

90

$\mathrm{C}_{4} \mathrm{H}_{11} \mathrm{P}$

$627-49-6$

Phosphine, diethyl-

PHE ${ }_{2}$

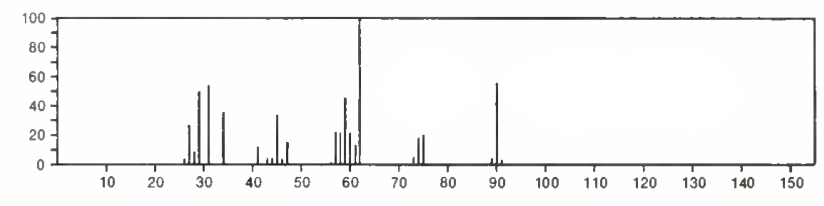

91

Hydrazinecarbothioamide

$\mathrm{CH}_{5} \mathrm{~N}_{3} \mathrm{~S}$

$79-19-6$

$\mathrm{H}_{2} \mathrm{NNHCSNH}_{2}$

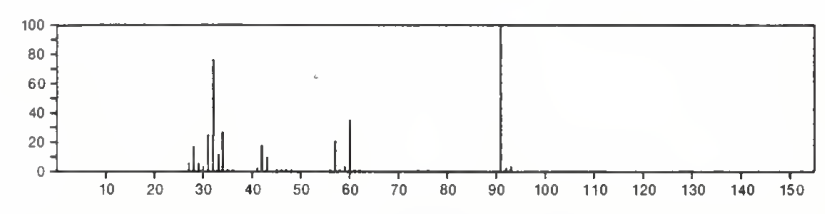

91

1,4,2-Oxathiazolidine

$\mathrm{C}_{2} \mathrm{H}_{5} \mathrm{NOS}$

$36720-42-0$
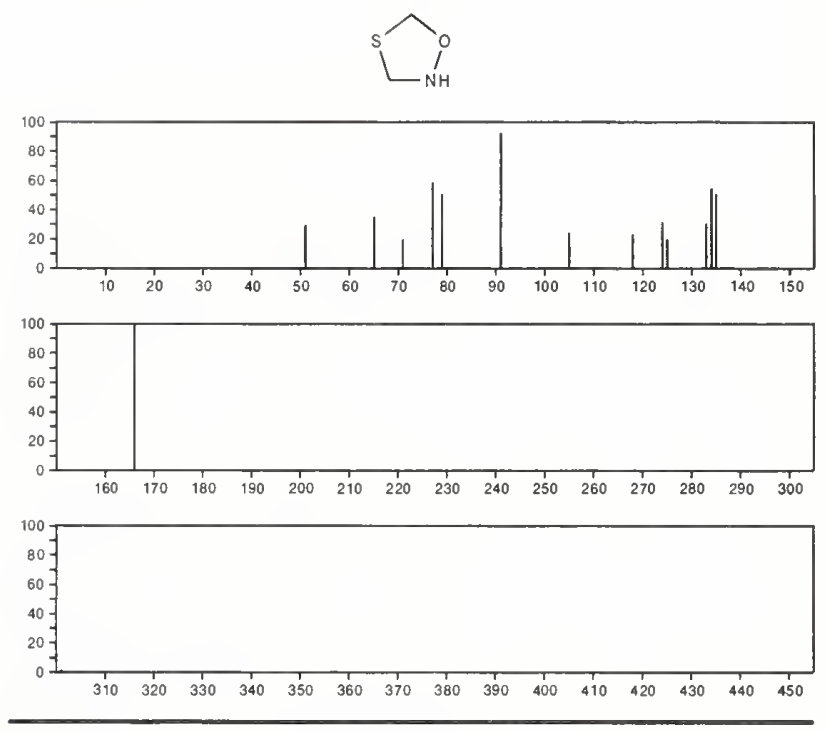

91

Ethanol, 2-nitro-

$\mathrm{C}_{2} \mathrm{H}_{5} \mathrm{NO}_{3}$

$625-48-9$

$\mathrm{HOCH}_{2} \mathrm{CH}_{2} \mathrm{NO}_{2}$

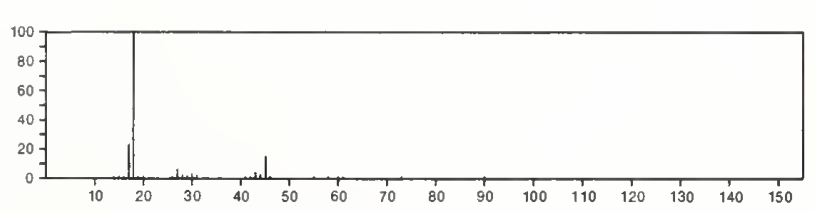


91

Nitric acid, ethyl ester

$\mathrm{C}_{2} \mathrm{H}_{5} \mathrm{NO}_{3}$

$\mathrm{E}_{1} \mathrm{ONO}_{2}$

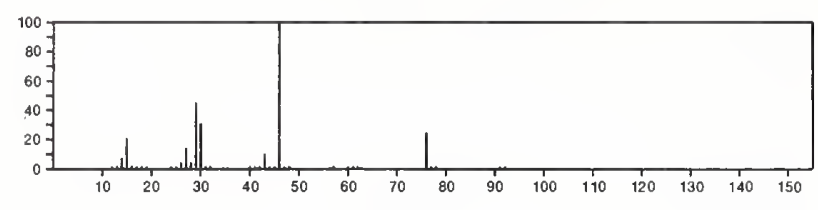

91

Azetidine, 1-chloro-

$\mathrm{C}_{3} \mathrm{H}_{6} \mathrm{ClN}$
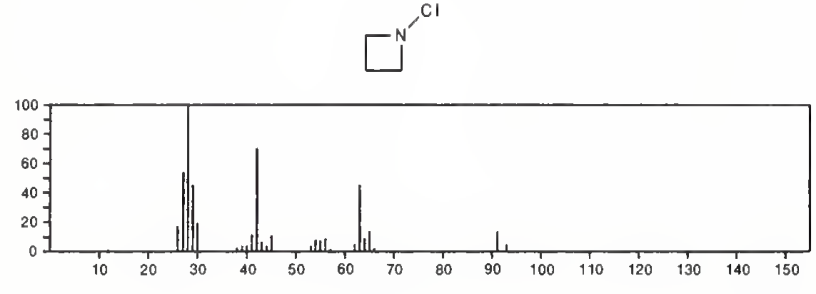

92

$\mathrm{C}_{2} \mathrm{H}_{4} \mathrm{~S}_{2}$

$594-03-6$

Ethane(dithioic) acid

$\mathrm{HS}_{2} \mathrm{CMe}$

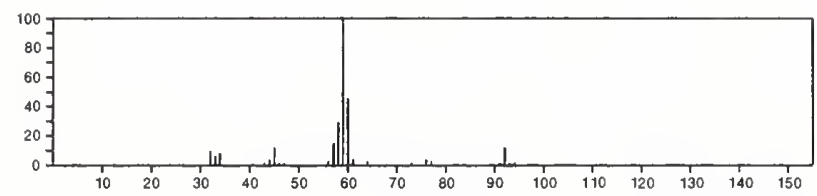

92

2-Propanone, 1-chloro-

$\mathrm{C}_{3} \mathrm{H}_{5} \mathrm{ClO}$

$78-95-5$

$\mathrm{Cl} \mathrm{CH}_{2}$ COMe

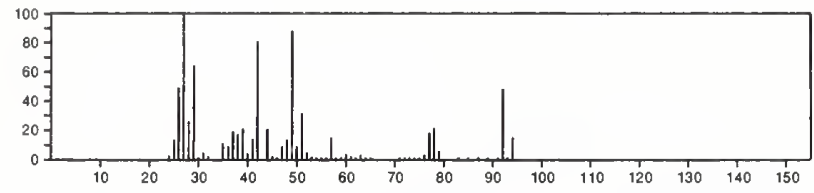

92

Propanoyl chloride

$\mathrm{C}_{3} \mathrm{H}_{5} \mathrm{ClO}$

$79-03-8$

$\mathrm{EtCOCl}$

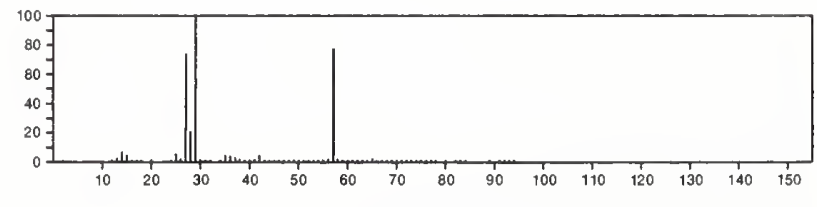

92

$\mathrm{C}_{3} \mathrm{H}_{5} \mathrm{ClO}$

$106-89-8$

Oxirane, (chloromethyl)-
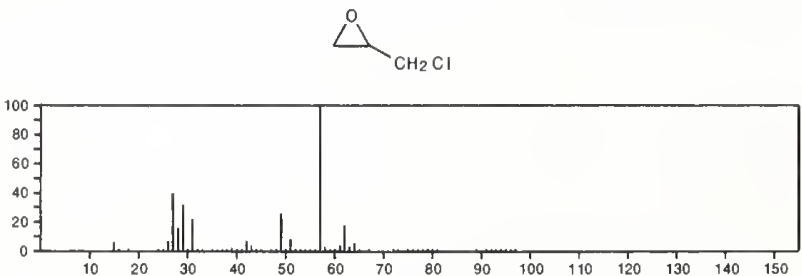

1,2,3-Propanetriol

$\mathrm{C}_{3} \mathrm{H}_{8} \mathrm{O}_{3}$

$56-81-5$

$\mathrm{OCH}_{2} \mathrm{CH}(\mathrm{OH}) \mathrm{CH}_{2} \mathrm{OH}$

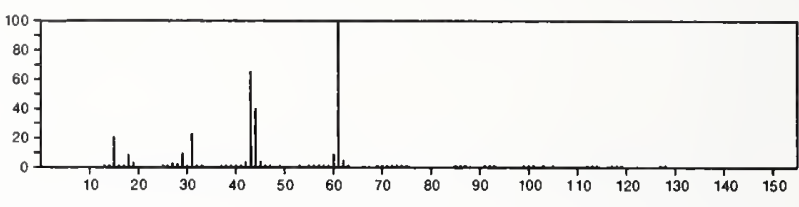

92

Silane, fluorotrimethyl-

$\mathrm{C}_{3} \mathrm{H}_{9} \mathrm{FSi}$

420-56-4

Me 3 Si F

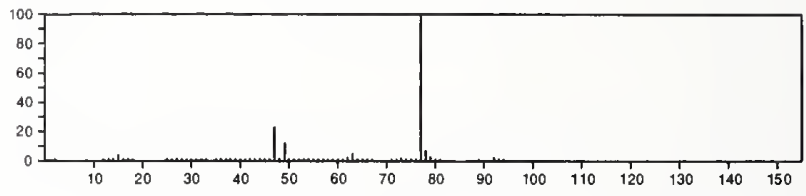

92

$\mathrm{C}_{4} \mathrm{H}_{9} \mathrm{Cl}$

$78-86-4$

Butane, 2-chloro-

s-BuCl

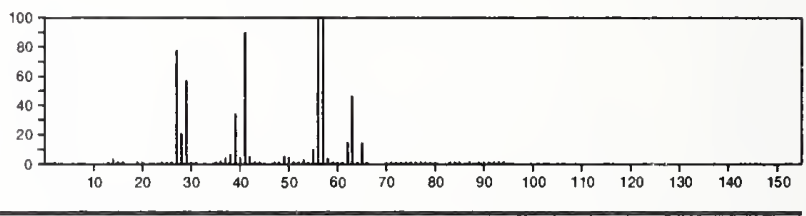

92

Butane, 1-chloro-

$\mathrm{C}_{4} \mathrm{H}_{9} \mathrm{Cl}$

109-69-3

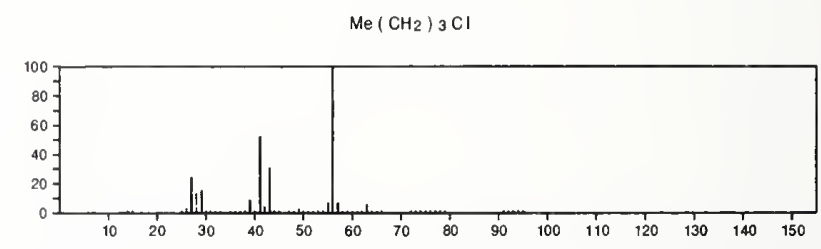

92

Propane, 2-chloro-2-methyl

$\mathrm{C}_{4} \mathrm{H}_{9} \mathrm{Cl}$

507-20-0

I-BuCl

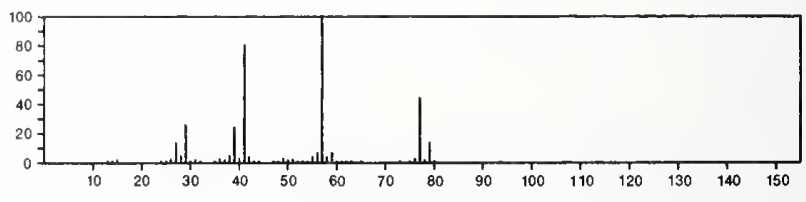

92 $\mathrm{C}_{4} \mathrm{H}_{9} \mathrm{Cl}$

Propane, 1-chloro-2-methyl

$\mathrm{i}-\mathrm{BuCl}$

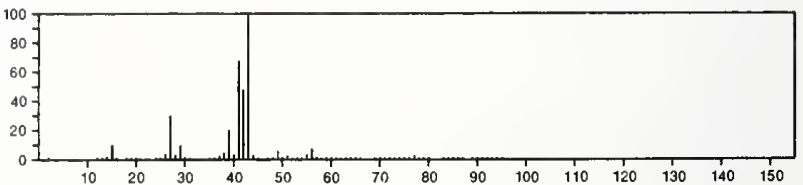


92

2-Pentenedinitrile

$\mathrm{C}_{5} \mathrm{H}_{4} \mathrm{~N}_{2}$

$\mathrm{NCCH}_{2} \mathrm{CH}=\mathrm{CHCN}$

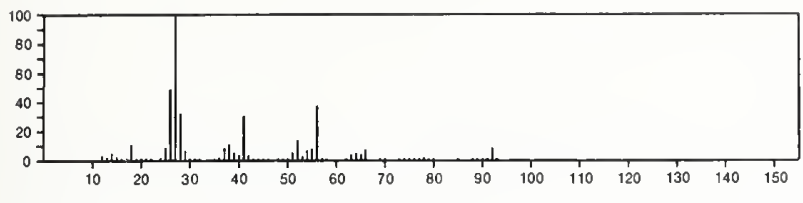

92

3,5-Hexadiyn-2-one

$\mathrm{C}_{6} \mathrm{H}_{4} \mathrm{O}$

$31097-80-0$

$H C: C C \equiv C C O M$

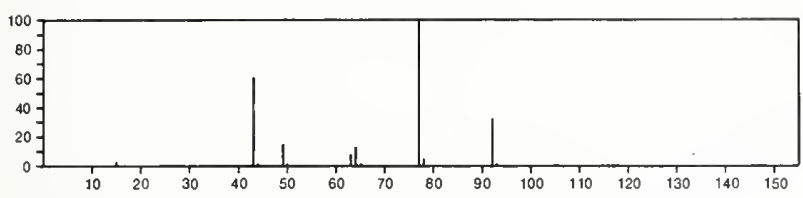

92

Benzene, methyl-

$\mathrm{C}_{7} \mathrm{H}_{8}$

108-88-3

PhMe
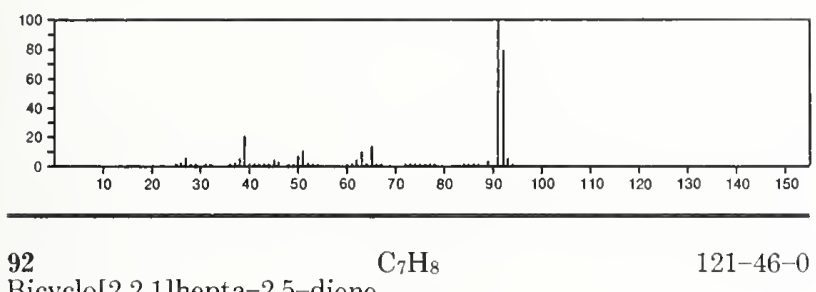

Bicyclo[2.2.1]hepta-2,5-diene
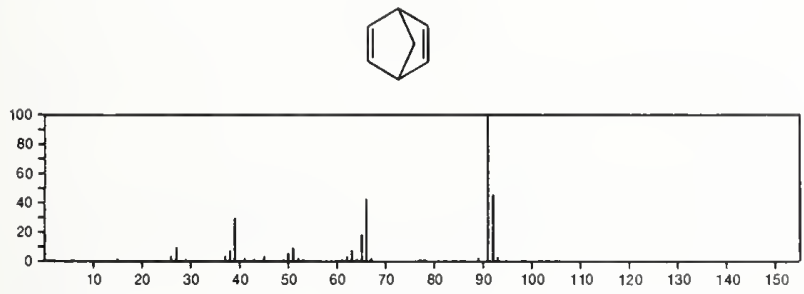

92

1,3,5 Cycloheptatriene

$\mathrm{C}_{7} \mathrm{H}_{8}$
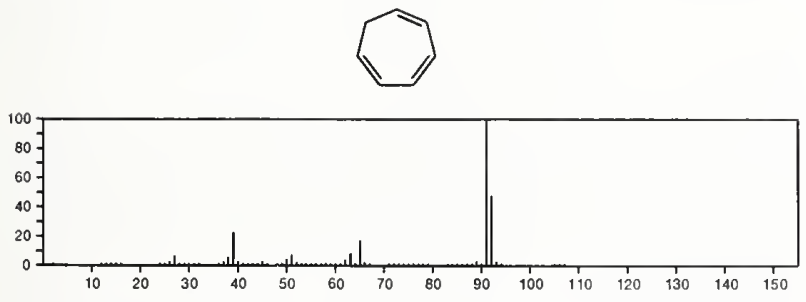

92

1,6-Heptadiyne

$\mathrm{C}_{7} \mathrm{H}_{8}$

2396-63-6

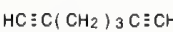

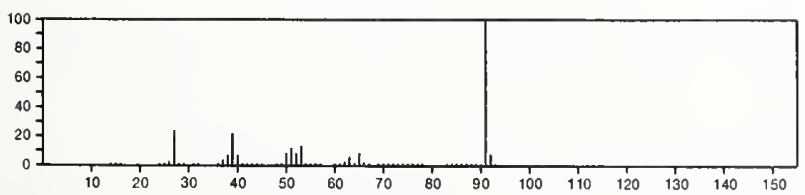

92

Bicyclo[3.20]hepta-2,6-diene $\mathrm{C}_{7} \mathrm{H}_{8}$

2422-86-8
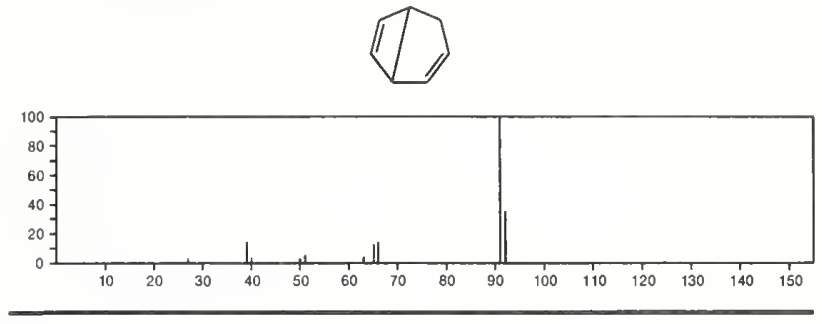

92

Spiro[3.3]hepta-1,5-diene

$\mathrm{C}_{7} \mathrm{H}_{8}$

$22635-78-5$
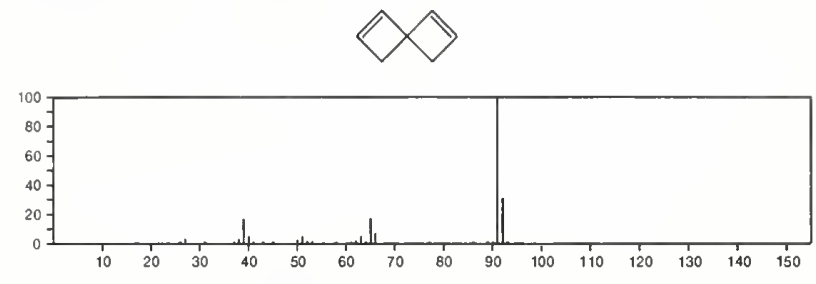

92

$\mathrm{C}_{7} \mathrm{H}_{8}$

$52097-85-5$

Cyclobutene, 2-propenylidene-
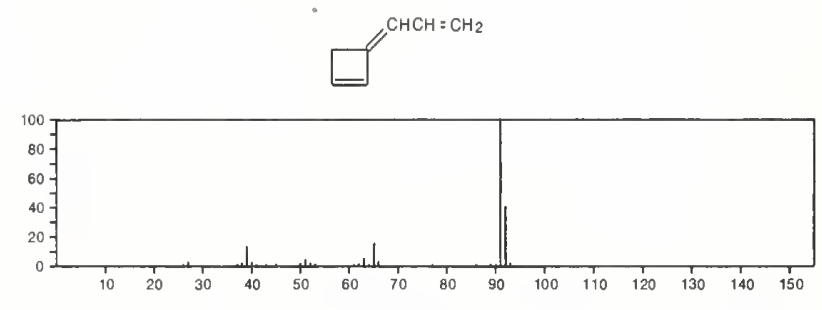

92

Trisilane

$\mathrm{H}_{8} \mathrm{Si}_{3}$

$7783-26-8$

$\mathrm{SiH}_{2}\left(\mathrm{SiH}_{3}\right)_{2}$

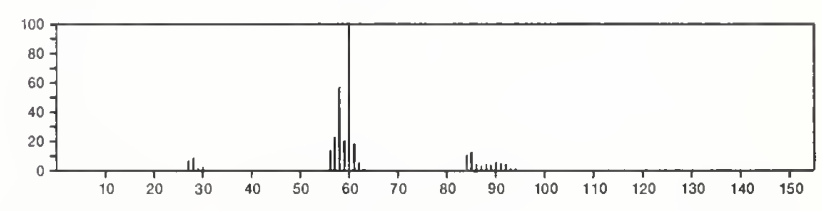

93

$\mathrm{C}_{4} \mathrm{H}_{3} \mathrm{~N}_{3}$

$31108-57-3$

1H-Pyrazole-4-carbonitrile
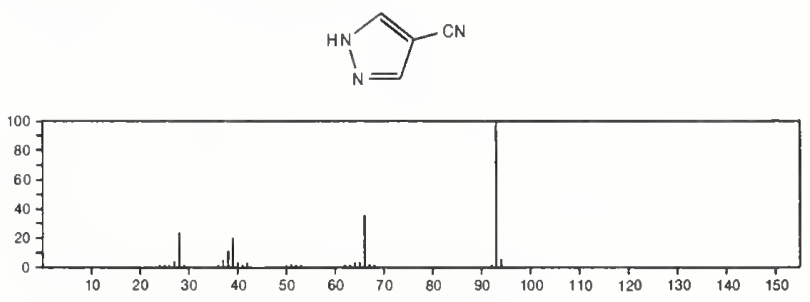
$\mathrm{C}_{5} \mathrm{H}_{5} \mathrm{~N} . \mathrm{BH}_{3}$

Pyridine, compd. with borane $(1: 1)$
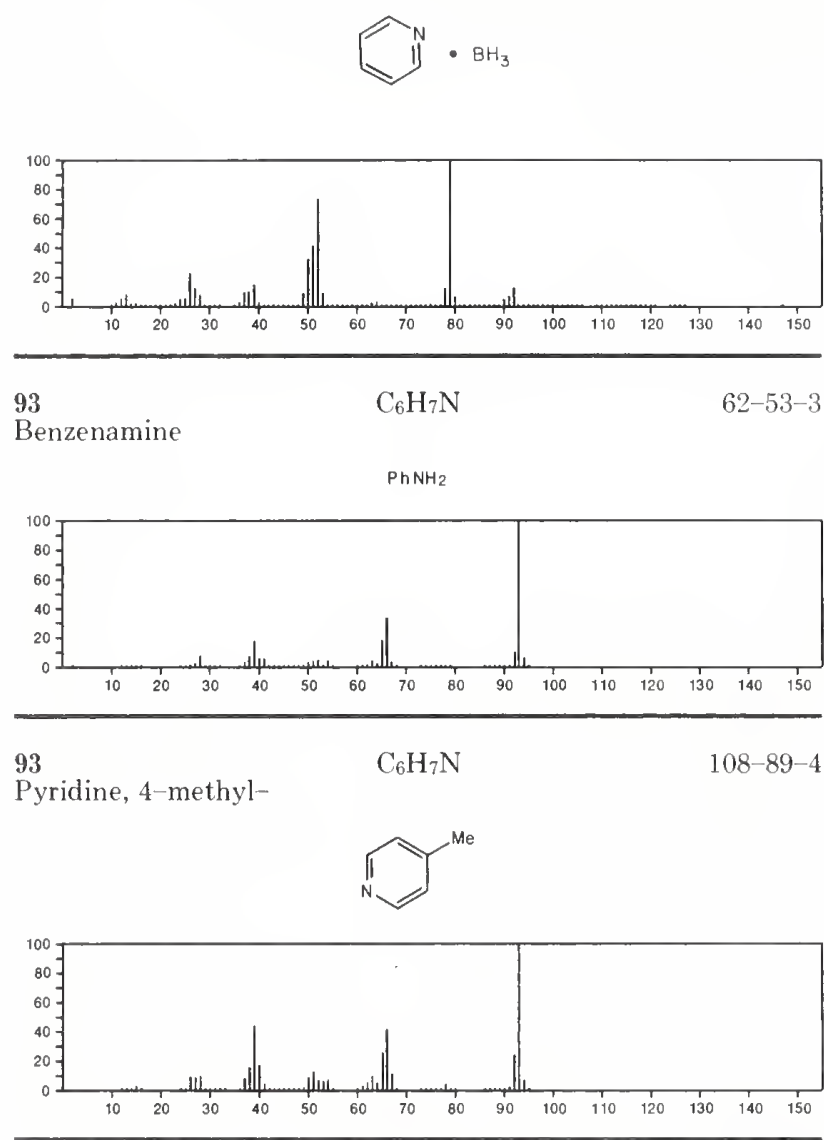

$93 \quad \mathrm{C}_{6} \mathrm{H}_{7} \mathrm{~N} \quad 108-99-6$

Pyridine, 3-methyl-
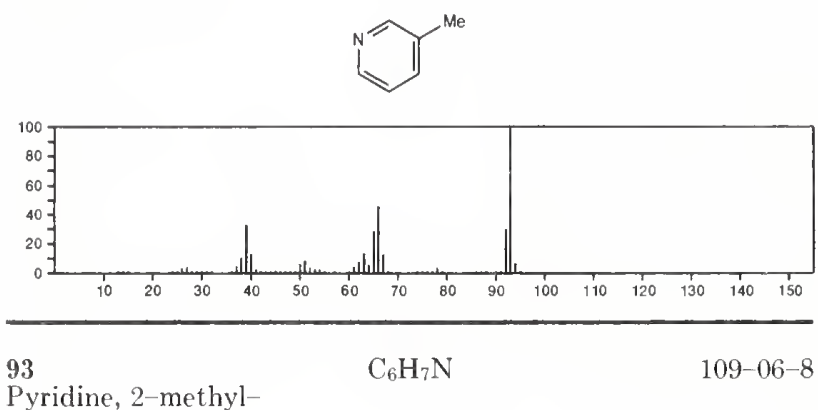

Pyridine, 2-methyl-
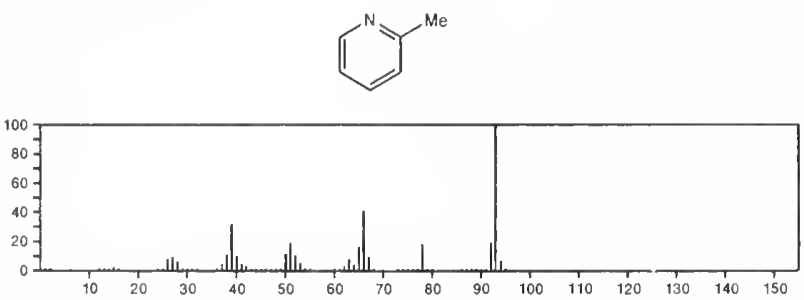

93

4-Pentenenitrile, 2-methylene

$\mathrm{C}_{6} \mathrm{H}_{7} \mathrm{~N}$

$28769-50-8$

$\mathrm{H}_{2} \mathrm{C}=\mathrm{C}(\mathrm{CN}) \mathrm{CH}_{2} \mathrm{CH}=\mathrm{CH}_{2}$

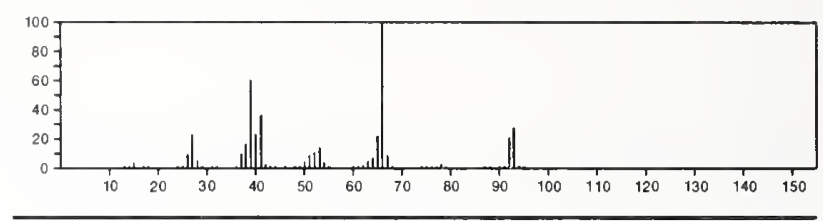

94

Methane, bromo-

$\mathrm{CH}_{3} \mathrm{Br}$

$74-83-9$

BrMe

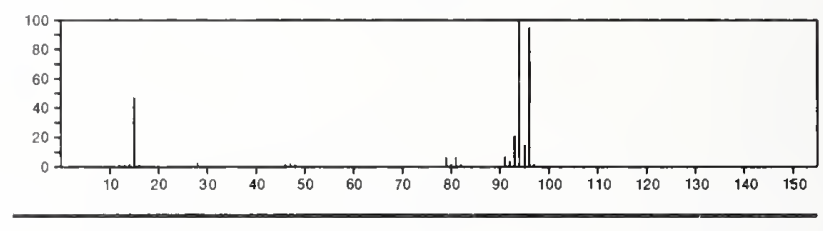

94

Ethyne, dichloro

$\mathrm{C}_{2} \mathrm{Cl}_{2}$

$7572-29-4$

$\mathrm{CIC} \equiv \mathrm{CCI}$

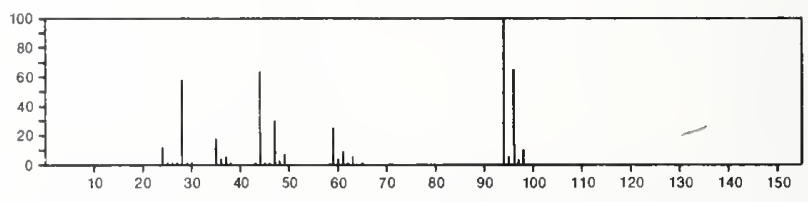

94

$\mathrm{C}_{2} \mathrm{H}_{3} \mathrm{ClO}_{2}$

$79-11-8$

Acetic arid, chloro-

$\mathrm{Cl} \mathrm{CH}_{2} \mathrm{CO}_{2} \mathrm{H}$

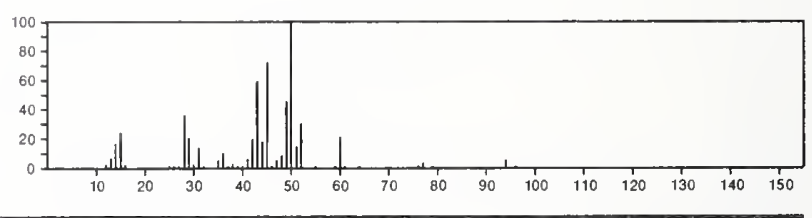

94

$\mathrm{C}_{2} \mathrm{H}_{3} \mathrm{ClO}$

Carbonochloridic acid, methyl ester

79-22-1

$\mathrm{MeOC}(\mathrm{O}) \mathrm{Cl}$

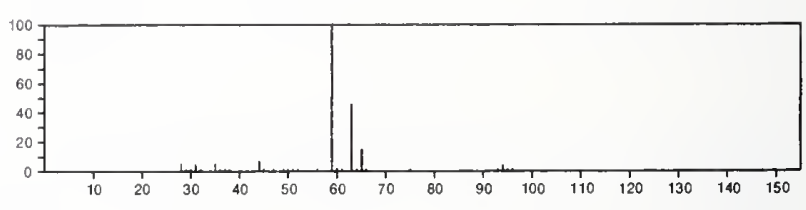

$94 \quad \mathrm{C}_{2} \mathrm{H}_{6} \mathrm{O}_{2} \mathrm{~S}$

$67-71-0$

Methane, sulfonylbis-

$\mathrm{MeSO}_{2} \mathrm{Me}$

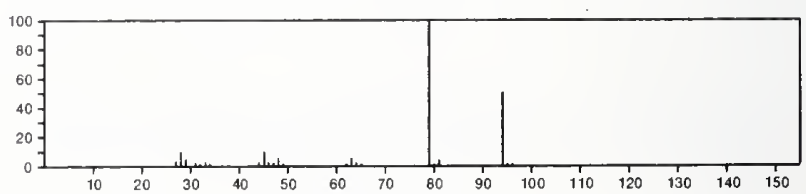


94

Disulfide, dimethyl

$\mathrm{C}_{2} \mathrm{H}_{6} \mathrm{~S}_{2}$

Me SSMe

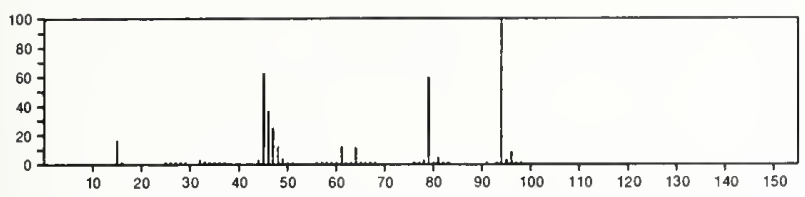

94

$\mathrm{C}_{3} \mathrm{HF}_{3}$

$661-54-1$

1-Propyne, 3,3,3-trifluoro-

$\mathrm{F}_{3} \mathrm{CC}: \mathrm{CH}$
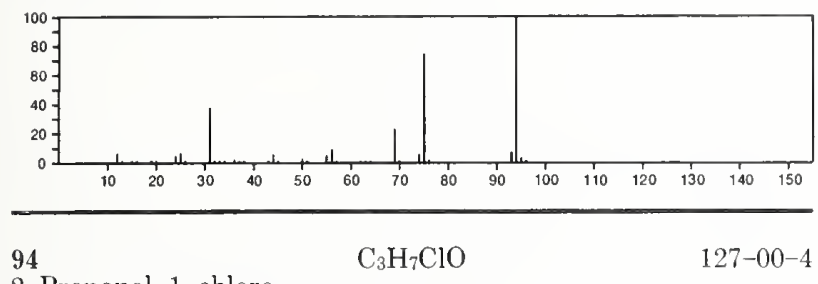

2-Propanol, 1-chloro-

$\mathrm{Cl} \mathrm{CH}_{2} \mathrm{CH}(\mathrm{OH}) \mathrm{Me}$

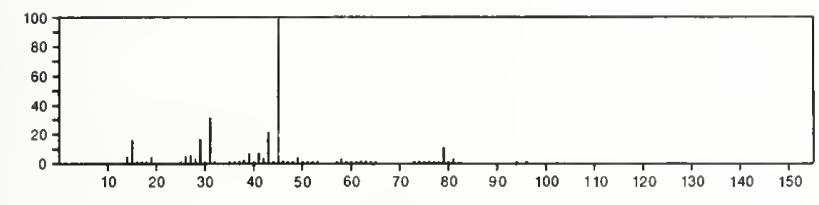

94

1-Propanol, 3-chloro-

$\mathrm{C}_{3} \mathrm{H}_{7} \mathrm{ClO}$

$627-30-5$

$\mathrm{Cl}\left(\mathrm{CH}_{2}\right)_{3} \mathrm{OH}$

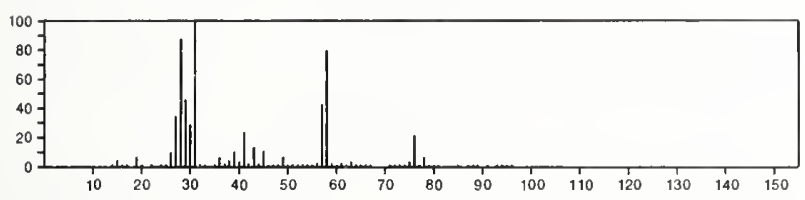

94

Pyrazine, methyl-

$\mathrm{C}_{5} \mathrm{H}_{6} \mathrm{~N}_{2}$

$109-08-0$
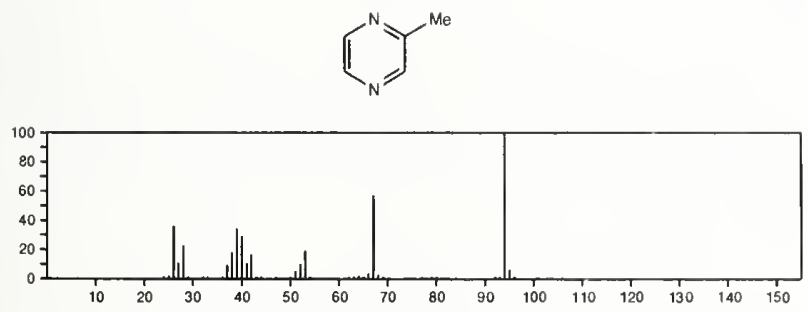

94

3-Pyridinamine

$\mathrm{C}_{5} \mathrm{H}_{6} \mathrm{~N}_{2}$
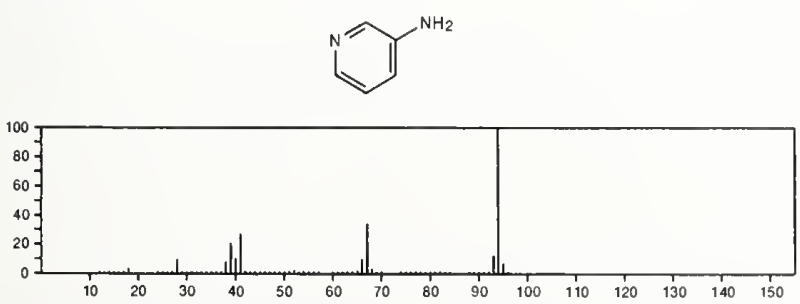

94

4-Pyridinamine

$\mathrm{C}_{5} \mathrm{H}_{6} \mathrm{~N}_{2}$

504-24-5
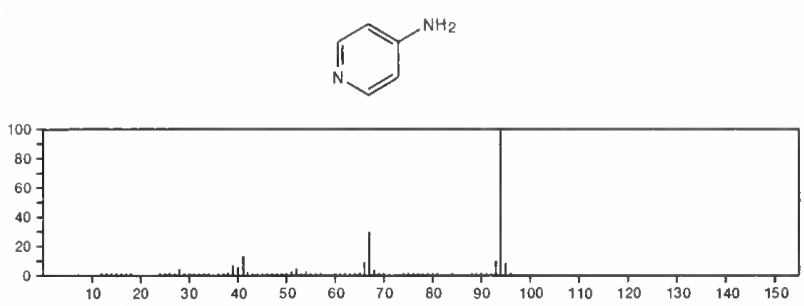

94

2-Pyridinamine

$\mathrm{C}_{5} \mathrm{H}_{6} \mathrm{~N}_{2}$

504-29-0
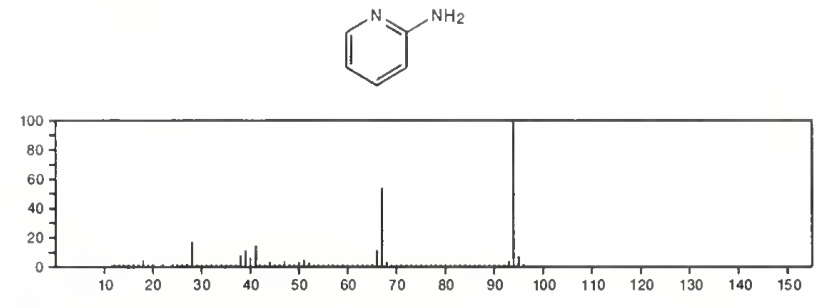

94

Pentanedinitrile

$\mathrm{C}_{5} \mathrm{H}_{6} \mathrm{~N}_{2}$

544-13-8

$\mathrm{NC}\left(\mathrm{CH}_{2}\right)_{3} \mathrm{CN}$

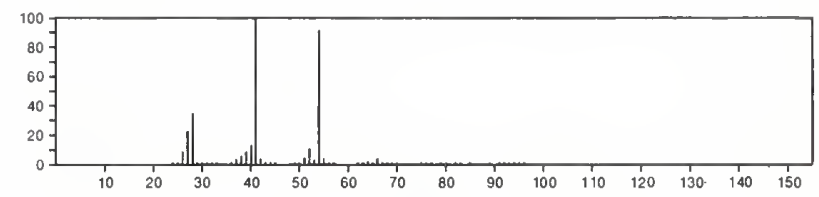

94

$\mathrm{C}_{5} \mathrm{H}_{6} \mathrm{~N}_{2}$

2036-41-1

Pyrimidine, 5-methyl-<smiles>Cc1cncnc1</smiles>

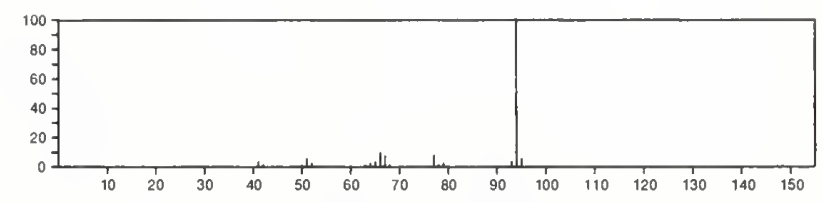

94

Pyrimidine, 4-methyl

$\mathrm{C}_{5} \mathrm{H}_{6} \mathrm{~N}_{2}$

3438-46-8
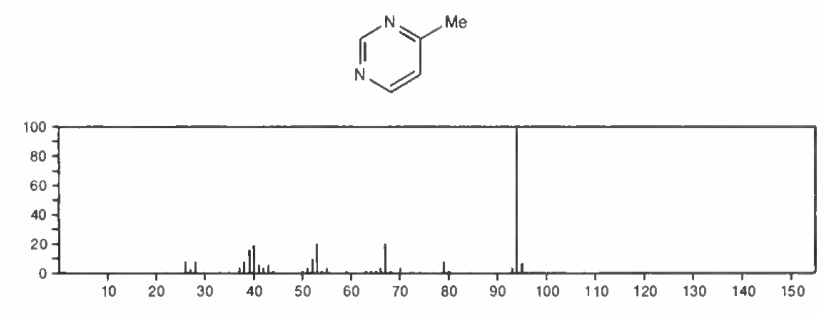

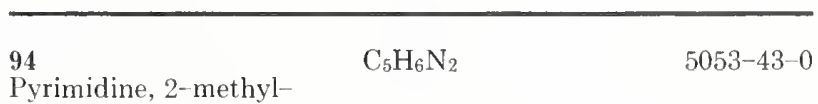
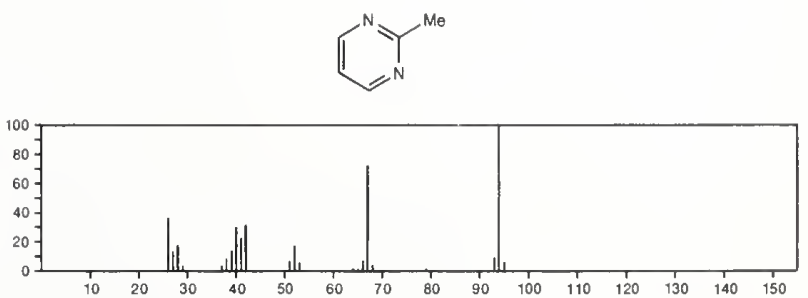
94

Propanedinitrile, dimethyl- ${ }^{\mathrm{C}_{5} \mathrm{H}_{6} \mathrm{~N}_{2}}$

$\mathrm{NC}_{2} \mathrm{C}(\mathrm{Me})_{2}$

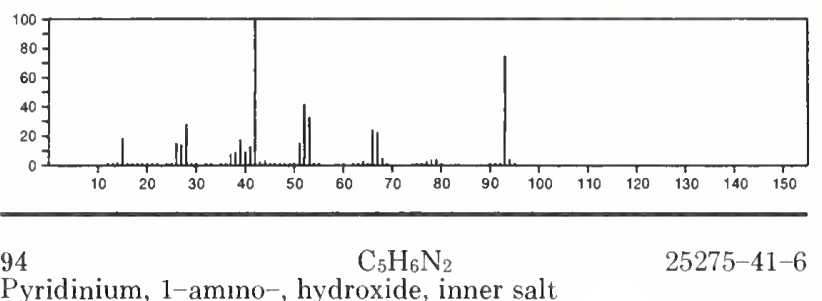

Pyridinium, 1-ammo--, hydroxide, inner salt
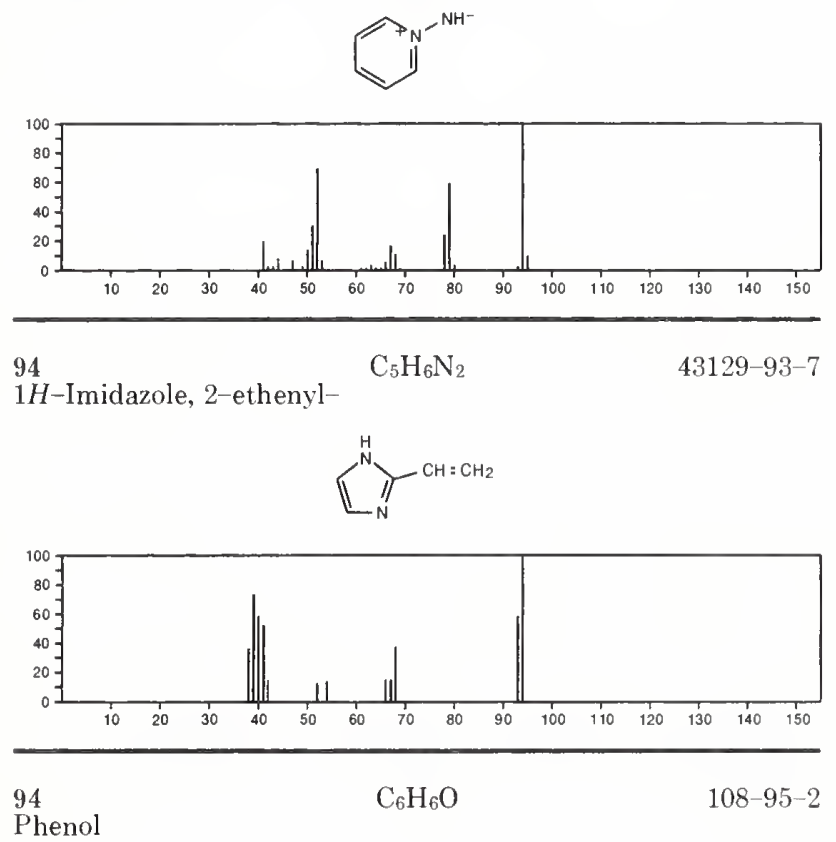

Phenol

$\mathrm{PhOH}$

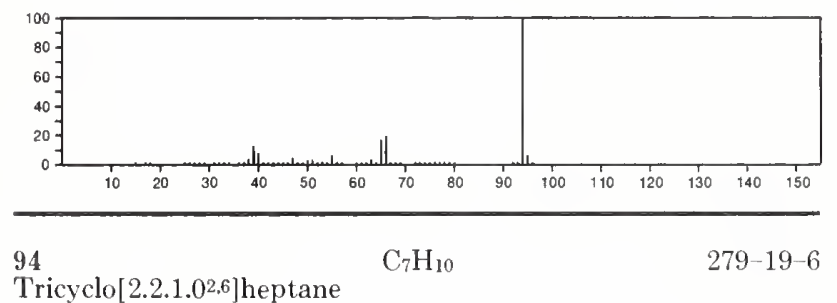

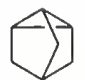

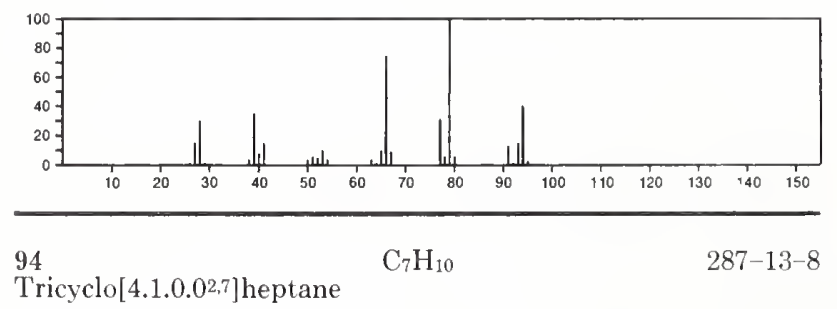

$\longrightarrow$

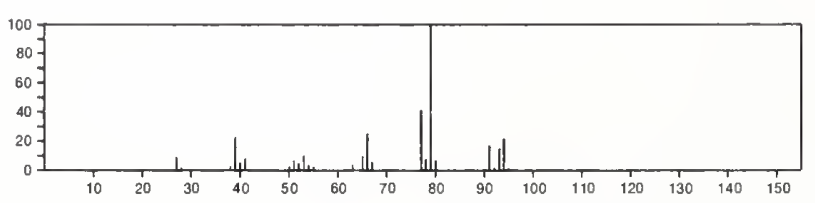

94

Bicyclo[2.2.1]hept-2-ene

$\mathrm{C}_{7} \mathrm{H}_{10}$

$498-66-8$
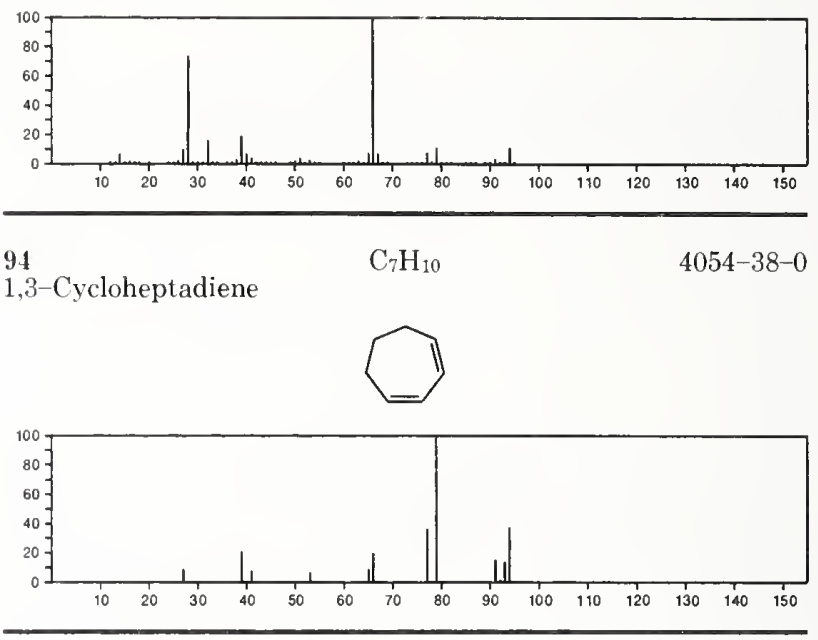

94

$\mathrm{C}_{7} \mathrm{H}_{10}$

4125-18-2

1,3-Cyclopentadiene, 5,5-dimethyl-
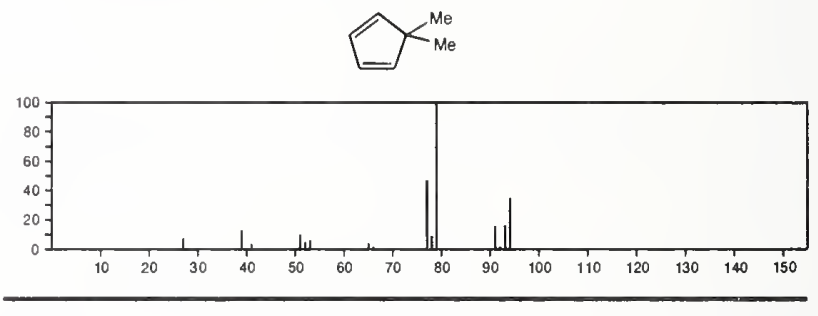

94

1,4-Cyclohexadiene, 1-methyl-

$4313-57-9$
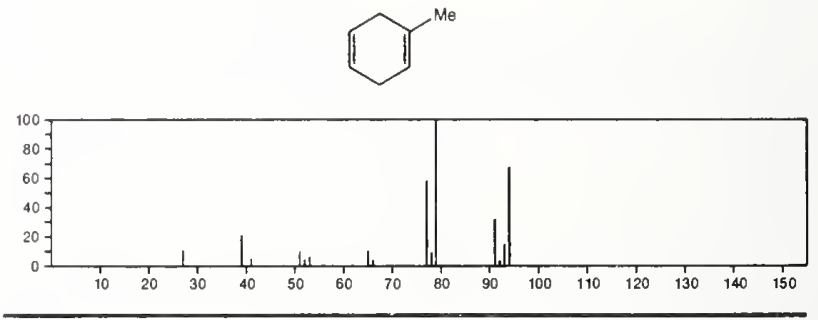

94

$\mathrm{C}_{7} \mathrm{H}_{10}$

1,3-Cyclopentadiene, 1,2-dimethyl-

$4784-86-5$
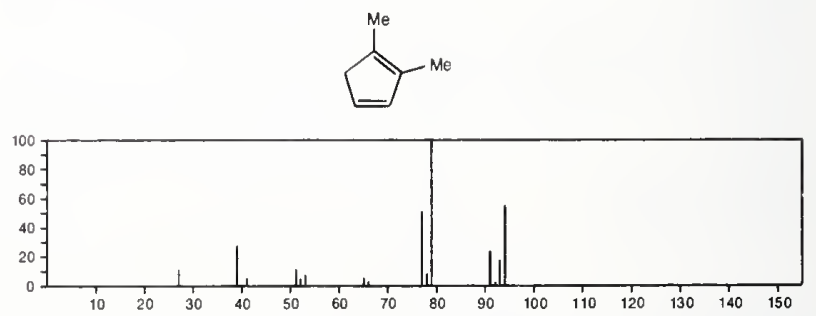
94

Bicyclo[3.2.0]hept-6-ene

$\mathrm{C}_{7} \mathrm{H}_{10}$

$\sqrt{12}$

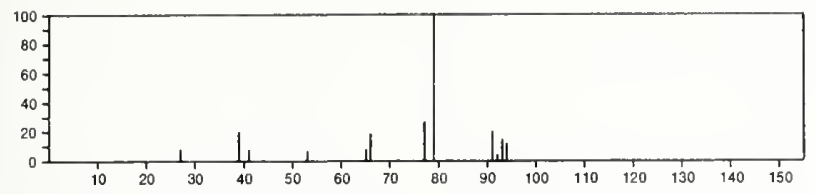

95

$\mathrm{CH}_{8} \mathrm{~B}_{3} \mathrm{~N}_{3}$

$21127-94-6$

Borazine, 1-methyl-
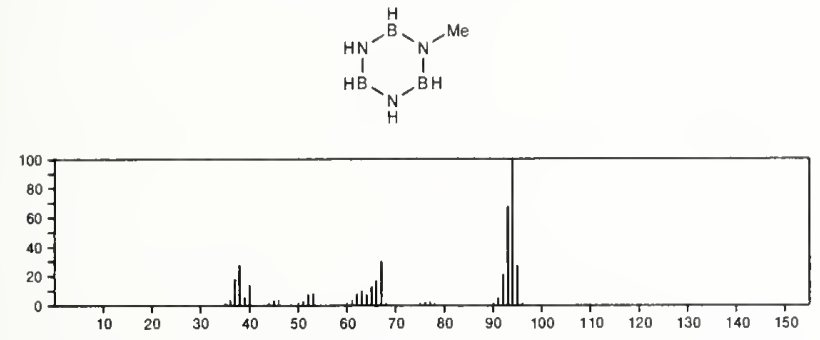

95

Borazine, 2-methyl-

$\mathrm{CH}_{8} \mathrm{~B}_{3} \mathrm{~N}_{3}$

$21127-95-7$
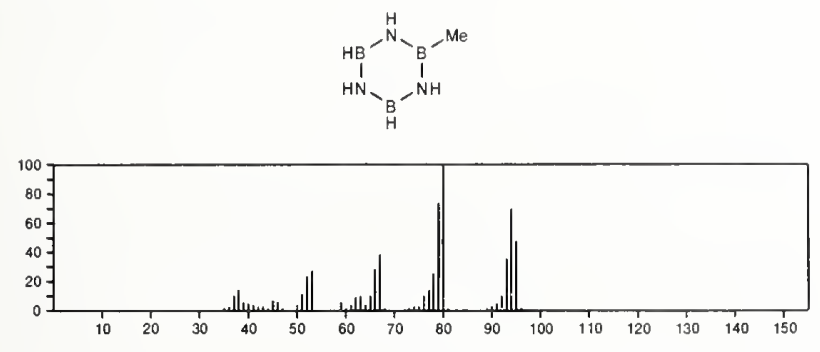

95

Acetonitrile, trifluoro-

$\mathrm{C}_{2} \mathrm{~F}_{3} \mathrm{~N}$

$353-85-5$

$\mathrm{F}_{3} \mathrm{CCN}$

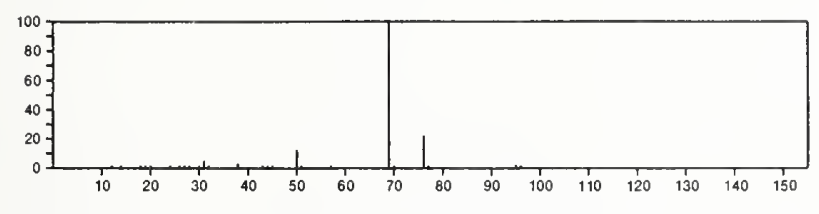

95

2-Pyrimidinamine

$\mathrm{C}_{4} \mathrm{H}_{5} \mathrm{~N}_{3}$
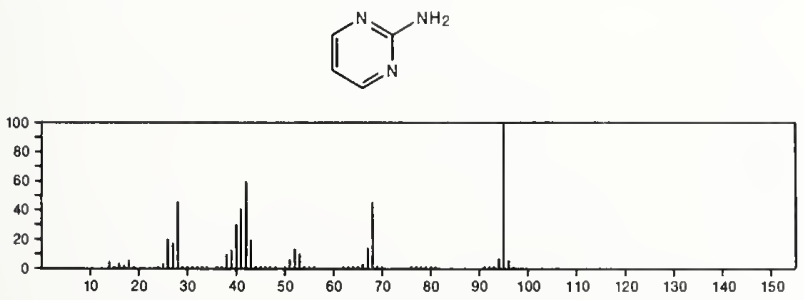

95

3-Pyridinol

$\mathrm{C}_{5} \mathrm{H}_{5} \mathrm{NO}$

$109-00-2$
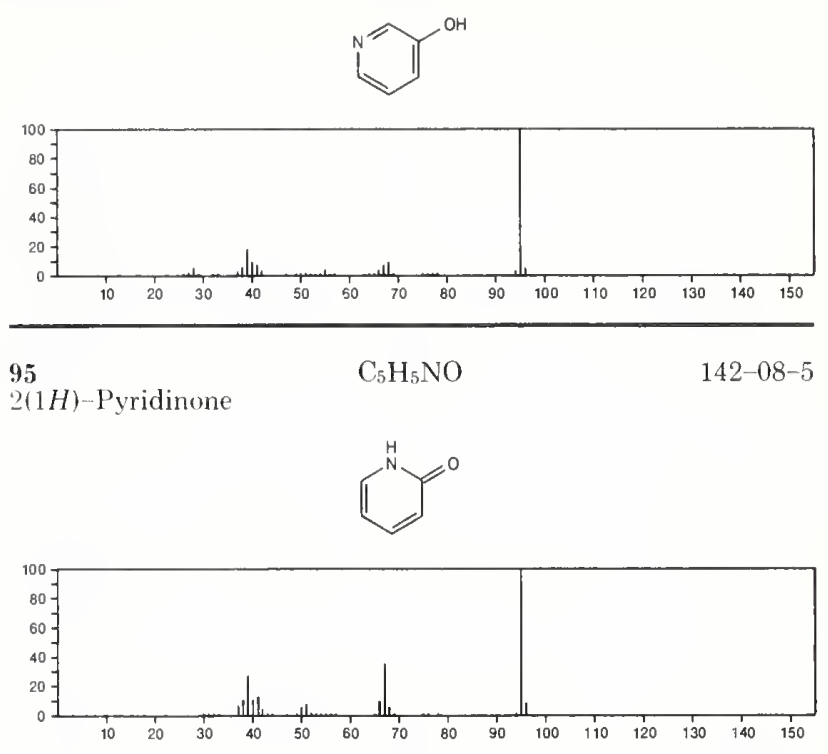

95

$\mathrm{C}_{6} \mathrm{H}_{9} \mathrm{~N}$

$617-92-5$

1H-Pyrrole, 1-ethyl-
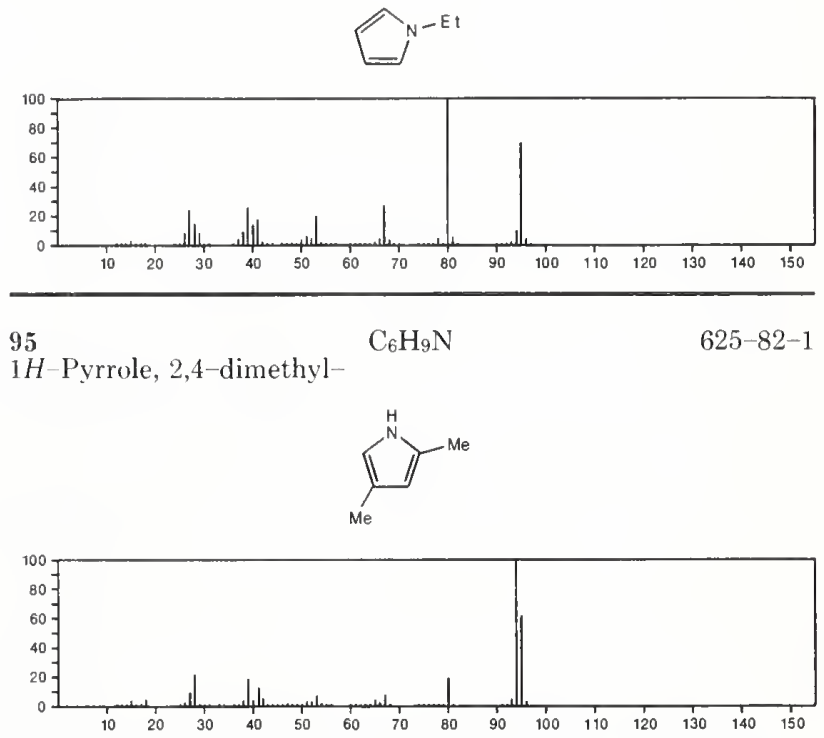

95
$1 H$-Pyrrole, 2,5-dimethyl--

$625-84-3$
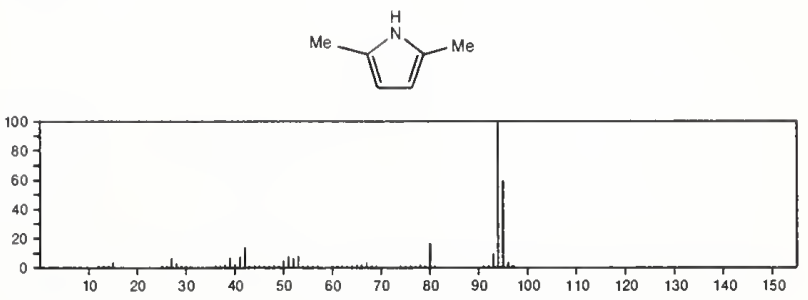
95

$\mathrm{C}_{6} \mathrm{H}_{9} \mathrm{~N}$

Butanenitrile, 3-methyl-2-methylene

$\mathrm{Me}_{2} \mathrm{CHC}(\mathrm{CN})=\mathrm{CH}_{2}$

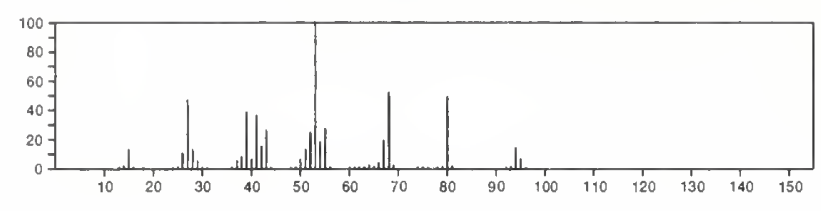

96

Ethene, 1,1-dichloro-

$\mathrm{C}_{2} \mathrm{H}_{2} \mathrm{Cl}_{2}$

$\mathrm{Cl}_{2} \mathrm{C}=\mathrm{CH}_{2}$

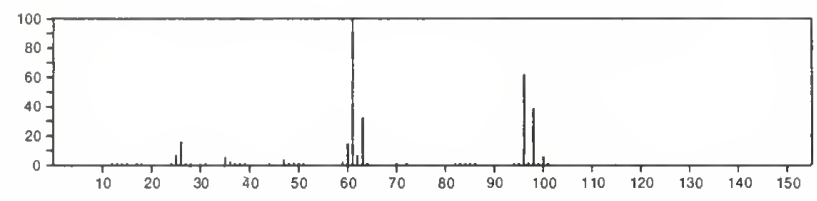

96

Ethene, 1,2-dichloro-, $(Z)$

$\mathrm{C}_{2} \mathrm{H}_{2} \mathrm{Cl}_{2}$

$\mathrm{Cl} \mathrm{CH}=\mathrm{CHCI}$

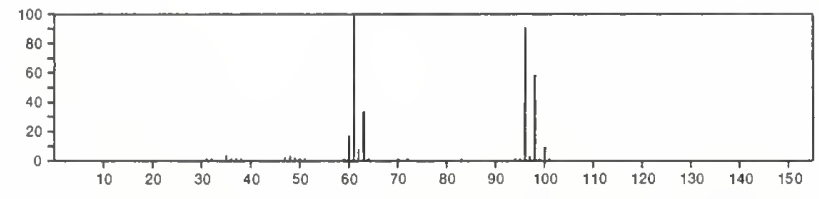

96

Ethene, 1,2-dichloro-, $(E)$

$\mathrm{C}_{2} \mathrm{H}_{2} \mathrm{Cl}_{2}$

$\mathrm{Cl} \mathrm{CH}=\mathrm{CHCl}$

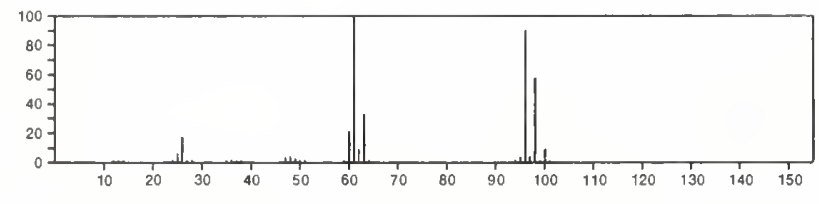

$96 \quad \mathrm{C}_{2} \mathrm{H}_{6} \mathrm{~F}_{2} \mathrm{Si}$

$353-66-2$

Silane, difluorodimethyl-

$\mathrm{F}_{2} \mathrm{SiMe}_{2}$
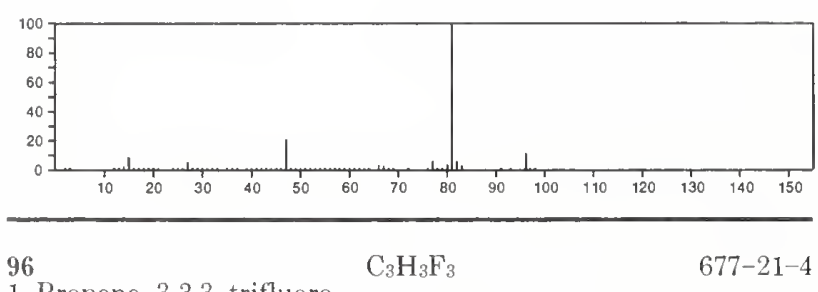

$677-21-4$

1-Propene, 3,3,3-trifluoro

$\mathrm{F}_{3} \mathrm{CCH}=\mathrm{CH}_{2}$

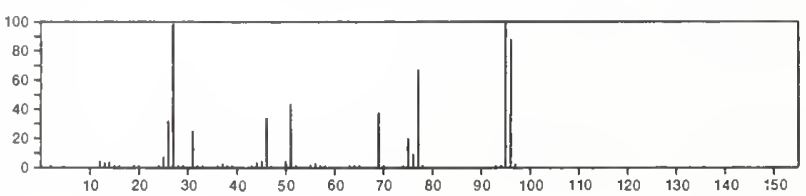

96

4(1H)-Pyrimidinone

$\mathrm{C}_{4} \mathrm{H}_{4} \mathrm{~N}_{2} \mathrm{O}$

4562-27-0

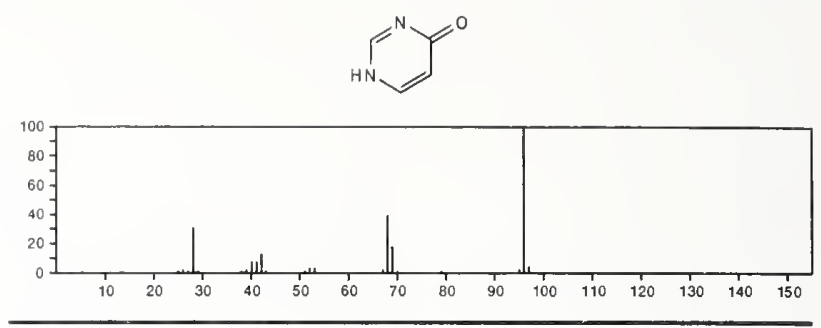

96

$\mathrm{C}_{4} \mathrm{H}_{4} \mathrm{~N}_{2} \mathrm{O}$

10111-08-7

$1 \mathrm{H}$-Imidazole-2-carboxaldehyde
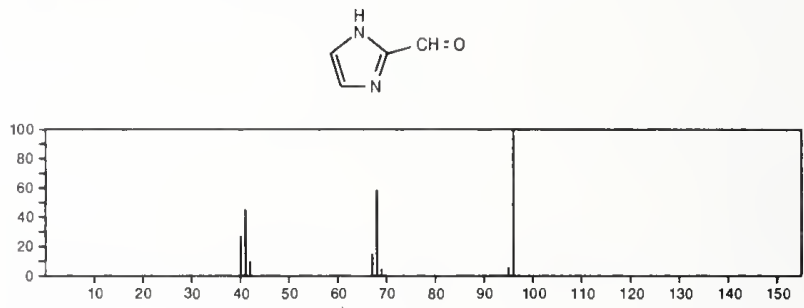

96

$\mathrm{C}_{5} \mathrm{H}_{4} \mathrm{O}_{2}$

$98-01-1$

2-Furancarboxaldehyde
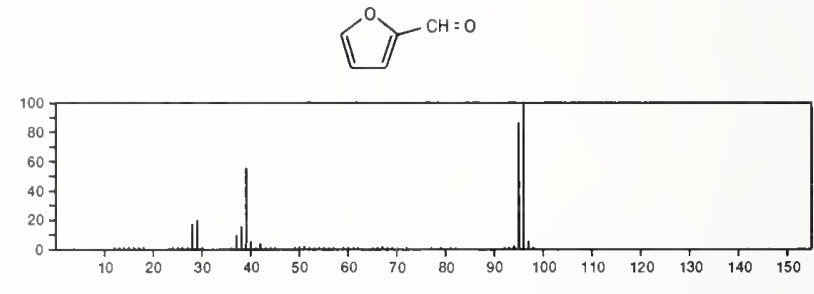

96

$\mathrm{C}_{5} \mathrm{H}_{4} \mathrm{O}_{2}$

$108-97-4$

4H-Pyran-4-one
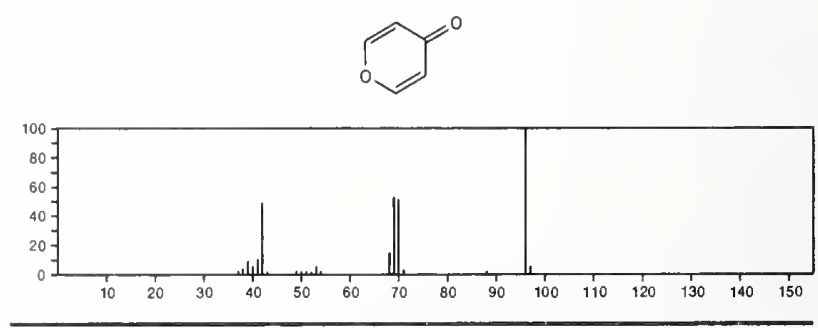

96

$\mathrm{C}_{5} \mathrm{H}_{4} \mathrm{O}_{2}$

504-31-4

2H-Pyran-2-one
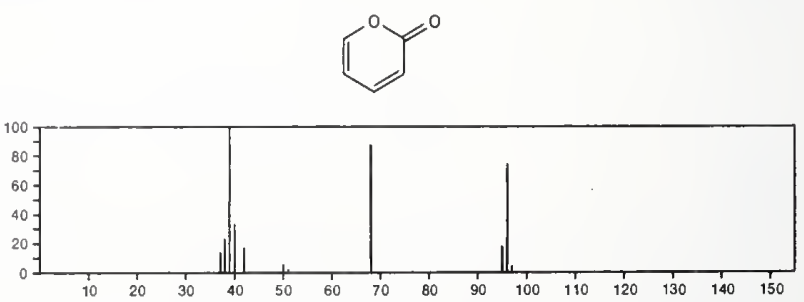
96

1H-Pyrazole, 3,5-dimethyl-

$\mathrm{C}_{5} \mathrm{H}_{8} \mathrm{~N}_{2}$
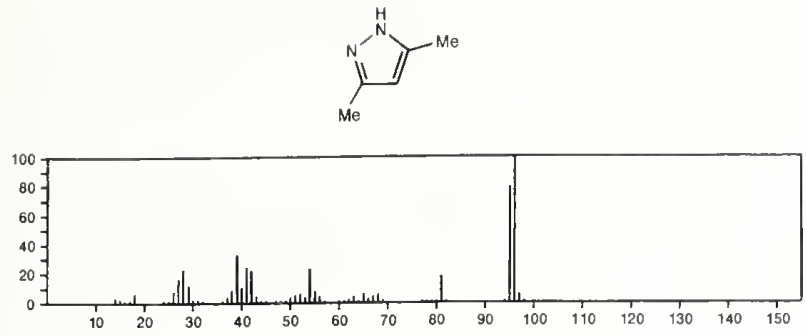

96

$\mathrm{C}_{5} \mathrm{H}_{8} \mathrm{~N}_{2}$

$930 \quad 62-1$

$1 H$-Imidazole, 2,4-dimethyl-
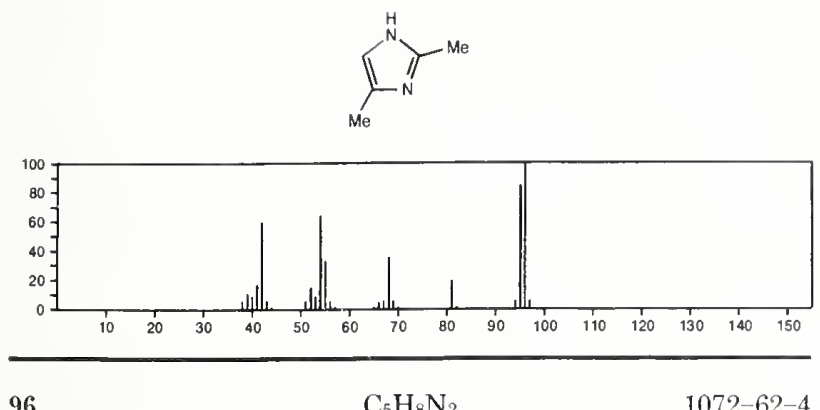

IH-Imidazole, 2-ethyl
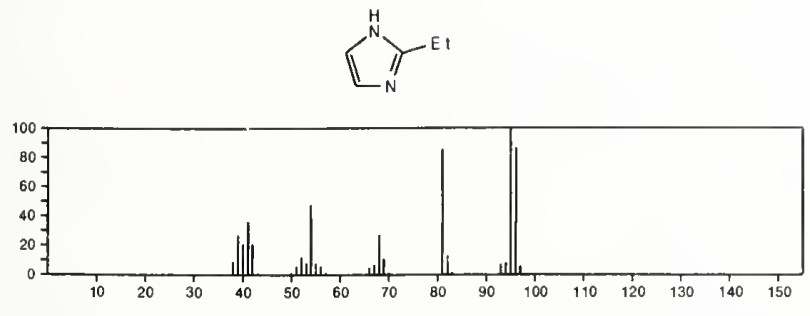

96

$\mathrm{C}_{5} \mathrm{H}_{8} \mathrm{~N}_{2}$

$7098 \quad 07-9$

$1 \mathrm{H}$-Imidazole, 1 -ethyl-

$\overbrace{N=J^{N}}$

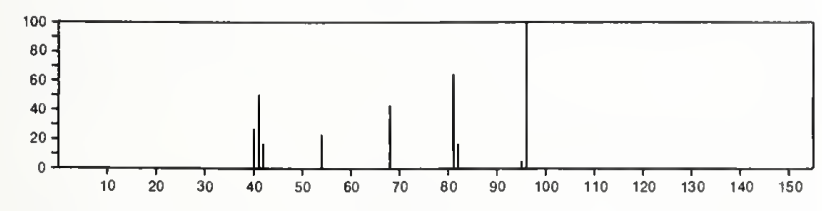

96

Benzene, fluoro

$\mathrm{C}_{6} \mathrm{H}_{5} \mathrm{~F}$

462-06-6

PhF

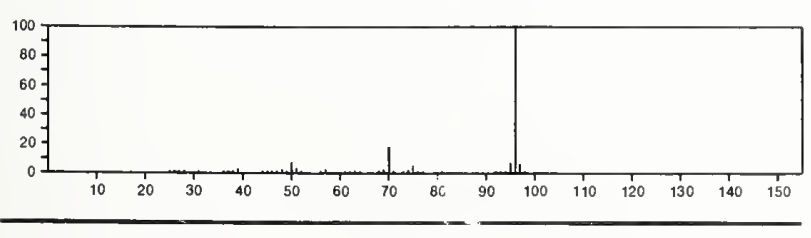

96

2,4-Hexadienal

$\mathrm{C}_{6} \mathrm{H}_{8} \mathrm{O}$

142-83-6

$\mathrm{Me} \mathrm{CH}=\mathrm{CHCH}=\mathrm{CHCHO}$

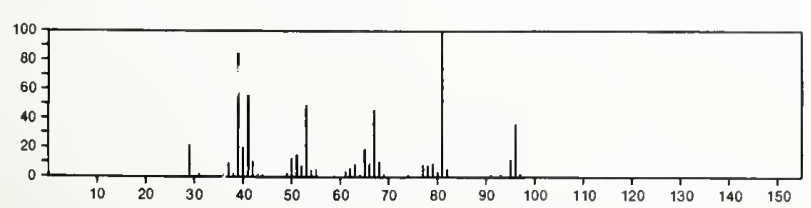

96

Furan, 2,5-dimethyl-

$\mathrm{C}_{6} \mathrm{H}_{8} \mathrm{O}$

625-86-5

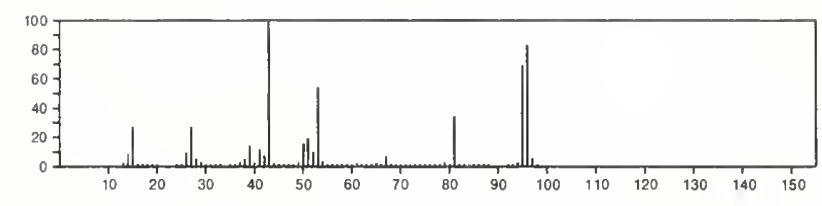

\begin{tabular}{lll}
\hline 96 & $\mathrm{C}_{6} \mathrm{H}_{8} \mathrm{O}$ & $930-68-7$
\end{tabular}

$\mathrm{Y}^{\circ}$

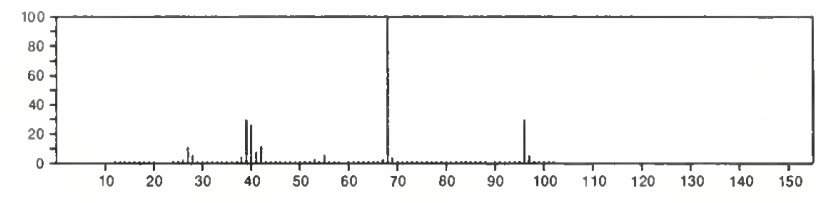

96

$\mathrm{C}_{6} \mathrm{H}_{8} \mathrm{O}$

2-Cyclopenten-1-one, 2-methyl

$1120-73-6$
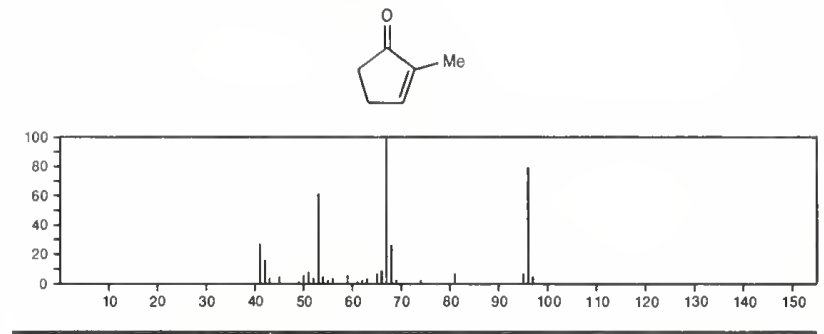

96

Bicyclo[3.1.0]hexan-3-one

$\mathrm{C}_{6} \mathrm{H}_{8} \mathrm{O}$

1755-04-0
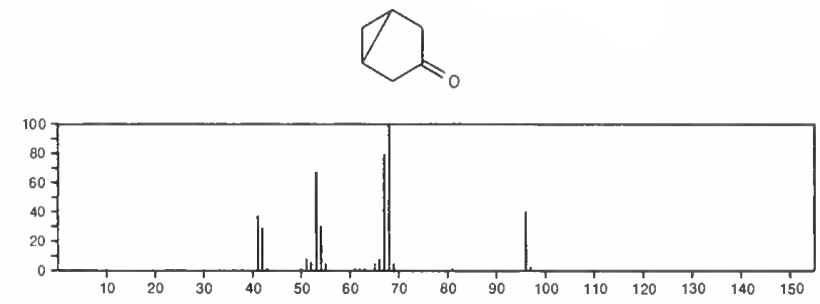

96

2-Cyclopenten-1-one, 3-methyl-

$2758-18-1$

$\overbrace{}^{\mathrm{Me}}$

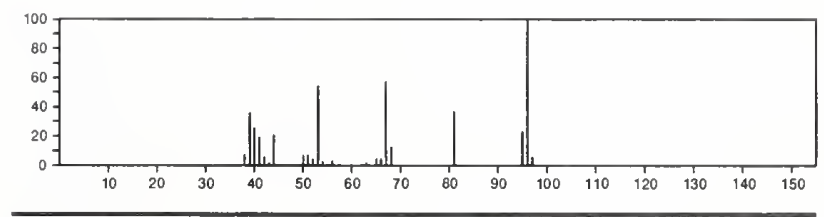

96

2,4-Hexadienal, $(E, E)$ -

$\mathrm{C}_{6} \mathrm{H}_{8} \mathrm{O}$

$4488-48-6$

$\mathrm{Me} C \mathrm{CH}=\mathrm{CHCH}=\mathrm{CHCHO}$

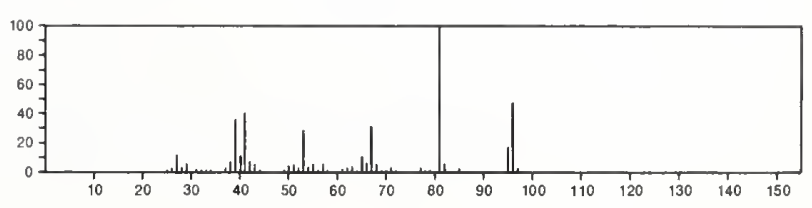




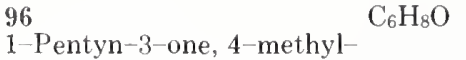

$13531-82-3$

$\mathrm{HC} \equiv \mathrm{CCOCHMe}_{2}$

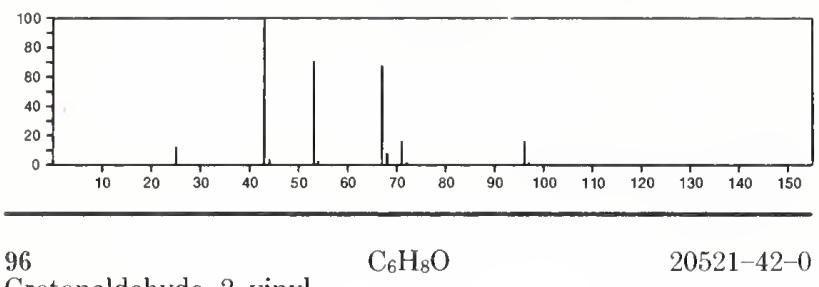

Crotonaldehyde, 2-vinyl-

$\mathrm{H}_{2} \mathrm{C}=\mathrm{CHC}(\mathrm{CHO})=\mathrm{CHMe}$

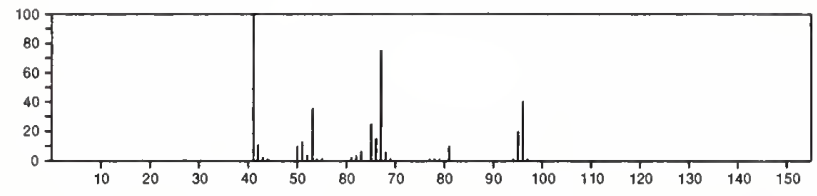

96

$\mathrm{C}_{7} \mathrm{H}_{12}$

$279-23-2$

Bicyclo[2.2.1]heptane<smiles>C1CC2CCC1CC2</smiles>
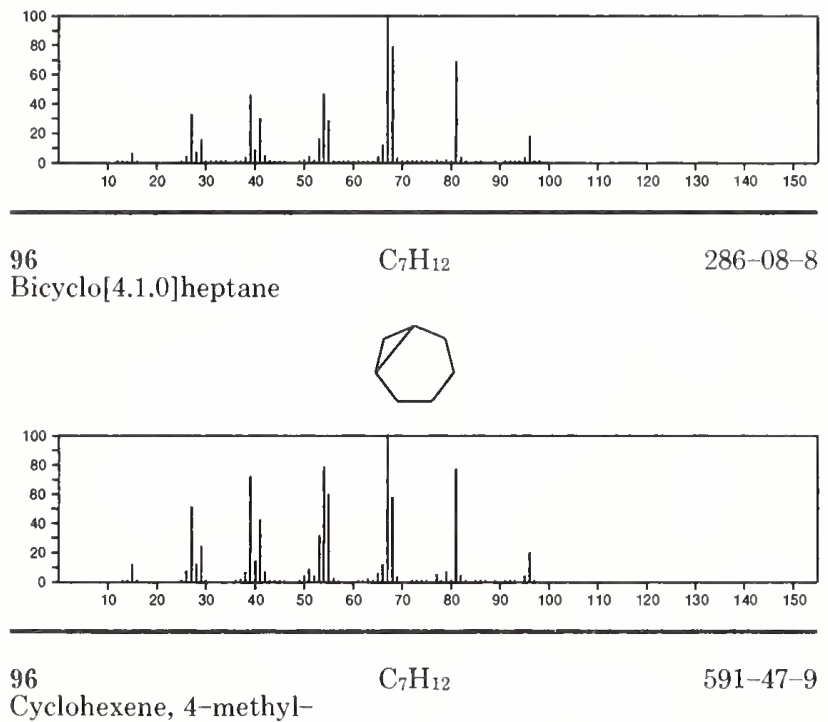

Cyclohexene, 4-methyl-
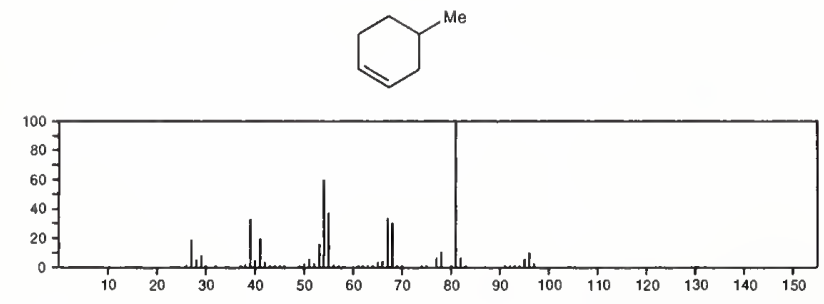

96

Cyclohexene, 3-methyl-

$\mathrm{C}_{7} \mathrm{H}_{12}$

$591-48-0$

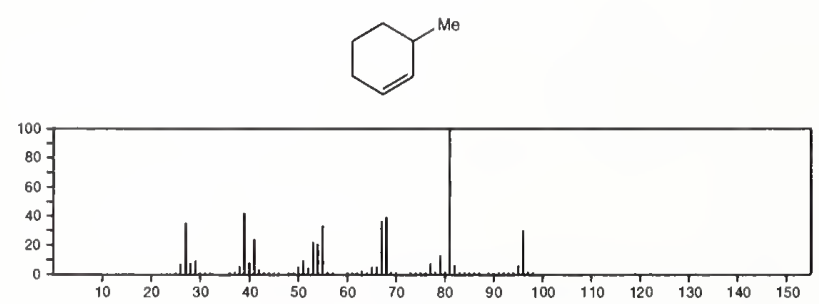

96

$591-49-1$

Cyclohexene, 1-methyl
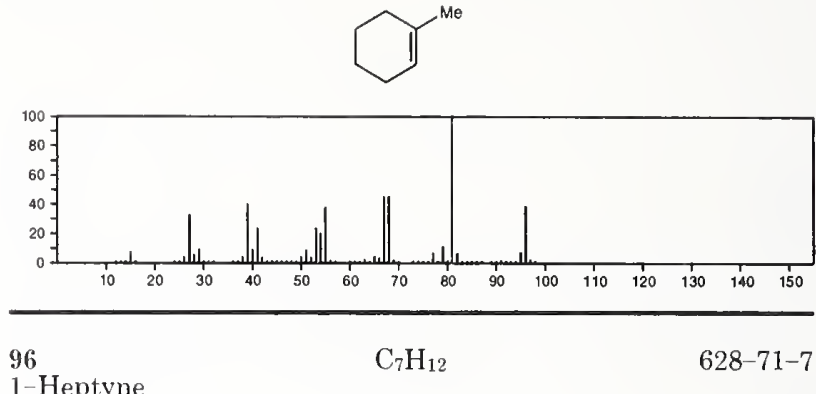

1-Heptyne

$\mathrm{HC} \equiv \mathrm{C}\left(\mathrm{CH}_{2}\right) 4 \mathrm{Me}$

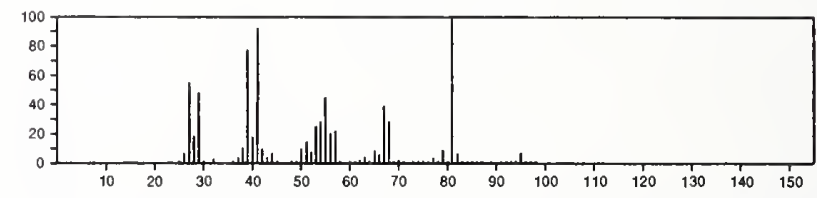

96

$\mathrm{C}_{7} \mathrm{H}_{12}$

628-92-2

Cycloheptene
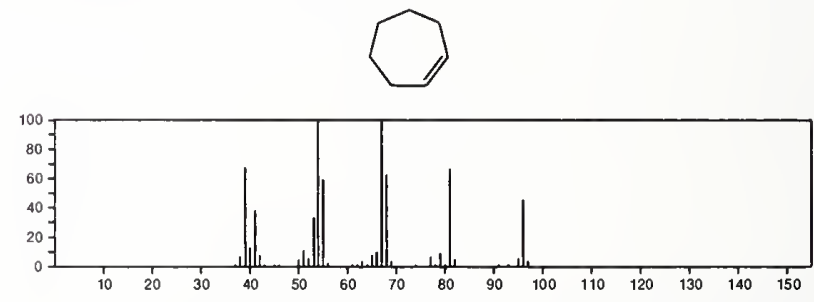

96

$\mathrm{C}_{7} \mathrm{H}_{12}$

694-35-9

Cyclopentene, 3-ethyl-
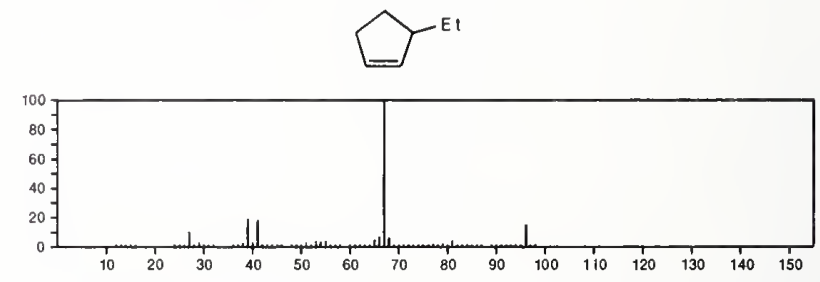

96

1,4-Hexadiene, 5-methyl-

$\mathrm{C}_{7} \mathrm{H}_{12}$

$763-88-2$

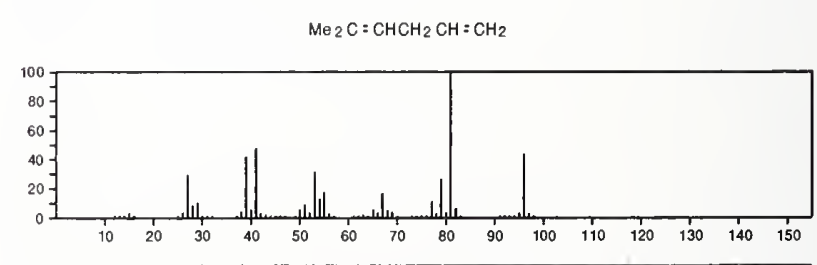

96

$\mathrm{C}_{7} \mathrm{H}_{12}$

1116-90-1

1,4-Hexadiene, 4-methyl

$\mathrm{H}_{2} \mathrm{C}=\mathrm{CHCH}_{2} \mathrm{CM}=\mathrm{CHMO}$

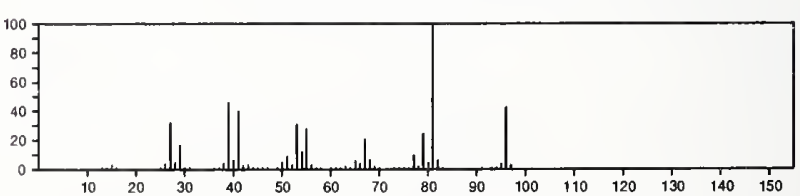


96

1,4-Hexadiene, 2-methyl-

$\mathrm{MeCH}=\mathrm{CHCH}_{2} \mathrm{CMe}_{\mathrm{C}}=\mathrm{CH}_{2}$

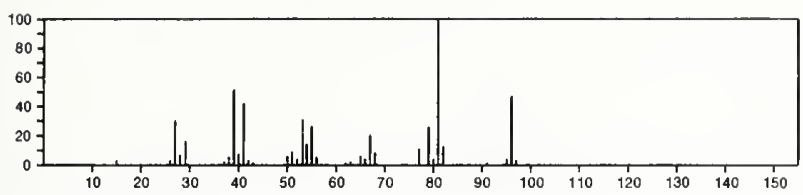

96

2-Heptyne

$\mathrm{C}_{7} \mathrm{H}_{12}$

$1119-65-9$

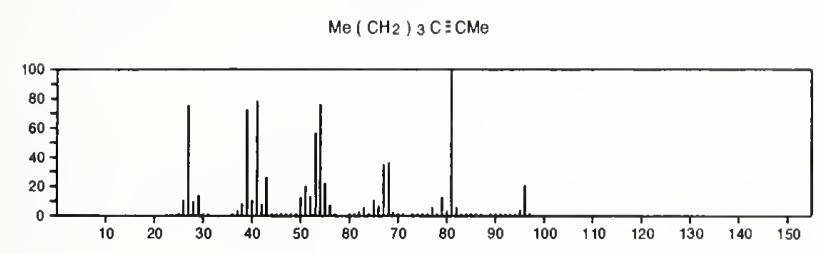

$96 \quad \mathrm{C}_{7} \mathrm{H}_{12}$

Cyclohexane, methylene-
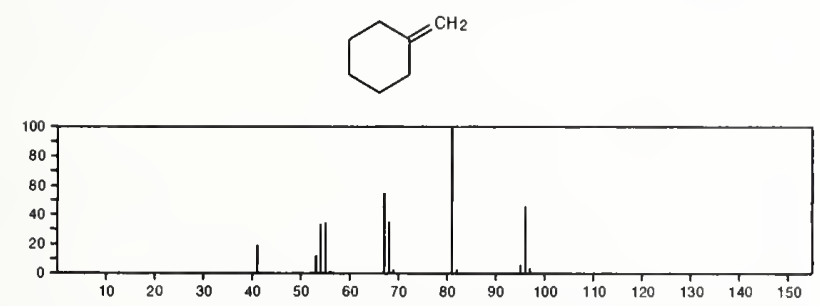

96

$\mathrm{C}_{7} \mathrm{H}_{12}$

2146-37-4

Cyclopentane, ethylidene-
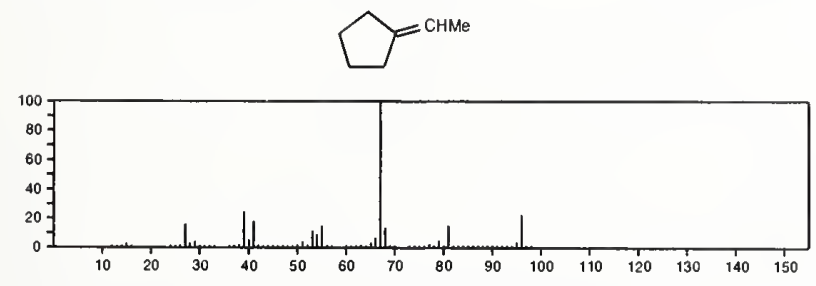

$96 \quad \mathrm{C}_{7} \mathrm{H}_{12}$

$2146-38-5$

Cyclopentene, 1-ethyl-
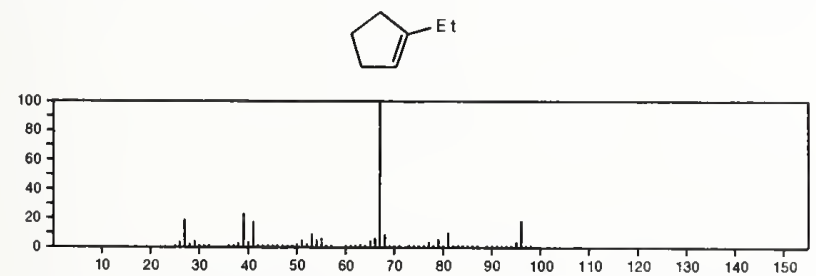

96

1-Hexyne, 5-methyl-

$\mathrm{C}_{7} \mathrm{H}_{12}$

2203-80-7

$\mathrm{Me}_{2} \mathrm{CHCH}_{2} \mathrm{CH}_{2} \mathrm{C} \equiv \mathrm{CH}$

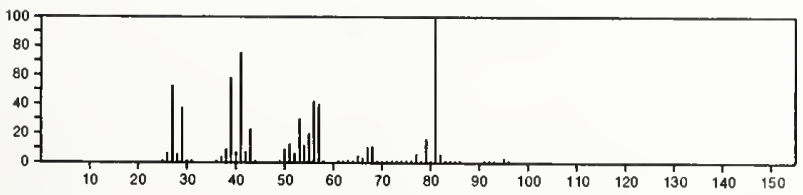

96

1,2- $\mathrm{H}$ ptadiene

$\mathrm{C}_{7} \mathrm{H}_{12}$

$2384-90-9$

$\mathrm{Me}\left(\mathrm{CH}_{2}\right)_{3} \mathrm{CH}: \mathrm{C}: \mathrm{CH}_{2}$

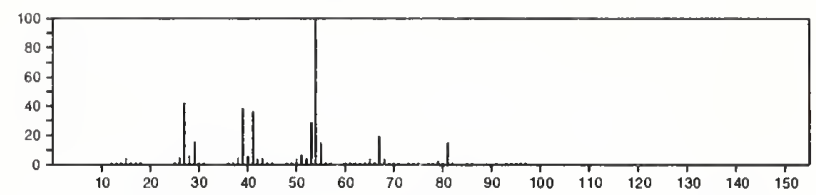

96

3-Heptyne

$\mathrm{C}_{7} \mathrm{H}_{12}$

2586-89-2

ET $\mathrm{C} \equiv \mathrm{CPr}$

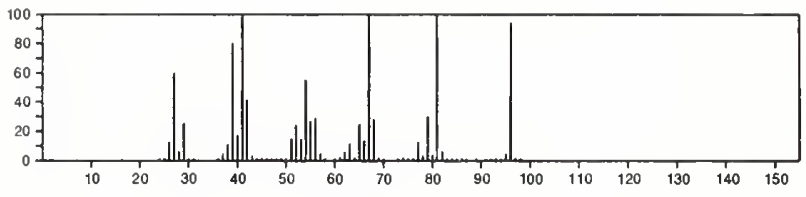

$\begin{aligned} & 96 \\ & 1,6-\text { Heptadiene }\end{aligned} \mathrm{C}_{7} \mathrm{H}_{12} \quad 3070-53-9$

$\mathrm{H}_{2} \mathrm{C}=\mathrm{CH}\left\langle\mathrm{CH}_{2}\right)_{3} \mathrm{CH}=\mathrm{CH}_{2}$

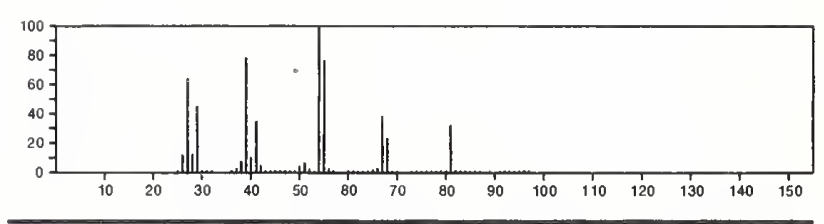

96

Cyclopentane, ethenyl-

$\mathrm{C}_{7} \mathrm{H}_{12}$

$3742-34-5$
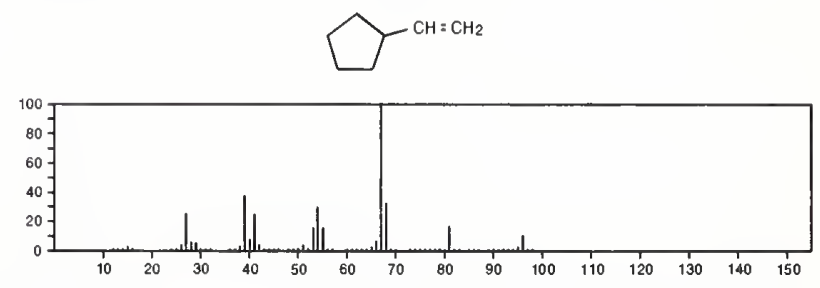

96

$\mathrm{C}_{7} \mathrm{H}_{12}$

$5685-47-2$

Cyclopropane, 1,1'-methylenebis-

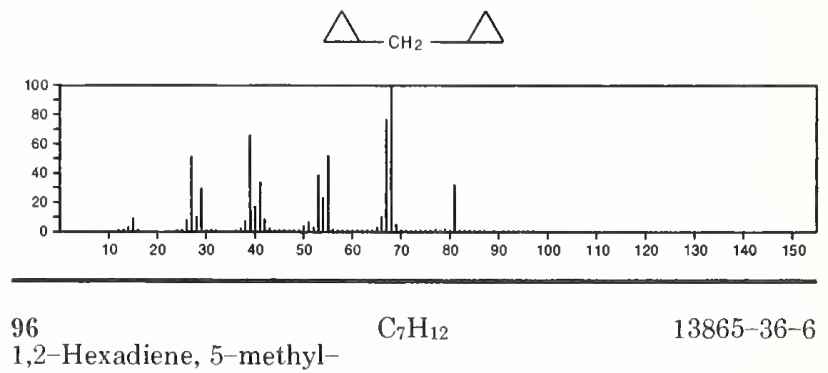

$\mathrm{Me}_{2} \mathrm{CHCH}_{2} \mathrm{CH}=\mathrm{C}=\mathrm{CH}_{2}$

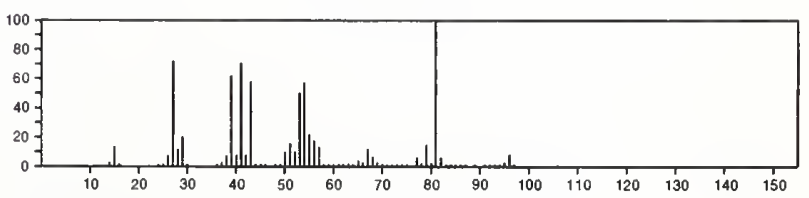


96

Cyclopentene, 1,5-dimethyl- $\mathrm{C}_{7} \mathrm{H}_{12}$

$16491-15-9$
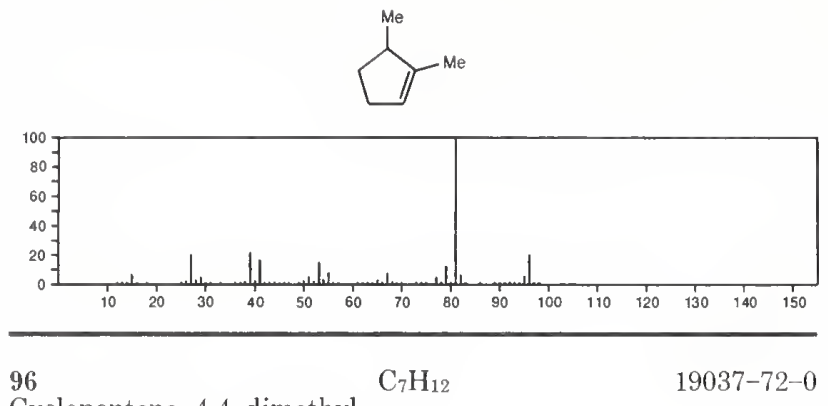

Cyclopentene, 4,4-dimethyl-
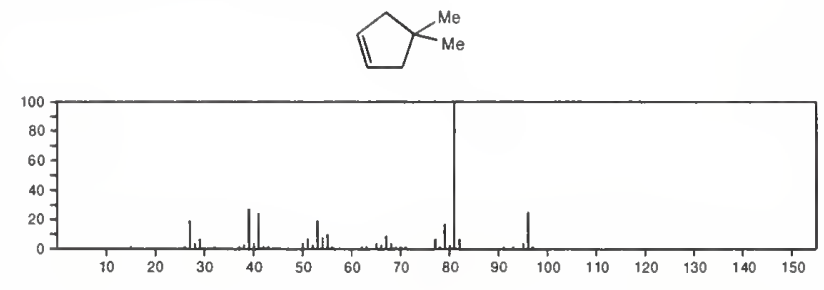

96

2-Hexyne, 4-methyl-

$\mathrm{C}_{7} \mathrm{H}_{12}$

20198-49-6

$\mathrm{MeC} \equiv \mathrm{CCHM} \mathrm{CH}_{2} \mathrm{Me}$

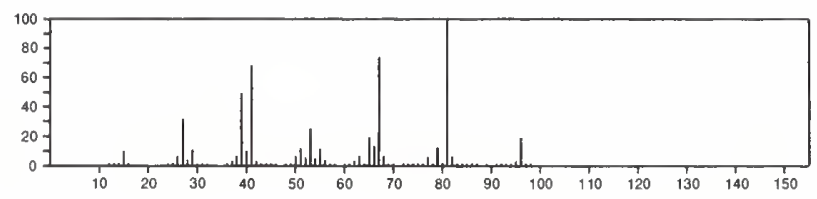

96

1,2-Pentadiene, 4,4-dimethyl-

26981-77-1

$\mathrm{H}_{2} \mathrm{C}=\mathrm{C}=\mathrm{CHCMe}_{3}$

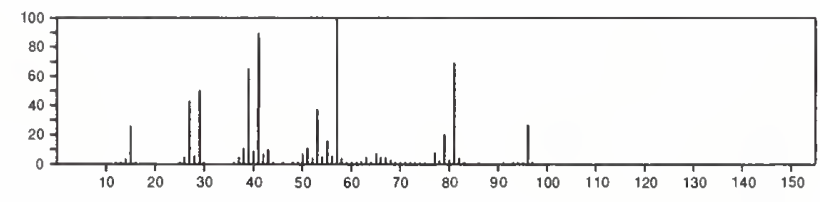

$\mathrm{C}_{7} \mathrm{H}_{12}$

96

2,4-Hexadiene, 2-methyl-

$\mathrm{Me}_{2} \mathrm{C}=\mathrm{CHCH}=\mathrm{CHMe}$

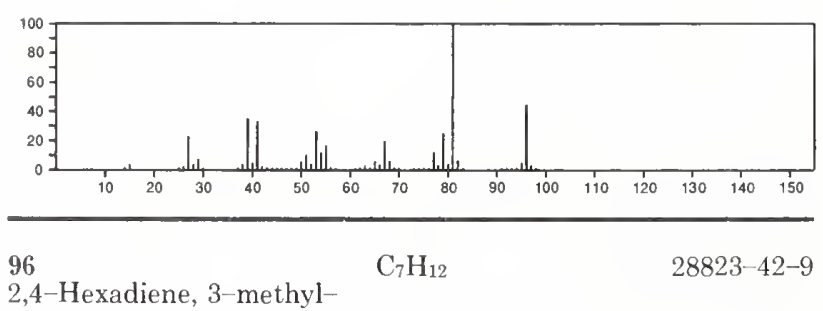

$\mathrm{Me} \mathrm{CH}: \mathrm{CHCMe}: \mathrm{CHMe}$

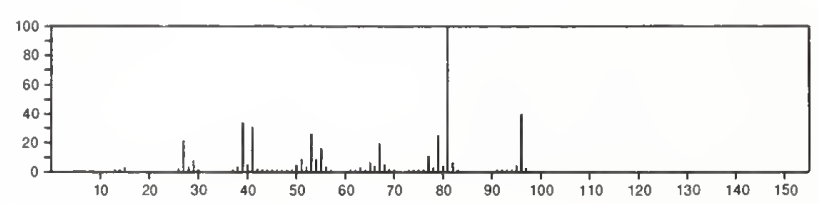

96

2-Hexyne, 5-methyl-

$\mathrm{C}_{7} \mathrm{H}_{12}$

$53566-37-3$

$\mathrm{Me} 2 \mathrm{CHCH}_{2} \mathrm{C} \equiv \mathrm{CMe}$

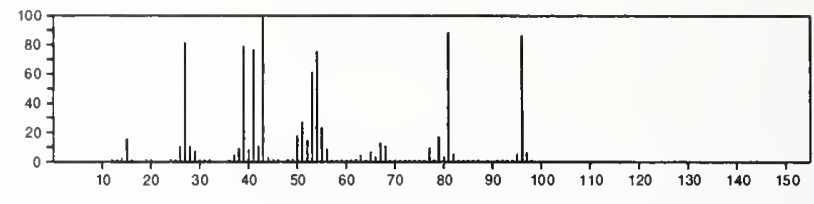

$\mathrm{C}_{7} \mathrm{H}_{12}$

Cyclobutane, 1-ethyl-3-methylene-

$56335-70-7$
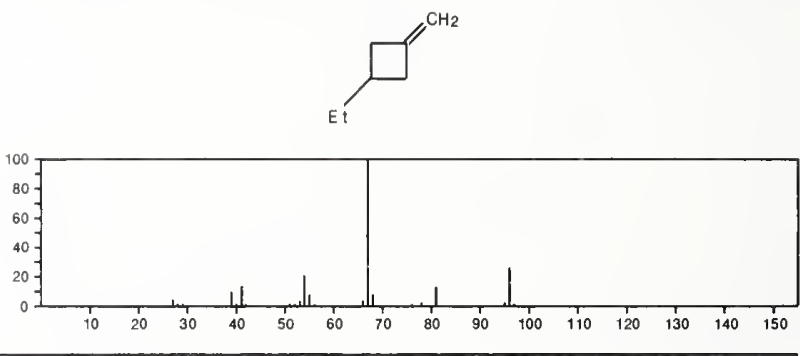

96

$\mathrm{O}_{4} \mathrm{~S}$

14808-79-8

Sulfate

$\mathrm{SO}_{4}{ }^{2-}$

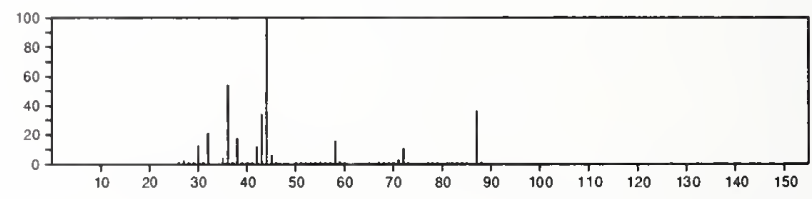

97

1H-1,2,4-Triazole, 3-ethyl-

$\mathrm{C}_{4} \mathrm{H}_{7} \mathrm{~N}_{3}$

$7411-16-7$
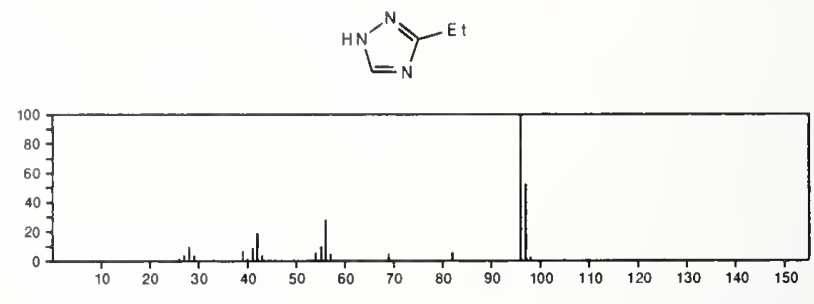

97

1H-1,2,4-Triazole, 1-ethyl-

$\mathrm{C}_{4} \mathrm{H}_{7} \mathrm{~N}_{3}$

16778-70-4
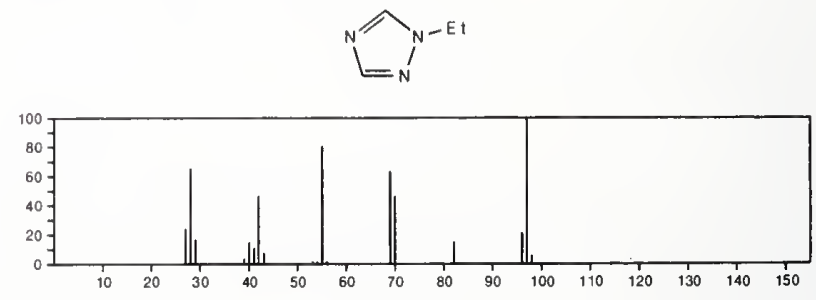

97

4H-1,2,4-Triazole, 4-ethyl

$\mathrm{C}_{4} \mathrm{H}_{7} \mathrm{~N}_{3}$

$43183-55-7$<smiles>CCn1cnnc1</smiles>

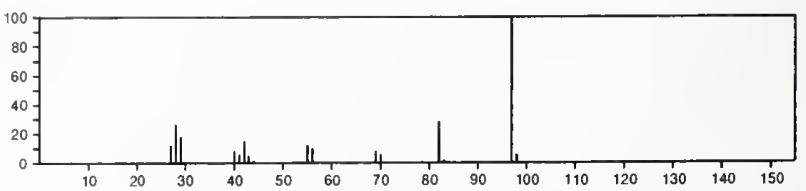


97
Isoxazole, 3,5-dimethyl-

$\mathrm{C}_{5} \mathrm{H}_{7} \mathrm{NO}$
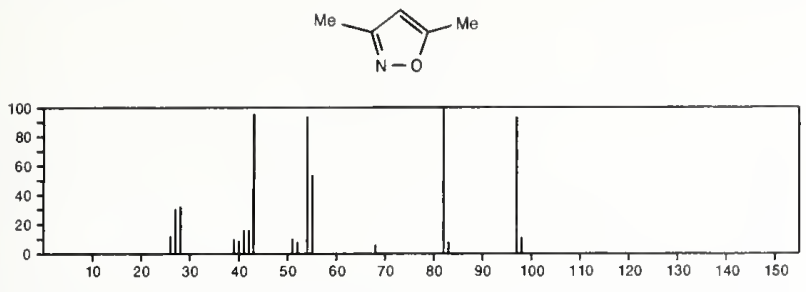

97

$\mathrm{C}_{5} \mathrm{H}_{2} \mathrm{NO}$

2H-Pyrrol-2-one, 1,5-dihydro-1-methyl
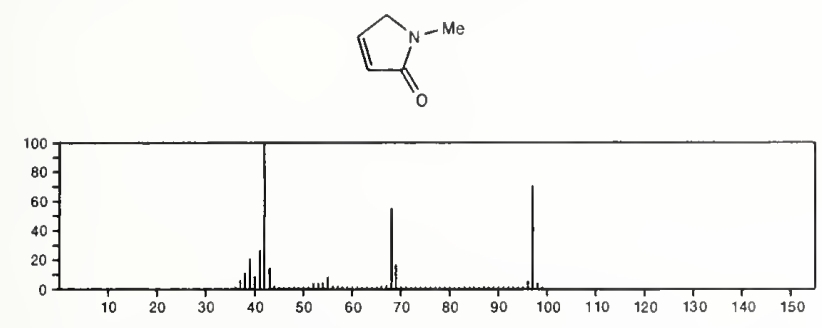

$97 \quad \mathrm{C}_{5} \mathrm{H}_{7} \mathrm{NO}$

4-Pentenenitrile, 3-hydroxy-

$\mathrm{NCCH}_{2} \mathrm{CH}(\mathrm{OH}) \mathrm{CH}=\mathrm{CH}_{2}$

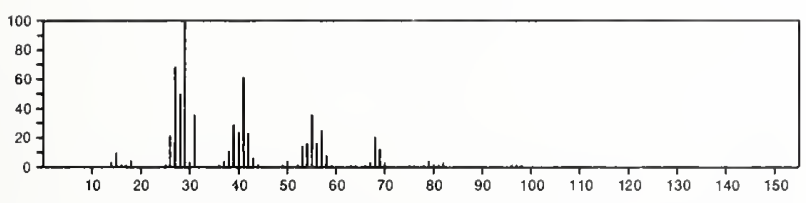

97

2-Cyclobutene-1-carboxamide

$\mathrm{C}_{5} \mathrm{H}_{7} \mathrm{NO}$

$53778-54-4$
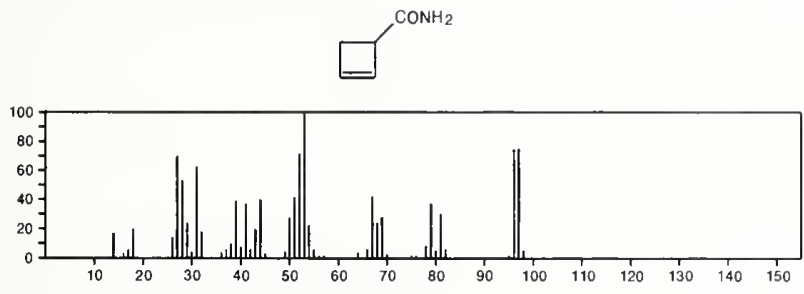

97

2-Pentenenitrile, 5-hydroxy-, $(Z)$ -

$53778-55-5$

$\mathrm{HOCH}_{2} \mathrm{CH}_{2} \mathrm{CH}=\mathrm{CHCN}$

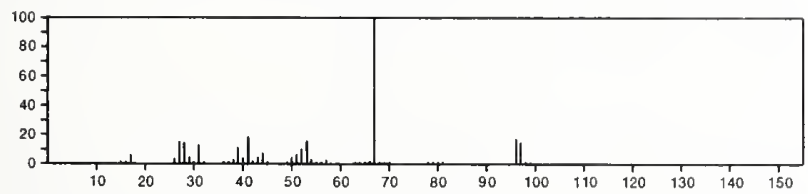

$97 \quad \mathrm{C}_{5} \mathrm{H}_{2} \mathrm{NO}$

2-Pentenenitrile, 5-hydroxy-, $(E)$ -

$53778-56-6$

$\mathrm{HOCH}_{2} \mathrm{CH}_{2} \mathrm{CH}=\mathrm{CHCN}$

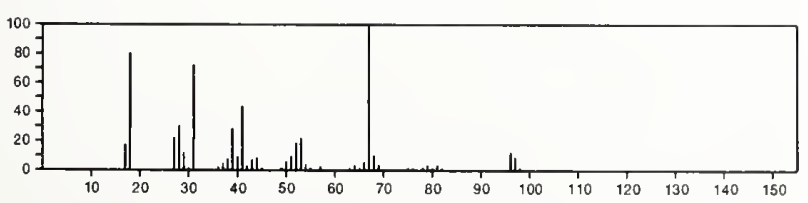

$97 \quad \mathrm{C}_{6} \mathrm{H}_{11} \mathrm{~N}$

2-Propen-1-amine, $N$-2-propenyl-

$124-02-7$

$\mathrm{H}_{2} \mathrm{C}=\mathrm{CHCH}_{2} \mathrm{NHCH}_{2} \mathrm{CH}=\mathrm{CH}_{2}$

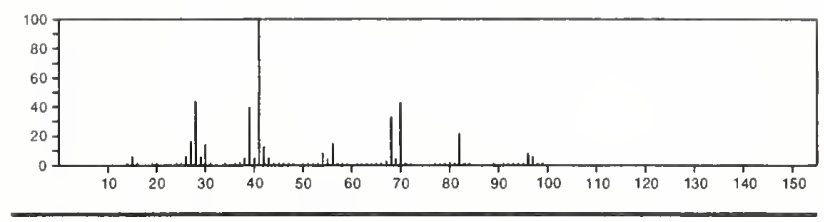

97

$\mathrm{C}_{6} \mathrm{H}_{11} \mathrm{~N}$

286-18-0

7-Azabicyclo[4.1.0]heptane
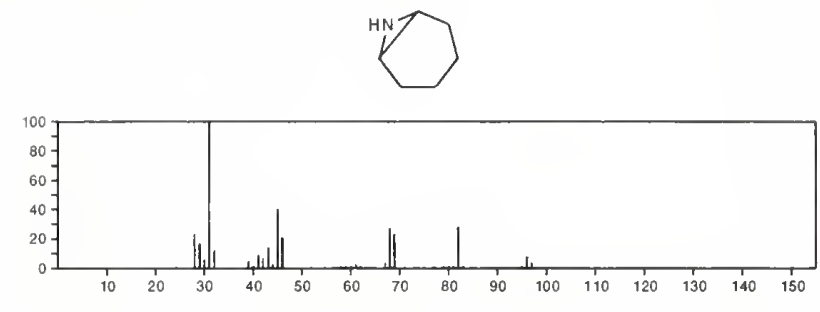

97

Pentanenitrile, 4-methyl

$\mathrm{C}_{6} \mathrm{H}_{11} \mathrm{~N}$

$542-54-1$

$\mathrm{NCCH}_{2} \mathrm{CH}_{2} \mathrm{CHMe}_{2}$

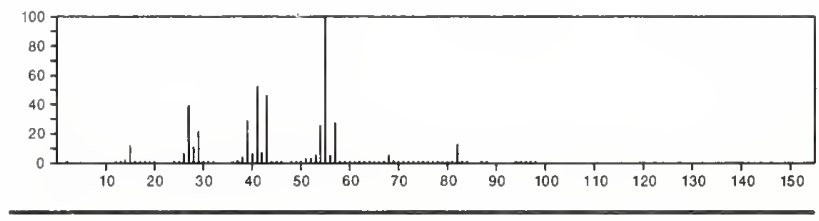

97

$\mathrm{C}_{6} \mathrm{H}_{11} \mathrm{~N}$

628-73-9

Hexanenitrile

$\mathrm{NC}\left(\mathrm{CH}_{2}\right)_{4} \mathrm{Me}$

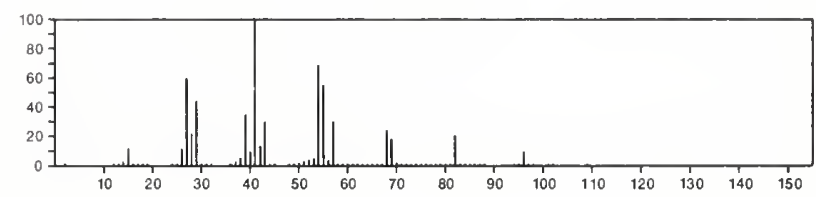

97

$\mathrm{C}_{6} \mathrm{H}_{11} \mathrm{~N}$

Methylamine, $N$-cyclopentylidene-

10599-83-4
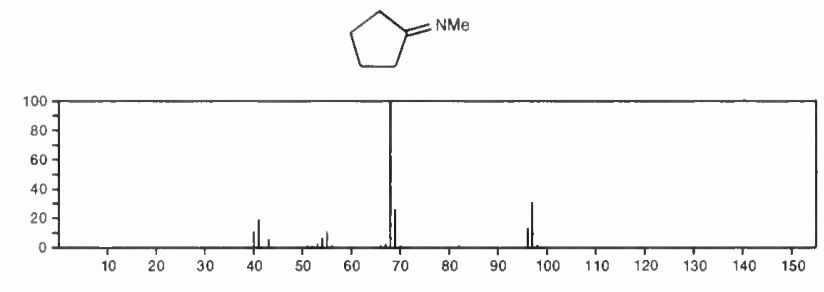

97

$\mathrm{C}_{6} \mathrm{H}_{11} \mathrm{~N}$

$55268-35-4$

Aziridine, 2-methylene-1-(1-methylethyl)
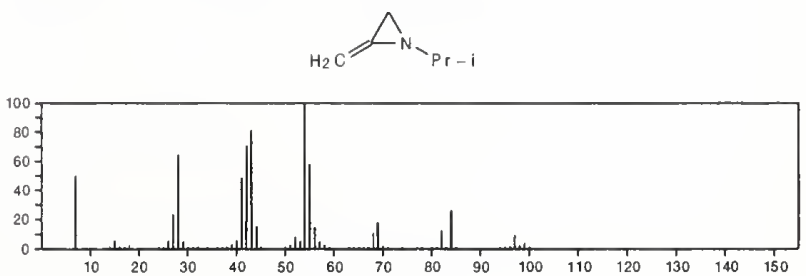
98

Carbonic dichloride

$\mathrm{CCl}_{2} \mathrm{O}$

$\mathrm{Clcoct}$

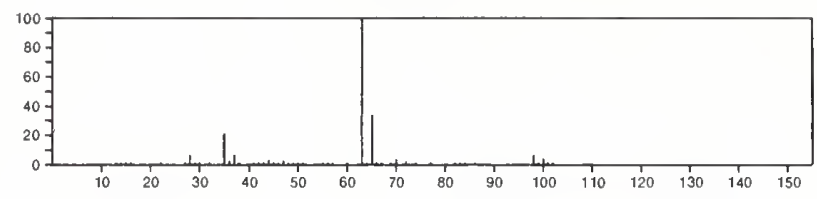

98

Ethene, 1-chloro-1,2-difluoro-

$\mathrm{C}_{2} \mathrm{HClF}_{2}$

$359-04-6$

$\mathrm{FCH}=\mathrm{CCIF}$

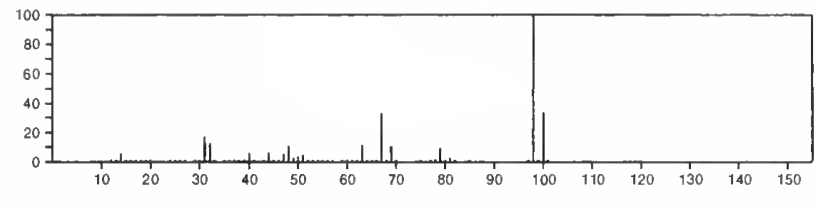

98

$\mathrm{C}_{2} \mathrm{HClF}_{2}$

$359-10-4$

Ethene, 2-chloro-1,1-difluoro-

$\mathrm{Cl} \mathrm{CH}=\mathrm{CF}_{2}$

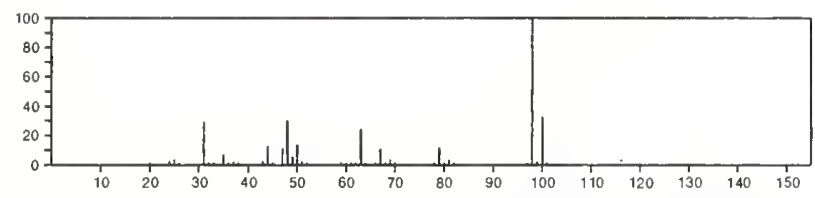

98

Eıhane, 1,1-dichloro

$\mathrm{C}_{2} \mathrm{H}_{4} \mathrm{Cl}_{2}$

$75-34-3$

$\mathrm{Cl}_{2} \mathrm{CHMe}$

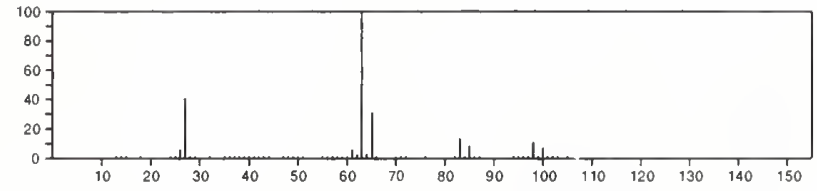

98

Ethane, 1,2-dichloro

$\mathrm{C}_{2} \mathrm{H}_{4} \mathrm{Cl}_{2}$

$107-06-2$

$\mathrm{Cl} \mathrm{CH}_{2} \mathrm{CH}_{2} \mathrm{Cl}$

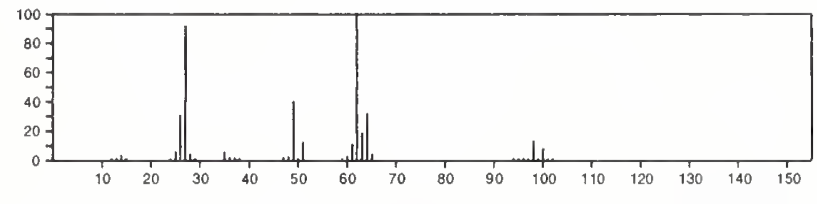

98

$\mathrm{C}_{2} \mathrm{H}_{7} \mathrm{BN}_{4}$

$6982-51-0$

1H-Tetrazaborole, 4,5-dihydro-1,4-dimethyl
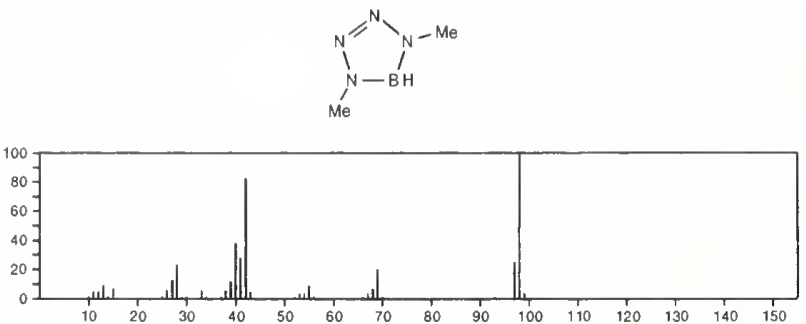

98

2H-Tetrazole, 2,5-dimethyl-

$\mathrm{C}_{3} \mathrm{H}_{6} \mathrm{~N}_{4}$
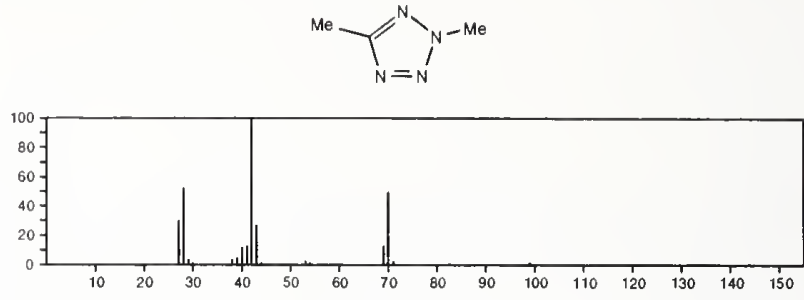

98

1H-Tetrazole, 1,5-dimethyl-

$\mathrm{C}_{3} \mathrm{H}_{6} \mathrm{~N}_{4}$

5144-11-6
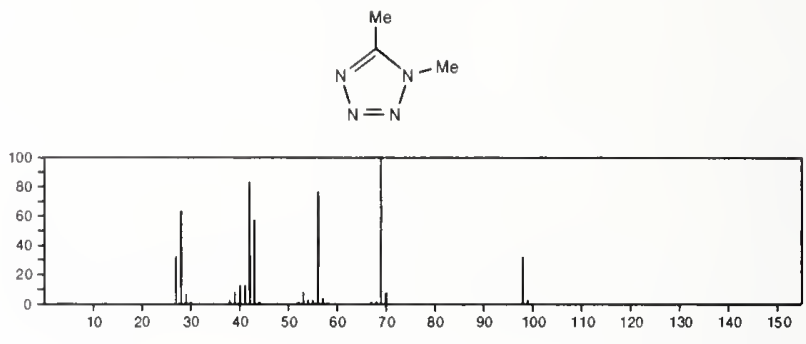

98

$\mathrm{C}_{3} \mathrm{H}_{6} \mathrm{~N}_{4}$

1H-1,2,4-Triazol-3-amine, $N$-methyl-

15285-16-2
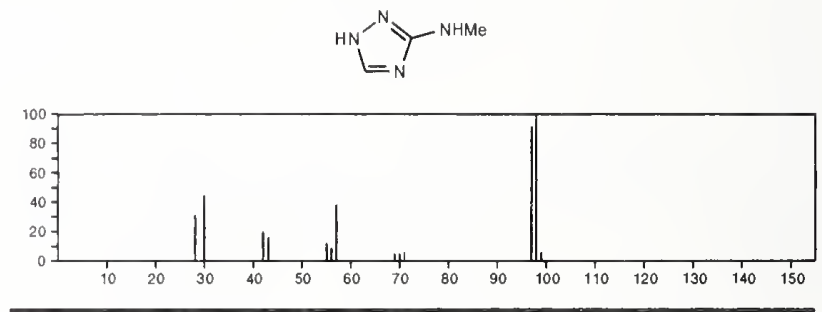

98

$\mathrm{C}_{3} \mathrm{H}_{6} \mathrm{~N}_{4}$

1H-1,2,4-Triazol-5-amine, 1-methyl-

$15795-39-8$
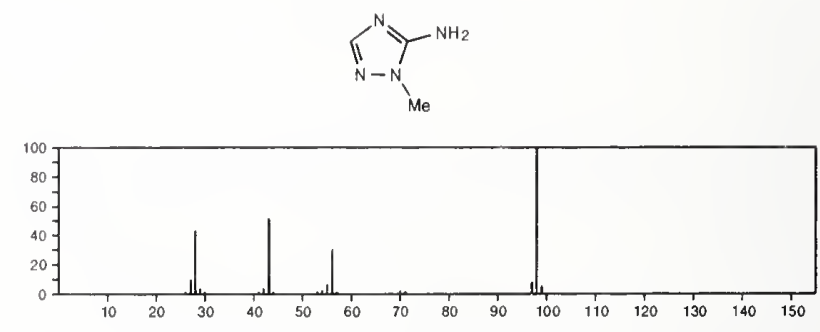

98

$\mathrm{C}_{3} \mathrm{H}_{6} \mathrm{~N}_{4}$

4H-1,2,4-Triazol-3-amine, 4-methyl-

$16681-76-8$
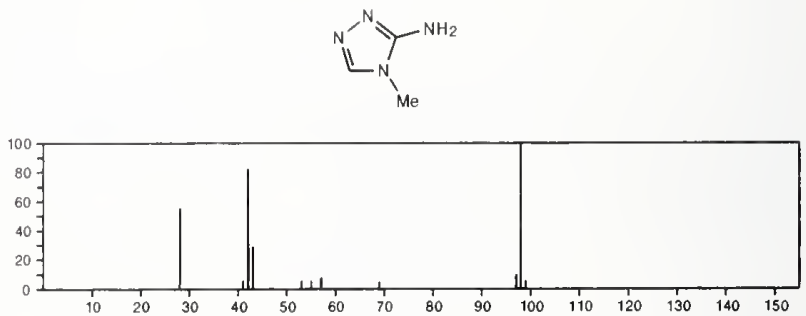
$\mathrm{C}_{3} \mathrm{H}_{6} \mathrm{~N}_{4}$

1H-1,2,4-Triazol-3-amine, 1-methyl-

$$
\mathrm{Me}-L_{\mathrm{N}}^{\mathrm{N}}
$$

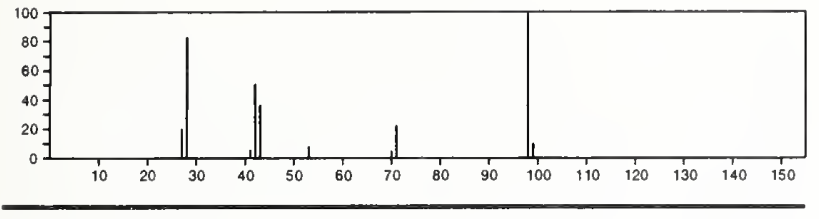

98

$\mathrm{C}_{4} \mathrm{H}_{2} \mathrm{O}_{3}$

$108-31-6$

2,5-Furandione
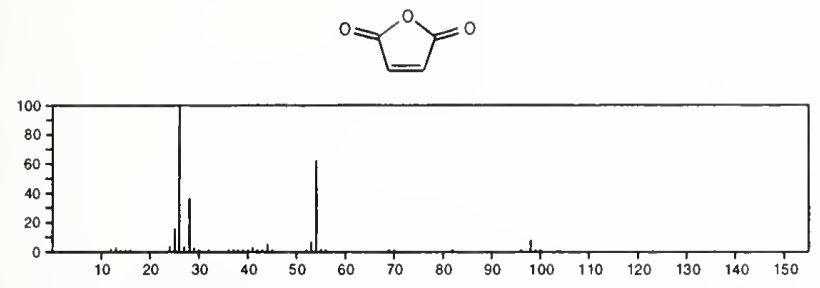

\section{8 \\ $\mathrm{C}_{4} \mathrm{H}_{6} \mathrm{~N}_{2} \mathrm{O}$}

$108-26-9$

3H-Pyrazol-3-one, 2,4-dihydro-5-methyl-

$$
\overbrace{\mathrm{HN}-\mathrm{N}}^{\mathrm{Me}}
$$
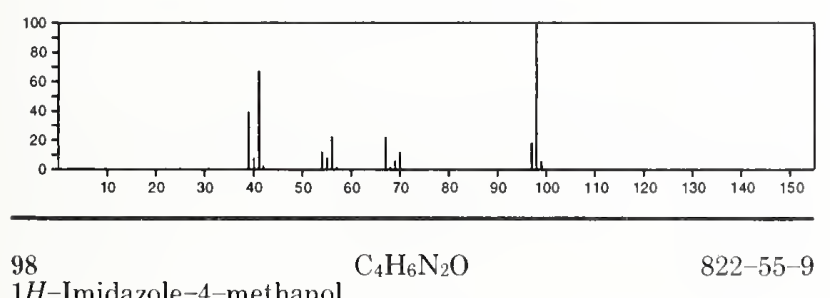

$822-55-9$
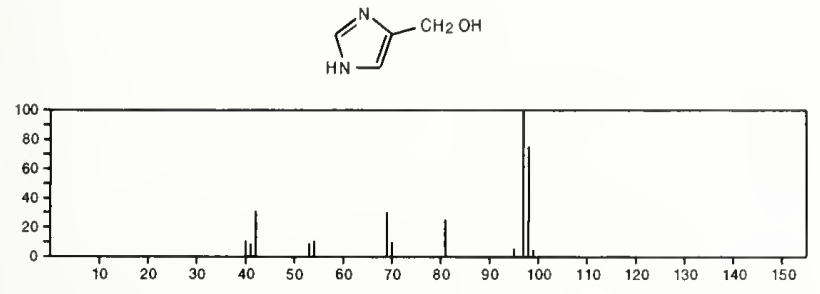

$98 \quad \mathrm{C}_{4} \mathrm{H}_{6} \mathrm{~N}_{2} \mathrm{O}$

$1072-67-9$

3-Isoxazolamine, 5-methyl-
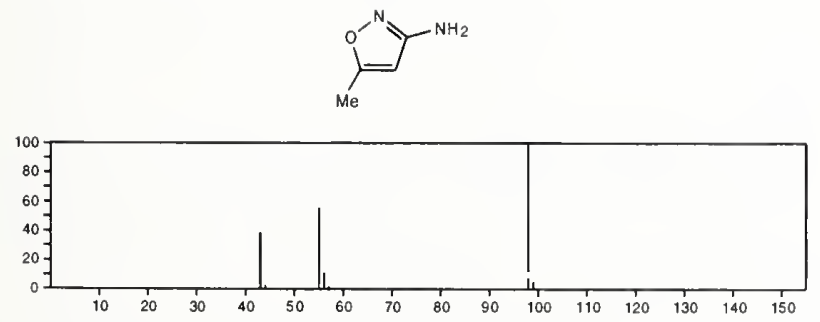

98

Furazan, dimethyl

$\mathrm{C}_{4} \mathrm{H}_{6} \mathrm{~N}_{2} \mathrm{O}$

$4975-21-7$
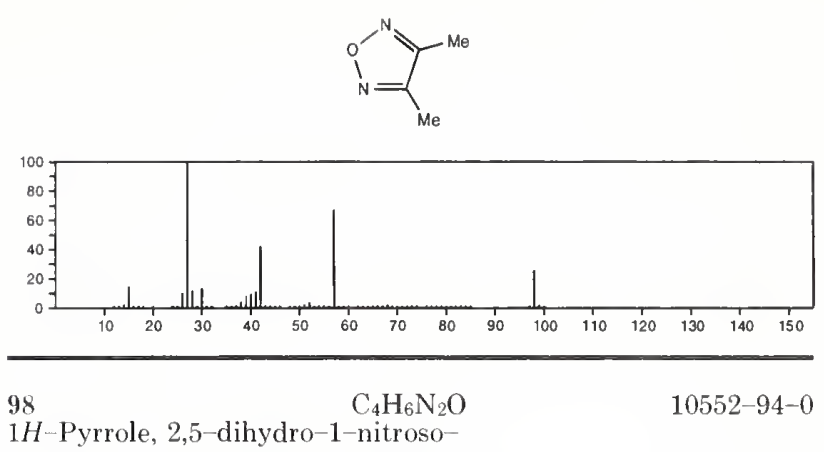

1 H-Pyrrole, 2,5-dihydro-1-nitroso-

$\int^{N-N O}$

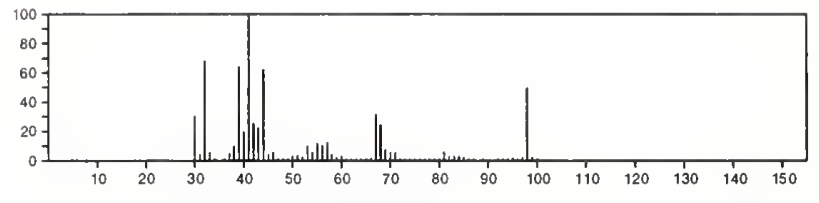

98

2-Furanmethanol

$\mathrm{C}_{5} \mathrm{H}_{6} \mathrm{O}_{2}$

$98-00-0$
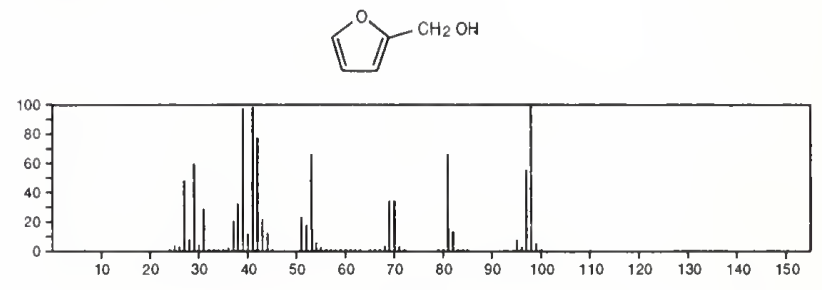

98

$\mathrm{C}_{5} \mathrm{H}_{6} \mathrm{O}_{2}$

547-65-9

2(3H)-Furanone, dihydro-3-methylene-
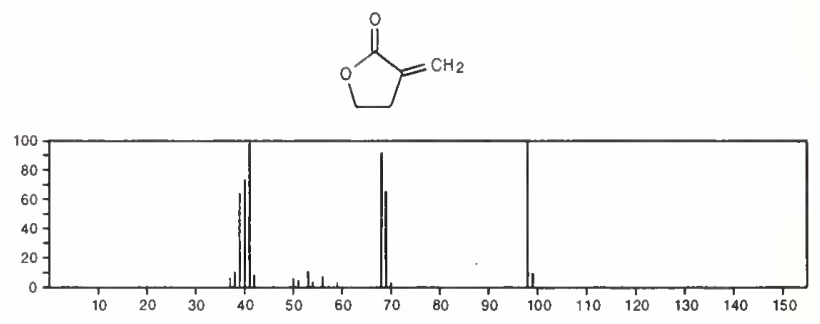

${ }_{2}^{98}(5 H)$-Furanone, 5-methyl- $\mathrm{C}_{5} \mathrm{H}_{6} \mathrm{O}_{2}$

$591-11-7$
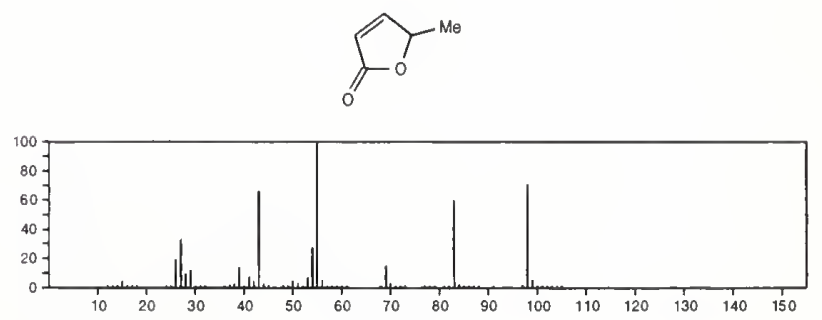

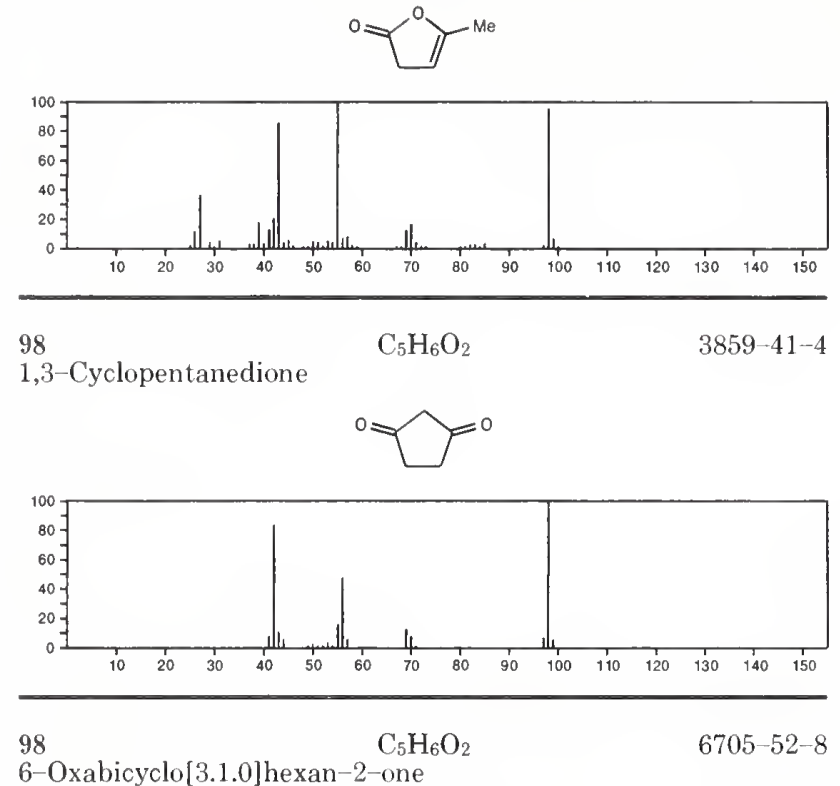

$1 y^{0}$

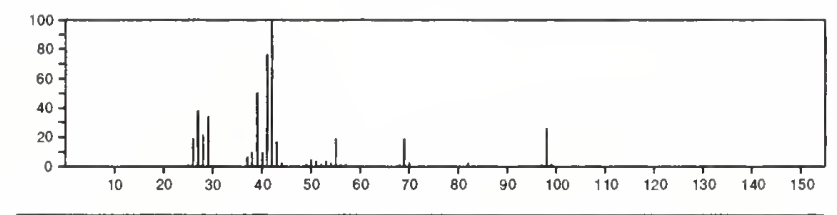

$98 \quad \mathrm{C}_{5} \mathrm{H}_{6} \mathrm{O}_{2} \quad 22122-36-7$

2(5H)-Furanone, 3-methyl-
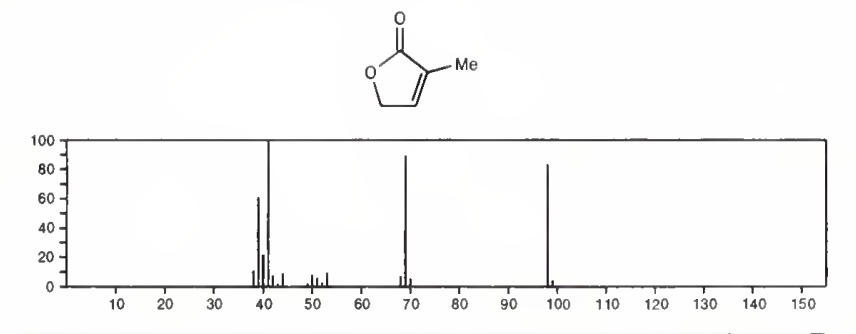

$98 \quad \mathrm{C}_{5} \mathrm{H}_{6} \mathrm{~S} \quad 554-14-3$

Thiophene, 2-methyl
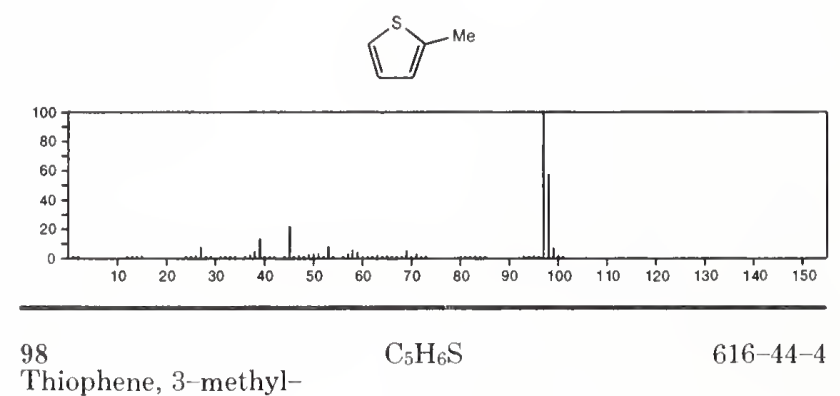

Thiophene, 3-methyl-
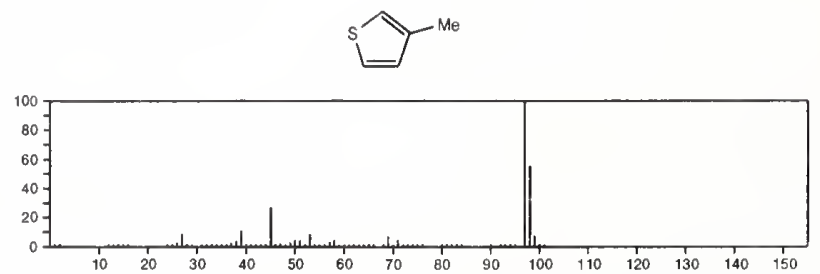

$1 H$-Imidazole, 4,5-dihydro-2,4-dimethyl-<smiles>[N+]=[N+]([O-])C1=NC([N+](=O)[O-])CN1</smiles>

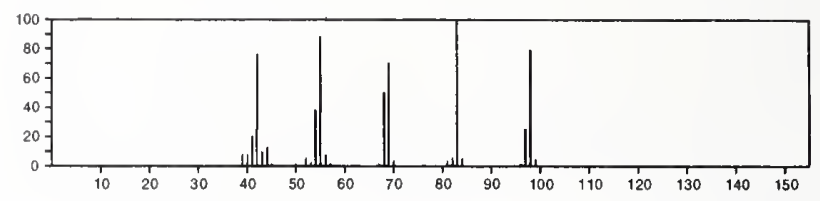

98

1-Pentyn-3-ol, 3-methyl-

$\mathrm{C}_{6} \mathrm{H}_{10} \mathrm{O}$

$77-75-8$

$\mathrm{Et} \mathrm{CMe}(\mathrm{OH}) \mathrm{C}: \mathrm{CH}$

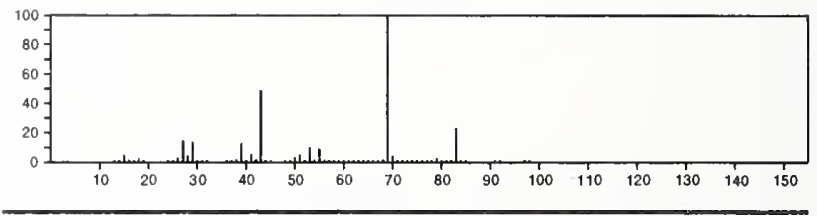

98

1-Hexyn-3-ol

$\mathrm{C}_{6} \mathrm{H}_{10} \mathrm{O}$

105-31-7

$\operatorname{PrCH}(\mathrm{OH}) \mathrm{C} \equiv \mathrm{CH}$

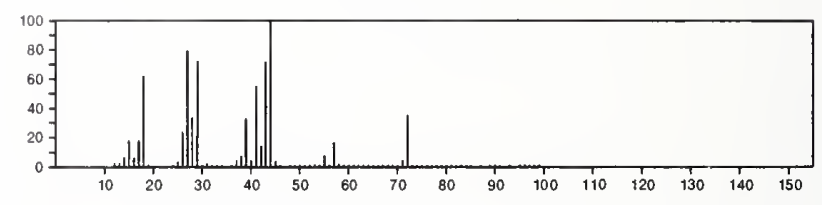

98

Cyclohexanone

$\mathrm{C}_{6} \mathrm{H}_{10} \mathrm{O}$

108-94-1
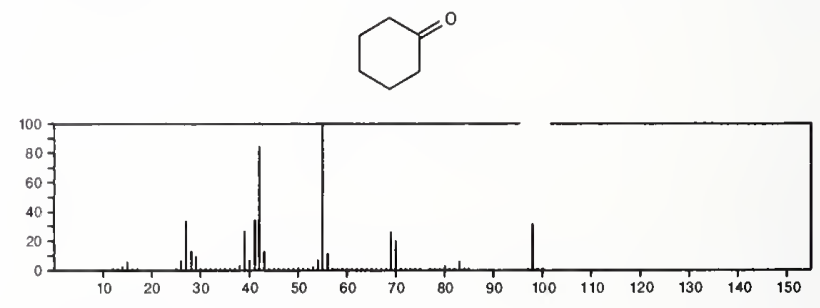

98

5-Hexen-2-one

$\mathrm{C}_{6} \mathrm{H}_{10} \mathrm{O}$

109-49-9

$\mathrm{H}_{2} \mathrm{C}=\mathrm{CHCH}_{2} \mathrm{CH}_{2} \mathrm{COMe}$

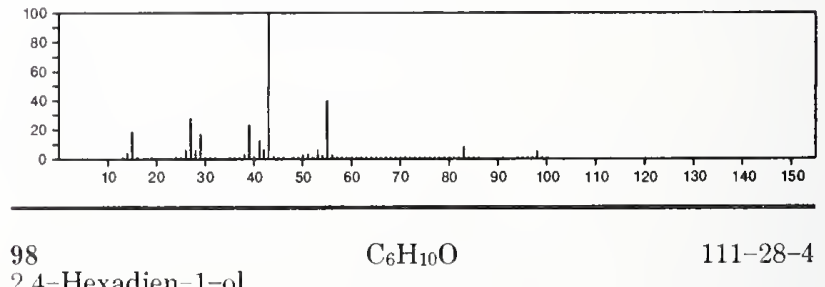

2,4-Hexadien-1-ol

$\mathrm{MeCH}=\mathrm{CHCH}=\mathrm{CHCH}_{2} \mathrm{OH}$

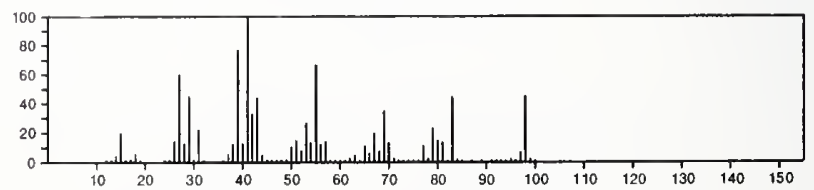


98 -Penten-2-one, 4-methyl- $\mathrm{C}_{6} \mathrm{H}_{10} \mathrm{O}$

$\mathrm{Me} \mathrm{COCH}: \mathrm{CMe}_{2}$

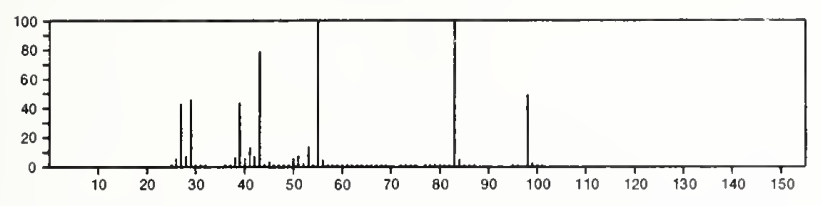

${ }_{7-O}$ Oxabicyclo[2.2.1]heptane $\mathrm{C}_{6} \mathrm{H}_{10} \mathrm{O}$
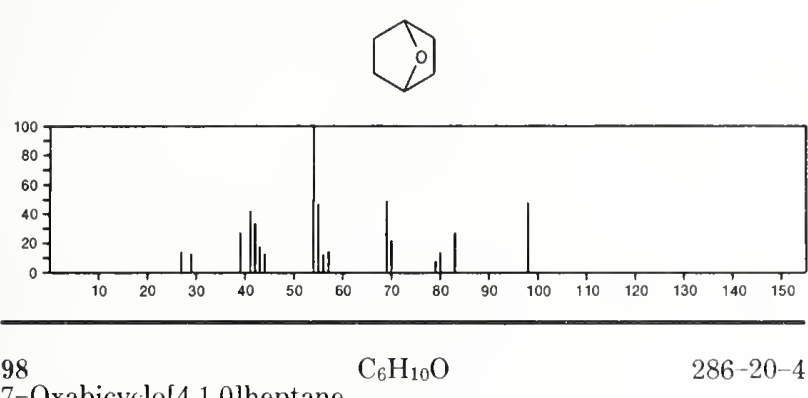

7-Oxabicyclo[4.1.0]heptane
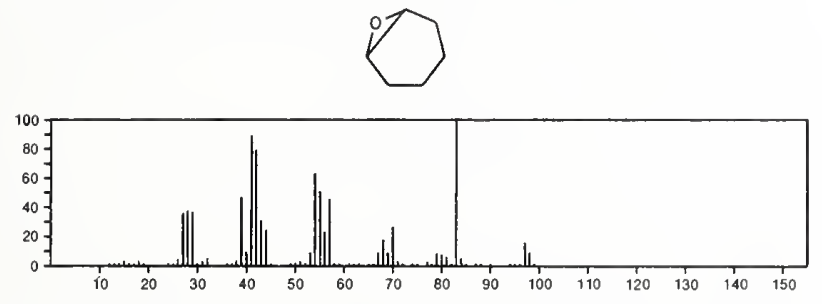

98

$\mathrm{C}_{6} \mathrm{H}_{10} \mathrm{O}$

$505-57-7$

2-Hexenal

$\mathrm{OCHCH}=\mathrm{CHP}$ r

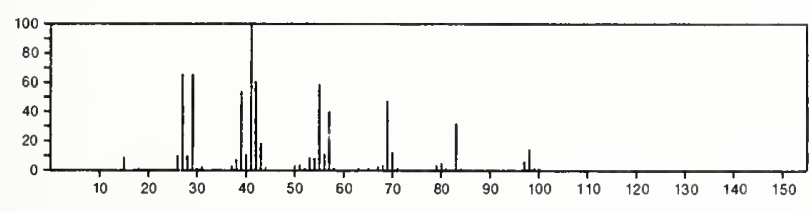

98

1-Propene, 3,3'-oxybis-

$\mathrm{C}_{6} \mathrm{H}_{10} \mathrm{O}$

$557-40-4$

$\mathrm{H}_{2} \mathrm{C}=\mathrm{CHCH}_{2} \mathrm{OCH}_{2} \mathrm{CH}=\mathrm{CH}_{2}$

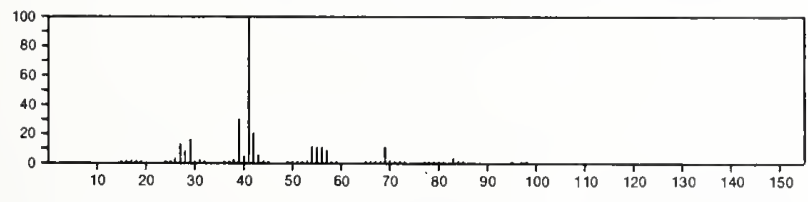

98

3-Penten-2-one, 3-methyl-

$\mathrm{C}_{6} \mathrm{H}_{10} \mathrm{O}$

$565-62-8$

$\mathrm{MeCOCMe}=\mathrm{CHMe}$

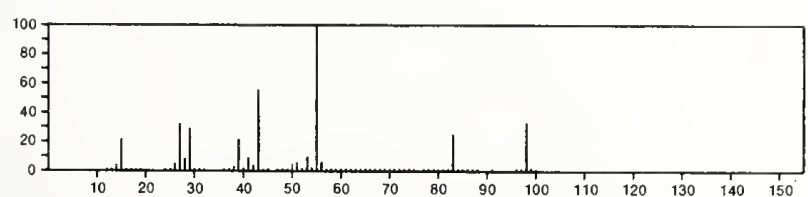

98

1-Pentyn-3-ol, 4-methyl-

$\mathrm{C}_{6} \mathrm{H}_{10} \mathrm{O}$

$565-68-4$

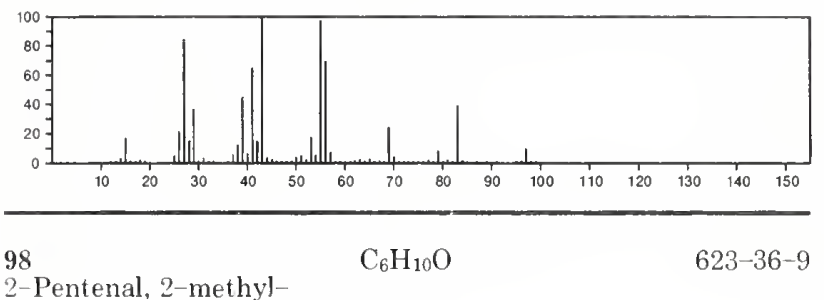

$\mathrm{E} / \mathrm{CH}: \mathrm{CMe} \mathrm{CHO}$

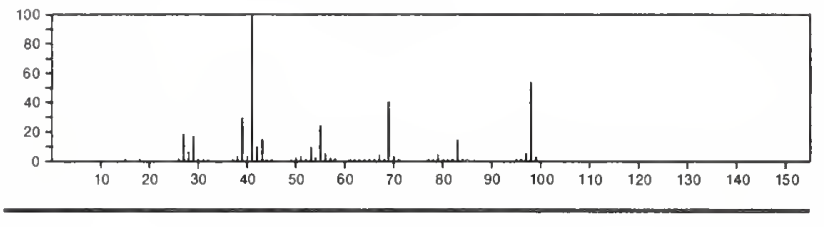

98

4-Penten-2-one, 3-methyl-

$\mathrm{C}_{6} \mathrm{H}_{10} \mathrm{O}$

$758-87-2$

$\mathrm{Me} \mathrm{COCHMe} \mathrm{CH}=\mathrm{CH}_{2}$

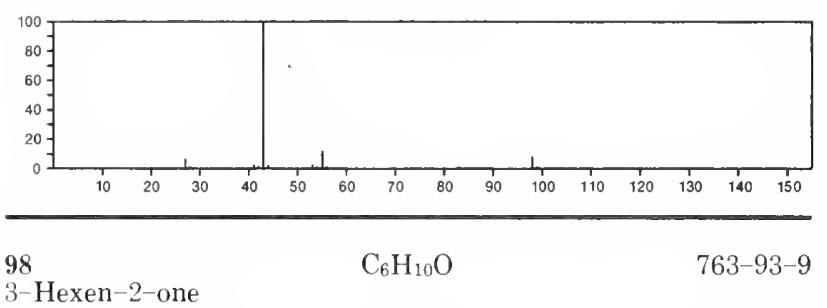

$\mathrm{MeCOCH}=\mathrm{CHE} \mathrm{t}$

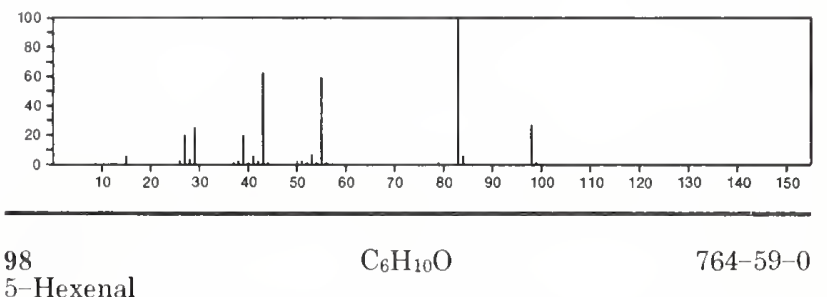

$\mathrm{H}_{2} \mathrm{C}=\mathrm{CH}\left(\mathrm{CH}_{2}\right)_{3} \mathrm{CHO}$

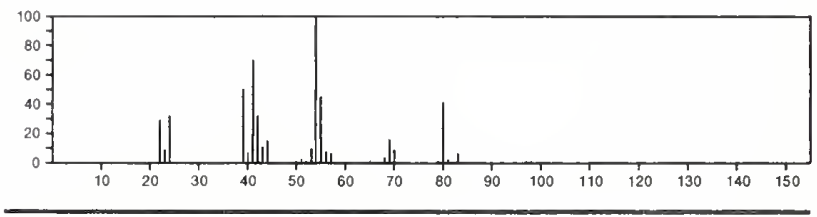

98

3-Cyclohexen-1-ol

$\mathrm{C}_{6} \mathrm{H}_{10} \mathrm{O}$

$822-66-2$
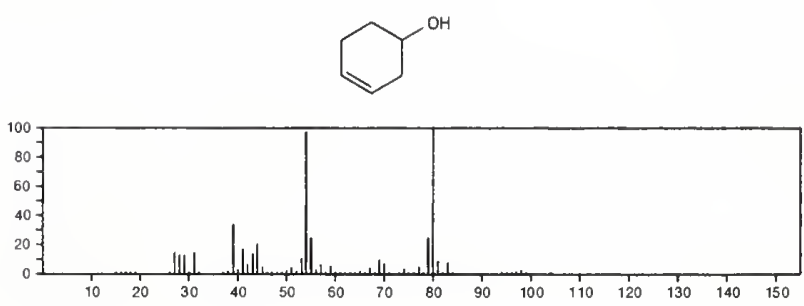
98

2-Cyclohexen-1-ol

$\mathrm{C}_{6} \mathrm{H}_{10} \mathrm{O}$
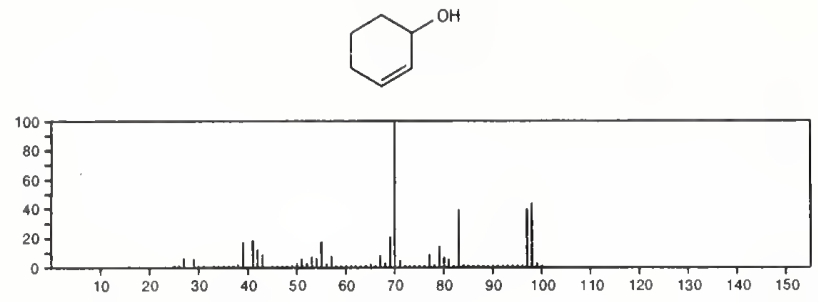

98

Cyclopentanecarboxaldehyde

$\mathrm{C}_{6} \mathrm{H}_{10} \mathrm{O}$

$\Upsilon^{C H}: 0$

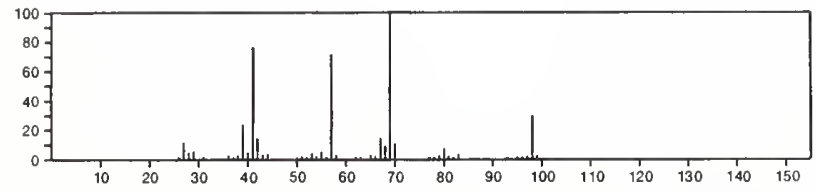

98

$\mathrm{C}_{6} \mathrm{H}_{10} \mathrm{O}$

Ethanone, 1-(2-methylcyclopropyl)-
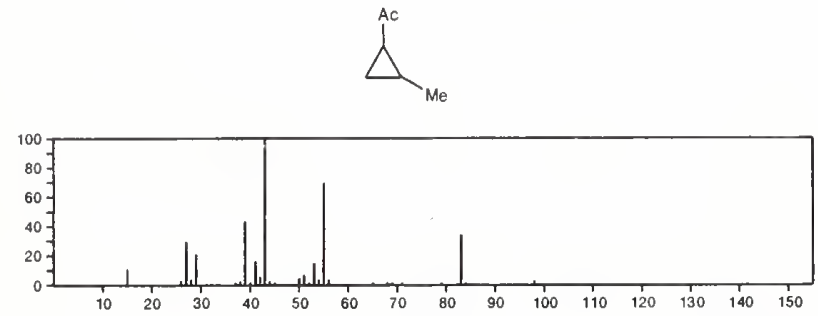

98

3-Hexyn-1-ol

$\mathrm{C}_{6} \mathrm{H}_{10} \mathrm{O}$

$1002-28-4$

$\mathrm{HOCH}_{2} \mathrm{CH}_{2} \mathrm{C}: \mathrm{CE}$

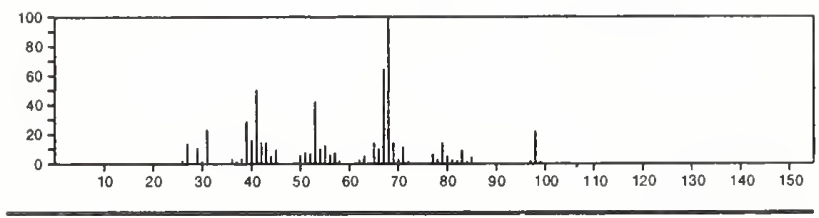

$98 \quad \mathrm{C}_{6} \mathrm{H}_{10} \mathrm{O}$

Cyclopentanone, 2-methyl-
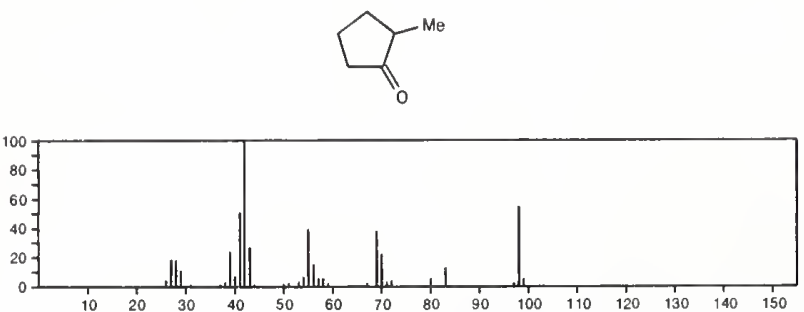

98

Cyclobutanone, 2,2 dimethyl- $\mathrm{C}_{6} \mathrm{H}_{10} \mathrm{O}$

$1192-14-9$
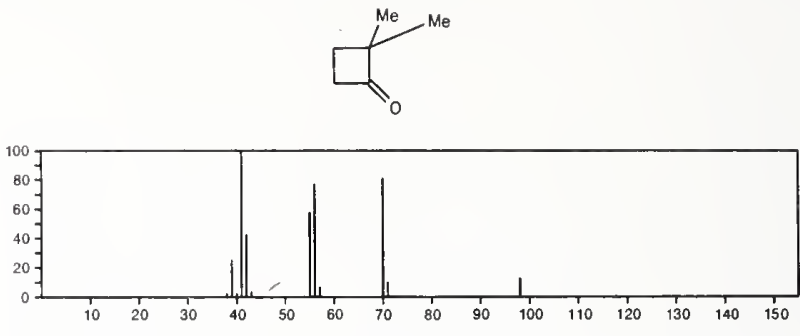

98

$\mathrm{C}_{6} \mathrm{H}_{10} \mathrm{O}$

1192-33-2

Cyclobutanone, 3,3-dimethyl-
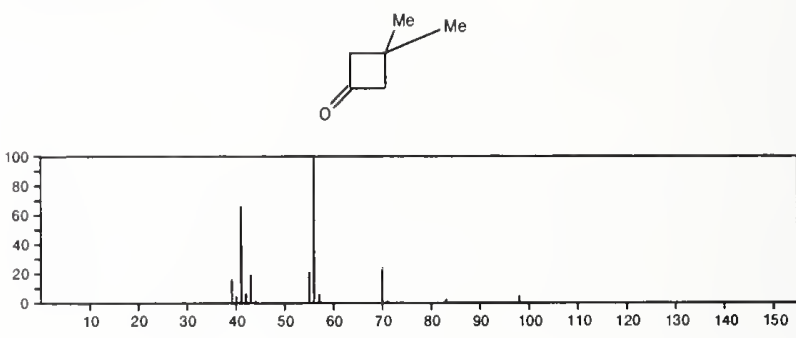

98

1-Penten-3-one, 4-methyl

$\mathrm{C}_{6} \mathrm{H}_{10} \mathrm{O}$

$1606-47-9$

$\mathrm{H}_{2} \mathrm{C}=\mathrm{CHCOCHMe} 2$

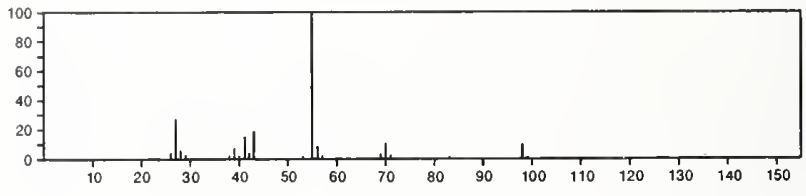

98

$\mathrm{C}_{6} \mathrm{H}_{10} \mathrm{O}$

1629-60-3

1-Hexen-3-one

$\mathrm{H}_{2} \mathrm{C}=\mathrm{CHCOP} \mathrm{r}$

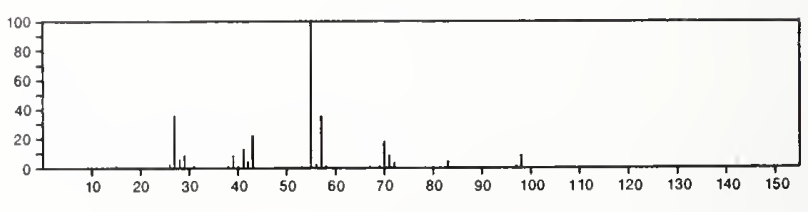

98
Cyclopentanone, 3-methyl-

$1757-42-2$
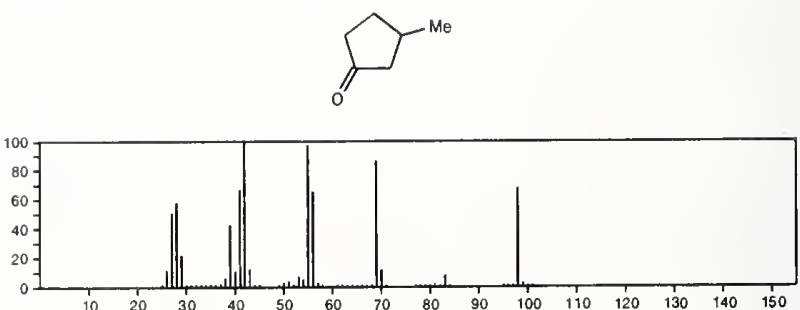
$98 \quad \mathrm{C}_{6} \mathrm{H}_{10} \mathrm{O}$

Cyclobutanone, 2,3-dimethyl-, trans-
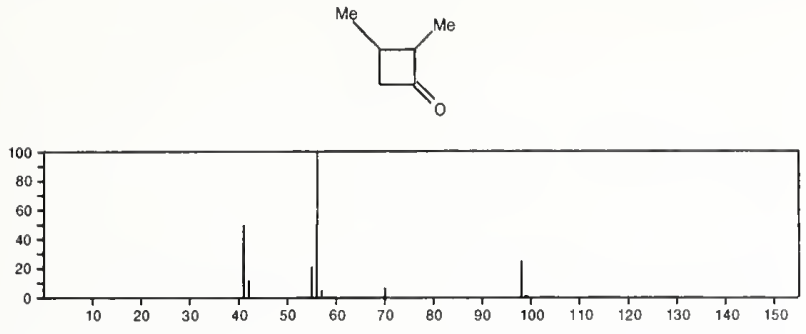

$98 \quad \mathrm{C}_{6} \mathrm{H}_{10} \mathrm{O}$

$2 H$-Pyran, 3,4-dihydro-4-methyl
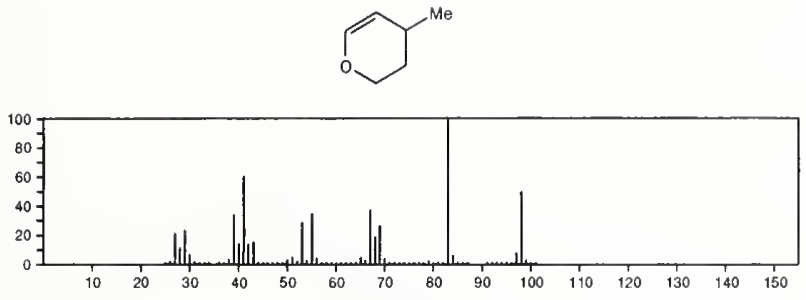

98

$\mathrm{C}_{6} \mathrm{H}_{10} \mathrm{O}$

2497-21-4

4-Hexen-3-one

$\mathrm{E} t \mathrm{COCH}: \mathrm{CHM}$

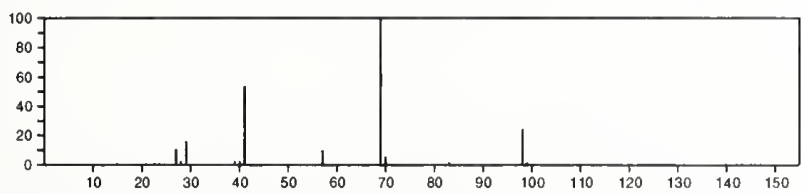

\section{8}

Ethanone, 1-cyclobutyl-

$\mathrm{C}_{6} \mathrm{H}_{10} \mathrm{O}$

$3019-25-8$
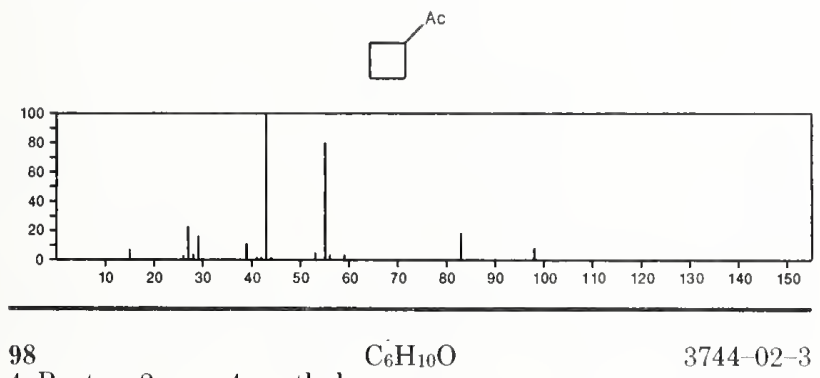

3744-02-3

4-Penten-2-one, 4-methyl-

$\mathrm{H}_{2} \mathrm{C}: \mathrm{CMe} \mathrm{CH}_{2} \mathrm{COM}$
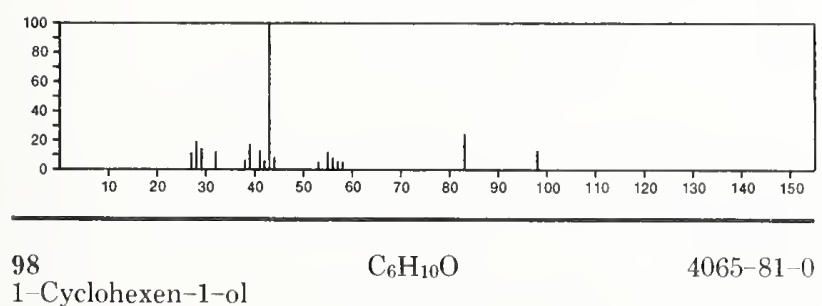

1-Cyclohexen-1-ol
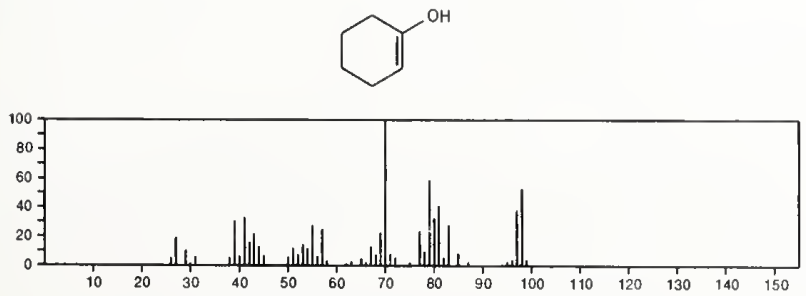

${ }_{2-\text { Propanone, 1-cyclopropyl- }}^{98} \mathrm{C}_{6} \mathrm{H}_{10} \mathrm{O}$

4160-75-2

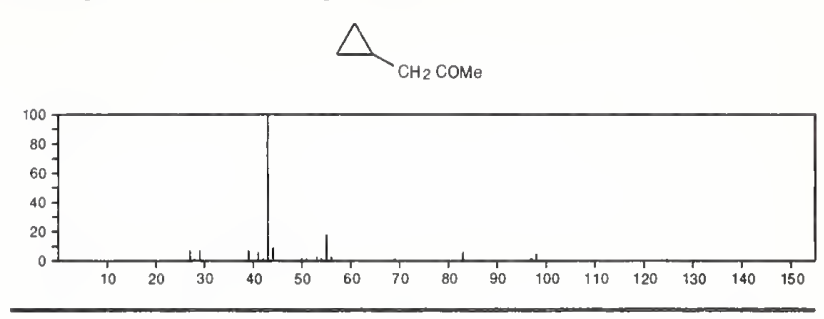

98

2-Pentanone, 3-methylene-

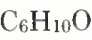

$4359-77-7$

Me COCE $\mathrm{t}: \mathrm{CH}_{2}$

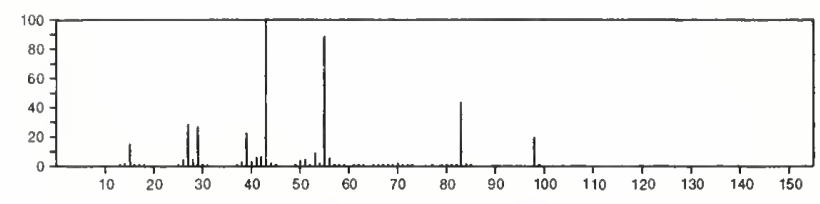

98 Pentenal, 2-methyl- $\quad \mathrm{C}_{6} \mathrm{H}_{10} \mathrm{O}$

$5187-71-3$

$\mathrm{H}_{2} \mathrm{C}: \mathrm{CHCH}_{2} \mathrm{CHMeCHO}$

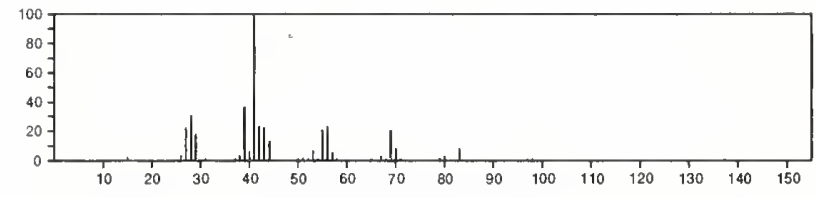

98

$\mathrm{C}_{6} \mathrm{H}_{10} \mathrm{O}$

$5362-50-5$

3-Pentenal, 4-methyl

$\mathrm{OCH} \mathrm{CH}_{2} \mathrm{CH}=\mathrm{CMe}_{2}$

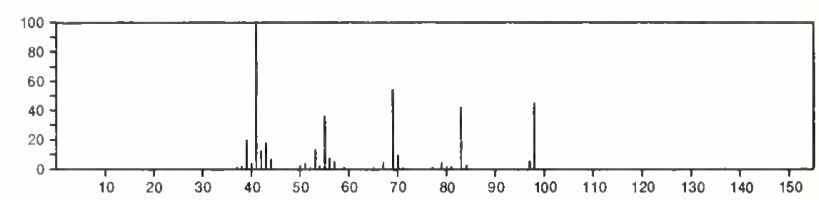

98

$\mathrm{C}_{6} \mathrm{H}_{10} \mathrm{O}$

6704-19-4

1-Propanone, 1-cyclopropyl
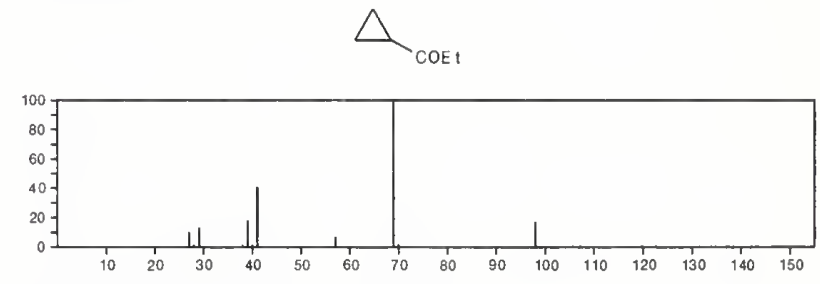

$98 \quad \mathrm{C}_{6} \mathrm{H}_{10} \mathrm{O} \quad 10374-14-8$

Cyclobutanone, 2-ethyl-
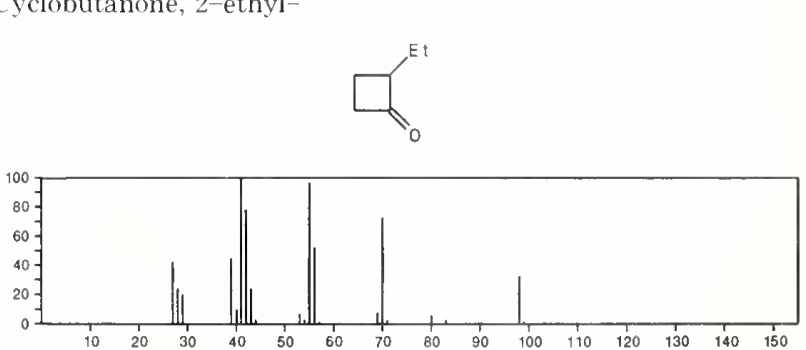


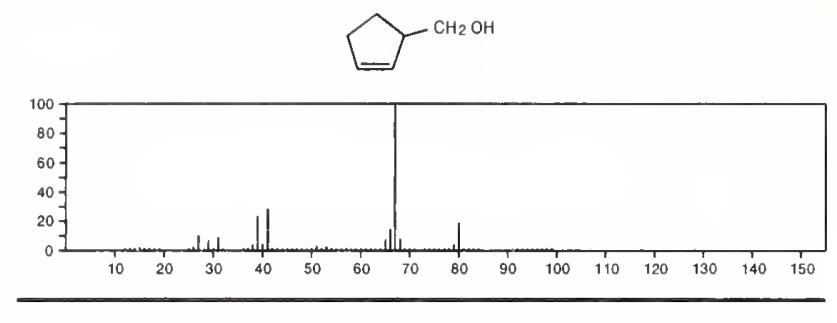

98

2H-Pyran, 3,4-dih

$16015-11-5$
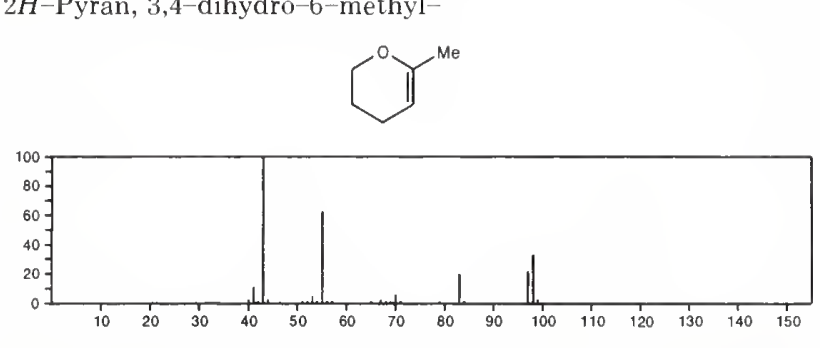

$98 \quad \mathrm{C}_{6} \mathrm{H}_{10} \mathrm{O}$

2,4-Hexadien-1-ol, $(E, E)$ -

$\mathrm{MeCH}=\mathrm{CHCH}=\mathrm{CHCH}_{2} \mathrm{OH}$

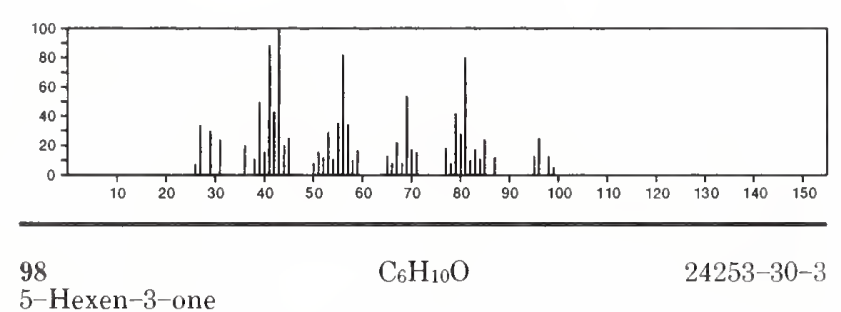

$\mathrm{EtCOCH} 2 \mathrm{CH}: \mathrm{CH}_{2}$

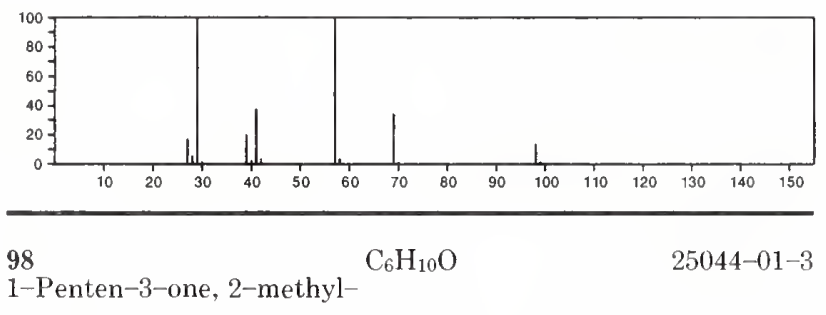

$\mathrm{H}_{2} \mathrm{C}=\mathrm{CMe}$ COE t

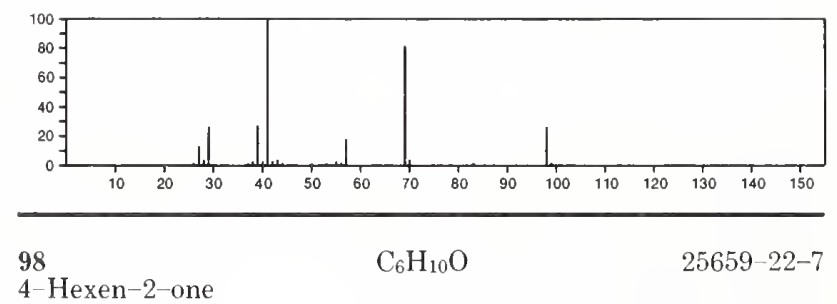

$\mathrm{Me} \mathrm{CH}=\mathrm{CHCH}_{2} \mathrm{COM}$

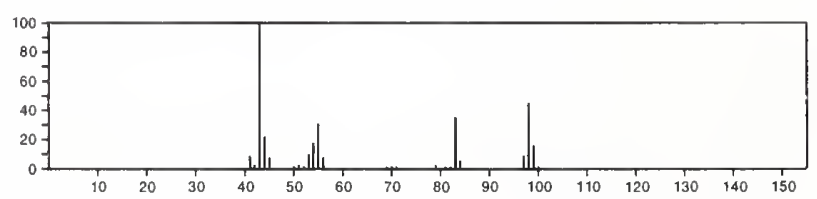

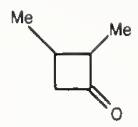

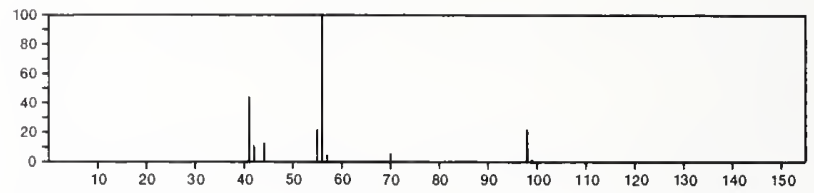

98

$\mathrm{C}_{6} \mathrm{H}_{10} \mathrm{O}$

1-Penten-1-one, 2-methyl-

$\operatorname{PrCMe}=\mathrm{C}: \mathrm{O}$

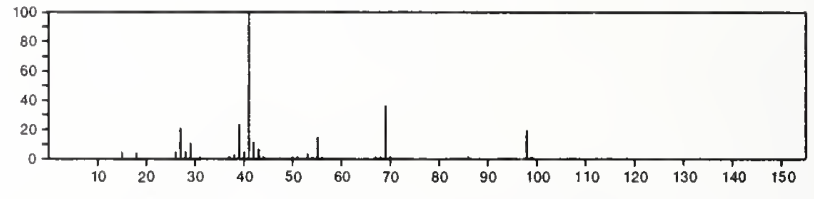

98

$\mathrm{C}_{6} \mathrm{H}_{10} \mathrm{O}$

2H-Pyran, tetrahydro-4-methylene-

$36838-71-8$<smiles>C=C1CCOCC1</smiles>

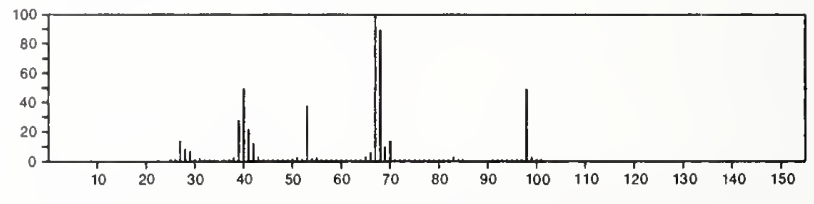

98

$\mathrm{C}_{6} \mathrm{H}_{10} \mathrm{O}$

$38559-13-6$

Cyclobutanone, 2,3-dimethyl
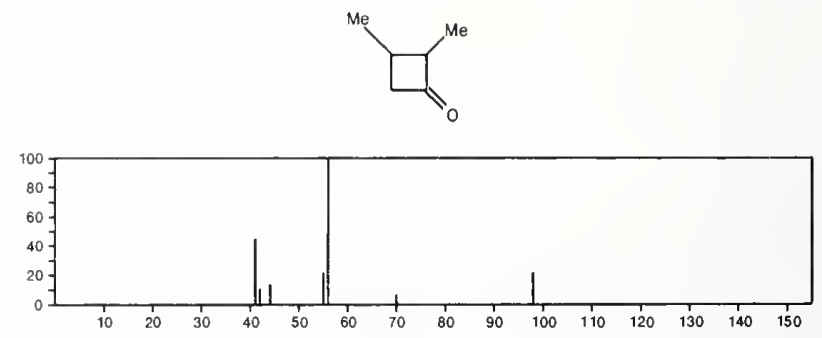

98

$\mathrm{C}_{6} \mathrm{H}_{10} \mathrm{O}$

$43042-67-7$

Cyclobutanone, 2,4-dimethyl
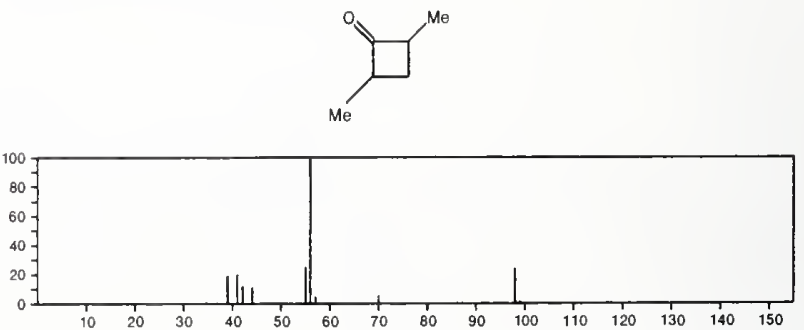
98

1-Pentyn-1-ol, 4-methyl-

$\mathrm{Me}_{2} \mathrm{CHCH}_{2} \mathrm{C} \equiv \mathrm{COH}$

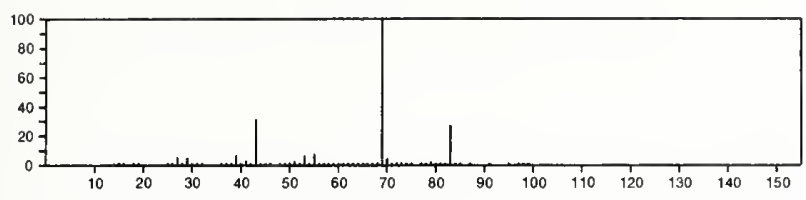

98

Cyclobutanone, 3-ethyl-

$\mathrm{C}_{6} \mathrm{H}_{10} \mathrm{O}$

$56335-73-0$

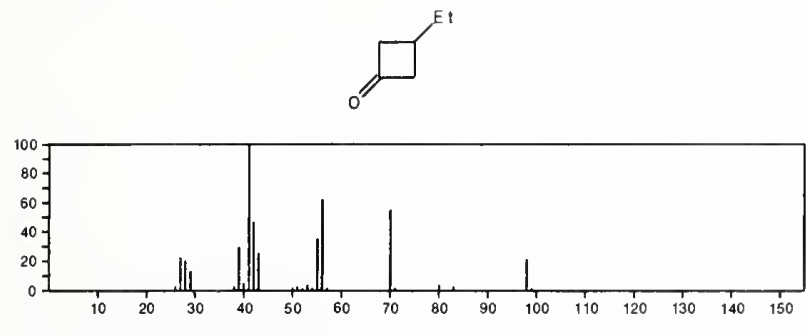

98

Borane, triethyl-

$\mathrm{C}_{6} \mathrm{H}_{15} \mathrm{~B}$

$97-94-9$

$B E: 3$

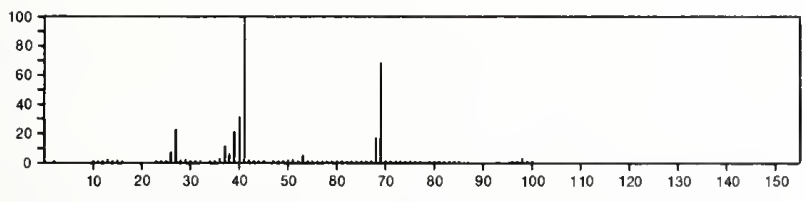

98

$\mathrm{C}_{7} \mathrm{H}_{14}$

$108-87-2$

Cyclohexane, methyl-
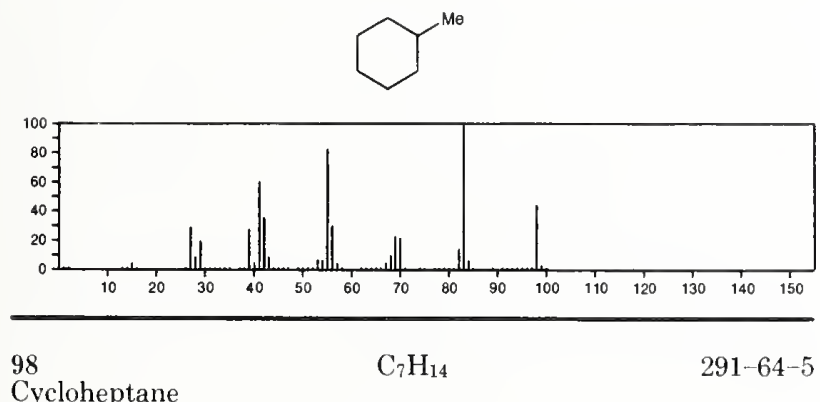

Cycloheptane
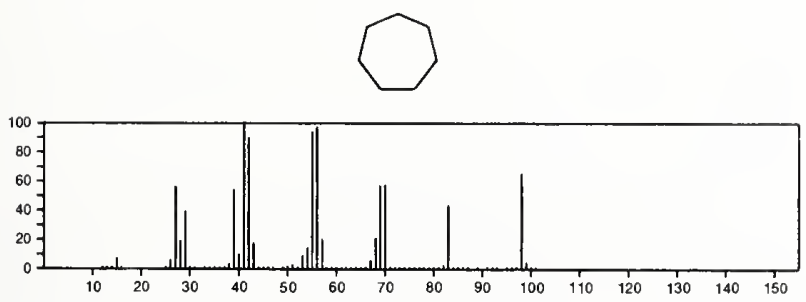

98

1-Heptene

$\mathrm{C}_{7} \mathrm{H}_{14}$

$\mathrm{H}_{2} \mathrm{C}=\mathrm{CH}\left(\mathrm{CH}_{2}\right){ }_{4} \mathrm{Me}$

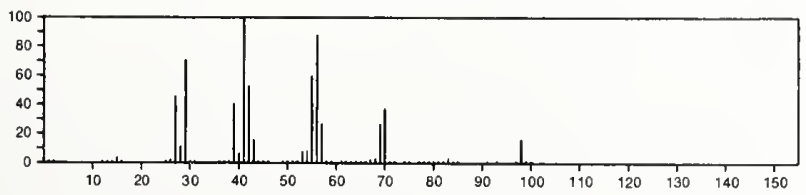

98

2-Heptene

$\mathrm{C}_{7} \mathrm{H}_{14}$

$592-77-8$

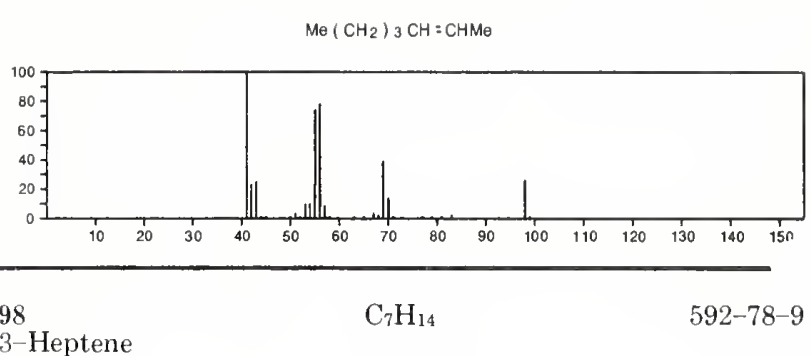

$\mathrm{E}+\mathrm{CH}=\mathrm{CHPr}$

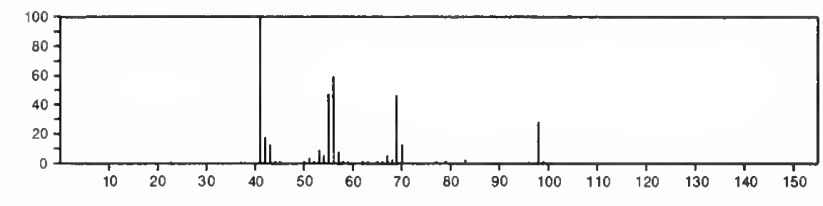

98

1-Butene, 2,3,3-trimethyl-

$\mathrm{C}_{7} \mathrm{H}_{14}$

$594-56-9$

$\mathrm{Me}_{3} \mathrm{CCMe}_{\mathrm{e}}=\mathrm{CH}_{2}$

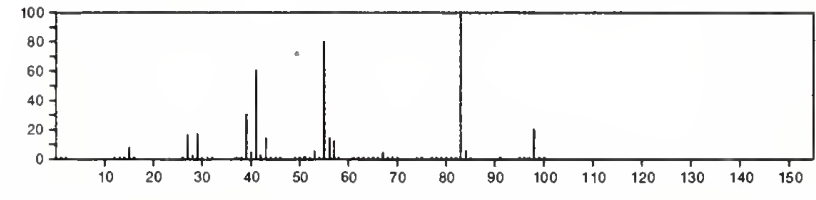

98

$\mathrm{C}_{7} \mathrm{H}_{14}$

$625-65-0$

2-Pentene, 2,4-dimethyl-

$\mathrm{Me}_{2} \mathrm{CHCH}=\mathrm{CMe} 2$

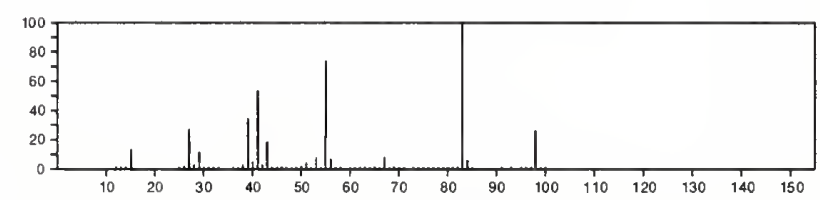

98

2-Pentene, 4,4-dimethyl-, (E)-

690-08-4

$\mathrm{MeCH}=\mathrm{CHCMe}_{3}$

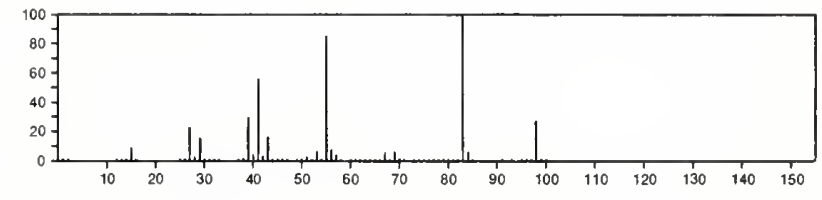

$98 \quad \mathrm{C}_{7} \mathrm{H}_{14} \quad 692-24-0$

3-Hexene, 2-methyl-, (E)-

$\mathrm{C}_{7} \mathrm{H}_{14}$

$\mathrm{E}+\mathrm{CH}=\mathrm{CHCHMe} 2$

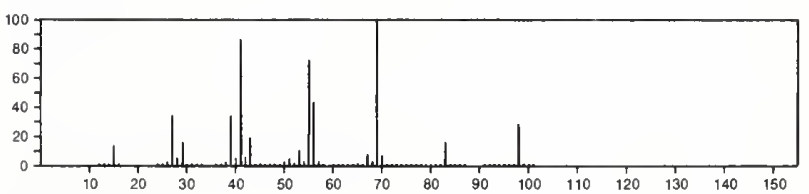


98

$\mathrm{C}_{7} \mathrm{H}_{14}$

1-Pentene, 4,4-dimethyl

$\mathrm{H}_{2} \mathrm{C}=\mathrm{CHCH}_{2} \mathrm{CMe}_{3}$

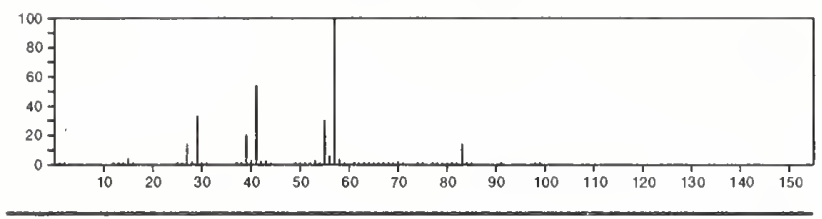

98

2-Pentene, 4,4-dimethyl-, (Z)-

$762-63-0$

$\mathrm{Me} \mathrm{CH}=\mathrm{CHCMe}_{3}$
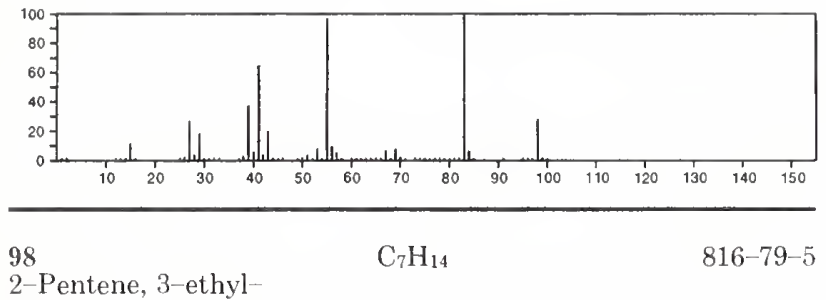

2-Pentene, 3-ethy

$\mathrm{MeCH}=\mathrm{CE} \mathrm{t}_{2}$

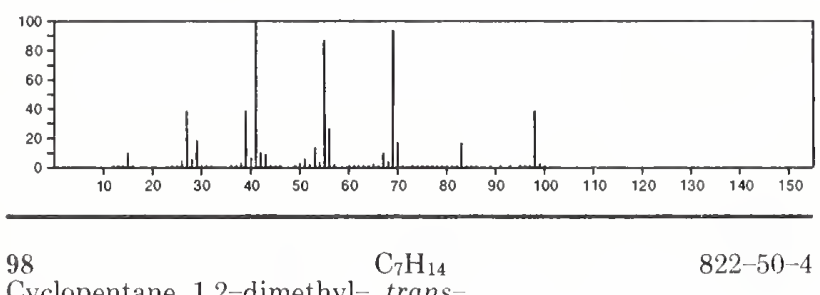

Cyclopentane, 1,2-dimethyl-, trans-
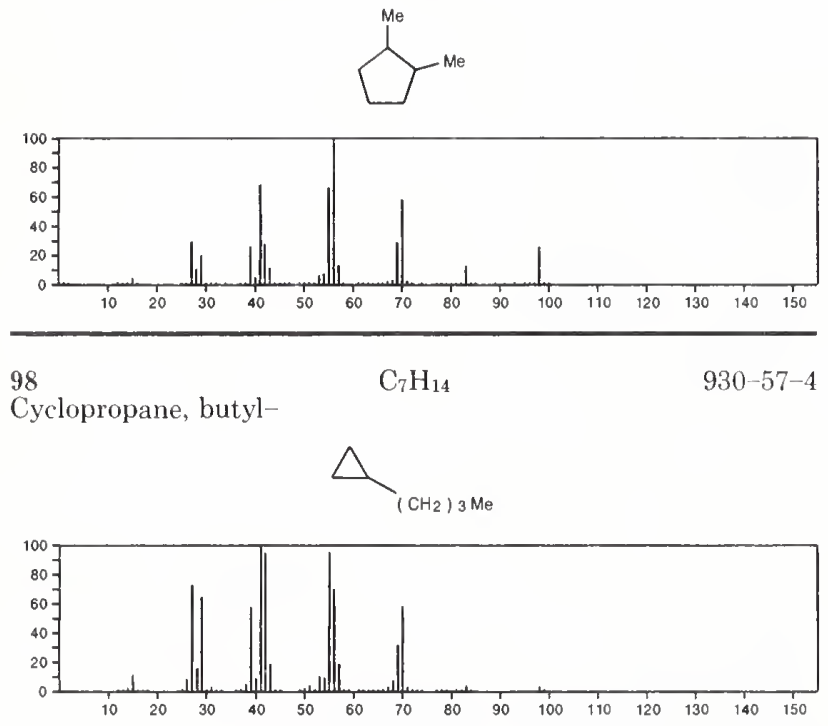

98

Cyclopentane, 1,2-dimethyl-,

$1192-18-3$
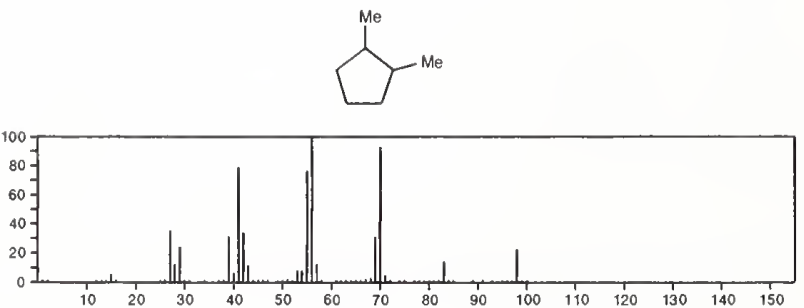

$98 \quad \mathrm{C}_{7} \mathrm{H}_{14}$

$1638-26-2$

Cyclopentane, 1,1-dimethyl-
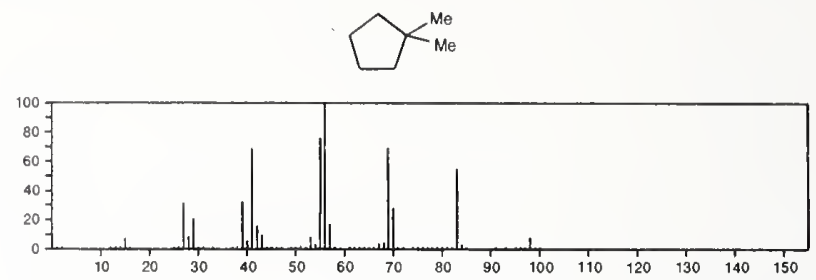

98

Cyclopentane, ethyl-

$\mathrm{C}_{7} \mathrm{H}_{14}$

$1640-89-7$

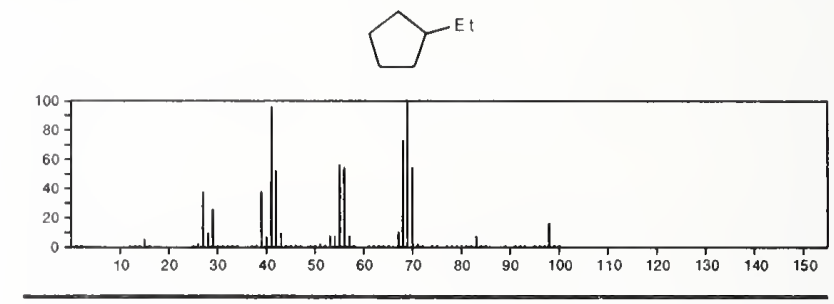

98

$\mathrm{C}_{7} \mathrm{H}_{14}$

$1759-58-6$

Cyclopentane, 1,3-dimethyl-, trans-
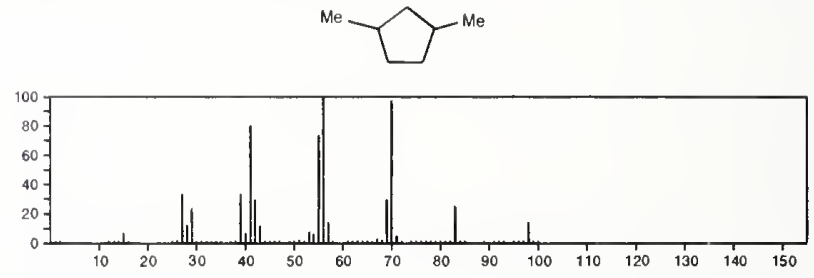

98

$\mathrm{C}_{7} \mathrm{H}_{14}$

$2213-32-3$

$\mathrm{H}_{2} \mathrm{C}=\mathrm{CMe} \mathrm{CH}_{2} \mathrm{CHM}{ }_{2}$

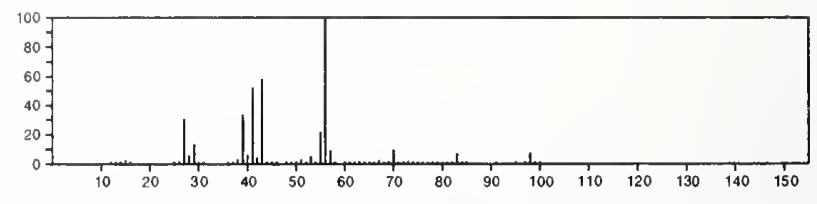

$98 \quad \mathrm{C}_{7} \mathrm{H}_{14}$

2532-58-3

Cyclopentane, 1,3-dimethyl-, cis-
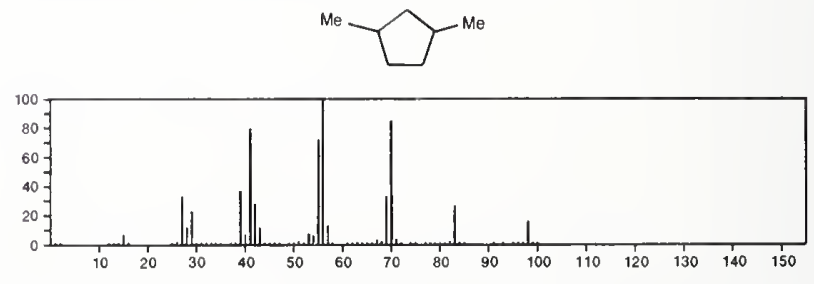

98

2-Hexene, 2-methyl-

$\mathrm{C}_{7} \mathrm{H}_{14}$

2738-19-4

$\mathrm{Me}_{2} \mathrm{C}=\mathrm{CHPr}$

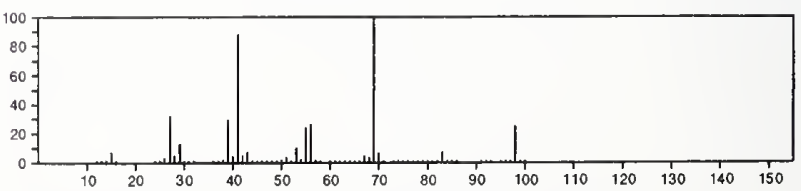




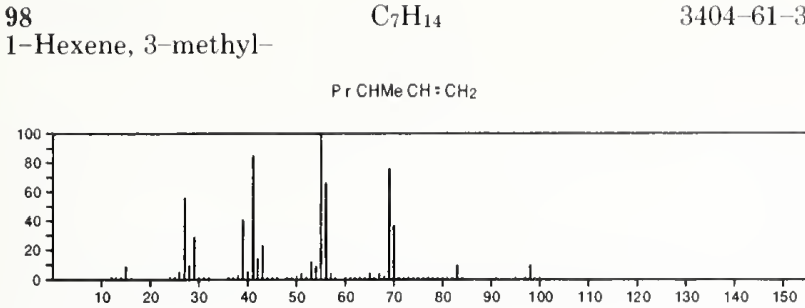

${ }_{38}^{98}$-Hexene, 3-methyl-, $(E)-{ }^{\mathrm{C}_{7} \mathrm{H}_{14}}$

$3899-36-3$
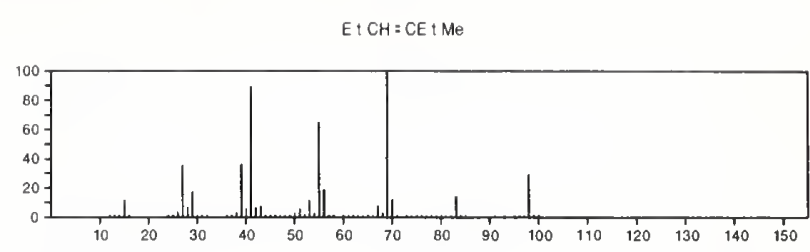

98

$\mathrm{C}_{7} \mathrm{H}_{14}$

$3404-72-6$

1-Pentene, 2,3-dimethyl-

$\mathrm{H}_{2} \mathrm{C}: \mathrm{CM}$ C $\mathrm{CHM}_{2} \mathrm{CH}_{2} \mathrm{Me}$

1-Pentene, 3-ethyl

$\mathrm{C}_{7} \mathrm{H}_{14}$

4038-04-4
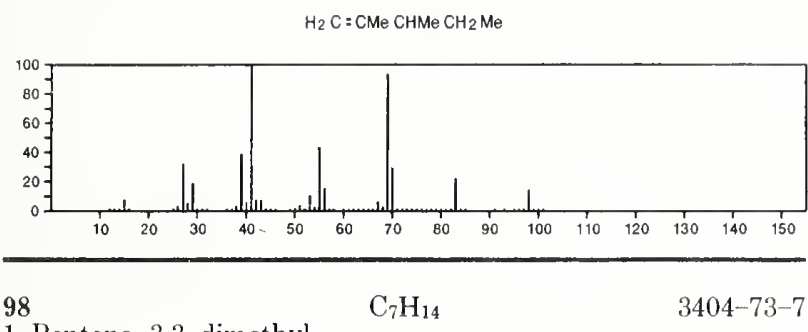

$404-73-7$

1-Pentene, 3,3-dimethyl-

$\mathrm{E}_{\mathrm{T}} \mathrm{CMe} 2 \mathrm{CH}=\mathrm{CH}_{2}$

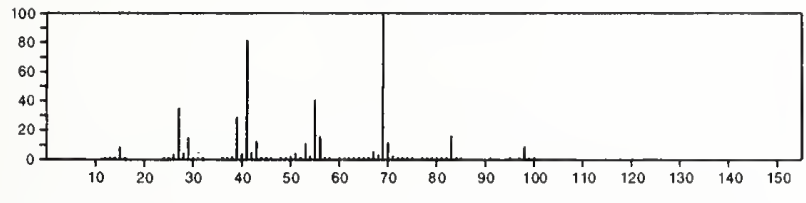

98

$\mathrm{C}_{7} \mathrm{H}_{14}$

$3524-73-0$

1-Hexene, 5-methyl-

$\mathrm{Me}_{2} \mathrm{CHCH}_{2} \mathrm{CH}_{2} \mathrm{CH}=\mathrm{CH}_{2}$

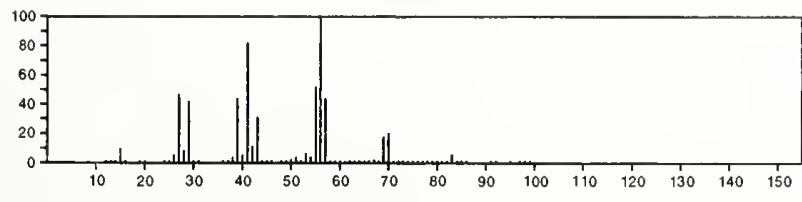

98

$\mathrm{C}_{7} \mathrm{H}_{14}$

$3683-22-5$

2-Hexene, 4-methyl-, $(E)-$

$\mathrm{MeCH}=\mathrm{CHCHMeCH} \mathrm{CHO}_{2}$
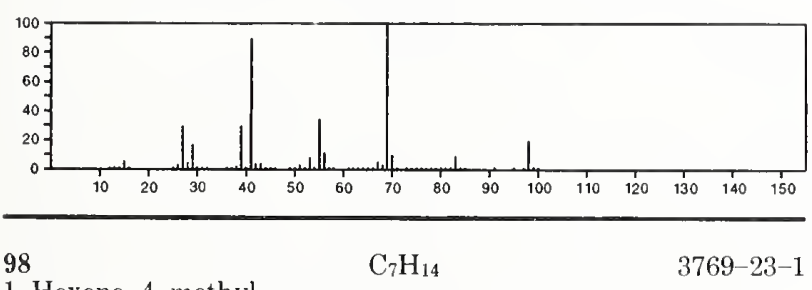

1-Hexene, 4-methyl-

$\mathrm{H}_{2} \mathrm{C}=\mathrm{CHCH}_{2} \mathrm{CHMeCH}_{2} \mathrm{Me}$

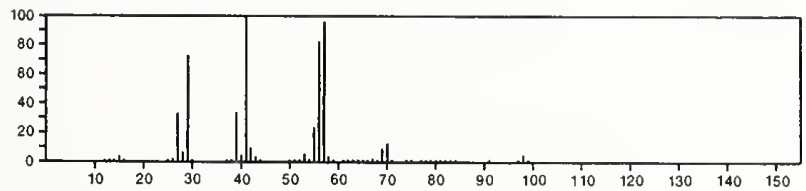

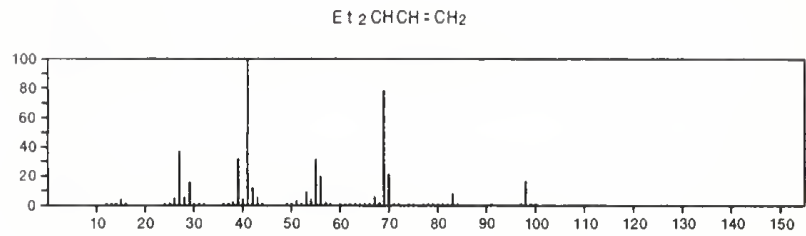

98
Cyclopropane, 1,1,2,2-tetramethyl-

$4127-47-3$
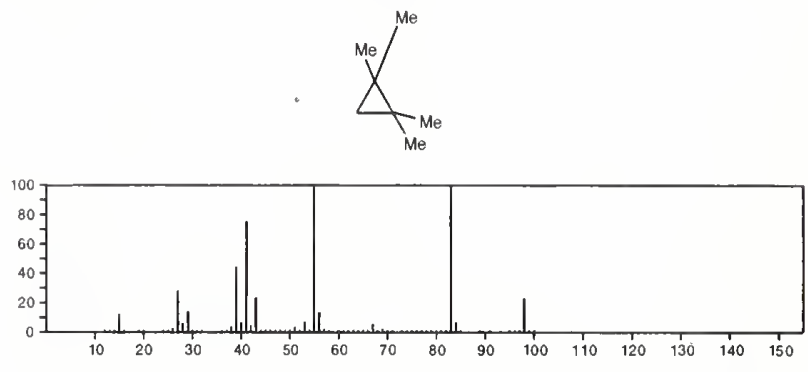

98

3-Hexene, 3-methyl-, (Z)-

$\mathrm{C}_{7} \mathrm{H}_{14}$

$4914-89-0$

E I $C H=C E$ I Me

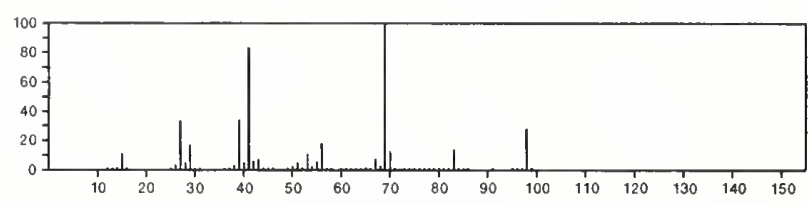

98

2-Pentene, 3,4-dimethyl-, $\mathrm{C}_{7} \mathrm{H}_{1}$

4914-91-4

$\mathrm{MeCH}=\mathrm{CMeCHMe}_{2}$

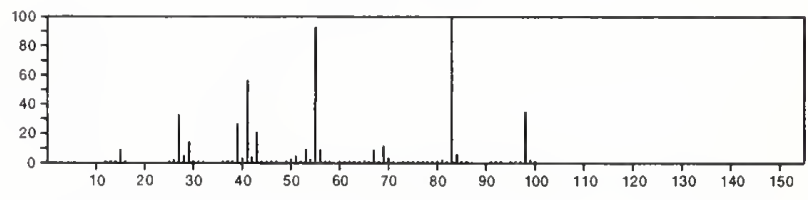

98

2-Pentene, 3,4-dimethyl-, ${ }_{(E)-}^{\mathrm{C}_{7} \mathrm{H}_{14}}$

$4914-92-5$

$\mathrm{Me} \mathrm{CH}=\mathrm{CMe} \mathrm{CHMe} 2$

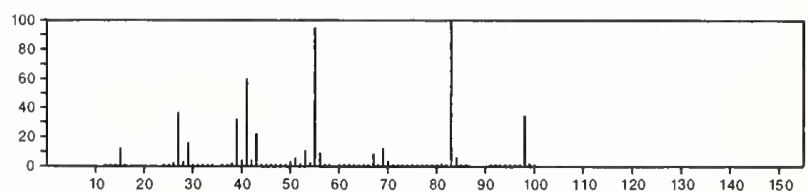


98

1-Hexene, 2-methyl-

$\mathrm{C}_{7} \mathrm{H}_{14}$

$\mathrm{Me}\left(\mathrm{CH}_{2}\right)_{3} \mathrm{CMe}=\mathrm{CH}_{2}$

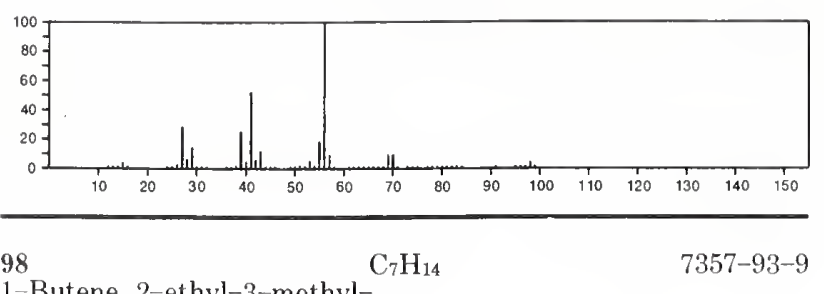

1-Butene, 2-ethyl-3-methyl-

$\mathrm{Me}_{2} \mathrm{CHCE}:=\mathrm{CH}_{2}$

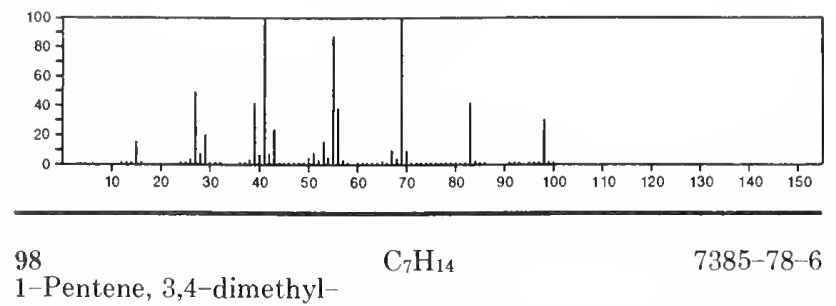

$\mathrm{H}_{2} \mathrm{C}=\mathrm{CHCHMe} \mathrm{CHMe} 2$

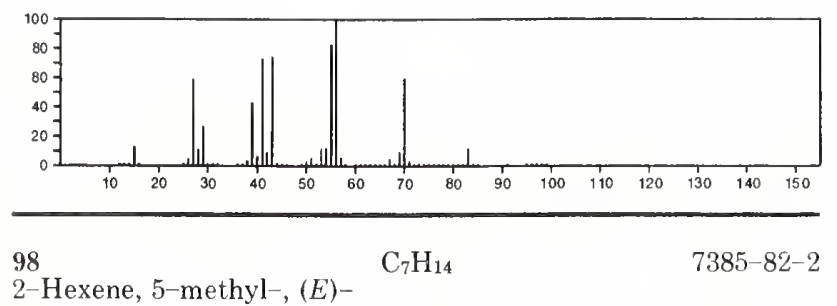

$\mathrm{Me}_{2} \mathrm{CHCH}_{2} \mathrm{CH}=\mathrm{CHMe}$

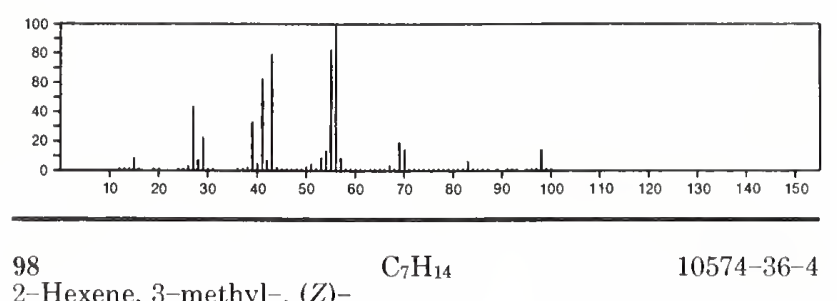

$\mathrm{Me} \mathrm{CH}=\mathrm{CPrMe}$
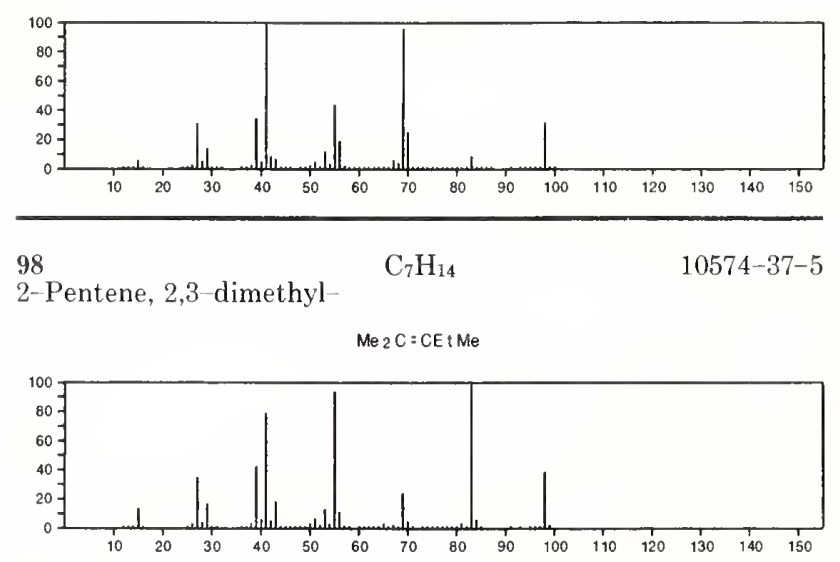

98

2 Heptene, $(E)$

$\mathrm{C}_{7} \mathrm{H}_{14}$

14686-13-6

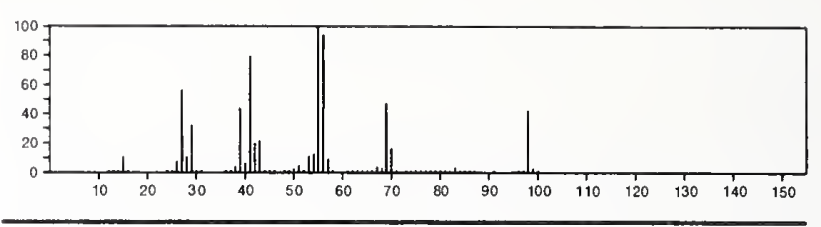

98

3-Heptene, (E)

$\mathrm{C}_{7} \mathrm{H}_{14}$

$14686-14-7$

$\mathrm{Et} \mathrm{CH}=\mathrm{CHP}$ r

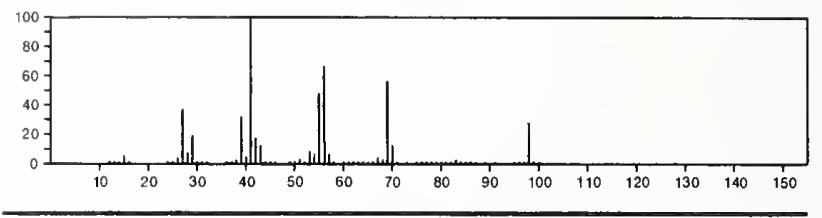

98

$\mathrm{C}_{7} \mathrm{H}_{14}$

26232-98-4

2-Pentene, 4,4-dimethyl-

$\mathrm{Me} \mathrm{CH}=\mathrm{CHCMe}_{3}$

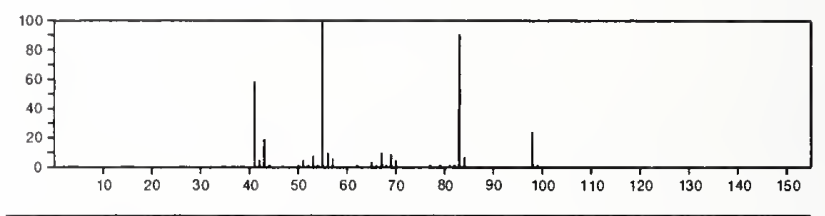

99

lmidosulfurous difluoride, methyl-

$758-20-3$

$\mathrm{MeN}=\mathrm{SF}_{2}$

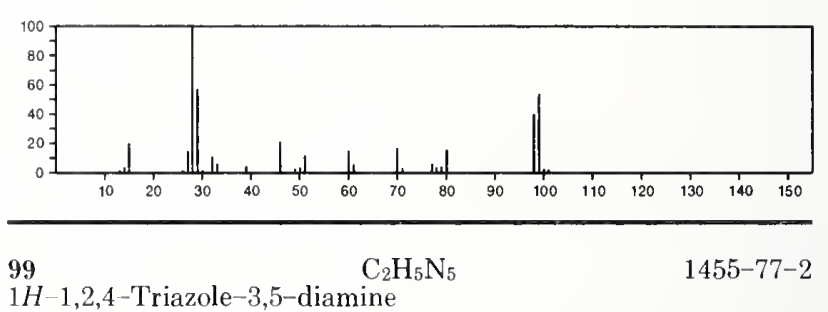

$1 H$-1,2,4-Triazole-3,5-diamine
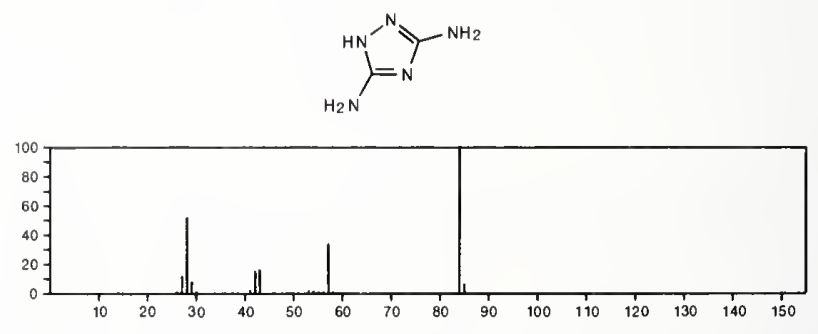

99

$\mathrm{C}_{3} \mathrm{H}_{9} \mathrm{~N} . \mathrm{B}_{3} \mathrm{H}_{7}$

$12076-72-1$

Methanamine, $N, N$-dimethyl-, compd. with triborane(7) (1:1)

$$
\mathrm{Me}_{3} \mathrm{~N} \cdot \mathrm{B}_{3} \mathrm{H}_{7}
$$

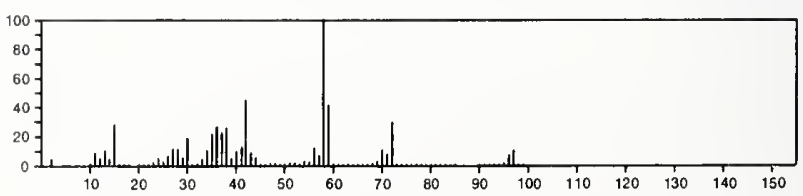


99

$\mathrm{C}_{4} \mathrm{H}_{5} \mathrm{NO}_{2}$

Acetic acid, cyano-, methyl ester

$\mathrm{NCCH}_{2} \mathrm{C}(\mathrm{O})$ OMe

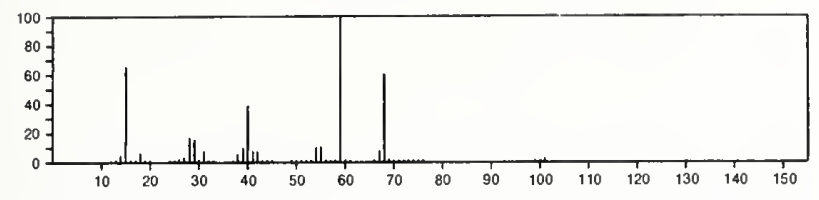

99

2,5-Pyrrolidinedione

$\mathrm{C}_{4} \mathrm{H}_{5} \mathrm{NO}_{2}$

$123-56-8$

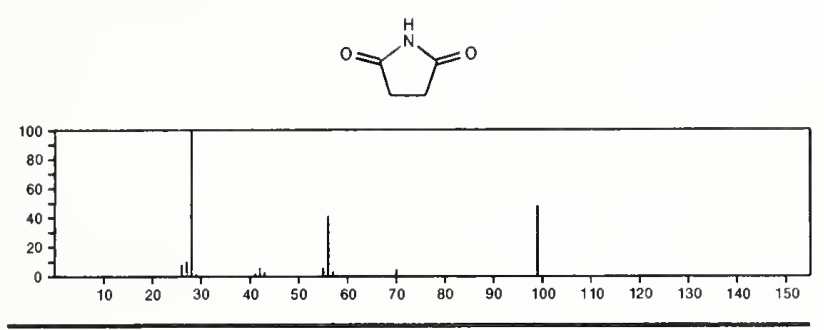

99

$\mathrm{C}_{4} \mathrm{H}_{5} \mathrm{NS}$

693-90-3

Isothiazole, 4-methyl-
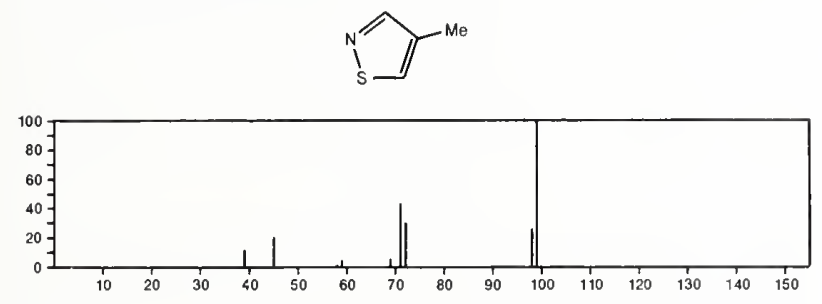

99

Isothiazole, 3-methyl-

$\mathrm{C}_{4} \mathrm{H}_{5} \mathrm{NS}$

693-92-5
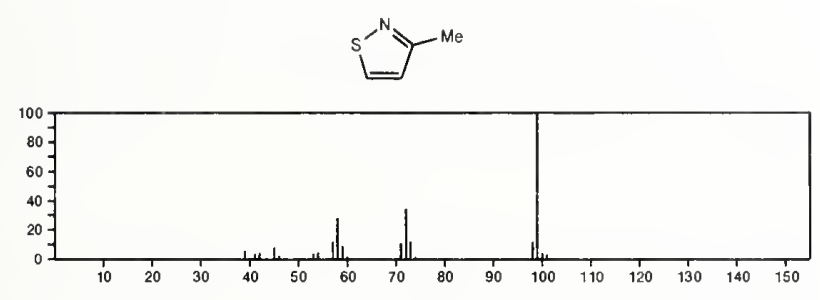

99

$\mathrm{C}_{4} \mathrm{H}_{5} \mathrm{NS}$

693-97-0

Isothiazole, 5-methyl-
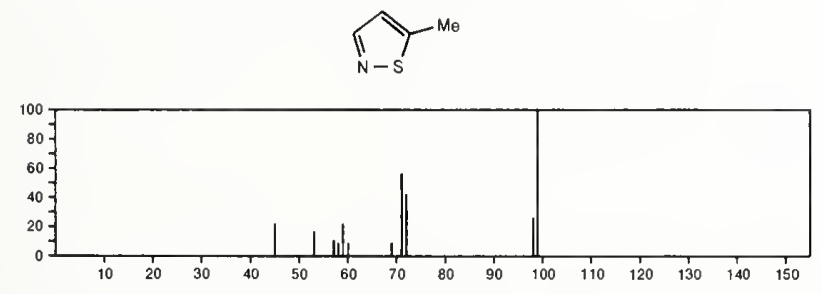

99

$\mathrm{C}_{4} \mathrm{H}_{5} \mathrm{NS}$

3581-89-3

Thiazole, 5-methyl-
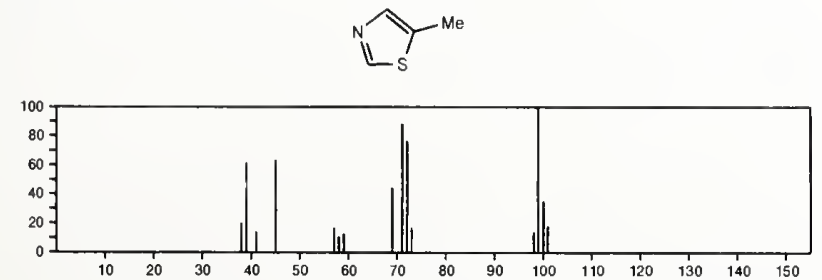

$99 \quad \mathrm{C}_{4} \mathrm{H}_{9} \mathrm{~N}_{3}$

35468-56-5

Hydrazinium, 2-cyano-1,1,1-trimethyl-, hydroxide, inner salt
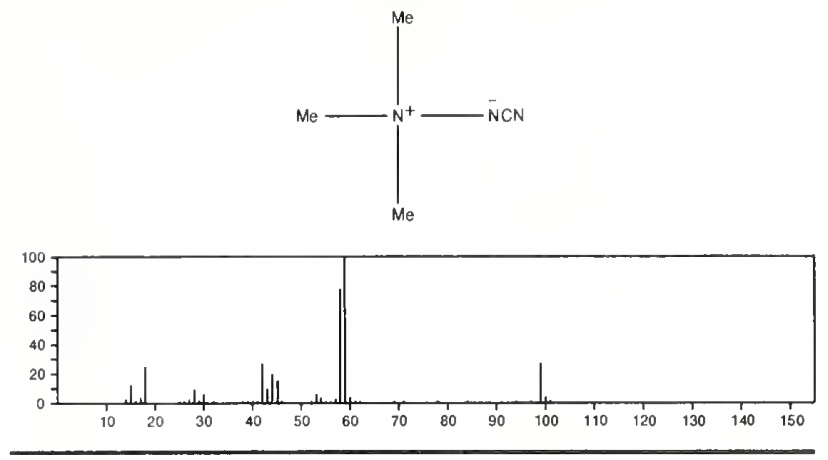

99

$\mathrm{C}_{5} \mathrm{H}_{9} \mathrm{NO}$

$111-36-4$

Butane, 1-isocyanato-

OCN $\left(\mathrm{CH}_{2}\right)_{3} \mathrm{Me}$

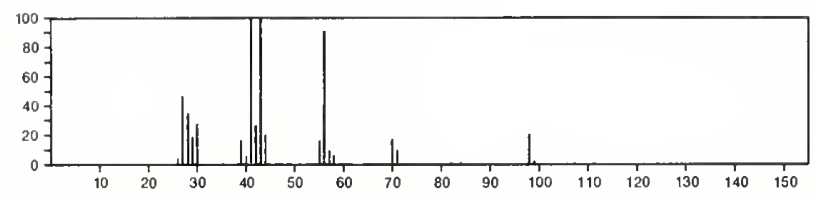

99

2-Piperidinone

$\mathrm{C}_{5} \mathrm{H}_{9} \mathrm{NO}$

$675-20-7$
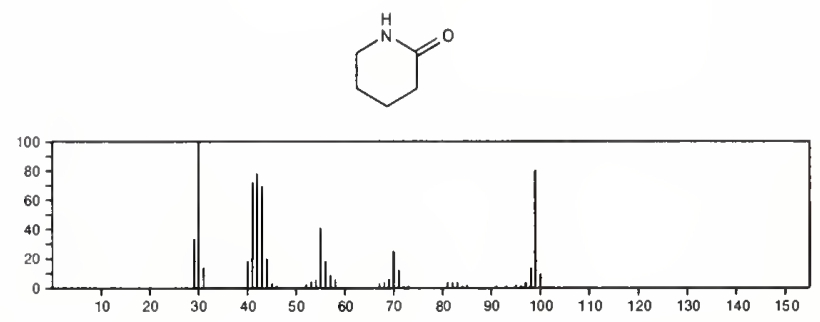

$99 \quad \mathrm{C}_{5} \mathrm{H}_{9} \mathrm{NO}$

$872-50-4$

2-Pyrrolidinone, 1-methyl-
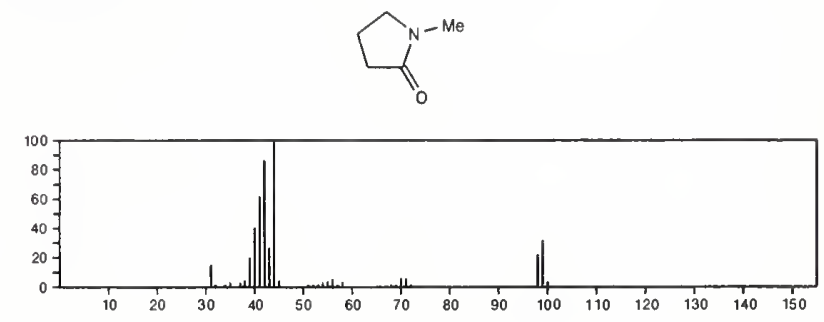

99

3-Penten-2-one, 4-amino-

$\mathrm{C}_{5} \mathrm{H}_{9} \mathrm{NO}$

$1118-66-7$

$\mathrm{Me} \mathrm{COCH}=\mathrm{C}\left(\mathrm{NH}_{2}\right) \mathrm{Me}$

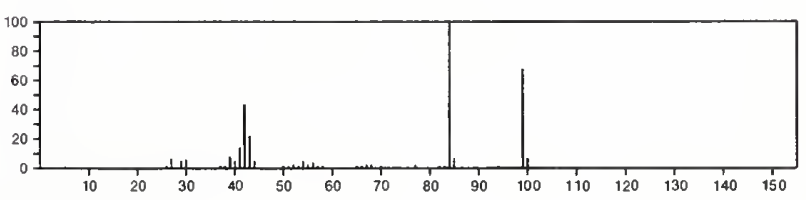


99

Cyclopentanone, oxime

$\mathrm{C}_{5} \mathrm{H}_{9} \mathrm{NO}$

$\Longrightarrow \mathrm{NOH}$

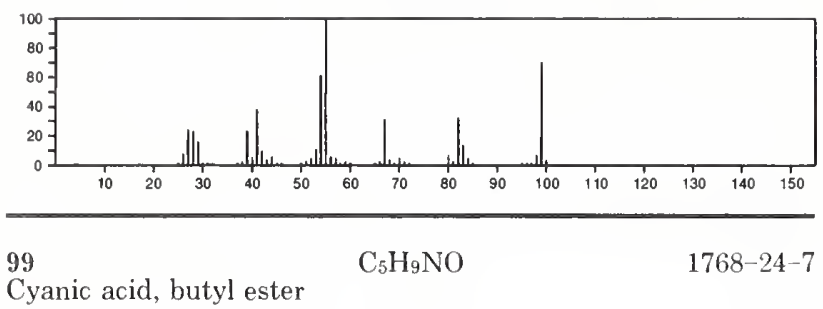

$\mathrm{Me}\left(\mathrm{CH}_{2}\right)_{3} \mathrm{OCN}$

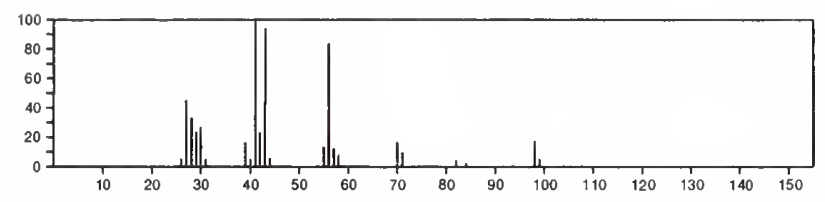

99

Cyanic acid, 2-methylpropyl $\mathrm{H}_{9} \mathrm{NO}$

$i-B \cup O C N$

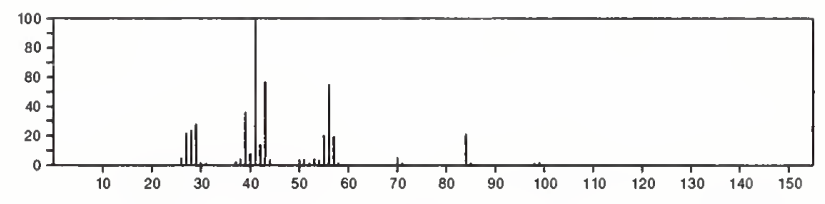

$\underset{\text { Cyanic acid, sec-butyl ester }}{\mathrm{C}_{5} \mathrm{H}_{9} \mathrm{NO}}$

$S-B \cup O C N$

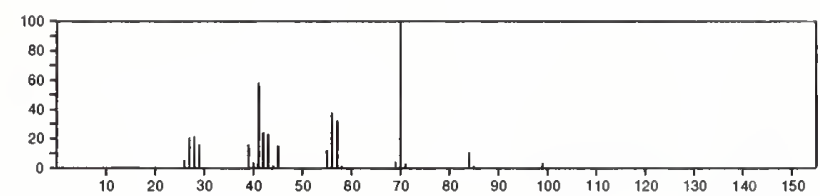

$99 \quad \mathrm{C}_{5} \mathrm{H}_{9} \mathrm{NO}$

Propane, 1-isocyanato-2-methyl-

$1873-29-6$

$\mathrm{i}-\mathrm{BuNCO}$

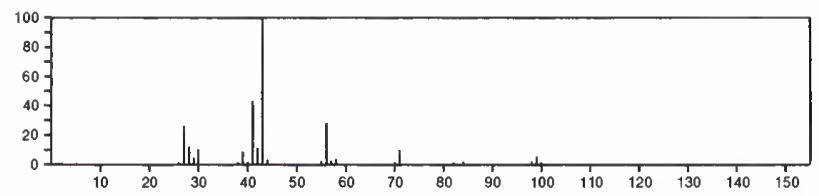

99

$\mathrm{C}_{5} \mathrm{H}_{9} \mathrm{NO}$

2141-62-0

Propanenitrile, 3-ethoxy-

$\mathrm{NCCH}_{2} \mathrm{CH}_{2} \mathrm{OE} \mathrm{t}$

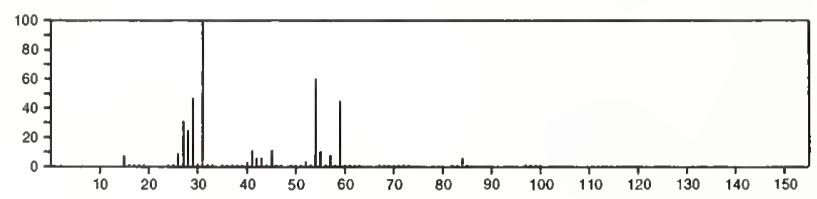

99

2-Prolenamide, $\mathrm{N}, \mathrm{N}$-dimethyl-

$\mathrm{C}_{5} \mathrm{H}_{9} \mathrm{NO}$

$2680-03-7$

$\mathrm{H}_{2} \mathrm{C}=\mathrm{CHCONMe}_{2}$

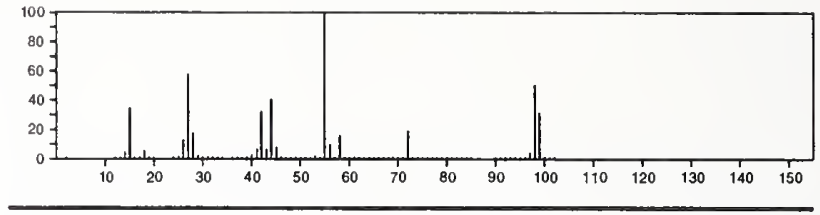

99

$\mathrm{C}_{5} \mathrm{H}_{9} \mathrm{NO}$

5883-17-0

$\mathrm{E}$ t $\mathrm{NHCOCH}=\mathrm{CH}_{2}$
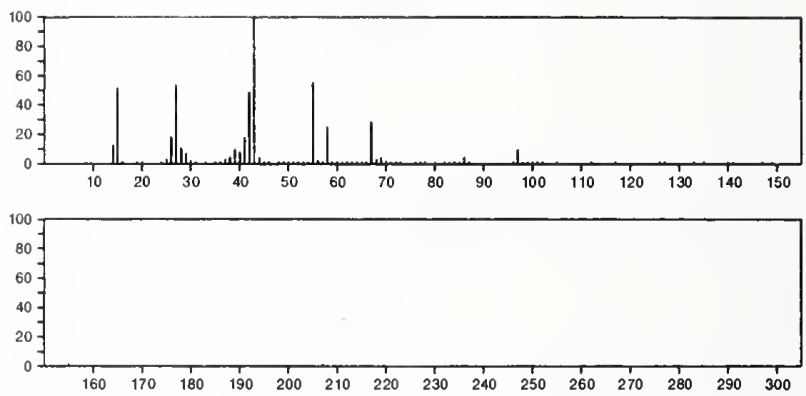

$99 \quad \mathrm{C}_{5} \mathrm{H}_{9} \mathrm{NO}$

2-Azetidinone, 3,3-dimethyl-

$7486-91-1$
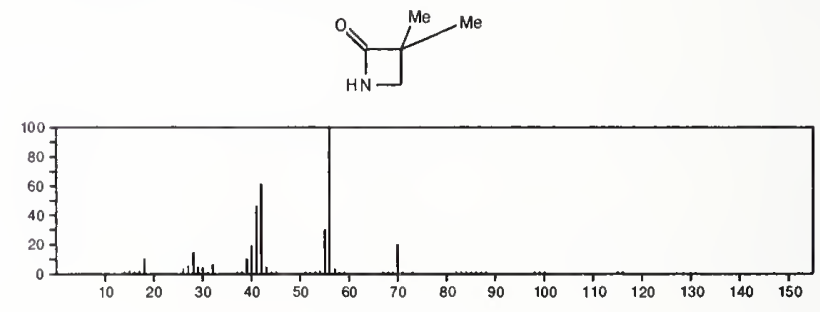

99

$\mathrm{C}_{5} \mathrm{H}_{9} \mathrm{NO}$

$13416-47-2$

Aziridine, 1-acetyl-2-methyl-
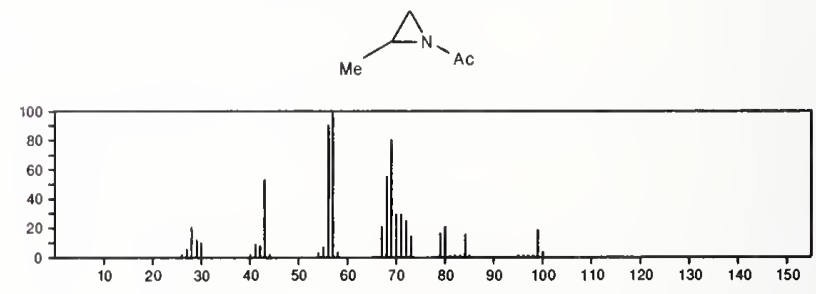

99

$\mathrm{C}_{5} \mathrm{H}_{9} \mathrm{NO}$

15585-98-5

Butane, 2-isocyanato-

s-BuNCO

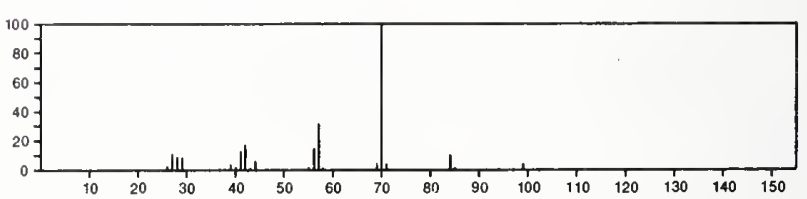


99

Piperidinone

$\mathrm{C}_{5} \mathrm{H}_{9} \mathrm{NO}$

$27154-43-4$

$\overbrace{}^{N H}+=0$
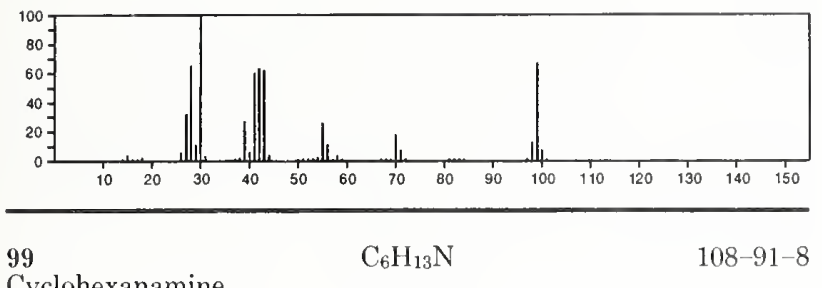

Cyclohexanamine<smiles>NC1CCCCC1</smiles>

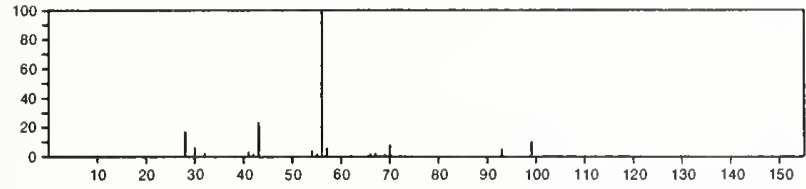

99

$\mathrm{C}_{6} \mathrm{H}_{13} \mathrm{~N}$

$109-05-7$

Piperidine, 2-methyl-
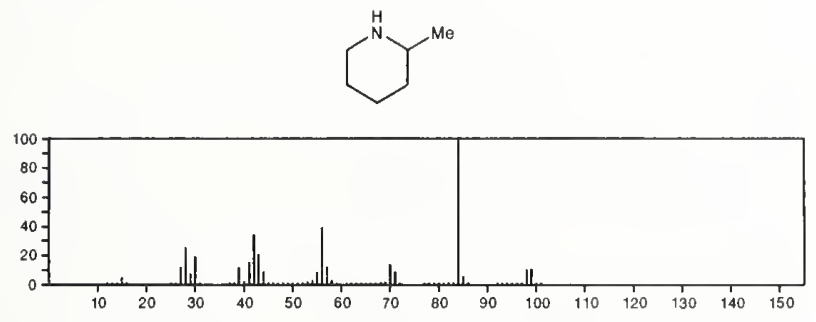

$99 \quad \mathrm{C}_{6} \mathrm{H}_{13} \mathrm{~N} \quad 111-49-9$ $1 H$-Azepine, hexahydro-
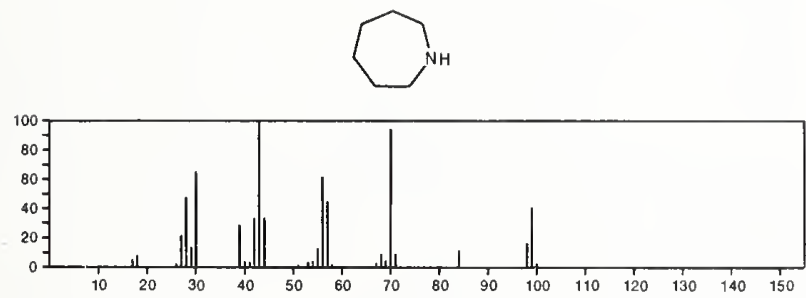

\section{9}

Piperidine, 3-methyl-

$\mathrm{C}_{6} \mathrm{H}_{13} \mathrm{~N}$

$626-56-2$
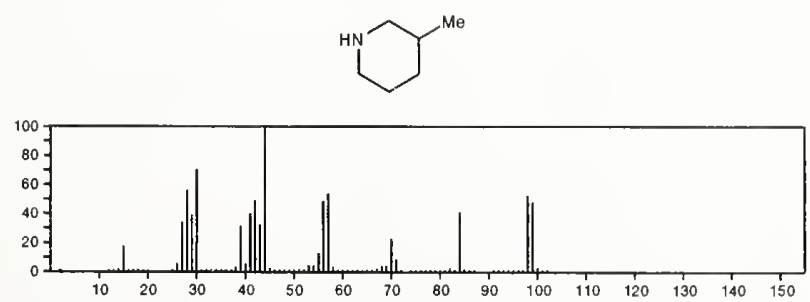

99

Piperidine, 1-methyl-

$\mathrm{C}_{6} \mathrm{H}_{13} \mathrm{~N}$

626-67-5

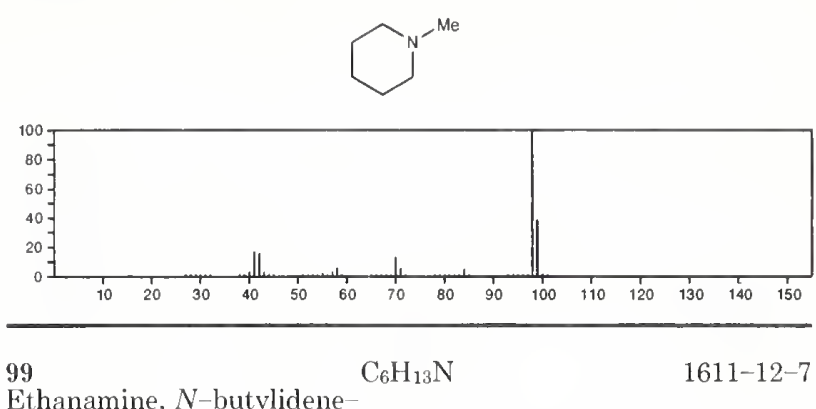

$\mathrm{E}+\mathrm{N}=\mathrm{CHPr}$

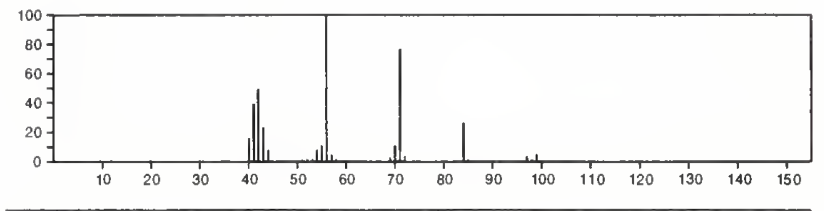

99

Aziridine, 2,2,3,3-tetramethyl-

$\mathrm{C}_{6} \mathrm{H}_{13} \mathrm{~N}$

5910-14-5
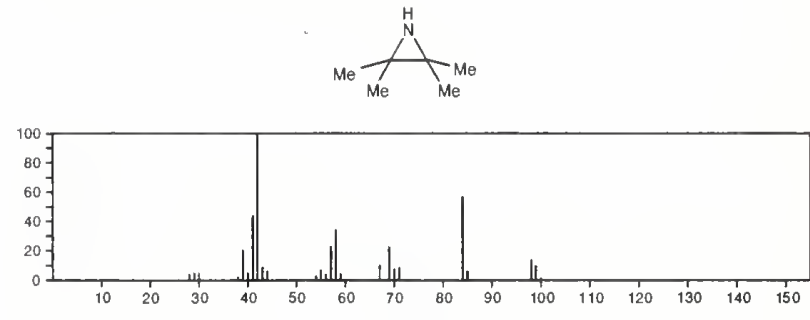

99

1-Butanamine, $\mathrm{N}$-ethylidene-

$6898-74-4$

$\mathrm{Me}\left(\mathrm{CH}_{2}\right){ }_{3} \mathrm{~N}=\mathrm{CHMe}$

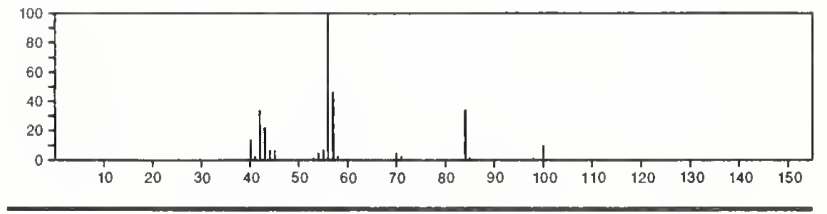

99

$\mathrm{C}_{6} \mathrm{H}_{13} \mathrm{~N}$

10027-95-9

Aziridine, 2-methyl-3-(1-methylethyl)-, trans
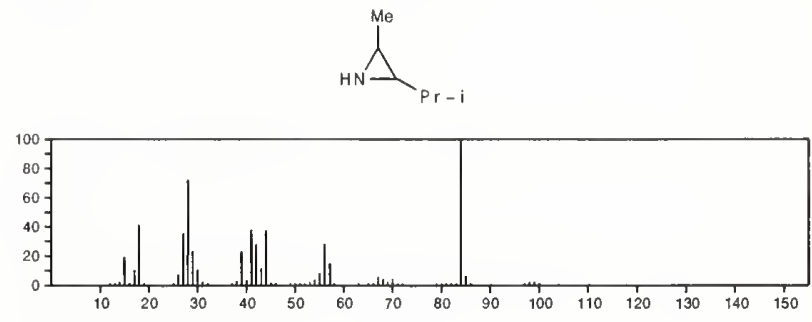

99

Methanamine, $N$-pentylidene-

$10599-75-4$

$\mathrm{Me}\left(\mathrm{CH}_{2}\right){ }_{3} \mathrm{CH}=\mathrm{NMe}$

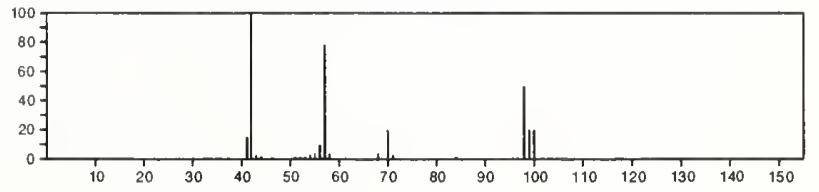


$\mathrm{C}_{6} \mathrm{H}_{13} \mathrm{~N}$

Methylamine, $N$-(1-methylbutylidene)

$\mathrm{MeN}=\mathrm{CPrMe}$

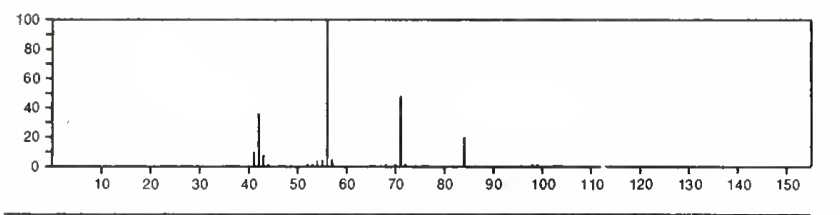

$99 \quad \mathrm{C}_{6} \mathrm{H}_{13} \mathrm{~N}$

$40571-45^{-7}$

Cyclopentanamine, 1-methyl-
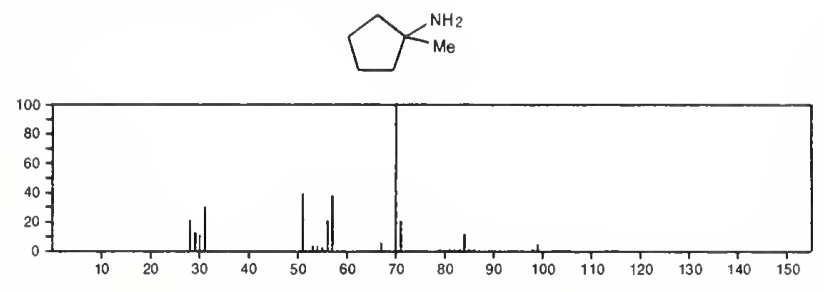

100

Silane, trifluoromethyl-

$\mathrm{CH}_{3} \mathrm{~F}_{3} \mathrm{Si}$

$373-74-0$

F3sime

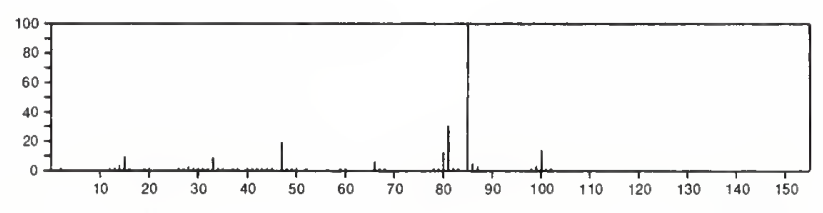

100

Ethene, tetrafluoro-

$\mathrm{C}_{2} \mathrm{~F}_{4}$

$116-14-3$

$\mathrm{F}_{2} \mathrm{C}: \mathrm{CF}_{2}$

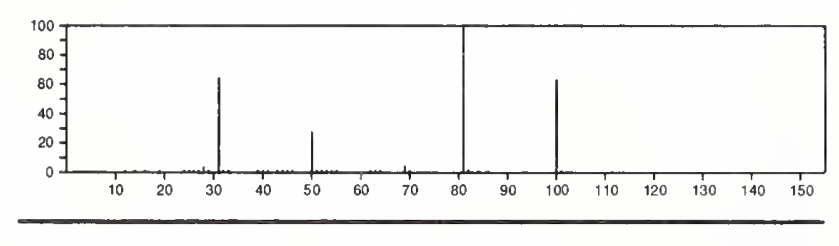

100

$\mathrm{C}_{2} \mathrm{H}_{3} \mathrm{ClF}_{2}$

$75-68-3$

Ethane, 1-chloro-1,1-difluoro-

$\mathrm{MeCF}_{2}(\mathrm{Me})$
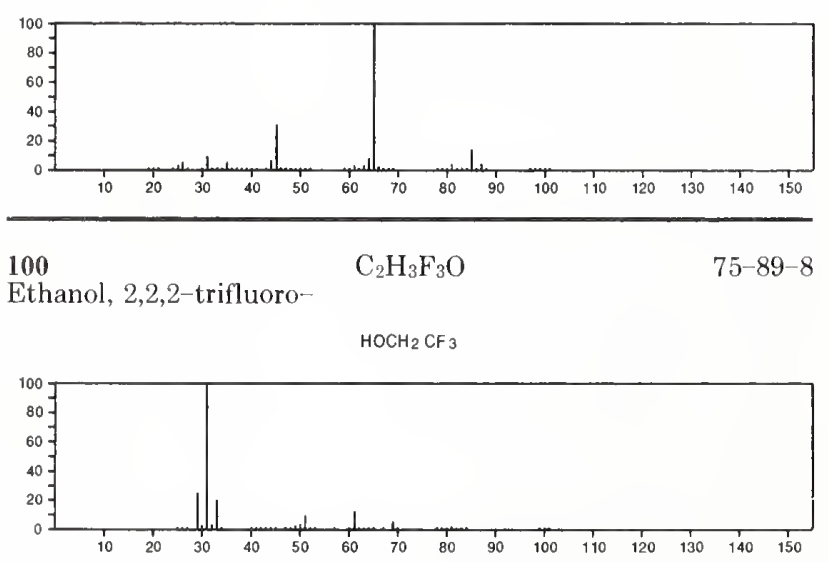

100

$\mathrm{C}_{3} \mathrm{H}_{4} \mathrm{~N}_{2} \mathrm{O}_{2}$

$6939-12-4$

Sydnone, 3-methyl-
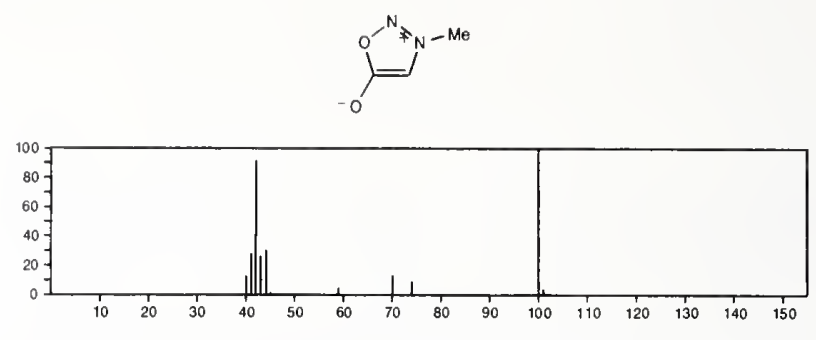

100

$\mathrm{C}_{3} \mathrm{H}_{4} \mathrm{~N}_{2} \mathrm{~S}$

50406-54-7

1,2,3-Thiadiazole, 5-methyl-
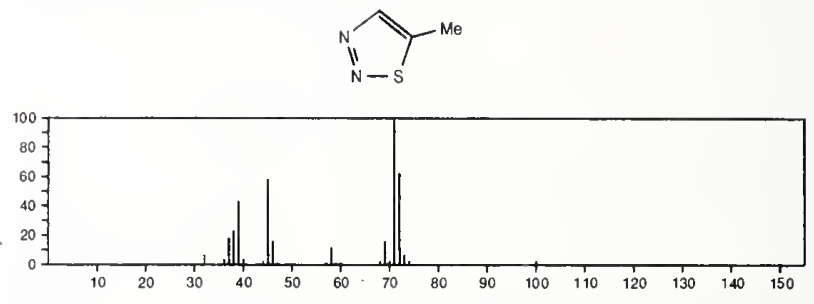

100

$\mathrm{C}_{4} \mathrm{H}_{4} \mathrm{O}_{3}$

$108-30-5$

2,5-Furandione, dihydro-
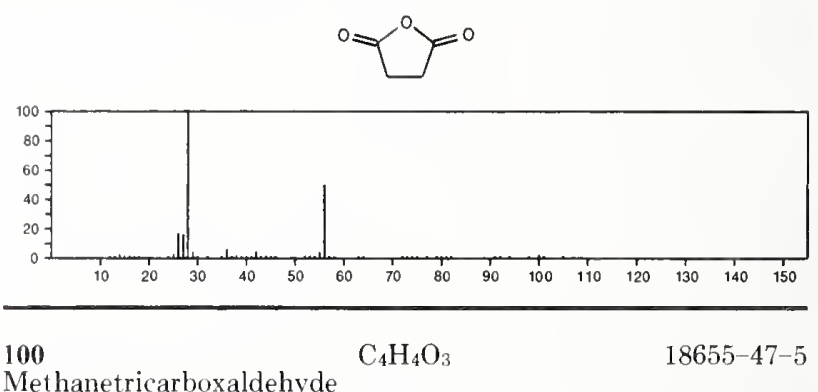

Methanetricarboxaldehyde

$\mathrm{HC}(\mathrm{CHO})_{3}$

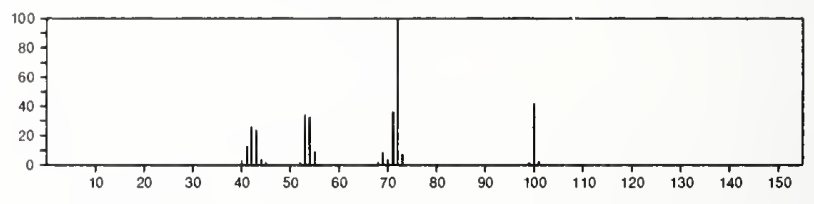

100

Pyrrolidine, 1-nitroso-

$\mathrm{C}_{4} \mathrm{H}_{8} \mathrm{~N}_{2} \mathrm{O}$

$930-55-2$
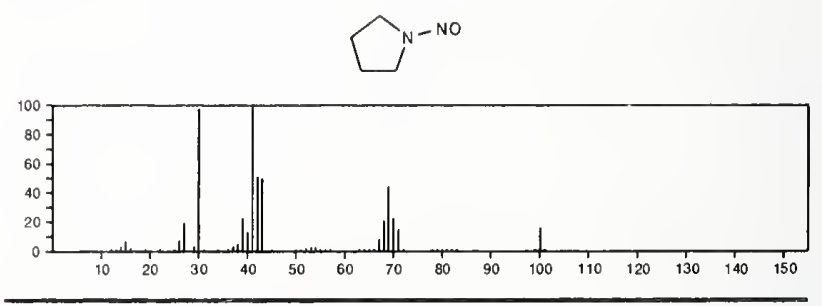

100

$\mathrm{C}_{5} \mathrm{H}_{8} \mathrm{O}_{2}$

$80-62-6$

2-Propenoic acid, 2-methyl-, methyl ester

$\mathrm{H}_{2} \mathrm{C}=\mathrm{CMe} \mathrm{C}(\mathrm{O}) \mathrm{OMe}$

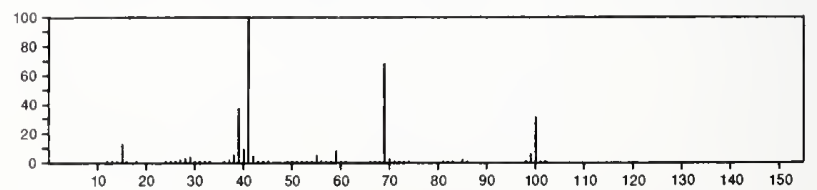


100

Propanoic acid, ethenyl ester

$\mathrm{C}_{5} \mathrm{H}_{8} \mathrm{O}_{2}$

$\mathrm{E}+\mathrm{C}(\mathrm{O}) \mathrm{OCH}=\mathrm{CH}_{2}$

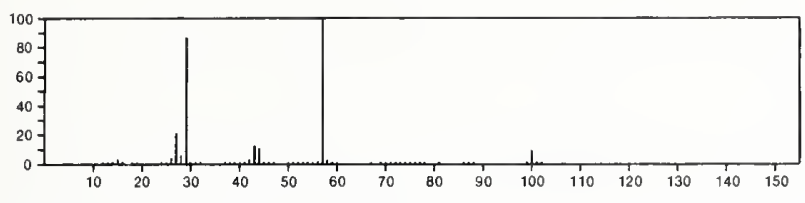

100

1-Propen-2-ol, acetate

$\mathrm{C}_{5} \mathrm{H}_{8} \mathrm{O}_{2}$

$108-22-5$

$\mathrm{H}_{2} \mathrm{C}=\mathrm{CMeOAC}$

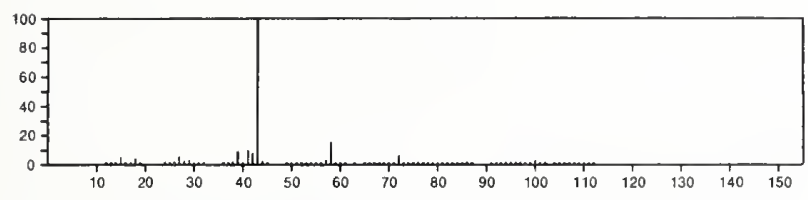

100

$\mathrm{C}_{5} \mathrm{H}_{8} \mathrm{O}_{2}$

2(3H)-Furanone, dihydro-5-methyl-

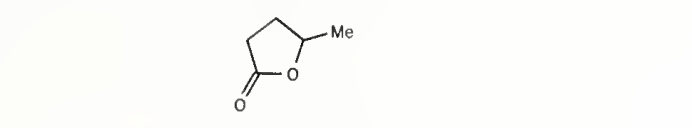

$108-29-2$
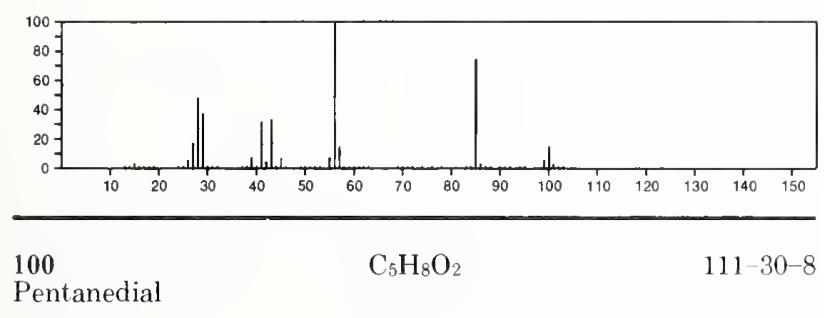

$\mathrm{C}_{5} \mathrm{H}_{8} \mathrm{O}_{2}$

$111-30-8$

$\mathrm{OCH}\left(\mathrm{CH}_{2}\right)_{3} \mathrm{CHO}$
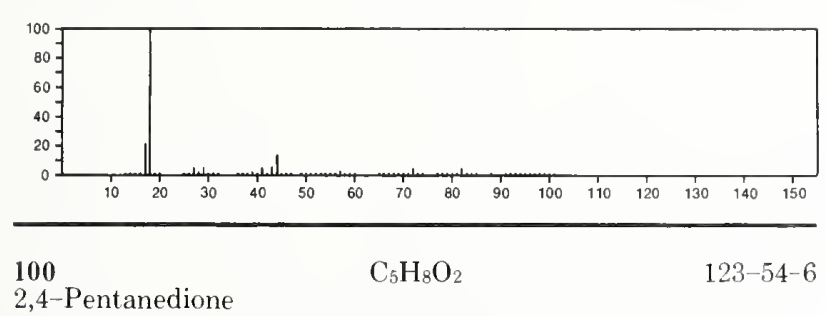

$\mathrm{MeCOCH}{ }_{2} \mathrm{COMe}$

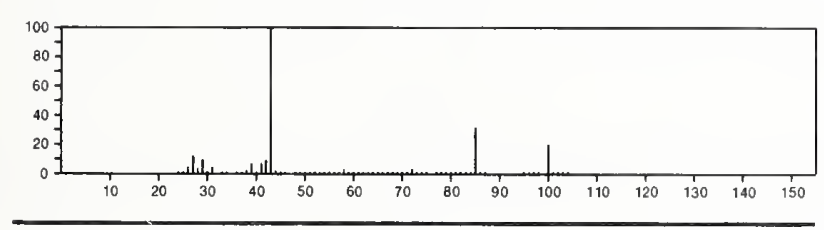

100

2-Propenoic acid, ethyl ester

$140-88-5$

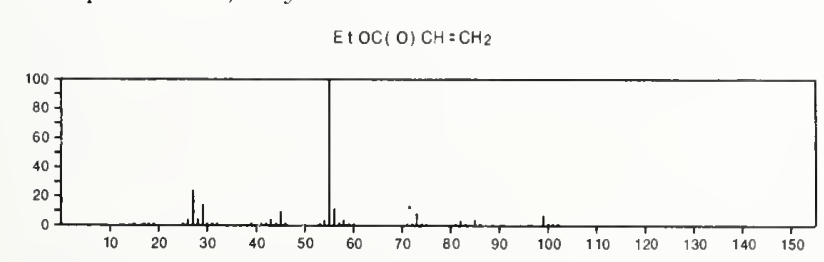

100

2-Butenoic acid, 3-methyl--

$541-47-9$

$\mathrm{Me}_{2} \mathrm{C}=\mathrm{CHCO}_{2} \mathrm{H}$

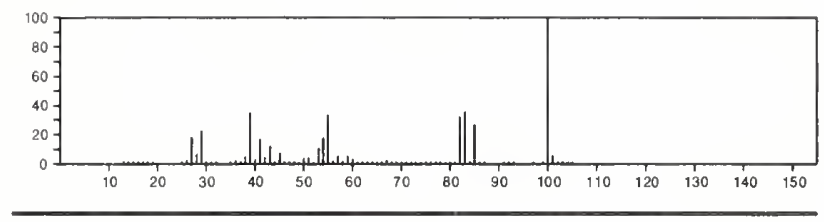

100

$\mathrm{C}_{5} \mathrm{H}_{8} \mathrm{O}_{2}$

$542-28-9$

2H-Pyran-2-one, tetrahydro-
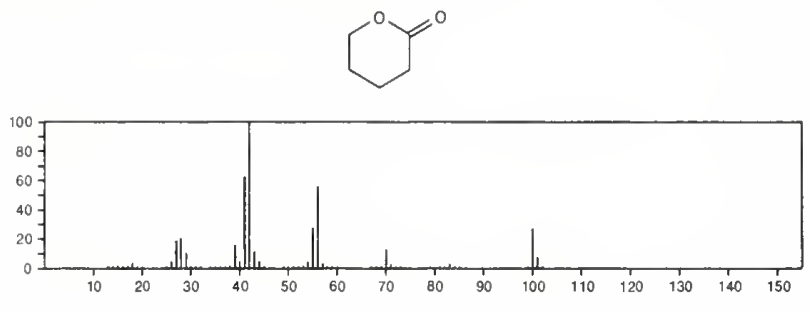

100
Acetic acid, 2-propenyl ester

$591-87-7$

$\mathrm{ACOCH} \mathrm{CH}_{2}=\mathrm{CH}_{2}$

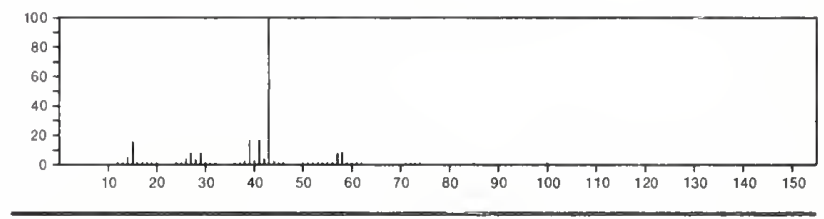

100

2,3-Pentanedione

$\mathrm{C}_{5} \mathrm{H}_{8} \mathrm{O}_{2}$

$600-14-6$

MeCOCOE:
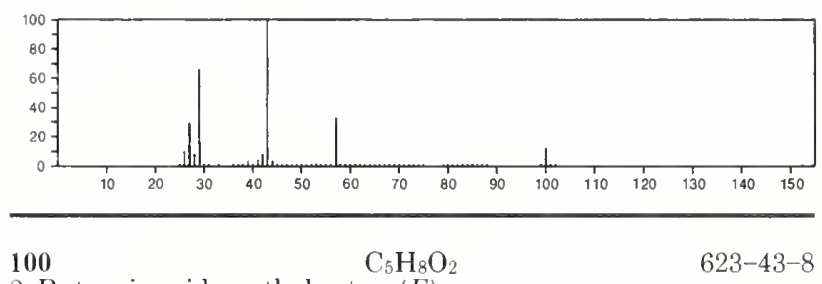

$623-43-8$

2- Butenoic acid, methyl ester, $(E)$ -

$\mathrm{MeCH}=\mathrm{CHC}(\mathrm{O}) \mathrm{OMe}$

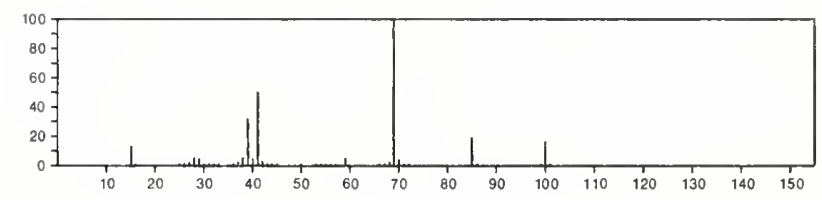

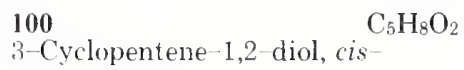

694-29-1
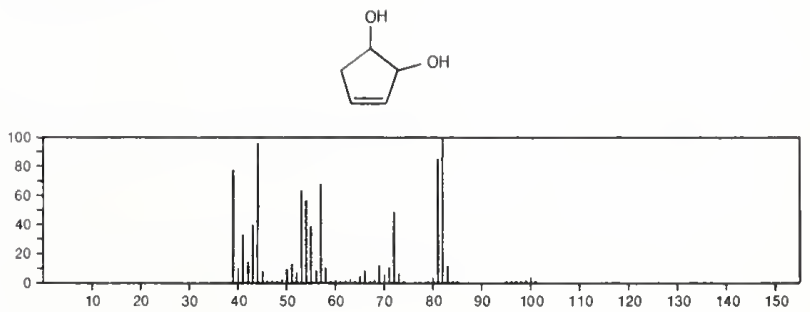
100

$\mathrm{C}_{5} \mathrm{H}_{8} \mathrm{O}$

4-Cyclopentene-1,3-diol, trans-

$694-47-3$
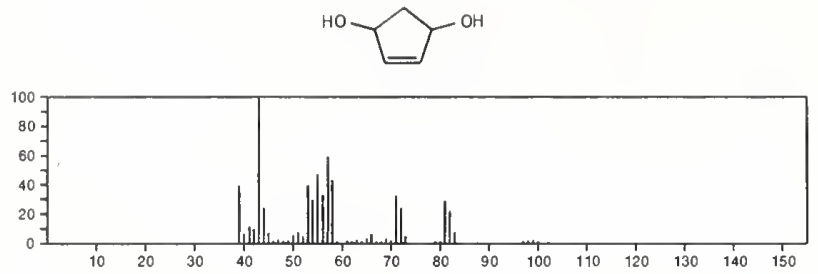

100

100

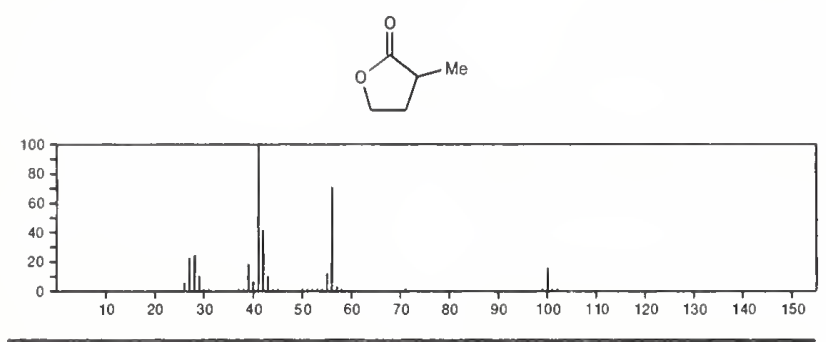

100

$\mathrm{C}_{5} \mathrm{H}_{8} \mathrm{O}_{2}$

$1823-52-5$

2-Oxetanone, 4,4-dimethyl-
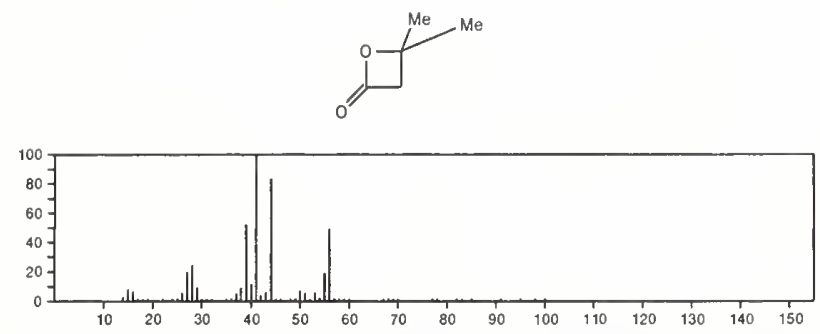

100
$2-$ Oxetanone, 3,3-dimethyl-

$1955-45-9$
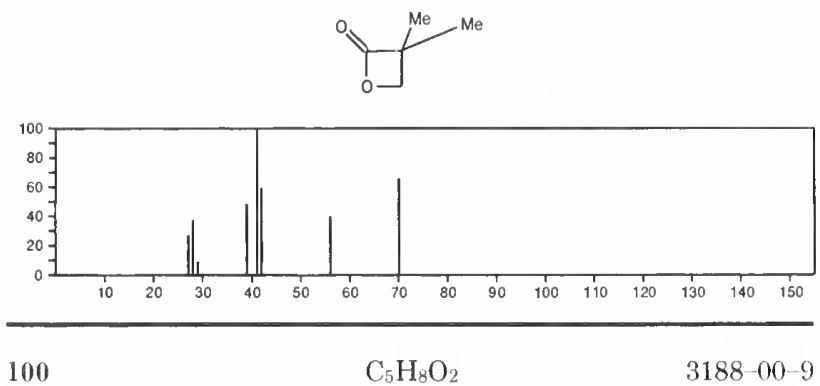

$3188-00-9$

$3(2 \mathrm{H})$-Furanone, dihydro-2-methyl-
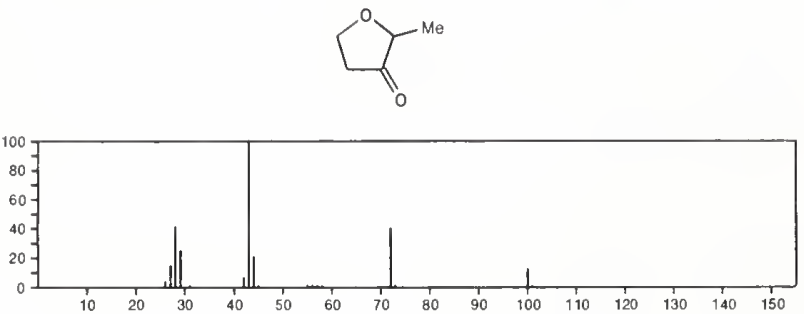

100

$\mathrm{C}_{5} \mathrm{H}_{8} \mathrm{O}_{2}$

$3973-18-0$

Ethanol, 2-(2-propynyloxy)--

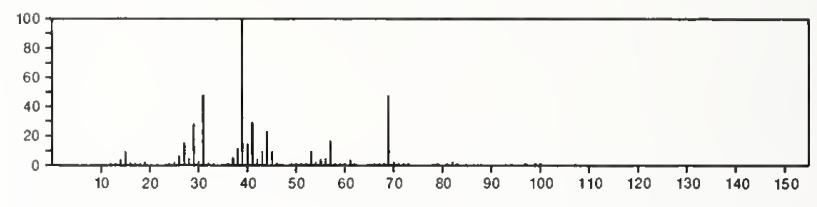

100

$\mathrm{C}_{5} \mathrm{H}_{8} \mathrm{O}_{2}$

p-Dioxin, 2,3-dihydro-5-methyl-

$3973-22-6$<smiles>[N+]=[N+]1C=COCCO1</smiles>

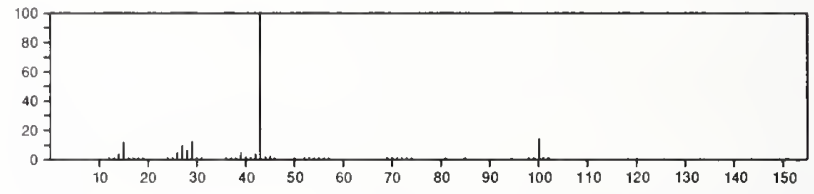

100

$\mathrm{C}_{5} \mathrm{H}_{8} \mathrm{O}_{2}$

$p$-Dioxane, methylene-
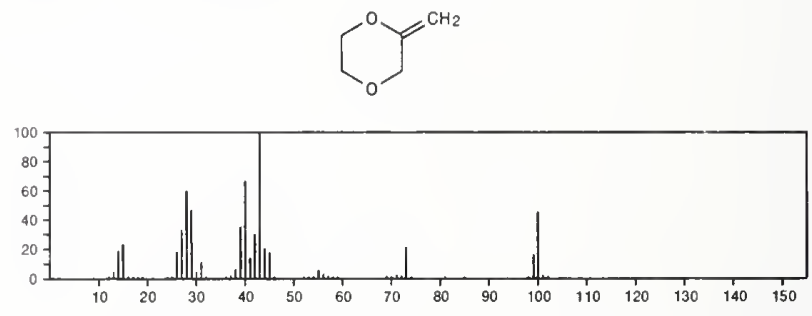

100

$\mathrm{C}_{5} \mathrm{H}_{8} \mathrm{O}_{2}$

$3984-22-3$

1,3-Dioxolane, 2-ethenyl
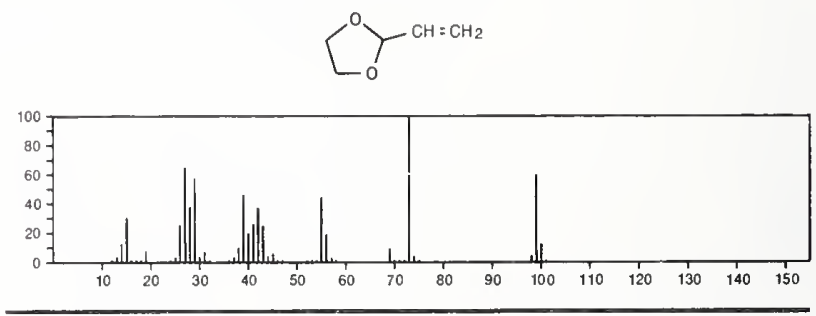

100

$\mathrm{C}_{5} \mathrm{H}_{8} \mathrm{O}_{2}$

$4040-81-7$

5H-1,4-Dioxepin, 2,3-dihydro-
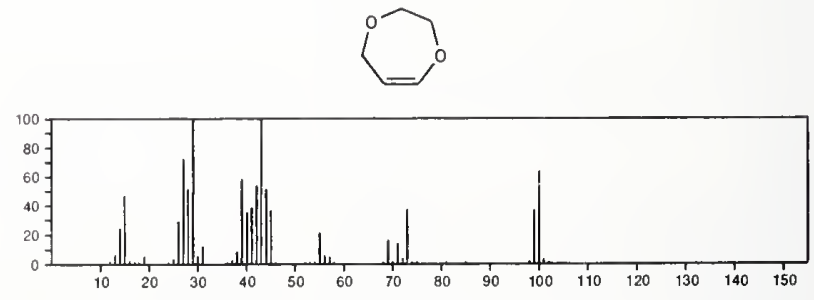

100

$\mathrm{C}_{5} \mathrm{H}_{8} \mathrm{O}_{2}$

$4358-59-2$

2-Butenoic acid, methyl ester, $(Z)$

$\mathrm{Me} \mathrm{CH}=\mathrm{CHC}(\mathrm{O}) \mathrm{OMe}$

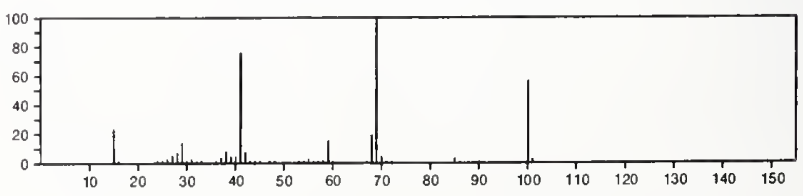


100

1,3-Dioxepin, 4,7-dihydro

$\mathrm{C}_{5} \mathrm{H}_{8} \mathrm{O}_{2}$
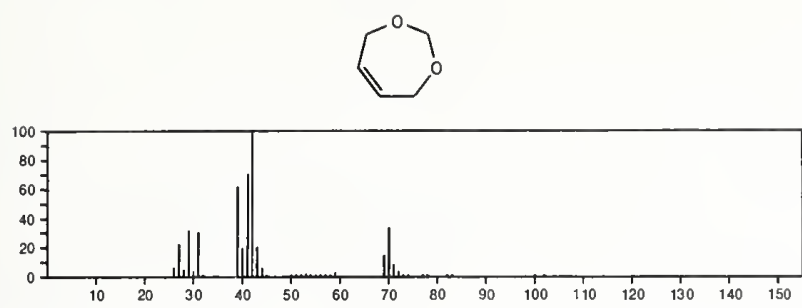

\section{0}

100
$2-$ Butenoic acid, 2-methyl-

$\mathrm{C}_{5} \mathrm{H}_{8} \mathrm{O}_{2}$

$\mathrm{MeCH}=\mathrm{CMeCO}_{2} \mathrm{H}$

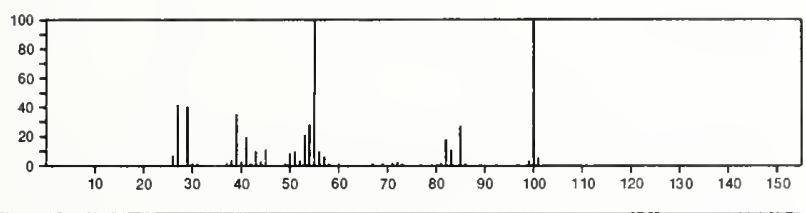

100

$\mathrm{C}_{5} \mathrm{H}_{8} \mathrm{O}_{2}$

Ethanone, 1-(3-methyloxiranyl)-

$17257-79-3$
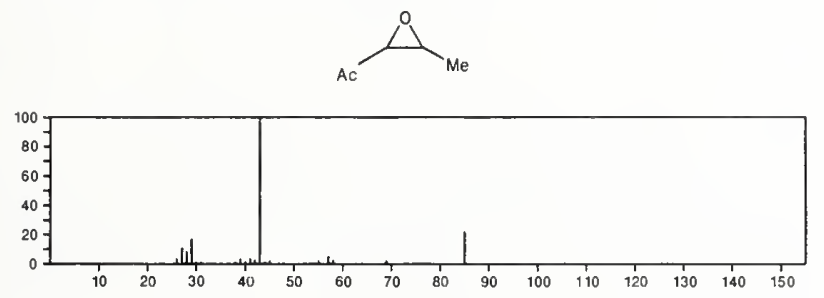

$100 \quad \mathrm{C}_{5} \mathrm{H}_{8} \mathrm{O}_{2}$

23462-75-1

$2 H$-Pyran-3(4H)-one, dihydro-
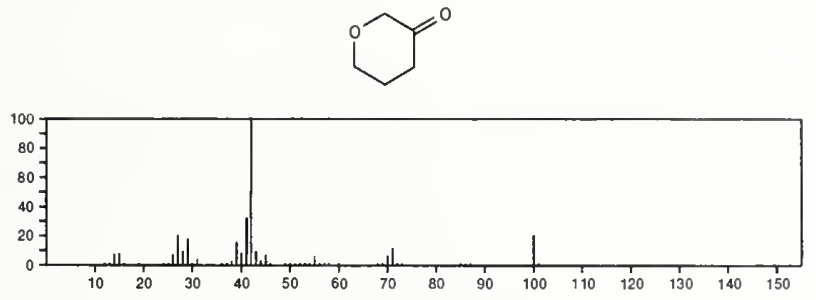

${ }_{4-\text { Cyclopentene-1,3-diol, } \text { cis-- }^{-}}^{\mathrm{C}_{5} \mathrm{H}_{8} \mathrm{O}_{2}}$

29783-26-4
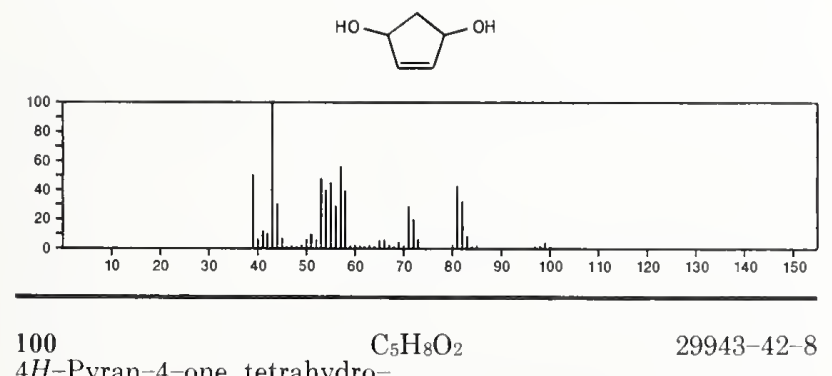

4H-Pyran-4-one, tetrahydro-
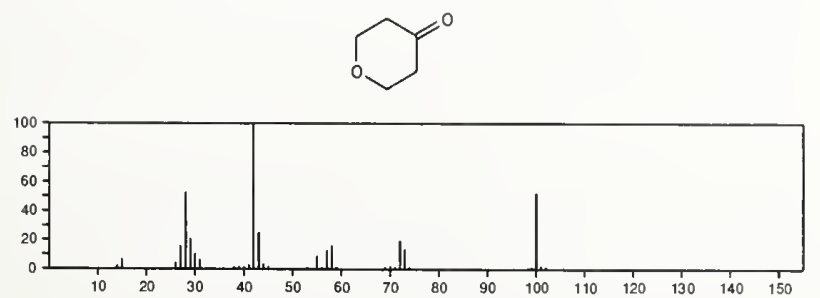

$100 \quad \mathrm{C}_{5} \mathrm{H}_{8} \mathrm{O}_{2}$

$3(2 \mathrm{H})$-Furanone, dihydro-5-methyl

$34003-72-0$
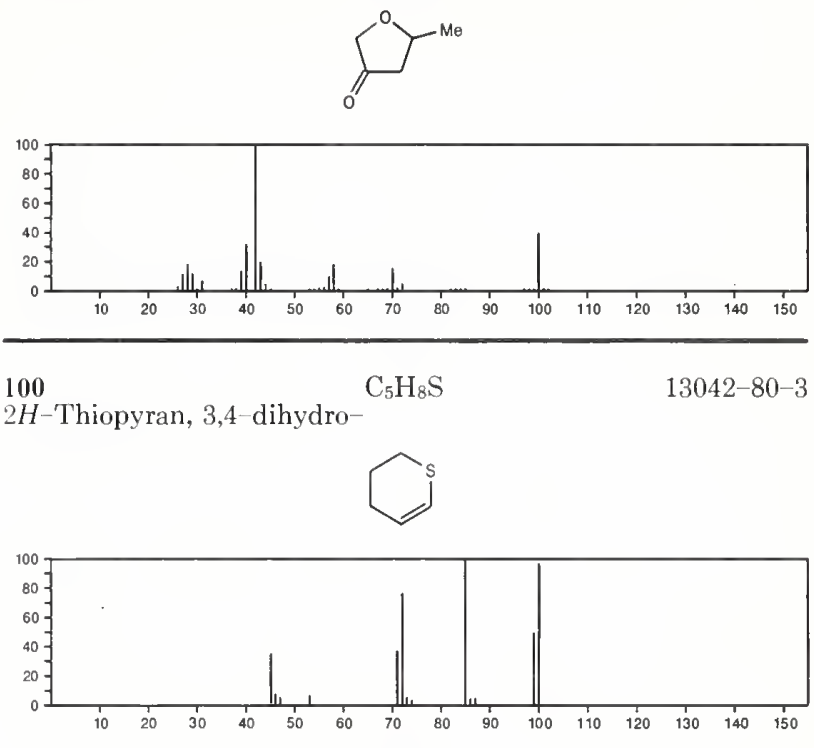

${ }_{100} \mathrm{C}_{5} \mathrm{H}_{8} \mathrm{~S}$

$40697-99-2$

2H-Thiopyran, 5,6-dihydro-
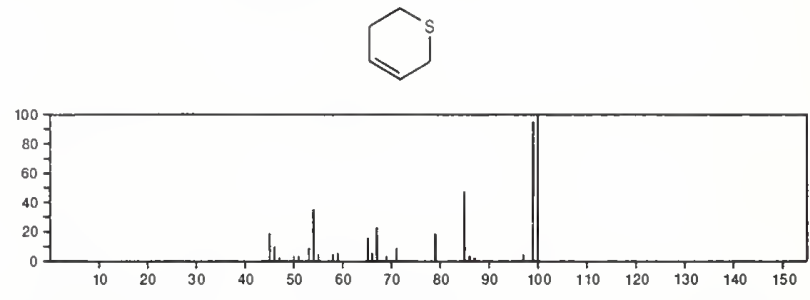

100

$\mathrm{C}_{5} \mathrm{H}_{12} \mathrm{~N}_{2}$

109-07-9

Piperazine, 2-methyl-
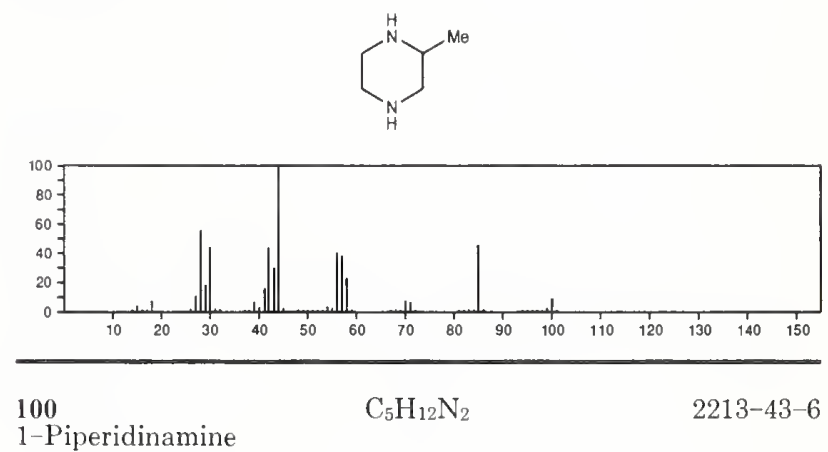

1-Piperidinamine
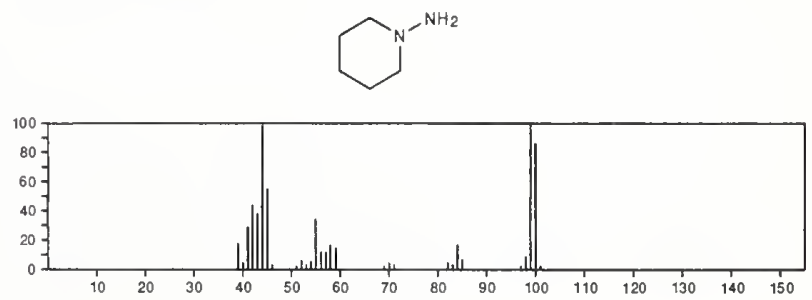
100

Silane, ethenyltrimethyl-

$\mathrm{C}_{5} \mathrm{H}_{12} \mathrm{Si}$

$\mathrm{Me}_{3} \mathrm{Si} \mathrm{CH}=\mathrm{CH}_{2}$

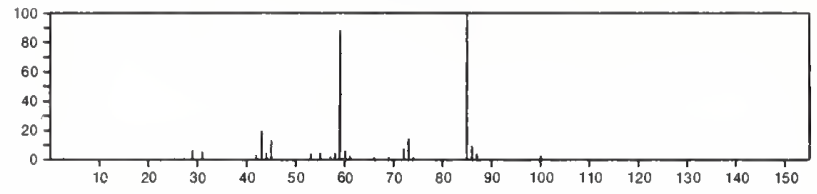

$100 \quad \mathrm{C}_{5} \mathrm{H}_{13} \mathrm{BO}$

Borinic acid, diethyl-, methyl ester

MeOBE 12

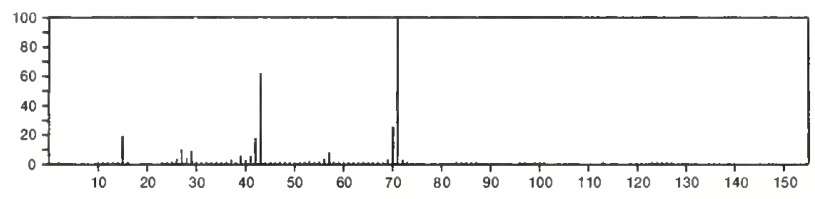

100

Cyclohexene, 1-fluoro-

$\mathrm{C}_{6} \mathrm{H}_{9} \mathrm{~F}$

$694-51-9$
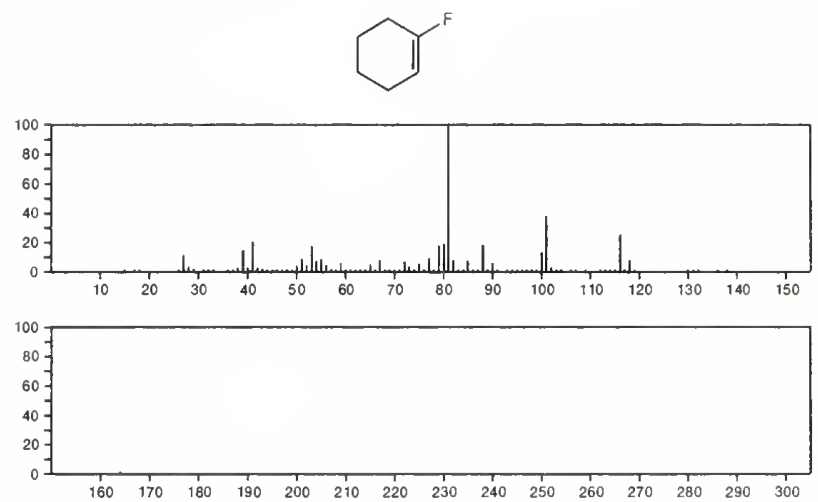

100

Hexanal

$\mathrm{C}_{6} \mathrm{H}_{12} \mathrm{O}$

$\mathrm{OCH}\left(\mathrm{CH}_{2}\right) 4 \mathrm{Me}$

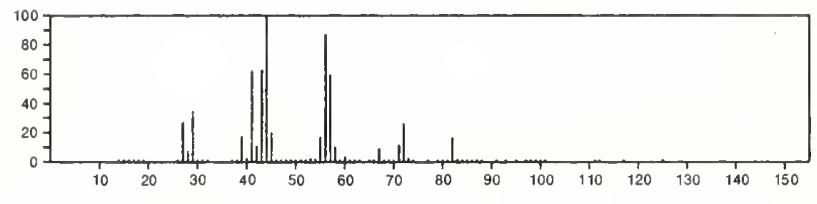

100

$\mathrm{C}_{6} \mathrm{H}_{12} \mathrm{O}$

$75-97-8$

2-Butanone, 3,3-dimethyl-
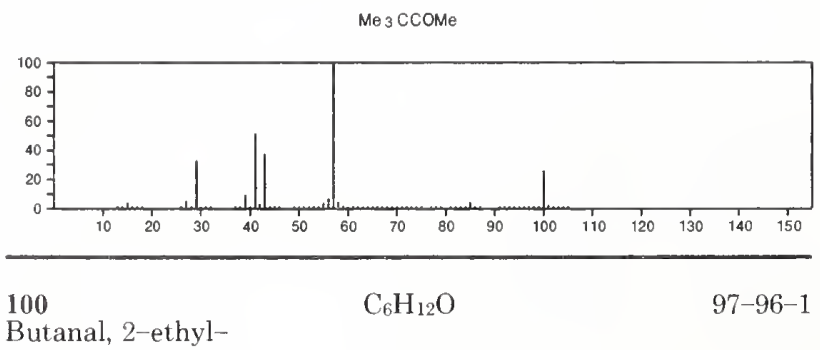

Butanal, 2-ethyl-

$\mathrm{Et}{ }_{2} \mathrm{CHCHO}$

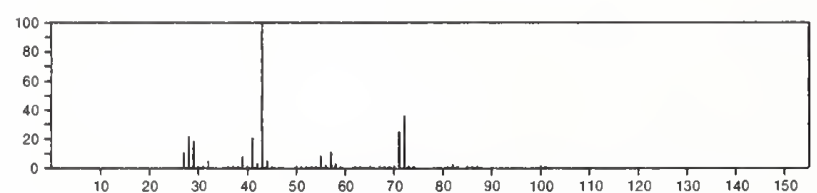

100

2-Pentanone, 4-methyl-

$\mathrm{C}_{6} \mathrm{H}_{12} \mathrm{O}$

$108-10-1$

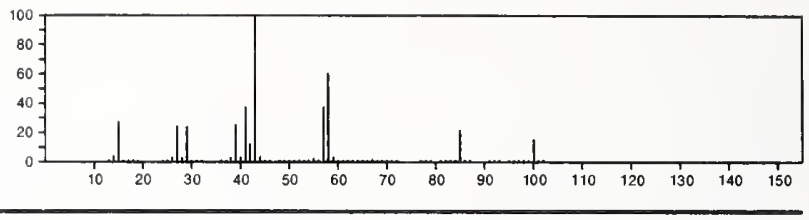

100

$\mathrm{C}_{6} \mathrm{H}_{12} \mathrm{O}$

108-93-0

Cyclohexanol
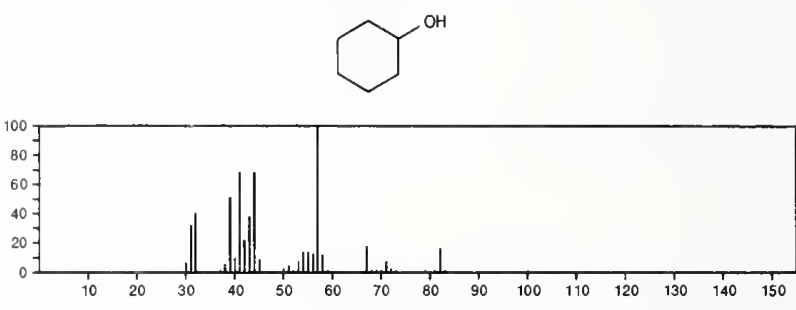

100

$\mathrm{C}_{6} \mathrm{H}_{12} \mathrm{O}$

Propane, 1-(ethenyloxy)-2-methyl-

$109-53-5$

$\mathrm{H}_{2} \mathrm{C}=\mathrm{CHOB} \mathrm{U}-\mathrm{i}$

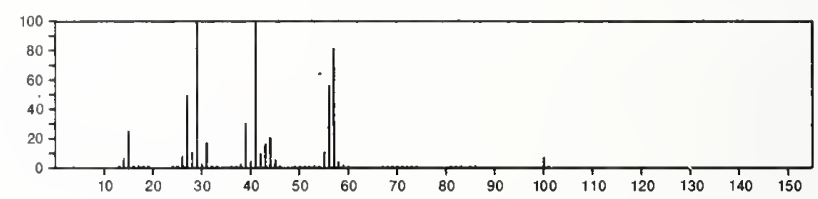

100

$\mathrm{C}_{6} \mathrm{H}_{12} \mathrm{O}$

$111-34-2$

Butane, 1-(ethenyloxy)-

$\mathrm{Me}\left(\mathrm{CH}_{2}\right)_{3} \mathrm{OCH}=\mathrm{CH}_{2}$

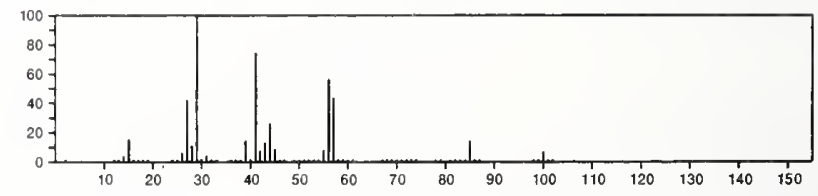

100

$\mathrm{C}_{6} \mathrm{H}_{12} \mathrm{O}$

$123-15-9$

Pentanal, 2-methyl-

$\operatorname{PrCHME}(\mathrm{CHO})$

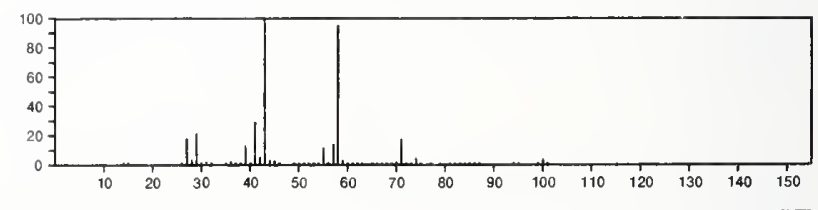

100

$\mathrm{C}_{6} \mathrm{H}_{12} \mathrm{O}$

544-12-7

3-Hexen-1-ol

$\mathrm{HOCH}_{2} \mathrm{CH}_{2} \mathrm{CH}=\mathrm{CHEt}$

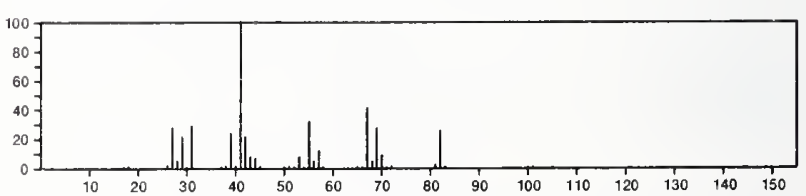


100

$\mathrm{C}_{6} \mathrm{H}_{12} \mathrm{O}$

2-Pentanone, 3-methyl-

$\mathrm{Me}$ COCHMe $\mathrm{CH}_{2} \mathrm{Me}$
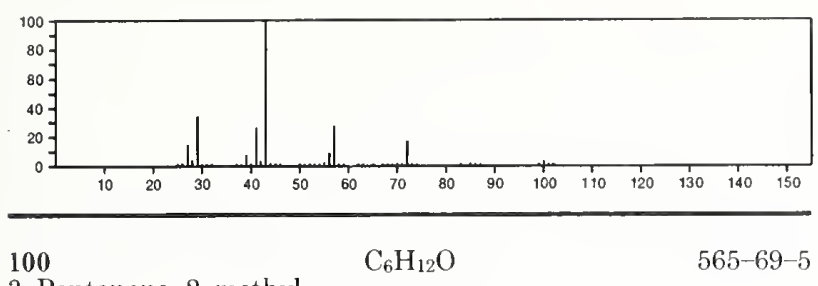

3-Pentanone, 2-methyl-

Me 2 CHCOE t

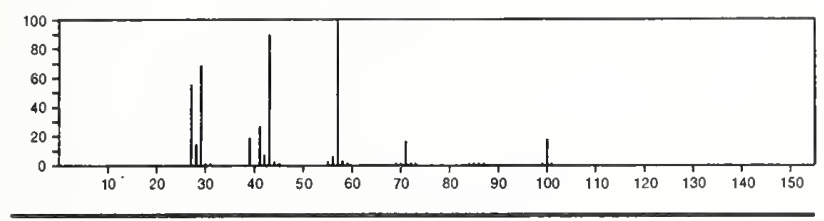

100

3-Hexanone

$\mathrm{C}_{6} \mathrm{H}_{12} \mathrm{O}$

$589-38-8$

PrCOE t
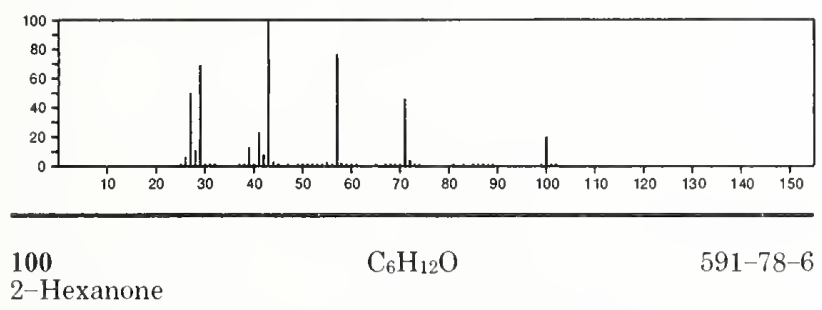

$\mathrm{Me}\left(\mathrm{CH}_{2}\right)_{3}$ COMe
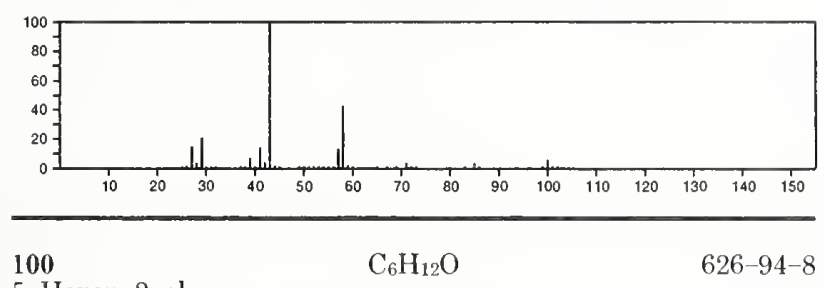

5-Hexen-2-ol

$\mathrm{MeCH}(\mathrm{OH}) \mathrm{CH}_{2} \mathrm{CH}_{2} \mathrm{CH}=\mathrm{CH}_{2}$

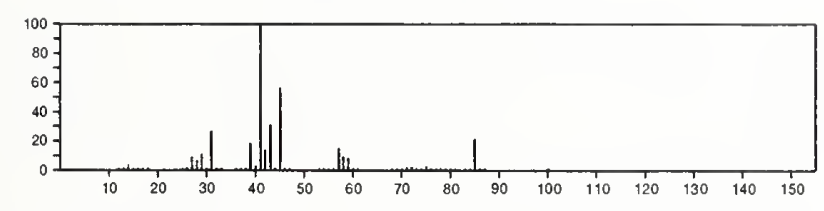

100

$\mathrm{C}_{6} \mathrm{H}_{12} \mathrm{O}$

928-95-0

2-Hexen-1-ol, $(E)-$

$\operatorname{Pr} \mathrm{CH}=\mathrm{CHCH}_{2} \mathrm{OH}$

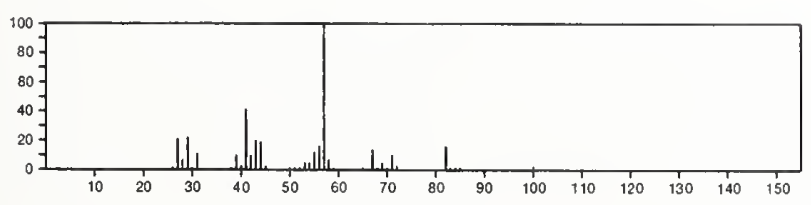

$100 \quad \mathrm{C}_{6} \mathrm{H}_{12} \mathrm{O}$

Cyclopropanemethanol, $\alpha, \alpha$-dimethyl-
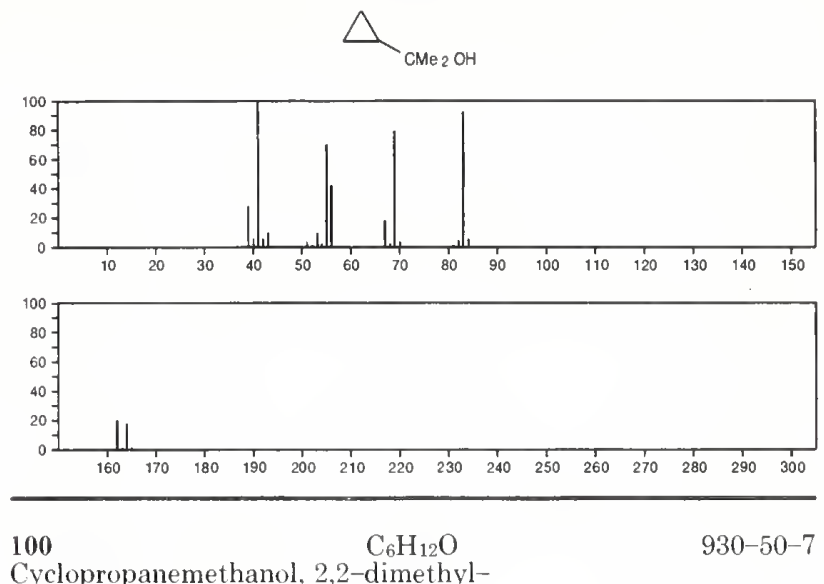

Cyclopropanemethanol, 2,2-dimethyl-
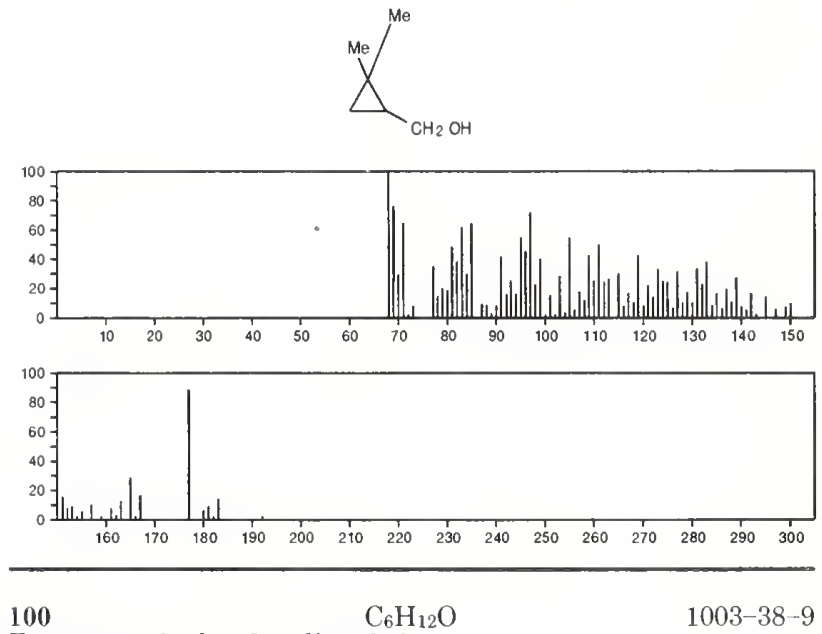

$1003-38-9$

Furan, tetrahydro-2,5-dimethyl-
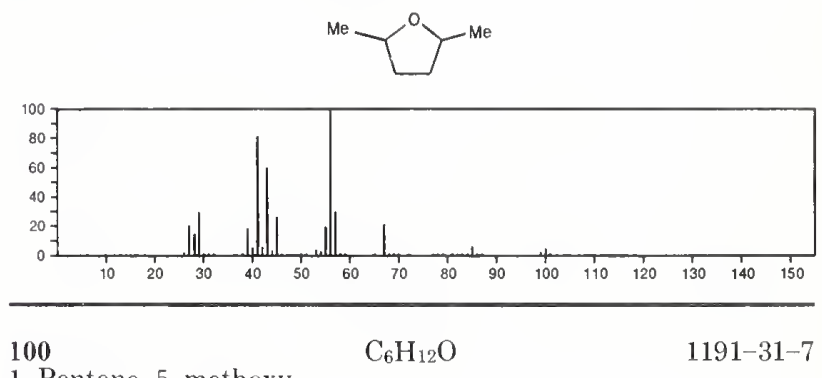

1-Pentene, 5-methoxy-

$\mathrm{H}_{2} \mathrm{C}=\mathrm{CH}\left(\mathrm{CH}_{2}\right)_{3} \mathrm{OMe}_{2}$

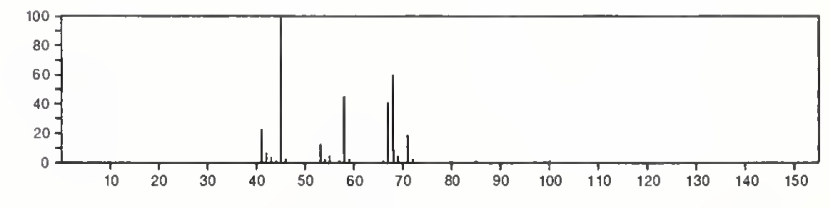

100

Oxirane, 3-ethyl-2,2-dimethyl-

$\mathrm{C}_{6} \mathrm{H}_{12} \mathrm{O}$

1192-22-9
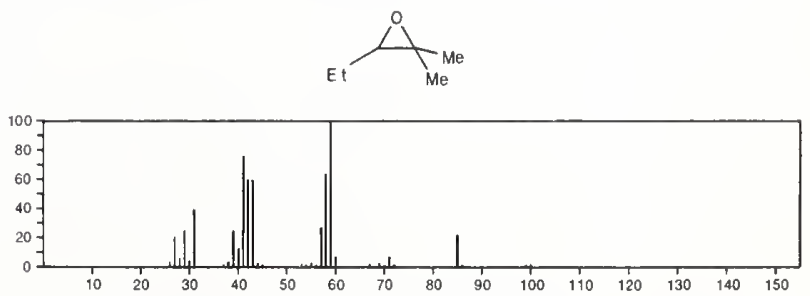
$100 \quad \mathrm{C}_{6} \mathrm{H}_{12} \mathrm{O}$

Oxirane, 2-methyl-3-(1-methylethyl)
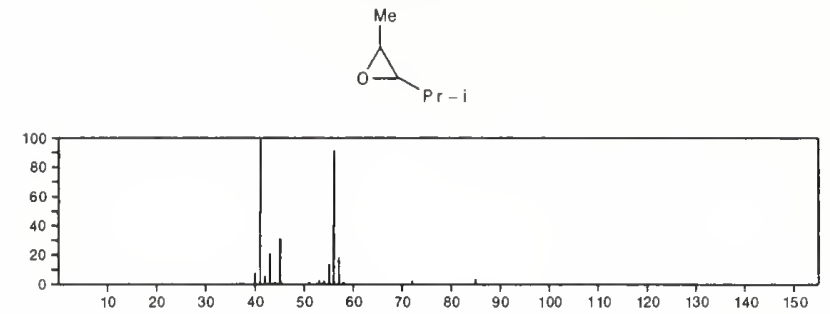

100

Oxirane, butyl-

$\mathrm{C}_{6} \mathrm{H}_{12} \mathrm{O}$
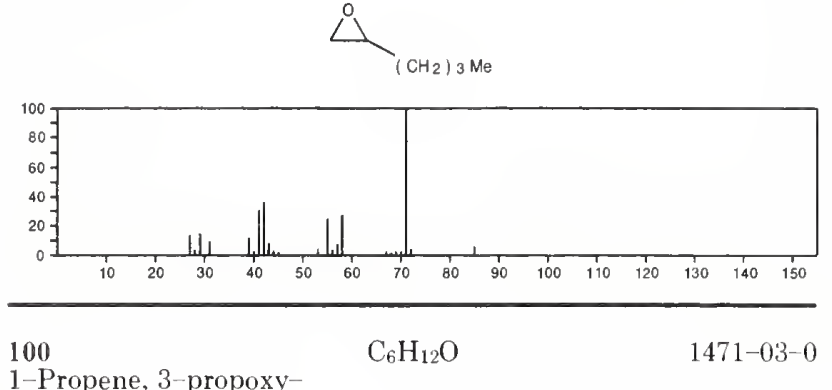

1-Propene, 3-propoxy-

$\mathrm{PrOCH}_{2} \mathrm{CH}=\mathrm{CH}_{2}$

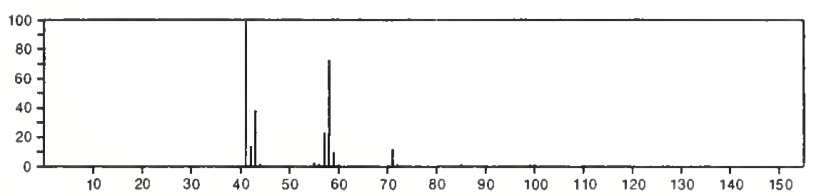

100

4-Penten-2-ol, 3-methyl-

$\mathrm{C}_{6} \mathrm{H}_{12} \mathrm{O}$

$\mathrm{H}_{2} \mathrm{C}: \mathrm{CHCHMe} \mathrm{CH}(\mathrm{OH}) \mathrm{Me}$

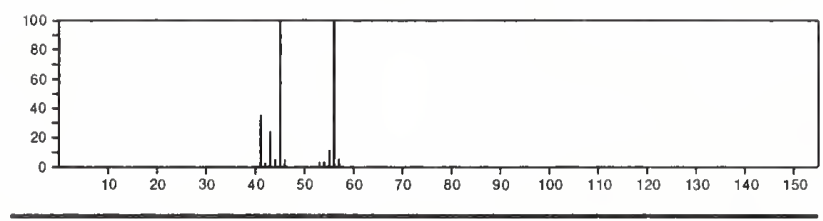

100

$\mathrm{C}_{6} \mathrm{H}_{12} \mathrm{O}$

2088-07-5

1-Penten-3-ol, 2-methyl-

$\mathrm{Et} \mathrm{CH}(\mathrm{OH}) \mathrm{CMe}=\mathrm{CH}_{2}$

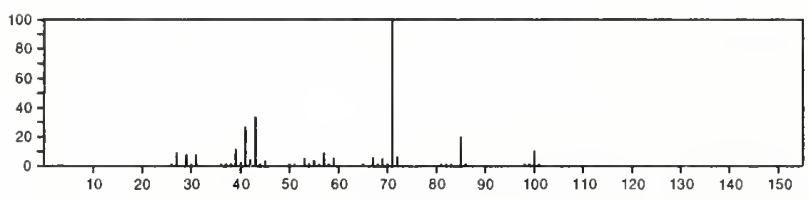

$100 \quad \mathrm{C}_{6} \mathrm{H}_{12} \mathrm{O}$

Furan, tetrahydro-2,5-dimethyl-, cis-

$2144-41-4$

$$
\mathrm{Me} \mathrm{C}^{\mathrm{Me}}
$$

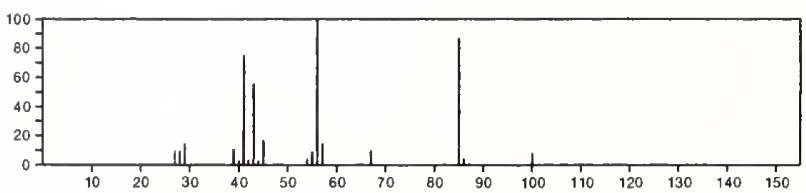

100

Cyclopentanemethanol

$\mathrm{C}_{6} \mathrm{H}_{12} \mathrm{O}$

$3637-61-4$
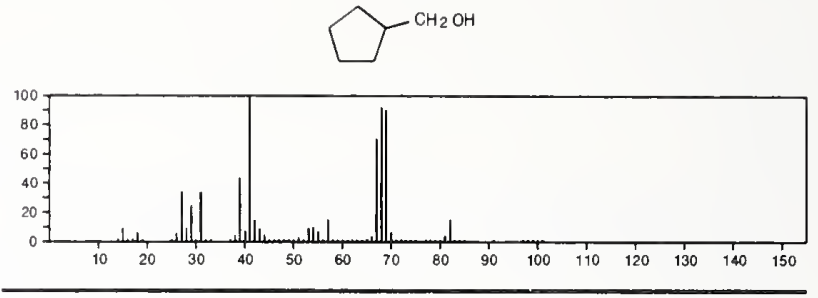

100

$\mathrm{C}_{6} \mathrm{H}_{12} \mathrm{O}$

Oxirane, 2-methyl-2-propyl-
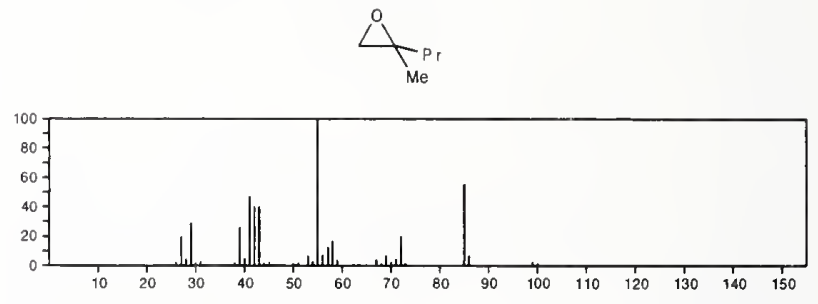

100

$\mathrm{C}_{6} \mathrm{H}_{12} \mathrm{O}$

Oxetane, 2-propyl-
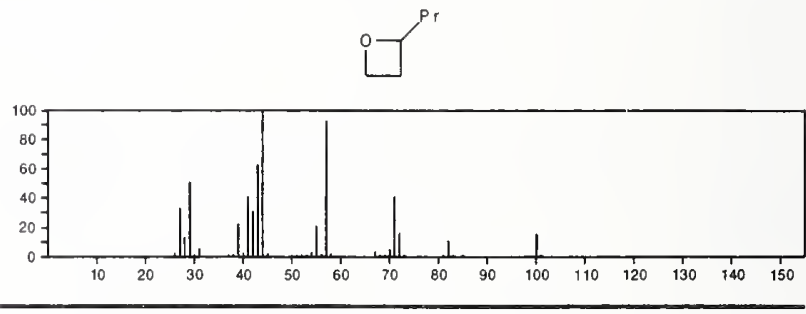

100
Oxirane, 2,3-diethyl- $\quad \mathrm{C}_{6} \mathrm{H}_{12} \mathrm{O}$

4468-66-0
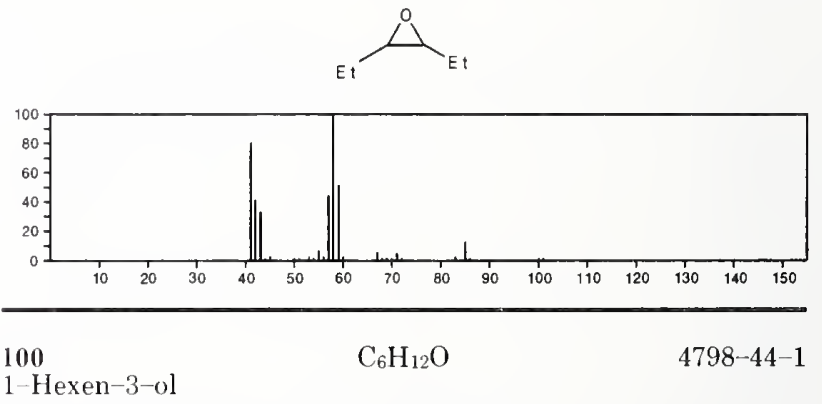

1-Hexen-3-ol

$\operatorname{Pr} \mathrm{CH}(\mathrm{OH}) \mathrm{CH}=\mathrm{CH}_{2}$

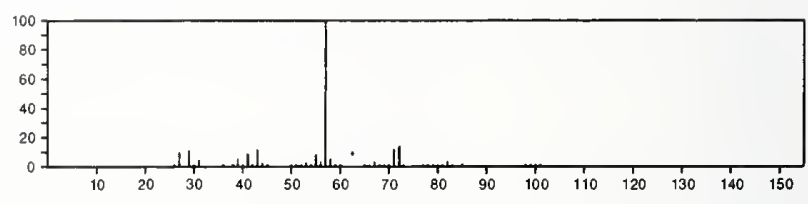

100

$\mathrm{C}_{6} \mathrm{H}_{12} \mathrm{O}$

$5076-20-0$

Oxirane, tetramethyl-
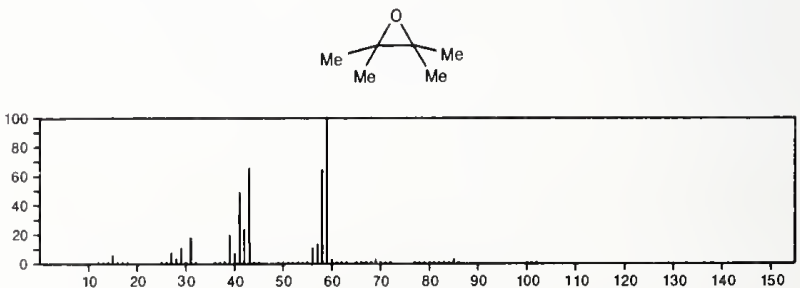
$100 \quad \mathrm{C}_{6} \mathrm{H}_{12} \mathrm{O}$

Oxirane, 2-methyl-3-propyl-, cis-
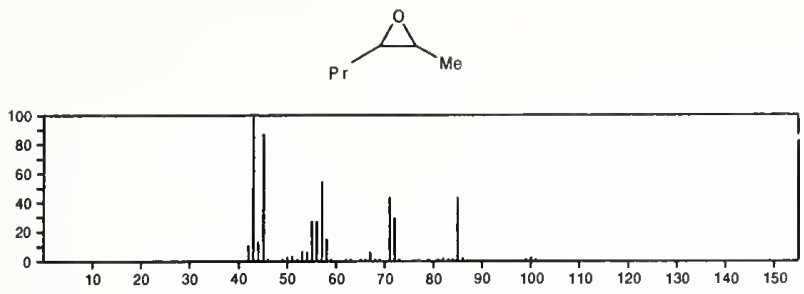

$100 \quad \mathrm{C}_{6} \mathrm{H}_{12} \mathrm{O}$

Oxirane, 2-methyl-3-propyl-, trans-
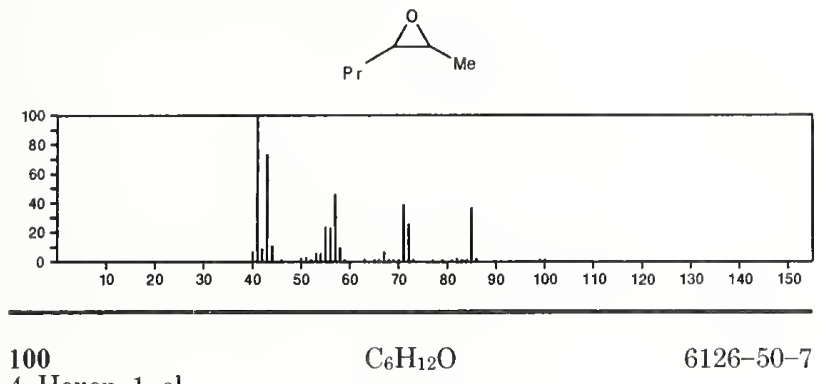

4-Hexen-1-ol

$\mathrm{HO}\left(\mathrm{CH}_{2}\right)_{3} \mathrm{CH}=\mathrm{CHMe}$
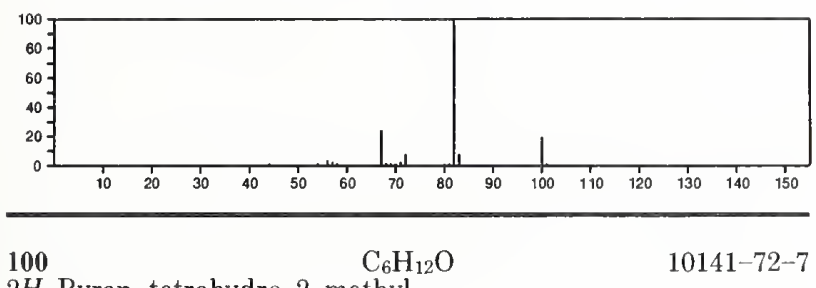

$2 \mathrm{H}$-Pyran, tetrahydro-2-methyl-
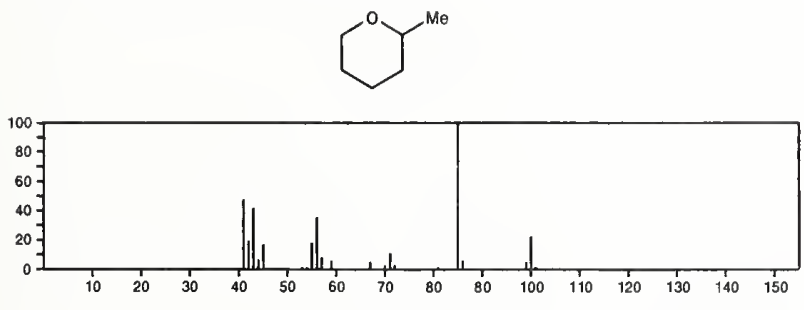

100

$\mathrm{C}_{6} \mathrm{H}_{12} \mathrm{O}$

$10317-17-6$

Oxetane, 3-(1-methylethyl)-
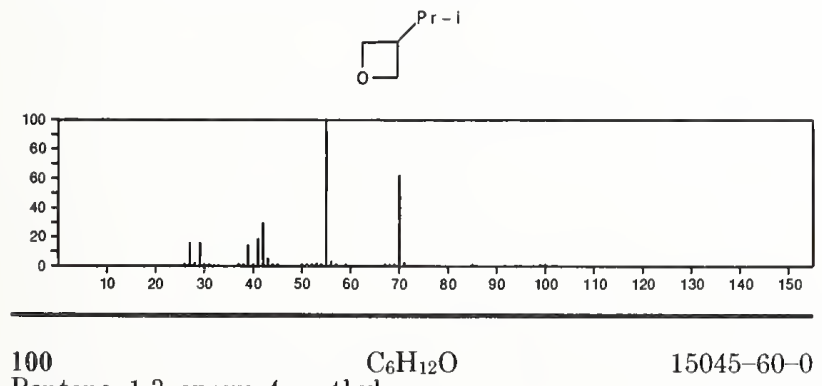

Pentane, 1,3-epoxy-4-methyl-
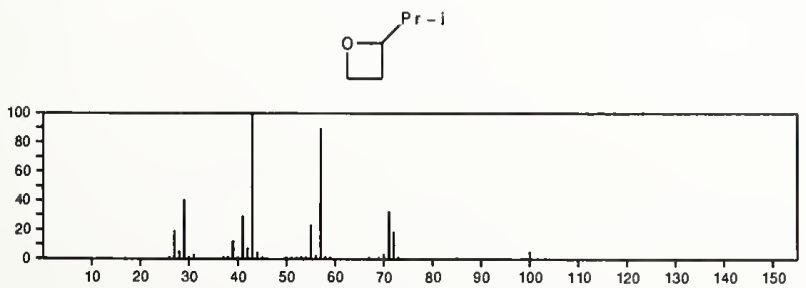

100

Pentanal, 3-methyl-

$\mathrm{C}_{6} \mathrm{H}_{12} \mathrm{O}$

$15877-57-3$

$\mathrm{OCHCH}_{2} \mathrm{CHMe} \mathrm{CH}_{2} \mathrm{Me}$

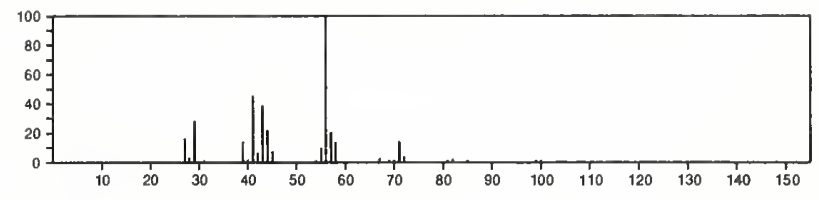

100

$\mathrm{C}_{6} \mathrm{H}_{12} \mathrm{O}$

$23120-43-6$

Oxepane, 2,2,3-trimethyl-
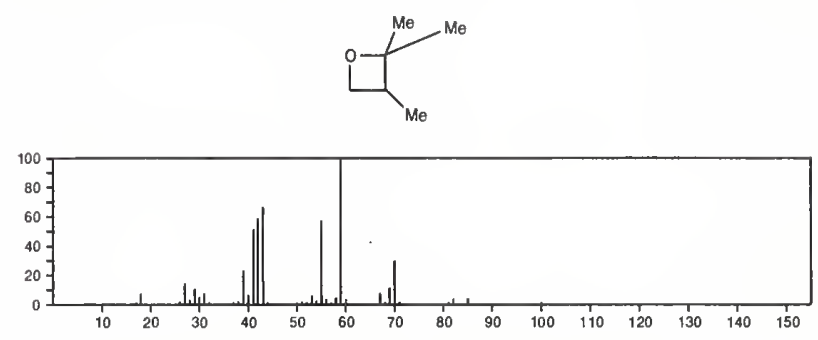

100

$\mathrm{C}_{6} \mathrm{H}_{12} \mathrm{O}$

23120-44-7

Oxepane, 2,2,4-trimethyl-
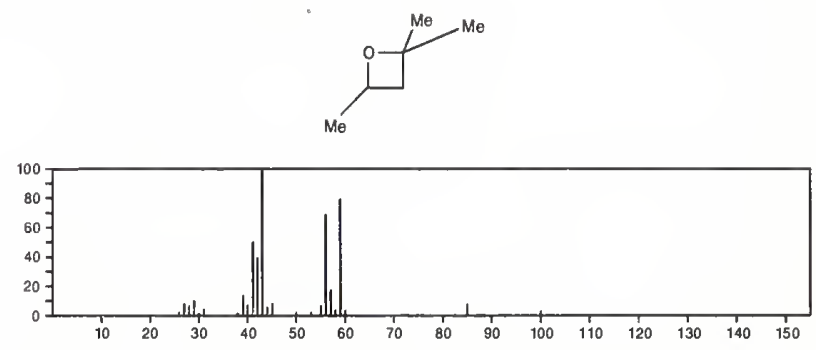

$\begin{aligned} & 100 \\ & \text { Oxirane, (2-methylpropyl)- }\end{aligned} \mathrm{C}_{6} \mathrm{H}_{12} \mathrm{O} \quad 23850-78-4$
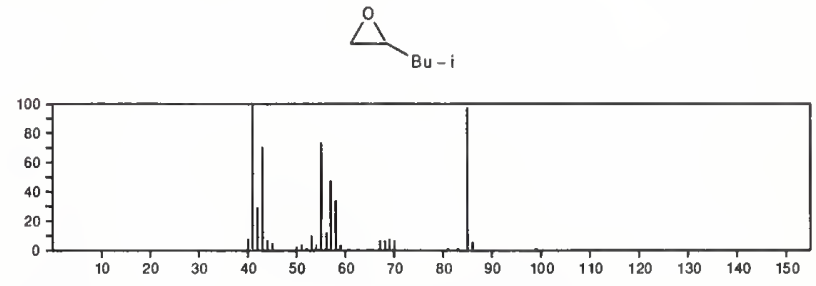

$\begin{aligned} & 100 \\ & \text { Cyclopentanol, 2-methyl-- }\end{aligned} \mathrm{C}_{6} \mathrm{H}_{12} \mathrm{O} \quad 24070-77-7$

$\mathrm{C}^{\mathrm{OH}}$
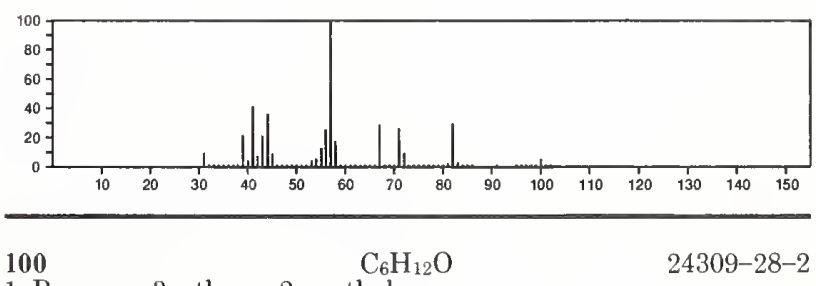

24309-28-2

1-Propene, 3-ethoxy-2-methyl-

$\mathrm{H}_{2} \mathrm{C}=\mathrm{CMeCH}_{2} \mathrm{OE} \mathrm{t}$

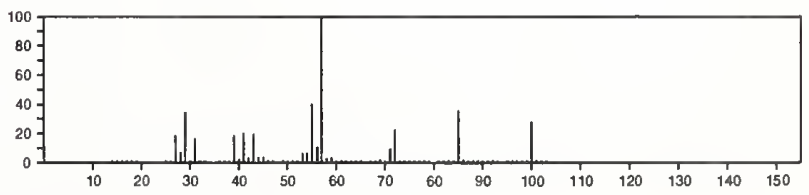


$\mathrm{C}_{6} \mathrm{H}_{12} \mathrm{O}$

Cyclopentanol, 2-methyl-, trans-<smiles>CC1CCCC1O</smiles>

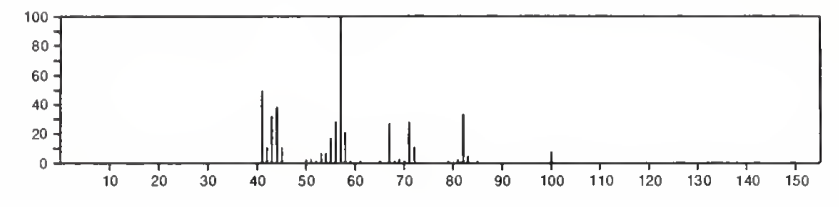

$100 \quad \mathrm{C}_{6} \mathrm{H}_{12} \mathrm{O}$

$25144-05-2$

Cyclopentanol, 2-methyl-, cis-
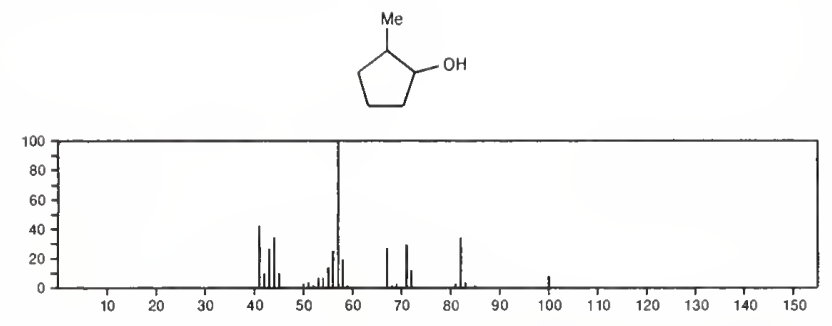

$100 \quad \mathrm{C}_{6} \mathrm{H}_{12} \mathrm{O}$

2H-Pyran, tetrahydro-3-methyl-

26093-63-0
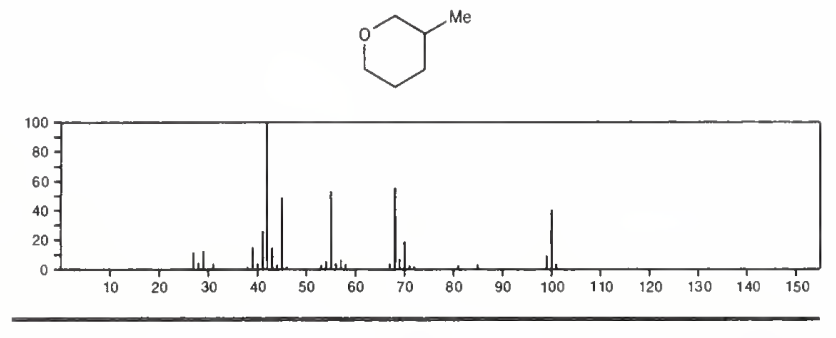

100

$\mathrm{C}_{6} \mathrm{H}_{12} \mathrm{O}$

Furan, tetrahydro-3,4-dimethyl-, cis-
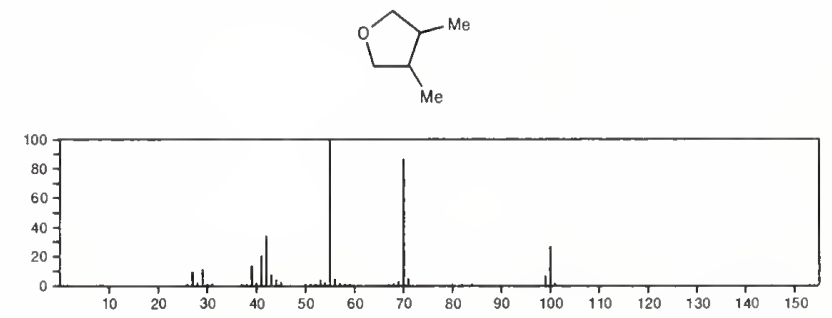

$100 \quad \mathrm{C}_{6} \mathrm{H}_{12} \mathrm{O}$

Oxetane, 2,3,4-trimethyl-, $(2 \alpha, 3 \alpha, 4 \beta)-$

$32347-12-9$
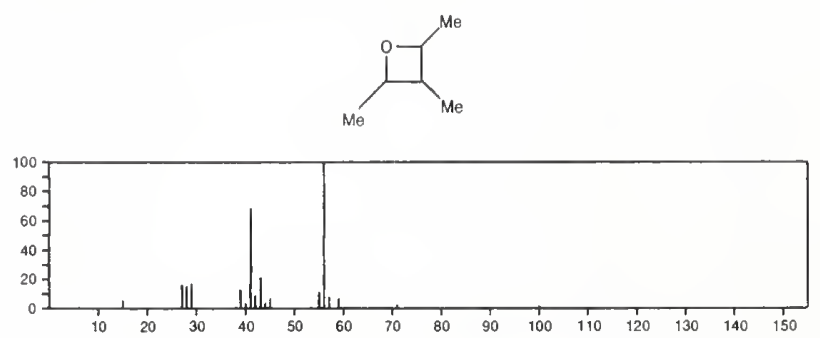

100

$\mathrm{C}_{6} \mathrm{H}_{12} \mathrm{O}$

$35301-43-0$

Cyclobutanol, 2-ethyl-
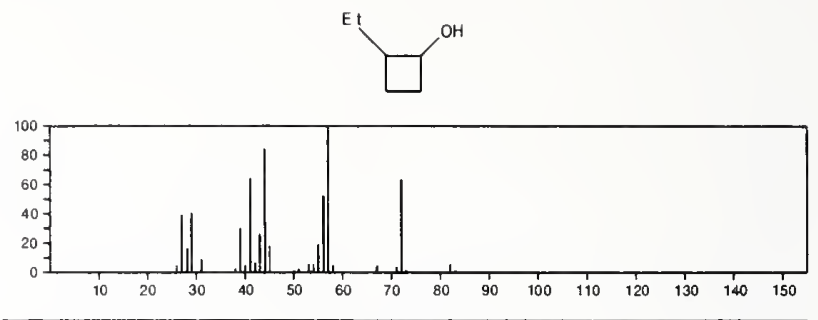

100

$\mathrm{C}_{6} \mathrm{H}_{12} \mathrm{O}$

$38484-59-2$

Furan, tetrahydro-2,5-dimethyl-, trans- $( \pm)-$
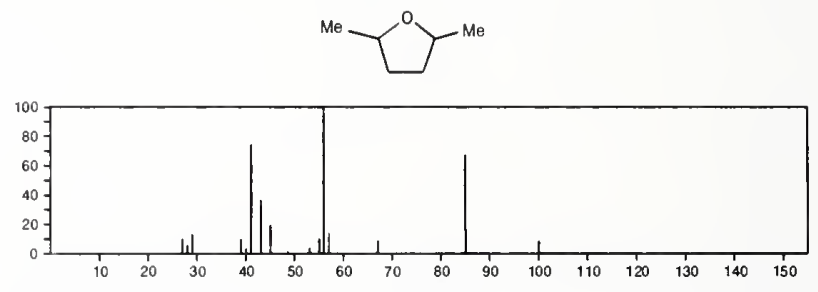

100

$\mathrm{C}_{6} \mathrm{H}_{12} \mathrm{O}$

39168-01-9

Furan, tetrahydro-2,4-dimethyl-, cis-
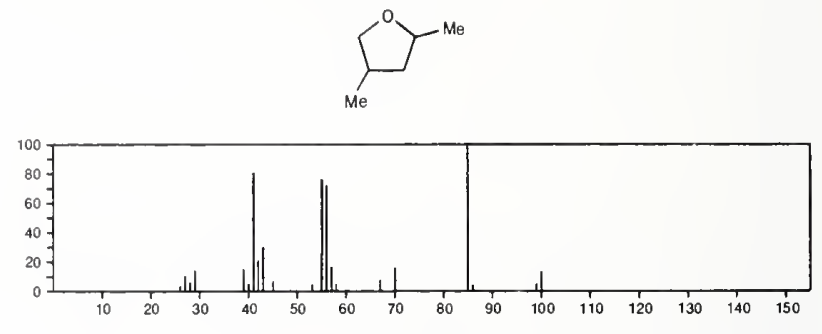

100

$\mathrm{C}_{6} \mathrm{H}_{12} \mathrm{O}$

$39168-02-0$

Furan, tetrahydro-2,4-dimethyl-, trans-
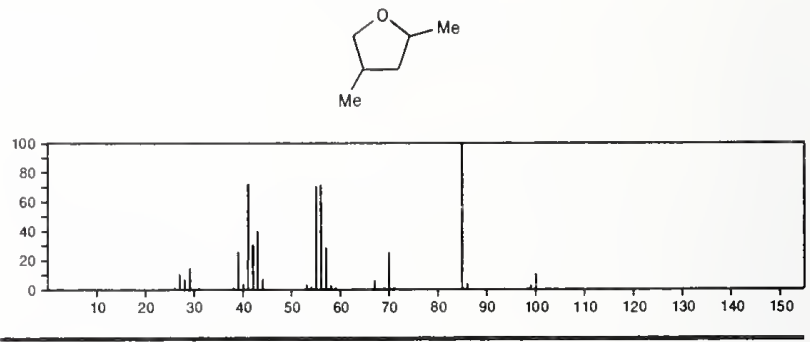

100

$\mathrm{C}_{6} \mathrm{H}_{12} \mathrm{O}$

$53778-61-3$

Oxetane, 2,3,4-trimethyl-
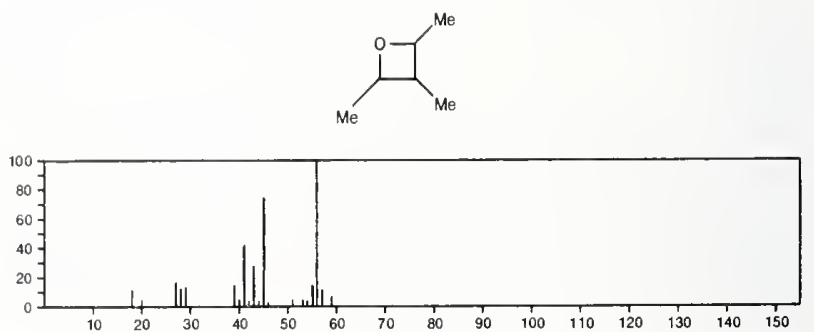
100 $\mathrm{C}_{6} \mathrm{H}_{12} \mathrm{O}$

$53778-62-4$
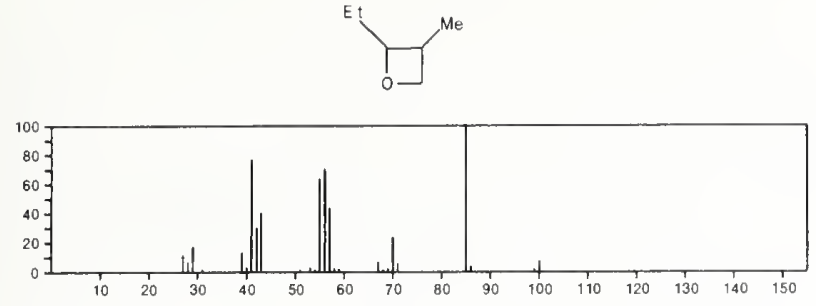

100

5-Hexen-2-ol, ( $( \pm)$

$\mathrm{C}_{6} \mathrm{H}_{12} \mathrm{O}$

$54774 \cdot 27-5$

$\mathrm{MeCH}(\mathrm{OH}) \mathrm{CH}_{2} \mathrm{CH}_{2} \mathrm{CH}=\mathrm{CH}_{2}$

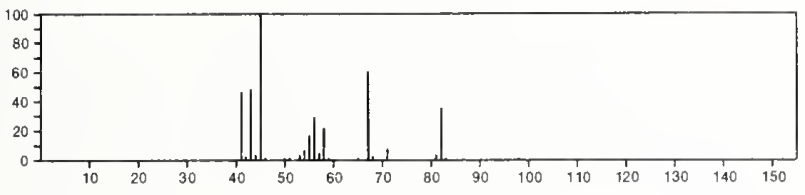

100

Pentane, 2,4-dimethyl-

$\mathrm{C}_{7} \mathrm{H}_{16}$

108087

$\mathrm{Me}_{2} \mathrm{CHCH}_{2} \mathrm{CHMe}_{2}$

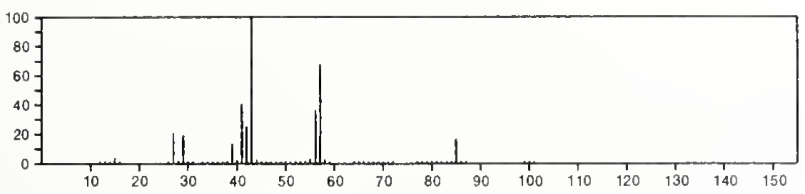

100

$\mathrm{C}_{7} \mathrm{H}_{16}$

$142-82-5$

Heptane

$\mathrm{Me}\left(\mathrm{CH}_{2}\right)$ \& Me

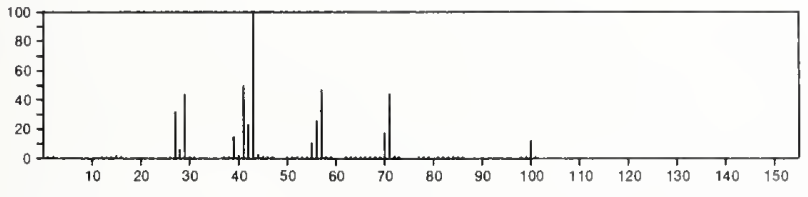

100

$\mathrm{C}_{7} \mathrm{H}_{16}$

464062

Butane, 2,2,3-trimethyl-

$\mathrm{Me}_{2} \mathrm{CHCMe}_{3}$

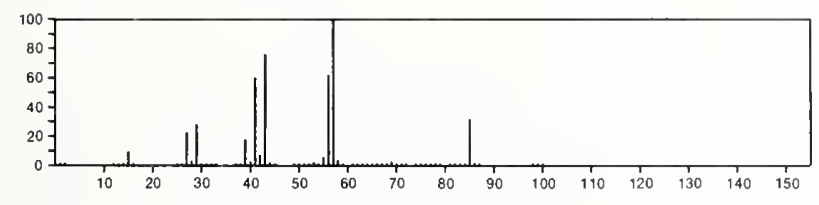

100

$\mathrm{C}_{7} \mathrm{H}_{16}$

562-49-2

Pentane, 3,3-dimethyl

$\mathrm{Et}_{2} \mathrm{CMe}_{2}$

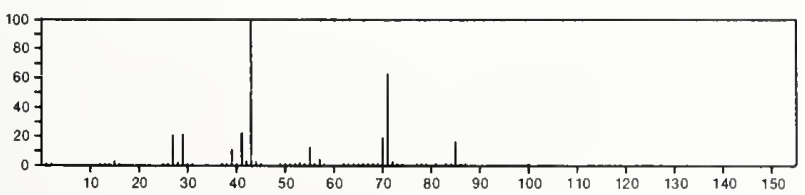

100

$\mathrm{C}_{7} \mathrm{H}_{16}$

$565-59-3$

Pentane, 2,3-dimethyl

$\mathrm{MeCH}_{2} \mathrm{CHMeCHMe}_{2}$

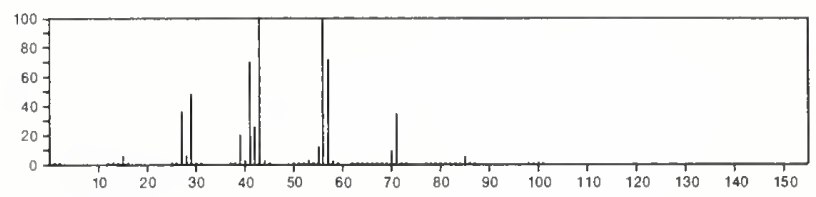

100

Hexane, 3-methyl

$\mathrm{C}_{7} \mathrm{H}_{16}$

589-34-4

$\mathrm{MeCH}_{2} \mathrm{CHP}_{\mathrm{H}} \mathrm{Me}$

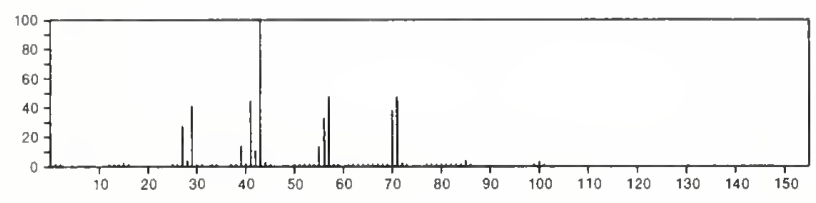

100

$\mathrm{C}_{7} \mathrm{H}_{16}$

$590-35-2$

Pentane, 2,2-dimethyl-

$\mathrm{Me}_{3} \mathrm{CP}$ r

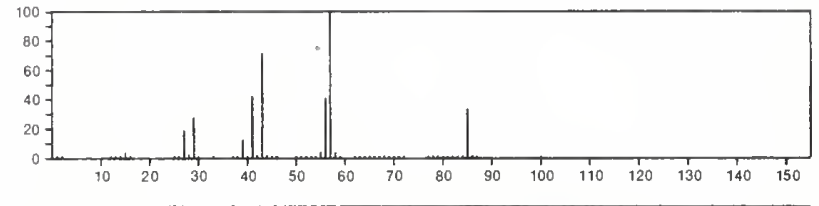

100

Hexane, 2-methyl

$\mathrm{C}_{7} \mathrm{H}_{16}$

$591-76-4$

$\mathrm{Me}_{2} \mathrm{CH}\left(\mathrm{CH}_{2}\right)_{3} \mathrm{Me}$

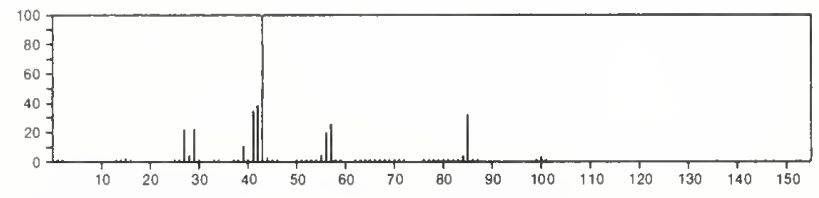

100

$\mathrm{C}_{7} \mathrm{H}_{16}$

$617-78-7$

Pentane, 3-ethyl

CHE t 3

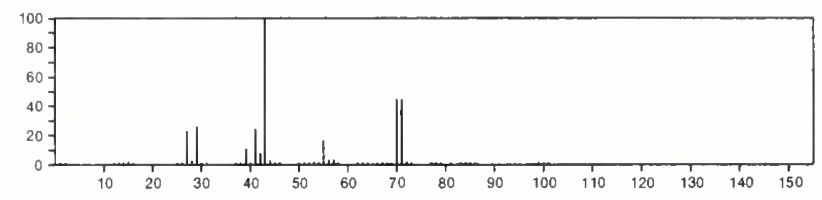

101

$\mathrm{C}_{4} \mathrm{H}_{7} \mathrm{NO}_{2}$

2-Propenamide, $\mathrm{N}$-(hydroxymethyl)-

$924-42-5$

$\mathrm{HOCH}_{2} \mathrm{NHCOCH}=\mathrm{CH}_{2}$

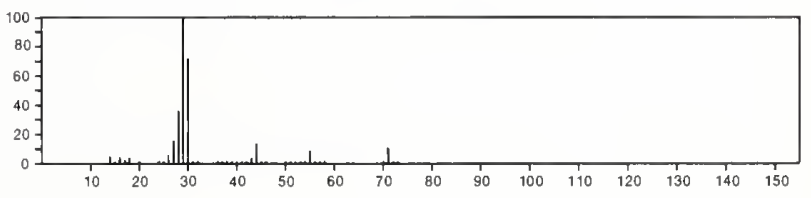


101

$\mathrm{C}_{4} \mathrm{H}_{7} \mathrm{NO}_{2}$

$19836-78-3$

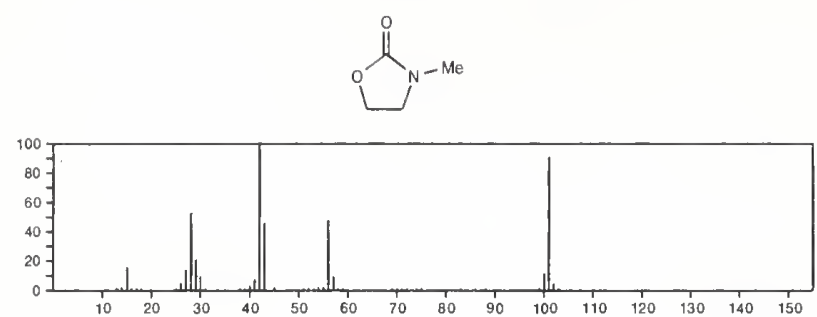

101

Cyclopropanecarboxylic acid,

$\mathrm{C}_{4} \mathrm{H}_{7} \mathrm{NO}_{2}$

22059-21-8

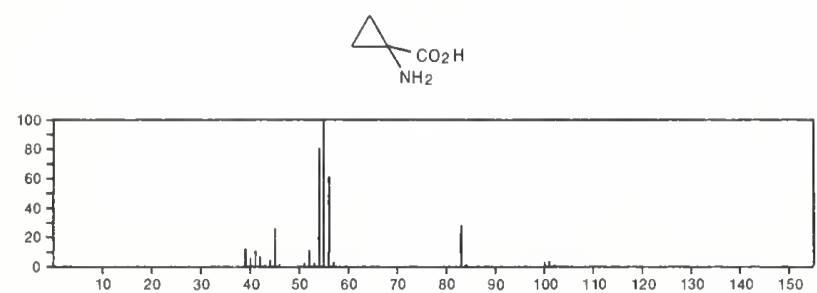

101

$\mathrm{C}_{4} \mathrm{H}_{7} \mathrm{NS}$

$628-30-8$

Propane, 1-isothiocyanato-

PrNCS

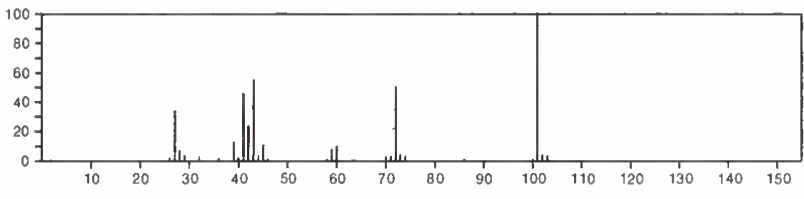

101

$\mathrm{C}_{4} \mathrm{H}_{7} \mathrm{NS}$

2295354

2-Pyrrolidinethione
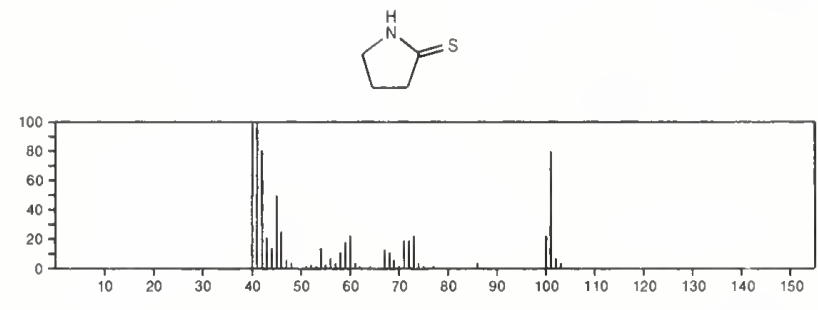

101

$\mathrm{C}_{4} \mathrm{H}_{7} \mathrm{NS}$

$4251-16-5$

Thiocyanic acid, propyl ester

PrSCN

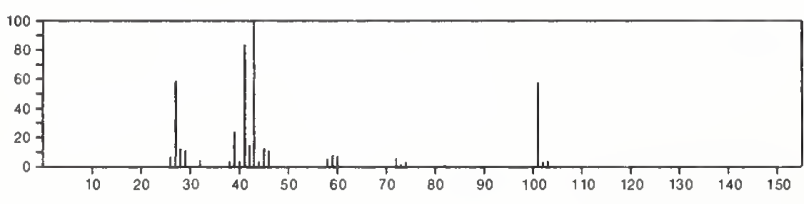

101

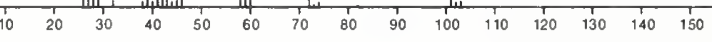

Morpholine, 4-methyl-

$\mathrm{C}_{5} \mathrm{H}_{11} \mathrm{NO}$

$109-02-4$
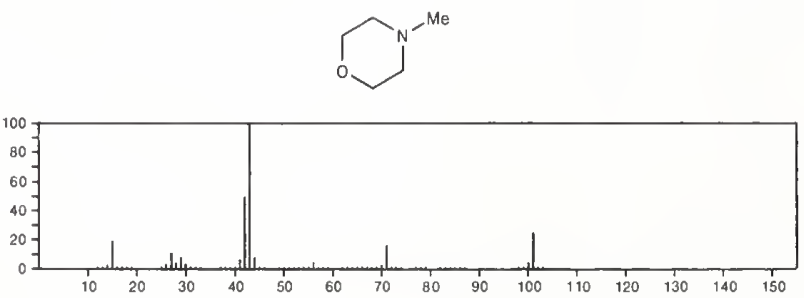

101

$\mathrm{C}_{5} \mathrm{H}_{11} \mathrm{NO}$

$541-46-8$

Butanamide, 3-methyl

$\mathrm{H}_{2} \mathrm{NCOCH}_{2} \mathrm{CHMe}_{2}$

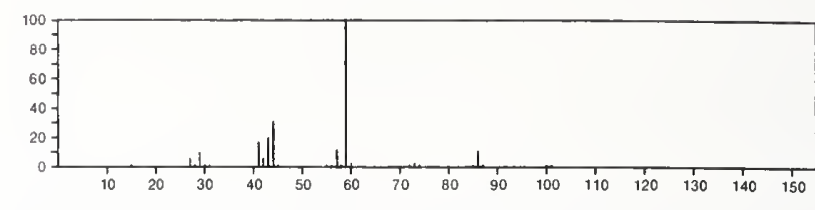

101
Formamide, $N, N$-diethyl-

$617-84-5$

$\mathrm{E}:{ }_{2} \mathrm{NCH}: \mathrm{O}$

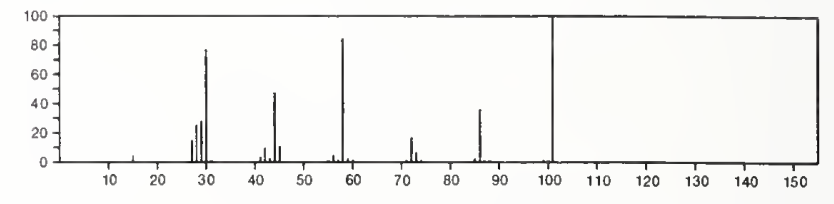

101

$\mathrm{C}_{5} \mathrm{H}_{11} \mathrm{NO}$

626-97-1

Pentanamide

$\mathrm{Me}\left(\mathrm{CH}_{2}\right)_{3} \mathrm{CONH}_{2}$

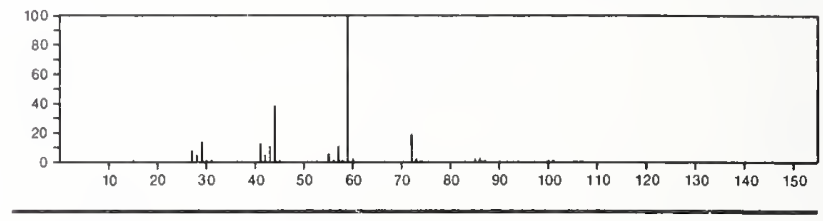

101

$\mathrm{C}_{5} \mathrm{H}_{11} \mathrm{NO}$

628-79-5

Pentanal, oxime

$\mathrm{Me}\left(\mathrm{CH}_{2}\right)_{3} \mathrm{CH}: \mathrm{NOH}$
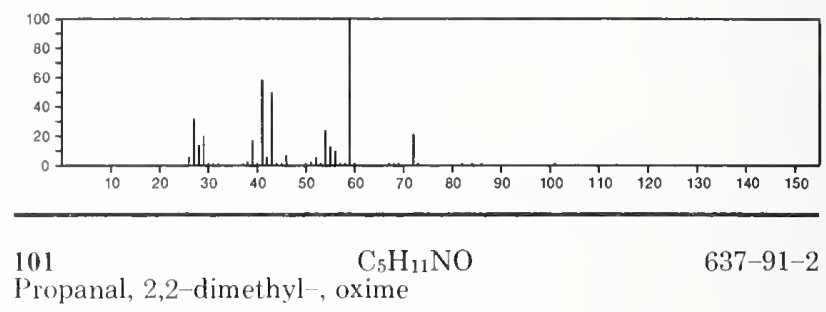

$\mathrm{HON}: \mathrm{CHCMe}_{3}$

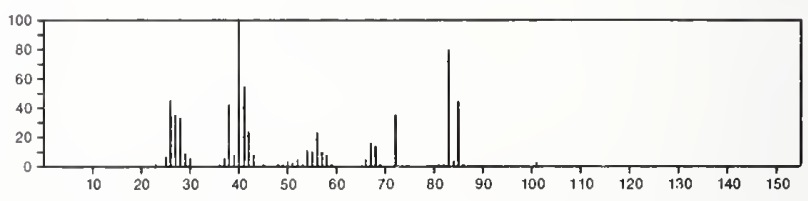

101

Propanamide, 2,2-dimethyl

$\mathrm{C}_{5} \mathrm{H}_{11} \mathrm{NO}$

$754-10-9$

$\mathrm{Me}_{3} \mathrm{CCONH}_{2}$

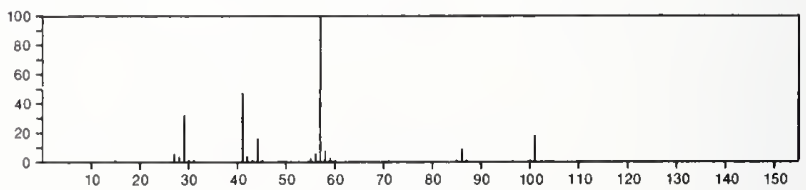


101

Formamide, $N$-butyl-

\section{$\mathrm{C}_{5} \mathrm{H}_{11} \mathrm{NO}$}

$\mathrm{Me}\left(\mathrm{CH}_{2}\right)_{3} \mathrm{NHCH}: 0$

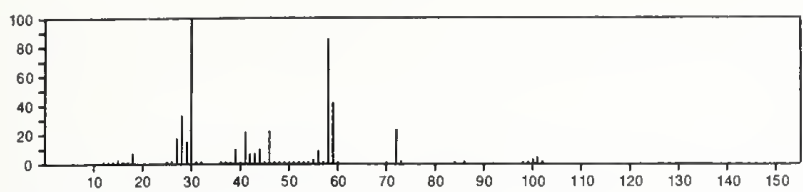

101

$\mathrm{C}_{5} \mathrm{H}_{11} \mathrm{NO}$

Formamide, $N$-(1,1-dimethylethyl)-

$2425-74-3$

$0: C H N H B u-1$

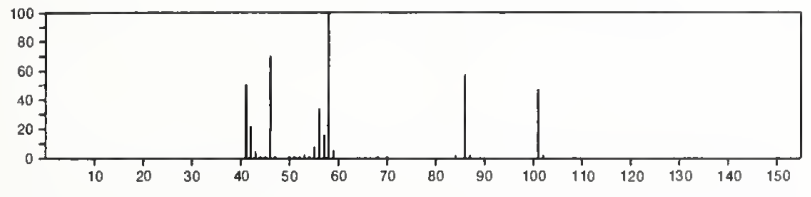

101

Propanamide, N,2-dimethyl-

$\mathrm{C}_{5} \mathrm{H}_{11} \mathrm{NO}$

MeNHCOCHME 2

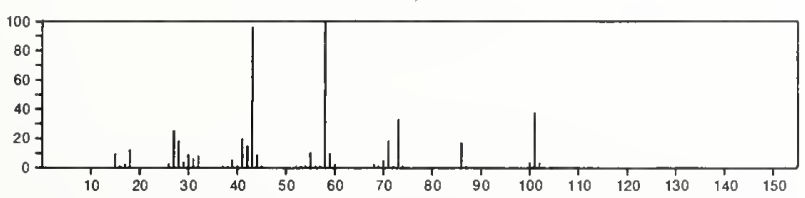

101

$\mathrm{C}_{5} \mathrm{H}_{11} \mathrm{NO}$

$5129-72-6$

Propanamide, $\mathrm{N}$-ethyl-

Et NHCOE t
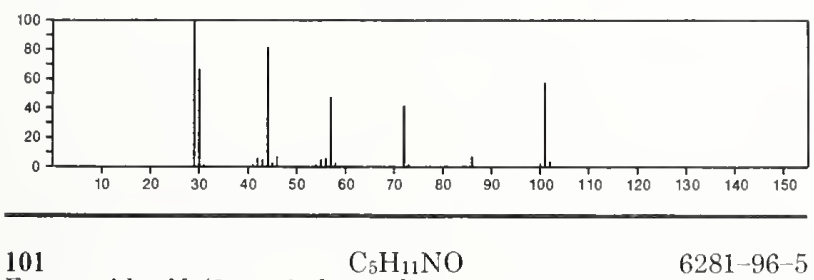

Formamide, $N-(2-$ methylpropyl)-

$6281-96-5$

$0: C H N H B U-i$

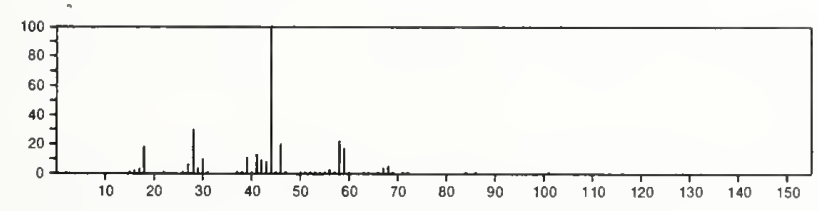

101

3-Piperidinol

$\mathrm{C}_{5} \mathrm{H}_{11} \mathrm{NO}$

6859-99-0
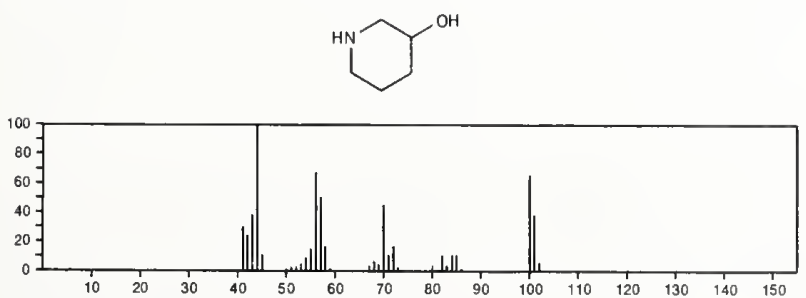

101

Butanal, $O$-methyloxime

$\mathrm{C}_{5} \mathrm{H}_{11} \mathrm{NO}$

$31376-98-4$

$\mathrm{PrCH}=\mathrm{NOME}$

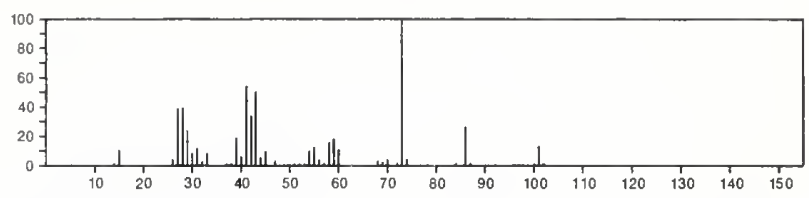

$101 \quad \mathrm{C}_{5} \mathrm{H}_{11} \mathrm{NO}$

Formamide, $\mathrm{N}$-(1-methylpropyl)

$53798-89-3$

$\mathrm{O}=\mathrm{CHNHB}-\mathrm{S}$

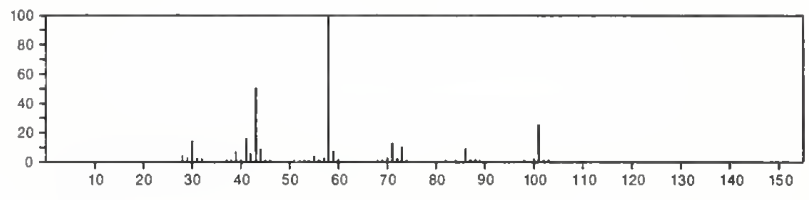

101

2-Pentanamine, 4-methyl-

$\mathrm{C}_{6} \mathrm{H}_{15} \mathrm{~N}$

$108-09-8$

$\mathrm{Me}_{2} \mathrm{CHCH}_{2} \mathrm{CH}\left(\mathrm{NH}_{2}\right) \mathrm{Me}$

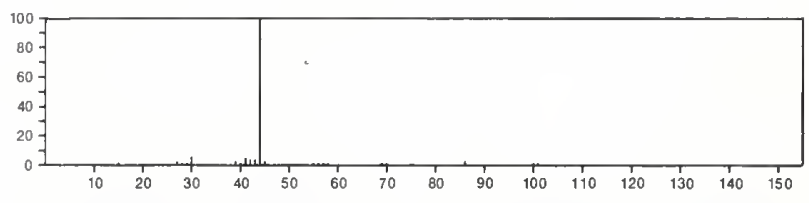

101

$\mathrm{C}_{6} \mathrm{H}_{15} \mathrm{~N}$

2-Propanamine, $N$-(1-methylethyl)-

$108-18-9$

$\mathrm{NH}(\mathrm{Pr}-\mathrm{i})_{2}$
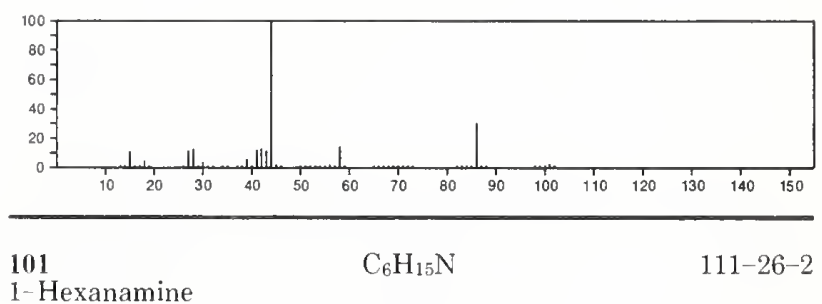

$111-26-2$

$\mathrm{Me}\left(\mathrm{CH}_{2}\right)_{5} \mathrm{NH}_{2}$

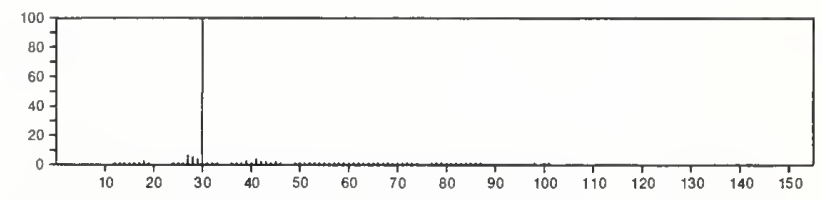

101

$121-44-8$

NE 13

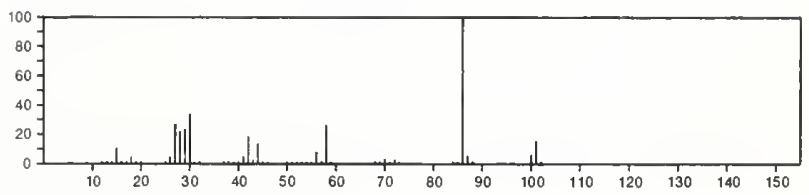


101

1-Propanamine, $N$-propyl-- ${ }^{\mathrm{C}_{6} \mathrm{H}_{15} \mathrm{~N}}$
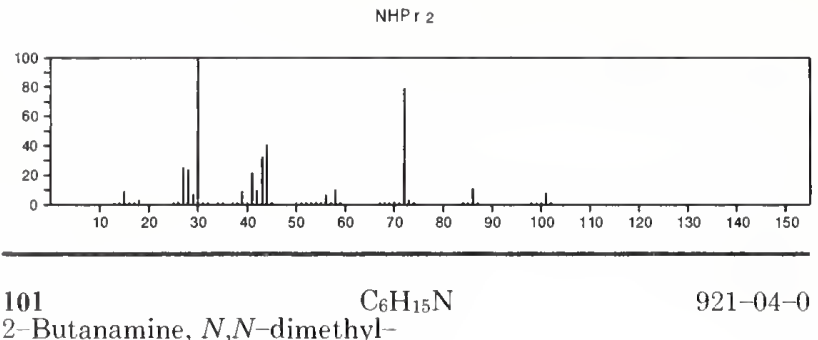

2-Butanamine, $N, N$-dimethyl-

$\mathrm{Me}{ }_{2} \mathrm{NBu}-\mathrm{s}$

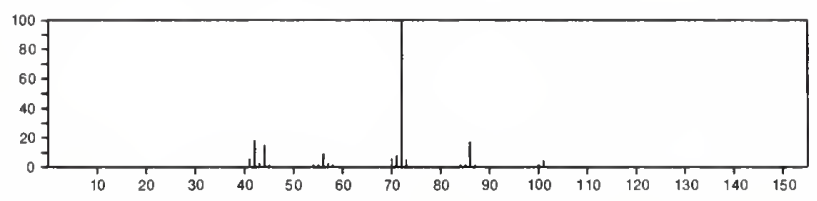

101

1-Butanamine, $N, N$-dimethyl

$\mathrm{C}_{6} \mathrm{H}_{15} \mathrm{~N}$

$\mathrm{Me} 2 \mathrm{~N}\left(\mathrm{CH}_{2}\right)_{3} \mathrm{Me}$

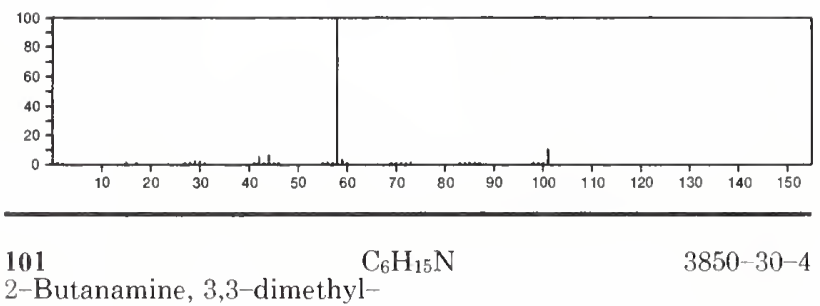

$\mathrm{Me} \mathrm{CH}\left(\mathrm{NH}_{2}\right) \mathrm{CMe}_{3}$

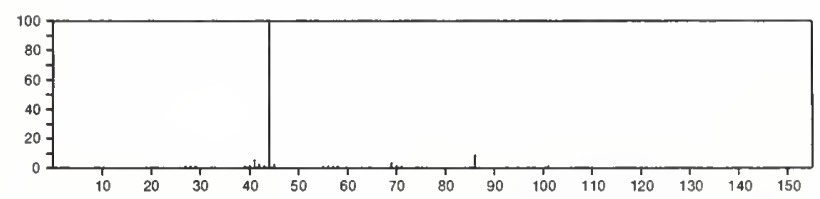

$101 \quad \mathrm{C}_{6} \mathrm{H}_{15} \mathrm{~N}$

1-Butanamine, N,3-dimethyl-

4104-44-3

$\mathrm{Me}_{2} \mathrm{CHCH}_{2} \mathrm{CH}_{2} \mathrm{NHMe}$

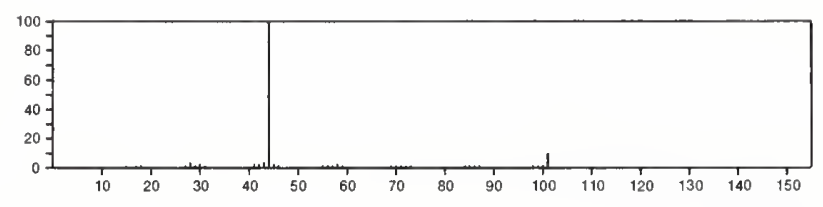

101

$\mathrm{C}_{6} \mathrm{H}_{15} \mathrm{~N}$

1-Propanamine, $N$-ethyl- $N$-methyl-

4458-32-6

PrNEt (Me)

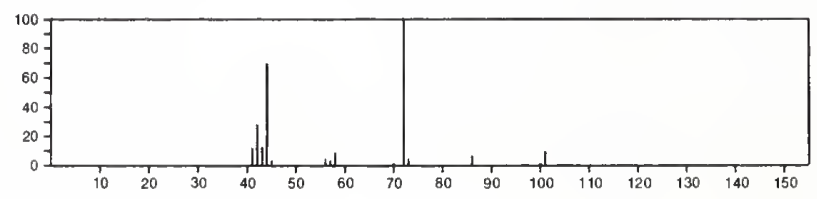

101

2-Hexanamine

$\mathrm{C}_{6} \mathrm{H}_{15} \mathrm{~N}$

$5329-79-3$

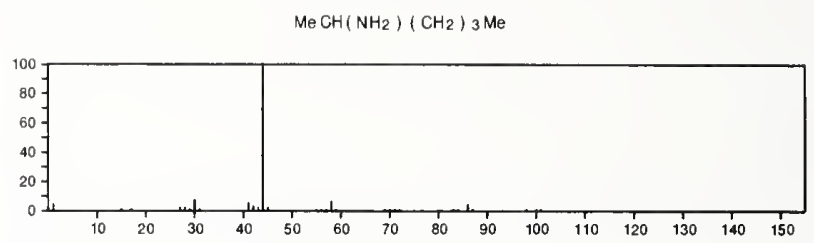

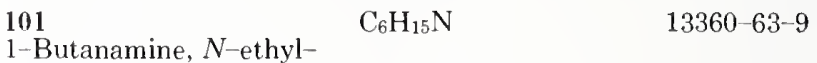

$\mathrm{Me}\left(\mathrm{CH}_{2}\right)_{3} \mathrm{NHEt}$

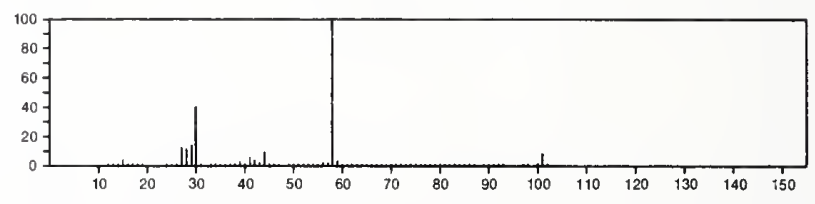

101

3-Hexanamine

$\mathrm{C}_{6} \mathrm{H}_{15} \mathrm{~N}$

$16751-58-9$

$\operatorname{PrCHE}+\left(\mathrm{NH}_{2}\right)$

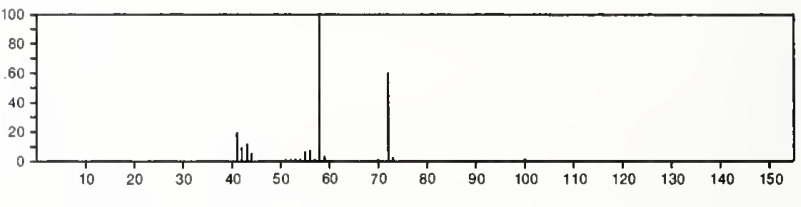

101

$\mathrm{C}_{6} \mathrm{H}_{45} \mathrm{~N}$

25419-06-1

1 Pentanamine, $N$-methyl

$\mathrm{MeNH}\left(\mathrm{CH}_{2}\right){ }_{4} \mathrm{Me}$

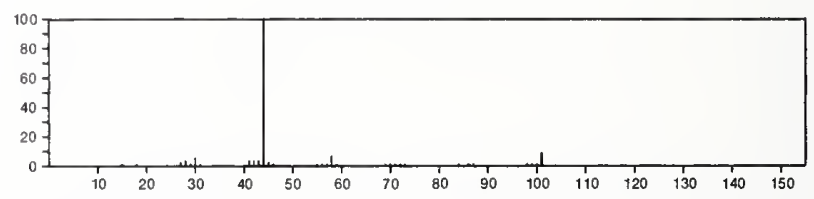

102

$\mathrm{CHCl}_{2} \mathrm{~F}$

75-43-4

Methane, dichlorofluoro-

$\mathrm{FCHCl}_{2}$

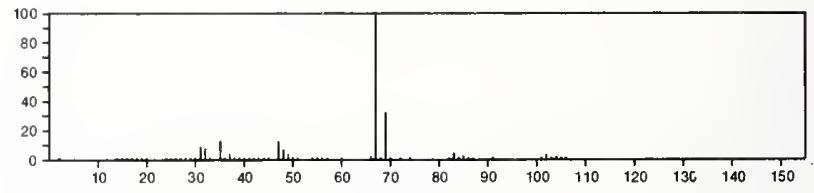

102

$\mathrm{CHF}_{3} \mathrm{~S}$

$1493-15-8$

Methanethiol, trifluoro-

$\mathrm{F}_{3} \mathrm{CSH}$

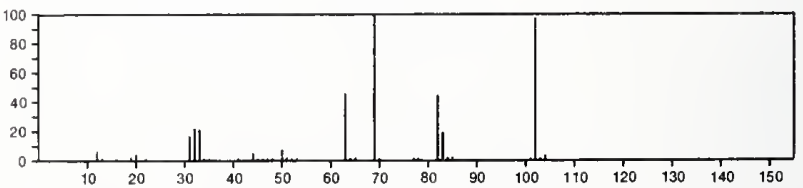


102

$\mathrm{C}_{2} \mathrm{H}_{2} \mathrm{~F}_{4}$

359-35-3

Ethane, 1,1,2,2-tetrafluoro-

$\mathrm{F}_{2} \mathrm{CHCHF}_{2}$

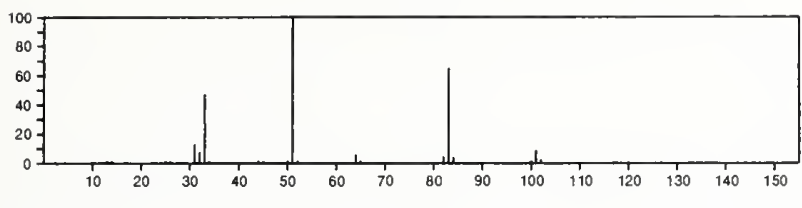

102

$\mathrm{C}_{2} \mathrm{H}_{2} \mathrm{~F}_{4}$

$811-97-2$

Ethane, 1,1,1,2-tetrafluoro-

$\mathrm{FCH}_{2} \mathrm{CF}_{3}$

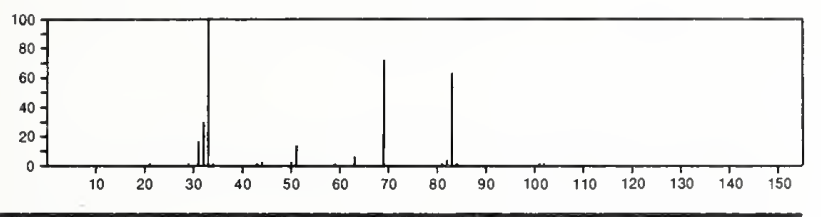

102

$\mathrm{C}_{3} \mathrm{H}_{2} \mathrm{O}_{4}$

$25260-20-2$

1,3-Dioxolane-4,5-dione
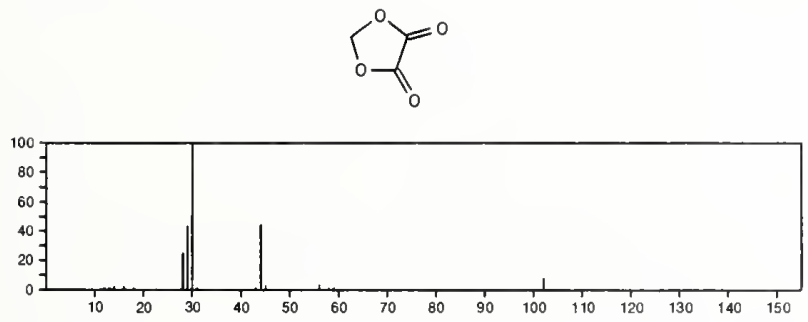

102

1H-Pyrazole, 4-chloro-

$\mathrm{C}_{3} \mathrm{H}_{3} \mathrm{ClN}_{2}$

$15878-00-9$
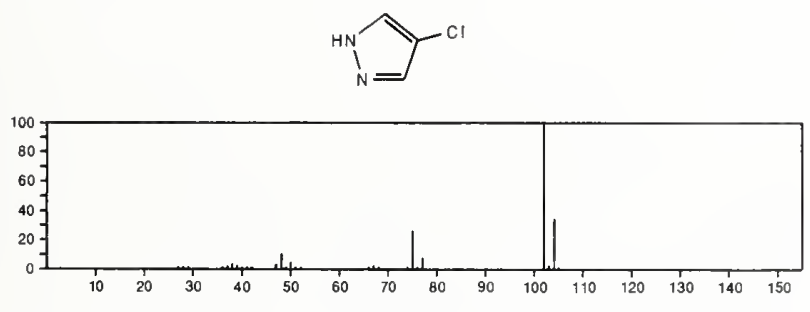

102

Acetic acid, anhydride

$\mathrm{C}_{4} \mathrm{H}_{6} \mathrm{O}_{3}$

$108-24-7$

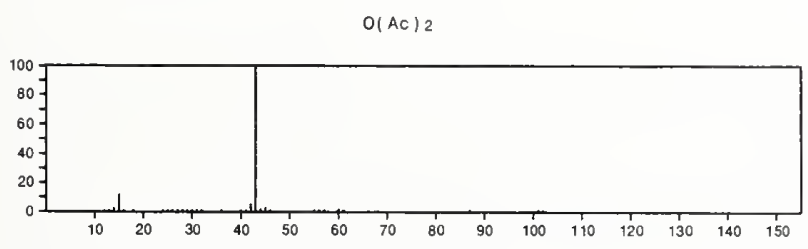

$102 \quad \mathrm{C}_{4} \mathrm{H}_{6} \mathrm{O}_{3}$

$108-32-7$

1,3-Dioxolan-2-one, 4-methyl-
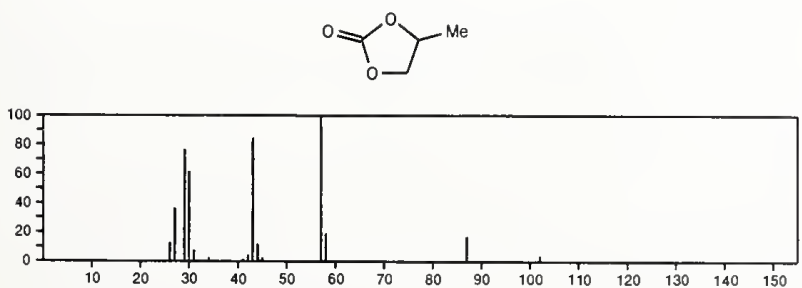

102

$\mathrm{C}_{4} \mathrm{H}_{6} \mathrm{O}_{3}$

Propanoic acid, 2-oxo-, methyl ester

$600-22-6$

$\mathrm{MeCOC}(\mathrm{O}) \mathrm{OMe}$

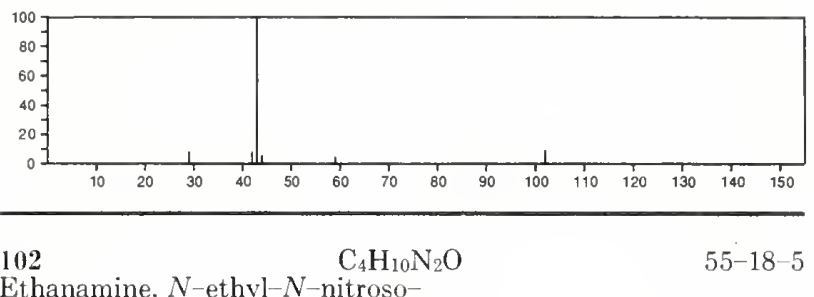

E ${ }_{2}$ NNO

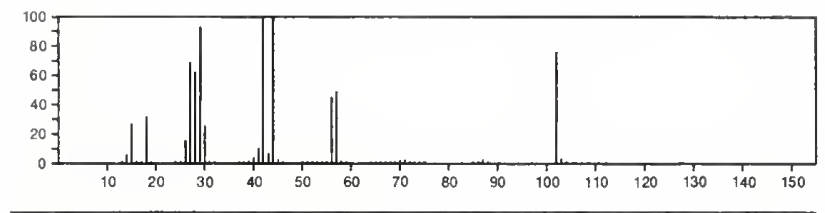

102

Urea, trimethyl-

$\mathrm{C}_{4} \mathrm{H}_{10} \mathrm{~N}_{2} \mathrm{O}$

$632-14-4$

Me NHCONMe 2

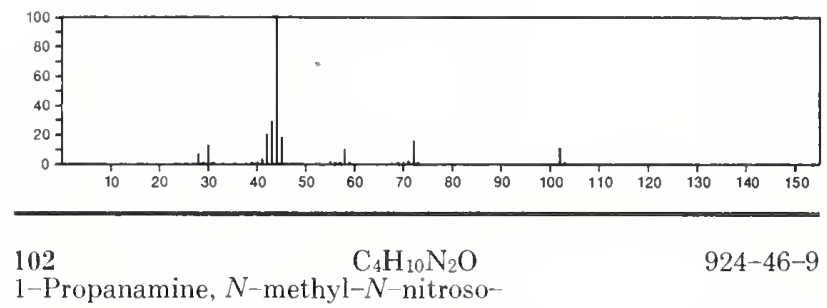

PrNMe(NO)

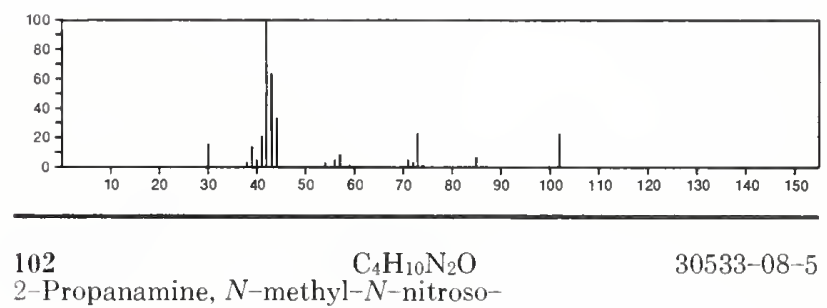

MeN(NO) Pr-i

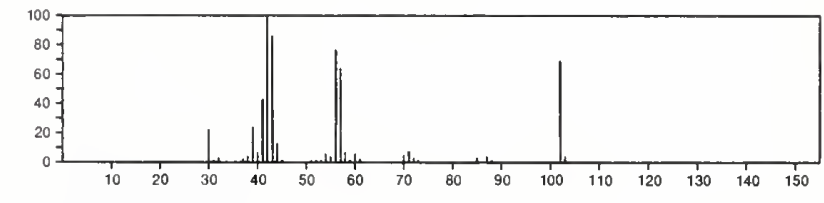

102

$\mathrm{C}_{4} \mathrm{H}_{11} \mathrm{BO}_{2}$

Boronic acid, ethyl-, dimethyl ester

$7318-82-3$

Me OBE I OMe
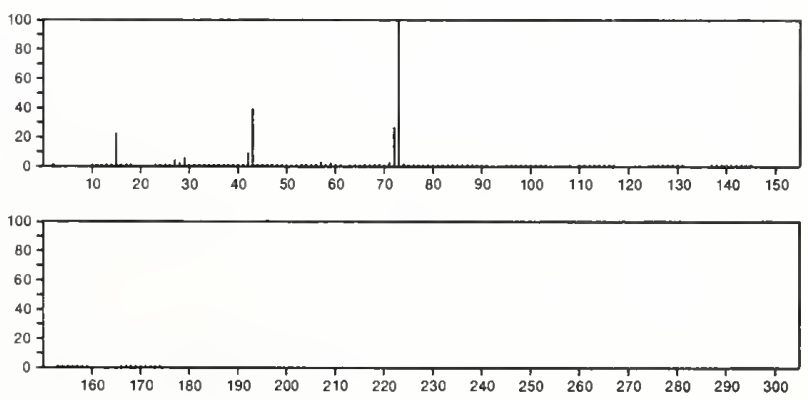
102

Propanoic acid, 2,2-dimethyl-

$\mathrm{C}_{5} \mathrm{H}_{10} \mathrm{O}_{2}$

$\mathrm{Me}_{3} \mathrm{CCO}_{2} \mathrm{H}$

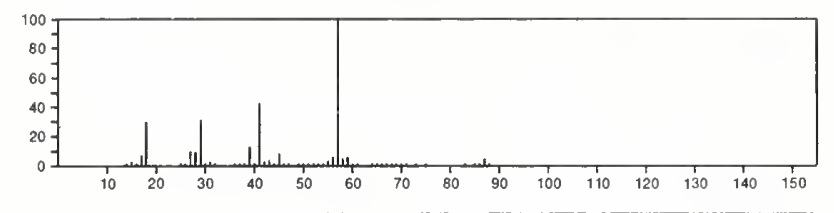

102

$\mathrm{C}_{5} \mathrm{H}_{10} \mathrm{O}_{2}$

$97-99-4$

2-Furanmethanol, tetrahydro-

$\sum^{0} \mathrm{CH}^{\mathrm{CH}_{2} \mathrm{OH}}$

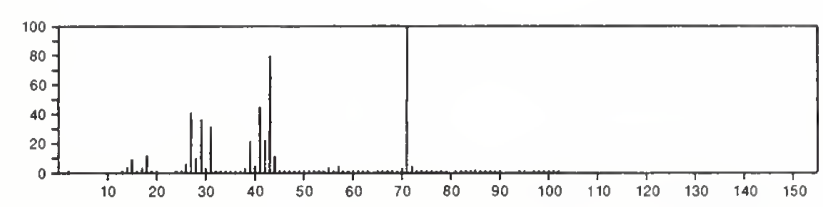

$102 \quad \mathrm{C}_{5} \mathrm{H}_{10} \mathrm{O}_{2}$

$105-37-3$

Propanoic acid, ethyl ester

Etoc(O)Et

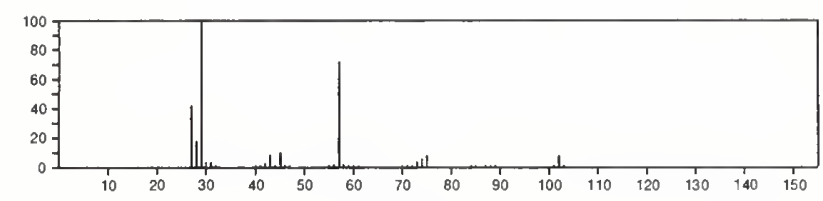

102

Acetic acid, 1-methylethyl $\mathrm{C}_{5} \mathrm{H}_{10} \mathrm{O}$

$108-21-4$
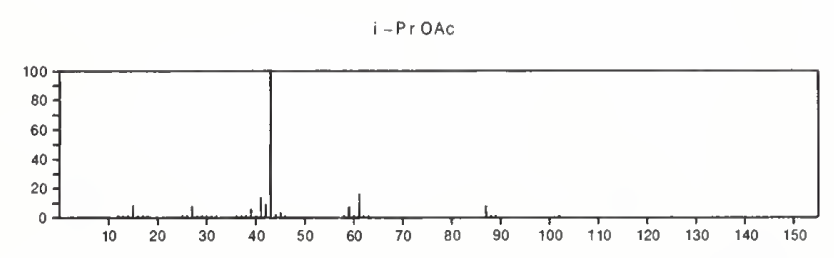

102

Pentanoic acid

$\mathrm{C}_{5} \mathrm{H}_{10} \mathrm{O}_{2}$

$109-52-4$

$\mathrm{HO}_{2} \mathrm{C}\left(\mathrm{CH}_{2}\right)_{3} \mathrm{Me}$

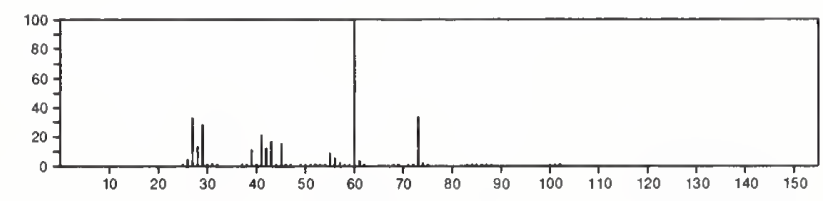

$102 \quad \mathrm{C}_{5} \mathrm{H}_{10} \mathrm{O}_{2}$

$109-60-4$

Acetic acid, propyl ester

PrOAC

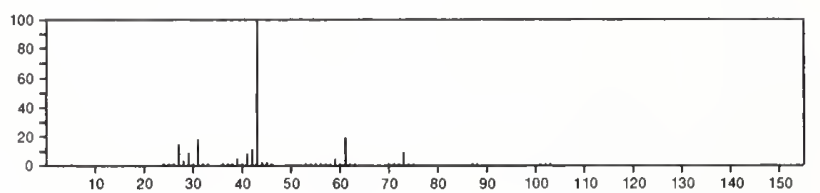

102

2-Butanone, 3-hydi

$115-22-0$

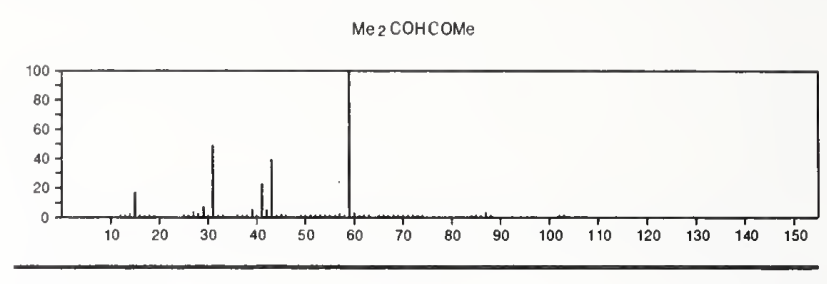

102

Butanoic acid, 2-methyl-

$\mathrm{C}_{5} \mathrm{H}_{10} \mathrm{O}_{2}$

$116-53-0$

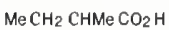

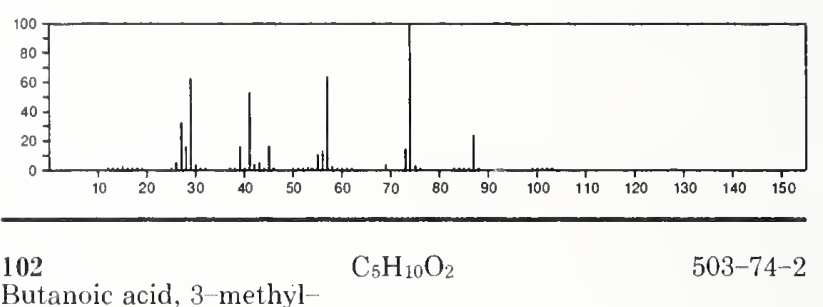

$\mathrm{Me}_{2} \mathrm{CHCH}_{2} \mathrm{CO}_{2} \mathrm{H}$

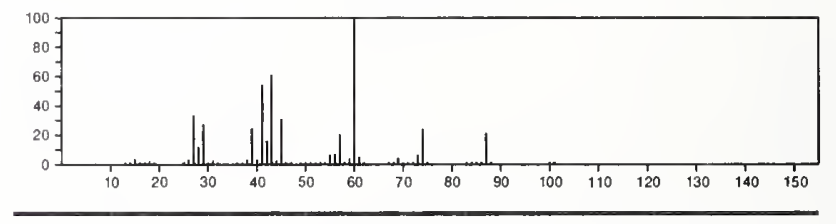

102

$\mathrm{C}_{5} \mathrm{H}_{10} \mathrm{O}_{2}$

Folmic acid, 2-methylpropyl ester

$542-55-2$

$\mathrm{O}=\mathrm{CHOBu}-\mathrm{i}$

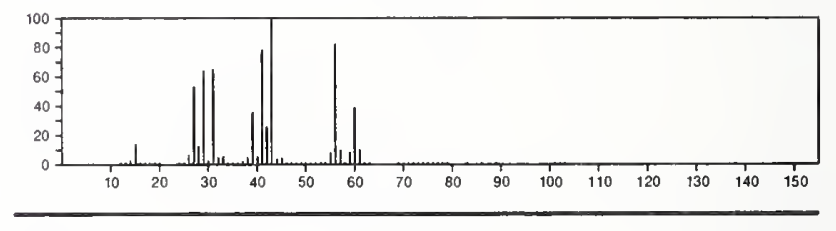

102

$\mathrm{C}_{5} \mathrm{H}_{10} \mathrm{O}$

Propanoic acid, 2-methyl-, methyl ester

$547-63-7$

$\mathrm{MeOC}(\mathrm{O}) \mathrm{CHMe}$

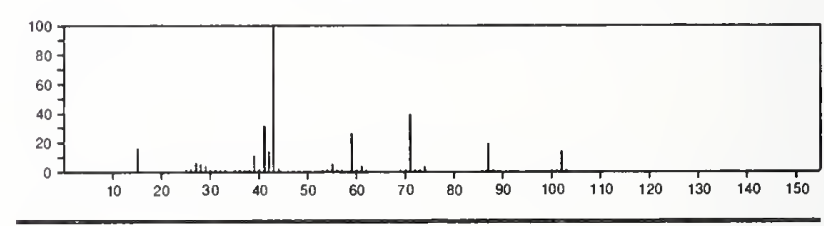

102

$\mathrm{C}_{5} \mathrm{H}_{10} \mathrm{O}_{2}$

Formic acid, 1-methylpropyl ester

$589-40-2$

$0=$ CHOBu $-\mathrm{s}$

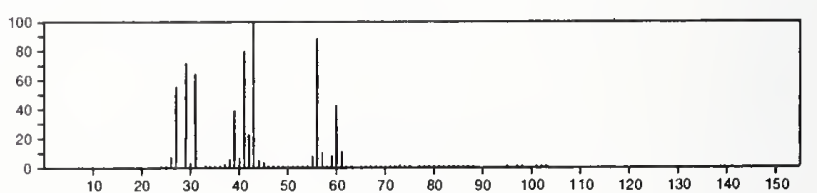


102

Formic acid, butyl ester

$\mathrm{C}_{5} \mathrm{H}_{10} \mathrm{O}_{2}$

$\mathrm{Me}\left(\mathrm{CH}_{2}\right)_{3} \mathrm{OCH}=0$

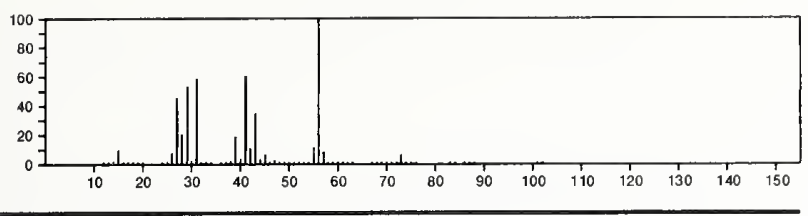

102

Butanoic acid, methyl ester

$$
\mathrm{C}_{5} \mathrm{H}_{10} \mathrm{O}_{2}
$$

$623-42-7$

$\mathrm{MeOC}(\mathrm{O}) \mathrm{Pr}$

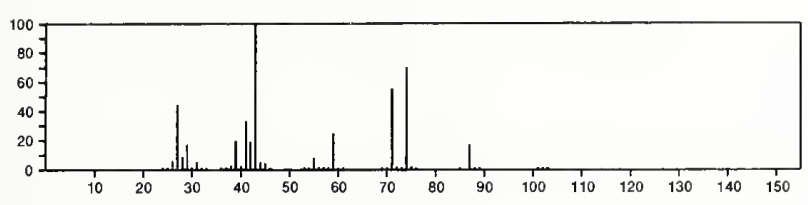

102

$2 \mathrm{H}$-Pyran-2-ol, tetrahydro-

\section{$\mathrm{C}_{5} \mathrm{H}_{10} \mathrm{O}_{2}$}

$694-54-2$
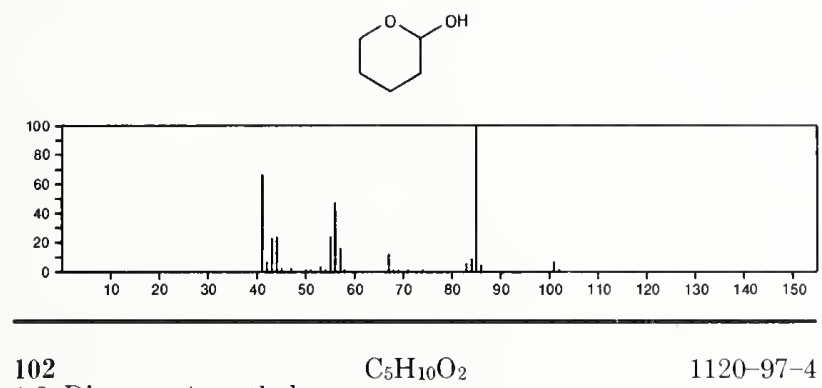

1,3-Dioxane, 4-methyl-
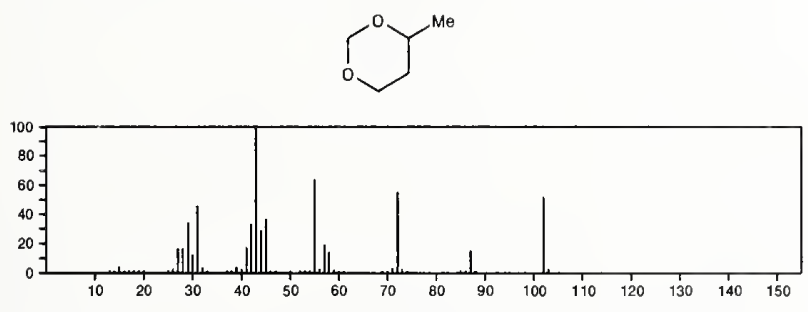

102

Ethene, (2-methoxyethoxy)-

$\mathrm{C}_{5} \mathrm{H}_{10} \mathrm{O}_{2}$

1663-35-0

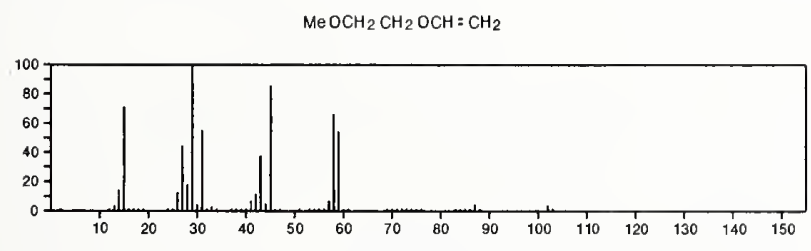

\section{2}

1,3-Dioxolane, 2-ethyl-

$\mathrm{C}_{5} \mathrm{H}_{10} \mathrm{O}_{2}$

2568-96-9
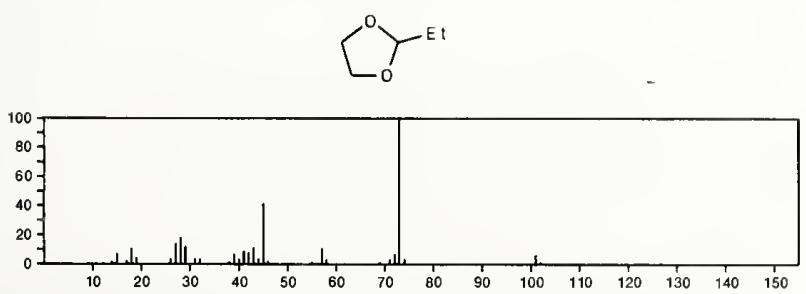

102

Propanal, 3-ethoxy-

$\mathrm{C}_{5} \mathrm{H}_{10} \mathrm{O}_{2}$

2806-85-1

$\mathrm{OCHCH}_{2} \mathrm{CH}_{2} \mathrm{OE} \mathrm{t}$

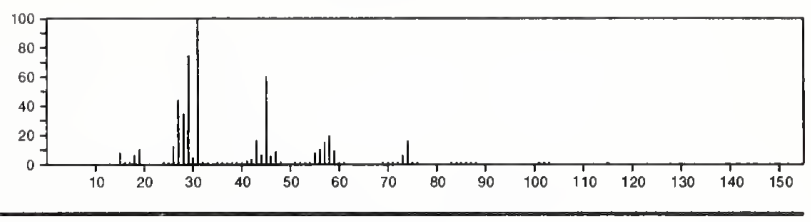

102

$\mathrm{C}_{5} \mathrm{H}_{10} \mathrm{O}_{2}$

2-Butanone, 4-hydroxy-3-methyl-

3393-64-4

$\mathrm{Me} \mathrm{COCHMe} \mathrm{CH}_{2} \mathrm{OH}$

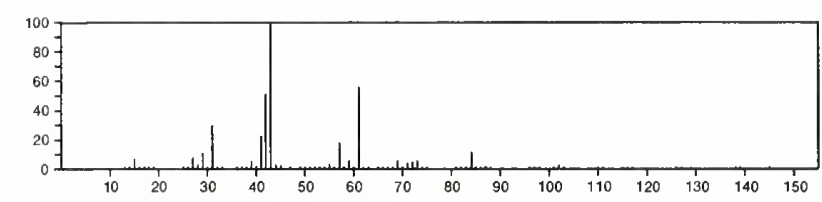

102

Oxirane, (ethoxymethyl)-

$\mathrm{C}_{5} \mathrm{H}_{10} \mathrm{O}_{2}$

4016-11-9
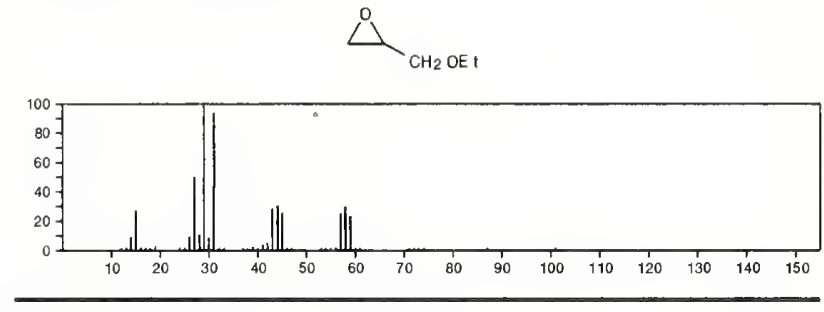

102

$\mathrm{C}_{5} \mathrm{H}_{10} \mathrm{O}_{2}$

$5057-99-8$

1,2-Cyclopentanediol, trans-
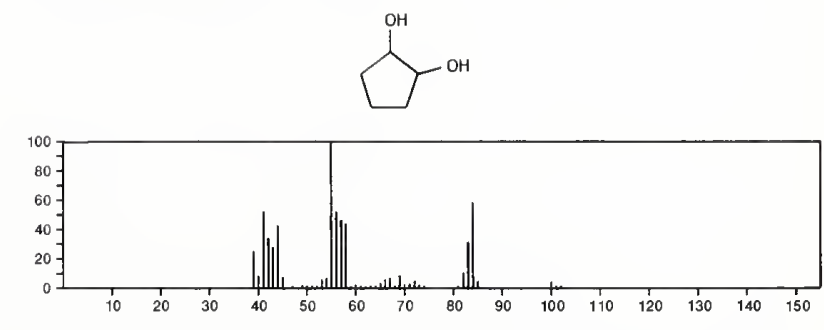

102

2-Furanol, tetrahydro-2-methyl-

$7326-46-7$

${ }^{\mathrm{O}} \mathrm{K}_{\mathrm{Me}}^{\mathrm{OH}}$

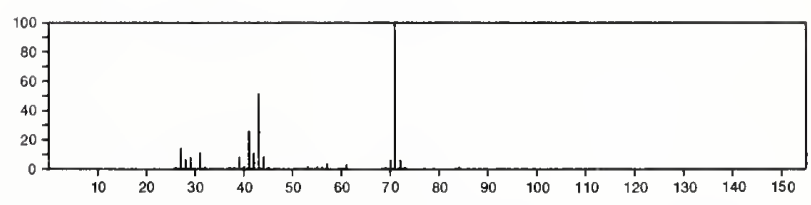

102

$\mathrm{C}_{5} \mathrm{H}_{10} \mathrm{O}_{2}$

16326-97-9

1,3-Cyclopentanediol, cis-
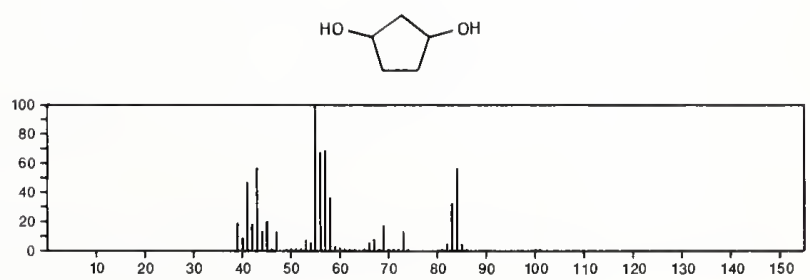
102

$1,3-\mathrm{Cyclopentanediol,} \quad \mathrm{C}_{5} \mathrm{H}_{10} \mathrm{O}_{2}$

$16326-98-0$
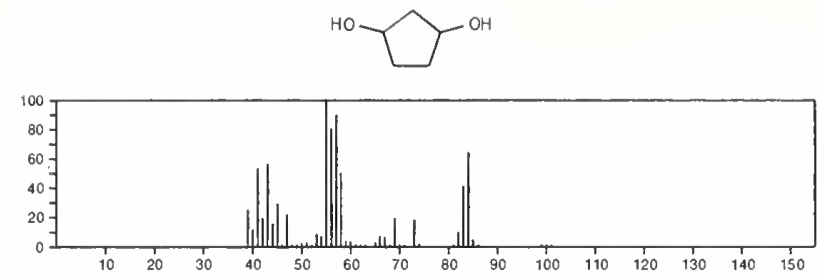

102

1,3-Dioxolane, 4-ethyl-

$\mathrm{C}_{5} \mathrm{H}_{10} \mathrm{O}_{2}$
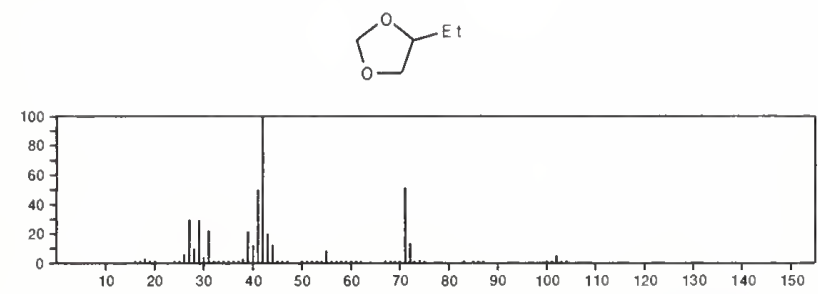

$102 \quad \mathrm{C}_{5} \mathrm{H}_{10} \mathrm{O}_{2}$

Butanal, 4-hydroxy-3-methyl-

$56805-34-6$

$\mathrm{OCHCH}_{2} \mathrm{CHMeCH}_{2} \mathrm{OH}$

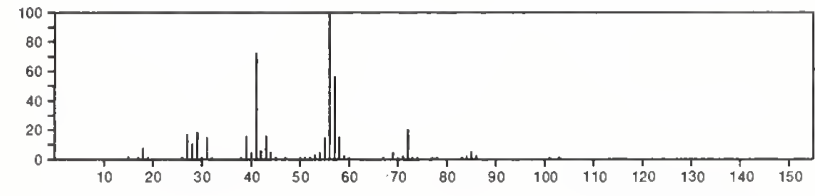

102

$\mathrm{C}_{5} \mathrm{H}_{10} \mathrm{~S}$

$1613-51-0$

2H-Thiopyran, tetrahydro-
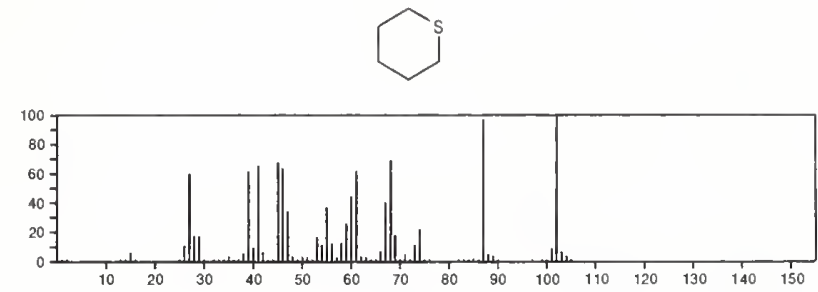

102

Cyclopentanethiol

$\mathrm{C}_{5} \mathrm{H}_{10} \mathrm{~S}$

1679-07-8<smiles>SC1CCCC1</smiles>

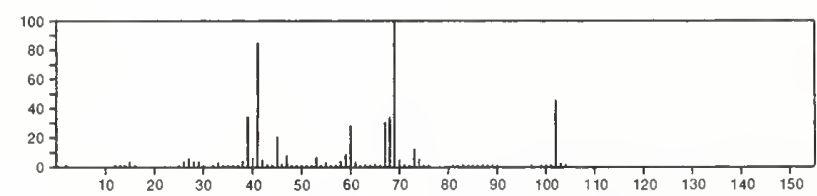

102

Thiophene, tetrahydro-2-methyl

$\mathrm{C}_{5} \mathrm{H}_{10} \mathrm{~S}$

1795-09-1
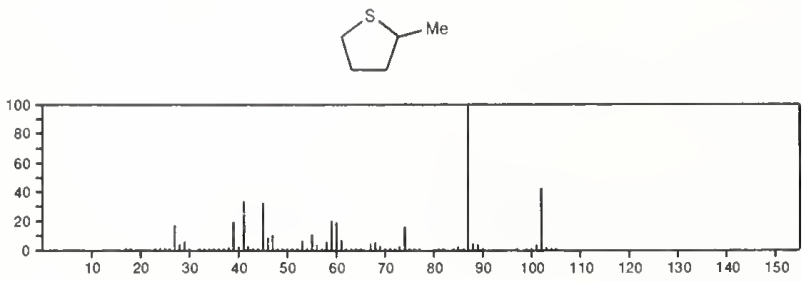

102

Thiophene, tetrahydro-3-methyl

$4740-00-5$

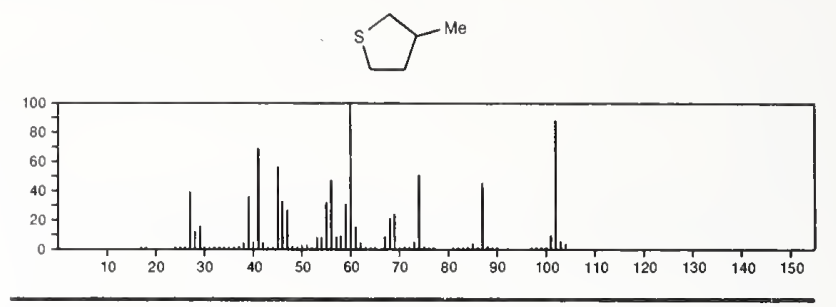

102

$\mathrm{C}_{5} \mathrm{H}_{10 \mathrm{~S}}$

$43044-24-2$

Thietane, 2,4-dimethyl-
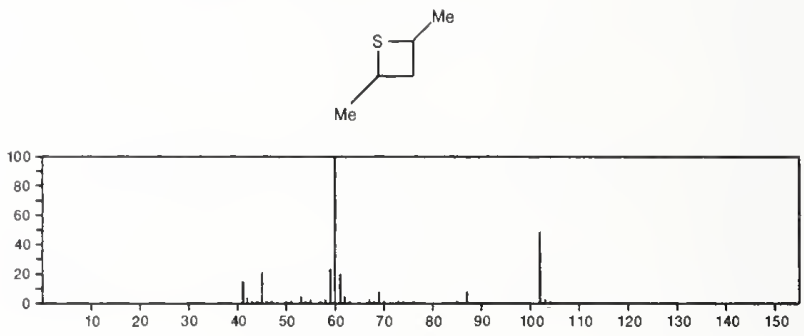

$102 \quad \mathrm{C}_{5} \mathrm{H}_{14} \mathrm{~N}_{2}$

Methanediamine, $N, N, N^{\prime}, N^{\prime}$-tetramethyl-

$51-80-9$

$\mathrm{Me}{ }_{2} \mathrm{NCH}_{2} \mathrm{NMe}_{2}$

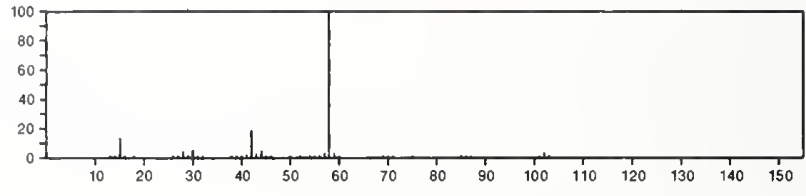

102

$\mathrm{C}_{5} \mathrm{H}_{14} \mathrm{~N}_{2}$

$109-55-7$

1,3-Propanediamine, $N, N$-dimethyl-

$\mathrm{Me}_{2} \mathrm{~N}\left(\mathrm{CH}_{2}\right)_{3} \mathrm{NH}_{2}$

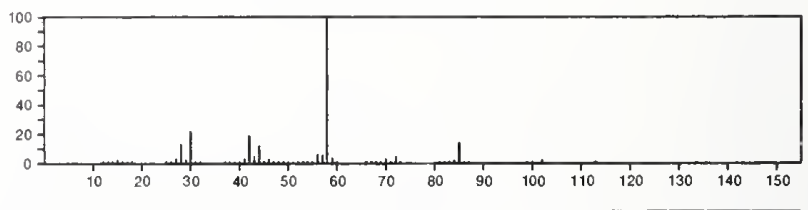

102

$\mathrm{C}_{6} \mathrm{H}_{11} \mathrm{~F}$

$372-46-3$

Cyclohexane, fluoro-
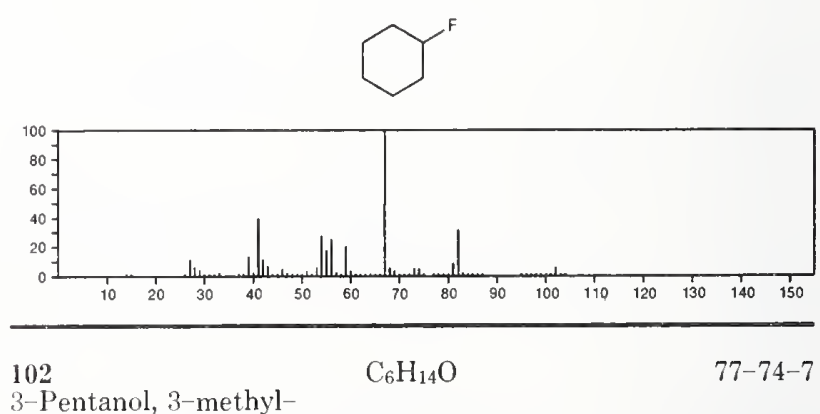

3-Pentanol, 3-methyl-

$\mathrm{E}: 2 \mathrm{CMe}(\mathrm{OH})$

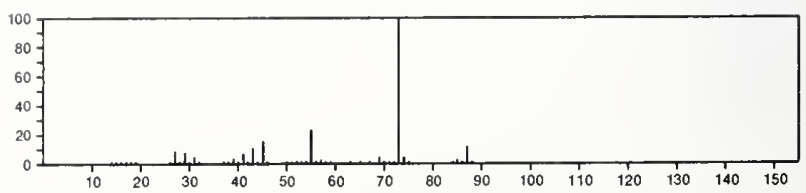


102

1-Butanol, 2-ethyl-

$\mathrm{C}_{6} \mathrm{H}_{14} \mathrm{O}$

$\mathrm{HOCH}_{2} \mathrm{CHE}_{2}$

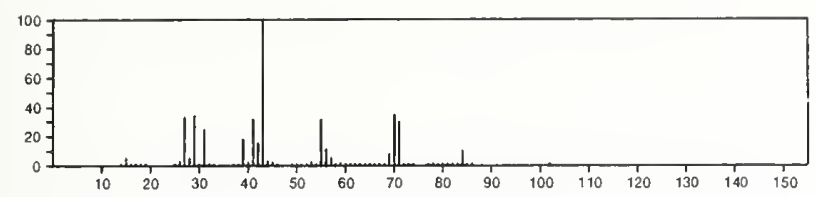

102

1-Pentanol, 2-methyl-

$\mathrm{C}_{6} \mathrm{H}_{14} \mathrm{O}$

105-30-6

$\mathrm{HOCH}_{2} \mathrm{CHP}_{\mathrm{H}} \mathrm{Me}$

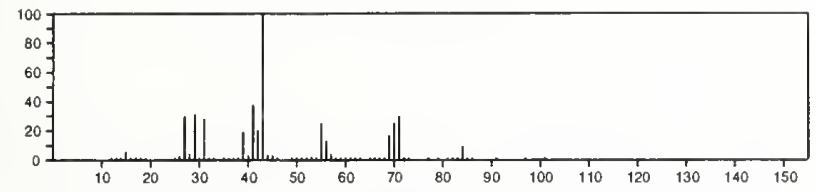

102

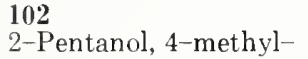

$\mathrm{C}_{6} \mathrm{H}_{14} \mathrm{O}$

$\mathrm{Me}_{2} \mathrm{CHCH}_{2} \mathrm{CH}(\mathrm{OH}) \mathrm{Me}$

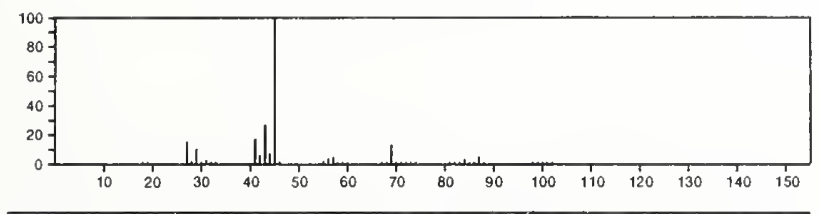

102

Propane, 2,2'-oxybis-

$\mathrm{C}_{6} \mathrm{H}_{14} \mathrm{O}$

$0(\operatorname{Pr}-i) 2$

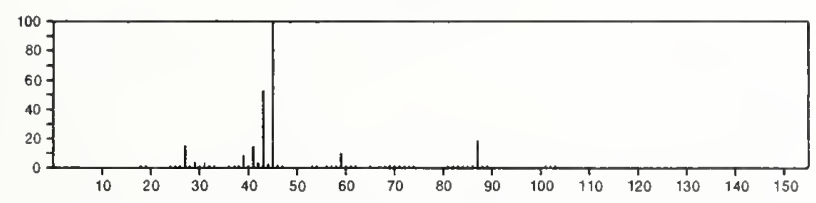

102

1-Hexanol

$\mathrm{C}_{6} \mathrm{H}_{14} \mathrm{O}$

111-27-3

$\mathrm{Me}\left(\mathrm{CH}_{2}\right) 5 \mathrm{OH}$

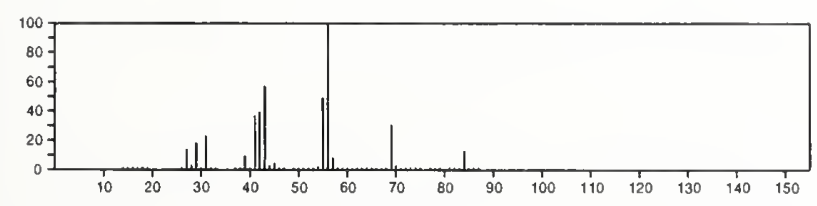

10

102
Propane, 1,1'-oxybis-

$\mathrm{C}_{6} \mathrm{H}_{14} \mathrm{O}$

$\mathrm{OPr}_{2}$

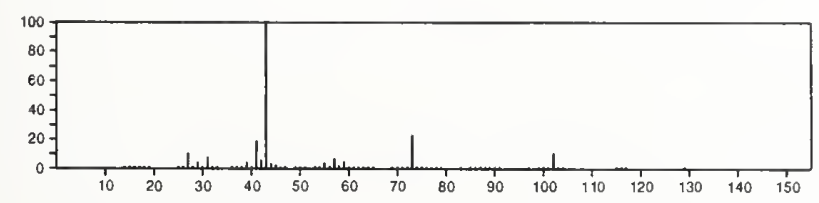

102

2-Butanol, 3,3-dimethyl

$\mathrm{C}_{6} \mathrm{H}_{14} \mathrm{O}$

464-07-3

$\mathrm{MeCH}(\mathrm{OH}) \mathrm{CMe}_{3}$

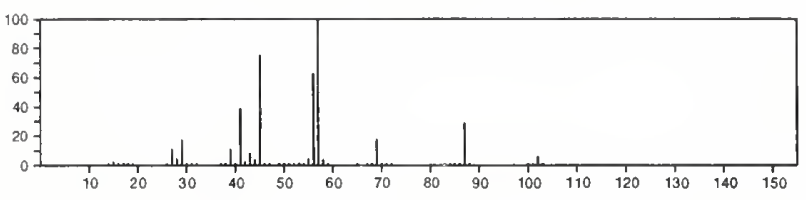

102

2-Pentanol, 3-methyl-

$\mathrm{C}_{6} \mathrm{H}_{14} \mathrm{O}$

565-60-6

$\mathrm{MeCH}_{2} \mathrm{CHMeCH}(\mathrm{OH}) \mathrm{Me}$

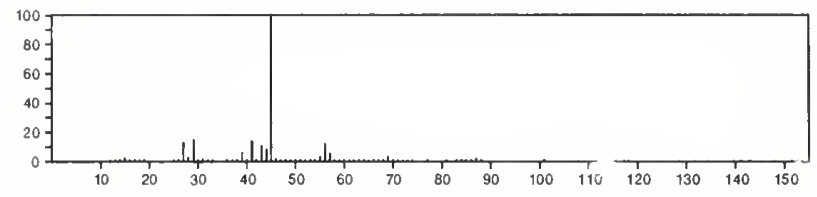

102

3-Pentanol, 2-methyl-

$\mathrm{C}_{6} \mathrm{H}_{14} \mathrm{O}$

565-67-3

$\mathrm{Me}_{2} \mathrm{CHCH}(\mathrm{OH}) \mathrm{Et}$

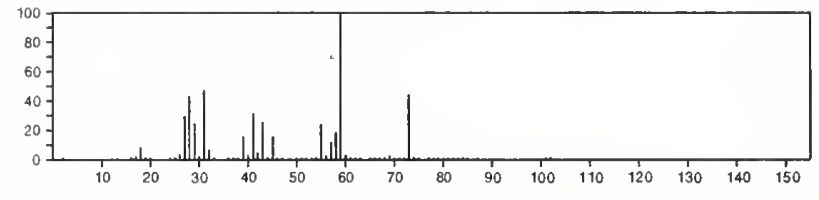

102

1-Pentanol, 3-methyl-

$\mathrm{C}_{6} \mathrm{H}_{14} \mathrm{O}$

589-35-5

$\mathrm{HOCH}_{2} \mathrm{CH}_{2} \mathrm{CHMeCH}_{2} \mathrm{Me}$

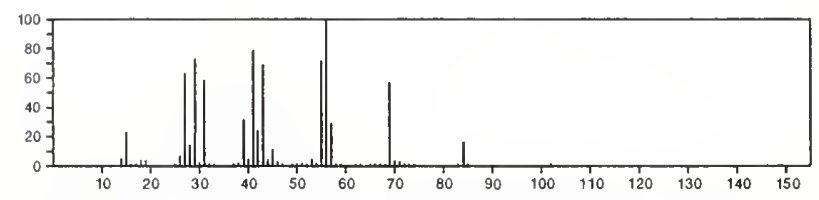

102

2-Pentanol, 2-methyl-

$\mathrm{C}_{6} \mathrm{H}_{14} \mathrm{O}$

$590-36-3$

$\operatorname{PrCMe} 2(\mathrm{OH})$

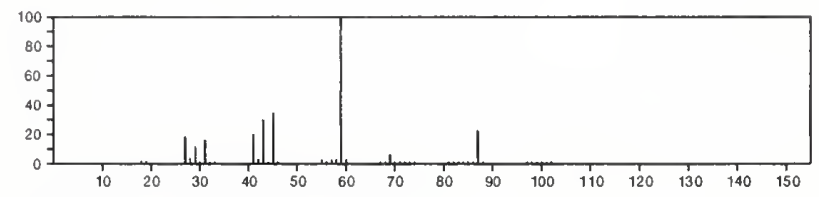

$102 \quad \mathrm{C}_{6} \mathrm{H}_{14} \mathrm{O}$

2-Butanol, 2,3-dimethyl-

$\mathrm{Me}_{2} \mathrm{CHCMe}_{2} \mathrm{OH}$

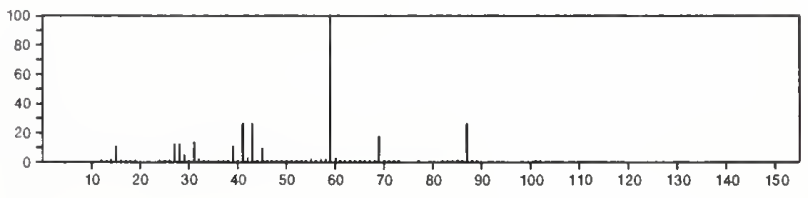


102

3-Hexanol

$\mathrm{C}_{6} \mathrm{H}_{14} \mathrm{O}$

$\operatorname{PrCHE}:(\mathrm{OH})$

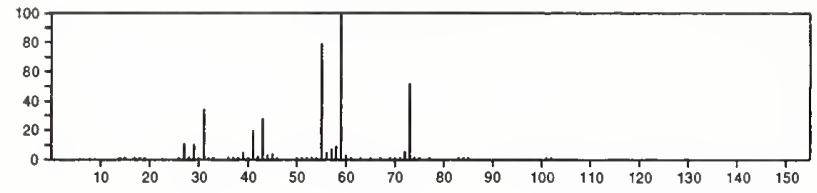

102

$\mathrm{C}_{6} \mathrm{H}_{14} \mathrm{O}$

1-Butanol, 3,3-dimethyl-

$\mathrm{HOCH}_{2} \mathrm{CH}_{2} \mathrm{CMe}_{3}$

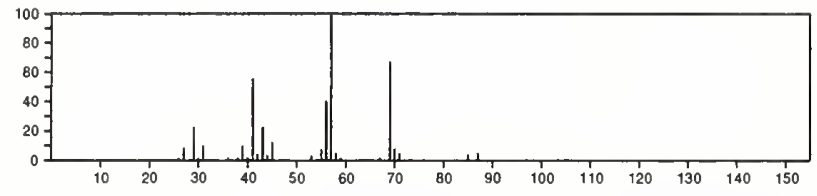

102

1-Pentanol, 4-methyl-

$\mathrm{C}_{6} \mathrm{H}_{14} \mathrm{O}$

626-89-1

$\mathrm{Me} 2 \mathrm{CH}\left(\mathrm{CH}_{2}\right)_{3} \mathrm{OH}$

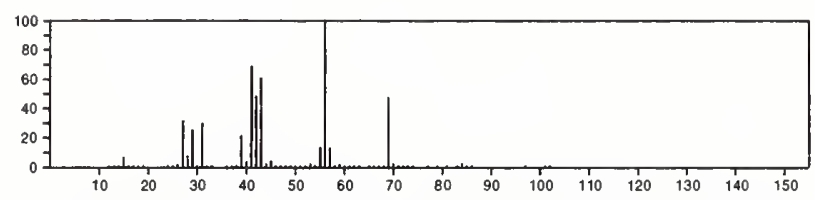

102

2-Hexanol

$\mathrm{C}_{6} \mathrm{H}_{14} \mathrm{O}$

$626-93-7$

$\mathrm{Me} \mathrm{CH}(\mathrm{OH})\left(\mathrm{CH}_{2}\right)_{3} \mathrm{Me}$

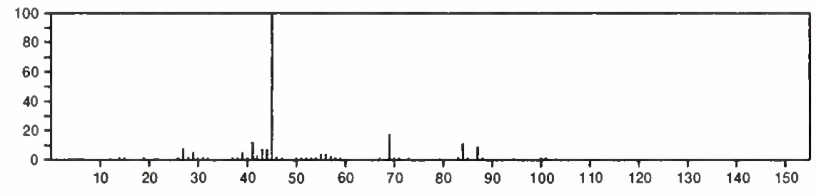

102

Propane, 1-ethoxy-2-methyl-

$\mathrm{C}_{6} \mathrm{H}_{14} \mathrm{O}$

627-02-1

E $O B \cup-i$

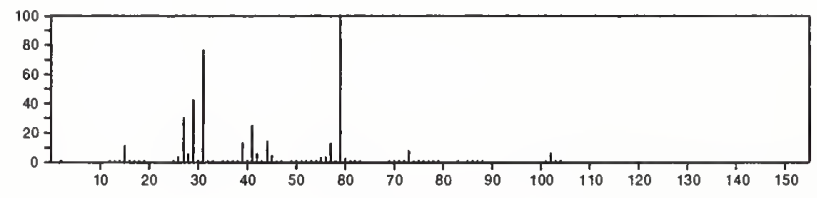

102

Butane, 1-ethoxy-

$\mathrm{C}_{6} \mathrm{H}_{14} \mathrm{O}$

628-81-9

$\mathrm{Me}\left(\mathrm{CH}_{2}\right)_{3} \mathrm{OE}$ !

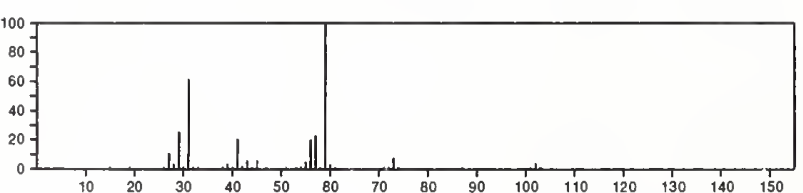

102

Propane, 2-ethoxy-2-methyl-

$\mathrm{C}_{6} \mathrm{H}_{14} \mathrm{O}$

$637-92-3$

$E t O B u-t$

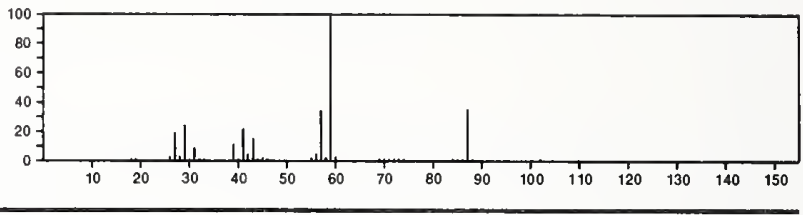

102

$\mathrm{C}_{6} \mathrm{H}_{14} \mathrm{O}$

1185-33-7

1-Butanol, 2,2-dimethyl-

$\mathrm{HOCH}_{2} \mathrm{CE}$ T Me 2

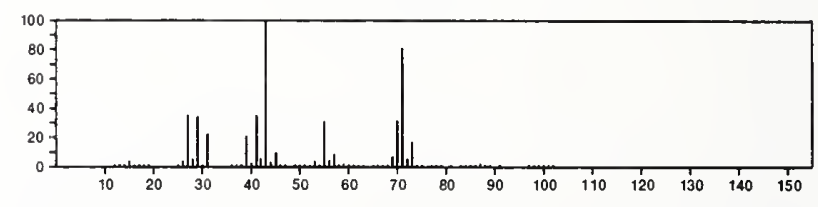

102

Butane, 2-ethoxy-

$\mathrm{C}_{6} \mathrm{H}_{14} \mathrm{O}$

2679-87-0

EtoBu-s

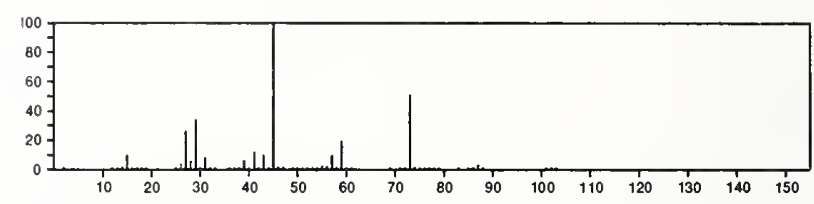

102

$\mathrm{C}_{8} \mathrm{H}_{6}$

$536-74-3$

Benzene, ethynyl-

$\mathrm{PhC} \equiv \mathrm{CH}$

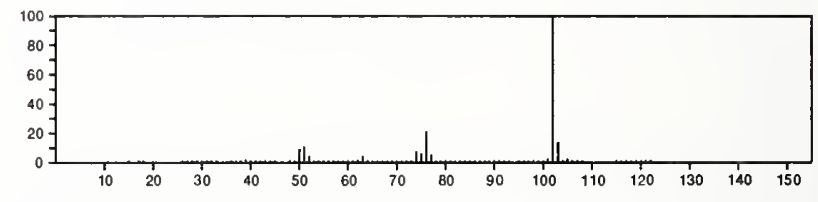

102

Sulfur chloride $\left(\mathrm{SCl}_{2}\right)$

$\mathrm{Cl}_{2} \mathrm{~S}$

10545-99-0

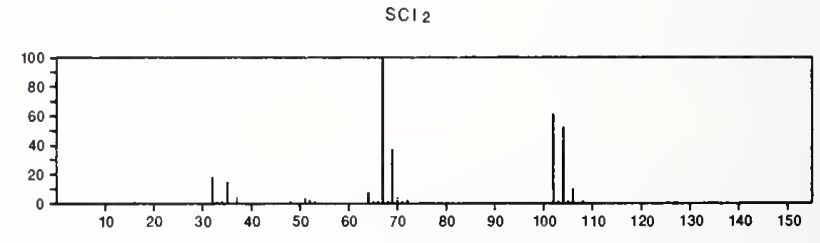

102

Phosphonothioic difluoride

$\mathrm{F}_{2} \mathrm{HPS}$

$13780-63-7$

$\mathrm{F}_{2} \mathrm{PH}=\mathrm{S}$

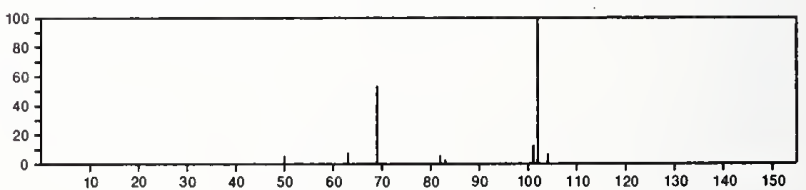


102

Sulfuryl fluoride

$\mathrm{F}_{2} \mathrm{O}_{2} \mathrm{~S}$

$\mathrm{FSO}_{2} \mathrm{~F}$

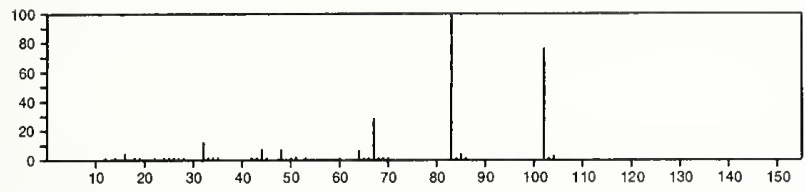

103

Acetic acid, aminooxo-, bydr

$\mathrm{C}_{2} \mathrm{H}_{5} \mathrm{~N}_{3} \mathrm{O}_{2}$

$\mathrm{H}_{2} \mathrm{NCOCONHNH}_{2}$
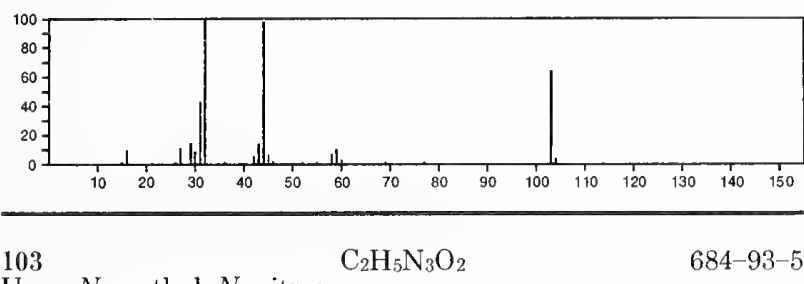

Urea, $N$-methyl-N-nitroso-

$\mathrm{MeN}(\mathrm{NO}) \mathrm{CONH}_{2}$

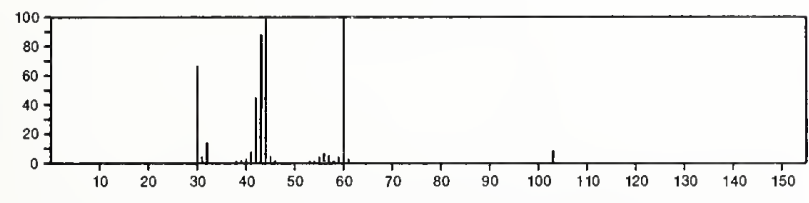

103
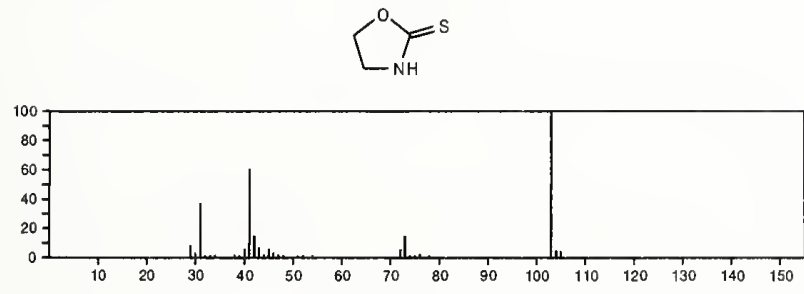

10

$103 \quad \mathrm{C}_{4} \mathrm{H}_{6} \mathrm{ClN}$

53778-71-5

$\mathrm{Me} \mathrm{CHCl} \mathrm{CH}_{2} \mathrm{CN}$

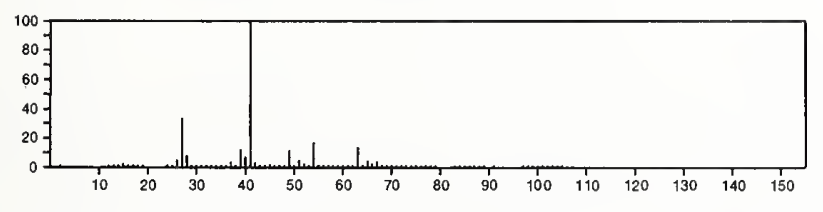

103

Alanine, 2-methyl-

$\mathrm{C}_{4} \mathrm{H}_{9} \mathrm{NO}_{2}$

$62-57-7$

$\mathrm{Me}_{2} \mathrm{C}\left(\mathrm{NH}_{2}\right) \mathrm{CO}_{2} \mathrm{H}$

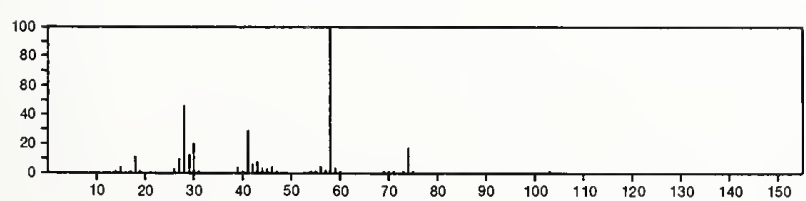

103

Butanoic acid, 2-amino-

$\mathrm{C}_{4} \mathrm{H}_{9} \mathrm{NO}_{2}$

$80-60-4$

$\mathrm{EtCH}\left(\mathrm{NH}_{2}\right) \mathrm{CO}_{2} \mathrm{H}$

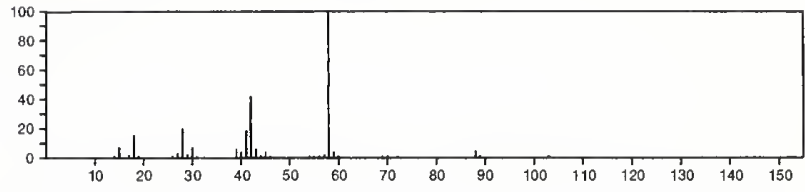

103

Nitrous acid, butyl ester

$\mathrm{C}_{4} \mathrm{H}_{9} \mathrm{NO}_{2}$

544-16-1

$\mathrm{Me}\left(\mathrm{CH}_{2}\right)_{3}$ ONO

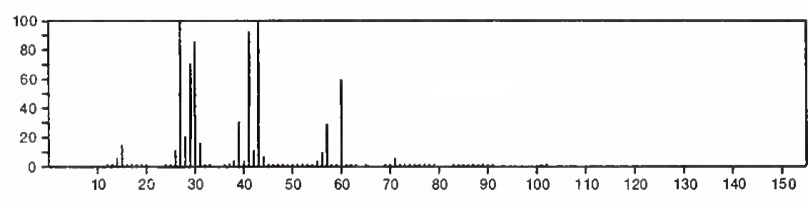

103

Propane, 2-methyl-2-nitro-

$\mathrm{C}_{4} \mathrm{H}_{9} \mathrm{NO}_{2}$

594-70-7

$\mathrm{t}-\mathrm{BuNO} 2$
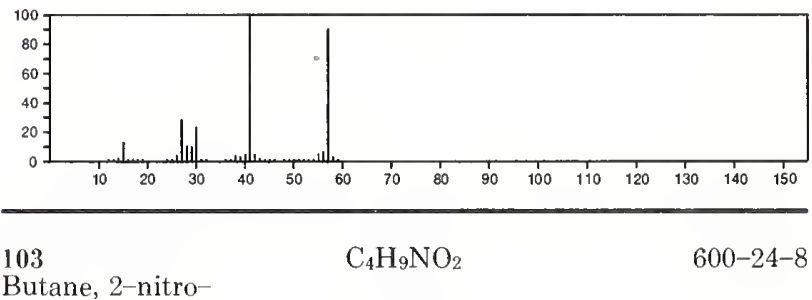

Butane, 2-nitro

$\mathrm{s}-\mathrm{BuNO} 2$

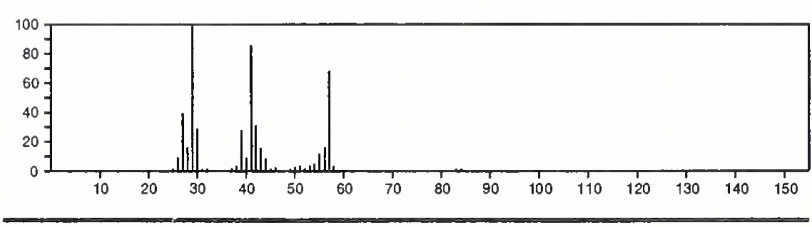

103

$\mathrm{C}_{4} \mathrm{H}_{9} \mathrm{NO}_{2}$

627-05-4

Butane, 1-nitro-

$\mathrm{O}_{2} \mathrm{~N}\left(\mathrm{CH}_{2}\right)_{3} \mathrm{Me}$

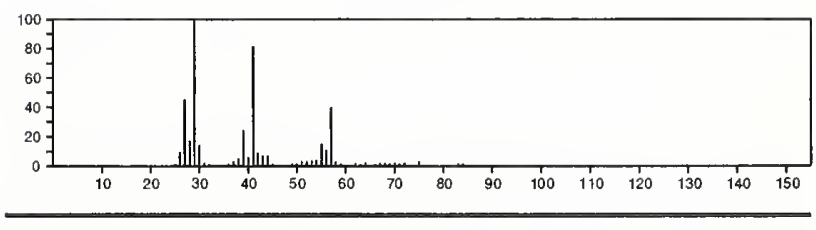

103

L-Alanine, $N$-methyl-

$\mathrm{C}_{4} \mathrm{H}_{9} \mathrm{NO}_{2}$

$3913-67-5$

$\mathrm{MeCH}$ ( NHMe) $\mathrm{CO}_{2} \mathrm{H}$

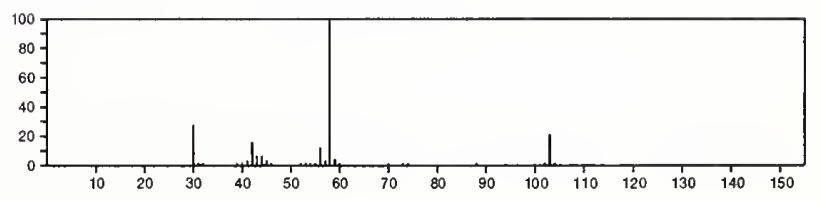


103

L-Alanine, methyl ester

$\mathrm{C}_{4} \mathrm{H}_{9} \mathrm{NO}_{2}$

$\mathrm{MeOC}(\mathrm{O}) \mathrm{CH}\left(\mathrm{NH}_{2}\right) \mathrm{Me}$
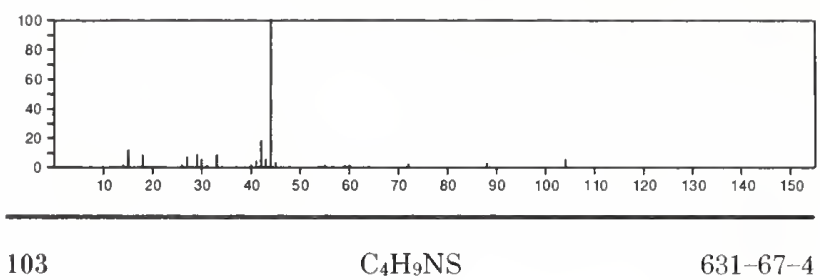

Ethanethioamide, $N, N$-dimethyl-

$631-67-4$

Me ${ }_{2}$ NCSMe

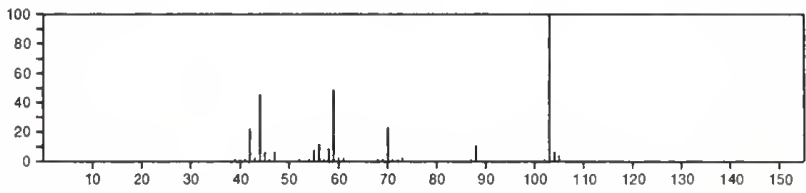

103

$\mathrm{C}_{4} \mathrm{H}_{13} \mathrm{~N}_{3}$

1,2-Ethanediamine, $\mathrm{N}$-(2-aminoethyl)-

$111-40-0$

$\mathrm{H}_{2} \mathrm{NCH}_{2} \mathrm{CH}_{2} \mathrm{NHCH}_{2} \mathrm{CH}_{2} \mathrm{NH}_{2}$

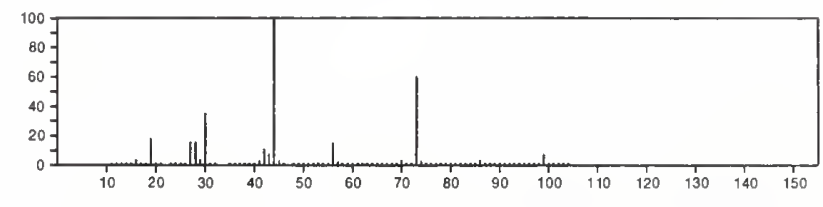

${ }_{\text {Hydroxylamine, } O \text { - pentyl-- }} \mathrm{C}_{5} \mathrm{H}_{13} \mathrm{NO}$

$5963-74-6$

$\mathrm{H}_{2} \mathrm{NO}\left(\mathrm{CH}_{2}\right)_{4} \mathrm{Me}$

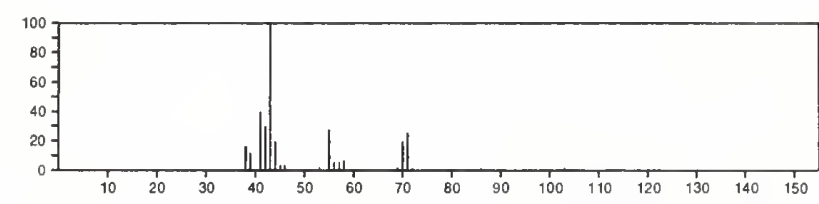

$103 \quad \mathrm{C}_{5} \mathrm{H}_{13} \mathrm{NO}$

Hydroxylamine, $\mathrm{O}-(3-$ methylbutyl $)-$

$19411-65-5$

$\mathrm{Me}_{2} \mathrm{CHCH}_{2} \mathrm{CH}_{2} \mathrm{ONH}_{2}$

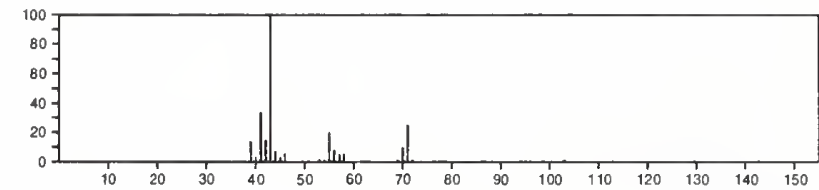

103

Benzonitrile

$\mathrm{C}_{7} \mathrm{H}_{5} \mathrm{~N}$

$100-47-0$

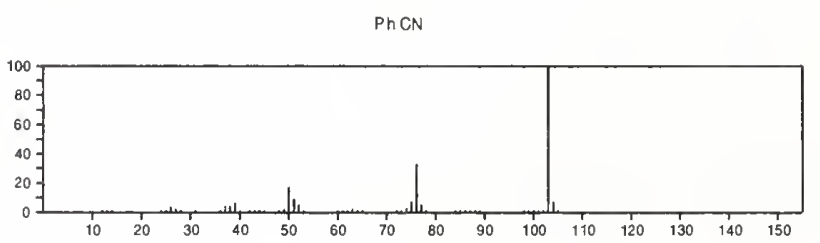

104

$\mathrm{CClF}_{3}$

$75-72-9$

Methane, chlorotrifluoro-

$\mathrm{ClCF}_{3}$

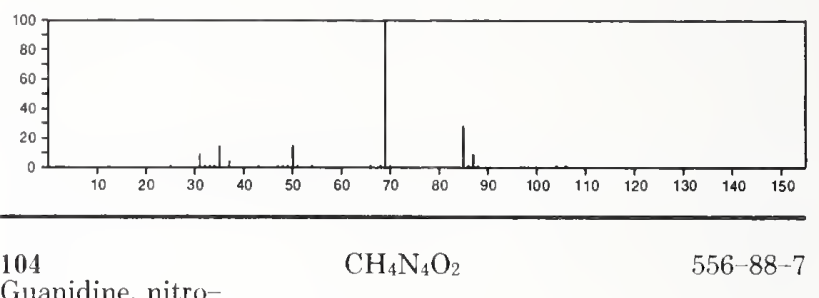

$\mathrm{HN}=\mathrm{C}\left(\mathrm{NH}_{2}\right) \mathrm{NHNO}_{2}$

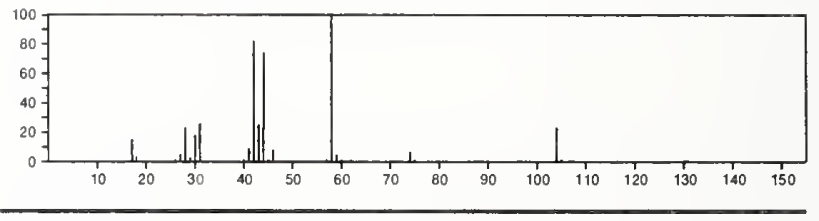

104

$\mathrm{C}_{3} \mathrm{H}_{4} \mathrm{O}_{4}$

$141-82-2$

Propanedioic acid

$\mathrm{CH}_{2}\left(\mathrm{CO}_{2} \mathrm{H}\right)_{2}$

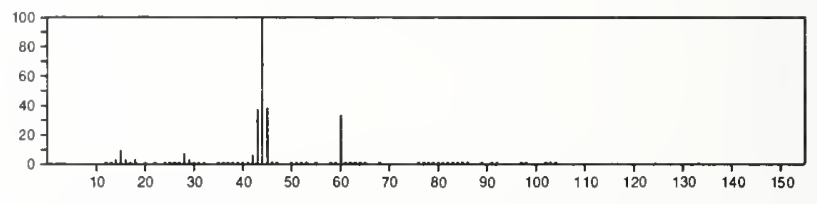

$104 \quad \mathrm{C}_{3} \mathrm{H}_{8} \mathrm{~N}_{2} \mathrm{O}_{2}$

Ethanamine, $N$-methyl-N-nitro-

19092-01-4

EtNMe $\left(\mathrm{NO}_{2}\right)$

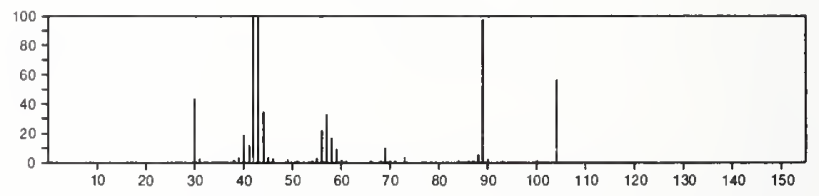

104

Thiourea, $N, N^{\prime}$-dimethyl-

$\mathrm{C}_{3} \mathrm{H}_{8} \mathrm{~N}_{2} \mathrm{~S}$

$534-13-4$

MENHCSNHME

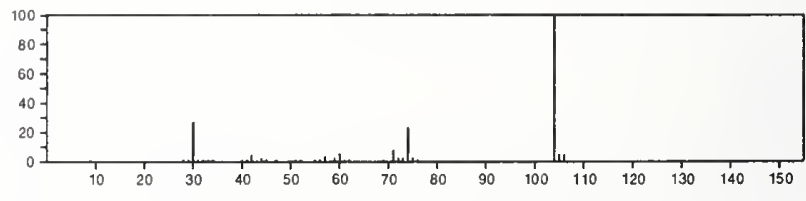

104

$\mathrm{C}_{3} \mathrm{H}_{8} \mathrm{~N}_{2} \mathrm{~S}$

625-53-6

Thiourea, ethyl-

$\mathrm{H}_{2}$ NCSNHE I

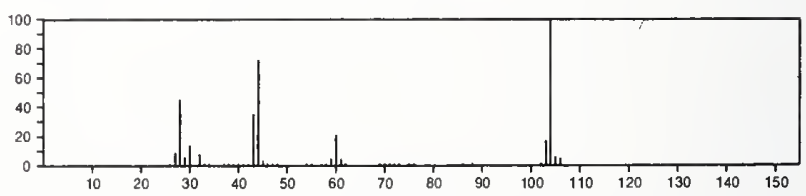


104

Thiourea, $N, N$-dimethyl-

$\mathrm{C}_{3} \mathrm{H}_{8} \mathrm{~N}_{2} \mathrm{~S}$

$\mathrm{M}{ }_{2} \mathrm{NCSNH}_{2}$

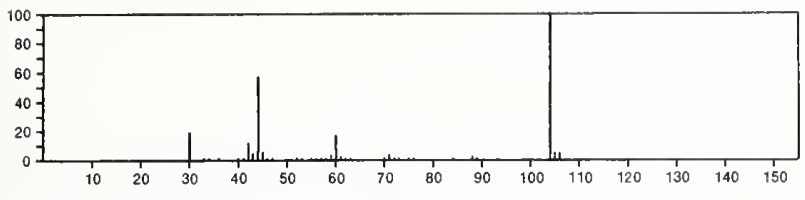

104

$\mathrm{C}_{3} \mathrm{H}_{9} \mathrm{BO}_{3}$

Boric acid $\left(\mathrm{H}_{3} \mathrm{BO}_{3}\right)$, trimethyl ester

$121-43-7$

OMe
1
Me

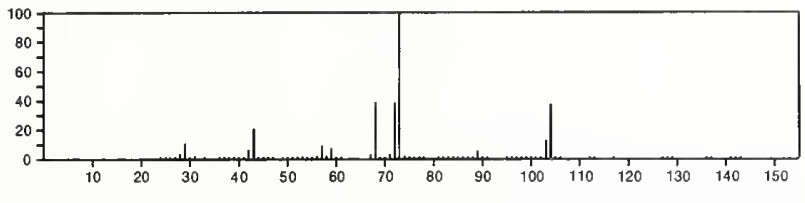

104

$\mathrm{C}_{3} \mathrm{H}_{12} \mathrm{Si}_{2}$

5654-05-7

Silane, methylenebis [methyl-

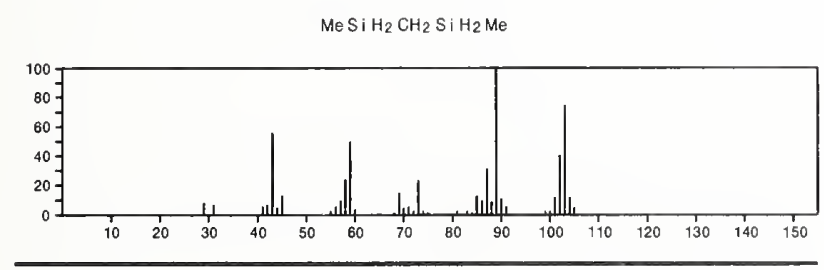

104

$\mathrm{C}_{4} \mathrm{H}_{5} \mathrm{ClO}$

$53175-28-3$

2-Butenal, 2-chloro-

$\mathrm{Me} \mathrm{CH}=\mathrm{CClCHO}$

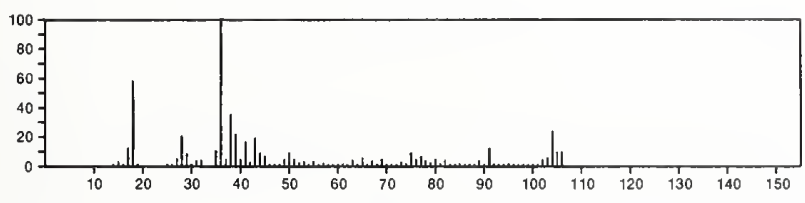

$104 \quad \mathrm{C}_{4} \mathrm{H}_{8} \mathrm{OS}$

Ethanethioic acid, $S$-ethyl ester

$625-60-5$

EtSAC

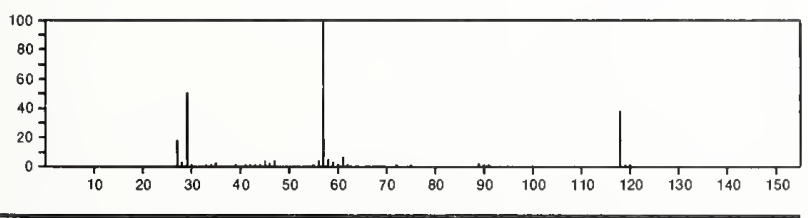

104

1,3-Oxathiane

$\mathrm{C}_{4} \mathrm{H}_{8} \mathrm{OS}$

$646-12-8$
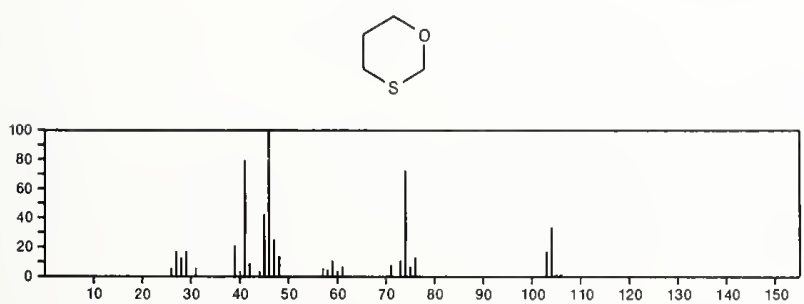

104

Thiophene, tetrahydro-, 1-oxide

$1600-44-8$
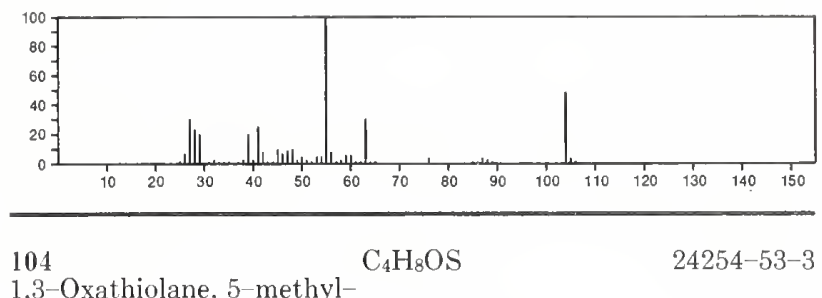

1,3-Oxathiolane, 5-methyl-
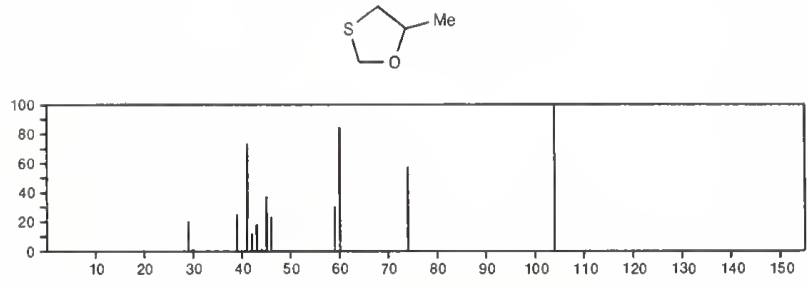

${ }_{1,3-\text { Oxathiolane, 4-methyl- }} \mathrm{C}_{4} \mathrm{H}_{8} \mathrm{OS}$

$24254-54-4$
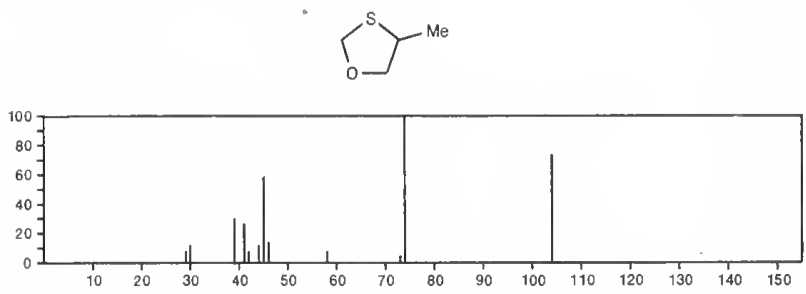

104

Butanoic acid, 3-hydroxy-

$\mathrm{C}_{4} \mathrm{H}_{8} \mathrm{O}_{3}$

$300-85-6$

$\mathrm{MeCH}(\mathrm{OH}) \mathrm{CH}_{2} \mathrm{CO}_{2} \mathrm{H}$
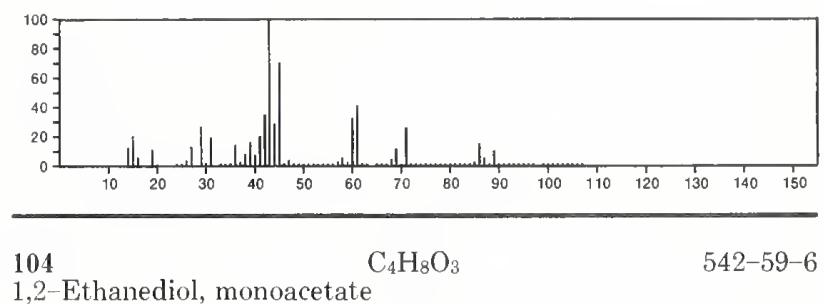

1,2-Ethanediol, monoacetate

AC $\mathrm{OCH}_{2} \mathrm{CH}_{2} \mathrm{OH}$

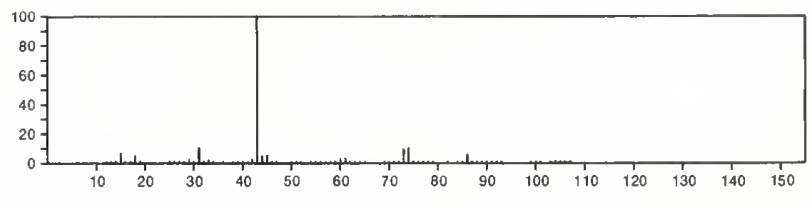

104

$\mathrm{C}_{4} \mathrm{H}_{8} \mathrm{O}_{3}$

Propanoic acid, 2-hydroxy-, methyl ester

547-64-8

$\mathrm{MeOC}(\mathrm{O}) \mathrm{CH}(\mathrm{OH}) \mathrm{Me}$

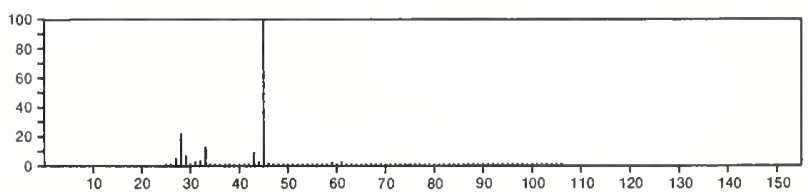


$\mathrm{Me}_{2} \mathrm{C}(\mathrm{OH}) \mathrm{CO}_{2} \mathrm{H}$

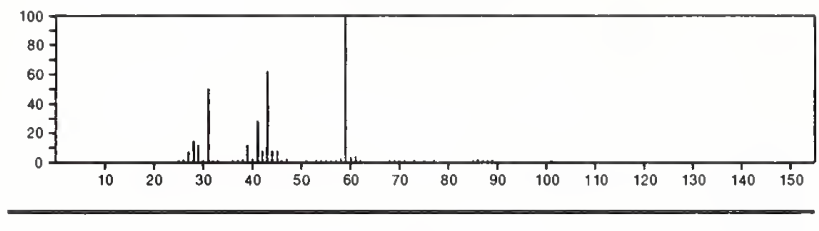

104

$\mathrm{C}_{4} \mathrm{H}_{8} \mathrm{O}_{3}$

Acetic acid, hydroxy-, ethyl ester

$\mathrm{E} 1 \mathrm{OC}(\mathrm{O}) \mathrm{CH}_{2} \mathrm{OH}$

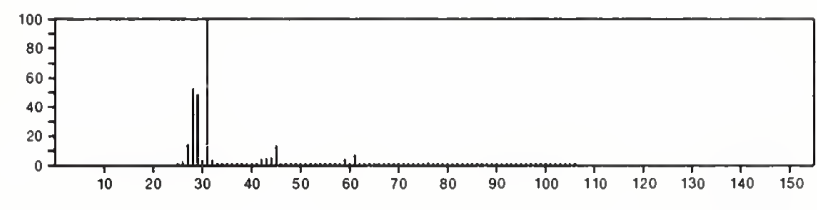

104

Acetic acid, ethoxy-

$\mathrm{C}_{4} \mathrm{H}_{8} \mathrm{O}_{3}$

$\mathrm{E}_{1} \mathrm{OCH}_{2} \mathrm{CO}_{2} \mathrm{H}$

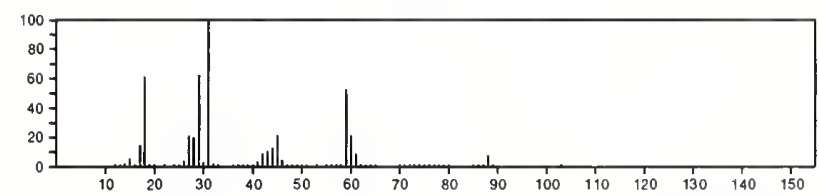

$\mathrm{C}_{4} \mathrm{H}_{8} \mathrm{O}_{3}$

104

1,3-Dioxolane-2-methanol
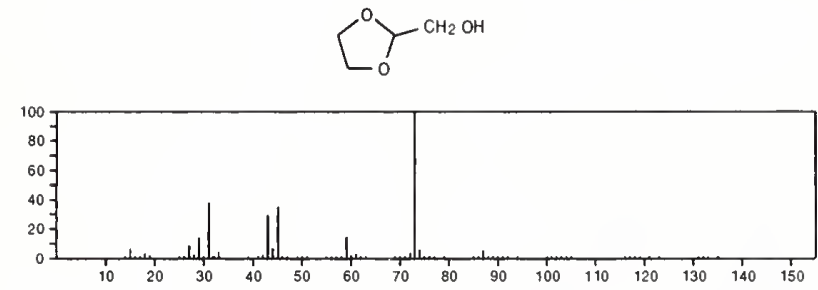

104

1,3,5-Trioxepane

$\mathrm{C}_{4} \mathrm{H}_{8} \mathrm{O}_{3}$

$5981-06-6$
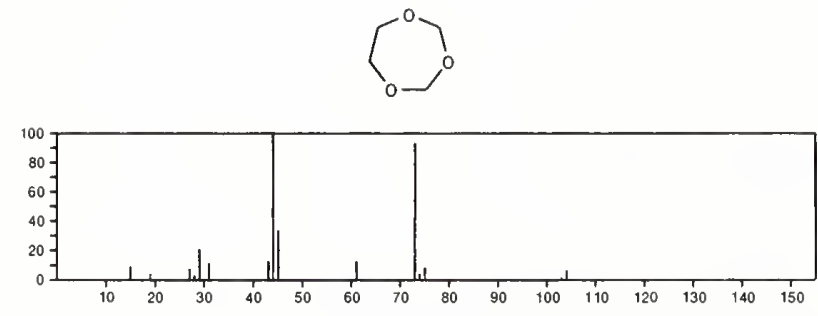

104

$\mathrm{C}_{4} \mathrm{H}_{8} \mathrm{O}_{3}$

$6149-41-3$

Propanoic acid, 3-hydroxy-, methyl ester

$\mathrm{HOCH}_{2} \mathrm{CH}_{2} \mathrm{C}(\mathrm{O}) \mathrm{OMe}$

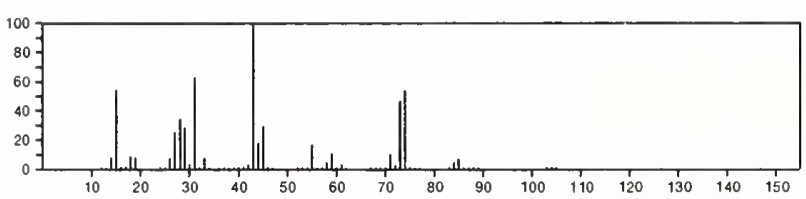

$\mathrm{MeOCH}_{2} \mathrm{ClO}$ OMe

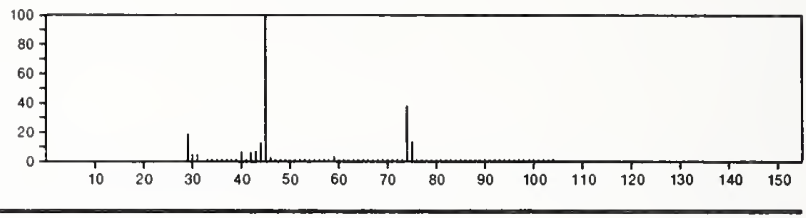

104

Phosphine, acetyldimethyl-

$\mathrm{C}_{4} \mathrm{H}_{9} \mathrm{OP}$

18983-86-3

$\mathrm{Me}_{2} \mathrm{PAC}$

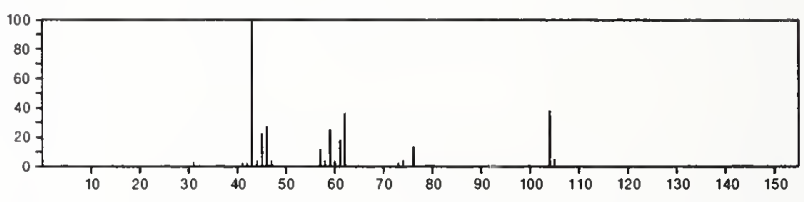

104
Ethanol, 2-[(2-aminoethyl)amino $]-$

$111-41-1$

$\mathrm{H}_{2} \mathrm{NCH}_{2} \mathrm{CH}_{2} \mathrm{NHCH}_{2} \mathrm{CH}_{2} \mathrm{OH}$

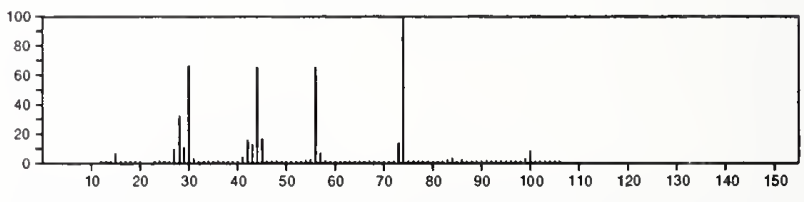

104

$\mathrm{C}_{4} \mathrm{H}_{12} \mathrm{OSi}$

$1825-61-2$

Silane, methoxytrimethyl-

Me OSiMe 3

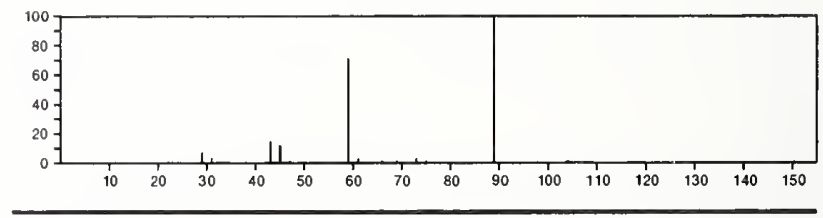

104

$\mathrm{C}_{5} \mathrm{H}{ }_{9} \mathrm{Cl}$

$503-60-6$

2-Butene, 1-chloro-3-methyl-

$\mathrm{Cl} \mathrm{CH}_{2} \mathrm{CH}=\mathrm{CMN}_{2}$

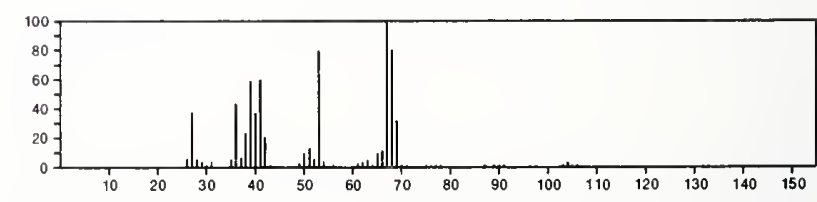

104

1 -Pentene, 5-chloro-

$\mathrm{C}_{5} \mathrm{H}_{9} \mathrm{Cl}$

$928-50-7$

$\mathrm{Cl}\left(\mathrm{CH}_{2}\right)_{3} \mathrm{CH}: \mathrm{CH}_{2}$

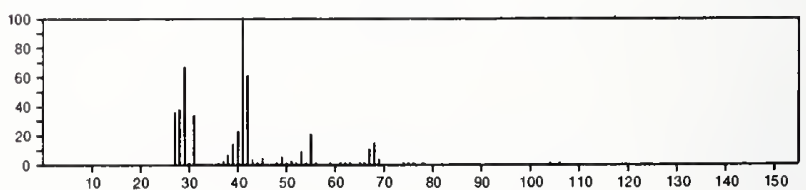


104

Cyclopentane, chloro-

$\mathrm{C}_{5} \mathrm{H}_{9} \mathrm{Cl}$

$\mathrm{Y}^{\mathrm{Cl}}$

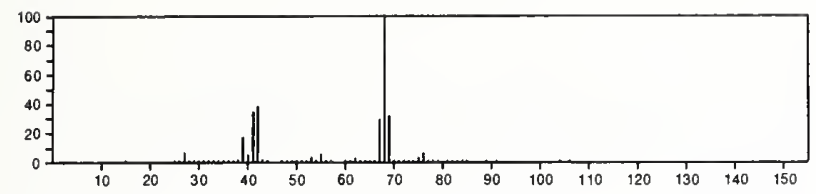

104

1-Butene, 3-chloro-2-methyl-

$\mathrm{C}_{5} \mathrm{H}_{9} \mathrm{Cl}$

$\mathrm{Me} \mathrm{CHCl} \mathrm{CMe}=\mathrm{CH}_{2}$

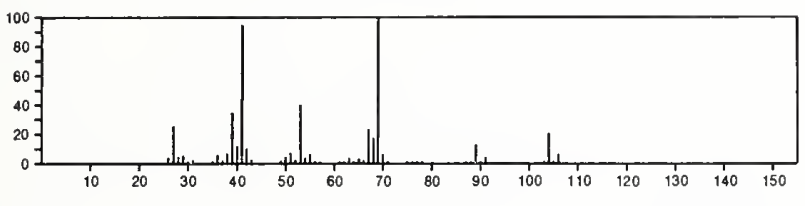

104

$\mathrm{C}_{5} \mathrm{H}_{9} \mathrm{Cl}$

1-Butene, 4-chloro-2-methyl-

10523-96-3

$\mathrm{H}_{2} \mathrm{C}=\mathrm{CMO}_{\mathrm{CH}} \mathrm{CH}_{2} \mathrm{Cl}$

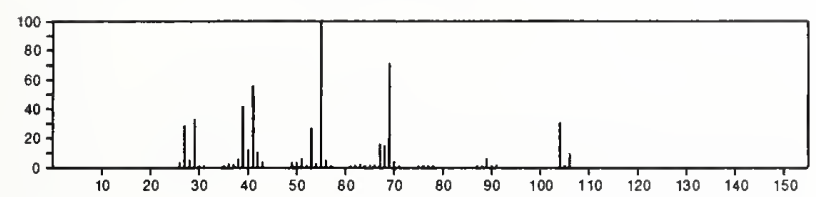

104

1-Butene, 4-chloro-3-methyl-

$\mathrm{C}_{5} \mathrm{H}_{9} \mathrm{Cl}$

$\mathrm{H}_{2} \mathrm{C}=\mathrm{CHCHMeCH} \mathrm{CH}_{2} \mathrm{Cl}$

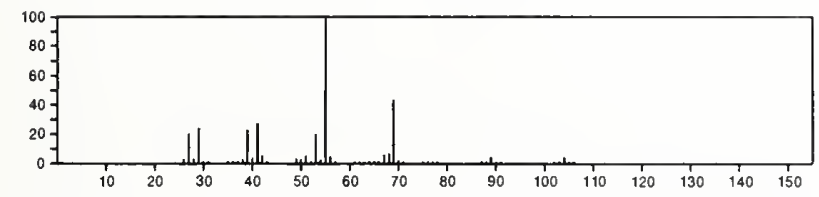

104

2-Butene, 1-chloro-2-methyl-

13417-43-1

$\mathrm{Me} \mathrm{CH}=\mathrm{CMe} \mathrm{CH}_{2} \mathrm{Cl}$

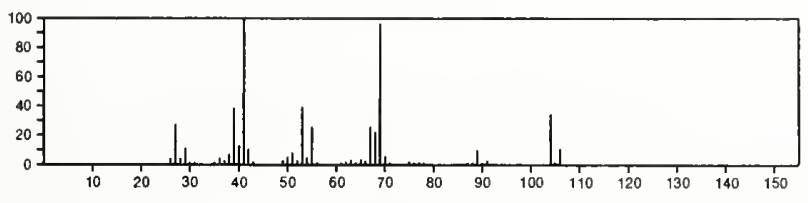

104

$$
\mathrm{C}_{5} \mathrm{H}_{9} \mathrm{Cl}
$$

17773-64-7

1-Butene, 2-chloro-3-methyl-

$\mathrm{Me}_{2} \mathrm{CHCCl}=\mathrm{CH}_{2}$

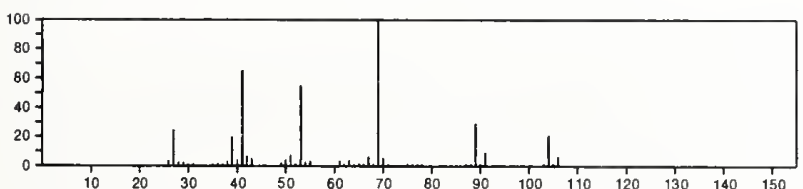

104

2-Butene, 2-chloro-3-methyl-

$\mathrm{C}_{5} \mathrm{H}_{9} \mathrm{Cl}$

17773-65-8

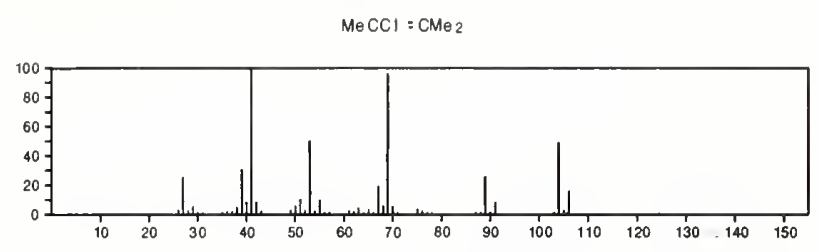

104

1-Butene, 1-chloro-3-methyl-

$\mathrm{C}_{5} \mathrm{H}_{9} \mathrm{Cl}$

23010-00-6

$\mathrm{CI} \mathrm{CH}=\mathrm{CHCHME}_{2}$

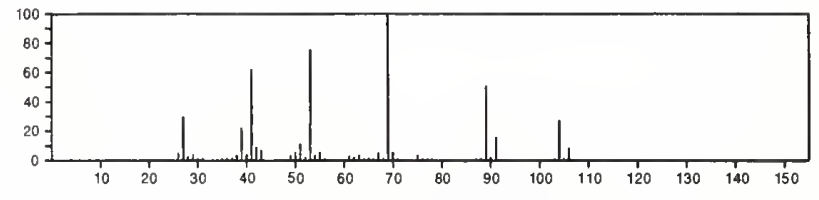

104

1-Butene, 2-(chloromethyl)-

$23010-02-8$

$\mathrm{Cl} \mathrm{CH}_{2} \mathrm{CE} \mathrm{t}=\mathrm{CH}_{2}$

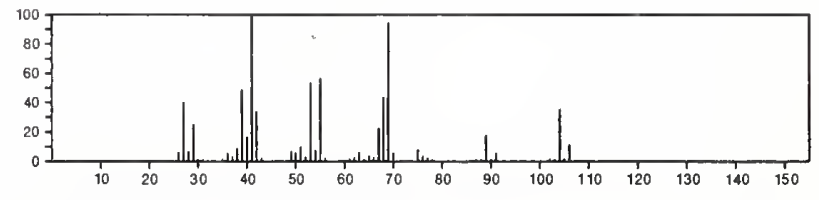

104

$\mathrm{C}_{5} \mathrm{H}_{9} \mathrm{Cl}$

23378-11-2

1-Butene, 1-chloro-2-methyl-

$\mathrm{Cl} C H=C E \& M e$

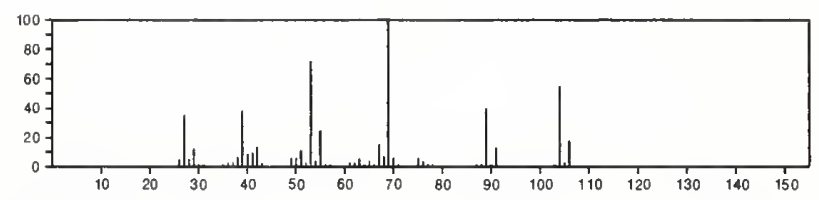

104

$\mathrm{C}_{5} \mathrm{H}_{12} \mathrm{O}_{2}$

$74-80-6$

Hydroperoxide, pentyl

$\mathrm{HOO}\left(\mathrm{CH}_{2}\right) 4 \mathrm{Me}$

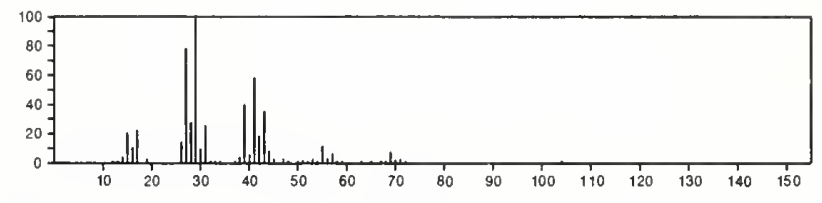

104

Propane, 2,2-dimethoxy-

$\mathrm{C}_{5} \mathrm{H}_{12} \mathrm{O}_{2}$

$77-76-9$

$\mathrm{MeO}_{2} \mathrm{C}(\mathrm{Me})_{2}$

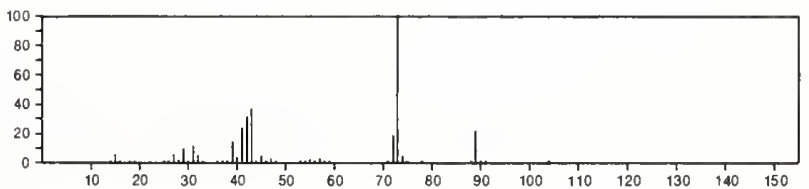


104
Ethanol, 2-(1-methylethoxy)-

$i-\mathrm{PrOCH}_{2} \mathrm{CH}_{2} \mathrm{OH}$

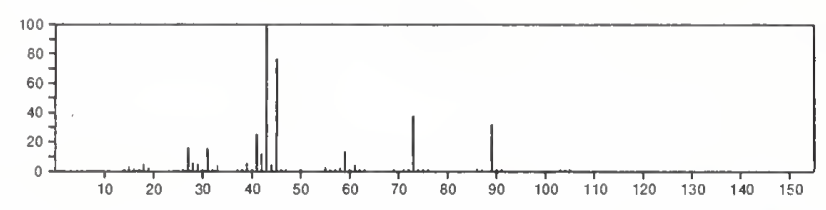

104

1,5-Pentanediol

$\mathrm{C}_{5} \mathrm{H}_{12} \mathrm{O}_{2}$

$\mathrm{HO}\left(\mathrm{CH}_{2}\right) 5 \mathrm{OH}$

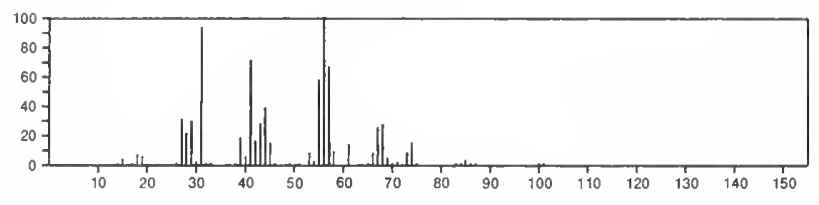

104

1-Butanol, 4-methoxy-

$\mathrm{C}_{5} \mathrm{H}_{12} \mathrm{O}_{2}$

111-32-0

$\mathrm{MeO}\left(\mathrm{CH}_{2}\right)_{4} \mathrm{OH}$
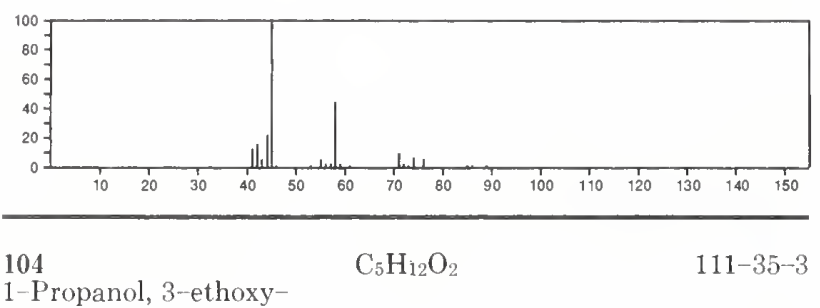

1-Propanol, 3-ethoxy-

$\mathrm{HO}\left(\mathrm{CH}_{2}\right)_{3} \mathrm{OE}$

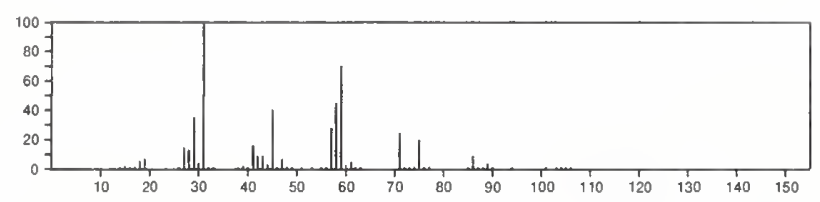

104

1,3-Propanediol, 2,2-dimethyl-

$126-30-7$

$\mathrm{HOCH}_{2} \mathrm{CMe}_{2} \mathrm{CH}_{2} \mathrm{OH}$

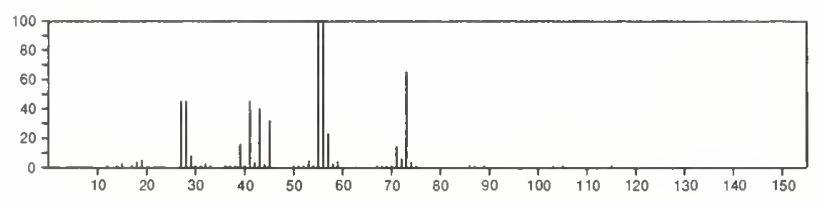

104

$\mathrm{C}_{5} \mathrm{H}_{12} \mathrm{O}_{2}$

Ethane, 1,1'-[methylenebis(oxy) ]bis-

462-95-3

$\mathrm{E}+\mathrm{OCH}_{2} \mathrm{OE}$ t

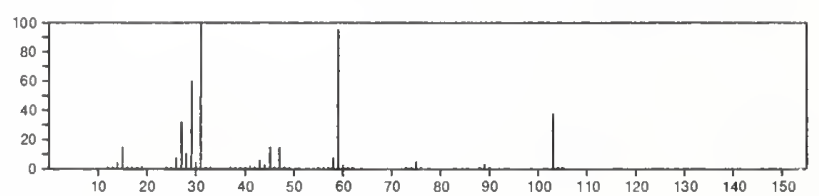

104

2,4-Pentanediol

$\mathrm{C}_{5} \mathrm{H}_{12} \mathrm{O}_{2}$

625-69-4

$\mathrm{MeCH}(\mathrm{OH}) \mathrm{CH}_{2} \mathrm{CH}(\mathrm{OH}) \mathrm{Me}$

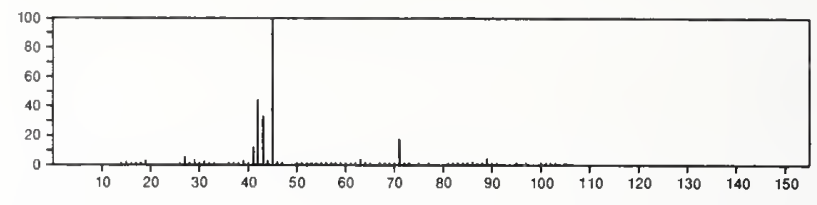

104

1,3-Butanediol, 2-methyl-

$\mathrm{C}_{5} \mathrm{H}_{12} \mathrm{O}_{2}$

684-84-4

$\mathrm{HOCH}_{2} \mathrm{CHMe} \mathrm{CH}$ ( $\left.\mathrm{OH}\right) \mathrm{Me}$

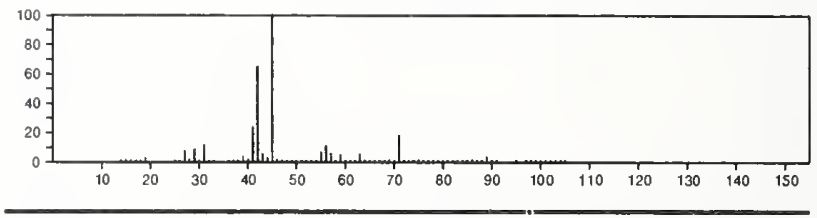

104

2-Propanol, 1-ethoxy-

$\mathrm{C}_{5} \mathrm{H}_{12} \mathrm{O}_{2}$

1569-02-4

$\mathrm{E}$ t $\mathrm{OCH}_{2} \mathrm{CH}(\mathrm{OH}) \mathrm{Me}$

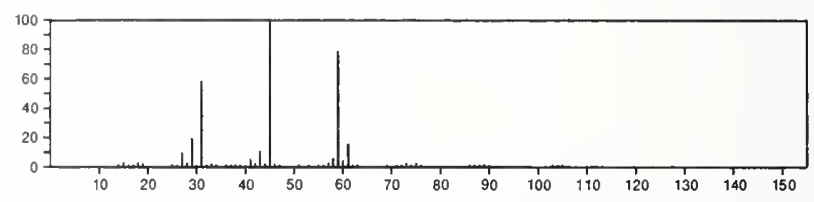

104

1-Butanol, 3-methoxy-

$\mathrm{C}_{5} \mathrm{H}_{12} \mathrm{O}_{2}$

2517-43-3

$\mathrm{HOCH}_{2} \mathrm{CH}_{2} \mathrm{CH}$ ( OMe) Me

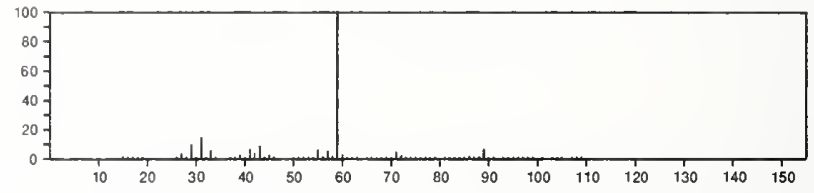

104

Ethanol, 2 propoxy.

$\mathrm{C}_{5} \mathrm{H}_{12} \mathrm{O}_{2}$

$2807-30-9$

Pr $\mathrm{OCH}_{2} \mathrm{CH}_{2} \mathrm{OH}$

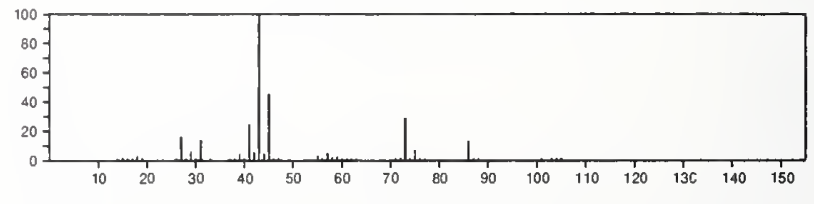

104

$\mathrm{C}_{5} \mathrm{H}_{12} \mathrm{O}_{2}$

2-Propanol, 1-methoxy-2-methyl-

$3587-64-2$

$\mathrm{Me} \mathrm{OCH}_{2} \mathrm{CMe}_{2} \mathrm{OH}$

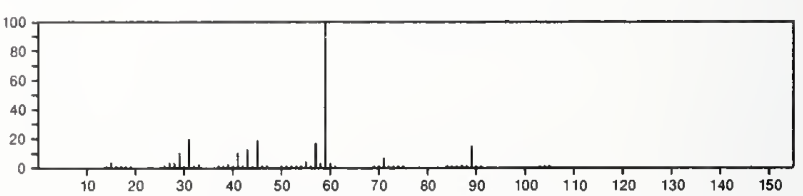


104

Propane, 1,1-dimethoxy-

$\mathrm{C}_{5} \mathrm{H}_{12} \mathrm{O}_{2}$

$\mathrm{EtCH}(\mathrm{OMe})_{2}$

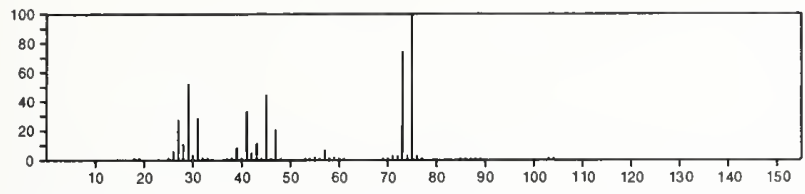

104

$\mathrm{C}_{5} \mathrm{H}_{12} \mathrm{O}_{2}$

Propane, 1,2-dimethoxy-

$\mathrm{Me} \mathrm{OCH} 2 \mathrm{CH}$ ( OMe) Me

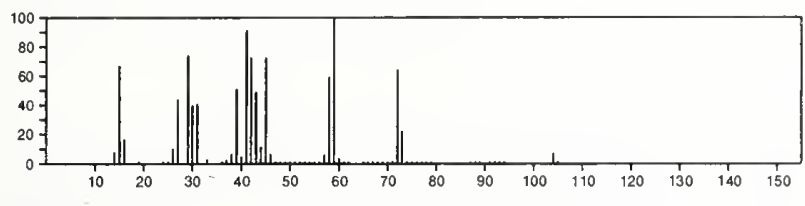

104

Hydroperoxide, 1-methylbutyl

$14018-58-7$

HOOCHP IMe

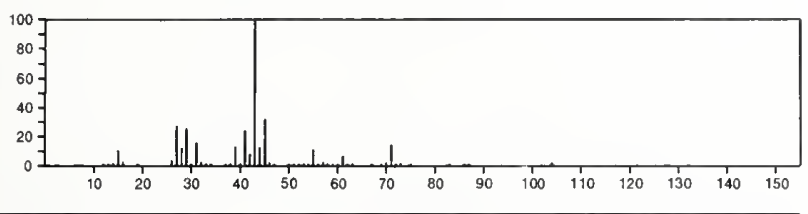

104

$\mathrm{C}_{5} \mathrm{H}_{12} \mathrm{O}_{2}$

Propane, 1,3-dimethoxy-

$\mathrm{MeO}\left(\mathrm{CH}_{2}\right){ }_{3} \mathrm{OMe}$

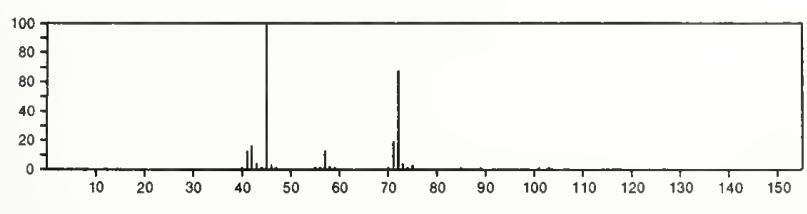

104

1-Propanol, 2-ethoxy-

$\mathrm{C}_{5} \mathrm{H}_{12} \mathrm{O}_{2}$

$19089-47-5$

$\mathrm{HOCH}_{2} \mathrm{CH}(\mathrm{OE} t)$ Me
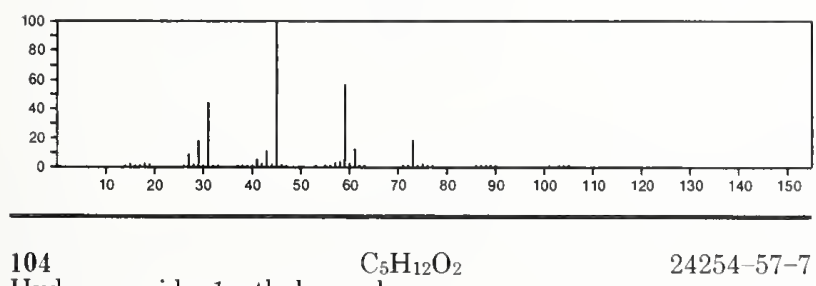

Hydroperoxide, 1-ethylpropyl

HOOCHE 2

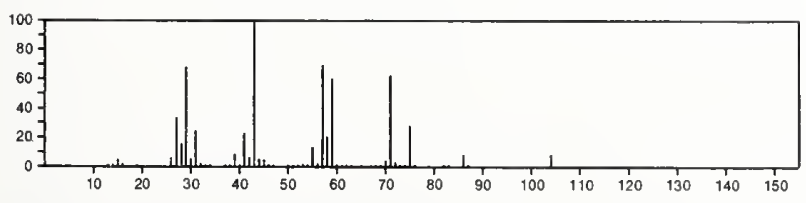

$104 \quad \mathrm{C}_{5} \mathrm{H}_{12} \mathrm{O}_{2}$

$53778-72-6$

2-Butanol, 3-methoxy-

$\mathrm{MeCH}(\mathrm{OH}) \mathrm{CH}$ ( OMe) Me

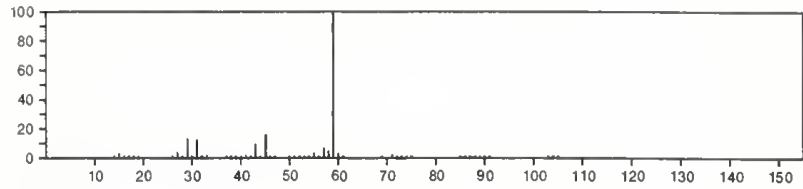

104

$\mathrm{C}_{5} \mathrm{H}_{12} \mathrm{O}_{2}$

$53778-73-7$

2-Butanol, 1-methoxy-

$\mathrm{MeOCH} 2 \mathrm{CH}(\mathrm{OH}) \mathrm{Et}$

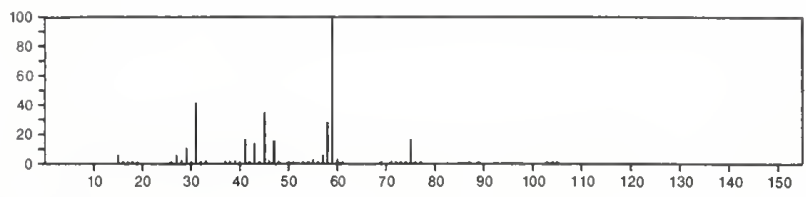

104

1-Pentanethiol

$\mathrm{C}_{5} \mathrm{H}_{12} \mathrm{~S}$

$110-66-7$

$\mathrm{Me}\left(\mathrm{CH}_{2}\right)_{4} \mathrm{SH}$

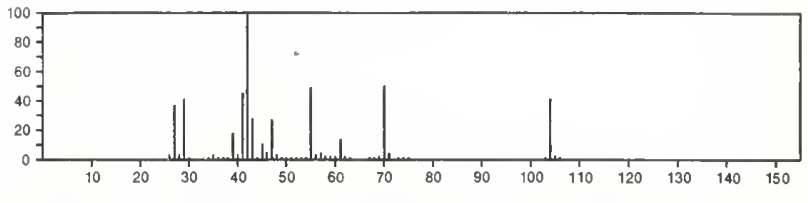

104

1-Butanethiol, 3-methyl

$\mathrm{C}_{5} \mathrm{H}_{12} \mathrm{~S}$

$541-31-1$

$\mathrm{HSCH}_{2} \mathrm{CH}_{2} \mathrm{CHMe}_{2}$

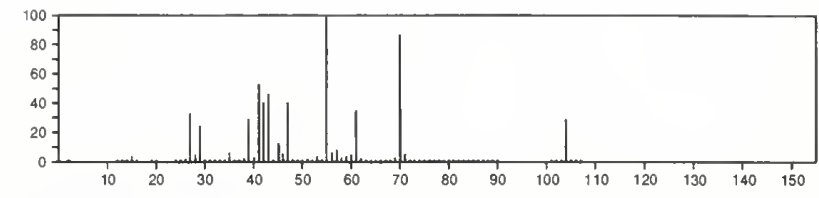

104

3-Pentanethiol

$\mathrm{C}_{5} \mathrm{H}_{12} \mathrm{~S}$

$616-31-9$

$\mathrm{Et}_{2} \mathrm{CHSH}$

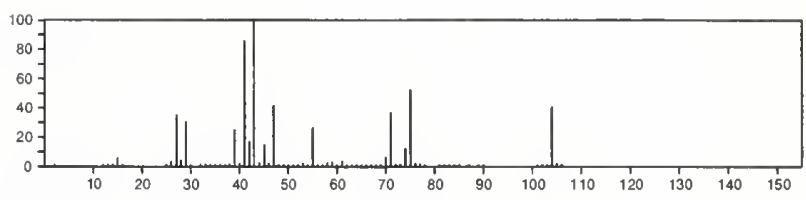

101

$\mathrm{C}_{5} \mathrm{H}_{12} \mathrm{~S}$

$628-29-5$

Butane, 1-(methylthio)

$\mathrm{MeS}\left(\mathrm{CH}_{2}\right)_{3} \mathrm{Me}$

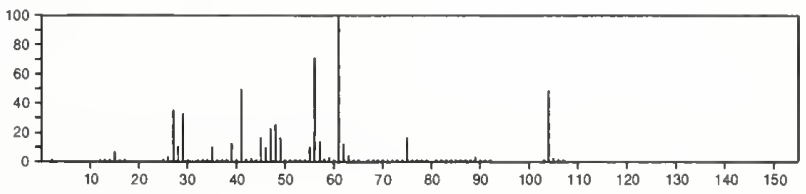


104

1-Propanethiol, 2,2-dimethyl-

$\mathrm{C}_{5} \mathrm{H}_{12} \mathrm{~S}$

1679-08-9

$\mathrm{HSCH}_{2} \mathrm{CMe}_{3}$

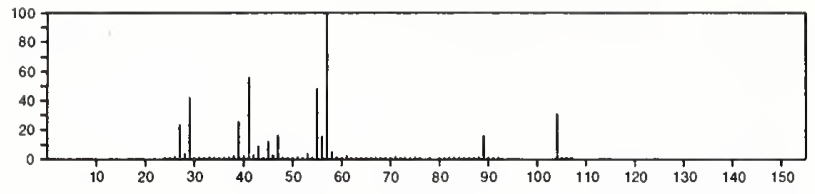

104

2-Butanethiol, 2-methyl-

$\mathrm{C}_{5} \mathrm{H}_{12} \mathrm{~S}$

1679-09-0

$\mathrm{EtCMe} 2$ ( $\mathrm{SH}$ )

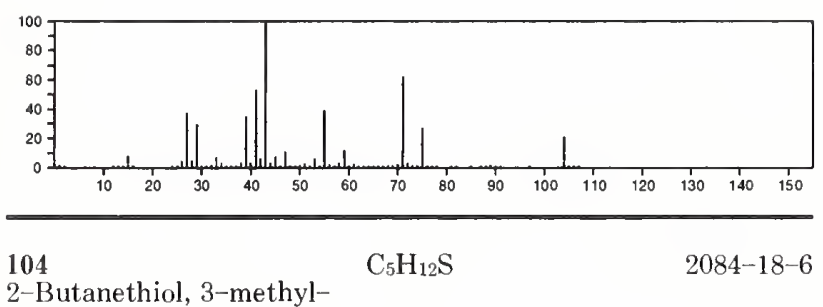

$\mathrm{MeCH}$ ( $\mathrm{SH}$ ) CHMe 2

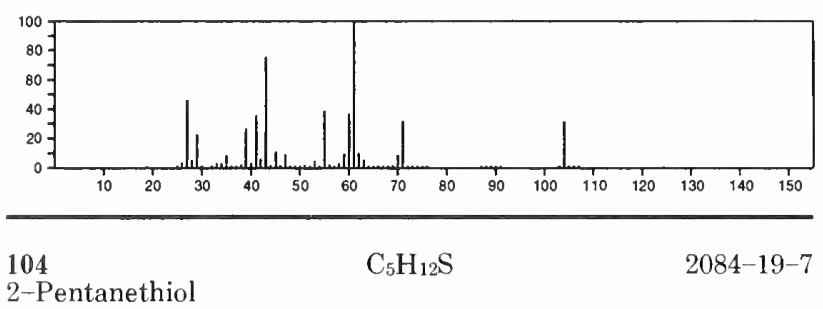

$\operatorname{PrCHMe}(\mathrm{SH})$

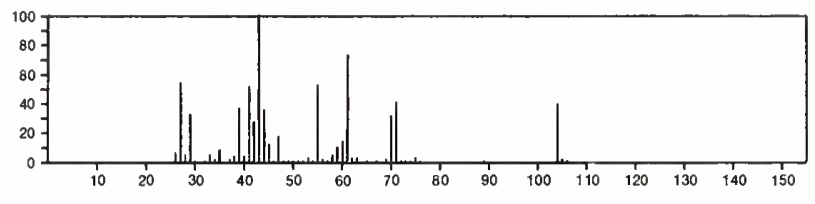

104

Propane, 1-(ethylthio)

$\mathrm{C}_{5} \mathrm{H}_{12} \mathrm{~S}$

$4110-50-3$

PrSEt

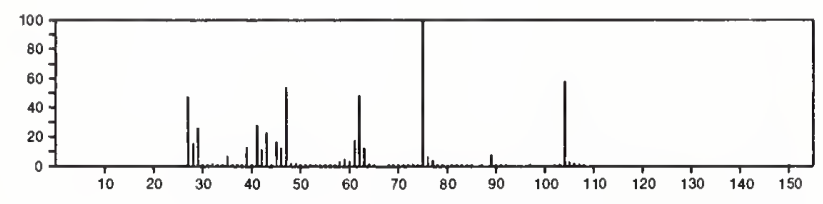

104
Propane, 2-methyl-1-(methylthio)-

$\mathrm{MeSBu}-\mathrm{i}$

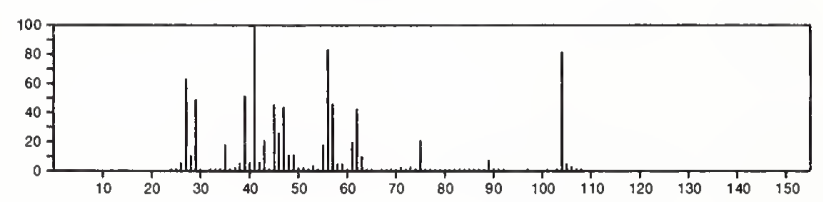

104

Propane, 2-(ethylthio)-

$\mathrm{C}_{5} \mathrm{H}_{12} \mathrm{~S}$

5145-99-3

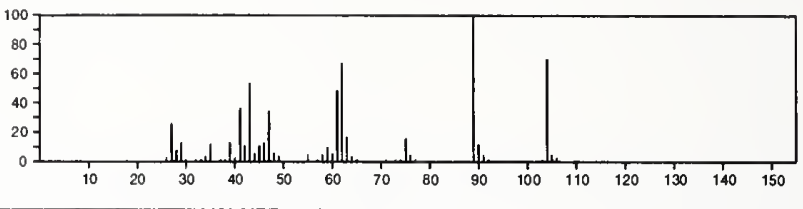

104

$\mathrm{C}_{5} \mathrm{H}_{12} \mathrm{~S}$

Propane, 2-methyl-2-(methylthio)-

6163-64-0

$\mathrm{MeSBu}-\mathrm{t}$

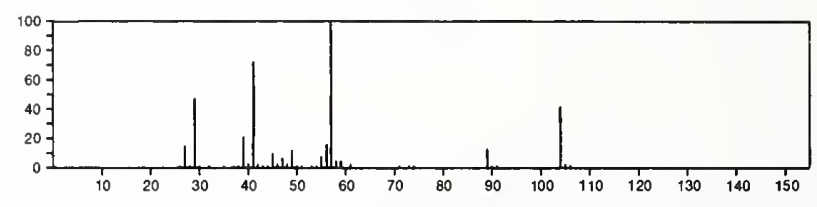

104

Butane, 2-(methylthio)-

$\mathrm{C}_{5} \mathrm{H}_{12} \mathrm{~S}$

10359-64-5

MesBu-s

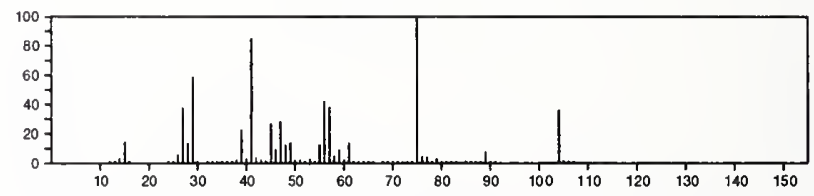

104

2-Pyridinecarbonitrile

$\mathrm{C}_{6} \mathrm{H}_{4} \mathrm{~N}_{2}$

100-70-9
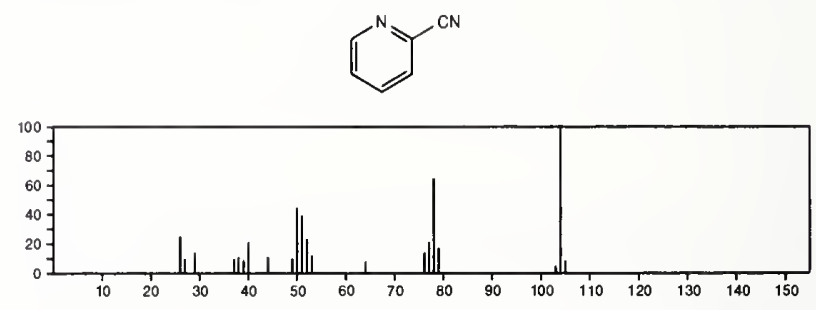

104

$\mathrm{C}_{6} \mathrm{H}_{13} \mathrm{~F}$

373-14-8

Hexane, 1-fluoro-

$\mathrm{Me}\left(\mathrm{CH}_{2}\right){ }_{5} \mathrm{~F}$

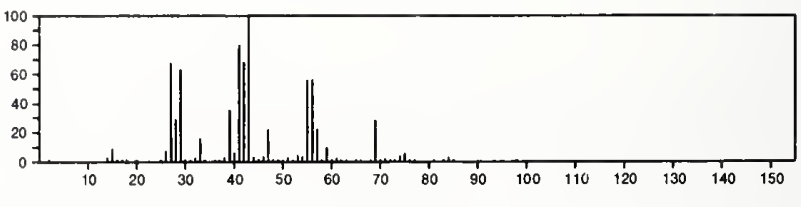

104

Benzene, ethenyl-

$\mathrm{C}_{8} \mathrm{H}_{8}$

$100-42-5$

$\mathrm{PhCH}=\mathrm{CH}_{2}$

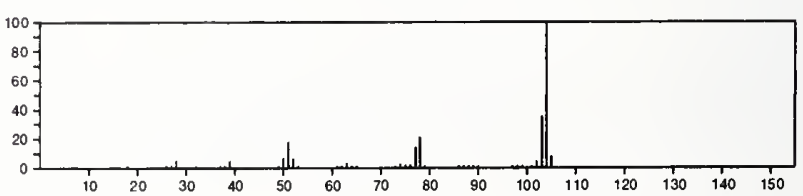


104

1,3,5,7-Cyclooctatetraene

$\mathrm{C}_{8} \mathrm{H}_{8}$

$(1)$

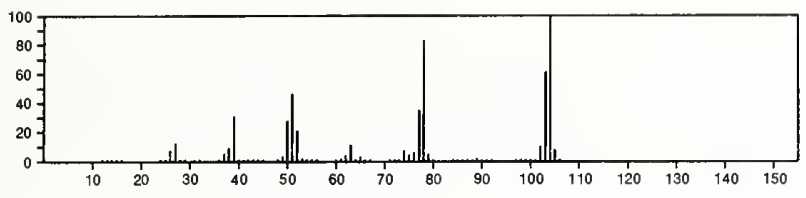

$104 \quad \mathrm{C}_{8} \mathrm{H}_{8}$

$694-87-1$

Bicyclo[4.2.0]octa-1,3,5-triene
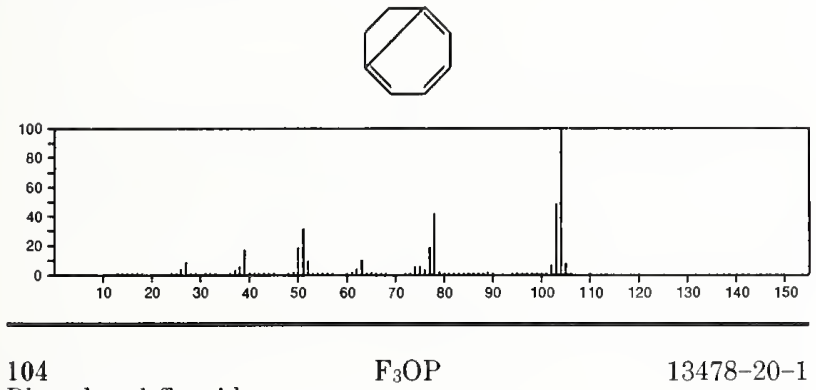

Phosphoryl fluoride

$F_{3} P=0$

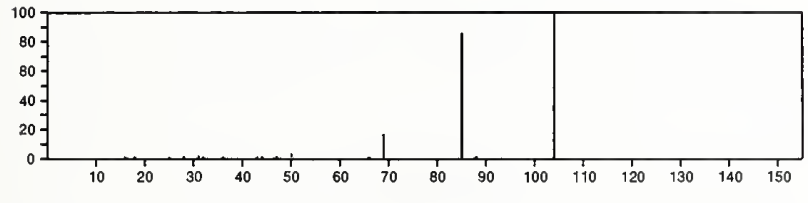

104

Silane, tetrafluoro-

$\mathrm{F}_{4 \mathrm{Si}}$

7783-61-1

$\mathrm{SiF}_{4}$

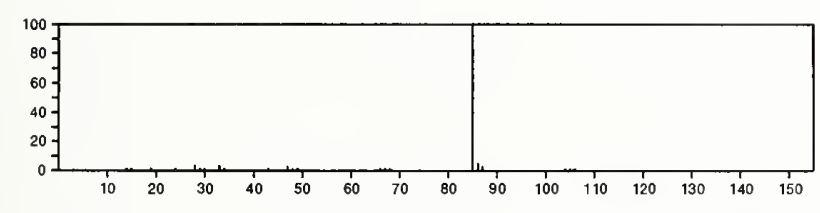

105

Cyanogen bromide

$\mathrm{CBrN}$

506-68-3

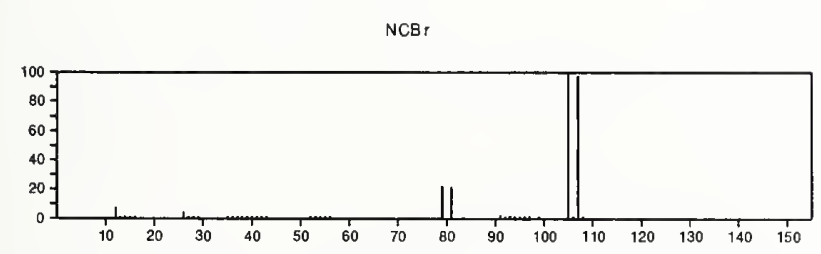

10:

105
L-Serine

$\mathrm{C}_{3} \mathrm{H}_{7} \mathrm{NO}_{3}$

$\mathrm{HOCH}_{2} \mathrm{CH}\left(\mathrm{NH}_{2}\right) \mathrm{CO}_{2} \mathrm{H}$

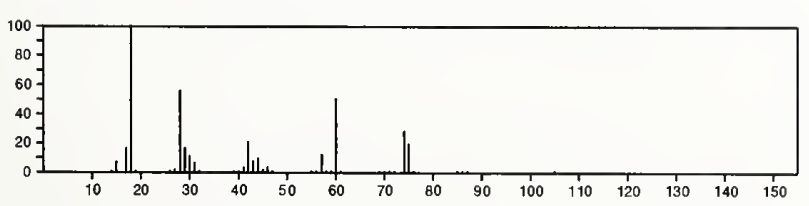

105

DL-Serine

$\mathrm{C}_{3} \mathrm{H}_{7} \mathrm{NO}_{3}$

302-84-1

$\mathrm{HOCH}_{2} \mathrm{CH}\left(\mathrm{NH}_{2}\right) \mathrm{CO}_{2} \mathrm{H}$

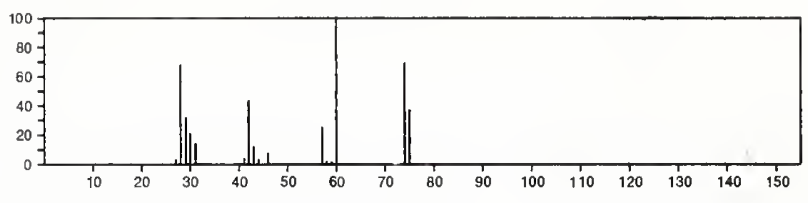

105

Nitric acid, propyl ester

$\mathrm{C}_{3} \mathrm{H}_{7} \mathrm{NO}_{3}$

$627-13-4$

$\mathrm{PrONO}_{2}$

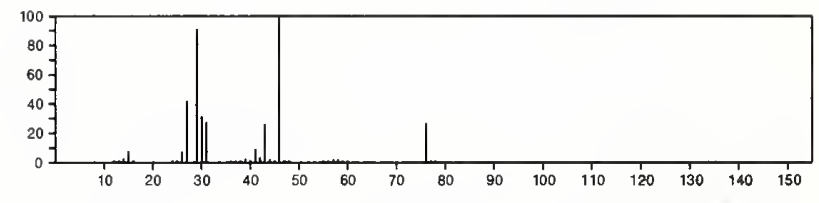

105

Nitric acid, 1-methylethyl ester

1712-64-7

$\mathrm{i}-\mathrm{PrONO} 2$

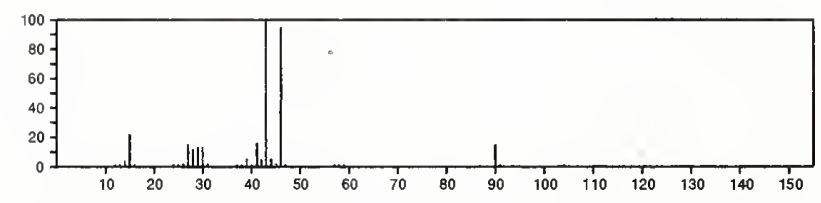

105

Azetidine, 1-chloro-2-methyl-

$\mathrm{C}_{4} \mathrm{H}_{8} \mathrm{ClN}$

$38382-62-6$
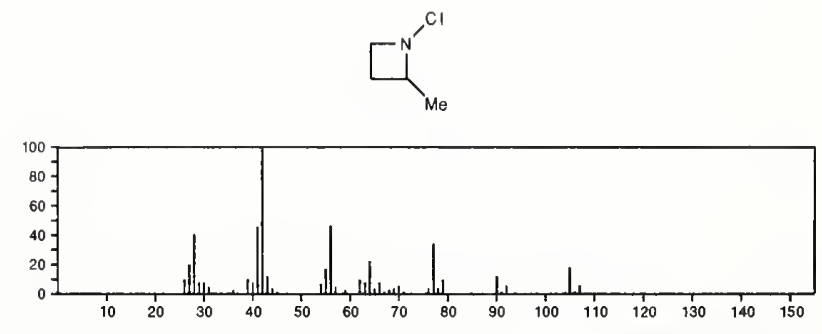

105

Ethanol, 2,2'-iminobis-

$\mathrm{C}_{4} \mathrm{H}_{11} \mathrm{NO}_{2}$

$111-42-2$

$\mathrm{HOCH}_{2} \mathrm{CH}_{2} \mathrm{NHCH}_{2} \mathrm{CH}_{2} \mathrm{OH}$
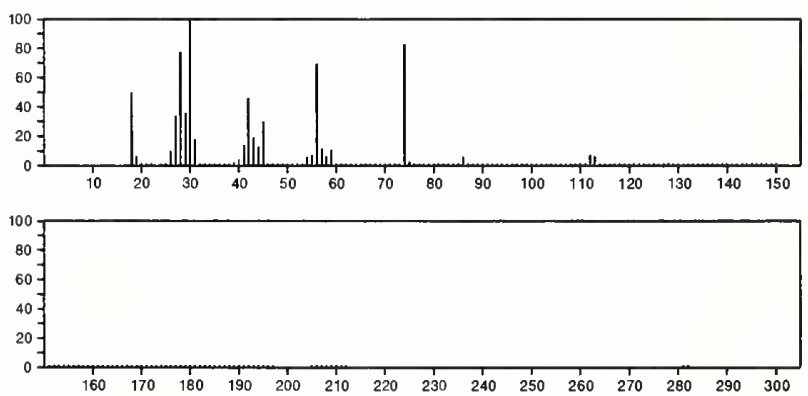

106

Ethene, bromo-

$\mathrm{C}_{2} \mathrm{H}_{3} \mathrm{Br}$

593-60-2

$\mathrm{Br} \mathrm{CH}=\mathrm{CH}_{2}$

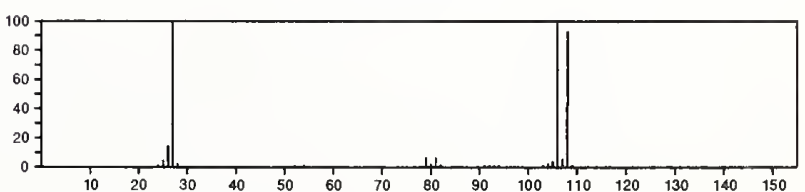


106

Ethene, (methylsulfonyl)-

$\mathrm{C}_{3} \mathrm{H}_{6} \mathrm{O}_{2} \mathrm{~S}$

$\mathrm{H}_{2} \mathrm{C}=\mathrm{CHSO}_{2} \mathrm{Me}$

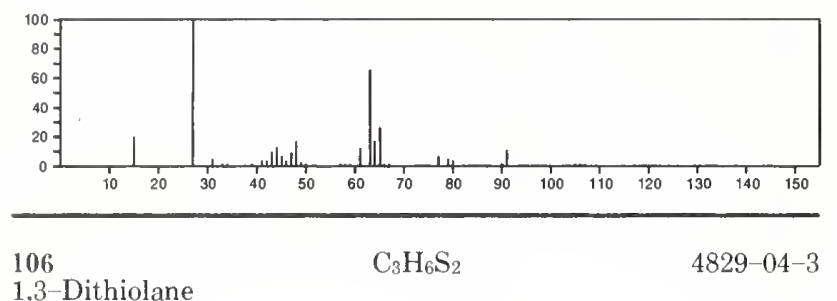

1,3-Dithiolane
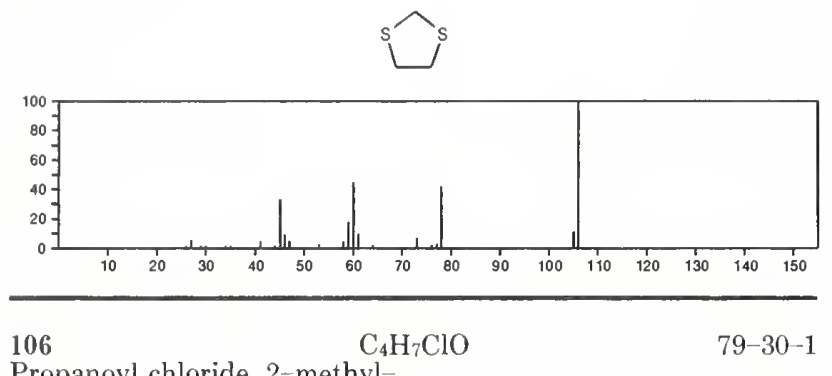

Propanoyl chloride, 2-methyl-

$\mathrm{Me}_{2} \mathrm{CHCOCI}$

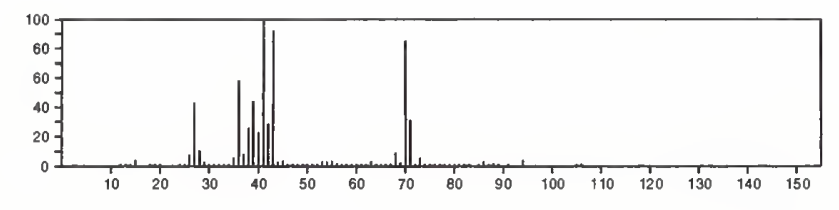

106

Ethene, (2-chloroethoxy)

$\mathrm{C}_{4} \mathrm{H}_{7} \mathrm{ClO}$

$110-75-8$

$\mathrm{H}_{2} \mathrm{C}=\mathrm{CHOCH}_{2} \mathrm{CH}_{2} \mathrm{Cl}$
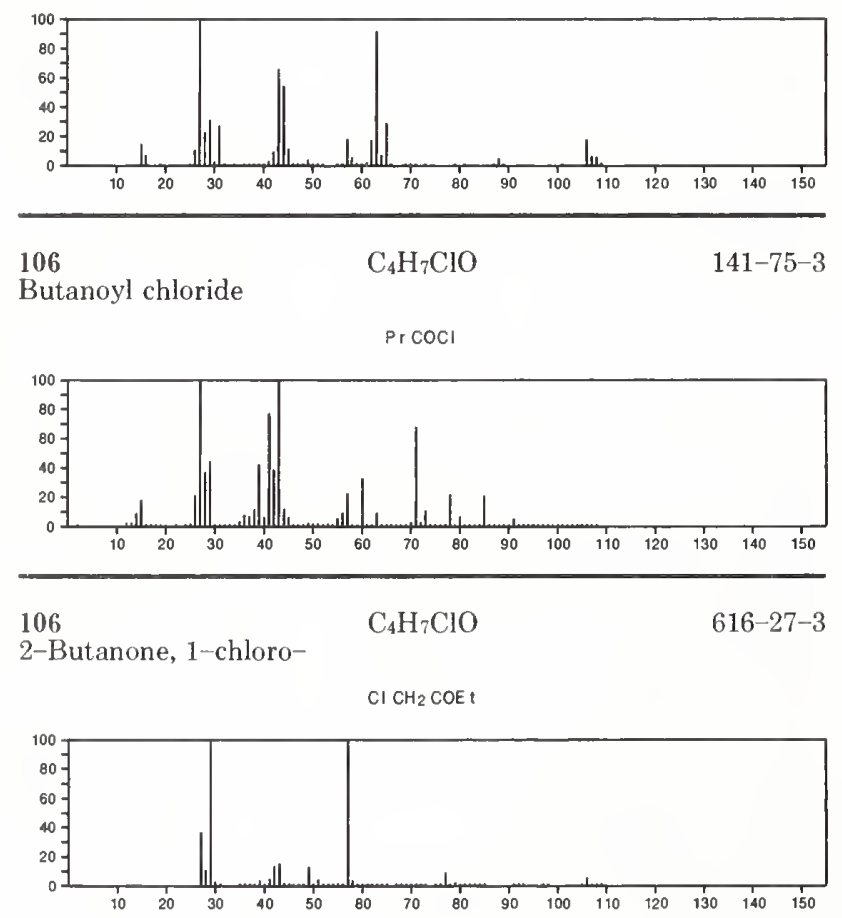

106

2-Butanone, 3-chloro-

$\mathrm{C}_{4} \mathrm{H}_{7} \mathrm{ClO}$

4091-39-8

$\mathrm{Me} \mathrm{CHCl}$ COMe

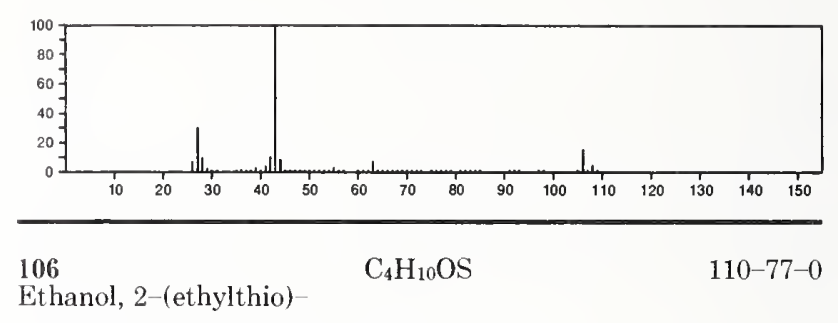

$\mathrm{E}$ i $\mathrm{SCH}_{2} \mathrm{CH}_{2} \mathrm{OH}$

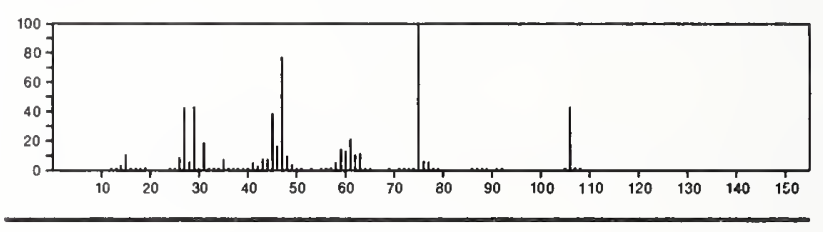

106

1-Propanol, 3-(methylthio)-

$\mathrm{C}_{4} \mathrm{H}_{10} \mathrm{OS}$

505-10-2

$\mathrm{MeS}\left(\mathrm{CH}_{2}\right)_{3} \mathrm{OH}$

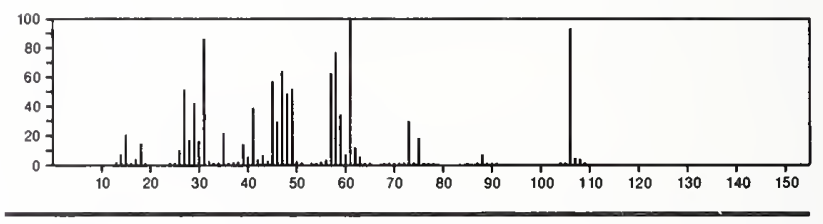

106

$\mathrm{C}_{4} \mathrm{H}_{10} \mathrm{O}_{3}$

111-46-6

Ethanol, 2,2'-oxybis-

$\mathrm{HOCH}_{2} \mathrm{CH}_{2} \mathrm{OCH}_{2} \mathrm{CH}_{2} \mathrm{OH}$

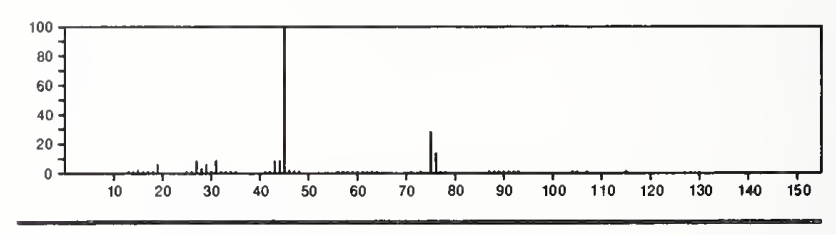

106
Methane, trimethoxy- $\mathrm{C}_{4} \mathrm{H}_{10} \mathrm{O}_{3}$

$149-73-5$

$\mathrm{HC}(\mathrm{OMe})_{3}$

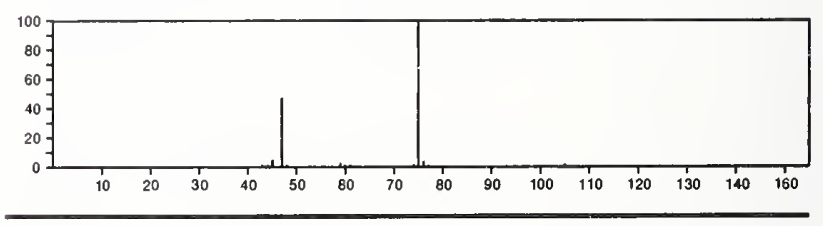

106

$\mathrm{C}_{4} \mathrm{H}_{10} \mathrm{O}_{3}$

$623-39-2$

1,2-Propanediol, 3-methoxy-

$\mathrm{MeOCH} 2 \mathrm{CH}(\mathrm{OH}) \mathrm{CH}_{2} \mathrm{OH}$

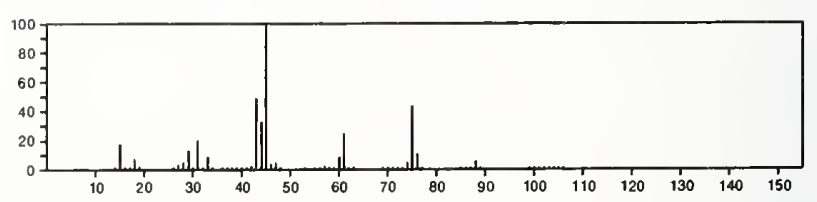


106

1,2,4-Butanetriol

$\mathrm{C}_{4} \mathrm{H}_{10} \mathrm{O}_{3}$

$\mathrm{HOCH}_{2} \mathrm{CH}_{2} \mathrm{CH}(\mathrm{OH}) \mathrm{CH}_{2} \mathrm{OH}$
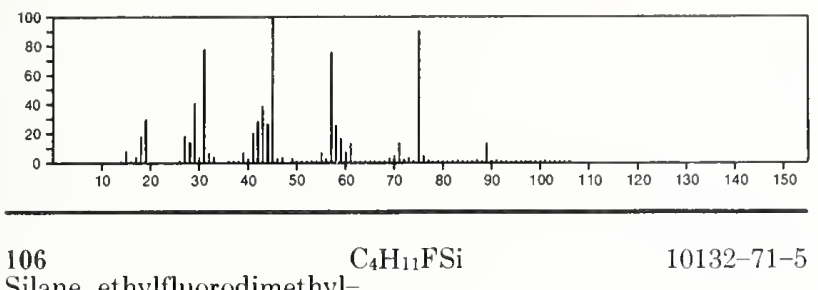

Silane, ethylfluorodimethyl-

EtSiF(Et)
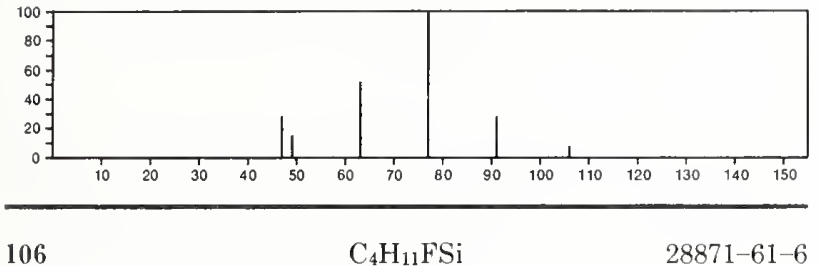

Silane, (fluoromethyl)trimethyl-

$\mathrm{FCH}_{2} \mathrm{SiMe}_{3}$

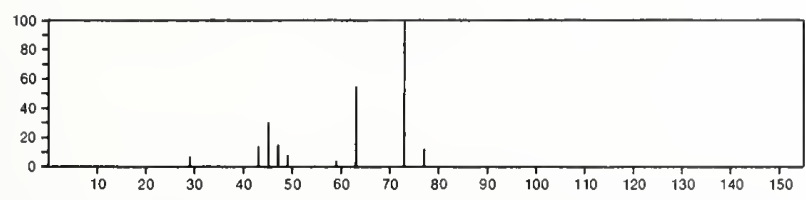

106

Butane, 1-chloro-3-methyl

$\mathrm{C}_{5} \mathrm{H}_{11} \mathrm{Cl}$

$\mathrm{Cl} \mathrm{CH}_{2} \mathrm{CH}_{2} \mathrm{CHMe}_{2}$
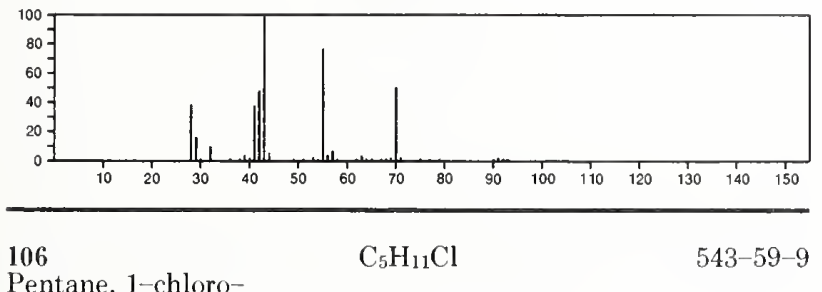

Pentane, 1-chloro-

$\mathrm{Me}\left(\mathrm{CH}_{2}\right){ }_{4} \mathrm{Cl}$

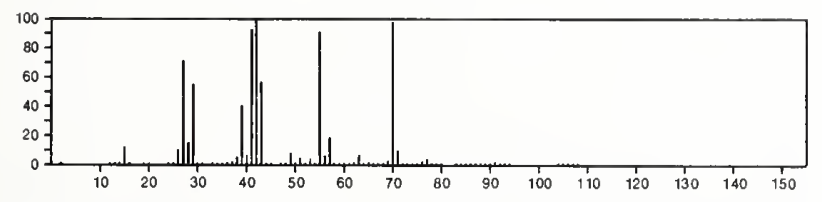

106

Butane, 2-chloro-2-methyl-

$\mathrm{C}_{5} \mathrm{H}_{11} \mathrm{Cl}$

$594-36-5$

$E t C C I(E t)$

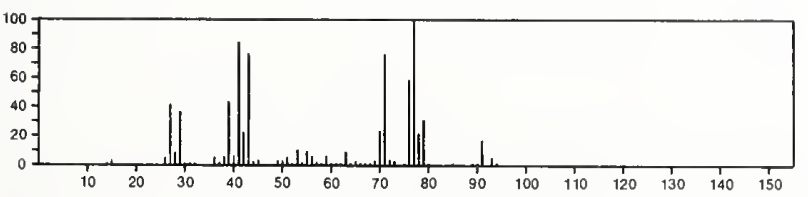

106

$\mathrm{C}_{5} \mathrm{H}_{11} \mathrm{Cl}$

616-13-7

Butane, 1-chloro-2-methyl-

$\mathrm{Me}_{2} \mathrm{CH}_{2} \mathrm{CHMe} \mathrm{CH}_{2} \mathrm{Cl}$
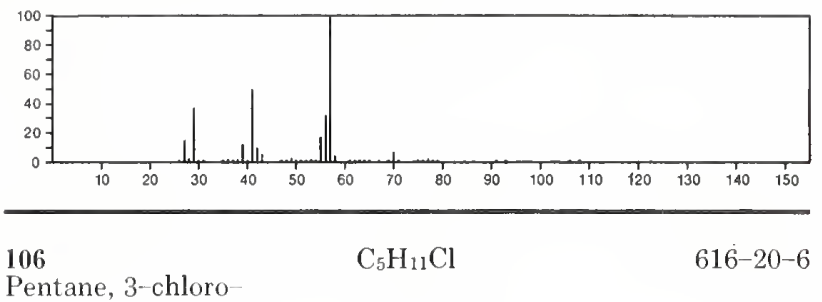

Pentane, 3-chloro-

$\mathrm{Et}_{2} \mathrm{CHCl}$

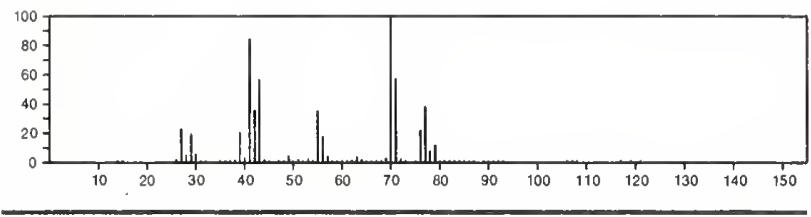

106

$\mathrm{C}_{5} \mathrm{H}_{11} \mathrm{Cl}$

$625-29-6$

Pentane, 2-chloro-

$\mathrm{PrCHCl}(\mathrm{Me})$

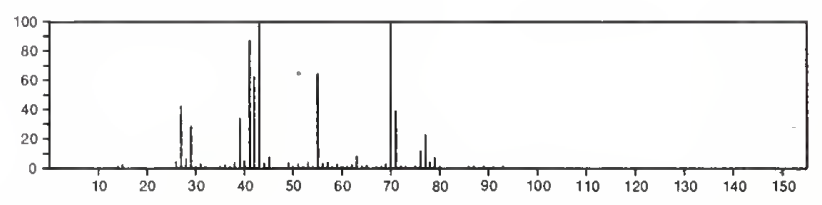

106

$\mathrm{C}_{5} \mathrm{H}_{11} \mathrm{Cl}$

$631-65-2$

Butane, 2-chloro-3-methyl-

$\mathrm{Me} \mathrm{CHCl}_{\mathrm{CHM}}$ ?

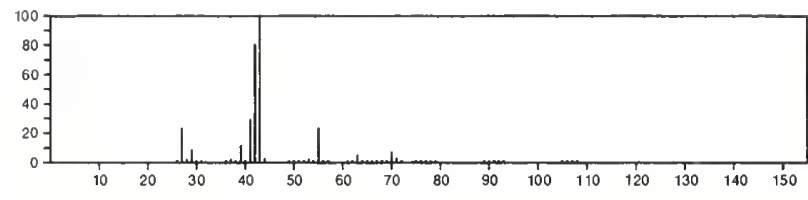

$106 \quad \mathrm{C}_{5} \mathrm{H}_{11} \mathrm{Cl}$

Propane, 1-chloro-2,2-dimethyl-

$753-89-9$

$\mathrm{Cl} \mathrm{CH}_{2} \mathrm{CMe}_{3}$

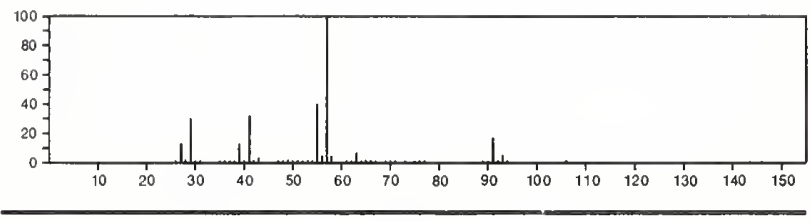

106

$\mathrm{C}_{6} \mathrm{H}_{6} \mathrm{~N}_{2}$

3211-19-6

1,2-Cyclobutanedicarbonitrile, cis
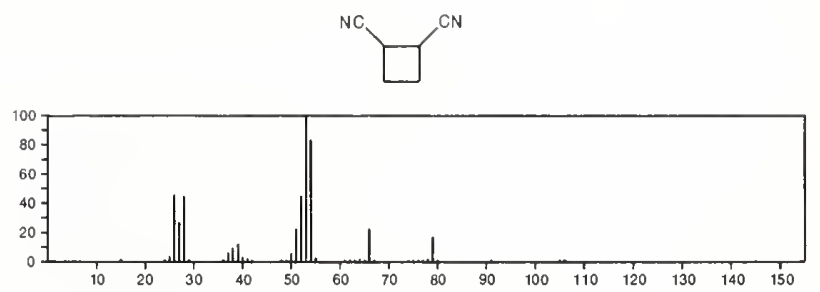
$106 \quad \mathrm{C}_{6} \mathrm{H}_{6} \mathrm{~N}_{2}$

1,2-Cyclobutanedicarbonitrile, trans-
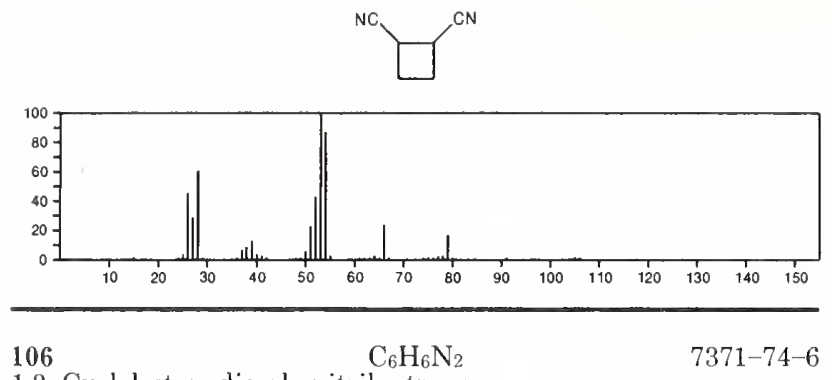

1,3-Cyclobutanedicarbonitrile, trans-
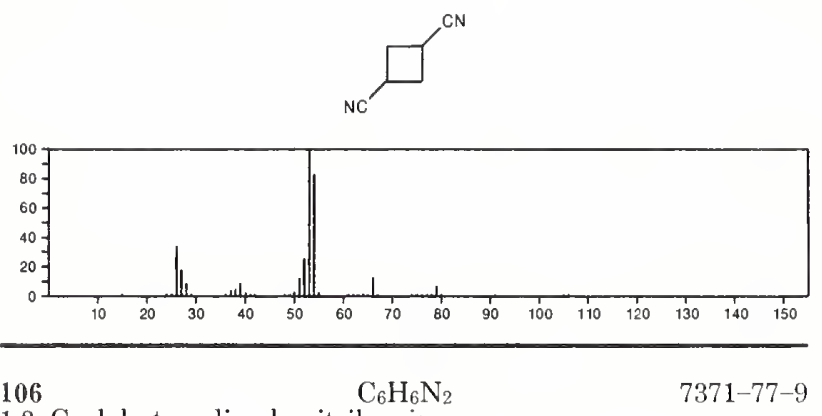

1,3-Cyclobutanedicarbonitrile, cis-
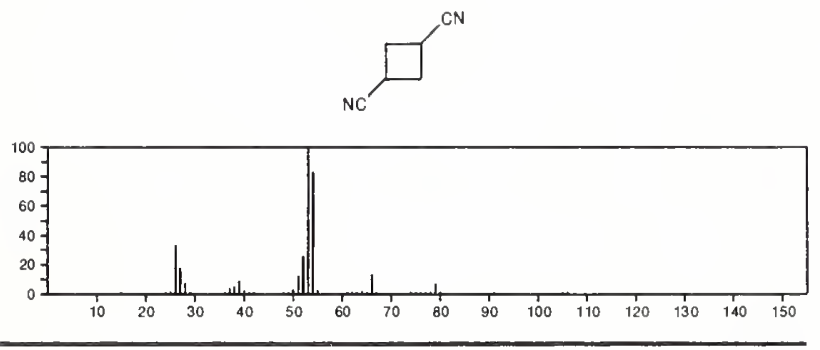

106

Benzaldehyde

$\mathrm{C}_{7} \mathrm{H}_{6} \mathrm{O}$

$100-52-7$

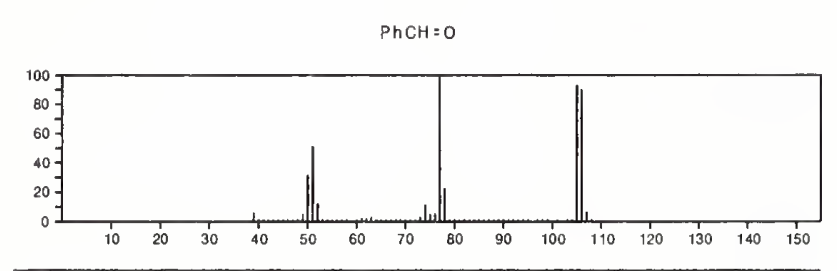

106

2,4,6-Cycloheptatrien-1-one

$\mathrm{C}_{7} \mathrm{H}_{6} \mathrm{O}$

$539-80-0$
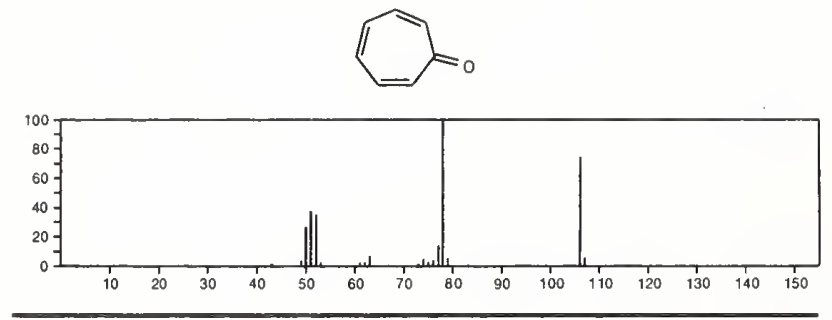

106

$\mathrm{C}_{7} \mathrm{H}_{6} \mathrm{O}$

$7200-04-6$

2,4-Heptadien-6-ynal, $(E, E)$

$\mathrm{OCHCH}=\mathrm{CHCH}=\mathrm{CHC} \equiv \mathrm{CH}$

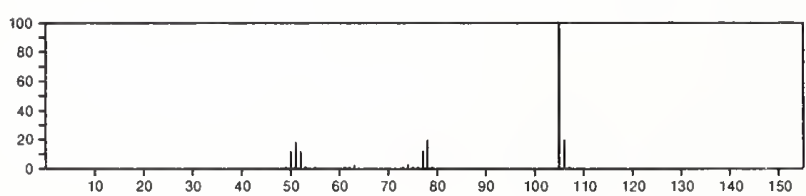

106

3,5-Heptadiyn-2-one

$\mathrm{C}_{7} \mathrm{H}_{6} \mathrm{O}$

$13879-71-5$

$\mathrm{Me} \mathrm{COC} \equiv \mathrm{CC} \equiv \mathrm{CMe}$

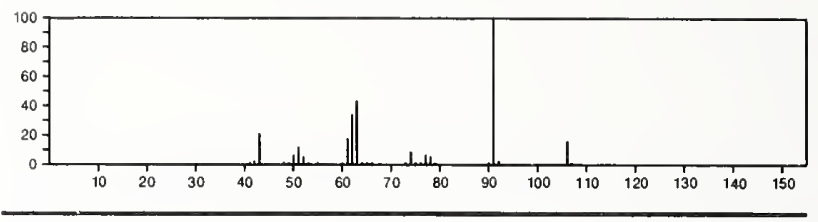

106

$\mathrm{C}_{7} \mathrm{H}_{6} \mathrm{O}$

29743-27-9

4,6-Heptadiyn-3-one

$H C \equiv C C \equiv C C O E t$

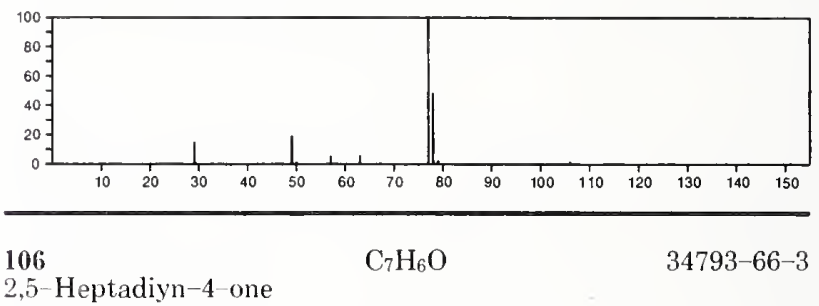

$\mathrm{Me} \mathrm{C} \equiv \mathrm{CCOC} \equiv \mathrm{CMe}$

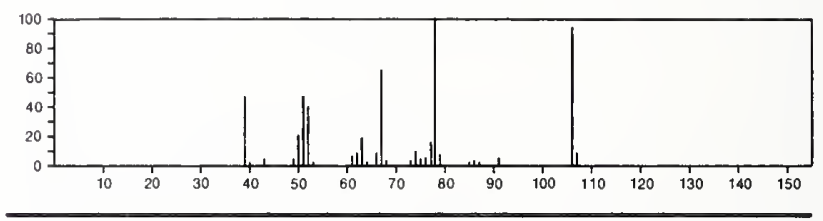

106

$\mathrm{C}_{8} \mathrm{H}_{10}$

$95-47-6$

Benzene, 1,2-dimethyl
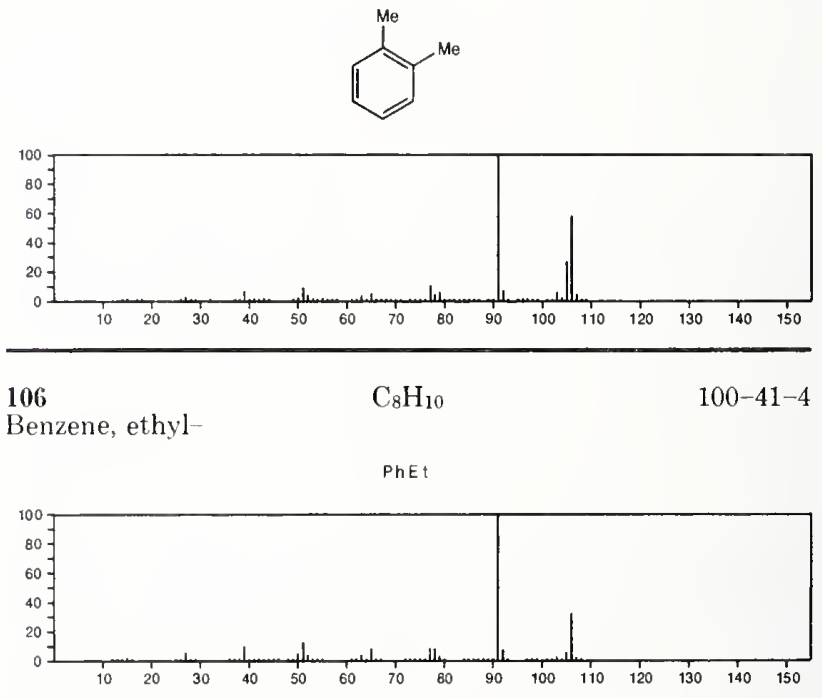

106

$\mathrm{C}_{8} \mathrm{H}_{10}$

$106-42-3$

Benzene, 1,4-dimethyl-
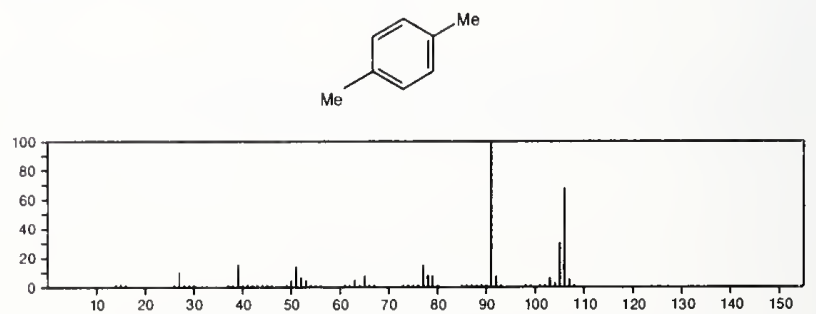
106

$\mathrm{C}_{8} \mathrm{H}_{10}$

$108-38-3$
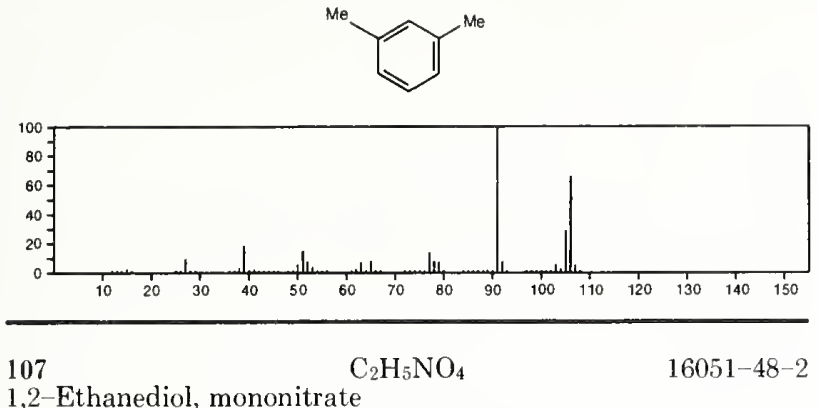

1,2-Ethanediol, mononitrate

$\mathrm{O}_{2} \mathrm{NOCH}_{2} \mathrm{CH}_{2} \mathrm{OH}$

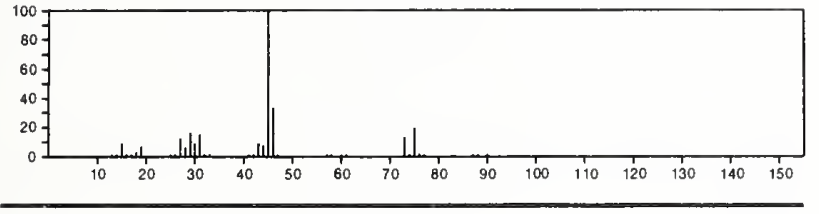

107

$\mathrm{C}_{3} \mathrm{~F}_{3} \mathrm{~N}$

2-Propenenitrile, 2,3,3-trifluoro-

$\mathrm{F}_{2} \mathrm{C}=\mathrm{CFCN}$

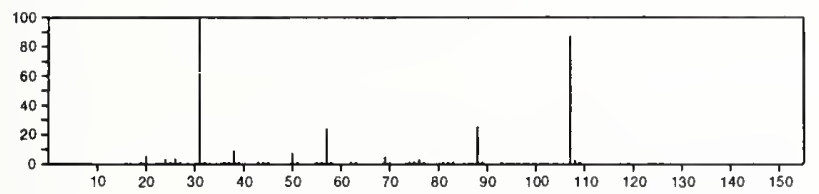

107

$\mathrm{C}_{3} \mathrm{H}_{3} \mathrm{~F}_{2} \mathrm{NO}$

Ethane, 1,1-difluoro-1-isocyanato-

1645-88-1

$\mathrm{Me} \mathrm{CF}_{2}$ ( NCO)
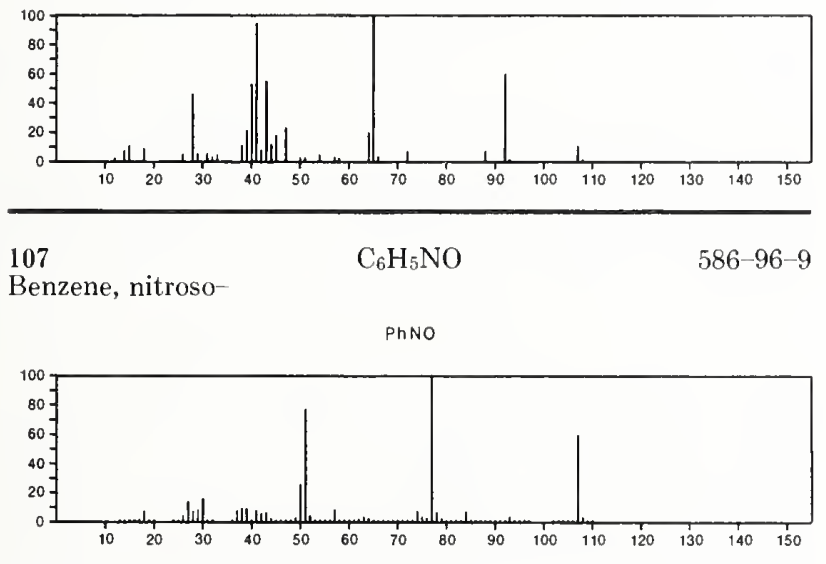

107

$\mathrm{C}_{6} \mathrm{H}_{5} \mathrm{NO}$

$872-85-5$

4-Pyridinecarboxaldehyde
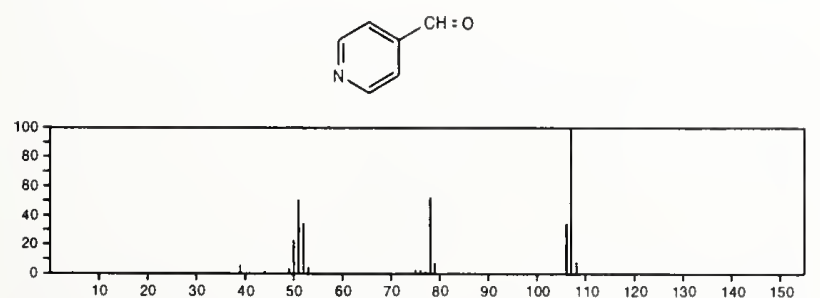

107

Benzenamine, 2-methyl-

$\mathrm{C}_{7} \mathrm{H}_{9} \mathrm{~N}$

$95-53-4$
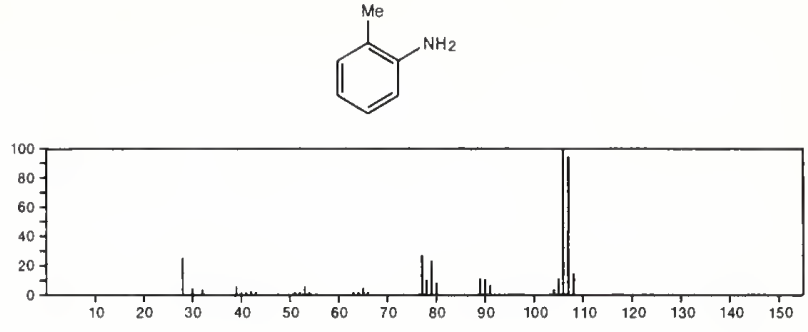

107

$\mathrm{C}_{7} \mathrm{H}_{9} \mathrm{~N}$

$100-46-9$

Benzenemethanamine

$\mathrm{PhCH}_{2} \mathrm{NH}_{2}$

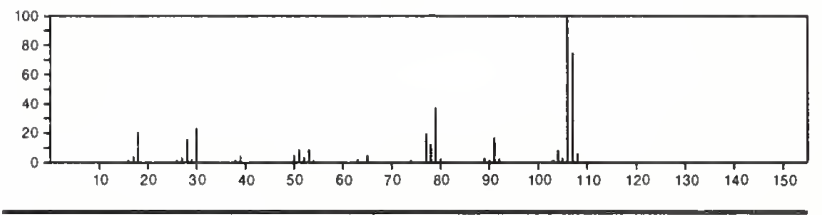

107

$\mathrm{C}_{7} \mathrm{H}_{9} \mathrm{~N}$

$100-61-8$

Benzenamine, $N$-methyl-

MeNHPh

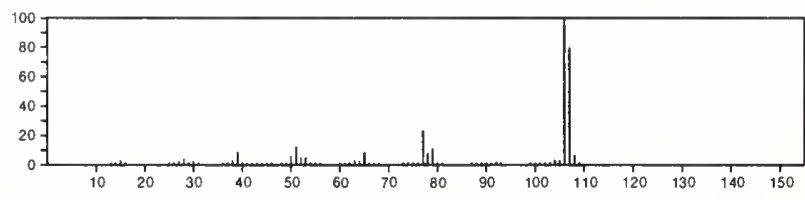

107

$\mathrm{C}_{7} \mathrm{H}_{9} \mathrm{~N}$

$100-71-0$

Pyridine, 2-ethyl-
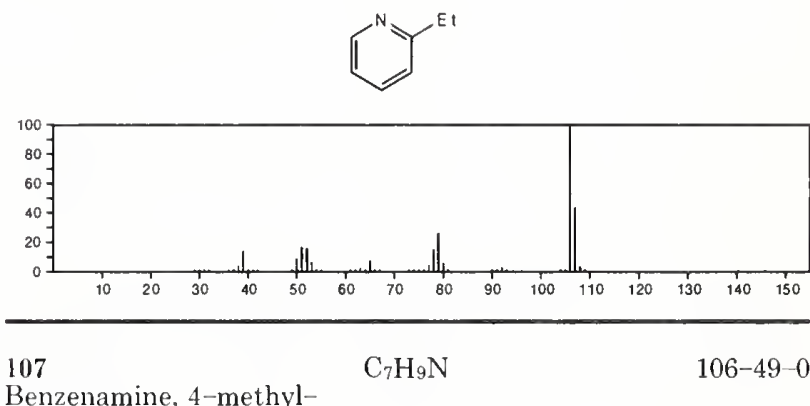

Benzenamine, 4-methyl-
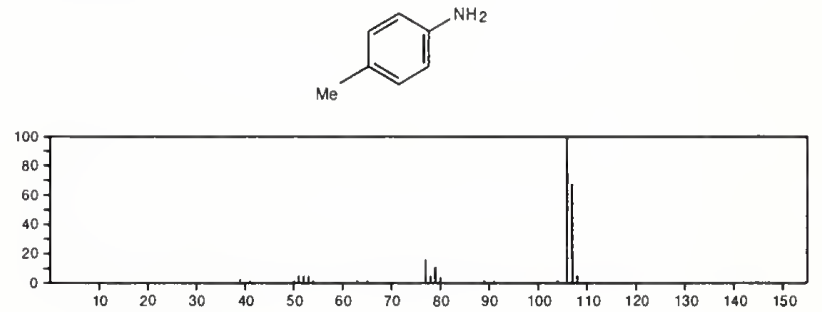
107

Pyridine, 2,4-dimethyl

$\mathrm{C}_{7} \mathrm{H}_{9} \mathrm{~N}$
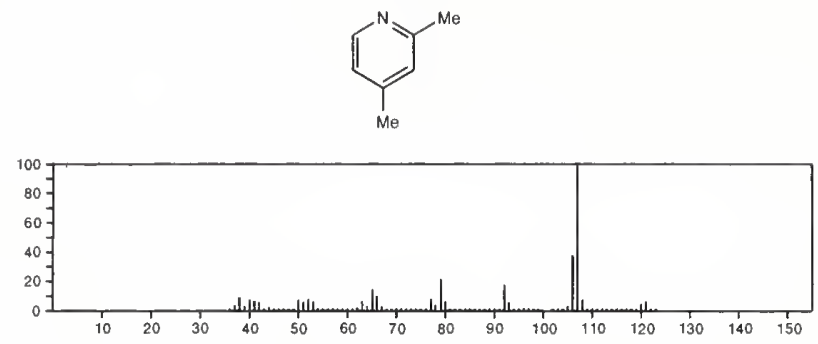

107

Pyridine, 2,6-dimethyl

$\mathrm{C}_{7} \mathrm{H}_{9} \mathrm{~N}$

$108-48-5$
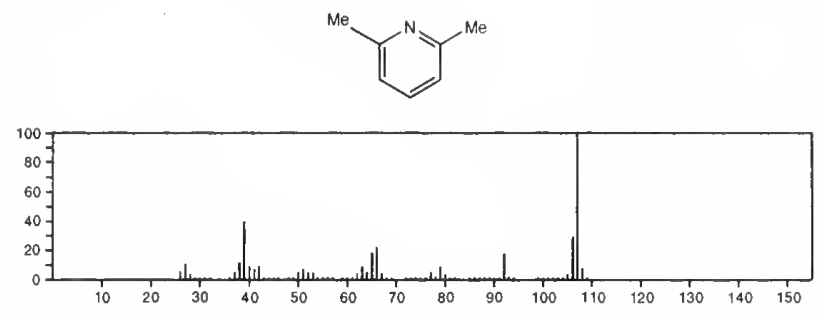

107

Pyridine, 4-ethyl-

$\mathrm{C}_{7} \mathrm{H}_{9} \mathrm{~N}$

$536-75-4$
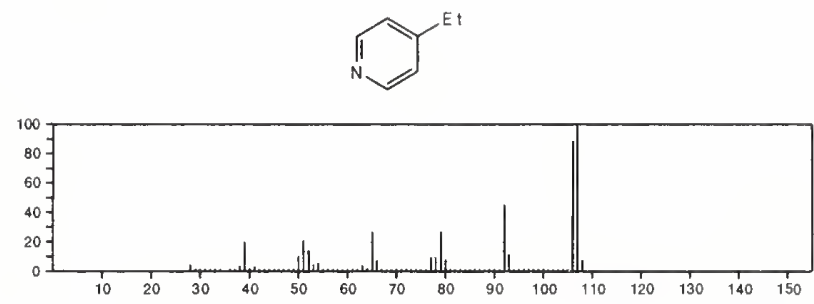

108

Arsine, silyl-

$\mathrm{AsH}_{5} \mathrm{Si}$

$\mathrm{H}_{2} \mathrm{AsSiH}_{3}$

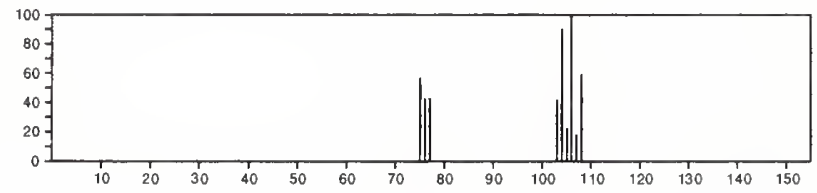

108

1,3,2-Dioxathiolane, 2-oxide

$\mathrm{C}_{2} \mathrm{H}_{4} \mathrm{O}_{3} \mathrm{~S}$

3741-38-6
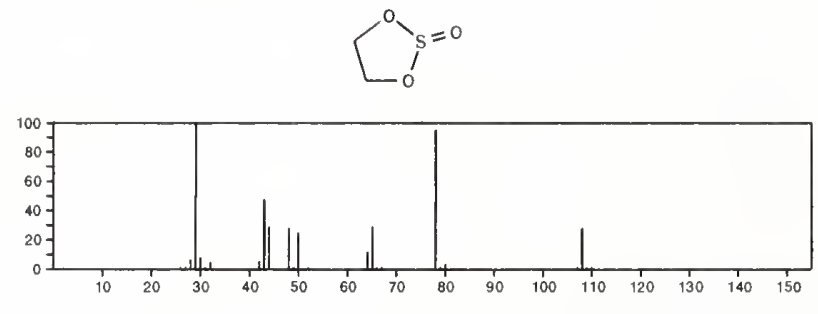

108

$\mathrm{C}_{2} \mathrm{H}_{5} \mathrm{Br}$

$74-96-4$

Ethane, bromo-

EtBr

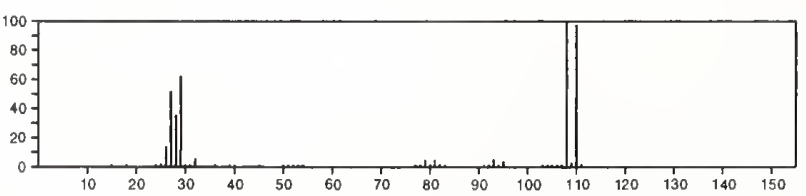

108

Borane, chlorodimethoxy-

$\mathrm{C}_{2} \mathrm{H}_{6} \mathrm{BClO}_{2}$

$868-81-5$

$\mathrm{MeOBCI}$ OMe
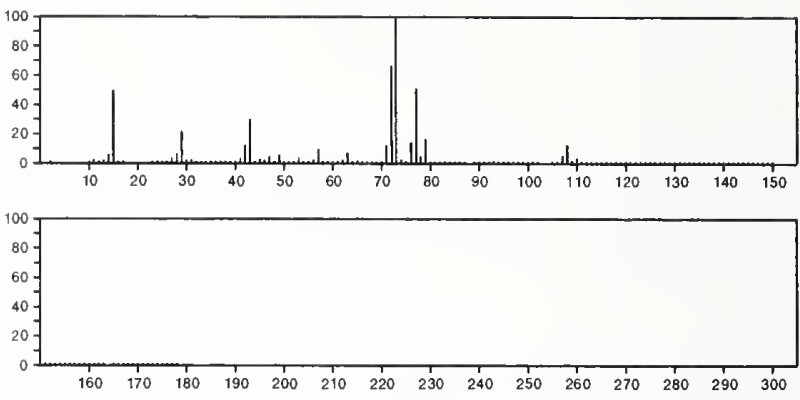

$108 \quad \mathrm{C}_{3} \mathrm{H}_{5} \mathrm{ClO}_{2}$

Acetic acid, chloro-, methyl ester

$96-34-4$

$\mathrm{Cl} \mathrm{CH}_{2} \mathrm{C}(\mathrm{O}) \mathrm{OMe}$

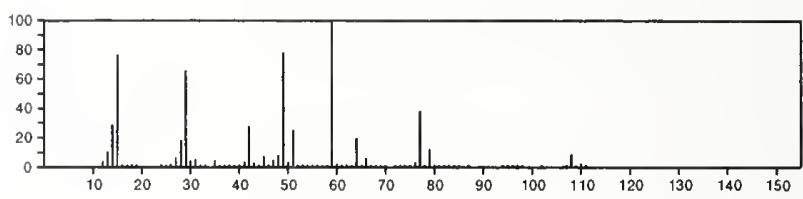

108

$\mathrm{C}_{3} \mathrm{H}_{5} \mathrm{ClO}_{2}$

$107-94-8$

Propanoic acid, 3-chloro-

$\mathrm{Cl} \mathrm{CH}_{2} \mathrm{CH}_{2} \mathrm{CO}_{2} \mathrm{H}$
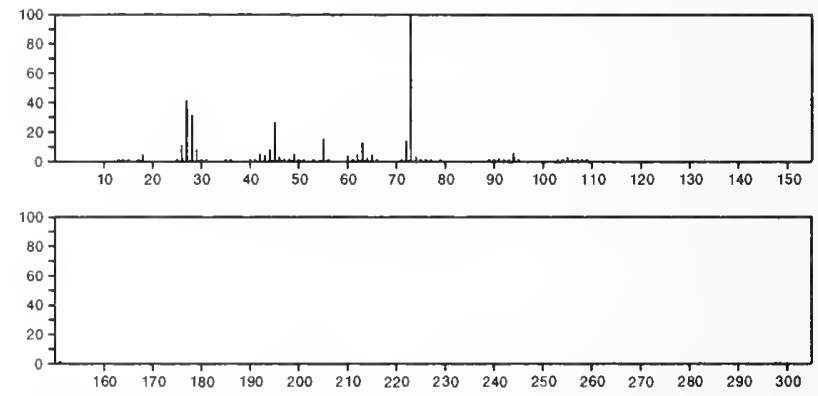

$108 \quad \mathrm{C}_{3} \mathrm{H}_{5} \mathrm{ClO}_{2}$

Propanoic acid, 2-chloro-

598-78-7

$\mathrm{MeCHCl}\left(\mathrm{CO}_{2} \mathrm{H}\right)$
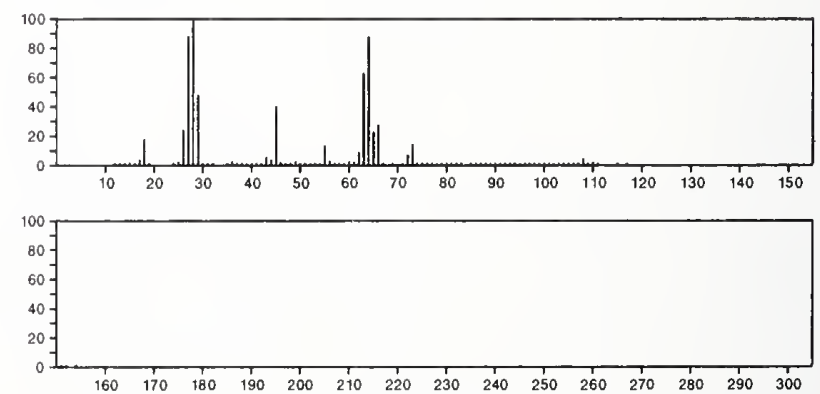

108

$\mathrm{C}_{3} \mathrm{H}_{8} \mathrm{O}_{2} \mathrm{~S}$

$31401-21-5$

Ethanesulfinic acid, methyl ester

$\mathrm{MeOS}(\mathrm{O}) \mathrm{E}$ :

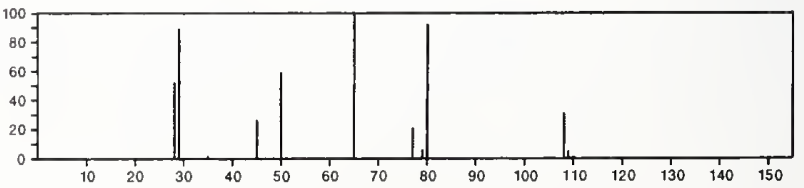


108

Silane, chlorotrimethyl-

$\mathrm{C}_{3} \mathrm{H}_{9} \mathrm{ClSi}$

$75-77-4$

$\mathrm{Me}{ }_{3} \mathrm{SiCl}$
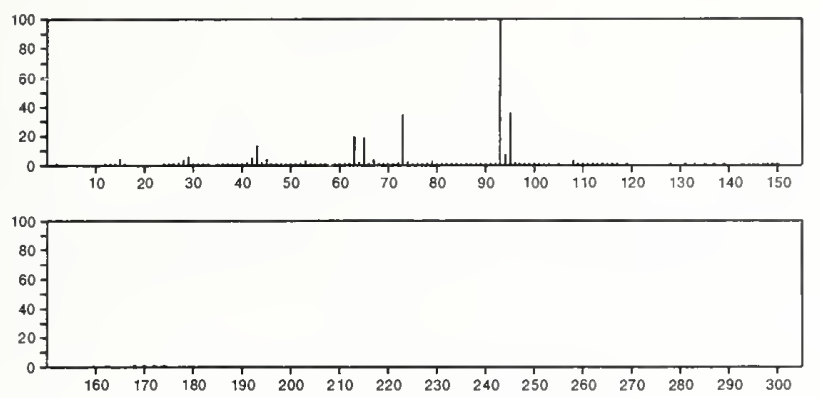

108

Silane, (chloromethyl)dimethyl-

$$
\mathrm{C}_{3} \mathrm{H}_{9} \mathrm{ClSi}
$$

3144-74-9

$\mathrm{ClCH}_{2} \mathrm{SiHMe}_{2}$

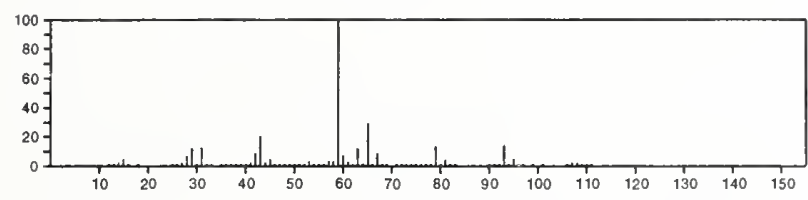

108

1,3-Butadiene, 1,1,2-trifluoro-

$565-65-1$

$\mathrm{H}_{2} \mathrm{C}=\mathrm{CHCF}=\mathrm{CF}_{2}$

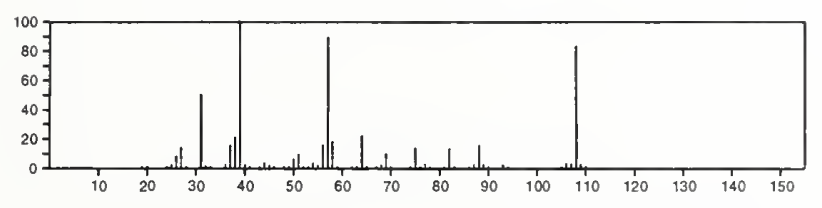

108

Imidazo[4,5-d]imidazole, 1,6-dihydro-

$\mathrm{C}_{4} \mathrm{H}_{4} \mathrm{~N}_{4}$

$35369-36-9$
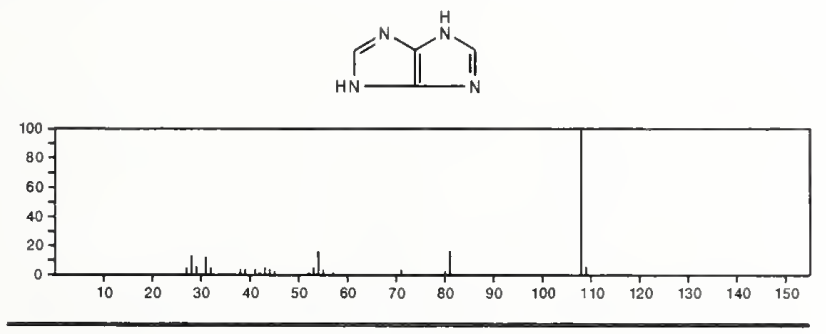

108

$\mathrm{C}_{4} \mathrm{H}_{9} \mathrm{ClO}$

$563-84-8$

2-Butanol, 3-chloro-

$\mathrm{MeCH}(\mathrm{OH}) \mathrm{CHCIMe}$

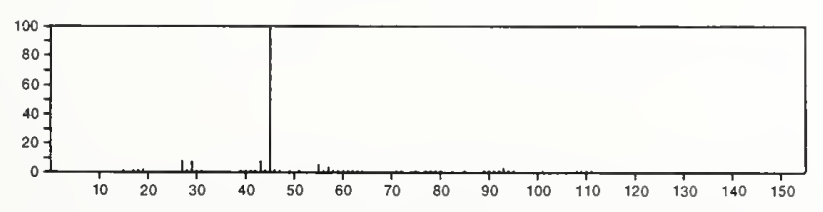

108

2-Butanol, 1-chloro-

$\mathrm{C}_{4} \mathrm{H}_{9} \mathrm{ClO}$

$1873-25-2$

$\mathrm{ClCH}_{2} \mathrm{CH}(\mathrm{OH}) \mathrm{EI}$

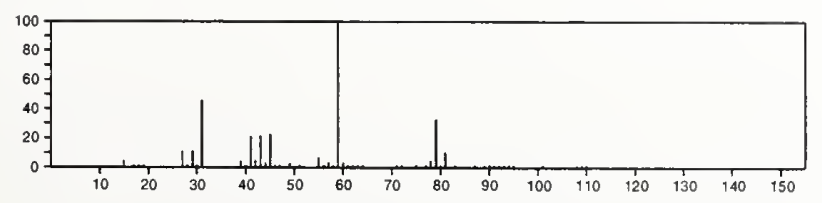

108

Propane, 2-chloro-1-methoxy-

$\mathrm{C}_{4} \mathrm{H}_{9} \mathrm{ClO}$

5390-71-6

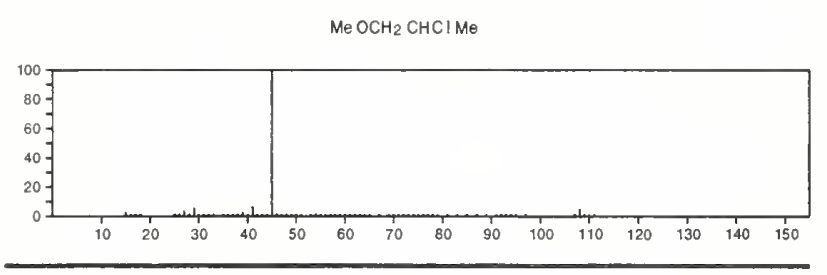

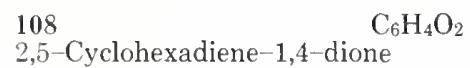

$106-51-4$
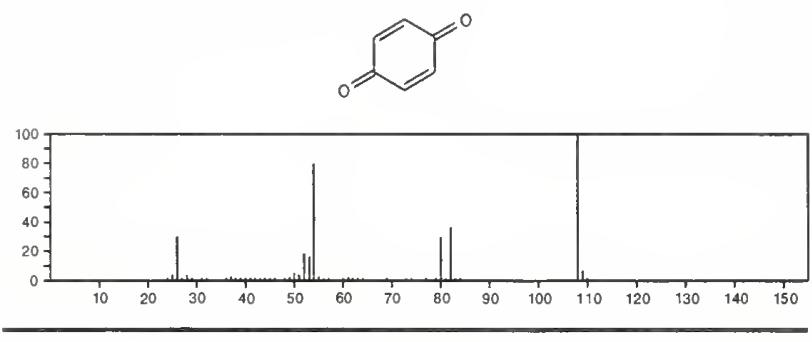

108

1,2-Benzenediamine

$\mathrm{C}_{6} \mathrm{H}_{8} \mathrm{~N}_{2}$

$95-54-5$
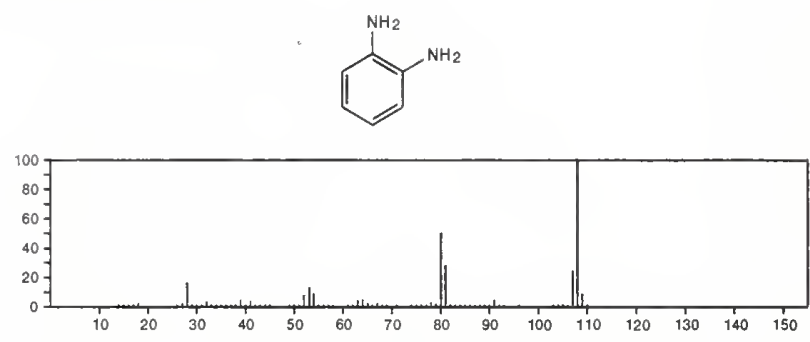

108

Hydrazine, phenyl-

$\mathrm{C}_{6} \mathrm{H}_{8} \mathrm{~N}_{2}$

$100-63-0$

PhNHNH2

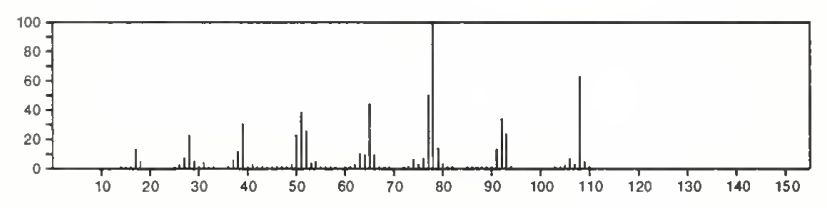

108

1,4-Benzenediamine

$\mathrm{C}_{6} \mathrm{H}_{8} \mathrm{~N}_{2}$

106-50-3
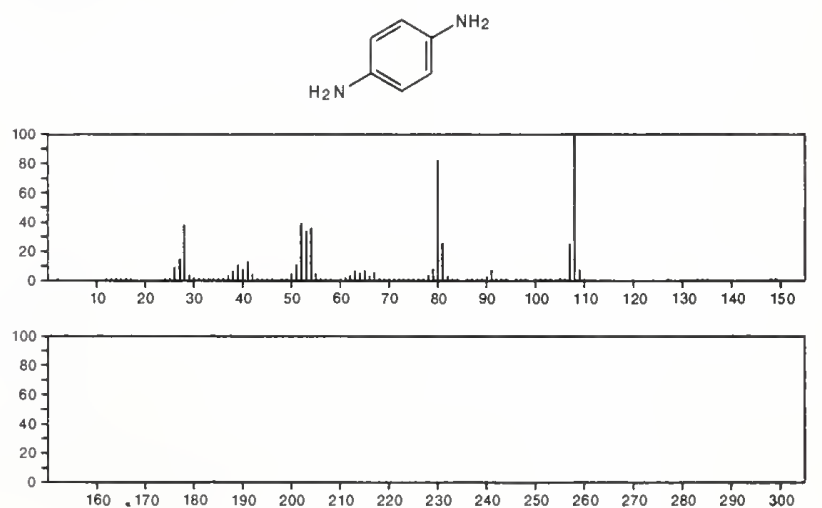
108

Pyrazine, 2,6-dimethyl-

$$
\mathrm{C}_{6} \mathrm{H}_{8} \mathrm{~N}_{2}
$$
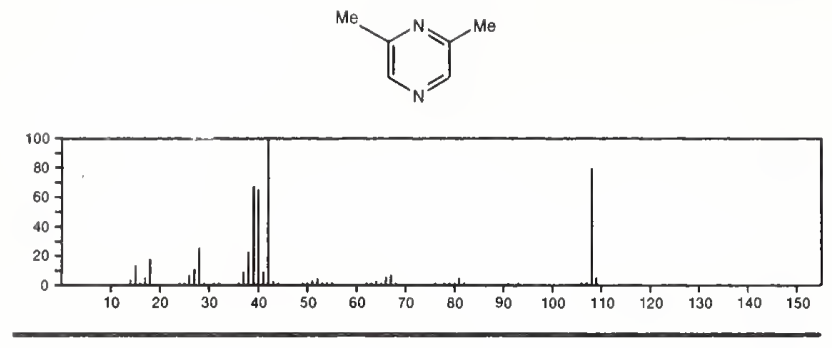

108

Hexanedinitrile

$$
\mathrm{C}_{6} \mathrm{H}_{8} \mathrm{~N}_{2}
$$

$111-69-3$

$\mathrm{NC}\left(\mathrm{CH}_{2}\right)_{4} \mathrm{CN}$

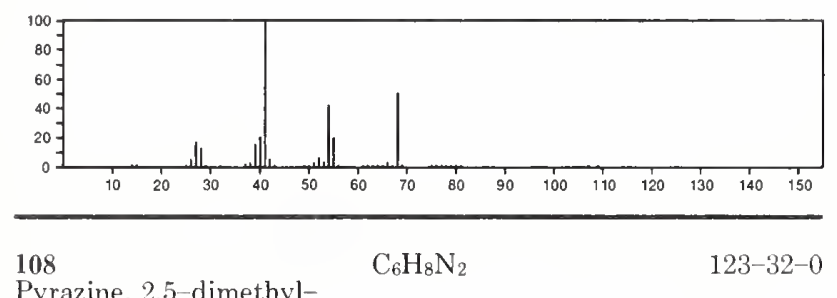

Pyrazine, 2,5-dimethyl-
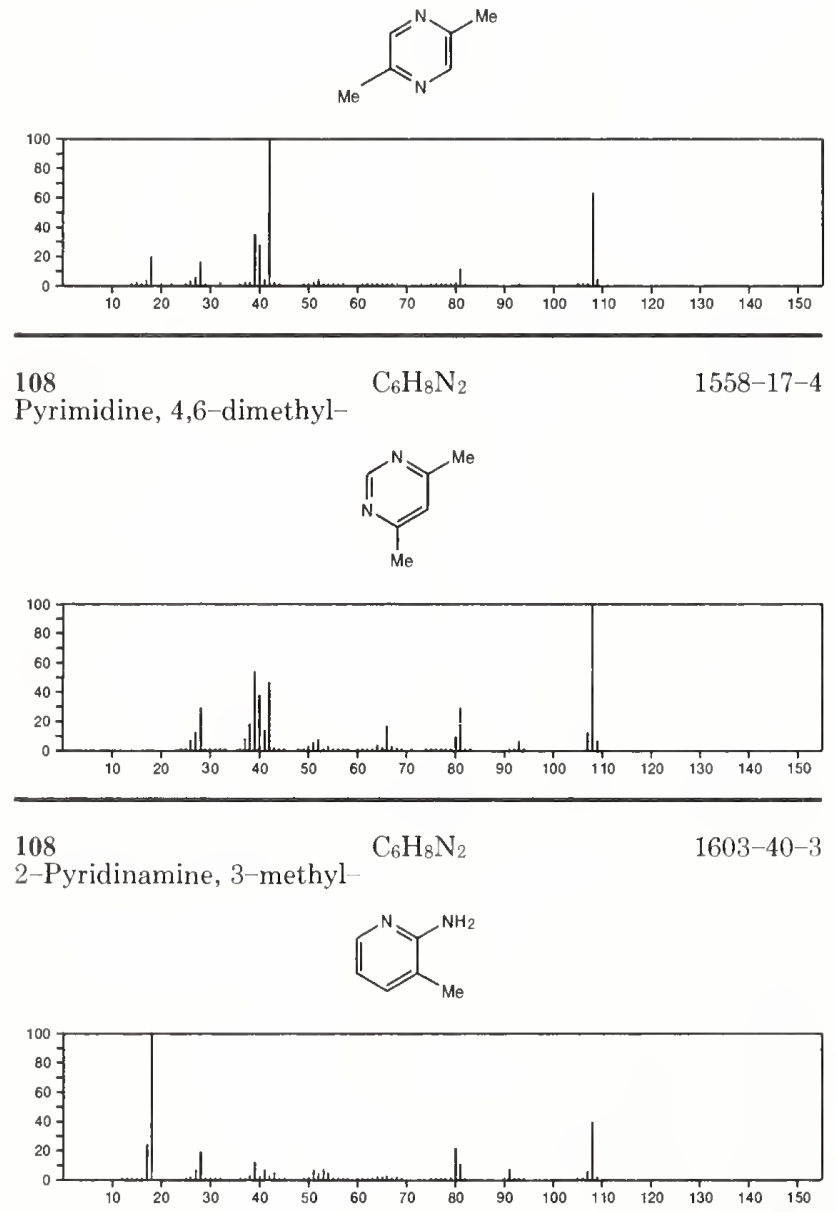

108

2-Pyridinamine, 6-methyl

$\mathrm{C}_{6} \mathrm{H}_{8} \mathrm{~N}_{2}$

$1824-81-3$
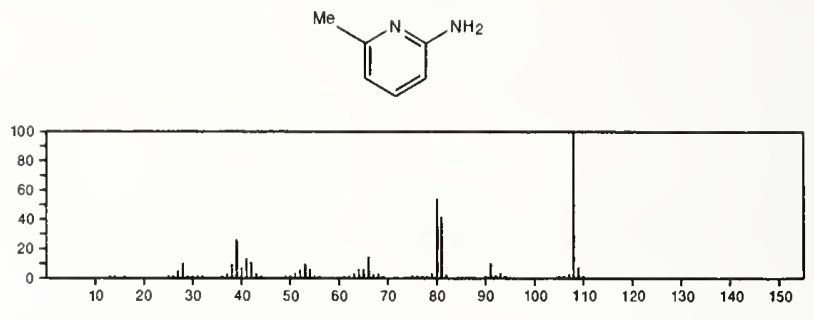

108

$\mathrm{C}_{6} \mathrm{H}_{8} \mathrm{~N}_{2}$

Cyclopentanecarbonitrile, 2-imino-

$2321-76-8$
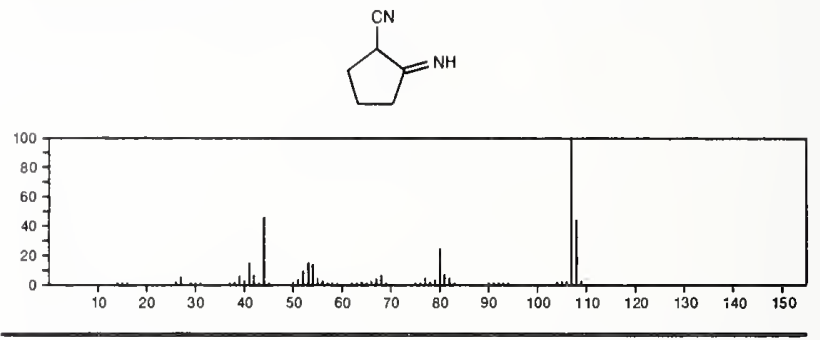

108

3-Pyridinemethanamine

$\mathrm{C}_{6} \mathrm{H}_{8} \mathrm{~N}_{2}$

$3731-52-0$
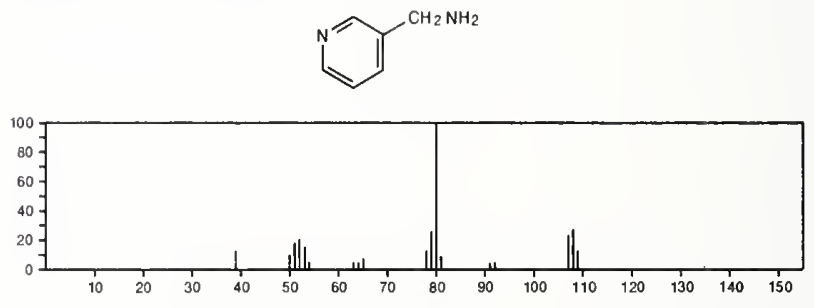

108

$\mathrm{C}_{6} \mathrm{H}_{8} \mathrm{~N}_{2}$

$4597-87-9$

2-Pyridinamine, $N$-methyl-
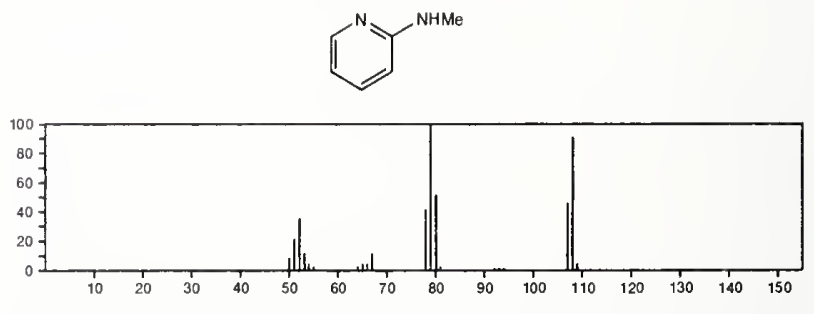

108

$\mathrm{C}_{6} \mathrm{H}_{8} \mathrm{~N}_{2}$

16411-13-5

Succinonitrile, 2,3-dimethyl-

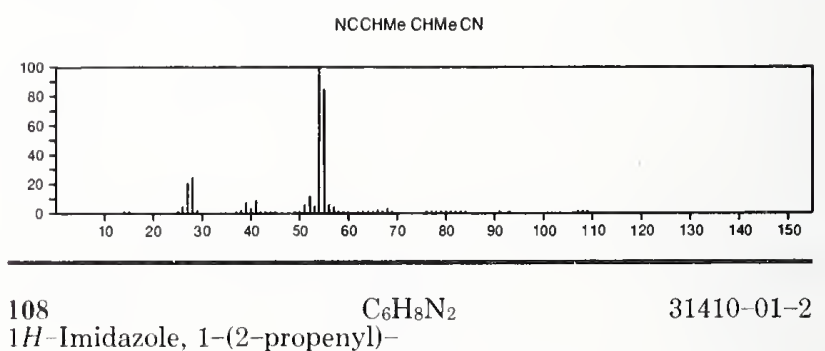

$\overbrace{N}-\mathrm{CH}_{2} \mathrm{CH}=\mathrm{CH}_{2}$

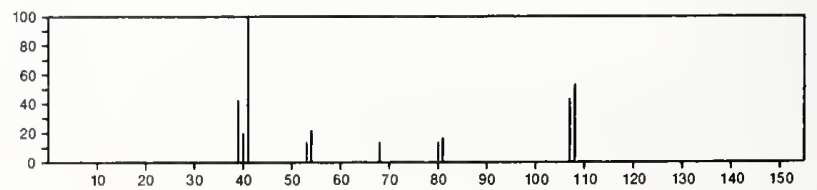


108

$\mathrm{C}_{6} \mathrm{H}_{8} \mathrm{~N}_{2}$

1H-Imidazole, 4-(2-propenyl)-

$$
\mathrm{HN}^{\mathrm{N}} \mathrm{CH}_{2} \mathrm{CH}=\mathrm{CH}_{2}
$$

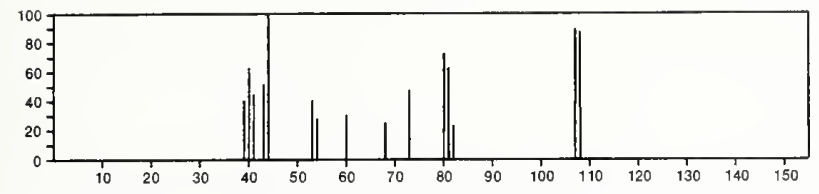

108

Pyridinium, 1-amino-2-methyl-, hydroxide, inner salt
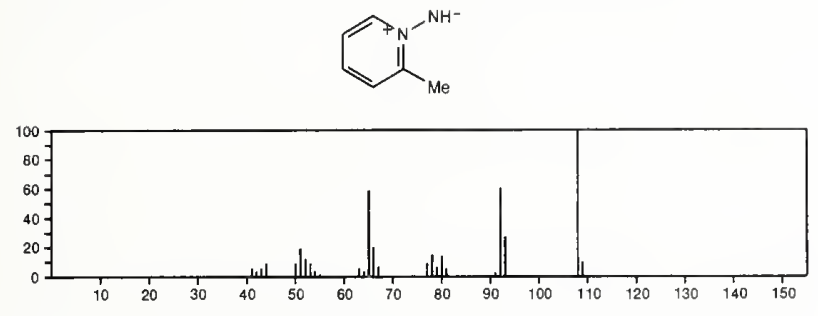

$108 \quad \mathrm{C}_{6} \mathrm{H}_{8} \mathrm{~N}_{2} \quad 57156-85-1$

Pyridinium, 1-amino-4-methyl-, hydroxide, inner salt
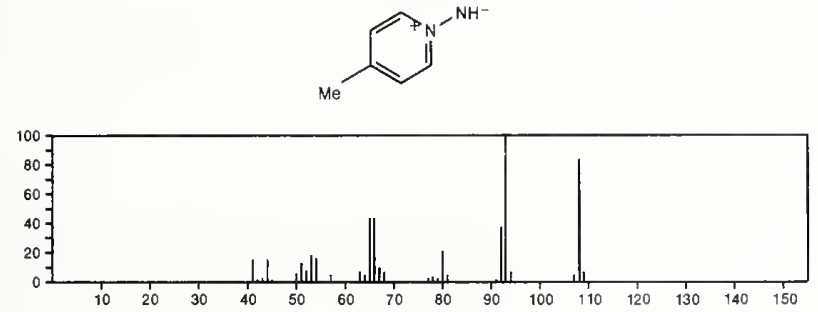

\section{8}

Phenol, 2-methyl-

$\mathrm{C}_{7} \mathrm{H}_{8} \mathrm{O}$

$95-48-7$
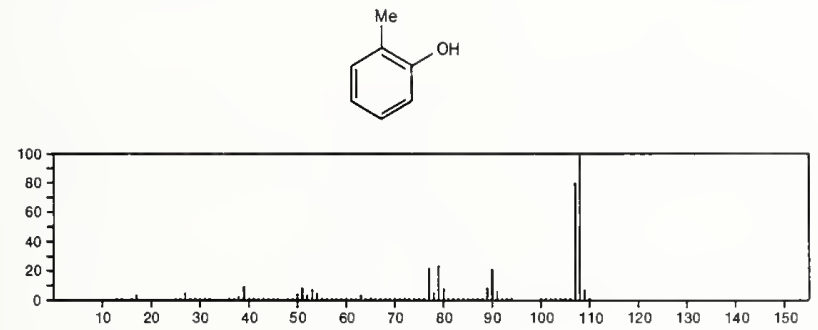

108

$\mathrm{C}_{7} \mathrm{H}_{8} \mathrm{O}$

$100-51-6$

Benzenemethanol

$\mathrm{PhCH}_{2} \mathrm{OH}$

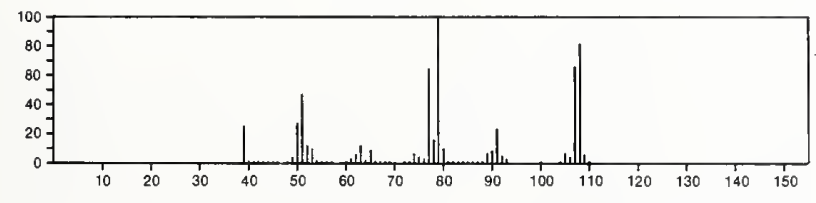

108

Benzene, methoxy-

$\mathrm{C}_{7} \mathrm{H}_{8} \mathrm{O}$

Me OPh

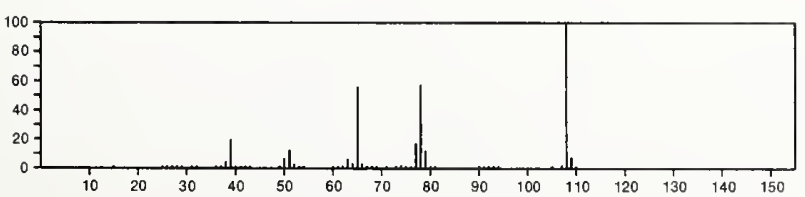

$100-66-3$
108

$\mathrm{C}_{7} \mathrm{H}_{8} \mathrm{O}$

$106-44-5$

Phenol, 4-methyl
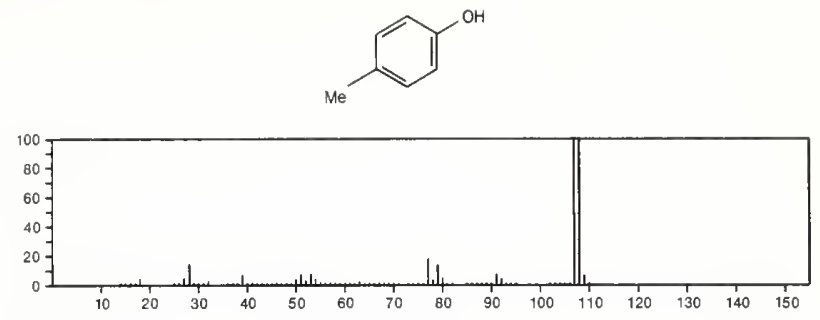

108

$\mathrm{C}_{7} \mathrm{H}_{8} \mathrm{O}$

108-39-4

Phenol, 3-methyl-
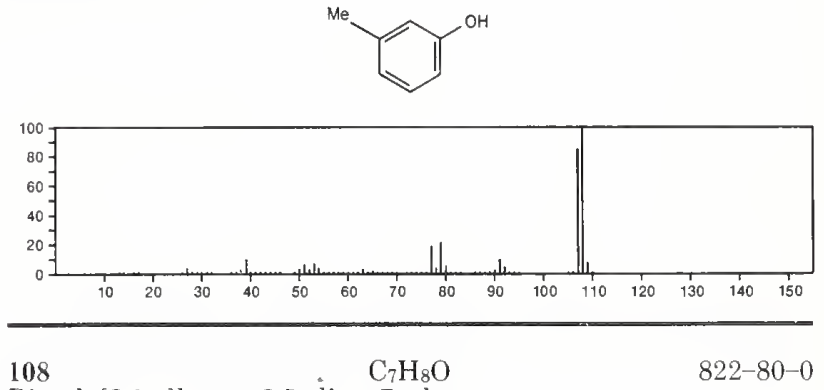

Bicyclo[2.2.1]hepta-2,5-dien-7-ol

Ho. $\rightarrow$
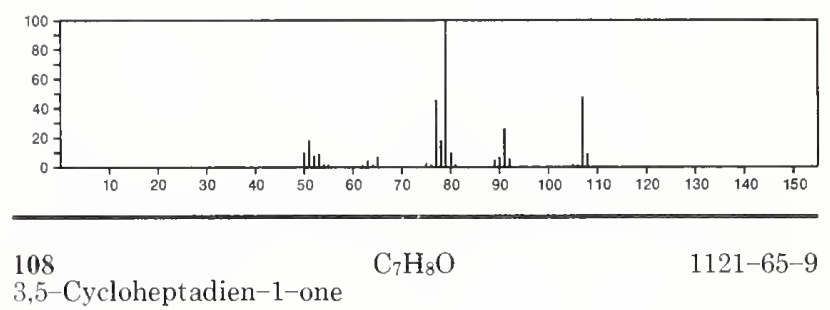

3,5-Cycloheptadien-1-one
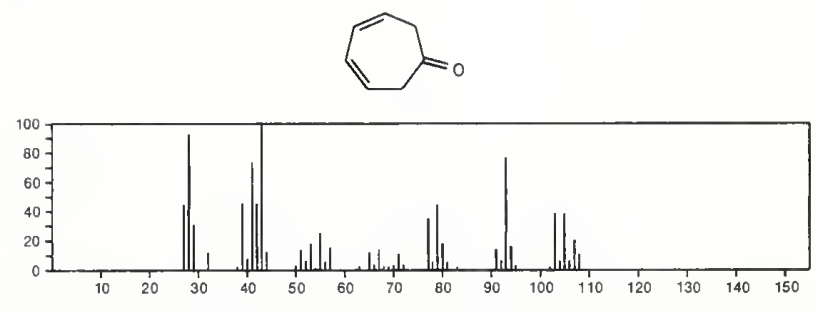

108

$\mathrm{C}_{8} \mathrm{H}_{12}$

$100-40-3$

Cyclohexene, 4-ethenyl-
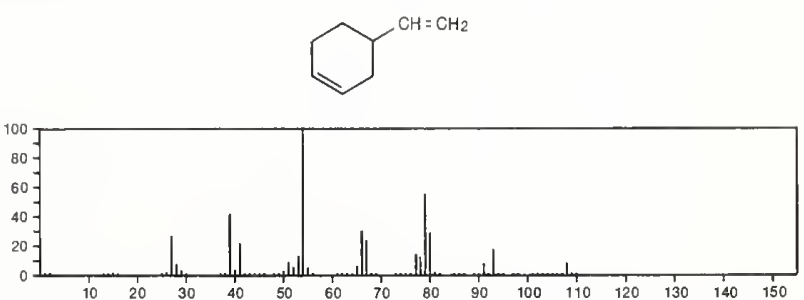
108

Bicyclo[5.1.0]oct-3-ene

$\mathrm{C}_{8} \mathrm{H}_{12}$<smiles>C1=CCC2CCCCCC2C1</smiles>

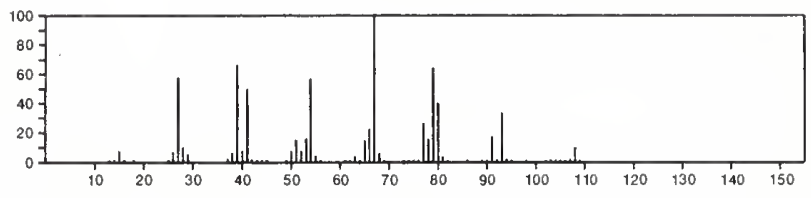

108

$\mathrm{C}_{8} \mathrm{H}_{12}$

Bicyclo[2.2.1]hept-2-ene, 1-methyl-

Me

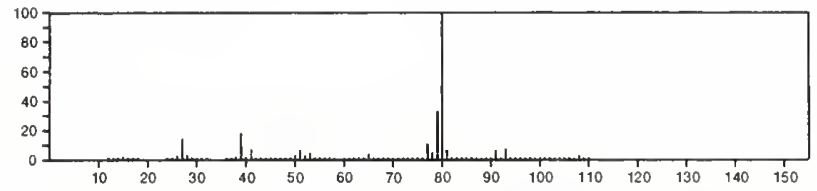

108

Cyclopropane, 1,1'-ethenylidenebis-

$822-93-5$
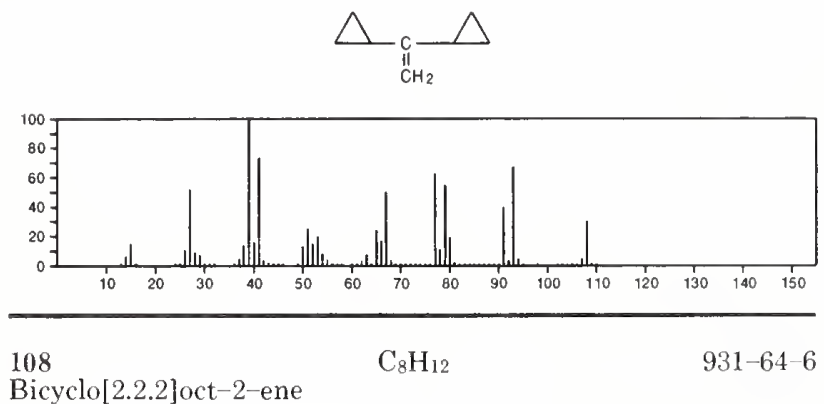

S1
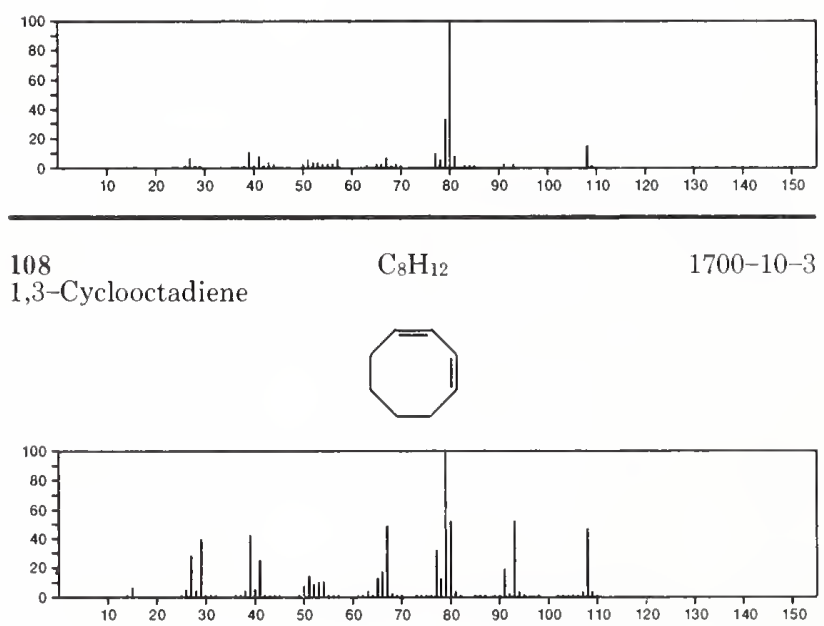

$108 \quad \mathrm{C}_{8} \mathrm{H}_{12}$

$4982-20-1$

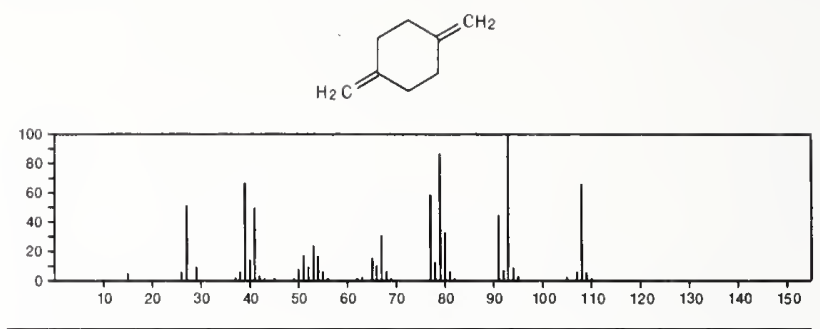

108

Tricyclo[3.2.1.01,5]octane

$\mathrm{C}_{8} \mathrm{H}_{12}$

$19074-25-0$
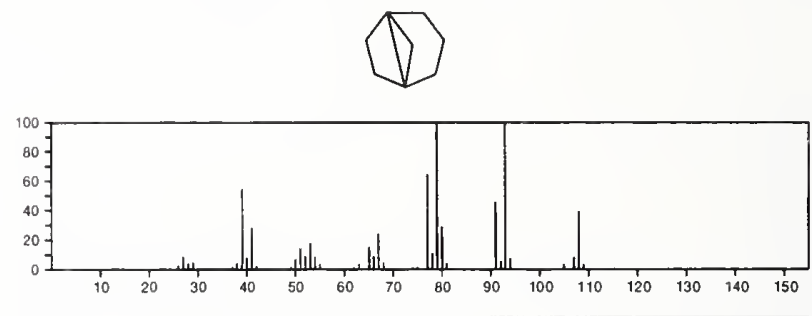

108

Sulfur fluoride $\left(\mathrm{SF}_{4}\right),(T-4)$

$\mathrm{F}_{4} \mathrm{~S}$

$7783-60-0$

$\mathrm{SF}$

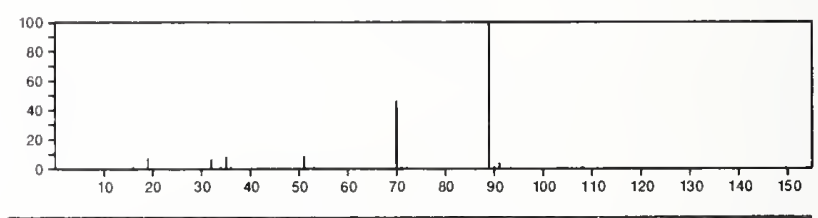

109

$\mathrm{C}_{2} \mathrm{H}_{4} \mathrm{ClNO}_{2}$

$625-47-8$

Ethane, 1-chloro-2-nitro-

$\mathrm{Cl} \mathrm{CH}_{2} \mathrm{CH}_{2} \mathrm{NO}_{2}$

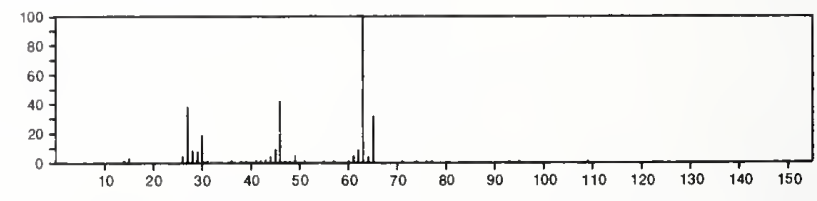

109

$\mathrm{C}_{2} \mathrm{H}_{7} \mathrm{~N}_{3} \cdot \mathrm{ClH}$

Guanidine, methyl-, monohydrochloride

$21770-81-0$

$\left(\mathrm{H}_{2} \mathrm{~N}\right) \mathrm{CNHME}=\mathrm{NH} \quad \cdot \mathrm{HCl}$

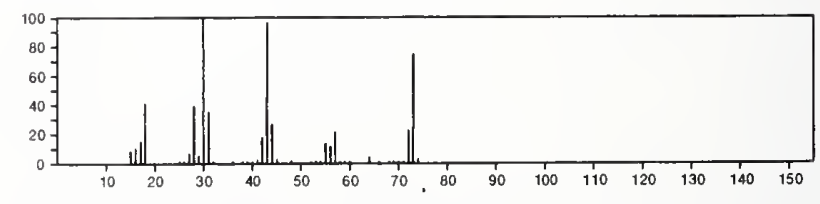

109

$\mathrm{C}_{2} \mathrm{H}_{10} \mathrm{~B}_{3} \mathrm{~N}_{3}$

$23208-27-7$

Borazine, 2,4-dimethyl-
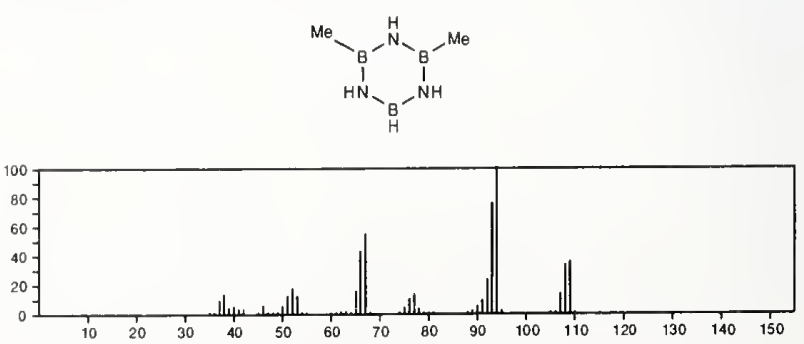
109

Borazine, 1,3-dimethyl-

$\mathrm{C}_{2} \mathrm{H}_{10} \mathrm{~B}_{3} \mathrm{~N}_{3}$

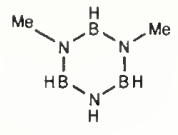

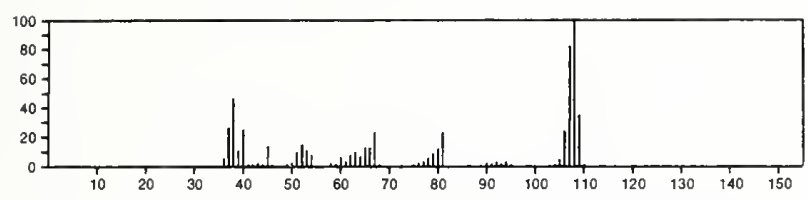

109

Phenol, 2-amino-

$\mathrm{C}_{6} \mathrm{H}_{7} \mathrm{NO}$

95-55-6
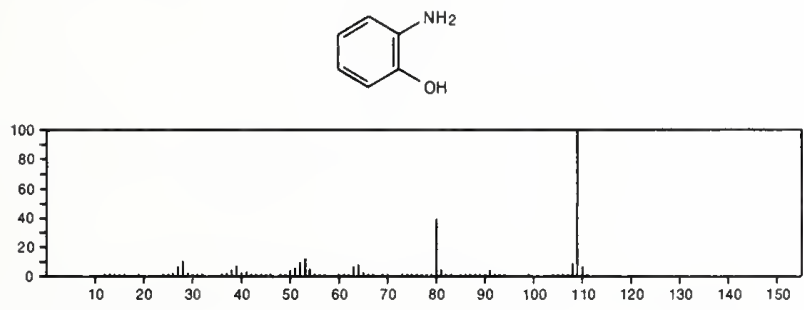

$$
109
$$

$109 \quad \mathrm{C}_{6} \mathrm{H}_{7} \mathrm{NO}$

$100-65-2$

Benzenamine, $N$-hydroxy-
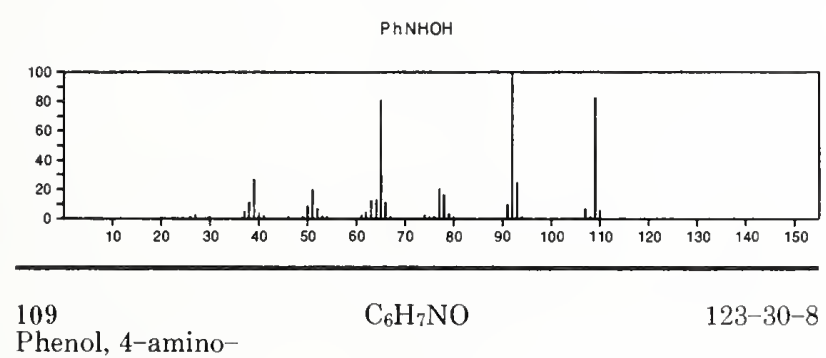

Phenol, 4-amino-
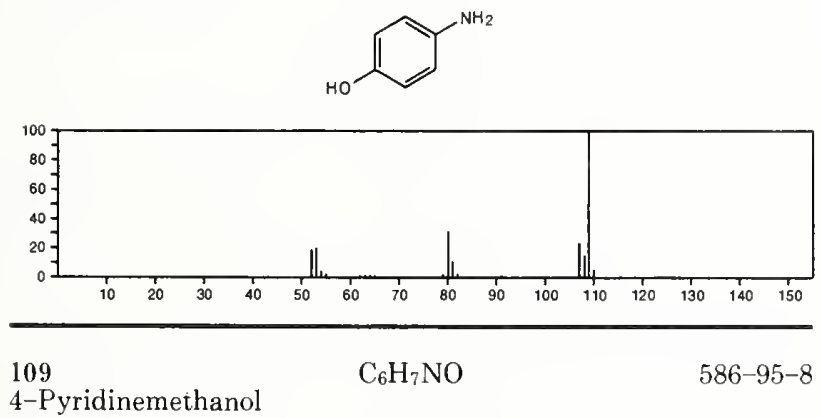

4-Pyridinemethanol
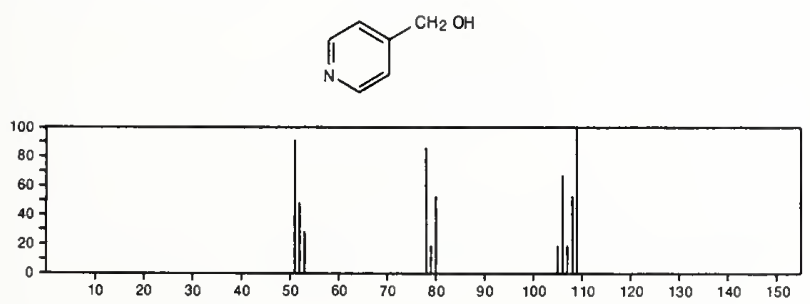

109

2-Pyridinemethanol

$\mathrm{C}_{6} \mathrm{H}_{7} \mathrm{NO}$

$586-98-1$

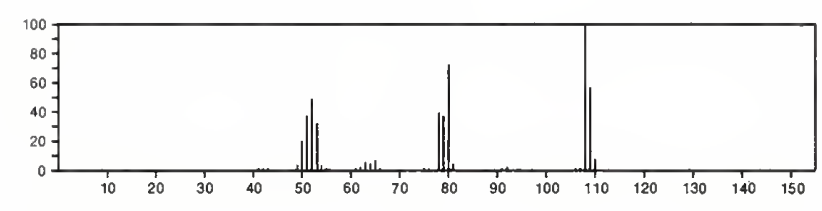

109

$\mathrm{C}_{6} \mathrm{H}_{7} \mathrm{NO}$

$591-27-5$

Phenol, 3-amino-
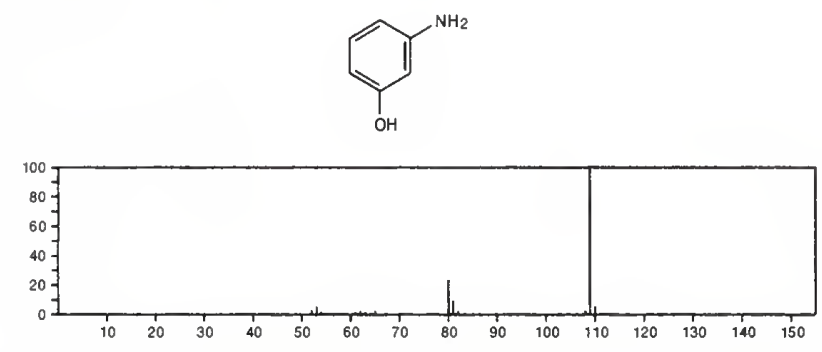

109

$\mathrm{C}_{6} \mathrm{H}_{7} \mathrm{NO}$

620-08-6

Pyridine, 4-methoxy-
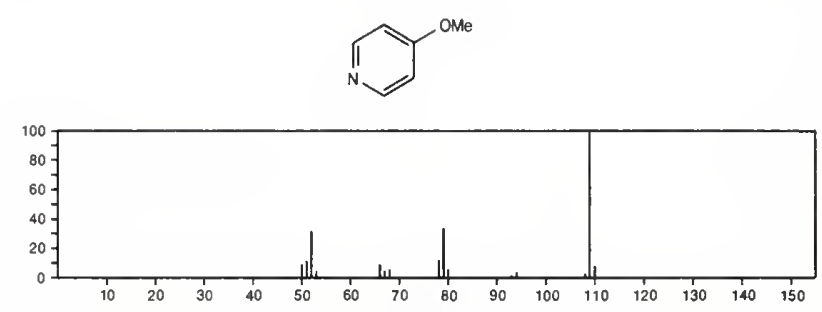

109

2(1H)-Pyridinone, 1-methyl

$\mathrm{C}_{6} \mathrm{H}_{7} \mathrm{NO}$

694-85-9
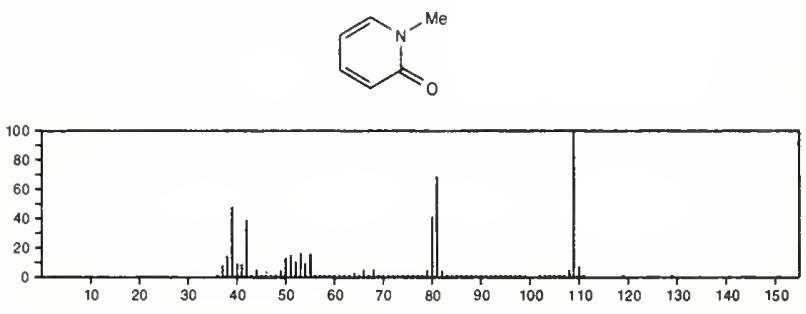

109

Pyridine, 2-methyl-, 1-oxide

$\mathrm{C}_{6} \mathrm{H}_{7} \mathrm{NO}$

931-19-1
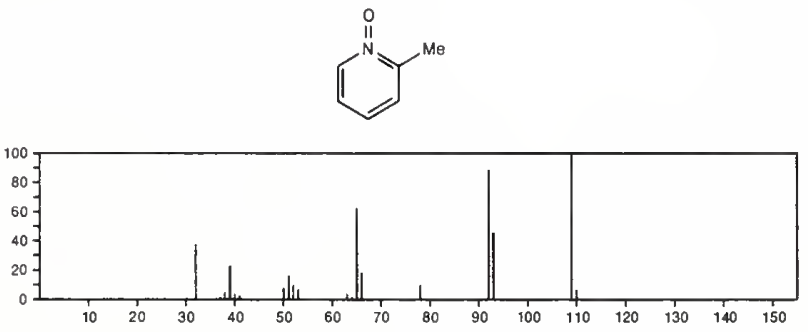
109

$\mathrm{C}_{6} \mathrm{H}_{7} \mathrm{NO}$

Pyridine, 4-methyl-, 1-oxide
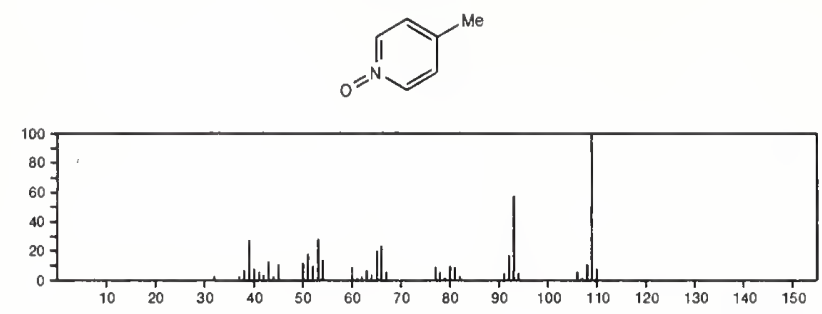

109

$\mathrm{C}_{6} \mathrm{H}_{7} \mathrm{NO}$

Pyridine, 3-methyl-, 1-oxide

$1003-73-2$<smiles>Cc1ccc[n+]([O-])c1</smiles>

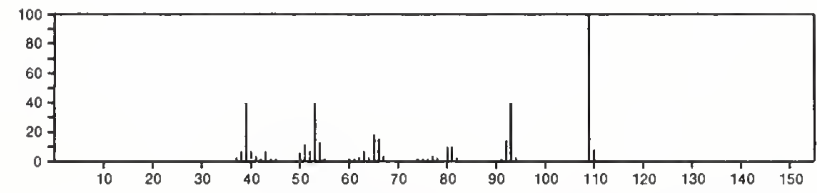

109

$\mathrm{C}_{6} \mathrm{H}_{7} \mathrm{NO}$

$1121-25-1$

3-Pyridinol, 2-methyl-
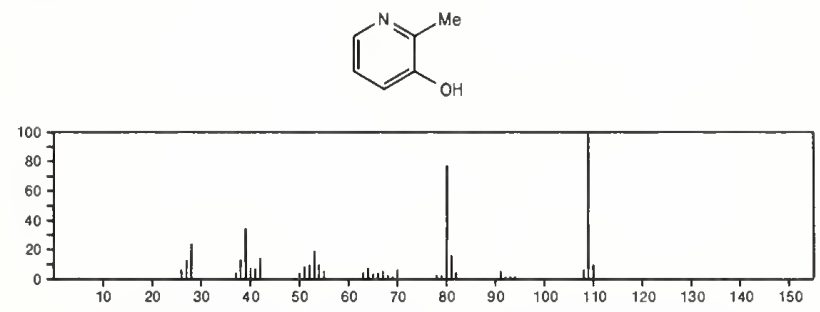

109

$\mathrm{C}_{6} \mathrm{H}_{7} \mathrm{NO}$

3-Pyridinol, 6-methyl
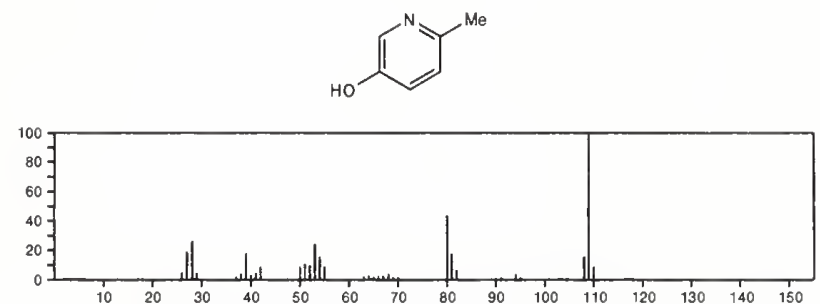

109

Pyridine, 2-methoxy-

$$
\mathrm{C}_{6} \mathrm{H}_{7} \mathrm{NO}
$$

$1628-89-3$
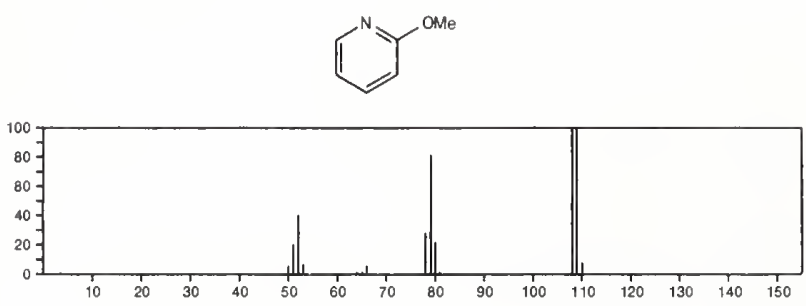

109

$\mathrm{C}_{6} \mathrm{H}_{7} \mathrm{NO}$

3279-76-3

2(1H)-Pyridinone, 6-methyl-
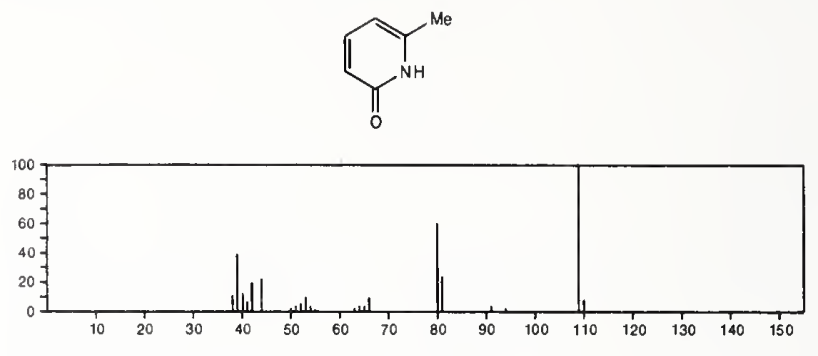

109

$\mathrm{C}_{6} \mathrm{H}_{7} \mathrm{NO}$

7295-76-3

Pyridine, 3-methoxy-
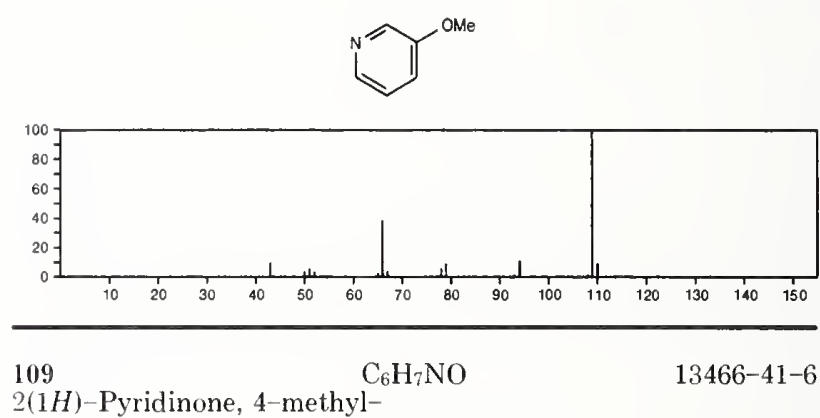

2(1H)-Pyridinone, 4-methyl-
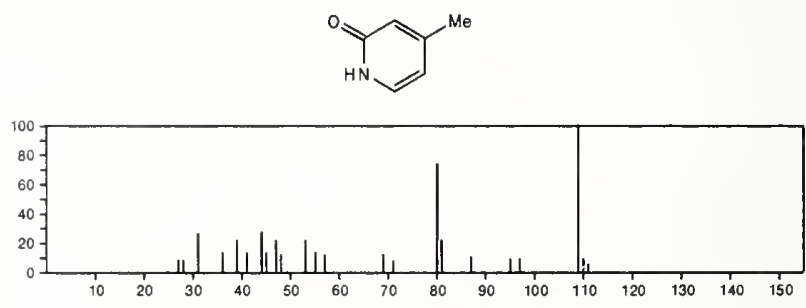

$\stackrel{{ }_{6}^{109}-\text { Oxabicyclo[3.1.0]hexane- } 3 \text {-carbonitrile }}{\mathrm{C}_{6} \mathrm{H}_{7} \mathrm{NO}}$

$53834-54-1$
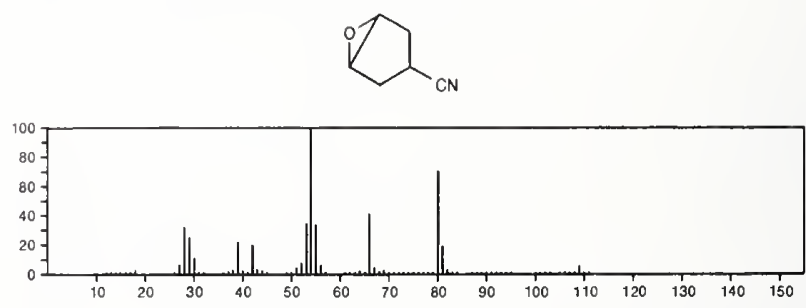

${ }_{5-\text { Hexenenitrile, 2-methyl- }}^{\mathrm{C}_{7} \mathrm{H}_{11} \mathrm{~N}}$

$30316-00-8$

$\mathrm{NCCHMe} \mathrm{CH} \mathrm{CH}_{2} \mathrm{CH}=\mathrm{CH}_{2}$

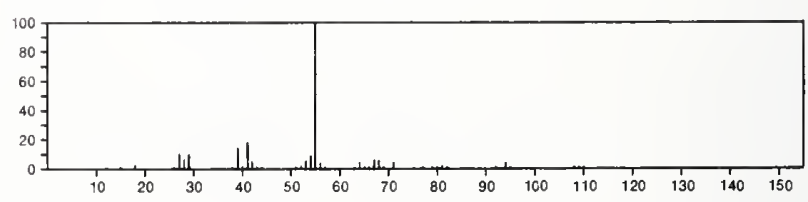


$109 \quad \mathrm{C}_{7} \mathrm{H}_{11} \mathrm{~N}$

Cyclobutanecarbonitrile, 3,3-dimethyl-
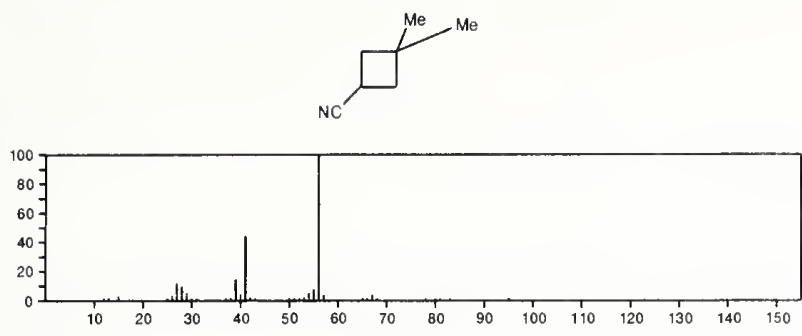

110

$\mathrm{C}_{2} \mathrm{H}_{3} \mathrm{ClOS}$

$2812-72-8$

Carbonochloridothioic acid, $\mathrm{O}$-methyl ester

$\mathrm{MeOC}(\mathrm{S}) \mathrm{Cl}$

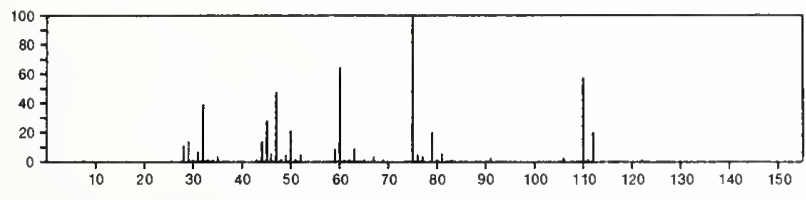

$110 \quad \mathrm{C}_{2} \mathrm{H}_{3} \mathrm{ClOS}$

Carbonochloridothioic acid, $S$-methyl ester

$18369-83-0$

$\mathrm{MeSC}(0) \mathrm{Cl}$

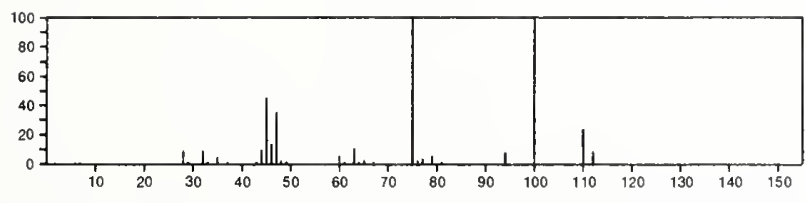

110

$\mathrm{C}_{2} \mathrm{H}_{6} \mathrm{O}_{3} \mathrm{~S}$

616-42-2

Sulfurous acid, dimethyl ester

Meos (O) OMe

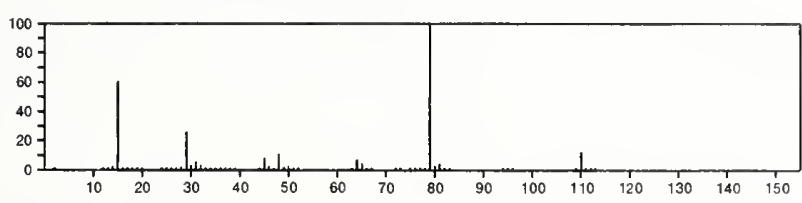

110

$\mathrm{C}_{2} \mathrm{H}_{7} \mathrm{O}_{3} \mathrm{P}$

Phosphonic acid, dimethyl ester

$868-85-9$

Me OPHOME

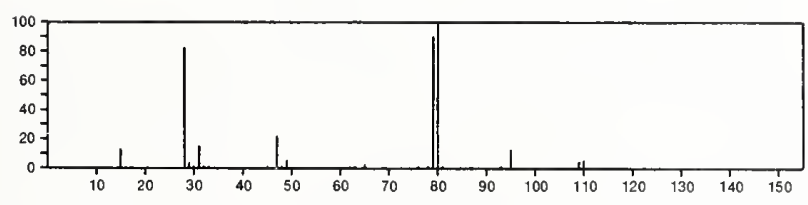

110

1-Propene, 2,3-dichloro-

$\mathrm{C}_{3} \mathrm{H}_{4} \mathrm{Cl}_{2}$

$78-88-6$

$\mathrm{ClCH}_{2} \mathrm{CCl}: \mathrm{CH}_{2}$

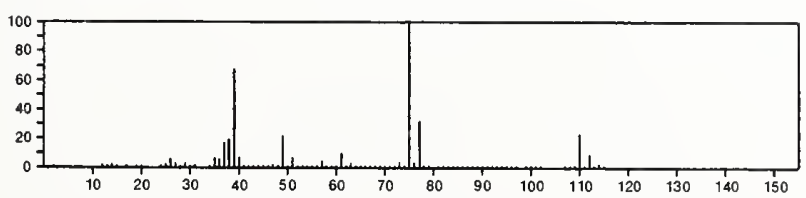

110

1-Propene, 1,3-dichloro

$\mathrm{C}_{3} \mathrm{H}_{4} \mathrm{Cl}_{2}$

$542-75-6$
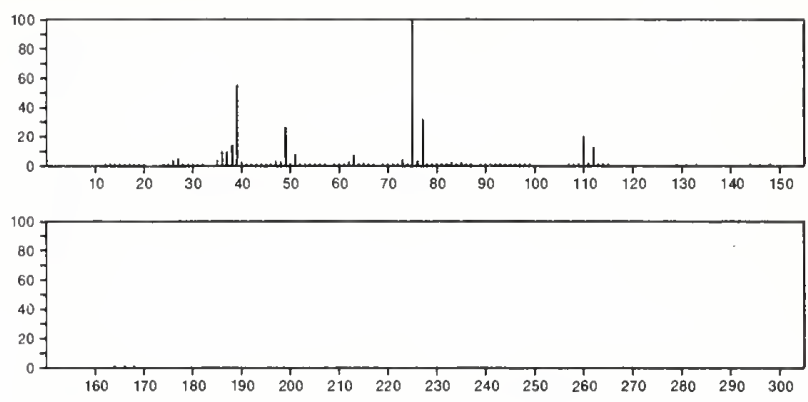

110

1-Propene, 1,2-dichloro-

$\mathrm{C}_{3} \mathrm{H}_{4} \mathrm{Cl}_{2}$

$563-54-2$

$\mathrm{Cl} \mathrm{CH}=\mathrm{CCIMe}$

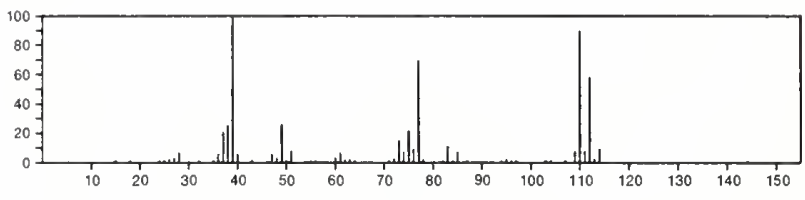

110

1-Propene, 3,3-dichloro-

$\mathrm{C}_{3} \mathrm{H}_{4} \mathrm{Cl}_{2}$

$563-57-5$

$\mathrm{Cl}_{2} \mathrm{CHCH}=\mathrm{CH}_{2}$

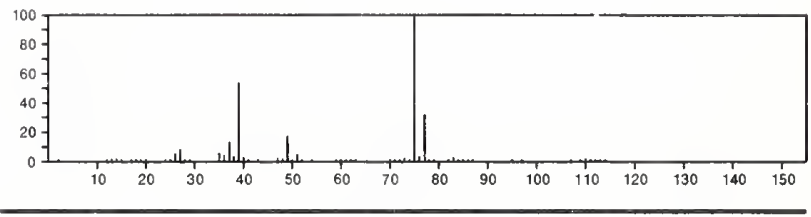

110

$\mathrm{C}_{3} \mathrm{H}_{4} \mathrm{Cl}_{2}$

$563-58-6$

1-Propene, 1,1-dichloro-

$\mathrm{MeCH}=\mathrm{CCl}_{2}$

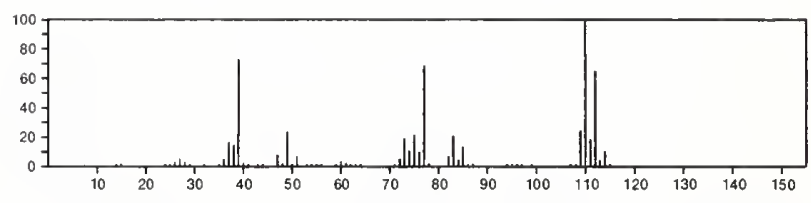

110

1-Propene, 1,3-dichloro-, (Z)-

$10061-01-5$
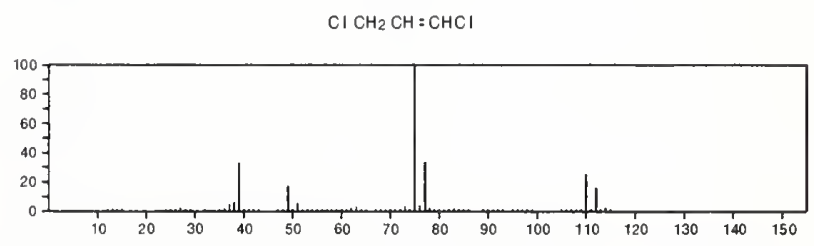

110

1-Propene, 1,3-dichloro-, $(E)$ -

$10061-02-6$

$\mathrm{Cl} \mathrm{CH}_{2} \mathrm{CH}=\mathrm{CHCl}$

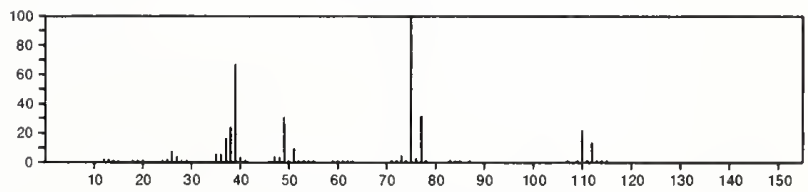


110

1,2-Propanediol, 3-chloro-

$\mathrm{C}_{3} \mathrm{H}_{7} \mathrm{ClO}_{2}$

$\mathrm{Cl} \mathrm{CH}_{2} \mathrm{CH}(\mathrm{OH}) \mathrm{CH}_{2} \mathrm{OH}$
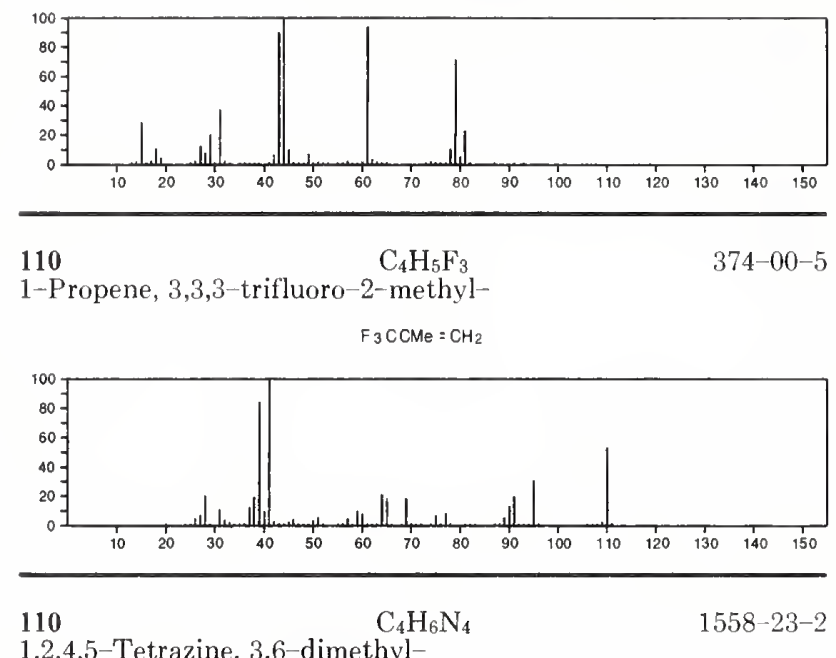

1,2,4,5-Tetrazine, 3,6-dimethyl-
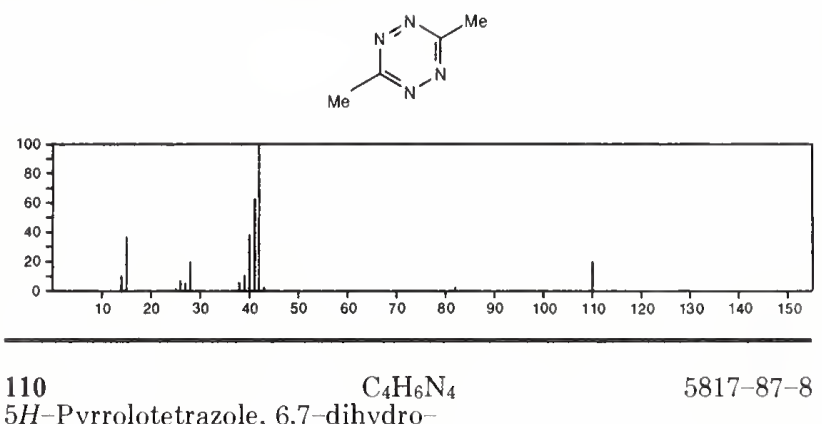

$\mathrm{C}_{N}^{N} \mathrm{~N}_{N}^{N}$

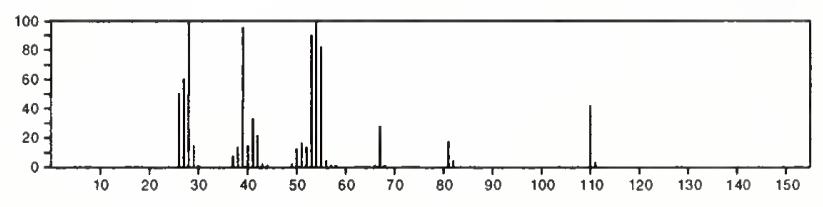

$110 \quad \mathrm{C}_{4} \mathrm{H}_{6} \mathrm{~N}_{4} \quad 13754-19-3$

4,5-Pyrimidinediamine
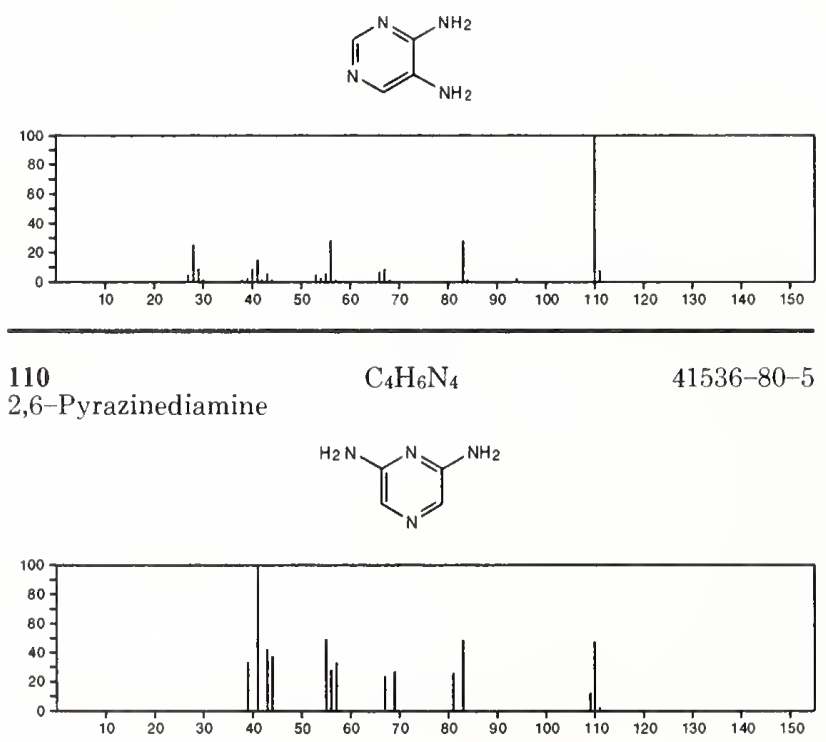

110

$\mathrm{C}_{5} \mathrm{H}_{6} \mathrm{~N}_{2} \mathrm{O}$

$3524-87-6$

4(1H)-Pyrimidinone, 6-methyl<smiles></smiles>

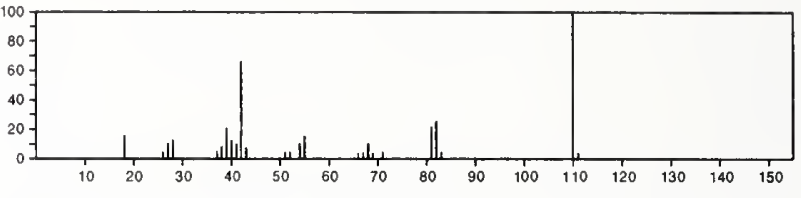

110

$\mathrm{C}_{5} \mathrm{H}_{6} \mathrm{~N}_{2} \mathrm{O}$

Pyrimidine, 5-methyl-, 1-oxide

$17758-50-8$<smiles>Cc1cnc[n+]([O-])c1</smiles>

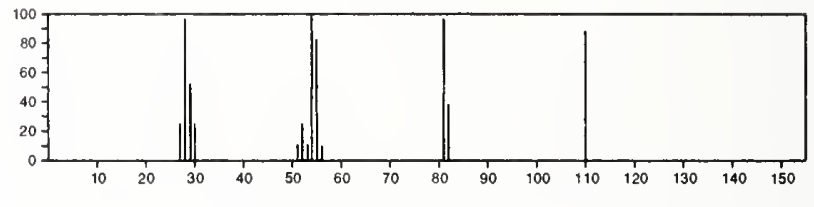

110

$\mathrm{C}_{5} \mathrm{H}_{6} \mathrm{~N}_{2} \mathrm{O}$

19064-65-4

Pyridazine, 3-methoxy-
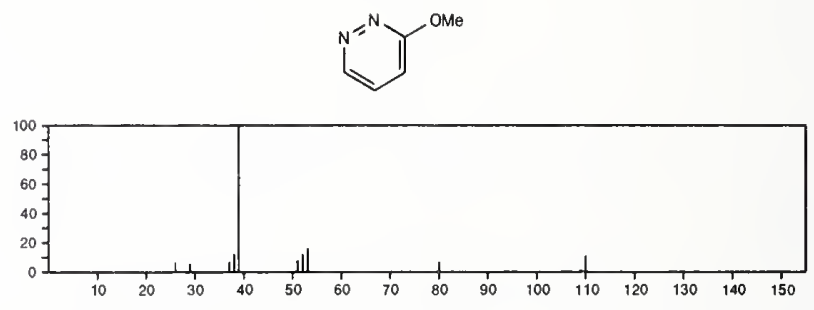

110

$\mathrm{C}_{5} \mathrm{H}_{6} \mathrm{~N}_{2} \mathrm{O}$

19875-04-8

4(1H)-Pyrimidinone, 2-methyl-
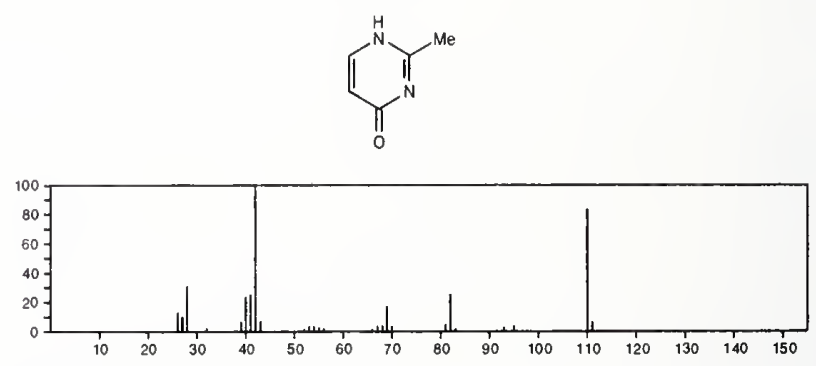

110

Ethanone, 1-(1H-pyrazol-4-yl $)$

$\mathrm{C}_{5} \mathrm{H}_{6} \mathrm{~N}_{2} \mathrm{O}$

25016-16-4
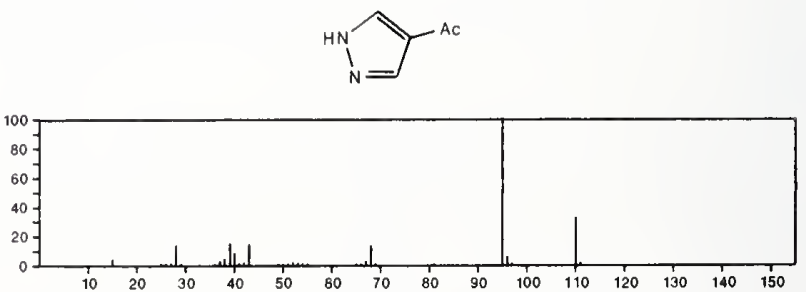
110

$\mathrm{C}_{5} \mathrm{H}_{6} \mathrm{~N}_{2} \mathrm{O}$

$35231-56-2$

110

$\mathrm{C}_{6} \mathrm{H}_{6} \mathrm{~S}$

$108-98-5$

5-Pyrimidinol, 2-methyl-

Benzenethiol

$\mathrm{PhSH}$

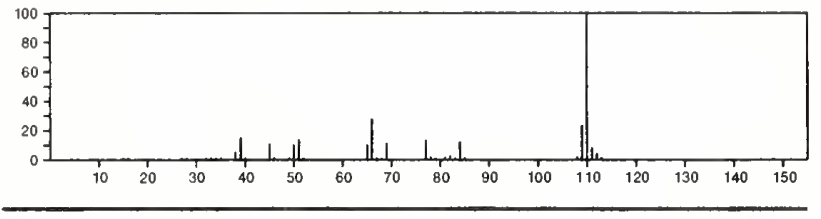

110

$\mathrm{C}_{6} \mathrm{H}_{10} \mathrm{~N}_{2}$

1072-91-9

$1 H$-Pyrazole, 1,3,5-trimethyl
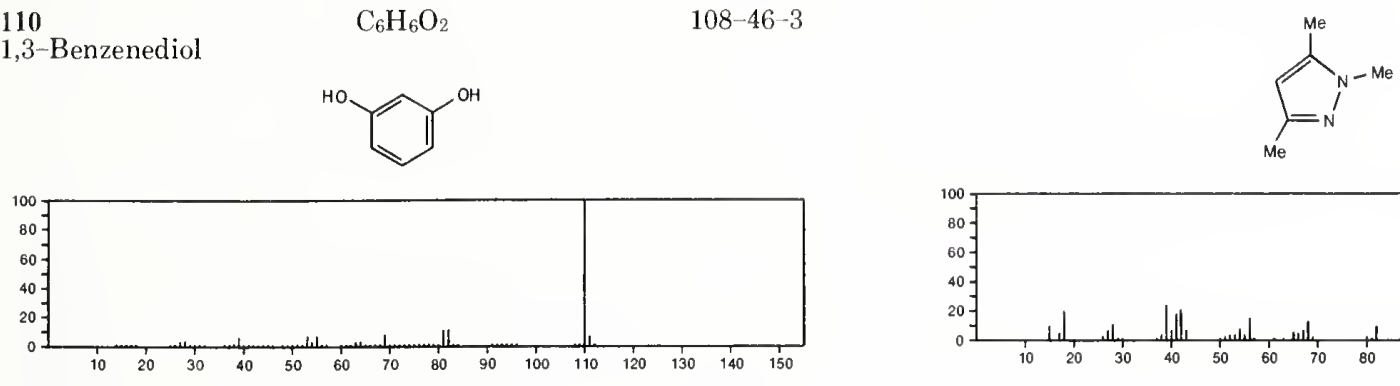

110

$\mathrm{C}_{6} \mathrm{H}_{6} \mathrm{O}_{2}$

$120-80-9$
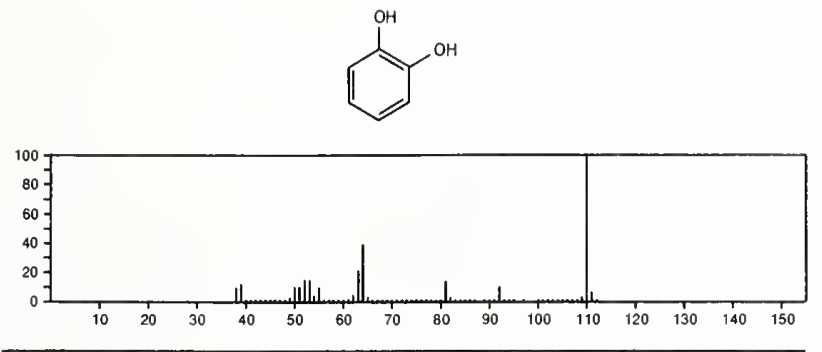

110

$\mathrm{C}_{6} \mathrm{H}_{6} \mathrm{O}_{2}$

123-31-9
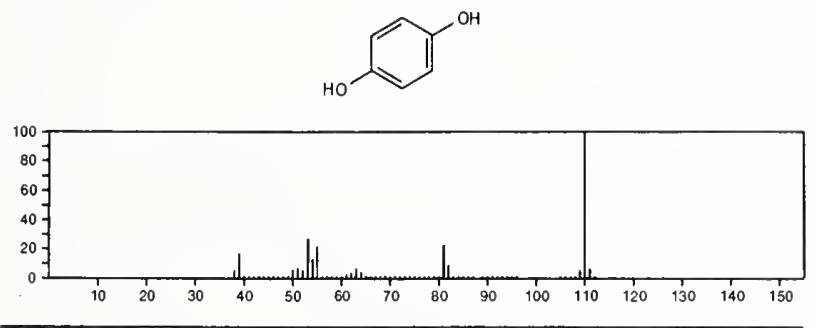

110

Ethanone, 1-(2-furanyl)-

$\mathrm{C}_{6} \mathrm{H}_{6} \mathrm{O}_{2}$

$1192-62-7$
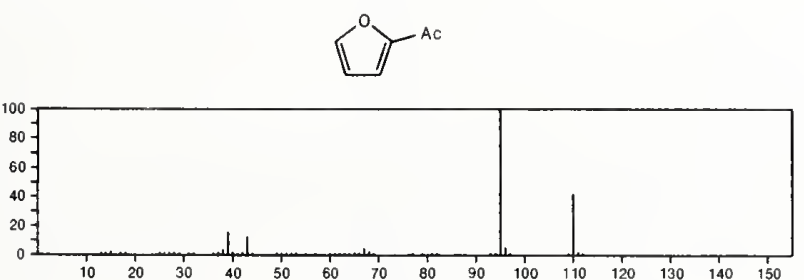

1,2-Benzenediol

1,4-Benzenediol

$108-46-3$

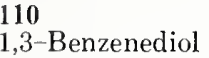

$\mathrm{C}_{6} \mathrm{H}_{6} \mathrm{O}_{2}$

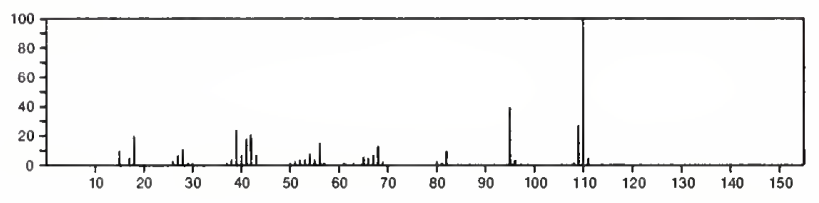

110

$1 H$-Imidazole, 2-propyl-

$\mathrm{C}_{6} \mathrm{H}_{10} \mathrm{~N}_{2}$

50995-95-4
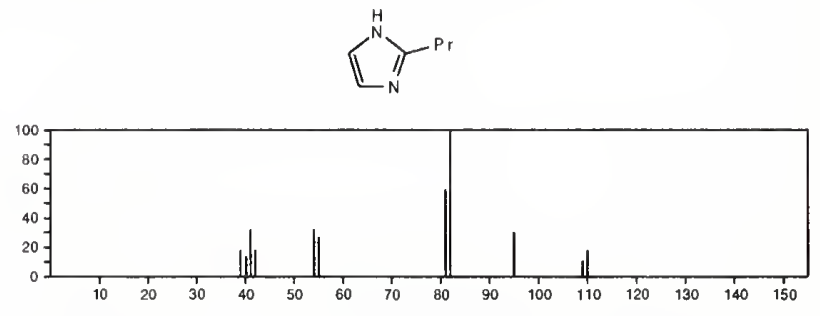

110

$\mathrm{C}_{7} \mathrm{H}_{7} \mathrm{~F}$

95-52-3

Benzene, 1-fluoro-2-methyl-
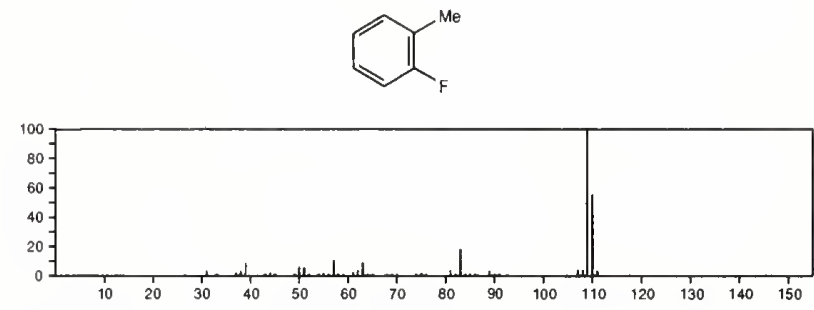

110

Benzene, (fluoromethyl)-

$\mathrm{C}_{7} \mathrm{H}_{7} \mathrm{~F}$

$350-50-5$

$\mathrm{FCH}_{2} \mathrm{Ph}$

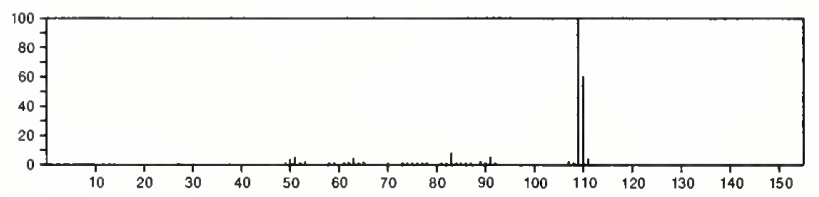


110 $\mathrm{C}_{7} \mathrm{H}_{7} \mathrm{~F}$

Benzene, 1-fluoro-4-methyl-
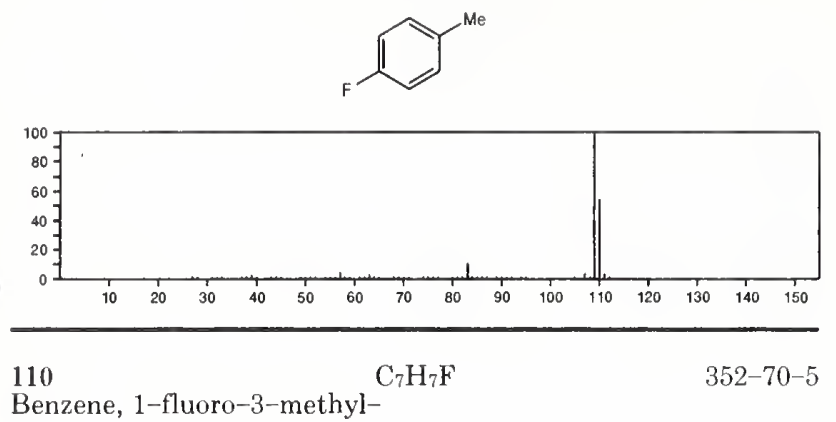

Benzene, 1-fluoro-3-methyl
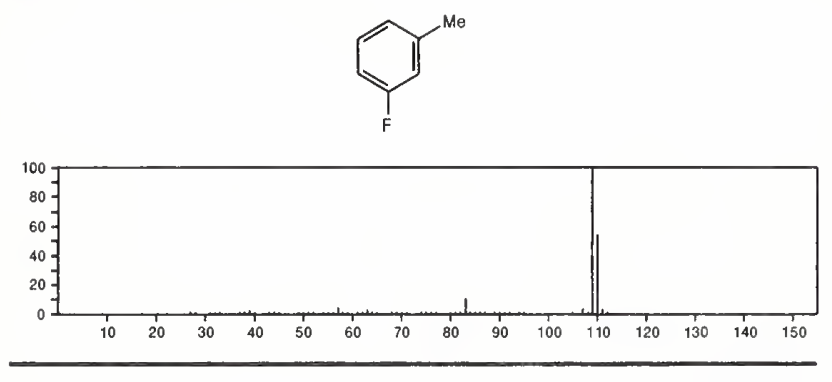

110

$\mathrm{C}_{7} \mathrm{H}_{10} \mathrm{O}$

3-Cyclohexene-1-carboxaldehyde

$100-50-5$
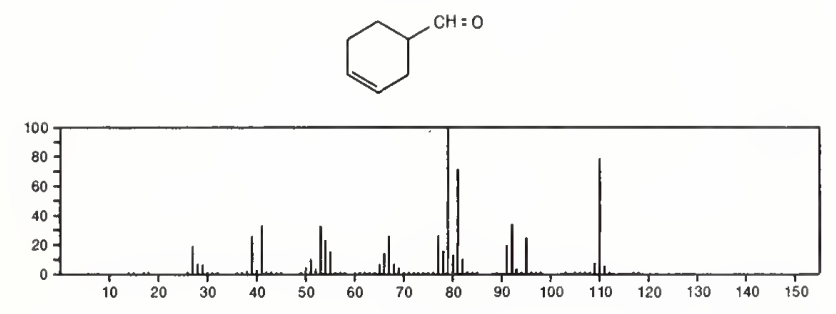

$\begin{aligned} & 110 \\ & \text { Bicyclo[2.2.1]heptan-2-one }\end{aligned} \mathrm{C}_{7} \mathrm{H}_{10} \mathrm{O} \quad 497-38-1$
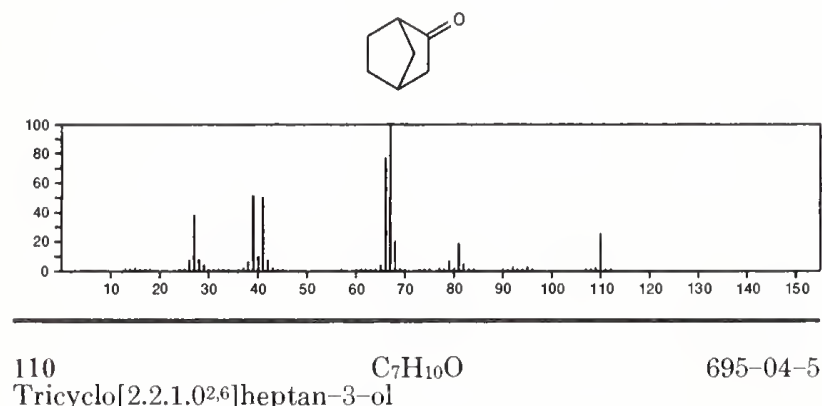

$\mathrm{DC}_{\mathrm{OH}}$

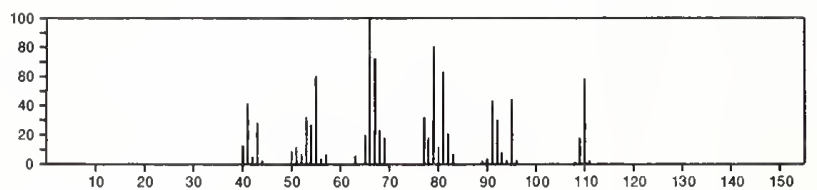

110 Methanone, dicyclopropyl- $\mathrm{C}_{7} \mathrm{H}_{10} \mathrm{O}$

$1121-37-5$
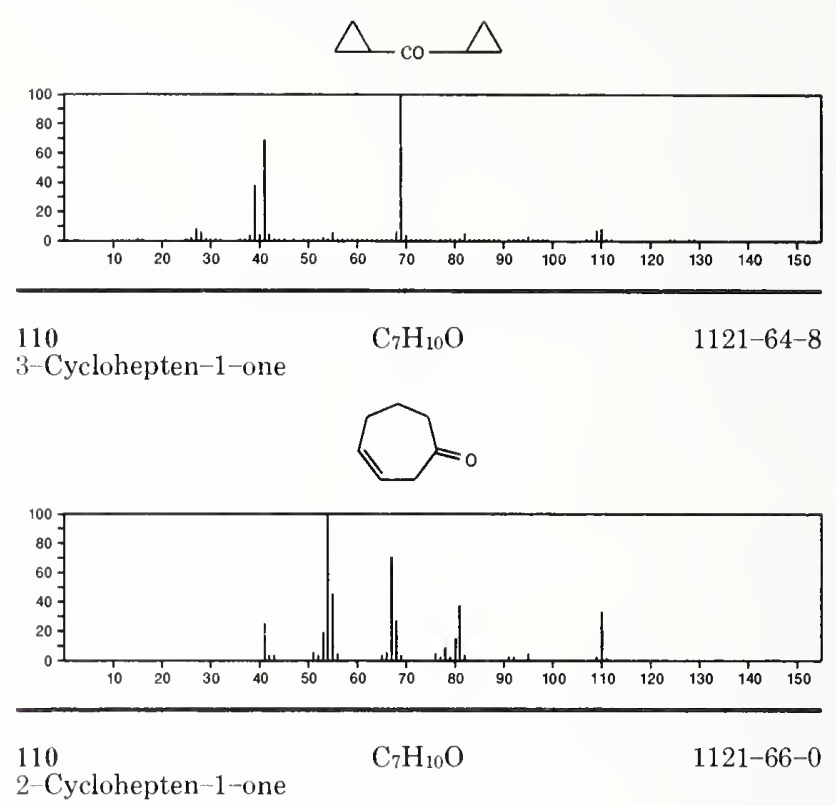

2-Cyclohepten-1-one
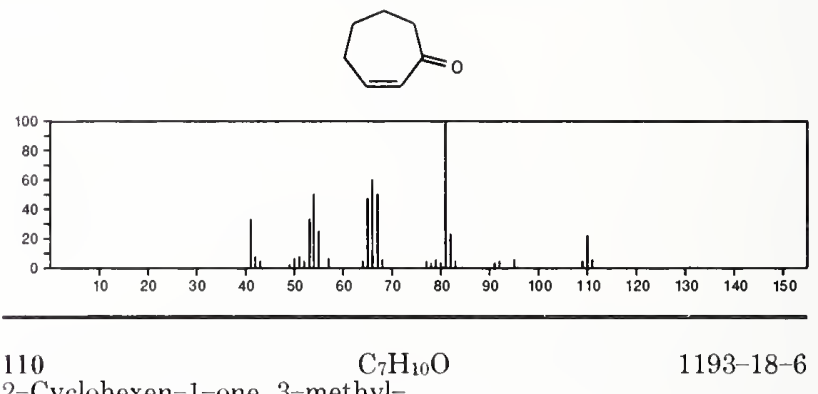

2-Cyclohexen-1-one, 3-methyl-
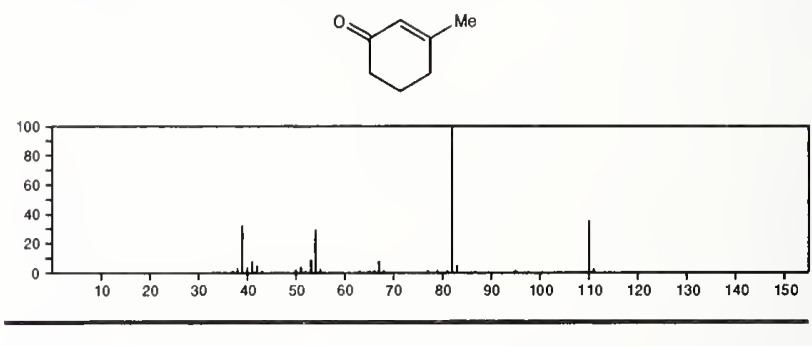

110

$\mathrm{C}_{7} \mathrm{H}_{10} \mathrm{O}$

$3146-39-2$

3-Oxatricyclo[3.2.1.02,4] octane, $(1 \alpha, 2 \beta, 4 \beta, 5 \alpha)-$
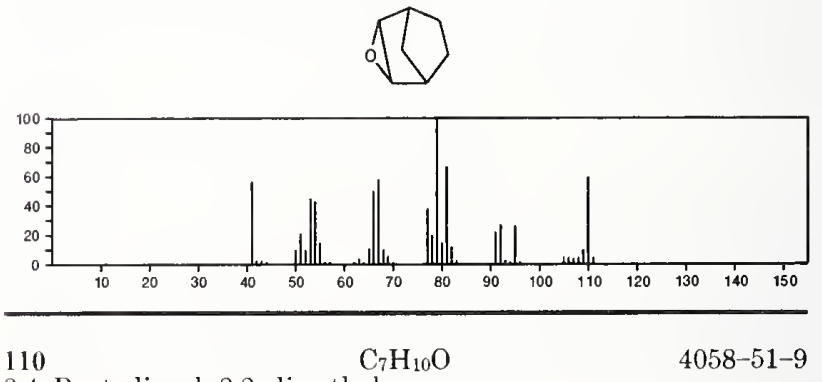

3,4-Pentadienal, 2,2-dimethyl-

$\mathrm{H}_{2} \mathrm{C}: \mathrm{C}=\mathrm{CHCMe}_{2} \mathrm{CHO}$

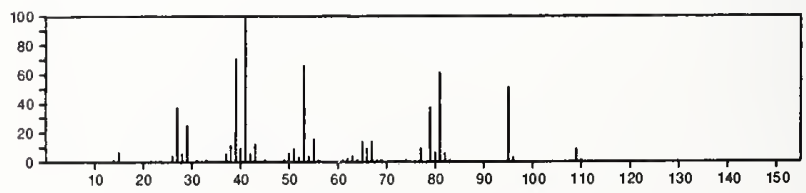


110

Bicyclo[4.1.0]heptan-2-one

$\mathrm{C}_{7} \mathrm{H}_{10} \mathrm{O}$
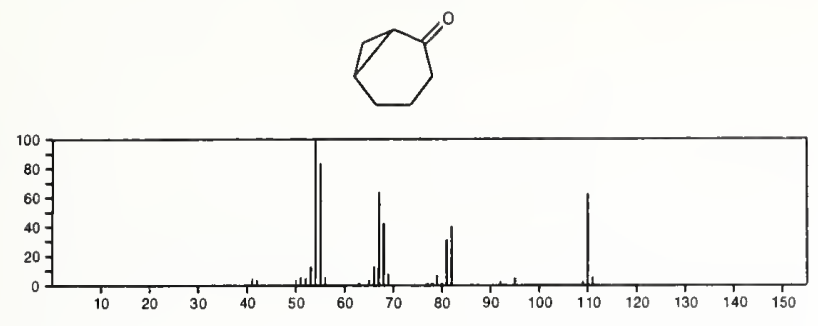

$110 \quad \mathrm{C}_{7} \mathrm{H}_{10} \mathrm{O}$

1,4-Pentadien-3-one, 2,4-dimethyl-

$\mathrm{H}_{2} \mathrm{C}: \mathrm{CMe}$ COCMe $=\mathrm{CH}_{2}$

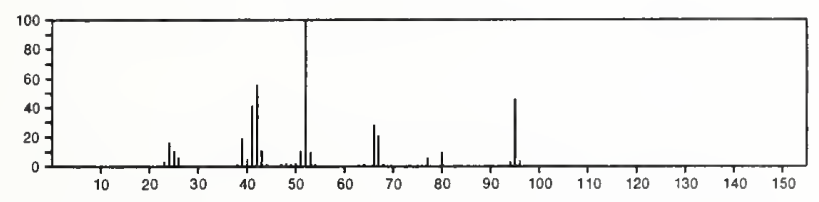

110

Bicyclo[2.2.1]hept-2-en-7-ol

$\mathrm{C}_{7} \mathrm{H}_{10} \mathrm{O}$

HO-

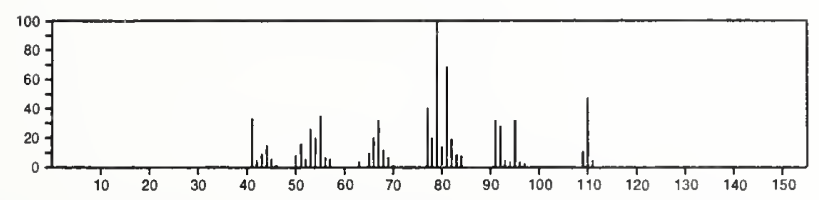

110

$\mathrm{C}_{8} \mathrm{H}_{14}$

280-33-1

Bicyclo[2.2.2]octane<smiles>C1CC2CCC1CC2</smiles>

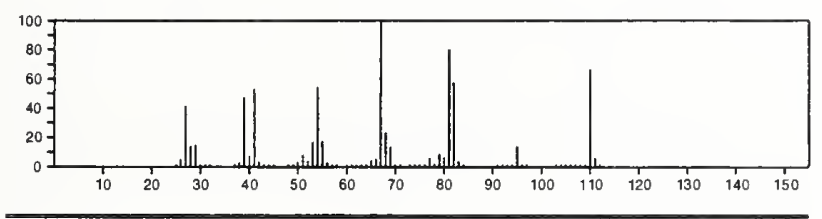

110

Bicyclo[5.1.0]octane

$\mathrm{C}_{8} \mathrm{H}_{14}$

$286-43-1$
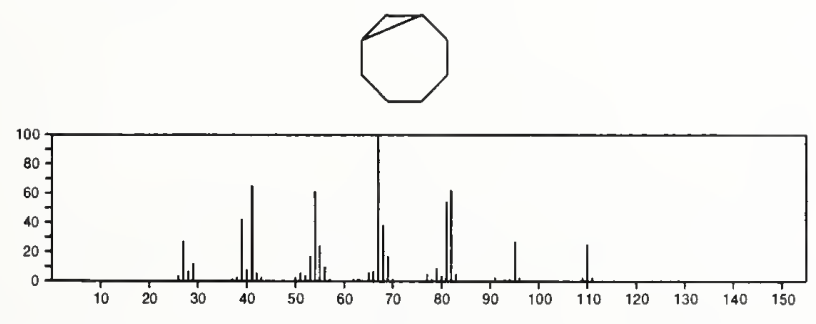

110 $\mathrm{C}_{8} \mathrm{H}_{14}$

$627-58-7$

1,5-Hexadiene, 2,5-dimethyl-

$\mathrm{H}_{2} \mathrm{C}=\mathrm{CMeCH}_{2} \mathrm{CH}_{2} \mathrm{CMe}=\mathrm{CH}_{2}$

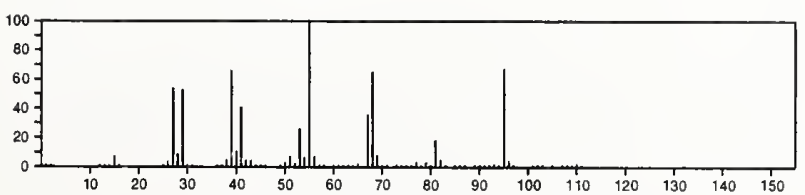

110

1 - Octyne

$\mathrm{C}_{8} \mathrm{H}_{14}$

629-05-0

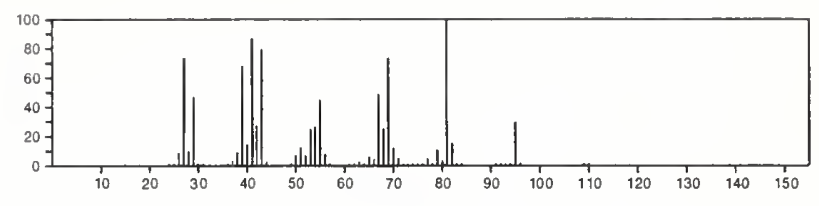

110

Cyclohexane, ethenyl-

$\mathrm{C}_{8} \mathrm{H}_{14}$

$695-12-5$
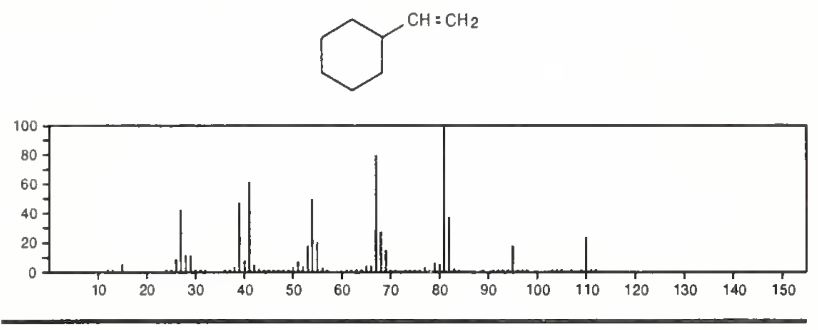

110

$\mathrm{C}_{8} \mathrm{H}_{14}$

$764-13-6$

2,4-Hexadiene, 2,5-dimethyl-

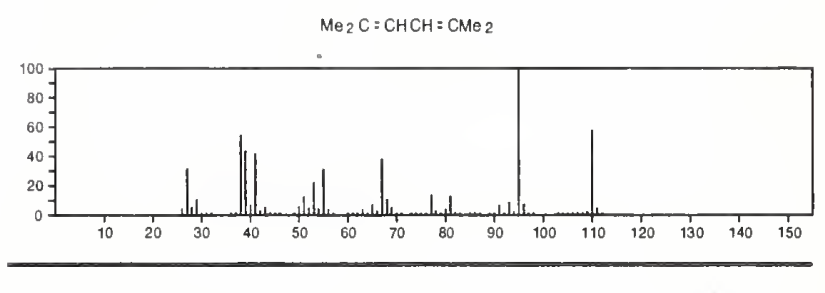

110

$\mathrm{C}_{8} \mathrm{H}_{14}$

$872-78-6$

Bicyclo[2.2.1]heptane, 2-methyl-, exo-
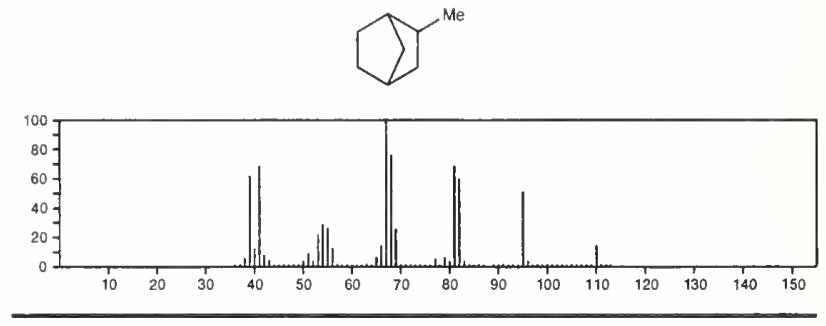

$110 \quad \mathrm{C}_{8} \mathrm{H}_{14} \quad 931-88-4$

Cyclooctene
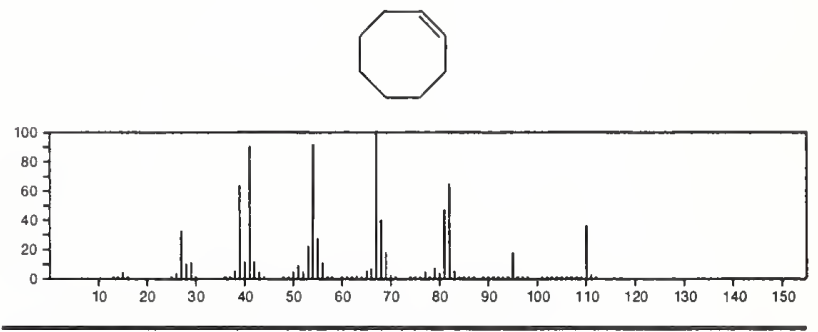

110

Cyclohexane, ethylidene-

$\mathrm{C}_{8} \mathrm{H}_{14}$

$1003-64-1$
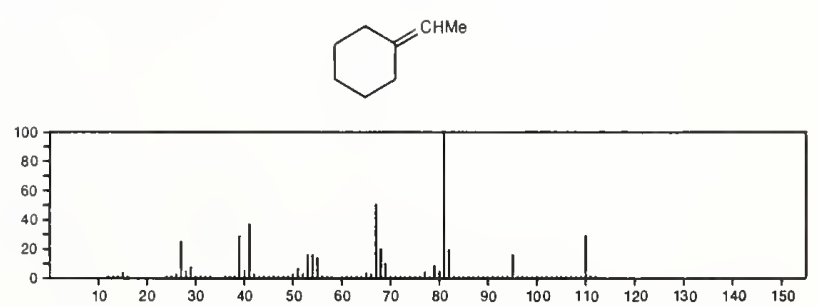
110

Cyclohexene, 1-ethyl-

$\mathrm{C}_{8} \mathrm{H}_{14}$<smiles>CCC1=CCCCC1</smiles>

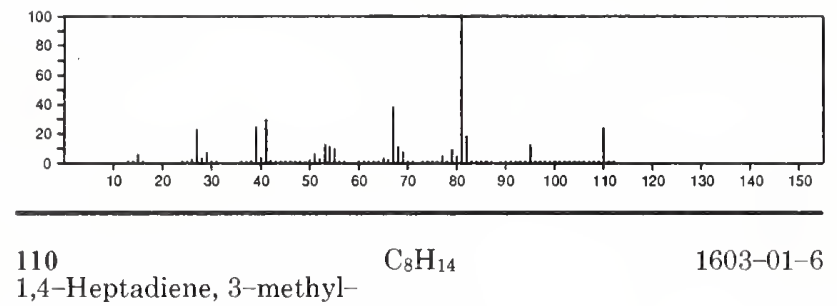

$\mathrm{E}+\mathrm{CH}=\mathrm{CHCHMe} \mathrm{CH}=\mathrm{CH}_{2}$

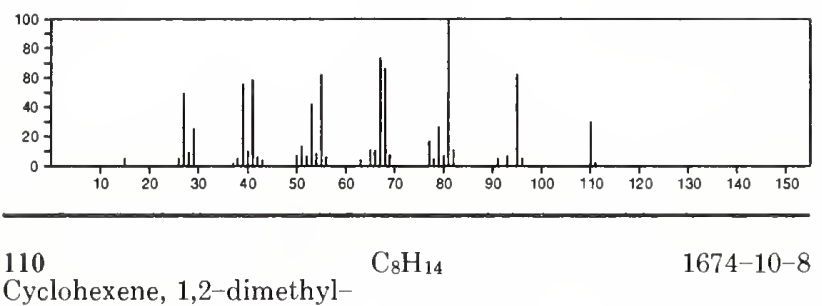

$\mathrm{H}^{\mathrm{Me}}$
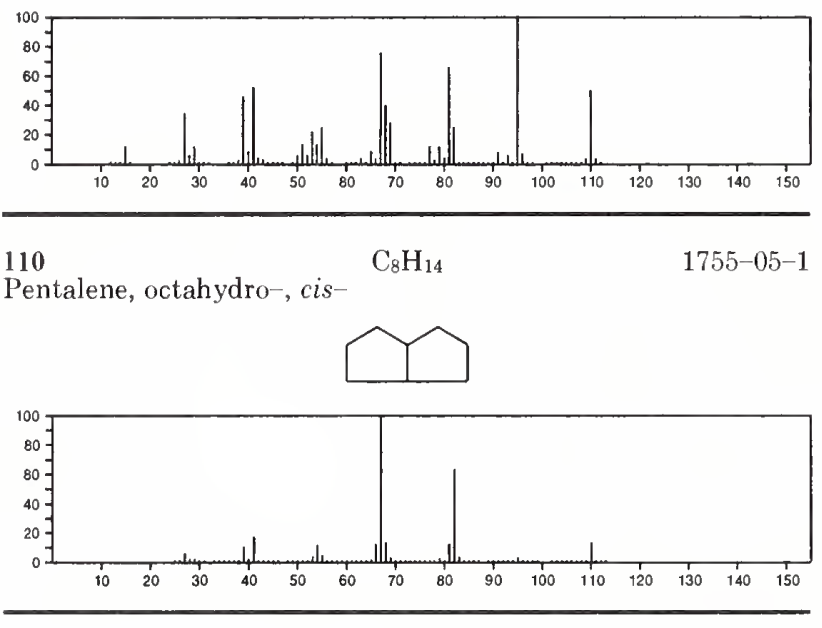

110

$\mathrm{C}_{8} \mathrm{H}_{14}$

$1942-45-6$

$\operatorname{PrCs}: \cos ^{-10}$

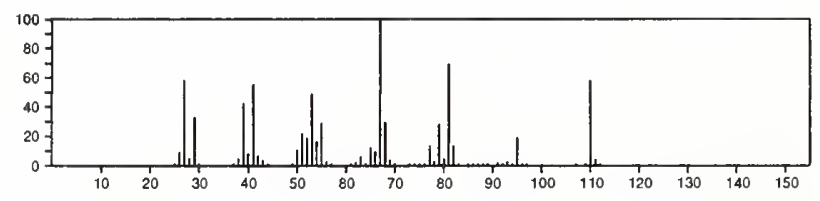

$110 \quad \mathrm{C}_{8} \mathrm{H}_{14} \quad 2080-89-9$

1,4-Hexadiene, 3-ethyl-

$\mathrm{MeCH}=\mathrm{CHCHE}: \mathrm{CH}=\mathrm{CH}_{2}$

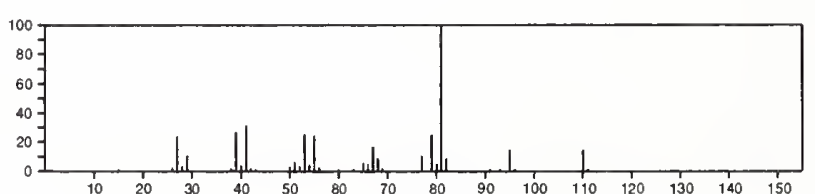

110

$2417-88-1$

2,4-Hexadiene, 3,4-dimethyl-, $(E, Z)$

$\mathrm{MeCH}=\mathrm{CMe} \mathrm{CMe}=\mathrm{CHMe}$

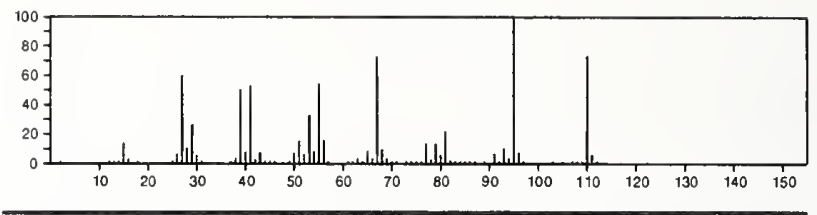

110

Cyclohexene, 3-ethyl-

$\mathrm{C}_{8} \mathrm{H}_{14}$

2808-71-1
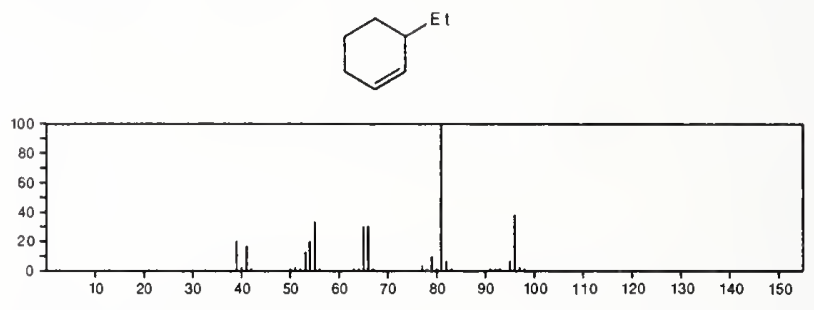

110

Cyclohexane, 1-methyl-4-methylene

2808-80-2
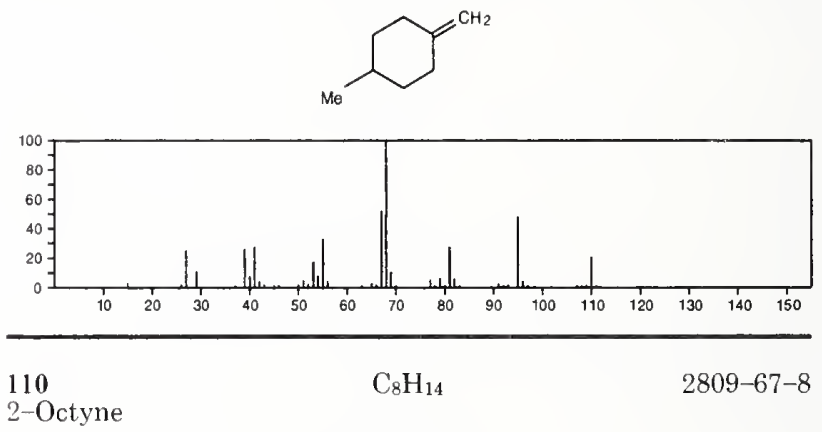

$\mathrm{Me}\left(\mathrm{CH}_{2}\right)_{4} \mathrm{C} \equiv \mathrm{CMe}$

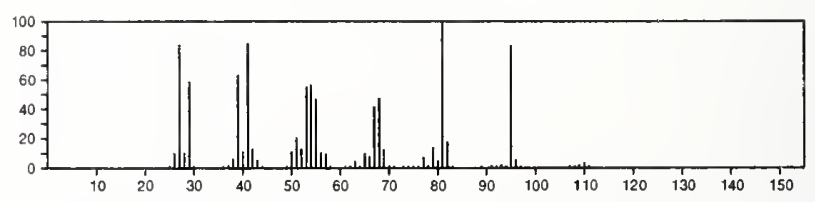

$110 \quad \mathrm{C}_{8} \mathrm{H}_{14}$

Cyclopentane, 2-propenyl-

$3524-75-2$

$\longrightarrow \mathrm{CH}_{2} \mathrm{CH}: \mathrm{CH}_{2}$

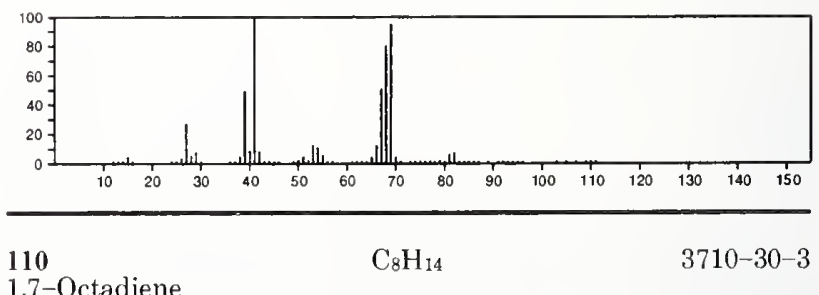

$\mathrm{H}_{2} \mathrm{C}=\mathrm{CH}\left(\mathrm{CH}_{2}\right)_{4} \mathrm{CH}=\mathrm{CH}_{2}$

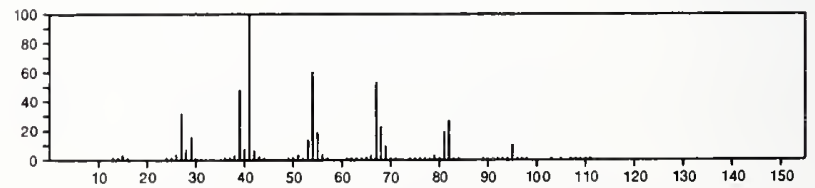


110

Spiropentane, propyl

$\mathrm{C}_{8} \mathrm{H}_{14}$
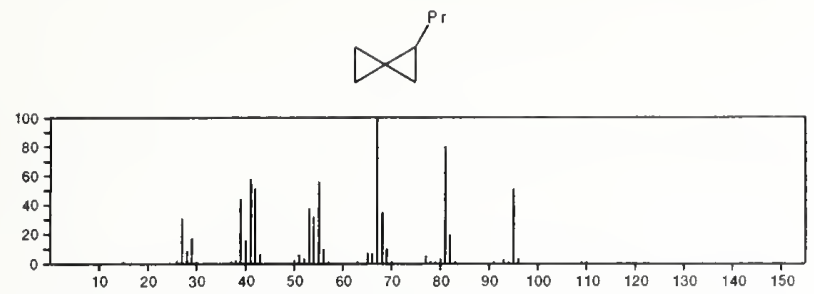

110

Bicyclo[3.2.1]octane

$\mathrm{C}_{8} \mathrm{H}_{14}$

$6221-55-2$
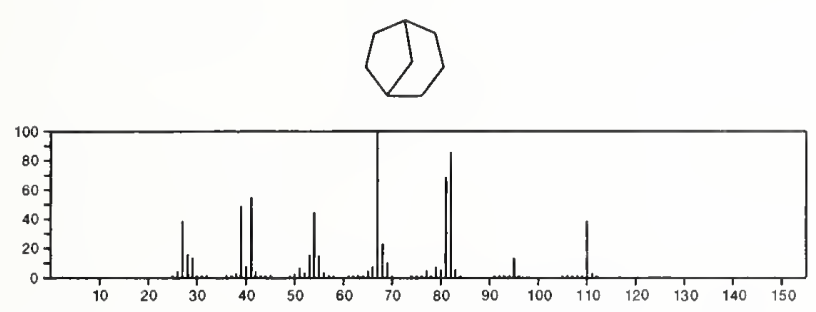

110

Bicyclo[2.2.1]heptane, 2-methyl-

$\mathrm{C}_{8} \mathrm{H}_{1}$

$D^{\mathrm{Me}}$

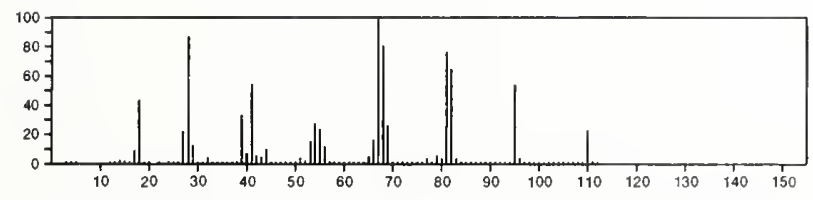

110

3-Octyne

$\mathrm{C}_{8} \mathrm{H}_{14}$

$15232-76-5$

$\mathrm{Me}\left(\mathrm{CH}_{2}\right)_{3} \mathrm{C} \equiv \mathrm{CEI}$

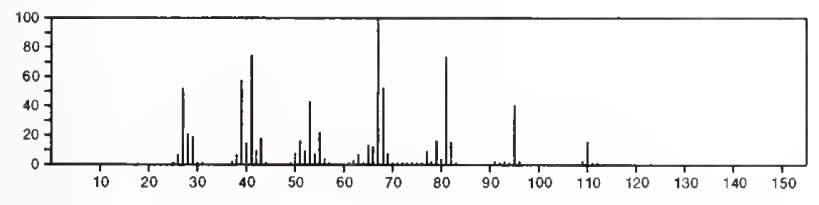

110

$\mathrm{C}_{8} \mathrm{H}_{14}$

$18669-52-8$

1,4-Hexadiene, 2,3-dimethy]-

$\mathrm{MeCH} \equiv \mathrm{CHCHMe} \mathrm{CMe}_{\mathrm{C}}=\mathrm{CH}_{2}$

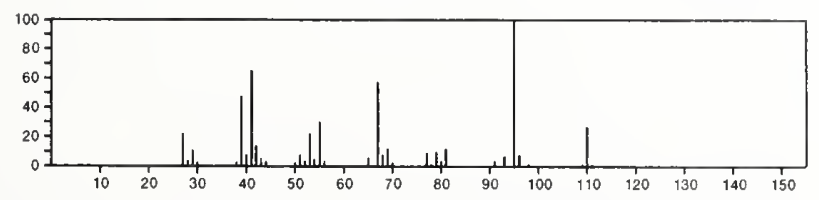

110

$\mathrm{C}_{8} \mathrm{H}_{14}$

2,4-Hexadiene, 3,4-dimethyl-, $(Z, Z)$ -

21293-01-6

$\mathrm{Me} \mathrm{CH}=\mathrm{CMe} \mathrm{CMe}=\mathrm{CHMe}$

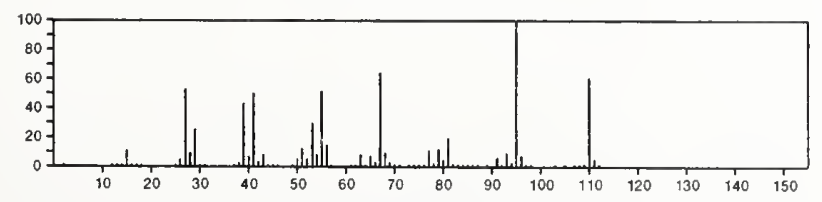

110

Cyclopentene, 3-propyl-

$\mathrm{C}_{8} \mathrm{H}_{14}$

$34067-75-9$<smiles>[P]C1C=CCC1</smiles>

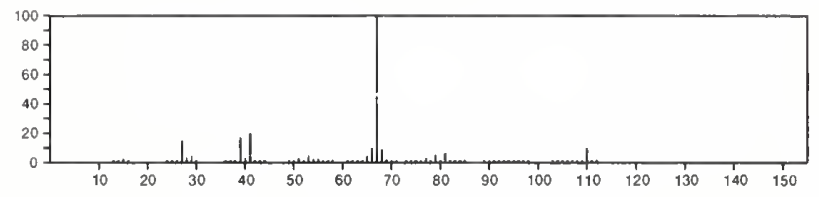

$110 \quad \mathrm{C}_{8} \mathrm{H}_{14}$

Bicyclo[4.1.0]heptane, 2-methyl-

$41977-46-2$<smiles>CC1CCCCC1</smiles>

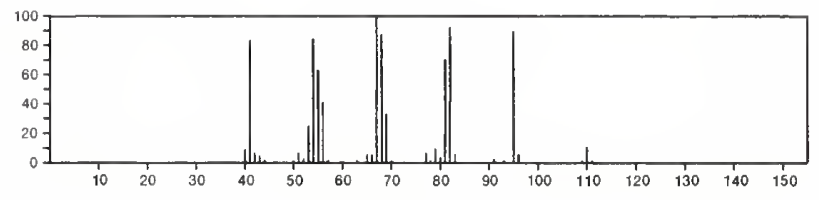

110

Bicyclo[4.1.0]heptane, 3-methy]-

$41977-47-3$

$\underset{\mathrm{C}}{\mathrm{CH}}$
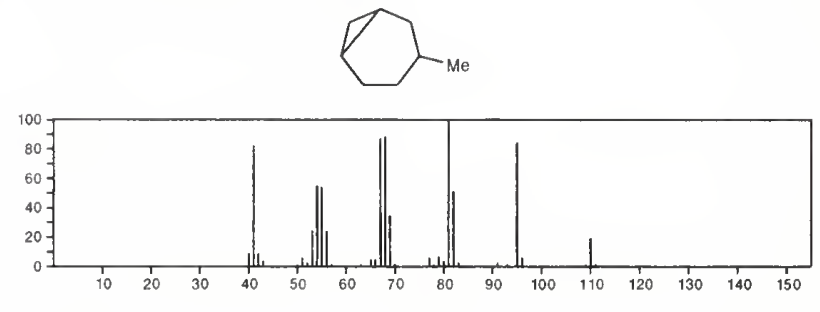

$111 \quad \mathrm{C}_{2} \mathrm{ClF}_{2} \mathrm{~N}$

$421-05-6$

Acetonitrile, chlorodifluoro-

$\mathrm{ClCF}_{2}(\mathrm{CN})$

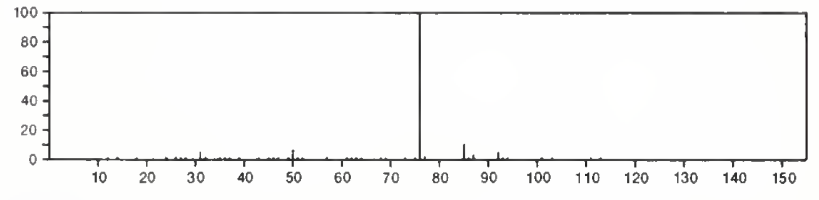

111

$\mathrm{C}_{4} \mathrm{H}_{5} \mathrm{~N}_{3} \mathrm{O}$

71-30-7

2(1H)-Pyrimidinone, 4-amino-
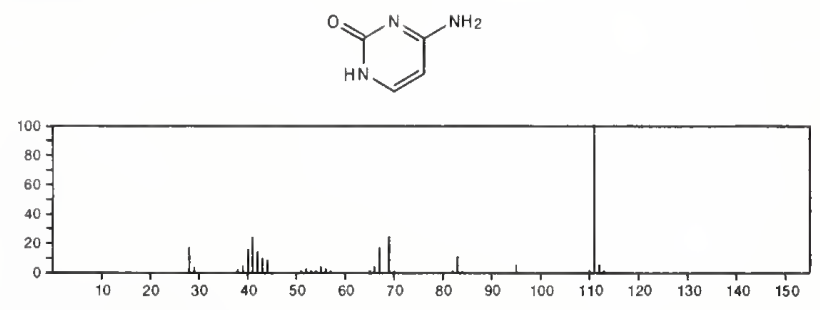

111

$\mathrm{C}_{4} \mathrm{H}_{5} \mathrm{~N}_{3} \mathrm{O}$

56804-98-9

1H-1,2,4-Triazole-3-carboxaldehyde, 5-methyl-
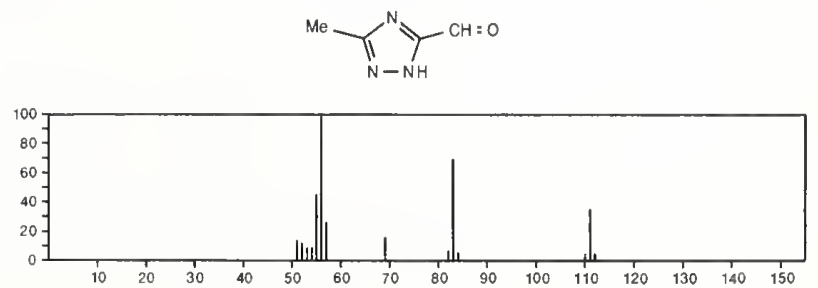
111 Acrylonitrile, 3-hydroxy-, acetate (ester)

$\mathrm{ACOCH}=\mathrm{CHCN}$

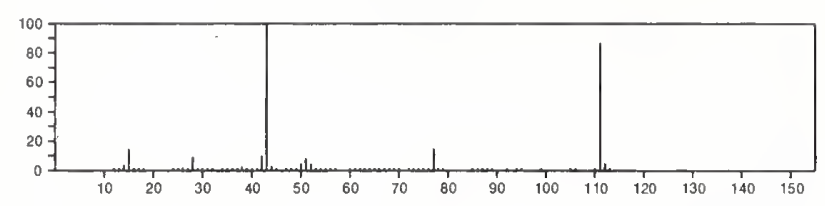

111

2(1H)-Pyridinone, 3-hydroxy-

$$
\mathrm{C}_{5} \mathrm{H}_{5} \mathrm{NO}_{2}
$$

$16867-04-2$<smiles>O=c1[nH]cccc1O</smiles>

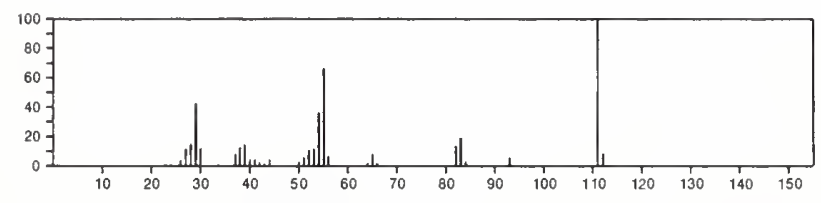

111

2(1H)-Pyridinethione

$\mathrm{C}_{5} \mathrm{H}_{5} \mathrm{NS}$

$2637-34-5$

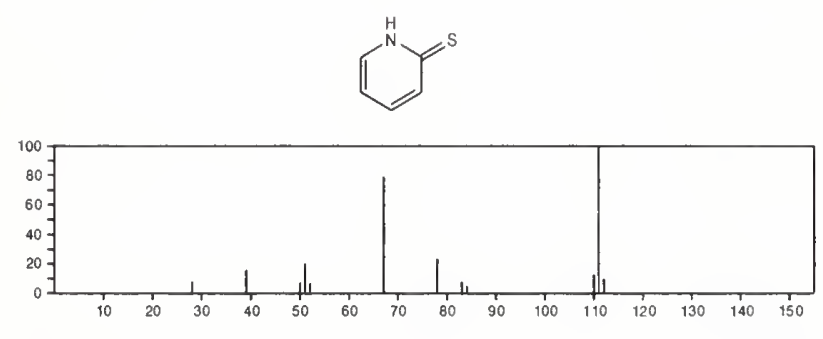

$111 \quad \mathrm{C}_{5} \mathrm{H}_{9} \mathrm{~N}_{3}$

$51-45-6$

$1 H$-Imidazole-4-ethanamine
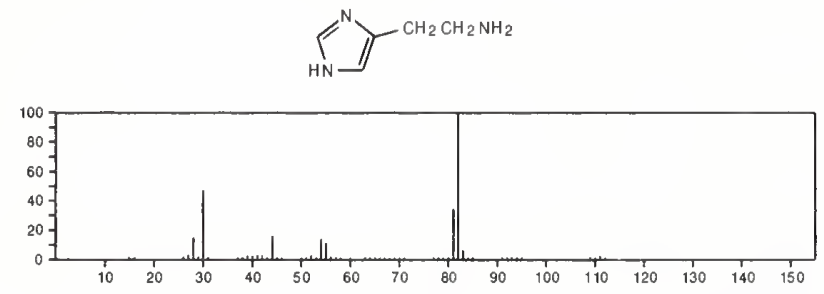

$111 \quad \mathrm{C}_{5} \mathrm{H}_{9} \mathrm{~N}_{3}$

1H-1,2,4-Triazole, 3-propyl-

19932-60-6

$$
\sum_{=N}^{H^{-N}}
$$

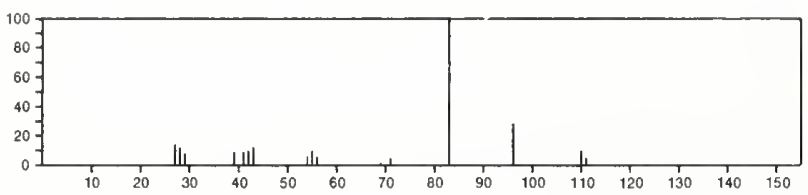

111 1H-1,2,4-Triazole, 3-(1-methylethyl)-

$23161-10-6$

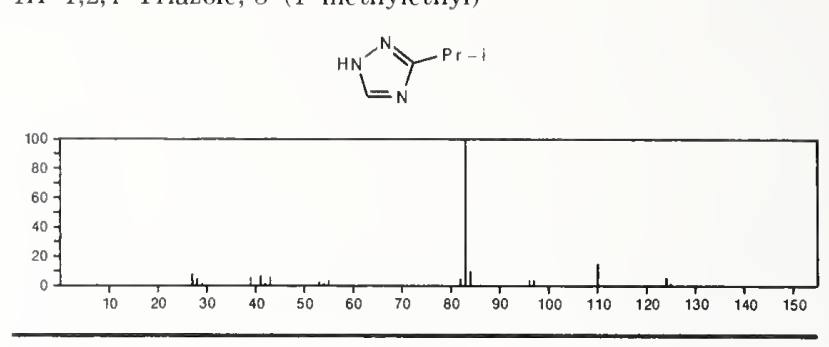

111

$\mathrm{C}_{6} \mathrm{H}_{6} \mathrm{FN}$

$371-40-4$

Benzenamine, 4-fluoro-
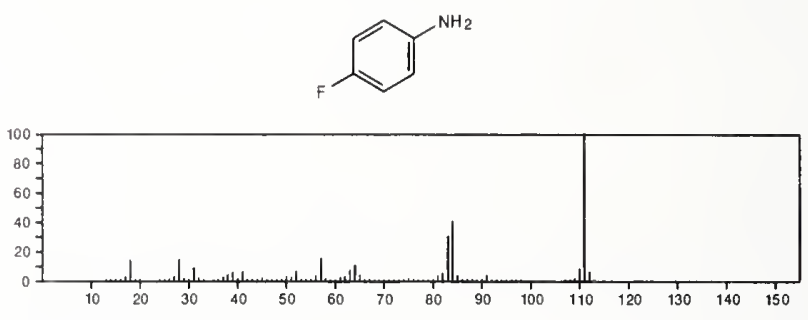

111

$\mathrm{C}_{6} \mathrm{H}_{8} \mathrm{~N} . \mathrm{HO}$

Pyridinium, 1-methyl-, hydroxide

$36880-49-6$
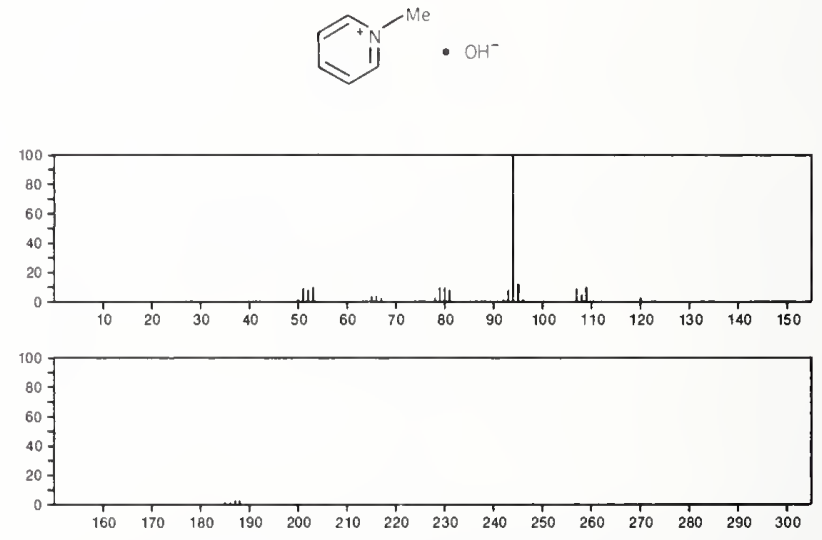

111

$\mathrm{C}_{6} \mathrm{H}_{9} \mathrm{NO}$

88-12-0

2-Pyrrolidinone, 1-ethenyl-
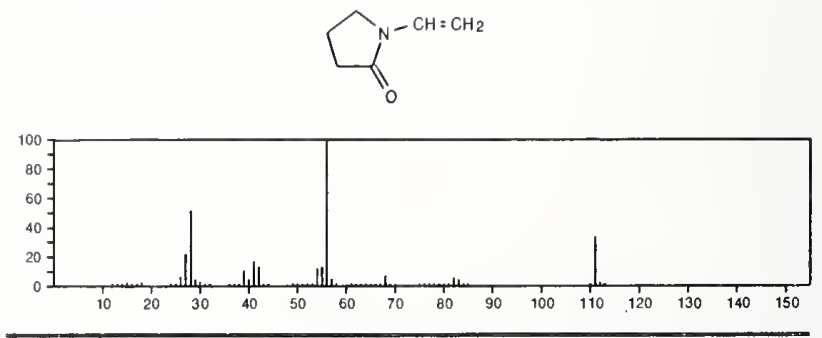

111

$\mathrm{C}_{6} \mathrm{H}_{9} \mathrm{NO}$

2H-Azepin-2-one, 1,5,6,7-tetrahydro-

2228-79-7
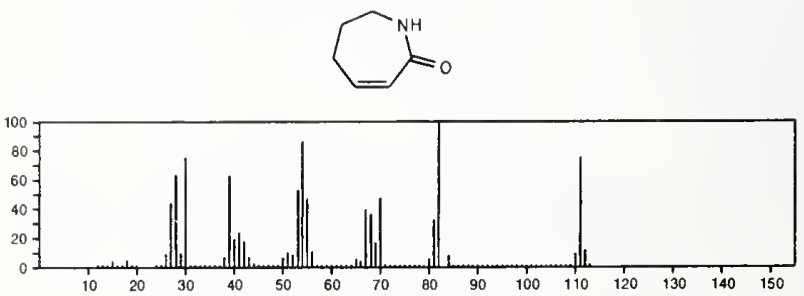
111

$\mathrm{C}_{6} \mathrm{H}_{9} \mathrm{NO}$

$3349-62-0$

2-Cyclohexen-1-one, oxime
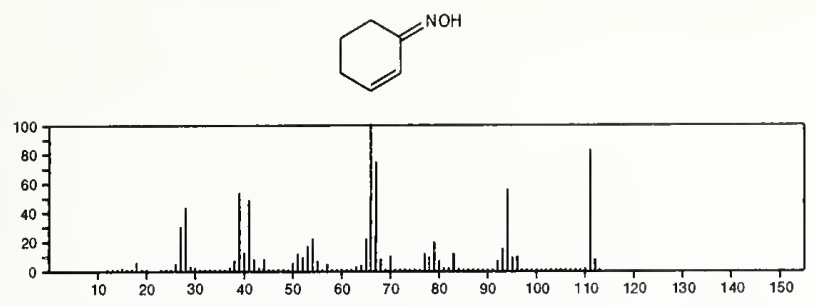

111

Isoxazole, trimethyl-

$\mathrm{C}_{6} \mathrm{H}_{9} \mathrm{NO}$

10557-82-1<smiles>Cc1noc(C)c1N</smiles>
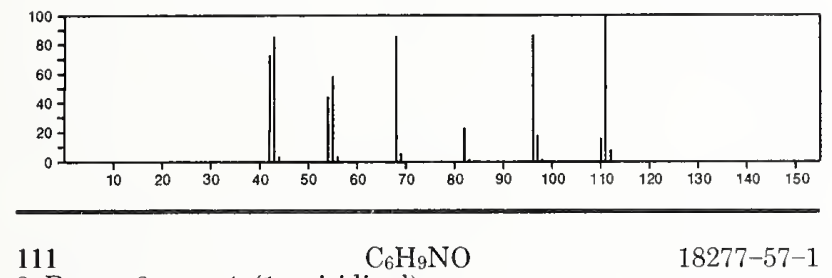

3-Buten-2-one, 4-(1-aziridinyl)-
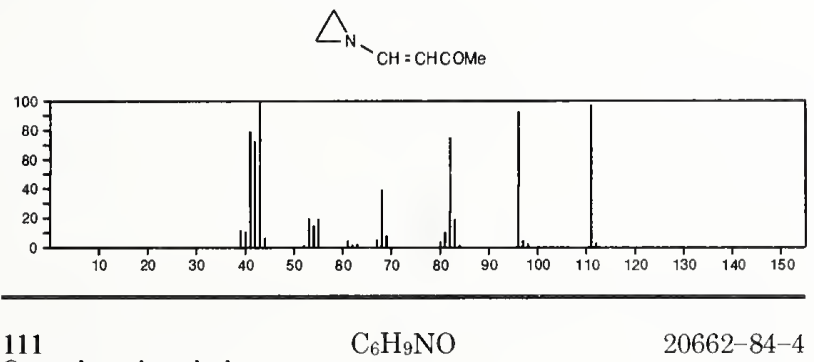

Oxazole, trimethyl-
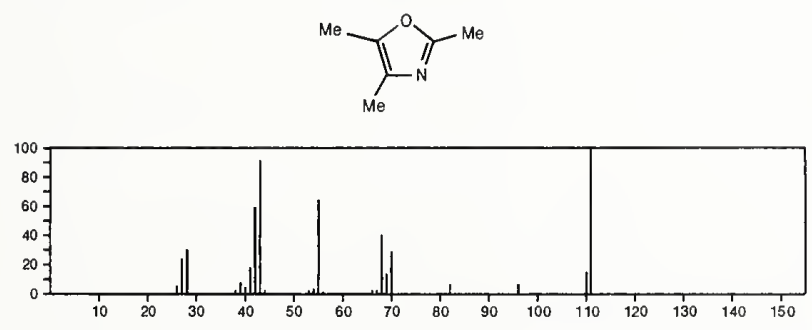

111

1-Azabicyclo[2.2.2]octane

$\mathrm{C}_{7} \mathrm{H}_{13} \mathrm{~N}$

$100-76-5$
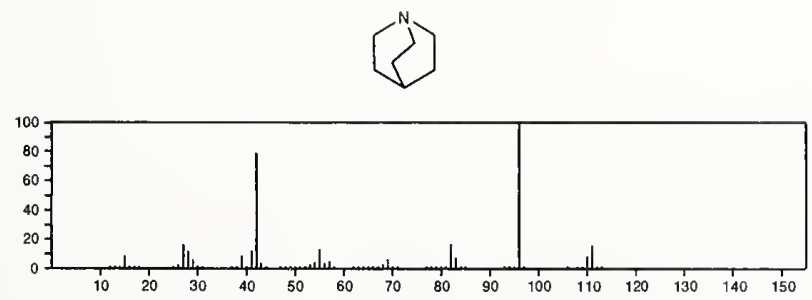

111

6-Azabicyclo[3.2.1]octane

$\mathrm{C}_{7} \mathrm{H}_{13} \mathrm{~N}$

279-85-6

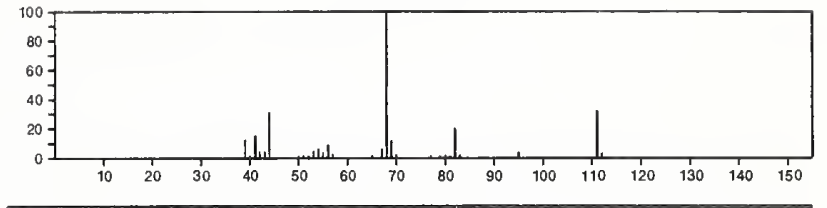

111

8-Azabicyclo[3.2.1]octane

$\mathrm{C}_{7} \mathrm{H}_{13} \mathrm{~N}$

280-05-7
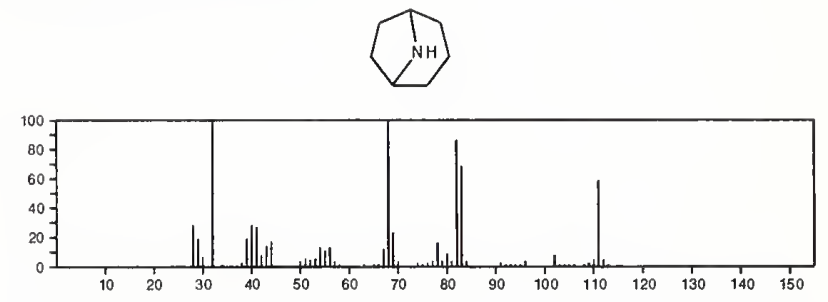

111

$\mathrm{C}_{7} \mathrm{H}_{13} \mathrm{~N}$

629-08-3

Heptanenitrile

$\mathrm{NC}\left(\mathrm{CH}_{2}\right)_{5} \mathrm{Me}$

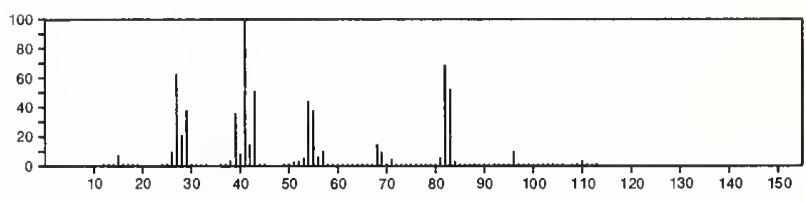

111

$1 \mathrm{H}$-Pyrrolizine, hexahydro-

$\mathrm{C}_{7} \mathrm{H}_{13} \mathrm{~N}$

643-20-9
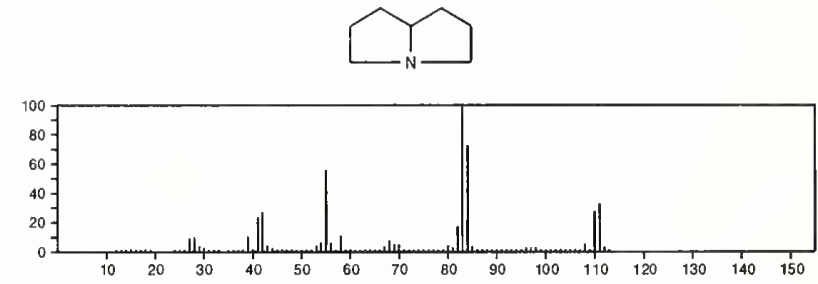

111

$\mathrm{C}_{7} \mathrm{H}_{13} \mathrm{~N}$

$694-84-8$

Pyridine, 1,2,3,6-tetrahydro-1,2-dimethyl-
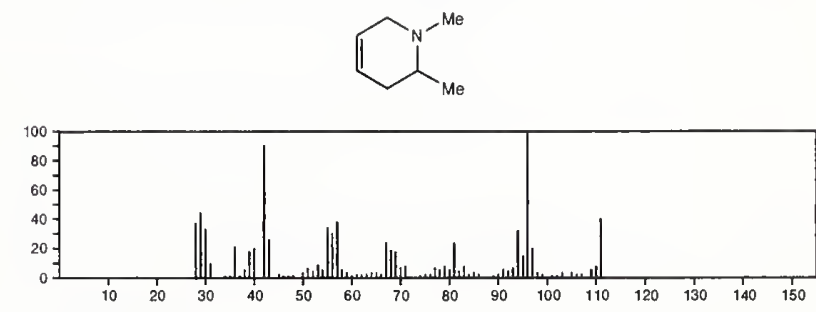

111

2-Propyn-1-amine, $N$-diethyl-

4079-68-9

$\mathrm{HC} \equiv \mathrm{CCH}_{2} \mathrm{NE}+$

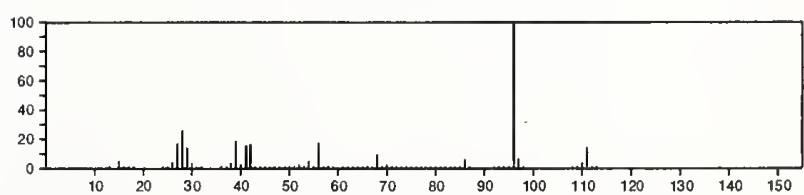


111 $\mathrm{C}_{7} \mathrm{H}_{13} \mathrm{~N}$ Methanamine, $N$-cyclohexylidene-
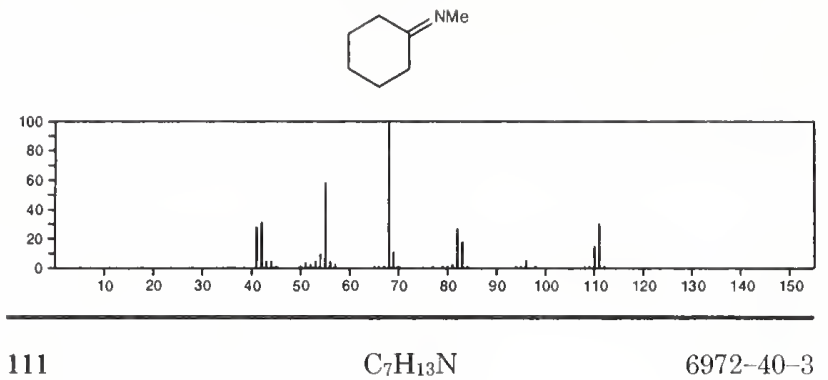

Pyridine, 1-ethyl-1,2,3,6-tetrahydro-

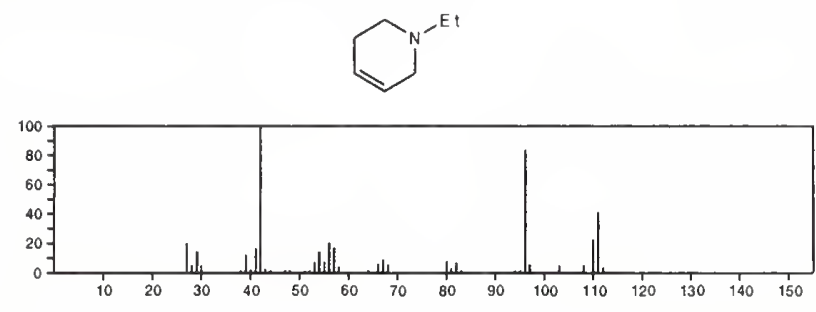

111

Pyrrolidine, 1-(1-propenyl)-

$\mathrm{C}_{7} \mathrm{H}_{13} \mathrm{~N}$

$13937-88-7$

$\overbrace{N}-\mathrm{CH}=\mathrm{CHMe}$

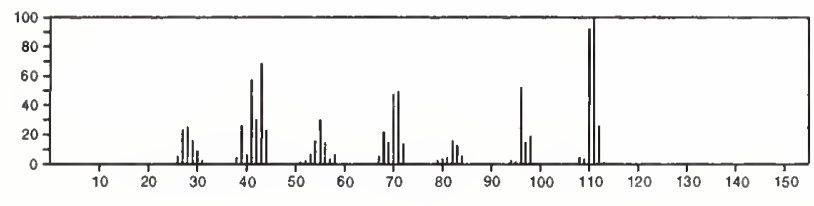

111

$\mathrm{C}_{7} \mathrm{H}_{13} \mathrm{~N}$

$15031-95-5$

Pyridine, 1,2,5,6-tetrahydro-1,2-dimethyl-<smiles>CC1C=CCCN1C</smiles>

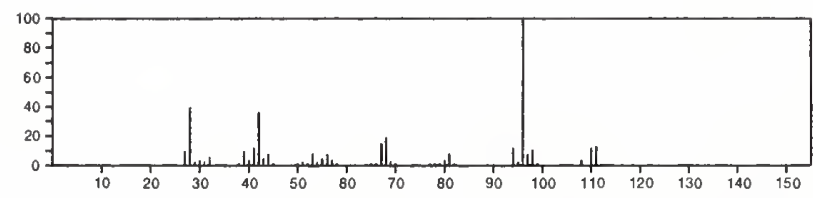

III

$\mathrm{C}_{7} \mathrm{H}_{13} \mathrm{~N}$

$15586-23-9$

Hexane, 1-isocyano-

$\mathrm{CN}\left(\mathrm{CH}_{2}\right){ }_{5} \mathrm{Me}$
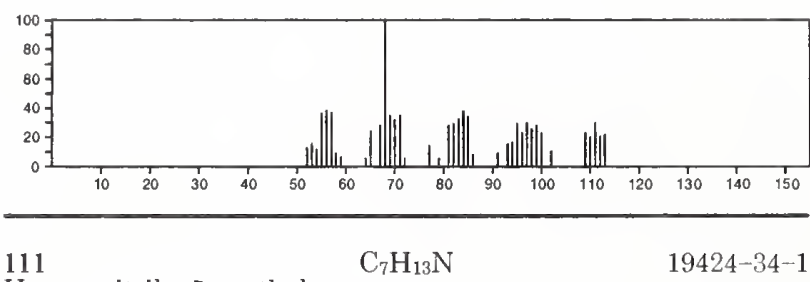

Hexanenitrile, 5-methyl-

$\mathrm{Me}_{2} \mathrm{CH}\left(\mathrm{CH}_{2}\right)_{3} \mathrm{CN}$

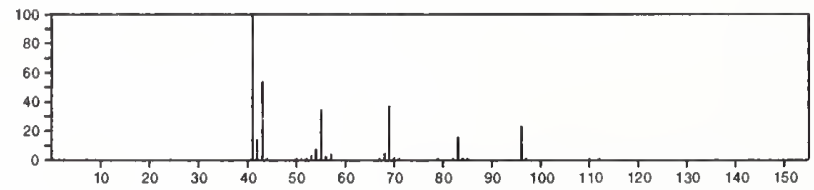

$111 \quad \mathrm{C}_{7} \mathrm{H}_{13} \mathrm{~N}$

7-Azabicyclo[4.1.0]heptane, 1-methyl-
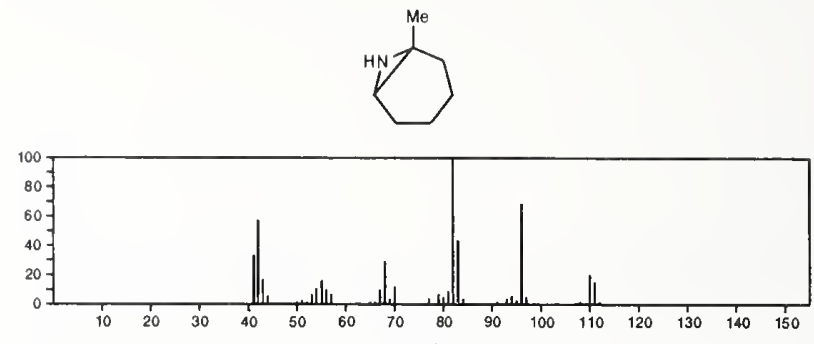

111

$\mathrm{C}_{7} \mathrm{H}_{13} \mathrm{~N}$

$53783-90-7$

4-Cyclohepten-1-amine
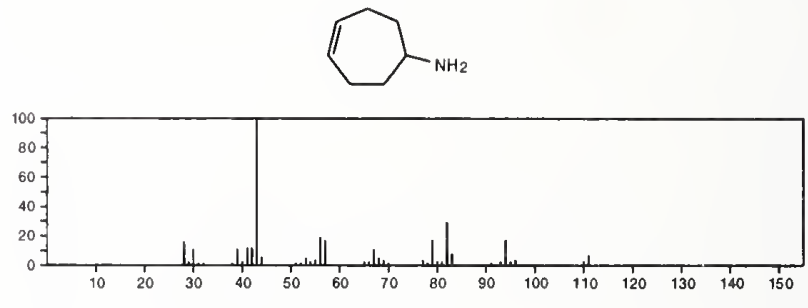

$111 \quad \mathrm{C}_{7} \mathrm{H}_{13} \mathrm{~N}$

7-Azabicyclo[4.1.0]heptane, 3-methyl-

$54644-35-8$
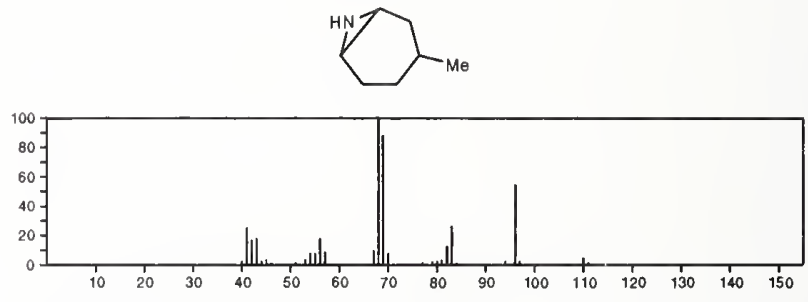

111
Ethanamine, $N$-cyclopentylidene

$54966-05-1$
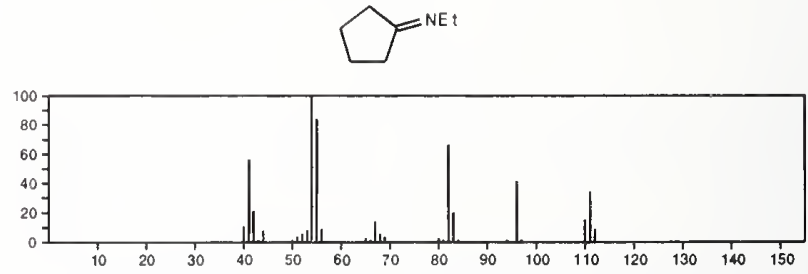

112

Methane, bromofluoro-

$\mathrm{CH}_{2} \mathrm{BrF}$

$373-52-4$

$\mathrm{CH}_{2} \mathrm{Br} F$

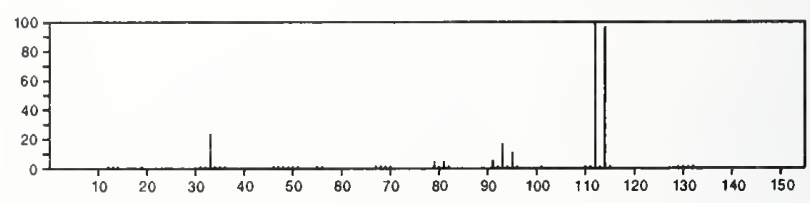

112

Acetyl chloride, chloro-

$\mathrm{C}_{2} \mathrm{H}_{2} \mathrm{Cl}_{2} \mathrm{O}$

$79-04-9$

$\mathrm{ClCH}_{2} \mathrm{COCl}$

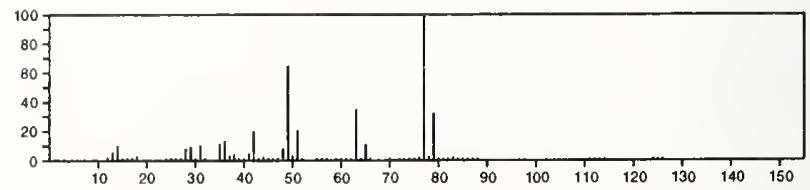


112

Ethanesulfonyl fluoride

$\mathrm{C}_{2} \mathrm{H}_{5} \mathrm{FO}_{2} \mathrm{~S}$

$\mathrm{EtSO} \mathrm{O}_{2} \mathrm{~F}$

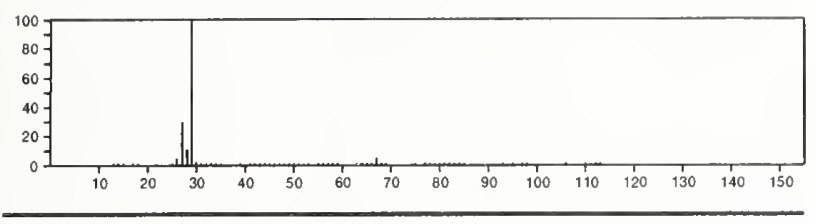

112

$\mathrm{C}_{3} \mathrm{H}_{3} \mathrm{~F}_{3} \mathrm{O}$

421-50-1

2-Propanone, 1,1,1-trifluoro-

$\mathrm{F}_{3} \mathrm{CCOMe}$
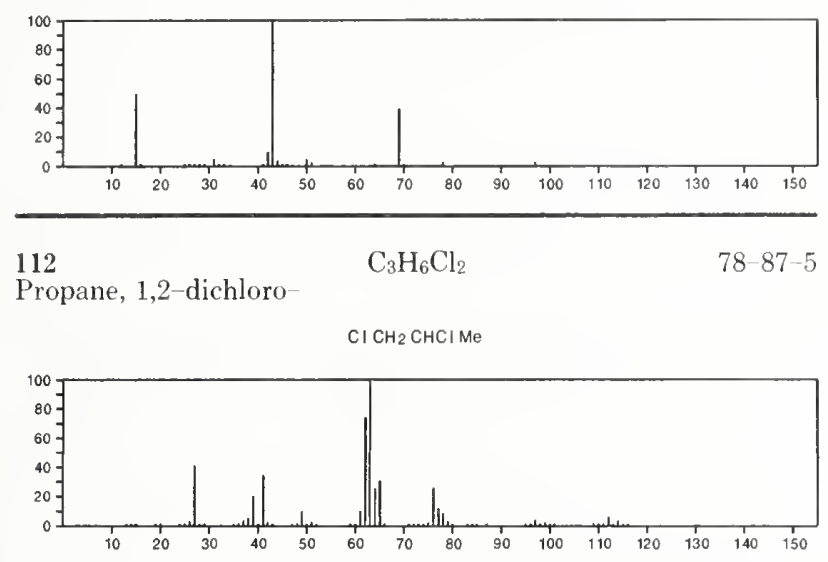

112

Propane, 1,1-dichloro-

$\mathrm{C}_{3} \mathrm{H}_{6} \mathrm{Cl}_{2}$

$7899-9$

$\mathrm{Cl}_{2} \mathrm{CHE}$ :

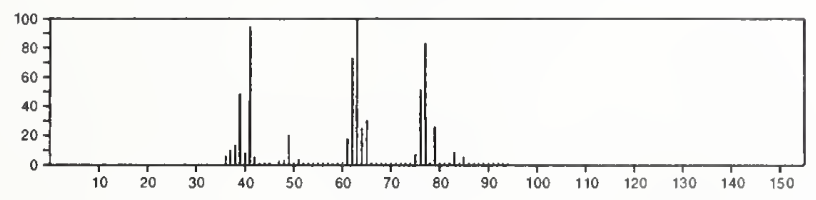

112

Propane, 1,3-dichloro-

$\mathrm{C}_{3} \mathrm{H}_{6} \mathrm{Cl}_{2}$

$142-28-9$

$\mathrm{Cl}\left\{\mathrm{CH}_{2}\right\}_{3} \mathrm{Cl}$

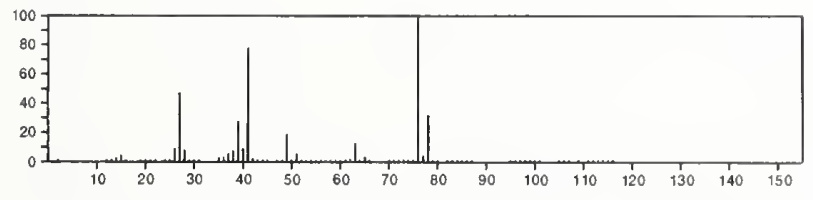

112

Propane, 2,2-dichloro-

$\mathrm{C}_{3} \mathrm{H}_{6} \mathrm{Cl}_{2}$

$\mathrm{Cl}_{2} \mathrm{CMe}_{2}$

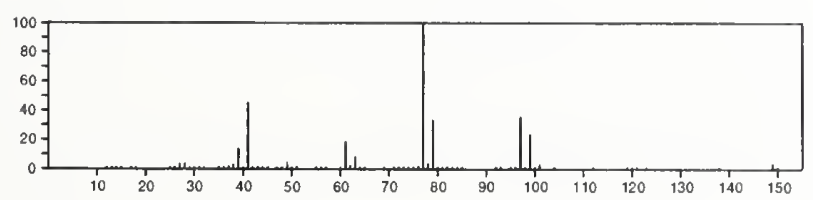

$112 \quad \mathrm{C}_{3} \mathrm{H}_{9} \mathrm{BN}_{4}$

$1 \mathrm{H}$-Tetrazaborole, 4,5-dihydro-1,4,5-trimethyl

$20546-18-3$
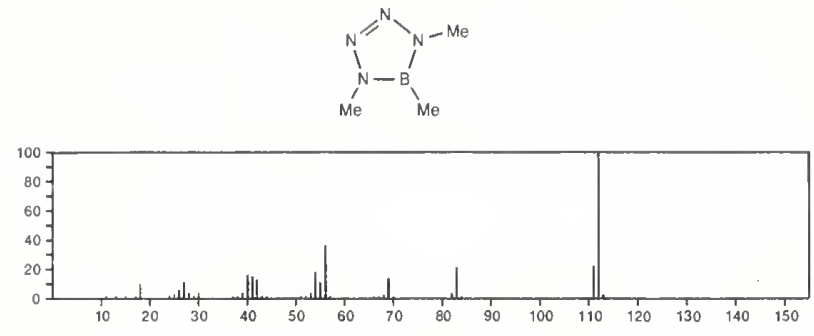

$112 \quad \mathrm{C}_{4} \mathrm{H}_{4} \mathrm{~N}_{2} \mathrm{O}_{2}$

$2,4(1 H, 3 H)$-Pyrimidinedione
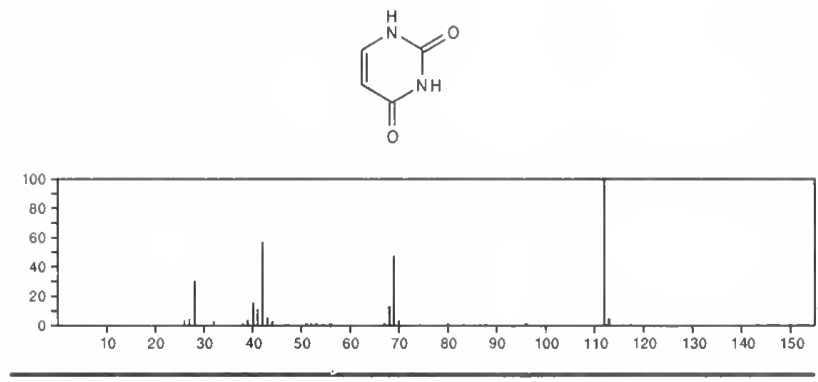

112

$\mathrm{C}_{4} \mathrm{H}_{4} \mathrm{~N}_{2} \mathrm{O}_{2}$

$1072-840$

1H-Imidazole-4-carboxylic acid
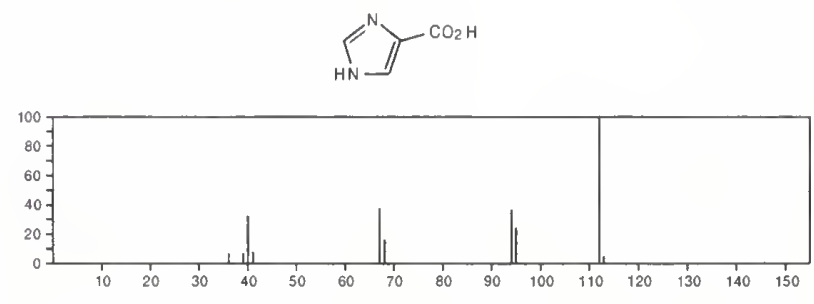

112

$\mathrm{C}_{4} \mathrm{H}_{8} \mathrm{~N}_{4}$

$37454-64-1$

1,2,4,5-Tetrazine, 1,4-dihydro-3,6-dimethyl
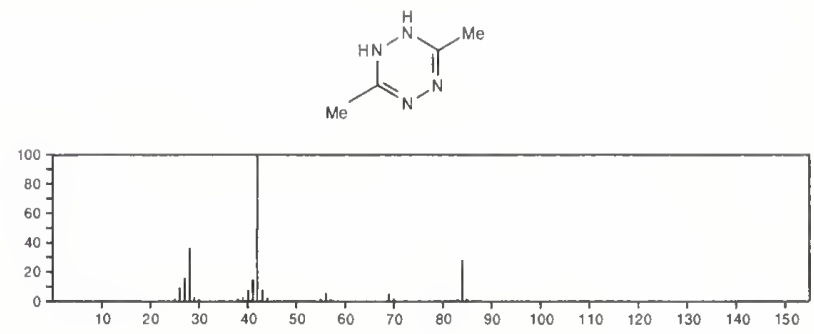

112

4H-Thiopyran-4-one

$\mathrm{C}_{5} \mathrm{H}_{4} \mathrm{OS}$

$1003-41-4$
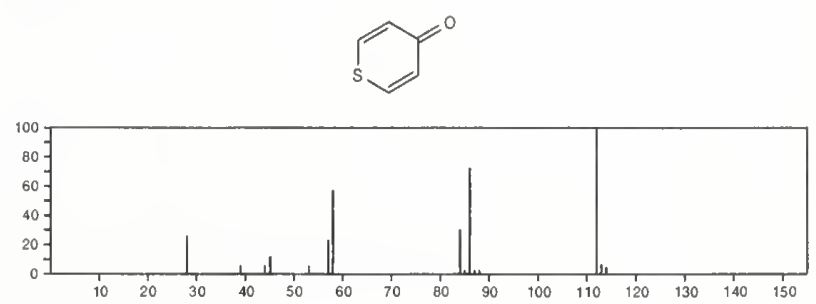
112

2-Furancarboxylic acid

$\mathrm{C}_{5} \mathrm{H}_{4} \mathrm{O}_{3}$
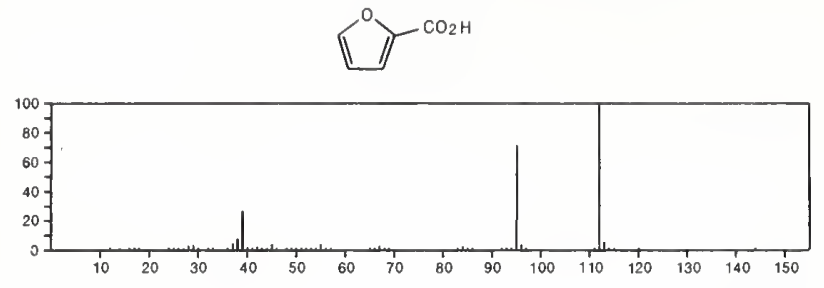

112

$\mathrm{C}_{5} \mathrm{H}_{4} \mathrm{O}_{3}$

488-93-7

3-Furancarboxylic acid
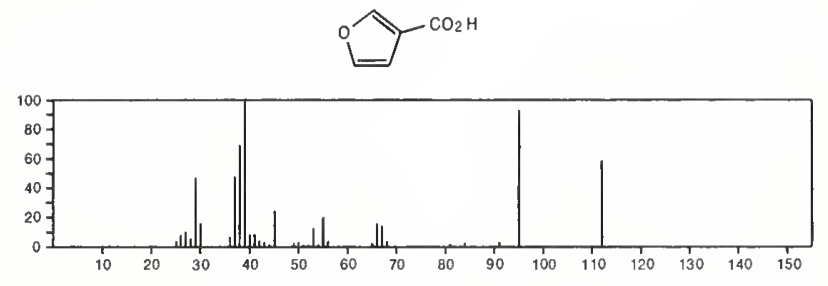

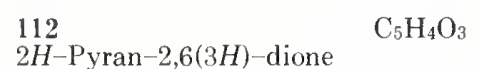

$5926-95-4$
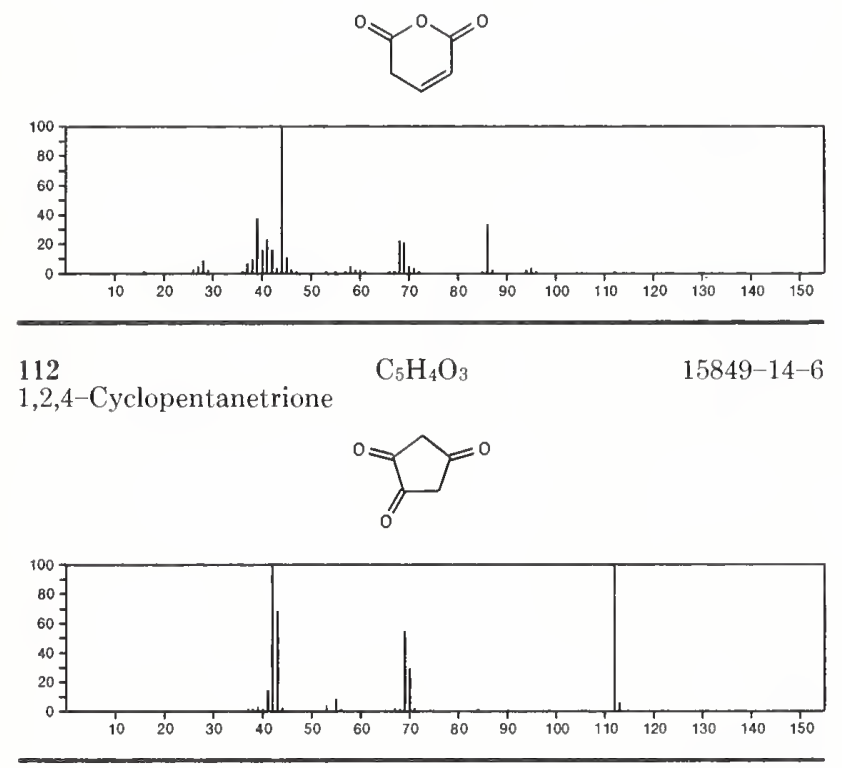

112

$\mathrm{C}_{5} \mathrm{H}_{8} \mathrm{~N}_{2} \mathrm{O}$

$2749-59-9$

3H-Pyrazol-3-one, 2,4-dihydro-2,5-dimethyl-
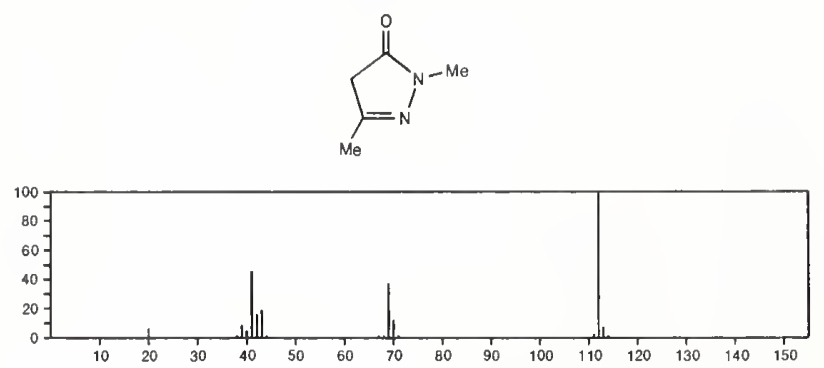

112

$\mathrm{C}_{5} \mathrm{H}_{8} \mathrm{~N}_{2} \mathrm{O}$

$3310-38-1$

3H-Pyrazol-3-one, 2,4-dihydro-2,4-dimethyl-
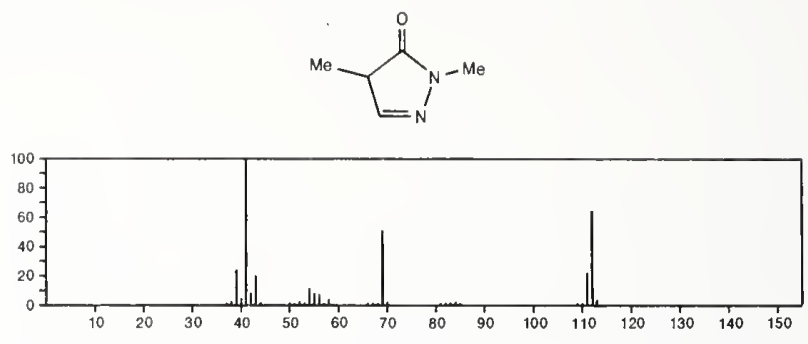

112

$\mathrm{C}_{5} \mathrm{H}_{8} \mathrm{~N}_{2} \mathrm{O}$

$5157-08-4$

3(2H)-Pyridazinone, 4,5-dihydro-6-methyl<smiles>CC1=NNC(=O)CC1</smiles>

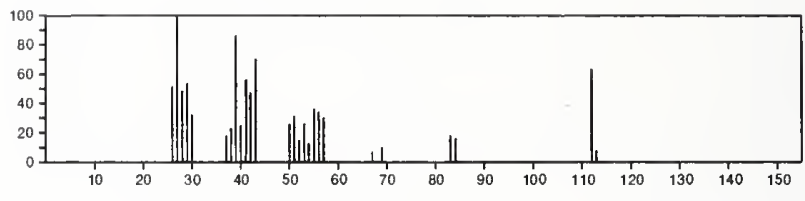

112

$\mathrm{C}_{5} \mathrm{H}_{8} \mathrm{~N}_{2} \mathrm{O}$

$6628-22-4$

3H-Pyrazol-3-one, 2,4-dihydro-4,5-dimethyl-
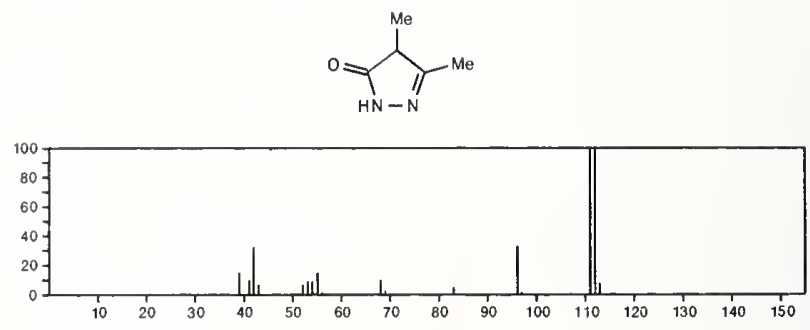

$112 \quad \mathrm{C}_{5} \mathrm{H}_{8} \mathrm{~N}_{2} \mathrm{O}$

$17334-08-6$

1H-Imidazole-2-methanol, 1-methyl-
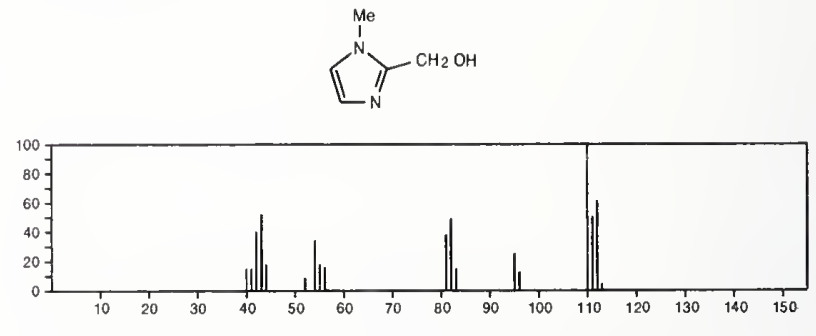

112

$\mathrm{C}_{5} \mathrm{H}_{8} \mathrm{~N}_{2} \mathrm{O}$

Butanamide, 4-cyano-

$\mathrm{NC}\left(\mathrm{CH}_{2}\right)_{3} \mathrm{CONH}_{2}$

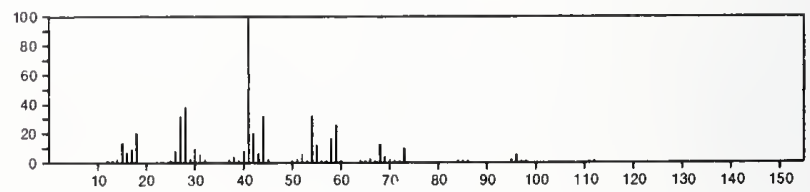


112
Pyridine,
$\mathrm{C}_{5} \mathrm{H}_{8} \mathrm{~N}_{2} \mathrm{O}$
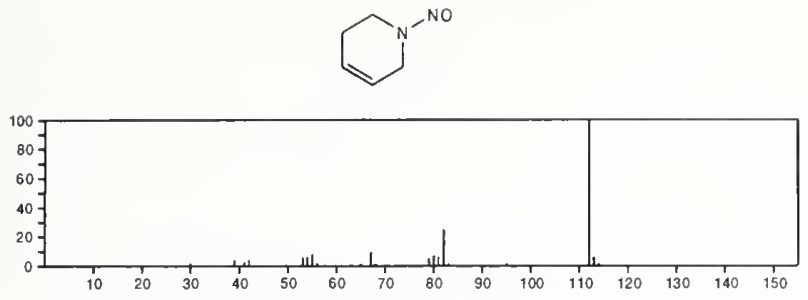

112

Benzene, chloro-

$\mathrm{C}_{6} \mathrm{H}_{5} \mathrm{Cl}$

$\mathrm{PhCl}$

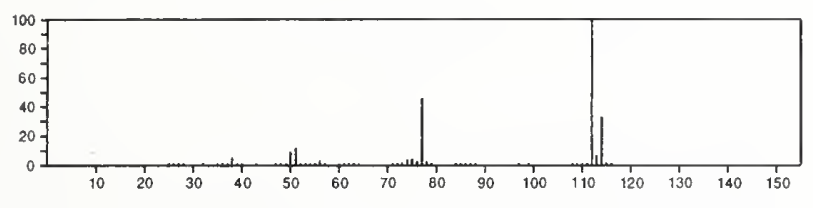

112

Phenol, 2-fluoro-

$\mathrm{C}_{6} \mathrm{H}_{5} \mathrm{FO}$

$367-12-4$
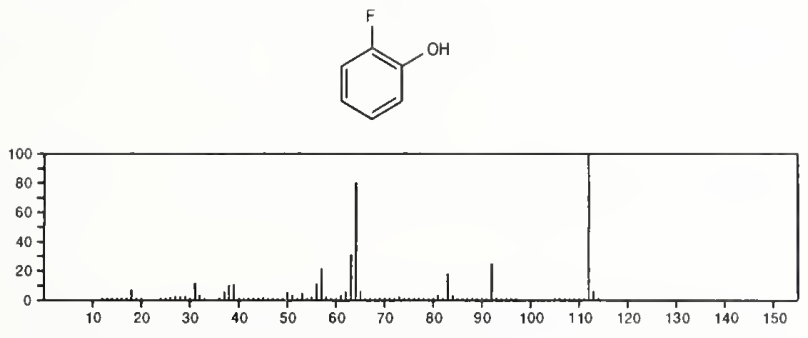

112

Phenol, 4-fluoro-

$\mathrm{C}_{6} \mathrm{H}_{5} \mathrm{FO}$

$371-41-5$
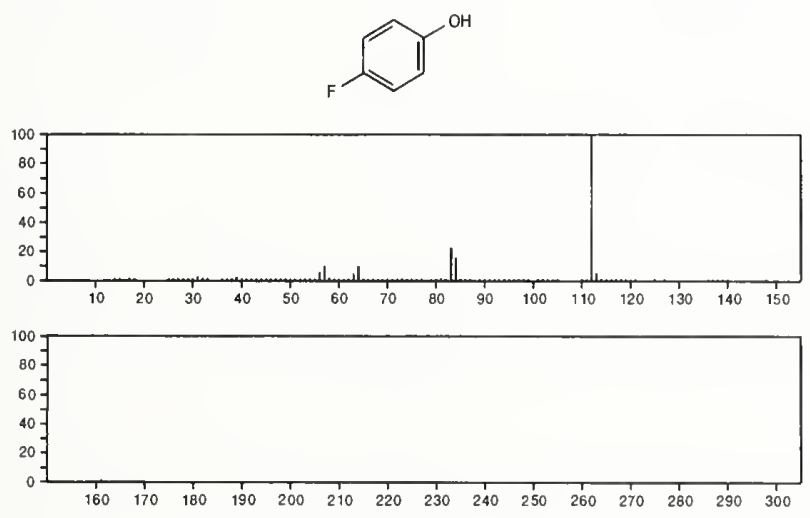

112

$\mathrm{C}_{6} \mathrm{H}_{8} \mathrm{O}_{2}$

2-Cyclopenten-1-one, 2-hydroxy-3-methyl-

$80-71-7$
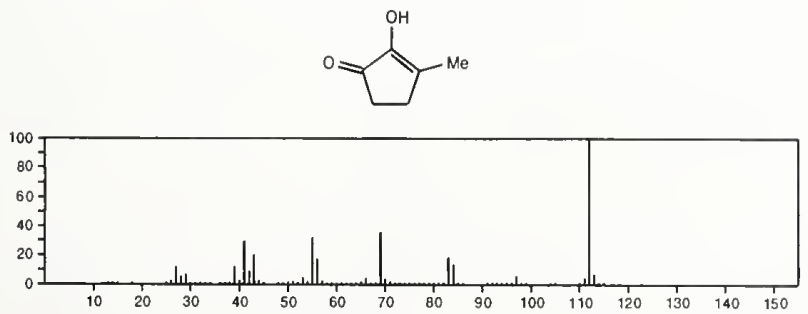

$112 \quad \mathrm{C}_{6} \mathrm{H}_{8} \mathrm{O}_{2}$

$100-73-2$

2H-Pyran-2-carboxaldehyde, 3,4-dihydro-
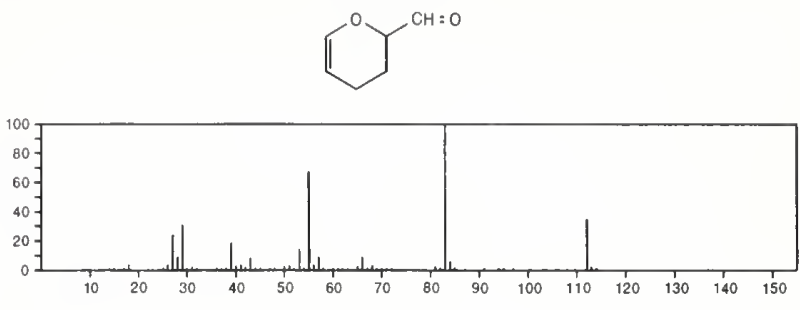

112

2,4-Hexadienoic acid, $(E, E)$

$110-44-1$

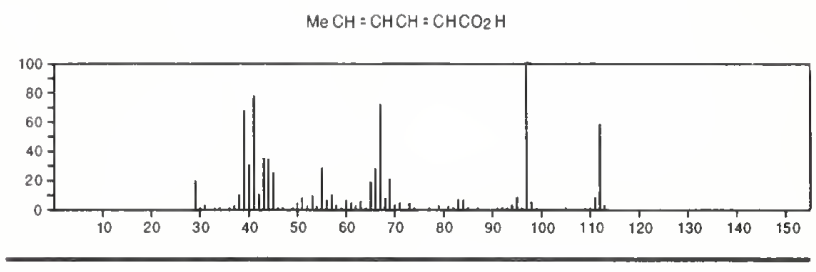

112

$\mathrm{C}_{6} \mathrm{H}_{8} \mathrm{O}_{2}$

637-88-7

1,4-Cyclohexanedione
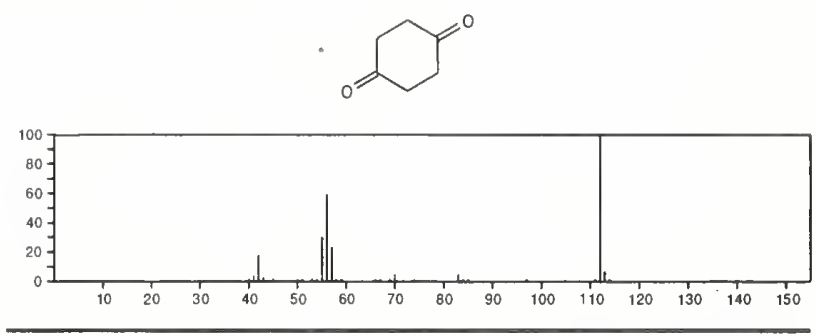

112

$\mathrm{C}_{6} \mathrm{H}_{8} \mathrm{O}_{2}$

1,3-Cyclopentanedione, 2-methyl-

765-69-5
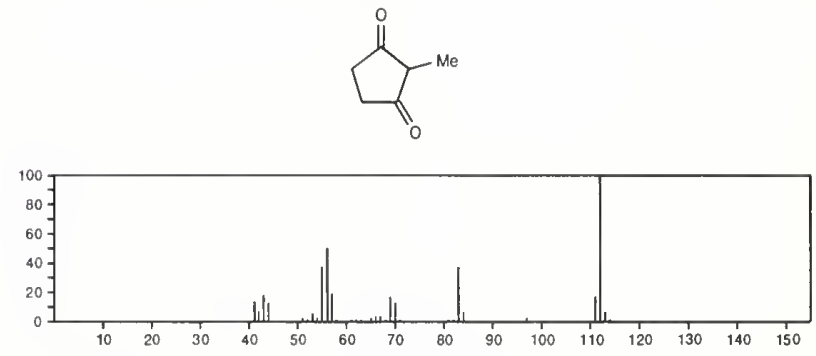

112

1,2-Cyclohexanedione

$\mathrm{C}_{6} \mathrm{H}_{8} \mathrm{O}_{2}$

765-87-7
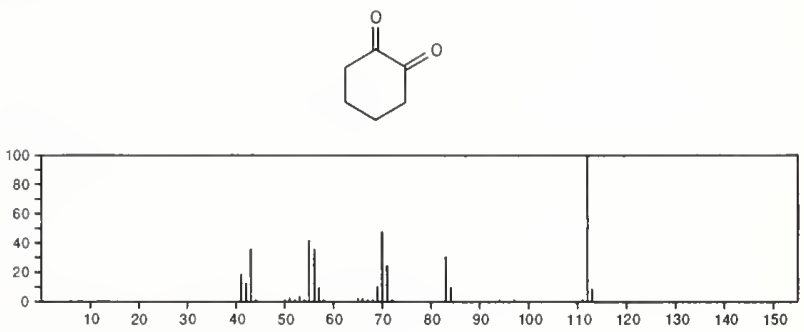
112

$\mathrm{C}_{6} \mathrm{H}_{8} \mathrm{O}_{2}$

2-Propenoic acid, 2-propenyl ester

$999-55-3$

$\mathrm{H}_{2} \mathrm{C}=\mathrm{CHC}(\mathrm{O}) \mathrm{OCH}_{2} \mathrm{CH}=\mathrm{CH}_{2}$

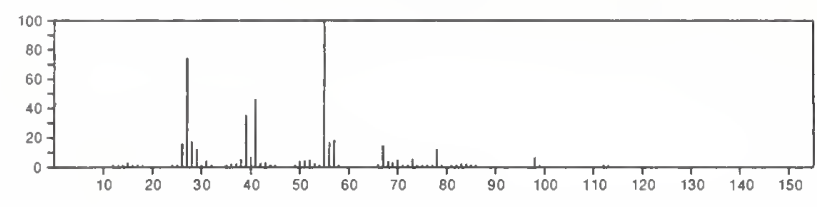

112

2(5H)-Furanone, 5-ethyl-

$\mathrm{C}_{6} \mathrm{H}_{8} \mathrm{O}_{2}$

$2407-43-4$
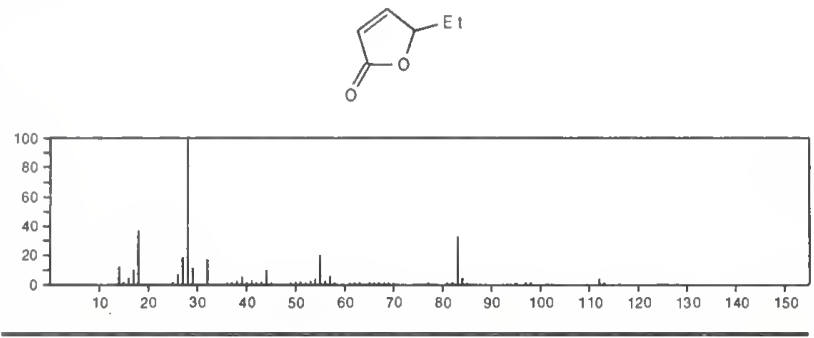

$112 \quad \mathrm{C}_{6} \mathrm{H}_{8} \mathrm{O}_{2}$

2-Propenoic acid, 2-methyl-, ethenyl ester

$4245-37-8$

$\mathrm{H}_{2} \mathrm{C}=\mathrm{CHOC}(\mathrm{O}) \mathrm{CMe}=\mathrm{CH}_{2}$

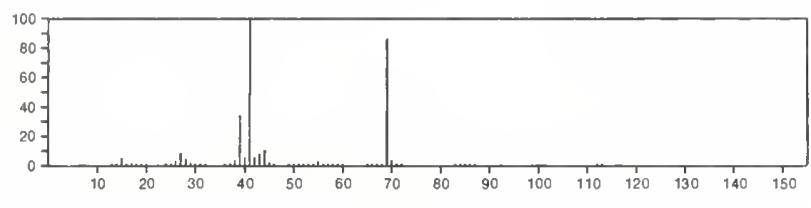

112

3-Hexene-2,5-dione

$\mathrm{C}_{6} \mathrm{H}_{8} \mathrm{O}_{2}$

$4436-75-3$

$\mathrm{MeCOCH}=\mathrm{CHCOMe}$

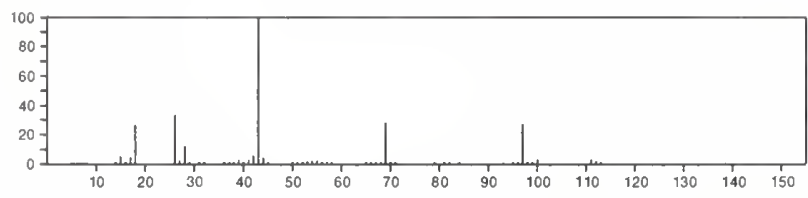

${ }_{2-}^{112}{ }^{-} \mathrm{C}_{6} \mathrm{H}_{8} \mathrm{O}_{2}$

$4683-50-5$
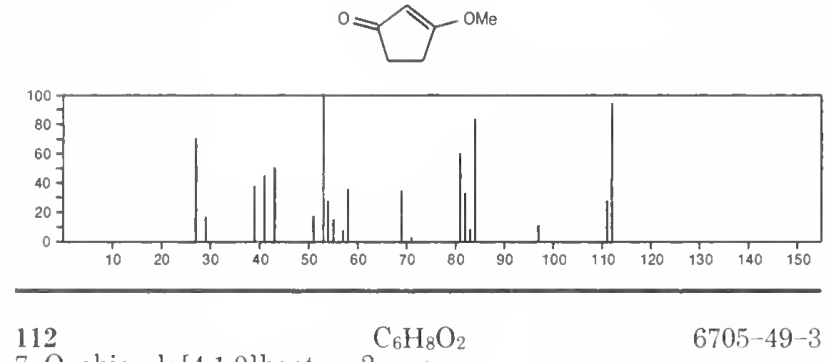

$6705-49-3$

7-Oxabicyclo[4.1.0]heptan-2-one
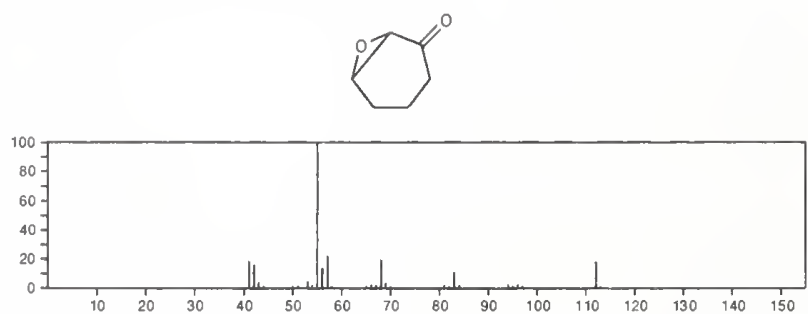

112

Furan, 2-(methoxymethyl)- $\mathrm{C}_{6} \mathrm{H}_{8} \mathrm{O}_{2}$

$13679-46-4$
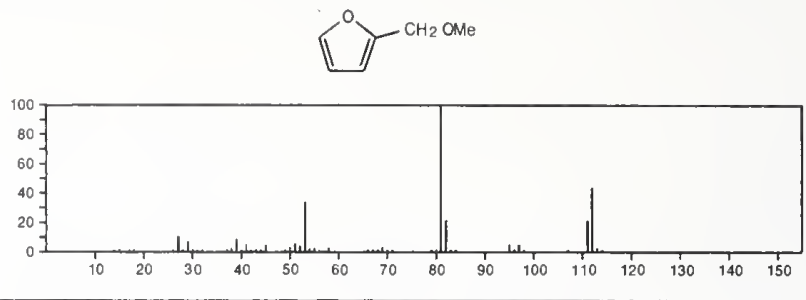

112

$\mathrm{C}_{6} \mathrm{H}_{8} \mathrm{O}_{2}$

20019-64-1

2(5H)-Furanone, 5,5-dimethyl-
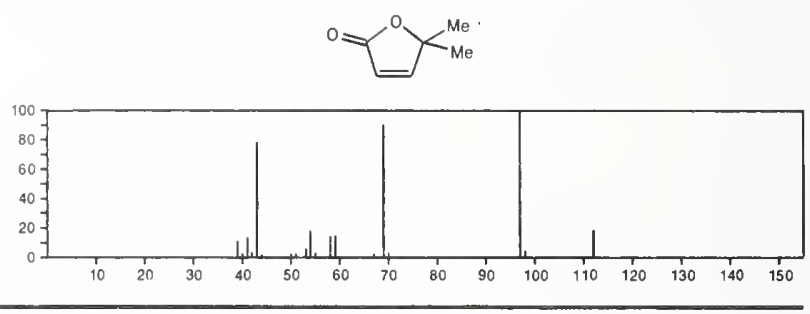

$112 \quad \mathrm{C}_{6} \mathrm{H}_{8} \mathrm{O}_{2}$

1,3-Cyclopentanedione, 4-methyl-

35029-03-9
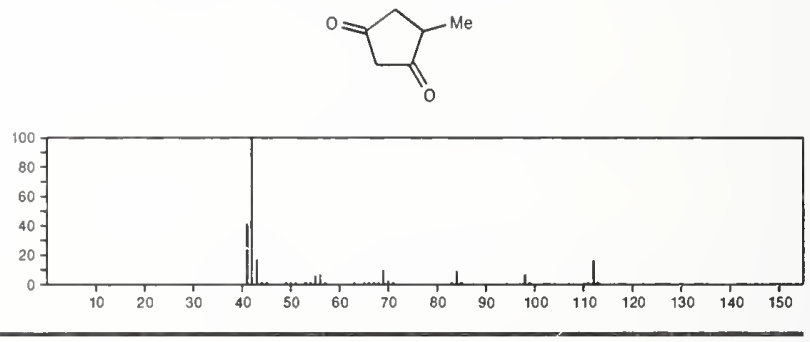

112

5-Hexynoic acid

$\mathrm{C}_{6} \mathrm{H}_{8} \mathrm{O}_{2}$

53293-00-8

$\mathrm{HC} \equiv \mathrm{C}\left(\mathrm{CH}_{2}\right)_{3} \mathrm{CO}_{2} \mathrm{H}$

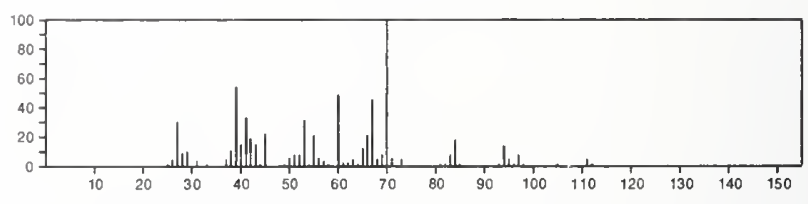

112

$\mathrm{C}_{6} \mathrm{H}_{8} \mathrm{O}_{2}$

$53897-26-0$

2H-Pyran-2-carboxaldehyde, 5,6-dihydro-
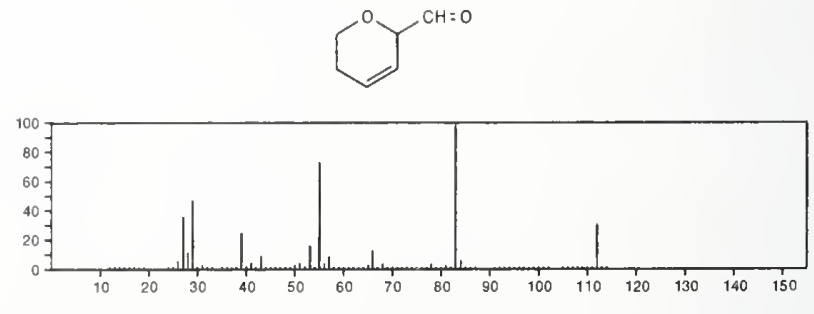

112

$\mathrm{C}_{6} \mathrm{H}_{8} \mathrm{~S}$

632-16-6

Thiophene, 2,3-dimethyl-
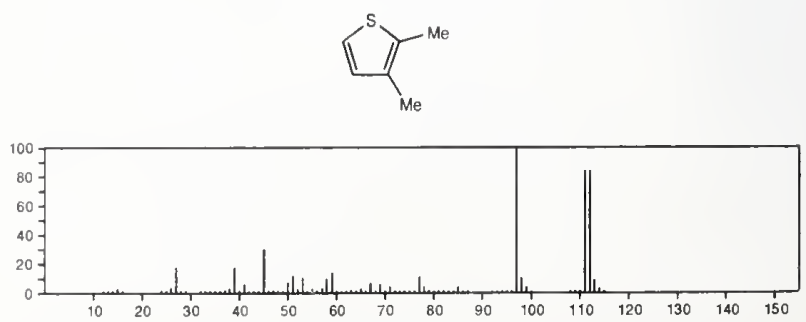
112

Thiophene, 2,4-dimethyl-

$$
\mathrm{C}_{6} \mathrm{H}_{8} \mathrm{~S}
$$
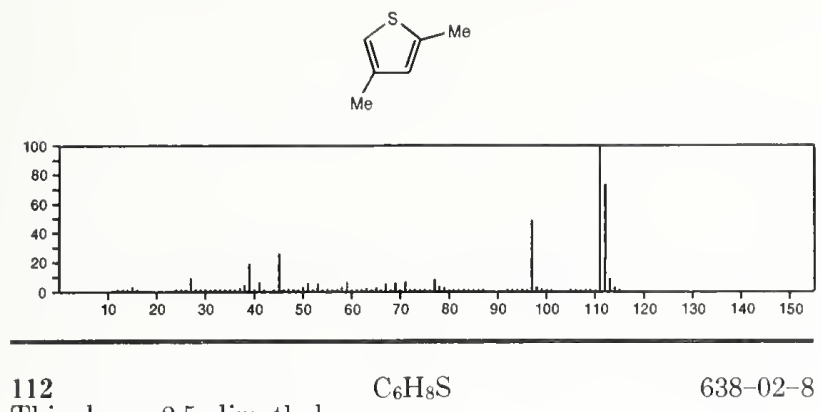

Thiophene, 2,5-dimethyl-
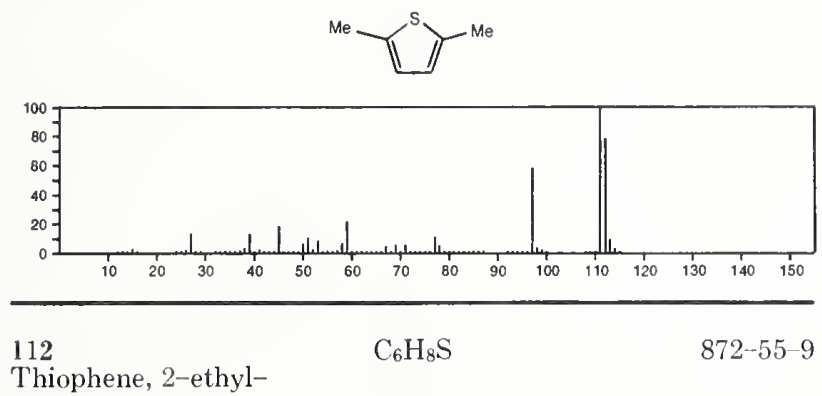

Thiophene, 2-ethyl-
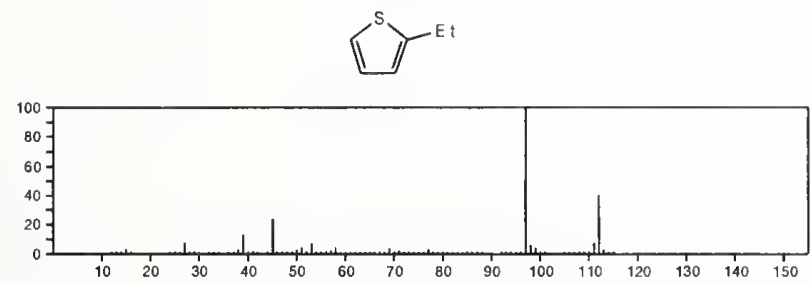

112

$\mathrm{C}_{6} \mathrm{H}_{8} \mathrm{~S}$

1795-01-3

Thiophene, 3-ethyl-
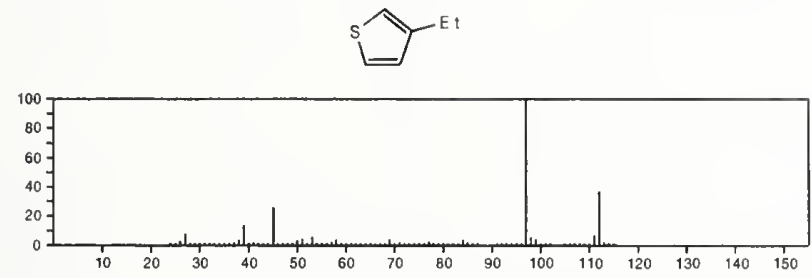

112

2-Cyclopentene-1-thione, 3-methyl-

$30221-52-4$
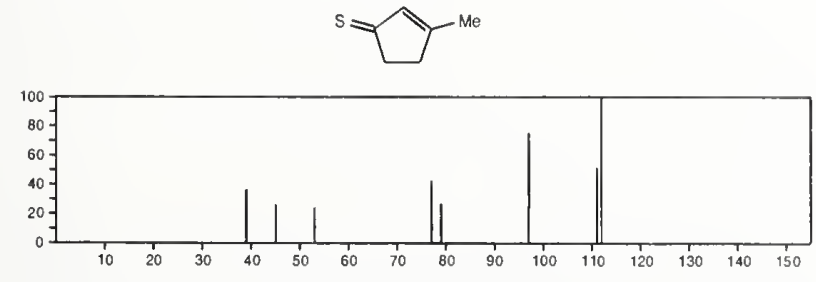

112 $\mathrm{C}_{6} \mathrm{H}_{12} \mathrm{~N}_{2}$

2-Propanone, (1-methylethylidene)hydrazone

$627-70-3$

$\mathrm{Me}_{2} \mathrm{C}=\mathrm{NN}=\mathrm{CMe}_{2}$

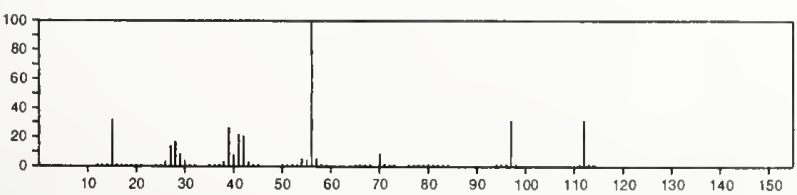

$112 \quad \mathrm{C}_{6} \mathrm{H}_{12} \mathrm{~N}_{2}$

$1 \mathrm{H}$-Imidazole, 2-ethyl-4,5-dihydro-4-methyl
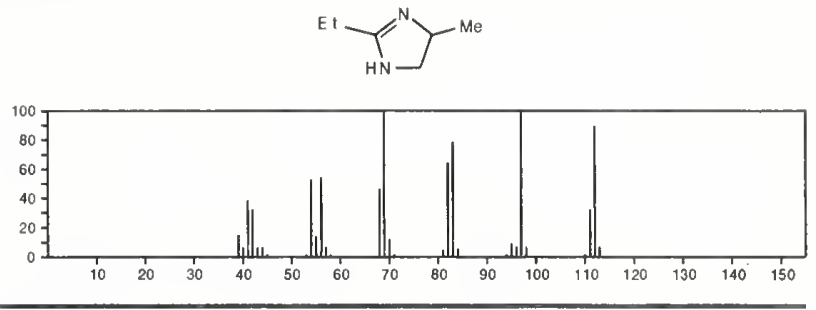

112

Hexanenitrile, 6-amino-

$\mathrm{C}_{6} \mathrm{H}_{12} \mathrm{~N}_{2}$

2432-74-8

$\mathrm{NC}\left(\mathrm{CH}_{2}\right) 5 \mathrm{NH}_{2}$

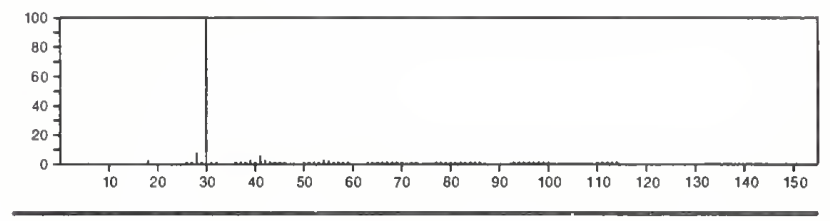

112

Cyclohexanone, hydrazone

$\mathrm{C}_{6} \mathrm{H}_{12} \mathrm{~N}_{2}$

6156-08-7
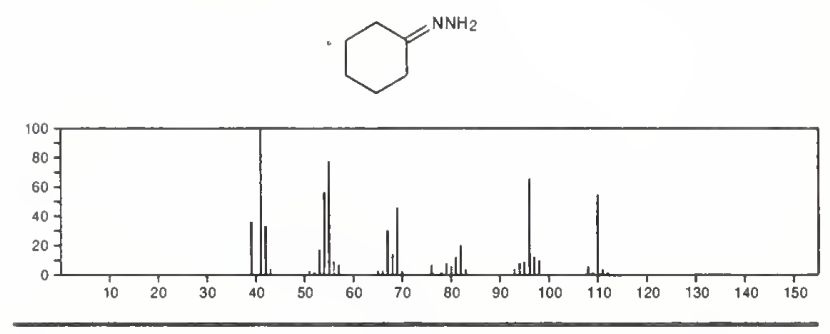

$112 \quad \mathrm{C}_{6} \mathrm{H}_{12} \mathrm{~N}_{2}$

Valeronitrile, 5-amino-2-methyl-

10483-15-5

$\mathrm{NCCHMe}\left(\mathrm{CH}_{2}\right)_{3} \mathrm{NH}_{2}$

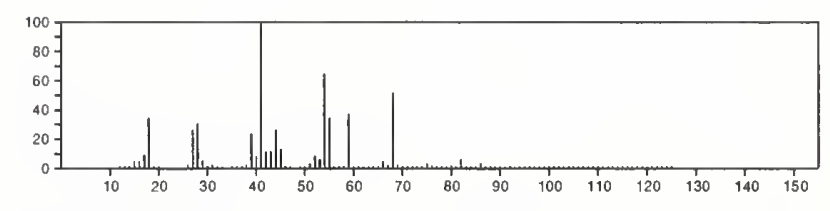

$112 \quad \mathrm{C}_{6} \mathrm{H}_{12} \mathrm{~N}_{2}$

Butyronitrile, 4-(dimethylamino)-

$13989-82-7$

$\mathrm{Me} 2 \mathrm{~N}\left(\mathrm{CH}_{2}\right)_{3} \mathrm{CN}$

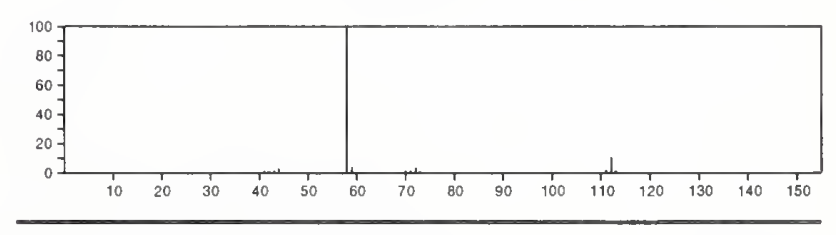

112

$\mathrm{C}_{6} \mathrm{H}_{12} \mathrm{~N}_{2}$

18237-68-8

1H-1,3-Diazepine, 4,5,6,7-tetrahydro-2-methyl-
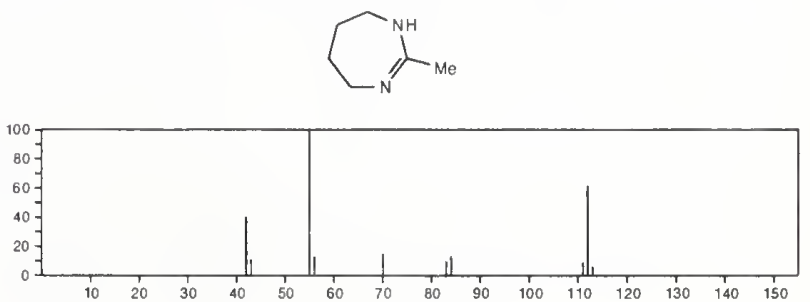
112

8-Oxabicyclo[5.1.0]octane

$\mathrm{C}_{7} \mathrm{H}_{12} \mathrm{O}$

$286-45-3$
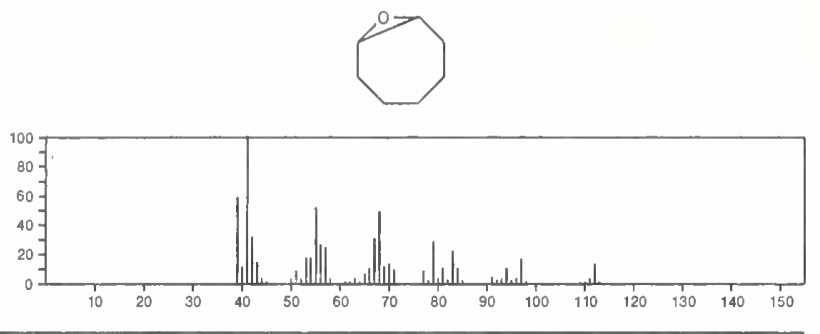

$112 \quad \mathrm{C}_{7} \mathrm{H}_{12} \mathrm{O}$

Bicyclo[2.2.1] heptan-2-ol, endo--
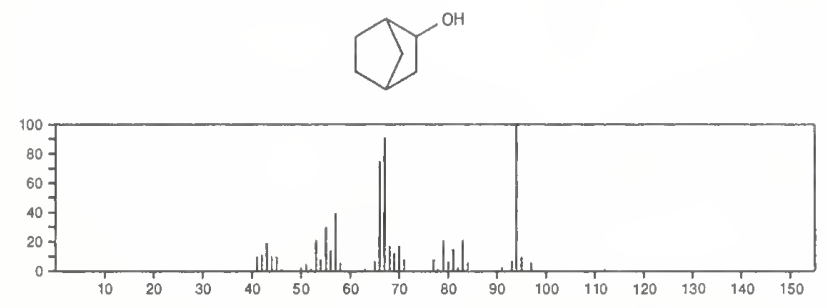

112

Bicyclo[2.2.1]heptan-2-0l; ext

$\mathrm{C}_{7} \mathrm{H}_{12} \mathrm{O}$

$497-37-0$
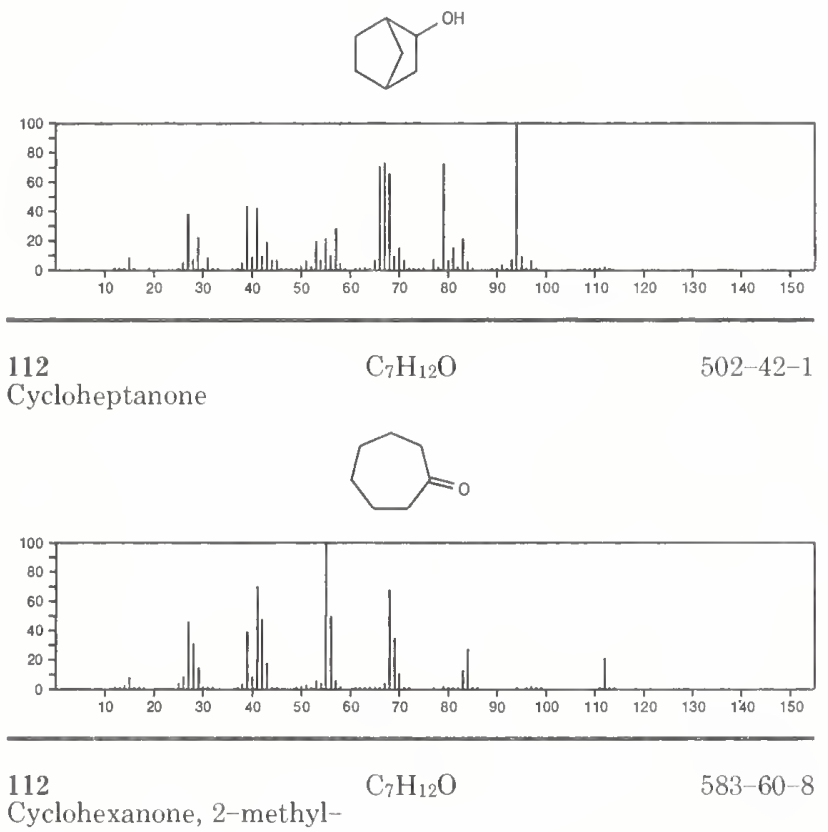

Cyclohexanone, 2-methyl-<smiles>NC1CCCCC1=O</smiles>

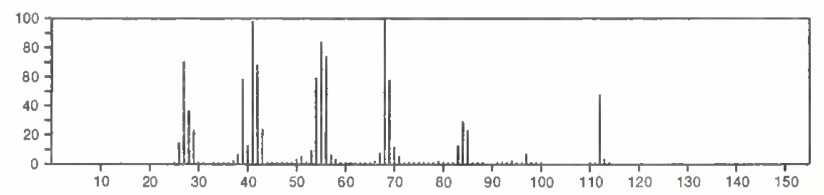

112

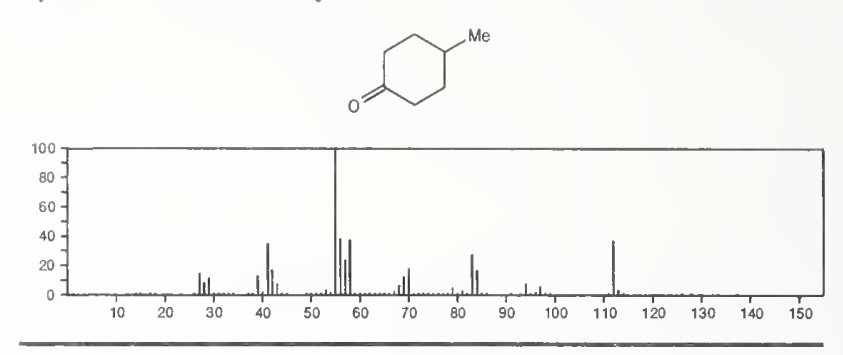

112

$\mathrm{C}_{7} \mathrm{H}_{12} \mathrm{O}$

$591-24-2$

Cyclohexanone, 3-methyl-
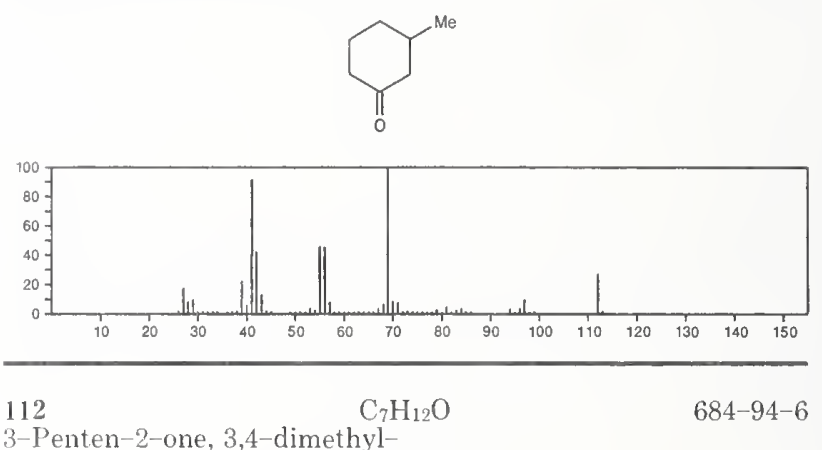

3-Penten-2-one, 3,4-dimethyl-

Me $\mathrm{COCMe}=\mathrm{CMe}_{2}$

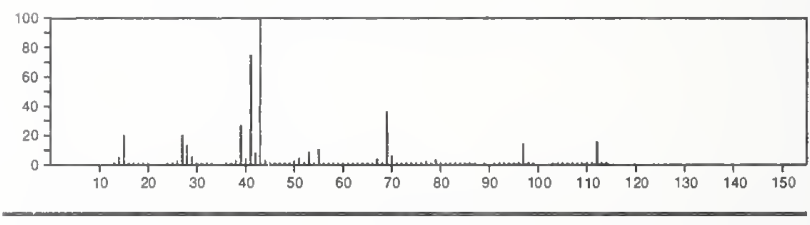

112

3-Hepten-2-one

$\mathrm{C}_{7} \mathrm{H}_{12} \mathrm{O}$

1119-44-4

$\mathrm{Pr} \mathrm{CH}: \mathrm{CHCOMe}$
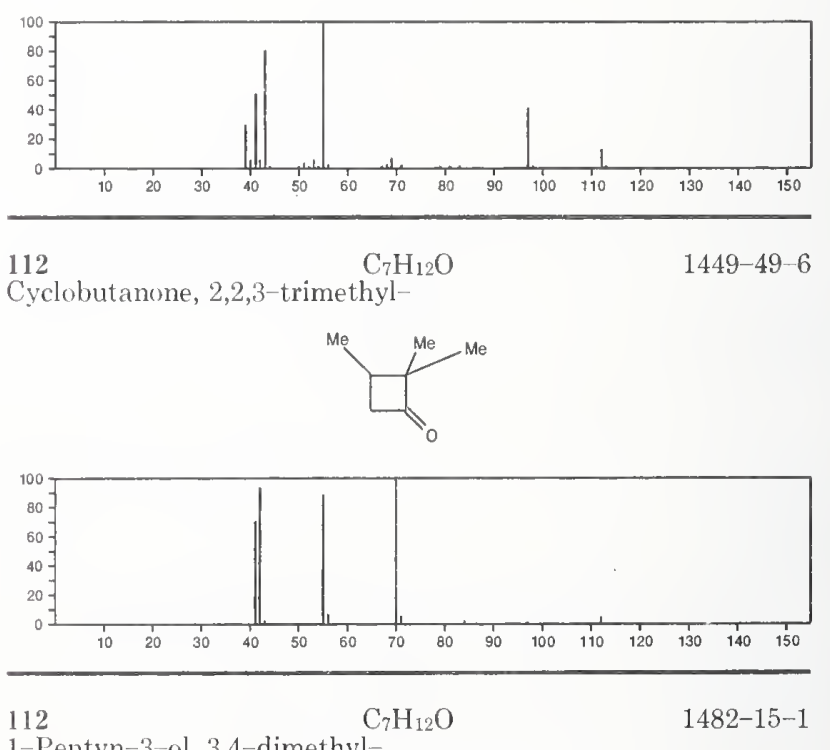

1-Pentyn-3-ol, 3,4-dimethyl-

$\mathrm{HC} \equiv \mathrm{CCMe}(\mathrm{OH}) \mathrm{CHMe} 2$

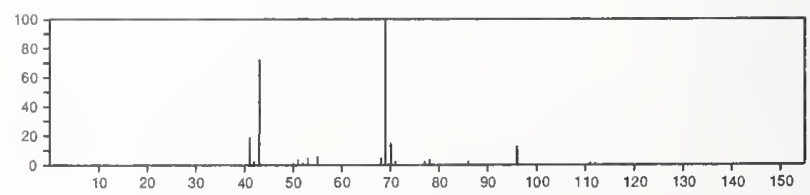


112

3-Cyclohexene-1-methanol

$$
\mathrm{C}_{7} \mathrm{H}_{12} \mathrm{O}
$$

$\overbrace{}^{\mathrm{CH}_{2} \mathrm{OH}}$

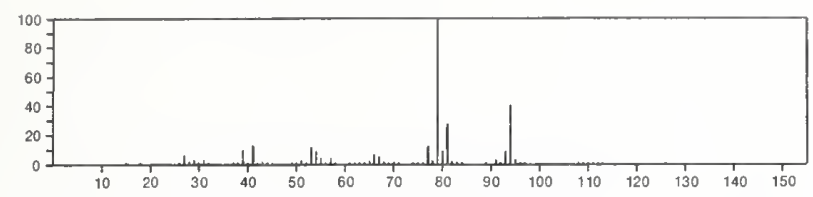

112

$\mathrm{C}_{7} \mathrm{H}_{12} \mathrm{O}$

7-Oxabicyclo[4.1.0]heptane, 1-methyl-
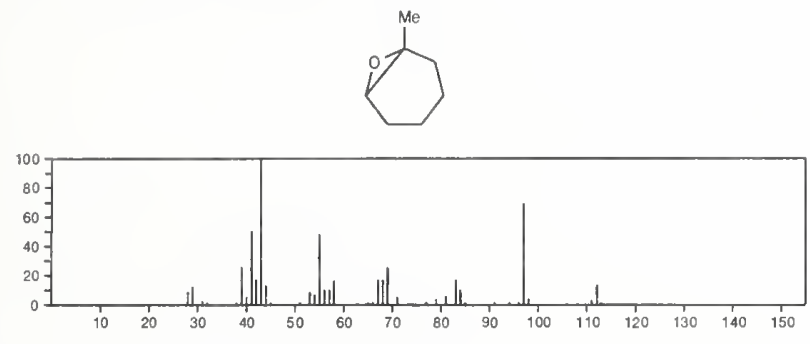

112

Cyclohexanecarboxaldehyde

$\mathrm{C}_{7} \mathrm{H}_{12} \mathrm{O}$

2043-61-0
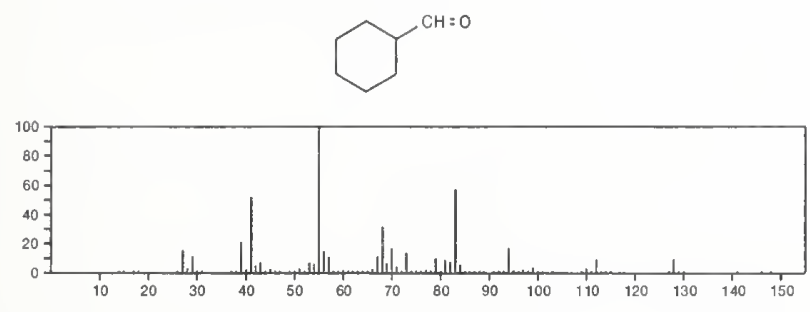

112

Bicyclo[2.2.1]heptan-7-ol

$$
\mathrm{C}_{7} \mathrm{H}_{12} \mathrm{O}
$$

$2566-48-5$
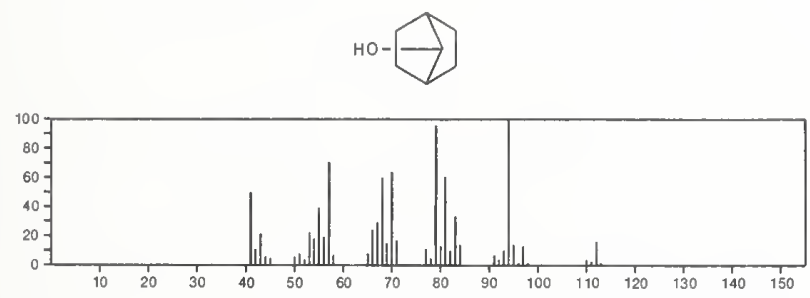

112 Cyclopentanone, 2,5-dimethyl- $\mathrm{C}_{7} \mathrm{H}_{12} \mathrm{O}$

4041-09-2
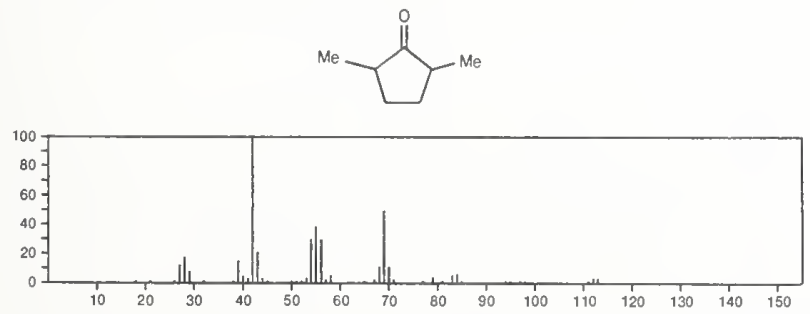

112

$4058-52-0$

$\mathrm{H}_{2} \mathrm{C}=\mathrm{C}=\mathrm{CHCMe}_{2} \mathrm{CH}_{2} \mathrm{OH}$

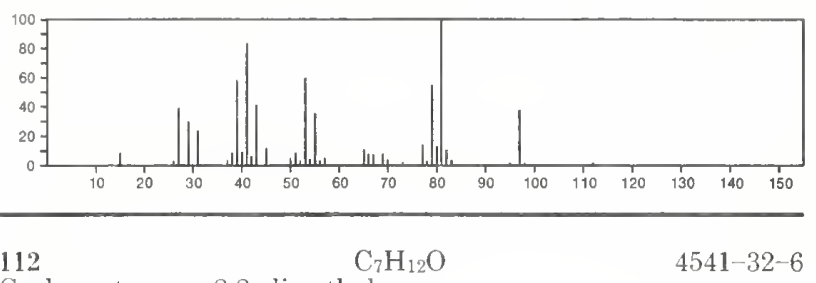

Cyclopentanone, 2,2-dimethyl-
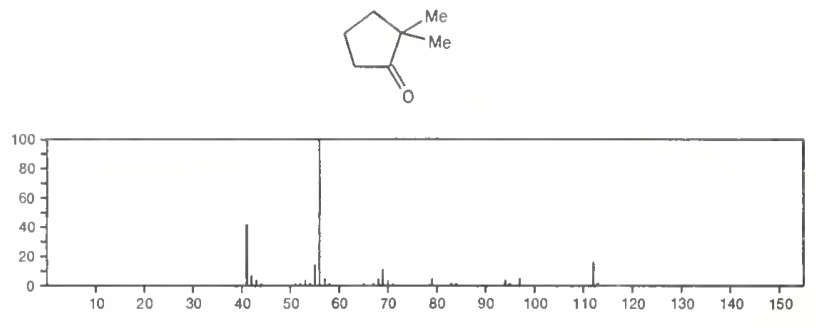

112 - $\mathrm{C}_{7} \mathrm{H}_{12} \mathrm{O}$

5166-53-0

$\mathrm{Me}_{2} \mathrm{CHCH}=\mathrm{CHCOMe}_{\mathrm{C}}$

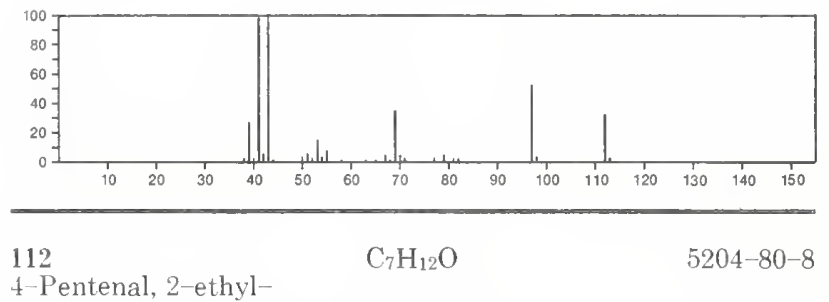

$\mathrm{H}_{2} \mathrm{C}=\mathrm{CHCH}_{2} \mathrm{CHE}+\mathrm{CHO}$

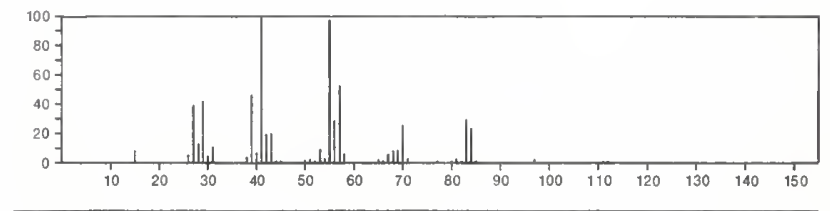

112

$\mathrm{C}_{7} \mathrm{H}_{12} \mathrm{O}$

$5410-22-0$

7-Oxabicyclo[4.1.0]heptane, 2-methyl-
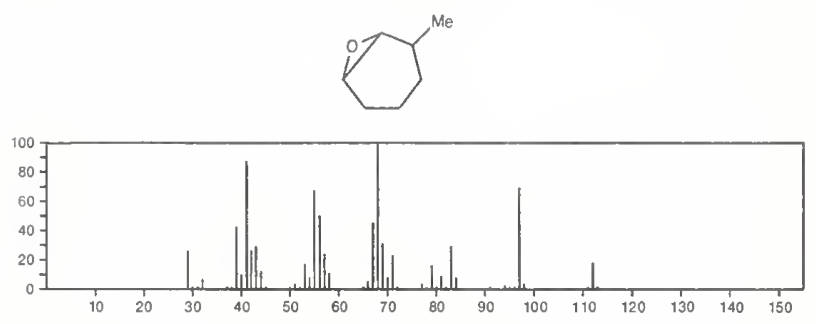

112

4-Pentenal, 2,2-dimethyl-

$\mathrm{C}_{7} \mathrm{H}_{12} \mathrm{O}$

5497-67-6

$\mathrm{H}_{2} \mathrm{C}=\mathrm{CHCH}_{2} \mathrm{CMe}_{2} \mathrm{CHO}$

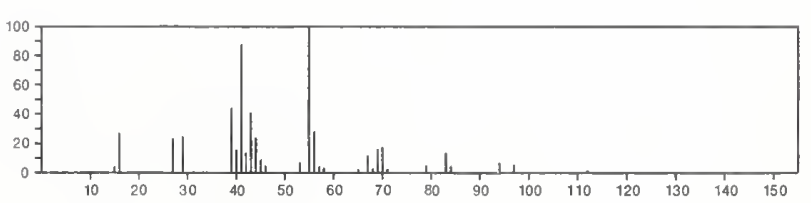


112

$\mathrm{C}_{7} \mathrm{H}_{12} \mathrm{O}$

Ethanone, 1-cyclopentyl
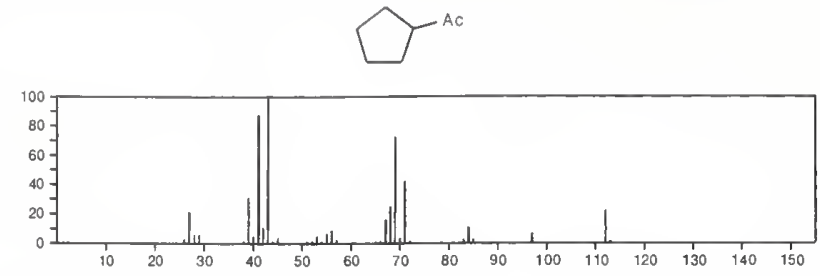

112

1-Pentyn-3-ol, 3-ethyl-

$\mathrm{C}_{7} \mathrm{H}_{12} \mathrm{O}$

$6285-06-9$

$\mathrm{E}+{ }_{2} \mathrm{COHC} \equiv \mathrm{CH}$
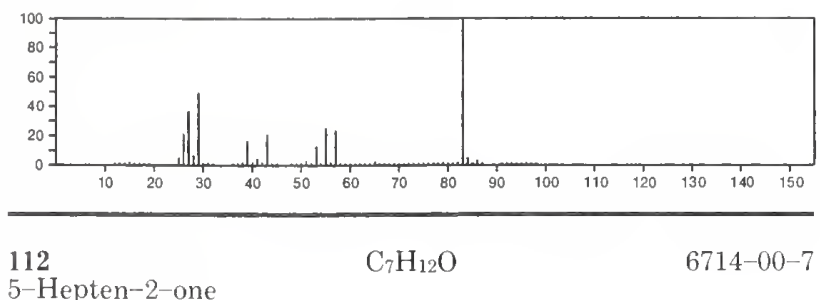

5-Hepten-2-one

$\mathrm{Me} \mathrm{COCH}_{2} \mathrm{CH}_{2} \mathrm{CH}=\mathrm{CHMe}$

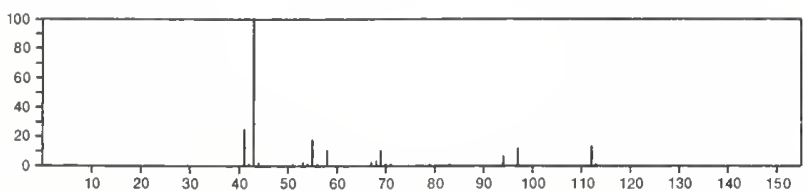

112

1-Heptyn-3-ol

$\mathrm{C}_{7} \mathrm{H}_{12} \mathrm{O}$

7383-19-9

$\mathrm{Me}\left(\mathrm{CH}_{2}\right)_{3} \mathrm{CH}(\mathrm{OH}) \mathrm{C} \equiv \mathrm{CH}$

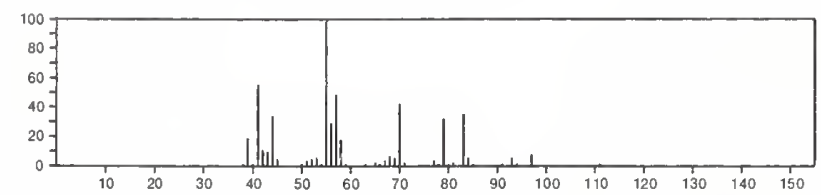

112

$\mathrm{C}_{7} \mathrm{H}_{12} \mathrm{O}$

Bicyclo[4.1.0]heptan-2-ol, $(1 \alpha, 2 \beta, 6 \alpha)-$

$7432-49-7$
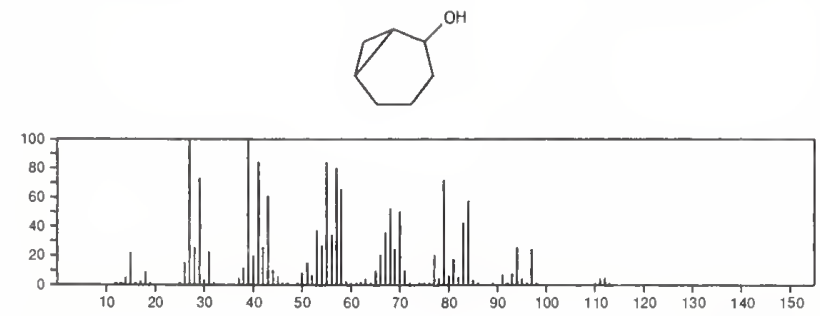

112

1-Butyne, 3-ethoxy-3-methyl-

$\mathrm{C}_{7} \mathrm{H}_{12} \mathrm{O}$

$7740-69-4$

$\mathrm{Me} 2 \mathrm{COE}: \mathrm{C}: \mathrm{CH}$

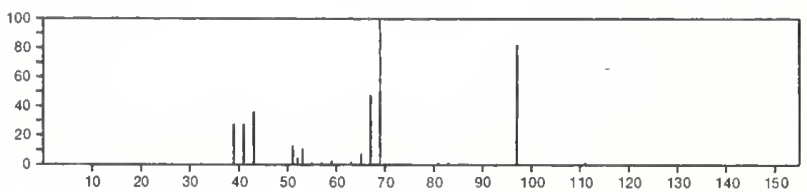

${ }_{\text {Cyclohexanone, 3-methyl--, }}^{112}(R)_{-}$

$13368-65-5$
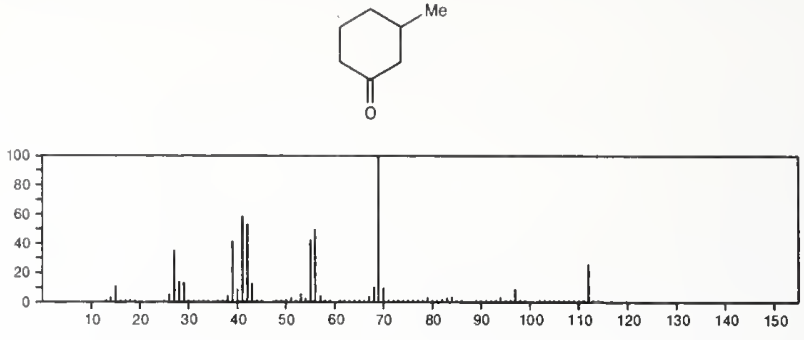

112

4-Hexen-3-one, 5-methy]-

$\mathrm{C}_{7} \mathrm{H}_{12} \mathrm{O}$

13905-10-7

$\mathrm{Me}_{2} \mathrm{C}=\mathrm{CHCOE} 1$

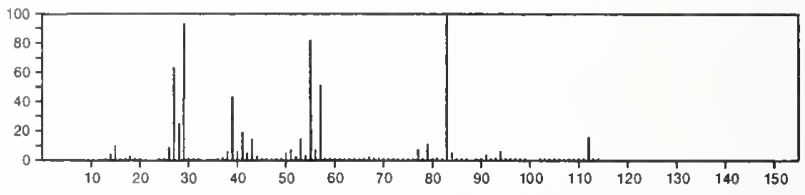

$112 \quad \mathrm{C}_{7} \mathrm{H}_{12} \mathrm{O}$

1-Pentyne, 3-methoxy-3-methyl-

22802-35-3

$\mathrm{EtCMe}(\mathrm{OMe}) \mathrm{C} \equiv \mathrm{CH}$

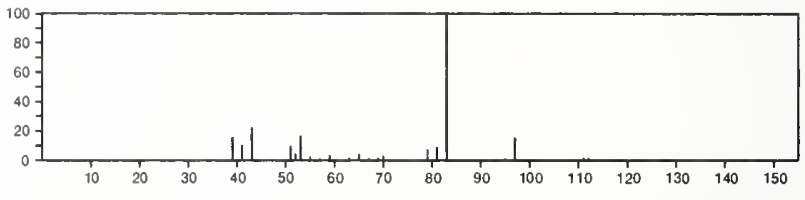

112

$\mathrm{C}_{7} \mathrm{H}_{12} \mathrm{O}$

Furan, 2,5-dihydro-2,2,4-trimethyl-

$23230-79-7$
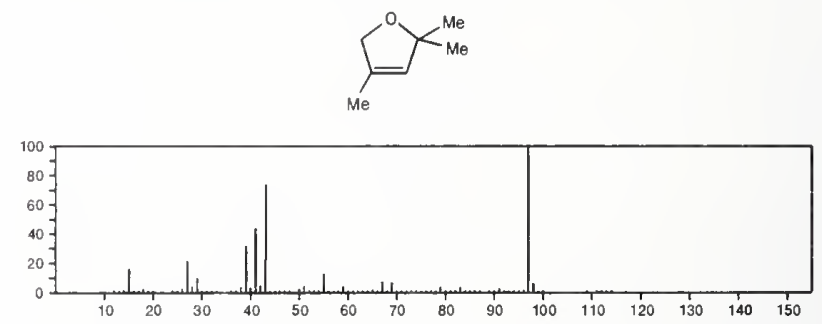

112

$\mathrm{C}_{7} \mathrm{H}_{12} \mathrm{O}$

$23758-27-2$

2-Cyclohexen-1-ol, 1-methyl-
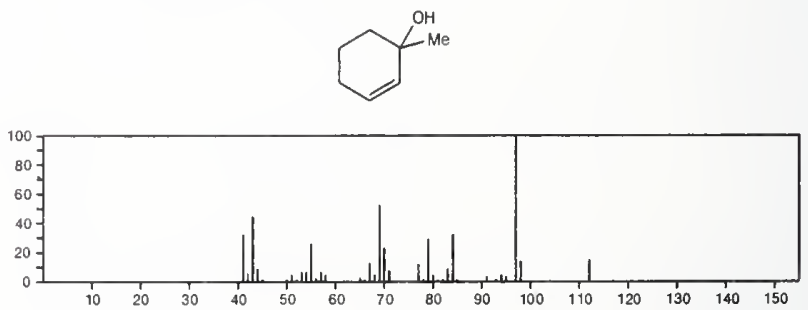
112

$\mathrm{C}_{7} \mathrm{H}_{12} \mathrm{O}$

Cyclobutanone, 2,3,3-trimethyl
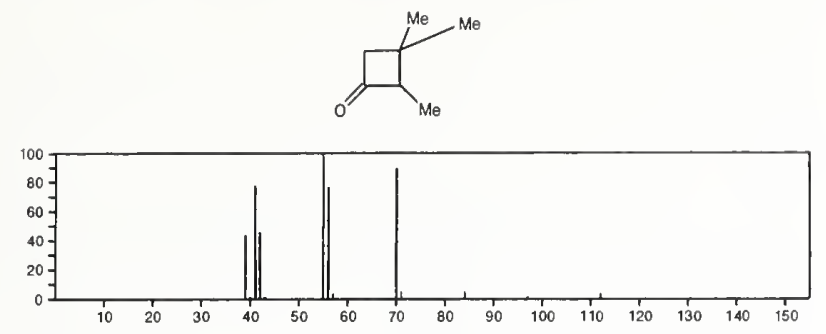

112

3-Cyclohexen-1-ol, 1-methyl-

$\mathrm{C}_{7} \mathrm{H}_{12} \mathrm{O}$

$33061-16-4$
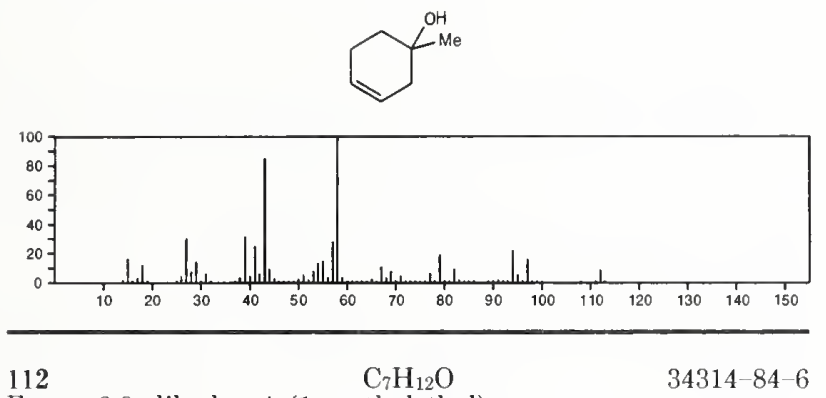

Furan, 2,3-dihydro-4-(1-methylethyl)-
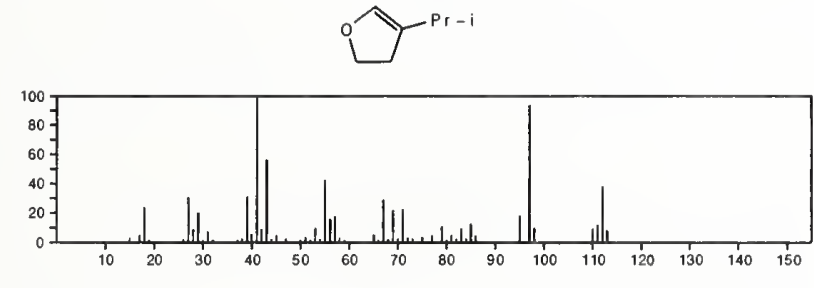

$112 \quad \mathrm{C}_{7} \mathrm{H}_{12} \mathrm{O}$

7-Oxabicyclo[4.1.0]heptane, 3-methyl-
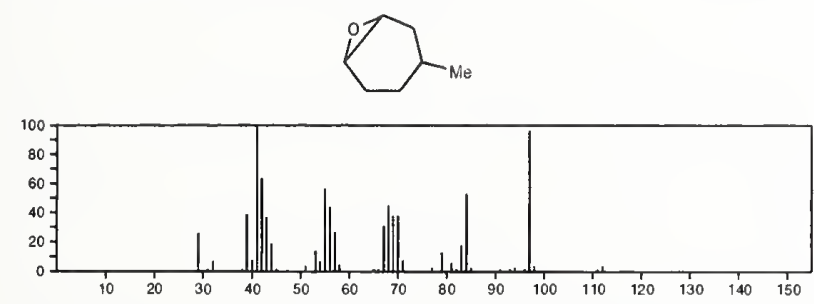

\section{$112 \quad \mathrm{C}_{7} \mathrm{H}_{12} \mathrm{O}$}

Bicyclo[3.1.0]hexan-2-ol, 5-methyl-, $(1 \alpha, 2 \beta, 5 \alpha)-$

41299-39-2<smiles>[14CH3]C12CCC(O)C(CC1)C2</smiles>

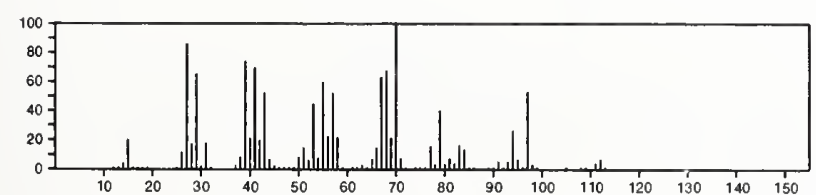

112

1,2-Pentadiene, 4-methoxy-4-methyl-

$49833-91-2$

$\mathrm{H}_{2} \mathrm{C}=\mathrm{C}=\mathrm{CHCMe}_{2} \mathrm{OMe}$

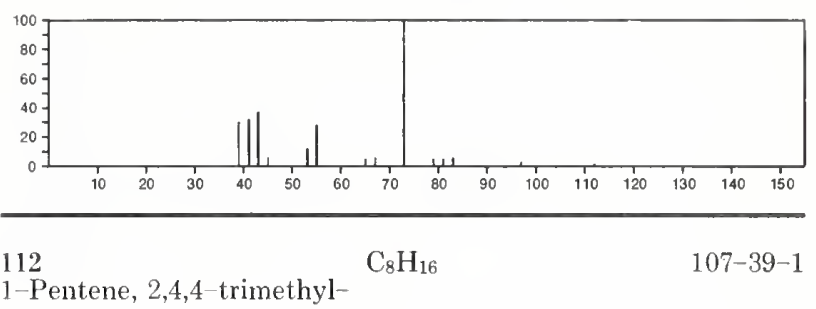

$\mathrm{H}_{2} \mathrm{C}=\mathrm{CMe} \mathrm{CH}_{2} \mathrm{CMe}_{3}$

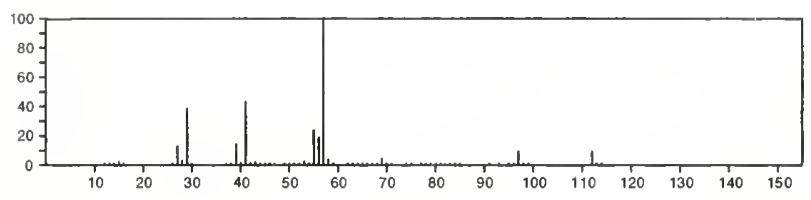

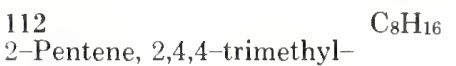

$107-40-4$

$\mathrm{Me} 3 \mathrm{CCH}=\mathrm{CMe}_{2}$

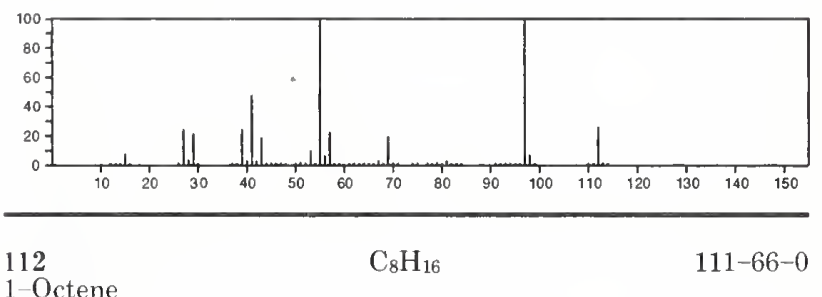

$\mathrm{H}_{2} \mathrm{C}=\mathrm{CH}\left(\mathrm{CH}_{2}\right){ }_{5} \mathrm{Me}$
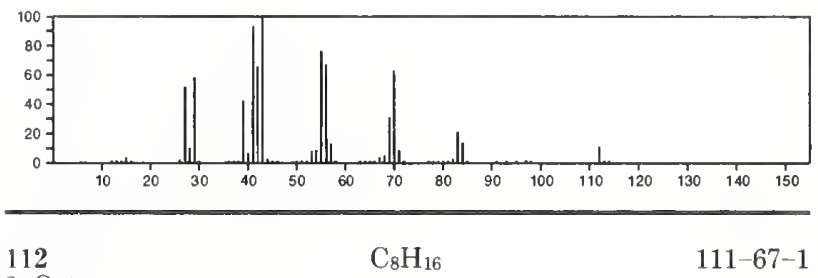

2-Octene

$\mathrm{Me}\left(\mathrm{CH}_{2}\right){ }_{4} \mathrm{CH}=\mathrm{CHMe}$

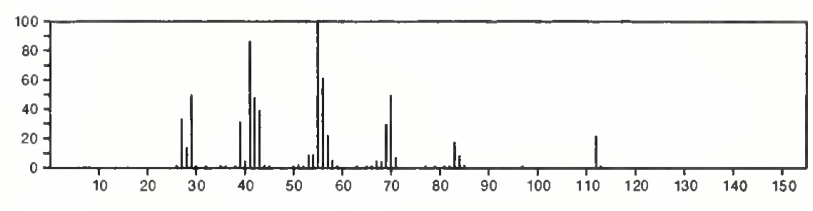

112

$\mathrm{C}_{8} \mathrm{H}_{16}$

292-64-8

Cyclooctane
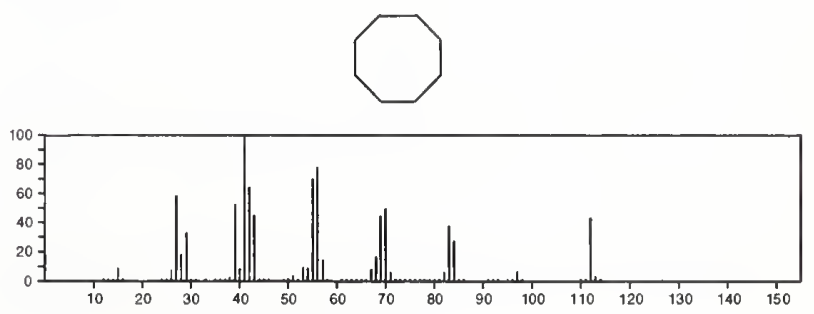
112

2-Pentene, 2,3,4-trimethyl-

$\mathrm{C}_{8} \mathrm{H}_{16}$

$\mathrm{Me}_{2} \mathrm{CHCMe}_{2}=\mathrm{CMe}_{2}$

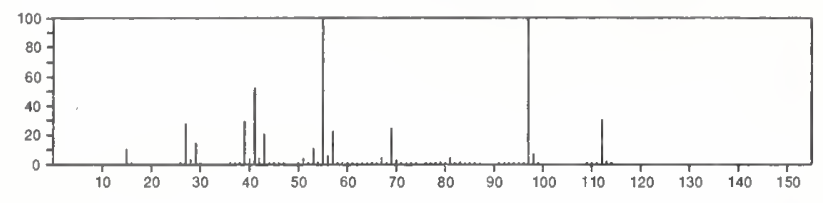

112

Cyclohexane, 1,1-dimethyl-

$\mathrm{C}_{8} \mathrm{H}_{16}$

$590-66-9$
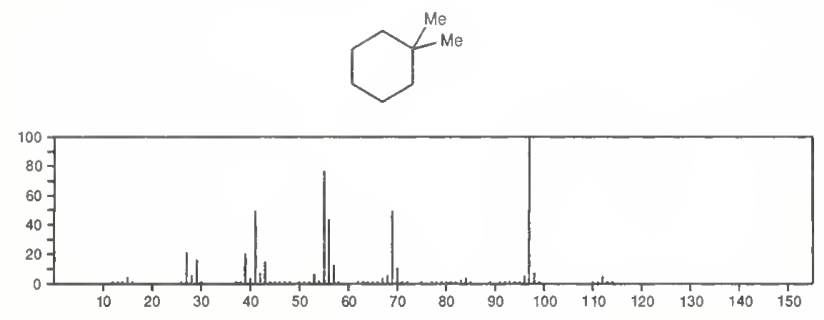

112

2-Pentene, 3,4,4-trimethyl-

$\mathrm{C}_{8} \mathrm{H}_{16}$

598-96-9

$\mathrm{MeCH}=\mathrm{CMe} \mathrm{CMe}_{3}$

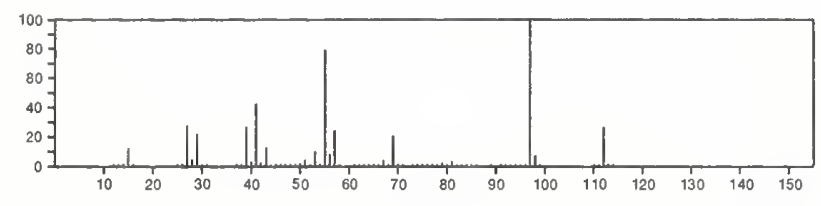

112

Cyclohexane, 1,4-dimethyl-, cis-

$624-29-3$
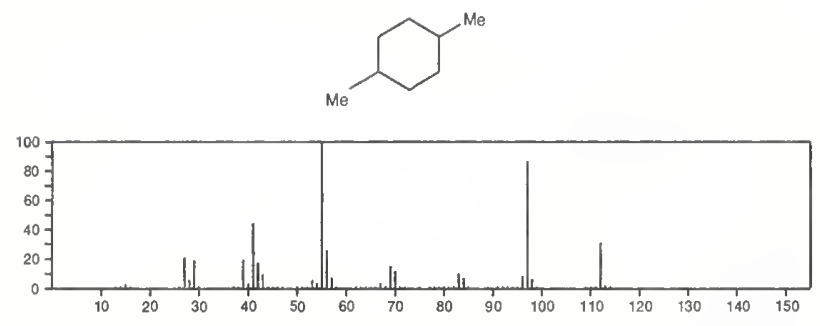

112

Cyclohexane, 1,3-dimethyl-, cis-

$638-04-0$
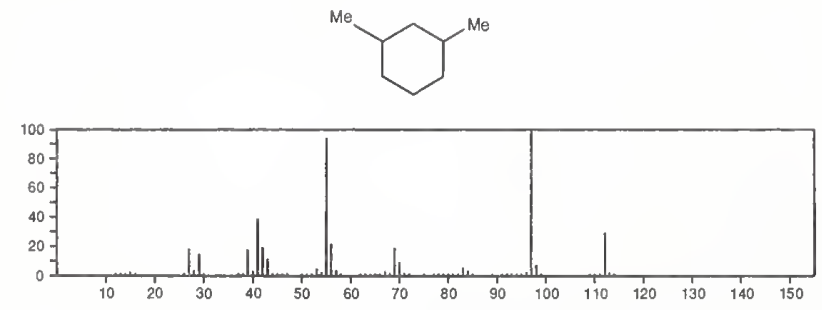

112

3-Hexene, 2,2-dimethyl-, (Z)-

$690-92-6$

$\mathrm{E}+\mathrm{CH}: \mathrm{CHCMe}_{3}$

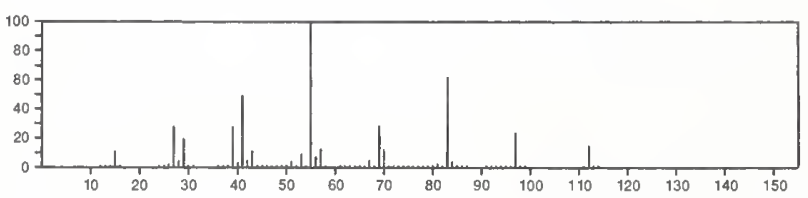

112

3-Hexene, 2,2-dimethyl-, $(E)-\mathrm{C}_{8} \mathrm{H}_{16}$

$690-93-7$

$\mathrm{E}, \mathrm{CH}=\mathrm{CHCM}_{\mathrm{O}} 3$

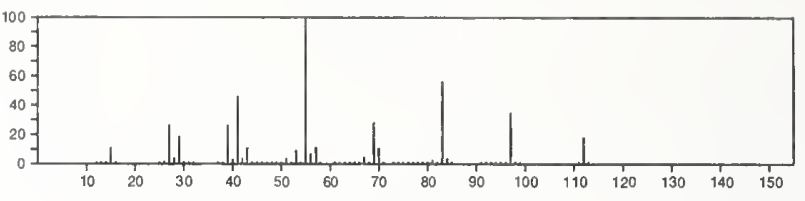

112

3-Hexene, 2,5-dimethyl- $(E)-\mathrm{C}_{8} \mathrm{H}_{16}$

$692-70-6$

$\mathrm{Me} 2 \mathrm{CHCH}=\mathrm{CHCHM}_{2}$

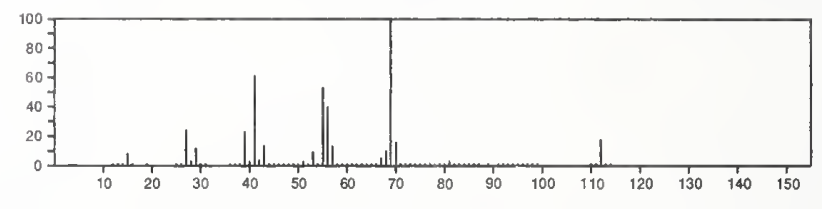

112
3-Heptene, 2-methyl-, $(E)-$

$692-96-6$

$$
\mathrm{PrCH}=\mathrm{CHCHMe} 2
$$

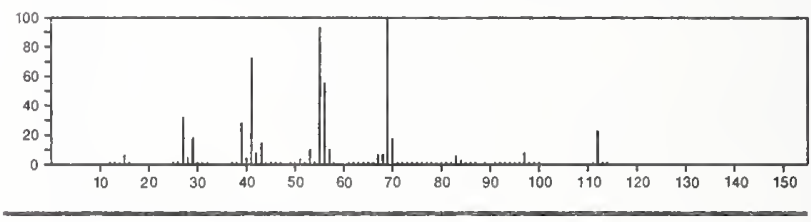

112

$\mathrm{C}_{8} \mathrm{H}_{16}$

$930-89-2$

Cyclopentane, 1-ethyl-2-methyl-, cis-
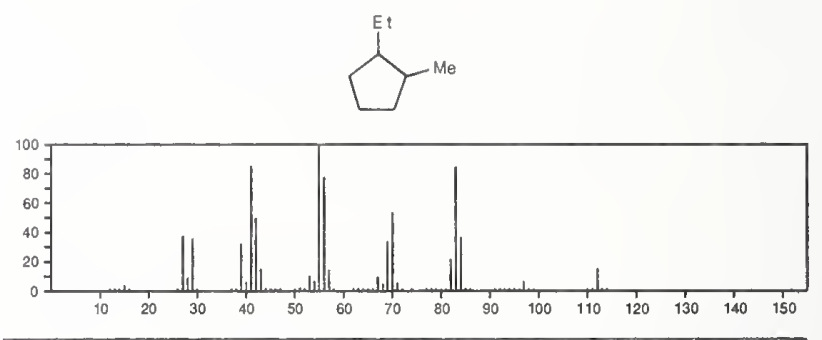

112

$\mathrm{C}_{8} \mathrm{H}_{16}$

$1632-16-2$

Heptane, 3-methylene-

$\operatorname{Me}\left(\mathrm{CH}_{2}\right)_{3} \mathrm{CEt}=\mathrm{CH}_{2}$

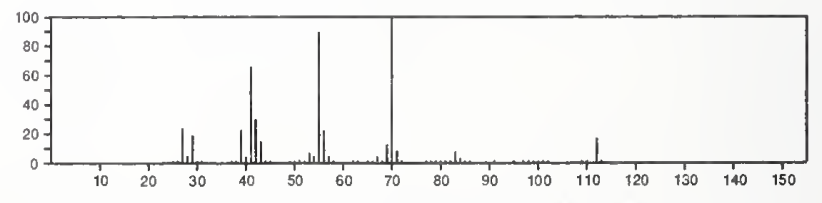

112

$\mathrm{C}_{8} \mathrm{H}_{16}$

$1678-91-7$

Cyclohexane, ethyl
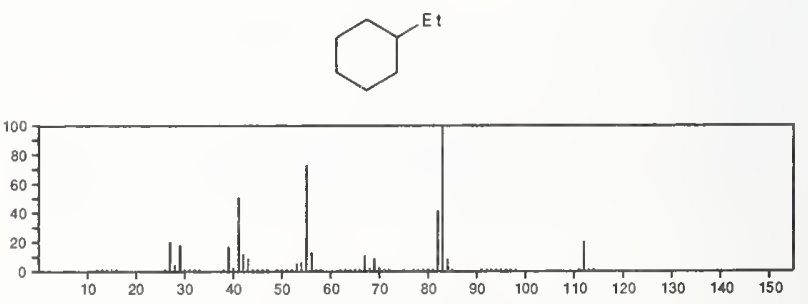
112

Cyclopentane, propyl-

$\mathrm{C}_{8} \mathrm{H}_{16}$
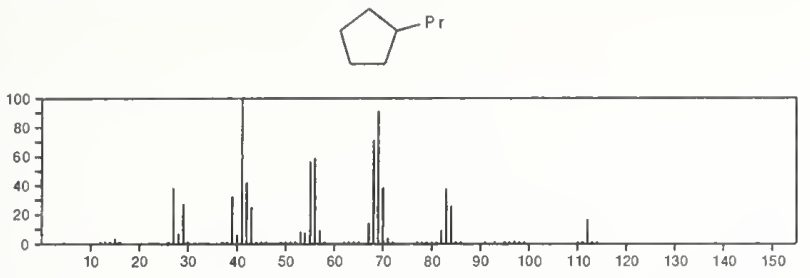

112

Cyclohexane, 1,2-dimethyl-, cis-
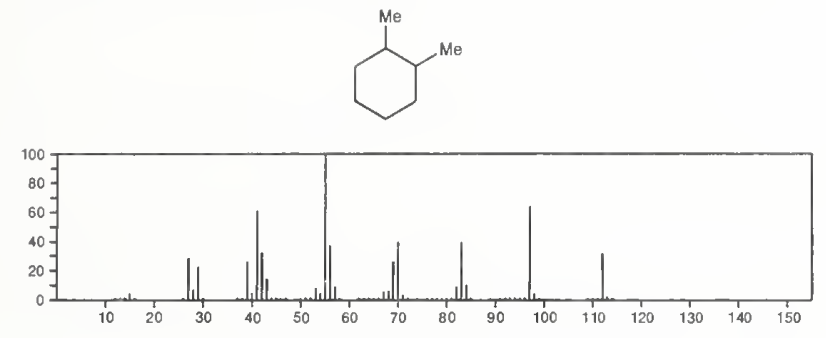

112

$\mathrm{C}_{8} \mathrm{H}_{16}$

Cyclohexane, 1,3-dimethyl-, trans-
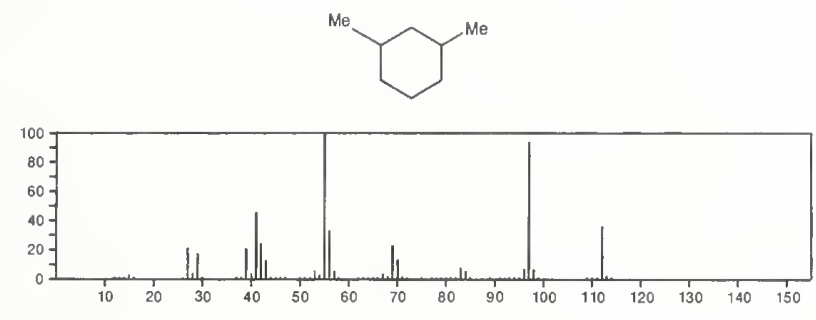

112

$\mathrm{C}_{8} \mathrm{H}_{16}$

$2207-04-7$

Cyclohexane, 1,4-dimethyl-, trans-
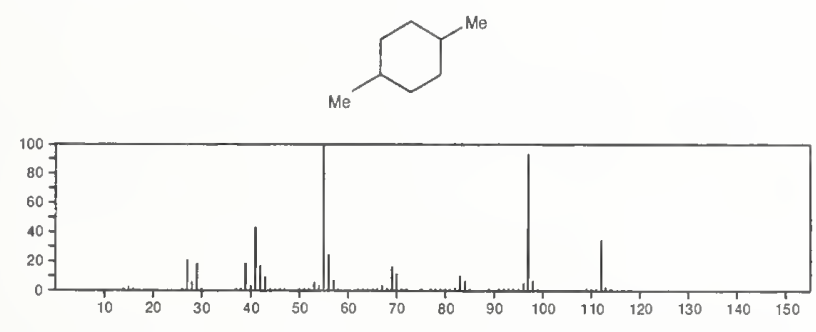

112

$\mathrm{C}_{8} \mathrm{H}_{16}$

Cyclopropane, pentyl-
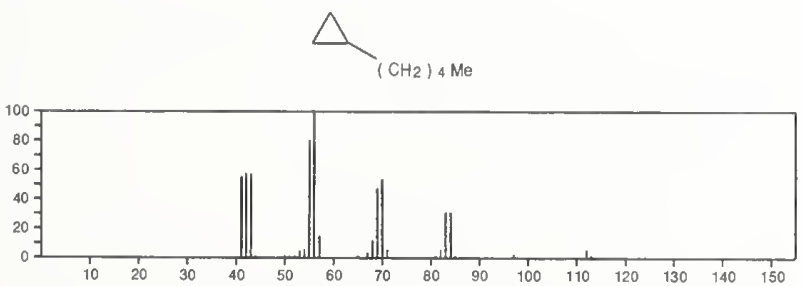

$112 \quad \mathrm{C}_{8} \mathrm{H}_{16}$

Cyclopentane, 1-ethyl-3-methyl-, trans-

$2613-65-2$
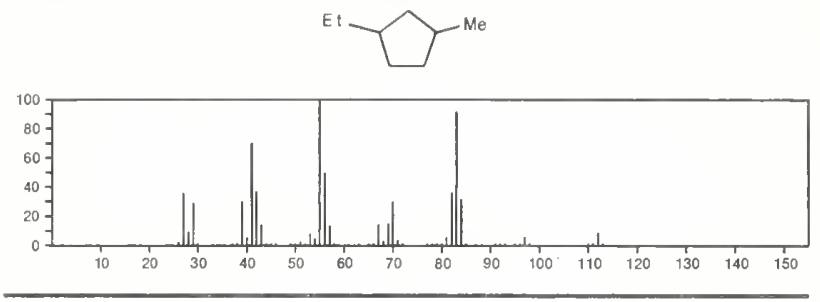

$112 \quad \mathrm{C}_{8} \mathrm{H}_{16}$

Cyclopentane, 1-ethyl-3-methyl-, cis-

2613-66-3
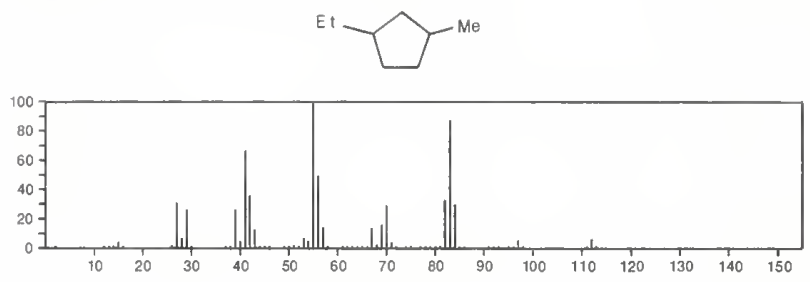

112

$\mathrm{C}_{8} \mathrm{H}_{16}$

Cyclopentame, 1,2,3-trimethyl-, $(1 \alpha, 2 \alpha, 3 \alpha)$ -

2613-69-6
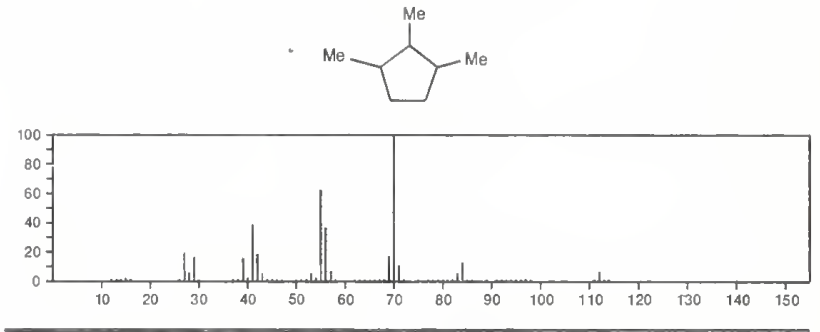

112

1-Hexene, 3,3-dimethyl-

$\mathrm{C}_{8} \mathrm{H}_{16}$

$3404-77-1$

$\mathrm{PrCMe} 2 \mathrm{CH}=\mathrm{CH}_{2}$

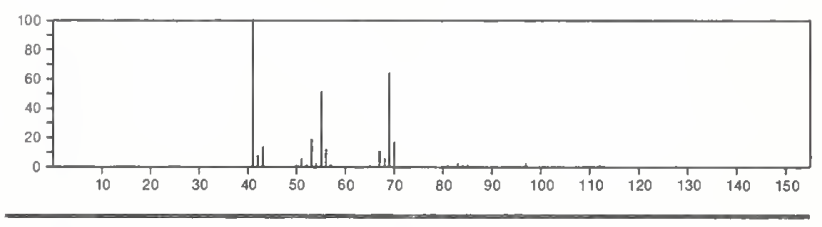

112

2-Hexene, 2,5-dimethyl-

$\mathrm{C}_{8} \mathrm{H}_{16}$

$3404-78-2$

$\mathrm{Me}_{2} \mathrm{C}=\mathrm{CHCH}_{2} \mathrm{CHMe}_{2}$

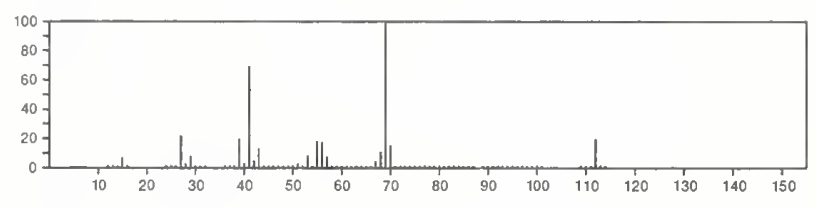

112

$\mathrm{C}_{8} \mathrm{H}_{16}$

$3875-51-2$

Cyclopentane, (1-methylethyl)-
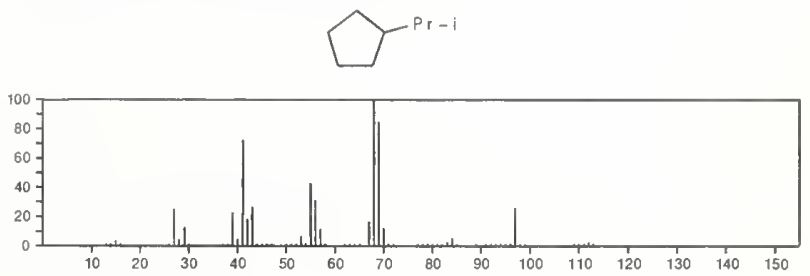
112

Cycloheptane, methyl

$\mathrm{C}_{8} \mathrm{H}_{16}$
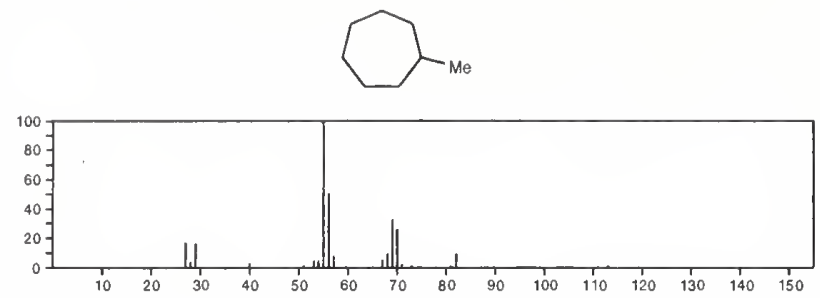

$112 \quad \mathrm{C}_{8} \mathrm{H}_{16}$

Cyclopentane, 1,1,2-trimethyl-
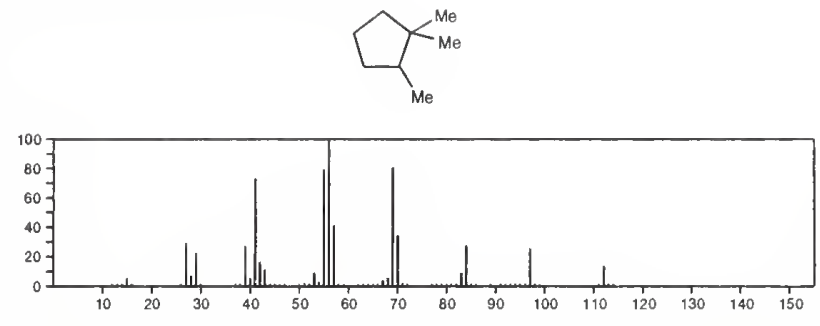

112

Cyclopentane, 1,1,3-trimethyl-

$\mathrm{C}_{8} \mathrm{H}_{16}$

4516-69-2
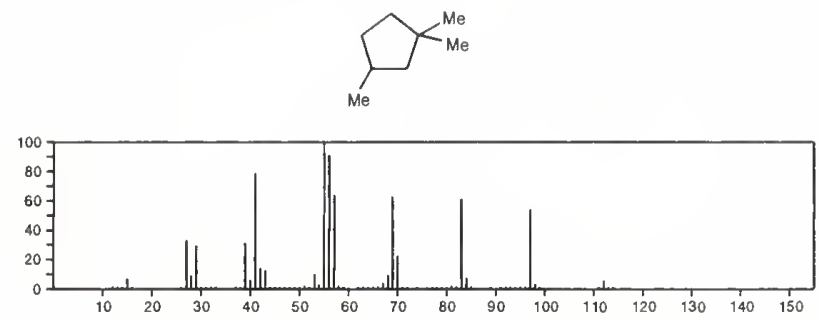

112

$\mathrm{C}_{8} \mathrm{H}_{16}$

Cyclopentane, 1,2,4-trimethyl--, $(1 \alpha, 2 \alpha, 4 \beta)$
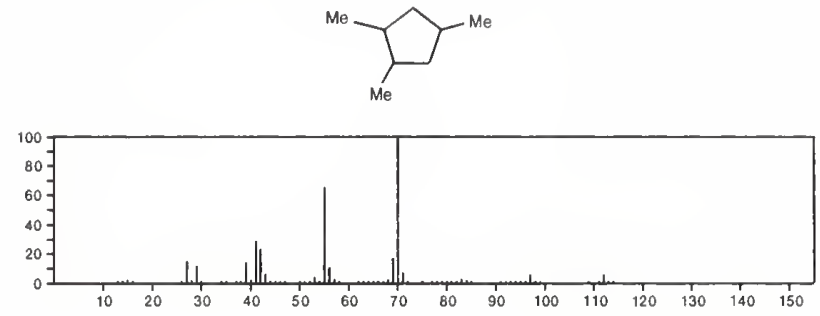

112

1-Heptene, 6-methyl-

$\mathrm{C}_{8} \mathrm{H}_{16}$

5026-76-6

$\mathrm{H}_{2} \mathrm{C}=\mathrm{CH}\left(\mathrm{CH}_{2}\right)_{3} \mathrm{CHMe}_{2}$

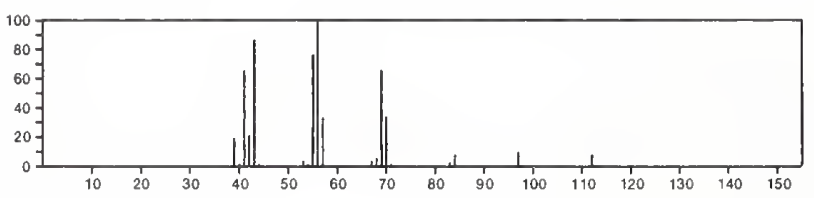

112

Cyclohexane, 1,2-dimethyl-- $\mathrm{C}_{8} \mathrm{H}_{16}$

6876-23-9
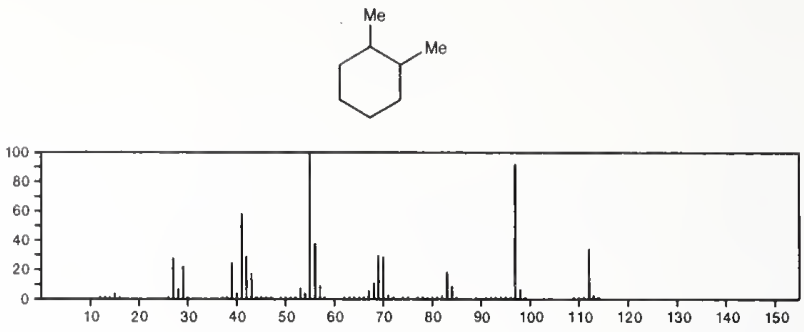

112

1-Hexene, 2,5-dimethyl

$\mathrm{C}_{8} \mathrm{H}_{16}$

6975-92-4

$\mathrm{Me}_{2} \mathrm{CHCH}_{2} \mathrm{CH}_{2} \mathrm{CMe}: \mathrm{CH}_{2}$

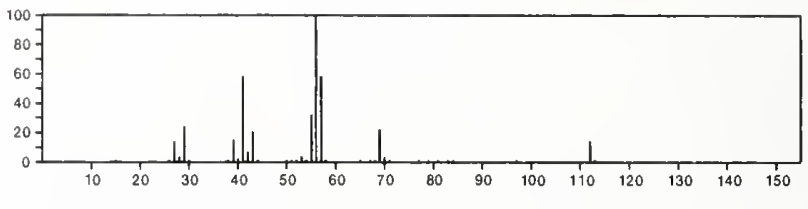

112

2-Hexene, 2,3-dimethyl-

$\mathrm{C}_{8} \mathrm{H}_{16}$

$7145-20-2$

$\mathrm{Me}_{2} \mathrm{C}=\mathrm{CP} \mathrm{rme}$

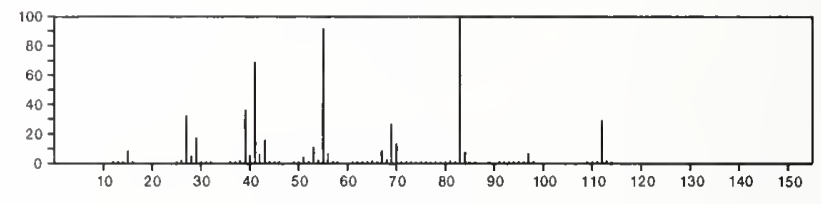

112

$\mathrm{C}_{8} \mathrm{H}_{16}$

$14850-23-8$

4 - Octene, $(E)$

$\mathrm{PrCH}=\mathrm{CHPr}$

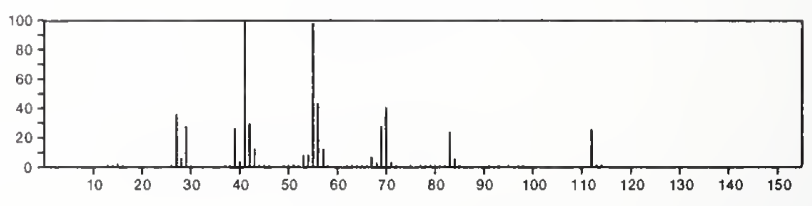

112

1-Heptene, 2-methyl-

$\mathrm{C}_{8} \mathrm{H}_{16}$

15870-10-7

$\mathrm{Me}\left(\mathrm{CH}_{2}\right)+\mathrm{CM}_{\theta}=\mathrm{CH}_{2}$

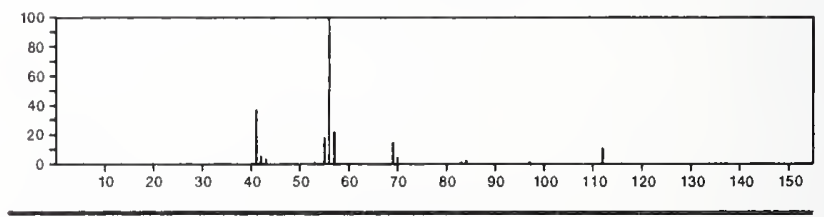

112

$\mathrm{C}_{8} \mathrm{H}_{15}$

Cyclopentane, 1,2,3-trimethyl-, $(1 \alpha, 2 \alpha, 3 \beta)$ -

15890-40-1
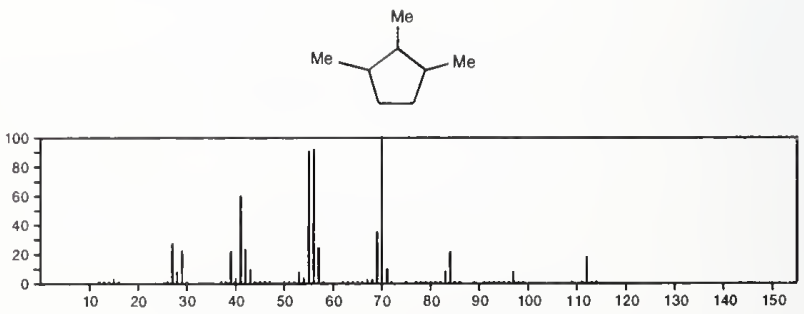
112

Heptane, 4-methylene-

$\mathrm{C}_{8} \mathrm{H}_{16}$

$\mathrm{Pr}_{2} \mathrm{C}=\mathrm{CH}_{2}$

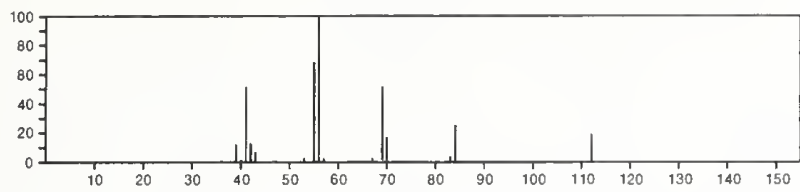

112

1-Hexene, 4,5-dimethyl-

$\mathrm{C}_{8} \mathrm{H}_{16}$

$16106-59-5$

$\mathrm{Me}_{2} \mathrm{CHCHMe} \mathrm{CH}_{2} \mathrm{CH}=\mathrm{CH}_{2}$

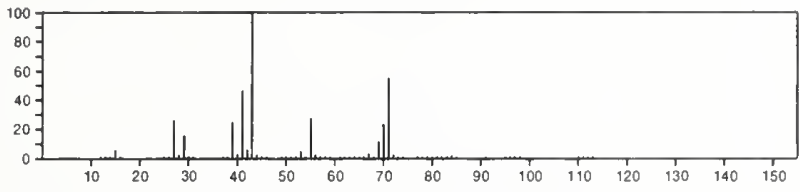

112

1-Hexene, 3,4-dimethyl-

$\mathrm{C}_{8} \mathrm{H}_{16}$

$16745-94-1$

$\mathrm{H}_{2} \mathrm{C}=\mathrm{CHCHMe} \mathrm{CHMe}_{2} \mathrm{CH}_{2} \mathrm{Me}$

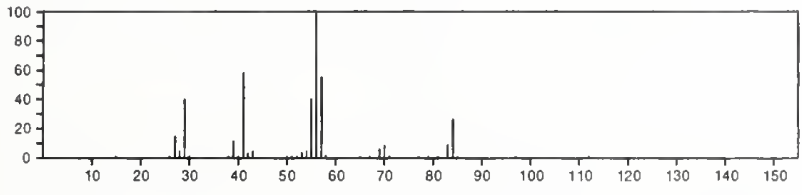

112

Cyclopentane, 1-ethyl-1-methyl-

$16747-50-5$
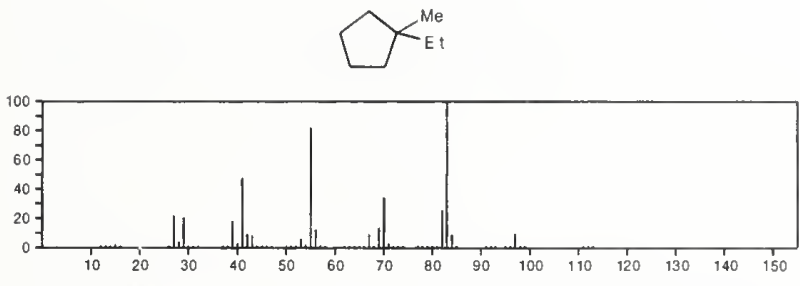

112

$\mathrm{C}_{8} \mathrm{H}_{16}$

$16883-48-0$

Cyclopentane, 1,2,4-trimethyl-, (1 $\alpha, 2 \beta, 4 \alpha)$ -
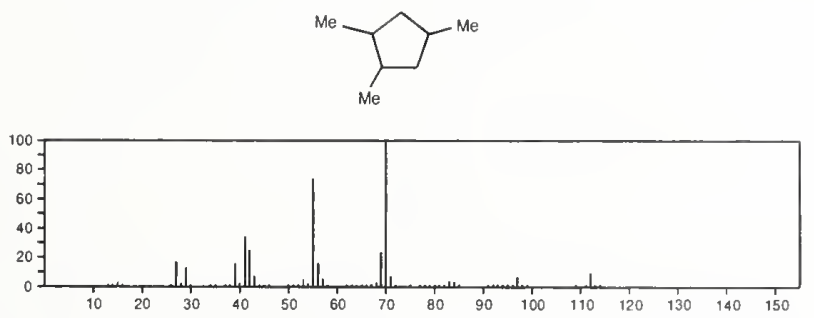

112

1-Pentene, 3-ethyl-2-methyl-

19780-66-6

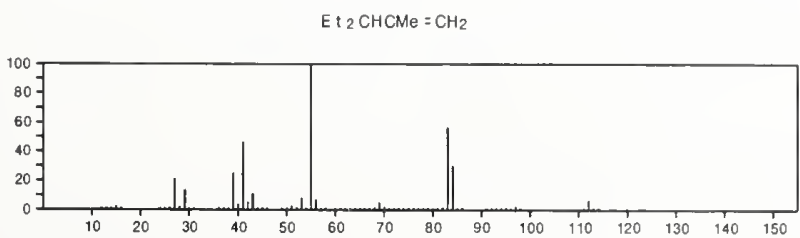

113

$\mathrm{C}_{2} \mathrm{H}_{6} \mathrm{~F}_{2} \mathrm{NP}$

Phosphoramidous difluoride, dimethyl

814-97-1

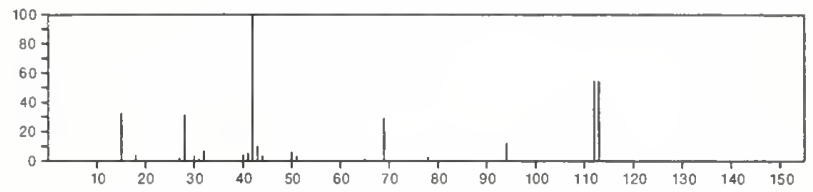

113

1 H Imidazole, 2-nitro-

$\mathrm{C}_{3} \mathrm{H}_{3} \mathrm{~N}_{3} \mathrm{O}_{2}$

$527-73-1$
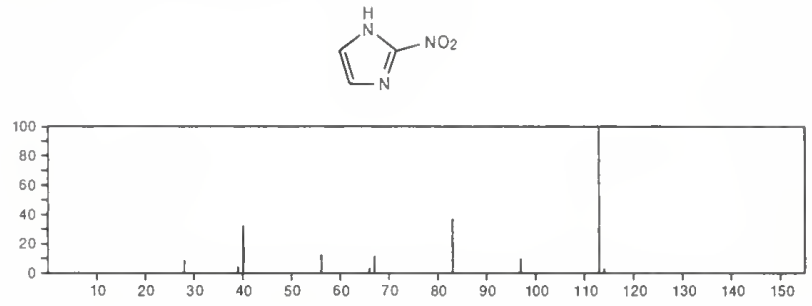

113

$1 H$-Pyrazole, 4-nitro-

$\mathrm{C}_{3} \mathrm{H}_{3} \mathrm{~N}_{3} \mathrm{O}_{2}$

2075-46-9
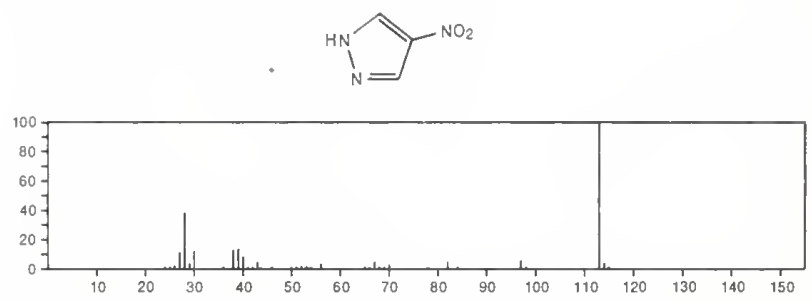

113

$\mathrm{C}_{4} \mathrm{H}_{7} \mathrm{~N}_{3} \mathrm{O}$

$60-27-5$

4H-Imidazol-4-one, 2-amino-1,5-dihydro-1-methyl-
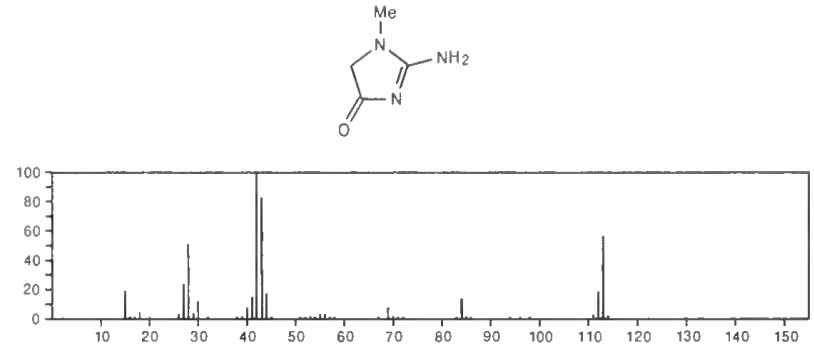

113

Pyridine, 3-chloro-

$\mathrm{C}_{5} \mathrm{H}_{4} \mathrm{ClN}$

$626-60-8$
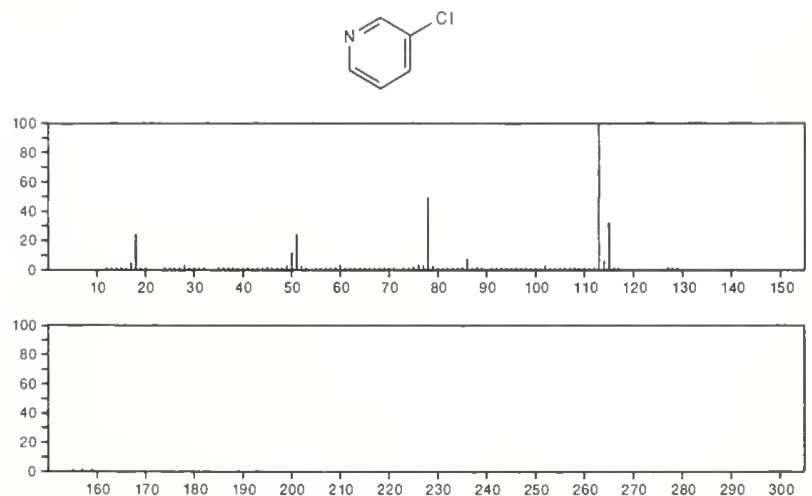
113

$\mathrm{C}_{5} \mathrm{H}_{7} \mathrm{NO}_{2}$

$3(2 H)$-Isoxazolone, 4,5-dimethyl
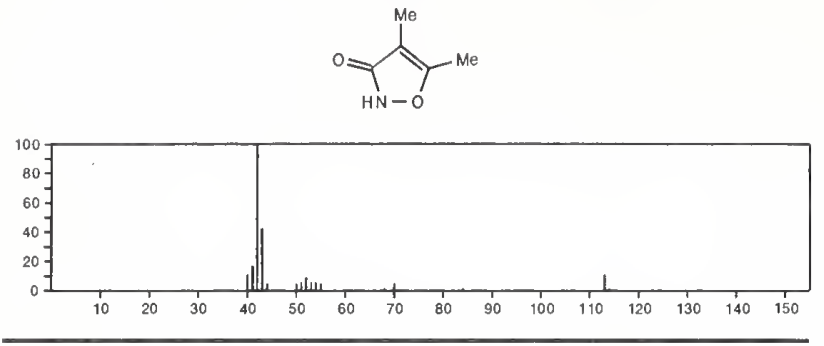

$113 \quad \mathrm{C}_{5} \mathrm{H}_{7} \mathrm{NO}_{2}$

2,5-Pyrrolidinedione, 1-methyl-

$1121-07-9$
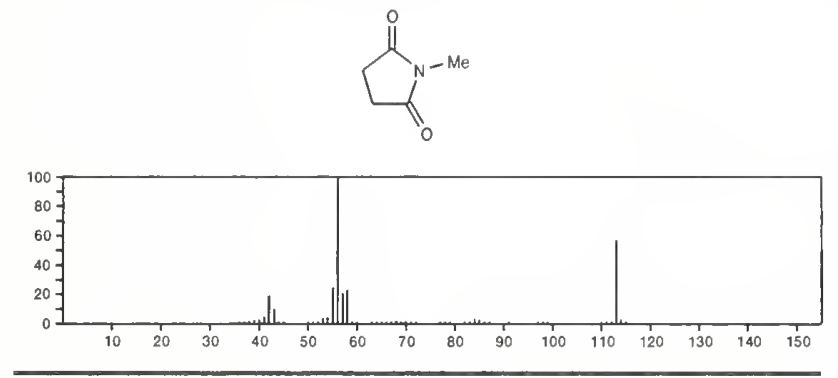

113

$\mathrm{C}_{5} \mathrm{H}_{7} \mathrm{NO}_{2}$

Propanoic acid, 3-cyano-, methyl ester

$4107-62-4$

$\mathrm{NCCH}_{2} \mathrm{CH}_{2} \mathrm{C}(\mathrm{O}) \mathrm{OMe}$

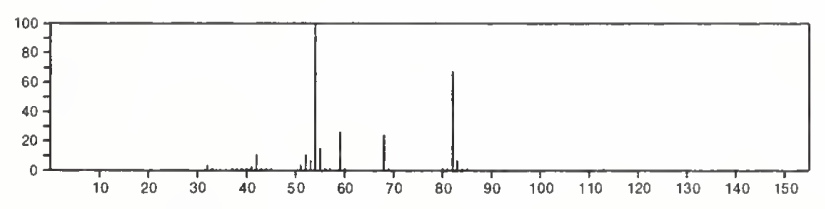

$113 \quad \mathrm{C}_{5} \mathrm{H}_{7} \mathrm{NO}_{2}$

$4271-26-5$

2-Oxazolidinone, 3-ethenyl
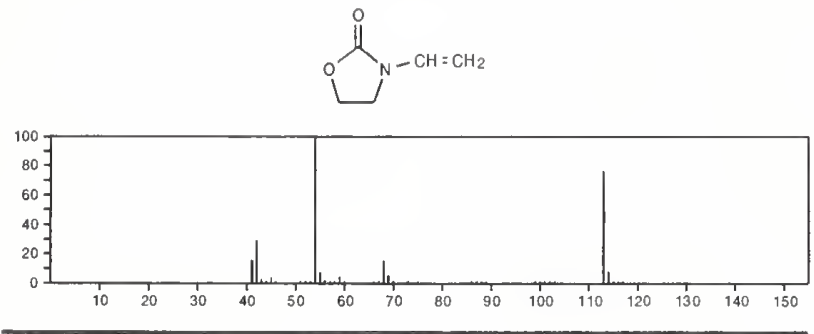

113

$\mathrm{C}_{5} \mathrm{H}_{7} \mathrm{NS}$

$3581-91-7$

Thiazole, 4,5-dimethyl-
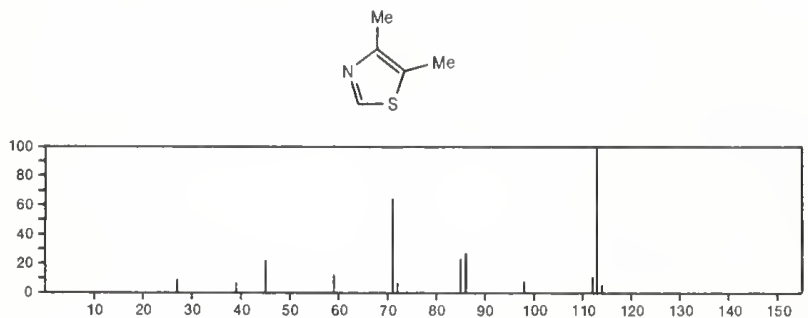

113

Thiazole, 2,5-dimethyl

$\mathrm{C}_{5} \mathrm{H}_{7} \mathrm{NS}$

4175-66-0
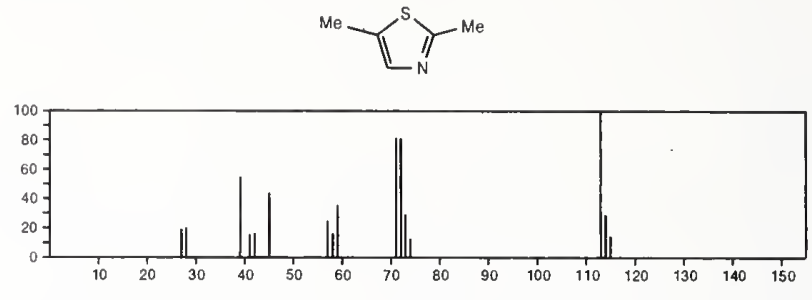

113

$\mathrm{C}_{5} \mathrm{H}_{7} \mathrm{NS}$

$15679-09-1$

Thiazole, 2-ethyl
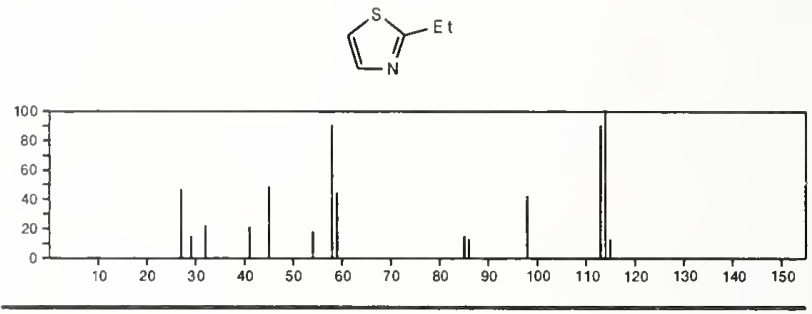

113

$\mathrm{C}_{5} \mathrm{H}_{7} \mathrm{NS}$

17626-73-2

Thiazole, 5-ethyl
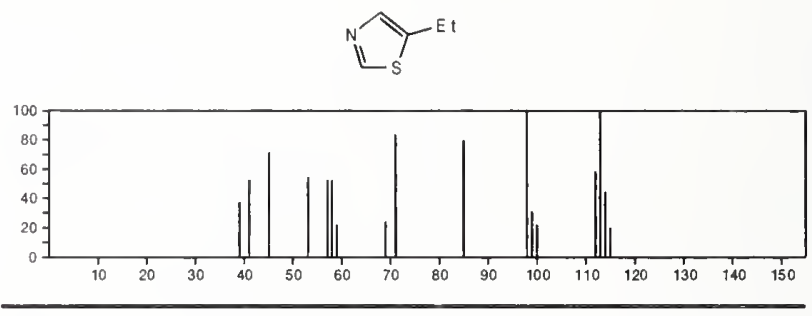

113

$\mathrm{C}_{5} \mathrm{H}_{7} \mathrm{NS}$

24260-24-0

Isothiazole, 3,5-dimethyl-
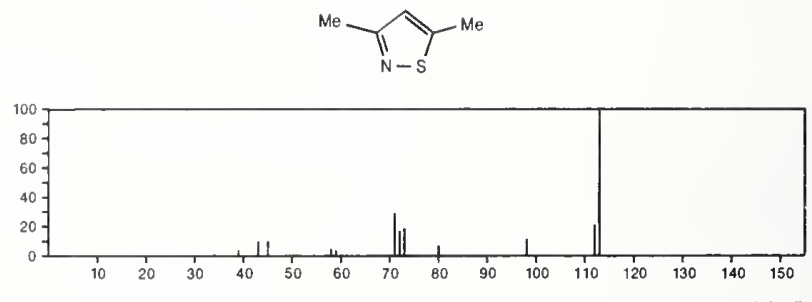

113

$\mathrm{C}_{5} \mathrm{H}_{7} \mathrm{NS}$

$27330-46-7$

lsothiazole, 3,4-dimethyl-
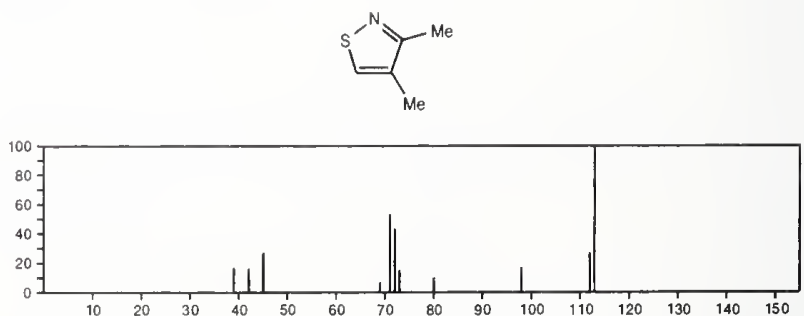
113

Isothiazole, 4,5-dimethyl-

$\mathrm{C}_{5} \mathrm{H}_{7} \mathrm{NS}$

$27330-47-8$
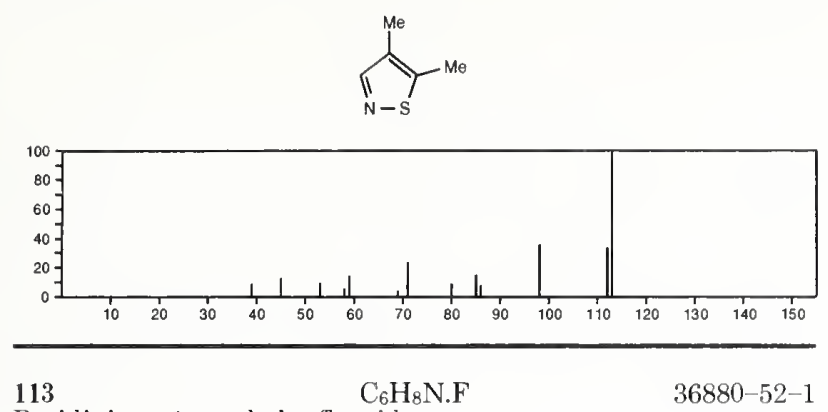

Pyridinium, 1-methyl-, fluoride

$36880-52-1$
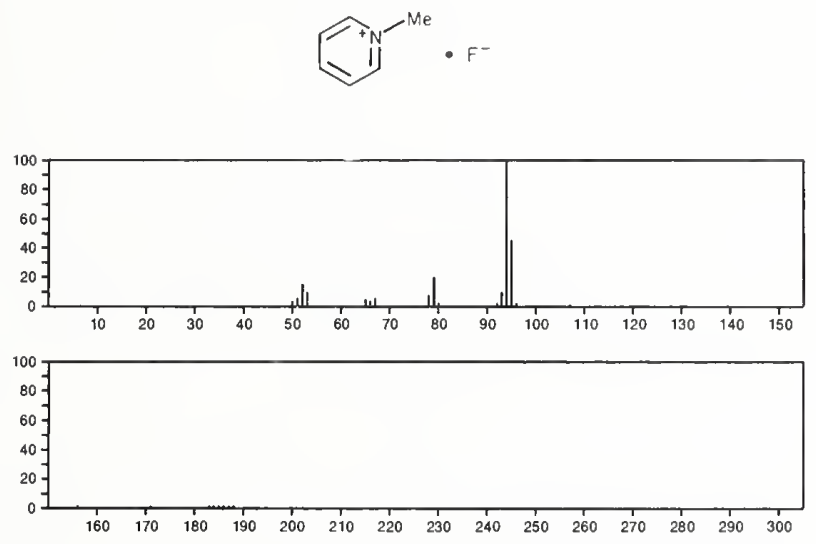

113

Cyclohexanone, oxime

$\mathrm{C}_{6} \mathrm{H}_{11} \mathrm{NO}$

100-64-1
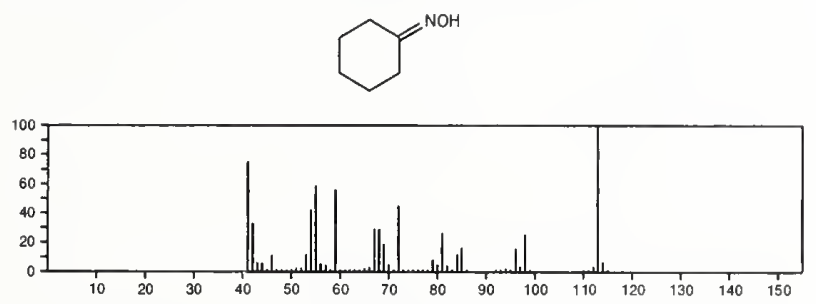

$113 \quad \mathrm{C}_{6} \mathrm{H}_{11} \mathrm{NO}$

2H-Azepin-2-one, hexahydro-

$105-60-2$
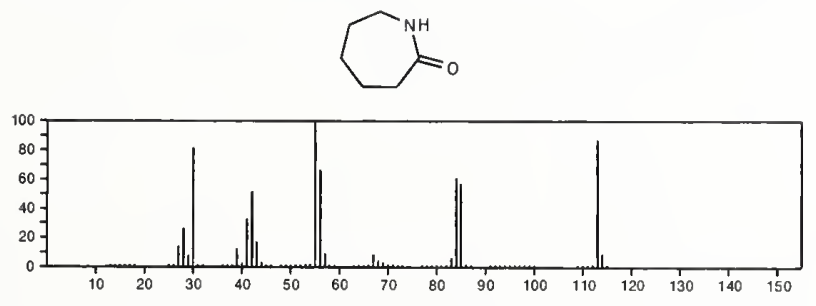

113

2-Piperidinone, 1-methyl-

$\mathrm{C}_{6} \mathrm{H}_{11} \mathrm{NO}$

$931-20-4$
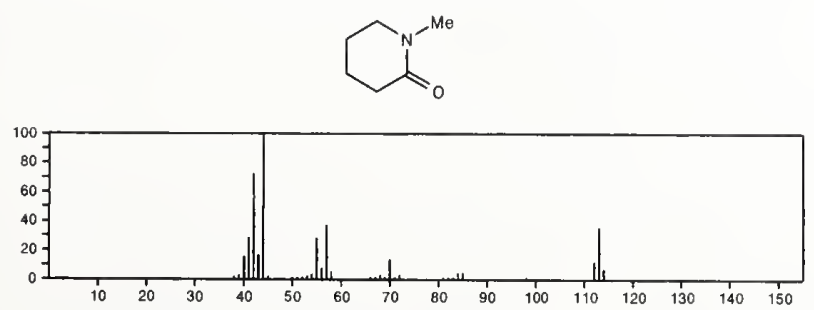

113

3-Buten-2-one,

$\mathrm{C}_{6} \mathrm{H}_{11} \mathrm{NO}$
-

$1190-91-6$

$\mathrm{Me} 2 \mathrm{NCH}=\mathrm{CH}$ COMe

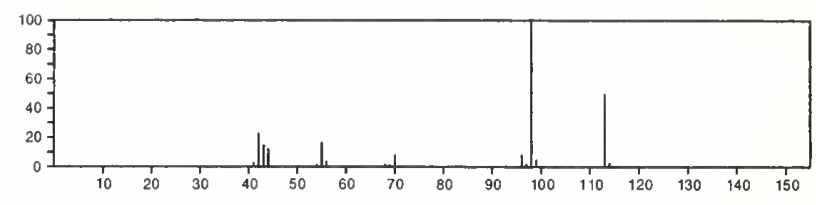

113

4-Piperidinone, 1-methyl-

$\mathrm{C}_{6} \mathrm{H}_{11} \mathrm{NO}$

1445-73-4
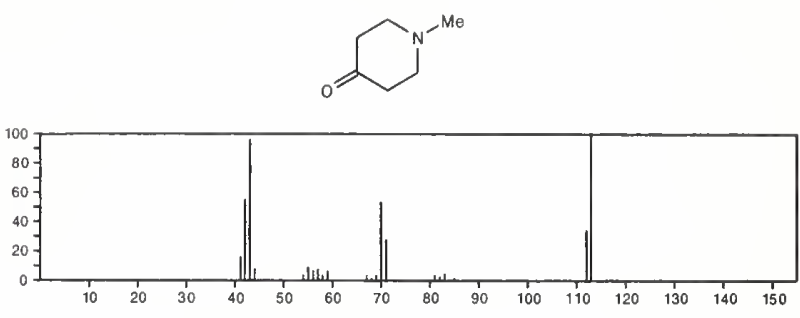

113

$\mathrm{C}_{6} \mathrm{H}_{12} \mathrm{NO}$

Cyanic acid, 2,2-dimethylpropyl ester

$1459-44-5$

$\mathrm{NCOCH}_{2} \mathrm{CM}_{3}$

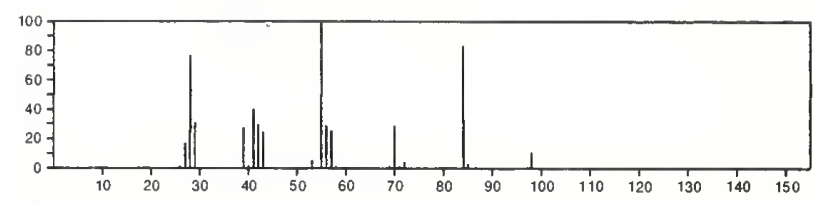

113

$\mathrm{C}_{6} \mathrm{H}_{11} \mathrm{NO}$

2591-86-8

1-Piperidinecarboxaldehyde
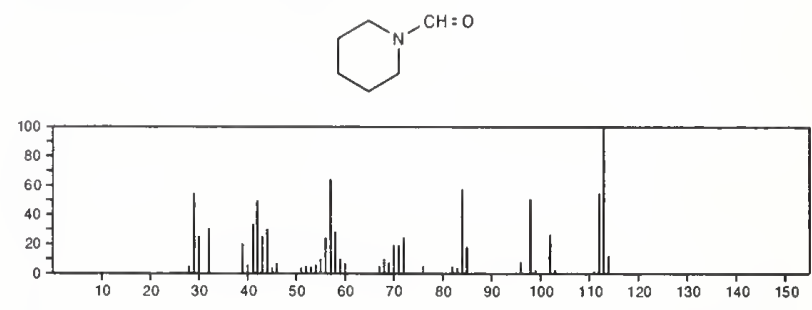

$113 \quad \mathrm{C}_{6} \mathrm{H}_{11} \mathrm{NO}$

$3376-37-2$

Cyclopentanone, $\mathrm{O}$-methyloxime
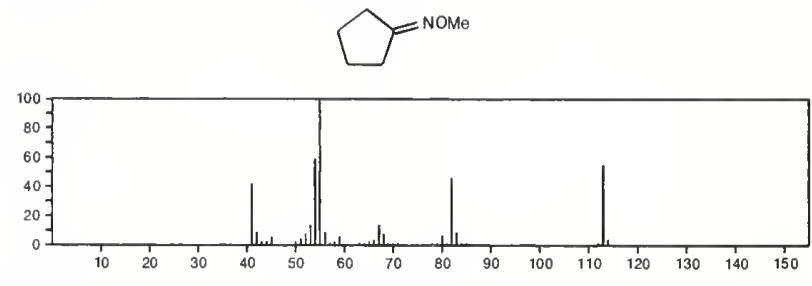

$113 \quad \mathrm{C}_{6} \mathrm{H}_{11} \mathrm{NO} \quad 4030-18-6$

Pyrrolidine, 1-acetyl-
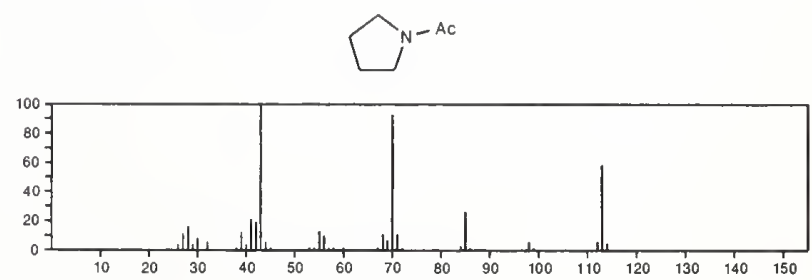


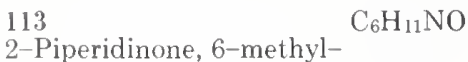
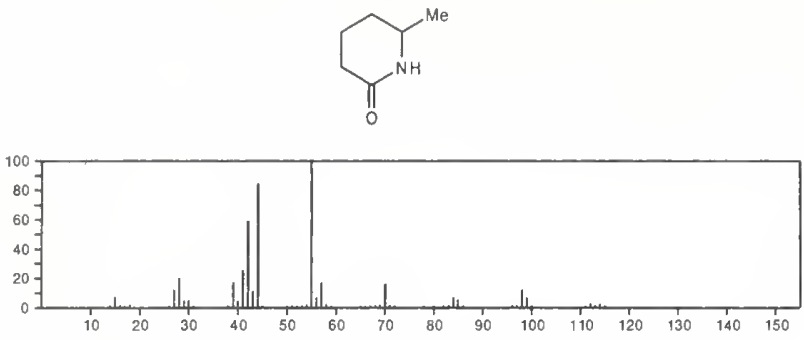

113

3-Piperidinone, 1-methyl-

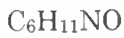

$5519-50-6$
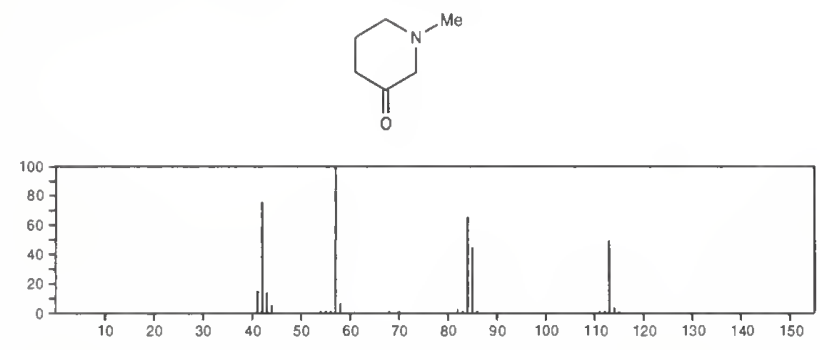

$113 \quad \mathrm{C}_{6} \mathrm{H}_{11} \mathrm{NO}$

$14092-14-9$

3-Penten-2-one, 4-(methylamino)-

$\mathrm{Me} \mathrm{COCH}=\mathrm{C}(\mathrm{NHMe}) \mathrm{Me}$

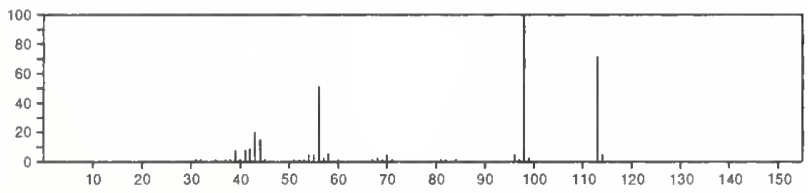

113

$\mathrm{C}_{6} \mathrm{H}_{11} \mathrm{NO}$

Azetidine, 1-acetyl-2-methyl-

$50837-77-9$
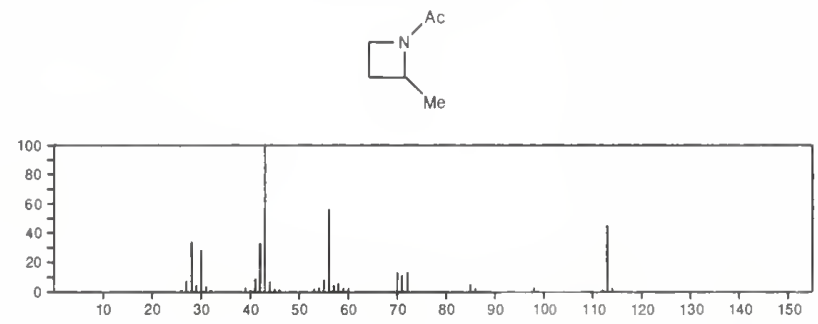

$113 \quad \mathrm{C}_{7} \mathrm{H}_{15} \mathrm{~N}$

Cyclohexanamine, $\mathrm{N}$-methyl-

$100-60-7$
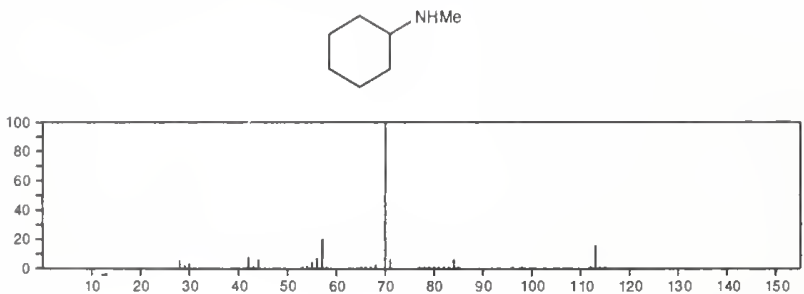

113

Piperidine, 2,6-dimethyl-

$\mathrm{C}_{7} \mathrm{H}_{15} \mathrm{~N}$

$504-03-0$
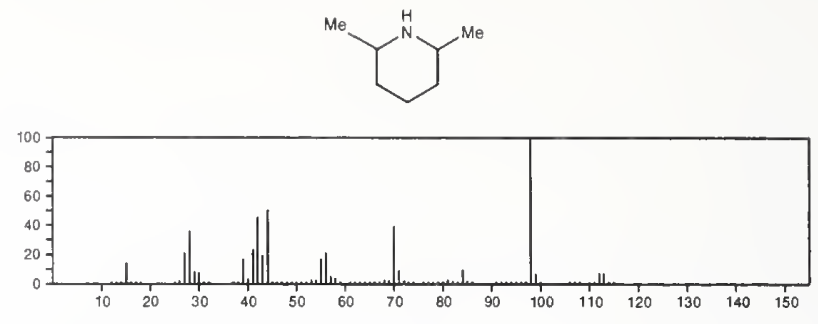

113

$\mathrm{C}_{7} \mathrm{H}_{15} \mathrm{~N}$

$671-36-3$

Piperidine, 1,2-dimethyl-
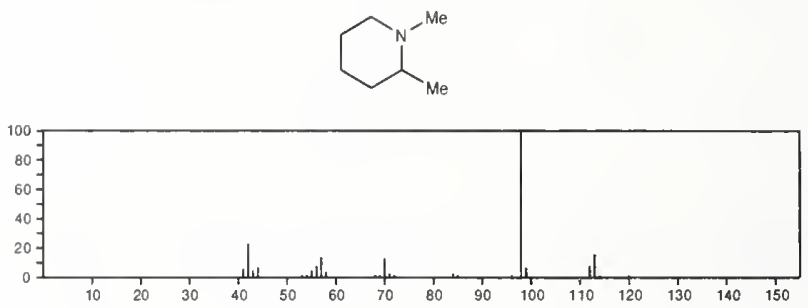

113

$\mathrm{C}_{7} \mathrm{H}_{15} \mathrm{~N}$

$766-09-6$

Piperidine, 1-ethyl-
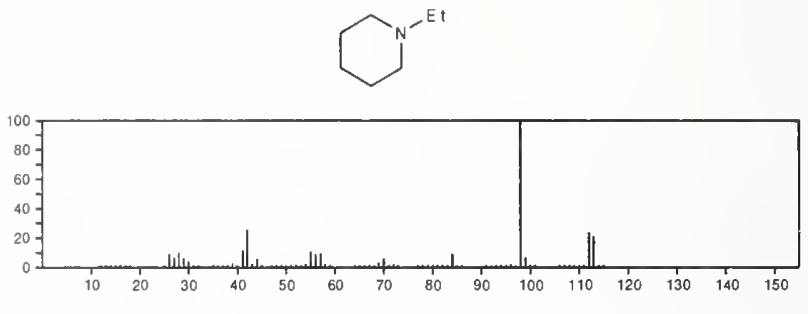

113

$\mathrm{C}_{7} \mathrm{H}_{15} \mathrm{~N}$

$931-30-6$

Aziridine, 2-isopropyl-1,3-dimethyl-, trans-
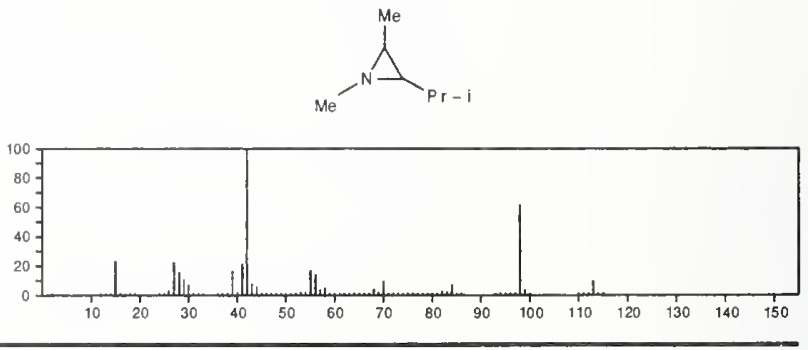

113

$\mathrm{C}_{7} \mathrm{H}_{15} \mathrm{~N}$

$1121-92-2$

Azocine, octahydro-
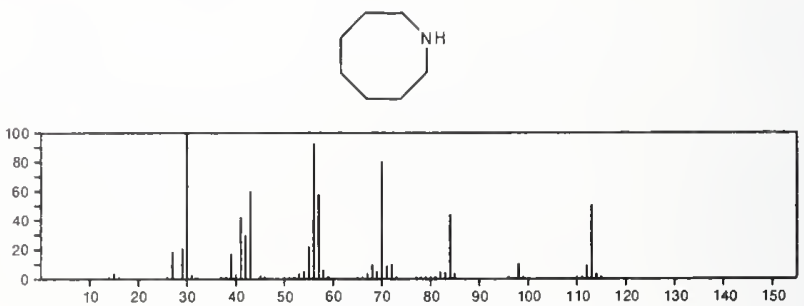
113

$\mathrm{C}_{7} \mathrm{H}_{15} \mathrm{~N}$

$1484-80-6$

Piperidine, 2-ethyl
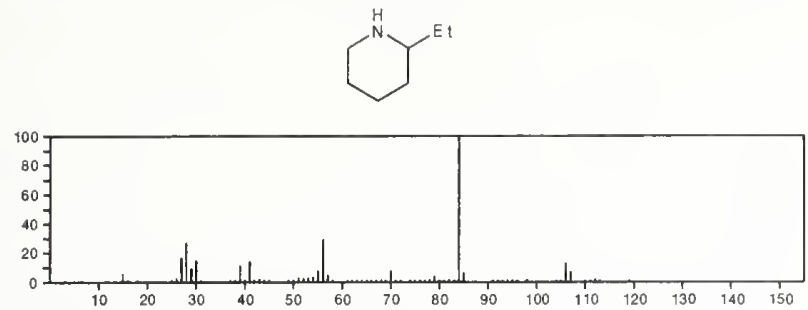

113

Ethanamine, $N$-pentylidene-

$\mathrm{C}_{7} \mathrm{H}_{15} \mathrm{~N}$

$\mathrm{Me}\left(\mathrm{CH}_{2}\right)_{3} \mathrm{CH}=\mathrm{NE} 1$

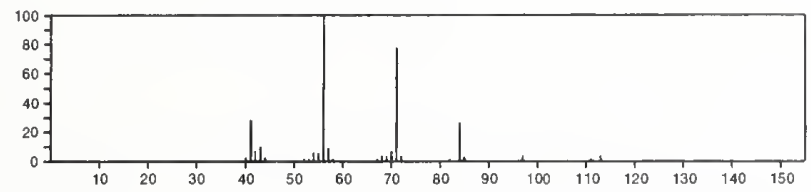

113

$\mathrm{C}_{7} \mathrm{H}_{15} \mathrm{~N}$

Pyrrolidine, 2-ethyl-1-methyl
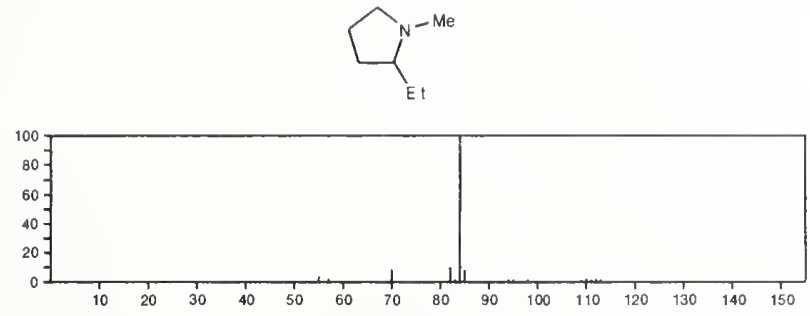

113

$\mathrm{C}_{7} \mathrm{H}_{15} \mathrm{~N}$

Cyclopentanamine, $\mathrm{N}$-ethyl-

$45592-46-9$
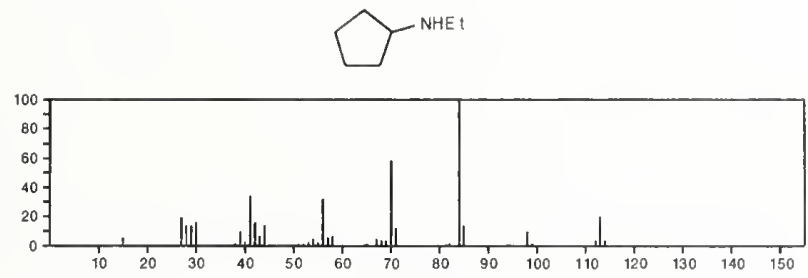

113

$\mathrm{C}_{7} \mathrm{H}_{15} \mathrm{~N}$

$55669-75-5$

Aziridine, 2,3-dimethyl-1-(1-methylethyl)-, cis-
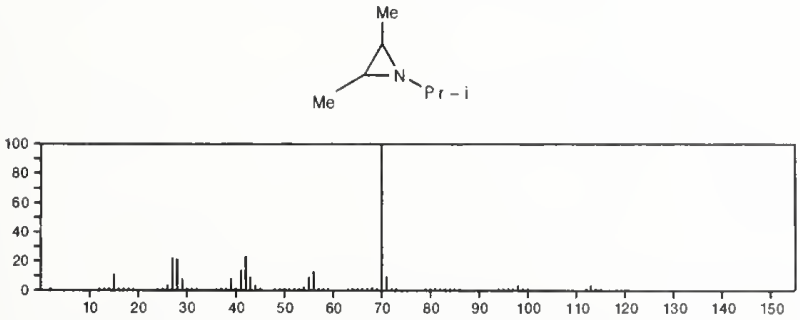

113

$\mathrm{C}_{7} \mathrm{H}_{15} \mathrm{~N}$

Aziridine, 2-(1,1-dimethylethyl)-3-methyl--, trans

$55669-76-6$
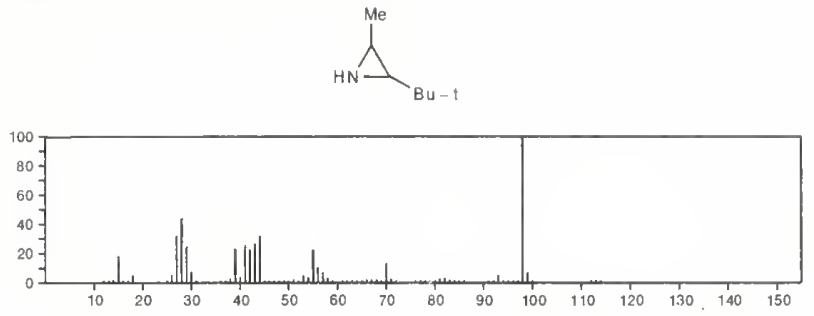

113

$\mathrm{C}_{7} \mathrm{H}_{15} \mathrm{~N}$

Azetidine, 2-methyl-1-(1-methylethyl)

$55683-32-4$
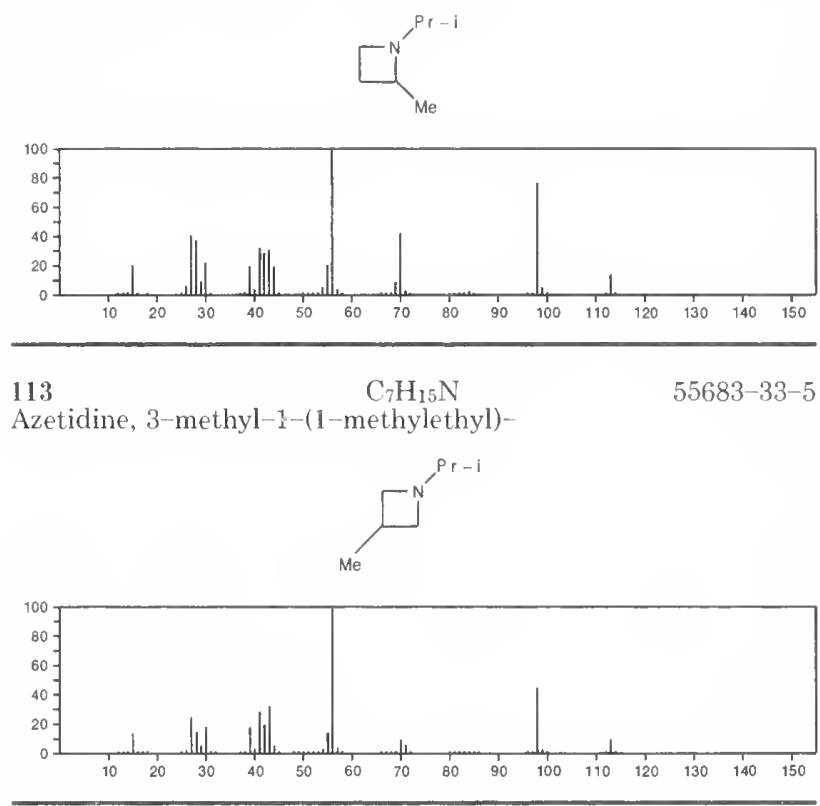

114

$\mathrm{C}_{2} \mathrm{HClF}_{2} \mathrm{O}$

811-96-1

Acetaldehyde, chlorodifluoro

$\mathrm{ClCF}_{2}(\mathrm{CHO})$

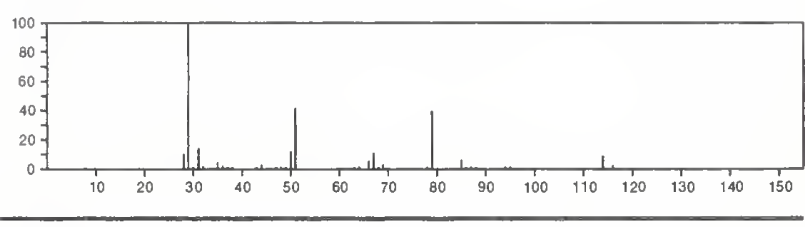

114

$\mathrm{C}_{2} \mathrm{HF}_{3} \mathrm{O}_{2}$

$76-05-1$

Acetic acid, trifluoro-

$\mathrm{F}_{3} \mathrm{CCO}_{2} \mathrm{H}$

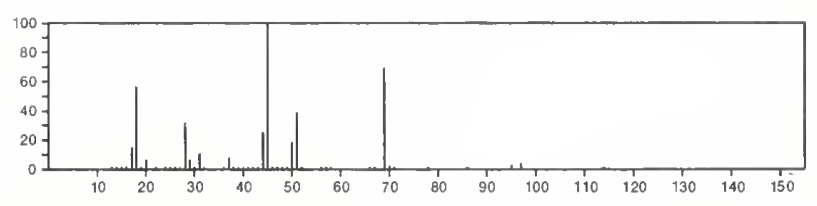

114

1H-1,2,4-Triazole, 3-nitro-

$\mathrm{C}_{2} \mathrm{H}_{2} \mathrm{~N}_{4} \mathrm{O}_{2}$

$24807-55-4$

$\underbrace{N^{N}}_{=N}$

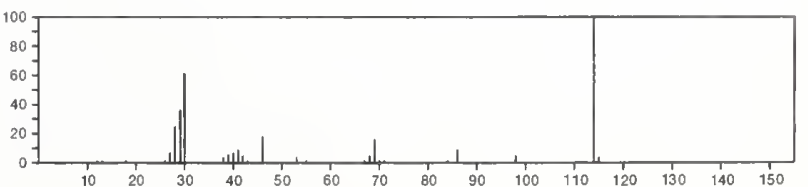


114

Methane, oxybis[chloro-

$\mathrm{C}_{2} \mathrm{H}_{4} \mathrm{Cl}_{2} \mathrm{O}$

$\mathrm{Cl} \mathrm{CH}_{2} \mathrm{OCH}_{2} \mathrm{Cl}$

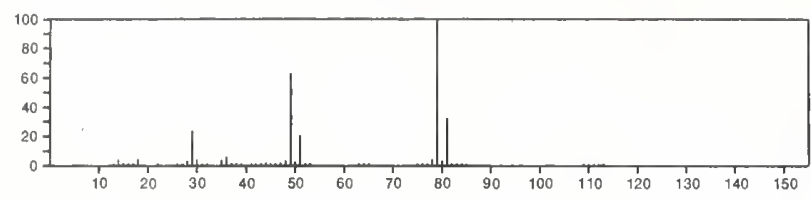

114

Ethanol, 2,2-dichloro-

$\mathrm{C}_{2} \mathrm{H}_{4} \mathrm{Cl}_{2} \mathrm{O}$

$598-38-9$

$\mathrm{HOCH}_{2} \mathrm{CHCl}$
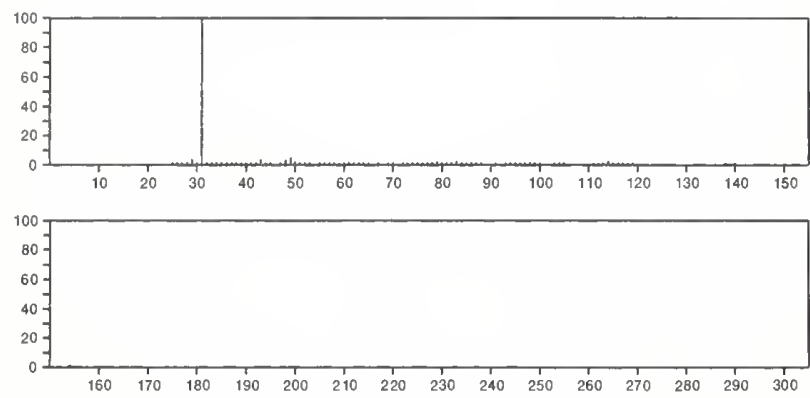

$114 \quad \mathrm{C}_{3} \mathrm{H}_{5} \mathrm{ClF}_{2}$

Propane, 1-chloro-2,2-difluoro

$420-99-5$

$\mathrm{Cl} \mathrm{CH}_{2} \mathrm{CF}_{2} \mathrm{Me}$

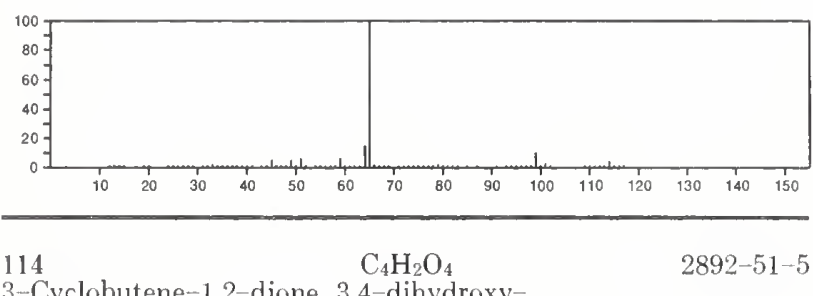

3-Cyclobutene-1,2-dione, 3,4-dihydroxy-
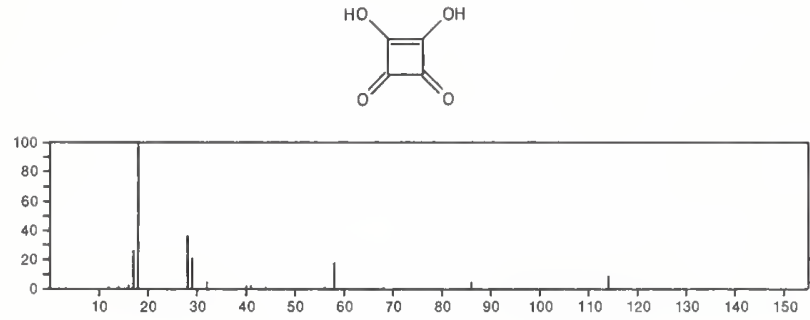

114

$\mathrm{C}_{4} \mathrm{H}_{6} \mathrm{~N}_{2} \mathrm{O}$

$616-03-5$

2,4-Imidazolidinedione, 5-methyl-
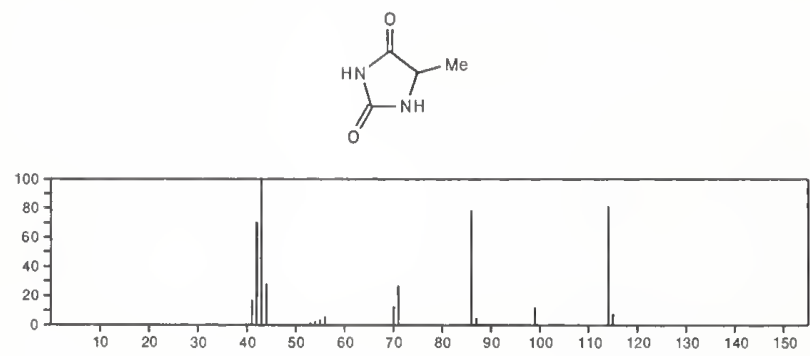

114

2,4-Imidazolidinedione, 1-methyl-
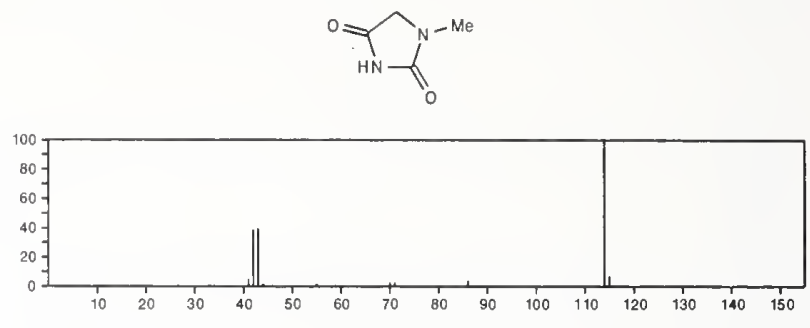

114

2-Butenediamide, $(E)$ -

$\mathrm{C}_{4} \mathrm{H}_{6} \mathrm{~N}_{2} \mathrm{O}_{2}$

$627-64-5$

$\mathrm{H}_{2} \mathrm{NCOCH}=\mathrm{CHCONH}$

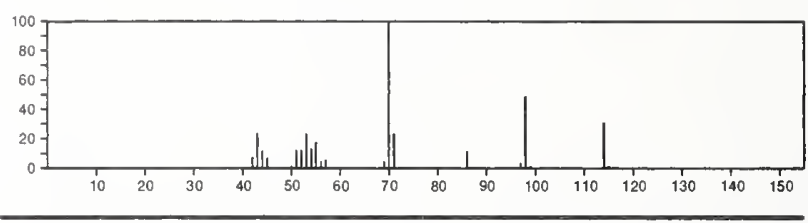

114

2-Butenediamide, $(Z)$ -

$\mathrm{C}_{4} \mathrm{H}_{6} \mathrm{~N}_{2} \mathrm{O}_{2}$

928-01-8

$\mathrm{H}_{2} \mathrm{NCOCH}=\mathrm{CHCONH}_{2}$

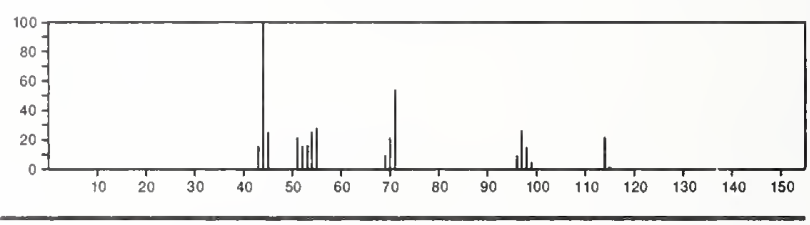

114

$\mathrm{C}_{4} \mathrm{H}_{6} \mathrm{~N}_{2} \mathrm{O}_{2}$

$4007-18-5$

Sydnone, 3,4-dimethyl
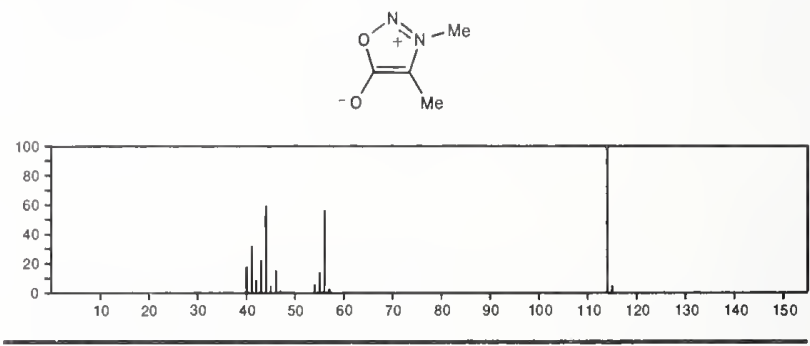

114

$\mathrm{C}_{4} \mathrm{H}_{6} \mathrm{~N}_{2} \mathrm{O}_{2}$

2,4 Imidazolidinedione, 3-methyl-

$6843-45-4$
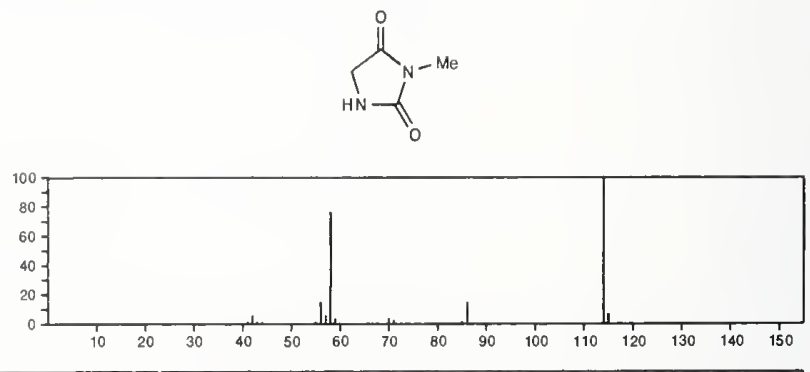

114

$\mathrm{C}_{4} \mathrm{H}_{6} \mathrm{~N}_{2} \mathrm{O}_{2}$

2-Propenamide, $\mathrm{N}$-(aminocarbonyl)-

20602-79-3

$\mathrm{H}_{2} \mathrm{NCONHCOCH}=\mathrm{CH}_{2}$

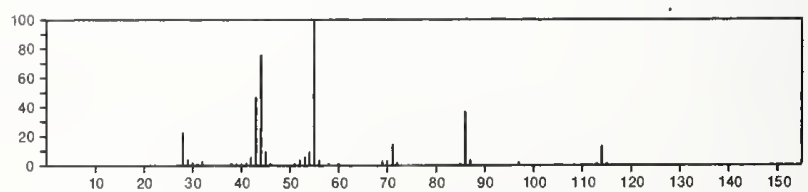


114

$\mathrm{C}_{4} \mathrm{H}_{6} \mathrm{~N}_{2} \mathrm{~S}$

Carbonocyanidothioic amide, dimethyl-

$16703-47-2$

Me $2 \mathrm{NCSCN}$

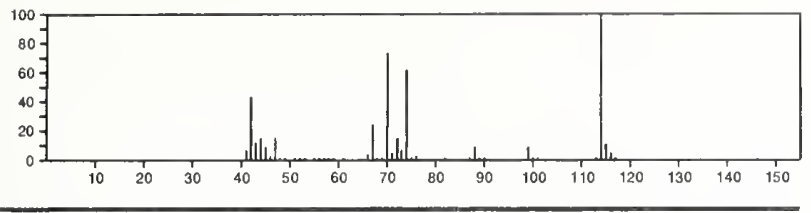

114

$\mathrm{C}_{4} \mathrm{H}_{10} \mathrm{~N}_{4}$

$37454-59-4$

1,2,4,5-Tetrazine, 1,2,3,4-tetrahydro-3,6-dimethyl-
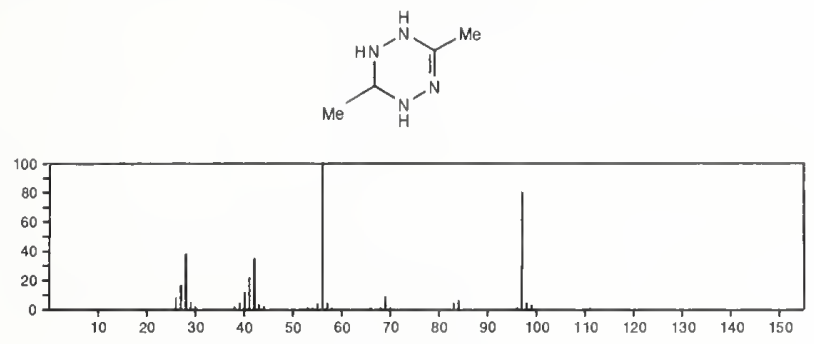

\section{4}

$\mathrm{C}_{4} \mathrm{H}_{10} \mathrm{~N}_{4}$

$56051-77-5$

1,2,4,5-Tetrazine, 1,2,3,6-tetrahydro-3,6-dimethyl-<smiles>CC1N=NC(C)NN1</smiles>

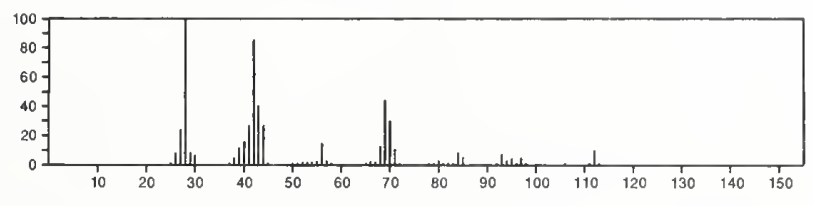

$114 \quad \mathrm{C}_{4} \mathrm{H}_{11} \mathrm{~B}_{5}$

$21687-53-6$

2,4-Dicarbaheptaborane(7), 2,4-dimethyl-
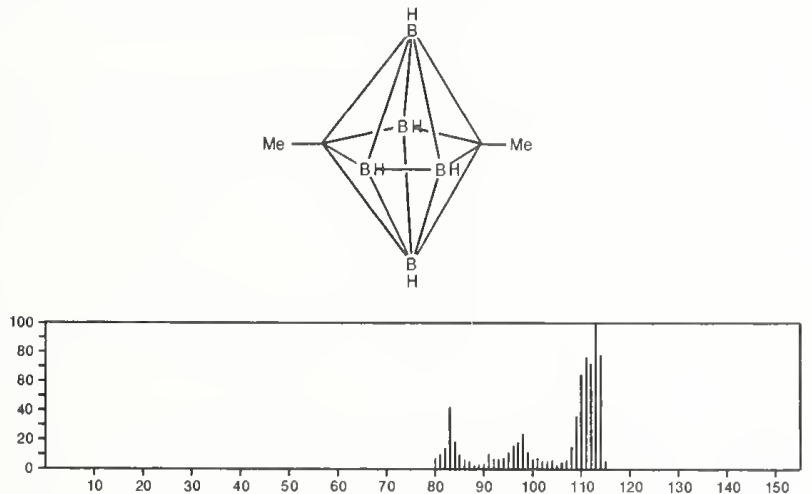

114

2,3-Dicarbaheptaborane(7), 2,3-dimethyl-

31566-10-6
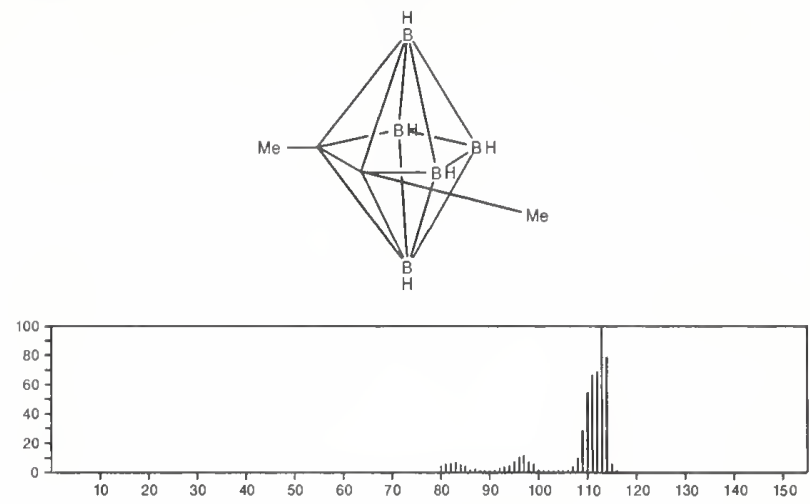

114

$\mathrm{C}_{5} \mathrm{H}_{6} \mathrm{OS}$

98-02-2

2-Furanmethanethiol
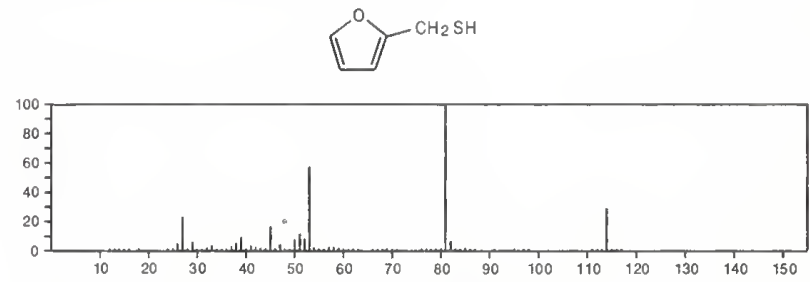

114

$\mathrm{C}_{5} \mathrm{H}_{6} \mathrm{O}_{3}$

108-55-4

2H-Pyran-2,6(3H)-dione, dihydro-
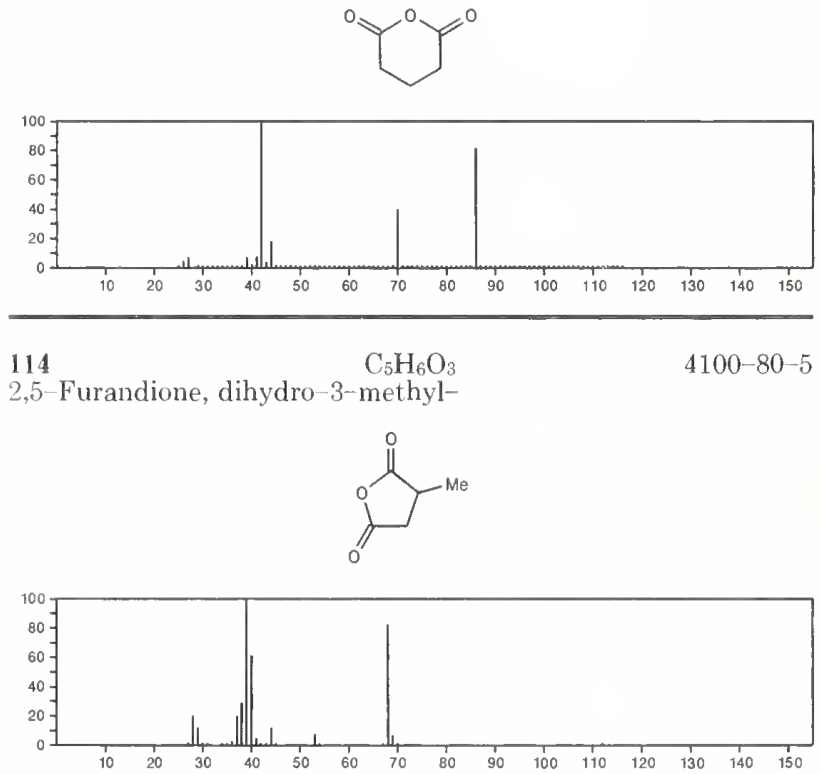

114

$\mathrm{C}_{5} \mathrm{H}_{10} \mathrm{~N}_{2} \mathrm{O}$

100-75-4

Piperidine, 1-nitroso-
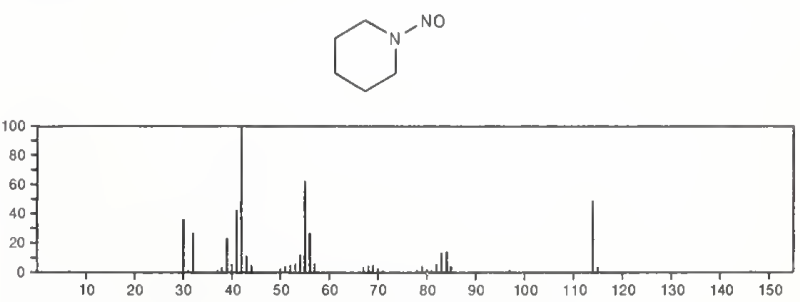
114

Benzene, 1,2-difluoro-

$\mathrm{C}_{6} \mathrm{H}_{4} \mathrm{~F}_{2}$

$367-11-3$
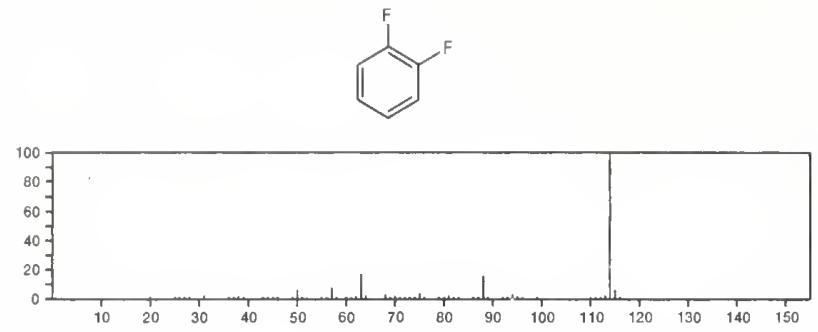

114

Benzene, 1,3-difluoro-

$\mathrm{C}_{6} \mathrm{H}_{4} \mathrm{~F}_{2}$

$372-18-9$
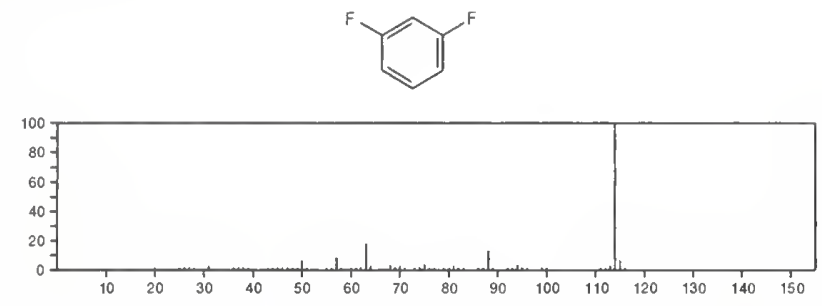

114

$\mathrm{C}_{6} \mathrm{H}_{4} \mathrm{~F}_{2}$

$540-36-3$

Benzene, 1,4-difluoro-
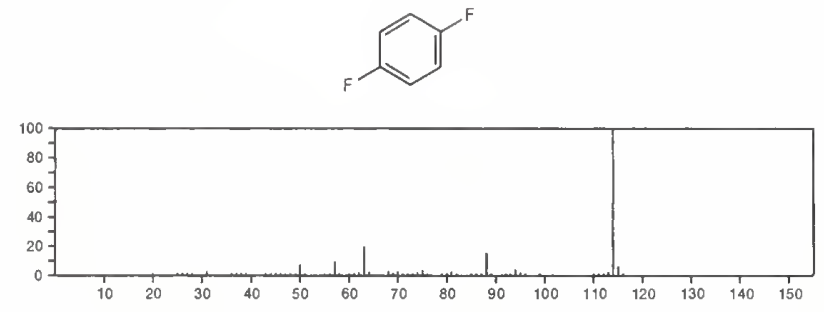

$114 \quad \mathrm{C}_{6} \mathrm{H}_{10} \mathrm{O}_{2}$

$97-63-2$

2-Propenoic acid, 2-methyl-, ethyl ester

$\mathrm{E}+\mathrm{OC}(\mathrm{O}) \mathrm{CMe}=\mathrm{CH}_{2}$

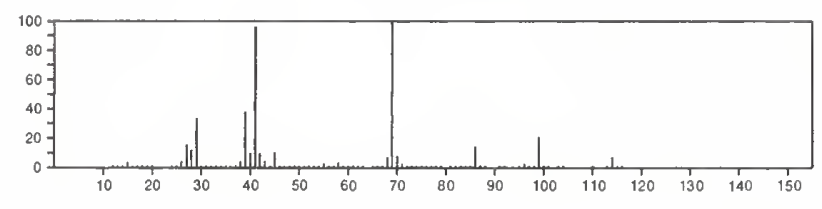

114

2,5-Hexanedione

$\mathrm{C}_{6} \mathrm{H}_{10} \mathrm{O}_{2}$

$110-13-4$

$\mathrm{Me} \mathrm{COCH}_{2} \mathrm{CH}_{2} \mathrm{COMe}_{\mathrm{N}}$

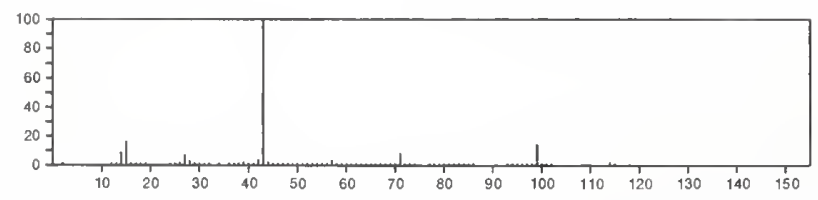

114

Butanoic acid, ethenyl ester

$\mathrm{C}_{6} \mathrm{H}_{10} \mathrm{O}$

$123-20-6$

$\operatorname{PrC}(\mathrm{O}) \mathrm{OCH}=\mathrm{CH}_{2}$

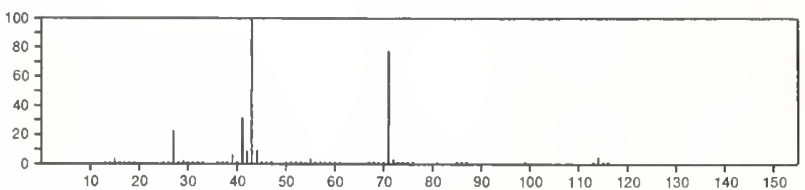

114

2 - Oxepanone

$\mathrm{C}_{6} \mathrm{H}_{10} \mathrm{O}_{2}$

$502-44-3$
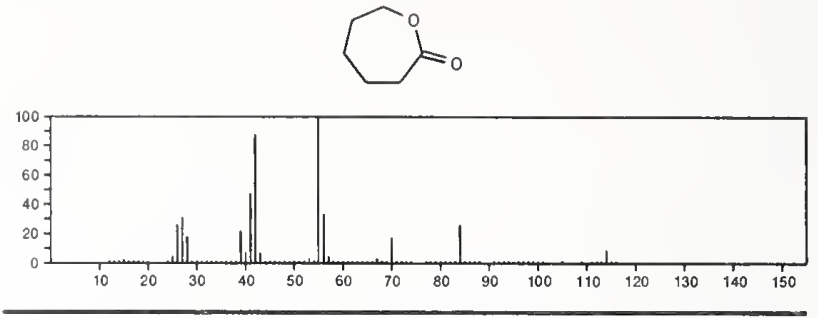

114

3-Pentenoic acid, 4-methyl

$\mathrm{C}_{6} \mathrm{H}_{10} \mathrm{O}_{2}$

$504-85-8$

$\mathrm{HO}_{2} \mathrm{CCH}_{2} \mathrm{CH}=\mathrm{CM}{ }_{2}$

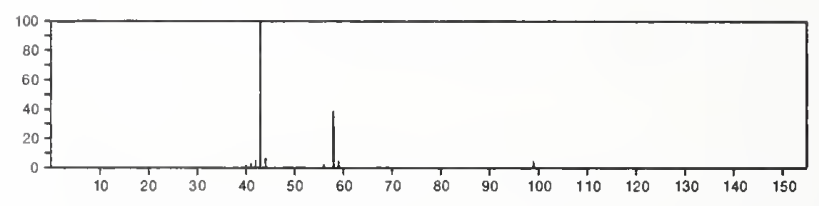

114

Cyclohexanone, 2-hydroxy-

$\mathrm{C}_{6} \mathrm{H}_{10} \mathrm{O}_{2}$

$533-60-8$<smiles>O=C1CCCCC1O</smiles>

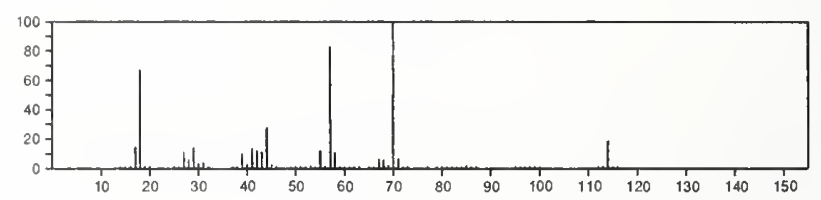

114

$\mathrm{C}_{6} \mathrm{H}_{10} \mathrm{O}_{2}$

2-Butenoic acid, ethyl ester, $(E)-$

$623-70-1$

$\mathrm{MeCH}=\mathrm{CHC}(\mathrm{O}) \mathrm{OE} \mathrm{t}$

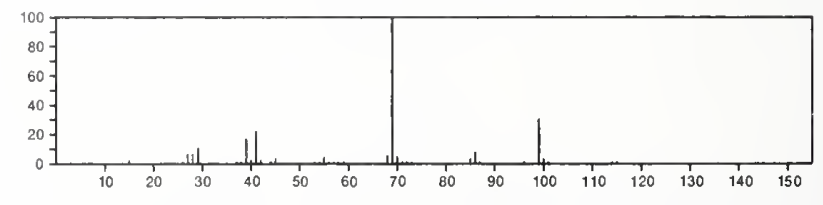

114

2(3H)-Furanone, 5-ethyldihydro

$695-06-7$

$$
\bigcap_{0}^{E t}
$$

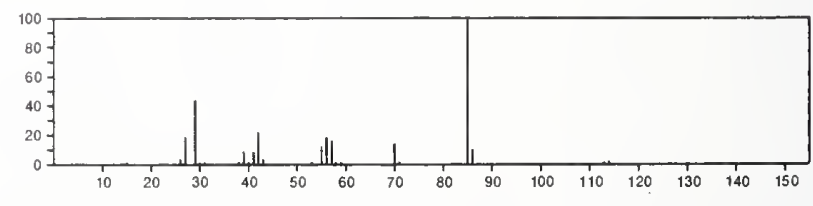

114

$\mathrm{C}_{6} \mathrm{H}_{10} \mathrm{O}$

Ethene, 1,1'-[1,2-ethanediylbis(oxy)]bis-

$764-78-3$

$\mathrm{H}_{2} \mathrm{C}=\mathrm{CHOCH}_{2} \mathrm{CH}_{2} \mathrm{OCH}=\mathrm{CH}_{2}$

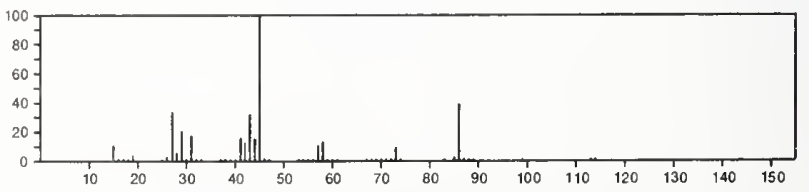


$114 \quad \mathrm{C}_{6} \mathrm{H}_{10} \mathrm{O}_{2}$

2,4-Pentanedione, 3-methyl-

$\mathrm{MeCOCHMe} \mathrm{COMe}$

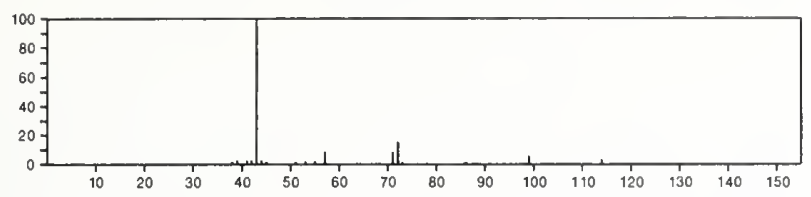

\section{4}

3-Pentenoic acid, methyl ester

818--58-6

Me $\mathrm{OC}(\mathrm{O}) \mathrm{CH}_{2} \mathrm{CH}=\mathrm{CHMe}$

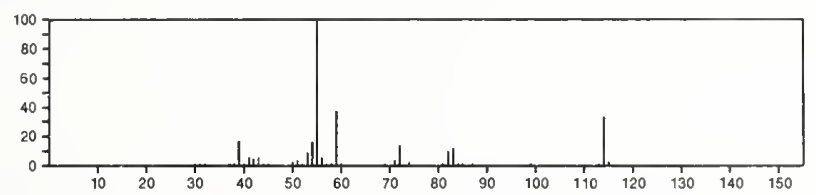

114

2-Pentenoic acid, methyl ester

$818-59-7$

$\mathrm{Et} \mathrm{CH}=\mathrm{CHC}(\mathrm{O}) \mathrm{OMe}$

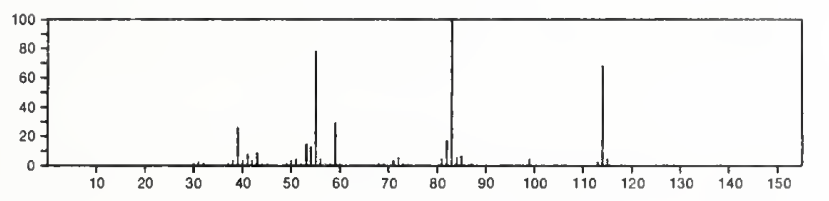

$114 \quad \mathrm{C}_{6} \mathrm{H}_{10} \mathrm{O}_{2}$

2-Propen-1-ol, 2-methyl-, acetate

$820-71-3$

$A C O \mathrm{CH}_{2} \mathrm{CMe}=\mathrm{CH}_{2}$

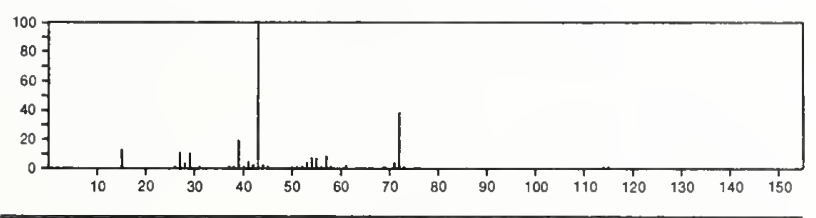

114

Cyclohexanone, 3-hydroxy-

$\mathrm{C}_{6} \mathrm{H}_{10} \mathrm{O}_{2}$

$823-19-8$
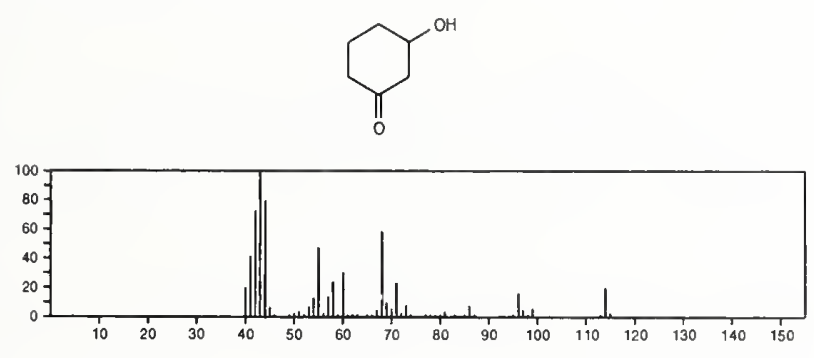

114

$\mathrm{C}_{6} \mathrm{H}_{10} \mathrm{O}_{2}$

2-Butenoic acid, 3-methyl-, methyl ester

$924-50-5$

$\mathrm{Me}_{2} \mathrm{C}=\mathrm{CHC}(\mathrm{O}) \mathrm{OMe}$

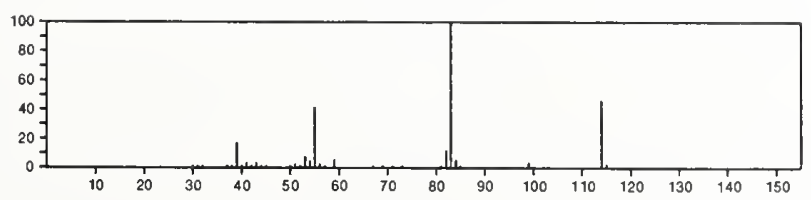

114

5 -Hexenoic acid

$\mathrm{C}_{6} \mathrm{H}_{10} \mathrm{O}_{2}$

$1577-22-6$

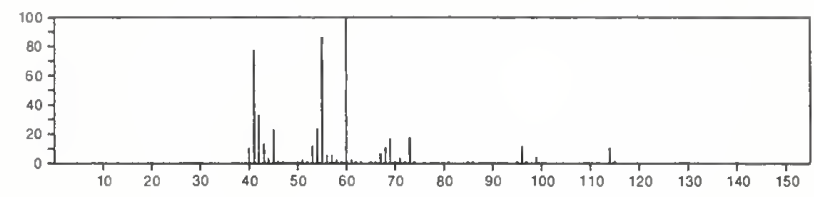

114

$\mathrm{C}_{6} \mathrm{H}_{10} \mathrm{O}_{2}$

$2177-67-5$

Butanoic acid, 2-methylene--, methyl ester

$\mathrm{H}_{2} \mathrm{C}=\mathrm{CE}+\mathrm{C}(\mathrm{O}) \mathrm{OMe}$

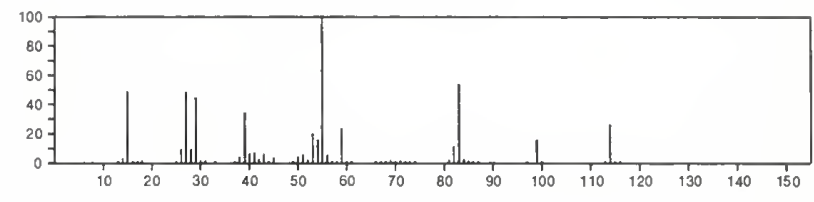

114

$\mathrm{C}_{6} \mathrm{H}_{10} \mathrm{O}_{2}$

2408-20-0

Propanoic acid, 2-propenyl ester

$\mathrm{H}_{2} \mathrm{C}=\mathrm{CHCH}_{2} \mathrm{OC}(\mathrm{O}) \mathrm{Et}$

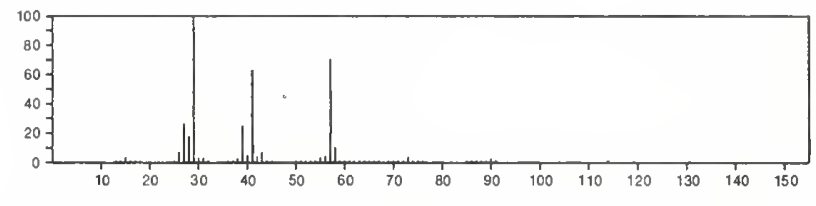

$114 \quad \mathrm{C}_{6} \mathrm{H}_{10} \mathrm{O}_{2}$

1,3-Dioxolane, 2-ethenyl-4-methyl-

2421-07-0

$\sum_{\mathrm{Me}}^{0} \gamma^{\mathrm{CH}=\mathrm{CH}_{2}}$

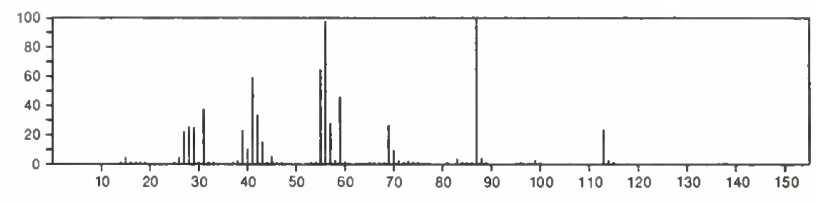

114

3-Penten-2-one, 4-methoxy-

$\mathrm{C}_{6} \mathrm{H}_{10} \mathrm{O}_{2}$

2845-83-2

$\mathrm{MeCOCH}=\mathrm{C}(\mathrm{ONe}) \mathrm{Me}$

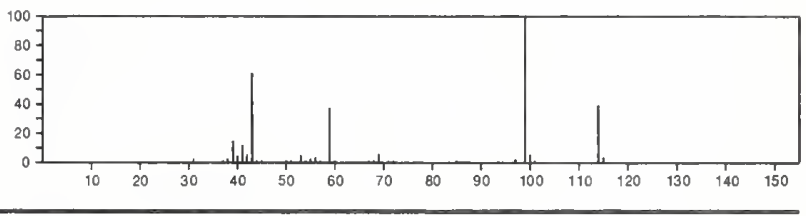

114

$\mathrm{C}_{6} \mathrm{H}_{10} \mathrm{O}_{2}$

$3123-97-5$

2(3H)-Furanone, dihydro-5,5 dimethyl-
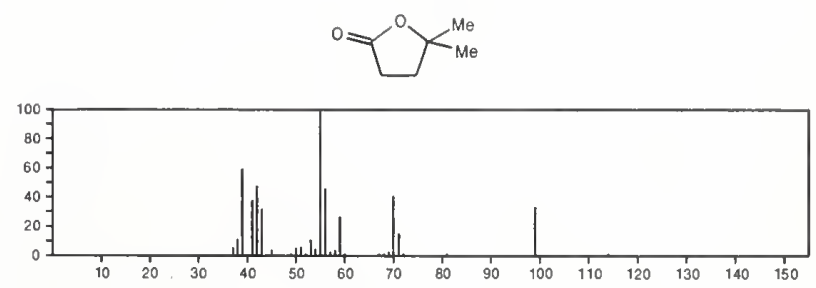
114 $\mathrm{C}_{6} \mathrm{H}_{10} \mathrm{O}_{2}$

Ethanone, 1-(3,3-dimethyloxiranyl)

$4478-63-1$<smiles>CC1OC1(C)C1CCCC1</smiles>

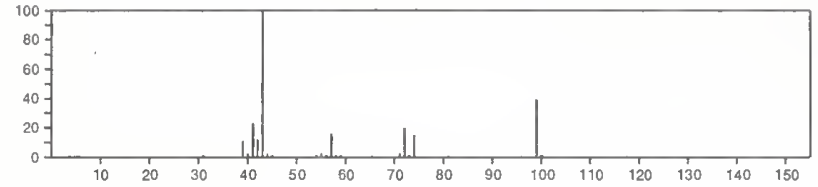

114

1,3-Dioxolane, 2-(1-propenyl)-

$\mathrm{C}_{6} \mathrm{H}_{10} \mathrm{O}_{2}$

4528-26-1

$\sum_{0}^{0} \mathrm{CH}=\mathrm{CHMe}$

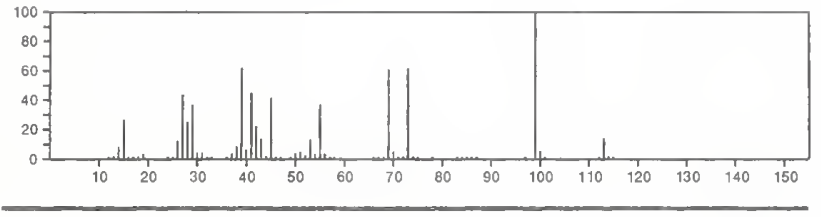

$114 \quad \mathrm{C}_{6} \mathrm{H}_{10} \mathrm{O}$

2(3H)-Furanone, dihydro-3,5-dimethyl-
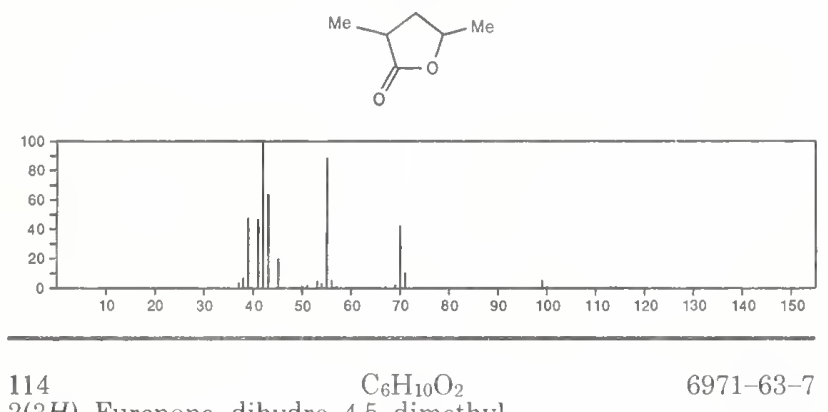

2(3H)-Furanone, dihydro-4,5-dimethy -
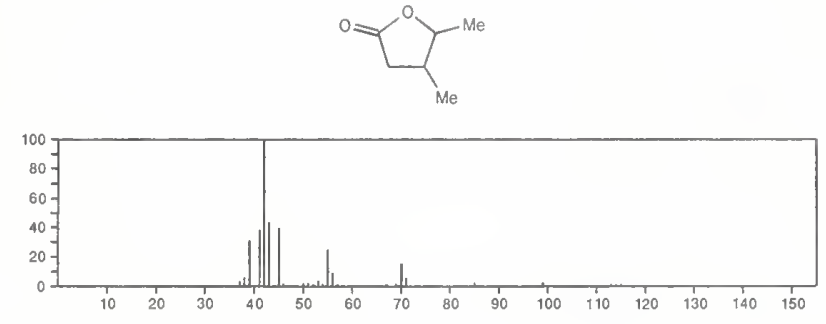

114

2,3-Pentanedione, 4-methyl-

$\mathrm{C}_{6} \mathrm{H}_{10} \mathrm{O}_{2}$

$7493-58-5$

$\mathrm{MeCOCOCHMe}_{2}$

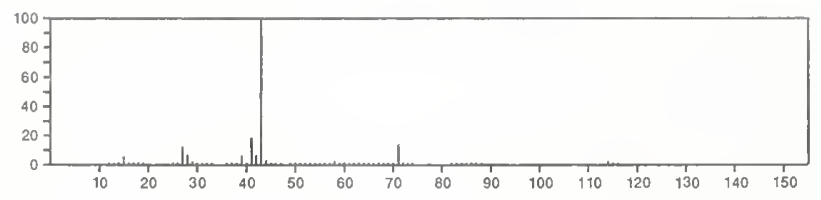

114

3-Butenoic acid, 2,2-dimethyl-

$\mathrm{C}_{6} \mathrm{H}_{10} \mathrm{O}_{2}$

$\mathrm{HO}_{2} \mathrm{CCMe} 2 \mathrm{CH}=\mathrm{CH}_{2}$

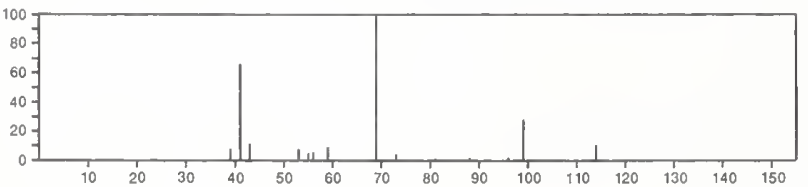

114

$\mathrm{C}_{6} \mathrm{H}_{10} \mathrm{O}_{2}$

$13482-22-9$

Cyclohexanone, 4-hydroxy-
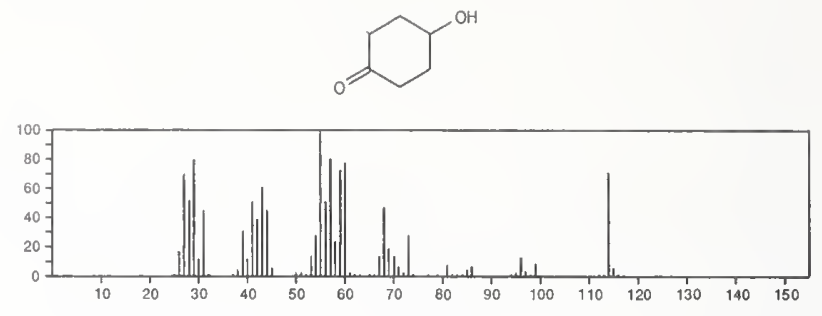

114
$2(3 H)-$ Furanone, dihydro-4,
$\mathrm{C}_{6} \mathrm{H}_{10} \mathrm{O}_{2}$
dimethyl-

$13861-97-7$
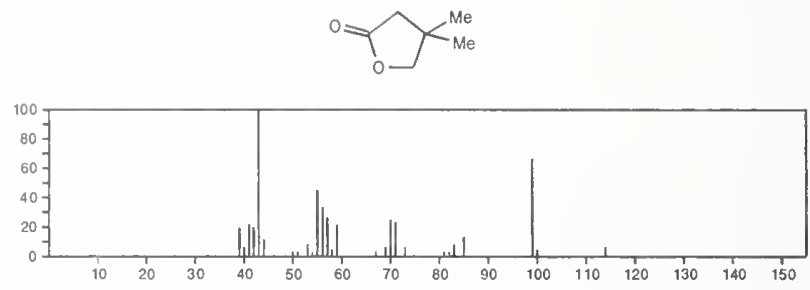

111

2-Hexanone, 3,4-epoxy-

$\mathrm{C}_{6} \mathrm{H}_{10} \mathrm{O}_{2}$

$17257-81-7$
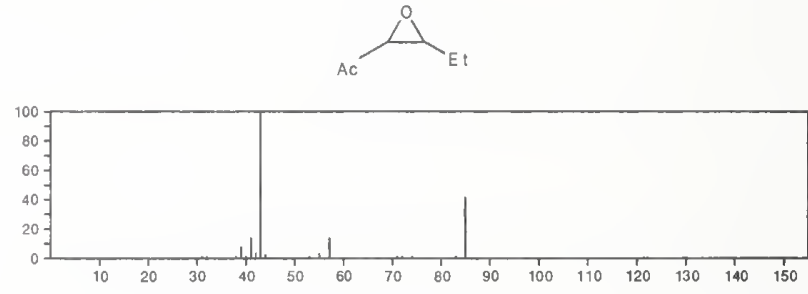

$114 \quad \mathrm{C}_{6} \mathrm{H}_{10} \mathrm{O}_{2}$

2-Butanone, 3,4-epoxy-3-ethyl-

$17257-82-8$
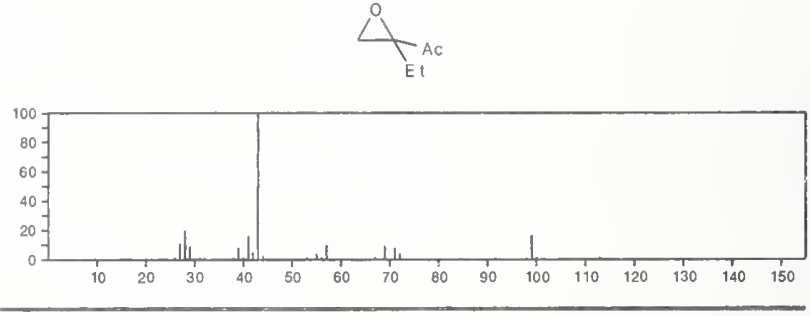

114

$\mathrm{C}_{6} \mathrm{H}_{10} \mathrm{O}_{2}$

Ethanol, 2-[(1-methyl-2-propynyl)oxy]

$18668-75-2$

$\mathrm{HC} \equiv \mathrm{CCHMe}_{\mathrm{OCH}} \mathrm{CH}_{2} \mathrm{OH}$

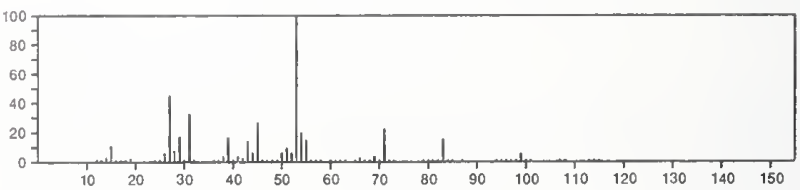


$114 \quad \mathrm{C}_{6} \mathrm{H}_{10} \mathrm{O}_{2}$

1,4-Dioxin, 2,3-dihydro-5,6-dimethyl

$25465-18-3$
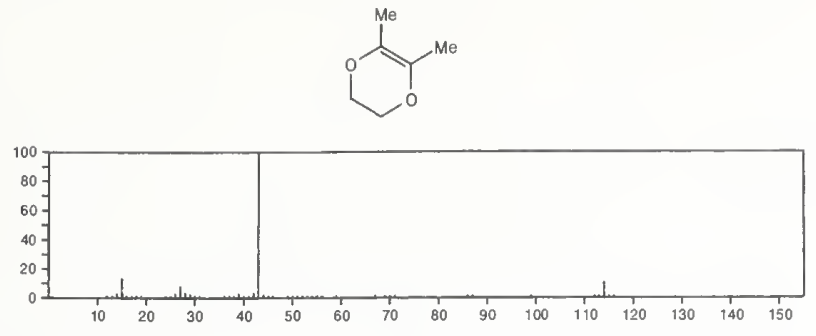

$114 \quad \mathrm{C}_{6} \mathrm{H}_{10} \mathrm{O}_{2}$

1,3-Dioxolane, 2-ethenyl-2-methyl-

$\sum_{0}^{\mathrm{O}} \mathrm{K}_{\mathrm{Me}}^{\mathrm{CH}: \mathrm{CH}_{2}}$

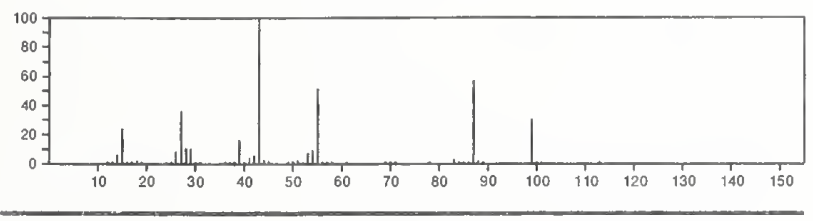

114

$\mathrm{C}_{6} \mathrm{H}_{10} \mathrm{O}_{2}$

1,4-Dioxane, 2-methyl-3-methylene-

$28125-74-8$<smiles>CC1OCC2CC1CC2=O</smiles>

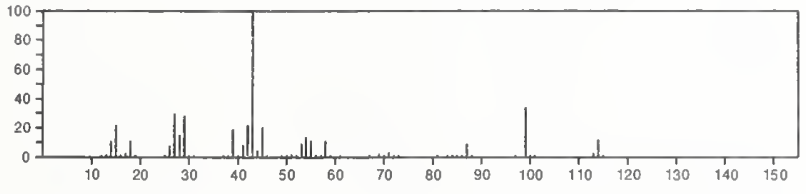

114

4- Hexenoic acid

$\mathrm{C}_{6} \mathrm{H}_{10} \mathrm{O}_{2}$

35194-36-6

$\mathrm{Me} C \mathrm{CH}=\mathrm{CHCH}_{2} \mathrm{CH}_{2} \mathrm{CO}_{2} \mathrm{H}$

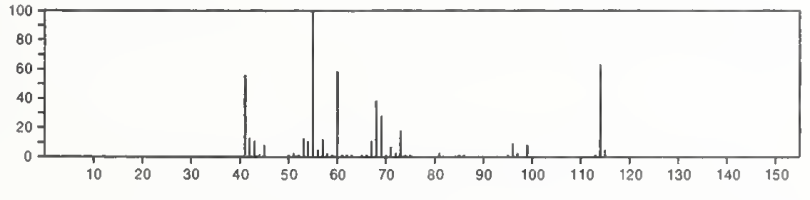

114

$\mathrm{C}_{6} \mathrm{H}_{10} \mathrm{O}_{2}$

38644-91-6

Ethanol, 2-(2-butynyloxy)-

$\mathrm{HOCH}_{2} \mathrm{CH}_{2} \mathrm{OCH}_{2} \mathrm{C} \equiv \mathrm{CMe}$

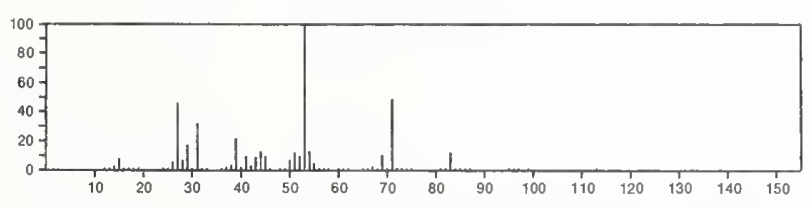

114

$\mathrm{C}_{6} \mathrm{H}_{10} \mathrm{O}_{2}$

$38653-35-9$

5H-1,4-Dioxepin, 2,3-dihydro-7-methyl-
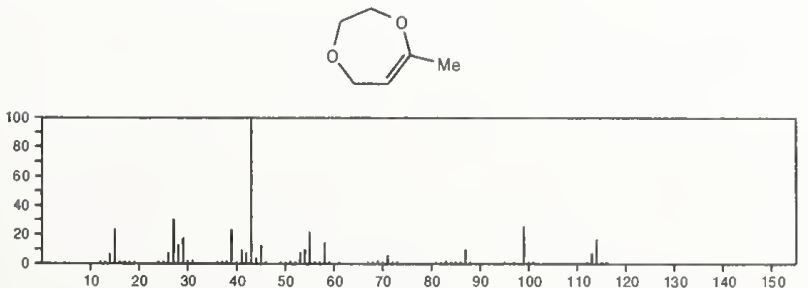

$114 \quad \mathrm{C}_{6} \mathrm{H}_{10} \mathrm{O}_{2}$

5H-1,4-Dioxepin, 2,3-dihydro-5-methyl

$38653-36-0$
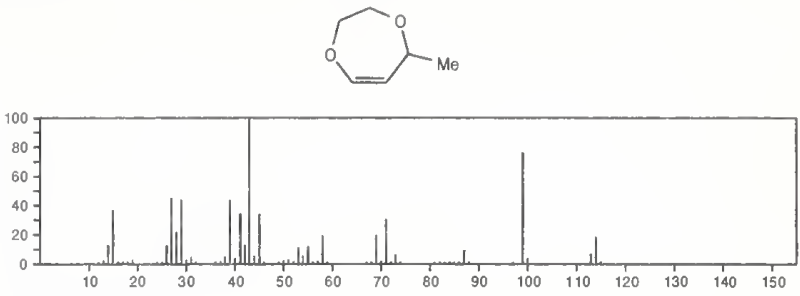

114

1,3-Dioxolane, 2-(2-propenyl)-

$\mathrm{C}_{6} \mathrm{H}_{10} \mathrm{O}_{2}$

$38653-49-5$

$\sum_{0}^{0} \mathrm{CH}_{2} \mathrm{CH}=\mathrm{CH}_{2}$

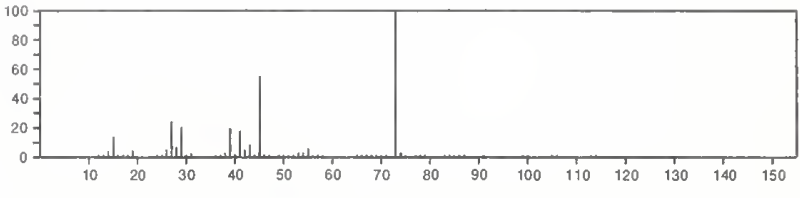

114

$\mathrm{C}_{6} \mathrm{H}_{10} \mathrm{O}_{2}$

Ethanol, 2-(2,3-butadienyloxy)-

$38653-50-8$

- $\mathrm{HOCH}_{2} \mathrm{CH}_{2} \mathrm{OCH}_{2} \mathrm{CH}=\mathrm{C}=\mathrm{CH}_{2}$

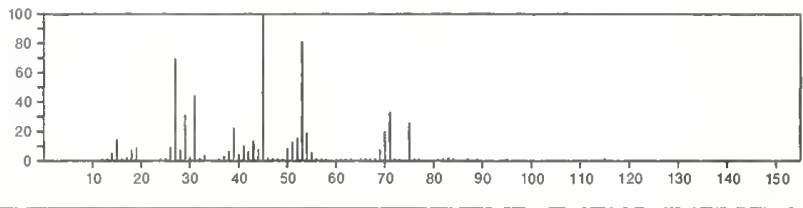

114

$\mathrm{C}_{6} \mathrm{H}_{10} \mathrm{O}_{2}$

$38653-51-9$

Ethanol, 2-[(1 methylene-2-propenyl)oxy]-

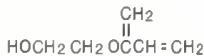

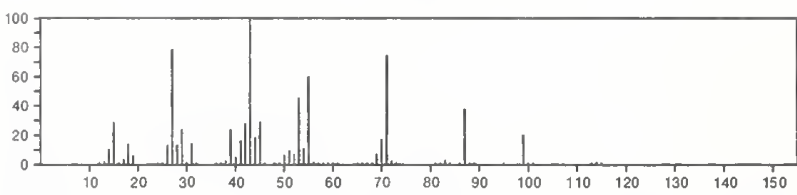

114

$\mathrm{C}_{6} \mathrm{H}_{10} \mathrm{O}_{2}$

$43152-89-2$

2H-Pyran-3(4H)-one, dihydro-6-methyl-
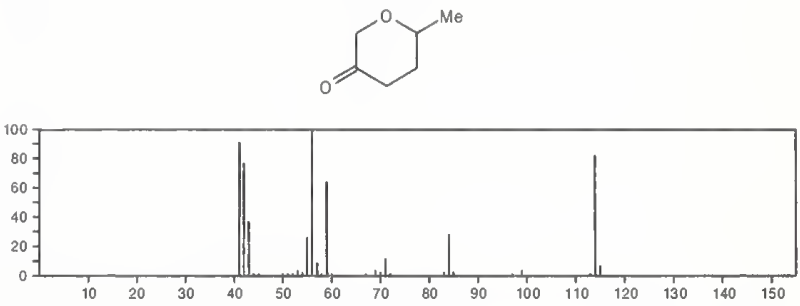

114

$\mathrm{C}_{6} \mathrm{H}_{10} \mathrm{O}_{2}$

$50521-50-1$

1,4-Butanediol, 2,3-bis(methylene)-
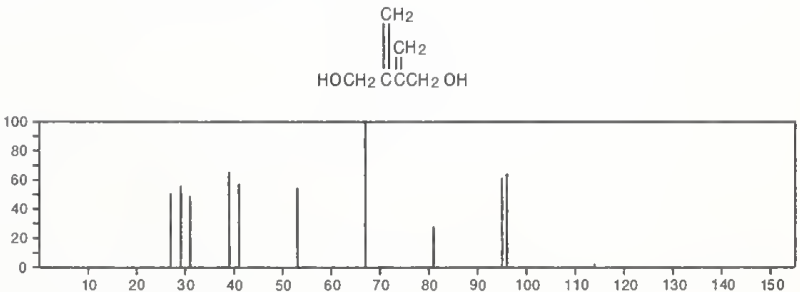
114

7-Thiabicyclo[2.2.1]heptane

$\mathrm{C}_{6} \mathrm{H}_{10} \mathrm{~S}$

s

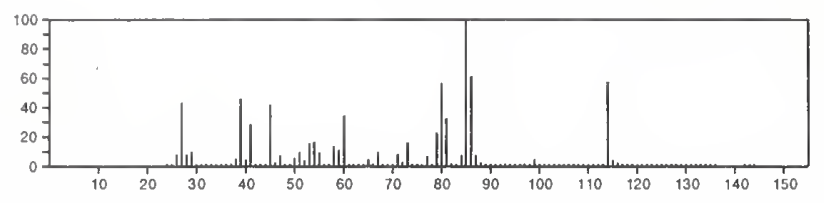

114

$\mathrm{C}_{6} \mathrm{H}_{10} \mathrm{~S}$

286-28-2

7-Thiabicyclo[4.1.0]heptane
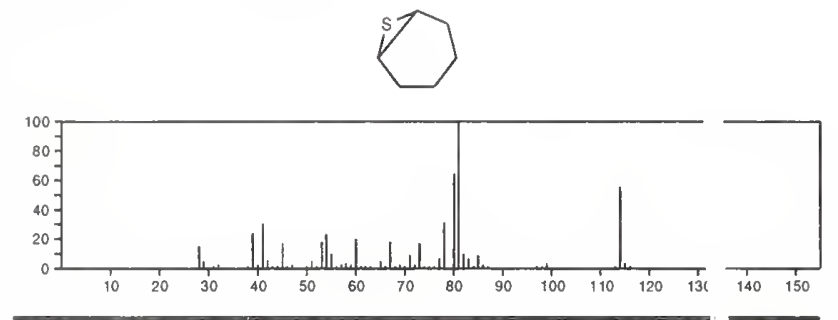

114

1,2-Cyclohexanediamine

$\mathrm{C}_{6} \mathrm{H}_{14} \mathrm{~N}_{2}$

( $14-83-7$
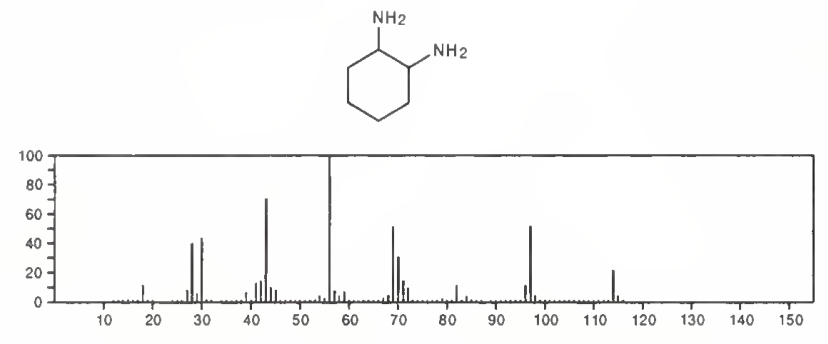

$114 \quad \mathrm{C}_{6} \mathrm{H}_{14} \mathrm{~N}_{2}$

Piperazine, 2,5-dimethyl-, trans-

2815-34-1<smiles>CC1CNC(C)CN1</smiles>

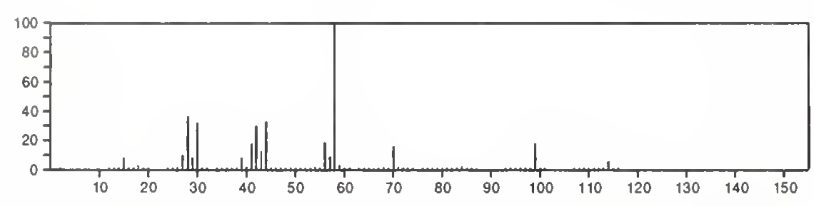

114

1,3-Cyclohexanediamine

$\mathrm{C}_{6} \mathrm{H}_{14} \mathrm{~N}_{2}$
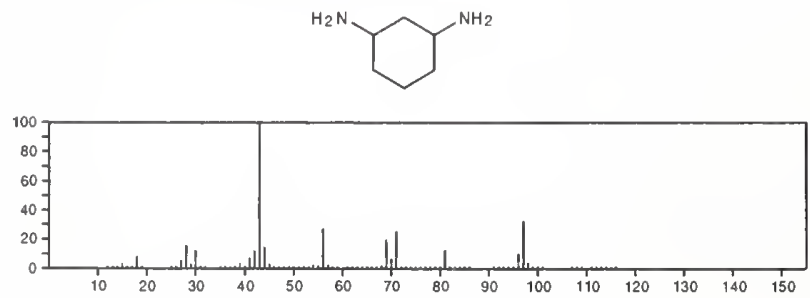

114

$\mathrm{C}_{6} \mathrm{H}_{14} \mathrm{~N}$
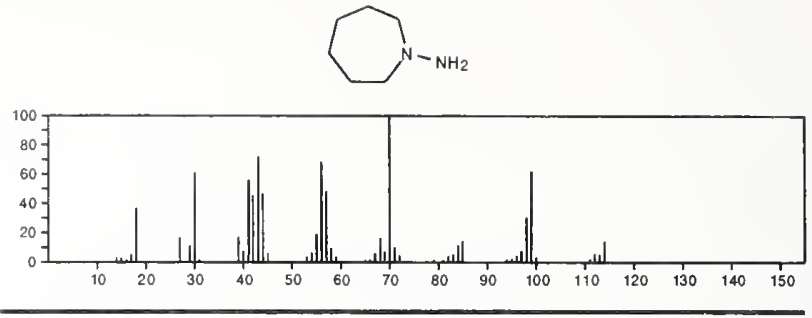

114

Piperazine, 2,5-dimethyl-, cis-

$\mathrm{C}_{6} \mathrm{H}_{14} \mathrm{~N}_{2}$

6284-84-0<smiles>CC1CNC(C)CN1</smiles>

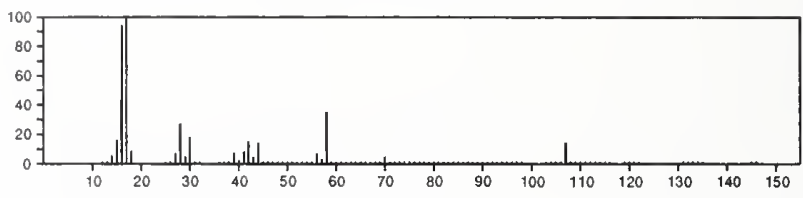

114

$\mathrm{C}_{6} \mathrm{H}_{14} \mathrm{~N}_{2}$

Butanal, dimethylhydrazone

$\operatorname{Pr} \mathrm{CH}=\mathrm{NNM} 2$

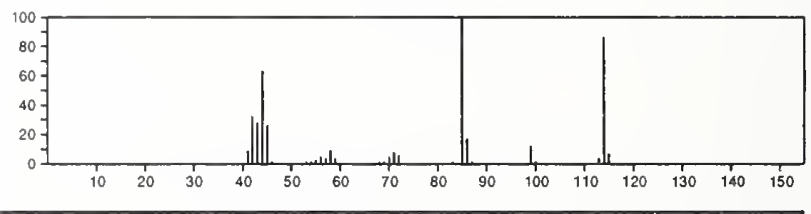

114

$\mathrm{C}_{6} \mathrm{H}_{14} \mathrm{~N}_{2}$

Cyclopentanemethanamine, 2-amino-

$21544-02-5$
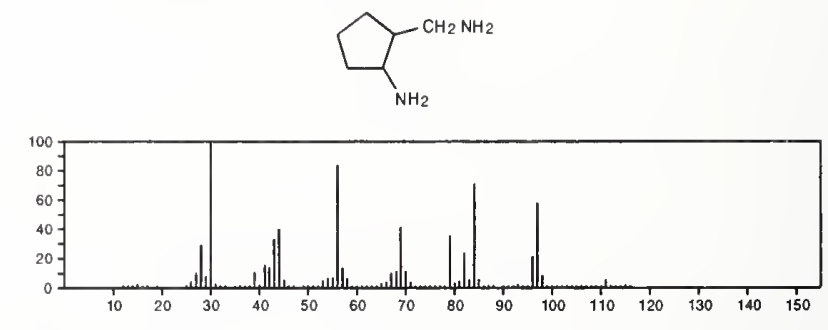

114

2-Piperidinemethanamine

$\mathrm{C}_{6} \mathrm{H}_{14} \mathrm{~N}_{2}$

22990-77-8
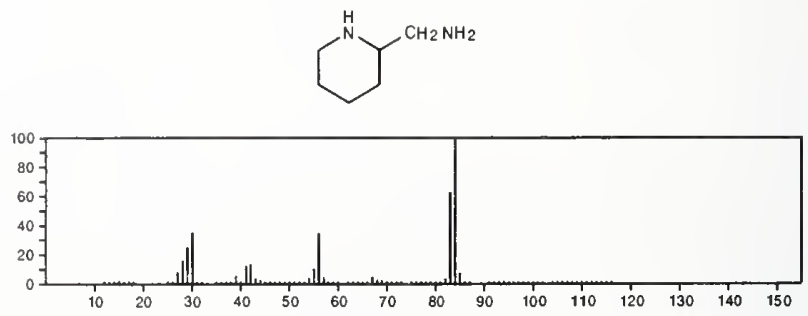
114

Cyclohexanemethanol

$\mathrm{C}_{7} \mathrm{H}_{14} \mathrm{O}$<smiles>OCC1CCCCC1</smiles>

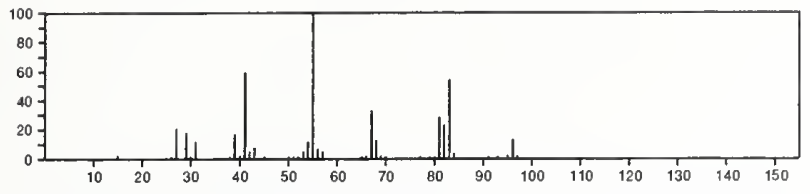

114

3-Heptanone

$\mathrm{C}_{7} \mathrm{H}_{14} \mathrm{O}$

$106-35-4$

$\mathrm{Me}\left(\mathrm{CH}_{2}\right)_{3} \mathrm{COE} \mathrm{t}$

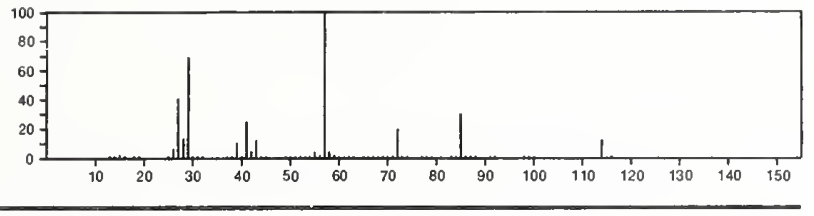

114

$\mathrm{C}_{7} \mathrm{H}_{14} \mathrm{O}$

$110-12-3$

2-Hexanone, 5-methyl-

$\mathrm{Me}_{2} \mathrm{CHCH}_{2} \mathrm{CH}_{2} \mathrm{COM}_{\mathrm{O}}$

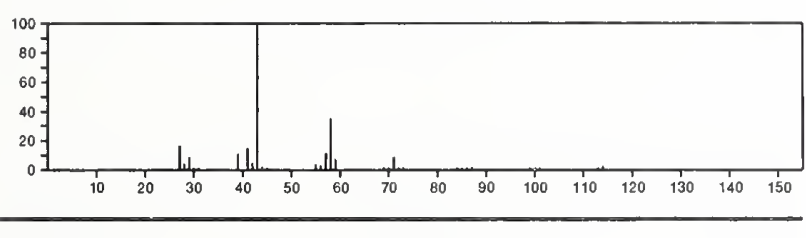

114

$\mathrm{C}_{7} \mathrm{H}_{14} \mathrm{O}$

$110-43-0$

2-Heptanone

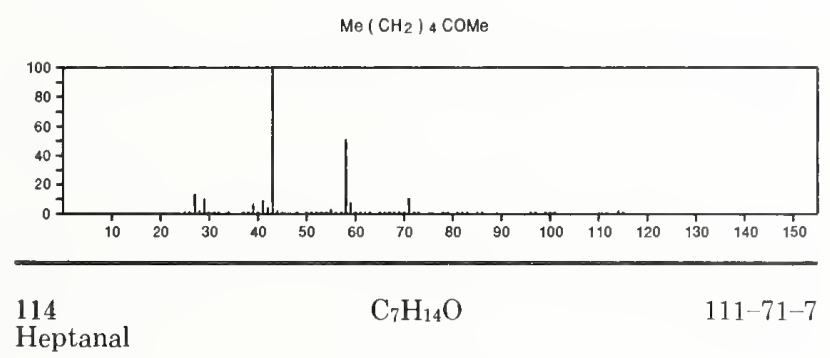

$\mathrm{OCH}\left(\mathrm{CH}_{2}\right) 5 \mathrm{Me}$

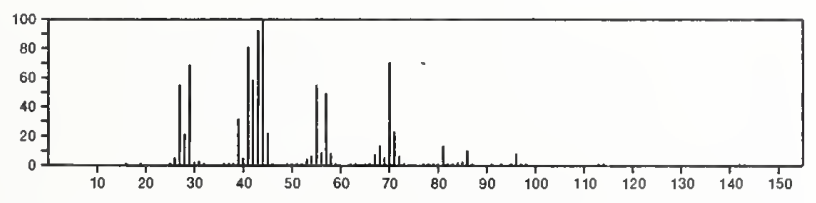

114

$\mathrm{C}_{7} \mathrm{H}_{14} \mathrm{O}$

$123-19-3$

4-Heptanone

PrCOPr

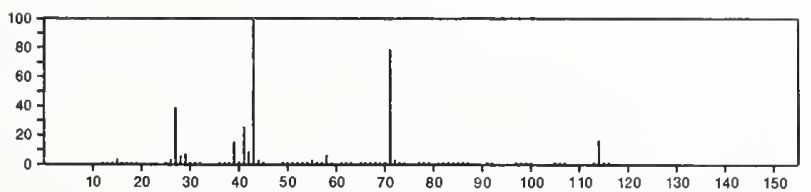

114

Cycloheptanol

$\mathrm{C}_{7} \mathrm{H}_{14} \mathrm{O}$

$502-41-0$<smiles>OC1CCCCCC1</smiles>

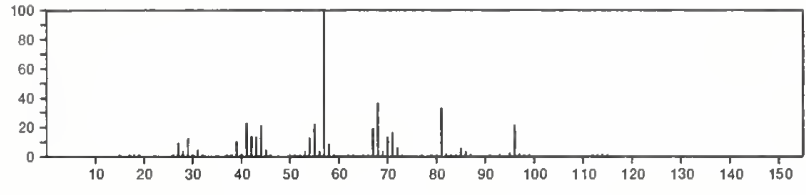

114

$\mathrm{C}_{7} \mathrm{H}_{14} \mathrm{O}$

565-80-0

3-Pentanone, 2,4-dimethyl

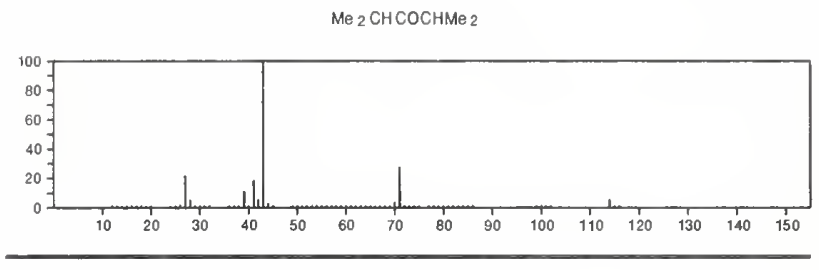

114

$\mathrm{C}_{7} \mathrm{H}_{14} \mathrm{O}$

583-59-5

Cyclohexanol, 2-methyl-
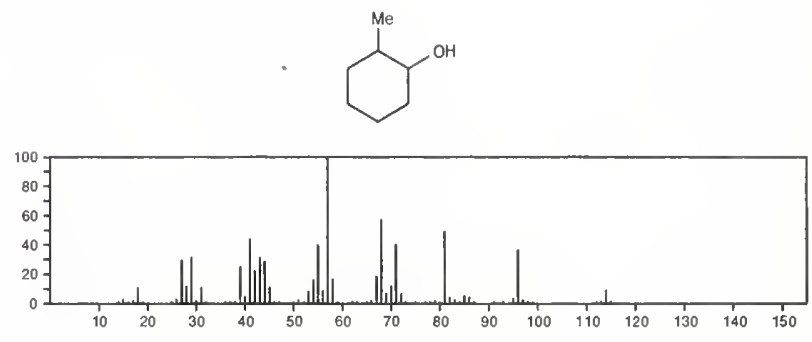

114

Cyclohexanol, 4-methyl-

$\mathrm{C}_{7} \mathrm{H}_{14} \mathrm{O}$

589-91-3
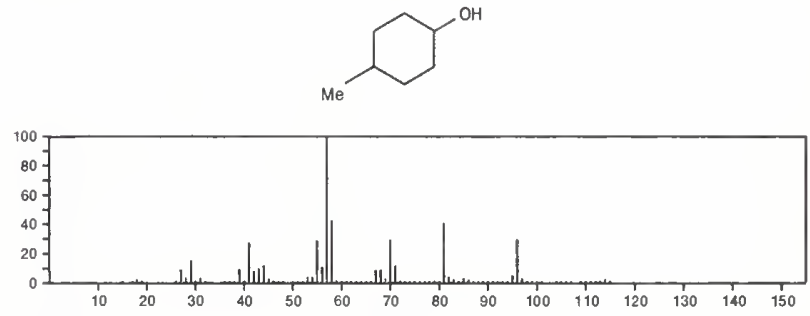

114

2-Pentanone, 4,4-dimethyl-

$\mathrm{C}_{7} \mathrm{H}_{14} \mathrm{O}$

590-50-1

$\mathrm{Me}_{\mathrm{COCH}} \mathrm{CMO}_{3}$

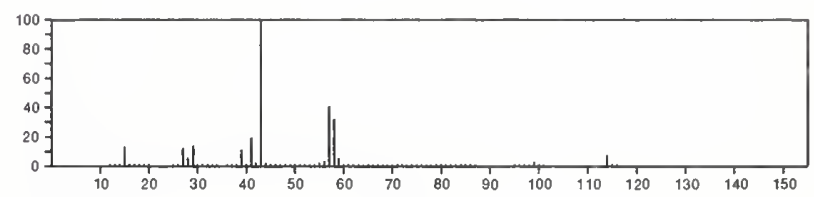

114

$\mathrm{C}_{7} \mathrm{H}_{14} \mathrm{O}$

591-23-1

Cyclohexanol, 3-methyl-<smiles>C[C@@H]1CCCC(O)C1</smiles>

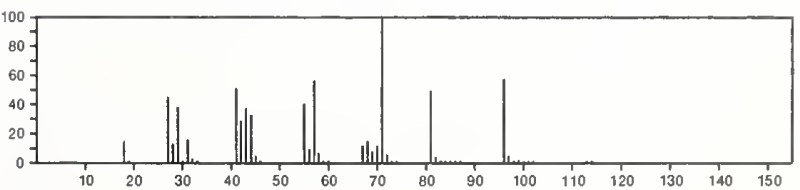


114

3-Hexanone, 5-methyl-

$\mathrm{C}_{7} \mathrm{H}_{14} \mathrm{O}$

$623-56-3$

$\mathrm{Me}_{2} \mathrm{CHCH}_{2} \mathrm{COE} 1$

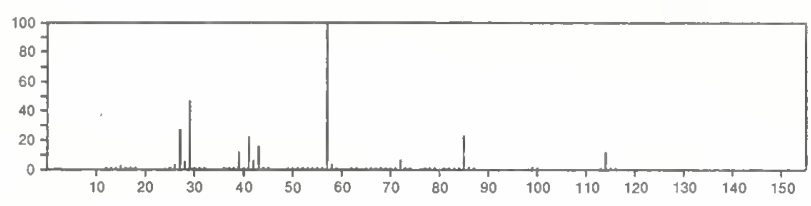

114

Hexanal, 2-methyl-

$\mathrm{C}_{7} \mathrm{H}_{14} \mathrm{O}$

$\mathrm{OCHCHMe}\left(\mathrm{CH}_{2}\right)_{3} \mathrm{Me}$

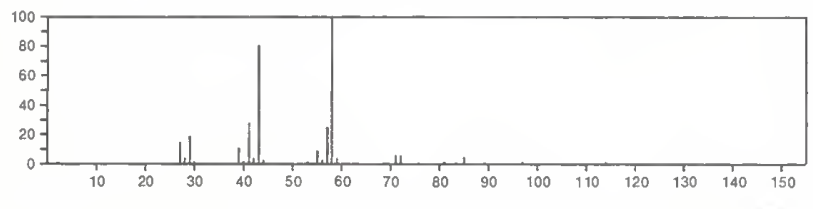

114

Cyclohexane, methoxy-

$\mathrm{C}_{7} \mathrm{H}_{14} \mathrm{O}$
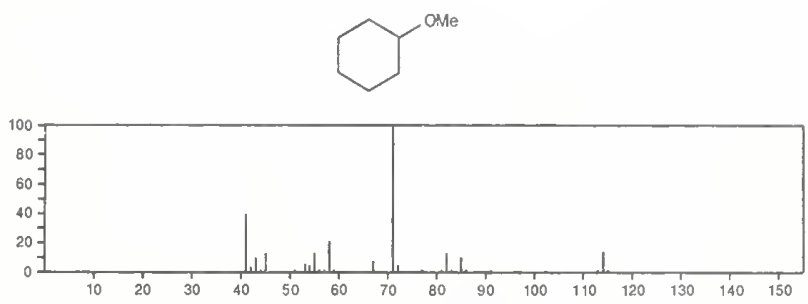

114

Cyclopentanol, 1-ethyl-

$\mathrm{C}_{7} \mathrm{H}_{14} \mathrm{O}$

1462-96-0
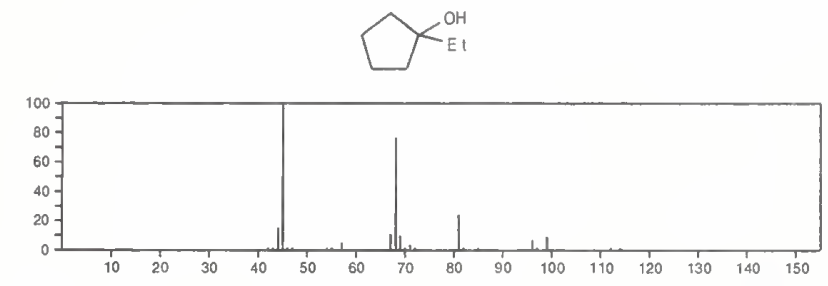

114

1-Propene, 3-(1,1-dimethylethoxy)

1471-04-1

i $-\mathrm{BuOCH} \mathrm{OCH}_{2} \mathrm{CH} \mathrm{CH}_{2}$

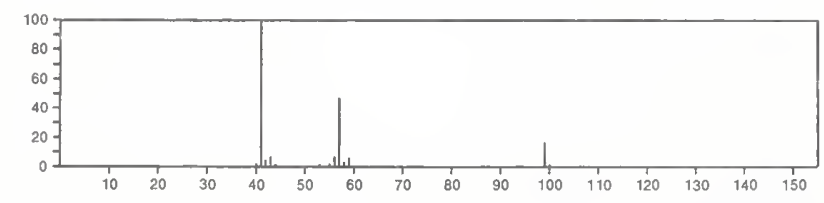

114

Hexanal, 5-methyl-

$$
\mathrm{C}_{7} \mathrm{H}_{14} \mathrm{O}
$$

1860-39-5

$\left.\mathrm{Me} 2 \mathrm{CH}_{(\mathrm{CH}}\right)_{3} \mathrm{CHO}$

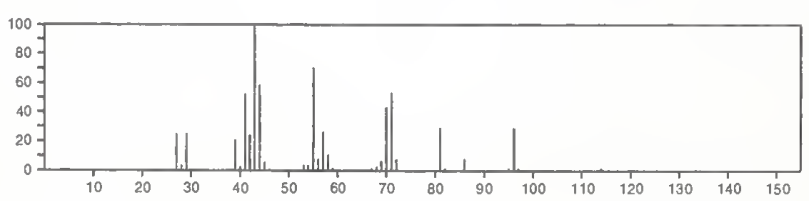

114 Oxirane, (2,2-dimethylpropyl)-

$\mathrm{C}_{7} \mathrm{H}_{14} \mathrm{O}$

2245-29-6
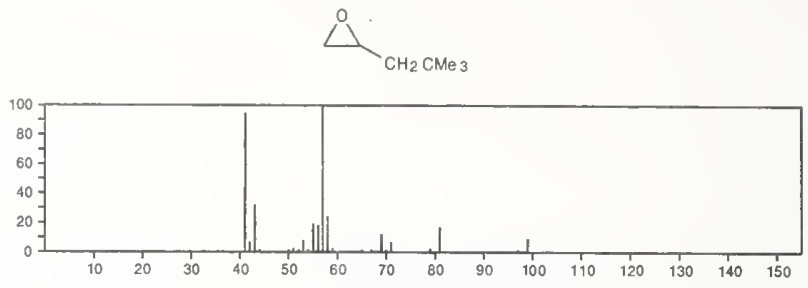

114

$\mathrm{C}_{7} \mathrm{H}_{14} \mathrm{O}$

3521-91-3

1-Hepten-4-ol

$\mathrm{H}_{2} \mathrm{C}=\mathrm{CHCH}_{2} \mathrm{CH}(\mathrm{OH}) \mathrm{Pr}$

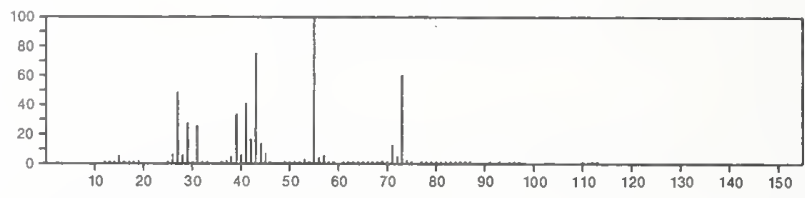

114

Butane, 1-(2-propenyloxy)-

$\mathrm{C}_{7} \mathrm{H}_{14} \mathrm{O}$

3739-64-8

$\mathrm{H}_{2} \mathrm{C}=\mathrm{CHCH}_{2} \mathrm{O}\left(\mathrm{CH}_{2}\right)_{3} \mathrm{Me}$

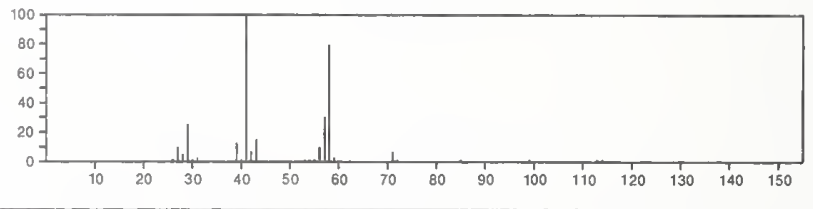

114

1-Hepten-3-ol

$\mathrm{C}_{7} \mathrm{H}_{14} \mathrm{O}$

4938-52-7

$\mathrm{Me}\left(\mathrm{CH}_{2}\right)$ 3 $\mathrm{CH}(\mathrm{OH}) \mathrm{CH}=\mathrm{CH}_{2}$

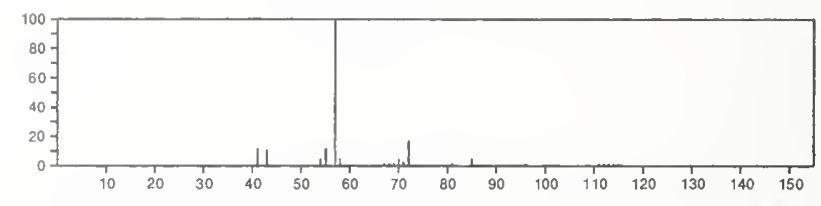

114

$\mathrm{C}_{7} \mathrm{H}_{14} \mathrm{O}$

5063-65-0

Oxirane, pentyl
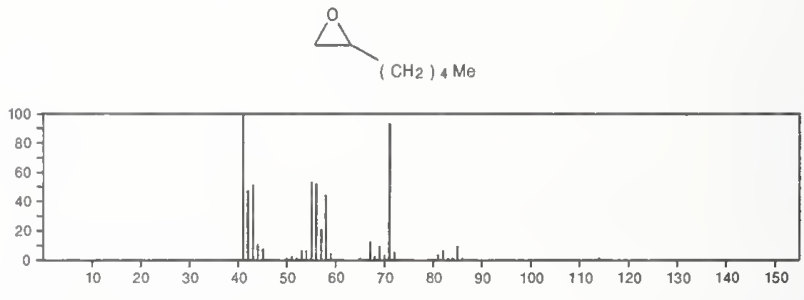

114

$\mathrm{C}_{7} \mathrm{H}_{14} \mathrm{O}$

5363-63-3

Pentane, 1-(ethenyloxy)-

$\mathrm{Me}\left(\mathrm{CH}_{2}\right)_{4} \mathrm{OCH}=\mathrm{CH}_{2}$

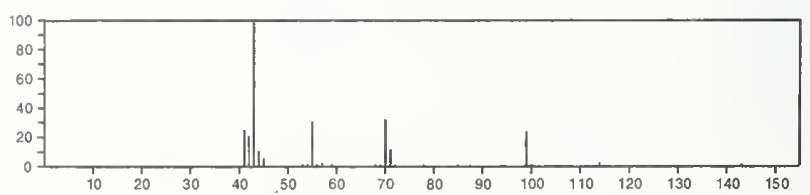


114 $\mathrm{C}_{7} \mathrm{H}_{14} \mathrm{O}$

Cyclohexanol, 2-methyl-, trans-

$7443-52-9$
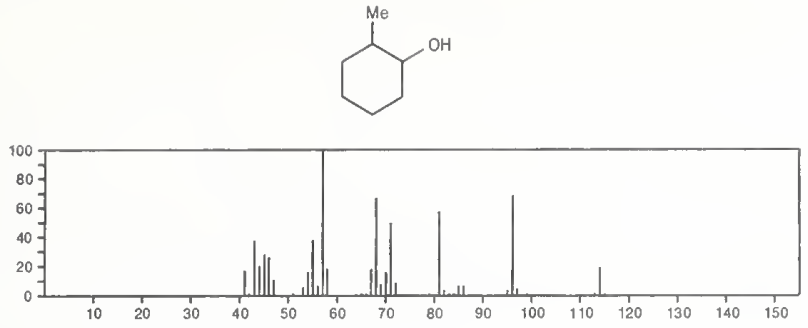

114

Cyclohexanol, 2-methyl-, cis-

$\mathrm{C}_{7} \mathrm{H}_{14} \mathrm{O}$

$7443-70-1$<smiles>NC1CCCCC1O</smiles>

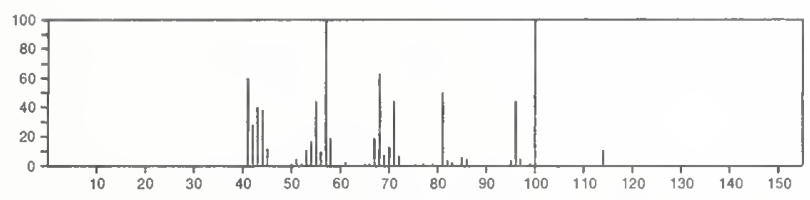

114

$\mathrm{C}_{7} \mathrm{H}_{14} \mathrm{O}$

$7731-28-4$

Cyclohexanol, 4-methyl-, cis-
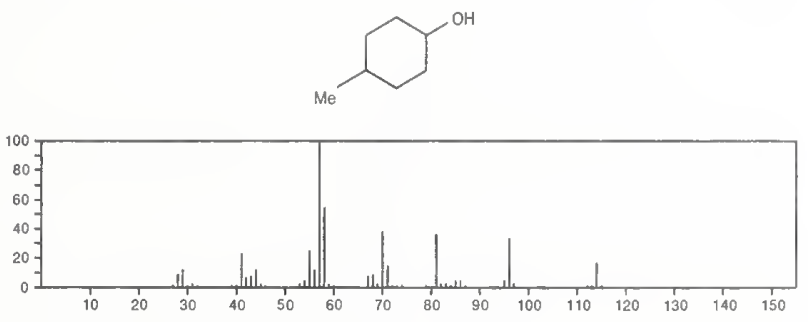

\section{4}

Cyclohexanol, 4-methyl-, $\mathrm{Crans}_{74}$

$7731-29-5$
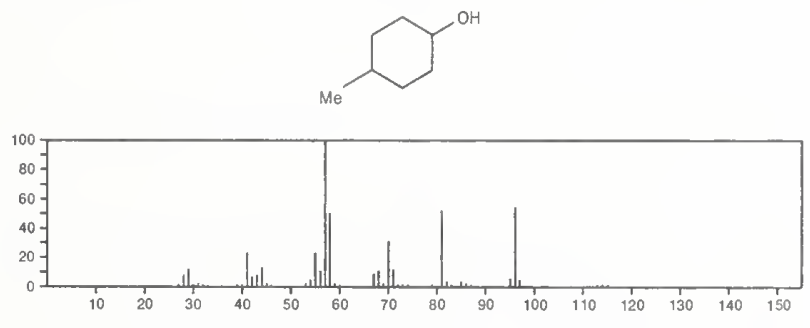

114

3-Hepten-1-ol

$\mathrm{C}_{7} \mathrm{H}_{14} \mathrm{O}$

$10606-47-0$

$\mathrm{HOCH}_{2} \mathrm{CH}_{2} \mathrm{CH}$ : $\mathrm{CHP}$ r

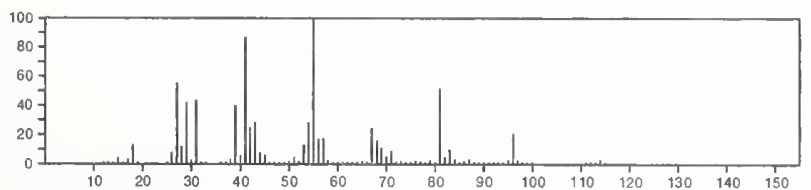

114

$\mathrm{C}_{7} \mathrm{H}_{14} \mathrm{O}$

$14250-88-5$

Pentanal, 2,2-dimethyl-

$\operatorname{PrCMe} 2(\mathrm{CHO})$

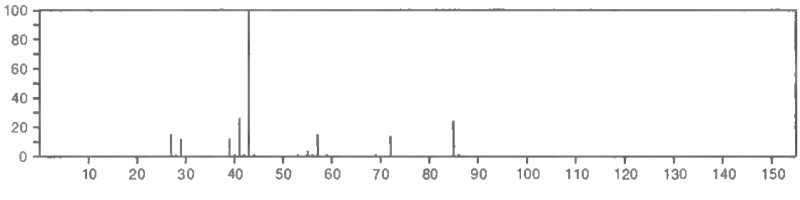

114

Oxirane, 2-butyl-3-methyl

$\mathrm{C}_{7} \mathrm{H}_{14} \mathrm{O}$

$14925-96-3$
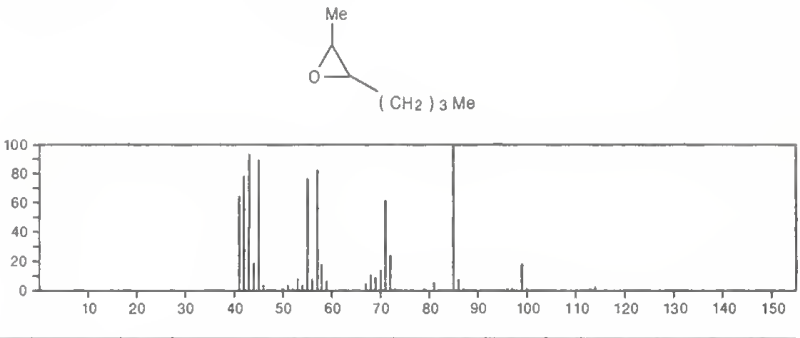

114

Ether, 1-butylvinyl methyl

$\mathrm{C}_{7} \mathrm{H}_{14} \mathrm{O}$

16519-66-7

$\mathrm{Me}\left(\mathrm{CH}_{2}\right)_{3} \mathrm{C}(\mathrm{OMe}): \mathrm{CH}_{2}$

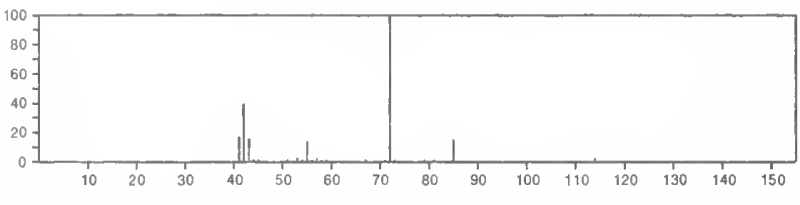

114

$\mathrm{C}_{7} \mathrm{H}_{14} \mathrm{O}$

$17612-35-0$

Oxirane, 2,2-dimethyl-3-propyl
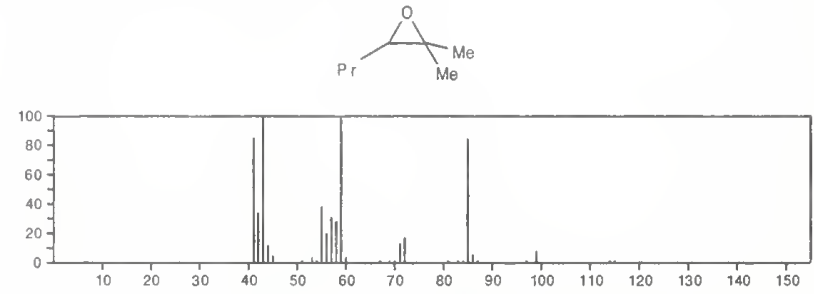

114

$\mathrm{C}_{7} \mathrm{H}_{14} \mathrm{O}$

19269-28-4

Hexanal, 3-methyl-

$\mathrm{OCHCH}_{2} \mathrm{CHPrMe}_{\mathrm{M}}$

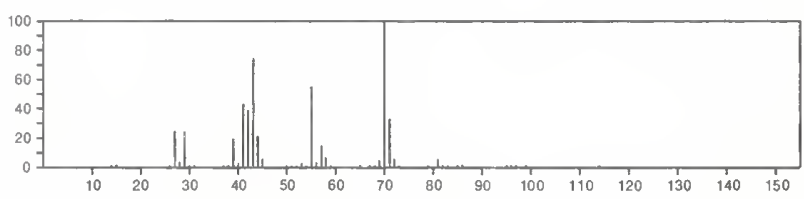

114

4-Hepten-1-ol

$\mathrm{C}_{7} \mathrm{H}_{14} \mathrm{O}$

20851-55-2

$\mathrm{HO}\left(\mathrm{CH}_{2}\right){ }_{3} \mathrm{CH}=\mathrm{CHEt}$

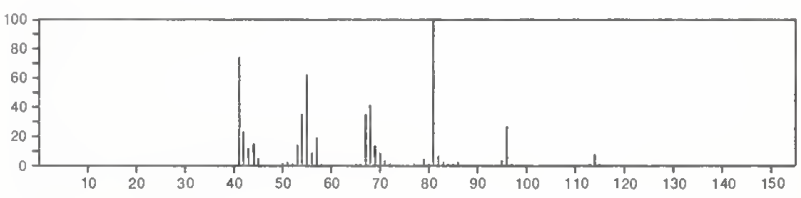


114

Cyclohexanol, methyl

$\mathrm{C}_{7} \mathrm{H}_{14} \mathrm{O}$

25639-42-3
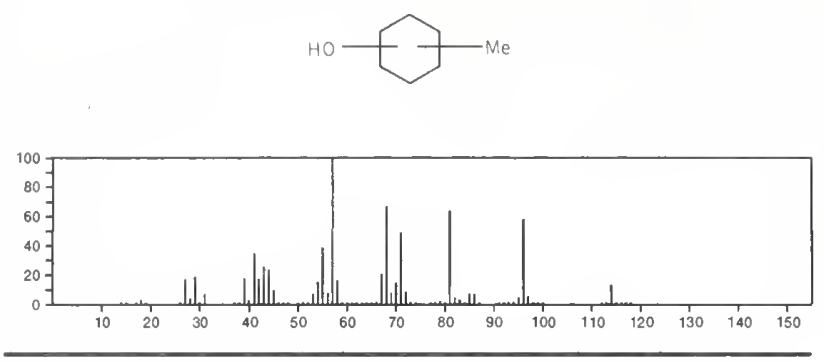

114

$\mathrm{C}_{7} \mathrm{H}_{14} \mathrm{O}$

$27944-79-2$

Pentanal, 2,4-dimethyl-

$\mathrm{OCHCHMe} \mathrm{CH}_{2} \mathrm{CHMe}_{2}$

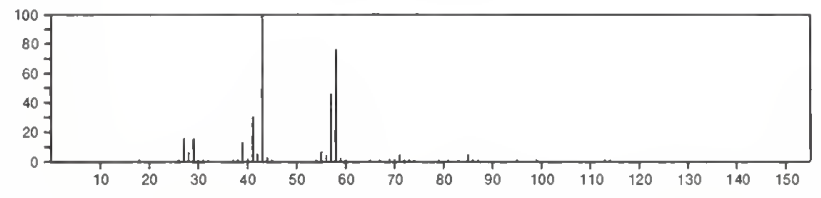

114

$\mathrm{C}_{7} \mathrm{H}_{14} \mathrm{O}$

Butane, 2-(ethenyloxy)-2-methyl-

$\mathrm{H}_{2} \mathrm{C}: \mathrm{CHOCE}+\mathrm{Me} 2$

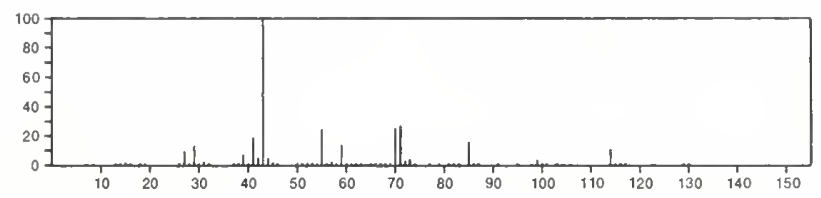

${ }_{2}^{114} \quad \underset{\mathrm{C}_{7} \mathrm{H}_{14} \mathrm{O}}{2-\mathrm{Hexen}-1-\mathrm{ol}, 3-\text { methyl- }}$

$30801-96-8$

$\mathrm{HOCH}_{2} \mathrm{CH}=\mathrm{CP}$ r Me

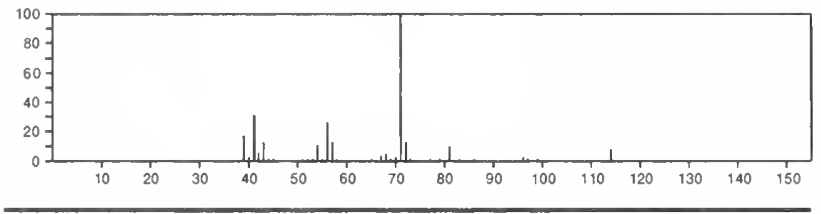

114

$\mathrm{C}_{7} \mathrm{H}_{14} \mathrm{O}$

$32749-94-3$

Pentanal, 2,3-dimethyl-

$\mathrm{Me} \mathrm{CH}_{2} \mathrm{CHMe}$ CHMeCHO

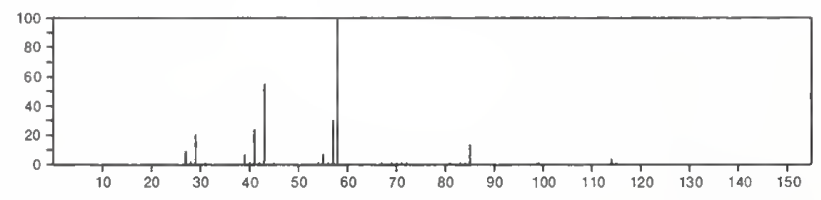

114

Ether, 3-butenyl propyl

$\mathrm{C}_{7} \mathrm{H}_{14} \mathrm{O}$

34061-75-1

$\mathrm{H}_{2} \mathrm{C}=\mathrm{CHCH}_{2} \mathrm{CH}_{2} \mathrm{OPr}$

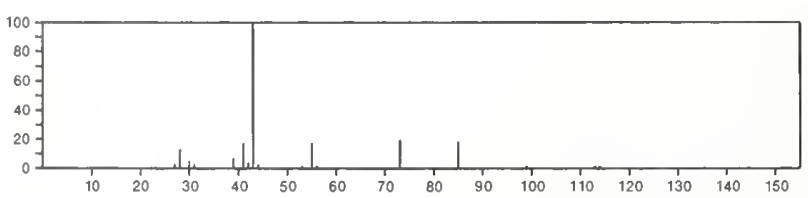

114

39782-38-2
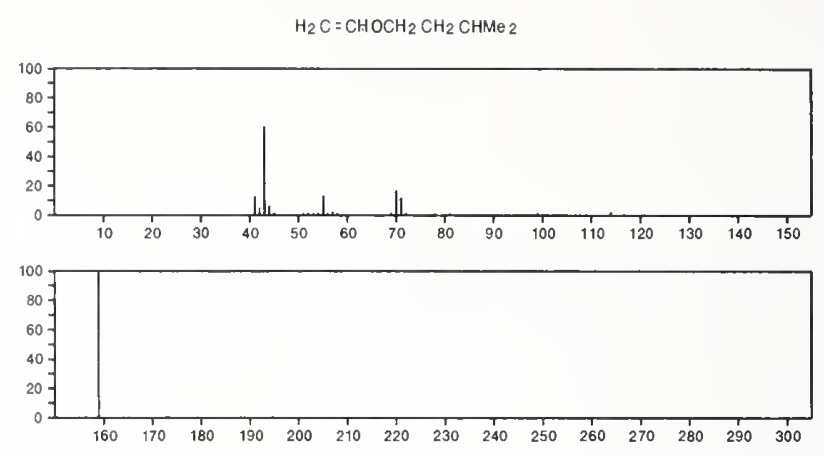

$\mathrm{C}_{7} \mathrm{H}_{14} \mathrm{O}$

41065-97-8

Hexanal, 4-methyl

$\mathrm{OCHCH}_{2} \mathrm{CH}_{2} \mathrm{CHMeCH}_{2} \mathrm{Me}$

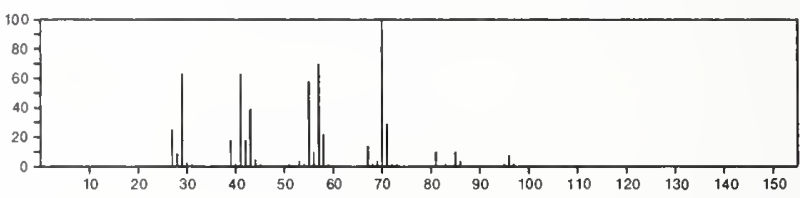

114

$\mathrm{C}_{7} \mathrm{H}_{14} \mathrm{O}$

42328-43-8

Oxirane, 2-methyl-2-(1-methylpropyl)-
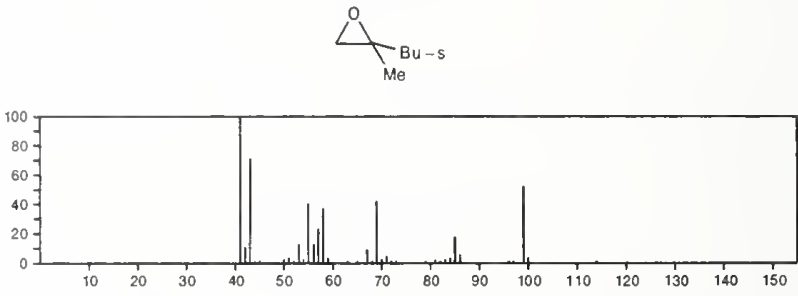

114

$\mathrm{C}_{7} \mathrm{H}_{14} \mathrm{O}$

Cyclopentanemethanol, $\alpha$-methyl-

52829-98-8

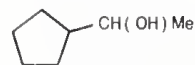

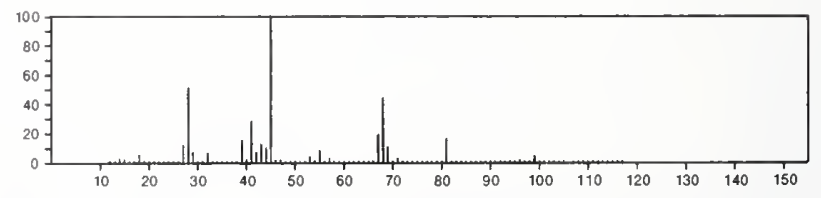

$114 \quad \mathrm{C}_{7} \mathrm{H}_{14} \mathrm{O}$

Oxirane, (1-methylbutyl)-
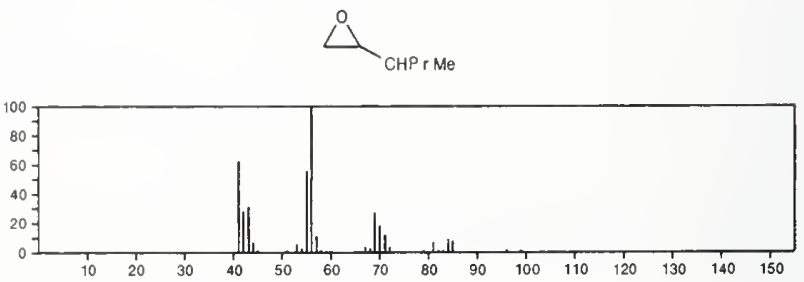
114

$\mathrm{C}_{7} \mathrm{H}_{14} \mathrm{O}$

53229-41-7

114

$\mathrm{C}_{7} \mathrm{H}_{14} \mathrm{O}$

$56052-83-6$

Oxirane, (3-methylbutyl)-
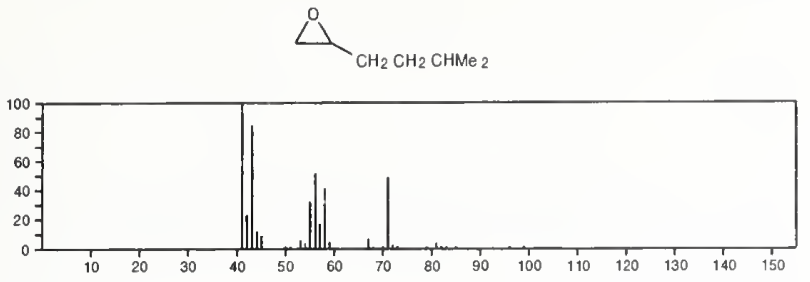

114

$\mathrm{C}_{7} \mathrm{H}_{14} \mathrm{O}$

$53229-42-8$

Oxirane, (2-methylbutyl)-
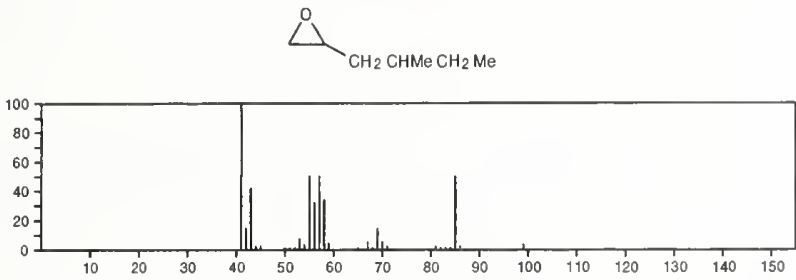

114

$\mathrm{C}_{7} \mathrm{H}_{14} \mathrm{O}$

1-Propene, 2-methyl-3-propoxy-

$53897-29-3$

$\mathrm{Pr} \mathrm{OCH} 2 \mathrm{CMe}=\mathrm{CH}_{2}$

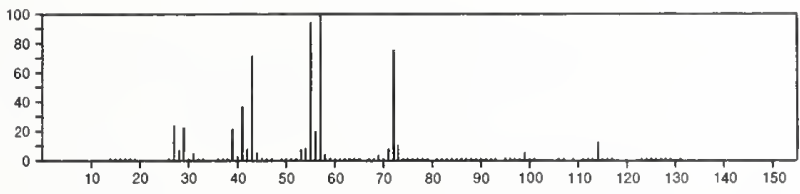

114

$\mathrm{C}_{7} \mathrm{H}_{14} \mathrm{O}$

$53897-30-6$

Oxirane, 2-(1,1-dimethylethyl)-3-methyl-
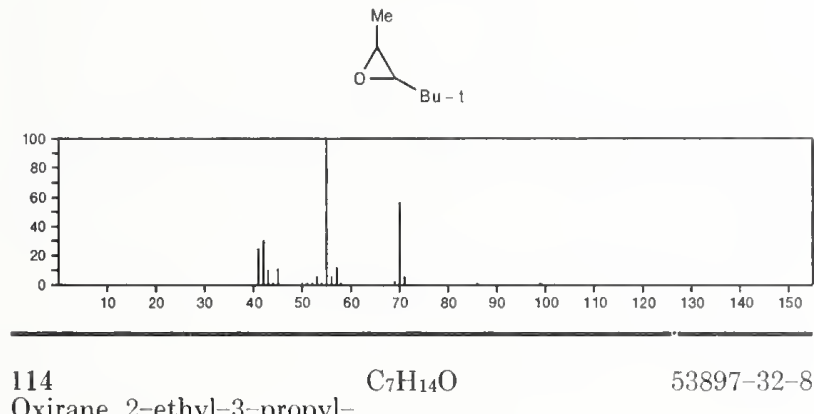

Oxirane, 2-ethyl-3-propyl-
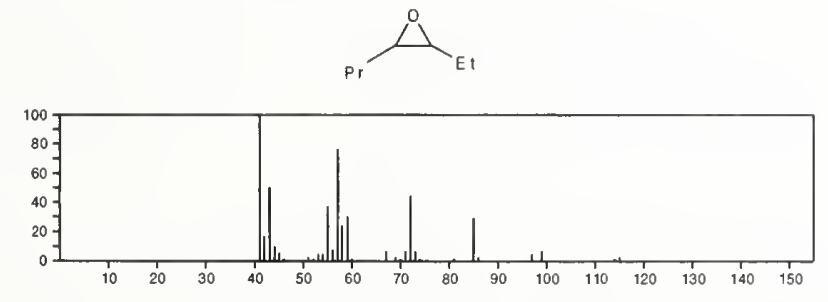

114

2-Butene, 1-propoxy-, (E)

$\mathrm{C}_{7} \mathrm{H}_{14} \mathrm{O}$

$56052-71-2$

$\operatorname{PrOCH}_{2} \mathrm{CH}=\mathrm{CHME}$

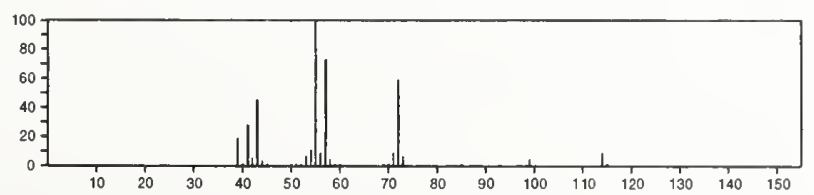

2-Hexene, 1-methoxy-, $(E)-$
MeOCH $2 \mathrm{CH}=\mathrm{CHP}$

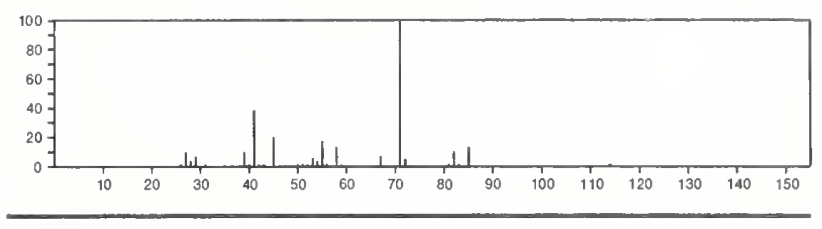

114

$\mathrm{C}_{7} \mathrm{H}_{14} \mathrm{O}$

$56052-93-8$

Oxirane, 2-butyl-3-methyl-, cis-
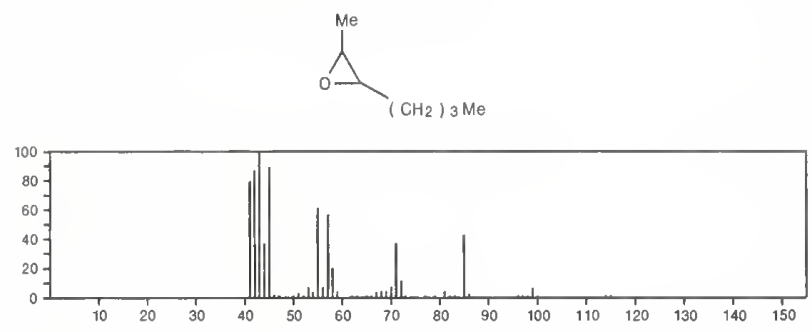

114
Oxirane, 2-ethyl-3-propyl-, $\mathrm{Cis}_{7} \mathrm{H}_{14} \mathrm{O}$

$56052-94-9$
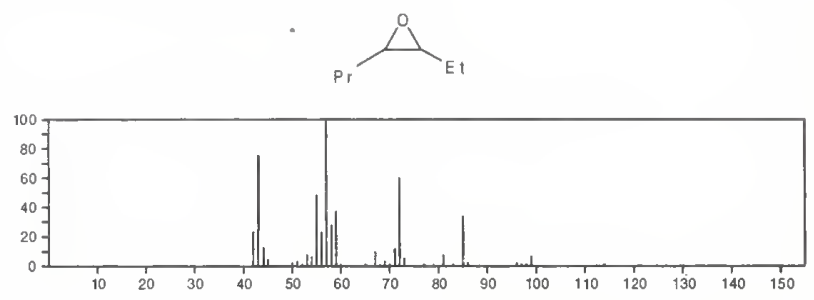

114

$\mathrm{C}_{7} \mathrm{H}_{14} \mathrm{O}$

Oxirane, 2-ethyl-3-propyl-, trans-

$56052-95-0$
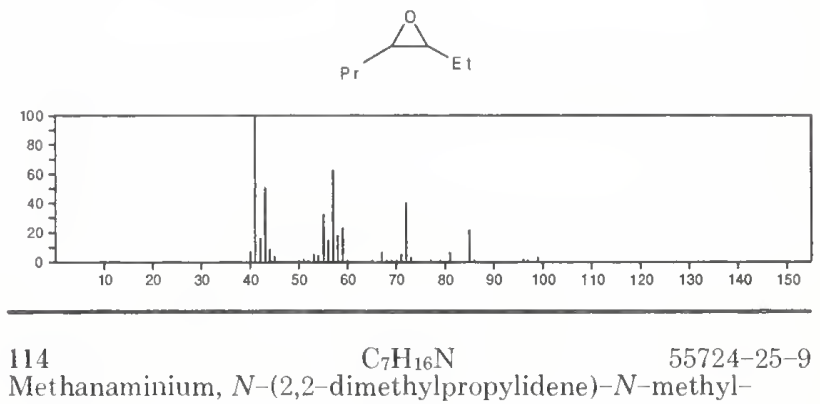

Methanaminium, $N$-(2,2-dimethylpropylidene)- $N$-methyl-

$\mathrm{Me} 3 \mathrm{CCH}^{+} \stackrel{+}{\mathrm{i}} \mathrm{Me}_{2}$

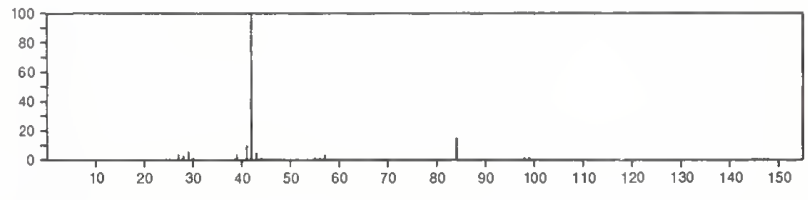

114

Octane

$\mathrm{C}_{8} \mathrm{H}_{18}$

$111-65-9$

$\mathrm{Me}\left(\mathrm{CH}_{2}\right)_{6} \mathrm{Me}$

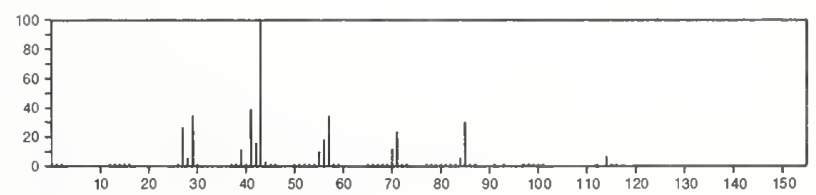


114

Pentane, 2,2,4-trimethyl-

$\mathrm{C}_{8} \mathrm{H}_{18}$

$\mathrm{Me}_{3} \mathrm{CCH}_{2} \mathrm{CHMe}_{2}$

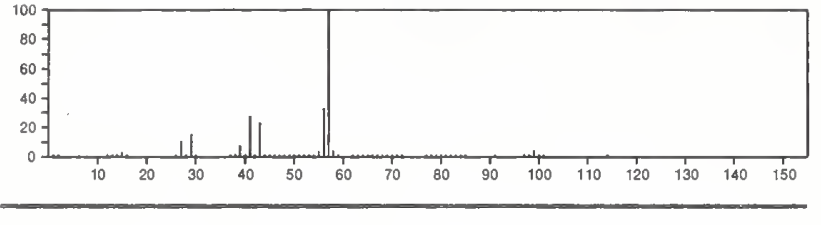

114

Pentane, 2,3,3-trimethyl

$\mathrm{C}_{8} \mathrm{H}_{18}$

$560-21-4$

$\mathrm{Me}_{2} \mathrm{CHCE}_{\mathrm{He}} 2$

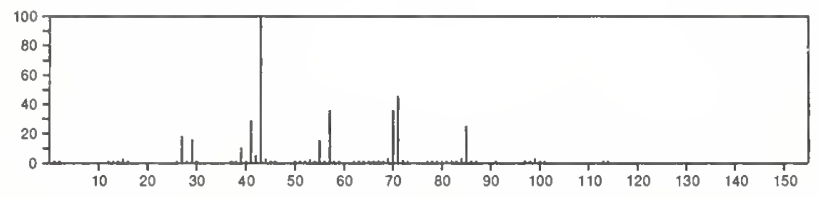

114

Hexane, 3,3-dimethyl-

$\mathrm{C}_{8} \mathrm{H}_{18}$

$\operatorname{PrCE}+(\mathrm{Me})_{2}$
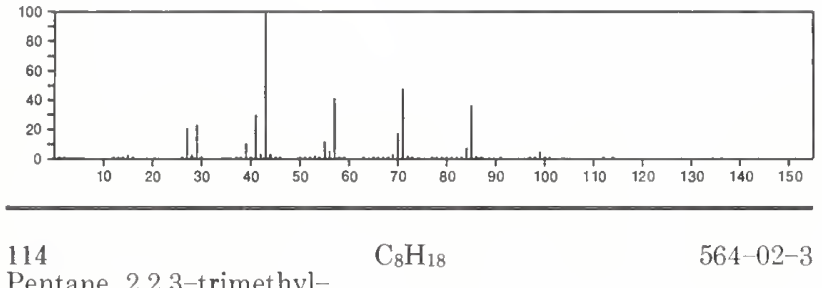

Pentane, 2,2,3-trimethyl-

$\mathrm{Me} \mathrm{CH}_{2} \mathrm{CHMeCMe}_{3}$

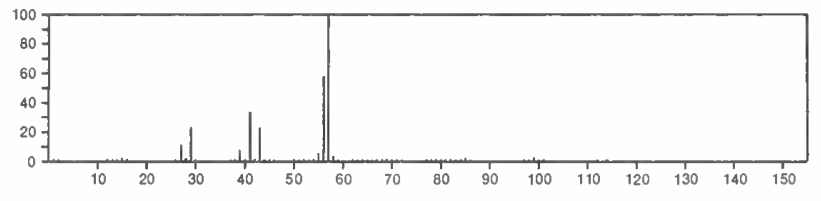

114

Pentane, 2,3,4-trimethyl-

$\mathrm{C}_{8} \mathrm{H}_{18}$

$565-75-3$

$\mathrm{Me}_{2} \mathrm{CHCHMe} \mathrm{CHMe}_{2}$

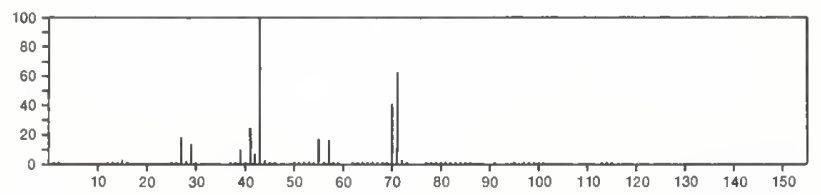

114

$\mathrm{C}_{8} \mathrm{H}_{18}$

Hexane, 3,4-dimethyl-

$\mathrm{MeCH} 2 \mathrm{CHMe} \mathrm{CHMe} \mathrm{CH}_{2} \mathrm{Me}$

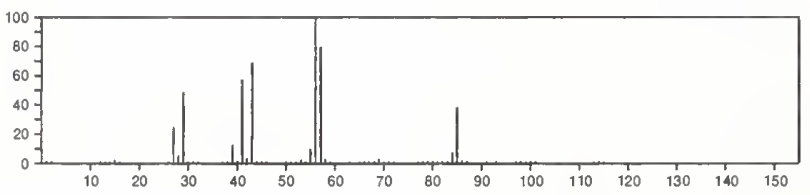

114

$\mathrm{C}_{8} \mathrm{H}_{18}$

584-94-1

Hexane, 2,3-dimethyl-

$\mathrm{Me}_{2} \mathrm{CHCHP} r \mathrm{Me}$

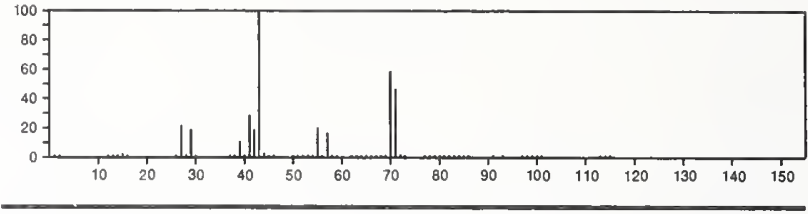

114

Hexane, 2,4-dimethyl

$\mathrm{C}_{8} \mathrm{H}_{18}$

589-43-5

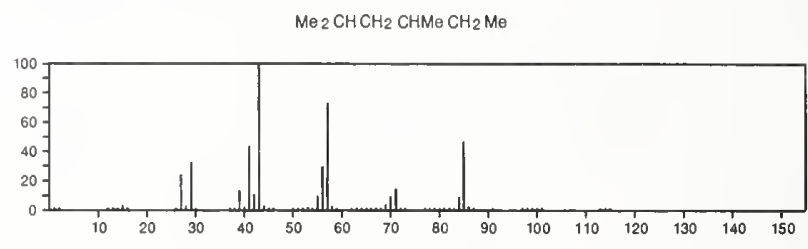

114

$\mathrm{C}_{8} \mathrm{H}_{18}$

589-53-7

Heptane, 4-methyl-

$\mathrm{Pr}_{2} \mathrm{CHMe}$

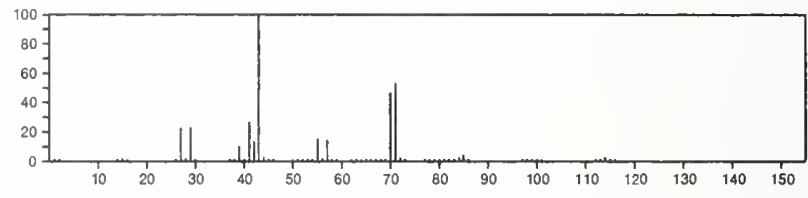

$114 \quad \mathrm{C}_{8} \mathrm{H}_{18}$

Heptane, 3-methyl-

$\mathrm{Me}\left(\mathrm{CH}_{2}\right)_{3} \mathrm{CHMeCH}_{2} \mathrm{Me}$

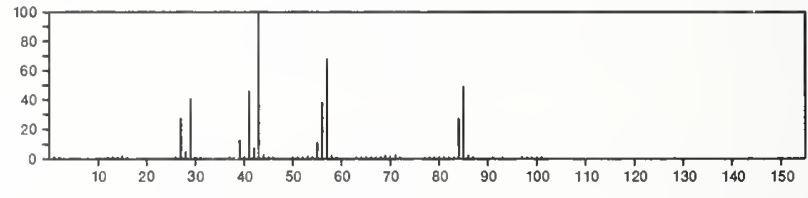

114

$\mathrm{C}_{8} \mathrm{H}_{18}$

590-73-8

Hexane, 2,2-dimethyl-

$\mathrm{Me}{ }_{3} \mathrm{C}\left(\mathrm{CH}_{2}\right){ }_{3} \mathrm{Me}$

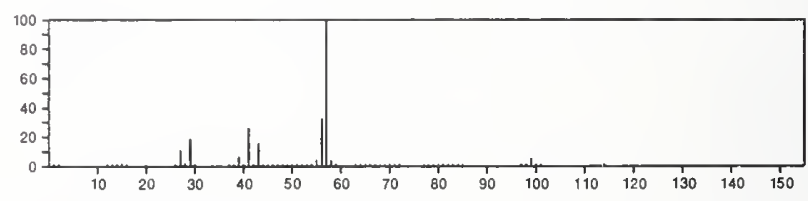

114

$\mathrm{C}_{8} \mathrm{H}_{18}$

Hexane, 2,5-dimethyl-

$\mathrm{Me}_{2} \mathrm{CHCH}_{2} \mathrm{CH}_{2} \mathrm{CHMe} 2$

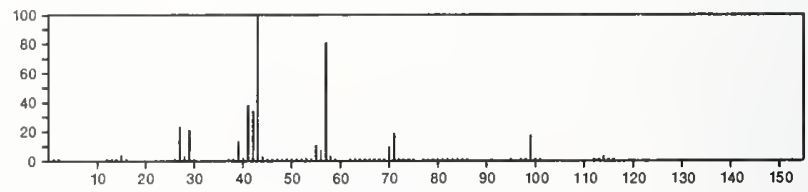


114

Heptane, 2-methyl-

$\mathrm{C}_{8} \mathrm{H}_{18}$

$\mathrm{Me}_{2} \mathrm{CH}\left(\mathrm{CH}_{2}\right)_{4} \mathrm{Me}$

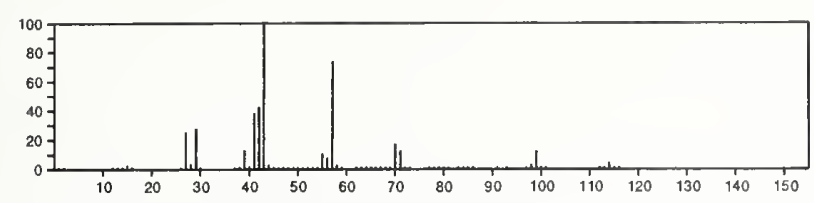

114

Butane, 2,2,3,3-tetramethyl-

$\mathrm{C}_{8} \mathrm{H}_{18}$

$\mathrm{Me}_{3} \mathrm{CCM} 3$

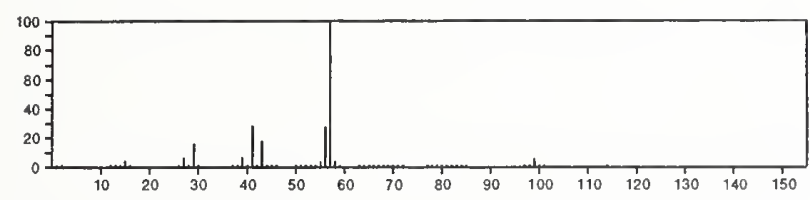

114

Pentane, 3-ethyl-2-methyl-

$\mathrm{C}_{8} \mathrm{H}_{18}$

$609-26-7$

$\mathrm{Me} 2 \mathrm{CHCHE}_{2} 2$

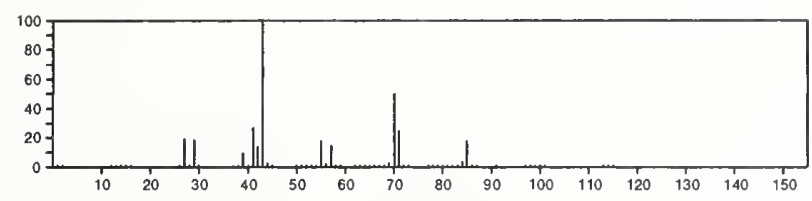

114

Hexane, 3-ethyl-

$\mathrm{C}_{8} \mathrm{H}_{18}$

$\mathrm{Et}_{2} \mathrm{CHPr}$

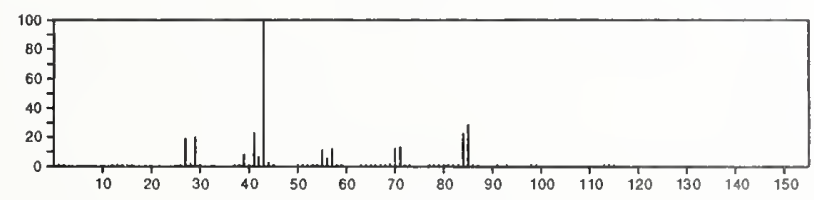

114
Pentane, 3-ethyl-3-methyl-

$\mathrm{C}_{8} \mathrm{H}_{18}$

$\mathrm{Et} 3 \mathrm{CMe}$

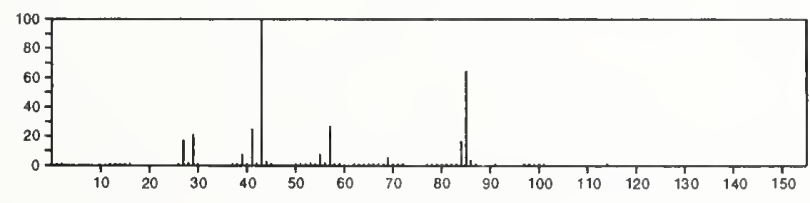

115

$\mathrm{C}_{3} \mathrm{H}_{5} \mathrm{~N}_{3} \mathrm{~S}$

$24854-43-1$

$3 H-1,2,4$-Triazole-3-thione, 2,4-dihydro-4-methyl-<smiles>Cn1cn[nH]c1=S</smiles>

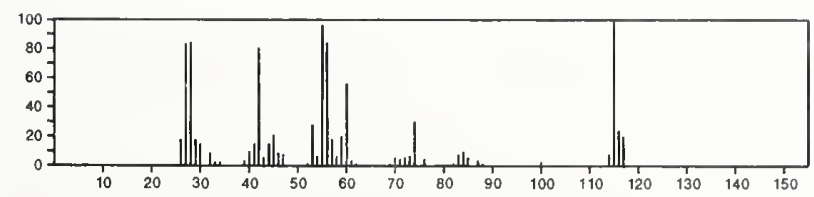

115

5-Isothiazolemethanol

$\mathrm{C}_{4} \mathrm{H}_{5} \mathrm{NOS}$

1710-66-3

$\prod_{\mathrm{N}-\mathrm{S}}^{\mathrm{CH}_{2} \mathrm{OH}}$

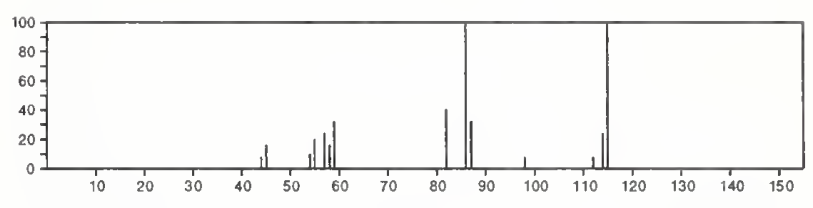

115

$\mathrm{C}_{4} \mathrm{H}_{5} \mathrm{NOS}$

14542-13-3

Thiazole, 2-methoxy-
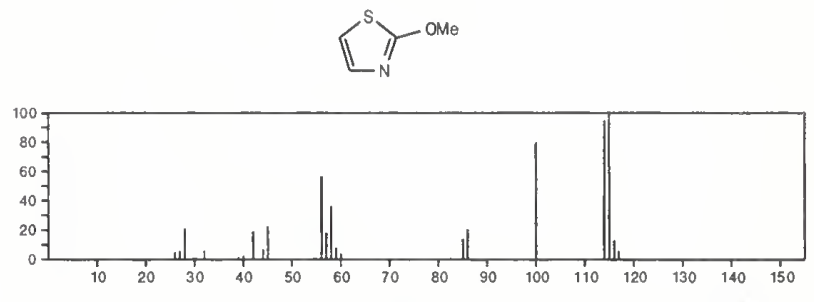

\begin{tabular}{lll}
\hline 15 & $\mathrm{C}_{4} \mathrm{H}_{5} \mathrm{NOS}$ & $14542-14-4$
\end{tabular}

Thiazole, 5-methoxy-
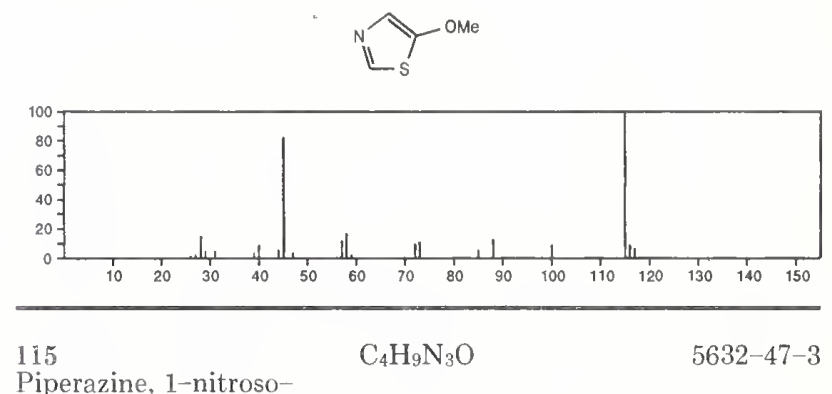

Piperazine, 1-nitroso-<smiles>O=[N+]([O-])N1CCNCC1</smiles>

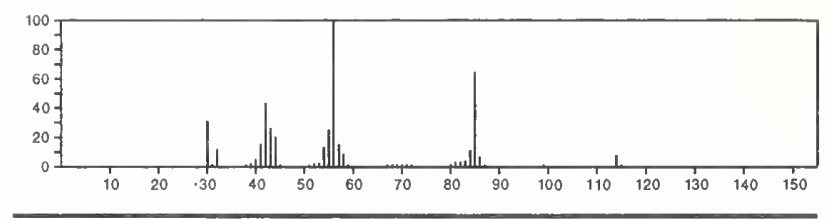

115

$\mathrm{C}_{5} \mathrm{H}_{9} \mathrm{NO}_{2}$

$147-85-3$

L-Proline

${ }^{\mathrm{N}} \mathrm{CO}^{\mathrm{CO}}$

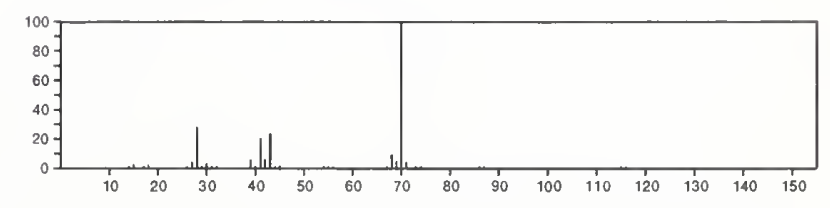

115

Cyclopentane, nitro-

$\mathrm{C}_{5} \mathrm{H}_{9} \mathrm{NO}_{2}$

2562-38-1
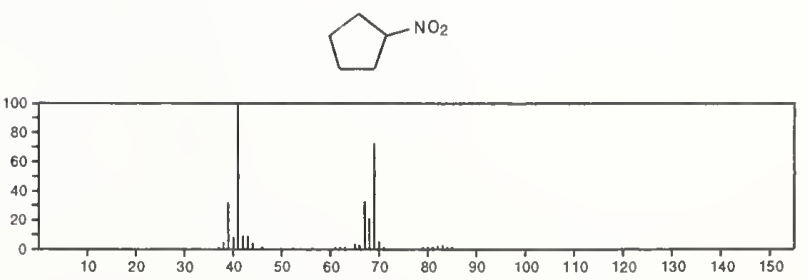
115

Propanamide, $\mathrm{N}$-acetyl-

$\mathrm{C}_{5} \mathrm{H}_{9} \mathrm{NO}_{2}$

ACNHCOE

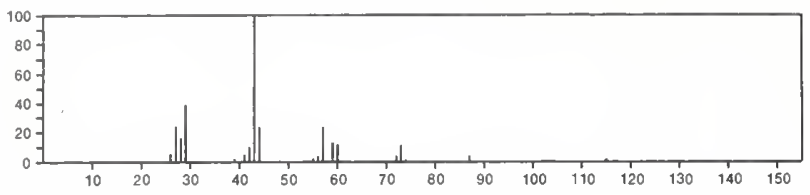

$115 \quad \mathrm{C}_{5} \mathrm{H}_{9} \mathrm{NO}_{2}$

Cyclobutanecarboxylic acid, 1-amino-
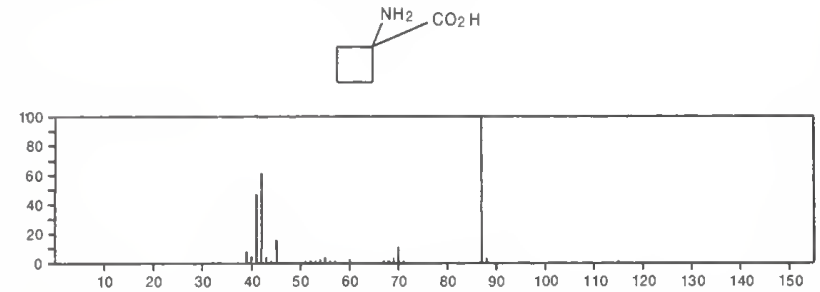

115

$\mathrm{C}_{5} \mathrm{H}_{9} \mathrm{NO}_{2}$

23542-51-0

1-Pentene, 5-nitro-

$\mathrm{H}_{2} \mathrm{C}=\mathrm{CH}\left(\mathrm{CH}_{2}\right){ }_{3} \mathrm{NO}_{2}$

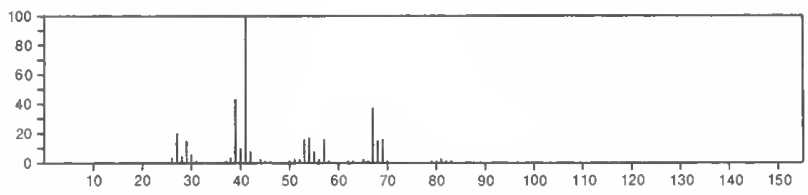

115

$\mathrm{C}_{5} \mathrm{H}_{9} \mathrm{NS}$

Butane, 1-isothiocyanato-

$\mathrm{SCN}\left(\mathrm{CH}_{2}\right)_{3} \mathrm{Me}$

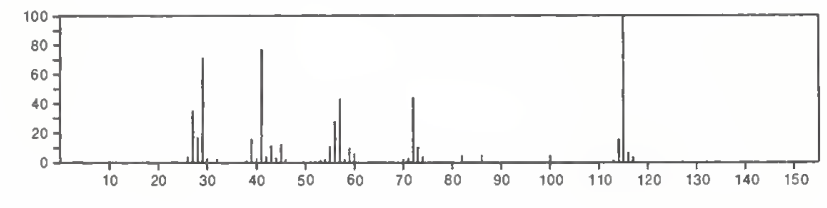

115

Thiocyanic acid, butyl ester

\section{$\mathrm{C}_{5} \mathrm{H}_{9} \mathrm{NS}$}

628-83-1

$\mathrm{NCS}\left(\mathrm{CH}_{2}\right)_{3} \mathrm{Me}$

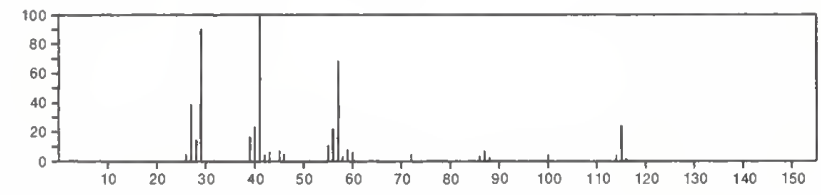

$115 \quad \mathrm{C}_{5} \mathrm{H}_{13} \mathrm{~N}_{3}$

Guanidine, $N, N, N^{\prime}, N^{\prime}$-tetramethyl-

$80-70-6$

$\mathrm{NMe} 2$
$\mathrm{Me}$
$2 \mathrm{NC}=\mathrm{NH}$

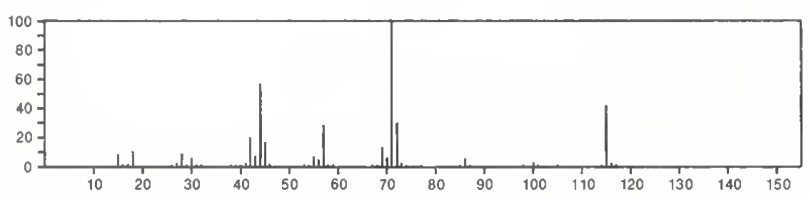

115

Morpholine, 4-ethyl-

$\mathrm{C}_{6} \mathrm{H}_{13} \mathrm{NO}$

$100-74-3$

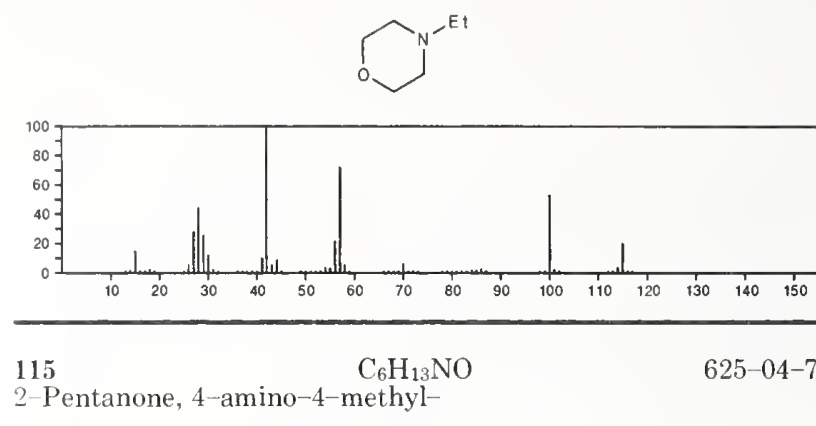

$\mathrm{MeCOCH}_{2} \mathrm{CMe}_{2} \mathrm{NH}_{2}$

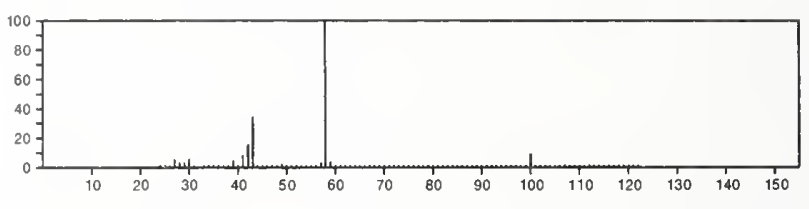

115

$\mathrm{C}_{6} \mathrm{H}_{13} \mathrm{NO}$

$628-02-4$

Hexanamide

$\mathrm{Me}\left(\mathrm{CH}_{2}\right)_{4} \mathrm{CONH}_{2}$

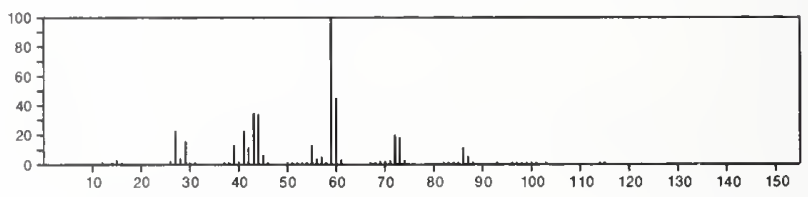

115
Acetamide, $N, N$-diethyl-

$685-91-6$

EI 2 NAC

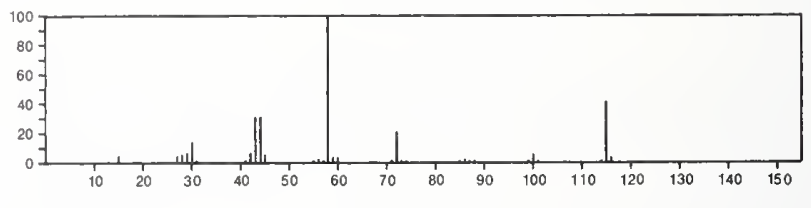

115

Cyclohexanol, 2-amino-, cis-

$\mathrm{C}_{6} \mathrm{H}_{13} \mathrm{NO}$

$931-15-7$<smiles>NC1CCCCC1O</smiles>

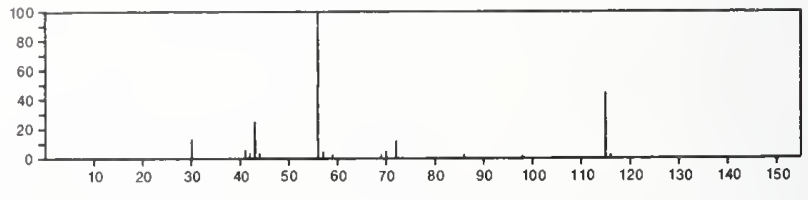

115

$\mathrm{C}_{6} \mathrm{H}_{13} \mathrm{NO}$

1119-29-5

Pentanamide, 4-methyl

$\mathrm{Me}_{2} \mathrm{CHCH}_{2} \mathrm{CH}_{2} \mathrm{CONH}_{2}$

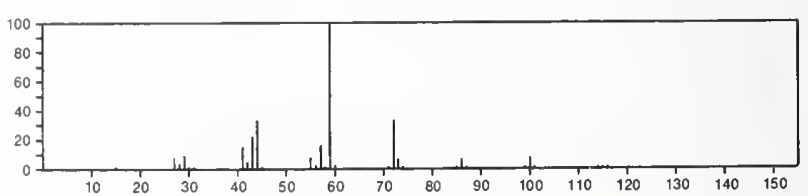


115

Acetamide, $N$-butyl-

$\mathrm{C}_{6} \mathrm{H}_{13} \mathrm{NO}$

$1119-49-9$

$\mathrm{Me}\left(\mathrm{CH}_{2}\right){ }_{3} \mathrm{NHAC}$

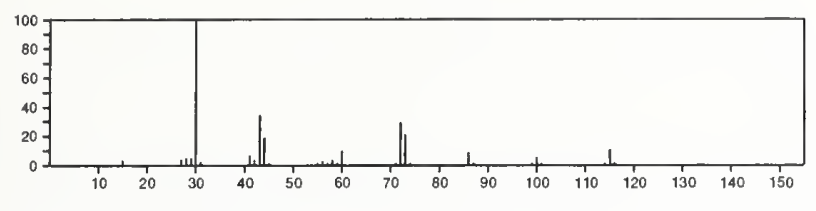

$115 \quad \mathrm{C}_{6} \mathrm{H}_{13} \mathrm{NO}$

Acetamide, $N$-(1-methylpropyl)-

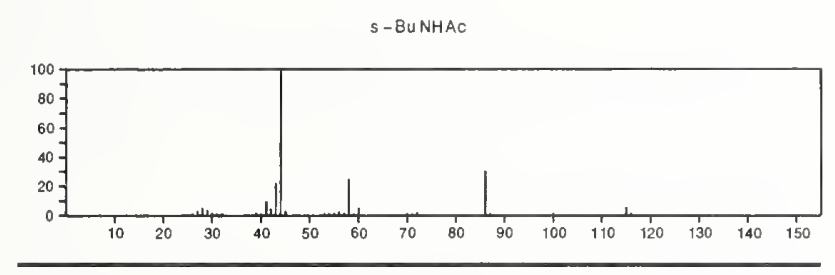

115

Acetamide, $\mathrm{N}-(2-$ methylpropyl)-

$1540-94-9$
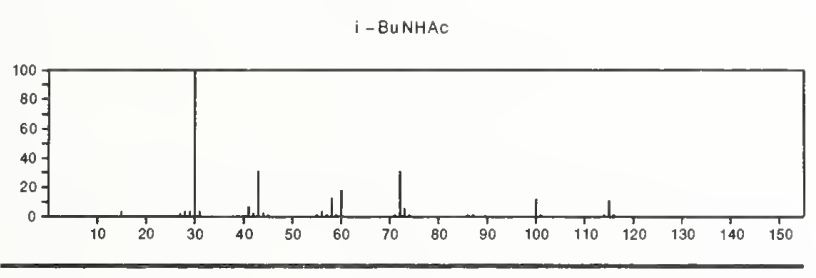

115

Butanamide, $N$-ethyl-

$\mathrm{C}_{6} \mathrm{H}_{13} \mathrm{NO}$

$13091-16-2$

ETHHCOPT
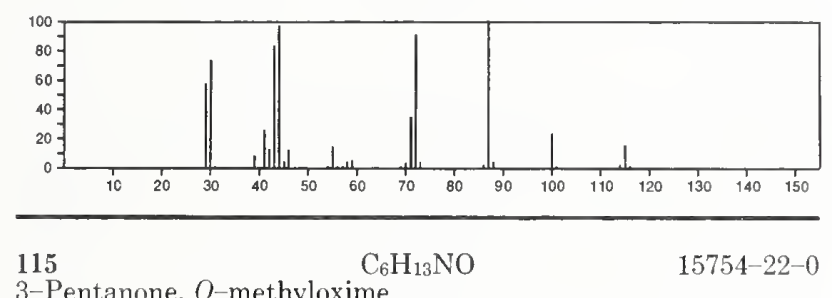

3-Pentanone, $\mathrm{O}$-methyloxime

Me ON: CEt 2

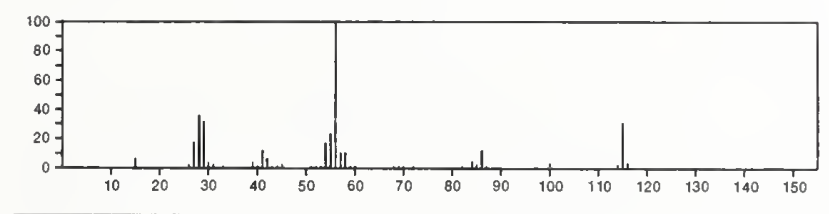

115

2-Butanone, 3-methyl-, $O$-methyloxime

27685-13-8

Me2 $\mathrm{CHCMe}=$ NOMe

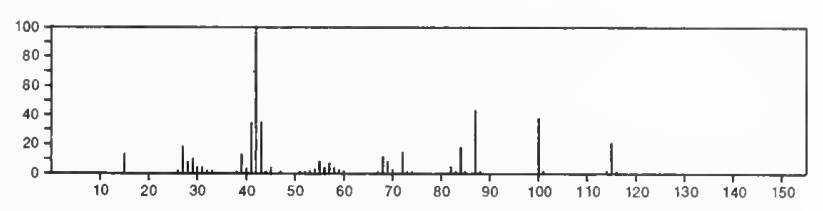

115

2-Pentanone, $\mathrm{O}$-methyloxime

$\mathrm{C}_{6} \mathrm{H}_{13} \mathrm{NO}$

ME ON = CP P Me

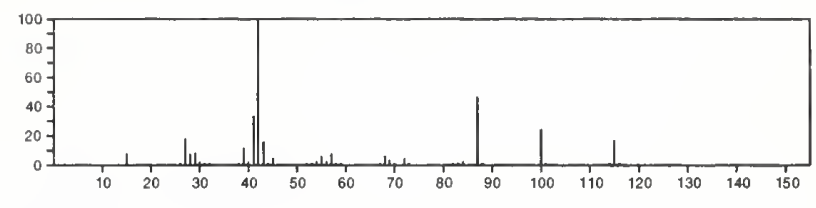

115

3-Piperidinol, 6-methyl-

$$
\mathrm{C}_{6} \mathrm{H}_{13} \mathrm{NO}
$$

$54751-93-8$
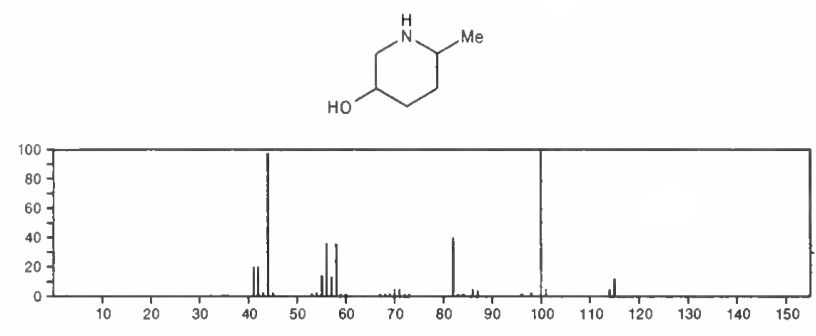

115

$\mathrm{C}_{6} \mathrm{H}_{13} \mathrm{NO}$

Formamide, $N$-methyl- $N$-(2-methylpropyl)-

$56771-96-1$

. MeN(Bu-i) $\mathrm{CH}=\mathrm{O}$
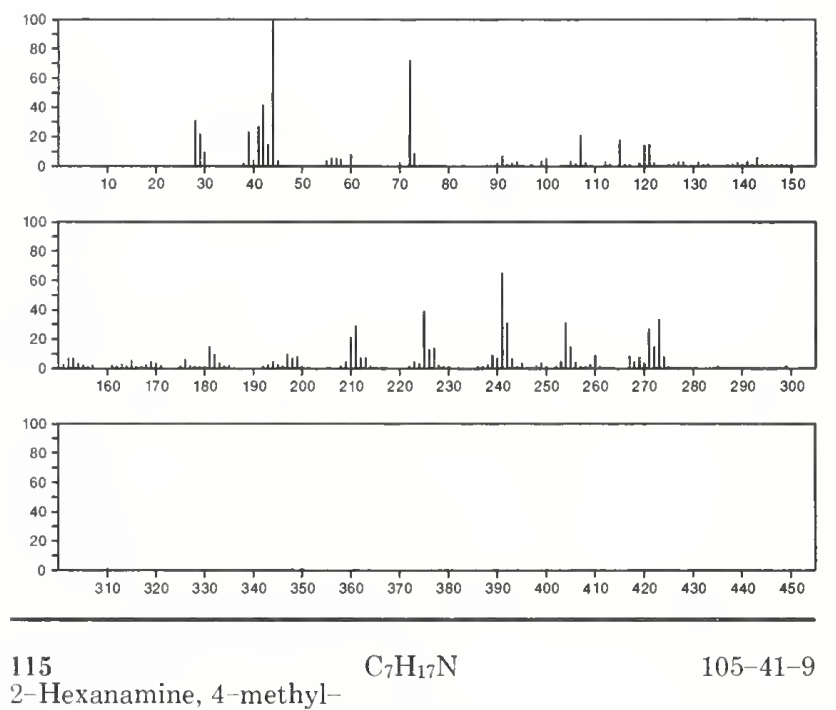

2-Hexanamine, 4-methyl-

$\mathrm{MeCH}\left(\mathrm{NH}_{2}\right) \mathrm{CH}_{2} \mathrm{CHMe} \mathrm{CH}_{2} \mathrm{Me}$

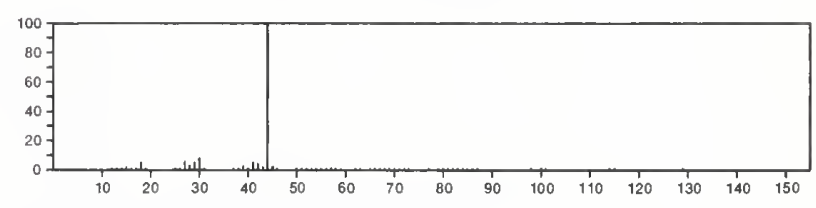

115

1-Heptanamine

$\mathrm{C}_{7} \mathrm{H}_{17} \mathrm{~N}$

$111-68-2$

$\mathrm{Me}\left(\mathrm{CH}_{2}\right){ }_{6} \mathrm{NH}_{2}$

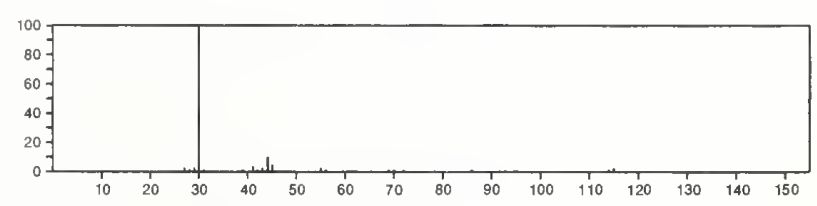


115

2-Heptanamine

$\mathrm{C}_{7} \mathrm{H}_{17} \mathrm{~N}$

$\mathrm{MeCH}\left(\mathrm{NH}_{2}\right)\left(\mathrm{CH}_{2}\right)_{4} \mathrm{Me}$

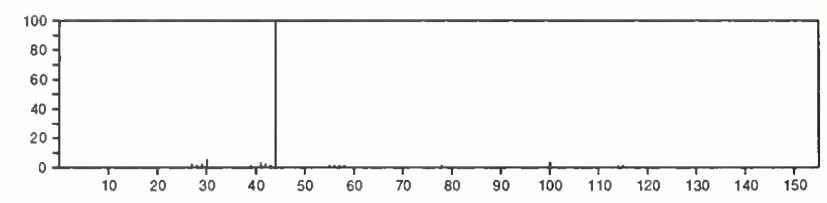

115

1-Propanamine, $N, N$-diethyl-

$\mathrm{C}_{7} \mathrm{H}_{17} \mathrm{~N}$

$4458-31-5$

${ }_{\mathrm{E}}{ }_{2} \mathrm{NPr}$

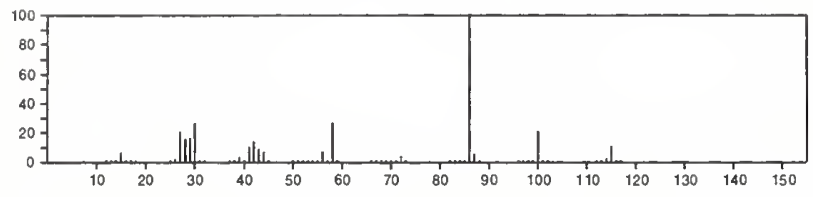

$\stackrel{115}{{ }_{2}-\text { Propanamine, } N \text {-methyl }-N-(1-\text { methylethyl })-}$

10342-97-9

$\operatorname{MeN}(\mathrm{Pr}-\mathrm{i})_{2}$

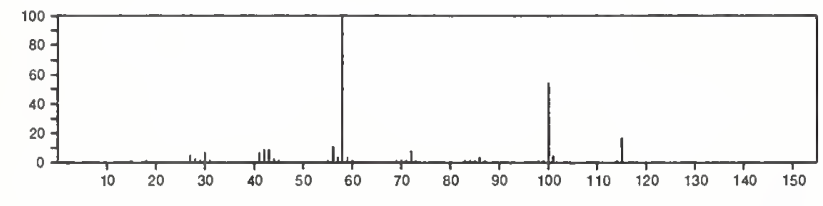

115

1-Pentanamine, $\mathrm{N}$-ethyl-

\section{$\mathrm{C}_{7} \mathrm{H}_{17} \mathrm{~N}$}

$17839-26-8$

$\mathrm{Me}\left(\mathrm{CH}_{2}\right) 4 \mathrm{NHE}$ t

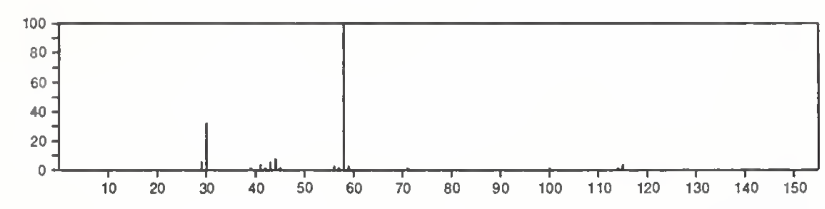

115

1-Butanamine, $N$-propyl-

$\mathrm{C}_{7} \mathrm{H}_{17} \mathrm{~N}$

20193-21-9

$\mathrm{Me}\left(\mathrm{CH}_{2}\right)_{3} \mathrm{NHPr}$

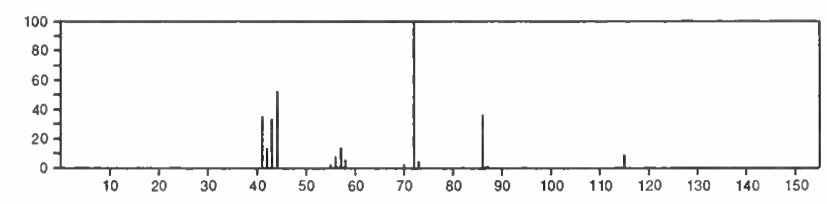

$115 \quad \mathrm{C}_{7} \mathrm{H}_{17} \mathrm{~N}$

1-Butanamine, $N$-(1-methylethyl)-

$39099-23-5$

$\mathrm{Me}\left(\mathrm{CH}_{2}\right)_{3} \mathrm{NHPr}-\mathrm{i}$

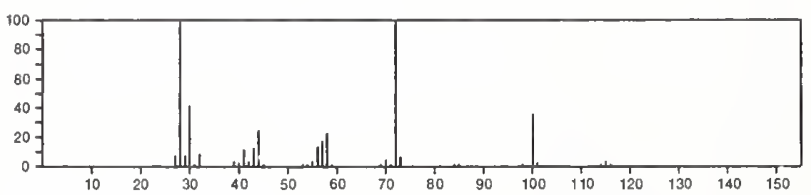

116

Borane, trichloro-

$\mathrm{BCl}_{3}$

10294-34-5

$\mathrm{BCl}_{3}$
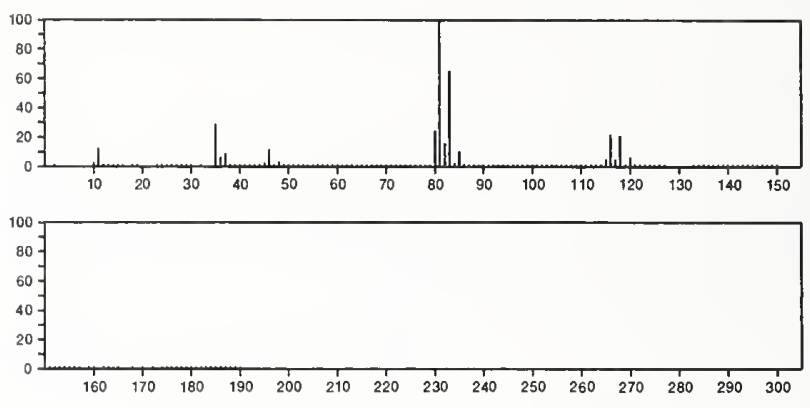

116

$\mathrm{CF}_{4} \mathrm{~N}_{2}$

17224-09-8

Diaziridine, tetrafluoro-
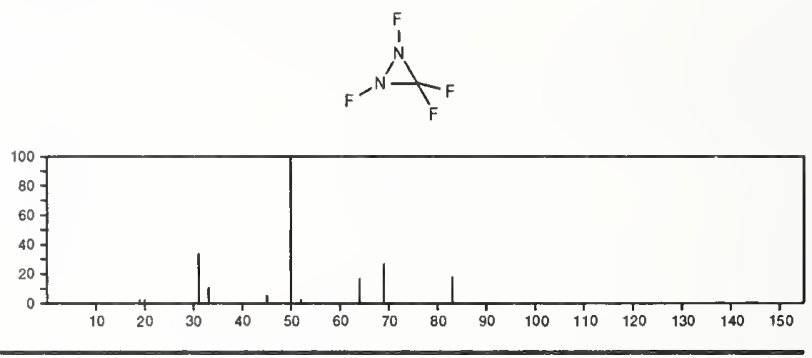

116

Ethene, chlorotrifluoro-

$\mathrm{C}_{2} \mathrm{ClF}_{3}$

79-38-9

$\mathrm{F}_{2} \mathrm{C}=\mathrm{CCIF}$

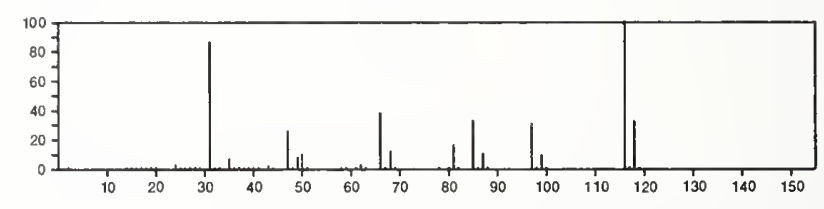

116

$\mathrm{C}_{2} \mathrm{H}_{3} \mathrm{Cl}_{2} \mathrm{~F}$

$430-57-9$

Ethane, 1,2-dichloro-1-fluoro-

$\mathrm{ClCH}_{2} \mathrm{CHClF}$

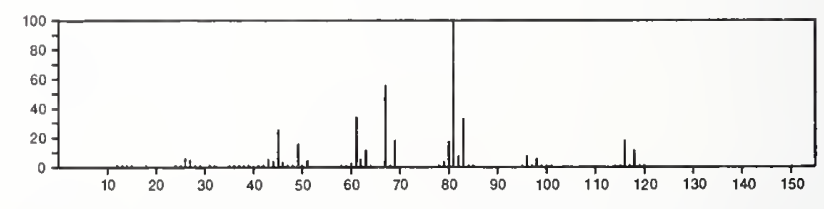

116

1,2,4-Thiadiazole-3,5-diamine

$34283-30-2$
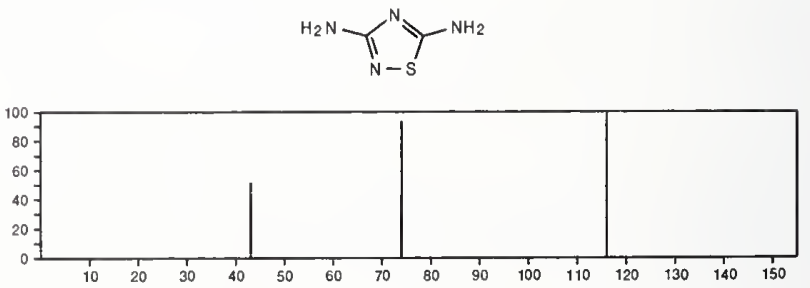
116 $\mathrm{C}_{2} \mathrm{H}_{8} \mathrm{~N}_{6}$

Ethanediimidic acid, dihydrazide

$3457-37-2$

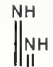

$\mathrm{H}_{2} \mathrm{NNHCCNHNH}$

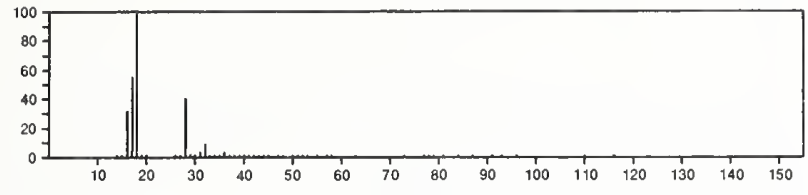

116

Propane, 1,1,2,2-tetrafluoro-

$\mathrm{C}_{3} \mathrm{H}_{4} \mathrm{~F}_{4}$

$40723-63-5$

$\mathrm{F}_{2} \mathrm{CHCF}_{2} \mathrm{Me}$

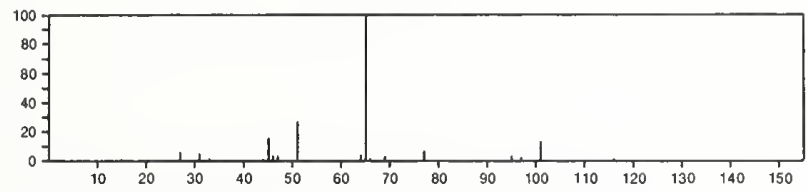

116

$\mathrm{C}_{3} \mathrm{H}_{4} \mathrm{~N}_{2} \mathrm{OS}$

503-87-7

4-Imidazolidinone, 2-thioxo-
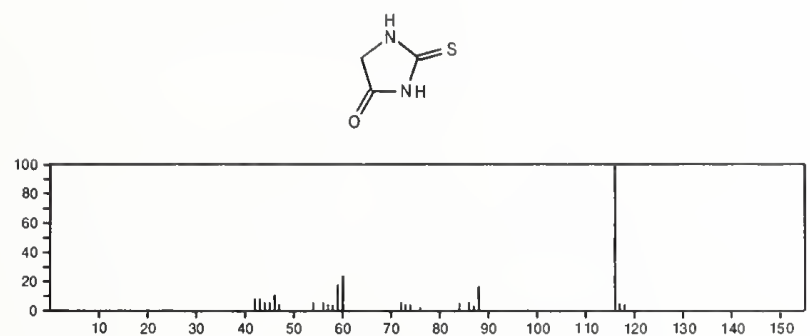

116

$\mathrm{C}_{4} \mathrm{H}_{4} \mathrm{O}_{4}$

110-16-7

2-Butenedioic acid $(Z)$

$\mathrm{HO}_{2} \mathrm{CCH}=\mathrm{CHCO}_{2} \mathrm{H}$

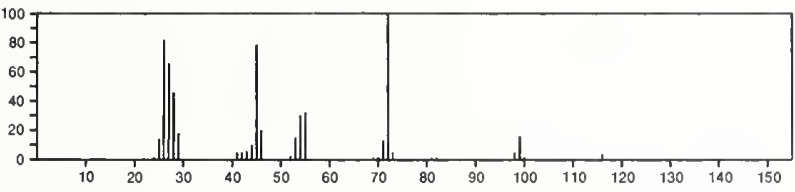

116

2-Butenedioic acid $(E)$

$\mathrm{C}_{4} \mathrm{H}_{4} \mathrm{O}_{4}$

$110-17-8$

$\mathrm{HO}_{2} \mathrm{CCH}=\mathrm{CHCO}_{2} \mathrm{H}$

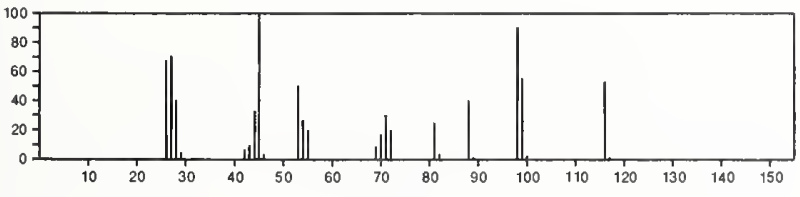

116

1,4-Dioxane-2,5-dione

$\mathrm{C}_{4} \mathrm{H}_{4} \mathrm{O}_{4}$

502-97-6
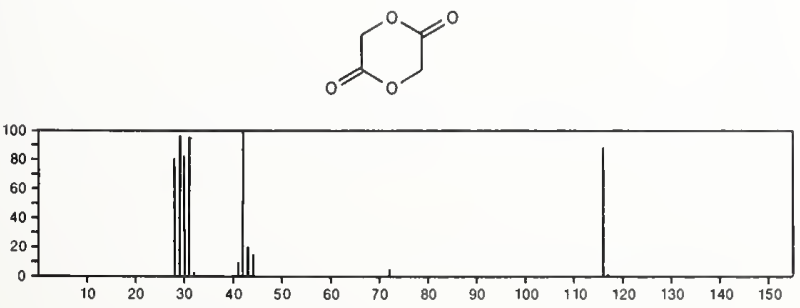

116

$\mathrm{C}_{4} \mathrm{H}_{4} \mathrm{O}_{4}$

$4480-83-5$

1,4-Dioxane-2,6-dione
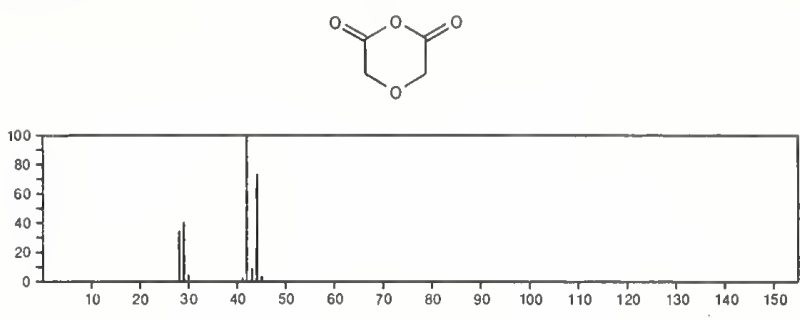

116

3-Thiophenethiol

$\mathrm{C}_{4} \mathrm{H}_{4} \mathrm{~S}_{2}$

$7774-73-4$
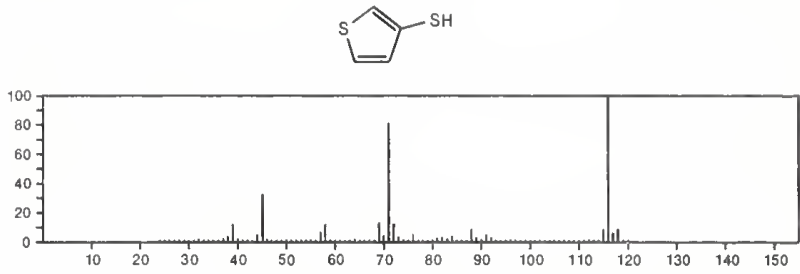

116

$\mathrm{C}_{4} \mathrm{H}_{4} \mathrm{~S}_{2}$

$7774-74-5$

2-Thiophenethiol
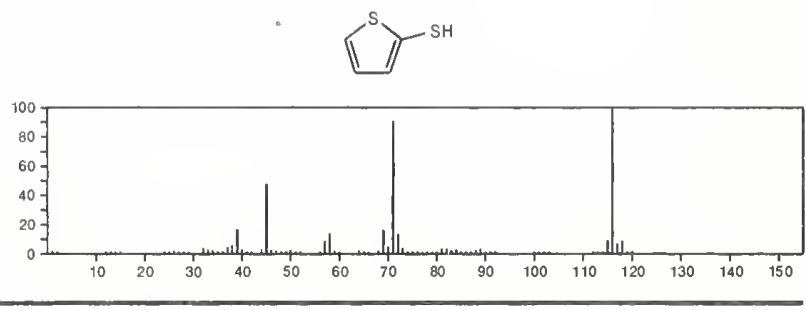

116

$\mathrm{C}_{4} \mathrm{H}_{8} \mathrm{~N}_{2} \mathrm{O}_{2}$

$59-89-2$

Morpholine, 4-nitroso-
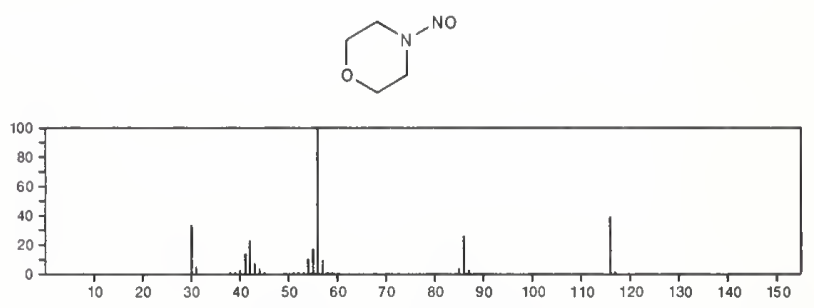

116

2,3-Butanedione, dioxime

$\mathrm{C}_{4} \mathrm{H}_{8} \mathrm{~N}_{2} \mathrm{O}_{2}$

95-45-4

$\mathrm{HON}: \mathrm{CMO} C \mathrm{CMe}: \mathrm{NOH}$

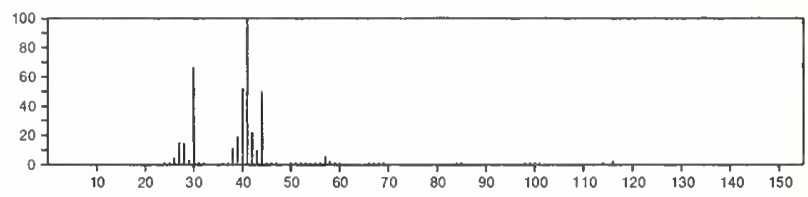

116

$\mathrm{C}_{4} \mathrm{H}_{8} \mathrm{~N}_{2} \mathrm{O}_{2}$

$3760-55-2$

Pyrrolidine, 1-nitro-
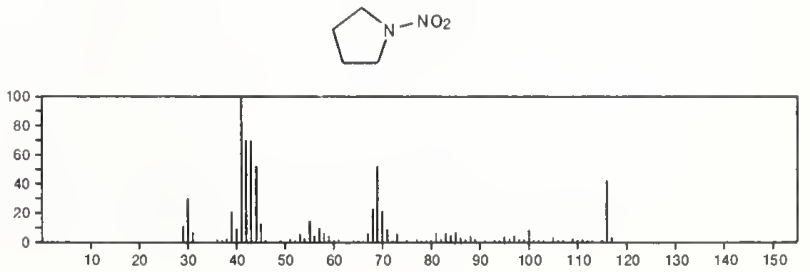
116

$\mathrm{C}_{4} \mathrm{H}_{8} \mathrm{~N}_{2} \mathrm{~S}$

$109-57-9$

$\mathrm{H}_{2} \mathrm{C}=\mathrm{CHCH}_{2} \mathrm{NHCSNH}_{2}$

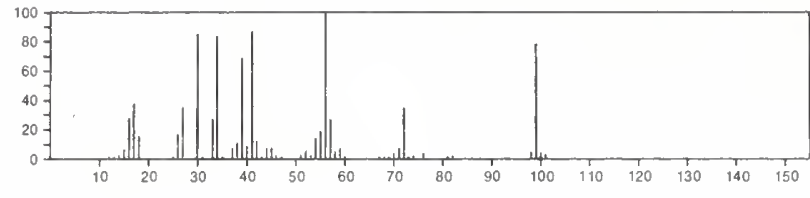

116

$\mathrm{C}_{4} \mathrm{H}_{8} \mathrm{~N}_{2} \mathrm{~S}$

2-Thiazolidinimine, 3-methyl-
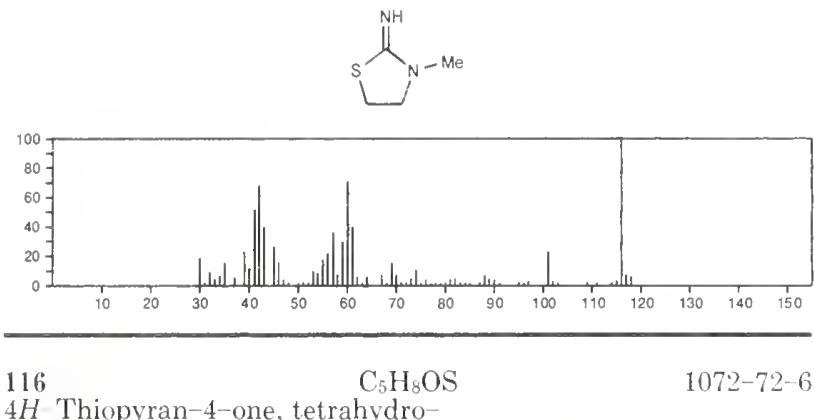

$4 H$ Thiopyran-4-one, tetrahydro-
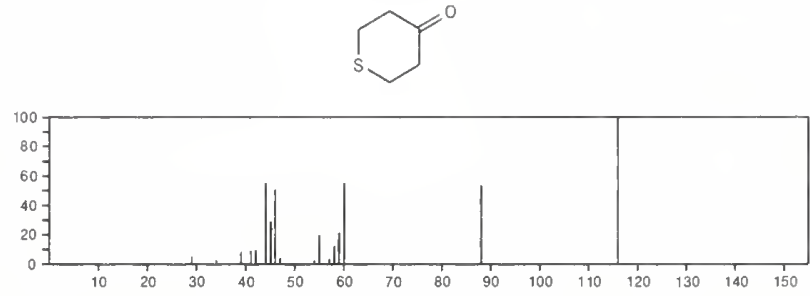

116

$\mathrm{C}_{5} \mathrm{H}_{8} \mathrm{OS}$

$19090-03-0$

2H-Thiopyran-3(4H)-one, dihydro-
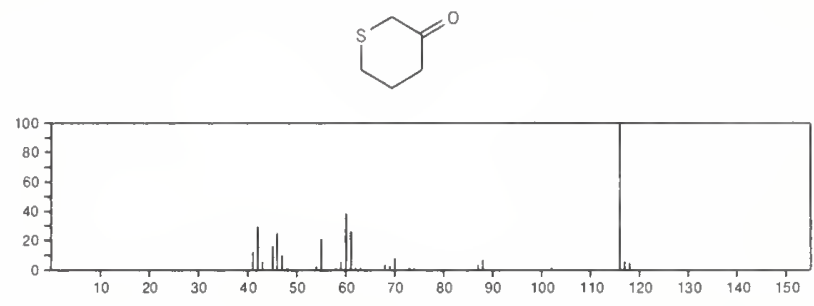

$116 \quad \mathrm{C}_{5} \mathrm{H}_{8} \mathrm{O}_{3}$

Butanoic acid, 3-Oxo-, methyl ester

$105-45-3$

$\mathrm{Me} \mathrm{COCH}_{2} \mathrm{C}(\mathrm{O}) \mathrm{OMe}$

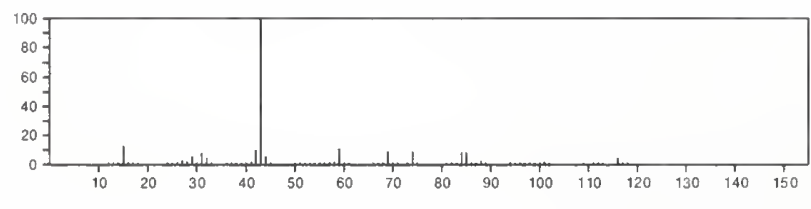

116

$\mathrm{C}_{5} \mathrm{H}_{8} \mathrm{O}_{3}$

$123-76-2$

Pentanoic acid, 4-oxo-

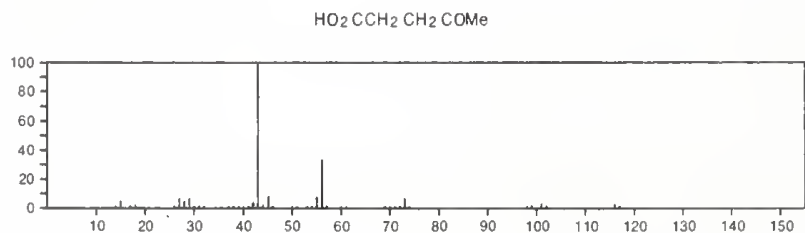

$116 \quad \mathrm{C}_{5} \mathrm{H}_{8} \mathrm{O}_{3}$

Butanoic acid, 2-oxo-, methyl ester

$3952-66-7$

EI COC (O) OMe

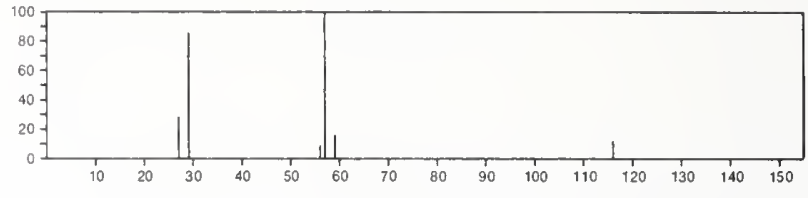

116

$\mathrm{C}_{5} \mathrm{H}_{8} \mathrm{O}_{3}$

1.3. Dioxolan 2 one, 4,5-dimethyl-

$4437-70-1$
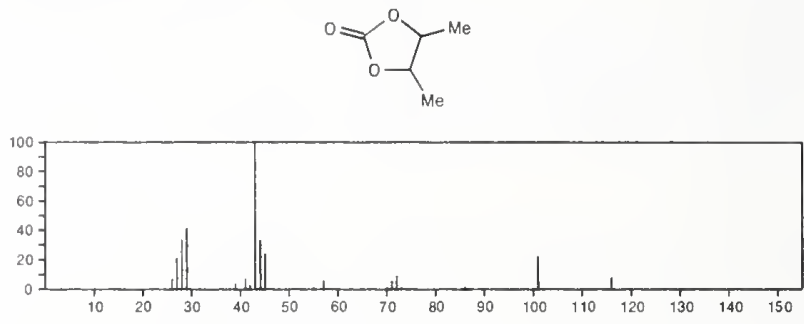

$116 \quad \mathrm{C}_{5} \mathrm{H}_{8} \mathrm{O}_{3}$

Butanoic acid, 4-hydroxy-2-methylene-

$24923-76-0$

$\mathrm{H}_{2} \mathrm{C}=\mathrm{C}\left(\mathrm{CO}_{2} \mathrm{H}\right) \mathrm{CH}_{2} \mathrm{CH}_{2} \mathrm{OH}$

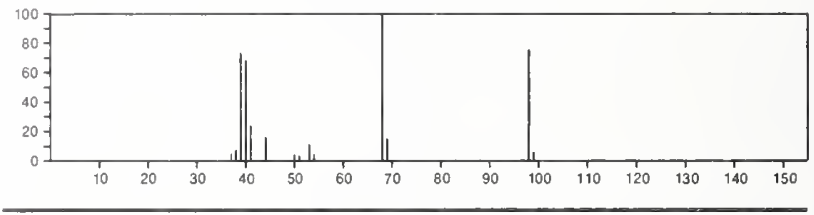

116

$\mathrm{C}_{5} \mathrm{H}_{12} \mathrm{~N}_{2} \mathrm{O}$

$623-76-7$

Urea, $N, N^{\prime}$-diethyl

E I NHCONHE

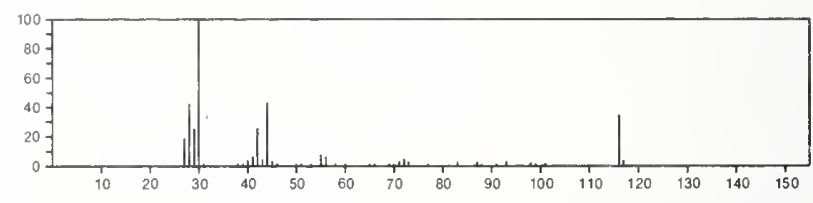

116

$\mathrm{C}_{5} \mathrm{H}_{12} \mathrm{~N}_{2} \mathrm{O}$

$632-22-4$

Urea, tetramethyl

$\mathrm{Me}_{2} \mathrm{NCONMe}_{2}$

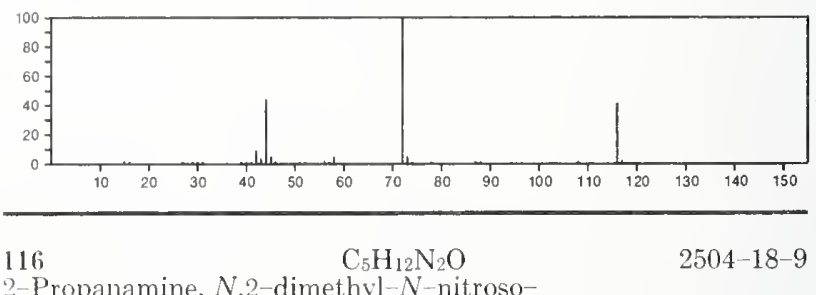

$\operatorname{MeN}(\mathrm{NO}) \mathrm{Bu}-\mathrm{t}$

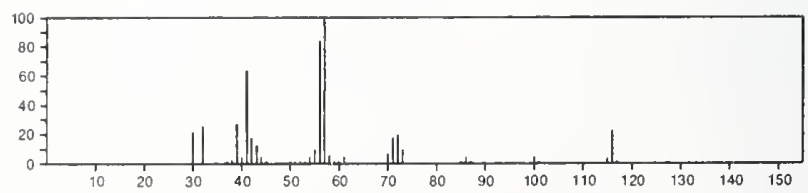


116

$\mathrm{C}_{5} \mathrm{H}_{12} \mathrm{~N}_{2} \mathrm{O}$

1-Butanamine, $N$-methyl- $N$-nitroso-

$\operatorname{MeN}(\mathrm{NO})\left(\mathrm{CH}_{2}\right){ }_{3} \mathrm{Me}$

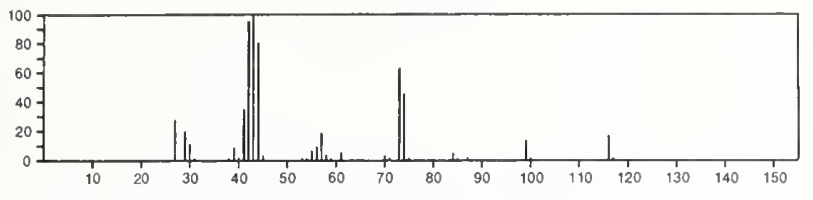

$116 \quad \mathrm{C}_{5} \mathrm{H}_{12} \mathrm{~N}_{2} \mathrm{O} \quad 13848-79-8$ Hydrazinium, 2-acetyl-1,1,1-trimethyl-, hydroxide, inner salt
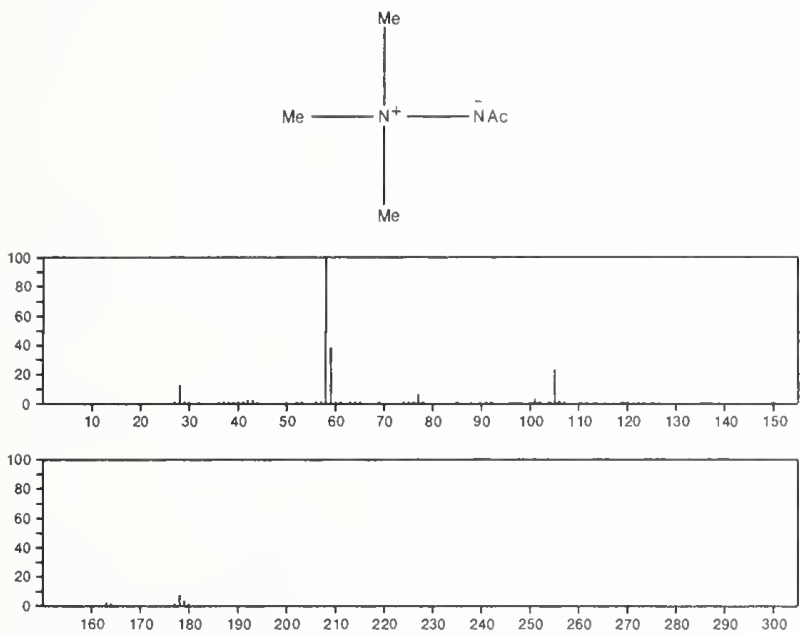

116

$\begin{array}{llllllllllllll}170 & 180 & 190 & 200 & 210 & 220 & 230 & 240 & 250 & 260 & 270 & 280 & 290 & 300\end{array}$

$16339-04-1$

2-Propanamine, $N$-ethyl- $N$-nitroso-

EIN(NO) Pr-

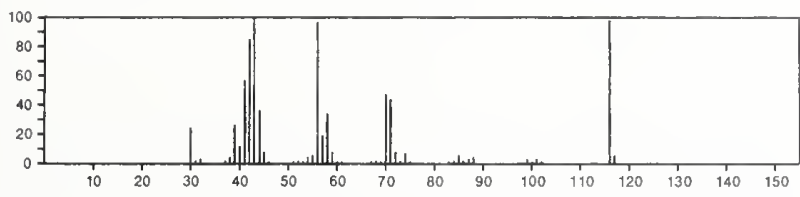

$116 \quad \mathrm{C}_{5} \mathrm{H}_{12} \mathrm{~N}_{2} \mathrm{O}$

1-Propanamine, $N$-ethyl $-N$-nitroso-

$\operatorname{PrNET(NO)}$

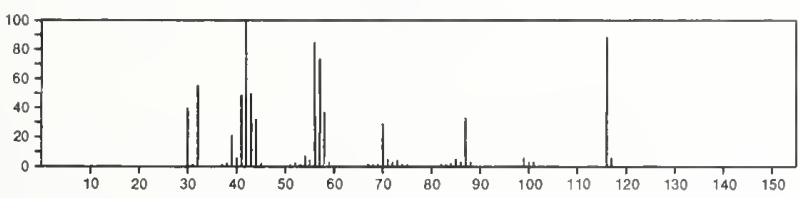

116

$\mathrm{C}_{5} \mathrm{H}_{12} \mathrm{~N}_{2} \mathrm{O}$

1-Propanamine, $N, 2$-dimethyl- $N$-nitroso-

$34419-76-6$

MeN (NO) Bu-

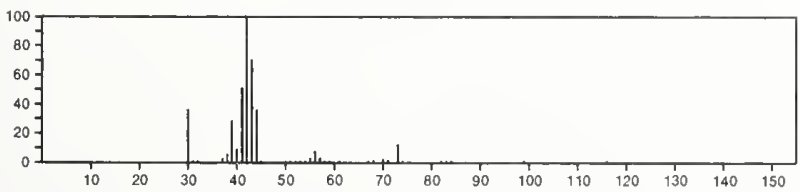

$116 \quad \mathrm{C}_{5} \mathrm{H}_{12} \mathrm{~N}_{2} \mathrm{O}$

2-Butanamine, $N$-methyl $-N$-nitroso

$35606-37-2$

MeN (NO) Bu-S

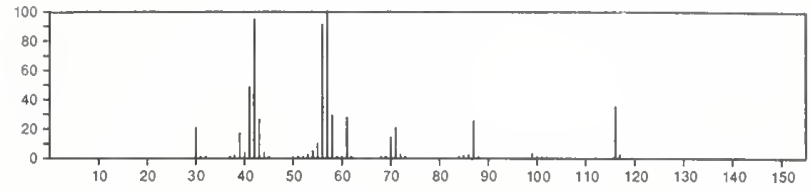

$116 \quad \mathrm{C}_{6} \mathrm{H}_{9} \mathrm{Cl} \quad 930-65-4$

Cyclohexene, 4-chloro-
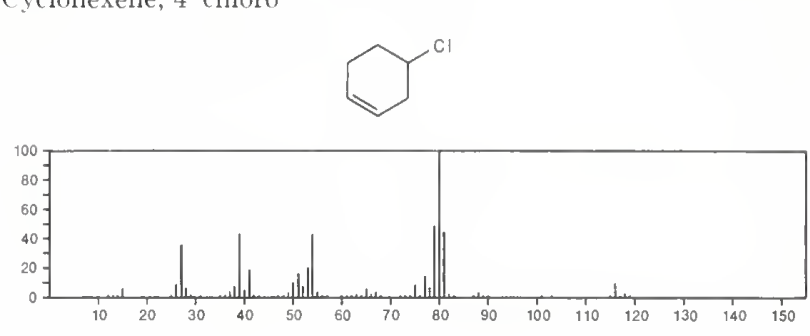

116

Cyclohexene, 1-chloro

$\mathrm{C}_{6} \mathrm{H}_{9} \mathrm{Cl}$

$930-66-5$

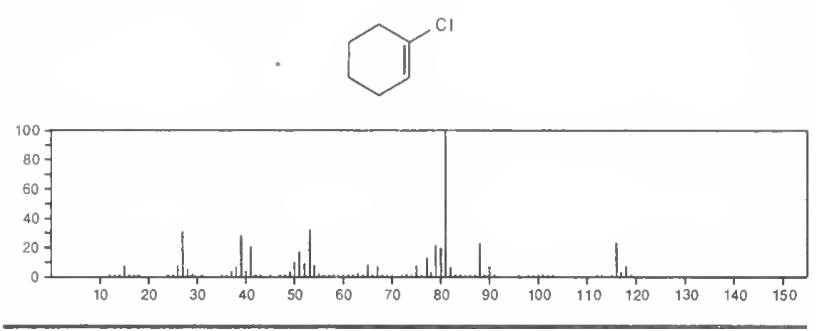

116

Cyclohexene, 3-chloro

$\mathrm{C}_{6} \mathrm{H}_{9} \mathrm{Cl}$

$2441-97-6$
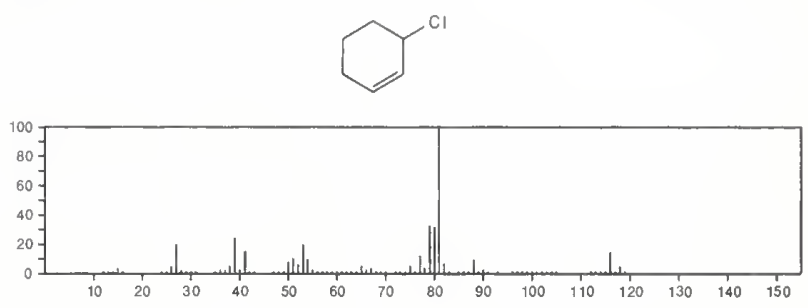

116

2-Hexyne, 6-chloro-

$\mathrm{C}_{6} \mathrm{H}_{9} \mathrm{Cl}$

$28077-73-8$

$\mathrm{Cl}\left(\mathrm{CH}_{2}\right){ }_{3} \mathrm{C}: \mathrm{CMe}$

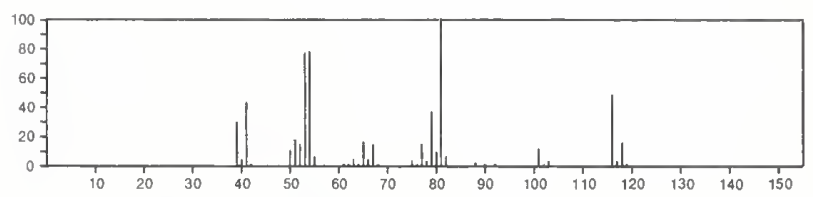

116

$\mathrm{C}_{6} \mathrm{H}_{9} \mathrm{Cl}$

1,5-Hexadiene, 3-chloro

$\mathrm{H}_{2} \mathrm{C}=\mathrm{CHCH}_{2} \mathrm{CHCl} \mathrm{CH}=\mathrm{CH}_{2}$

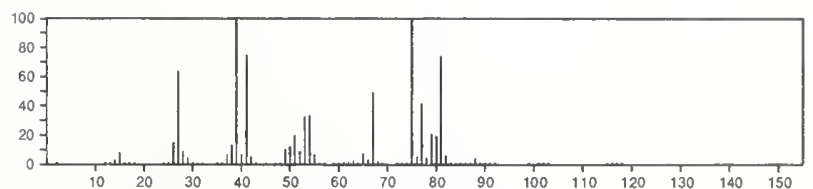


$116 \quad \mathrm{C}_{6} \mathrm{H}_{9} \mathrm{Cl} \quad 34632-89-8$

2,4-Hexadiene, 1-chloro-

$\mathrm{MeCH}=\mathrm{CHCH}=\mathrm{CHCH}_{2} \mathrm{Cl}$
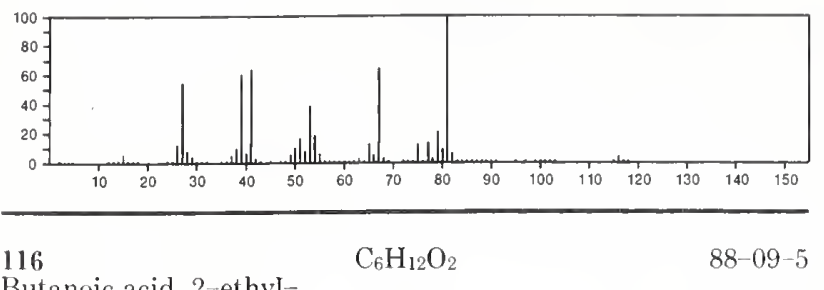

Butanoic acid, 2 ethyl-

$\mathrm{Et}_{2} \mathrm{CHCO}_{2} \mathrm{H}$

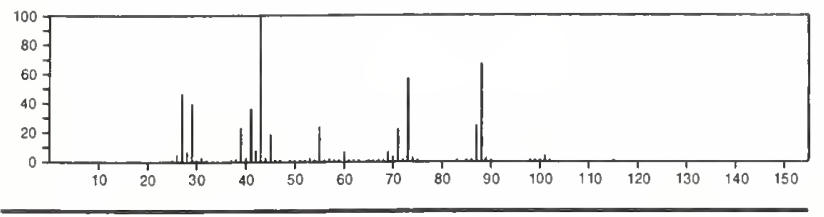

116

Pentanoic acid, 2-methyl-

$\mathrm{C}_{6} \mathrm{H}_{12} \mathrm{O}_{2}$

97-61-0

$\operatorname{PrCHMe}\left(\mathrm{CO}_{2} \mathrm{H}\right)$

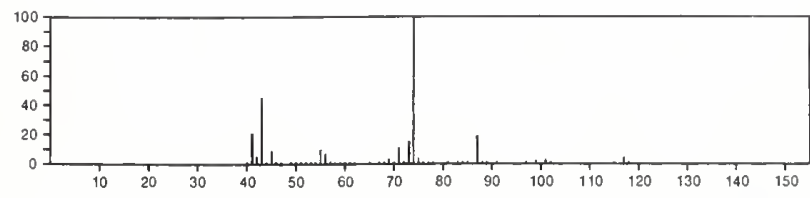

116

$\mathrm{C}_{6} \mathrm{H}_{12} \mathrm{O}_{2}$

2H-Pyran-2-methanol, tetrahydro-
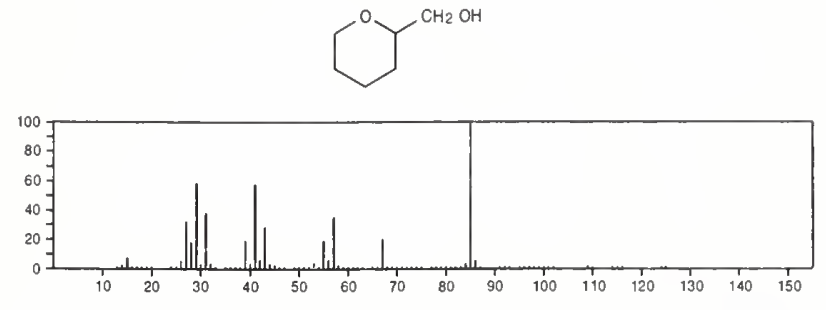

$116 \quad \mathrm{C}_{6} \mathrm{H}_{12} \mathrm{O}_{2} \quad 105-46-4$ Acetic acid, 1-methylpropyl ester

s- BuOAC

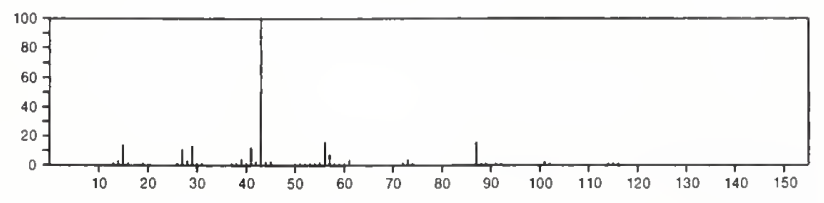

116

$\mathrm{C}_{6} \mathrm{H}_{12} \mathrm{O}_{2}$

$105-54-4$

Butanoic acid, ethyl ester

EtOC(O)Pr

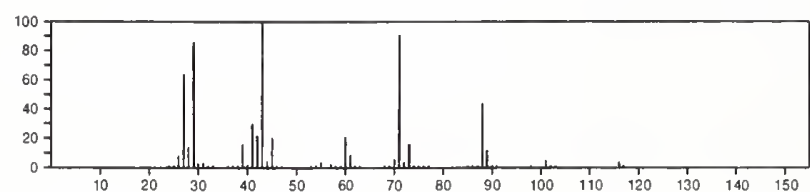

$116 \quad \mathrm{C}_{6} \mathrm{H}_{12} \mathrm{O}_{2}$

$106-36-5$

Propanoic acid, propyl ester

$\operatorname{PrOC}(0) E t$

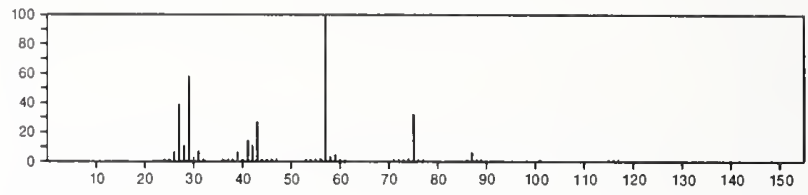

$116 \quad \mathrm{C}_{6} \mathrm{H}_{12} \mathrm{O}_{2}$

1-Butanol, 3-methyl-, formate

$110-45-2$

$\mathrm{O}: \mathrm{CHOCH}_{2} \mathrm{CH}_{2} \mathrm{CHMe}_{2}$

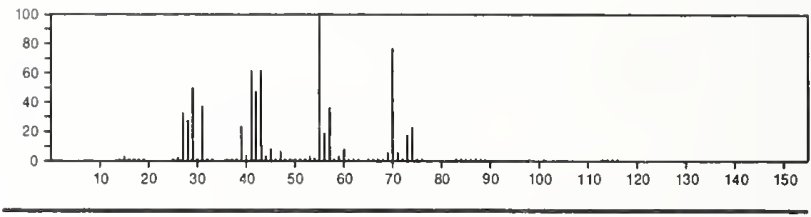

116

$\mathrm{C}_{6} \mathrm{H}_{12} \mathrm{O}_{2}$

2-Pentanone, 4-hydroxy-4-methyl-

$123-42-2$

$\mathrm{Me} \mathrm{COCH}_{2} \mathrm{CMe}_{2} \mathrm{OH}$

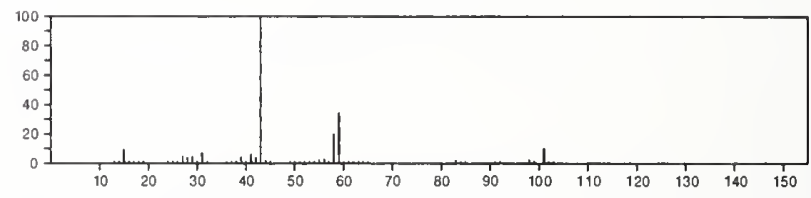

116

$\mathrm{C}_{6} \mathrm{H}_{12} \mathrm{O}_{2}$

Acetic acid, butyl ester

$\mathrm{Me}\left(\mathrm{CH}_{2}\right)_{3} \mathrm{OAC}$

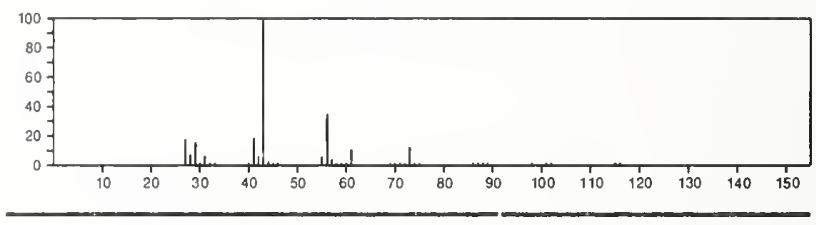

$116 \quad \mathrm{C}_{6} \mathrm{H}_{12} \mathrm{O}_{2}$

1,3-Dioxolane, 2-ethyl-2-methyl-

$126-39-6$
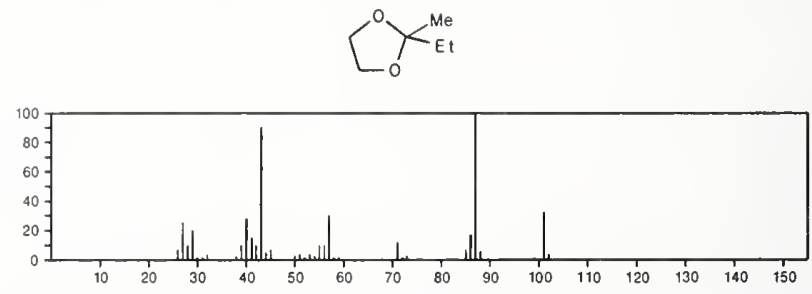

116

$\mathrm{C}_{6} \mathrm{H}_{12} \mathrm{O}_{2}$

$142-62-1$

Hexanoic acid

$\mathrm{HO}_{2} \mathrm{C}\left(\mathrm{CH}_{2}\right)_{4} \mathrm{Me}$

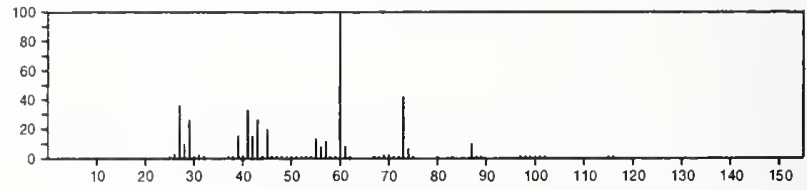


116

1,3-Cyclohexanediol

$\mathrm{C}_{6} \mathrm{H}_{12} \mathrm{O}_{2}$

$504-01-8$
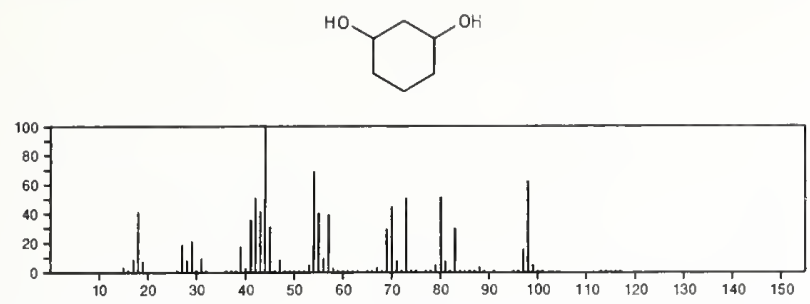

116

$\mathrm{C}_{6} \mathrm{H}_{12} \mathrm{O}_{2}$

Acetic acid, 1,1-dimethylethyl ester

$540-88-5$

$t-B u O A C$

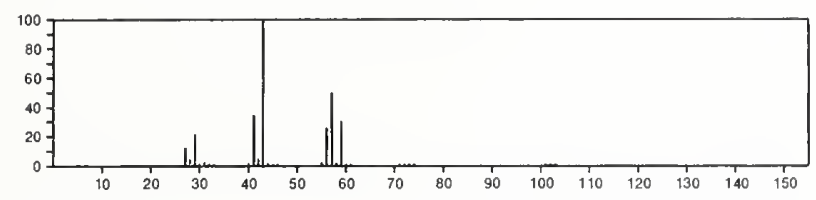

116

$\mathrm{C}_{6} \mathrm{H}_{12} \mathrm{O}_{2}$

Butanoic acid, 3-methyl-, methyl ester

$556-24-1$

$\mathrm{Me}_{2} \mathrm{CHCH}_{2} \mathrm{C}(\mathrm{O}) \mathrm{OMe}$

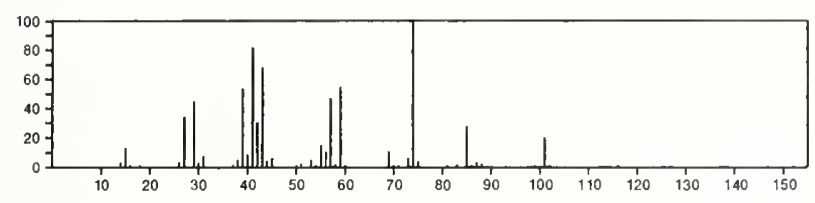

$116 \quad \mathrm{C}_{6} \mathrm{H}_{12} \mathrm{O}_{2}$

$556-48-9$<smiles>OC1CCC(O)CC1</smiles>

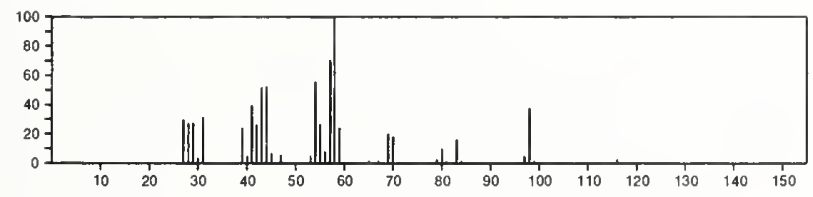

116

$\mathrm{C}_{6} \mathrm{H}_{12} \mathrm{O}_{2}$

598-98-1

Propanoic acid, 2,2-dimethyl-, methyl ester

$\mathrm{MeOC}(0) \mathrm{CMe}_{3}$

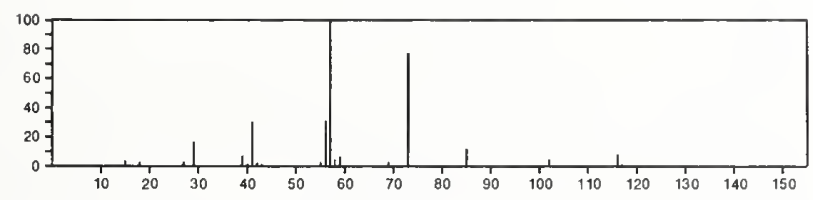

116

Pentanoic acid, methyl ester

$624-24-8$

$\mathrm{Me}\left(\mathrm{CH}_{2}\right)_{3} \mathrm{C}(\mathrm{O}) \mathrm{OMe}$

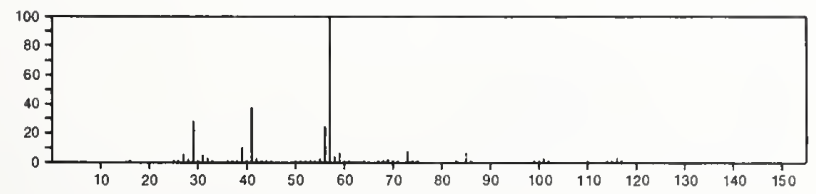

116

$\mathrm{C}_{6} \mathrm{H}_{12} \mathrm{O}_{2}$

Propanoic acid, 1-methylethyl ester

i-PrOC(O)Et

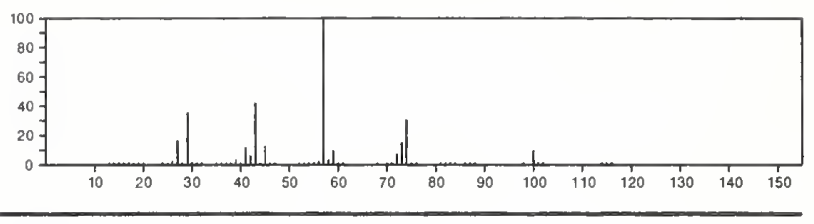

116

$\mathrm{C}_{6} \mathrm{H}_{12} \mathrm{O}_{2}$

646-07-1

Pentanoic acid, 4-methyl-

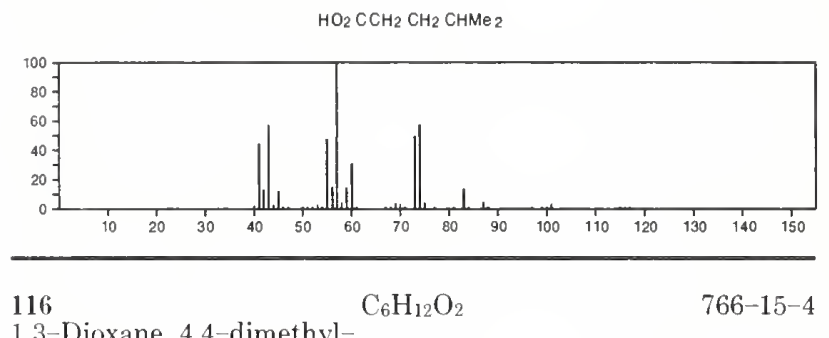

1,3-Dioxane, 4,4-dimethyl-
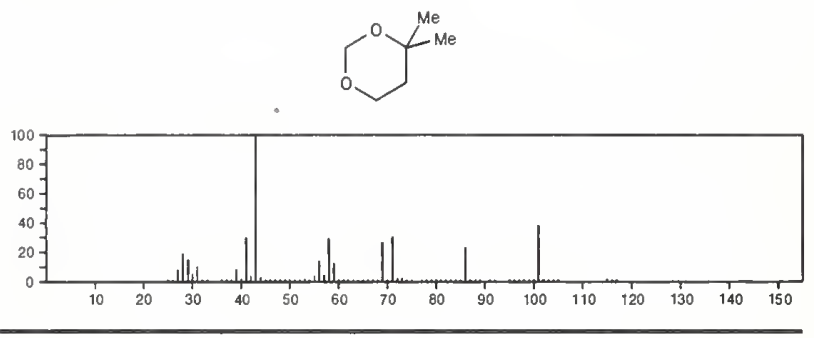

116

1,3-Dioxane, 2,4-dimethyl-

$\mathrm{C}_{6} \mathrm{H}_{12} \mathrm{O}_{2}$

766-20-1
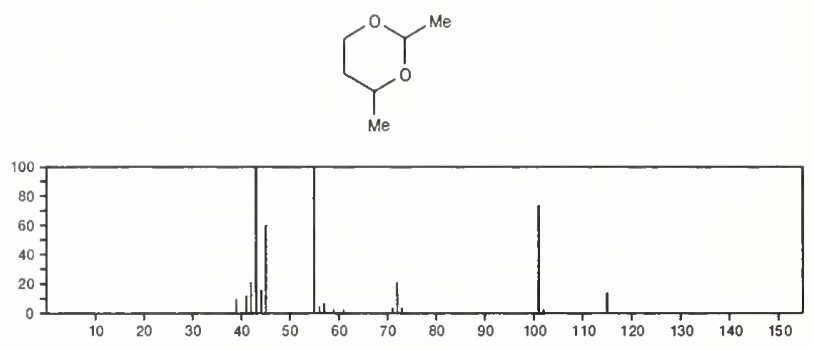

116

$\mathrm{C}_{6} \mathrm{H}_{12} \mathrm{O}_{2}$

1,3-Dioxolane, 2-(1-methylethyl)-

$822-83-3$
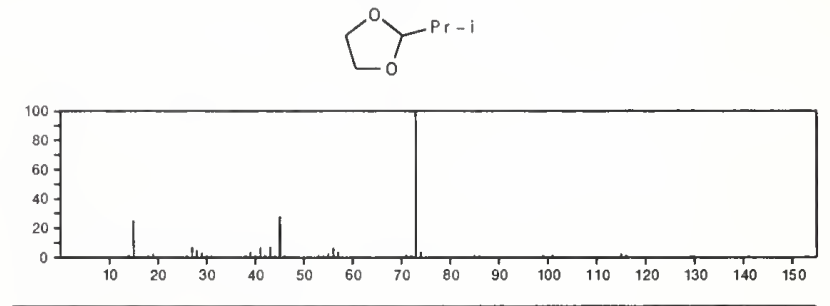

116

$\mathrm{C}_{6} \mathrm{H}_{12} \mathrm{O}_{2}$

Butanoic acid, 2-methyl-, methyl ester

$868-57-5$

$\mathrm{MeOC}(\mathrm{O}) \mathrm{CHMe} \mathrm{CH}_{2} \mathrm{Me}$

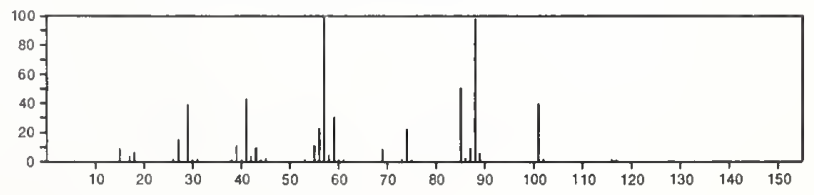


116

1,2-Cyclohexanediol

$\mathrm{C}_{6} \mathrm{H}_{12} \mathrm{O}_{2}$
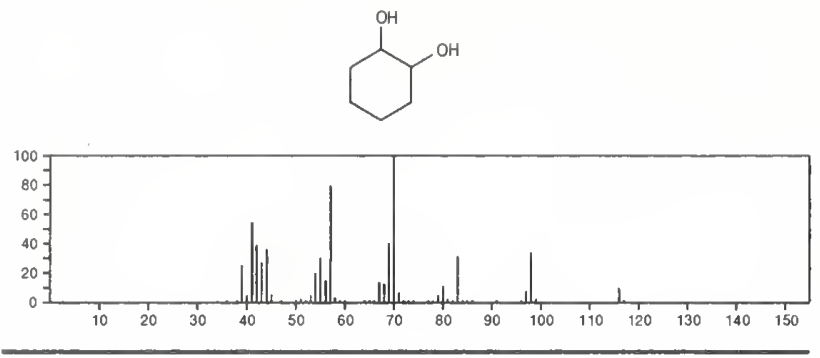

116

Butanoic acid, 3,3-dimethyl-

$\mathrm{C}_{6} \mathrm{H}_{12} \mathrm{O}_{2}$

$\mathrm{Me} 3 \mathrm{CCH}_{2} \mathrm{CO}_{2} \mathrm{H}$

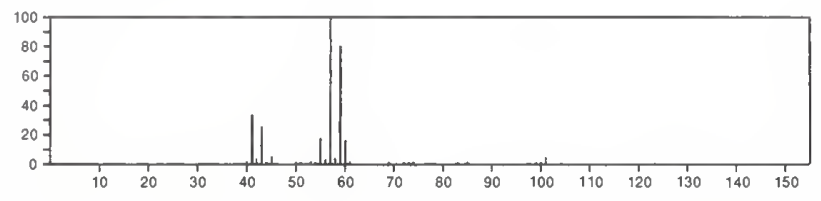

116

1,3-Dioxolane, 2,2,4-trimethyl

$\mathrm{C}_{6} \mathrm{H}_{12} \mathrm{O}_{2}$

$1193-11-9$
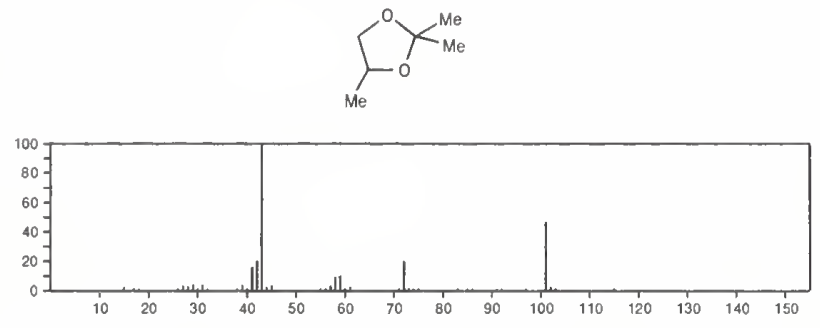

116
2 -Butanone, 4-hydroxy-3,3-dimethyl-

1823-90-1

$\mathrm{Me} \mathrm{COCMe}_{2} \mathrm{CH}_{2} \mathrm{OH}$

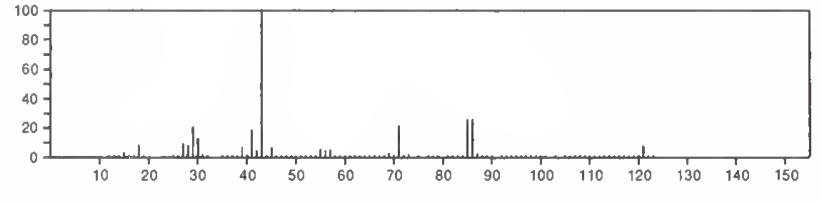

116

$\mathrm{C}_{6} \mathrm{H}_{12} \mathrm{O}_{2}$

$3390-13-4$

1,3-Dioxolane, 2-propyl-
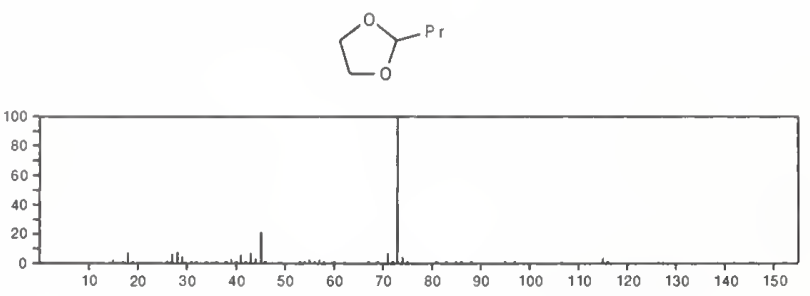

116

1,3-Dioxane, 4,6-dimethyl-, cis-

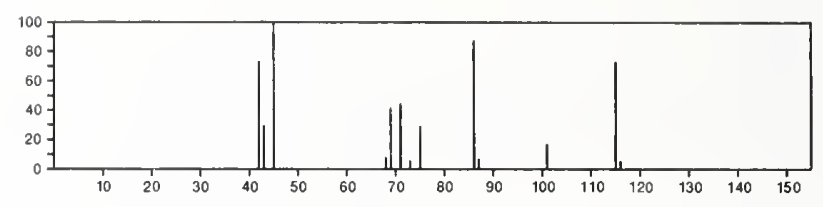

116

$\mathrm{C}_{6} \mathrm{H}_{12} \mathrm{O}_{2}$

$4359-46-0$

1,3-Dioxolane, 2-ethyl-4-methyl-
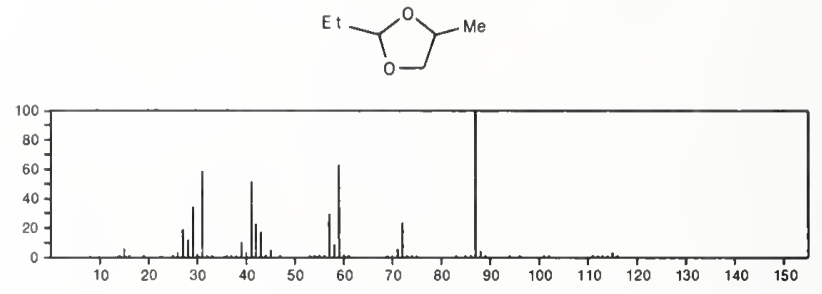

116

Ethanol, 2-[(2-methylallyl)oxy]

$\mathrm{C}_{6} \mathrm{H}_{12} \mathrm{O}_{2}$

5175-48-4

$\mathrm{H}_{2} \mathrm{C}=\mathrm{CMeCH}_{2} \mathrm{OCH}_{2} \mathrm{CH}_{2} \mathrm{OH}$
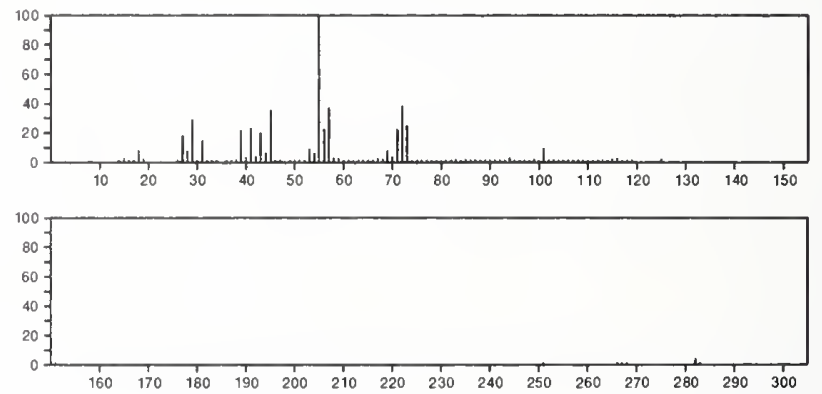

116

$\mathrm{C}_{6} \mathrm{H}_{12} \mathrm{O}_{2}$

2H-Pyran, tetrahydro-2-methoxy-

$6581-66-4$
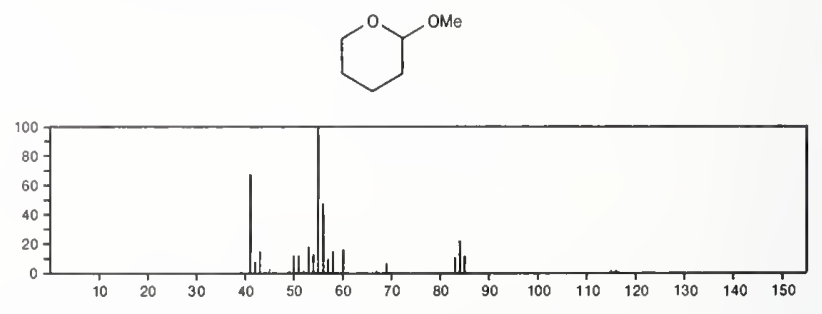

116

$\mathrm{C}_{6} \mathrm{H}_{12} \mathrm{O}_{2}$

$6995-79-5$

1,4-Cyclohexanediol, trans-
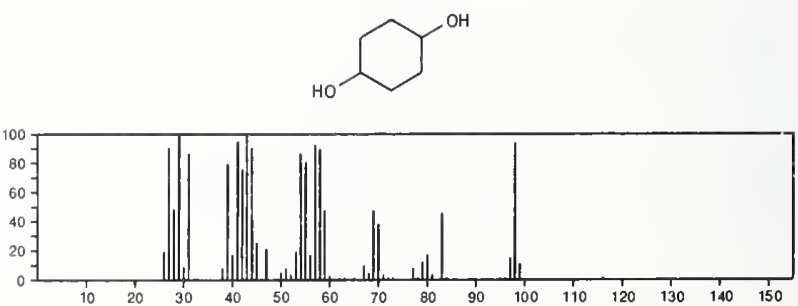
116

$\mathrm{C}_{6} \mathrm{H}_{12} \mathrm{O}_{2}$

3-Hexene-2,5-dio

$\mathrm{MeCH}(\mathrm{OH}) \mathrm{CH}: \mathrm{CHCH}(\mathrm{OH}) \mathrm{Me}$

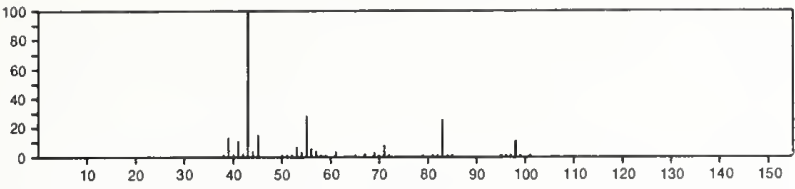

116

1,4-Dioxane, 2,6-dimethyl-

$\mathrm{C}_{6} \mathrm{H}_{12} \mathrm{O}_{2}$

$10138-17-7$
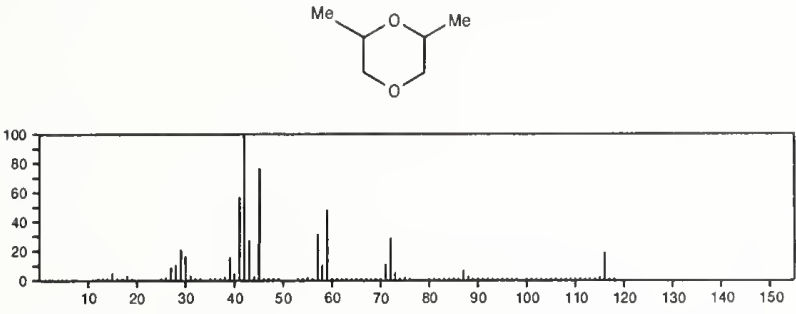

116

$\mathrm{C}_{6} \mathrm{H}_{12} \mathrm{O}_{2}$

$15176-21-3$

1,4-Dioxane, 2,5-dimethyl-
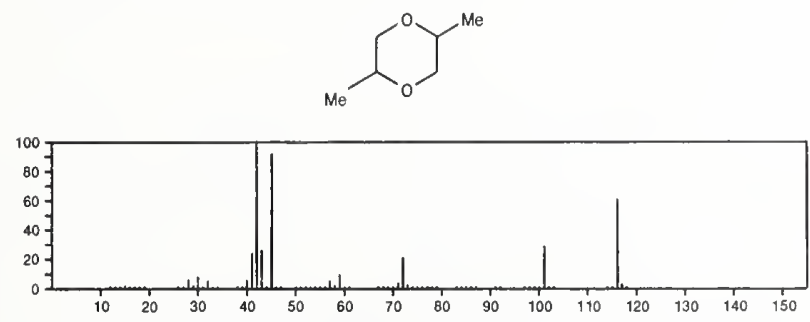

116

$\mathrm{C}_{6} \mathrm{H}_{12} \mathrm{O}_{2}$

16015 08-0

Furfuryl alcohol, tetrahydro-5-methyl-, cis-<smiles>C[C@H]1CCC(CO)O1</smiles>

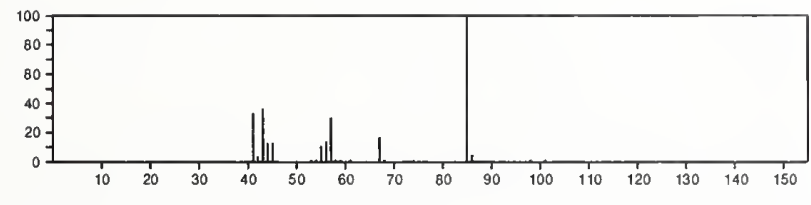

116

$\mathrm{C}_{6} \mathrm{H}_{12} \mathrm{O}_{2}$

2-Pentanone, 5-methoxy-

$17429-04-8$

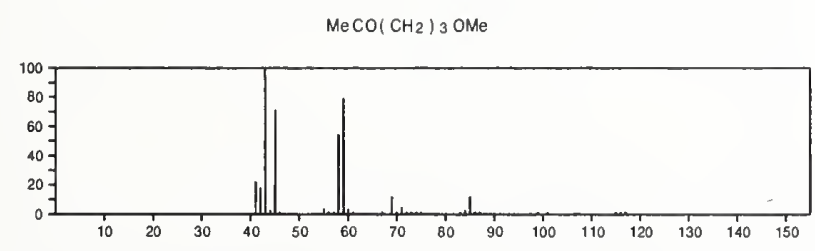

116

$\mathrm{C}_{6} \mathrm{H}_{12} \mathrm{O}_{2}$

$21460-36-6$

2-Propanol, 1-(2-propenyloxy)-

$\mathrm{H}_{2} \mathrm{C}=\mathrm{CHCH}_{2} \mathrm{OCH}_{2} \mathrm{CH}(\mathrm{OH}) \mathrm{Me}$

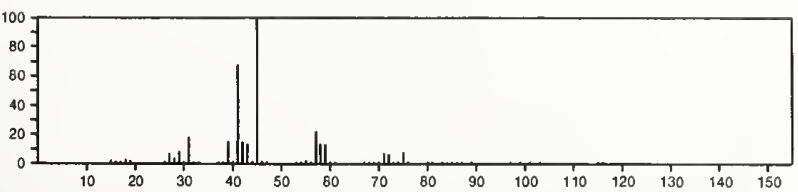

116

$\mathrm{C}_{6} \mathrm{H}_{12} \mathrm{O}_{2}$

$25136-55-4$

1,4-Dioxane, dimethyl
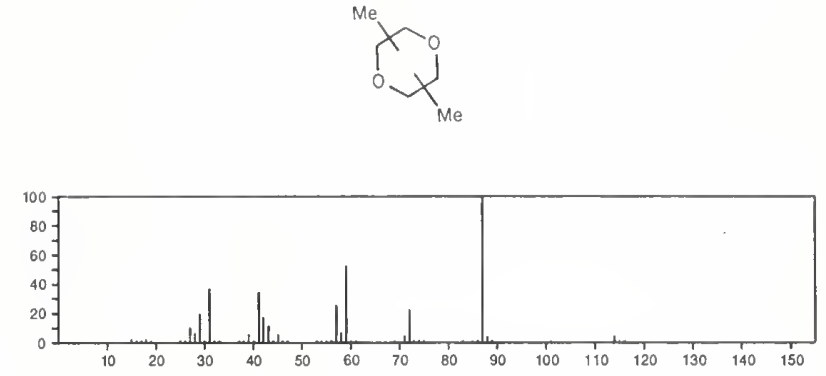

116

1.2-Cyclopentanediol, 3-methyl-

$27583-37-5$
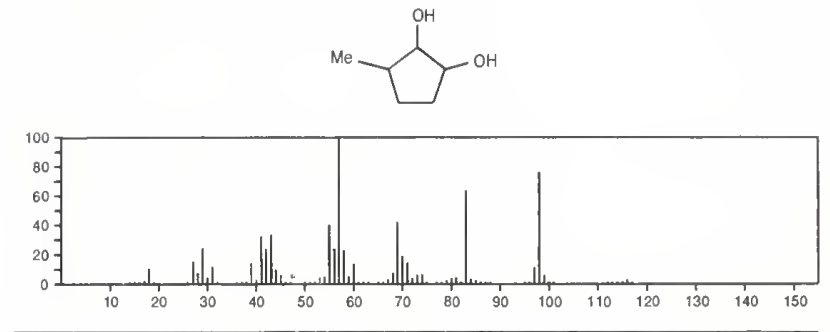

116

2-Butanone, 3-methoxy-3-methyl-

$36687-98-6$

$\mathrm{Me}{ }_{2} \mathrm{COMe} \mathrm{COMe}$

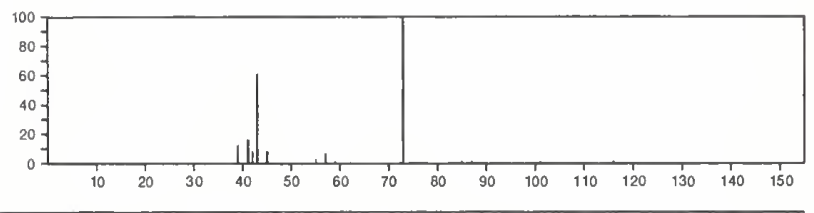

116

$\mathrm{C}_{6} \mathrm{H}_{12} \mathrm{O}_{2}$

$54774-28-6$

2-Furanmethanol, tetrahydro-5-methyl-, trans-
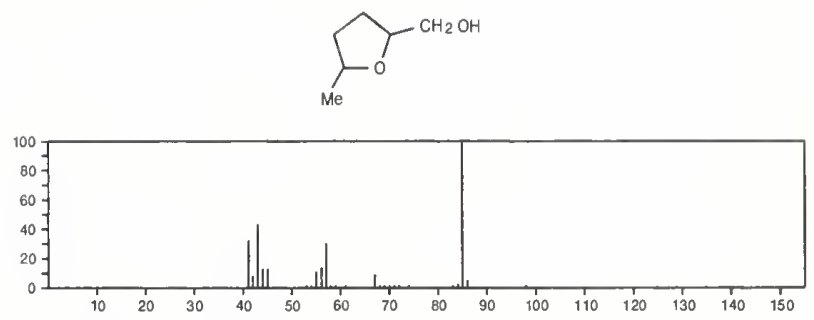

116

$\mathrm{C}_{6} \mathrm{H}_{12} \mathrm{~S}$

$1569-69-3$

Cyclohexanethiol
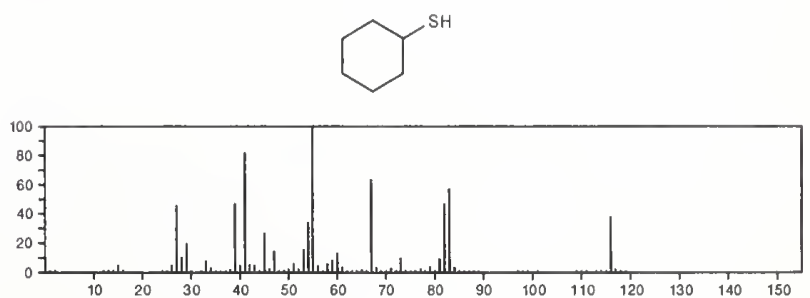
$116 \quad \mathrm{C}_{6} \mathrm{H}_{12} \mathrm{~S}$

Cyclopentanethiol, 2-methyl-, trans-
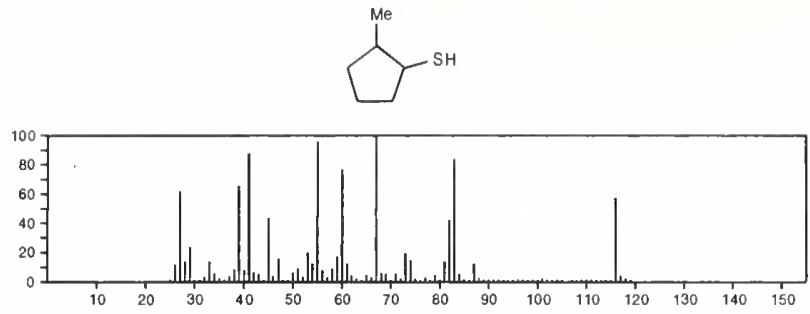

116

Cyclopentanethiol, 2-methyl--,
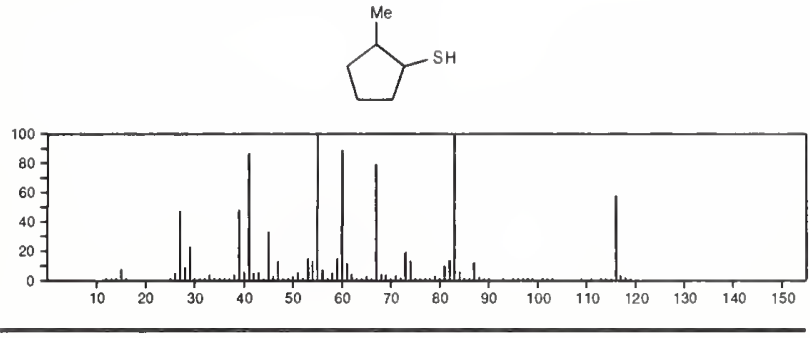

116

Cyclopentanethiol, 1-methyl-

$\mathrm{C}_{6} \mathrm{H}_{12} \mathrm{~S}$

$1638-95-5$
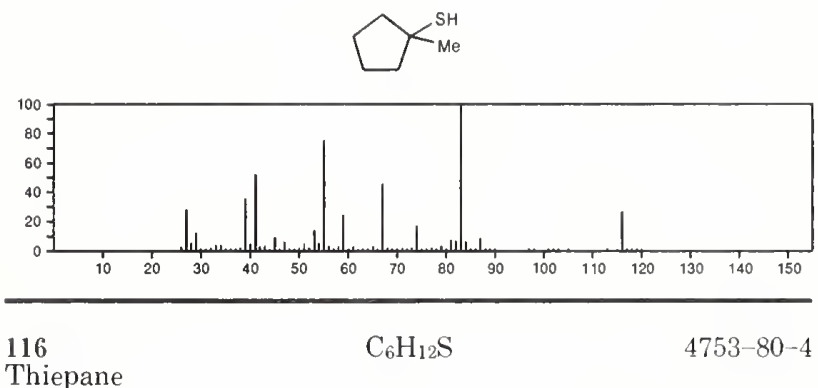

Thiepane
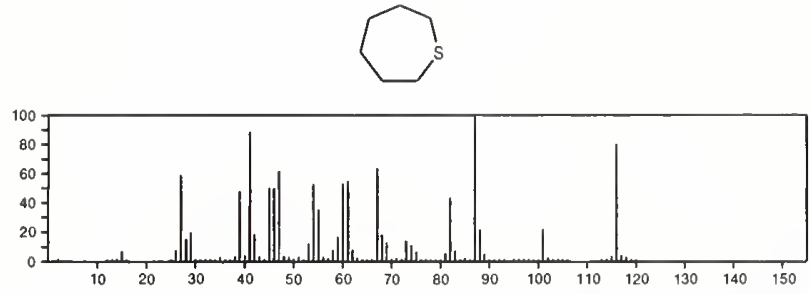

116

$\mathrm{C}_{6} \mathrm{H}_{12} \mathrm{~S}$

Thiophene, tetrahydro-2,5-dimethyl--, cis-

$5161-13-7$
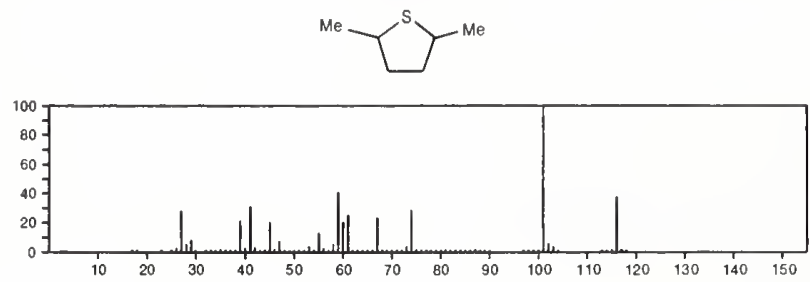

116

$\mathrm{C}_{6} \mathrm{H}_{12} \mathrm{~S}$

Thiophene, tetrahydro-2,5-dimethyl-, trans-

$5161-14-8$
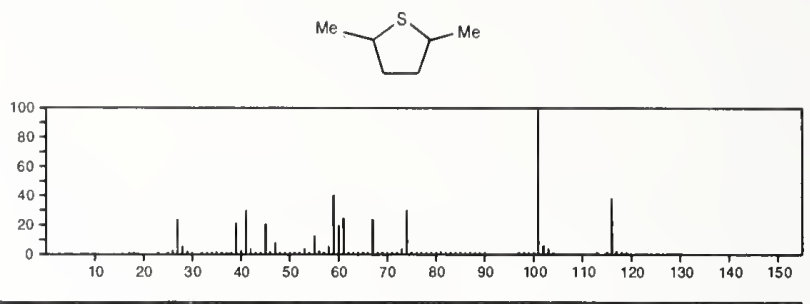

116

$\mathrm{C}_{6} \mathrm{H}_{12} \mathrm{~S}$

$2 H$-Thiopyran, tetrahydro-2-methyl-

$5161-16-0$

$\mathrm{C}^{\mathrm{se}}$

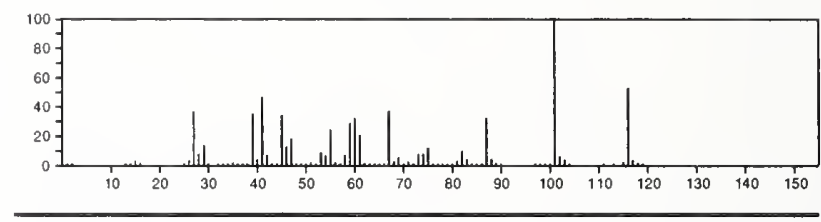

116

$\mathrm{C}_{6} \mathrm{H}_{12} \mathrm{~S}$

$2 \mathrm{H}$-Thiopyran, tetrahydro-4-methyl-

$5161-17-1$
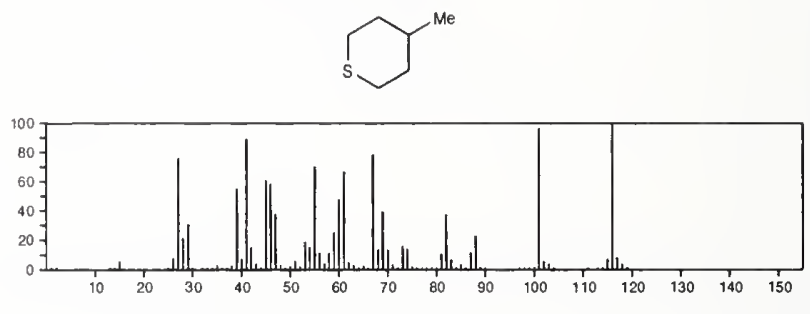

116

$\mathrm{C}_{6} \mathrm{H}_{12} \mathrm{~S}$

2H-Thiopyran, tetrahydro-3-methyl-

$5258-50-4$
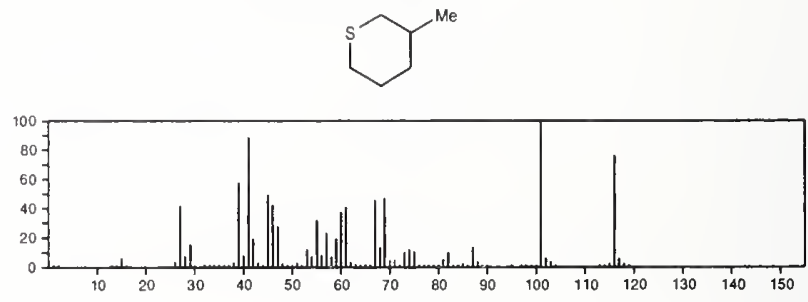

116

$\mathrm{C}_{6} \mathrm{H}_{12} \mathrm{~S}$

$7133-36-0$

Cyclopentane, (methylthio)
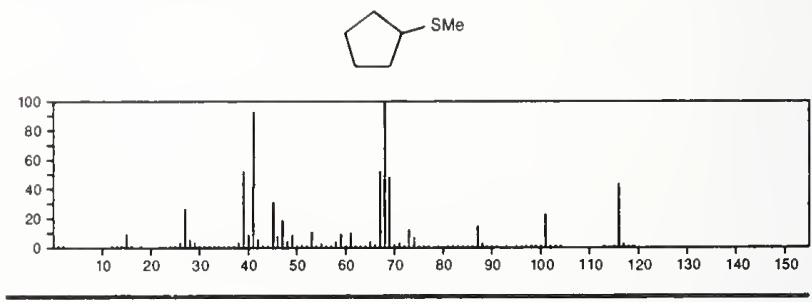

116

$\mathrm{C}_{6} \mathrm{H}_{12} \mathrm{~S}$

1-Propene, 3-[(1-methylethyl)thio]

$50996-72-0$

i $-\mathrm{Pr} \mathrm{SCH}_{2} \mathrm{CH}=\mathrm{CH}_{2}$

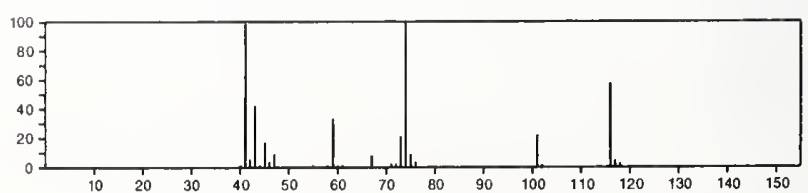


116

1,6-Hexanediamine

$\mathrm{C}_{6} \mathrm{H}_{16} \mathrm{~N}_{2}$

$\mathrm{H}_{2} \mathrm{~N}\left(\mathrm{CH}_{2}\right) 6 \mathrm{NH}_{2}$

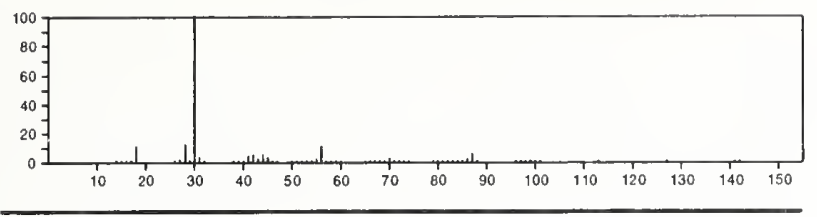

116

Silane, triethyl-

$\mathrm{C}_{6} \mathrm{H}_{16} \mathrm{Si}$

SIHE t3

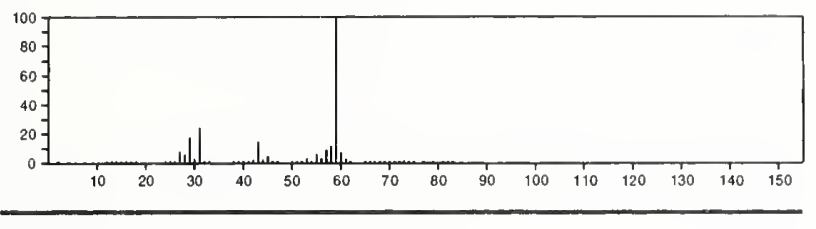

116

1-Heptanol

$\mathrm{C}_{7} \mathrm{H}_{16} \mathrm{O}$

$\mathrm{Me}\left(\mathrm{CH}_{2}\right) 6 \mathrm{OH}$

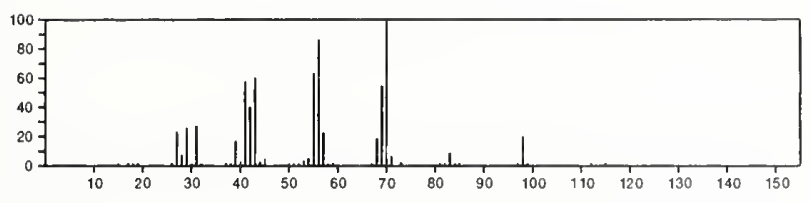

116

2-Heptanol

$\mathrm{C}_{7} \mathrm{H}_{16} \mathrm{O}$

$543-49-7$

$\mathrm{MeCH}(\mathrm{OH})\left(\mathrm{CH}_{2}\right) 4 \mathrm{Me}$

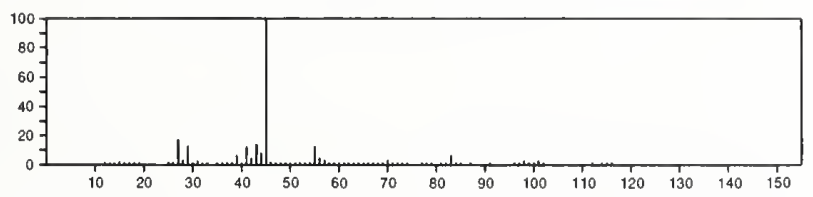

116

4-Heptanol

$\mathrm{C}_{7} \mathrm{H}_{16} \mathrm{O}$

$589-55-9$

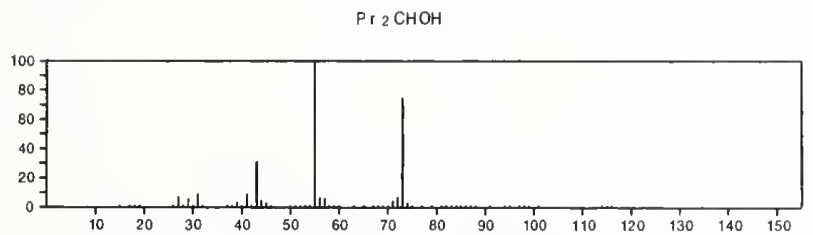

116

3-Heptanol

$\mathrm{C}_{7} \mathrm{H}_{16} \mathrm{O}$

$\mathrm{E}\left\{\mathrm{CH}(\mathrm{OH})\left\langle\mathrm{CH}_{2}\right) 3 \mathrm{Me}\right.$

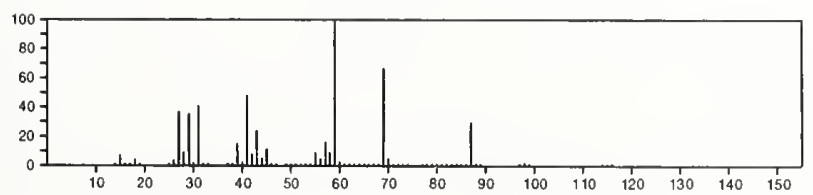

116

3-Pentanol, 2,3-dimethyl-

$\mathrm{C}_{7} \mathrm{H}_{16} \mathrm{O}$

595-41-5

$\mathrm{Me} 2 \mathrm{CHCE}+(\mathrm{OH}) \mathrm{Me}$

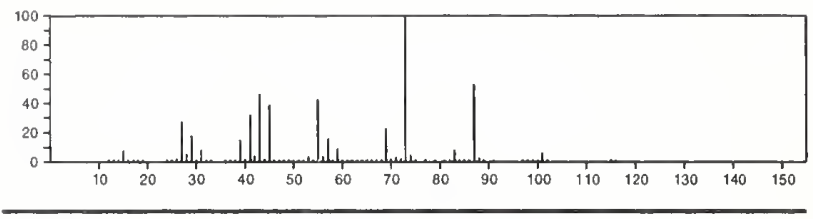

116

3-Pentanol, 3-ethyl-

$\mathrm{C}_{7} \mathrm{H}_{16} \mathrm{O}$

597-49-9

Et $3 \mathrm{COH}$

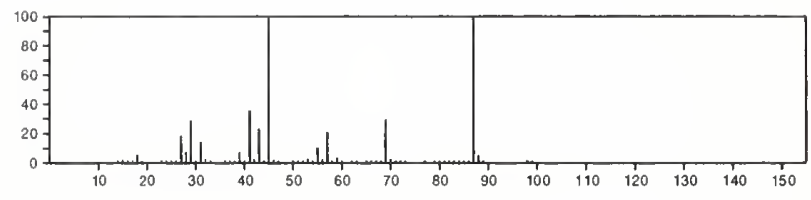

116

3-Hexanol, 3-methyl-

$\mathrm{C}_{7} \mathrm{H}_{16} \mathrm{O}$

597-96-6

CPr OHOHE:

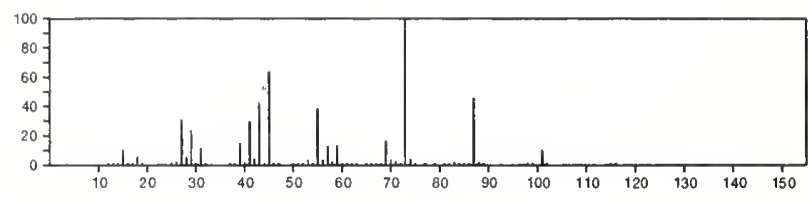

116

$\mathrm{C}_{7} \mathrm{H}_{16} \mathrm{O}$

600-36-2

3 Pentanol, 2,4-dimethyl-

$\mathrm{Me}_{2} \mathrm{CHCH}(\mathrm{OH}) \mathrm{CHMe}_{2}$

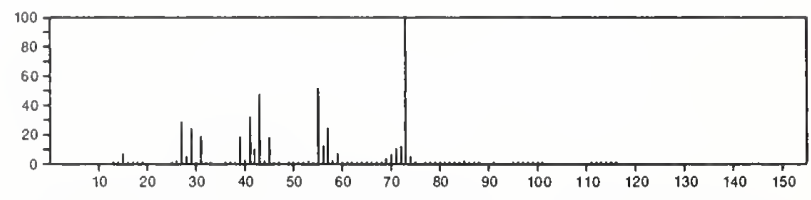

116

3 Hexanol, 4-methyl-

$\mathrm{C}_{7} \mathrm{H}_{16} \mathrm{O}$

615-29-2

$\left.\mathrm{MeCH} \mathrm{CHMeCH}_{2} \mathrm{OH}\right) \mathrm{Et}$

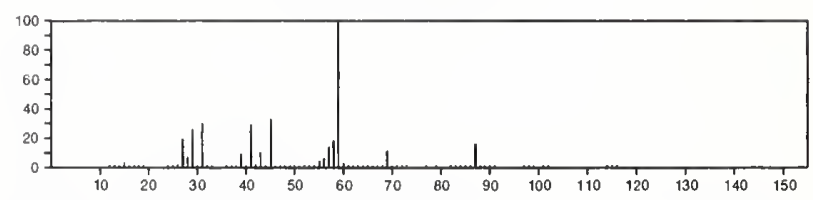

116

3-Hexanol, 2-methyl

$\mathrm{C}_{7} \mathrm{H}_{16} \mathrm{O}$

617-29-8

$\mathrm{Me} 2 \mathrm{CHCH}(\mathrm{OH}) \mathrm{Pr}$

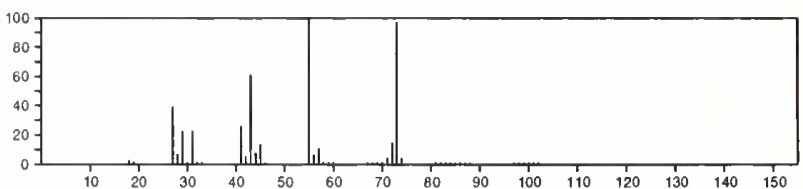


116

3-Hexanol, 5-methyl

$\mathrm{C}_{7} \mathrm{H}_{16} \mathrm{O}$

$\mathrm{EtCH}(\mathrm{OH}) \mathrm{CH}_{2} \mathrm{CHMe} 2$
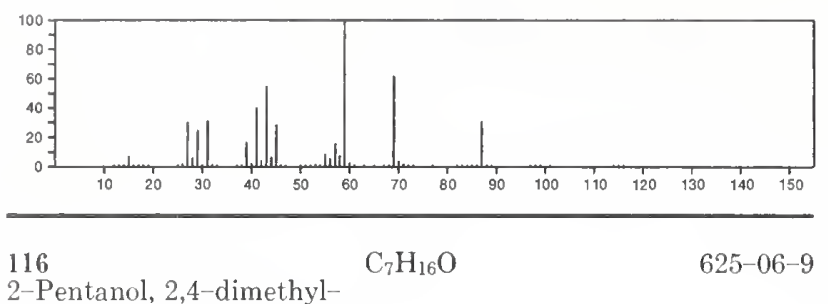

$\mathrm{Me}_{2} \mathrm{COHCH}_{2} \mathrm{CHMe}_{2}$
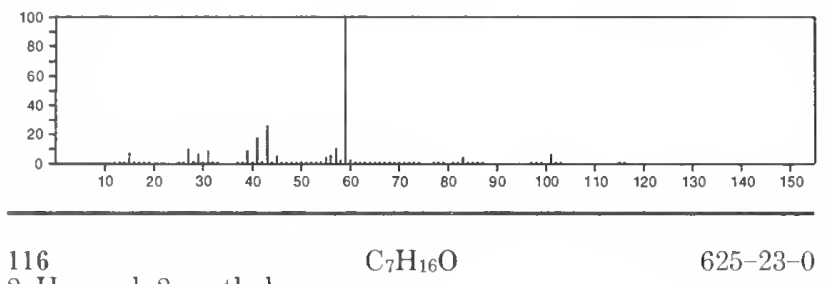

2-Hexanol, 2-methyl

$\mathrm{Me} 2 \mathrm{COH}\left(\mathrm{CH}_{2}\right)_{3} \mathrm{Me}$

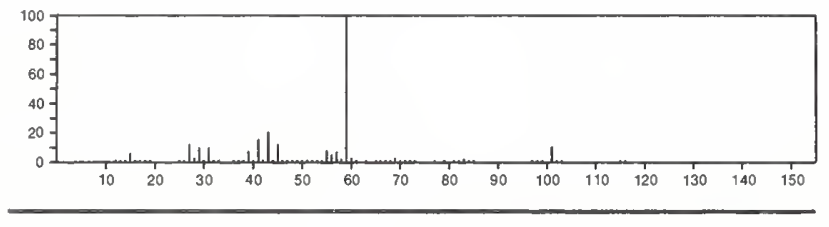

116

$\mathrm{C}_{7} \mathrm{H}_{16} \mathrm{O}$

$627-59-8$

2-Hexanol, 5-methyl-

$\mathrm{MeCH}(\mathrm{OH}) \mathrm{CH}_{2} \mathrm{CH}_{2} \mathrm{CHMe}_{2}$
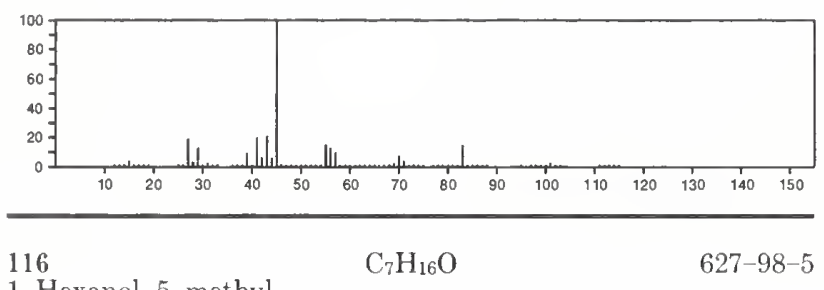

1-Hexanol, 5-methyl-

$\mathrm{Me} 2 \mathrm{CH}\left(\mathrm{CH}_{2}\right)_{4} \mathrm{OH}$
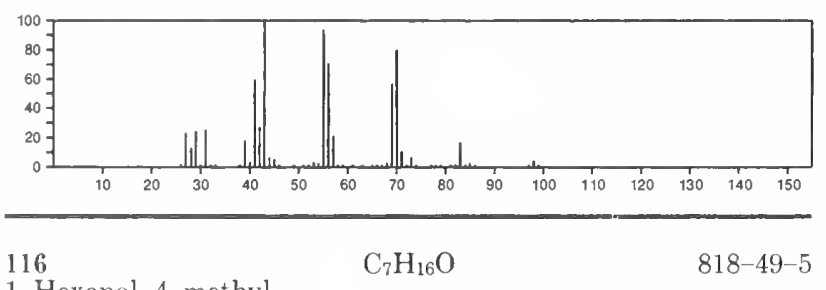

1-Hexanol, 4-methyl-

$\mathrm{HO}\left(\mathrm{CH}_{2}\right)_{3} \mathrm{CHMeCH}_{2} \mathrm{Me}$

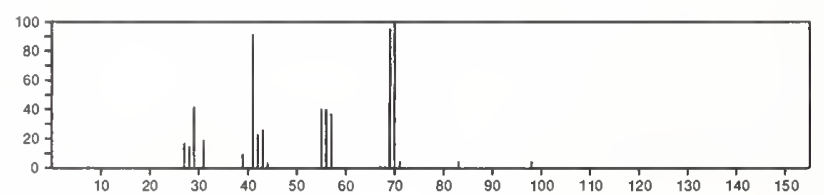

116

$\mathrm{C}_{7} \mathrm{H}_{16} \mathrm{O}$

$1860-27-1$
$\mathrm{Me}\left(\mathrm{CH}_{2}\right)_{3} \mathrm{OPr}_{-}$

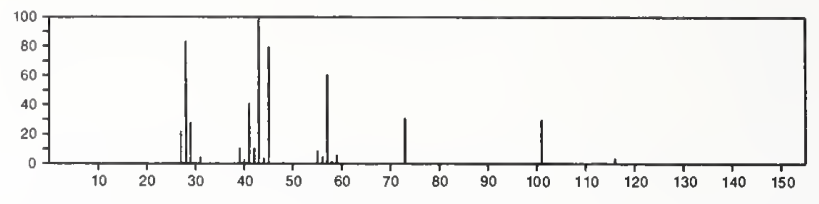

116

2-Hexanol, 3-methyl-

$\mathrm{C}_{7} \mathrm{H}_{16} \mathrm{O}$

$2313-65-7$

$\mathrm{MeCH}(\mathrm{OH}) \mathrm{CHP}$.Me

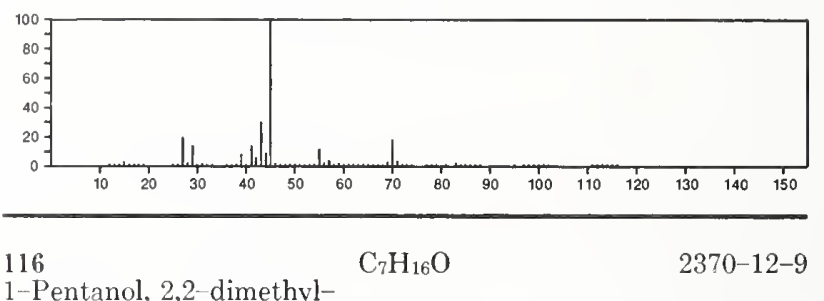

$\mathrm{HOCH}_{2} \mathrm{CP}_{\mathrm{rMe}} 2$

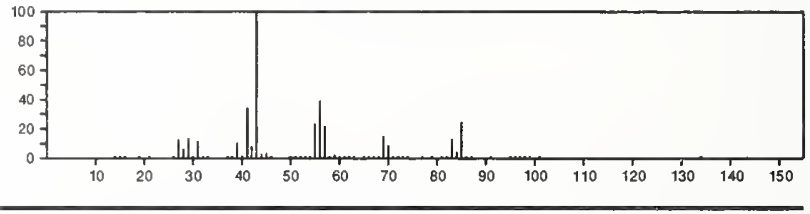

116

$\mathrm{C}_{7} \mathrm{H}_{16} \mathrm{O}$

$3073-92-5$

Butane, 1-propoxy-

$\mathrm{Me}\left(\mathrm{CH}_{2}\right)_{3} \mathrm{OPr}$

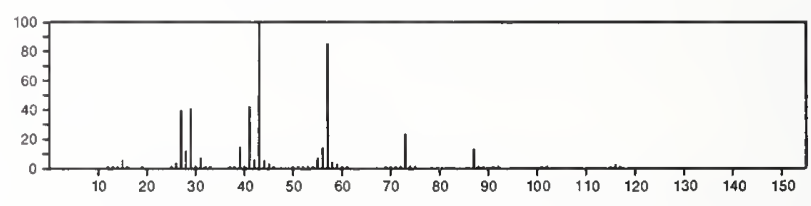

116

$\mathrm{C}_{7} \mathrm{H}_{16} \mathrm{O}$

$3970-62-5$

3-Pentanol, 2,2-dimethyl-

$\mathrm{Me} 3 \mathrm{CCH}(\mathrm{OH}) \mathrm{EI}$

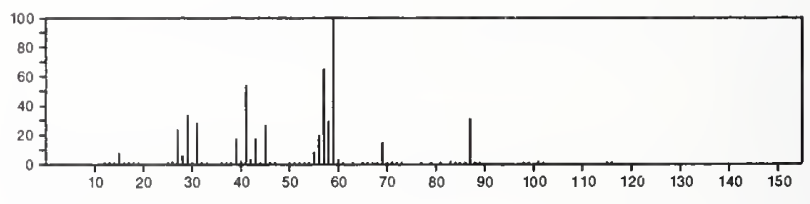

$116 \quad \mathrm{C}_{7} \mathrm{H}_{16} \mathrm{O}$

Hexane, 1-methoxy-

$\mathrm{MeO}\left(\mathrm{CH}_{2}\right) 5 \mathrm{Me}$

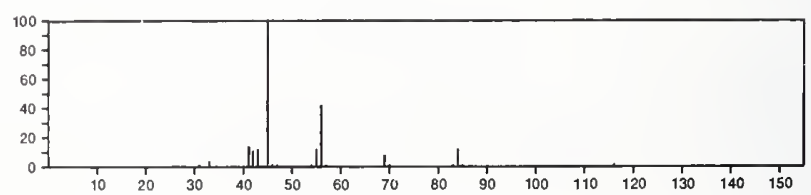


2-Pentanol, 2,3-dimethyl-

$\mathrm{C}_{7} \mathrm{H}_{16} \mathrm{O}$

$\mathrm{Me} \mathrm{CH}_{2} \mathrm{CHMe} \mathrm{CMe}_{2} \mathrm{OH}$

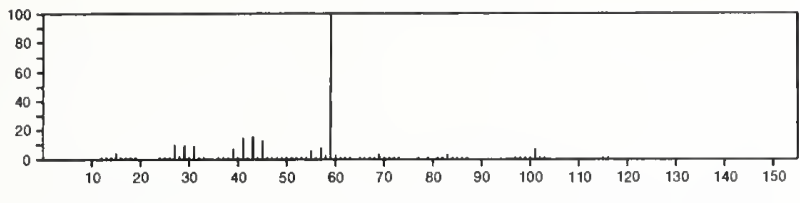

116

1-Hexanol, 3-methyl-

$\mathrm{C}_{7} \mathrm{H}_{16} \mathrm{O}$

$13231-81-7$

$\mathrm{HOCH}_{2} \mathrm{CH}_{2} \mathrm{CHP}$ r Me

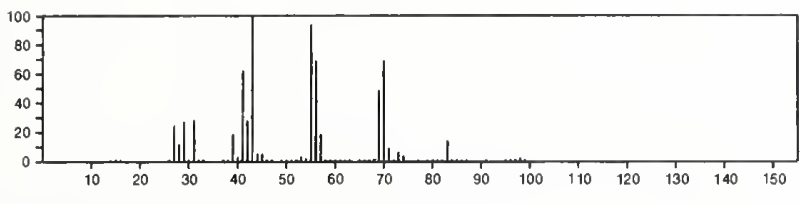

116

$\mathrm{C}_{7} \mathrm{H}_{16} \mathrm{O}$

$17952-11-3$

Pentane, 1-ethoxy-

$\mathrm{Me}\left(\mathrm{CH}_{2}\right)_{4} \mathrm{OEt}$

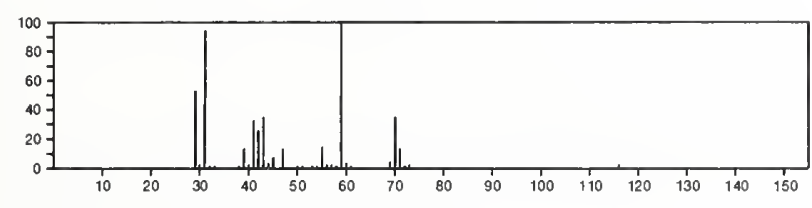

116

$\mathrm{C}_{7} \mathrm{H}_{16} \mathrm{O}$

$18641-81-1$

Ether, sec-butyl isopropyl

$s-B \cup O P r-i$

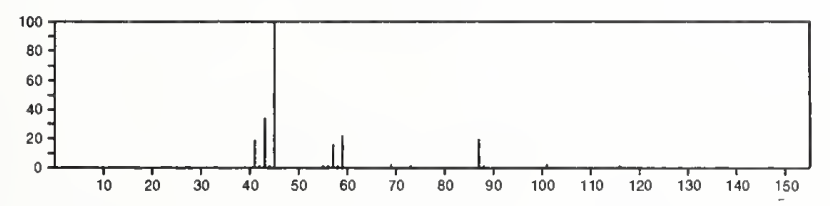

116

$\mathrm{C}_{7} \mathrm{H}_{16} \mathrm{O}$

36749-13-0

Pentane, 3-ethoxy-

Et 2 CHOE t

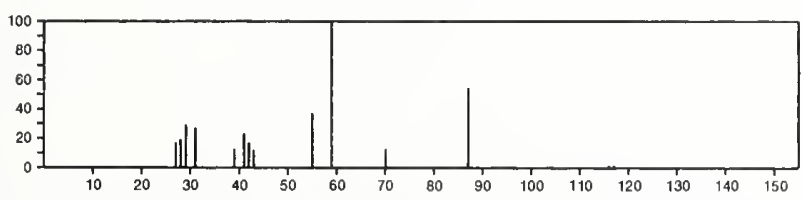

116

$\mathrm{C}_{7} \mathrm{H}_{16} \mathrm{O}$

54658-01-4

Hexane, 3-methoxy-

PrCHEt ( OMe)

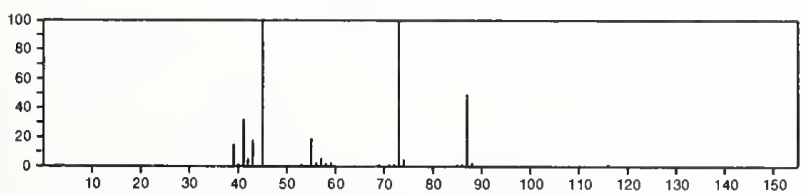

116

$1 H$-Indene

$\mathrm{C}_{9} \mathrm{H}_{8}$

95-13-6
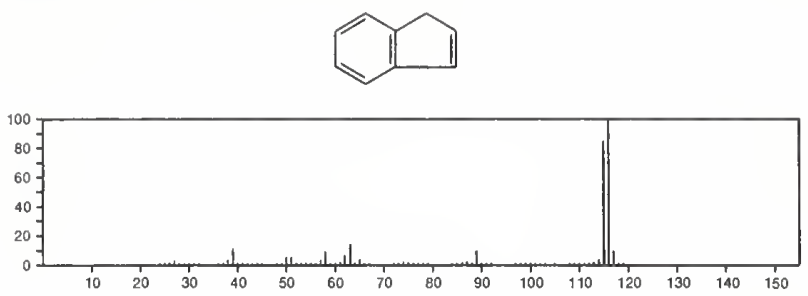

116

$\mathrm{C}_{9} \mathrm{H}_{8}$

$766-97-2$

Benzene, 1-ethynyl-4-methyl-
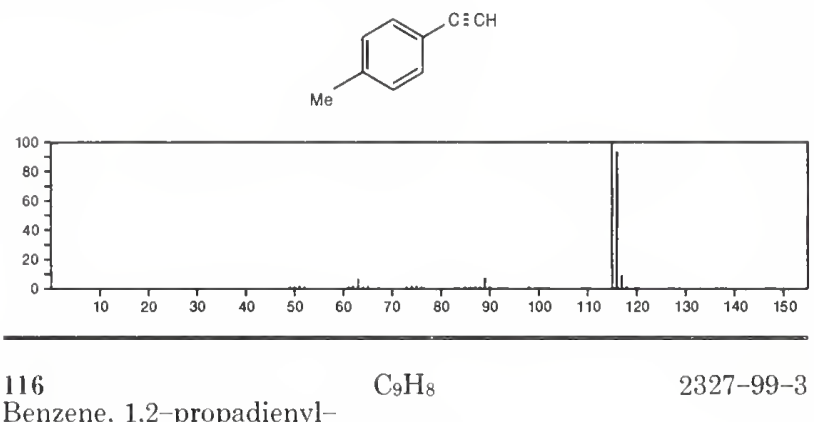

Benzene, 1,2-propadienyl-

$\mathrm{H}_{2} \mathrm{C}: \mathrm{C}=\mathrm{CHPh}$

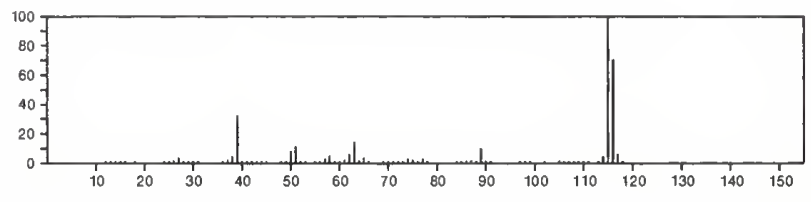

$117 \quad \mathrm{C}_{3} \mathrm{H}_{7} \mathrm{~N}_{3} \mathrm{O}_{2}$

Urea, $N$-ethyl- $N$-nitroso-

759-73-9

$\mathrm{E} \mathrm{IN}(\mathrm{NO}) \mathrm{CONH}_{2}$

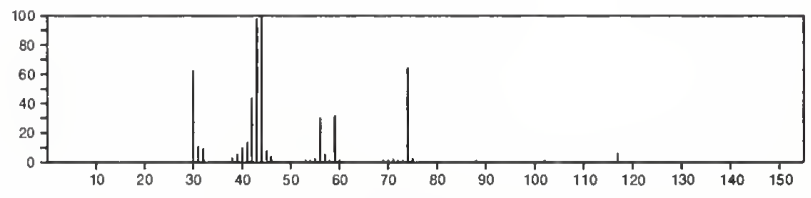

117

Glycine, $N$-acetyl-

$\mathrm{C}_{4} \mathrm{H}_{7} \mathrm{NO}_{3}$

$543-24-8$

$\mathrm{AcNHCH} 2 \mathrm{CO}_{2} \mathrm{H}$

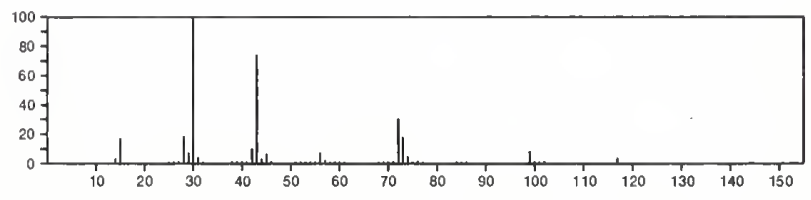

117

$\mathrm{C}_{4} \mathrm{H}_{7} \mathrm{NO}_{3}$

Propanoic acid, 2-(hydroxyimino)-, methyl ester

$5634-53-7$

$\mathrm{MeOC}(\mathrm{O}) \mathrm{CMe}=\mathrm{NOH}$

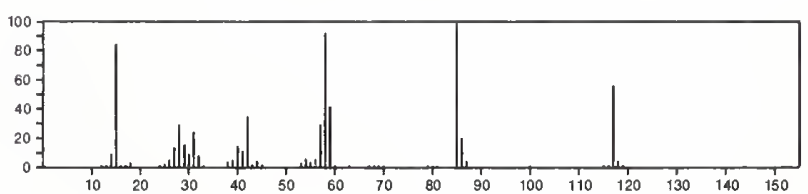


117

Butanenitrile, 3-chloro-3-methyl-

$\mathrm{Me}_{2} \mathrm{CCl} \mathrm{CH}_{2} \mathrm{CN}$
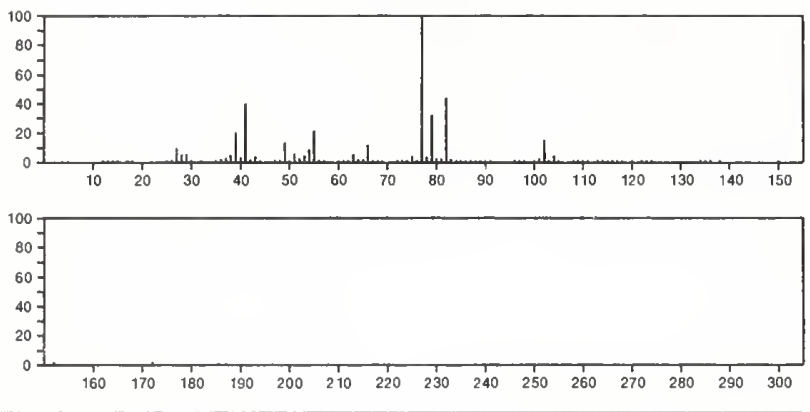

117 L-Valine

$\mathrm{C}_{5} \mathrm{H}_{11} \mathrm{NO}_{2}$

$72-18-4$

$\mathrm{Me} 2 \mathrm{CHCH}\left(\mathrm{NH}_{2}\right) \mathrm{CO}_{2} \mathrm{H}$

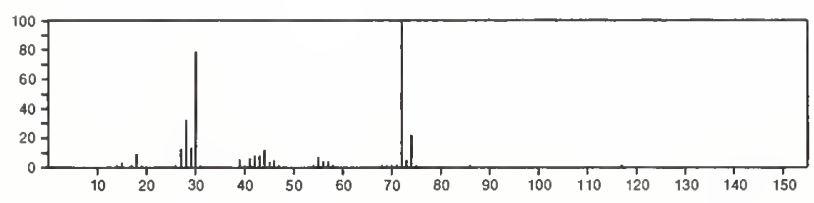

117

$\mathrm{C}_{5} \mathrm{H}_{11} \mathrm{NO}_{2}$

$107-43-7$

Methanaminium, 1-carboxy- $N, N, N$-trimethyl-, hydroxide, inner salt
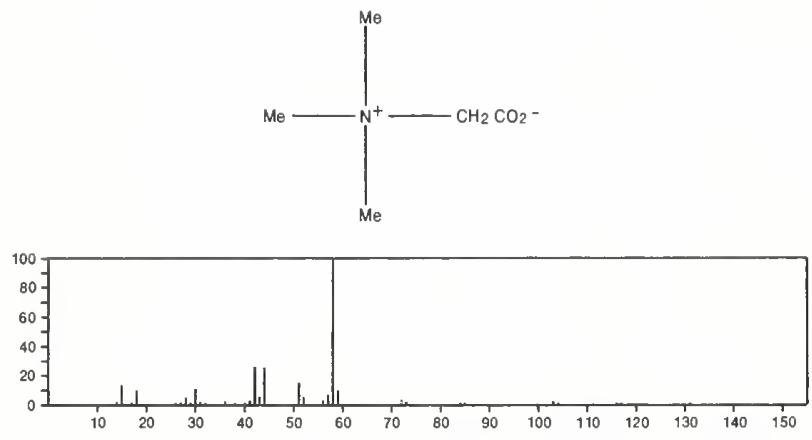

117

$\mathrm{C}_{5} \mathrm{H}_{11} \mathrm{NO}_{2}$

Nitrous acid, 3-methylbutyl ester

$110-46-3$

$\mathrm{Me}_{2} \mathrm{CHCH}_{2} \mathrm{CH}_{2} \mathrm{ONO}$

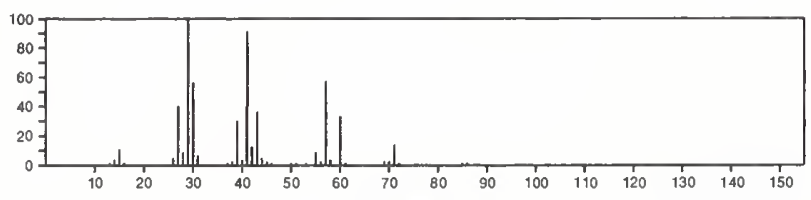

117

Pentane, 1-nitro-

$\mathrm{C}_{5} \mathrm{H}_{11} \mathrm{NO}_{2}$

628-05-7

$\mathrm{O}_{2} \mathrm{~N}\left(\mathrm{CH}_{2}\right)_{4} \mathrm{Me}$

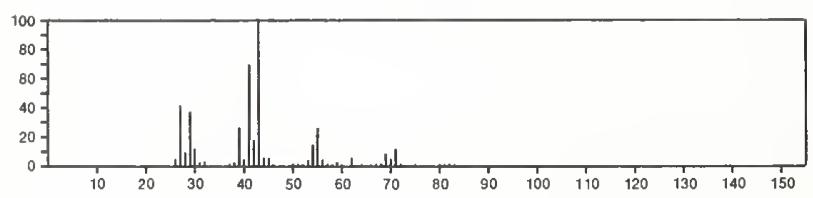

117

L-Alanine, ethyl ester

$\mathrm{C}_{5} \mathrm{H}_{11} \mathrm{NO}_{2}$

$3082-75-5$

$\mathrm{E}$ IOC $(\mathrm{O}) \mathrm{CH}\left(\mathrm{NH}_{2}\right) \mathrm{Me}$

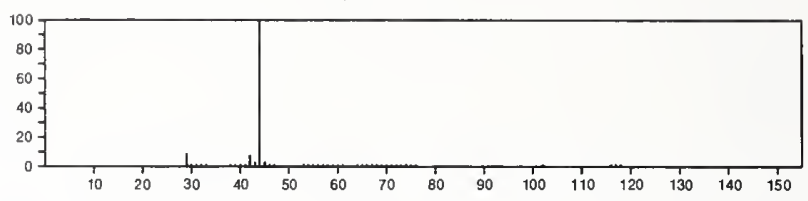

117

Glycine, $N, N$-dimethyl-, methyl ester

$\mathrm{C}_{5} \mathrm{H}_{11} \mathrm{NO}_{2}$

$\mathrm{Me}_{2} \mathrm{NCH}_{2} \mathrm{C}(0)$ OMe

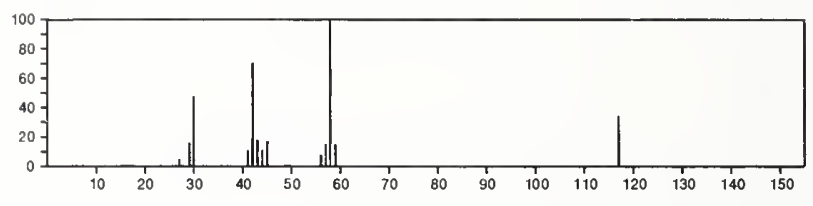

117
Pentanamide, 5-hydroxy-

$\mathrm{C}_{5} \mathrm{H}_{11} \mathrm{NO}_{2}$

$29686-12-2$

$\mathrm{HO}\left(\mathrm{CH}_{2}\right)_{4} \mathrm{CONH}_{2}$

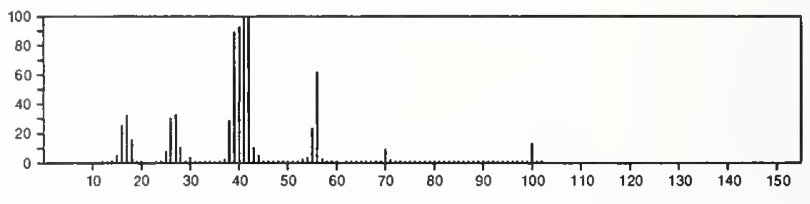

117

$\mathrm{C}_{6} \mathrm{H}_{15} \mathrm{NO}$

100-37-8

Ethanol, 2-(diethylamino)-

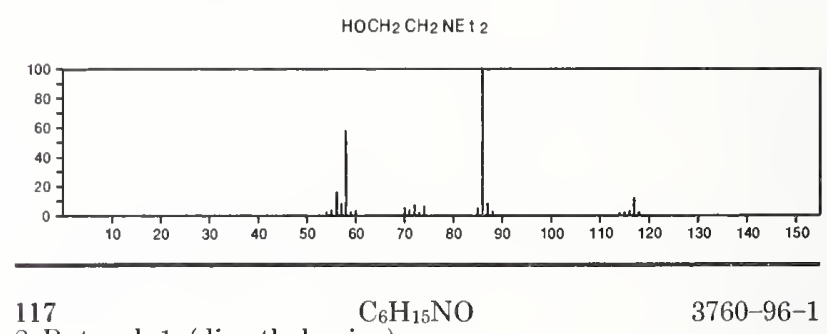

2-Butanol, 1-(dimethylamino)-

$\mathrm{E} \uparrow \mathrm{CH}(\mathrm{OH}) \mathrm{CH}_{2} \mathrm{NMe}_{2}$

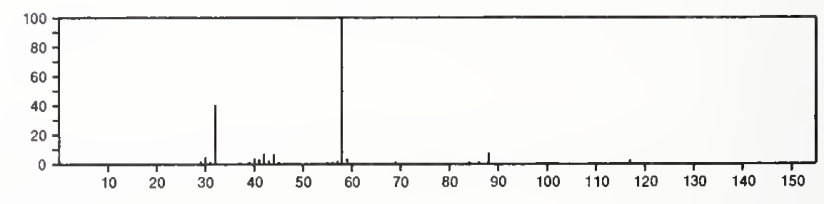

117

1-Hexanol, 6-amino-

$\mathrm{C}_{6} \mathrm{H}_{15} \mathrm{NO}$

4048-33-3

$\mathrm{H}_{2} \mathrm{~N}\left(\mathrm{CH}_{2}\right) 6 \mathrm{OH}$

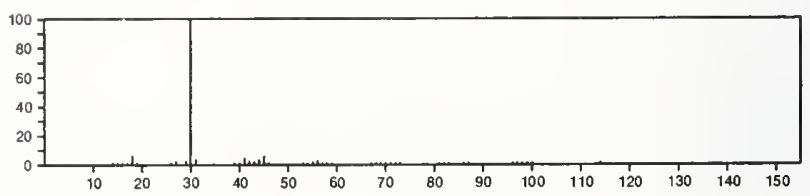


117

Hydroxylamine, $\mathrm{O}$-hexyl-

$\mathrm{C}_{6} \mathrm{H}_{15} \mathrm{NO}$

$\mathrm{H}_{2} \mathrm{NO}\left(\mathrm{CH}_{2}\right) 5 \mathrm{Me}$

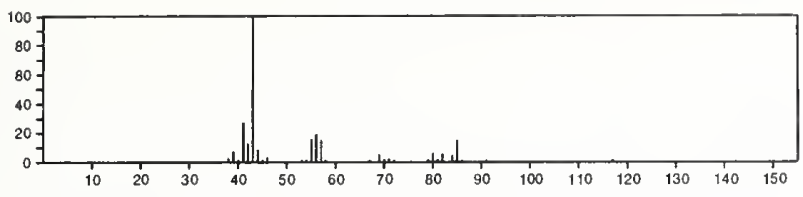

117

$\mathrm{C}_{8} \mathrm{H}_{7} \mathrm{~N}$

$104-85-8$

Benzonitrile, 4-methyl-
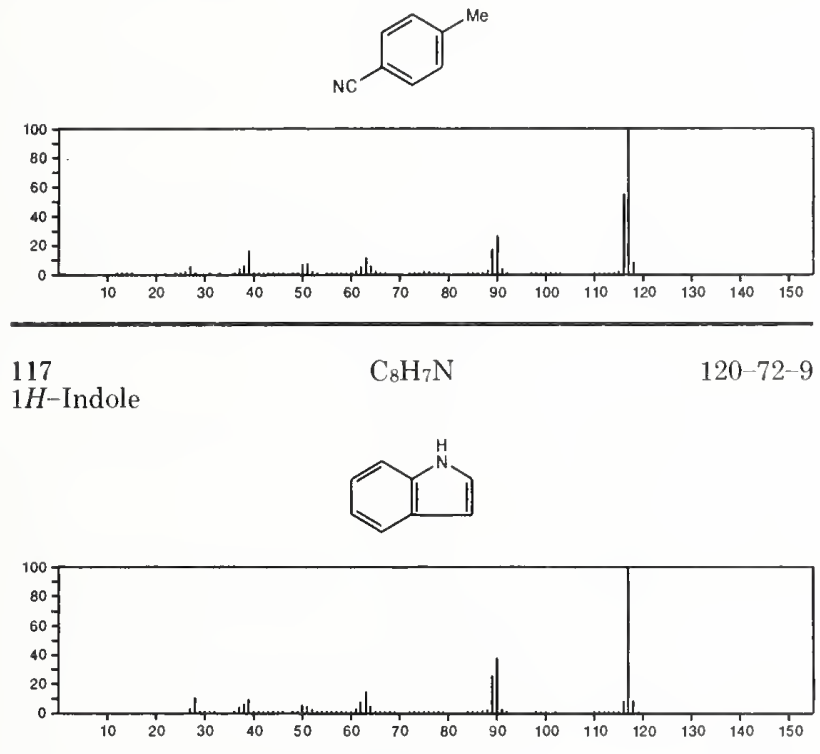

117

Benzeneacetonitrile

$\mathrm{C}_{8} \mathrm{H}_{7} \mathrm{~N}$

$140-29-4$

$\mathrm{PhCH}_{2} \mathrm{CN}$

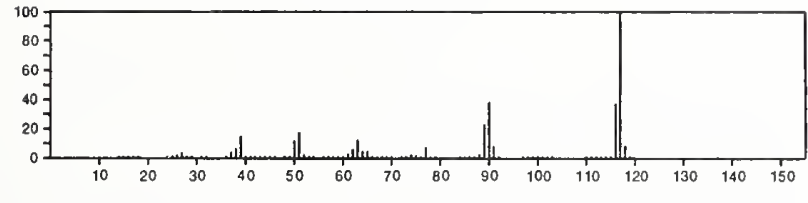

117

Indolizine

$\mathrm{C}_{8} \mathrm{H}_{7} \mathrm{~N}$

$274-40-8$
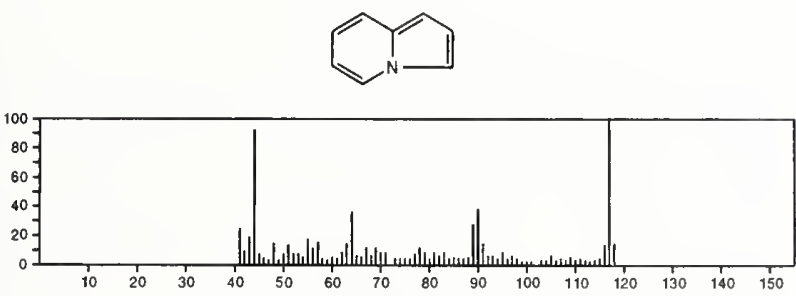

117

$\mathrm{C}_{8} \mathrm{H}_{7} \mathrm{~N}$

Benzonitrile, 2-methyl-
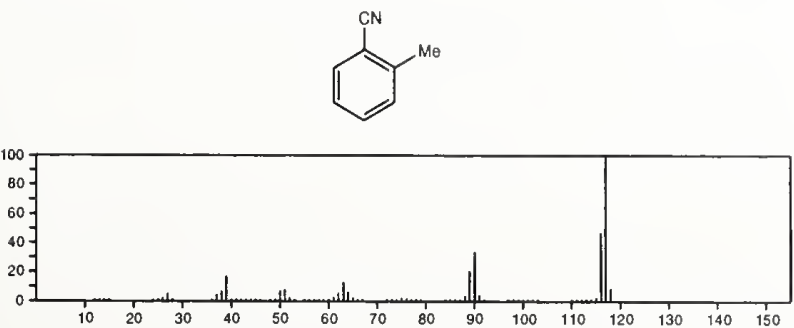

117

$\mathrm{C}_{8} \mathrm{H}_{7} \mathrm{~N}$

$620-22-4$

Benzonitrile, 3-methyl-
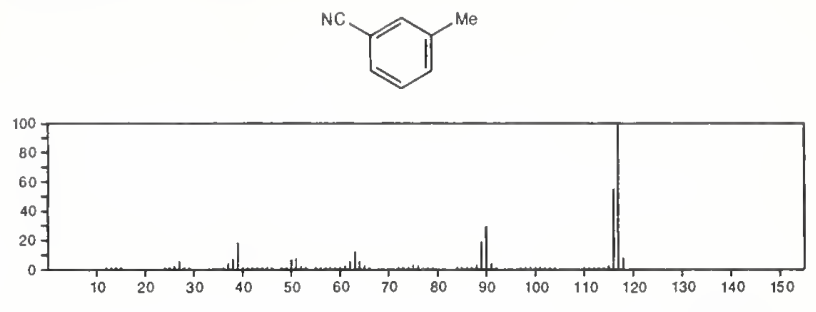

117

2,4,6-Cycloheptatriene-1-carbonitrile
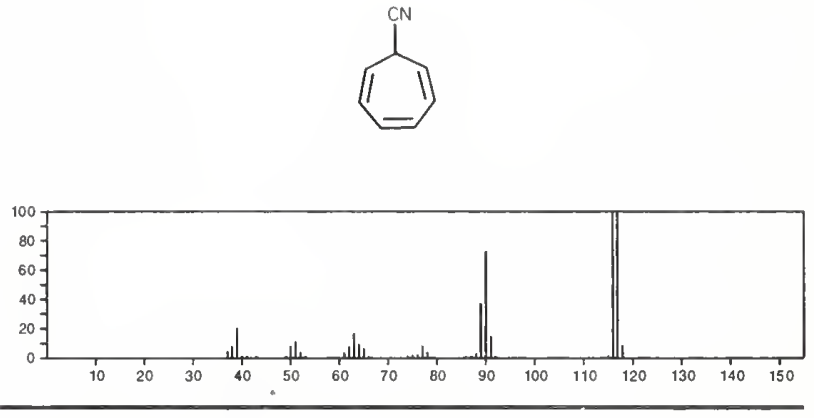

118

$\mathrm{CHCl}_{3}$

67-66-3

Methane, trichloro-

$\mathrm{CHCl}_{3}$

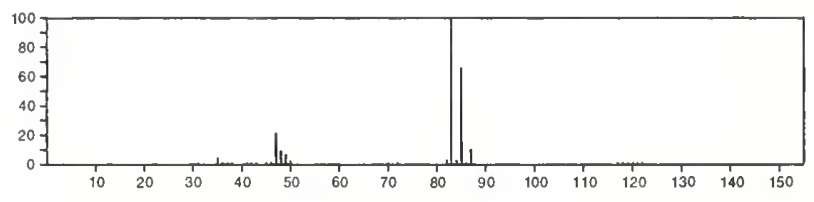

118

$\mathrm{C}_{2} \mathrm{H}_{2} \mathrm{ClF}_{3}$

$75-88-7$

Ethane, 2-chloro-1,1,1-trifluoro-

$\mathrm{Cl} \mathrm{CH}_{2} \mathrm{CF}_{3}$

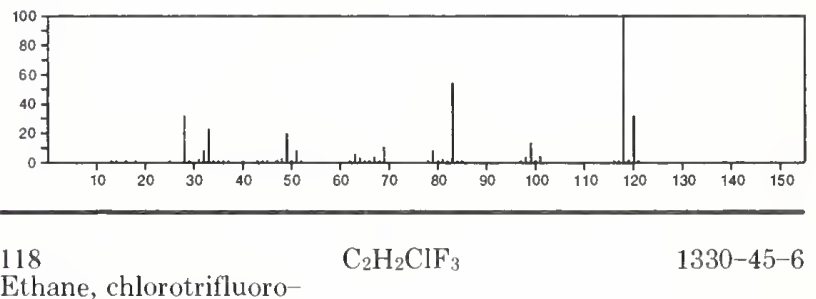

$\mathrm{ClCH}_{2} \mathrm{Me}+3 \mathrm{~F}$

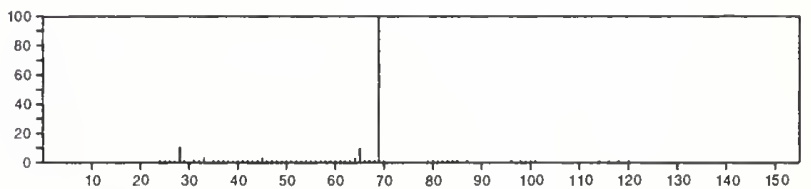


118

$\mathrm{C}_{2} \mathrm{H}_{6} \mathrm{~N}_{4} \mathrm{O}_{2}$

Ethanedioic acid, dihydrazide

$\mathrm{H}_{2} \mathrm{NNHCOCONHNH}_{2}$

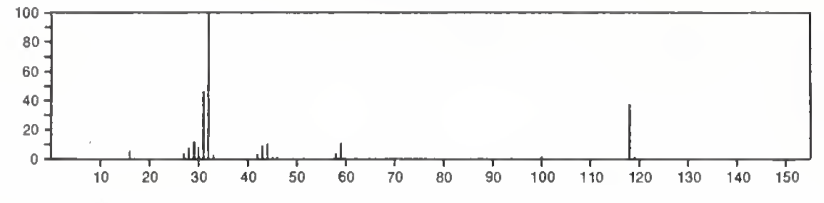

118

1-Propyne, 3-bromo-

\section{$\mathrm{C}_{3} \mathrm{H}_{3} \mathrm{Br}$}

$106-96-7$

$\mathrm{HC} \equiv \mathrm{CCH}_{2} \mathrm{~B}$

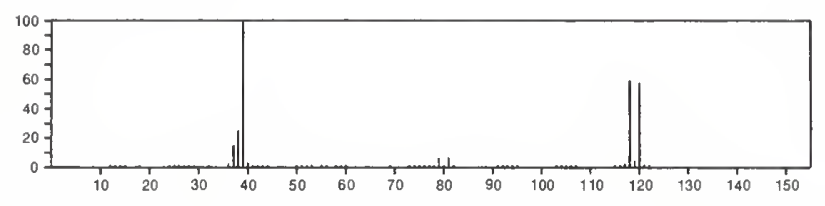

118

$\mathrm{C}_{3} \mathrm{H}_{6} \mathrm{~N}_{2} \mathrm{OS}$

Acetamide, 2-(methylamino) $-2-$ thioxo-

$\mathrm{H}_{2} \mathrm{NCOCSNHME}$

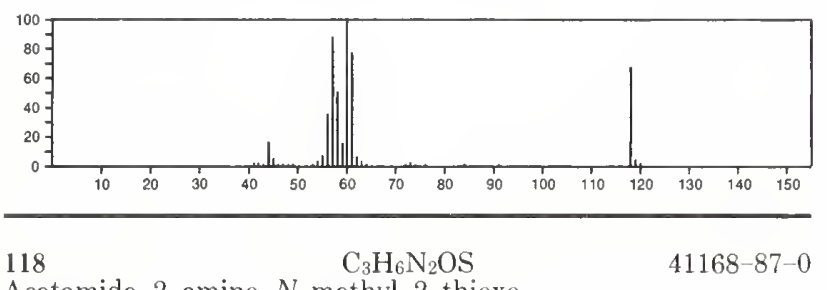

Acetamide, 2-amino- $N$-methyl-2-thioxo-

$\mathrm{H}_{2} \mathrm{NCSCONHMe}$

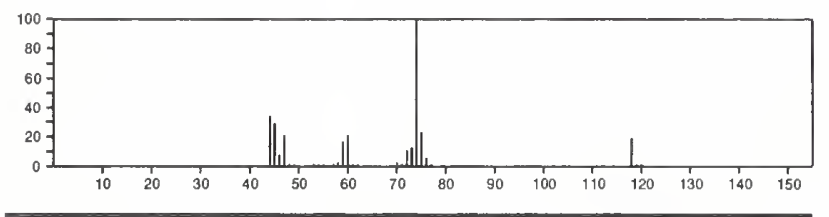

118

Glycine, $N$-methyl- $N$-nitroso-

$\mathrm{C}_{3} \mathrm{H}_{6} \mathrm{~N}_{2} \mathrm{O}_{3}$

$13256-22-9$

$\mathrm{HO}_{2} \mathrm{CCH}_{2} \mathrm{~N}(\mathrm{NO}) \mathrm{Me}$

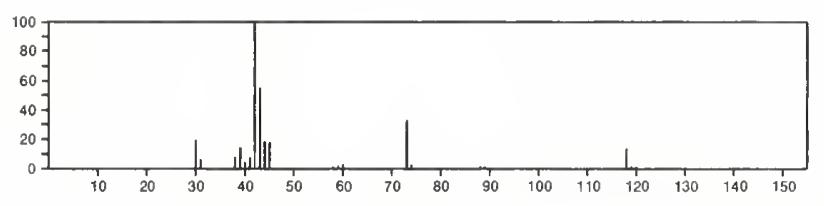

118

1,4-Oxathian-2 one

$\mathrm{C}_{4} \mathrm{H}_{6} \mathrm{O}_{2} \mathrm{~S}$
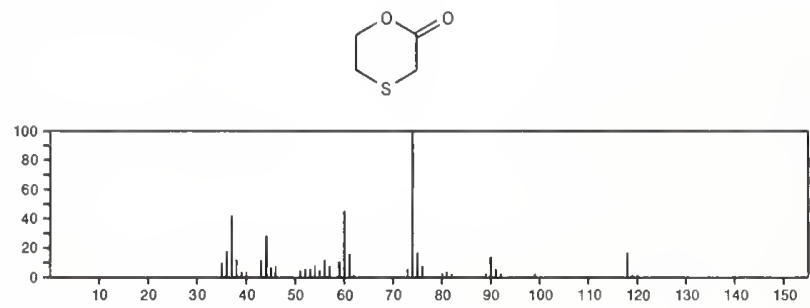

118

Butanedioic acid

$\mathrm{C}_{4} \mathrm{H}_{6} \mathrm{O}_{4}$

$110-15-6$

$\mathrm{HO}_{2} \mathrm{CCH}_{2} \mathrm{CH}_{2} \mathrm{CO}_{2} \mathrm{H}$

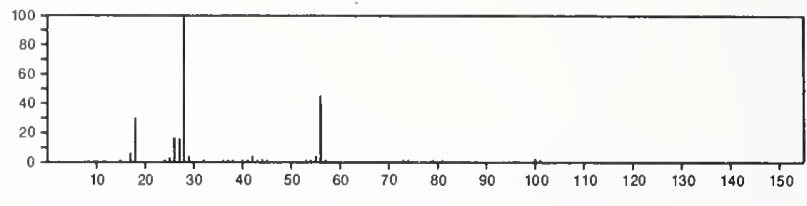

118

Ethanedioic acid, dimethyl ester

$553-90-2$

$\mathrm{MeOC}(\mathrm{O}) \mathrm{C}(\mathrm{O}) \mathrm{OM}$

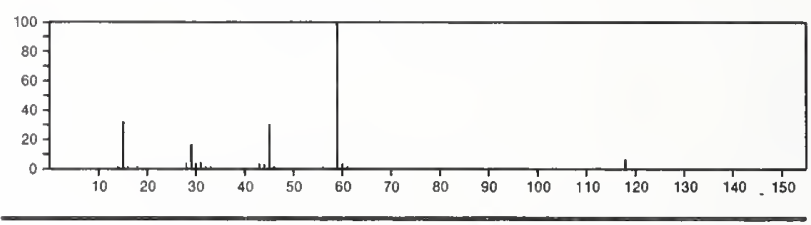

118

1,2-Ethanediol, diformate

$\mathrm{C}_{4} \mathrm{H}_{6} \mathrm{O}_{4}$

$629-15-2$

$\mathrm{O}=\mathrm{CHOCH}_{2} \mathrm{CH}_{2} \mathrm{OCH}=\mathrm{O}$

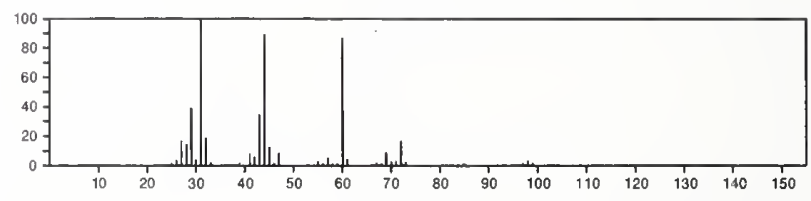

118
Ethanamine, $N$-ethyl- $N$-nitro-

$7119-92-8$

$\mathrm{E}_{2} \mathrm{NNO}_{2}$

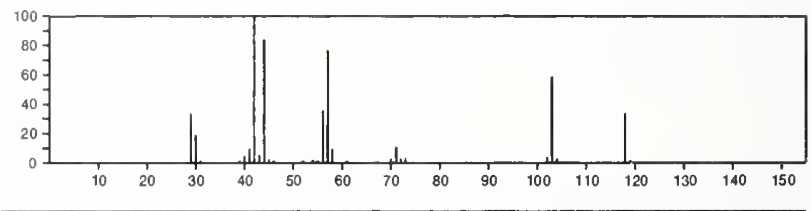

118

$\mathrm{C}_{4} \mathrm{H}_{10} \mathrm{~N}_{2} \mathrm{O}_{2}$

$30893-20-0$

2-Propanamine, $N$-methyl- $N$-nitro-

$\mathrm{MeN}\left(\mathrm{NO}_{2}\right) \mathrm{Pr}-\mathrm{i}$

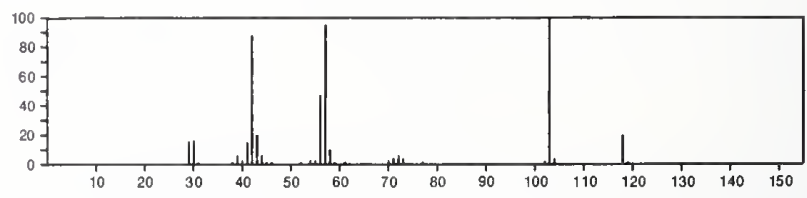

118

$\mathrm{C}_{4} \mathrm{H}_{10} \mathrm{~N}_{2} \mathrm{~S}$

$2489-77-2$

Thiourea, trimethyl-

MeNHCSNME 2

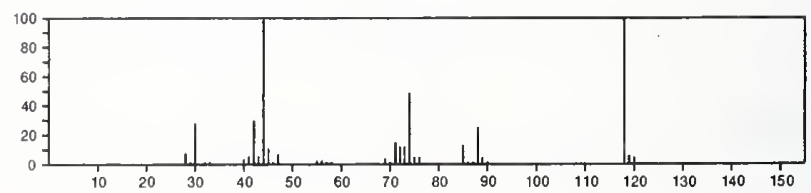


118

Silanol, trimethyl-, formate

$\mathrm{C}_{4} \mathrm{H}_{10} \mathrm{O}_{2} \mathrm{Si}$

$\mathrm{O}=\mathrm{CHOSiMe} 3$

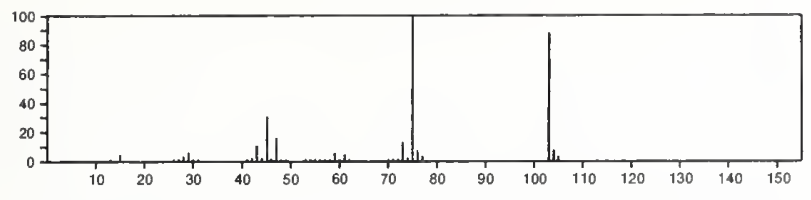

118

$\mathrm{C}_{4} \mathrm{H}_{14} \mathrm{Si}_{2}$

Silane, dimethyl[(methylsilyl)methyl]-

18148-13-5

$\mathrm{MeSiH} \mathrm{CH}_{2} \mathrm{SiHMe}$

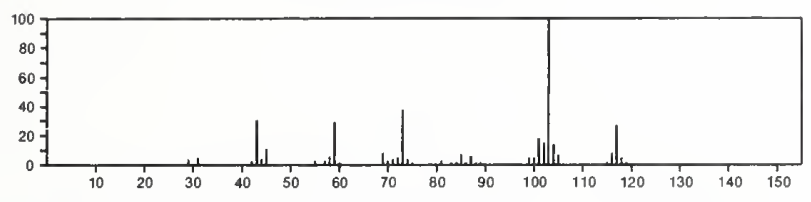

118

$\mathrm{C}_{5} \mathrm{H}_{7} \mathrm{ClO}$

2H-Pyran, 4-chloro-3,6-dihydro-

$24265-21-2$
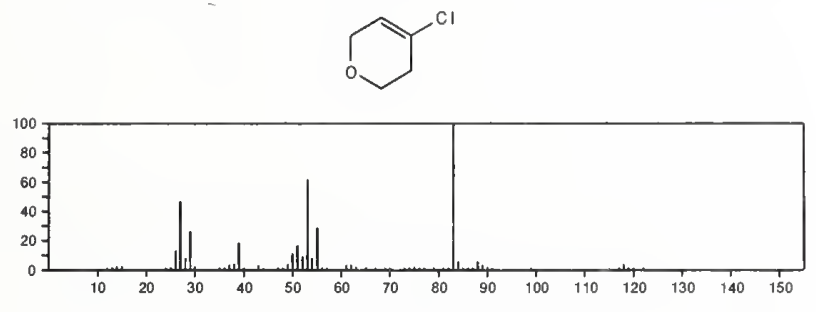

118

$118 \quad \mathrm{C}_{5} \mathrm{H}_{10} \mathrm{OS}$

Ethanethioic acid, S-(1-methylethyl) ester

926-73-8

$i-\operatorname{Pr} S A C$

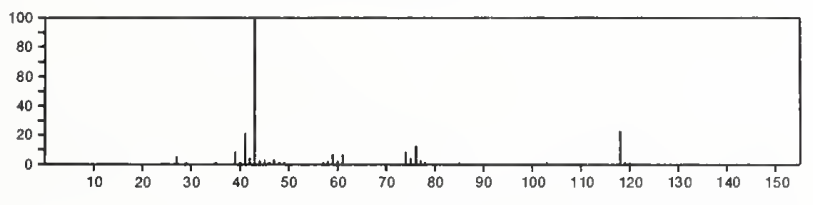

118

$\mathrm{C}_{5} \mathrm{H}_{10} \mathrm{OS}$

Ethanethioic acid, $S$-propyl ester

$2307-10-0$

PrSAC

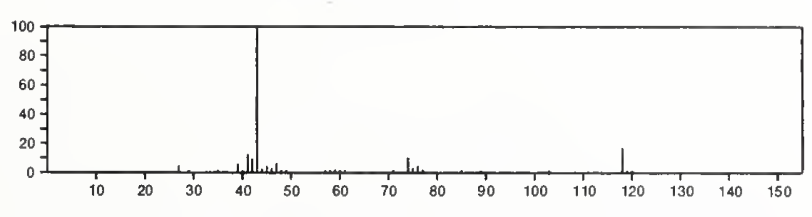

118

$\mathrm{C}_{5} \mathrm{H}_{10} \mathrm{OS}$

Butanethioic acid, $S$-methyl ester

2432-51-1

$\mathrm{MeSC}(0) \mathrm{Pr}$

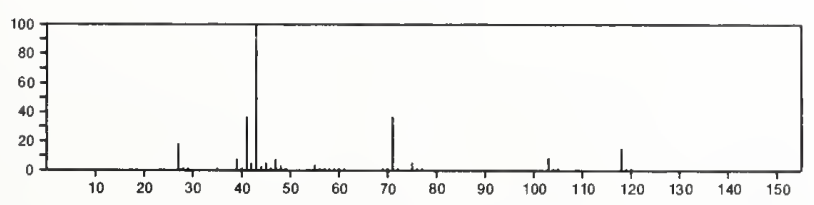

118

$\mathrm{C}_{5} \mathrm{H}_{10} \mathrm{OS}$

4988-34-5
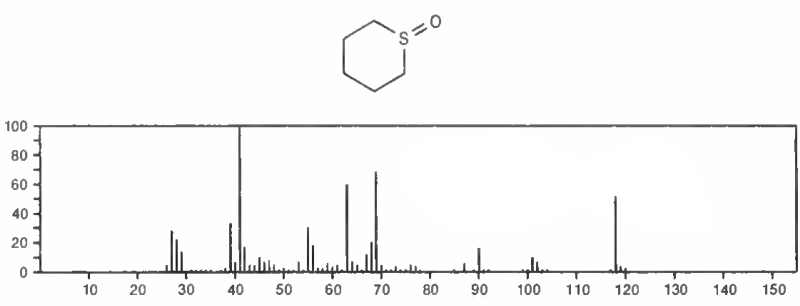

118

1,3-Oxathiolane, 2,2-dimethyl

$\mathrm{C}_{5} \mathrm{H}_{10} \mathrm{OS}$

5684-31-1

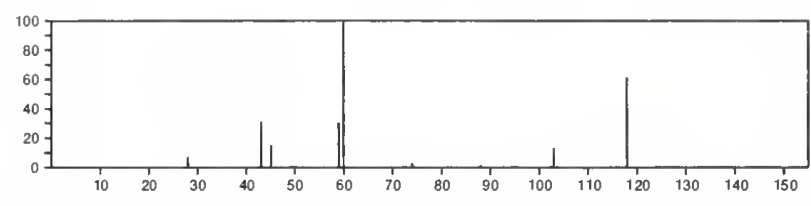

118

$\mathrm{C}_{5} \mathrm{H}_{10} \mathrm{OS}$

19134-37-3

1,3-Oxathiane, 2-methyl
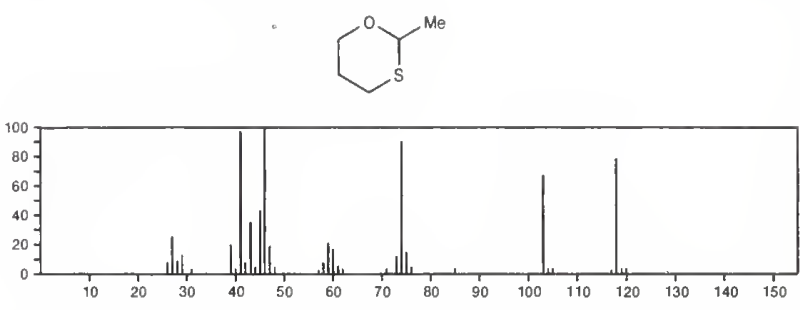

118

2-Propanone, 1-(ethylthio)-

$\mathrm{C}_{5} \mathrm{H}_{10} \mathrm{OS}$

20996-62-7

$\mathrm{Me} \mathrm{COCH}_{2} \mathrm{SE}$ :

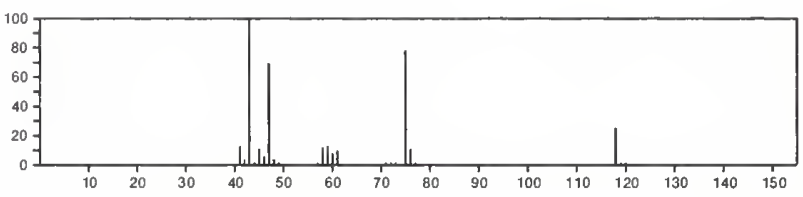

118

1,3-Oxathiane, 6-methyl

$\mathrm{C}_{5} \mathrm{H}_{10} \mathrm{OS}$

30098-75-0
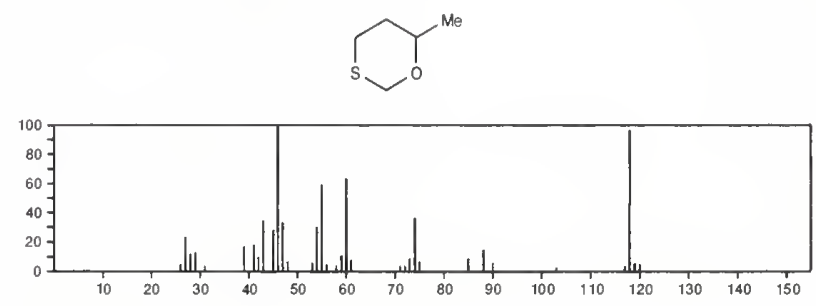

118

$\mathrm{C}_{5} \mathrm{H}_{10} \mathrm{O}_{3}$

$97-64-3$

Propanoic acid, 2-hydroxy-, ethyl ester

$\mathrm{E} I \mathrm{OC}(\mathrm{O}) \mathrm{CH}(\mathrm{OH}) \mathrm{Me}$

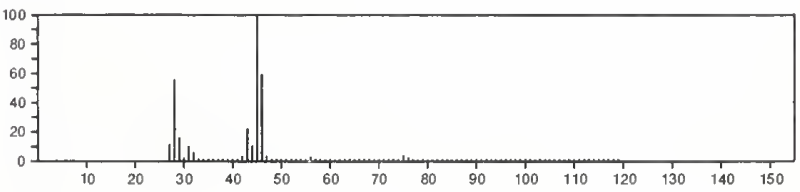


$118 \quad \mathrm{C}_{5} \mathrm{H}_{10} \mathrm{O}_{3}$

EIOC (O) OE $\mathrm{t}$

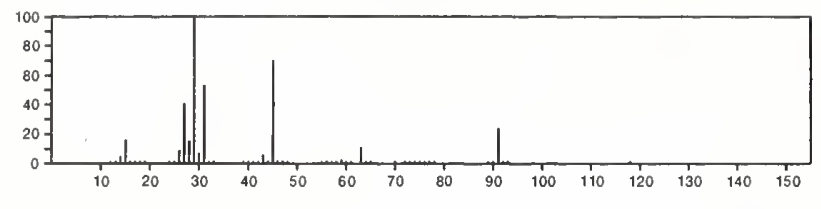

118

Ethanol, 2-methoxy-, acetate

$$
\mathrm{C}_{5} \mathrm{H}_{10} \mathrm{O}_{3}
$$

$110-49-6$

$\mathrm{Me} \mathrm{OCH}_{2} \mathrm{CH}_{2} \mathrm{OAC}$

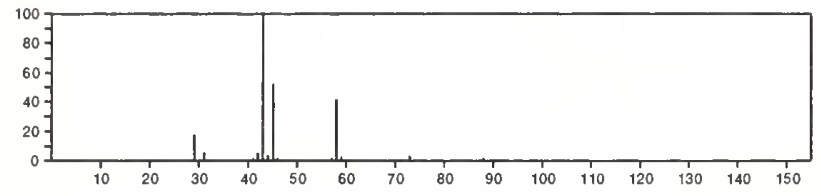

118

$\mathrm{C}_{5} \mathrm{H}_{10} \mathrm{O}_{3}$

Butanoic acid, 3-hydroxy-, methyl ester

$1487-49-6$

$\mathrm{MeCH}(\mathrm{OH}) \mathrm{CH}_{2} \mathrm{C}(\mathrm{O}) \mathrm{OMe}$

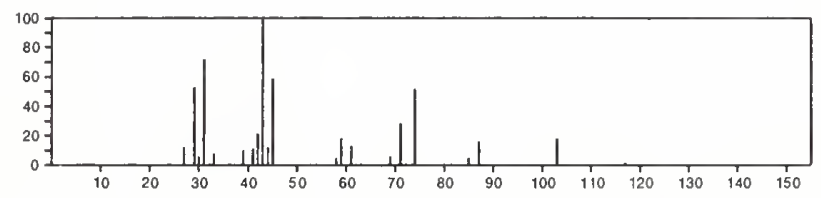

118

$\mathrm{C}_{5} \mathrm{H}_{10} \mathrm{O}_{3}$

1779-19-7

1,3,6-'Trioxocane
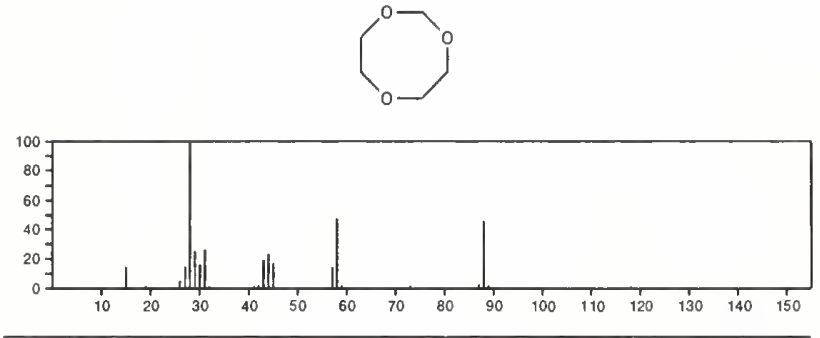

118

$\mathrm{C}_{5} \mathrm{H}_{10} \mathrm{O}_{3}$

$2110-78-3$

Propanoic acid, 2-hydroxy-2-methyl-, methyl ester

$\mathrm{MeOC}(\mathrm{O}) \mathrm{CMe}_{2} \mathrm{OH}$

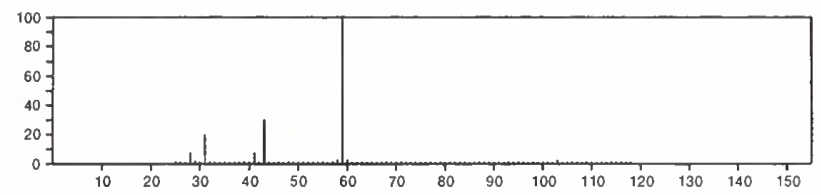

118

$\mathrm{C}_{5} \mathrm{H}_{10} \mathrm{O}$

3938-96-3

Acetic acid, methoxy-, ethyl ester

$\mathrm{MeOCH}_{2} \mathrm{C}(\mathrm{O}) \mathrm{OE}$ t

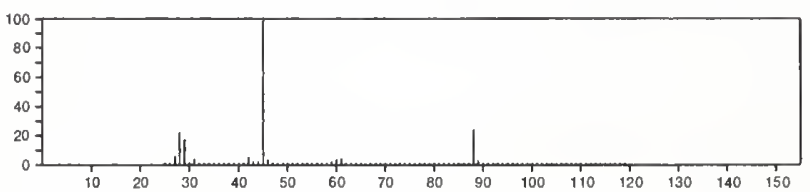

118

$\mathrm{C}_{5} \mathrm{H}_{10} \mathrm{O}_{3}$

$4382-77-8$

Ethanol, 1-methoxy-, acetate

$\mathrm{AcOCH}(\mathrm{OMe}) \mathrm{Me}$

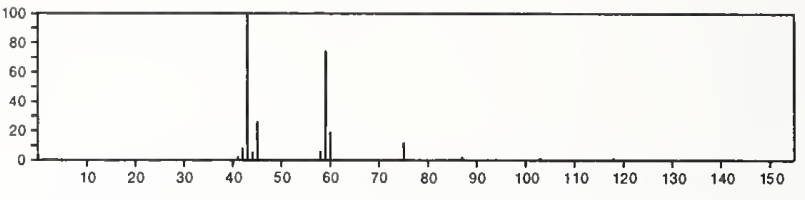

118

Butanoic acid, 3-methoxy-

$\mathrm{C}_{5} \mathrm{H}_{10} \mathrm{O}_{3}$

$10024-70-1$

$\mathrm{HO}_{2} \mathrm{CCH}_{2} \mathrm{CH}$ ( OMe) $\mathrm{Me}$

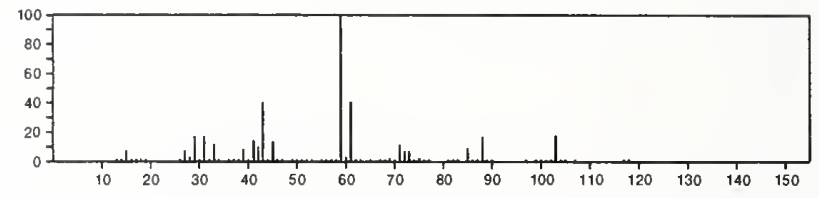

118

$\mathrm{C}_{5} \mathrm{H}_{10} \mathrm{O}_{3}$

$29006-02-8$

Butanoic acid, 4-methoxy-

$\mathrm{MeO}\left(\mathrm{CH}_{2}\right)_{3} \mathrm{CO}_{2} \mathrm{H}$

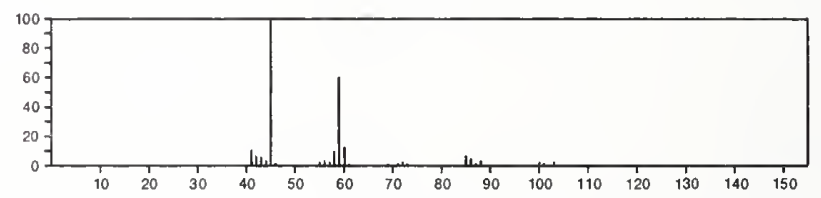

118

$\mathrm{C}_{5} \mathrm{H}_{10} \mathrm{O}_{3}$

Butanoic acid, 2-hydroxy-, methyl ester

$29674-47-3$

$\mathrm{MeOC}(\mathrm{O}) \mathrm{CH}(\mathrm{OH}) \mathrm{Et}$

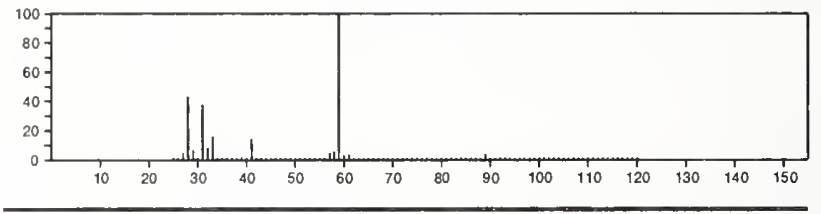

118

$\mathrm{C}_{5} \mathrm{H}_{10} \mathrm{O}_{3}$

$56772-26-0$

1,2,4-Cyclopentanetriol
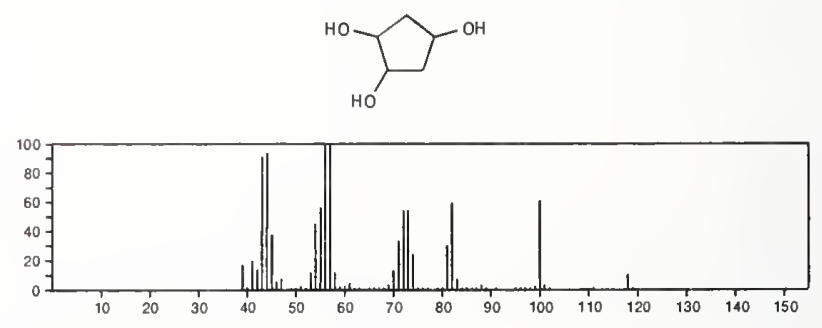

118

$\mathrm{C}_{5} \mathrm{H}_{10} \mathrm{O}_{3}$

56772-27-1

1,2,3-Cyclopentanetriol
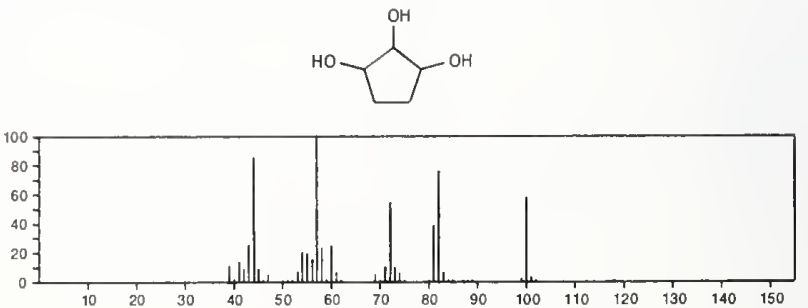
118

Silane, ethoxytrimethyl-

$\mathrm{C}_{5} \mathrm{H}_{14} \mathrm{OSi}$

Me 3 SI OE 1

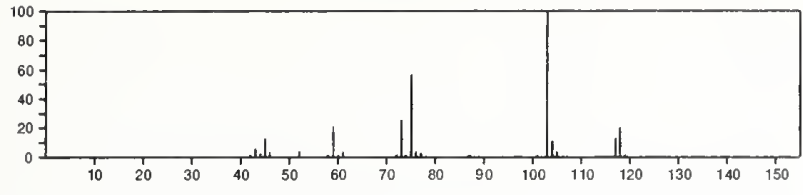

118 Ethanol, 2-(trimethylsilyl)-

$\mathrm{C}_{5} \mathrm{H}_{14} \mathrm{OSi}$

$\mathrm{HOCH}_{2} \mathrm{CH}_{2} \mathrm{Si} \mathrm{Me}_{3}$

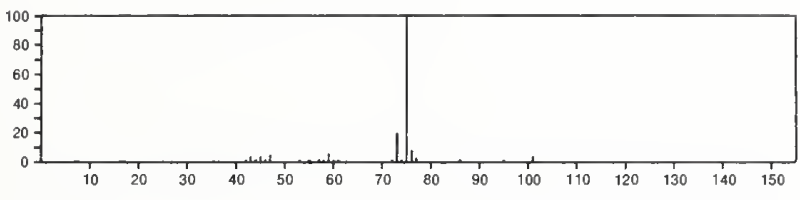

118

Cyclohexane, chloro

$\mathrm{C}_{6} \mathrm{H}_{11} \mathrm{Cl}$

$\mathrm{Q}^{\mathrm{Cl}}$

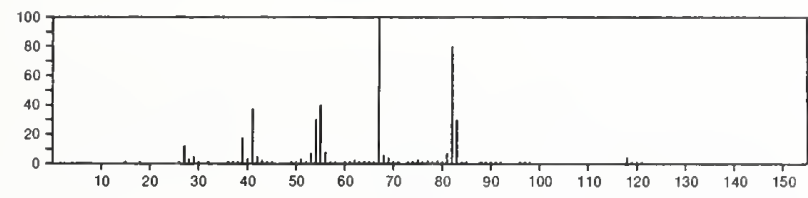

118

1-Hexene, 1-chloro-, (E)

$\mathrm{C}_{6} \mathrm{H}_{11} \mathrm{Cl}$

$50586-19-1$

$\mathrm{Me}\left(\mathrm{CH}_{2}\right)_{3} \mathrm{CH}=\mathrm{CHCl}$

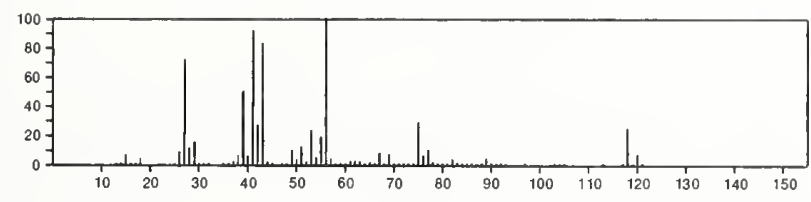

118

2,3-Butanediol, 2,3-dimethyl-

$\mathrm{C}_{6} \mathrm{H}_{14} \mathrm{O}_{2}$

$76 \quad 09-5$

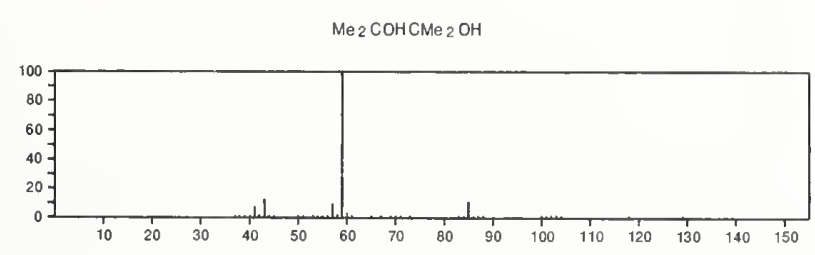

118

Ethane, 1,1-diethoxy-

$\mathrm{C}_{6} \mathrm{H}_{14} \mathrm{O}_{2}$

105-57-7

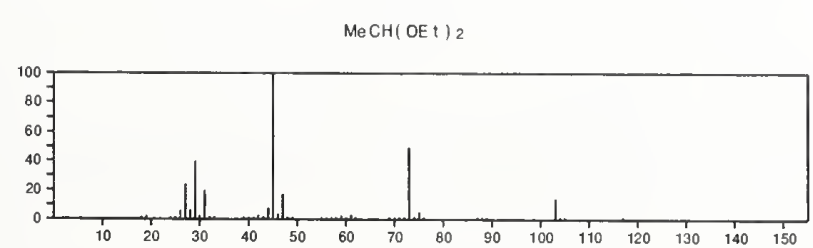

118

2,4-Pentanediol, 2-methyl-

$\mathrm{C}_{6} \mathrm{H}_{14} \mathrm{O}_{2}$

$107-41-5$

$\mathrm{Me}_{2} \mathrm{COHCH}_{2} \mathrm{CH}(\mathrm{OH}) \mathrm{Me}$
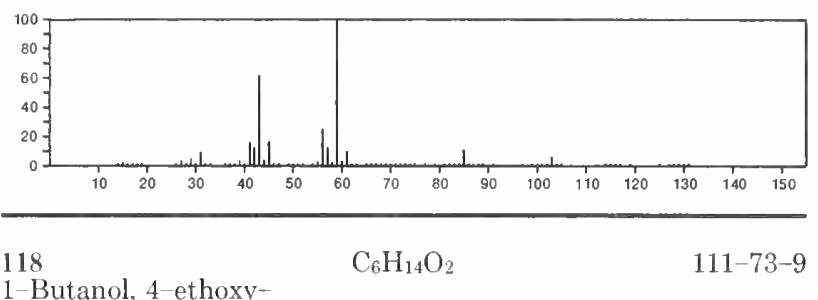

1-Butanol, 4-ethoxy-

$\mathrm{HO}\left(\mathrm{CH}_{2}\right)_{4} \mathrm{OEt}$

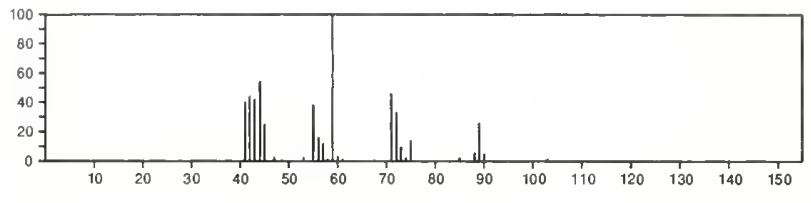

118

Ethanol, 2-butoxy-

$\mathrm{C}_{6} \mathrm{H}_{14} \mathrm{O}_{2}$

111-76-2

$\mathrm{HOCH}_{2} \mathrm{CH}_{2} \mathrm{O}\left(\mathrm{CH}_{2}\right)_{3} \mathrm{Me}$

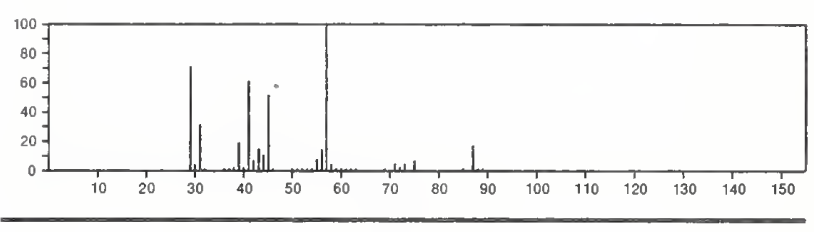

118

1,6-Hexanediol

$\mathrm{C}_{6} \mathrm{H}_{14} \mathrm{O}_{2}$

629-11-8

$\mathrm{HO}\left(\mathrm{CH}_{2}\right)_{6} \mathrm{OH}$

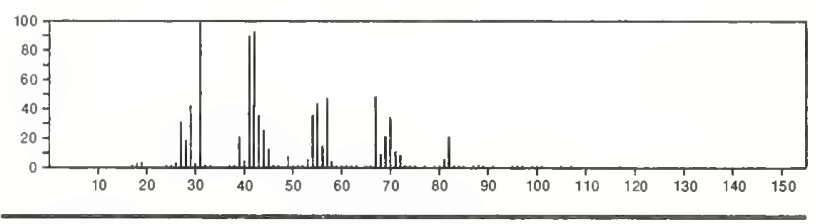

118

$\mathrm{C}_{6} \mathrm{H}_{14} \mathrm{O}_{2}$

629-14-1

Ethane, 1,2 diethoxy-

$\mathrm{E}: \mathrm{OCH}_{2} \mathrm{CH}_{2} \mathrm{OE}$ :

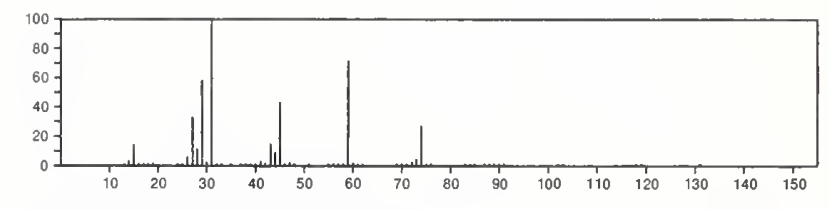

118

2-Propanol, 1-propoxy-

$\mathrm{C}_{6} \mathrm{H}_{14} \mathrm{O}_{2}$

1569-01-3

$\mathrm{PrOCH}_{2} \mathrm{CH}(\mathrm{OH}) \mathrm{Me}$

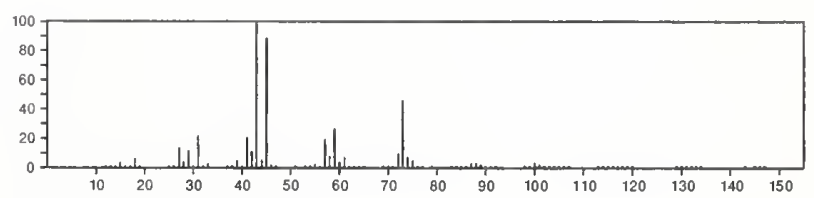


118

2,5-Hexanediol

$\mathrm{C}_{6} \mathrm{H}_{14} \mathrm{O}_{2}$

$\mathrm{Me} C \mathrm{CH}(\mathrm{OH}) \mathrm{CH}_{2} \mathrm{CH}_{2} \mathrm{CH}$ ( OH) Me

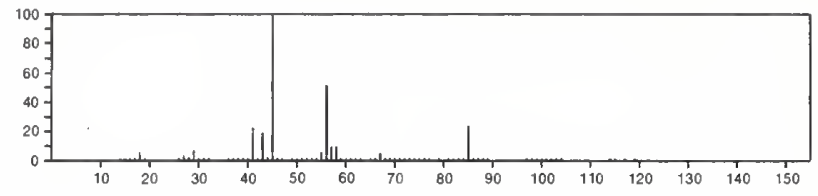

118

2-Propanol, 1-(1-methylethoxy)-

$\mathrm{C}_{6} \mathrm{H}_{14} \mathrm{O}$

i- $\mathrm{PrOCH} \mathrm{OCH}_{2} \mathrm{CH}(\mathrm{OH}) \mathrm{Me}$

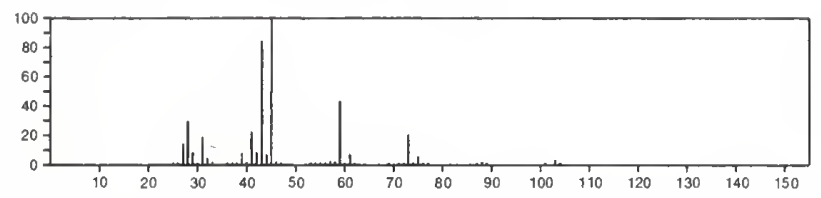

118

1-Propanol, 2-isopropoxy-

$\mathrm{C}_{6} \mathrm{H}_{14} \mathrm{O}_{2}$

$\mathrm{HOCH}_{2} \mathrm{CH}(\mathrm{OPr}-\mathrm{i}) \mathrm{Me}$

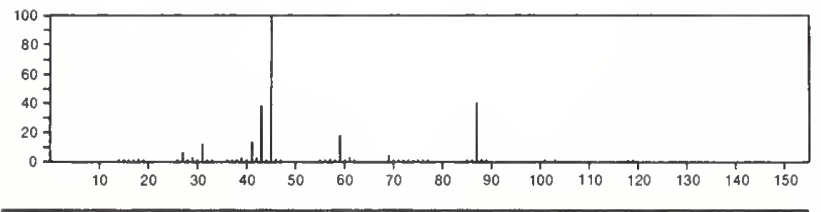

118

Hydroperoxide, hexyl

\section{$\mathrm{C}_{6} \mathrm{H}_{14} \mathrm{O}_{2}$}

4312-76-9

$\mathrm{HOO}\left(\mathrm{CH}_{2}\right){ }_{5} \mathrm{Me}$

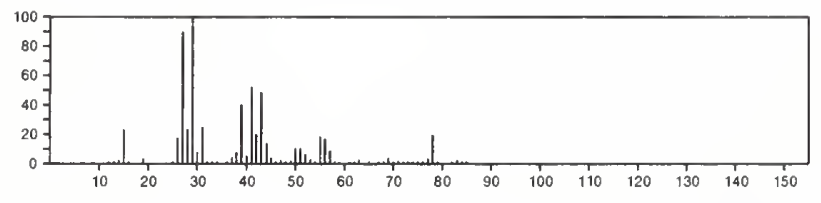

118

Butane, 1,1-dimethoxy-

$\mathrm{C}_{6} \mathrm{H}_{14} \mathrm{O}_{2}$

$\operatorname{PrCH}$ (OMe) 2

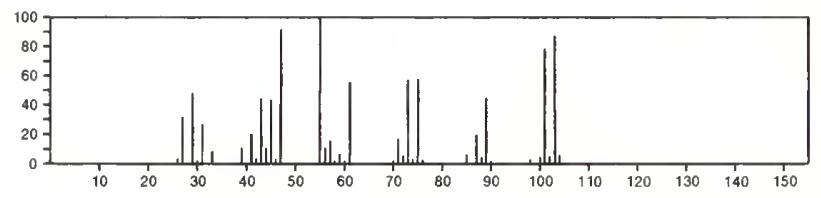

$118 \quad \mathrm{C}_{6} \mathrm{H}_{14} \mathrm{O}_{2}$

1-Pentanol, 5-methoxy-

$\mathrm{MeO}\left(\mathrm{CH}_{2}\right)_{5} \mathrm{OH}$

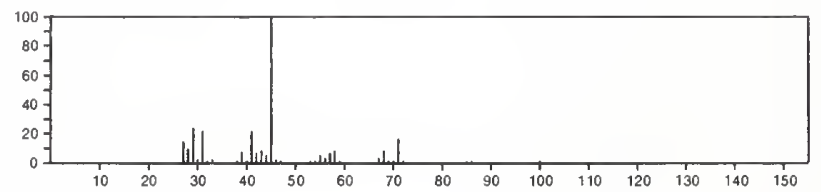

118

1,2-Hexanediol

$\mathrm{C}_{6} \mathrm{H}_{14} \mathrm{O}_{2}$

$6920-22-5$

$\mathrm{Me}\left(\mathrm{CH}_{2}\right)_{3} \mathrm{CH}(\mathrm{OH}) \mathrm{CH}_{2} \mathrm{OH}$

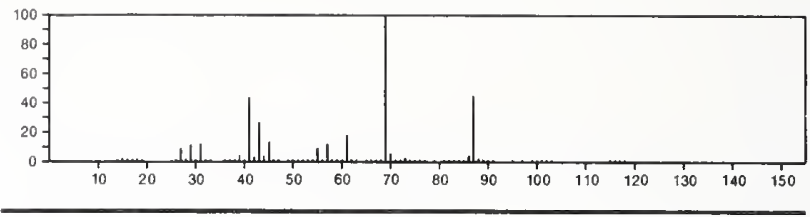

118

Ethanol, 2-(1,1-dimethylethoxy)

$7580-85-0$

$-\mathrm{BuOCH}_{2} \mathrm{CH}_{2} \mathrm{OH}$

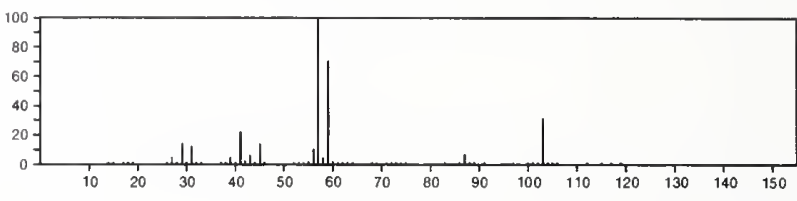

118

$\mathrm{C}_{6} \mathrm{H}_{14} \mathrm{O}_{2}$

Butane, 1,3-dimethoxy-

$\mathrm{MeCH}$ ( OMe ) $\mathrm{CH}_{2} \mathrm{CH}_{2} \mathrm{OMe}$

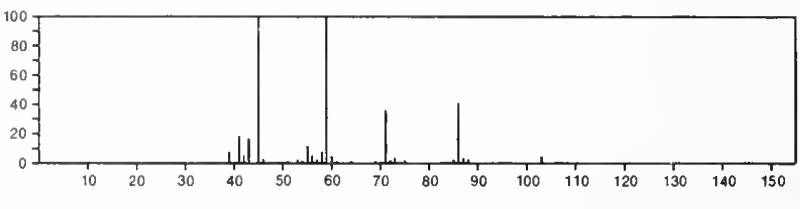

118

Butane, 1,4-dimethoxy-

$\mathrm{C}_{6} \mathrm{H}_{14} \mathrm{O}_{2}$

$13179-96-9$

$\mathrm{MeO}\left(\mathrm{CH}_{2}\right)_{4} \mathrm{OMe}$

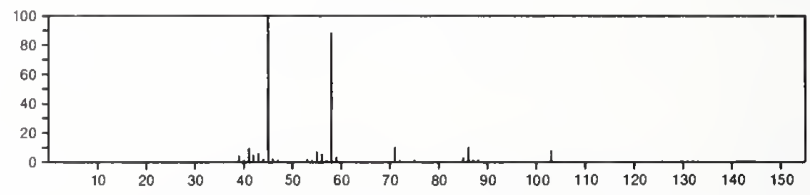

$118 \quad \mathrm{C}_{6} \mathrm{H}_{14} \mathrm{O}_{2}$

16642-57-2

Peroxide, bis(1-methylethyl)

i-PrOOPr-i

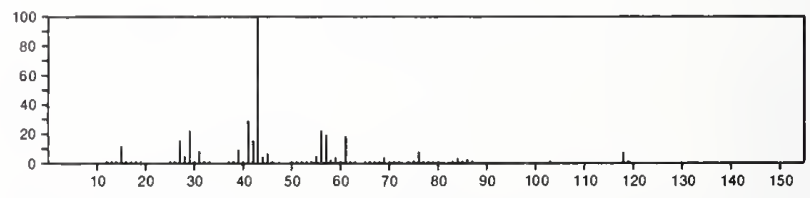

118

$\mathrm{C}_{6} \mathrm{H}_{14} \mathrm{O}_{2}$

Hydroperoxide, 1-methylpentyl

24254-55-5

$\mathrm{Me}\left(\mathrm{CH}_{2}\right)_{3} \mathrm{CHMeOOH}$

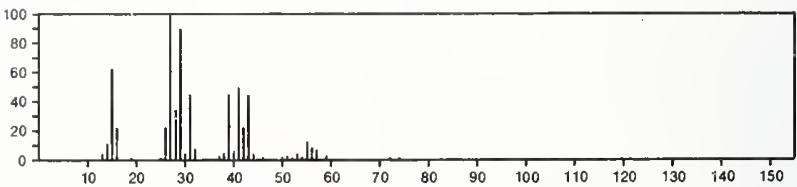


118

Hydroperoxide, 1-ethylbutyl

$\mathrm{C}_{6} \mathrm{H}_{14} \mathrm{O}_{2}$

HOOCHPIE I

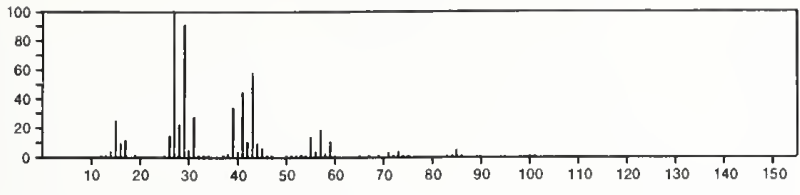

118

Acetone, ethyl methyl acetal

$\mathrm{C}_{6} \mathrm{H}_{14} \mathrm{O}_{2}$

$\mathrm{Me}_{2} \mathrm{C}(\mathrm{OE} \mathrm{t})$ OMe

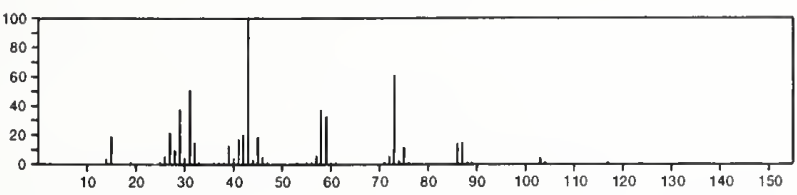

118

Peroxide, dipropyl

$\mathrm{C}_{6} \mathrm{H}_{14} \mathrm{O}_{2}$

PrOOP r

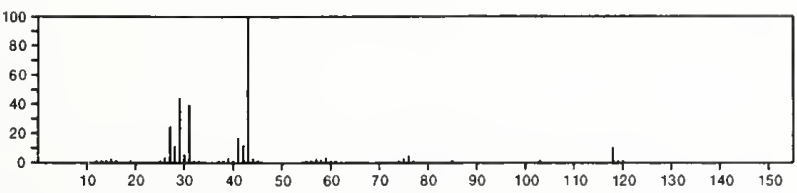

118

Propane, 1,1-dimethoxy-2-methyl-

$\mathrm{Me}_{2} \mathrm{CHCH}(\mathrm{OMe})_{2}$

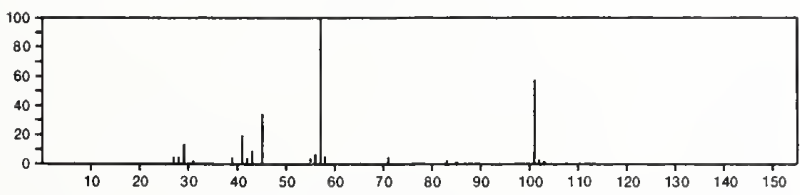

118

1-Hexanethiol

$\mathrm{C}_{6} \mathrm{H}_{14} \mathrm{~S}$

$\mathrm{Me}\left(\mathrm{CH}_{2}\right)_{5} \mathrm{SH}$

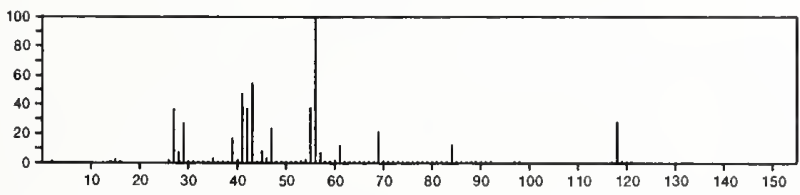

118

Propane, 1,1'-thiobis-

$\mathrm{C}_{6} \mathrm{H}_{14 \mathrm{~S}}$

$\mathrm{SPr} 2$

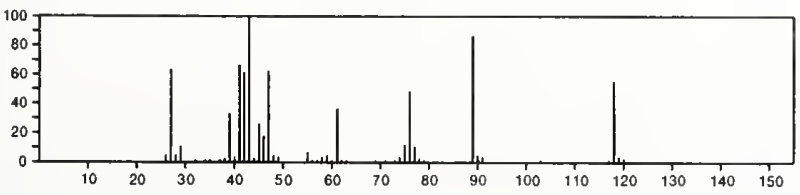

118

Propane, 2,2'-thiobis

$\mathrm{C}_{6} \mathrm{H}_{14} \mathrm{~S}$

$625-80-9$

$S(P r-i) 2$

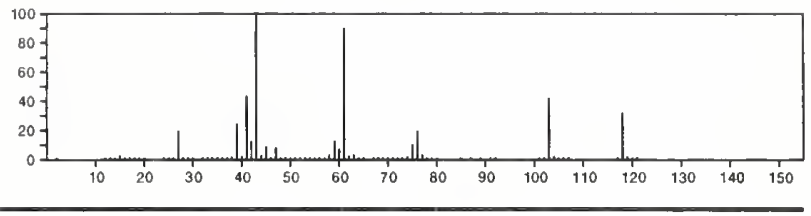

118

Butane, 1-(ethylthio)

$\mathrm{C}_{6} \mathrm{H}_{14} \mathrm{~S}$

$638-46-0$

$\mathrm{Me}\left(\mathrm{CH}_{2}\right)_{3} \mathrm{SEt}$

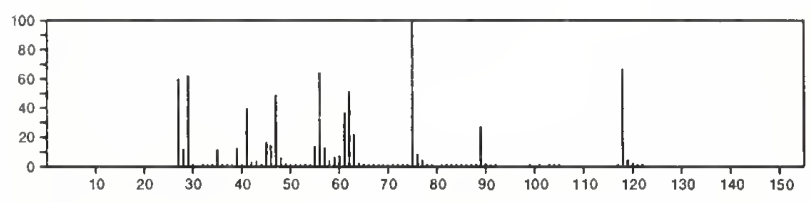

$118 \quad \mathrm{C}_{6} \mathrm{H}_{14} \mathrm{~S}$

Propane, 1-(ethylthio)-2-methyl-

$1613-45-2$

EtSBu-i
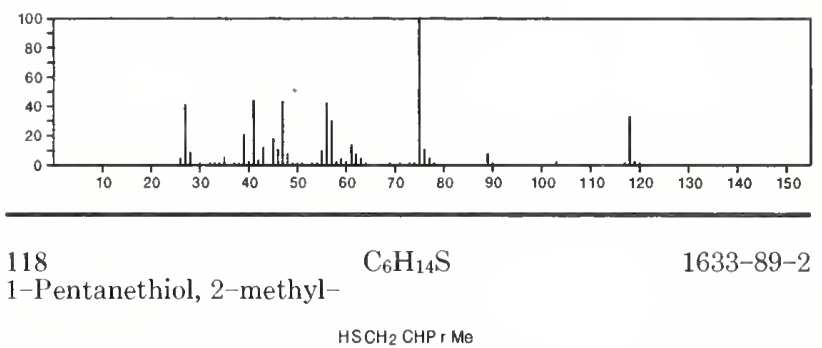

$\mathrm{HSCH}_{2} \mathrm{CHP}$. $\mathrm{Me}$
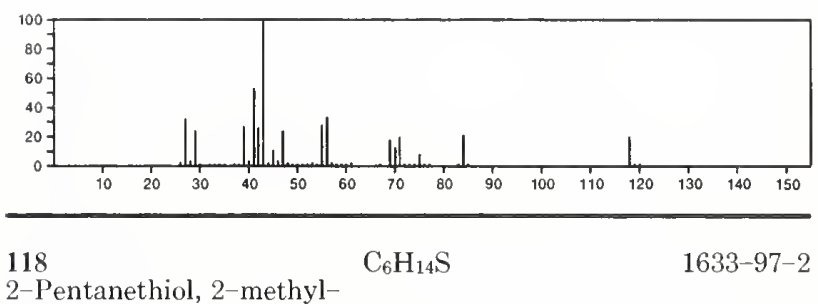

$1633-97-2$

$\mathrm{PrCMe}_{2}$ ( $\mathrm{SH}$ )

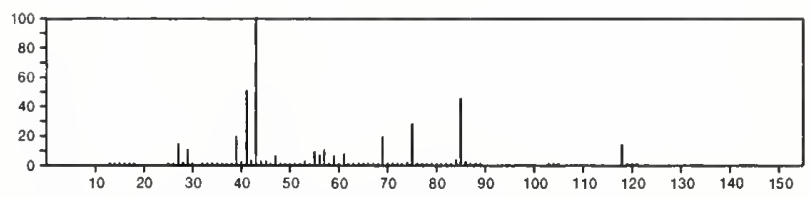

$\underset{2-\text { Butanethiol, 2,3-dimethyl- }}{\mathrm{C}_{6} \mathrm{H}_{14} \mathrm{~S}}$

$1639-01-6$

$\mathrm{Me}_{2} \mathrm{CHCMe}_{2} \mathrm{SH}$

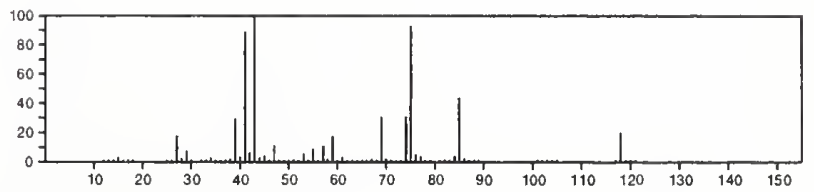


118

3-Pentanethiol, 3-methyl-

$\mathrm{C}_{6} \mathrm{H}_{14} \mathrm{~S}$

$\mathrm{Et}{ }_{2} \mathrm{CMe}(\mathrm{SH})$

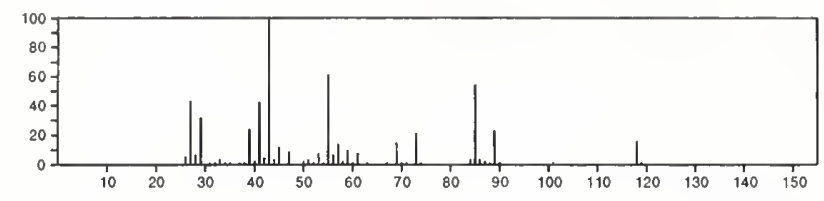

118

3-Pentanethiol, 2-methyl-

$\mathrm{C}_{6} \mathrm{H}_{14} \mathrm{~S}$

$\mathrm{Me}_{2} \mathrm{CHCH}$ (SH) El

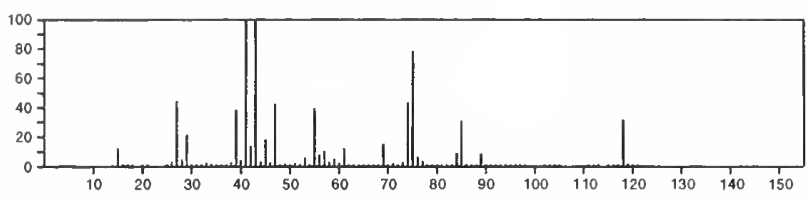

118

2-Pentanethiol, 4-methyl

$\mathrm{C}_{6} \mathrm{H}_{14} \mathrm{~S}$

$\mathrm{Me}_{2} \mathrm{CHCH}_{2} \mathrm{CH}$ ( SH) Me

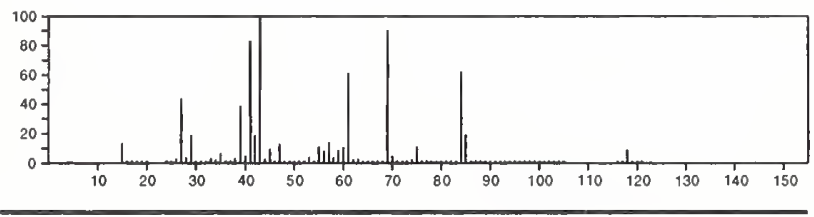

118

2-Hexanethiol

$\mathrm{C}_{6} \mathrm{H}_{14} \mathrm{~S}$

1679-06-7

$\mathrm{MeCH}(\mathrm{SH})\left(\mathrm{CH}_{2}\right){ }_{3} \mathrm{Me}$

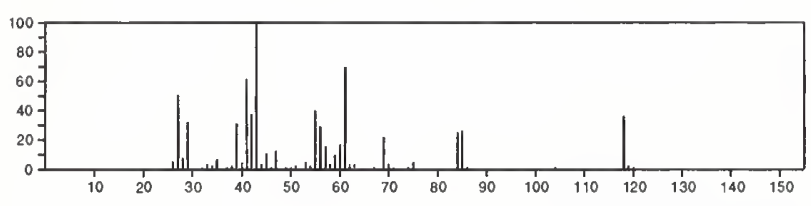

118

Pentane, 1-(methylthio)-

$\mathrm{C}_{6} \mathrm{H}_{14 \mathrm{~S}}$

1741-83-9

$\mathrm{MeS}\left(\mathrm{CH}_{2}\right) \& \mathrm{Me}$

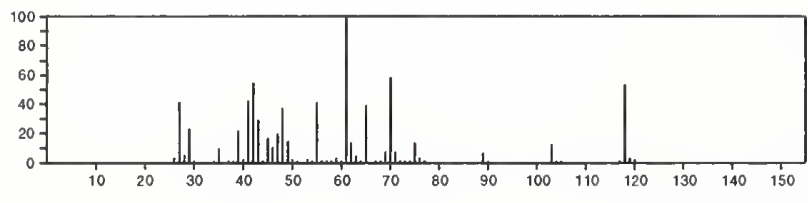

118

Butane, 2-(ethylthio)

$\mathrm{C}_{6} \mathrm{H}_{14} \mathrm{~S}$

$5008-72-0$

EtSBu-s

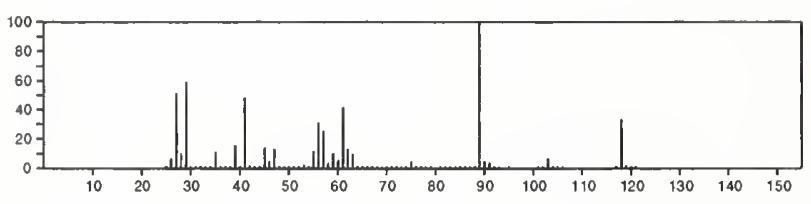

118

Sulfide, isopropyl propyl

$\mathrm{C}_{6} \mathrm{H}_{14} \mathrm{~S}$

5008-73-1

Pr SPr - i

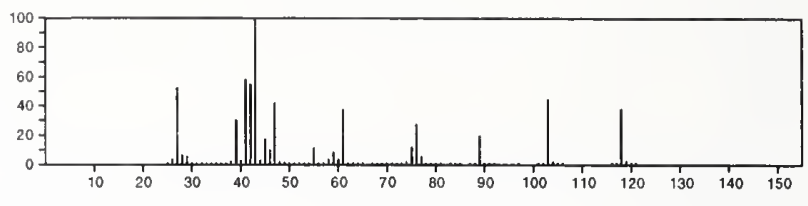

118

$\mathrm{C}_{6} \mathrm{H}_{14} \mathrm{~S}$

Propane, 2-(ethylthio)-2-methyl-

$14290-92-7$

EtSBu-1

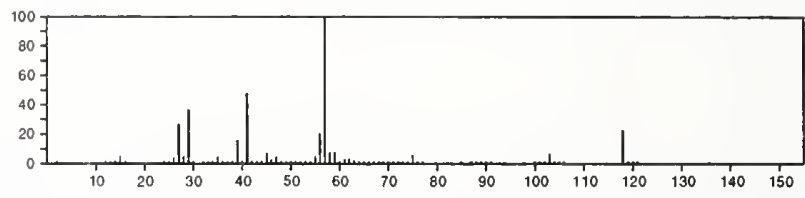

118

Phosphine, triethyl

$\mathrm{C}_{6} \mathrm{H}_{15} \mathrm{P}$

$554-70-1$

PEI 3

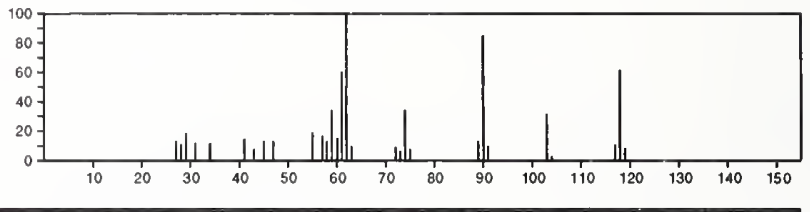

118

Phosphine, bis (1-methylethyl)-

$20491-53-6$

$\mathrm{PH}\left(\mathrm{Pr}_{\mathrm{r}-i}\right)_{2}$

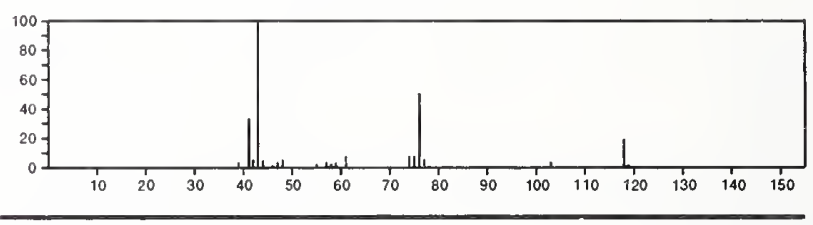

118

1H-Benzimidazole

$\mathrm{C}_{7} \mathrm{H}_{6} \mathrm{~N}_{2}$

$51-17-2$
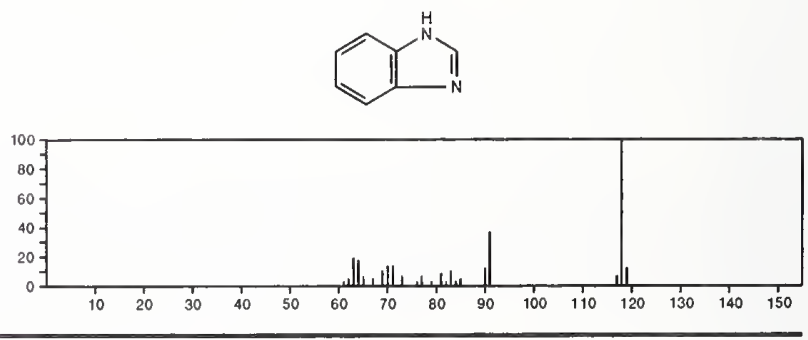

118

2H-Cyclopenta[d]pyridazine

\section{$\mathrm{C}_{7} \mathrm{H}_{6} \mathrm{~N}_{2}$}

270-64-4
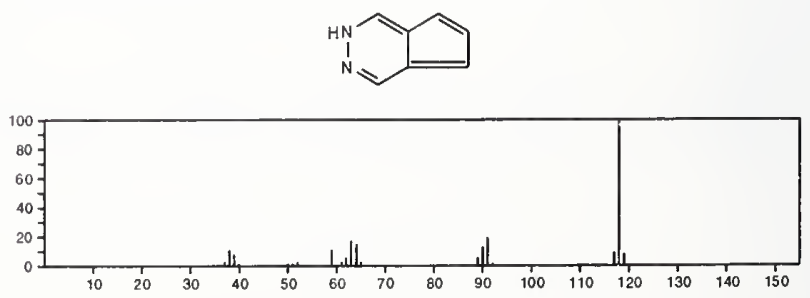
118

$1 H$-Indazole

$\mathrm{C}_{7} \mathrm{H}_{6} \mathrm{~N}_{2}$

$271-44-3$
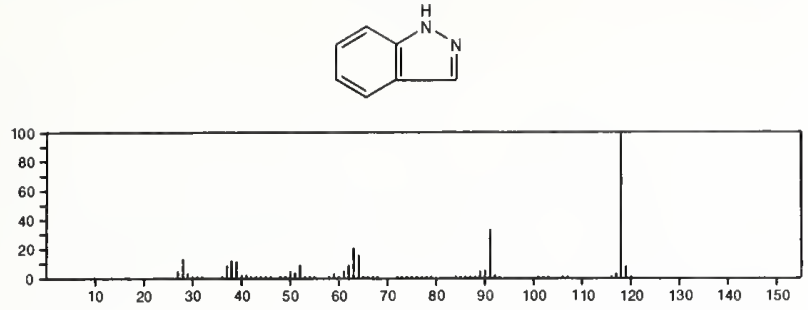

118

$\mathrm{C}_{7} \mathrm{H}_{6} \mathrm{~N}_{2}$

$271-63-6$

1H-Pyrrolo[2,3-b]pyridine
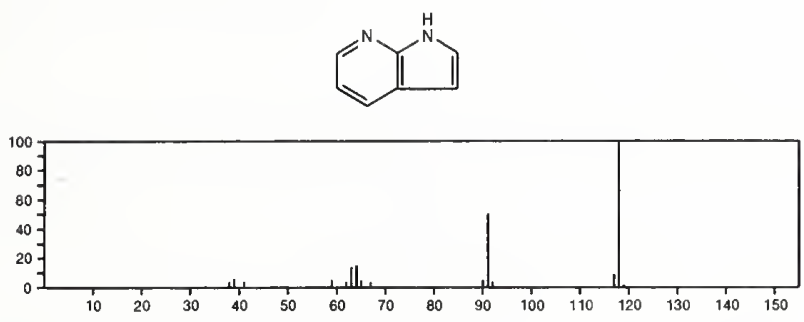

118

$\mathrm{C}_{7} \mathrm{H}_{6} \mathrm{~N}_{2}$

$274-56-6$

Pyrazolo[ $[1,5-a]$ pyridine
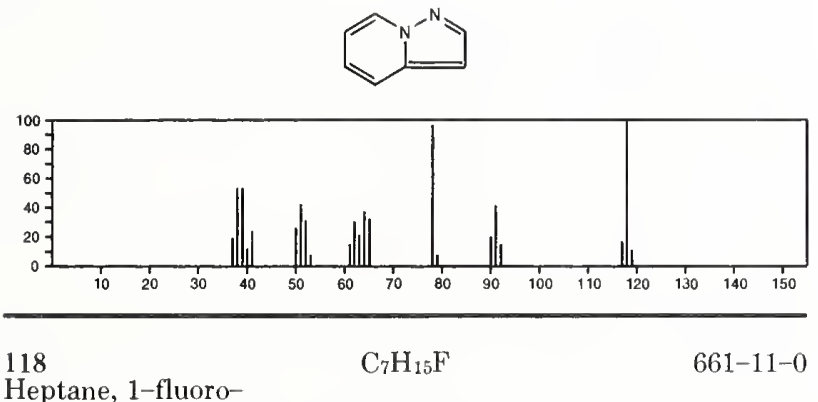

Heptane, 1-fluoro-

$\mathrm{Me}\left(\mathrm{CH}_{2}\right\}_{6} \mathrm{~F}$

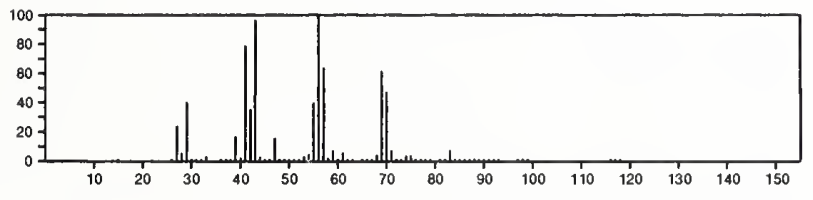

118

$\mathrm{C}_{8} \mathrm{H}_{6} \mathrm{O}$

$271-89-6$

Benzofuran
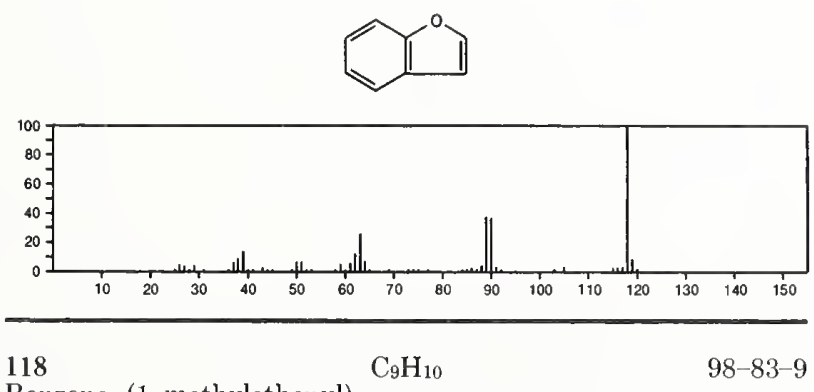

98-83-9

Benzene, (1-methylethenyl)-

$\mathrm{PhCMB}=\mathrm{CH}_{2}$

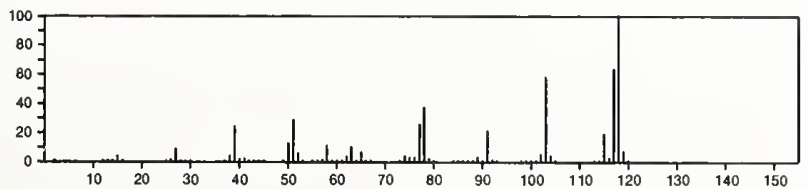

118 $\mathrm{C}_{9} \mathrm{H}_{10}$

$100-80-1$

Benzune, 1-ethenyl-3-methyl-
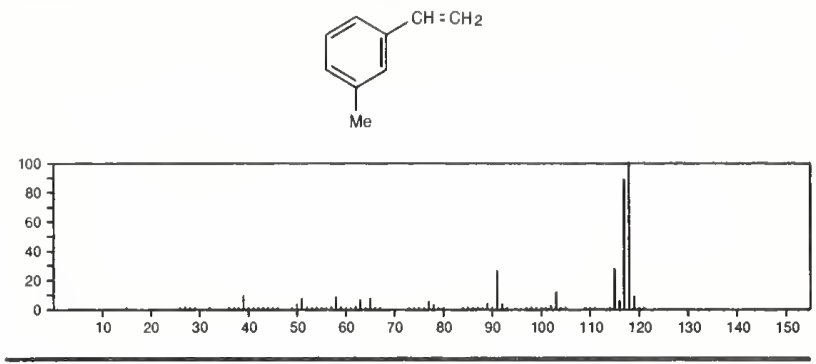

118

$\mathrm{C}_{9} \mathrm{H}_{10}$

$300-57-2$

Benzene, 2-propenyl-

$\mathrm{H}_{2} \mathrm{C}=\mathrm{CHCH}_{2} \mathrm{Ph}$

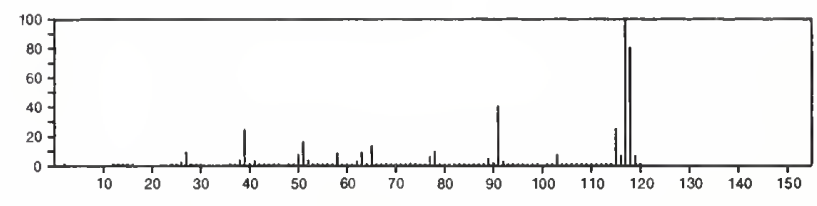

118

$\mathrm{C}_{9} \mathrm{H}_{10}$

496-11-7

$1 \mathrm{H}$-Indene, 2,3-dihydro-
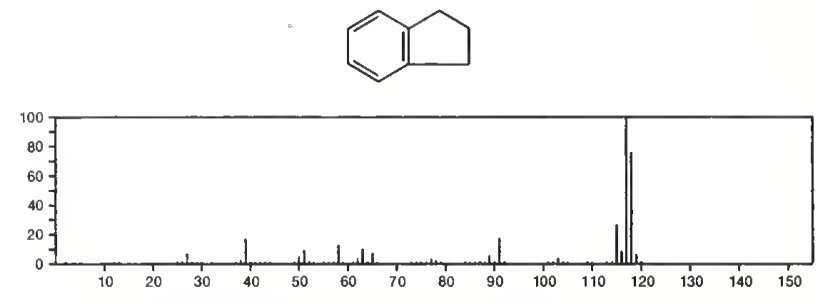

118

$\mathrm{C}_{9} \mathrm{H}_{10}$

611-15-4

Benzene, 1-ethenyl-2-methyl-
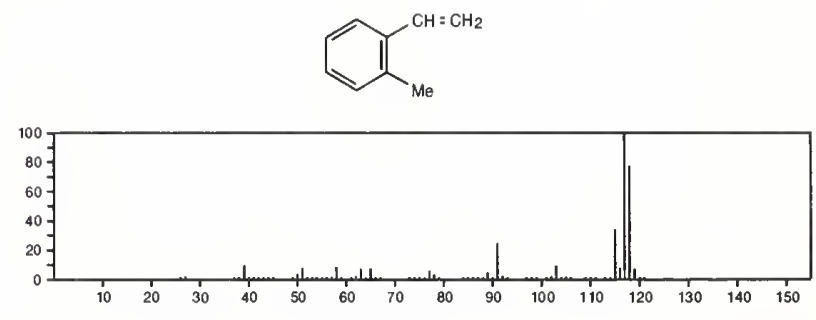

118

$\mathrm{C}_{9} \mathrm{H}_{10}$

622-97-9

Benzene, 1-ethenyl-4-methyl-
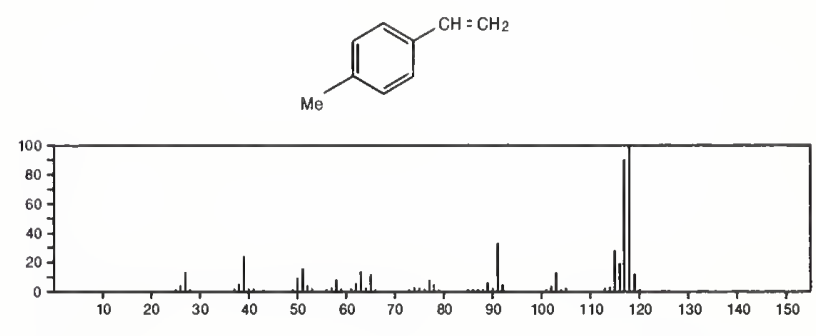

118

$\mathrm{C}_{9} \mathrm{H}_{10}$

Benzene, 1-propenyl

$\mathrm{Me} \mathrm{CH}=\mathrm{CHPh}$

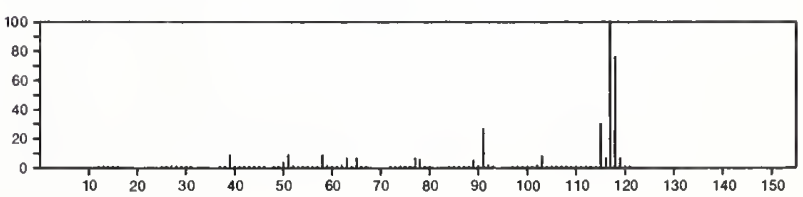


118

Benzene, cyclopropyl

$\mathrm{C}_{9} \mathrm{H}_{10}$

$\triangle$

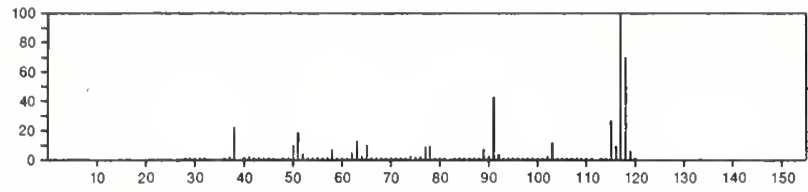

118

Benzene, ethenylmethyl-

$\mathrm{C}_{9} \mathrm{H}_{10}$

25013-15-4
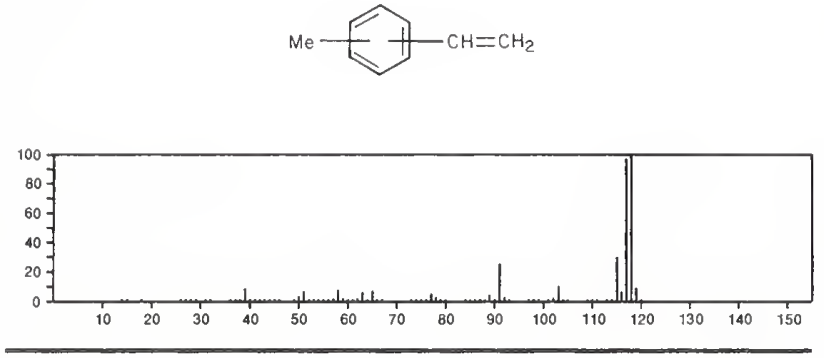

118

$\mathrm{ClFO}_{2} \mathrm{~S}$

$13637-84-8$

Sulfuryl chloride fluoride

$\mathrm{ClSO}_{2} \mathrm{~F}$

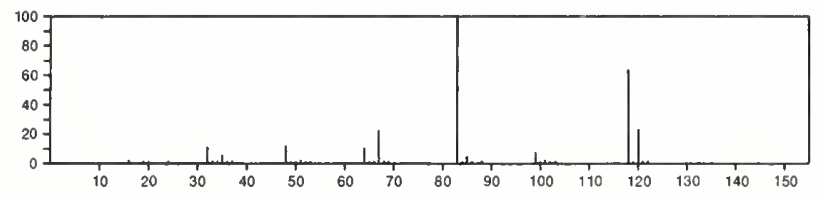

118

Thionyl chloride

$\mathrm{Cl}_{2} \mathrm{OS}$

7719-09-7

$\mathrm{ClS}(\mathrm{O}) \mathrm{Cl}$

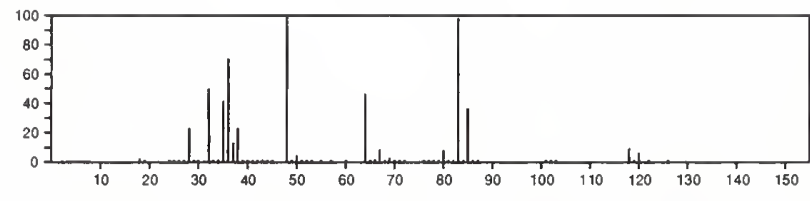

119

2-Thiazolidinethione

$\mathrm{C}_{3} \mathrm{H}_{5} \mathrm{NS}_{2}$

96-53-7
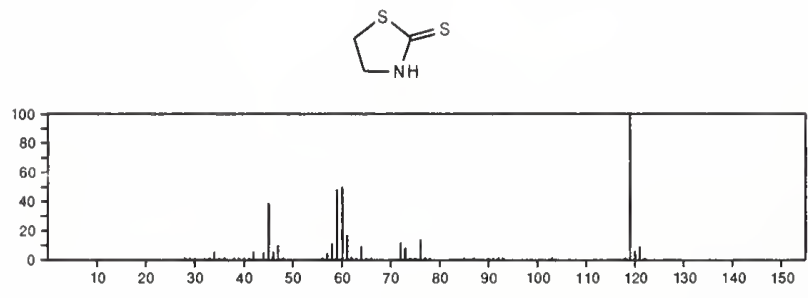

$119 \quad \mathrm{C}_{4} \mathrm{H}_{9}$ NOS

1-Butanamine, $N$-sulfinyl-

$13165-70-3$

$\mathrm{Me}\left(\mathrm{CH}_{2}\right)_{3} \mathrm{~N}=\mathrm{S}=0$

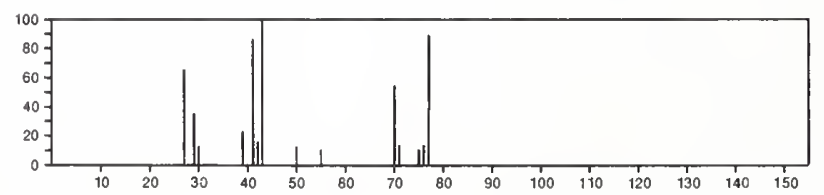

119

1-Propanamine, 2-methyl- $N$-sulfinyl-

13165-71-4

$\mathrm{O}=\mathrm{S}=\mathrm{NBu}-\mathrm{i}$

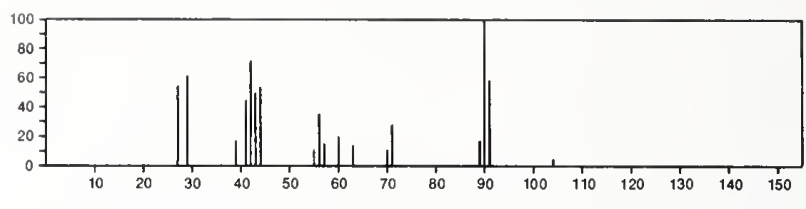

119

Sulfilimine, $N$-acetyl- $S, S$

$32810-66-5$

imethyl-

$\mathrm{ACN}=\mathrm{SMe} 2$

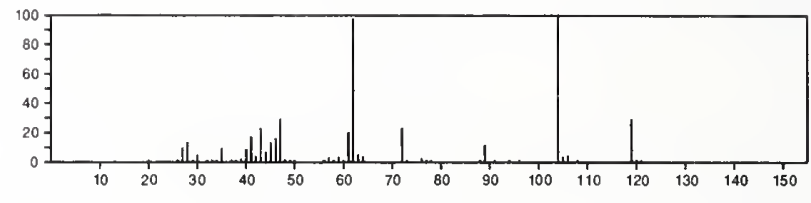

119

L-Threonine

$\mathrm{C}_{4} \mathrm{H}_{9} \mathrm{NO}_{3}$

$72-19-5$

$\mathrm{MeCH}(\mathrm{OH}) \mathrm{CH}\left(\mathrm{NH}_{2}\right) \mathrm{CO}_{2} \mathrm{H}$

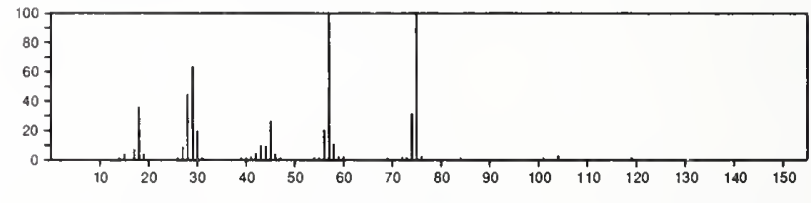

119

$\mathrm{C}_{4} \mathrm{H}_{9} \mathrm{NO}_{3}$

543-29-3

Nitric acid, 2-methylpropyl ester

$\mathrm{i}-\mathrm{BuONO} 2$

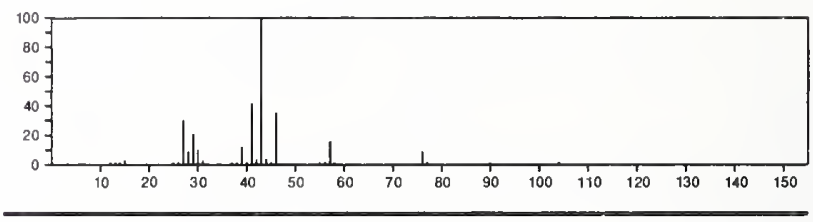

119

1-Butanol, 2-nitro-

$\mathrm{C}_{4} \mathrm{H}_{9} \mathrm{NO}_{3}$

609-31-4

$\mathrm{HOCH}_{2} \mathrm{CH}\left(\mathrm{NO}_{2}\right) \mathrm{Et}$

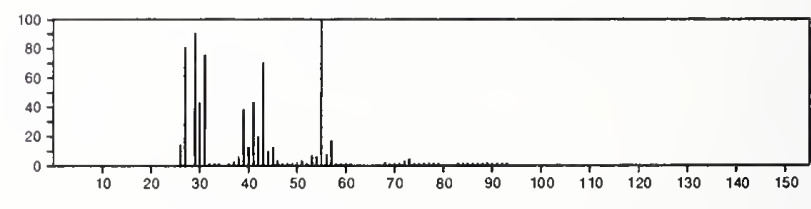

$119 \quad \mathrm{C}_{4} \mathrm{H}_{9} \mathrm{NO}_{3}$

Nitric acid, 1-methylpropyl ester

$924-52-7$

$\mathrm{s}-\mathrm{Bu} \mathrm{ONO}_{2}$

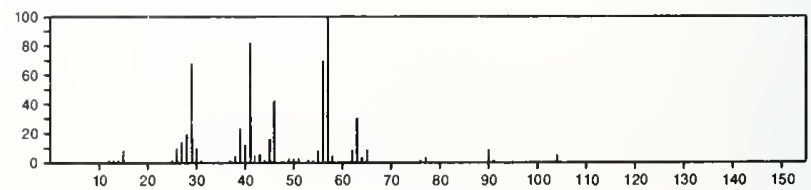


119

Nitric acid, butyl ester

$\mathrm{C}_{4} \mathrm{H}_{9} \mathrm{NO}_{3}$

$\mathrm{Me}\left(\mathrm{CH}_{2}\right)_{3} \mathrm{ONO}_{2}$

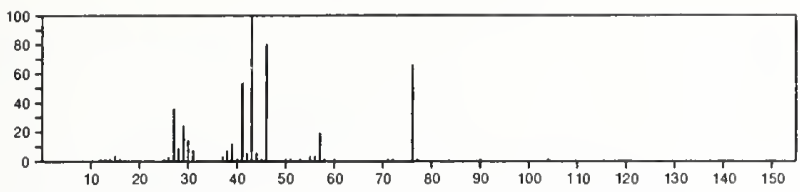

119

$\mathrm{C}_{4} \mathrm{H}_{9} \mathrm{NO}_{3}$

L-Serine, $N$-methyl-

$\mathrm{HOCH}_{2} \mathrm{CH}$ (NHMe) $\mathrm{CO}_{2} \mathrm{H}$

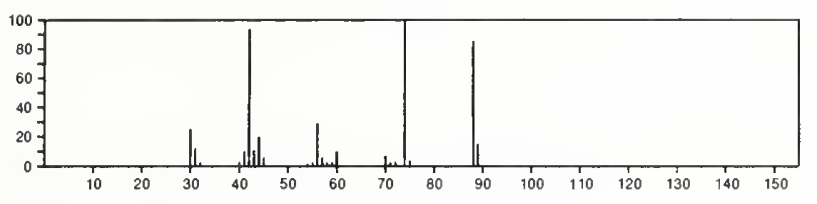

$119 \quad \mathrm{C}_{4} \mathrm{H}_{11} \mathrm{BClN}$

Borane, chloro(dimethylamino)ethyl-

Me 2 NBCIE!

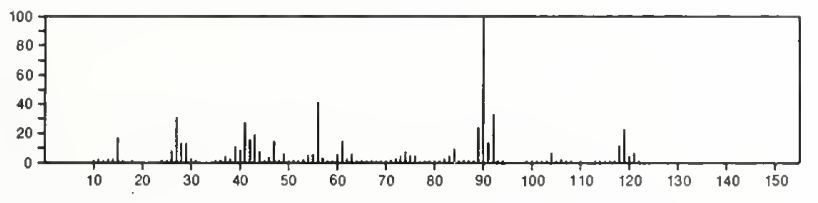

119

$1 H$-Benzotriazole

$\mathrm{C}_{6} \mathrm{H}_{5} \mathrm{~N}_{3}$

$95-14-7$
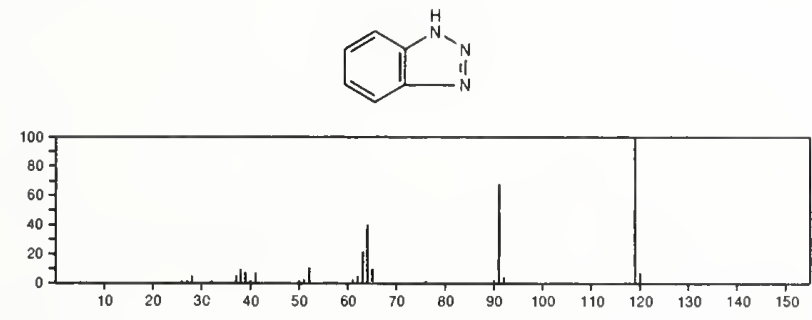

119

1,2,4-'Triazolo[4,3-a]pyridine

$\mathrm{C}_{6} \mathrm{H}_{5} \mathrm{~N}_{3}$
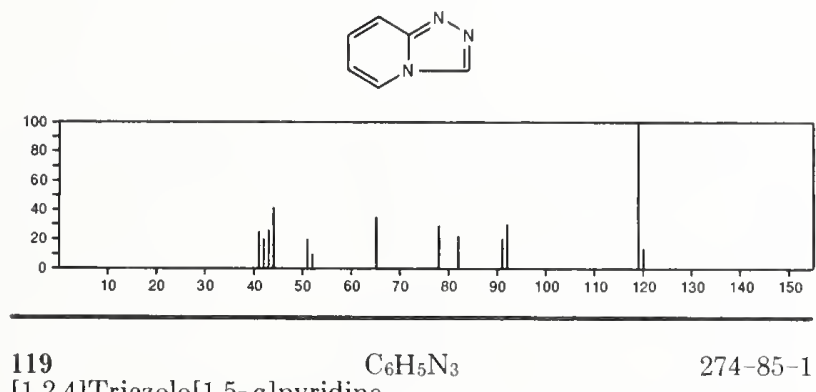

$[1,2,4]$ Triazolo $[1,5-a]$ pyridine
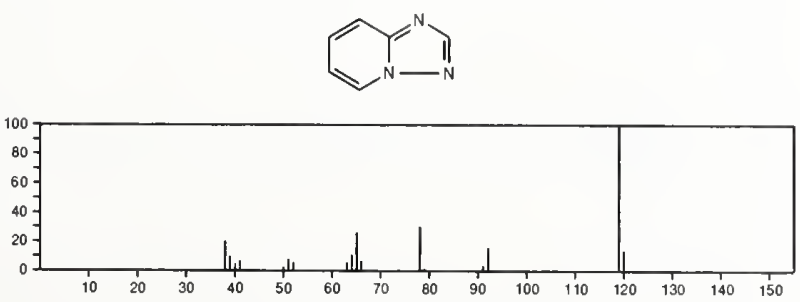

119

$\mathrm{C}_{6} \mathrm{H}_{5} \mathrm{~N}_{3}$

$622-37-7$
$\mathrm{PhN}_{3}$
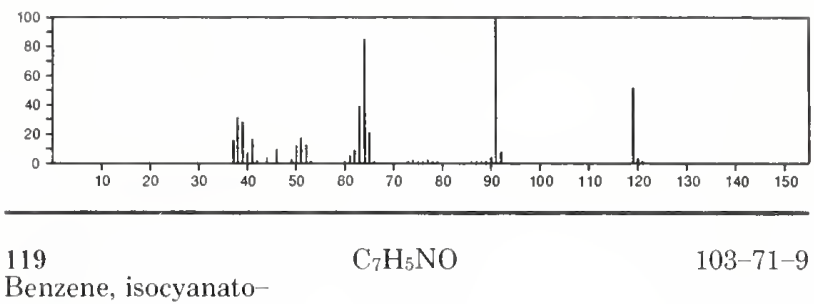

Benzene, isocyanato

PhNCO

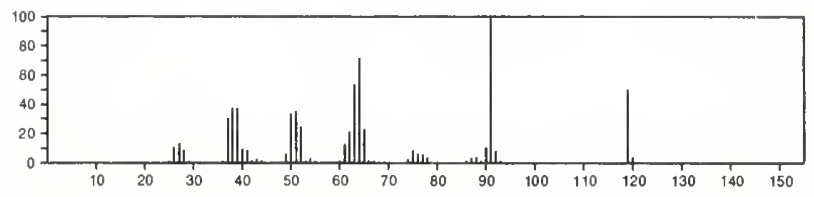

$\begin{aligned} & 119 \\ & \text { Benzoxazole }\end{aligned} \mathrm{C}_{7} \mathrm{H}_{5} \mathrm{NO} \quad 273-53-0$
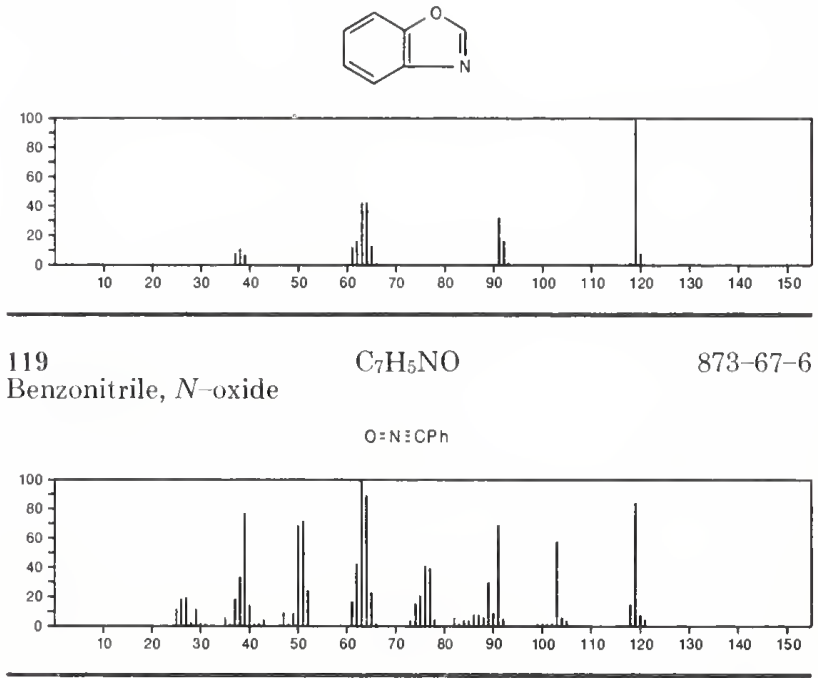

119

Cyanic acid, phenyl ester

$\mathrm{C}_{7} \mathrm{H}_{5} \mathrm{NO}$

$1122-85-6$

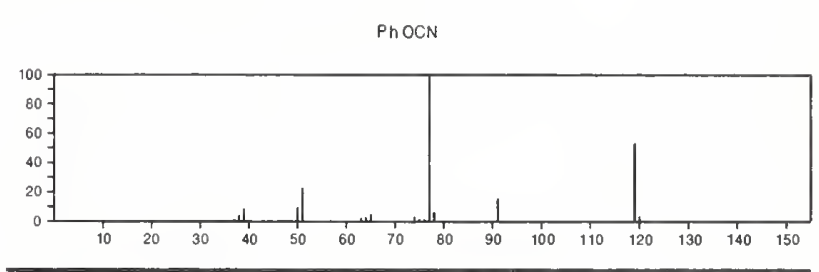

119

$\mathrm{C}_{8} \mathrm{H}_{9} \mathrm{~N}$

$140-76-1$

Pyridine, 5-ethenyl-2-methyl-
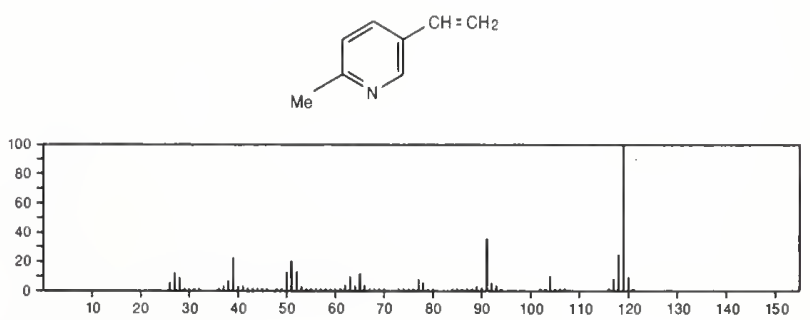
119

$\mathrm{C}_{8} \mathrm{H}_{9} \mathrm{~N}$

$496-12-8$

120

Silane, bis(silylmethyl)

$\mathrm{C}_{2} \mathrm{H}_{12} \mathrm{Si}_{3}$
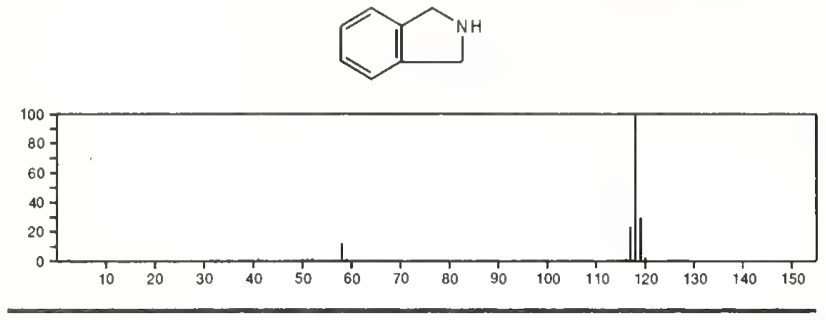

119

$1 H$-Indole, 2,3-dihydro-

$\mathrm{C}_{8} \mathrm{H}_{9} \mathrm{~N}$

496-15-1
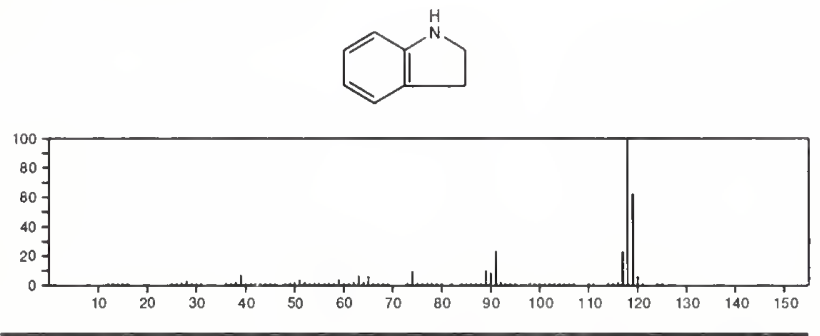

119

$\mathrm{C}_{8} \mathrm{H}_{9} \mathrm{~N}$

$696-18-4$

Aziridine, 1-phenyl-
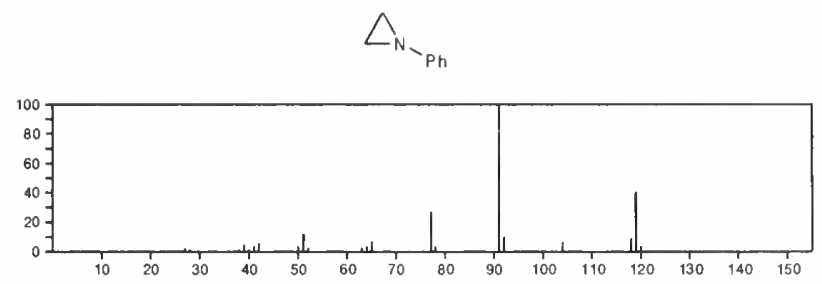

119

Aziridine, 2-phenyl-

$\mathrm{C}_{8} \mathrm{H}_{9} \mathrm{~N}$

1499-00-9
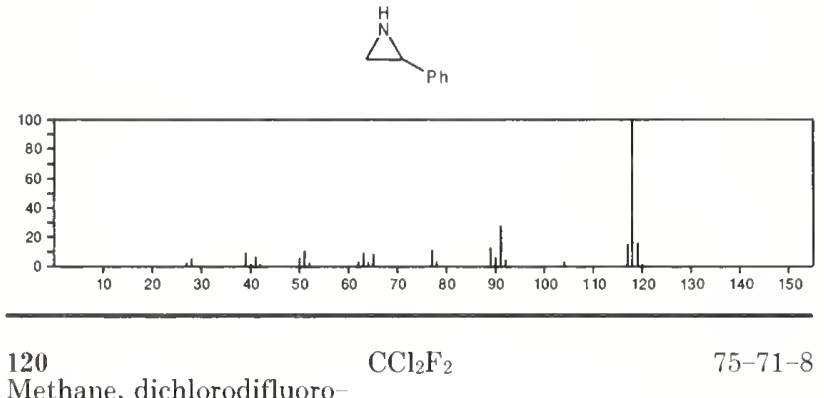

$\mathrm{F}_{2} \mathrm{CCl}_{2}$

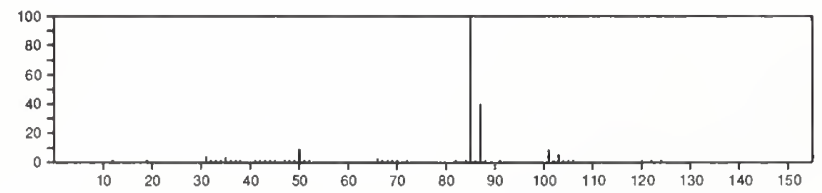

120

$\mathrm{CF}_{4} \mathrm{~S}$

Methanesulfenyl fluoride, trifluoro-
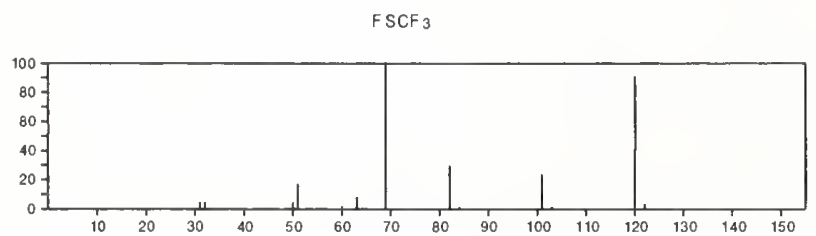

$\mathrm{H}_{3} \mathrm{SiCH}_{2} \mathrm{SiH}_{2} \mathrm{CH}_{2} \mathrm{SiH}$

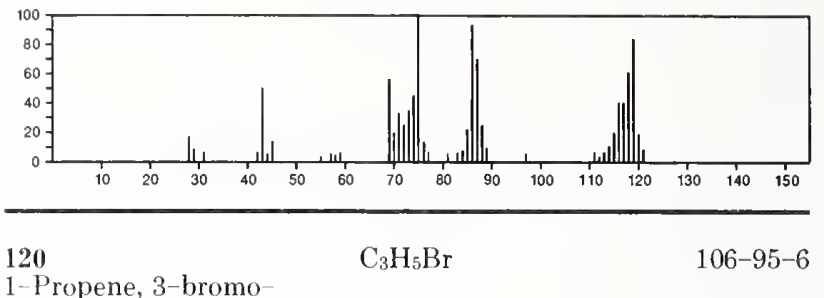

$\mathrm{H}_{2} \mathrm{C}=\mathrm{CHCH}_{2} \mathrm{Br}$

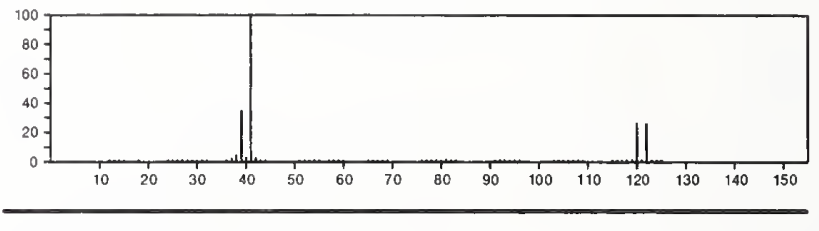

120

$\mathrm{C}_{3} \mathrm{H}_{5} \mathrm{Br}$

$557-93-7$

1-Propene, 2-bromo

$\mathrm{MeCBr}=\mathrm{CH}_{2}$

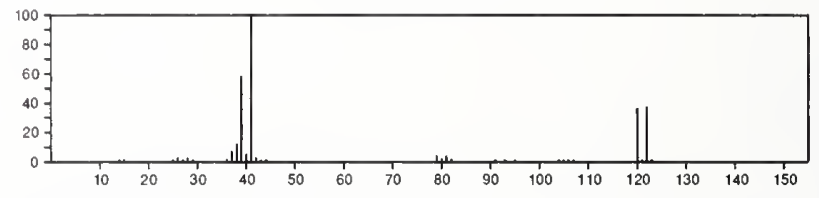

120

$\mathrm{C}_{3} \mathrm{H}_{5} \mathrm{Br}$

$590-14-7$

1-Propene, 1-bromo

$\mathrm{MeCH}=\mathrm{CHB} \mathbf{r}$

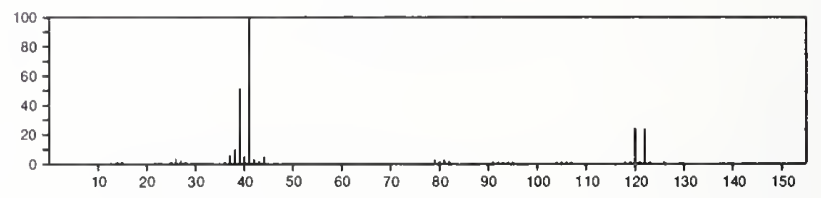

120

Arsine, trimethyl

$\mathrm{C}_{3} \mathrm{H}_{9} \mathrm{As}$

$593-88-4$

$\mathrm{AsMe}_{3}$

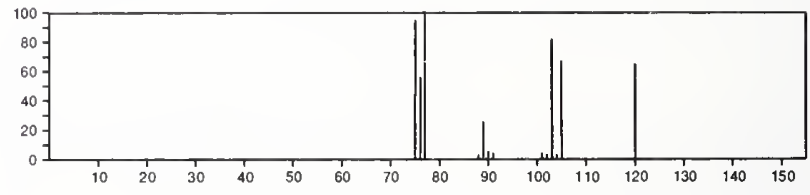

120

$\mathrm{C}_{4} \mathrm{H}_{8} \mathrm{O}_{2} \mathrm{~S}$

$109-03-5$

1,4-Oxathiane, 4 oxide<smiles>O=S1CCOCC1</smiles>

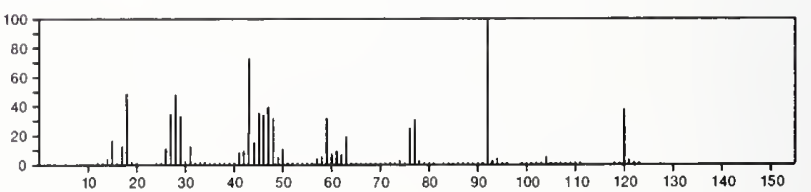


$120 \quad \mathrm{C}_{4} \mathrm{H}_{8} \mathrm{O}_{2} \mathrm{~S}$

Thiophene, tetrahydro--, 1,1-dioxide
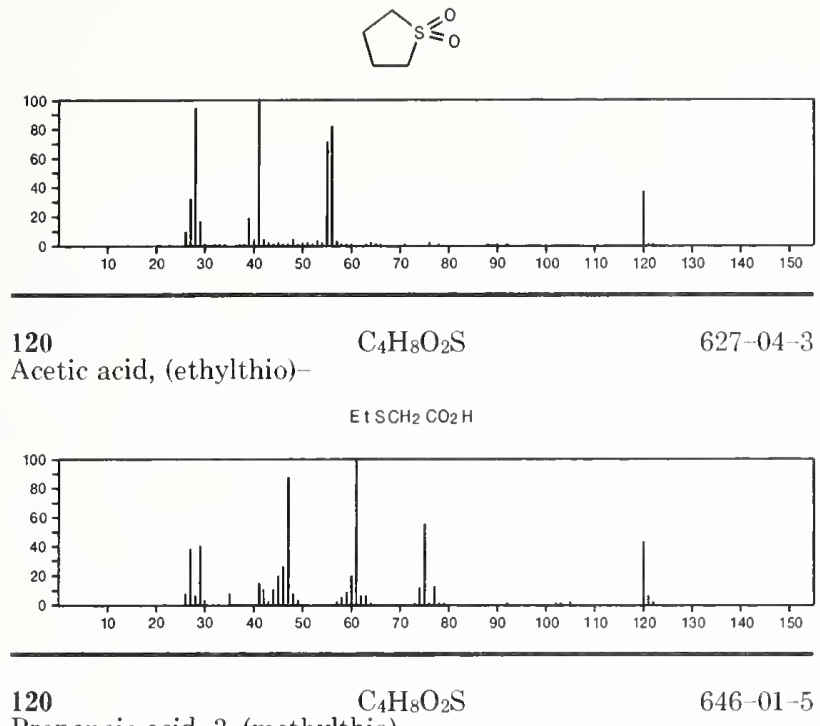

Propanoic acid, 3-(methylthio)

$\mathrm{HO}_{2} \mathrm{CCH}_{2} \mathrm{CH}_{2} \mathrm{SMe}$

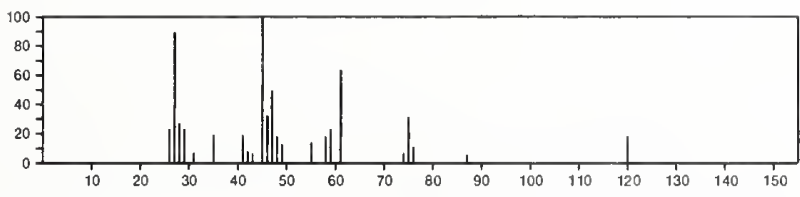

120

$\mathrm{C}_{4} \mathrm{H}_{8} \mathrm{O}_{2} \mathrm{~S}$

$2935-90-2$

Propanoic acid, 3-mercapto-, methyl ester

$\mathrm{HSCH}_{2} \mathrm{CH}_{2} \mathrm{C}(\mathrm{O}) \mathrm{OMe}$

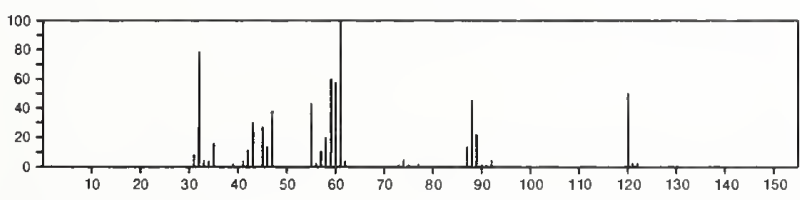

120

$\mathrm{C}_{4} \mathrm{H}_{8} \mathrm{O}_{2} \mathrm{~S}$

$53907-46-3$

Propanoic acid, 2-mercapto-, methyl ester

$\mathrm{MeOC}(\mathrm{O}) \mathrm{CH}(\mathrm{SH}) \mathrm{Me}$

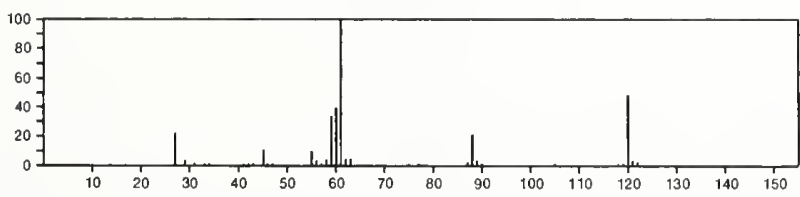

120

1,3-Dithiane

$\mathrm{C}_{4} \mathrm{H}_{8} \mathrm{~S}_{2}$

$505-23-7$
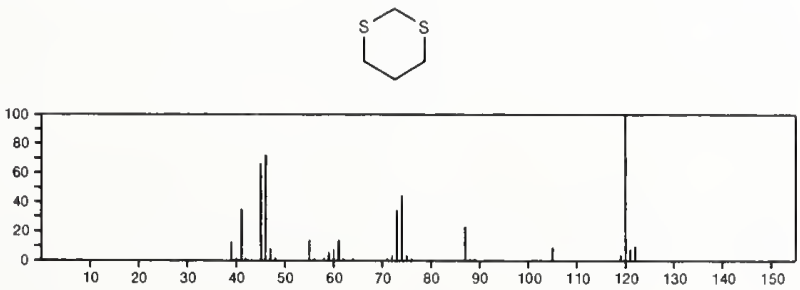

120

1,4-Dithiane

$\mathrm{C}_{4} \mathrm{H}_{8} \mathrm{~S}_{2}$

$505-29-3$<smiles>C1CCSCC1</smiles>

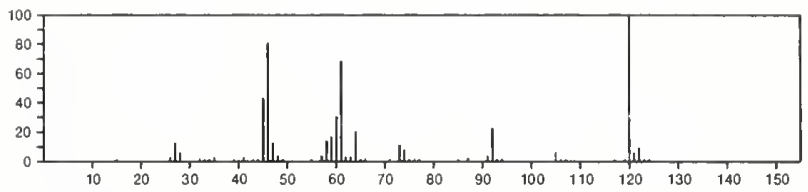

120

Ethylene, 1,2-bis(methylthio)-

$\mathrm{C}_{4} \mathrm{H}_{8} \mathrm{~S}_{2}$

$19698-38-5$

$\mathrm{MeSCH}=\mathrm{CHSMe}$

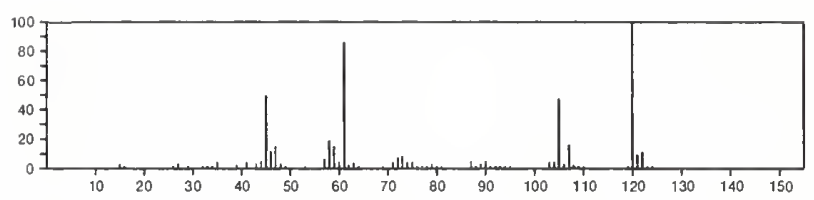

120

$\mathrm{C}_{4} \mathrm{H}_{12} \mathrm{O}_{2} \mathrm{Si}$

1112-39-6

Silane, dimethoxydimethyl

Me OSi Me 2 OMe
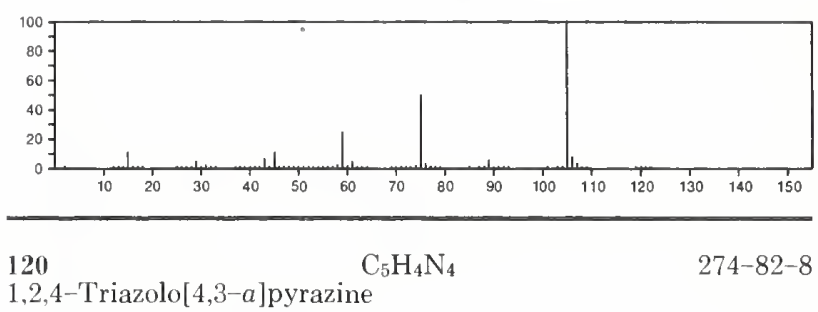

$274-82-8$
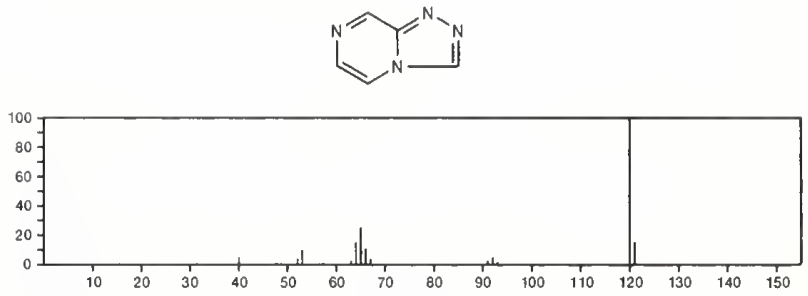

${ }_{[1,2,4] \text { Triazolo[1,5-a]pyrazine }}^{120} \mathrm{C}_{5} \mathrm{H}_{4} \mathrm{~N}_{4}$

399-66-6
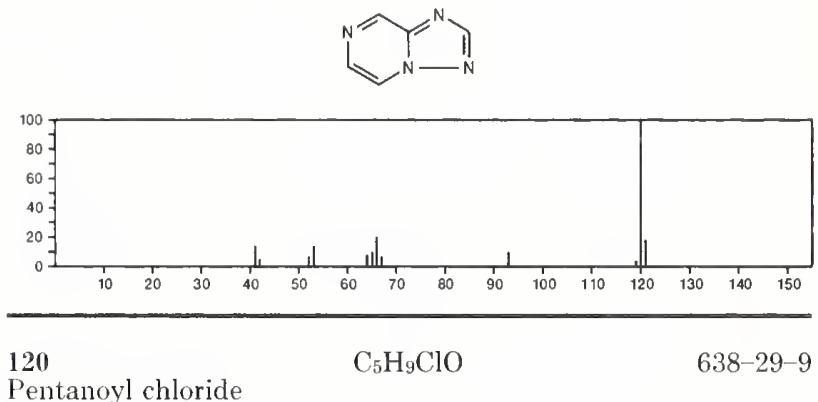

Pentanoyl chloride

$\mathrm{Me}\left(\mathrm{CH}_{2}\right)_{3} \mathrm{COCI}$

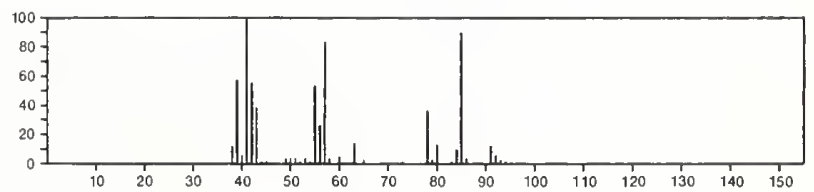


$120 \quad \mathrm{C}_{5} \mathrm{H}_{9} \mathrm{ClO}$

Propanoyl chloride, 2,2-dimethyl-

$\mathrm{Me} 3 \mathrm{CCOCI}$

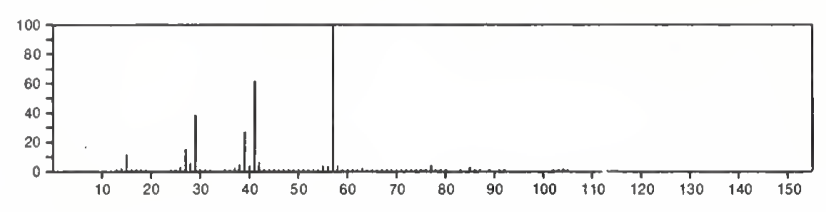

120

2-Pentanone, 5-chloro-

$\mathrm{C}_{5} \mathrm{H}_{9} \mathrm{ClO}$

$\mathrm{Cl}\left(\mathrm{CH}_{2}\right)_{3} \mathrm{COMe}_{0}$

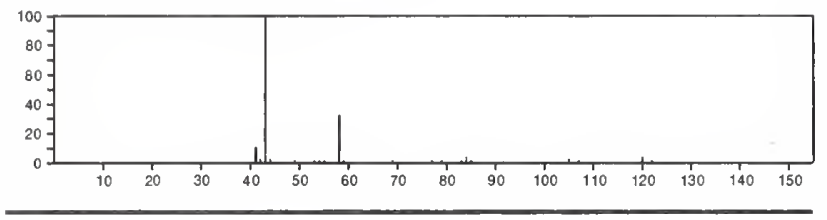

$120 \quad \mathrm{C}_{5} \mathrm{H}_{9} \mathrm{FO}_{2}$

1,3-Dioxane, 5-fluoro-2-methyl-, cis-
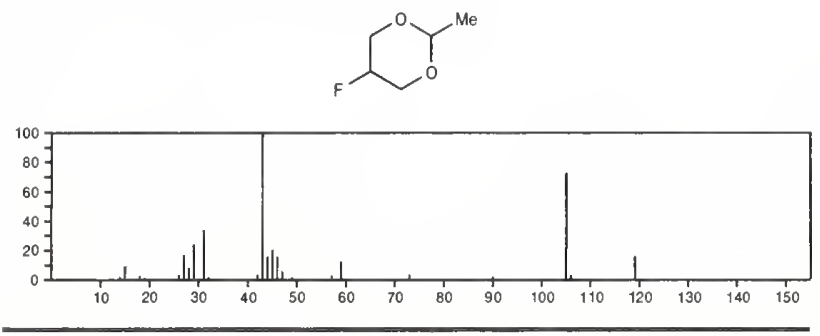

120

$\mathrm{C}_{5} \mathrm{H}_{12} \mathrm{OS}$

2976-98-9

Butane, 1-(methylsulfinyl)-

$\mathrm{Me}\left(\mathrm{CH}_{2}\right)_{3} \mathrm{~S}(\mathrm{O}) \mathrm{Me}$

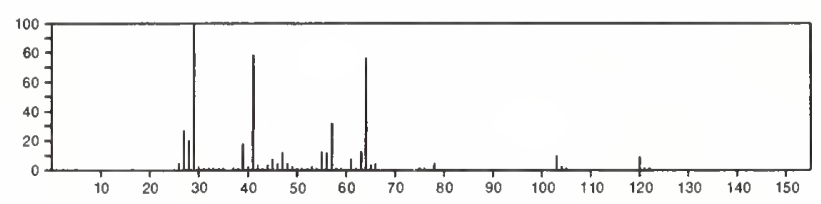

120

Ethane, [(ethoxymethyl)thio]

$\mathrm{C}_{5} \mathrm{H}_{12} \mathrm{OS}$

$54699-20-6$
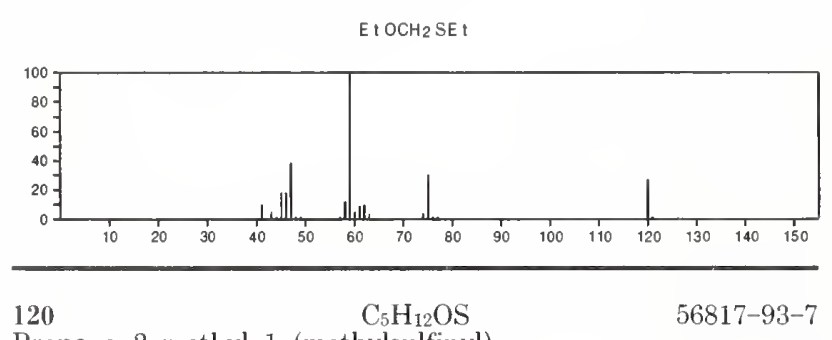

Propane, 2-methyl-1-(methylsulfinyl)-

$$
\mathrm{i}-\mathrm{BuS}(\mathrm{O}) \mathrm{Me}
$$

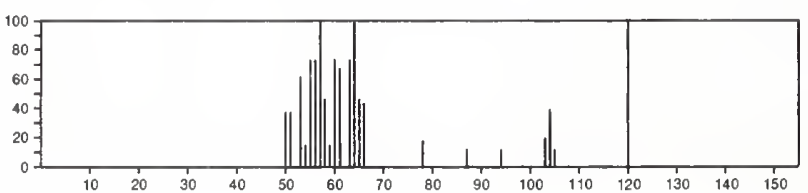

120

Ethanol, 2-(2-methoxyethoxy)-

$\mathrm{C}_{5} \mathrm{H}_{12} \mathrm{O}_{3}$

$111-77-3$

$\mathrm{HOCH}_{2} \mathrm{CH}_{2} \mathrm{OCH}_{2} \mathrm{CH}_{2} \mathrm{OMe}_{\mathrm{O}}$

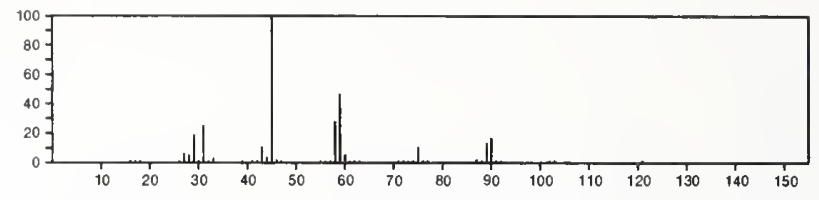

120
2-Propanol, 1,3-dimethoxy-

$623-69-8$

$\mathrm{MeOCH} 2 \mathrm{CH}(\mathrm{OH}) \mathrm{CH}_{2} \mathrm{OMe}_{\mathrm{N}}$

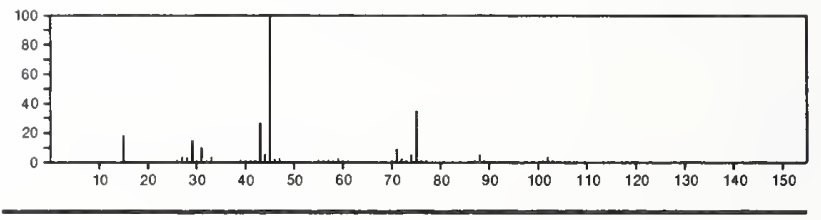

120

Ethane, 1,1,1-trimethoxy-

$\mathrm{C}_{5} \mathrm{H}_{12} \mathrm{O}_{3}$

$1445-45-0$

$\mathrm{MeC}(\mathrm{OMe})_{3}$

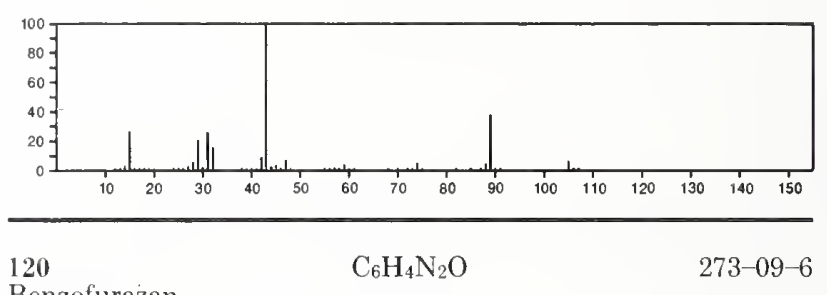

Benzofurazan
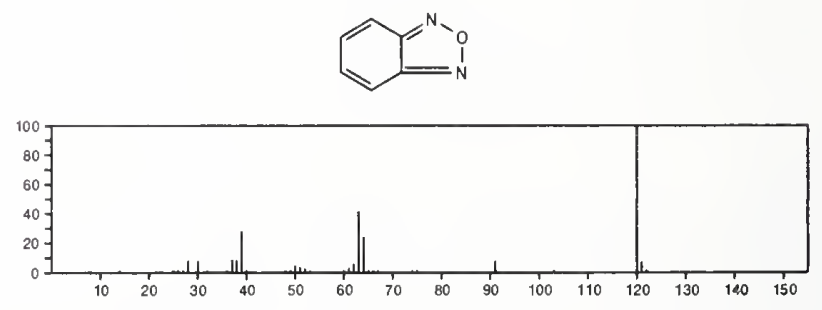

$120 \quad \mathrm{C}_{6} \mathrm{H}_{4} \mathrm{~N}_{2} \mathrm{O}$

$6925-01-5$

Benzenediazonium, 4-hydroxy-, hydroxide, inner salt
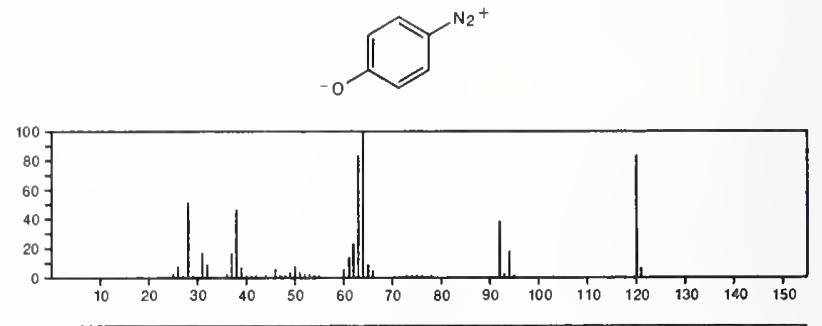

$120 \quad \mathrm{C}_{6} \mathrm{H}_{4} \mathrm{~N}_{2} \mathrm{O}$

29906-36-3

Benzenediazonium, 2-hydroxy-, hydroxide, inner salt<smiles>[N+]c1ccccc1[O-]</smiles>

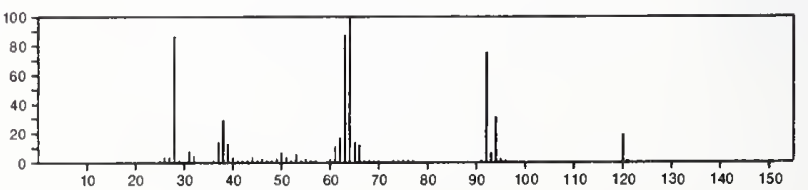


120

Hexane, 1-chloro-

$\mathrm{C}_{6} \mathrm{H}_{13} \mathrm{Cl}$

$\mathrm{Me}\left(\mathrm{CH}_{2}\right)_{5} \mathrm{Cl}$

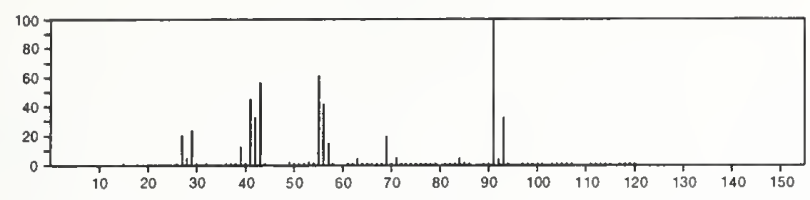

120

Pentane, 3-chloro-3-methyl-

$\mathrm{C}_{6} \mathrm{H}_{13} \mathrm{Cl}$

$918-84-3$

$\mathrm{E}_{2} \mathrm{CCl}(\mathrm{Me})$

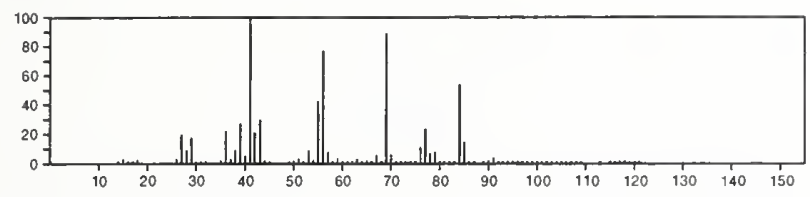

120

$\mathrm{C}_{7} \mathrm{H}_{8} \mathrm{~N}_{2}$

1,1-Cyclopropanedicarbonitrile, 2,2-dimethyl
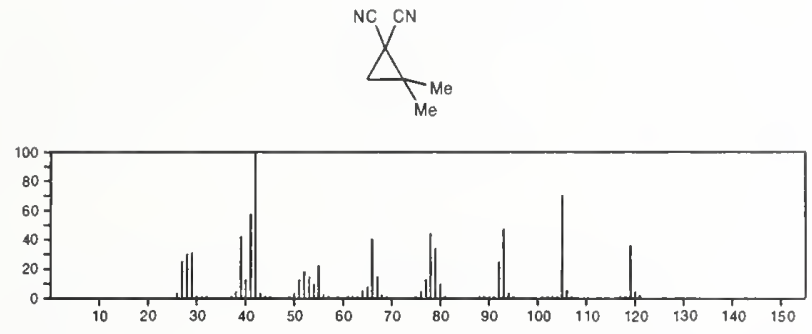

120

$\mathrm{C}_{8} \mathrm{H}_{5} \mathrm{~F}$

$766-98-3$

Benzene, 1-ethynyl-4-fluoro-
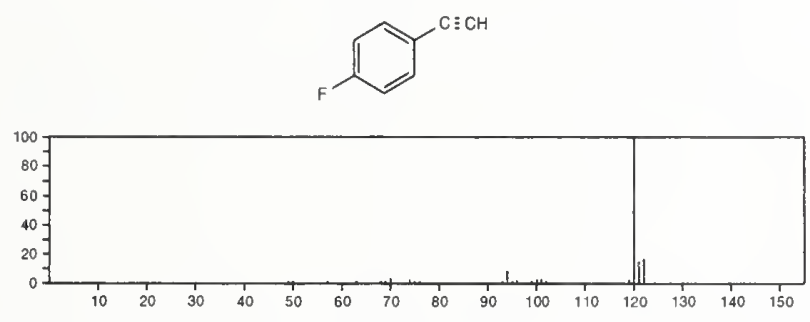

$120 \quad \mathrm{C}_{8} \mathrm{H}_{8} \mathrm{O} \quad 96-09-3$

Oxirane, phenyl-
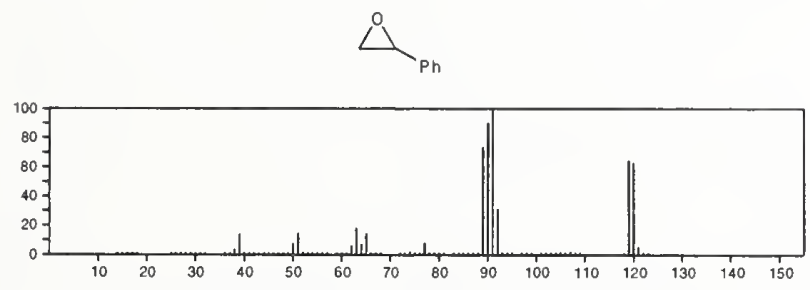

\section{0}

Ethanone, 1-phenyl-

$$
\mathrm{C}_{8} \mathrm{H}_{8} \mathrm{O}
$$

$98-86-2$

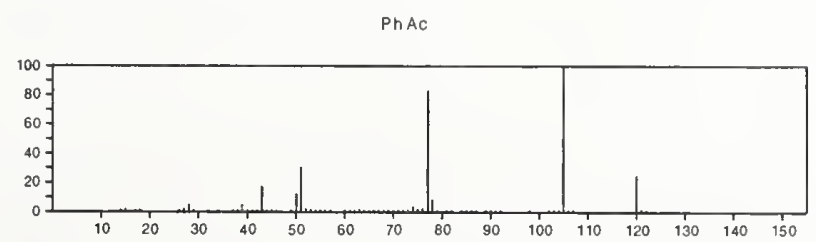

120

$\mathrm{C}_{8} \mathrm{H}_{8} \mathrm{O}$

$104-87-0$

Benzaldehyde, 4-methyl-
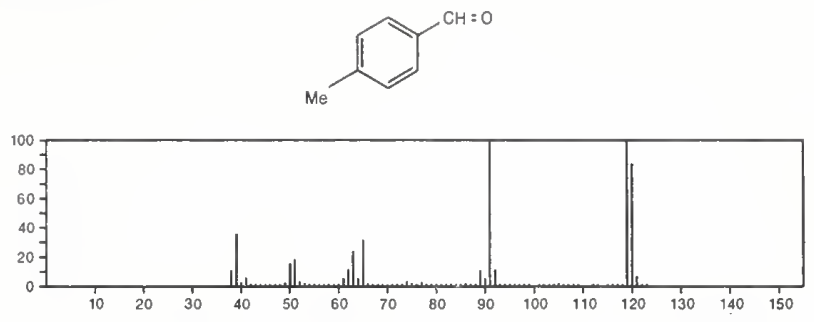

120

$\mathrm{C}_{8} \mathrm{H}_{8} \mathrm{O}$

$122-78-1$

Benzeneacetaldehyde

$\mathrm{PhCH}_{2} \mathrm{CHO}$

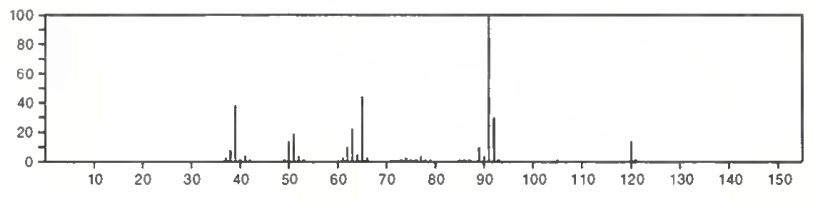

120

$\mathrm{C}_{8} \mathrm{H}_{8} \mathrm{O}$

496-16-2

Benzofuran, 2,3-dihydro-
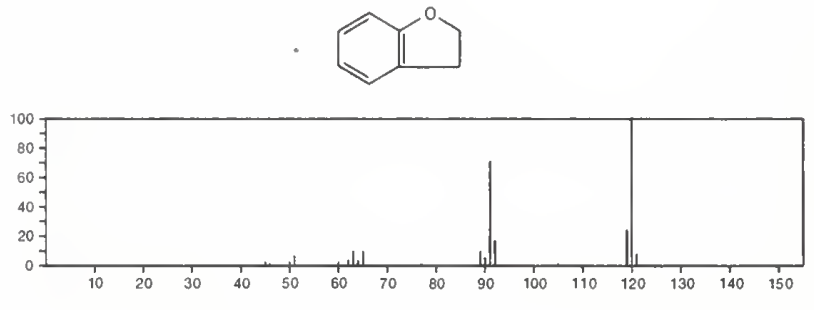

120

$\mathrm{C}_{8} \mathrm{H}_{8} \mathrm{O}$

$529-20-4$

Benzaldehyde, 2-methyl-
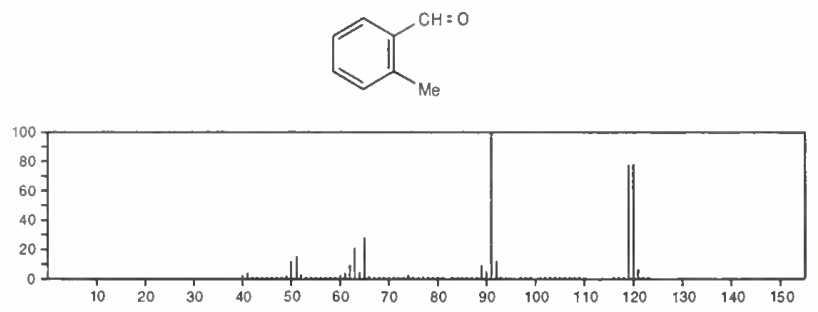

120

$\mathrm{C}_{8} \mathrm{H}_{8} \mathrm{O}$

$620-23-5$

Benzaldehyde, 3-methyl-
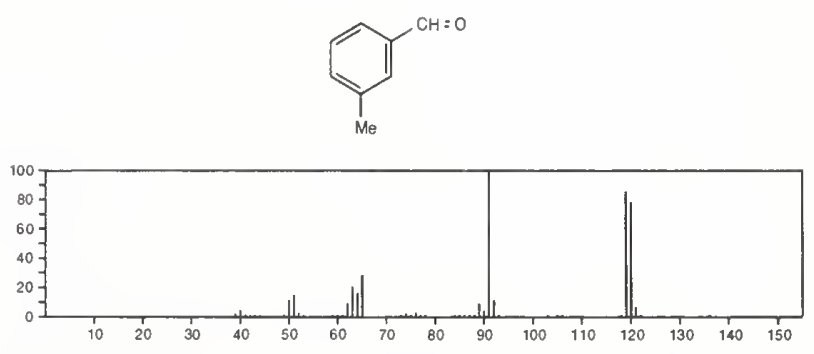

120

$\mathrm{C}_{8} \mathrm{H}_{8} \mathrm{O}$

766-94-9

Benzene, (ethenyloxy)-

$\mathrm{H}_{2} \mathrm{C}=\mathrm{CHOPh}$

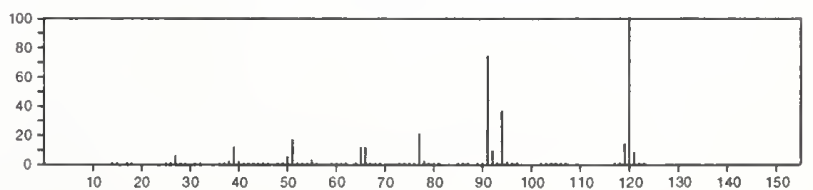


$\mathrm{C}_{8} \mathrm{H}_{8} \mathrm{O}$

Tricyclo[4.2.0.02,4 $]$ oct-7-en-5-one

$56666-78-5$
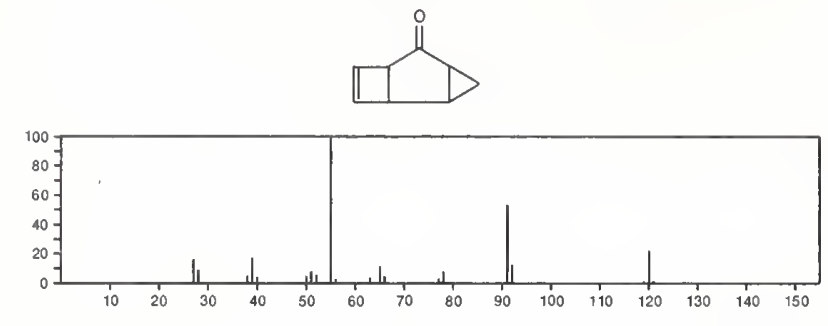

120

Benzene, 1,2,4-trimethyl

\section{$\mathrm{C}_{9} \mathrm{H}_{12}$}

$95-63-6$
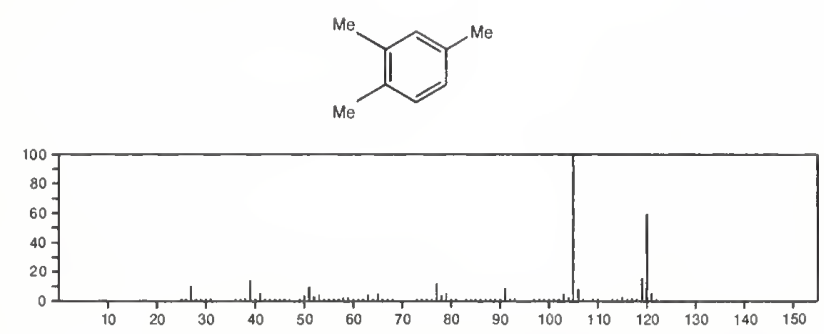

120

Benzene, (1-methylethyl)-

$\mathrm{C}_{9} \mathrm{H}_{12}$

$\mathrm{PhPr}-\mathrm{i}$
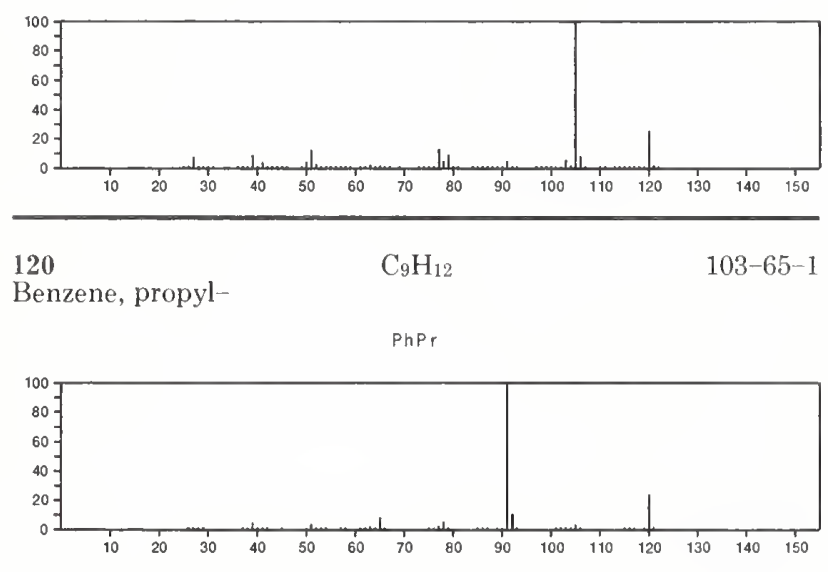

120

$\mathrm{C}_{9} \mathrm{H}_{12}$

$108-67-8$

Benzene, 1,3,5-trimethyl-
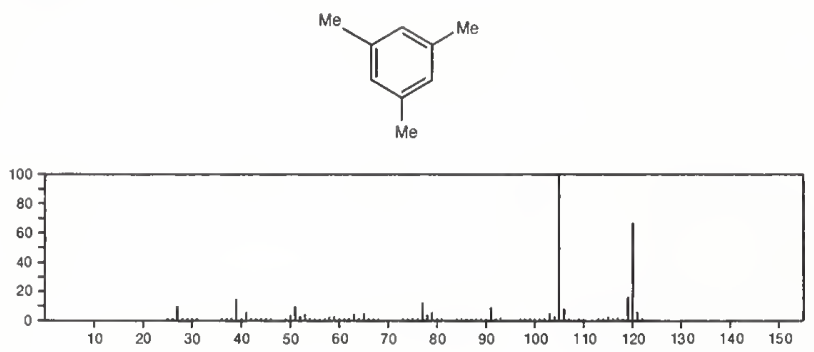

120

$\mathrm{C}_{9} \mathrm{H}_{12}$

$526-73-8$

Benzene, 1,2,3-trimethyl-
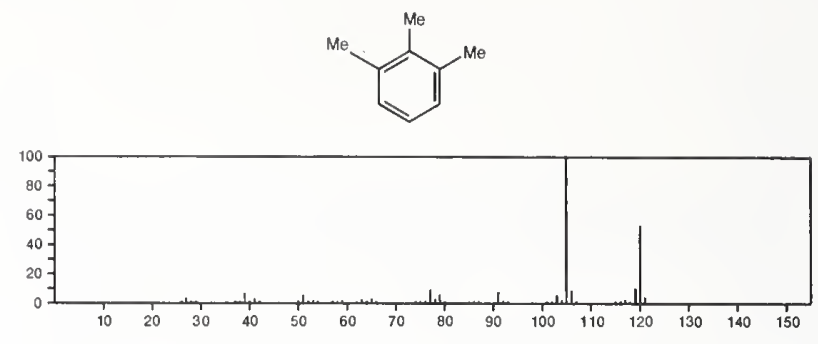

120

$\mathrm{C}_{9} \mathrm{H}_{12}$

611-14-3

Benzene, 1-ethyl-2-methyl-
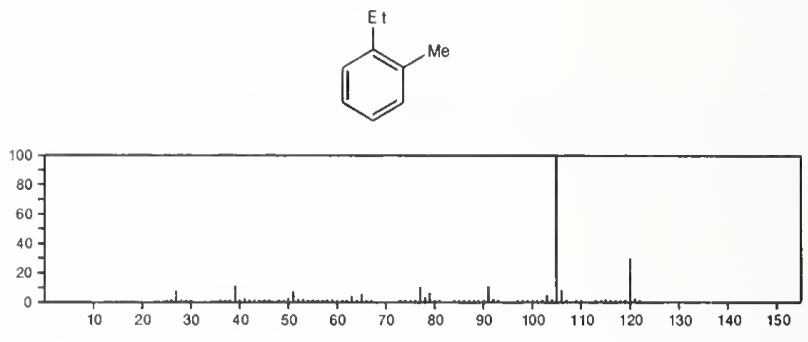

120

$\mathrm{C}_{9} \mathrm{H}_{12}$

$620-14-4$

Benzene, 1-ethyl-3-methyl-
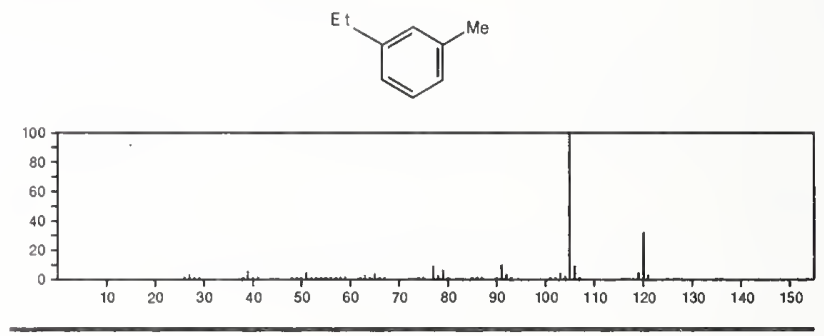

120

$\mathrm{C}_{9} \mathrm{H}_{12}$

$622-96-8$

Benzene, 1-ethyl-4-methyl-
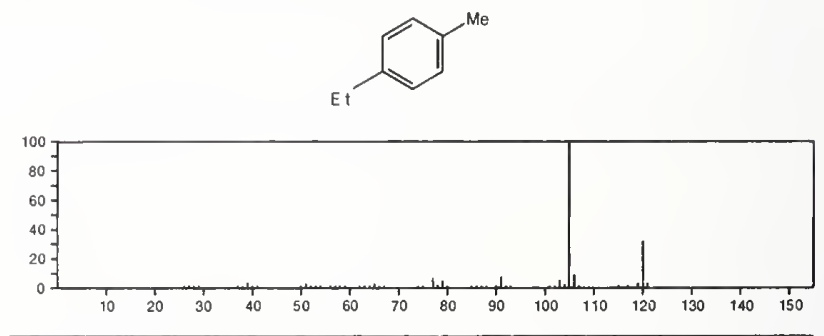

120

$\mathrm{C}_{9} \mathrm{H}_{12}$

1655-05-6

Cyclohexene, 1-(1-propynyl)-
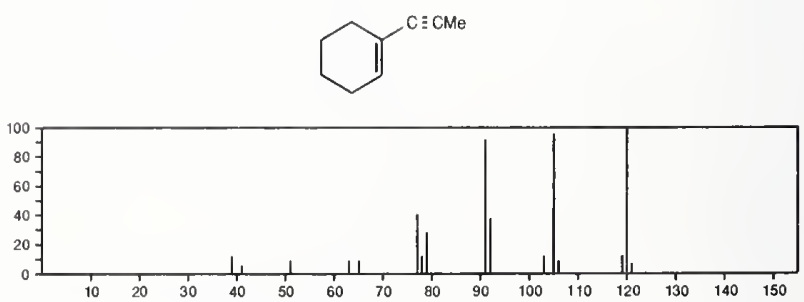
$120 \quad \mathrm{C}_{9} \mathrm{H}_{12}$

Cyclohexane, 2-propynylidene-

2806-45-3<smiles>C=C=C1CCCCC1</smiles>

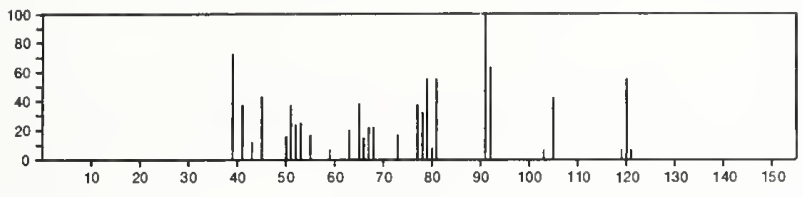

120

1,3,5-Cycloheptatriene, 7-ethyl-

$17634-51-4$
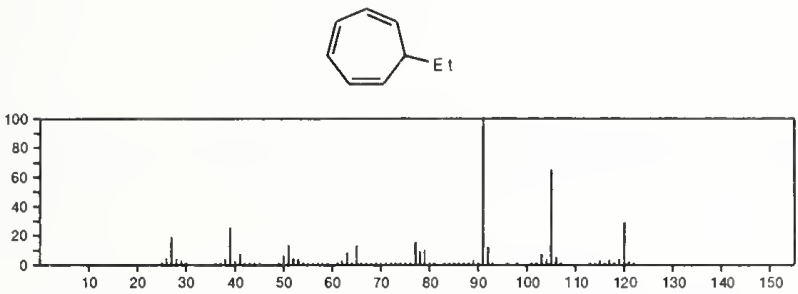

120

$\mathrm{Cg}_{9} \mathrm{H}_{12}$

Bicyclo[3.2.1]oct-2-ene, 3-methylene-

22819-81-4
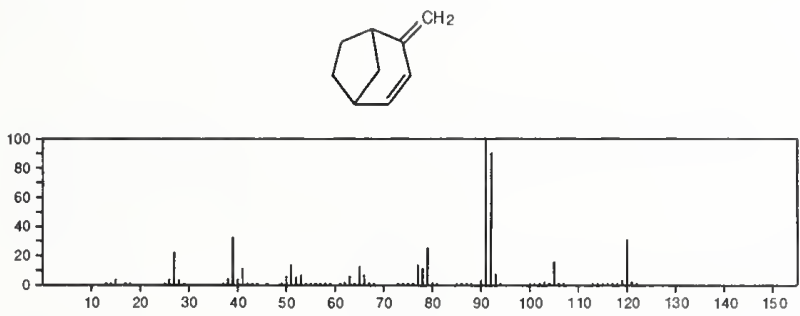

\section{0}

Spiro[4.4]nona-1,6-diene, $(S)$

$\mathrm{C}_{9} \mathrm{H}_{12}$

$39746-39-9$
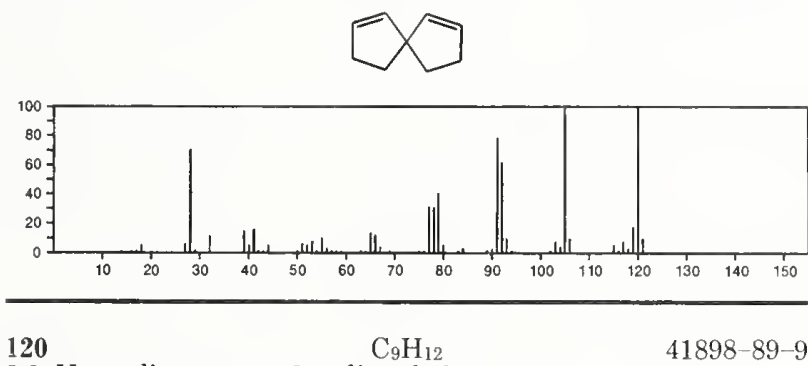

2,3-Heptadien-5-yne, 2,4-dimethyl-

41898-89-9

$\mathrm{MeC}: \mathrm{CCMe}=\mathrm{C}=\mathrm{CMe}_{2}$

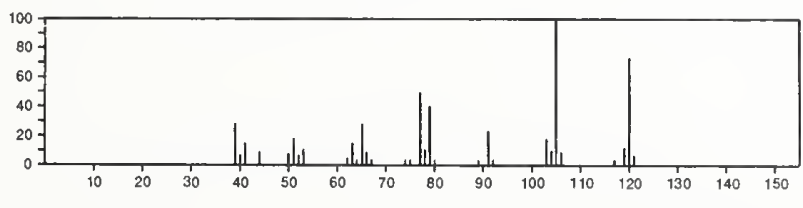

120

$\mathrm{C}_{9} \mathrm{H}_{12}$

$55956-43-9$

Cyclohexene, 3-(2-propynyl)-
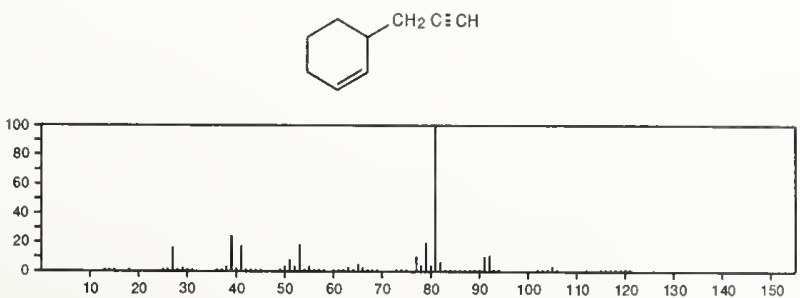

$120 \quad \mathrm{ClF}_{2} \mathrm{OP}$

Phosphoryl chloride fluoride $\left(\mathrm{POClF}_{2}\right)$

$13769-75-0$

$C I P F_{2}=0$

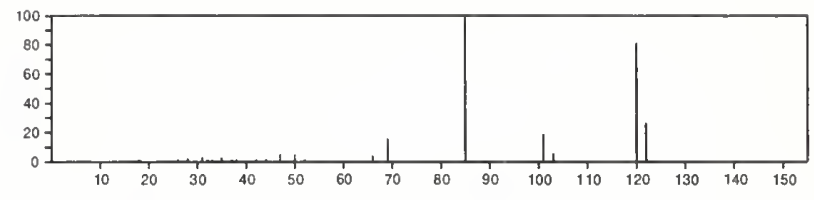

121

$\mathrm{BrN}_{3}$

13973-87-0

Bromine azide $\left(\operatorname{Br}\left(\mathrm{N}_{3}\right)\right)$

$\mathrm{N}_{3} \mathrm{Br}$

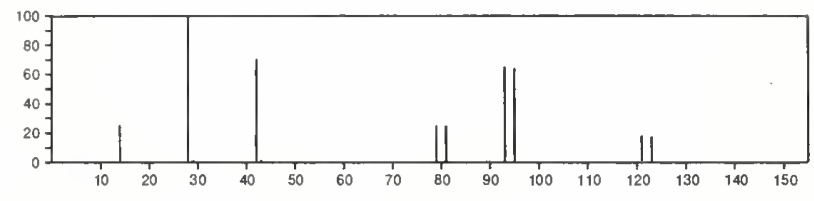

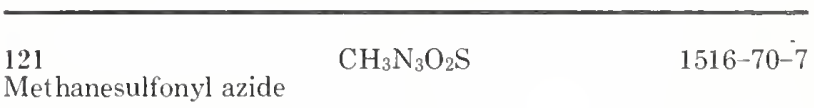

$\mathrm{N}_{3} \mathrm{SO}_{2} \mathrm{Me}$

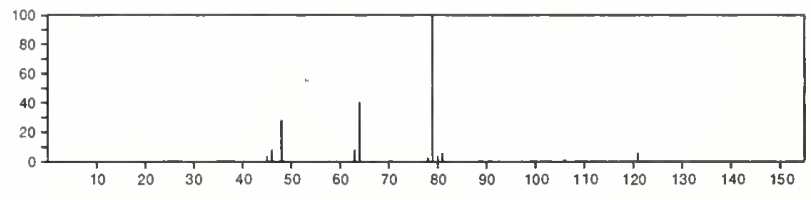

121

$\mathrm{C}_{4} \mathrm{H}_{5} \mathrm{~F}_{2} \mathrm{NO}$

Propane, 1,1-difluoro-1-isocyanato-

55669-94-8

$\mathrm{E}_{1} \mathrm{CF}_{2}$ ( $\mathrm{NCO}$

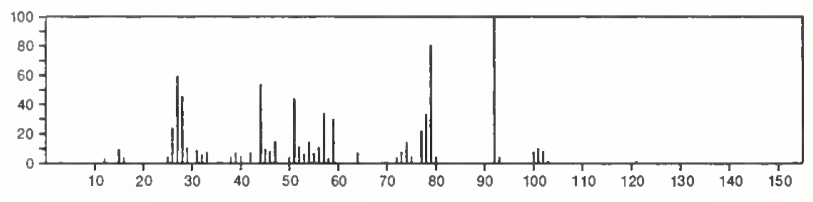

121

$\mathrm{C}_{6} \mathrm{H}_{7} \mathrm{~N}_{3}$

$1 H$-Imidazo[1,2-b]pyrazole, 6-methyl-

42351-84-8<smiles>Cc1cc2[nH]ccn2n1</smiles>

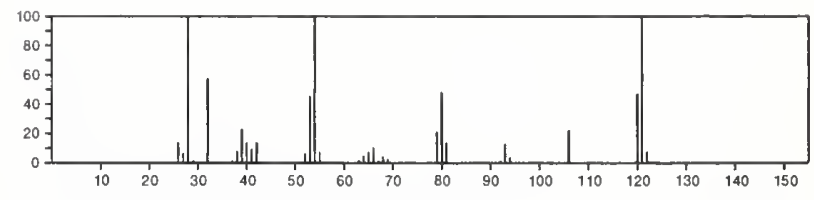

2 Pyridinecarboximidamide

$\mathrm{C}_{6} \mathrm{H}_{7} \mathrm{~N}_{3}$

52313-50-5
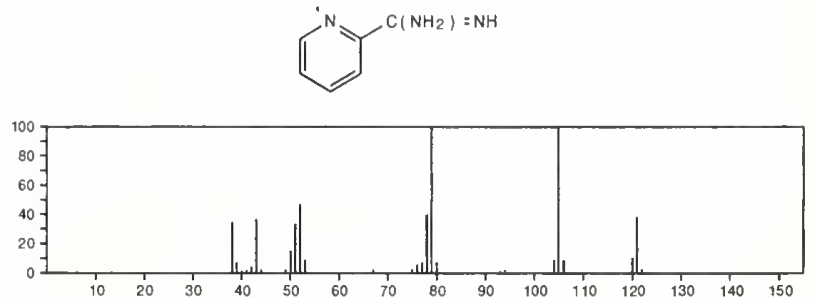
$121 \quad \mathrm{C}_{6} \mathrm{H}_{7} \mathrm{~N}_{3}$

$1 H$-Imidazo[1,2-b]pyrazole, 1-methyl-
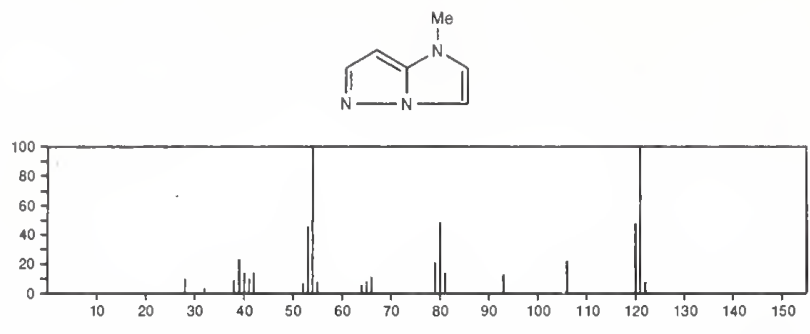

121

$\mathrm{C}_{7} \mathrm{H}_{4} \mathrm{FN}$

$1194-02-1$

Benzonitrile, 4-fluoro
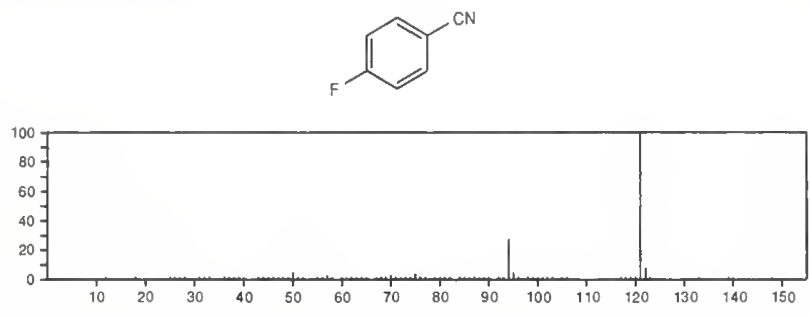

\begin{tabular}{|c|c|}
\hline $\begin{array}{l}121 \\
\text { Benzamide }\end{array}$ & $\mathrm{C}_{7} \mathrm{H}_{7} \mathrm{NO}$ \\
\hline
\end{tabular}

$\mathrm{H}_{2} \mathrm{NCOPh}$

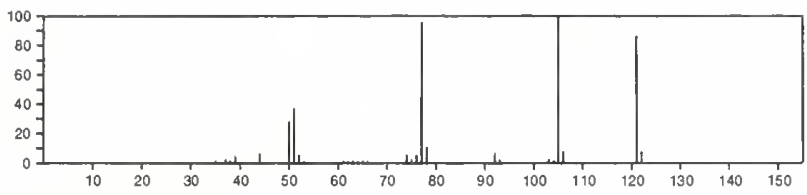

121

$\mathrm{C}_{7} \mathrm{H}_{7} \mathrm{NO}$

$103-70-8$

Formamide, $N$-phenyl-

$0=$ CHNHPh

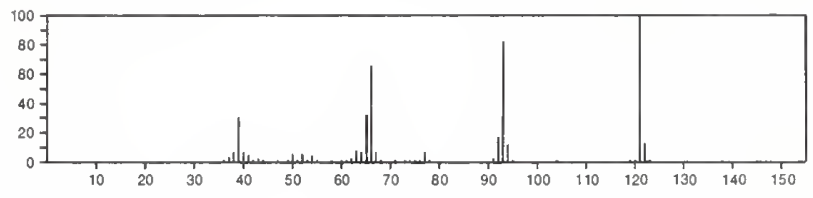

$121 \quad \mathrm{C}_{7} \mathrm{H}_{7} \mathrm{NO}$

Ethanone, 1-(3-pyridinyl)-
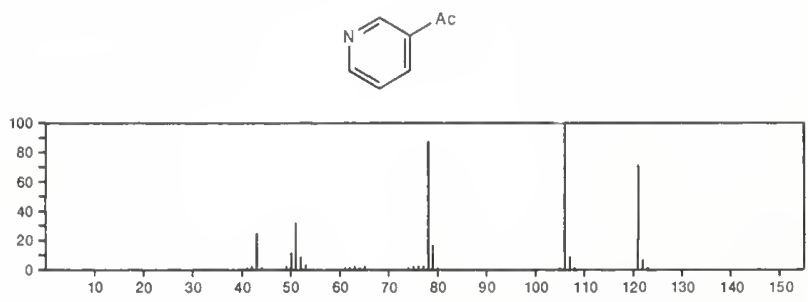

121

$\mathrm{C}_{7} \mathrm{H}_{7} \mathrm{NO}$

$622-31-1$

Benzaldehyde, oxime, $(E)$

$H O N=C H P h$

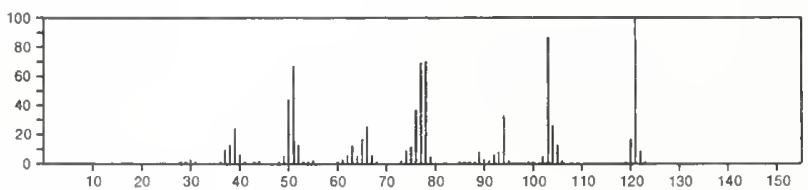

121

Benzaldehyde, oxime, $(Z)-$

$\mathrm{C}_{7} \mathrm{H}_{7} \mathrm{NO}$

$\mathrm{HON}=\mathrm{CHPh}$

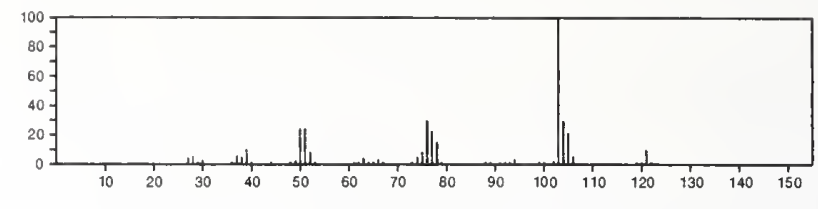

121

Benzaldehyde, oxime

$\mathrm{C}_{7} \mathrm{H}_{7} \mathrm{NO}$

932-90-1

HON $=\mathrm{CHPh}$

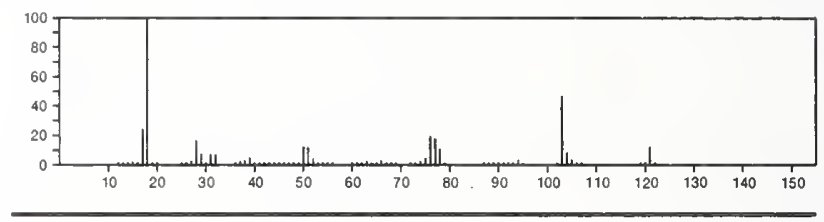

121

$\mathrm{C}_{7} \mathrm{H}_{7} \mathrm{NO}$

$1122-54-9$

Ethanone, 1-(4-pyridinyl)-
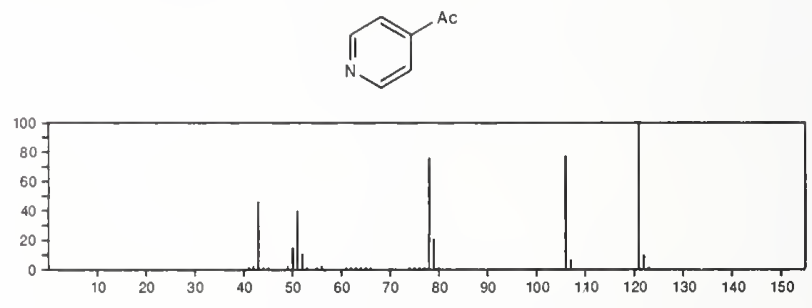

121

$\mathrm{C}_{7} \mathrm{H}_{7} \mathrm{NO}$

$1122-62-9$

Ethanone, 1-(2-pyridinyl)-
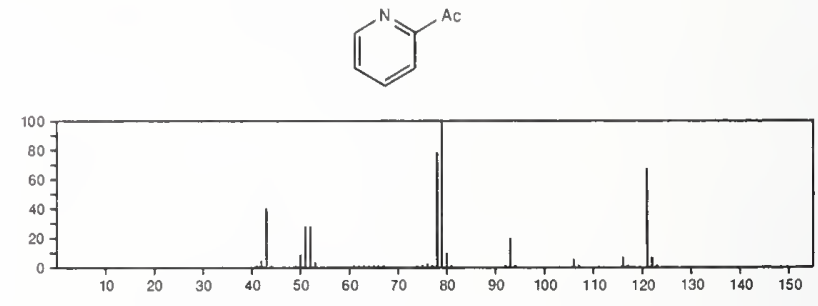

121

$\mathrm{C}_{7} \mathrm{H}_{7} \mathrm{NO}$

2,4,6-Cycloheptatrien-1-one, 2-amino-

6264-93-3
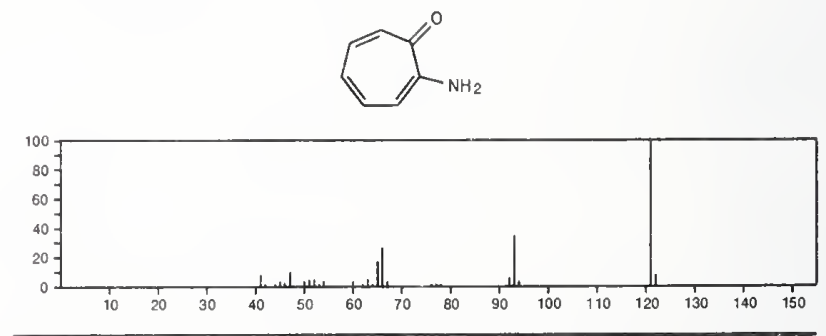

121

2(1H)-Pyridinone, 1 -ethenyl-

\section{$\mathrm{C}_{7} \mathrm{H}_{7} \mathrm{NO}$}

7379-71-7
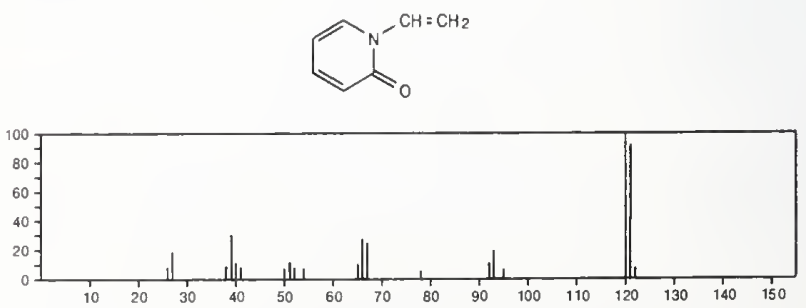
121

Benzeneethanamine

$\mathrm{C}_{8} \mathrm{H}_{11} \mathrm{~N}$

$\mathrm{H}_{2} \mathrm{NCH}_{2} \mathrm{CH}_{2} \mathrm{Ph}$

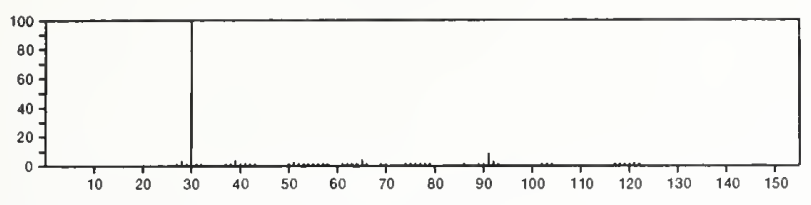

$121 \quad \mathrm{C}_{8} \mathrm{H}_{11} \mathrm{~N}$

Benzenemethanamine, $\alpha$-methyl-

$\mathrm{PhCHME}\left(\mathrm{NH}_{2}\right)$

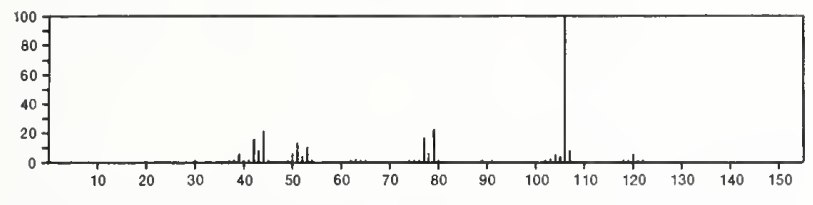

$121 \quad \mathrm{C}_{8} \mathrm{H}_{11} \mathrm{~N}$

Benzenemethanamine, $N$-methyl-

$103-67-3$

$\mathrm{MeNHCH} 2 \mathrm{Ph}$

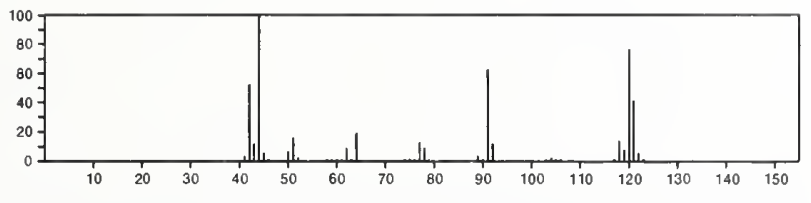

121

$\mathrm{C}_{8} \mathrm{H}_{11} \mathrm{~N}$

$103-69-5$

Benzenamine, $N$-ethyl-

EtNHPh

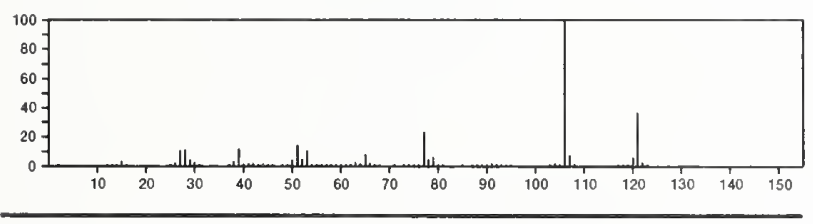

121

\section{$\mathrm{C}_{8} \mathrm{H}_{11} \mathrm{~N}$}

$104-90-5$

Pyridine, 5-ethyl-2-methyl-
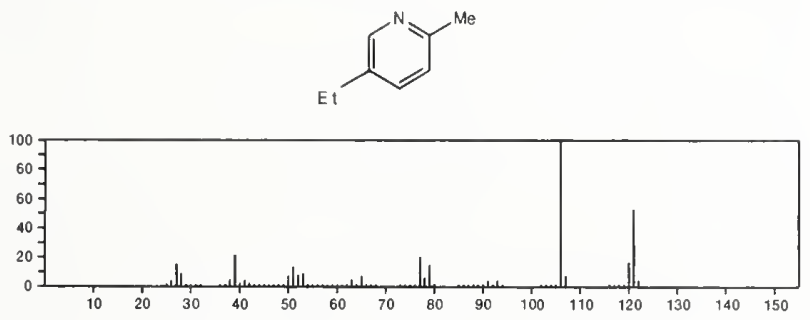

\section{1}

Pyridine, 3-ethyl-4-methyl

$\mathrm{C}_{8} \mathrm{H}_{11} \mathrm{~N}$

529-21-5
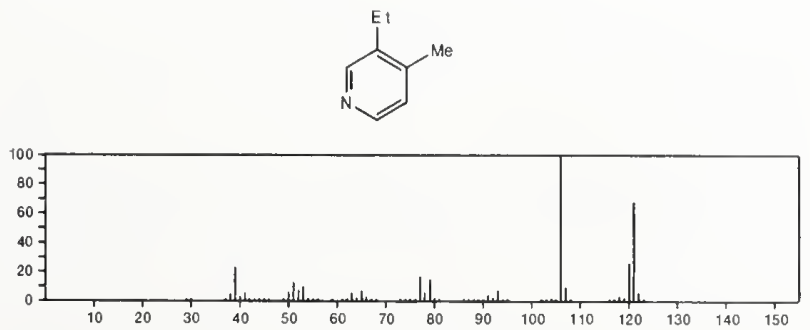

121

Pyridine, 2-propyl-

$\mathrm{C}_{8} \mathrm{H}_{11} \mathrm{~N}$

622-39-9

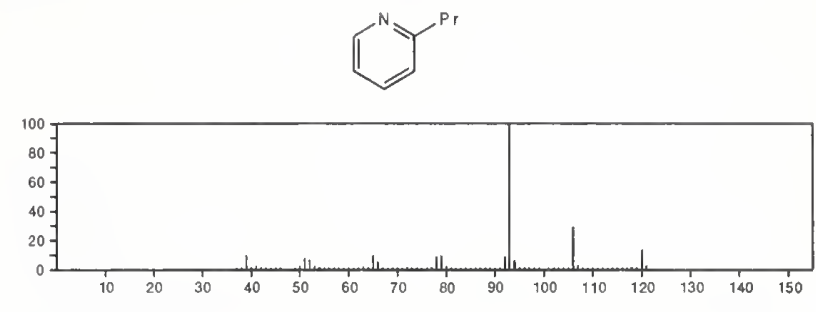

121

Pyridine, 2,3,5-trimethyl

$\mathrm{C}_{8} \mathrm{H}_{11} \mathrm{~N}$

695-98-7<smiles>Cc1cnc(N)c(C)c1</smiles>

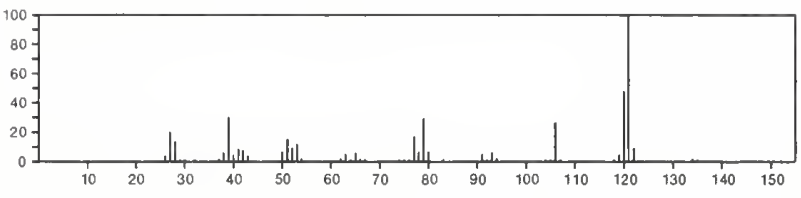

121

Pyridine, 4-propyl--

$\mathrm{C}_{8} \mathrm{H}_{11} \mathrm{~N}$

$1122-81-2$
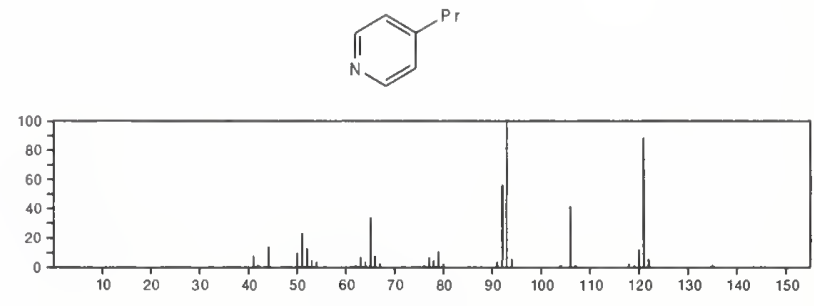

121

Pyridine, 3-ethyl-5-methyl-

$\mathrm{C}_{8} \mathrm{H}_{11} \mathrm{~N}$

$3999-78-8$<smiles>CCc1cncc(C)c1</smiles>

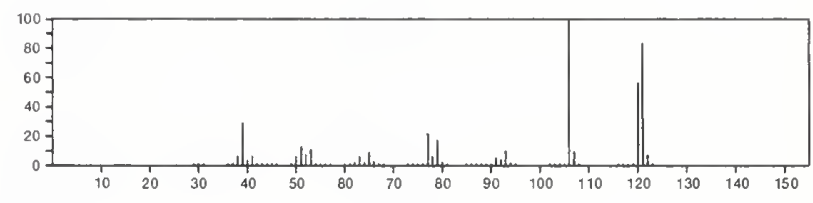

121

$\mathrm{C}_{8} \mathrm{H}_{11} \mathrm{~N}$

$6975-71-9$

1-Cyclohexene-1-acetonitrile
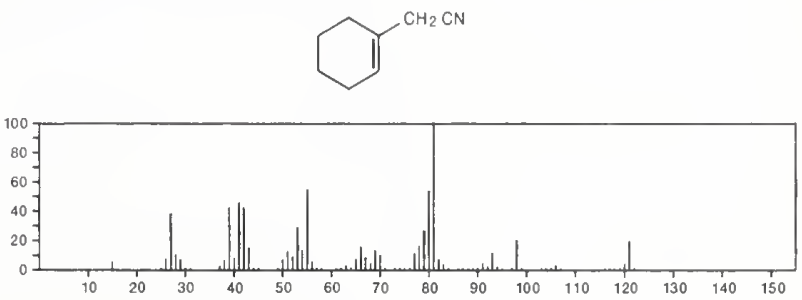
121

$\mathrm{C}_{8} \mathrm{H}_{11} \mathrm{~N}$

$56995-22-3$

4-Azabicyclo[6.1.0]nona-5,7-diene
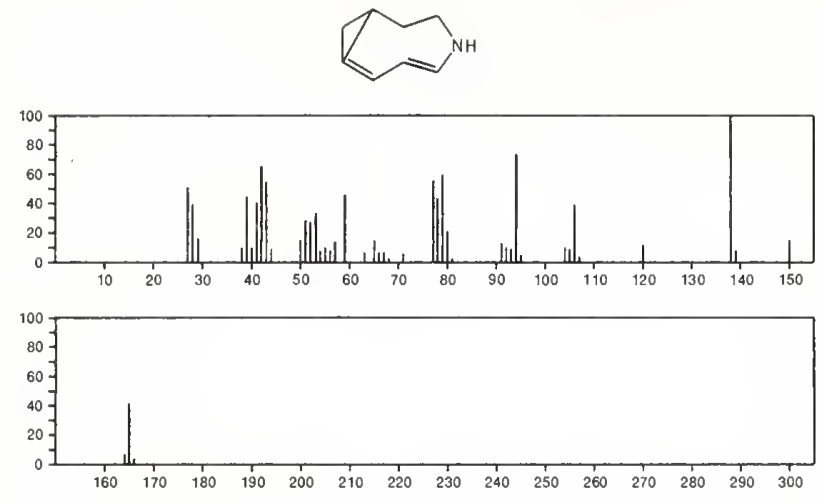

122

Acetyl bromide

$\mathrm{C}_{2} \mathrm{H}_{3} \mathrm{BrO}$

506-96-7
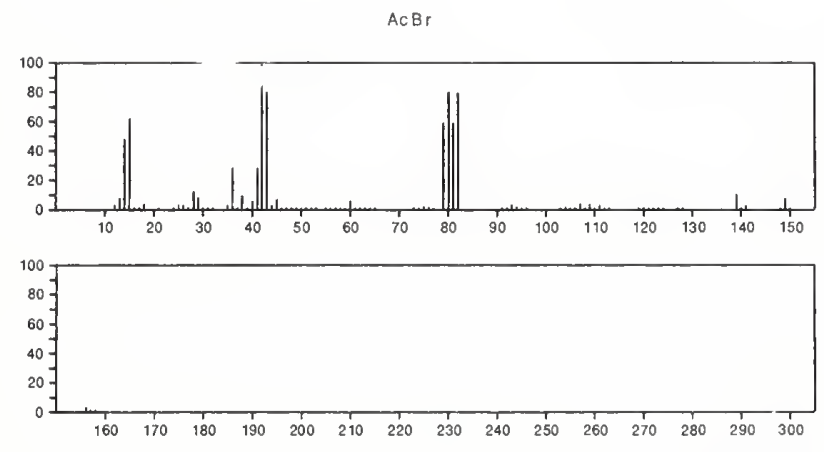

122

$\mathrm{C}_{2} \mathrm{H}_{6} \mathrm{~N}_{2} \mathrm{~S}_{2}$

Hydrazinecarbodithioic acid, methyl ester

$\mathrm{H}_{2} \mathrm{NNHC}$ ( $\mathrm{S}$ ) SMe

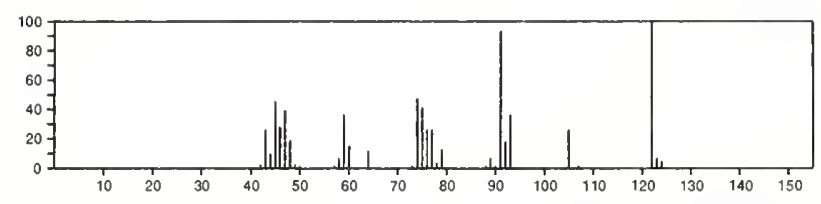

122

$\mathrm{C}_{3} \mathrm{H}_{6} \mathrm{OS}_{2}$

Carbonodithioic acid, S,S-dimethyl ester

$868-84-8$

MeSC(O) SMe

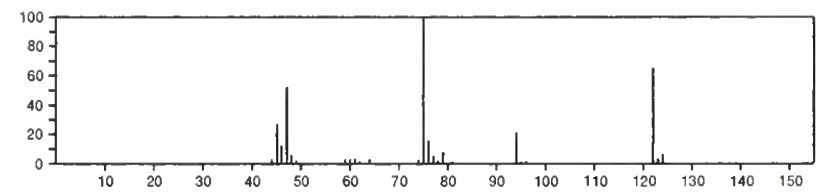

$122 \quad \mathrm{C}_{3} \mathrm{H}_{6} \mathrm{OS}_{2}$

Carbonodithioic acid, $\mathrm{O}, \mathrm{S}$-dimethyl ester

$19708-81-7$

Me OC(S) SMe

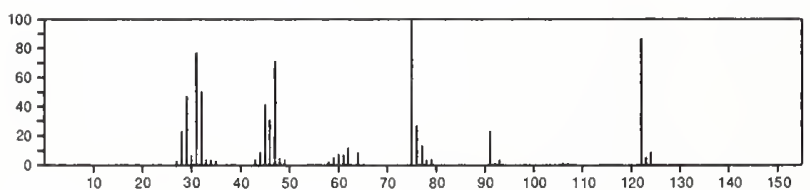

122

$\mathrm{C}_{3} \mathrm{H}_{6} \mathrm{O}_{3} \mathrm{~S}$

$1469-73-4$

1,3,2-Dioxathiolane, 4-methyl-, 2-oxide
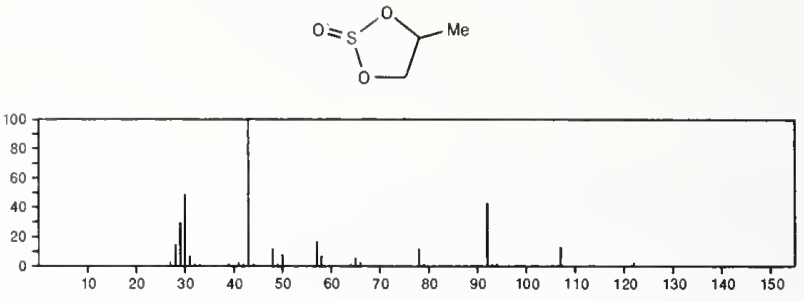

122

Propane, 2-bromo

$\mathrm{C}_{3} \mathrm{H}_{7} \mathrm{Br}$

$75-26-3$

$i-\operatorname{PrBr}$

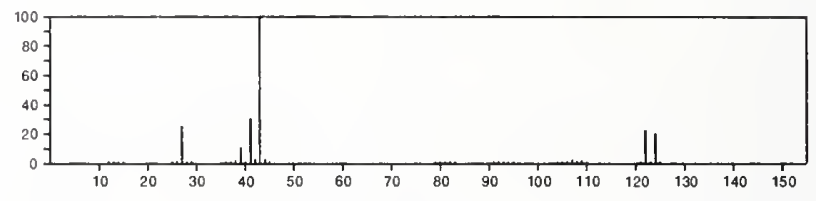

122

Propane, 1-bromo

$\mathrm{C}_{3} \mathrm{H}_{7} \mathrm{Br}$

$106-94-5$

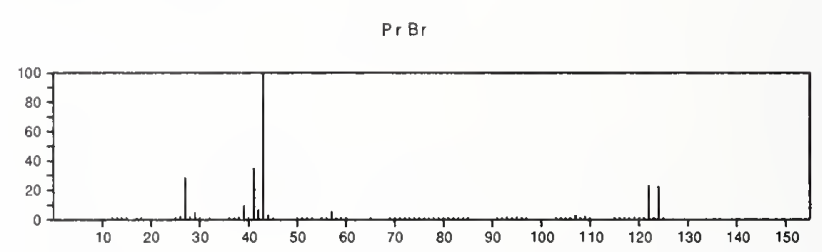

122

$\mathrm{C}_{3} \mathrm{H}_{7} \mathrm{ClN}_{2} \mathrm{O}$

$16339-16-5$

Ethanamine, 2-chloro- $N$-methyl- $N$-nitroso-

$\mathrm{C}_{1} \mathrm{CH}_{2} \mathrm{CH}_{2} \mathrm{~N}(\mathrm{NO}) \mathrm{Me}$

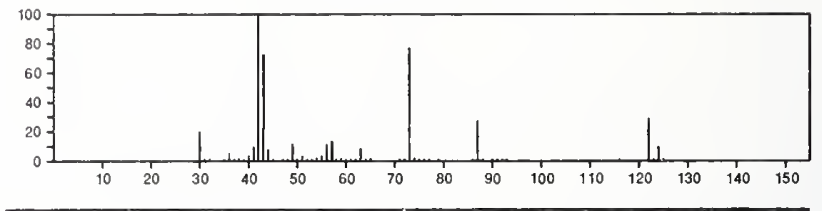

122

2-Butyne, 1,4-dichloro-

$\mathrm{C}_{4} \mathrm{H}_{4} \mathrm{Cl}_{2}$

$821-10-3$

$\mathrm{Cl} \mathrm{CH}_{2} \mathrm{C} \equiv \mathrm{CCH}_{2} \mathrm{Cl}$

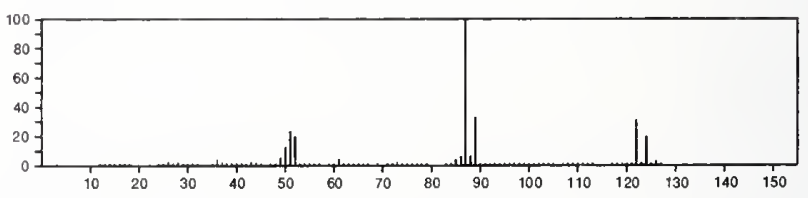

122

$\mathrm{C}_{4} \mathrm{H}_{7} \mathrm{ClO}_{2}$

$105-39-5$

Acetic acid, chloro-, ethyl ester

$\mathrm{EtOC}(\mathrm{O}) \mathrm{CH}_{2} \mathrm{Cl}$

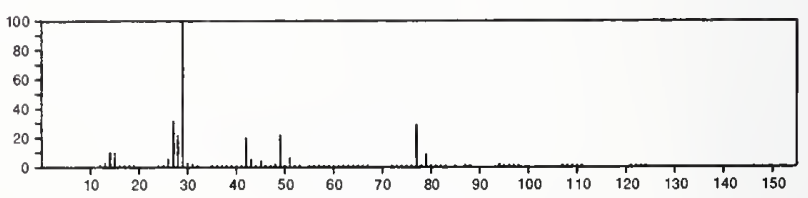


122 $\mathrm{C}_{4} \mathrm{H}_{7} \mathrm{ClO}_{2}$

Carbonochloridic acid, propyl ester

$109-61-5$

$\mathrm{CIC}(\mathrm{O}) \mathrm{OP} \mathrm{r}$

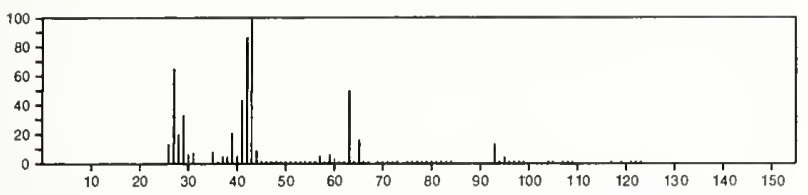

\section{2}

Ethanol, 2-chloro-, acetate

$\mathrm{C}_{4} \mathrm{H}_{7} \mathrm{ClO}_{2}$

$\mathrm{Ac} \mathrm{OCH}_{2} \mathrm{CH}_{2} \mathrm{Cl}$
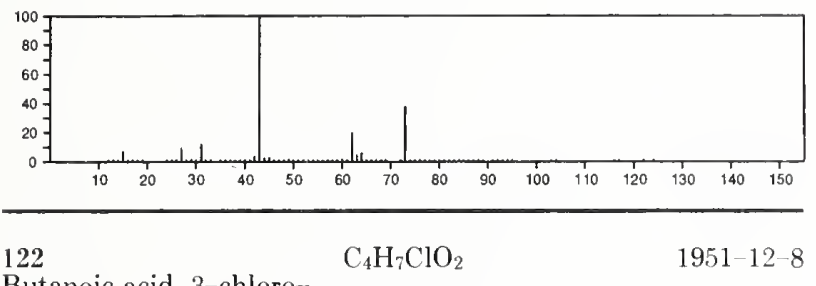

Butanoic acid, 3-chloro-

$\mathrm{MeCHCl} \mathrm{CH}_{2} \mathrm{CO}_{2} \mathrm{H}$
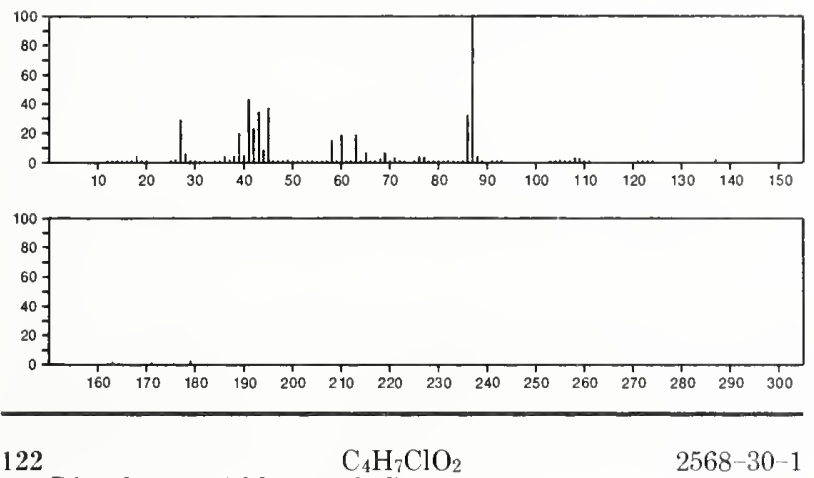

1,3-Dioxolane, 2-(chloromethyl)-

2568-30-1
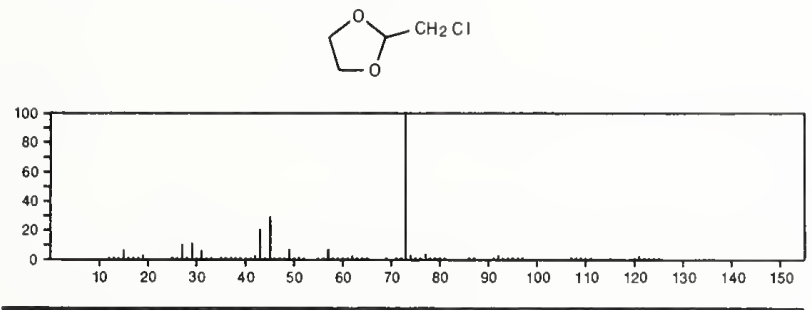

122

Butanoic acid, 2-chloro-

$\mathrm{C}_{4} \mathrm{H}_{7} \mathrm{ClO}_{2}$

$4170-24-5$

$\mathrm{EtCHCl}\left(\mathrm{CO}_{2} \mathrm{H}\right)$
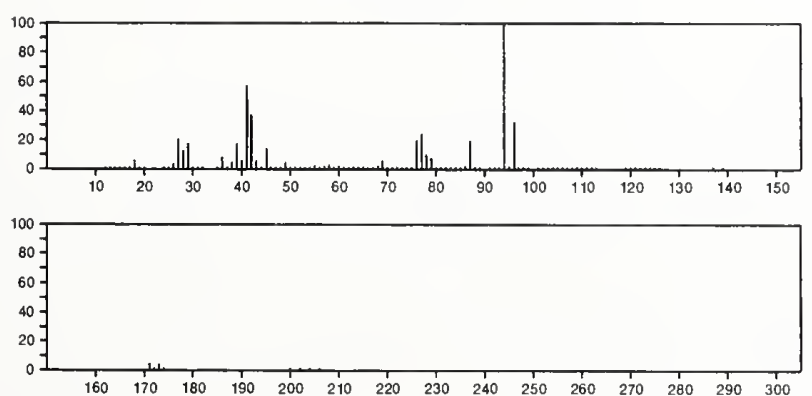

$122 \quad \mathrm{C}_{4} \mathrm{H}_{7} \mathrm{ClO}_{2}$

Propanoic acid, 3-chloro-, methyl ester

$6001-87-2$

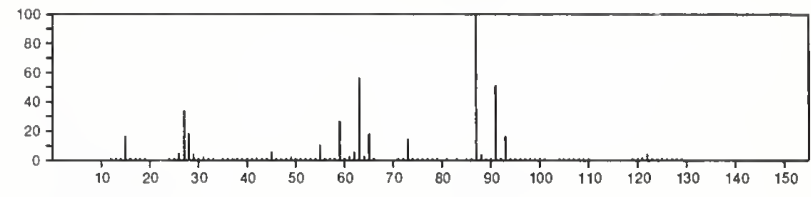

122

$\mathrm{C}_{4} \mathrm{H}_{7} \mathrm{ClO}_{2}$

17639-93-9

Propanoic acid, 2-chloro-, methyl ester

$\mathrm{MeOC}(\mathrm{O}) \mathrm{CHClMe}$
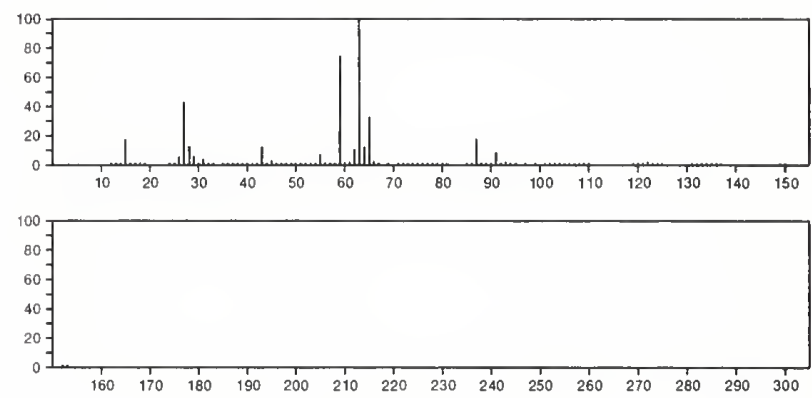

122

Ethanol, 2,2-thiobis

$\mathrm{C}_{4} \mathrm{H}_{10} \mathrm{O}_{2} \mathrm{~S}$

$111-48-8$

$\mathrm{HOCH}_{2} \mathrm{CH}_{2} \mathrm{SCH}_{2} \mathrm{CH}_{2} \mathrm{OH}$

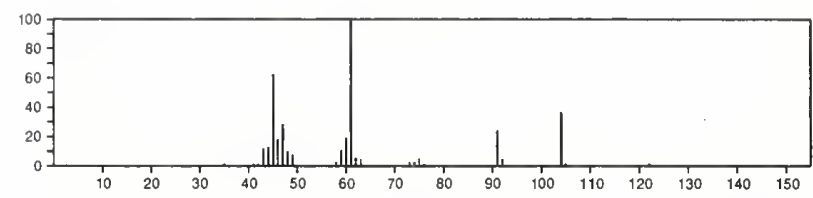

122

$\mathrm{C}_{4} \mathrm{H}_{10} \mathrm{O}_{2} \mathrm{~S}$

$597-35-3$

Ethane, 1,1'-sulfonylbis-

$\mathrm{E} t \mathrm{SO}_{2} \mathrm{Et}$

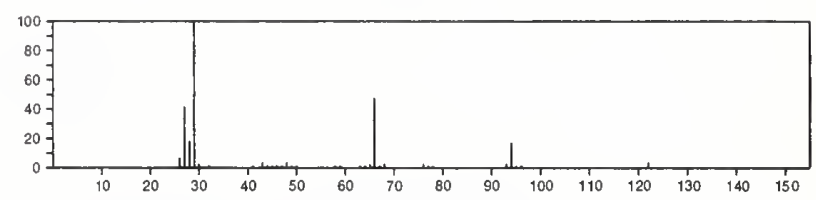

122

$\mathrm{C}_{4} \mathrm{H}_{10} \mathrm{O}_{2} \mathrm{~S}$

$41892-32-4$

1-Propanesulfinic acid, methyl ester

MeOS(0) Pr

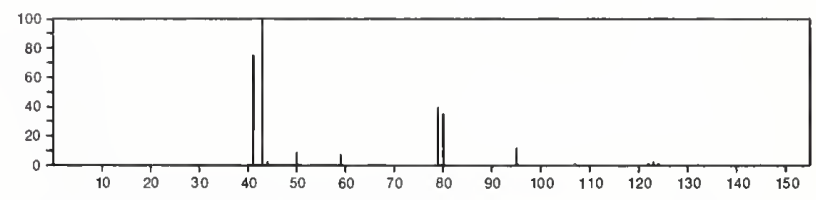

122

$\mathrm{C}_{4} \mathrm{H}_{10} \mathrm{O}_{2} \mathrm{~S}$

2-Propanesulfinic acid, methyl ester

$52693-47-7$

$\mathrm{MeOS}(\mathrm{O}) \mathrm{Pr}-\mathrm{i}$

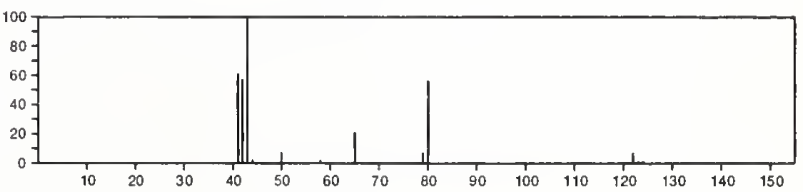


122

Disulfide, diethyl

$\mathrm{C}_{4} \mathrm{H}_{10} \mathrm{~S}_{2}$

EtSSE:

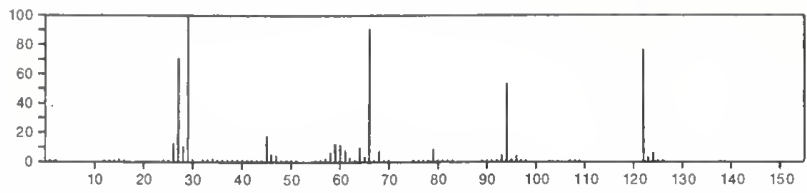

122

Disulfide, methyl propyl

$\mathrm{C}_{4} \mathrm{H}_{10} \mathrm{~S}_{2}$

$217960-4$

MeSSPr

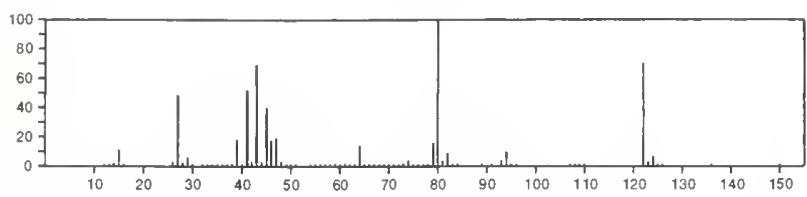

122

Ethane, 1,2-bis(methylthio)

$\mathrm{C}_{4} \mathrm{H}_{10} \mathrm{~S}_{2}$

$6628-18-8$

$\mathrm{MeSCH}_{2} \mathrm{CH}_{2} \mathrm{SMe}$

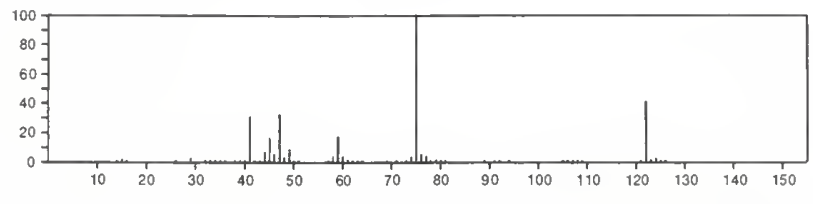

122

Butane, 1-chloro-4-methoxy-

$\mathrm{C}_{5} \mathrm{H}_{11} \mathrm{ClO}$

$\mathrm{MeO}\left(\mathrm{CH}_{2}\right)_{4} \mathrm{Cl}$

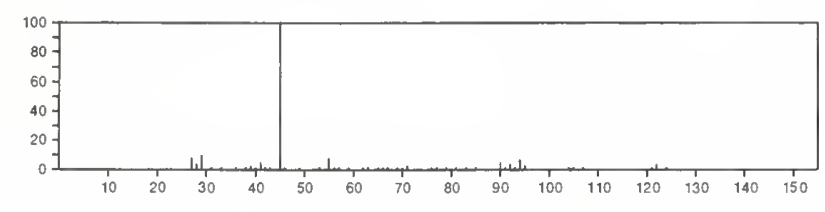

122

$\mathrm{C}_{6} \mathrm{H}_{6} \mathrm{~N}_{2} \mathrm{O}$

98-92-0

3-Pyridinecarboxamide
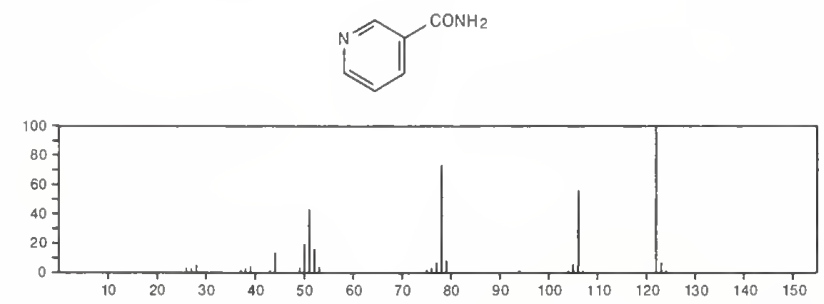

$$
122
$$

122
Boronic acid, phenyl-

$\mathrm{C}_{6} \mathrm{H}_{7} \mathrm{BO}_{2}$

$\mathrm{PhB}(\mathrm{OH})_{2}$

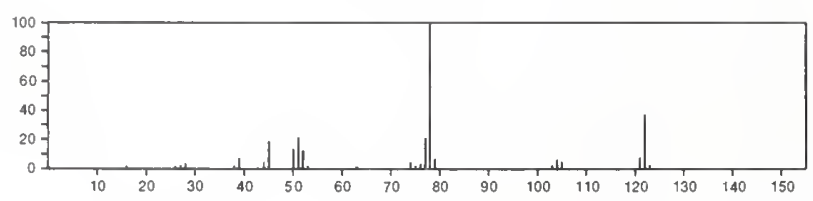

122

$\mathrm{C}_{7} \mathrm{H}_{6} \mathrm{O}_{2}$

65-85-0

Benzoic acid

$\mathrm{PhCO}_{2} \mathrm{H}$

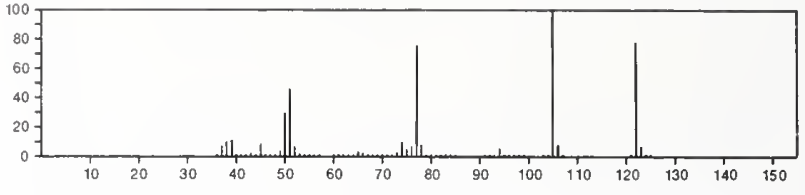

122

$\mathrm{C}_{7} \mathrm{H}_{6} \mathrm{O}_{2}$

$90-02-8$

Benzaldehyde, 2-hydroxy-
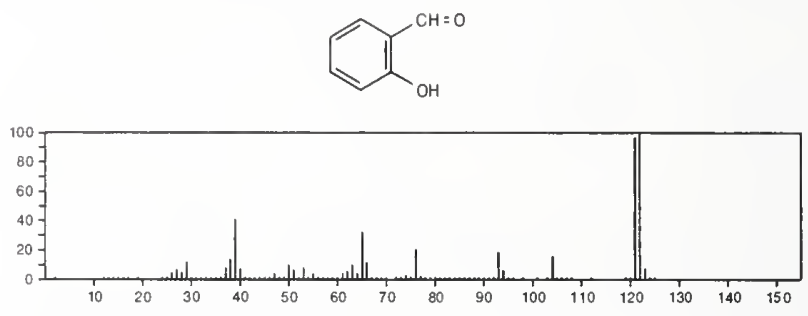

122

$\mathrm{C}_{7} \mathrm{H}_{6} \mathrm{O}_{2}$

100-83-4

Benzaldehyde, 3-hydroxy-
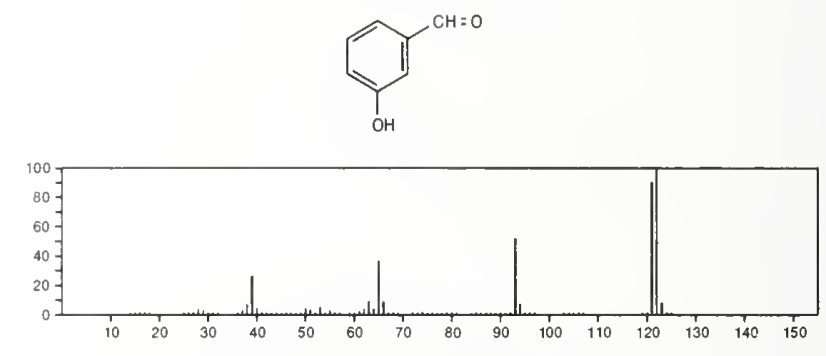

122

$\mathrm{C}_{7} \mathrm{H}_{6} \mathrm{O}_{2}$

123-08-0

Benzaldehyde, 4-hydroxy-
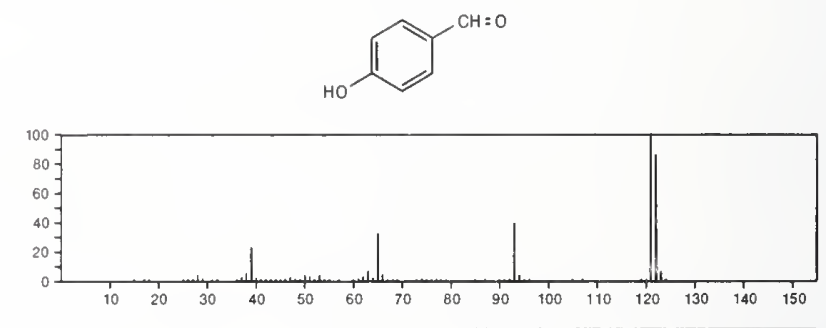

122

$\mathrm{C}_{7} \mathrm{H}_{6} \mathrm{O}_{2}$

274-09-9

1,3-Benzodioxole
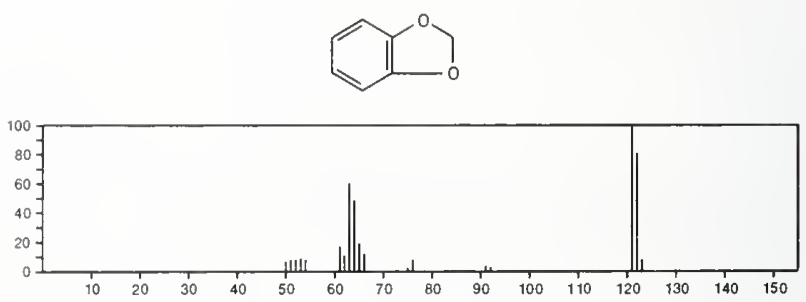
122

$\mathrm{C}_{7} \mathrm{H}_{6} \mathrm{O}_{2}$

2,4,6-Cycloheptatrien-1-one, 2-hydroxy-
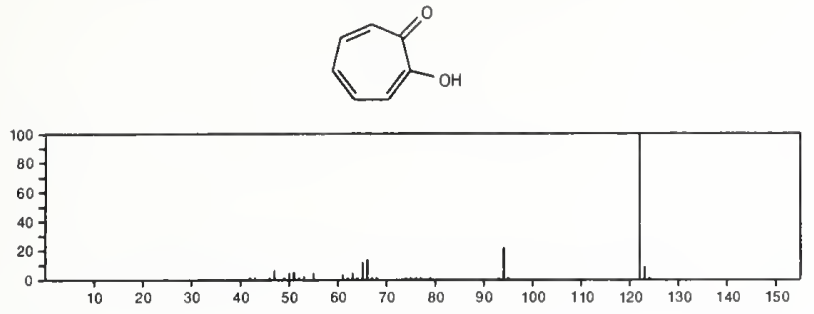

122

2-Propenal, 3-(2-furanyl)-

$\mathrm{C}_{7} \mathrm{H}_{6} \mathrm{O}_{2}$

623-30-3
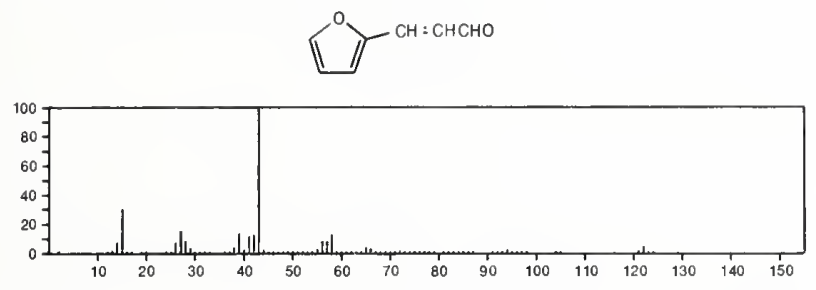

122

1,3-Benzenediamine, 4-methyl-
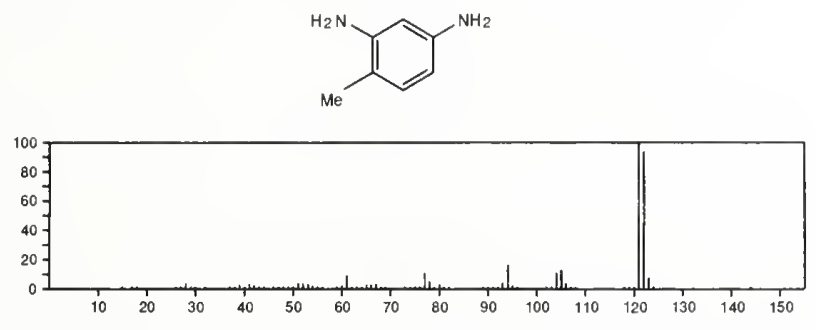

122 Hydrazine, (phenylmethyl)- $\mathrm{C}_{7} \mathrm{H}_{10} \mathrm{~N}_{2}$

$555-96-4$

$\mathrm{H}_{2} \mathrm{NNHCH}_{2} \mathrm{Ph}$
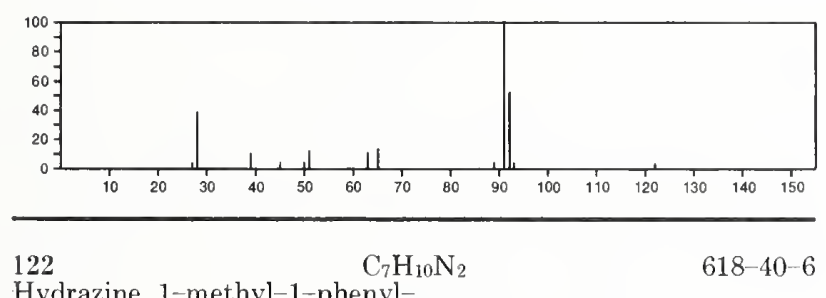

$618-40-6$

Hydrazine, 1-methyl-1-phenyl-

$\mathrm{PhNMe}\left(\mathrm{NH}_{2}\right)$

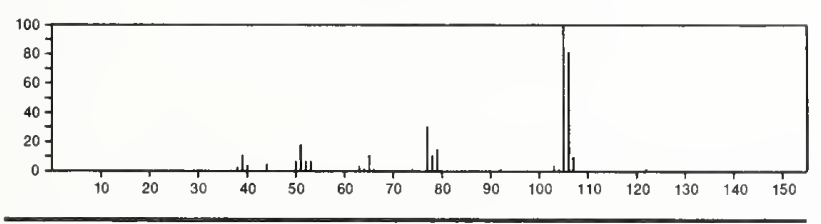

122

Heptanedinitrile

$\mathrm{C}_{7} \mathrm{H}_{10} \mathrm{~N}_{2}$

$646-20-8$

$\mathrm{NC}\left(\mathrm{CH}_{2}\right)_{5} \mathrm{CN}$

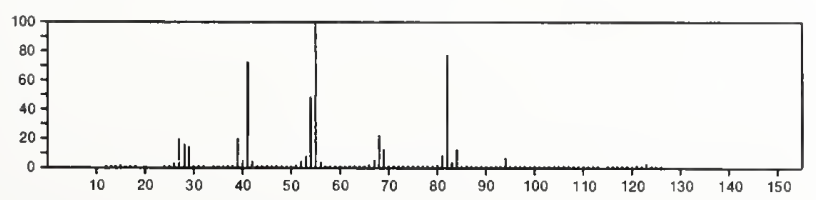

$122 \quad \mathrm{C}_{7} \mathrm{H}_{10} \mathrm{~N}_{2}$

4-Pyridinamine, $N, N$-dimethyl-

$1122-58-3$
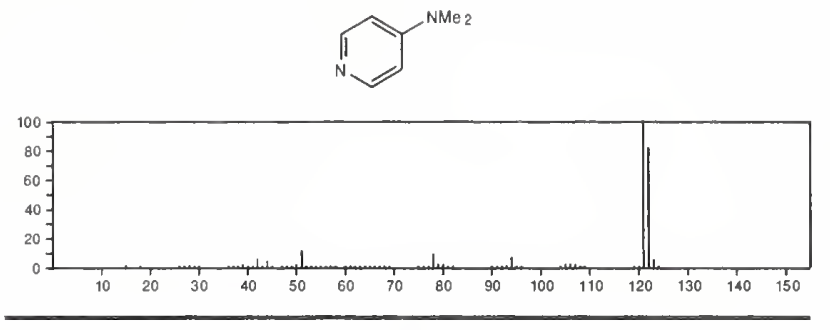

122

$\mathrm{C}_{7} \mathrm{H}_{10} \mathrm{~N}_{2}$

$2305-79-5$

$1 H_{\text {-Indazole, 4,5,6,7-tetrahydro- }}$
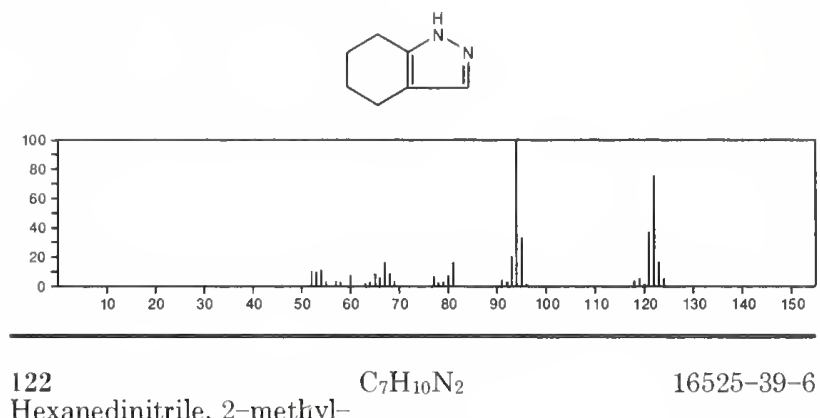

Hexanedinitrile, 2-methyl-

NCCHMe $\left\{\mathrm{CH}_{2}\right\}_{3} \mathrm{CN}$
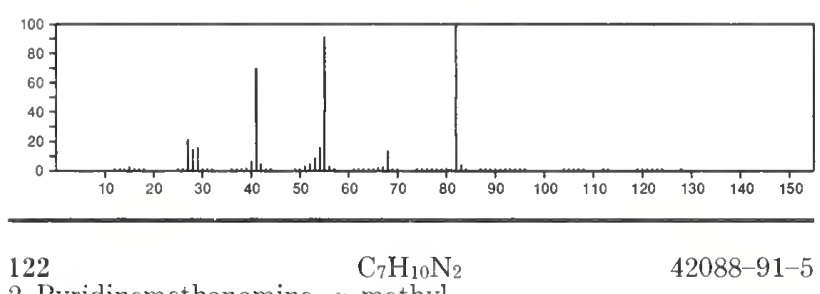

42088-91-5

2-Pyridinemethanamine, $\alpha$-methyl-
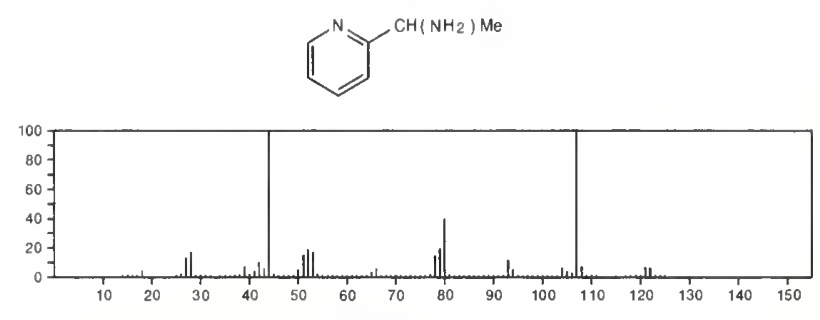

122

$\mathrm{C}_{7} \mathrm{H}_{10} \mathrm{~N}_{2}$

51135-76-3

Pyridinium, 1-amino-2,6-dimethyl-, hydroxide, inner salt
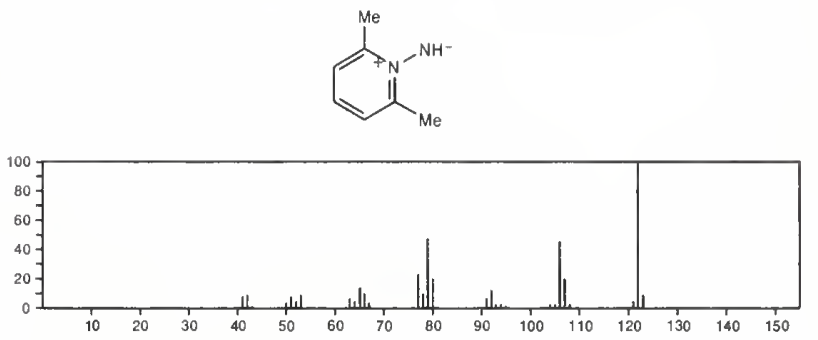
122

Benzene, 1-ethenyl-4-fluoro- ${ }^{-} \mathrm{H}_{7} \mathrm{~F}$
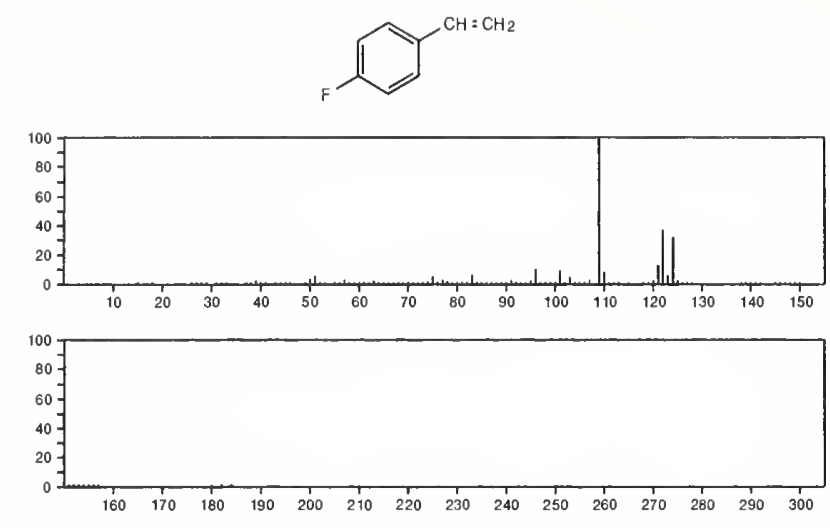

122

Benzeneethanol

$\mathrm{C}_{8} \mathrm{H}_{10} \mathrm{O}$

$60-12-8$

$\mathrm{HOCH}_{2} \mathrm{CH}_{2} \mathrm{Ph}$

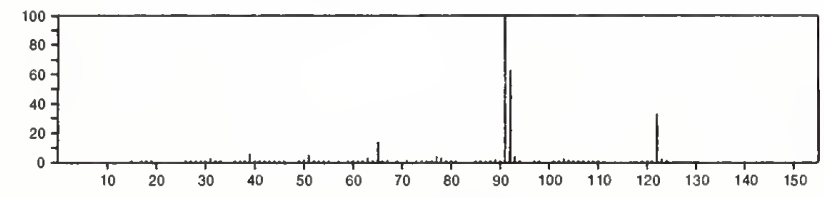

122

$\mathrm{C}_{8} \mathrm{H}_{10} \mathrm{O}$

89-95-2

Benzenemethanol, 2-methyl-<smiles>Nc1ccccc1C=O</smiles>

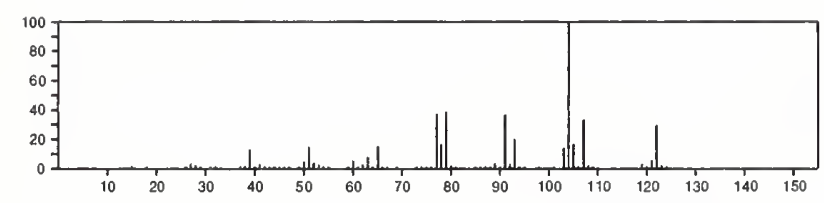

122

Phenol, 2-ethyl-

$\mathrm{C}_{8} \mathrm{H}_{10} \mathrm{O}$

90-00-6
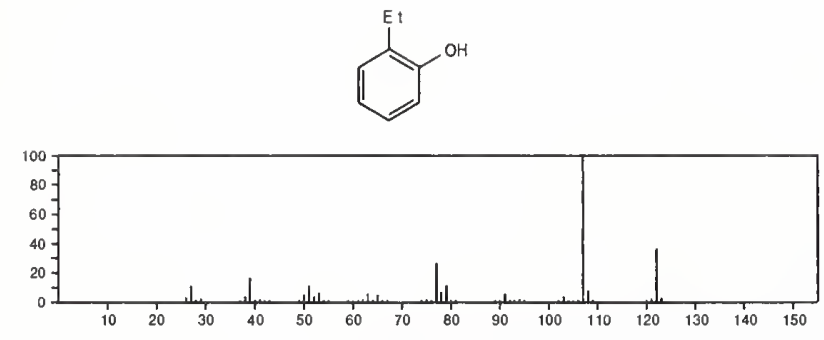

122

Phenol, 3,4-dimethyl-

$$
\mathrm{C}_{8} \mathrm{H}_{10} \mathrm{O}
$$

$95-65-8$
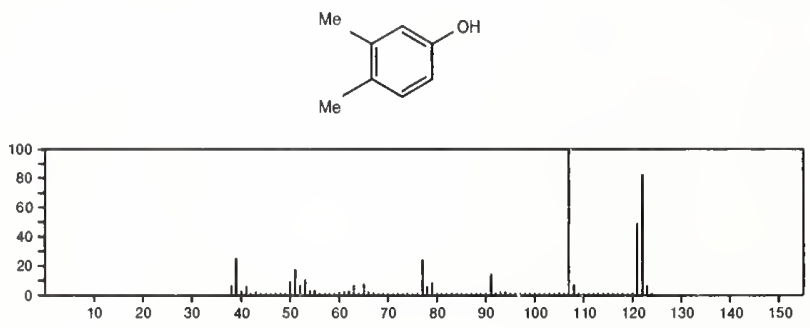

122

$\mathrm{C}_{8} \mathrm{H}_{10} \mathrm{O}$

$95-87-4$

Phenul, 2,5-dimethyl-
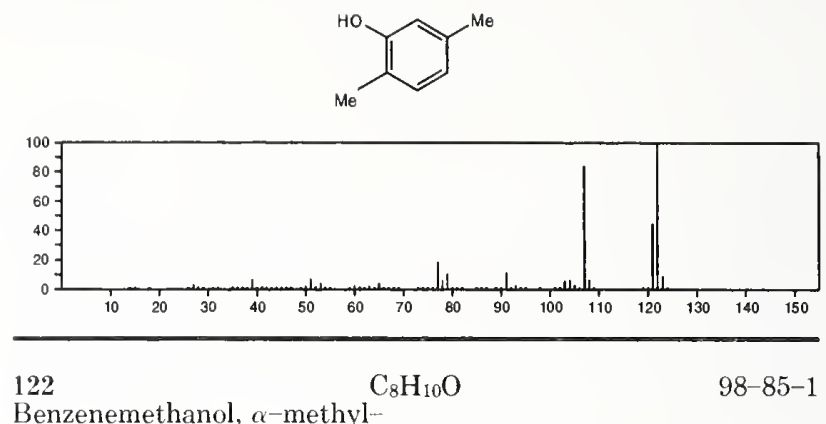

Benzenemethanol, $\alpha$-methyl

PhCHMe (OH)

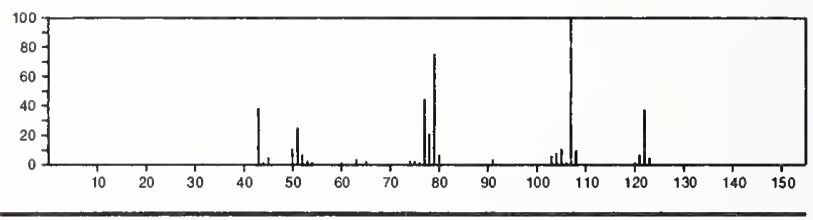

122

$\mathrm{C}_{8} \mathrm{H}_{10} \mathrm{O}$

$100-84-5$

Benzene, 1-methoxy-3-methyl-
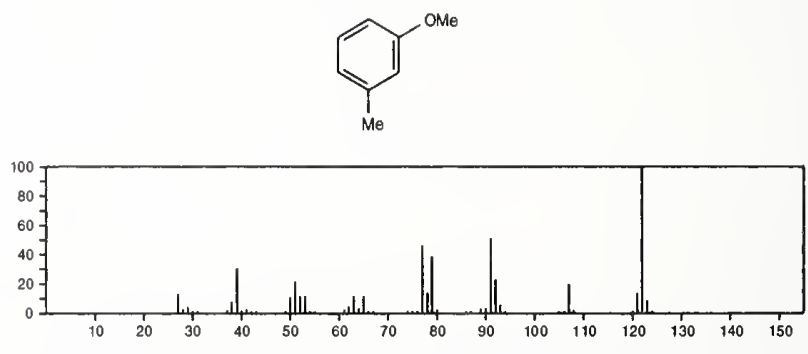

122

$\mathrm{C}_{8} \mathrm{H}_{10} \mathrm{O}$

103-73-1

Benzene, ethoxy

EtOPh

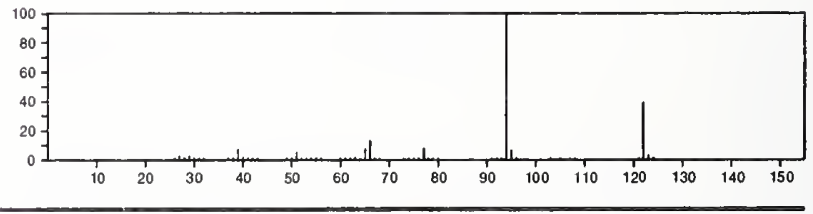

122

$\mathrm{C}_{8} \mathrm{H}_{10} \mathrm{O}$

104-93-8

Benzene, 1-methoxy-4-methyl-
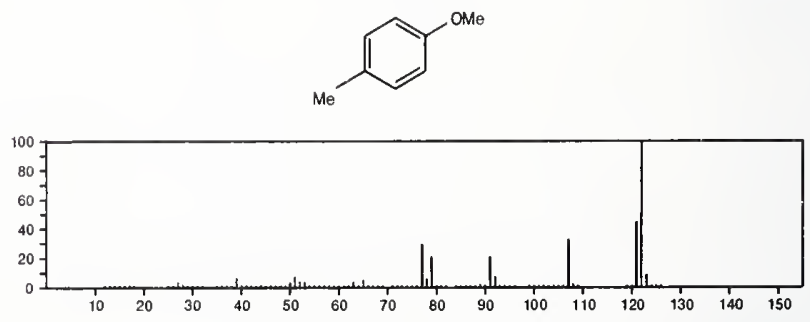
122

Phenol, 2,4-dimethyl-

$\mathrm{C}_{8} \mathrm{H}_{10} \mathrm{O}$
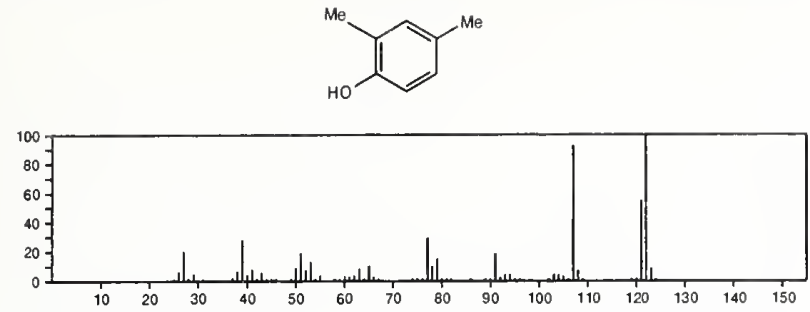

122

Phenol, 3,5-dimethyl-

$$
\mathrm{C}_{8} \mathrm{H}_{10} \mathrm{O}
$$

$108-68-9$
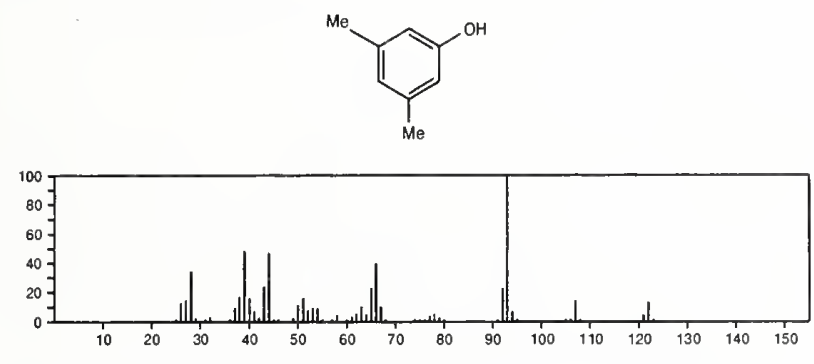

122

Phenol, 4-ethyl-

$$
\mathrm{C}_{8} \mathrm{H}_{10} \mathrm{O}
$$

123-07-9
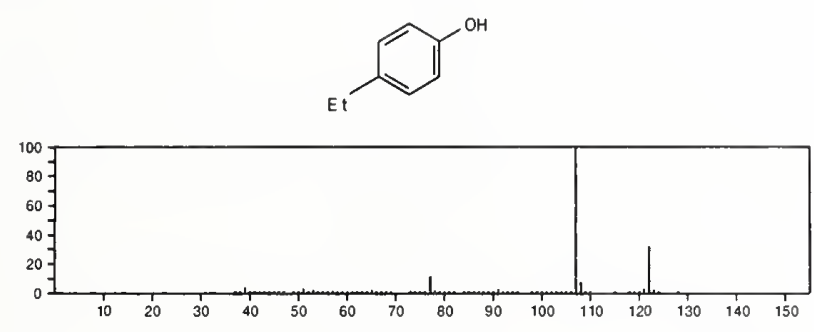

122

Phenol, 2,3-dimethyl-

$$
\mathrm{C}_{8} \mathrm{H}_{10} \mathrm{O}
$$

526-75-0
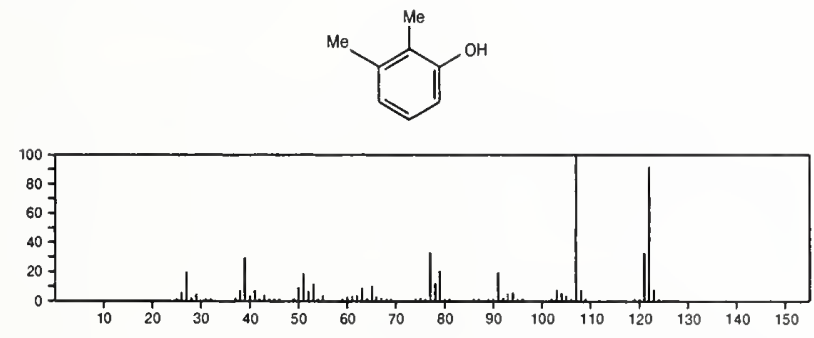

122

Benzene, (methoxymethyl)-

$$
\mathrm{C}_{8} \mathrm{H}_{10} \mathrm{O}
$$

$\mathrm{Me} \mathrm{OCH}_{2} \mathrm{Ph}$

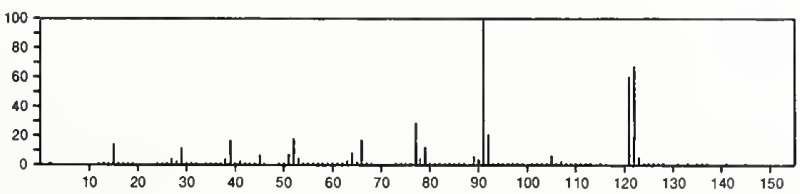

122

Phenol, 2,6-dimethyl-

$\mathrm{C}_{8} \mathrm{H}_{10} \mathrm{O}$

$576-26-1$
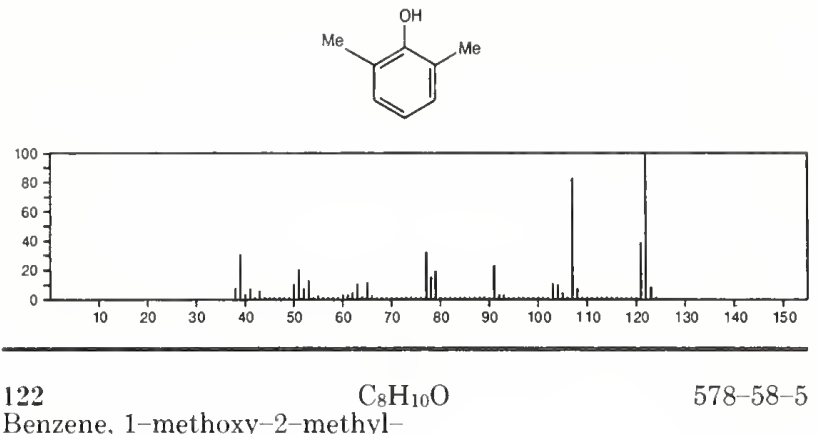

Benzene, 1-methoxy-2-methyl-
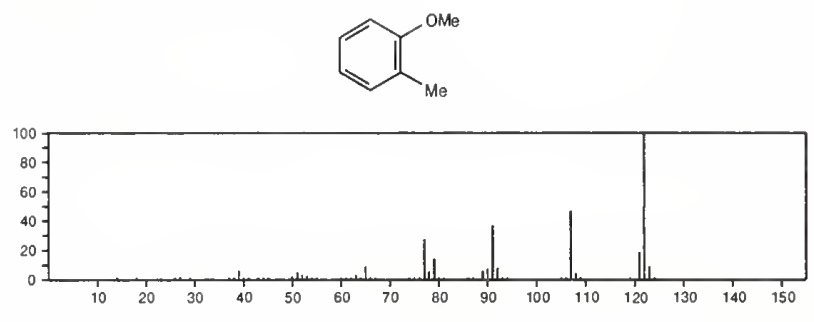

122

$\mathrm{C}_{8} \mathrm{H}_{10} \mathrm{O}$

589-18-4

Benzenemethanol, 4-méthyl-
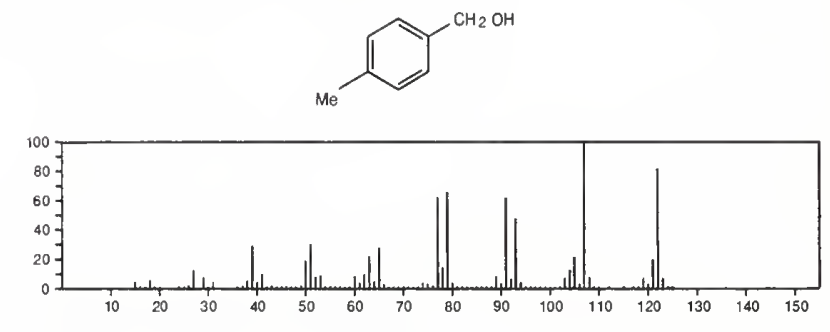

122

Phenol, 3-ethyl-

$\mathrm{C}_{8} \mathrm{H}_{10} \mathrm{O}$

620-17-7
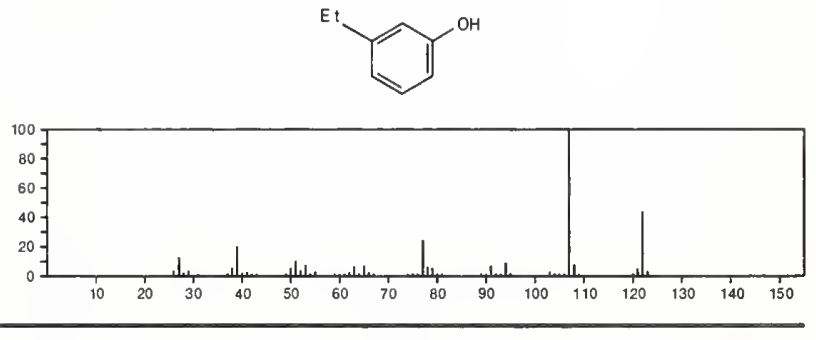

122

$2220-40-8$

Bicyclo[2.2.2]oct-5-en-2-one
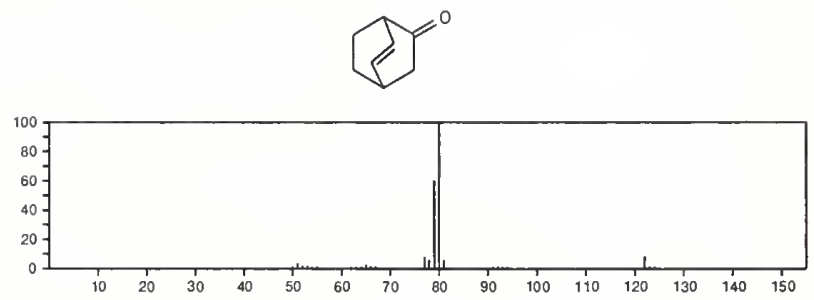
122

$\mathrm{C}_{8} \mathrm{H}_{10} \mathrm{O}$

Tricyclo[4.2.0.02,4]octan-5-one, $(1 \alpha, 2 \beta, 4 \beta, 6 \mathbf{a})$
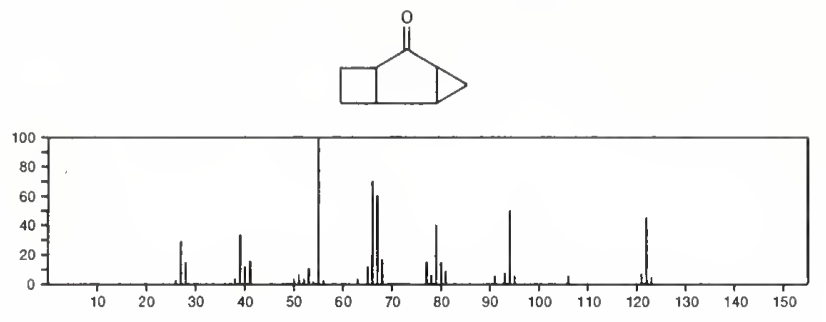

$122 \quad \mathrm{C}_{8} \mathrm{H}_{10} \mathrm{O} \quad 19093-14-2$

Tricyclo[4.2.0.02,4 $]$ octan-5-one
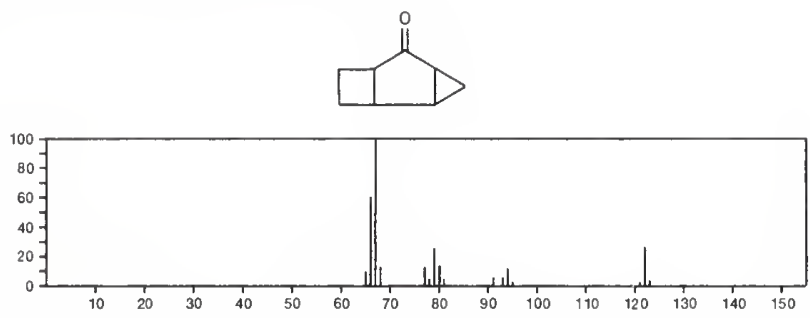

$122 \quad \mathrm{C}_{9} \mathrm{H}_{14}$

Bicyclo[2.2.1]hept-2-ene, 2,3-dimethyl-
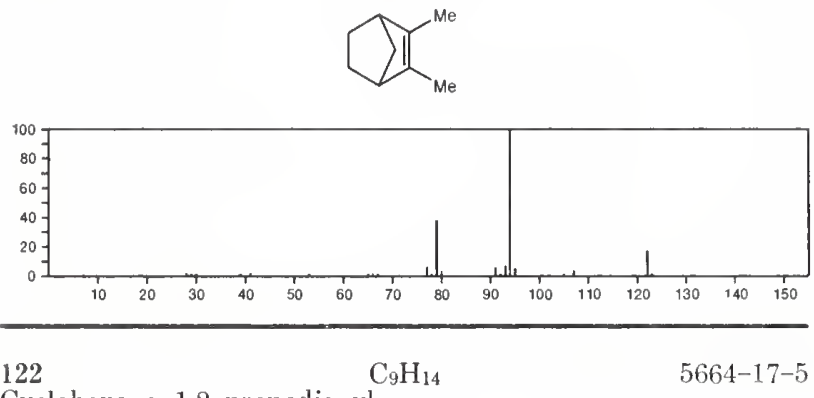

Cyclohexane, 1,2-propadienyl-
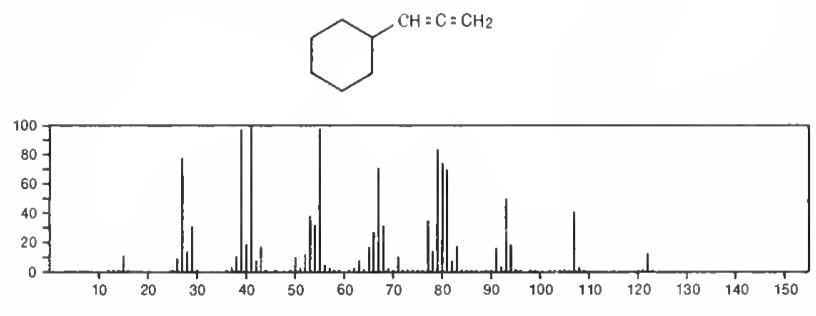

$122 \quad \mathrm{C}_{9} \mathrm{H}_{14}$

Cyclobutane, 1,2-diethenyl-3-methyl-
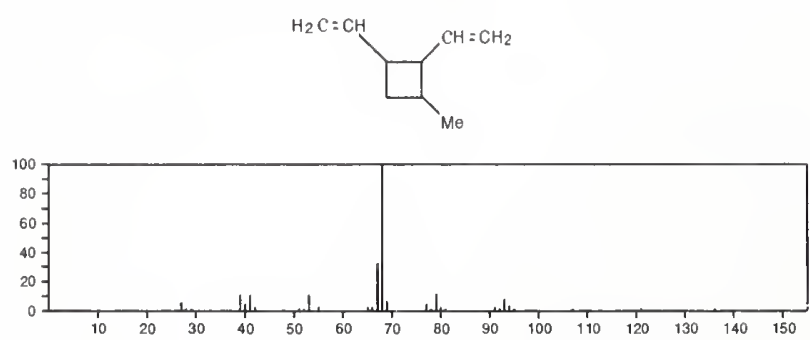

122

$\mathrm{C}_{9} \mathrm{H}_{14}$

Bicyclo[3.1.0]hexane, 6-isopropylidene-

$24524-58-1$
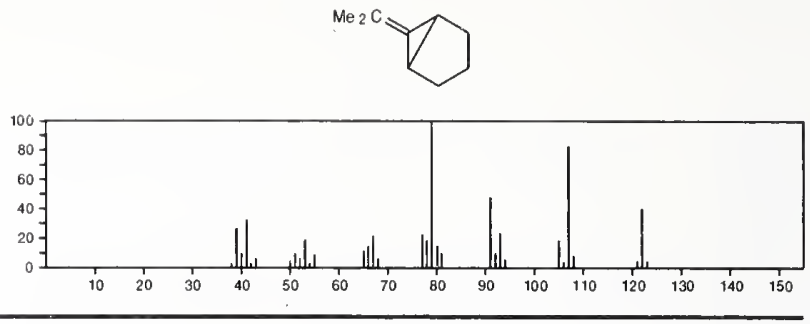

122

$\mathrm{CrF}_{2} \mathrm{O}_{2}$

$7788-96-7$

Chromium, difluorodioxo-

$0=\mathrm{CrF}_{2}=0$

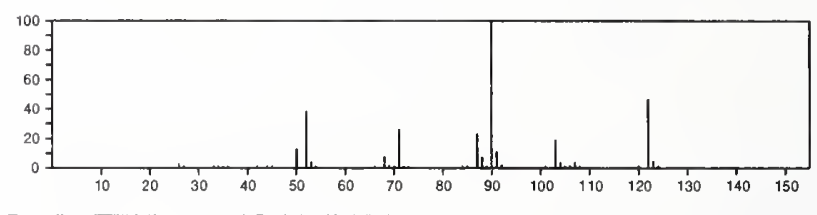

$123 \quad \mathrm{C}_{3} \mathrm{H}_{9} \mathrm{NO}_{2} \mathrm{~S}$

Methanesulfonamide, $N, N$-dimethyl-

918-05-8

$\mathrm{Me}_{2} \mathrm{NSO}_{2} \mathrm{Me}$

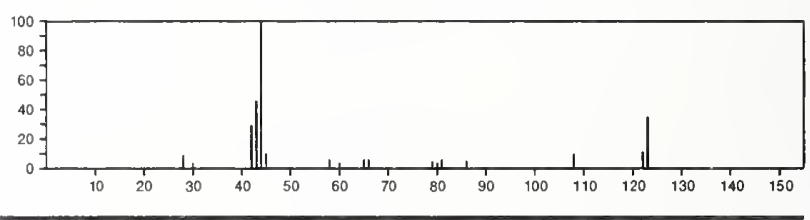

123

$\mathrm{C}_{3} \mathrm{H}_{12} \mathrm{~B}_{3} \mathrm{~N}_{3}$

1004-35-9

Borazine, 1,3,5-trimethyl
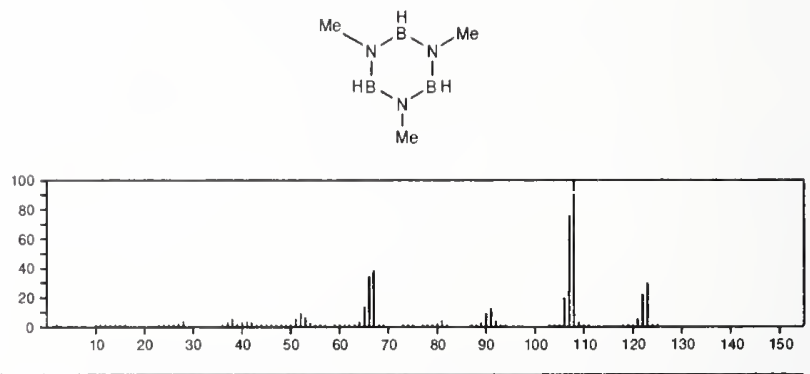

123

$\mathrm{C}_{3} \mathrm{H}_{12} \mathrm{~B}_{3} \mathrm{~N}_{3}$

5314-85-2

Borazine, 2,4,6-trimethyl-
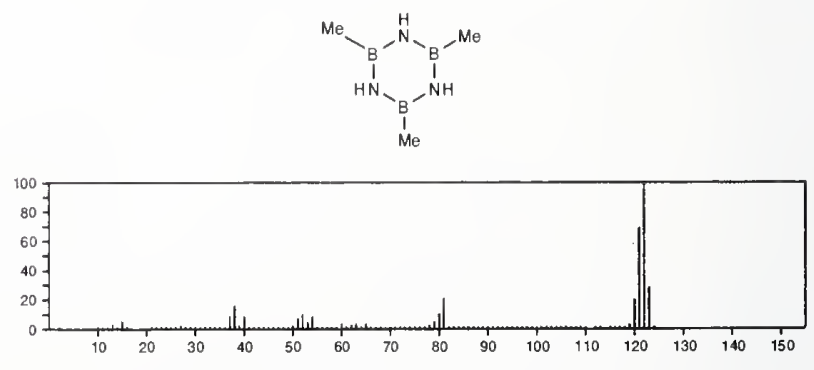

123

Butyronitrile, 4,4,4-trifluoro-

$\mathrm{C}_{4} \mathrm{H}_{4} \mathrm{~F}_{3} \mathrm{~N}$

690-95-9

$\mathrm{NCCH}_{2} \mathrm{CH}_{2} \mathrm{CF}_{3}$

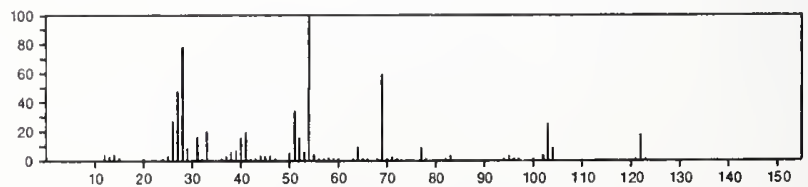


123

4-Pyridinecarboxylic acid

$\mathrm{C}_{6} \mathrm{H}_{5} \mathrm{NO}_{2}$
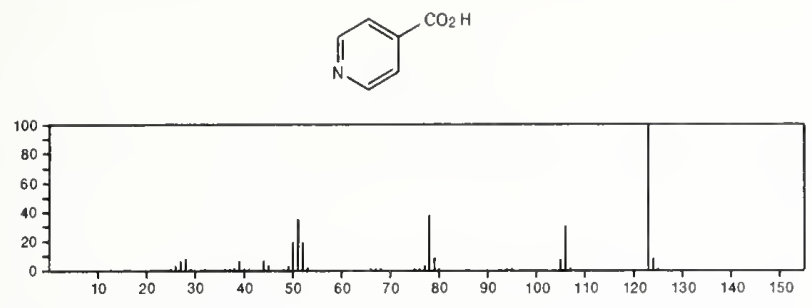

123

3-Pyridinecarboxylic acid

$\mathrm{C}_{6} \mathrm{H}_{5} \mathrm{NO}_{2}$

$59-67-6$
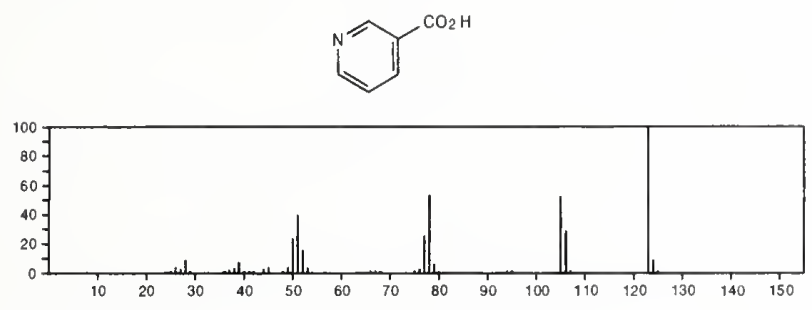

123

Benzene, nitro

$\mathrm{C}_{6} \mathrm{H}_{5} \mathrm{NO}_{2}$

98-95-3

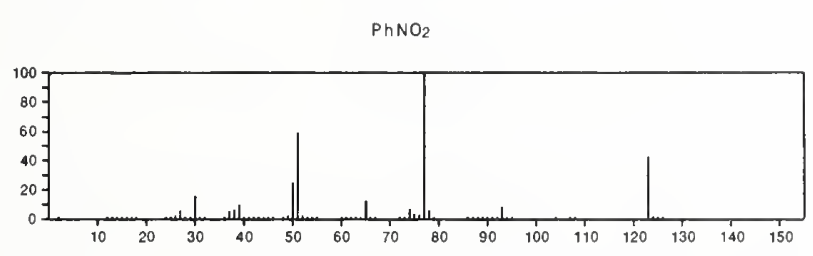

123

2-Pyridinecarboxylic acid

$\mathrm{C}_{6} \mathrm{H}_{5} \mathrm{NO}_{2}$
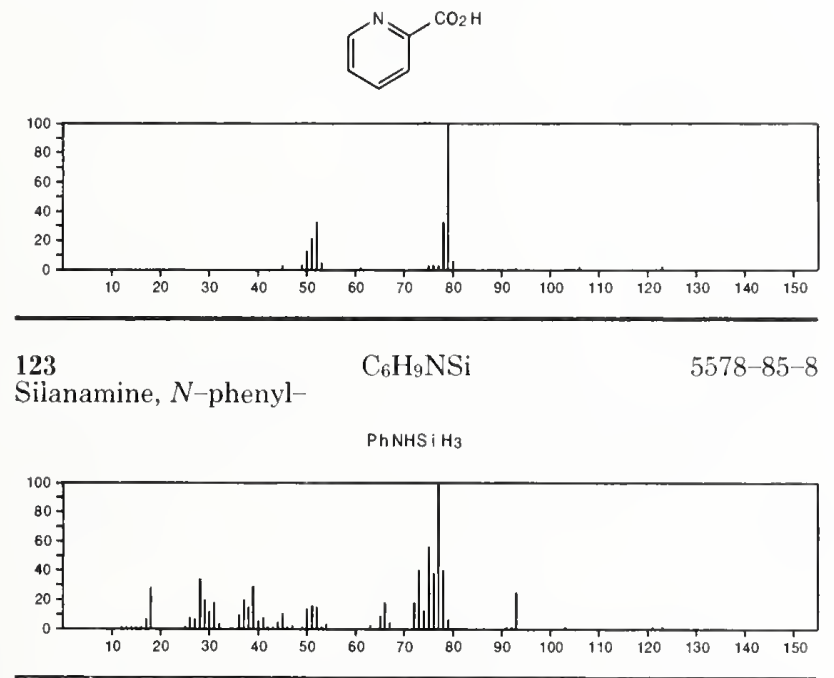

123

$\mathrm{C}_{6} \mathrm{H}_{9} \mathrm{~N}_{3}$

111-94-4

Propanenitrile, 3,3'-iminobis-

$\mathrm{NCCH}_{2} \mathrm{CH}_{2} \mathrm{NHCH}_{2} \mathrm{CH}_{2} \mathrm{CN}$

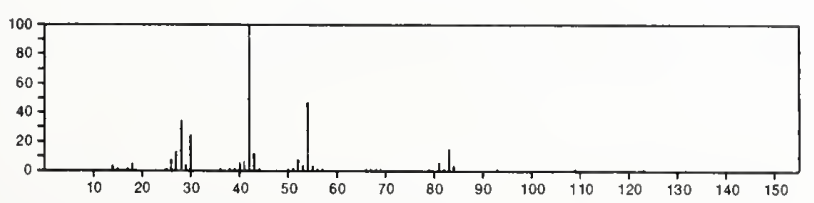

123

4 Pyrimidinamine, 2,6-dimethyl

$461-98-3$
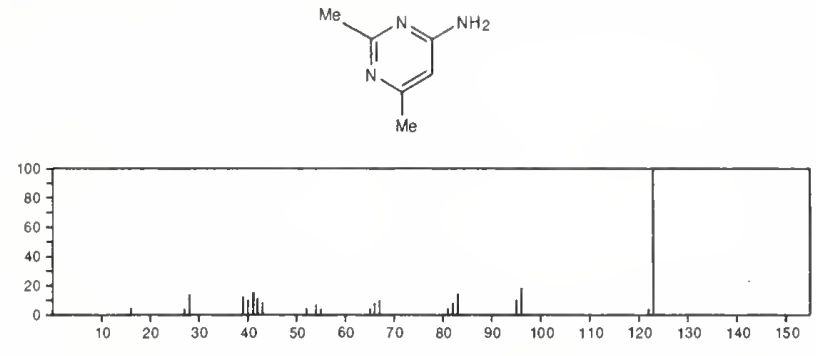

123

$\mathrm{C}_{6} \mathrm{H}_{9} \mathrm{~N}_{3}$

$767-15-7$

2-Pyrimidinamine, 4,6-dimethyl-<smiles>Nc1cc(N)nc(N)n1</smiles>

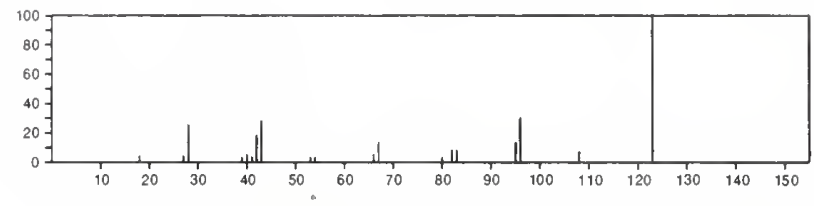

123

Benzenamine, 2-methoxy-

$\mathrm{C}_{7} \mathrm{H}_{9} \mathrm{NO}$

90-04-0<smiles>COc1ccccc1N</smiles>

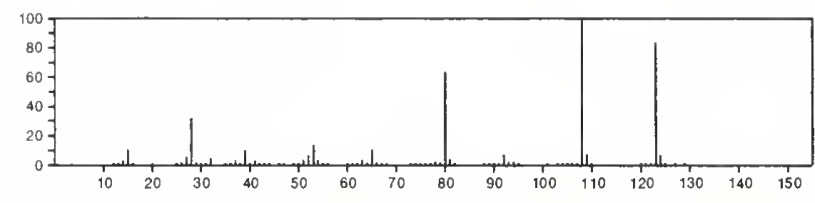

123

2-Pyridineethanol

$\mathrm{C}_{7} \mathrm{H}_{9} \mathrm{NO}$

103-74-2
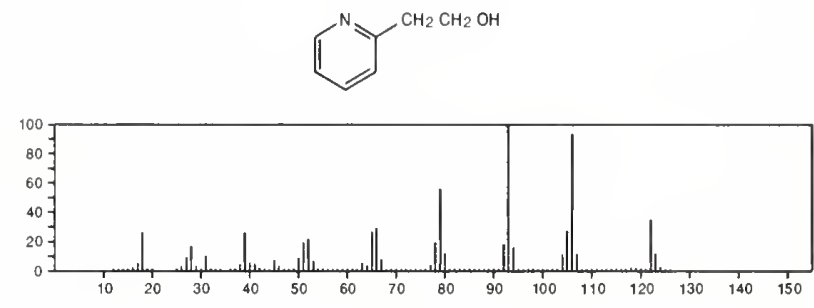

123

$\mathrm{C}_{7} \mathrm{H}_{9} \mathrm{NO}$

104-94-9

Benzenamine, 4-methoxy-
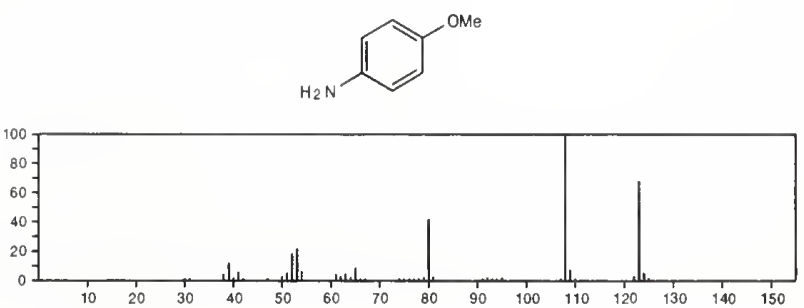
204

EPA/NIH MASS SPECTRAL DATA BASE

123

123

Benzenamine, 3-methoxy-
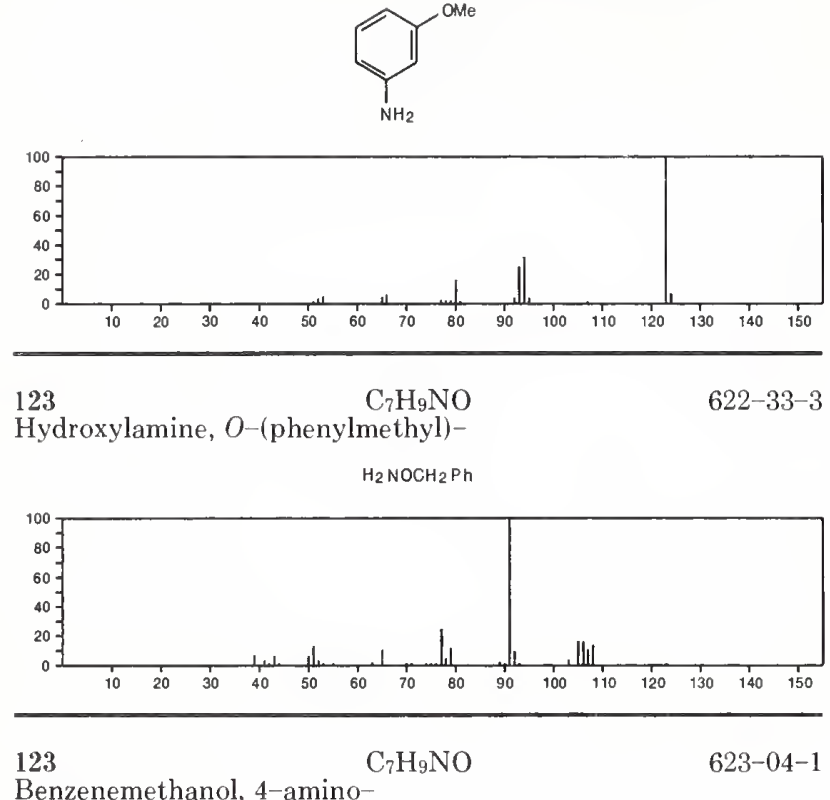

Benzenemethanol, 4-amino--
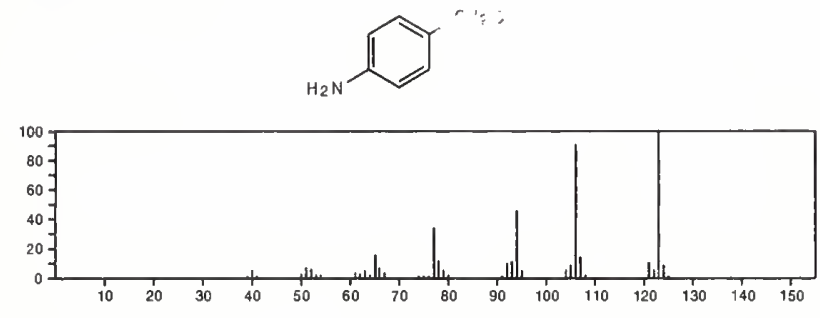

123

$\mathrm{C}_{7} \mathrm{H}_{9} \mathrm{NO}$

$1877-77-6$

Benzenemethanol, 3-amino-
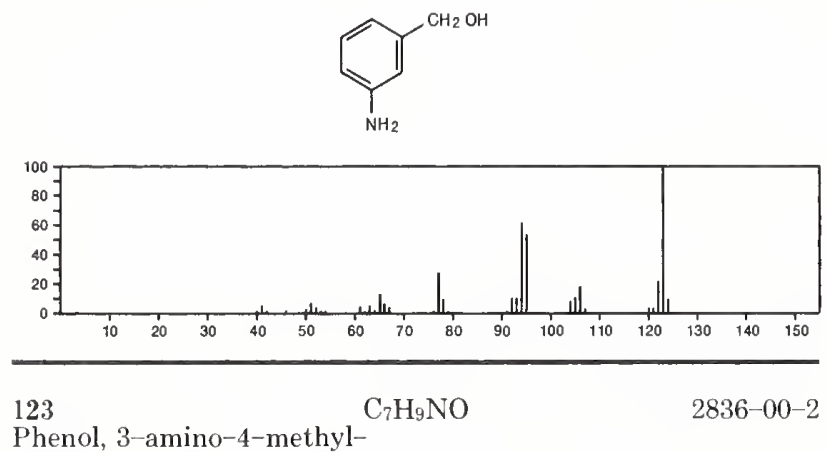

Phenol, 3-amino-4-methyl-
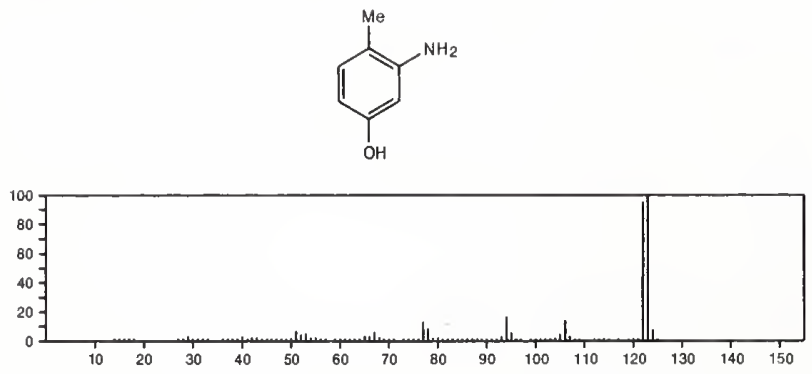

123
Pyridine, 2-ethyl--, 1-oxide

$4833-24-3$
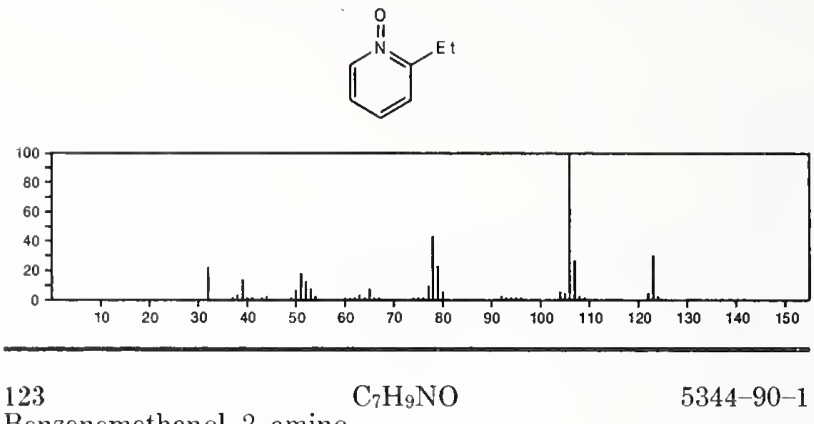

Benzenemethanol, 2-amino-
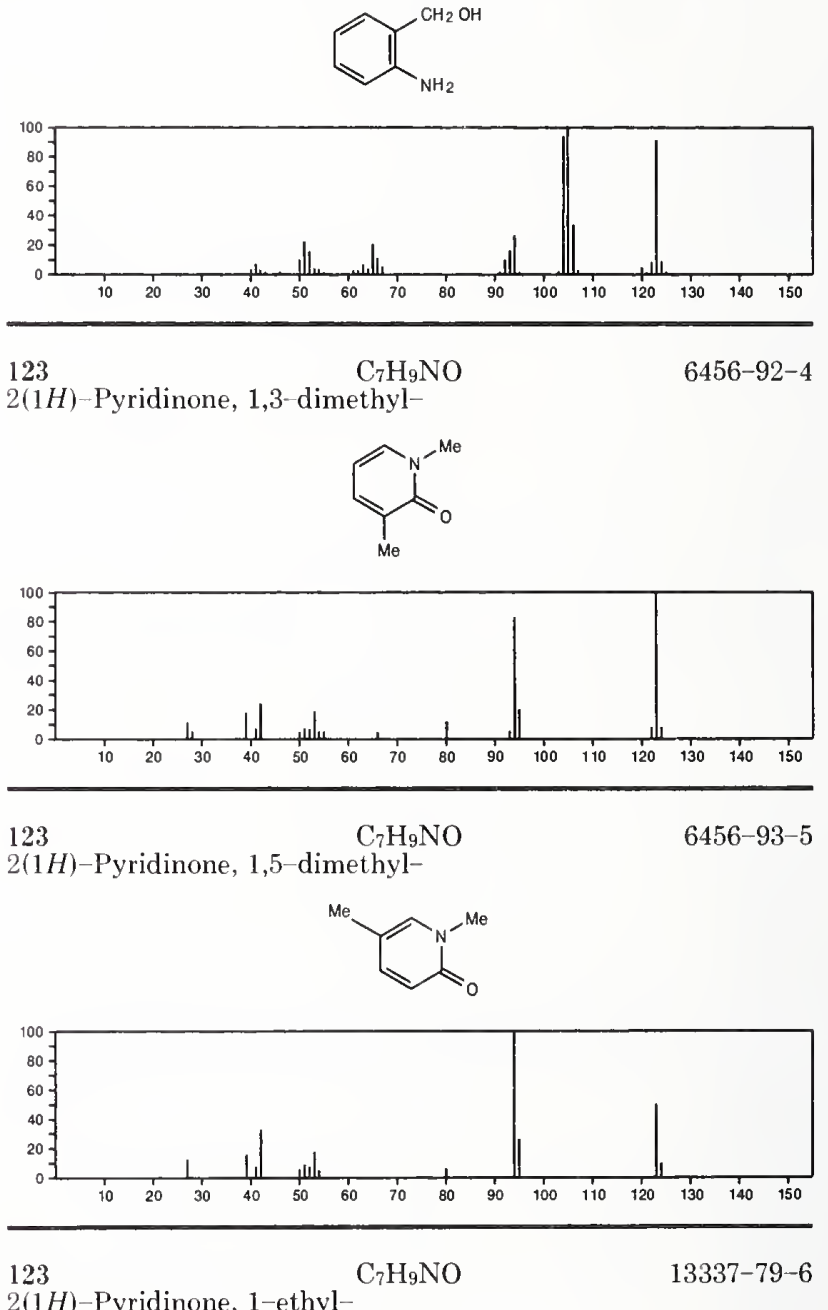

2(1H)-Pyridinone, 1-ethyl-
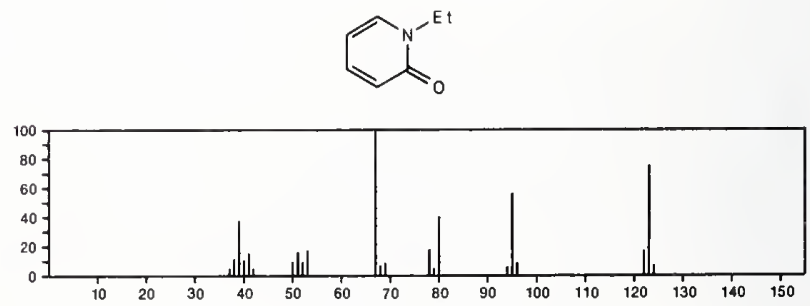
123

Pyridine, 4-ethyl-, 1-oxide
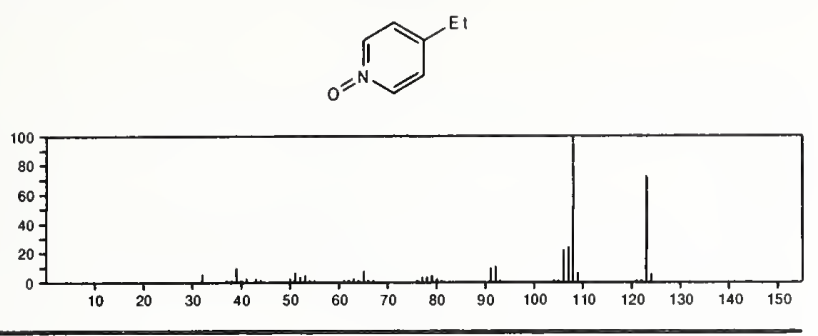

123

Pyridine, 3-ethyl-, 1-oxide

\section{$\mathrm{C}_{7} \mathrm{H}_{9} \mathrm{NO}$}
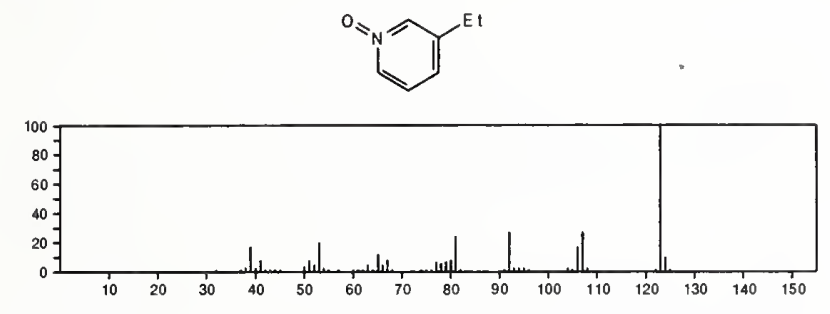

123

2(1H)-Pyridinone, 1,4-dimethyl-

$15031-42-2$

$\mathrm{C}_{7} \mathrm{H}_{9} \mathrm{NO}$
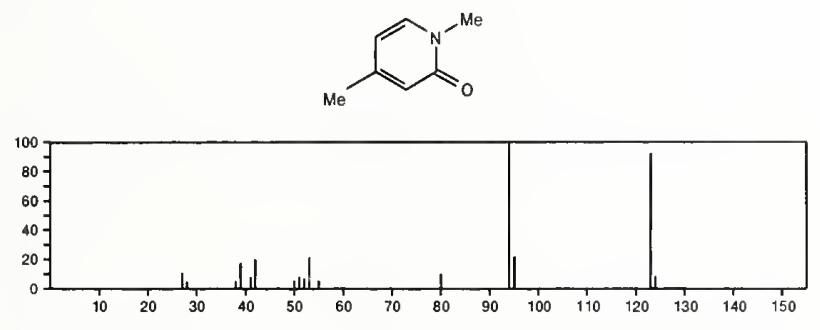

$123 \quad \mathrm{C}_{7} \mathrm{H}_{9} \mathrm{NO}$

$15031-43-3$

2(1H)-Pyridinone, 1,6-dimethyl-
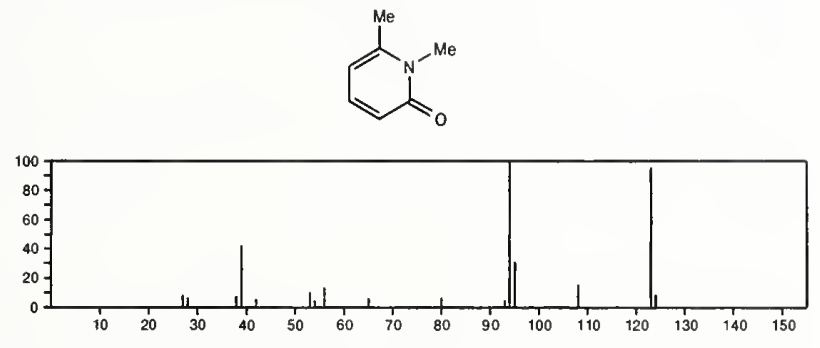

$123 \quad \mathrm{C}_{8} \mathrm{H}_{13} \mathrm{~N}$

1H-Pyrrole, 3-ethyl-2,4-dimethyl-
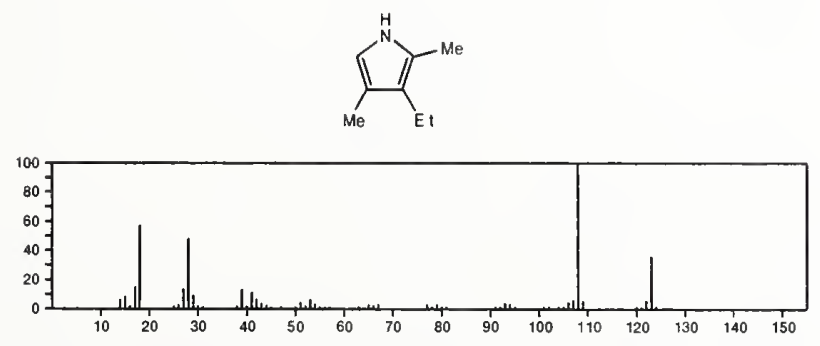

123

1H-Pyrrole, 1-butyl

$\mathrm{C}_{8} \mathrm{H}_{13} \mathrm{~N}$

589-33-3
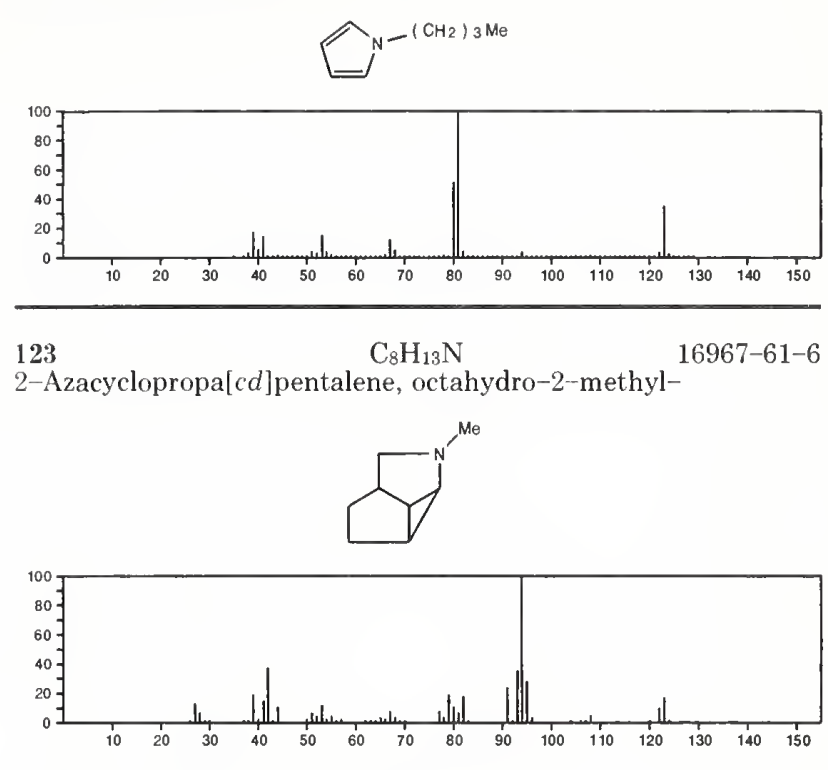

124

$\mathrm{B}_{10} \mathrm{H}_{14}$

Decaborane(14)

17702-41-9
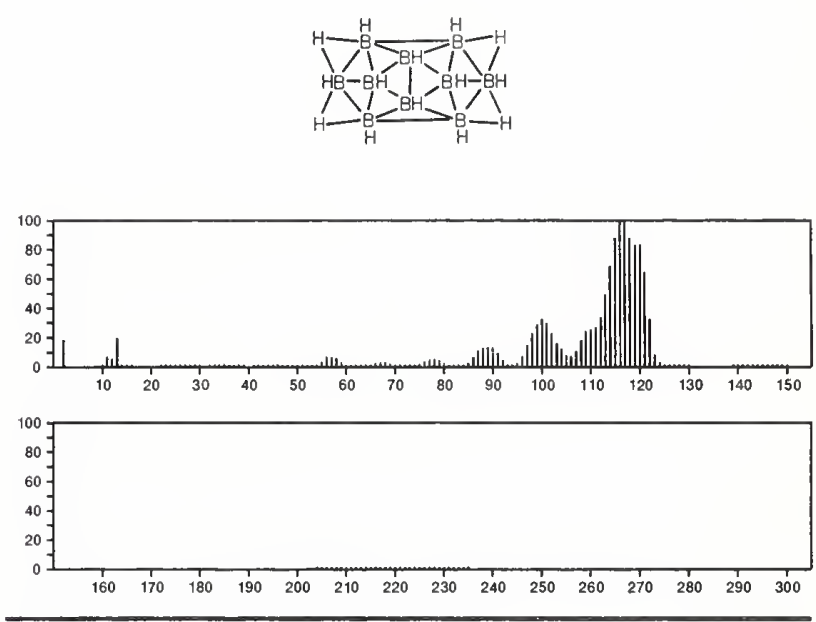

124

Silane, (bromomethyl)-

$\mathrm{CH}_{5} \mathrm{BrSi}$

7570-21-0

$\mathrm{BrCH}_{2} \mathrm{SiH}_{3}$

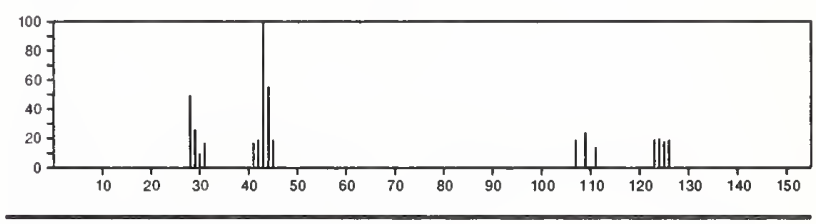

124

1,2,4-Trithiolane

$\mathrm{C}_{2} \mathrm{H}_{4} \mathrm{~S}_{3}$

289-16-7
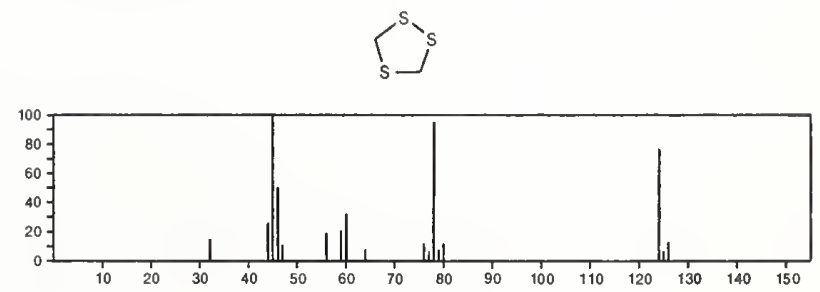
124

Ethanol, 2-bromo-

$\mathrm{C}_{2} \mathrm{H}_{5} \mathrm{BrO}$

$\mathrm{HOCH}_{2} \mathrm{CH}_{2} \mathrm{Br}$

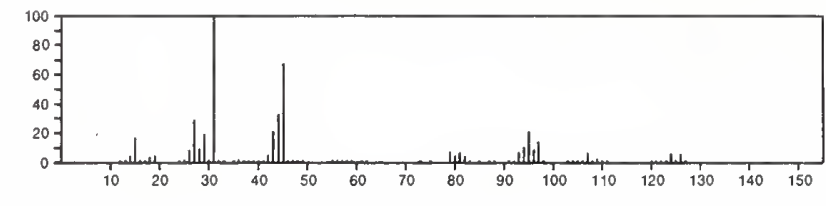

124

5,6-Dicarbadecaborane(12)

$\mathrm{C}_{2} \mathrm{H}_{12} \mathrm{~B}_{8}$

41655-26-9
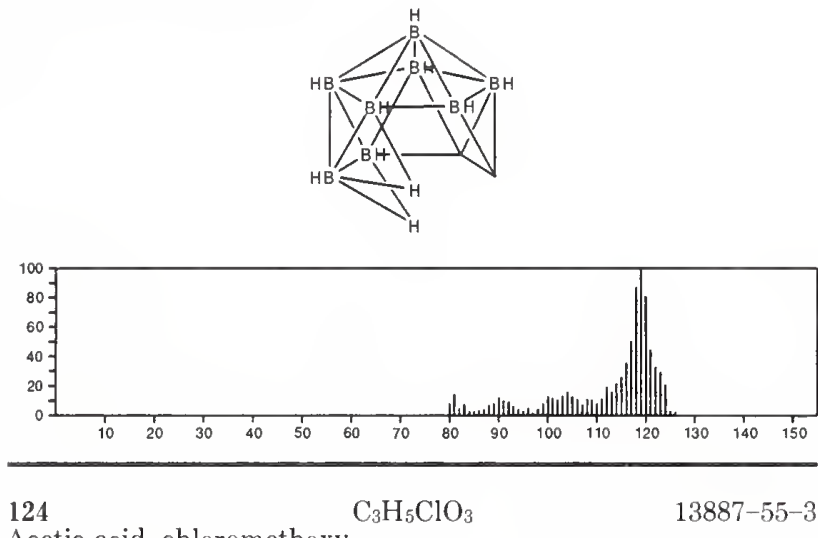

$13887-55-3$

Acetic acid, chloromethoxy-

$\mathrm{Cl} \mathrm{CH}$ ( OMe $) \mathrm{CO}_{2} \mathrm{H}$

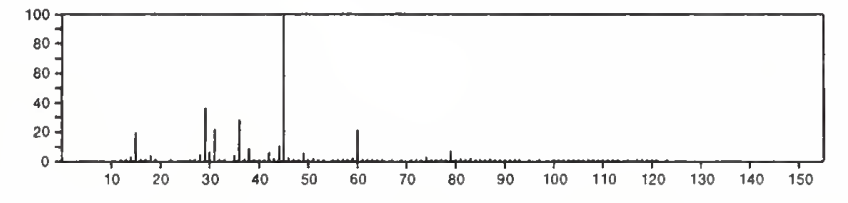

124

1-Butene, 3,4-dichloro-

$\mathrm{C}_{4} \mathrm{H}_{6} \mathrm{Cl}_{2}$

$760-23-6$

$\mathrm{H}_{2} \mathrm{C}=\mathrm{CHCHCl} \mathrm{CH} \mathrm{Cl}_{2}$

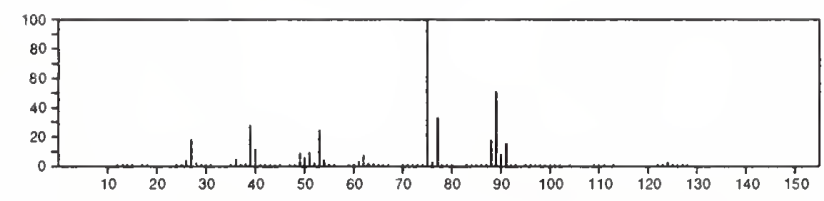

124

$\mathrm{C}_{4} \mathrm{H}_{6} \mathrm{Cl}_{2}$

$764-41-0$

2-Butene, 1,4-dichloro-

$\mathrm{Cl} \mathrm{CH}_{2} \mathrm{CH}=\mathrm{CHCH}_{2} \mathrm{Cl}$

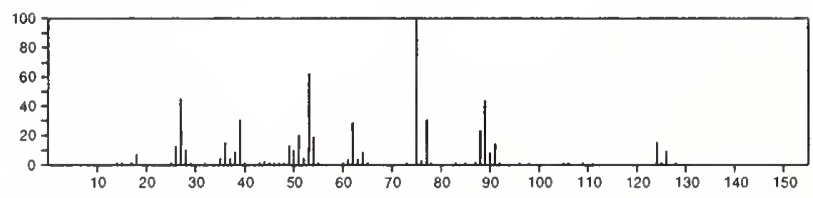

124

Cyclobutane, 1,1-dichloro-

$\mathrm{C}_{4} \mathrm{H}_{6} \mathrm{Cl}_{2}$

$1506-77-0$
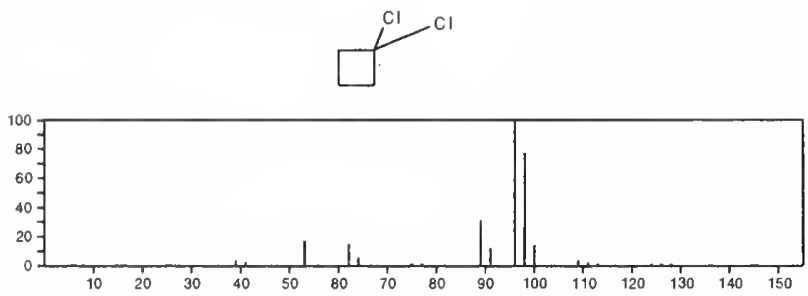

124

$\mathrm{C}_{4} \mathrm{H}_{6} \mathrm{Cl}_{2}$

$1871-57-4$
$\underset{\mathrm{Ci} \mathrm{CH}}{\stackrel{\mathrm{II}}{\mathrm{CC}_{2}}}$

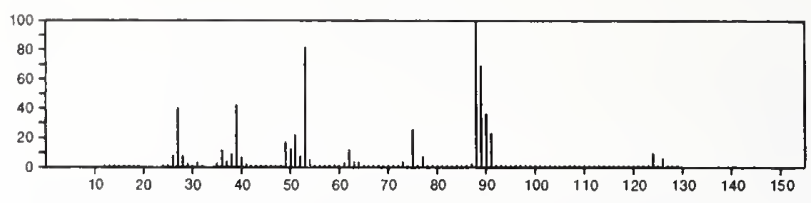

124

2-Butene, 2,3-dichloro-

$\mathrm{C}_{4} \mathrm{H}_{6} \mathrm{Cl}_{2}$

4279-21-4

$\mathrm{MeCCI}=\mathrm{CCIMe}$

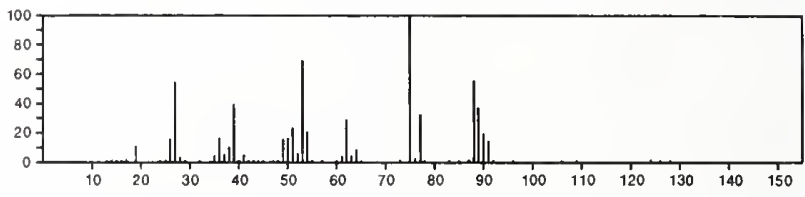

124

1-Butene, 1,4-dichloro

$\mathrm{C}_{4} \mathrm{H}_{6} \mathrm{Cl}_{2}$

13676-58-9

$\mathrm{Cl} \mathrm{CH}=\mathrm{CHCH}_{2} \mathrm{CH}_{2} \mathrm{Cl}$

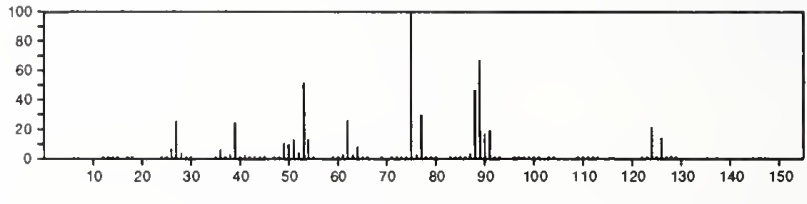

124

Cyclobutane, 1,2-dichloro-

$\mathrm{C}_{4} \mathrm{H}_{6} \mathrm{Cl}_{2}$

$17437-39-7$
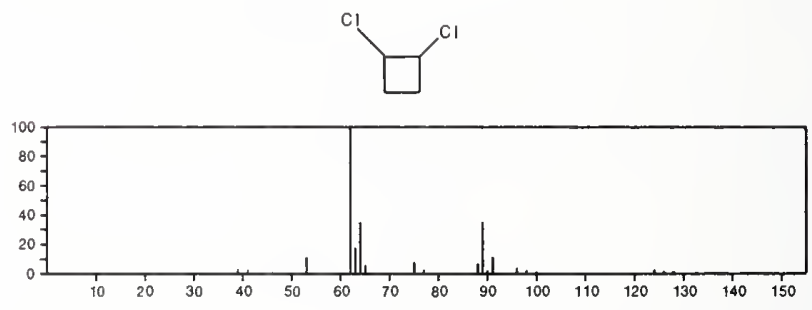

124

Cyclobutane, 1,3-dichloro

$\mathrm{C}_{4} \mathrm{H}_{6} \mathrm{Cl}_{2}$

$55887-82-6$
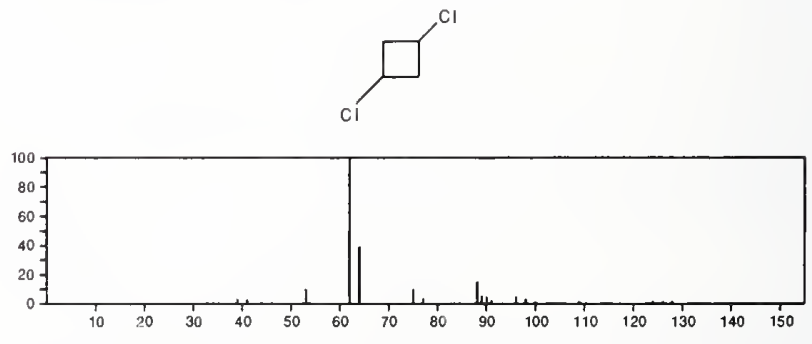

124

$\mathrm{C}_{4} \mathrm{H}_{6} \mathrm{~F}_{2} \mathrm{O}_{2}$

Acetic acid, difluoro-, ethyl ester

$454-31-9$

$\mathrm{EtOC}(\mathrm{O}) \mathrm{CHF}_{2}$

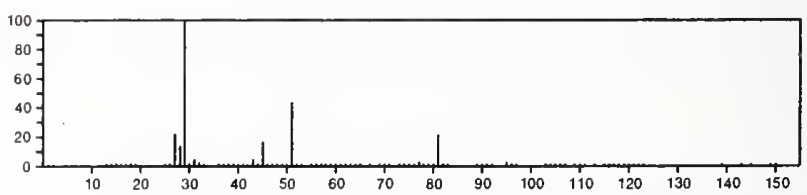




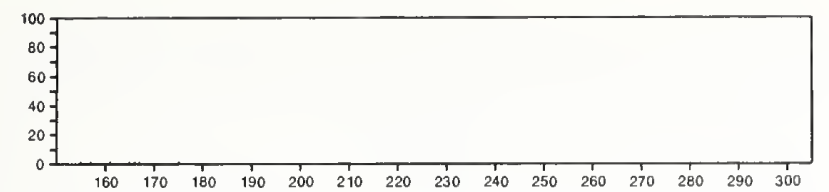

${ }_{1,3-\text {-Dioxane, 5,5-difluoro- }} \mathrm{C}_{4} \mathrm{H}_{6} \mathrm{~F}_{2} \mathrm{O}_{2} \quad 36301-44-7$<smiles>FC1(F)COCOC1</smiles>

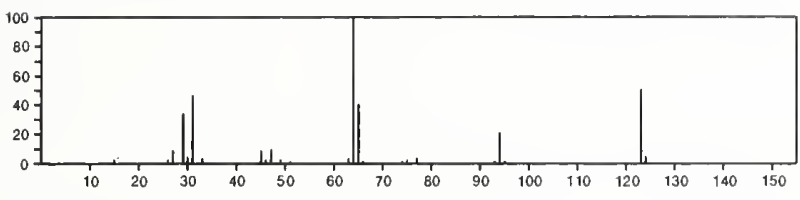

\section{$124 \quad \mathrm{C}_{4} \mathrm{H}_{9} \mathrm{ClO}_{2}$}

$97-97-2$

Ethane, 2-chloro-1,1-dimethoxy-

$\mathrm{ClCH}_{2} \mathrm{CH}$ ( OMe ) 2
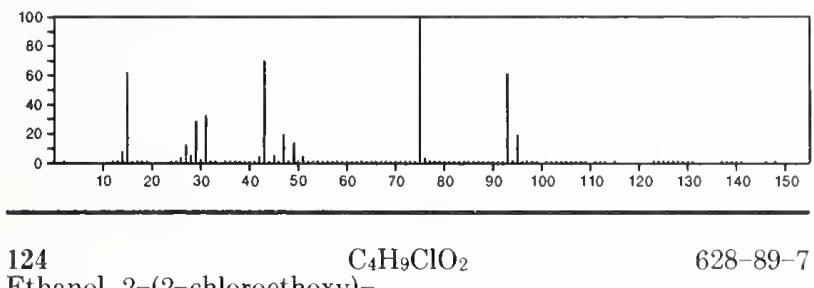

Ethanol, 2-(2-chloroethoxy)-

$\mathrm{Cl} \mathrm{CH}_{2} \mathrm{CH}_{2} \mathrm{OCH}_{2} \mathrm{CH}_{2} \mathrm{OH}$

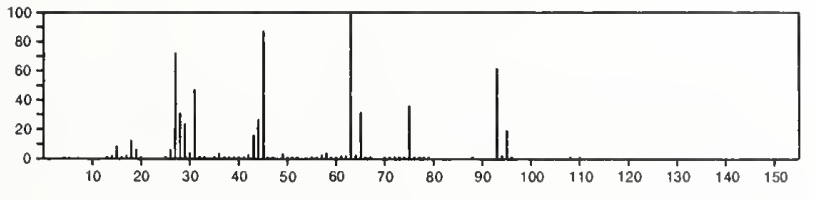

$\mathrm{C}_{4} \mathrm{H}_{12} \mathrm{~N}_{2} . \mathrm{ClH}$

124

Hydrazine, (1,1-dimethylethyl)-, monohydrochloride

$7400-27-3$

$\mathrm{H}_{2} \mathrm{NNHBu}^{-\dagger} \cdot \mathrm{HC}$

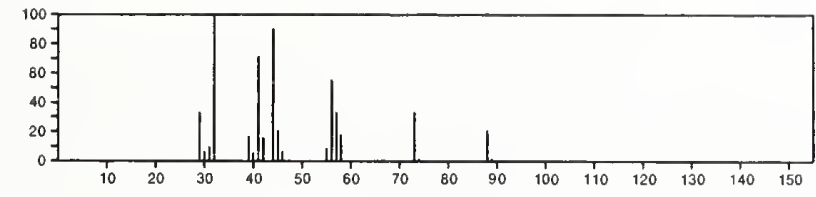

124

$\mathrm{C}_{5} \mathrm{H}_{8} \mathrm{~N}_{4}$

$7465-48-7$

Tetrazolo[1,5-a]pyridine, 5,6,7,8-tetrahydro-<smiles>C1CCn2nnnc2C1</smiles>

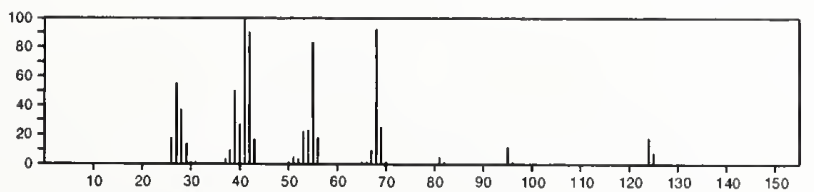

124

$\mathrm{C}_{5} \mathrm{H}_{8} \mathrm{~N}_{4}$

Pyrimidine, 4,5-diamino-6-methyl
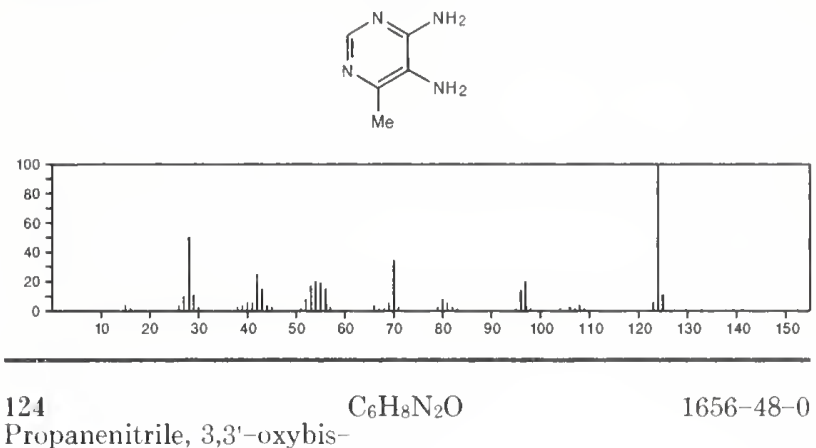

Propanenitrile, 3,3'-oxybis-

$\mathrm{NCCH}_{2} \mathrm{CH}_{2} \mathrm{OCH}_{2} \mathrm{CH}_{2} \mathrm{CN}$

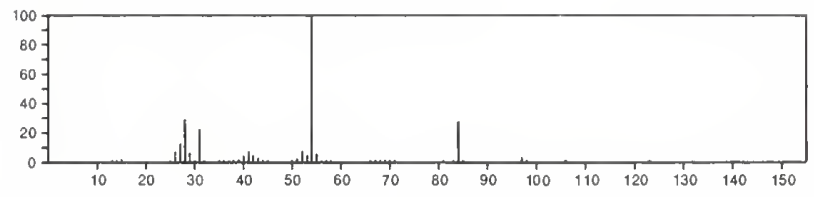

$121 \quad \mathrm{C}_{6} \mathrm{H}_{8} \mathrm{~N}_{2} \mathrm{O}$

2258-73-3

Benzofurazan, 4,5,6,7-tetrahydro-
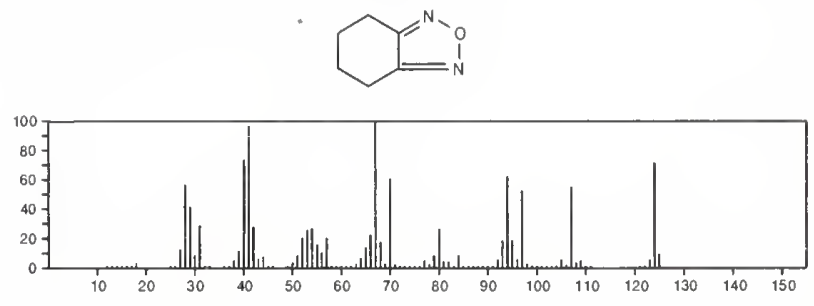

124

$\mathrm{C}_{6} \mathrm{H}_{8} \mathrm{~N}_{2} \mathrm{O}$

$2524-90-5$

Ethanone, 1-(4-methyl-1H-imidazol-2-yl)-
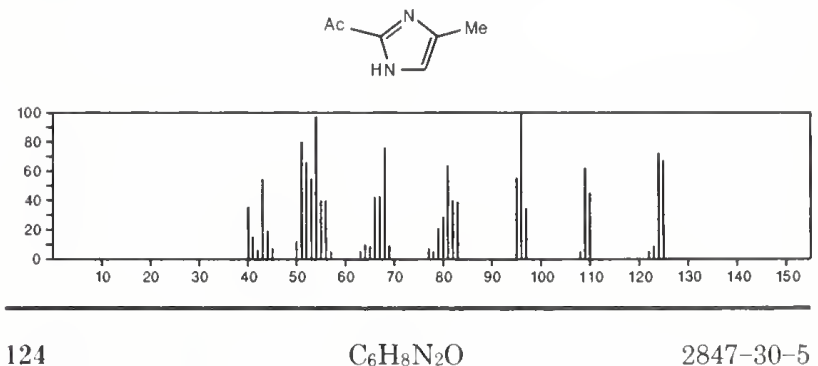

$2847-30-5$

Pyrazine, 2-methoxy-3-methyl
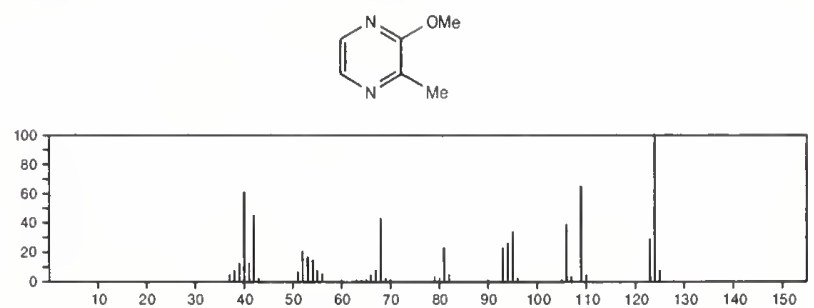
124

$\mathrm{C}_{6} \mathrm{H}_{8} \mathrm{~N}_{2} \mathrm{O}$

Pyrazine, 2-methoxy-6-methyl

$2882-21-5$<smiles>COc1cncc([N+](=O)[O-])n1</smiles>

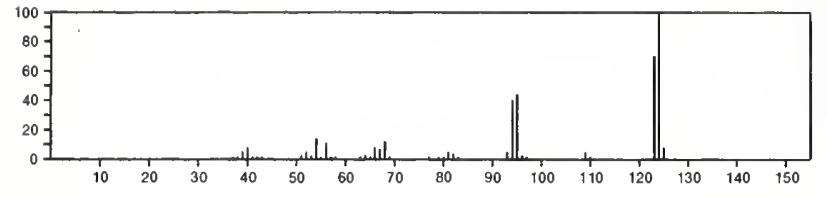

124

$\mathrm{C}_{6} \mathrm{H}_{8} \mathrm{~N}_{2} \mathrm{O}$

4(1H)-Pyrimidinone, 2,6-dimethyl-

$6622-92-0$
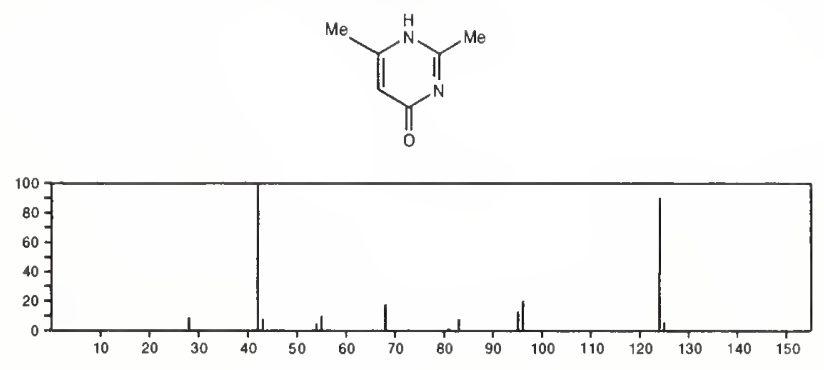

$124 \quad \mathrm{C}_{6} \mathrm{H}_{8} \mathrm{~N}_{2} \mathrm{O}$

Pyrimidine, 4-methoxy-2-methyl-
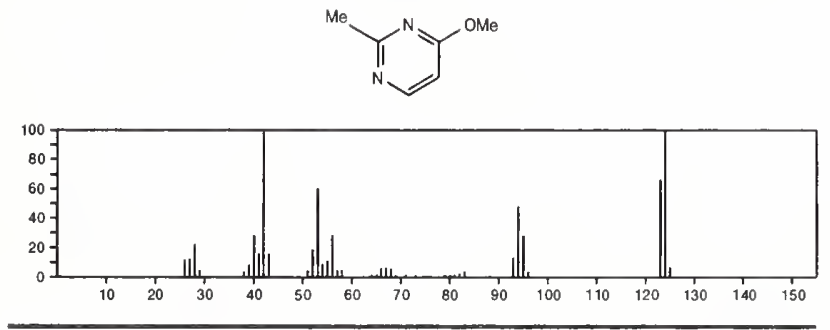

$124 \quad \mathrm{C}_{6} \mathrm{H}_{8} \mathrm{~N}_{2} \mathrm{O}$

4(3H)-Pyrimidinone, 2,3-dimethyl-
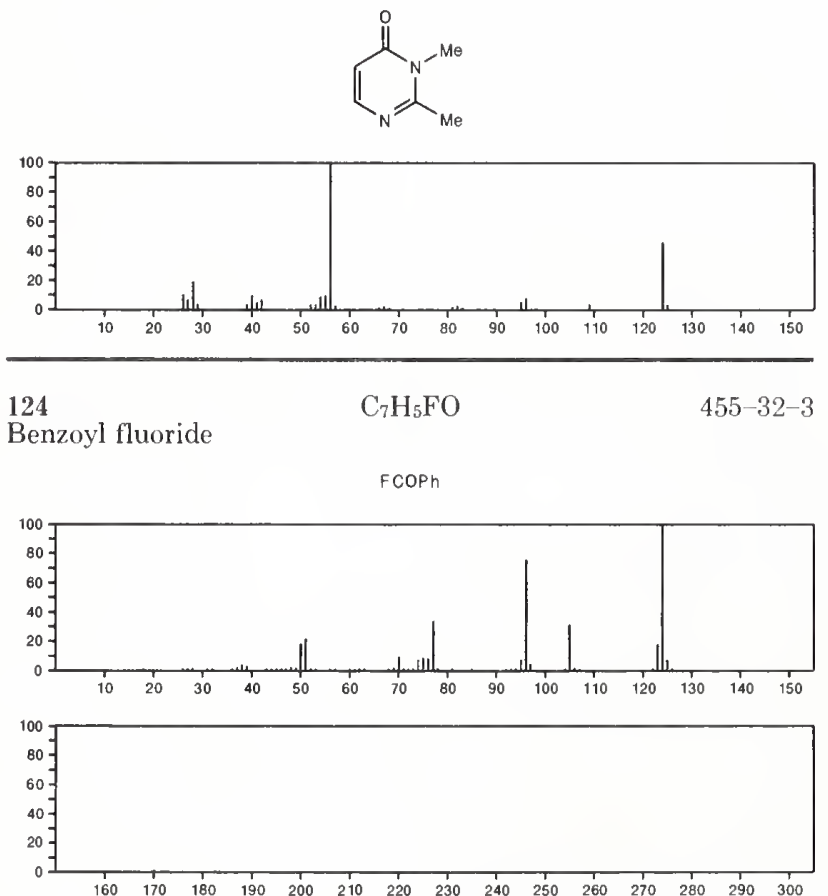

124

$\mathrm{Z}_{7} \mathrm{H}_{8} \mathrm{O}_{2}$

90-01-7

Benzuemethanol, 2-hydroxy-
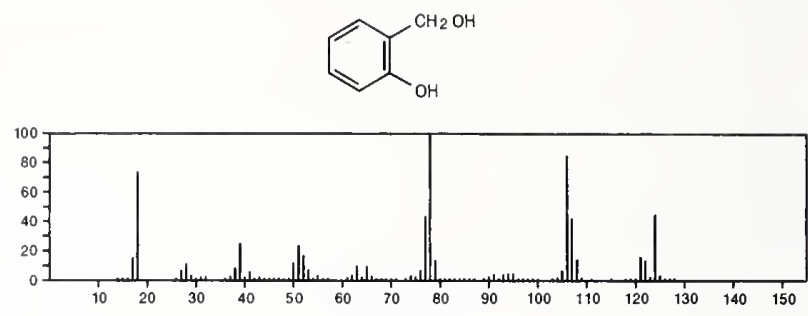

124

$\mathrm{C}_{7} \mathrm{H}_{8} \mathrm{O}_{2}$

90-05-1

Phenol, 2-methoxy-
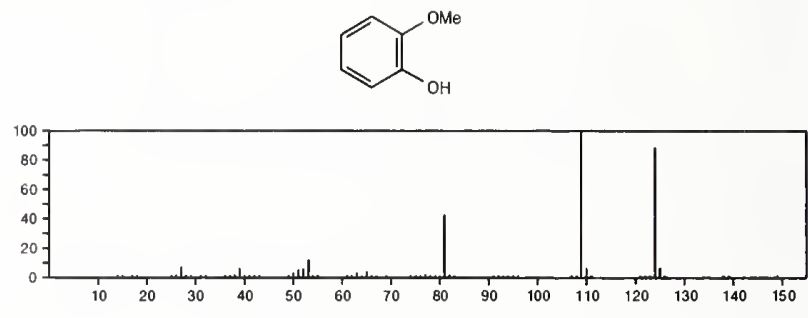

124

$\mathrm{C}_{7} \mathrm{H}_{8} \mathrm{O}_{2}$

$150-19-6$

Phenol, 3-methoxy-
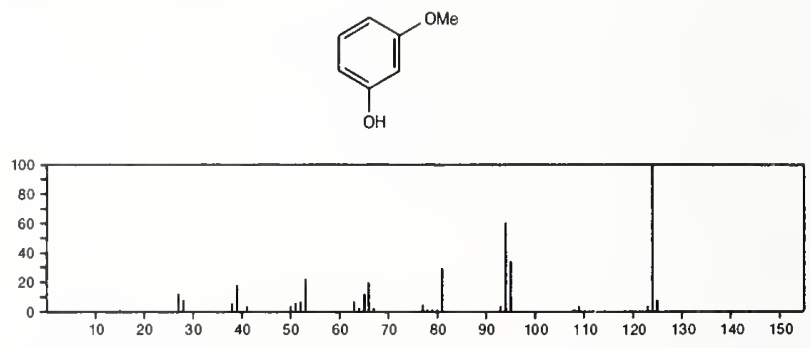

124

$\mathrm{C}_{7} \mathrm{H}_{8} \mathrm{O}_{2}$

$150-76-5$

Phenol, 4-methoxy-
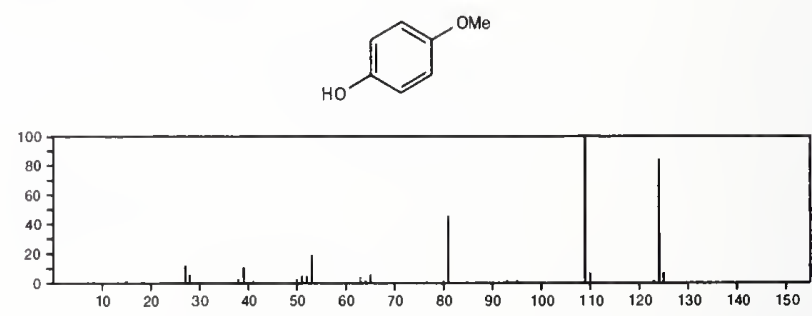

124

$\mathrm{C}_{7} \mathrm{H}_{8} \mathrm{O}_{2}$

1,2-Benzenediol, 3-methyl-
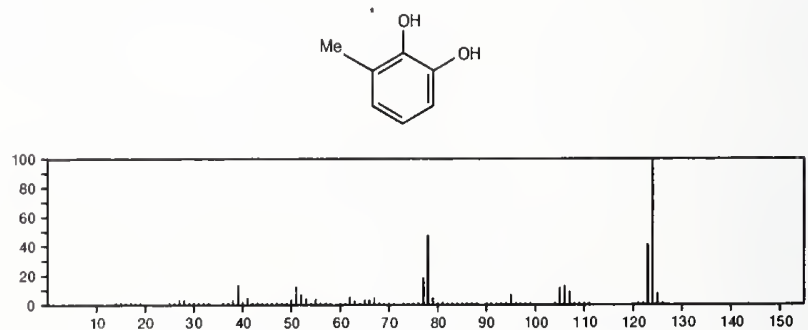
124

1,3-Benzenediol, 5-methyl-

$\mathrm{C}_{7} \mathrm{H}_{8} \mathrm{O}_{2}$
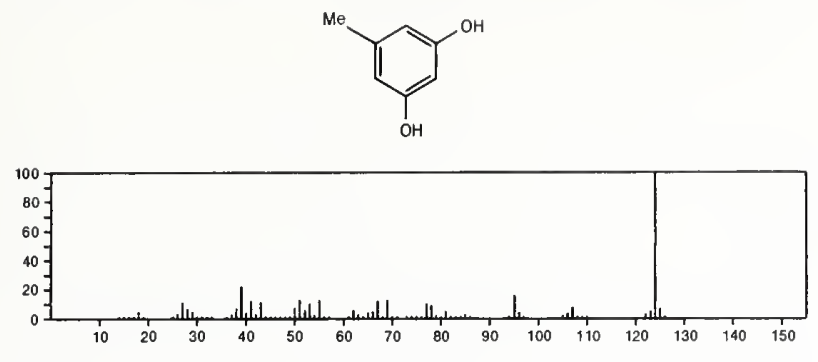

124

1,3-Benzenediol, 2-methyl-

$\mathrm{C}_{7} \mathrm{H}_{8} \mathrm{O}_{2}$

$608-25-3$<smiles>O=[N+]([O-])c1c(O)cccc1O</smiles>

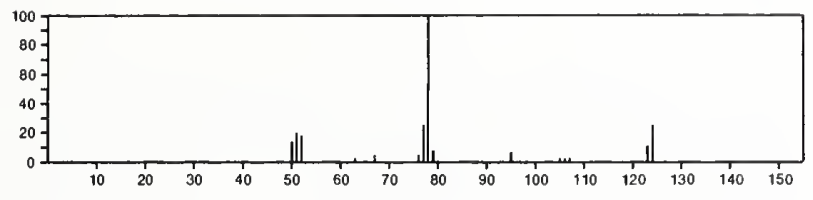

124

Benzenemethanol, 3-hydroxy-

$\mathrm{C}_{7} \mathrm{H}_{8} \mathrm{O}_{2}$

$620-24-6$
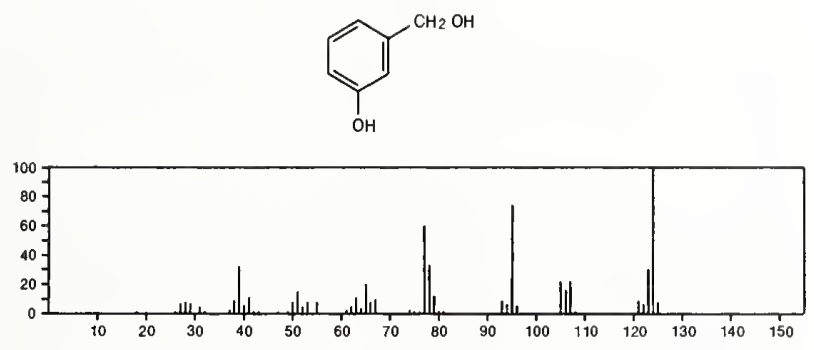

124

$\mathrm{C}_{7} \mathrm{H}_{8} \mathrm{O}_{2}$

$623-05-2$

Benzenemethanol, 4-hydroxy-
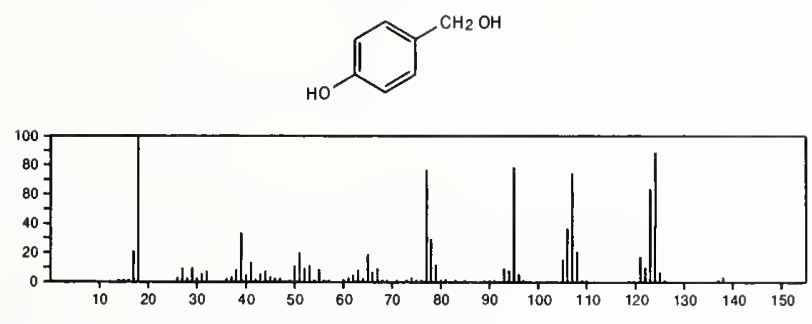

124

$\mathrm{C}_{7} \mathrm{H}_{8} \mathrm{O}_{2}$

2H-Pyran-2-one, 4,6-dimethyl-

675-09-2
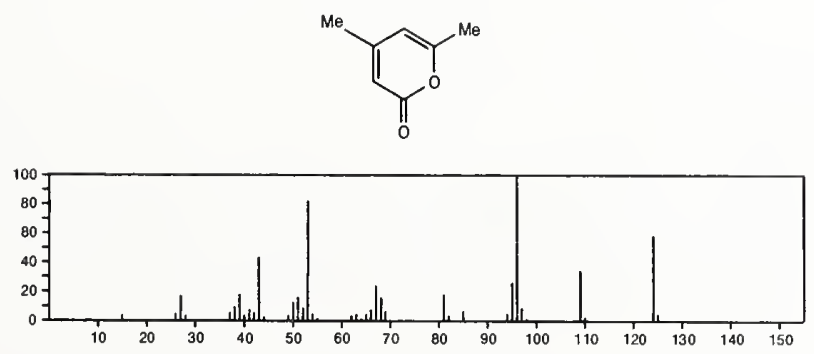

124

$\mathrm{C}_{7} \mathrm{H}_{8} \mathrm{O}_{2}$

1004-36-0
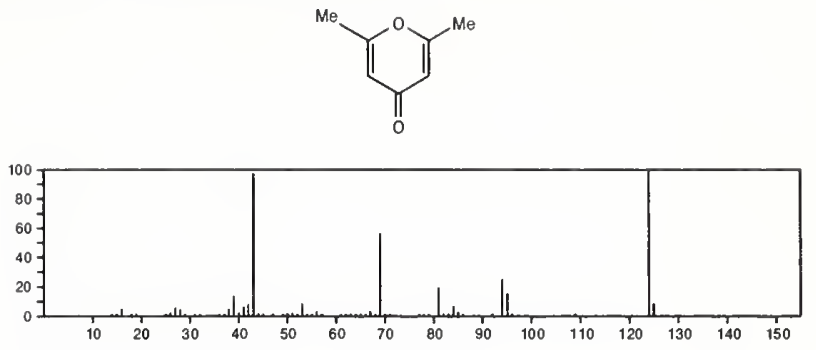

124

1-Propanone, 1-(2-furanyl)

$\mathrm{C}_{7} \mathrm{H}_{8} \mathrm{O}_{2}$

3194-15-8
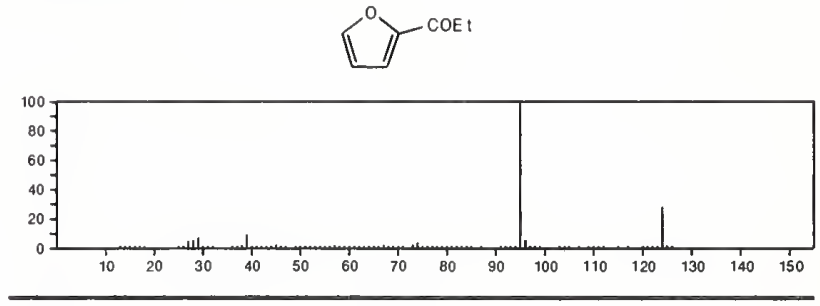

124

4H-Pyran-4-one, 3,5-dimethyl-

$19083-61-5$
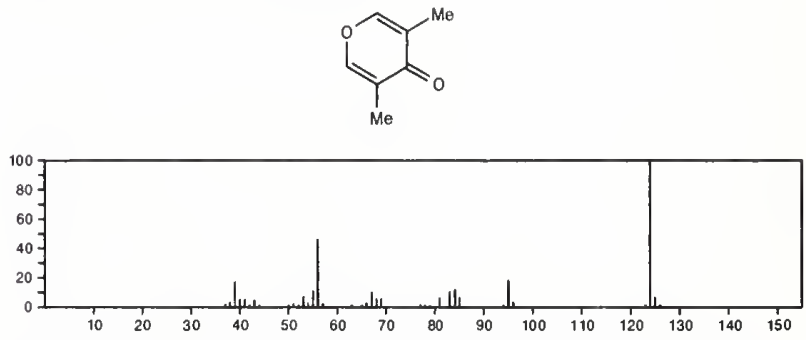

124

$\mathrm{C}_{7} \mathrm{H}_{8} \mathrm{~S}$

$100-53-8$

Benzenemethanethiol

$\mathrm{PhCH}_{2} \mathrm{SH}$

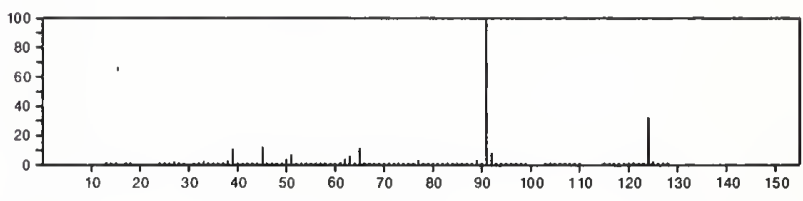

124

$\mathrm{C}_{7} \mathrm{H}_{8} \mathrm{~S}$

$100-68-5$

Benzene, (methylthio)-

Me SPh

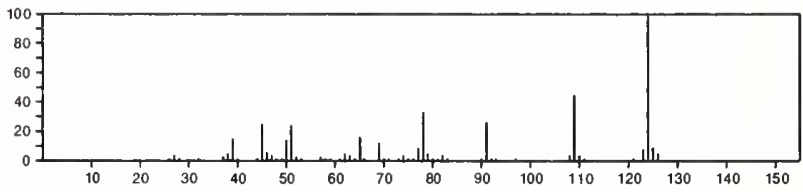


124

1H-Pyrazole, 1-ethyl-3,5-dimethyl-

$$
\sum_{M e}^{M e}
$$

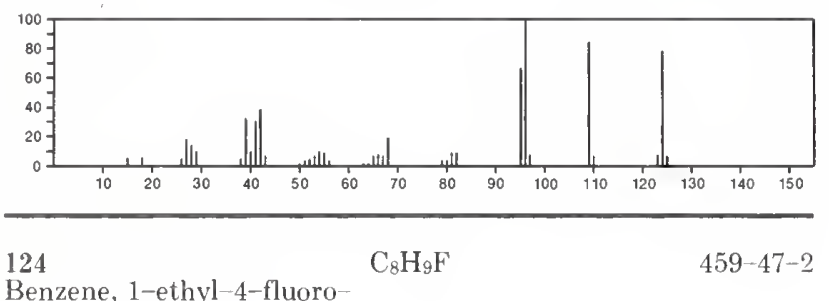

Benzene, 1-ethyl-4-fluoro
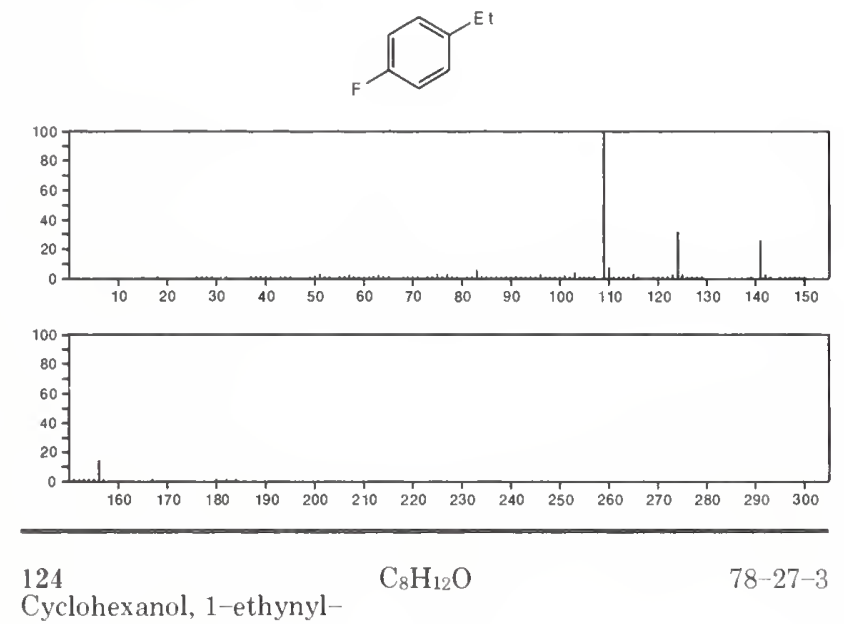

hexanol, 1-ethynyl-
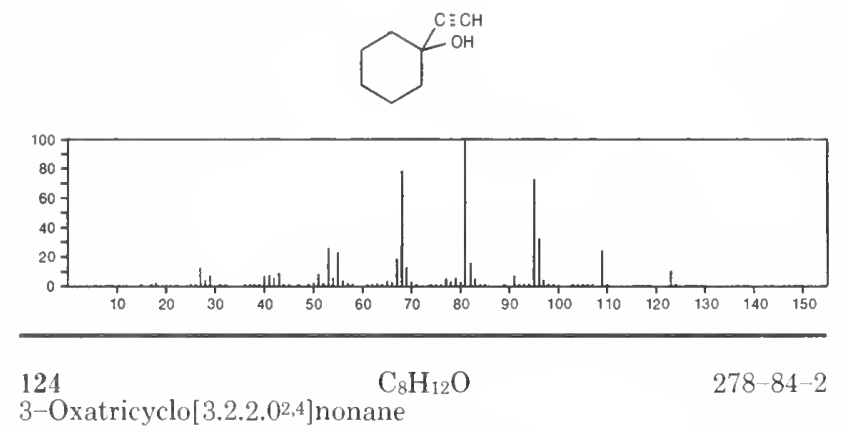

3-Oxatricyclo[3.2.2.02,4] nonane
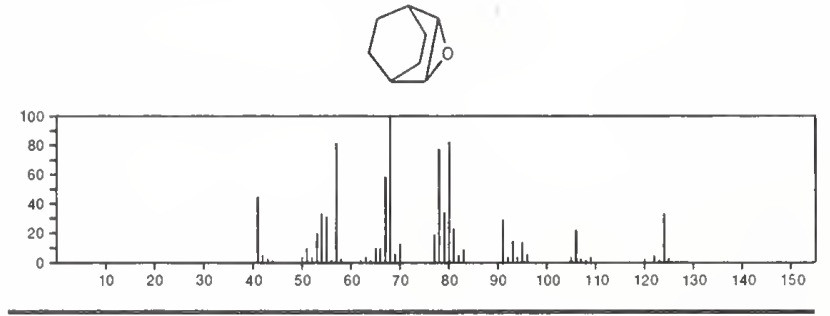

$124 \quad \mathrm{C}_{8} \mathrm{H}_{12} \mathrm{O}$

$637-90-1$

9-Oxabicyclo[6.1.0]non-4-ene
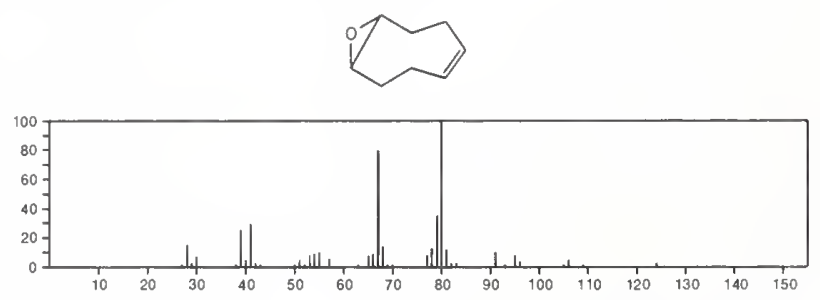

$124 \quad \mathrm{C}_{8} \mathrm{H}_{12} \mathrm{O}$

$931-96-4$

3-Cyclohexene-1-carboxaldehyde, 1-methyl-
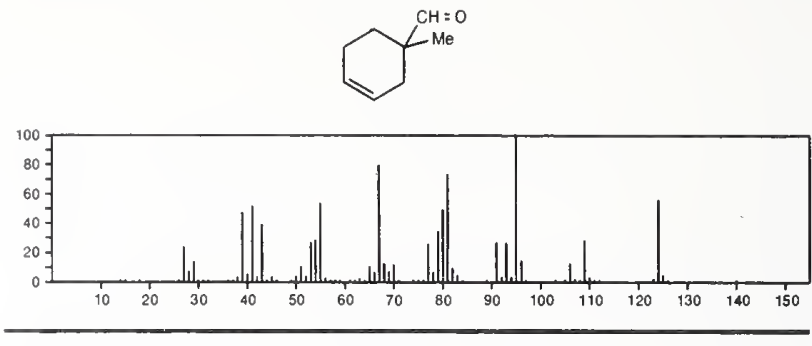

124

$\mathrm{C}_{8} \mathrm{H}_{12} \mathrm{O}$

$932-66-1$

Ethanone, 1-(1-cyclohexen-1-yl)-
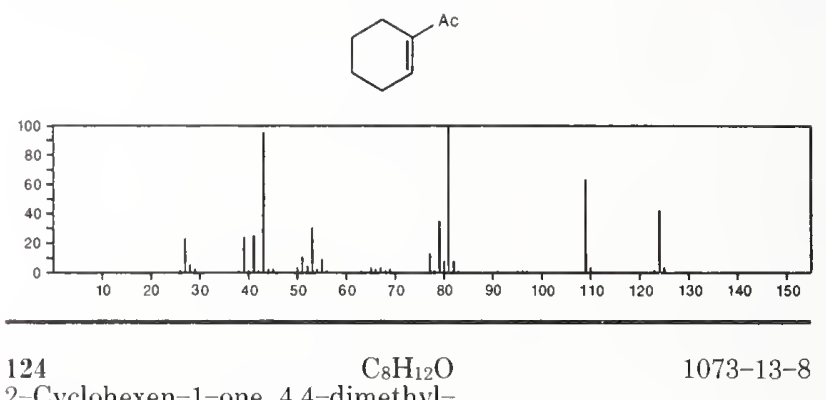

2-Cyclohexen-1-one, 4,4-dimethyl-
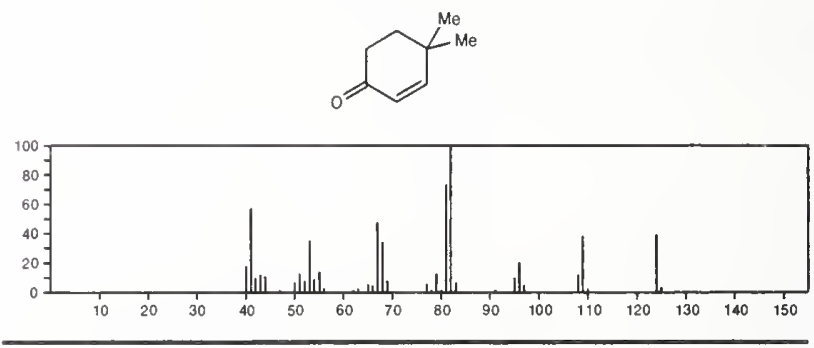

124

$\mathrm{C}_{8} \mathrm{H}_{12} \mathrm{O}$

2-Cyclohexen-1-one, 3,5-dimethyl-

1123-09-7
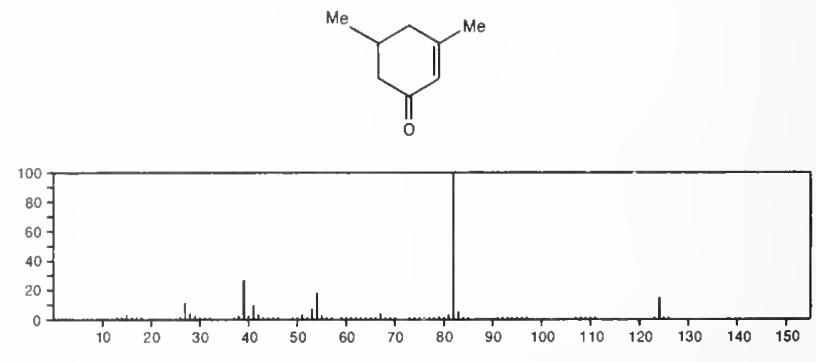

124

$\mathrm{C}_{8} \mathrm{H}_{12} \mathrm{O}$

$1740-63-2$

Cyclohexanone, 3-ethenyl
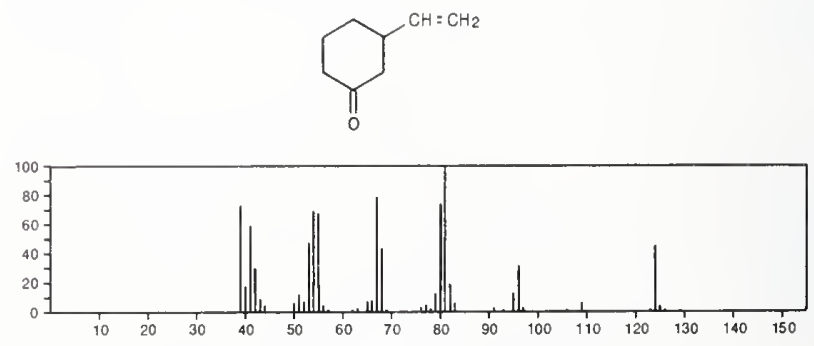
124 $\mathrm{C}_{8} \mathrm{H}_{12} \mathrm{O}$

Ethanone, 1-(2-methyl-2-cyclopenten-1-yl)-
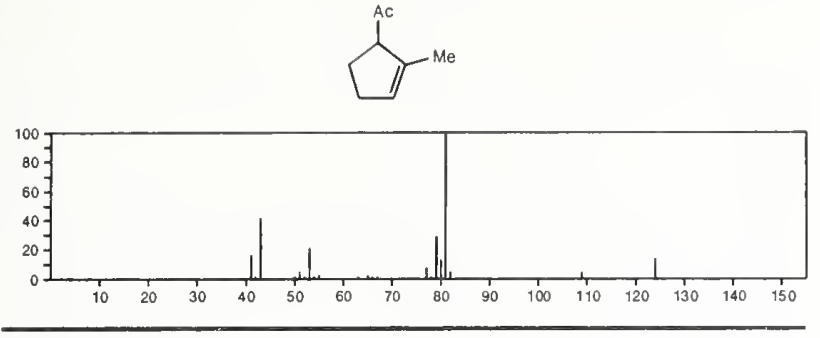

124

$\mathrm{C}_{8} \mathrm{H}_{12} \mathrm{O}$

$2716-23-6$

Bicyclo[2.2.2]octanone
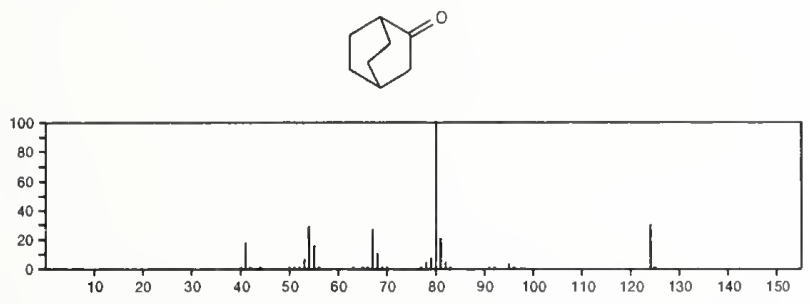

124

$\mathrm{C}_{8} \mathrm{H}_{12} \mathrm{O}$

$3168-90-9$

Ethanone, 1-(2-methyl-1-cyclopenten-1-yl)-
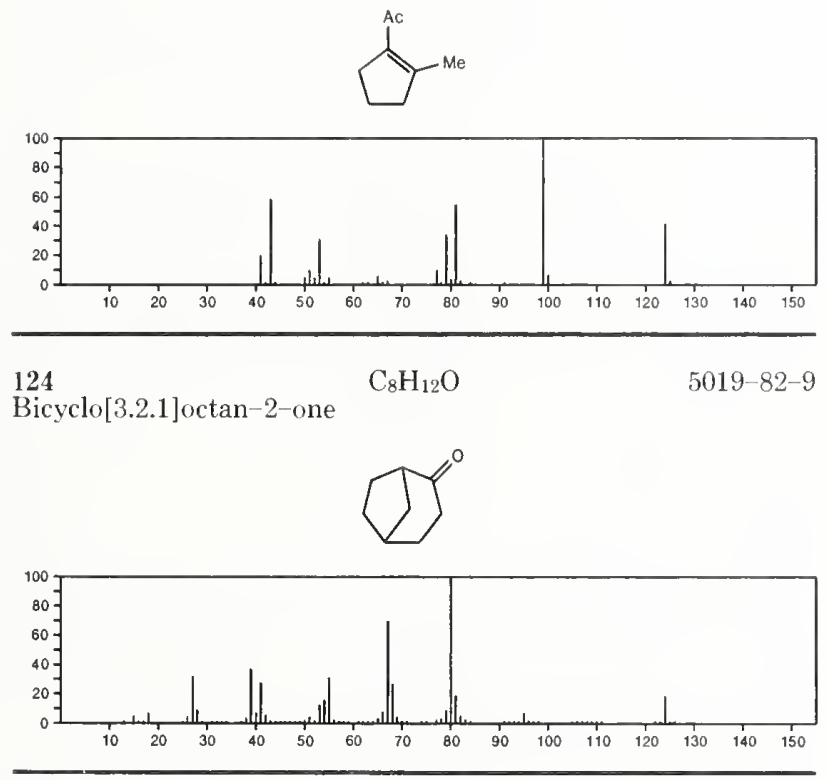

124

$\mathrm{C}_{8} \mathrm{H}_{12} \mathrm{O}$

2-Cyclohexen-1-one, 4,5-dimethyl-
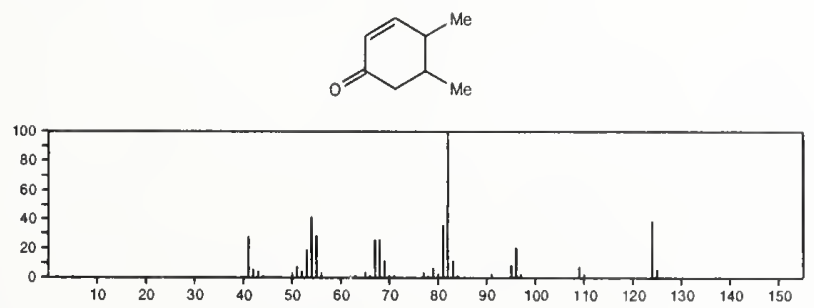

124

$\mathrm{C}_{8} \mathrm{H}_{12} \mathrm{O}$

$7353-76-6$

Ethanone, 1-(3-cyclohexen-1-yl)-

$\vartheta^{A C}$

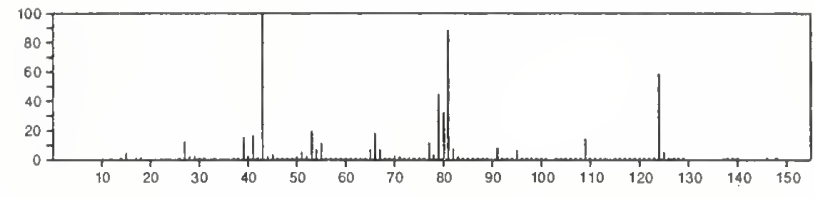

124

Bicyclo[3.2.1]octan-3-one

$\mathrm{C}_{8} \mathrm{H}_{12} \mathrm{O}$

$14252-05-2$
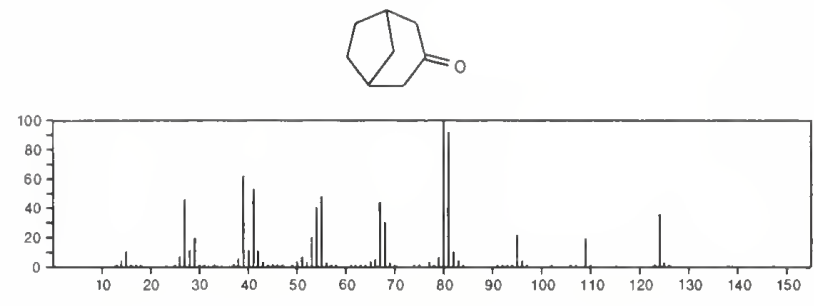

124

$\mathrm{C}_{8} \mathrm{H}_{12} \mathrm{O}$

$14845-40-0$

Bicyclo[4.1.0]heptan-2-one, 1-methyl-
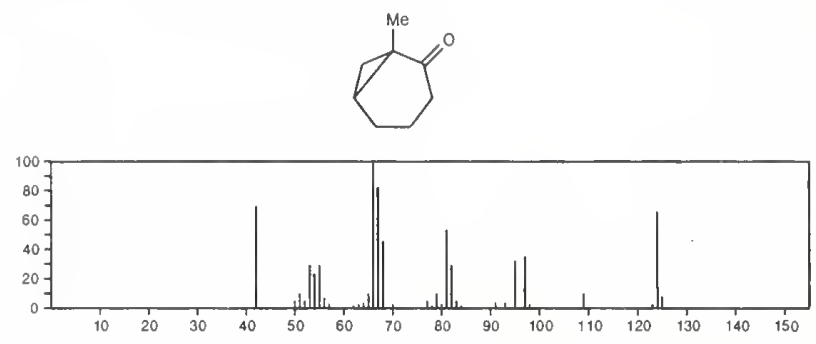

124

$\mathrm{C}_{8} \mathrm{H}_{12} \mathrm{O}$

$14845-41-1$

Bicyclo[4.1.0]heptan-2-one, 6-methyl-
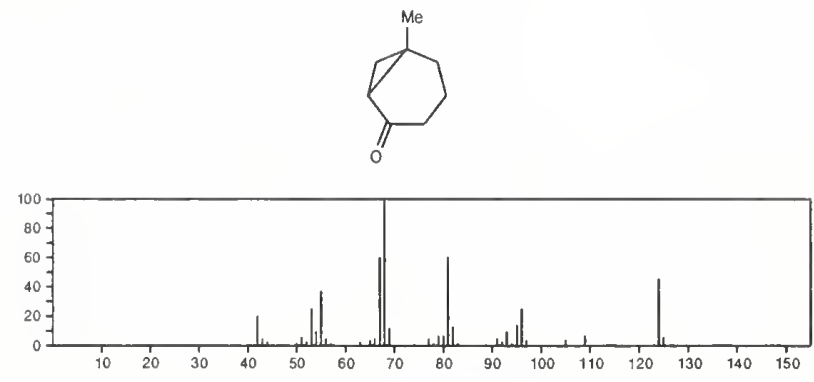

124

$\mathrm{C}_{8} \mathrm{H}_{12} \mathrm{O}$

3,5-Heptadien-2-one, 6-methyl-, (E)-

$16647-04-4$

$\mathrm{Me} \mathrm{COCH}=\mathrm{CHCH}=\mathrm{CMe}_{2}$

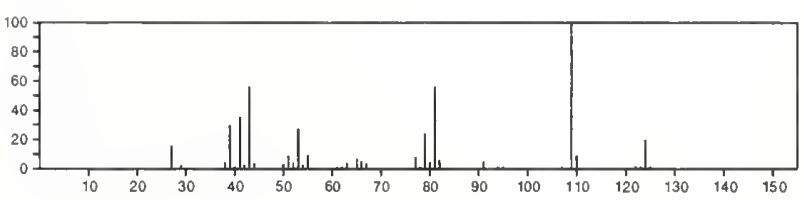


124

$\mathrm{C}_{8} \mathrm{H}_{12} \mathrm{O}$

2-Cyclopenten-1-one, 3,5,5-trimethyl-
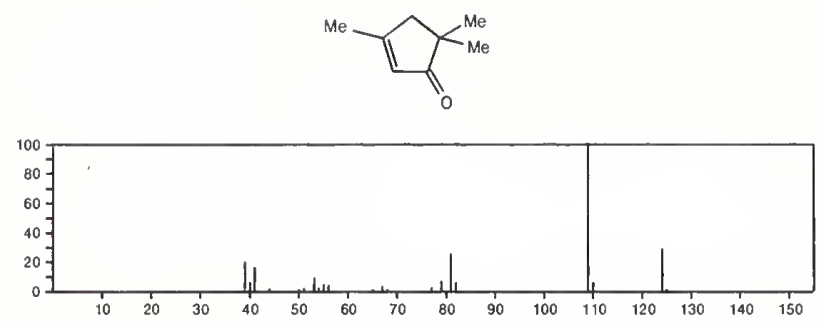

124

3,7-Octadien-2-one, $(E)$ -

$\mathrm{C}_{8} \mathrm{H}_{12} \mathrm{O}$

$\mathrm{H}_{2} \mathrm{C}=\mathrm{CHCH}_{2} \mathrm{CH}_{2} \mathrm{CH}=\mathrm{CHCOMe}$

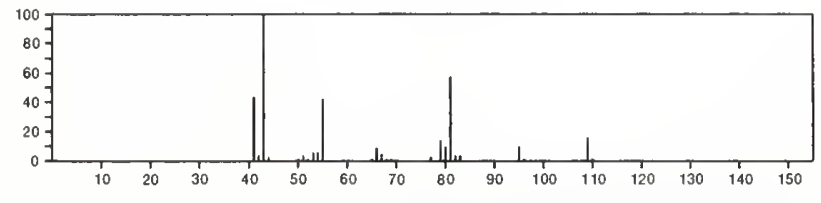

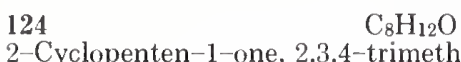

$28790-86-5$<smiles>CC1=C(C)C(C)CC1=O</smiles>

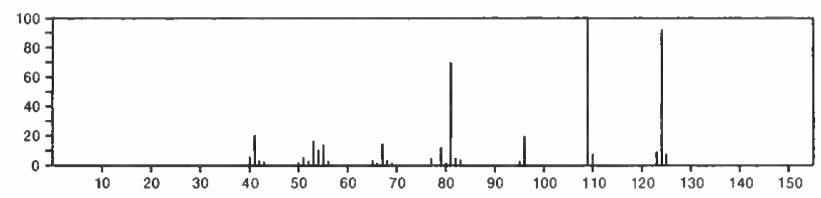

124

$\mathrm{C}_{8} \mathrm{H}_{12} \mathrm{O}$

$29750-22-9$

2-Norcaranone, 3-methyl-, stereoisomer
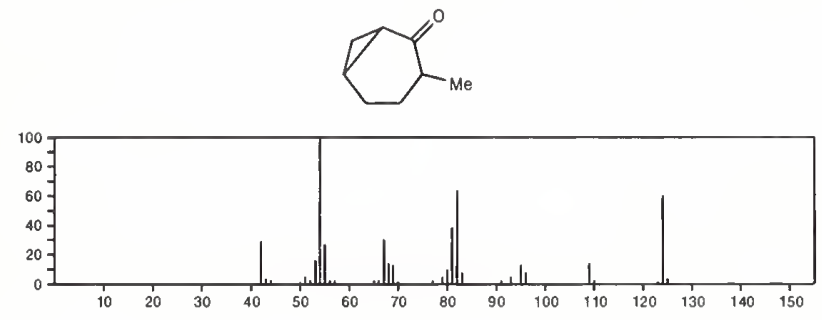

124

2-Cyclopenten-1-one, 3,4,4-trimethyl-
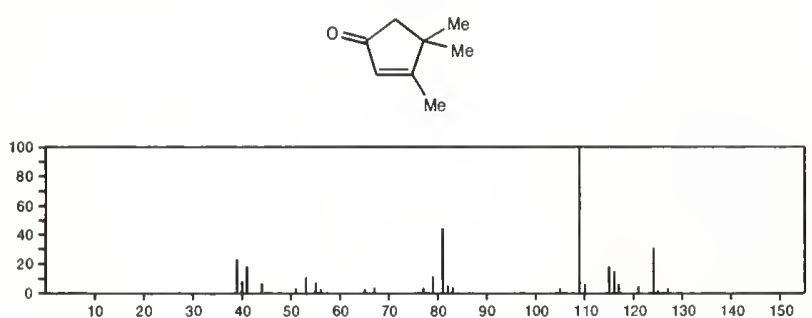

124 5-Hexen-2-one, 5-methyl-3-methylene-

$51756-18-4$

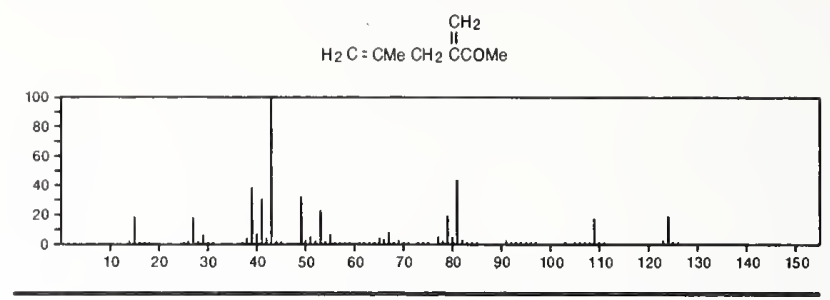

124

Bicyclo[2.2.2]oct-5-en-2-ol $\mathrm{C}_{8} \mathrm{H}_{12} \mathrm{O}$

$55320-40-6$
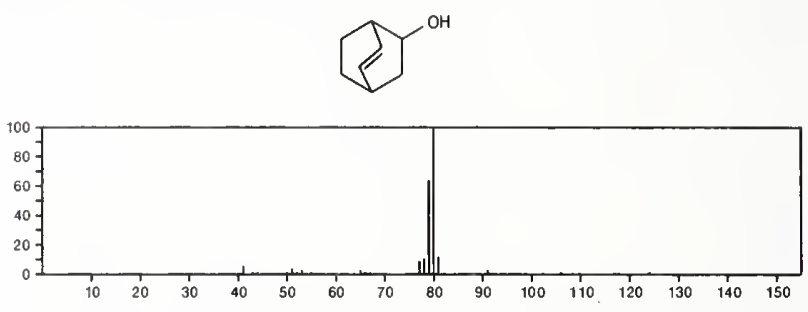

124

$\mathrm{C}_{8} \mathrm{H}_{12} \mathrm{O}$

$55449-70-2$

Pentaleno[ $[1,2-b]$ oxirene, octahydro--, $(1 \mathrm{a} \alpha, 1 \mathrm{~b} \beta, 4 \mathrm{a} \alpha, 5 \mathrm{a} \alpha)_{-}^{-}$
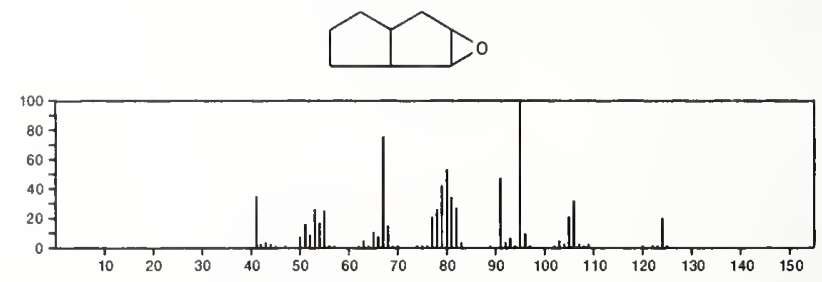

124

$\mathrm{C}_{8} \mathrm{H}_{12} \mathrm{O}$

55449-71-3

Pentaleno[1,2-b]oxirene, octahydro-, $(1 \mathrm{a} \alpha, 1 \mathrm{~b} \alpha, 4 \mathrm{a} \beta, 5 \mathrm{a} \alpha)-$
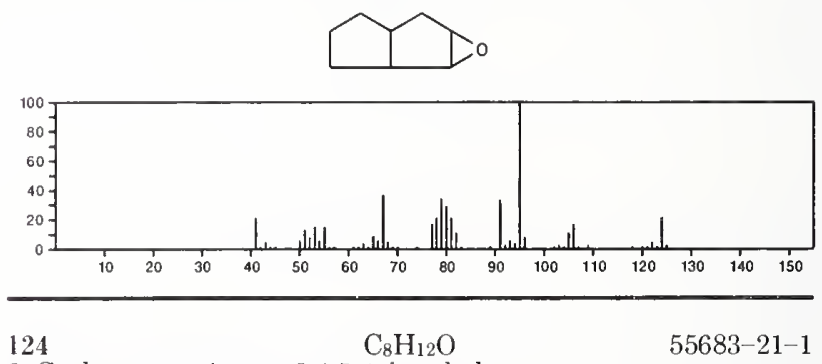

$55683-21-1$

2-Cyclopenten-1-one, 3,4,5-trimethyl-
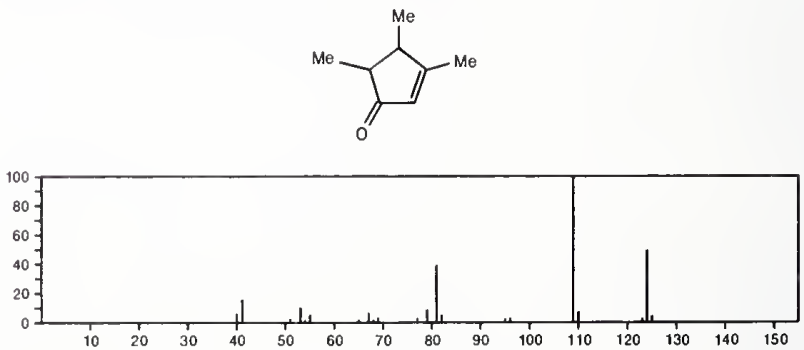
124

Bicyclo[3.3.1]nonane

$\mathrm{C}_{9} \mathrm{H}_{16}$
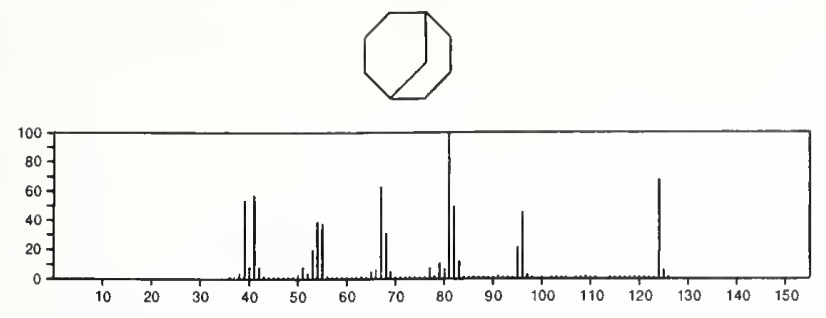

124

$1 H_{-}$-Indene, octahydro-

$\mathrm{C}_{9} \mathrm{H}_{16}$
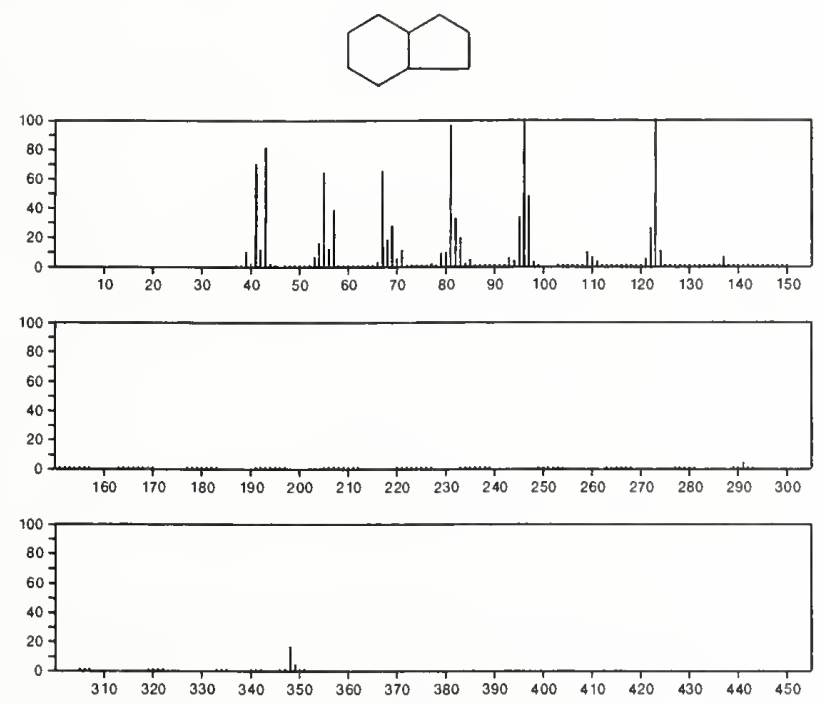

\section{4}

Cyclohexene, 3,3,5-trimethyl-

\section{$\mathrm{C}_{9} \mathrm{H}_{16}$}

$503-45-7$
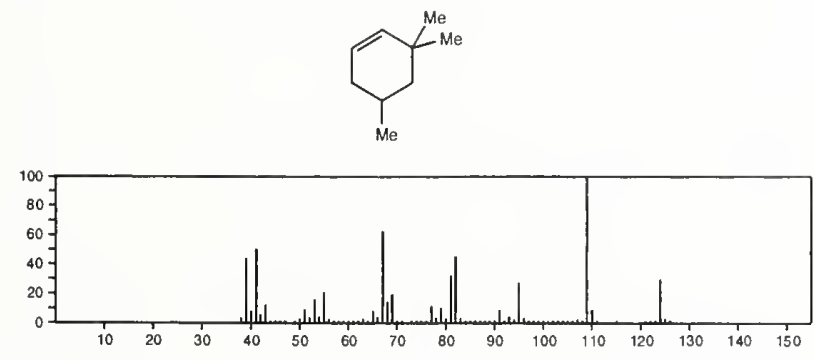

124

Cyclohexene, 3,5,5-trimethyl-

$\mathrm{C}_{9} \mathrm{H}_{16}$

933-12-0<smiles>CC1CC=CCC1(C)C</smiles>

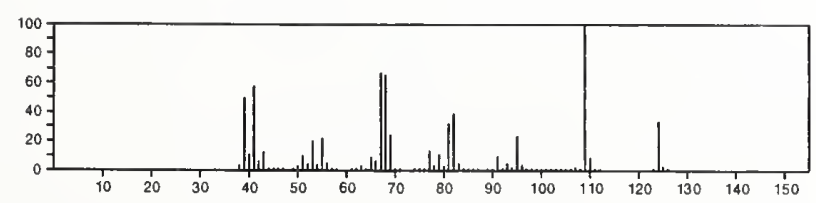

124

Cyclohexane, 2-propenyl-

$\mathrm{C}_{9} \mathrm{H}_{16}$

$2114-42-3$
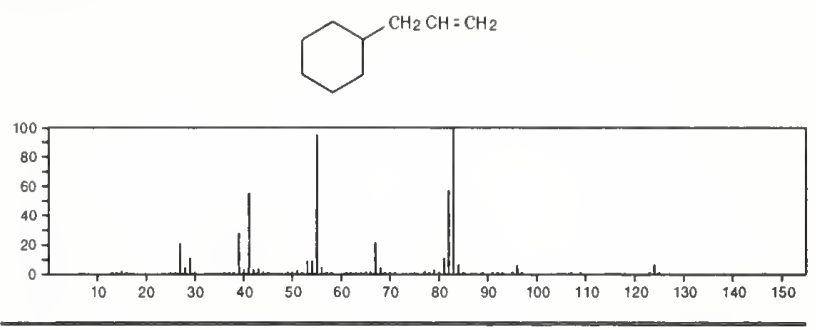

$124 \quad \mathrm{C}_{9} \mathrm{H}_{16}$

$3296-50-2$

$1 H_{\text {-Indene, octahydro-, trans- }}$
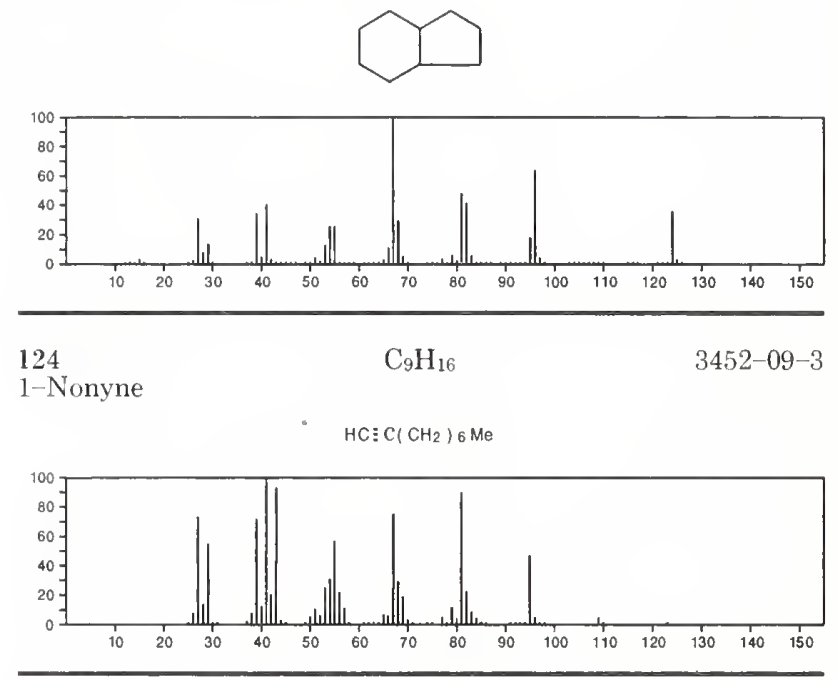

124

$\mathrm{C}_{9} \mathrm{H}_{16}$

Pentalene, octahydro-2-methyl-

$3868-64-2$
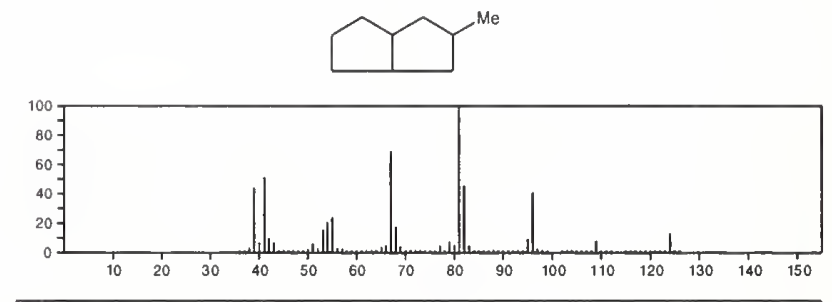

124

$1 H^{-I n d e n e, ~ o c t a h y d r o-, ~}$ cis- $^{-}$

$\mathrm{C}_{9} \mathrm{H}_{16}$

$4551-51-3$
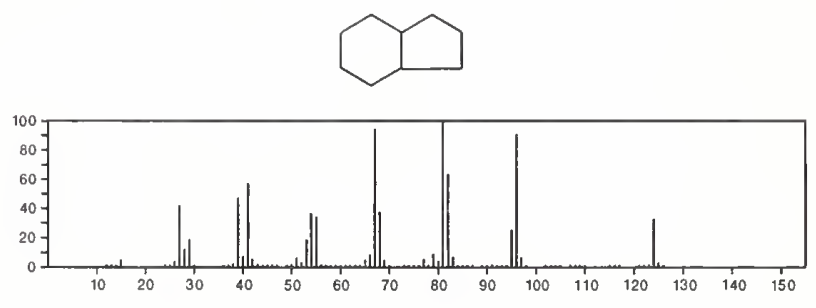

124

Cyclohexane, (1-propenyl)-

$\mathrm{C}_{9} \mathrm{H}_{16}$

5364-83-0
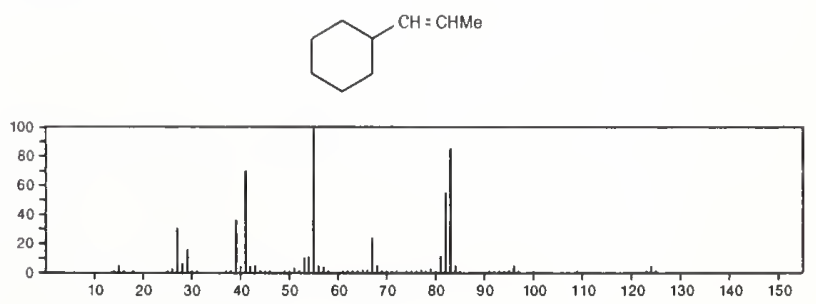
124

Spiropentane, butyl

$\mathrm{C}_{9} \mathrm{H}_{16}$

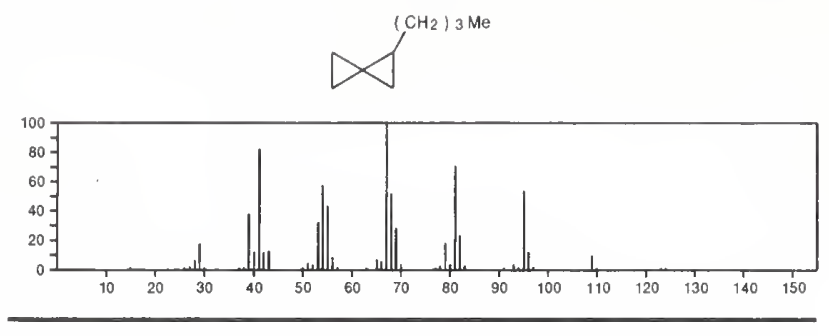

124

4-Octyne, 2-methyl-

$\mathrm{C}_{9} \mathrm{H}_{16}$

10306-94-2

$\mathrm{Me}_{2} \mathrm{CHCH}_{2} \mathrm{C} \equiv \mathrm{CP}$

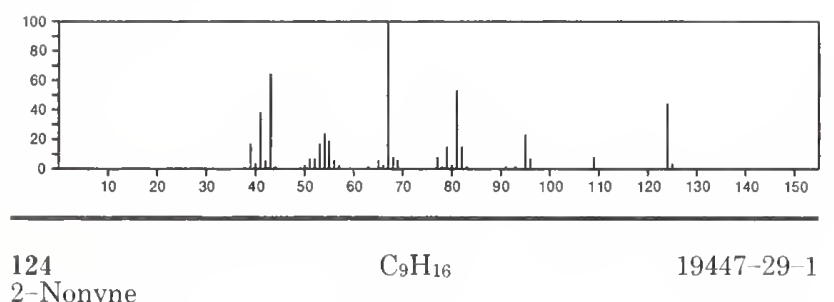

2-Nonyne

$\mathrm{Me}\left(\mathrm{CH}_{2}\right){ }_{5} \mathrm{C} \equiv \mathrm{CMe}$

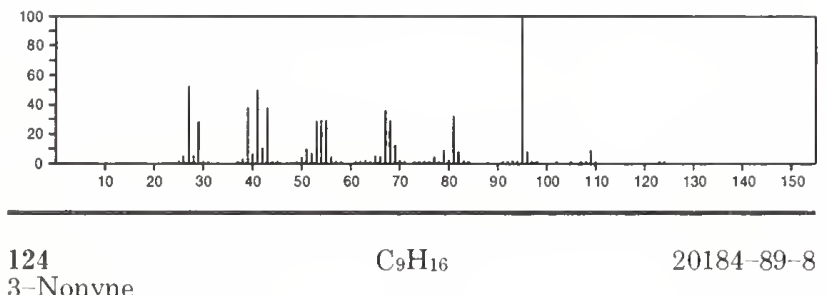

$\mathrm{Me}\left(\mathrm{CH}_{2}\right){ }_{4} \mathrm{C} \equiv \mathrm{CE}$

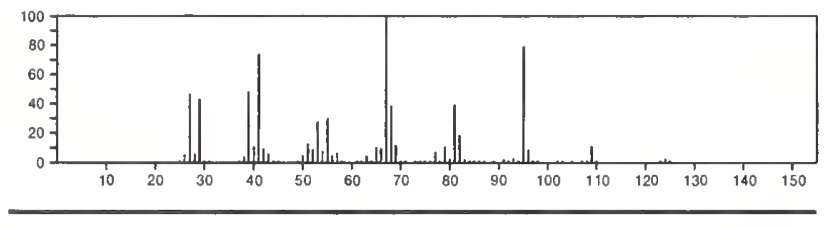

124 4-Nonyne

$\mathrm{C}_{9} \mathrm{H}_{16}$

20184-91-2

$\mathrm{Me}\left(\mathrm{CH}_{2}\right){ }_{3} \mathrm{C}: \mathrm{CP}$

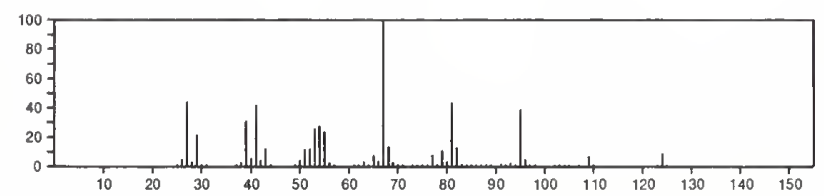

124

Cycloheptane, 1-methyl-4-methylene
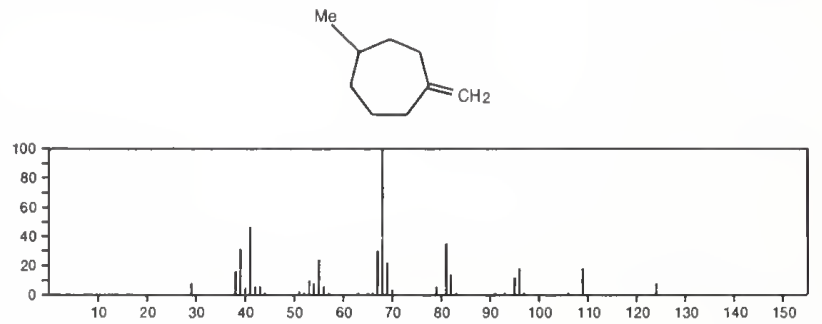

124

$\mathrm{C}_{9} \mathrm{H}_{16}$
$\mathrm{PrC}: \mathrm{CCMe}_{3}$

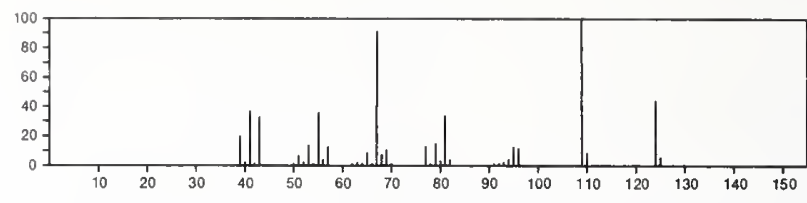

124

$\mathrm{C}_{9} \mathrm{H}_{16}$

Pentalene, octahydro-1-methyl-

$32273-77-1$
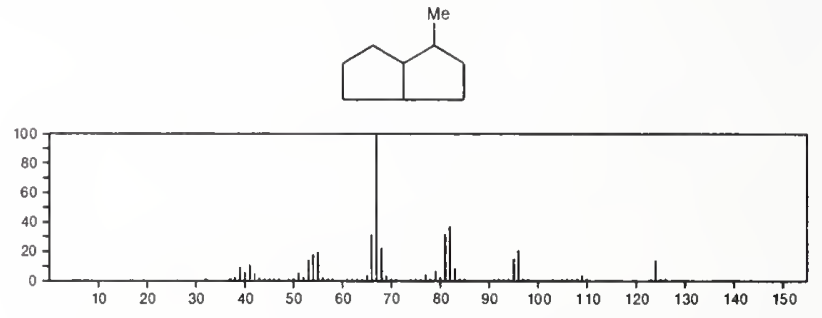

$124 \quad \mathrm{C}_{9} \mathrm{H}_{16} \quad 32669-86-6$

Cyclohexane, cyclopropyl
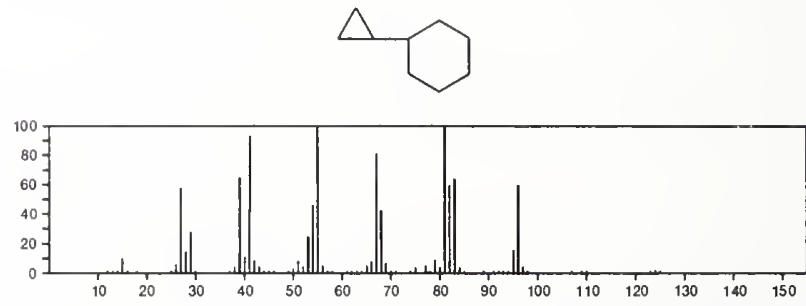

124

Cyclohexane, 1-ethenyl-2-methyl-, trans-

$34780-45-5$
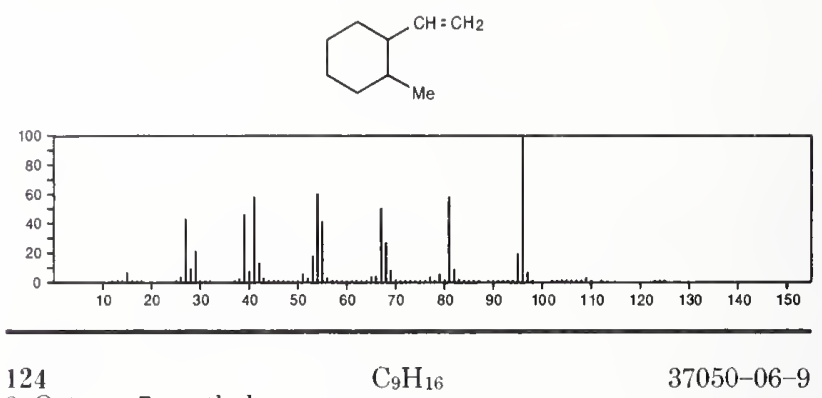

3-Octyne, 7-methyl

Et $\mathrm{C} \equiv \mathrm{CCH}_{2} \mathrm{CH}_{2} \mathrm{CHMe}_{2}$

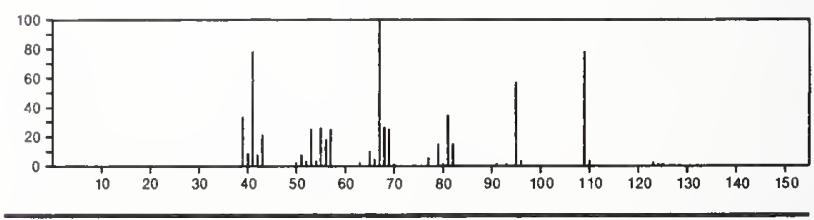

124

$\mathrm{C}_{9} \mathrm{H}_{16}$

$50746-53-7$

Cyclopentane, 1-methyl-2-(2-propenyl)-, trans-
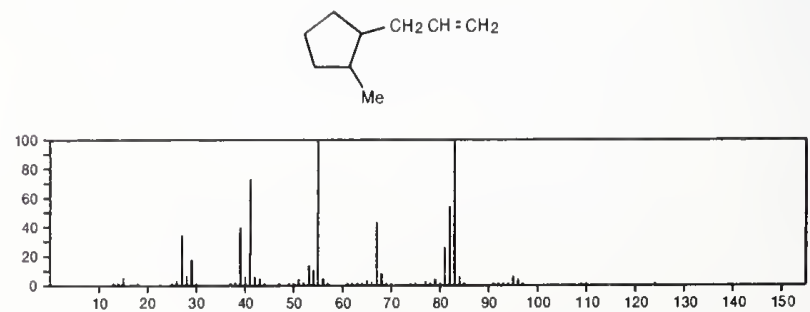
124

3-Octyne, 2-methyl-

$\mathrm{C}_{9} \mathrm{H}_{16}$

$55402-15-8$

Me $\left.2 \mathrm{CHC} \equiv \mathrm{C}_{(} \mathrm{CH}_{2}\right)_{3} \mathrm{Me}$

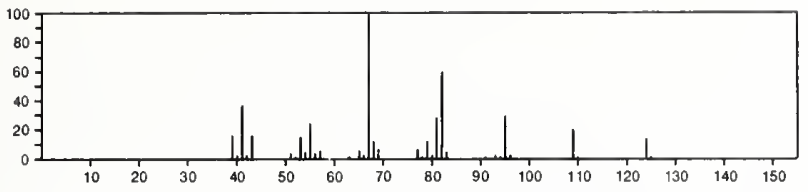

124

$\mathrm{C}_{9} \mathrm{H}_{16}$

$56324-66-4$

Cyclopentane, 2-ethylidene-1,1-dimethyl-
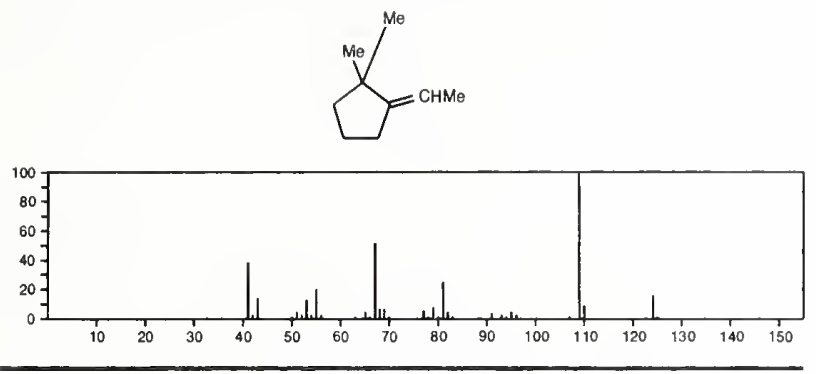

124

1,3-Nonadiene, $(E)$

$\mathrm{C}_{9} \mathrm{H}_{16}$

$56700-77-7$

$\mathrm{H}_{2} \mathrm{C}=\mathrm{CHCH}=\mathrm{CH}\left(\mathrm{CH}_{2}\right)_{4} \mathrm{M}$

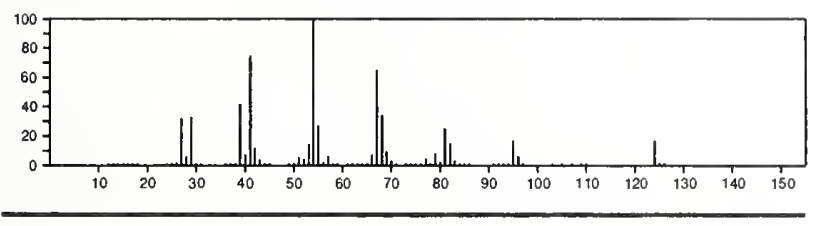

124

2,4-Nonadiene, $(E, E)$

$\mathrm{C}_{9} \mathrm{H}_{16}$

$56700-78-8$

$\mathrm{Me}\left(\mathrm{CH}_{2}\right)_{3} \mathrm{CH}=\mathrm{CHCH}=\mathrm{CHMe}$

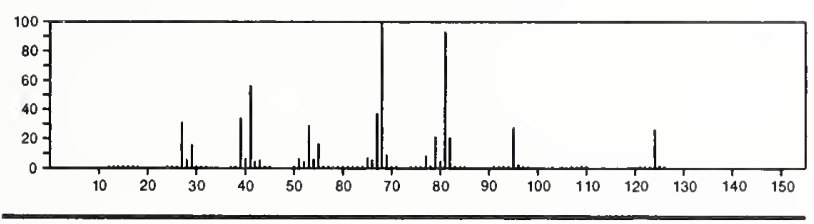

124

$\mathrm{F}_{4} \mathrm{OS}$

$13709-54-1$

Sulfur fluoride oxide $\left(\mathrm{SF}_{4} \mathrm{O}\right)$

$F_{4} S=0$
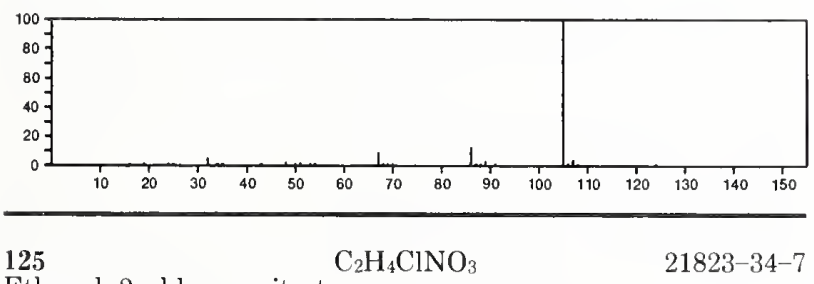

21823-34-7

Ethanol, 2-chloro-, nitrate

$\mathrm{O}_{2} \mathrm{NOCH}_{2} \mathrm{CH}_{2} \mathrm{Cl}$

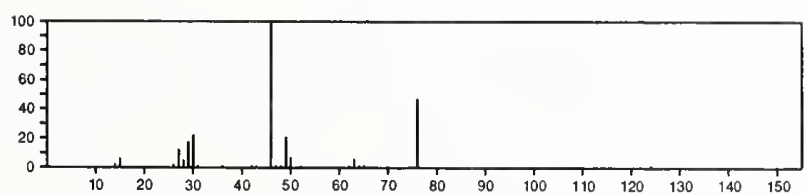

125

$\mathrm{C}_{2} \mathrm{H}_{8} \mathrm{NO}_{3} \mathrm{P}$

Phosphoramidic acid, dimethyl ester

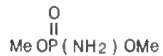

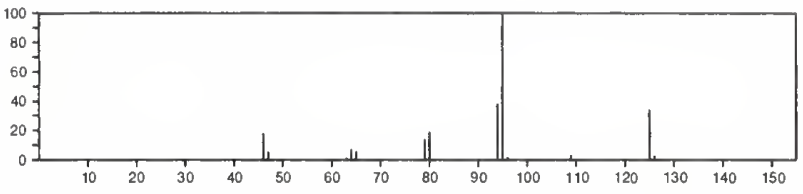

125

$\mathrm{C}_{5} \mathrm{H}_{7} \mathrm{~N}_{3} \mathrm{O}$

$554-01-8$

2(1H)-Pyrimidinone, 4-amino-5-methyl
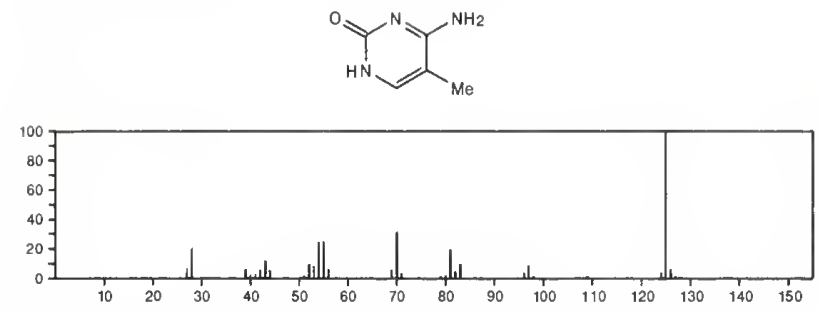

125

$\mathrm{C}_{6} \mathrm{H}_{7} \mathrm{NO}_{2}$

2(1H)-Pyridinone, 4-hydroxy-6-methyl-

$3749-51-7$
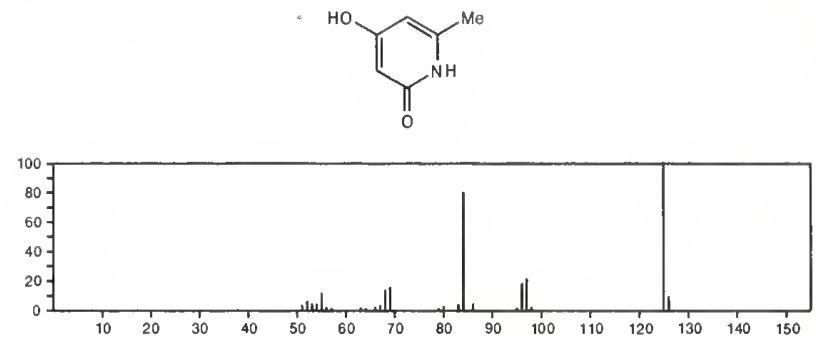

125

2-Furaldehyde, $\mathrm{O}$-methyloxime

$\mathrm{C}_{6} \mathrm{H}_{7} \mathrm{NO}_{2}$

33581-39-4

${ }^{\circ} \mathrm{CH}=\mathrm{NOMe}$

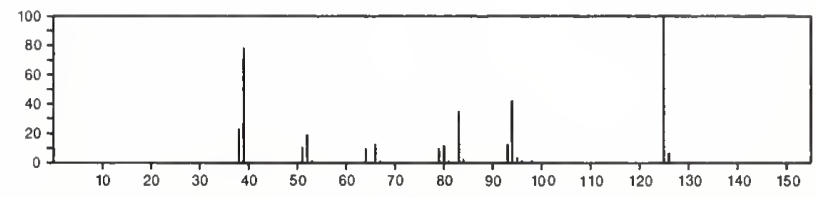

125

$\mathrm{C}_{6} \mathrm{H}_{7} \mathrm{NS}$

$137-07-5$

Benzenethiol, 2-amino-
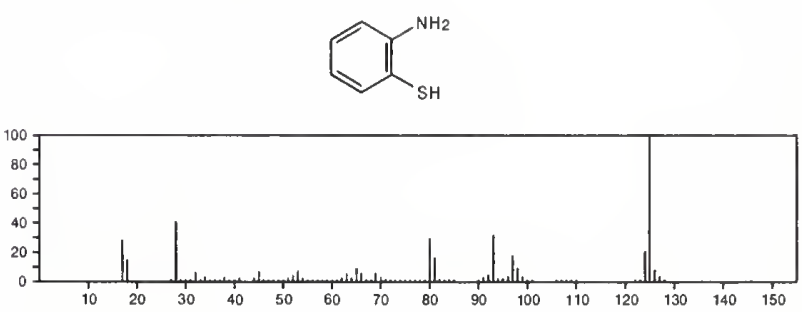
$\mathrm{C}_{6} \mathrm{H}_{7} \mathrm{NS}$

2(1H)-Pyridinethione, 1-methyl-
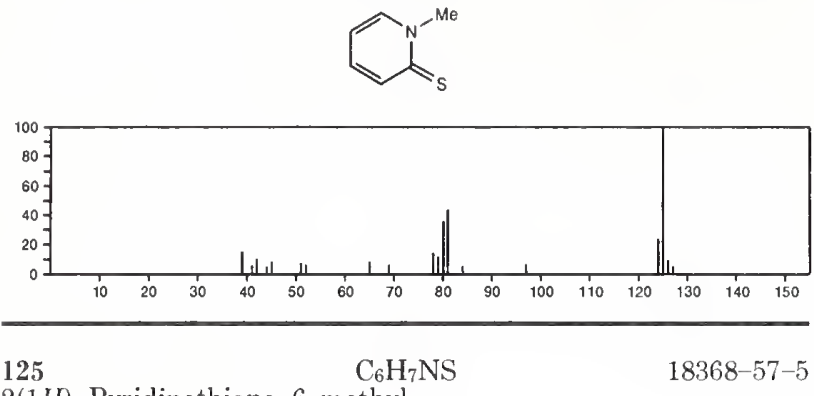

2(1 H)-Pyridinethione, 6-methyl-
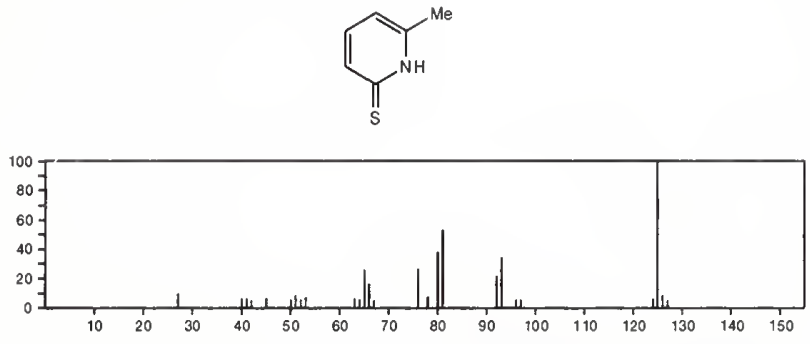

125

2(1H)-Pyridinethione, 4-methyl-

$18368-65-5$
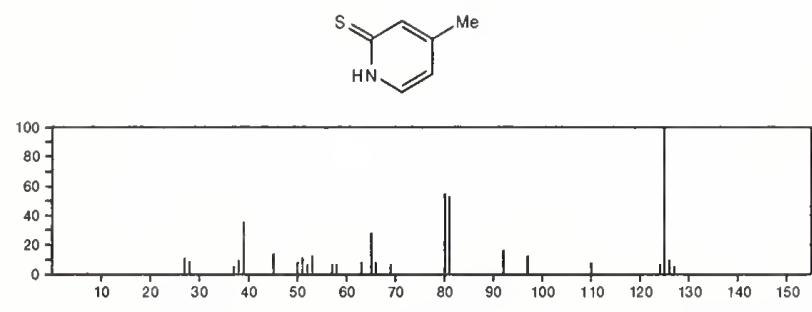

$125 . \mathrm{C}_{6} \mathrm{H}_{7} \mathrm{NS}$

$18438-38-5$

Pyridine, 2-(methylthio)-
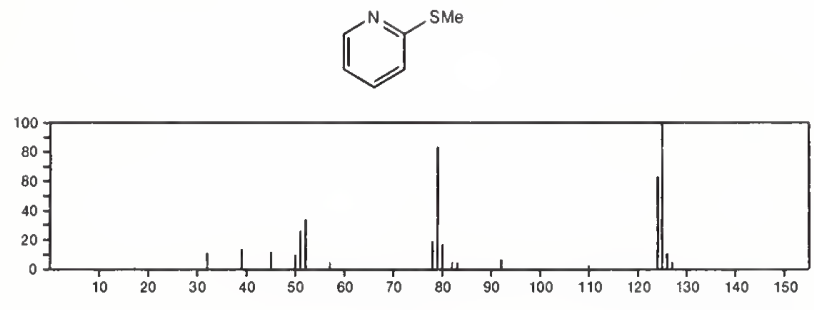

125

$\mathrm{C}_{6} \mathrm{H}_{7} \mathrm{NS}$

Pyridine, 3-(methylthio)-
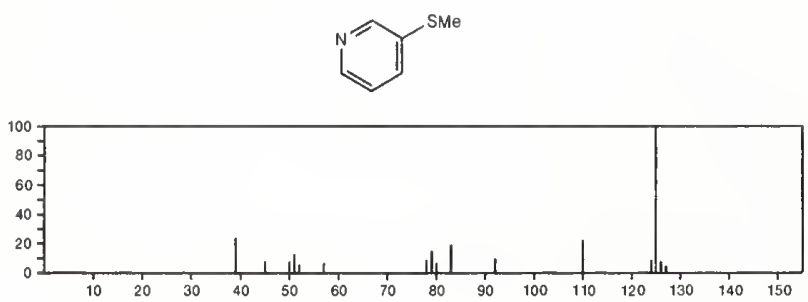

125

$\mathrm{C}_{6} \mathrm{H}_{7} \mathrm{NS}$

$36880-58-7$

Pyridinium, 3-mercapto-1-methyl-, hydroxide, inner salt
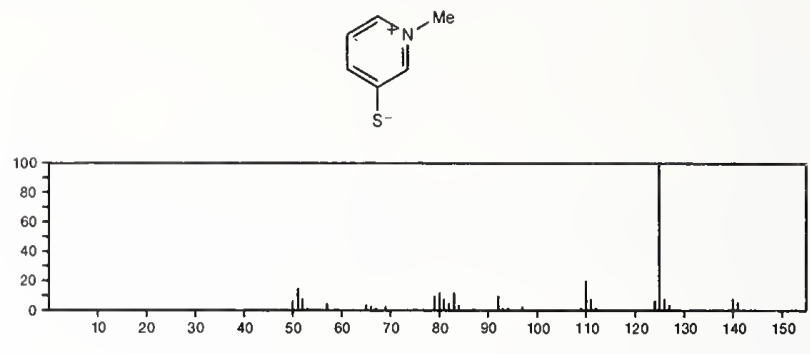

125

$\mathrm{C}_{6} \mathrm{H}_{11} \mathrm{~N}_{3}$

1 H-Imidazole-4-ethanamine, 1-methyl-

$501-75-7$<smiles>Cn1cnc(CCN)c1</smiles>

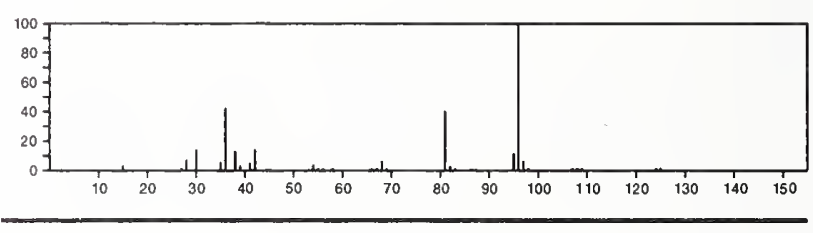

125

$\mathrm{C}_{6} \mathrm{H}_{11} \mathrm{~N}_{3}$

$644-42-8$

$1 H$-Imidazole-5 ethanamine, 1-methyl-
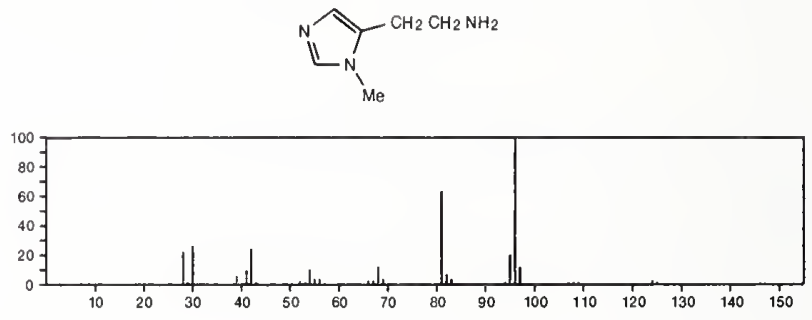

125

$1 H$-Imidazole-4-ethanamine, $N$-methyl

$673-50-7$
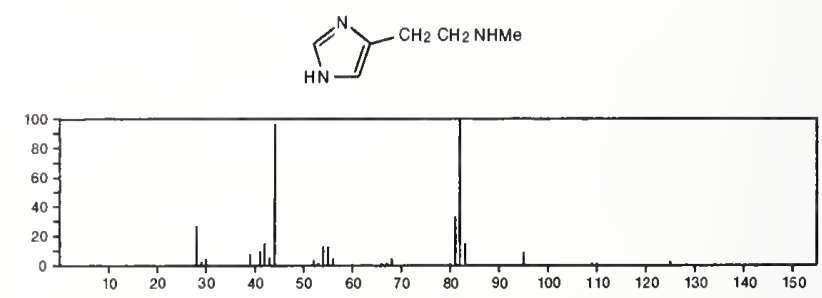

125

$\mathrm{C}_{6} \mathrm{H}_{11} \mathrm{~N}_{3}$

$6086-22-2$

1H-1,2,4-Triazole, 1-butyl-
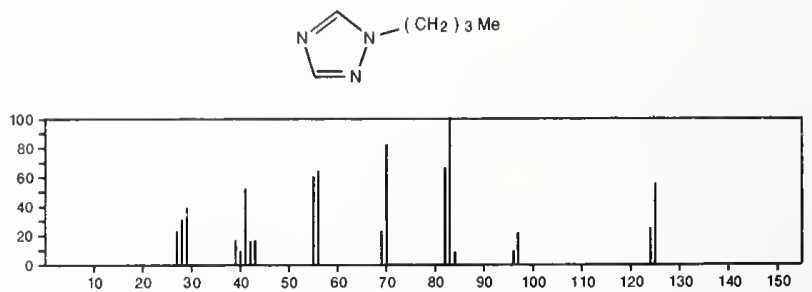
125

$\mathrm{C}_{6} \mathrm{H}_{11} \mathrm{~N}_{3}$

$1 H$-Imidazole-4-ethanamine, $\alpha$-methyl-

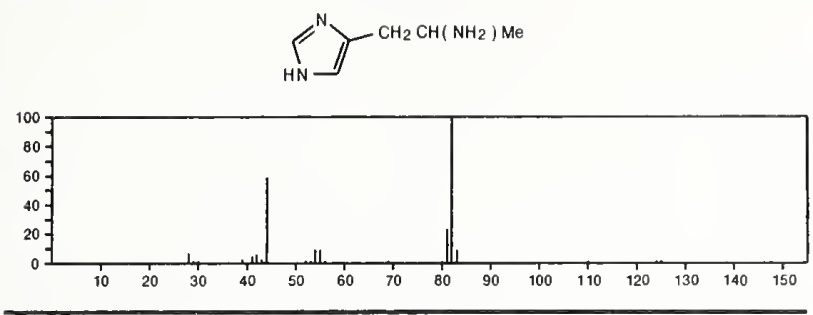

125

Cyclohexane, azido-

$\mathrm{C}_{6} \mathrm{H}_{11} \mathrm{~N}_{3}$

19573-22-9
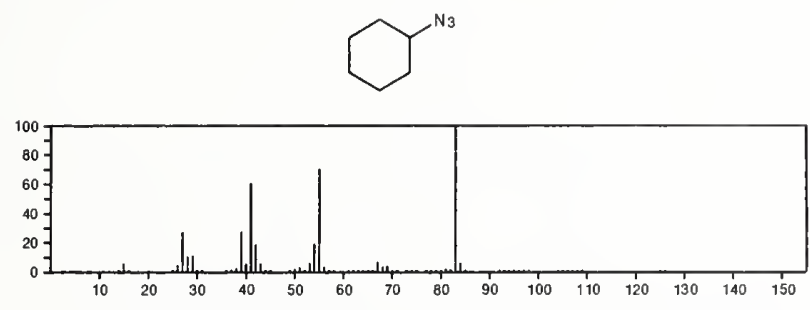

125

$\mathrm{C}_{6} \mathrm{H}_{11} \mathrm{~N}_{3}$

$1 H$-Imidazole-4-ethanamine, $\beta$-methyl-

$24160-42-7$
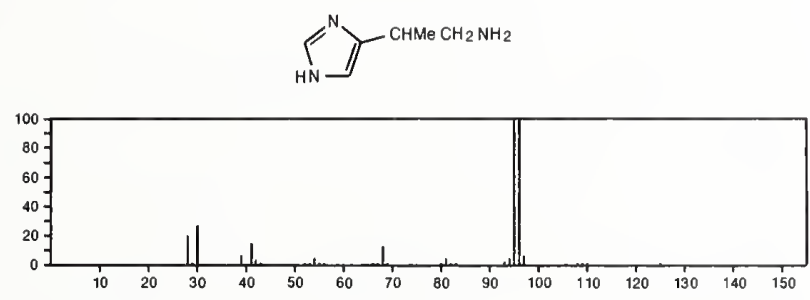

$125 \quad \mathrm{C}_{6} \mathrm{H}_{11} \mathrm{~N}_{3}$

$1 H$-Imidazole-4-ethanamine, 2-methyl-
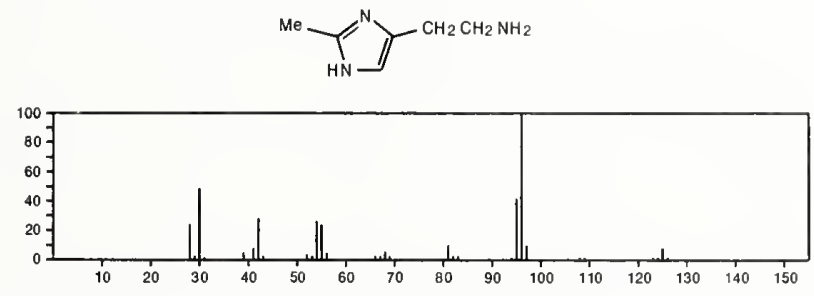

125

$\mathrm{C}_{6} \mathrm{H}_{11} \mathrm{~N}_{3}$

$1 \mathrm{H}$-Imidazole-4-ethanamine, 5-methyl-

$36507-31-0$
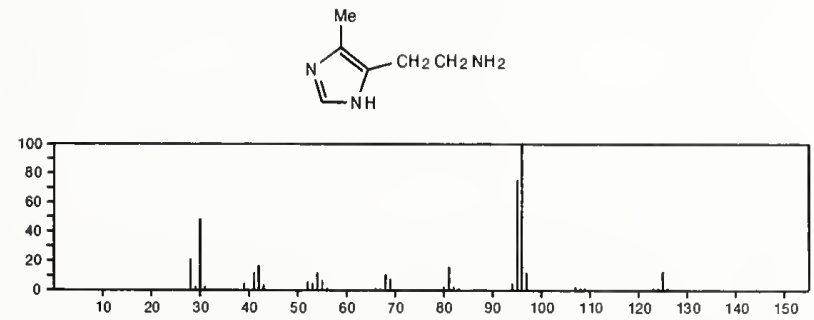

125

Pyridinium, 1-ethyl-, hydroxide

$36880-53-2$
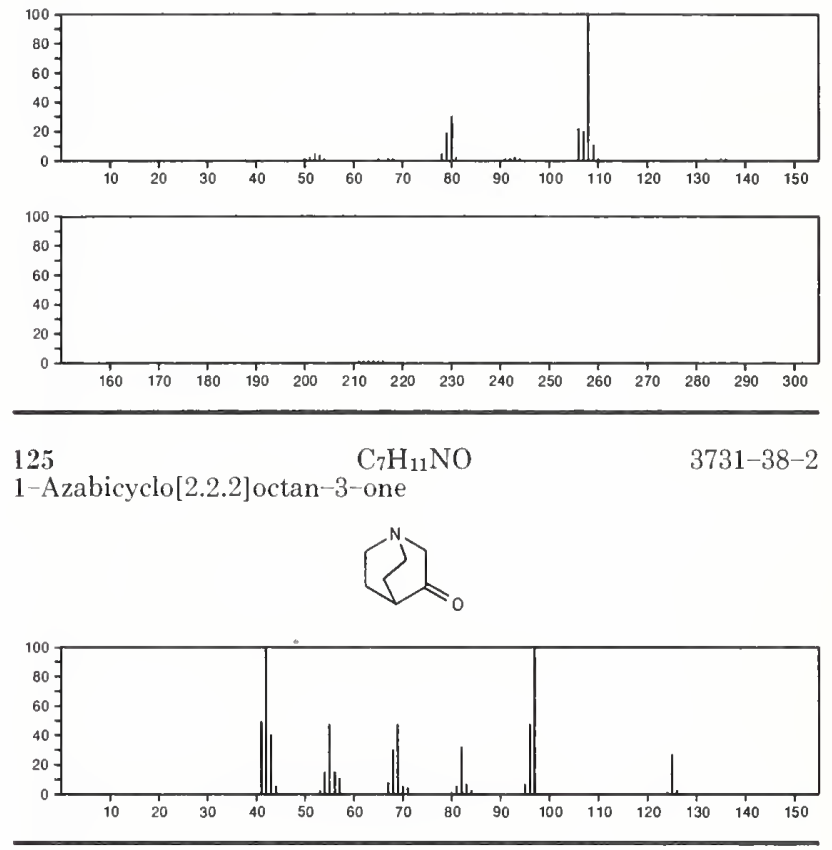

125

$\mathrm{C}_{7} \mathrm{H}_{11} \mathrm{NO}$

Pyridine, 1-acetyl-1,2,3,4-tetrahydro-

$19615-27-1$

$\overbrace{}^{-A C}$

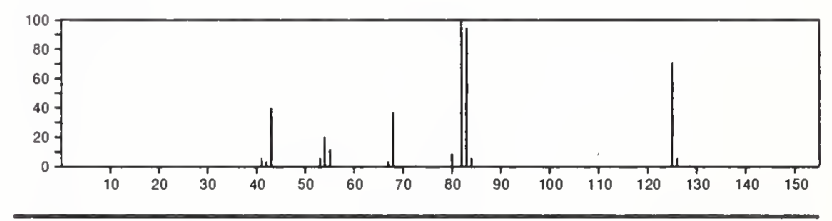

125

$\mathrm{C}_{8} \mathrm{H}_{15} \mathrm{~N}$

283-24-9

3-Azabicyclo[3.2.2]nonane
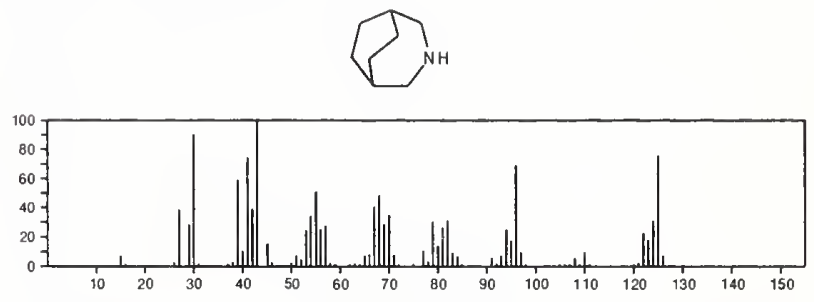

125

$\mathrm{C}_{8} \mathrm{H}_{15} \mathrm{~N}$

8-Azabicyclo[3.2.1] octane, 8-methyl-

$529-17-9$
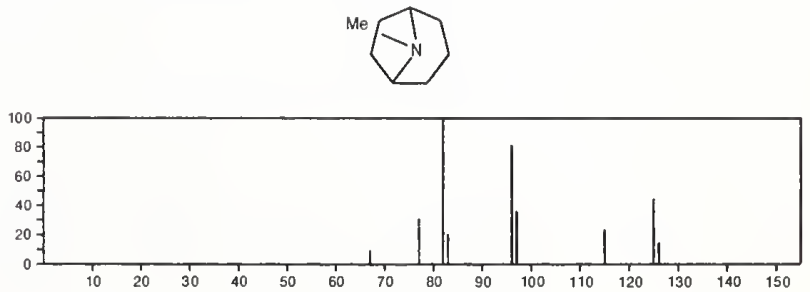
125

$\mathrm{C}_{8} \mathrm{H}_{15} \mathrm{~N}$

1-Azabicyclo[2.2.2]octane, 3-methyl-

695-88-5
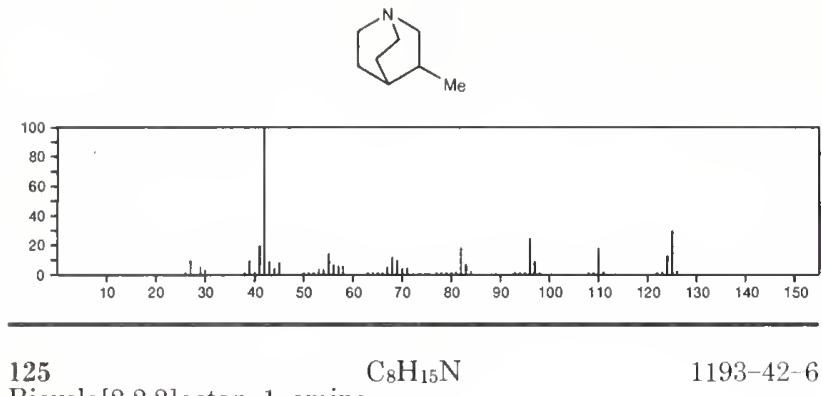

Bicyclo[2.2.2]octan-1-amine
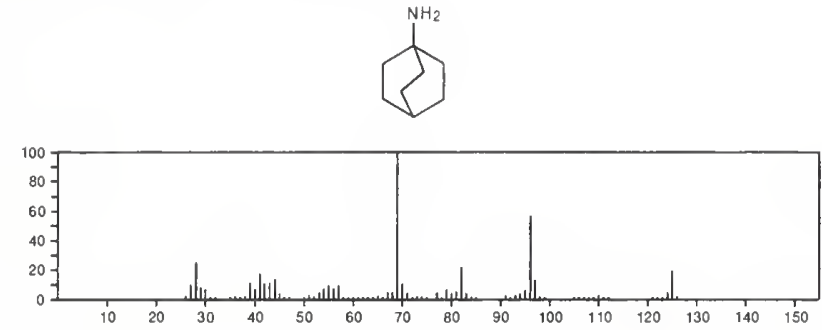

$125 \quad \mathrm{C}_{8} \mathrm{H}_{15} \mathrm{~N}$

Ethanamine, $N$-cyclohexylidene-

2201-14-1
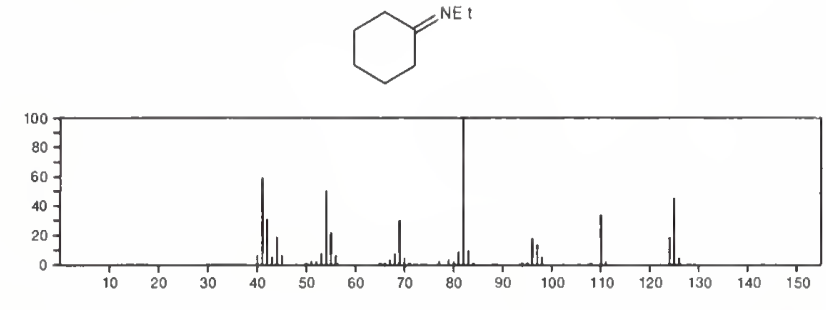

$125 \quad \mathrm{C}_{8} \mathrm{H}_{15} \mathrm{~N}$

Pyrrolidine, 1-(2-methyl-1-propenyl)-

$2403-57-8$

$\overbrace{\mathrm{N}}-\mathrm{CH}=\mathrm{CMe} 2$
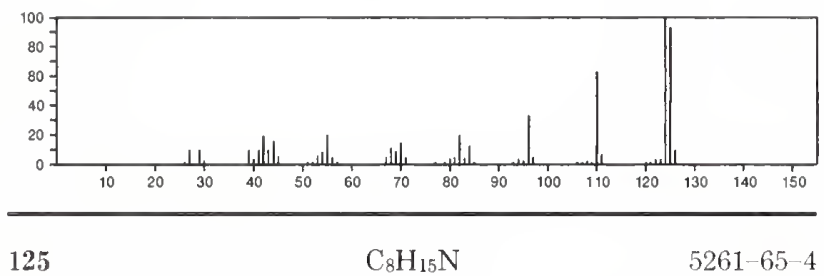

1-Azabicyclo[2.2.2]octane, 2-methy]-

$5261-65-4$
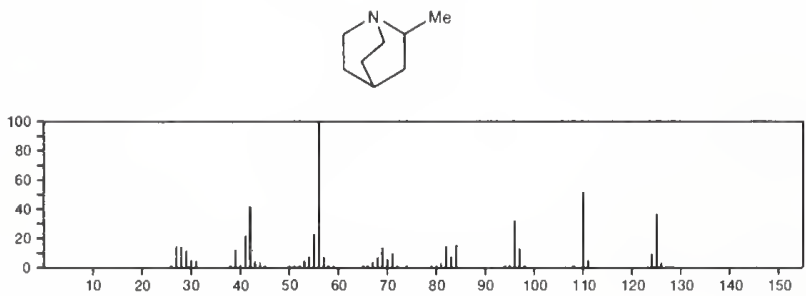

125

Piperidine, 1-(1-propenyl)

$\mathrm{C}_{8} \mathrm{H}_{15} \mathrm{~N}$

$7182-09-4$
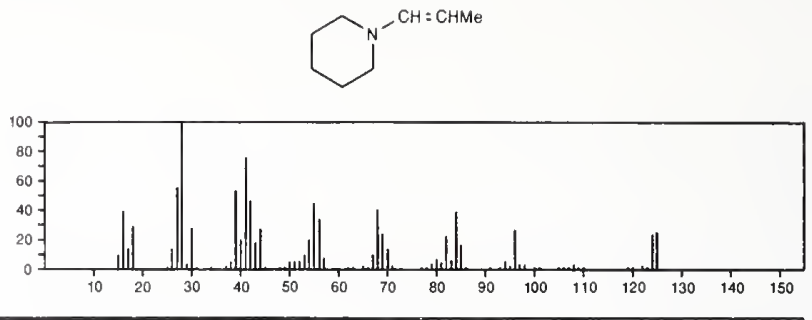

125

Indolizine, octahydro-

$\mathrm{C}_{8} \mathrm{H}_{15} \mathrm{~N}$

13618-93-4
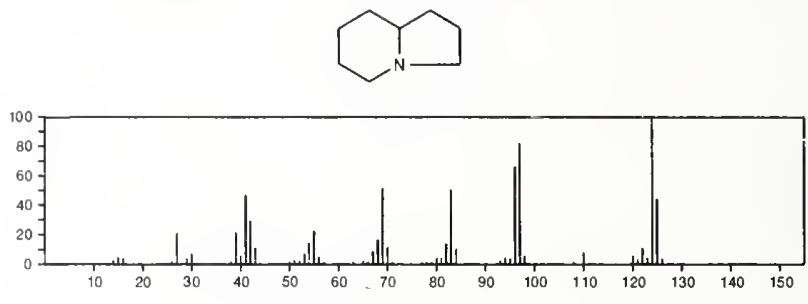

125

Pyrrolidine, 1-(1-butenyl)-

$\mathrm{C}_{8} \mathrm{H}_{15} \mathrm{~N}$

$13937-89-8$

$\overbrace{N}-\mathrm{CH}=\mathrm{CHEt}$

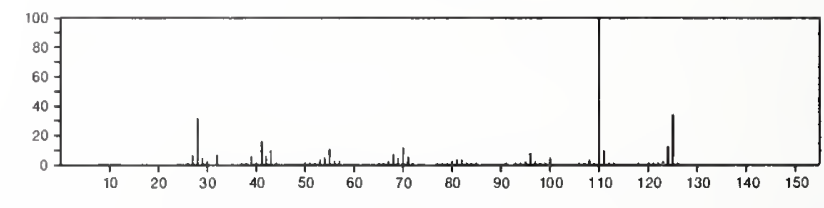

125

$\mathrm{C}_{8} \mathrm{H}_{15} \mathrm{~N}$

6 Azabicyclo[3.2.1]octane, 6-methyl-

$24173-54-4$
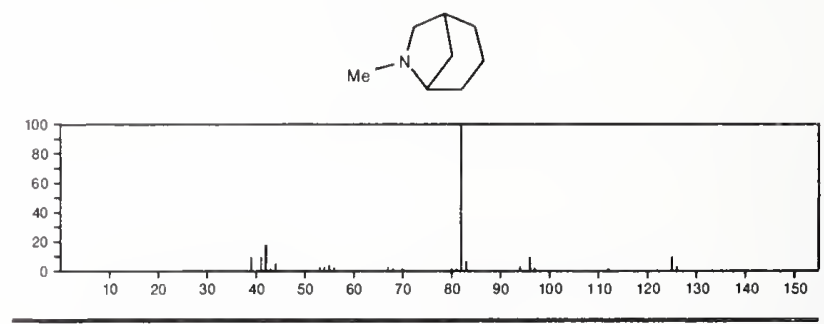

125

$\mathrm{C}_{8} \mathrm{H}_{15} \mathrm{~N}$

1 Cyclohepten-1-amine, 5-methyl-

$53907-56-5$
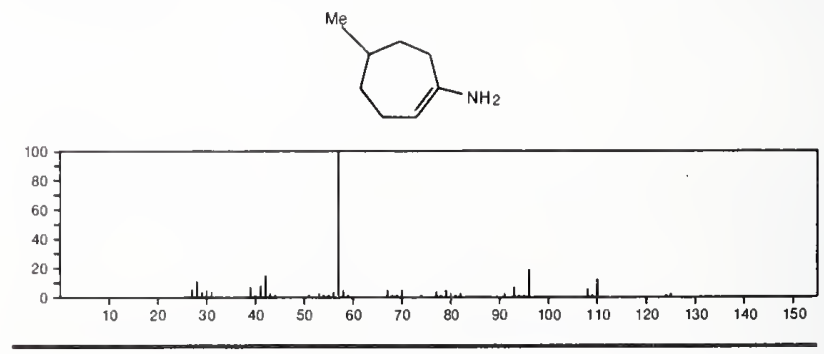

126

Ethanedioyl dichloride

$\mathrm{C}_{2} \mathrm{Cl}_{2} \mathrm{O}_{2}$

$79-37-8$

$\mathrm{CI} \operatorname{cococ} \mathrm{C}$

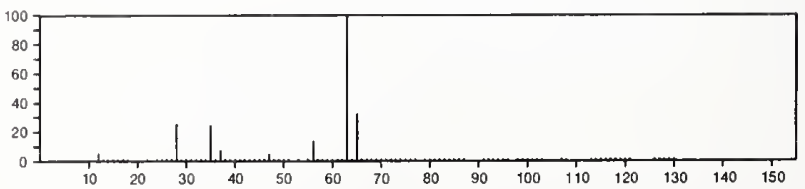


$126 \quad \mathrm{C}_{2} \mathrm{H}_{3} \mathrm{ClS}_{2}$

Carbonochloridodithioic acid, methyl ester

$16696-91-6$

$\mathrm{MeSC}$ (S) Cl

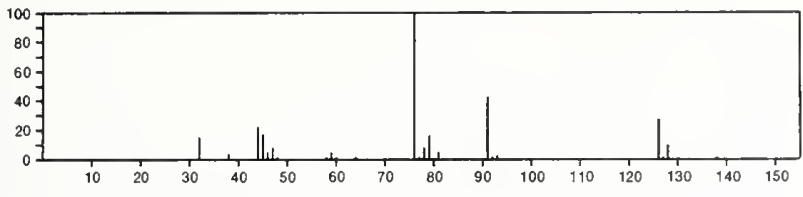

126

$\mathrm{C}_{2} \mathrm{H}_{4} \mathrm{BrF}$

$762-49-2$

Ethane, 1-bromo-2-fluoro-

$\mathrm{FCH}_{2} \mathrm{CH}_{2} \mathrm{Br}$

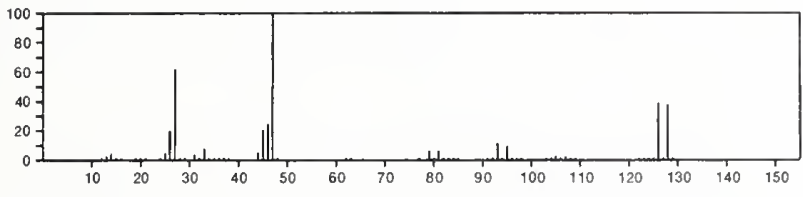

Sulfuric acid, dimethyl ester

$\mathrm{C}_{2} \mathrm{H}_{6} \mathrm{O}_{4} \mathrm{~S}$

$77-78-1$

$\mathrm{Me} \mathrm{OSO}_{2} \mathrm{OMe}$

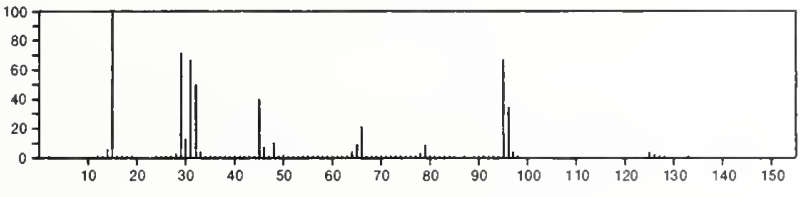

126

Trisulfide, dimethyl

$\mathrm{C}_{2} \mathrm{H}_{6} \mathrm{~S}_{3}$

Me SSSMe

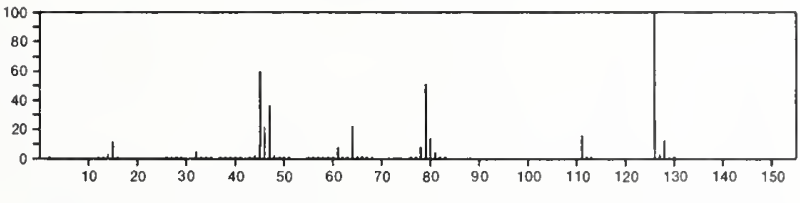

126

$\mathrm{C}_{3} \mathrm{H}_{4} \mathrm{Cl}_{2} \mathrm{O}$

$513-88-2$

2-Propanone, 1,1-dichloro

$\mathrm{Cl}_{2} \mathrm{CHCOMe}$

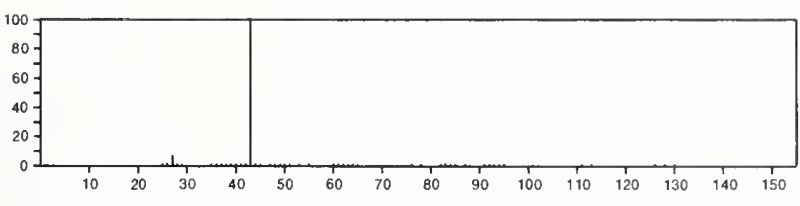

126

$\mathrm{C}_{3} \mathrm{H}_{4} \mathrm{Cl}_{2} \mathrm{O}$

$534-07-6$

2-Propanone, 1,3-dichloro-

$\mathrm{Cl} \mathrm{CH}_{2} \mathrm{COCH}_{2} \mathrm{Cl}$

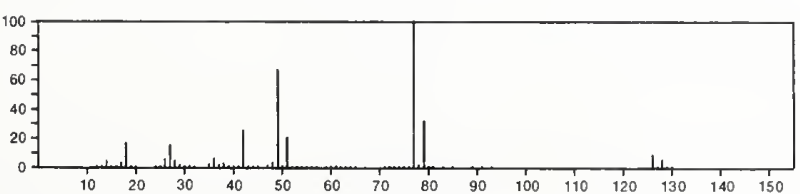

126

1,3,5-Triazine-2,4,6-triamine

$\mathrm{C}_{3} \mathrm{H}_{6} \mathrm{~N}_{6}$

$108-78-1$
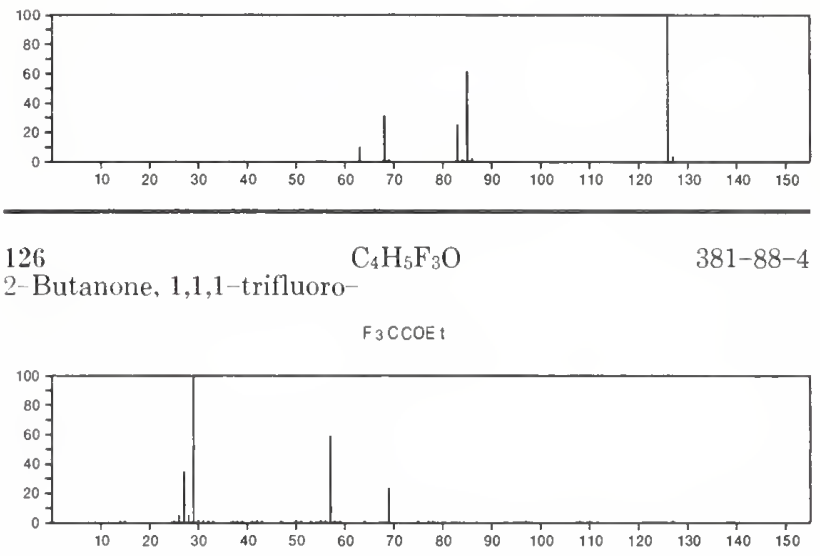

126

$\mathrm{C}_{4} \mathrm{H}_{6} \mathrm{~N}_{4} \mathrm{O}$

$56-06-4$

4(1H)-Pyrimidinone, 2,6-diamino-
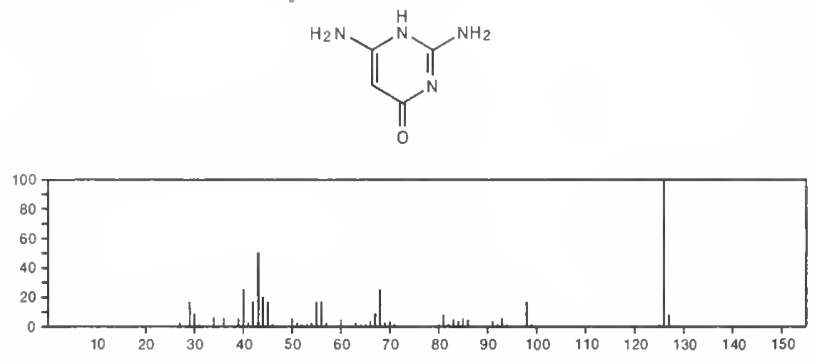

126

$\mathrm{C}_{4} \mathrm{H}_{6} \mathrm{~N}_{4} \mathrm{O}$

$360-97-4$

$1 \mathrm{H}$ Imidazole-4-carboxamide, 5-amino-
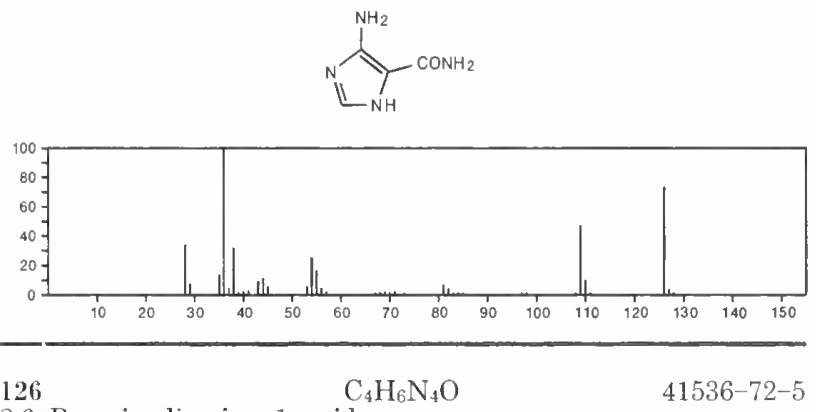

2,6-Pyrazinediamine, 1-oxide

$41536-72-5$
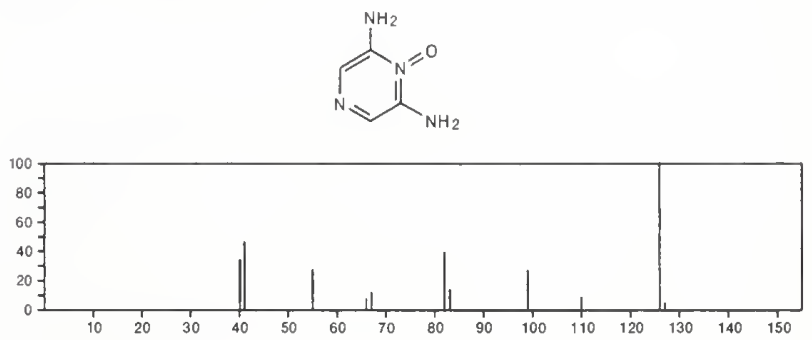
126

$\mathrm{C}_{4} \mathrm{H}_{8} \mathrm{Cl}_{2}$

Butane, 1,4-dichloro-

$\mathrm{Cl}\left(\mathrm{CH}_{2}\right){ }_{4} \mathrm{Cl}$

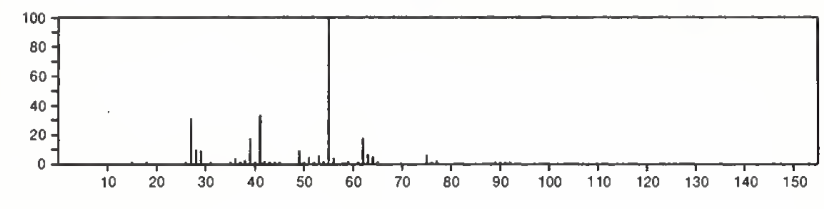

126

Butane, 1,1-dichloro-

$\mathrm{C}_{4} \mathrm{H}_{8} \mathrm{Cl}_{2}$

$\mathrm{Cl}_{2} \mathrm{CHPr}$

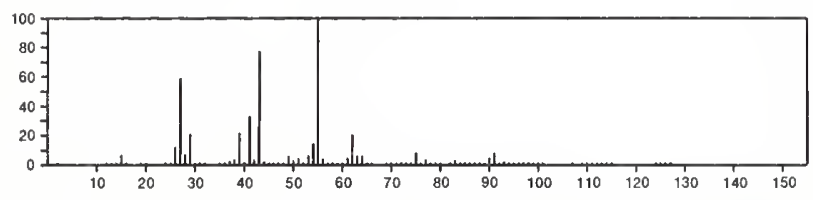

126

Propane, 1,2-dichloro-2-methyl-

$\mathrm{C}_{4} \mathrm{H}_{8} \mathrm{Cl}_{2}$

$\mathrm{ClCH}_{2} \mathrm{CClMe} 2$

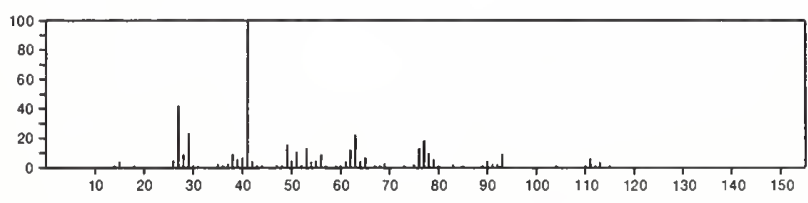

$126 \quad \mathrm{C}_{4} \mathrm{H}_{8} \mathrm{Cl}_{2}$

616-19-3

Propane, 1,3-dichloro-2-methyl-

$\mathrm{Cl} \mathrm{CH}_{2} \mathrm{CHMeCH}_{2} \mathrm{Cl}$
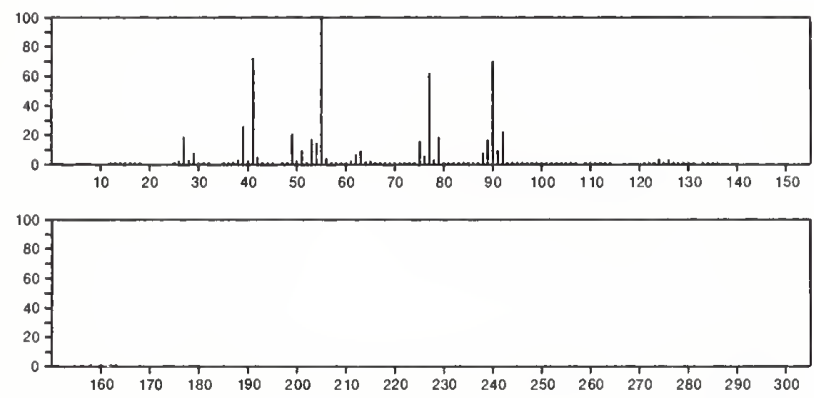

126

Butane, 1,2-dichloro-

$\mathrm{C}_{4} \mathrm{H}_{8} \mathrm{Cl}_{2}$

$616-21-7$

$\mathrm{ClCH}_{2} \mathrm{CHClEt}$

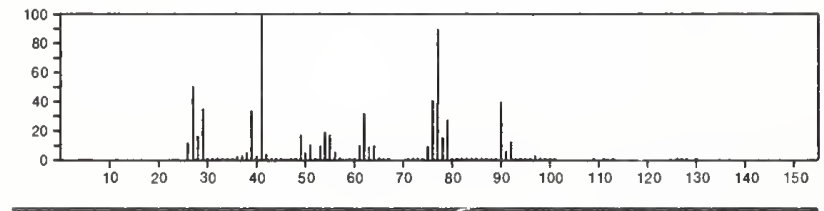

126

$\mathrm{C}_{4} \mathrm{H}_{8} \mathrm{C}_{22}$

$1190-22-3$

Butane, 1,3-dichloro-

$\mathrm{Cl} \mathrm{CH}_{2} \mathrm{CH}_{2} \mathrm{CHCl} \mathrm{Me}$

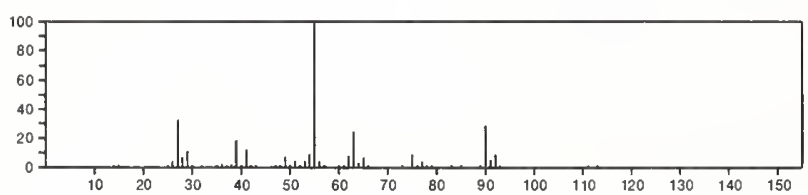

126

$\mathrm{C}_{4} \mathrm{H}_{8} \mathrm{Cl}_{2}$

Butane, 2,3-dichloro-, $\left(R^{*}, R^{*}\right)-( \pm)$ -

$2211-67-8$

$\mathrm{MeCHCI} \mathrm{CHCIMe}$

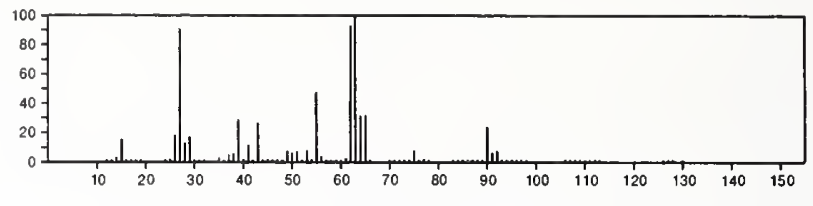

$126 \quad \mathrm{C}_{4} \mathrm{H}_{8} \mathrm{Cl}_{2}$

Butane, 2,3-dichloro-, $\left(R^{*}, S^{*}\right)$ -

4028-56-2

$\mathrm{MeCHCI} \mathrm{CHCIMe}$

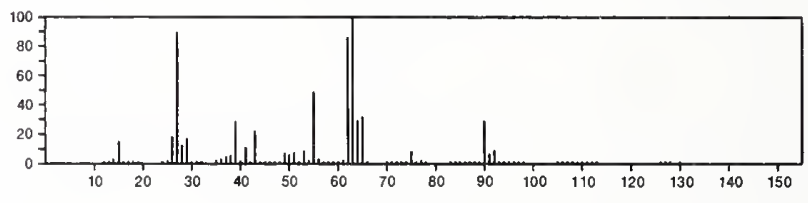

126

Butane, 2,2-dichloro-

$\mathrm{C}_{4} \mathrm{H}_{8} \mathrm{Cl}_{2}$

4279-22-5

$\mathrm{E}(\mathrm{CCl} 2\{\mathrm{E}\}$

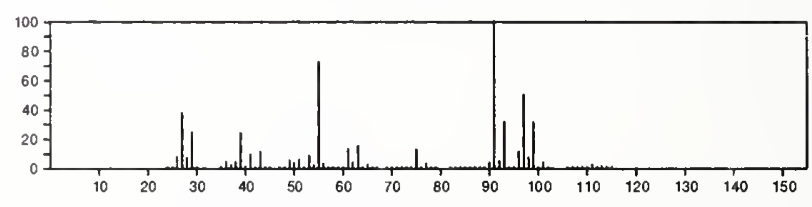

126

Butane, 2,3-dichloro-

$\mathrm{C}_{4} \mathrm{H}_{8} \mathrm{Cl}_{2}$

$7581-97-7$

$\mathrm{MeCHCI} \mathrm{CHCl} \mathrm{Me}$

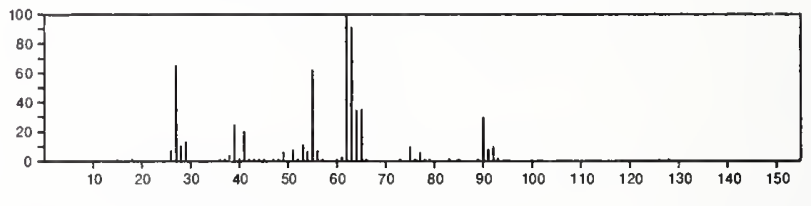

126

${ }^{2}$-Tetrazaboroline, 1,4-diethyl-

$19258-82-3$<smiles>CCN1[B]N(CC)N=N1</smiles>

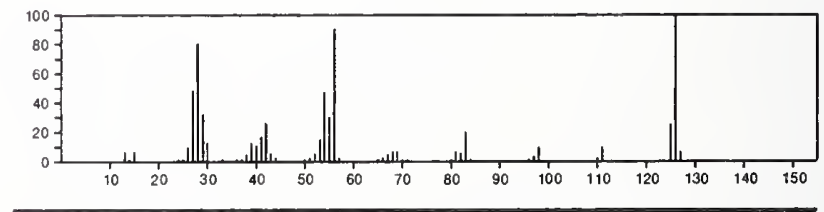

126

$\mathrm{C}_{5} \mathrm{H}_{6} \mathrm{~N}_{2} \mathrm{O}_{2}$

2,4(1H,3H)-Pyrimidinedione, 5-methyl-

$65-71-4$<smiles>Cc1c[nH]c(=O)[nH]c1=O</smiles>

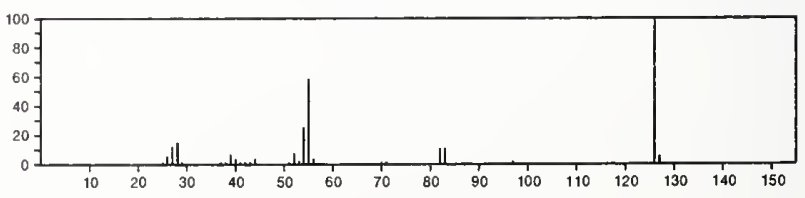


$126 \quad \mathrm{C}_{5} \mathrm{H}_{6} \mathrm{~N}_{2} \mathrm{O}_{2}$

2,4 $(1 H, 3 H)$-Pyrimidinedione, 6 -methyl-
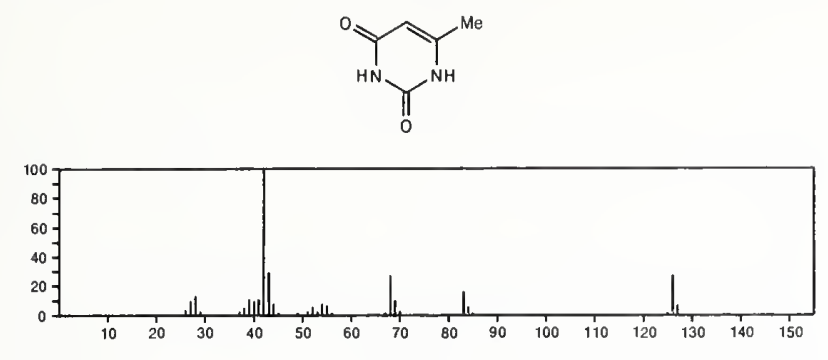

$126 \quad \mathrm{C}_{5} \mathrm{H}_{6} \mathrm{~N}_{2} \mathrm{O}_{2}$

$5754-18-7$

3,6-Pyridazinedione, 1,2-dihydro-4-methyl-
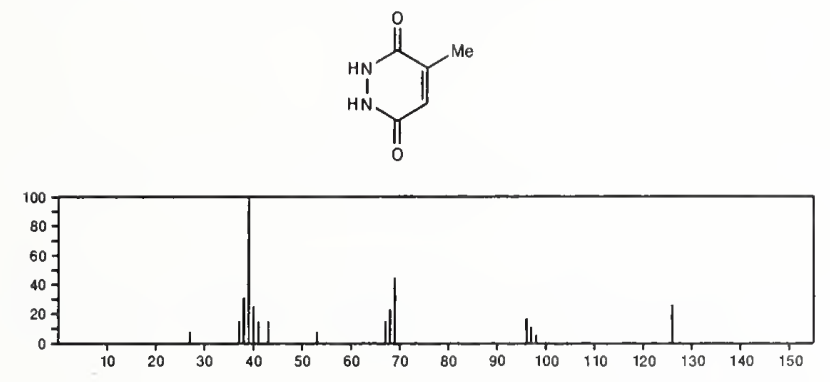

126

$\mathrm{C}_{5} \mathrm{H}_{6} \mathrm{~N}_{2} \mathrm{O}_{2}$

4(1H)-Pyrimidinone, 5-hydroxy-2-methyl-
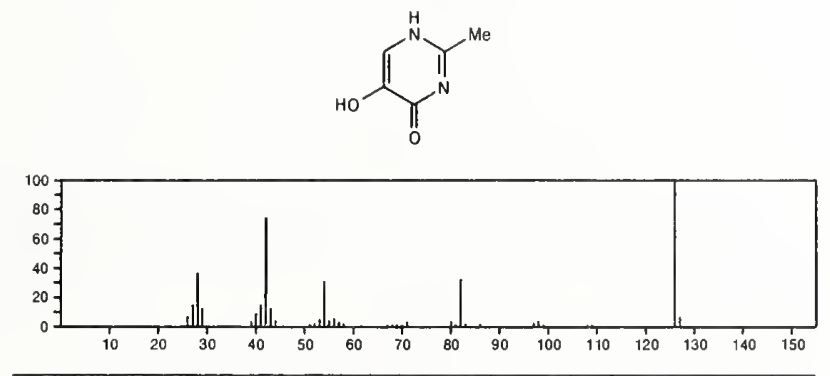

$126 \quad \mathrm{C}_{5} \mathrm{H}_{6} \mathrm{~N}_{2} \mathrm{O}_{2} \quad 29397-21-5$

2,4-Pentanedione, 3-diazo-

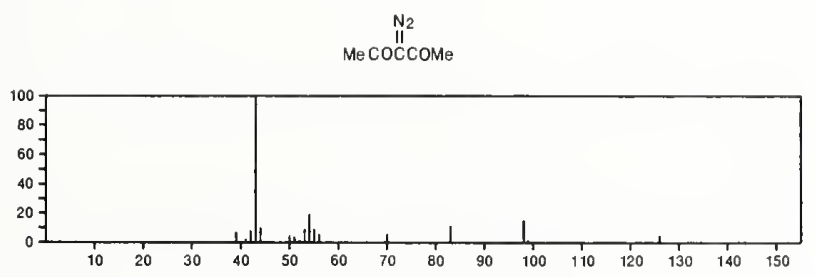

126

$\mathrm{C}_{5} \mathrm{H}_{6} \mathrm{~N}_{2} \mathrm{O}_{2}$

40704-11-8

$1 \mathrm{H}$-Pyrazole-4-carboxylic acid, 3-methyl
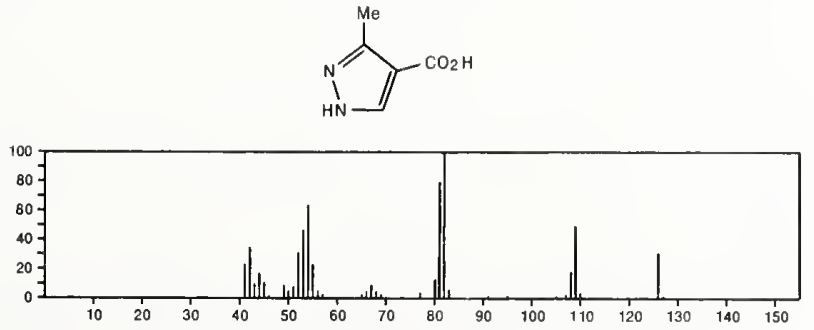

126

$\mathrm{C}_{5} \mathrm{H}_{6} \mathrm{~N}_{2} \mathrm{O}_{2}$

Formamide, $N$-(3-methyl-5-isoxazolyl)-

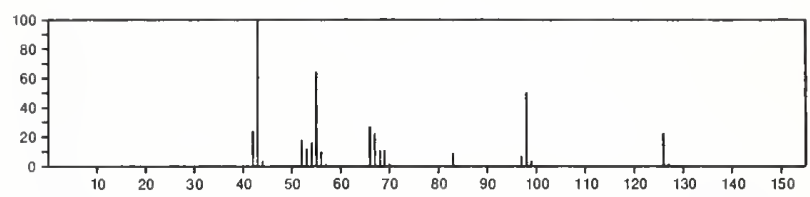

126

$\mathrm{C}_{5} \mathrm{H}_{6} \mathrm{~N}_{2} \mathrm{~S}$

4(1H)-Pyrimidinethione, 2-methyl-

$33643-86-6$
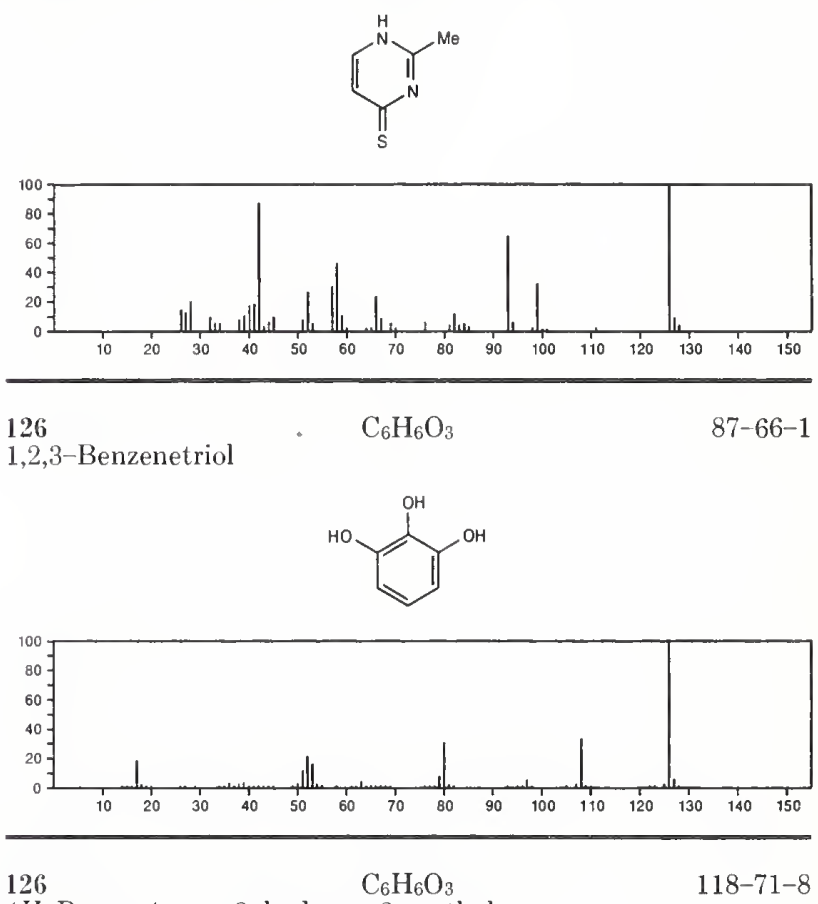

4H-Pyran-4-one, 3-hydroxy-2-methyl-

$118-71-8$
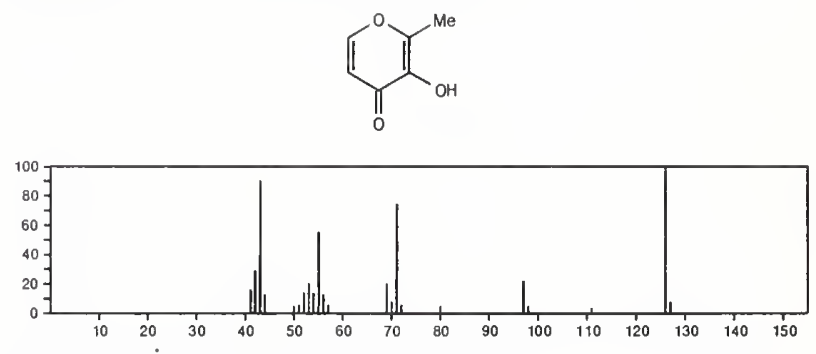

$126 \quad \mathrm{C}_{6} \mathrm{H}_{6} \mathrm{O}_{3}$

2-Furancarboxylic acid, methyl ester

$611-13-2$

(I)

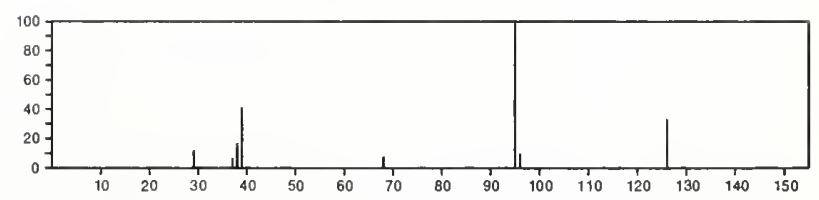


$\mathrm{C}_{6} \mathrm{H}_{6} \mathrm{O}_{3}$

4H-Pyran-4-one, 5-hydroxy-2-methyl<smiles>O=c1cc([N+](=O)[O-])occ1O</smiles>

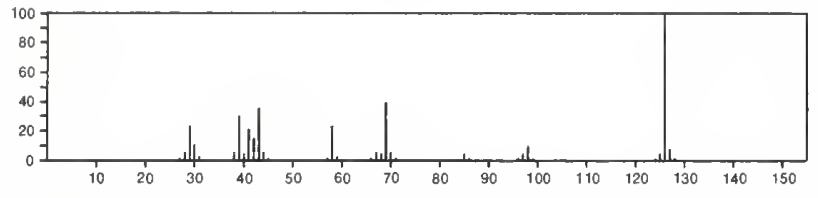

$126 \quad \mathrm{C}_{6} \mathrm{H}_{6} \mathrm{O}_{3}$

2H-Pyran-2-one, 4-hydroxy-6-methyl
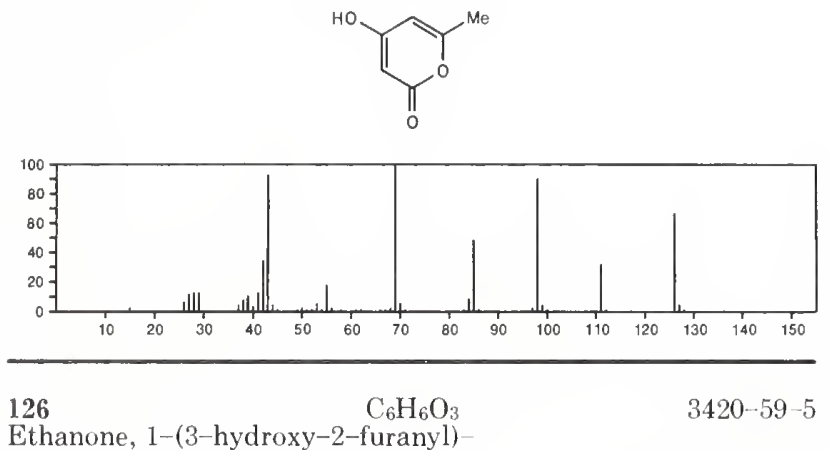

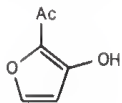

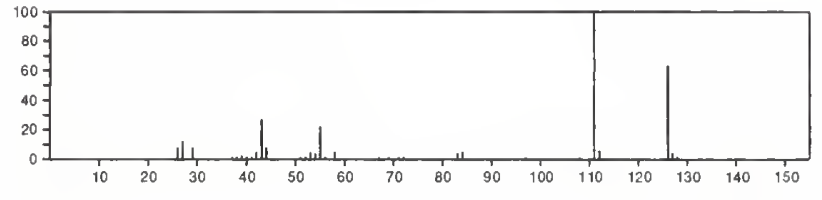

$126 \quad \mathrm{C}_{6} \mathrm{H}_{6} \mathrm{O}_{3}$

1,2,4-Cyclopentanetrione, 3-methyl-
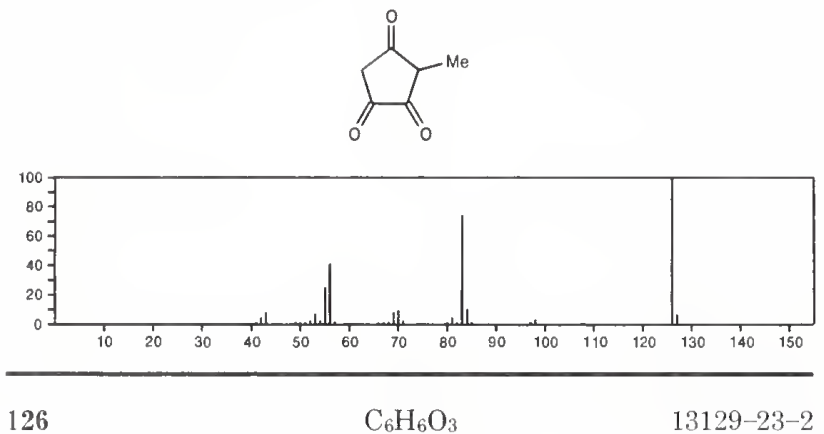

3-Furancarboxylic acid, methyl ester

$13129-23-2$

YC(O) OMe

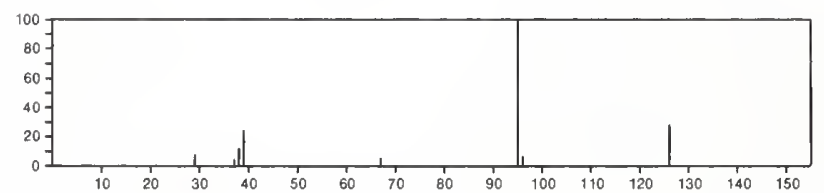

126

$1632-26-4$

2-Diazabicyclo[2.2.2]octan-3-one
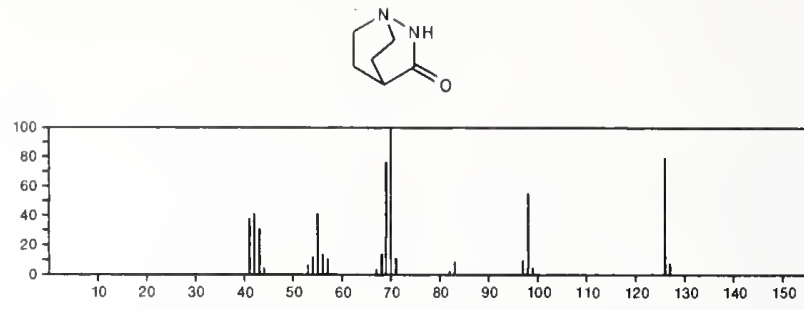

126

$\mathrm{C}_{6} \mathrm{H}_{10} \mathrm{~N}_{2} \mathrm{O}$

$3201-20-5$

3H-Pyrazol-3-one, 2,4-dihydro-4,4,5-trimethyl-
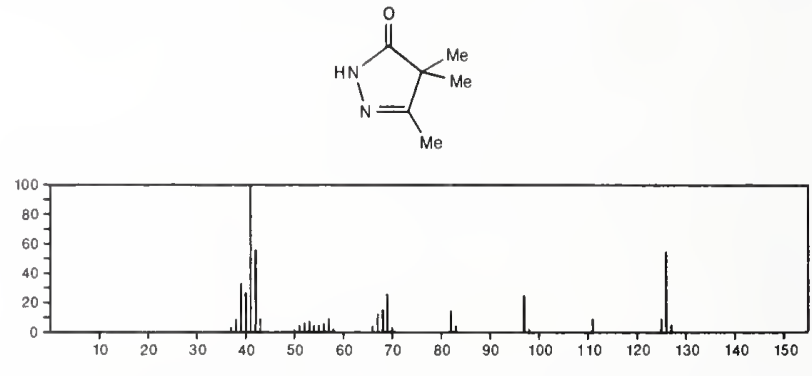

126
$1 H$-Pyrazole, 3 -ethoxy-5-methyl-

$3201-21-6$
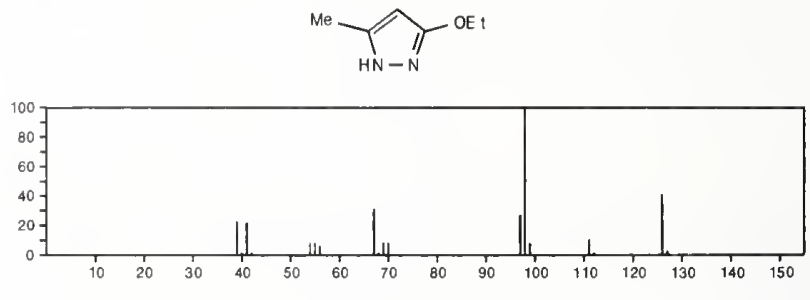

126

$\mathrm{C}_{6} \mathrm{H}_{10} \mathrm{~N}_{2} \mathrm{O}$

$3201-26-1$

3H-Pyrazol-3-one, 1,2-dihydro-1,2,5-trimethyl-
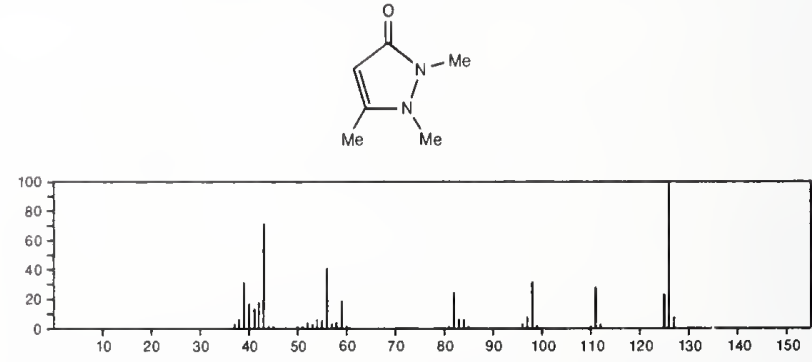

126

$\mathrm{C}_{6} \mathrm{H}_{10} \mathrm{~N}_{2} \mathrm{O}$

$17826-82-3$

3H-Pyrazol-3-one, 2,4-dihydro-2,4,5-trimethyl-
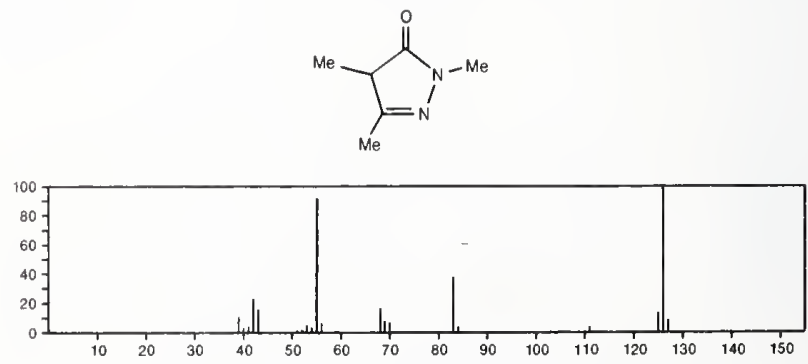
126

$\mathrm{C}_{6} \mathrm{H}_{10} \mathrm{~N}_{2} \mathrm{O}$

$53091-80-8$

$1 H$-Pyrazole, 5-methoxy-1,3-dimethyl-
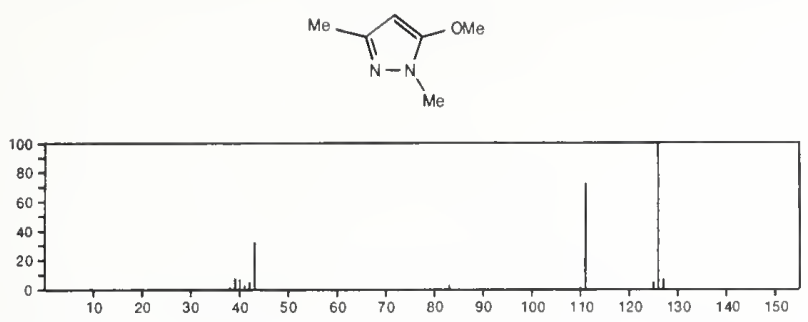

\section{6}

$\mathrm{C}_{6} \mathrm{H}_{10} \mathrm{~N}_{2} \mathrm{O}$

$53907-65-6$ methyl-

$\mathrm{NC}\left(\mathrm{CH}_{2}\right)$ 3 CONHME

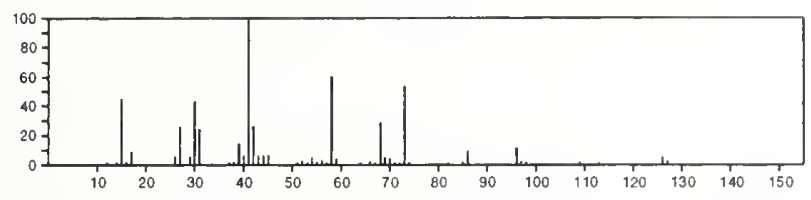

126

Boric acid $\left(\mathrm{HBO}_{2}\right)$, cyclohe

$\mathrm{C}_{6} \mathrm{H}_{11} \mathrm{BO}$
exyl ester
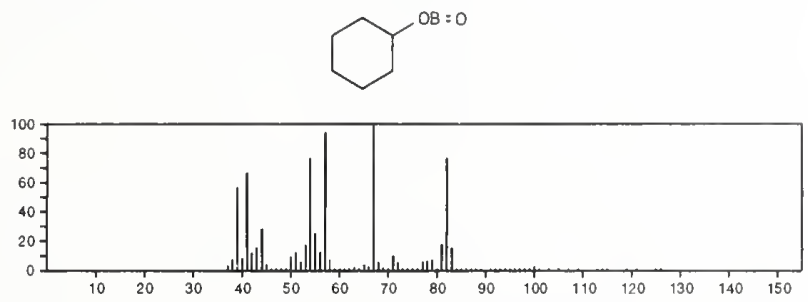

126

$\mathrm{C}_{7} \mathrm{H}_{7} \mathrm{Cl}$

Benzene, 1-chloro-2-methyl-
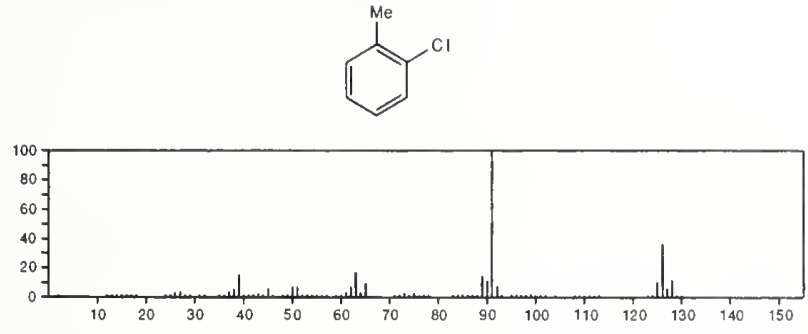

126

Benzene, (chloromethyl)-

$\mathrm{C}_{7} \mathrm{H}_{7} \mathrm{Cl}$

$100-44-7$

$\mathrm{ClCH}_{2} \mathrm{Ph}$

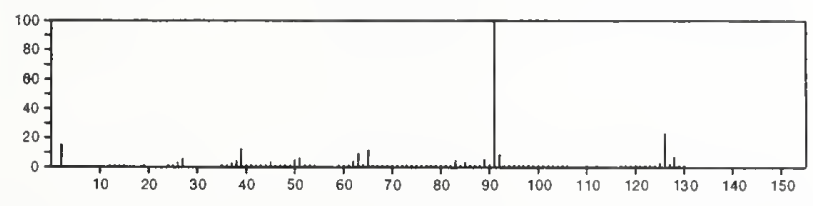

126

$\mathrm{C}_{7} \mathrm{H}_{7} \mathrm{Cl}$

$106-43-4$

Benzene, 1-chloro-4-methyl-
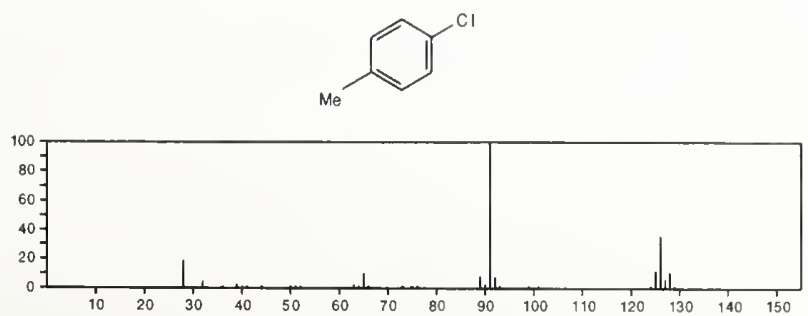

126

$\mathrm{C}_{7} \mathrm{H}_{7} \mathrm{Cl}$

$108-41-8$

Benzene, 1-chloro-3-methyl-
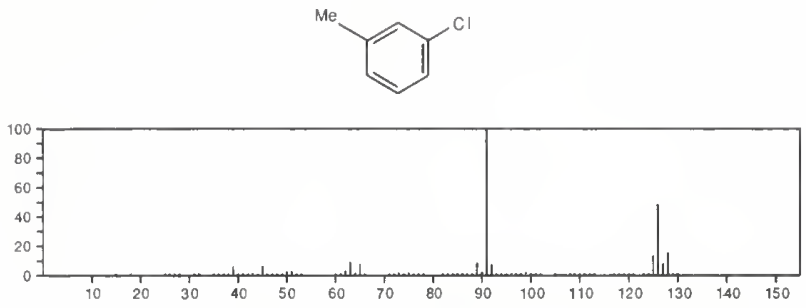

$126 \quad \mathrm{C}_{7} \mathrm{H}_{7} \mathrm{FO}$

$321-28-8$

Benzene, 1-fluoro-2-methoxy
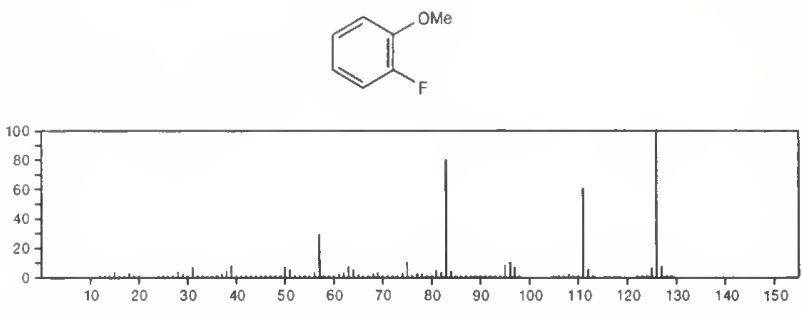

126

$\mathrm{C}_{7} \mathrm{H}_{7} \mathrm{FO}$

$456-47-3$

Benzenemethanol, 3-fluoro
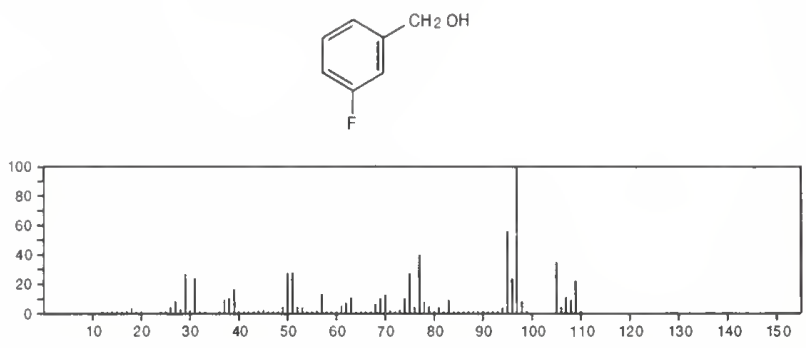

126

$\mathrm{C}_{7} \mathrm{H}_{7} \mathrm{FO}$

459-60-9

Benzene, 1-fluoro-4-methoxy-
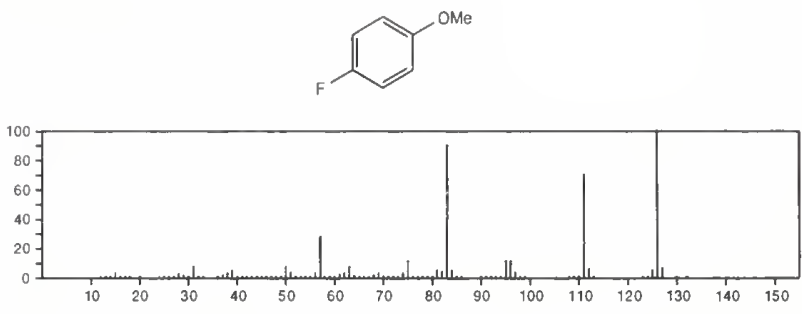

126

$\mathrm{C}_{7} \mathrm{H}_{10} \mathrm{O}_{2}$

96-05-9

2-Propenoic acid, 2-methyl-, 2-propenyl ester

$\mathrm{H}_{2} \mathrm{C}=\mathrm{CMe} \mathrm{C}(\mathrm{O}) \mathrm{OCH}_{2} \mathrm{CH}=\mathrm{CH}_{2}$

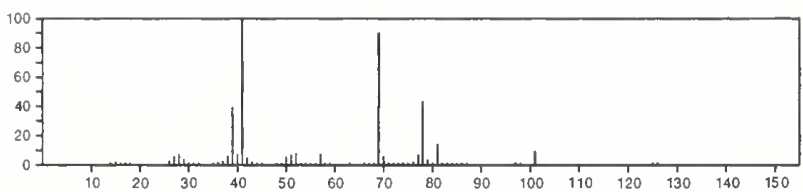


126

$\mathrm{C}_{7} \mathrm{H}_{10} \mathrm{O}_{2}$

1-Cyclohexene-1-carboxylic acid

$636-82-8$
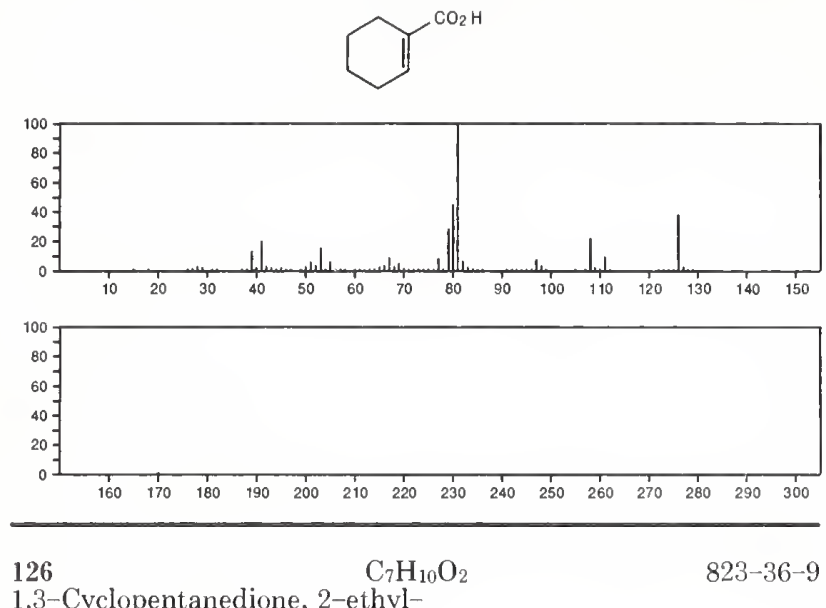

1,3-Cyclopentanedione, 2-ethyl-
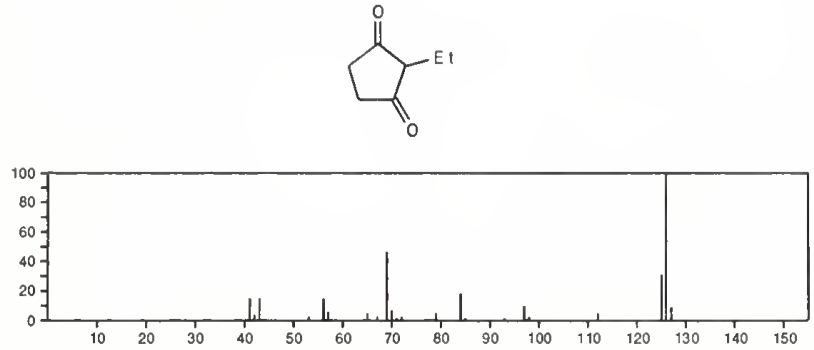

126

2(3H)-Furanone, 5-ethenyldihydro-5-methyl-
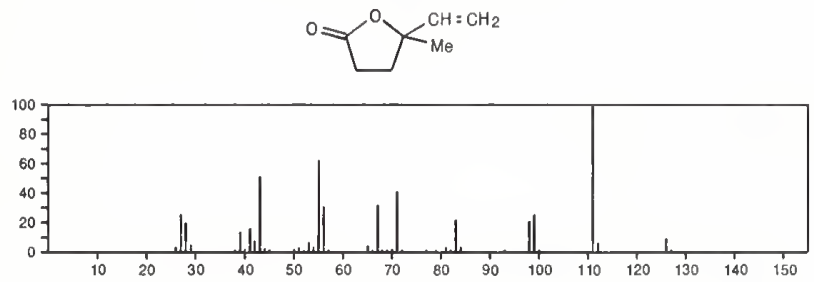

$126 \quad \mathrm{C}_{7} \mathrm{H}_{10} \mathrm{O}_{2}$

$1515-80-6$

2,4-Hexadienoic acid, methyl ester

$\mathrm{MeCH}=\mathrm{CHCH}=\mathrm{CHC}(\mathrm{O}) \mathrm{OMe}$

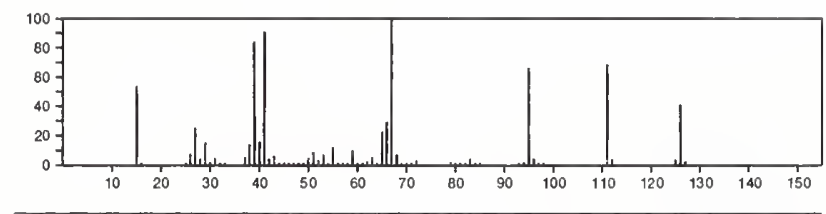

$126 \quad \mathrm{C}_{7} \mathrm{H}_{10} \mathrm{O}_{2}$

1,3-Cyclopentanedione, 2,2-dimethyl-

$3883-58-7$
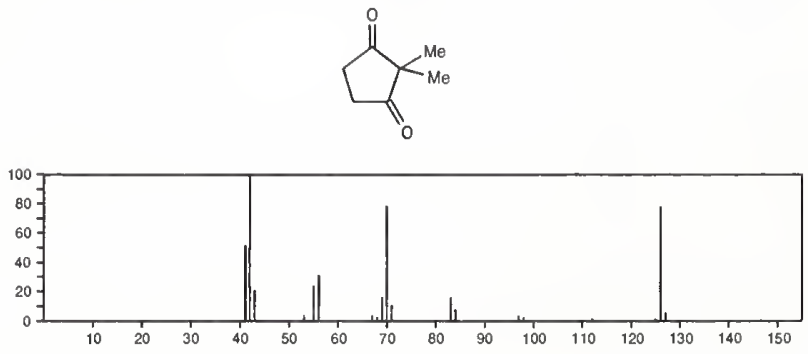

126

$\mathrm{C}_{7} \mathrm{H}_{10} \mathrm{O}_{2}$

1,3-Cyclopentanedione, 4,4-dimethyl-
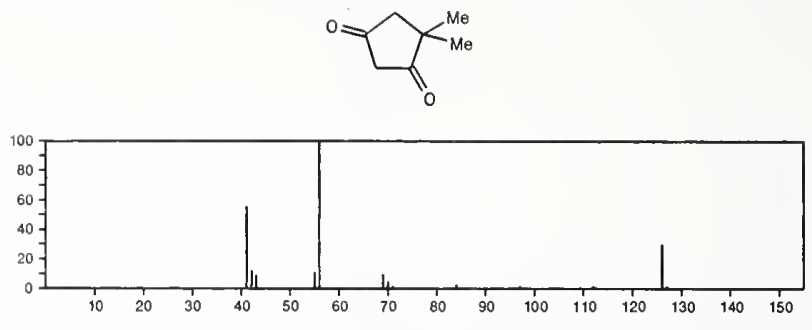

126

$\mathrm{C}_{7} \mathrm{H}_{10} \mathrm{O}_{2}$

$\mathrm{C}_{7} \mathrm{H}_{10}$

$4771-80-6$
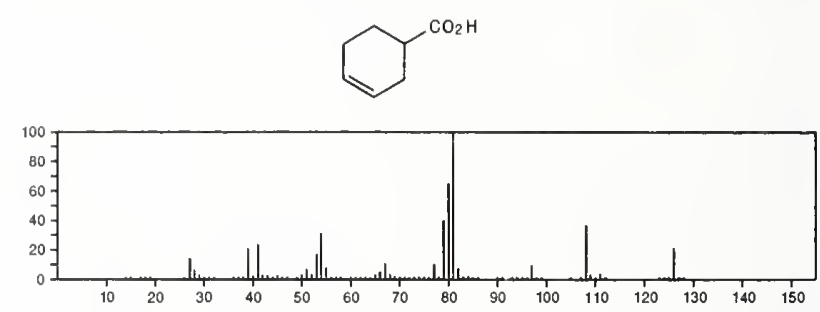

126

$\mathrm{C}_{7} \mathrm{H}_{10} \mathrm{O}_{2}$

$7180-60-1$

2-Cyclopenten-1-one, 3-methoxy-5-methyl-
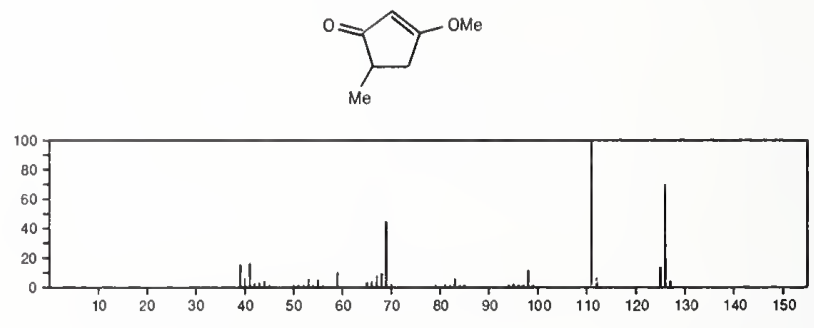

126

$\mathrm{C}_{7} \mathrm{H}_{10} \mathrm{O}_{2}$

$7180-61-2$

2-Cyclopenten-1-one, 3-methoxy-4-methyl-
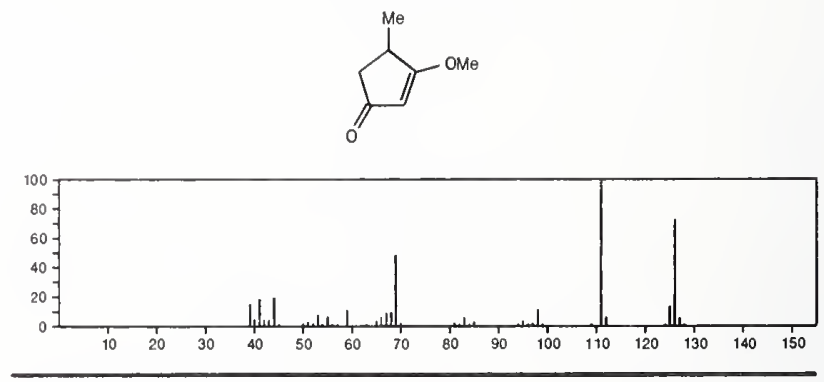

126

$\mathrm{C}_{7} \mathrm{H}_{10} \mathrm{O}_{2}$

17714-49-7

5,8-Dioxaspiro[3.4]octane, 1-methylene-
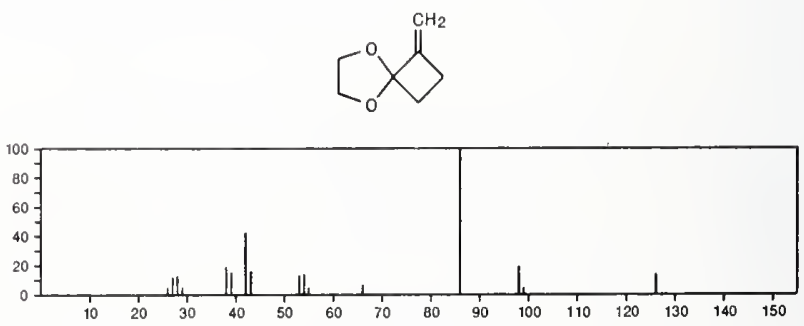
126

$\mathrm{C}_{7} \mathrm{H}_{10} \mathrm{O}_{2}$

2-Butenoic acid, 2-propenyl ester

$\mathrm{H}_{2} \mathrm{C}=\mathrm{CHCH}_{2} \mathrm{OC}(\mathrm{O}) \mathrm{CH}=\mathrm{CHM}$

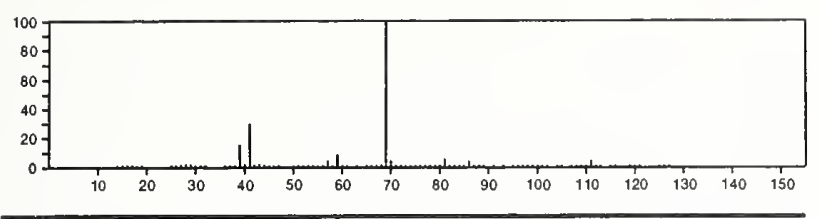

126

$\mathrm{C}_{7} \mathrm{H}_{10} \mathrm{O}_{2}$

21889-89-4

7-Oxabicyclo[4.1.0]heptan-2-one, 6-methyl-
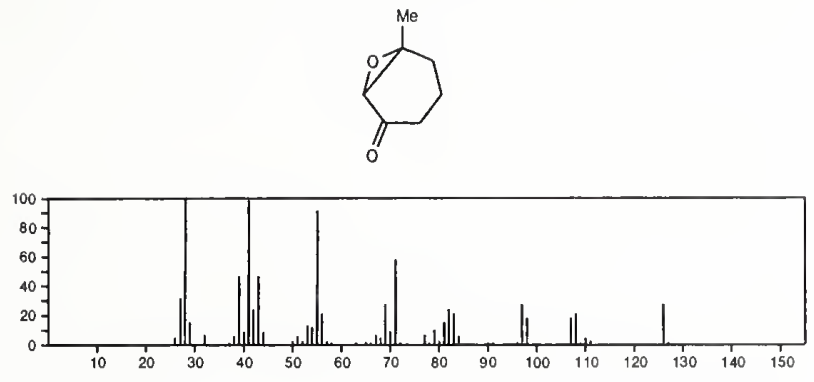

126

1,3-Cyclopentanedione, 2,4-dimethyl-
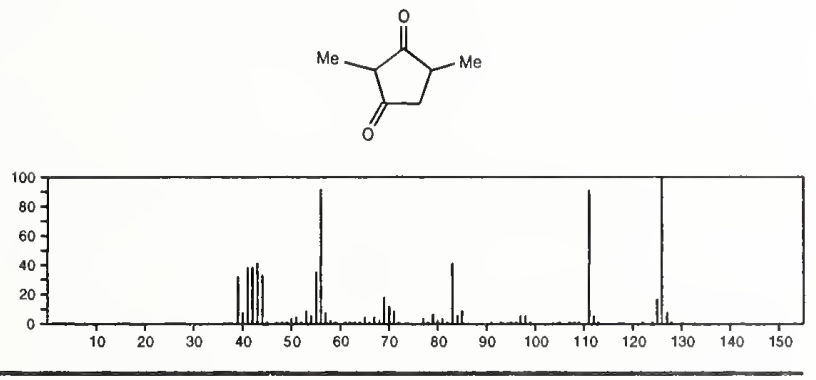

$126 \quad \mathrm{C}_{7} \mathrm{H}_{10} \mathrm{O}_{2}$

1,3-Cyclopentanedione, 4,5-dimethyl-

$35029-05-1$
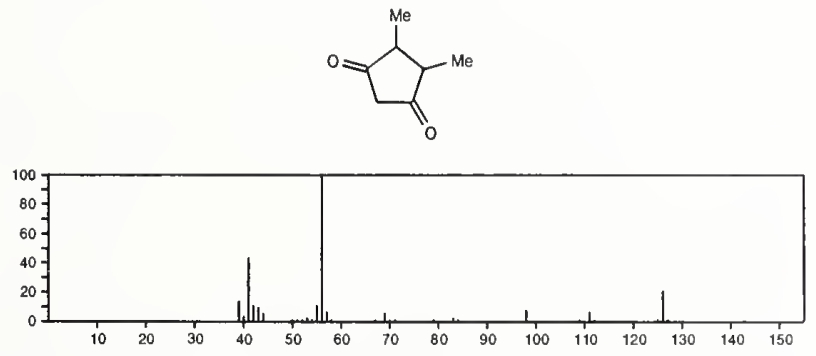

$126 \quad \mathrm{C}_{7} \mathrm{H}_{10} \mathrm{O}_{2}$

2(5H)-Furanone, 3,5,5-trimethyl-
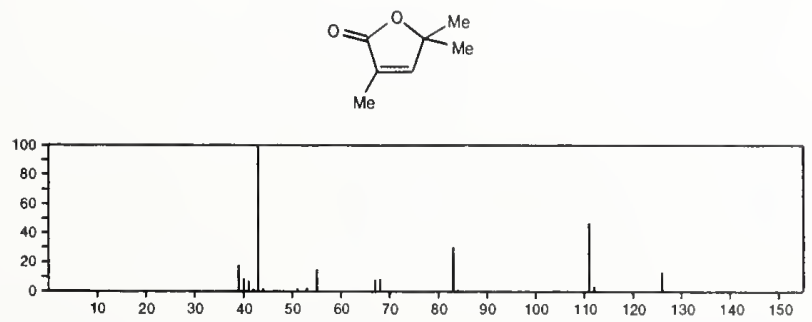

$126 \quad \mathrm{C}_{7} \mathrm{H}_{10} \mathrm{O}_{2}$

4-Pentenoic acid, 2-methylene--, methyl ester

$51122-89-5$ $\mathrm{CH}_{2}$

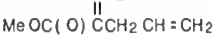

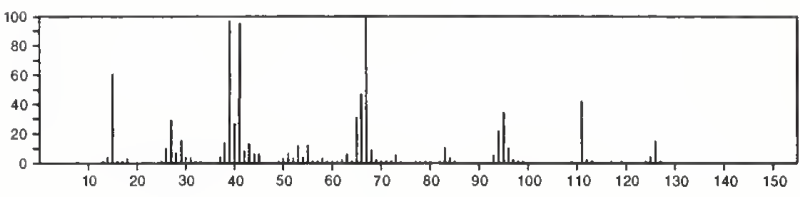

126

1,3-Cyclopentanedione, 4-ethyl-

$57157-03-6$
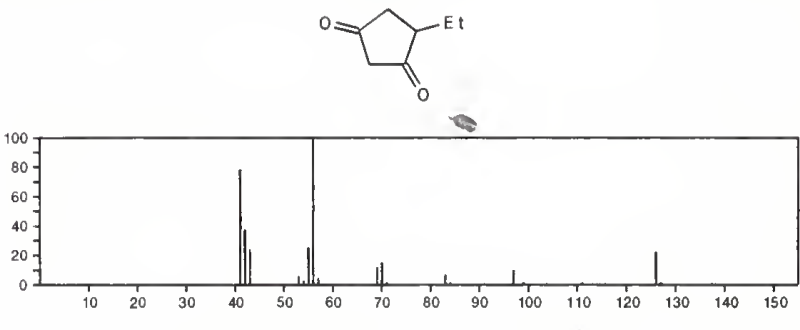

126

Thiophene, 2-propyl

$\mathrm{C}_{7} \mathrm{H}_{10} \mathrm{~S}$

1551-27-5
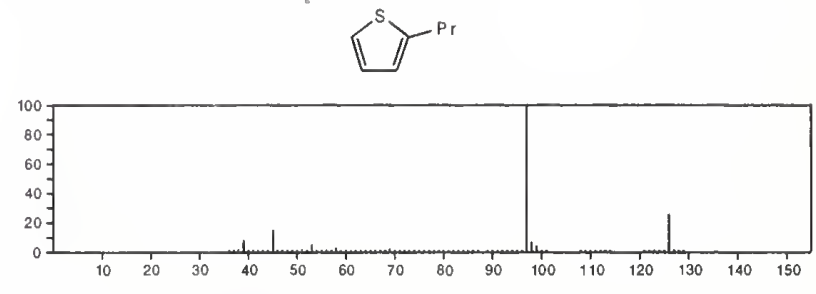

126

Thiophene, 2,3,4-trimethyl-

$\mathrm{C}_{7} \mathrm{H}_{10 \mathrm{~S}}$

1795-04-6
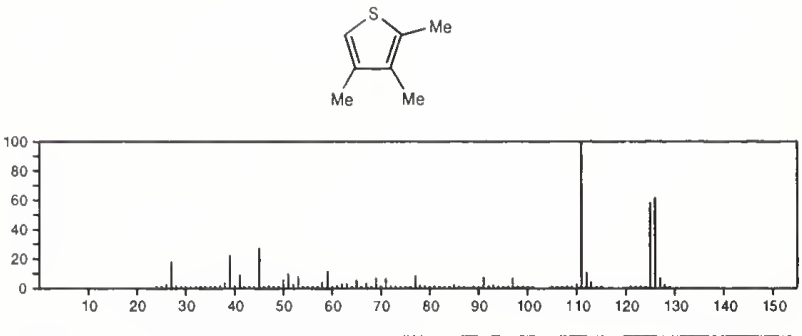

126

$\mathrm{C}_{7} \mathrm{H}_{10} \mathrm{~S}$

4095-22-1

Thiophene, 2-(1-methylethyl)
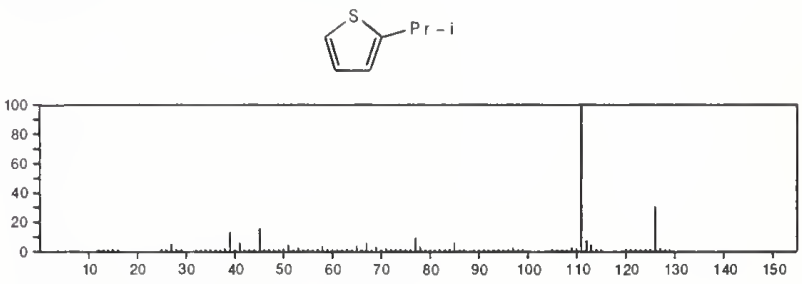
126

$\mathrm{C}_{7} \mathrm{H}_{10} \mathrm{~S}$

38693-65-1

2-Cyclopentene-1-thione, 2,3-dimethyl-
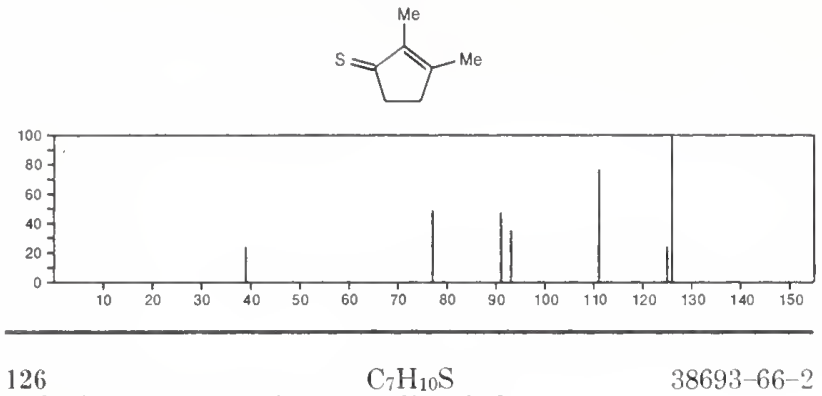

2-Cyclopentene-1-thione, 3,4-dimethyl
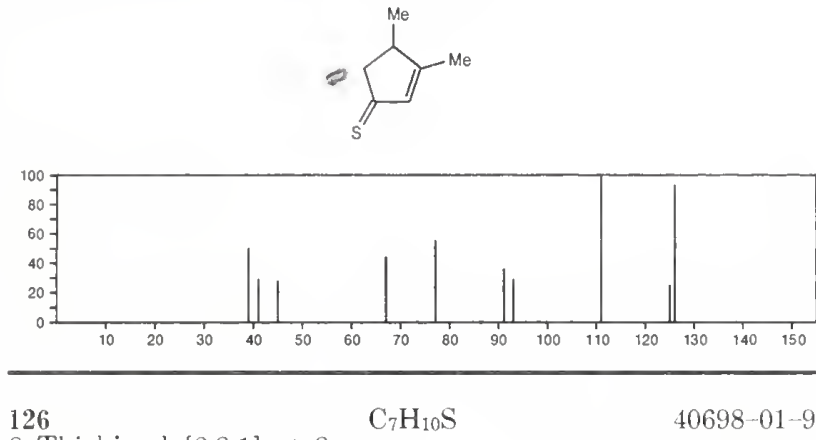

8-Thiabicyclo[3.2.1]oct-2-ene
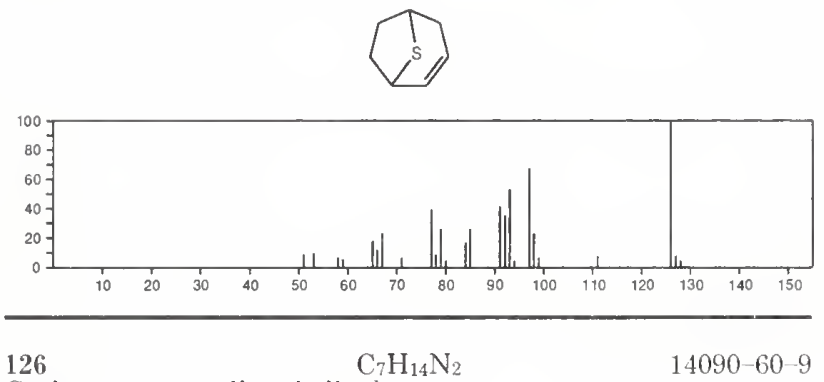

Cyclopentanone, dimethylhydrazone
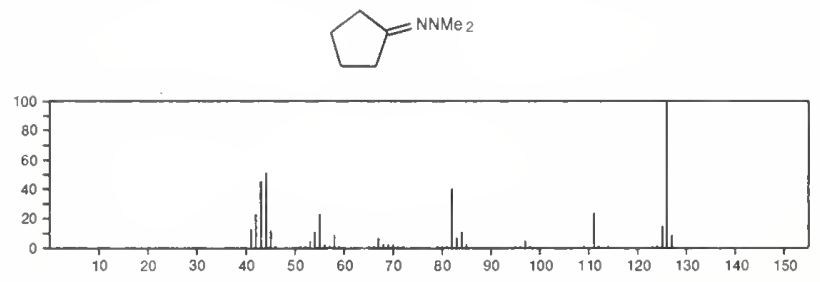

126

Azetidine, $1,1^{\dagger}$-methylenebis

$\mathrm{C}_{7} \mathrm{H}_{14} \mathrm{~N}_{2}$

$38455-24-2$

$$
\square \stackrel{\mathrm{N}}{-\mathrm{CH}_{2}-\mathrm{N}}-
$$

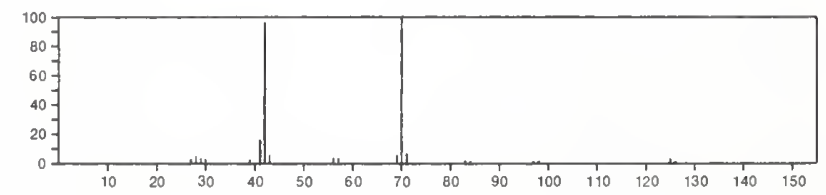

126

5-Hepten-2-one, 6-methyl

$\mathrm{C}_{8} \mathrm{H}_{14} \mathrm{O}$

$\mathrm{Me} \mathrm{COCH}_{2} \mathrm{CH}_{2} \mathrm{CH}=\mathrm{CMe}_{2}$

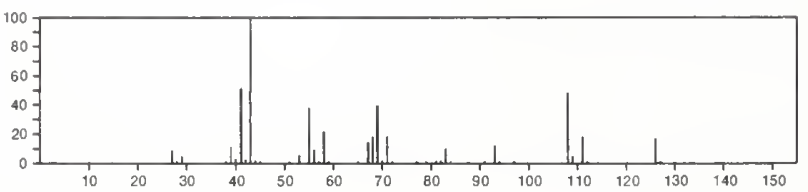

126

$\mathrm{C}_{8} \mathrm{H}_{14} \mathrm{O}$

$286-62-4$

9-Oxabicyclo[6.1.0]nonane
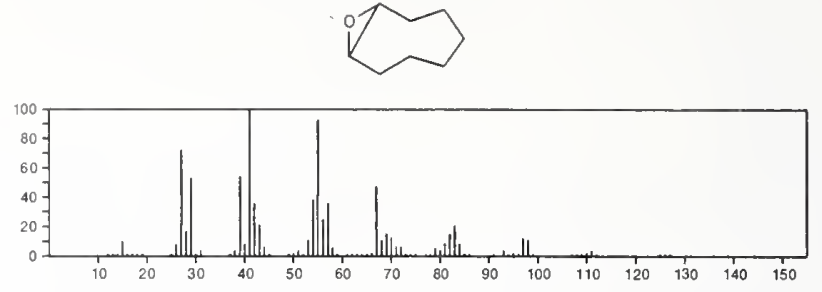

126

$\mathrm{C}_{8} \mathrm{H}_{14} \mathrm{O}$

$502-49-8$

Cyclooctanone
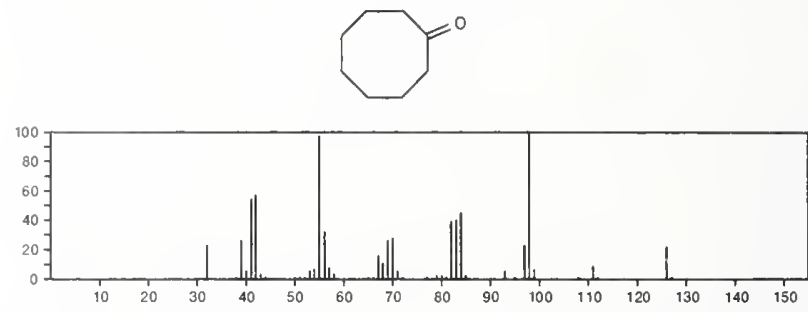

126

2-Hexenal, 2-ethy

$\mathrm{C}_{8} \mathrm{H}_{14} \mathrm{O}$

$645-62-5$

$\operatorname{Pr} \mathrm{CH}=\mathrm{CE} \perp \mathrm{CHO}$

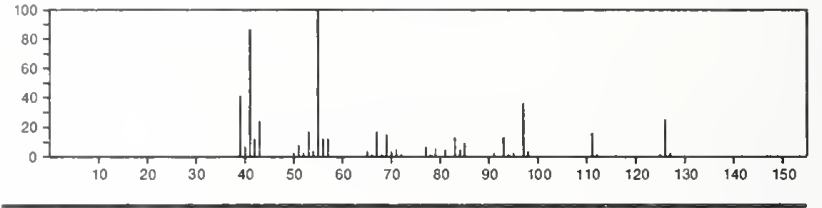

126

$\mathrm{C}_{8} \mathrm{H}_{14} \mathrm{O}$

$823-76-7$

Ethanone, 1-cyclohexyl
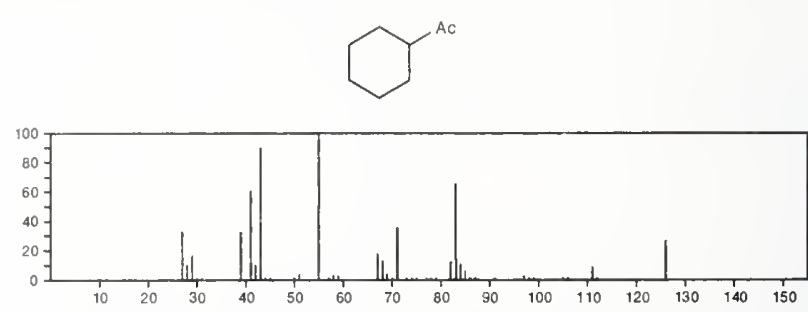

126

$\mathrm{C}_{8} \mathrm{H}_{14} \mathrm{O}$

1004-24-6

Cyclohexanemethanol, 4-methylene
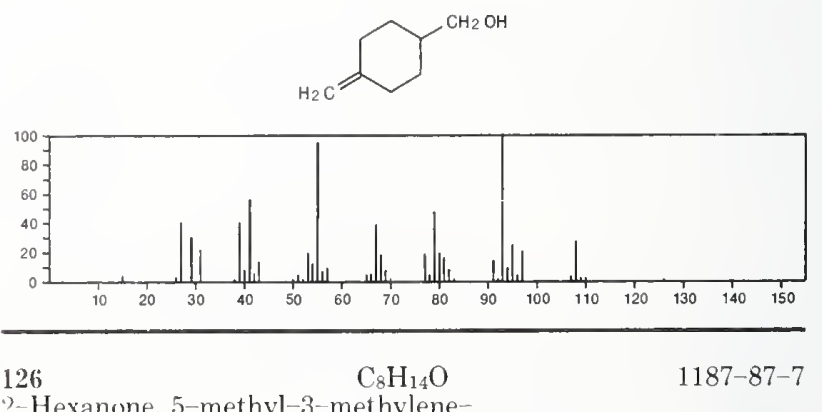

2-Hexanone, 5-methyl-3-methylene-

$\mathrm{Me}_{2} \mathrm{CHCH}_{2} \stackrel{\stackrel{\mathrm{CH}}{\mathrm{C}} \mathrm{COMe}}{\mathrm{C}}$

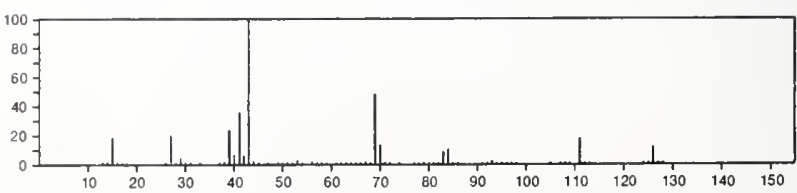


$126 \quad \mathrm{C}_{8} \mathrm{H}_{14} \mathrm{O}$

Cyclobutanone, 2,2,3,4-tetramethyl-
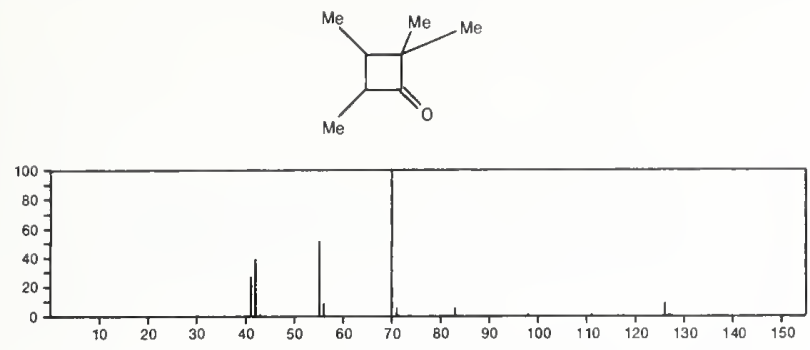

126

Cyclohexanone, 2,2-dimethyl-

$\mathrm{C}_{8} \mathrm{H}_{14} \mathrm{O}$

1193-47-1
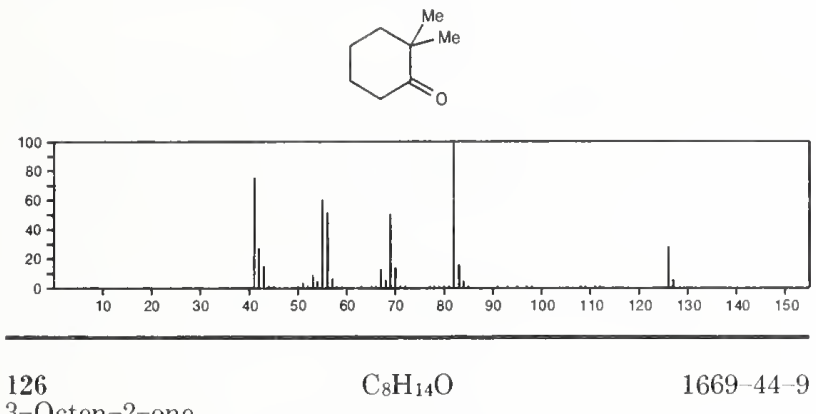

3-Octen-2-one

$\mathrm{MeCOCH}: \mathrm{CH}\left(\mathrm{CH}_{2}\right){ }_{3} \mathrm{Me}$
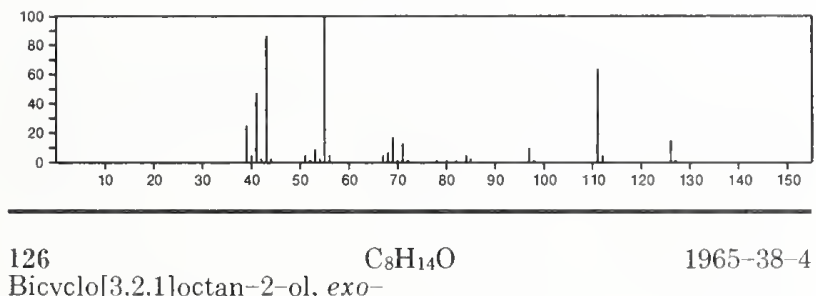

Bicyclo[3.2.1] octan-2-ol, exo-
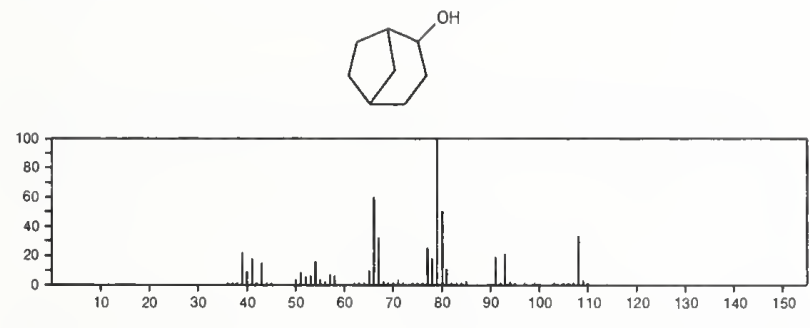

126

$\mathrm{C}_{8} \mathrm{H}_{14} \mathrm{O}$

$2816-57-1$

Cyclohexanone, 2,6-dimethyl-
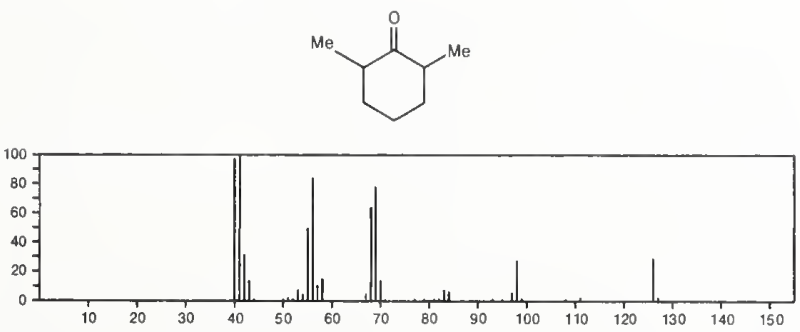

126

7-Octen-2-one

$\mathrm{C}_{8} \mathrm{H}_{14} \mathrm{O}$

$3664-60-6$

$\mathrm{MeCO}\left(\mathrm{CH}_{2}\right){ }_{4} \mathrm{CH} \equiv \mathrm{CH}_{2}$

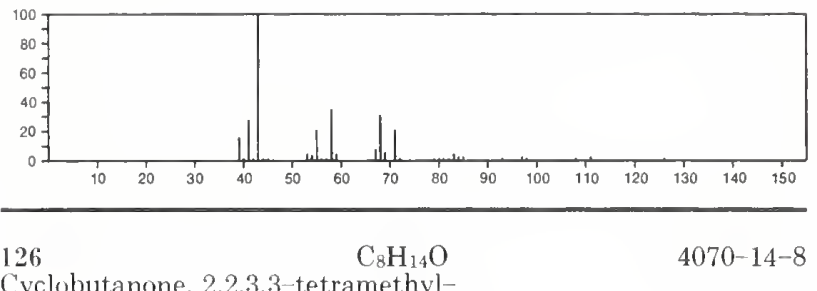

Cyclobutanone, 2,2,3,3-tetramethyl-
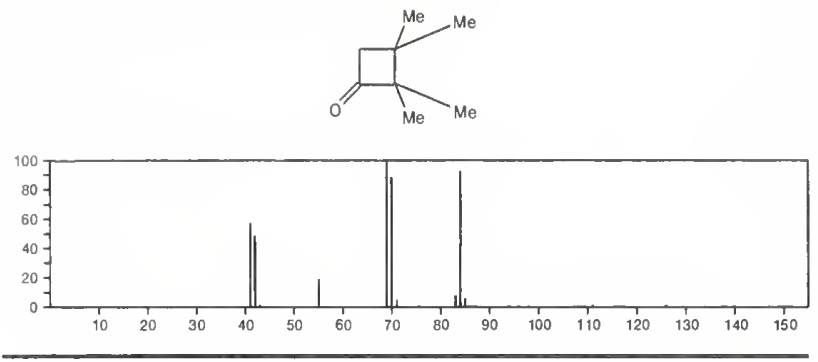

126

$\mathrm{C}_{8} \mathrm{H}_{14} \mathrm{O}$

Cyclobutanone, 2,2,4,4-tetramethyl-

4298-75-3
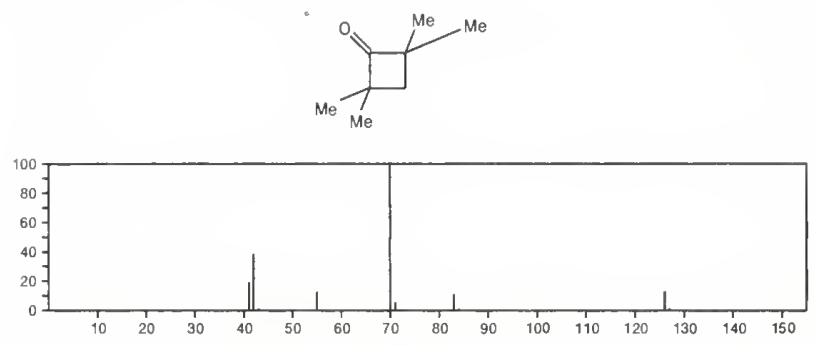

126

Cyclohexanone, 2-ethyl-

$\mathrm{C}_{8} \mathrm{H}_{14} \mathrm{O}$

4423-94-3<smiles>CCC1CCCCC1=O</smiles>

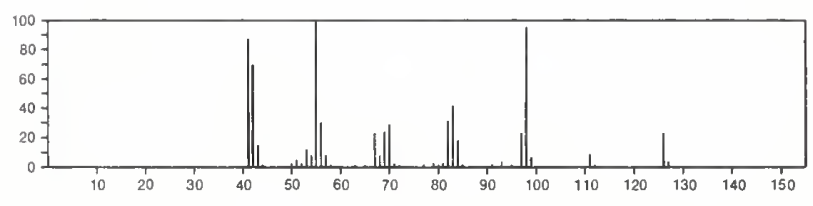

126

$\mathrm{C}_{8} \mathrm{H}_{14} \mathrm{O}$

Bicyclo[2.2.1]heptane-2-methanol

$5240-72-2$<smiles>OCC1CC2CCC1C2</smiles>

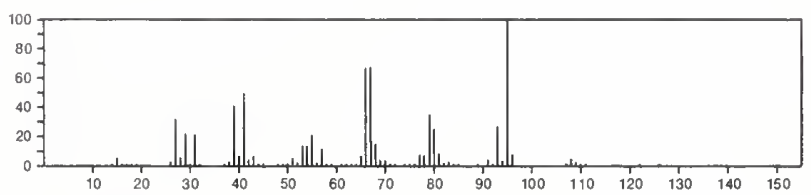


126

Cyclohexanone, 4-ethyl-

$\mathrm{C}_{8} \mathrm{H}_{14} \mathrm{O}$

$5441-51-0$

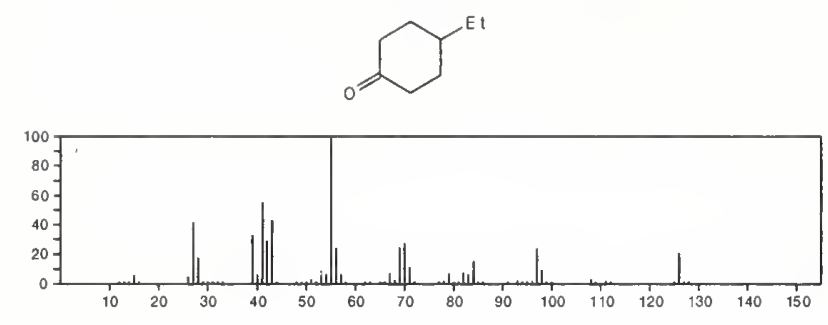

126

Bicyclo[3.2.1]octan-2-ol

$\mathrm{C}_{8} \mathrm{H}_{14} \mathrm{O}$

$5602-48-2$
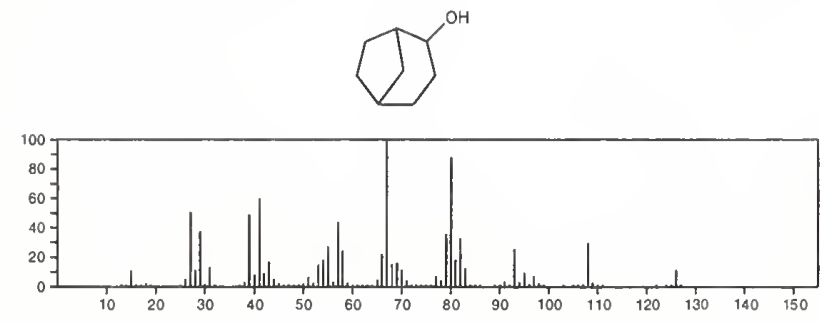

126

Cyclohexanone, 2,3-dimethyl-

$\mathrm{C}_{8} \mathrm{H}_{14} \mathrm{O}$

$13395-76-1$
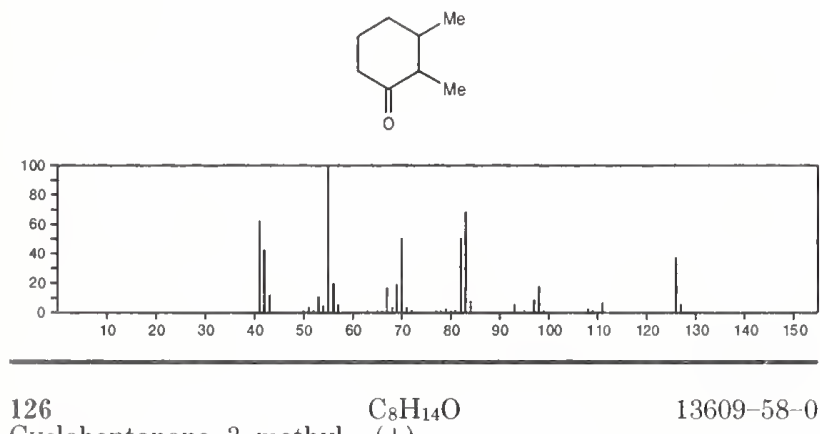

Cycloheptanone, 3-methyl-, $(+)-$
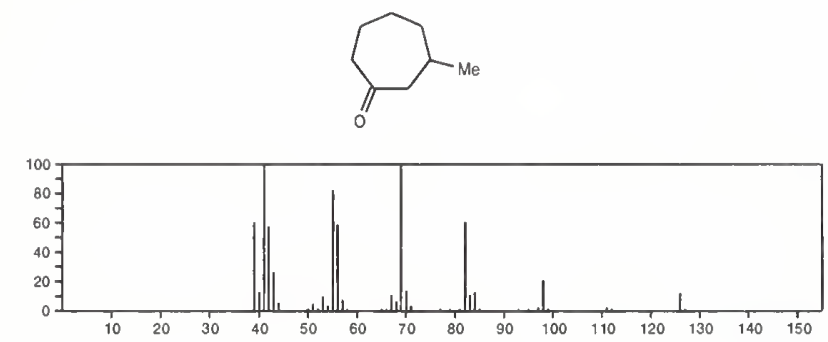

126

Cycloheptanone, 4-methyl-, (-)-

$13609-59-1$
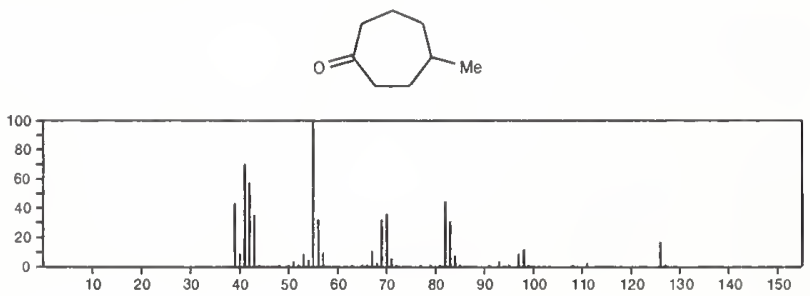

126

$\mathrm{C}_{8} \mathrm{H}_{14} \mathrm{O}$

14129-48-7

4-Octen-3-one

$E$ t $\mathrm{COCH}=\mathrm{CHP}$

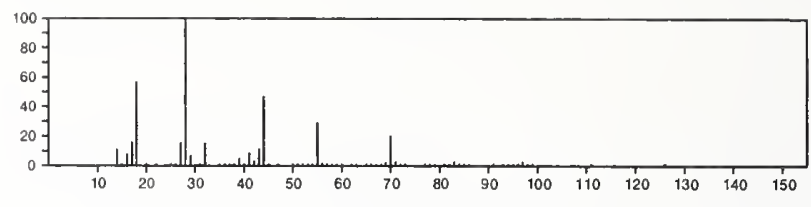

126

4-Hexen-3-one, 4,5-dimethyl-

$\mathrm{C}_{8} \mathrm{H}_{14} \mathrm{O}$

$17325-90-5$

$\mathrm{Et}$ COCMe $=\mathrm{CMe}_{2}$

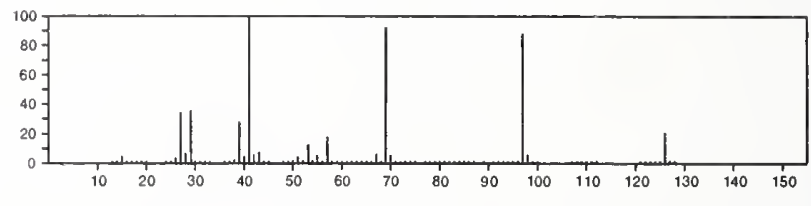

126

$\mathrm{C}_{8} \mathrm{H}_{14} \mathrm{O}$

20534-58-1

Bicyclo[2.2.2]octan-1-ol
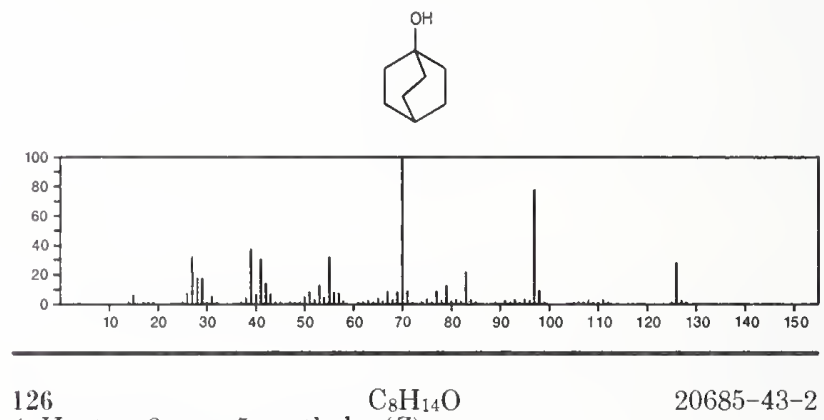

4-Hepten-3-one, 5-methyl-, $(Z)$ -

$\mathrm{E} t \mathrm{COCH}=\mathrm{CE} \mathrm{IMe}$

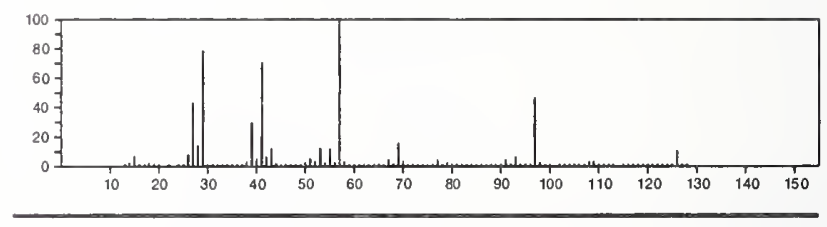

126

4-Hepten-3-one, 5-methyl-, (E)-

$20685-44-3$

Et COCH : CE TMe

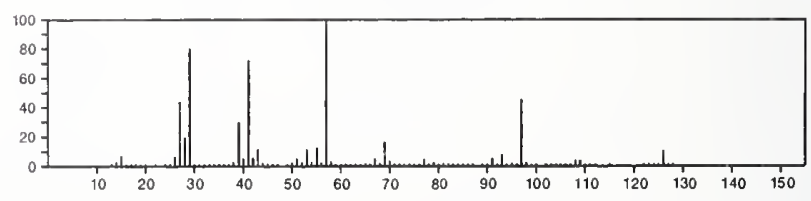

$126 \quad \mathrm{C}_{8} \mathrm{H}_{14} \mathrm{O}$

3-Hexen-2-one, 3,4-dimethyl-, (Z)-

$20685-45-4$

$\mathrm{Me}$ COCMe $=\mathrm{CE}$ tMe

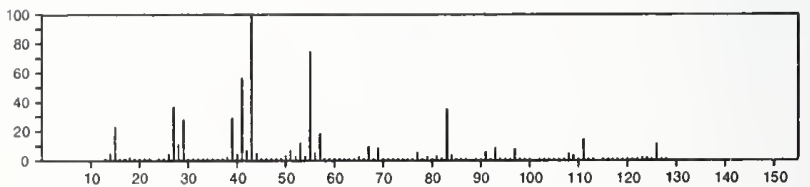


126

$\mathrm{C}_{8} \mathrm{H}_{14} \mathrm{O}$

3-Hexen-2-one, 3,4-dimethyl-, $(E)$ -

$20685-46-5$

$\mathrm{MeCOCMe}=\mathrm{CE}+\mathrm{Me}$

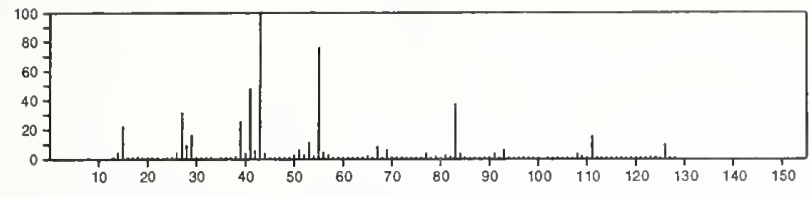

126

$\mathrm{C}_{8} \mathrm{H}_{14} \mathrm{O}$

Bicyclo[5.1.0]octan-4-ol, stereoisomer

21940-19-2<smiles>OC1CCCC2CCC1CC2</smiles>

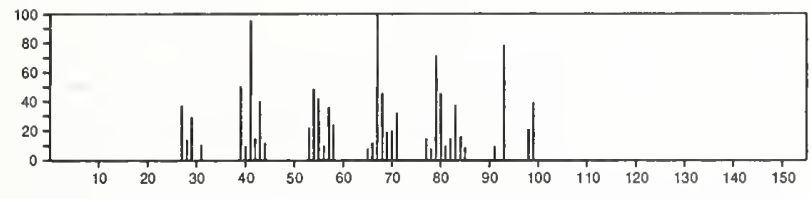

126

$\mathrm{C}_{8} \mathrm{H}_{14} \mathrm{O}$

3-Penten-2-one, 3-ethyl-4-methyl-

$22287-11-2$

$\mathrm{MeCOCE} \mathrm{t}=\mathrm{CMe} 2$

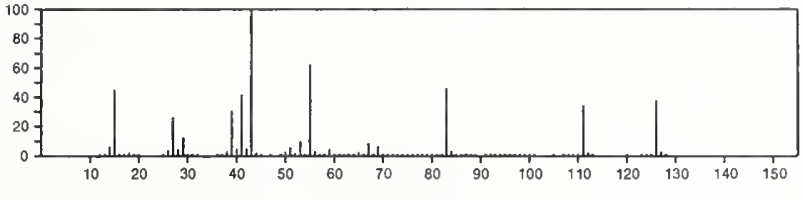

126

2-Hepten-4-one, 2-methyl-

$\mathrm{C}_{8} \mathrm{H}_{14} \mathrm{O}$

22319-24-0

$\mathrm{Pr} \mathrm{COCH}=\mathrm{CMe} 2$

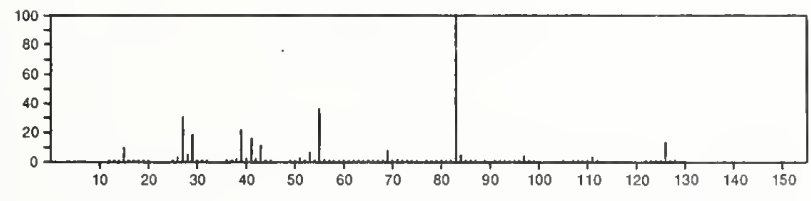

126

$\mathrm{C}_{8} \mathrm{H}_{14} \mathrm{O}$

22319-25-1

3-Hepten-2-one, 4-methyl-

$\mathrm{MeCOCH}=\mathrm{CPr} \mathrm{Me}$

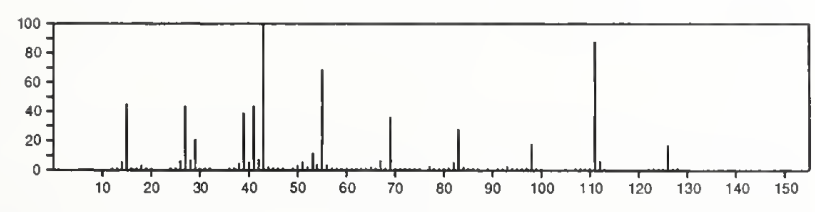

126

$\mathrm{C}_{8} \mathrm{H}_{14} \mathrm{O}$

22319-31-9

4-Hepten-3-one, 4-methyl-

$\mathrm{E}+\mathrm{COCMe}=\mathrm{CHE} t$

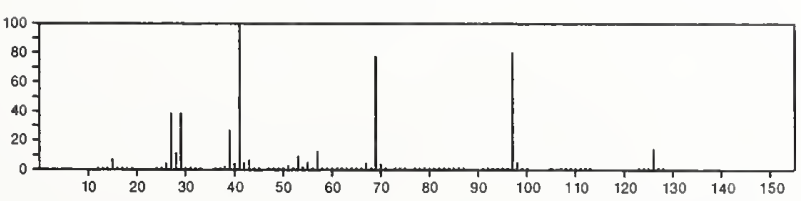

126

Cyclobutanone, 2,2,3,4-tetramethyl-, cis-

25143-83-3
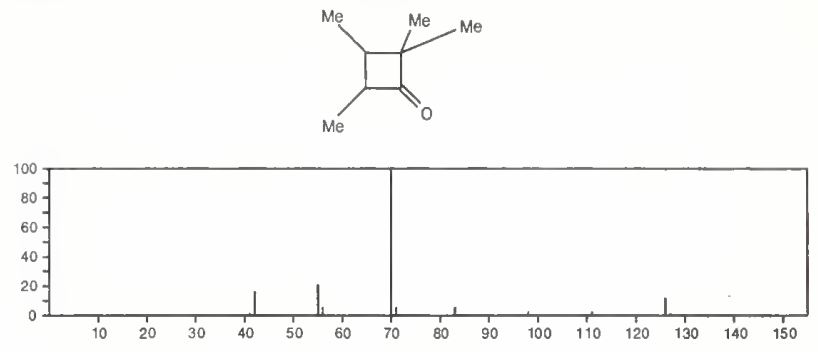

126

$\mathrm{C}_{8} \mathrm{H}_{14} \mathrm{O}$

28113-34-0

Cyclobutanone, 2,2,3,4-tetramethyl--, trans
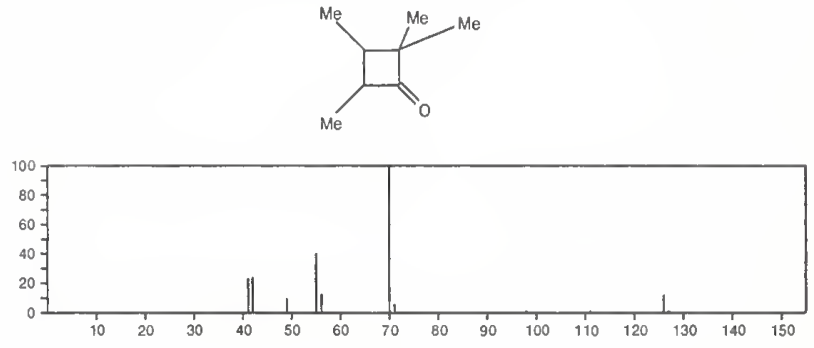

126

$\mathrm{C}_{8} \mathrm{H}_{14} \mathrm{O}$

34314-82-4

Furan, 3-(1,1-dimethylethyl)-2,3-dihydro-

$\overbrace{}^{8 u-t}$

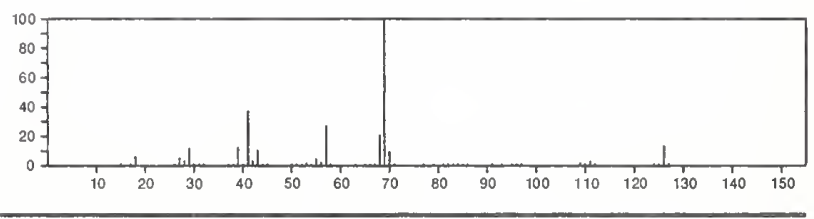

126

$\mathrm{C}_{8} \mathrm{H}_{14} \mathrm{O}$

34379-54-9

Furan, 2,3-dihydro-4-(1-methylpropyl)-, (S)-

$\underbrace{80-5}$

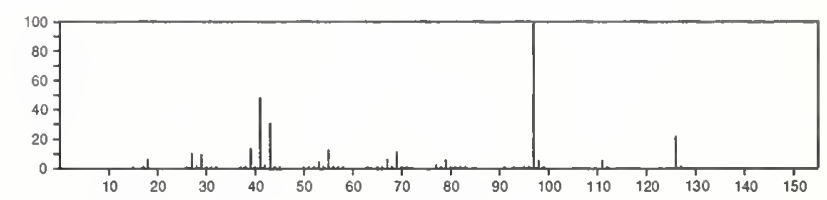

126

6-Octen-2-one

$\mathrm{C}_{8} \mathrm{H}_{14} \mathrm{O}$

35194-31-1

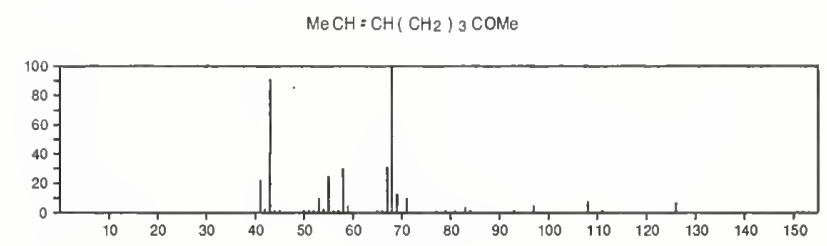

126

3-Hepten-2-one, 3-methyl-

$\mathrm{C}_{8} \mathrm{H}_{14} \mathrm{O}$

39899-08-6

$\mathrm{Me}$ COCMe $=\mathrm{CHP}$ r

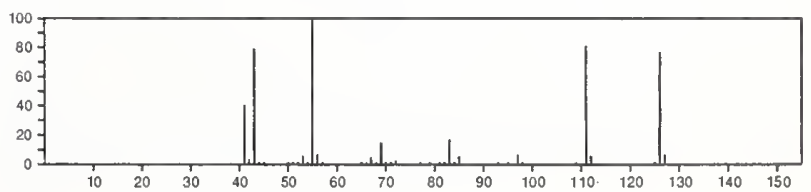


126

$\mathrm{C}_{8} \mathrm{H}_{14} \mathrm{O}$

Bicyclo[5.1.0]octan-3-ol, $(1 \alpha, 3 \alpha, 7 \alpha)$ -
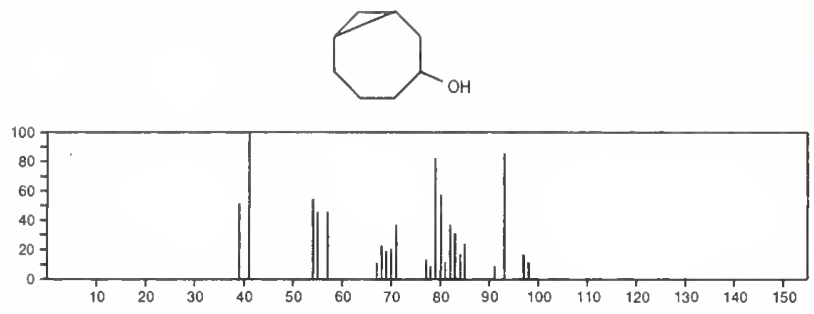

$126 \quad \mathrm{C}_{8} \mathrm{H}_{14} \mathrm{O}$

Cyclobutanone, 2,3,3,4-tetramethyl-
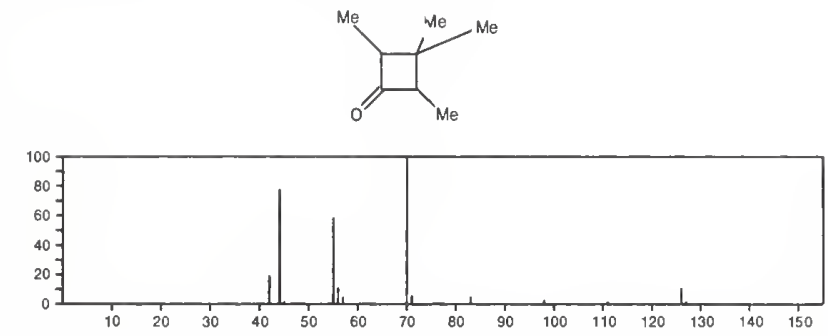

126

1-Butyne, 3-methyl-3-(1-methylethoxy)-

$53907-63-4$

$\mathrm{Me} 2 \mathrm{COPr}-\mathrm{iC} \equiv \mathrm{CH}$

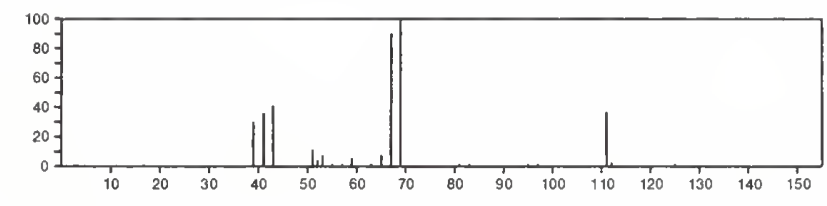

126

1-Butyne, 3-methyl-3-propoxy-

$53907-64-5$

$\mathrm{Me}_{2} \mathrm{COPr} \mathrm{C} \equiv \mathrm{CH}$

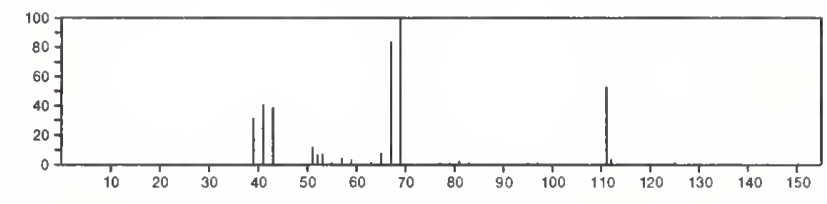

126

$\mathrm{C}_{8} \mathrm{H}_{14} \mathrm{O}$

$53941-20-1$

1-Pentyne, 3-ethyl-3-methoxy-

$\mathrm{E}_{2} \mathrm{COM} \mathrm{C} \equiv \mathrm{CH}$

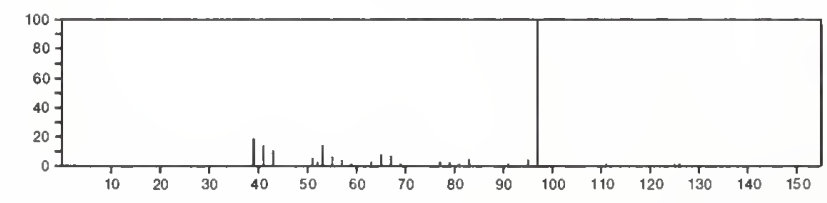

126

Ethanone, 1-(3-ethylcyclobutyl)-

$$
\mathrm{C}_{8} \mathrm{H}_{14} \mathrm{O}
$$

$56335-71-8$
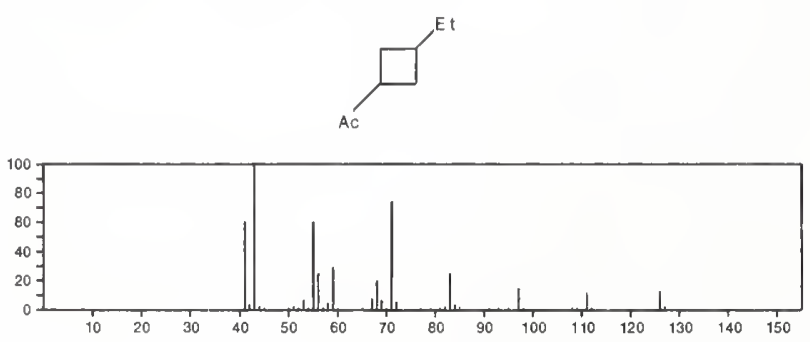

126

Furan, 2,3-dihydro-3-(1-methylpropyl)-

$56805-32-4$

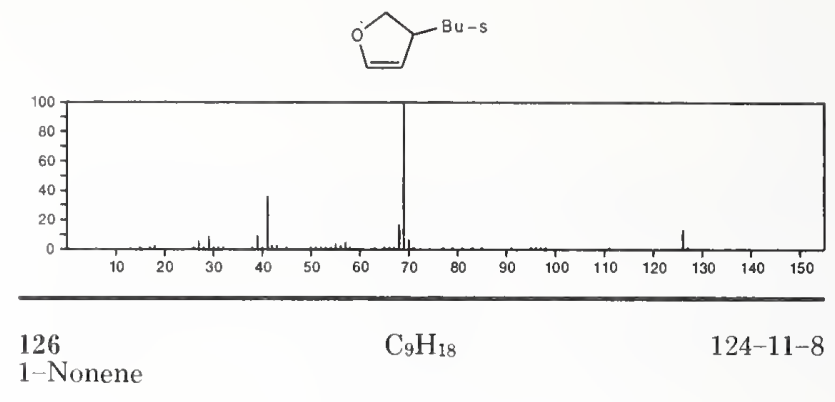

$\mathrm{H}_{2} \mathrm{C}=\mathrm{CH}\left(\mathrm{CH}_{2}\right) 6 \mathrm{Me}$

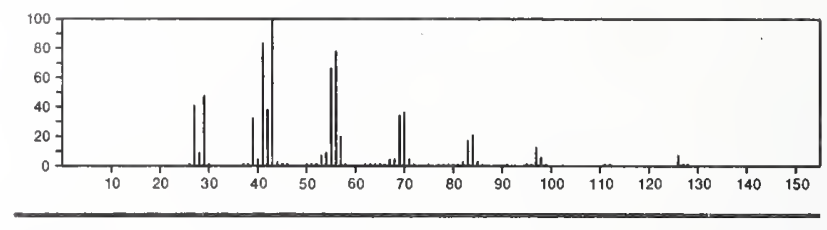

126

Cyclohexane, (1-methylethyl)-

696-29-7
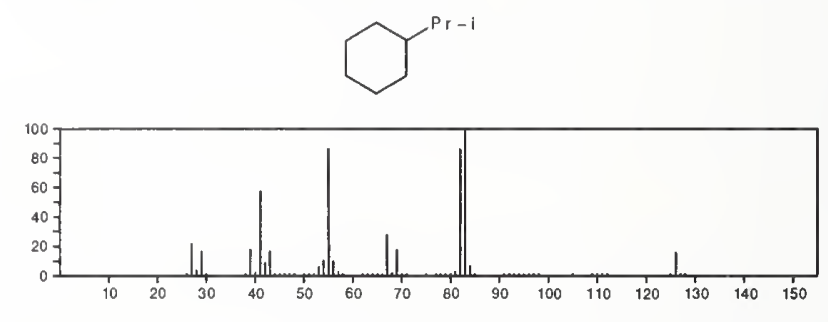

126

$\mathrm{C}_{9} \mathrm{H}_{18}$

Cyclohexane, 1,2,3-trimethyl-, $(\mathbf{1} \alpha, 2 \beta, 3 \alpha)-$

$1678-81-5$
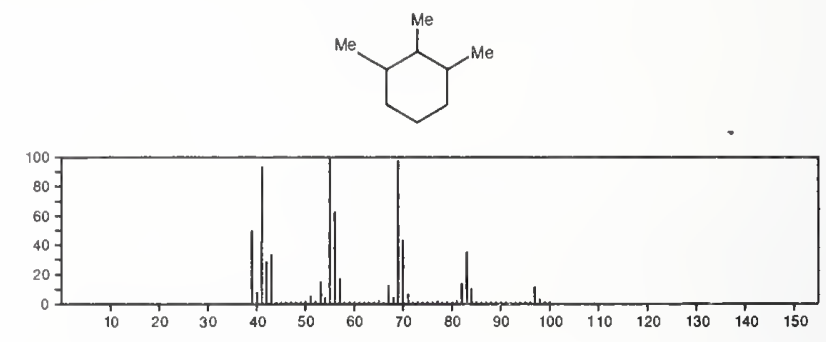

126

Cyclohexane, propyl--

$\mathrm{C}_{9} \mathrm{H}_{18}$

$1678-92-8$
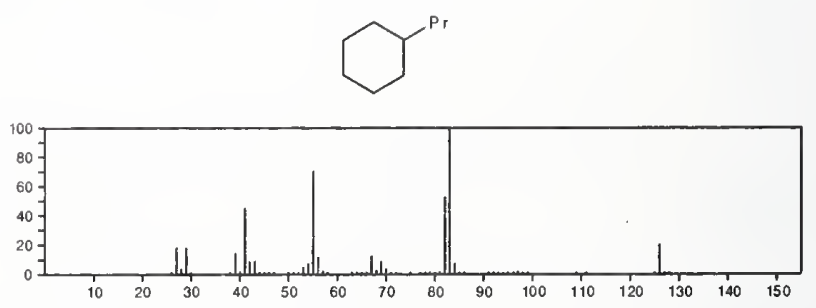
126

$\mathrm{C}_{9} \mathrm{H}_{18}$

Cyclohexane, 1,2,3-trimethyl-
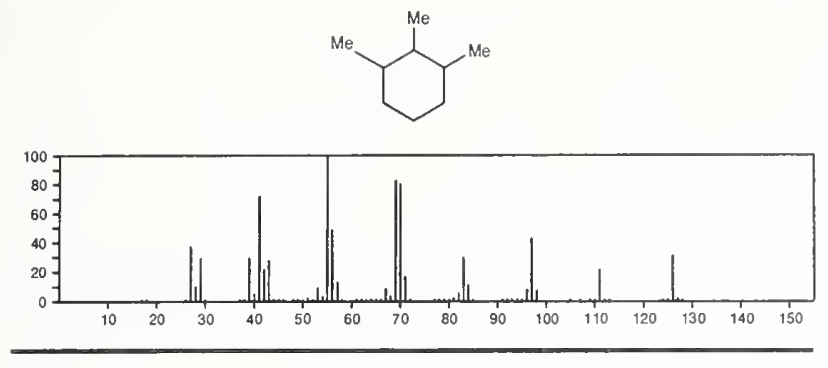

$126 \quad \mathrm{C}_{9} \mathrm{H}_{18}$

$1795-26-2$

Cyclohexane, 1,3,5-trimethyl-, $(1 \alpha, 3 \alpha, 5 \beta)$ -
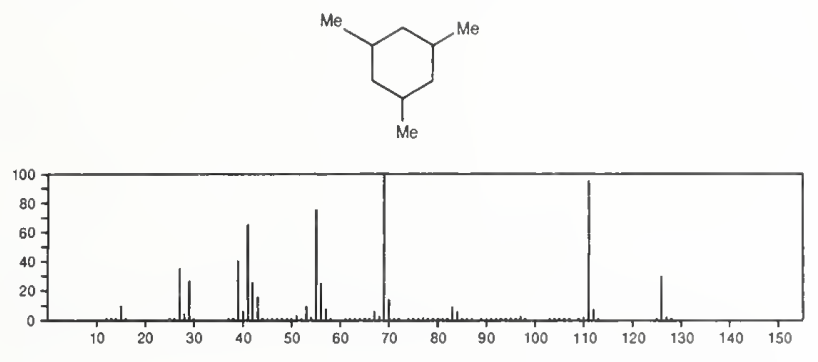

126

$\mathrm{C}_{9} \mathrm{H}_{18}$

$1795-27-3$

Cyclohexane, 1,3,5-trimethyl-, $(1 \alpha, 3 \alpha, 5 \alpha)-$
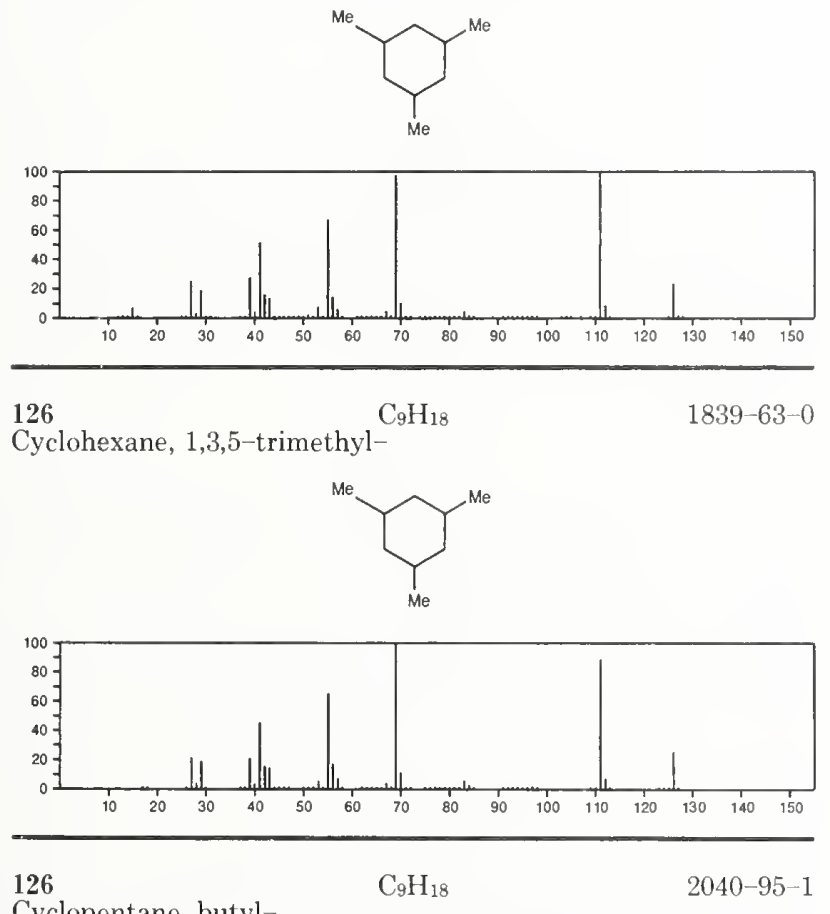

Cyclopentane, butyl-
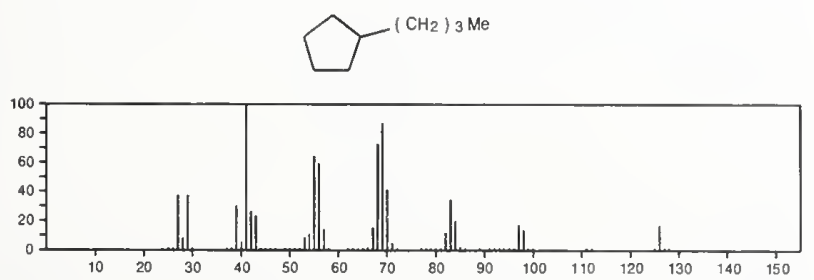

126

4-Nonene

$\mathrm{C}_{9} \mathrm{H}_{18}$

2198-23-4

$\mathrm{Me}\left(\mathrm{CH}_{2}\right)_{3} \mathrm{CH}: \mathrm{CHPr}$

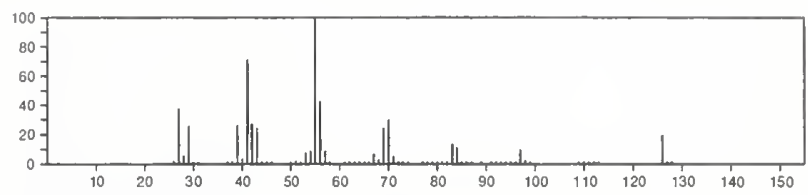

$126 \quad \mathrm{C}_{9} \mathrm{H}_{18}$

$2234-75-5$

Cyclohexane, 1,2,4-trimethyl-
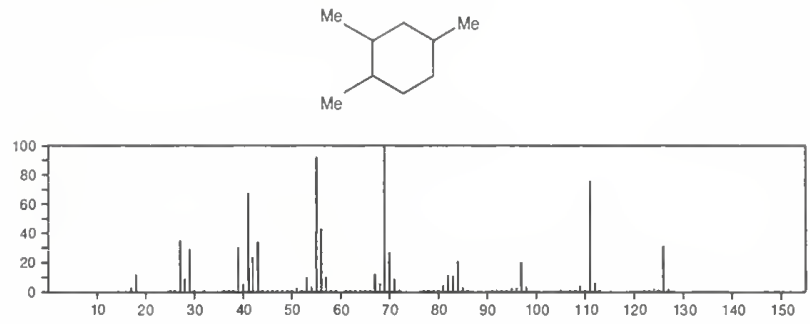

126

2738-18-3

3-Heptene, 2,6-dimethyl-

$\mathrm{Me}_{2} \mathrm{CHCH}_{2} \mathrm{CH}=\mathrm{CHCHMe}_{2}$

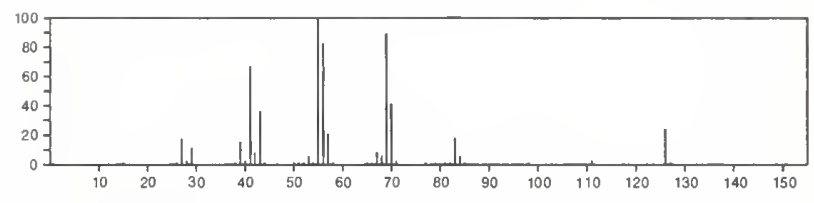

126

$\mathrm{C}_{9} \mathrm{H}_{18}$

3073-66-3
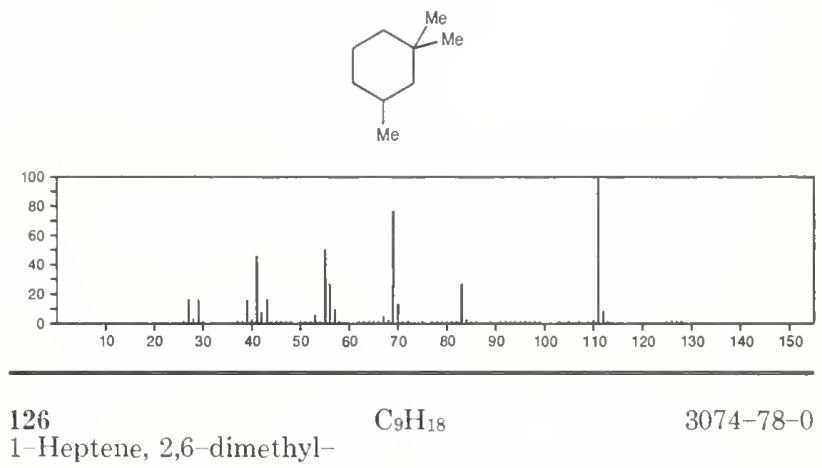

$\mathrm{H}_{2} \mathrm{C}=\mathrm{CMe}\left(\mathrm{CH}_{2}\right)_{3} \mathrm{CHMe}_{2}$

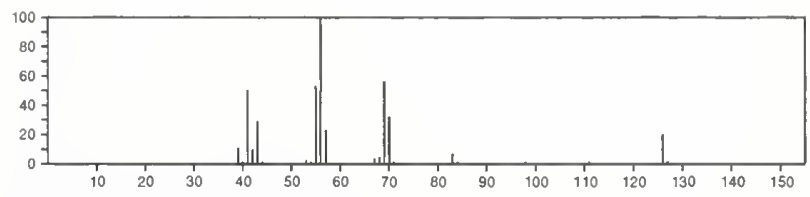

126

Cyclopentane, (2-methylpropyl)-

$$
\mathrm{C}_{9} \mathrm{H}_{18}
$$

$3788-32-7$

$\bigcup^{\mathrm{Bu-1}}$

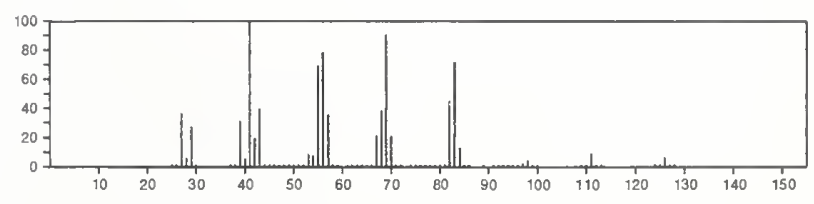


232

EPA/NIH MASS SPECTRAL DATA BASE

126

126

1-Hexene, 3,5,5-trimethyl

$\mathrm{C}_{9} \mathrm{H}_{18}$

$4316-65-8$

$\mathrm{Me}{ }_{3} \mathrm{CCH}_{2} \mathrm{CHMeCH}: \mathrm{CH}_{2}$

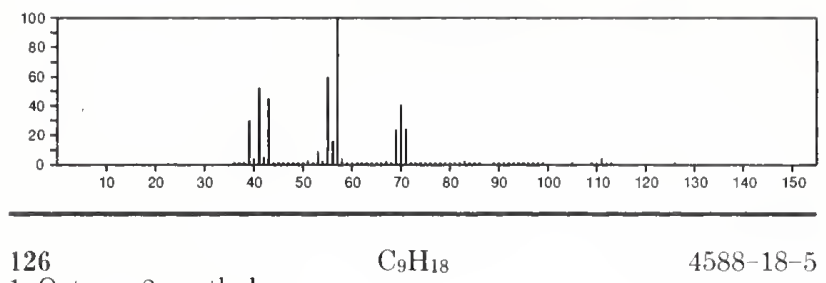

1-Octene, 2-methyl-

$\mathrm{Me}\left(\mathrm{CH}_{2}\right) 5 \mathrm{CMe}=\mathrm{CH}_{2}$

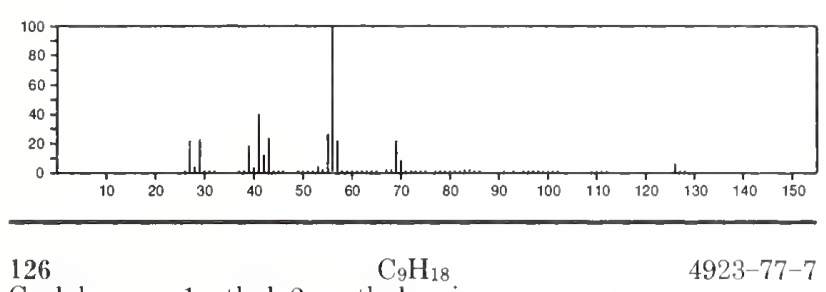

Cyclohexane, 1-ethyl-2-methyl-, cis-
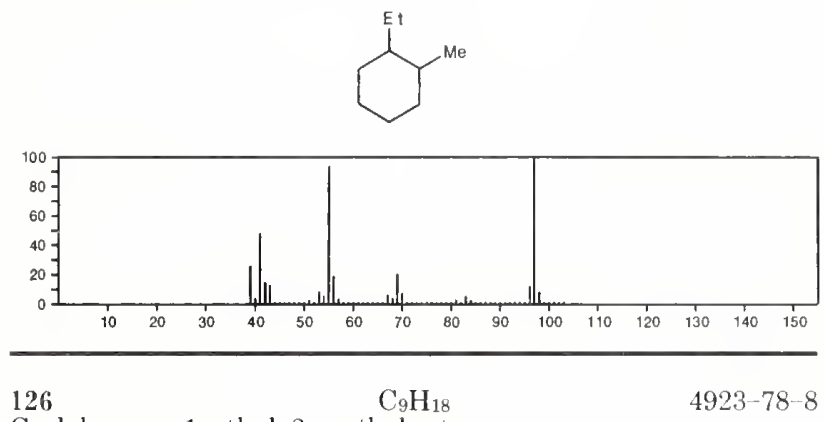

Cyclohexane, 1-ethyl-2-methyl-, trans-
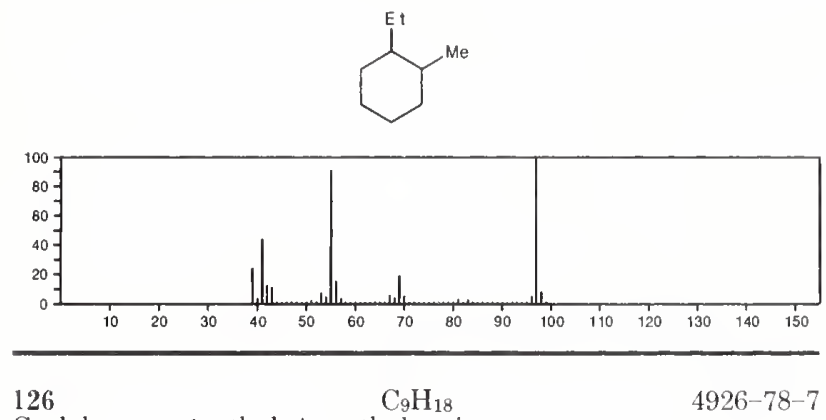

Cyclohexane, 1-ethyl-4-methyl-, cis-
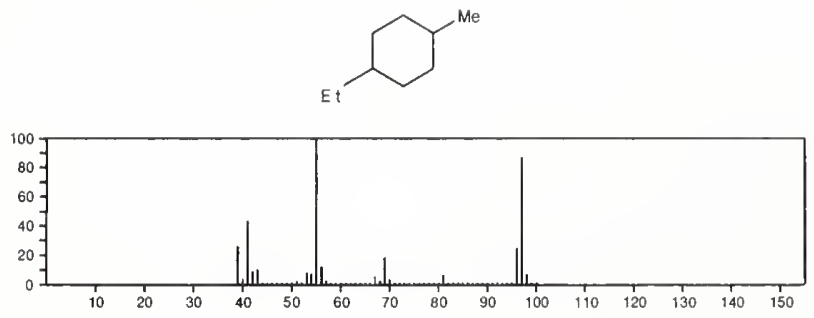

126

$\mathrm{C}_{9} \mathrm{H}_{18}$

Cyclohexane, 1-ethyl-1-methyl-

4926-90-3
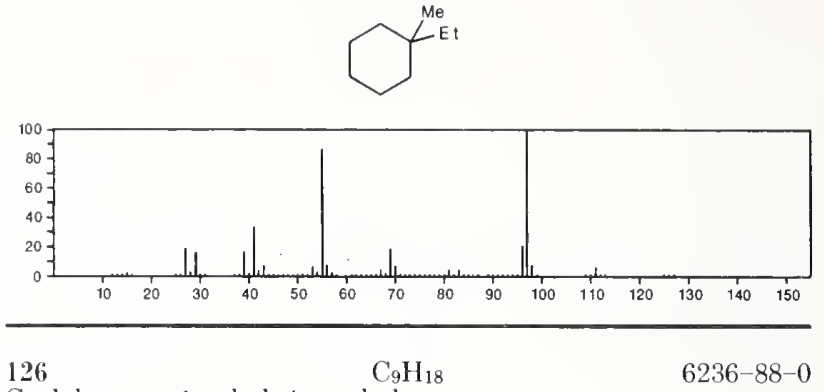

Cyclohexane, 1-ethyl-4-methyl-, trans-
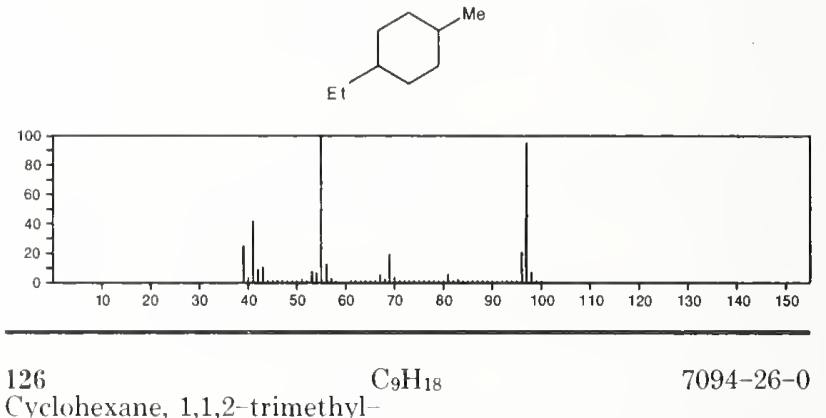

Cyclohexane, 1,1,2-trimethyl-
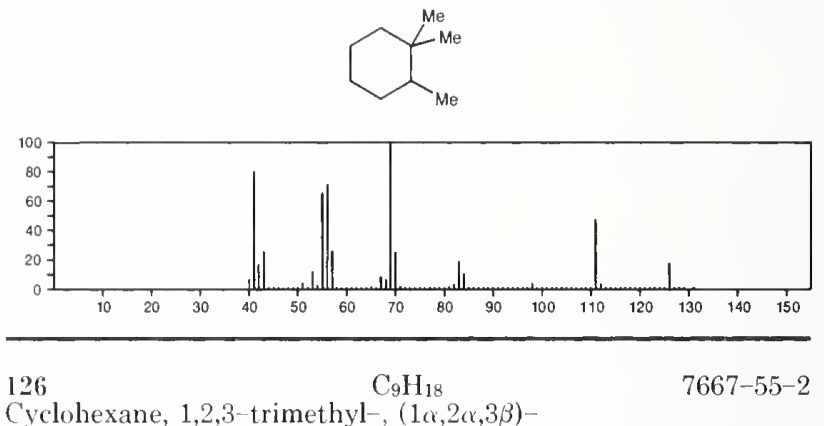

Cyclohexane, 1,2,3-trimethyl-, $(1 \alpha, 2 \alpha, 3 \beta)-$
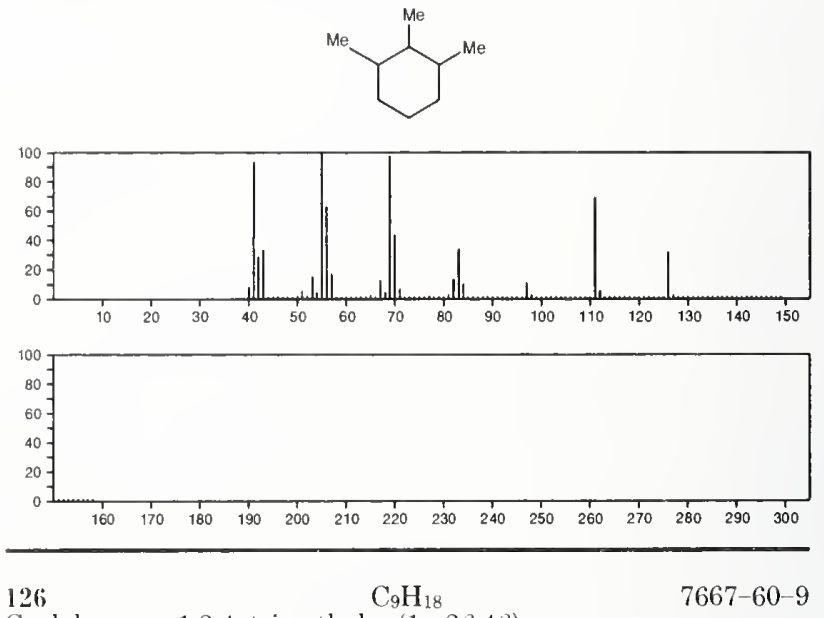

Cyclohexane, 1,2,4-trimethyl-, $(1 \alpha, 2 \beta, 4 \beta)$ -
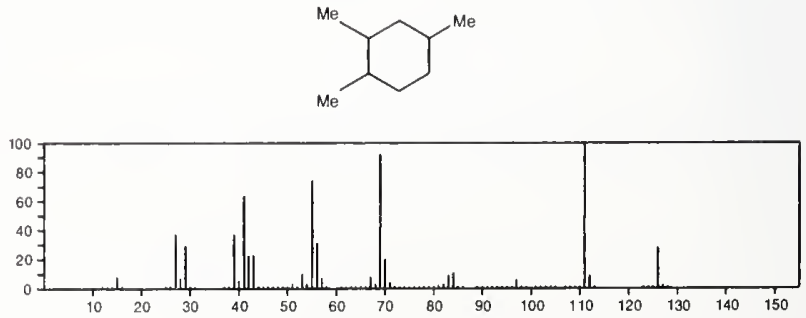
126

1-Octene, 7-methyl-

$\mathrm{C}_{9} \mathrm{H}_{18}$

$\mathrm{H}_{2} \mathrm{C}=\mathrm{CH}\left(\mathrm{CH}_{2}\right)_{4} \mathrm{CHMe}$

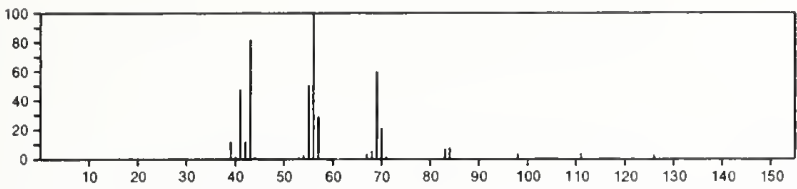

126

$\mathrm{C}_{9} \mathrm{H}_{18}$

Cyclopentane, 1,1,3,4-tetramethyl-, trans-<smiles>CC1CC(C)(C)CC1C</smiles>

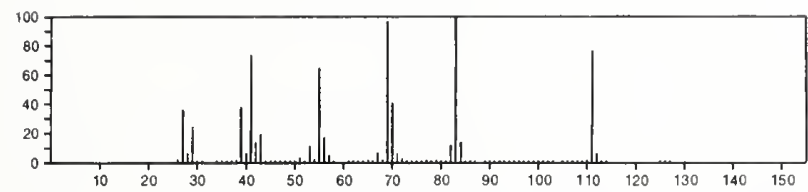

126

$\mathrm{C}_{9} \mathrm{H}_{18}$

Cyclopropane, 1-methyl-2-pentyl-

$41977-37-1$<smiles>CCC1CC1C</smiles>

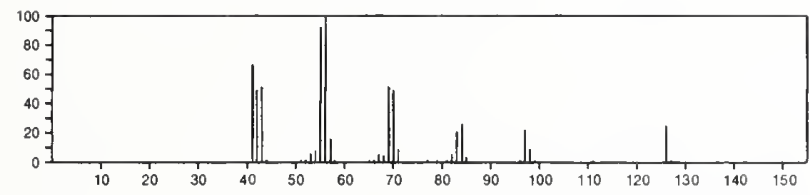

126

$\mathrm{C}_{9} \mathrm{H}_{18}$

Cyclopentane, 1,1,3,3-tetramethyl-

$50876-33-0$
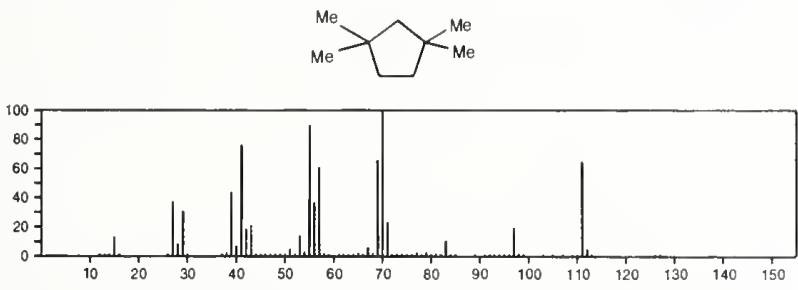

126

$\mathrm{C}_{9} \mathrm{H}_{18}$

2-Pentene, 3-ethyl-4,4-dimethyl-

$\mathrm{MeCH}=\mathrm{CE}+\mathrm{CMe}_{3}$

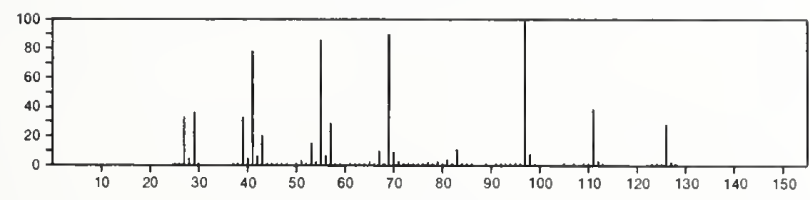

126

$\mathrm{C}_{9} \mathrm{H}_{18}$

$53907-60-1$

Cyclopentane, 1,1,3,4-tetramethyl-, cis-
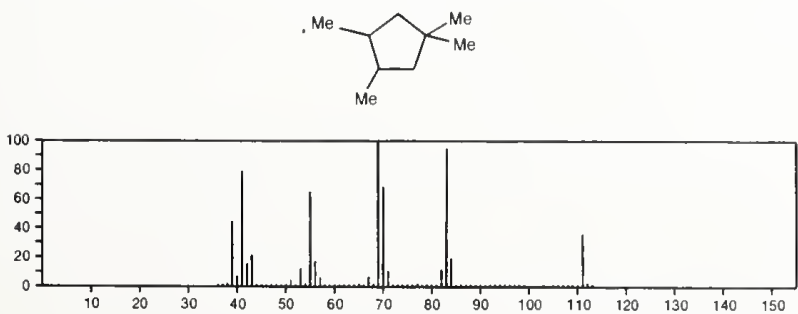

126

2-Hexene, 3,4,4-trimethyl-

$\mathrm{C}_{9} \mathrm{H}_{18}$

$53941-19-8$

$\mathrm{MeCH}=\mathrm{CMeCE}: \mathrm{Me}_{2}$

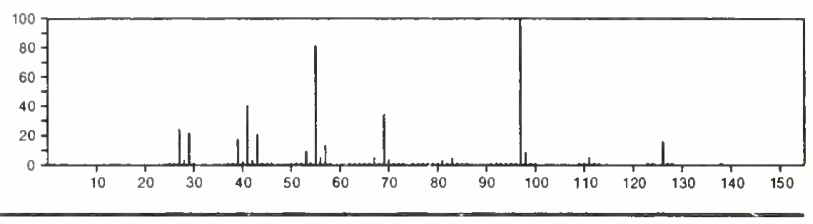

126

$\mathrm{C}_{9} \mathrm{H}_{18}$

Cyclopentane, 2 ethyl-1,1-dimethyl

$54549-80-3$<smiles>CCC1CCCC1(C)C</smiles>

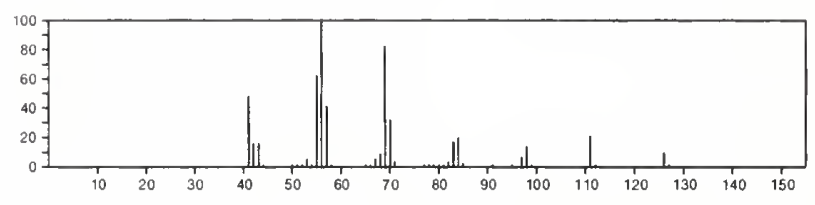

126

2-Hexene, 4,4,5-trimethyl-

$\mathrm{C}_{9} \mathrm{H}_{18}$

55702-61-9

Me $2 \mathrm{CHCMe}_{2} \mathrm{CH}: \mathrm{CHMe}$

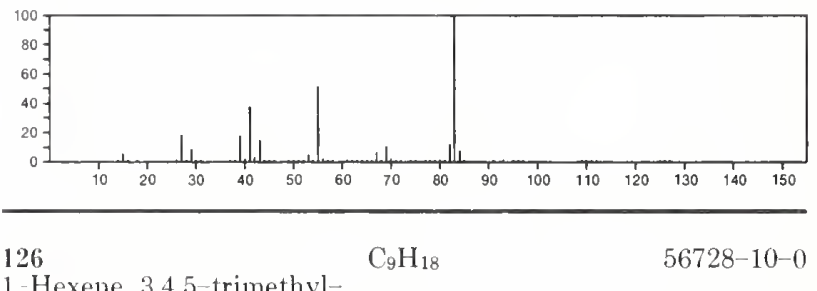

$\mathrm{Me} 2 \mathrm{CHCHMe} \mathrm{CHMe} \mathrm{CH}: \mathrm{CH}_{2}$

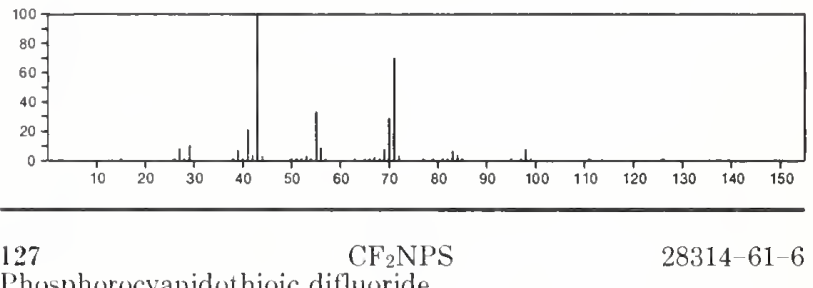

Phosphorocyanidothioic difluoride

$\mathrm{NCPF}_{2}=\mathrm{S}$

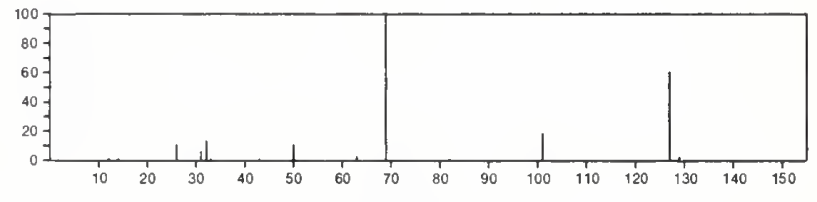

127

Acetonitrile, dichlorofluoro-

$\mathrm{C}_{2} \mathrm{Cl}_{2} \mathrm{FN}$

$353-82-2$

$\mathrm{Cl}_{2} \mathrm{CF}(\mathrm{CN})$

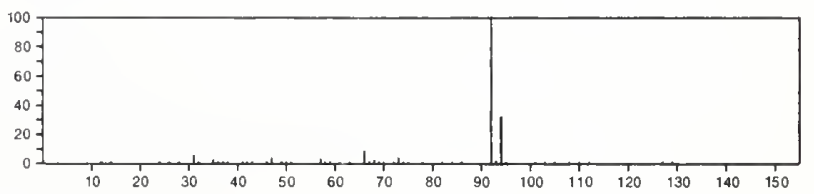


234

EPA/NIH MASS SPECTRAL DATA BASE

127

12

Acetamide, 2,2,2-trifluoro- $\mathrm{N}$-methyl-

$815-06-5$

$\mathrm{MeNHCOCF} 3$

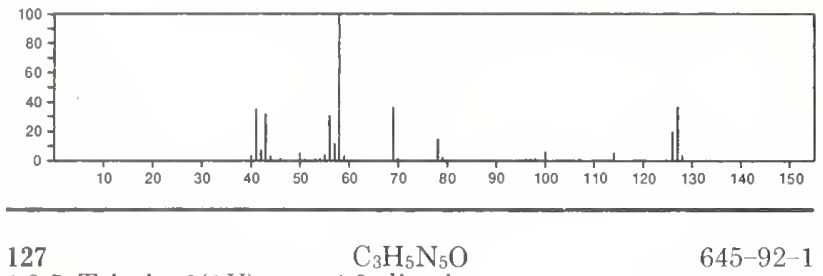

1,3,5-Triazin-2(1H)-one, 4,6-diamino-
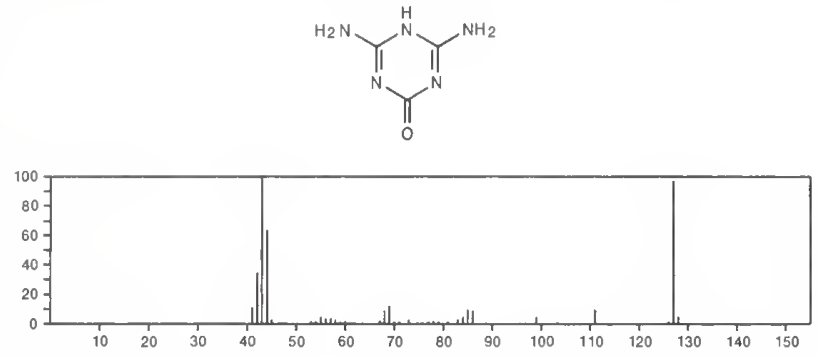

127

$\mathrm{C}_{4} \mathrm{H}_{5} \mathrm{~N}_{3} \mathrm{O}_{2}$

2,4(1H,3H)-Pyrimidinedione, 5-amino-
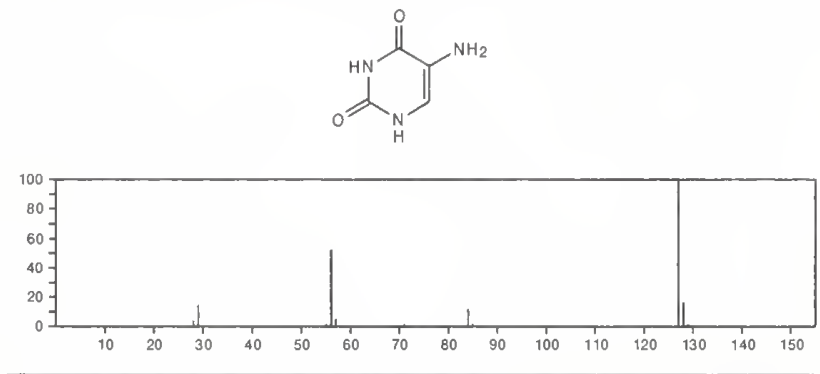

127

$333-49-3$

2(1H)-Pyrimidinethione, $4-\mathrm{amino}_{4}$
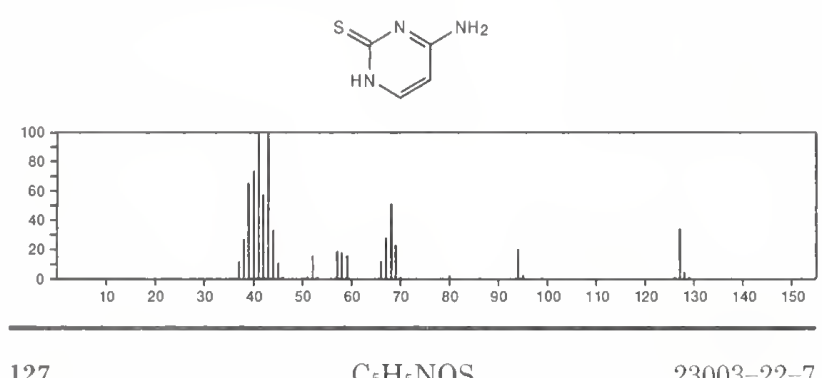

127

$\mathrm{C}_{5} \mathrm{H}_{5} \mathrm{NOS}$

932-52-5

2(1H)-Pyridinethione, 3-hydroxy-
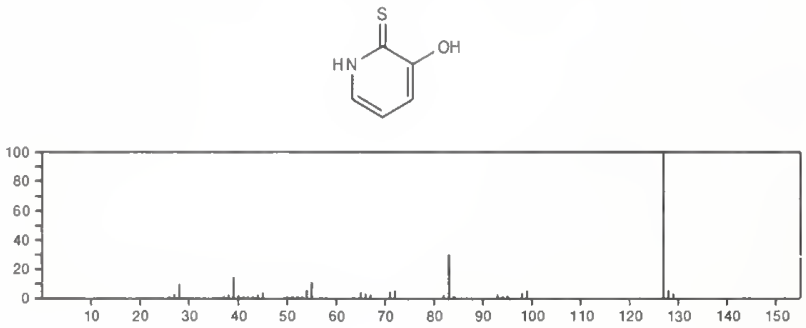

127 -Pyrrole-2,5-dione, 1-(hydroxymethyl)-

5063-96-7
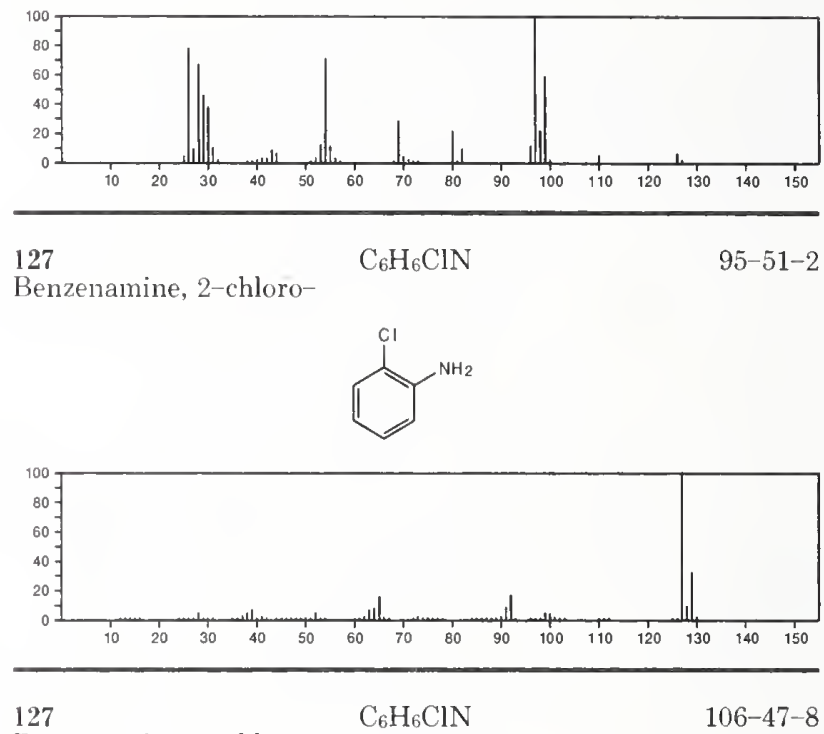

Benzenamine, 4-chloro-
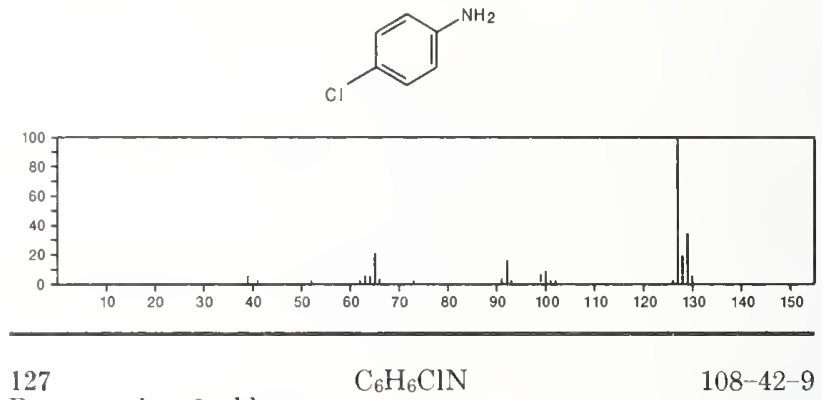

Benzenamine, 3-chloro-
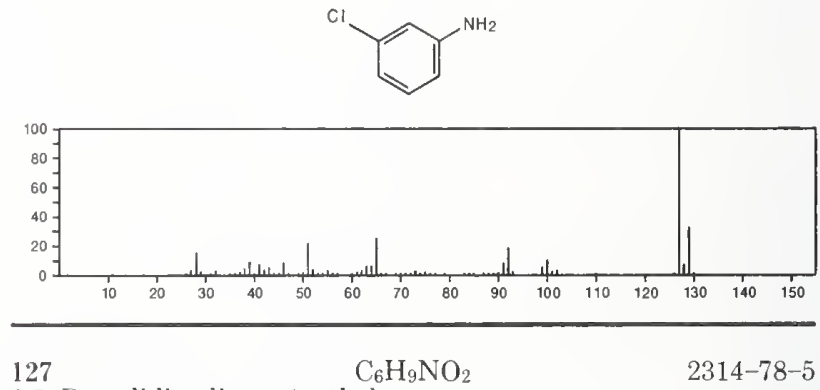

2,5-Pyrrolidinedione, 1-ethyl-<smiles>CCN1C(=O)CCC1=O</smiles>

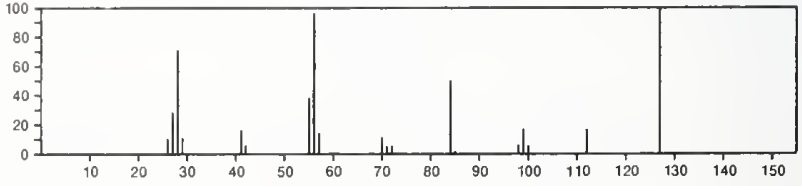


127

$\mathrm{C}_{6} \mathrm{H}_{9} \mathrm{NO}_{2}$

2-Propenoic acid, 3-(1-aziridinyl)-, methyl ester

$2407-60-5$

$\triangle_{\mathrm{N}} \mathrm{CH}_{\mathrm{CH}} \mathrm{CHC}(\mathrm{O}) \mathrm{OMe}$

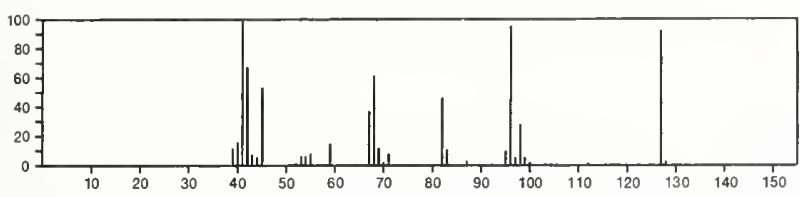

127

2-Oxazolidinone, 3-ethenyl-5-methyl-
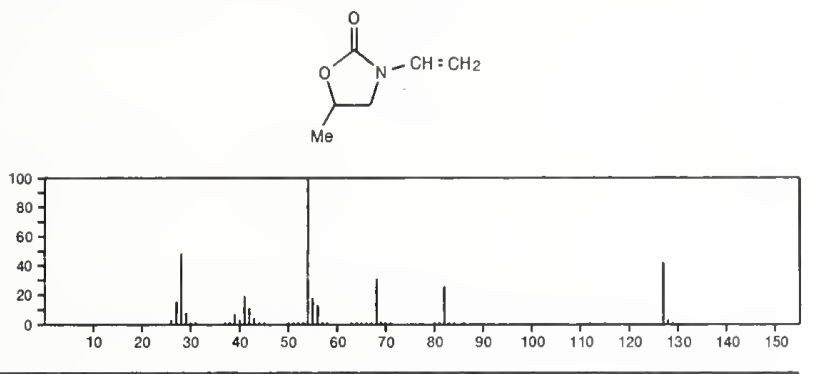

127

$\mathrm{C}_{6} \mathrm{H}_{9} \mathrm{NO}_{2}$

4-Isoxazolemethanol, 3,5-dimethyl-
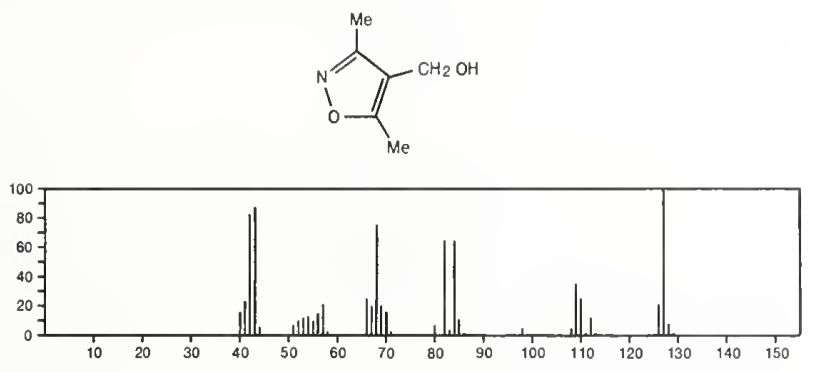

127

$\mathrm{C}_{6} \mathrm{H}_{9} \mathrm{NO}_{2}$

Butanoic acid, 2-cyano-, methyl ester

$53692-87-8$

Me OC ( O) CHE ICN

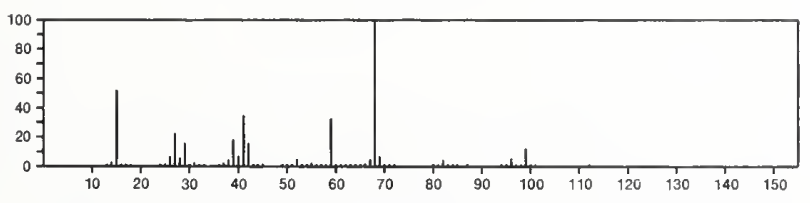

127

Thiazole, 2,4,5-trimethyl

$\mathrm{C}_{6} \mathrm{H}_{9} \mathrm{NS}$

13623-11-5
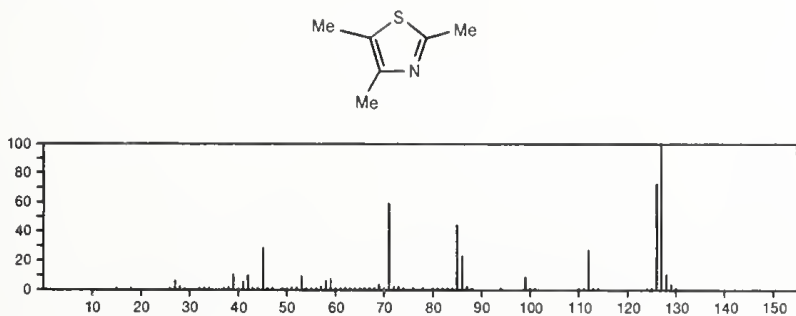

127

Thiazole, 2-ethyl-4-methyl-

$\mathrm{C}_{6} \mathrm{H}_{9} \mathrm{NS}$

$15679-12-6$
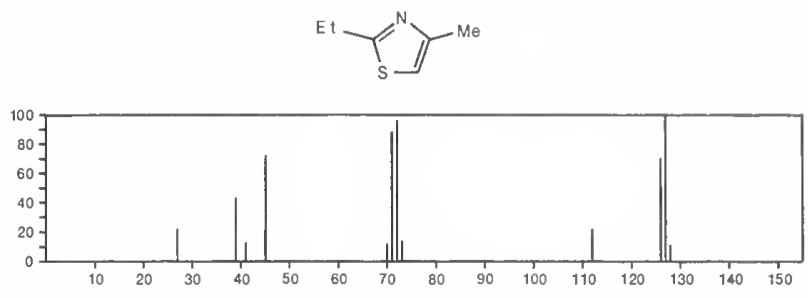

127

Thiazole, 2-propyl

$\mathrm{C}_{6} \mathrm{H}_{9} \mathrm{NS}$

$17626-75-4$
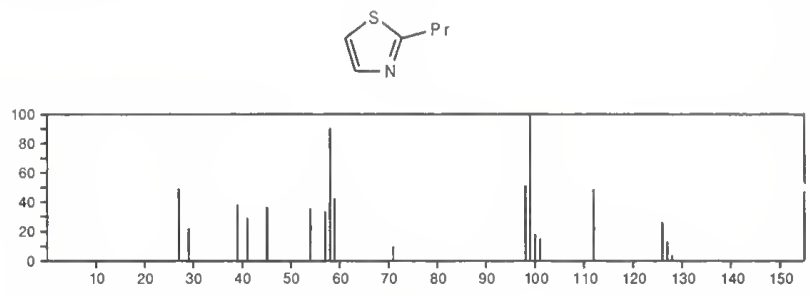

127

Thiazole, 2-ethyl-5-methyl-

$\mathrm{C}_{6} \mathrm{H}_{9} \mathrm{NS}$

19961-53-6
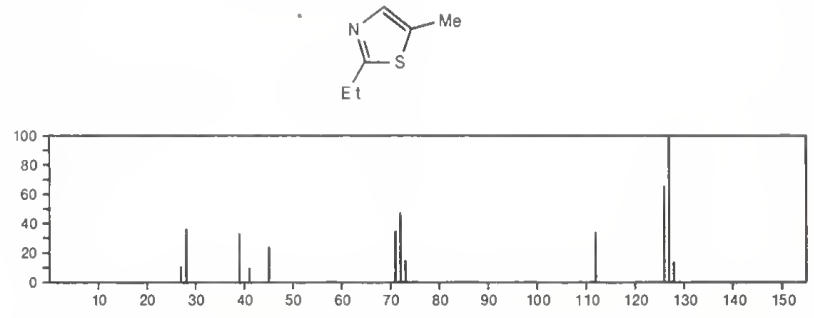

127 Thiazole, 5-ethyl-4-methyl- $\mathrm{C}_{6} \mathrm{H}_{9} \mathrm{NS}$

31883-01-9
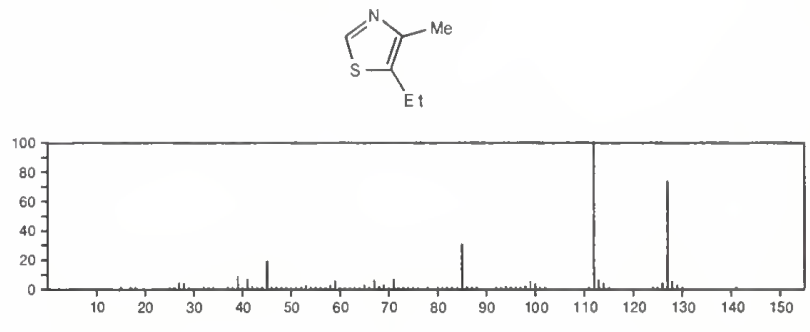

127 Thiazole, 4-ethyl-2-methyl-

$\mathrm{C}_{6} \mathrm{H}_{9} \mathrm{NS}$

$32272-48-3$
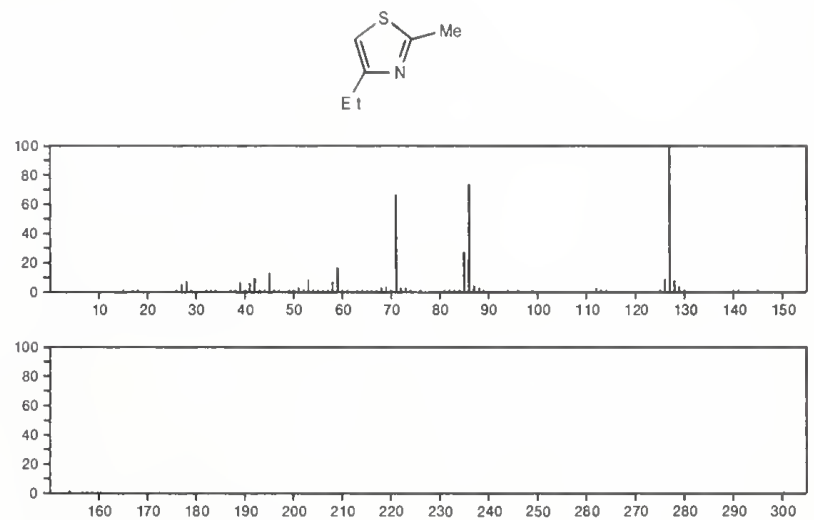
127

Isothiazole, trimethyl-

$\mathrm{C}_{6} \mathrm{H}_{9} \mathrm{NS}$
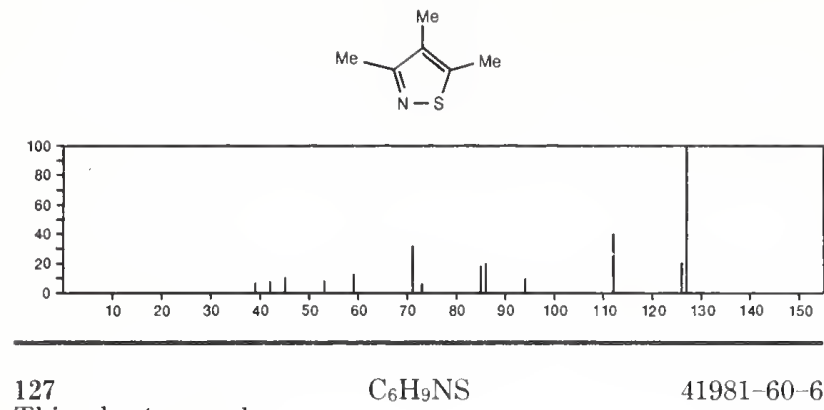

Thiazole, 4-propyl-
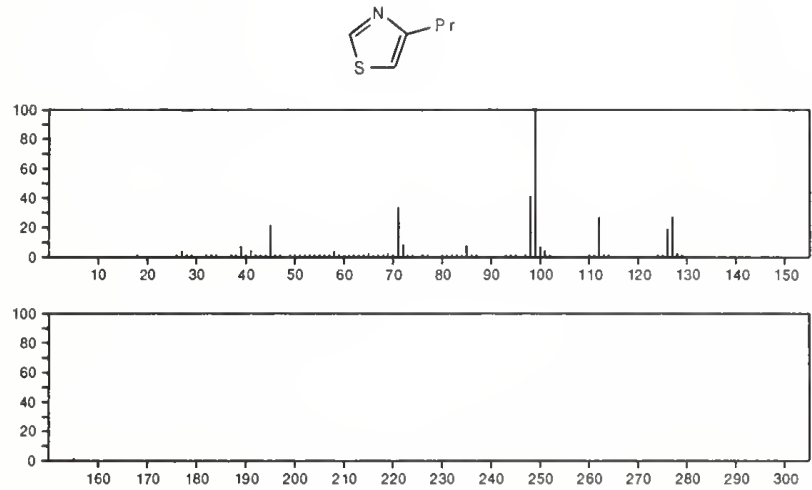

127

Thiazole, 5-propyl-

$\mathrm{C}_{6} \mathrm{H}_{9} \mathrm{NS}$

$52414-82-1$
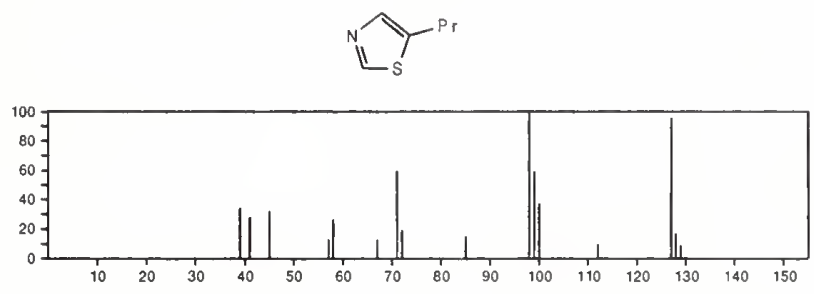

127

Thiazole, 4-ethyl-5-methyl-

$\mathrm{C}_{6} \mathrm{H}_{9} \mathrm{NS}$

$52414-91-2$
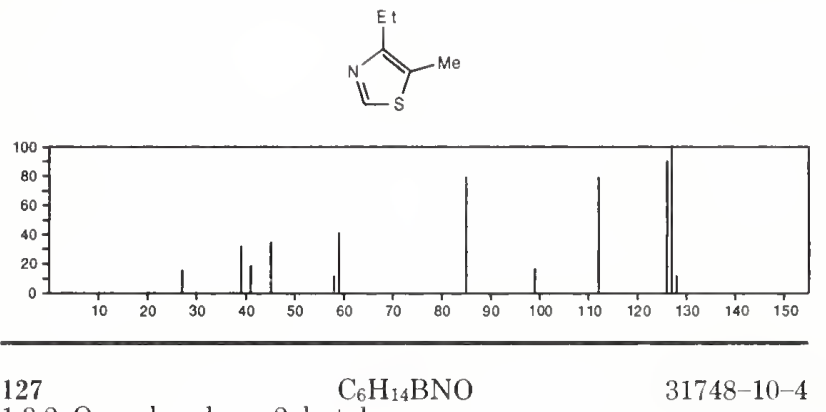

1,3,2-Oxazaborolane, 2-butyl-

$\underbrace{\mathrm{O}}_{\mathrm{NH}} \sum_{\mathrm{B}}^{-\left(\mathrm{CH}_{2}\right)_{3} \mathrm{Me}}$

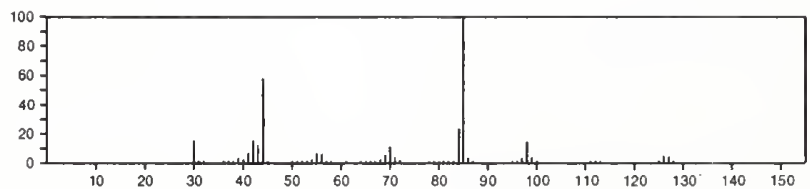

127

Piperidine, 1-acetyl-

$\mathrm{C}_{7} \mathrm{H}_{13} \mathrm{NO}$

$618-42-8$

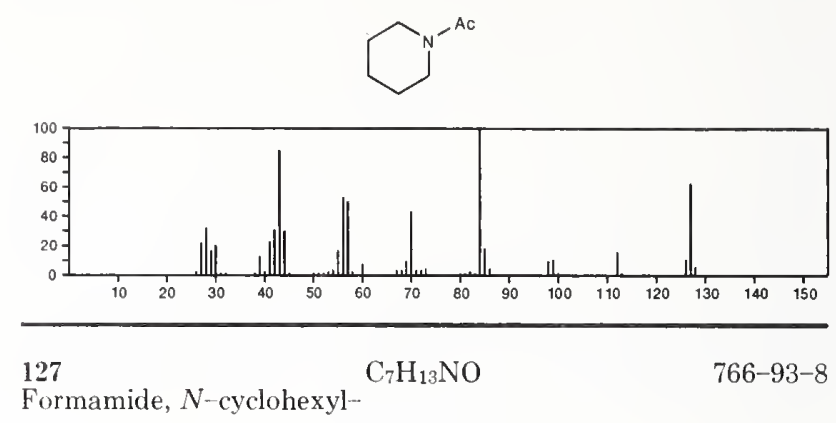

$\overbrace{}^{\mathrm{NHCH}=\mathrm{O}}$

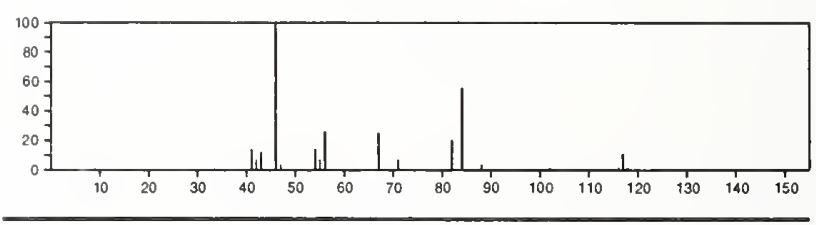

127

Cyclohexanone, 2 methyl-

$1122-26-5$
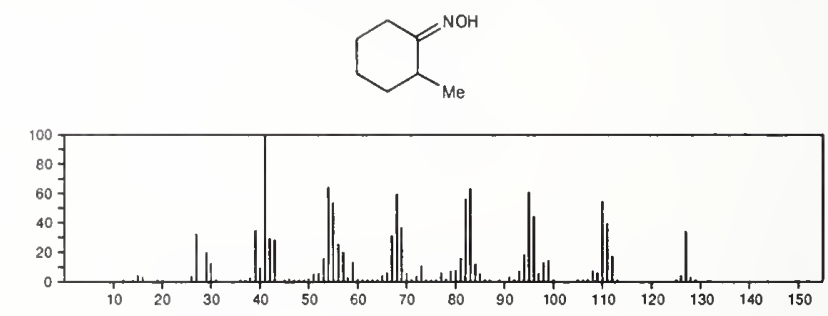

127

1-Azabicyclo[2.2.2]octan-3-o]

$\mathrm{C}_{7} \mathrm{H}_{13} \mathrm{NO}$

$1619-34-7$
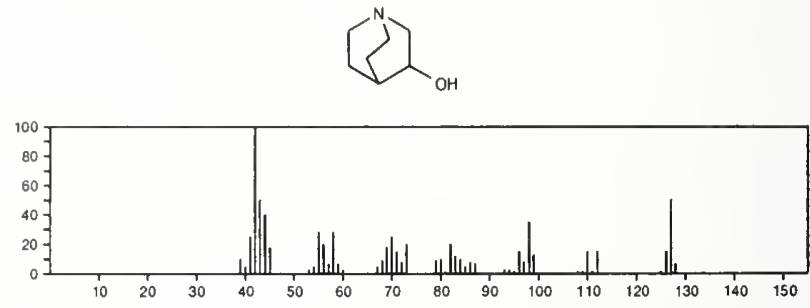

127

$\mathrm{C}_{7} \mathrm{H}_{13} \mathrm{NO}$

$1985-48-4$

2H-Azepin-2-one, hexahydro-7-methyl-
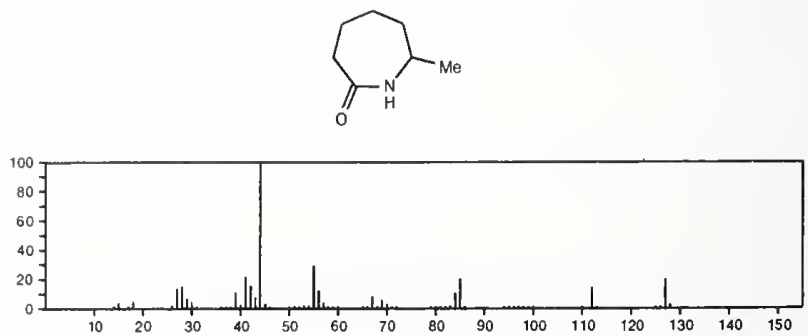
127

$\mathrm{C}_{7} \mathrm{H}_{13} \mathrm{NO}$

2H-Azepin-2-one, hexahydro-3-methyl-
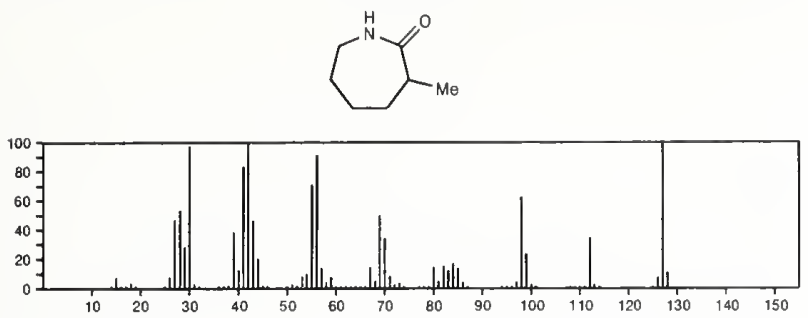

127

Cycloheptanone, oxime

$\mathrm{C}_{7} \mathrm{H}_{13} \mathrm{NO}$

$2158-31-8$
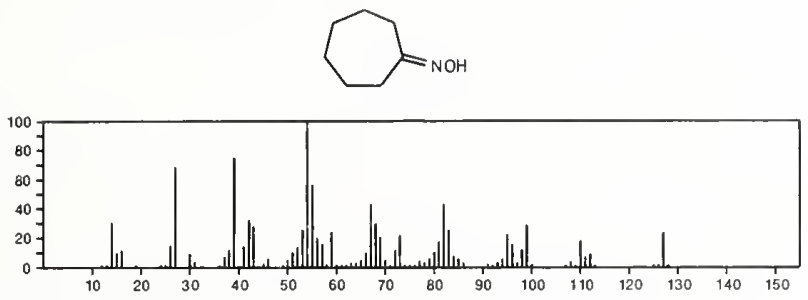

$127 \quad \mathrm{C}_{7} \mathrm{H}_{13} \mathrm{NO}$

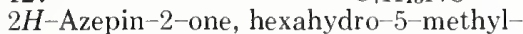
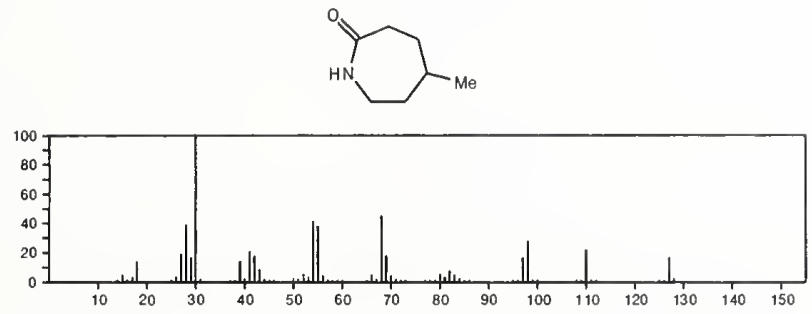

127

$\mathrm{C}_{7} \mathrm{H}_{13} \mathrm{NO}$

2H-Azepin-2-one, hexahydro-1-methyl-
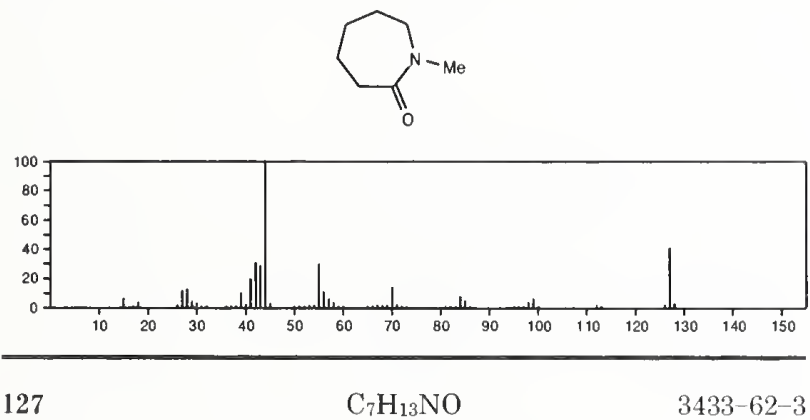

3-Penten-2-one, 4-(dimethylamino)-

$3433-62-3$

$\mathrm{Me} 2 \mathrm{NCMe}: \mathrm{CHCOMe}$

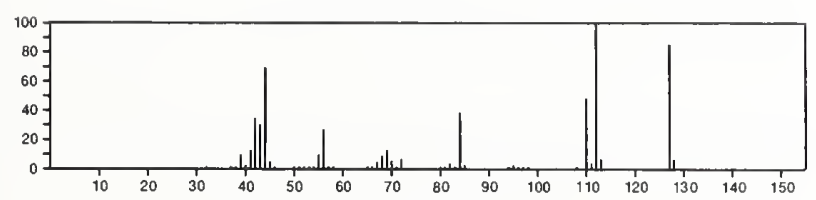

127

2-Pyrrolidinone, 1-propyl-

$\mathrm{C}_{7} \mathrm{H}_{13} \mathrm{NO}$

3470-99-3
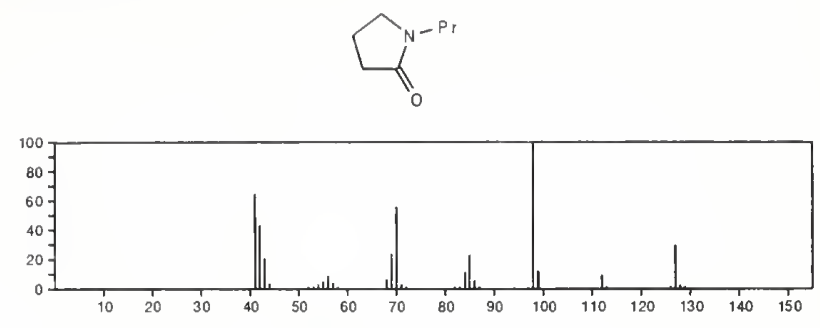

$127 \quad \mathrm{C}_{7} \mathrm{H}_{13} \mathrm{NO}$

$\mathrm{C}_{7} \mathrm{H}_{13} \mathrm{NO}$
dro-4-methyl

3623-05-0
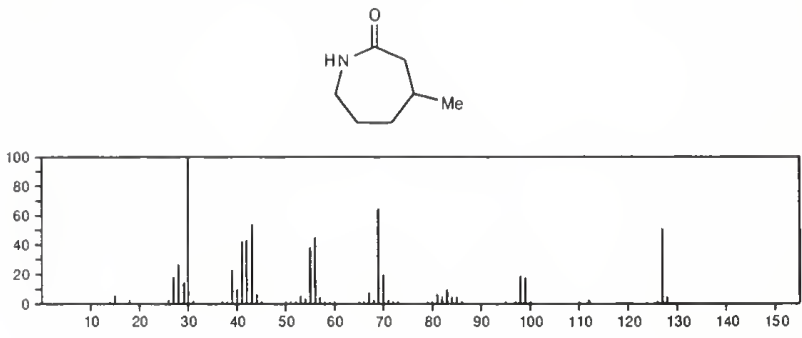

127

- $\mathrm{C}_{7} \mathrm{H}_{13} \mathrm{NO}$

$4553-05-3$

Pyrrolidine, 1-(1-oxopropyl)

$\widehat{C}^{-C O E t}$

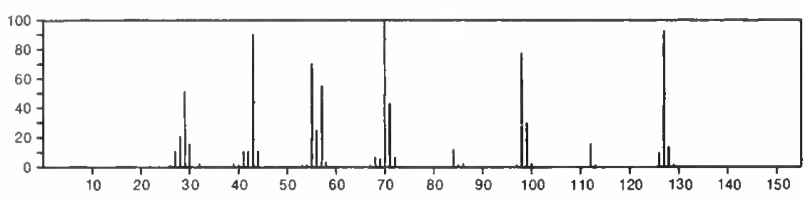

$127 \quad \mathrm{C}_{7} \mathrm{H}_{13} \mathrm{NO}$

$4701-95-5$

Cyclohexanone, 3-methyl-, oxime<smiles>CC1CCCC(=N)C1</smiles>

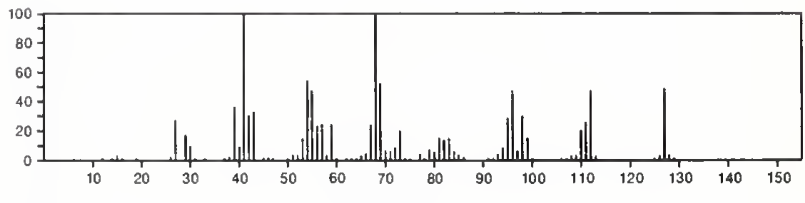

127

$\mathrm{C}_{7} \mathrm{H}_{13} \mathrm{NO}$

4994-13-2

Cyclohexanone, 4-methyl-, oxime<smiles>CC1CCC(=N)CC1</smiles>

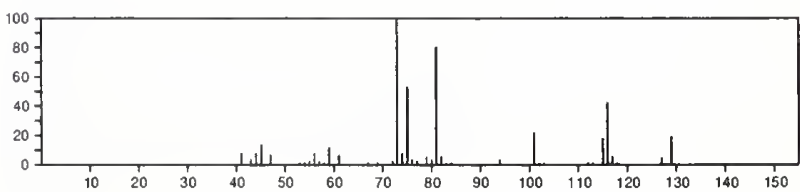


$\mathrm{C}_{7} \mathrm{H}_{13} \mathrm{NO}$

2H-Azepin-2-one, hexahydro-6-methyl
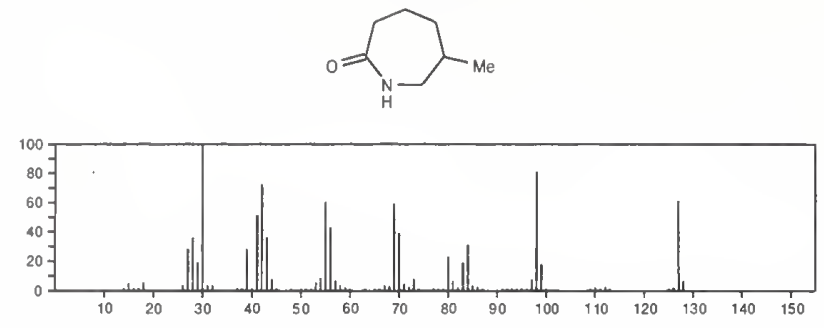

127

Propanenitrile, 3-butoxy-

$\mathrm{C}_{7} \mathrm{H}_{13} \mathrm{NO}$

$6959-71-3$

$\mathrm{NCCH}_{2} \mathrm{CH}_{2} \mathrm{O}\left(\mathrm{CH}_{2}\right)_{3} \mathrm{Me}$

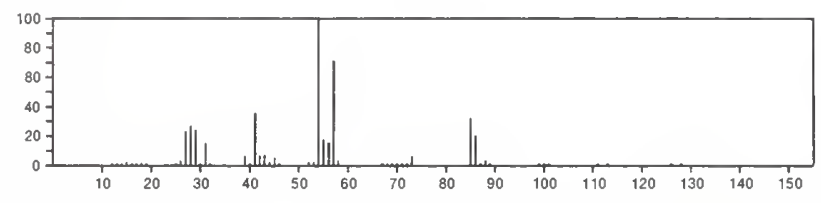

127

$\mathrm{C}_{7} \mathrm{H}_{13} \mathrm{NO}$

Cyclohexanone, $\mathrm{O}$-methyloxime
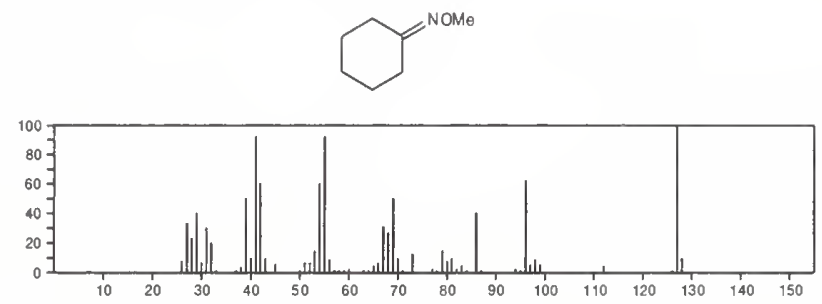

127

Acetamide, $N$-cyclopentyl

$\mathrm{C}_{7} \mathrm{H}_{13} \mathrm{NO}$

$\gamma^{N H A C}$

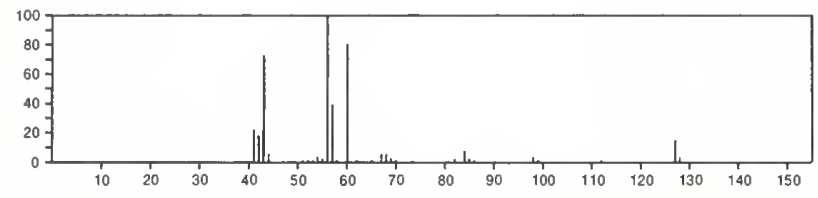

127

$\mathrm{C}_{7} \mathrm{H}_{13} \mathrm{NO}$

3-Penten-2-one, 3-methyl-, $\mathrm{O}$-methyloxime

$\mathrm{MeCH}: \mathrm{CMeCMe}^{\mathrm{N}} \mathrm{NOM}$

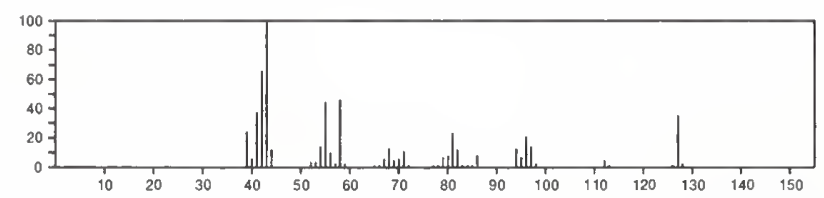

127

$\mathrm{C}_{7} \mathrm{H}_{13} \mathrm{NO}$

4-Hexen-3-one, $\mathrm{O}$-methyloxime

$39209-04-6$

$\mathrm{MeCH}=$ CHCE $\mathrm{t}=$ NOME

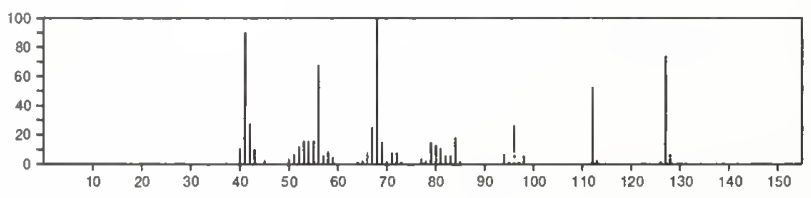

127

3-Piperidinone, 1,6-dimethyl-

$\mathrm{C}_{7} \mathrm{H}_{13} \mathrm{NO}$

$43152-92-7$
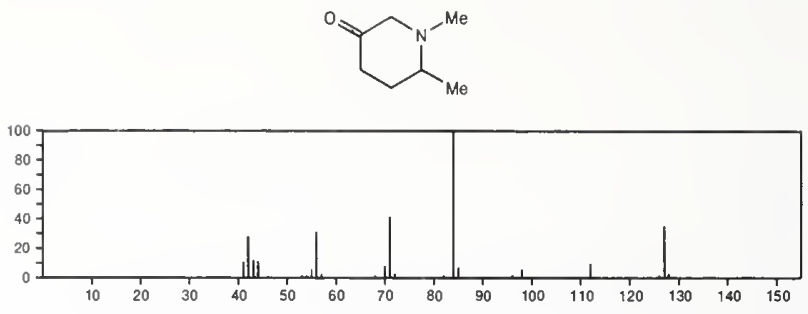

127

3-Piperidinone, 1-ethyl-

$\mathrm{C}_{7} \mathrm{H}_{13} \mathrm{NO}$

$43152-93-8$
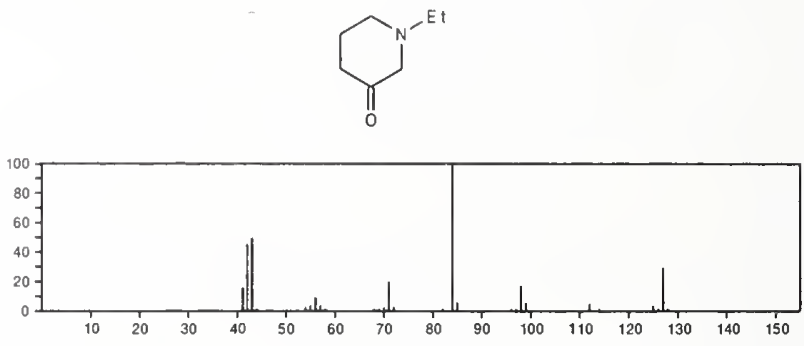

127

5-Hexen-2-one, $O$-methyloxime

$56335-97-8$

$\mathrm{H}_{2} \mathrm{C}=\mathrm{CHCH}_{2} \mathrm{CH}_{2} \mathrm{CMe}=\mathrm{NOM}$

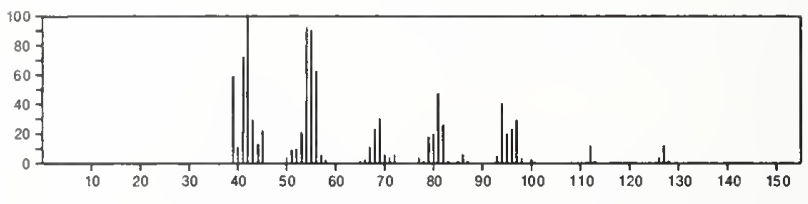

127

$\mathrm{C}_{7} \mathrm{H}_{13} \mathrm{NO}$

$56335-98-9$

4-Penten-2-one, 3-methyl-, O-methyloxime

$\mathrm{H}_{2} \mathrm{C}=\mathrm{CHCHMe} \mathrm{CMe}=\mathrm{NOMe}$

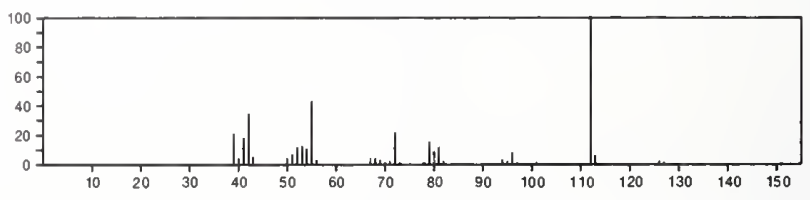

127

4-Hexen-2-one, $\mathrm{O}$-methyloxime

$56335-99-0$

$\mathrm{MeCH}=\mathrm{CHCH}_{2} \mathrm{CMe}=\mathrm{NOM}$

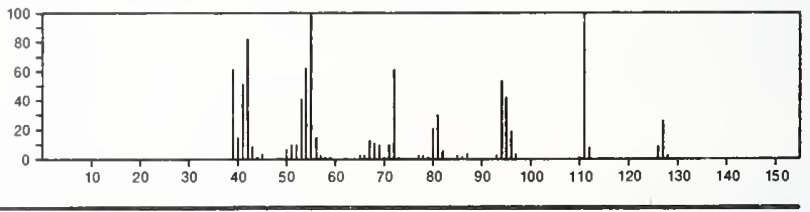

127

$\mathrm{C}_{7} \mathrm{H}_{23} \mathrm{NO}$

$56336-10-8$

1-Propanone, 1-cyclopropyl-, $O$-methyloxime

$\triangle \triangle_{C E T=N O M e}$

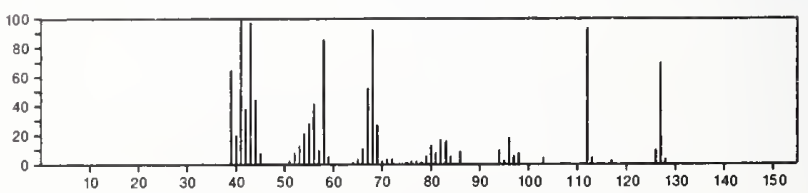


$\mathrm{C}_{7} \mathrm{H}_{13} \mathrm{NO}$

3-Penten-2-one, 4-methyl-, $\mathrm{O}$-methyloxime

$\mathrm{MeON}=\mathrm{CMe} \mathrm{CH}=\mathrm{CMe} 2$

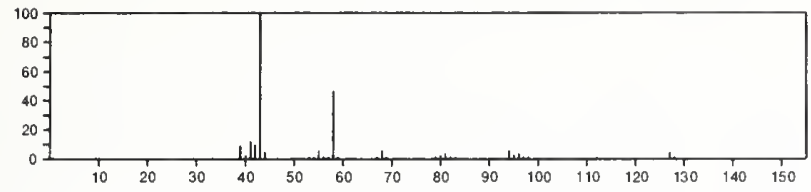

$127 \quad \mathrm{C}_{8} \mathrm{H}_{17} \mathrm{~N}$

Cyclohexanamine, $N, N$-dimethyl-
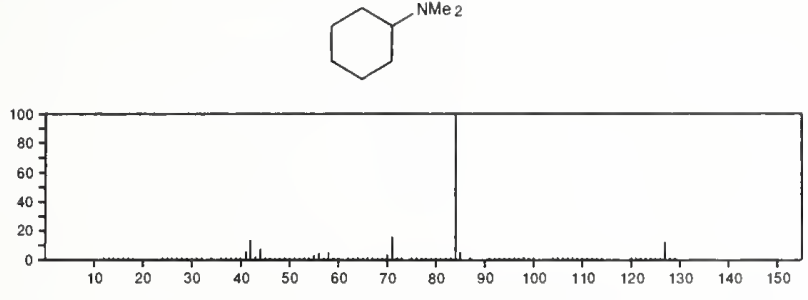

127

Piperidine, 1-ethyl-2-methyl-

$\mathrm{C}_{8} \mathrm{H}_{17} \mathrm{~N}$

$766-52-9$
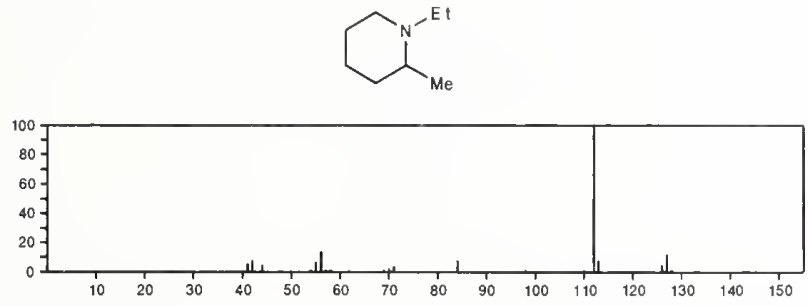

127

$\mathrm{C}_{8} \mathrm{H}_{17} \mathrm{~N}$

2439-13-6

Piperidine, 1,2,6-trimethyl-, cis-
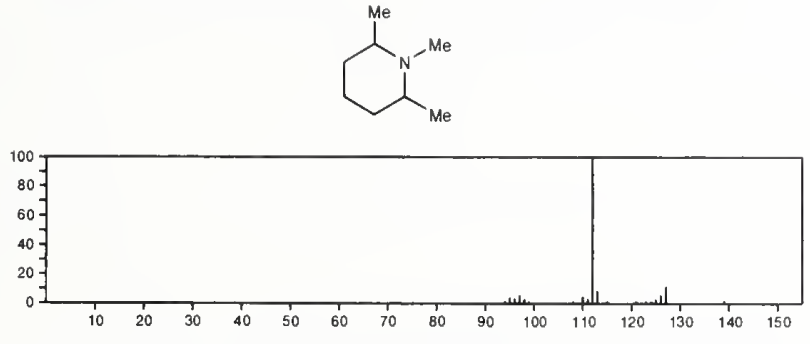

127

$\mathrm{C}_{8} \mathrm{H}_{17} \mathrm{~N}$

$3203-94-9$

Aziridine, 2-tert-butyl-1,3-dimethyl-, trans-
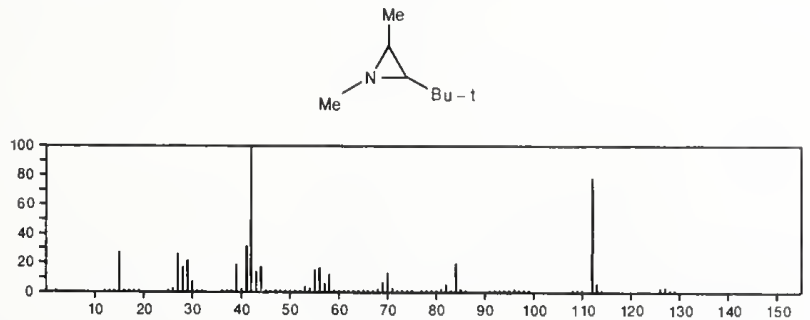

127

$\mathrm{C}_{8} \mathrm{H}_{17} \mathrm{~N}$

$4853-56-9$

1-Butanamine, $N$-butylidene-

$\mathrm{Me}\left(\mathrm{CH}_{2}\right)_{3} \mathrm{~N}=\mathrm{CHPr}$

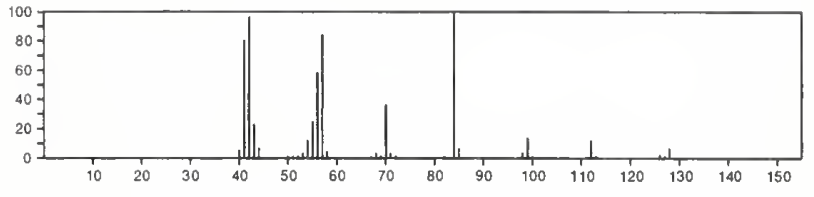

127 Cyclohexanamine, $N$-ethyl- $\mathrm{C}_{8} \mathrm{H}_{17} \mathrm{~N}$

$5459-93-8$
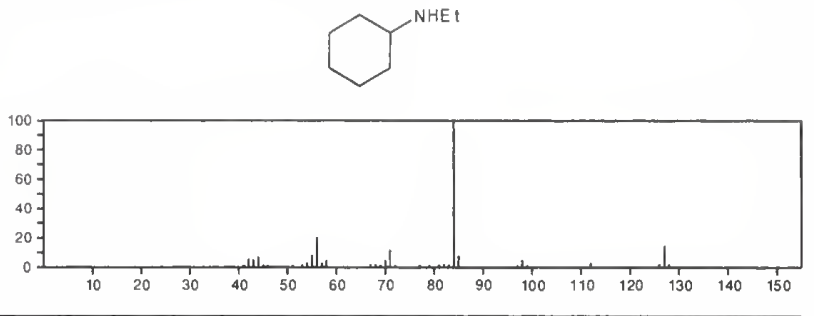

127

$1 H^{- \text {-Azonine, octahydro- }}$

$\mathrm{C}_{8} \mathrm{H}_{17} \mathrm{~N}$

$5661-71-2$<smiles>C1CCCCNCCCC1</smiles>

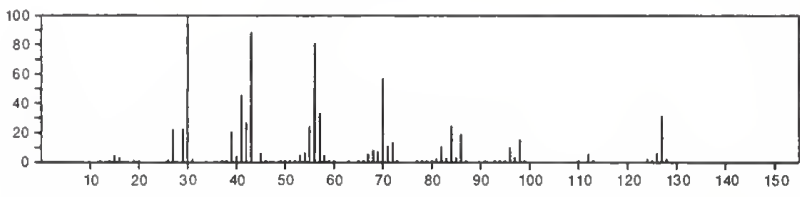

127

$\mathrm{C}_{8} \mathrm{H}_{17} \mathrm{~N}$

$6125-02-6$

Aziridine, 1-(1,1-dimethylethyl)-2,3-dimethyl-, trans-
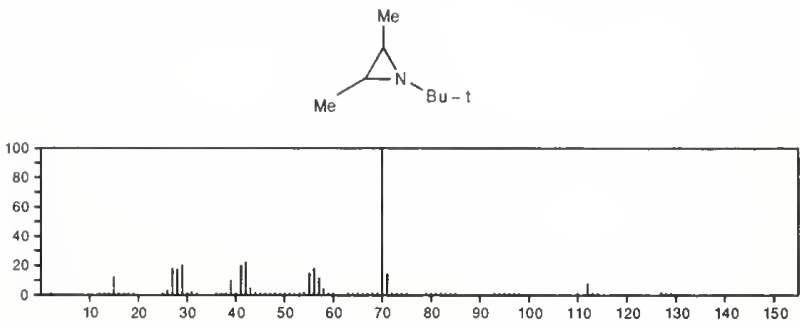

$127 \quad \mathrm{C}_{8} \mathrm{H}_{17} \mathrm{~N}$

$6898-71-1$

Methylamine, $\mathrm{N}$-heptylidene-

$\mathrm{Me}\left(\mathrm{CH}_{2}\right) 5 \mathrm{CH}: \mathrm{NM}$

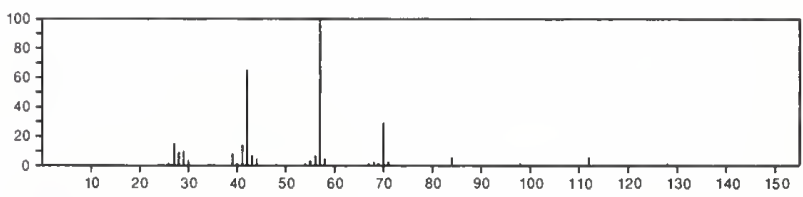

127

$\mathrm{C}_{8} \mathrm{H}_{17} \mathrm{~N}$

$6898-82-4$

1-Propanamine, 2 -methyl- $N$-(2-methylpropylidene)-

$\mathrm{Me}_{2} \mathrm{CHCH}=\mathrm{NBU}-\mathrm{i}$

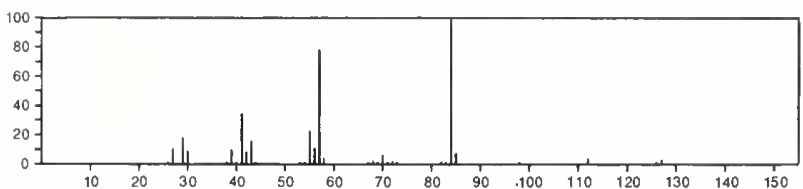


Methylamine, $N$-(1-propylbutylidene)-

$M \in N=C P r_{2}$

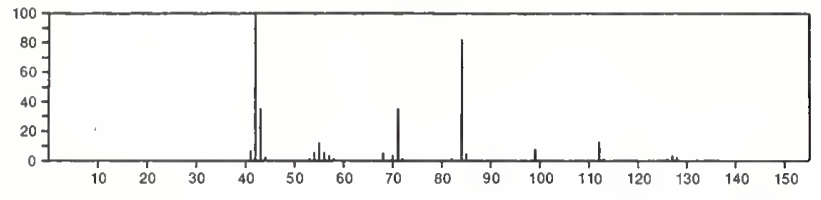

127

Aziridine, 2-hexyl-

$\mathrm{C}_{8} \mathrm{H}_{17} \mathrm{~N}$

$13906-89-3$<smiles>CCCC1CN1</smiles>
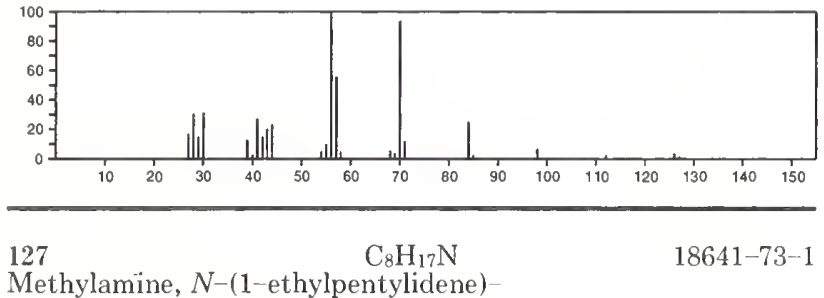

$\mathrm{Me}\left(\mathrm{CH}_{2}\right)_{3} \mathrm{CEt}=\mathrm{NME}$

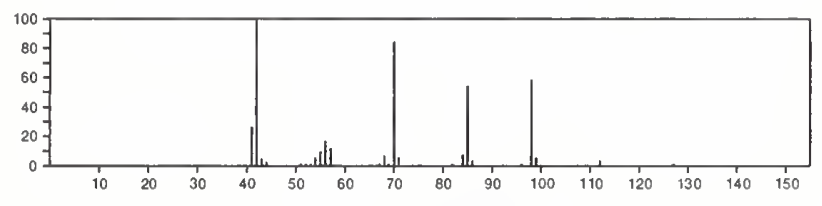

127

$\mathrm{C}_{8} \mathrm{H}_{17} \mathrm{~N}$

Methylamine, $N$-(1-methylhexylidene)-

$22058-71-5$

$\mathrm{Me}\left(\mathrm{CH}_{2}\right)_{4} \mathrm{CMe}=\mathrm{NMe}$

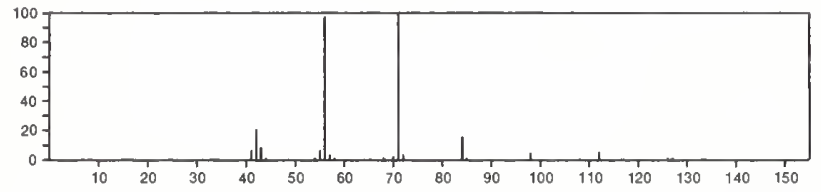

127

$\mathrm{C}_{8} \mathrm{H}_{17} \mathrm{~N}$

$30691-59-9$

Aziridine, 1-hexyl-
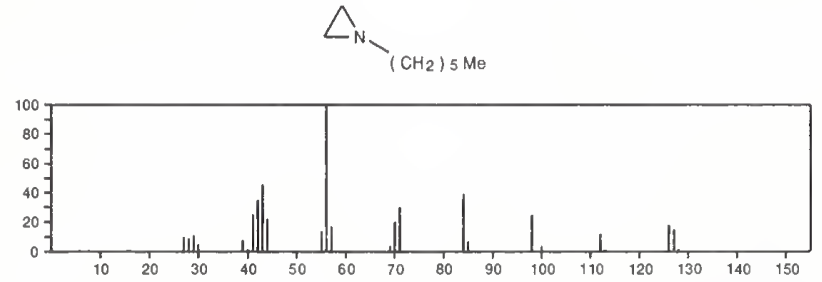

127

$\mathrm{C}_{8} \mathrm{H}_{17} \mathrm{~N}$

$55702-65-3$

Azetidine, 1-(1,1-dimethylethyl)-3-methyl
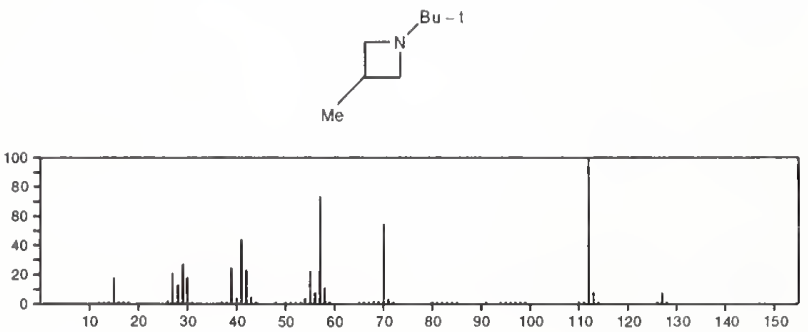

Aziridine, 1-ethyl-2-methyl-3-(1-methylethyl)-, trans-<smiles>CCN1C(=PI)C1C</smiles>

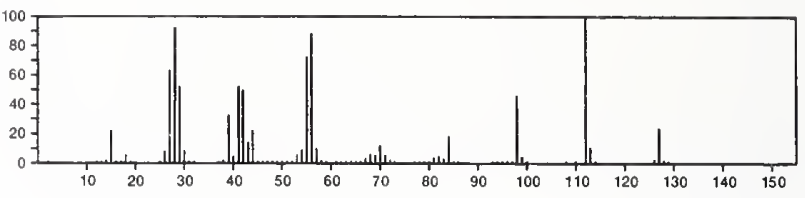

127

$\mathrm{C}_{8} \mathrm{H}_{17} \mathrm{~N}$

$55712-58-8$

Aziridine, 2-(1,1-dimethylethyl)-1,3-dimethyl-
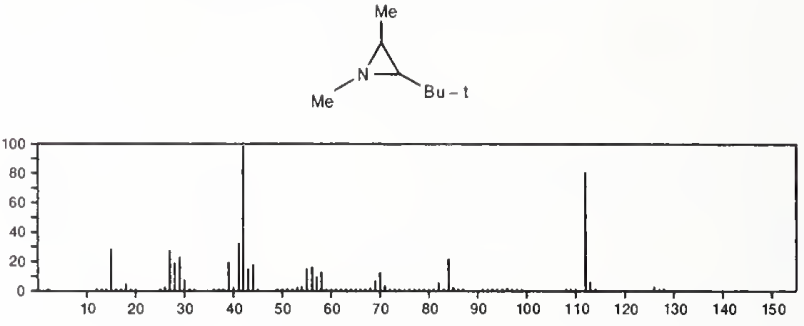

127

$\mathrm{C}_{8} \mathrm{H}_{17} \mathrm{~N}$

$56082-94-1$

Aziridine, 1-(1,1-dimethylethyl)-2,3-dimethyl-, cis-<smiles>CC1C(C)N1Br</smiles>

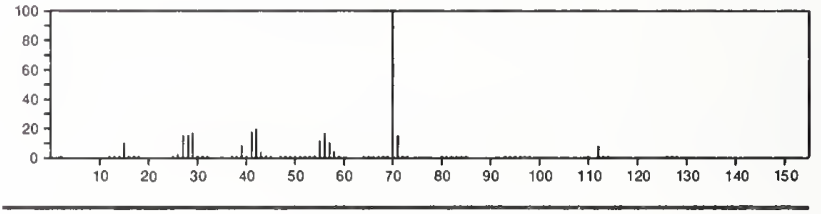

128

$\mathrm{CH}_{2} \mathrm{BrCl}$

74-97-5

Methane, bromochloro-

$\mathrm{CH}_{2} \mathrm{BrCl}$

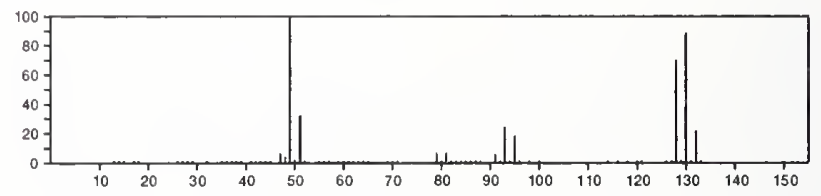

128

Acetic acid, dichloro

$\mathrm{C}_{2} \mathrm{H}_{2} \mathrm{Cl}_{2} \mathrm{O}_{2}$

79-43-6

$\mathrm{Cl}_{2} \mathrm{CHCO}_{2} \mathrm{H}$

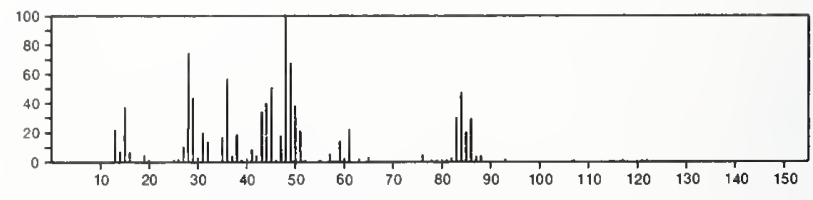

128

$\mathrm{C}_{2} \mathrm{H}_{5} \mathrm{ClO}_{2} \mathrm{~S}$

594-44-5

Ethanesulfonyl chloride

$\mathrm{EtSO} \mathrm{SO}_{2} \mathrm{Cl}$

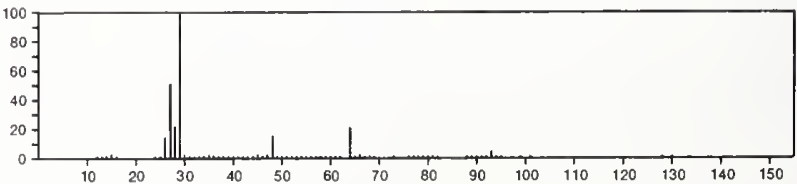


128

Silane, dichlorodimethyl-

$\mathrm{C}_{2} \mathrm{H}_{6} \mathrm{Cl}_{2} \mathrm{Si}$

$\mathrm{Cl}_{2} \mathrm{SiMe}_{2}$
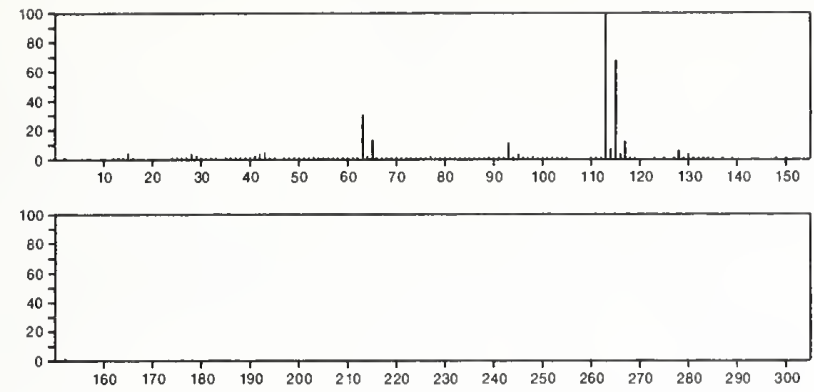

128

Cyclopropene, 1-chloro-2,3,3-trifluoro

$\mathrm{C}_{3} \mathrm{ClF}_{3}$
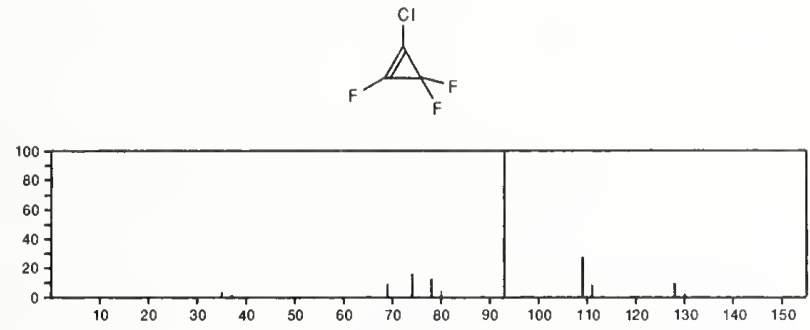

128

Propene, 1,1-dichloro-2-fluoro

\section{$\mathrm{C}_{3} \mathrm{H}_{3} \mathrm{Cl}_{2} \mathrm{~F}$}

430-95-5

$\mathrm{Cl}_{2} \mathrm{C}=\mathrm{CFMe}$

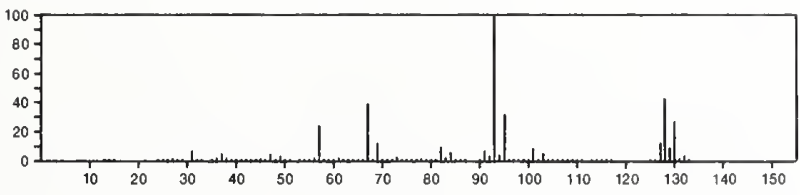

128

2-Propanol, 1,3-dichloro-

$\mathrm{C}_{3} \mathrm{H}_{6} \mathrm{Cl}_{2} \mathrm{O}$

96-23-1

$\mathrm{Cl} \mathrm{CH}_{2} \mathrm{CH}(\mathrm{OH}) \mathrm{CH}_{2} \mathrm{Cl}$

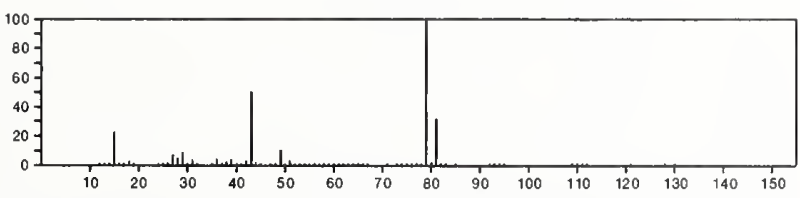

128

1-Propanol, 2,3-dichloro-

$\mathrm{C}_{3} \mathrm{H}_{6} \mathrm{Cl}_{2} \mathrm{O}$

$616-23-9$

$\mathrm{Cl} \mathrm{CH}_{2} \mathrm{CHCl} \mathrm{CH}_{2} \mathrm{OH}$

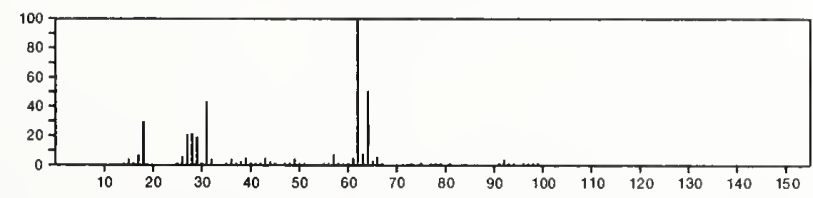

128

1-Butene, 3,3,4,4-tetrafluoro-

40723-71-5

$\mathrm{H}_{2} \mathrm{C}=\mathrm{CHCF}_{2} \mathrm{CHF}_{2}$

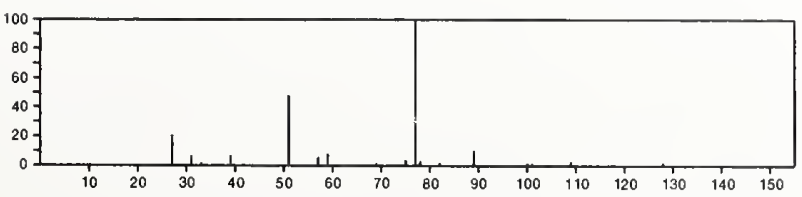

128

$\mathrm{C}_{4} \mathrm{H}_{4} \mathrm{~N}_{2} \mathrm{OS}$

$141-90-2$

4(1H)-Pyrimidinone, 2,3-dihydro-2-thioxo-
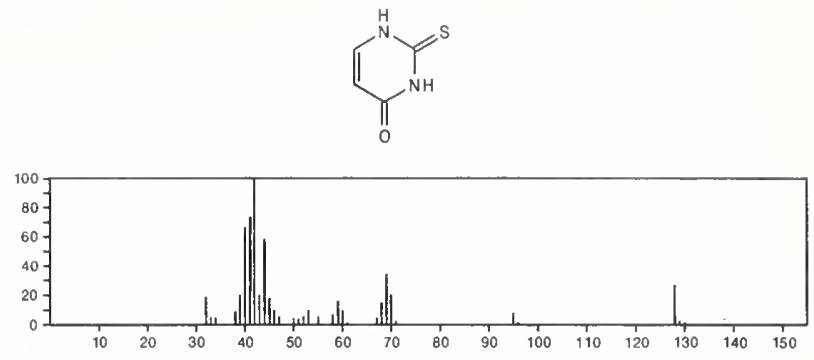

128

5-lsothiazolecarboxamide

$\mathrm{C}_{4} \mathrm{H}_{4} \mathrm{~N}_{2} \mathrm{OS}$

3683-98-5
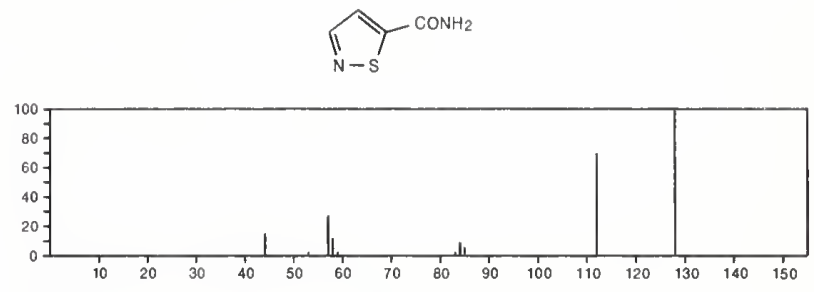

128

4 -Isothiazolecarboxamide

$\mathrm{C}_{4} \mathrm{H}_{4} \mathrm{~N}_{2} \mathrm{OS}$

24340-75-8
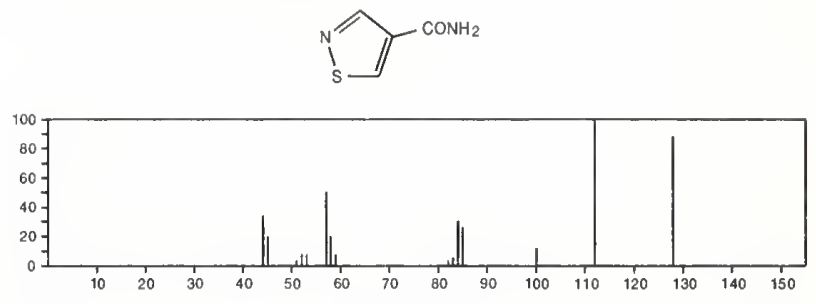

128

3-lsothiazolecarboxamide

$\mathrm{C}_{4} \mathrm{H}_{4} \mathrm{~N}_{2} \mathrm{OS}$

24342-43-6

$\underbrace{\mathrm{CONH}_{2}}$

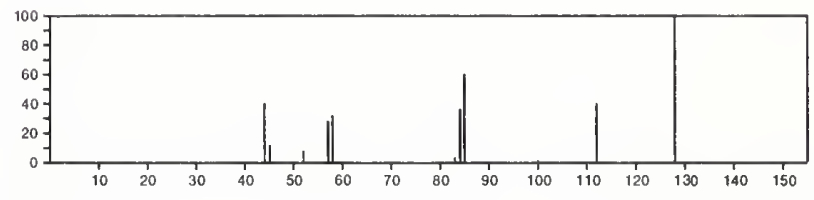

$128 \quad \mathrm{C}_{4} \mathrm{H}_{4} \mathrm{~N}_{2} \mathrm{O}_{3}$

$2,4,6(1 H, 3 H, 5 H)$-Pyrimidinetrione

$67-52-7$
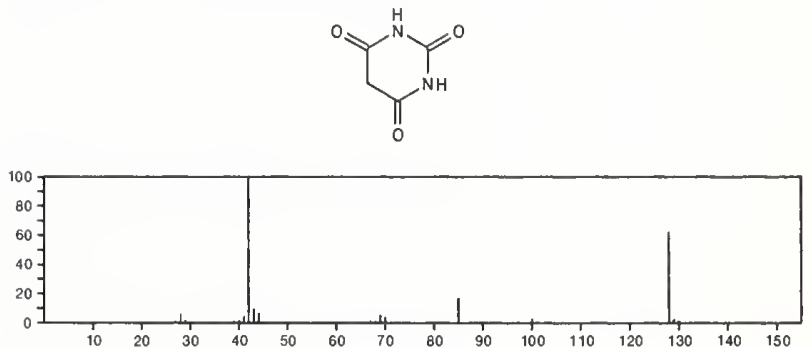
$128 \quad \mathrm{C}_{5} \mathrm{H}_{5} \mathrm{ClN}_{2}$

Pyrimidine, 4-chloro-2-methyl-

4994-86-9<smiles>Nc1nccc(Cl)n1</smiles>

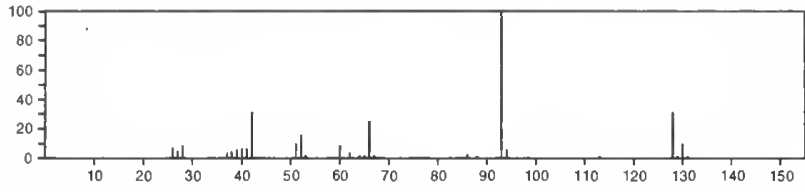

$128 \quad \mathrm{C}_{5} \mathrm{H}_{8} \mathrm{~N}_{2} \mathrm{O}_{2}$

3786-29-6

Butanediamide, 2-methylene-

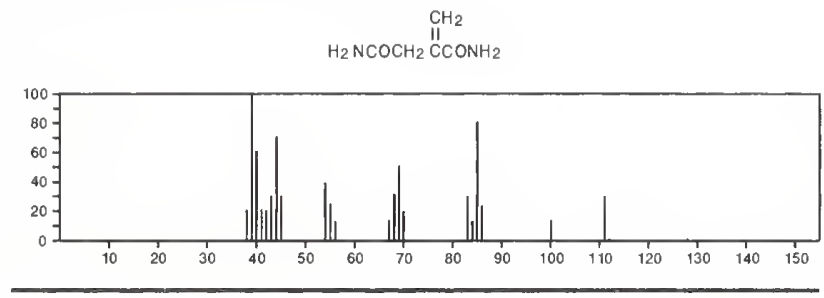

128

$\mathrm{C}_{5} \mathrm{H}_{8} \mathrm{~N}_{2} \mathrm{O}_{2}$

6939-17-9

Sydnone, 3-(1-methylethyl)-
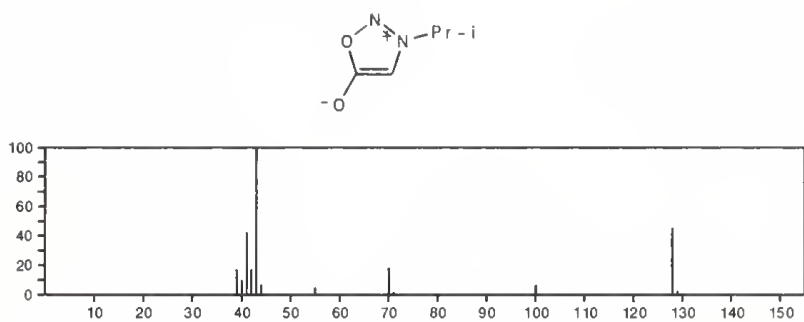

128

$\mathrm{C}_{5} \mathrm{H}_{8} \mathrm{~N}_{2} \mathrm{O}_{2}$

2-Butenediamide, 2-methyl-, $(Z)$

$\mathrm{H}_{2} \mathrm{NCOCH}=\mathrm{CMe} \mathrm{CONH}_{2}$

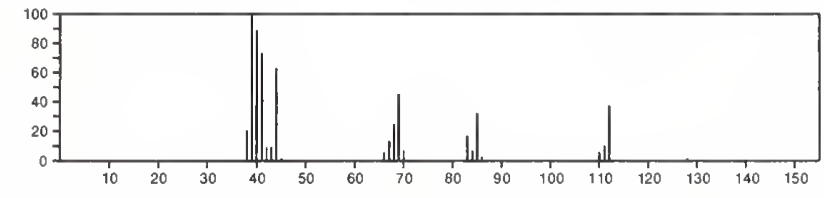

$128 \quad \mathrm{C}_{5} \mathrm{H}_{8} \mathrm{~N}_{2} \mathrm{O}_{2}$

2-Butenediamide, 2-methyl-, $(E)$ -

41138-18-5

$\mathrm{H}_{2} \mathrm{NCOCH}=\mathrm{CMe} \mathrm{CONH}_{2}$

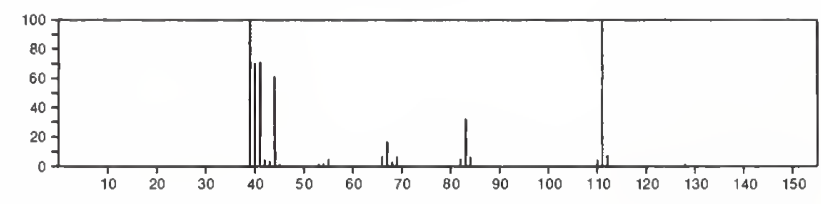

128

$\mathrm{C}_{5} \mathrm{H}_{8} \mathrm{~N}_{2} \mathrm{O}_{2}$

$55556-91-7$

4-Piperidinone, 1-nitroso
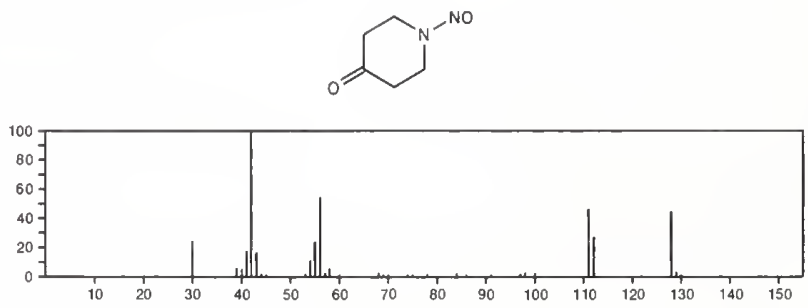

128

$\mathrm{C}_{6} \mathrm{H}_{5} \mathrm{ClO}$

95-57-8

Phenol, 2-chloro
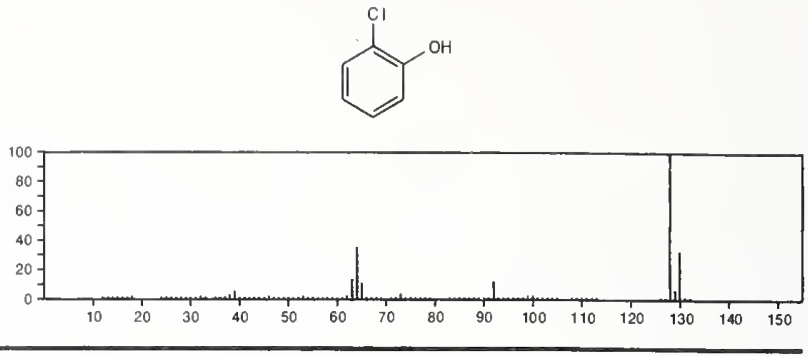

128

$\mathrm{C}_{6} \mathrm{H}_{5} \mathrm{ClO}$

$106-48-9$

Phenol, 4-chloro-
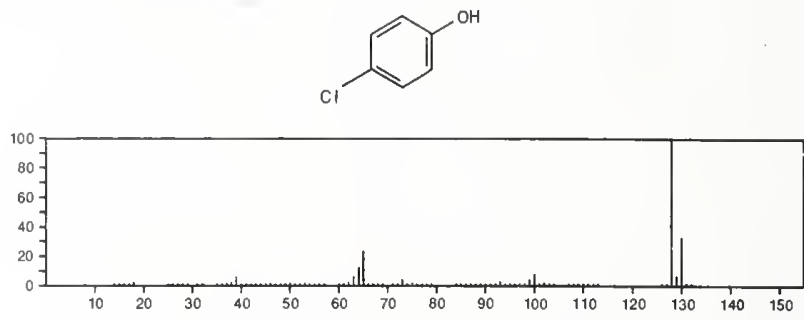

128

$\mathrm{C}_{6} \mathrm{H}_{5} \mathrm{ClO}$

$108-43-0$

Phenol, 3-chloro
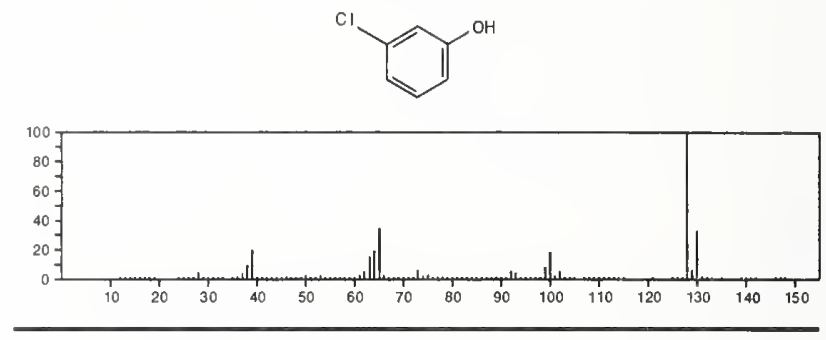

128

$\mathrm{C}_{6} \mathrm{H}_{5} \mathrm{FO}_{2}$

$363-52-0$

1,2-Benzenediol, 3-fluoro-
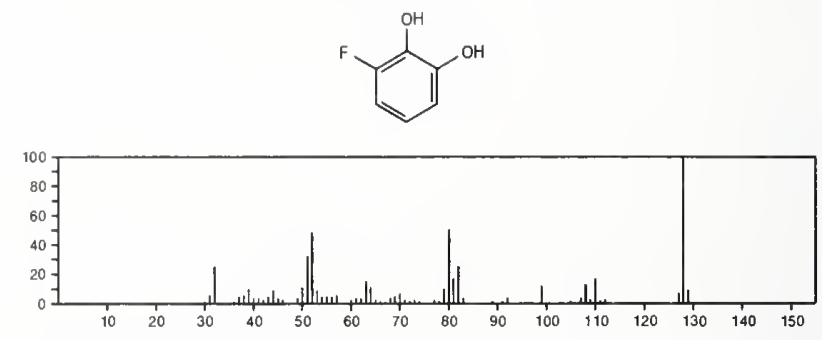

128

$\mathrm{C}_{6} \mathrm{H}_{8} \mathrm{OS}$

$31053-55-1$

Thiophene, 2-methoxy-5-methyl-<smiles>COc1ccc(C)s1</smiles>

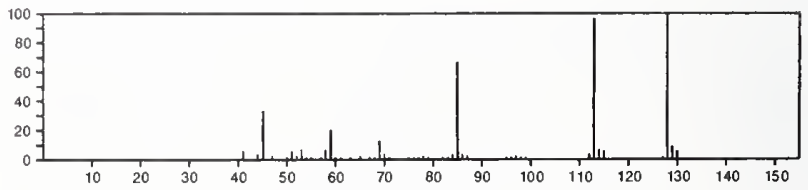


2(3H)-Furanone, 3-acetyldihydro-
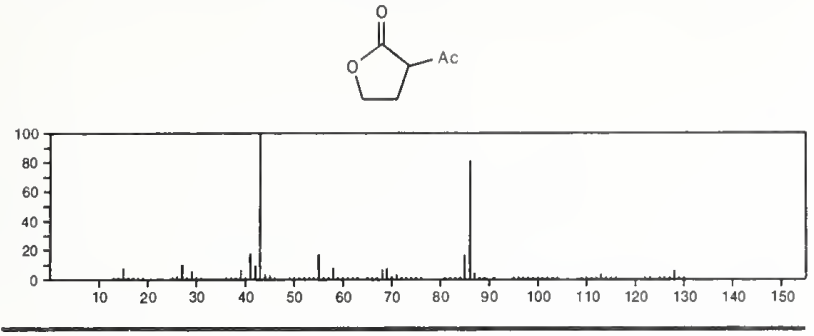

$128 \quad \mathrm{C}_{6} \mathrm{H}_{8} \mathrm{O}_{3}$

$4800-04-8$

1,3-Cyclopentanedione, 4-hydroxy-2-methyl-
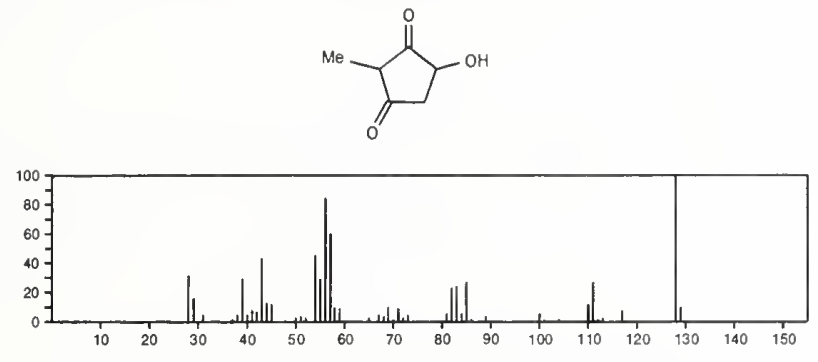

$\mathrm{C}_{6} \mathrm{H}_{8} \mathrm{O}_{3}$
Propanoic acid, $3-(2-$ propynyloxy $)-$

$\mathrm{HO}_{2} \mathrm{CCH}_{2} \mathrm{CH}_{2} \mathrm{OCH}_{2} \mathrm{C} \equiv \mathrm{CH}$

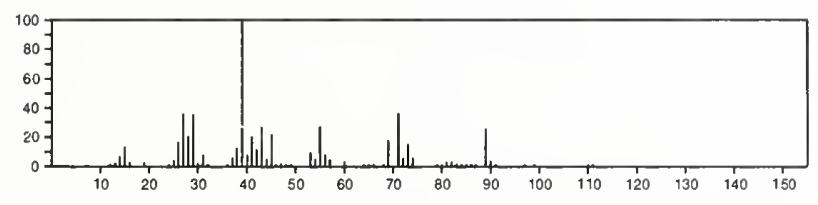

$128 \quad \mathrm{C}_{6} \mathrm{H}_{8} \mathrm{O}_{3} \quad 57156-98-6$ 1,3-Cyclopentanedione, 4-hydroxy-5-methyl-
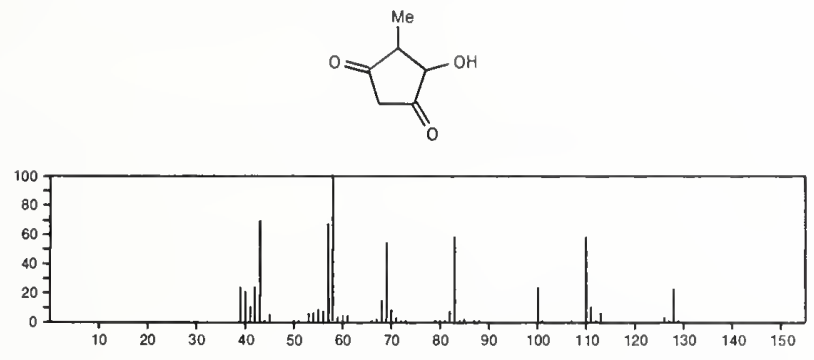

128

$\mathrm{C}_{6} \mathrm{H}_{12} \mathrm{~N}_{2} \mathrm{O}$

932-83-2

1H-Azepine, hexahydro-1-nitroso-
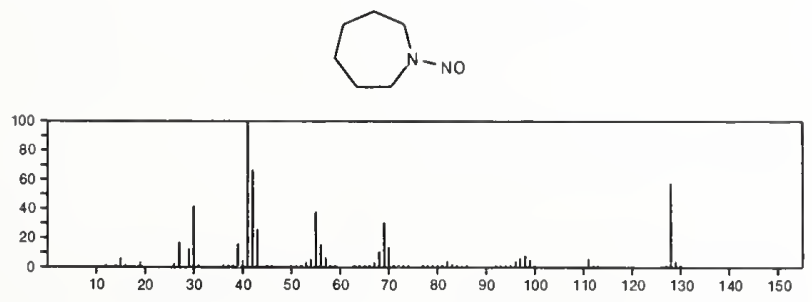

(1)<smiles>CC1CCCCN1O</smiles>

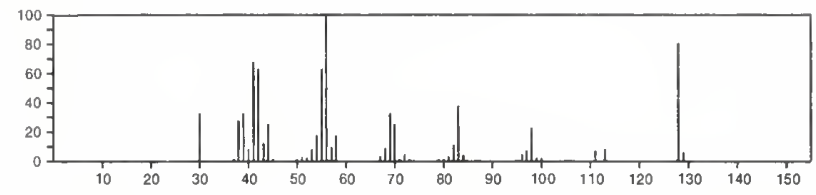

128

$\mathrm{C}_{6} \mathrm{H}_{12} \mathrm{~N}_{2} \mathrm{O}$

Piperidine, 3-methyl-1-nitroso-

$13603-07-1$<smiles>CC1CCCN(O)C1</smiles>

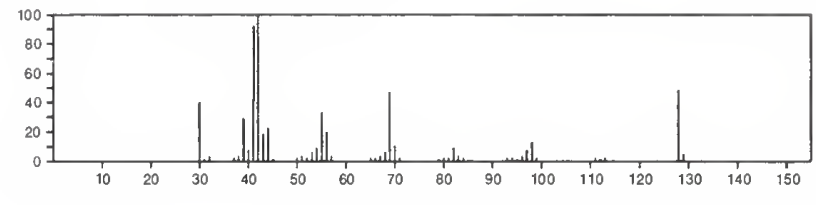

128

$\mathrm{C}_{6} \mathrm{H}_{12} \mathrm{~N}_{2} \mathrm{O}$

15104-03-7

Piperidine, 4-methyl-1-nitroso-
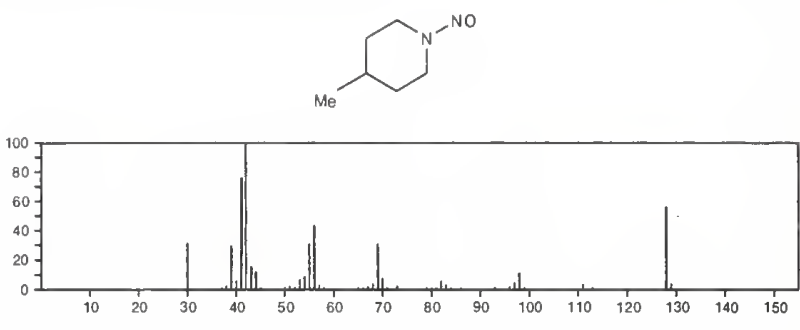

128

$\mathrm{C}_{6} \mathrm{H}_{12} \mathrm{~N}_{2} \mathrm{O}$

49582-51-6

2-Propenal, 3-(dimethylamino)-3-(methylamino)-

$\mathrm{OCHCH}=\mathrm{C}(\mathrm{NHMe}) \mathrm{NMO}_{2}$

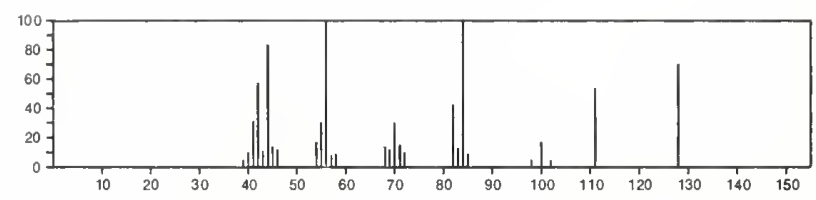

128

$\mathrm{C}_{6} \mathrm{H}_{12} \mathrm{~N}_{2} \mathrm{O}$

2-Propenal, 3-(dimethylamino)-2-(methylamino)-

$49582-62-9$

OCHC (NHME $)=$ CHNME 2

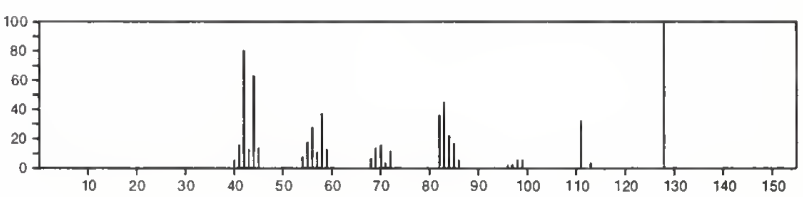


128

$\mathrm{C}_{6} \mathrm{H}_{12} \mathrm{~N}_{2} \mathrm{O}$

Pyrrolidine, 2,5-dimethyl-1-nitroso-

$55556-86-0$
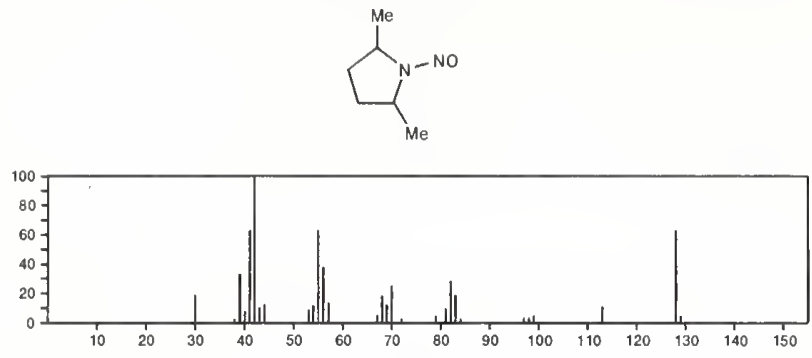

\begin{tabular}{ll}
\hline 128 & $\mathrm{C}_{7} \mathrm{H}_{12} \mathrm{O}_{2}$ \\
Cyclohexanecarboxylic acid
\end{tabular}
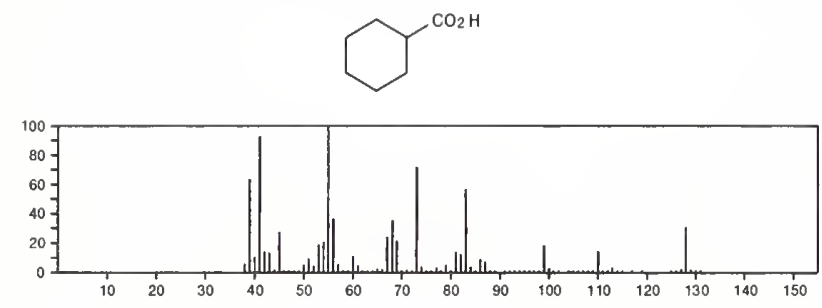

128

2-Propenoic acid, butyl ester

$\mathrm{C}_{7} \mathrm{H}_{12} \mathrm{O}_{2}$

$\mathrm{Me}\left(\mathrm{CH}_{2}\right)_{3} \mathrm{OC}(\mathrm{O}) \mathrm{CH}=\mathrm{CH}_{2}$

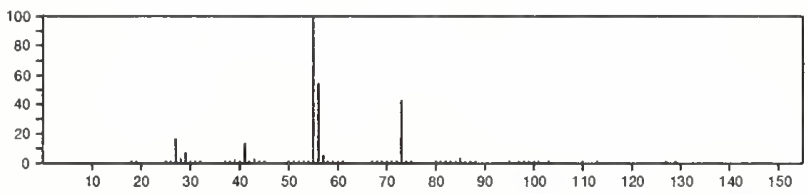

$128 \quad \mathrm{C}_{7} \mathrm{H}_{12} \mathrm{O}_{2}$

2-Butenoic acid, 3-methyl-, ethyl ester

638-10-8

Me $2 \mathrm{C}: \mathrm{CHC}(\mathrm{O}) \mathrm{OE}$ :

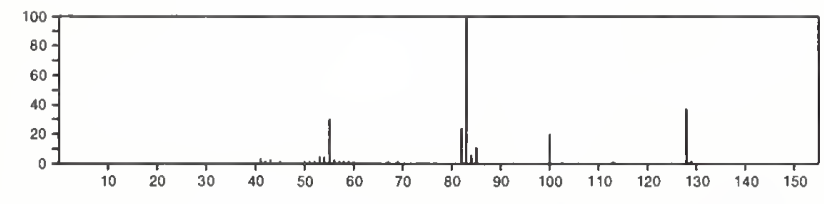

128

2,4-Pentanedione, 3-ethyl-

$\mathrm{C}_{7} \mathrm{H}_{12} \mathrm{O}_{2}$

1540-34-7

Me COCHE I COMe

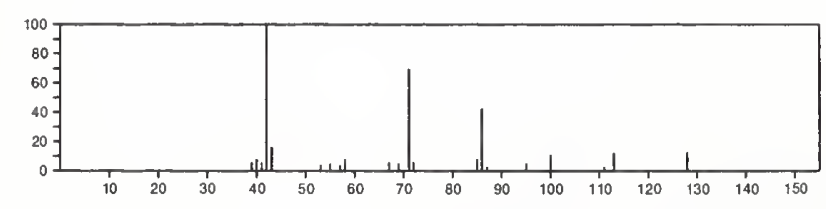

128

$\mathrm{C}_{7} \mathrm{H}_{12} \mathrm{O}_{2}$

$2396-77-2$

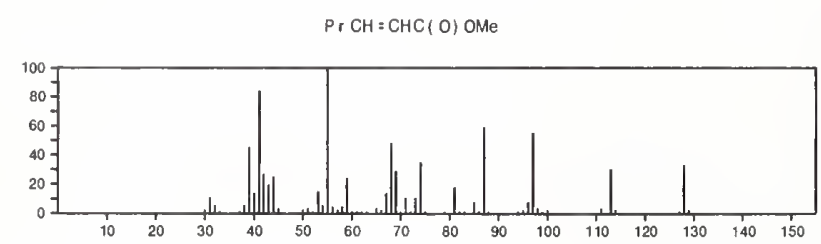

$128 \quad \mathrm{C}_{7} \mathrm{H}_{12} \mathrm{O}_{2}$

3-Hexenoic acid, methyl ester

$\mathrm{Me} \mathrm{OC}(0) \mathrm{CH}_{2} \mathrm{CH}=\mathrm{CHE} \mathrm{t}$

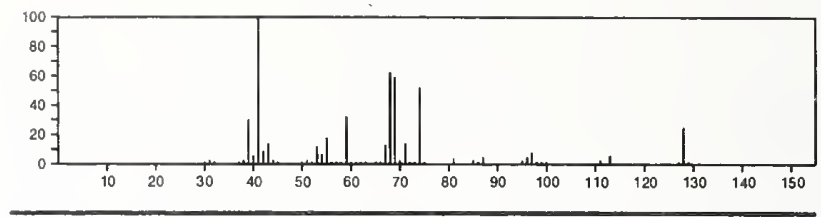

128

5-Hexenoic acid, methyl ester

$\mathrm{C}_{7} \mathrm{H}_{12} \mathrm{O}_{2}$

$2396-80-7$

$\mathrm{H}_{2} \mathrm{C}=\mathrm{CH}\left(\mathrm{CH}_{2}\right)_{3} \mathrm{C}(\mathrm{O}) \mathrm{OMe}$

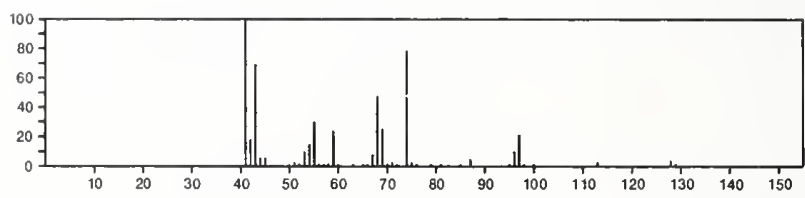

128

$\mathrm{C}_{7} \mathrm{H}_{12} \mathrm{O}_{2}$

2610-95-9

2H-Pyran-2-one, tetrahydro-6,6-dimethyl-
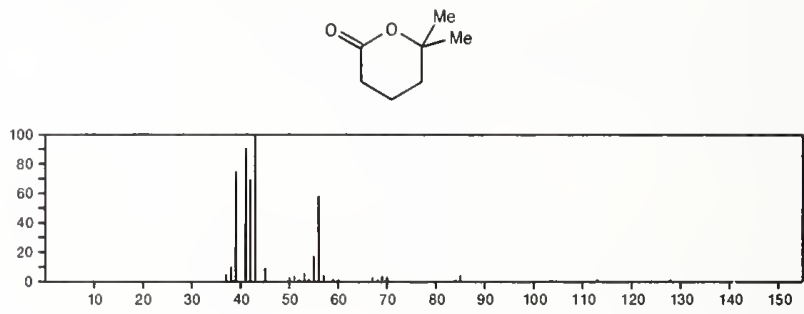

128

$\mathrm{C}_{7} \mathrm{H}_{12} \mathrm{O}_{2}$

$2865-82-9$

2(3H)-Furanone, 5-ethyldihydro-5-methyl-
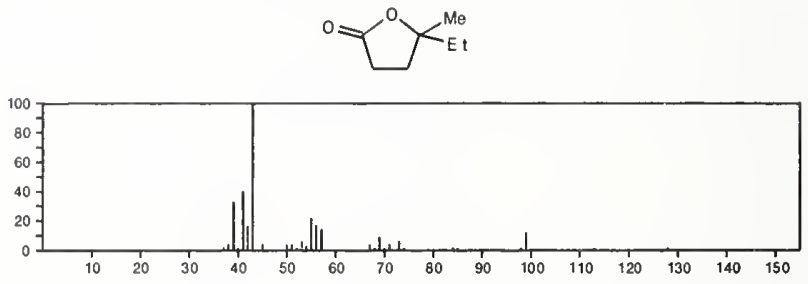

128

$\mathrm{C}_{7} \mathrm{H}_{12} \mathrm{O}_{2}$

2998-08-5

2-Propenoic acid, 1-methylpropyl ester

$s-\mathrm{Bu} O \mathrm{OC}(\mathrm{O}) \mathrm{CH}: \mathrm{CH}_{2}$

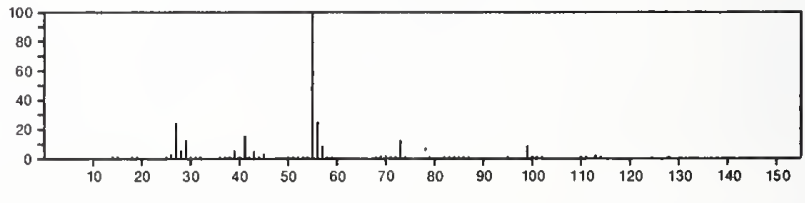

128

$\mathrm{C}_{7} \mathrm{H}_{12} \mathrm{O}_{2}$

$3070-67-5$

Butanoic acid, 3-methyl-2-methylene-, methyl ester

$\operatorname{MeOC}(0) \stackrel{\mathrm{CH}_{2}}{\mathrm{C} C H M \mathrm{H}_{2}}$

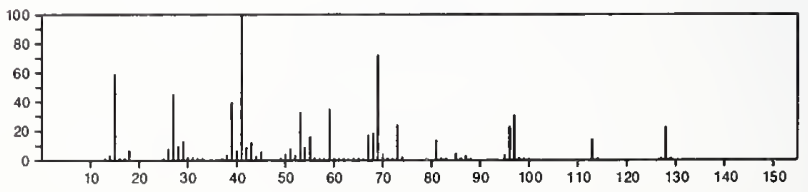


128

$\mathrm{C}_{7} \mathrm{H}_{12} \mathrm{O}_{2}$

$2 \mathrm{H}$-Pyran-2-one, tetrahydro-3,5-dimethyl-<smiles>CC1COC(=O)C(C)C1</smiles>

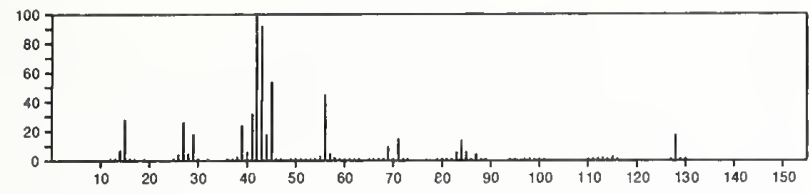

\section{$128 \quad \mathrm{C}_{7} \mathrm{H}_{12} \mathrm{O}_{2}$}

$2 H$-Pyran-2-one, tetrahydro-3,6-dimethyl-
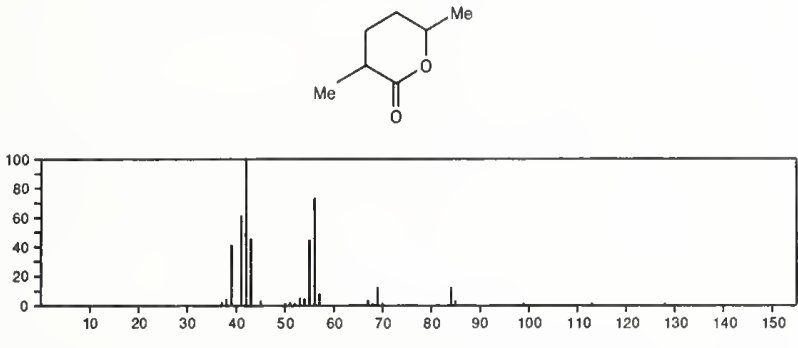

128

$\mathrm{C}_{7} \mathrm{H}_{12} \mathrm{O}_{2}$

2-Propanol, 1-[(1-methyl-2-propynyl)oxy]-

$3973-21-5$

$\mathrm{MeCH}(\mathrm{OH}) \mathrm{CH}_{2} \mathrm{OCHMe} \equiv \mathrm{CH}$

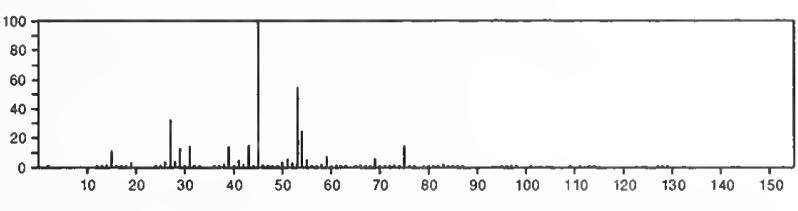

128

$\mathrm{C}_{7} \mathrm{H}_{12} \mathrm{O}_{2}$

$3973-27-1$

p-Dioxin, 2,3-dihydro-2,5,6-trimethyl-
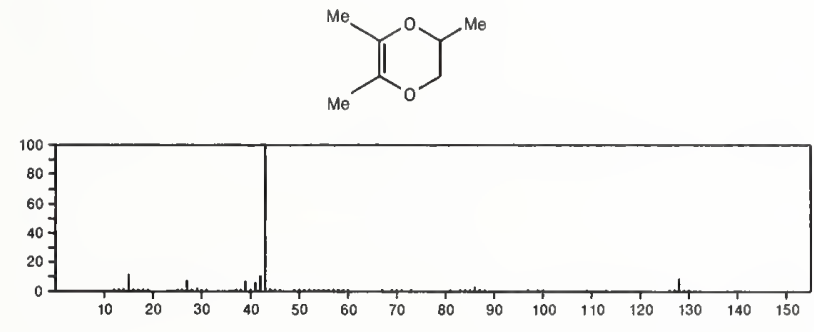

128

p-Dioxane, 2,5-dimethyl-3-methylene-
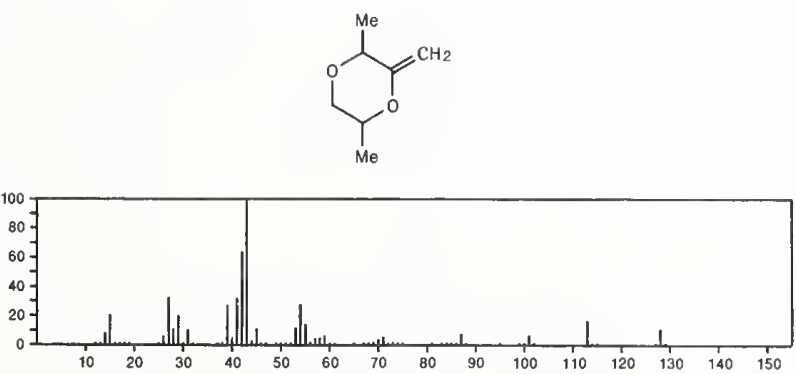

128

$\mathrm{C}_{7} \mathrm{H}_{12} \mathrm{O}_{2}$

4168-01-8

3-Butenoic acid, 2,2,3-trimethyl-

$\mathrm{HO}_{2} \mathrm{CCMe}_{2} \mathrm{CMe}=\mathrm{CH}_{2}$

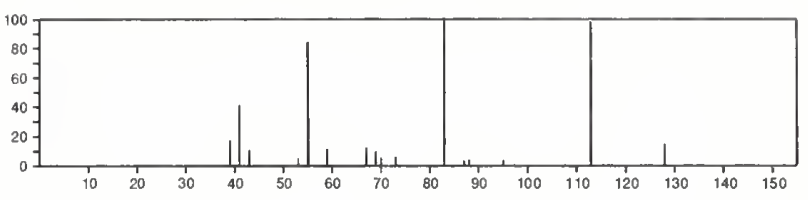

128

$\mathrm{C}_{7} \mathrm{H}_{12} \mathrm{O}_{2}$

4351-54-6

Formic acid, cyclohexyl ester
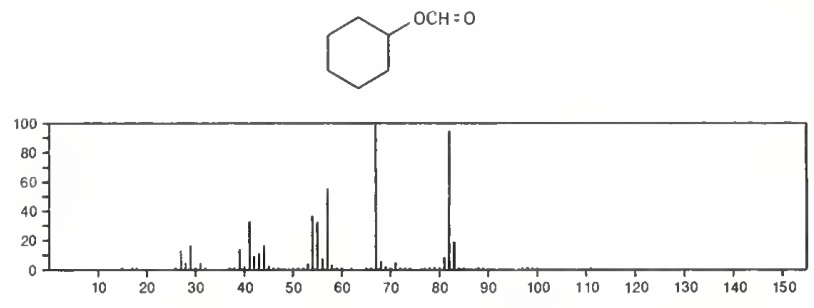

$128 \quad \mathrm{C}_{7} \mathrm{H}_{12} \mathrm{O}_{2}$

5331-08-8
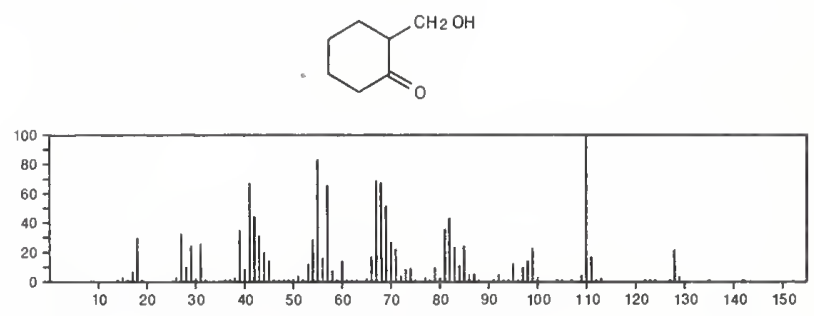

$128 \quad \mathrm{C}_{7} \mathrm{H}_{12} \mathrm{O}_{2}$

13482-23-0

Cyclohexanone, 4-methoxy-
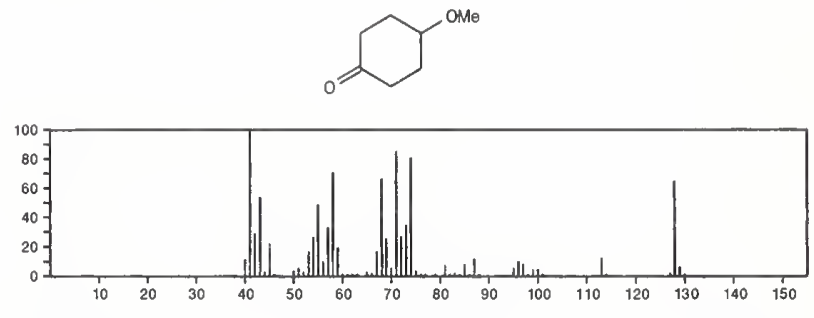

128

3-Hexenoic acid, methyl ester, $(Z)-$

13894-62-7

$\mathrm{Me} \mathrm{OC}(\mathrm{O}) \mathrm{CH}_{2} \mathrm{CH}=\mathrm{CHE}_{1}$

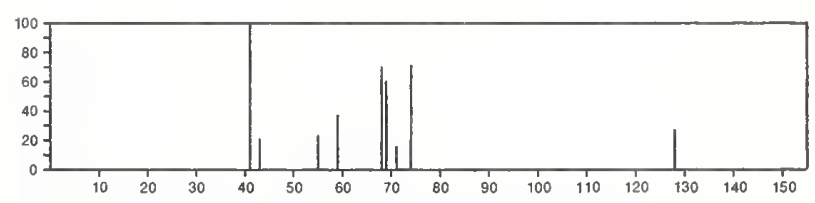

128

2-Hexenoic acid, methyl ester, $(E)$ -

13894-63-8

$\mathrm{PrCH}=\mathrm{CHC}(\mathrm{O}) \mathrm{OMe}$

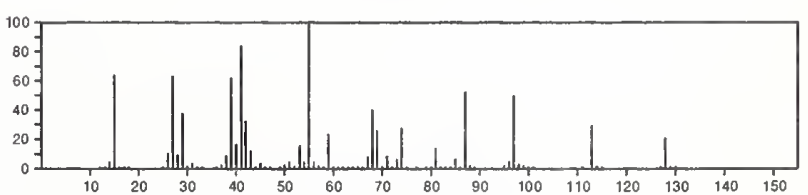


128

$\mathrm{C}_{7} \mathrm{H}_{12} \mathrm{O}_{2}$

$14132-44-6$

Cyclobutanecarboxylic acid, 2-methyl--, methyl ester
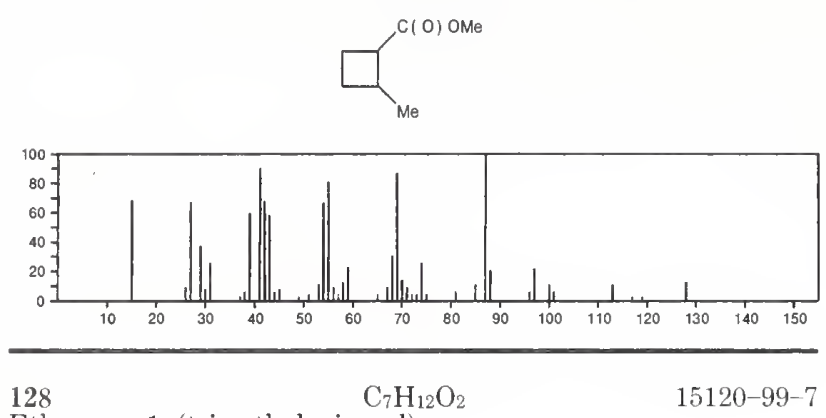

Ethanone, 1-(trimethyloxiranyl)
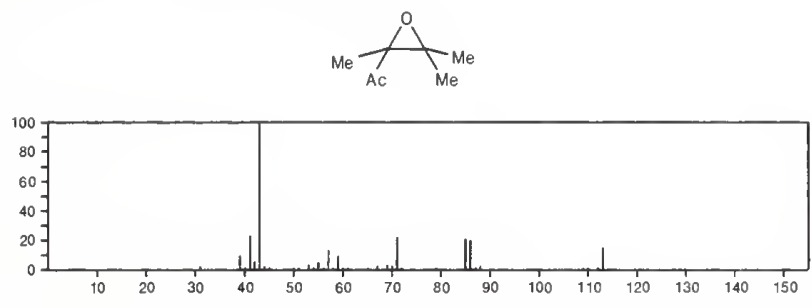

128

$\mathrm{C}_{7} \mathrm{H}_{12} \mathrm{O}_{2}$

3-Pentenoic acid, 2,2-dimethyl-

$\mathrm{MeCH}=\mathrm{CHCMe} 2 \mathrm{CO}_{2} \mathrm{H}$

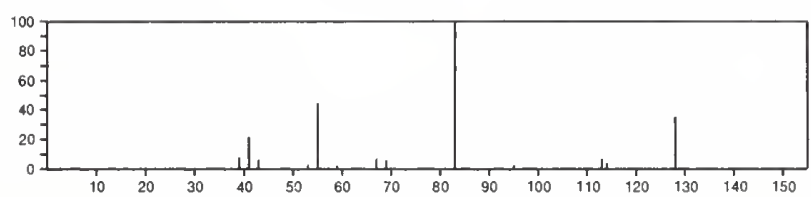

128

Cyclohexanone, 3-methoxy-

$\mathrm{C}_{7} \mathrm{H}_{12} \mathrm{O}_{2}$

17429-00-4
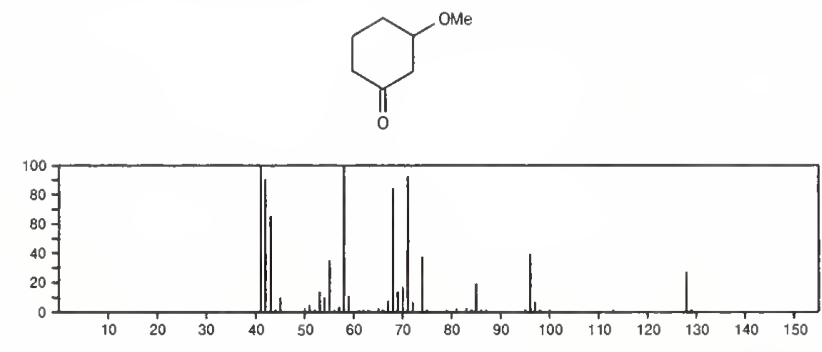

128

$\mathrm{C}_{7} \mathrm{H}_{12} \mathrm{O}_{2}$

2-Butenoic acid, 1-methylethyl ester

$18060-77-0$

$\mathrm{MeCH}=\mathrm{CHC}(0) \mathrm{OPr}-\mathrm{i}$

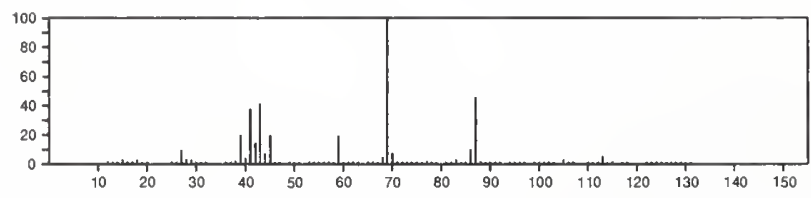

128

$\mathrm{C}_{7} \mathrm{H}_{12} \mathrm{O}_{2}$

3-Pentenoic acid, 3-methyl-, methyl ester, $(E)$ -

$41654-12-0$

$\mathrm{MeCH}=\mathrm{CMeCH}_{2} \mathrm{C}(\mathrm{O}) \mathrm{OMe}$

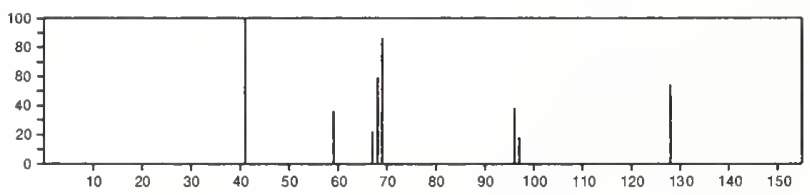

$128 \quad \mathrm{C}_{7} \mathrm{H}_{12} \mathrm{O}_{2}$

2-Pentenoic acid, 4-methyl-, methyl ester

$50652-78-3$

$\mathrm{Me}_{2} \mathrm{CHCH}=\mathrm{CHC}(\mathrm{O}) \mathrm{OMe}$

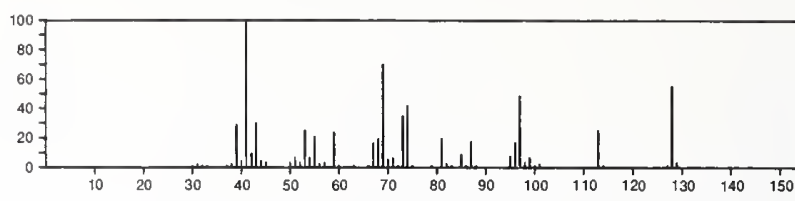

128

$\mathrm{C}_{7} \mathrm{H}_{12} \mathrm{O}_{2}$

$50652-79-4$

2-Pentenoic acid, 3-methyl-, methyl ester

$\mathrm{E}+\mathrm{CMe}=\mathrm{CHC}(\mathrm{O}) \mathrm{OMe}$

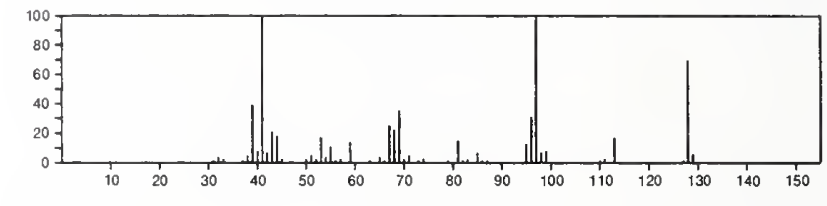

128

1,5-Heptadiene-3,4-diol

$\mathrm{C}_{7} \mathrm{H}_{12} \mathrm{O}_{2}$

$51945-98-3$

$\mathrm{H}_{2} \mathrm{C}=\mathrm{CHCH}(\mathrm{OH}) \mathrm{CH}(\mathrm{OH}) \mathrm{CH}=\mathrm{CHM}$

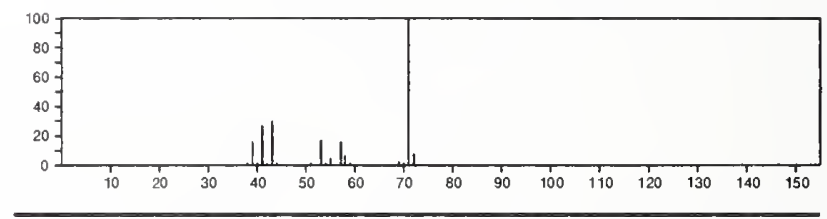

128

$\mathrm{C}_{7} \mathrm{H}_{12} \mathrm{O}_{2}$

$55670-09-2$

1-Butanol, 2- methylene-, acetate

$\mathrm{H}_{2} \mathrm{C}=\mathrm{CE} t \mathrm{CH}_{2} \mathrm{OAC}$

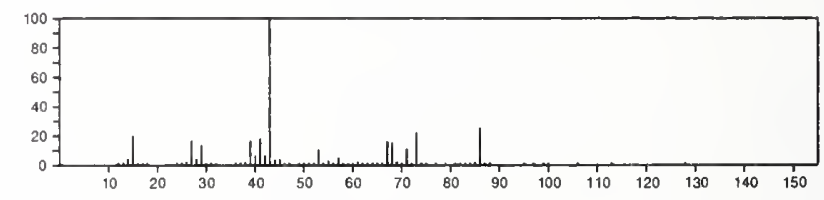

$128 \quad \mathrm{C}_{7} \mathrm{H}_{12} \mathrm{O}_{2}$

1,3-Dioxolane, 2-ethenyl-2,4-dimethyl-, trans-

$55683-34-6$

$\sum_{M e}^{0} \gamma_{\mathrm{Me}}^{\mathrm{CH}=\mathrm{CH}_{2}}$

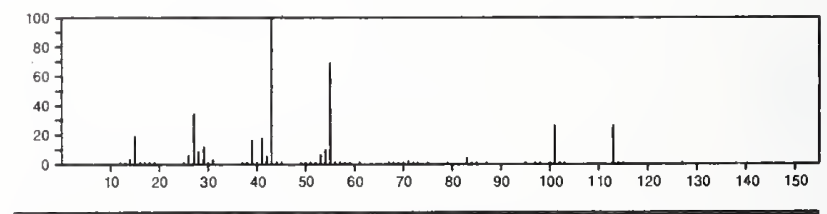

128

$\mathrm{C}_{7} \mathrm{H}_{12} \mathrm{O}_{2}$

$55683-35-7$

5H-1,4-Dioxepin, 2,3-dihydro-2,5-dimethyl-
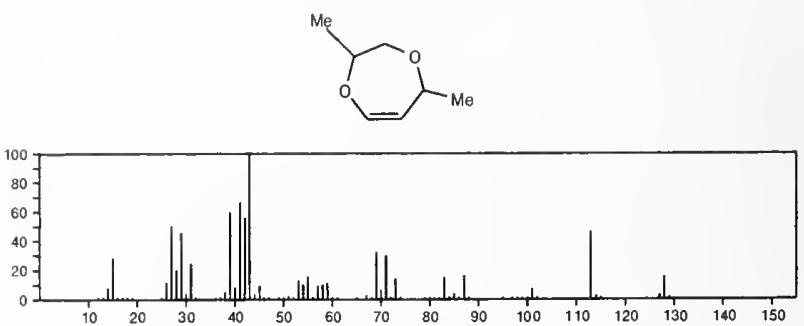
128

$\mathrm{C}_{7} \mathrm{H}_{12} \mathrm{O}_{2}$

2-Pentanone, 1-methoxy-3-methylene-

$\mathrm{H}_{2} \mathrm{C}=\mathrm{CE}+\mathrm{COCH}_{2} \mathrm{OMe}$

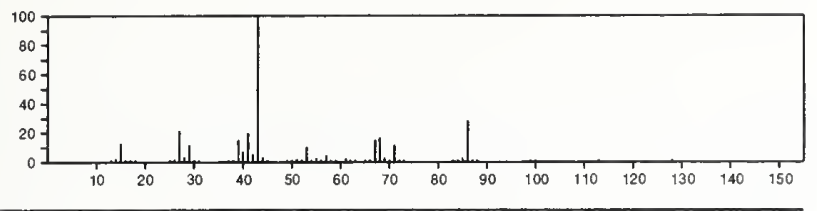

$128 \quad \mathrm{C}_{7} \mathrm{H}_{12} \mathrm{O}_{2}$

$56728-17-7$

3-Pentenoic acid, 3-methyl-, methyl ester, $(Z)$ -

$\mathrm{MeCH}: \mathrm{CMeCH}_{2} \mathrm{C}(0) \mathrm{OMe}$

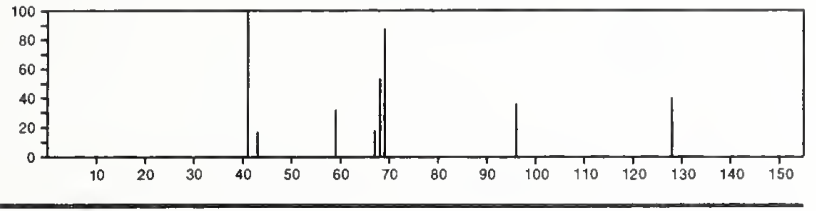

128

6-Thiabicyclo[3.2.1]octane

$\mathrm{C}_{7} \mathrm{H}_{12} \mathrm{~S}$

279-91-4
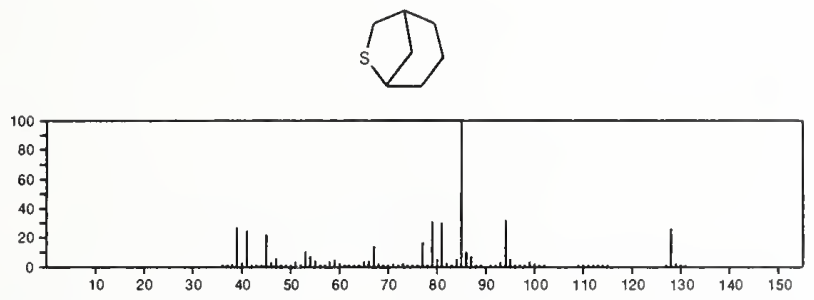

\section{8}

$\mathrm{C}_{7} \mathrm{H}_{12} \mathrm{~S}$

$280-24-0$

8-Thiabicyclo[3.2.1]octane
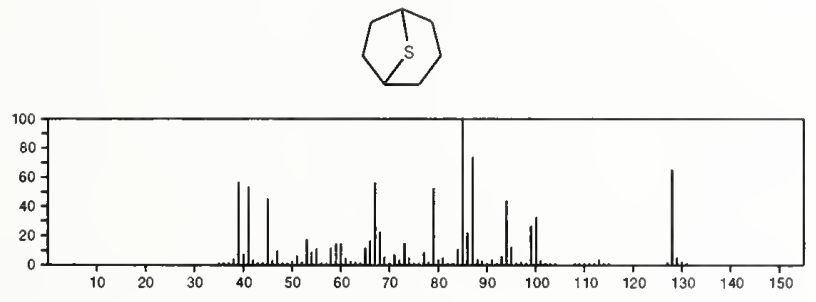

\section{8}

2-Thiabicyclo[2.2.2]octane

$\mathrm{C}_{7} \mathrm{H}_{12} \mathrm{~S}$

$280-41-1$
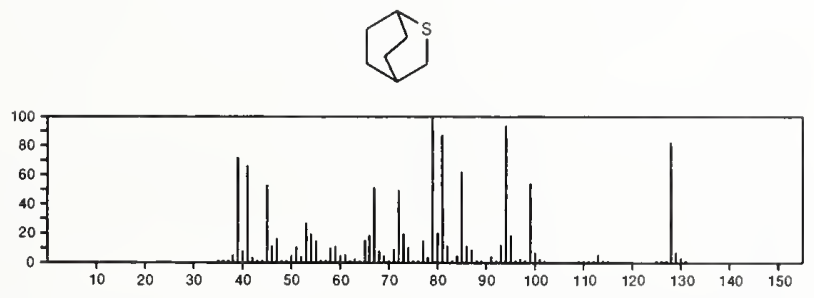

128

7-Thiabicyclo[4.1.0]heptane, 1-methyl-

$7272-23-3$
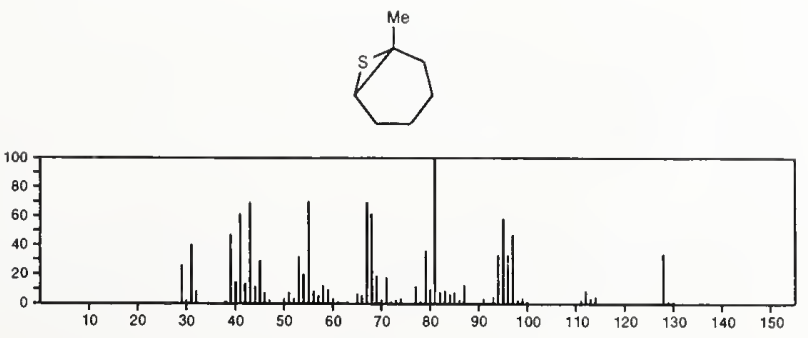

$128 \quad \mathrm{C}_{7} \mathrm{H}_{12} \mathrm{~S}$

$1 \mathrm{H}$-Cyclopenta[c]thiophene, hexahydro-, cis $^{-}$

$53907-80-5$
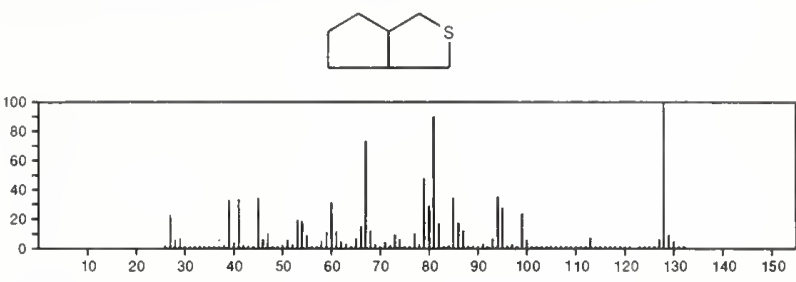

128

$\mathrm{C}_{7} \mathrm{H}_{12} \mathrm{~S}$

$53956-11-9$

$2 H$-Cyclopenta $[b]$ thiophene, hexahydro-, cis
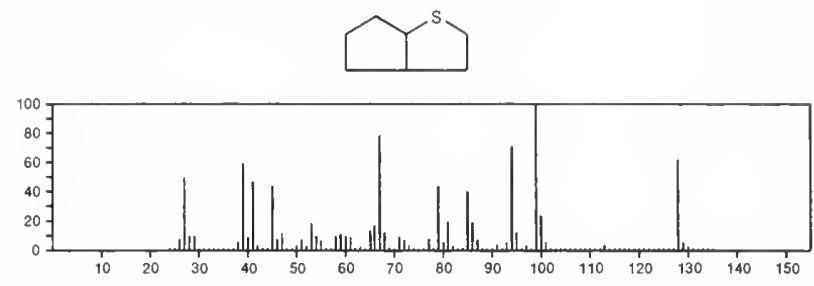

128

$\mathrm{C}_{7} \mathrm{H}_{12} \mathrm{~S}$

$53956-12-0$

$2 H_{-}^{-}$Cyclopenta $[b]$ thiophene, hexahydro-, trans-
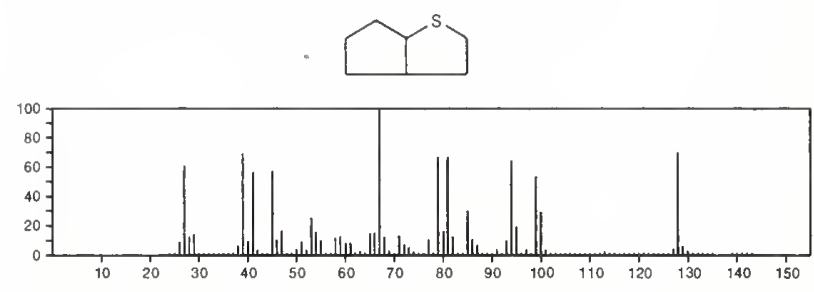

128

$\mathrm{C}_{7} \mathrm{H}_{12} \mathrm{~S}$

$54725-38-1$

7-Thiabicyclo[4.1.0]heptane, 3-methyl-
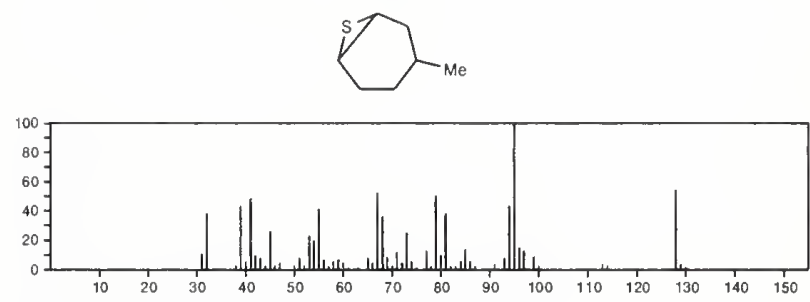

128

$\mathrm{C}_{7} \mathrm{H}_{12} \mathrm{~S}$

7-Thiabicyclo[4.1.0]heptane, 2-methy]-

$54773-76-1$
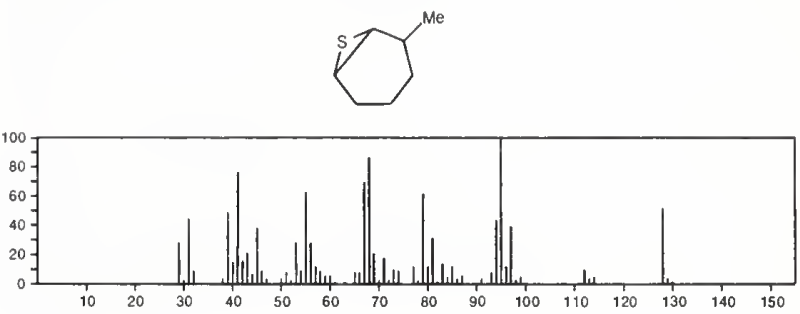
<smiles>CCN1CCCC(N)C1</smiles>

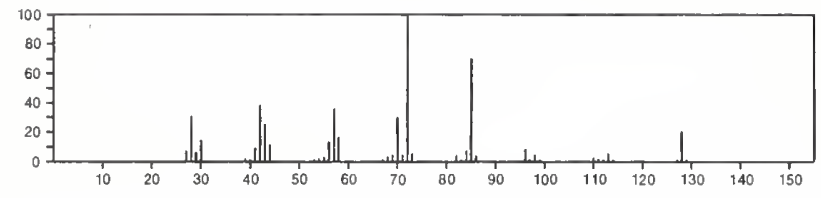

128

$\mathrm{C}_{7} \mathrm{H}_{16} \mathrm{~N}_{2}$

Valeraldehyde, dimethylhydrazone

$\mathrm{Me}_{2} \mathrm{NN}=\mathrm{CH}\left(\mathrm{CH}_{2}\right)_{3} \mathrm{Me}$

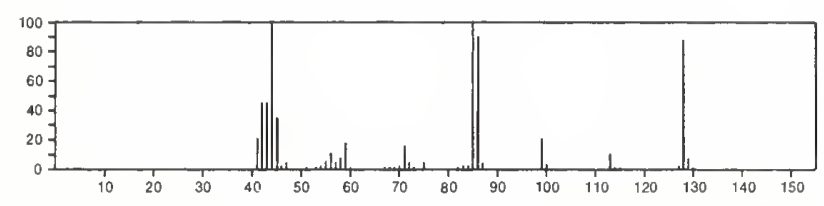

128

$\mathrm{C}_{7} \mathrm{H}_{16} \mathrm{~N}_{2}$

2-Pyrrolidinemethanamine, 1-ethyl-
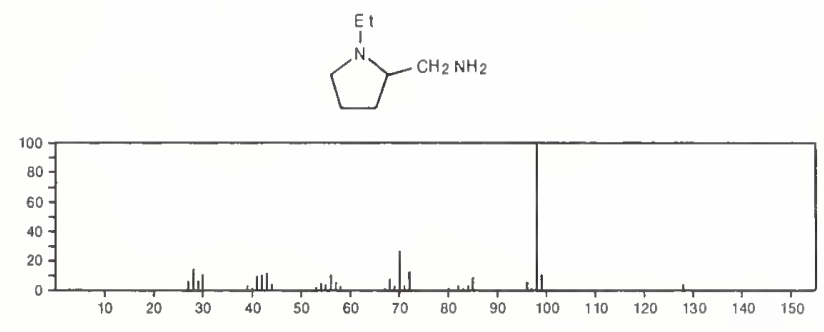

128

$\mathrm{C}_{7} \mathrm{H}_{16} \mathrm{~N}_{2}$

Hydrazine, 1-(5-hexenyl)-1-methyl-

$\mathrm{H}_{2} \mathrm{C}=\mathrm{CH}\left(\mathrm{CH}_{2}\right){ }_{4} \mathrm{~N}\left(\mathrm{NH}_{2}\right) \mathrm{Me}$

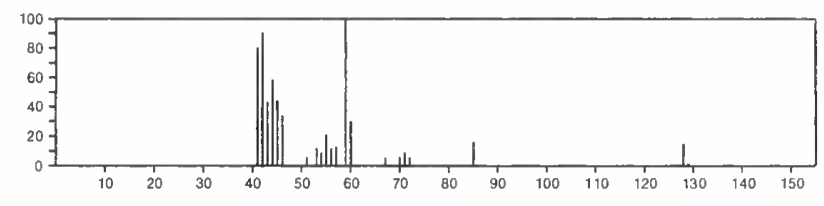

128

$\mathrm{C}_{7} \mathrm{H}_{16} \mathrm{~N}_{2}$

Pentanal, 2,2 dimethyl-, hydrazone

$\mathrm{H}_{2} \mathrm{NN}=\mathrm{CHCP} \mathrm{PMe}_{2}$
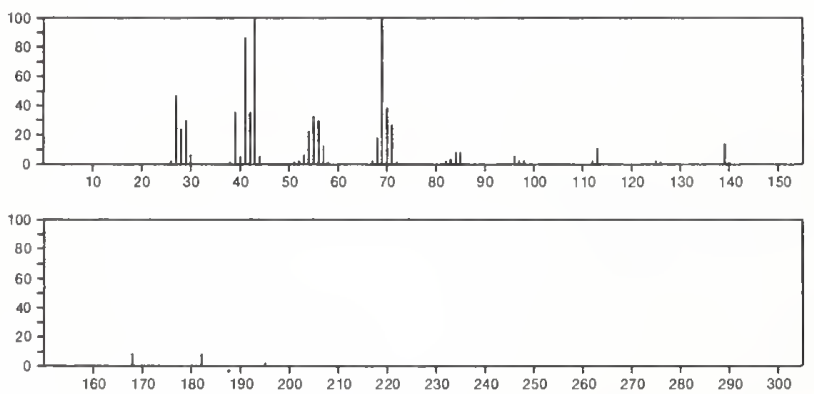

26116-12-1

53907-78-1

$55724-26-0$ 
128

Octanal

$\mathrm{C}_{8} \mathrm{H}_{16} \mathrm{O}$

$\mathrm{OCH}\left(\mathrm{CH}_{2}\right) 6 \mathrm{Me}$

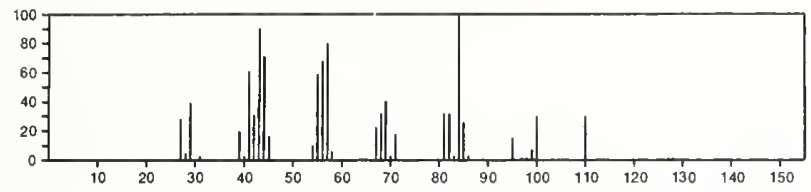

128

3-Heptanone, 5-methyl-

$\mathrm{C}_{8} \mathrm{H}_{16} \mathrm{O}$

$\mathrm{MeCH}_{2} \mathrm{CHMe} \mathrm{CH}_{2} \mathrm{COE}_{1}$
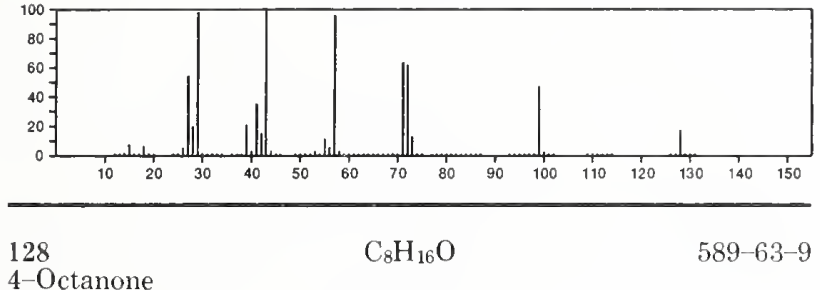

4-Octanone

$\mathrm{Me}\left(\mathrm{CH}_{2}\right)_{3} \mathrm{COP}$

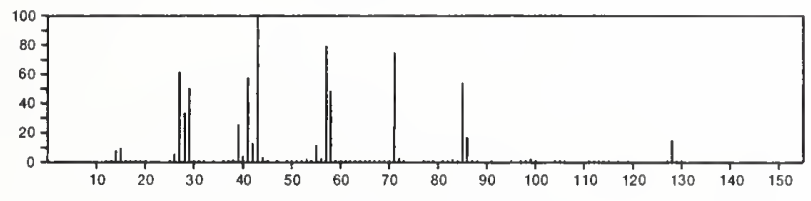

$\mathrm{C}_{8} \mathrm{H}_{16} \mathrm{O} \quad 624-42-0$

3-Heptanone, 6-methyl-

$\mathrm{E}_{1} \mathrm{COCH}_{2} \mathrm{CH}_{2} \mathrm{CHME}_{2}$

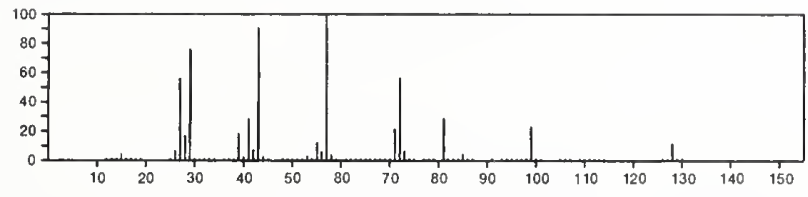

128

4-Heptanone, 2-methyl-

$\mathrm{C}_{8} \mathrm{H}_{16} \mathrm{O}$

626-33-5

$\mathrm{PrCOCH}_{2} \mathrm{CHMe}_{2}$

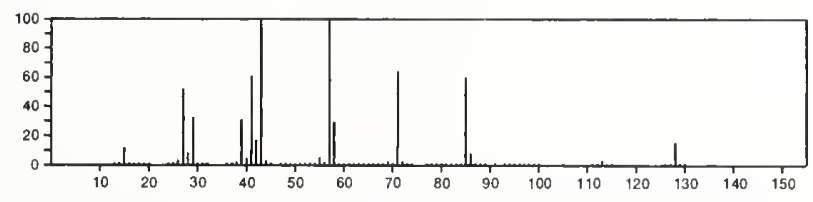

128

2-Heptanone, 6-methyl-

$\mathrm{C}_{8} \mathrm{H}_{16} \mathrm{O}$

928-68-7

$\mathrm{Me} \mathrm{CO}\left(\mathrm{CH}_{2}\right)_{3} \mathrm{CHMe}_{2}$

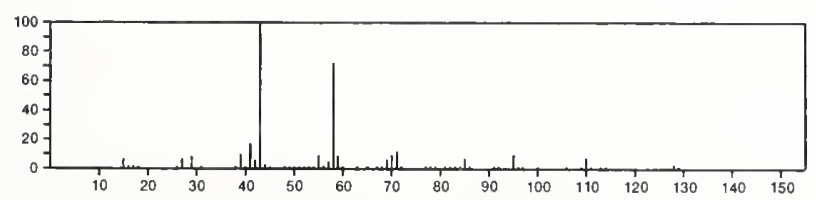

128

$\mathrm{C}_{8} \mathrm{H}_{16} \mathrm{O}$

$996-12-3$

Hexanal, 2,2-dimethyl-

$\left.\mathrm{OCHCMe}_{2}\left(\mathrm{CH}_{2}\right)\right)_{3} \mathrm{Me}$

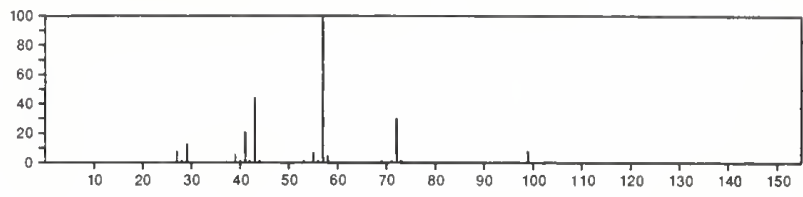

128

Furan, 2-butyltetrahydro- $\mathrm{C}_{8} \mathrm{H}_{16} \mathrm{O}$

1004-29-1
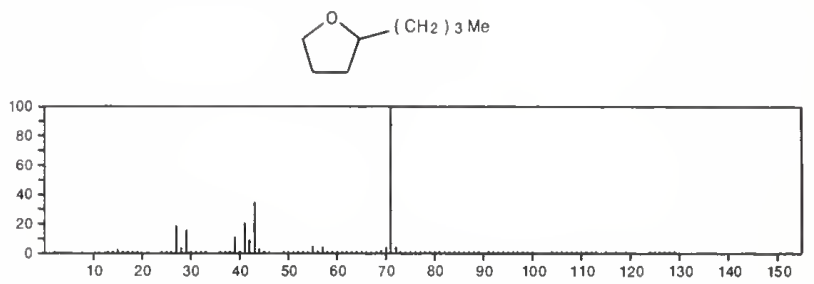

128

1569-60-4

$\mathrm{Me}_{2} \mathrm{C}=\mathrm{CHCH}_{2} \mathrm{CH}_{2} \mathrm{CH}(\mathrm{OH}) \mathrm{Me}$

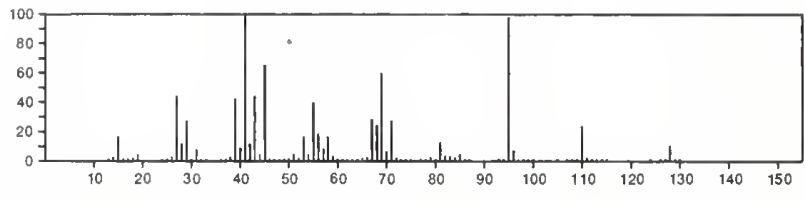

128

3-Hexanone, 2,5-dimethyl-

$\mathrm{C}_{8} \mathrm{H}_{16} \mathrm{O}$

$1888-57-9$

$\mathrm{Me}_{2} \mathrm{CHCH}_{2} \mathrm{COCHMe} 2$

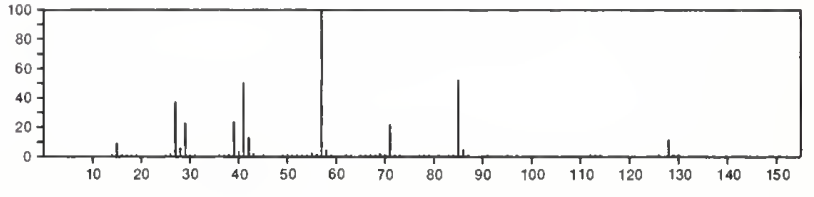

Cyclohexanemethanol, 2-methyl-

$2105-40-0$<smiles>CC1CCCCC1CO</smiles>

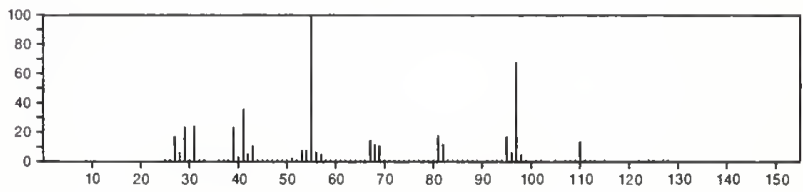

128

2-Heptanone, 3-methyl

$\mathrm{C}_{8} \mathrm{H}_{16} \mathrm{O}$

2371-19-9

$\mathrm{Me} \mathrm{COCHMe}\left(\mathrm{CH}_{2}\right)$ 3 $\mathrm{Me}$

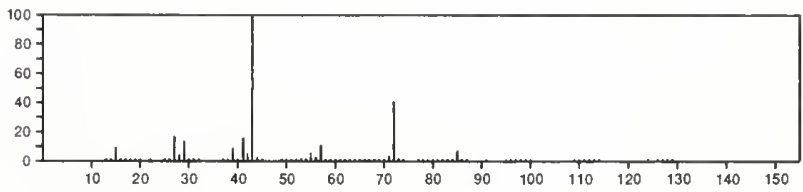


128

$\mathrm{C}_{8} \mathrm{H}_{16} \mathrm{O}$

Furan, tetrahydro-2,2,4,4-tetramethyl-

$3358-28-9$
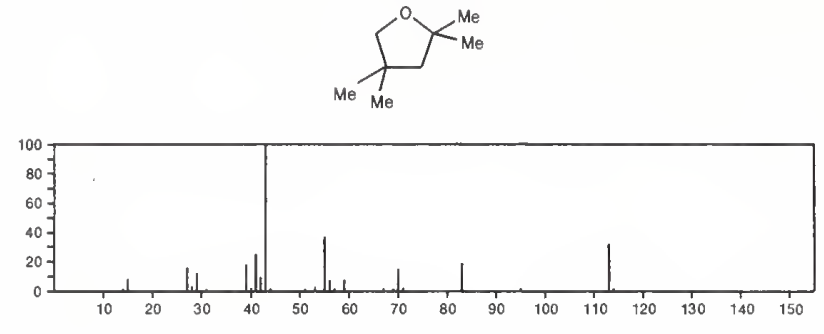

128

1-Octen-3-ol

$\mathrm{C}_{8} \mathrm{H}_{16} \mathrm{O}$

$3391-86-4$

$\mathrm{Me}\left(\mathrm{CH}_{2}\right){ }_{4} \mathrm{CH}(\mathrm{OH}) \mathrm{CH}: \mathrm{CH}_{2}$

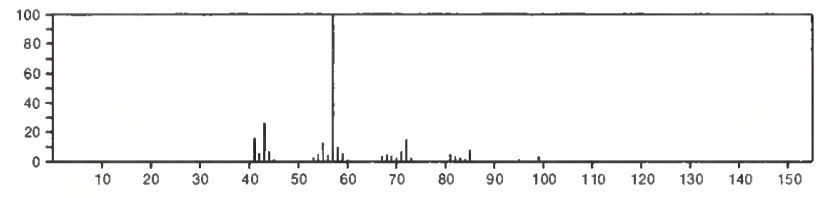

128

$\mathrm{C}_{8} \mathrm{H}_{16} \mathrm{O}$

Cyclohexanemethanol, 4-methyl-, cis-

$3937-48-2$
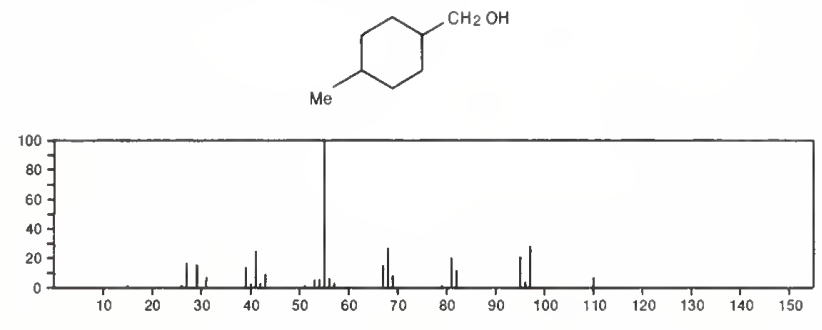

128

$\mathrm{C}_{8} \mathrm{H}_{16} \mathrm{O}$

Cyclohexanemethanol, 4-methyl-, trans-

$3937-49-3$
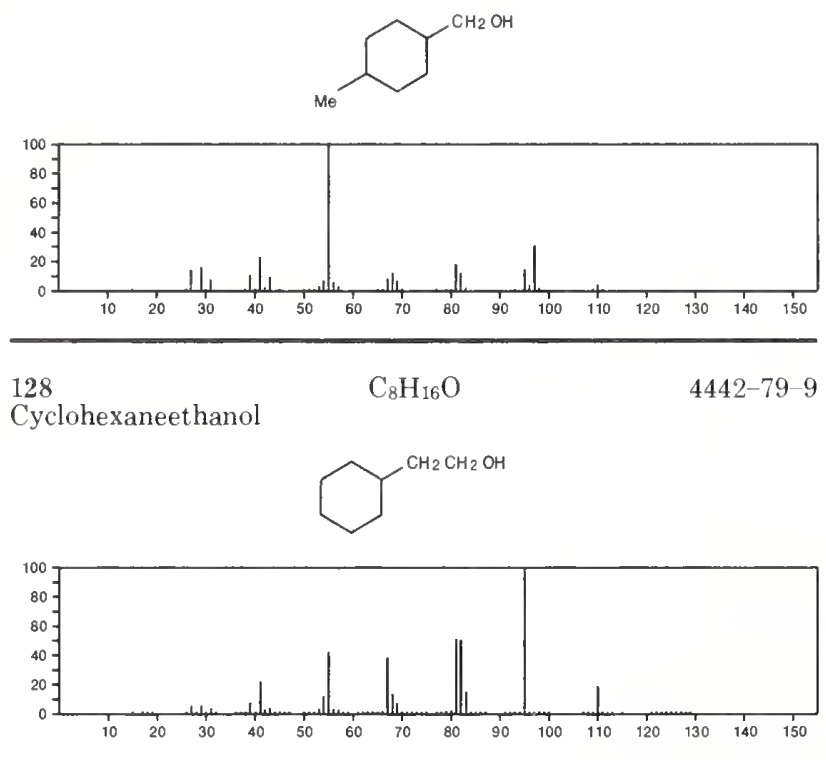

128

2-Octen-4-ol

$\mathrm{C}_{8} \mathrm{H}_{16} \mathrm{O}$

4798-61-2

$\mathrm{MeCH}=\mathrm{CHCH}(\mathrm{OH})\left(\mathrm{CH}_{2}\right){ }_{3} \mathrm{Me}$

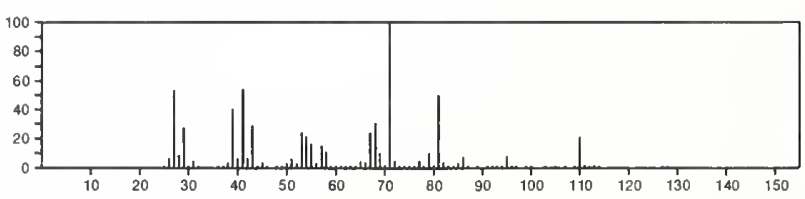

128
Cyclohexanol, 2,6-dimethyl-

$\mathrm{C}_{8} \mathrm{H}_{16} \mathrm{O}$

$5337-72-4$
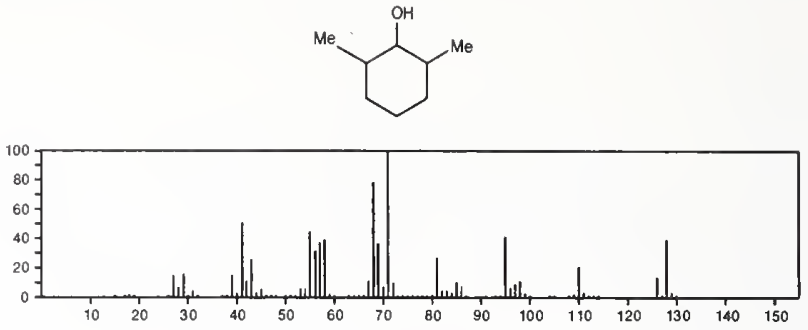

128

$\mathrm{C}_{8} \mathrm{H}_{16} \mathrm{O}$

Hexane, 1-(ethenyloxy)-

$\mathrm{Me}\left(\mathrm{CH}_{2}\right)_{5} \mathrm{OCH}=\mathrm{CH}_{2}$

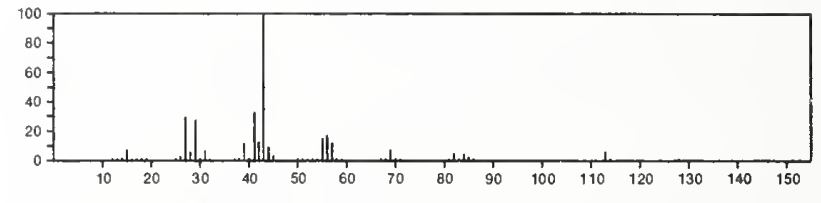

$128 \quad \mathrm{C}_{8} \mathrm{H}_{16} \mathrm{O}$

3-Hexanone, 2,2-dimethyl-

5405-79-8

$\mathrm{Me}_{3} \mathrm{CCOPr}$

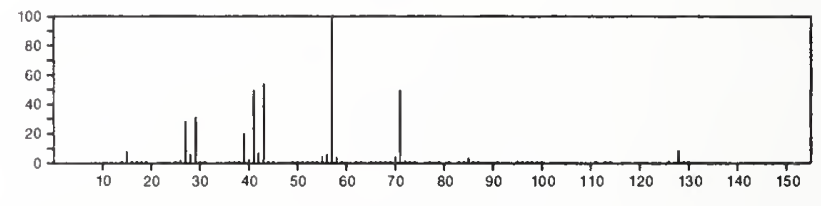

128

Cyclohexanol, 3,5-dimethyl

$\mathrm{C}_{8} \mathrm{H}_{16} \mathrm{O}$

5441-52-1<smiles>CC1CC(C)CC(O)C1</smiles>
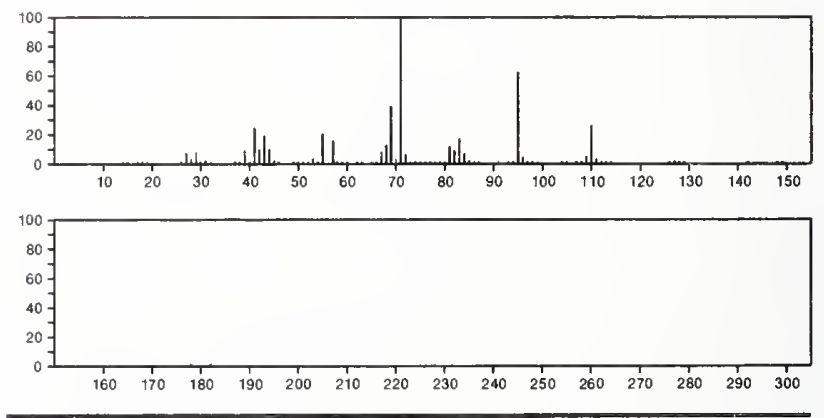

128

$\mathrm{C}_{8} \mathrm{H}_{16} \mathrm{O}$

5842-53-5

3-Penten-1-ol, 2,2,4-trimethyl-

$\mathrm{Me} 2 \mathrm{C}=\mathrm{CHCMe}_{2} \mathrm{CH}_{2} \mathrm{OH}$

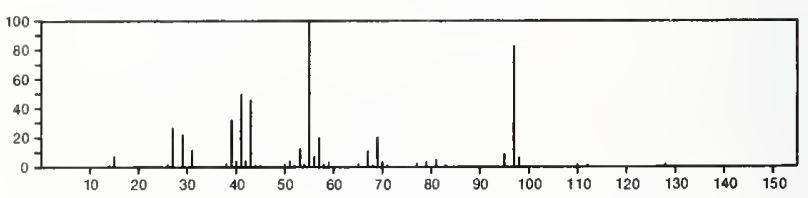


128

$\mathrm{C}_{8} \mathrm{H}_{16} \mathrm{O}$

Hexanal, 4,4-dimethyl-

$\mathrm{OCHCH}_{2} \mathrm{CH}_{2} \mathrm{CE}$ t Me 2

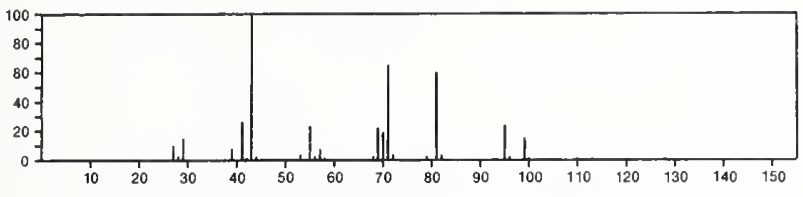

128

2-Heptanone, 4-methyl-

$\mathrm{C}_{8} \mathrm{H}_{16} \mathrm{O}$

$6137-06-0$

$\mathrm{Me} \mathrm{COCH}_{2} \mathrm{CHP}$, Me

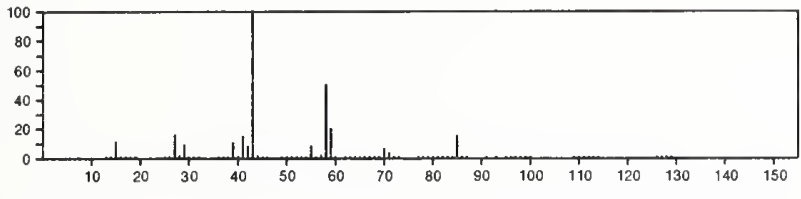

128

3-Heptanone, 4-methyl-

$\mathrm{C}_{8} \mathrm{H}_{16} \mathrm{O}$

Pr CHME COE I

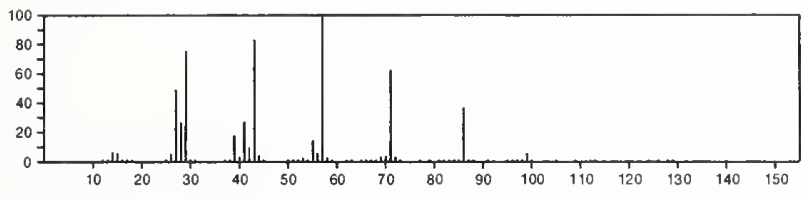

128

3-Hexanone, 4-ethyl-

$\mathrm{C}_{8} \mathrm{H}_{16} \mathrm{O}$

$6137-12-8$

Et 2 CHCOE :

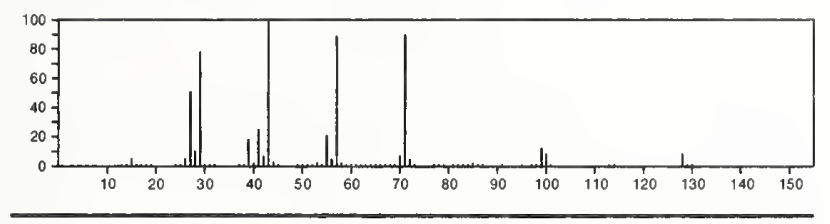

128

$\mathrm{C}_{8} \mathrm{H}_{16} \mathrm{O}$

$6573-50-8$

Oxonane
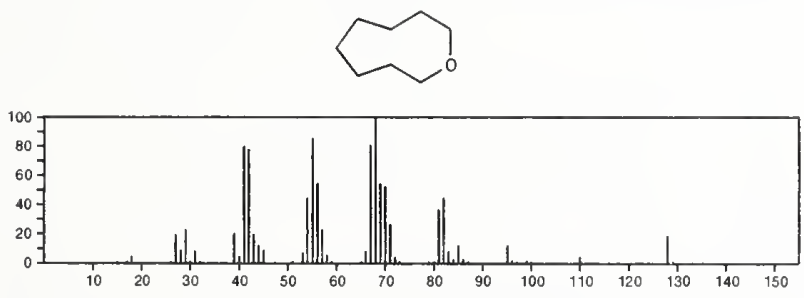

128

Ether, 1-butylallyl methyl

$\mathrm{C}_{8} \mathrm{H}_{16} \mathrm{O}$

$\mathrm{Me}\left(\mathrm{CH}_{2}\right)_{3} \mathrm{CH}$ ( OMe ) $\mathrm{CH}: \mathrm{CH}_{2}$

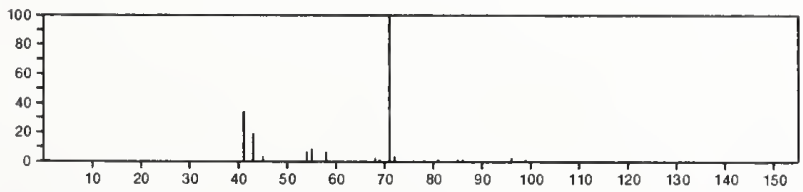

128

$\mathrm{C}_{8} \mathrm{H}_{16} \mathrm{O}$

$15045-43-9$

Furan, tetrahydro-2,2,5,5-tetramethyl-
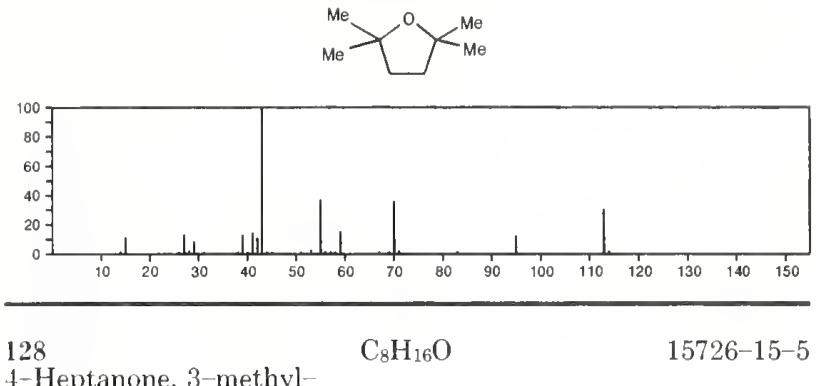

4-Heptanone, 3-methyl-

P, $\mathrm{COCHMe} \mathrm{CH}_{2} \mathrm{Me}$

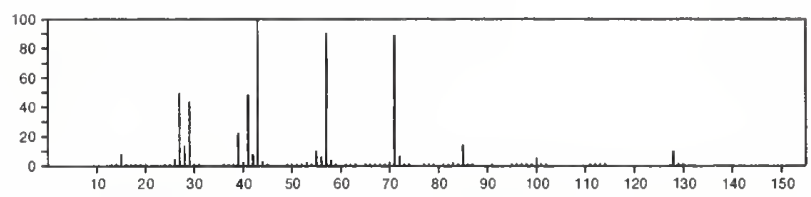

${ }_{2-128}^{1-H e p t a n o n e, 5-m e t h y l-~} \quad \mathrm{C}_{8} \mathrm{H}_{16} \mathrm{O}$

$18217-12-4$

$\mathrm{Me}_{2} \mathrm{CHMe} \mathrm{CH}_{2} \mathrm{CH}_{2}$ COMe

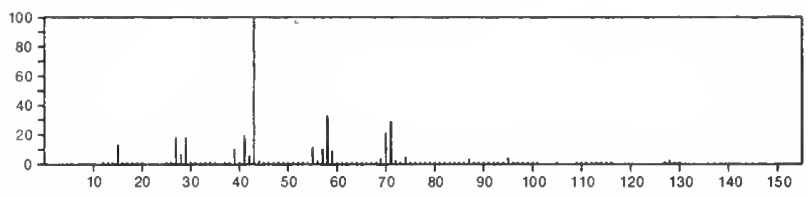

128

3-Hexanone, 2,4-dimethyl-

$\mathrm{C}_{8} \mathrm{H}_{16} \mathrm{O}$

$18641-70-8$

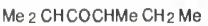

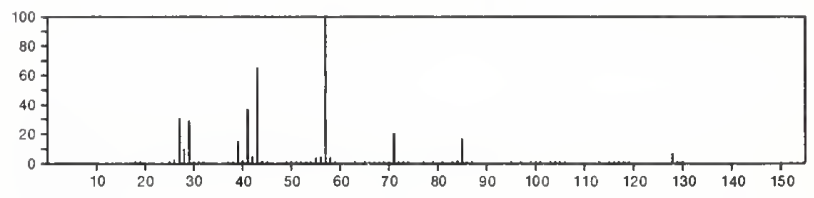

128
2-Hexanone, 3,4-dimethyl-

$19550-10-8$

$\mathrm{Me} \mathrm{CH}_{2} \mathrm{CHMe} \mathrm{CHMe}$ COMe

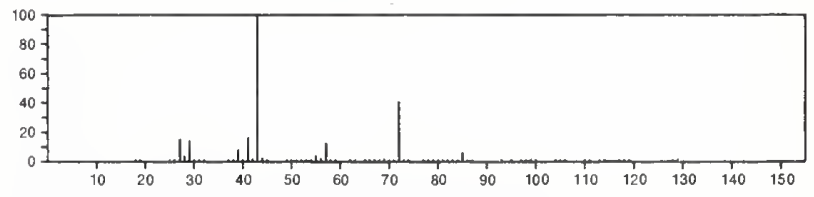

$128 \quad \mathrm{C}_{8} \mathrm{H}_{16} \mathrm{O} \quad 20434-34-8$

Cyclobutanol, 1-butyl-
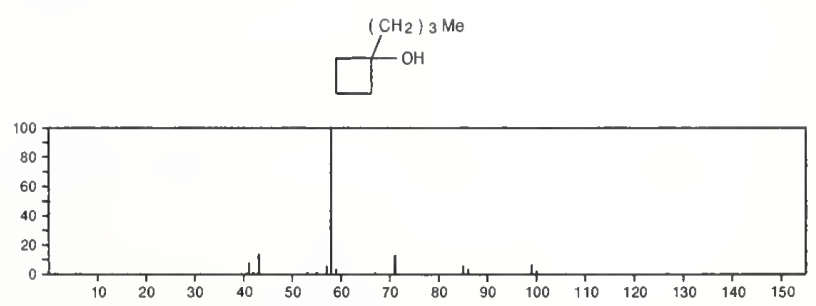
128

$\mathrm{C}_{8} \mathrm{H}_{16} \mathrm{O}$

Pentane, 1-(2-propenyloxy)

$\mathrm{H}_{2} \mathrm{C}=\mathrm{CHCH}_{2} \mathrm{O}\left(\mathrm{CH}_{2}\right)_{4} \mathrm{Me}$

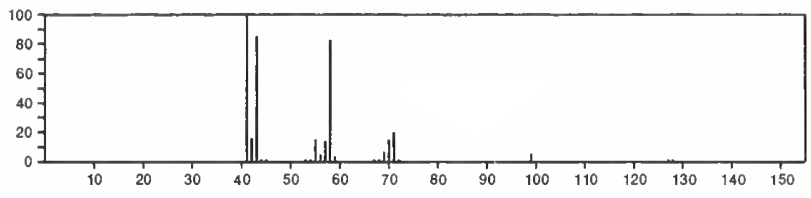

128

Cyclopropanemethanol, $\alpha$-methyl- $\alpha$-propyl
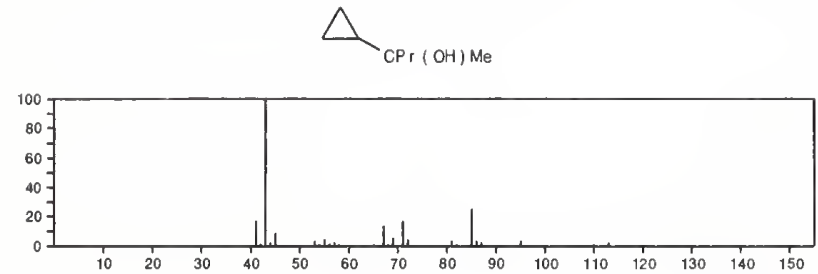

128

2-Hexanone, 3,3-dimethyl-

$\mathrm{C}_{8} \mathrm{H}_{16} \mathrm{O}$

$26118-38-7$

Pr CMe 2 COMe
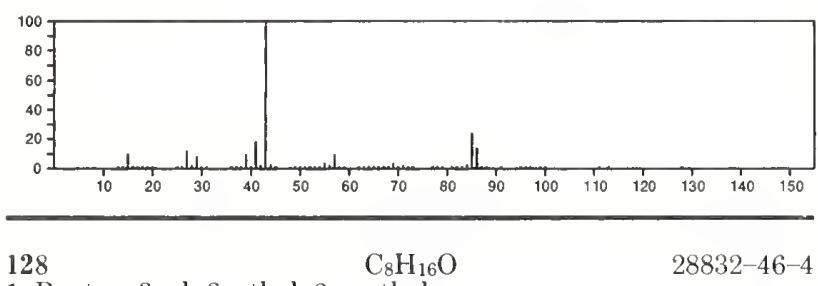

$28832-46-4$

1-Penten-3-ol, 3-ethyl-2-methyl-

$\mathrm{E}_{2} \mathrm{COHCMe}=\mathrm{CH}_{2}$

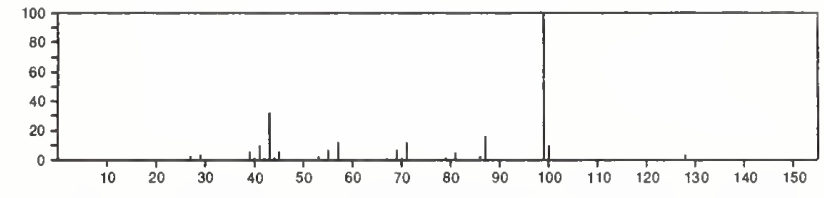

128

1-Butene, 4-butoxy

$\mathrm{C}_{8} \mathrm{H}_{16} \mathrm{O}$

$34061-76-2$

$\mathrm{Me}\left(\mathrm{CH}_{2}\right)_{3} \mathrm{OCH}_{2} \mathrm{CH}_{2} \mathrm{CH}=\mathrm{CH}_{2}$

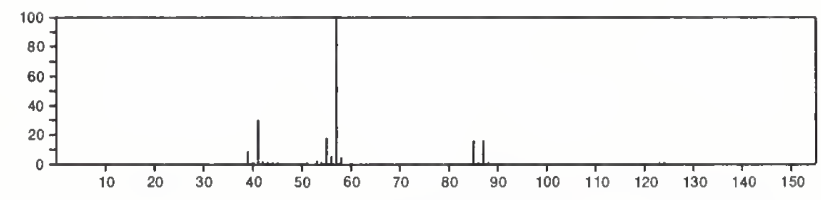

128

$\mathrm{C}_{8} \mathrm{H}_{16} \mathrm{O}$

36099-44-2

Oxirane, 2-(1,1-dimethylethyl)-3-ethyl-, cis-
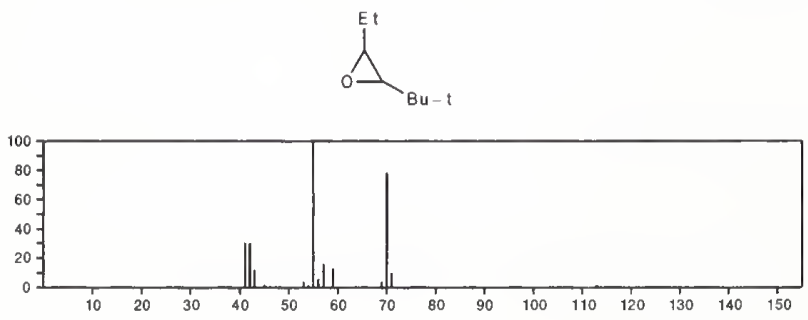

128

Furan, 2,5-diethyltetrahydro-

$\mathrm{C}_{8} \mathrm{H}_{16} \mathrm{O}$

$41239-48-9$

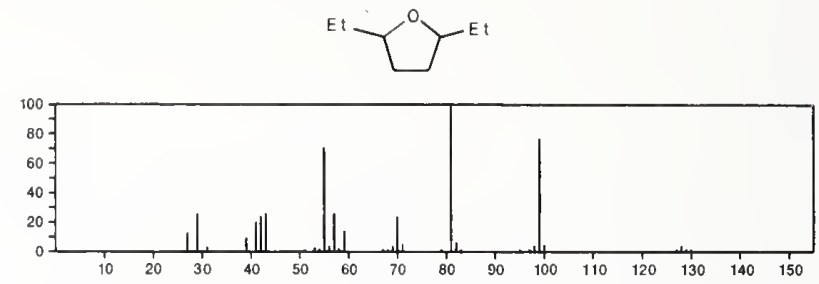

128

$\mathrm{C}_{8} \mathrm{H}_{16} \mathrm{O}$

42604-04-6

Cycloheptane, methoxy-
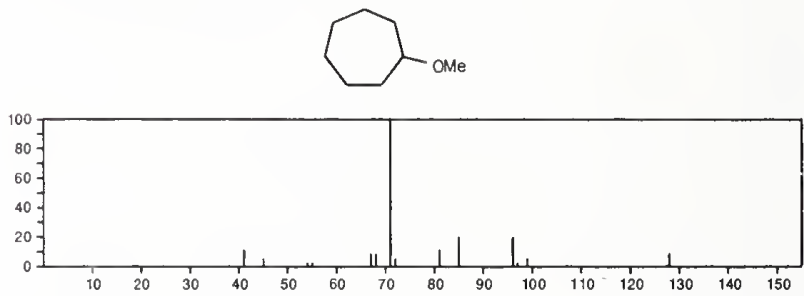

128

$\mathrm{C}_{8} \mathrm{H}_{16} \mathrm{O}$

$50639-00-4$

2-Hexen-1-ol, 2-ethyl-

$\mathrm{Pr} \mathrm{CH}=\mathrm{CE}+\mathrm{CH}_{2} \mathrm{OH}$
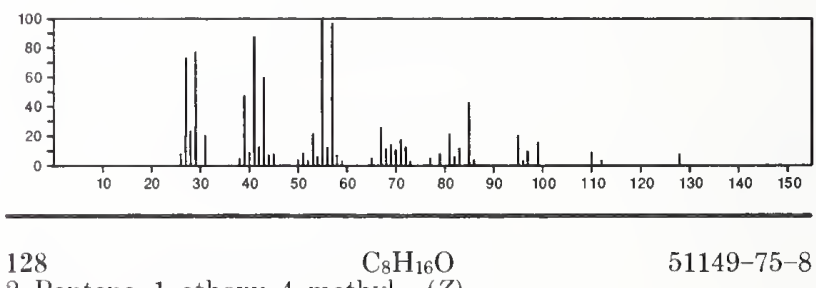

$51149-75-8$

2-Pentene, 1-ethoxy-4-methyl-, (Z)

$\mathrm{E}$ t $\mathrm{OCH}_{2} \mathrm{CH}=\mathrm{CHCHMe} 2$

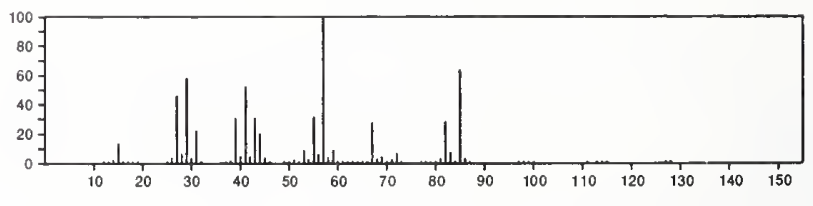

128

4-Penten-1-ol, 2,2,4-trimethyl-

$53907-70-3$

$\mathrm{HOCH}_{2} \mathrm{CMe}_{2} \mathrm{CH}_{2} \mathrm{CM}_{\mathrm{e}}=\mathrm{CH}_{2}$

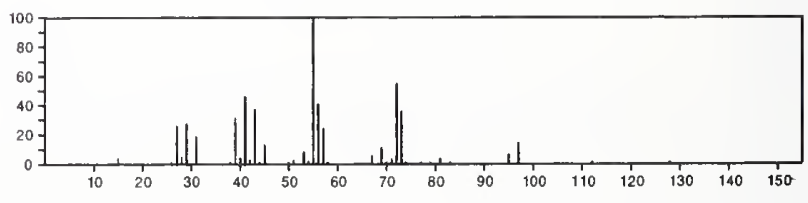

128

$\mathrm{C}_{8} \mathrm{H}_{16} \mathrm{O}$

$53907-72-5$

7-Octen-4-ol

$\operatorname{PrCH}(\mathrm{OH}) \mathrm{CH}_{2} \mathrm{CH}_{2} \mathrm{CH}=\mathrm{CH}_{2}$

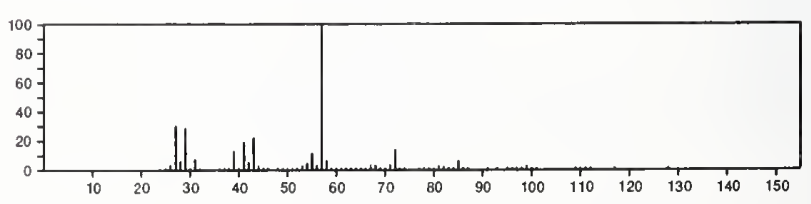


128

3-Hexen-1-ol, 2-ethyl-

$\mathrm{C}_{8} \mathrm{H}_{16} \mathrm{O}$

$\mathrm{Et} \mathrm{CH}=\mathrm{CHCHE}+\mathrm{CH}_{2} \mathrm{OH}$

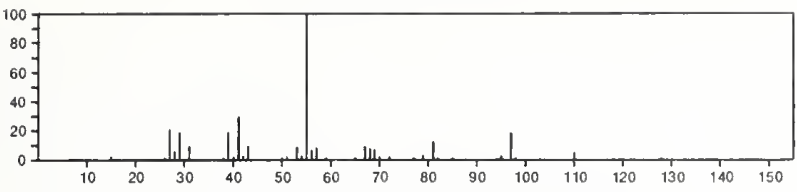

128

$\mathrm{C}_{8} \mathrm{H}_{16} \mathrm{O}$

$53907-74-7$

Butane, 1-[(2-methyl-2-propenyl $\left.)_{o x y}\right]-$

$\mathrm{H}_{2} \mathrm{C}=\mathrm{CMeCH}_{2} \mathrm{O}\left(\mathrm{CH}_{2}\right){ }_{3} \mathrm{Me}$

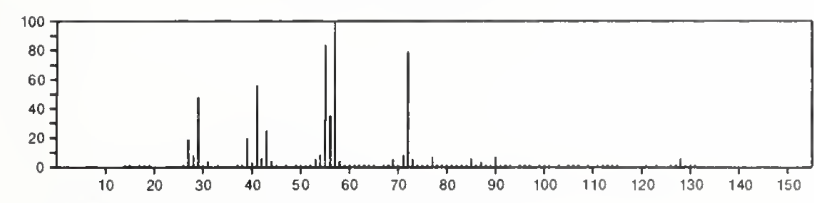

128

$\mathrm{C}_{8} \mathrm{H}_{16} \mathrm{O}$

Oxirane, 2-methyl-2-pentyl-

$53907-75-8$
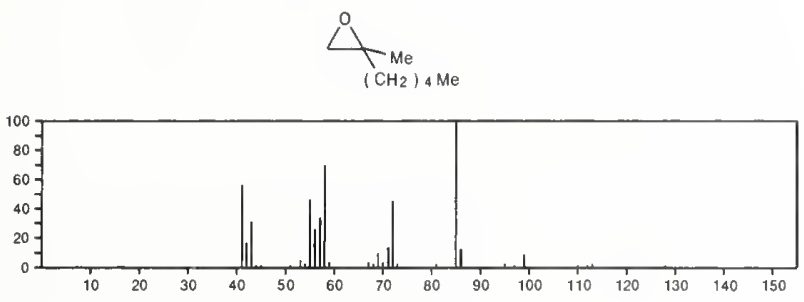

128

Oxirane, (1,1-dimethylbutyl)-

$53907-76-9$

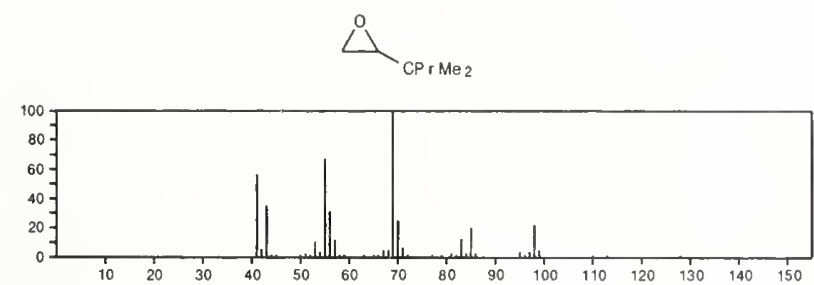

128

$\mathrm{C}_{8} \mathrm{H}_{16} \mathrm{O}$

$53907-77-0$

Oxirane, (3,3-dimethylbutyl)-
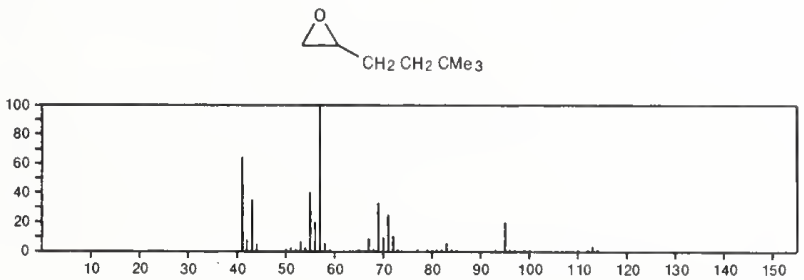

$\mathrm{C}_{8} \mathrm{H}_{16} \mathrm{O}$
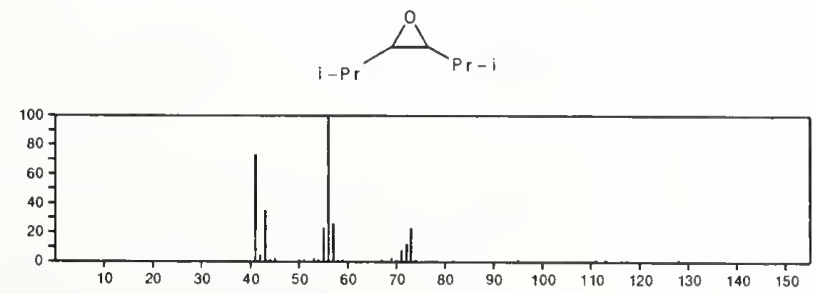

128

Hexanal, 3,3-dimethyl-

$\mathrm{C}_{8} \mathrm{H}_{16} \mathrm{O}$

$55320-57-5$

$\mathrm{OCHCH}_{2} \mathrm{CPrMe}_{2}$

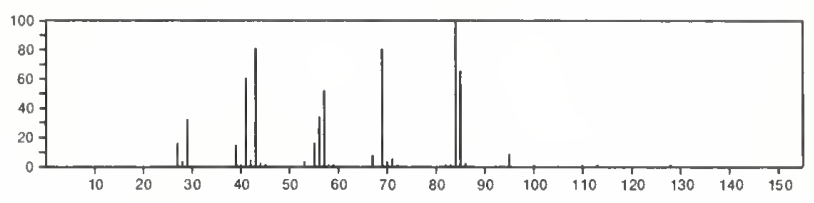

128

Hexanal, 5,5-dimethyl-

$\mathrm{C}_{8} \mathrm{H}_{16} \mathrm{O}$

$55320-58-6$

$\mathrm{Me}_{3} \mathrm{C}\left(\mathrm{CH}_{2}\right)_{3} \mathrm{CHO}$

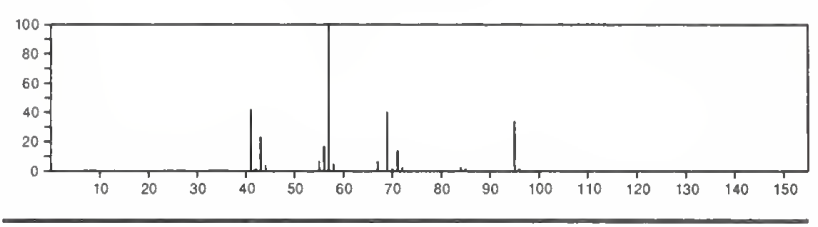

128

$\mathrm{C}_{8} \mathrm{H}_{16} \mathrm{O}$

$56052-72-3$

2-Butene, 1-butoxy-, (E)

$\mathrm{Me}\left(\mathrm{CH}_{2}\right)_{3} \mathrm{OCH}_{2} \mathrm{CH}=\mathrm{CHMe}$

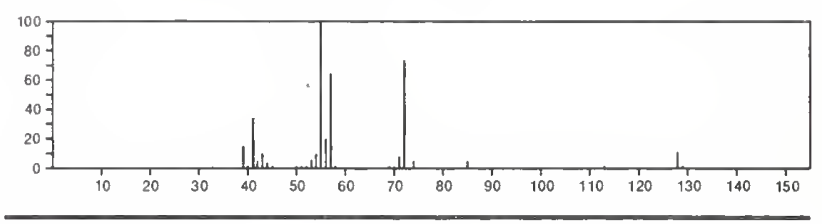

128

2-Hexene, 1-methoxy-3-methyl-, (E)-

$56052-84-7$

P. $\mathrm{ClNie}=\mathrm{CHCH}_{2} \mathrm{OMe}$

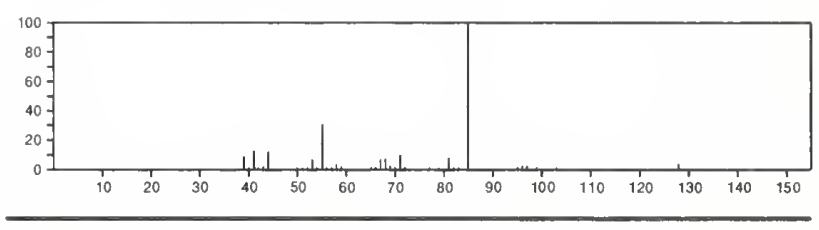

128

Nonane

$\mathrm{C}_{9} \mathrm{H}_{20}$

$111-84-2$

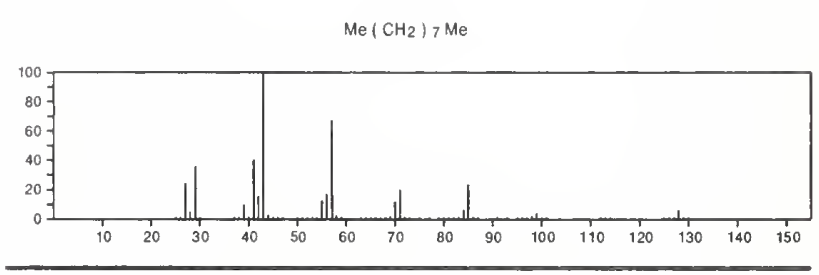

128

$\mathrm{C}_{9} \mathrm{H}_{20}$

$921-47-1$

Hexane, 2,3,4-trimethyl

$\mathrm{Me}_{2} \mathrm{CHCHMe} \mathrm{CHMeCH}_{2} \mathrm{Me}$

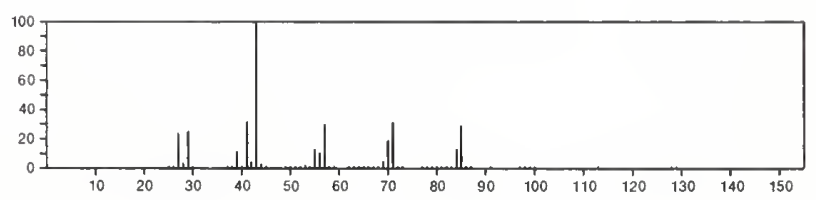


128

Heptane, 3,4-dimethyl-

$\mathrm{C}_{9} \mathrm{H}_{20}$

$922-28-1$

$\mathrm{MeCH} \mathrm{CHMeCHPrMe}_{2}$

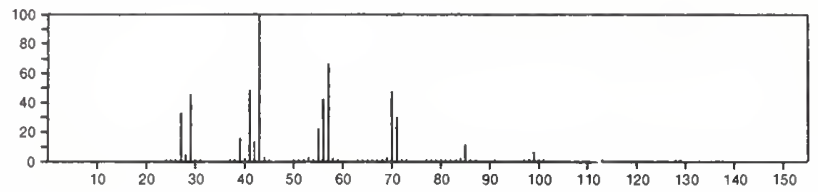

128

Heptane, 3,5-dimethyl-

$\mathrm{C}_{9} \mathrm{H}_{20}$

$926-82-9$

$\mathrm{MeCH} \mathrm{CHMe} \mathrm{CH}_{2} \mathrm{CHMe} \mathrm{CH}_{2} \mathrm{Me}$

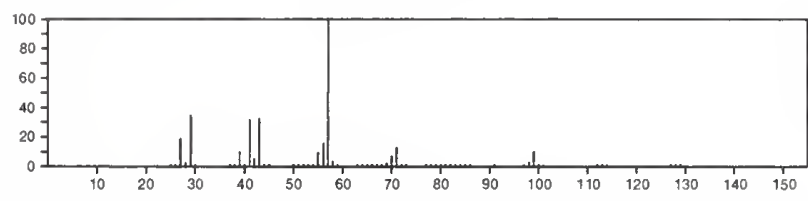

128

Pentane, 3,3-diethyl-

$\mathrm{C}_{9} \mathrm{H}_{20}$

$1067-20-5$

CE t 4
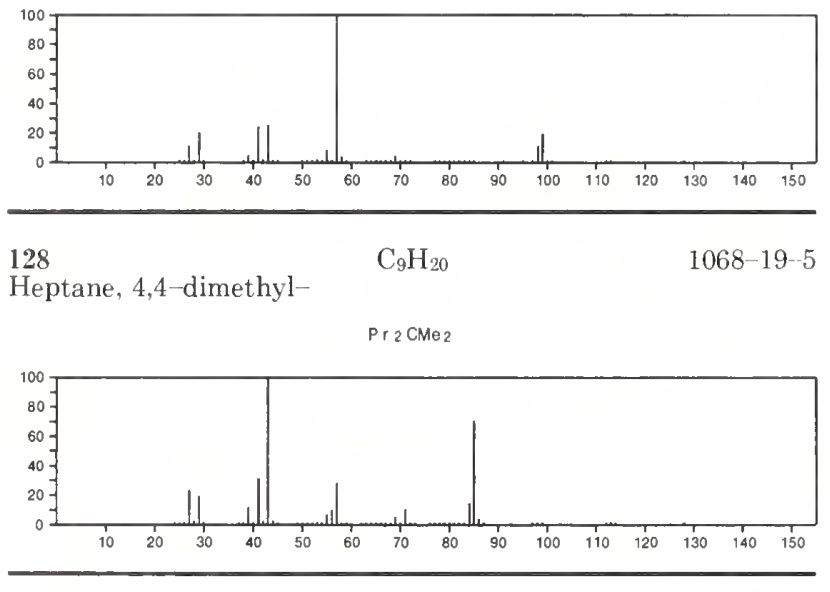

128

$\mathrm{C}_{9} \mathrm{H}_{20}$

$1068-87-7$

Pentane, 3-ethyl-2,4-dimethyl-

$\mathrm{Me}_{2} \mathrm{CHCHE}_{t} \mathrm{CHMe}_{2}$

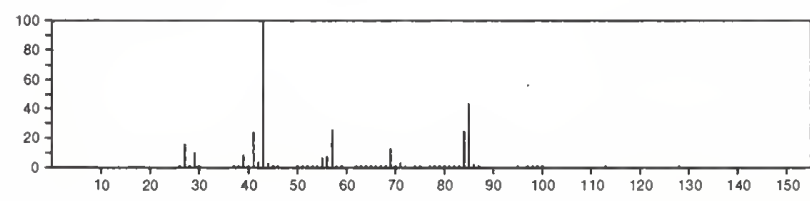

128

Hexane, 2,3,5-trimethyl-

$\mathrm{C}_{9} \mathrm{H}_{20}$

1069-53-0

$\mathrm{Me}_{2} \mathrm{CHCH}_{2} \mathrm{CHMe} \mathrm{CHMe}_{2}$

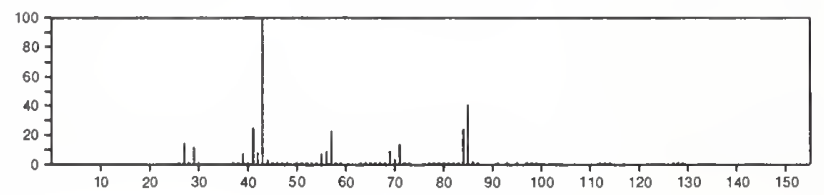

128

$1070-87-7$

$\mathrm{Me}{ }_{3} \mathrm{CCH}_{2} \mathrm{CMe}_{3}$

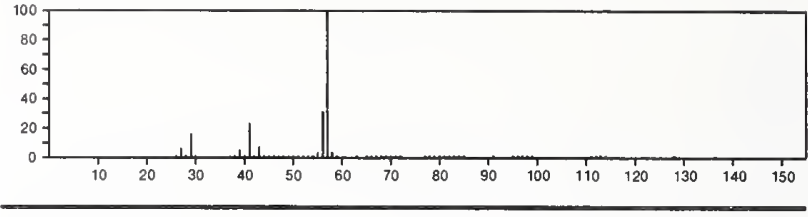

128

Heptane, 2,2-dimethyl

$\mathrm{C}_{9} \mathrm{H}_{20}$

1071-26-7

$\mathrm{Me}{ }_{3} \mathrm{C}\left(\mathrm{CH}_{2}\right){ }_{4} \mathrm{Me}$

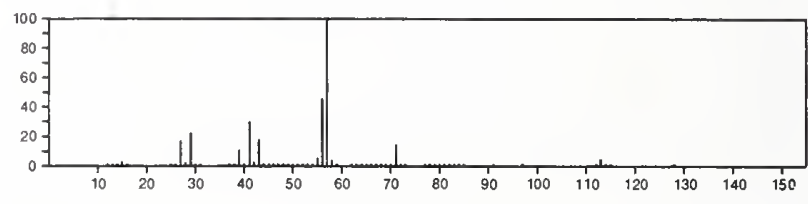

128

Heptane, 2,6-dimethyl-

$\mathrm{C}_{9} \mathrm{H}_{20}$

$1072-05-5$

$\mathrm{Me}_{2} \mathrm{CH}\left(\mathrm{CH}_{2}\right)_{3} \mathrm{CHMe}$

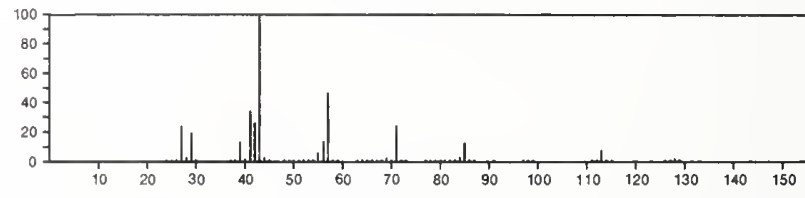

$128 \quad \mathrm{C}_{9} \mathrm{H}_{20}$

$1186-53-4$

Pentane, 2,2,3,4-tetramethyl-

$\mathrm{Me}$ 3 $\mathrm{CCHMe} \mathrm{CHMe}$

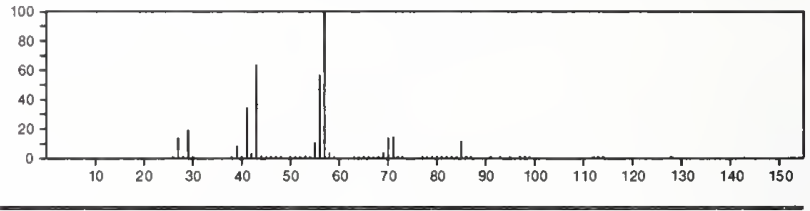

128

$\mathrm{C}_{9} \mathrm{H}_{20}$

2213-23-2

Heptane, 2,4-dimethyl-

$\mathrm{Pr} \mathrm{CHMe} \mathrm{CH}_{2} \mathrm{CHMe}_{2}$

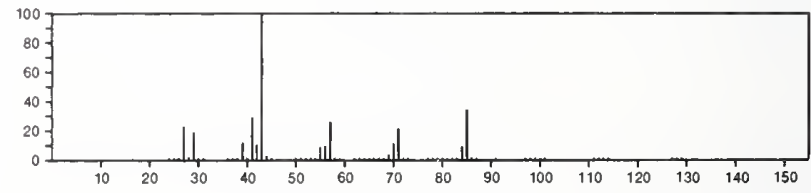

128

$\mathrm{C}_{9} \mathrm{H}_{20}$

$2216-30-0$

Heptane, 2,5-dimethyl

$\mathrm{Me}_{2} \mathrm{CHCH}_{2} \mathrm{CH}_{2} \mathrm{CHMe} \mathrm{CH}_{2} \mathrm{Me}$

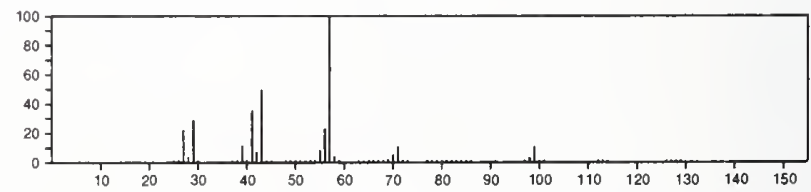


128

$\mathrm{C}_{9} \mathrm{H}_{20}$

$\operatorname{Pr}_{2} \mathrm{CHEt}$

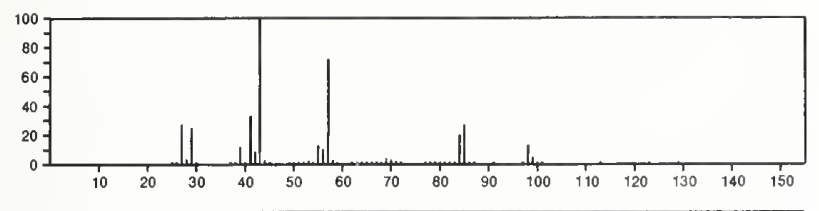

128

Octane, 3-methyl-

$\mathrm{C}_{9} \mathrm{H}_{20}$

2216-33-3

$\mathrm{Me}\left(\mathrm{CH}_{2}\right)_{4} \mathrm{CHMe} \mathrm{CH}_{2} \mathrm{Me}$

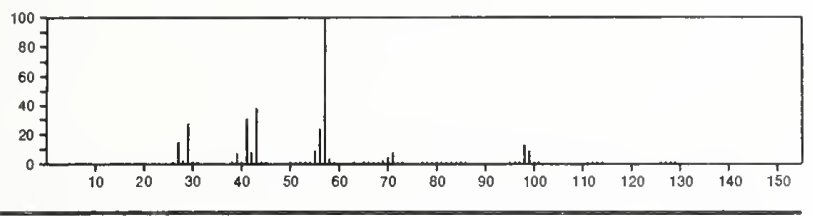

128

Octane, 4-methyl-

$\mathrm{C}_{9} \mathrm{H}_{20}$

$2216-34-4$

$\operatorname{PrCHMe}\left(\mathrm{CH}_{2}\right)$ 3 Me

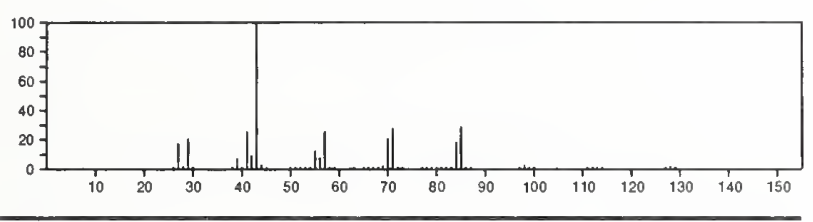

128

$\mathrm{C}_{9} \mathrm{H}_{20}$

3074-71-3

Heptane, 2,3-dimethyl-

$\mathrm{Me}\left(\mathrm{CH}_{2}\right)_{3} \mathrm{CHMeCHMe}_{2}$

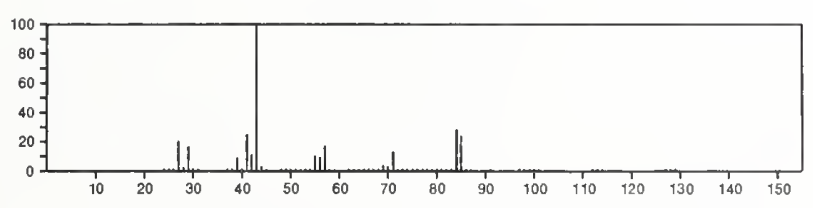

128

Hexane, 4-ethyl-2-methyl-

$\mathrm{C}_{9} \mathrm{H}_{20}$

3074-75-7

$\mathrm{E} \uparrow_{2} \mathrm{CHCH}_{2} \mathrm{CHM}_{2}$

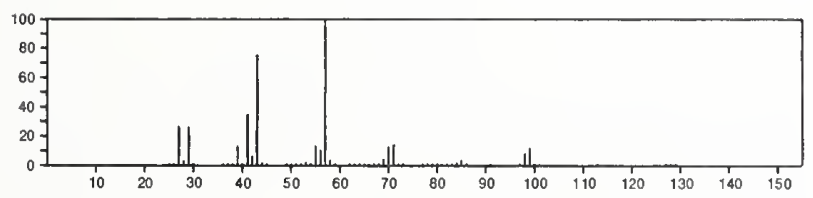

128

Hexane, 3-ethyl-3-methyl-

$\mathrm{C}_{9} \mathrm{H}_{20}$

3074-76-8

$\operatorname{PrCE} 2$ (Me)

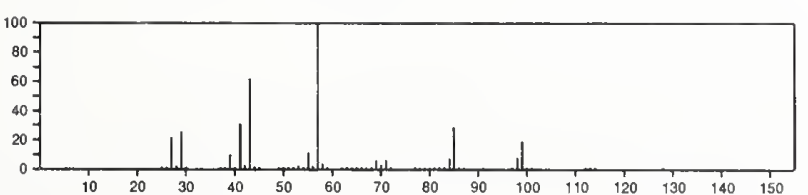

128

Hexane, 3-ethyl-4-methyl-

$\mathrm{C}_{9} \mathrm{H}_{20}$

3074-77-9

$\mathrm{Me} \mathrm{CH}_{2} \mathrm{CHMe} \mathrm{CHE} 2_{2}$

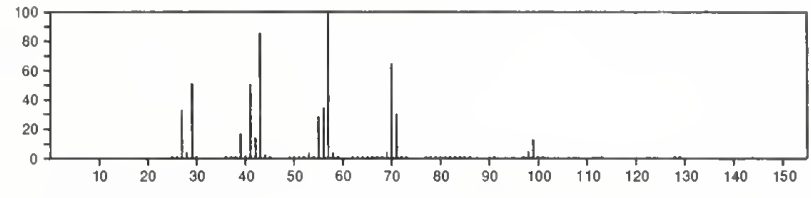

128

Octane, 2-methyl-

$\mathrm{C}_{9} \mathrm{H}_{20}$

3221-61-2

$\mathrm{Me}_{2} \mathrm{CH}\left(\mathrm{CH}_{2}\right) 5 \mathrm{Me}$

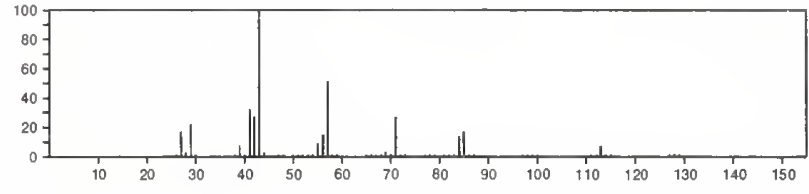

128

$\mathrm{C}_{9} \mathrm{H}_{20}$

$3522-94-9$

Hexane, 2,2,5-trimethyl-

$\mathrm{Me}_{2} \mathrm{CHCH}_{2} \mathrm{CH}_{2} \mathrm{CMe}_{3}$

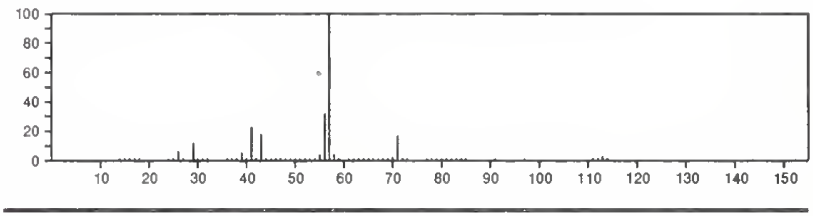

128

$\mathrm{C}_{9} \mathrm{H}_{20}$

4032-86-4

Heptane, 3,3-dimethyl-

$\mathrm{E}_{1} \mathrm{CMe}_{2}\left(\mathrm{CH}_{2}\right)_{3} \mathrm{Me}$

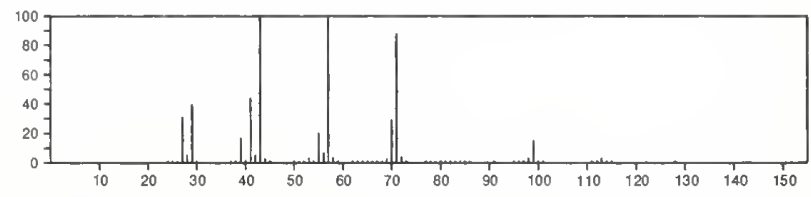

128

$\mathrm{C}_{9} \mathrm{H}_{20}$

7154-79-2

Pentane, 2,2,3,3-tetramethyl-

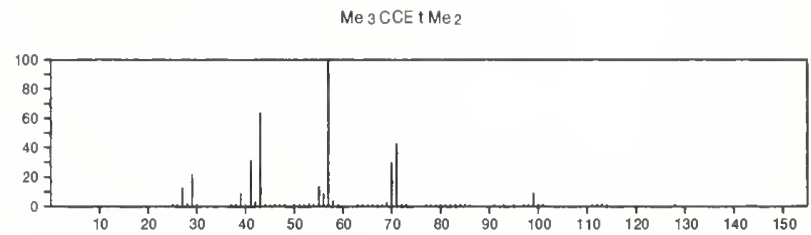

128

$\mathrm{C}_{9} \mathrm{H}_{20}$

15869-80-4

Heptane, 3-ethyl

$\mathrm{E}: 2 \mathrm{CH}\left(\mathrm{CH}_{2}\right)$ 3 $\mathrm{Me}$

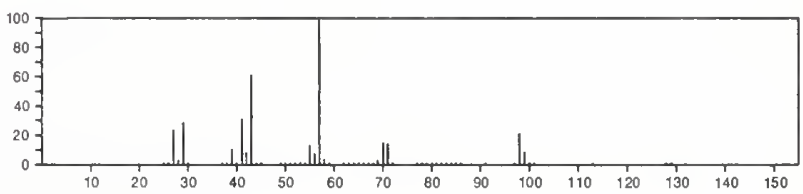


128

Hexane, 2,2,3-trimethyl

$\mathrm{C}_{9} \mathrm{H}_{20}$

$\mathrm{Me}_{3} \mathrm{CCHP} \mathrm{Me}$

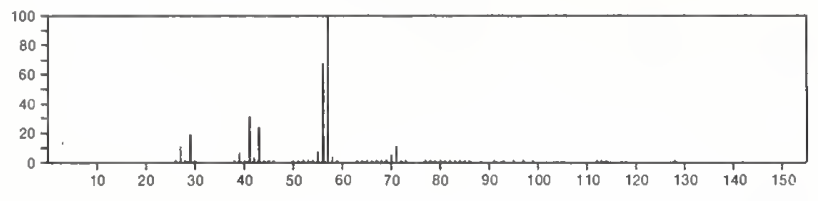

$128 \quad \mathrm{C}_{9} \mathrm{H}_{20} \quad 16747-26-5$

Hexane, 2,2,4-trimethyl-

$\mathrm{Me} 3 \mathrm{CCH}_{2} \mathrm{CHMe} \mathrm{CH}_{2} \mathrm{Me}$
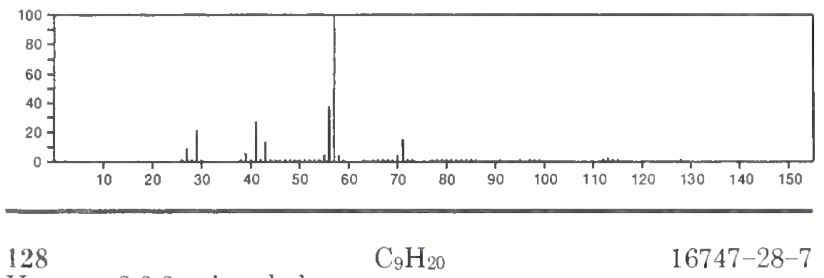

Hexane, 2,3,3-trimethyl-

$\mathrm{Me}_{2} \mathrm{CHCP}_{\mathrm{MMe}}$
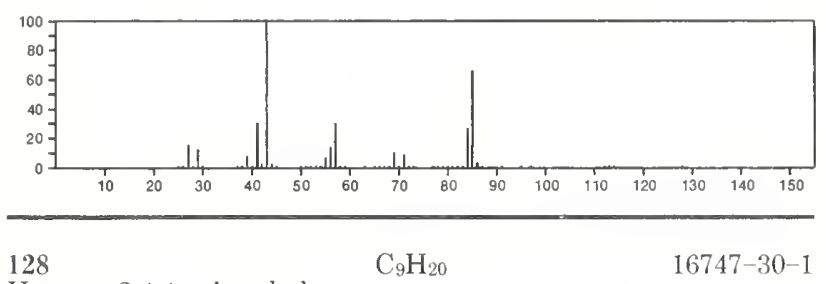

Hexane, 2,4,4-trimethyl-

E t $\mathrm{CMe}_{2} \mathrm{CH}_{2} \mathrm{CHMe}_{2}$

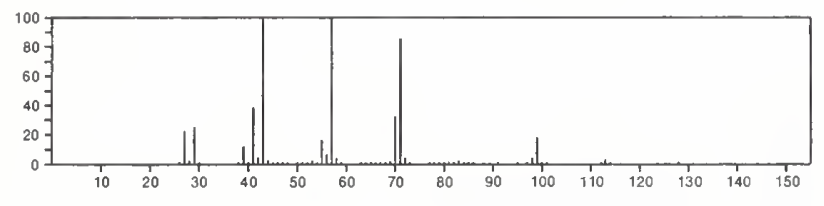

128

Hexane, 3,3,4-trimethyl

$\mathrm{C}_{9} \mathrm{H}_{20}$

$16747-31-2$

$\mathrm{MeCH}_{2} \mathrm{CHMe} \mathrm{CE}_{\mathrm{TMe}} 2$

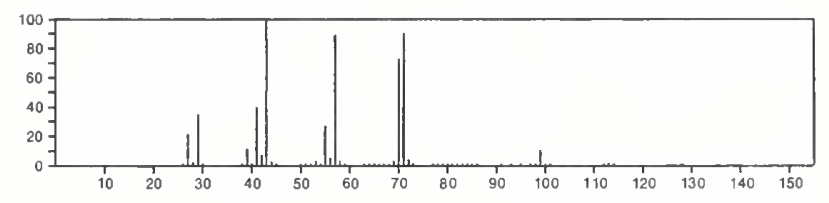

128

Pentane, 3-ethyl-2,2-dimethyl-

$16747-32-3$

$$
\text { Me } 3 \text { CCHEI } 2
$$

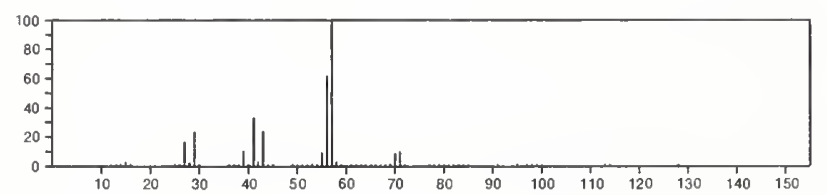

128

Pentane, 3-ethyl-2,3-dimethyl-

$16747-33-4$

$\mathrm{Me}_{2} \mathrm{CHCE}: 2 \mathrm{Me}$

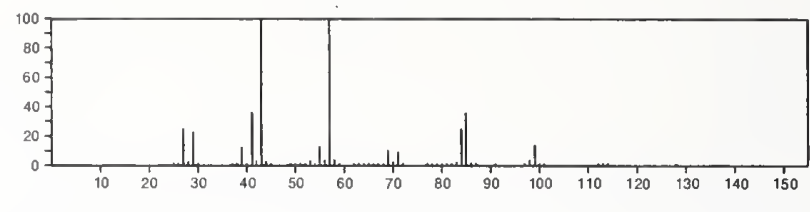

128
Pentane, 2,3,3,4-tetramethyl- $\mathrm{C}_{9} \mathrm{H}_{20}$

16747-38-9

$\mathrm{Me}_{2} \mathrm{CHCMe}_{2} \mathrm{CHMe}_{2}$

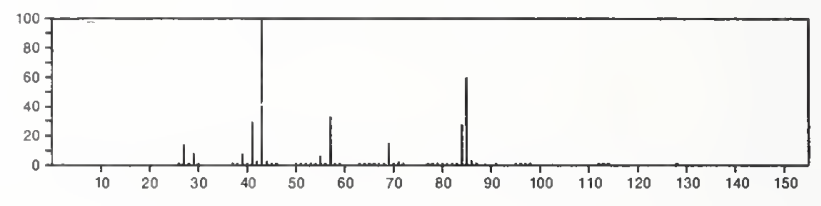

128

$\mathrm{C}_{9} \mathrm{H}_{20}$

16789-46-1

Hexane, 3-ethyl-2-methyl-

$\mathrm{Me}_{2} \mathrm{CHCHP}$ Et

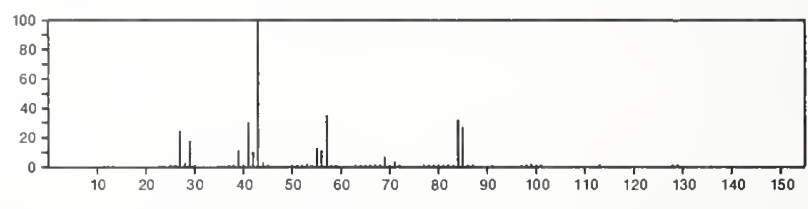

128

Naphthalene

$\mathrm{C}_{10} \mathrm{H}_{8}$

$91-20-3$
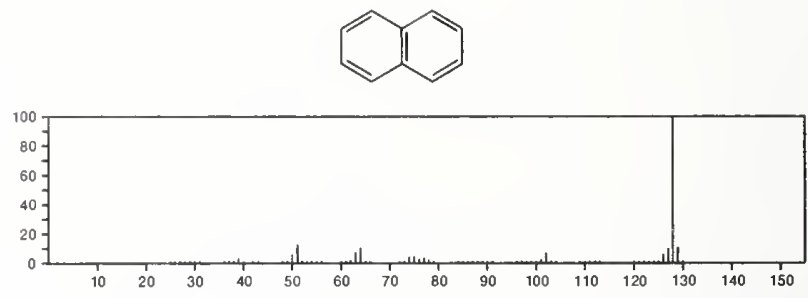

128

$\mathrm{C}_{10} \mathrm{H}_{8}$

$275-51-4$

Azulene
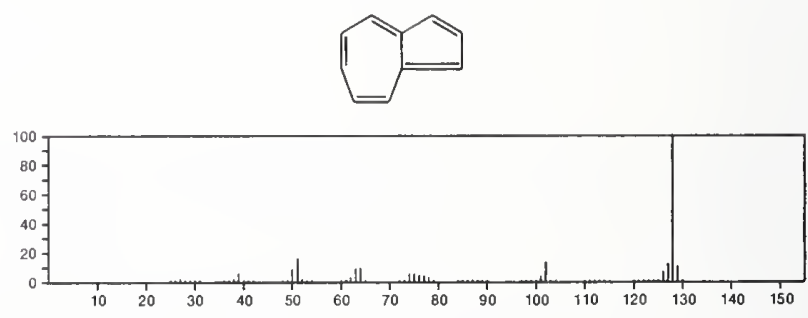

$129 \quad \mathrm{C}_{4} \mathrm{H}_{3} \mathrm{NO}_{2} \mathrm{~S}$

3-Isothiazolecarboxylic acid

$4576-90-3$
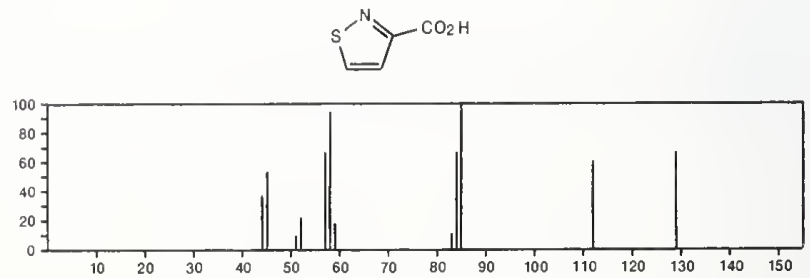
$\mathrm{C}_{4} \mathrm{H}_{4} \mathrm{ClN}_{3}$

3-Pyridazinamine, 6-chloro-
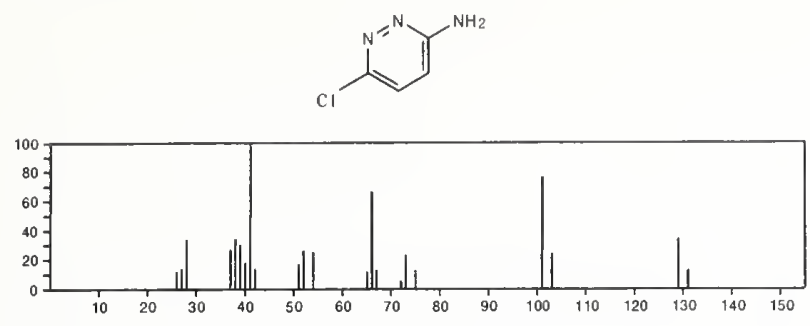

$129 \quad \mathrm{C}_{4} \mathrm{H}_{7} \mathrm{~N}_{3} \mathrm{O}_{2}$

2,6-Piperazinedione, monooxime

$56700-84-6$
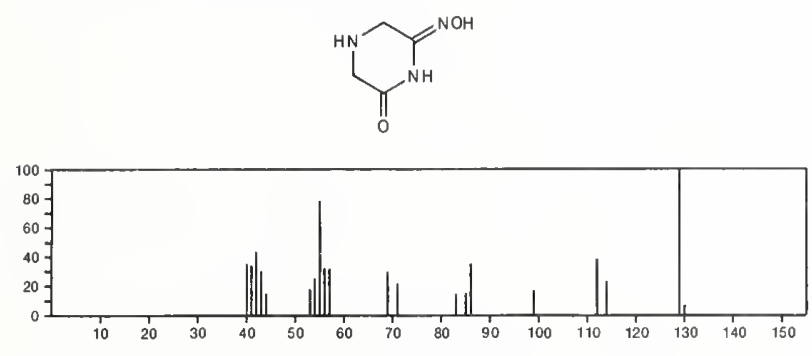

129

$\mathrm{C}_{4} \mathrm{H}_{11} \mathrm{~N}_{5}$

Methanimine, 1-(1,4,4-trimethyl-2-tetrazenyl)

$42448-53-3$

$\mathrm{Me} 2 \mathrm{NN}=\mathrm{NNME} \mathrm{CH}=\mathrm{NH}$

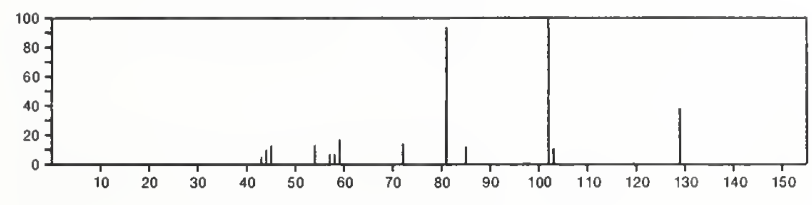

129

$\mathrm{C}_{5} \mathrm{H}_{7} \mathrm{NOS}$

2-Oxazolidinethione, 5-ethenyl-, $(S)$ -

SO $\mathrm{CH}=\mathrm{CH}_{2}$

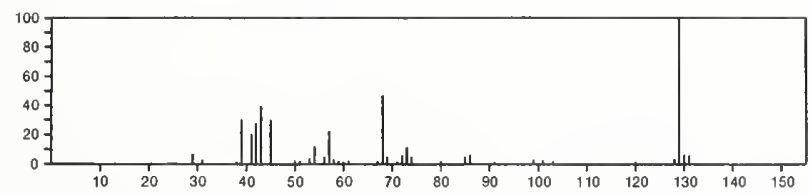

129

$\mathrm{C}_{5} \mathrm{H}_{7} \mathrm{NOS}$

$25115-63-3$

Thiazole, 5-ethoxy-
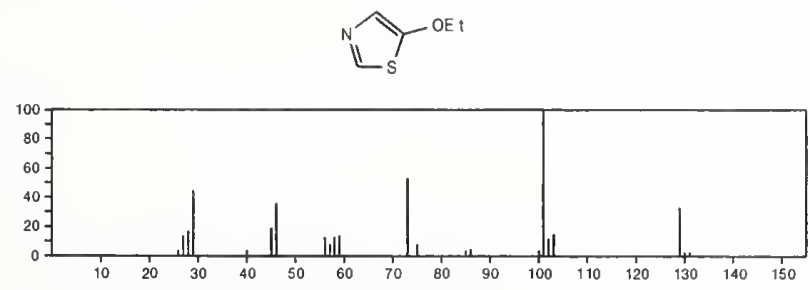

129

2-Propenoic acid, 2-(acetylamino)-

5429-56-1

$\mathrm{ACNHC}\left(\mathrm{CO}_{2} \mathrm{H}\right)=\mathrm{CH}_{2}$

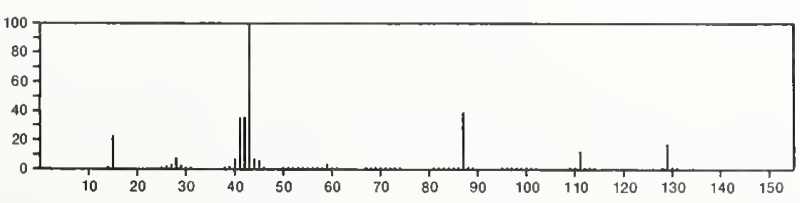

129

Butyraldehyde, semicarbazone

$\mathrm{C}_{5} \mathrm{H}_{11} \mathrm{~N}_{3} \mathrm{O}$

$13183-21-6$

$\mathrm{H}_{2} \mathrm{NCONHN}=\mathrm{CHP}$

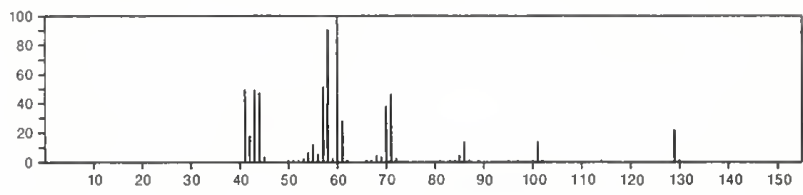

129

$\mathrm{C}_{5} \mathrm{H}_{11} \mathrm{~N}_{3} \mathrm{O}$

16339-07-4

Piperazine, 1-methyl-4-nitroso-
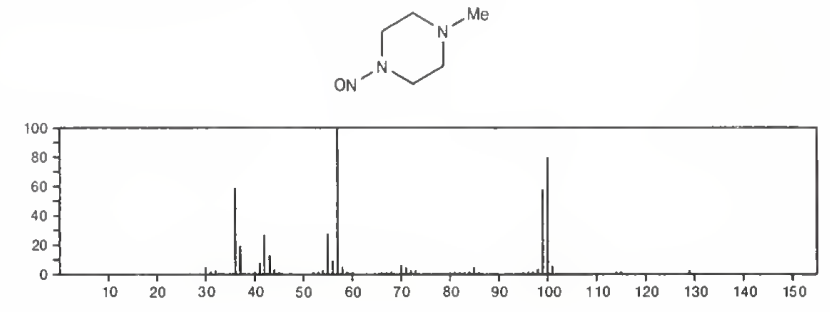

129

Benzenamine, hydrochloride

$\mathrm{C}_{6} \mathrm{H}_{7} \mathrm{~N} . \mathrm{ClH}$

142-04-1

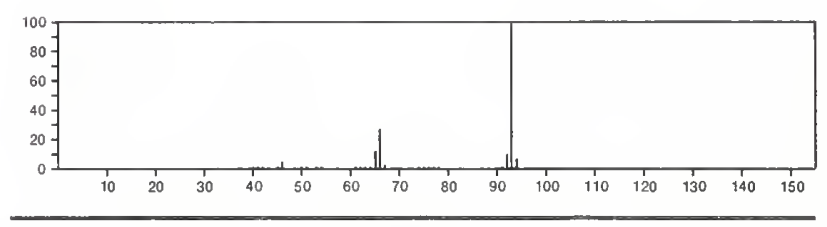

$129 \quad \mathrm{C}_{6} \mathrm{H}_{11} \mathrm{NO}_{2}$

Cyclopentanecarboxylic acid, 1-amino

52-52-8
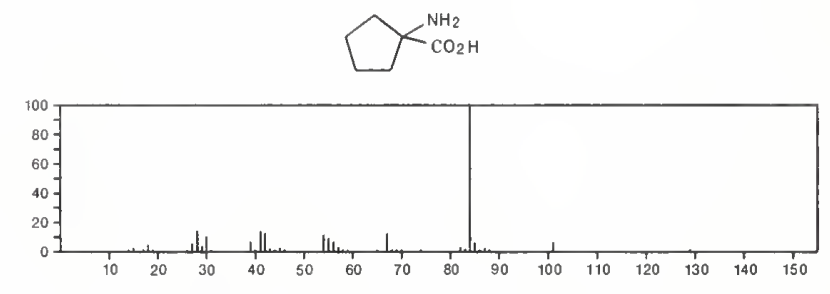

$129 \quad \mathrm{C}_{6} \mathrm{H}_{11} \mathrm{NO}_{2}$

2-Propenoic acid, 3-(dimethylamino)-, methyl ester

999-59-7

$\mathrm{Me} 2 \mathrm{NCH}=\mathrm{CHC}(\mathrm{O}) \mathrm{OMe}$

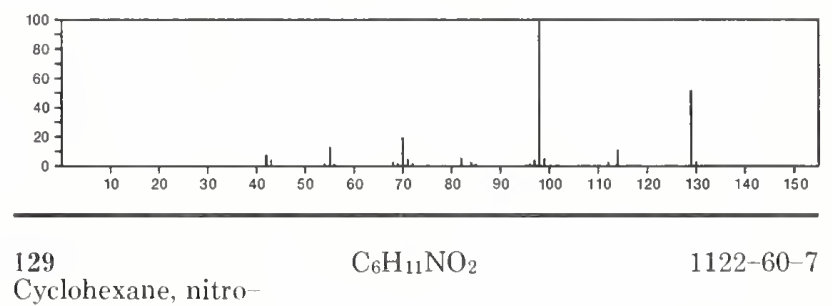

Cyclohexane, nitro
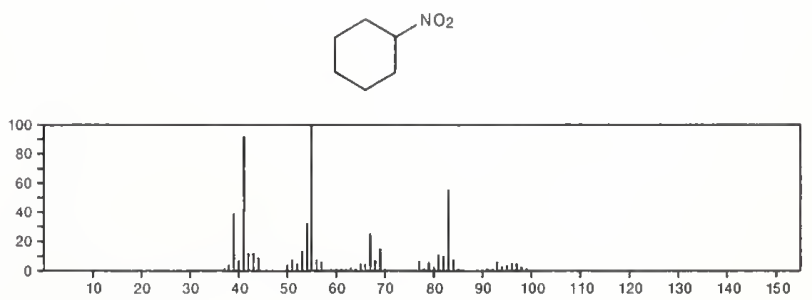
129

1-Hexene, 6-nitro

$\mathrm{C}_{6} \mathrm{H}_{11} \mathrm{NO}_{2}$

$\mathrm{H}_{2} \mathrm{C}=\mathrm{CH}\left(\mathrm{CH}_{2}\right){ }_{4} \mathrm{NO}_{2}$

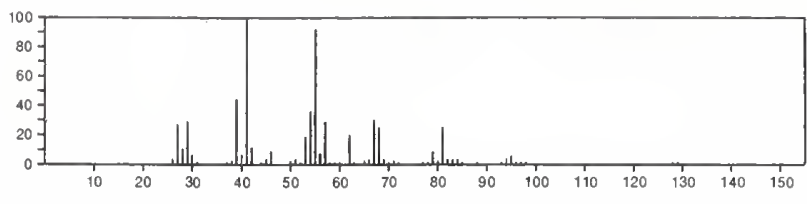

129

Nitrous acid, cyclohexyl ester

$\mathrm{C}_{6} \mathrm{H}_{11} \mathrm{NO}_{2}$

$5156-40-1$
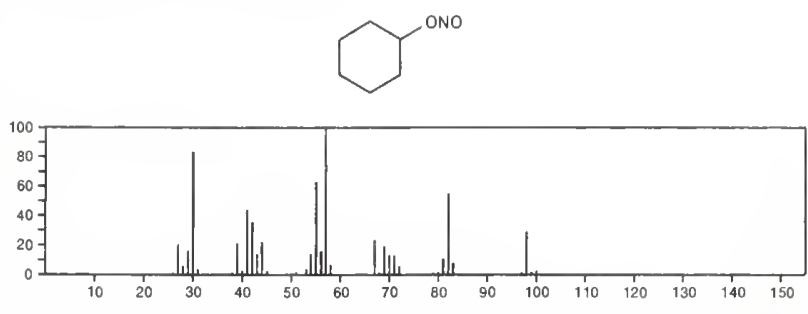

129
$2-$ Butenoic acid, 3-amino-,

$7318-00-5$

$\mathrm{MeC}\left(\mathrm{NH}_{2}\right)=\mathrm{CHC}(\mathrm{O}) \mathrm{OE}$

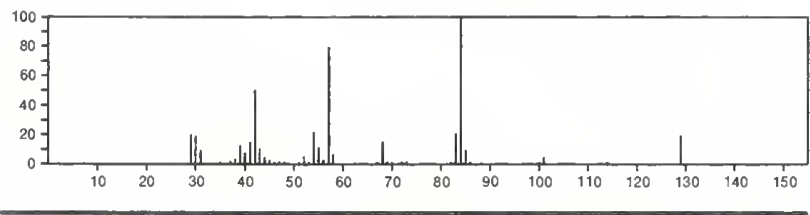

129

$\mathrm{C}_{6} \mathrm{H}_{11} \mathrm{NO}_{2}$

Butyronitrile, 4-ethoxy-3-hydroxy-

$\mathrm{E} t \mathrm{OCH}_{2} \mathrm{CH}(\mathrm{OH}) \mathrm{CH}_{2} \mathrm{CN}$

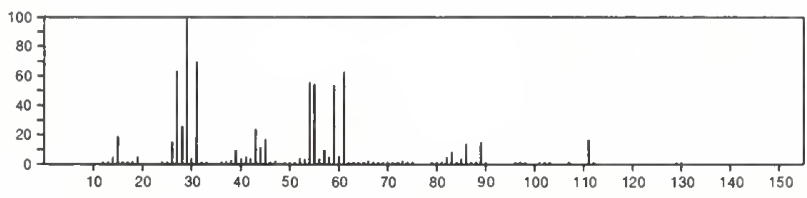

129

2-Pentene, 2-methyl-5-nitro $\mathrm{C}_{6} \mathrm{H}_{11} \mathrm{NO}$

$40244-93-7$

$\mathrm{Me}_{2} \mathrm{C}=\mathrm{CHCH}_{2} \mathrm{CH}_{2} \mathrm{NO}_{2}$

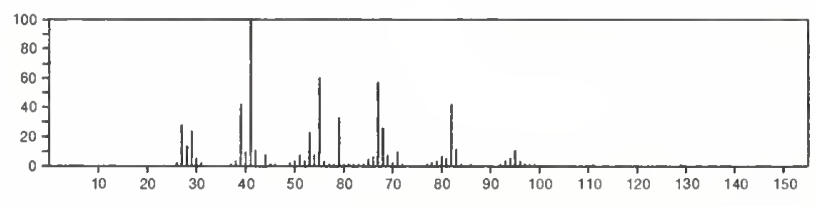

129

2-Hexene, 6-nitro

$\mathrm{C}_{6} \mathrm{H}_{11} \mathrm{NO}_{2}$

$40244-96-0$

$\mathrm{O}_{2} \mathrm{~N}\left(\mathrm{CH}_{2}\right)_{3} \mathrm{CH}=\mathrm{CHMe}$

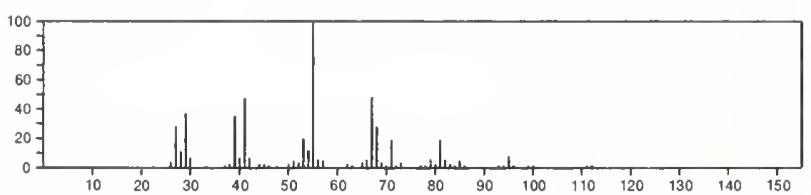

129

$\mathrm{C}_{6} \mathrm{H}_{11} \mathrm{NS}$

$7203-96-5$

2H-Azepine-2-thione, hexahydro-
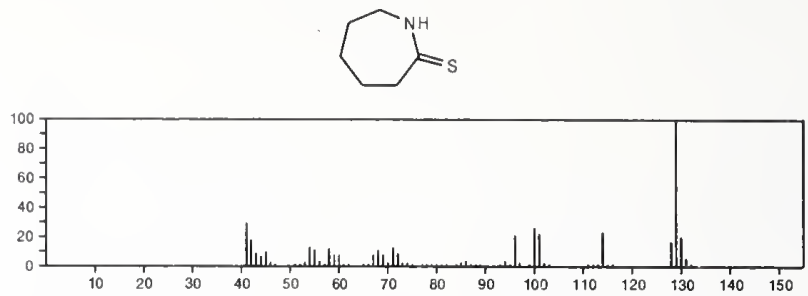

129

$\mathrm{C}_{6} \mathrm{H}_{11} \mathrm{NS}$

2 -Pyrrolidinethione, 5,5-dimethyl-

$35418-37-2$
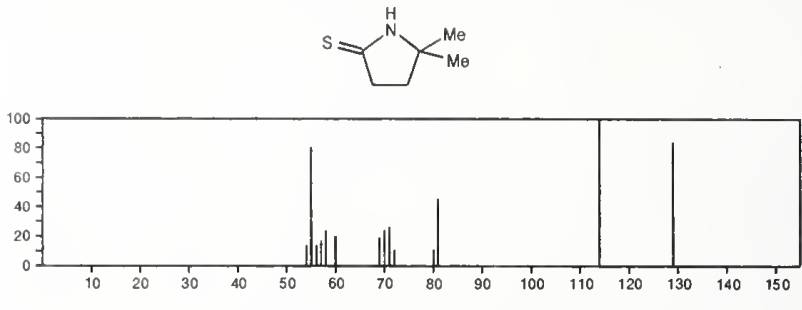

129

$\mathrm{C}_{6} \mathrm{H}_{15} \mathrm{~N}_{3}$

108-74-7

1,3,5-Triazine, hexahydro-1,3,5-trimethyl-
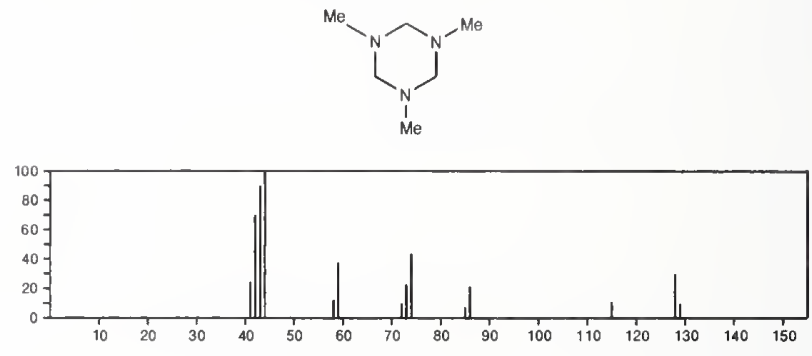

129

$\mathrm{C}_{7} \mathrm{H}_{15} \mathrm{NO}$

1188-63-2

4-Heptanone, oxime

$H O N=C P r_{2}$

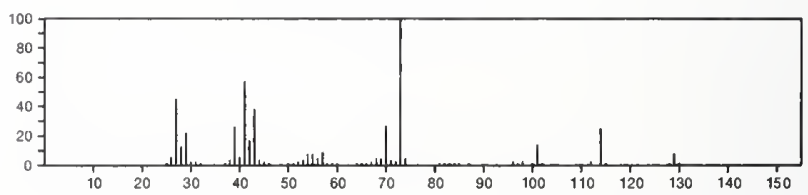

129

$\mathrm{C}_{7} \mathrm{H}_{15} \mathrm{NO}$

13444-24-1

3-Piperidinol, 1-ethyl-
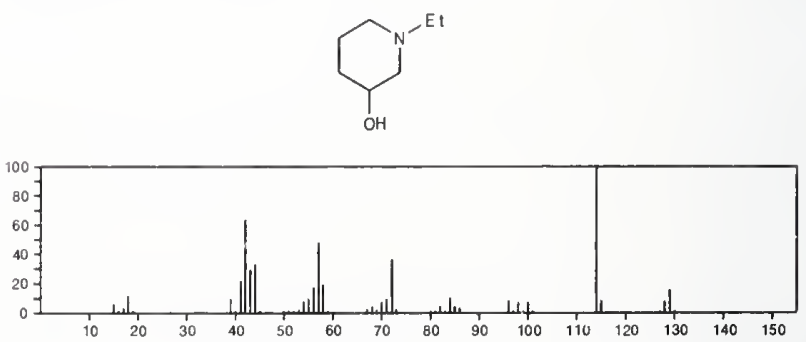
129

$\mathrm{C}_{7} \mathrm{H}_{15} \mathrm{NO}$

Valeraldehyde, 2,2-dimethyl-, oxime

HON $=$ CHCPrMe 2

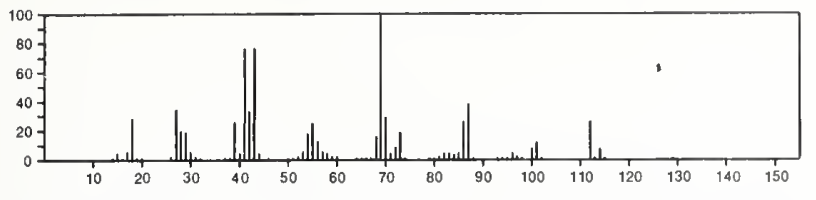

$129 \quad \mathrm{C}_{7} \mathrm{H}_{15} \mathrm{NO}$

4-Piperidinemethanol, 1-methyl-
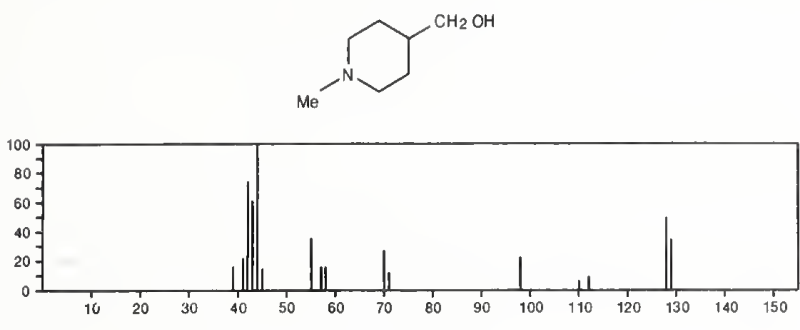

129

$\mathrm{C}_{7} \mathrm{H}_{15} \mathrm{NO}$

$36382-57-7$

2-Pentanone, 3-methyl-, O-methyloxime

$\mathrm{MeCH}_{2} \mathrm{CHMe} \mathrm{CMe}=\mathrm{NOM}$

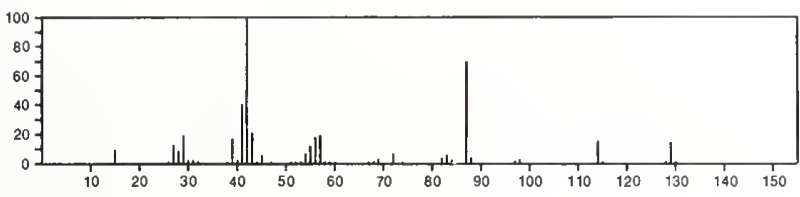

129

$\mathrm{C}_{7} \mathrm{H}_{15} \mathrm{NO}$

3-Piperidinol, 1,4-dimethyl-, trans-<smiles>C[C@@H]1CCN(N)CC1O</smiles>

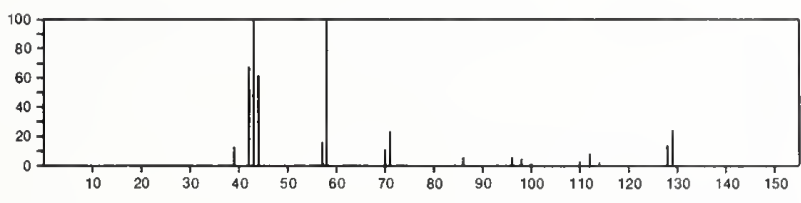

129

$\mathrm{C}_{7} \mathrm{H}_{15} \mathrm{NO}$

$37835-50-0$

3-Piperidinol, 1,4-dimethyl-, cis-<smiles>CC1CCN(N)CC1O</smiles>

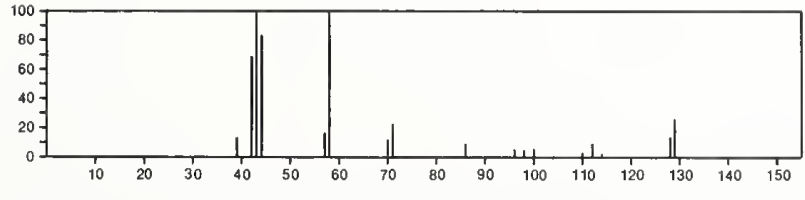

129

Pentanamide, $N$-ethyl-

$\mathrm{C}_{7} \mathrm{H}_{15} \mathrm{NO}$

$\mathrm{Me}\left(\mathrm{CH}_{2}\right)_{3}$ CONHE

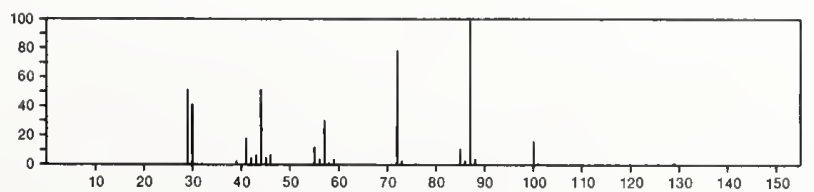

129

3-Piperidinol, $\mathrm{C}_{7} \mathrm{H}_{15} \mathrm{NO}$

$54751-70-1$

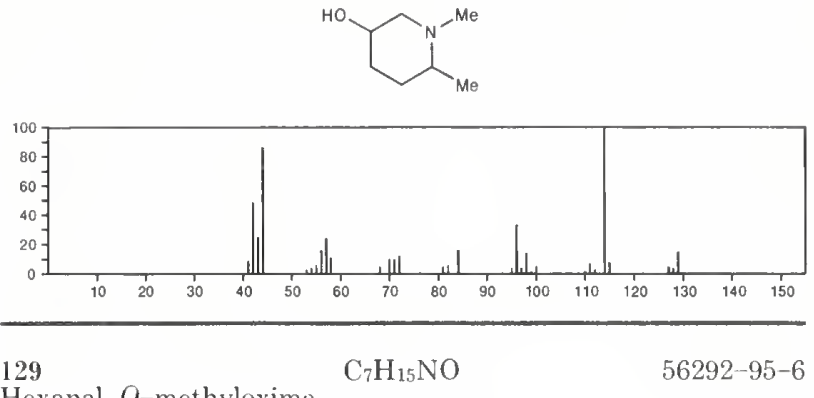

Hexanal, $\mathrm{O}$-methyloxime

$\mathrm{Me} \mathrm{ON}=\mathrm{CH}\left(\mathrm{CH}_{2}\right)+\mathrm{Me}$

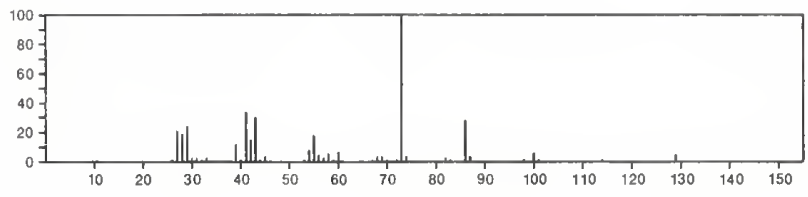

129

$\mathrm{C}_{7} \mathrm{H}_{15} \mathrm{NO}$

$56701-01-0$

Isoxazolidine, 4-ethyl-2,5-dimethyl-, cis-
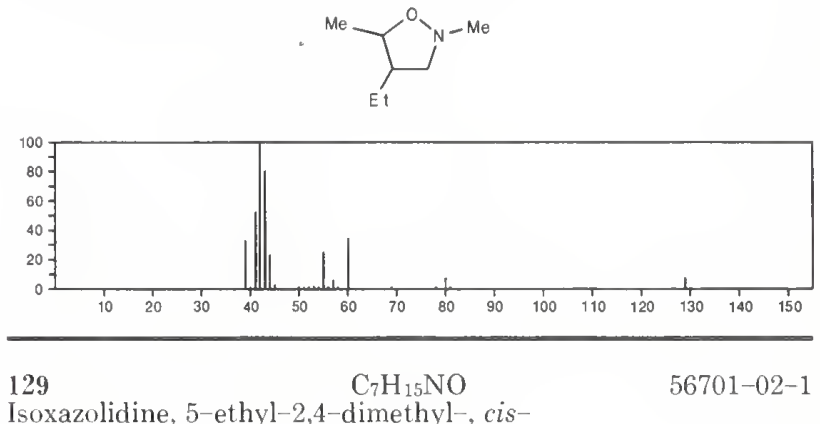

Isoxazolidine, 5-ethyl-2,4-dimethyl-, cis-
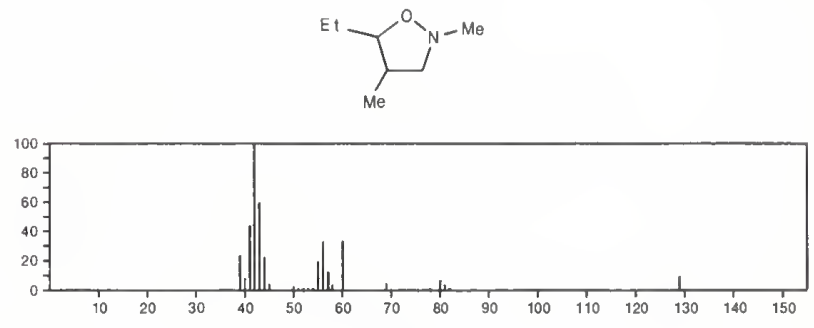

129

$\mathrm{C}_{7} \mathrm{H}_{15} \mathrm{NO}$

$56728-13-3$

Isoxazolidine, 4-ethyl-2,5-dimethyl-, trans
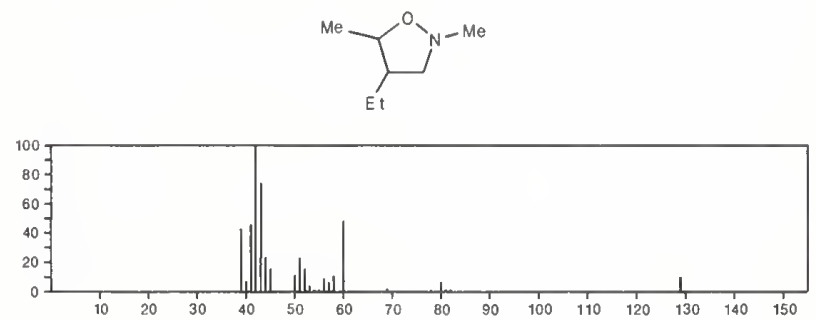
129

Isoxazolidine, 5-ethyl-2,4-dimethyl-, trans-
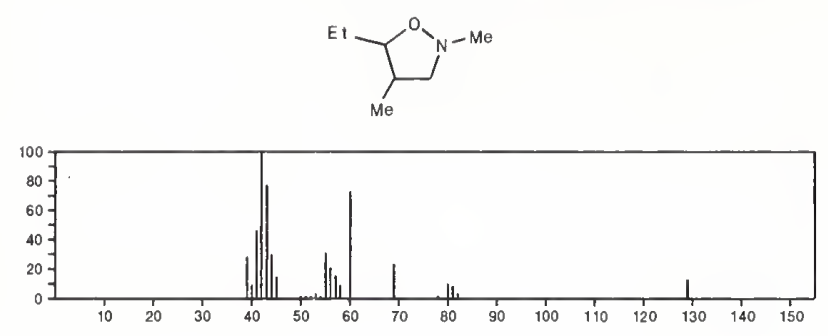

$129 \quad \mathrm{C}_{8} \mathrm{H}_{19} \mathrm{~N} \quad 104-75-6$

1-Hexanamine, 2-ethyl-

$\mathrm{Me}\left(\mathrm{CH}_{2}\right)_{3} \mathrm{CHE}$ I $\mathrm{CH}_{2} \mathrm{NH}_{2}$

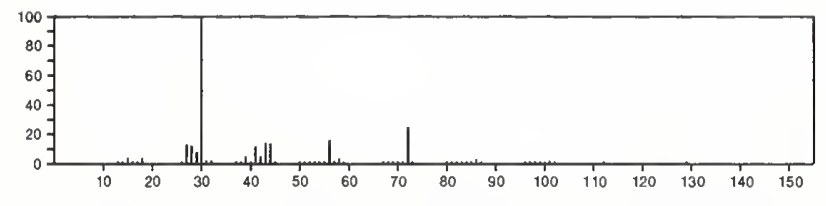

$129 \quad \mathrm{C}_{8} \mathrm{H}_{19} \mathrm{~N} \quad 107-45^{-9}$

2-Pentanamine, 2,4,4-trimethyl-

$\mathrm{Me}_{3} \mathrm{CCH}_{2} \mathrm{CMe}_{2} \mathrm{NH}_{2}$

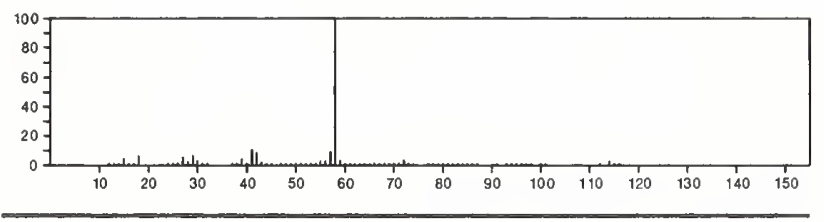

129

$\mathrm{C}_{8} \mathrm{H}_{19} \mathrm{~N}$

$110-96-3$

1-Propanamine, 2-methyl-N-(2-methylpropyl)-

$\mathrm{NH}(\mathrm{Bu}-\mathrm{i})_{2}$

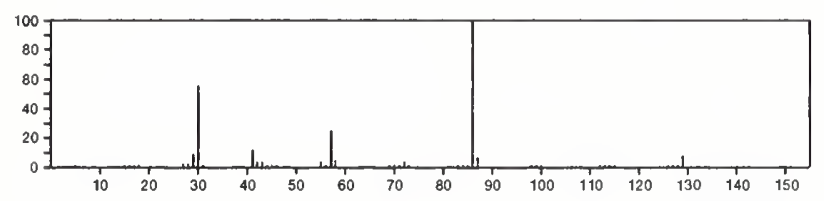

129

$\mathrm{C}_{8} \mathrm{H}_{19} \mathrm{~N}$

$111-86-4$

1-Octanamine

$\mathrm{Me}\left(\mathrm{CH}_{2}\right)>\mathrm{NH}_{2}$

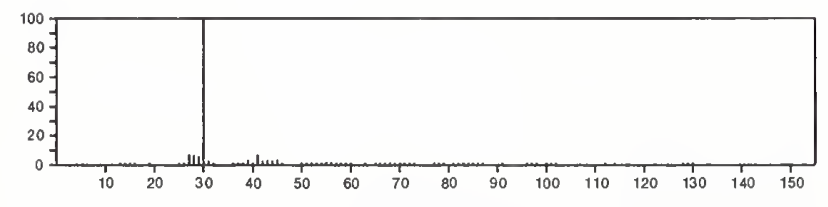

129

$\mathrm{C}_{8} \mathrm{H}_{19} \mathrm{~N}$

$111-92-2$

1-Butanamine, $N$-butyl-

$\mathrm{Me}\left(\mathrm{CH}_{2}\right)_{3} \mathrm{NH}\left(\mathrm{CH}_{2}\right)_{3} \mathrm{Me}$

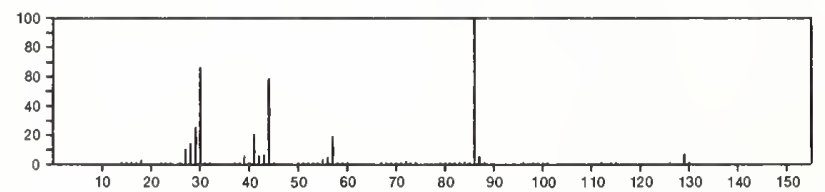

129

2-Hertanamine, 6-methyl-

$\mathrm{C}_{8} \mathrm{H}_{19} \mathrm{~N}$

$543-82-8$

$\mathrm{Me} 2 \mathrm{CH}\left(\mathrm{CH}_{2}\right)_{3} \mathrm{CH}\left(\mathrm{NH}_{2}\right) \mathrm{Me}$

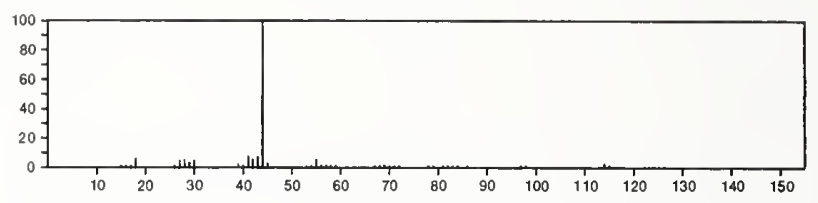

129

$\mathrm{C}_{8} \mathrm{H}_{19} \mathrm{~N}$

2-Butanamine, $N$-(1-methylpropyl)

$626-23-3$

$\mathrm{NH}(\mathrm{Bu}-\mathrm{s}) 2$

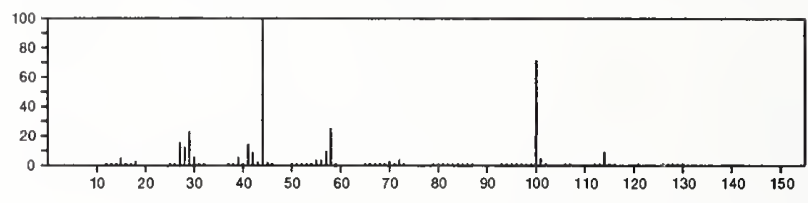

$129 \quad \mathrm{C}_{8} \mathrm{H}_{19} \mathrm{~N}$

$693-16-3$

$\mathrm{MeCH}\left(\mathrm{NH}_{2}\right)\left(\mathrm{CH}_{2}\right) 5 \mathrm{Me}$

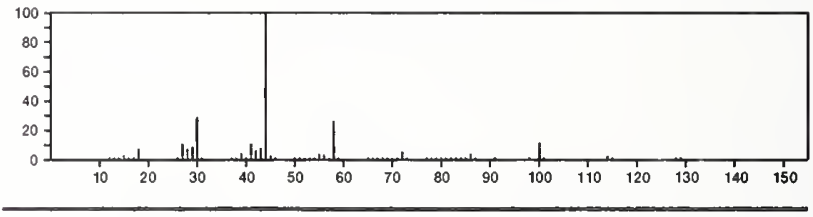

129

1-Butanamine, $N, N$-diethyl-

$\mathrm{C}_{8} \mathrm{H}_{19} \mathrm{~N}$

4444-68-2

$\mathrm{E}_{2} \mathrm{~N}_{2}\left(\mathrm{CH}_{2}\right) 3 \mathrm{Me}$

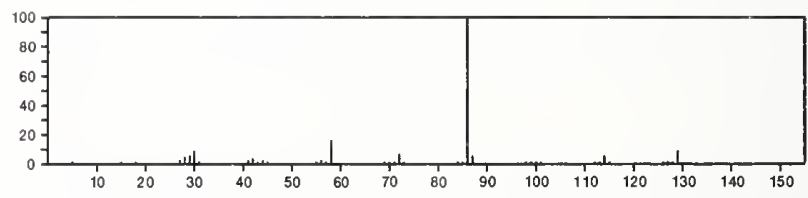

129

$\mathrm{C}_{8} \mathrm{H}_{19} \mathrm{~N}$

$5756-45-6$

1-Butanamine, $N$-methyl- $N$-(1-methylethyl)-

$\mathrm{MeN}(\mathrm{Pr}-\mathrm{i})\left(\mathrm{CH}_{2}\right){ }_{3} \mathrm{Me}$

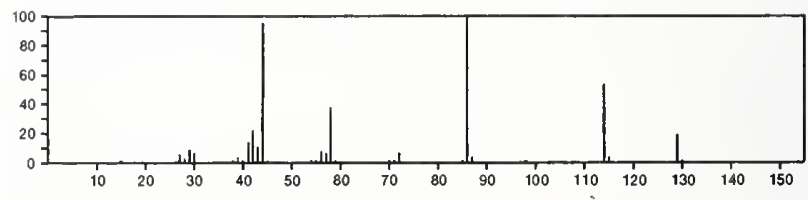

129

2 -Propanamine, $N$-ethyl-N-(1-methylethyl)-

7087-68-5

$E+N(\operatorname{Pr}-\mathrm{i})_{2}$

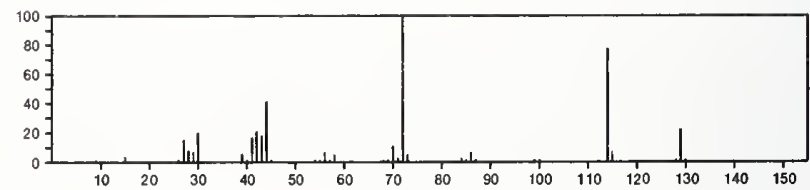


129

$\mathrm{C}_{8} \mathrm{H}_{19} \mathrm{~N}$

$\mathrm{Me}\left(\mathrm{CH}_{2}\right) 5 \mathrm{NHE}$

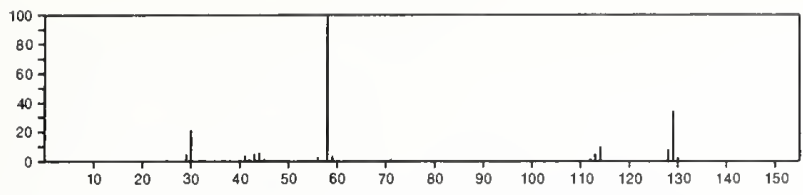

$129 \quad \mathrm{C}_{8} \mathrm{H}_{19} \mathrm{~N}$

$21981-37-3$

2-Propanamine, $N$-(1,1-dimethylethyl)-2-methyl-

$\mathrm{NH}(\mathrm{Bu}-\mathrm{t})_{2}$

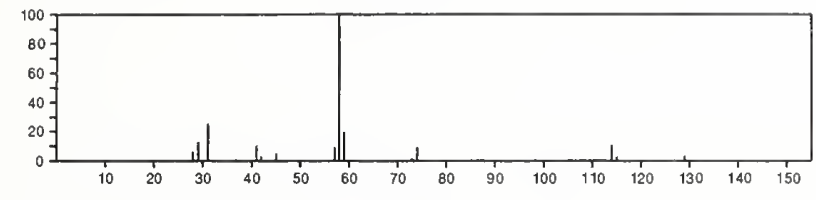

129
Butylamine, $N$-methyl- $N$-propyl-

$\operatorname{PrNMe}\left(\mathrm{CH}_{2}\right)_{3} \mathrm{Me}$

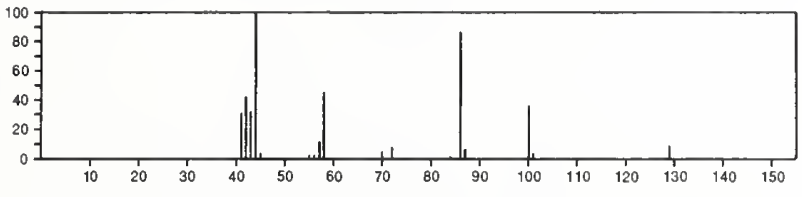

$129 \quad \mathrm{C}_{8} \mathrm{H}_{19} \mathrm{~N}$

Butylamine, 1-ethyl-N,N-dimethyl-

$\mathrm{Me}_{2} \mathrm{NCHP}_{\mathrm{E}} \mathrm{I}$

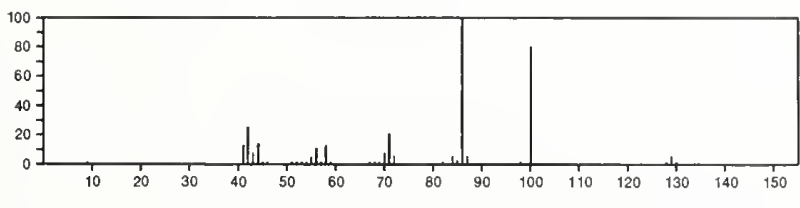

129

$\mathrm{C}_{8} \mathrm{H}_{19} \mathrm{~N}$

$24552-04-3$

3-Octanamine

$\mathrm{EtCH}\left(\mathrm{NH}_{2}\right)\left(\mathrm{CH}_{2}\right){ }_{4} \mathrm{Me}$

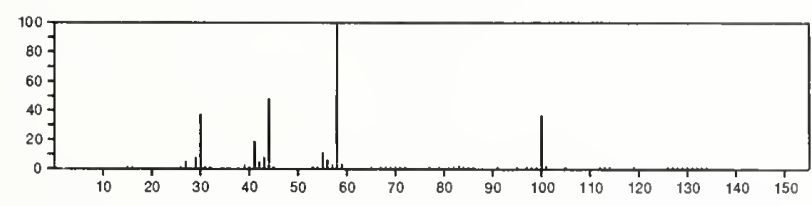

129

$\mathrm{C}_{8} \mathrm{H}_{19} \mathrm{~N}$

$27581-29-9$

Hexylamine, 1,1-dimethyl-

$\mathrm{Me}_{2} \mathrm{CNH}_{2}\left(\mathrm{CH}_{2}\right){ }_{4} \mathrm{Me}$

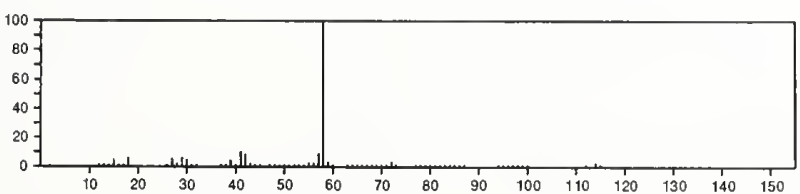

129

$\mathrm{C}_{8} \mathrm{H}_{19} \mathrm{~N}$

2-Pentanamine, $N$-ethyl-4-methyl

42966-64-3

$\mathrm{MeCH}$ (NHEt) $\mathrm{CH}_{2} \mathrm{CHMe}_{2}$

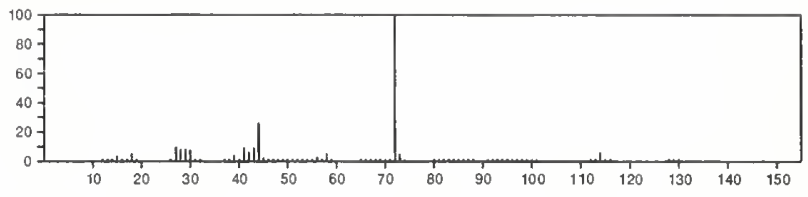

$129 \quad \mathrm{C}_{8} \mathrm{H}_{19} \mathrm{~N}$

2-Heptanamine, 5-methyl-

$\mathrm{Me} C \mathrm{CH}\left(\mathrm{NH}_{2}\right) \mathrm{CH}_{2} \mathrm{CH}_{2} \mathrm{CHM}_{\theta} \mathrm{CH}_{2} \mathrm{Me}$

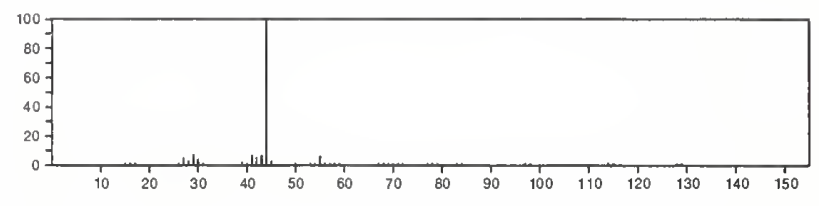

$129 \quad \mathrm{C}_{8} \mathrm{H}_{19} \mathrm{~N} \quad 56667-17-5$

3-Hexanamine, 3-ethyl-

$\operatorname{PrCEt} 2\left(\mathrm{NH}_{2}\right)$

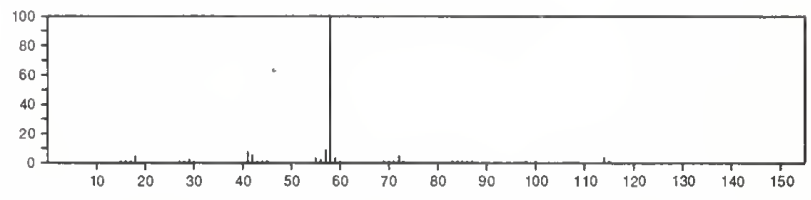

129
Quinoline $\quad \mathrm{C}_{9} \mathrm{H}_{7} \mathrm{~N}$

$\sim^{N}$

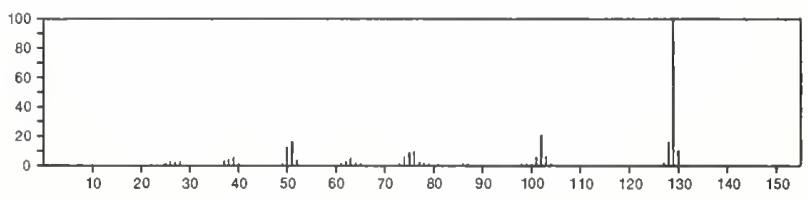

129

Isoquinoline

$\mathrm{C}_{9} \mathrm{H}_{7} \mathrm{~N}$

$119-65-3$
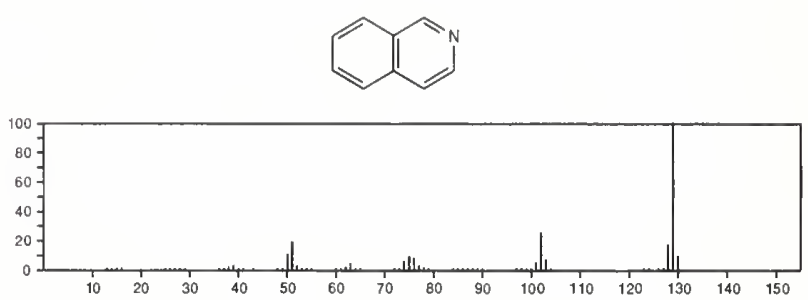

$129 \quad \mathrm{C}_{9} \mathrm{H}_{7} \mathrm{~N}$

$495-10-3$

Benzeneacetonitrile, $\alpha-$ methylene-

$\mathrm{NCCPh}=\mathrm{CH}_{2}$

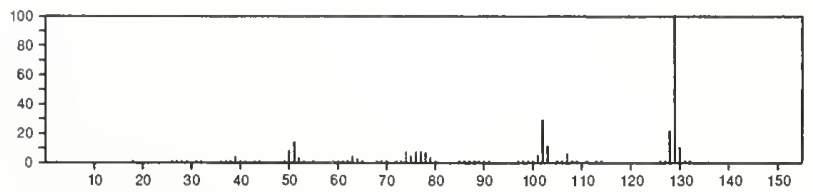


130

Methane, bromodifluoro-

$\mathrm{CHBrF}_{2}$

$\mathrm{Br}_{\mathrm{CHF}} 2$

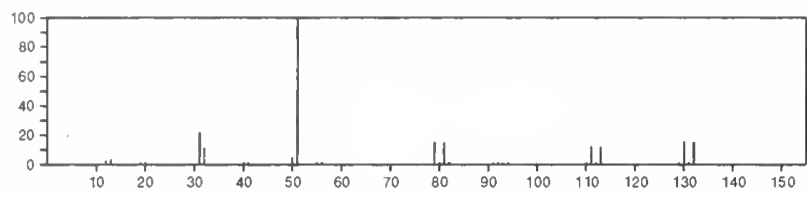

130
Acetic acid, chlorodifluoro--

$\mathrm{ClCF}_{2}\left(\mathrm{CO}_{2} \mathrm{H}\right)$

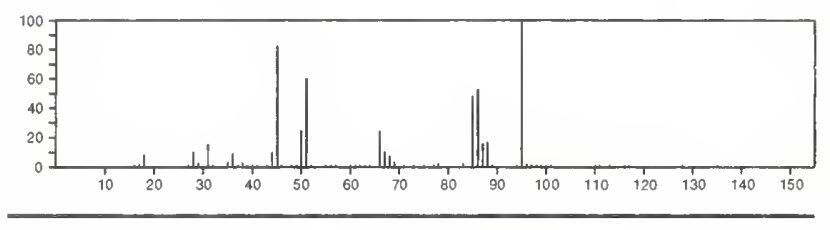

130

$\mathrm{C}_{2} \mathrm{HCl}_{3}$

$79-01-6$

Ethene, trichloro-

$\mathrm{Cl} \mathrm{CH}=\mathrm{CCl}$

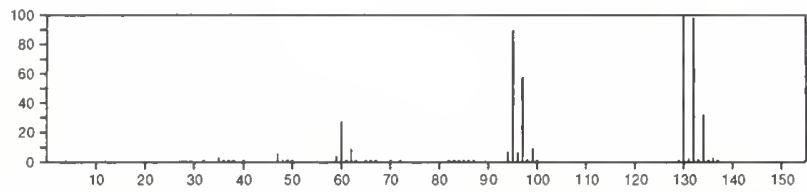

130

$\mathrm{C}_{3} \mathrm{H}_{2} \mathrm{ClF}$

$273043-0$

$\mathrm{Cl} \mathrm{CH}=\mathrm{CHCF}_{3}$
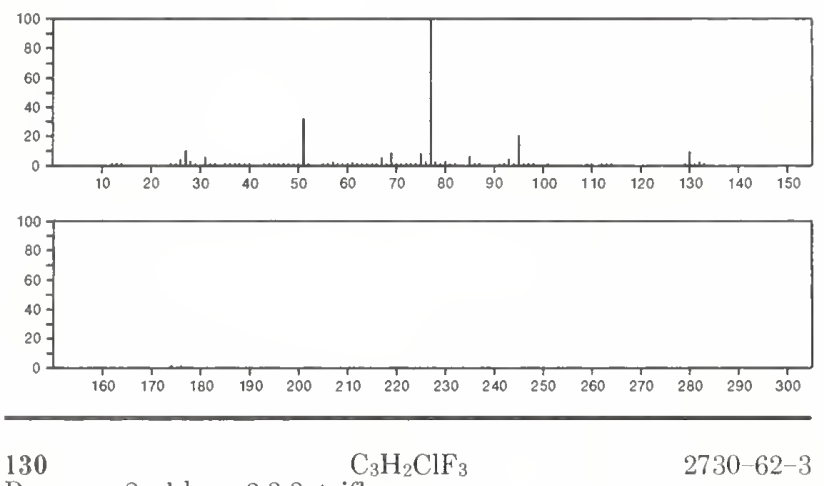

Propene, 2-chloro-3,3,3-trifluoro-

$\mathrm{F}_{3} \mathrm{CCCl}=\mathrm{CH}_{2}$

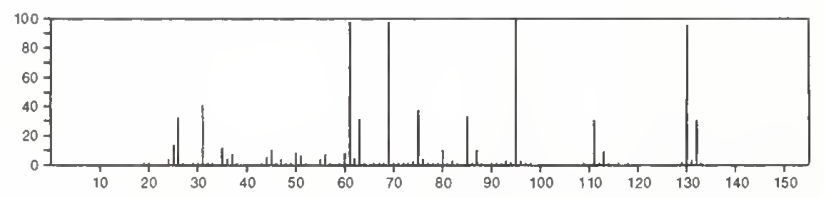

$130 \quad \mathrm{C}_{3} \mathrm{H}_{2} \mathrm{~N}_{2} \mathrm{O}_{2} \mathrm{~S}$

Isothiazole, 4-nitro-
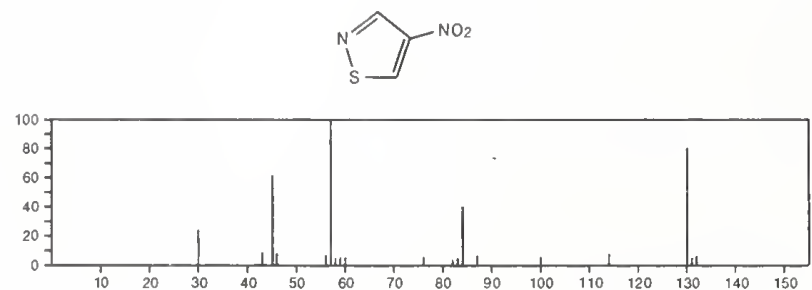

130

$\mathrm{C}_{3} \mathrm{H}_{2} \mathrm{~N}_{2} \mathrm{O}_{2} \mathrm{~S}$

$1606-76-4$

Thiazole, 2-nitro-<smiles>O=[N+]([O-])c1nccs1</smiles>

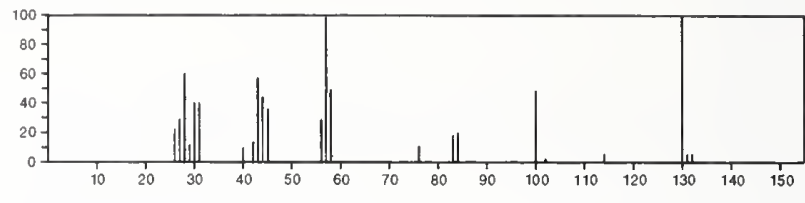

130

$\mathrm{C}_{3} \mathrm{H}_{2} \mathrm{~N}_{2} \mathrm{O}_{2} \mathrm{~S}$

14527-46-9

Thiazole, 5-nitro-

$\mathrm{NO}_{\mathrm{S}}^{\mathrm{NO}}$
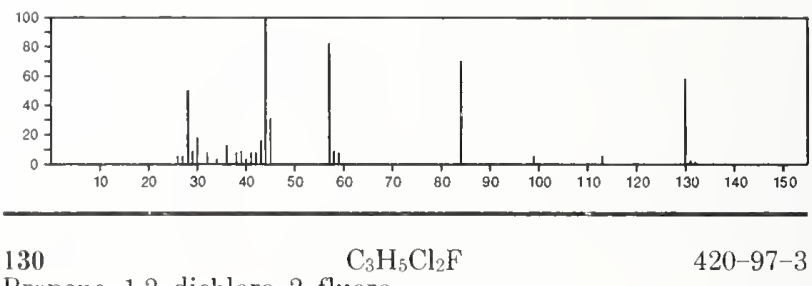

$420-97-3$

Propane, 1,2-dichloro-2-fluoro-

$\mathrm{Cl} \mathrm{CH}_{2} \mathrm{CCl} F \mathrm{Me}$
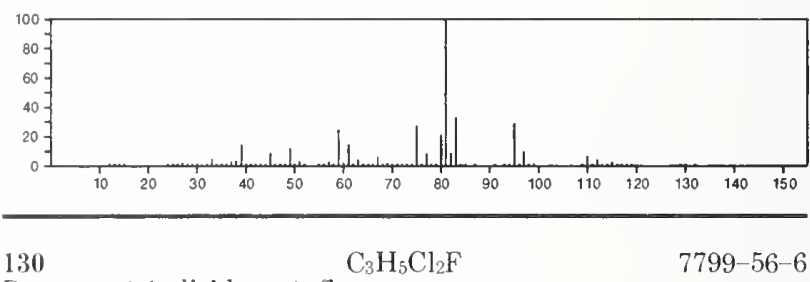

Propane, 1,1-dichloro-1-fluoro-

$E t C F(E t)$

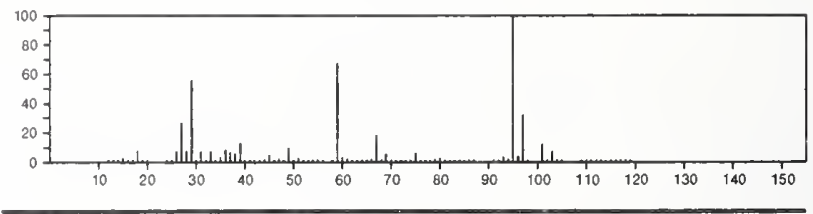

130

$\mathrm{C}_{4} \mathrm{H}_{3} \mathrm{ClN}_{2} \mathrm{O}$

$19064-67-6$

$3(2 \mathrm{H})$ Pyridazinone, 6-chloro
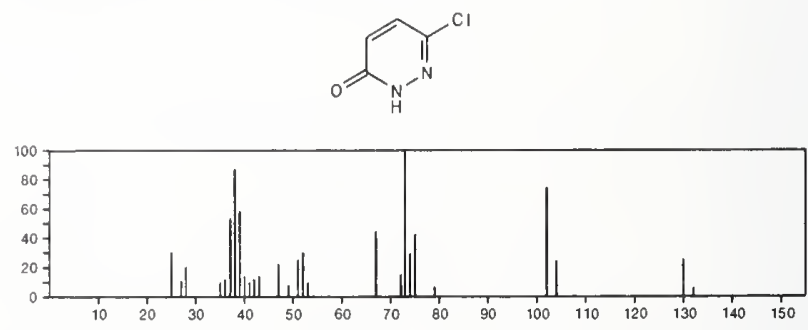

130

$\mathrm{C}_{4} \mathrm{H}_{6} \mathrm{~N}_{2} \mathrm{OS}$

33368-94-4

4-Imidazolidinone, 5-methyl-2-thioxo-
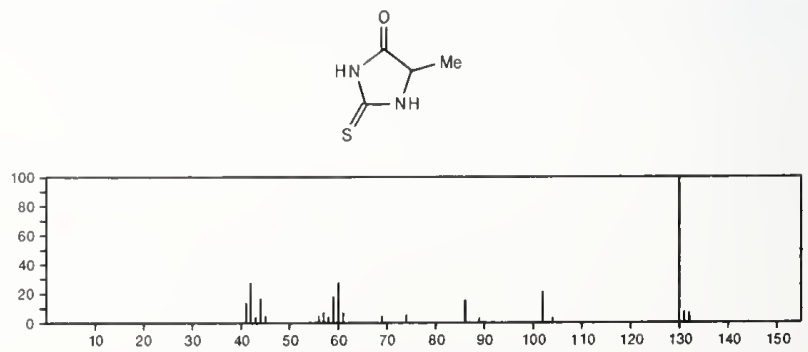
130

$\mathrm{C}_{4} \mathrm{H}_{6} \mathrm{~N}_{2} \mathrm{O}_{3}$

2-Azetidinecarboxylic acid, 1-nitroso-

$55556-98-4$
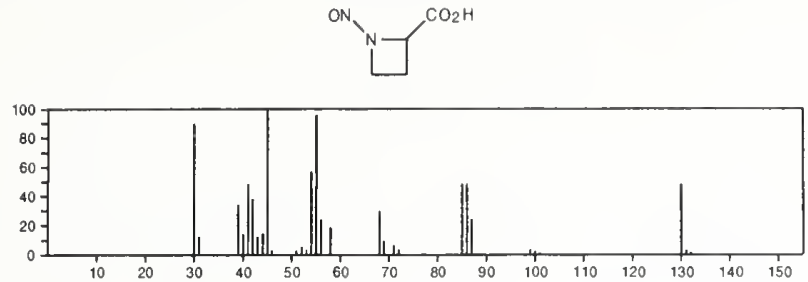

130

2H-Pyran-2-one, 6-chloro-

$\mathrm{C}_{5} \mathrm{H}_{3} \mathrm{ClO}_{2}$

20357-65-7<smiles>O=c1cccc(Cl)o1</smiles>
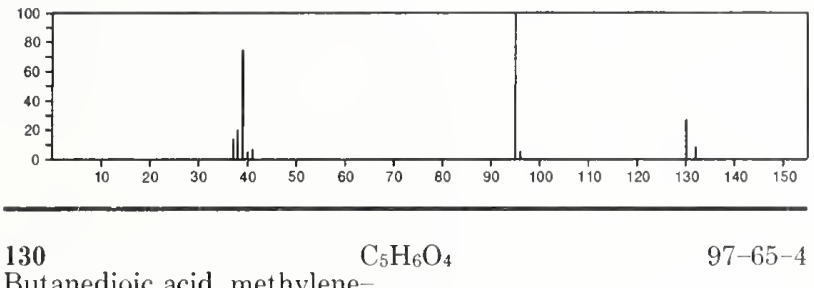

$\mathrm{HO}_{2} \mathrm{CCH}_{2} \mathrm{C}\left(\mathrm{CO}_{2} \mathrm{H}\right)=\mathrm{CH}_{2}$

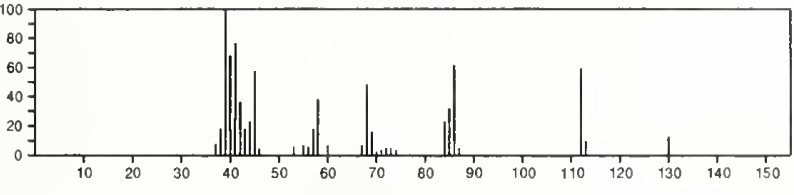

130

$\mathrm{C}_{5} \mathrm{H}_{6} \mathrm{O}_{4}$

$498-23-7$

2-Butenedioic acid, 2-methyl-, (Z)

$\mathrm{HO}_{2} \mathrm{CCH}=\mathrm{CMe} \mathrm{CO}_{2} \mathrm{H}$

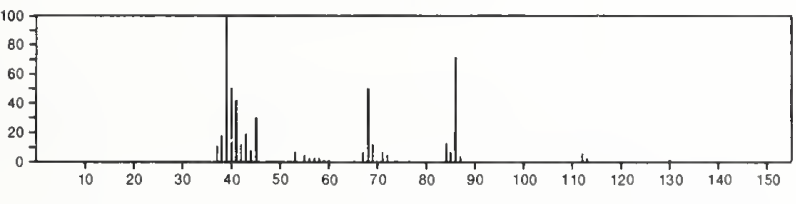

130

$\mathrm{C}_{5} \mathrm{H}_{6} \mathrm{O}_{4}$

2-Butenedioic acid, 2-methyl-, (E)-

$498-24-8$

$\mathrm{HO}_{2} \mathrm{CCH}=\mathrm{CMe} \mathrm{CO}_{2} \mathrm{H}$

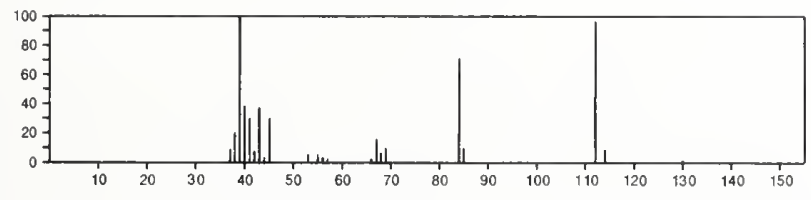

130

$\mathrm{C}_{5} \mathrm{H}_{6} \mathrm{~S}_{2}$

$5780-36-9$

Thiophene, 2-(methylthio)
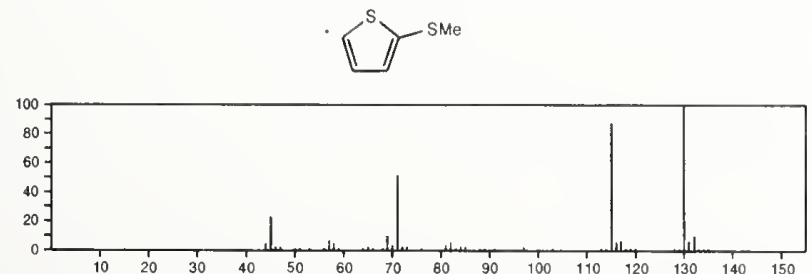

130

$\mathrm{C}_{5} \mathrm{H}_{6} \mathrm{~S}_{2}$

6258-63-5

2-Thiophenemethanethiol
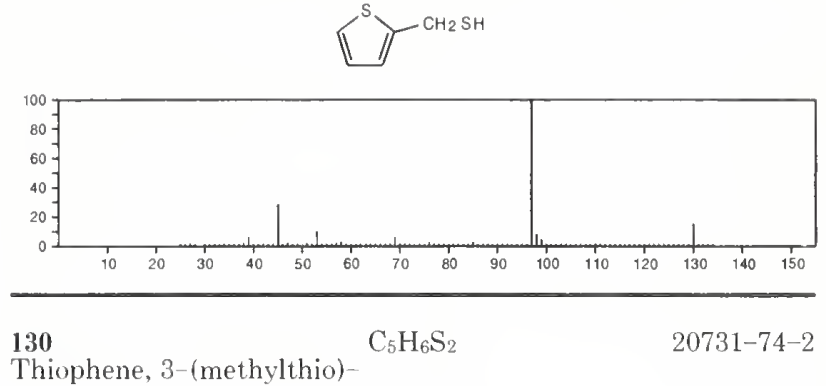

Thiophene, $3-$ (methylthio)
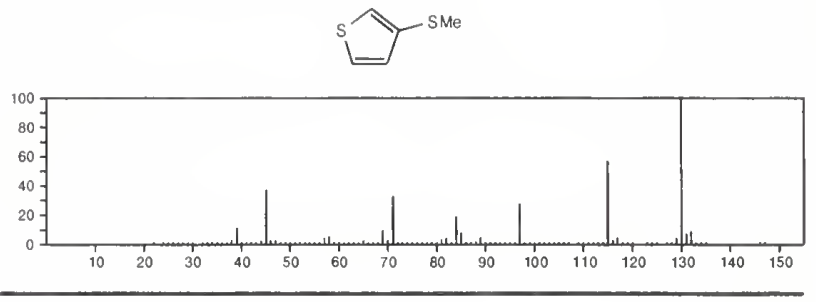

130

$\mathrm{C}_{5} \mathrm{H}_{7} \mathrm{~N}_{2} \cdot \mathrm{Cl}$

28460-19-7

Pyridinium, 1-amino-, chloride
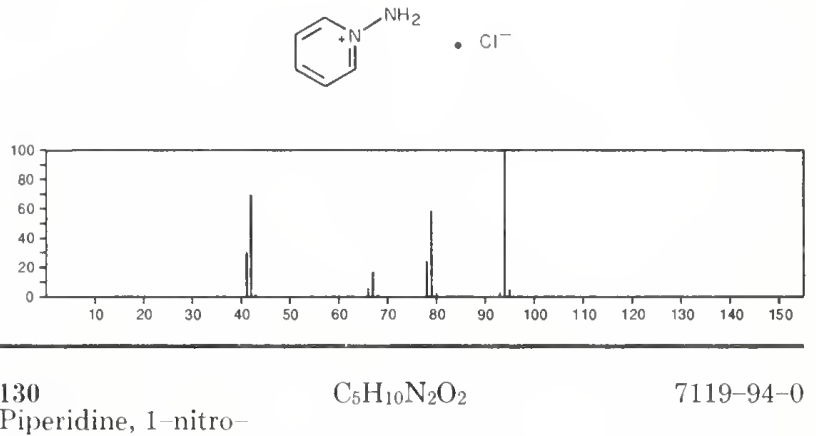

Piperidine, 1-nitro-
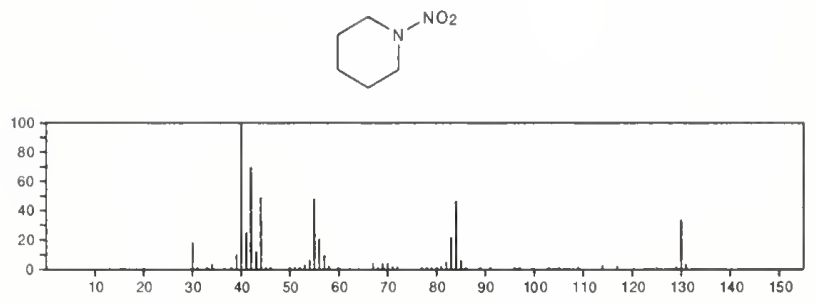

130

$\mathrm{C}_{5} \mathrm{H}_{10} \mathrm{~N}_{2} \mathrm{O}_{2}$

10430-90-7

1-Piperazinecarboxylic acid
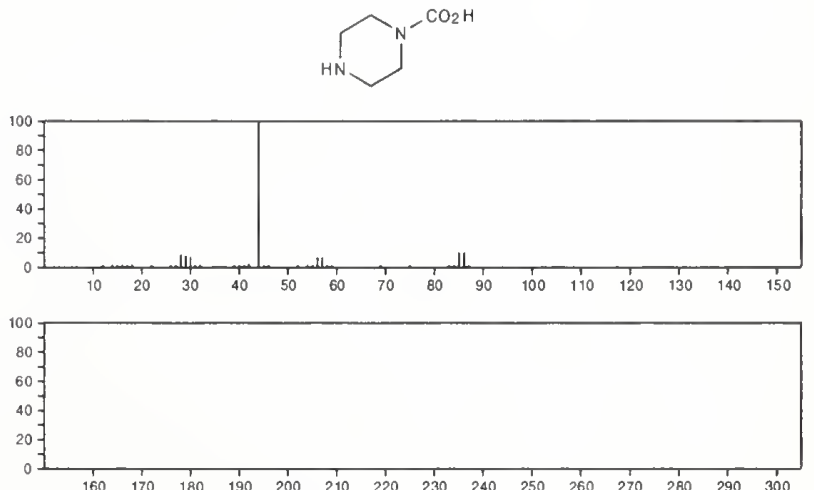


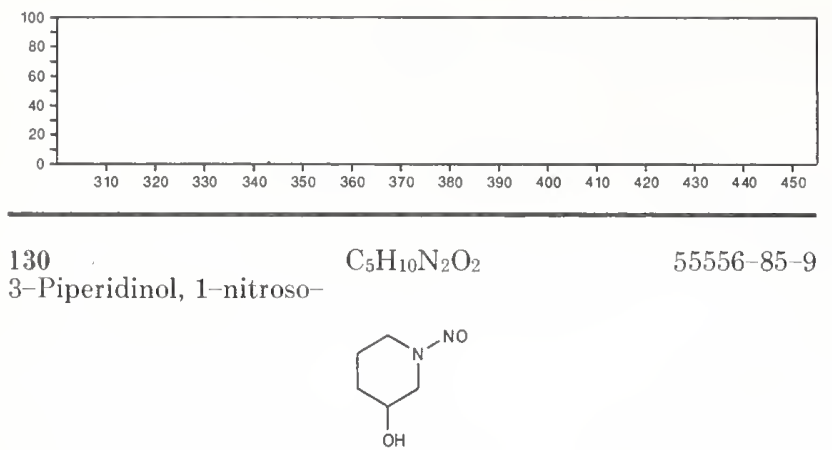

Benzene, chlorofluoro-
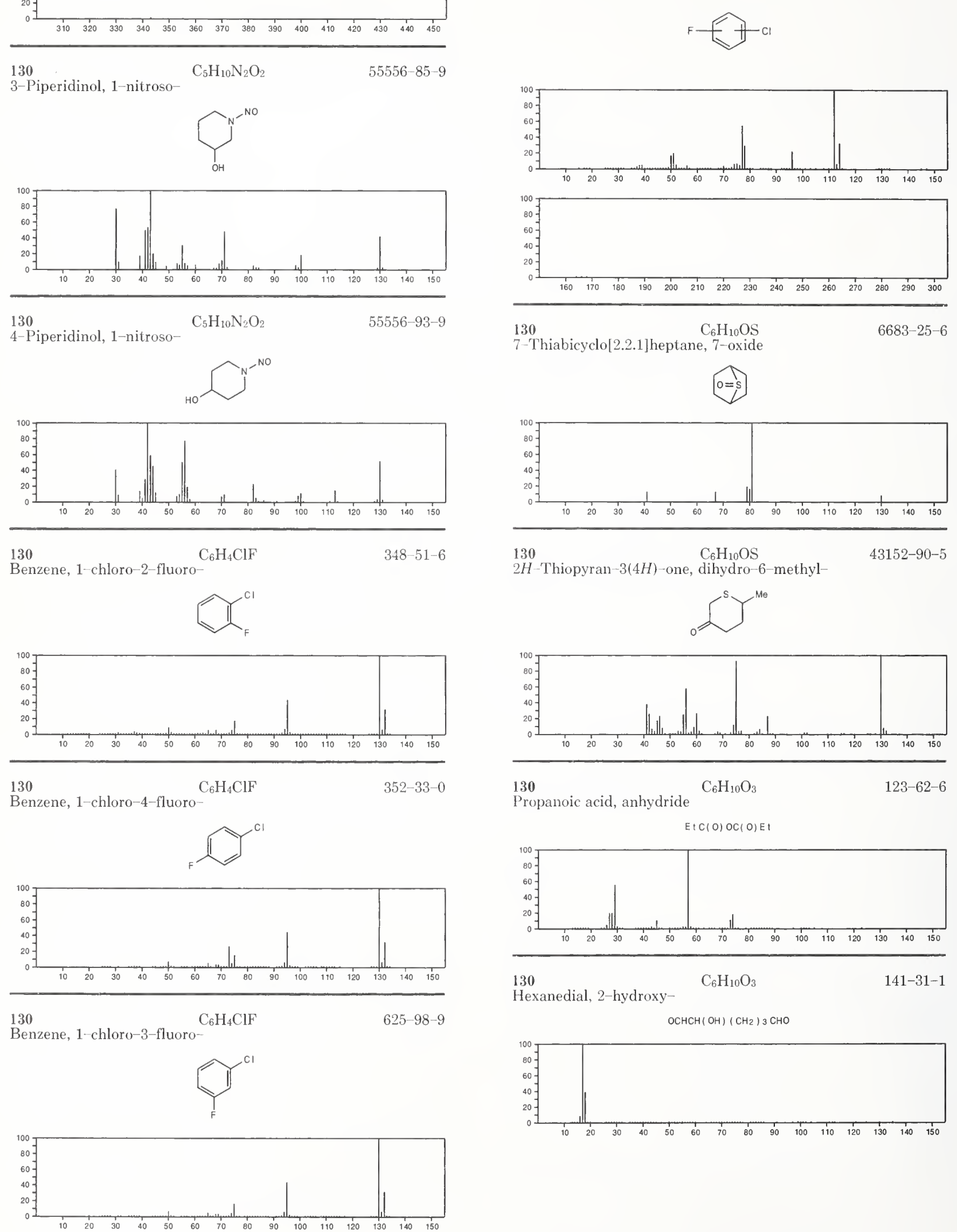
130
Butanoic acid, 3-oxo-, ethyl ester

$\mathrm{E}: \mathrm{OC}(\mathrm{O}) \mathrm{CH}_{2}$ COMe

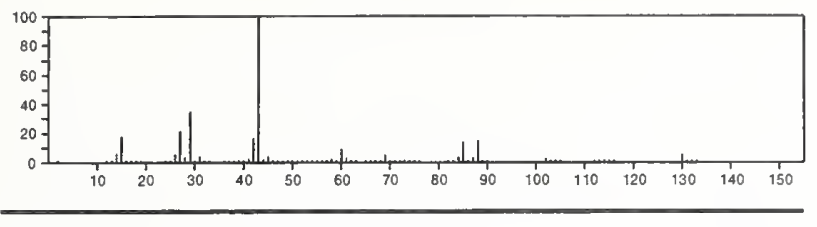

130

3,7,9-Trioxabicyclo[3.3.1]nonane

281-09-4
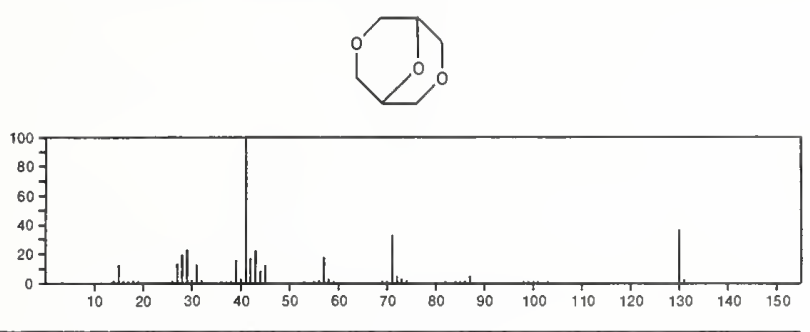

$130 \quad \mathrm{C}_{6} \mathrm{H}_{10} \mathrm{O}_{3}$

2(3H)-Furanone, dihydro-3-hydroxy-4,4-dimethyl-, $(R)$ -<smiles>CC1(C)CCCC1(C)O</smiles>

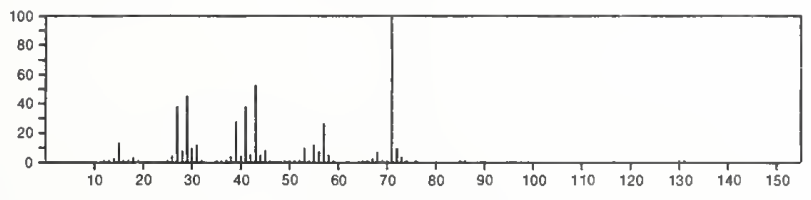

$130 \quad \mathrm{C}_{6} \mathrm{H}_{10} \mathrm{O}_{3}$

Pentanoic acid, 4-oxo-, methyl ester

$624-45-3$

$\mathrm{MeOC}$ ( 0 ) $\mathrm{CH}_{2} \mathrm{CH}_{2} \mathrm{COMe}$

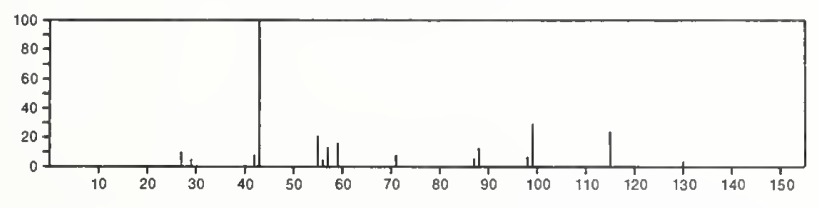

130

$\mathrm{C}_{6} \mathrm{H}_{10} \mathrm{O}_{3}$

2(3H)-Furanone, 5-ethoxydihydro-

932-85-4
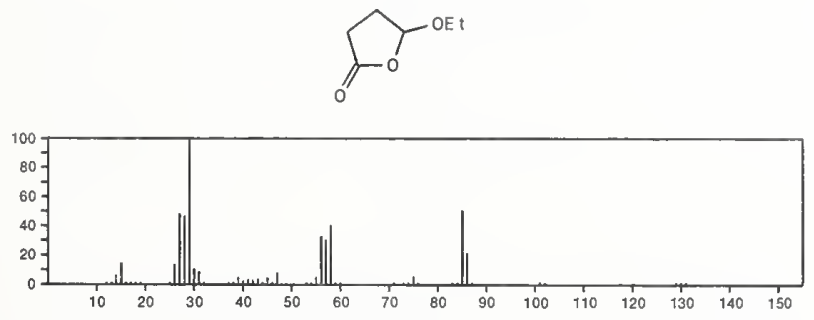

$$
130
$$

$\mathrm{C}_{6} \mathrm{H}_{10} \mathrm{O}_{3}$

Carbonic acid, ethyl 2-propenyl ester

1469-70-1

$\mathrm{E} t \mathrm{OC}(\mathrm{O}) \mathrm{OCH}_{2} \mathrm{CH}=\mathrm{CH}_{2}$

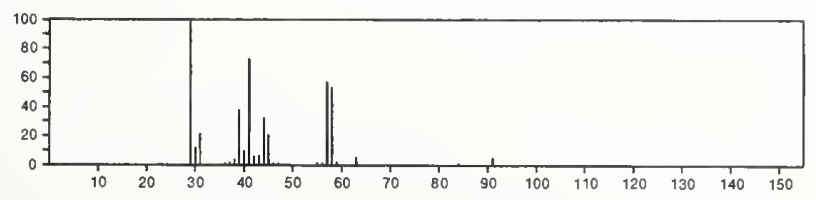

130

$\mathrm{C}_{6} \mathrm{H}_{10} \mathrm{O}_{3}$

$1575-57-1$

2-Butanone, 1-(acetyloxy)-

$\mathrm{E} t \mathrm{COCH}_{2} \mathrm{OAC}$

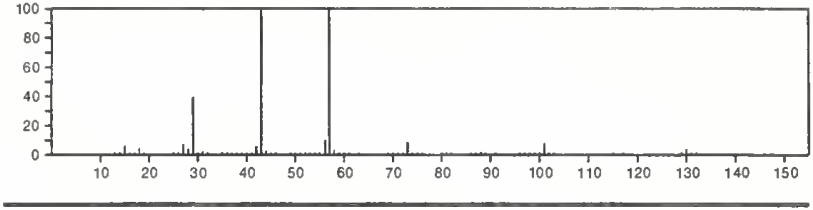

130

$\mathrm{C}_{6} \mathrm{H}_{10} \mathrm{O}_{3}$

2-Propenoic acid, 2-methoxyethyl ester

$3121-61-7$

$\mathrm{MeOCH} \mathrm{CH}_{2} \mathrm{OC}(\mathrm{O}) \mathrm{CH}=\mathrm{CH}_{2}$

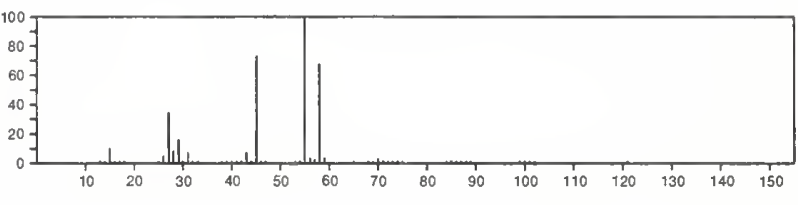

130

$\mathrm{C}_{6} \mathrm{H}_{10} \mathrm{O}_{3}$

$3952-67-8$

Butanoic acid, 3-methyl-2-oxo-, methyl ester

$\mathrm{Me} 2 \mathrm{CHCOC}(\mathrm{O}) \mathrm{OMe}$

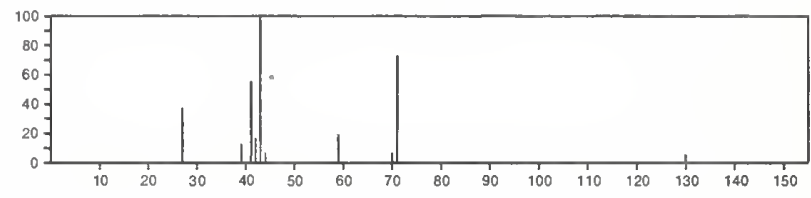

130

$\mathrm{C}_{6} \mathrm{H}_{10} \mathrm{O}_{3}$

1,3-Dioxolane-4-methanol, 2-vinyl-
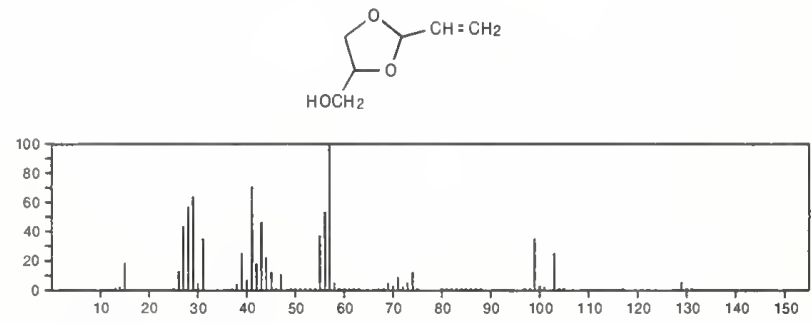

130

$\mathrm{C}_{6} \mathrm{H}_{10} \mathrm{O}_{3}$

$10150-87-5$

2-Butanone, 4-(acetyloxy)-

$\mathrm{Me} \mathrm{COCH}_{2} \mathrm{CH}_{2} \mathrm{OAC}$

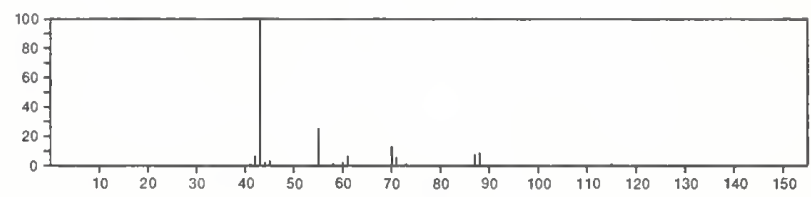

130

$\mathrm{C}_{6} \mathrm{H}_{10} \mathrm{O}_{3}$

2-Butenoic acid, 2-methoxy-, methyl ester, $(E)$

$56009-29-1$

$\mathrm{Me} \mathrm{OC}$ ( O) $\mathrm{C}(\mathrm{OMe})$ : CHMe

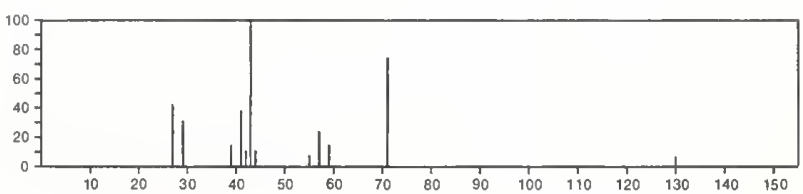


130

$\mathrm{C}_{6} \mathrm{H}_{10} \mathrm{O}_{3}$

2-Butenoic acid, 2-methoxy-, methyl ester, $(Z)$ -

$56009-30-4$ $\mathrm{Me} \mathrm{OC}(\mathrm{O}) \mathrm{C}(\mathrm{OMe})$ : $\mathrm{CHMe}$

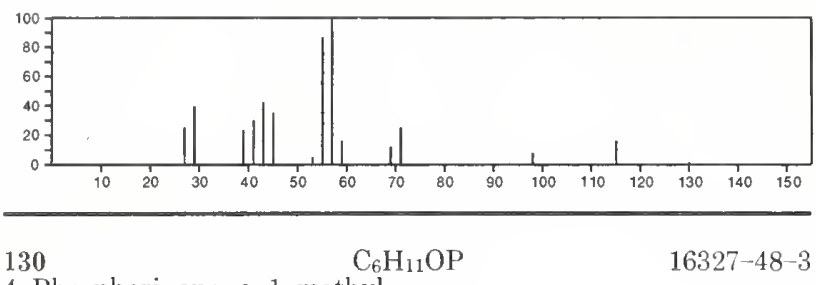

4-Phosphorinanone, 1-methyl-
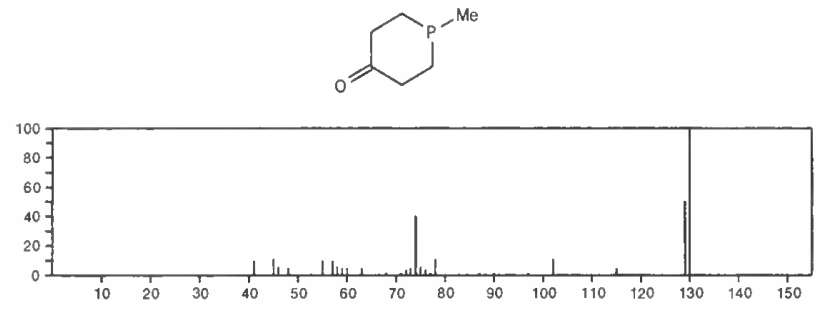

$130 \quad \mathrm{C}_{6} \mathrm{H}_{14} \mathrm{~N}_{2} \mathrm{O} \quad 601-77-4$ 2-Propanamine, $\mathrm{N}$-(1-methylethyl)-N-nitroso-

$$
-\operatorname{Pr}_{2} \text { NNO }
$$

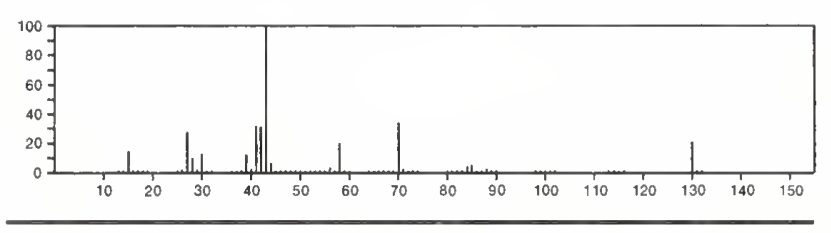

130

$\mathrm{C}_{6} \mathrm{H}_{14} \mathrm{~N}_{2} \mathrm{O}$

1-Propanamine, $N$-nitroso- $N$-propyl-

$621-64-7$

$\operatorname{Pr} 2$ NNO

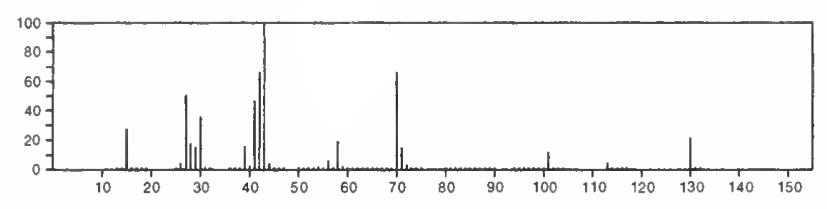

130

1-Butanamine, $N$-ethyl- $\mathrm{C}_{6} \mathrm{H}_{14} \mathrm{~N}_{2} \mathrm{O}$

$4549-44-4$

$\mathrm{E}\left(\mathrm{N}\langle\mathrm{NO})\left(\mathrm{CH}_{2}\right)_{3} \mathrm{Me}\right.$

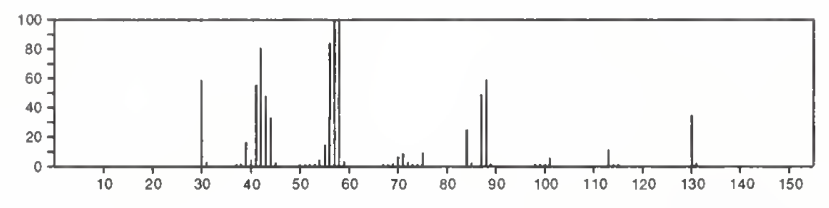

$130 \quad \mathrm{C}_{6} \mathrm{H}_{14} \mathrm{~N}_{2} \mathrm{O}$

1-Pentanamine, $N$-methyl-N-nitroso

$13256-07-0$

$\mathrm{MeN}(\mathrm{NO})\left(\mathrm{CH}_{2}\right) \& \mathrm{Me}$

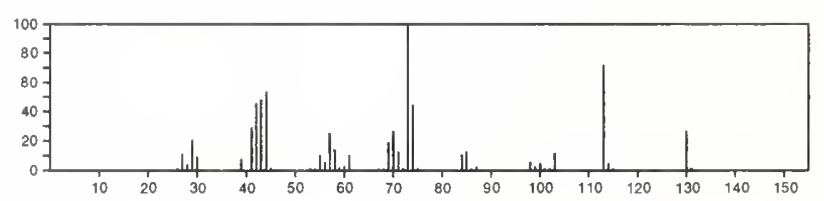

$130 \quad \mathrm{C}_{6} \mathrm{H}_{14} \mathrm{~N}_{2} \mathrm{O}$

1-Propanamine, $N-(1-$ methylethyl $)-2-$ nitroso-

$28023-82-7$

$\operatorname{PrN}(N O) \operatorname{Pr}-1$

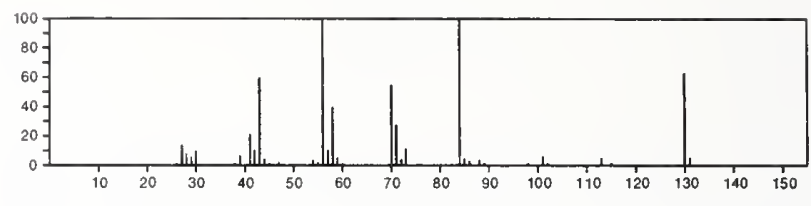

130

$\mathrm{C}_{6} \mathrm{H}_{15} \mathrm{BO}_{2}$

Boronic acid, ethyl--, diethyl ester

$53907-92-9$

E t OBE t OE t
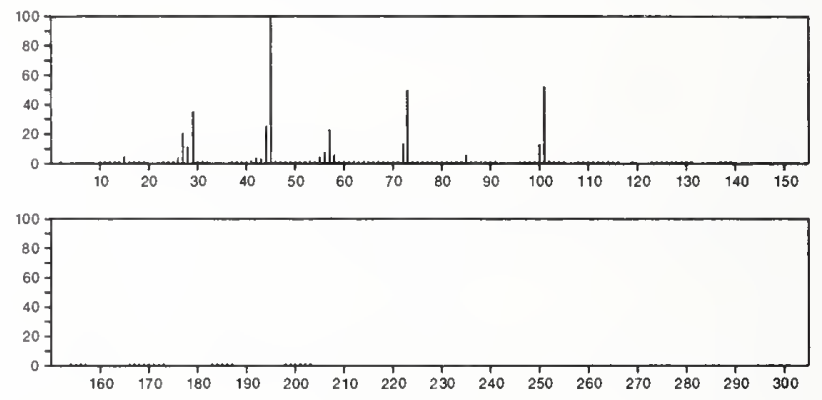

$130 \quad \mathrm{C}_{7} \mathrm{H}_{11} \mathrm{Cl} \quad 765-91-3$

Bicyclo[2.2.1] heptane, 2-chloro-, exo-
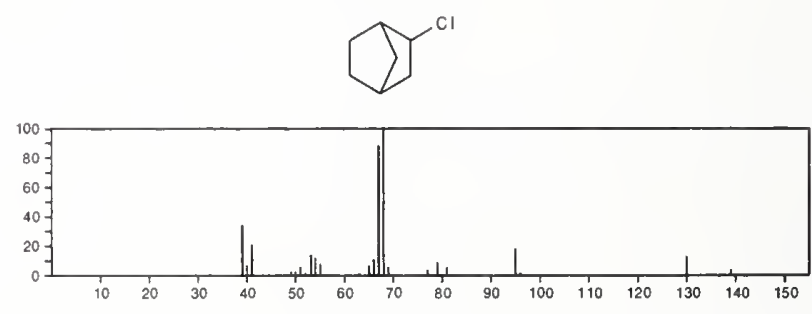

130

$\mathrm{C}_{7} \mathrm{H}_{11} \mathrm{Cl}$

$13294-30-9$

Cycloheptene, 1-chloro-
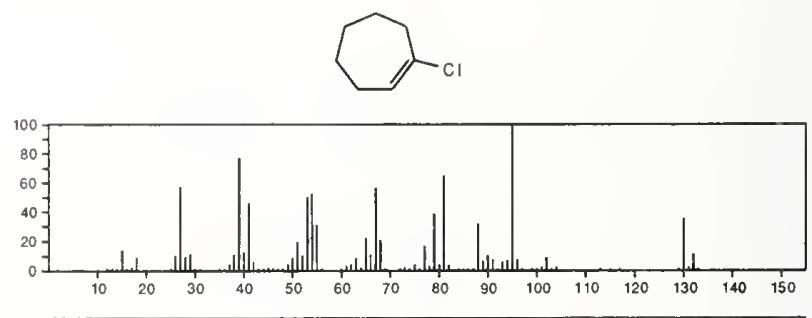

$130 \quad \mathrm{C}_{7} \mathrm{H}_{11} \mathrm{Cl}$

Cyclohexene, 1-chloro-2-methyl-

16642-49-2
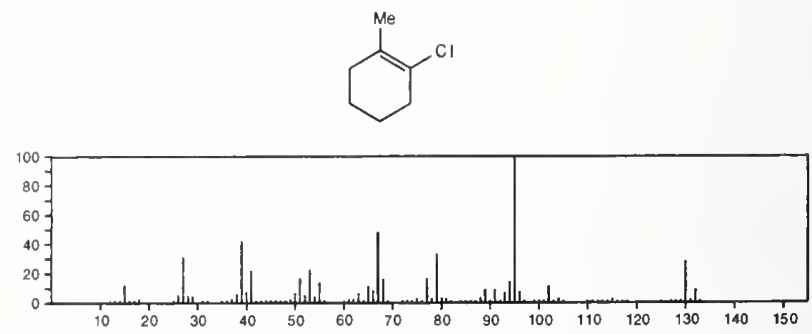
$130 \quad \mathrm{C}_{7} \mathrm{H} H \mathrm{Cl}$

Cyclohexene, 1-chloro-6-methyl-
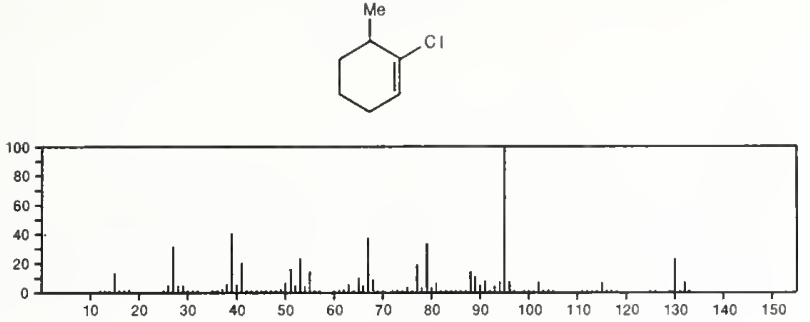

130

Cyclohexene, 3-(chloromethyl)-

$\mathrm{C}_{7} \mathrm{H}_{11} \mathrm{Cl}$

19509-49-0
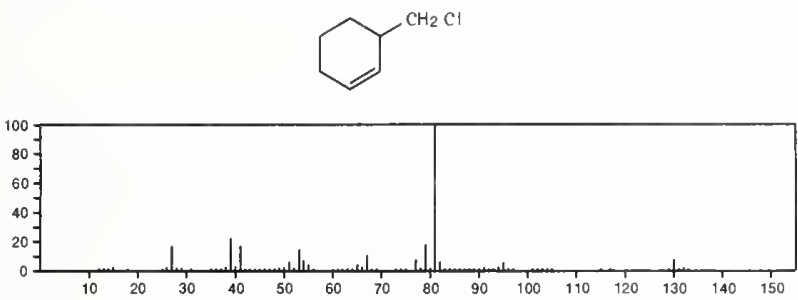

130

Bicyclo[4.1.0]heptane, 2-chloro-

$\mathrm{C}_{7} \mathrm{H}_{11} \mathrm{Cl}$

$34825-90-6$
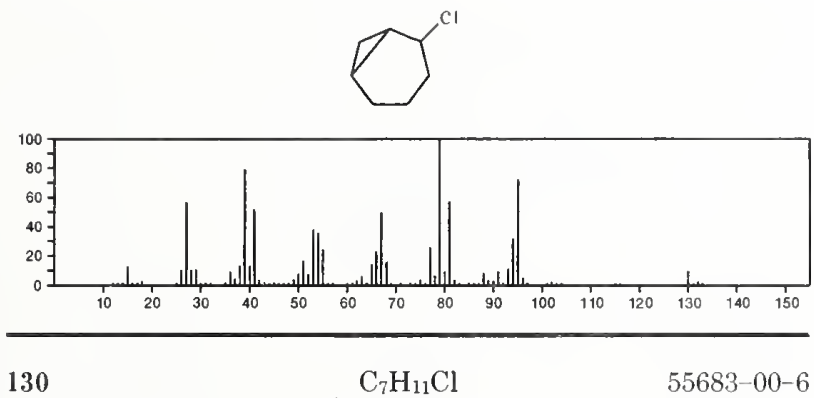

2-Pentyne, 1-chloro-4,4-dimethyl-

$55683-00-6$

$\mathrm{Me}_{3} \mathrm{CC} \cong \mathrm{CCH}_{2} \mathrm{Cl}$

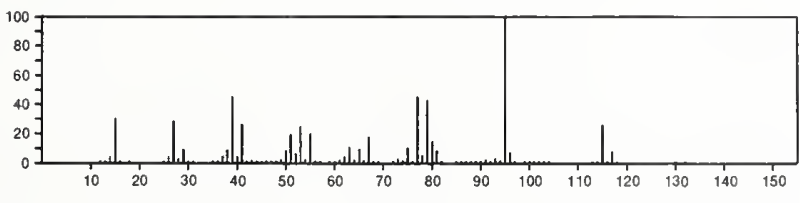

130

$\mathrm{C}_{7} \mathrm{H}_{14} \mathrm{O}_{2}$

$105-66-8$

Butanoic acid, propyl ester

PrOC(O)Pr

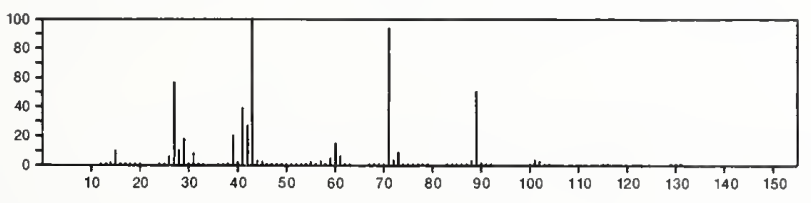

130

$\mathrm{C}_{7} \mathrm{H}_{14} \mathrm{O}_{2}$

$106-70-7$

Hexanoic acid, methyl ester

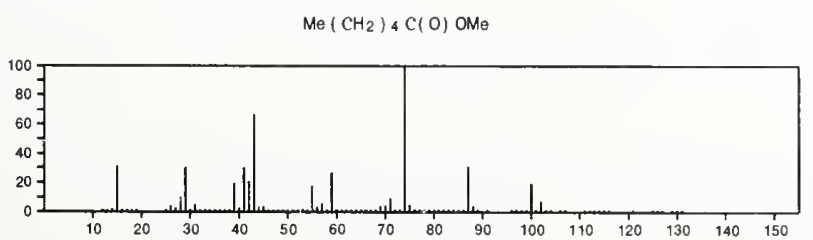

130

Heptanoic acid

$\mathrm{C}_{7} \mathrm{H}_{14} \mathrm{O}_{2}$

$111-14-8$

$\mathrm{HO}_{2} \mathrm{C}\left(\mathrm{CH}_{2}\right) 5 \mathrm{Me}$

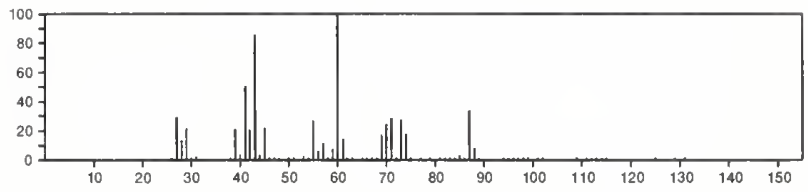

$130 \quad \mathrm{C}_{7} \mathrm{H}_{14} \mathrm{O}_{2}$

1-Butanol, 3-methyl-, acetate

$123-92-2$

$\mathrm{Me}_{2} \mathrm{CHCH}_{2} \mathrm{CH}_{2} \mathrm{OAC}$

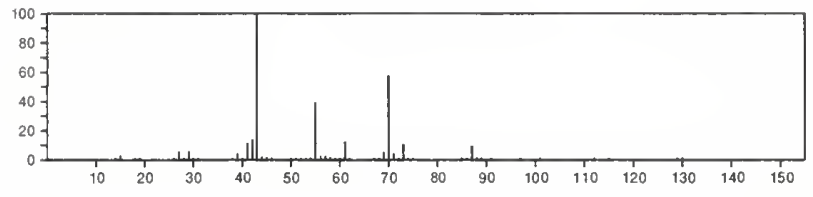

130

Pentanoic acid, ethyl ester

$\mathrm{C}_{7} \mathrm{H}_{14} \mathrm{O}_{2}$

539-82-2

$\mathrm{Me}\left(\mathrm{CH}_{2}\right)_{3} \mathrm{C}(\mathrm{O}) \mathrm{OE}$

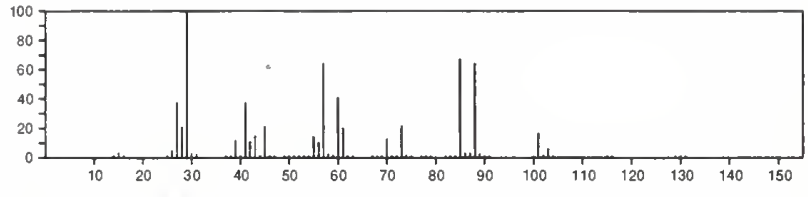

$130 \quad \mathrm{C}_{7} \mathrm{H}_{14} \mathrm{O}_{2}$

Propanoic acid, 2-methylpropyl ester

$540-42-1$

i-Bu OC(O) Et

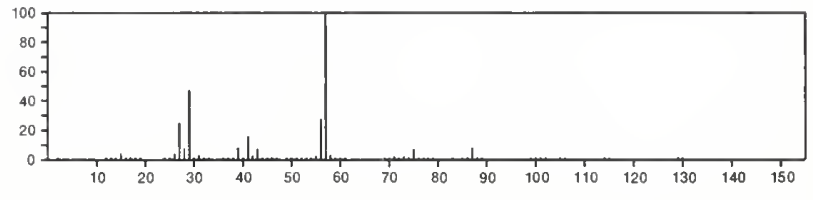

130

Propanoic acid, butyl ester

$\mathrm{C}_{7} \mathrm{H}_{14} \mathrm{O}_{2}$

$590-01-2$

$\mathrm{EtC}(\mathrm{O}) \mathrm{O}\left(\mathrm{CH}_{2}\right)_{3} \mathrm{Me}$

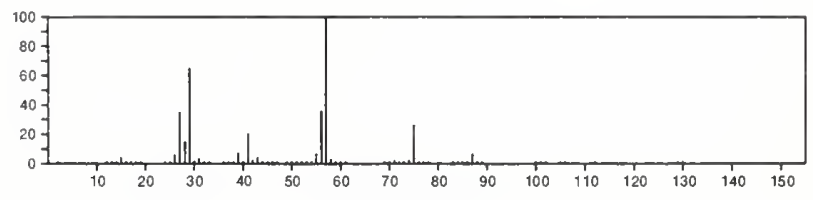

130

$\mathrm{C}_{7} \mathrm{H}_{14} \mathrm{O}_{2}$

$617-50-5$

Propanoic acid, 2-methyl-, 1-methylethyl ester

$i-\operatorname{PrOC}(0) \mathrm{CHM}_{2}$

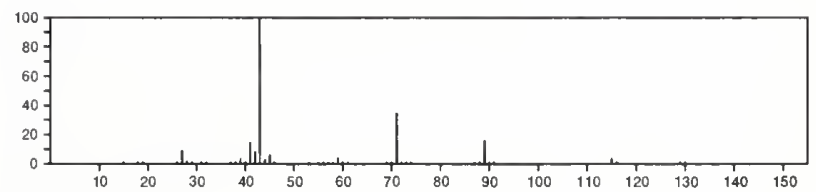


130

1-Butanol, 2-methyl-, acetate

$\mathrm{C}_{7} \mathrm{H}_{14} \mathrm{O}_{2}$

Ac $\mathrm{OCH}_{2} \mathrm{CHMe} \mathrm{CH}_{2} \mathrm{Me}$

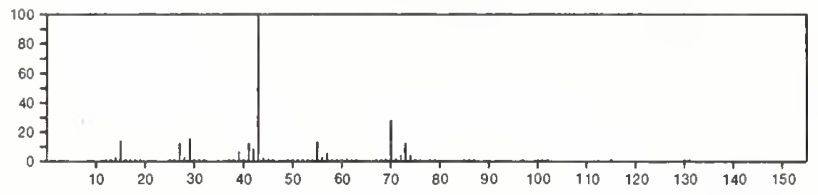

130

2-Butanol, 2-methyl-, acetate

$\mathrm{C}_{7} \mathrm{H}_{14} \mathrm{O}_{2}$

625-16-1

$\mathrm{E} \uparrow \mathrm{CM}_{2} \mathrm{OAC}$

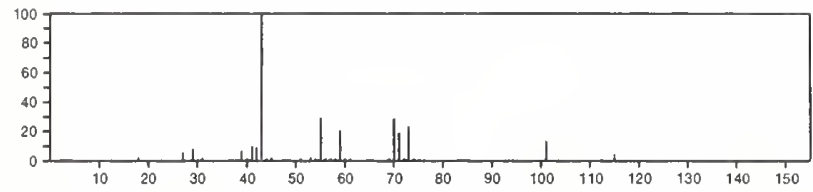

130

Acetic acid, pentyl ester

$\mathrm{C}_{7} \mathrm{H}_{14} \mathrm{O}_{2}$

$628-63-7$

$\mathrm{Me}\left(\mathrm{CH}_{2}\right) 4 \mathrm{OAC}$

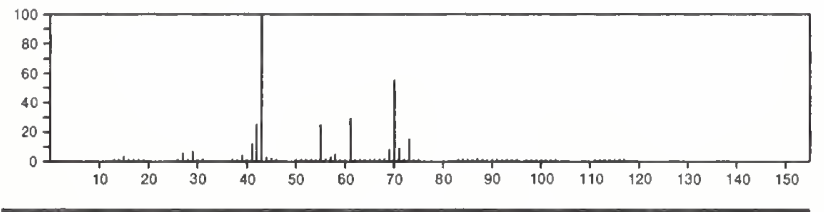

130

$\mathrm{C}_{7} \mathrm{H}_{14} \mathrm{O}_{2}$

$629-33-4$

Formic acid, hexyl ester

$\mathrm{Me}\left(\mathrm{CH}_{2}\right)_{5} \mathrm{OCH}=0$
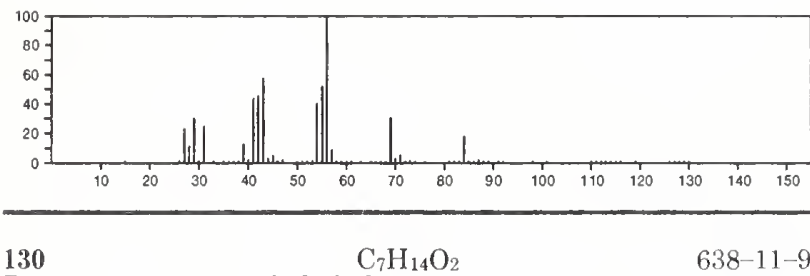

Butanoic acid, 1-methylethyl ester

$638-11-9$

$\operatorname{PrC}(0)$ OPr -1

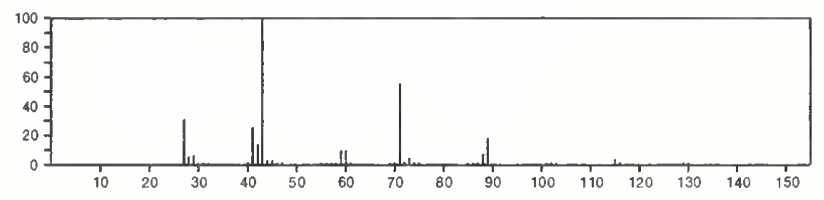

$130 \quad \mathrm{C}_{7} \mathrm{H}_{14} \mathrm{O}_{2}$

Butanoic acid, 2,2-dimethyl-, methyl ester

$813-67-2$

$\mathrm{MeOC}(\mathrm{O}) \mathrm{CE} \mathrm{Me}_{2}$

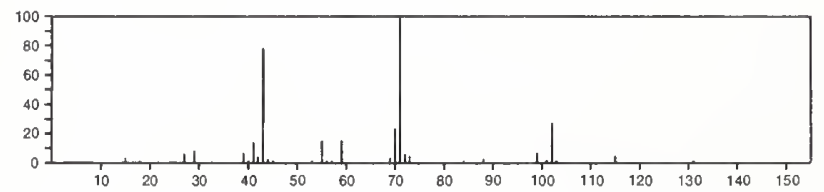

130

$\mathrm{C}_{7} \mathrm{H}_{14} \mathrm{O}_{2}$

$816-11-5$

Butanoic acid, 2-ethyl-, methyl ester

Me OC (O) CHEt

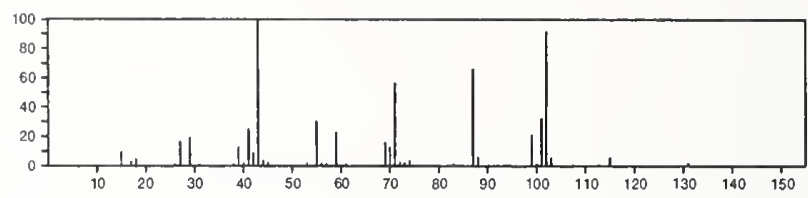

130

1-Propanol, 2,2-dimethyl-, acetate

$926-41-0$

$\mathrm{ACOCH}_{2} \mathrm{CMe}_{3}$

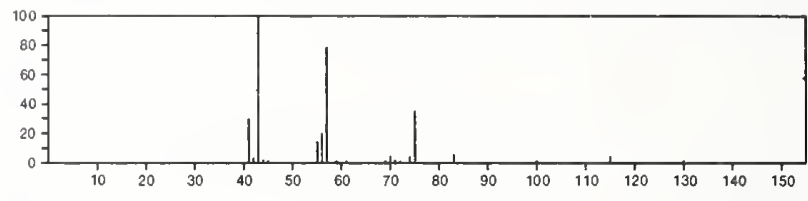

130

$\mathrm{C}_{7} \mathrm{H}_{14} \mathrm{O}_{2}$

$2177-77-7$

Pentanoic acid, 2-methyl-, methyl ester

$\mathrm{MeOC}(0) \mathrm{CHP}$ Me

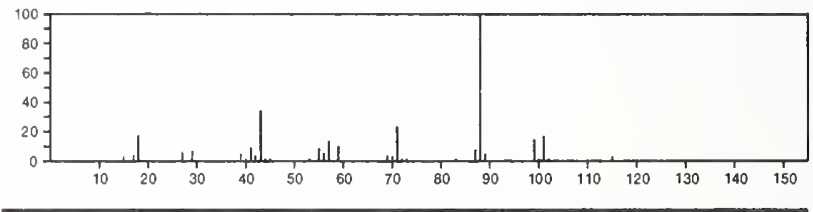

130

$\mathrm{C}_{7} \mathrm{H}_{14} \mathrm{O}_{2}$

$2177-78-8$

Pentanoic acid, 3-methyl-, methyl ester

$\mathrm{Me} \mathrm{CH}_{2} \mathrm{CHMe} \mathrm{CH}_{2} \mathrm{C}(\mathrm{O})$ OMe

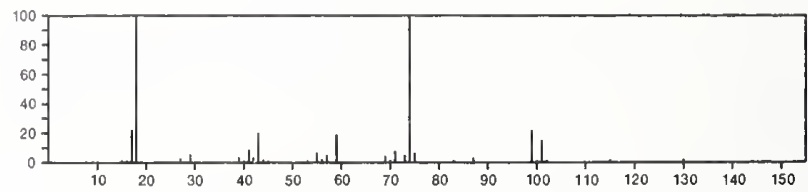

130

$\mathrm{C}_{7} \mathrm{H}_{14} \mathrm{O}_{2}$

Pentanoic acid, 4-methyl-, methyl ester

$\mathrm{Me}_{2} \mathrm{CHCH}_{2} \mathrm{CH}_{2} \mathrm{C}(0) \mathrm{OMe}$

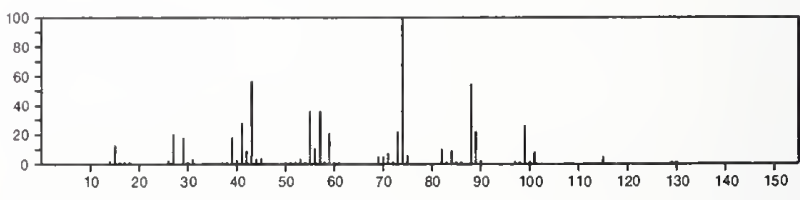

130

1,3-Dioxolane, 2-tert-butyl-

$\mathrm{C}_{7} \mathrm{H}_{14} \mathrm{O}_{2}$

$2568-29-8$

$\sum_{0}^{0} \gamma^{\mathrm{Bu-t}}$

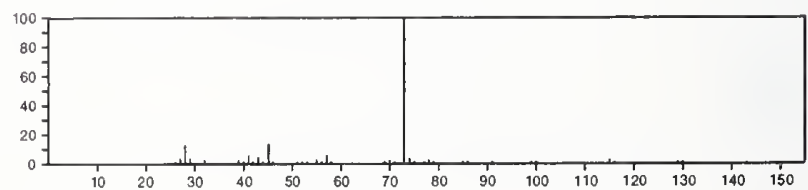


130

1-Propene, 3,3-diethoxy-

$\mathrm{C}_{7} \mathrm{H}_{14} \mathrm{O}_{2}$

(EtO) ${ }_{2} \mathrm{CHCH}=\mathrm{CH}_{2}$

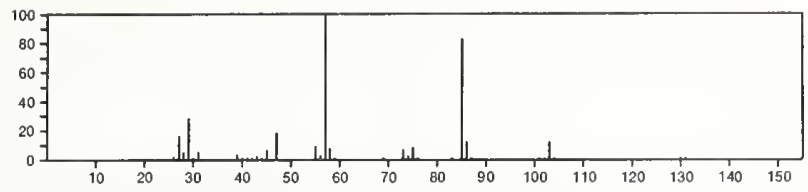

130

$\mathrm{C}_{7} \mathrm{H}_{14} \mathrm{O}_{2}$

1,3-Dioxolane, 2-methyl-2-propyl-

$\sum_{0}^{0} \gamma_{\mathrm{Pr}}^{\mathrm{Me}}$

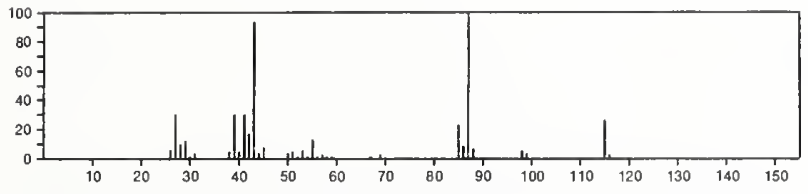

130

1,3-Dioxolane, 2-butyl-

$\mathrm{C}_{7} \mathrm{H}_{14} \mathrm{O}_{2}$

$4360-76-3$
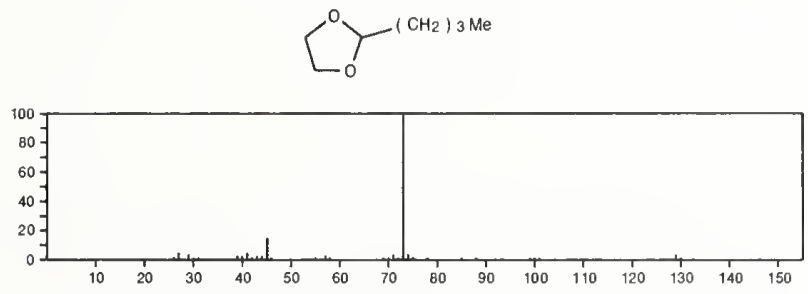

130

1,3-Dioxolane, 2,2-diethyl-

$\mathrm{C}_{7} \mathrm{H}_{14} \mathrm{O}_{2}$

$4362-57-6$
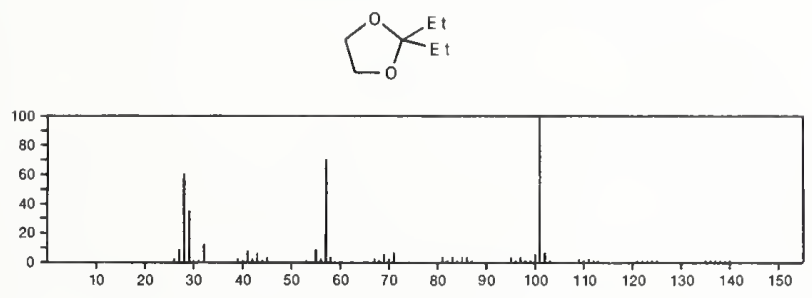

130

$\mathrm{C}_{7} \mathrm{H}_{14} \mathrm{O}_{2}$

1,3-Dioxolane, 2-methyl-2-(1-methylethyl)-
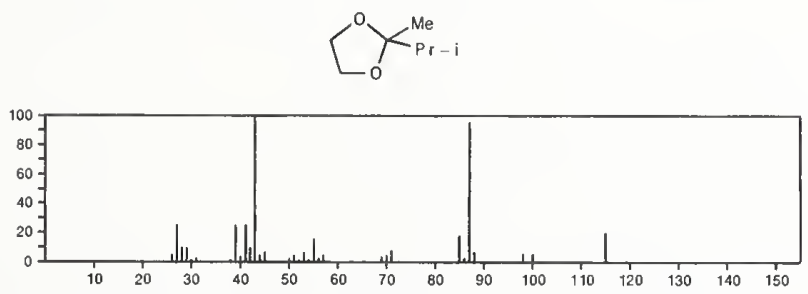

130

Hexanoic acid, 2-methyl-

$\mathrm{C}_{7} \mathrm{H}_{14} \mathrm{O}_{2}$

$\mathrm{HO}_{2} \mathrm{CCHMe}\left(\mathrm{CH}_{2}\right)_{3} \mathrm{Me}$

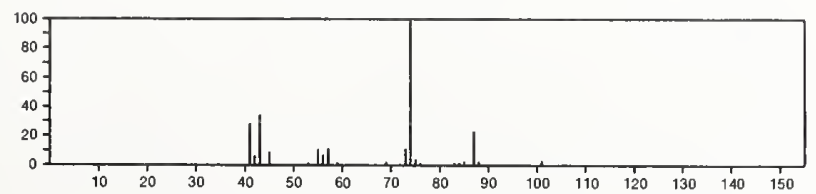

130

$\mathrm{C}_{7} \mathrm{H}_{14} \mathrm{O}_{2}$

2 H-Pyran, 2-ethoxytetrahydro- $^{-}$
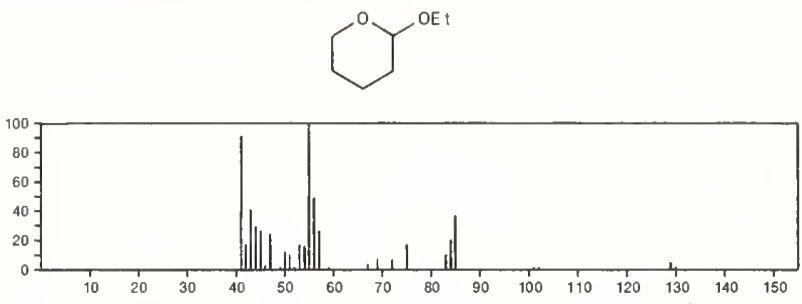

130

$\mathrm{C}_{7} \mathrm{H}_{14} \mathrm{O}_{2}$

1,3-Dioxolane, 4,4,5,5-tetramethyl-

$5660-63-9$<smiles>CC1(C)OCOC1(C)C</smiles>

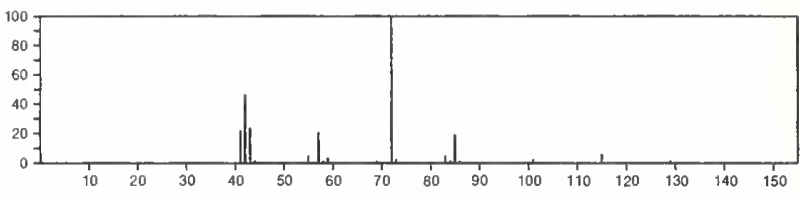

130

$\mathrm{C}_{7} \mathrm{H}_{14} \mathrm{O}_{2}$

$10250-48-3$

Butanoic acid, 3,3 dimethyl--, methyl ester

$\mathrm{Me}_{3} \mathrm{CCH}_{2} \mathrm{C}(\mathrm{O}) \mathrm{OMe}$

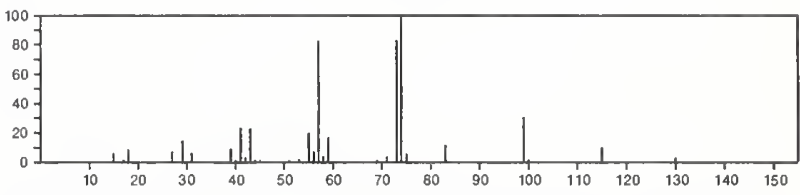

130

$\mathrm{C}_{7} \mathrm{H}_{14} \mathrm{O}_{2}$

$14447-25-7$

1,3-Dioxolane, 2-sec-butyl-

$\mathrm{L}_{0}^{\mathrm{O}} \mathrm{\gamma}^{\mathrm{Bu}-\mathrm{s}}$

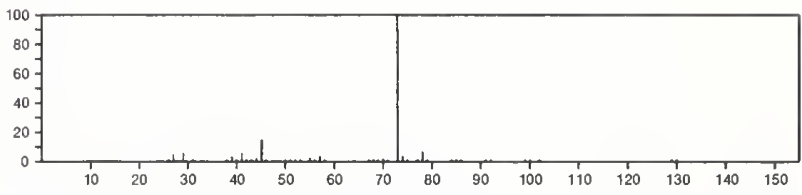

$130 \quad \mathrm{C}_{7} \mathrm{H}_{14} \mathrm{O}_{2} \quad$ 18068-06-9

Cyclohexanol, 4-methoxy-
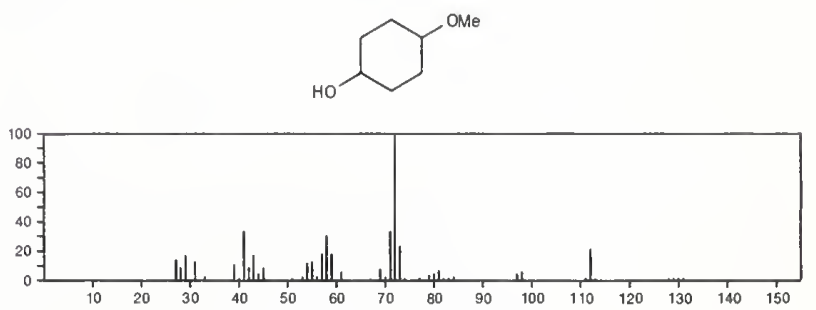
130

$\mathrm{C}_{7} \mathrm{H}_{14} \mathrm{O}_{2}$

1,3-Dioxane, 2,4,6-trimethyl-, $(2 \alpha, 4 \alpha, 6 \alpha)$
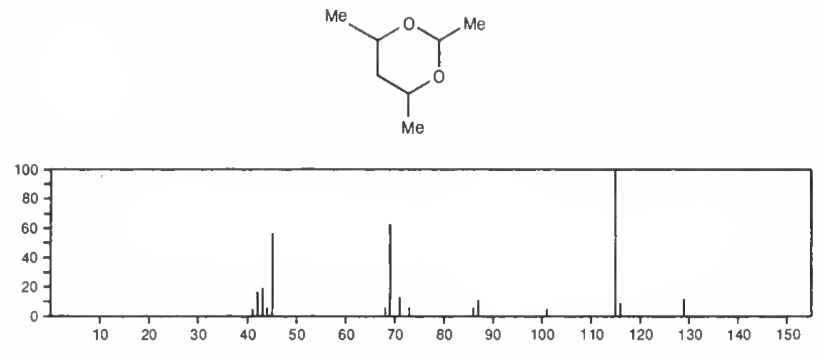

$130 \quad \mathrm{C}_{7} \mathrm{H}_{14} \mathrm{O}_{2}$

1,2-Cyclohexanediol, 1-methyl-, trans-<smiles>OC1CCCCC1(O)O</smiles>
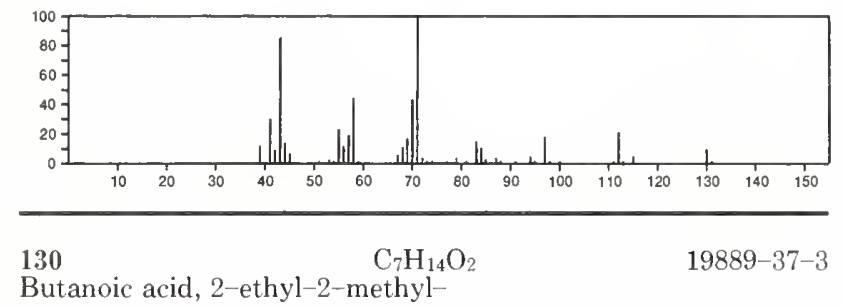

Butanoic acid, 2-ethyl-2-methyl-

$\mathrm{E}_{2}{ }_{2} \mathrm{CMe}\left(\mathrm{CO}_{2} \mathrm{H}\right)$

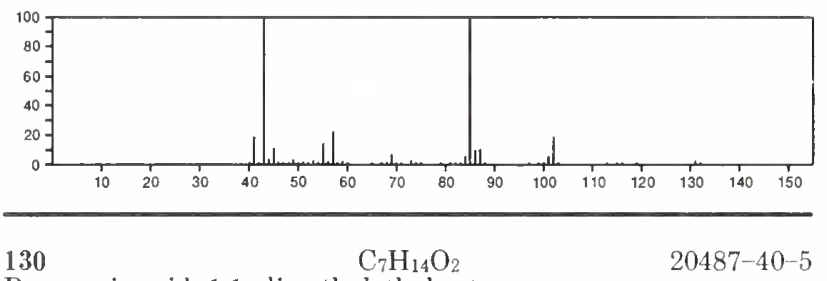

Propanoic acid, 1,1-dimethylethyl ester

$E+C(0) O B u-t$

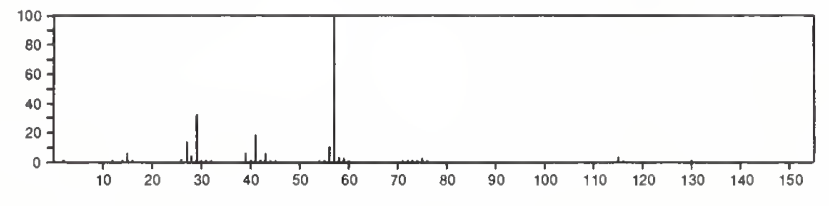

130

2-Hexanone, 6-methoxy-

$\mathrm{C}_{7} \mathrm{H}_{14} \mathrm{O}_{2}$

$29006-00-6$

$\mathrm{MeCO}\left(\mathrm{CH}_{2}\right)_{4} \mathrm{OMe}_{4}$

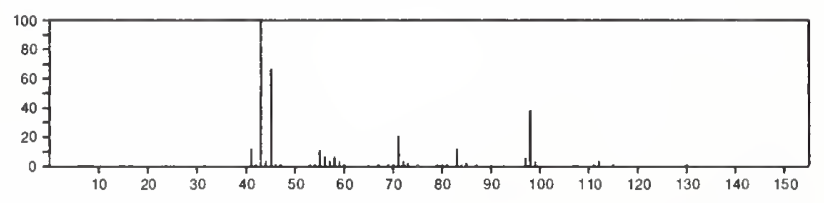

130

\section{$\mathrm{C}_{7} \mathrm{H}_{14} \mathrm{O}_{2}$}

Cyclopentane, 1,2-dimethoxy-, trans-

$29887-56-7$
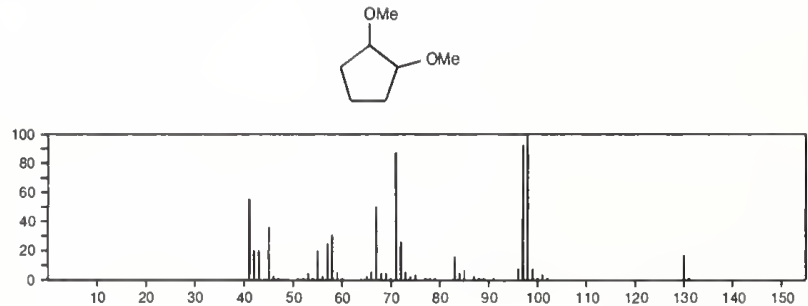

130

$\mathrm{C}_{7} \mathrm{H}_{14} \mathrm{O}_{2}$

$29887-57-8$

Cyclopentane, 1,3-dimethoxy-, trans-

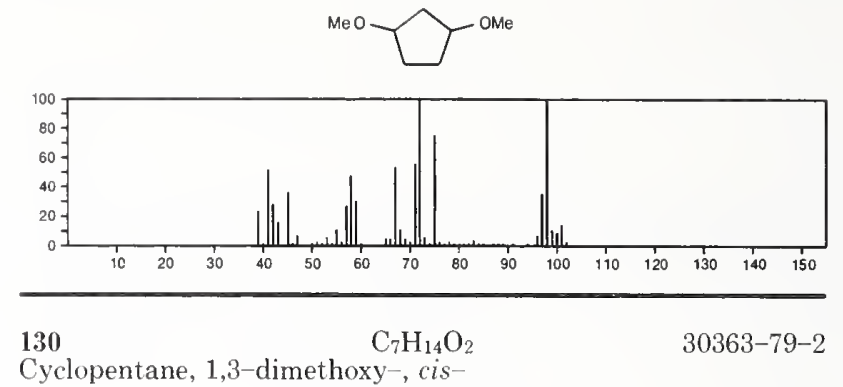

Cyclopentane, 1,3-dimethoxy-, cis-
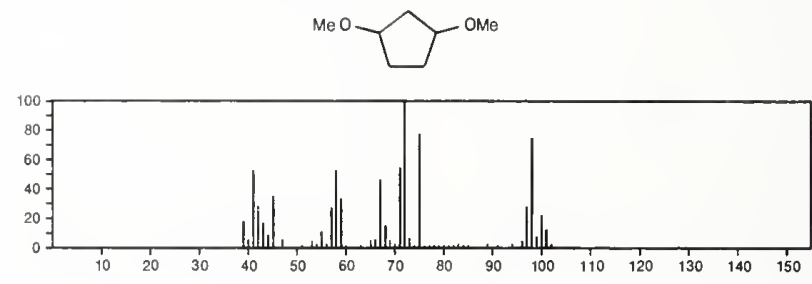

$130 \quad \mathrm{C}_{7} \mathrm{H}_{14} \mathrm{O}_{2}$

$30540-29-5$

Butanoic acid, 2,3-dimethyl-, methyl ester

$\left.\mathrm{Me} 2 \mathrm{CHCHMe} \mathrm{C}_{2} \mathrm{O}\right) \mathrm{OM}_{\mathrm{M}}$

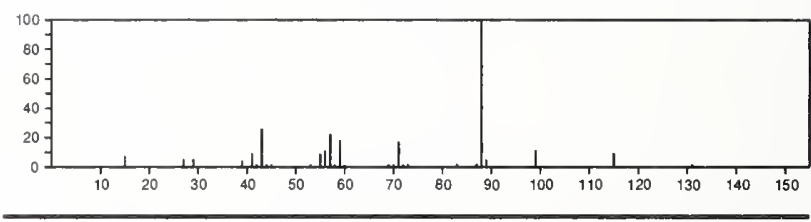

130

$\mathrm{C}_{7} \mathrm{H}_{14} \mathrm{O}_{2}$

36687-99-7

2-Butanone, 3-ethoxy-3-methyl

Me 2 COE t COMe

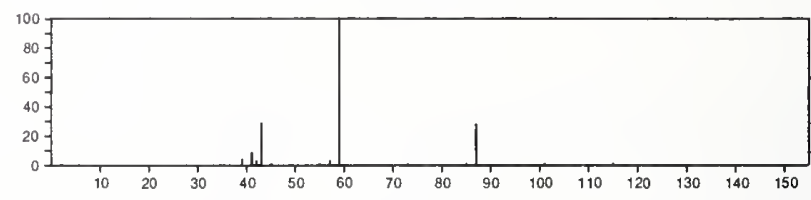

130

$\mathrm{C}_{7} \mathrm{H}_{14} \mathrm{O}_{2}$

$56666-73-0$

3-Oxepanemethanol
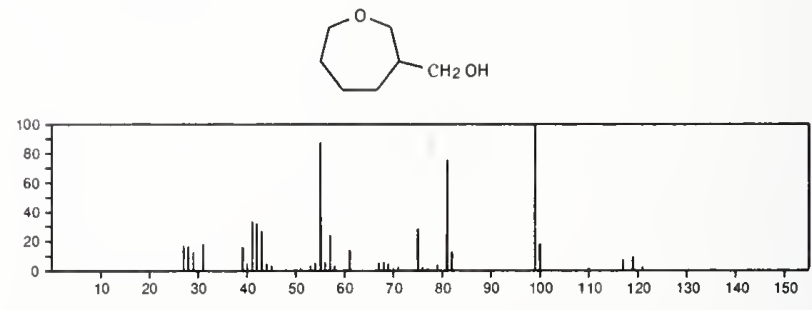

$130 \quad \mathrm{C}_{7} \mathrm{H}_{24} \mathrm{~S} \quad 2550-37-0$

Cyclohexanemethanethiol
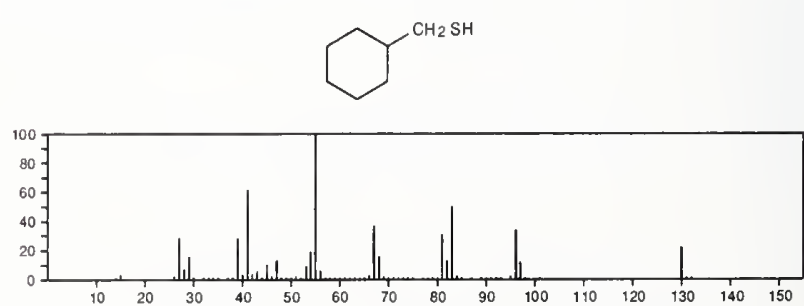
130

$\mathrm{C}_{7} \mathrm{H}_{14} \mathrm{~S}$

7133-13-3

130

$\mathrm{C}_{8} \mathrm{H}_{6} \mathrm{~N}_{2}$

253-66-7

Cyclopentane, (ethylthio)-<smiles>[CH2]C1CCCC1</smiles>
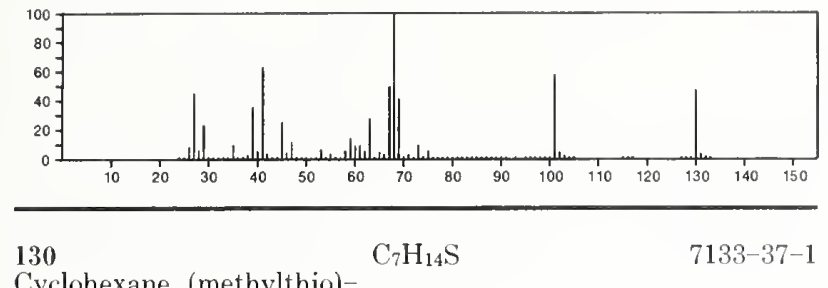

Cyclohexane, (methylthio)-
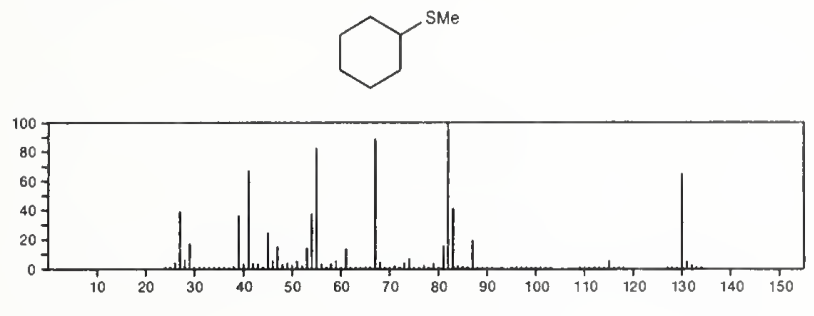

$130 \quad \mathrm{C}_{7} \mathrm{H}_{14} \mathrm{~S}$

Cyclohexanethiol, 2-methyl-, cis-
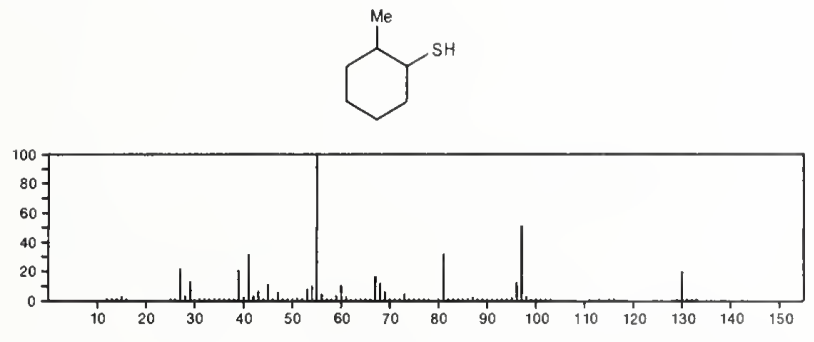

130

$\mathrm{C}_{7} \mathrm{H}_{18} \mathrm{~N}_{2}$

1,3-Propanediamine, $N, N$-diethyl-

104-78-9

$\mathrm{E}{ }_{2} \mathrm{~N}\left(\mathrm{CH}_{2}\right)_{3} \mathrm{NH}_{2}$
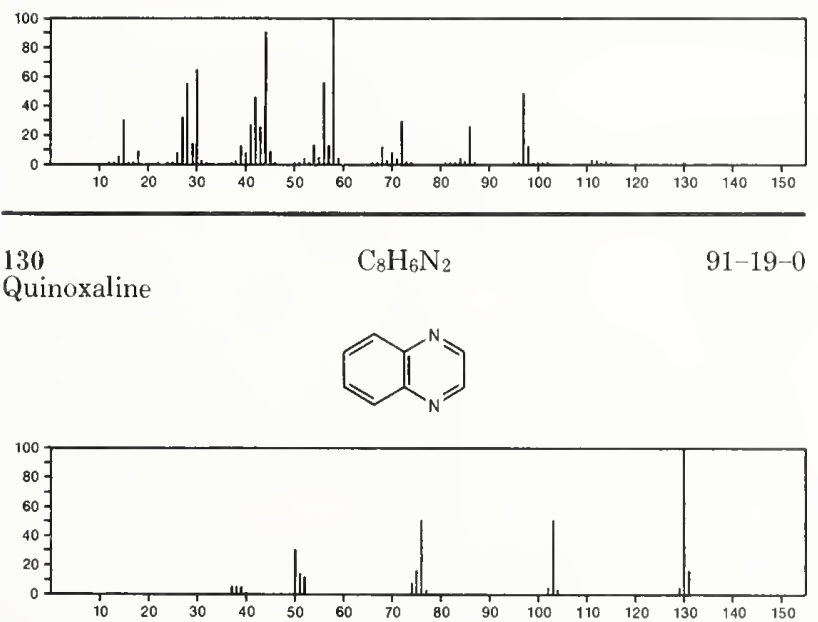

Cinnoline<smiles>c1ccc2nnccc2c1</smiles>

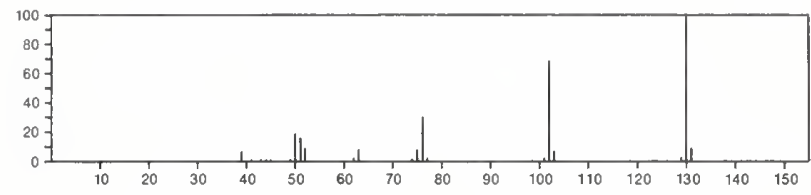

130

1,6-Naphthyridine

$\mathrm{C}_{8} \mathrm{H}_{6} \mathrm{~N}_{2}$

$253-72-5$<smiles>C1=CN2C=c3ccc2nc3=C1</smiles>
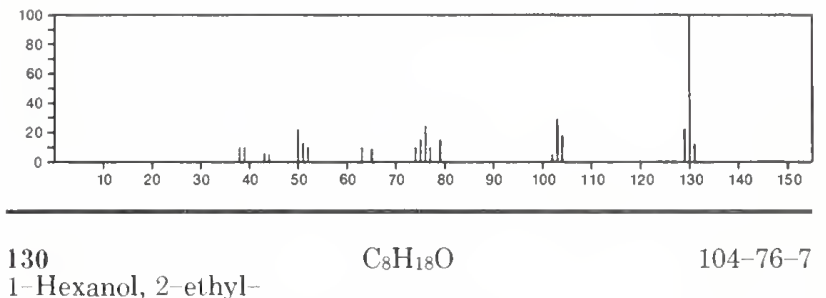

1-Hexanol, 2-ethyl

$\mathrm{Me}\left(\mathrm{CH}_{2}\right)_{3} \mathrm{CHE}_{\mathrm{CH}} \mathrm{CH}_{2} \mathrm{OH}$

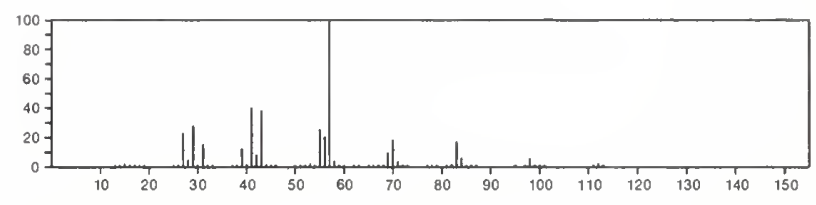

$130 \quad \mathrm{C}_{8} \mathrm{H}_{18} \mathrm{O} \quad 106-67-2$

1-Pentanol, 2-ethyl-4-methyl-

$\mathrm{Me}_{2} \mathrm{CHCH}_{2} \mathrm{CHE}$ ? $\mathrm{CH}_{2} \mathrm{OH}$

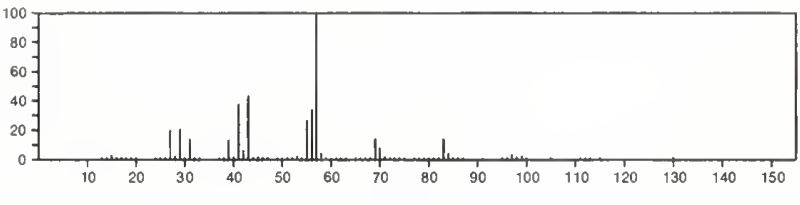

\begin{tabular}{lll}
\hline 130 & $\mathrm{C}_{8} \mathrm{H}_{18} \mathrm{O}$ & $111-87-5$
\end{tabular}

$\mathrm{Me}\left(\mathrm{CH}_{2}\right){ }_{7} \mathrm{OH}$

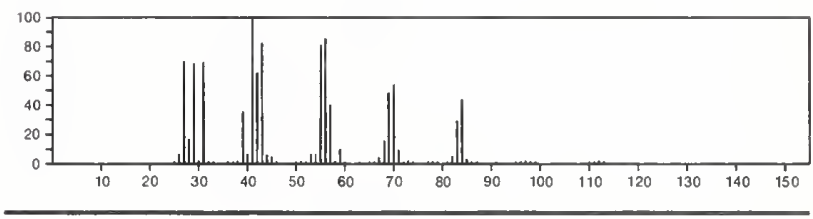

130

2-Octanol

$\mathrm{C}_{8} \mathrm{H}_{18} \mathrm{O}$

123-96-6

$\mathrm{MeCH}(\mathrm{OH})\left(\mathrm{CH}_{2}\right) 5 \mathrm{Me}$

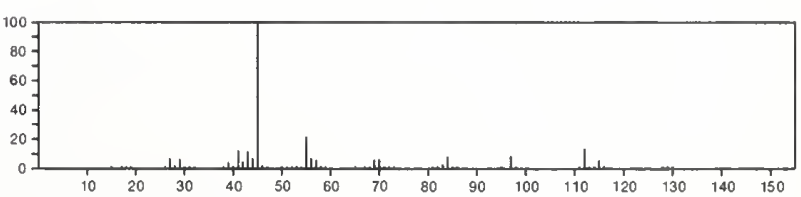


130

$\mathrm{C}_{8} \mathrm{H}_{18} \mathrm{O}$

$\mathrm{Me}\left(\mathrm{CH}_{2}\right)_{3} \mathrm{O}\left(\mathrm{CH}_{2}\right) 3 \mathrm{Me}$

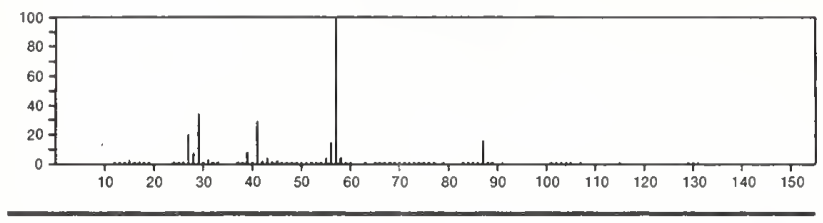

130

4-Octanol

$\mathrm{C}_{8} \mathrm{H}_{18} \mathrm{O}$

$589-62-8$

$\operatorname{PrCH}(\mathrm{OH})\left(\mathrm{CH}_{2}\right){ }_{3} \mathrm{Me}$

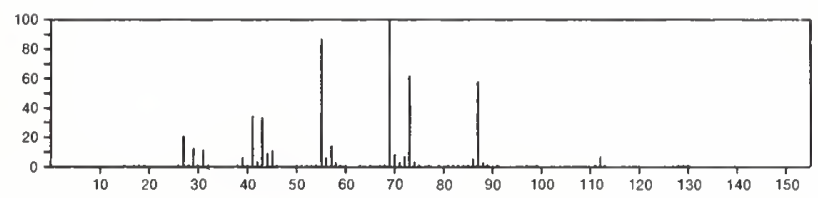

130

3-Octanol

$\mathrm{C}_{8} \mathrm{H}_{18} \mathrm{O}$

$589-98-0$

$\mathrm{EtCH}(\mathrm{OH})\left(\mathrm{CH}_{2}\right)_{4} \mathrm{Me}$

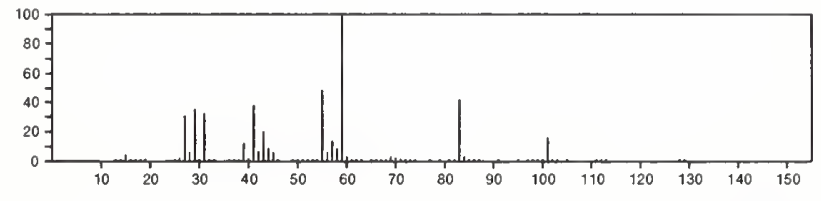

130

4-Heptanol, 4-methyl

$\mathrm{C}_{8} \mathrm{H}_{18} \mathrm{O}$

$\mathrm{Pr}_{2} \mathrm{CMe}(\mathrm{OH})$

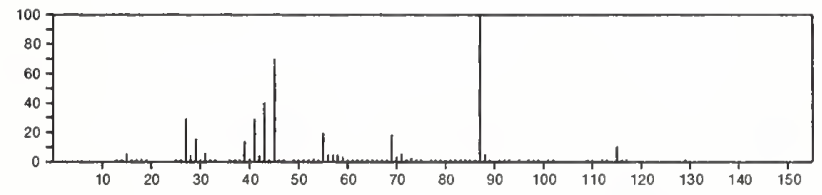

130

$\mathrm{C}_{8} \mathrm{H}_{18} \mathrm{O}$

625-25-2

2-Heptanol, 2-methyl-

$\mathrm{Me}_{2} \mathrm{COH}\left(\mathrm{CH}_{2}\right)_{4} \mathrm{Me}$

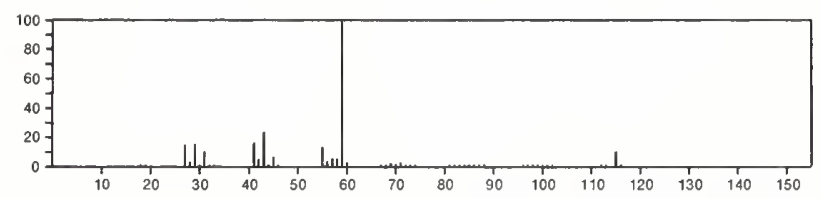

130

$\mathrm{C}_{8} \mathrm{H}_{18} \mathrm{O}$

$628-55-7$

Propane, 1,1'-oxybis [2-methyl-

$\mathrm{O}(\mathrm{Bu}-1) 2$

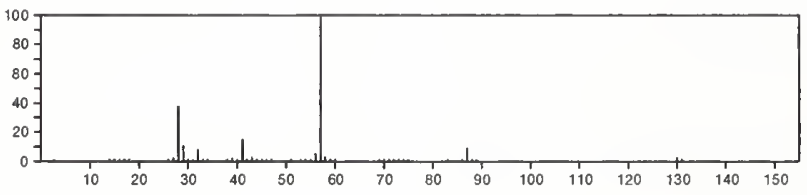

130

Pentanol, 2,2,4-trimethyl-

$\mathrm{C}_{8} \mathrm{H}_{18} \mathrm{O}$

$1331-40-4$

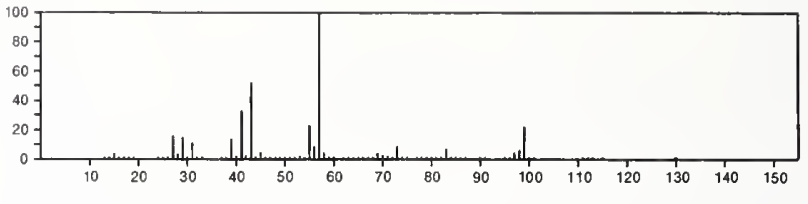

130

1 Heptanol, 6-methyl-

$\mathrm{C}_{8} \mathrm{H}_{18} \mathrm{O}$

$1653-40-3$

$\mathrm{Me}_{2} \mathrm{CH}\left(\mathrm{CH}_{2}\right){ }_{5} \mathrm{OH}$

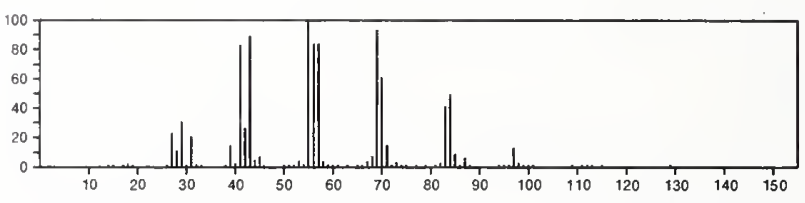

130

$\mathrm{C}_{8} \mathrm{H}_{18} \mathrm{O}$

1838-73-9

4-Heptanol, 3-methyl-

$\mathrm{MeCH} 2 \mathrm{CHMECH}(\mathrm{OH}) \mathrm{Pr}$

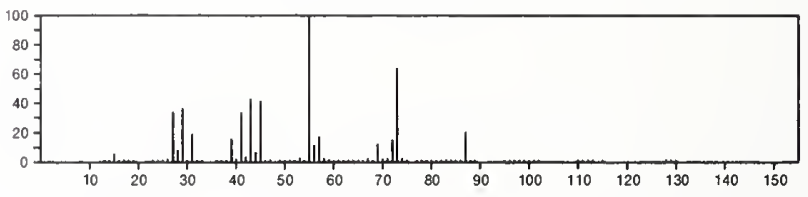

$130 \quad \mathrm{C}_{8} \mathrm{H}_{18} \mathrm{O}$

1-Hexanol, 2,2-dimethyl-

$\mathrm{Me}\left(\mathrm{CH}_{2}\right)_{3} \mathrm{CMe}_{2} \mathrm{CH}_{2} \mathrm{OH}$

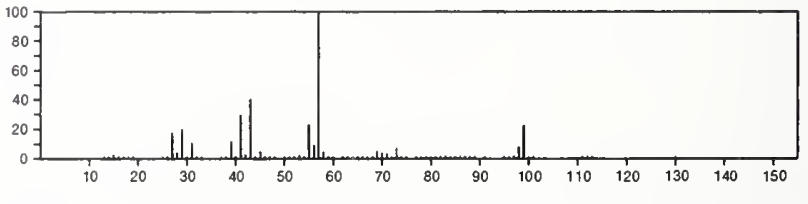

130

3-Pentanol, 2,3,4-trimethyl

$\mathrm{C}_{8} \mathrm{H}_{18} \mathrm{O}$

3054-92-0

$\left.\mathrm{Me} 2 \mathrm{CHCMe}_{2} \mathrm{OH}\right) \mathrm{CHMe}_{2}$

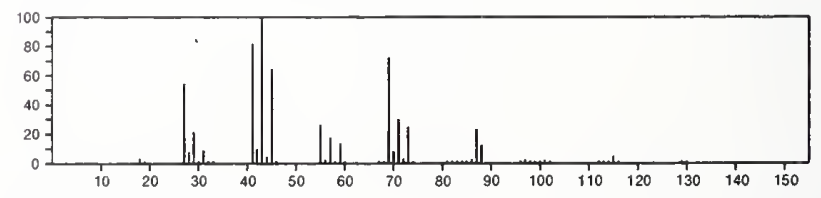

130

$\mathrm{C}_{8} \mathrm{H}_{18} \mathrm{O}$

$4166-46-5$

3-Hexanol, 2,3-dimethyl

$\mathrm{Me}_{2} \mathrm{CHCPr}(\mathrm{OH}) \mathrm{Me}$

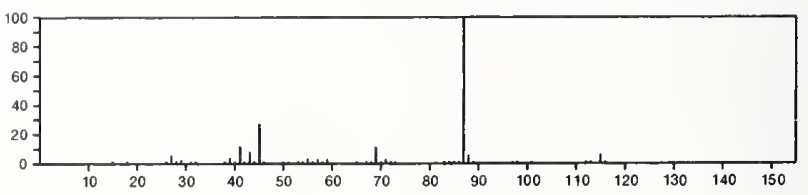


130

$\mathrm{C}_{8} \mathrm{H}_{18} \mathrm{O}$

3-Hexanol, 2,2-dimethyl-

$\mathrm{Me}{ }_{3} \mathrm{CCH}(\mathrm{OH}) \mathrm{Pr}$

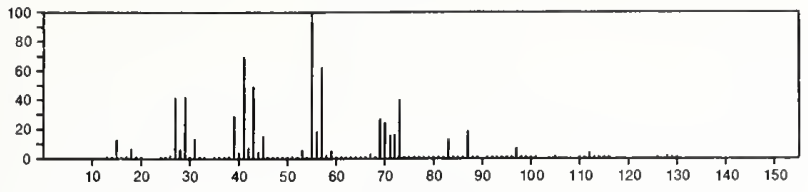

$\begin{aligned} & 130 \\ & 3-\text { Hexanol, 3,5-dimethyl- }\end{aligned} \mathrm{C}_{8} \mathrm{H}_{18} \mathrm{O} \quad 4209-91-0$

$\mathrm{E}$ t $\mathrm{CMe}(\mathrm{OH}) \mathrm{CH}_{2} \mathrm{CHMe}_{2}$

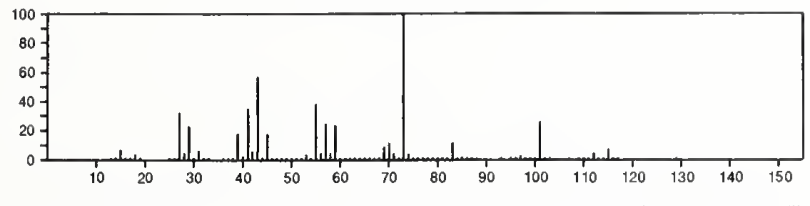

130

2-Heptanol, 6-methyl

$\mathrm{C}_{8} \mathrm{H}_{18} \mathrm{O}$

$\mathrm{Me}_{2} \mathrm{CH}\left(\mathrm{CH}_{2}\right)_{3} \mathrm{CH}(\mathrm{OH}) \mathrm{Me}$

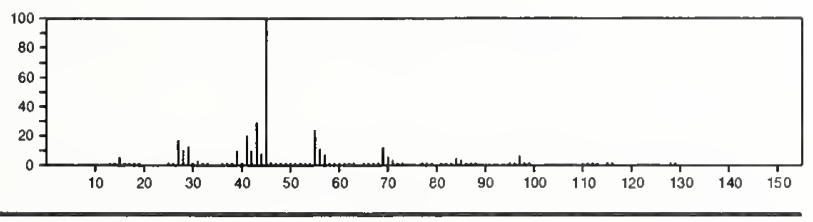

130

3-Heptanol, 3-methyl-

$\mathrm{C}_{8} \mathrm{H}_{18} \mathrm{O}$

$5582-82-1$

$\mathrm{EtCMe}(\mathrm{OH})\left(\mathrm{CH}_{2}\right)_{3} \mathrm{Me}$

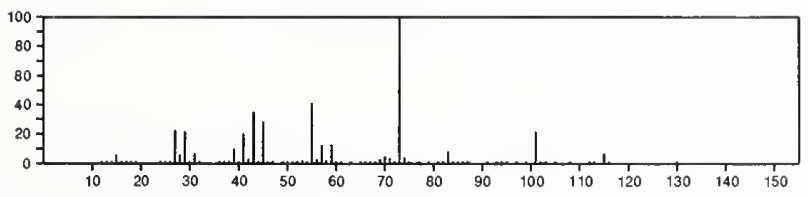

130

Pentane, 1-(1-methylethoxy)

$5756-37-6$

$\mathrm{C}_{8} \mathrm{H}_{18} \mathrm{O}$

$\mathrm{Me}\left(\mathrm{CH}_{2}\right)_{4} \mathrm{OPr}-$

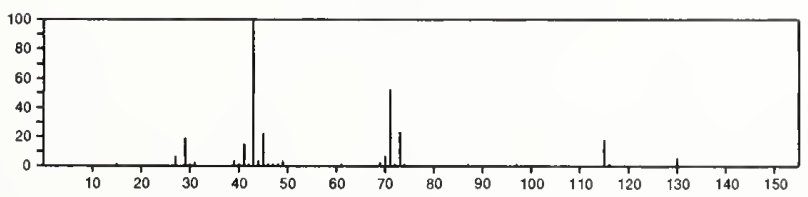

130

Hexane, 1-ethoxy-

$\mathrm{C}_{8} \mathrm{H}_{18} \mathrm{O}$

$5756-43-4$

$\mathrm{Me}\left(\mathrm{CH}_{2}\right)_{5} \mathrm{OEt}$

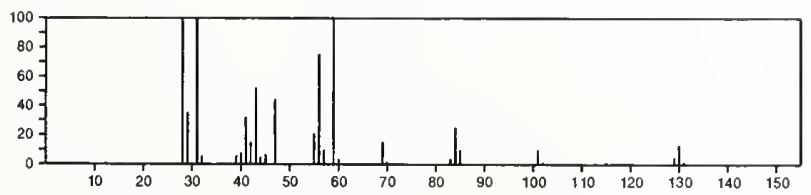

130

3-Hexanol, 2,4-dimethyl-

$\mathrm{C}_{8} \mathrm{H}_{18} \mathrm{O}$

$13432-25-2$

$\mathrm{Me}_{2} \mathrm{CHCH}(\mathrm{OH}) \mathrm{CHMeCH}_{2} \mathrm{Me}$

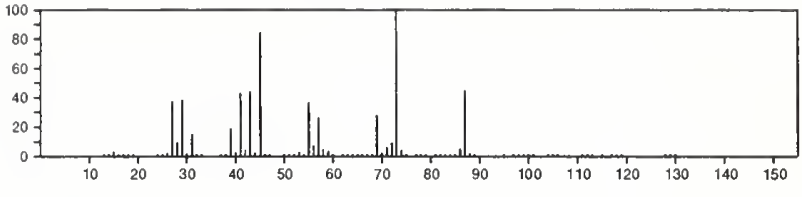

130

3-Heptanol, 4-methyl-

$\mathrm{C}_{8} \mathrm{H}_{18} \mathrm{O}$

$14979-39-6$

$\mathrm{EtCH}(\mathrm{OH}) \mathrm{CHP} r \mathrm{Me}$

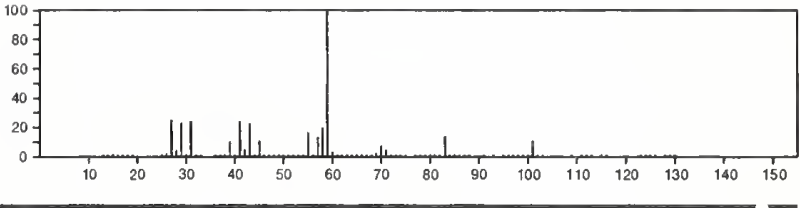

130

Pentane, 1-propoxy-

$\mathrm{C}_{8} \mathrm{H}_{18} \mathrm{O}$

$18641-82-2$

$\mathrm{Me}\left(\mathrm{CH}_{2}\right)_{4} \mathrm{OPr}$

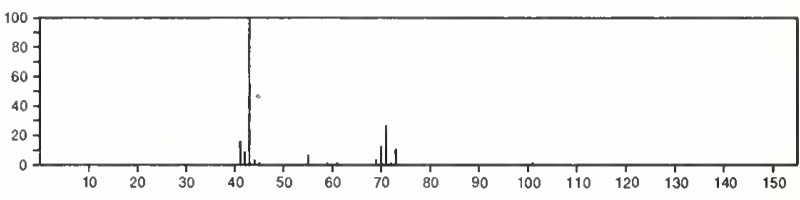

130

$\mathrm{C}_{8} \mathrm{H}_{18} \mathrm{O}$

$18720-62-2$

3-Heptanol, 2-methyl-

$\mathrm{Me}\left(\mathrm{CH}_{2}\right)_{3} \mathrm{CH}(\mathrm{OH}) \mathrm{CHMe}_{2}$

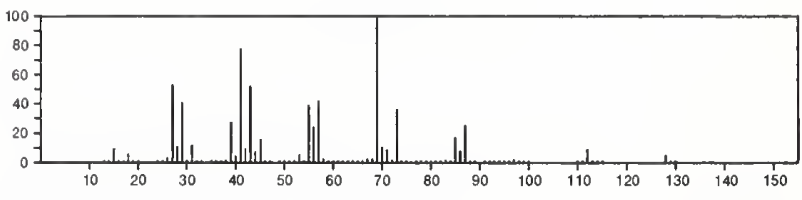

130

$\mathrm{C}_{8} \mathrm{H}_{18} \mathrm{O}$

$18720-65-5$

3-Heptanol, 5-methyl-

$\mathrm{EtCH}(\mathrm{OH}) \mathrm{CH}_{2} \mathrm{CHMe} \mathrm{CH}_{2} \mathrm{Me}$

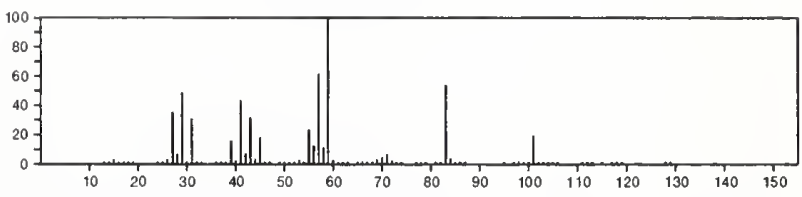

130

$\mathrm{C}_{8} \mathrm{H}_{18} \mathrm{O}$

$18720-66-6$

3-Heptanol, 6-methyl-

$\mathrm{Me}_{2} \mathrm{CHCH}_{2} \mathrm{CH}_{2} \mathrm{CH}(\mathrm{OH}) \mathrm{Et}$

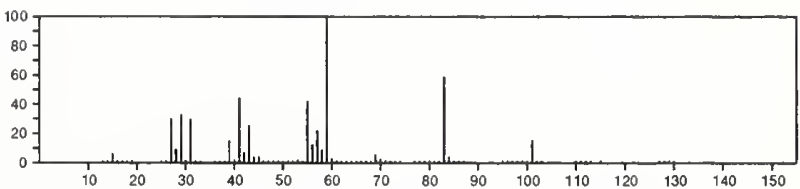


130

2-Hexanol, 2,3-dimethyl-

$\mathrm{C}_{8} \mathrm{H}_{18} \mathrm{O}$

Me 2 COHCHP r Me

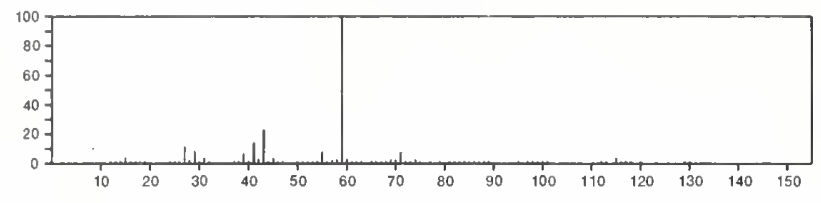

130

2-Hexanol, 3,4-dimethyl

$\mathrm{C}_{8} \mathrm{H}_{18} \mathrm{O}$

19550-05-1

$\mathrm{Me} \mathrm{CH}(\mathrm{OH}) \mathrm{CHMe} \mathrm{CHMe} \mathrm{CH}_{2} \mathrm{Me}$

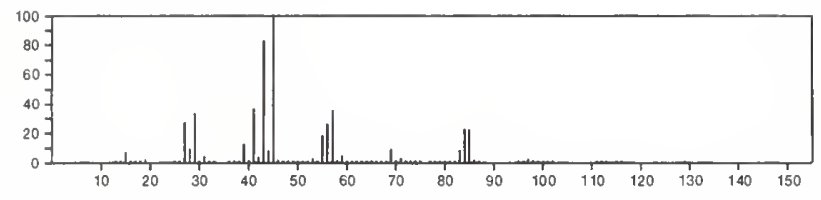

130

3-Hexanol, 2,5-dimethyl-

$\mathrm{C}_{8} \mathrm{H}_{18} \mathrm{O}$

$\mathrm{Me}_{2} \mathrm{CHCH}_{2} \mathrm{CH}(\mathrm{OH}) \mathrm{CHMe}_{2}$

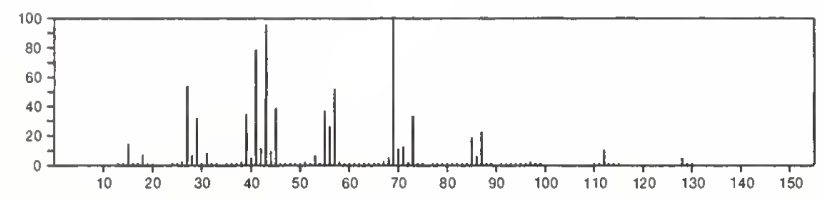

130

4-Heptanol, 2-methyl-

$\mathrm{C}_{8} \mathrm{H}_{18} \mathrm{O}$

21570-35-4

$\mathrm{PrCH}(\mathrm{OH}) \mathrm{CH}_{2} \mathrm{CHM}_{2}$

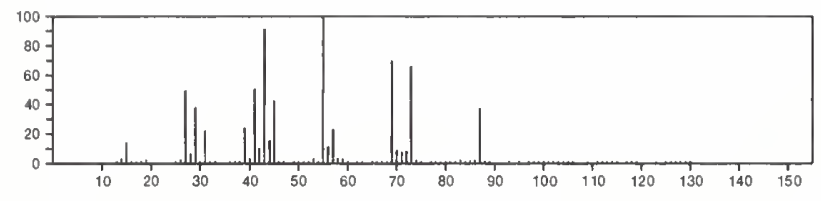

130

$\mathrm{C}_{8} \mathrm{H}_{18} \mathrm{O}$

26952-21-6

Isooctanol

(I SO- $\mathrm{C}_{8} \mathrm{H}_{1}$ ) $\mathrm{OH}$

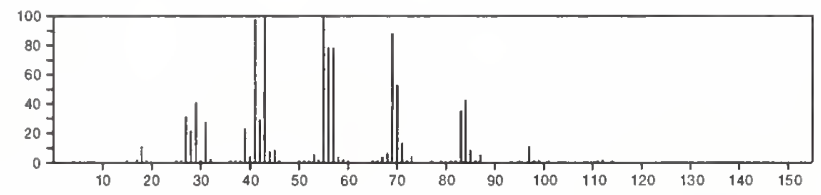

130

2-Heptanol, 3-methyl-

$\mathrm{C}_{8} \mathrm{H}_{18} \mathrm{O}$

$31367-46-1$

$\mathrm{Me}\left(\mathrm{CH}_{2}\right)_{3} \mathrm{CHMeCH}(\mathrm{OH}) \mathrm{Me}$

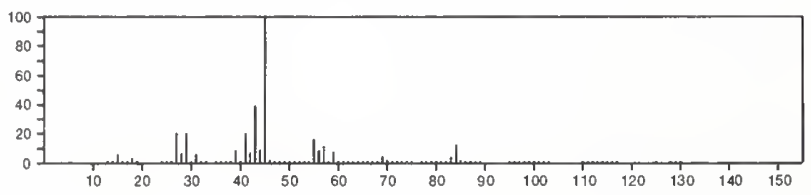

130

$\mathrm{C}_{8} \mathrm{H}_{18} \mathrm{O}$

$33021-02-2$

Propane, 1-(1,1-dimethylethoxy)-2-methyl

$1-84 O B u-1$

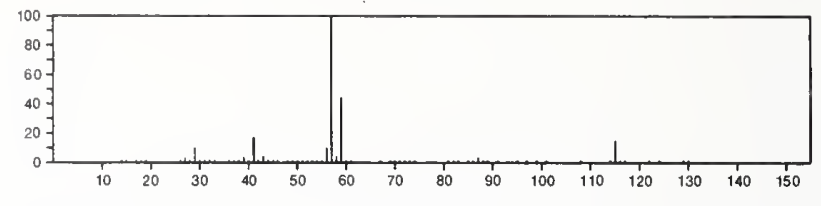

130

2-Heptanol, 5-methyl

$\mathrm{C}_{8} \mathrm{H}_{18} \mathrm{O}$

$54630-50-1$

$\mathrm{MeCH}\left(\mathrm{OH}\right.$ ) $\mathrm{CH}_{2} \mathrm{CH}_{2} \mathrm{CHMe} \mathrm{CH}_{2} \mathrm{Me}$

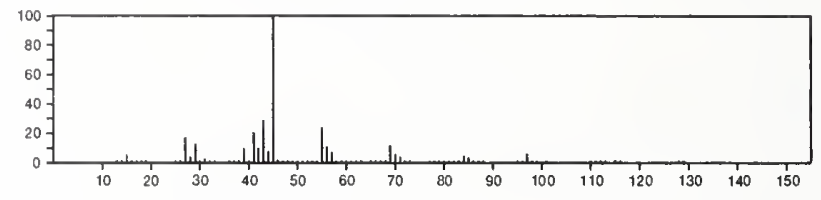

130

$\mathrm{C}_{8} \mathrm{H}_{18} \mathrm{O}$

2-Heptanol, 4-methyl-

$\mathrm{Pr} \mathrm{CHMeCH}_{2} \mathrm{CH}$ ( $\left.\mathrm{OH}\right) \mathrm{Me}$

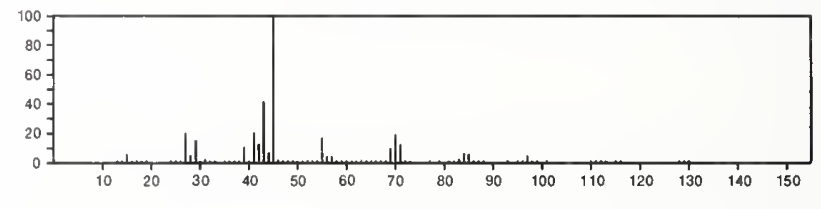

130

2-Propyn-1-one, 1-phenyl-

$\mathrm{C}_{9} \mathrm{H}_{6} \mathrm{O}$

3623-15-2

$\mathrm{HC}: \mathrm{CCOPh}$

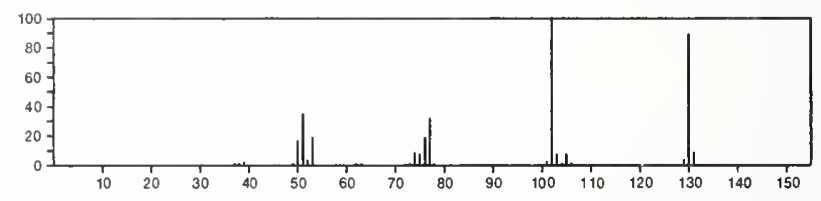

130

$\mathrm{C}_{10} \mathrm{H}_{10}$

$108-57-6$

Benzene, 1,3-diethenyl
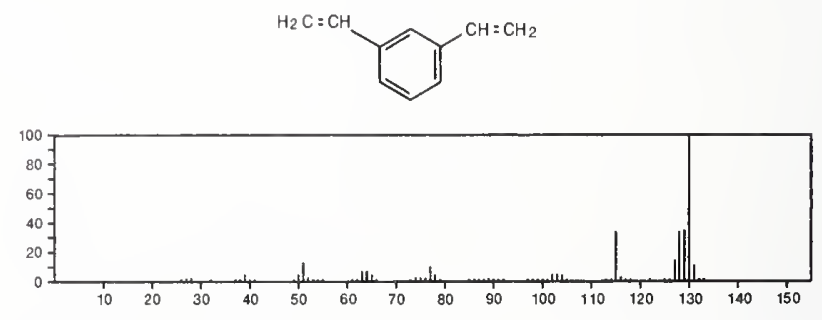

130

$\mathrm{C}_{10} \mathrm{H}_{10}$

447-53-0

Naphthalene, 1,2-dihydro-
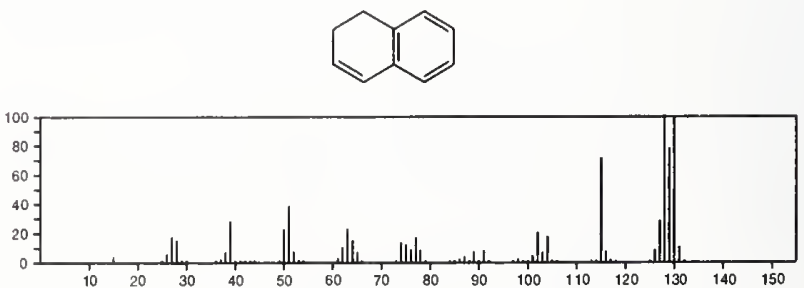
130

1 H-Indene, 1-methyl-

$\mathrm{C}_{10} \mathrm{H}_{10}$

767-59-9
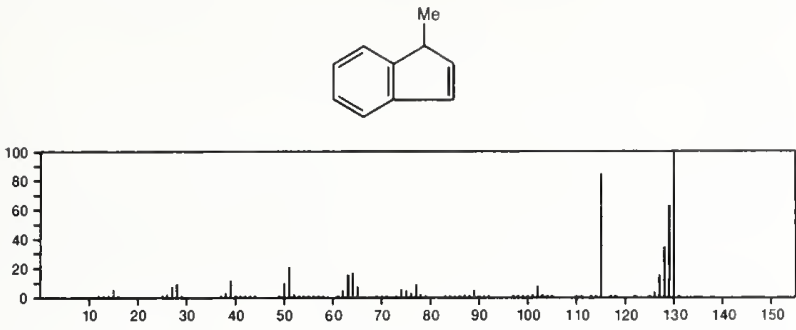

130

$1 H$-Indene, 3-methyl-

$\mathrm{C}_{10} \mathrm{H}_{10}$

767-60-2
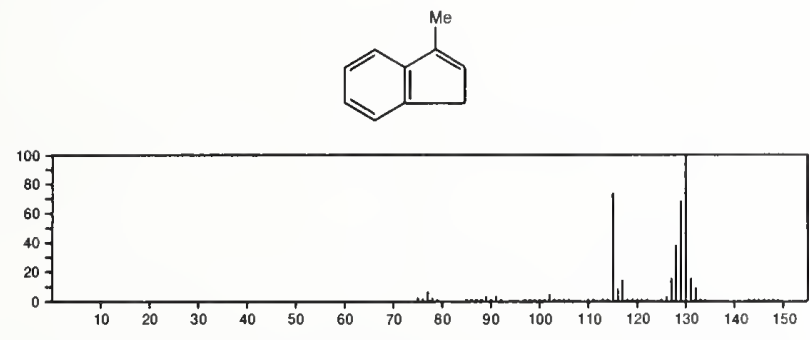

130

$\mathrm{C}_{10} \mathrm{H}_{10}$

1321-74-0

Benzene, diethenyl-
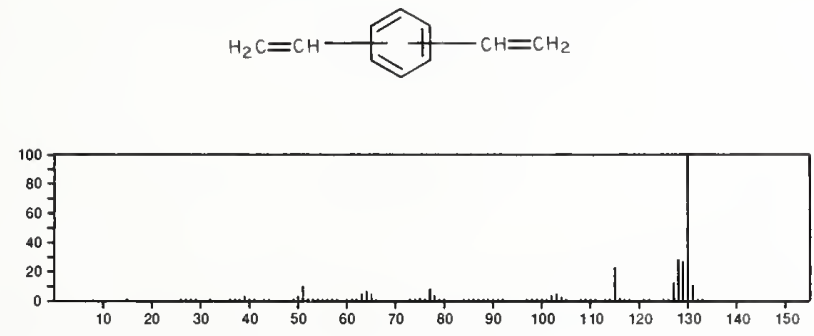

130

$\mathrm{C}_{10} \mathrm{H}_{10}$

3365-26-2

Benzene, 1-cyclobuten-1-yl-
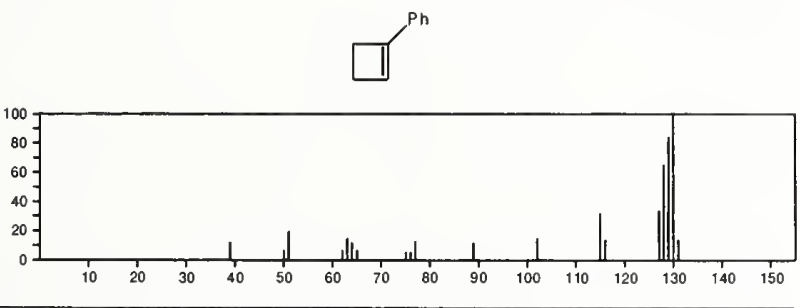

130

$\mathrm{C}_{10} \mathrm{H}_{10}$

Benzene, (cyclopropylidenemethyl)-

7555-67-1
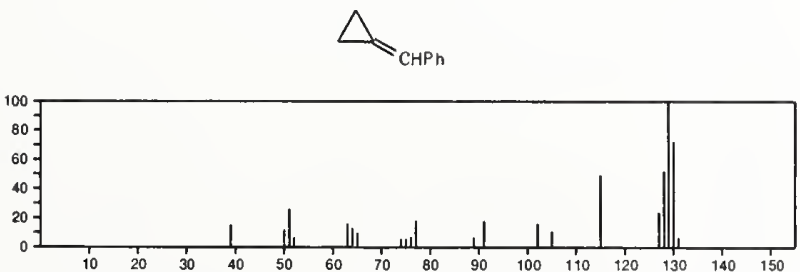

130 $\mathrm{C}_{10} \mathrm{H}_{10}$

Cycl prop $[a]$ indene, 1,1a,6,6a-tetrahydro
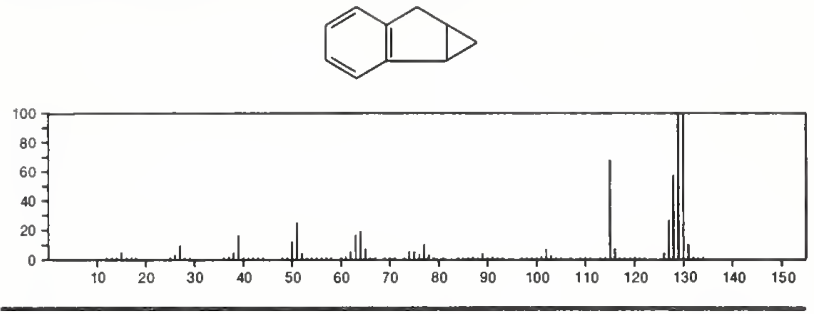

131

$\mathrm{CF}_{3} \mathrm{NOS}$

Imidosulfurous difluoride, (fluorocarbonyl)-

$3855-41-2$

$\mathrm{FCON}=\mathrm{SF}_{2}$

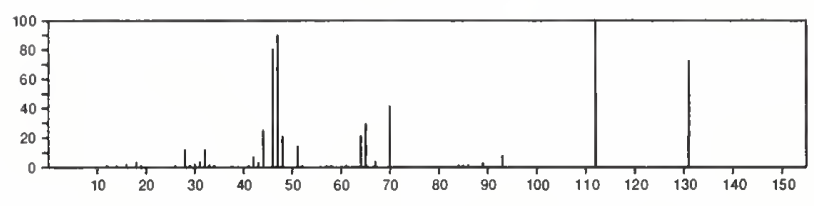

131

Urea, trimethylnitroso-

$\mathrm{C}_{4} \mathrm{H}_{9} \mathrm{~N}_{3} \mathrm{O}_{2}$

$3475-63-6$

MeN (NO) CONME 2

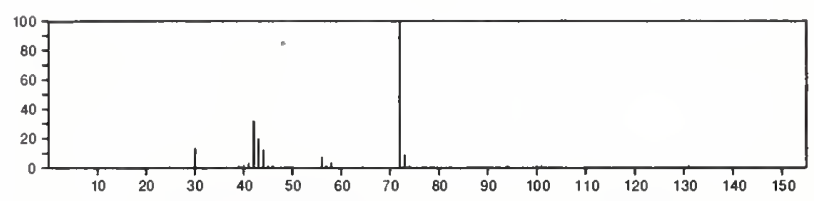

131

$\mathrm{C}_{4} \mathrm{H}_{9} \mathrm{~N}_{3} \mathrm{~S}$

Hydrazinecarbothioamide, 2-(1-methylethylidene)-

$1752-30-3$

$\mathrm{Me}_{2} \mathrm{C}: \mathrm{NNHCSNH}_{2}$

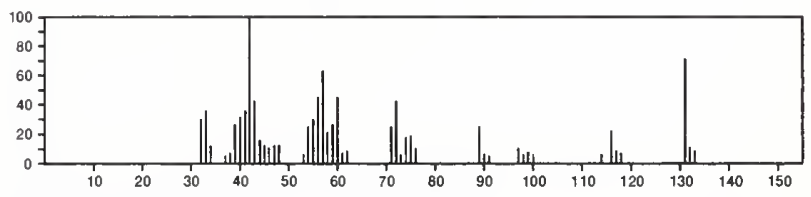

131

$\mathrm{C}_{5} \mathrm{H}_{9} \mathrm{NOS}$

Propanethioamide, $N, N$-dimethyl-3-oxo-

$52022-76-1$

$\mathrm{OCHCH}_{2} \mathrm{CSNM}_{2}$

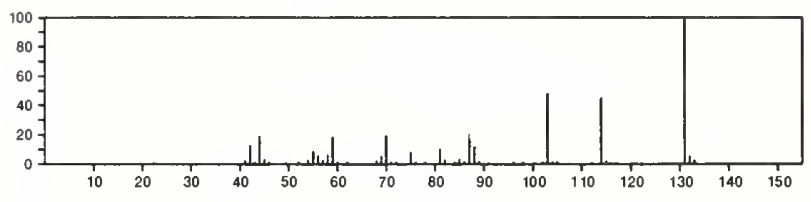

$131 \quad \mathrm{C}_{5} \mathrm{H}_{9} \mathrm{NOS}$

2-Oxazolidinethione, 4,4-dimethyl-

54013-55-7
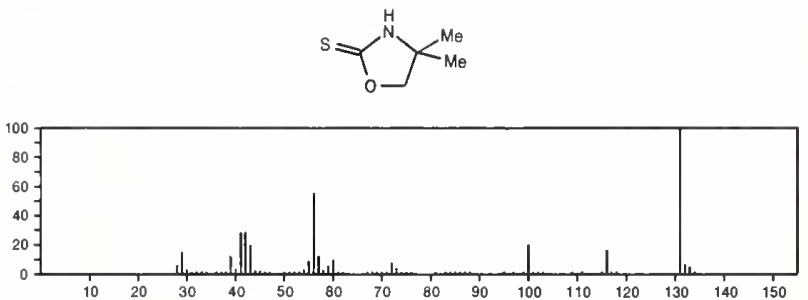
131 L-Proline, 4-hydroxy-, trans-
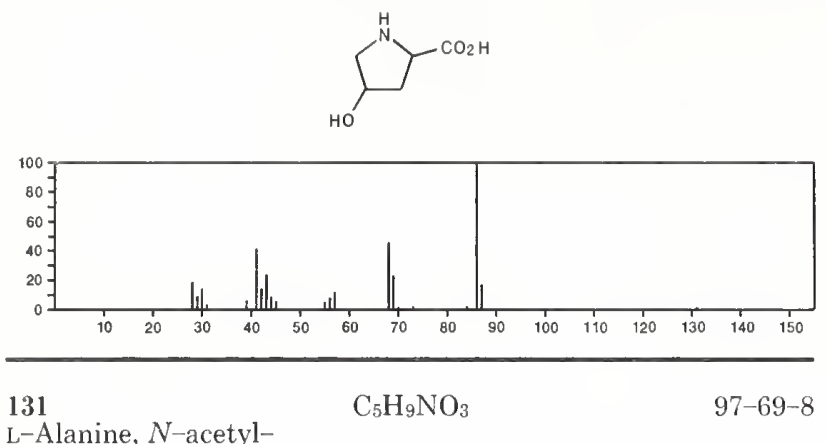

L-Alanine, $N$-acetyl-

$\mathrm{ACNHCHMeCO} \mathrm{H}_{2} \mathrm{H}$

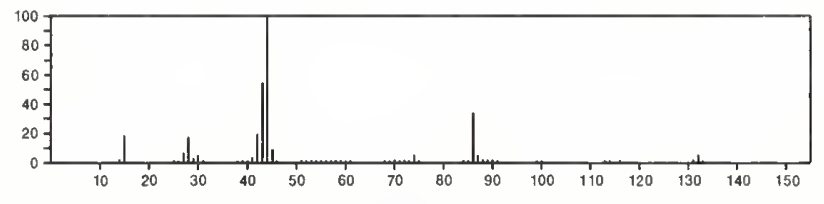

131

$\mathrm{C}_{6} \mathrm{H}_{13} \mathrm{NO}_{2}$

$61-90-5$

L-Leucine

$\mathrm{HO}_{2} \mathrm{CCH}\left(\mathrm{NH}_{2}\right) \mathrm{CH}_{2} \mathrm{CHMe}_{2}$

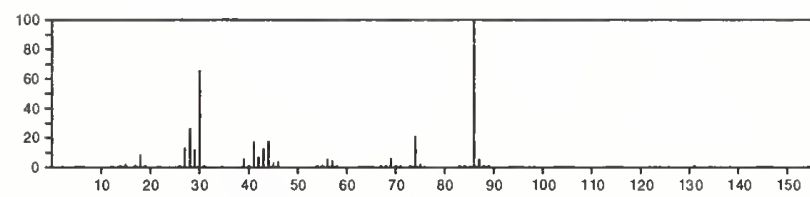

131

L-Isoleucine

$\mathrm{C}_{6} \mathrm{H}_{13} \mathrm{NO}_{2}$

$73-32-5$
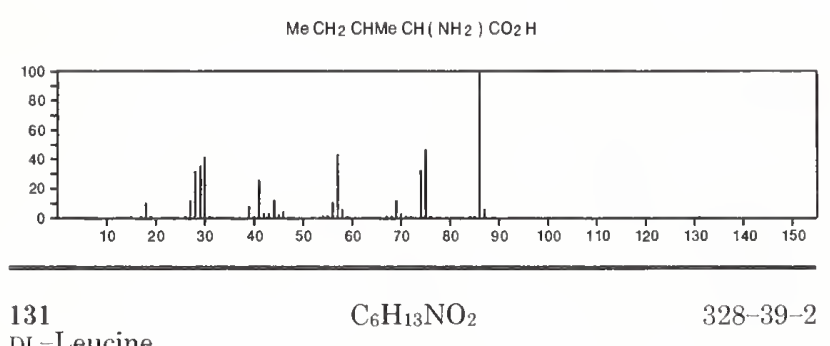

DL-Leucine

$\mathrm{HO}_{2} \mathrm{CCH}\left(\mathrm{NH}_{2}\right) \mathrm{CH}_{2} \mathrm{CHMe}_{2}$

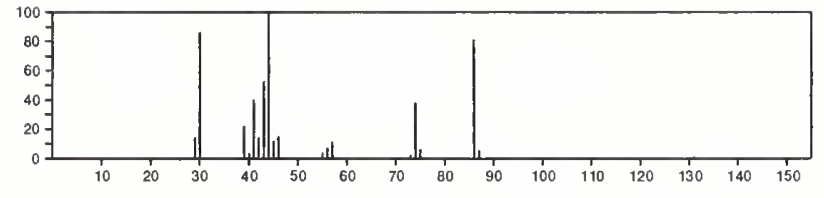

131

$\mathrm{C}_{6} \mathrm{H}_{13} \mathrm{NO}_{2}$

1421-89-2

Acetic acid, 2-(dimethylamino)ethyl ester

$\mathrm{Me}_{2} \mathrm{NCH}_{2} \mathrm{CH}_{2} \mathrm{OAC}$

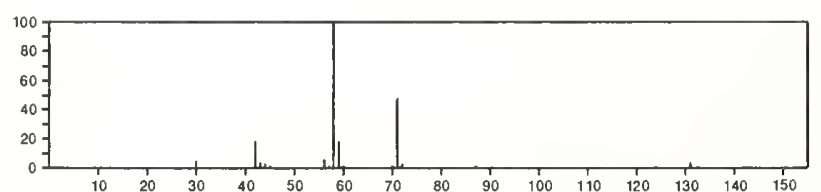

131

L-Valine, methyl ester

$\mathrm{C}_{6} \mathrm{H}_{13} \mathrm{NO}_{2}$

$4070-48-8$

$\mathrm{Me} 2 \mathrm{CHCH}\left(\mathrm{NH}_{2}\right) \mathrm{Cl}$ O) OMe

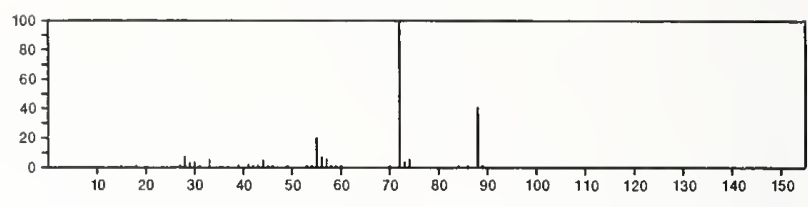

131

$\mathrm{C}_{6} \mathrm{H}_{13} \mathrm{NO}_{2}$

29582-96-5

L-Norvaline, methyl ester

$\mathrm{MeOC}(\mathrm{O}) \mathrm{CH}\left(\mathrm{NH}_{2}\right) \mathrm{Pr}$

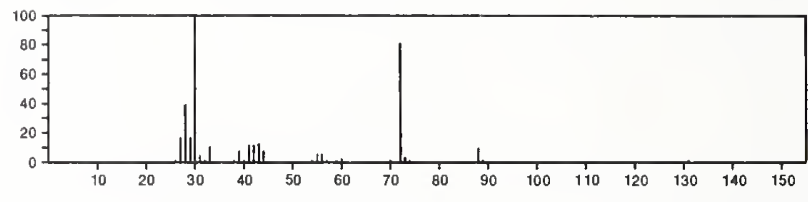

131

Butane, 2,3-dimethyl-2-nitro-

$34075-28-0$

$\mathrm{Me}_{2} \mathrm{CHCMe}_{2} \mathrm{NO}_{2}$

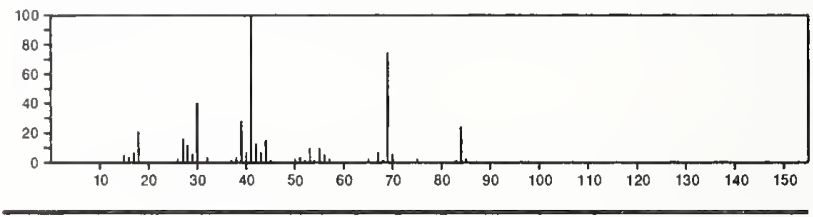

131

DL-Norvaline, methyl ester

$\mathrm{C}_{6} \mathrm{H}_{13} \mathrm{NO}_{2}$

51220-50-9

$\mathrm{MeOC}(\mathrm{O}) \mathrm{CH}\left(\mathrm{NH}_{2}\right) \mathrm{Pr}$

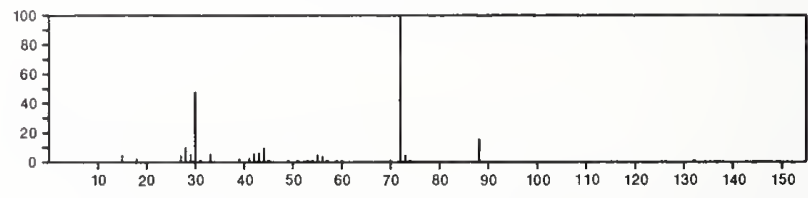

131

$\mathrm{C}_{7} \mathrm{H}_{5} \mathrm{~N}_{3}$

$254-61-5$

Pyrido[2,3-d]pyrimidine
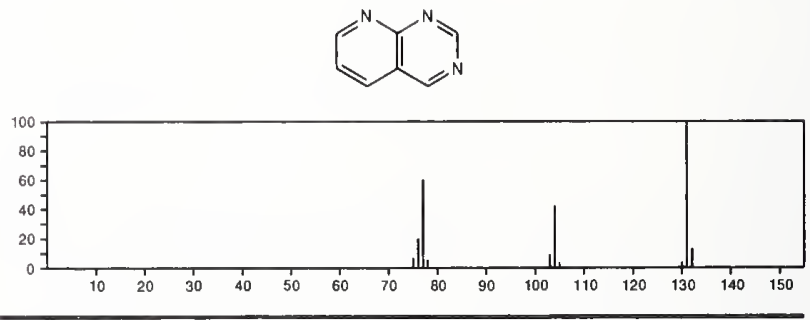

131

$\mathrm{C}_{7} \mathrm{H}_{17} \mathrm{NO}$

$7352-03-6$

Ethanamine, $N$-(ethoxymethyl) $-N$-ethyl-

$\mathrm{E}: \mathrm{OCH}_{2} \mathrm{NE} \mathrm{I}_{2}$

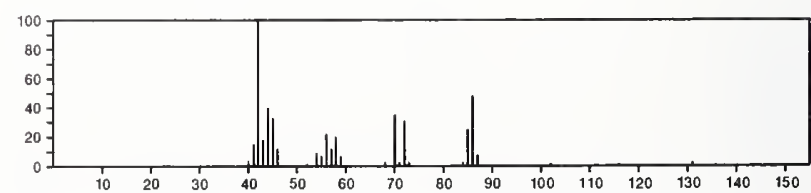


131

1H-Indole, 3-methyl-

$\mathrm{C}_{9} \mathrm{H}_{9} \mathrm{~N}$
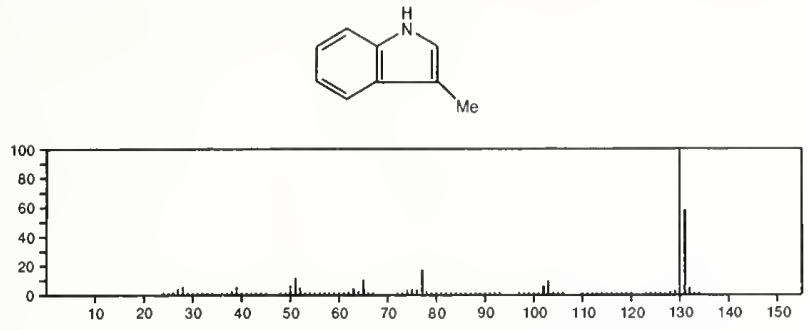

131

$1 H$-Indole, 2-methyl

$\mathrm{C}_{9} \mathrm{H}_{9} \mathrm{~N}$

95-20-5
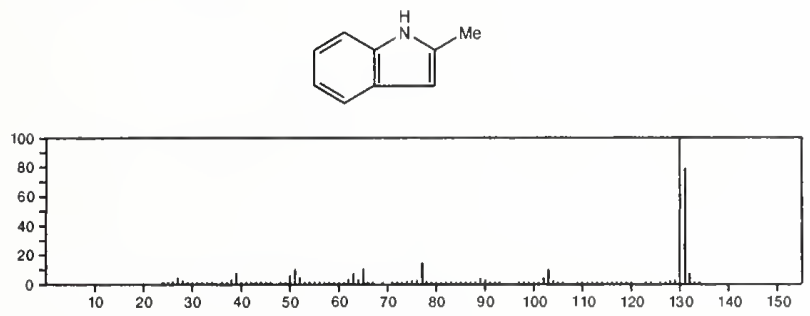

131

1H-Indole, 1-methyl-

$\mathrm{C}_{9} \mathrm{H}_{9} \mathrm{~N}$

603-76-9
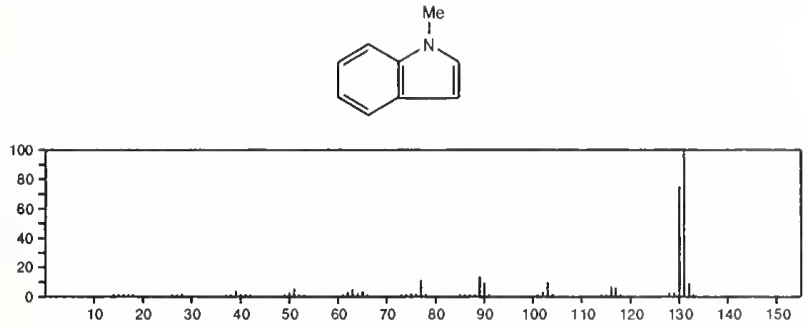

131

$1 \mathrm{H}$-Indole, 5-methyl-

$\mathrm{C}_{9} \mathrm{H}_{9} \mathrm{~N}$

614-96-0
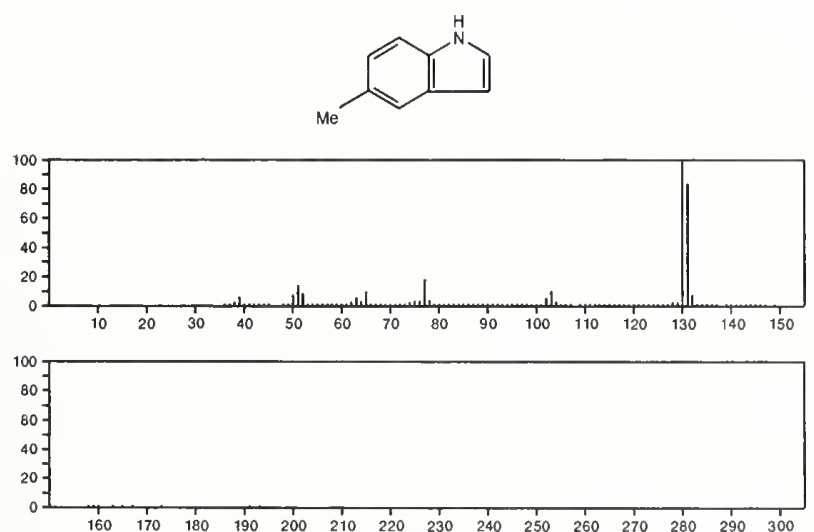

\section{1}

Indolizine, 1-methyl-

$\mathrm{C}_{9} \mathrm{H}_{9} \mathrm{~N}$<smiles>Nc1ccn2ccccc12</smiles>

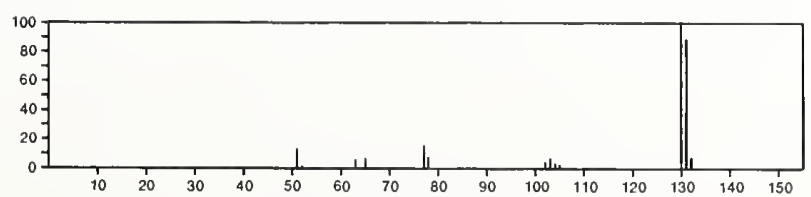

131

Indolizine, 2-methyl

$\mathrm{C}_{9} \mathrm{H}_{9} \mathrm{~N}$

768-18-3
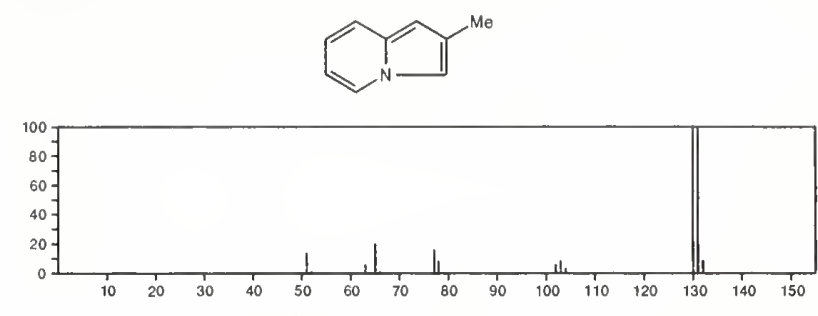

131

$\mathrm{C}_{9} \mathrm{H}_{9} \mathrm{~N}$

1761-10-0

Indolizine, 3-methyl-
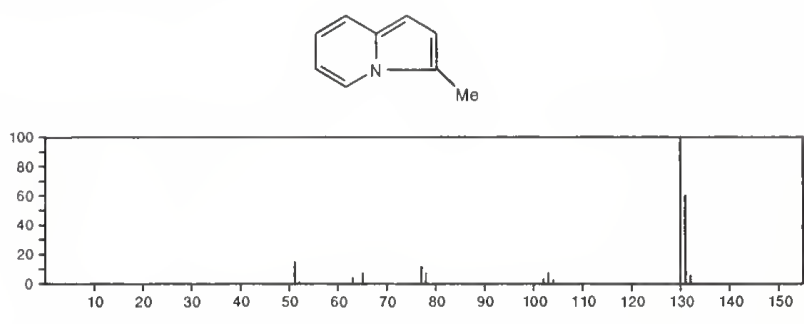

131

$\mathrm{C}_{9} \mathrm{H}_{9} \mathrm{~N}$

1761-11-1

Indolizine, 6-methyl-
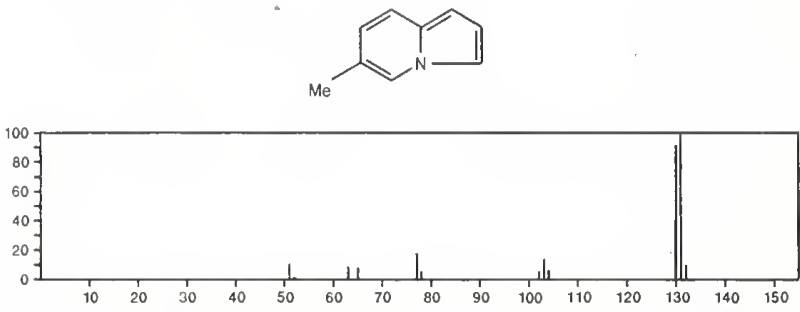

131

Indolizine, 7-methyl

$\mathrm{C}_{9} \mathrm{H}_{9} \mathrm{~N}$

1761-12-2
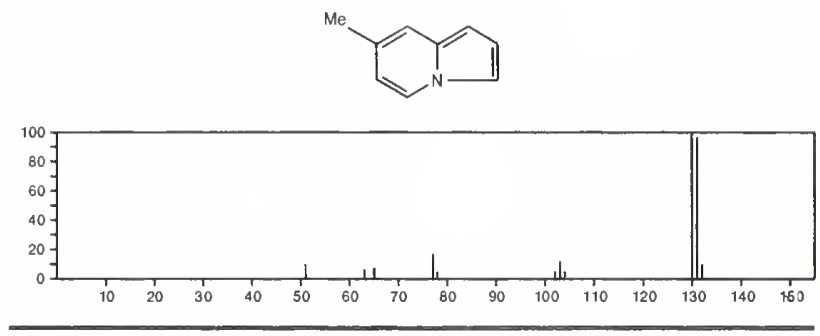

131

$\mathrm{C}_{9} \mathrm{H}_{9} \mathrm{~N}$

1761-19-9

Indolizine, 5-methyl-
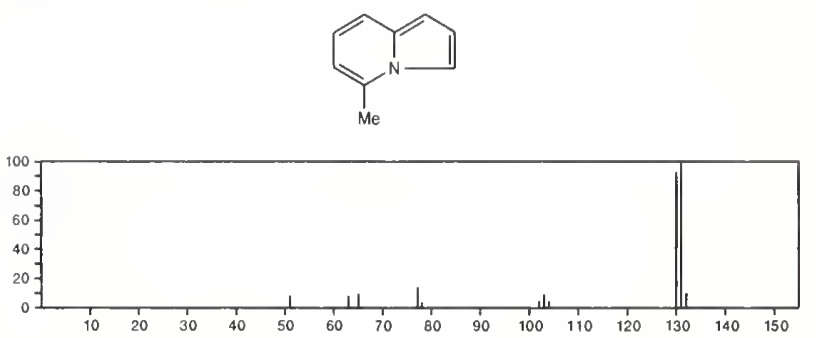
131

$1 H$-Indole, 6-methyl

$\mathrm{C}_{9} \mathrm{H}_{9} \mathrm{~N}$
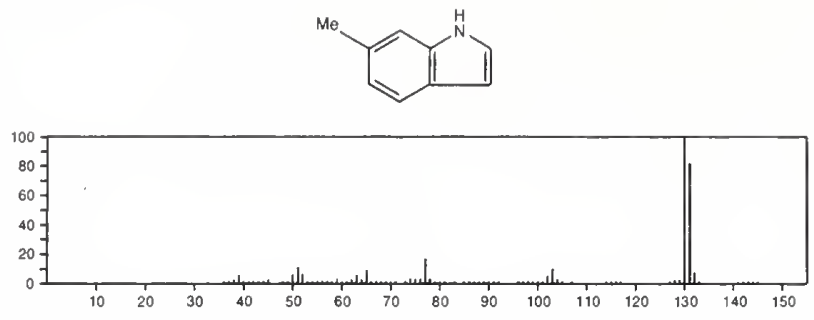

131

Indolizine, 8-methyl-

$\mathrm{C}_{9} \mathrm{H}_{9} \mathrm{~N}$
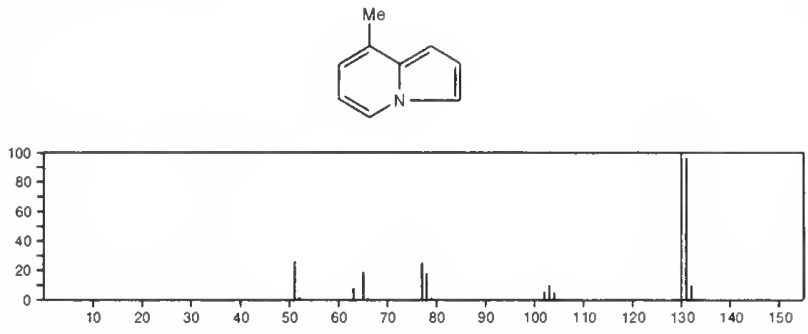

131

Azete, 2,3-dihydro-4-phenyl-

$\mathrm{C}_{9} \mathrm{H}_{9} \mathrm{~N}$
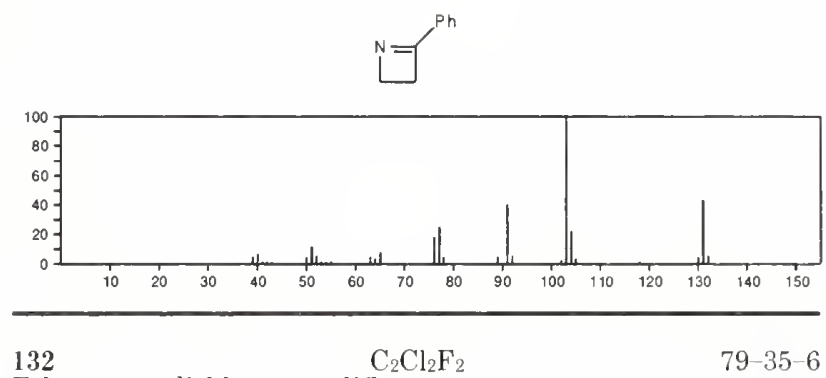

$79-35-6$

Ethene, 1,1-dichloro-2,2-difluoro-

$\mathrm{F}_{2} \mathrm{C}=\mathrm{CCl}_{2}$
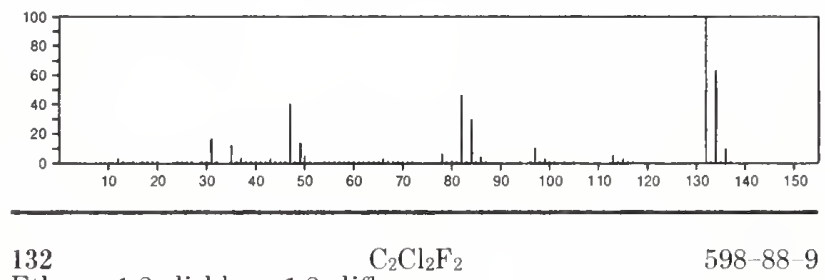

Ethene, 1,2-dichloro-1,2-difluoro-

$\mathrm{FCCl}=\mathrm{CCIF}$
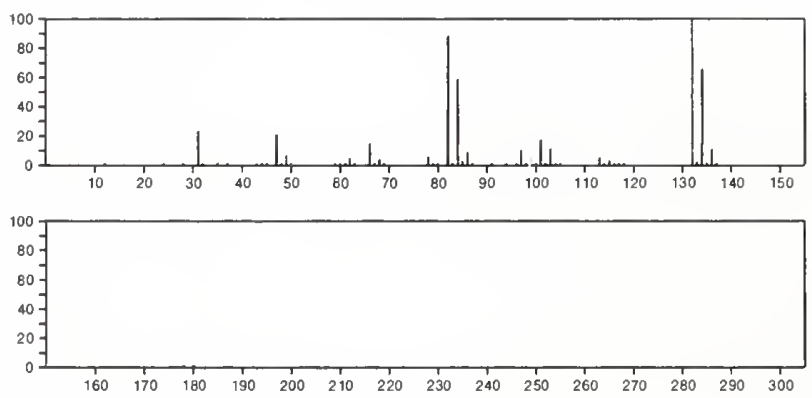

$132 \quad \mathrm{C}_{2} \mathrm{~F}_{4} \mathrm{O}_{2}$

Carbonofluoridic acid, trifluoromethyl ester

$3299-24-9$

$\mathrm{FC}(0) \mathrm{OCF}_{3}$

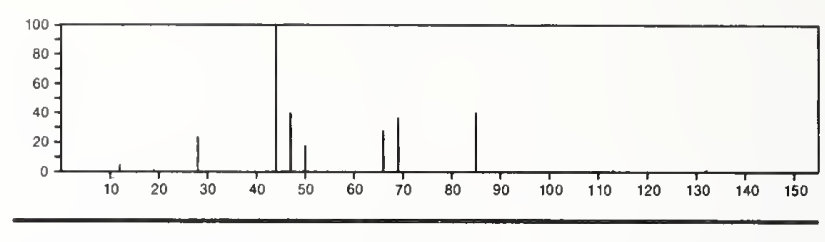

132

$\mathrm{C}_{2} \mathrm{H}_{3} \mathrm{Cl}_{3}$

71-55-6

Ethane, 1,1,1-trichloro-

$\mathrm{Cl}_{3} \mathrm{CMe}$

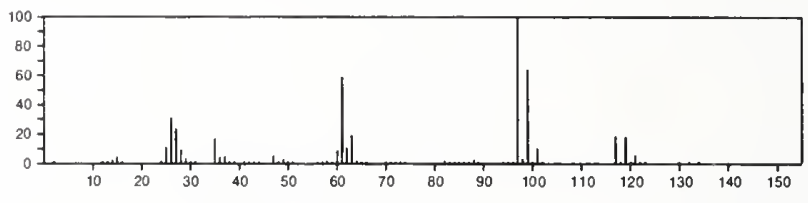

132

Ethane, 1,1,2-trichloro-

$\mathrm{C}_{2} \mathrm{H}_{3} \mathrm{Cl}_{3}$

$79-00-5$

$\mathrm{Cl} \mathrm{CH}_{2} \mathrm{CHCl}_{2}$

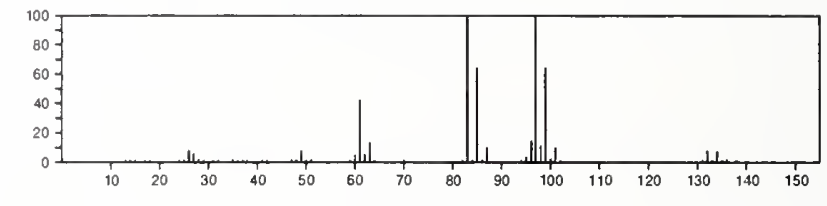

132

$\mathrm{C}_{2} \mathrm{H}_{6} \mathrm{BClN}_{4}$

$21960-49-6$

IH-Tetrazaborole, 5-chloro-4,5-dihydro-1,4-dimethyl-

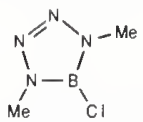

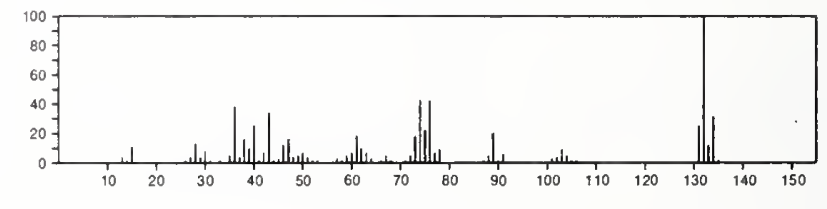

132

1 Propene, 1,1,3,3,3-pentafluoro-

$690-27-7$

$\mathrm{F}_{3} \mathrm{CCH}=\mathrm{CF}_{2}$

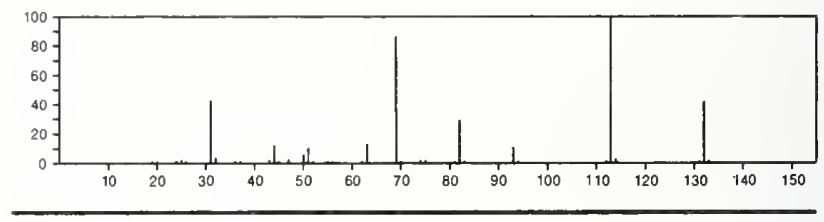

132

$\mathrm{C}_{3} \mathrm{H}_{4} \mathrm{ClF}_{3}$

$460-35-5$

Propane, 3-chloro-1,1,1-trifluoro-

$\mathrm{Cl} \mathrm{CH}_{2} \mathrm{CH}_{2} \mathrm{CF}_{3}$

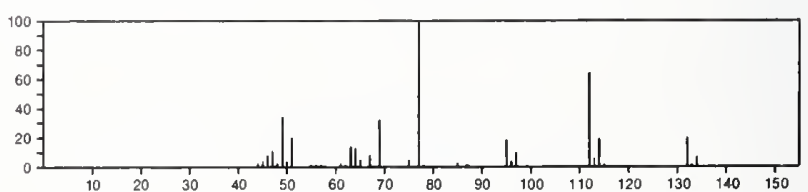


132

$\mathrm{C}_{3} \mathrm{H}_{4} \mathrm{~N}_{2} \mathrm{O}_{4}$

Acetic acid, [(aminocarbonyl)amino] xo- $^{-}$

$\mathrm{HO}_{2} \mathrm{CCONHCONH}_{2}$

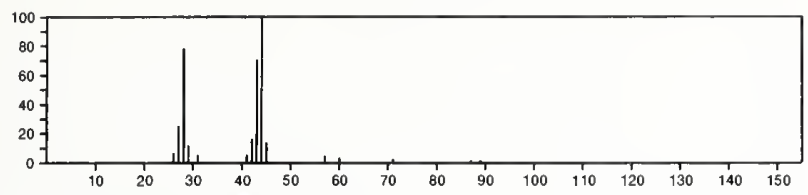

132

1,3,5-Trisilacyclohexane

$\mathrm{C}_{3} \mathrm{H}_{12} \mathrm{Si}_{3}$

$\mathrm{J}_{\substack{\mathrm{Si}_{2} \\ \mathrm{H}_{2}}}^{\mathrm{SiH}_{2}}$

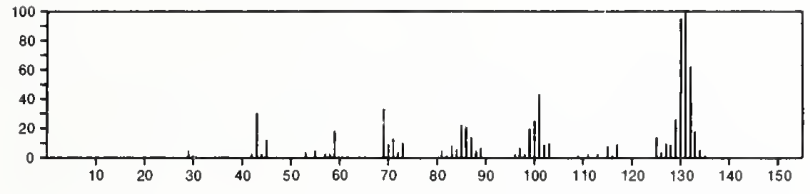

132

$\mathrm{C}_{4} \mathrm{H}_{4} \mathrm{OS}_{2}$

$53951-47-6$

2(3H)-Thiophenone, dihydro-5-thioxo-
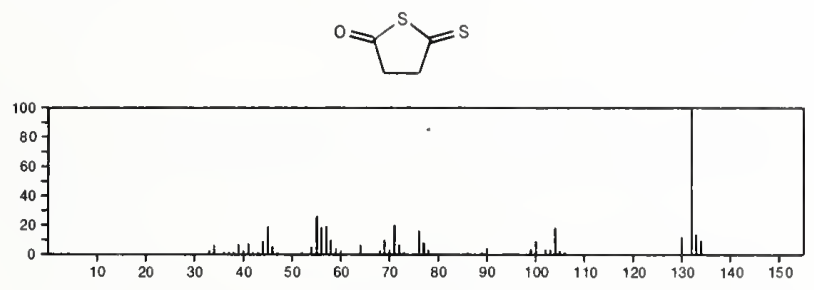

132

Thiomorpholine, 4-nitroso-

$\mathrm{C}_{4} \mathrm{H}_{8} \mathrm{~N}_{2} \mathrm{OS}$

$26541-51-5$
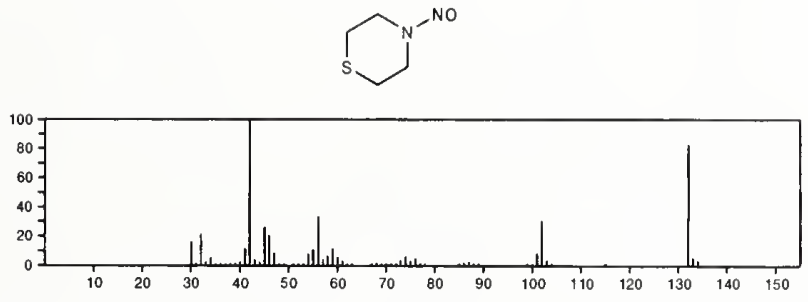

132

$\mathrm{C}_{4} \mathrm{H}_{8} \mathrm{~N}_{2} \mathrm{OS}$

$38762-37-7$

Acetamide, $\mathrm{N}$-methyl-2-(methylamino)-2-thioxo-

MeNHCS CONHME

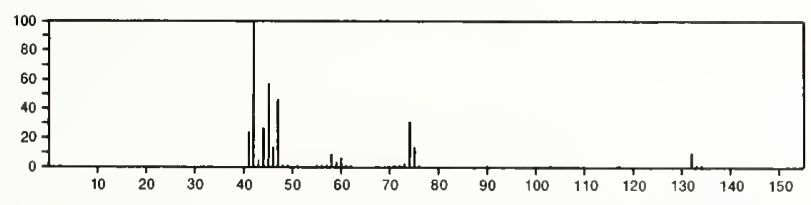

132

$\mathrm{C}_{4} \mathrm{H}_{8} \mathrm{~N}_{2} \mathrm{OS}$

$54699-19-3$

Acetamide, 2-amino-N-ethyl-2-thioxo-

EINHCOCSNH2

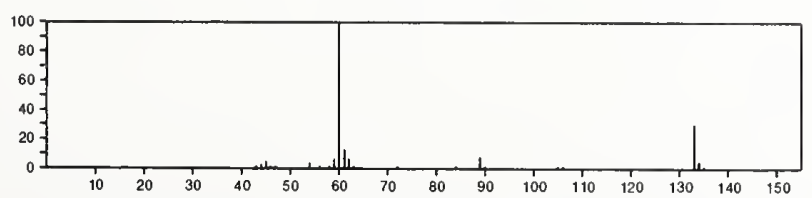

132

Glycine, $N$-glycyl-

$\mathrm{C}_{4} \mathrm{H}_{8} \mathrm{~N}_{2} \mathrm{O}_{3}$

$556-50-3$

$\mathrm{HO}_{2} \mathrm{CCH}_{2} \mathrm{NHCOCH}_{2} \mathrm{NH}_{2}$

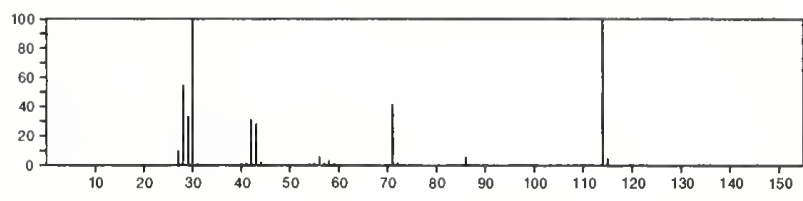

$132 \quad \mathrm{C}_{4} \mathrm{H}_{8} \mathrm{~N}_{2} \mathrm{O}_{3}$

$615-53-2$

Carbamic acid, methylnitroso-, ethyl ester

EtOC(O) N(NO) Me

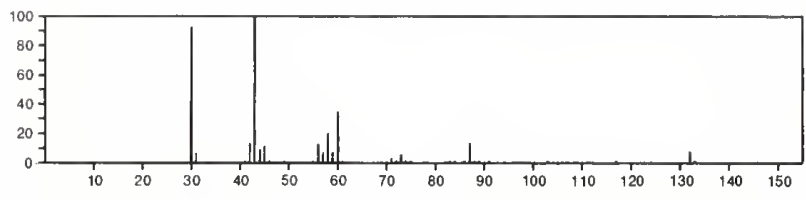

132

$\mathrm{C}_{4} \mathrm{H}_{8} \mathrm{~N}_{2} \mathrm{O}_{3}$

$4202-74-8$

Glycine, anhydride

$\mathrm{H}_{2} \mathrm{NCH}_{2} \mathrm{C}(\mathrm{O}) \mathrm{OC}(\mathrm{O}) \mathrm{CH}_{2} \mathrm{NH}_{2}$

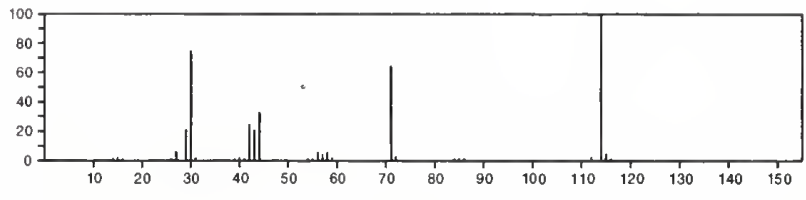

132

$\mathrm{C}_{4} \mathrm{H}_{10} \mathrm{Ge}$

3466-01-1

Germacyclopentane
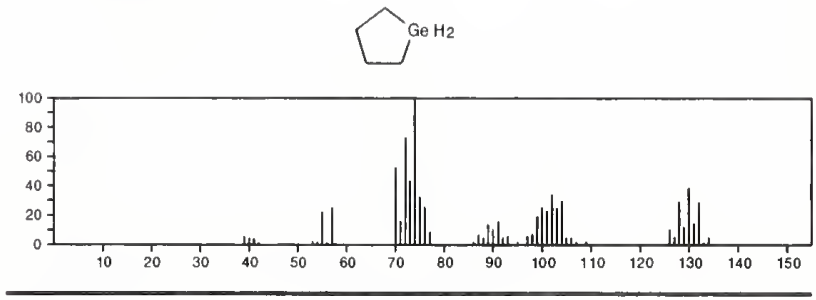

132

$\mathrm{C}_{5} \mathrm{H}_{5} \mathrm{ClO}_{2}$

14203-19-1

1,3-Cyclopentanedione, 2-chloro-
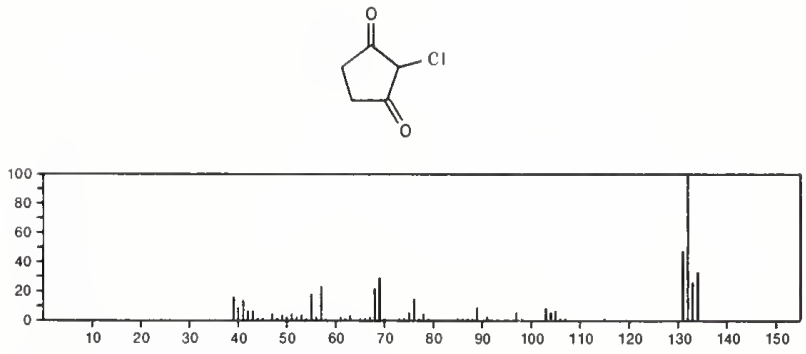

132

$\mathrm{C}_{5} \mathrm{H}_{8} \mathrm{O}_{2} \mathrm{~S}$

$5512-72-1$

7H-1,4-Oxathiepin-7-one, tetrahydro-
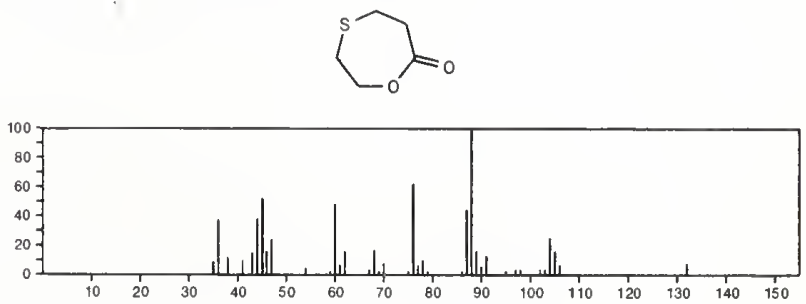
132

1,4-Oxathian-2-one, 6-methyl-

$\mathrm{C}_{5} \mathrm{H}_{8} \mathrm{O}_{2} \mathrm{~S}$
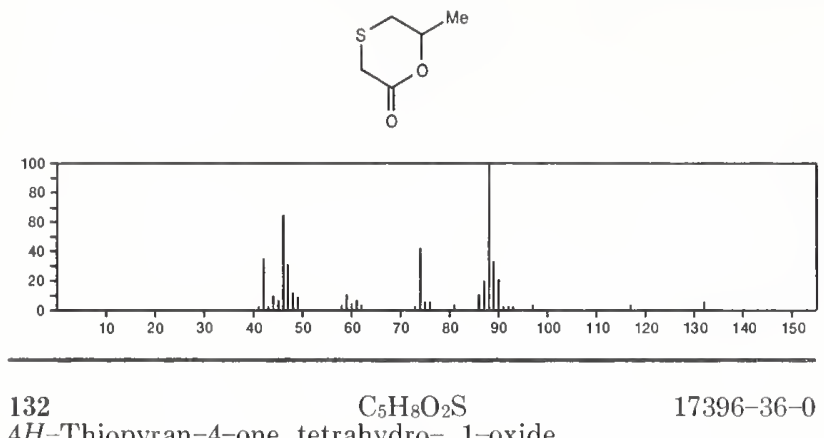

4H-Thiopyran-4-one, tetrahydro-, 1-oxide
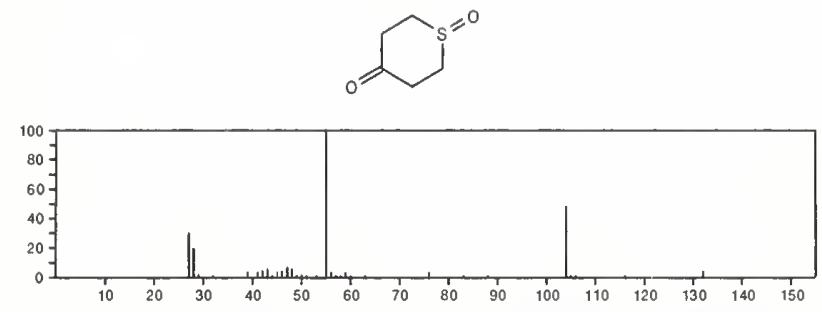

132

Acetic acid, (2-propenylthio)-

$\mathrm{C}_{5} \mathrm{H}_{8} \mathrm{O}_{2} \mathrm{~S}$

$\mathrm{H}_{2} \mathrm{C}=\mathrm{CHCH}_{2} \mathrm{SCH}_{2} \mathrm{CO}_{2} \mathrm{H}$

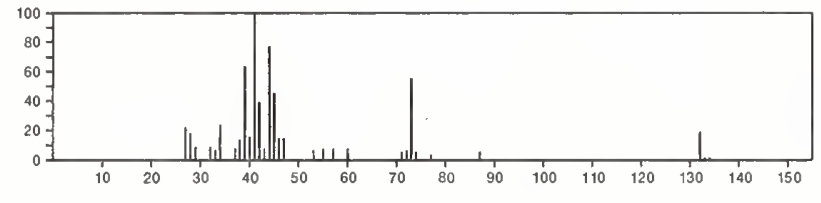

132

1,4-Oxathian-2-one, 3-methyl

$\mathrm{C}_{5} \mathrm{H}_{8} \mathrm{O}_{2} \mathrm{~S}$

$35562-74-4$
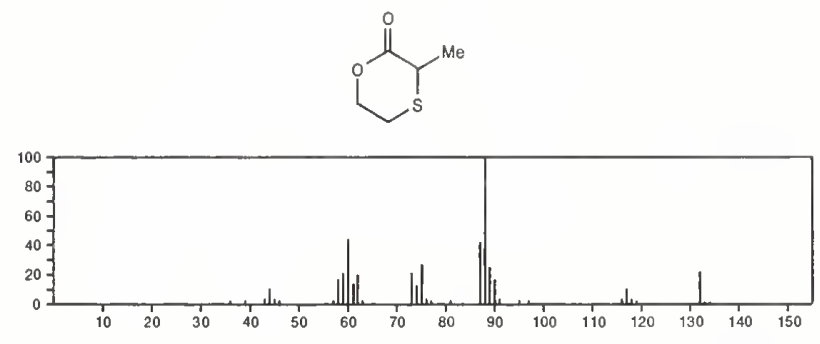

132

Propanedioic acid, dimethyl ester

$\mathrm{C}_{5} \mathrm{H}_{8} \mathrm{O}$

$\mathrm{MeOC}(\mathrm{O}) \mathrm{CH}_{2} \mathrm{C}(\mathrm{O})$ OMe

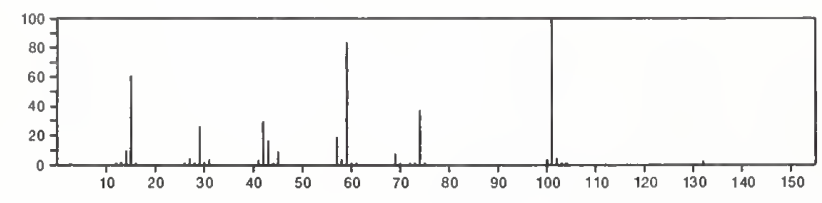

132

$\mathrm{C}_{5} \mathrm{H}_{8} \mathrm{O}_{4}$

$110-94-1$

Pentanedioic acid

$\mathrm{HO}_{2} \mathrm{C}\left(\mathrm{CH}_{2}\right)_{3} \mathrm{CO}_{2} \mathrm{H}$

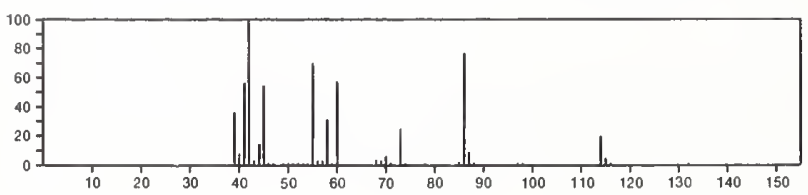

132

Butanedioic acid, methyl-

$\mathrm{C}_{5} \mathrm{H}_{8} \mathrm{O}_{4}$

$498-21-5$

$\mathrm{HO}_{2} \mathrm{CCH}_{2} \mathrm{CHMeCO}_{2} \mathrm{H}$

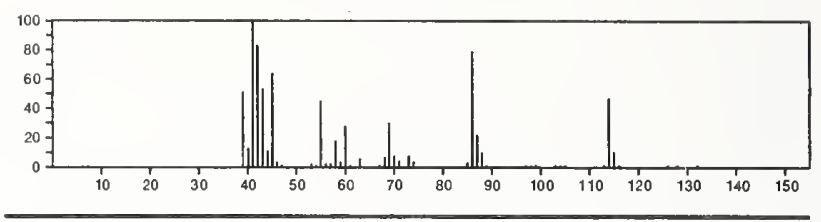

132

$\mathrm{C}_{5} \mathrm{H}_{8} \mathrm{O}_{4}$

Butanedioic acid, monomethyl ester

$3878-55-5$

$\mathrm{HO}_{2} \mathrm{CCH}_{2} \mathrm{CH}_{2} \mathrm{ClO}$ ) OMe

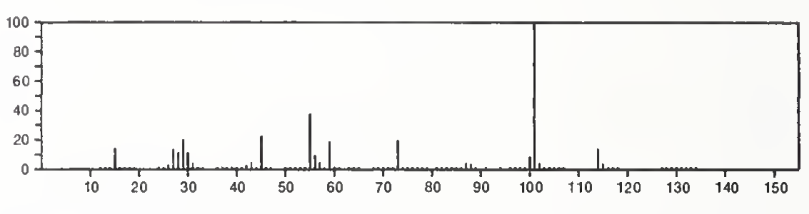

132

$\mathrm{C}_{5} \mathrm{H}_{8} \mathrm{O}_{4}$

Butanoic acid, 3,4-dihydroxy-2-methylene-

24923-78-2

$\mathrm{H}_{2} \mathrm{C}=\mathrm{C}\left(\mathrm{CO}_{2} \mathrm{H}\right) \mathrm{CH}(\mathrm{OH}) \mathrm{CH}_{2} \mathrm{OH}$

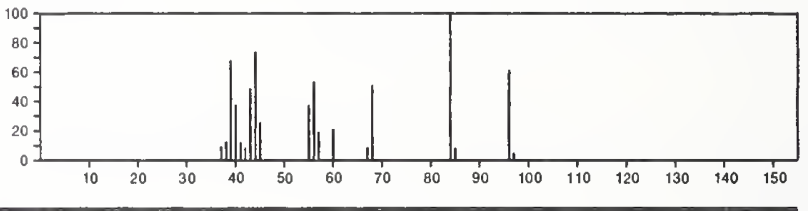

132

$\mathrm{C}_{5} \mathrm{H}_{12} \mathrm{~N}_{2} \mathrm{O}_{2}$

$52330-07-1$

1-Butanamine, $N$-methyl- $N$-nitro-

$\mathrm{MeN}\left(\mathrm{NO}_{2}\right)\left(\mathrm{CH}_{2}\right)_{3} \mathrm{Me}$

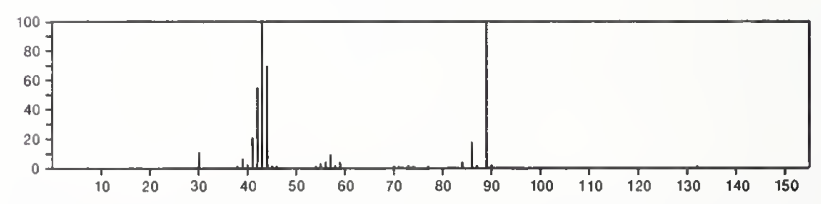

132

$\mathrm{C}_{5} \mathrm{H}_{12} \mathrm{~N}_{2} \mathrm{O}_{2}$

$53951-45-4$

1-Propanamine, $N, 2-$ dimethyl- $N$-nitro-

$\mathrm{MeN}\left(\mathrm{NO}_{2}\right) \mathrm{Bu}-\mathrm{i}$

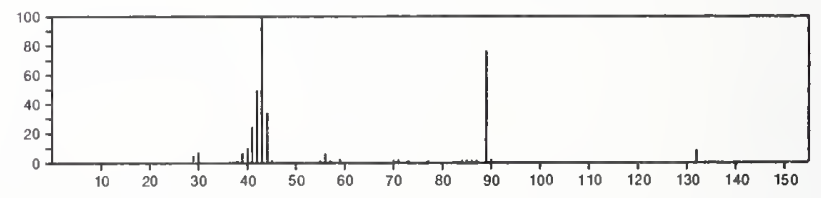

$132 \quad \mathrm{C}_{5} \mathrm{H}_{12} \mathrm{~N}_{2} \mathrm{~S}$

$105-55-5$

Thiourea, $N, N^{\prime}$-diethyl-

E \NHCSNHE \

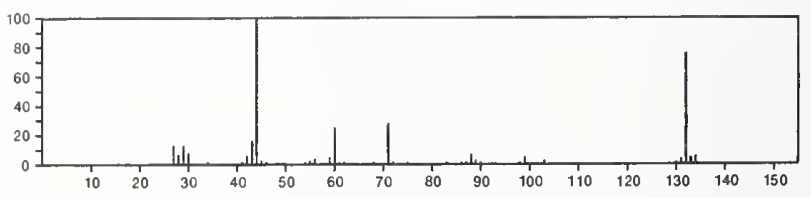


132

Thiourea, tetramethyl-

$\mathrm{C}_{5} \mathrm{H}_{12} \mathrm{~N}_{2} \mathrm{~S}$

2782-91-4

Me 2 NCSNME 2

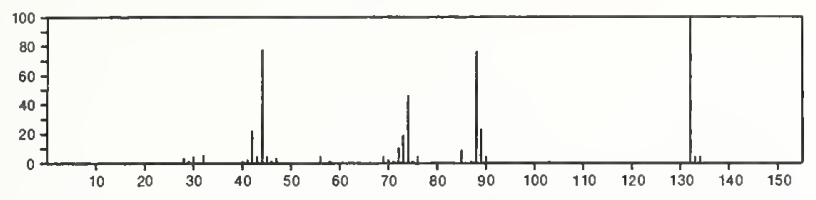

132

Acetic acid, (trimethylsilyl)-

$\mathrm{C}_{5} \mathrm{H}_{12} \mathrm{O}_{2} \mathrm{Si}$

$2345-38-2$

$\mathrm{Me}_{3} \mathrm{Si} \mathrm{CH}_{2} \mathrm{CO}_{2} \mathrm{H}$

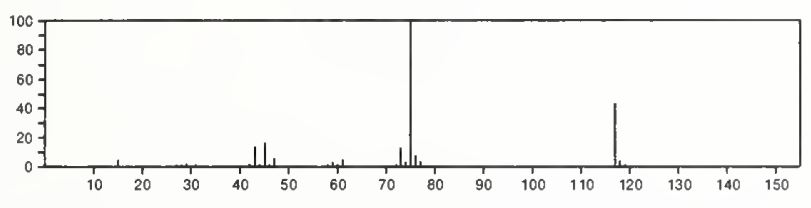

132

$\mathrm{C}_{5} \mathrm{H}_{16} \mathrm{Si}_{2}$

2,4-Disilapentane, 2,4-dimethyl-

18163-84-3

$\mathrm{Me}_{2} \mathrm{SiHCH} \mathrm{SiHMe}_{2}$

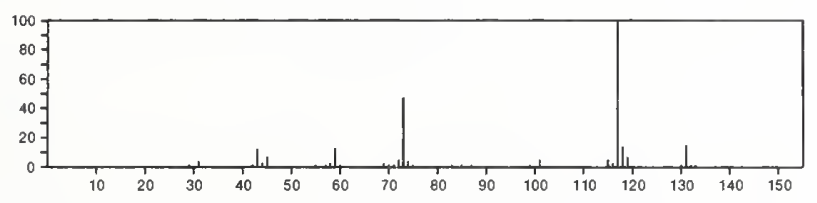

132

Pteridine

$\mathrm{C}_{6} \mathrm{H}_{4} \mathrm{~N}_{4}$

91-18-9
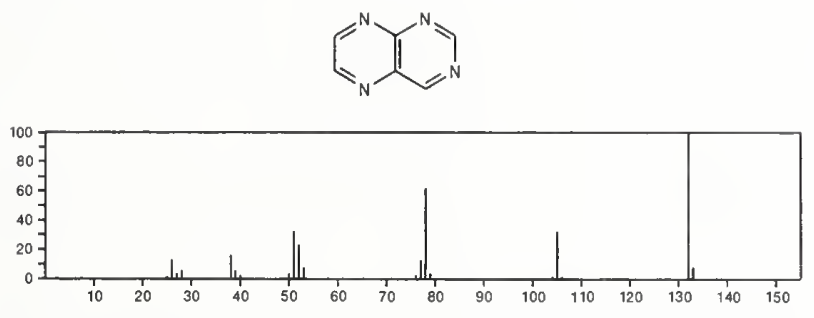

132

$\mathrm{C}_{6} \mathrm{H}_{9} \mathrm{ClO}$

$822-87-7$

Cyclohexanone, 2-chloro-
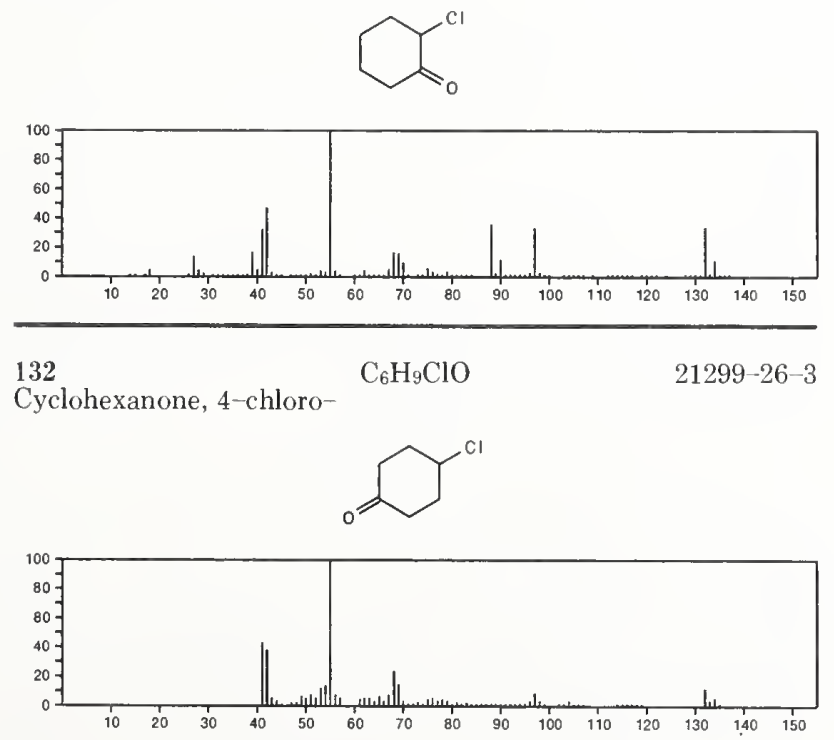

132

Ethanethioic acid, $S$-butyl ester

$\mathrm{C}_{6} \mathrm{H}_{12} \mathrm{OS}$

$\mathrm{Me}\left(\mathrm{CH}_{2}\right)_{3} \mathrm{SAC}$

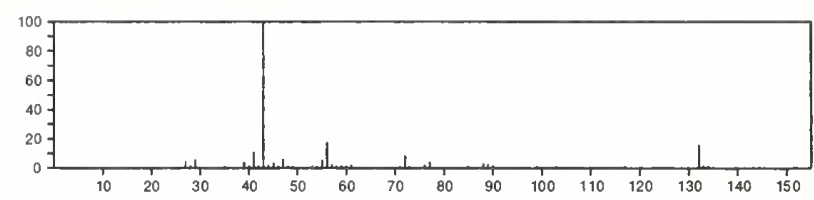

132

$\mathrm{C}_{6} \mathrm{H}_{12} \mathrm{OS}$

Ethanethioic acid, S-(2-methylpropyl) ester

$2432-37-3$

$i$-BUSAC

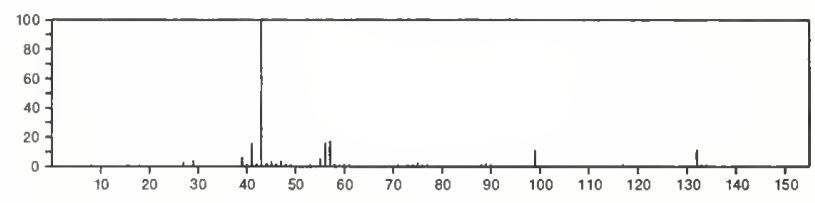

132

$\mathrm{C}_{6} \mathrm{H}_{12} \mathrm{OS}$

$2432-39-5$

Ethanethioic acid, $S$-(1-methylpropyl) ester

$S-B U S A C$

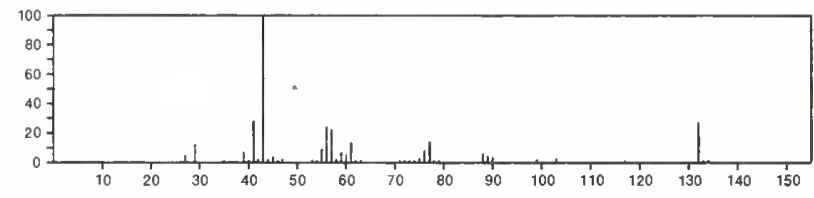

132

$\mathrm{C}_{6} \mathrm{H}_{12} \mathrm{OS}$

Propanethioic acid, $S$-propyl ester

$2432-43-1$

PrSC(O)Et

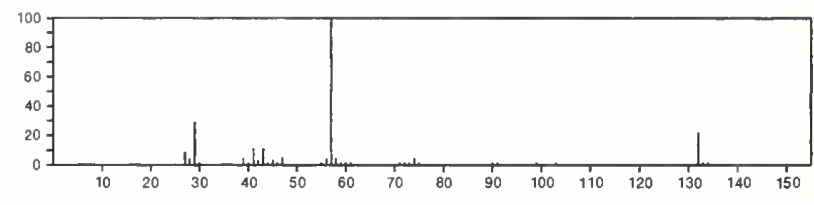

132

$\mathrm{C}_{6} \mathrm{H}_{12} \mathrm{OS}$

$2432-47-5$

Propanethioic acid, S-(1-methylethyl) ester

i-PrSC(O)Et

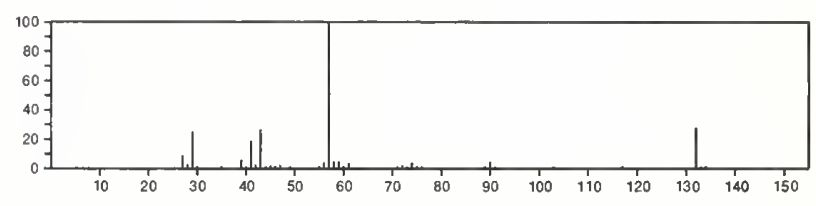

132

$\mathrm{C}_{6} \mathrm{H}_{12} \mathrm{OS}$

$2432-50-0$

Propanethioic acid, 2-methyl-, $S$-ethyl ester

Et SC(O) CHMO2

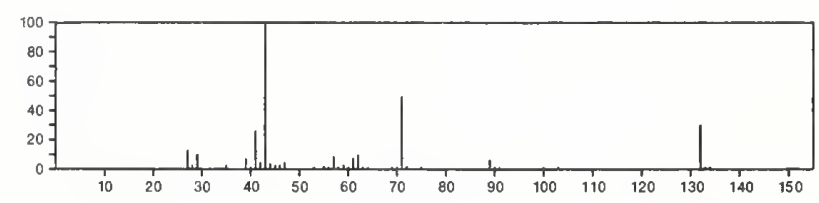


1,3-Oxathiane, 2,2-dimethyl-
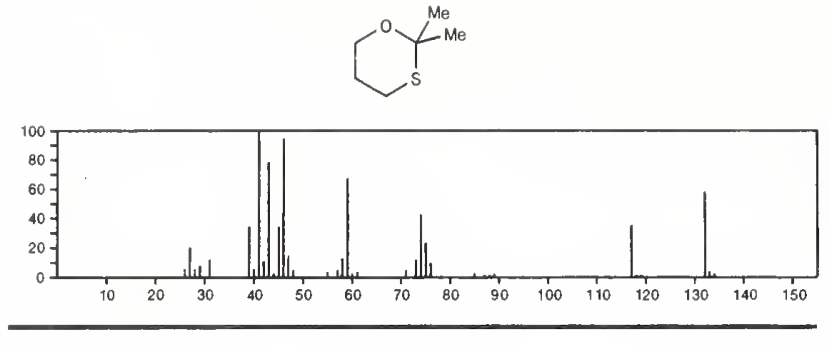

132

Thiepane, 1-oxide

$\mathrm{C}_{6} \mathrm{H}_{12} \mathrm{OS}$

$6251-34-9$
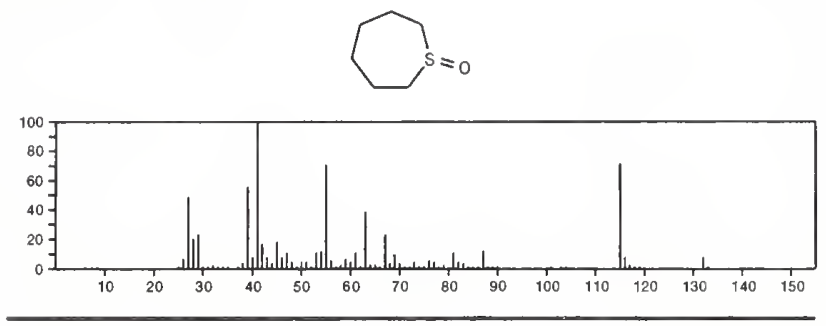

$132 \quad \mathrm{C}_{6} \mathrm{H}_{12} \mathrm{OS}$

1,3-Oxathiolane, 2-ethyl-2-methyl-

$6712-26-1$<smiles>CCC1([N+])OCCS1</smiles>
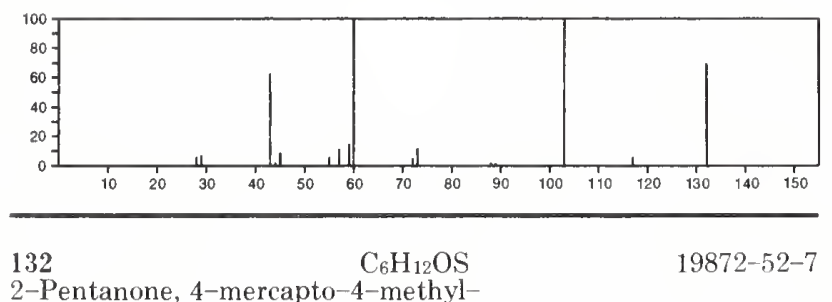

2-Pentanone, 4-mercapto-4-methyl-

$\mathrm{Me} \mathrm{COCH}_{2} \mathrm{CMe} 2 \mathrm{SH}$

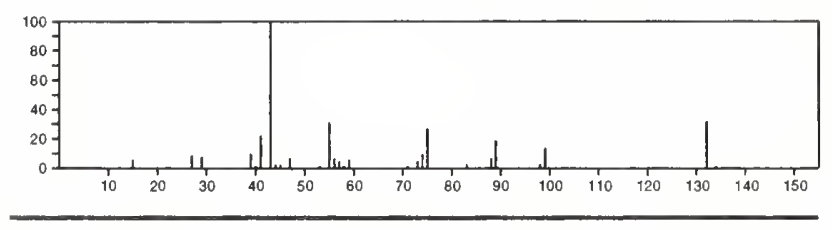

132

1,3-Oxathiane, 2-ethyl-

$\mathrm{C}_{6} \mathrm{H}_{12} \mathrm{OS}$

$30098-77-2$
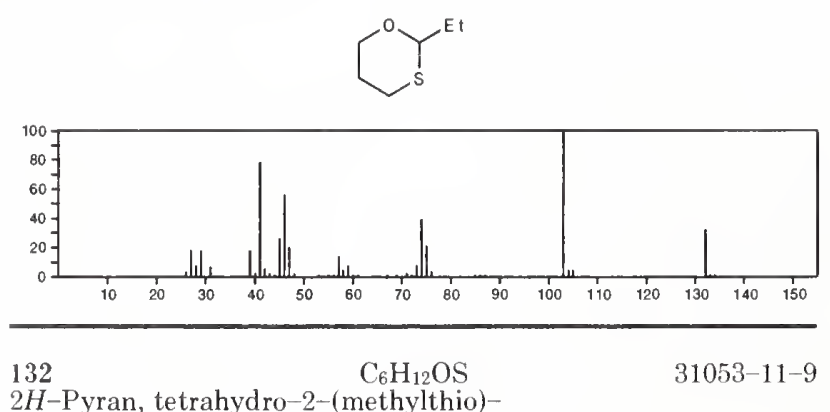

2H-Pyran, tetrahydro-2-(methylthio)-
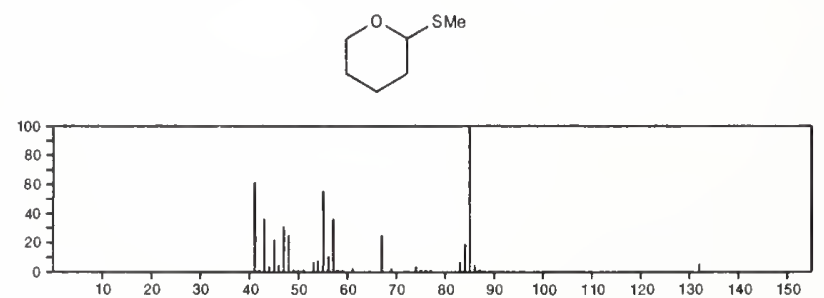
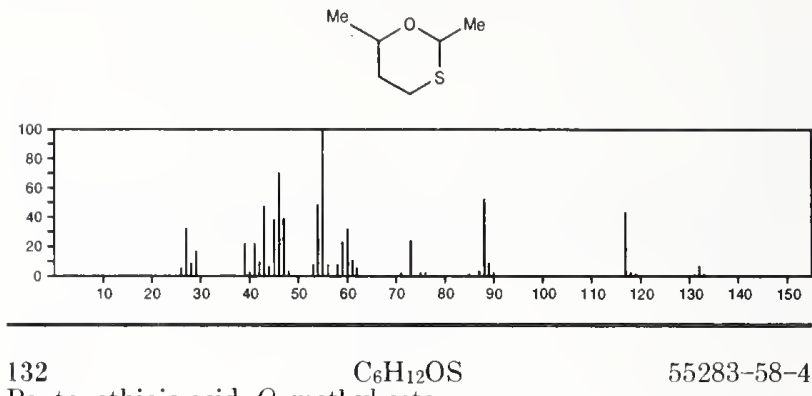

Pentanethioic acid, O-methyl ester

$\mathrm{Me}\left(\mathrm{CH}_{2}\right)_{3} \mathrm{C}(\mathrm{S}) \mathrm{OMe}$

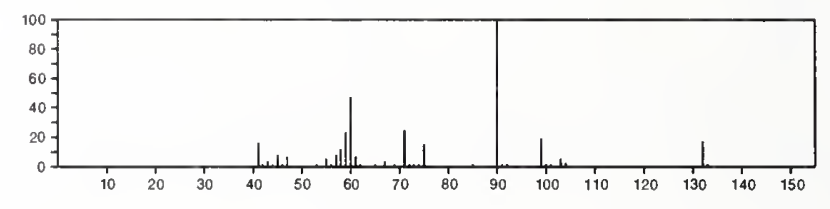

$132 \quad \mathrm{C}_{6} \mathrm{H}_{12} \mathrm{O}_{3}$

$80-55-7$

Propanoic acid, 2-hydroxy-2-methyl-, ethyl ester

$\mathrm{Et} \mathrm{OC}(\mathrm{O}) \mathrm{CMe}_{2} \mathrm{OH}$

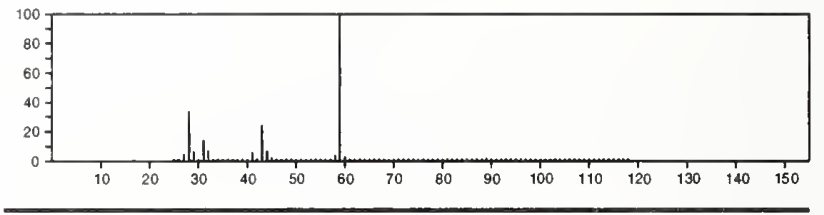

132

$\mathrm{C}_{6} \mathrm{H}_{12} \mathrm{O}_{3}$

$100-79-8$

1,3-Dioxolane-4-methanol, 2,2-dimethyl-
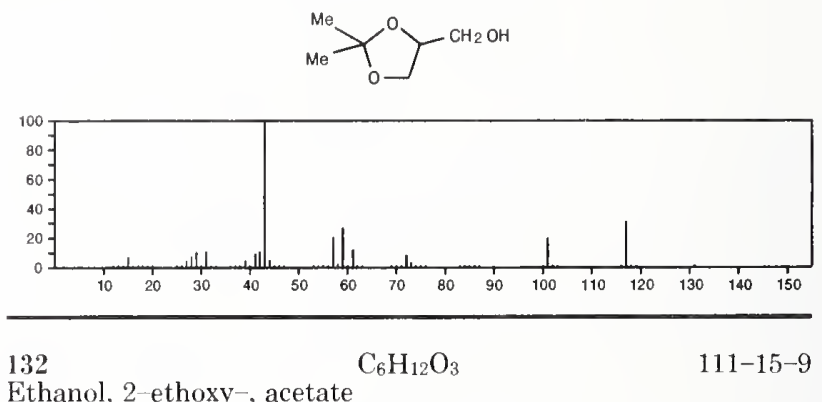

Ethanol, 2-ethoxy-, acetate

$\mathrm{E} T \mathrm{OCH}_{2} \mathrm{CH}_{2} \mathrm{OAC}$

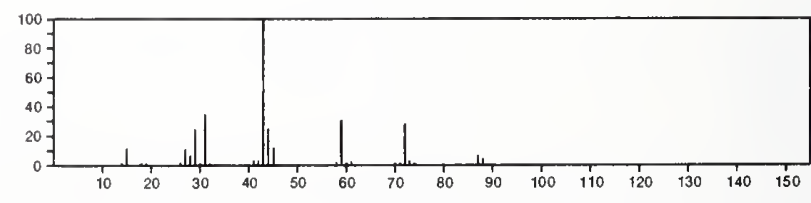

132

1,3,5-Trioxane, 2,4,6-trimethyl

$\mathrm{C}_{6} \mathrm{H}_{12} \mathrm{O}_{3}$

$123-63-7$
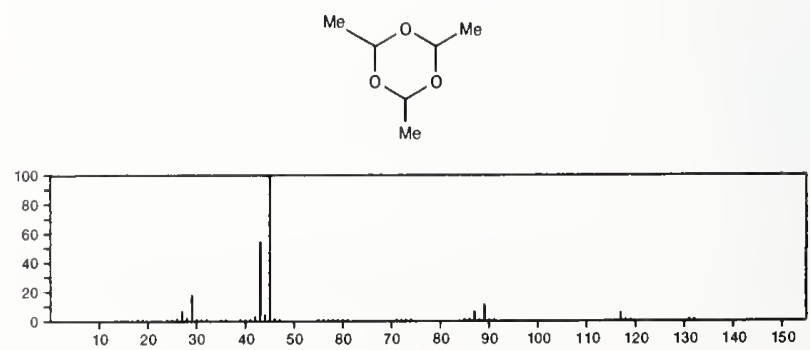
132

$\mathrm{C}_{6} \mathrm{H}_{12} \mathrm{O}_{3}$

$817-95-8$

Acetic acid, ethoxy-, ethyl ester

$\mathrm{E} t \mathrm{OCH}_{2} \mathrm{ClO}$ ) OEt

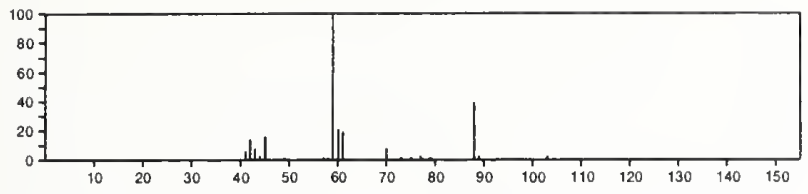

132

$\mathrm{C}_{6} \mathrm{H}_{12} \mathrm{O}_{3}$

Ethanol, 2--[2-(ethenyloxy)ethoxy]

$\mathrm{H}_{2} \mathrm{C}=\mathrm{CHOCH}_{2} \mathrm{CH}_{2} \mathrm{OCH}_{2} \mathrm{CH}_{2} \mathrm{OH}$
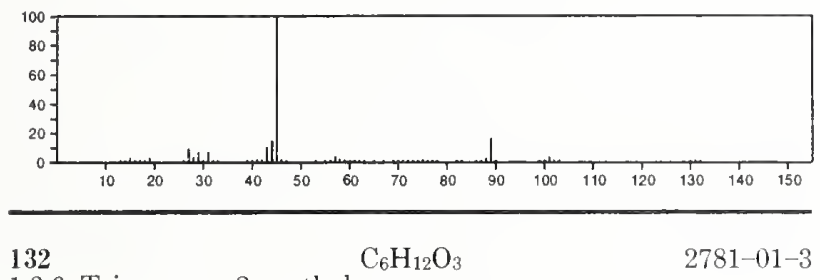

1,3,6-Trioxocane, 2-methyl-
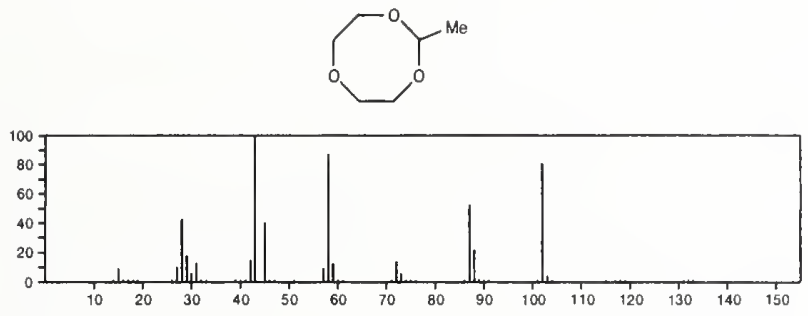

$132 \quad \mathrm{C}_{6} \mathrm{H}_{12} \mathrm{O}_{3}$

1,3-Dioxolane-2-ethanol, 2-methyl-

$5754-32-5$

$$
\sum_{0}^{\mathrm{O}}<_{\mathrm{Me}}^{\mathrm{CH}_{2} \mathrm{CH}_{2} \mathrm{OH}}
$$
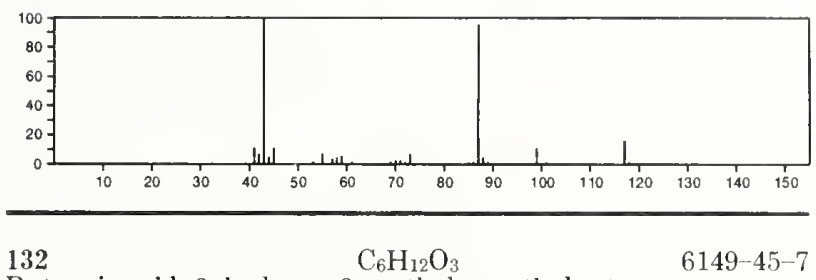

Butanoic acid, 3-hydroxy-3-methyl-, methyl ester

$\mathrm{Me}_{2} \mathrm{COHCH}_{2} \mathrm{C}(\mathrm{O}) \mathrm{OM}_{\mathrm{Me}}$

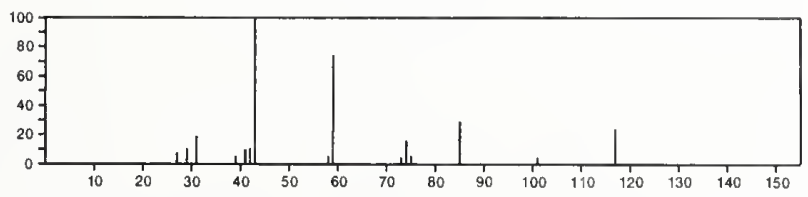

\section{$132 \quad \mathrm{C}_{6} \mathrm{H}_{12} \mathrm{O}_{3}$}

2-Butanone, 4-hydroxy-3-(hydroxymethyl)-3-methyl

$6868-97-9$

COMe

$\mathrm{HOCH}_{2} \mathrm{CMeCH}_{2} \mathrm{OH}$

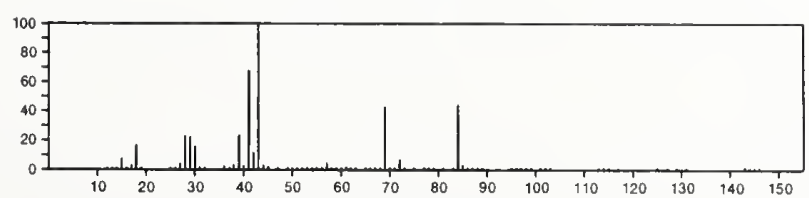

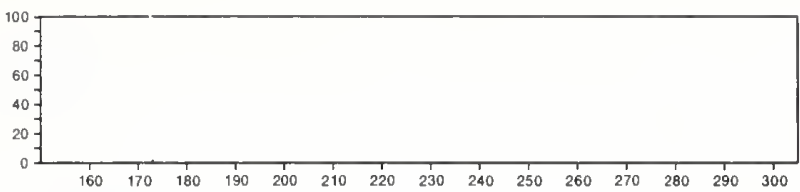

$\mathrm{C}_{6} \mathrm{H}_{12} \mathrm{O}_{3}$

132

methyl-, methyl ester

$17417-00-4$

Butyric acid, 2-hydroxy-3-methyl-methyl
\[ \mathrm{Me}_{2} \mathrm{CHCH}(\mathrm{OH}) \mathrm{C}(\mathrm{O}) \mathrm{OMe} \]

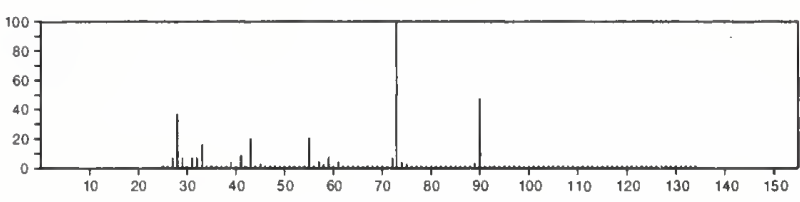

132

1-Propene, 1,3,3-trimethoxy-

$\mathrm{C}_{6} \mathrm{H}_{12} \mathrm{O}_{3}$

$17576-35-1$

(Me O) ${ }_{2} \mathrm{CHCH}=\mathrm{CHOMe}$

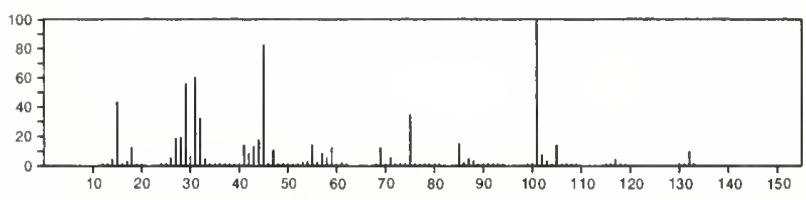

132

$\mathrm{C}_{6} \mathrm{H}_{12} \mathrm{O}_{3}$

$29006-01-7$

Butanoic acid, 4-methoxy-, methyl ester

$\mathrm{MeO}\left(\mathrm{CH}_{2}\right)_{3} \mathrm{C}(\mathrm{O}) \mathrm{OMe}$

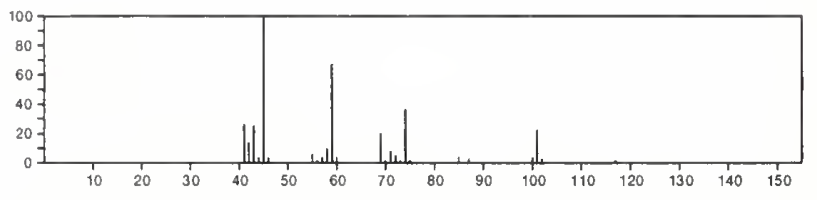

132

$\mathrm{C}_{6} \mathrm{H}_{12} \mathrm{O}_{3}$

$35608-64-1$

Butanoic acid, 3-hydroxy-, ethyl ester, $( \pm)$ -

$\mathrm{MeCH}(\mathrm{OH}) \mathrm{CH}_{2} \mathrm{C}(\mathrm{O}) \mathrm{OEt}$

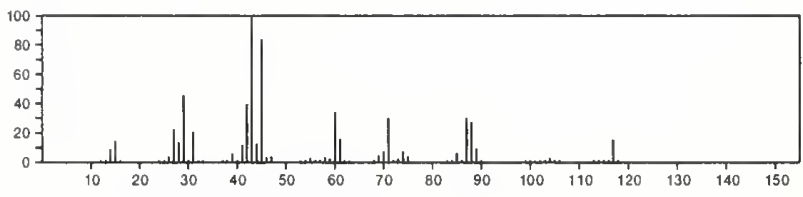

$132 \quad \mathrm{C}_{6} \mathrm{H}_{12} \mathrm{O}_{3}$

Butanoic acid, 2-hydroxy-, ethyl ester

$52089-54-0$

EtOC(O) $\mathrm{CH}(\mathrm{OH}) \mathrm{Et}$

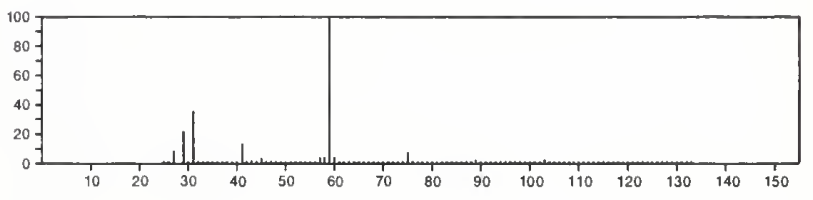


132

$\mathrm{C}_{6} \mathrm{H}_{12} \mathrm{O}_{3}$

$53951-42-1$

$2 H$-Pyran-3,4-diol, tetrahydro-2-methyl-<smiles>O=[N+]([O-])C1OCCC(O)C1O</smiles>

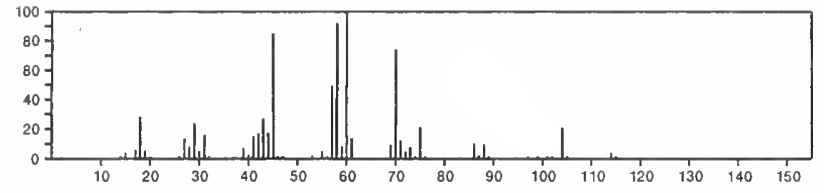

132

$\mathrm{C}_{6} \mathrm{H}_{12} \mathrm{O}_{3}$

$53951-43-2$

1,3-Dioxolane-2-methanol, 2,4-dimethyl-

$$
\sum_{\mathrm{Me}}^{0} \gamma_{\mathrm{Me}}^{\mathrm{CH}_{2} \mathrm{OH}}
$$

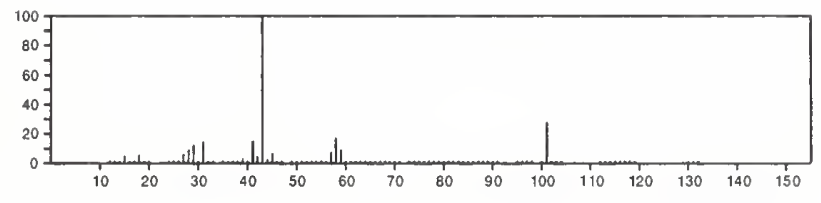

132
$1,3-$ Dioxolane-4-methanol,
$\mathrm{C}_{6} \mathrm{H}_{12} \mathrm{O}_{3}$
2 ethyl-

$53951-44-3$
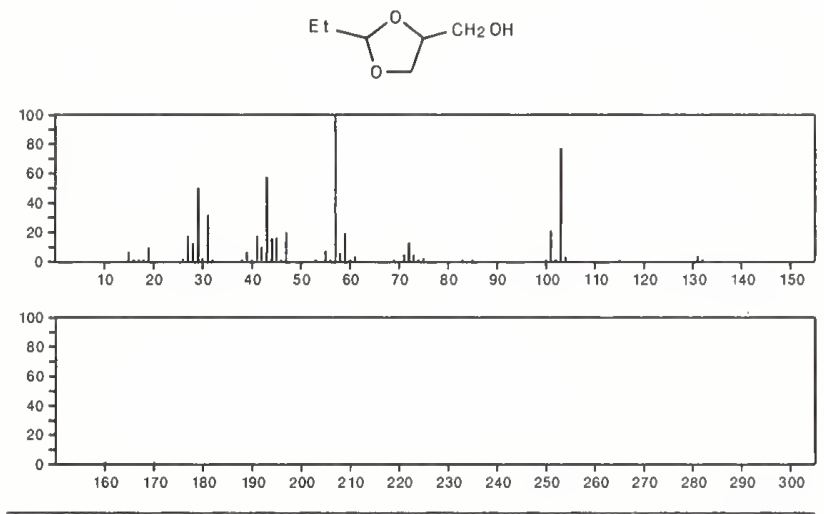

132

$\mathrm{C}_{6} \mathrm{H}_{12} \mathrm{O}_{3}$

$56009-31-5$

Pentanoic acid, 3-hydroxy-, methyl ester

$\mathrm{EtCH}(\mathrm{OH}) \mathrm{CH}_{2} \mathrm{C}(\mathrm{O}) \mathrm{OMe}$

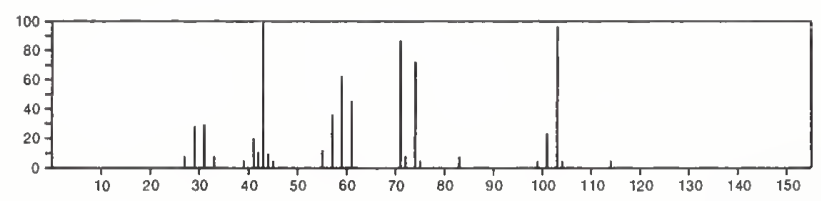

132

$\mathrm{C}_{6} \mathrm{H}_{16} \mathrm{OSi}$

1825-63-4

Silane, trimethylpropoxy-

Me 3 SI OP r

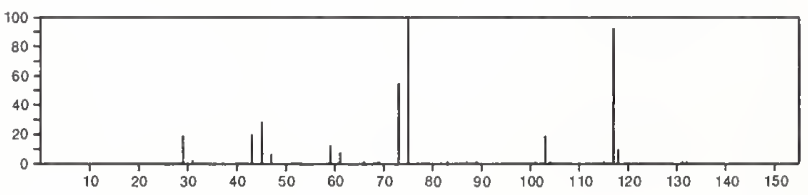

132

$\mathrm{C}_{6} \mathrm{H}_{16} \mathrm{OSi}$

$1825-64-5$

Silane, trimethyl(1-methylethoxy)-

Messiopr-i

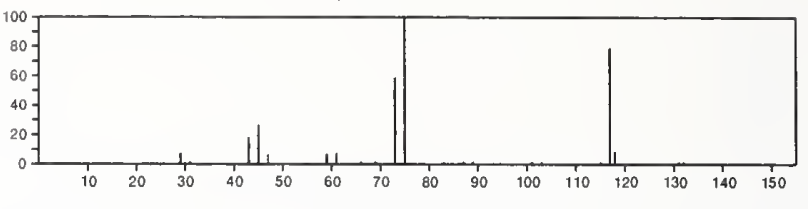

132

$\mathrm{C}_{6} \mathrm{H}_{16} \mathrm{OSi}$

Silane, (2-methoxyethyl)trimethyl

$18173-63-2$

$\mathrm{Me}_{3} \mathrm{Si} \mathrm{CH}_{2} \mathrm{CH}_{2} \mathrm{OMe}_{\mathrm{O}}$

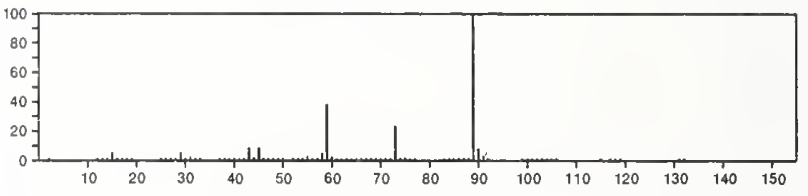

132

2-Heptene, 1-chloro-, (Z)

$\mathrm{C}_{7} \mathrm{H}_{13} \mathrm{Cl}$

$55638-53-4$

$\mathrm{Cl} \mathrm{CH}_{2} \mathrm{CH}=\mathrm{CH}\left(\mathrm{CH}_{2}\right)_{3} \mathrm{Me}$

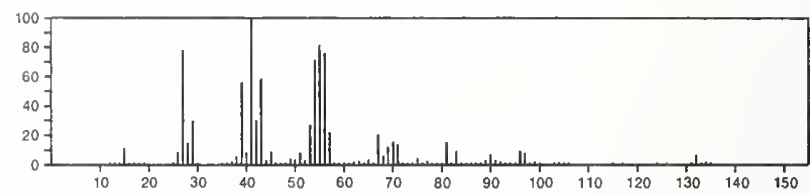

132

$\mathrm{C}_{7} \mathrm{H}_{13} \mathrm{Cl}$

$55682-98-9$

1-Heptene, 3-chloro-

$\mathrm{Me}\left(\mathrm{CH}_{2}\right){ }_{3} \mathrm{CHC}: \mathrm{CH}=\mathrm{CH}_{2}$

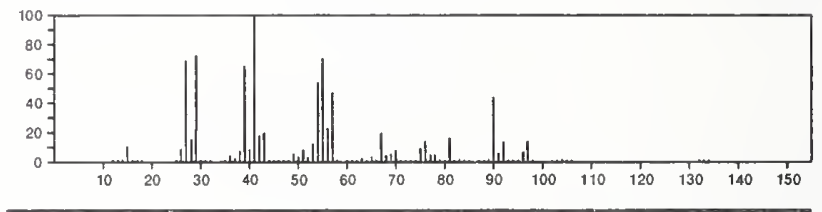

132

$\mathrm{C}_{7} \mathrm{H}_{16} \mathrm{O}_{2}$

1,3-Propanediol, 2-methyl-2-propyl-

$78-26-2$

$\mathrm{HOCH}_{2} \mathrm{CPrMeCH}_{2} \mathrm{OH}$

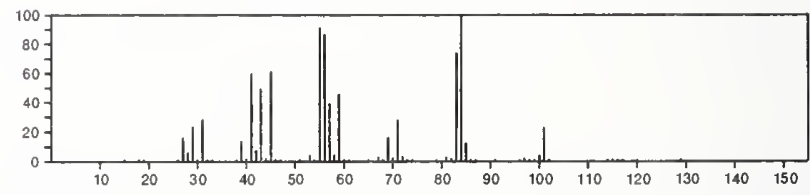

132

$\mathrm{C}_{7} \mathrm{H}_{16} \mathrm{O}_{2}$

$111-89-7$

Pentane, 1,5-dimethoxy-

$\mathrm{MeO}\left(\mathrm{CH}_{2}\right)_{5} \mathrm{OMe}$

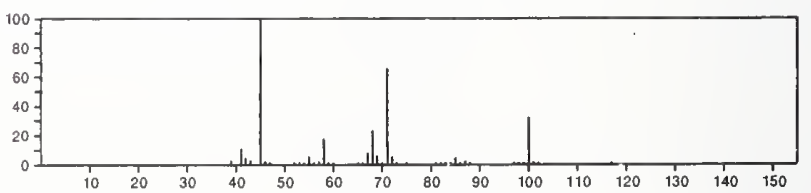


132

1,3-Propanediol, 2,2-diethyl-

$\mathrm{C}_{7} \mathrm{H}_{16} \mathrm{O}_{2}$

$\mathrm{HOCH}_{2} \mathrm{CEt}_{2} \mathrm{CH}_{2} \mathrm{OH}$
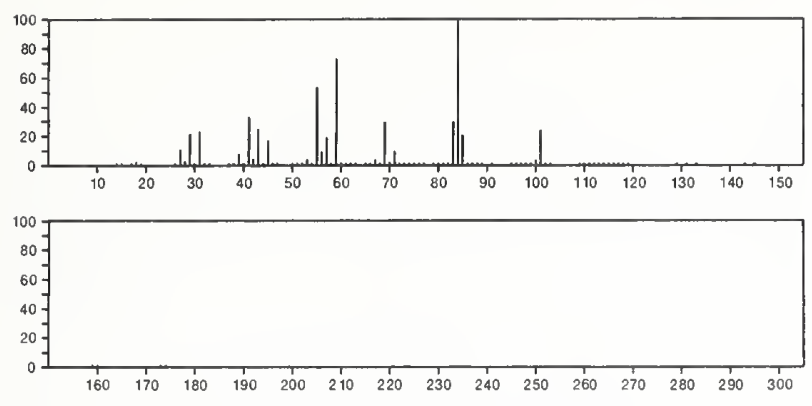

$132 \quad \mathrm{C}_{7} \mathrm{H}_{16} \mathrm{O}_{2} \quad 505-84-0$

Propane, 1,1'-[methylenebis(oxy) ]bis-

$\mathrm{PrOCH}_{2} \mathrm{OPr}$

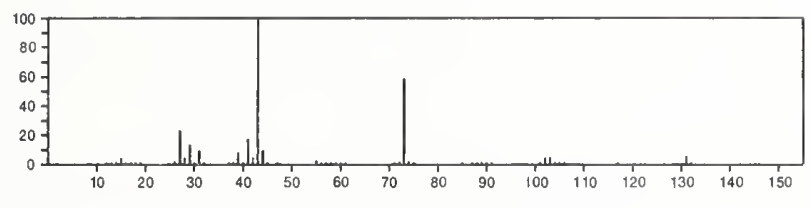

132

$\mathrm{C}_{7} \mathrm{H}_{16} \mathrm{O}_{2}$

$762-46-9$

Hydroperoxide, 1-methylhexyl

$\mathrm{Me}\left(\mathrm{CH}_{2}\right)_{4} \mathrm{CHMeOOH}$

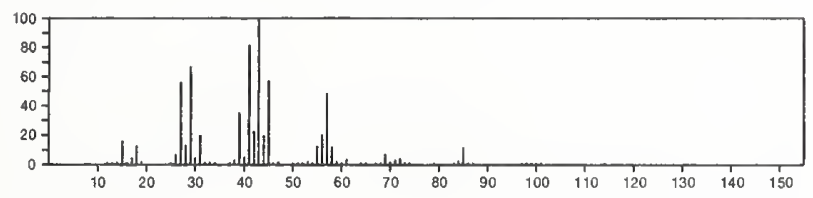

132

$\mathrm{C}_{7} \mathrm{H}_{16} \mathrm{O}_{2}$

764-81-8

Heptyl hydroperoxide

$\mathrm{HOO}\left(\mathrm{CH}_{2}\right) 6 \mathrm{Me}$

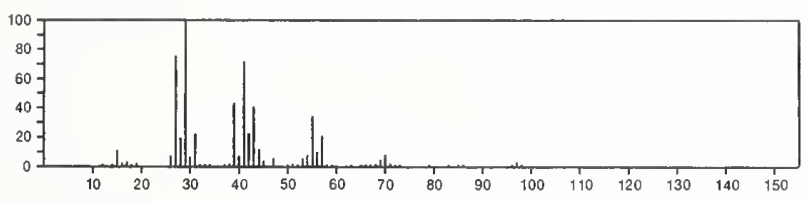

132

$\mathrm{C}_{7} \mathrm{H}_{16} \mathrm{O}_{2}$

Propane, 2,2'-[methylenebis(oxy)]bis -

2568-89-0

$1-\mathrm{Pr} \mathrm{OCH}_{2} \mathrm{OPr}-1$

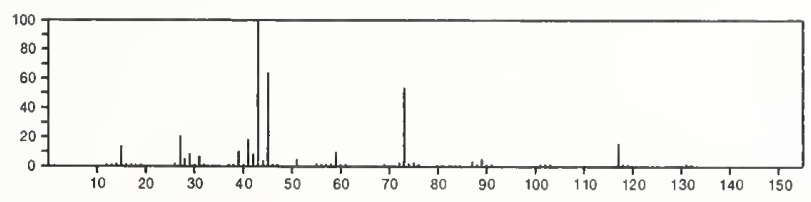

132

$\mathrm{C}_{7} \mathrm{H}_{16} \mathrm{O}_{2}$

2-Propanol, 1-isopropoxy-2-methyl-

$3587-75-5$

i- $\mathrm{PrOCH}_{2} \mathrm{CMe}_{2} \mathrm{OH}$

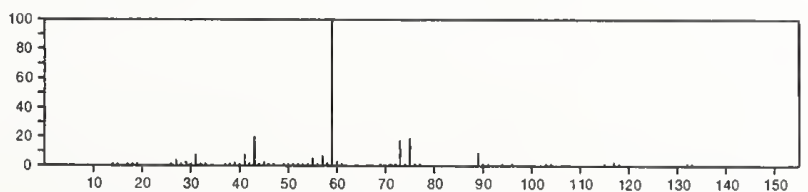

132

1,2-Heptanediol

$\mathrm{C}_{7} \mathrm{H}_{16} \mathrm{O}_{2}$

$3710-31-4$

$\mathrm{Me}\left(\mathrm{CH}_{2}\right)_{4} \mathrm{CH}(\mathrm{OH}) \mathrm{CH}_{2} \mathrm{OH}$

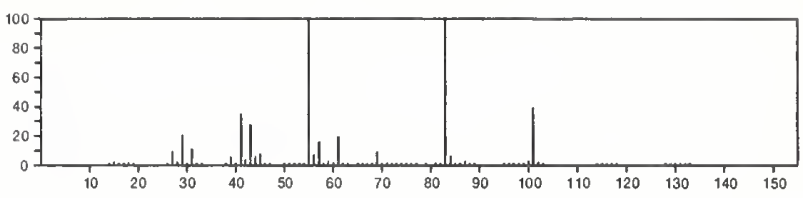

132

Propane, 1,1-diethoxy-

$\mathrm{C}_{7} \mathrm{H}_{16} \mathrm{O}_{2}$

$4744-08-5$

$\mathrm{EtCH}(\mathrm{OEt})_{2}$

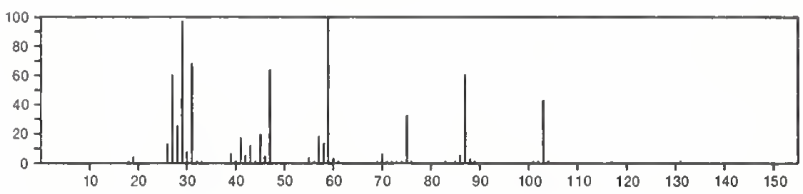

132

2-Propanol, 1-butoxy-

$\mathrm{C}_{7} \mathrm{H}_{16} \mathrm{O}_{2}$

$5131-66-8$

$\mathrm{MeCH}(\mathrm{OH}) \mathrm{CH}_{2} \mathrm{O}\left(\mathrm{CH}_{2}\right)_{3} \mathrm{Me}$

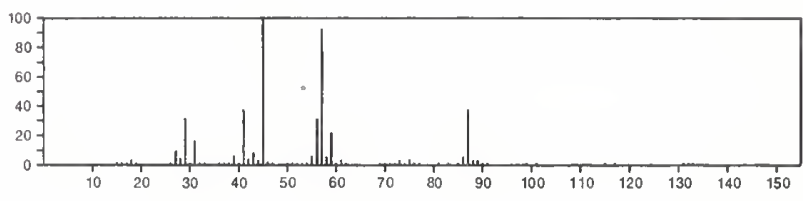

132

Butane, 1-(2-methoxyethoxy)-

$\mathrm{C}_{7} \mathrm{H}_{16} \mathrm{O}_{2}$

13343-98-1

$\mathrm{Me}\left(\mathrm{CH}_{2}\right)_{3} \mathrm{OCH}_{2} \mathrm{CH}_{2} \mathrm{OMe}$

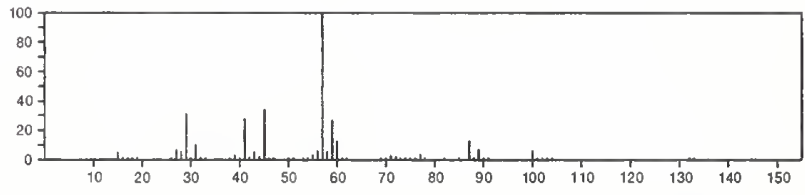

132

$\mathrm{C}_{7} \mathrm{H}_{16} \mathrm{O}_{2}$

$20637-32-5$

Propane, 1,3-dimethoxy-2,2-dimethyl-

$\mathrm{Me} \mathrm{OCH}_{2} \mathrm{CMe}_{2} \mathrm{CH}_{2} \mathrm{OMe}$

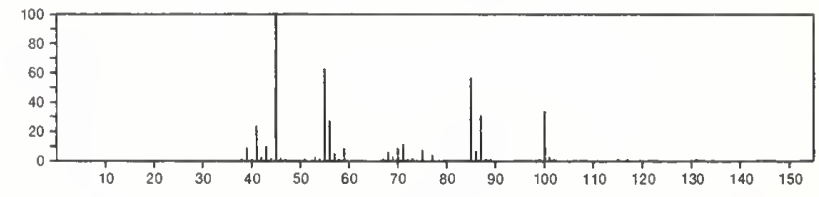

132

2-Propanol, 1-(2-methylpropoxy)-

$23436-19-3$

$\mathrm{MeCH}(\mathrm{OH}) \mathrm{CH}_{2} \mathrm{OBu}-\mathrm{i}$

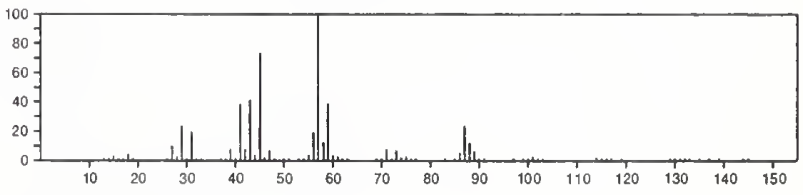


132

$\mathrm{C}_{7} \mathrm{H}_{16} \mathrm{O}_{2}$

$31600-69-8$

1-Butanol, 4-(1-methylethoxy)

$\mathrm{HO}\left(\mathrm{CH}_{2}\right){ }_{4} \mathrm{OPr}-\mathrm{i}$

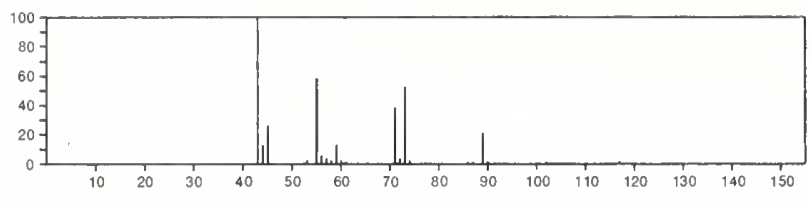

$132 \quad \mathrm{C}_{7} \mathrm{H}_{16} \mathrm{O}_{2} \quad 53907-95-2$

2-Propanol, 1-(1-methylpropoxy)

$\mathrm{MeCH}(\mathrm{OH}) \mathrm{CH}_{2} \mathrm{OBu}-\mathrm{s}$
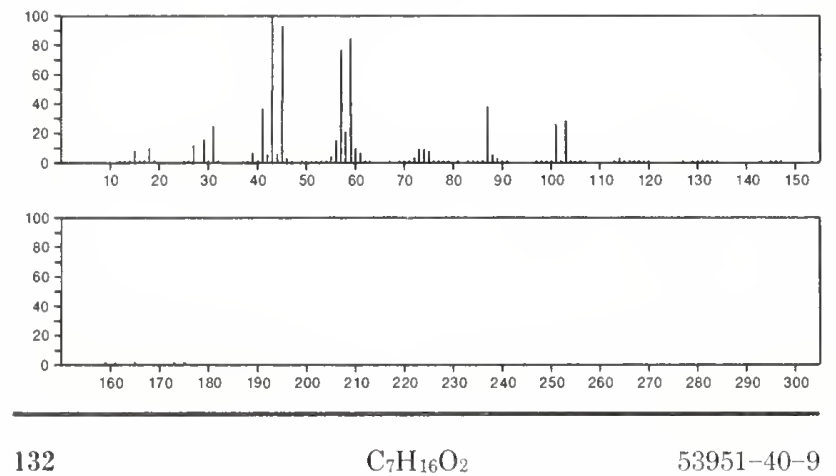

Propane, 2-methoxy-2-propoxy-

$\mathrm{Me} 2 \mathrm{C}(\mathrm{OPr}) \mathrm{OMe}$

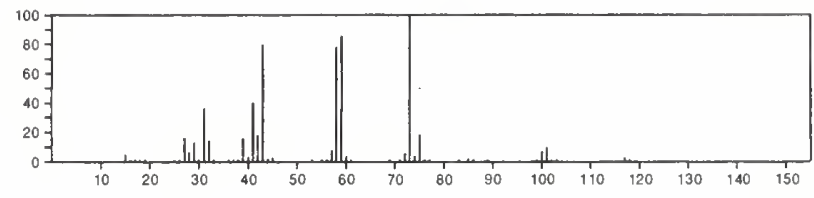

132

$\mathrm{C}_{7} \mathrm{H}_{16} \mathrm{O}_{2}$

- methyl-

55724-04-4

$\mathrm{MeO}\left(\mathrm{CH}_{2}\right)_{3} \mathrm{CMe}_{2} \mathrm{OH}$

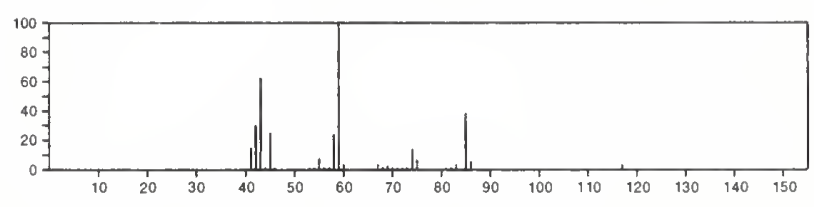

132

Butane, 1-(propylthio)

$\mathrm{C}_{7} \mathrm{H}_{16} \mathrm{~S}$

$1613-46-3$

$\operatorname{Me}\left(\mathrm{CH}_{2}\right)_{3} \mathrm{SPr}$

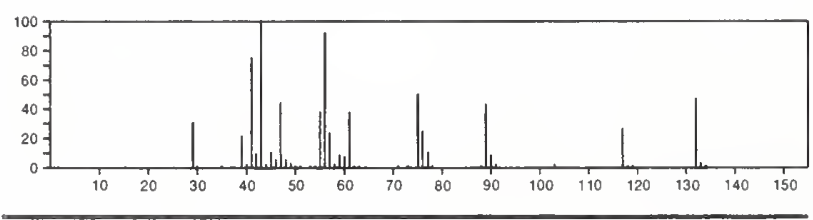

132

1-Heptanethiol

$\mathrm{C}_{7} \mathrm{H}_{16} \mathrm{~S}$

$1639-09-4$

$\mathrm{Me}\left(\mathrm{CH}_{2}\right)_{6} \mathrm{SH}$

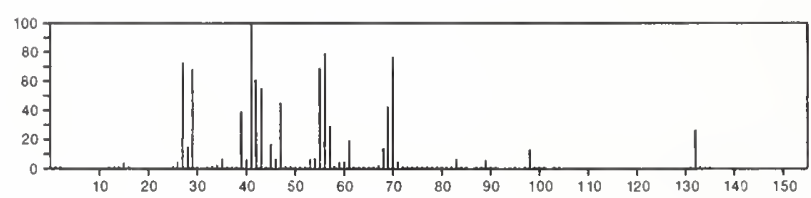

1.32

$\mathrm{C}_{7} \mathrm{H}_{16} \mathrm{~S}$

$1741-84-0$

Propane, 2-methyl-1-(propylthio)

PrSBu-i

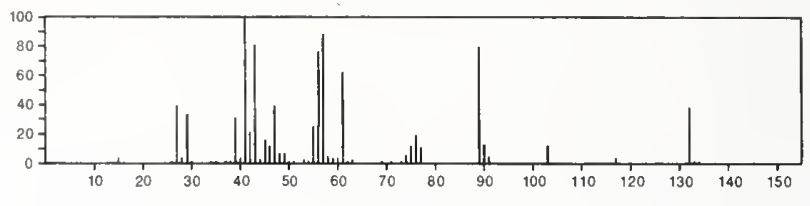

$132 \quad \mathrm{C}_{7} \mathrm{H}_{16 \mathrm{~S}}$

2-Hexanethiol, 2-methyl-

$1812-50-6$

$\mathrm{Me}_{2} \mathrm{CSH}\left(\mathrm{CH}_{2}\right)_{3} \mathrm{Me}$

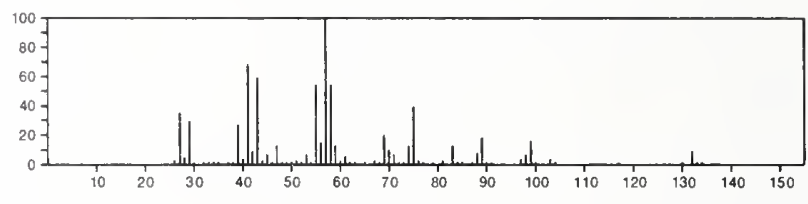

132

$\mathrm{C}_{7} \mathrm{H}_{16} \mathrm{~S}$

$7309-43-5$

Sulfide, butyl isopropyl

$\mathrm{Me}\left(\mathrm{CH}_{2}\right)_{3} \mathrm{SPr}-\mathrm{i}$

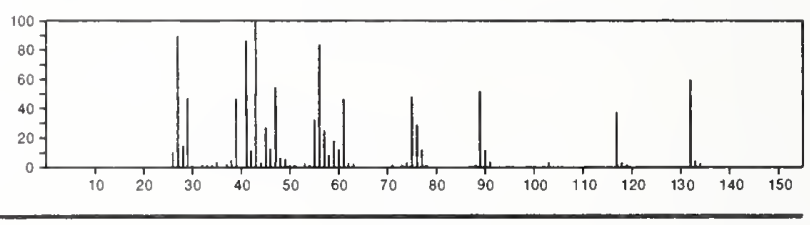

132

$\mathrm{C}_{7} \mathrm{H}_{16} \mathrm{~S}$

$20291-60-5$

Hexane, 1-(methylthio)

$\mathrm{MeS}\left(\mathrm{CH}_{2}\right) 5 \mathrm{Me}$

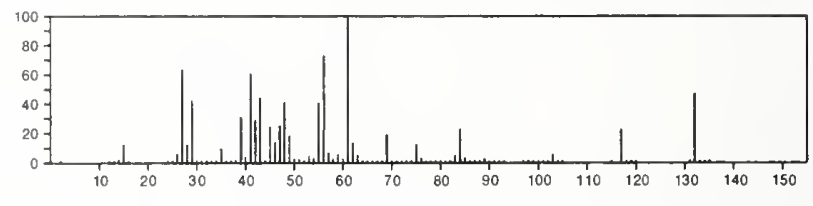

132

Sulfide, sec-butyl isopropyl

$\mathrm{C}_{7} \mathrm{H}_{16} \mathrm{~S}$

$22438-36-4$

$s-B u S P r-i$

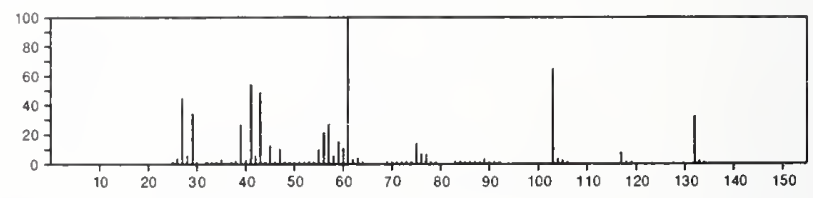

132

Pentane, 1-(ethylthio)

$\mathrm{C}_{7} \mathrm{H}_{16} \mathrm{~S}$

26158-99-6

$\mathrm{Me}\left(\mathrm{CH}_{2}\right){ }_{4} \mathrm{SEt}$

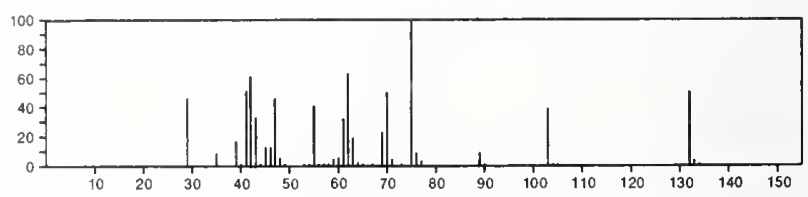


132

Propane, 2-methyl-2-[(1-methylethyl)thio]

t-BuSPr-i

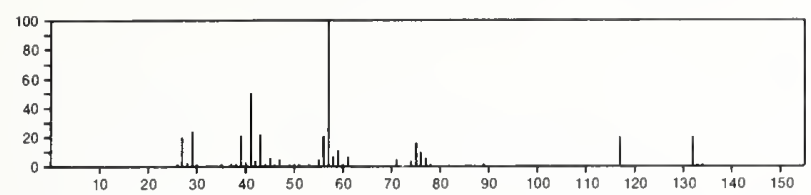

132

$1 H$-Benzimidazole, 2-methyl

$\mathrm{C}_{8} \mathrm{H}_{8} \mathrm{~N}_{2}$

$615-15-6$
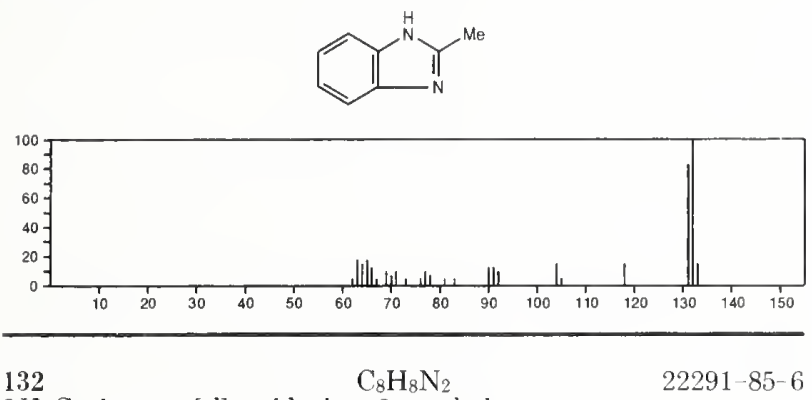

$2 H$-Cyclopenta[d]pyridazine, 2-methyl-
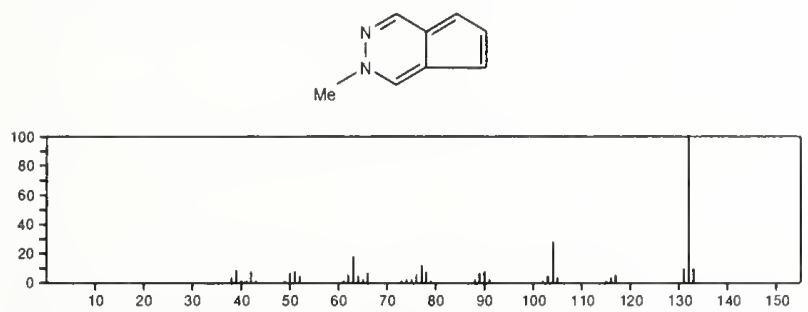

$132 \quad \mathrm{C}_{8} \mathrm{H}_{8} \mathrm{~N}_{2}$

$1 H$-Pyrrolo[2,3-b]pyridine, 2-methyl-
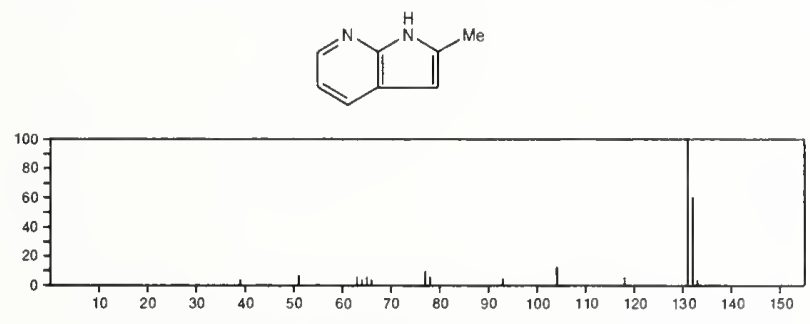

132

$\mathrm{C}_{8} \mathrm{H}_{8} \mathrm{~N}_{2}$

$1 H$-Pyrrolo[2,3-b]pyridine, 1-methyl-
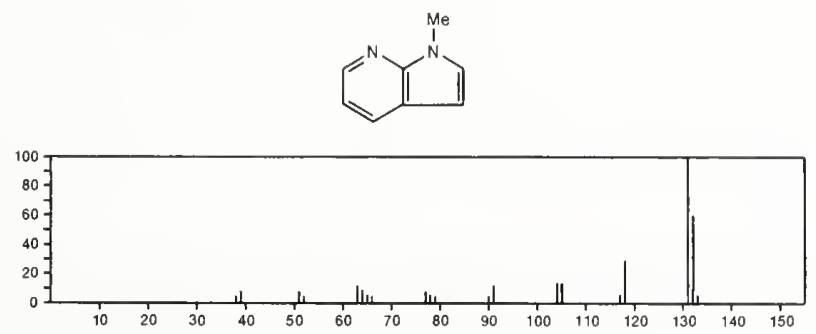

132

$\mathrm{C}_{9} \mathrm{H}_{8} \mathrm{O}$

83-33-0
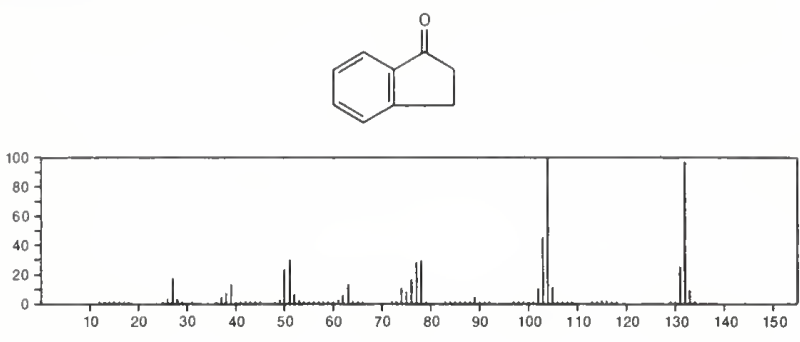

132

$\mathrm{C}_{9} \mathrm{H}_{8} \mathrm{O}$

$104-55-2$

2-Propenal, 3-phenyl

$\mathrm{OCHCH}=\mathrm{CHPh}$

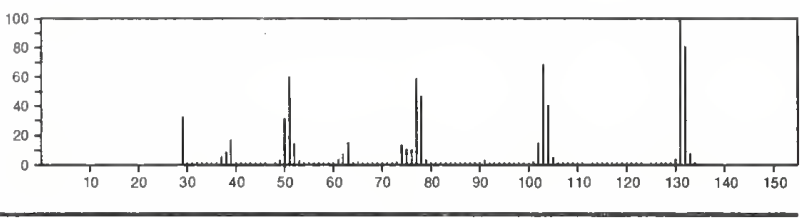

132

$\mathrm{C}_{9} \mathrm{H}_{8} \mathrm{O}$

$4187-87-5$

Benzenemethanol, $\alpha$-ethynyl-

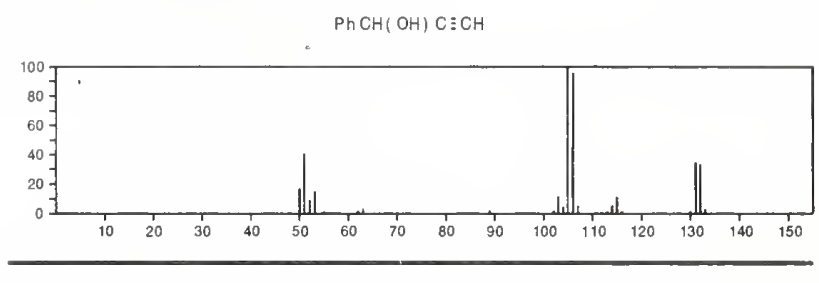

132

$\mathrm{C}_{9} \mathrm{H}_{8} \mathrm{O}$

$4265-25-2$

Benzofuran, 2-methyl-
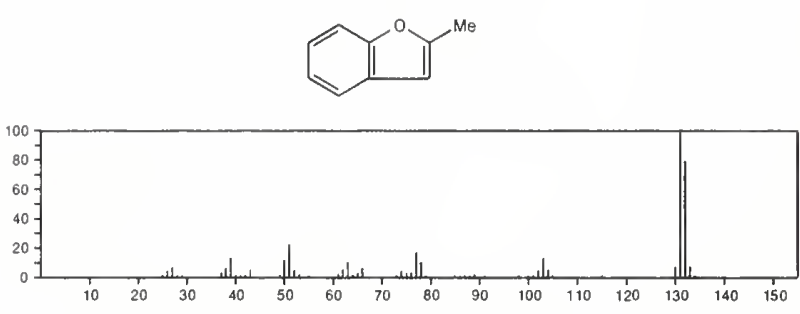

132

$\mathrm{C}_{9} \mathrm{H}_{8} \mathrm{O}$

$13610-02-1$

Benzene, (2-propynyloxy)

$\mathrm{PhOCH}_{2} \mathrm{C} \equiv \mathrm{CH}$

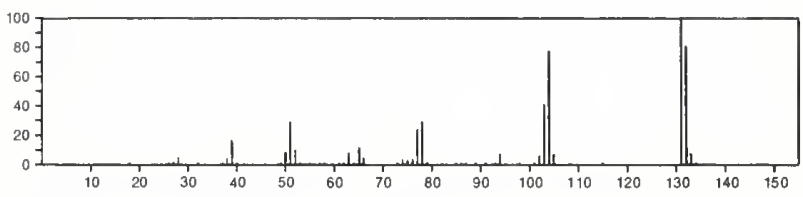

132

Benzofuran, 7-methyl-

$\mathrm{C}_{9} \mathrm{H}_{8} \mathrm{O}$

$17059-52-8$
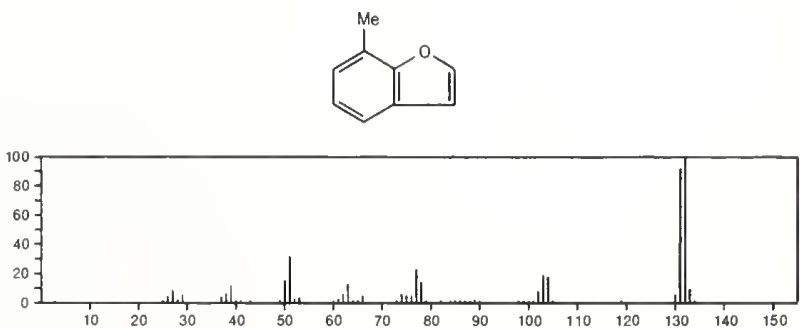
132

$\mathrm{C}_{9} \mathrm{H}_{8} \mathrm{O}$

$30844-12-3$

1,3,5,7-Cyclooctatetraene--1-carboxaldehyde
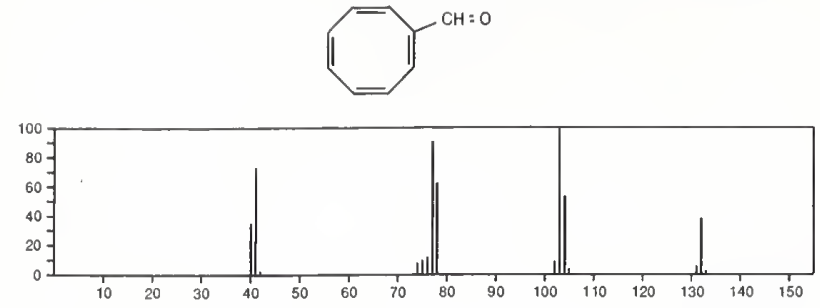

132

$\mathrm{C}_{9} \mathrm{H}_{8} \mathrm{O}$

$43145-54-6$

Benzaldehyde, ethenyl
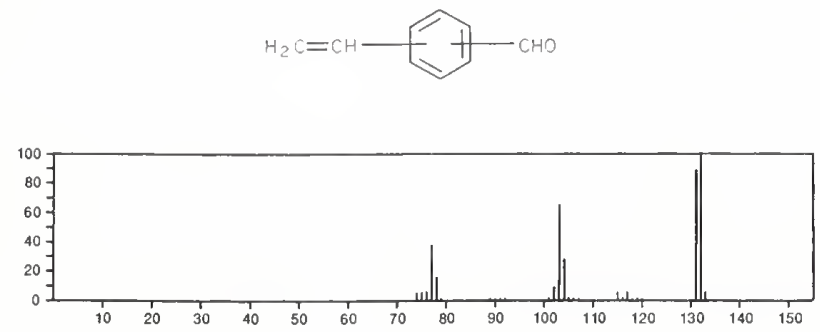

132

4,7-Methano-1H-indene, 3a,4,7,7a-tetrahydro-

$77-73-6$
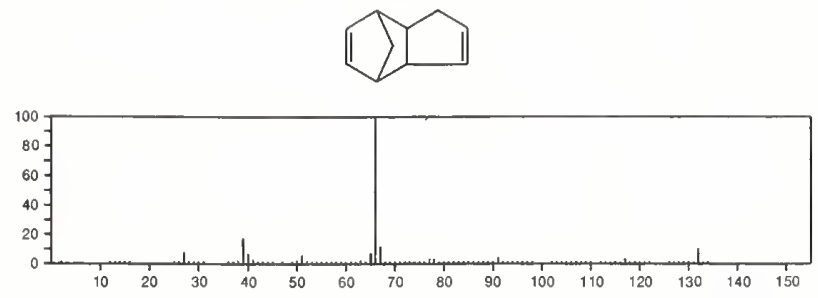

132

$\mathrm{C}_{10} \mathrm{H}_{12}$

119-64-2

Naphthalene, 1,2,3,4-tetrahydro-
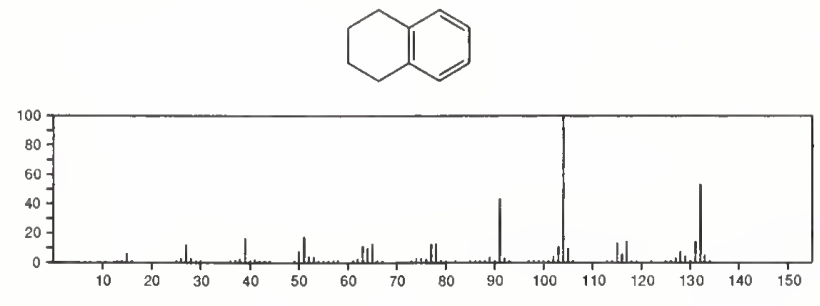

$132 \quad \mathrm{C}_{10} \mathrm{H}_{12}$

$1 H$-Indene, 2,3-dihydro-1-methyl-

$767-58-8$
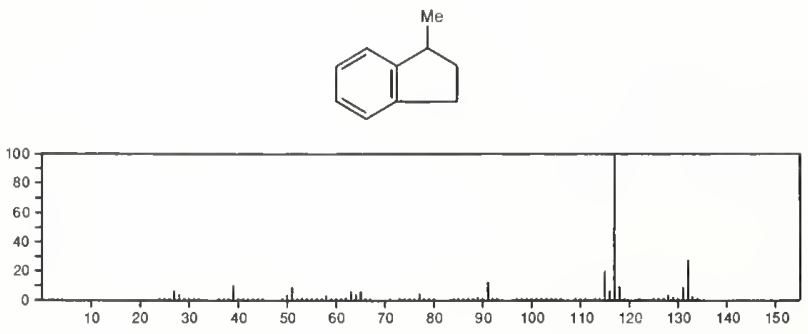

132

$\mathrm{C}_{10} \mathrm{H}_{12}$

$768-49-0$

Benzene, (2-methyl-1-propenyl)-

$\mathrm{Me}_{2} \mathrm{C}=\mathrm{CHPh}$

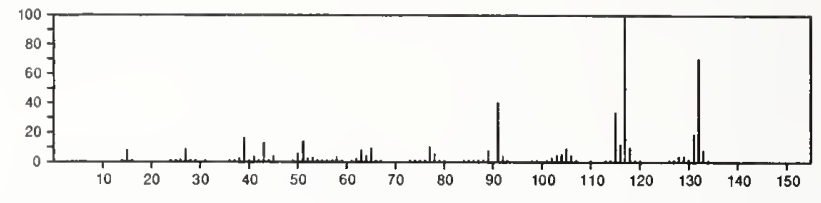

132

1H-Indene, 2,3-dihydro-4-methyl-

$824-22-6$
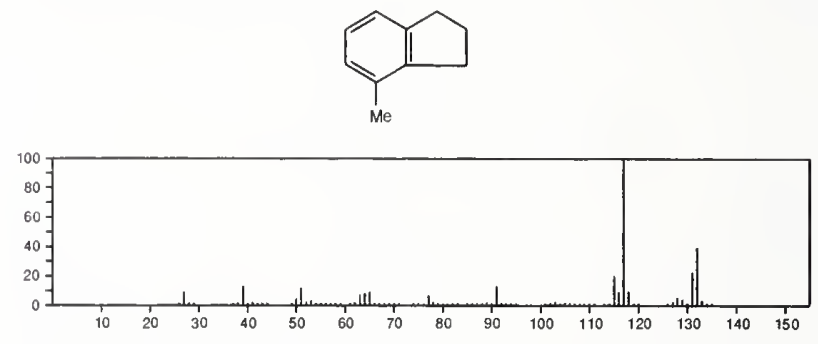

132

$\mathrm{C}_{10} \mathrm{H}_{12}$

1H-Indene, 2,3-dihydro-2-methyl-

$824-63-5$
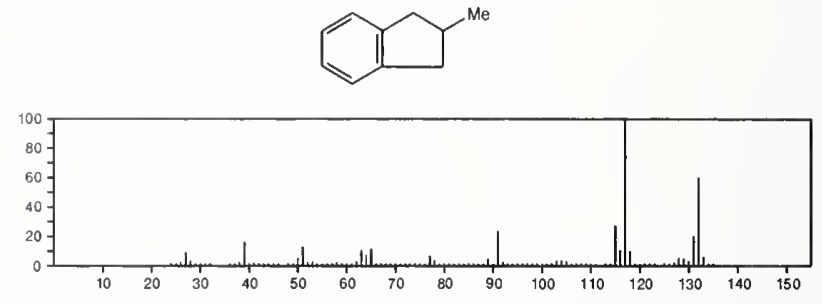

132

$\mathrm{C}_{10} \mathrm{H}_{12}$

$874-35-1$

1H-Indene, 2,3-dihydro-5-methyl-
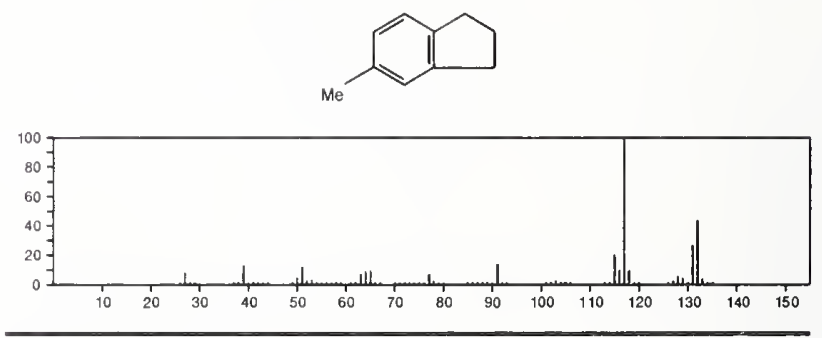

132

$\mathrm{C}_{10} \mathrm{H}_{12}$

Benzene, 1-methyl-4-(1-methylethenyl)

$1195-32-0$
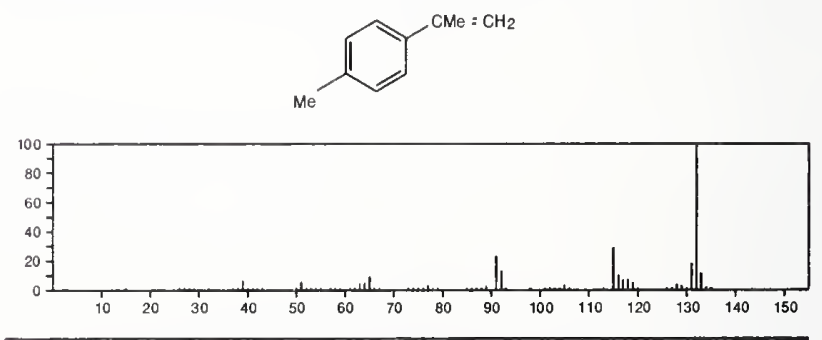

132

$\mathrm{C}_{10} \mathrm{H}_{12}$

1560-06-1

Benzene, 2-butenyl-

$\mathrm{PhCH}_{2} \mathrm{CH}=\mathrm{CHM}$

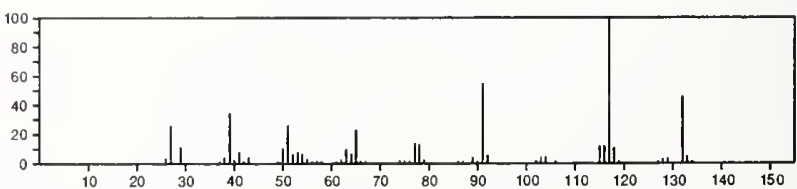


132 $\mathrm{C}_{10} \mathrm{H}_{12}$

Benzene, 1-methyl-2-(2-propenyl)-
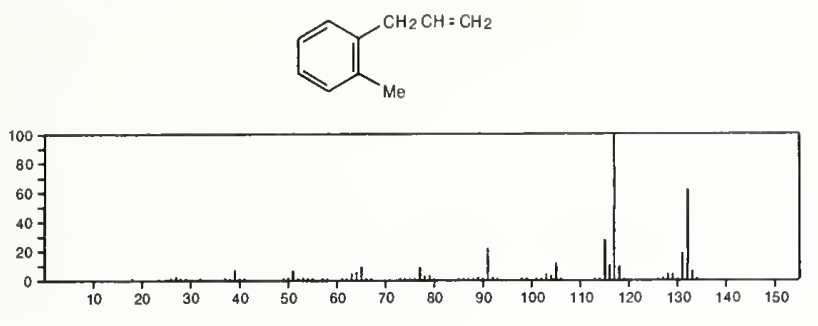

$$
132
$$

132

132
Benzene, 2-ethenyl-1,3-dimethyl-
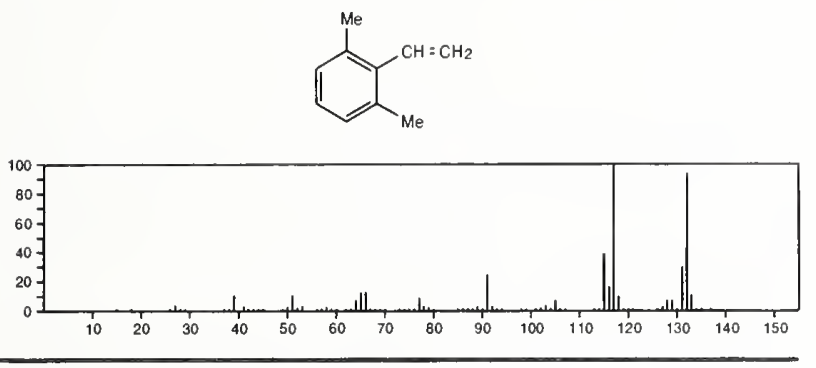

132

$\mathrm{C}_{10} \mathrm{H}_{12}$

Benzene, (2-methyl-2-propenyl)-

$\mathrm{H}_{2} \mathrm{C}=\mathrm{CMOCH}_{2} \mathrm{Ph}$

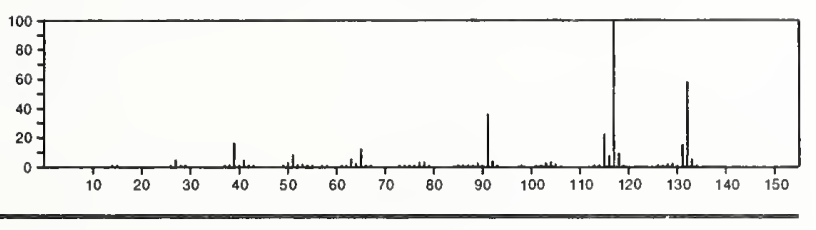

132

$\mathrm{C}_{10} \mathrm{H}_{12}$

$3454-07-7$

Benzene, 1-ethenyl-4-ethyl-
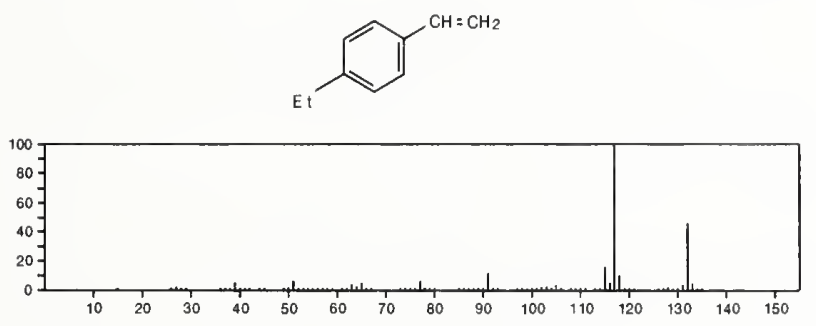

132

Benzene, cyclobutyl-

$\mathrm{C}_{10} \mathrm{H}_{12}$

4392-30-7

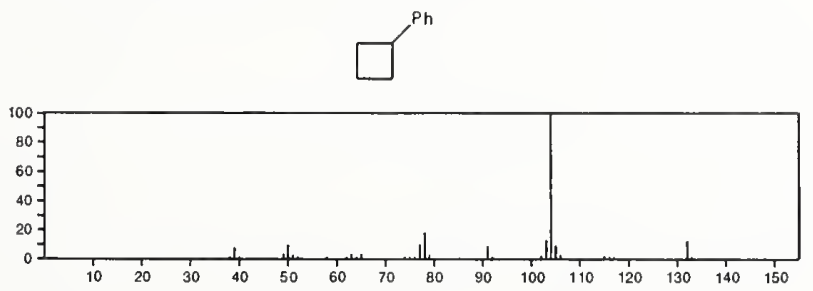

132

$\mathrm{C}_{10} \mathrm{H}_{12}$

Benzene, 1-ethenyl-3,5 dimethyl-

5379-20-4
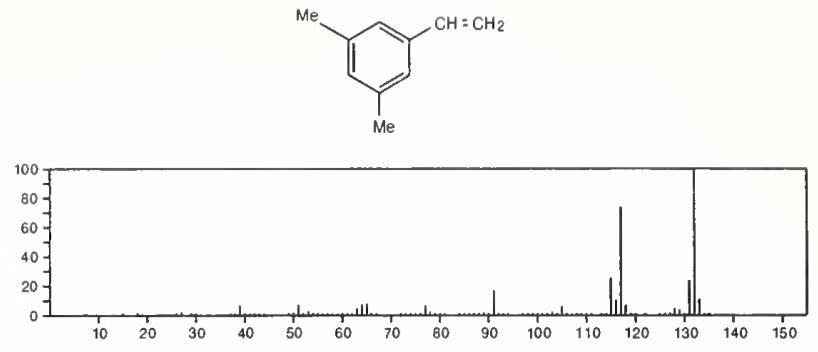

132
Benzene, 1-ethenyl-3-ethyl-
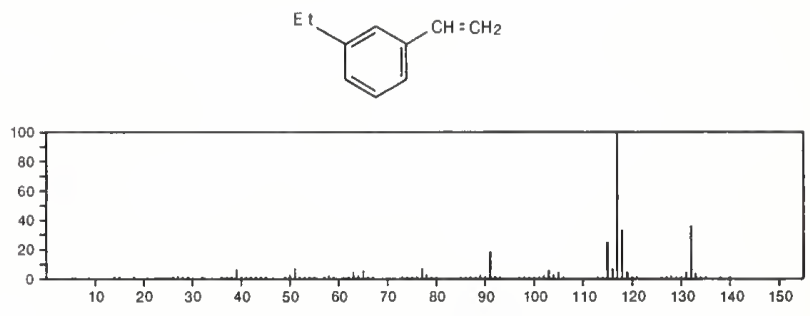

132

$=\mathrm{C}_{10} \mathrm{H}_{12}$

Benzene, methyl(1-methylethenyl)-

26444-18-8
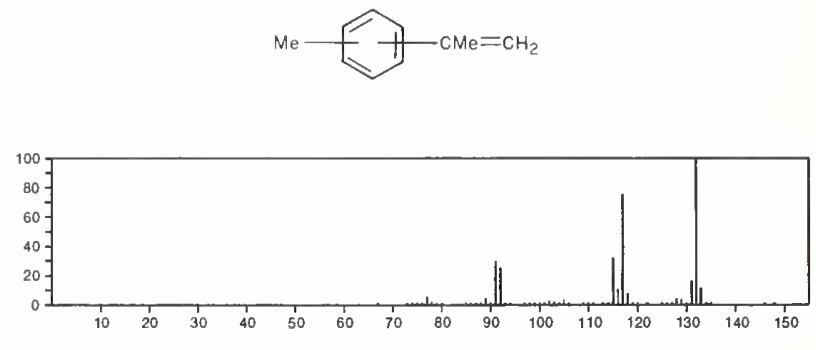

132

$\mathrm{C}_{10} \mathrm{H}_{12}$

Benzene, ethenyl-, dimethyl deriv.

27576-03-0

$\mathrm{PhCH}=\mathrm{CH}_{2}+2 \mathrm{Me}$

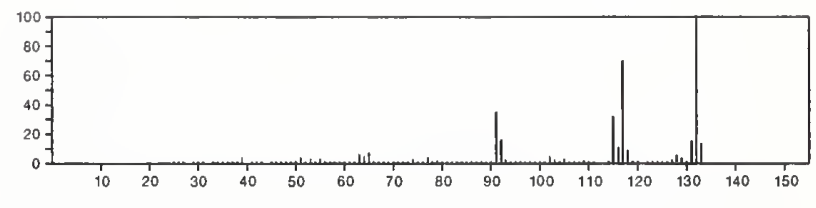

132

$\mathrm{C}_{10} \mathrm{H}_{12}$

27831-13-6

Benzene, 4-ethenyl-1,2-dimethyl-
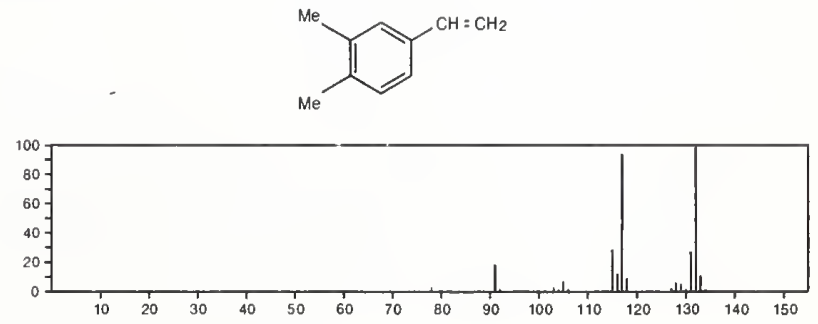
132

$\mathrm{C}_{10} \mathrm{H}_{12}$

33877-87-1

Azulene, 1,2,3,3a-tetrahydro-
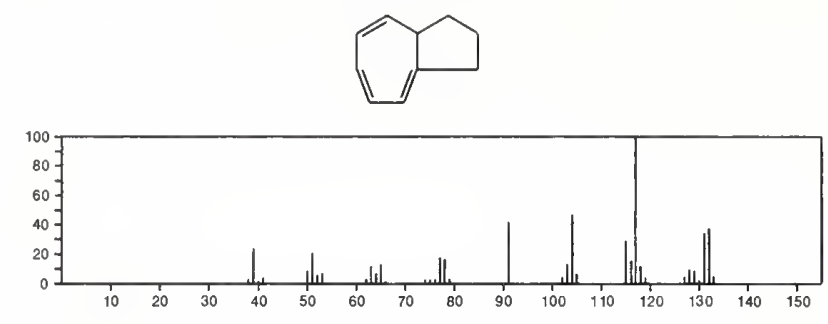

132

Xenon

$\mathrm{Xe}$

$x_{e}$

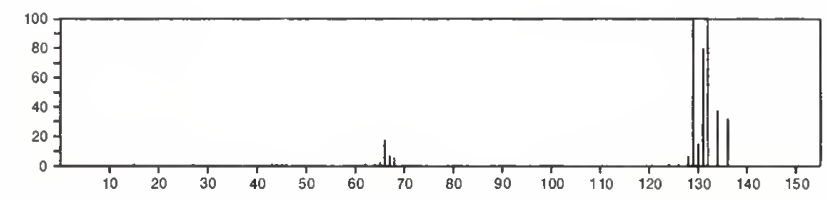

\begin{tabular}{lll}
\hline $\mathrm{C}_{2} \mathrm{H}_{3} \mathrm{ClF}_{3} \mathrm{~N}$ & $16276-45-2$
\end{tabular}

Ethylamine, $N$-chloro- $N, 1,1$-trifluoro-

$\mathrm{CINFCF}_{2} \mathrm{Me}$

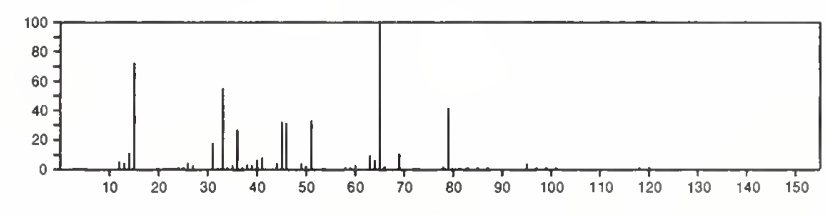

133

\section{$\mathrm{C}_{3} \mathrm{H}_{4} \mathrm{BrN}$}

$2417-90-5$

Propanenitrile, 3-bromo-

$\mathrm{Br} \mathrm{CH}_{2} \mathrm{CH}_{2} \mathrm{CN}$

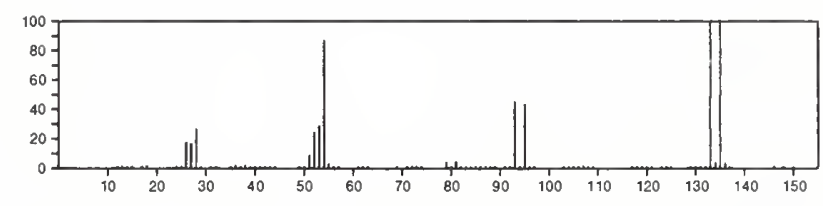

133

Carbamic acid, acetylthio-, $\mathrm{O}^{- \text {methyl ester }}$

$16696-87-0$

ACNHC( S) OMe

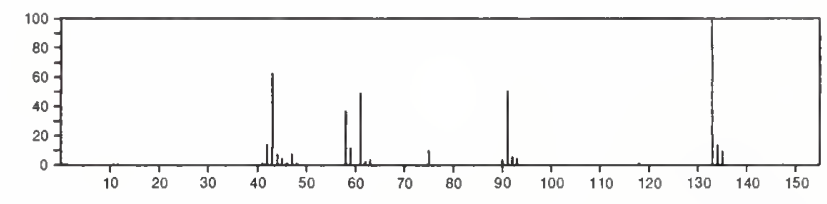

133

L-Aspartic acid

$\mathrm{C}_{4} \mathrm{H}_{7} \mathrm{NO}_{4}$

$56-84-8$

$\mathrm{HO}_{2} \mathrm{CCH}_{2} \mathrm{CH}\left(\mathrm{NH}_{2}\right) \mathrm{CO}_{2} \mathrm{H}$

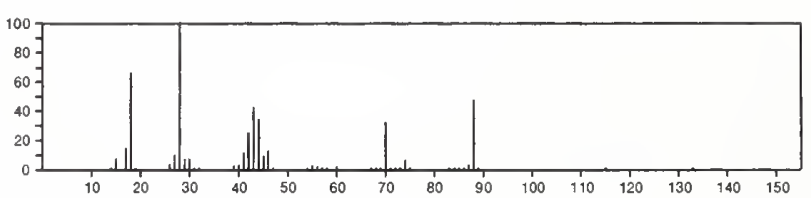

133

Butanoic acid, 4-nitro-

$\mathrm{C}_{4} \mathrm{H}_{7} \mathrm{NO}_{4}$

$16488-43-0$

$\mathrm{HO}_{2} \mathrm{C}\left(\mathrm{CH}_{2}\right){ }_{3} \mathrm{NO}_{2}$

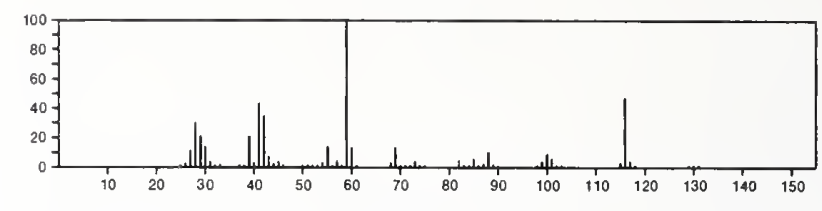

133

DL-Serine, $N$-formyl-

$\mathrm{C}_{4} \mathrm{H}_{7} \mathrm{NO}_{4}$

$57274-55-2$

$\mathrm{O}=\mathrm{CHNHCH}\left(\mathrm{CO}_{2} \mathrm{H}\right) \mathrm{CH}_{2} \mathrm{OH}$

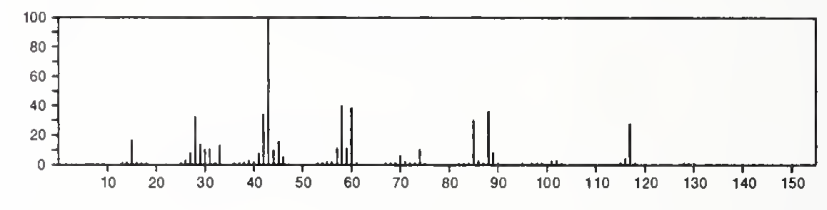

133

1-Butanol, 3-methyl-, nitrate

$543-87-3$

$\mathrm{Me}_{2} \mathrm{CHCH}_{2} \mathrm{CH}_{2} \mathrm{ONO}_{2}$

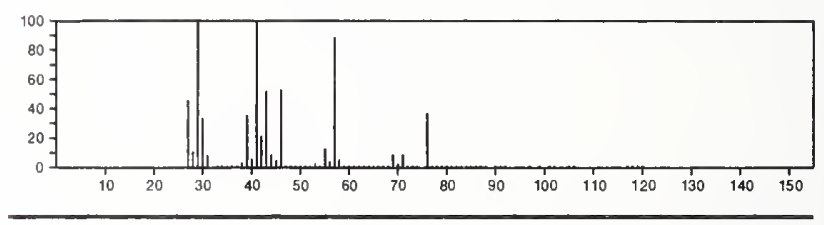

133

1-Propanol, 2,2-dimethyl-,

$926-42-1$

$\mathrm{O}_{2} \mathrm{NOCH}_{2} \mathrm{CMe}_{3}$

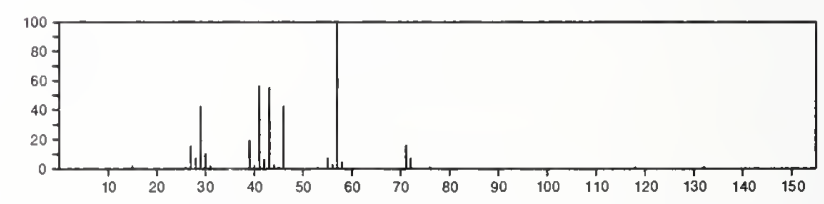

133

Nitric acid, pentyl ester

$\mathrm{C}_{5} \mathrm{H}_{11} \mathrm{NO}_{3}$

$1002-16-0$

$\mathrm{Me}\left(\mathrm{CH}_{2}\right)_{4} \mathrm{ONO}_{2}$

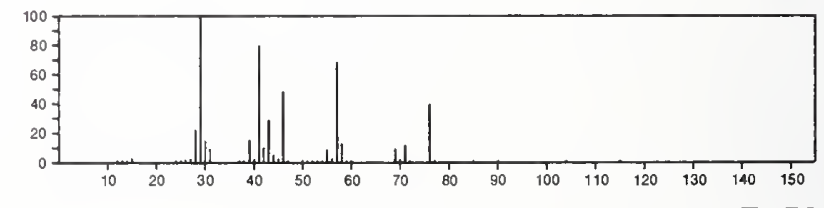

133

L-Serine, ethyl ester

$\mathrm{C}_{5} \mathrm{H}_{11} \mathrm{NO}_{3}$

4117-31-1

$\left.\mathrm{HOCH}_{2} \mathrm{CH}\left(\mathrm{NH}_{2}\right) \mathrm{ClO}\right) \mathrm{OEI}$

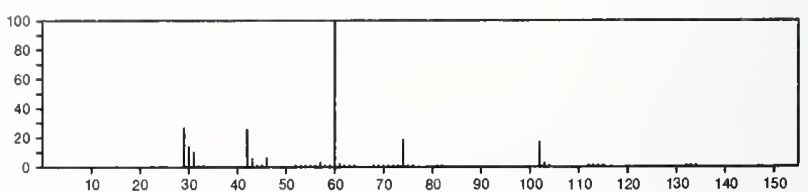


133

$\mathrm{C}_{6} \mathrm{H}_{15} \mathrm{NO}_{2}$

Ethanol, 2-(diethylamino)-, $\mathrm{N}$-oxide

$\mathrm{O}=\mathrm{NE}_{2} \mathrm{CH}_{2} \mathrm{CH}_{2} \mathrm{OH}$

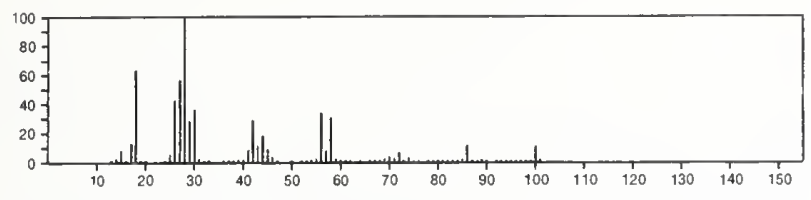

133

$\mathrm{C}_{7} \mathrm{H}_{7} \mathrm{~N}_{3}$

$[1,2,4]$ Triazolo[1,5-a]pyridine, 2-methyl-
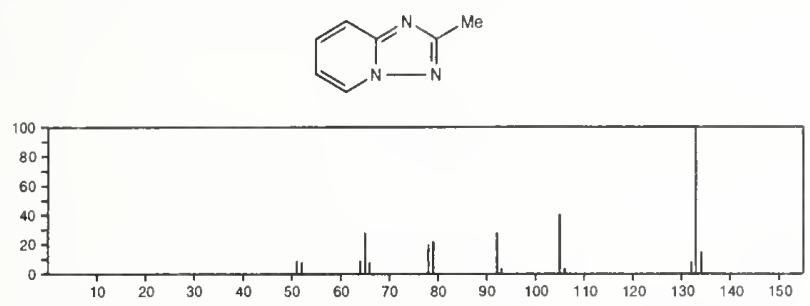

133

1,2,4-Triazolo[4,3-a]pyridine, 3-methyl-
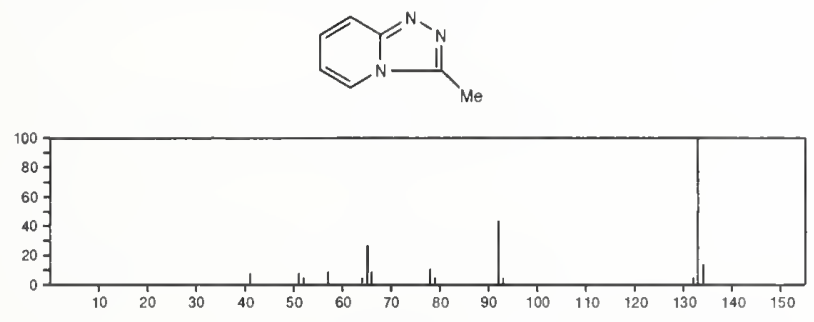

133

Benzene, 1-azido-4-methyl-

$\mathrm{C}_{7} \mathrm{H}_{7} \mathrm{~N}_{3}$

2101-86-2
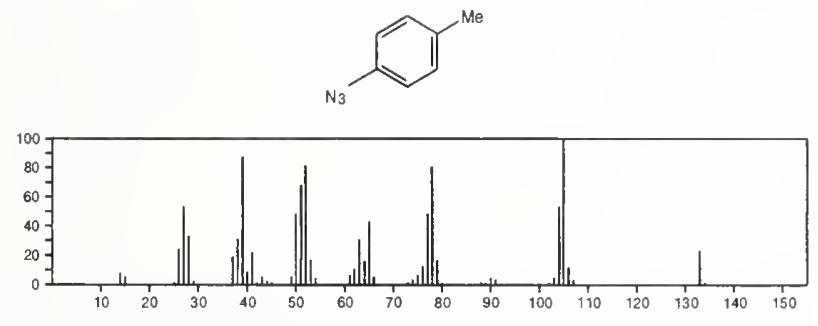

133

$\mathrm{C}_{7} \mathrm{H}_{7} \mathrm{~N}_{3}$

4113-72-8

Benzene, 1-azido-3-methyl-
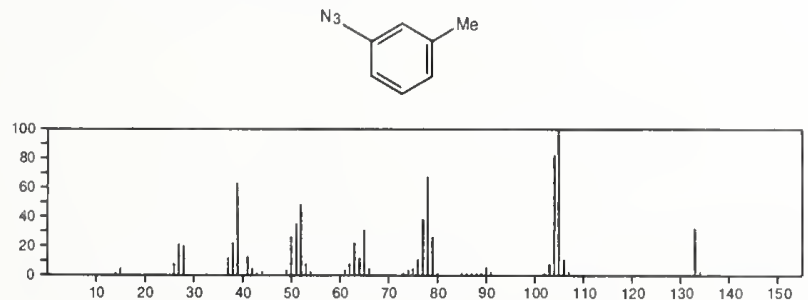

133

$\mathrm{C}_{7} \mathrm{H}_{7} \mathrm{~N}_{3}$

$s$-Triazolo[4,3-a]pyridine, 6-methyl

$4919-09-9$
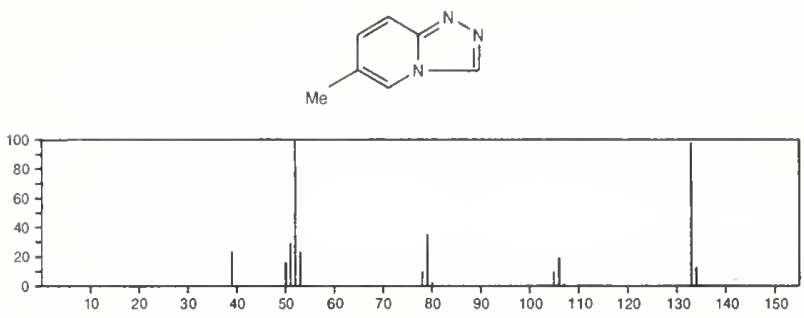

133

$\mathrm{C}_{7} \mathrm{H}_{7} \mathrm{~N}_{3}$

$s^{-}$Triazolo[4,3-a]pyridine, 7-methyl-

4919-10-2
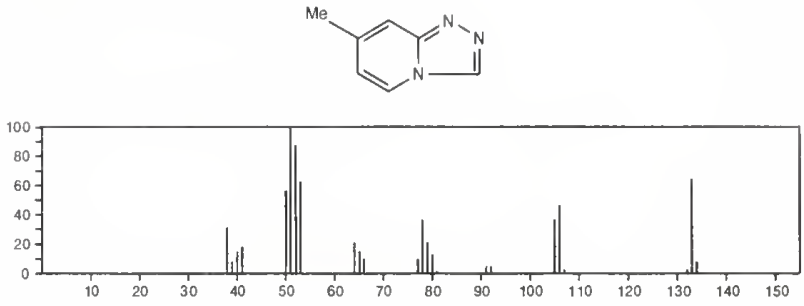

133

$1 H$-Benzotriazole, 1-methyl-

$\mathrm{C}_{7} \mathrm{H}_{7} \mathrm{~N}_{3}$

13351-73-0
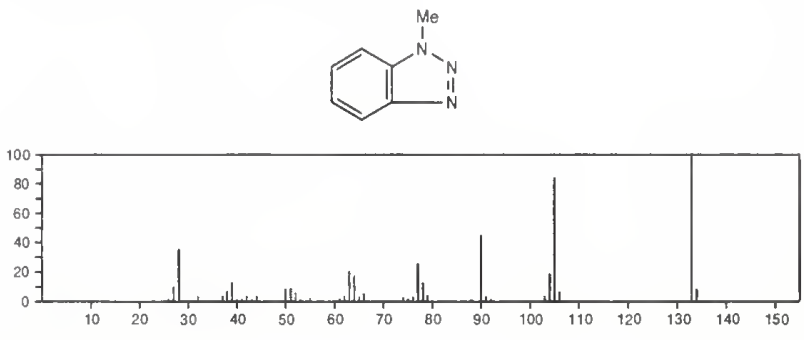

133

2H-Benzotriazole, 2-methyl-

$\mathrm{C}_{7} \mathrm{H}_{7} \mathrm{~N}_{3}$

16584-00-2
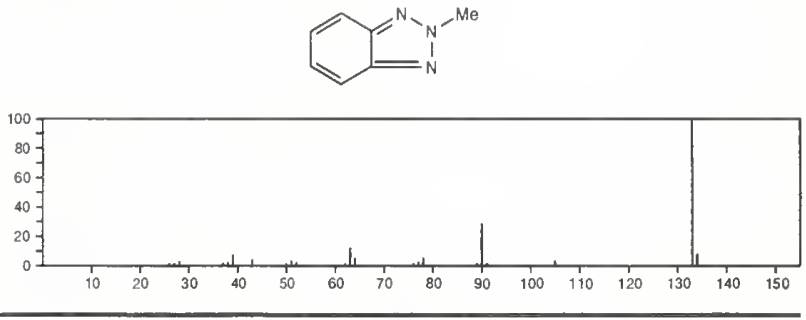

133

$\mathrm{C}_{7} \mathrm{H}_{7} \mathrm{~N}_{3}$

31656-92-5

Benzene, 1-azido-2-methyl-
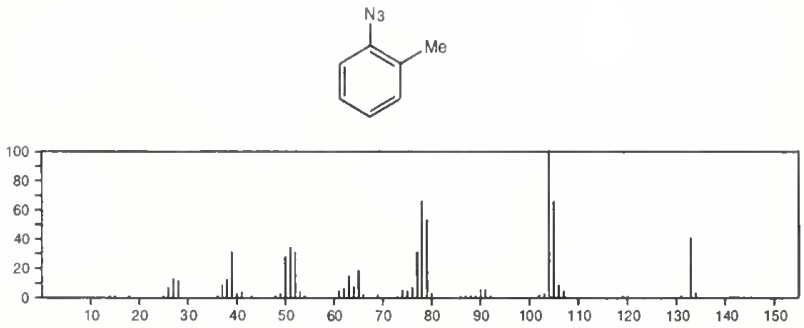
133

$\mathrm{C}_{8} \mathrm{H}_{7} \mathrm{NO}$

Benzoxazole, 2-methyl-<smiles>[N+]#[N+]c1nc2ccccc2o1</smiles>

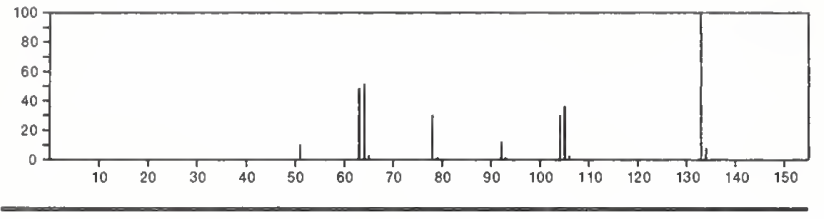

133

1,2-Benzisoxazole, 3-methyl-

$\mathrm{C}_{8} \mathrm{H}_{7} \mathrm{NO}$

$4825-75-6$
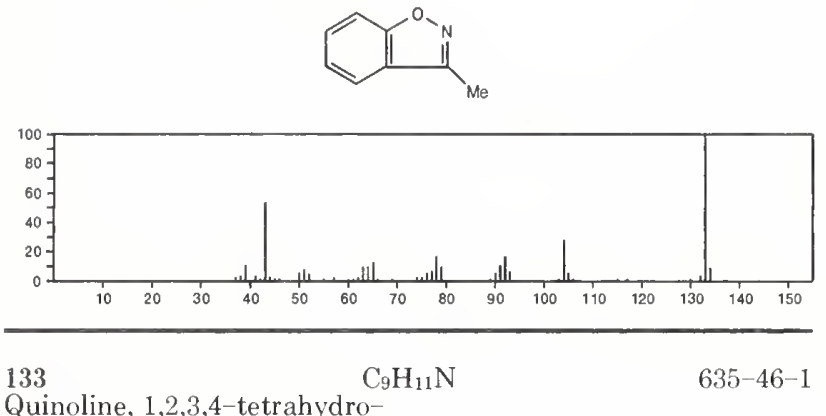

Quinoline, 1,2,3,4-tetrahydro-
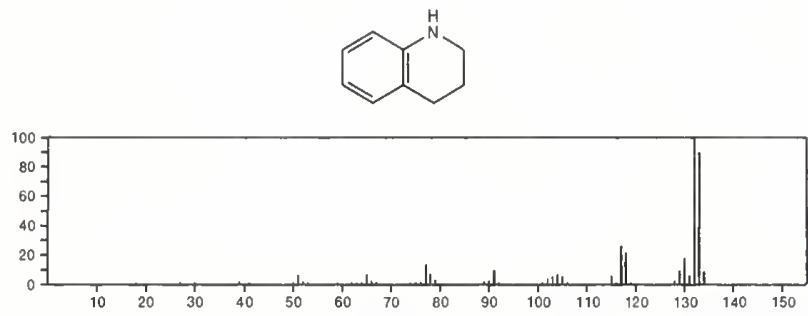

133

Aziridine, 1-(phenylmethyl)-

$\mathrm{C}_{9} \mathrm{H}_{11} \mathrm{~N}$

$\widehat{\triangle N}_{\mathrm{CH}_{2} \mathrm{Ph}}$

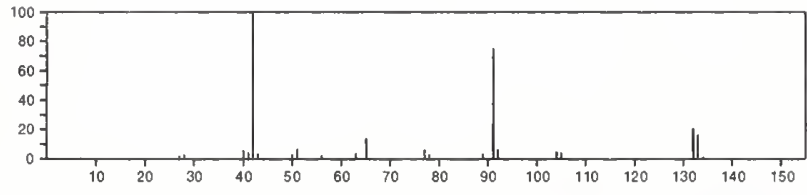

133

$\mathrm{C}_{9} \mathrm{H}_{11} \mathrm{~N}$

$6907-71-7$

Methanamine, $N-(1-$ phenylethylidene)

$\mathrm{MeN}=\mathrm{CMePh}$

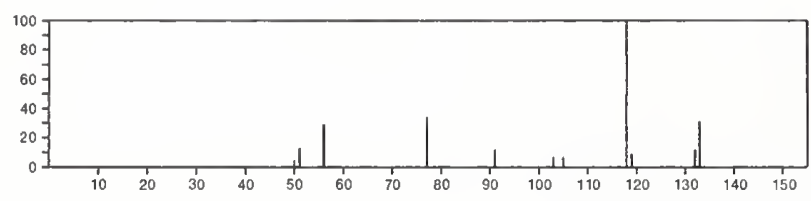

133

Aziridine, 2-(phenylmethyl)-

$\mathrm{C}_{9} \mathrm{H}_{11} \mathrm{~N}$

$13906-90-6$
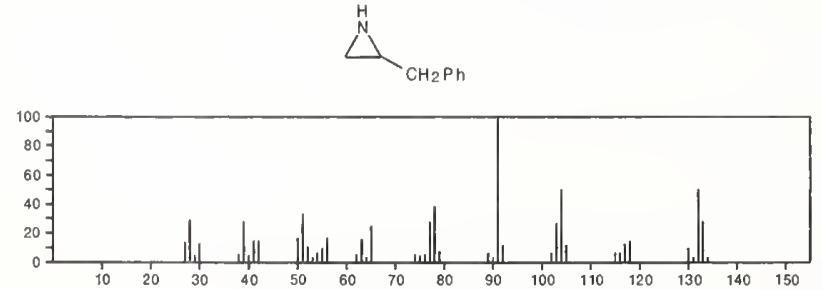

133

$\mathrm{C}_{9} \mathrm{H}_{11} \mathrm{~N}$

$22596-57-2$

Aziridine, 2-methyl-2-phenyl
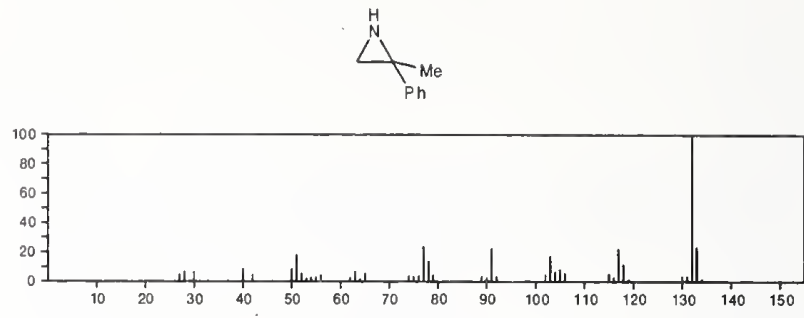

133

$\mathrm{C}_{9} \mathrm{H}_{11} \mathrm{~N}$

22610-18-0

Azetidine, 2-phenyl-
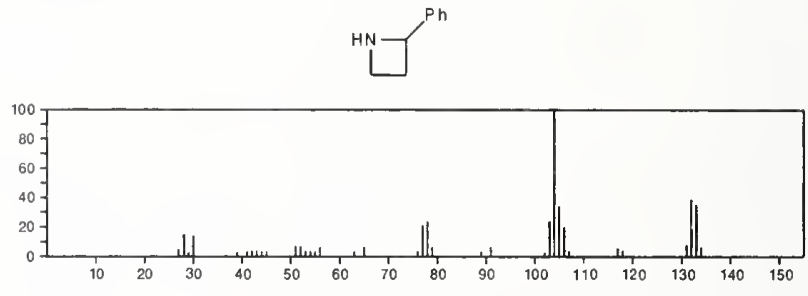

134

$\mathrm{C}_{2} \mathrm{H}_{2} \mathrm{Cl}_{2} \mathrm{~F}_{2}$

$471-43-2$

Ethane, 1,1-dichloro-2,2-difluoro

$\mathrm{F}_{2} \mathrm{CHCHCl}_{2}$
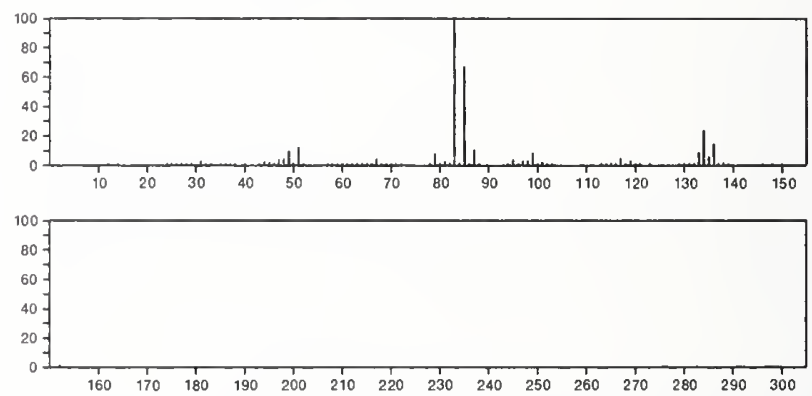

134

$\mathrm{C}_{2} \mathrm{H}_{2} \mathrm{Cl}_{2} \mathrm{~F}_{2}$

$1649-08-7$

Ethane, 1,2-dichloro-1,1-difluoro-

$\mathrm{Cl} \mathrm{CH}_{2} \mathrm{CClF}_{2}$

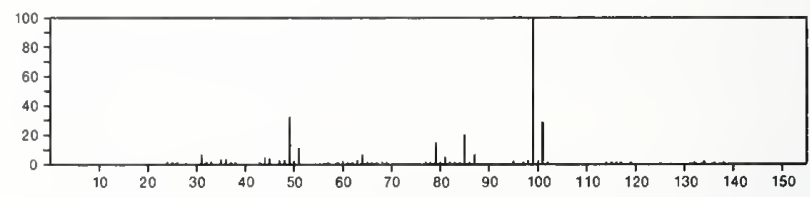

$134 \quad \mathrm{C}_{3} \mathrm{Cl}_{2} \mathrm{~N}_{2}$

$13063-43-9$

Propanedinitrile, dichloro

$\mathrm{NC}_{2} \mathrm{C}(\mathrm{Cl})_{2}$

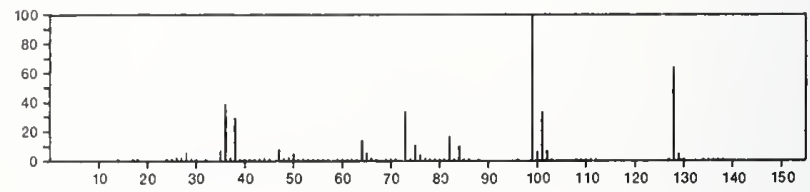


134

$\mathrm{C}_{3} \mathrm{H}_{3} \mathrm{~F}_{5}$

Propane, 1,1,2,2,3-pentafluoro-

$679-86-7$

$\mathrm{FCH}_{2} \mathrm{CF}_{2} \mathrm{CHF}_{2}$

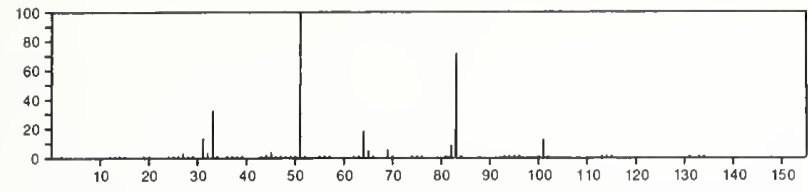

$\stackrel{\mathrm{C}_{3} \mathrm{H}_{6} \mathrm{~N}_{2} \mathrm{~S}_{2}}{134} \quad 16890-71-4$
Ethanedithioamide, methyl-

$\mathrm{H}_{2} \mathrm{NCSCSNHME}$

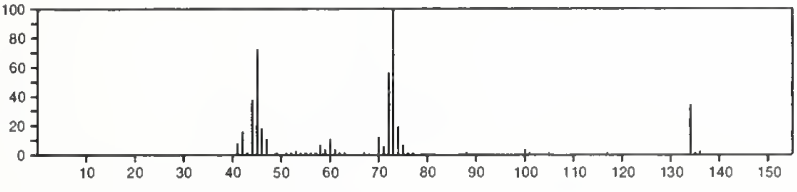

134

$\mathrm{C}_{3} \mathrm{H}_{14} \mathrm{Si}_{3}$

$5695-49-8$

Silane, [(methylsilyl)methyl](silylmethyl)-

$\mathrm{H}_{3} \mathrm{SiCH}_{2} \mathrm{SiH}_{2} \mathrm{CH}_{2} \mathrm{SiH}_{2} \mathrm{Me}$

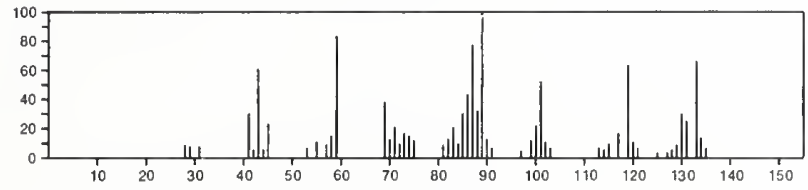

134

$\mathrm{C}_{4} \mathrm{H}_{12} \mathrm{Ge}$

$865-52-1$

Germane, tetramethyl

GeMe

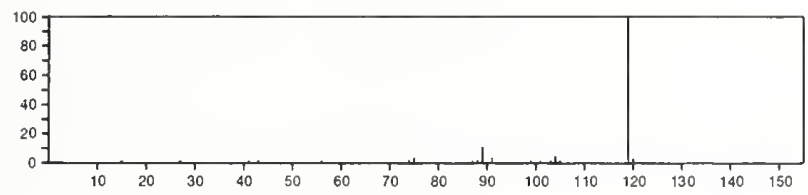

134

$\mathrm{C}_{5} \mathrm{H}_{7} \mathrm{ClO}_{2}$

2-Propen-1-ol, 2-chloro-, acetate

$692-72-8$

$\mathrm{ACOCH} \mathrm{CCl}_{2}=\mathrm{CH}_{2}$
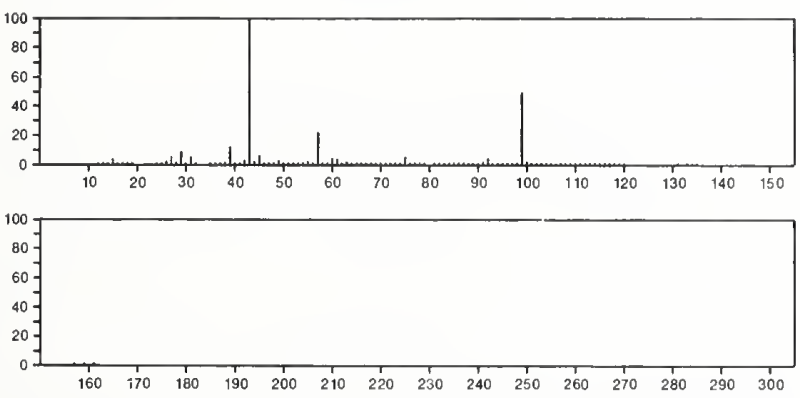

$134 \quad \mathrm{C}_{5} \mathrm{H}_{10} \mathrm{O}_{2} \mathrm{~S} \quad 2094-92-0$

1,3,6-Dioxathiocane
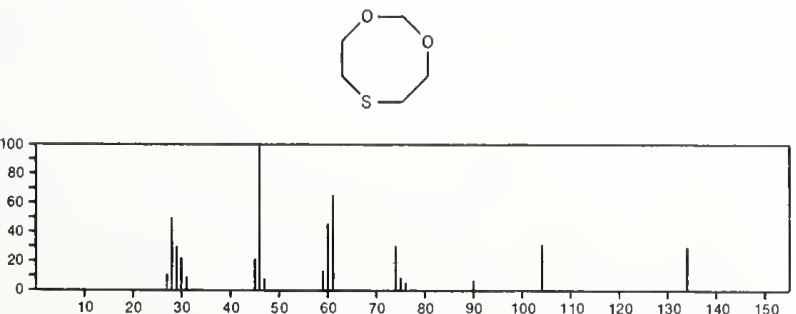

134

$\mathrm{C}_{5} \mathrm{H}_{10} \mathrm{O}_{2} \mathrm{~S}$

4988-33-4

2H-Thiopyran, tetrahydro-, 1,1-dioxide
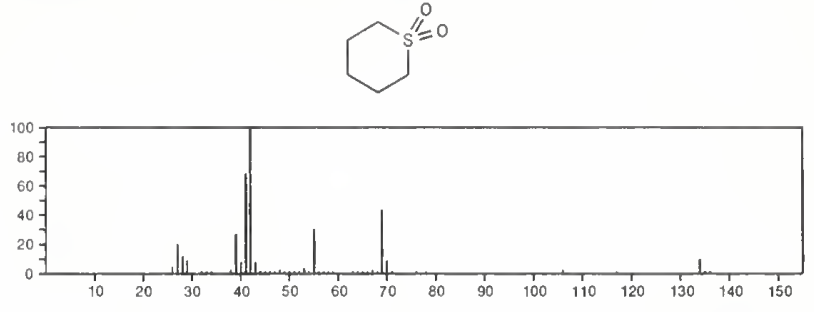

134

$\mathrm{C}_{5} \mathrm{H}_{10} \mathrm{O}_{2} \mathrm{~S}$

Propanoic acid, 3-mercapto-, ethyl ester

$5466-06-8$

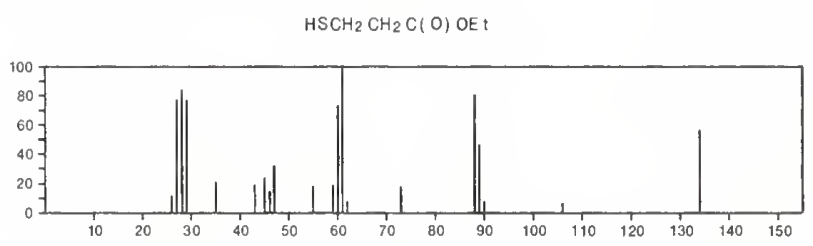

134

Propanoic acid, 3-(ethylthio)

$\mathrm{C}_{5} \mathrm{H}_{10} \mathrm{O}_{2} \mathrm{~S}$

7244-82-8

$\mathrm{HO}_{2} \mathrm{CCH}_{2} \mathrm{CH}_{2} \mathrm{SE}$

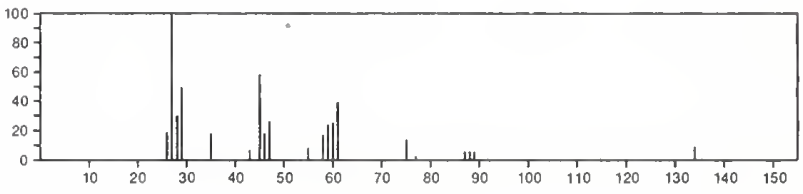

134

$\mathrm{C}_{5} \mathrm{H}_{10} \mathrm{O}_{2} \mathrm{~S}$

$7383-61-1$

Acetic acid, mercapto-, 1-methylethyl ester

i $-\mathrm{PrOC}(\mathrm{O}) \mathrm{CH}_{2} \mathrm{SH}$

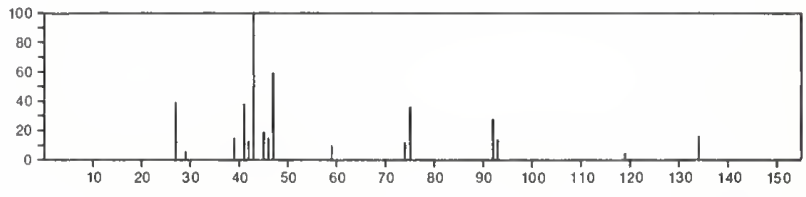

$134 \quad \mathrm{C}_{5} \mathrm{H}_{10} \mathrm{O}_{2} \mathrm{~S}$

Propanoic acid, 2-mercapto-, ethyl ester

19788-49-9

$\mathrm{E}$ OCC (O) CH $\{\mathrm{SH}) \mathrm{Me}$

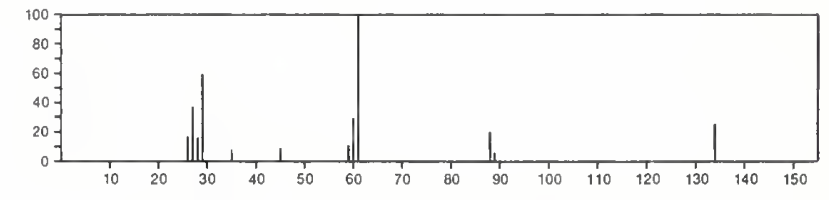

$134 \quad \mathrm{C}_{5} \mathrm{H}_{10} \mathrm{O}_{2} \mathrm{~S} \quad 20600-60-6$

Acetic acid, (propylthio)-

PrSCH $2 \mathrm{CO}_{2} \mathrm{H}$

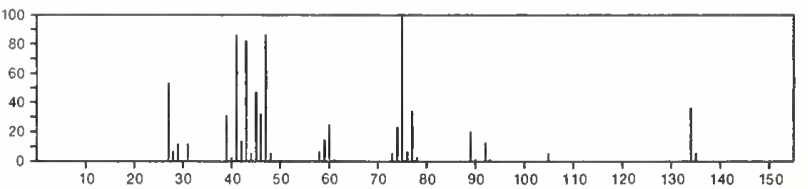


$134 \quad \mathrm{C}_{5} \mathrm{H}_{10} \mathrm{O}_{2} \mathrm{~S}$

Acetic acid, (ethylthio)-, methyl ester

$\mathrm{E} t \mathrm{SCH}_{2} \mathrm{C}(\mathrm{O}) \mathrm{OM}$

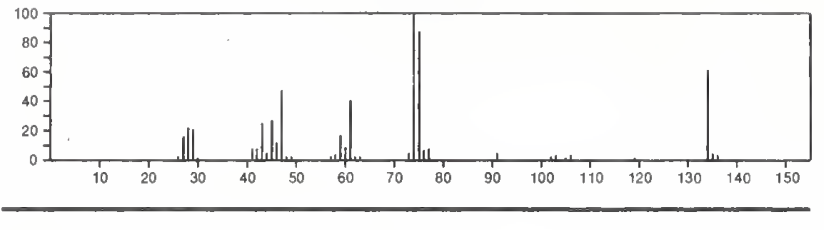

134

Acetic acid, [(1-methylethyl)thio]-

$i-\operatorname{PrSCH} \mathrm{CO}_{2} \mathrm{H}$

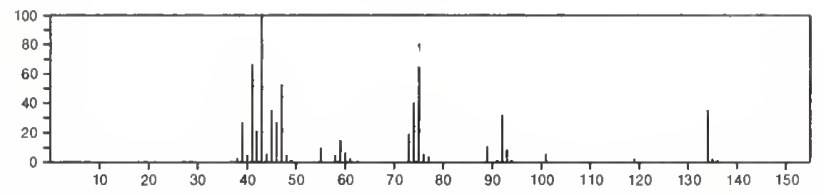

134

1,2,3-Propanetriol, 1-acetate

$\mathrm{C}_{5} \mathrm{H}_{10} \mathrm{O}_{4}$

$106-61-6$

$\mathrm{ACOCH}_{2} \mathrm{CH}(\mathrm{OH}) \mathrm{CH}_{2} \mathrm{OH}$
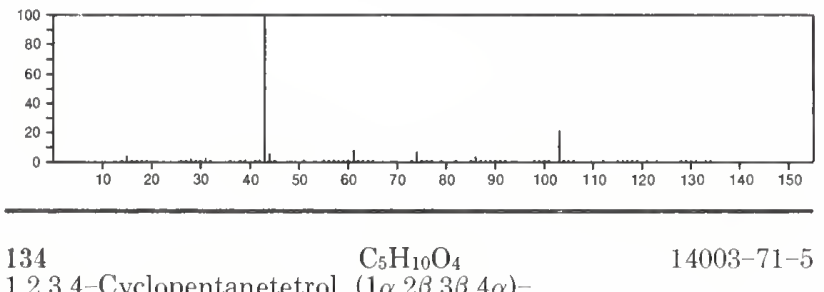

1,2,3,4-Cyclopentanetetrol, $(1 \alpha, 2 \beta, 3 \beta, 4 \alpha)$
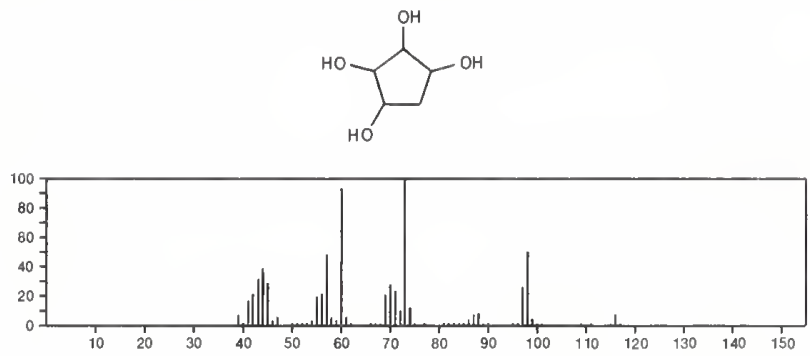

134

1,3-Dithiane, 2-methyl-

$\mathrm{C}_{5} \mathrm{H}_{10} \mathrm{~S}_{2}$

$6007-26-7$
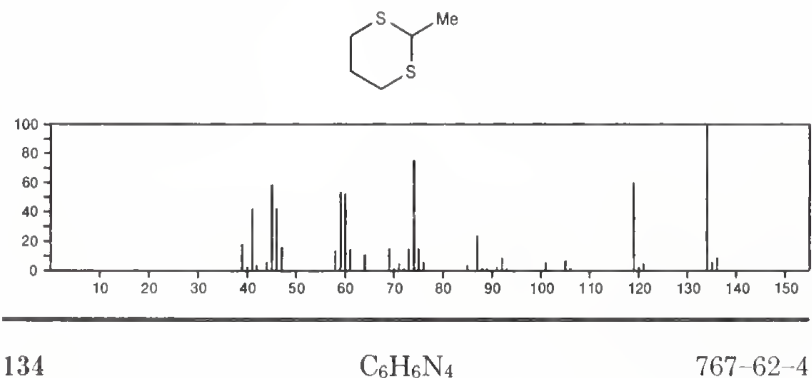

$s^{-T r i a z o l o}[4,3-a]$ pyridine, 3-amino-

$767-62-4$
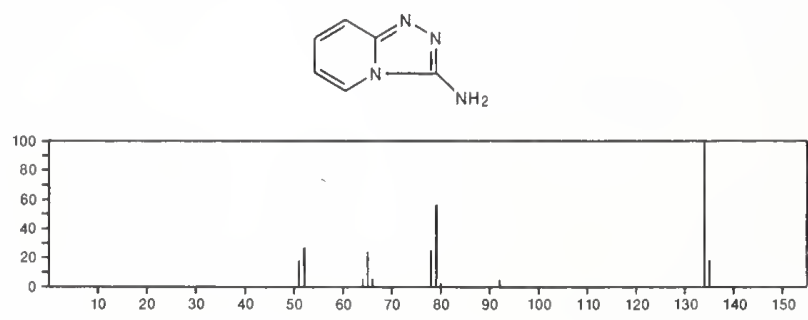

$134 \quad \mathrm{C}_{6} \mathrm{H}_{6} \mathrm{~N}_{4}$

$[1,2,4]$ Triazolo[1,5-a]pyridin-2-amine

$874-46-4$
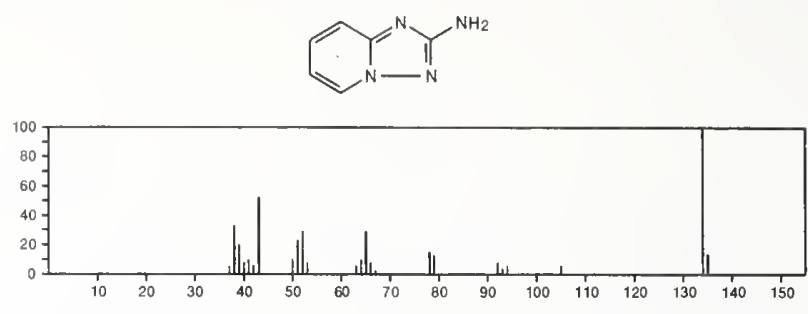

134

$1 H$-Purine, 6-methyl-

$\mathrm{C}_{6} \mathrm{H}_{6} \mathrm{~N}_{4}$

2004-03-7
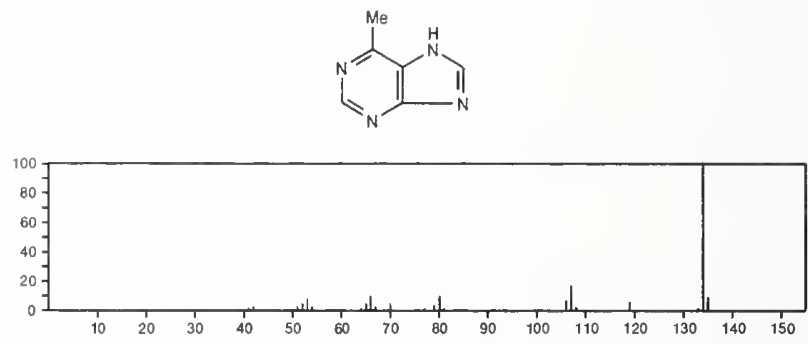

134

3,3'-Bipyrazole

$\mathrm{C}_{6} \mathrm{H}_{6} \mathrm{~N}_{4}$

$16267-26-8$
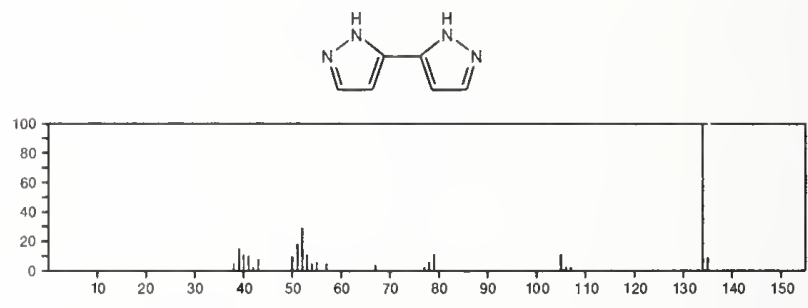

134

$\mathrm{C}_{6} \mathrm{H}_{6} \mathrm{~N}_{4}$

s-Triazolo[4,3-a]pyrazine, 8-methyl-

$23126-45-6$<smiles>[O-]c1nccn2cnnc12</smiles>

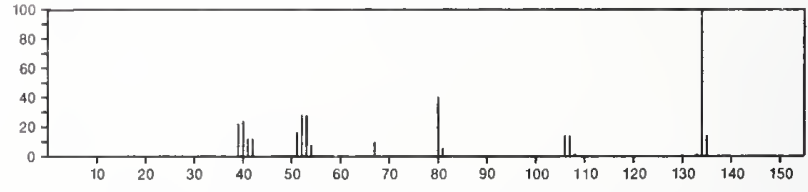

134

$\mathrm{C}_{6} \mathrm{H}_{6} \mathrm{~N}_{4}$

$s-$ Triazolo $[4,3-a]$ pyrazine, 3-methyl-

$33590-17-9$
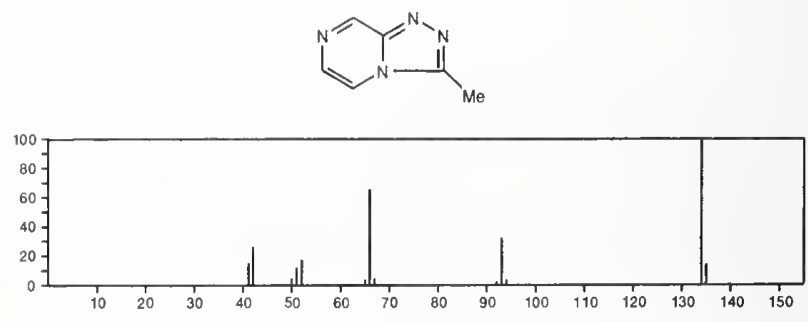
134

Hexanoyl chloride

$\mathrm{C}_{6} \mathrm{H}_{11} \mathrm{ClO}$

$142-61-0$

$\mathrm{Me}\left(\mathrm{CH}_{2}\right)_{4} \mathrm{COC}$

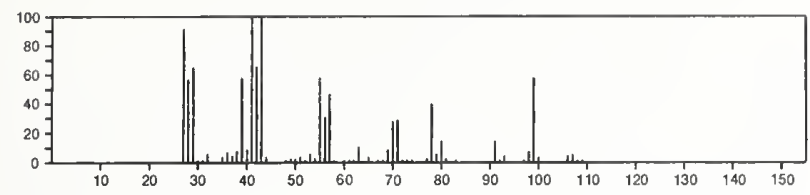

134

Cyclohexanol, 2-chloro-, trans-

\section{$\mathrm{C}_{6} \mathrm{H}_{11} \mathrm{ClO}$}

$6628-80-4$<smiles>OC1CCCCC1Cl</smiles>

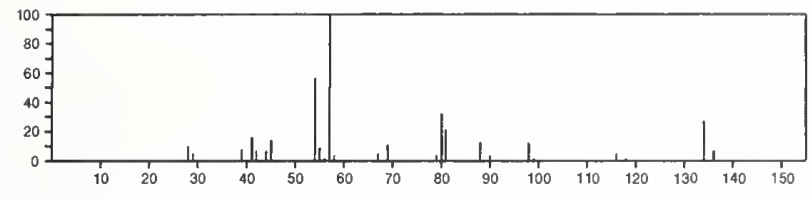

134

Cyclohexanol, 2-chloro-, cis-

\section{$\mathrm{C}_{6} \mathrm{H}_{11} \mathrm{ClO}$}

$16536-58-6$<smiles>OC1CCCCC1Cl</smiles>
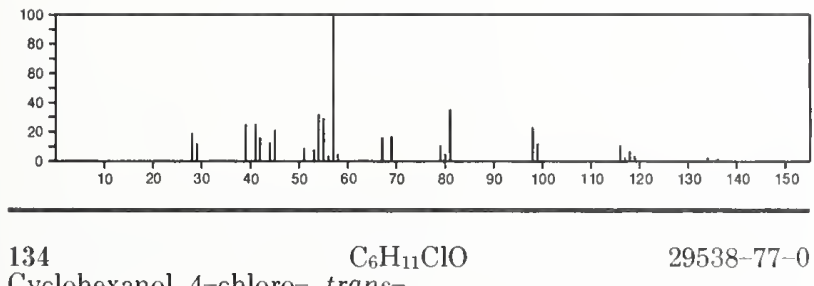

29538-77-0

Cyclohexanol, 4-chloro-, trans-
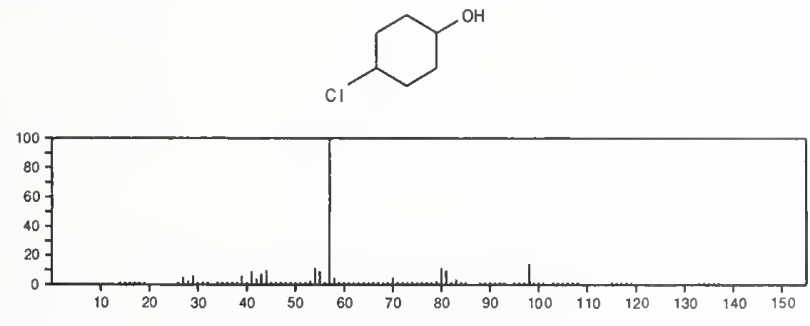

134

$\mathrm{C}_{6} \mathrm{H}_{11} \mathrm{ClO}$

$53957-23-6$

2-Butene, 1-chloro-4-ethoxy-

$\mathrm{E} t \mathrm{OCH}_{2} \mathrm{CH}=\mathrm{CHCH}_{2} \mathrm{Cl}$

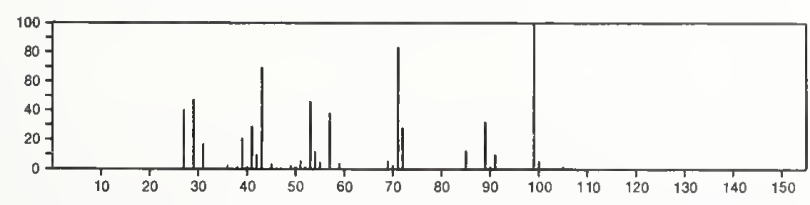

134

Butane, 1-(ethylsulfinyl)-

$\mathrm{C}_{6} \mathrm{H}_{14} \mathrm{OS}$

2976-99-0

$\mathrm{Me}\left(\mathrm{CH}_{2}\right)_{3} \mathrm{~S}(\mathrm{O}) \mathrm{Et}$

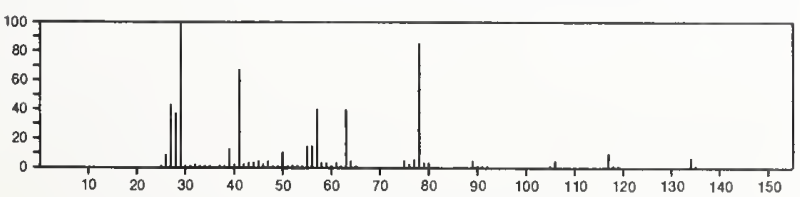

134

Propane, 1,1'-sulfinylbis-

$\mathrm{C}_{6} \mathrm{H}_{14} \mathrm{OS}$

$4253-91-2$

$\operatorname{PrS}(0) \mathrm{Pr}$

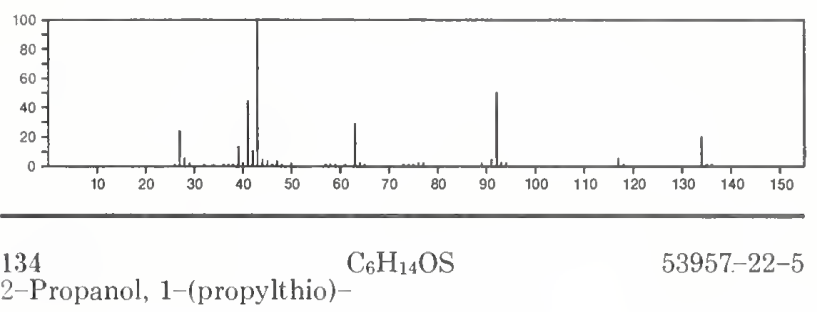

$\operatorname{PrSCH} 2 \mathrm{CH}(\mathrm{OH}) \mathrm{Me}$

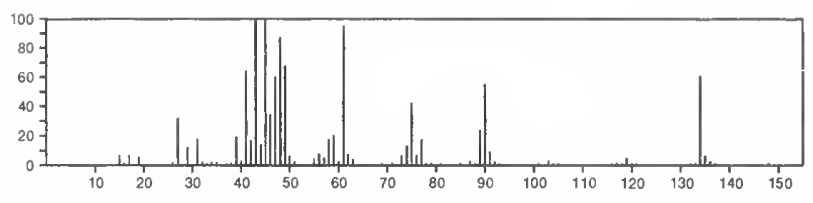

134

$\mathrm{C}_{6} \mathrm{H}_{14} \mathrm{O}_{3}$

$77-99-6$

1,3-Propanediol, 2-ethyl-2-(hydroxymethyl)-

$\mathrm{CH}_{2} \mathrm{OH}$

$\mathrm{HOCH}_{2} \mathrm{CE} \mathrm{C} \mathrm{CH}_{2} \mathrm{OH}$

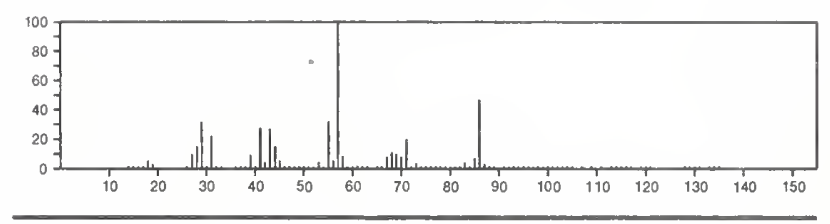

134

$\mathrm{C}_{6} \mathrm{H}_{14} \mathrm{O}_{3}$

1-Propanol, 2-(2-hydroxypropoxy)-

$106-62-7$

$\mathrm{MeCH}(\mathrm{OH}) \mathrm{CH}_{2} \mathrm{OCHMe} \mathrm{CH}_{2} \mathrm{OH}$

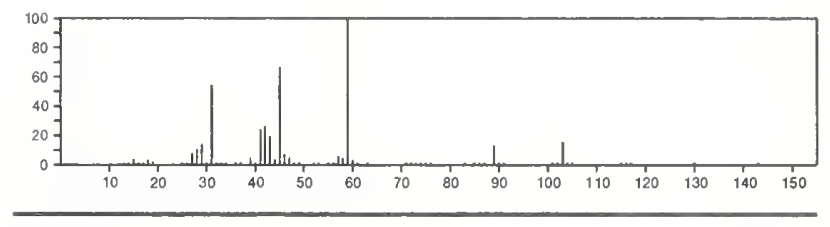

134

$\mathrm{C}_{6} \mathrm{H}_{14} \mathrm{O}_{3}$

$110-98-5$

2-Propanol, 1,1'-oxybis-

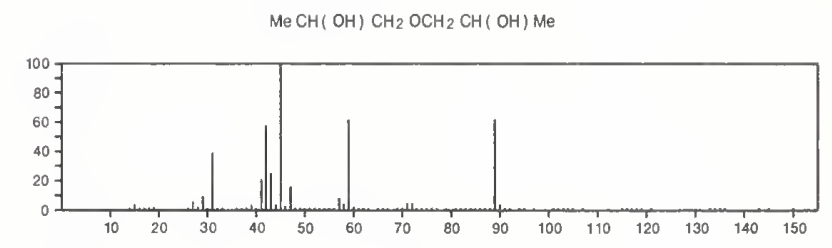

134

$\mathrm{C}_{6} \mathrm{H}_{14} \mathrm{O}_{3}$

111-90-0

Ethanol, 2-(2-ethoxyethoxy)-

$\mathrm{HOCH}_{2} \mathrm{CH}_{2} \mathrm{OCH}_{2} \mathrm{CH}_{2} \mathrm{OEt}$

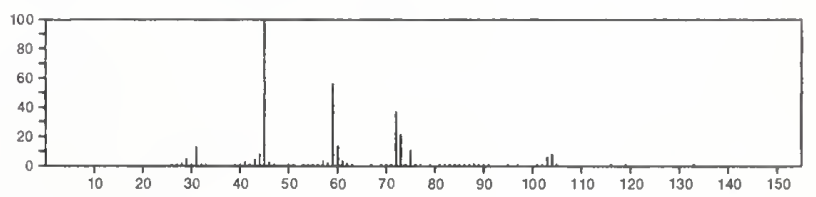


134 Ethane, 1,1'-oxybis [2-methoxy-

$\mathrm{C}_{6} \mathrm{H}_{14} \mathrm{O}_{3}$

$\mathrm{Me} O \mathrm{OCH}_{2} \mathrm{CH}_{2} \mathrm{OCH}_{2} \mathrm{CH}_{2} \mathrm{OMe}$

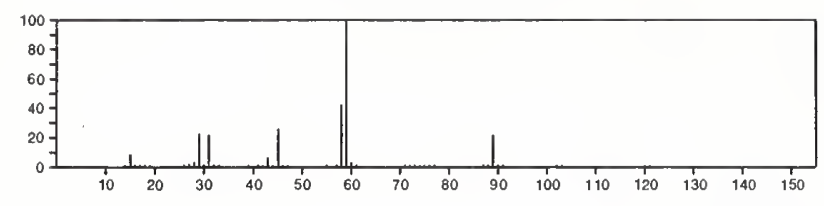

134

Propane, 1,1,1-trimethoxy-

$\mathrm{C}_{6} \mathrm{H}_{14} \mathrm{O}_{3}$

$24823-81-2$

EtC(OMe) 3

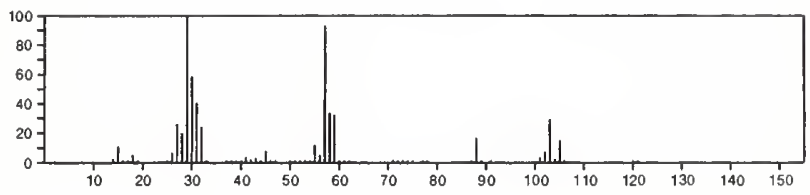

134

$\mathrm{C}_{7} \mathrm{H}_{6} \mathrm{~N}_{2} \mathrm{O}$

$767-98-6$

Nicotinonitrile, 1,4-dihydro-1-methyl-4-oxo-
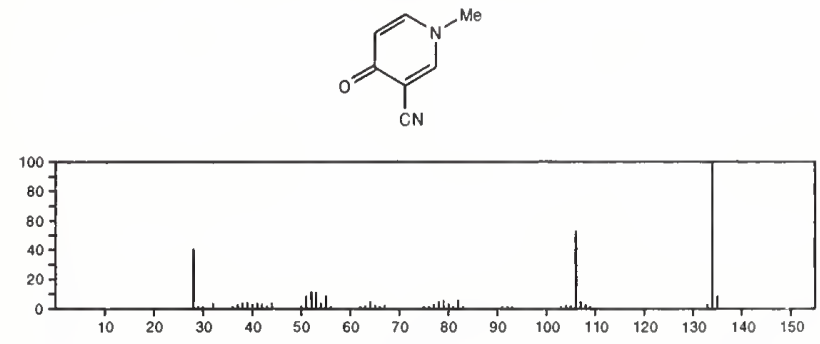

134

$\mathrm{C}_{7} \mathrm{H}_{6} \mathrm{~N}_{2} \mathrm{O}$

3999-06-2

Imidazo[ $1,2-a]$ pyridin-2(3H)-one
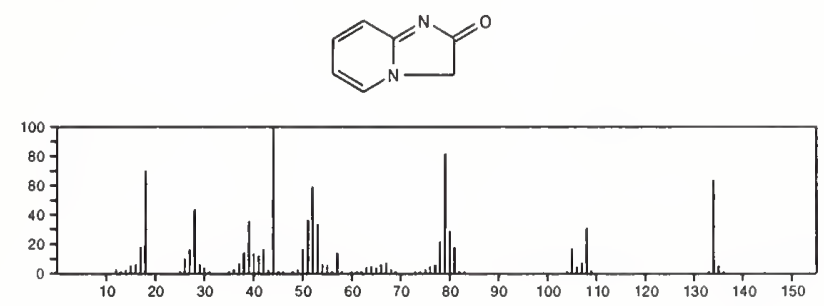

$134 \quad \mathrm{C}_{7} \mathrm{H}_{6} \mathrm{~N}_{2} \mathrm{O}$

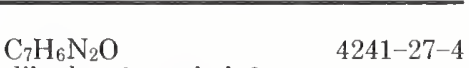

3-Pyridinecarbonitrile, 1,2-dihydro-6-methyl-2-oxo-<smiles>Cc1ccc(C)c(=O)[nH]1</smiles>

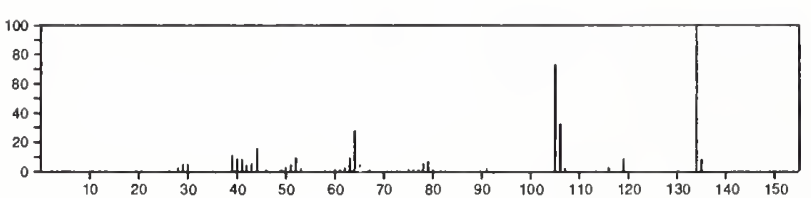

134

2-Benzoxazolamine

$\mathrm{C}_{7} \mathrm{H}_{6} \mathrm{~N}_{2} \mathrm{O}$

$4570-41-6$<smiles>Nc1nc2ccccc2o1</smiles>

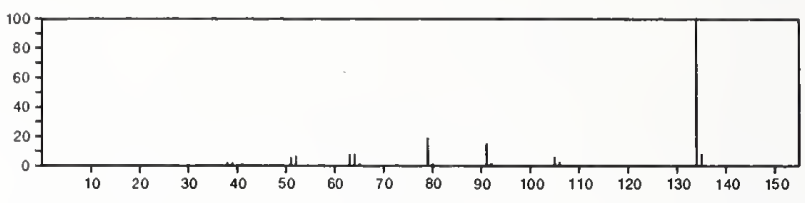

134

3H-Indazol-3-one, 1,2- dihydro-

$$
\mathrm{C}_{7} \mathrm{H}_{6} \mathrm{~N}_{2} \mathrm{O}
$$

$7364-25-2$
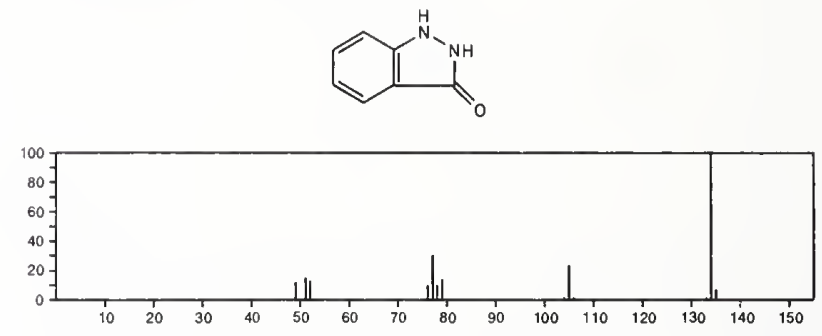

134 -Benzimidazole, 3-oxide

$\mathrm{C}_{7} \mathrm{H}_{6} \mathrm{~N}_{2} \mathrm{O}$

$18916-43-3$
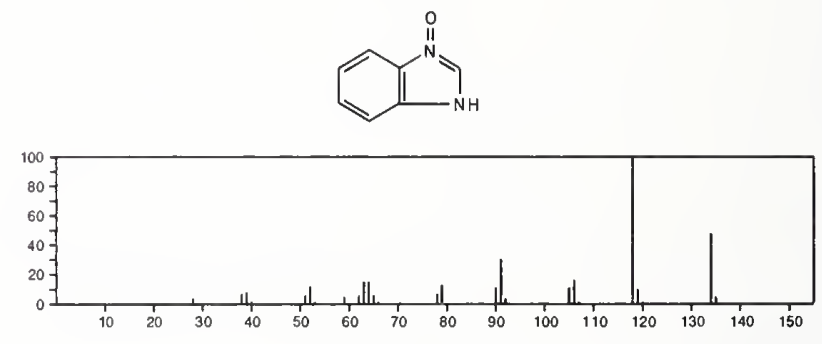

134

$\mathrm{C}_{7} \mathrm{H}_{15} \mathrm{Cl}$

629-06-1

Heptane, 1-chloro-

$\mathrm{Me}\left(\mathrm{CH}_{2}\right)_{6} \mathrm{Cl}$

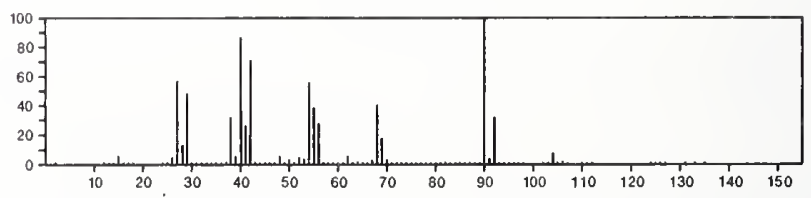

134

Heptane, 2-chloro-

$\mathrm{C}_{7} \mathrm{H}_{15} \mathrm{Cl}$

1001-89-4

$\mathrm{MeCHCl}\left(\mathrm{CH}_{2}\right){ }_{4} \mathrm{Me}$
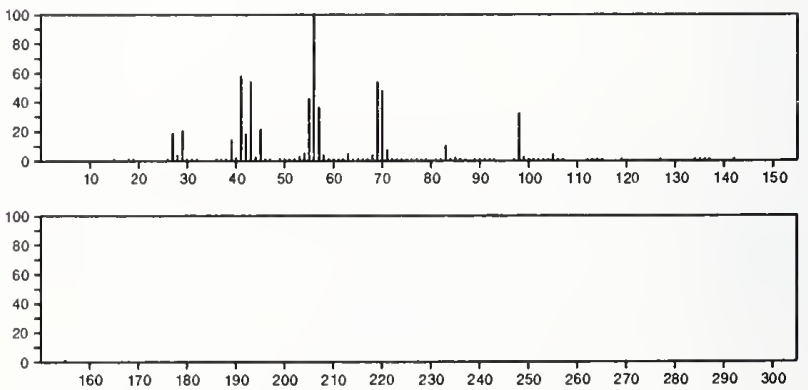
134

$1(3 H)$-Isobenzofuranone

$\mathrm{C}_{8} \mathrm{H}_{6} \mathrm{O}_{2}$

$87-41-2$
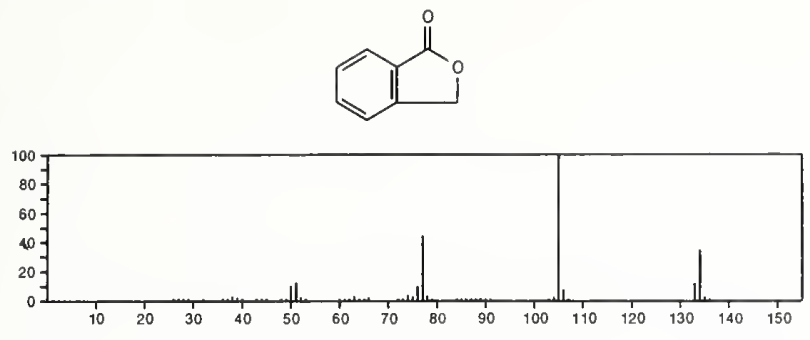

134

1,4-Benzodioxin

$\mathrm{C}_{8} \mathrm{H}_{6} \mathrm{O}_{2}$

$255-37-8$<smiles>C1=COc2ccccc2O1</smiles>

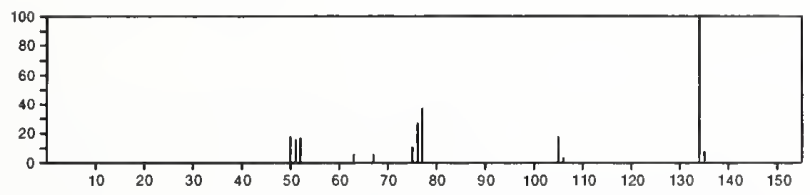

$134 \quad \mathrm{C}_{8} \mathrm{H}_{6} \mathrm{O}_{2}$

1,4-Benzenedicarboxaldehyde

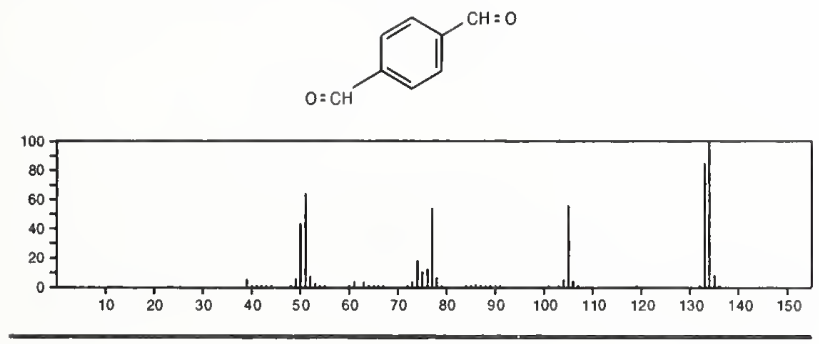

134

1,1-Cyclohexanedicarbonitrile

$\mathrm{C}_{8} \mathrm{H}_{10} \mathrm{~N}_{2}$

5222-53-7
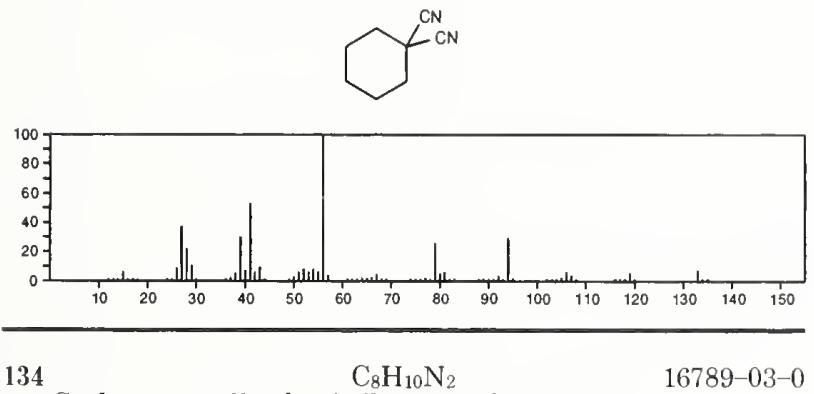

1,1-Cyclopropanedicarbonitrile, 2-ethyl-2-methyl-
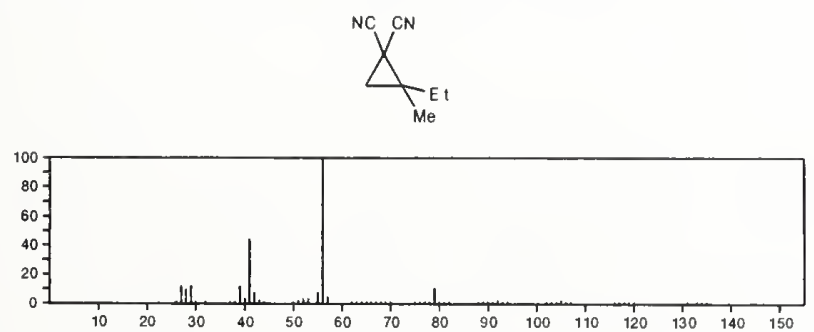

$134 \quad \mathrm{C}_{9} \mathrm{H}_{10} \mathrm{O}$

93-53-8

Benzeneacetaldehyde, $\alpha$-methyl-

$\mathrm{PhCHMO}(\mathrm{CHO})$

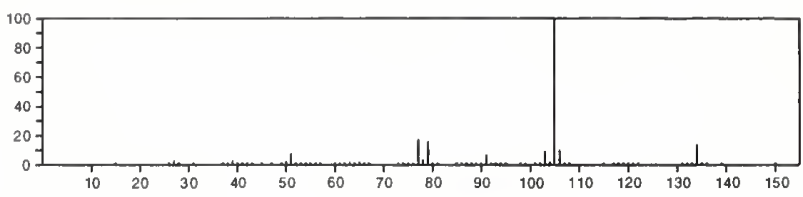

134

1-Propanone, 1-phenyl-

$\mathrm{C}_{9} \mathrm{H}_{10} \mathrm{O}$

$93-55-0$

Et COPh
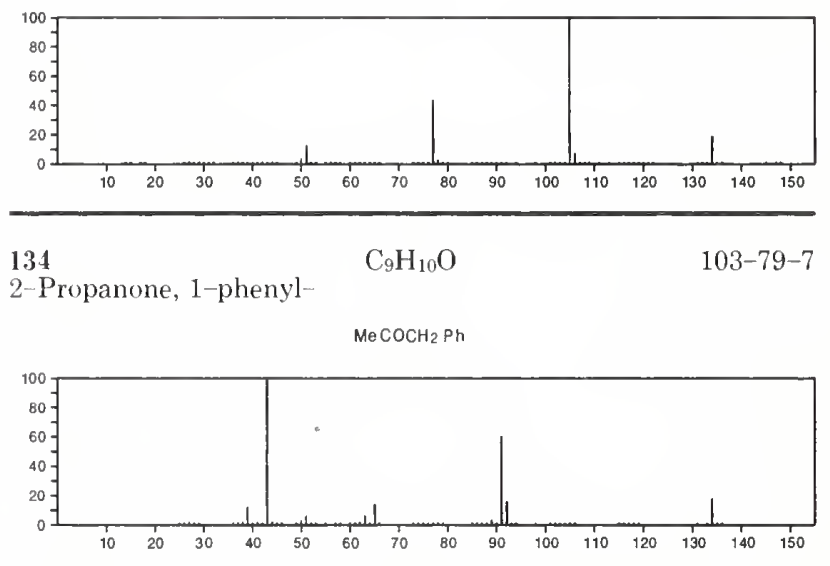

134

$\mathrm{C}_{9} \mathrm{H}_{10} \mathrm{O}$

$104-53-0$

Benzenepropanal

$\mathrm{OCHCH}_{2} \mathrm{CH}_{2} \mathrm{Ph}$

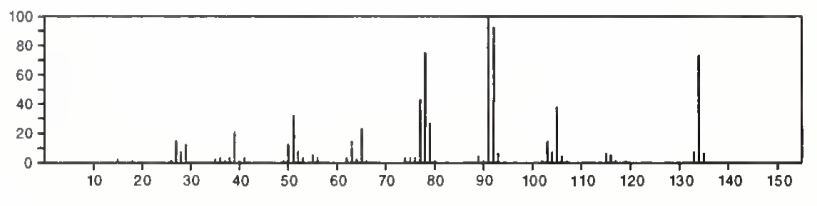

134

2-Propen-1-ol, 3-pheny]-

$\mathrm{C}_{9} \mathrm{H}_{10} \mathrm{O}$

$104-54-1$

$\mathrm{PhCH}=\mathrm{CHCH}_{2} \mathrm{OH}$

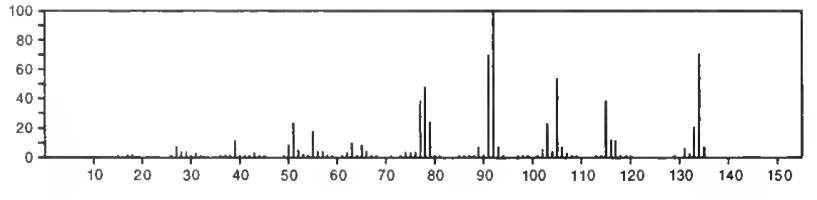

134

$\mathrm{C}_{9} \mathrm{H}_{10} \mathrm{O}$

122-00-9

Ethanone, 1-(4-methylphenyl)-
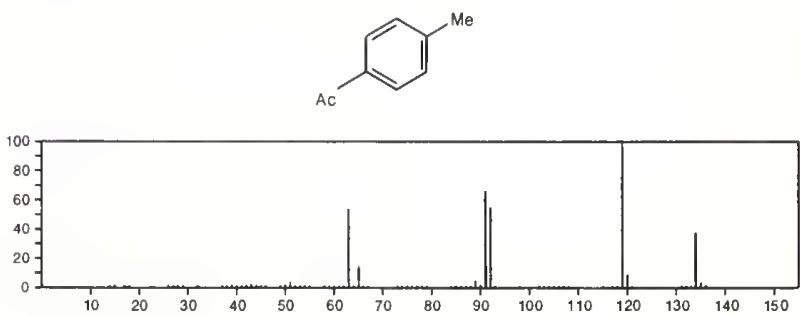
134

$\mathrm{C}_{9} \mathrm{H}_{10} \mathrm{O}$

2H-1-Benzopyran, 3,4-dihydro
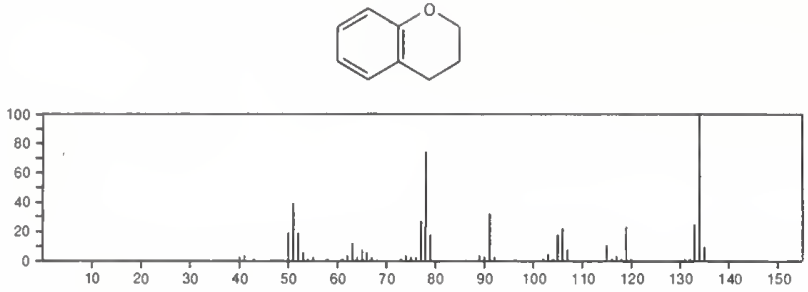

134

$\mathrm{C}_{9} \mathrm{H}_{20} \mathrm{O}$

Ethanone, 1-(2-methylphenyl)-
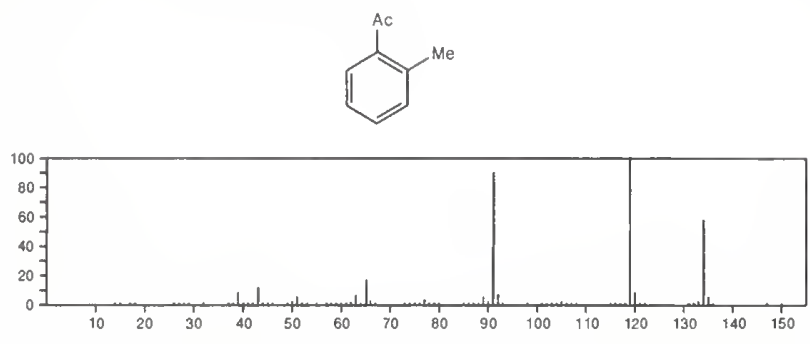

134

Phenol, 2-(2-propenyl)

$$
\mathrm{C}_{9} \mathrm{H}_{10} \mathrm{O}
$$

$1745-81-9$
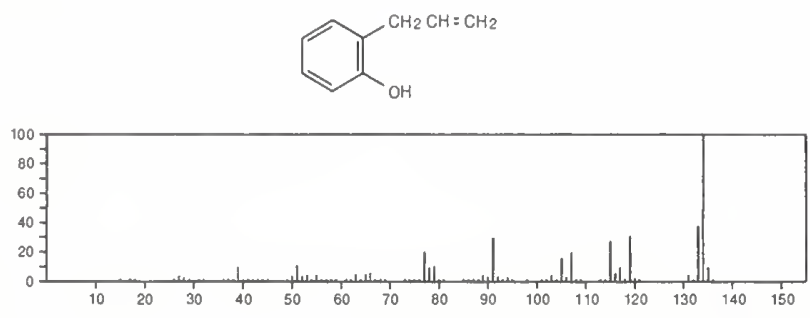

134

$\mathrm{C}_{9} \mathrm{H}_{10} \mathrm{O}$

$1746-11-8$
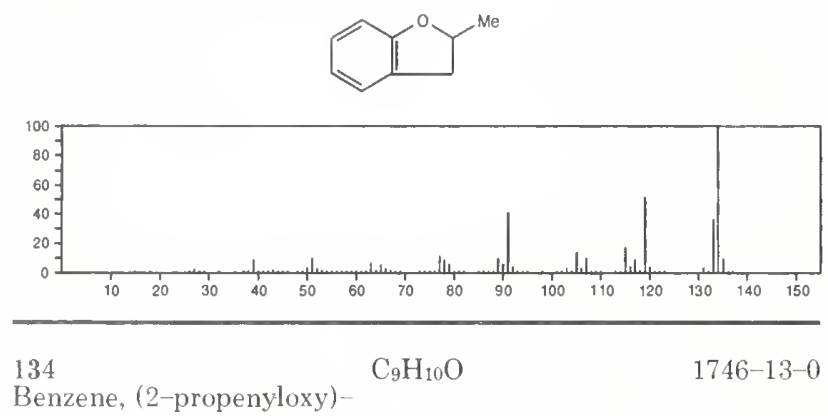

Benzene, (2-propenyloxy)-

$\mathrm{PhOCH} \mathrm{CH}_{2}=\mathrm{CH}_{2}$

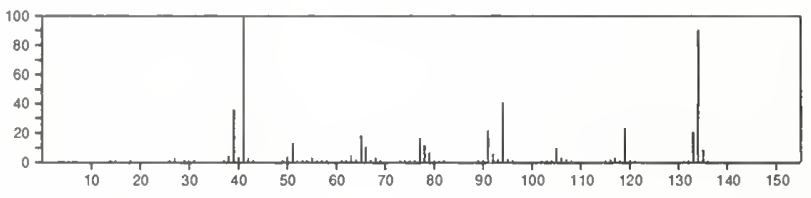

134

Oxirane, 2-methyl-2-phenyl-

$\mathrm{C}_{9} \mathrm{H}_{10} \mathrm{O}$

$2085-88-3$
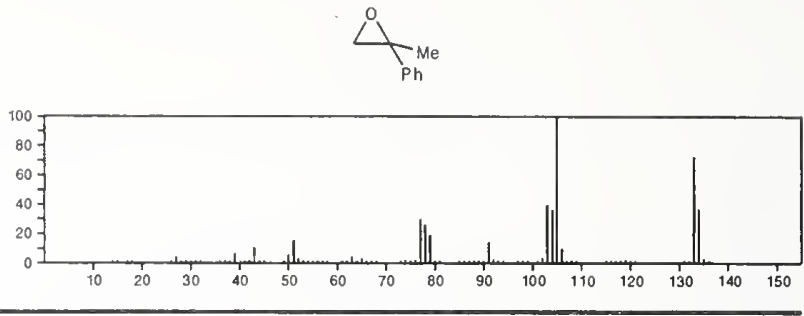

134

$\mathrm{C}_{9} \mathrm{H}_{10} \mathrm{O}$

4254-29-9

1H-Inden-2-ol, 2,3-dihydro
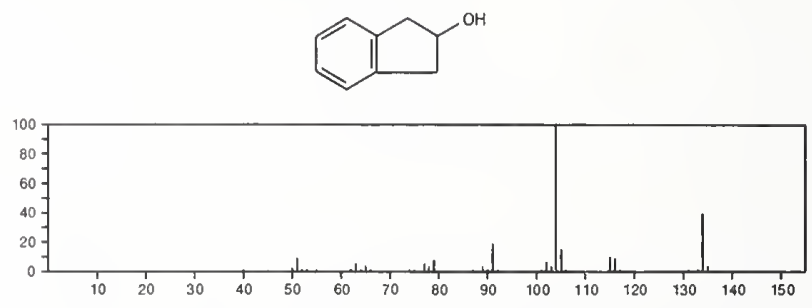

134
Oxirane 2-methyl-3-phenyl-

4436-22-0
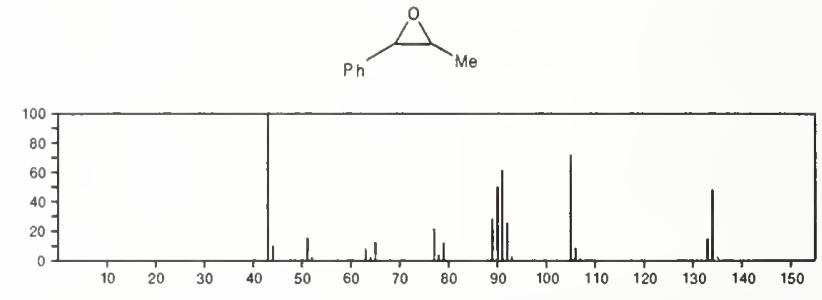

134

$\mathrm{C}_{9} \mathrm{H}_{10} \mathrm{O}$

Benzene, (1-methoxyethenyl)-

4747-13-1

$\mathrm{PhC}(\mathrm{OMe})=\mathrm{CH}_{2}$

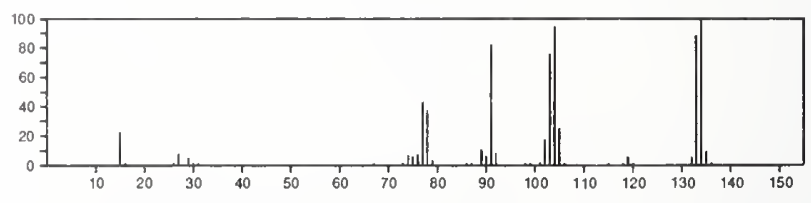

134

$\mathrm{C}_{9} \mathrm{H}_{10} \mathrm{O}$

$5779-94-2$

Benzaldehyde, 2,5-dimethyl-
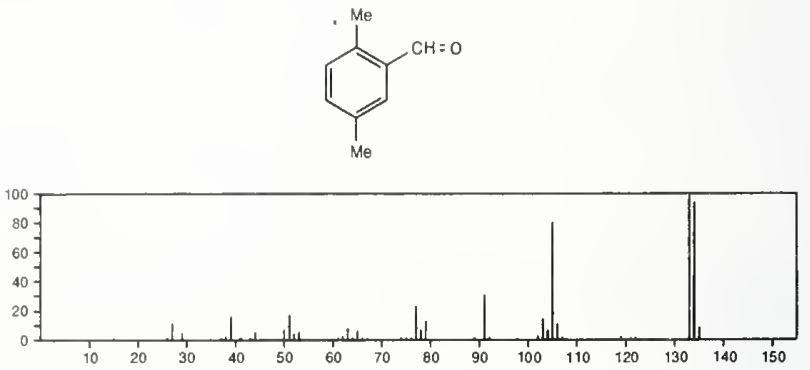
134 $\mathrm{C}_{9} \mathrm{H}_{10} \mathrm{O}$

Benzaldehyde, 3,4-dimethyl-

5973-71-7<smiles>Cc1ccc(C=O)cc1[N+](=O)[O-]</smiles>
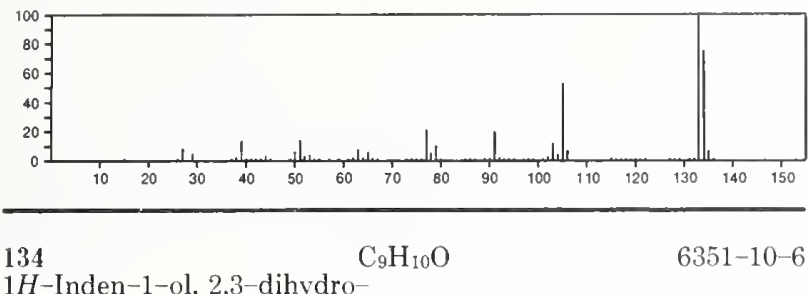

1H-Inden-1-ol, 2,3-dihydro-
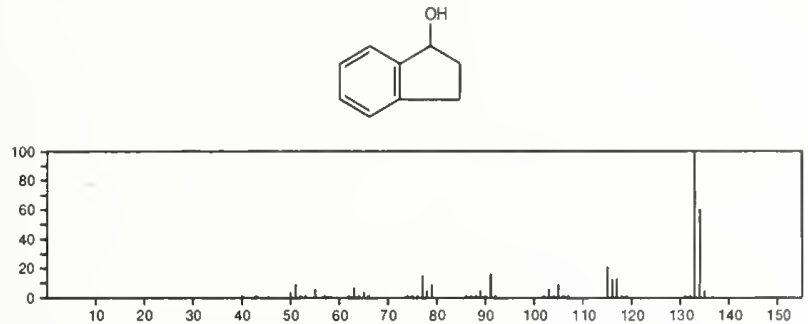

134

$\mathrm{C}_{9} \mathrm{H}_{10} \mathrm{O}$

Benzene, (2-methoxyethenyl)-, $(Z)$ -

$14371-19-8$

$\mathrm{PhCH}=\mathrm{CHOMe}$

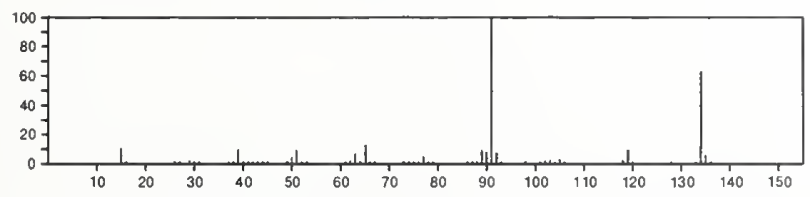

134

Benzaldehyde, 2,4-dimethyl-

$\mathrm{C}_{9} \mathrm{H}_{10} \mathrm{O}$

15764-16-6
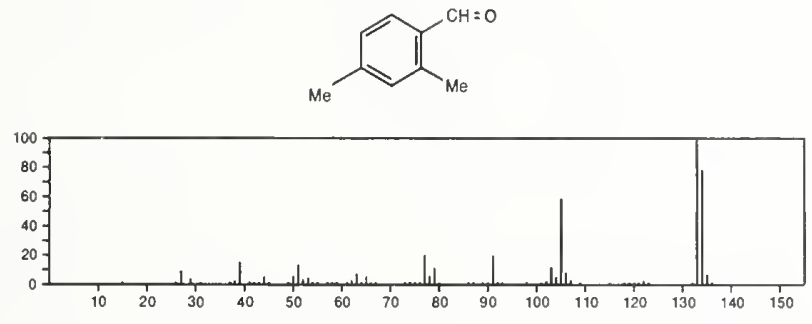

134

$\mathrm{C}_{9} \mathrm{H}_{10} \mathrm{O}$

26444-19-9

Ethanone, 1-(methylphenyl)-
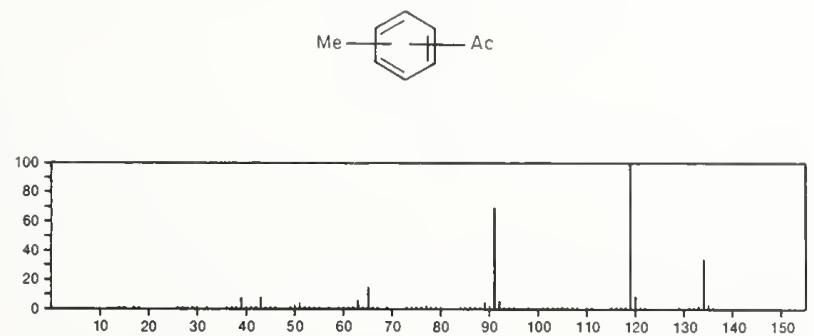

134

4,6-Octadiyn-3-one, 2-methyl-

29743-33-7

$\mathrm{Me}_{2} \mathrm{CHCOC} \equiv \mathrm{CC} \equiv \mathrm{CMe}$

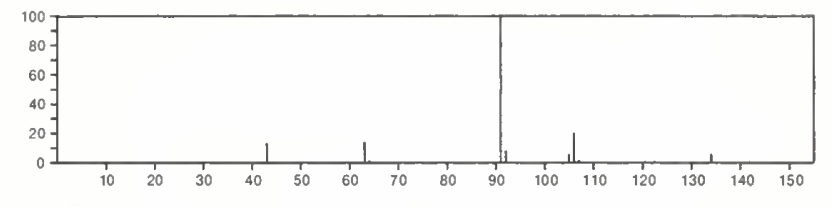

134

$\mathrm{C}_{9} \mathrm{H}_{10} \mathrm{O}$

$30584-69-1$

Benzenemethanol, ar-ethenyl
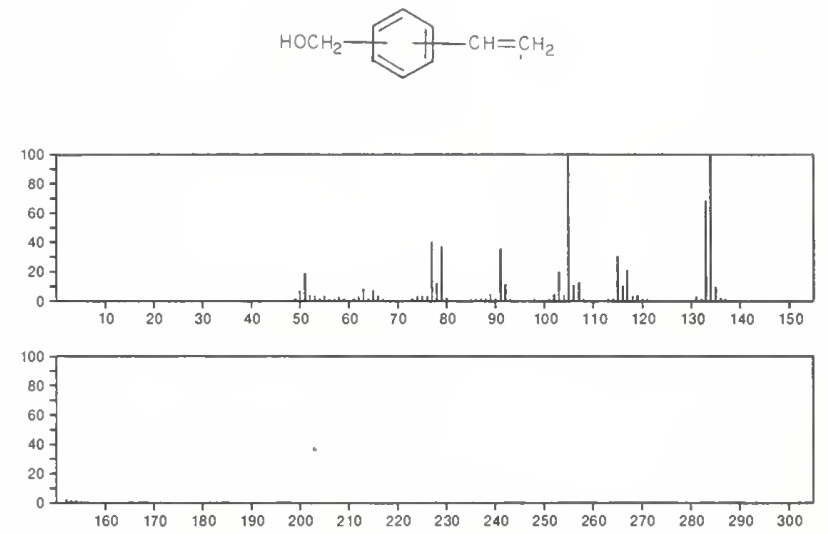

134

$\mathrm{C}_{9} \mathrm{H}_{10} \mathrm{O}$

$53951-50-1$

Benzaldehyde, ethyl-
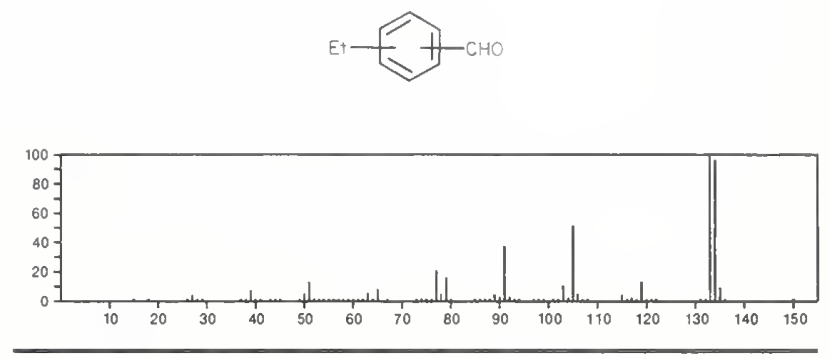

134

$\mathrm{C}_{9} \mathrm{H}_{10} \mathrm{O}$

$56666-74-1$

Bicyclo[6.1.0]nona-5,8-dien-4-one
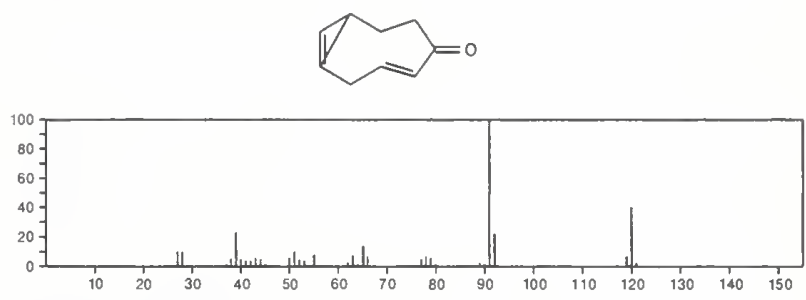

134

$\mathrm{C}_{10} \mathrm{H}_{14}$

$95-93-2$

Benzene, 1,2,4,5-tetramethyl-
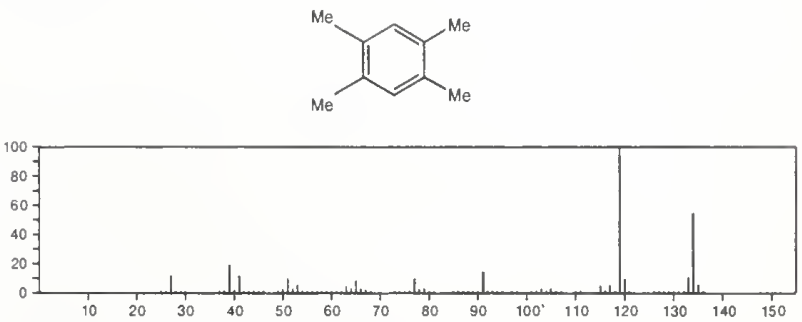
134

Benzene, (1,1-dimethylethyl)-

$\mathrm{C}_{10} \mathrm{H}_{14}$

PhBu-t

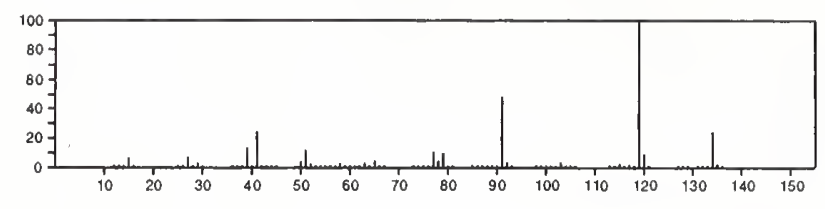

134

Benzene, 1-methyl-4-(1-methylethyl)-
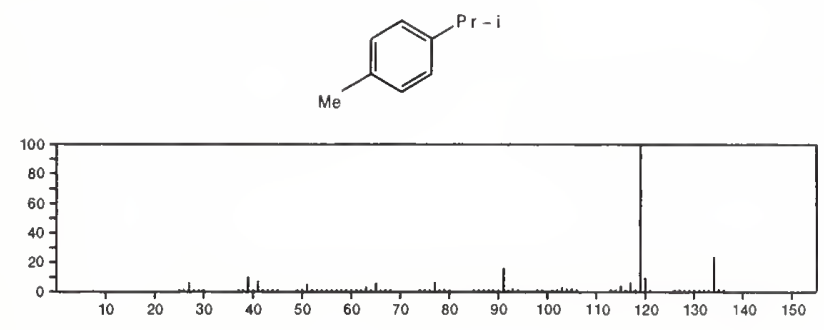

134

Benzene, butyl-

$\mathrm{C}_{10} \mathrm{H}_{14}$

$104-51-8$

$\mathrm{Ph}\left(\mathrm{CH}_{2}\right)_{3} \mathrm{Me}$

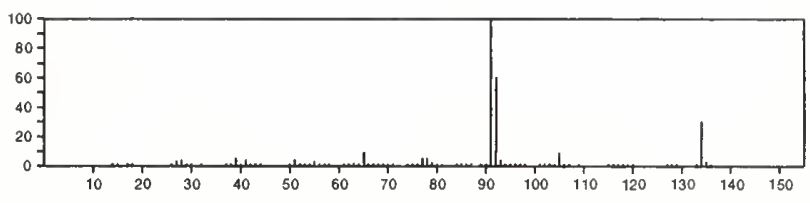

134

$\mathrm{C}_{10} \mathrm{H}_{14}$

$105-05-5$

Benzene, 1,4-diethyl-
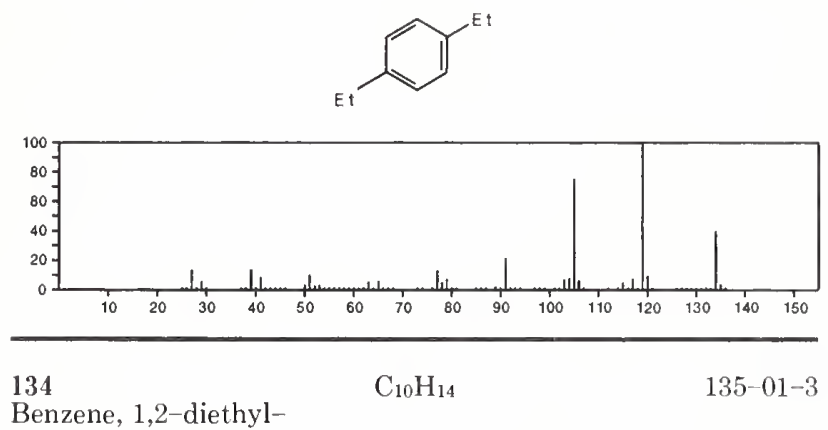

Benzene, 1,2-diethyl-
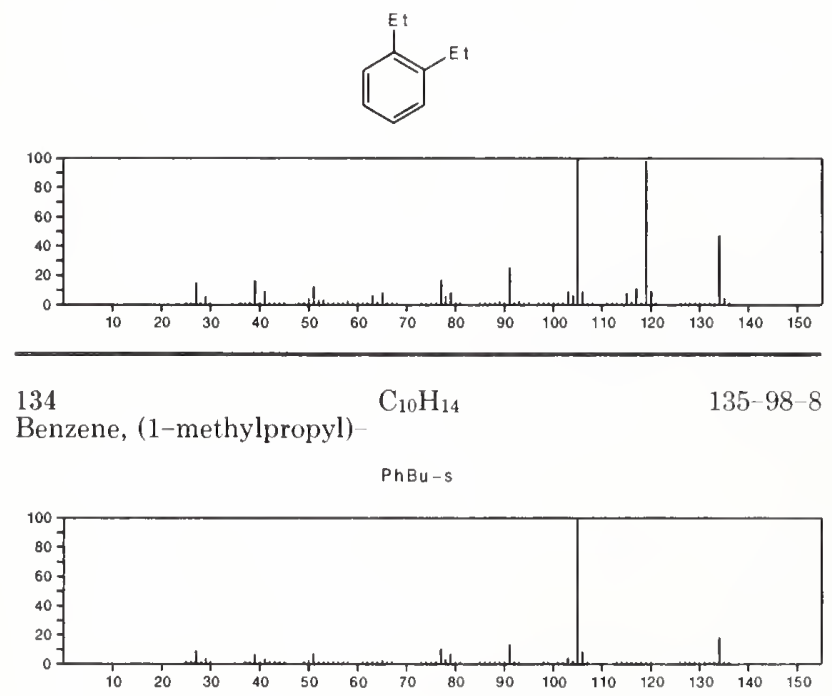

134

Benzene, 1,3-diethyl-

$\mathrm{C}_{10} \mathrm{H}_{14}$

$141-93-5$
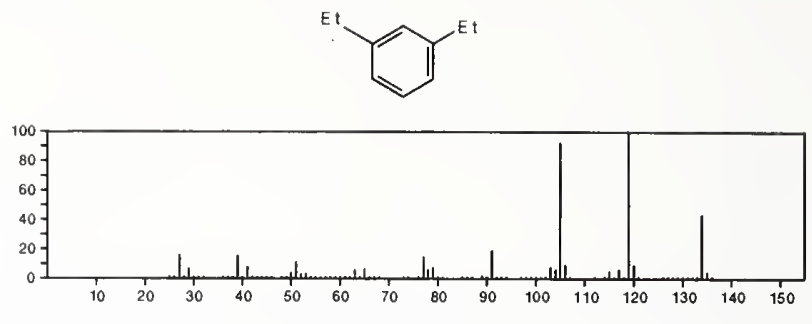

134

Benzene, 1,2,3,4-tetramethyl-

$\mathrm{C}_{10} \mathrm{H}_{14}$

$488-23-3$
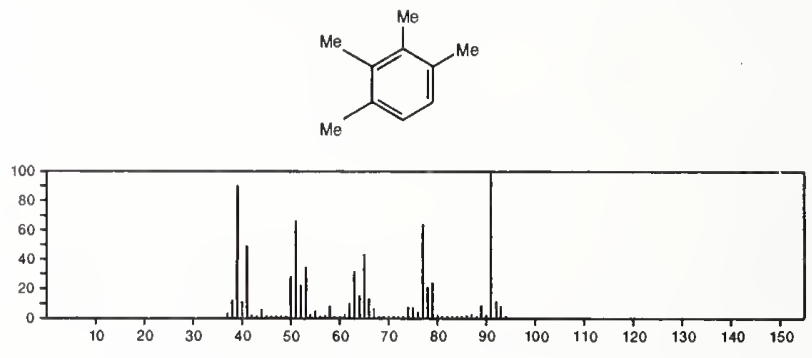

134

$\mathrm{C}_{10} \mathrm{H}_{14}$

$527-53-7$

Benzene, 1,2,3,5-tetramethyl<smiles>Cc1cc(C)c(C)c([N+](=O)[O-])c1</smiles>

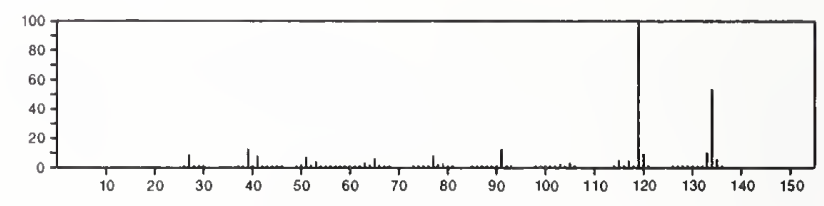

134

$\mathrm{C}_{10} \mathrm{H}_{14}$

Benzene, 1-methyl-2-(1-methylethyl)-

$527-84-4$<smiles>[N-]c1ccccc1Br</smiles>

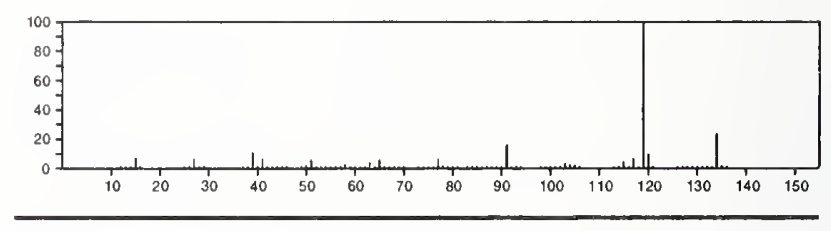

134

$\mathrm{C}_{10} \mathrm{H}_{14}$

$535-77-3$

Benzene, 1-methyl-3-(1-methylethyl)-
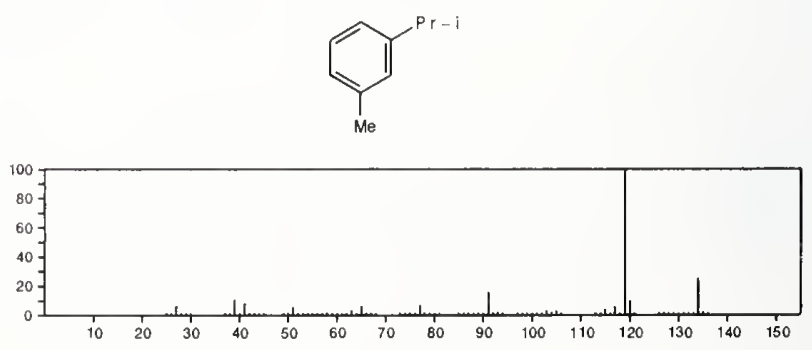
$134 \quad \mathrm{C}_{10} \mathrm{H}_{14}$

PhBu-i

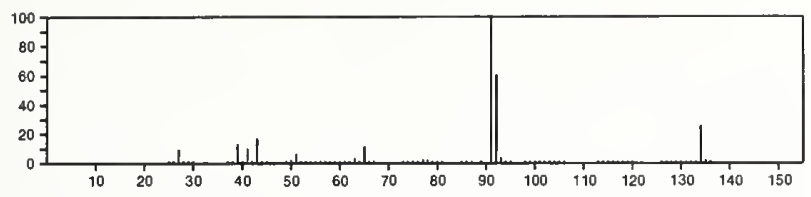

134

Benzene, 1-ethyl-2,4-dimethyl-

874-41-9
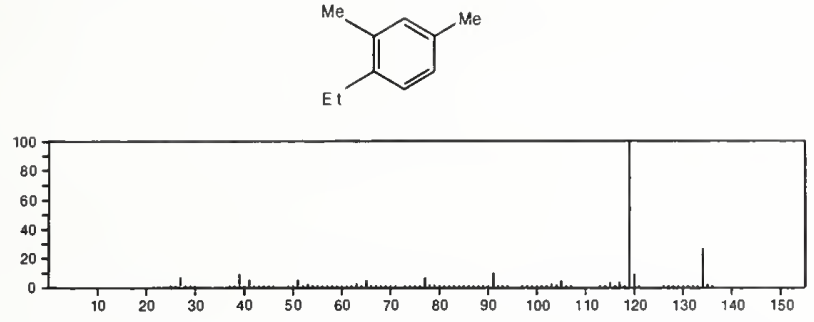

134

Benzene, 1-ethyl-2,3-dimethyl-
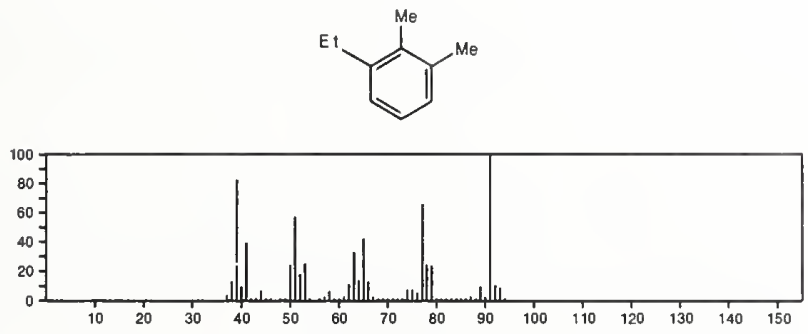

134

$\mathrm{C}_{10} \mathrm{H}_{14}$

$934-74-7$

Benzene, 1-ethyl-3,5-dimethyl-
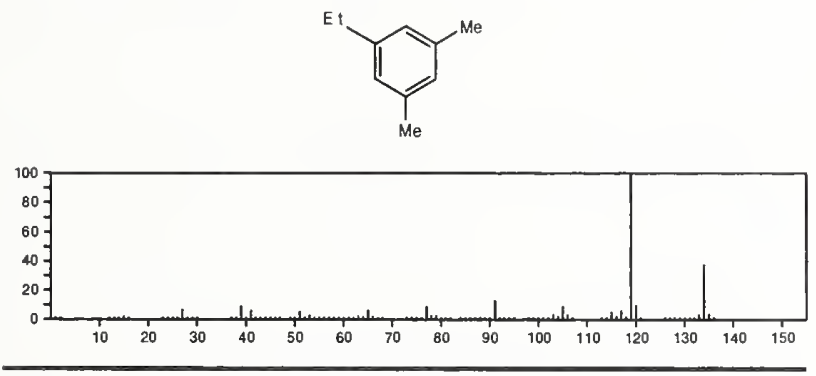

134

$\mathrm{C}_{10} \mathrm{H}_{14}$

Benzene, 4-ethyl-1,2-dimethyl-

$934-80-5$
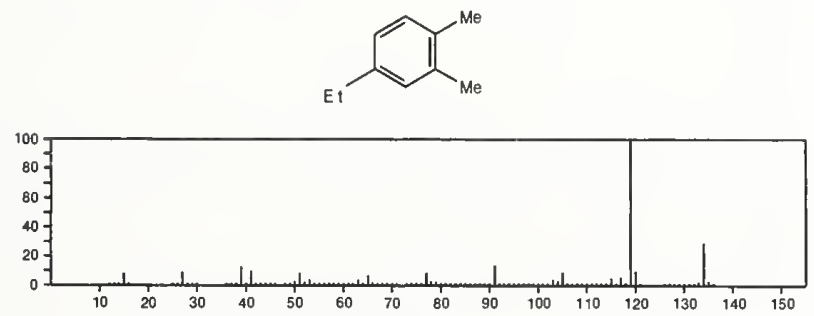

134 $\mathrm{C}_{10} \mathrm{H}_{14}$

$1074-17-5$
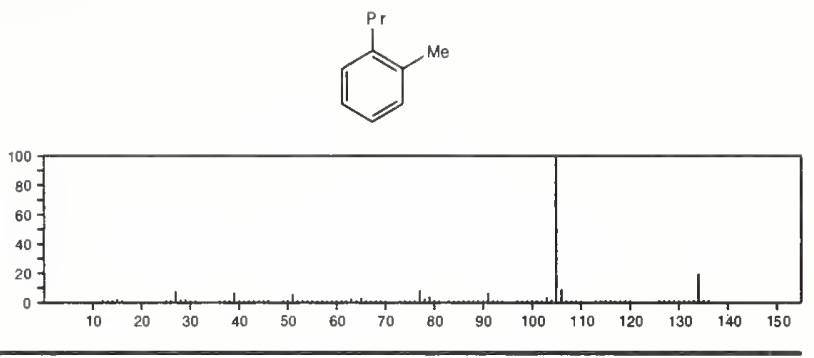

134

$\mathrm{C}_{10} \mathrm{H}_{14}$

$1074-43-7$

Benzene. I methyl 3-propyl-
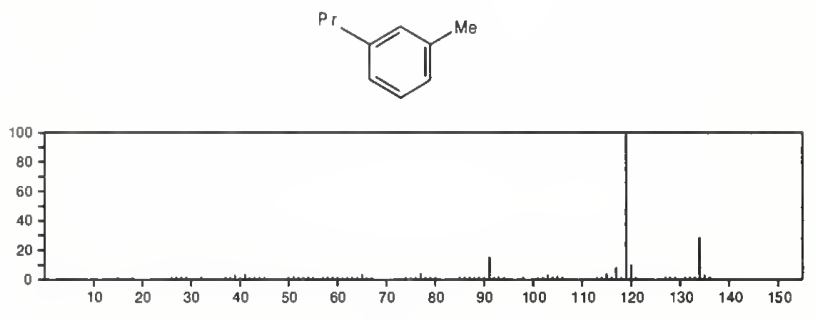

134

$\mathrm{C}_{10} \mathrm{H}_{14}$

$1074-55-1$

Benzene, 1-methyl-4-propyl-
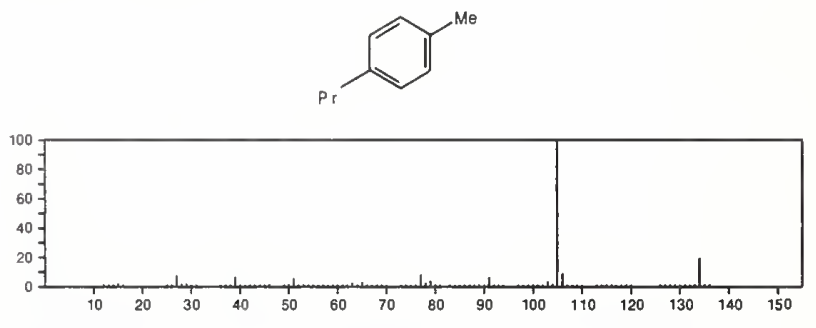

134

$\mathrm{C}_{10} \mathrm{H}_{14}$

$1758-88-9$

Benzene, 2-ethyl-1,4-dimethyl-<smiles>CCc1cc(C)ccc1[N+](=O)[O-]</smiles>

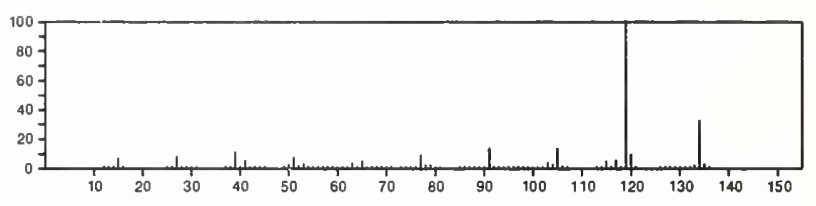

134

$\mathrm{C}_{10} \mathrm{H}_{14}$

2870-04-4

Benzene, 2-ethyl-1,3-dimethyl-
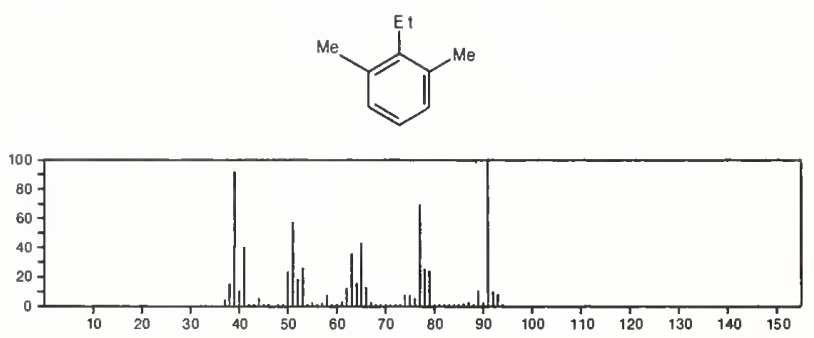
134

2,8-Decadiyne

$\mathrm{C}_{10} \mathrm{H}_{14}$

$\mathrm{MeC} \equiv \mathrm{C}\left(\mathrm{CH}_{2}\right)_{4} \mathrm{C} \equiv \mathrm{CM}$

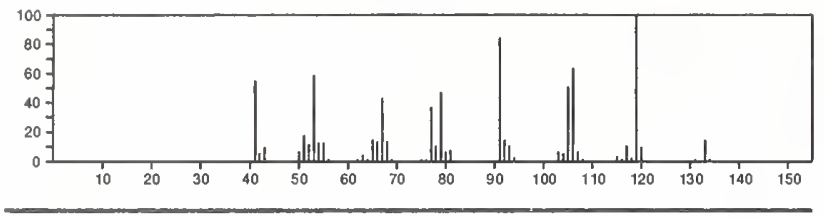

134

Benzene, diethyl-

$\mathrm{C}_{10} \mathrm{H}_{14}$

$25340-17-4$
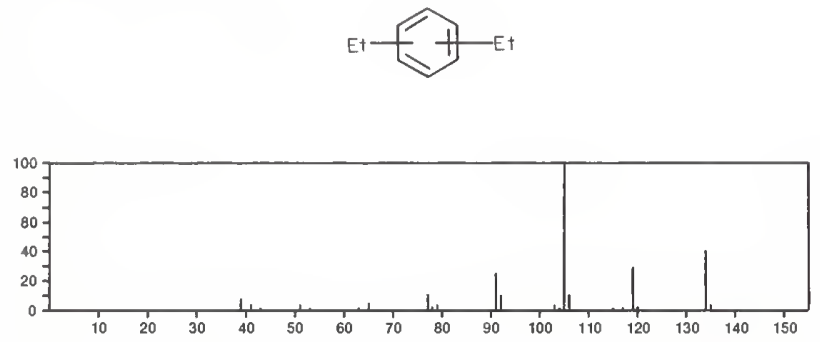

$134 \quad \mathrm{C}_{10} \mathrm{H}_{14}$

Bicyclo[3.2.1]oct-2-ene, 3-methyl-4-methylene-

$49826-53-1$
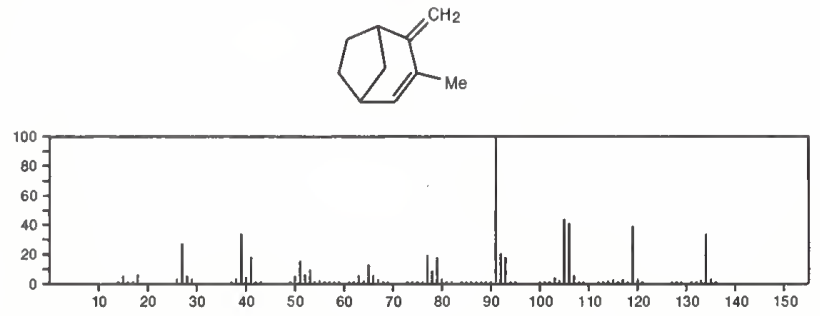

134

$\mathrm{C}_{10} \mathrm{H}_{14}$

Bicyclo[3.2.1]octane, 2,3-bis(methylene)
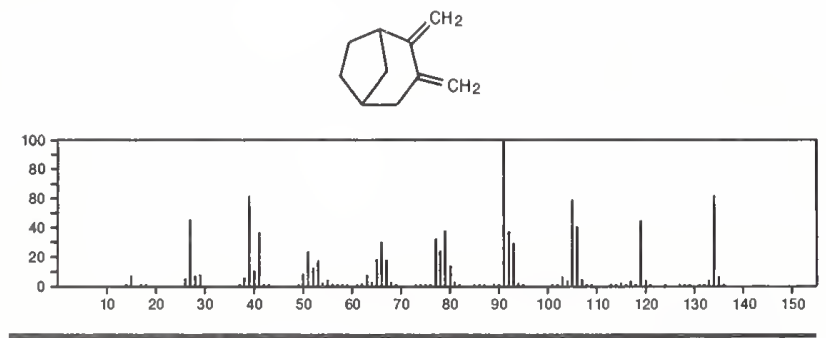

134

1,3-Decadiyne

$\mathrm{C}_{10} \mathrm{H}_{14}$

$55682-66-1$

$\mathrm{HC} \equiv \mathrm{CC} \equiv \mathrm{C}\left(\mathrm{CH}_{2}\right){ }_{5} \mathrm{Me}$

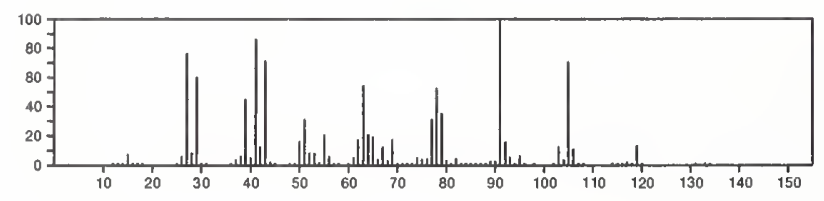

134

Sulfur chloride $\left(\mathrm{S}_{2} \mathrm{Cl}_{2}\right)$

$\mathrm{Cl}_{2} \mathrm{~S}_{2}$

10025-67-9

$\mathrm{ClSSCl}$

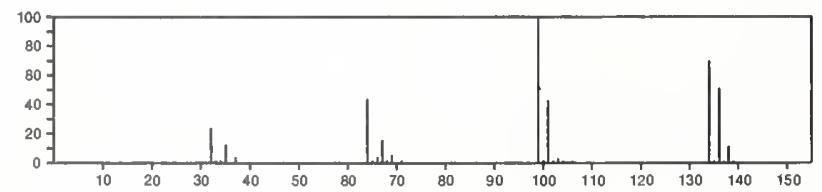

135

Azetidine, 1-bromo-

$\mathrm{C}_{3} \mathrm{H}_{6} \mathrm{BrN}$

$38455-26-4$

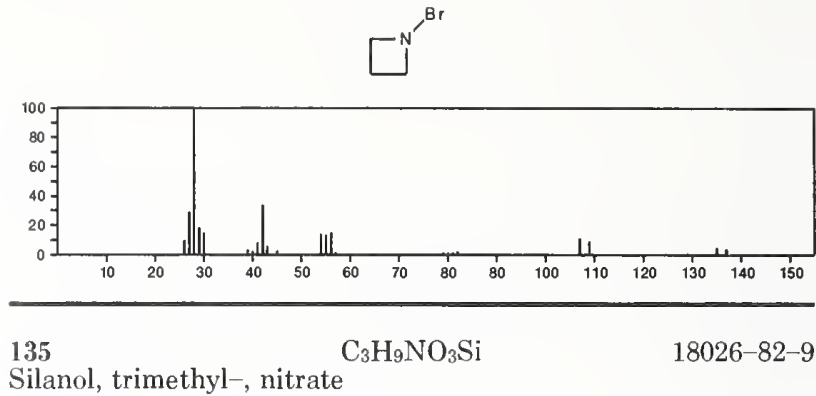

Silanol, trimethyl-, nitrate

$\mathrm{Me}_{3} \mathrm{SiONO}_{2}$

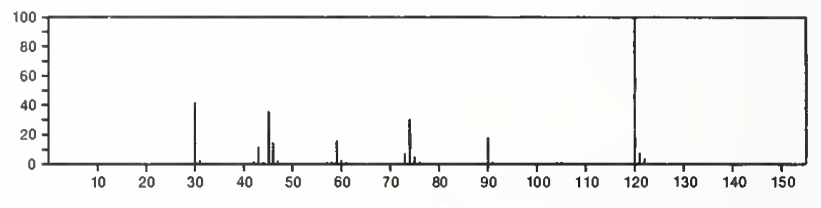

135

$\mathrm{C}_{4} \mathrm{H}_{9} \mathrm{NO}_{2} \mathrm{~S}$

$13595-45-4$

Azetidine, 1-(methylsulfonyl)-
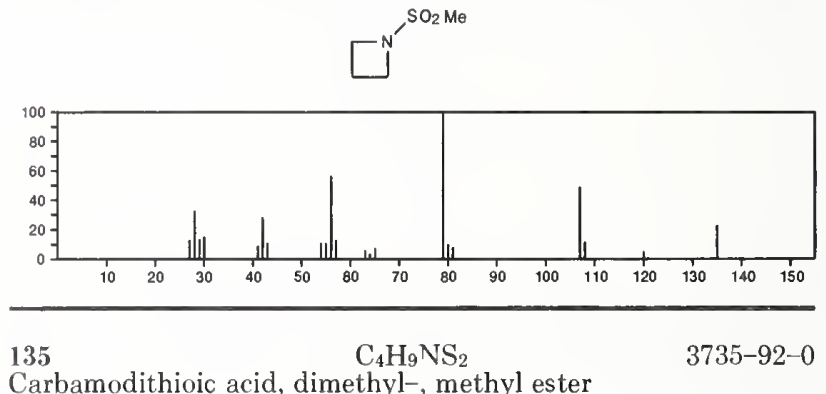

Carbamodithioic acid, dimethyl-, methyl ester

$\mathrm{MeSC}$ ( S) NMe2

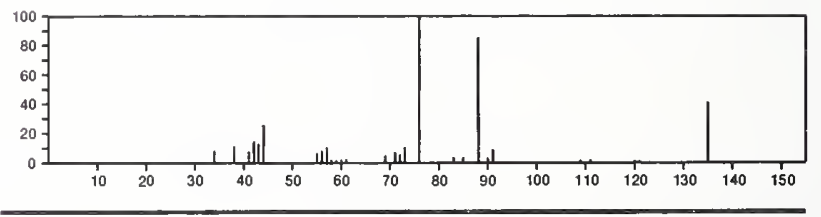

135

1H-Purin-6-amine

$\mathrm{C}_{5} \mathrm{H}_{5} \mathrm{~N}_{5}$

$73-24-5$
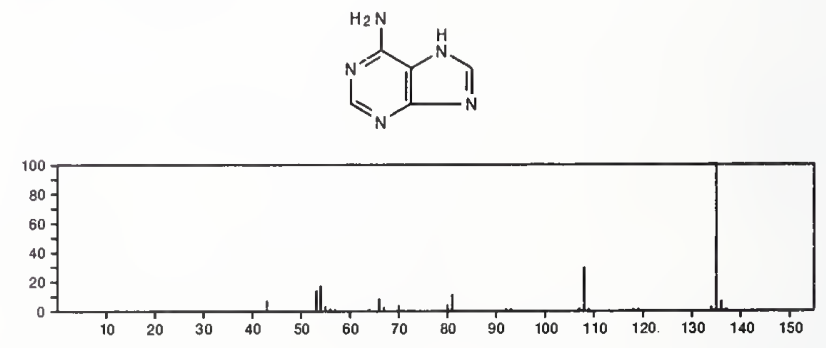

135

$\mathrm{C}_{6} \mathrm{H}_{5} \mathrm{~N}_{3} \mathrm{O}$

2592-95-2

1H-Benzotriazole, 1-hydroxy-
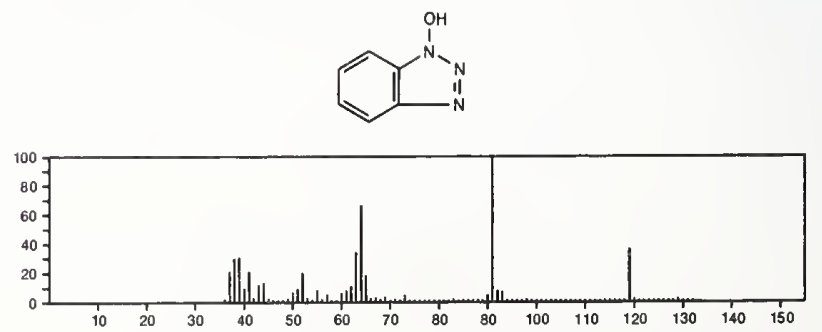
$135 \quad \mathrm{C}_{6} \mathrm{H}_{5} \mathrm{~N}_{3} \mathrm{O}$

1,2,4-Triazolo[4,3-a]pyridin-3(2H)-one
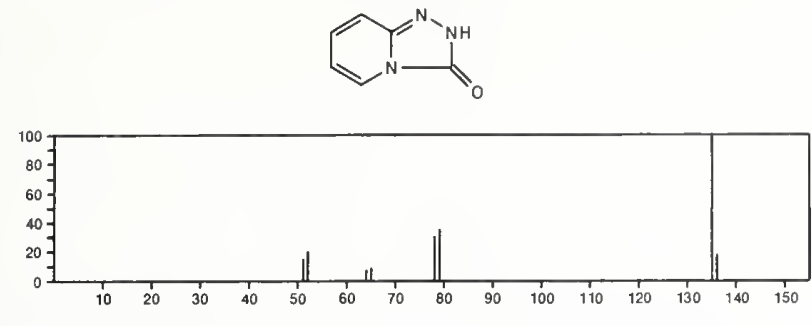

135

$\mathrm{C}_{6} \mathrm{H}_{5} \mathrm{~N}_{3} \mathrm{O}$

$16328-62-4$

$2 H$-Imidazo[4,5-b]pyridin-2-one, 1,3-dihydro-
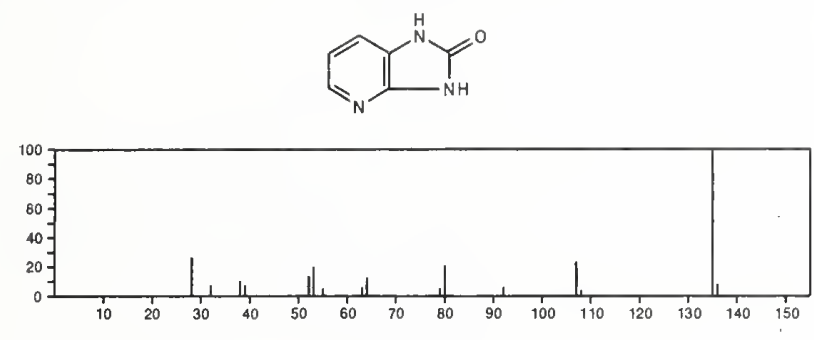

135

$\mathrm{C}_{6} \mathrm{H}_{5} \mathrm{~N}_{3} \mathrm{O}$

$53975-70-5$

3H-Pyrazolo[3,4-c]pyridin-3-one, 1,2-dihydro-
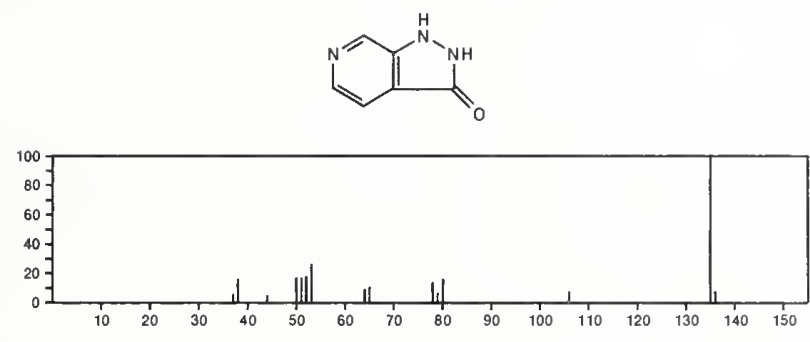

\section{5}

2(3H)-Benzoxazolone

$\mathrm{C}_{7} \mathrm{H}_{5} \mathrm{NO}_{2}$

$59-49-4$
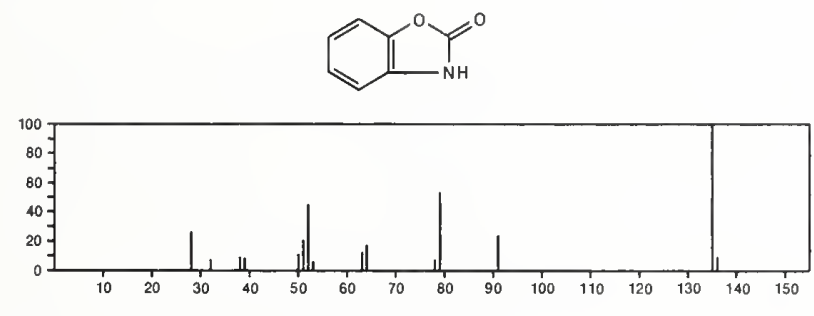

\section{5}

Benzaldehyde, $0^{-}$-nitroso-

$$
\mathrm{C}_{7} \mathrm{H}_{5} \mathrm{NO}_{2}
$$

29809-25-4<smiles>O=Cc1ccccc1N=O</smiles>

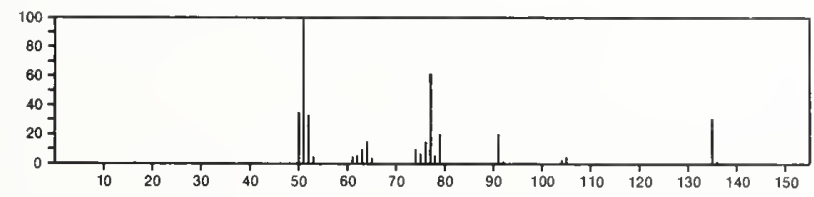

135

21-Benzisoxazol-3(1H)-one $\mathrm{C}_{7} \mathrm{H}_{5} \mathrm{NO}_{2}$

31499-90-8
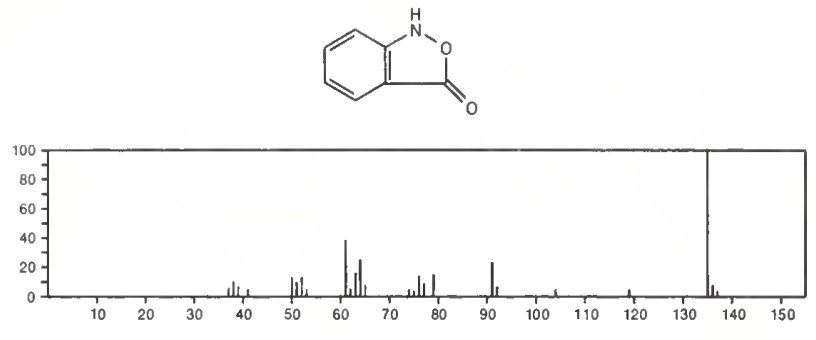

135

$\mathrm{C}_{7} \mathrm{H}_{5} \mathrm{NS}$

95-16-9

Benzothiazole
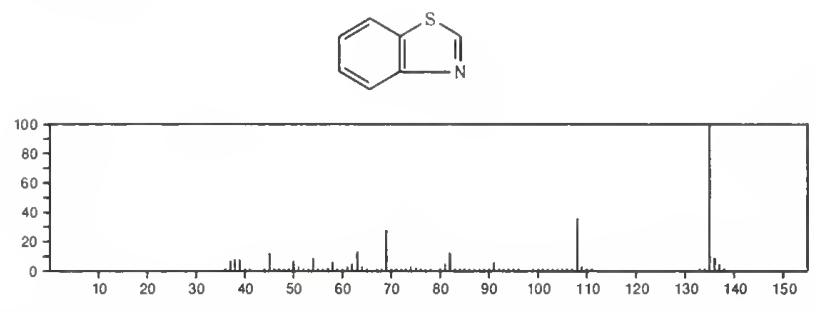

135

Thieno[2,3-c]pyridine .

$\mathrm{C}_{7} \mathrm{H}_{5} \mathrm{NS}$

272-12-8
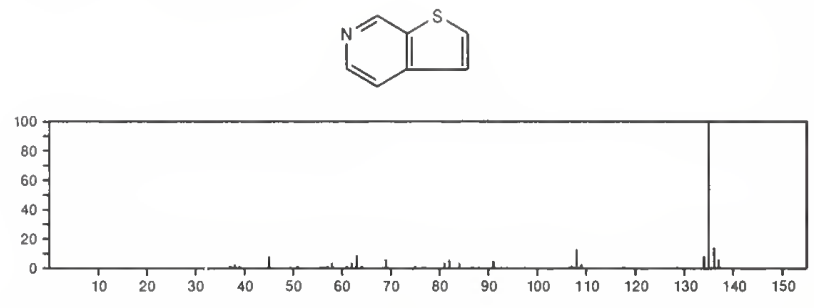

135

$\mathrm{C}_{7} \mathrm{H}_{5} \mathrm{NS}$

272-14-0

Thieno[3,2-c]pyridine
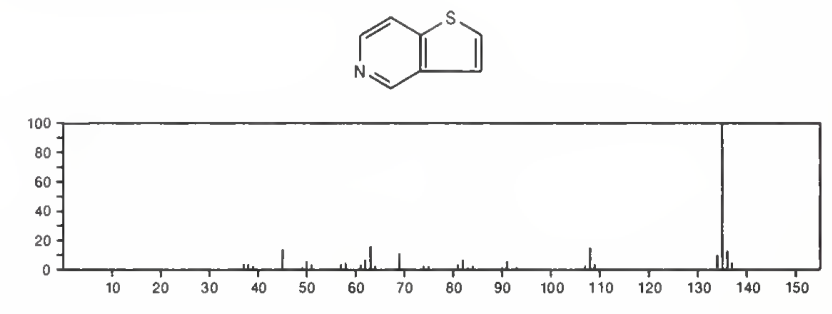

135

1,2-Benzisothiazole

$\mathrm{C}_{7} \mathrm{H}_{5} \mathrm{NS}$

272-16-2
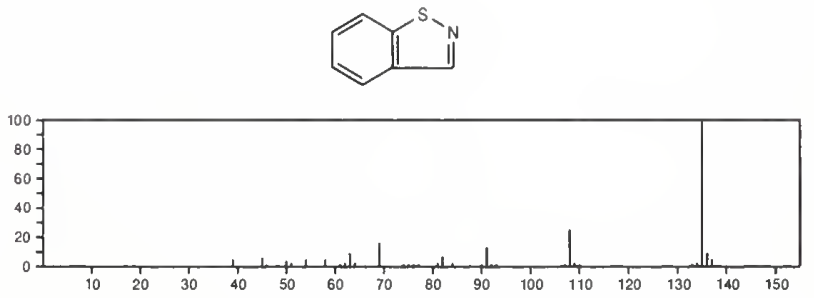
135

Thiocyanic acid, phenyl ester

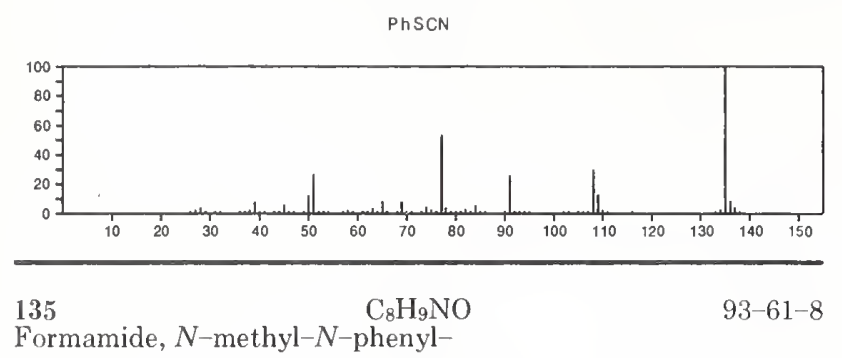

$\mathrm{PhNMeCH}=\mathrm{O}$

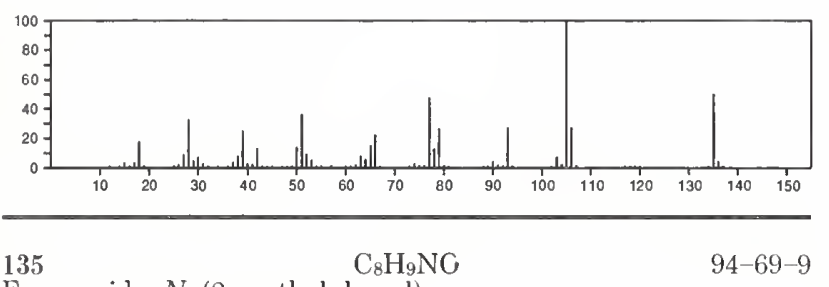

Formamide, $N$-(2-methylphenyl)-
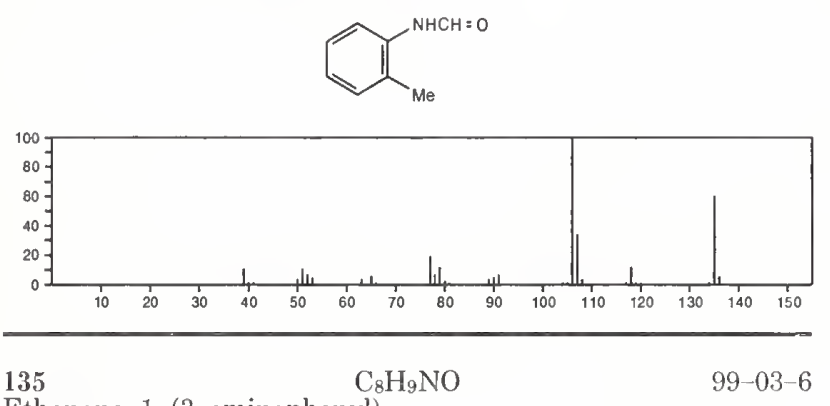

Ethanone, 1-(3-aminophenyl)-
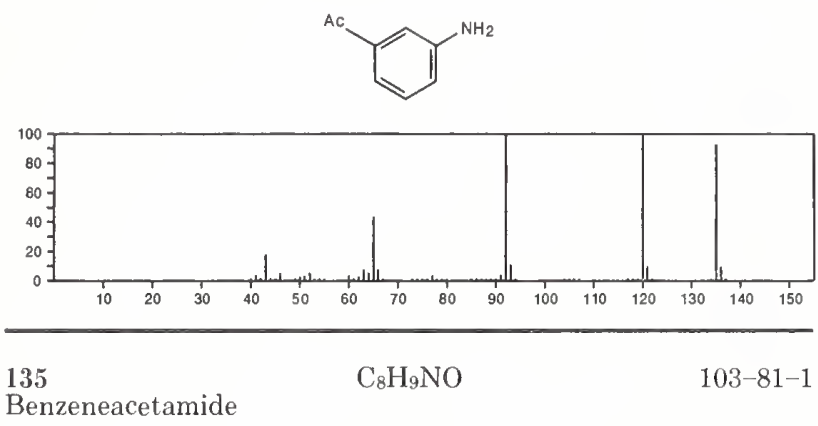

$\mathrm{H}_{2} \mathrm{NCOCH}_{2} \mathrm{Ph}$

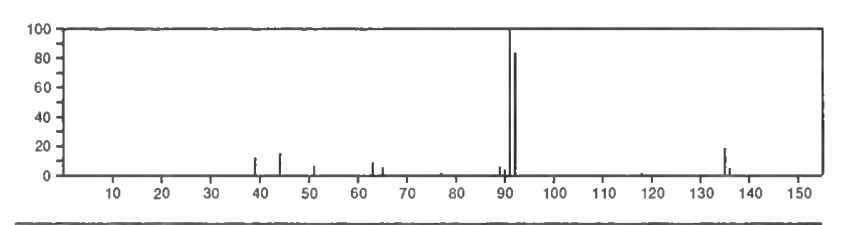

135

Acetamide, $N$-phenyl-

\section{$\mathrm{C}_{8} \mathrm{H}_{9} \mathrm{NO}$}

$103-84-4$

PhNHAC

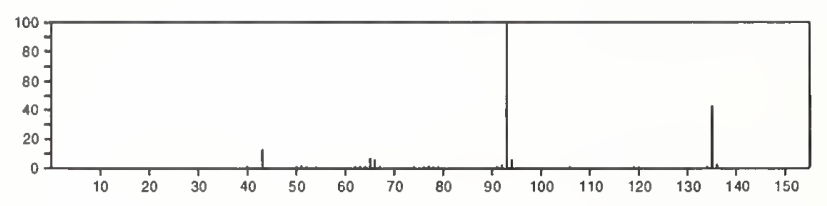

135

Benzamide, 2-methyl-

$\mathrm{C}_{8} \mathrm{H}_{9} \mathrm{NO}$

$527-85-5$

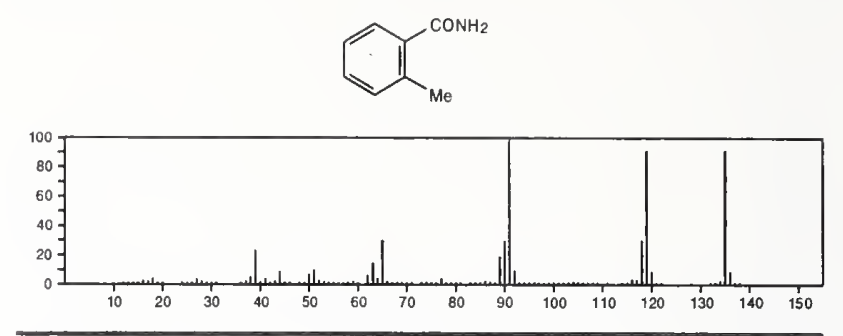

135

Ethanone, 1-phenyl-, oxime

$\mathrm{C}_{8} \mathrm{H}_{9} \mathrm{NO}$

$613-91-2$

$\mathrm{HON}=\mathrm{CMe} \mathrm{Ph}$

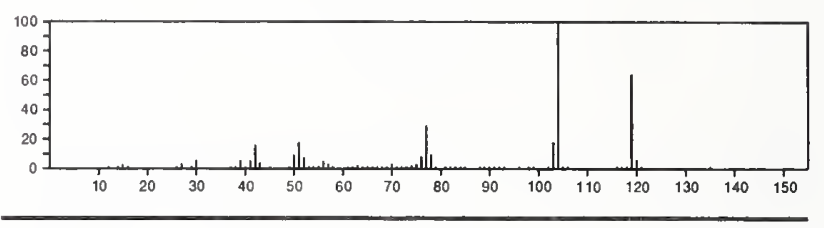

135

$\mathrm{C}_{8} \mathrm{H}_{9} \mathrm{NO}$

$613-93-4$

Benzamide, $N$-methyl-

MeNHCOPh

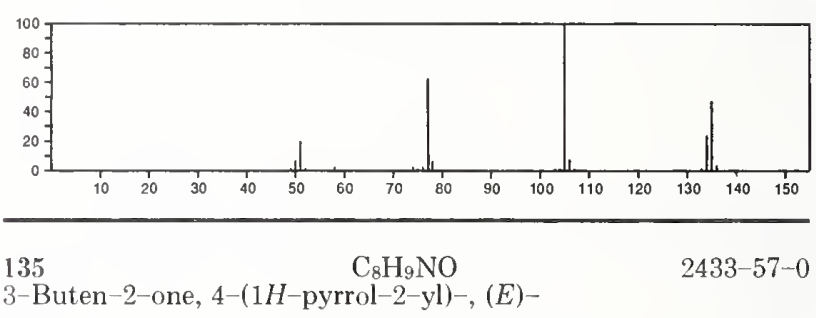

NH=CHCOMe

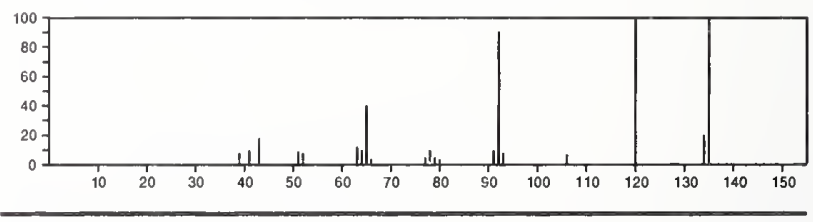

135

$\mathrm{C}_{8} \mathrm{H}_{9} \mathrm{NO}$

$3235-02-7$

Benzaldehyde, 4-methyl-, oxime
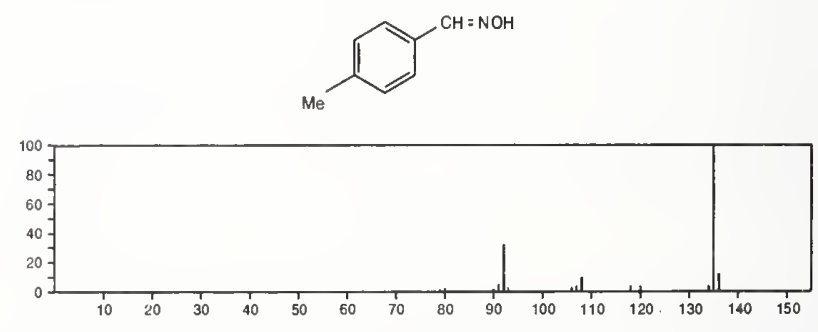

135

1-Propanone, 1-(2-pyridinyl)

$\mathrm{C}_{8} \mathrm{H}_{9} \mathrm{NO}$

$3238-55-9$
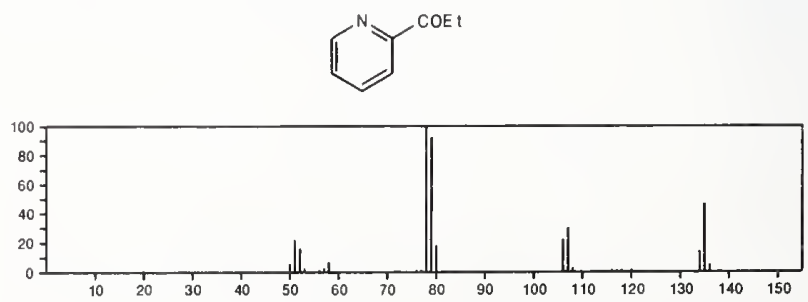
135

$\mathrm{C}_{8} \mathrm{H}_{9} \mathrm{NO}$

Methanamine, $N$-(phenylmethylene)-, $N$-oxide

$\mathrm{O}=\mathrm{NMe}=\mathrm{CHPh}$

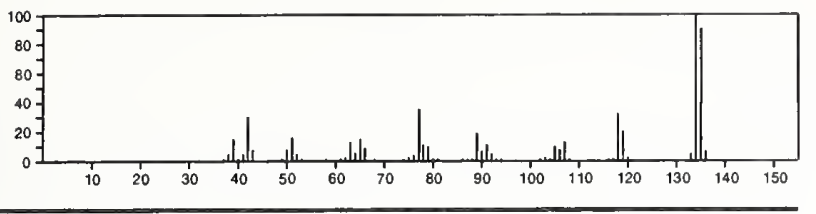

135

$\mathrm{C}_{8} \mathrm{H}_{9} \mathrm{NO}$

$3376-32-7$

Benzaldehyde, $\mathrm{O}$-methyloxime

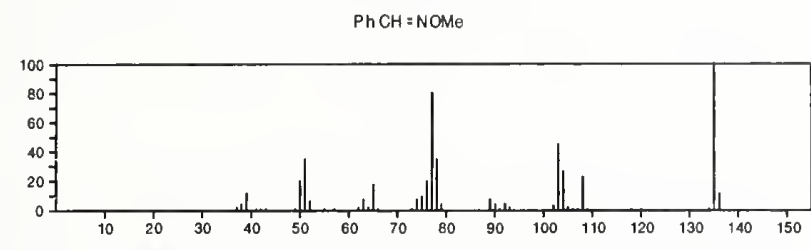

135

$\mathrm{C}_{8} \mathrm{H}_{9} \mathrm{NO}$

Benzaldehyde, 4-methyl-, oxime, $(E)$ -
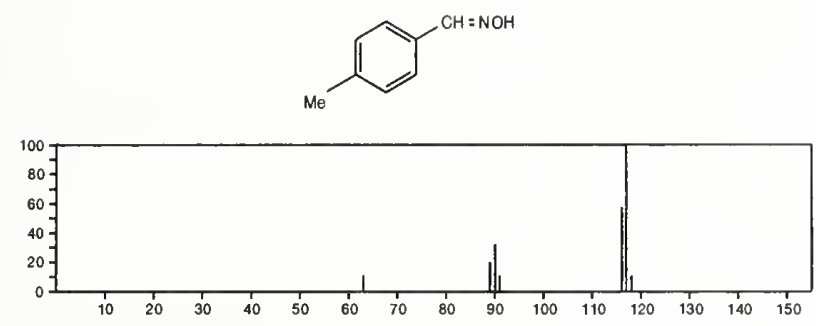

135

$\mathrm{C}_{8} \mathrm{H}_{9} \mathrm{NO}$

Benzaldehyde, 4-methyl-, oxime, (Z)-

$3717-16-6$
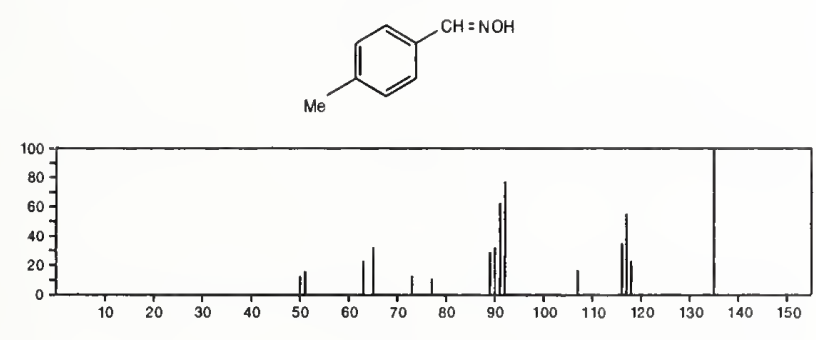

135

\section{$\mathrm{C}_{8} \mathrm{H}_{9} \mathrm{NO}$}

Azocine, 2-methoxy-
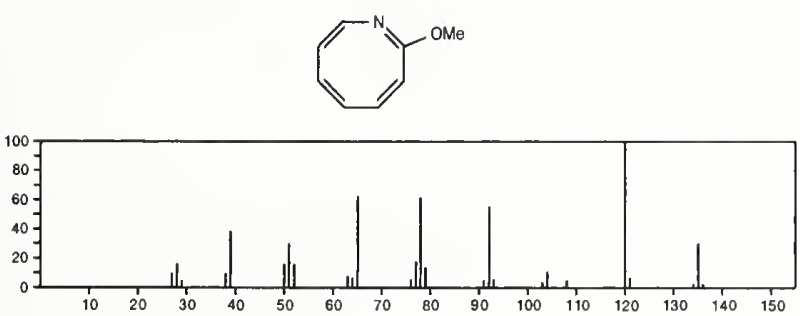

135

$\mathrm{C}_{8} \mathrm{H}_{9} \mathrm{NO}$

Benzaldehyde, 3-methyl-, oxime
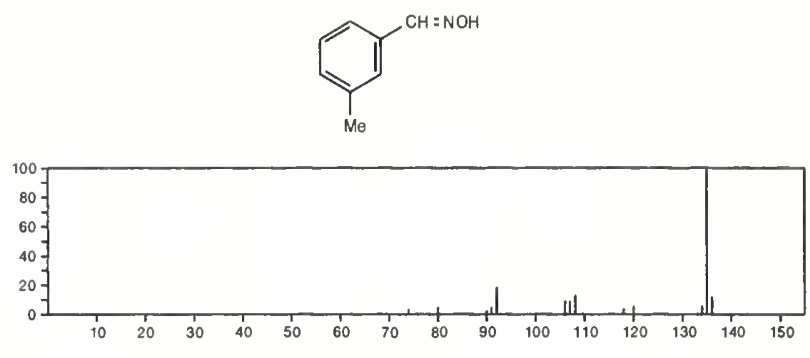

135

$\mathrm{C}_{9} \mathrm{H}_{13} \mathrm{~N}$

Benzenemethanamine, $N, N$ dimethyl-

$103-83-3$

$\mathrm{Me}_{2} \mathrm{NCH}_{2} \mathrm{Ph}$

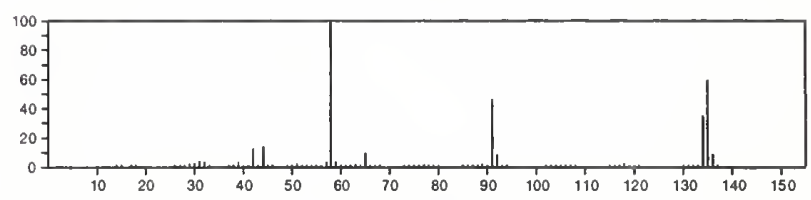

135

$\mathrm{C}_{9} \mathrm{H}_{13} \mathrm{~N}$

Benzeneethanamine, $\alpha$-methyl- , ( $( \pm)$

$300-62-9$

$\mathrm{MeCH}\left(\mathrm{NH}_{2}\right) \mathrm{CH}_{2} \mathrm{Ph}$

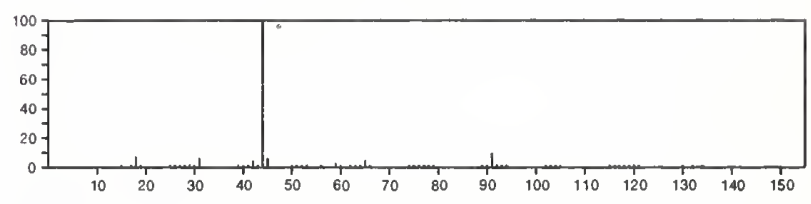

135

Pyridine, 3-butyl-

$\mathrm{C}_{9} \mathrm{H}_{13} \mathrm{~N}$

$539-32-2$
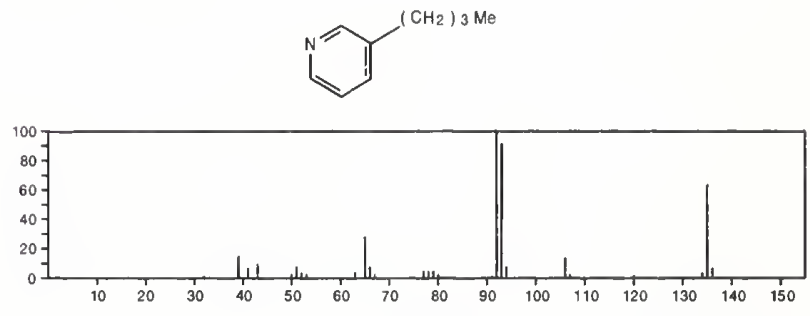

135

$\mathrm{C}_{9} \mathrm{H}_{13} \mathrm{~N}$

589-08-2

Benzeneethanamine, $N$-methyl-

$\mathrm{Ph} \mathrm{CH}_{2} \mathrm{CH}_{2} \mathrm{NHMe}$

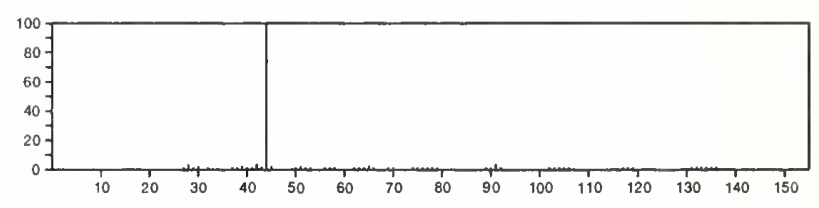

135

$\mathrm{C}_{9} \mathrm{H}_{13} \mathrm{~N}$

2038-57-5

Benzenepropanamine

$\mathrm{Ph}\left(\mathrm{CH}_{2}\right)_{3} \mathrm{NH}_{2}$

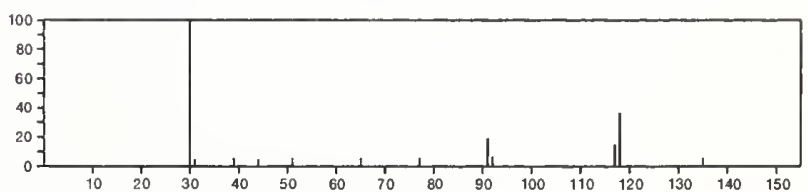


135

$\mathrm{C}_{9} \mathrm{H}_{13} \mathrm{~N}$

Pyridine, 4-(1,1-dimethylethyl)-

$3978-81-2$
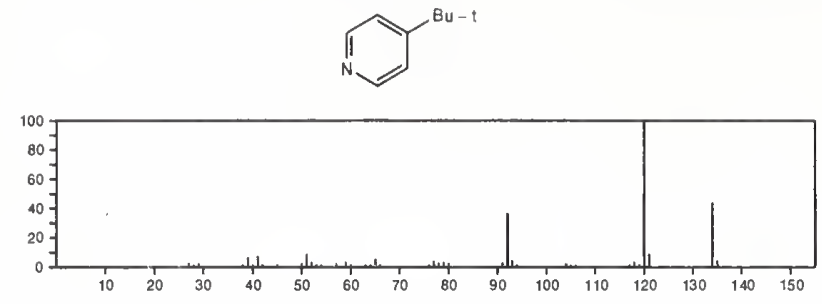

135

Pyridine, 2-butyl-

$\mathrm{C}_{9} \mathrm{H}_{13} \mathrm{~N}$

$5058-19-5$
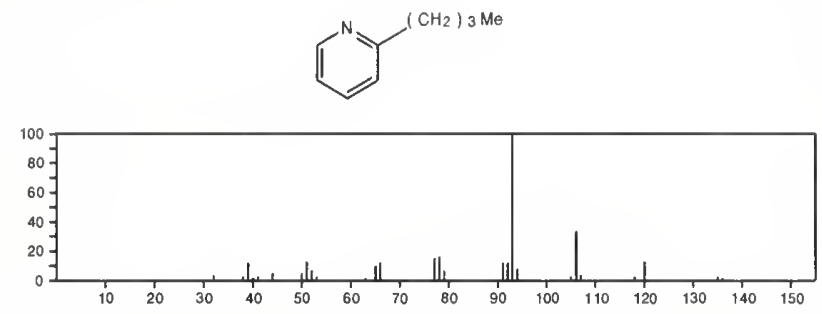

135

$\mathrm{C}_{9} \mathrm{H}_{1}$

$\mathrm{E} t \mathrm{NHCH}_{2} \mathrm{Ph}$

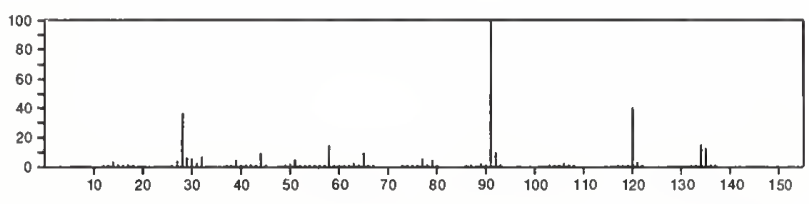

$136 \quad \mathrm{CClF}_{3} \mathrm{~S}$

Methanesulfenyl chloride, trifluoro-

$421-17-0$

$\mathrm{CISCF}_{3}$
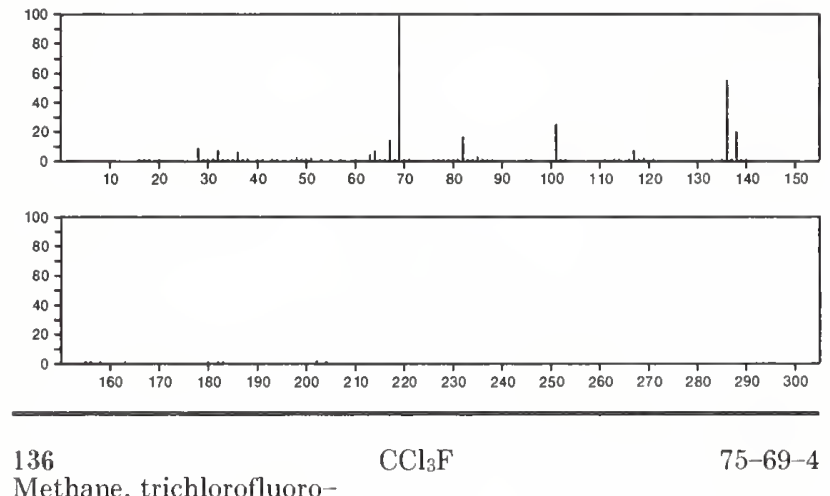

Methane, trichlorofluoro-

$\mathrm{FCCl}_{3}$

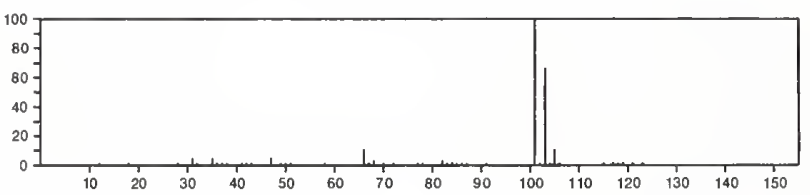

136

$\mathrm{CF}_{4} \mathrm{OS}$

Methanesulfinyl fluoride, trifluoro-

$\mathrm{F}_{3} \operatorname{Cs}(0) \mathrm{F}$

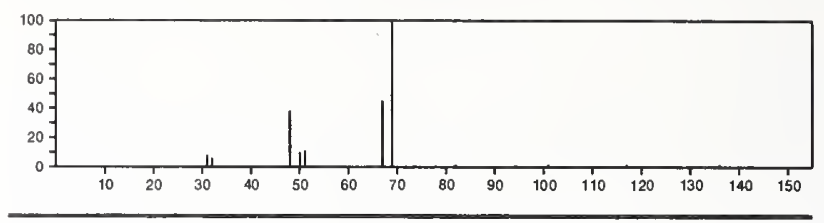

136

$\mathrm{C}_{2} \mathrm{HClF}_{4}$

Ethane, 1-chloro-1,1,2,2-tetrafluoro-

$354-25-6$

$\mathrm{F}_{2} \mathrm{CHCClF}_{2}$
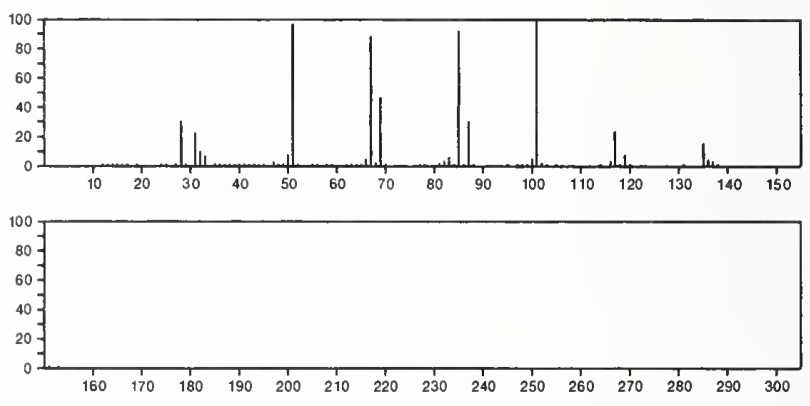

136

$\mathrm{C}_{2} \mathrm{H}_{2} \mathrm{O}_{4} \cdot \mathrm{CH}_{6} \mathrm{~N}_{2}$

Hydrazine, methyl--, oxalate $(1: 1)$

$32064-64-5$

$\mathrm{HO}_{2} \mathrm{CCO}_{2} \mathrm{H} \cdot \mathrm{MeNHNH}_{2}$

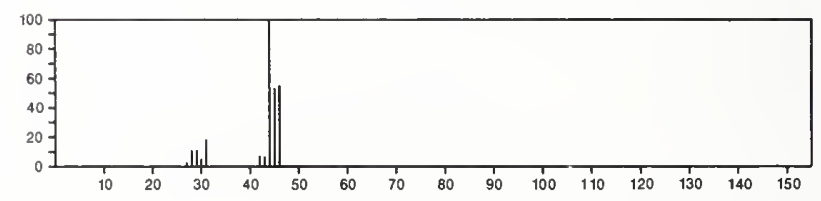

136

Ethanol, 2-nitro-, nitrate (ester)

$\mathrm{C}_{2} \mathrm{H}_{4} \mathrm{~N}_{2} \mathrm{O}_{5}$

4528-34-1

$\mathrm{O}_{2} \mathrm{NCH}_{2} \mathrm{CH}_{2} \mathrm{ONO}_{2}$

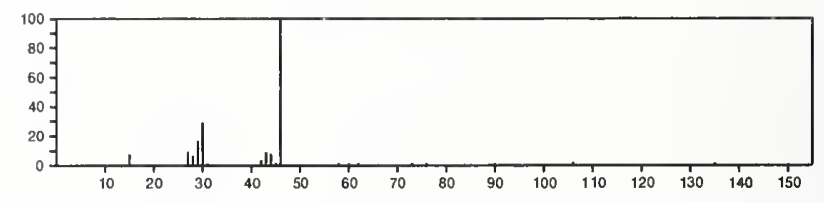

136

$\mathrm{C}_{3} \mathrm{H}_{5} \mathrm{BrO}$

Oxirane, (bromomethyl)-

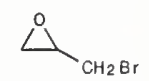

3132-64-7

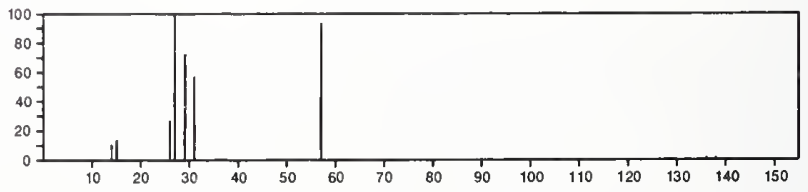


136

1,3,2-Dioxathiolane, 4,5-dimethyl-, 2-oxide
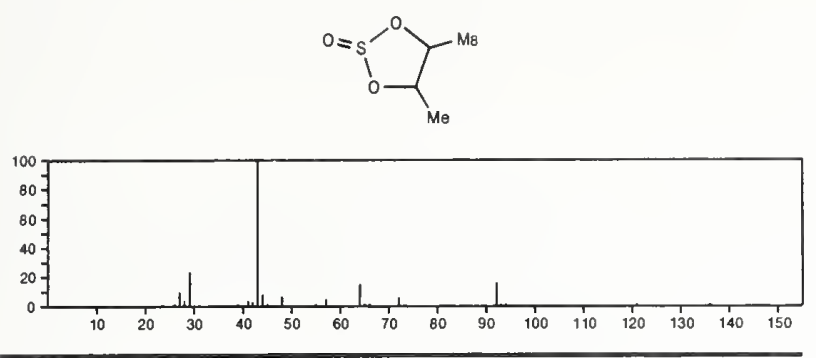

136

$\mathrm{C}_{4} \mathrm{H}_{8} \mathrm{Se}$

$3465-98-3$

Selenophene, tetrahydro-
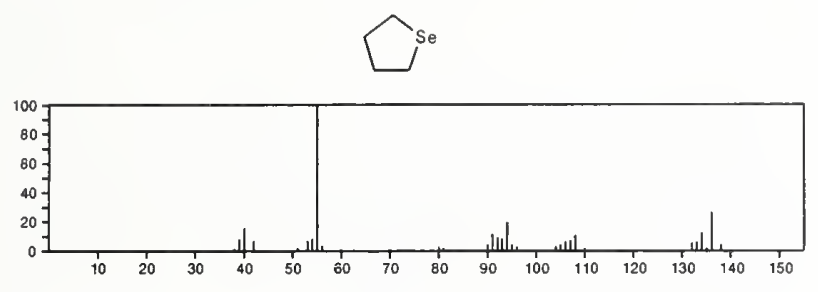

136

Butane, 2-bromo-

$\mathrm{C}_{4} \mathrm{H}_{9} \mathrm{Br}$

$78-76-2$

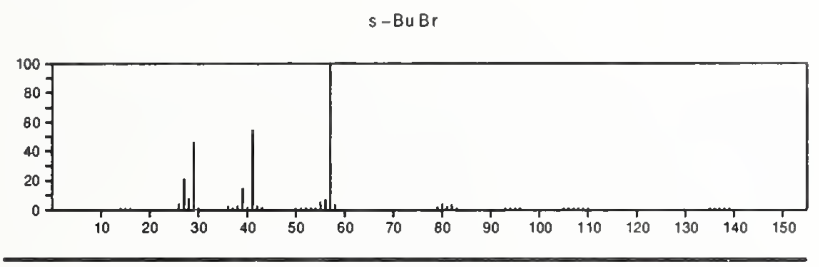

136

Propane, 1-bromo-2-methyl-

$\mathrm{C}_{4} \mathrm{H}_{9} \mathrm{Br}$

$78-77-3$

i-BuBr
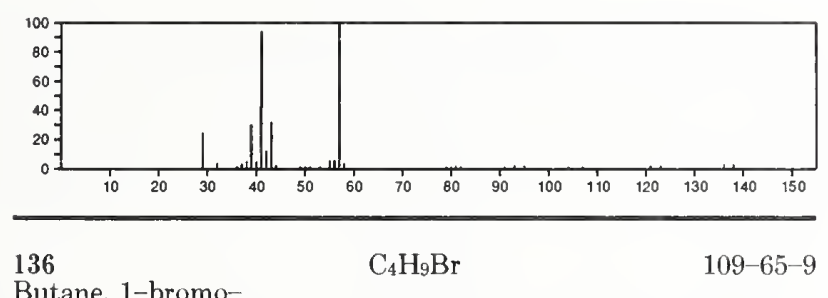

Butane, 1-bromo-

$\mathrm{Br}\left(\mathrm{CH}_{2}\right)_{3} \mathrm{MB}$

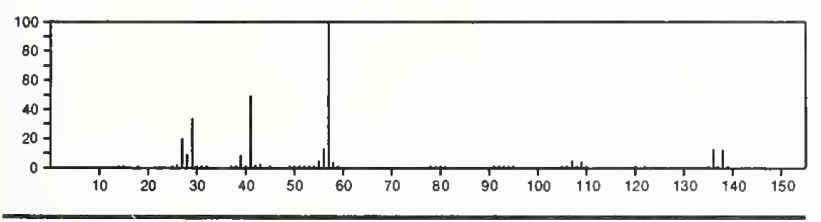

136

Propane, 2-bromo-2-methyl-

$\mathrm{C}_{4} \mathrm{H}_{9} \mathrm{Br}$

$t-8 u B r$

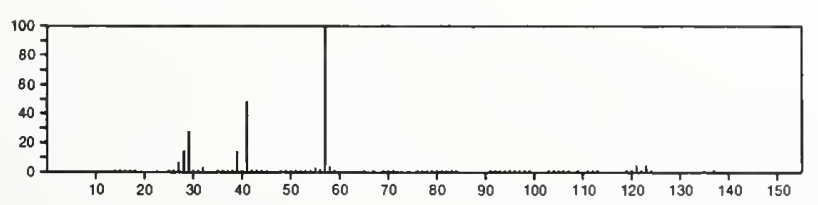

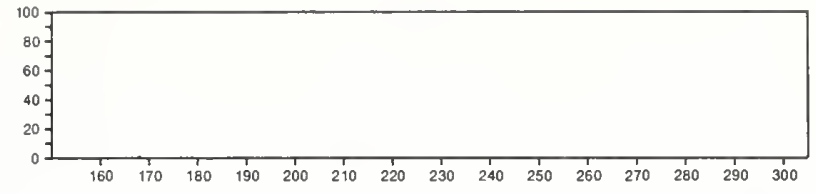

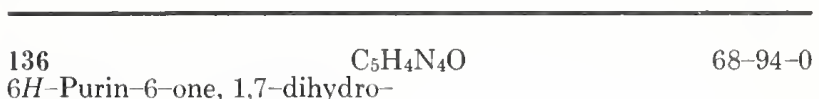

$6 \mathrm{H}^{-}$-Purin-6-one, 1,7-dihydro-
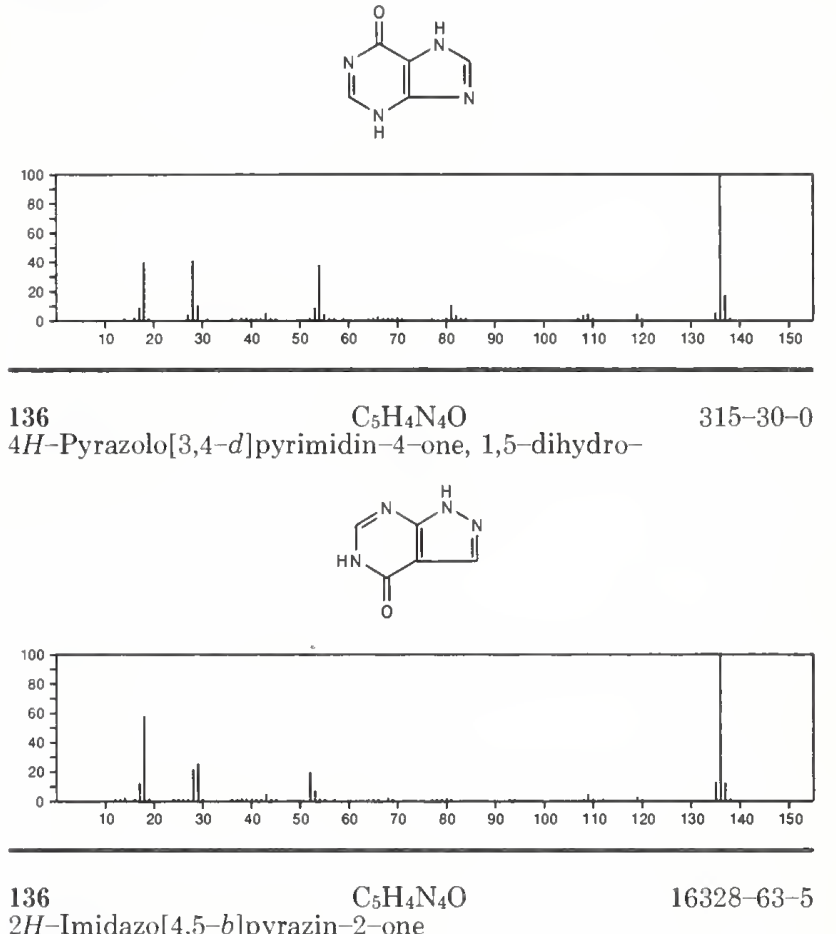

$2 H$-Imidazo $[4,5-b]$ pyrazin-2-one
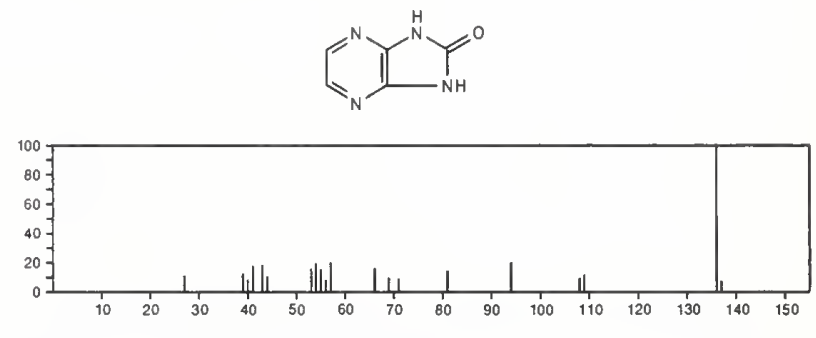

136
Cyclopropane, 1,1 -dichloro-2-ethenyl-

694-33-7
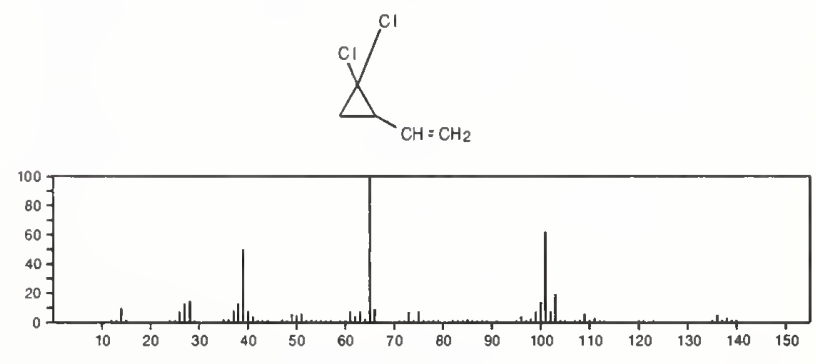

$136 \quad \mathrm{C}_{5} \mathrm{H}_{6} \mathrm{~F}_{2} \mathrm{O}_{2}$

2-Propen-1-ol, 3,3-difluoro-, acetate

$1597-40-6$

$\mathrm{F}_{2} \mathrm{C}=\mathrm{CHCH}_{2} \mathrm{OAC}$

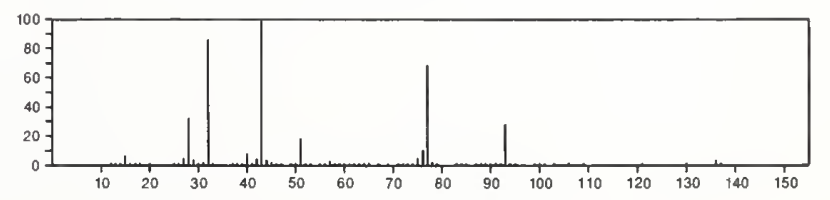


$136 \quad \mathrm{C}_{5} \mathrm{H}_{9} \mathrm{ClO}_{2}$

Propanoic acid, 3-chloro-, ethyl ester

$\mathrm{Cl} \mathrm{CH}_{2} \mathrm{CH}_{2} \mathrm{C}(\mathrm{O}) \mathrm{OE} \mathrm{t}$

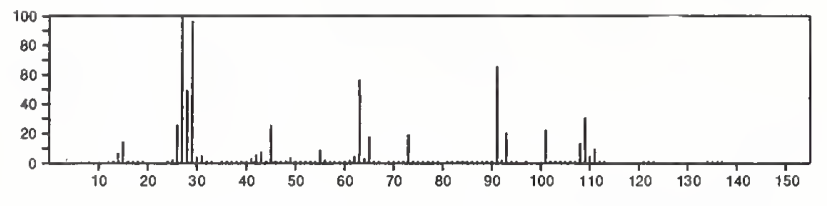

136

1-Propanol, 3-chloro-, acetate

628-09-1

\section{$\mathrm{C}_{5} \mathrm{H}_{9} \mathrm{ClO}_{2}$}

$\mathrm{Cl}\left(\mathrm{CH}_{2}\right)_{3} \mathrm{OAC}$

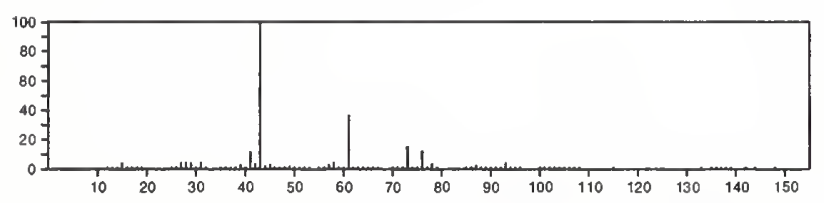

136

Ethanol, 2-chloro-, propanoate

$\mathrm{C}_{5} \mathrm{H}_{9} \mathrm{ClO}_{2}$

$\mathrm{Cl} \mathrm{CH}_{2} \mathrm{CH}_{2} \mathrm{OC}(\mathrm{O}) \mathrm{Et}$

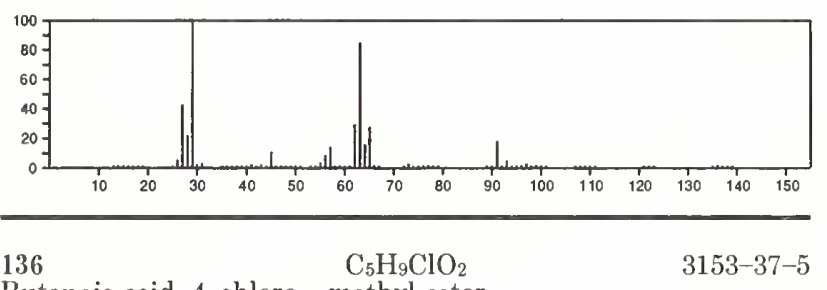

Butanoic acid, 4-chloro-, methyl ester

$\mathrm{Cl}\left(\mathrm{CH}_{2}\right)_{3} \mathrm{C}(\mathrm{O}) \mathrm{OM}_{\mathrm{O}}$

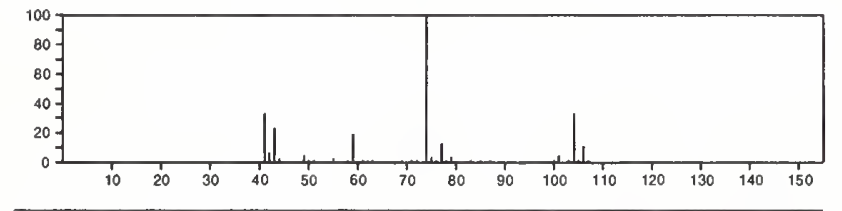

136

Pentanoic acid, 2-chloro-

\section{$\mathrm{C}_{5} \mathrm{H}_{9} \mathrm{ClO}_{2}$}

$\mathrm{PrCHCl}\left(\mathrm{CO}_{2} \mathrm{H}\right)$

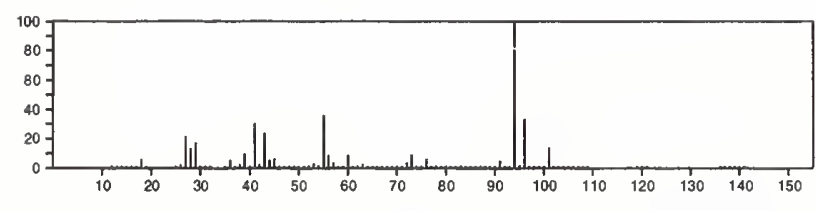

136

$\mathrm{C}_{5} \mathrm{H}_{9} \mathrm{ClO}_{2}$

1,3-Dioxane, 5-chloro-2-methyl-, trans-<smiles>CC1COC(Cl)CO1</smiles>

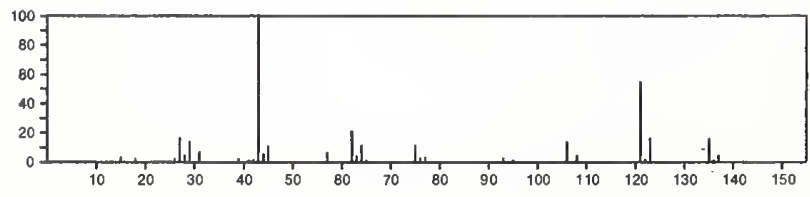

136

$\mathrm{C}_{5} \mathrm{H}_{12} \mathrm{O}_{2} \mathrm{~S}$

$673-80-3$

1-Butanesulfinic acid, methyl ester

$\mathrm{Me}\left(\mathrm{CH}_{2}\right)_{3} \mathrm{~S}(\mathrm{O}) \mathrm{OMe}$

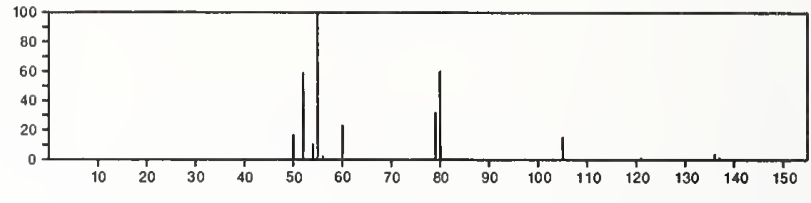

136

Butane, 1-(methylsulfonyl)-

$\mathrm{C}_{5} \mathrm{H}_{12} \mathrm{O}_{2} \mathrm{~S}$

$7560-59-0$

$\mathrm{Me}\left(\mathrm{CH}_{2}\right)_{3} \mathrm{SO}_{2} \mathrm{Me}$

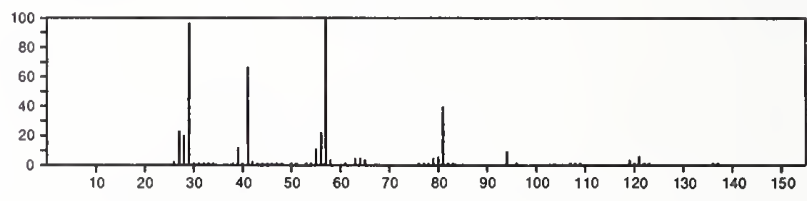

136

$\mathrm{C}_{5} \mathrm{H}_{12} \mathrm{O}_{2} \mathrm{~S}$

$52056-71-0$

2-Propanesulfinic acid, 2-methyl-, methyl ester

MeOS $(0) B u-t$

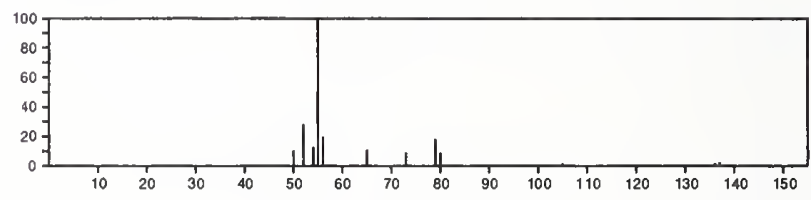

$136 \quad \mathrm{C}_{5} \mathrm{H}_{12} \mathrm{O}_{2} \mathrm{~S}$

1-Propanesulfinic acid, 2-methyl-, methyl ester

$56909-12-7$

Me OS $(0) B u-1$

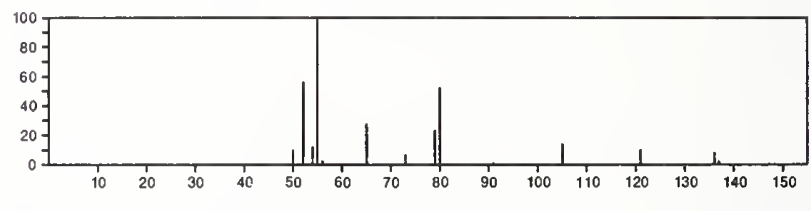

136

$\mathrm{C}_{5} \mathrm{H}_{12} \mathrm{O}_{4}$

$115-77-5$

1,3-Propanediol, 2,2-bis(hydroxymethyl)-
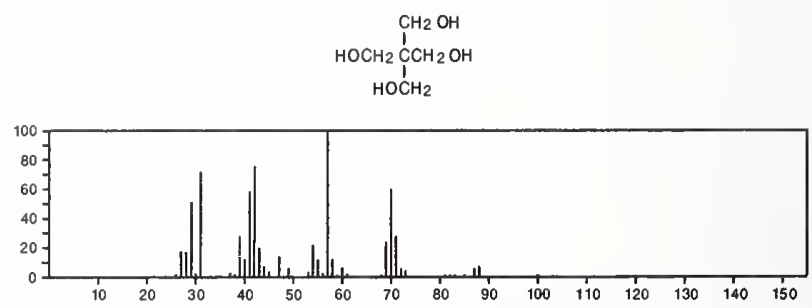

136

$\mathrm{C}_{5} \mathrm{H}_{12} \mathrm{~S}_{2}$

Ethane, 1,1'-[methylenebis(thio)]bis-

4396-19-4

$\mathrm{EtSCH} \mathrm{SE}_{2}$

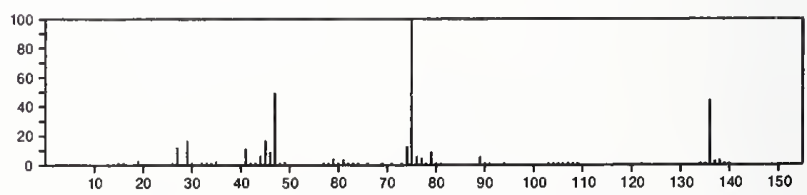


$136 \quad \mathrm{C}_{5} \mathrm{H}_{12} \mathrm{~S}_{2}$

Propane, 2,2-bis(methylthio)-

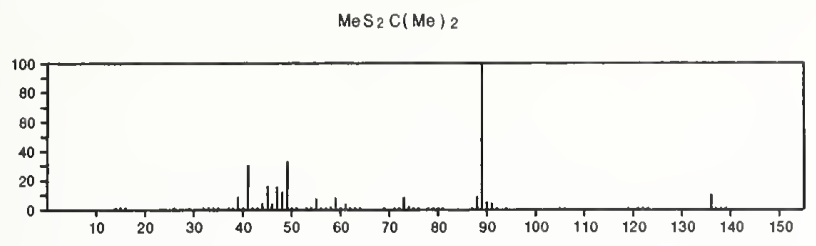

136

Propane, 1,3-bis(methylthio)-

24949-35-7

$\mathrm{MeS}\left(\mathrm{CH}_{2}\right)_{3} \mathrm{SMe}$

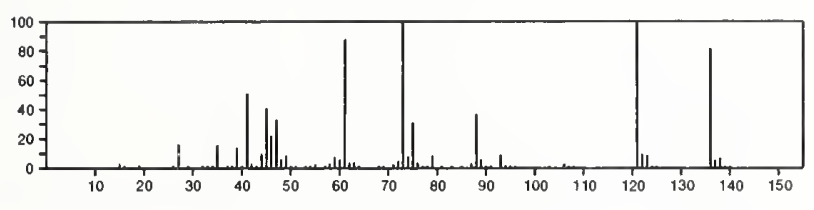

136

Disulfide, 1,1-dimethylethyl methyl

35166-82-6

MeSSBu-t

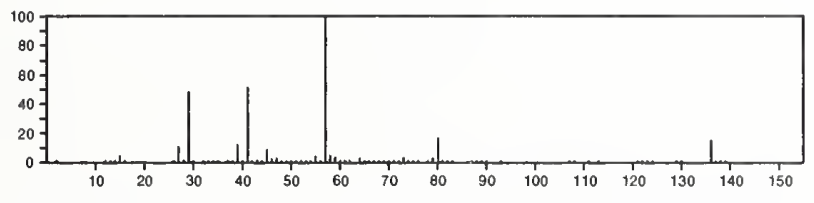

$136 \quad \mathrm{C}_{5} \mathrm{H}_{12} \mathrm{~S}_{2}$

$53966-36-2$

Disulfide, ethyl 1-methylethyl

EtSSPr-1
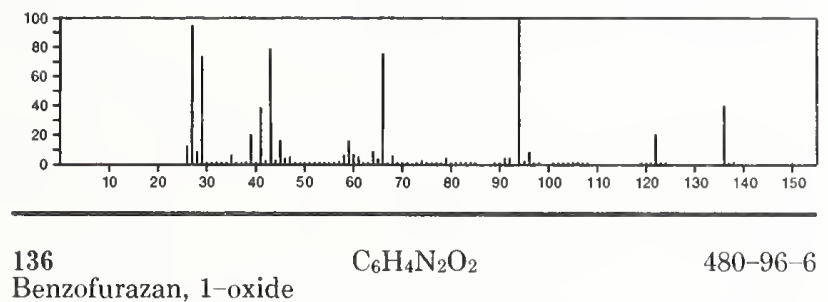

Benzofurazan, 1-oxide
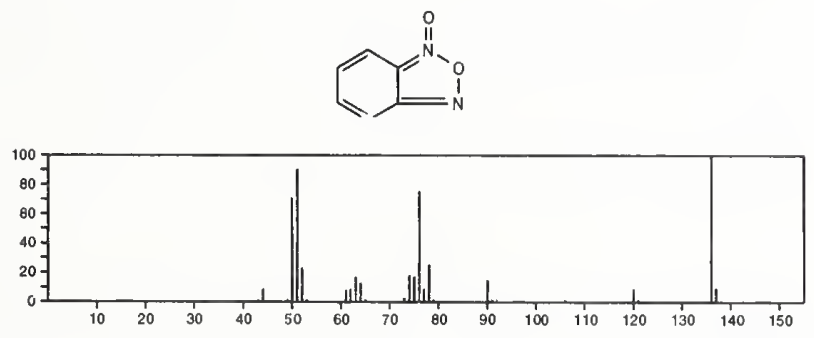

136

1,2,3-Benzothiadiazole

$\mathrm{C}_{6} \mathrm{H}_{4} \mathrm{~N}_{2} \mathrm{~S}$

$273-77-8$
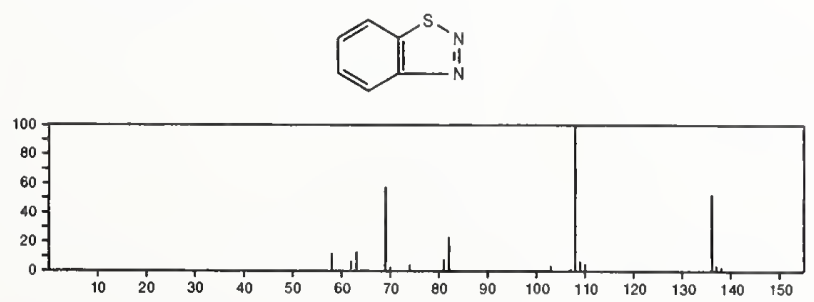

136

$\mathrm{C}_{6} \mathrm{H}_{7} \mathrm{~F}_{3}$

39763-15-0<smiles>FC1CC=CCC1(F)F</smiles>

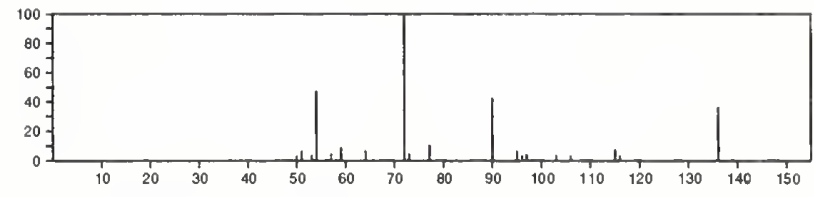

136

$\mathrm{C}_{6} \mathrm{H}_{7} \mathrm{~F}_{3}$

56196-27-1

Cyclobutane, 3-ethenyl-1,1,2-trifluoro-
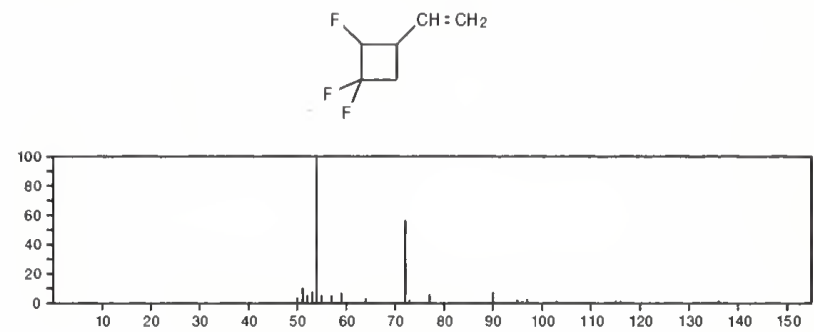

136

$\mathrm{C}_{6} \mathrm{H}_{7} \mathrm{~F}_{3}$

Cyclobutane, 2-ethenyl-1,1,4-trifluoro-

$56196-28-2$
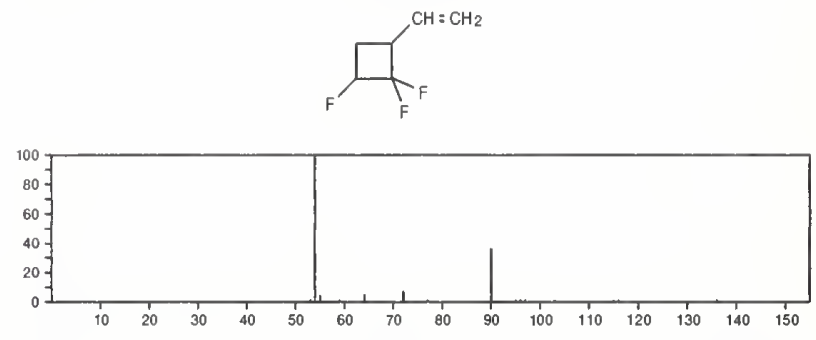

136

$\mathrm{C}_{6} \mathrm{H}_{10} \mathrm{ClF}$

371-89-1

Cyclohexane, 1-chloro-1-fluoro-
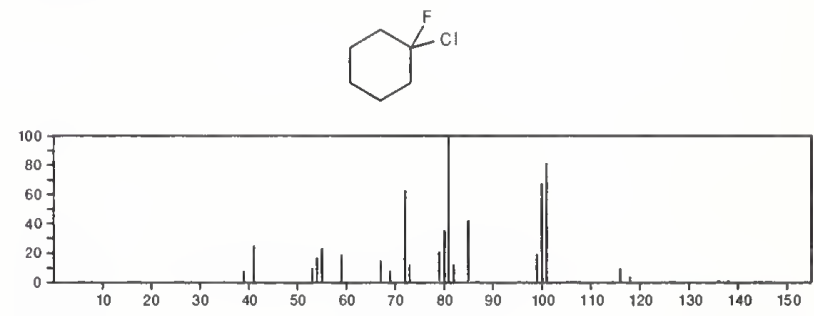

$136 \quad \mathrm{C}_{6} \mathrm{H}_{10} \mathrm{ClF}$

4536-11-2

Cyclohexane, 1-chloro-2-fluoro-
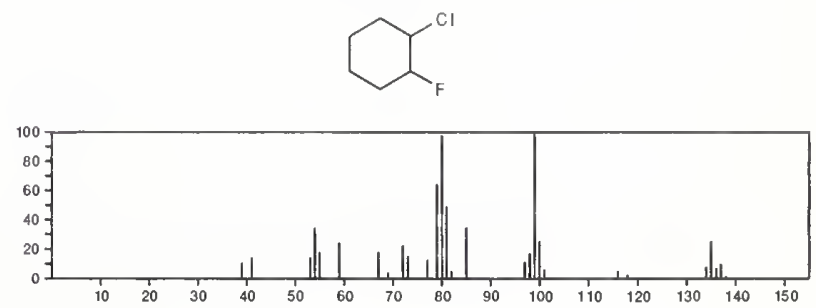
136

Cyclohexane, 1-chloro-3-fluoro-
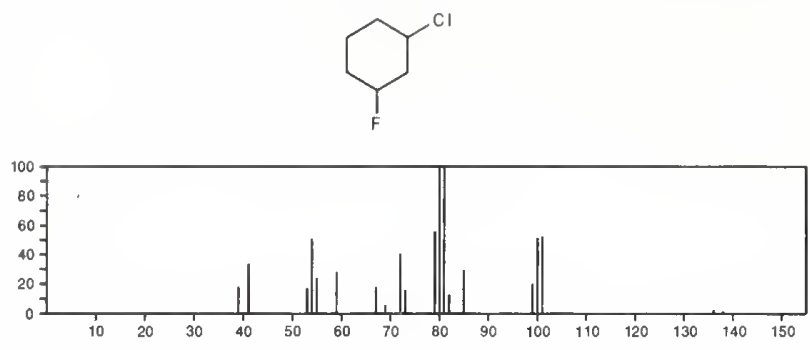

136

Cyclohexane, 1-chloro-4-fluoro-

$\mathrm{C}_{6} \mathrm{H}_{10} \mathrm{Cl}$

$55887-80-4$
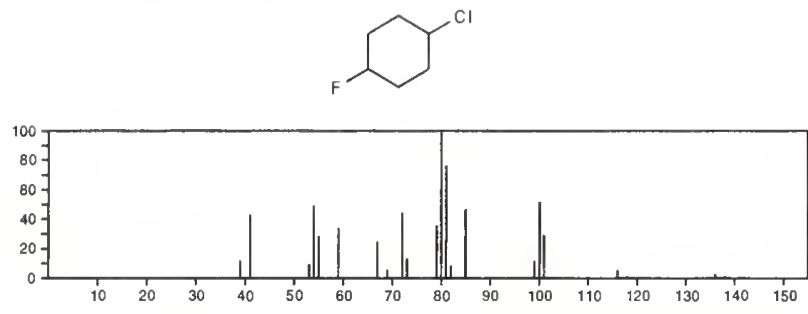

136

$\mathrm{C}_{7} \mathrm{H}_{4} \mathrm{O}_{3}$

2171-74-6

1,3-Benzodioxol-2-one
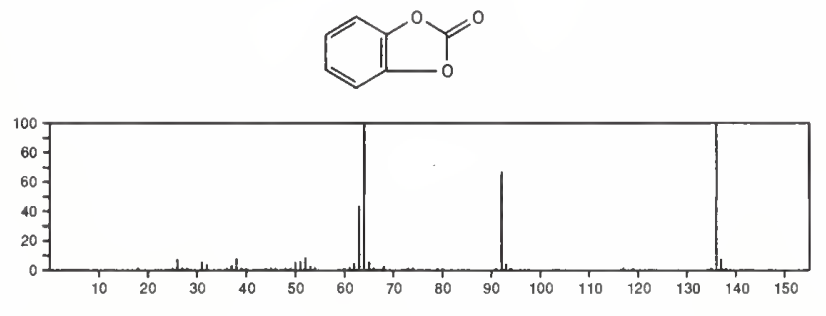

136

Benzamide, 2-amino-

$\mathrm{C}_{7} \mathrm{H}_{8} \mathrm{~N}_{2} \mathrm{O}$

88-68-6
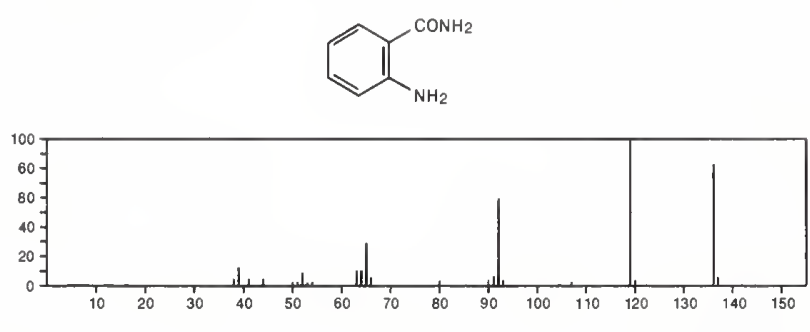

136

$\mathrm{C}_{7} \mathrm{H}_{8} \mathrm{~N}_{2} \mathrm{O}$

3-Pyridinecarboxamide, $\mathrm{N}$-methyl-

114-33-0
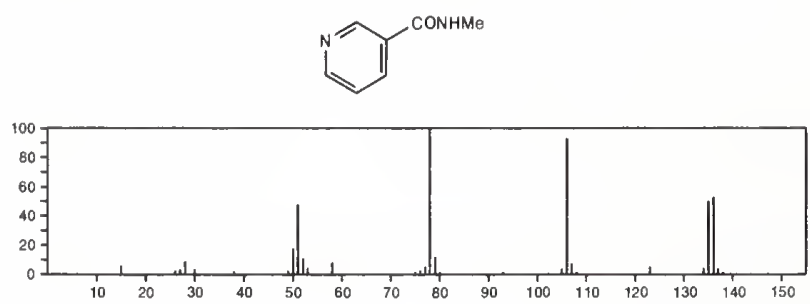

136

Benzoic acid, hydrazide

$\mathrm{C}_{7} \mathrm{H}_{8} \mathrm{~N}_{2} \mathrm{O}$

$613-94-5$

$\mathrm{H}_{2} \mathrm{NNHCOPh}$

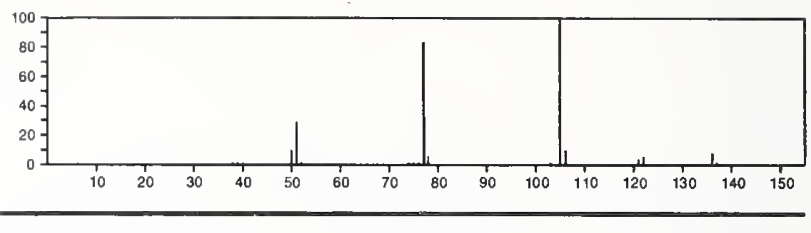

136

$\mathrm{C}_{7} \mathrm{H}_{8} \mathrm{~N}_{2} \mathrm{O}$

Benzenamine, $N$-methyl- $N$-nitroso-

614-00-6

PhNMe(NO)

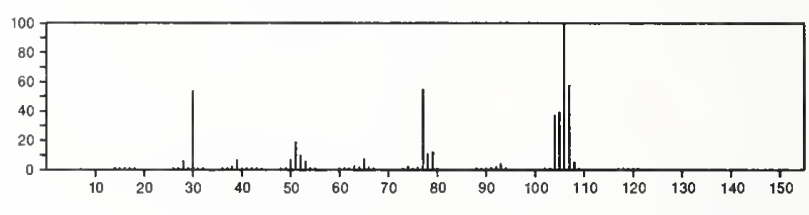

136

$\mathrm{C}_{7} \mathrm{H}_{8} \mathrm{~N}_{2} \mathrm{O}$

1468-29-7

Pyridinium, 1-(acetylamino)-, hydroxide, inner salt
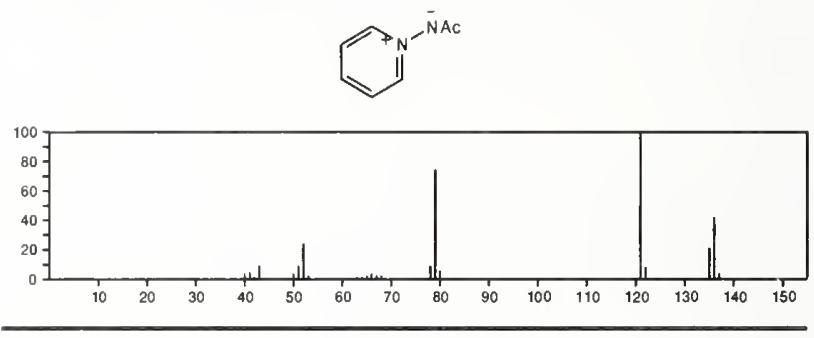

136

$\mathrm{C}_{7} \mathrm{H}_{8} \mathrm{~N}_{2} \mathrm{O}$

$2835-66-7$

Benzaldehyde, 3-amino-, oxime
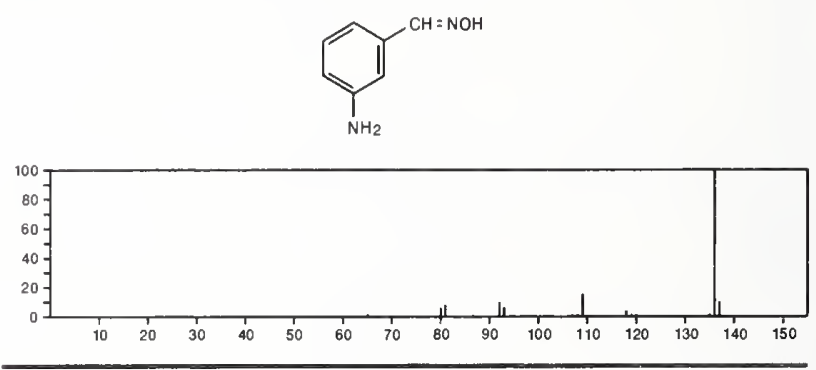

136

$\mathrm{C}_{7} \mathrm{H}_{8} \mathrm{~N}_{2} \mathrm{O}$

$2835-68-9$

Benzamide, 4-amino-
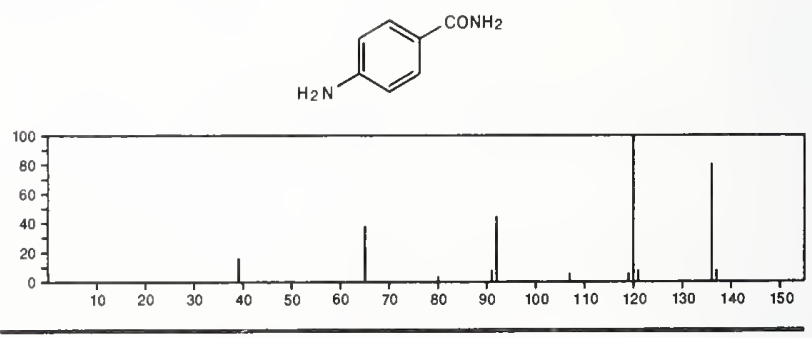

136

$\mathrm{C}_{7} \mathrm{H}_{8} \mathrm{~N}_{2} \mathrm{O}$

Benzaldehyde, 4-amino-, oxime

3419-18-9
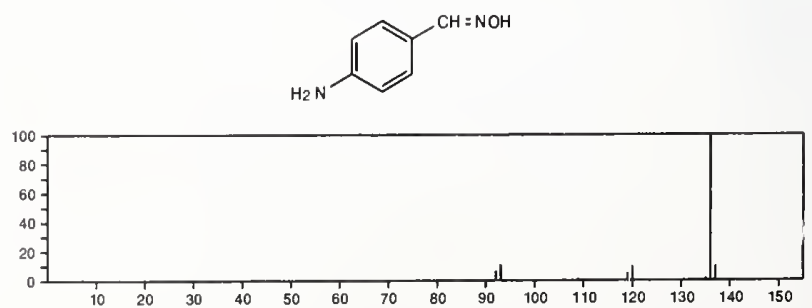
136

Benzamide, 3-amino-

$\mathrm{C}_{7} \mathrm{H}_{8} \mathrm{~N}_{2} \mathrm{O}$

$3544-24-9$<smiles>NC(=O)c1cccc(N)c1</smiles>
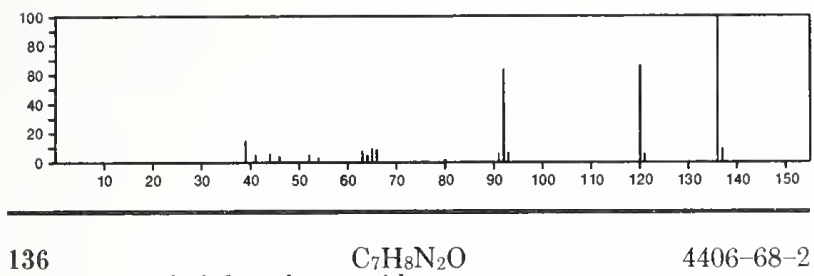

Diazene, methylphenyl-, 2-oxide

Me $N=N P h=0$

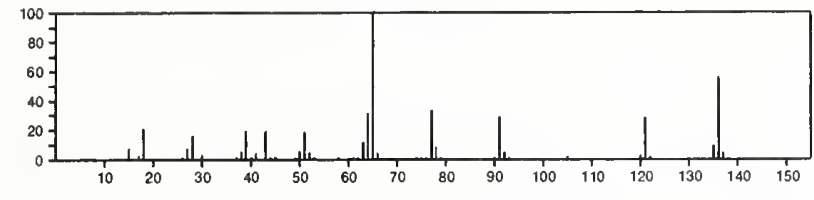

136

$\mathrm{C}_{7} \mathrm{H}_{8} \mathrm{~N}_{2} \mathrm{O}$

Diazene, methylphenyl-, 2-oxide, $(Z)$ -

$35150-71-1$

$\mathrm{MeN}=\mathrm{NPh}=0$

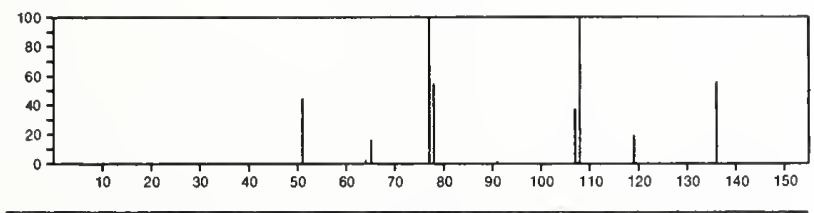

136

$\mathrm{C}_{7} \mathrm{H}_{8} \mathrm{~N}_{2} \mathrm{O}$

$35150-73-3$

Diazene, methylphenyl-, 2-oxide, $(E)$ -

$M \in N=N P h=0$

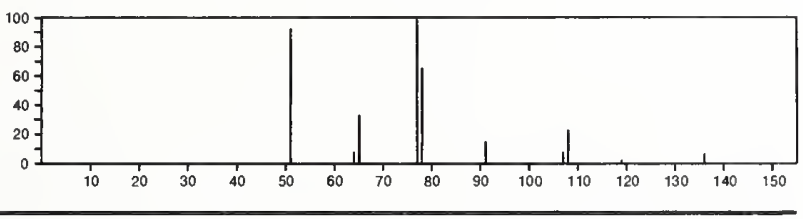

136

$\mathrm{C}_{7} \mathrm{H}_{8} \mathrm{~N}_{2} \mathrm{O}$

Diazene, methylphenyl-, 1-oxide, $(Z)$ -

$35150-74-4$

$\mathrm{O}: \mathrm{NMe}: \mathrm{NPh}$

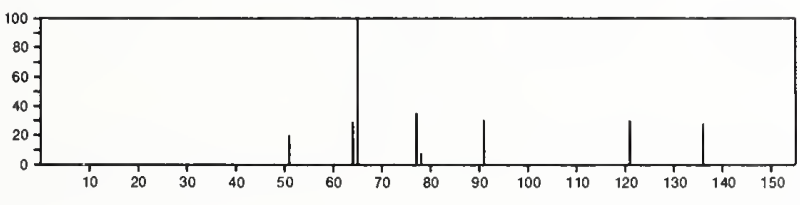

136

$\mathrm{C}_{7} \mathrm{H}_{8} \mathrm{~N}_{2} \mathrm{O}$

Diazene, methylphenyl-, 1-oxide, $(E)$ -

$35150-75-5$

$O=N M e=N P h$

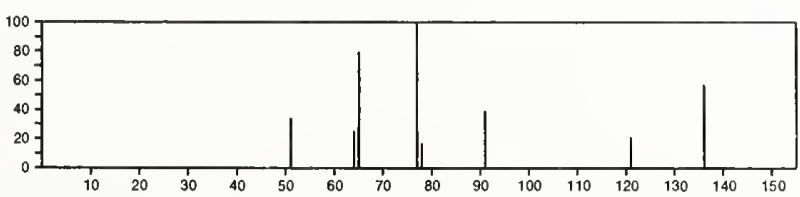

136

$\mathrm{C}_{8} \mathrm{H}_{5} \mathrm{Cl}$

873-73-4

Benzene, 1-chloro-4-ethynyl-
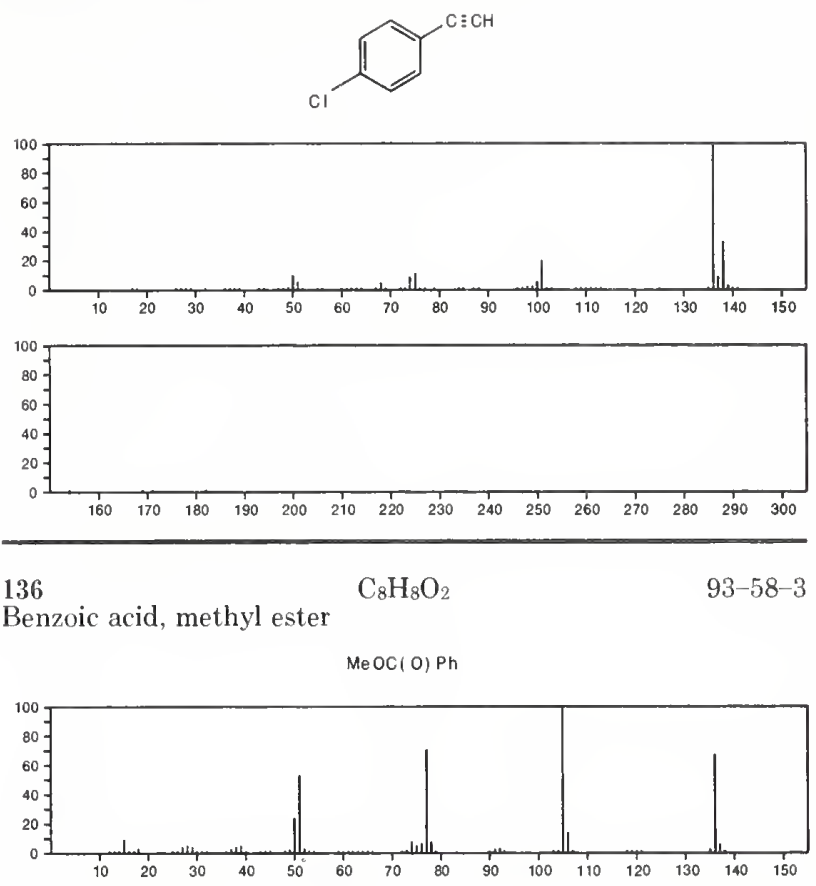

136

$\mathrm{C}_{8} \mathrm{H}_{8} \mathrm{O}_{2}$

99-04-7

Benzoic acid, 3-methyl-
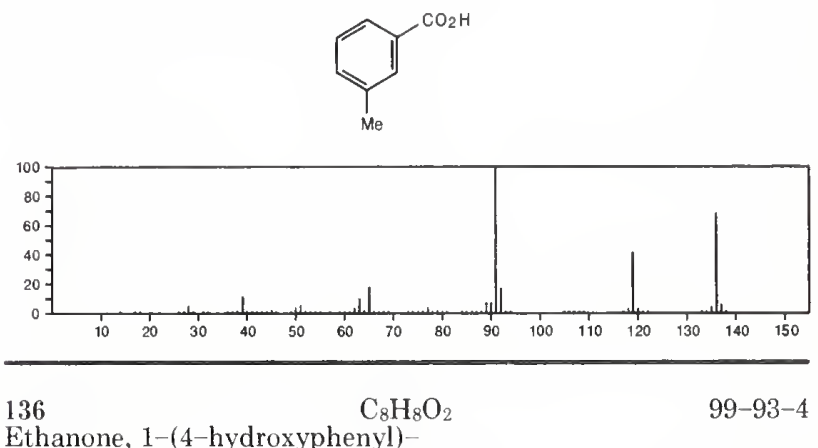

Ethanone, 1-(4-hydroxyphenyl)-
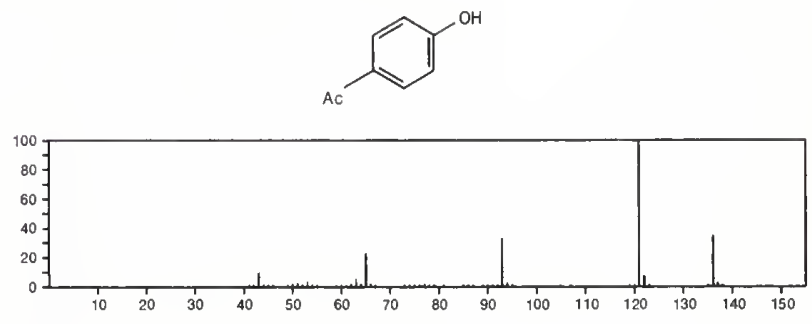

136

$\mathrm{C}_{8} \mathrm{H}_{8} \mathrm{O}_{2}$

$99-94-5$

Benzoic acid, 4-methyl-
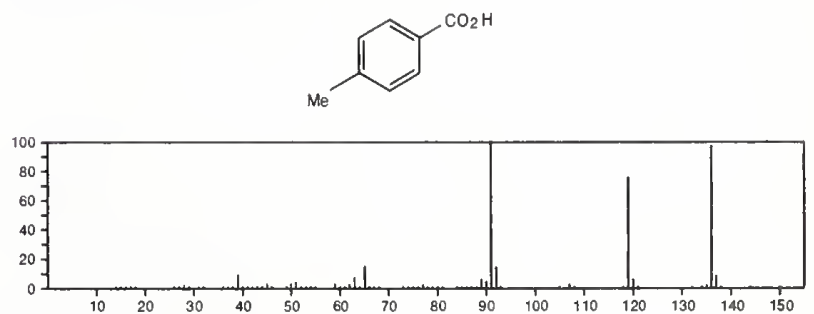
136

Benzeneacetic acid

$\mathrm{C}_{8} \mathrm{H}_{8} \mathrm{O}_{2}$

$103-82-2$

$\mathrm{PhCH}_{2} \mathrm{CO}_{2} \mathrm{H}$
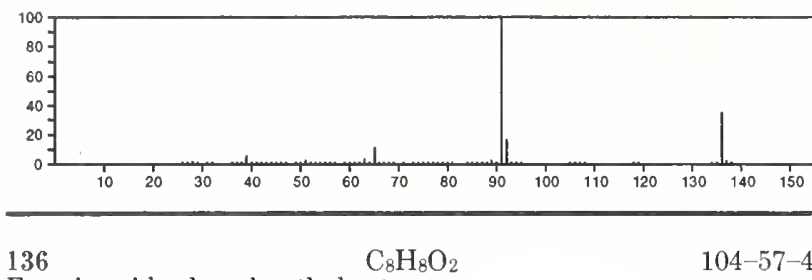

Formic acid, phenylmethyl ester

$\mathrm{PhCH}_{2} \mathrm{OCH}=\mathrm{O}$

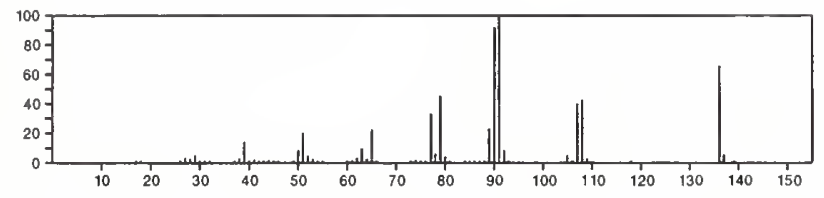

136

Benzoic acid, 2-methyl-

$\mathrm{C}_{8} \mathrm{H}_{8} \mathrm{O}_{2}$

118-90-1
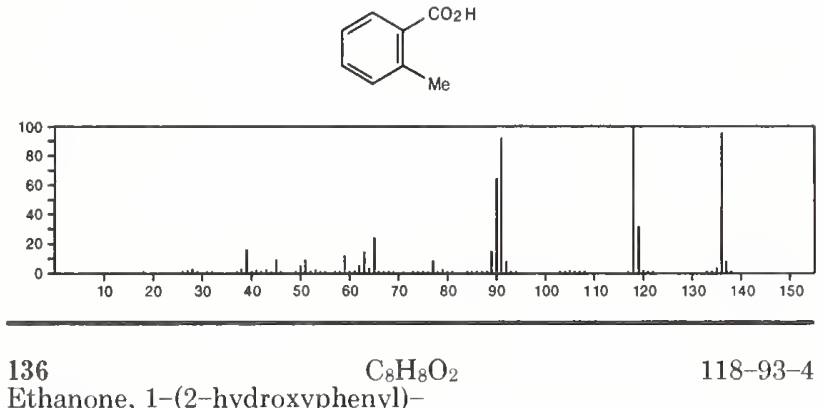

Ethanone, 1-(2-hydroxyphenyl)-
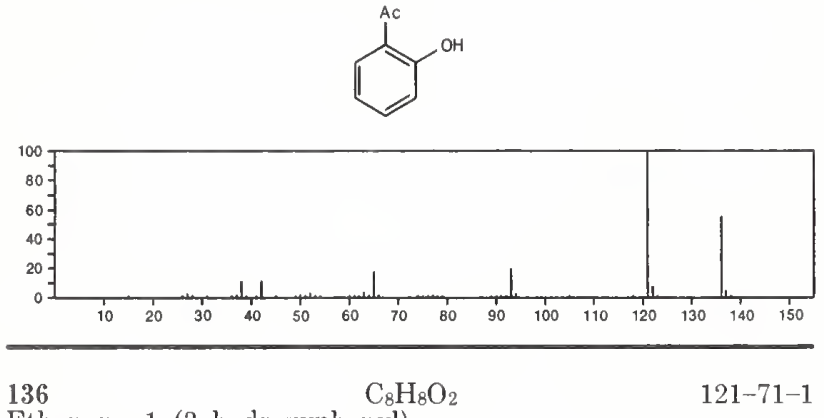

Ethanone, 1-(3-hydroxyphenyl)-
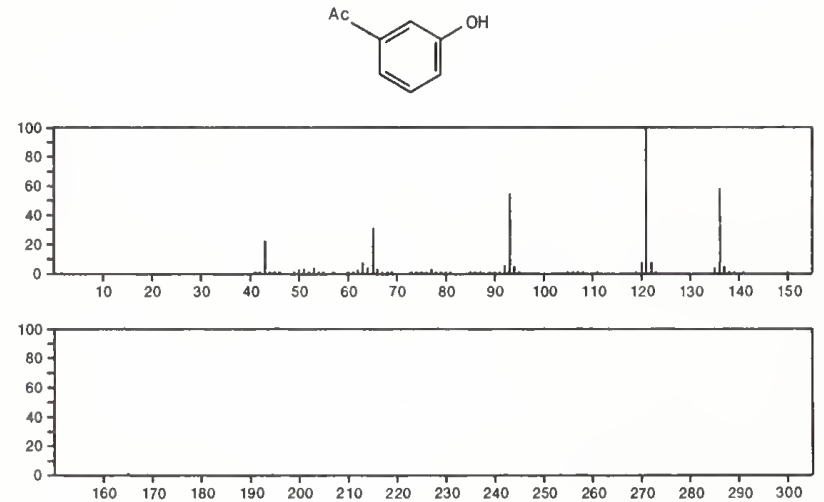

136

Acetic acid, phenyl ester

$\mathrm{C}_{8} \mathrm{H}_{8} \mathrm{O}_{2}$

122-79-2

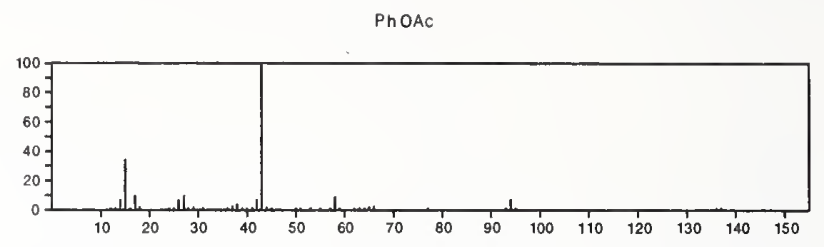

136

Benzaldehyde, 4-methoxy-

$\mathrm{C}_{8} \mathrm{H}_{8} \mathrm{O}_{2}$

$123-11-5$

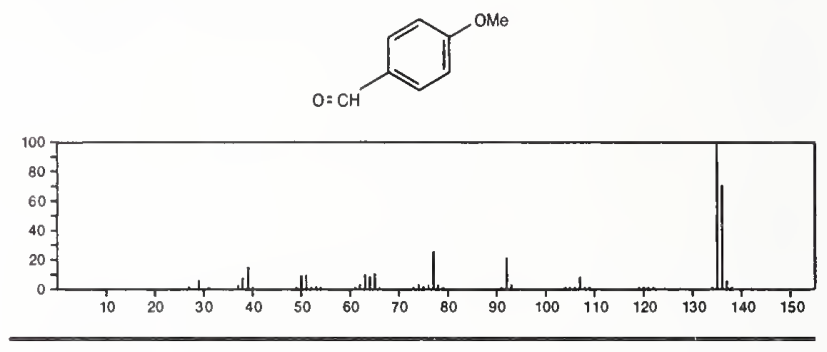

136

$\mathrm{C}_{8} \mathrm{H}_{8} \mathrm{O}_{2}$

135-02-4

Benzaldehyde, 2-methoxy-
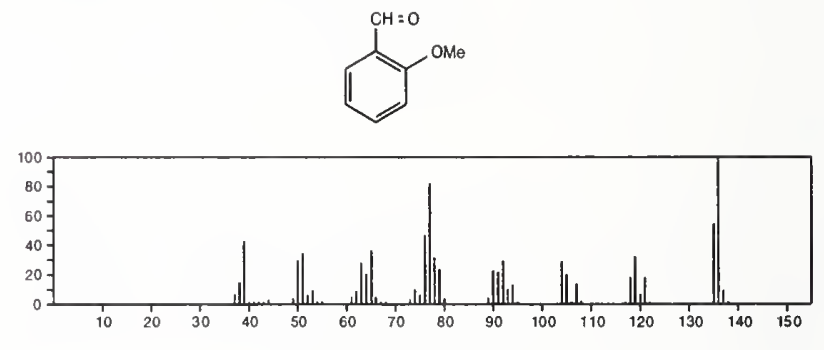

136

$\mathrm{C}_{8} \mathrm{H}_{8} \mathrm{O}_{2}$

493-09-4

1,4-Benzodioxin, 2,3-dihydro-
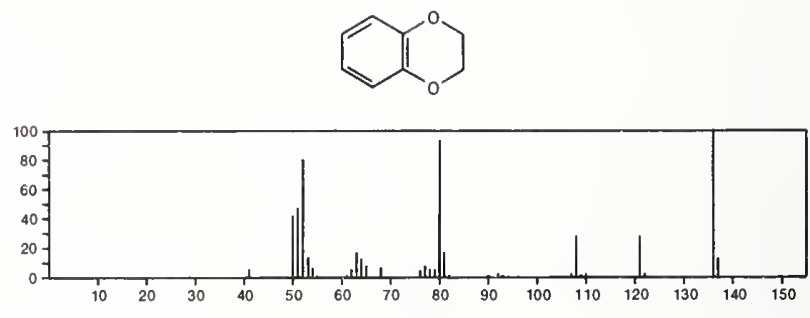

136

$\mathrm{C}_{8} \mathrm{H}_{8} \mathrm{O}_{2}$

582-24-1

Ethanone, 2-hydroxy-1-phenyl-

$\mathrm{HOCH}_{2} \mathrm{COPh}$

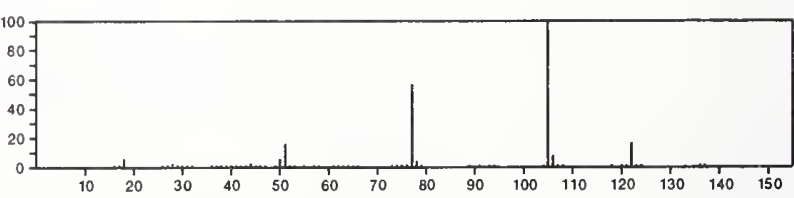

136

$\mathrm{C}_{8} \mathrm{H}_{8} \mathrm{O}_{2}$

$591-31-1$

Benzaldehyde, 3-methoxy-
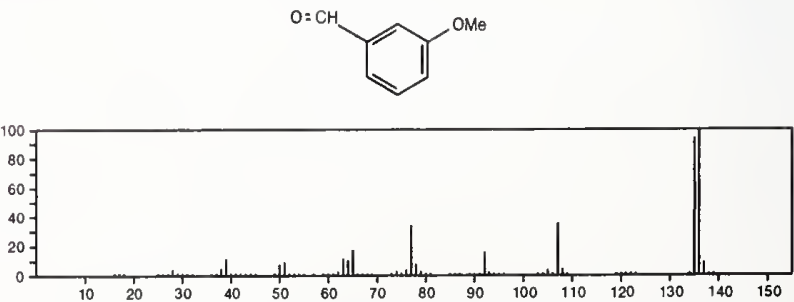


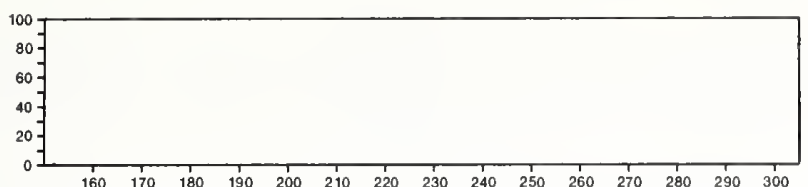

136

$\mathrm{C}_{8} \mathrm{H}_{8} \mathrm{O}_{2}$

2,5-Cyclohexadiene-1,4-dione, 2-ethyl-<smiles>CCC1=CC(=O)C=CC1=O</smiles>

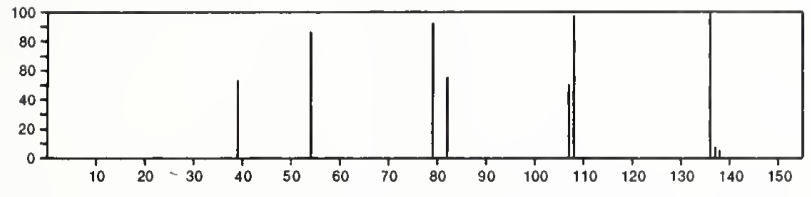

136

$\mathrm{C}_{8} \mathrm{H}_{8} \mathrm{O}_{2}$

Bicyclo[2.2.2] oct-7-ene-2,5-dione

$17660-74-1$
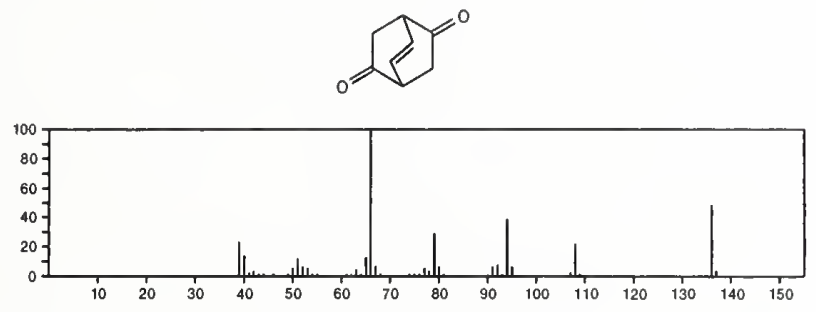

$136 \quad \mathrm{C}_{8} \mathrm{H}_{8} \mathrm{O}_{2}$

7-Oxabicyclo[4.2.1]nona-2,4-dien-8-one
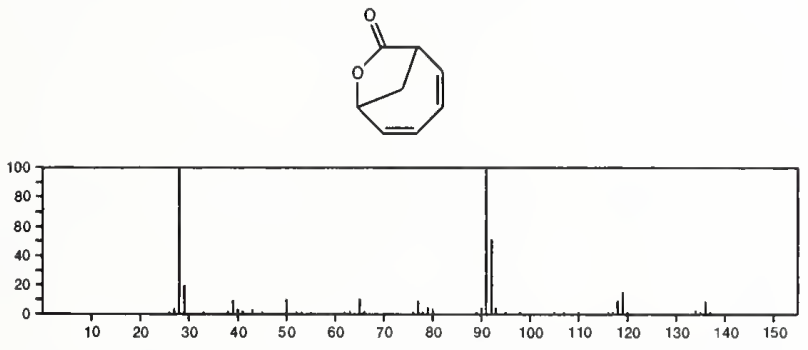

$136 \quad \mathrm{C}_{8} \mathrm{H}_{8} \mathrm{~S}$

Benzo $[c]$ thiophene, 1,3-dihydro-
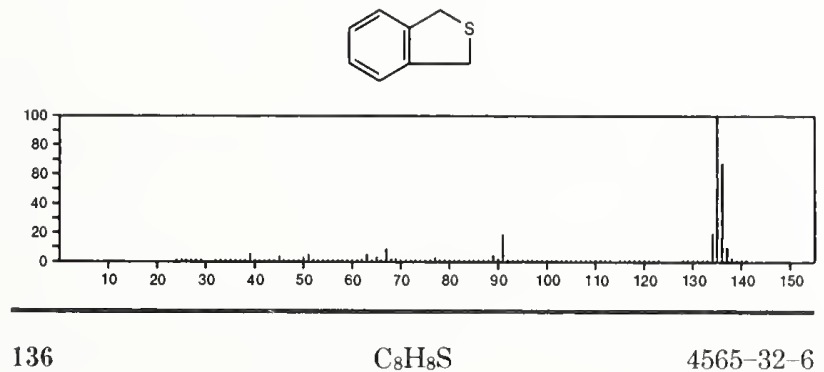

$4565-32-6$

Benzo $[b]$ thiophene, 2,3-dihydro-
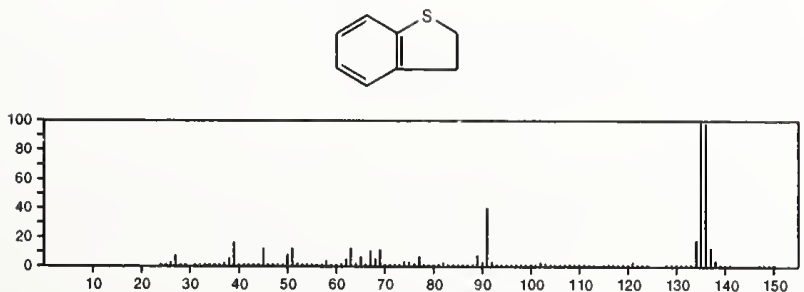

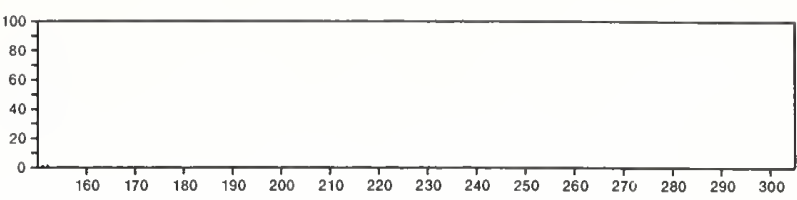

136

$\mathrm{C}_{8} \mathrm{H}_{12} \mathrm{~N}_{2}$

629-40-3

Octanedinitrile

$\mathrm{NC}\left(\mathrm{CH}_{2}\right){ }_{6} \mathrm{CN}$

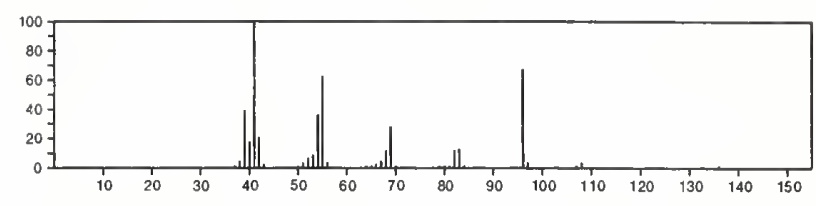

136

$\mathrm{C}_{8} \mathrm{H}_{12} \mathrm{~N}_{2}$

1124-11-4

Pyrazine, tetramethyl-<smiles>Cc1nc(C)c([N+](=O)[O-])nc1C</smiles>

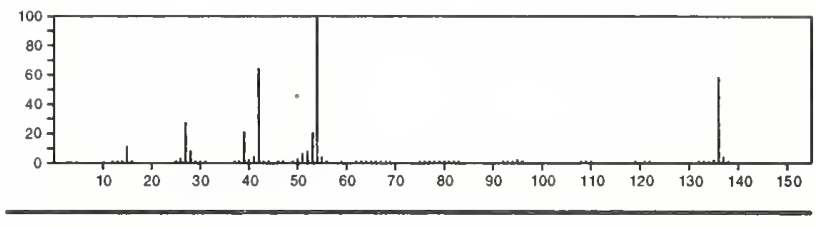

136

1,2-Ethanediamine, $N$-phenyl-

$\mathrm{C}_{8} \mathrm{H}_{12} \mathrm{~N}_{2}$

$1664-40-0$

$\mathrm{PhNHCH}_{2} \mathrm{CH}_{2} \mathrm{NH}_{2}$

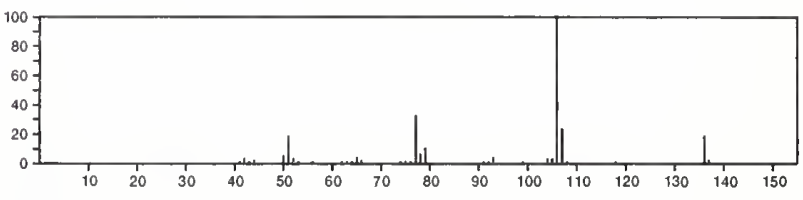

136

$\mathrm{C}_{8} \mathrm{H}_{12} \mathrm{~N}_{2}$

$32286-94-5$

$1 \mathrm{H}$-Indazole, 4,5,6,7-tetrahydro-7-methyl
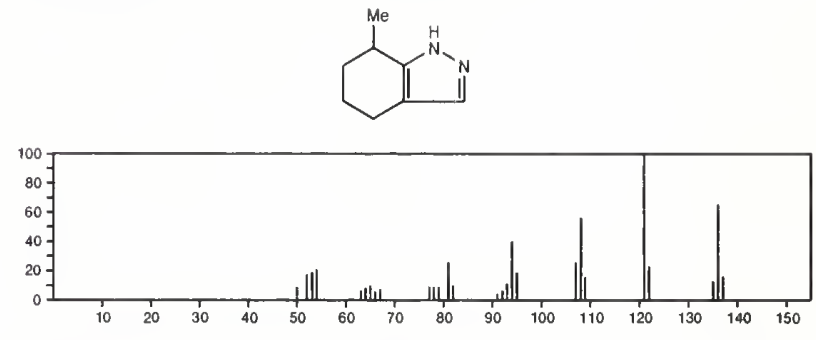

136

$\mathrm{C}_{9} \mathrm{H}_{12} \mathrm{O}$

$88-69-7$

Phenol, 2-(1-methylethyl)-
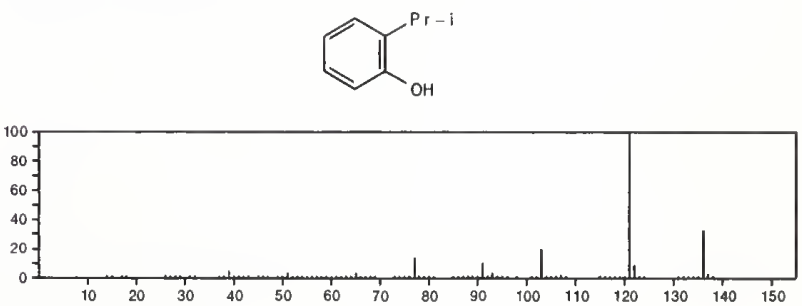
136

Benzenemethanol, $\alpha$-ethyl-

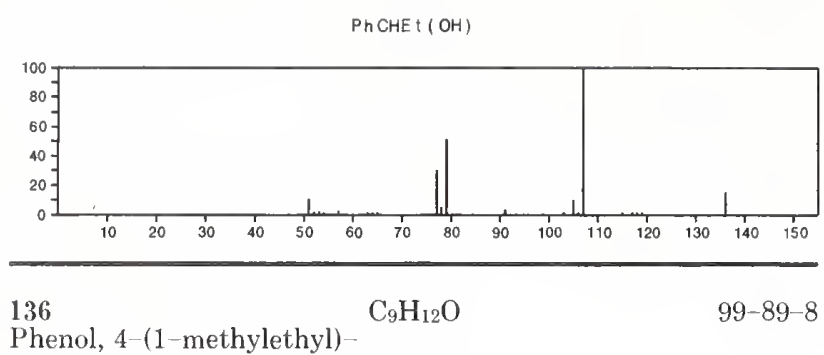

Phenol, 4-(1-methylethyl)
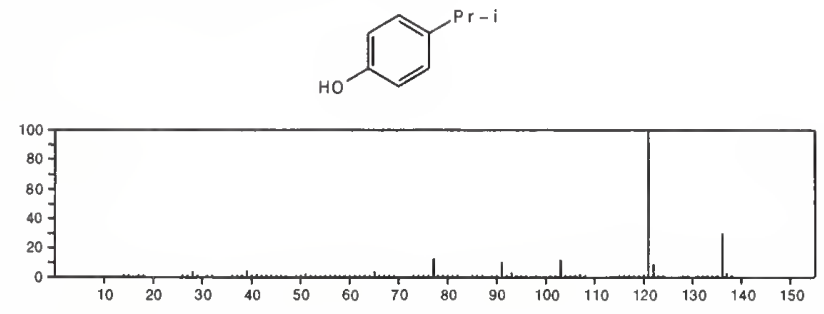

136

Benzenepropanol

$\mathrm{C}_{9} \mathrm{H}_{12} \mathrm{O}$

$\mathrm{Ph}\left(\mathrm{CH}_{2}\right)_{3} \mathrm{OH}$

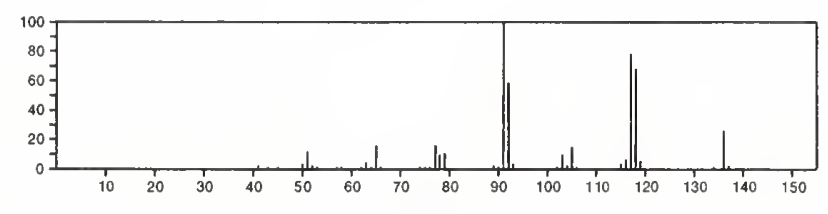

136

Phenol, 2,4,5-trimethyl-

$$
\mathrm{C}_{9} \mathrm{H}_{12} \mathrm{O}
$$

496-78-6
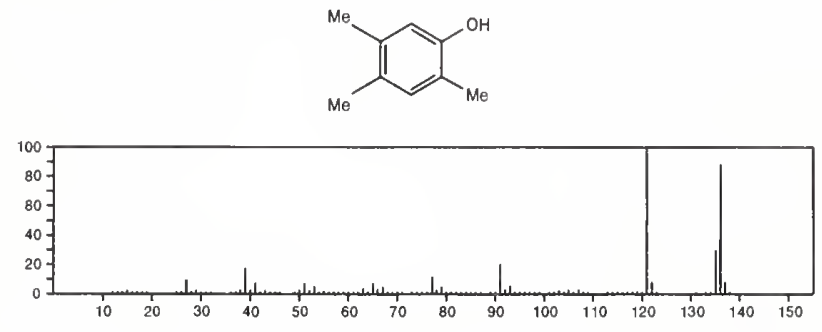

136

Phenol, 3,4,5-trimethyl-

$\mathrm{C}_{9} \mathrm{H}_{12} \mathrm{O}$

$527-54-8$
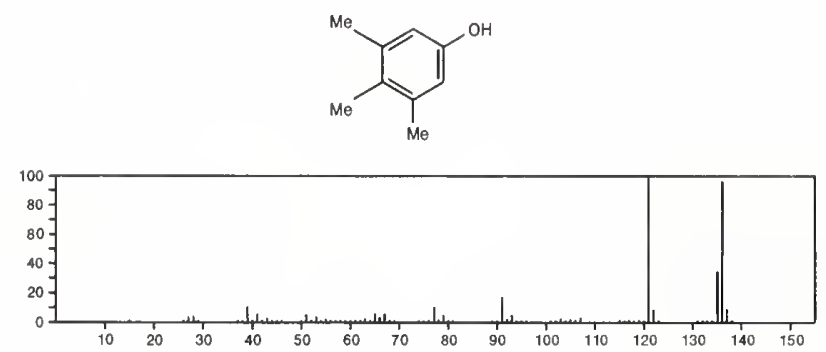

136

Phenol, 2,4,6-trimethyl-

$\mathrm{C}_{9} \mathrm{H}_{12} \mathrm{O}$

$527-60-6$<smiles>O=[N+]([O-])c1cc([N+](=O)[O-])c(O)c([N+](=O)[O-])c1</smiles>

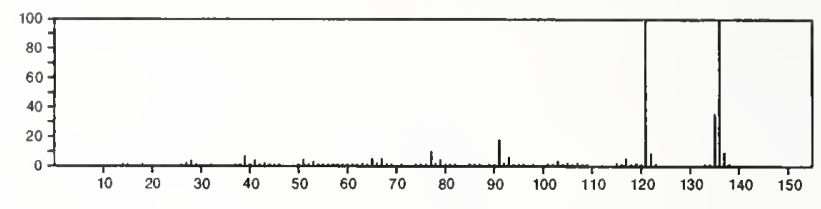

136

Benzenemethanol, $\alpha, 4$-dimethy

$536-50-5$

$\mathrm{C}_{9} \mathrm{H}_{12} \mathrm{O}$



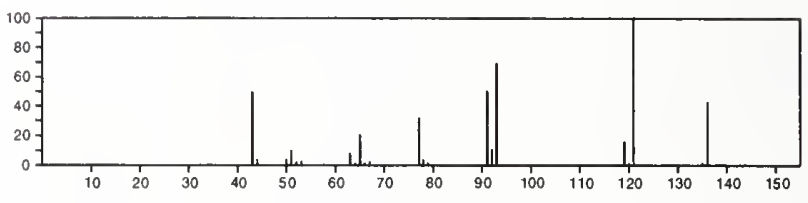

136

Benzene, (ethoxymethyl)-

$\mathrm{C}_{9} \mathrm{H}_{12} \mathrm{O}$

$539-30-0$

$\mathrm{E} 1 \mathrm{OCH}_{2} \mathrm{Ph}$

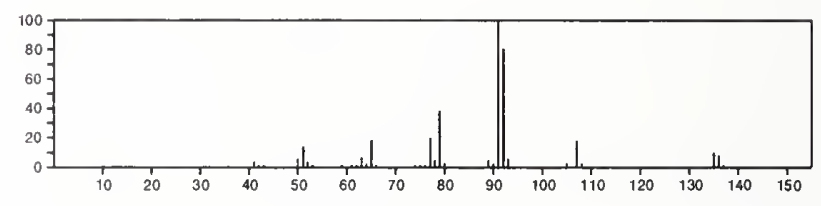

136

$\mathrm{C}_{9} \mathrm{H}_{12} \mathrm{O}$

$614-71-1$

Benzene, 1-ethoxy-2-methyl-
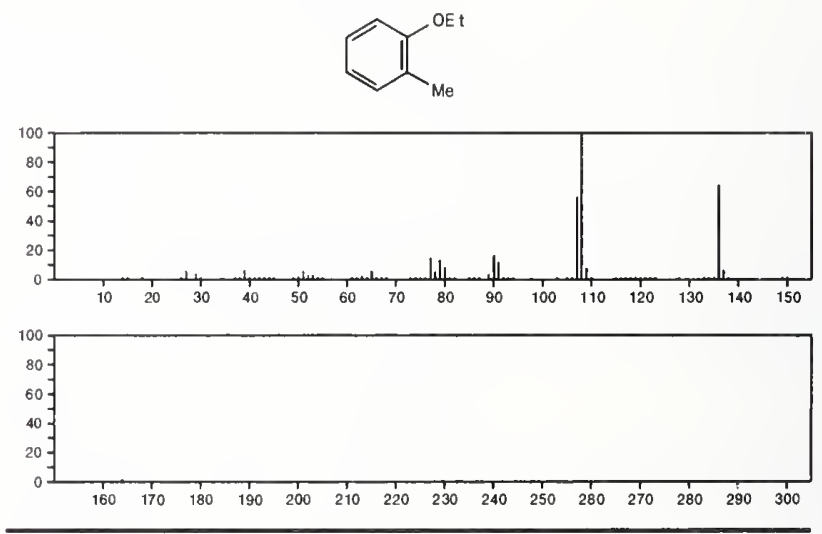

136

$\mathrm{C}_{9} \mathrm{H}_{12} \mathrm{O}$

Benzenemethanol, $\alpha, \alpha$-dimethyl-

$617-94-7$

$\mathrm{PhCMe} 2(\mathrm{OH})$

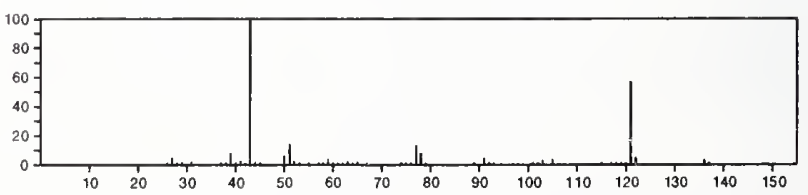


$136 \quad \mathrm{C}_{9} \mathrm{H}_{12} \mathrm{O}$

Benzene, 1-ethoxy-4-methyl-
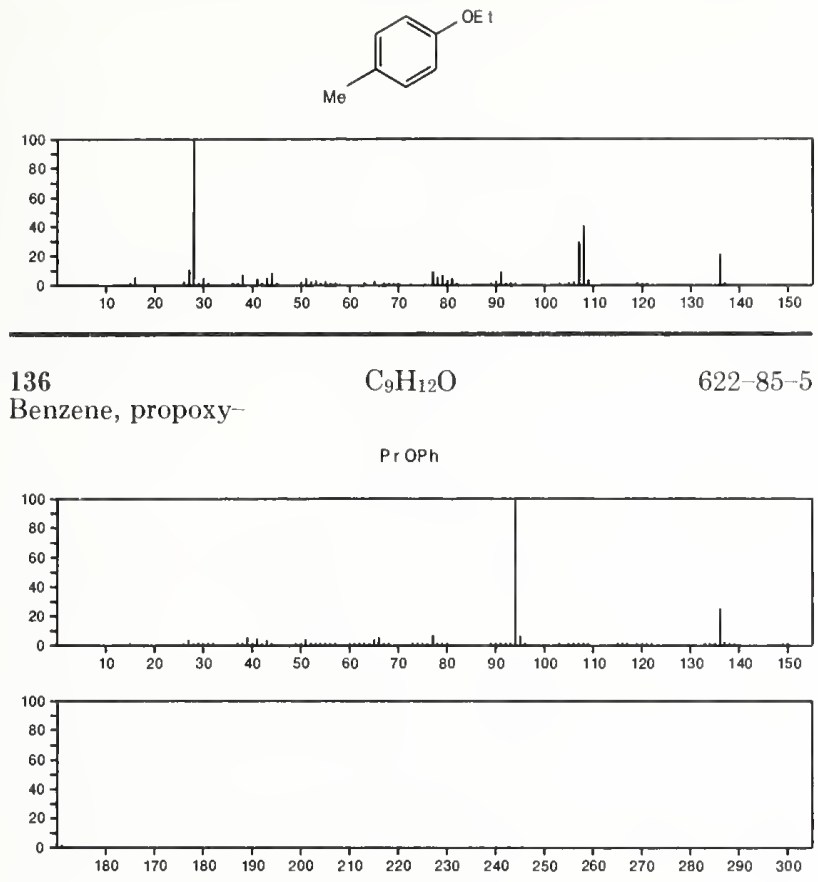

136

Phenol, 2,3,5-trimethyl-

\section{$\mathrm{C}_{9} \mathrm{H}_{12} \mathrm{O}$}

$697-82-5$
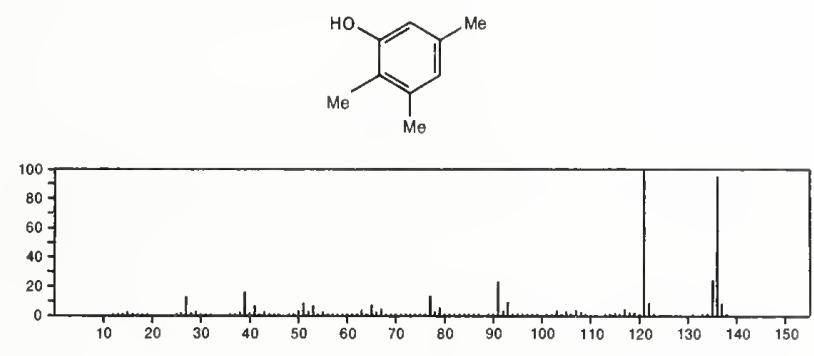

136

$\mathrm{C}_{9} \mathrm{H}_{12} \mathrm{O}$

698-71-5

Phenol, 3-ethyl-5-methyl-
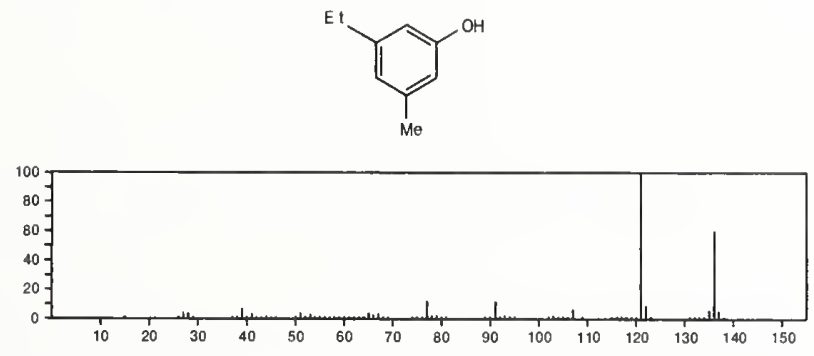

\section{6}

$136 \quad \mathrm{C}_{9} \mathrm{H}_{12} \mathrm{O}$

$699-02-5$

Benzeneethanol, 4-methyl-
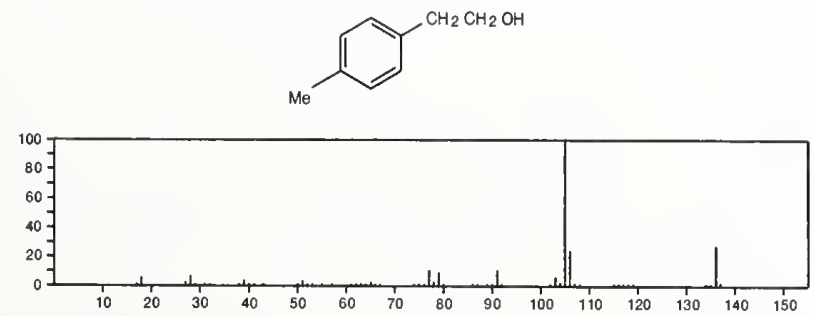

136

$\mathrm{C}_{9} \mathrm{H}_{12} \mathrm{O}$

768-59-2<smiles>CCc1ccc(C=O)cc1</smiles>

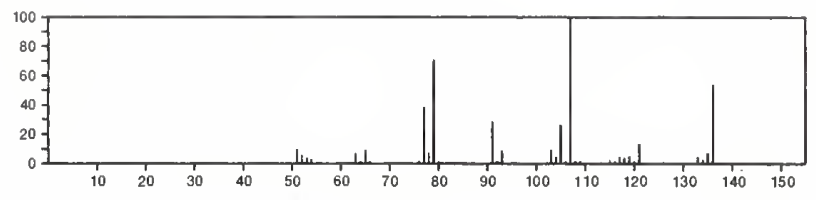

136

$\mathrm{C}_{9} \mathrm{H}_{12} \mathrm{O}$

1124-23-8

Ketone, 1,3-cycloheptadien-1-yl methyl
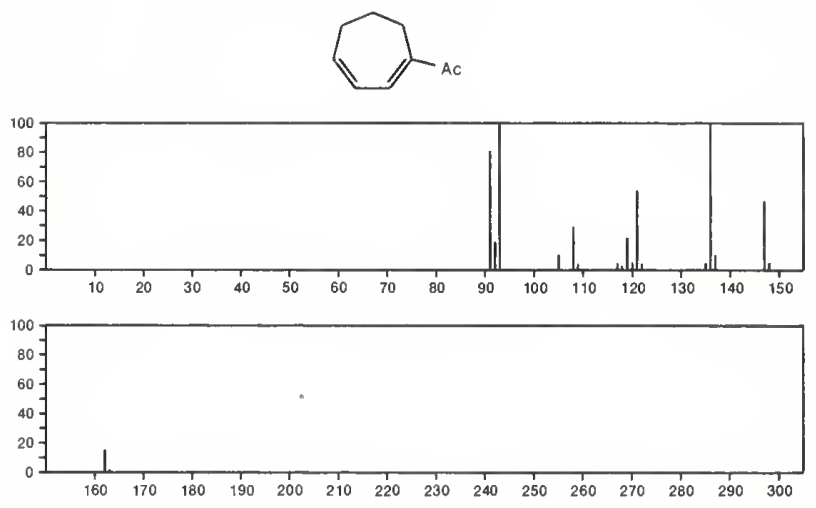

136

Phenol, 2-ethyl-5-methyl-

$\mathrm{C}_{9} \mathrm{H}_{12} \mathrm{O}$

$1687-61-2$<smiles>CCc1ccc(I)cc1O</smiles>

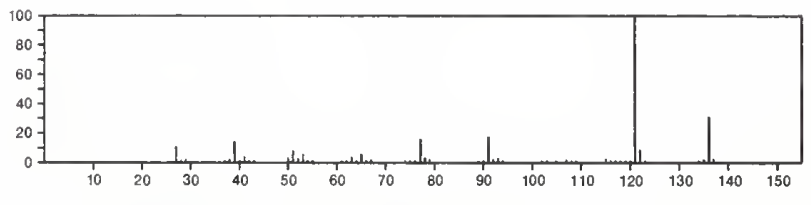

136

Benzeneethanol, 3-methyl-

$\mathrm{C}_{9} \mathrm{H}_{12} \mathrm{O}$

1875-89-4
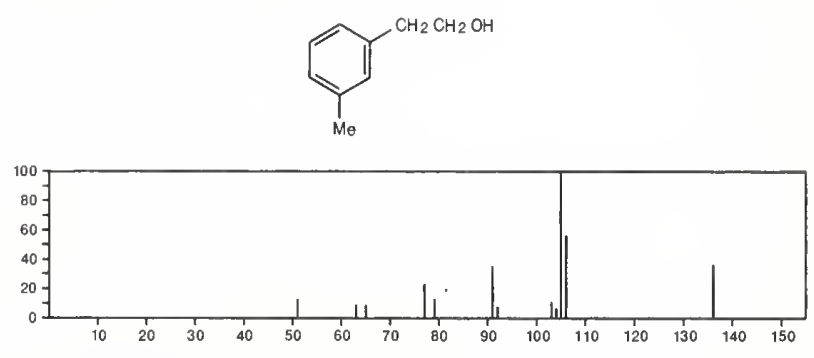

136

$\mathrm{C}_{9} \mathrm{H}_{12} \mathrm{O}$

2219-73-0

Phenol, 4-ethyl-2-methyl-
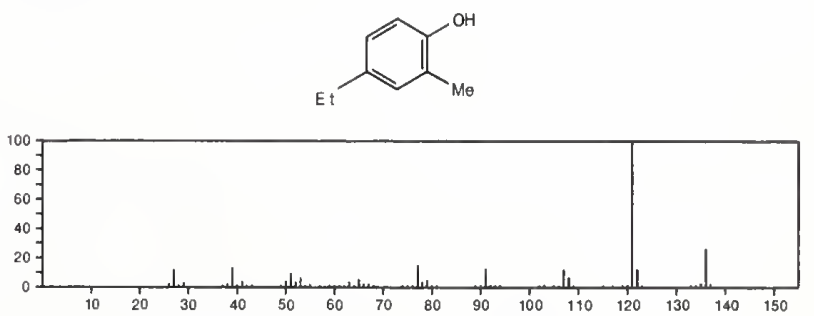
136

Benzene, (2-methoxyethyl)-

$\mathrm{C}_{9} \mathrm{H}_{12} \mathrm{O}$

$\mathrm{PhCH}_{2} \mathrm{CH}_{2} \mathrm{OM}$

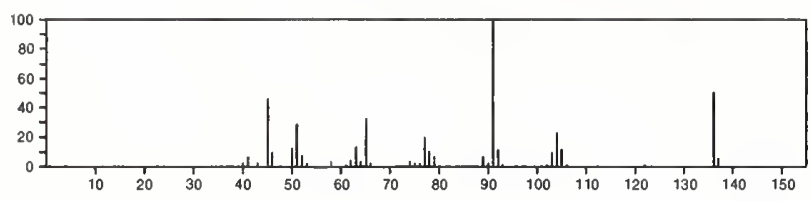

136

Phenol, 2-ethyl-4-methyl-

$\mathrm{C}_{9} \mathrm{H}_{12} \mathrm{O}$

$3855-26-3$
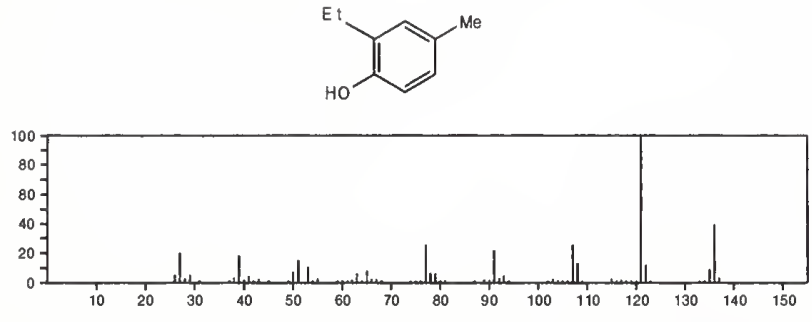

136

$\mathrm{C}_{9} \mathrm{H}_{12} \mathrm{O}$

4013-34-7

Benzene, (1-methoxyethyl)-

PhCHMe ( OMle)

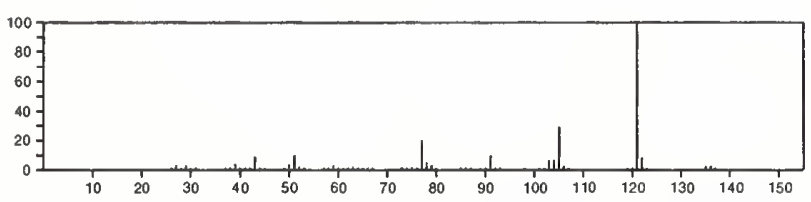

136

$\mathrm{C}_{9} \mathrm{H}_{12} \mathrm{O}$

$4844-11-5$

Bicyclo[3.3.1]non-2-en-9-one
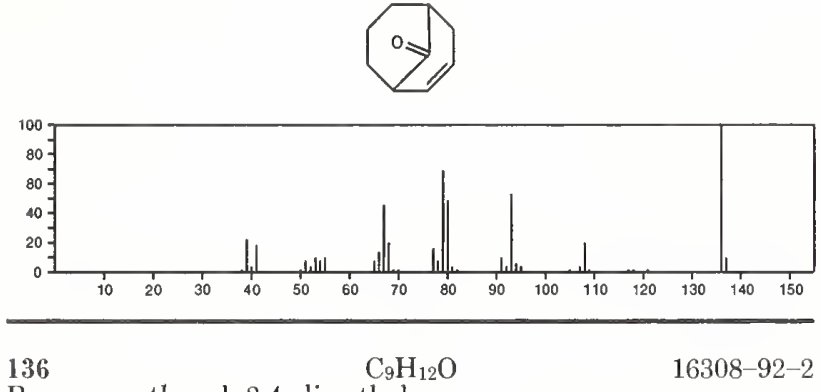

$16308-92-2$

Benzenemethanol, 2,4-dimethyl<smiles>Cc1ccc(CO)c([N+](=O)[O-])c1</smiles>

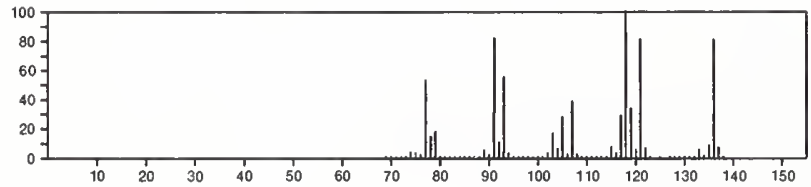

136

$\mathrm{C}_{9} \mathrm{H}_{12} \mathrm{O}$

17429-31-1

2,5-Cyclohexadien-1-one, 3,4,4-trimethyl<smiles>[N+]=[N+]([O-])C1([N+](=O)[O-])C=CC(=O)C=C1</smiles>

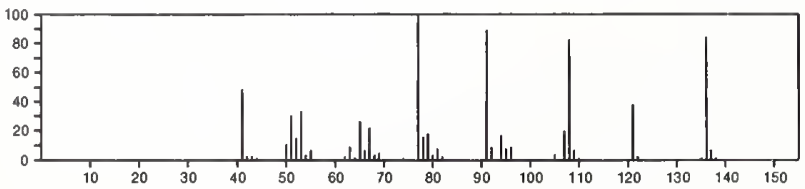

136 2-Indanone, 4,5,6,7-tetrahydro-

$\mathrm{C}_{9} \mathrm{H}_{2} \mathrm{O}$

$20990-33-4$
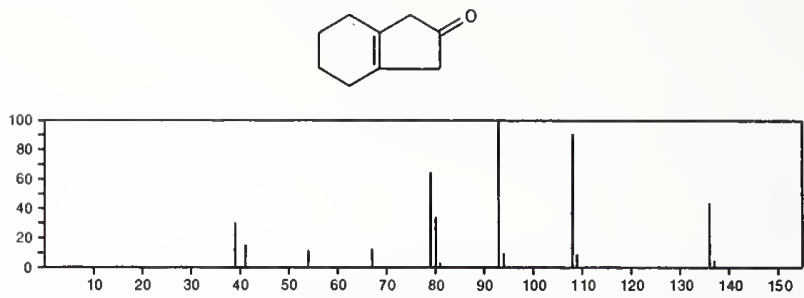

136
$1 H_{\text {-Inden-1-one, }}^{2,3,4,5,6,7-h e x a h y d r o-}$

$22118-00-9$

$\overbrace{1}^{\circ}$

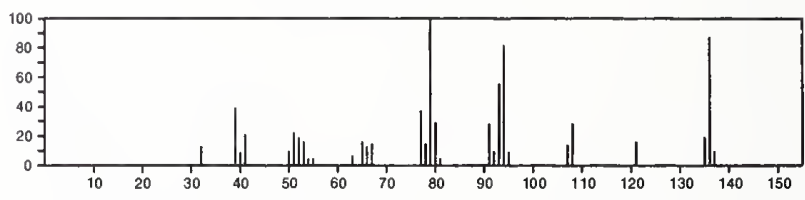

136

$\mathrm{C}_{9} \mathrm{H}_{12} \mathrm{O}$

1-Indanone, 3a,4,7,7a-tetrahydro-, trans-

$25050-74-2$
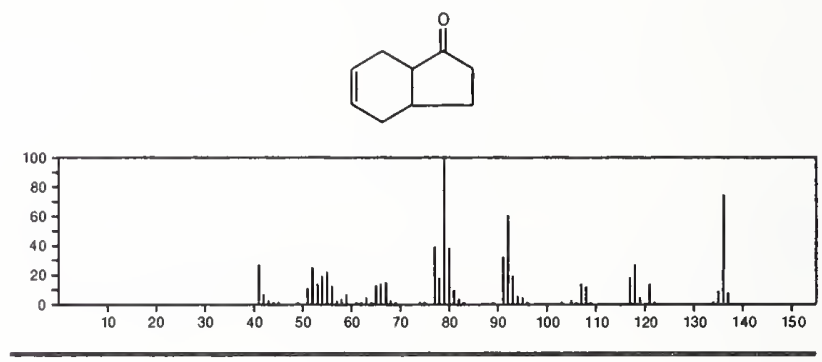

136

$\mathrm{C}_{9} \mathrm{H}_{12} \mathrm{O}$

27129-87-9

Benzenemethanol, 3,5-dimethyl-
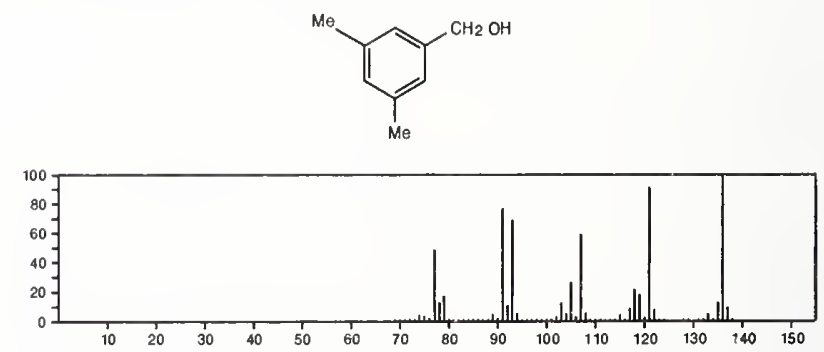

136

$\mathrm{C}_{9} \mathrm{H}_{12} \mathrm{O}$

$29765-85-3$

2-Cyclopenten-1-one, 2,3,5-trimethyl-4-methylene-
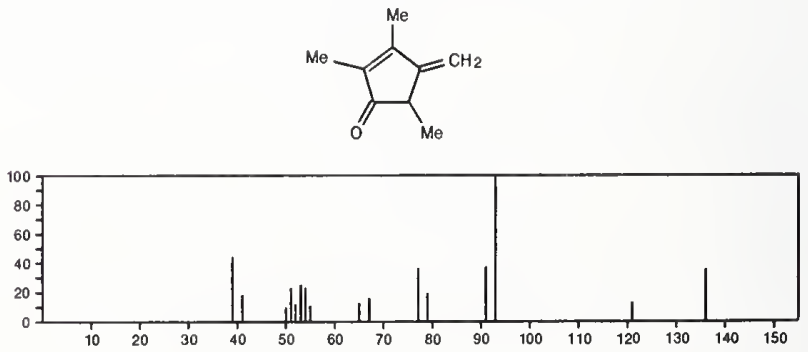
$136 \quad \mathrm{C}_{9} \mathrm{H}_{12} \mathrm{O}$

Benzeneethanol, $\beta$-methyl-, $(S)$ -

$\mathrm{HOCH}_{2} \mathrm{CHMePh}$
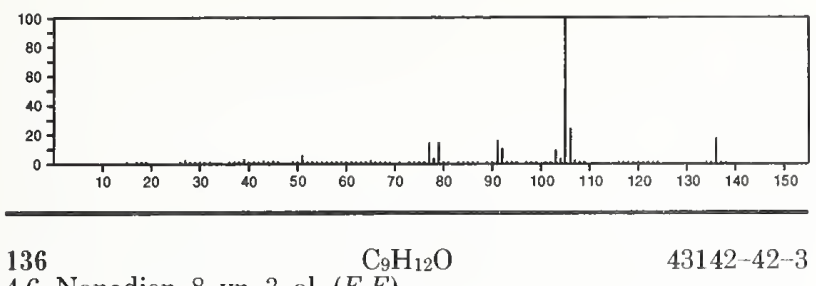

4,6-Nonadien-8-yn-3-ol, $(E, E)$ -

$\mathrm{E}: \mathrm{CH}(\mathrm{OH}) \mathrm{CH}=\mathrm{CHCH}=\mathrm{CHC} \equiv \mathrm{CH}$
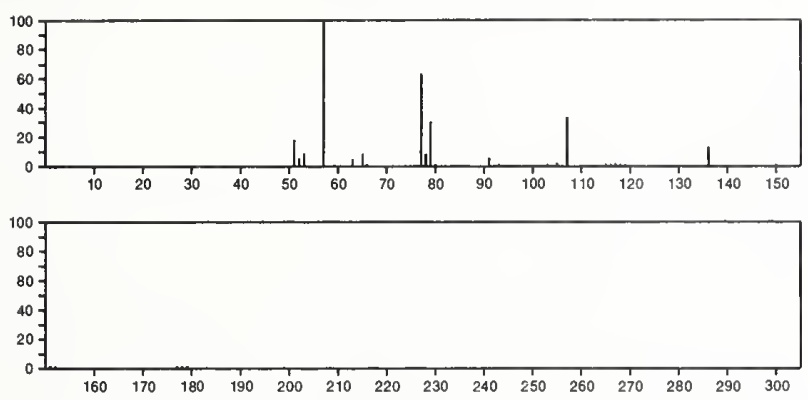

$\begin{array}{lllllllllllllll}160 & 170 & 180 & 190 & 200 & 210 & 220 & 230 & 240 & 250 & 260 & 270 & 280 & 290 & 300\end{array}$

136

3,5-Nonadien-7-yn-2-ol $\left(\mathrm{C}_{9} \mathrm{H}_{12} \mathrm{O}\right.$

$\mathrm{C}_{9} \mathrm{H}_{12} \mathrm{O}$

$\mathrm{MeC} \equiv \mathrm{CCH}=\mathrm{CHCH}=\mathrm{CHCH}(\mathrm{OH}) \mathrm{Me}$

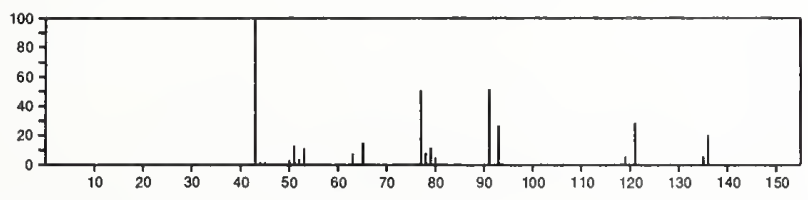

136

2,4-Nonadien-6-yn-1-ol, $(E, E)-$

$\mathrm{C}_{9} \mathrm{H}_{12} \mathrm{O}$

$\mathrm{E}+\mathrm{C} \equiv \mathrm{CCH}=\mathrm{CHCH}=\mathrm{CHCH}_{2} \mathrm{OH}$

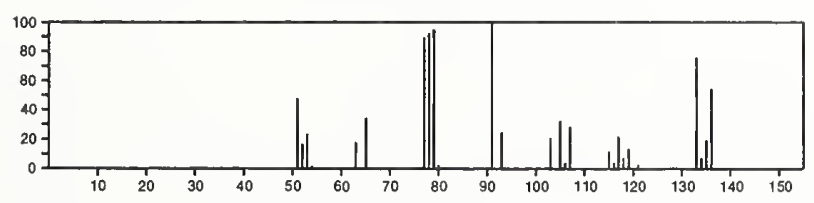

$136 \quad \mathrm{C}_{9} \mathrm{H}_{12} \mathrm{O}$

1H-Inden-1-one, 2,3,3a,4,7,7a-hexahydro-, cis-
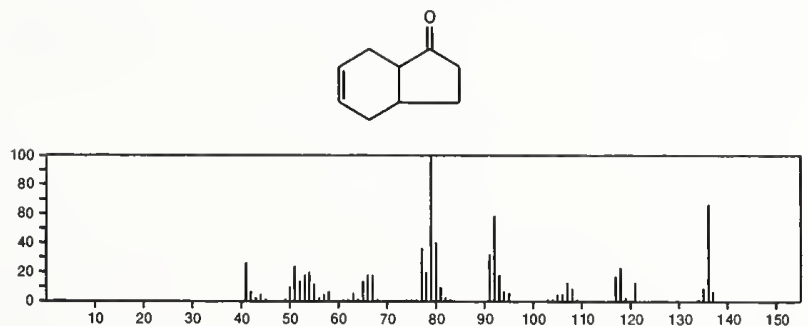

$136 \quad \mathrm{C}_{9} \mathrm{H}_{12} \mathrm{O}$

$53957-33-8$
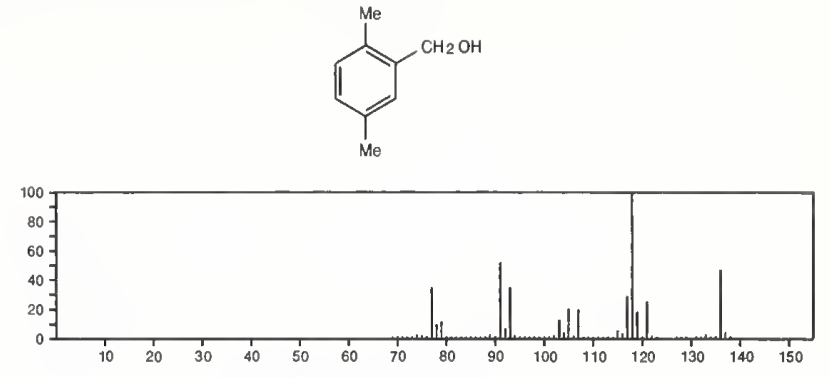

136

$\mathrm{C}_{9} \mathrm{H}_{12} \mathrm{O}$

$53957-34-9$

Benzenemethanol, ar-ethyl-
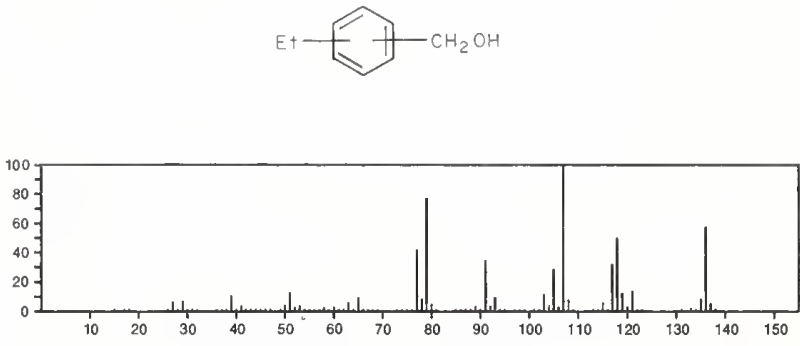

136

$\mathrm{C}_{9} \mathrm{H}_{12} \mathrm{O}$

$56771-49-4$

Spiro[oxirane-2,1'(2'H)-pentalene], 3',4',5',6'-tetrahydro-
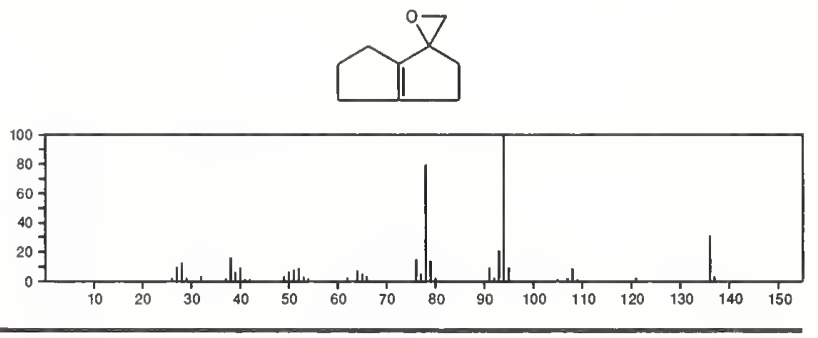

136

$\mathrm{C}_{10} \mathrm{H}_{16}$

$79-92-5$

Bicyclo[2.2.1]heptane, 2,2-dimethyl-3-methylene-<smiles>C=C1C2CCC(C2)C1(C)C</smiles>

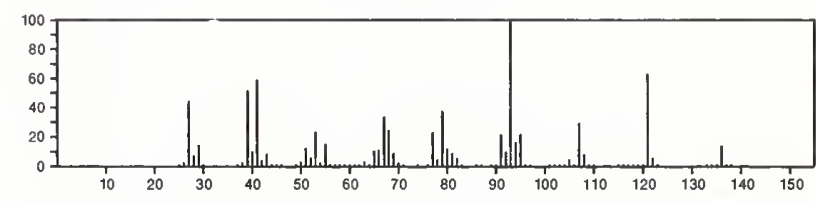

136

$\mathrm{C}_{10} \mathrm{H}_{16}$

$80-56-8$

Bicyclo[3.1.1]hept-2-ene, 2,6,6-trimethyl-
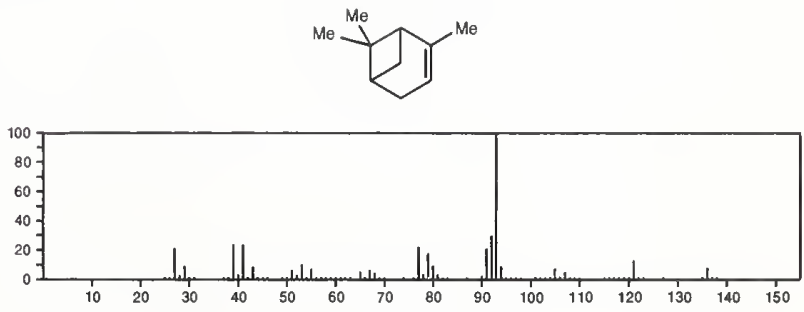
136

$\mathrm{C}_{10} \mathrm{H}_{16}$

1,3-Cyclohexadiene, 2-methyl-5-(1-methylethyl)-
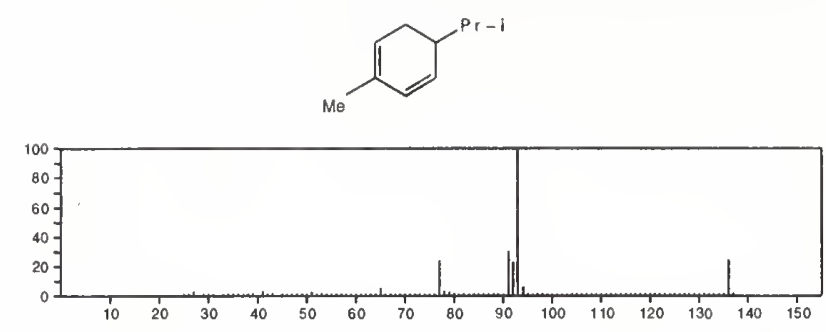

136

$\mathrm{C}_{10} \mathrm{H}_{16}$

1,4-Cyclohexadiene, 1-methyl-4-(1-methylethyl)-

$99-85-4$
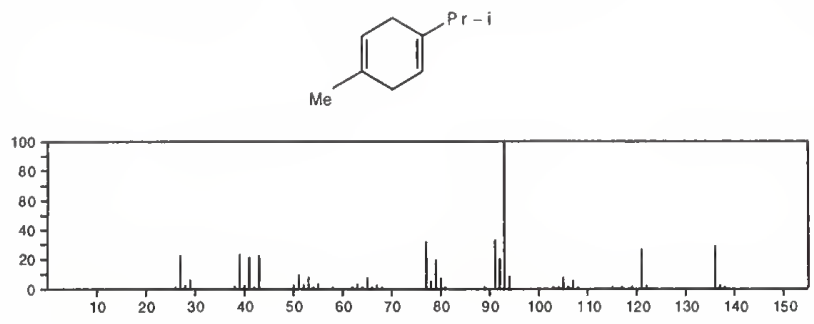

136

$\mathrm{C}_{10} \mathrm{H}_{16}$

1,3-Cyclohexadiene, 1-methyl-4-(1-methylethyl)-

99-86-5
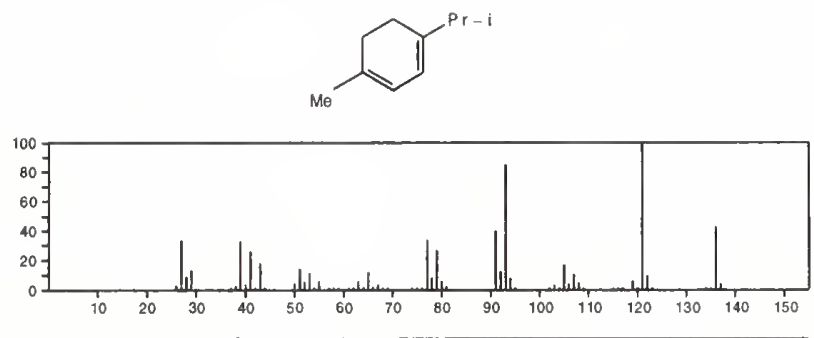

$136 \quad \mathrm{C}_{10} \mathrm{H}_{16}$

1,6-Octadiene, 7-methyl-3-methylene-

$123-35-3$
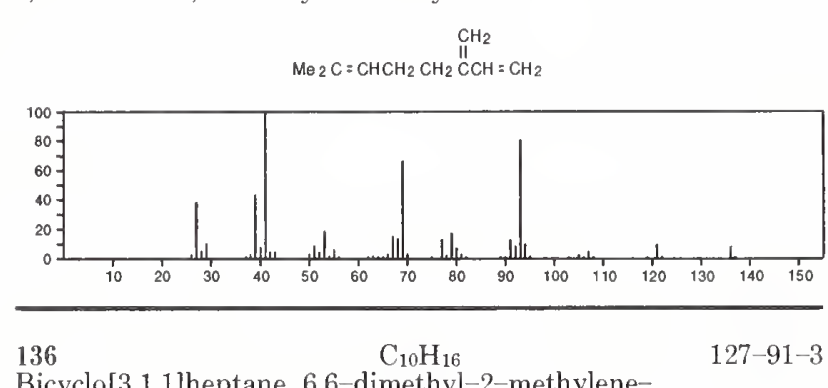

Bicyclo[3.1.1]heptane, 6,6-dimethyl-2-methylene-
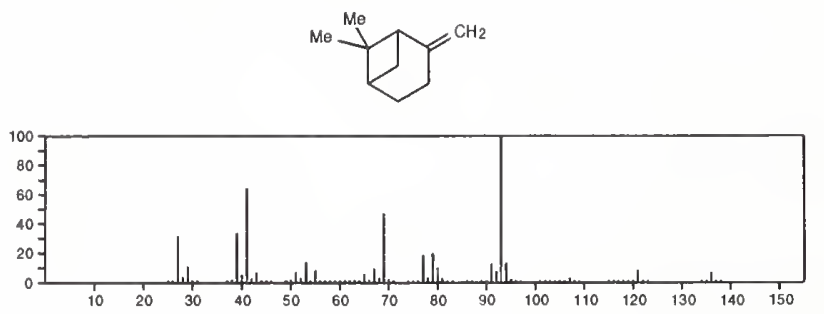

136 Cyclohexene, 1-methyl-4-(1-methylethenyl)-
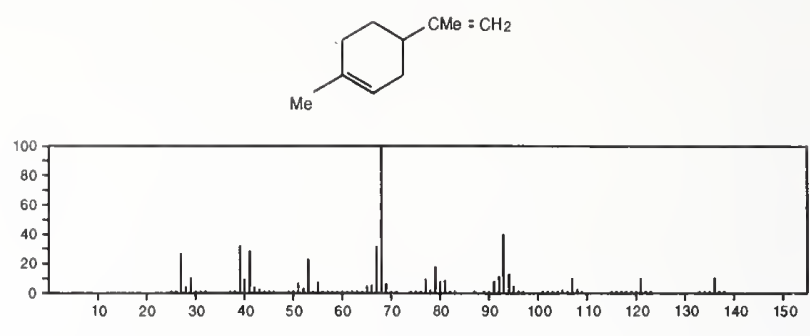

136

Tricyclo[3.3.1.13,7]decane

$\mathrm{C}_{10} \mathrm{H}_{16}$

$281-23-2$
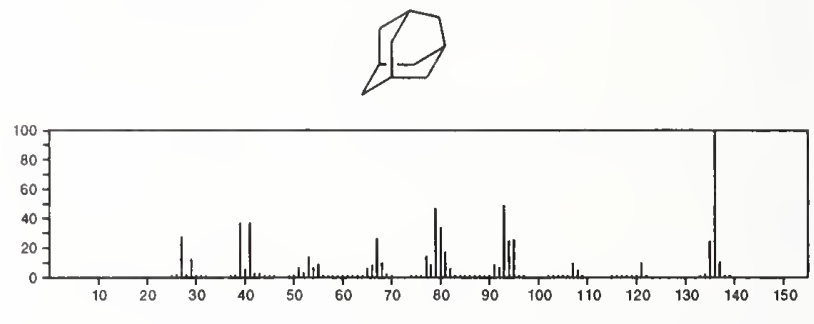

136

$\mathrm{C}_{10} \mathrm{H}_{16}$

$471-84-1$

Bicyclo[2.2.1]heptane, 7,7-dimethyl-2-methylene-
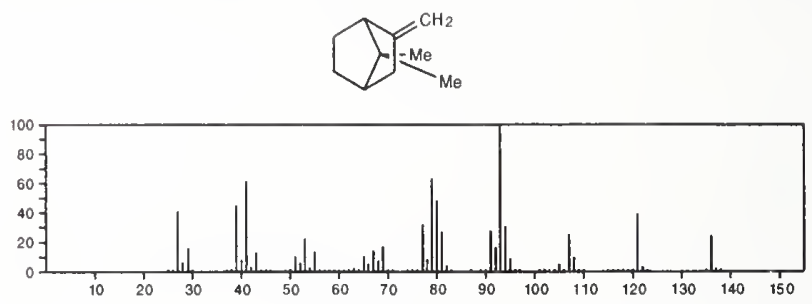

136

$\mathrm{C}_{10} \mathrm{H}_{16}$

Tricyclo[2.2.1.02,6]heptane, 1,3,3-trimethyl-

$488-97-1$
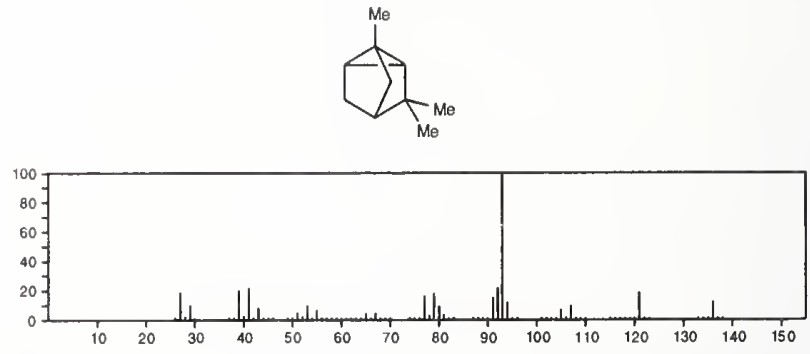

136

$\mathrm{C}_{10} \mathrm{H}_{16}$

Cyclohexene, 1-methyl-3-(1-methylethenyl)-, ( \pm )-

499-03-6
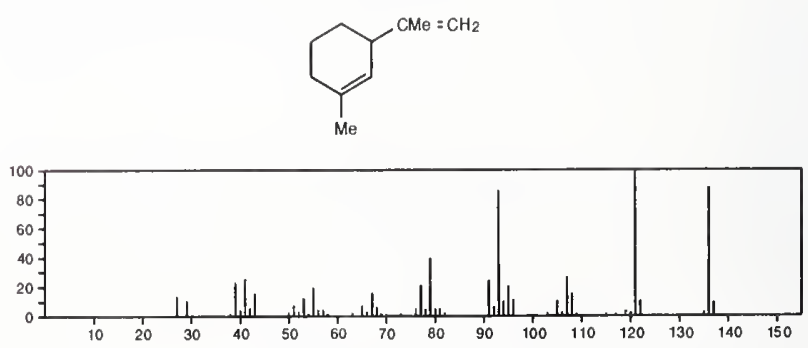
136 $\mathrm{C}_{10} \mathrm{H}_{16}$

$499-97-8$

Cyclohexane, 1-methylene-4-(1-methylethenyl)-
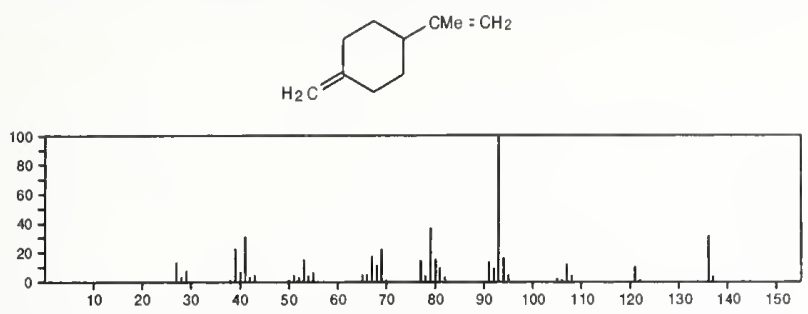

$136 \quad \mathrm{C}_{10} \mathrm{H}_{16}$

1,3,7-Octatriene, 3,7-dimethyl-

$502-99-8$

$\mathrm{H}_{2} \mathrm{C}=\mathrm{CM}_{2} \mathrm{CH}_{2} \mathrm{CH}_{2} \mathrm{CH}=\mathrm{CM} \mathrm{CH}=\mathrm{CH}_{2}$

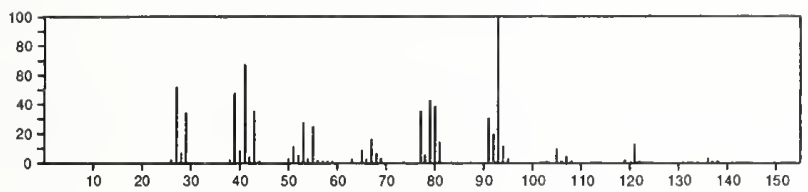

136

$\mathrm{C}_{10} \mathrm{H}_{16}$

$508-32-7$

Tricyclo[2.2.1.02,6]heptane, 1,7,7-trimethyl-
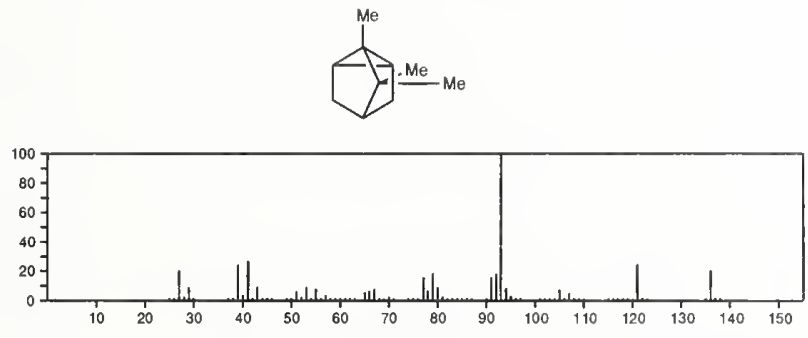

136

$\mathrm{C}_{10} \mathrm{H}_{16}$

$514-94-3$

1,3-Cyclohexadiene, 1,5,5,6-tetramethyl-<smiles>CC1=CC=CC(C)(C)C1C</smiles>

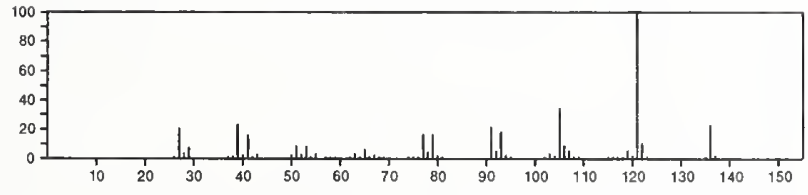

136

$\mathrm{C}_{10} \mathrm{H}_{16}$

$514-96-5$

1,3-Cyclohexadiene, 1,2,6,6-tetramethyl-<smiles>CC1=C([N+](=O)[O-])C=CCC1(C)C</smiles>

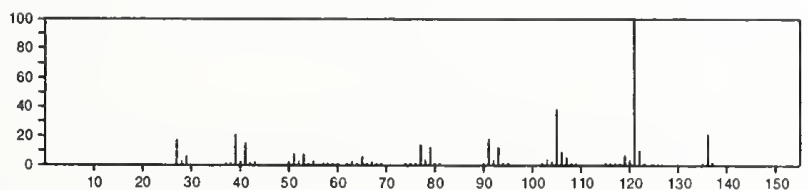

136

$\mathrm{C}_{10} \mathrm{H}_{16}$

$554-61-0$

Bicyclo[4.1.0]hept-2-ene, 3,7,7-trimethyl
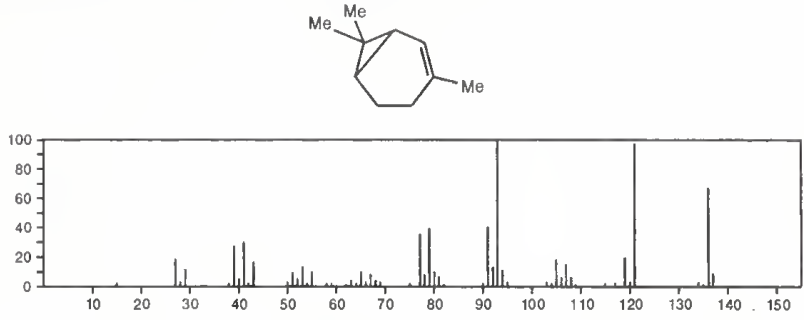

136

$\mathrm{C}_{10} \mathrm{H}_{16}$

$555-10-2$

Cyclohexene, 3-methylene-6-(1-methylethyl)-
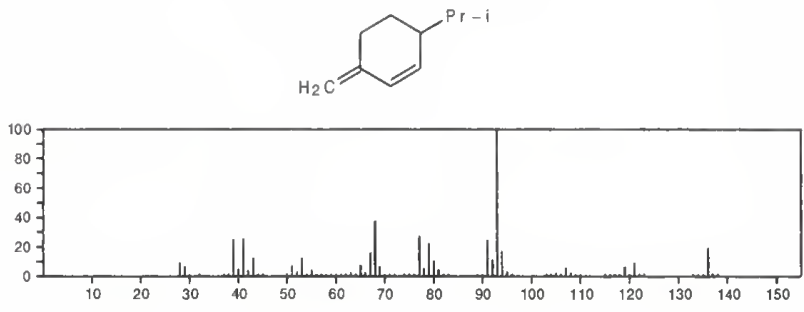

136

$\mathrm{C}_{10} \mathrm{H}_{16}$

$586-62-9$

Cyclohexene, 1-methyl-4-(1-methylethylidene)
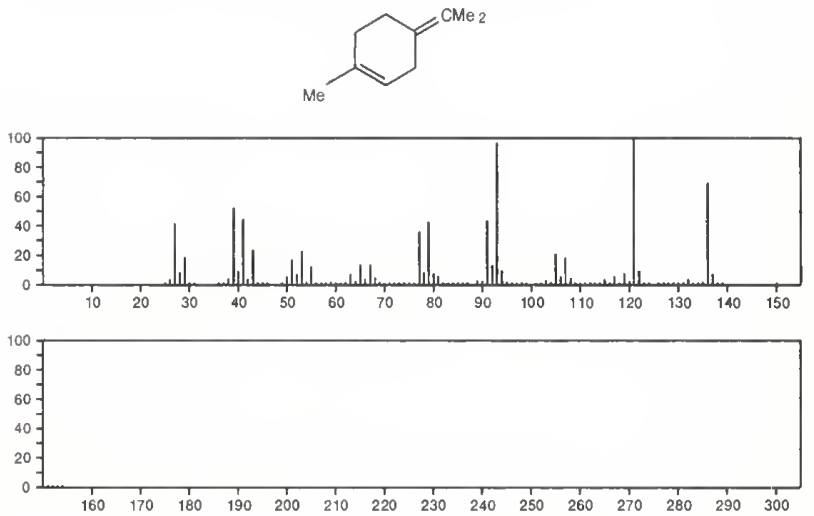

$\mathrm{C}_{10} \mathrm{H}_{16}$

673-84-7

2,4,6-Octatriene, 2,6-dimethyl-

$\mathrm{Me} \mathrm{CH}=\mathrm{CMe} \mathrm{CH}=\mathrm{CHCH}=\mathrm{CMe}$

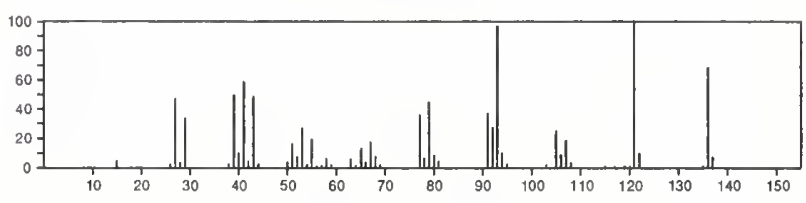

136

$\mathrm{C}_{10} \mathrm{H}_{16}$

Cyclohexene, 1-methyl-5-(1-methylethenyl)-, $(R)$

$1461-27-4$
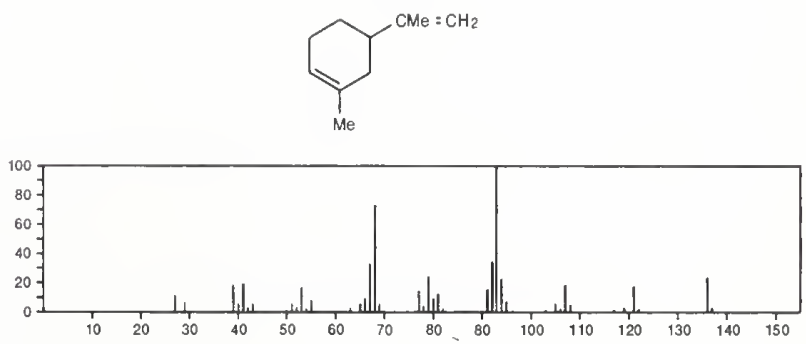
136

$\mathrm{C}_{10} \mathrm{H}_{16}$

$3387-41-5$

Bicyclo[3.1.0]hexane, 4-methylene-1-(1-methylethyl)-
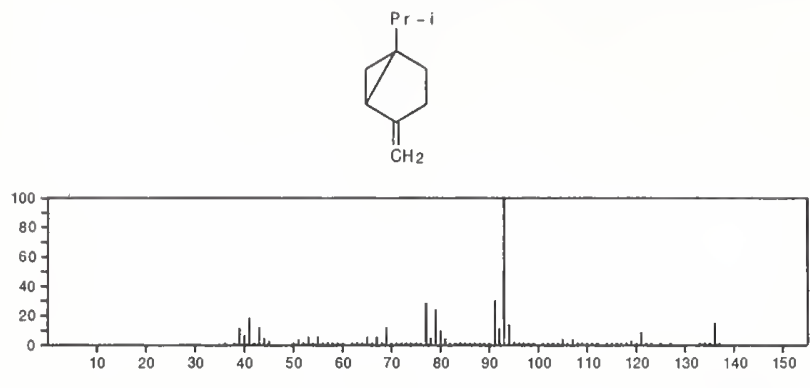

$136 \quad \mathrm{C}_{10} \mathrm{H}_{16}$

1,3,6-Octatriene, 3,7-dimethyl-, $(E)$ -

$3779-61-1$

$\mathrm{H}_{2} \mathrm{C}=\mathrm{CHCMe}=\mathrm{CHCH}_{2} \mathrm{CH}=\mathrm{CMe}_{2}$

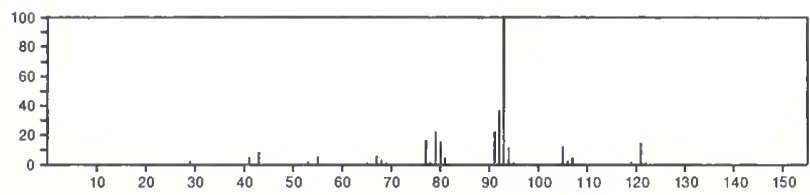

136

Cyclohexene, 3-methyl-6-(1-methylethenyl)-, (3R-trans)-
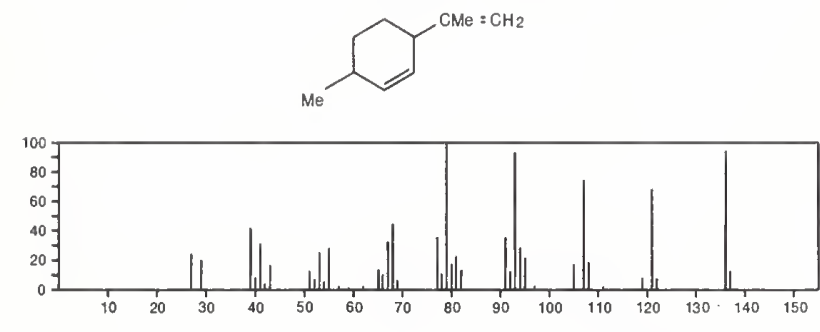

136
$4-$ Carene, $(1 S, 3 S, 6 R)-(-)-$
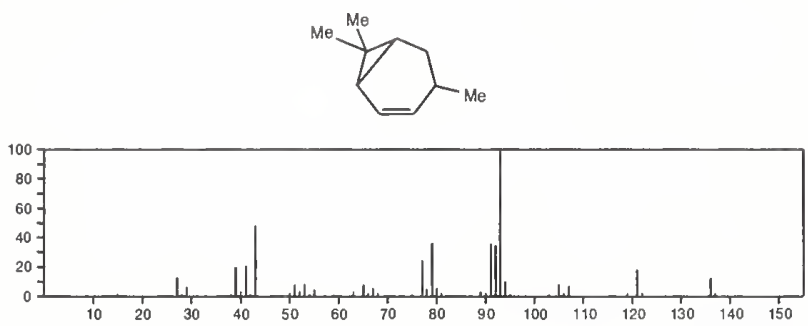

$$
136 \quad \mathrm{C}_{10} \mathrm{H}_{16}
$$

$m$-Mentha-4,8-diene, $(1 S, 3 S)-(+)$ -
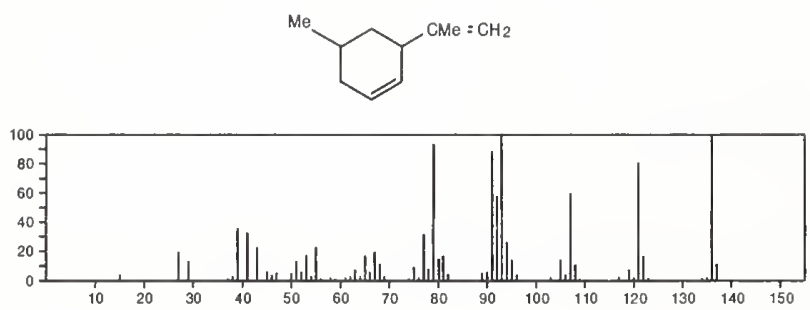

$136 \quad \mathrm{C}_{10} \mathrm{H}_{16}$

Cyclohexene, 1-methyl-4-(1-methylethenyl)-, $(R)$ -

$5989-27-5$
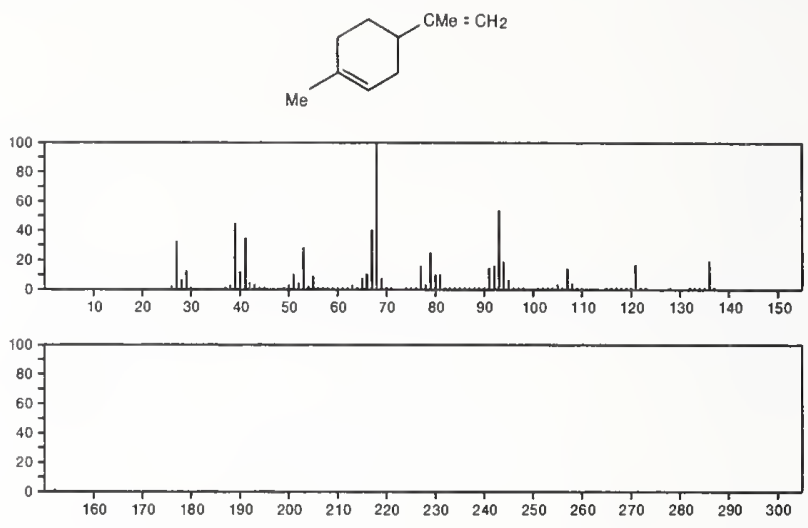

136

$\mathrm{C}_{10} \mathrm{H}_{16}$

Cyclohexene, 1-methyl-4-(1-methylethenyl)-, (S)-

$5989-54-8$<smiles>CCC1CC=C(N)CC1</smiles>

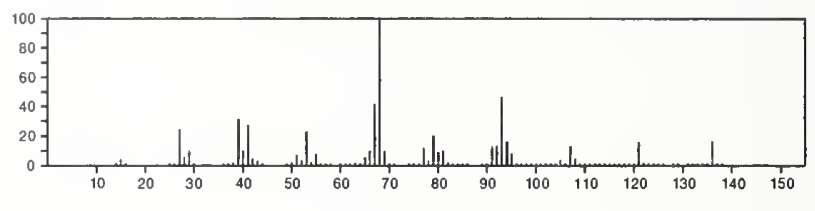

136

$\mathrm{C}_{10} \mathrm{H}_{16}$

$13466-78-9$

Bicyclo[4.1.0]hept-3-ene, 3,7,7-trimethy]-
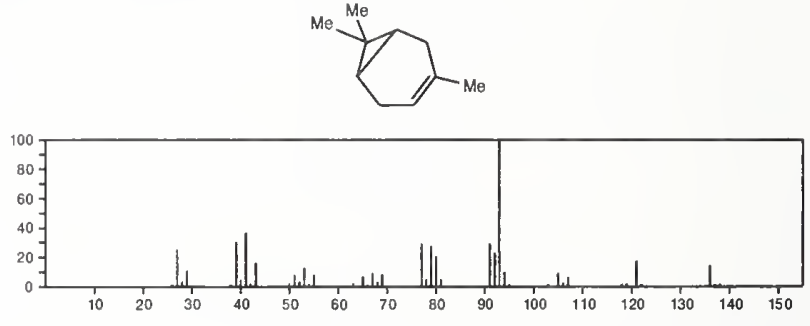

136

$\mathrm{C}_{10} \mathrm{H}_{16}$

$13837-95-1$

Cyclohexane, 1-methylene-3-(1-methylethenyl)-, $(R)$ -<smiles>C=C1CCCC(OC)C1</smiles>

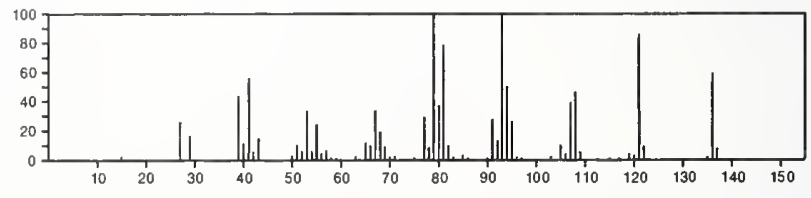

136

1,3,6-Octatriene, 3,7-dimethyl-

$\mathrm{C}_{10} \mathrm{H}_{16}$

$13877-91-3$

$\mathrm{H}_{2} \mathrm{C}=\mathrm{CHCMe}=\mathrm{CHCH}_{2} \mathrm{CH}=\mathrm{CMe}_{2}$

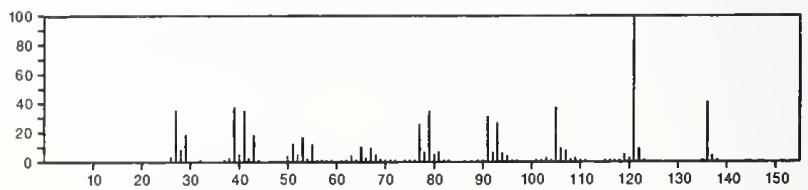


136 $\mathrm{C}_{10} \mathrm{H}_{16}$ $14803-30-6$ Cyclopropane, trimethyl(2-methyl-1-propenylidene)-
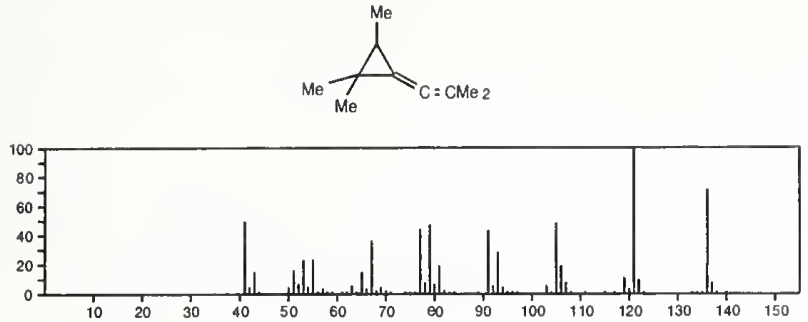

\section{$136 \quad \mathrm{C}_{10} \mathrm{H}_{16}$}

Cycloheptene, 5-ethylidene-1-methyl-

$15402-94-5$
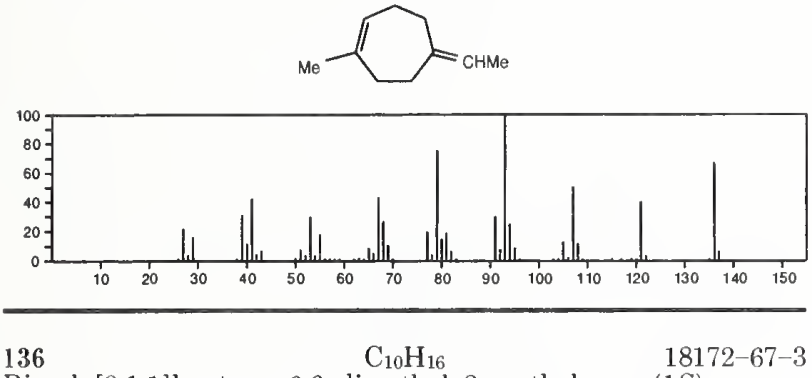

Bicyclo[3.1.1] heptane, 6,6-dimethyl-2-methylene-, $(1 S)$ -
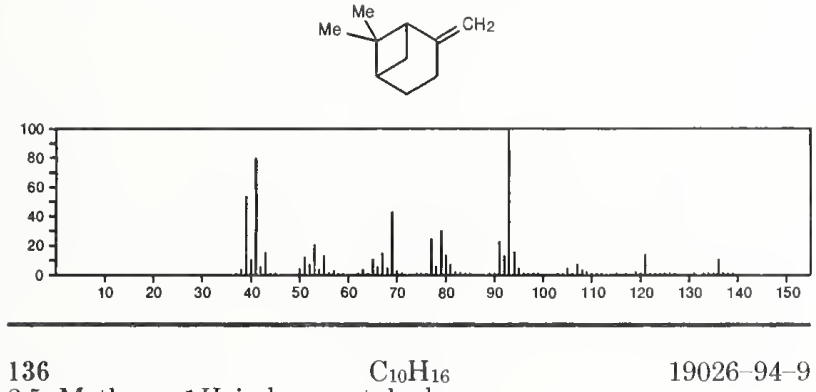

2,5-Methano- $1 H$-indene, octahydro-
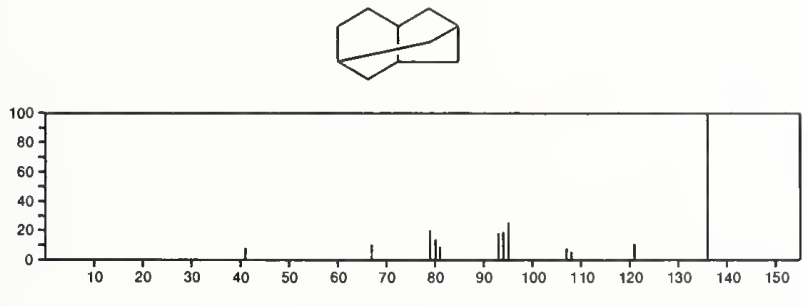

$136 \quad \mathrm{C}_{10} \mathrm{H}_{16} \quad 22769-00-2$ Cyclobutane, 1,2-dipropenyl-
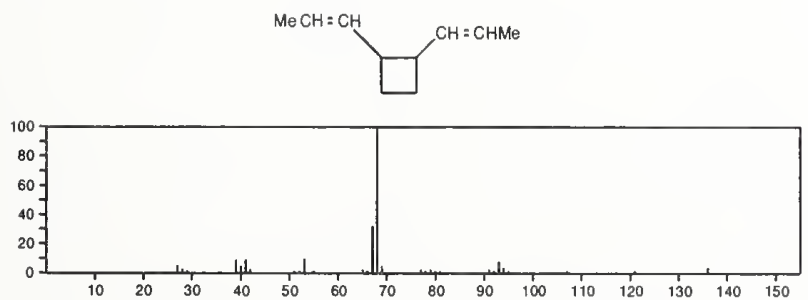

136

$\mathrm{C}_{10} \mathrm{H}_{16}$

$24524-57-0$
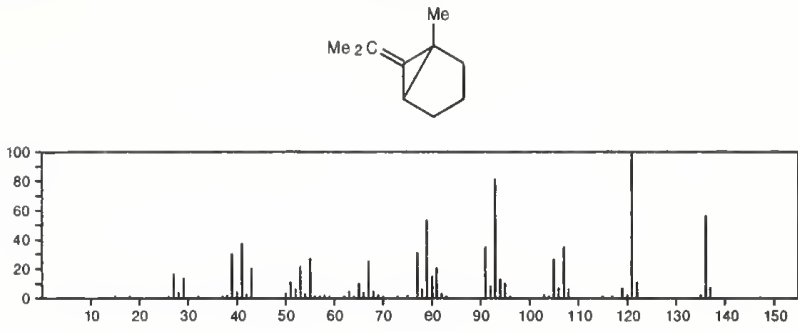

136
$3-$ Octen-5-yne, 2,7-dimethyl--,
$\mathrm{C}_{10} \mathrm{H}_{16}$
$(Z)-$

$28935-76-4$

$\mathrm{Me} 2 \mathrm{CHC} \equiv \mathrm{CCH}=\mathrm{CHCHME} 2$

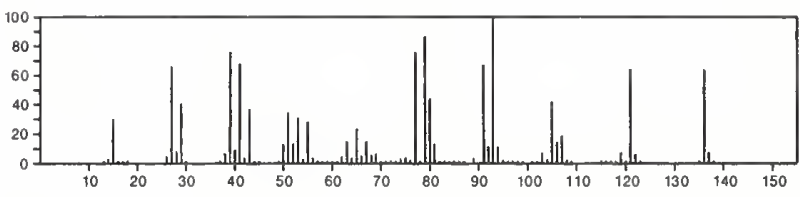

136

$\mathrm{C}_{10} \mathrm{H}_{16}$

$29714-87-2$

Octane, 2,6-dimethyl-, hexadehydro deriv.

$\mathrm{Me}_{2} \mathrm{CH}\left(\mathrm{CH}_{2}\right)_{3} \mathrm{CHMeCH}_{2} \mathrm{Me} \quad-6 \mathrm{H}$

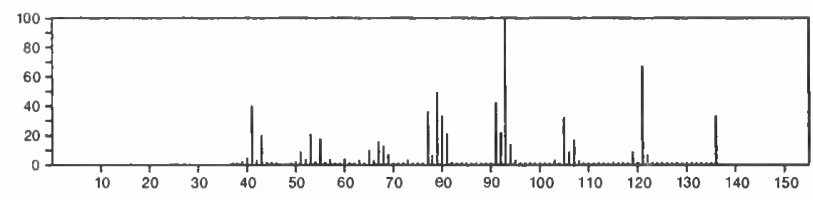

136

$\mathrm{C}_{10} \mathrm{H}_{16}$

$53282-47-6$

Bicyclo[4.1.0]heptane, 7-(1-methylethylidene)
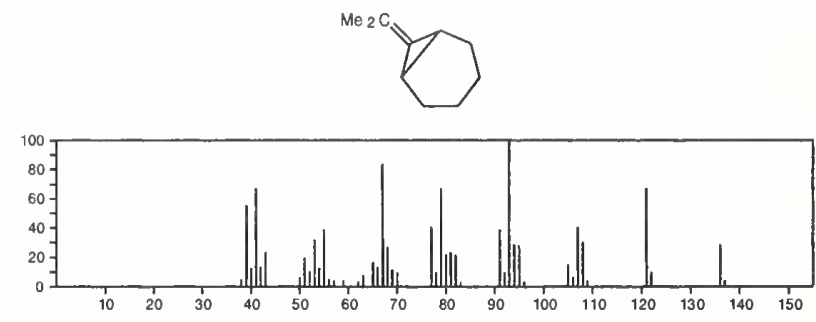

136

3-Octen-5-yne, 2,7-dimethyl-, $(E)$ -

$55956-33-7$

$\mathrm{Me}_{2} \mathrm{CHC} \equiv \mathrm{CCH}=\mathrm{CHCHMe} 2$

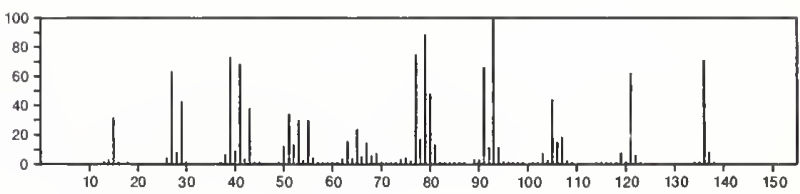


Bicyclo[3.1.0]hexane, 1-methyl-6-(1-methylethylidene -
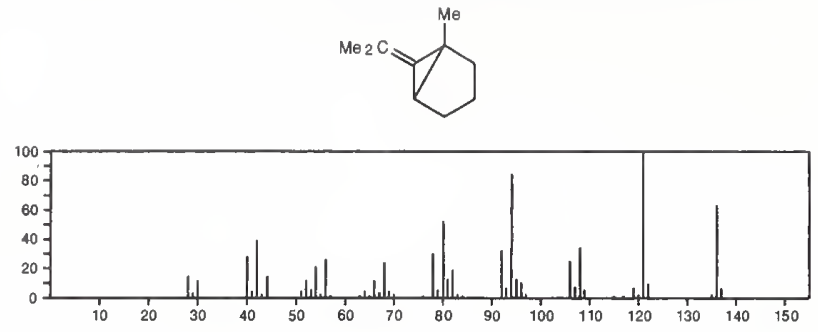

136

$\mathrm{C}_{10} \mathrm{H}_{16}$

$56710-83-9$

Cyclopentane, 2-methyl-1-methylene-3-(1-methylethenyl)-<smiles>C=CC1CCC(=C)C1[N+](=O)[O-]</smiles>

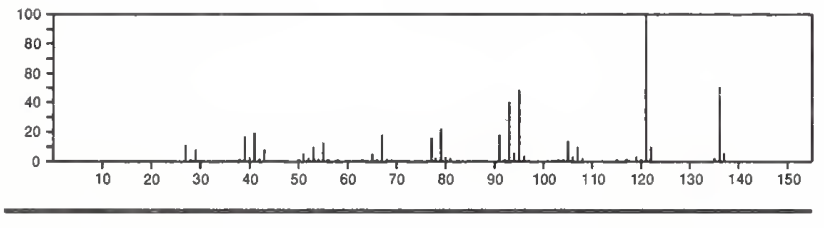

136

$\mathrm{C}_{10} \mathrm{H}_{16}$

$56816-08-1$

Cyclohexene, 5-methyl-3-(1-methylethenyl)-, trans-(-)-
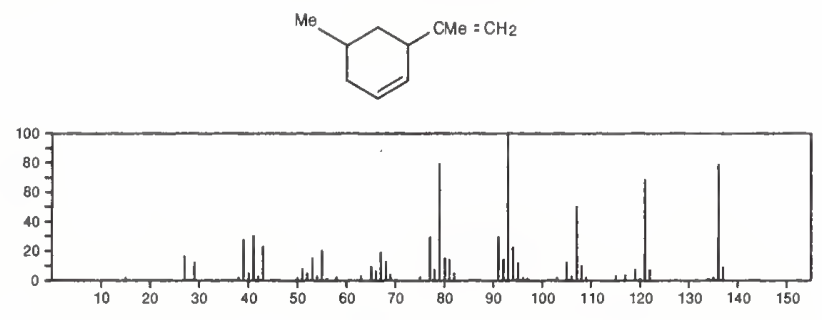

136

2,4,6-Octatriene, 3,4-dimethyl

$\mathrm{C}_{10} \mathrm{H}_{16}$

$57396-75-5$

$\mathrm{Me} \mathrm{CH}=\mathrm{CHCH}=\mathrm{CMe} \mathrm{CMe}=\mathrm{CHMe}$

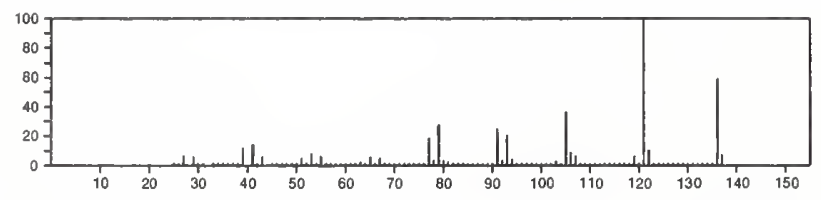

137

$\mathrm{C}_{3} \mathrm{H}_{7} \mathrm{NO}_{5}$

$624-43-1$

1,2,3-Propanetriol, 1-nitrate

$\mathrm{O}_{2} \mathrm{NOCH}_{2} \mathrm{CH}(\mathrm{OH}) \mathrm{CH}_{2} \mathrm{OH}$

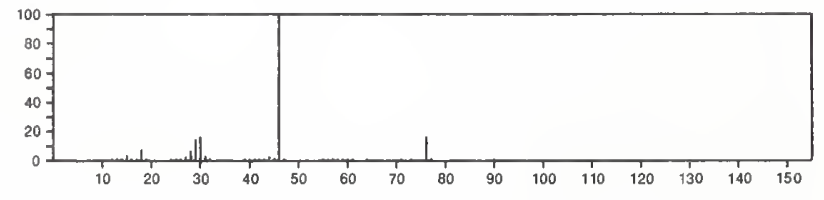

$\begin{aligned} & 137 . \\ & \text { Thiazolo[5,4-d]pyrimidine }\end{aligned} \mathrm{C}_{5} \mathrm{H}_{3} \mathrm{~N}_{3} \mathrm{~S} \quad 273-86-9$
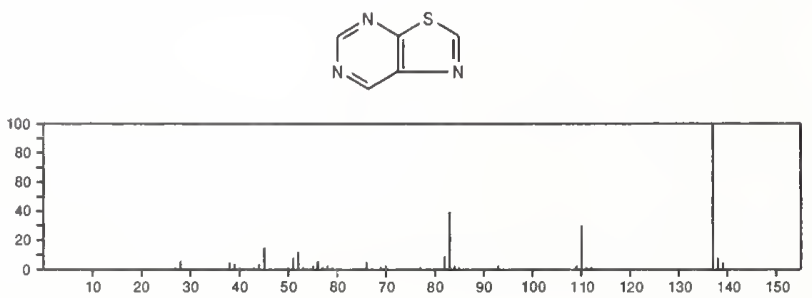

Butyronitrile, 4,4,4-trifluoro-2-methyl-

$\mathrm{F}_{3} \mathrm{CCH}_{2} \mathrm{CHM} \theta \mathrm{CN}$

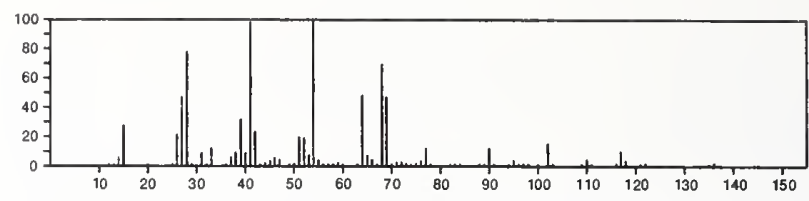

137

$\mathrm{C}_{6} \mathrm{H}_{7} \mathrm{~N}_{3} \mathrm{O}$

4-Pyridinecarboxylic acid, hydrazide

$54-85-3$
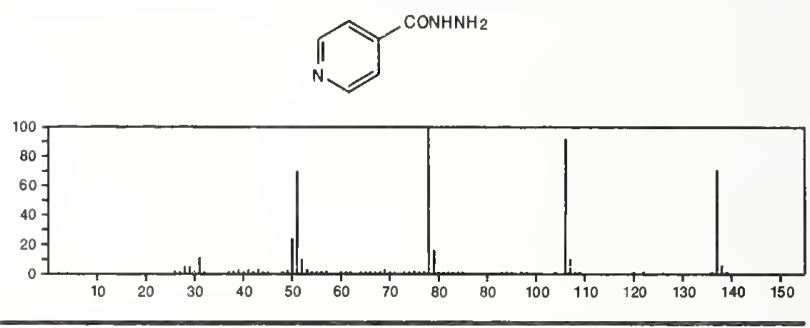

137

$\mathrm{C}_{6} \mathrm{H}_{7} \mathrm{~N}_{3} \mathrm{O}$

3-Pyridinecarboxylic acid, hydrazide

553-53-7
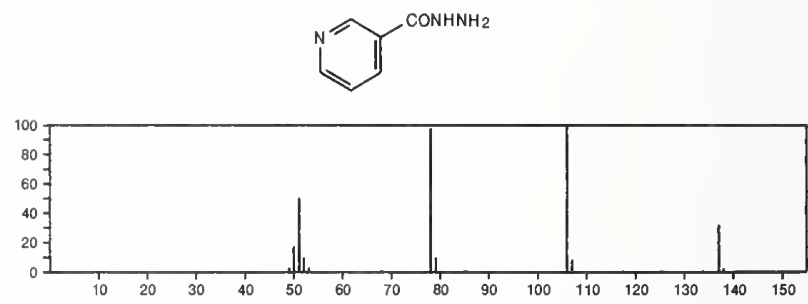

137

$\mathrm{C}_{6} \mathrm{H}_{7} \mathrm{~N}_{3} \mathrm{O}$

$31378-80-0$

Pyridinium, 1-ureido-, hydroxide, inner salt
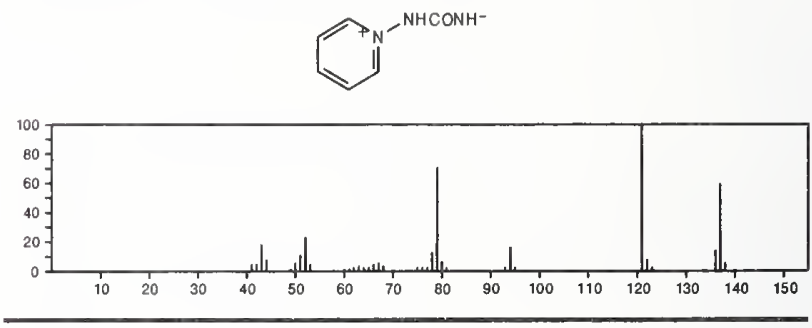

137

$\mathrm{C}_{7} \mathrm{H}_{4} \mathrm{ClN}$

$623-03-0$

Benzonitrile, 4-chloro-
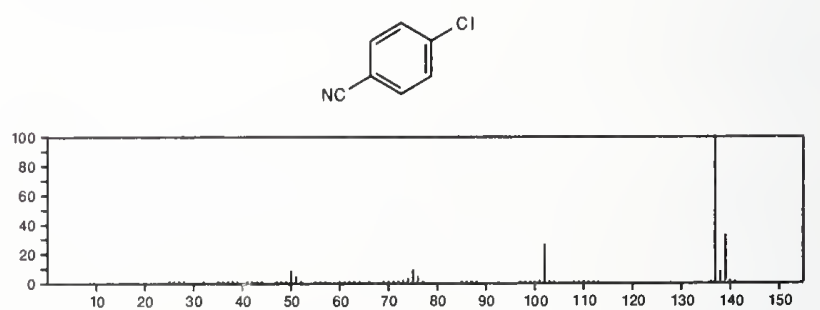
137

Benzamide, 2-hydroxy-

$\mathrm{C}_{7} \mathrm{H}_{7} \mathrm{NO}_{2}$

65-45-2
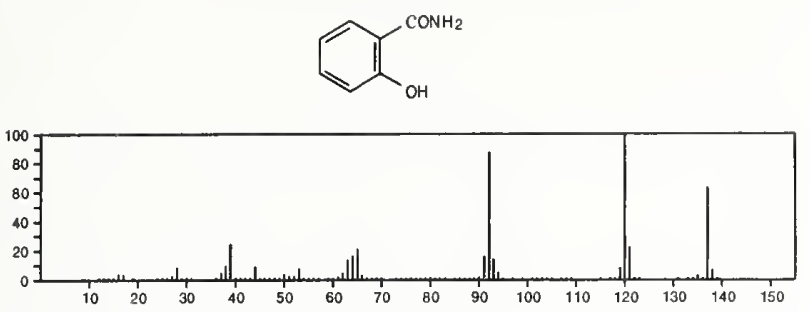

137

$\mathrm{C}_{7} \mathrm{H}_{7} \mathrm{NO}_{2}$

Benzene, 1-methyl-2-nitro-<smiles>O=[N+]([O-])c1ccccc1[N+](=O)[O-]</smiles>

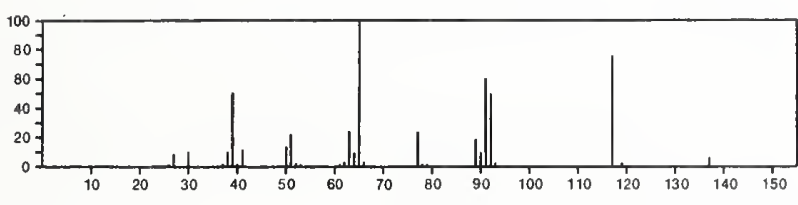

137

$\mathrm{C}_{7} \mathrm{H}_{7} \mathrm{NO}_{2}$

3-Pyridinecarboxylic acid, methyl ester

93-60-7
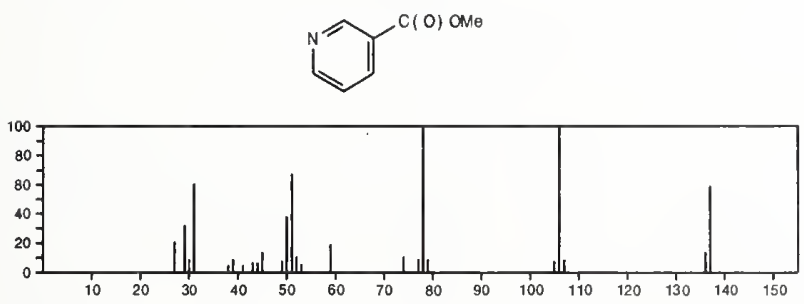

137

$\mathrm{C}_{7} \mathrm{H}_{7} \mathrm{NO}_{2}$

Benzaldehyde, 2-hydroxy-, oxime
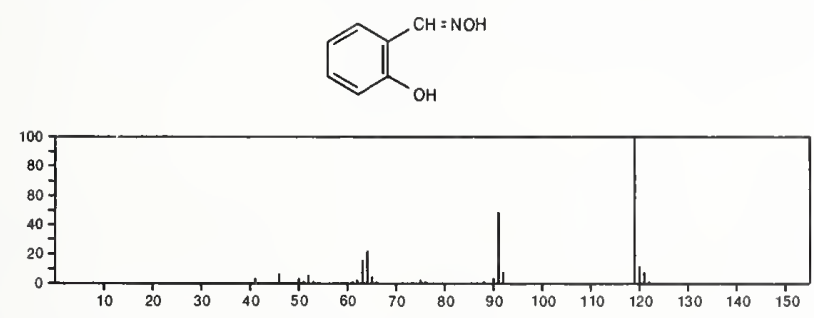

137

$\mathrm{C}_{7} \mathrm{H}_{7} \mathrm{NO}_{2}$

99-05-8

Benzoic acid, 3-amino-
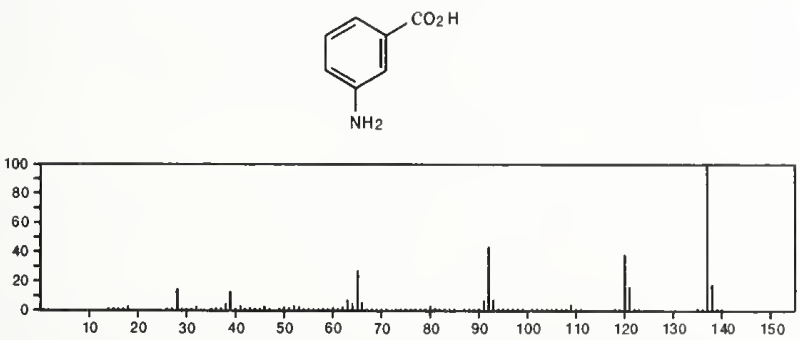

137

$\mathrm{C}_{7} \mathrm{H}_{7} \mathrm{NO}_{2}$

99-99-0<smiles>Cc1ccc([N+](=O)[O-])cc1</smiles>

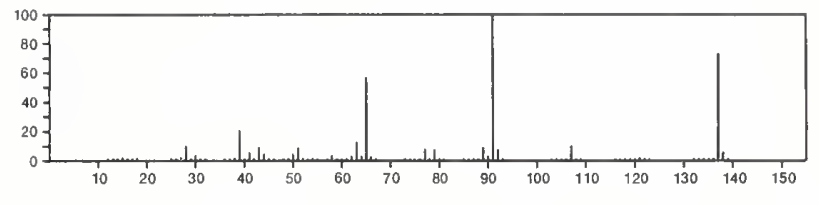

$137 \quad \mathrm{C}_{7} \mathrm{H}_{7} \mathrm{NO}_{2} \quad 118-92-3$ Benzoic acid, 2-amino-
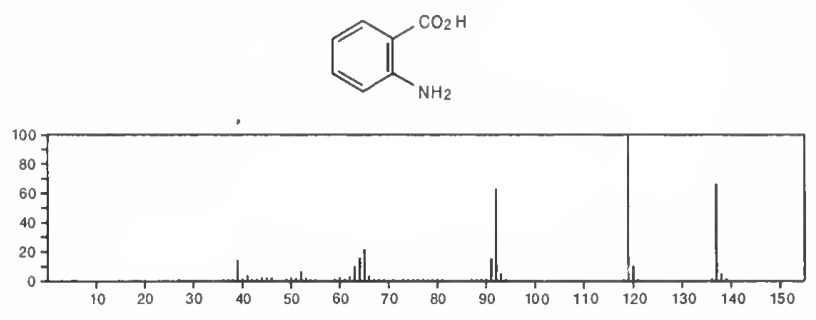

137

$\mathrm{C}_{7} \mathrm{H}_{7} \mathrm{NO}_{2}$

$150-13-0$

Benzoic acid, 4-amino-
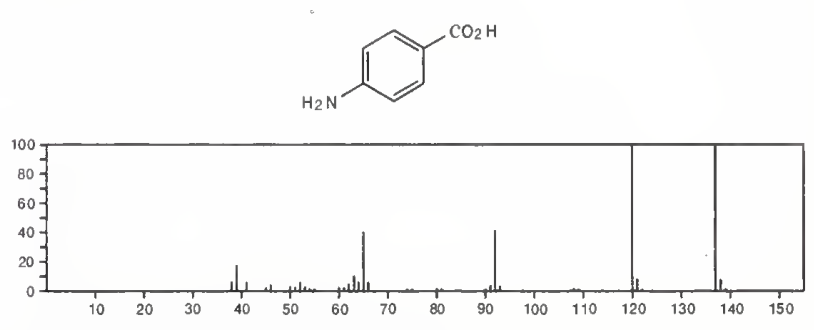

$137 \quad \mathrm{C}_{7} \mathrm{H}_{7} \mathrm{NO}_{2}$

Pyridinium, 2-carboxy-1-methyl-, hydroxide, inner salt

$445-30-7$
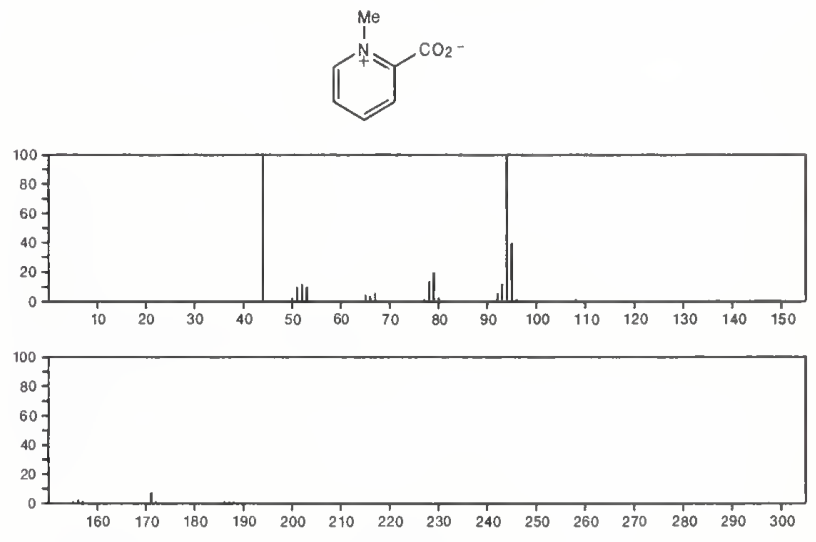

137

3-Pyridineacetic acid

$\mathrm{C}_{7} \mathrm{H}_{7} \mathrm{NO}_{2}$

$501-81-5$
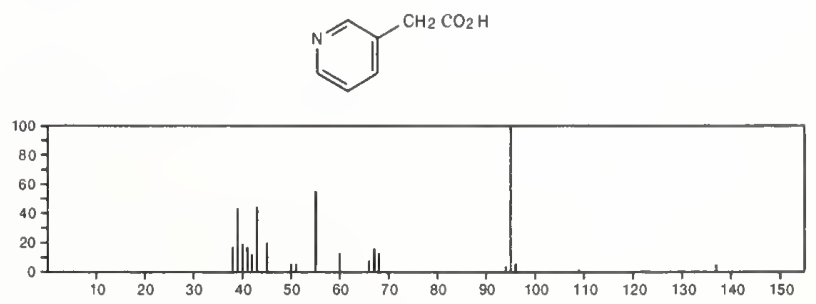
137

$\mathrm{C}_{7} \mathrm{H}_{7} \mathrm{NO}_{2}$

Pyridinium, 3-carboxy-1-methyl-, hydroxide, inner salt
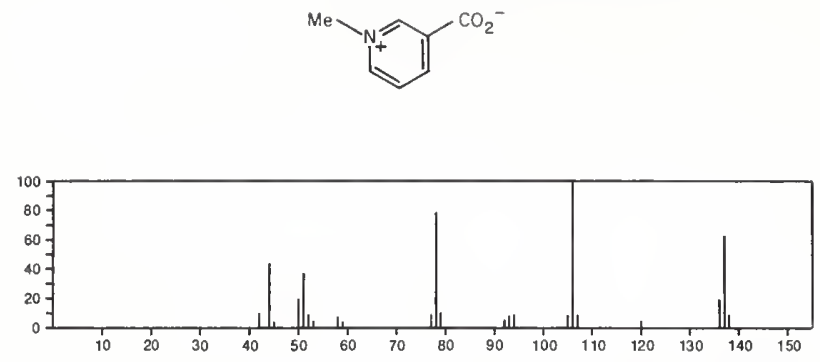

137

$\mathrm{C}_{7} \mathrm{H}_{7} \mathrm{NO}_{2}$

$622-42-4$

Benzene, (nitromethyl)-

$\mathrm{PhCH}_{2} \mathrm{NO}_{2}$

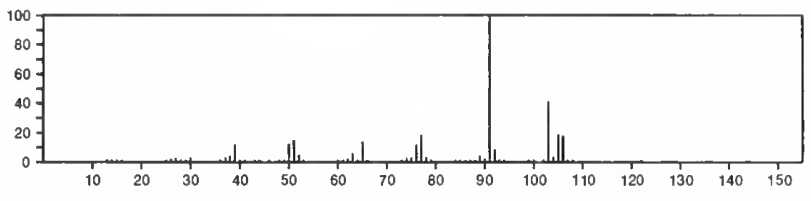

137

$\mathrm{C}_{7} \mathrm{H}_{7} \mathrm{NO}_{2}$

699-06-9

Benzaldehyde, 4-hydroxy-, oxime
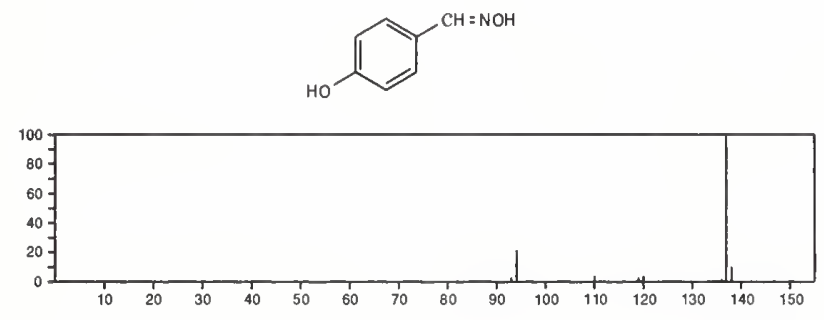

137

$\mathrm{C}_{7} \mathrm{H}_{7} \mathrm{NO}_{2}$

2-Pyridinecarboxylic acid, 6-methyl-
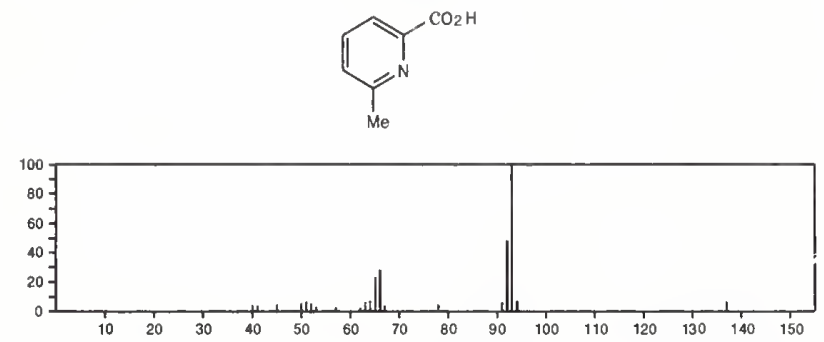

\section{7}

2-Pyridinecarboxylic acid, methyl ester

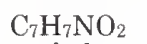

${ }^{\mathrm{N}}{ }^{\mathrm{C}(0) \mathrm{OMe}}$

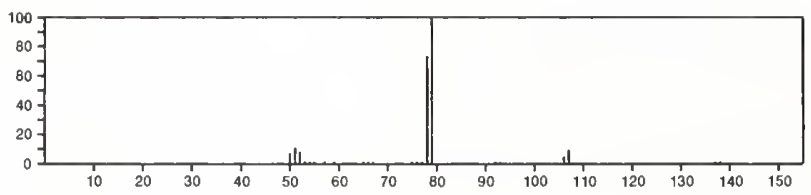

137

$\mathrm{C}_{7} \mathrm{H}_{7} \mathrm{NO}_{2}$

4-Pyridinecarboxylic acid, methyl ester

2459-09-8
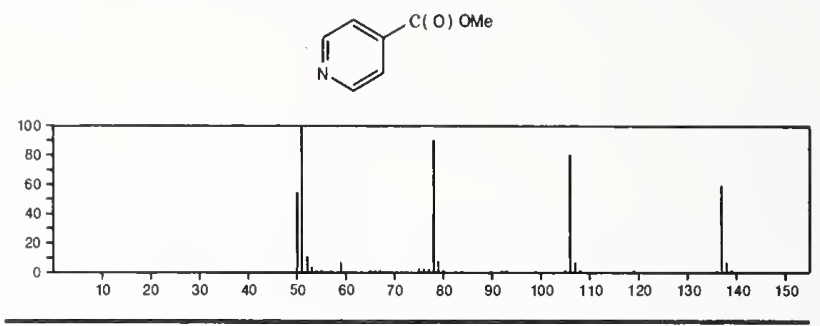

137

$\mathrm{C}_{7} \mathrm{H}_{7} \mathrm{NO}_{2}$

$14210-20-9$

4-Pyridinol, acetate (ester)
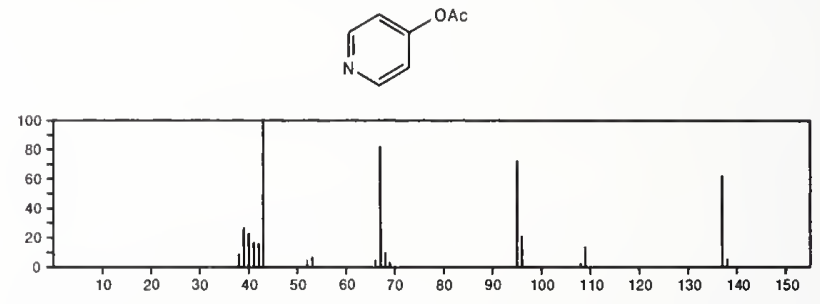

137

$\mathrm{C}_{7} \mathrm{H}_{7} \mathrm{NO}_{2}$

$21494-57-5$

$1 \mathrm{H}$-Pyrrole-2,5-dione, 3 -ethenyl-4-methyl-
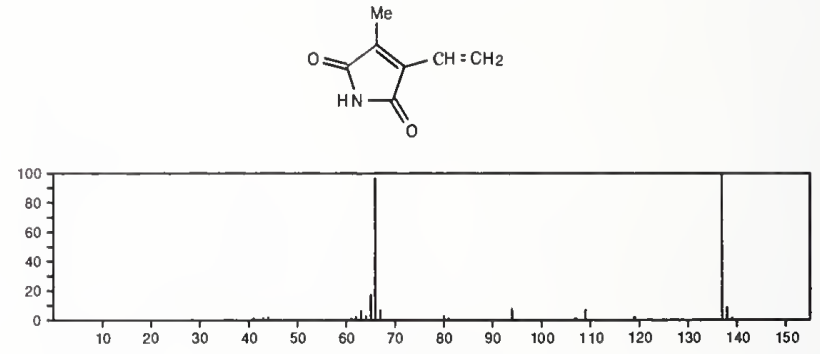

137

$\mathrm{C}_{7} \mathrm{H}_{7} \mathrm{NO}_{2}$

Benzaldehyde, 3-hydroxy-, oxime

$22241-18-5$
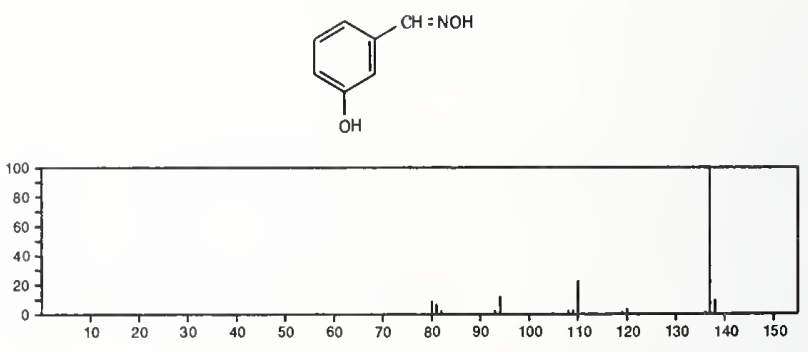

137

$\mathrm{C}_{7} \mathrm{H}_{7} \mathrm{NO}_{2}$

24608-93-3

Pyridinium, 1-(carboxymethyl)-, hydroxide, inner salt
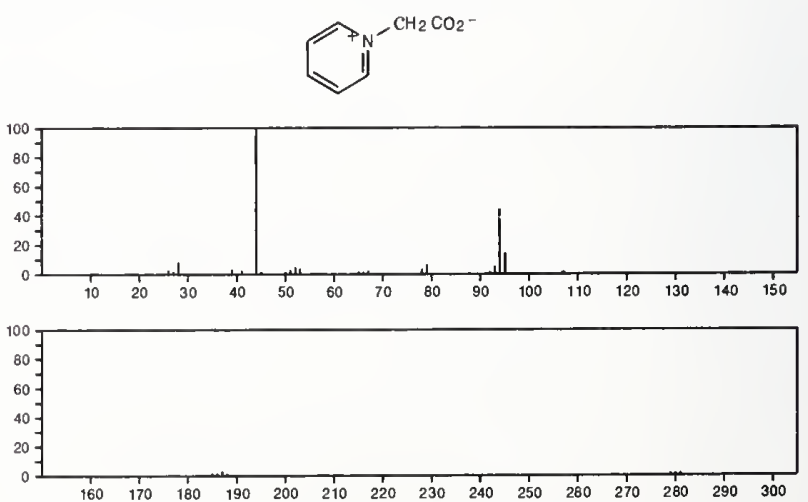
137

EPA/NIH MASS SPECTRAL DATA BASE

325

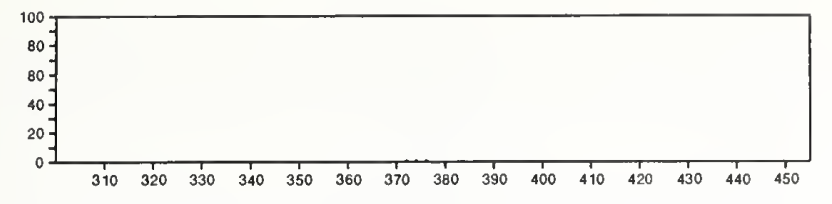

\begin{tabular}{ll}
\hline $\mathbf{1 3 7}$ & $\mathrm{C}_{7} \mathrm{H}_{7} \mathrm{NO}_{2}$ \\
$1 \mathrm{H}-$ Pyrrole-2-carboxylic acid, 1-ethenyl- & $34600-55-0$
\end{tabular}

$1 H$-Pyrrole-2-carboxylic acid, 1-ethenyl-
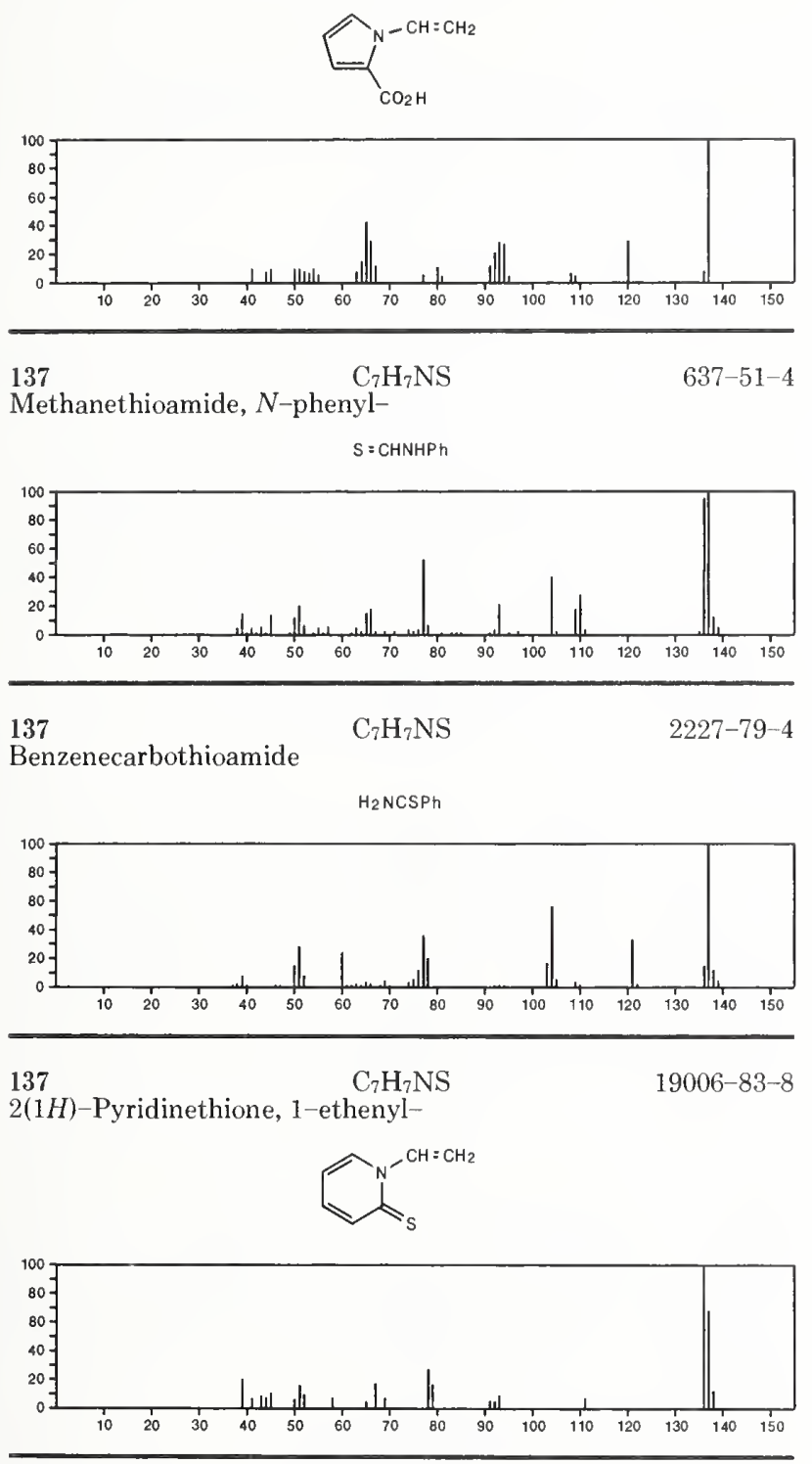

137
Phenol, 4-(2-aminoethyl)-
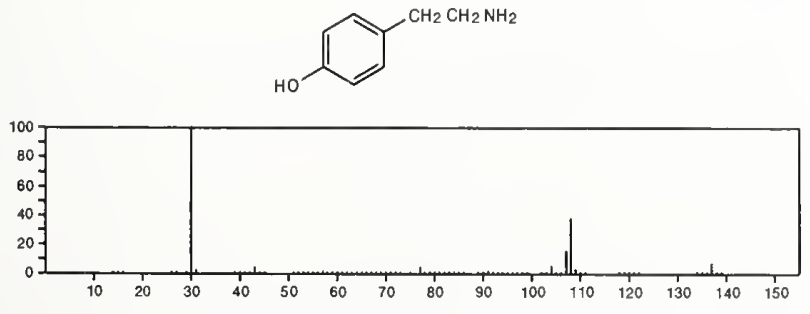

$137 \underset{\mathrm{C}_{8} \mathrm{H}_{11} \mathrm{NO}}{\text { Phenol, 3-(dimethylamino)- }}$ 99-07-0
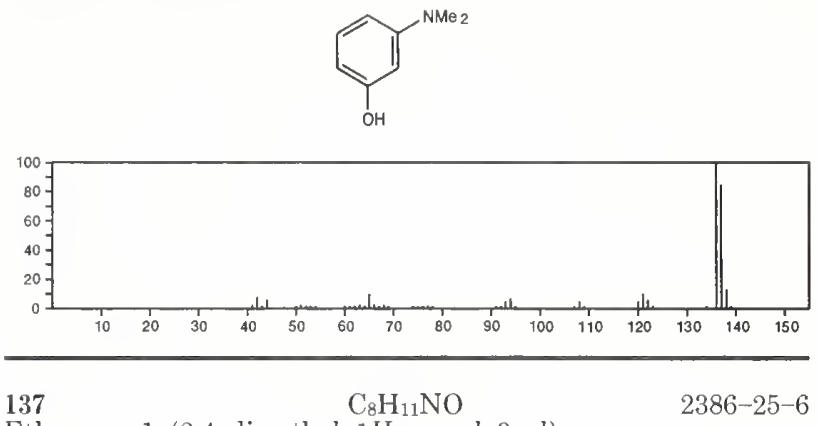

Ethanone, 1-(2,4-dimethyl-1H-pyrrol-3-yl)-
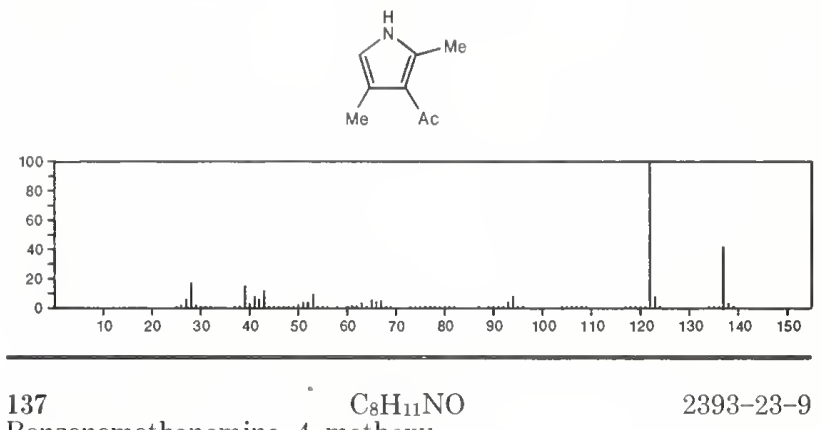

Benzenemethanamine, 4-methoxy-
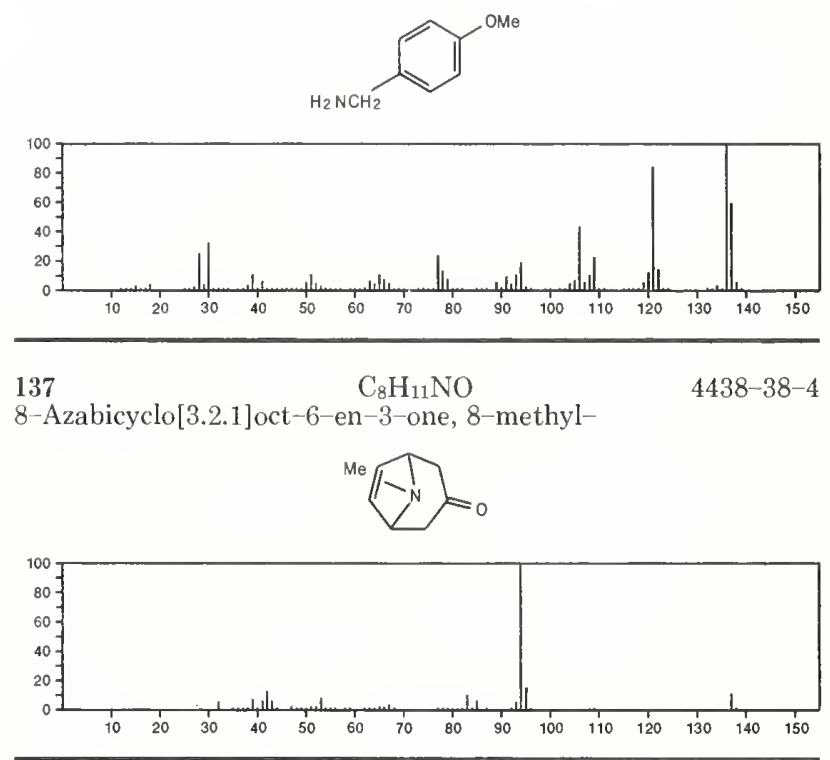

$\mathrm{C}_{8} \mathrm{H}_{11} \mathrm{NO}$
Benzenamine,
4-methoxy- $N$-methyl-

$5961-59-1$
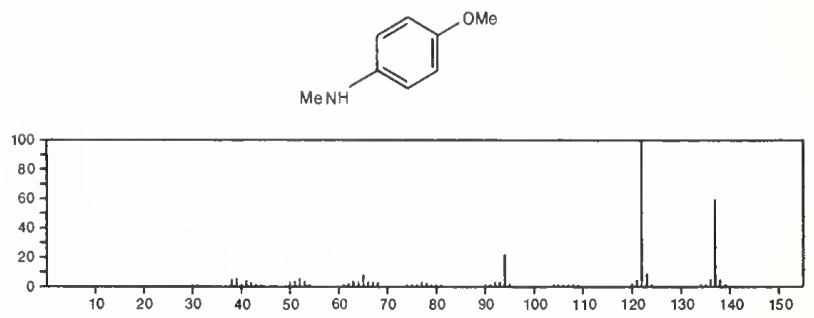
137

Benzenemethanol,

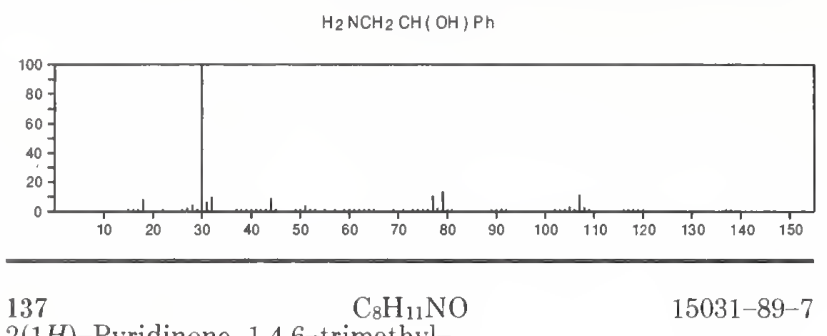

2(1H)-Pyridinone, 1,4,6-trimethyl-
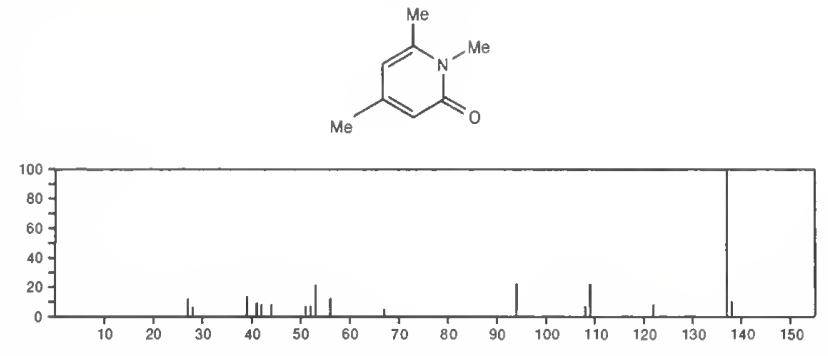

$137 \quad \mathrm{C}_{8} \mathrm{H}_{11} \mathrm{NO}$

2(1H)-Pyridone, 1-ethyl-4-methyl-
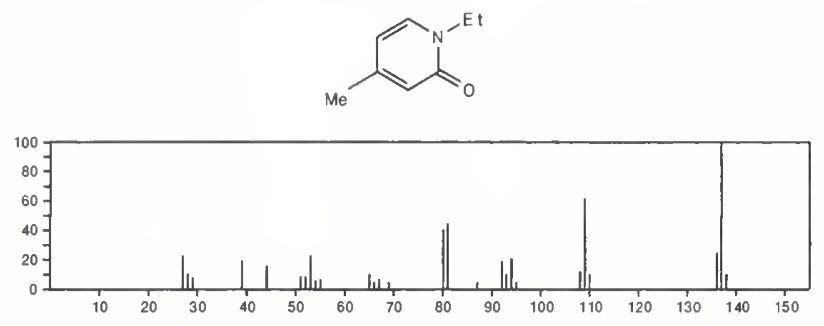

137

2(1H)-Pyridinone, 1-propyl-

$\mathrm{C}_{8} \mathrm{H}_{11} \mathrm{NO}$
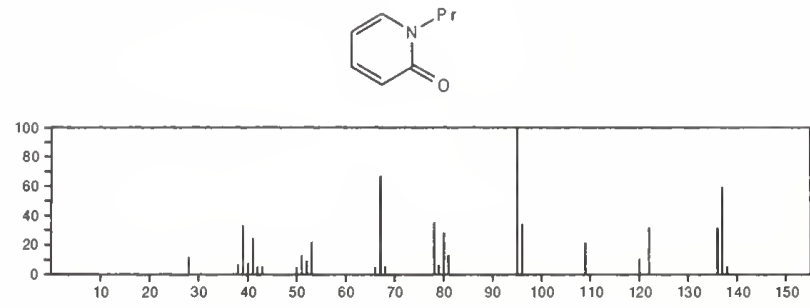

137

$\mathrm{C}_{8} \mathrm{H}_{11} \mathrm{NO}$

2(1H)-Pyridinone, 1-ethyl-6-methyl-<smiles>CCn1c(C)cccc1=O</smiles>

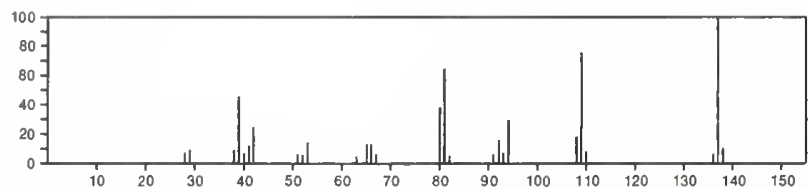

137

$\mathrm{C}_{8} \mathrm{H}_{11} \mathrm{NO}$

29055-08-1

Benzenemethanol, 2-(methylamino)
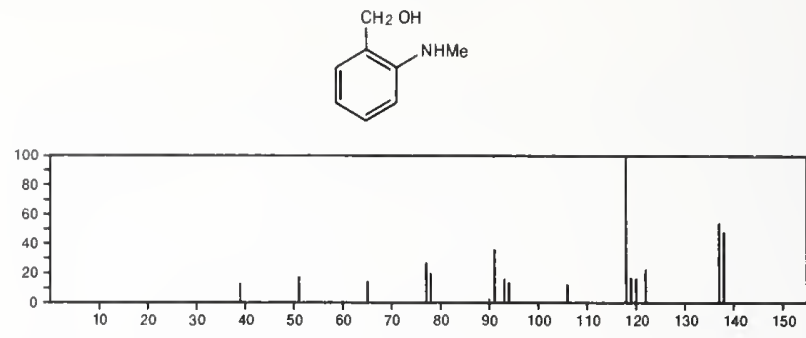

137

Cyclohexaneacetonitrile, 2-oxo-

$\mathrm{C}_{8} \mathrm{H}_{11} \mathrm{NO}$

$42185-27-3$<smiles>N#CC1CCCCC1=O</smiles>

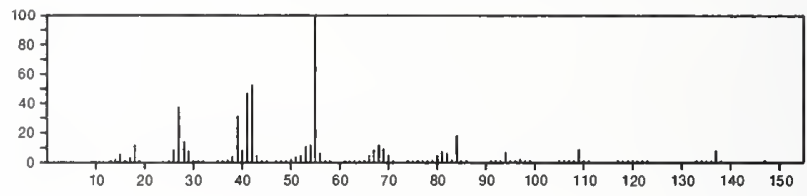

137

2-Propen-1-amine, N,N-di-2-propenyl-

$102-70-5$

$$
\mathrm{CH}_{2} \mathrm{CH}: \mathrm{CH}_{2}
$$

$\mathrm{H}_{2} \mathrm{C}=\mathrm{CHCH}_{2} \mathrm{NCH}_{2} \mathrm{CH}=\mathrm{CH}_{2}$

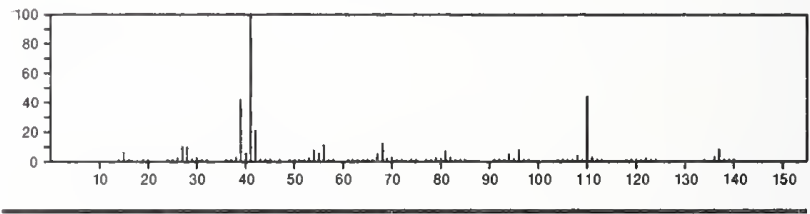

137

$\mathrm{C}_{9} \mathrm{H}_{15} \mathrm{~N}$

699-22-9

1H-Pyrrole, 1-pentyl-
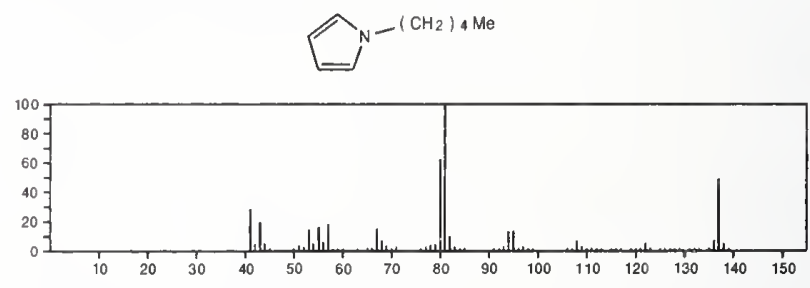

137 Octanenitrile, 2-methylene-- $\mathrm{C}_{9} \mathrm{H}_{15} \mathrm{~N}$

$5633-86-3$

$\mathrm{Me}\left(\mathrm{CH}_{2}\right) 5 \mathrm{C}(\mathrm{CN}): \mathrm{CH}_{2}$

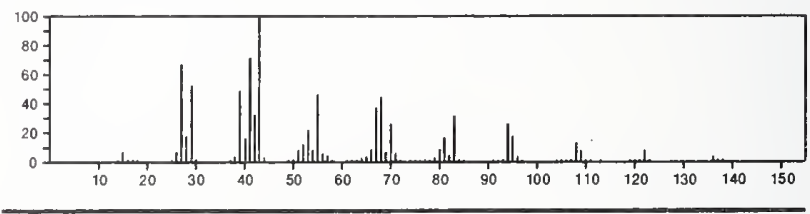

137

$\mathrm{C}_{9} \mathrm{H}_{15} \mathrm{~N}$

$7148-07-4$

Pyrrolidine, 1-(1-cyclopenten-1-yl)-
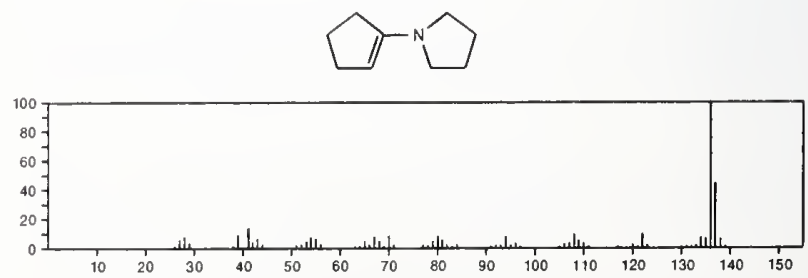
$137 \quad \mathrm{C}_{9} \mathrm{H}_{15} \mathrm{~N} \quad 16967-50-3$ 1H-4-Azacycloprop [cd]indene, octahydro-4-methyl-
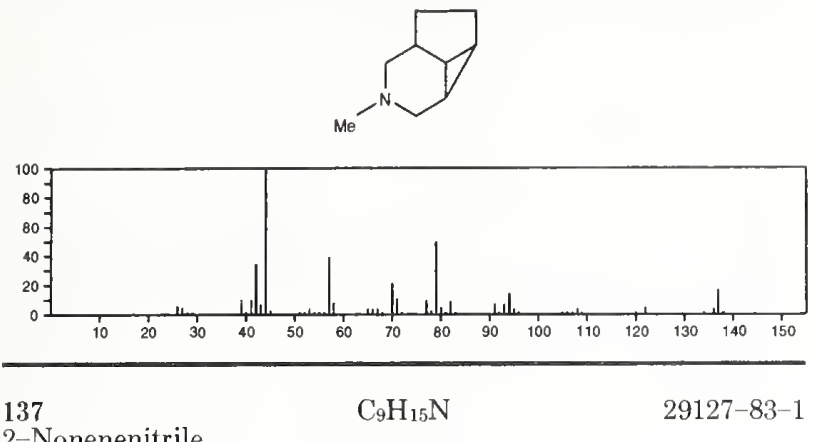

2-Nonenenitrile

$\mathrm{Me}\left(\mathrm{CH}_{2}\right) 5 \mathrm{CH}=\mathrm{CHCN}$

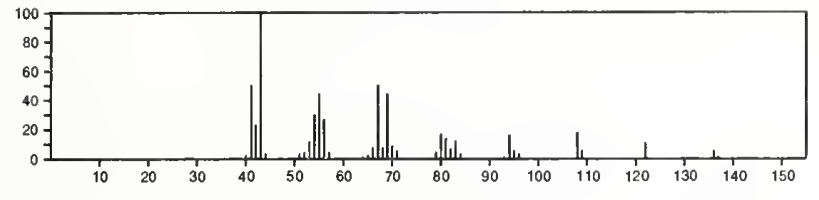

$137 \quad \mathrm{C}_{9} \mathrm{H}_{15} \mathrm{~N} \quad 41455-23-6$ Bicyclo[2.2.1]hept-2-en-2-amine, $N, N$-dimethyl-
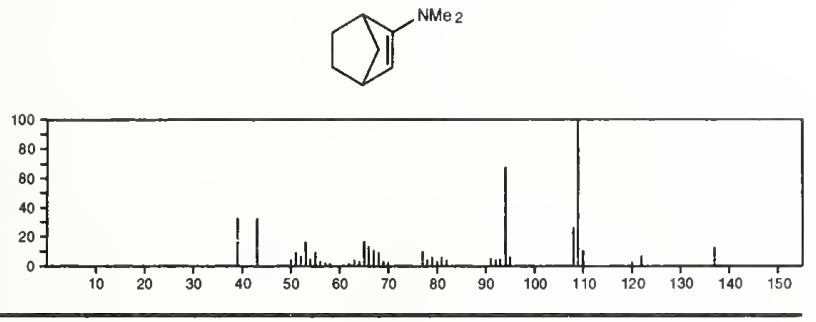

138

$\mathrm{C}_{2} \mathrm{~F}_{6}$

76-16-4

Ethane, hexafluoro-

$\mathrm{F}_{3} \mathrm{CCF}_{3}$

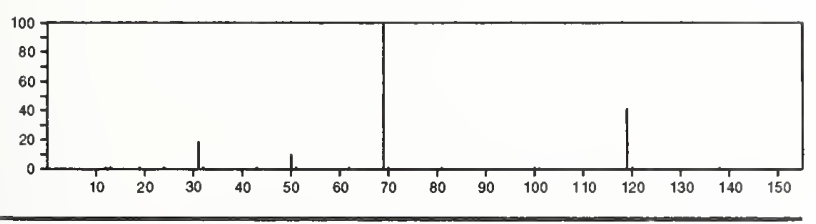

138

$\mathrm{C}_{2} \mathrm{HF}_{3} \mathrm{~N}_{4}$

$1 \mathrm{H}$-Tetrazole, 5-(trifluoromethyl)-

2925-21-5
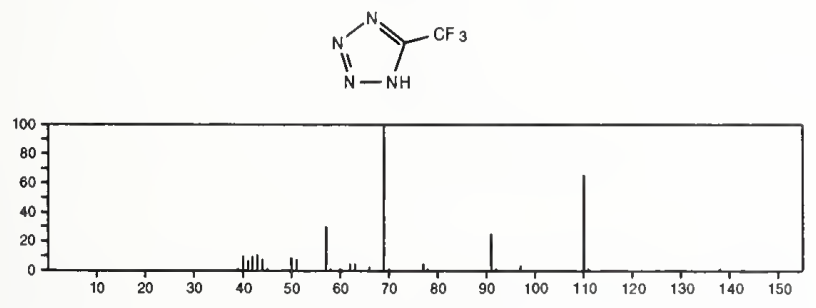

138

Acetic acid, bromo-

$\mathrm{C}_{2} \mathrm{H}_{3} \mathrm{BrO}_{2}$

79-08-3

$\mathrm{Br} \mathrm{CH}_{2} \mathrm{CO}_{2} \mathrm{H}$

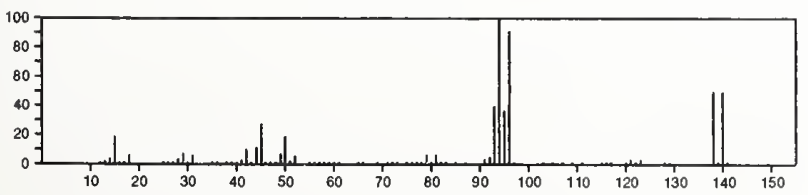

138

1,3,5-Trithiane

$\mathrm{C}_{3} \mathrm{H}_{6} \mathrm{~S}_{3}$

291-21-4

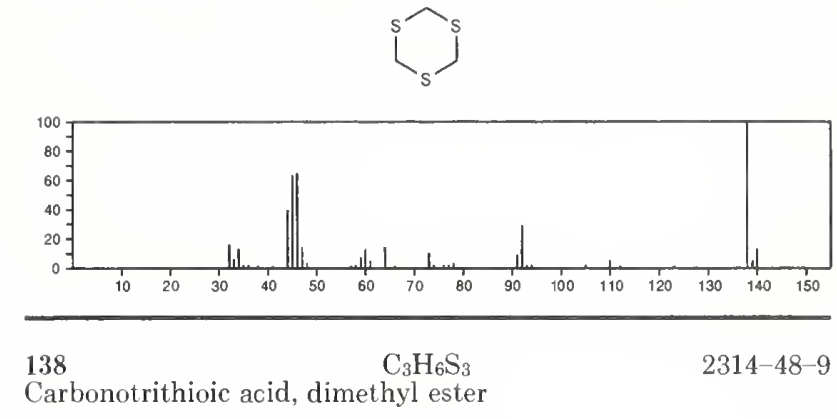

Me SCis) SMe

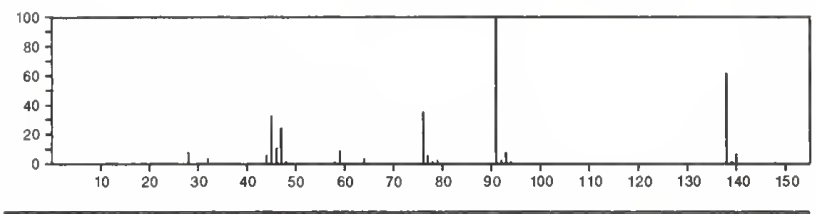

138

$\mathrm{C}_{3} \mathrm{H}_{7} \mathrm{BrO}$

$627-18-9$

1-Propanol, 3-bromo-

$\mathrm{Br}\left(\mathrm{CH}_{2}\right)_{3} \mathrm{OH}$
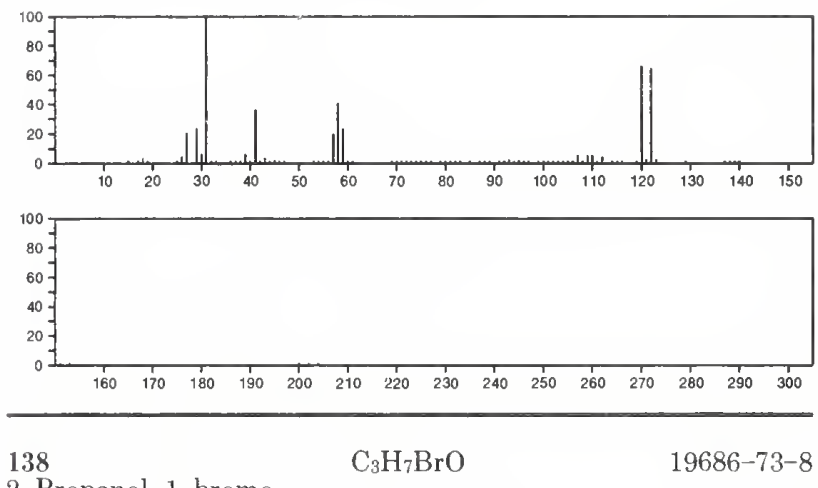

2-Propanol, 1-bromo-

$\mathrm{BrCH} 2 \mathrm{CH}(\mathrm{OH}) \mathrm{Me}$

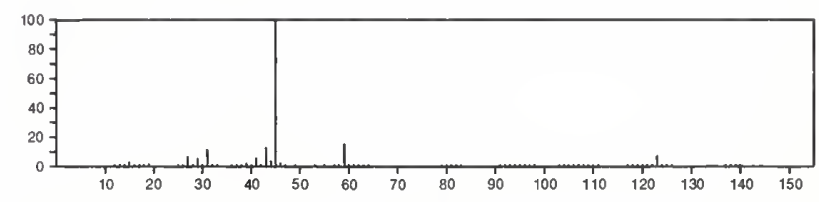

138

$\mathrm{C}_{4} \mathrm{H}_{4} \mathrm{Cl}_{2} \mathrm{O}$

$53966-57-7$

3-Buten-2-one, 3,4(or 4,4)-dichloro-

$\mathrm{MeCOCH}=\mathrm{CHCl}+\mathrm{Cl}$

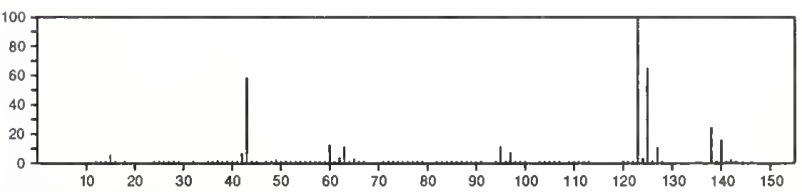


138
Sulfurous acid, diethyl ester

$\mathrm{C}_{4} \mathrm{H}_{10} \mathrm{O}_{3} \mathrm{~S}$

$E \perp O S(O) O E:$

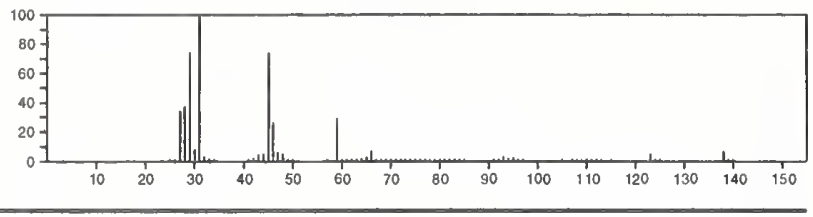

138

$\mathrm{C}_{4} \mathrm{H}_{10} \mathrm{Se}$

$627-53-2$

Ethane, 1,1'-selenobis-

SeE 12

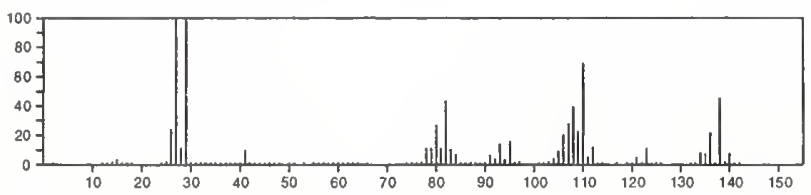

$138 \quad \mathrm{C}_{4} \mathrm{H}_{11} \mathrm{O}_{3} \mathrm{P}$

762-04-9

Phosphonic acid, diethyl ester

ETOPHOE I

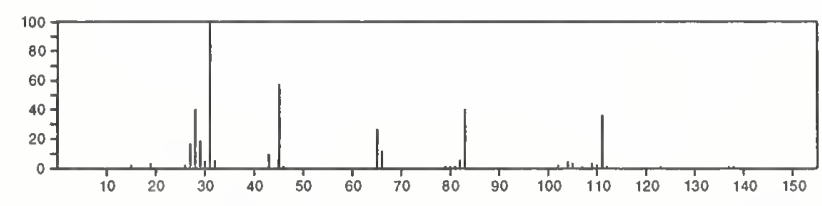

138

$\mathrm{C}_{4} \mathrm{H}_{12} \mathrm{FN}_{2} \mathrm{P}$

Phosphorodiamidous fluoride, tetramethyl-

$1735-82-6$

Me 2 NPF NMe 2

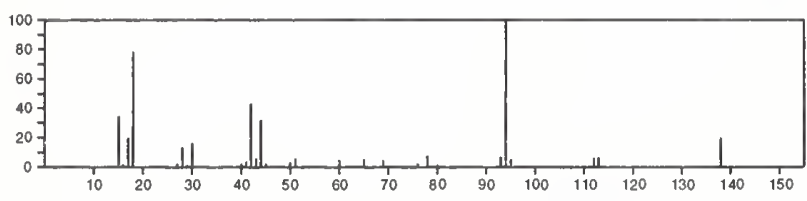

$138 \quad \mathrm{C}_{5} \mathrm{H}_{8} \mathrm{Cl}_{2}$

Cyclopropane, 1,1-dichloro-2,2-dimethyl-
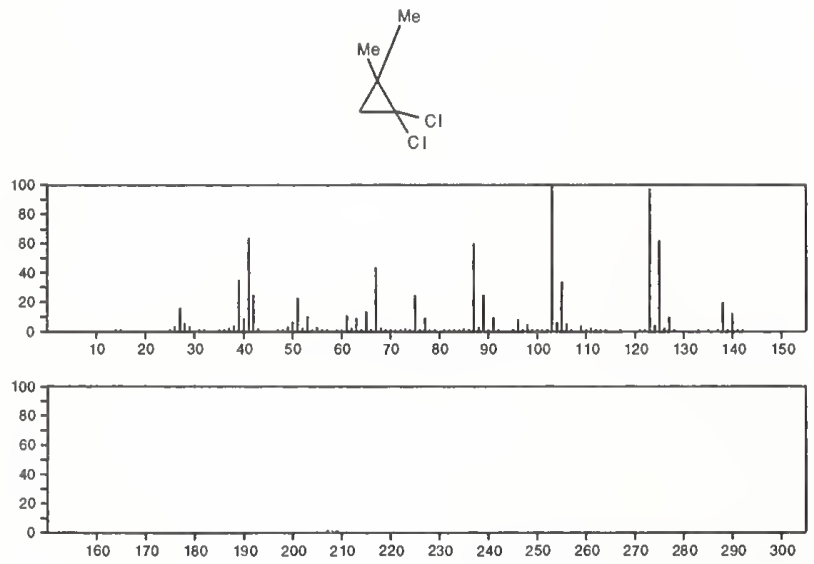

138

Cyclopentane, 1,1-dichloro-- $\mathrm{C}_{5} \mathrm{H}_{8} \mathrm{Cl}_{2}$

$31038-06-9$

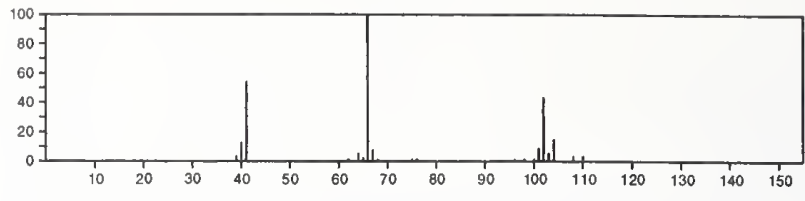

138

2-Propanol, 1-chloro-3-ethoxy-

$4151-98-8$

$\mathrm{EtOCH} 2 \mathrm{CH}(\mathrm{OH}\} \mathrm{CH}_{2} \mathrm{Cl}$

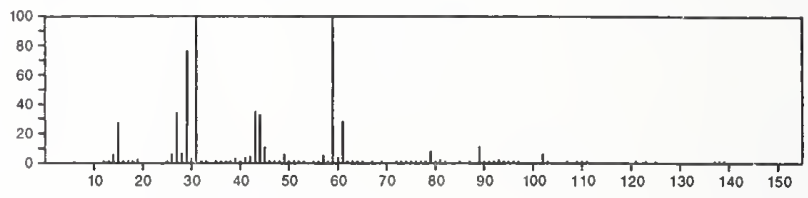

138

$\mathrm{C}_{6} \mathrm{H}_{6} \mathrm{~N}_{2} \mathrm{O}_{2}$

88-74-4

Benzenamine, 2-nitro-
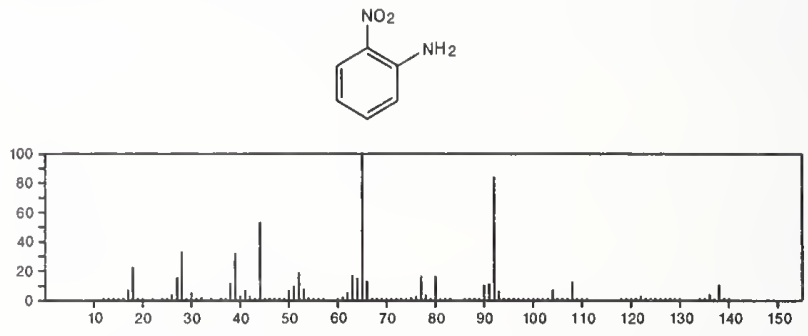

138

$\mathrm{C}_{6} \mathrm{H}_{6} \mathrm{~N}_{2} \mathrm{O}_{2}$

99-09-2

Benzenamine, 3-nitro-
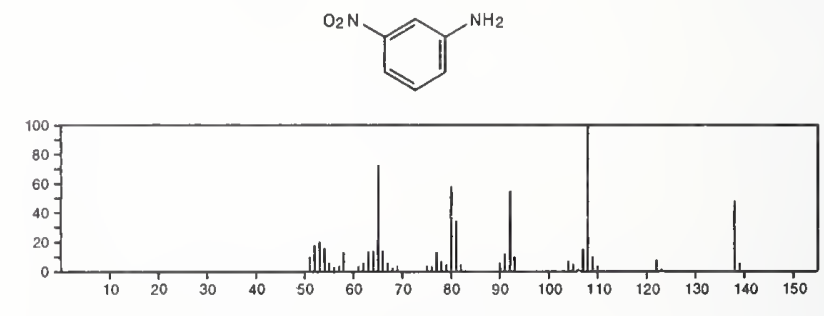

138

$\mathrm{C}_{6} \mathrm{H}_{6} \mathrm{~N}_{2} \mathrm{O}_{2}$

100-01-6

Benzenamine, 4-nitro-
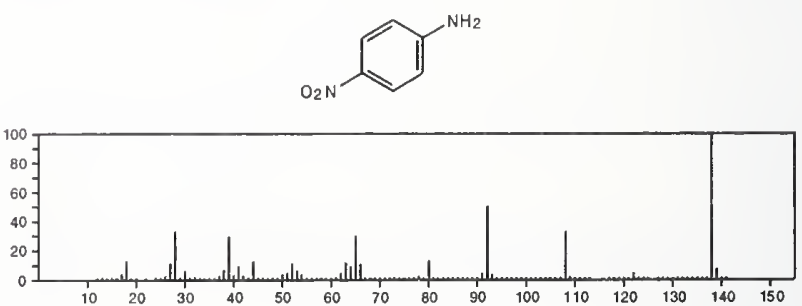
138

$\mathrm{C}_{6} \mathrm{H}_{6} \mathrm{~N}_{2} \mathrm{O}_{2}$

2-Propenoic acid, 3-(1H-imidazol-4-yl)-

104-98-3

N $\mathrm{N}=\mathrm{CHCO}_{2} \mathrm{H}$

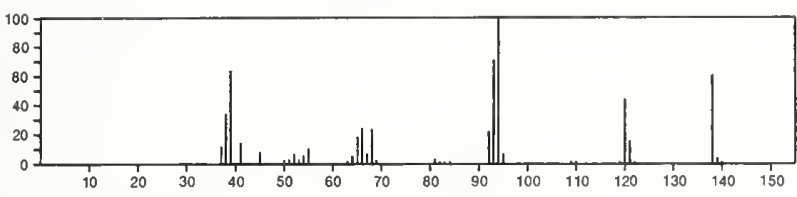

138

3-Pyridinecarboxamide, 1-oxide

$\mathrm{C}_{6} \mathrm{H}_{6} \mathrm{~N}_{2} \mathrm{O}_{2}$
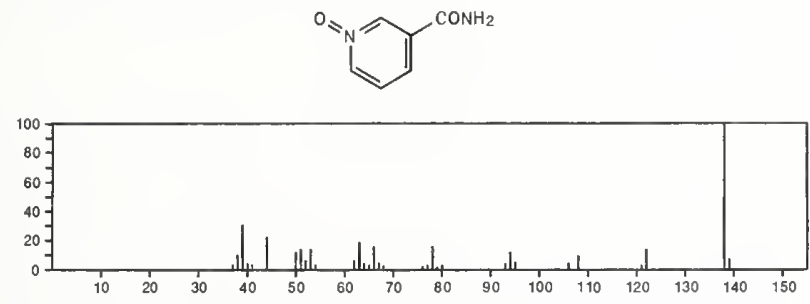

138

$\mathrm{C}_{6} \mathrm{H}_{6} \mathrm{~N}_{2} \mathrm{O}_{2}$

$3670-59-5$

3-Pyridinecarboxamide, 1,6-dihydro-6-oxo-<smiles>NC(=O)c1ccc(=O)[nH]c1</smiles>

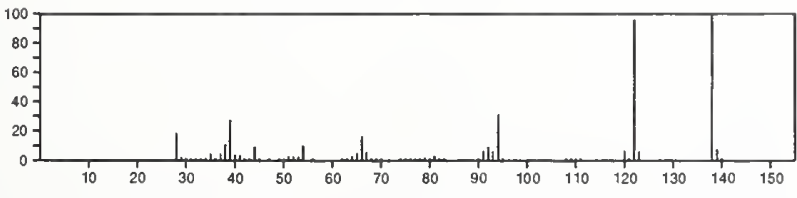

138

4-Pyridinecarboxamide, $\underset{N \text {-hydroxy- }}{\mathrm{C}_{6} \mathrm{H}_{6} \mathrm{~N}_{2} \mathrm{O}_{2}}$

$4427-22-9$
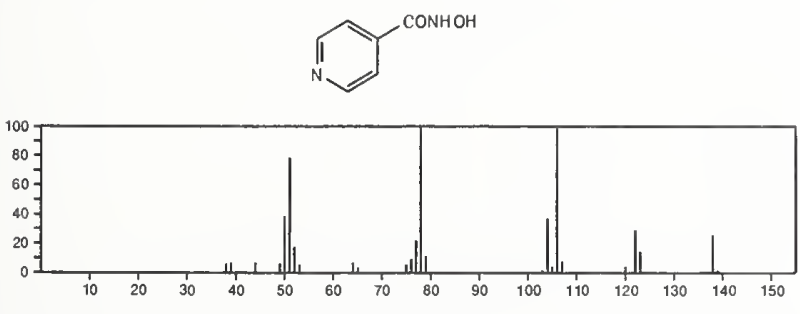

138

$\mathrm{C}_{6} \mathrm{H}_{6} \mathrm{~N}_{2} \mathrm{O}_{2}$

$5345-47-1$

3-Pyridinecarboxylic acid, 2-amino-
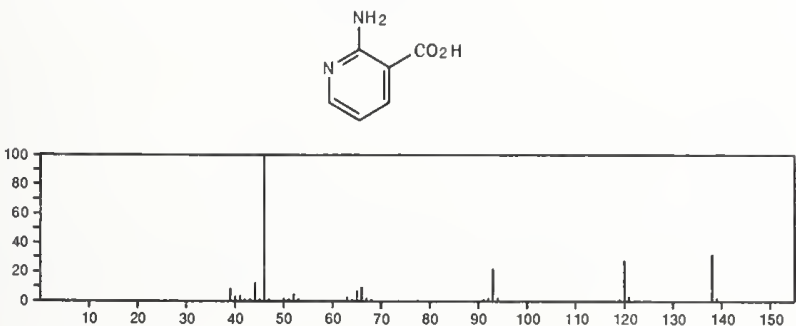

138

$\mathrm{C}_{6} \mathrm{H}_{6} \mathrm{~N}_{2} \mathrm{O}_{2}$

Propanedinitrile, (acetyloxy)methyl-

7790-01-4

$\mathrm{Ac} O \mathrm{CMe}(\mathrm{CN}) 2$

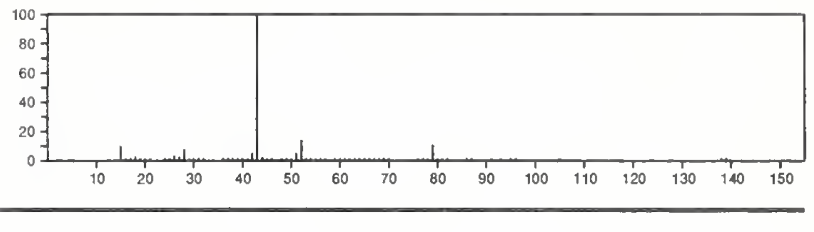

138

$\mathrm{C}_{6} \mathrm{H}_{6} \mathrm{~N}_{2} \mathrm{O}_{2}$

2-Pyridinecarboxylic acid, 6-amino-

23628-31-1
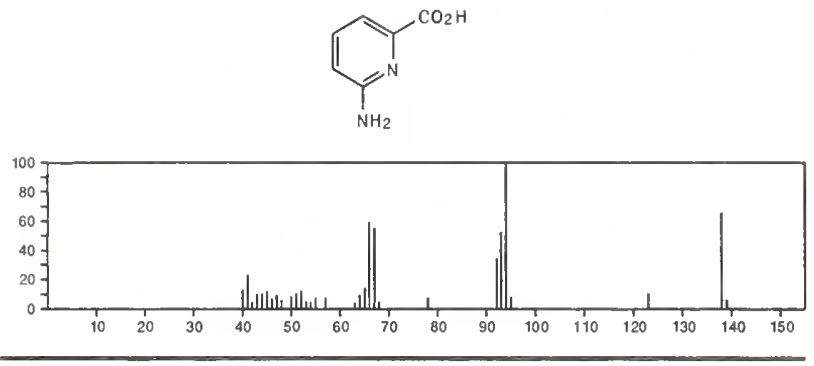

138

$\mathrm{C}_{6} \mathrm{H}_{6} \mathrm{~N}_{2} \mathrm{~S}$

2196-13-6

4-Pyridinecarbothioamide
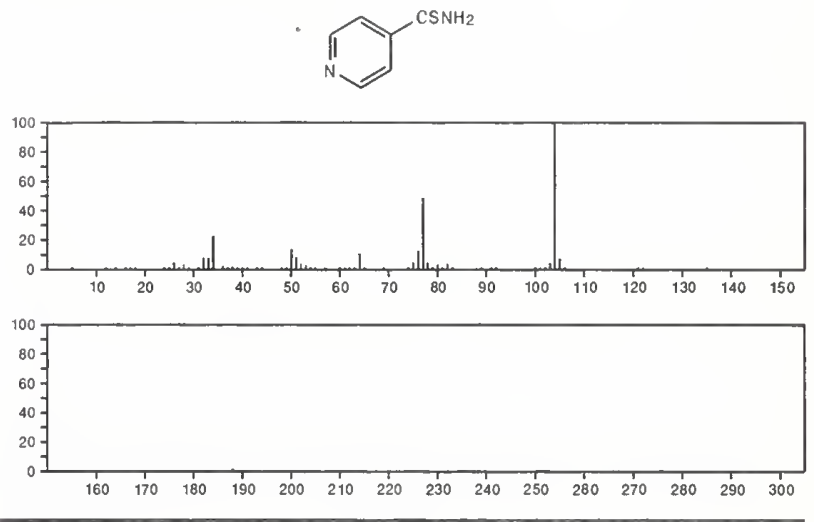

138

$\mathrm{C}_{6} \mathrm{H}_{10} \mathrm{~N}_{4}$

54-95-5

5H-Tetrazolo[1,5-a]azepine, 6,7,8,9-tetrahydro-
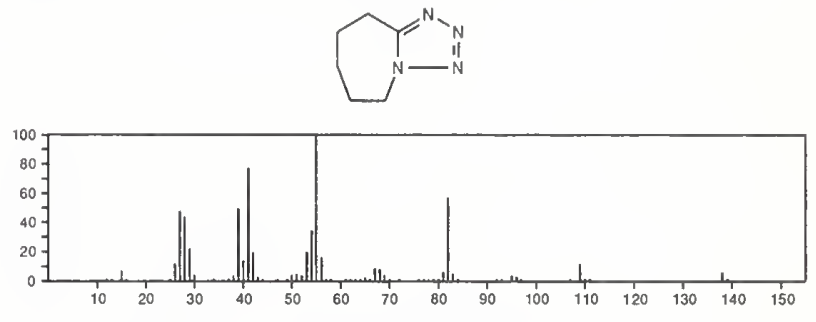

138

1,2,4,5-Tetrazine, 3,6-diethyl-

$\mathrm{C}_{6} \mathrm{H}_{10} \mathrm{~N}_{4}$

13717-91-4<smiles>CCc1nnc(CC)nn1</smiles>

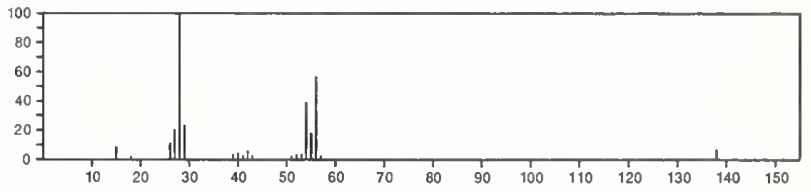


138

Benzenecarbothioic acid

$\mathrm{C}_{7} \mathrm{H}_{6} \mathrm{OS}$

Ph COSH

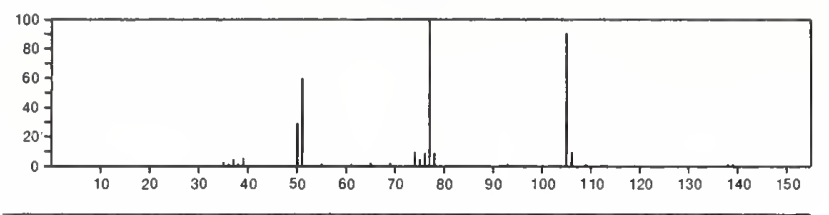

138

Benzoic acid, 2-hydroxy

$\mathrm{C}_{7} \mathrm{H}_{6} \mathrm{O}_{3}$

$69-72-7$
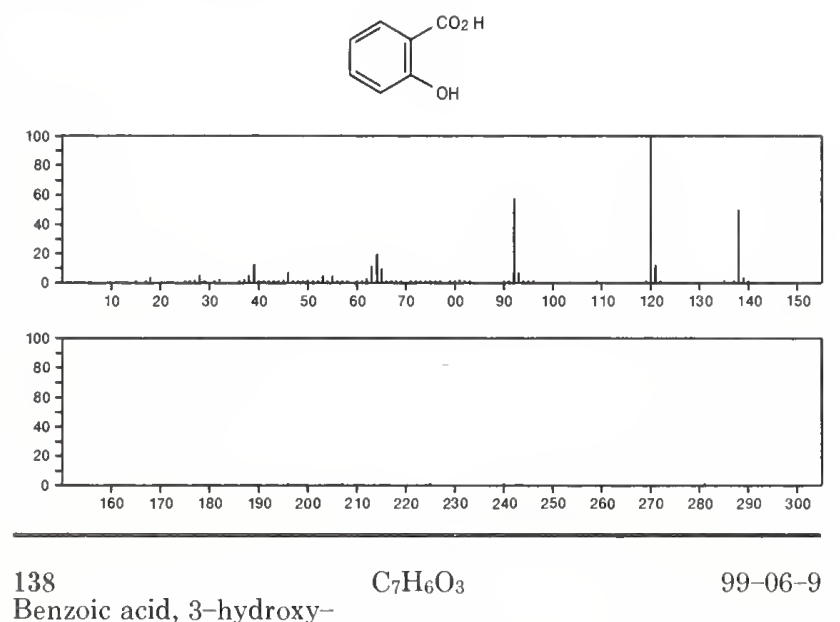

Benzoic acid, 3-hydroxy-
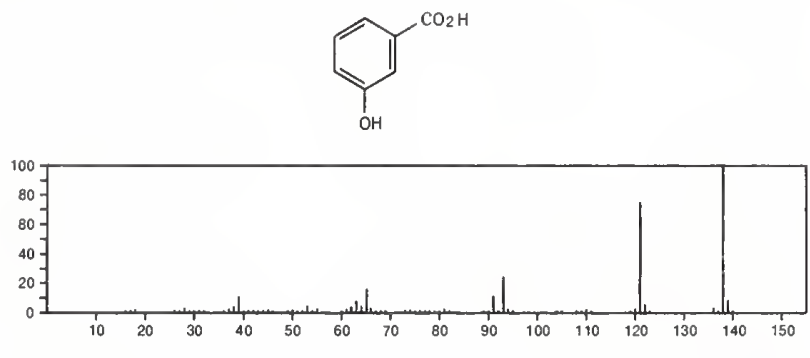

138

$\mathrm{C}_{7} \mathrm{H}_{6} \mathrm{O}_{3}$

99-96-7

Benzoic acid, 4-hydroxy-
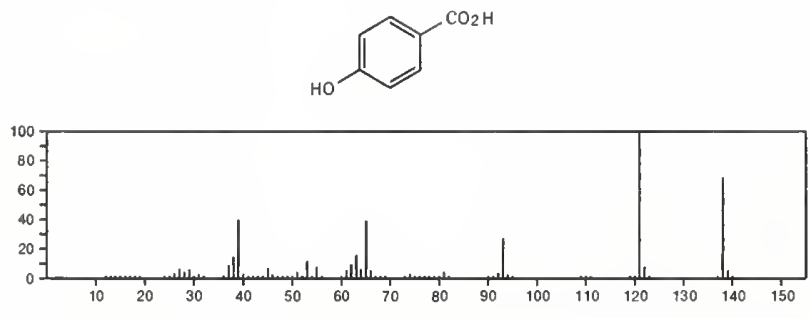

138

4(1H)-Pyrimidinone, 2-ethyl-6-methyl-
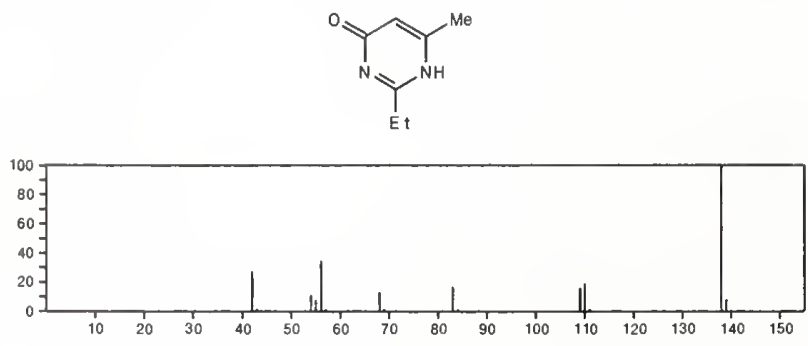

138

$\mathrm{C}_{7} \mathrm{H}_{10} \mathrm{~N}_{2} \mathrm{O}$

$4(3 H)$-Pyrimidinone, 2,3,6-trimethyl-<smiles>Cc1cc(=O)n(C)c([N+](=O)[O-])n1</smiles>

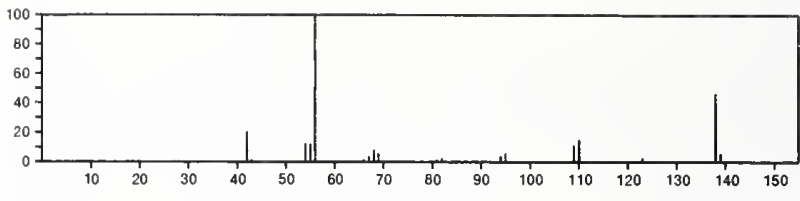

138

Pyrimidine, 5-ethoxy-2-methyl-

$35231-57-3$<smiles>CCOc1cnc(C)nc1</smiles>

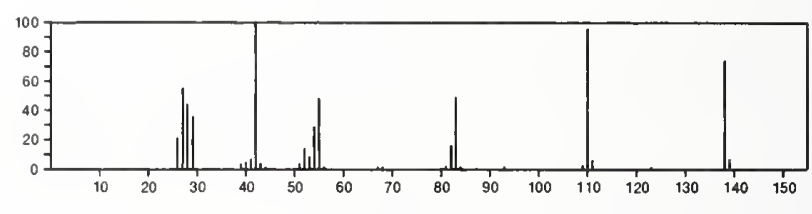

138

$\mathrm{C}_{7} \mathrm{H}_{10} \mathrm{~N}_{2} \mathrm{O}$

$35663-85-5$

2-Propenamide, 3-(3,4-dihydro-2H-pyrrol-5-yl)-, (E)-

${ }^{\mathrm{N}} \mathrm{CH}=\mathrm{CHCONH}_{2}$

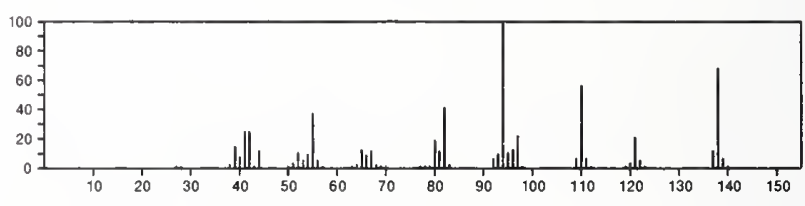

138
Benzene, (2-chloroethenyl)-

$622-25-3$

$\mathrm{ClCH}=\mathrm{CHPh}$

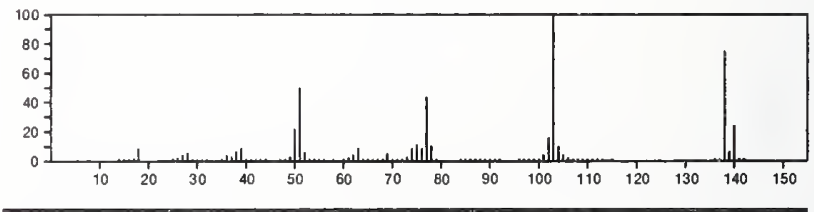

138

$\mathrm{C}_{8} \mathrm{H}_{7} \mathrm{Cl}$

$1073-67-2$

Benzene, 1-chloro-4-ethenyl-
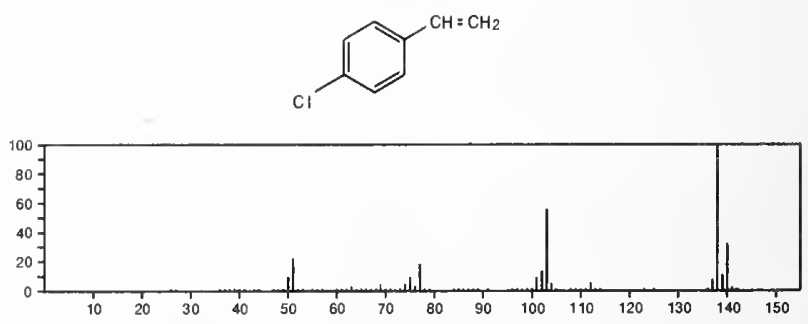
138

Ethanone, 1-(4-fluoroph

$\mathrm{C}_{8} \mathrm{H}$

$\overbrace{}^{A C}$

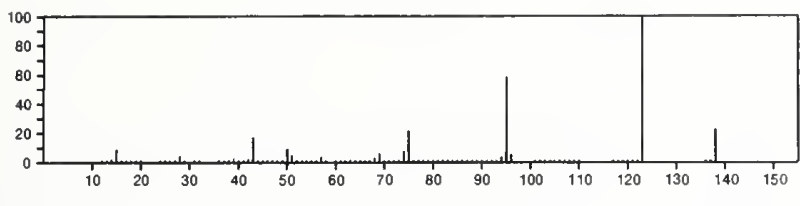

138

Benzene, 1,2-dimethoxy-

\section{$\mathrm{C}_{8} \mathrm{H}_{10} \mathrm{O}_{2}$}

91-16-7
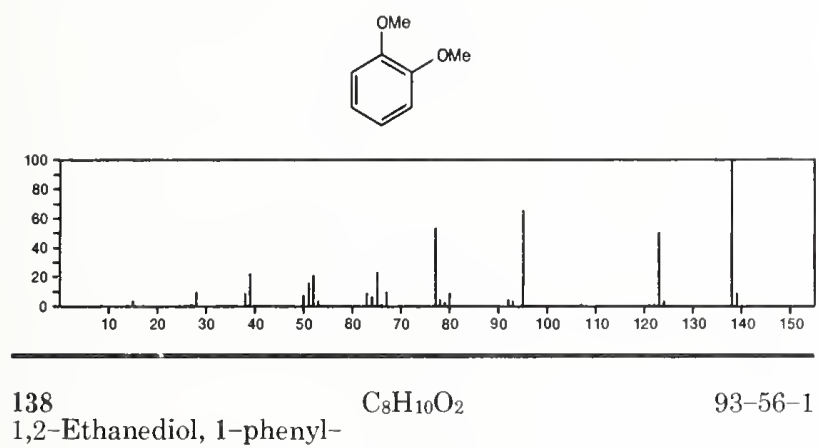

$\mathrm{HOCH}_{2} \mathrm{CH}(\mathrm{OH}) \mathrm{Ph}$

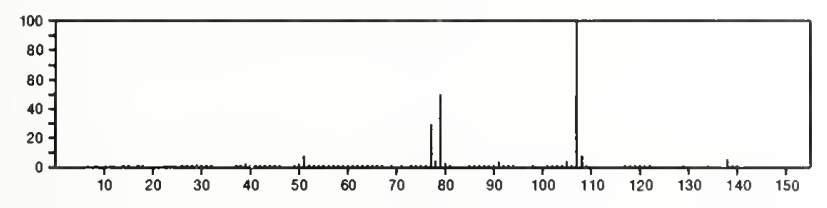

138

Benzenemethanol, 4-methoxy-

\section{$\mathrm{C}_{8} \mathrm{H}_{10} \mathrm{O}_{2}$}

$105-13-5$
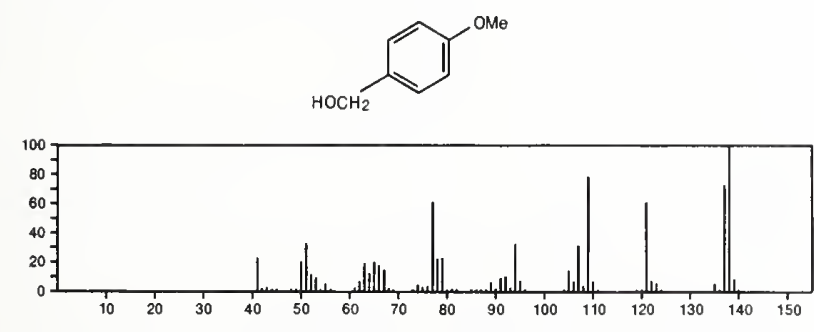

138

Ethanol, 2-phenoxy-

$\mathrm{C}_{8} \mathrm{H}_{10} \mathrm{O}_{2}$

122-99-6

$\mathrm{PhOCH}_{2} \mathrm{CH}_{2} \mathrm{OH}$

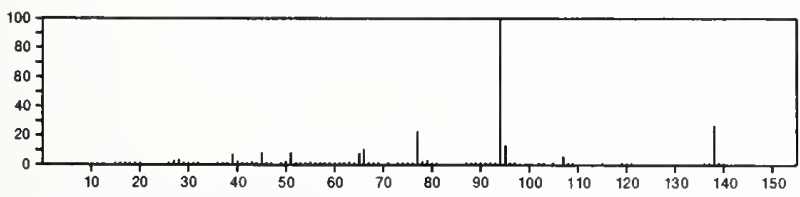

138

Benzene, 1,4-dimethoxy-

$\mathrm{C}_{8} \mathrm{H}_{10} \mathrm{O}_{2}$

$150-78-7$
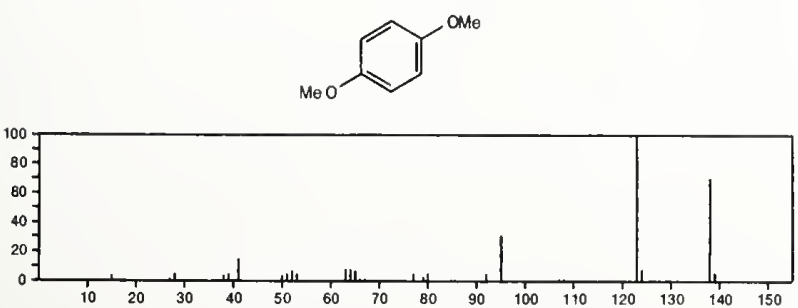

138

Benzene, 1,3-dimethoxy-

$$
\mathrm{C}_{8} \mathrm{H}_{10} \mathrm{O}_{2}
$$

$151-10-0$
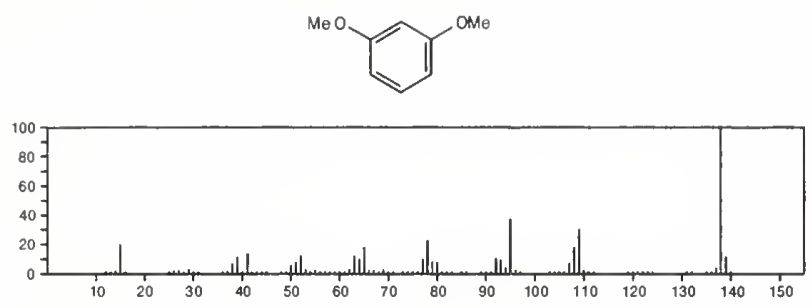

138
$1,3-$ Benzenediol, 4,5-dimethyl- $\mathrm{C}_{8} \mathrm{H}_{10} \mathrm{O}_{2}$

527-55-9
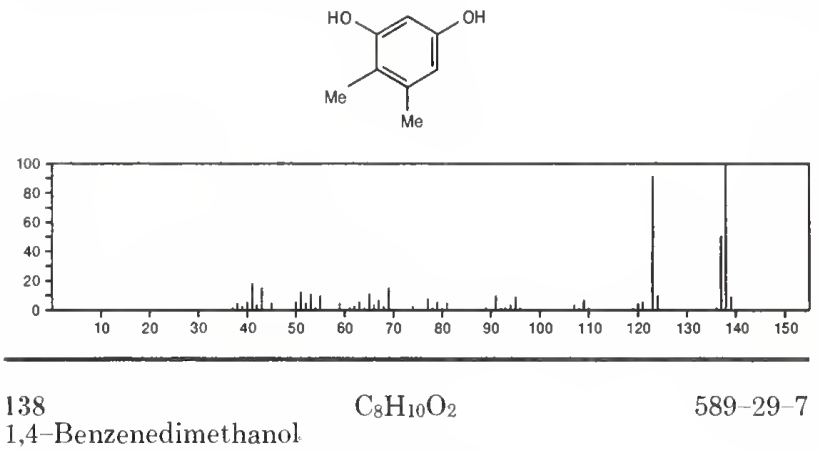

1,4-Benzenedimethanol

$\mathrm{C}_{8} \mathrm{H}_{10} \mathrm{O}_{2}$

589-29-7
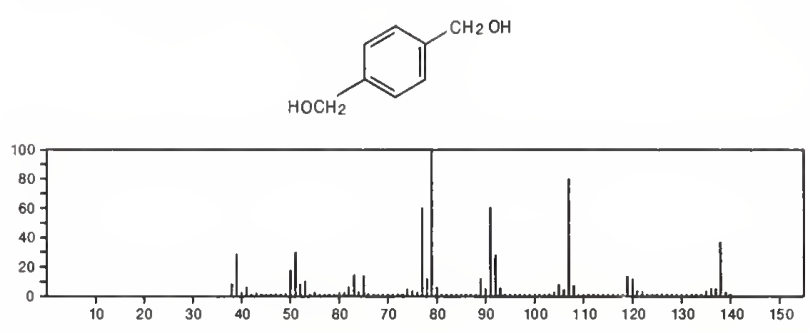

138

Phenol, 4-ethoxy-

$\mathrm{C}_{8} \mathrm{H}_{10} \mathrm{O}_{2}$

$622-62-8$
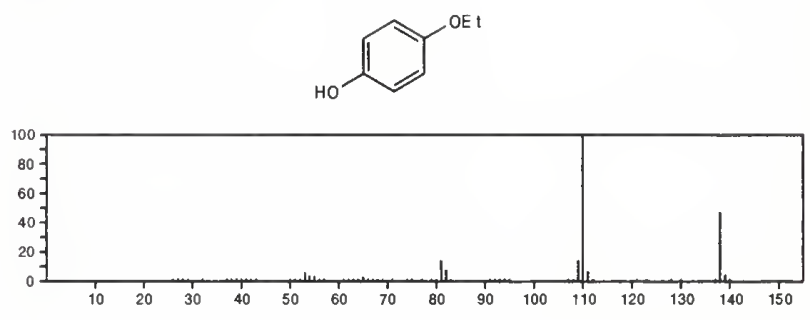

$138 \quad \mathrm{C}_{8} \mathrm{H}_{10} \mathrm{O}_{2}$

$2188-15-0$

1-Propyne, 3,3'-[ethylidenebis(oxy)] bis-

$\mathrm{HC} \equiv \mathrm{CCH}_{2} \mathrm{OCHM}_{\theta} \mathrm{OCH}_{2} \mathrm{C} \equiv \mathrm{CH}$

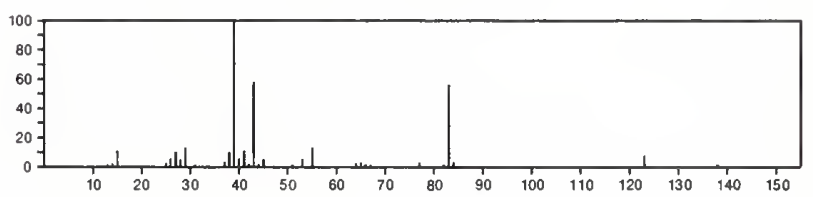


138-Benzenediol, 4-ethyl-

$\mathrm{C}_{8} \mathrm{H}_{10} \mathrm{O}_{2}$
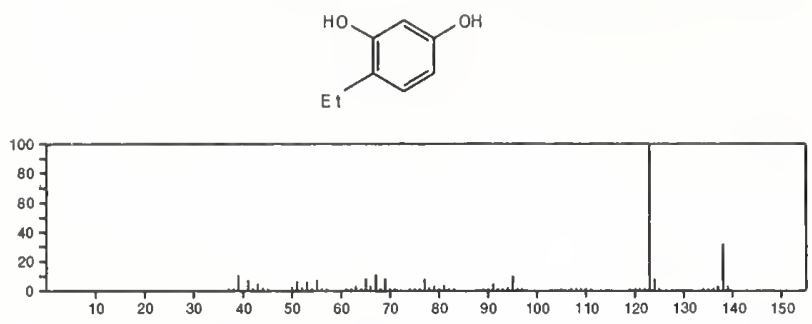

$138 \quad \mathrm{C}_{8} \mathrm{H}_{10} \mathrm{O}_{2}$

2-Butanone, 1-(2-furanyl)-

$\left.{ }^{\circ}\right)^{\mathrm{CH}_{2} \mathrm{COE} \mathrm{t}}$

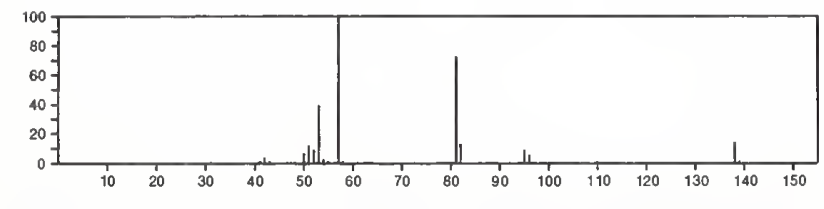

138

Benzeneethanol, 3-hydroxy-

$\mathrm{C}_{8} \mathrm{H}_{10} \mathrm{O}_{2}$

13398-94-2
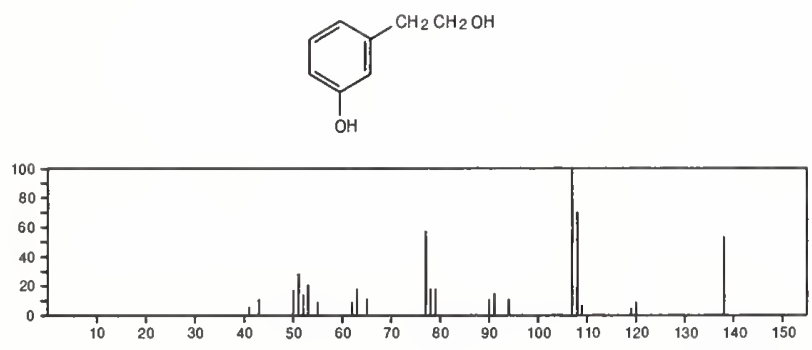

138

$\mathrm{C}_{8} \mathrm{H}_{10} \mathrm{O}_{2}$

50267-08-8

3,10-Dioxatricyclo[4.3.1.02,4] $\mathrm{dec}^{-7}$-ene, $(1 \alpha, 2 \alpha, 4 \alpha, 6 \alpha)^{-}$
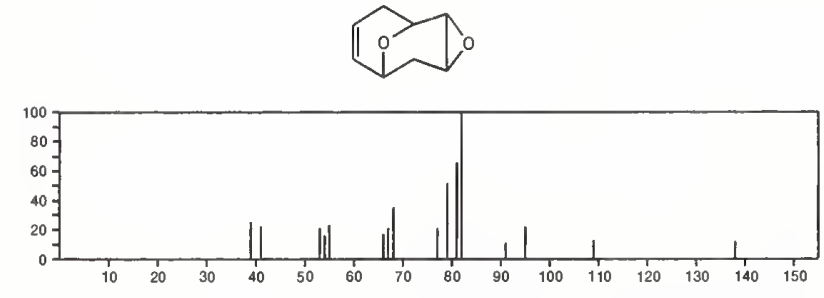

$138 \quad \mathrm{C}_{8} \mathrm{H}_{10 \mathrm{~S}}$

622-38-8

Benzene, (ethylthio)-

EtSPh

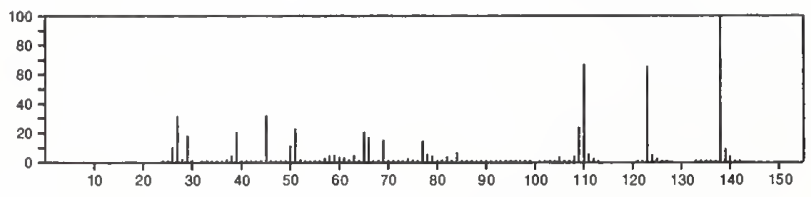

138

$\mathrm{C}_{8} \mathrm{H}_{10} \mathrm{~S}$

Benzene, 1-methyl-4-(methylthio)-
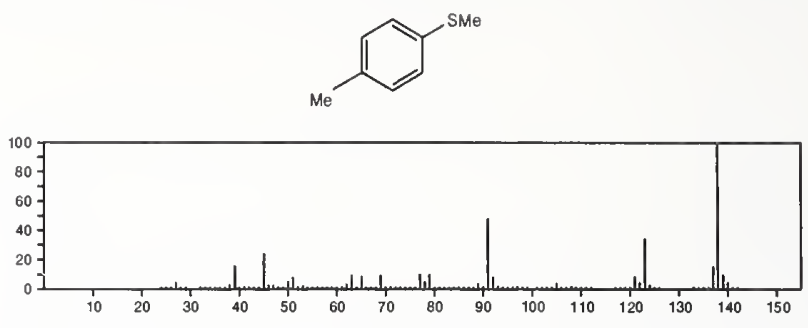

138

$\mathrm{C}_{8} \mathrm{H}_{10} \mathrm{~S}$

766-92-7

Benzene, [(methylthio) methyl]-

$\mathrm{MeSCH}_{2} \mathrm{Ph}$

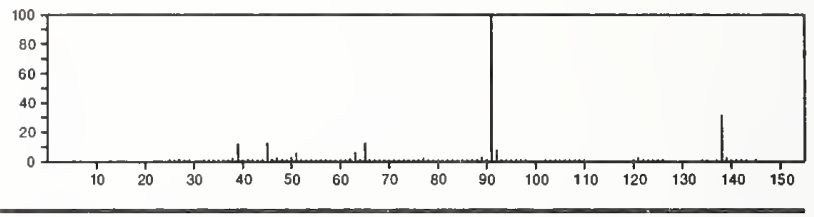

138

$\mathrm{C}_{8} \mathrm{H}_{10} \mathrm{~S}$

Benzene, 1-methyl-3-(methylthio)-

$4886-77-5$<smiles>[NH3+]c1cccc(O)c1</smiles>

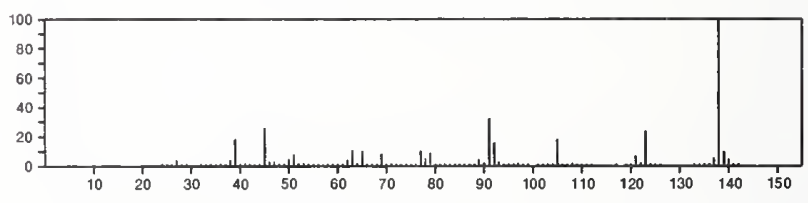

138

$\mathrm{C}_{8} \mathrm{H}_{10} \mathrm{~S}$

Benzene, 1-methyl-2-(methylthio)-

$14092-00-3$
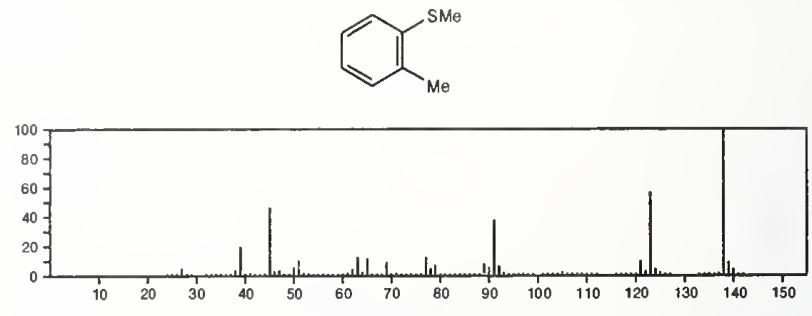

$138 \quad \mathrm{C}_{8} \mathrm{H}_{10} \mathrm{~S}$

'Thiophene, 2-(2-butenyl)-, (E)-

$52008-15-8$

¿ ${ }^{\mathrm{C}} \mathrm{CH}_{2} \mathrm{CH}=\mathrm{CHMe}$
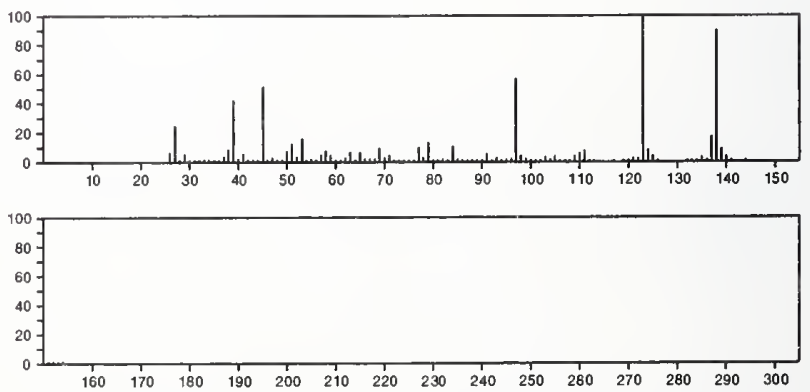
138

$\mathrm{C}_{8} \mathrm{H}_{10} \mathrm{~S}$

Thiophene, 3-(2-butenyl)-, (E)-
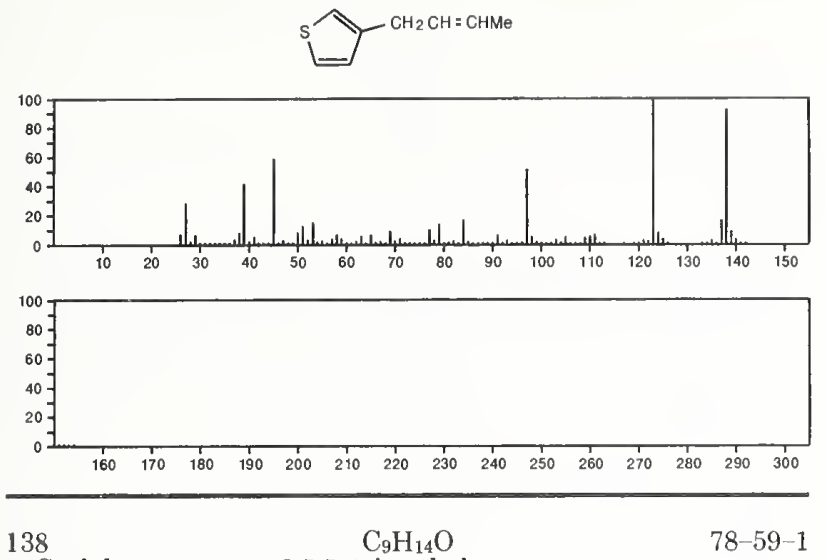

2-Cyclohexen-1-one, 3,5,5-trimethyl-
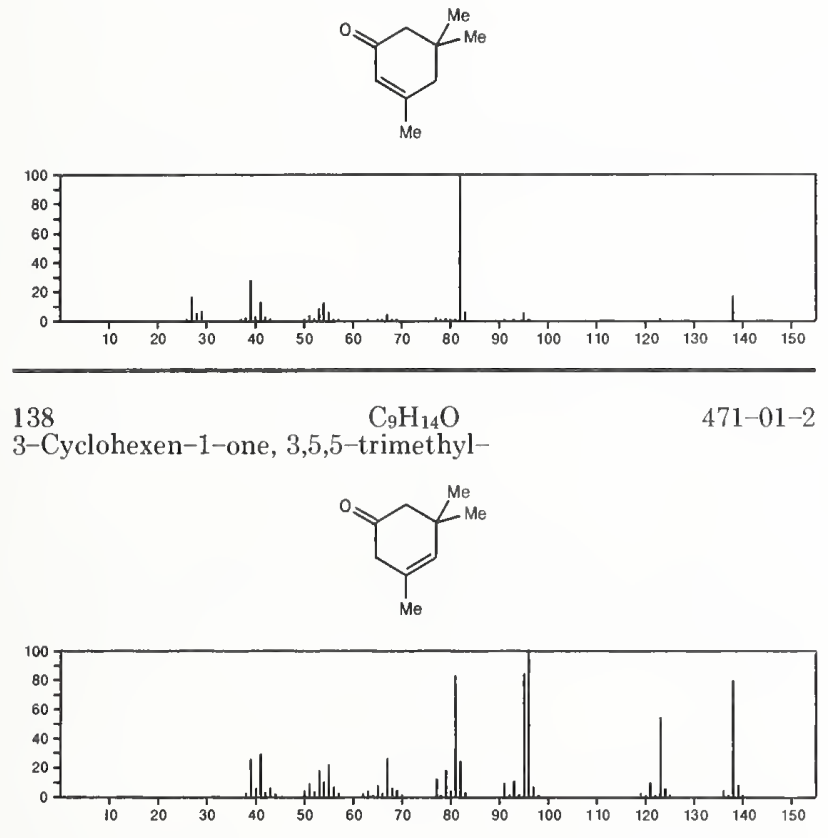

138

$\mathrm{C}_{9} \mathrm{H}_{14} \mathrm{O}$

2,5-Heptadien-4-one, 2,6-dimethyl-

$504-20-1$

$\mathrm{Me}_{2} \mathrm{C}=\mathrm{CHCOCH}=\mathrm{CMe}_{2}$
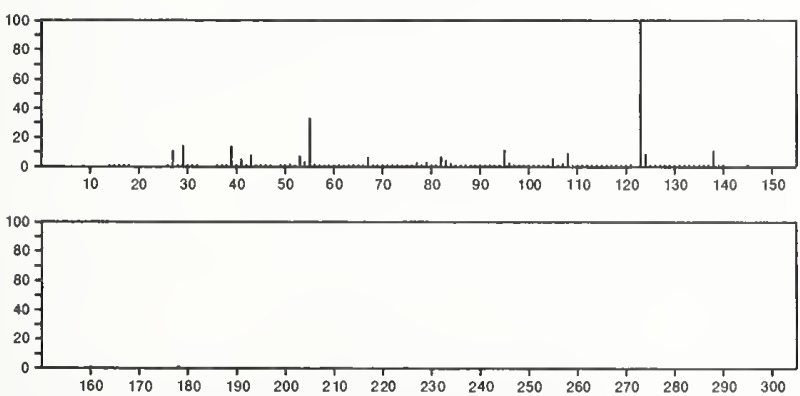

$138 \quad \mathrm{C}_{9} \mathrm{H}_{14} \mathrm{O}$

2-Propanone, 1-(1-cyclohexen-1-yl)-

$768-50-3$
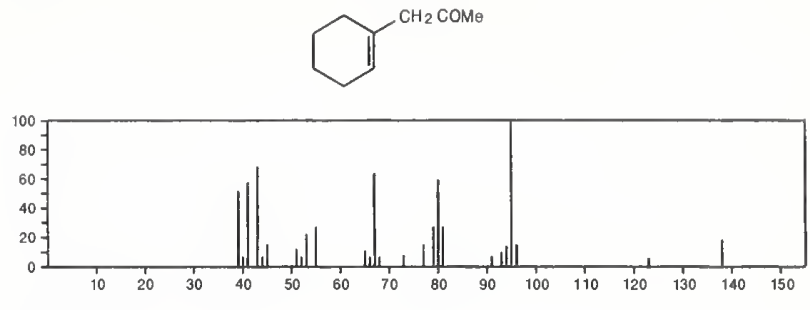

138

$\mathrm{C}_{9} \mathrm{H}_{14} \mathrm{O}$

2-Propanone, 1-cyclohexylidene-

$874-68-0$
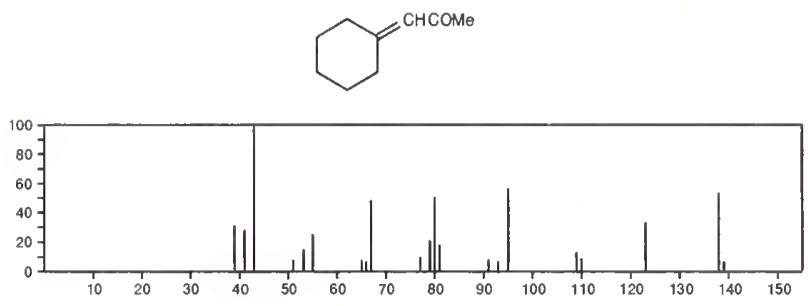

138

$\mathrm{C}_{9} \mathrm{H}_{14} \mathrm{O}$

1-Propanone, 1-(1-cyclohexen-1-yl)-

$1655-03-4$
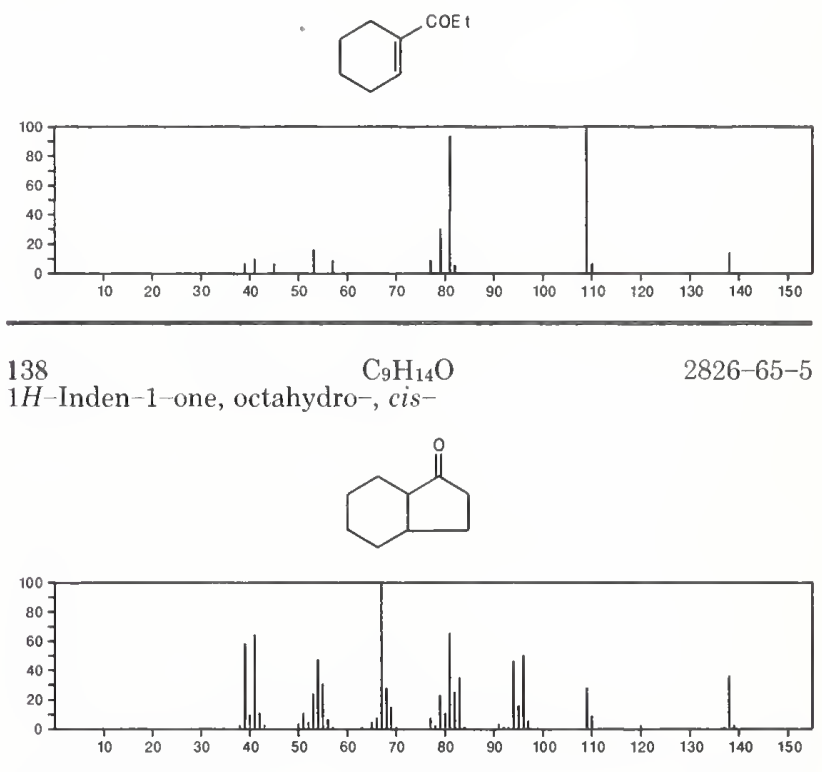

138

Furan, 2-pentyl-

$\mathrm{C}_{9} \mathrm{H}_{14} \mathrm{O}$

$3777-69-3$
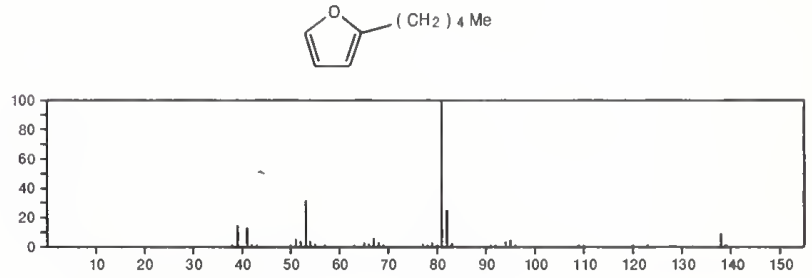
$138 \quad \mathrm{C}_{9} \mathrm{H}_{14} \mathrm{O}$

$5 H^{-}$-Inden-5-one, octahydro-, trans-

4668-81-9
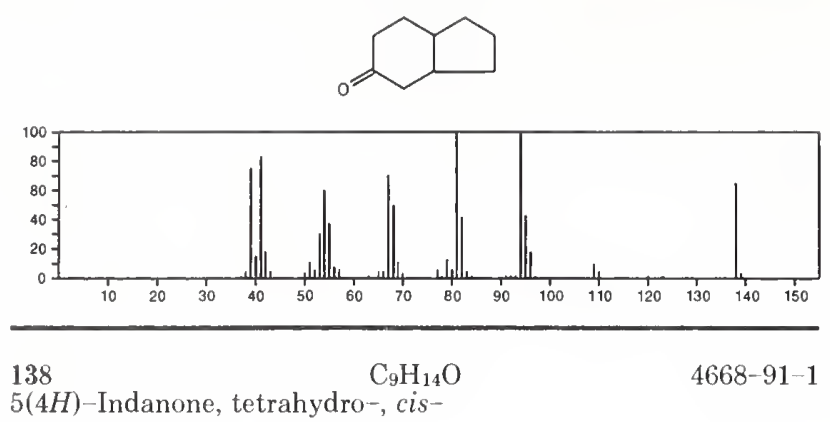

$5(4 h)$-Indanone, tetrah
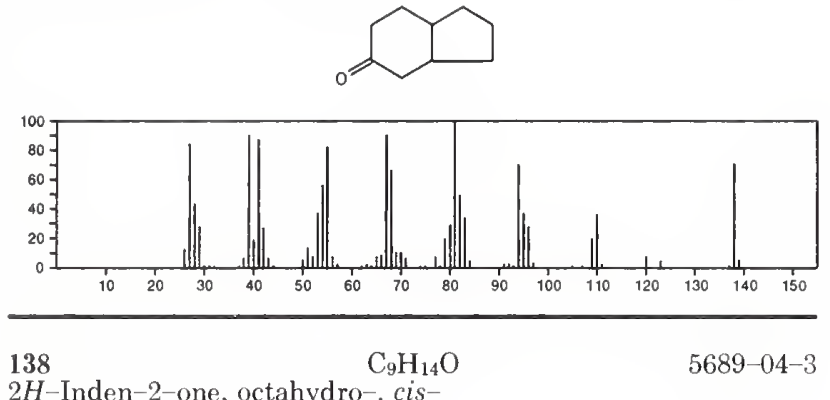

$2 \mathrm{H}^{-I n d e n-2-o n e, ~ o c t a h y d r o-, ~}$ cis- $^{-}$
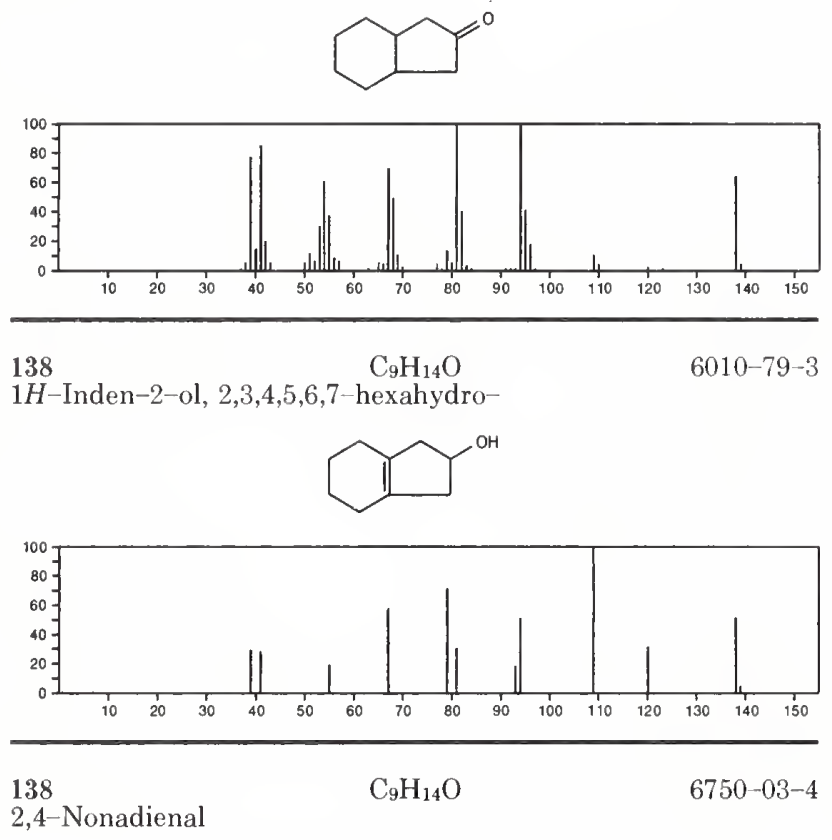

$\mathrm{Me}\left(\mathrm{CH}_{2}\right)_{3} \mathrm{CH}=\mathrm{CHCH}=\mathrm{CHCHO}$

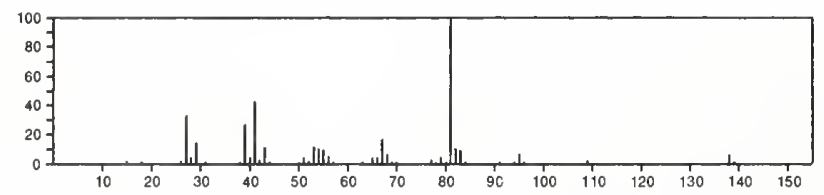

138

$\mathrm{C}_{9} \mathrm{H}_{14} \mathrm{O}$

$13211-15-9$

Bicyclo[2.2.1]heptan-2-one, 3,3-dimethyl
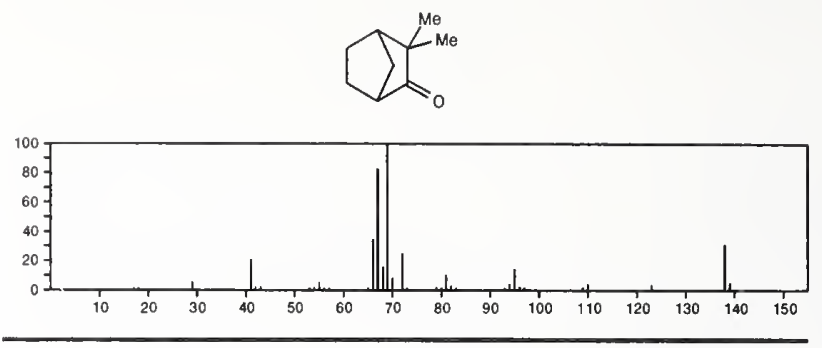

138

Cyclohexanone, 2-(1-methylethylidene)-

$13747-73-4$
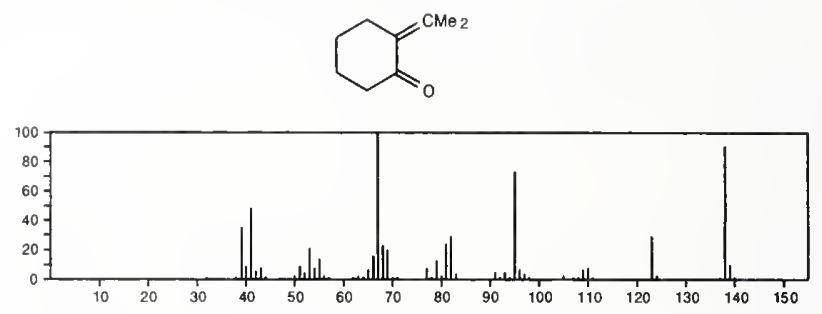

138

$\mathrm{C}_{9} \mathrm{H}_{14} \mathrm{O}$

$14252-11-0$

Bicyclo[4.2.1]nonan-9-one
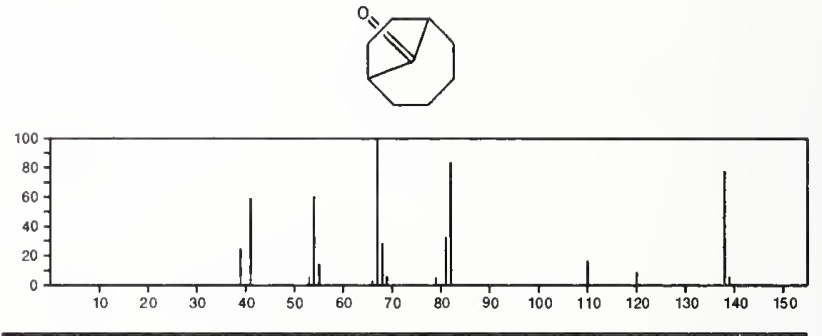

138

Spiro[4.4]nonan-1-one

$\mathrm{C}_{9} \mathrm{H}_{14} \mathrm{O}$

14727-58-3
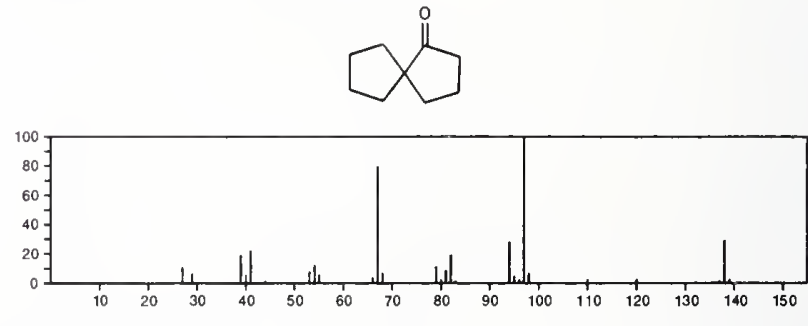

${ }_{23}^{138}$-Inden-2-one, octahydro-- trans-

16484-17-6
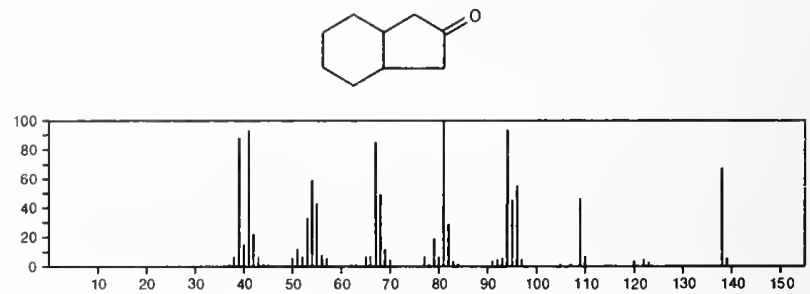
138

$\mathrm{C}_{9} \mathrm{H}_{14} \mathrm{O}$

$1 H^{-}$-Inden-1-one, octahydro-, trans-<smiles>O=C1CCC2CCCCC12</smiles>

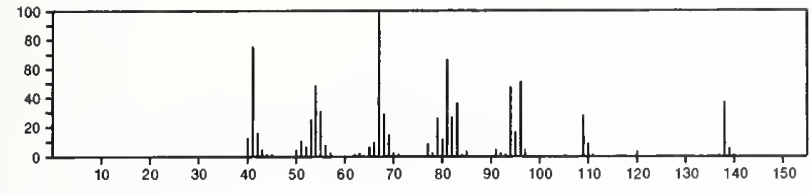

$138 \quad \mathrm{C}_{9} \mathrm{H}_{14} \mathrm{O}$

2-Cyclohexen-1-one, 3,4,4-trimethyl-<smiles>CC1=CC(=O)CCC1(C)C</smiles>

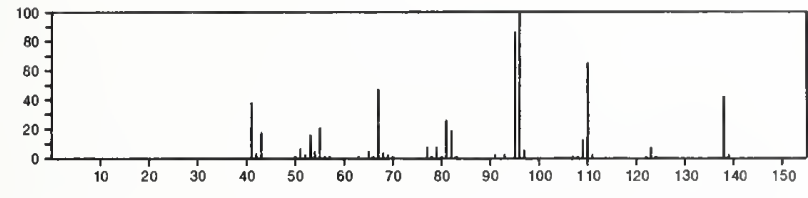

138

$\mathrm{C}_{9} \mathrm{H}_{14} \mathrm{O}$

2-Cyclohexen-1-one, 4,4,5-trimethyl
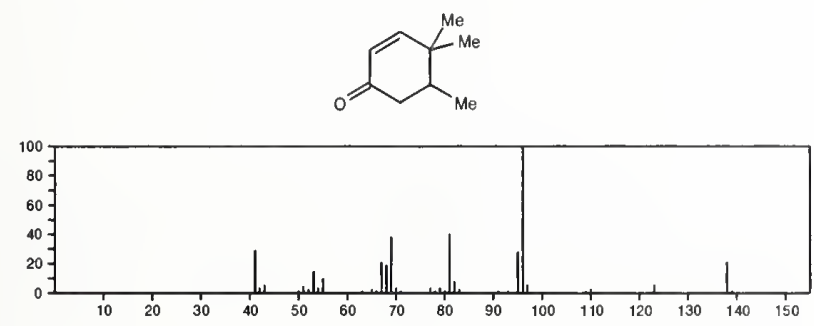

138

$\mathrm{C}_{9} \mathrm{H}_{14} \mathrm{O}$

2-Cyclohexen-1-one, 4-ethyl-4-methyl-

17429-32-2
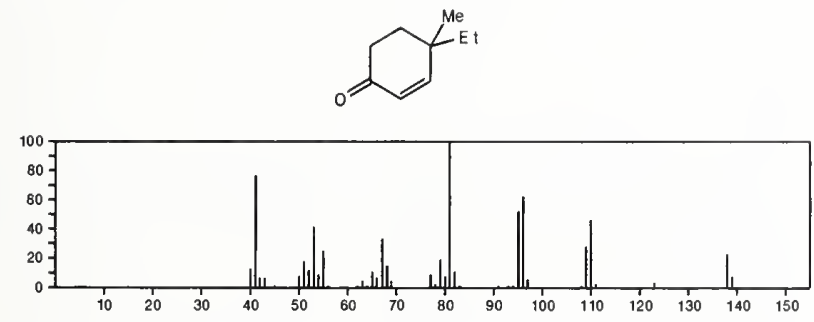

138

$\mathrm{C}_{9} \mathrm{H}_{14} \mathrm{O}$

$17587-33-6$

2,6-Nonadienal, $(E, E)-$

$\mathrm{OCHCH}=\mathrm{CHCH}_{2} \mathrm{CH}_{2} \mathrm{CH}=\mathrm{CHE}$

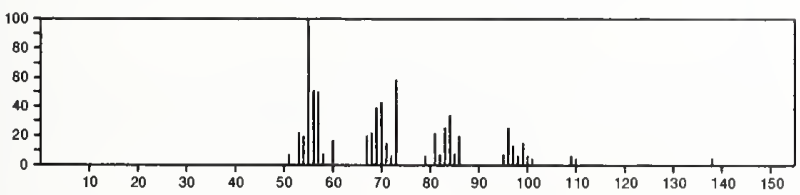

$138 \quad \mathrm{C}_{9} \mathrm{H}_{14} \mathrm{O}$

$17931-55-4$

Bicyclo[3.3.1]nonan-9 one
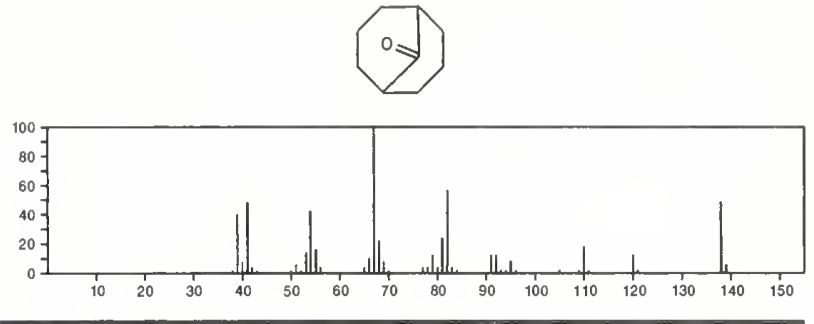

138

$\mathrm{C}_{9} \mathrm{H}_{14} \mathrm{O}$

Bicyclo[3.3.1]non-2-en-9-ol, syn-

$19877-78-2$

HO

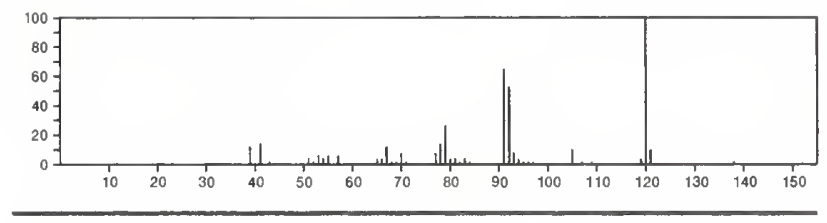

138

$\mathrm{C}_{9} \mathrm{H}_{14} \mathrm{O}$

Bicyclo[3.3.1]non-2-en-9-ol, anti--

24844-19-7

Ho

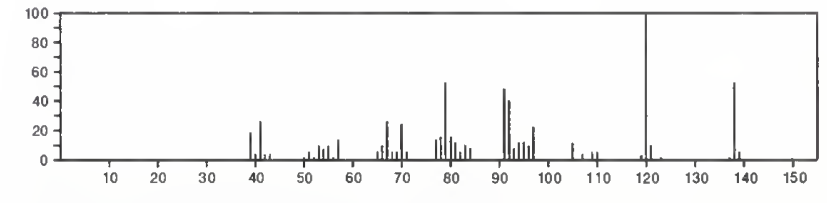

138

$\mathrm{C}_{9} \mathrm{H}_{14} \mathrm{O}$

26051-25-2

Bicyclo[2.2.2]octanone, 3-methyl
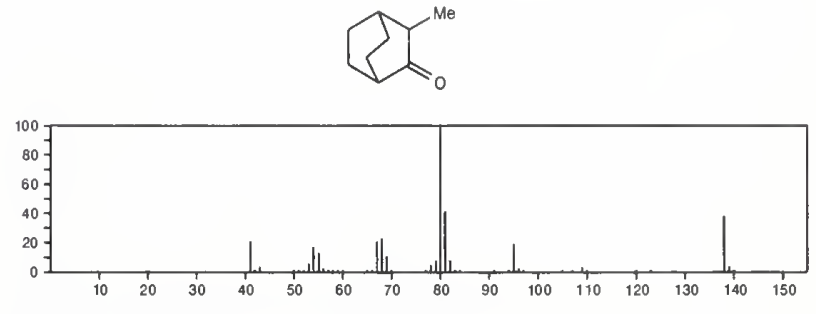

${ }_{13}^{138}$-Inden-1-one, octahydro-- ${ }^{-}{ }_{9} \mathrm{H}_{14} \mathrm{O}$

29927-85-3
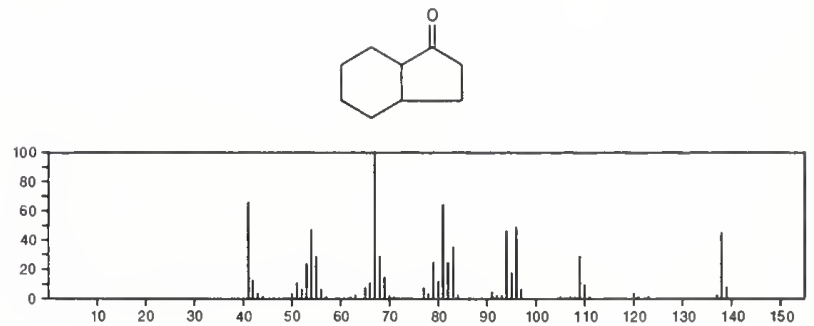
138

Spiro[4.4]nonan-2-one

$\mathrm{C}_{9} \mathrm{H}_{14} \mathrm{O}$
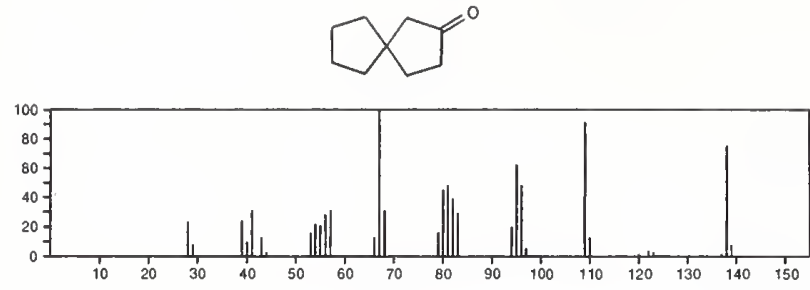

$138 \quad \mathrm{C}_{9} \mathrm{H}_{14} \mathrm{O}$

2,4-Heptadienal, 2,4-dimethyl-

OCHCME $=$ CHCME $:$ CHE
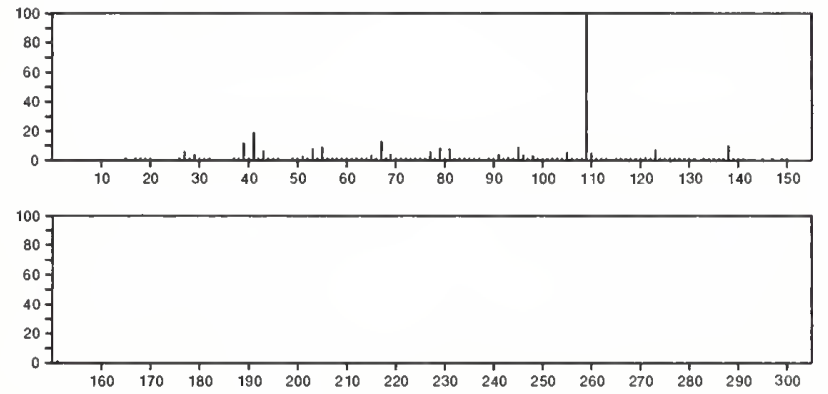

138

3,8-Nonadien-2-one, $(E)$

$\mathrm{C}_{9} \mathrm{H}_{14} \mathrm{O}$

$55282-90-1$

$\mathrm{H}_{2} \mathrm{C}=\mathrm{CH}\left(\mathrm{CH}_{2}\right)_{3} \mathrm{CH}=\mathrm{CHCOMe}$

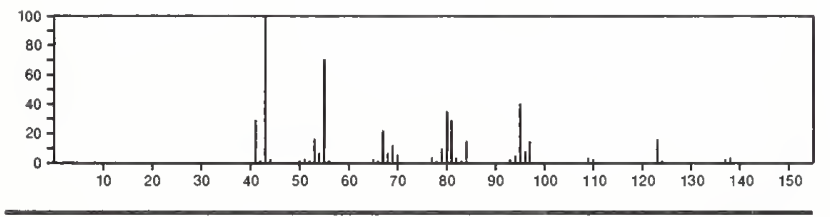

$138 \quad \mathrm{C}_{9} \mathrm{H}_{14} \mathrm{O} \quad 55402-31-8$

$2 H$-Indeno[1,2-b]oxirene, octahydro-, $(1 \mathrm{a} \alpha, 1 \mathrm{~b} \beta, 5 \mathrm{a} \alpha, 6 \mathrm{a} \alpha)-$
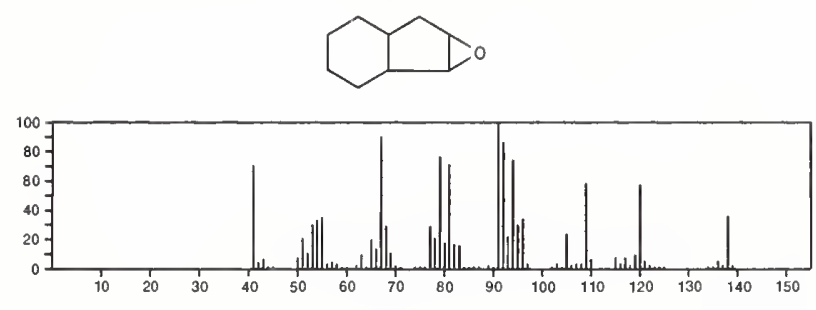

$138 \quad \mathrm{C}_{10} \mathrm{H}_{18} \quad$ 91-17-8

Naphthalene, decahydro--
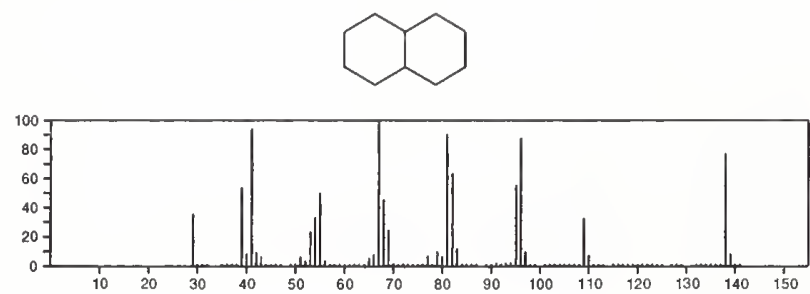

138

Spiro[4.5]decane

$\mathrm{C}_{10} \mathrm{H}_{18}$

$176-63-6$
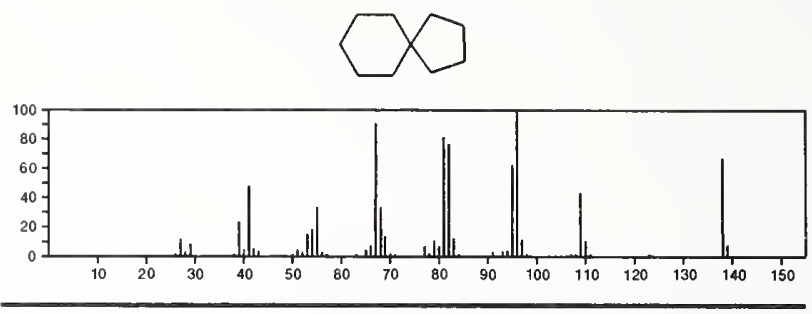

138

$\mathrm{C}_{10} \mathrm{H}_{18}$

$286-76-0$

Bicyclo[7.1.0]decane
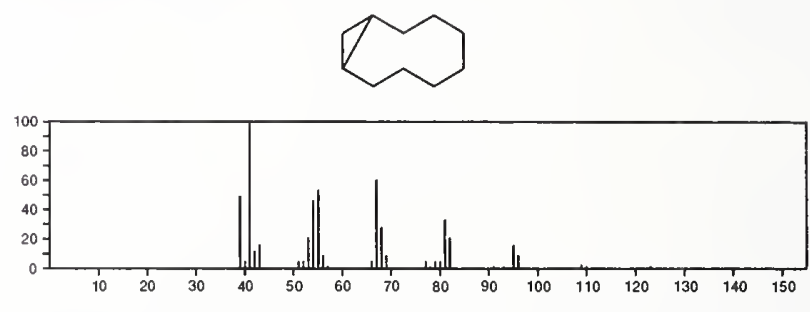

138

$\mathrm{C}_{10} \mathrm{H}_{18}$

Bicyclo[3.1.1] heptane, 2,6,6-trimethyl-

$473-55-2$
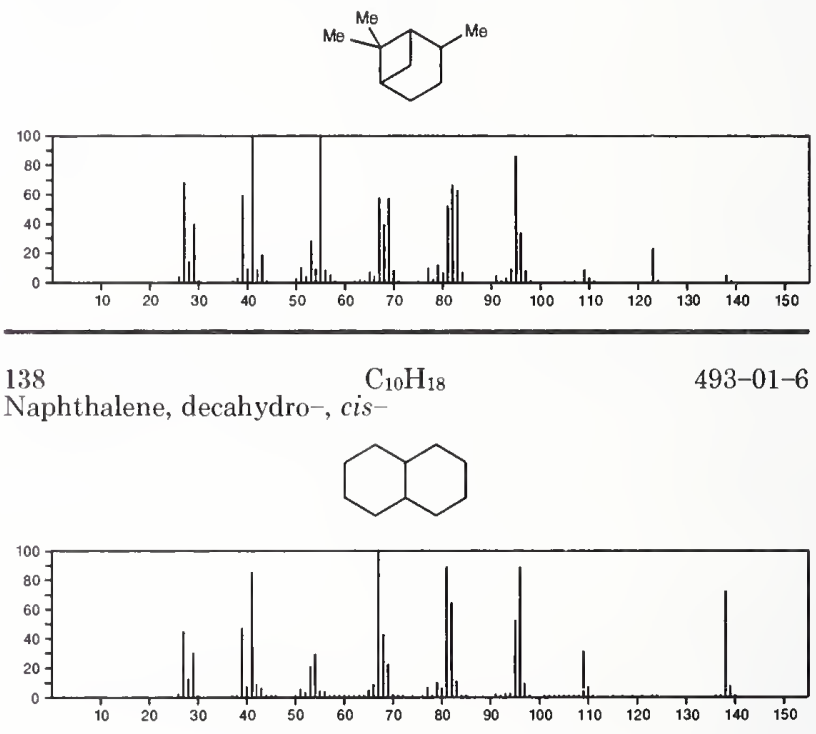

$138 \underset{\mathrm{C}_{10} \mathrm{H}_{18}}{\mathrm{C}_{18}}$

493-02-7
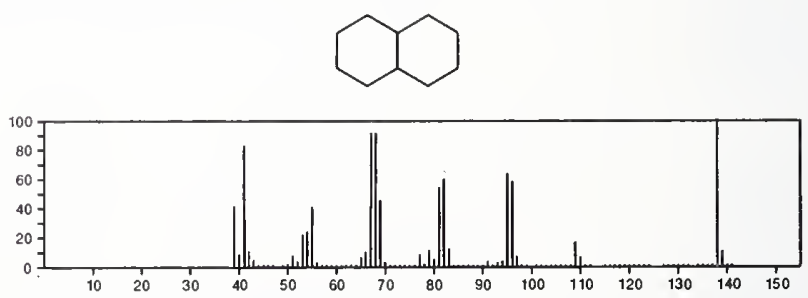
138

Cyclohexene, 4-methyl-1-(1-methylethyl)-
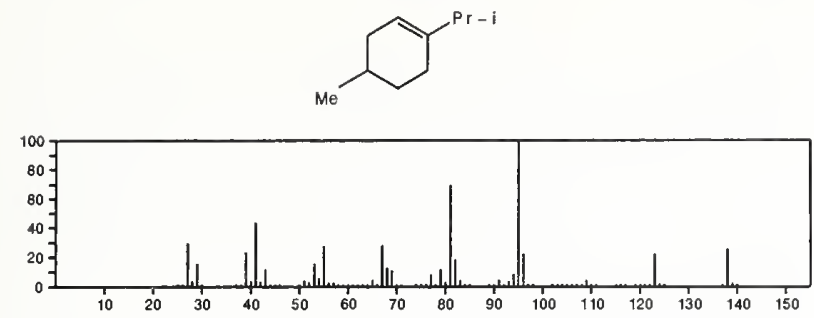

138

1-Decyne

$\mathrm{C}_{10} \mathrm{H}_{18}$

764-93-2

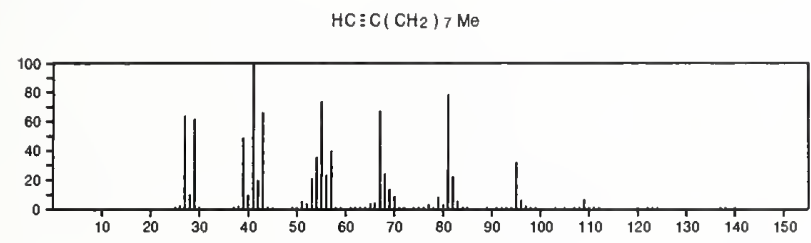

138

Cyclodecene, $(Z)-$

$\mathrm{C}_{10} \mathrm{H}_{18}$<smiles>C1=CCCCCCCCC1</smiles>

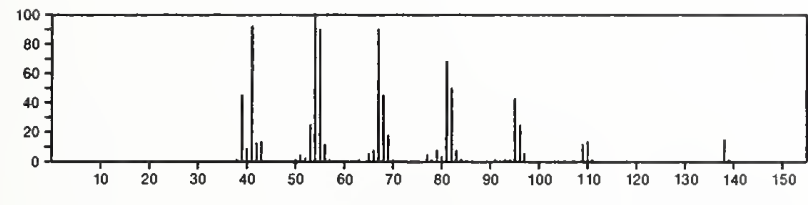

138

$\mathrm{C}_{10} \mathrm{H}_{18}$

$1124-26-1$

Cyclohexene, 3-methyl-6-(1-methylethyl)-, trans-
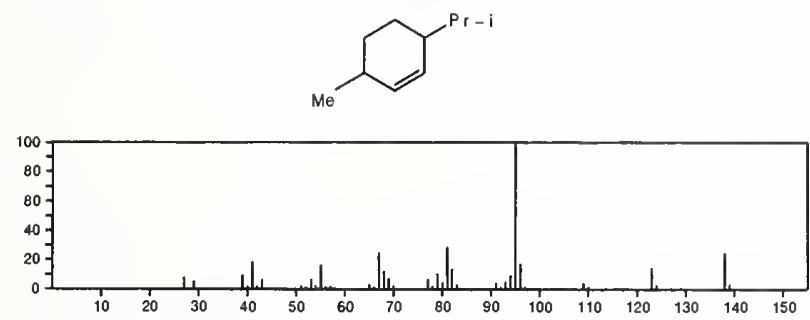

138

$\mathrm{C}_{10} \mathrm{H}_{18}$

Cyclohexane, 1-methyl-4-(1-methylethylidene)-

$1124-27-2$<smiles>COC1CCC(C)CC1</smiles>

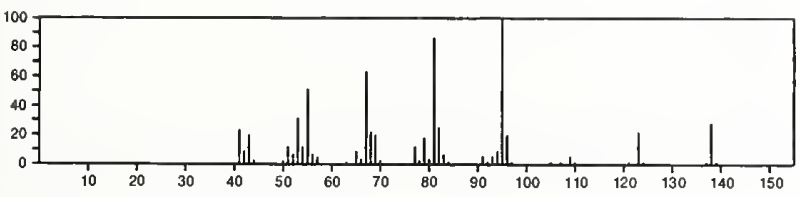

138

$\mathrm{C}_{10} \mathrm{H}_{18}$

Cyclohexene, 1-methyl-4-(1-methylethyl)-, (+)

1195-31-9
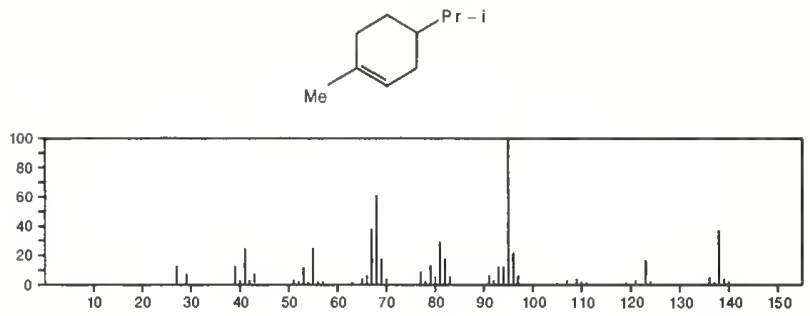

138

1,1'-Bicyclopentyl

$\mathrm{C}_{10} \mathrm{H}_{18}$

1636-39-1
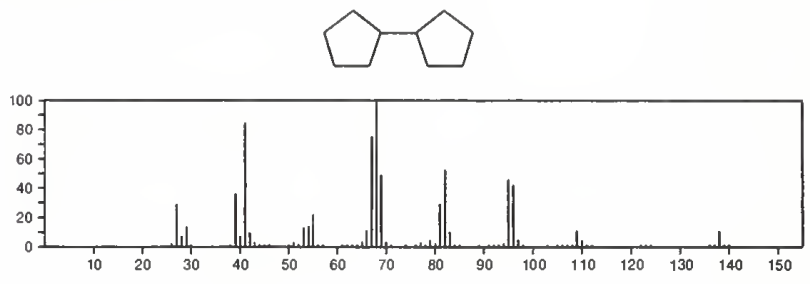

138

$\mathrm{C}_{10} \mathrm{H}_{18}$

1942-46-7

5-Decyne

$\mathrm{Me}\left(\mathrm{CH}_{2}\right)_{3} \mathrm{C} \equiv \mathrm{C}\left(\mathrm{CH}_{2}\right)_{3} \mathrm{Me}$

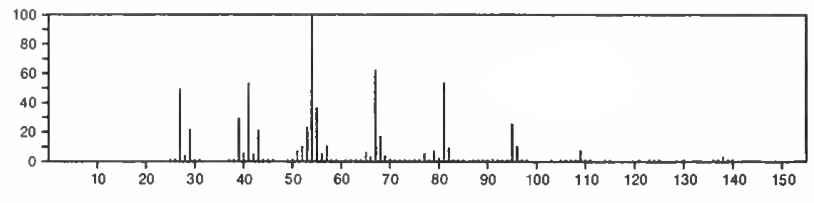

138

Cyclodecene, $(E)-$

$\mathrm{C}_{10} \mathrm{H}_{18}$

2198-20-1<smiles>C1=CCCCCCCCC1</smiles>

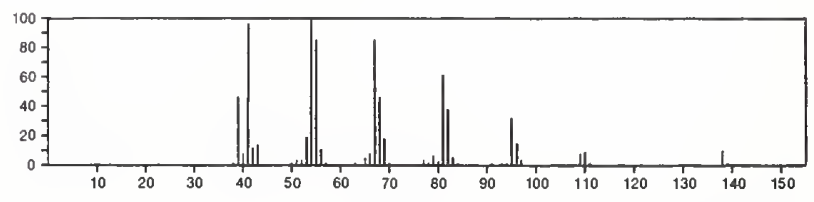

138

$\mathrm{C}_{10} \mathrm{H}_{18}$

Cyclohexene, 4-(1,1-dimethylethyl)-

2228-98-0<smiles>BrC1CC=CCC1</smiles>

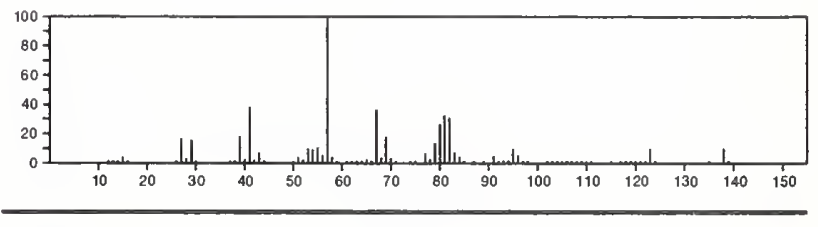

138

$\mathrm{C}_{10} \mathrm{H}_{18}$

2272-03-9

Cyclohexane, butylidene-<smiles>C=C1CCCCC1</smiles>

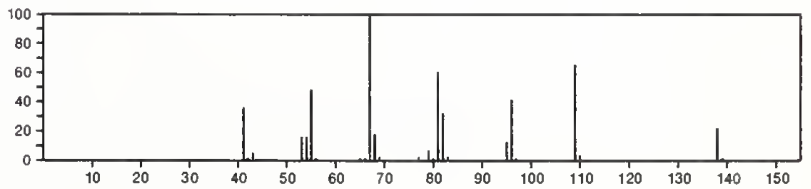


138

2-Decyne

$\mathrm{C}_{10} \mathrm{H}_{18}$

$2384-70-5$

$\mathrm{Me}\left(\mathrm{CH}_{2}\right){ }_{6} \mathrm{C} \equiv \mathrm{CMe}$

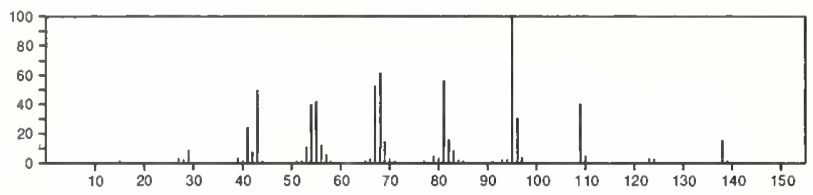

138

3-Decyne

$\mathrm{C}_{10} \mathrm{H}_{18}$

2384-85-2

$\mathrm{Me}\left(\mathrm{CH}_{2}\right){ }_{5} \mathrm{C} \equiv \mathrm{CEt}$

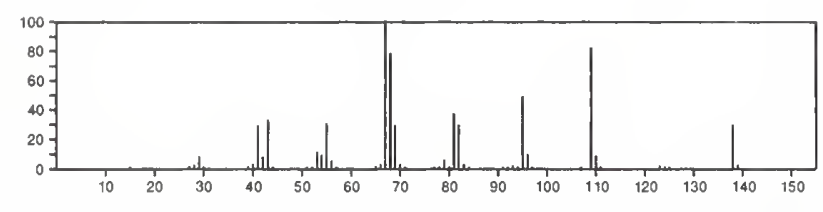

138

4-Decyne

$\mathrm{C}_{10} \mathrm{H}_{18}$

2384-86-3

$\mathrm{Me}\left(\mathrm{CH}_{2}\right){ }_{4} \mathrm{C} \equiv \mathrm{CPr}$

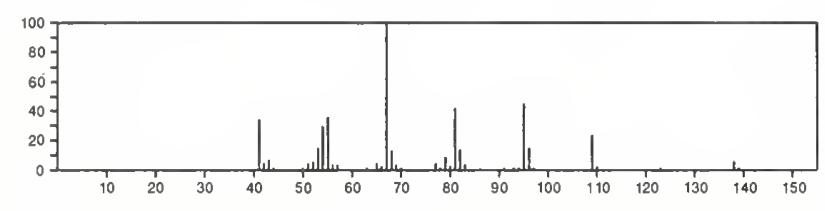

138

$\mathrm{C}_{10} \mathrm{H}_{18}$

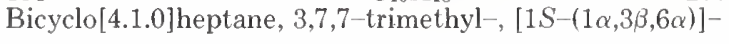
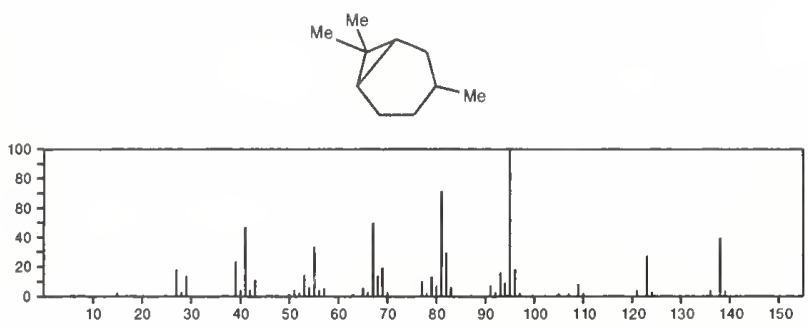

138

Cyclohexene, 1-butyl-

$\mathrm{C}_{10} \mathrm{H}_{18}$

$3282-53-9$

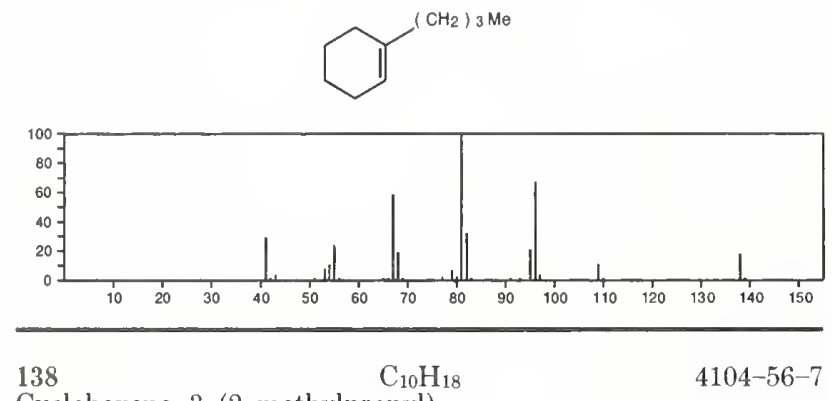

Cyclohexene, 3-(2-methylpropyl)-
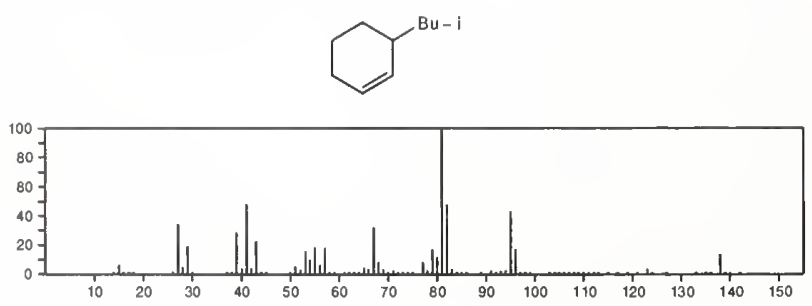

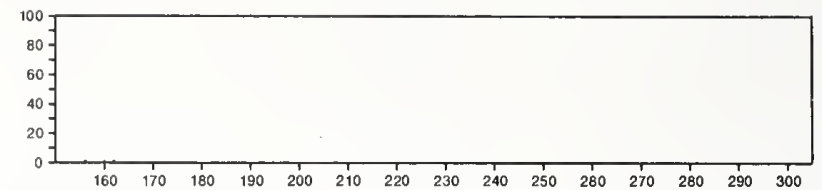

138
Cyclohexene, 1-methyl-4-(1-methylethyl)-

$5502-88-5$
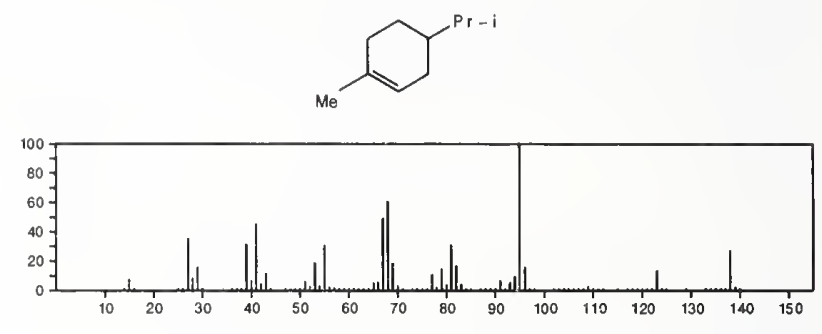

138

$\mathrm{C}_{10} \mathrm{H}_{18}$

Cyclohexene, 1-methyl-3-(1-methylethyl)-

$13828-31-4$
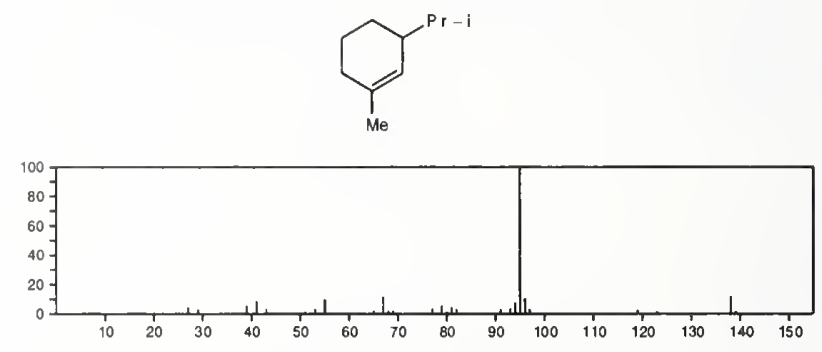

$138 \quad \mathrm{C}_{10} \mathrm{H}_{18}$

Cyclohexane, 1-methyl-3-(1-methylethylidene)-

$13828-34-7$
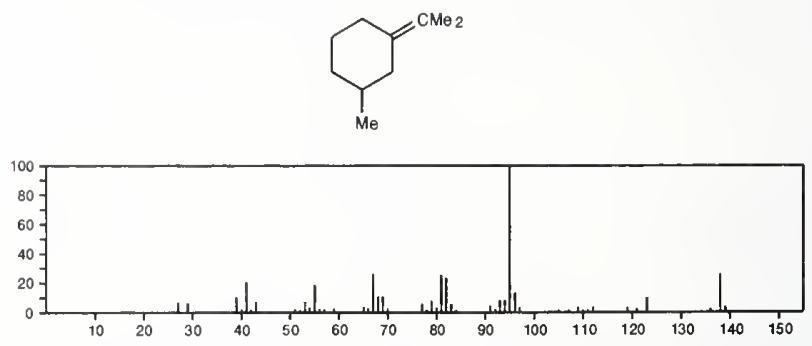

138

$\mathrm{C}_{10} \mathrm{H}_{18}$

$13837-70-2$

$m$-Menth-6-ene, $(R)-(+)-$
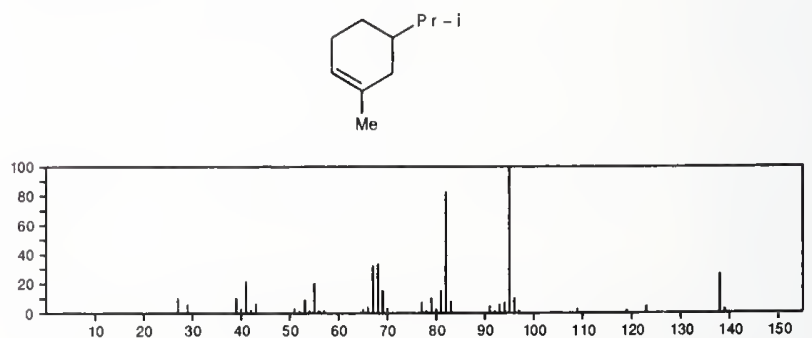
138
$m$-Menth-1(7)-ene, $(R)-(-)-$

$13837-71-3$<smiles>O=C1CCCC(Br)C1</smiles>

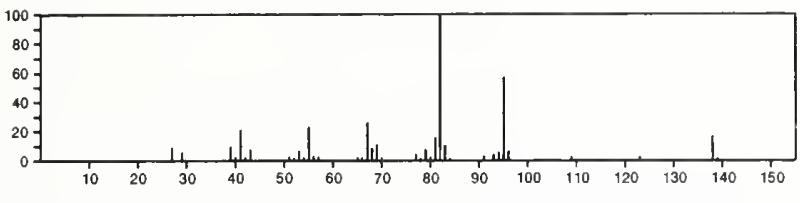

138

$\mathrm{C}_{10} \mathrm{H}_{18}$

$18968-23-5$

Bicyclo[4.1.0]heptane, 3,7,7-trimethyl-, $(1 \alpha, 3 \alpha, 6 \alpha)$ -
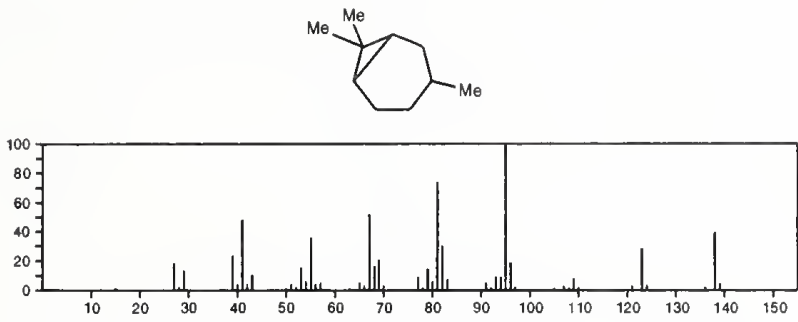

138

$\mathrm{C}_{10} \mathrm{H}_{18}$

$19482-57-6$

3-Octyne, 2,2-dimethyl-

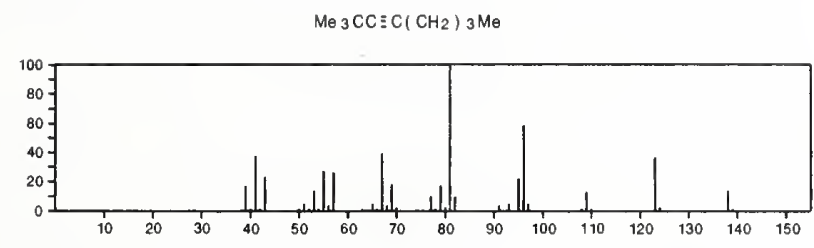

138

$\mathrm{C}_{10} \mathrm{H}_{18}$

Cyclohexane, 1-methyl-3-(1-methylethenyl)-, cis-

$24399-15-3$
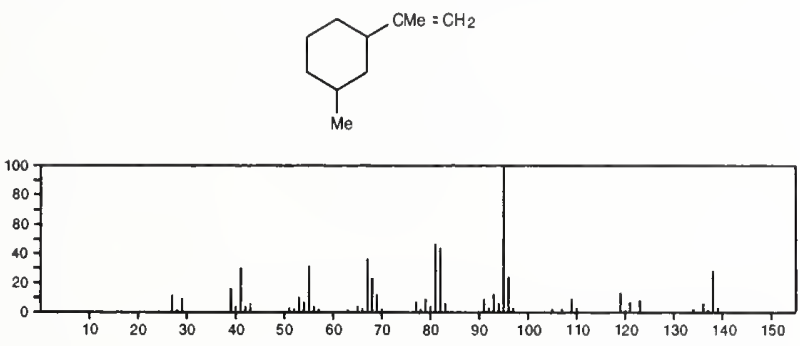

138

$\mathrm{C}_{10} \mathrm{H}_{18}$

Cyclopropane, tetramethylpropylidene-

24519-04-8
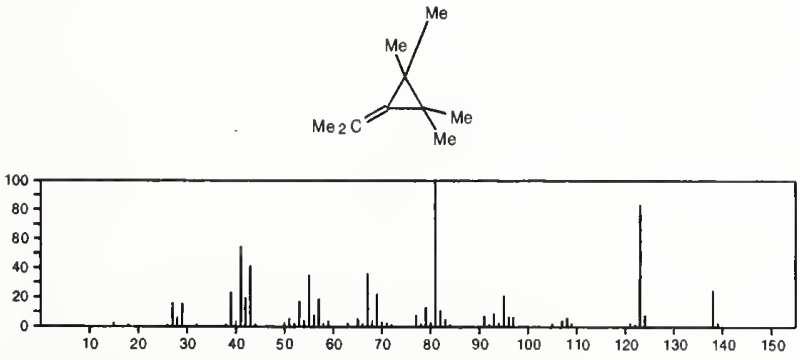

$138 \quad \mathrm{C}_{10} \mathrm{H}_{18} \quad 24524-51-4$ Propane, 2-(2-isopropylidene-3-methylcyclopropyl)-, trans -
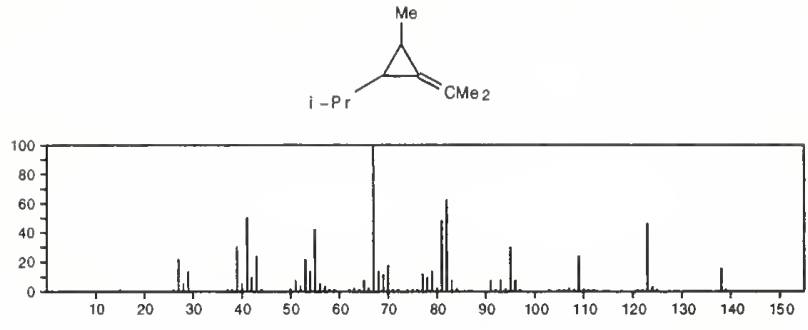

138

$\mathrm{C}_{10} \mathrm{H}_{18}$ $24524-52-5$

Propane, 2-(2-isopropylidene-3-methylcyclopropyl)-, cis-
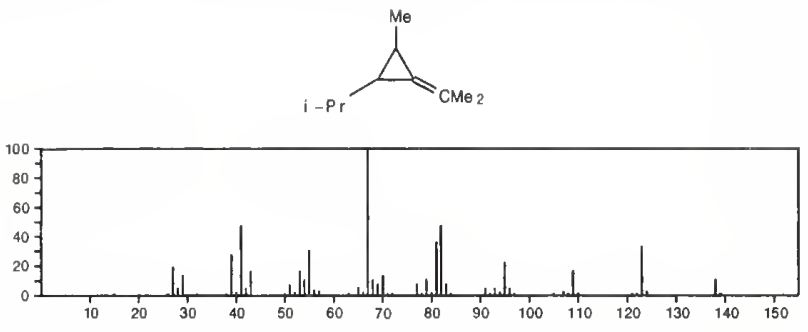

$138 \quad \mathrm{C}_{10} \mathrm{H}_{18}$

Pentalene, octahydro-2,5-dimethyl-

$28588 \div 55-8$
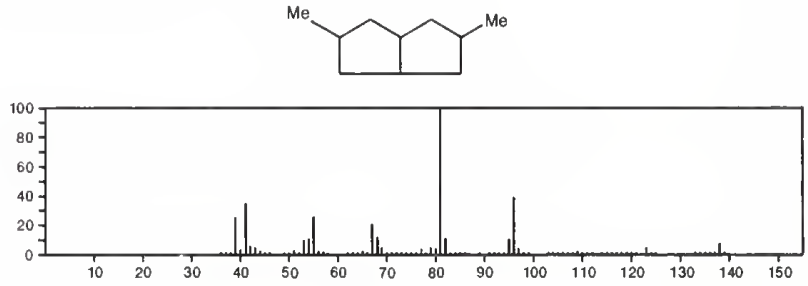

138

3,5-Octadiene, 2,7-dimethyl-, $(Z, Z)-$

28980-73-6

$\mathrm{Me} 2 \mathrm{CHCH}=\mathrm{CHCH}=\mathrm{CHCHMe} 2$

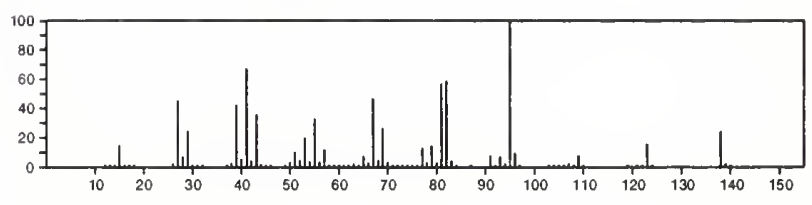

138

$\mathrm{C}_{10} \mathrm{H}_{18}$

1,4-Hexadiene, 2,3,4,5-tetramethyl-

$51504-54-2$

$\mathrm{Me} 2 \mathrm{C}=\mathrm{CMe} \mathrm{CHM}_{\theta} \mathrm{CMe}=\mathrm{CH}_{2}$

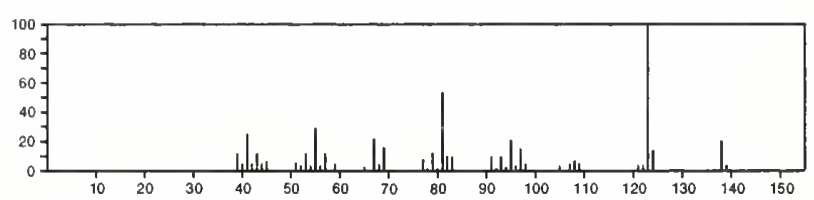


138

$\mathrm{C}_{10} \mathrm{H}_{18}$

$54764-57-7$

Cyclopropane, 1,1,2-trimethyl-3-(2-methyl-1-propenyl)-
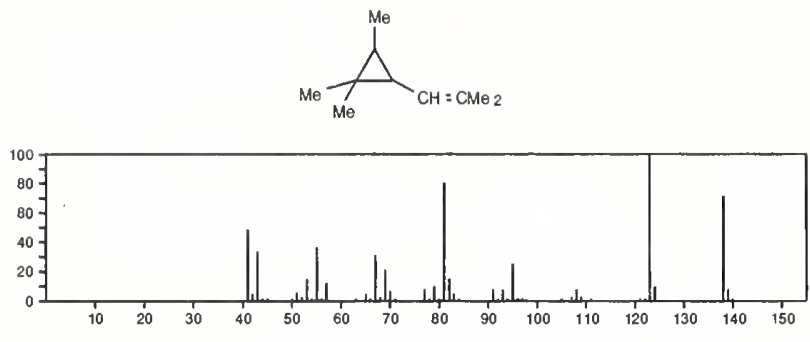

138

$\mathrm{C}_{10} \mathrm{H}_{18}$

3,5-Octadiene, 2,7-dimethyl-, $(E, Z)$ -

$55682-64-9$

$\mathrm{Me} 2 \mathrm{CHCH}=\mathrm{CHCH}=\mathrm{CHCHMe}$

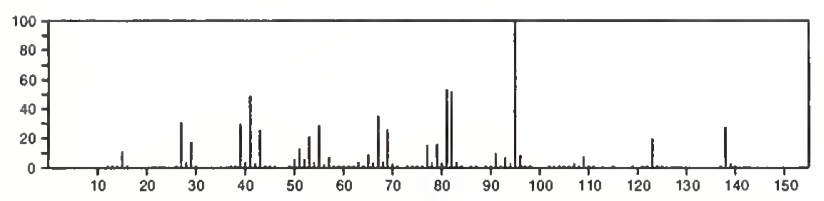

138

4,6-Decadiene

$\mathrm{C}_{10} \mathrm{H}_{18}$

$55682-65-0$

$\mathrm{PrCH}=\mathrm{CHCH}=\mathrm{CHP}$

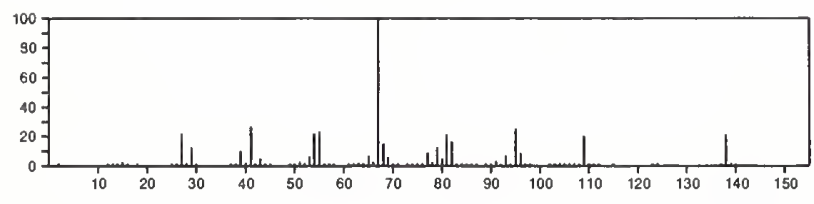

138

$\mathrm{C}_{10} \mathrm{H}_{18}$

$55956-32-6$

4,5-Nonadiene, 2-methyl-

$\operatorname{PrCH}=\mathrm{C}=\mathrm{CHCH}_{2} \mathrm{CHM}_{2}$

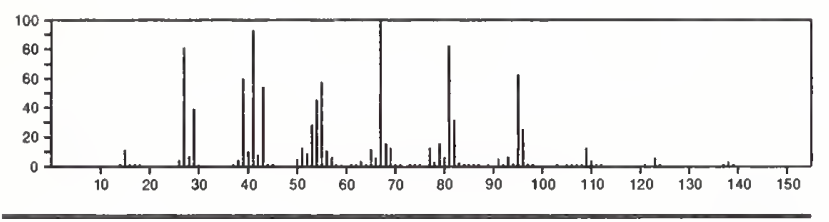

139

$\mathrm{C}_{5} \mathrm{H}_{5} \mathrm{~N}_{3} \mathrm{O}_{2}$

15862-54-1

3-Pyridinamine, $\mathrm{N}$-nitro-
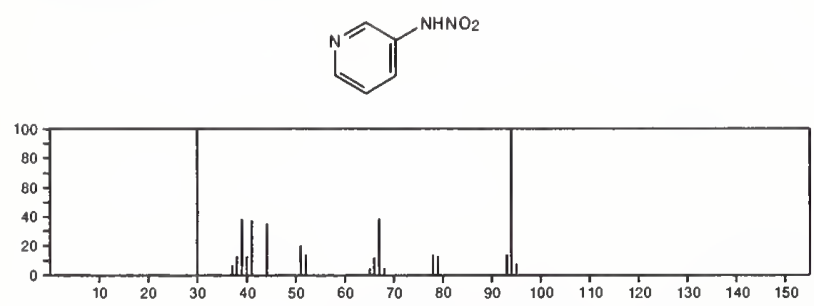

$139 \quad \mathrm{C}_{5} \mathrm{H}_{5} \mathrm{~N}_{3} \mathrm{O}_{2}$

2-Pyridinamine, $\mathrm{N}$-nitro-
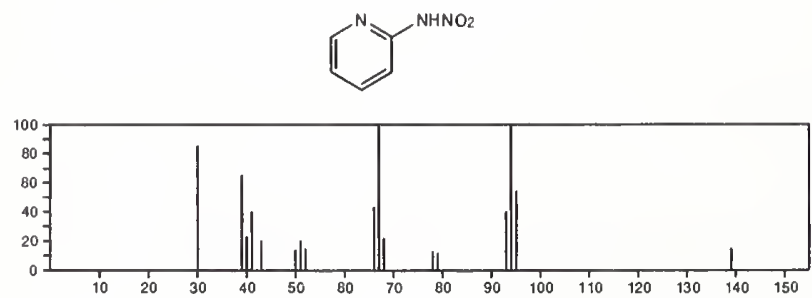

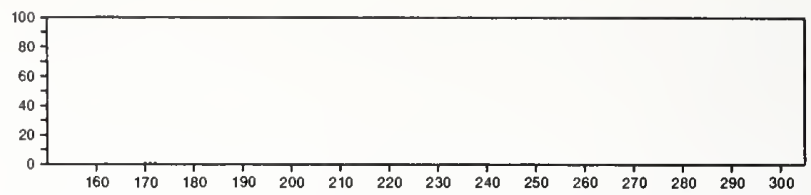

139

$\mathrm{C}_{5} \mathrm{H}_{5} \mathrm{~N}_{3} \mathrm{O}_{2}$

$26482-55-3$

4-Pyridinamine, $\mathrm{N}$-nitro-
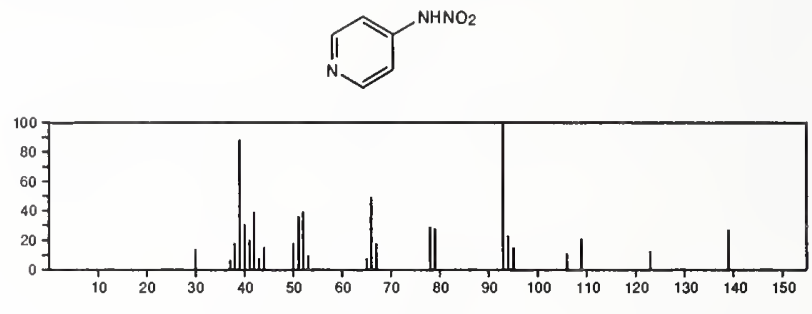

139

$\mathrm{C}_{6} \mathrm{H}_{5} \mathrm{NO}_{3}$

$88-75-5$

Phenol, 2-nitro-
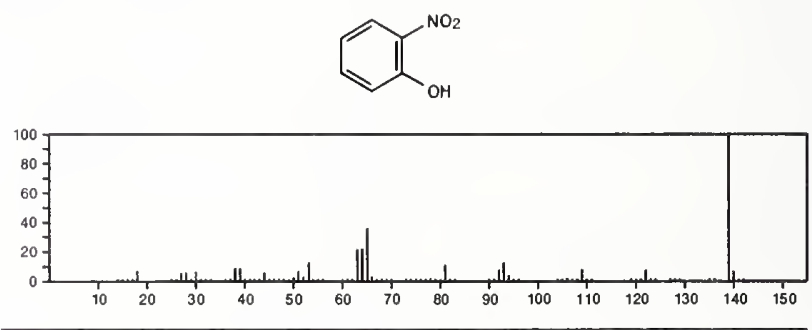

139

$\mathrm{C}_{6} \mathrm{H}_{5} \mathrm{NO}_{3}$

100-02-7

Phenol, 4-nitro-
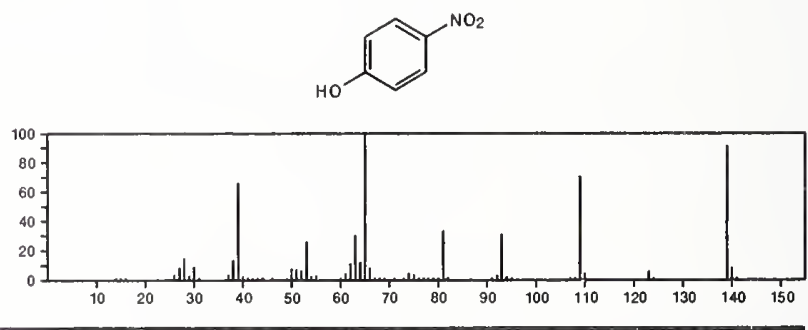

139

$\mathrm{C}_{6} \mathrm{H}_{5} \mathrm{NO}_{3}$

$554-84-7$

Phenol, 3-nitro-<smiles>O=[N+]([O-])c1cccc(O)c1</smiles>

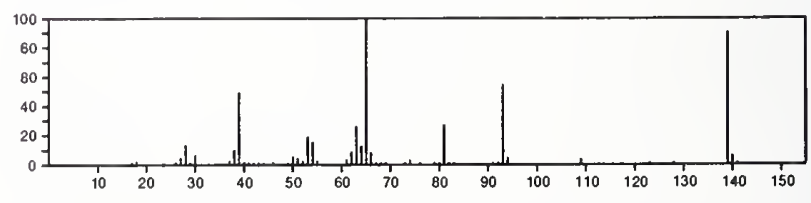

$139 \quad \mathrm{C}_{6} \mathrm{H}_{5} \mathrm{NO}_{3}$

5006-66-6

3-Pyridinecarboxylic acid, 1,6-dihydro-6-oxo-
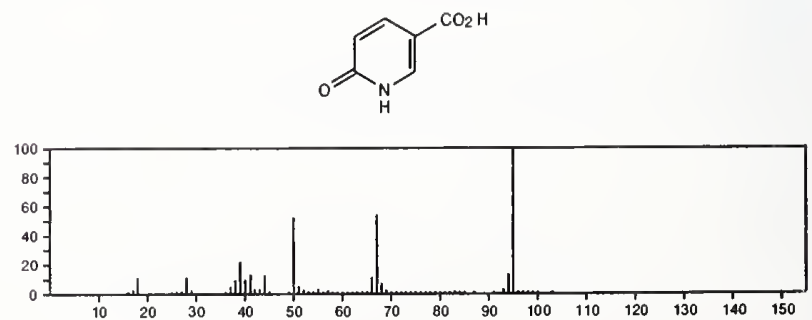
$\mathrm{C}_{6} \mathrm{H}_{9} \mathrm{~N}_{3} \mathrm{O}$

2-Pyrimidinamine, 4-methoxy-6-methyl-
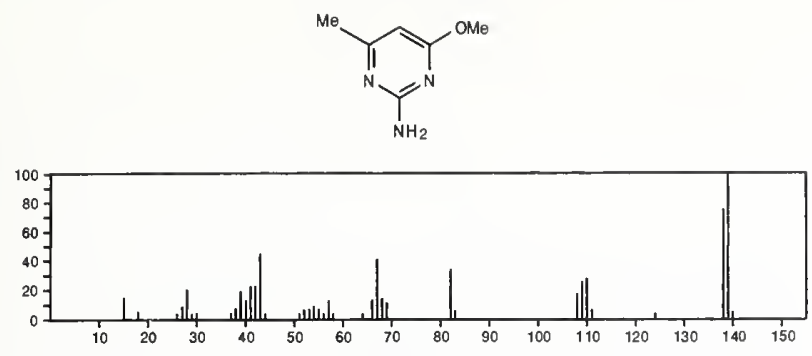

139

$\mathrm{C}_{7} \mathrm{H}_{9} \mathrm{NO}_{2}$

$6052-75-1$

2(1H)-Pyridinone, 4-hydroxy-1,6-dimethyl-
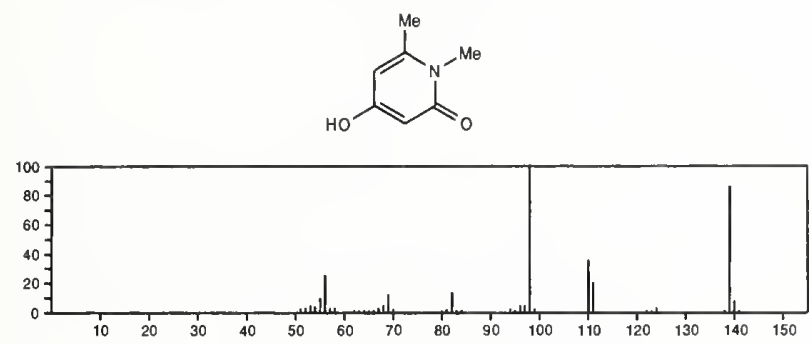

139

2-Furanacetamide, $N$-methyl-

$\mathrm{C}_{7} \mathrm{H}_{9} \mathrm{NO}_{2}$

50618-94-5
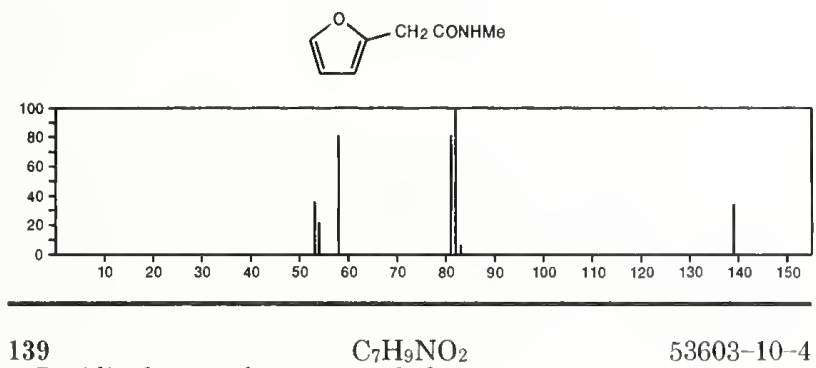

4-Pyridinol, 5-methoxy-2-methyl-

53603-10-4<smiles>COc1cnc(N)cc1O</smiles>

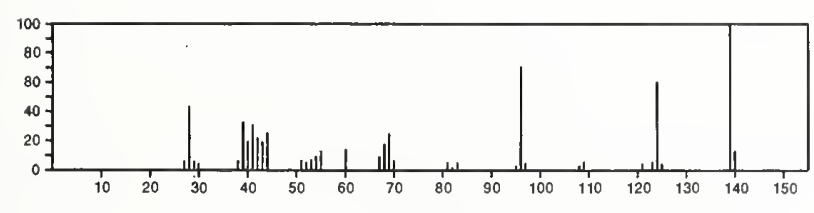

139

4-Pyridinol, 3-methoxy-2-methyl-

$53603-11-5$
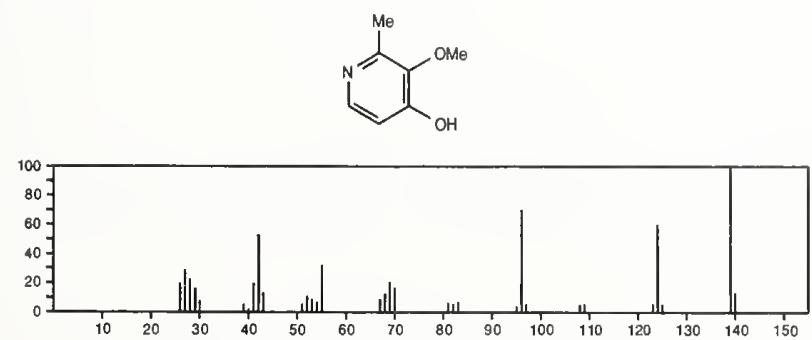

$139 \quad \mathrm{C}_{7} \mathrm{H}_{9} \mathrm{NO}_{2}$

4-Pyridinol, 2-methoxy-6-methyl-

53603-12-6
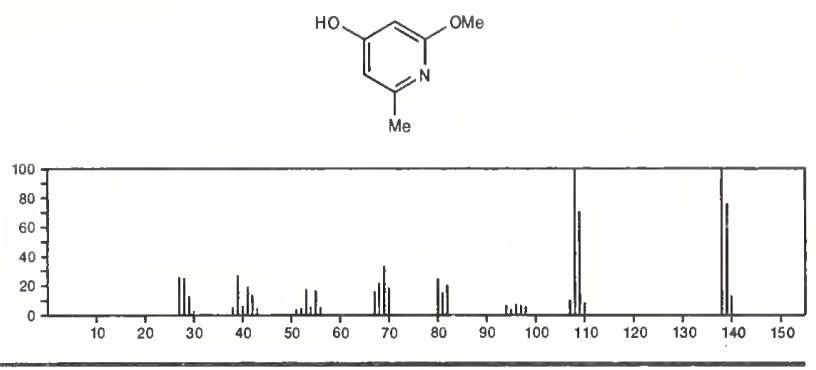

139

$\mathrm{C}_{7} \mathrm{H}_{9} \mathrm{NS}$

2(1H)-Pyridinethione, 1,3-dimethyl-

19006-66-7
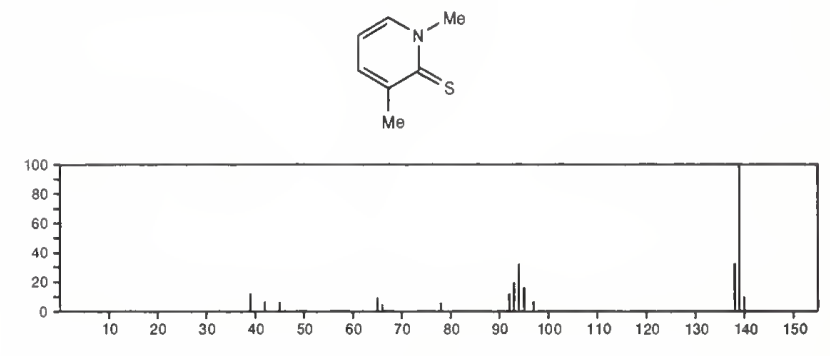

$139 \quad \mathrm{C}_{7} \mathrm{H}_{9} \mathrm{NS}$

2(1H)-Pyridinethione, 1,4-dimethyl-

19006-67-8

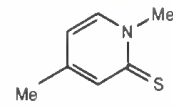

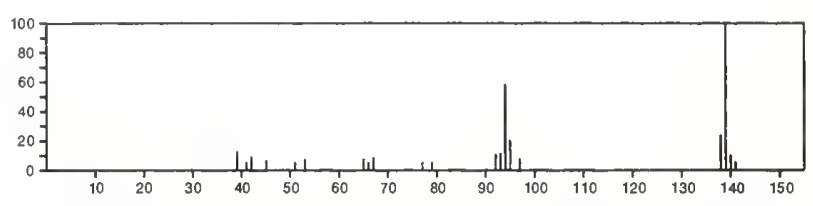

139

$\mathrm{C}_{7} \mathrm{H}_{9} \mathrm{NS}$

2(1H)-Pyridinethione, 1,5-dimethyl-

19006-68-9
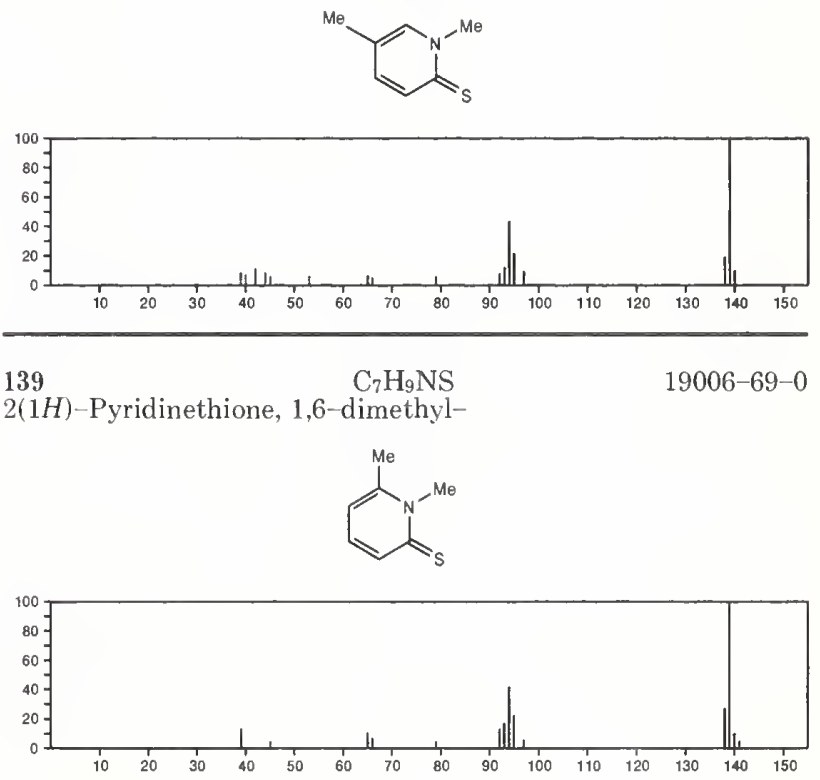
$\mathrm{C}_{7} \mathrm{H}_{9} \mathrm{NS}$

2(1H)-Pyridinethione, 1-ethyl-<smiles></smiles>

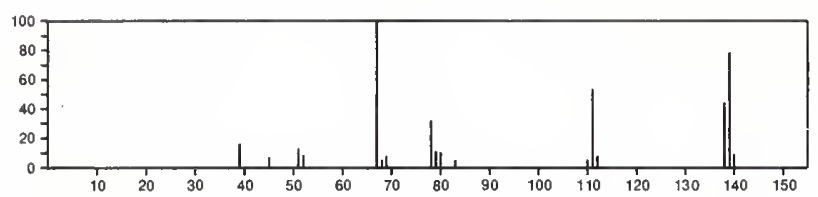

139

Pyridine, 2-(ethylthio)-

$\mathrm{C}_{7} \mathrm{H}_{9} \mathrm{NS}$

$19006-76-9$
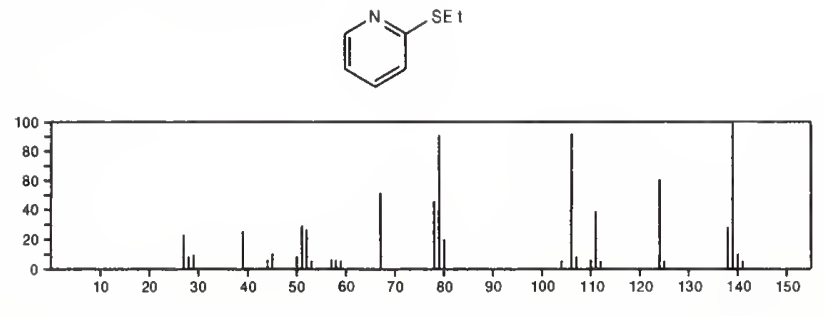

139

4-Picoline, 2-(methylthio)-

$\mathrm{C}_{7} \mathrm{H}_{9} \mathrm{NS}$

19006-77-0
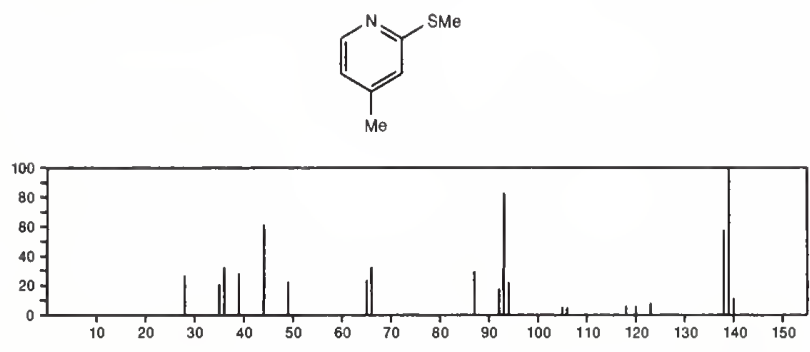

139

2-Picoline, 6-(methylthio)-

$\mathrm{C}_{7} \mathrm{H}_{9} \mathrm{NS}$

20329-37-7
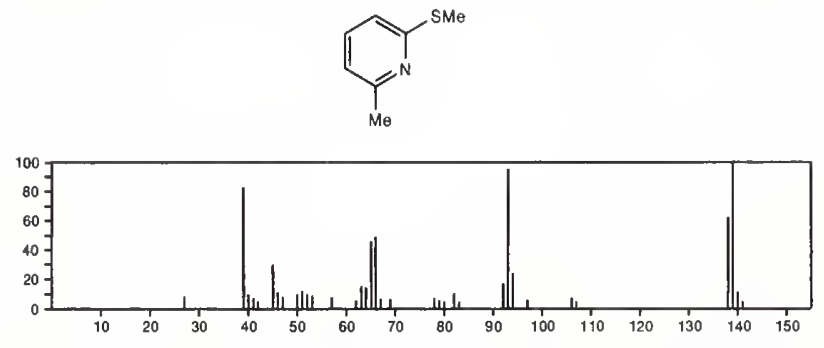

139

$\mathrm{C}_{7} \mathrm{H}_{13} \mathrm{~N}_{3}$

673-46-1

$1 \mathrm{H}$-Imidazole-4-ethanamine, $N, N$-dimethyl-



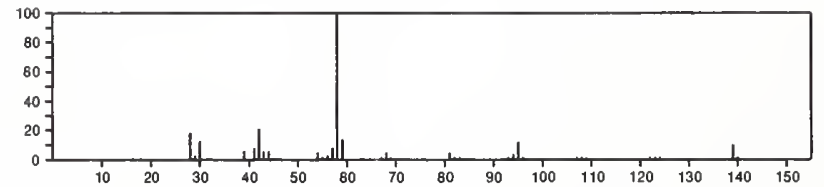

139

$\mathrm{C}_{7} \mathrm{H}_{13} \mathrm{~N}_{3}$

$1 H$-Imidazole-4-ethanamine, $\beta, \beta$-dimethyl-

$21150-01-6$
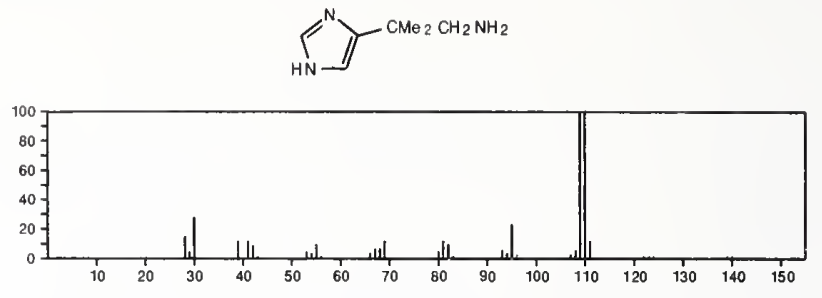

139

$\mathrm{C}_{7} \mathrm{H}_{13} \mathrm{~N}_{3}$

40515-30-8

1H-1,2,4-Triazole, 3-(2,2-dimethylpropyl)-
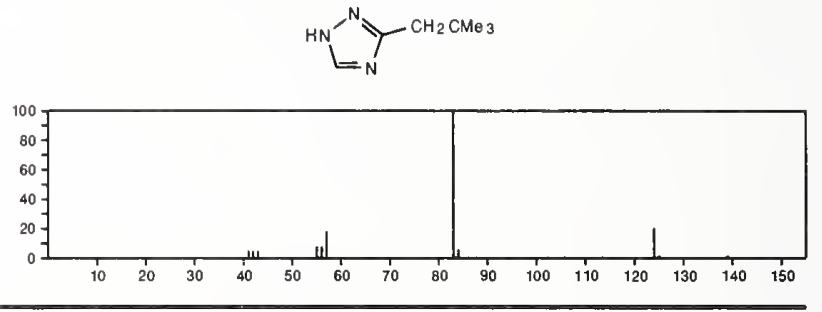

139

$\mathrm{C}_{7} \mathrm{H}_{13} \mathrm{~N}_{3}$

$53966-45-3$

$1 \mathrm{H}$-Imidazole-4-ethanamine, 1,5-dimethyl-
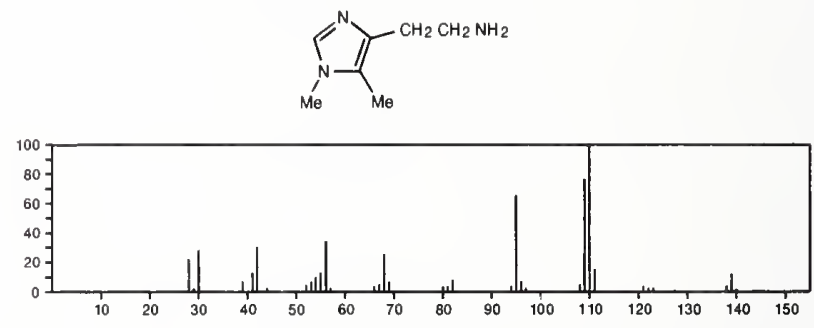

139

$\mathrm{C}_{7} \mathrm{H}_{13} \mathrm{~N}_{3}$

$53966^{-46-4}$

I $H$-Imidazole-4-ethanamine, $N, 5$-dimethyl-
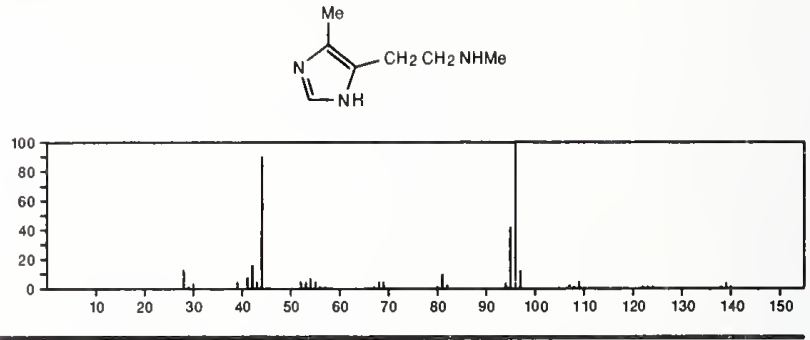

139

$\mathrm{C}_{8} \mathrm{H}_{13} \mathrm{NO}$

$532-24-1$

8-Azabicyclo[3.2.1] octan-3-one, 8-methyl-
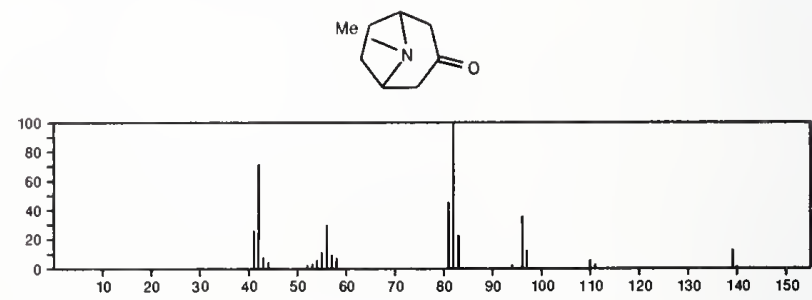
139 $\mathrm{C}_{8} \mathrm{H}_{13} \mathrm{NO}$

Morpholine, 4-(1,3-butadienyl)-

19352-93-3<smiles>C=CC#CCN1CCOCC1</smiles>

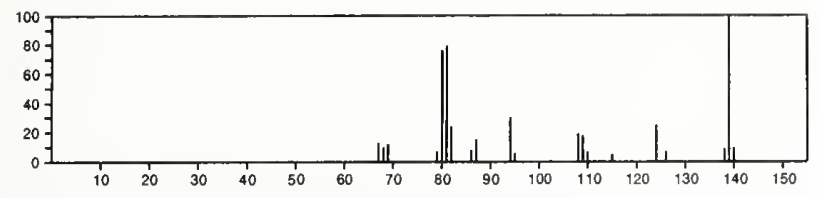

$139 \quad \mathrm{C}_{8} \mathrm{H}_{13} \mathrm{NO}$ 20513-09-1 8-Azabicyclo[3.2.1]oct-6-en-3-ol, 8-methyl-, endo-
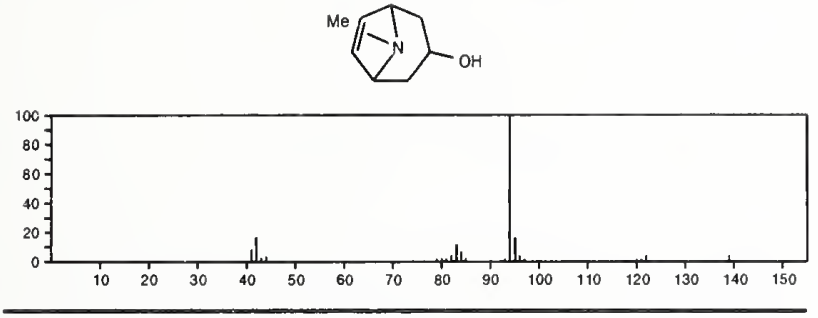

139

$\mathrm{C}_{8} \mathrm{H}_{13} \mathrm{NO}$

26625-33-2

6-Azabicyclo[3.2.1]octan-3-one, 6-methyl-
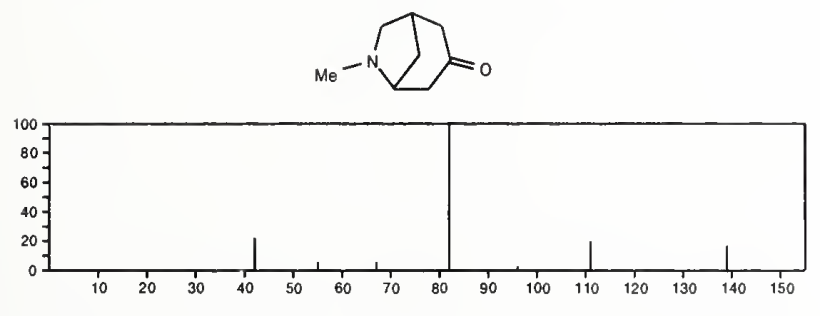

139

$\mathrm{C}_{8} \mathrm{H}_{13} \mathrm{NO}$

$32810-62-1$

6-Azabicyclo[3.2.1]octan-4-one, 6-methyl-
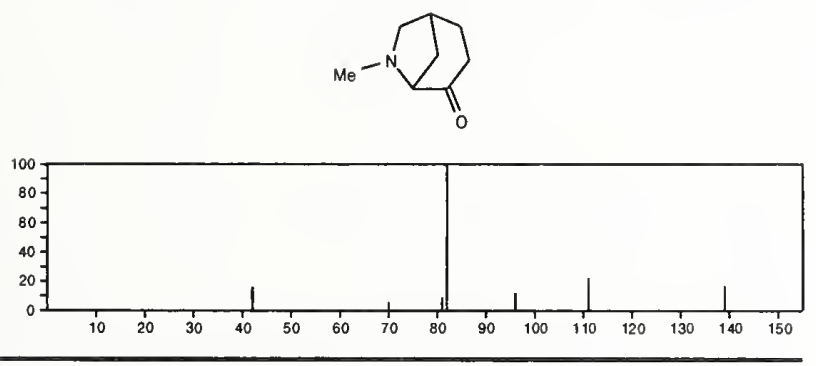

$139 \quad \mathrm{C}_{8} \mathrm{H}_{13} \mathrm{NO} \quad 38225-15-9$

2,5-Methano-2H-furo[3,2-b]pyrrole, hexahydro-4-methyl-
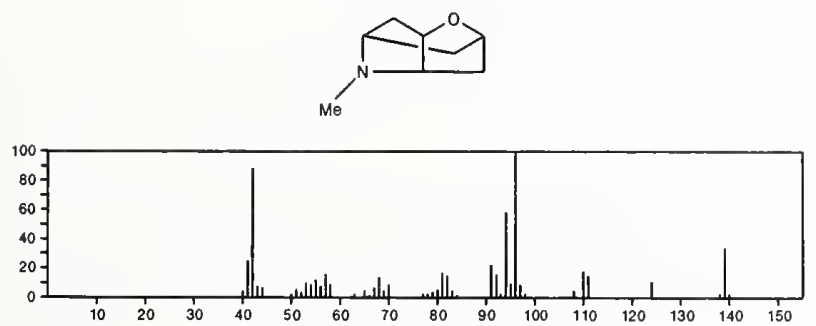

139

$\mathrm{C}_{8} \mathrm{H}_{13} \mathrm{NO}$

$50838-17-0$
$\widehat{\mathrm{Me}}_{\mathrm{Me}} \mathrm{CH}=\mathrm{CHCOMe}$

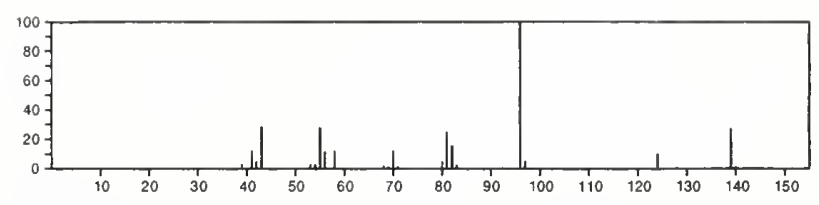

139

$\mathrm{C}_{8} \mathrm{H}_{13} \mathrm{NO}$

8-Azabicyclo[3.2.1]oct-6-en-3-ol, 8-methyl-
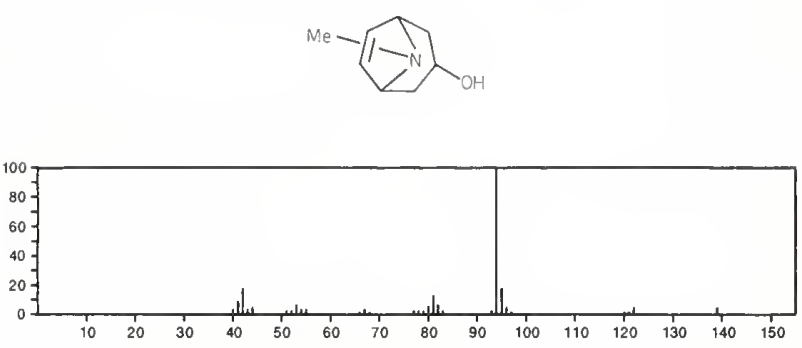

139

$\mathrm{C}_{8} \mathrm{H}_{13} \mathrm{NO}$

2-Cyclohexen-1-one, 3-methyl-, O-methyloxime

$56336-07-3$
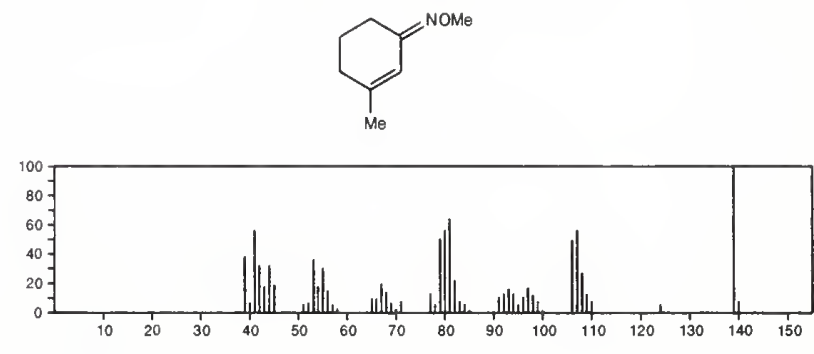

139

$\mathrm{C}_{8} \mathrm{H}_{13} \mathrm{NO}$

$56771-95-0$

8-Azabicyclo[3.2.1]octane-8-carboxaldehyde

$\mathrm{O}=\mathrm{CH}$

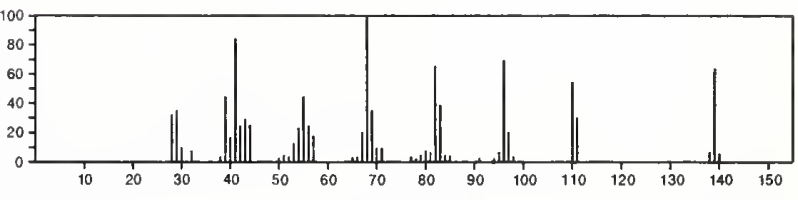

139

$\mathrm{C}_{8} \mathrm{H}_{18} \mathrm{BN}$

42843-12-9

Boranamine, 1-ethyl- $N, N$-dimethyl-1-(1-methyl-2-propenyl)-

$\mathrm{Me}_{2} \mathrm{NBE} t \mathrm{CHMe} \mathrm{CH}=\mathrm{CH}_{2}$

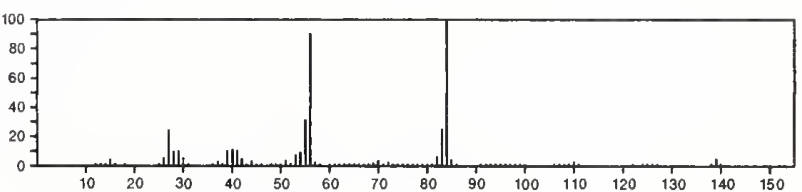


344

EPA/NIH MASS SPECTRAL DATA BASE

139

139

Piperidine, 1-(2-methyl-1-propenyl)-
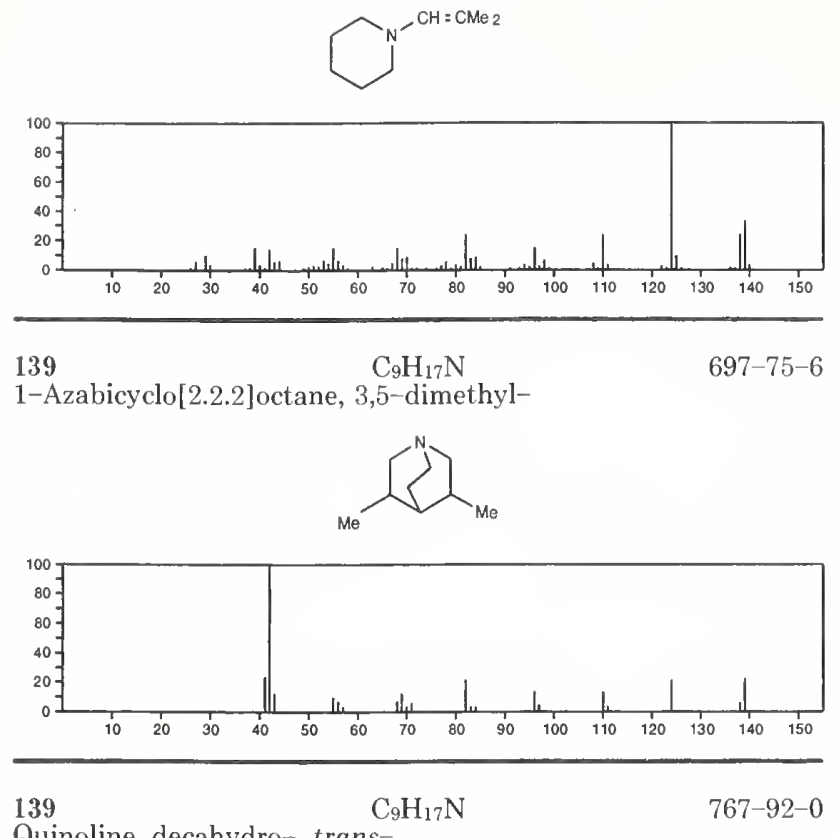

Quinoline, decahydro-, trans ${ }^{-}$
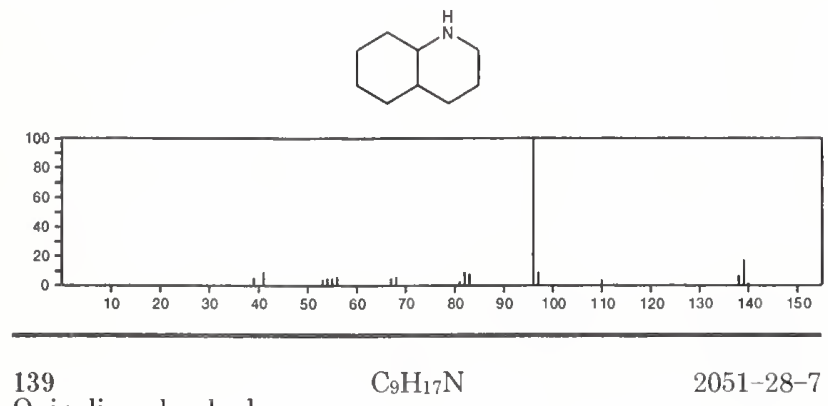

Quinoline, decahydro-
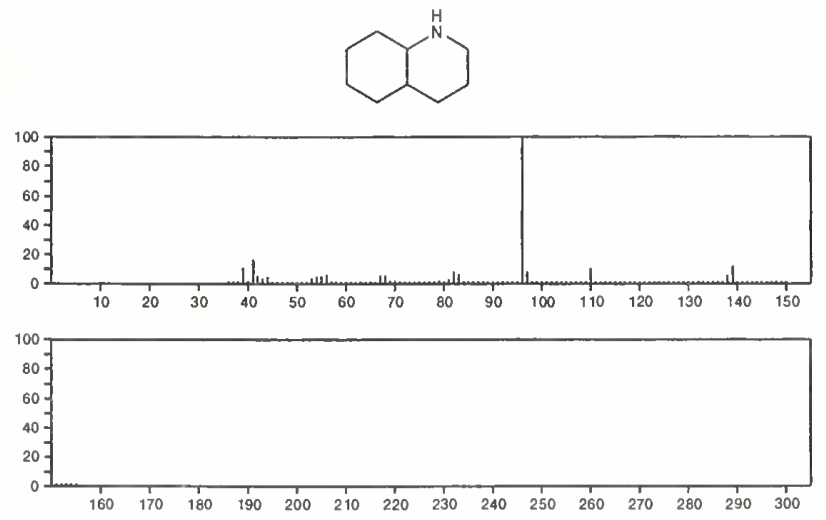

\begin{tabular}{ll}
\hline 139 & $\mathrm{C}_{9} \mathrm{H}_{17} \mathrm{~N}$
\end{tabular}

2-Propynylamine, $\mathrm{N}, \mathrm{N}$-diisopropyl-

$\mathrm{HC} \equiv \mathrm{CCH}_{2} \mathrm{~N}(\mathrm{Pr}-\mathrm{i}) 2$

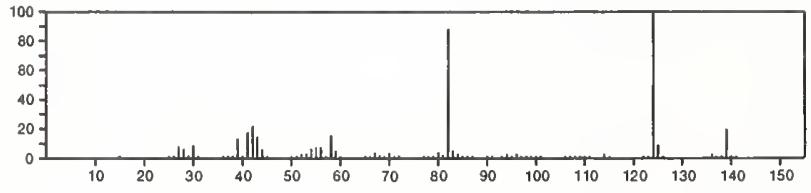

139 - $\mathrm{C}_{9} \mathrm{H}_{17} \mathrm{~N}$

Piperidine, 1-(1-butenyl)-
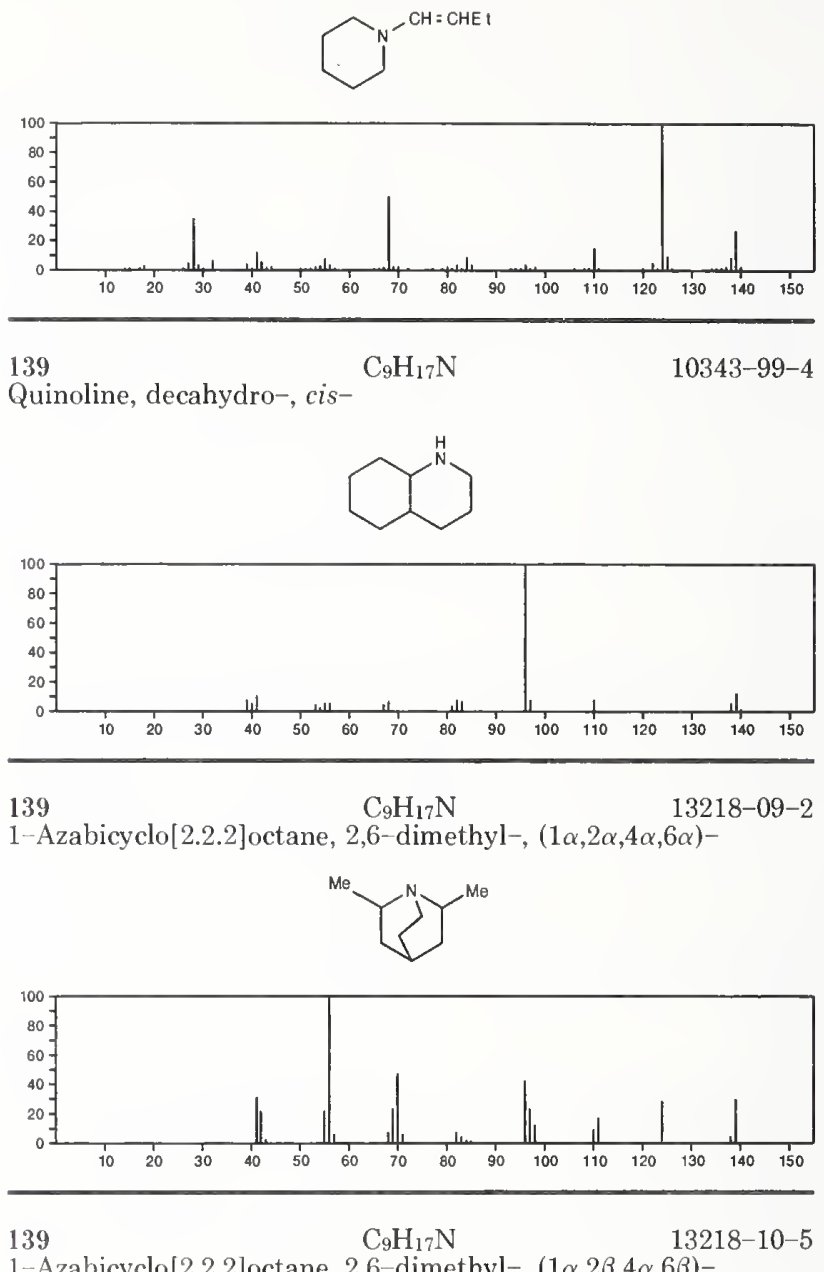

1-Azabicyclo[2.2.2] octane, 2,6-dimethyl-, $(1 \alpha, 2 \beta, 4 \alpha, 6 \beta)$ -
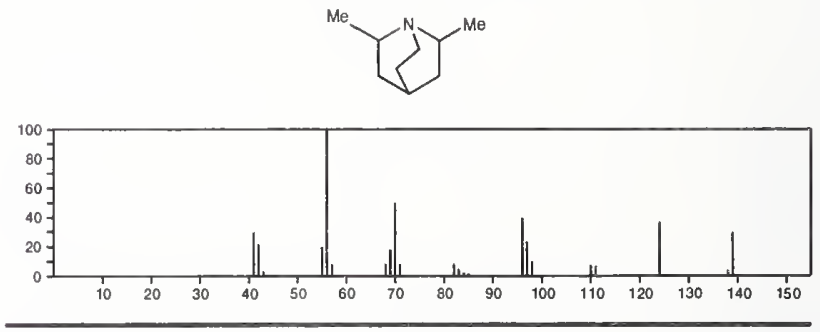

139

13937-90-1

Pyrrolidine, 1-(1-pentenyl)-
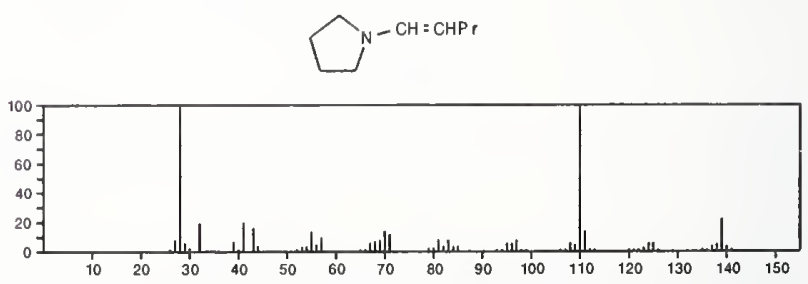
$139 \quad \mathrm{C}_{9} \mathrm{H}_{17} \mathrm{~N}$

Pyrrolidine, 1-(2-methyl-1-butenyl)-

$\overbrace{N-C H: C E t M e}$

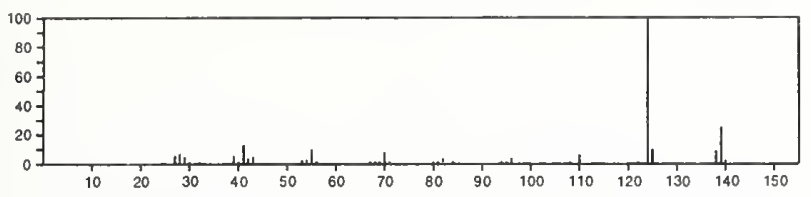

139

Pentane, 2-isocyano-2,4,4-trimethyl-

$\mathrm{C}_{9} \mathrm{H}_{17} \mathrm{~N}$

$\mathrm{Me}_{2} \mathrm{CNCCH}_{2} \mathrm{CM}_{3}$

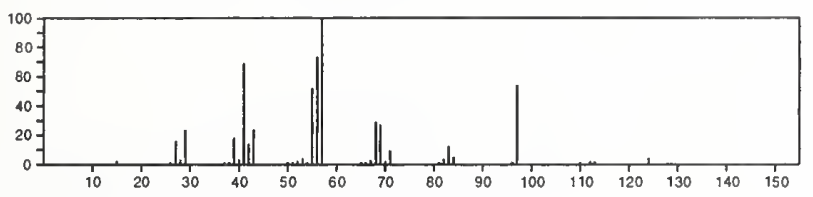

139

1-Azabicyclo[2.2.2] octane, 2,5-dimethyl-
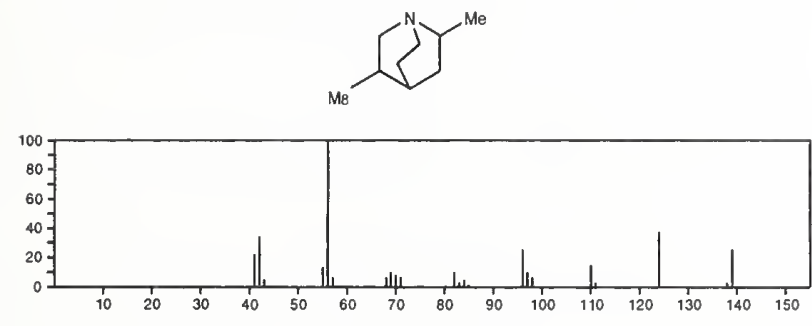

139

Azetidine, 1-cyclohexyl-

$\mathrm{C}_{9} \mathrm{H}_{17} \mathrm{~N}$

35196-98-6
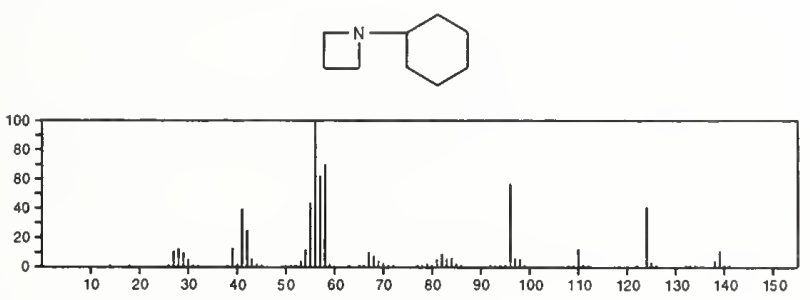

139

$\mathrm{C}_{9} \mathrm{H}_{17} \mathrm{~N}$

$55669-77-7$

Aziridine, 2-methyl-3-(1-methylethyl)-1-(2-propenyl)-, trans-
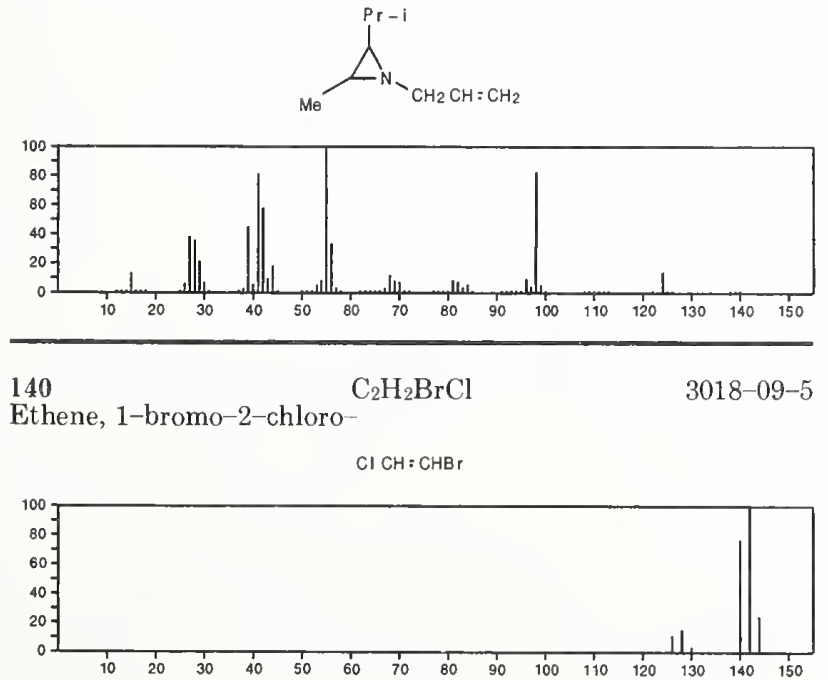

140

$\mathrm{C}_{3} \mathrm{H}_{2} \mathrm{Cl}_{2} \mathrm{O}_{2}$

$13167-36-7$

2-Propenoic acid, 2,3-dichloro-

$\mathrm{ClCH}=\mathrm{CCl} \mathrm{CO} 2 \mathrm{H}$

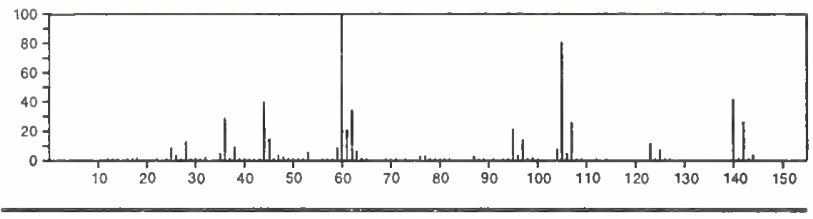

140

$\mathrm{C}_{3} \mathrm{H}_{9} \mathrm{O}_{4} \mathrm{P}$

$512-56-1$

Phosphoric acid, trimethyl ester
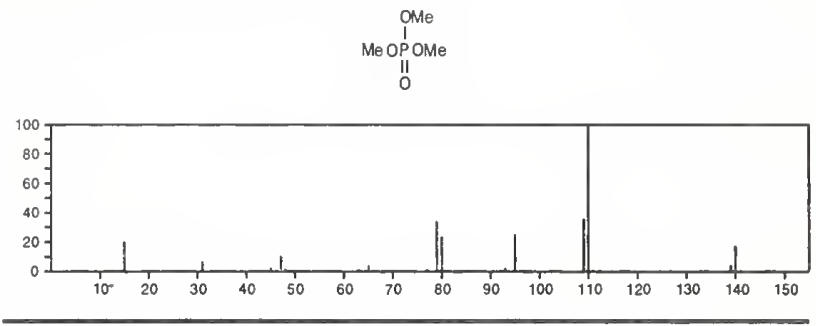

140

$\mathrm{C}_{4} \mathrm{H}_{6} \mathrm{Cl}_{2} \mathrm{O}$

$10141-22-7$

Propanal, 2,3-dichloro-2-methyl-

$\mathrm{Cl} \mathrm{CH}_{2} \mathrm{CC}$ ( $(\mathrm{CHO}) \mathrm{M}$

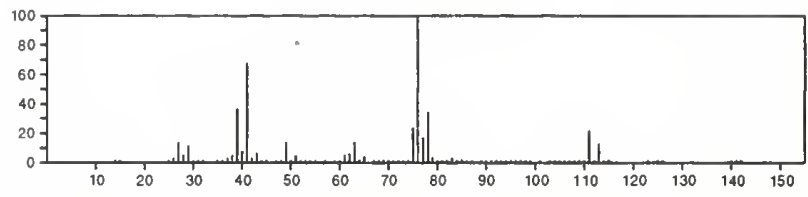

140

$\mathrm{C}_{4} \mathrm{H}_{7} \mathrm{~F}_{3} \mathrm{Si}$

$55712-74-8$

Silane, 2-butenyltrifluoro-

$\mathrm{F}_{3} \mathrm{Si} \mathrm{CH}_{2} \mathrm{CH}=\mathrm{CHM}$

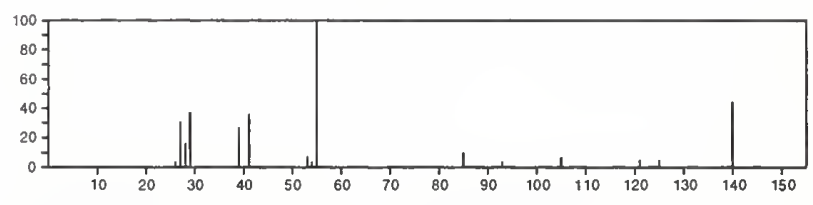

140

$\mathrm{C}_{5} \mathrm{H}_{4} \mathrm{~N}_{2} \mathrm{OS}$

$3364-82-7$

Acetonitrile, (4-oxo-2-thiazolidinylidene)-
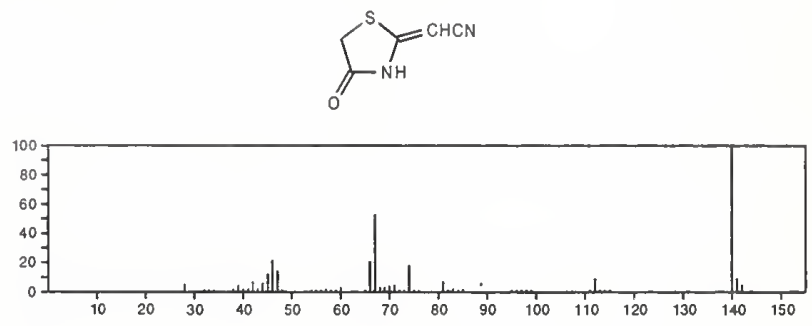

140

$\mathrm{C}_{5} \mathrm{H}_{4} \mathrm{~N}_{2} \mathrm{O}_{3}$

$1195-08-0$

5-Pyrimidinecarboxaldehyde, 1,2,3,4-tetrahydro-2,4-dioxo-
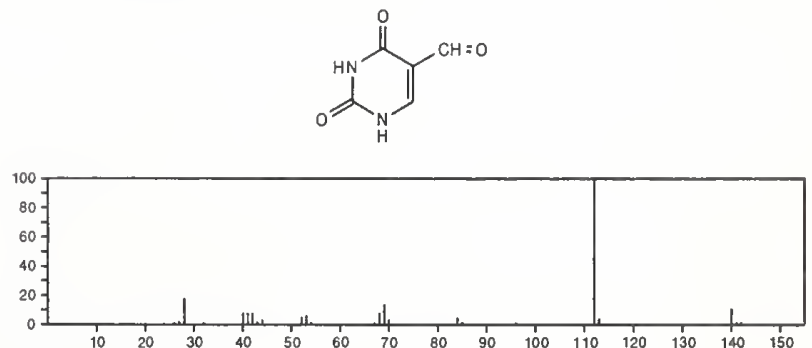
140

$\mathrm{C}_{5} \mathrm{H}_{8} \mathrm{~N}_{4} \mathrm{O}$

$54004-20-5$

$4(1 H)$-Pyrimidinone, 2-amino-6-(methylamino)-
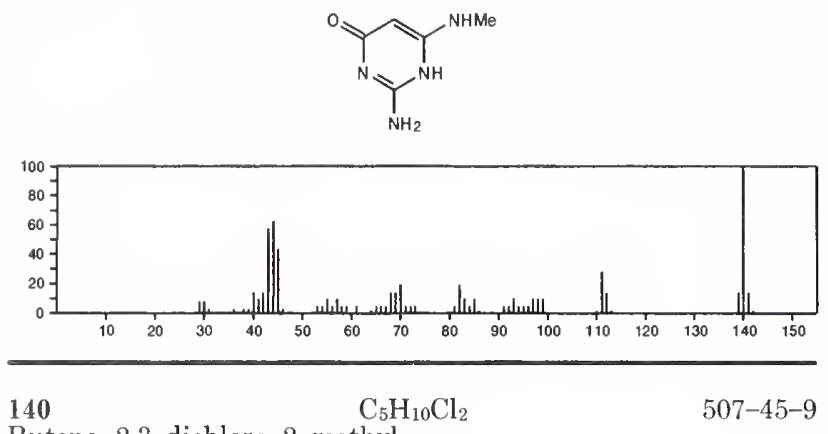

Butane, 2,3-dichloro-2-methyl-

$\mathrm{MeCHCl} \mathrm{CClMe} 2$

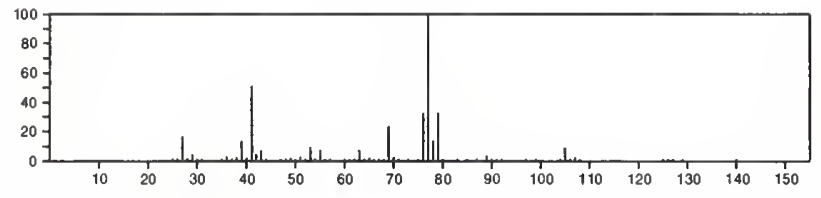

$140 \quad \mathrm{C}_{5} \mathrm{H}_{10} \mathrm{Cl}_{2}$

$623-34-7$

Butane, 1,4-dichloro-2-methyl

$\mathrm{Cl} \mathrm{CH}_{2} \mathrm{CH}_{2} \mathrm{CHMe} \mathrm{CH}_{2} \mathrm{Cl}$

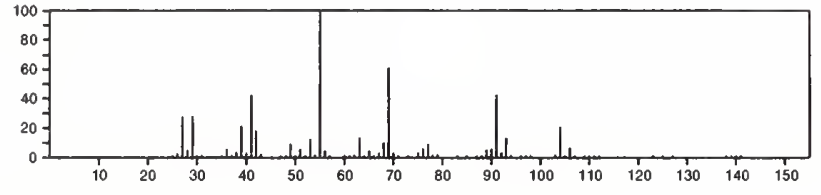

140

$\mathrm{C}_{5} \mathrm{H}_{10} \mathrm{Cl}_{2}$

$625-66-1$

Butane, 1,1-dichloro-3-methyl

$\mathrm{Me} 2 \mathrm{CHCH}_{2} \mathrm{CHCl}$

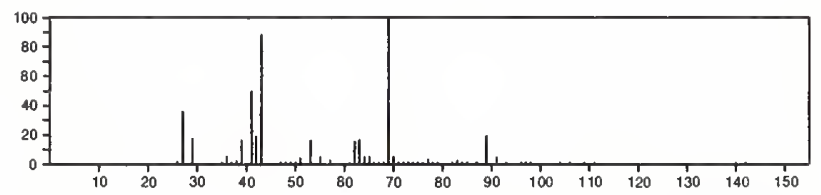

140

$\mathrm{C}_{5} \mathrm{H}_{10} \mathrm{Cl}_{2}$

$625-67-2$

Pentane, 2,4-dichloro-

$\mathrm{MeCHCl} \mathrm{CH}_{2} \mathrm{CHCl} \mathrm{Me}$
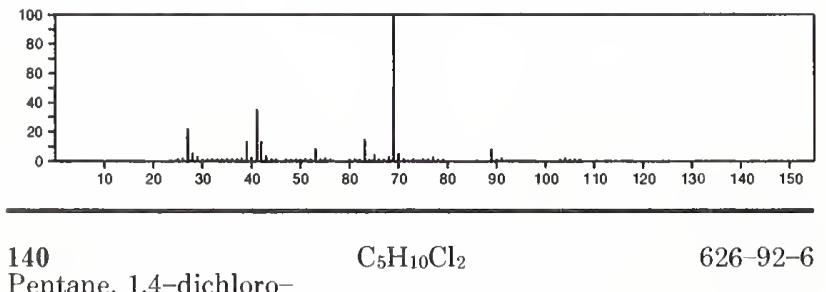

Pentane, 1,4-dichloro-

$\mathrm{MeCHCl}\left(\mathrm{CH}_{2}\right)_{3} \mathrm{Cl}$

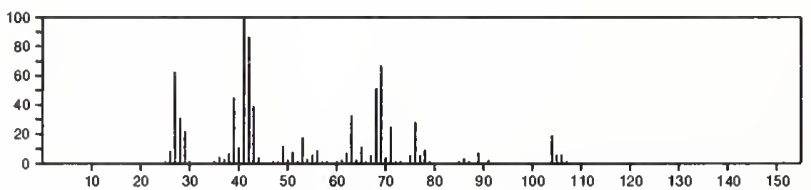

140

Pentane, 1,5-dichloro-

$\mathrm{C}_{5} \mathrm{H}_{10} \mathrm{Cl}_{2}$

$628-76-2$

$\mathrm{Cl}\left(\mathrm{CH}_{2}\right)_{5} \mathrm{Cl}$

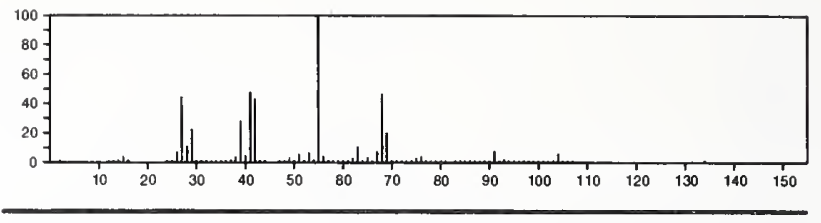

140

$\mathrm{C}_{5} \mathrm{H}_{10} \mathrm{Cl}_{2}$

$1674-33-5$

Pentane, 1,2-dichloro-

$\mathrm{Cl} \mathrm{CH}_{2} \mathrm{CHClPr}$

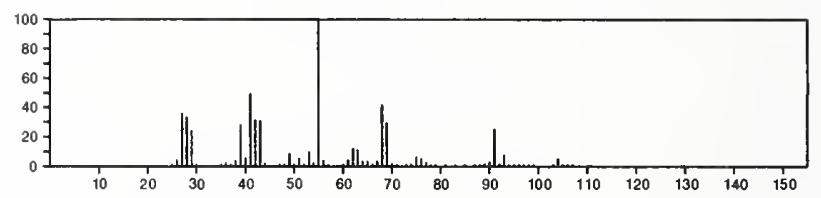

140

$\mathrm{C}_{5} \mathrm{H}_{10} \mathrm{Cl}_{2}$

Butane, 2,2-dichloro-3-methyl-

17773-66-9

$\mathrm{Me}_{2} \mathrm{CHCCl}_{2} \mathrm{Me}$

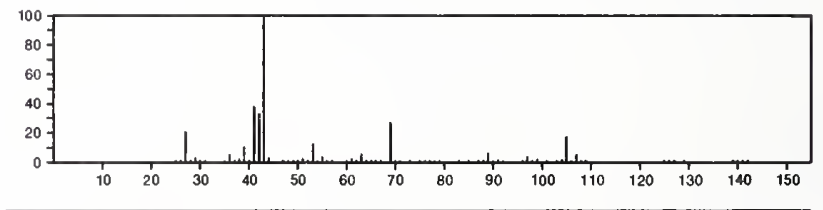

140

$\mathrm{C}_{5} \mathrm{H}_{10} \mathrm{Cl}_{2}$

23010-04-0

Butane, 1,2-dichloro-2-methyl-

$\mathrm{Cl} \mathrm{CH}_{2} \mathrm{CCIE}$ Me

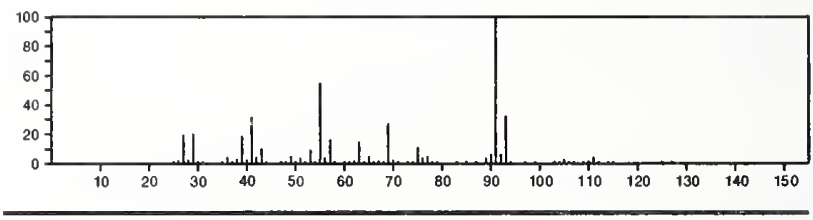

140

$\mathrm{C}_{5} \mathrm{H}_{10} \mathrm{Cl}_{2}$

$23010-07-3$

Butane, 1,3-dichloro-2-methyl

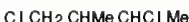

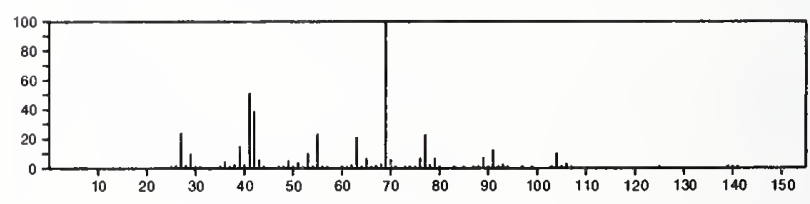

140

Pentane, 2,2-dichloro-

$\mathrm{C}_{5} \mathrm{H}_{10} \mathrm{Cl}_{2}$

34887-14-4

$\operatorname{PrCCl}_{2}(\mathrm{Pr})$

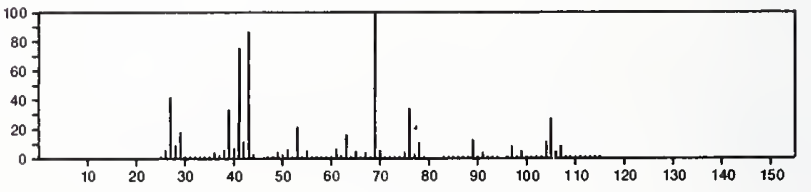


140

$\mathrm{C}_{6} \mathrm{H}_{4} \mathrm{O}_{4}$

2H-Pyran-5-carboxylic acid, 2-oxo-<smiles>O=C(O)c1ccc(=O)oc1</smiles>

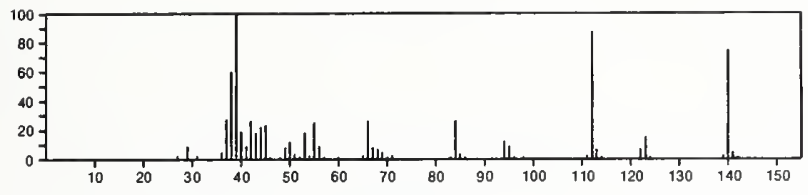

140

$\mathrm{C}_{6} \mathrm{H}_{4} \mathrm{O}_{4}$

$35069-70-6$

2,5-Cyclohexadiene-1,4-dione, 2,6-dihydroxy-
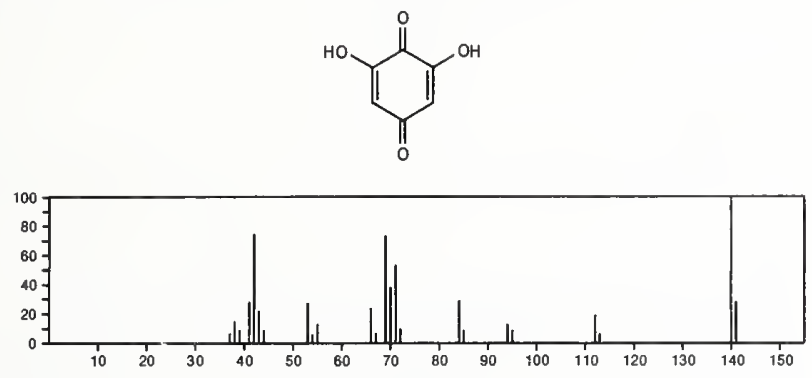

$140 \quad \mathrm{C}_{6} \mathrm{H}_{8} \mathrm{~N}_{2} \mathrm{O}_{2}$

2,4(1H,3H)-Pyrimidinedione, 1,3-dimethyl-
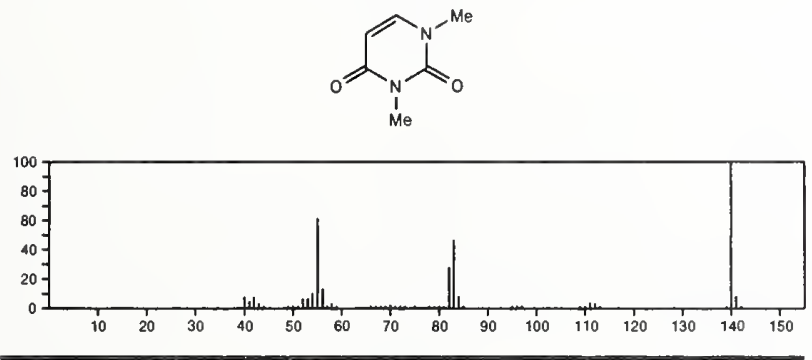

140

$\mathrm{C}_{6} \mathrm{H}_{8} \mathrm{~N}_{2} \mathrm{O}_{2}$

2-Pyrazolin-5-one, 1-acetyl-3-methyl-

$5203-92-9$<smiles>CN1N=C(N)CC1=O</smiles>

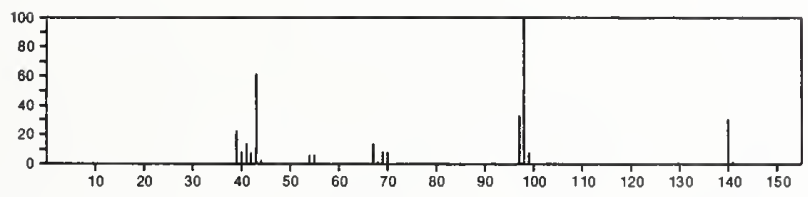

140

$\mathrm{C}_{6} \mathrm{H}_{8} \mathrm{~N}_{2} \mathrm{O}_{2}$

13223-74-0

Acetamide, $N$-(5-methyl-3-isoxazolyl)-
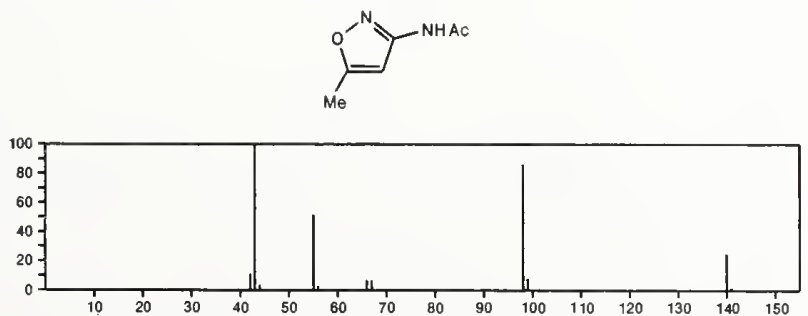

$140 \quad \mathrm{C}_{6} \mathrm{H}_{8} \mathrm{~N}_{2} \mathrm{O}_{2}$

2,4(1H,3H)-Pyrimidinedione, 3,6-dimethyl-

$19674-60-3$<smiles>Cc1cc(=O)n(C)c(=O)[nH]1</smiles>

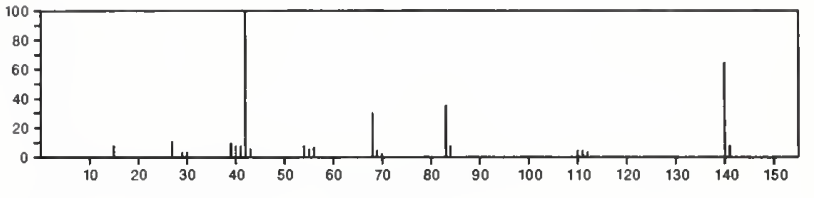

140

$\mathrm{C}_{6} \mathrm{H}_{8} \mathrm{~N}_{2} \mathrm{~S}$

Pyrazine, 2-methyl-3-(methylthio)-

$2882-20-4$<smiles>[13CH3]c1nccnc1[Mg]</smiles>

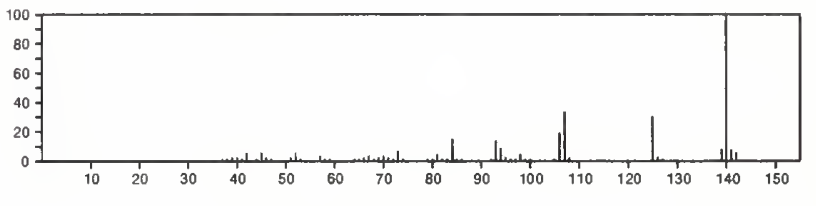

140

$\mathrm{C}_{6} \mathrm{H}_{8} \mathrm{~N}_{2} \mathrm{~S}$

Pyrazine, 2-methyl-6-(methylthio)-

$2884-13-1$<smiles>COc1cncc(O)n1</smiles>

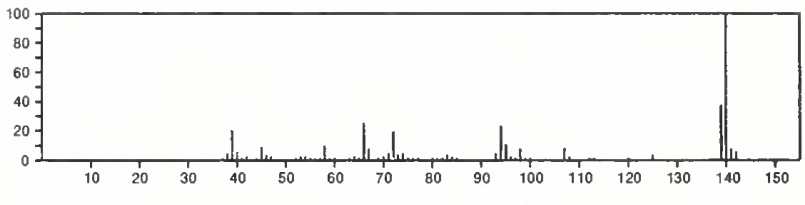

$140 \quad \mathrm{C}_{6} \mathrm{H}_{8} \mathrm{~N}_{2} \mathrm{~S}$

Pyrimidine, 2-methyl-4-(methylthio)-

$33779-33-8$
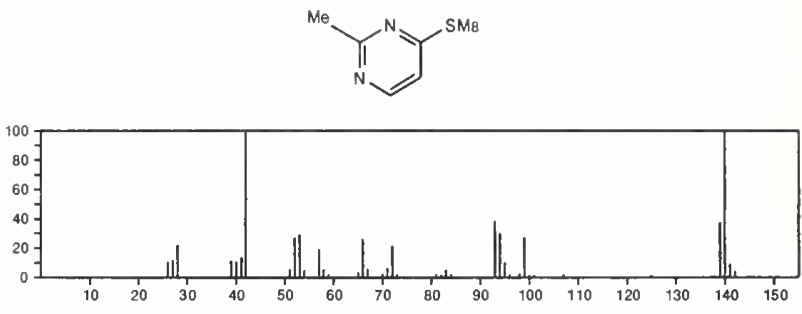

140
$1 H^{-}$-Imidazole, 1-(trimethylsilyl)-

$18156-74-6$

$\widehat{N}_{N}^{N-S i M e 3}$

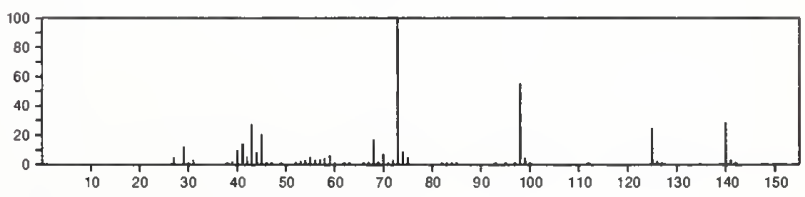


140

$\mathrm{C}_{6} \mathrm{H}_{12} \mathrm{~N}_{2} \mathrm{Si}$

1H-Pyrazole, 1-(trimethylsilyl)-
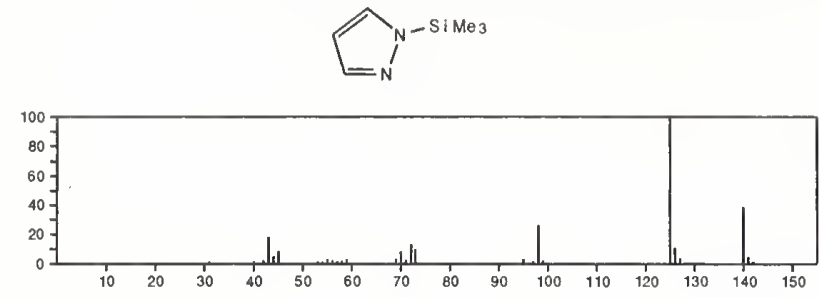

$140 \quad \mathrm{C}_{6} \mathrm{H}_{12} \mathrm{~N}_{2} \mathrm{Si}$

1H-Pyrazole, 4-(trimethylsilyl)-

$34690-52-3$
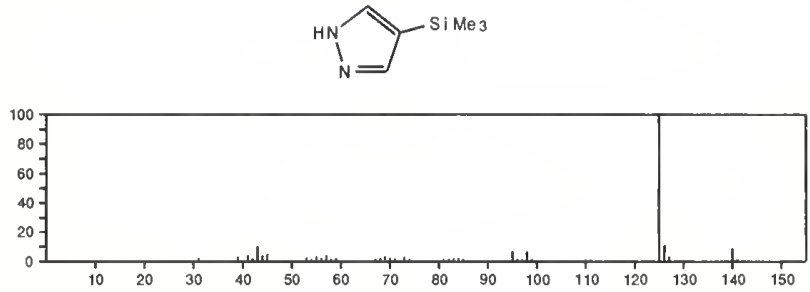

140

$\mathrm{C}_{6} \mathrm{H}_{12} \mathrm{~N}_{4}$

100-97-0

1,3,5,7-Tetraazatricyclo[3.3.1.13,7]decane
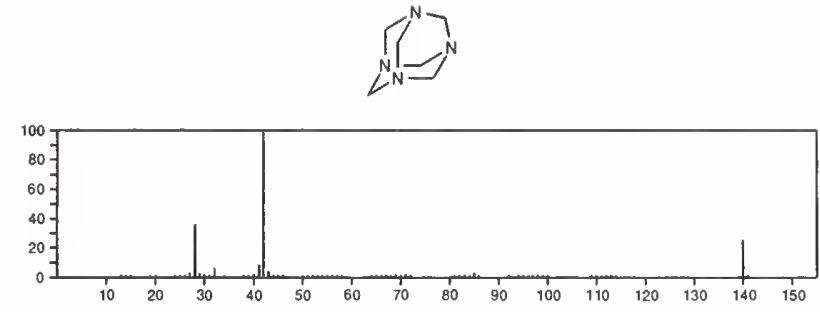

140

Benzaldehyde, 2-chloro-

$\mathrm{C}_{7} \mathrm{H}_{5} \mathrm{ClO}$

$89-98-5$
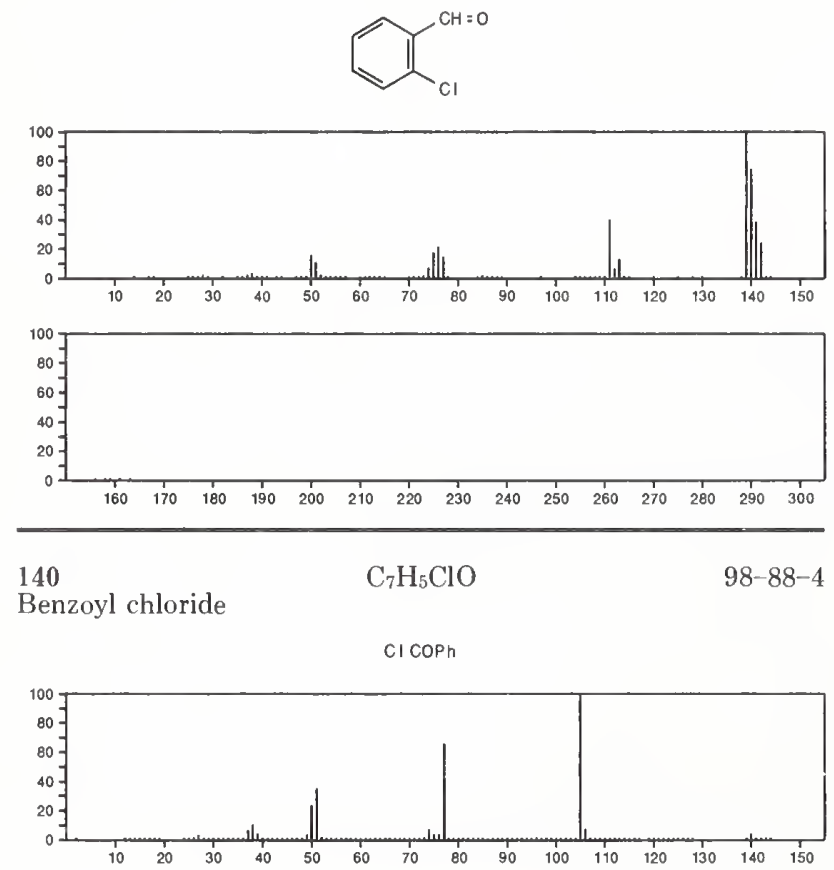

140

Benzaldehyde, 4-chloro

$\mathrm{C}_{7} \mathrm{H}_{5} \mathrm{ClO}$

$104-88-1$
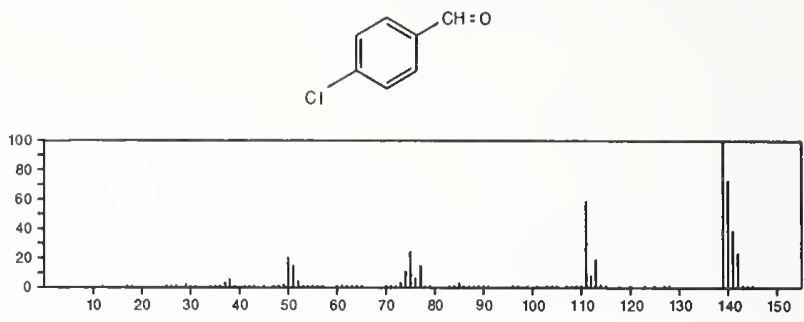

140

Benzaldehyde, 3-chloro-

$\mathrm{C}_{7} \mathrm{H}_{5} \mathrm{ClO}$

$587-04-2$
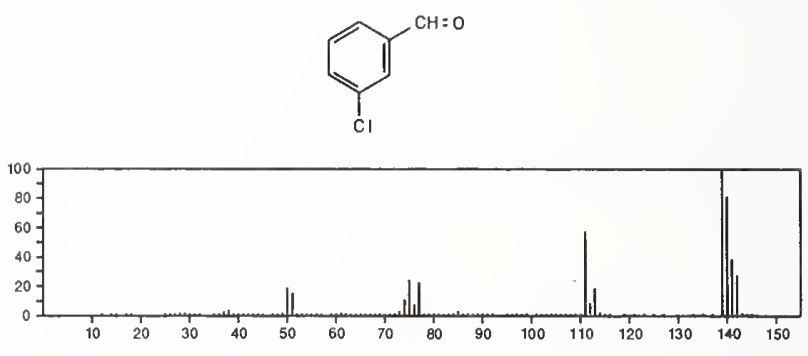

140

Benzoic acid, 2-fluoro-

$\mathrm{C}_{7} \mathrm{H}_{5} \mathrm{FO}_{2}$

445-29-4<smiles>O=C(O)c1ccccc1F</smiles>

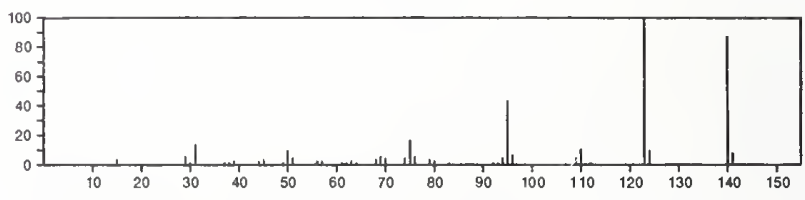

140

Phenol, 2-(methylthio)-

$\mathrm{C}_{7} \mathrm{H}_{8} \mathrm{OS}$

1073-29-6
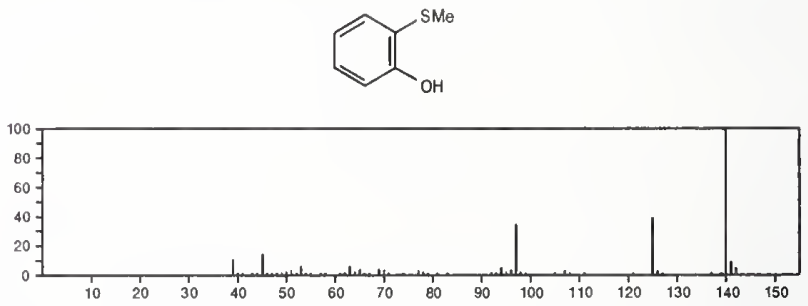

140

$\mathrm{C}_{7} \mathrm{H}_{8} \mathrm{OS}$

1073-72-9

Phenol, 4-(methylthio)-
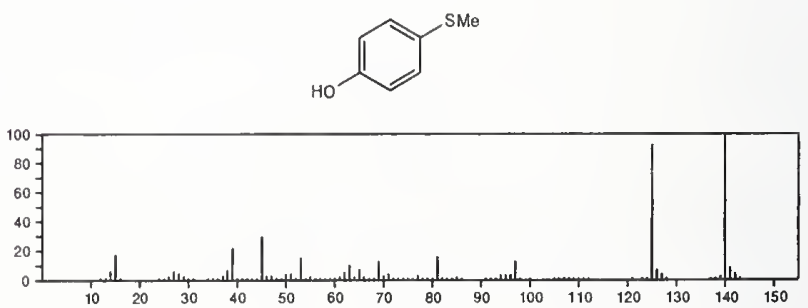
140

$\mathrm{C}_{7} \mathrm{H}_{8} \mathrm{O}_{3}$

$623-17-6$

2-Furanmethanol, acetate

$\mathbb{C}^{\mathrm{C}} \mathrm{CH}_{2} \mathrm{OAC}$

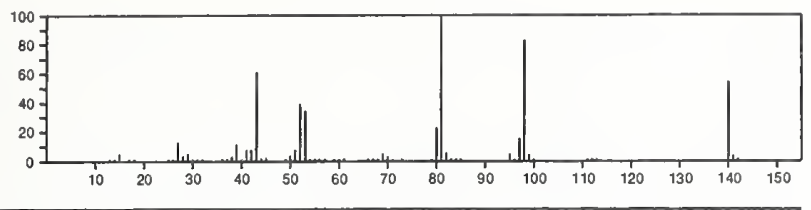

$140 \quad \mathrm{C}_{7} \mathrm{H}_{8} \mathrm{O}_{3}$

2H-Pyran-2-one, 4-methoxy-6-methyl-
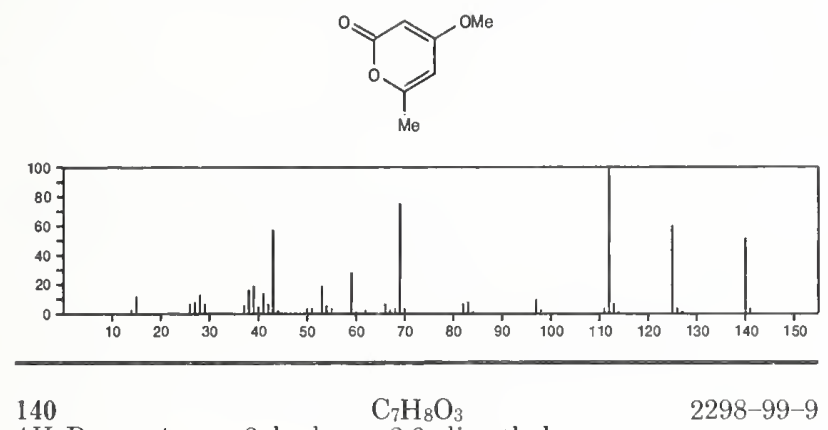

4H-Pyran-4-one, 3-hydroxy-2,6-dimethyl-
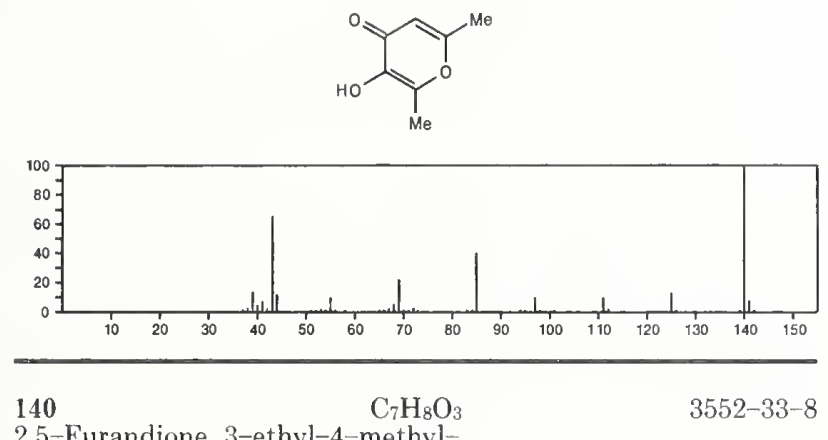

$3552-33-8$

2,5-Furandione, 3-ethyl-4-methyl-
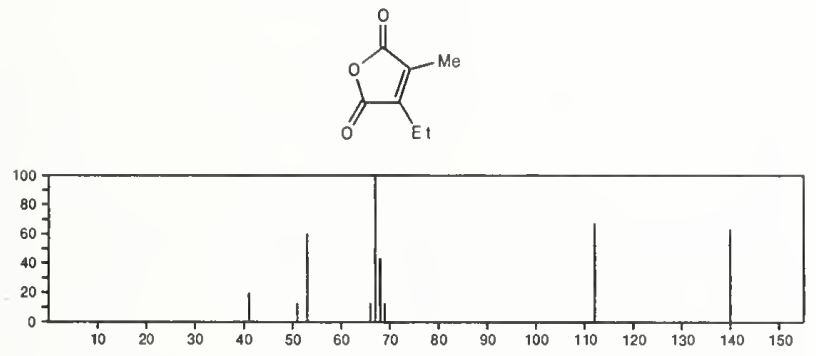

140

1,3-Cyclopentanedione, 2-acetyl-

$\mathrm{C}_{7} \mathrm{H}_{8} \mathrm{O}_{3}$
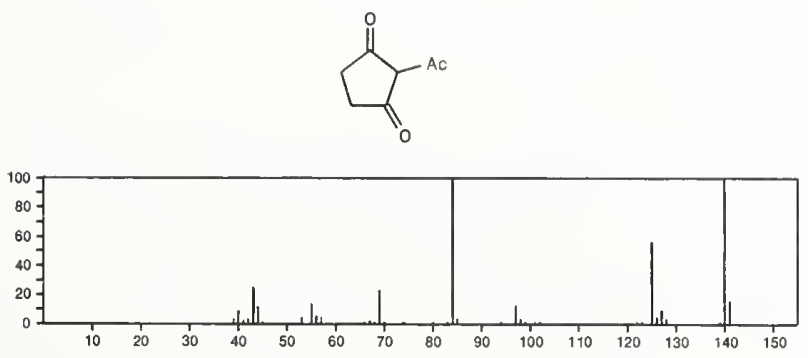

140

$\mathrm{C}_{7} \mathrm{H}_{8} \mathrm{O}_{3}$

4H-Pyran-4-one, 2-methoxy-6-methyl-

$4225-42-7$<smiles>COc1cc(=O)cc(O)o1</smiles>

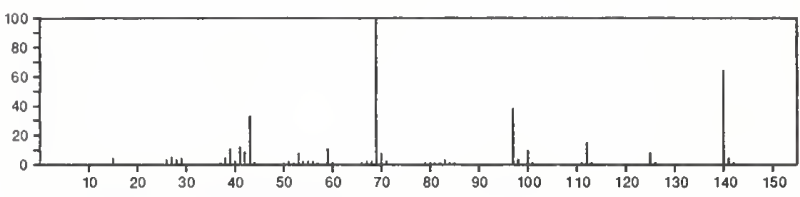

140

$\mathrm{C}_{7} \mathrm{H}_{8} \mathrm{O}_{3}$

$4505-53-7$

1,2,4-Cyclopentanetrione, 3-ethyl-
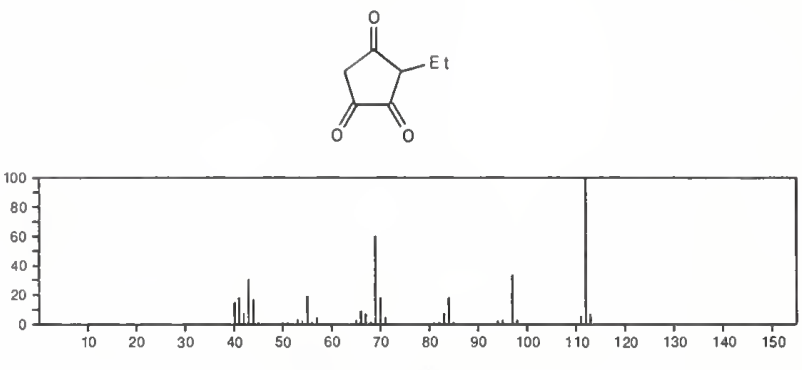

140

$\mathrm{C}_{7} \mathrm{H}_{8} \mathrm{O}_{3}$

$4940-11-8$

$4 \mathrm{H}$-Pyran-4-one, 2-ethyl-3-hydroxy-
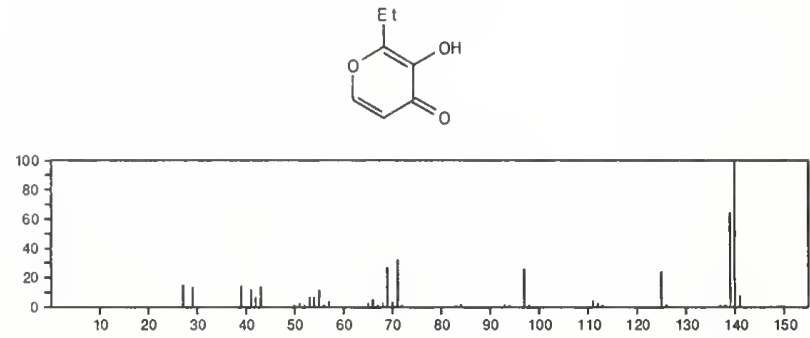

140

$\mathrm{C}_{7} \mathrm{H}_{8} \mathrm{O}_{3}$

$5192-62-1$

2H-Pyran-2-one, 4-hydroxy-3,6-dimethyl-<smiles>Cc1cc(O)c(C)c(=O)o1</smiles>

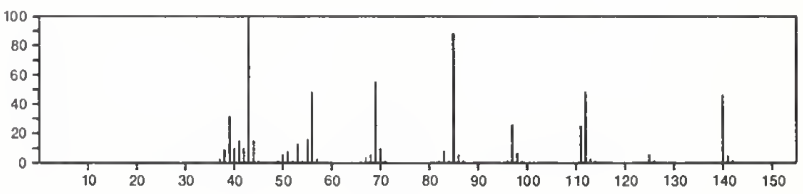

${ }_{4} \mathrm{C}_{7} \mathrm{H}_{8} \mathrm{O}_{3}$
4-Cyclopentene-1,3-dione,
$4-$ methoxy-5-methyl-

$7180-62-3$
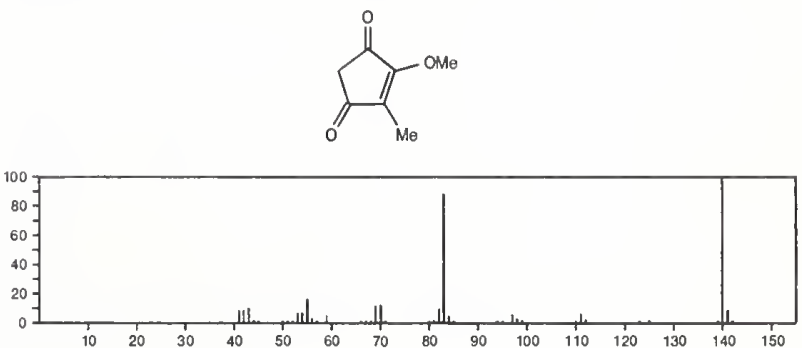
$140 \quad \mathrm{C}_{7} \mathrm{H}_{8} \mathrm{O}_{3}$

1,2,4-Cyclopentanetrione, 3,3-dimethyl
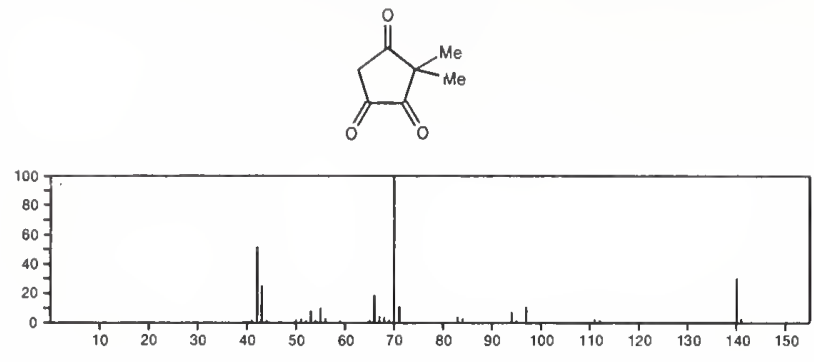

$140 \quad \mathrm{C}_{7} \mathrm{H}_{8} \mathrm{O}_{3}$

2-Pentynoic acid, 4-oxo-, ethyl ester

$54966-49-3$

Et OC $(0) C \equiv C C O M$

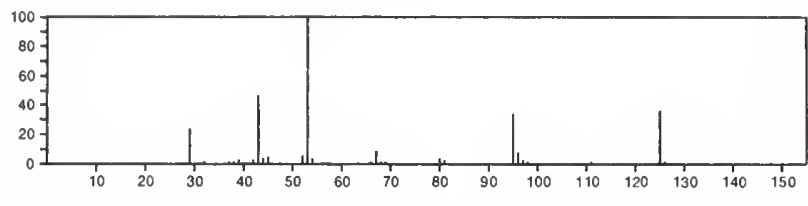

140

$\mathrm{C}_{7} \mathrm{H}_{8} \mathrm{O}_{3}$

$56666-81-0$

2-Oxabicyclo[3.1.0]hex-3-ene-4-carboxylic acid, methyl ester
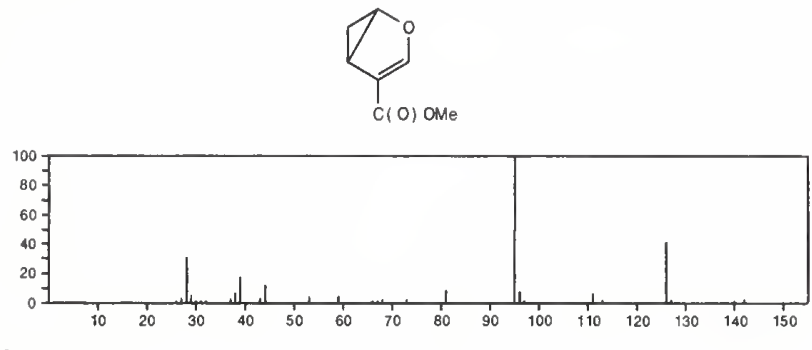

140

Urea, $N, N^{\prime}$-di-2-propenyl-

$\mathrm{C}_{7} \mathrm{H}_{12} \mathrm{~N}_{2} \mathrm{O}$

$1801-72-5$

$\mathrm{H}_{2} \mathrm{C}=\mathrm{CHCH}_{2} \mathrm{NHCONHCH}_{2} \mathrm{CH}=\mathrm{CH}_{2}$

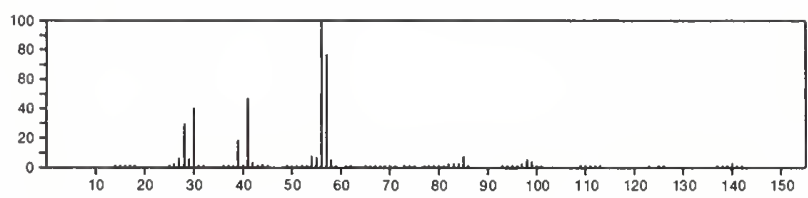

$\mathrm{C}_{7} \mathrm{H}_{12} \mathrm{~N}_{2} \mathrm{O}$

$3201-25-0$

140

hydro-2,4,4,5-tetramethyl-
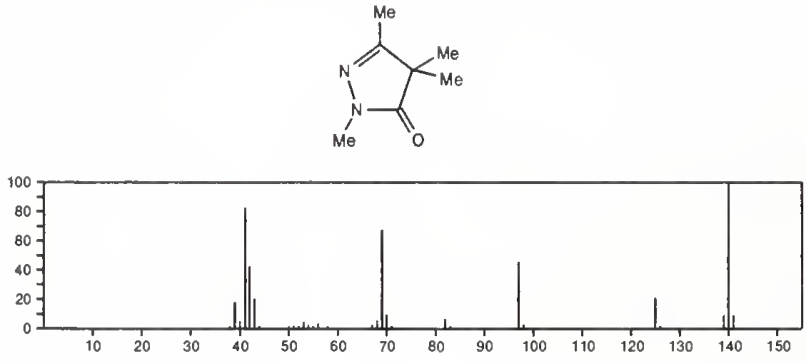

$140 \quad \mathrm{C}_{7} \mathrm{H}_{12} \mathrm{~N}_{2} \mathrm{O}$

$49582-42-5$

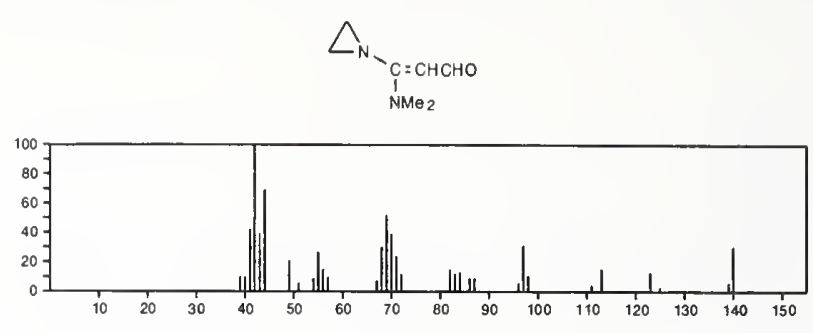

140

Benzene, (2,2-difluoroethenyl)-

$\mathrm{C}_{8} \mathrm{H}_{6} \mathrm{~F}_{2}$

$405-42-5$

$\mathrm{F}_{2} \mathrm{C}=\mathrm{CHPh}$

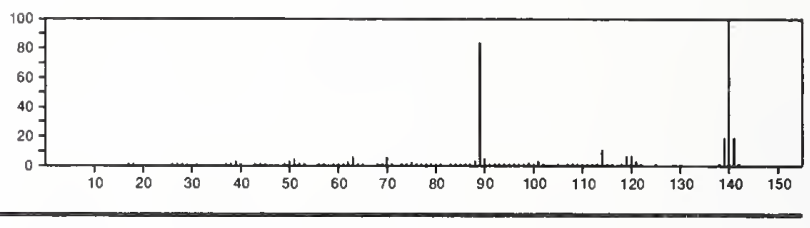

140

$\mathrm{C}_{8} \mathrm{H}_{9} \mathrm{Cl}$

$89-96-3$

Benzene, 1-chloro-2-ethyl-
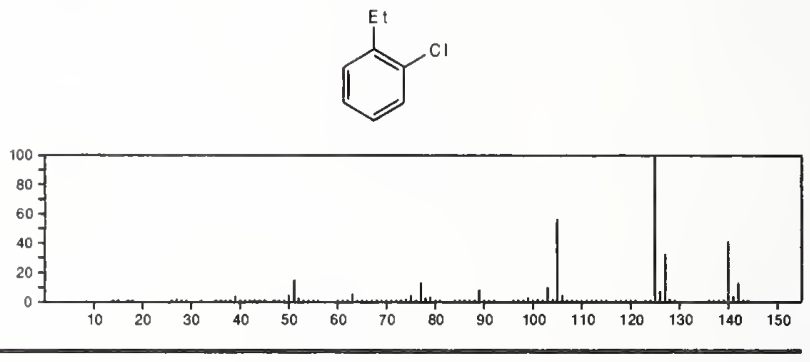

140

$\mathrm{C}_{8} \mathrm{H}_{9} \mathrm{Cl}$

Benzene, 1-chloro-2,4-dimethyl-

$95-66-9$
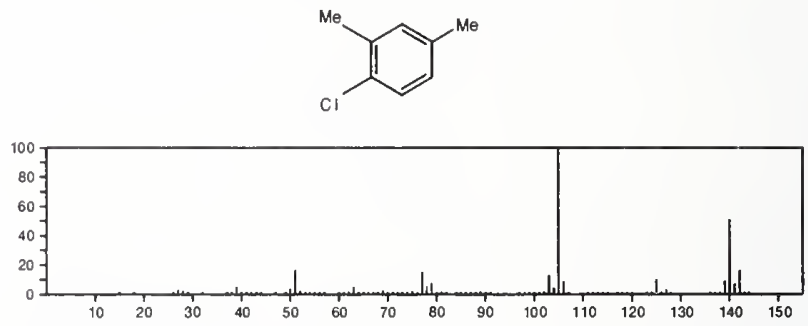

140

$\mathrm{C}_{8} \mathrm{H}_{9} \mathrm{Cl}$

$95-72-7$

Benzene, 2-chloro-1,4-dimethyl-
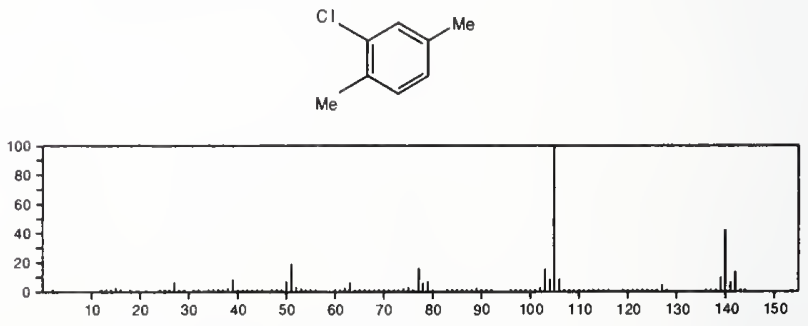
140 $\mathrm{C}_{8} \mathrm{H}_{9} \mathrm{Cl}$

Benzene, 1-(chloromethyl)-4-methyl-
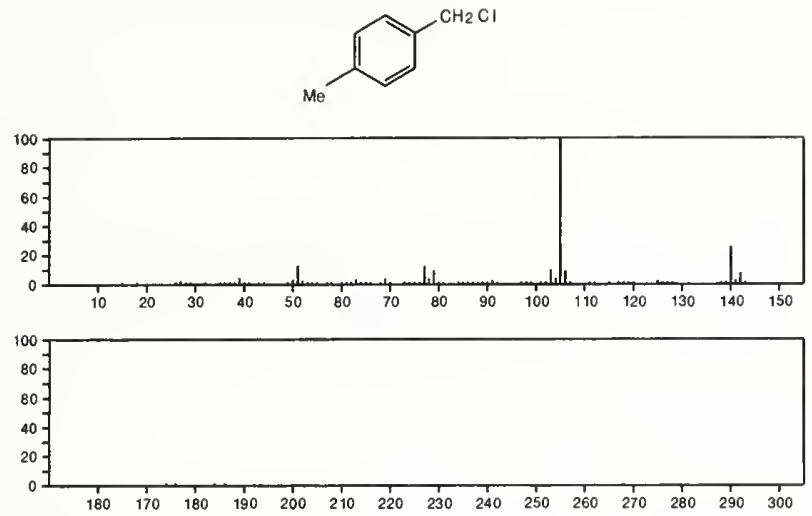

\section{$140 \quad \mathrm{C}_{8} \mathrm{H}_{9} \mathrm{Cl}$}

Benzene, 1-(chloromethyl)-2-methyl-
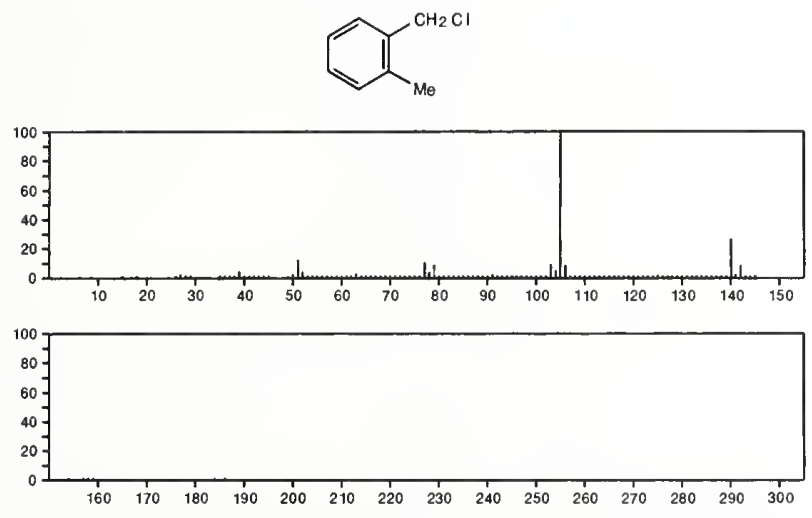

140

$\mathrm{C}_{8} \mathrm{H}_{9} \mathrm{Cl}$

Benzene, 4-chloro-1,2-dimethyl-
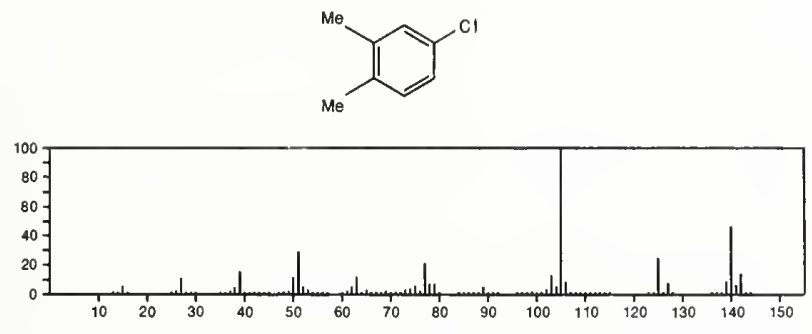

140

Benzene, 1-chloro-3-ethyl-

$$
\mathrm{C}_{8} \mathrm{H}_{9} \mathrm{Cl}
$$

$620-16-6$
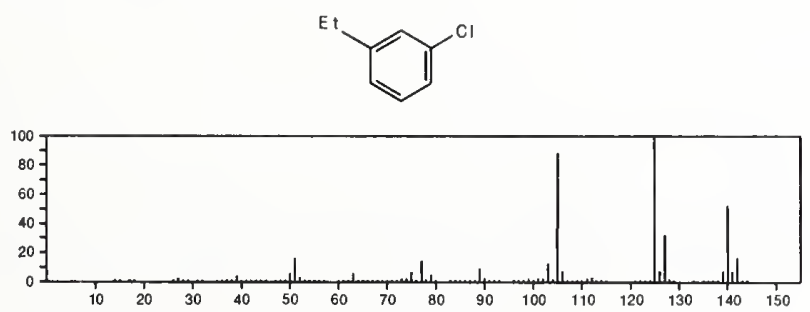

140 $\mathrm{C}_{8} \mathrm{H}_{9} \mathrm{Cl}$

Benzene, 1-(chloromethyl)-3-methyl-

$620-19-9$
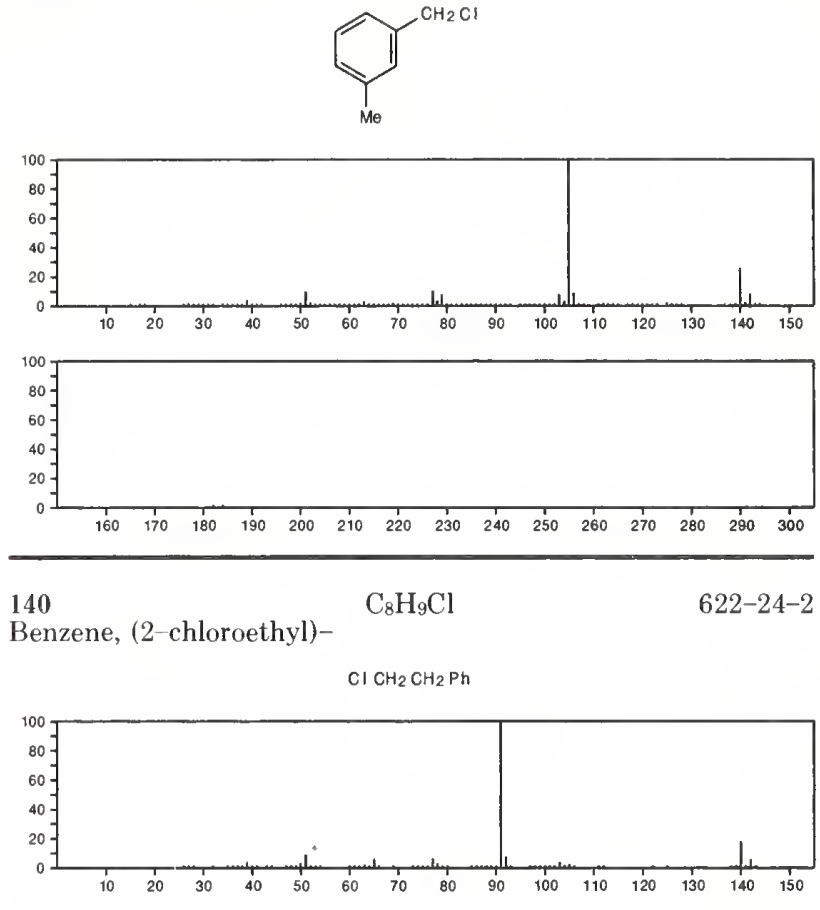

140

$\mathrm{C}_{8} \mathrm{H}_{9} \mathrm{Cl}$

622-98-0

Benzene, 1-chloro-4-ethyl
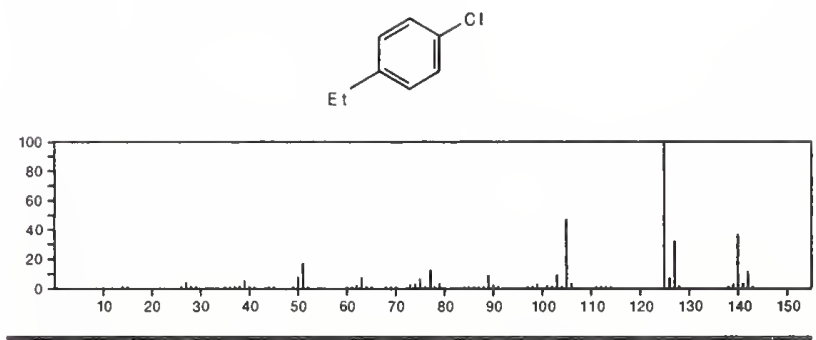

140

$\mathrm{C}_{8} \mathrm{H}_{9} \mathrm{Cl}$

$672-65-1$

Benzene, (1-chloroethyl)-
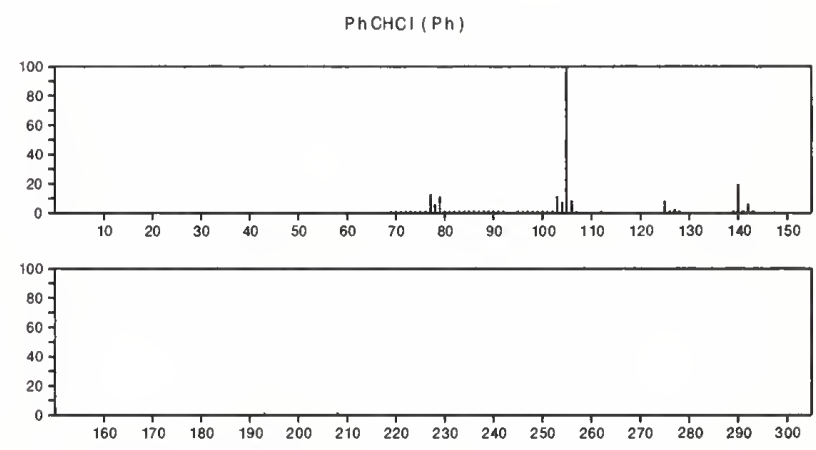

140

$\mathrm{C}_{8} \mathrm{H}_{9} \mathrm{Cl}$

6781-98-2

Benzene, 2-chloro-1,3-dimethyl-
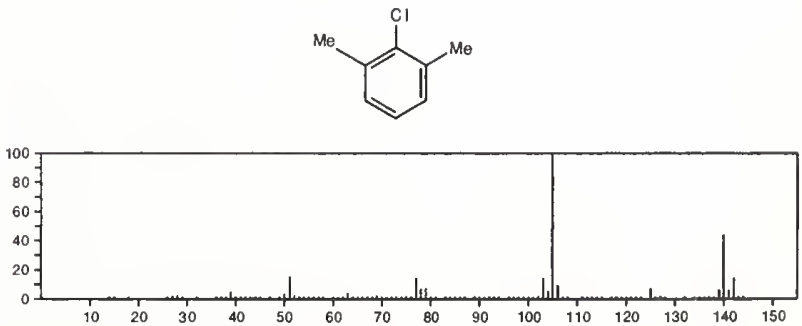
140

o-Xylene, chloro-

$\mathrm{C}_{8} \mathrm{H}_{9} \mathrm{Cl}$

$26445-11-4$

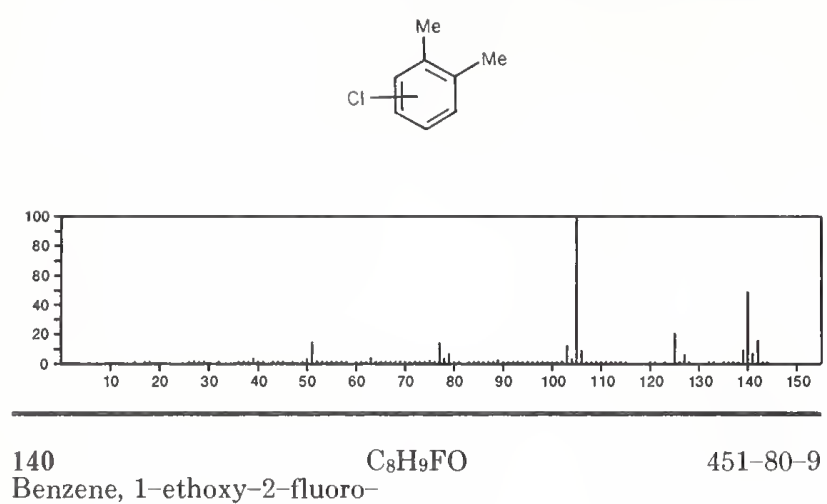

Benzene, 1-ethoxy-2-fluoro-
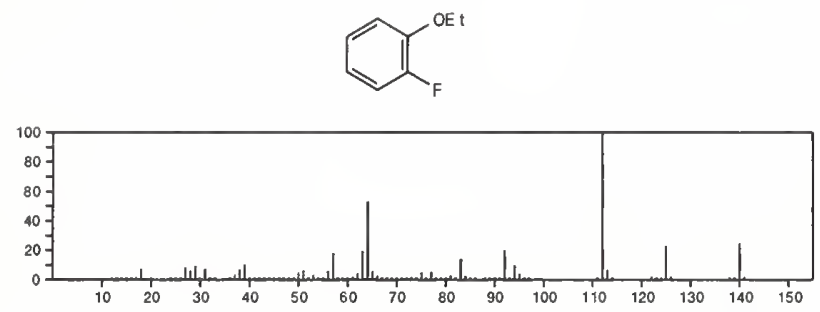

140

Benzene, 1-ethoxy-4-fluoro-

$\mathrm{C}_{8} \mathrm{H}_{9} \mathrm{FO}$

459-26-7
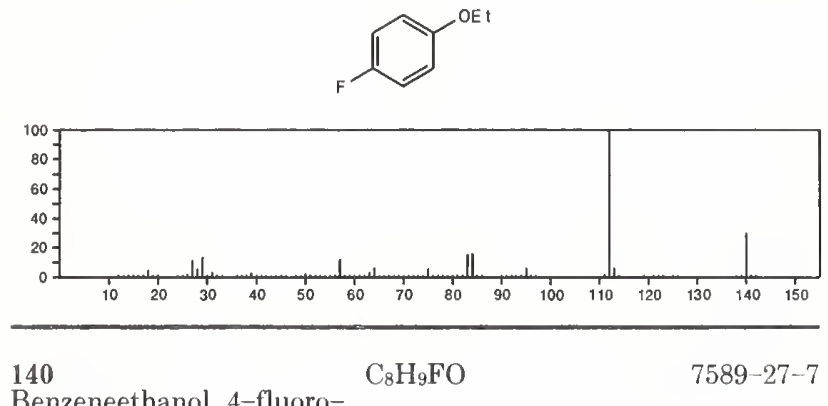

Benzeneethanol, 4-fluoro-
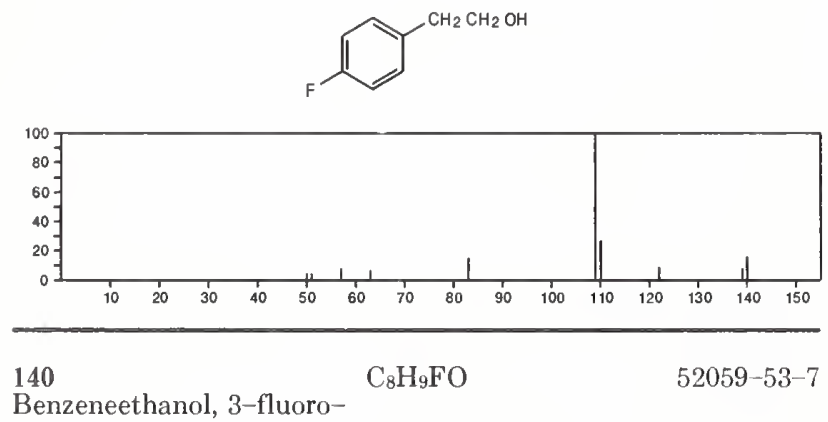

Benzeneethanol, 3-fluoro-
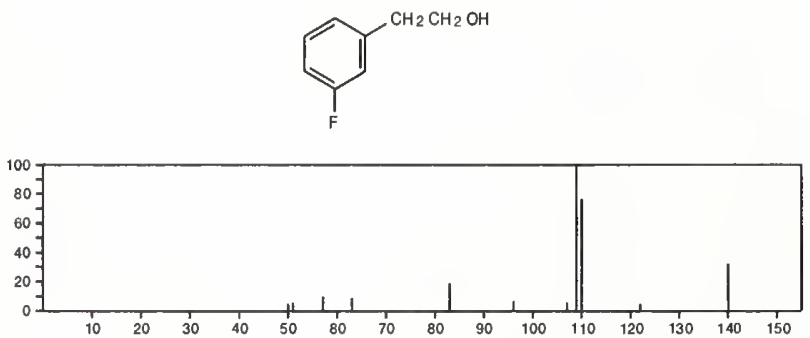

140

Bicyclo[3.1.0]hexan-2-ol, acetate, $(1 \alpha, 2 \beta, 5 \alpha)-$

698-56-6
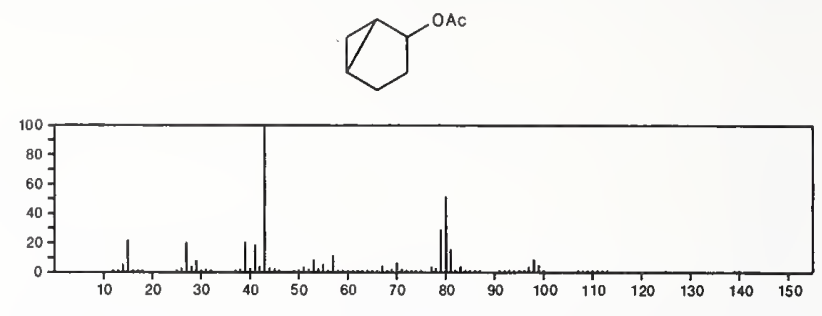

140

Cyclohexanone, 2-acetyl-

$\mathrm{C}_{8} \mathrm{H}_{12} \mathrm{O}_{2}$

$874-23-7$
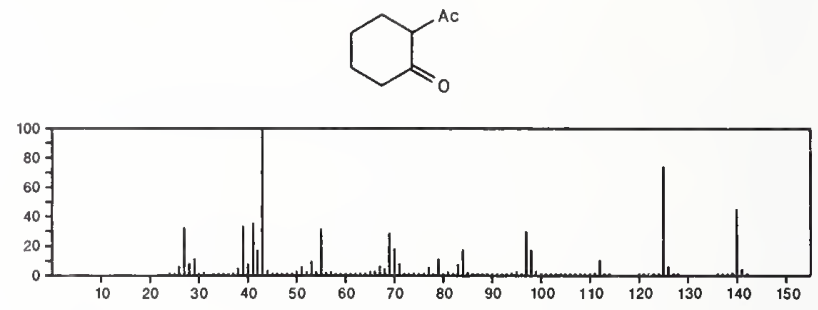

140

$\mathrm{C}_{8} \mathrm{H}_{12} \mathrm{O}_{2}$

$1004-58-6$

1,4-Dioxaspiro[4.5]dec-6-ene
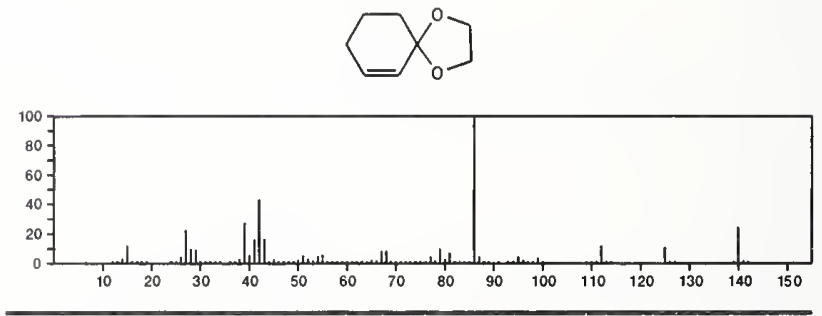

140

$\mathrm{C}_{8} \mathrm{H}_{12} \mathrm{O}_{2}$

$1424-22-2$

1-Cyclohexen-1-ol, acetate
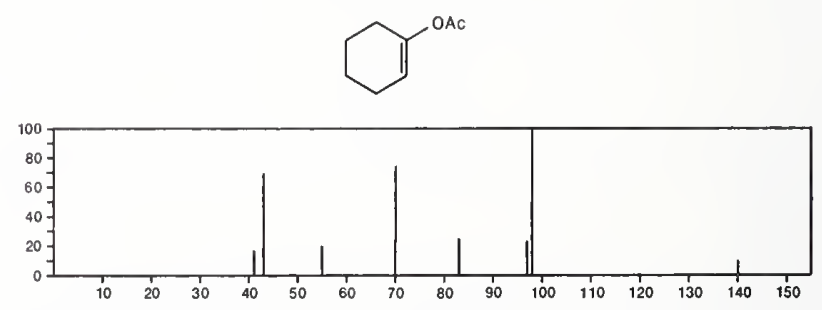

$140 \quad \mathrm{C}_{8} \mathrm{H}_{12} \mathrm{O}_{2} \quad 1920-21-4$ 2H-Pyran-2-carboxaldehyde, 3,4-dihydro-2,5-dimethyl-
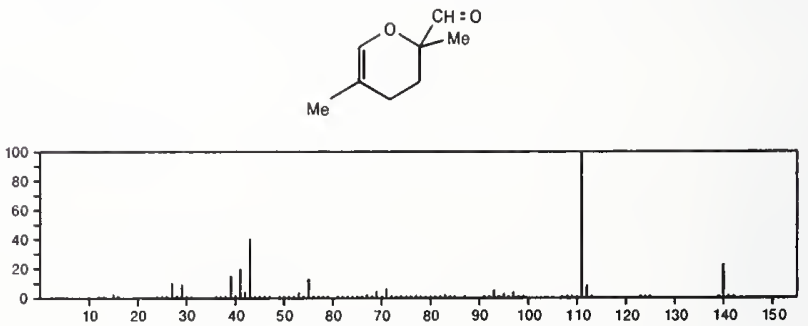
140

$\mathrm{C}_{8} \mathrm{H}_{12} \mathrm{O}_{2}$

2,4-Pentanedione, 3-(2-propenyl)-

come

$\mathrm{H}_{2} \mathrm{C}=\mathrm{CHCH}_{2} \mathrm{CHCOM}_{\mathrm{O}}$

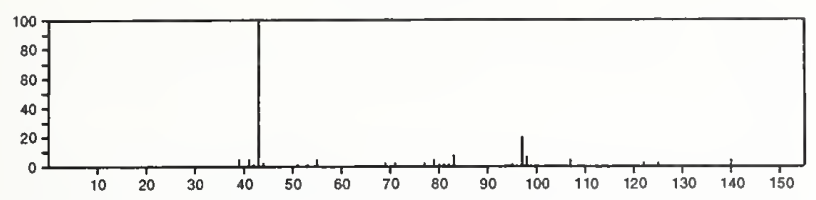

$140 \quad \mathrm{C}_{8} \mathrm{H}_{12} \mathrm{O}_{2}$

$2 H$-Pyran, tetrahydro-2-(2-propynyloxy)-
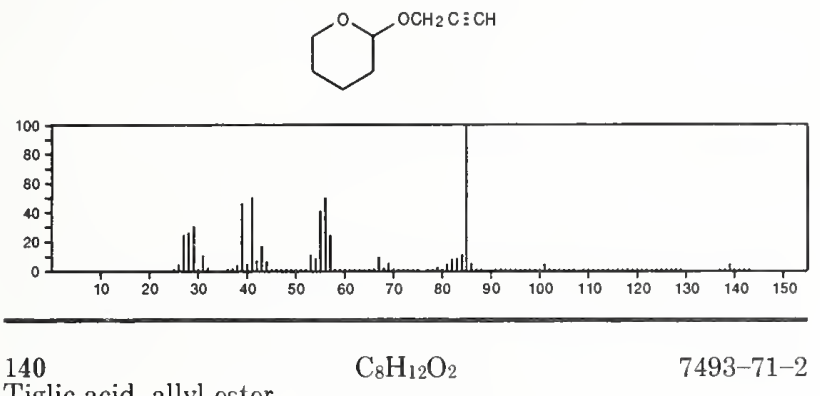

Tiglic acid, allyl ester

$\mathrm{H}_{2} \mathrm{C}=\mathrm{CHCH}_{2} \mathrm{OC}(\mathrm{O}) \mathrm{CMe}=\mathrm{CHMe}$

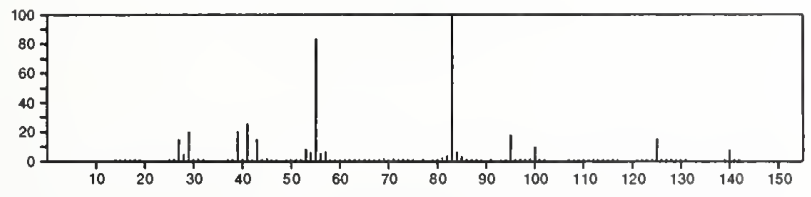

140-Cyclohexen-1-ol, acetate $\mathrm{C}_{8} \mathrm{H}_{12} \mathrm{O}_{2} \quad 10437-78-2$
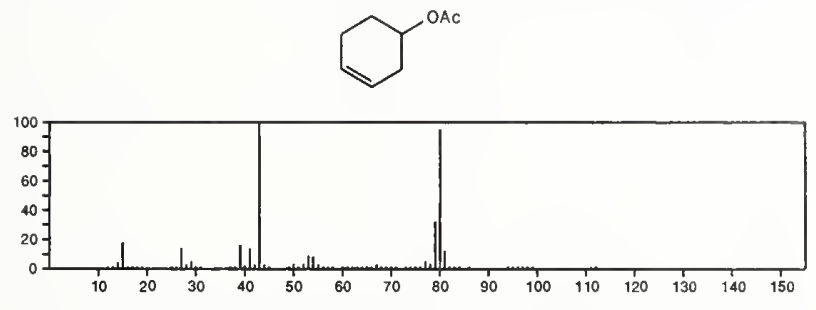

140

$\mathrm{C}_{8} \mathrm{H}_{12} \mathrm{O}_{2}$

$15121-01-4$

Ethanone, 1-(7-oxabicyclo[4.1.0]hept-1-yl)-
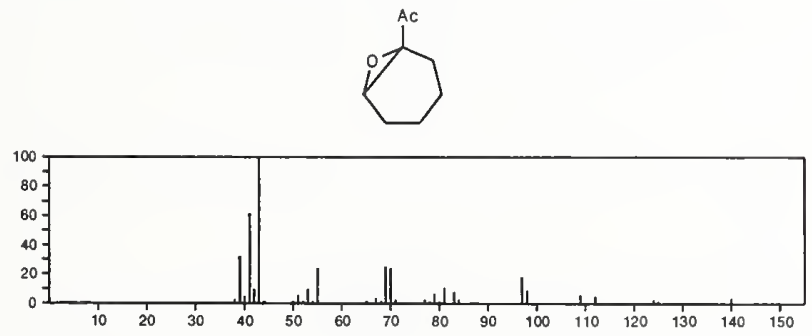

140

$\mathrm{C}_{8} \mathrm{H}_{12} \mathrm{O}_{2}$

Cyclopentanecarboxylic acid, ethenyl ester

16523-06-1
140

p-Dioxane, 2,5-divinyl-

$\mathrm{C}_{8} \mathrm{H}_{12} \mathrm{O}_{2}$

$21485-51-8$
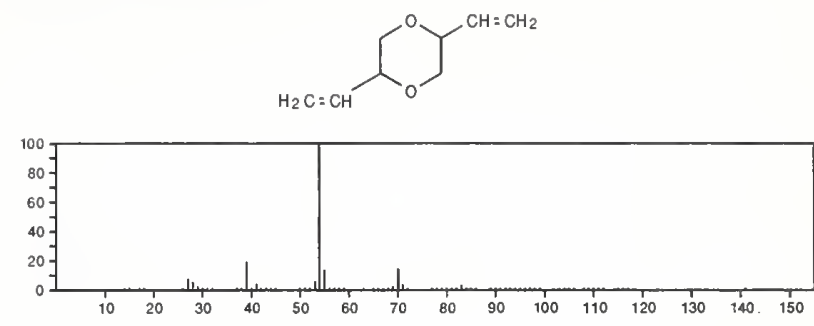

140

1,4-Dioxaspiro[4.4]nonane, 6-methylene-

$23153-75-5$
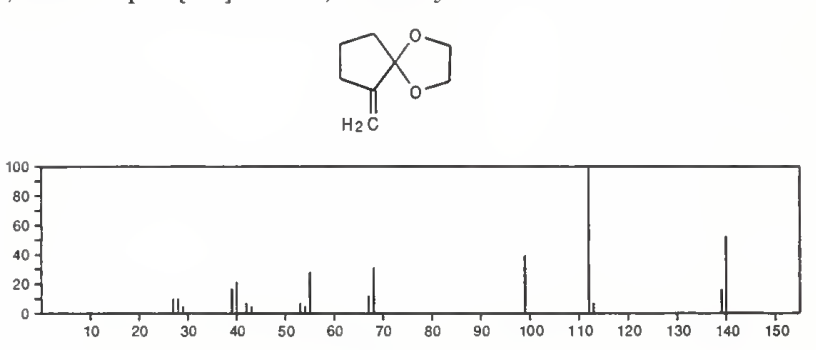

140

$\mathrm{C}_{8} \mathrm{H}_{12} \mathrm{O}_{2}$

1,3-Cyclopentanedione, 2-ethyl-2-methyl-

$25112-87-2$
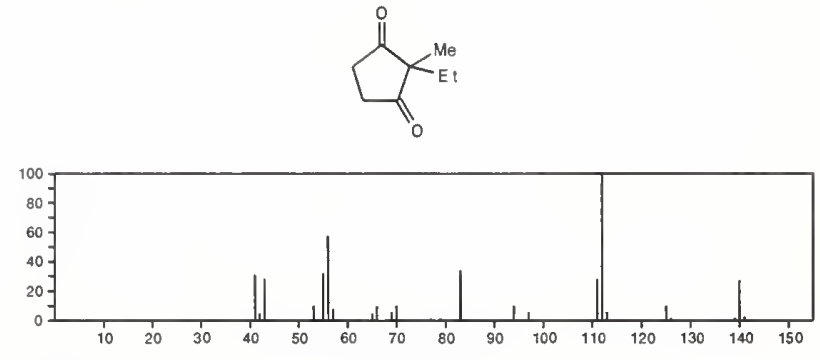

140

$\mathrm{C}_{8} \mathrm{H}_{12} \mathrm{O}_{2}$

1,3-Pentadien-2-ol, 4-methyl-, acetate

$34645-17-5$ $\mathrm{CH}_{2}$

$\mathrm{Me}_{2} \mathrm{C}=\mathrm{CHCOAC}$

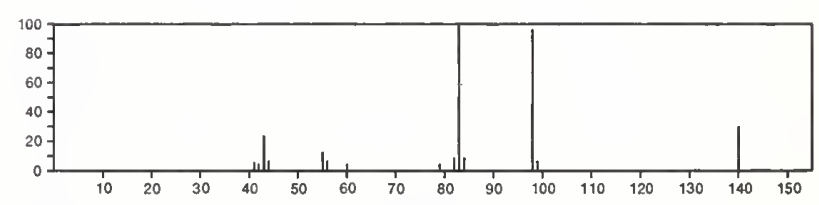

140

$\mathrm{C}_{8} \mathrm{H}_{12} \mathrm{O}_{2}$

$38653-28-0$

Cyclopentanol, 2-(2-propynyloxy)-, trans-
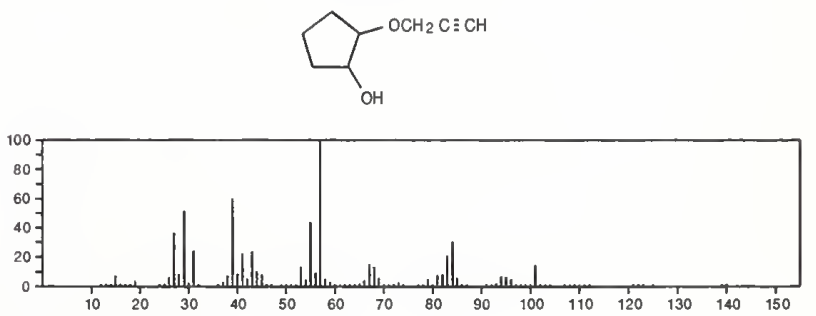

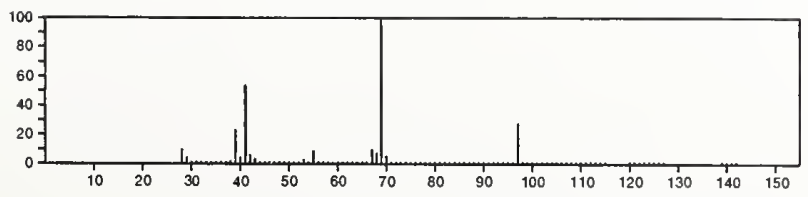


140

$\mathrm{C}_{8} \mathrm{H}_{12} \mathrm{O}_{2}$

$38653-39-3$

$2 H, 6 H$-Cyclopenta[b][1,4]dioxepin, 5a,7,8,8a-tetrahydro-, trans-
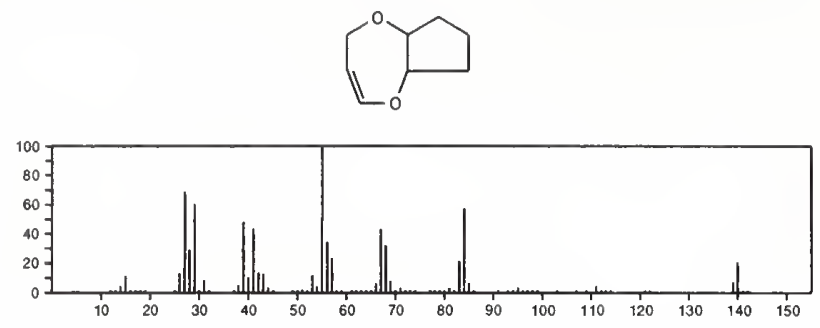

140

$\mathrm{C}_{8} \mathrm{H}_{12} \mathrm{O}_{2}$

38653-47-3

5H-Cyclopenta-1,4-dioxin, 4a,6,7,7a-tetrahydro-2-methyl-, trans-<smiles>CC1=COC2CCCC2O1</smiles>

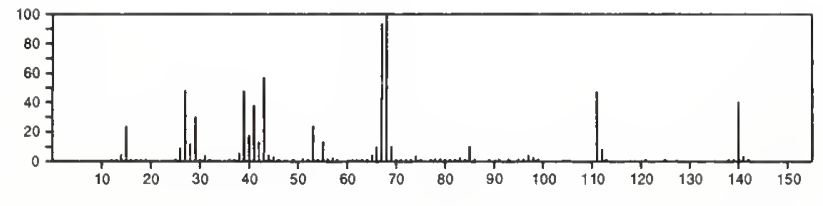

140

$\mathrm{C}_{8} \mathrm{H}_{12} \mathrm{O}_{2}$

2-Pentanone, 5-(1,2-propadienyloxy)-

$55702-69-7$

$\mathrm{MeCO}\left(\mathrm{CH}_{2}\right)_{3} \mathrm{OCH}=\mathrm{C}=\mathrm{CH}_{2}$

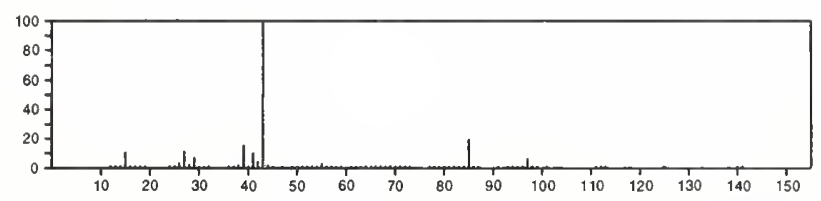

140

$\mathrm{C}_{8} \mathrm{H}_{12} \mathrm{O}_{2}$

55702-70-0

2-Pentanone, 5-(2-propynyloxy)-

$\mathrm{Me} \mathrm{CO}\left(\mathrm{CH}_{2}\right)_{3} \mathrm{OCH}_{2} \mathrm{C} \equiv \mathrm{CH}$

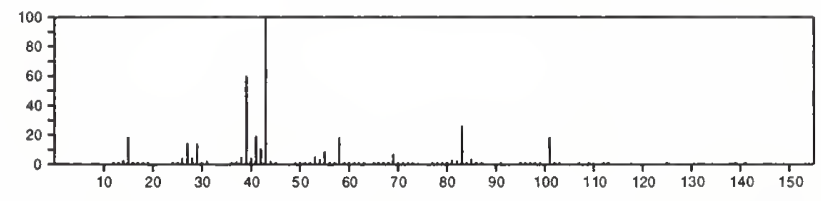

$140 \quad \mathrm{C}_{8} \mathrm{H}_{12} \mathrm{O}_{2}$

1,4-Benzodioxin, 2,3,4a,5,6,7-hexahydro-

$55702-71-1$<smiles>C1=C2OCCOC2CCC1</smiles>

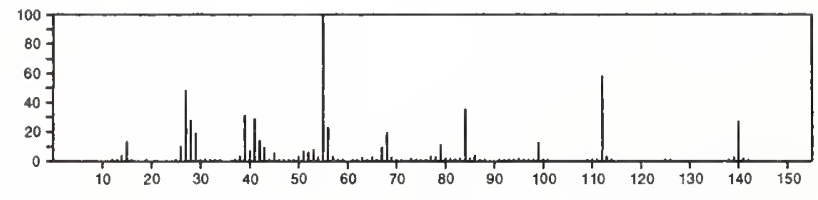

$140 \quad \mathrm{C}_{8} \mathrm{H}_{12} \mathrm{O}_{2}$

6-Heptynoic acid, methyl ester

$\mathrm{HC} \equiv \mathrm{C}\left(\mathrm{CH}_{2}\right)_{4} \mathrm{C}(\mathrm{O}) \mathrm{OMe}$

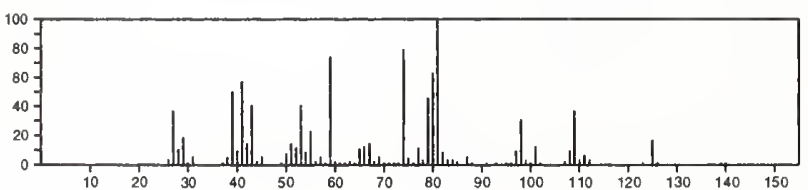

140

Thiophene, 2-butyl-

$\mathrm{C}_{8} \mathrm{H}_{12} \mathrm{~S}$

$1455-20-5$

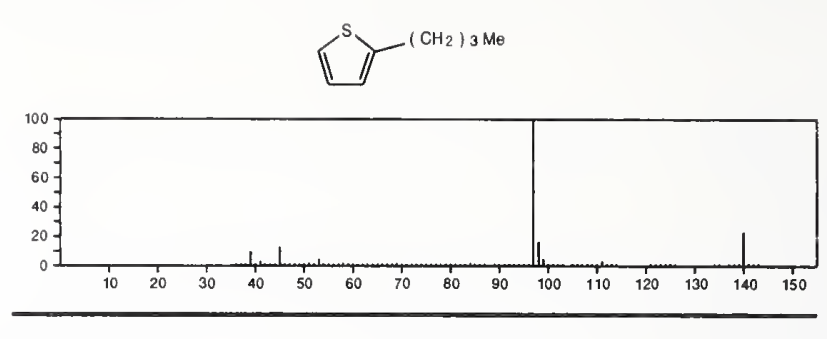

140

$\mathrm{C}_{8} \mathrm{H}_{12} \mathrm{~S}$

Thiophene, 2-(1,1-dimethylethyl)-

1689-78-7
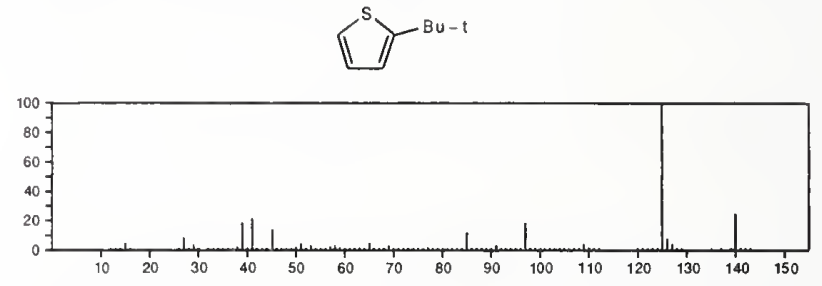

140

$\mathrm{C}_{8} \mathrm{H}_{12} \mathrm{~S}$

Thiophene, 3-(1,1-dimethylethyl)-

$1689-79-8$
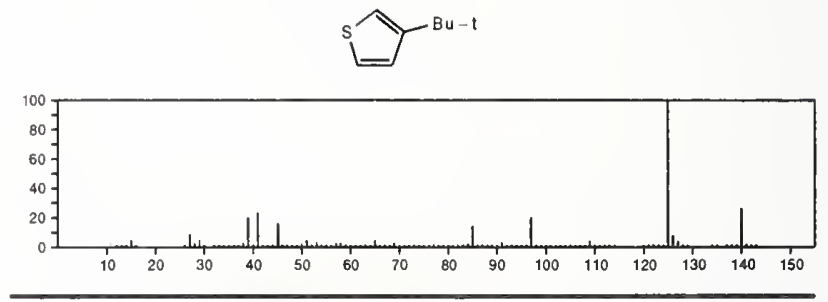

140

$\mathrm{C}_{8} \mathrm{H}_{12} \mathrm{~S}$

$30221-53-5$

2-Cyclopentene-1-thione, 3,4,4-trimethyl-
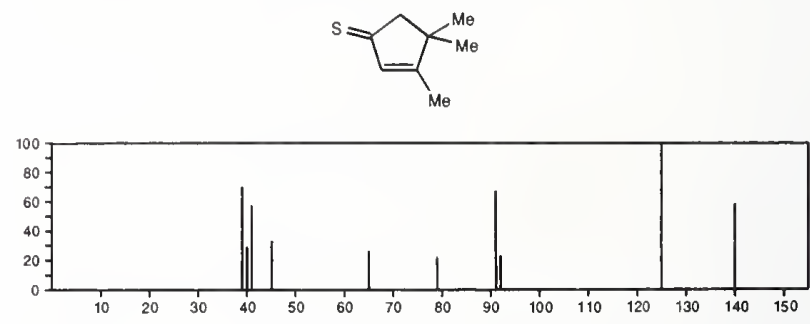

${ }_{2}^{140}$
$2-$ Cyclopentene-1-thione,
$2-$ ethyl-3-methyl-

38693-67-3
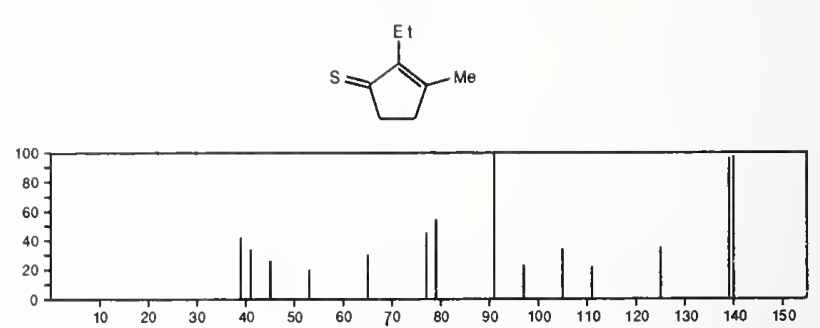
140 $\mathrm{C}_{8} \mathrm{H}_{16} \mathrm{~N}_{2}$

Cyclohexanone, dimethylhydrazone
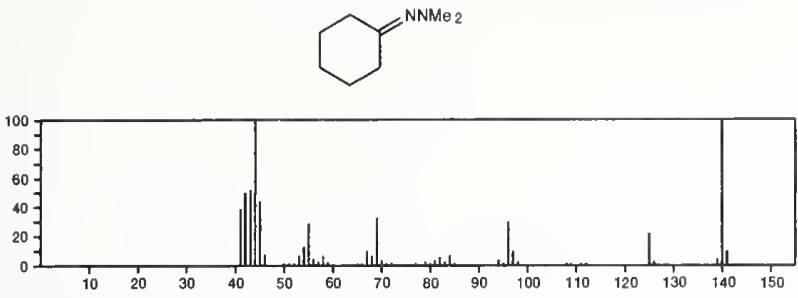

140

$\mathrm{C}_{9} \mathrm{H}_{16} \mathrm{O}$

Cyclohexanone, 2-propyl-
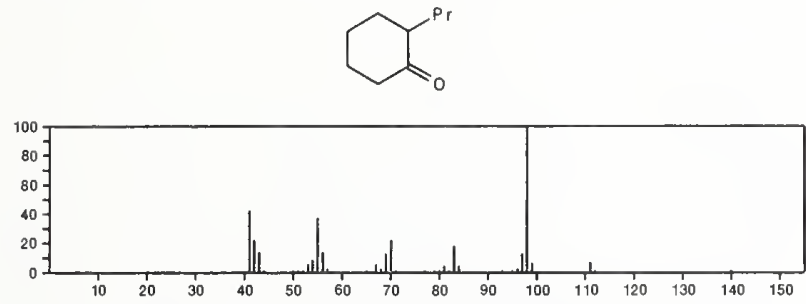

\section{0}

$\mathrm{C}_{9} \mathrm{H}_{16} \mathrm{O}$

$515-28-6$

Bicyclo[2.2.1]heptan-2-ol, 3,3-dimethyl-, exo-
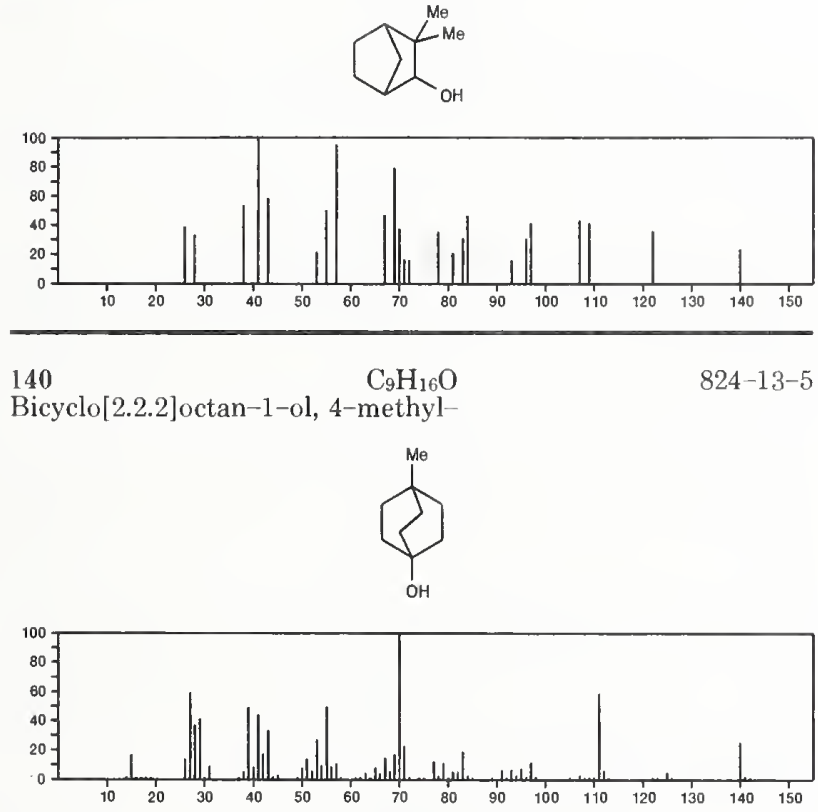

140

Cyclohexanone, 3,3,5-trimethyl- $\mathrm{C}_{9} \mathrm{H}_{16} \mathrm{O}$

873-94-9
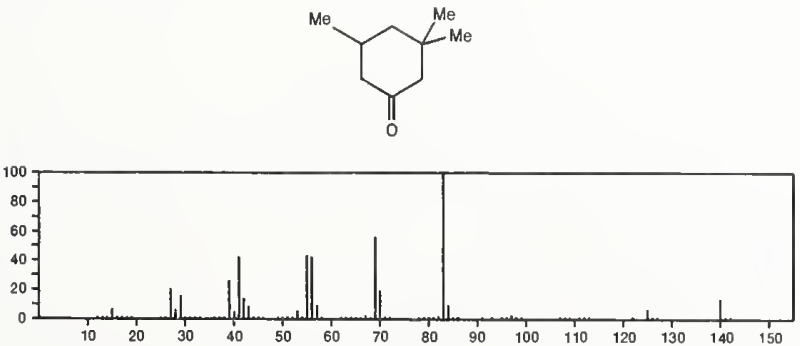

140

$\mathrm{C}_{9} \mathrm{H}_{16} \mathrm{O}$

Cyclohexanone, 2-(1-methylethyl)
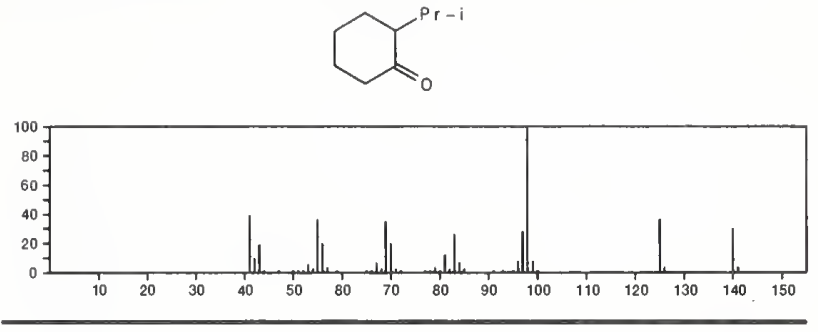

140

4-Nonenal, $(E)$

$\mathrm{C}_{9} \mathrm{H}_{16} \mathrm{O}$

2277-16-9

$\mathrm{Me}\left(\mathrm{CH}_{2}\right)_{3} \mathrm{CH}=\mathrm{CHCH}_{2} \mathrm{CH}_{2} \mathrm{CHO}$

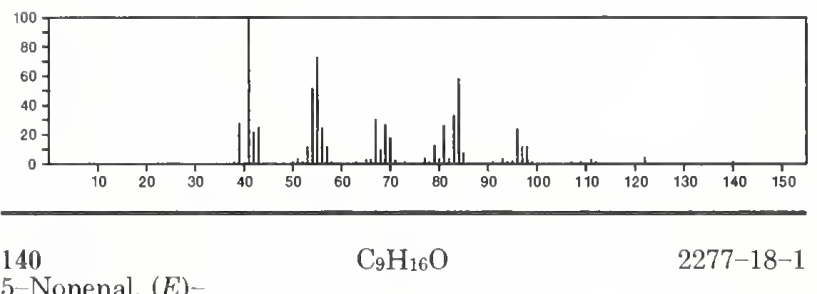

$\mathrm{OCH}\left(\mathrm{CH}_{2}\right)_{3} \mathrm{CH}=\mathrm{CHP}$

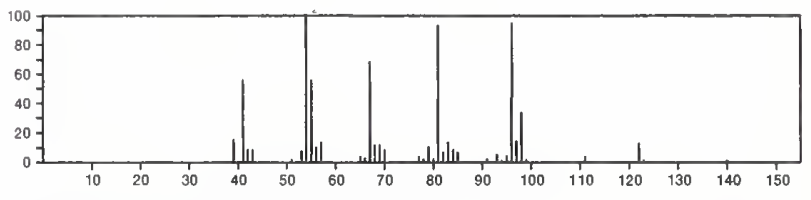

140

6-Nonenal, $(Z)$

$\mathrm{C}_{9} \mathrm{H}_{16} \mathrm{O}$

2277-19-2

$\mathrm{OCH}\left(\mathrm{CH}_{2}\right)+\mathrm{CH}=\mathrm{CHE}$

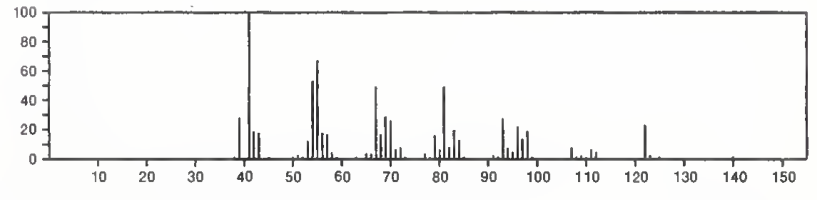

140

6-Nonenal, $(E)$ -

$\mathrm{C}_{9} \mathrm{H}_{16} \mathrm{O}$

2277-20-5

$\mathrm{OCH}\left(\mathrm{CH}_{2}\right)+\mathrm{CH}=\mathrm{CHE}$

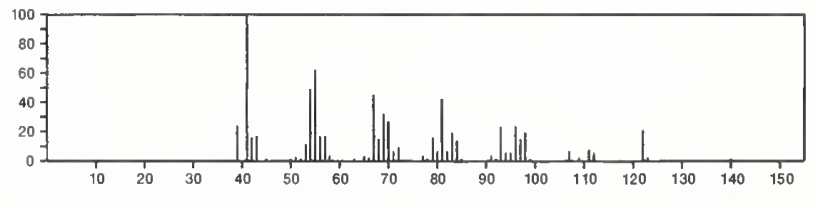

140

Cyclohexanone, 2,2,6-trimethyl--

2408-37-9<smiles>CC1(N)CCCC(N)C1=O</smiles>

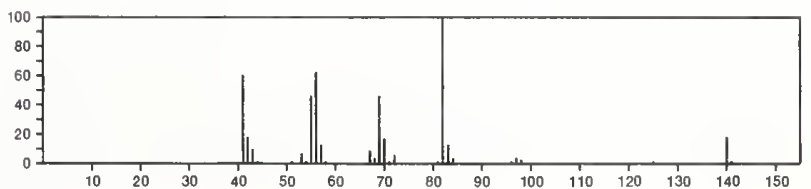


140

2-Nonenal

$\mathrm{C}_{9} \mathrm{H}_{16} \mathrm{O}$

$\mathrm{Me}\left(\mathrm{CH}_{2}\right) 5 \mathrm{CH}: \mathrm{CHCHO}$

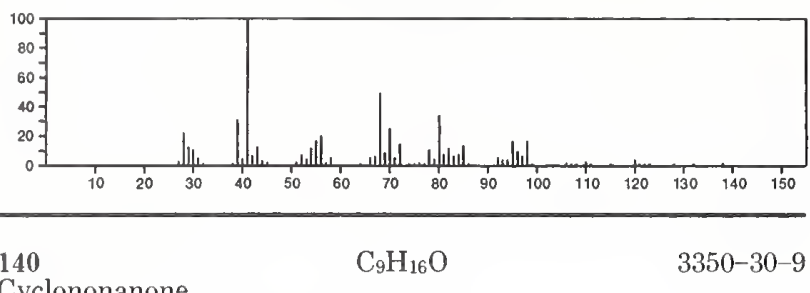

Cyclononanone
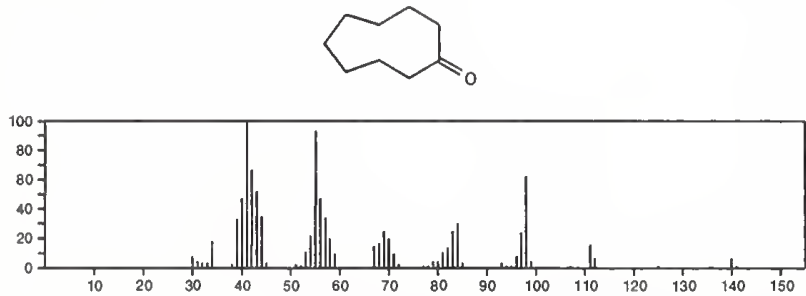

140

$\mathrm{C}_{9} \mathrm{H}_{16} \mathrm{O}$

$3664-75-3$

Ketone, 2,2-dimethylcyclopentyl methyl
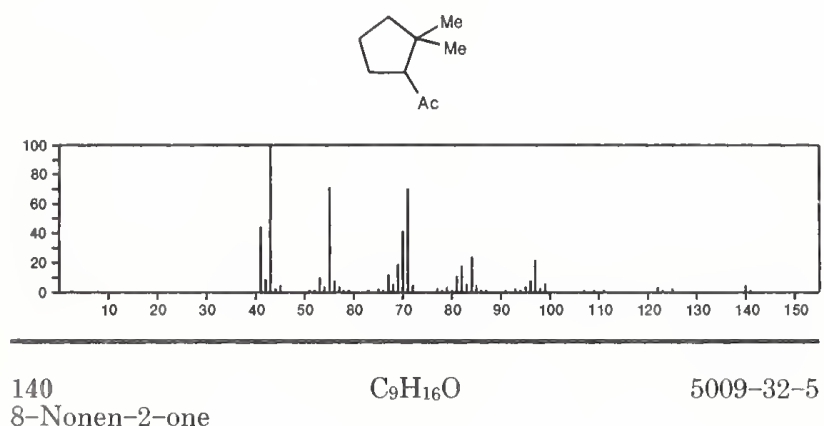

8-Nonen-2-one

$\mathrm{MeCO}\left(\mathrm{CH}_{2}\right){ }_{5} \mathrm{CH}=\mathrm{CH}_{2}$

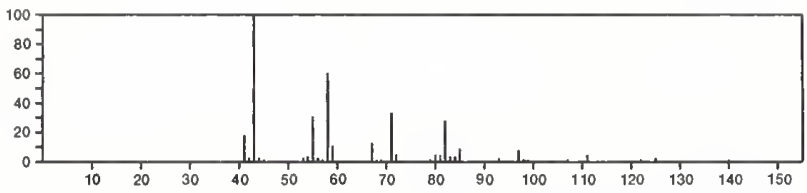

140

$\mathrm{C}_{9} \mathrm{H}_{16} \mathrm{O}$

Cyclopentanone, 2-(1-methylpropyl)
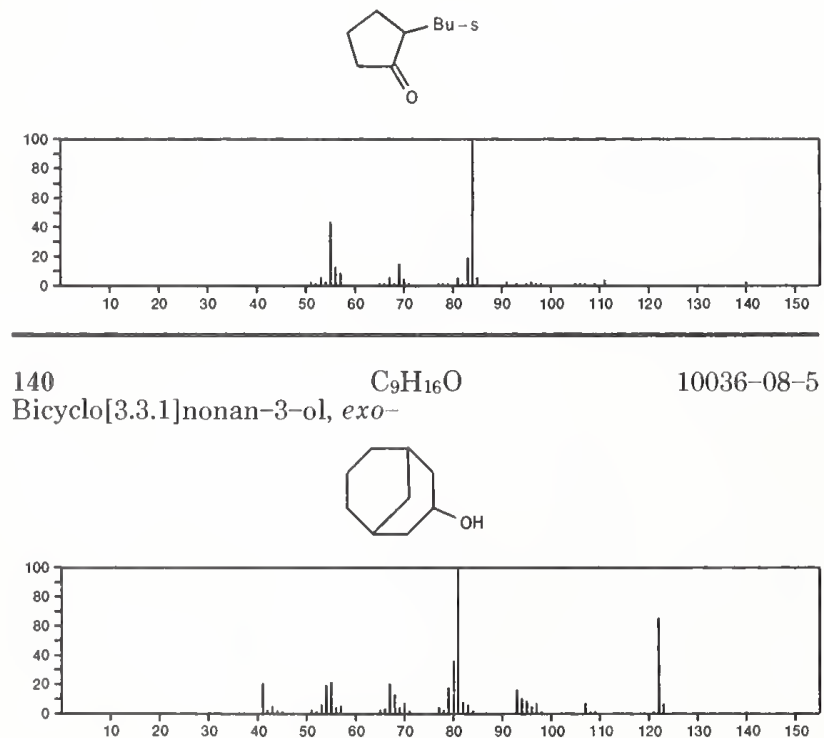

140

Bicyclo[3.3.1]noman-3-ol,

10036-10-9
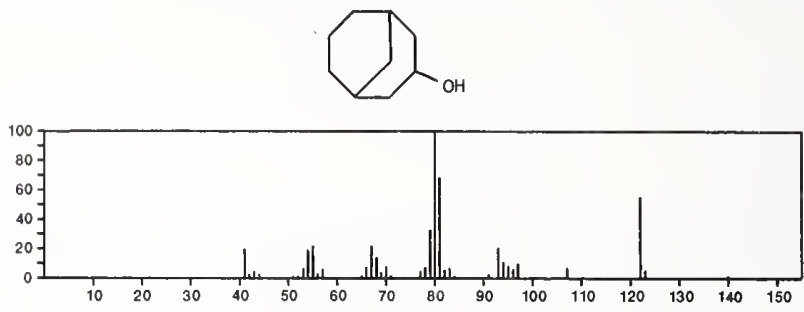

140

Bicyclo[3.3.1]nonan-2-ol, exo-

$\mathrm{C}_{9} \mathrm{H}_{16} \mathrm{O}$

10036-15-4
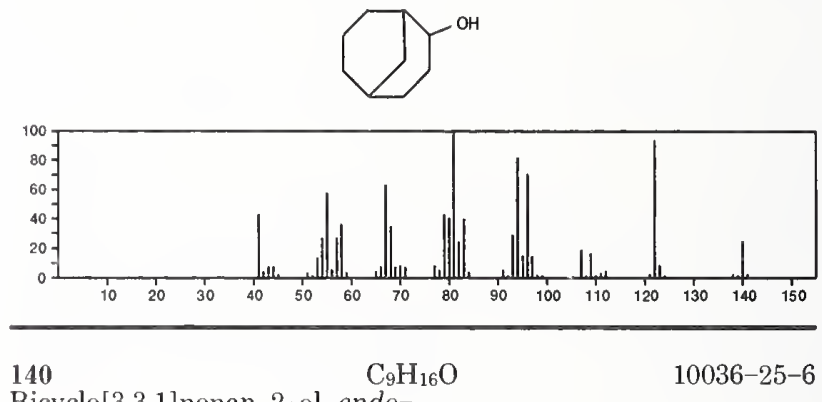

Bicyclo[3.3.1]nonan-2-ol, endo-
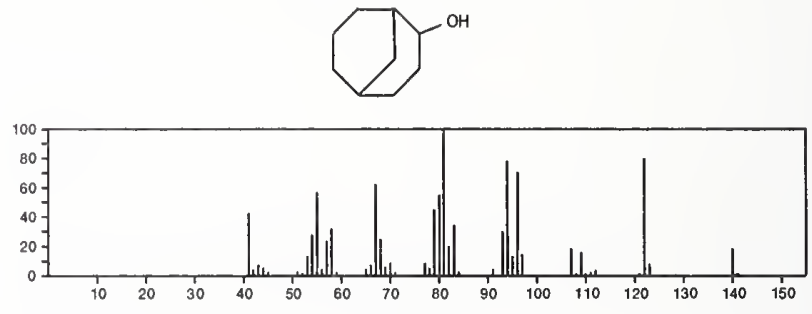

140 Nonen-2-one $\quad \mathrm{C}_{9} \mathrm{H}_{16} \mathrm{O}$

$14309-57-0$

$\mathrm{Me} \mathrm{COCH}=\mathrm{CH}\left(\mathrm{CH}_{2}\right){ }_{4} \mathrm{Me}$

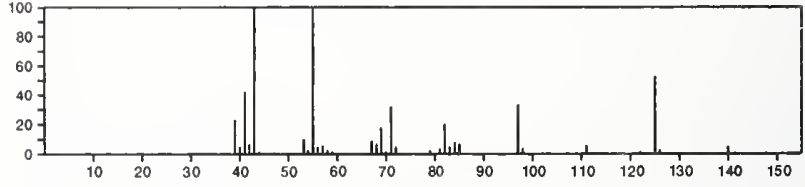

140

$\mathrm{C}_{9} \mathrm{H}_{16} \mathrm{O}$

$15598-80-8$

Bicyclo[3.3.1]nonan-9-ol
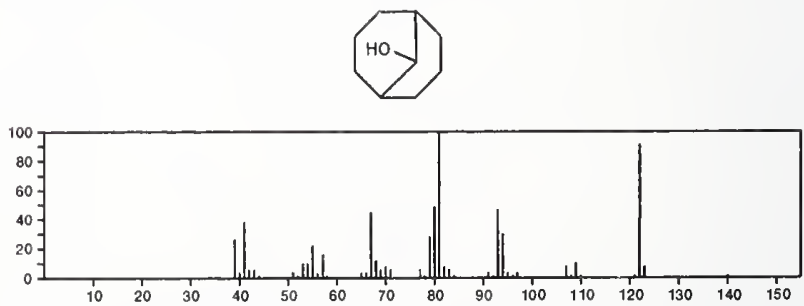

140

2-Octen-4-one, 2-methyl-

$\mathrm{C}_{9} \mathrm{H}_{16} \mathrm{O}$

19860-71-0

$\mathrm{Me}_{2} \mathrm{C}: \mathrm{CHCO}\left(\mathrm{CH}_{2}\right\}_{3} \mathrm{Me}$

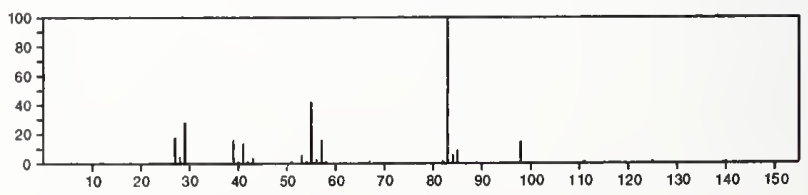


140

$\mathrm{C}_{9} \mathrm{H}_{16} \mathrm{O}$

1-Octyn-3-ol, 3-methyl-

$\mathrm{Me}\left(\mathrm{CH}_{2}\right)_{4} \mathrm{CM} \theta(\mathrm{OH}) \mathrm{C} \equiv \mathrm{CH}$

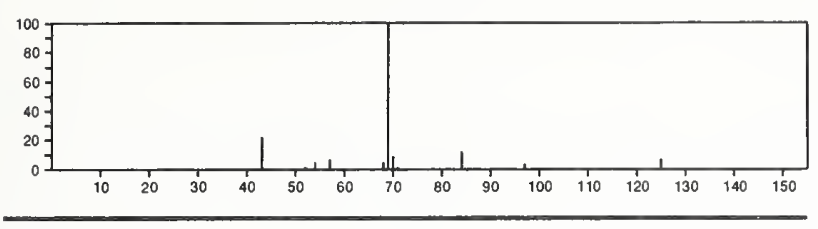

140

5-Nonen-2-one

$\mathrm{C}_{9} \mathrm{H}_{16} \mathrm{O}$

$27039-84-5$

$\operatorname{PrCH}=\mathrm{CHCH}_{2} \mathrm{CH}_{2} \mathrm{COM} \theta$

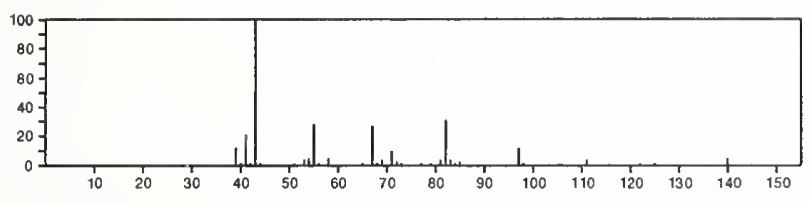

140

2-Nonen-4-one

$\mathrm{C}_{9} \mathrm{H}_{16} \mathrm{O}$

$32064-72-5$
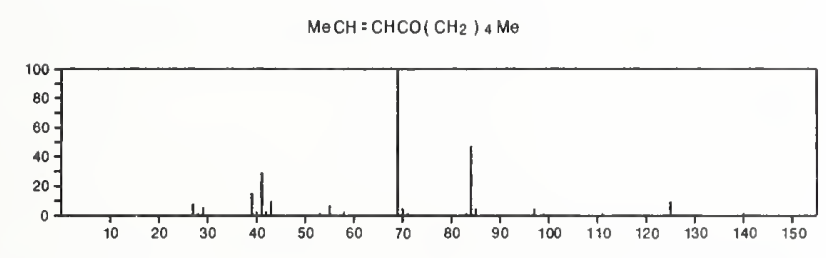

140

$\mathrm{C}_{9} \mathrm{H}_{16} \mathrm{O}$

32064-77-0

5-Nonen-4-one

$\mathrm{Pr} \mathrm{COCH}=\mathrm{CHPr}$

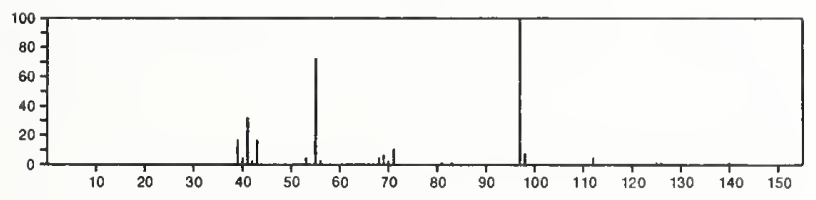

$140 \quad \mathrm{C}_{9} \mathrm{H}_{16} \mathrm{O}$

32064-78-1

5-Octen-4-one, 7-methyl-

$\operatorname{Pr} \mathrm{COCH} \equiv \mathrm{CHCHMO} 2$

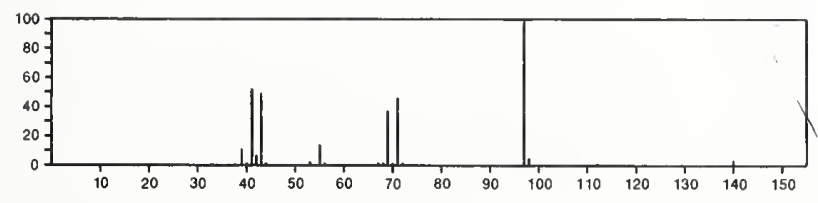

$140 \quad \mathrm{C}_{9} \mathrm{H}_{16} \mathrm{O}$

3-Octen-2-one, 7-methyl-

$\mathrm{Me}_{2} \mathrm{CHCH}_{2} \mathrm{CH}_{2} \mathrm{CH}=\mathrm{CHCOMe}$

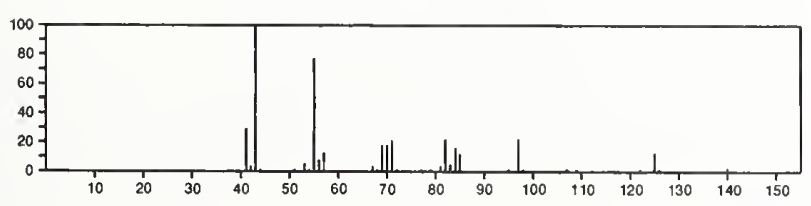

140

7-Octen-2-one, 6-methyl-

$\mathrm{C}_{9} \mathrm{H}_{16} \mathrm{O}$

$35215-49-7$

$\mathrm{MeCO}\left(\mathrm{CH}_{2}\right)_{3} \mathrm{CHMeCH}: \mathrm{CH}_{2}$

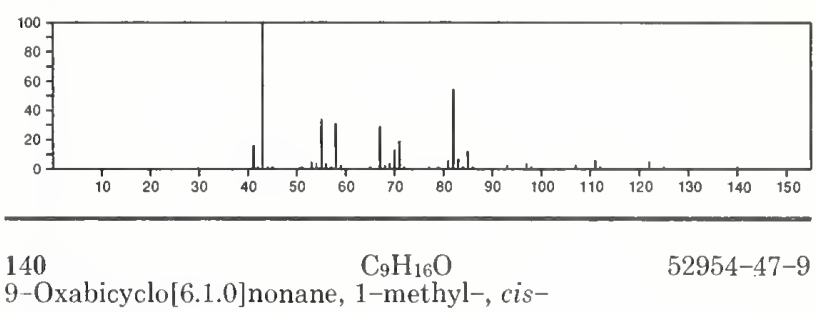

${ }^{\mathrm{Me}}$

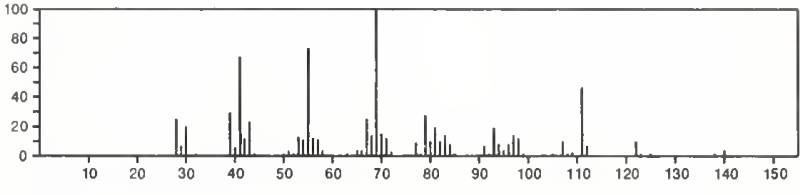

140

$\mathrm{C}_{9} \mathrm{H}_{16} \mathrm{O}$

$53966-55-5$

1-Pentyne, 3-methyl-3-(1-methylethoxy)-

$\mathrm{E}(\mathrm{CMe}(\mathrm{OPr}-\mathrm{i}) \mathrm{C} \equiv \mathrm{CH}$

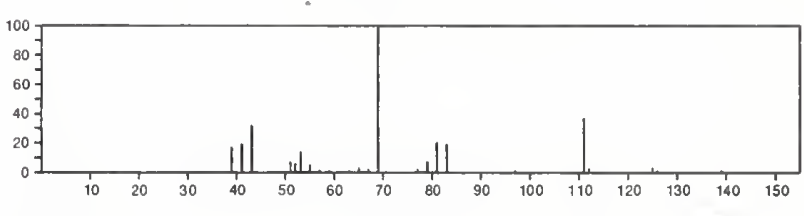

140

1-Pentyne, 3-ethoxy-3-ethyl-

$\mathrm{C}_{9} \mathrm{H}_{16} \mathrm{O}$

$53966-56-6$

$\mathrm{E} \mathrm{2}_{2} \mathrm{COE}+\mathrm{C}: \mathrm{CH}$

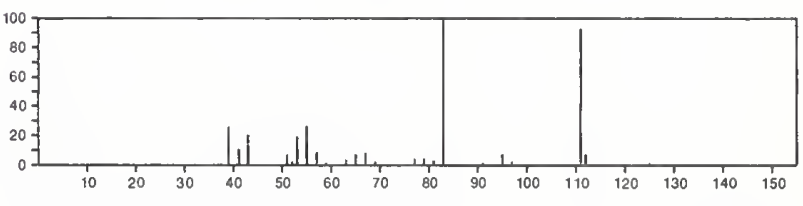

140

2-Isononenal

$\mathrm{C}_{9} \mathrm{H}_{16} \mathrm{O}$

$53966-58-8$

$\left(\mathrm{C}_{6} \mathrm{H}_{13}\right) \mathrm{CH}=\mathrm{CHCHO}$

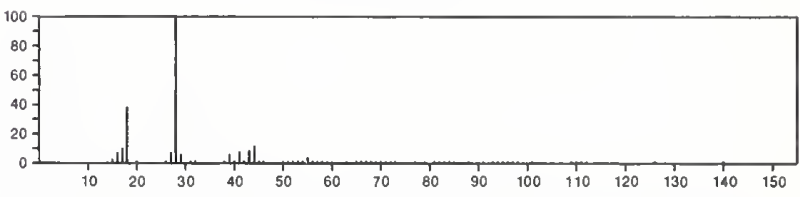

140

$\mathrm{C}_{9} \mathrm{H}_{16} \mathrm{O}$

2-Cyclohexen-1-ol, 2,6,6-trimethyl-

$54345-59-4$<smiles>C[N+](C)([Na])C1CCC=C([N+])C1O</smiles>

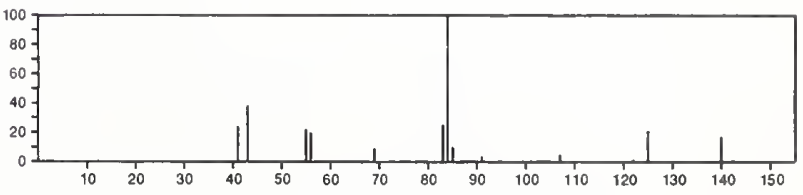


140

Cyclopentanone, 2-methyl-3-(1-methylethyl)-

$54549-81-4$<smiles>O=C1CCC(Br)C1[Al]</smiles>

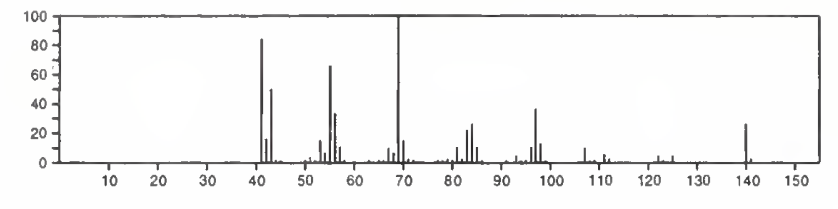

140

4-Hepten-3-one, 2,6-dimethyl-

$56259-14-4$

$\mathrm{Me}_{2} \mathrm{CHCOCH}^{\circ} \mathrm{CHCHMe}$

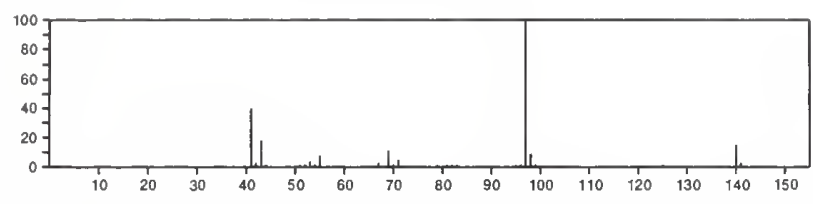

140

3,6-Nonadien-1-ol, $(E, Z)-$

$\mathrm{C}_{9} \mathrm{H}_{16} \mathrm{O}$

$56805-23-3$

$\mathrm{Et} \mathrm{CH}=\mathrm{CHCH}_{2} \mathrm{CH}=\mathrm{CHCH}_{2} \mathrm{CH}_{2} \mathrm{OH}$

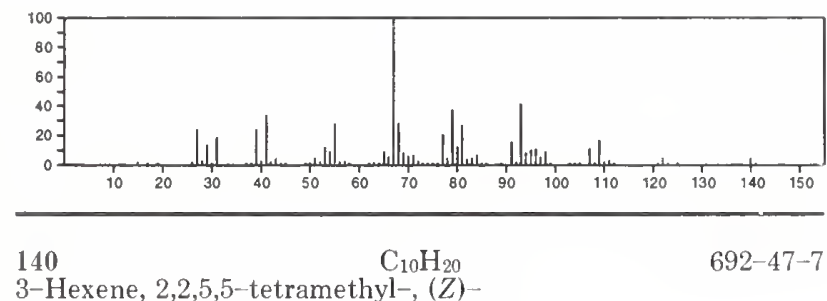

$\mathrm{Me} 3 \mathrm{CCH}=\mathrm{CHCMe}_{3}$

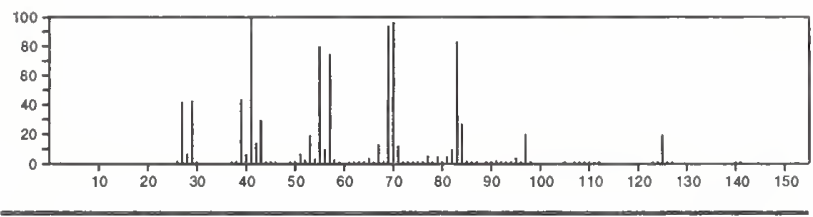

140

$\mathrm{C}_{10} \mathrm{H}_{20}$

$872-05-9$

1-Decene

$\mathrm{H}_{2} \mathrm{C}=\mathrm{CH}\left(\mathrm{CH}_{2}\right) 7 \mathrm{Me}$

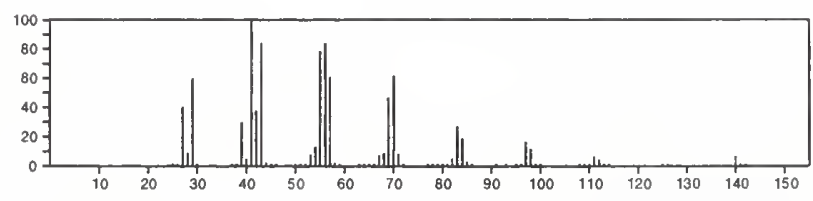

140

Cyclohexane, diethyl-

$\mathrm{C}_{10} \mathrm{H}_{20}$

$1331-43-7$
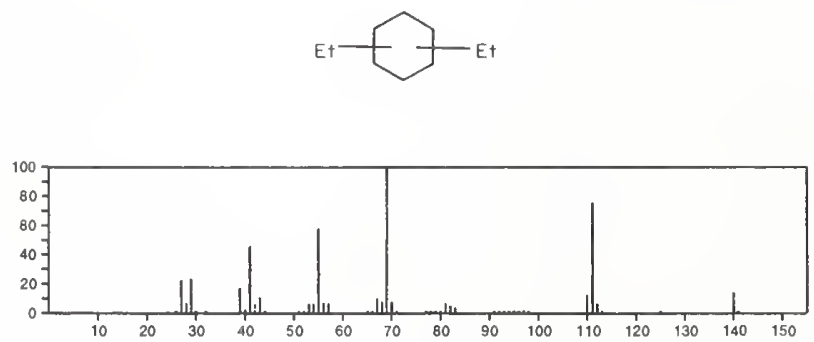

140

Cyclohexane, 1-methyl-4-(1-methylethyl)-, trans-

$1678-82-6$
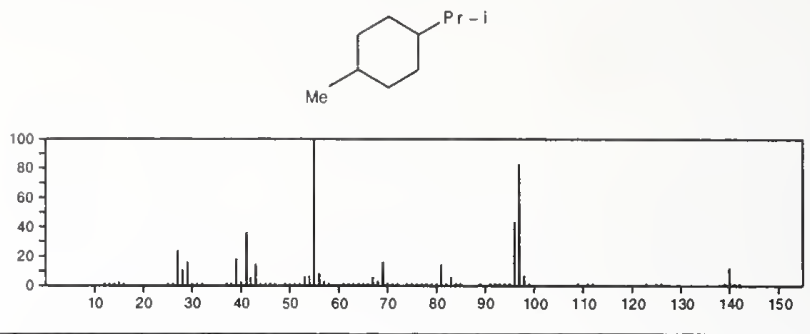

140

Cyclohexane, butyl-

$\mathrm{C}_{10} \mathrm{H}_{20}$

1678-93-9
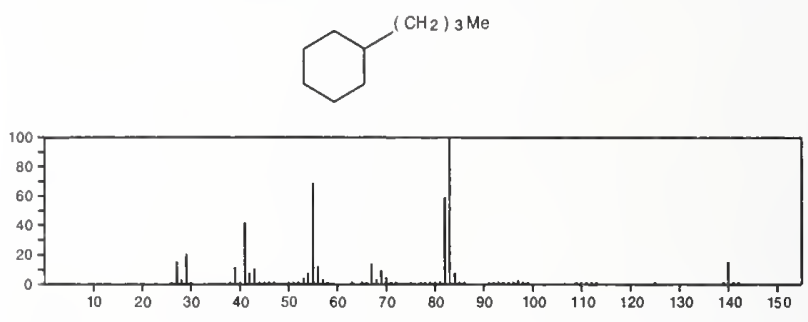

140

Cyclohexane, (2-methylpropyl)

$\mathrm{C}_{10} \mathrm{H}_{20}$

$1678-98-4$
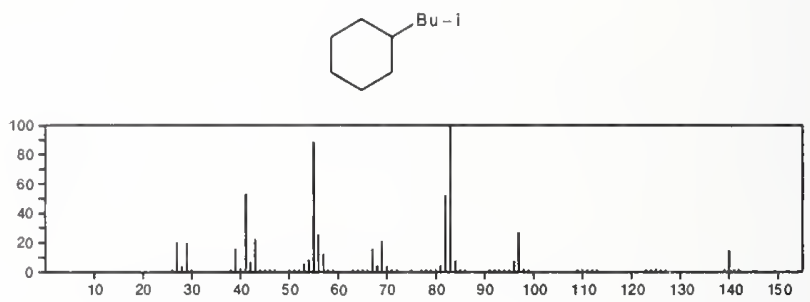

140

$\mathrm{C}_{10} \mathrm{H}_{20}$

Cyclohexane, (1,1-dimethylethyl)-

$3178-22-1$
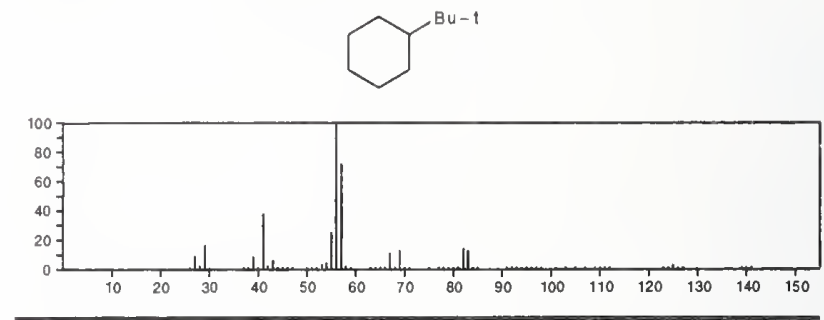

140

3 Heptene, 4-propyl-

$\mathrm{C}_{10} \mathrm{H}_{20}$

$4485-13-6$

$\mathrm{EtCH}=\mathrm{CPr}_{2}$
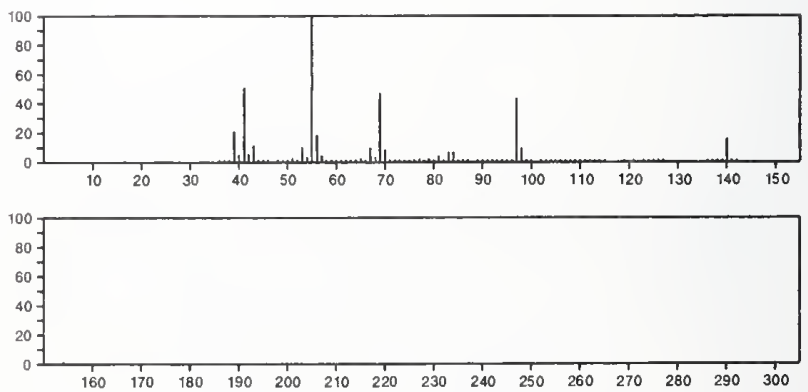


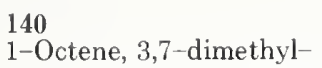

$\mathrm{C}_{10} \mathrm{H}_{20}$

$\left.\mathrm{Me}_{2} \mathrm{CH}_{1} \mathrm{CH}_{2}\right)_{3} \mathrm{CHMeCH}=\mathrm{CH}_{2}$

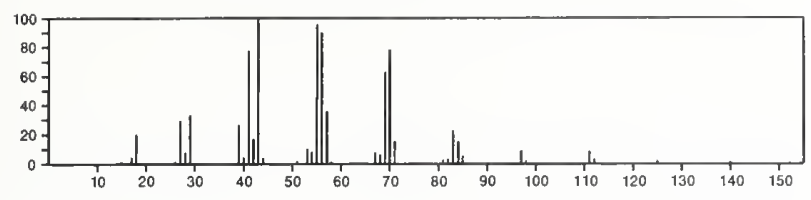

140

$\mathrm{C}_{10} \mathrm{H}_{20}$

$6069-98-3$

Cyclohexane, 1-methyl-4-(1-methylethyl)-, cis-
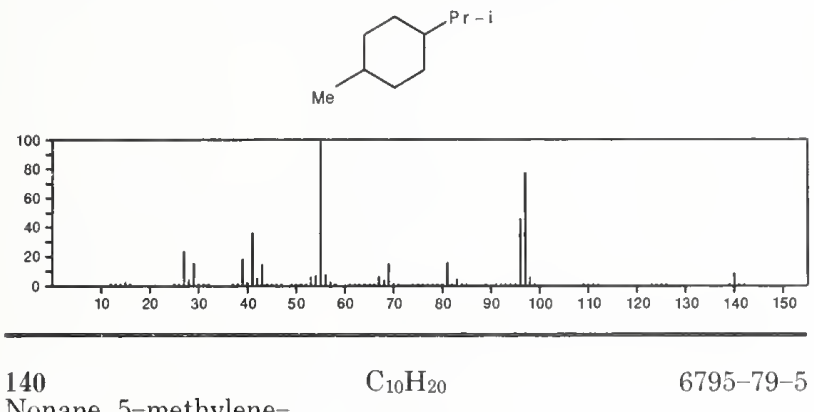

Nonane, 5-methylene-

$\mathrm{CH}_{2}$

$\mathrm{Me}\left(\mathrm{CH}_{2}\right)_{3}{ }_{3} \mathrm{C}\left(\mathrm{CH}_{2}\right)_{3} \mathrm{Me}$

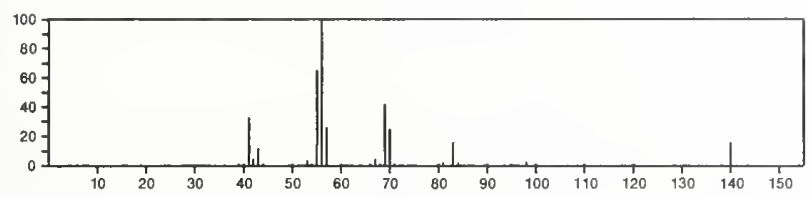

140

1-Octene, 2,6-dimethyl-

$\mathrm{C}_{10} \mathrm{H}_{20}$

$6874-29-9$

$\mathrm{H}_{2} \mathrm{C}=\mathrm{CMe}\left(\mathrm{CH}_{2}\right)_{3} \mathrm{CHMe} \mathrm{CH}_{2} \mathrm{Me}$

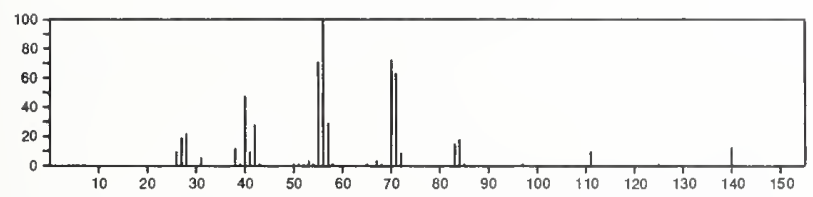

$140 \quad \mathrm{C}_{10} \mathrm{H}_{20}$

7058-01-7

Cyclohexane, (1-methylpropyl)-
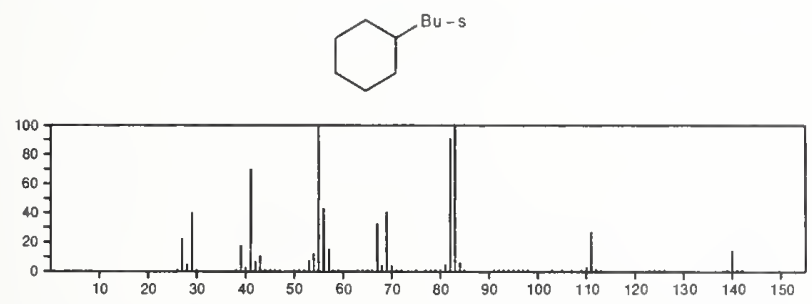

140

$m$-Menthane, $(1 S, 3 R)-(+)-$

$13837-66-6$
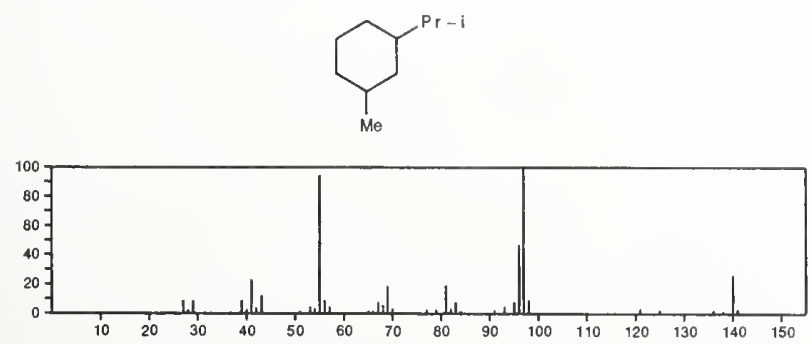

140

$13837-67-7$
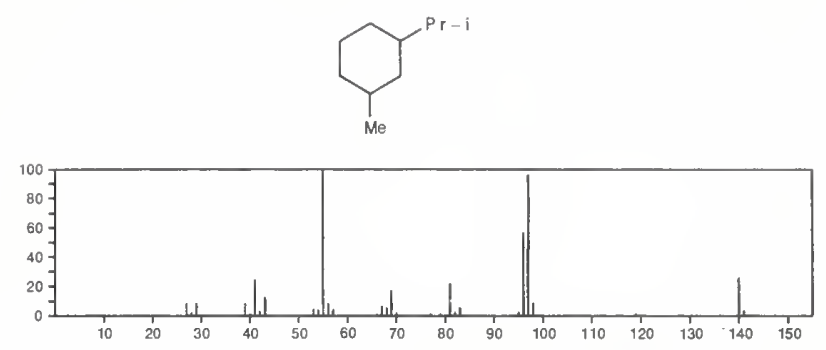

140

4-Nonene, 5-methyl-

$\mathrm{C}_{10} \mathrm{H}_{20}$

$15918-07-7$

$\mathrm{Me}\left(\mathrm{CH}_{2}\right)_{3} \mathrm{CMe}=\mathrm{CHPr}$

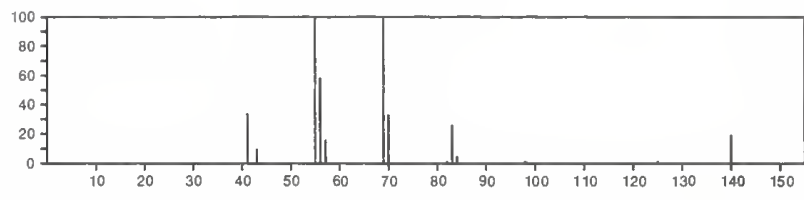

140

$\mathrm{C}_{10} \mathrm{H}_{20}$

19689-18-0

4-Decene

$\mathrm{Me}\left(\mathrm{CH}_{2}\right){ }_{4} \mathrm{CH}=\mathrm{CHPr}$

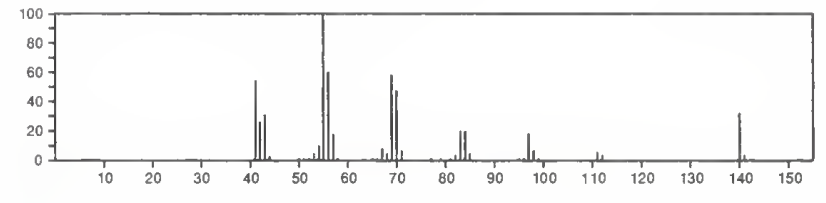

140

$\mathrm{C}_{10} \mathrm{H}_{20}$

19689-19-1

5-Decene

$\mathrm{Me}\left(\mathrm{CH}_{2}\right)_{3} \mathrm{CH}=\mathrm{CH}\left(\mathrm{CH}_{2}\right)_{3} \mathrm{Me}$

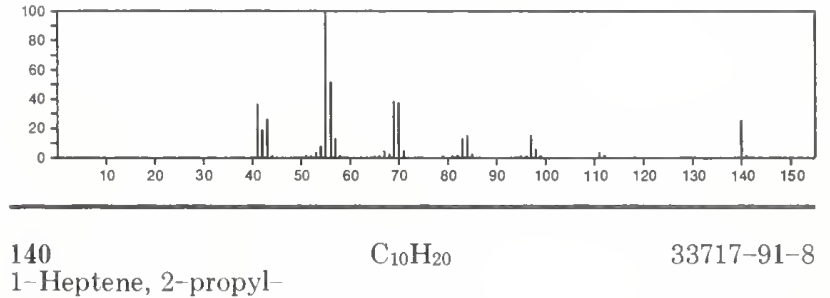

$\mathrm{Me}\left(\mathrm{CH}_{2}\right){ }_{4} \mathrm{CPr}=\mathrm{CH}_{2}$

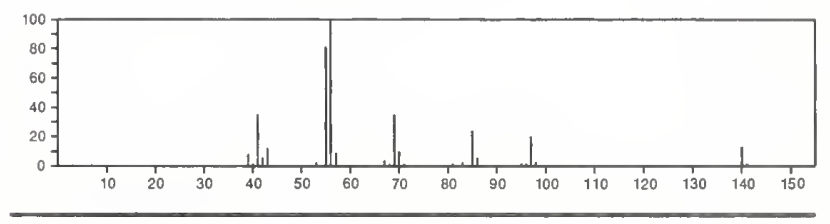

140

$\mathrm{C}_{10} \mathrm{H}_{20}$

33718-03-5

1-Octene, 2,7-dimethyl-

$\mathrm{H}_{2} \mathrm{C}=\mathrm{CMe}\left(\mathrm{CH}_{2}\right)_{4} \mathrm{CHM}_{2}$

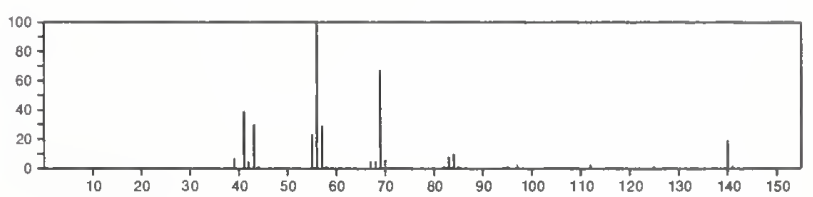


140

$\mathrm{C}_{10} \mathrm{H}_{20}$

Cyclopropane, 1,1,2-trimethyl-3-(2-methylpropyl)-

$41977-43-9$

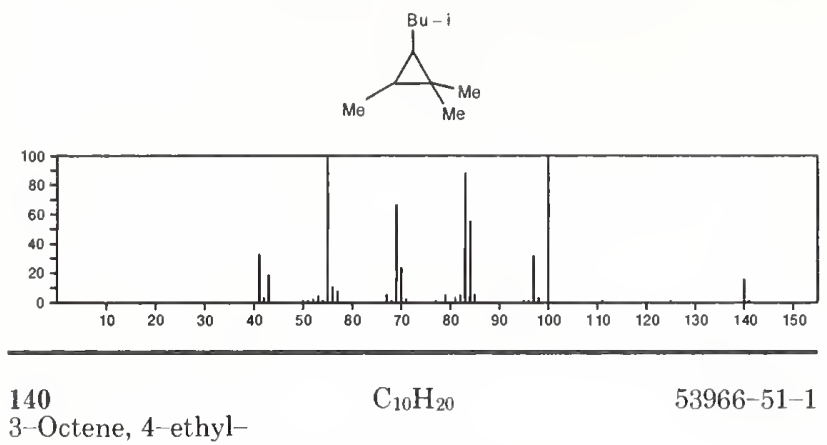

$\mathrm{Me}\left(\mathrm{CH}_{2}\right)_{3} \mathrm{CEt}=\mathrm{CHE} \mathrm{t}$

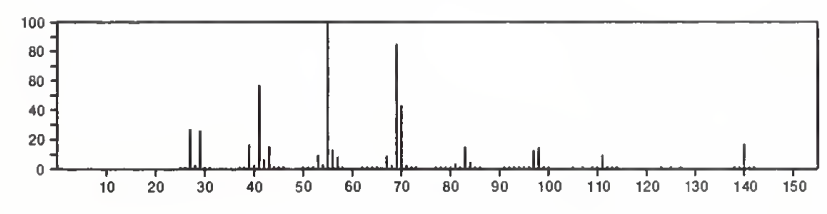

140

2-Octene, 4-ethyl-

$\mathrm{C}_{10} \mathrm{H}_{20}$

$53966-52-2$

$\mathrm{MeCH}: \mathrm{CHCHE}+\left(\mathrm{CH}_{2}\right)_{3} \mathrm{Me}$

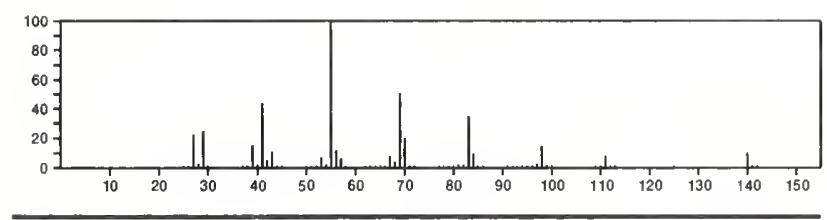

140

3-Nonene, 2-methyl-

$\mathrm{C}_{10} \mathrm{H}_{20}$

$53966-53-3$

$\mathrm{Me}\left(\mathrm{CH}_{2}\right){ }_{4} \mathrm{CH}=\mathrm{CHCHMe} 2$

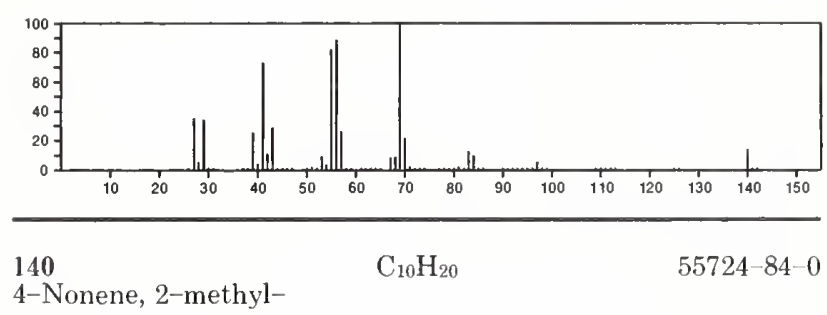

$\mathrm{Me}\left(\mathrm{CH}_{2}\right)_{3} \mathrm{CH}=\mathrm{CHCH}_{2} \mathrm{CHMe}_{2}$

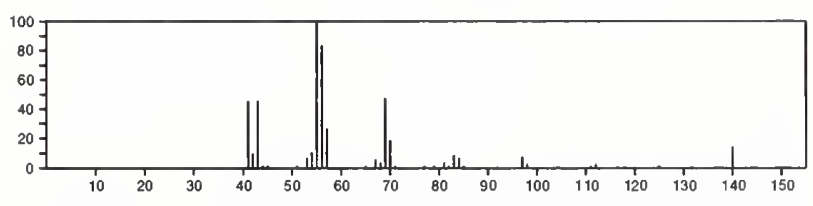

$140 \quad \mathrm{C}_{10} \mathrm{H}_{20}$

56728-11-1

1-Octene, 3,4-dimethyl-

$\mathrm{H}_{2} \mathrm{C}=\mathrm{CHCHMe} \mathrm{CHMe}\left(\mathrm{CH}_{2}\right)_{3} \mathrm{Me}$

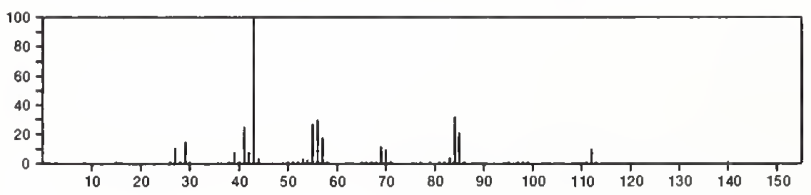

141

Butyronitrile, 2,4,4,4-tetrafluoro-

$\mathrm{F}_{3} \mathrm{CCH}_{2} \mathrm{CHFCN}$

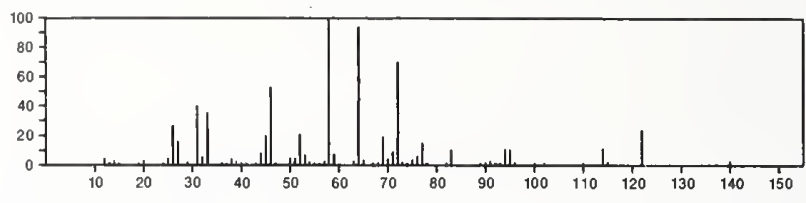

141
Acetamide, $N$-ethyl-2,2,2-trifluoro-

$1682-66-2$

E $: \mathrm{NHCOCF}_{3}$

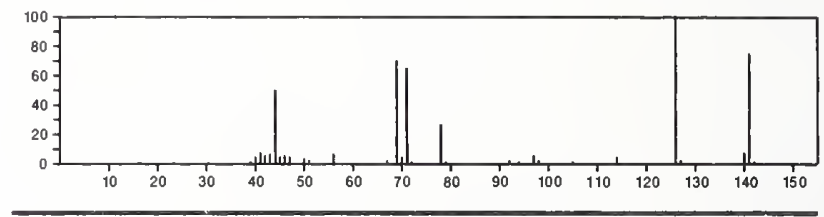

141

$\mathrm{C}_{5} \mathrm{H}_{7} \mathrm{~N}_{3} \mathrm{~S}$

4-Pyrimidinamine, 2-(methylthio)-

$2183-66-6$
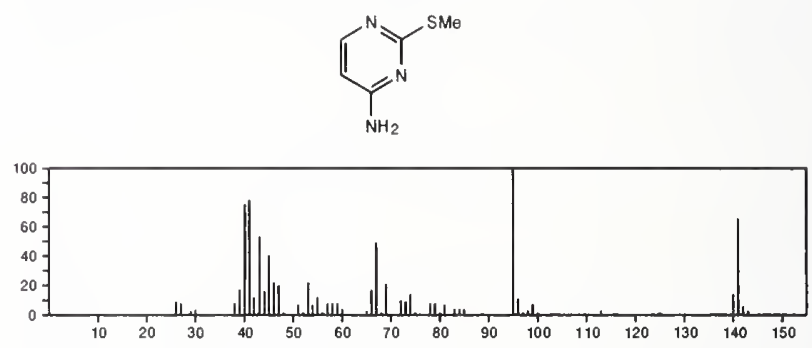

$141 \quad \mathrm{C}_{6} \mathrm{H}_{4} \mathrm{FNO}_{2}$

$350-46-9$

Benzene, 1-fluoro-4-nitro-
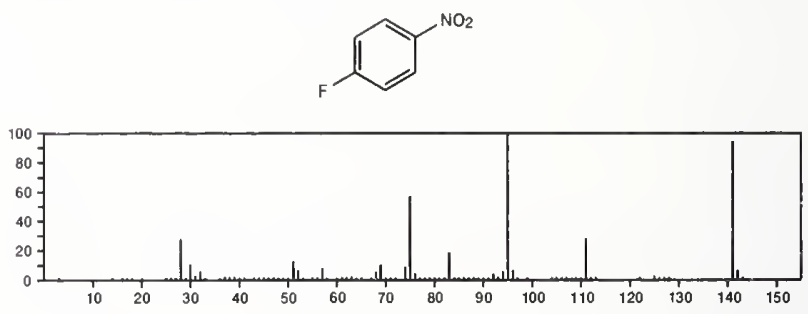

141
Benzene, 1-fluoro-3-nitro-

$402-67-5$
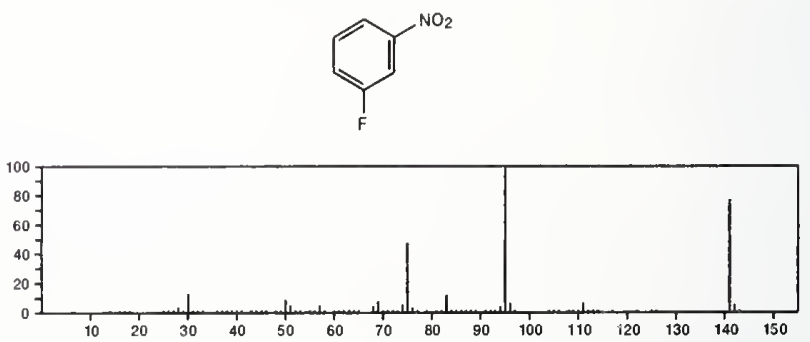
141

$\mathrm{C}_{6} \mathrm{H}_{7} \mathrm{NOS}$

2(1H)-Pyridinethione, 3-hydroxy-6-methyl-
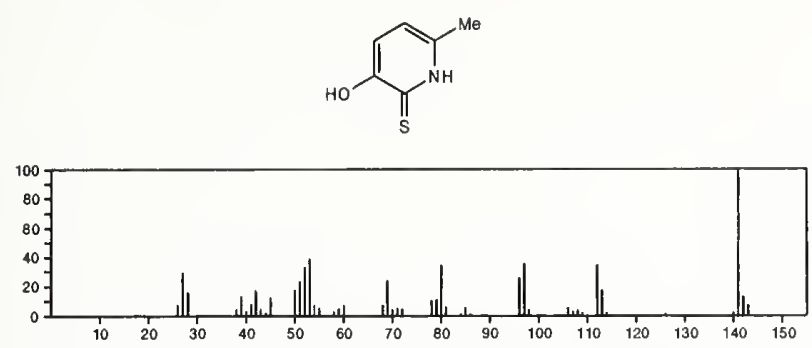

$141 \quad \mathrm{C}_{6} \mathrm{H}_{7} \mathrm{NOS}$

3-Pyridinol, 2-(methylthio)-
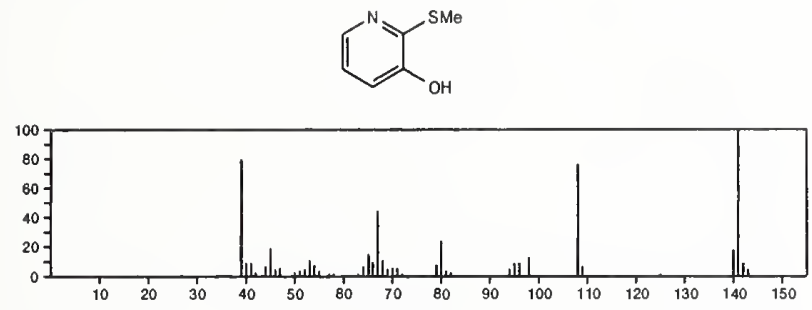

141

$\mathrm{C}_{6} \mathrm{H}_{7} \mathrm{NO}_{3}$

$19788-35-3$

3-Isoxazolecarboxylic acid, 5-methyl-, methyl ester
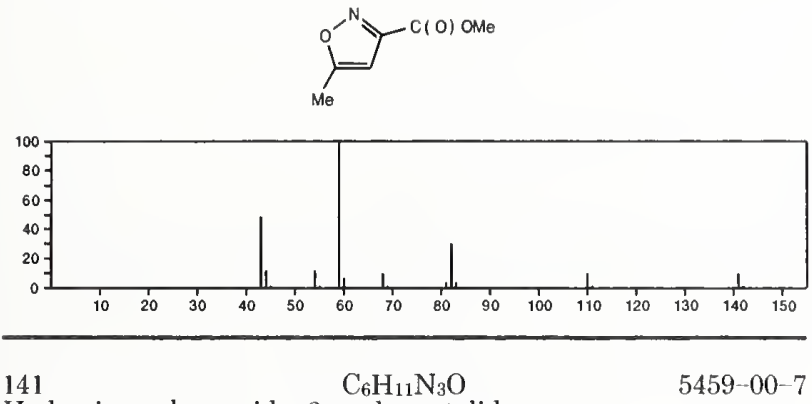

Hydrazinecarboxamide, 2-cyclopentylidene-
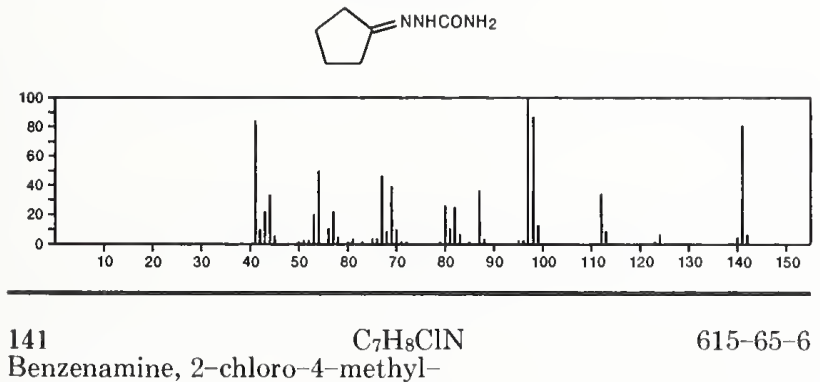

Benzenamine, 2-chloro-4-methyl-
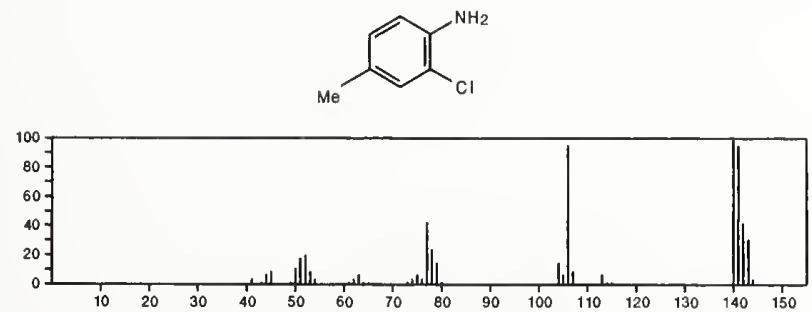

$141 \quad \mathrm{C}_{7} \mathrm{H}_{11} \mathrm{NO}_{2}$

2,5-Pvrrolidinedione, 3-ethyl-3-methyl-

$77-67-8$
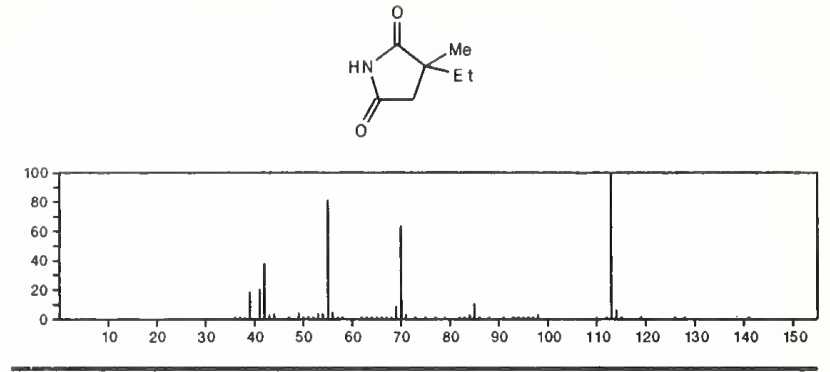

$141 \quad \mathrm{C}_{7} \mathrm{H}_{11} \mathrm{NO}_{2}$

2,6-Piperidinedione, 4,4-dimethyl-

$1123-40-6$<smiles>CC1(C)CC(=O)NC(=O)C1</smiles>

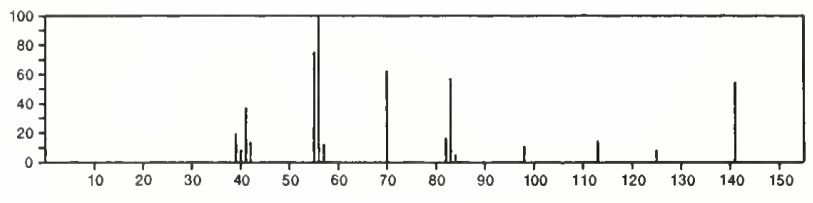

141

$\mathrm{C}_{7} \mathrm{H}_{11} \mathrm{NO}_{2}$

Pentanoic acid, 5-cyano-, methyl ester

3009-88-9

$\mathrm{NC}\left(\mathrm{CH}_{2}\right){ }_{4} \mathrm{C}(\mathrm{O}) \mathrm{OMe}$

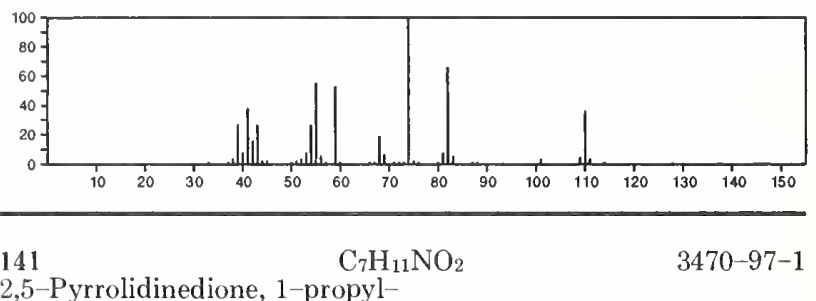

2,5-Pyrrolidinedione, 1-propyl-
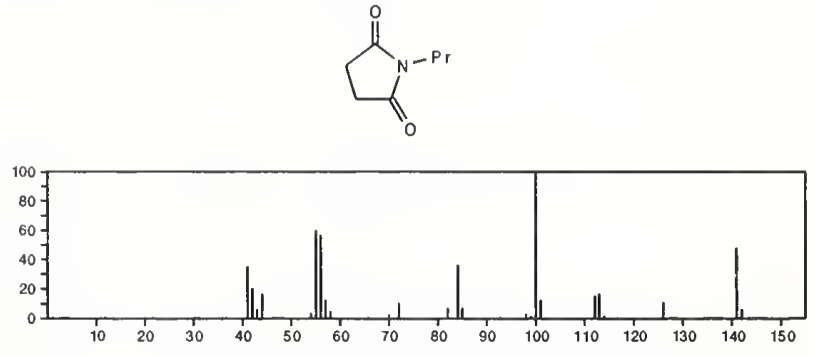

141

$\mathrm{C}_{7} \mathrm{H}_{11} \mathrm{NO}_{2}$

5602-19-7

Hexanoic acid, 6-cyano-

$\mathrm{HO}_{2} \mathrm{C}\left(\mathrm{CH}_{2}\right){ }_{5} \mathrm{CN}$

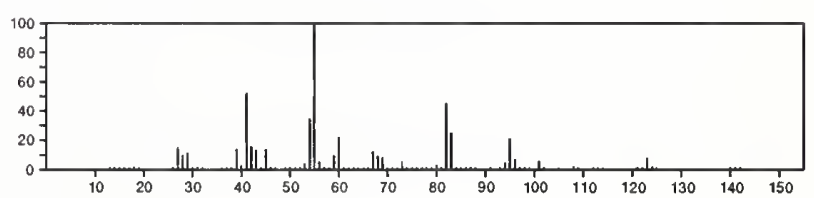


141

$\mathrm{C}_{7} \mathrm{H}_{11} \mathrm{NO}_{2}$

13917-74-3

2H-Pyrrol-2-one, 1,5-dihydro-5-methoxy-3,5-dimethyl-
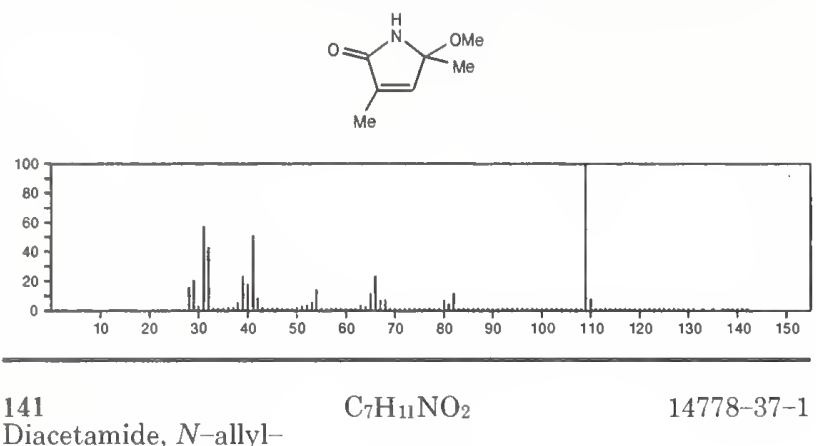

$\mathrm{H}_{2} \mathrm{C}=\mathrm{CHCH}_{2} \mathrm{~N}(\mathrm{AC}) 2$

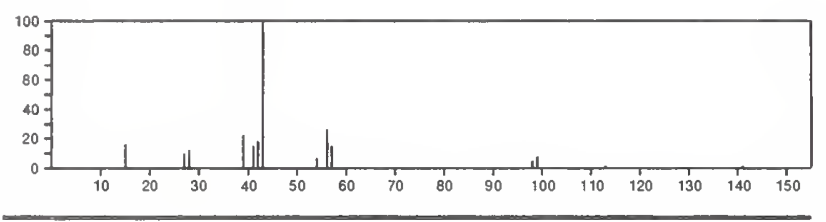

141

$\mathrm{C}_{7} \mathrm{H}_{11} \mathrm{NO}_{2}$

5-Hexynoic acid, 2-amino-4-methyl-

$23840-12-2$

$\mathrm{HO}_{2} \mathrm{CCH}\left(\mathrm{NH}_{2}\right) \mathrm{CH}_{2} \mathrm{CHMeO}: \mathrm{CH}$
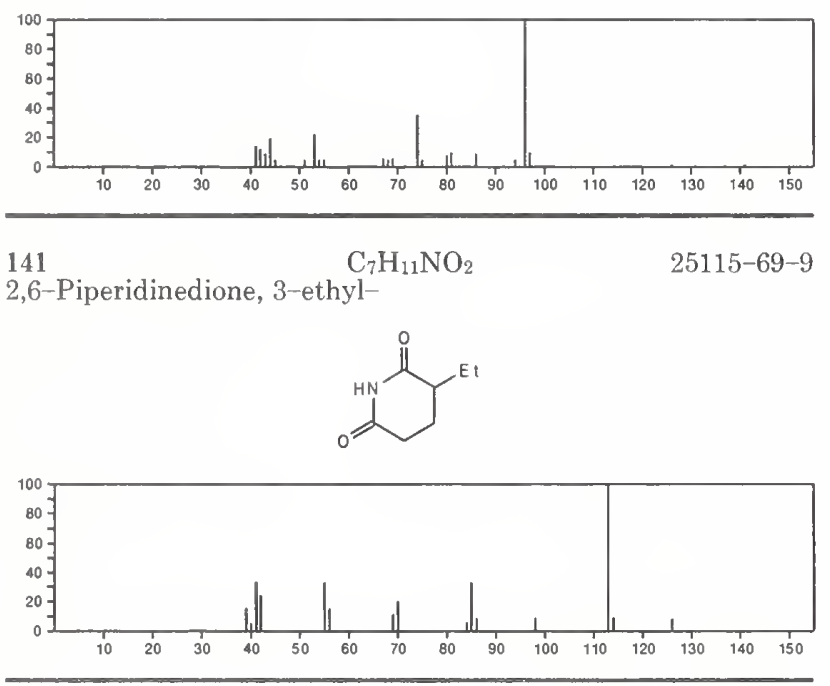

141

$\mathrm{C}_{7} \mathrm{H}_{11} \mathrm{NO}_{2}$

$52752-25-7$

Butanoic acid, 2-cyano-3-methyl-, methyl ester

$\mathrm{Me} 2 \mathrm{CHCH}(\mathrm{CN}) \mathrm{C}(\mathrm{O}) \mathrm{OMe}$

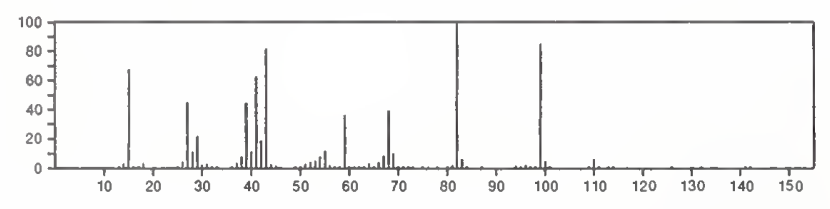

141

$\mathrm{C}_{7} \mathrm{H}_{11} \mathrm{NO}_{2}$

$55956-20-2$

2-Oxazolidinone, 5-methyl-3-(2-propenyl)-
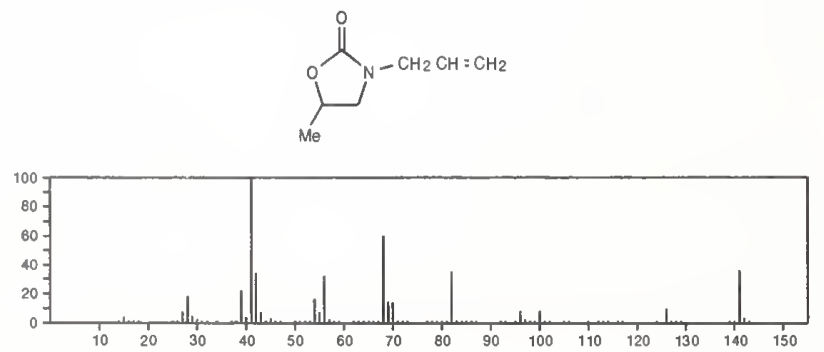

141

Thiazole, 2-ethyl-4,5-dimethyl-

$873-64-3$<smiles>CCc1nc(C)c(C)s1</smiles>

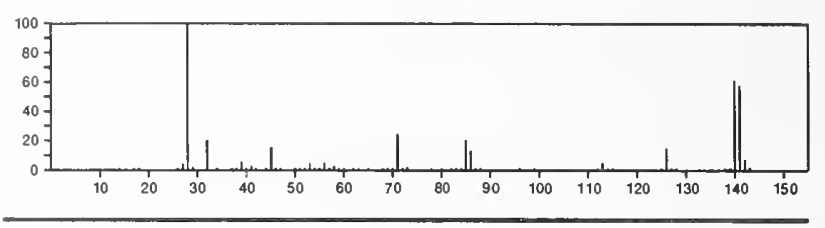

141

$\mathrm{C}_{7} \mathrm{H}_{11} \mathrm{NS}$

$6081-24-9$

Thiazole, 4-(1,1-dimethylethyl)-
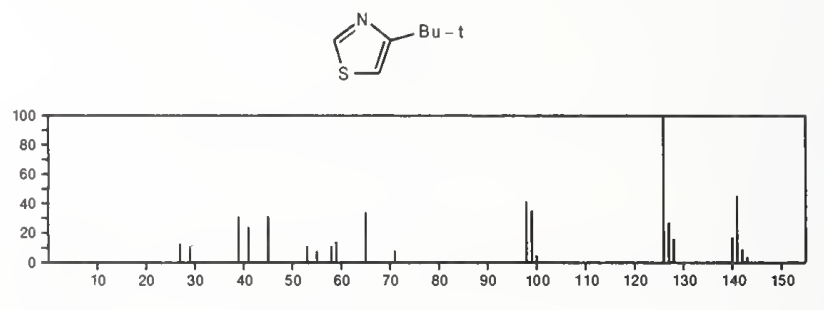

141

$\mathrm{C}_{7} \mathrm{H}_{11} \mathrm{NS}$

$13623-12-6$

Thiazole, 2-(1,1-dimethylethyl)
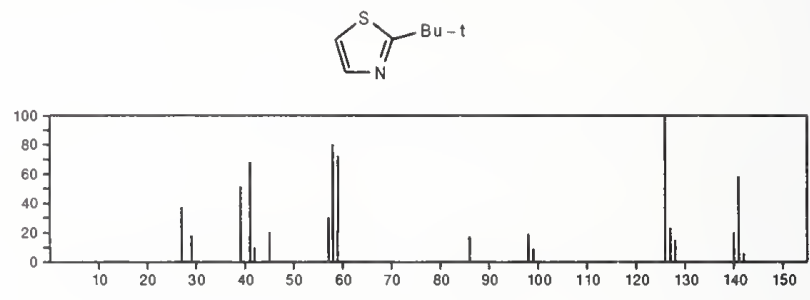

$141 \quad \mathrm{C}_{7} \mathrm{H}_{11} \mathrm{NS}$

Thiazole, 4-methyl-2-(1-methylethyl)-

15679-13-7
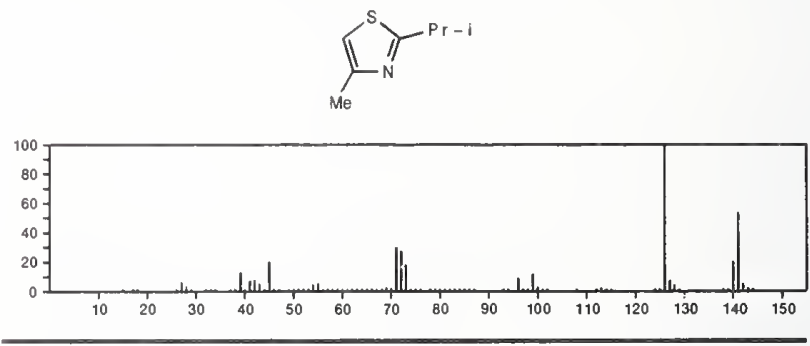

141

Thiazole, 2,5-diethyl-

$\mathrm{C}_{7} \mathrm{H}_{11} \mathrm{NS}$

15729-76-7
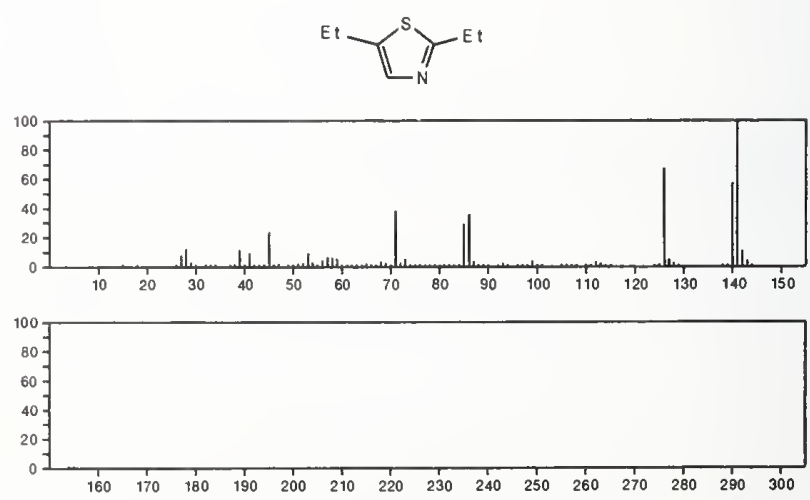
141

Thiazole, 2-(2-methylpropyl)-

$\mathrm{C}_{7} \mathrm{H}_{11} \mathrm{NS}$
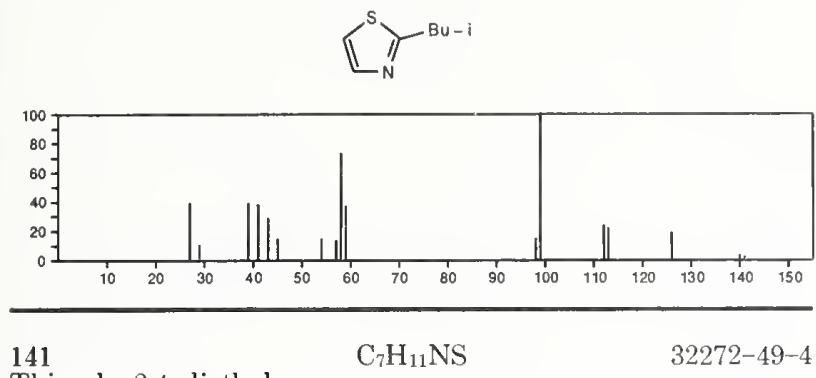

Thiazole, 2,4-diethyl-
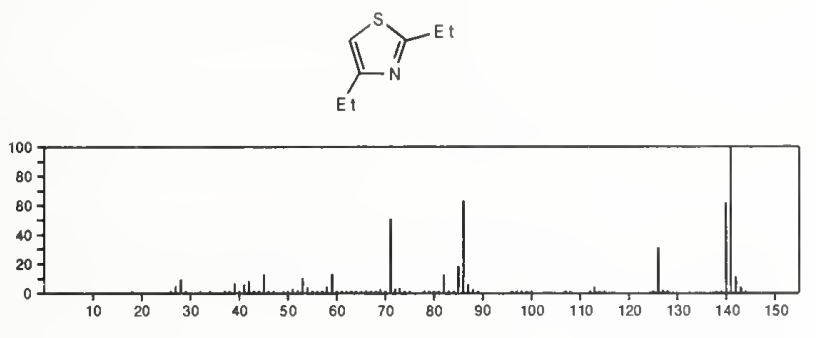

141

$\mathrm{C}_{7} \mathrm{H}_{11} \mathrm{NS}$

Thiazole, 2-methyl-4-(1-methylethyl)-

$32272-52-9$
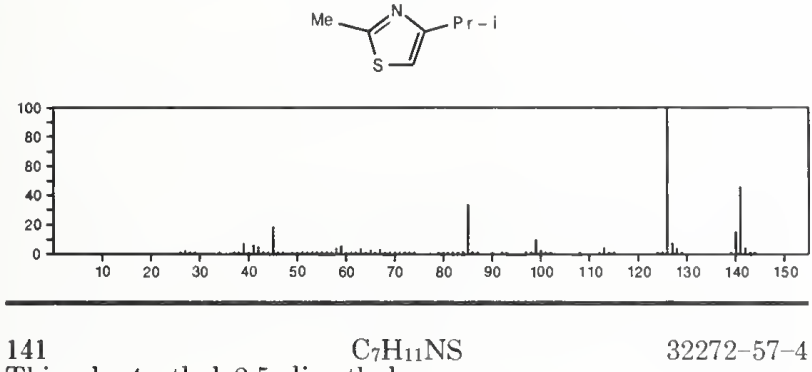

Thiazole, 4-ethyl-2,5-dimethyl-
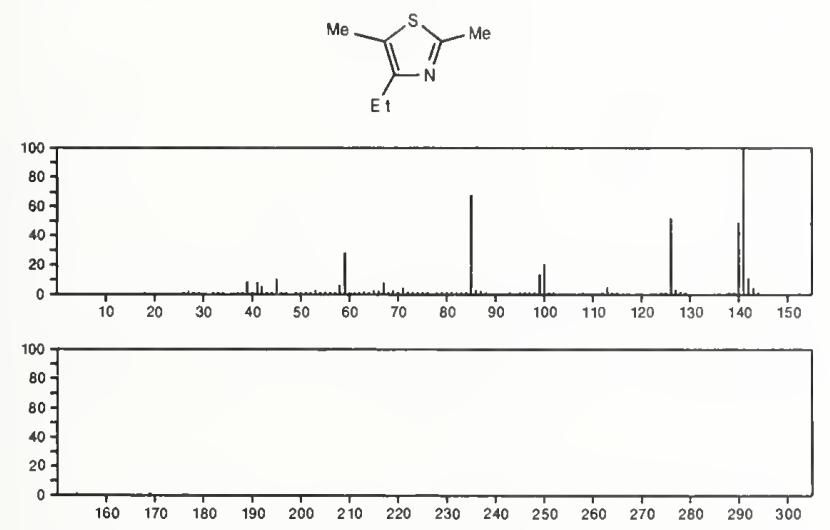

141

Thiazole, 5-ethyl-2,4-dimethyl-

38205-61-7
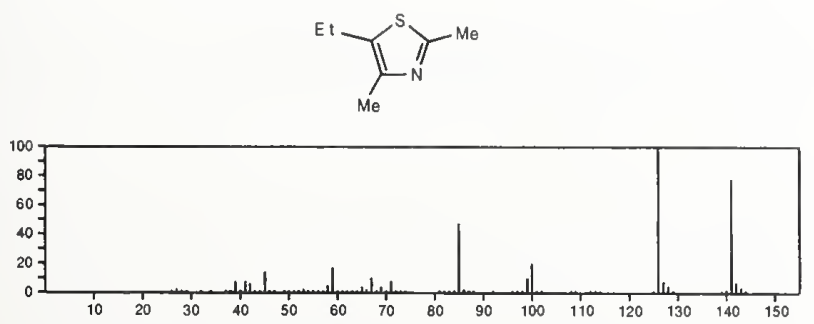

141

Thiazole, 2-methyl-4-propyl

$\mathrm{C}_{7} \mathrm{H}_{11} \mathrm{NS}$

$41981-63-9$
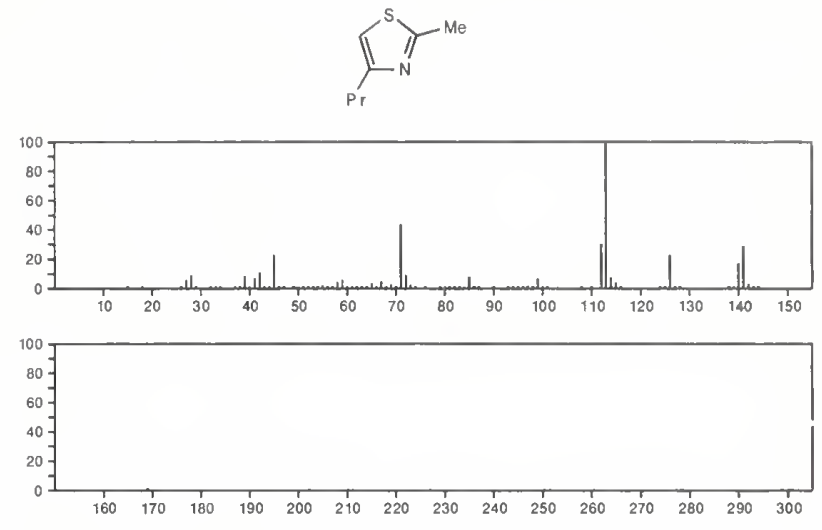

141

Thiazole, 4-methyl-2-propyl-

$\mathrm{C}_{7} \mathrm{H}_{11} \mathrm{NS}$

$52414-87-6$
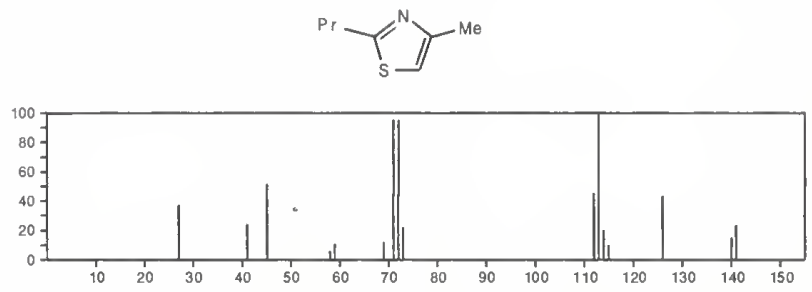

141

Thiazole, 5-butyl-

$\mathrm{C}_{7} \mathrm{H}_{11} \mathrm{NS}$

$52414-90-1$

$\underbrace{\left(\mathrm{CH}_{2}\right)_{3} \mathrm{Me}}_{S}$

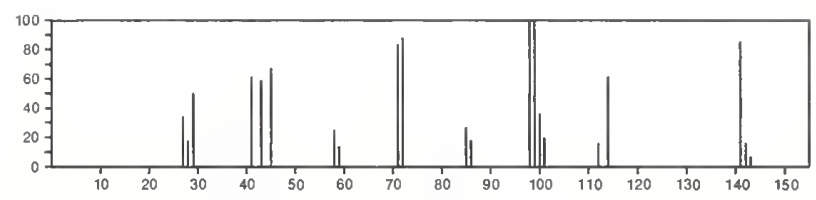

141

$\mathrm{C}_{7} \mathrm{H}_{11} \mathrm{NS}$

54031-27-5

2-Propanethione, 1-(2-pyrrolidinylidene)-
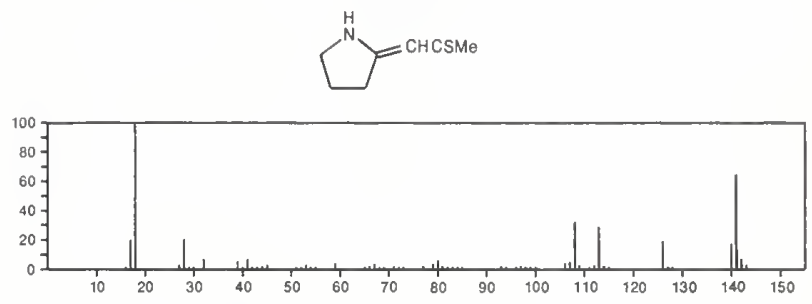

141

Heptane, 4-azido-

$\mathrm{C}_{7} \mathrm{H}_{15} \mathrm{~N}_{3}$

$27126-22-3$

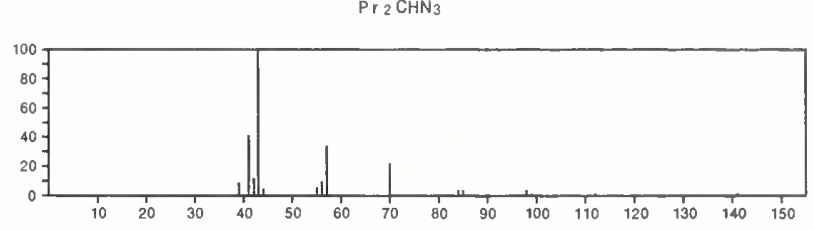


141

Butane, 2-azido-2,3,3-trimethyl-

$51677-41-9$

$\mathrm{Me}_{3} \mathrm{CCM}_{2} \mathrm{~N}_{3}$

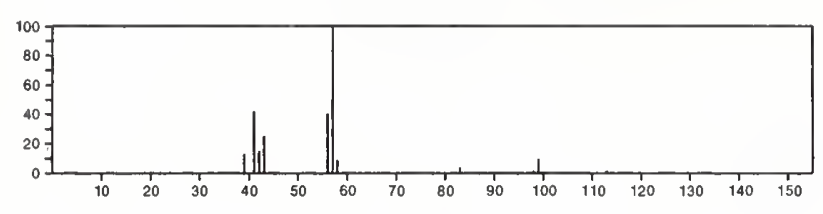

$141 \quad \mathrm{C}_{7} \mathrm{H}_{16} \mathrm{BNO}$

1,3,2-Oxazaborinane, 2-butyl-
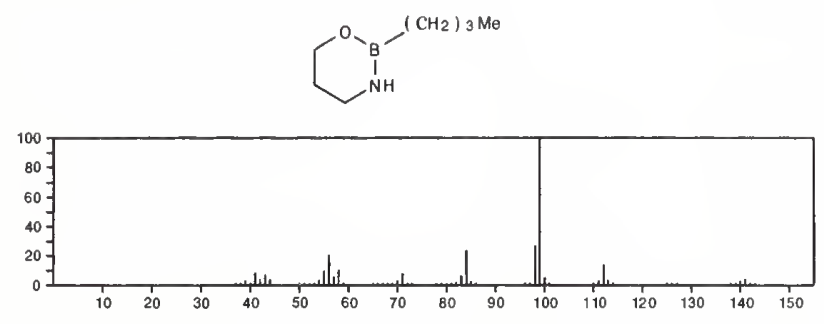

$141 \quad \mathrm{C}_{7} \mathrm{H}_{16} \mathrm{BNO}$

1,3,2-Oxazaborolane, 2-butyl-4-methyl-
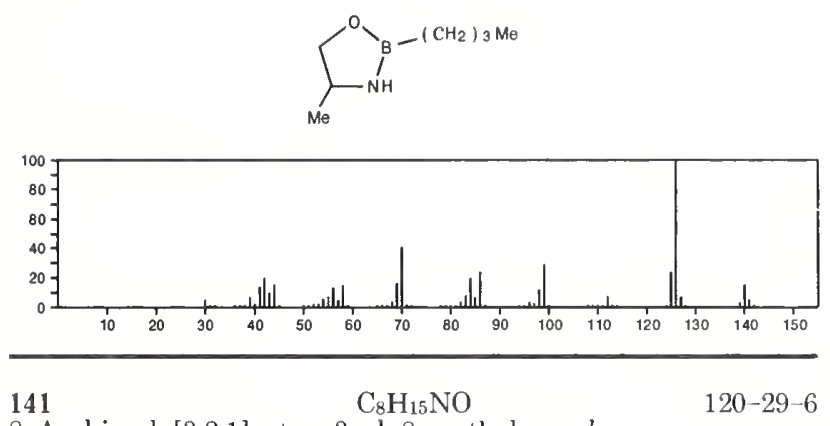

8-Azabicyclo[3.2.1]octan-3-ol, 8-methyl-, endo-

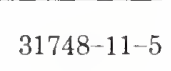

${ }_{N}$

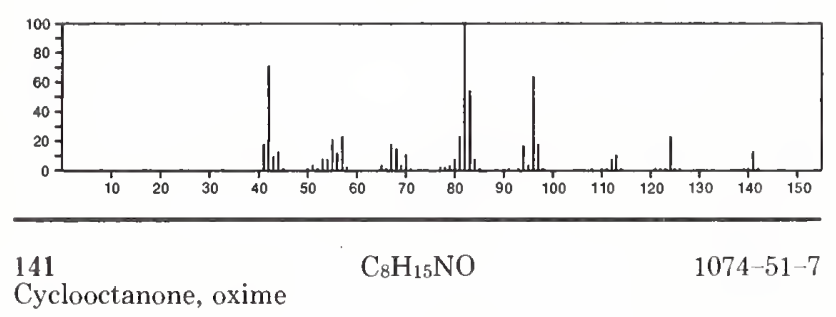

Cyclooctanone, oxime
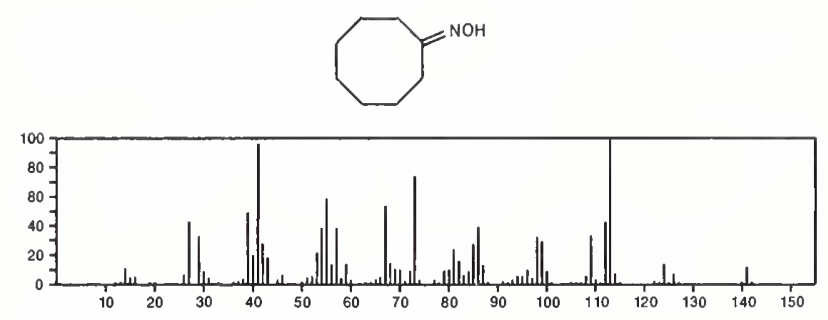

141

Acetamide, $N$-cyclohexyl- $\mathrm{C}_{8} \mathrm{H}_{15} \mathrm{NO}$

$1124-53-4$

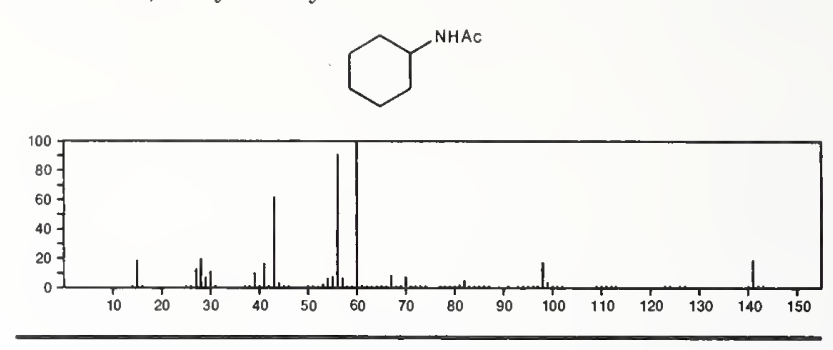

141

$\mathrm{C}_{8} \mathrm{H}_{15} \mathrm{NO}$

Morpholine, 4-(2-methyl-1-propenyl)-

$2403-55-6$

$\overbrace{\mathrm{N}}^{-\mathrm{CH}=\mathrm{CM}_{2}}$

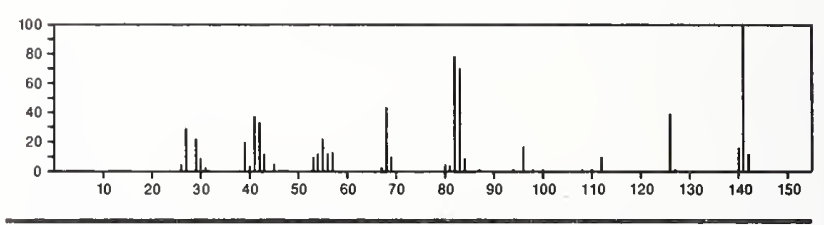

141

$\mathrm{C}_{8} \mathrm{H}_{15} \mathrm{NO}$

Cyclohexanone, $\mathrm{O}$-ethyloxime

$3376-38-3$
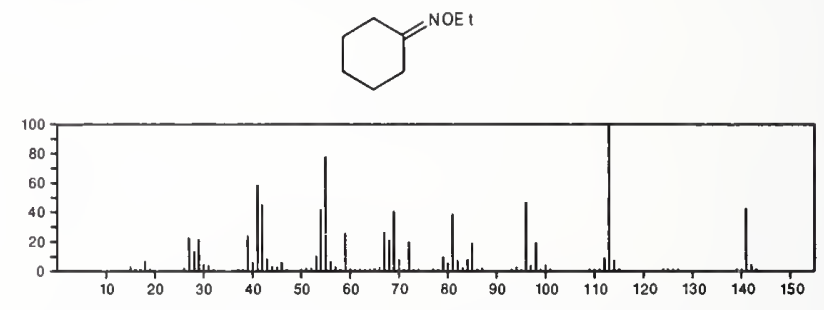

141

2-Pyrrolidinone, 1-butyl-

$\mathrm{C}_{8} \mathrm{H}_{15} \mathrm{NO}$

$3470-98-2$
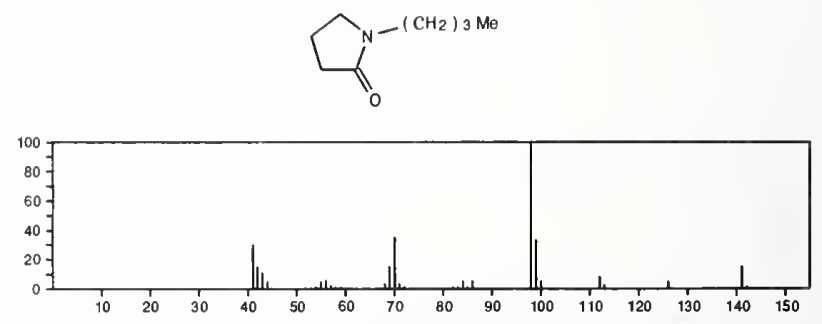

141

2-Propanone, 1-(2-piperidinyl)-

4396-01-4
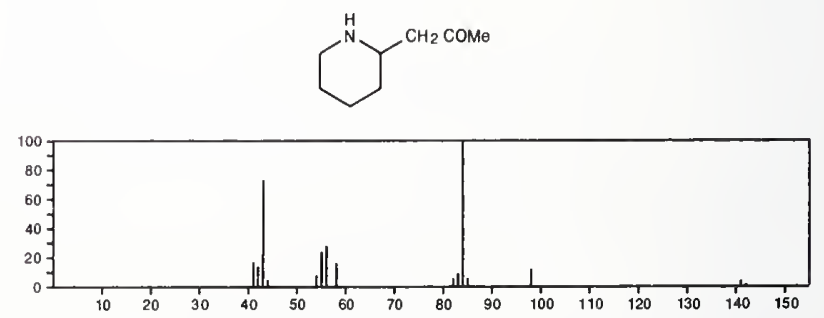
$141 \quad \mathrm{C}_{8} \mathrm{H}_{15} \mathrm{NO}$

1 H-Azepine, 1-acetylhexahydro-
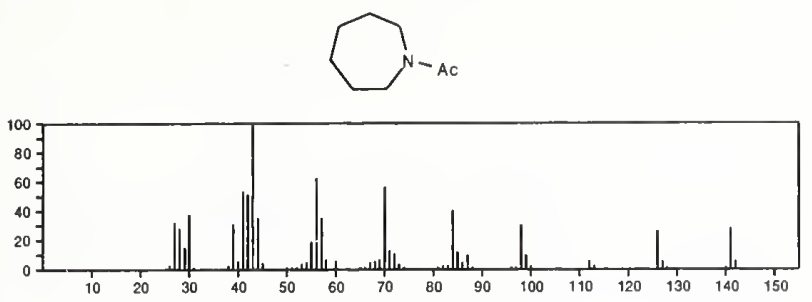

\section{1}

8-Azabicyclo[3.2.1]octan-3-ol, 8-methyl-
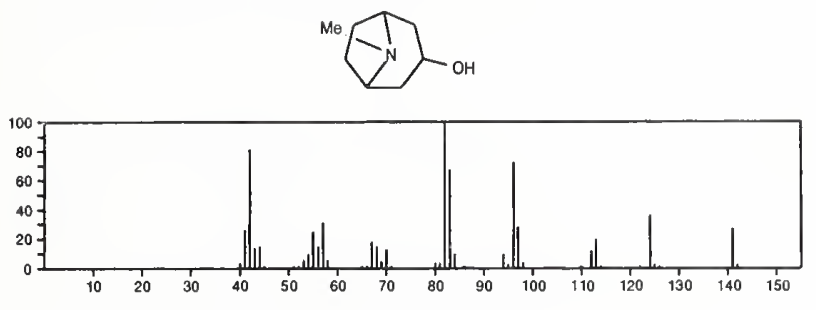

$\overline{141 \quad \mathrm{C}_{8} \mathrm{H}_{15} \mathrm{NO}}$

3-Azabicyclo[3.2.1]octan-8 $\alpha$-ol, 3-methyl-, anti-
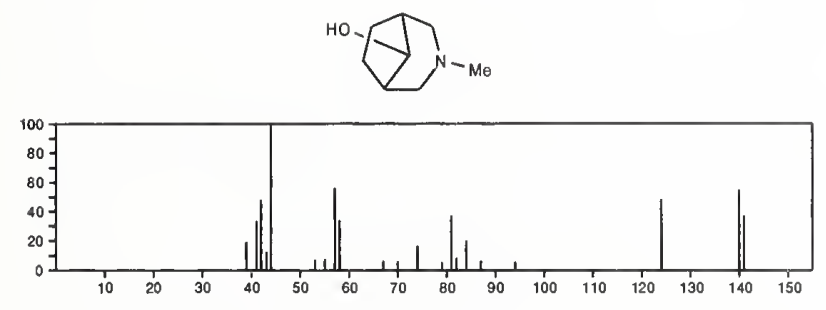

141

$\mathrm{C}_{8} \mathrm{H}_{15} \mathrm{NO}$

13493-39-5

3-Azabicyclo[3.2.1]octan-8 $\beta$-ol, 3-methyl-, syn-
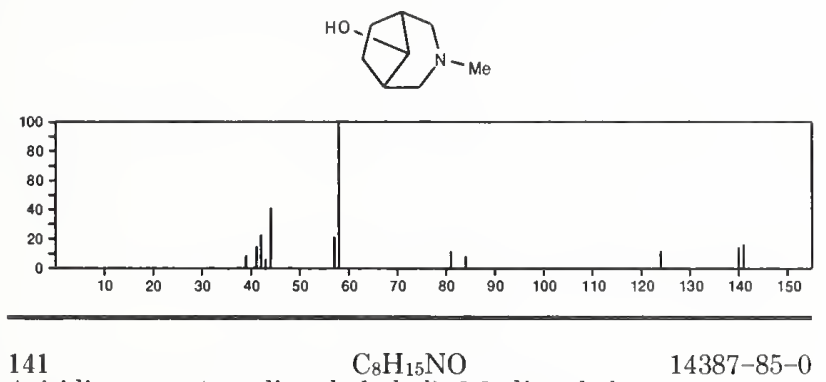

Aziridinone, 1-(1,1-dimethylethyl)-3,3-dimethyl-
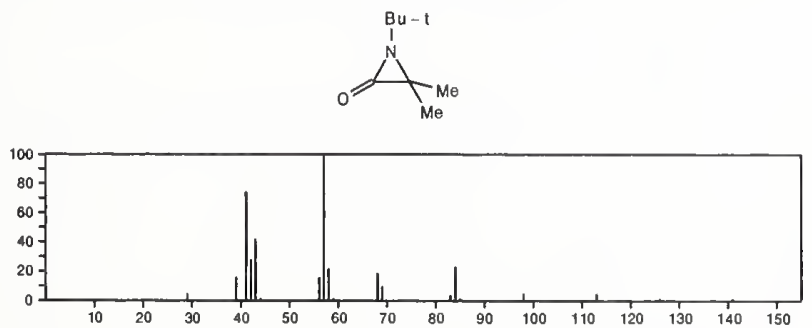

141

Morpholine, 4-(1-butenyl)-

$15431-03-5$
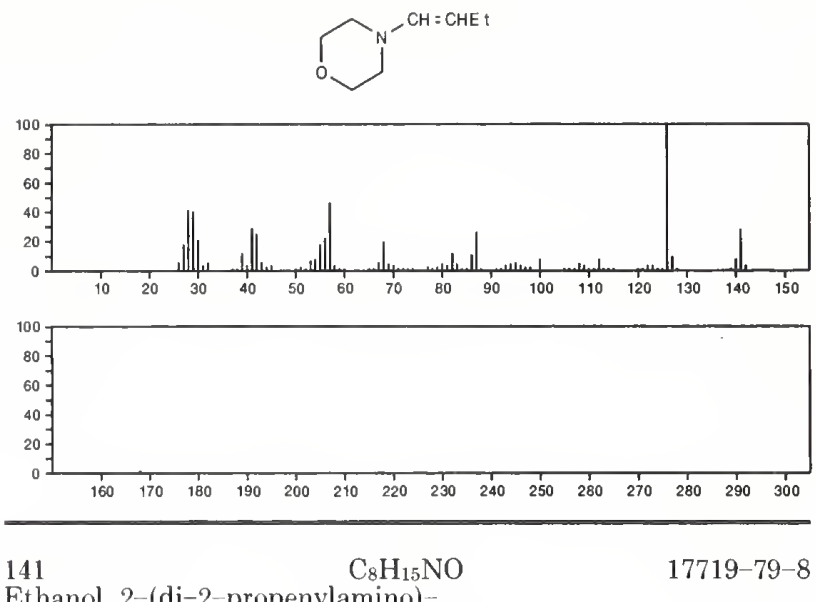

Ethanol, 2-(di-2-propenylamino)-

$\mathrm{CH}_{2} \mathrm{CH}=\mathrm{CH}_{2}$

$\mathrm{H}_{2} \mathrm{C}=\mathrm{CHCH}_{2} \mathrm{NCH}_{2} \mathrm{CH}_{2} \mathrm{OH}$

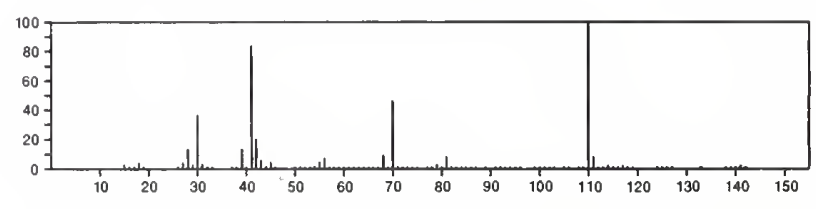

141

$\mathrm{C}_{8} \mathrm{H}_{15} \mathrm{NO}$

2--Oxazoline, 4,5-diethyl-2-methyl-, cis-

25943-07-1<smiles>CCC1N=C([N+](=O)[O-])OC1CC</smiles>

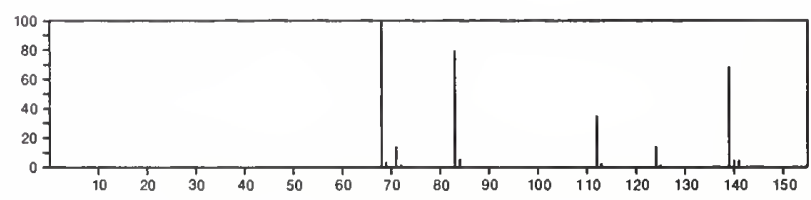

141

$\mathrm{C}_{8} \mathrm{H}_{15} \mathrm{NO}$

$25943-13-9$

2-Oxazoline, 4,5-diethyl-2-methyl-, trans-<smiles>CCC1N=C(C)OC1CC</smiles>

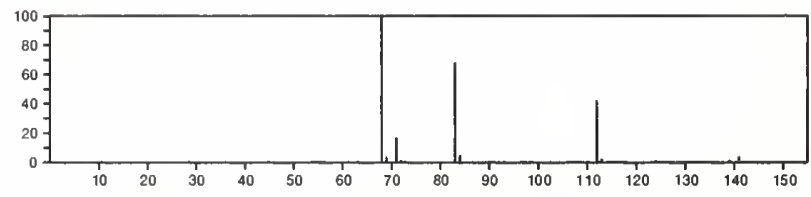

$141 \quad \mathrm{C}_{8} \mathrm{H}_{15} \mathrm{NO}$

$33527-93-4$

Pyrrolidine, 1-(1-oxobutyl)-
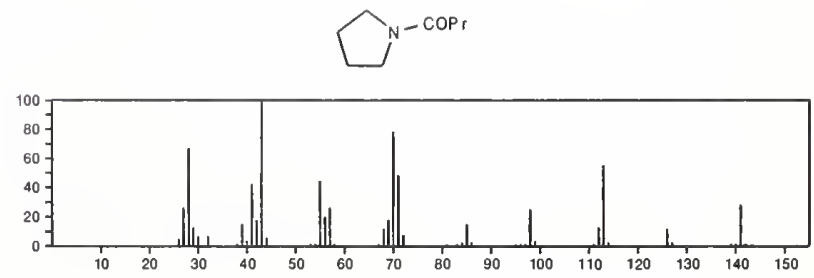
141

Cyclohexanone, 2-methyl-, O-methyloxime

$39209-07-9$<smiles>CC1CCCCC1=O</smiles>

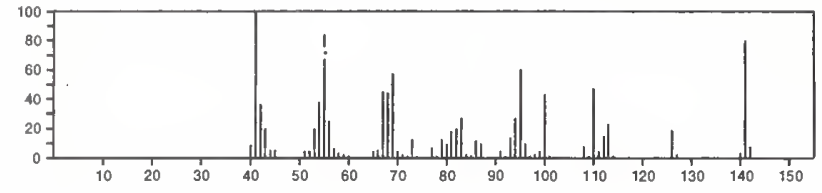

141

$\mathrm{C}_{8} \mathrm{H}_{15} \mathrm{NO}$

$39477-43-5$

Cyclohexanone, 4-methyl-, $O$-methyloxime<smiles>CC1CCC(=NC2CC2)CC1</smiles>

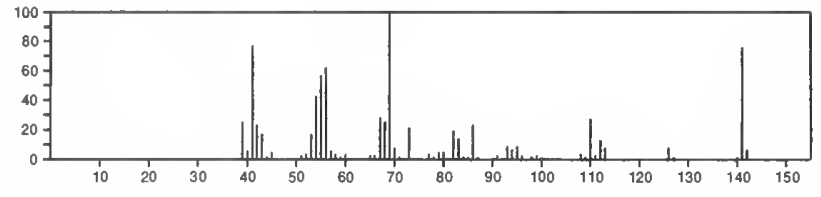

$141 \quad \mathrm{C}_{8} \mathrm{H}_{15} \mathrm{NO}$

3-Piperidinone, 1-ethyl-6-methyl-

$43152-94-9$
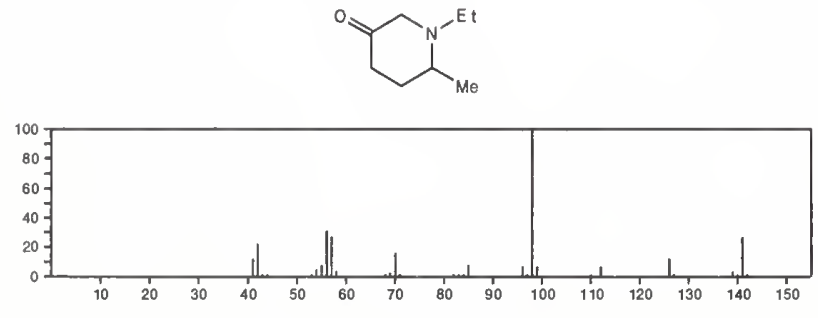

$141 \quad \mathrm{C}_{8} \mathrm{H}_{15} \mathrm{NO}$

6-Oxa-1-azabicyclo[3.1.0]hexane, 2,2,4,4-tetramethyl-
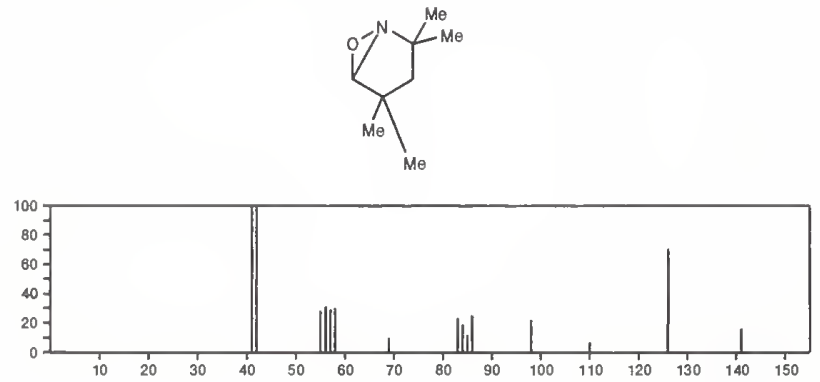

\section{$141 \quad \mathrm{C}_{8} \mathrm{H}_{15} \mathrm{NO}$}

1-Azetidinecarboxaldehyde, 2,2,4,4-tetramethyl-
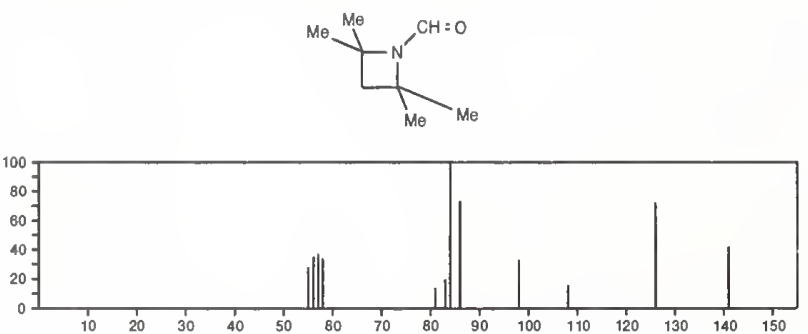

141 3-Hepten-2-one, $\mathrm{O}$-methyloxime

$56336-01-7$

$\operatorname{Pr} \mathrm{CH}=\mathrm{CHCM}=\mathrm{NOM}$

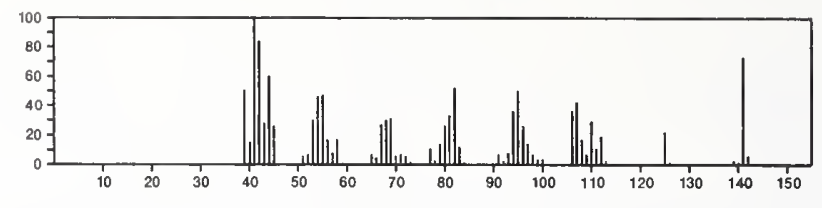

141

$\mathrm{C}_{8} \mathrm{H}_{20} \mathrm{BN}$

4023-39-6

Boranamine, $N, N, 1,1$-tetraethyl-

Et 2 NBE $t 2$

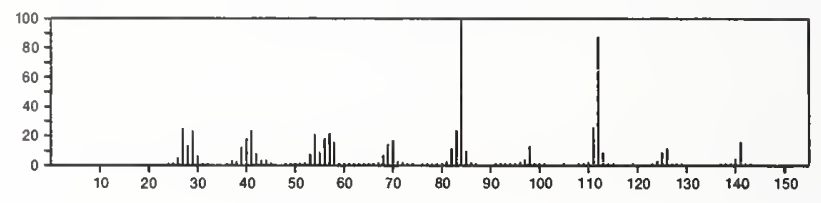

141

$\mathrm{C}_{9} \mathrm{H}_{19} \mathrm{~N}$

1432-48-0

2-Propanamine, $N$-(2,2-dimethylpropylidene)-2-methyl-

$t-\mathrm{BuN}=\mathrm{CHCM}_{3}$

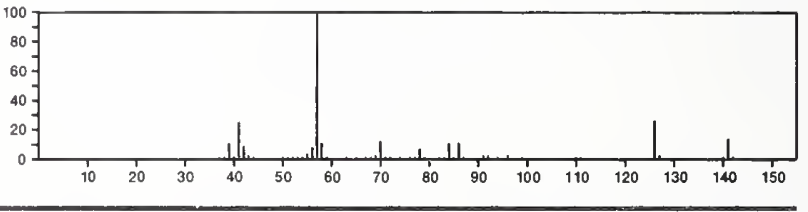

141

$\mathrm{C}_{9} \mathrm{H}_{19} \mathrm{~N}$

Pyrrolidine, 2-butyl-1-methyl-

$3447-03-8$
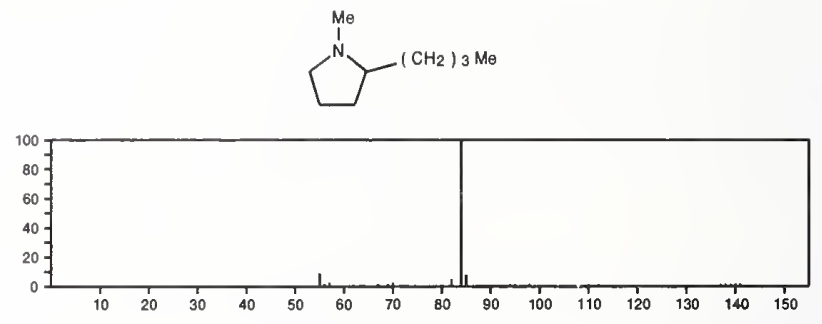

141

Piperidine, 1-butyl-

$\mathrm{C}_{9} \mathrm{H}_{19} \mathrm{~N}$

4945-48-6
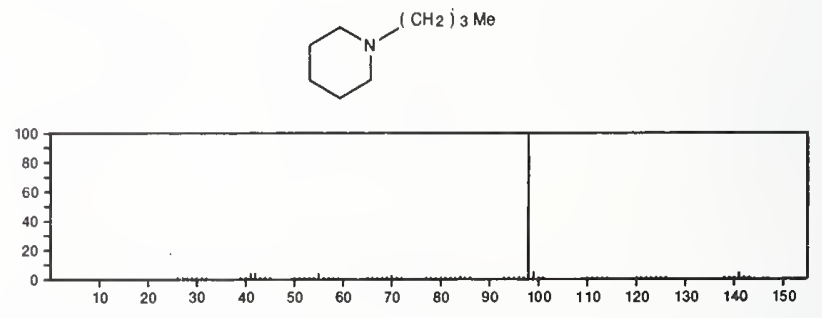

141

$\mathrm{C}_{9} \mathrm{H}_{19} \mathrm{~N}$

6124-84-1

Aziridine, 1,2-diisopropyl-3-methyl-, trans-<smiles>CC1C(Br)N1PI</smiles>

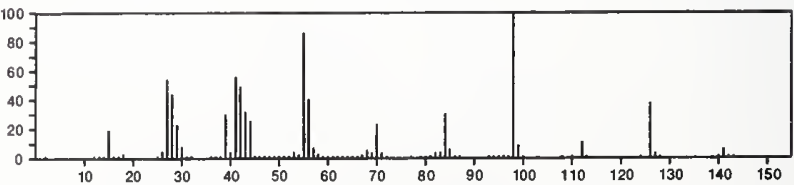


141 1-Butanamine, $\mathrm{N}$-pentylidene-

$\mathrm{C}_{9} \mathrm{H}_{19} \mathrm{~N}$

10599-77-6

$\mathrm{Me}\left\{\mathrm{CH}_{2}\right)_{3} \mathrm{~N}=\mathrm{CH}\left(\mathrm{CH}_{2}\right)_{3} \mathrm{Me}$

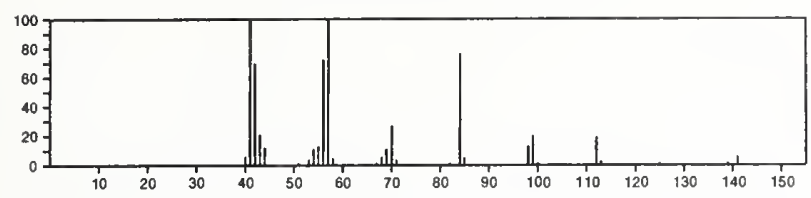

141

$\mathrm{C}_{9} \mathrm{H}_{19} \mathrm{~N}$

Ethanamine, $N$-(1-propylbutylidene)-

$10599-79-8$

$E t N=C P r_{2}$

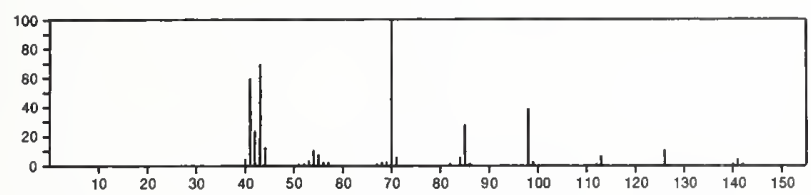

141

$\mathrm{C}_{9} \mathrm{H}_{19} \mathrm{~N}$

Methylamine, $N$-(1-methylheptylidene)-

$18641-72-0$

$\mathrm{Me}\left\langle\mathrm{CH}_{2}\right) 5 \mathrm{CM \theta}=\mathrm{NMe}$
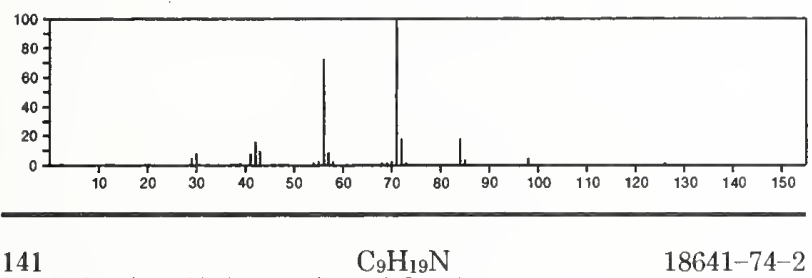

Methylamine, $N$-(1-ethylhexylidene)-

$\left.\mathrm{Me}\left\{\mathrm{CH}_{2}\right\}\right)_{4} \mathrm{CE} \mathrm{t}=\mathrm{NME}$
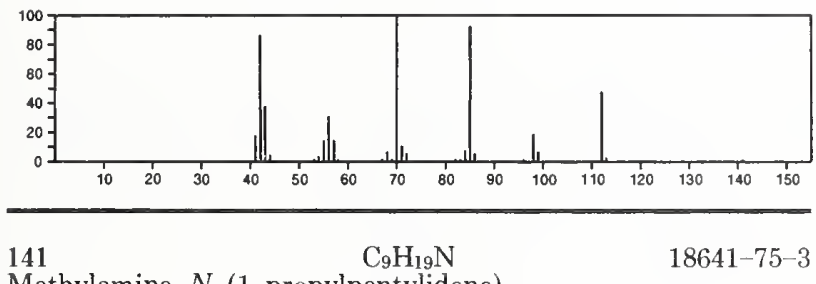

Methylamine, $N-(1-$ propylpentylidene $)-$

$\mathrm{Me}\left(\mathrm{CH}_{2}\right)_{3} \mathrm{CPr}=\mathrm{NME}$
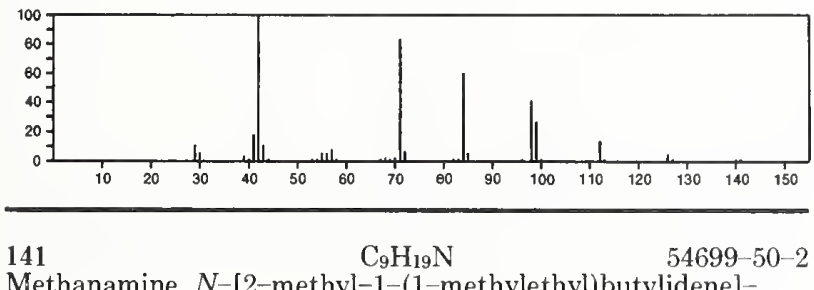

Methanamine, $N-[2-$ methyl-1-(1-methylethyl)butylidene]-

$\mathrm{CHMe}_{2}$

- $\mathrm{MeCH}_{2} \mathrm{CHMe} \mathrm{C}=\mathrm{NM}$

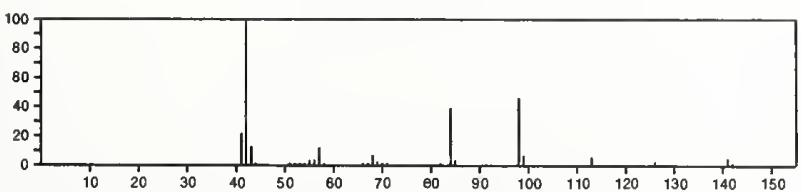

141

$\mathrm{C}_{9} \mathrm{H}_{19} \mathrm{~N}$

$55669-78-8$

Aziridine, 2-(1,1-dimethylethyl)-1-ethyl-3-methyl-, cis-<smiles>CCN1C([18O])C1Br</smiles>

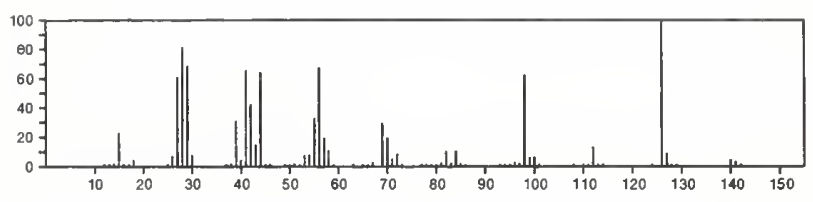

141

$\mathrm{C}_{9} \mathrm{H}_{19} \mathrm{~N}$

55669-79-9

Aziridine, 2-(1,1-dimethylethyl)-1-ethyl-3-methyl-, trans-<smiles>CCN1C([14CH2])C1Br</smiles>

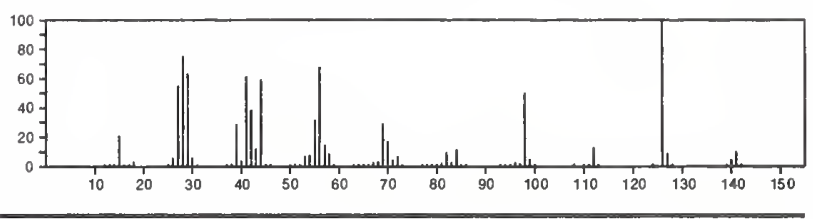

142

$\mathrm{CH}_{3} \mathrm{I}$

$74-88-4$

Methane, iodo

Me

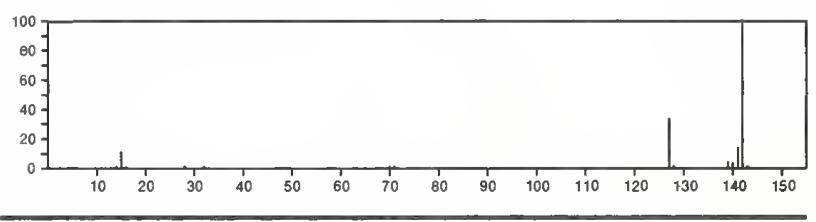

142

$\mathrm{C}_{2} \mathrm{HBrF}_{2}$

$358-99-6$

Ethylene, 1-bromo-1,2-difluoro-

$\mathrm{FCH}=\mathrm{CB} \mathrm{rF}$
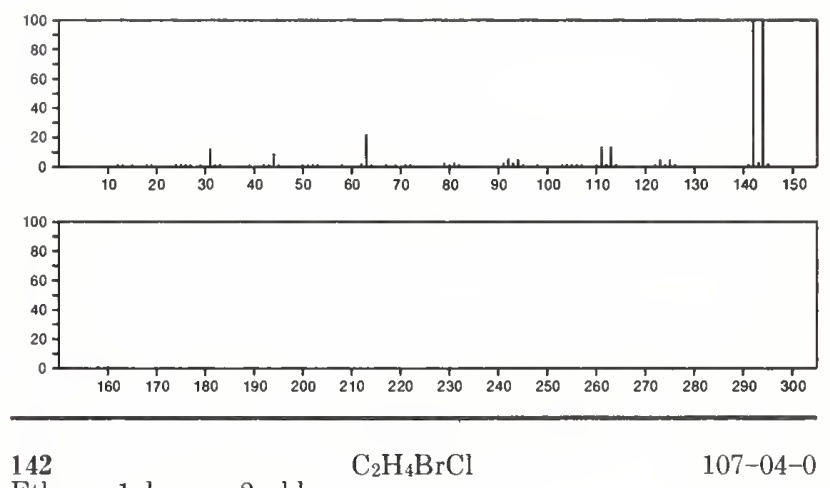

Ethane, 1-bromo-2-chloro-

$\mathrm{ClCH}_{2} \mathrm{CH}_{2} \mathrm{~B}$

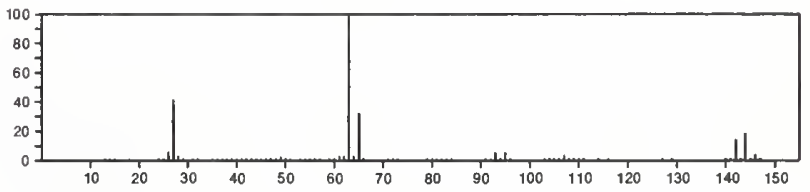


142

$\mathrm{C}_{3} \mathrm{H}_{4} \mathrm{Cl}_{2} \mathrm{O}_{2}$

75-99-0

$\mathrm{MeCCl}_{2}\left(\mathrm{CO}_{2} \mathrm{H}\right)$

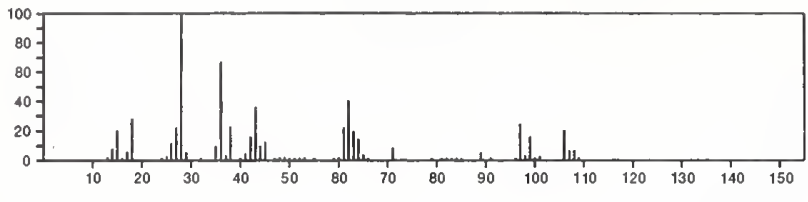

142

$\mathrm{C}_{3} \mathrm{H}_{4} \mathrm{Cl}_{2} \mathrm{O}_{2}$

Acetic acid, dichloro-, methyl ester

$\mathrm{MeOC}(0) \mathrm{CHCl}_{2}$

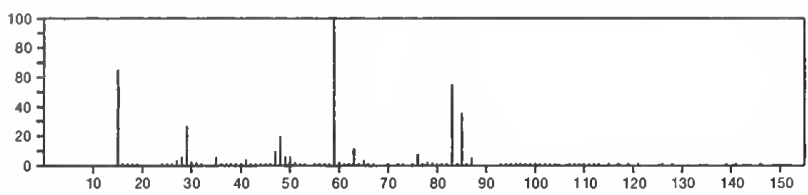

142

Propanoic acid, 2,3-dichloro-

$\mathrm{C}_{3} \mathrm{H}_{4} \mathrm{Cl}_{2} \mathrm{O}_{2}$

$565-64-0$

$\mathrm{ClCH}_{2} \mathrm{CHClCO}_{2} \mathrm{H}$

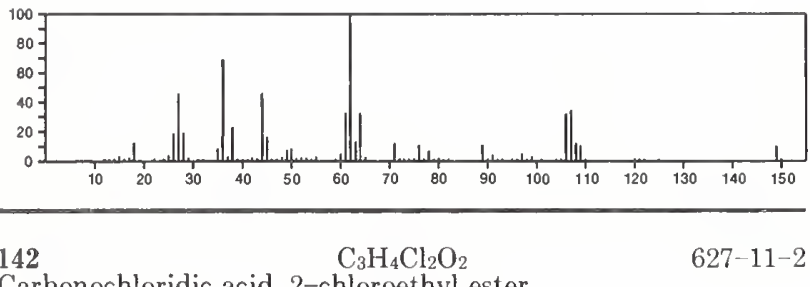

Carbonochloridic acid, 2-chloroethyl ester

$\mathrm{Cl} \mathrm{CH}_{2} \mathrm{CH}_{2} \mathrm{OC}(0) \mathrm{Cl}$

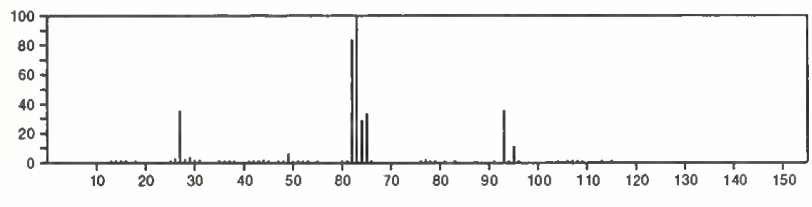

$142 \quad \mathrm{C}_{3} \mathrm{H}_{9} \mathrm{~F}_{2} \mathrm{~N}_{2} \mathrm{P}$

$22692-24-6$

Phosphorodifluoridous hydrazide, trimethyl-

$\mathrm{Me} 2 \mathrm{NNM} \mathrm{PF}_{2}$

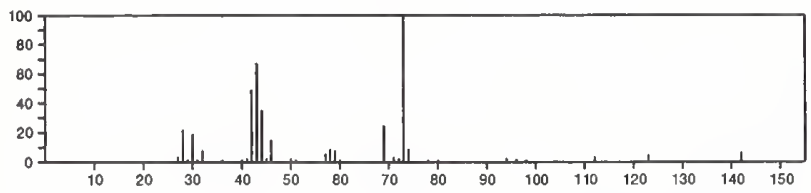

142

$\mathrm{C}_{4} \mathrm{H}_{5} \mathrm{ClF}_{2} \mathrm{O}$

Ethene, 1-chloro-2-ethoxy-1,2-difluoro-

$C I C F=C F(O E t)$
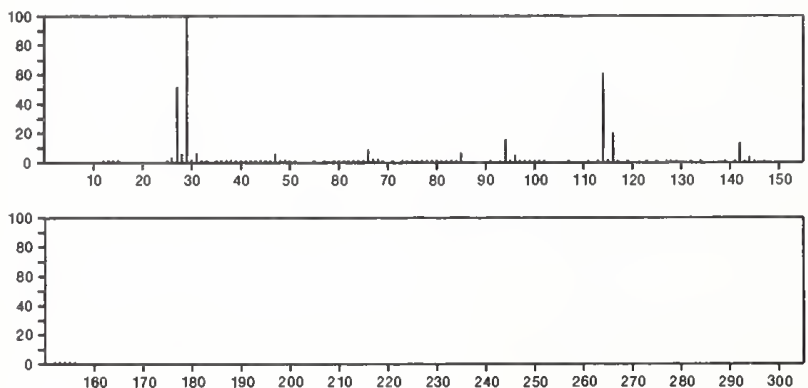

142

$\mathrm{C}_{4} \mathrm{H}_{5} \mathrm{ClF}_{2} \mathrm{O}$

$1515-16-8$

2-Butanone, 4-chloro-4,4-difluoro-

$\mathrm{MeCOCH}_{2} \mathrm{CClF}_{2}$
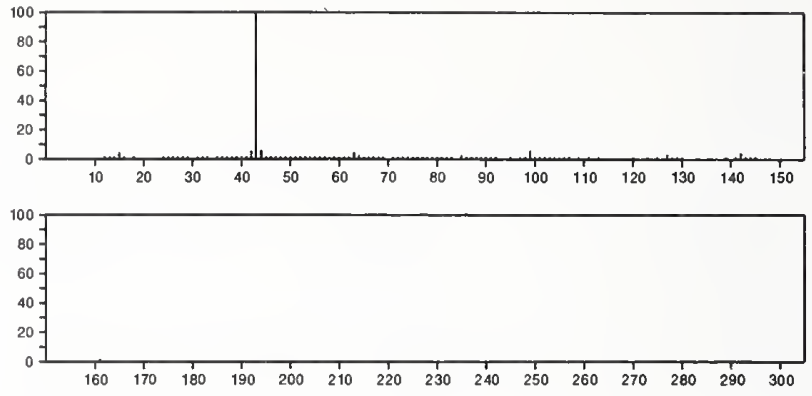

142

$\mathrm{C}_{4} \mathrm{H}_{5} \mathrm{~F}_{3} \mathrm{O}_{2}$

$383-63-1$

Acetic acid, trifluoro-, ethyl ester

$\mathrm{EtOC}(\mathrm{O}) \mathrm{CF}_{3}$

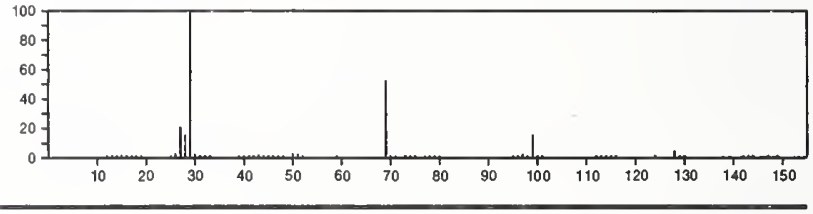

142

$\mathrm{C}_{4} \mathrm{H}_{6} \mathrm{~N}_{4} \mathrm{O}_{2}$

2,6-Pyrazinediamine, $N$-hydroxy-, 1 -oxide

41536-70-3<smiles>Nc1cncc(NO)[n+]1[O-]</smiles>

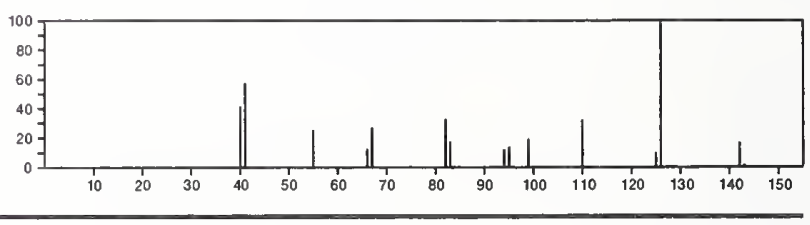

$142 \quad \mathrm{C}_{4} \mathrm{H}_{6} \mathrm{~N}_{4} \mathrm{O}_{2}$

$55702-53-9$

1,3,5-Triazine-2,4(1H,3H)-dione, 6 -(methylamino $)$ -
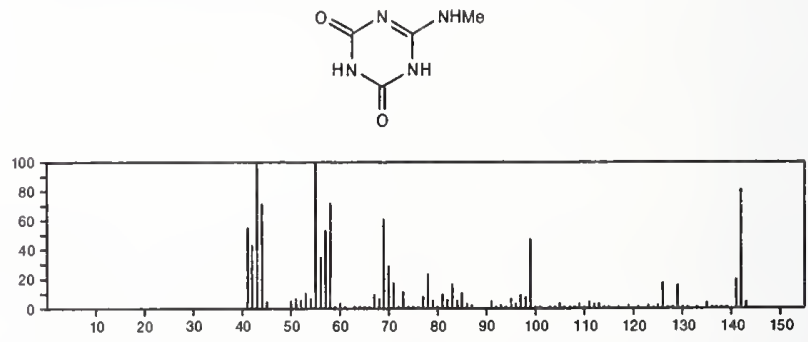

142

Ethane, 1,1'-oxybis[2-chloro-

$\mathrm{C}_{4} \mathrm{H}_{8} \mathrm{Cl}_{2} \mathrm{O}$

$111-44-4$

$\mathrm{Cl} \mathrm{CH}_{2} \mathrm{CH}_{2} \mathrm{OCH}_{2} \mathrm{CH}_{2} \mathrm{Cl}$

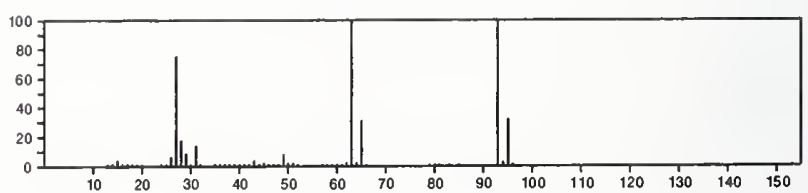


142

$\mathrm{C}_{4} \mathrm{H}_{8} \mathrm{Cl}_{2} \mathrm{O}$

Ethane, 1,2-dichloro-1-ethoxy-

623-46-1

$\mathrm{ClCH}_{2} \mathrm{CHCl}$ ( $\mathrm{OEt}$ )

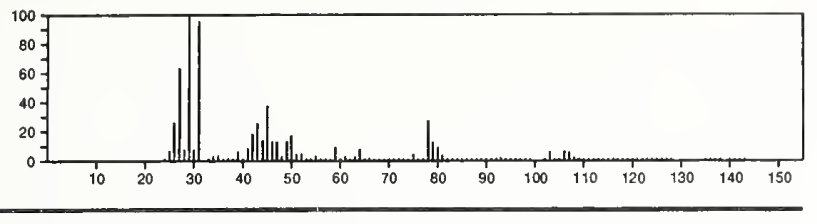

142

$\mathrm{C}_{5} \mathrm{H}_{2} \mathrm{O}_{5}$

$488-86-8$

4-Cyclopentene-1,2,3-trione, 4,5-dihydroxy-
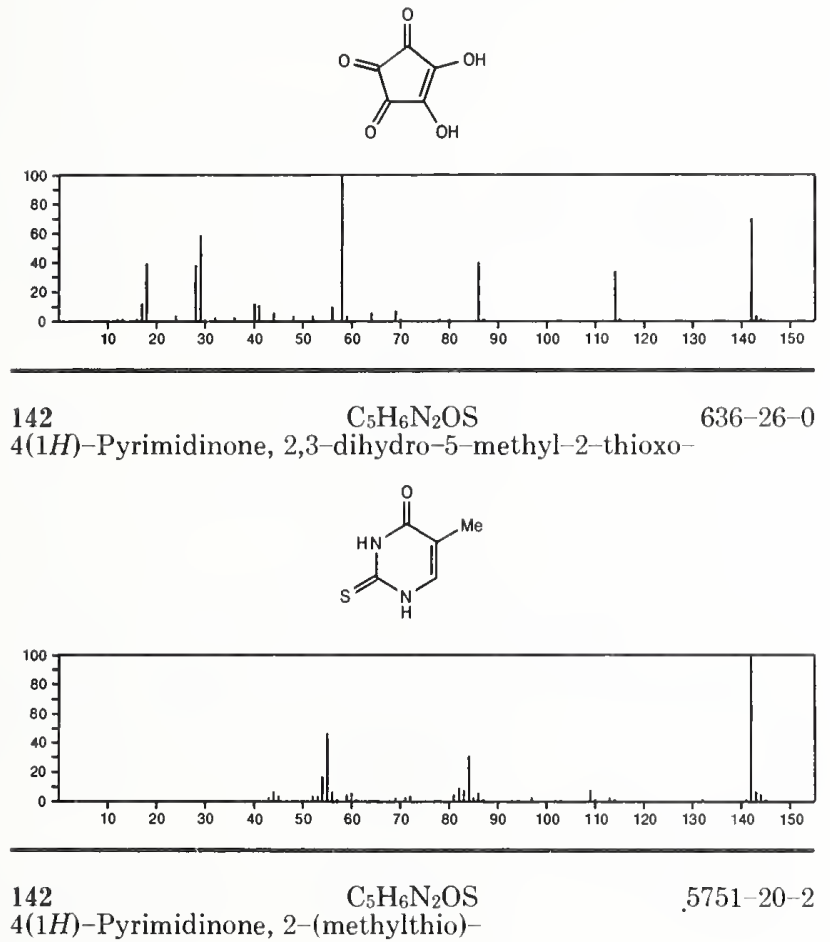

4(1H)-Pyrimidinone, 2-(methylthio)-
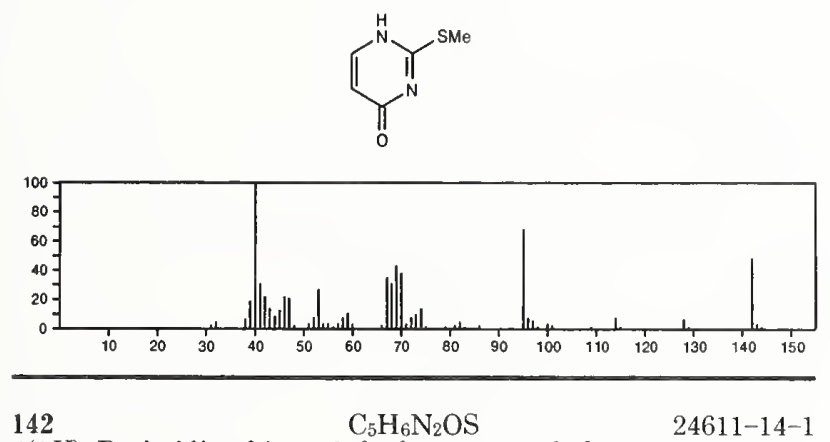

4(1H)-Pyrimidinethione, 5-hydroxy-2-methyl
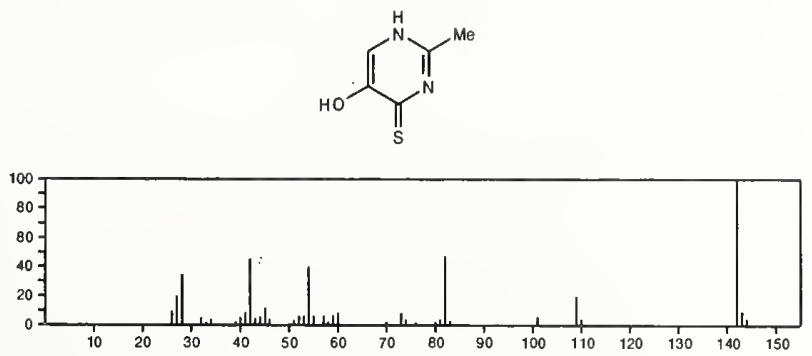

142

$\mathrm{C}_{5} \mathrm{H}_{6} \mathrm{~N}_{2} \mathrm{OS}$

$35455-86-8$

2(1H)-Pyrimidinone, 3,4-dihydro-1-methyl-4-thioxo-<smiles>Cn1ccc(=S)[nH]c1=O</smiles>

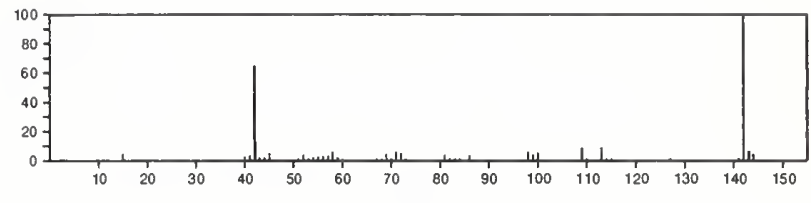

142

$\mathrm{C}_{5} \mathrm{H}_{6} \mathrm{~N}_{2} \mathrm{OS}$

$40757-61-7$

Ethanone, 1-(5-methyl-1,2,3-thiadiazol-4-yl)-
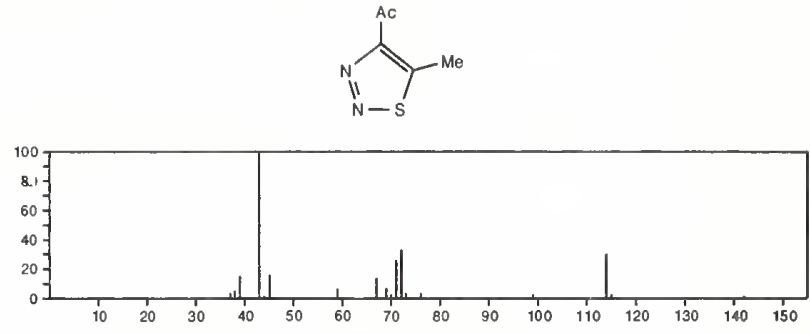

142

$\mathrm{C}_{5} \mathrm{H}_{6} \mathrm{~N}_{2} \mathrm{OS}$

4(1H)-Pyrimidinone, 6-mercapto-2-methyl-
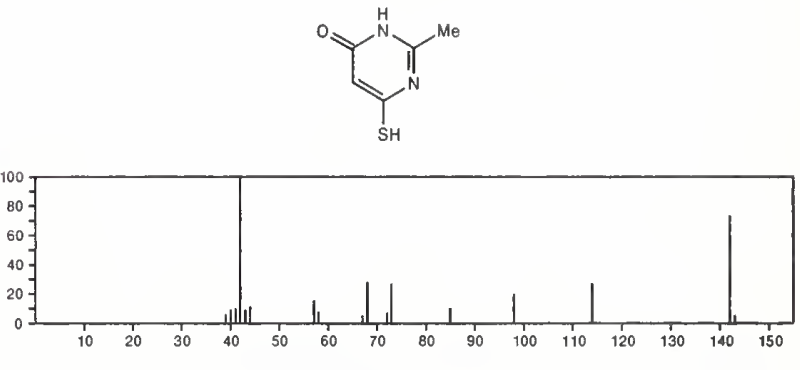

142

$\mathrm{C}_{5} \mathrm{H}_{6} \mathrm{~N}_{2} \mathrm{O}_{3}$

$1123-49-5$

Isoxazole, 3,5-dimethyl-4-nitro-
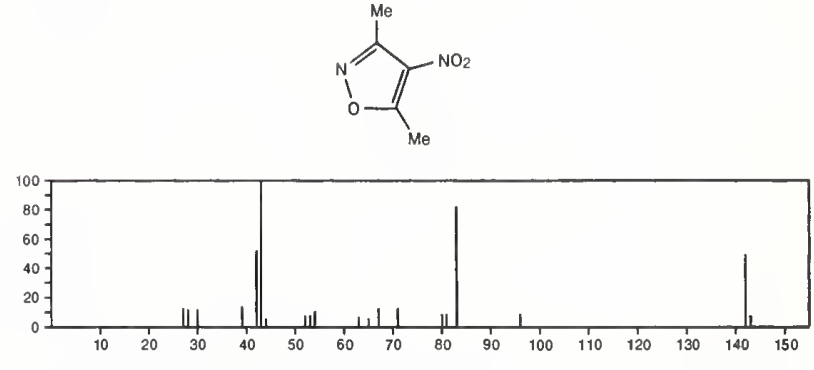

142

$\mathrm{C}_{6} \mathrm{H}_{3} \mathrm{ClO}_{2}$

2,5-Cyclohexadiene-1,4-dione, 2 -chloro-

$695-99-8$<smiles>O=C1C=CC(=O)C(Cl)=C1</smiles>

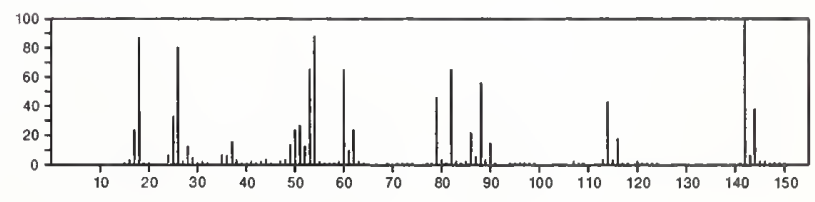



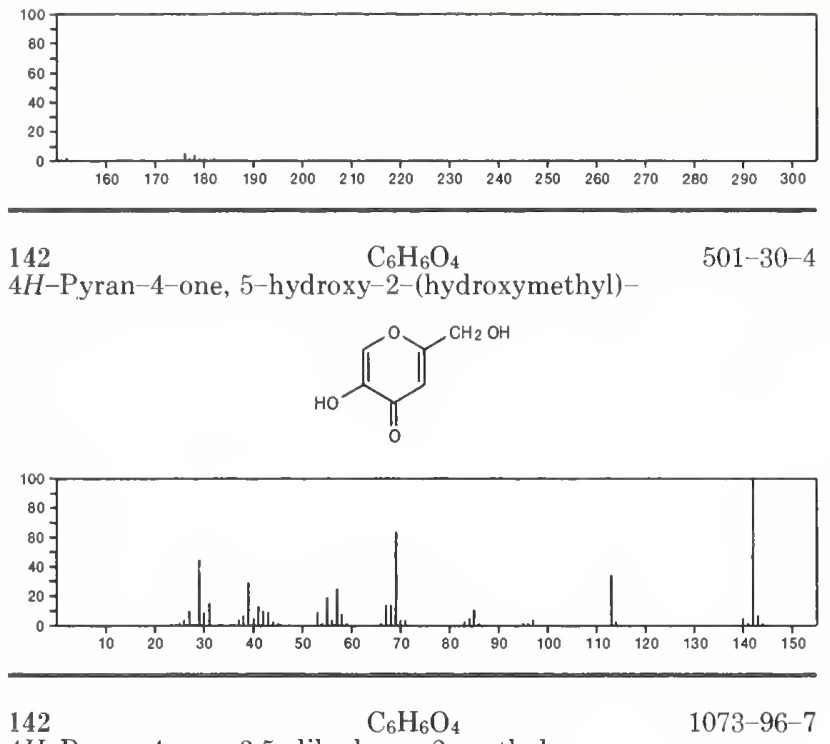

4H-Pyran-4-one, 3,5-dihydroxy-2-methyl-
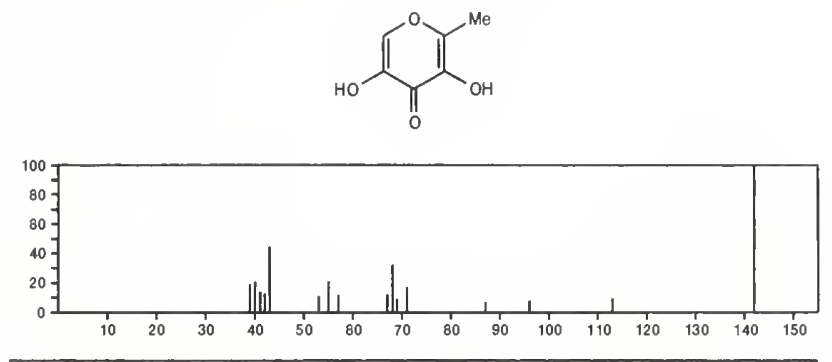

$142 \quad \mathrm{C}_{6} \mathrm{H}_{6} \mathrm{O}_{4}$

2,4-Hexadienedioic acid, $(Z, Z)$

$1119-72-8$

$\mathrm{HO}_{2} \mathrm{CCH}=\mathrm{CHCH}=\mathrm{CHCO}_{2} \mathrm{H}$

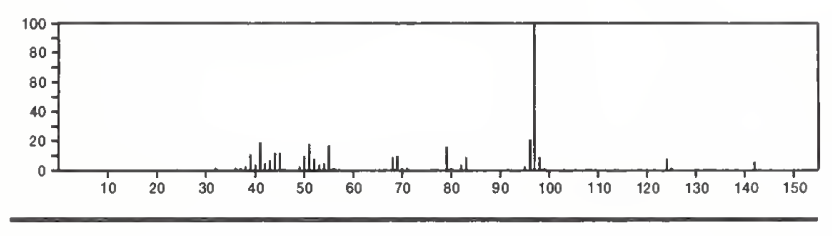

112

$\mathrm{C}_{6} \mathrm{H}_{6} \mathrm{O}_{4}$

$6338-41-6$

2-Furancarboxylic acid, 5-(hydroxymethyl)-
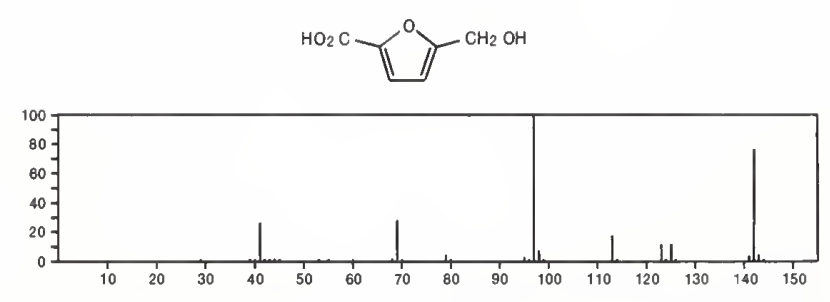

$142 \quad \mathrm{C}_{6} \mathrm{H}_{6} \mathrm{O}_{4}$

$16508-05-7$

1-Cyclobutene-1,2-dicarboxylic acid
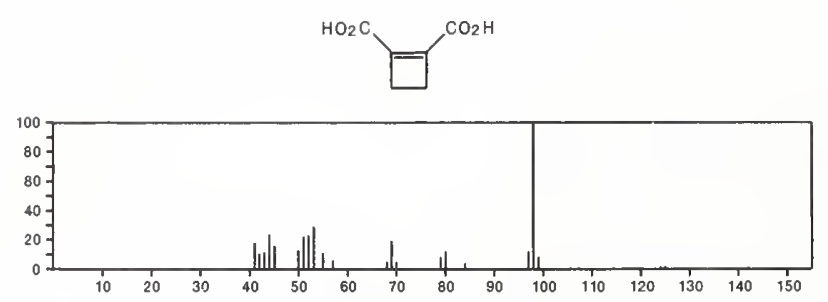

142

2-Butyne-1,4-diol, diformate

$\mathrm{C}_{6} \mathrm{H}_{6} \mathrm{O}_{4}$

$36677-73-3$

$\mathrm{O}=\mathrm{CHOCH}_{2} \mathrm{C} \equiv \mathrm{CCH}_{2} \mathrm{OCH}=\mathrm{O}$

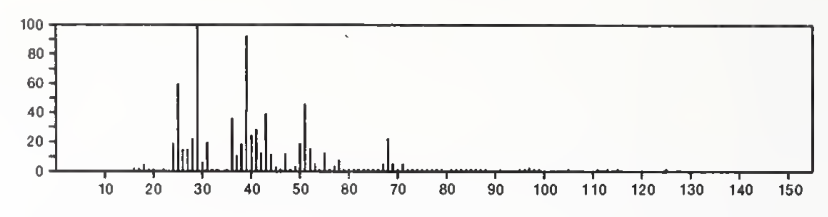

$\begin{aligned} & 142 \\ & \text { Phosphinic acid, phenyl-- }\end{aligned} \mathrm{C}_{6} \mathrm{H}_{7} \mathrm{O}_{2} \mathrm{P} \quad 1779-48-2$

$\operatorname{PhPH}(\mathrm{OH})=0$

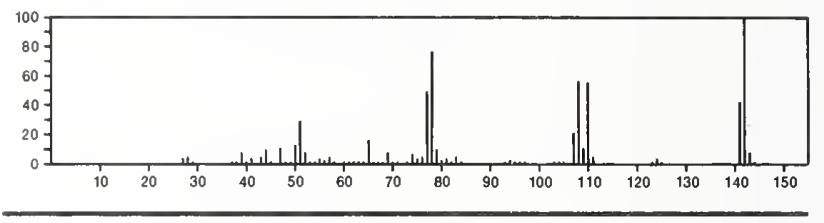

142

$\mathrm{C}_{6} \mathrm{H}_{10} \mathrm{~N}_{2} \mathrm{O}_{2}$

$6345-19-3$

2,4-Imidazolidinedione, 3,5,5-trimethyl-
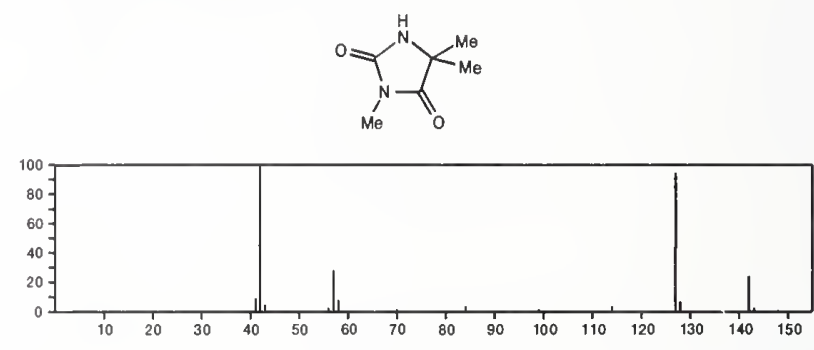

$142 \quad \mathrm{C}_{6} \mathrm{H}_{10} \mathrm{~N}_{2} \mathrm{O}_{2}$

2,4-Imidazolidinedione, 1,5,5-trimethyl-

$6851-81-6$
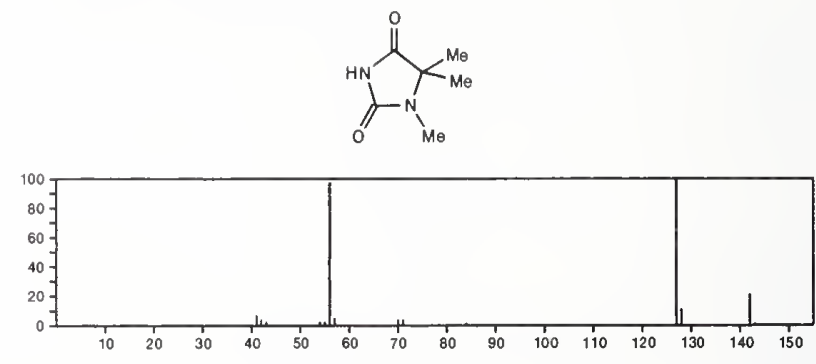

$142 \quad \mathrm{C}_{6} \mathrm{H}_{10} \mathrm{~N}_{2} \mathrm{O}_{2}$

Sydnone, 3-(1,1-dimethylethyl)-

6939-25-9
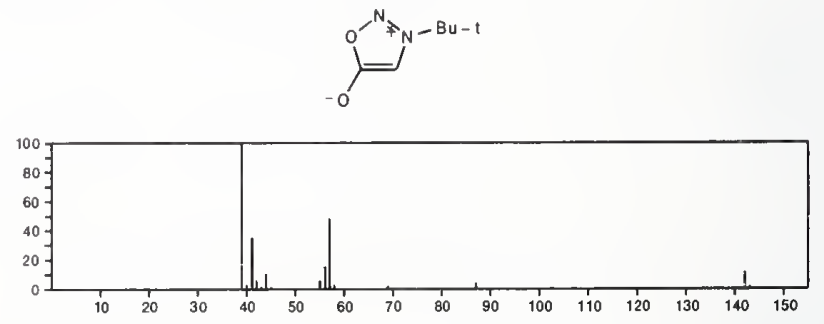
142

Phenol, 4-chloro-3-methyl-

$\mathrm{C}_{7} \mathrm{H}_{7} \mathrm{ClO}$
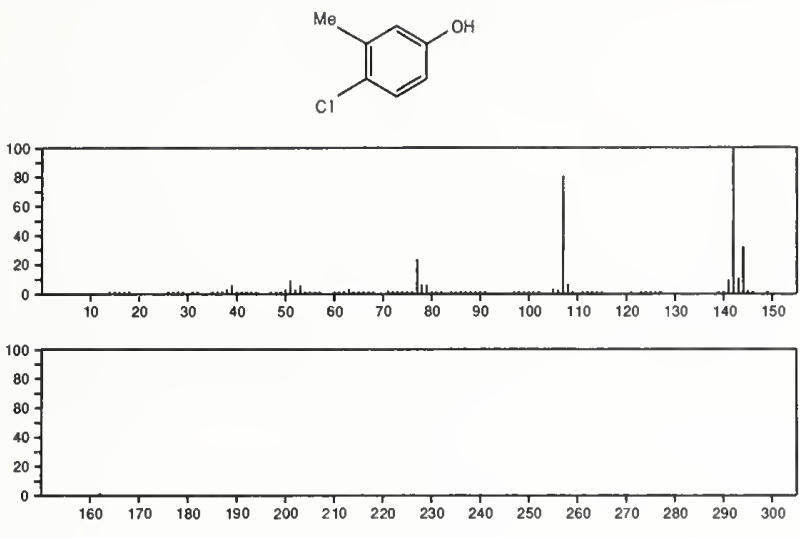

142

Phenol, 2-chloro-6-methyl-

$$
\mathrm{C}_{7} \mathrm{H}_{7} \mathrm{ClO}
$$

87- $64-9$
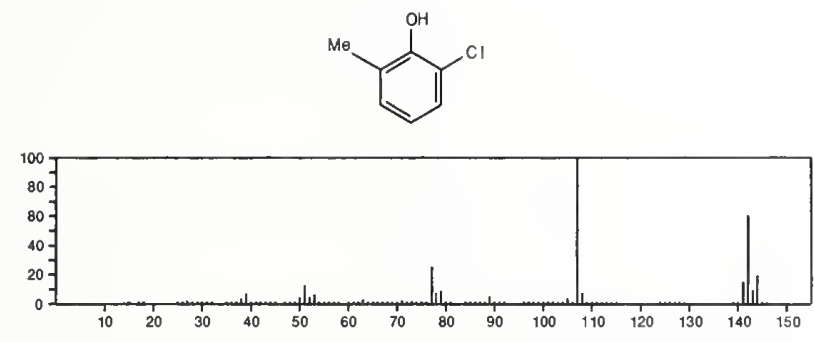

142

Benzene, 1-chloro-4-methoxy-

$\mathrm{C}_{7} \mathrm{H}_{7} \mathrm{ClO}$

623-12-1
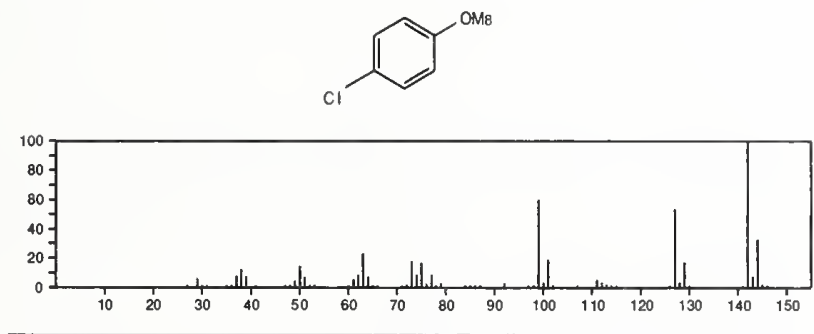

142

$\mathrm{C}_{7} \mathrm{H}_{7} \mathrm{ClO}$

$1570-64-5$

Phenol, 4-chloro-2-methyl-
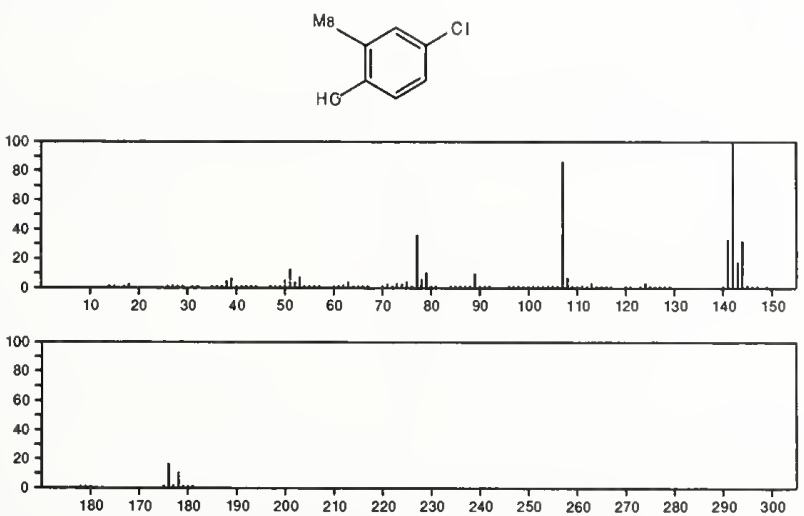

142

$\mathrm{C}_{7} \mathrm{H}_{7} \mathrm{ClO}$

17849-38-6

Benzenemethanol, 2-chloro-<smiles>OCc1ccccc1Cl</smiles>

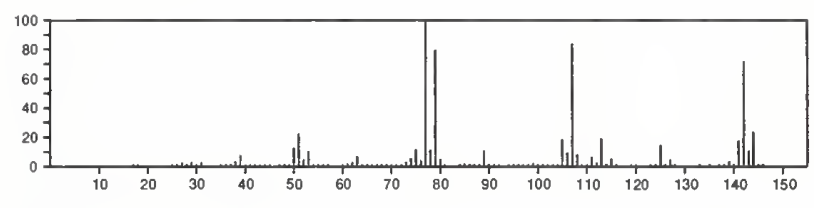

142

$\mathrm{C}_{7} \mathrm{H}_{10} \mathrm{O}_{3}$

1,3-Benzodioxol-2-one, hexahydro-, cis- $^{-}$

$19456-20-3$
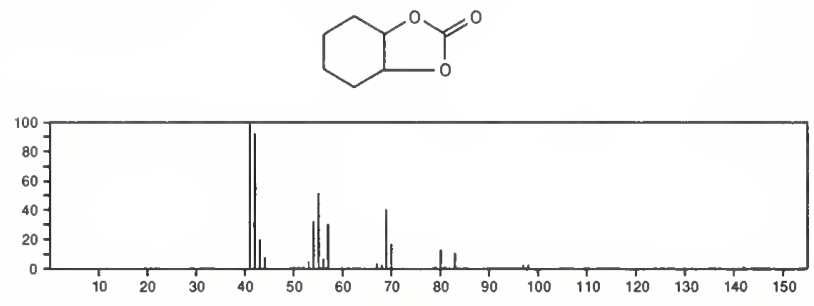

142

$\mathrm{C}_{7} \mathrm{H}_{10} \mathrm{O}_{3}$

20192-66-9

1,3-Benzodioxol-2-one, hexahydro-, trans-
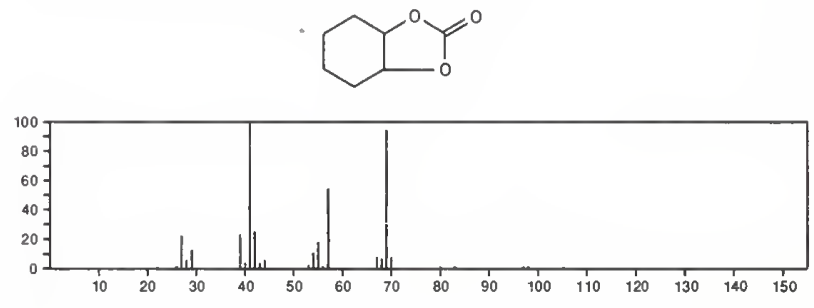

$142 \quad \mathrm{C}_{7} \mathrm{H}_{14} \mathrm{~N}_{2} \mathrm{O}$

$5432-28-0$

Cyclohexanamine, $N$-methyl- $N$-nitroso-
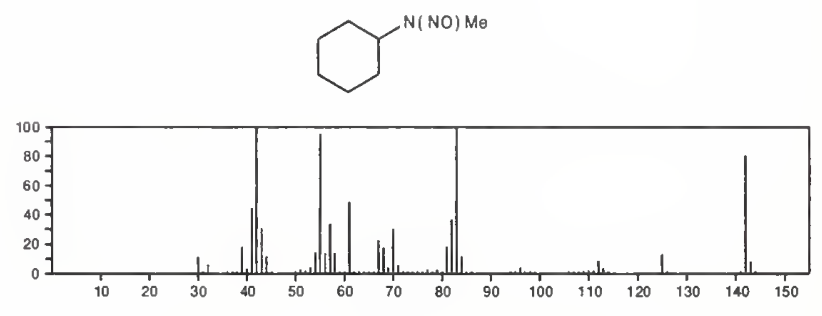

$142 \quad \mathrm{C}_{7} \mathrm{H}_{14} \mathrm{~N}_{2} \mathrm{O}$

Piperidine, 2,6-dimethyl-1-nitroso-

17721-95-8<smiles>CC1CCCC(C)N1O</smiles>

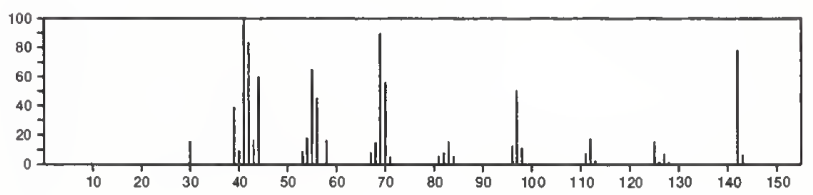


142

Azocine, octahydro-1-nitroso-

$\mathrm{C}_{7} \mathrm{H}_{14} \mathrm{~N}_{2} \mathrm{O}$
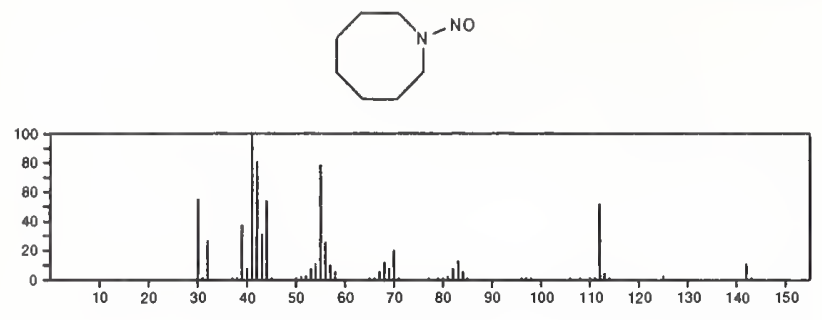

142

$\mathrm{C}_{7} \mathrm{H}_{14} \mathrm{~N}_{2} \mathrm{O}$

Diazene, cyclohexylmethyl-, 1-oxide, $(E)$ -
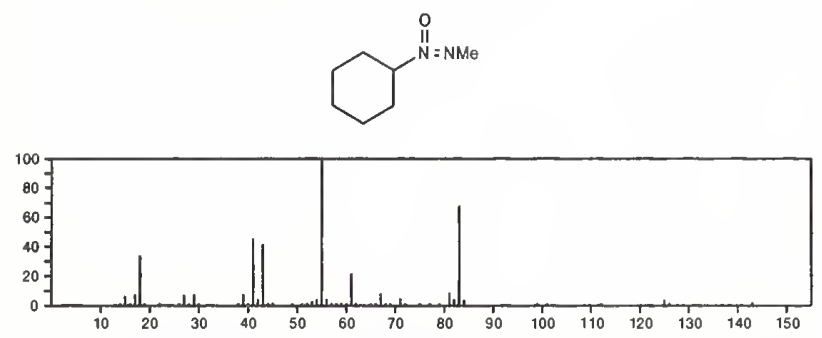

$\underset{3 \text {-Buten-2-one, 4-(dimethylamino)-4-(methylamino)- }}{\mathrm{C}_{7} \mathrm{H}_{14} \mathrm{~N}_{2} \mathrm{O}} \stackrel{40347-20-4}{-4}$

$\mathrm{Me} 2 \mathrm{NC}(\mathrm{NHMe})=\mathrm{CHCOM}$

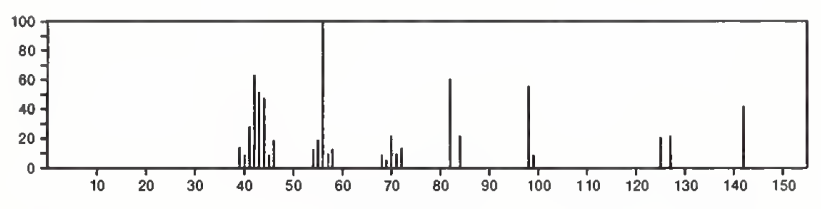

$142 \quad \mathrm{C}_{7} \mathrm{H}_{14} \mathrm{~N}_{2} \mathrm{O}$

2-Propenal, 2,3-bis(dimethylamino)-

42145-18-6

$\mathrm{Me} 2 \mathrm{NCH}=\mathrm{C}(\mathrm{CHO}) \mathrm{NMe}_{2}$

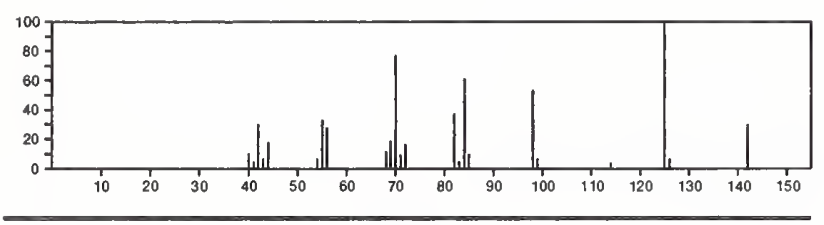

$142 \quad \mathrm{C}_{7} \mathrm{H}_{14} \mathrm{~N}_{2} \mathrm{O}$

2-Propenal, 3,3-bis(dimethylamino)-

$49582-45-8$

$\underset{\mathrm{OCHCH}}{\stackrel{\mathrm{NM}}{1} \mathrm{C} \mathrm{CM}_{2}}$

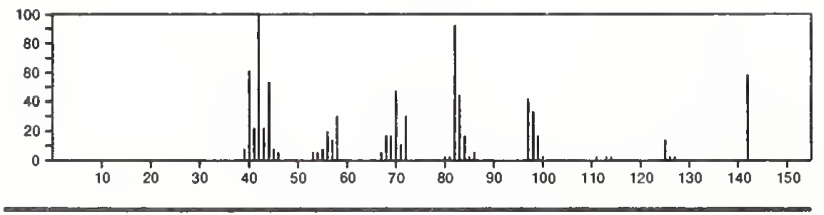

$\mathrm{C}_{7} \mathrm{H}_{14} \mathrm{~N}_{2} \mathrm{O}$

49582-63-0

3-Buten-2-one, 4-(dimethylamino)-3-(methylamino)-

$\mathrm{Me}_{2} \mathrm{NCH}=\mathrm{C}(\mathrm{NHMe}) \mathrm{COM \theta}$

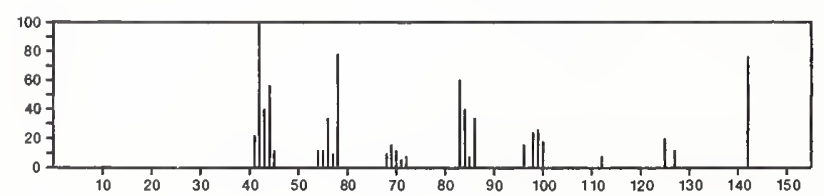

142

3-Pyrazolidinone, 1,2,4,5-tetramethyl-

56666-79-6<smiles>CC1C(=O)N(C)N(C)C1=O</smiles>

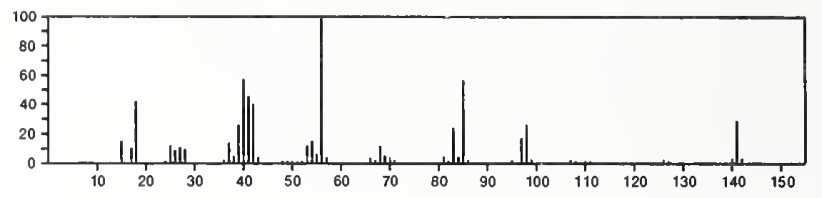

142

$\mathrm{C}_{7} \mathrm{H}_{14} \mathrm{~N}_{2} \mathrm{O}$

3-Pyrazolidinone, 1,2,4,4-tetramethyl-

$56666-82-1$
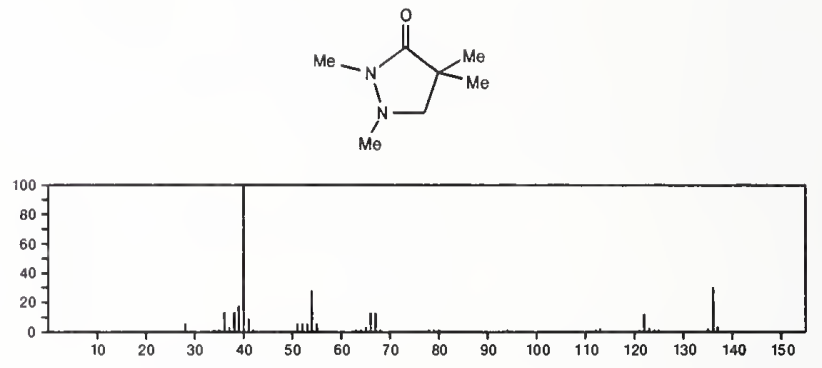

142
Bicyclo[2.2.2] oct-2-ene, 2-chloro-

$23804-47-9$
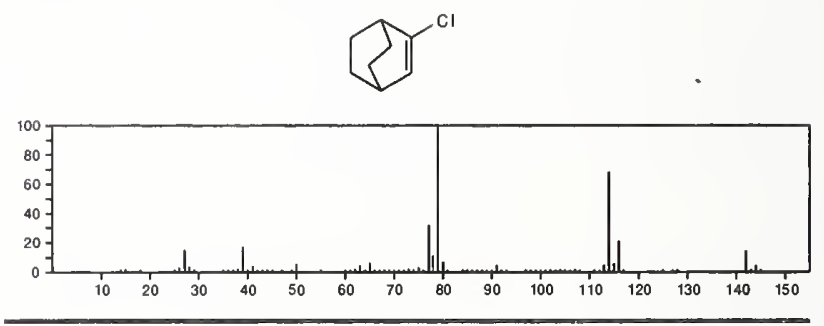

142

$\mathrm{C}_{8} \mathrm{H}_{11} \mathrm{Cl}$

$35242-17-2$

Bicyclo[3.2.1] oct-2-ene, 3-chloro-
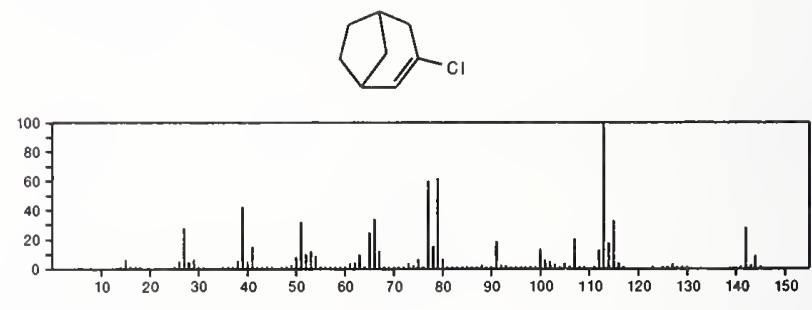

142

$\mathrm{C}_{8} \mathrm{H}_{11} \mathrm{Cl}$

49826-39-3

Bicyclo[3.2.1] oct-2-ene, 2-chloro
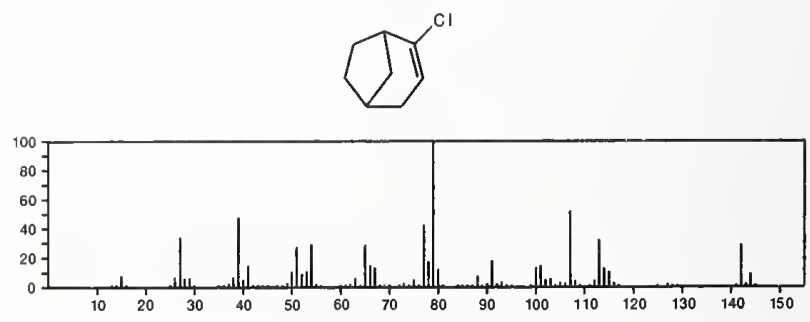
$142 \quad \mathrm{C}_{8} \mathrm{H}_{14} \mathrm{O}_{2}$

2-Propenoic acid, 2-methyl-, 2-methylpropyl ester

97-86-9

$i-\mathrm{BuOC}(0) \mathrm{CMe}=\mathrm{CH}_{2}$

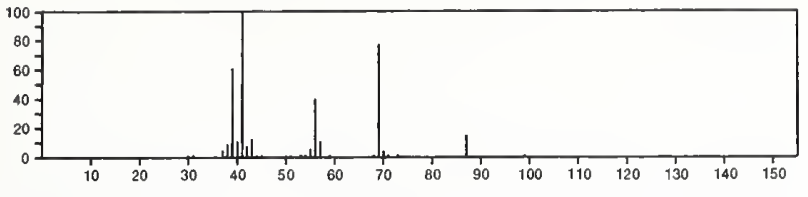

$\mathrm{C}_{8} \mathrm{H}_{14} \mathrm{O}_{2}$

$97-88-1$

142

2-Propenoic acid, 2-methyl-, butyl ester

$\mathrm{Me}\left(\mathrm{CH}_{2}\right)_{3} \mathrm{OC}(\mathrm{O}) \mathrm{CMe}=\mathrm{CH}_{2}$

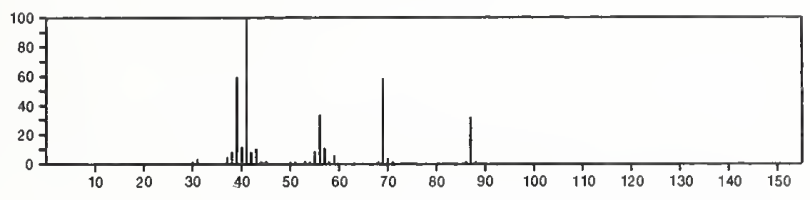

142

$\mathrm{C}_{8} \mathrm{H}_{14} \mathrm{O}_{2}$

104-50-7

2(3H)-Furanone, 5-butyldihydro-
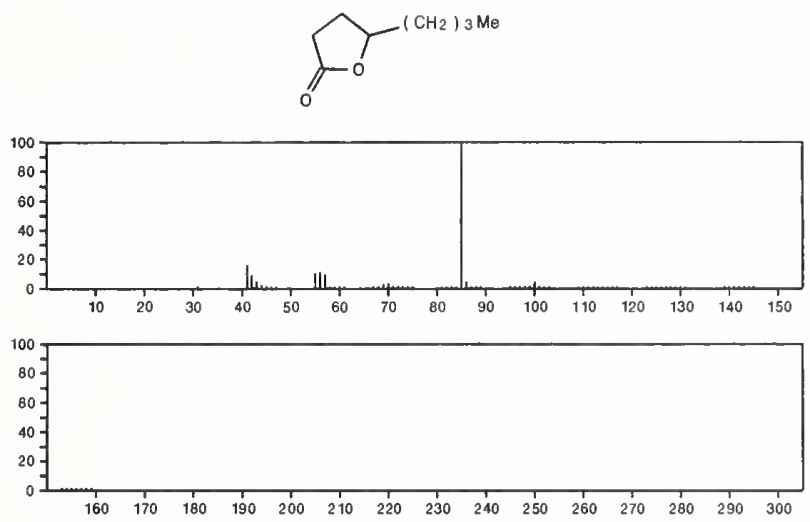

142

$\mathrm{C}_{8} \mathrm{H}_{14} \mathrm{O}_{2}$

$177-10-6$

1,4-Dioxaspiro[4.5]decane
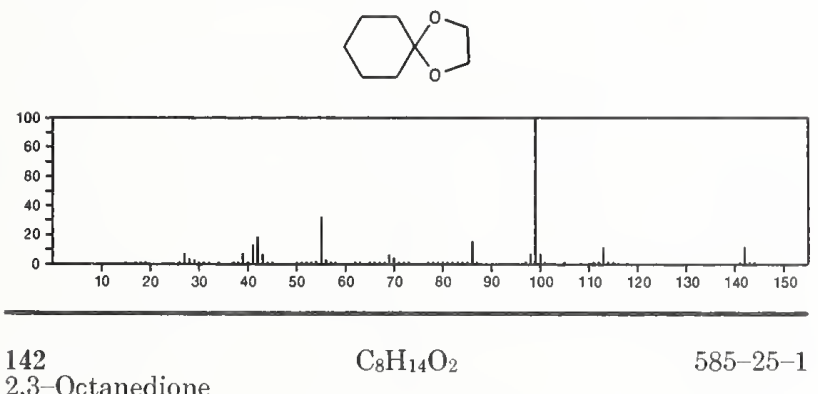

2,3-Octanedione

$\mathrm{Me}\left(\mathrm{CH}_{2}\right) 4 \mathrm{COCOMe}$
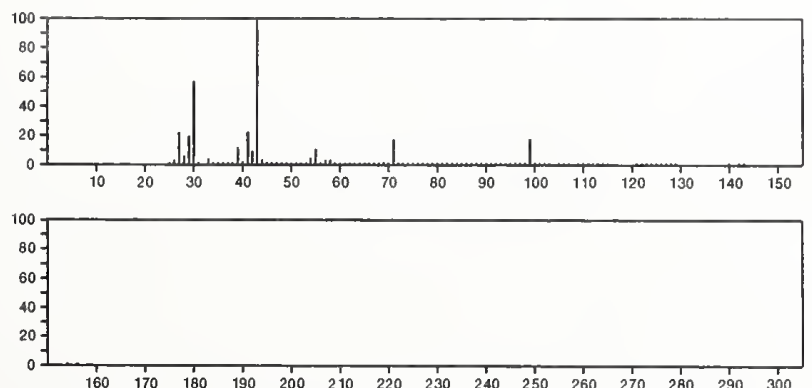

142

Acetic acid, cyclohexyl ester

$\mathrm{C}_{8} \mathrm{H}_{14} \mathrm{O}_{2}$

622-45-7

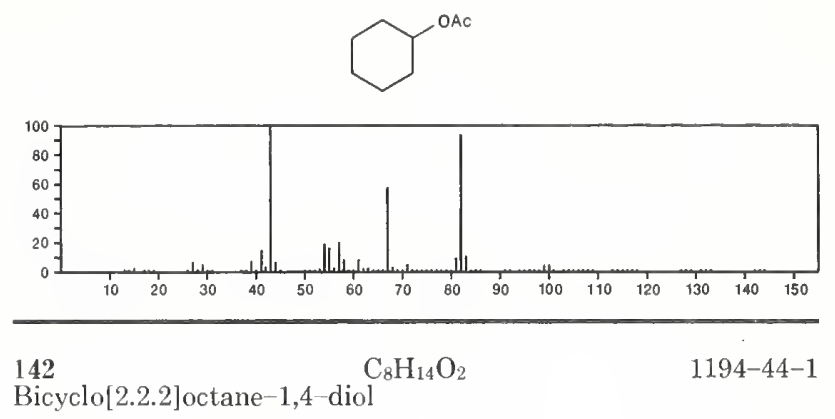<smiles>OC12CCC(O)(CC1)CC2</smiles>

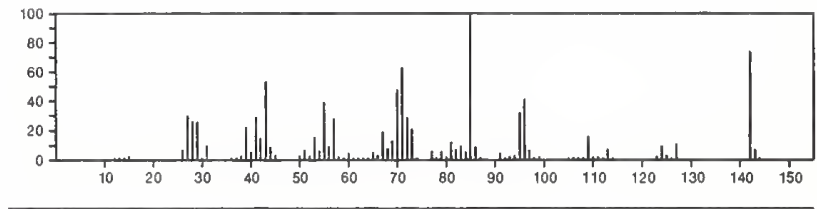

142

2,7-Octanedione

$\mathrm{C}_{8} \mathrm{H}_{14} \mathrm{O}_{2}$

1626-09-1

$\mathrm{MeCO}\left(\mathrm{CH}_{2}\right){ }_{4} \mathrm{COMe}$

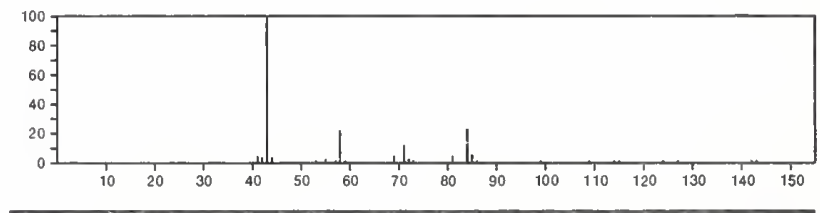

142

$\mathrm{C}_{8} \mathrm{H}_{14} \mathrm{O}_{2}$

6-Heptenoic acid, methyl ester

1745-17-1

$\mathrm{H}_{2} \mathrm{C}=\mathrm{CH}\left(\mathrm{CH}_{2}\right)_{4} \mathrm{C}(\mathrm{O}) \mathrm{OMe}_{\mathrm{N}}$

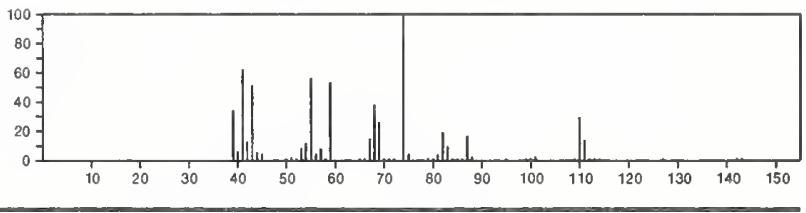

142

$\mathrm{C}_{8} \mathrm{H}_{14} \mathrm{O}_{2}$

2160-94-3

3-Cyclohexene-1,1-dimethanol
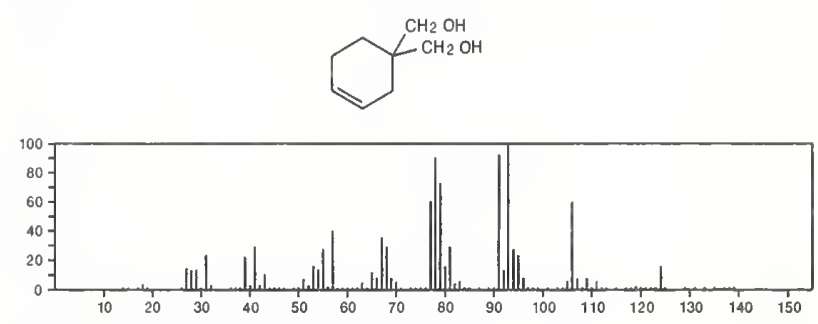

142

2-Hexen-1-ol, acetate, $(E)-$

2497-18-9

$\mathrm{PrCH}=\mathrm{CHCH}_{2} \mathrm{OAC}$

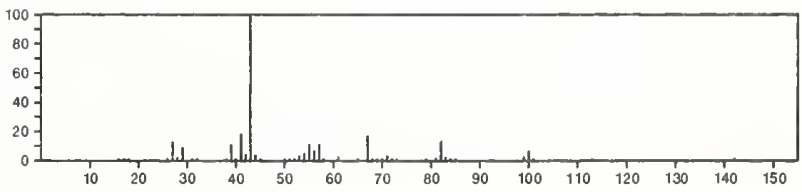


142

1,5-Hexadiene-3,4-diol, 3,4-dimethyl-

$\mathrm{H}_{2} \mathrm{C}=\mathrm{CHCMe}(\mathrm{OH}) \mathrm{CMe}(\mathrm{OH}) \mathrm{CH}=\mathrm{CH}_{2}$

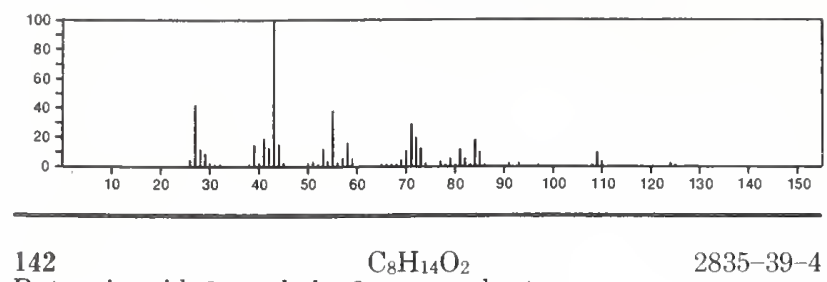

Butanoic acid, 3-methyl-, 2-propenyl ester

$\mathrm{Me}_{2} \mathrm{CHCH}_{2} \mathrm{C}(\mathrm{O}) \mathrm{OCH}_{2} \mathrm{CH}=\mathrm{CH}_{2}$

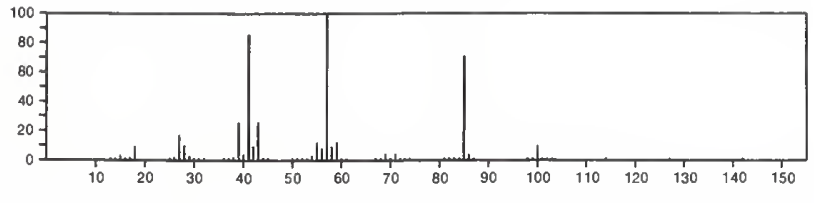

142

$\mathrm{C}_{8} \mathrm{H}_{14} \mathrm{O}_{2}$

2-Propenoic acid, 2-methyl-, 1-methylpropyl ester

$s-B u O C(O) \mathrm{CMe}^{-} \mathrm{CH}_{2}$

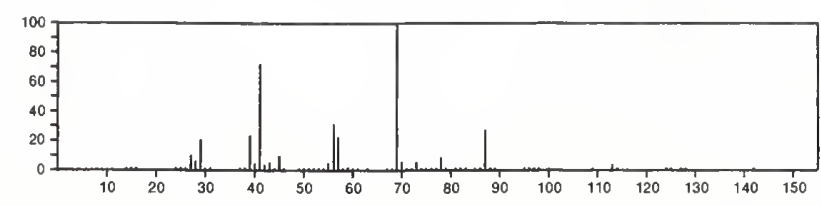

142

2,4-Heptanedione, 6-methyl

$\mathrm{C}_{8} \mathrm{H}_{14} \mathrm{O}_{2}$

$3002-23-1$

$\mathrm{Me} \mathrm{COCH}_{2} \mathrm{COCH}_{2} \mathrm{CHMe}_{2}$

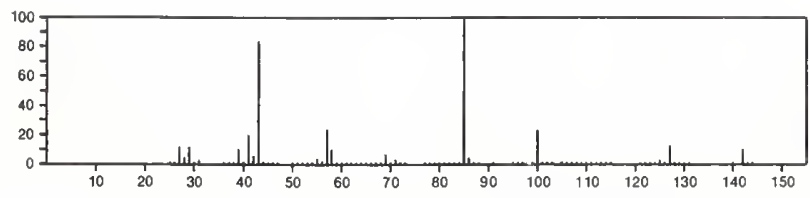

142
3 -Pentenoic acid, 2,2,4-trimethyl-

$4177-03-1$

$\mathrm{HO}_{2} \mathrm{CCMe}_{2} \mathrm{CH}=\mathrm{CMe}$

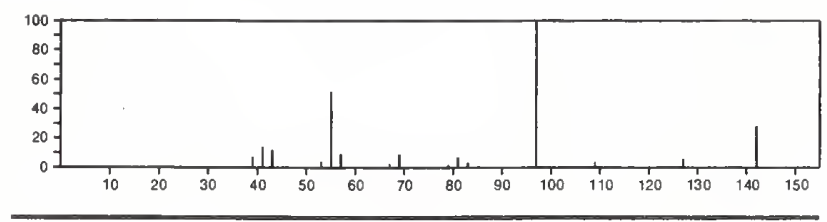

142

3,4-Hexanedione, 2,5-dimethyl-

$4388-87-8$

$\mathrm{Me}_{2} \mathrm{CHCOCOCHMe}_{2}$

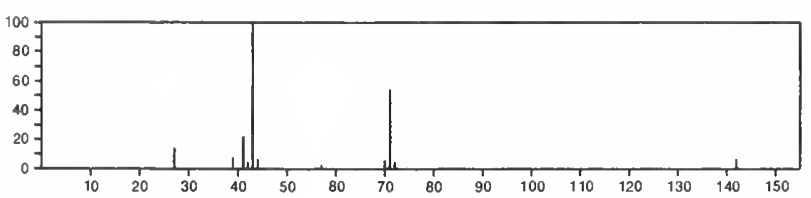

$142 \quad \mathrm{C}_{8} \mathrm{H}_{44} \mathrm{O}_{2}$

Cyclohexanecarboxylic acid, methyl ester

4630-82-4
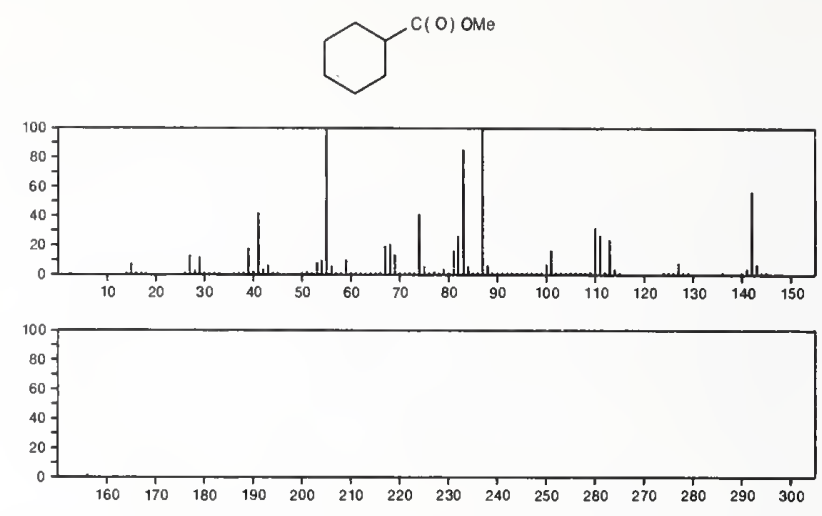

142

$\mathrm{C}_{8} \mathrm{H}_{14} \mathrm{O}_{2}$

4723-10-8

1,5-Hexadiene-3,4-diol, 2,5-dimethyl-

$\mathrm{H}_{2} \mathrm{C}=\mathrm{CM} \theta \mathrm{CH}(\mathrm{OH}) \mathrm{CH}(\mathrm{OH}) \mathrm{CMe}_{\mathrm{O}}=\mathrm{CH}_{2}$
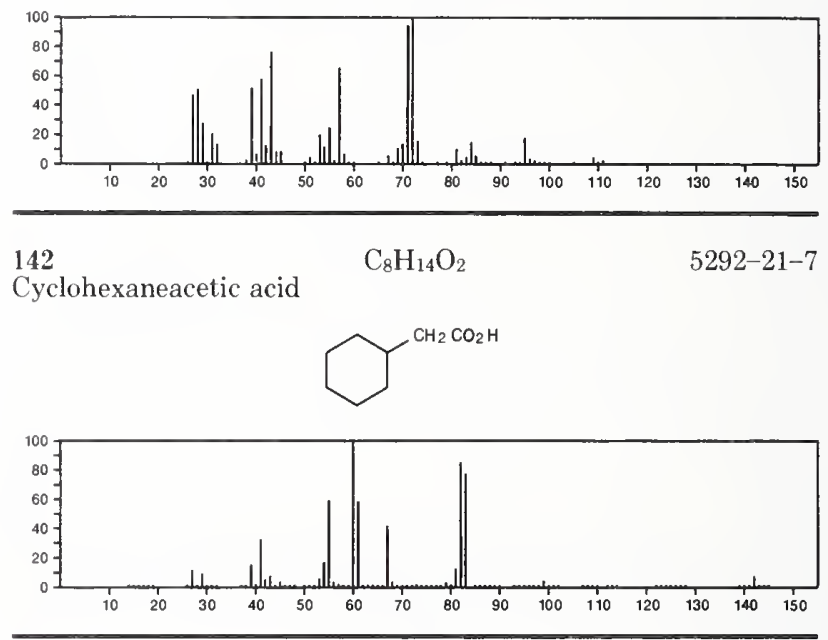

142

4,5-Octanedione

$\mathrm{C}_{8} \mathrm{H}_{14} \mathrm{O}_{2}$

5455-24-3

$\operatorname{PrCOCOP} r$

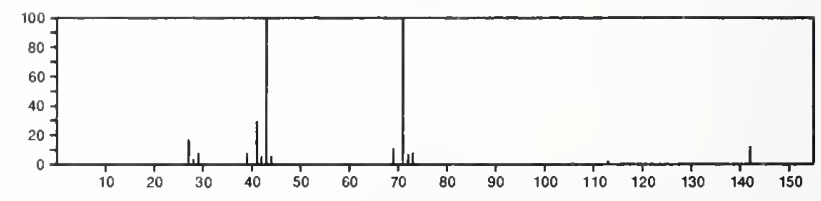

142

$\mathrm{C}_{8} \mathrm{H}_{14} \mathrm{O}_{2}$

5698-29-3

2-Oxonanone
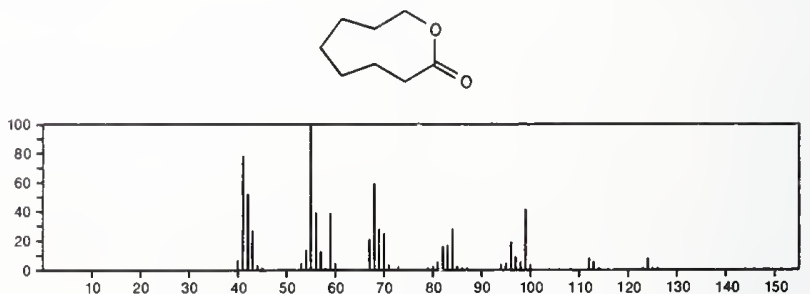
2-Butenoic acid, butyl ester

$\mathrm{C}_{8} \mathrm{H}_{14} \mathrm{O}_{2}$

$\mathrm{Me}\left(\mathrm{CH}_{2}\right)_{3} \mathrm{OC}(\mathrm{O}) \mathrm{CH}=\mathrm{CHMe}$

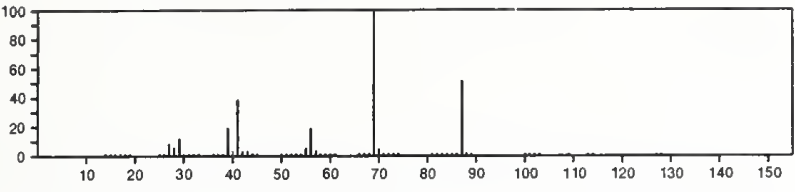

142

$\mathrm{C}_{8} \mathrm{H}_{14} \mathrm{O}_{2}$

10371-45-6

2-Butenoic acid, 1-methylpropyl ester, $(E)$ -

$\mathrm{Me} C \mathrm{CH}=\mathrm{CHC}(\mathrm{O}) \mathrm{OBu}-\mathrm{S}$
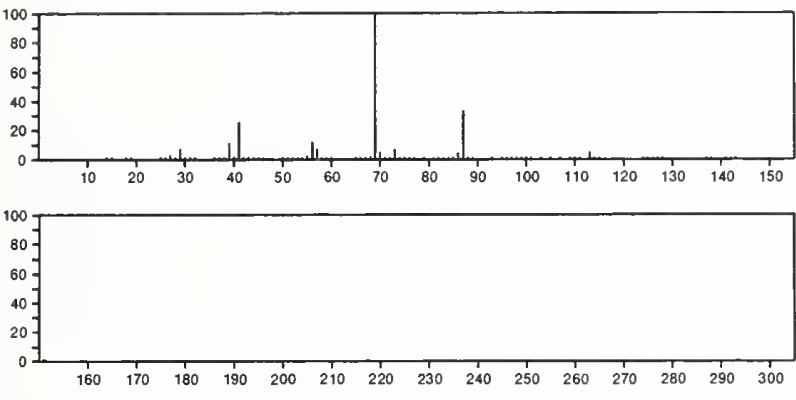

142

2-Pentenoic acid, 3-ethyl-, methyl ester

$\mathrm{C}_{8} \mathrm{H}_{14} \mathrm{O}_{2}$
methyl este
${ }_{2} \mathrm{C}=\mathrm{CHC}(\mathrm{O}) \mathrm{OM}$

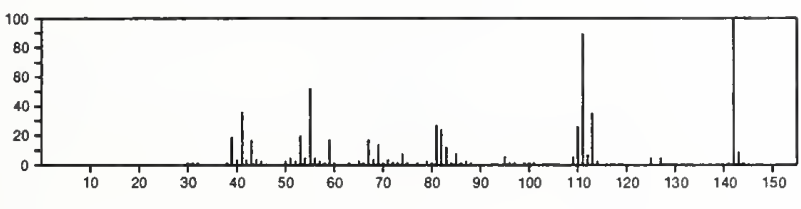

142

$\mathrm{C}_{8} \mathrm{H}_{14} \mathrm{O}_{2}$

$16812-85-4$

2-Pentenoic acid, 4,4-dimethyl-, methyl ester

$\mathrm{MeOC}(\mathrm{O}) \mathrm{CH}_{\mathrm{C}}=\mathrm{CHCMe}_{3}$

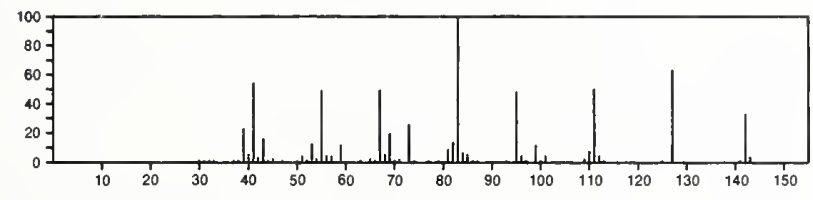

142

$\mathrm{C}_{8} \mathrm{H}_{14} \mathrm{O}_{2}$

$17257-80-6$

2-Octanone, 3,4-epoxy-
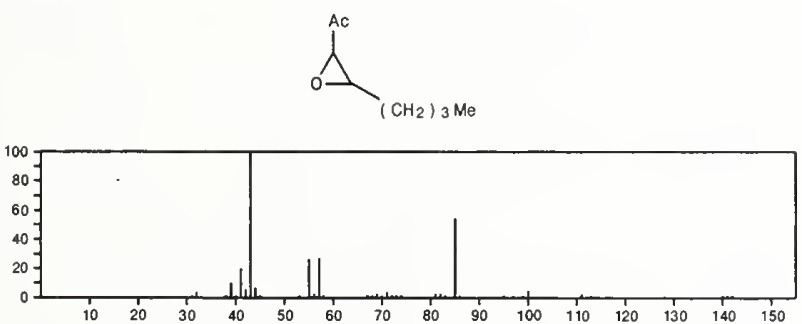

142

Cycloheptanone, 4-methoxy-

$\mathrm{C}_{8} \mathrm{H}_{14} \mathrm{O}_{2}$

17429-01-5
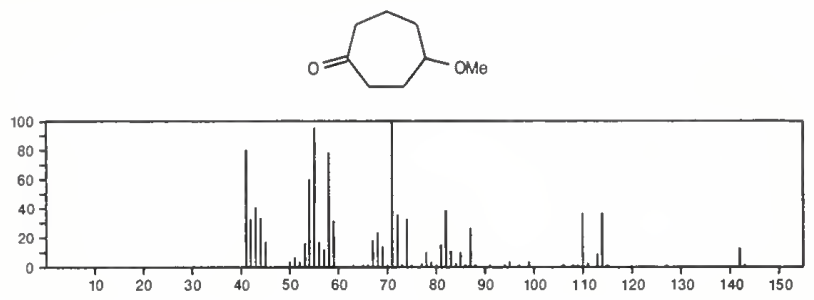

7-Octenoic acid

$\mathrm{C}_{8} \mathrm{H}_{14} \mathrm{O}_{2}$

$18719-24-9$

$\mathrm{H}_{2} \mathrm{C}=\mathrm{CH}\left(\mathrm{CH}_{2}\right)_{5} \mathrm{CO}_{2} \mathrm{H}$

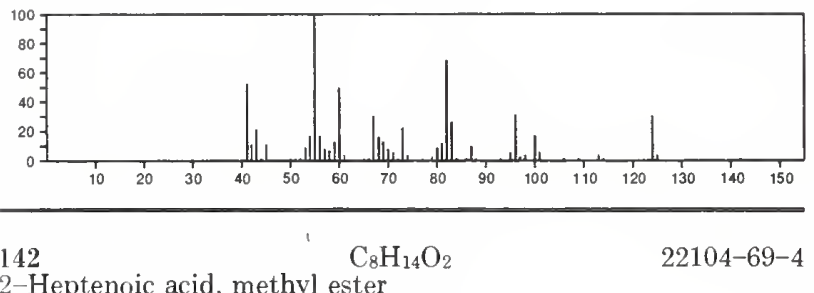

2-Heptenoic acid, methyl ester

$\mathrm{MeOC}(\mathrm{O}) \mathrm{CH}=\mathrm{CH}\left(\mathrm{CH}_{2}\right){ }_{3} \mathrm{Me}$

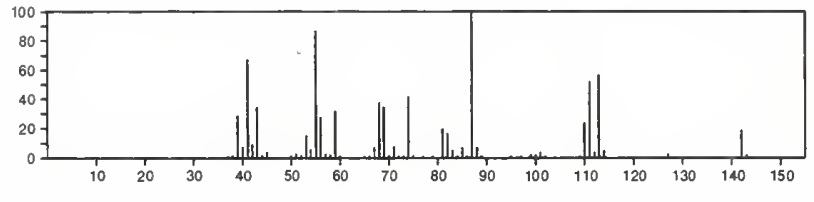

$142 \quad \mathrm{C}_{8} \mathrm{H}_{14} \mathrm{O}_{2}$

1,5-Heptadiene-3,4-diol, 2-methyl-

22726-05-2

$\mathrm{H}_{2} \mathrm{C}=\mathrm{CMe} \mathrm{CH}(\mathrm{OH}) \mathrm{CH}(\mathrm{OH}) \mathrm{CH}=\mathrm{CHM}$

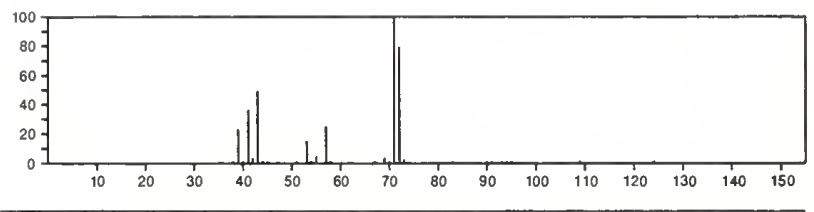

142

Cyclohexanone, 4-ethoxy-

$\mathrm{C}_{8} \mathrm{H}_{14} \mathrm{O}_{2}$

23510-92-1
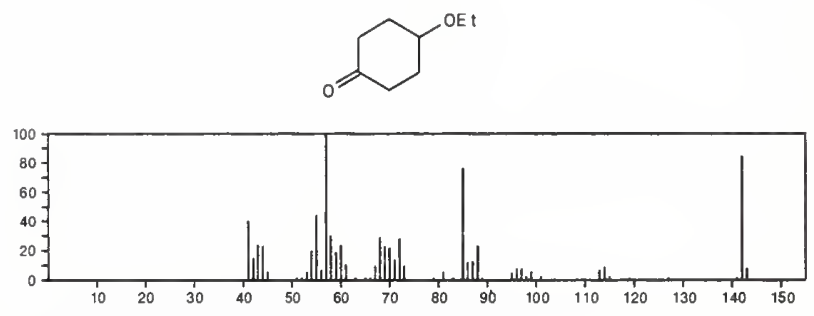

$142 \quad \mathrm{C}_{8} \mathrm{H}_{14} \mathrm{O}_{2}$

1,3-Dioxane, 2-ethenyl-4,6-dimethyl-, $(2 \alpha, 4 \alpha, 6 \alpha)$ -

26243-72-1
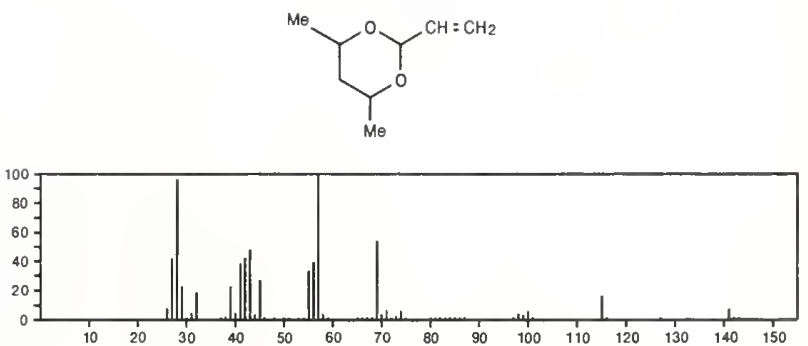
142

3-Butenoic acid, 2,2-diethyl-

$\mathrm{C}_{8} \mathrm{H}_{14} \mathrm{O}_{2}$

$\mathrm{HO}_{2} \mathrm{CCE} t_{2} \mathrm{CH}=\mathrm{CH}_{2}$

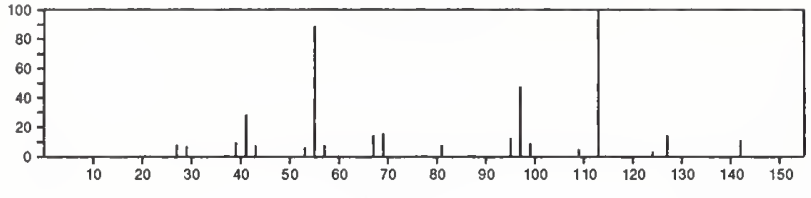

$142 \quad \mathrm{C}_{8} \mathrm{H}_{14} \mathrm{O}_{2}$

2-Heptenoic acid, methyl ester, $(E)$ -

$\mathrm{MeOC}(\mathrm{O}) \mathrm{CH}=\mathrm{CH}\left(\mathrm{CH}_{2}\right)_{3} \mathrm{Me}$

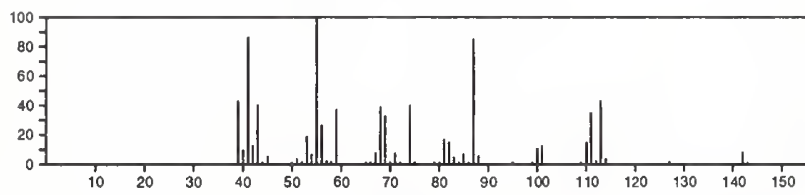

142

$\mathrm{C}_{8} \mathrm{H}_{14} \mathrm{O}_{2}$

$39924-30-6$

4-Heptenoic acid, methyl ester,

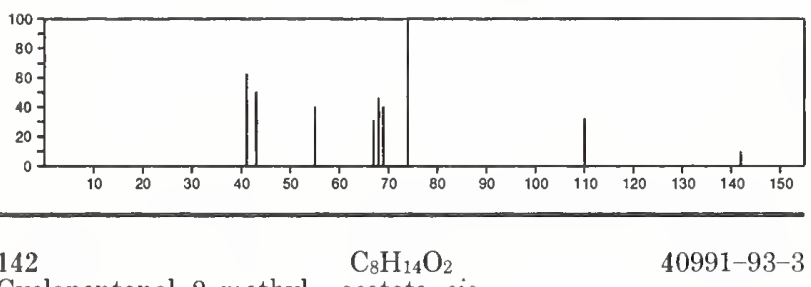

Cyclopentanol, 2-methyl-, acetate, cis-
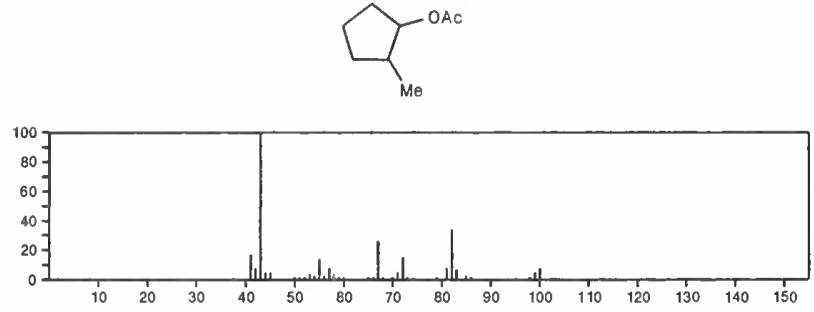

$142 \quad \mathrm{C}_{8} \mathrm{H}_{14} \mathrm{O}_{2}$

$40991-94-4$

Cyclopentanol, 2-methyl-, acetate, trans-
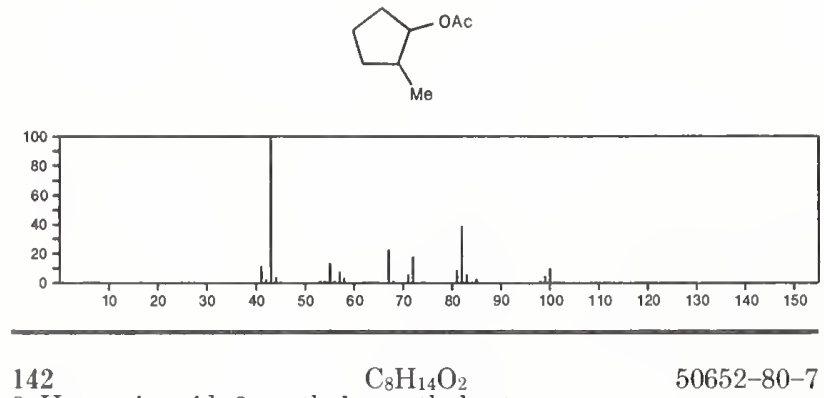

2-Hexenoic acid, 3-methyl-, methyl ester

$\operatorname{Pr} \mathrm{CMe}=\mathrm{CHC}(\mathrm{O})$ OMe

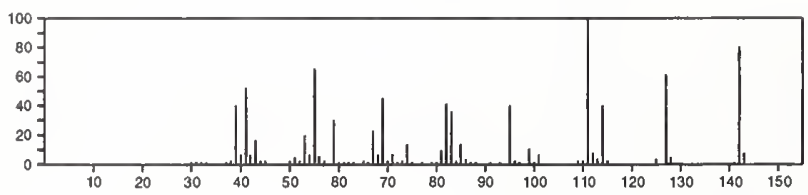

142

$\mathrm{C}_{8} \mathrm{H}_{14} \mathrm{O}_{2}$

2-Hexenoic acid, 2-methyl-, methyl ester

$50652-82-9$

$\mathrm{MeOC}(\mathrm{O}) \mathrm{CM}_{\theta}=\mathrm{CHPr}$

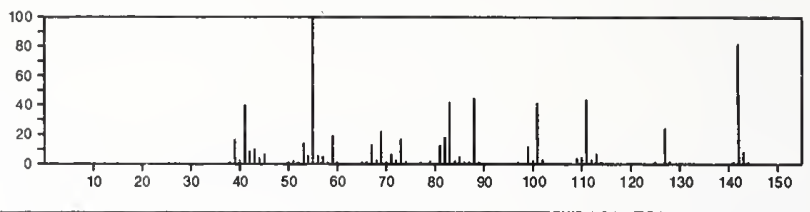

$142 \quad \mathrm{C}_{8} \mathrm{H}_{14} \mathrm{O}_{2}$

3-Heptenoic acid, methyl ester

$50652-83-0$

$\mathrm{MeOC}(\mathrm{O}) \mathrm{CH}_{2} \mathrm{CH}=\mathrm{CHPr}$

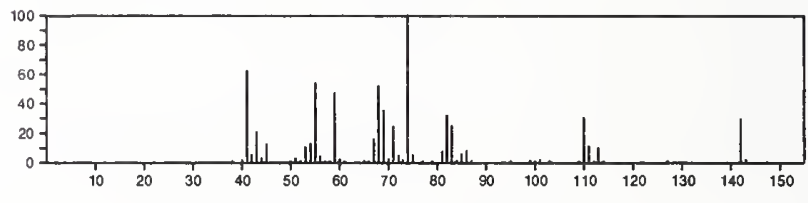

142

$\mathrm{C}_{8} \mathrm{H}_{14} \mathrm{O}_{2}$

$50652-84-1$

3-Hexenoic acid, 3-methyl-, methyl ester

$\mathrm{EtCH}=\mathrm{CMeCH}_{2} \mathrm{C}(\mathrm{O}) \mathrm{OM}$

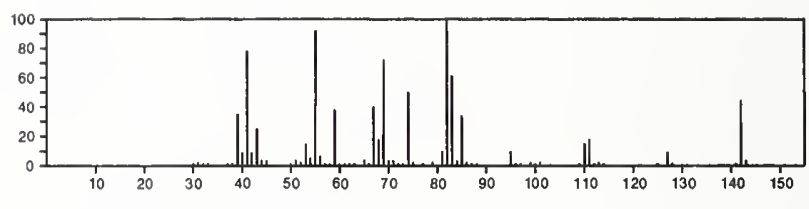

142

$\mathrm{C}_{8} \mathrm{H}_{14} \mathrm{O}_{2}$

$50652-85-2$

3-Pentenoic acid, 3-ethyl-, methyl ester

$\mathrm{Me} \mathrm{CH}=\mathrm{CE}_{t} \mathrm{CH}_{2} \mathrm{C}(\mathrm{O}) \mathrm{OM}_{0}$

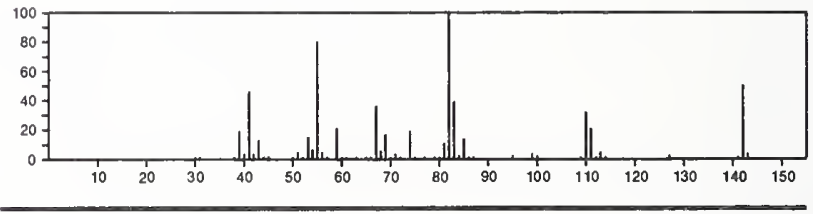

142

$\mathrm{C}_{8} \mathrm{H}_{14} \mathrm{O}_{2}$

$50652-86-3$

3-Hexenoic acid, 2-methyl-, methyl ester

$\mathrm{MeOC}(\mathrm{O}) \mathrm{CHMe} \mathrm{CH}=\mathrm{CHE}$

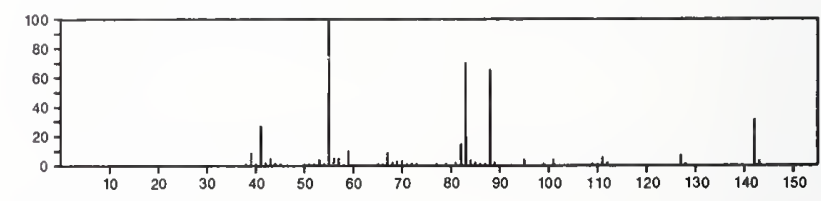

142

$\mathrm{C}_{8} \mathrm{H}_{14} \mathrm{O}_{2}$

$54004-27-2$

4-Hexenoic acid, 3-methyl-, methyl ester

$\mathrm{MeCH}=\mathrm{CHCHMe} \mathrm{CH}_{2} \mathrm{C}(\mathrm{O}) \mathrm{OMe}$

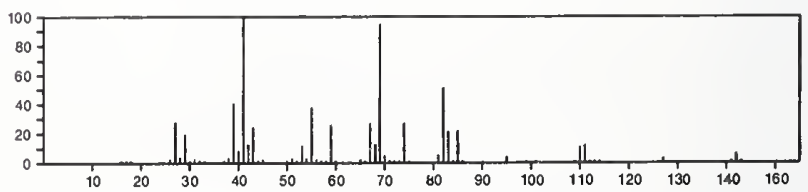


142

$\mathrm{C}_{8} \mathrm{H}_{14} \mathrm{O}_{2}$

5-Heptenoic acid, methyl ester, $(E)$ -

$\mathrm{MeOC}(\mathrm{O})\left(\mathrm{CH}_{2}\right)_{3} \mathrm{CH}=\mathrm{CHMe}$

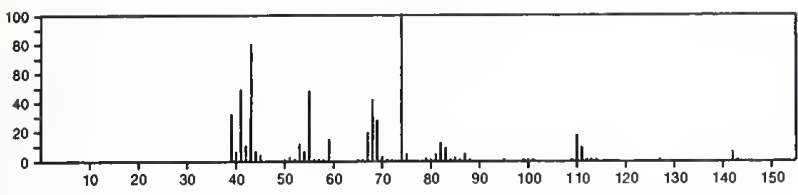

142 $\mathrm{C}_{8} \mathrm{H}_{14} \mathrm{O}_{2}$

4-Heptenoic acid, methyl ester, $(E)-$

$54004-29-4$

$\mathrm{Et} \mathrm{CH}=\mathrm{CHCH}_{2} \mathrm{CH}_{2} \mathrm{C}(\mathrm{O}) \mathrm{OMe}$

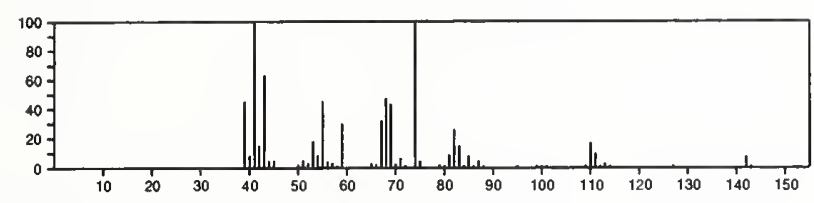

142

3 -Heptenoic acid, methyl ester

$\mathrm{C}_{8} \mathrm{H}_{14} \mathrm{O}_{2}$

$\mathrm{MeOC}(\mathrm{O}) \mathrm{CH}_{2} \mathrm{CH}=\mathrm{CHP}$ r

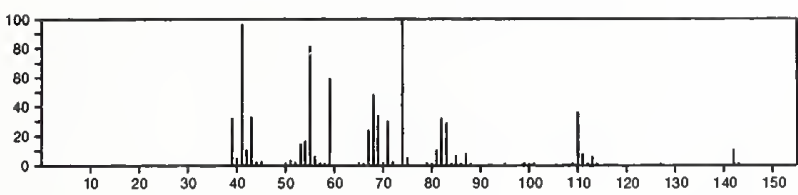

142

$\mathrm{C}_{8} \mathrm{H}_{14} \mathrm{O}_{2}$

$2 H$-Pyran-2-methanol, 3,4-dihydro-2,5-dimethyl-

$54004-34-1$
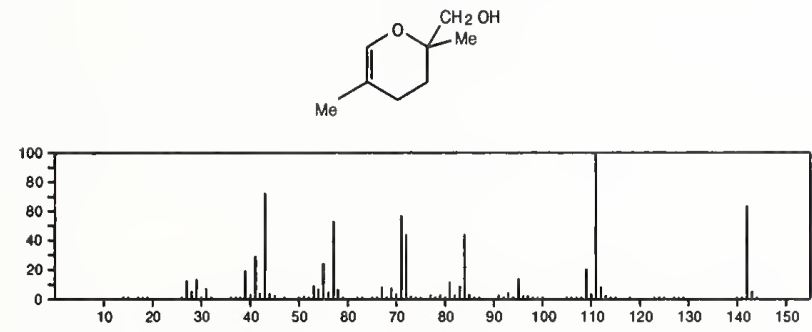

142

$\mathrm{C}_{8} \mathrm{H}_{14} \mathrm{O}_{2}$

1-Butyne, 3-(2-methoxypropoxy)-

$55702-66-4$

$\mathrm{HC} \equiv \mathrm{CCHMeOCH} 2 \mathrm{CH}(\mathrm{OMe}) \mathrm{Me}$

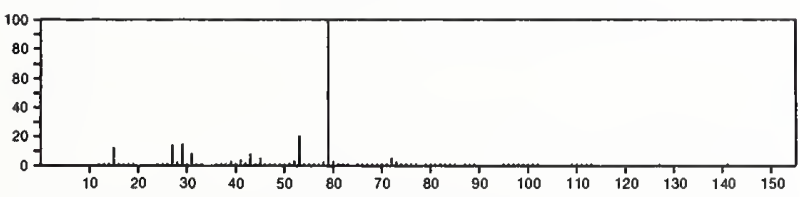

142

2-Pentanol, 5-(2-propynyloxy)-

$\mathrm{C}_{8} \mathrm{H}_{14} \mathrm{O}_{2}$

$55702-67-5$

$\mathrm{HC}: \mathrm{CCH}_{2} \mathrm{O}\left(\mathrm{CH}_{2}\right)_{3} \mathrm{CH}(\mathrm{OH}) \mathrm{Me}$

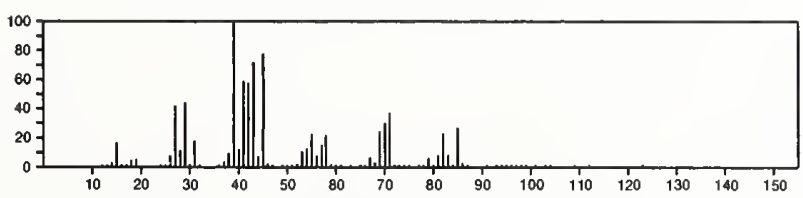

142

Cyclobutanol, 3-ethyl-, acetate

$\mathrm{C}_{8} \mathrm{H}_{14} \mathrm{O}_{2}$

$56335-72-9$
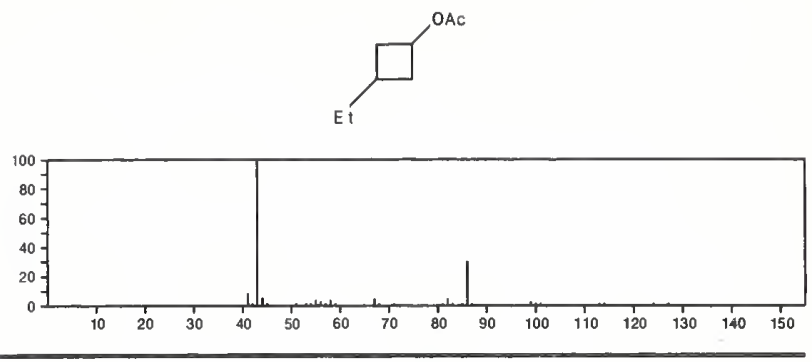

$142 \quad \mathrm{C}_{8} \mathrm{H}_{14} \mathrm{~S}$

Benzo[b]thiophene, octahydro-, cis $^{-}$

$19516-14-4$
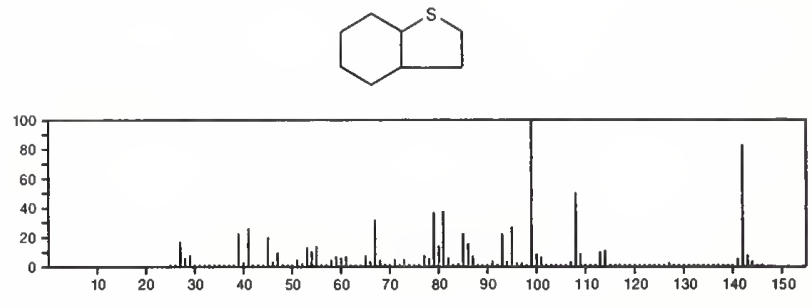

142

$\mathrm{C}_{8} \mathrm{H}_{14} \mathrm{~S}$

Benzo[c] thiophene, octahydro-, trans-

51153-54-9
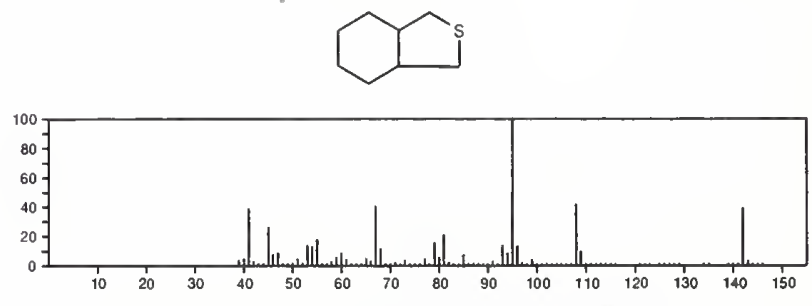

142

$\mathrm{C}_{8} \mathrm{H}_{14} \mathrm{~S}$

Benzo[b]thiophene, octahydro-, trans-

54004-35-2
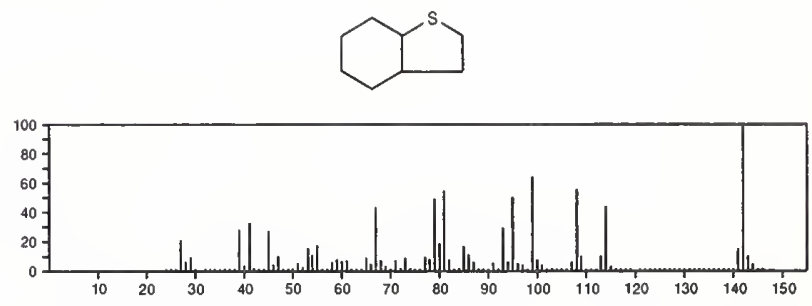

142

$\mathrm{C}_{8} \mathrm{H}_{14} \mathrm{~S}$

54004-36-3

Cyclopenta $[c]$ thiopyran, octahydro-, cis-
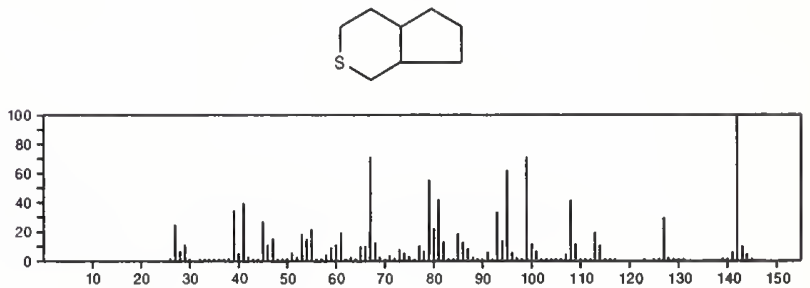
$142 \quad \mathrm{C}_{8} \mathrm{H}_{14} \mathrm{~S}$

Cyclopenta[c]thiopyran, octahydro-, trans ${ }^{-}$

54004-37-4
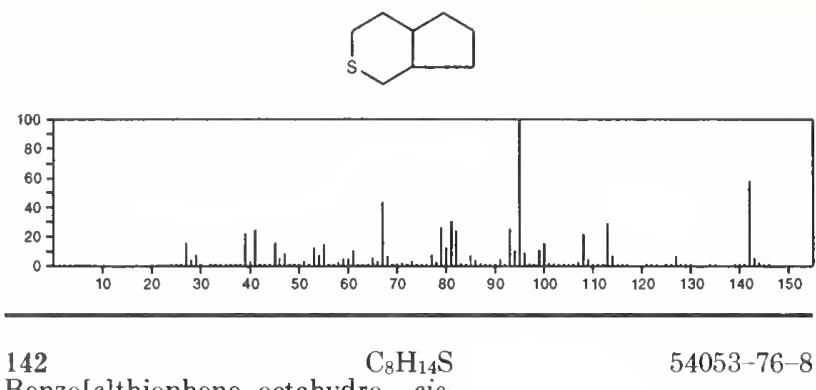

Benzo[c]thiophene, octahydro-, cis-
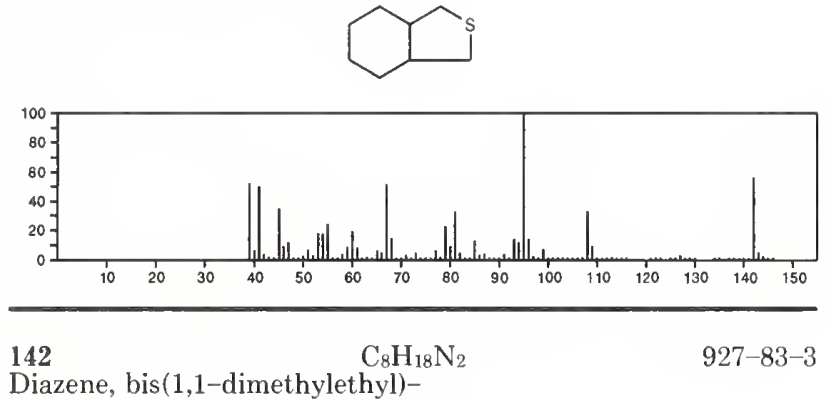

Diazene, bis (1,1-dimethylethyl)-

$t-B u N=N B U-t$

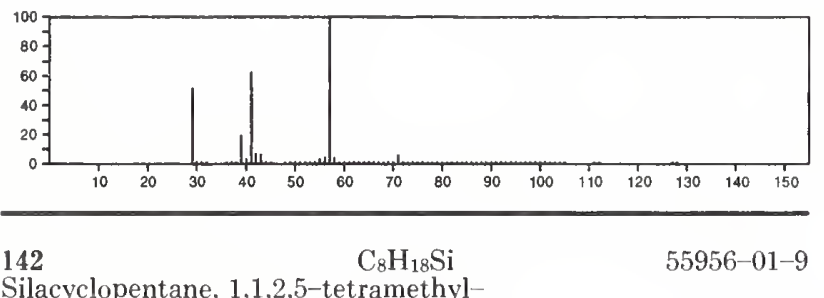

Silacyclopentane, 1,1,2,5-tetramethyl-
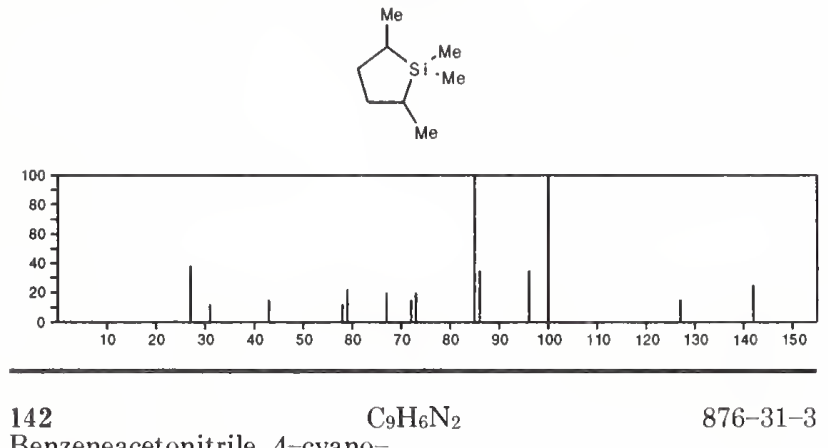

Benzeneacetonitrile, 4-cyano-

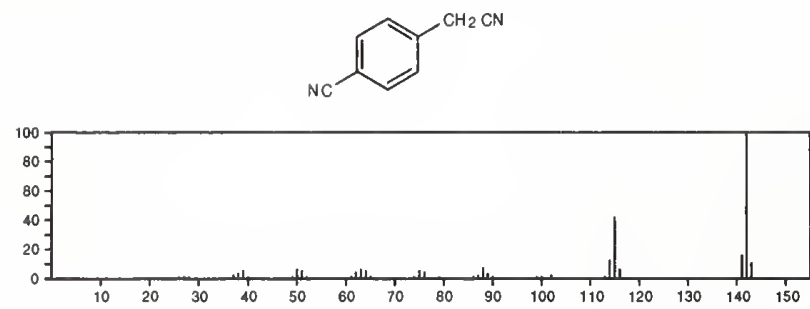

142

Benzeneacetonitrile, 2-cyano-

$\mathrm{C}_{9} \mathrm{H}_{6} \mathrm{~N}_{2}$

$3759-28-2$
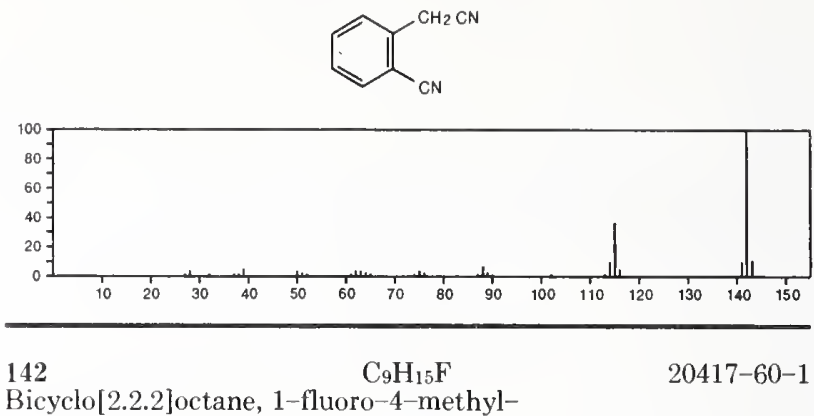

Bicyclo[2.2.2]octane, 1-fluoro-4-methyl-
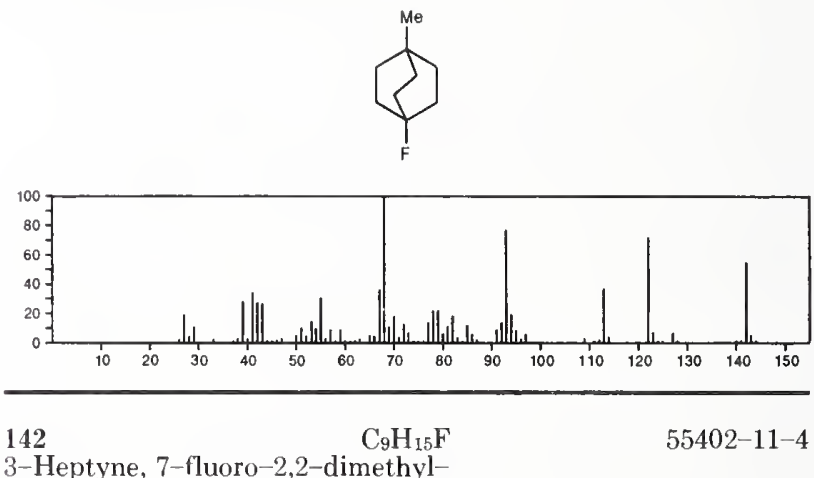

3-Heptyne, 7-fluoro-2,2-dimethyl-

Me ${ }_{3} \mathrm{CC} \equiv \mathrm{C}\left(\mathrm{CH}_{2}\right)$ 3 $\mathrm{F}$

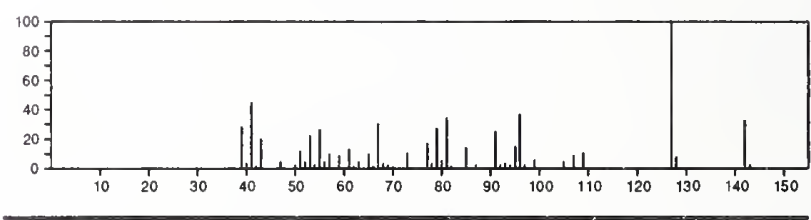

142

Cyclohexanol, 2-(1-methylethyl)-

$96-07-1$<smiles>OC1CCCCC1Br</smiles>

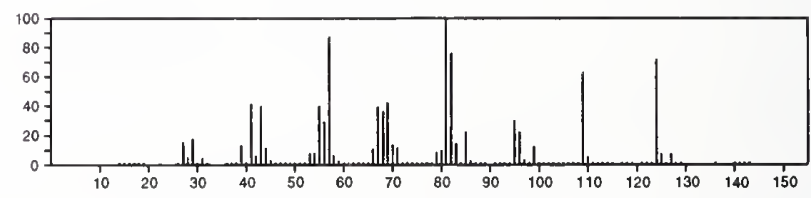

142

4-Heptanone, 2,6-dimethyl-

$\mathrm{C}_{9} \mathrm{H}_{18} \mathrm{O}$

108-83-8

$\mathrm{Me}_{2} \mathrm{CHCH}_{2} \mathrm{COCH}_{2} \mathrm{CHMe}_{2}$

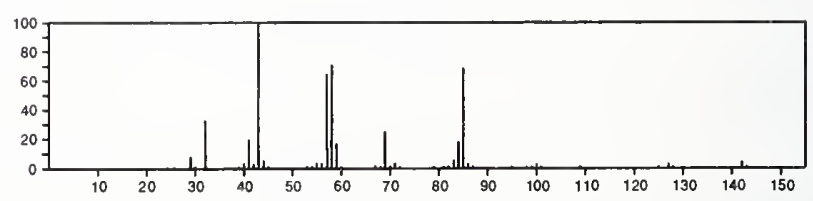


142

Cyclohexanol, 3,3,5-trimethyl-

$\mathrm{C}_{9} \mathrm{H}_{18} \mathrm{O}$

$116-02-9$<smiles>CC1(C)C[C@H](O)C[C@H](O)C1</smiles>

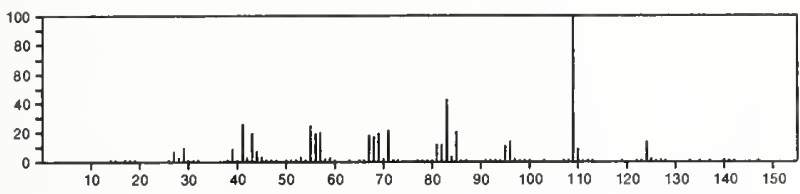

\section{2}

Nonanal

$\mathrm{C}_{9} \mathrm{H}_{18} \mathrm{O}$

124-19-6

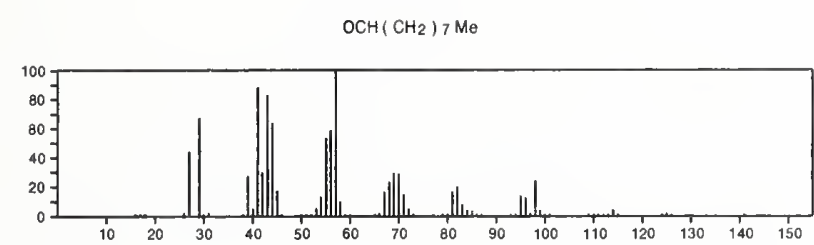

142

$\mathrm{C}_{9} \mathrm{H}_{18} \mathrm{O}$

$502-56-7$

5-Nonanone

$\left.\mathrm{Me}\left(\mathrm{CH}_{2}\right)_{3} \mathrm{CO}_{\left(\mathrm{CH}_{2}\right)}\right)_{3} \mathrm{Me}$

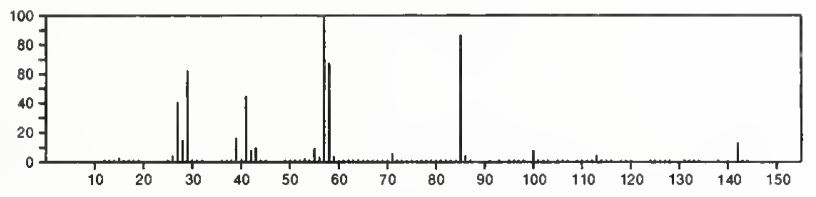

142

$\mathrm{C}_{9} \mathrm{H}_{18} \mathrm{O}$

$815-24-7$

3-Pentanone, 2,2,4,4-tetramethyl-

$\mathrm{Me}_{3} \mathrm{CCOCM}_{3}$
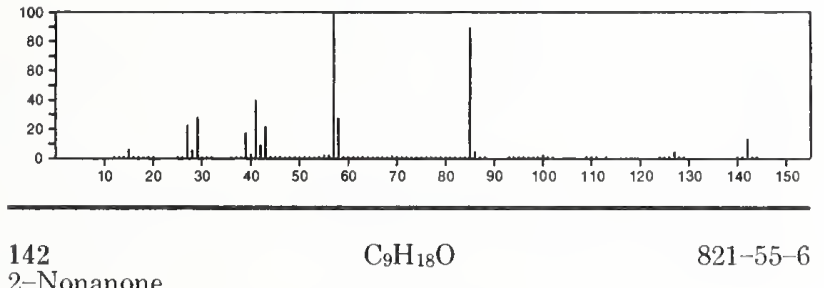

2-Nonanone

$\mathrm{Me}\left(\mathrm{CH}_{2}\right)_{6} \mathrm{COMe}$

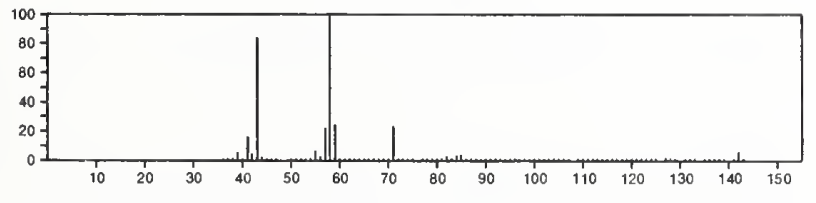

142

2-Pentanone, 3,3,4,4-tetramethyl-

$865-66-7$

$\mathrm{Me} \mathrm{COCM}_{2} \mathrm{CMe}_{3}$

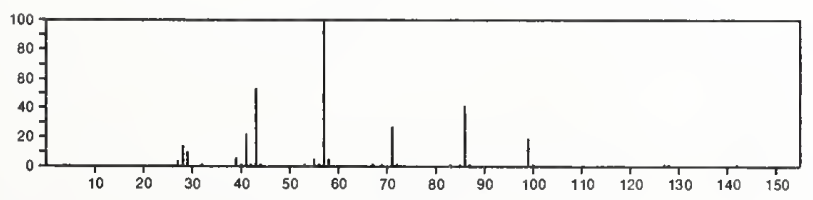

142

$\mathrm{C}_{9} \mathrm{H}_{18} \mathrm{O}$

923-28-4

3-Octanone, 2-methyl

$\mathrm{Me}\left(\mathrm{CH}_{2}\right) 4 \mathrm{COCHMe} 2$

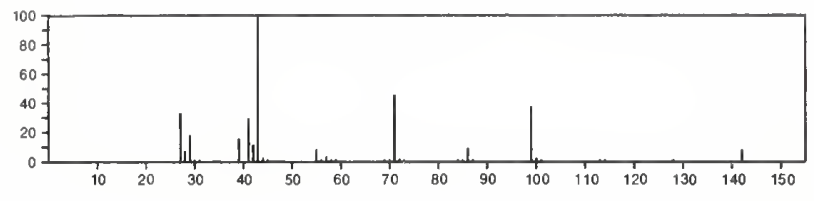

142

3-Nonanone

$\mathrm{C}_{9} \mathrm{H}_{18} \mathrm{O}$

925-78-0

$\mathrm{Me}\left(\mathrm{CH}_{2}\right) 5 \mathrm{COE}$

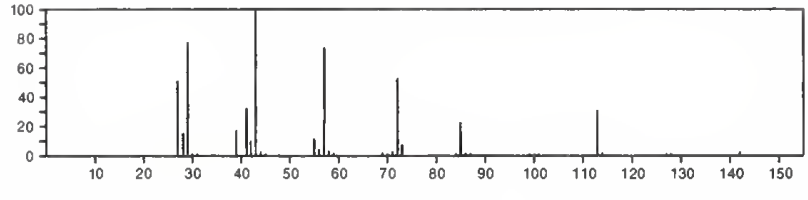

$\begin{array}{ll}142 & \mathrm{C}_{9} \mathrm{H}_{18} \mathrm{O} \\ 4-\text { Nonanone } & 4485-09-0\end{array}$

$\mathrm{Me}\left(\mathrm{CH}_{2}\right)_{4} \mathrm{COP}$

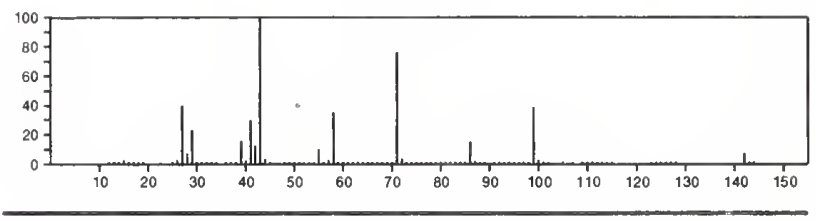

142

$\mathrm{C}_{9} \mathrm{H}_{18} \mathrm{O}$

4621-04-9

Cyclohexanol, 4-(1-methylethyl)-
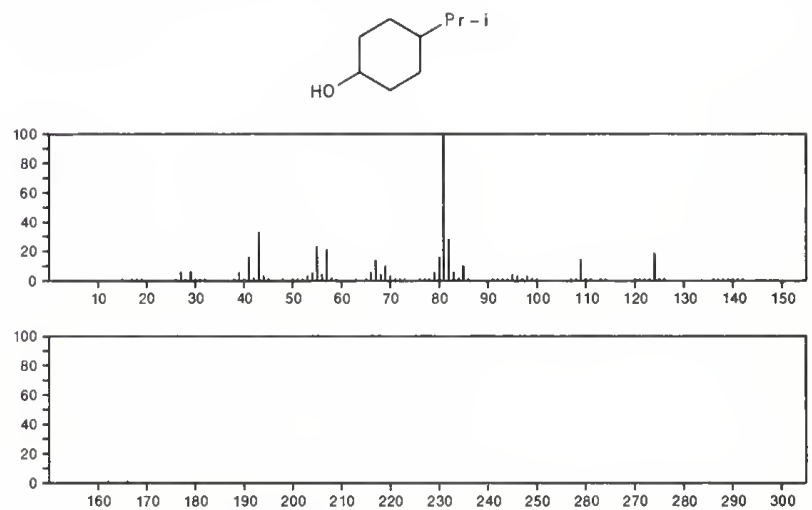

142

Hexanal, 3,5,5-trimethyl-

$\mathrm{C}_{9} \mathrm{H}_{18} \mathrm{O}$

5435-64-3

$\mathrm{Me}_{3} \mathrm{CCH}_{2} \mathrm{CHM}_{0} \mathrm{CH}_{2} \mathrm{CHO}_{3}$

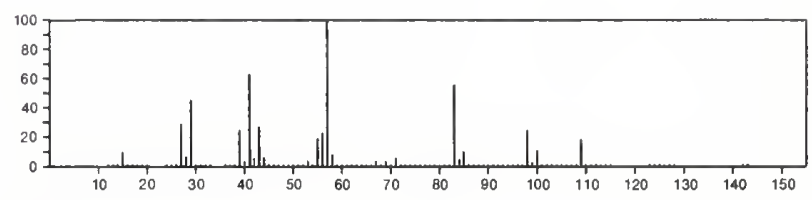

142

4-Octanone, 2-methyl-

$\mathrm{C}_{9} \mathrm{H}_{18} \mathrm{O}$

$7492-38-8$

$\mathrm{Me}_{2} \mathrm{CHCH}_{2} \mathrm{CO}\left(\mathrm{CH}_{2}\right)_{3} \mathrm{Me}$

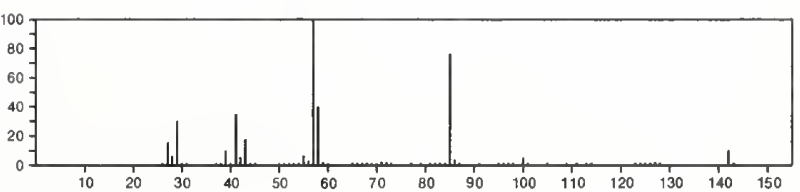


142 Cyclooctane, methoxy-

$\mathrm{C}_{9} \mathrm{H}_{18} \mathrm{O}$

13213-32-6
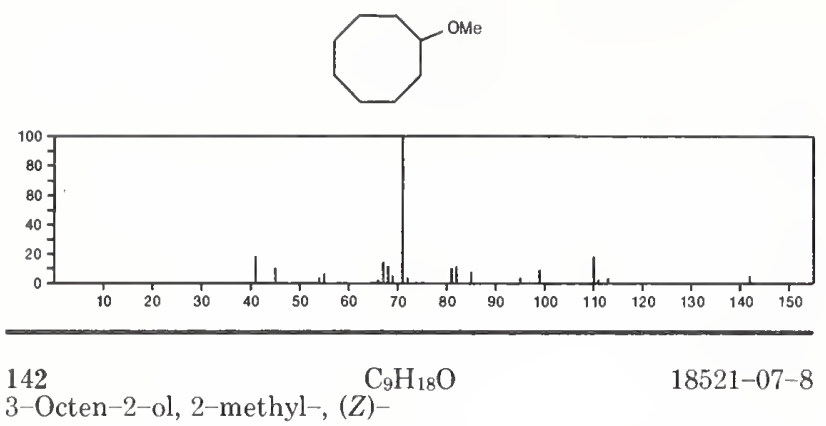

$\mathrm{Me}_{2} \mathrm{COHCH}=\mathrm{CH}\left(\mathrm{CH}_{2}\right)_{3} \mathrm{Me}$

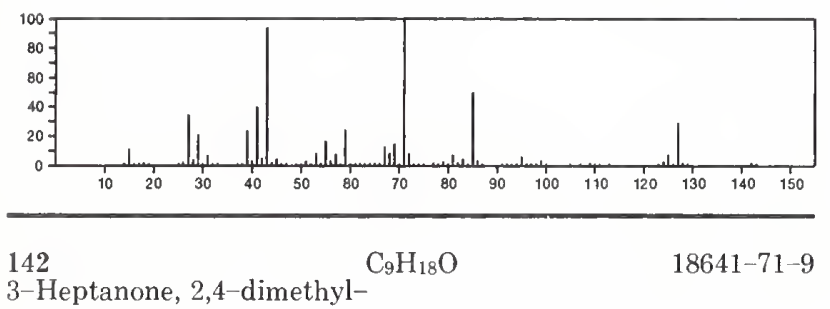

Pr CHMe COCHMe 2

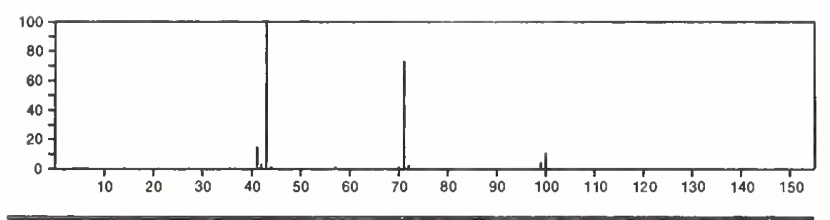

142

3-Heptanone, 2,6-dimethyl-

$\mathrm{C}_{9} \mathrm{H}_{18} \mathrm{O}$

$19549-83-8$

$\mathrm{Me}_{2} \mathrm{CHCOCH}_{2} \mathrm{CH}_{2} \mathrm{CHMe} 2$

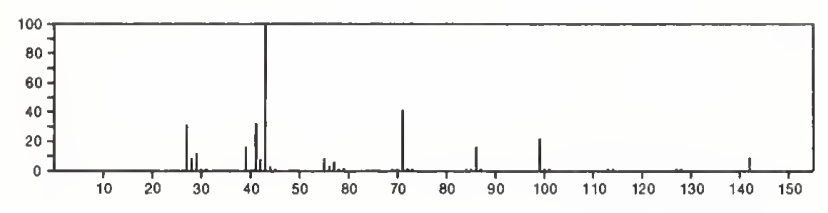

142

4-Octanone, 7-methyl-

$\mathrm{C}_{9} \mathrm{H}_{18} \mathrm{O}$

20809-46-5

\section{$\mathrm{Pr} \mathrm{COCH}_{2} \mathrm{CH}_{2} \mathrm{CHM}_{2}$}

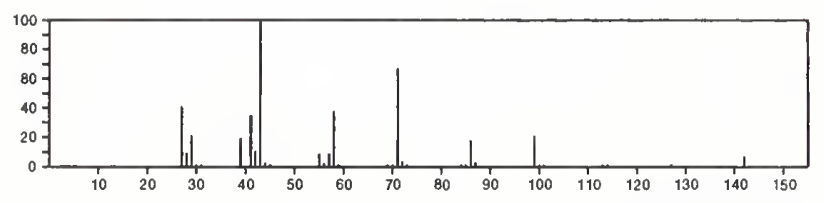

142

$\mathrm{C}_{9} \mathrm{H}_{18} \mathrm{O}$

$34061-78-4$

Ether, 3-butenyl pentyl

$\mathrm{Me}\left(\mathrm{CH}_{2}\right){ }_{4} \mathrm{OCH}_{2} \mathrm{CH}_{2} \mathrm{CH}=\mathrm{CH}_{2}$

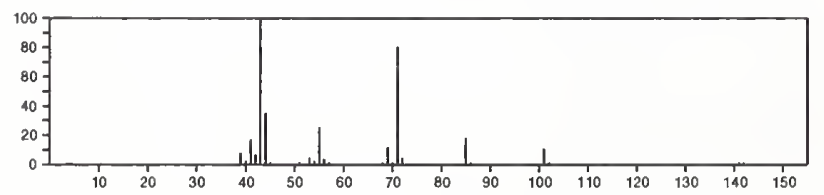

142

$\mathrm{C}_{9} \mathrm{H}_{18} \mathrm{O}$

$36712-20-6$

Furan, 3-butyltetrahydro-2-methyl-, trans-
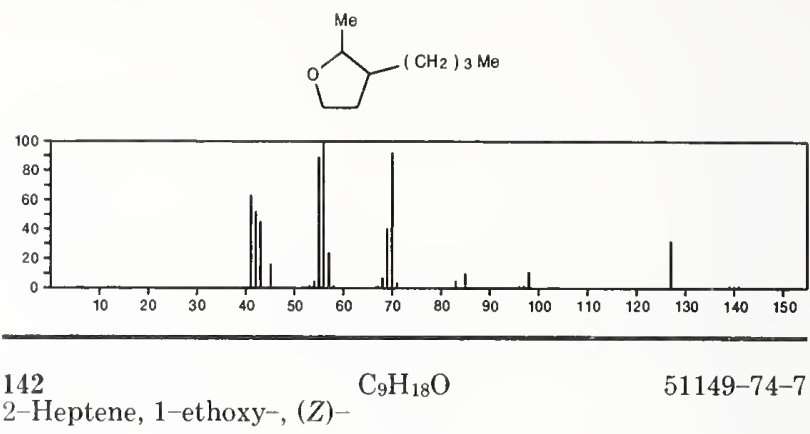

$\mathrm{Me}\left(\mathrm{CH}_{2}\right)_{3} \mathrm{CH}=\mathrm{CHCH}_{2} \mathrm{OE}$ I

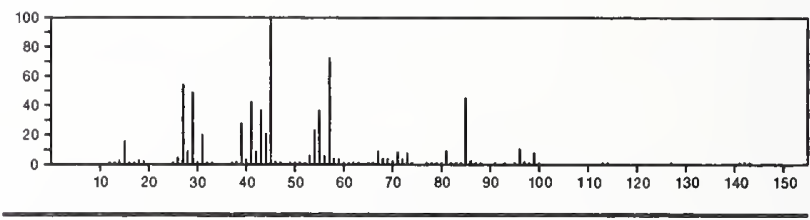

142

$\mathrm{C}_{9} \mathrm{H}_{18} \mathrm{O}$

$51284-32-3$

Cyclohexane, (2-methoxyethyl)
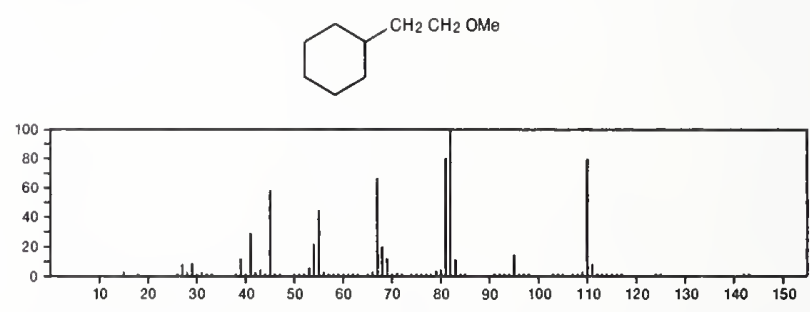

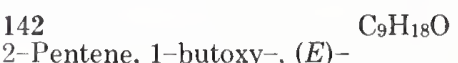

$54004-22-7$

$\mathrm{Me}\left\{\mathrm{CH}_{2}\right\}_{3} \mathrm{OCH}_{2} \mathrm{CH}=\mathrm{CHE}$ :

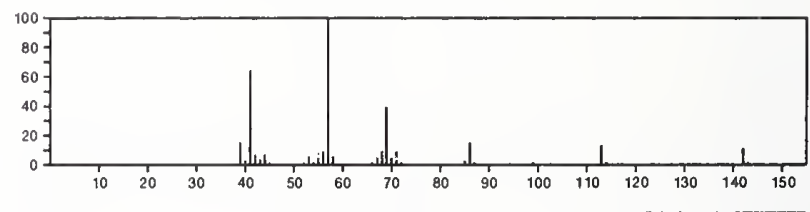

142

2-Pentene, 5-butoxy-, $(E)$ -

$\mathrm{C}_{9} \mathrm{H}_{18} \mathrm{O}$

$54004-23-8$

$\mathrm{MeCH}=\mathrm{CHCH}_{2} \mathrm{CH}_{2} \mathrm{O}\left(\mathrm{CH}_{2}\right)_{3} \mathrm{Me}$

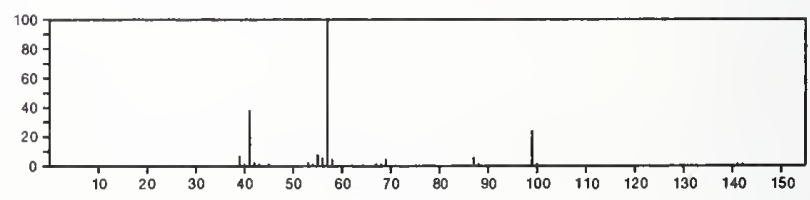

142

1-Pentene, 5-butoxy-

$\mathrm{C}_{9} \mathrm{H}_{18} \mathrm{O}$

$54004-24-9$

$\mathrm{H}_{2} \mathrm{C}=\mathrm{CH}\left(\mathrm{CH}_{2}\right)_{3} \mathrm{O}\left(\mathrm{CH}_{2}\right)_{3} \mathrm{Me}_{\mathrm{O}}$

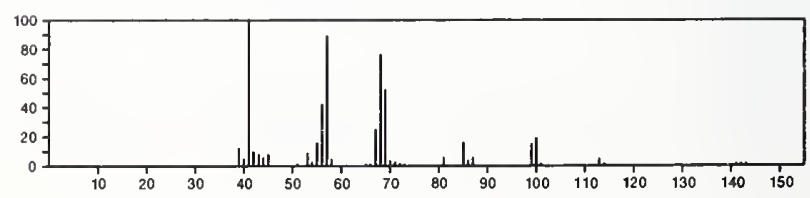


142 $\mathrm{C}_{9} \mathrm{H}_{18} \mathrm{O}$

Pentane, 1-(1-butenyloxy)-, (E)-

$\mathrm{EICH}=\mathrm{CHO}\left(\mathrm{CH}_{2}\right)_{4} \mathrm{Me}$

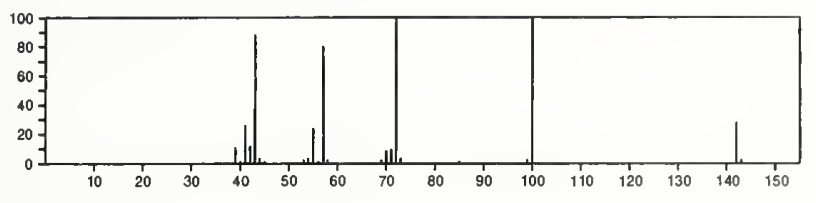

142

$\mathrm{C}_{9} \mathrm{H}_{18} \mathrm{O}$

$54004-26-1$

Pentane, 1-(2-butenyloxy)-, (E)-

$\mathrm{Me}\left(\mathrm{CH}_{2}\right)_{4} \mathrm{OCH}_{2} \mathrm{CH}=\mathrm{CHMe}$

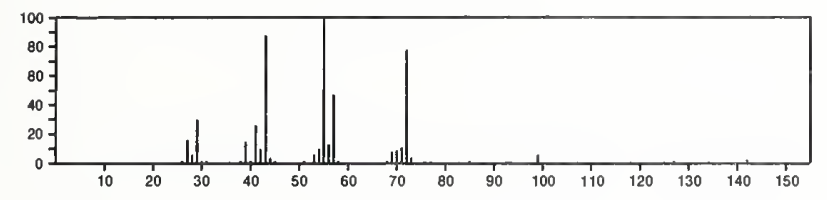

142

3-Heptene, 7-ethoxy-

$\mathrm{C}_{9} \mathrm{H}_{18} \mathrm{O}$

$55320-24-6$

$\mathrm{Et} \mathrm{O}\left(\mathrm{CH}_{2}\right)_{3} \mathrm{CH}=\mathrm{CHEt}$

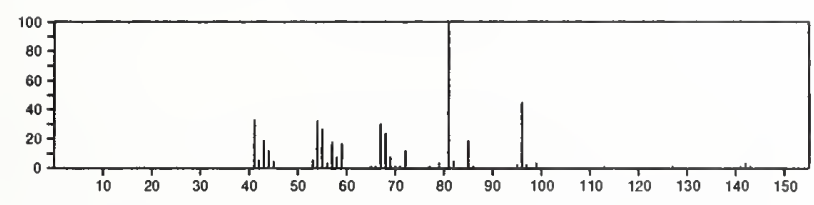

142

3-Heptene, 1-ethoxy-

$\mathrm{C}_{9} \mathrm{H}_{18} \mathrm{O}$

$55320-25-7$

$\mathrm{PrCH}=\mathrm{CHCH}_{2} \mathrm{CH}_{2} \mathrm{OEI}$

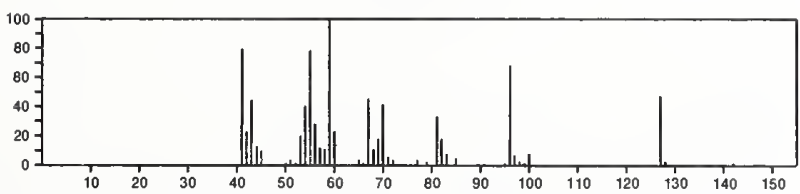

$142 \quad \mathrm{C}_{9} \mathrm{H}_{18} \mathrm{O}$

2-Pentene, 1-ethoxy-4,4-dimethyl-

$\mathrm{E} 1 \mathrm{OCH}_{2} \mathrm{CH}=\mathrm{CHCMe}_{3}$

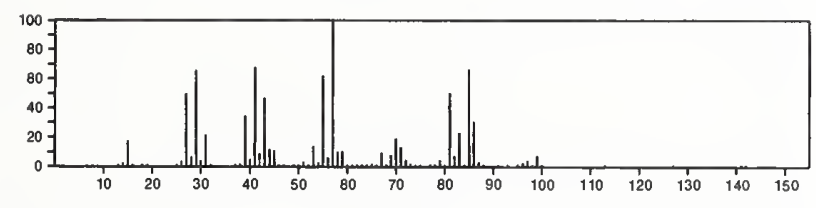

142

2-Hepten-3-ol, 4,5-dimethyl-

$55956-37-1$

$\mathrm{MeCH}_{2} \mathrm{CHMeCHMeC}_{\mathrm{OH}}=\mathrm{CHM}_{9}$

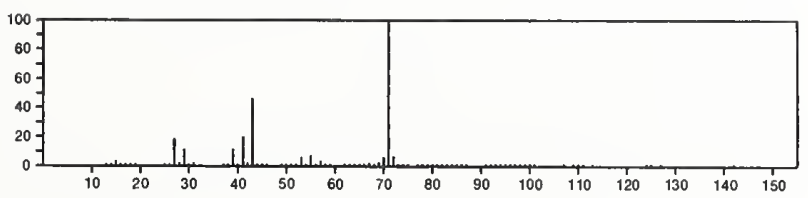

$142 \quad \mathrm{C}_{9} \mathrm{H}_{18} \mathrm{O}$

Pentane, 1-(1-butenyloxy)-, $(Z)-$

$56052-76-7$

$\mathrm{EtCH}=\mathrm{CHO}\left(\mathrm{CH}_{2}\right)_{4} \mathrm{Me}$

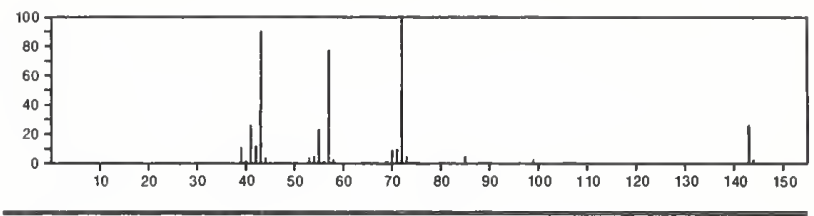

$142 \quad \mathrm{C}_{9} \mathrm{H}_{20} \mathrm{~N} \quad 55724-24-8$

Methanaminium, $N$-(2,2-dimethylpentylidene $)-N$-methyl-

$\operatorname{PrCM}{ }_{2} \mathrm{CH}=\stackrel{+}{\mathrm{NM}} 2$
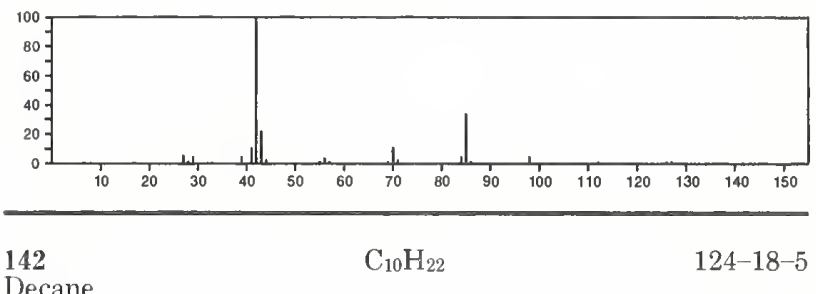

Decane

$\mathrm{Me}\left(\mathrm{CH}_{2}\right) \& \mathrm{Me}$

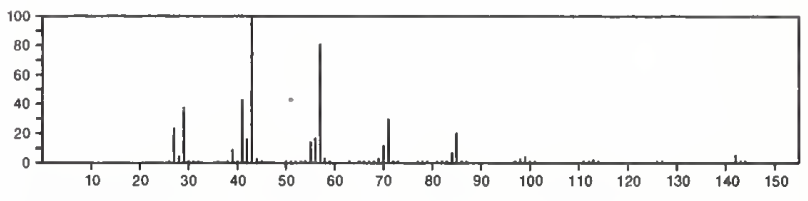

142

Nonane, 2-methyl-

$\mathrm{C}_{10} \mathrm{H}_{22}$

$871-83-0$

$\mathrm{Me}_{2} \mathrm{CH}\left(\mathrm{CH}_{2}\right)_{6} \mathrm{Me}$
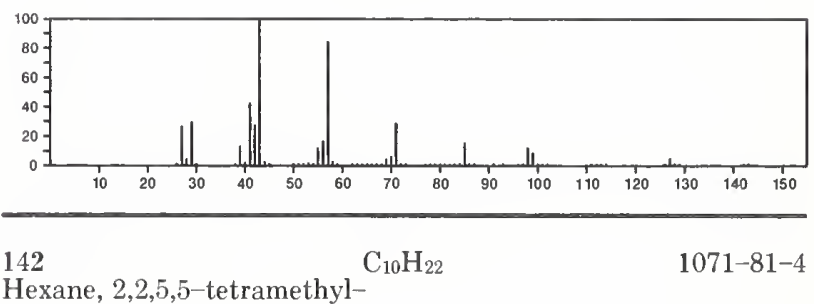

Hexane, 2,2,5,5-tetramethyl--

$\mathrm{Me}{ }_{3} \mathrm{CCH}_{2} \mathrm{CH}_{2} \mathrm{CMe}_{3}$

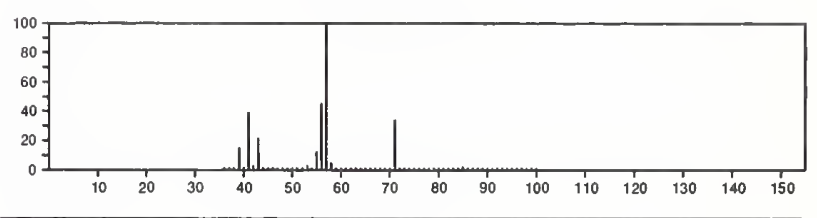

$142 \quad \mathrm{C}_{10} \mathrm{H}_{22} \quad 1072-16-8$

Octane, 2,7-dimethyl-

$\mathrm{Me}_{2} \mathrm{CH}\left(\mathrm{CH}_{2}\right)_{4} \mathrm{CHMe}_{2}$

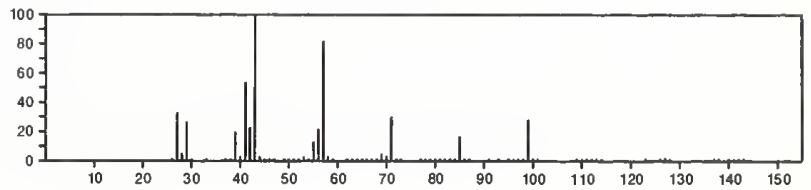


142

Octane, 2,6-dimethyl-

$\mathrm{C}_{10} \mathrm{H}_{22}$

$\mathrm{Me}_{2} \mathrm{CH}\left(\mathrm{CH}_{2}\right)_{3} \mathrm{CHM}_{\theta} \mathrm{CH}_{2} \mathrm{Me}$
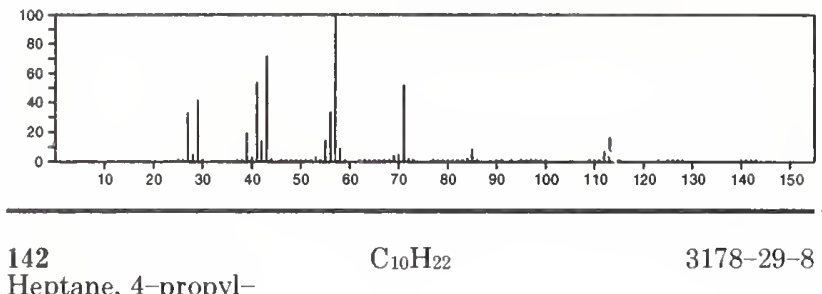

Heptane, 4-propyl-

CHPr 3

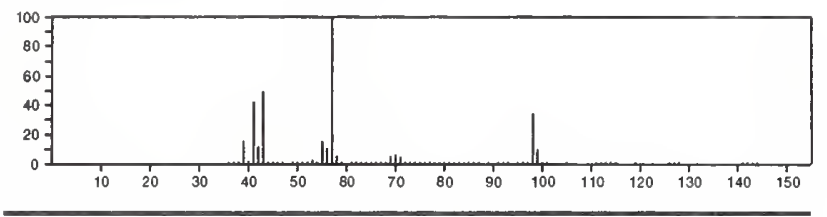

142

Nonane, 3-methyl-

$\mathrm{C}_{10} \mathrm{H}_{22}$

5911-04-6

$\mathrm{Me}\left(\mathrm{CH}_{2}\right)_{5} \mathrm{CHM}_{\theta} \mathrm{CH}_{2} \mathrm{Me}$

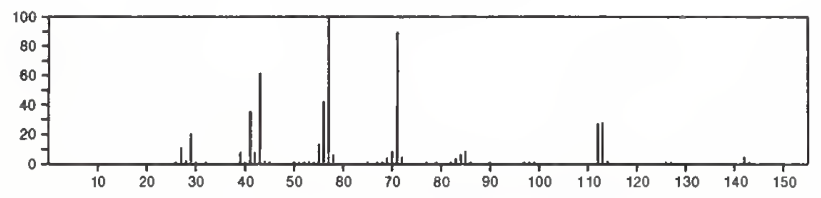

142

Octane, 2,3-dimethyl-

$\mathrm{C}_{10} \mathrm{H}_{22}$

7146-60-3

$\mathrm{Me}\left(\mathrm{CH}_{2}\right)_{4} \mathrm{CHM}_{\theta} \mathrm{CHMe}_{2}$

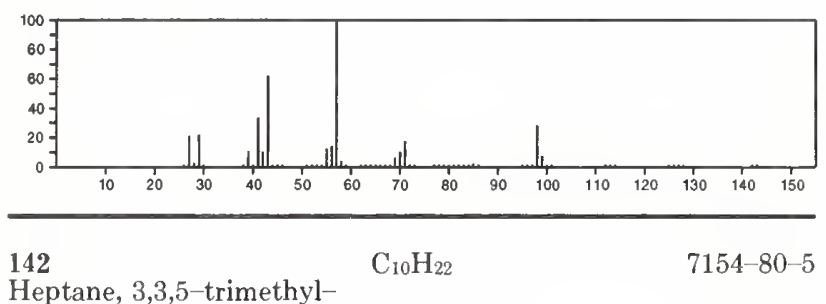

$\mathrm{E}$ t $\mathrm{CM}_{2} \mathrm{CH}_{2} \mathrm{CHMe}_{e} \mathrm{CH}_{2} \mathrm{Me}$

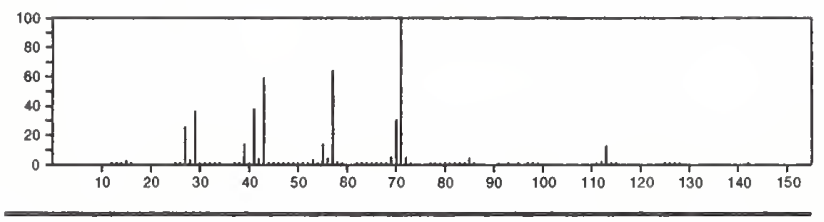

142

Heptane, 5-ethyl-2-methyl-

$\mathrm{C}_{10} \mathrm{H}_{22}$

$13475-78-0$

$\mathrm{Me}_{2} \mathrm{CHCH}_{2} \mathrm{CH}_{2} \mathrm{CHEt}_{2}$

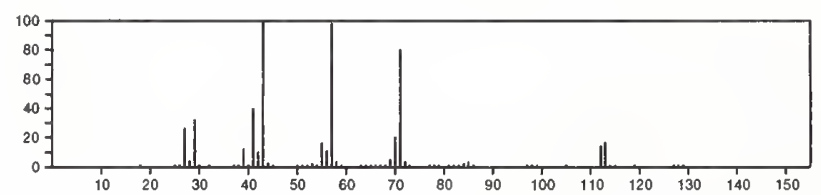

142

Hexane, 2,2,3,3-tetramethyl-

$\mathrm{C}_{10} \mathrm{H}_{22}$

13475-81-5

$\mathrm{Me}_{3} \mathrm{CCP}_{\mathrm{H}} \mathrm{Me}_{2}$

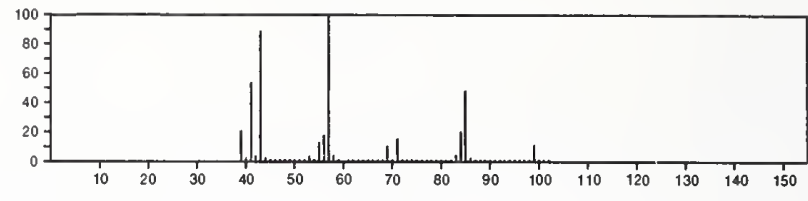

142

Heptane, 3-ethyl-2-methyl-

$\mathrm{C}_{10} \mathrm{H}_{22}$

$14676-29-0$

$\mathrm{Me}\left(\mathrm{CH}_{2}\right)_{3} \mathrm{CHE}+\mathrm{CHM}_{2}$

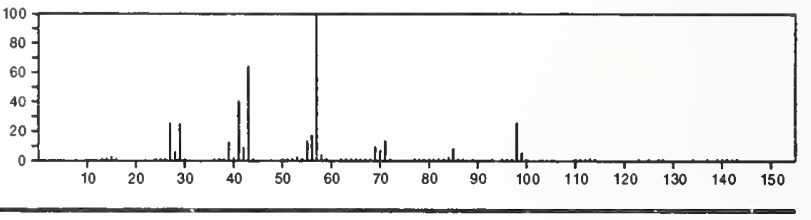

142

$\mathrm{C}_{10} \mathrm{H}_{22}$

14720-74-2

Heptane, 2,2,4-trimethyl-

Pr $\mathrm{CHM}_{0} \mathrm{CH}_{2} \mathrm{CM}_{3}$

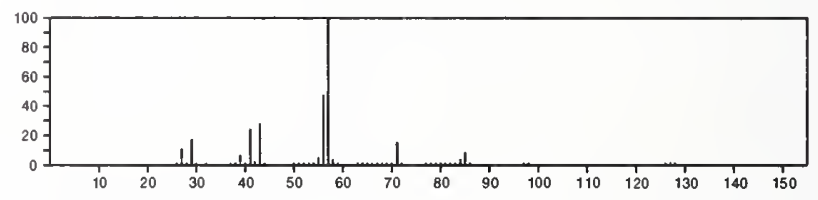

142

$\mathrm{C}_{10} \mathrm{H}_{22}$

15869-85-9

Nonane, 5-methyl-

$\mathrm{Me}\left(\mathrm{CH}_{2}\right)_{3} \mathrm{CHMe}_{0}\left(\mathrm{CH}_{2}\right)_{3} \mathrm{Me}$

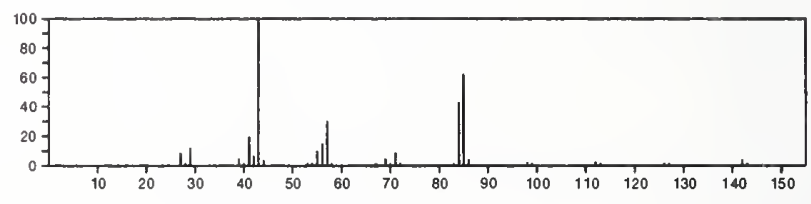

142

$\mathrm{C}_{10} \mathrm{H}_{22}$

15869-89-3

Octane, 2,5-dimethyl-

$\mathrm{Me}_{2} \mathrm{CHCH}_{2} \mathrm{CH}_{2} \mathrm{CHP}_{\mathrm{M}} \mathrm{Me}$

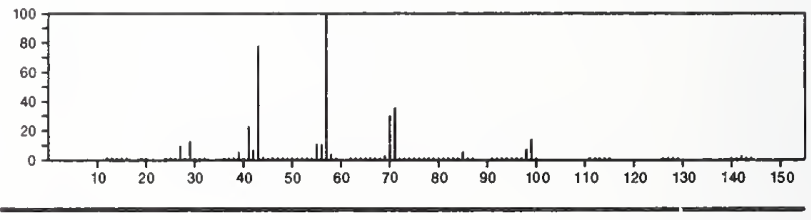

142

Nonane, 4-methyl-

$\mathrm{C}_{10} \mathrm{H}_{22}$

17301-94-9

$\operatorname{PrCHMe}\left(\mathrm{CH}_{2}\right)_{4} \mathrm{Me}$

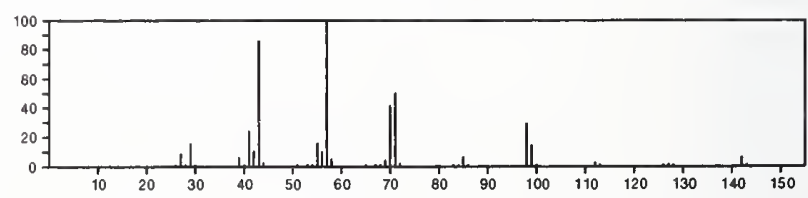


142

Heptane, 4-(1-methylethyl)-

$\mathrm{C}_{10} \mathrm{H}_{22}$

$\mathrm{Me}_{2} \mathrm{CHCHPr}_{2}$

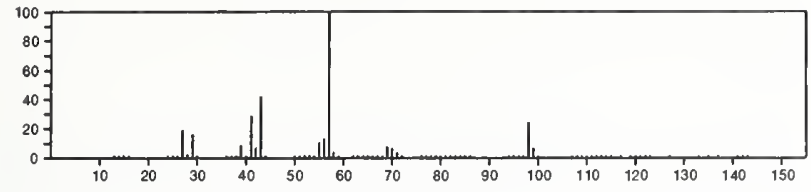

142

Hexane, 4-ethyl-2,2-dimethyl-

$\mathrm{C}_{10} \mathrm{H}_{22}$

$\mathrm{Et}{ }_{2} \mathrm{CHCH}_{2} \mathrm{CMe}_{3}$

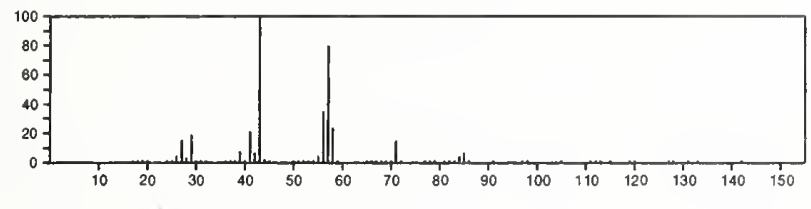

142

Naphthalene, 1-methyl-

$\mathrm{C}_{11} \mathrm{H}_{10}$

$90-12-0$
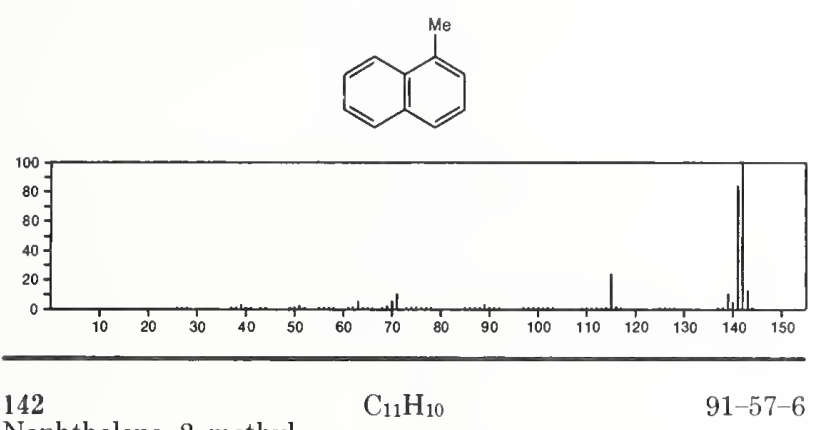

Naphthalene, 2-methyl-
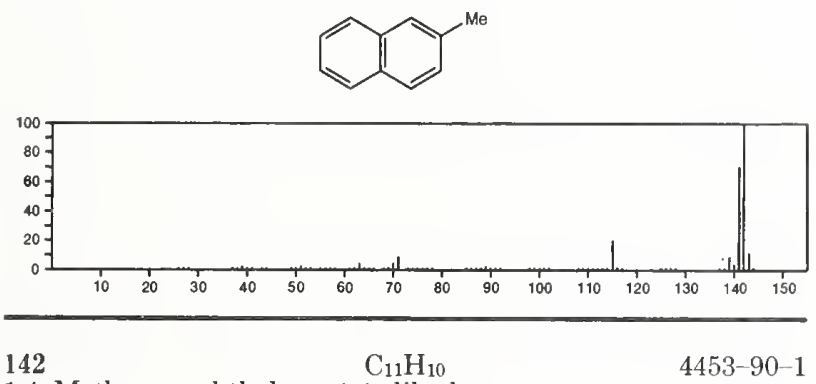

1,4-Methanonaphthalene, 1,4-dihydro-
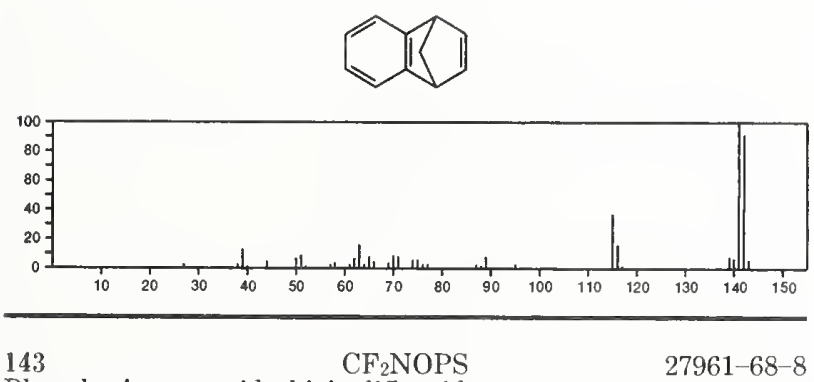

Phosphorisocyanatidothioic difluoride

$\mathrm{OCNPF}_{2}=\mathrm{S}$

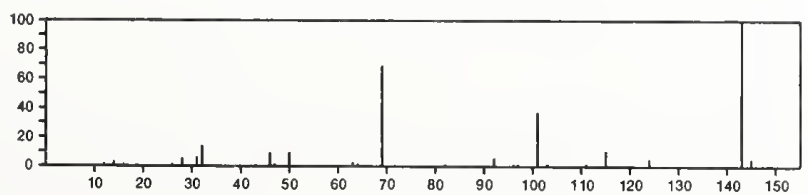

143

Acetonitrile, trichloro

$\mathrm{C}_{2} \mathrm{Cl}_{3} \mathrm{~N}$

$545-06-2$

$\mathrm{Cl} 3 \mathrm{CCN}$

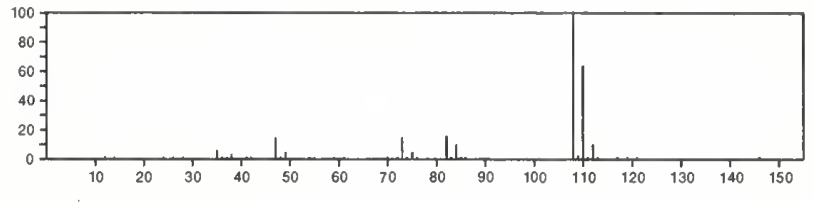

$143 \quad \mathrm{C}_{2} \mathrm{H}_{3} \mathrm{Cl}_{2} \mathrm{NO}_{2}$

Ethane, 1,1-dichloro-1-nitro-

$594-72-9$

$\mathrm{MeCCl} 2\left(\mathrm{NO}_{2}\right)$

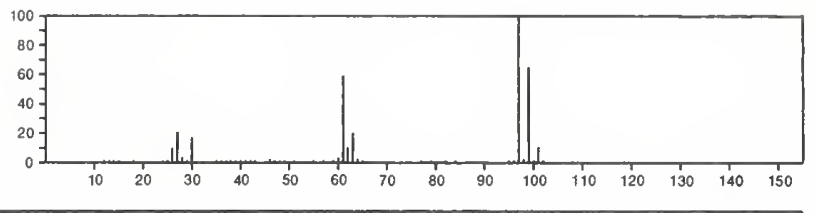

143

$\mathrm{C}_{4} \mathrm{H}_{5} \mathrm{~N}_{3} \mathrm{OS}$

$6973-81-5$

4(1H)-Pyrimidinone, 2-amino-6-mercapto-
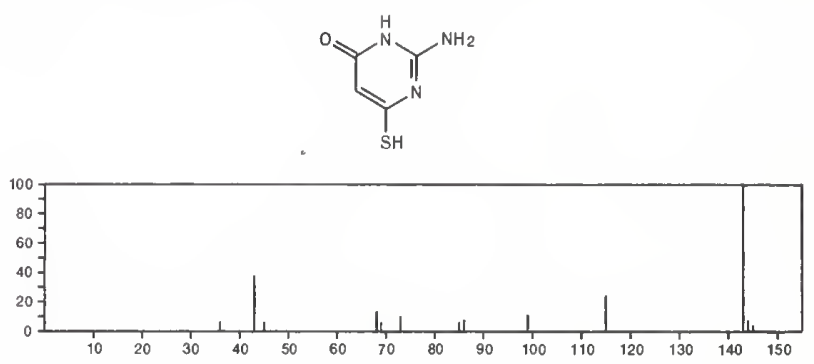

143

$\mathrm{C}_{5} \mathrm{H}_{5} \mathrm{NO}_{2} \mathrm{~S}$

4-Isothiazolecarboxylic acid, 3-methyl-

$15903-66-9$<smiles>O=C(O)c1csnc1[N+](=O)[O-]</smiles>

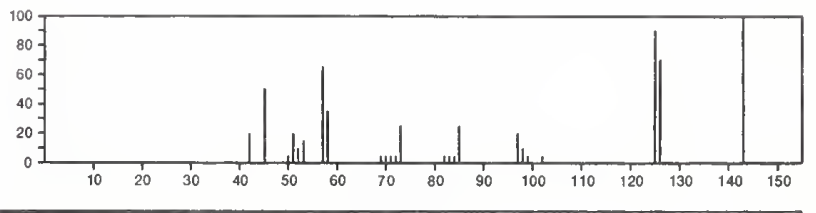

143

$\mathrm{C}_{6} \mathrm{H}_{6} \mathrm{ClNO}$

$17228-64-7$

Pyridine, 2-chloro-6-methoxy-
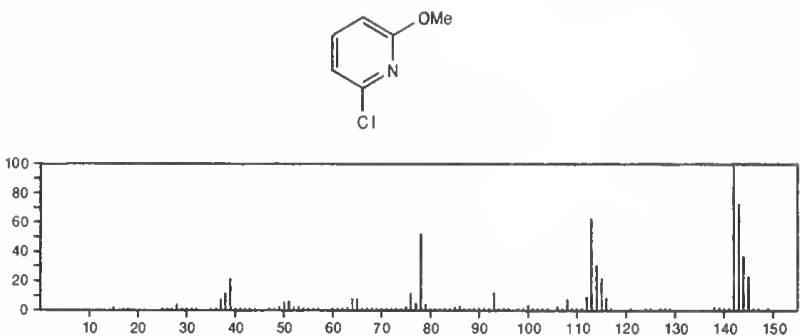
143

$\mathrm{C}_{6} \mathrm{H}_{9} \mathrm{NOS}$

5-Thiazoleethanol, 4-methyl-

$137-00-8$
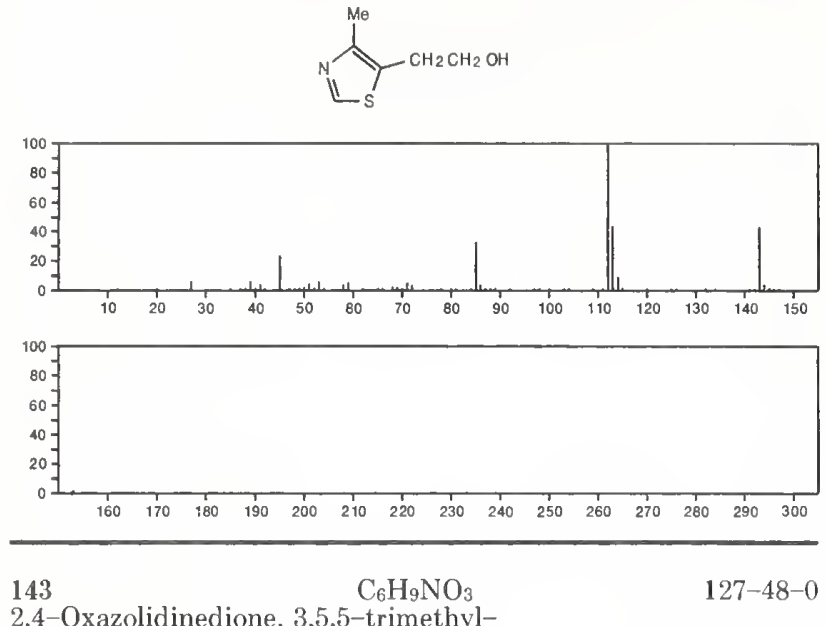

2,4-Oxazolidinedione, 3,5,5-trimethyl-
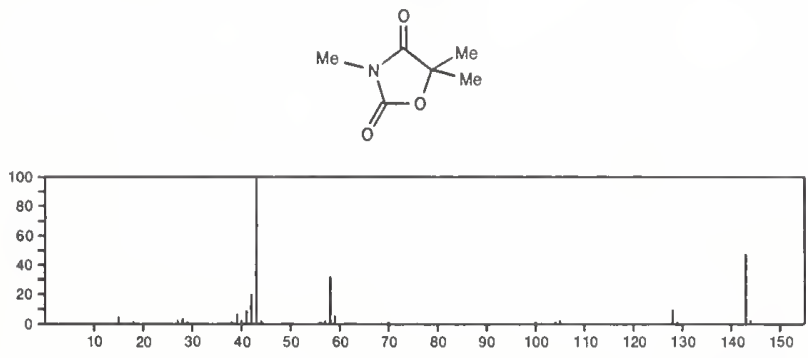

143

$\mathrm{C}_{6} \mathrm{H}_{9} \mathrm{NO}_{3}$

L-Proline, 5-oxo-, methyl ester

$$
\bigcap_{0} c(0) 0 M e
$$
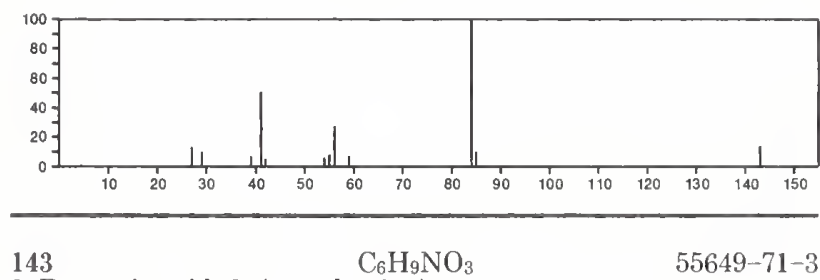

2-Butenoic acid, 2-(acetylamino)-

$55649-71-3$

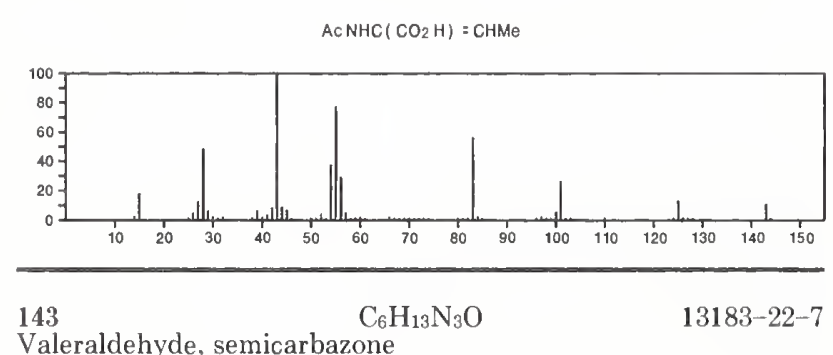

Valeraldehyde, semicarbazone

$\mathrm{Me}\left(\mathrm{CH}_{2}\right)_{3} \mathrm{CH}=\mathrm{NNHCONH}_{2}$

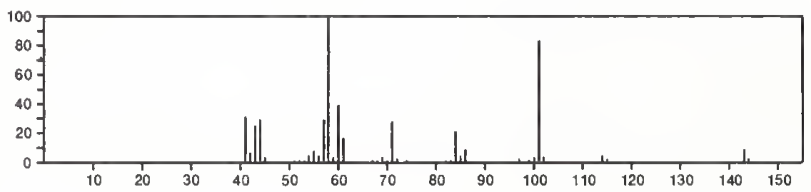

$4931-66-2$
143

Pivalaldehyde, semicarbazone

$\mathrm{C}_{6} \mathrm{H}_{13} \mathrm{~N}_{3} \mathrm{O}$

$23809-33-8$

$\mathrm{H}_{2} \mathrm{NCONHN}=\mathrm{CHCMe}_{3}$

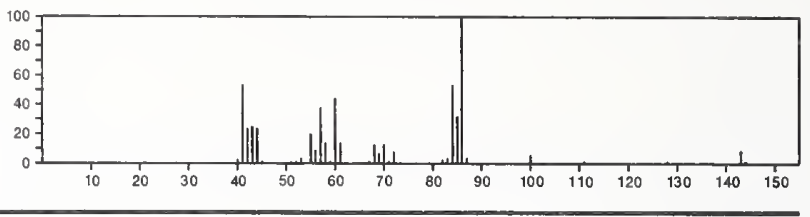

143

$\mathrm{C}_{7} \mathrm{H}_{9} \mathrm{~N} . \mathrm{ClH}$

Benzenamine, 4-methyl-, hydrochloride

$540-23-8$
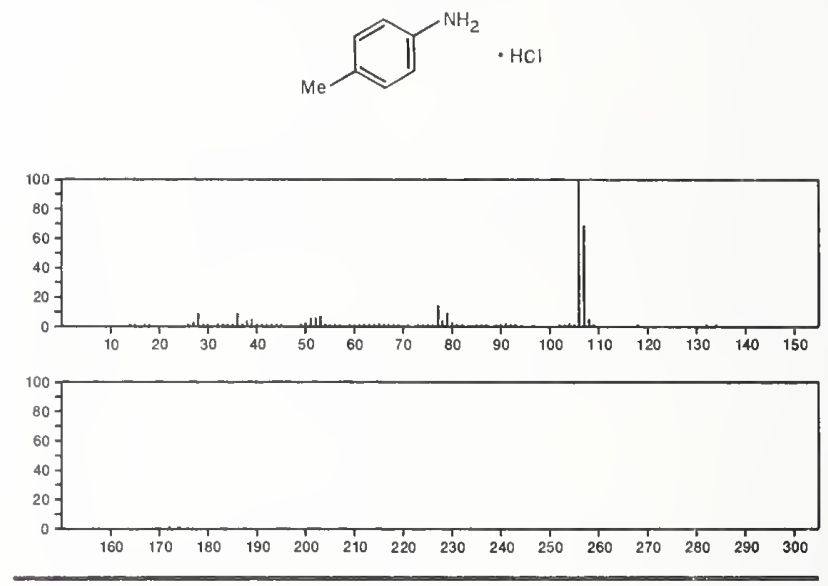

143

$\mathrm{C}_{7} \mathrm{H}_{9} \mathrm{~N} . \mathrm{ClH}$

Benzenamine, 2-methyl-, hydrochloride

$636-21-5$
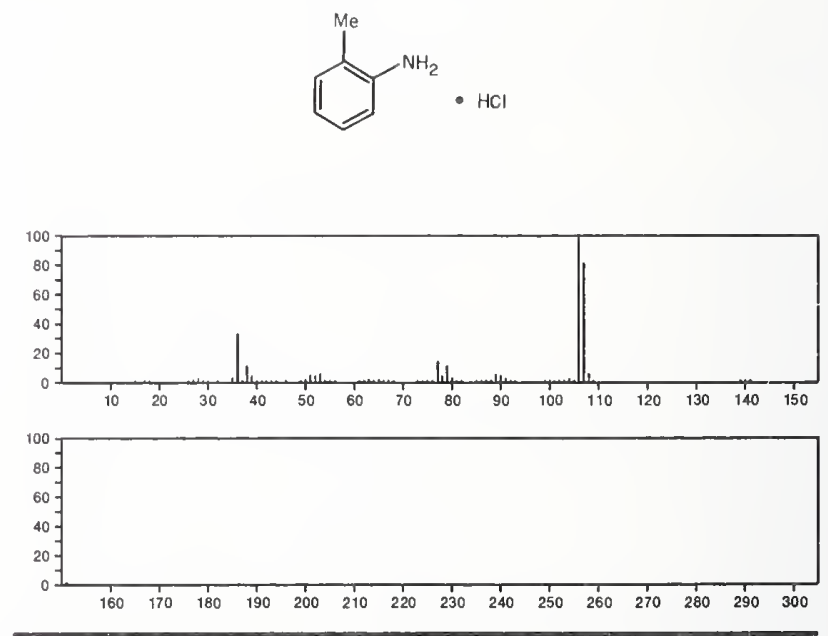

143

$\mathrm{C}_{7} \mathrm{H}_{9} \mathrm{~N} . \mathrm{ClH}$

Benzenamine, 3-methyl-, hydrochloride

638-03-9
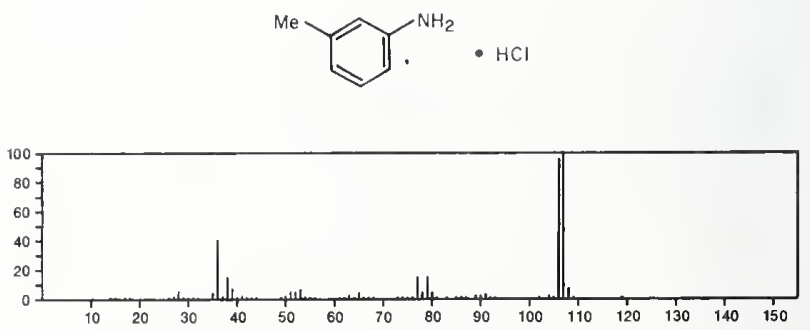


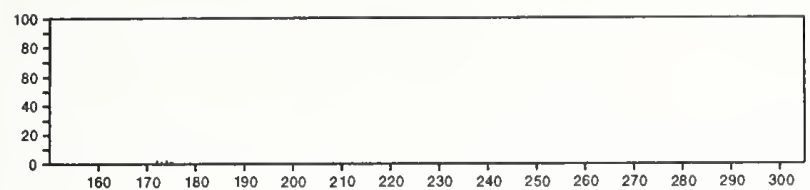

143

$\mathrm{C}_{7} \mathrm{H}_{13} \mathrm{NO}_{2}$

2-Butenoic acid, 3-(methylamino)-, ethyl ester

870-85-9

$\mathrm{MeC}(\mathrm{NHMe})=\mathrm{CHC}(\mathrm{O}) \mathrm{OE}$
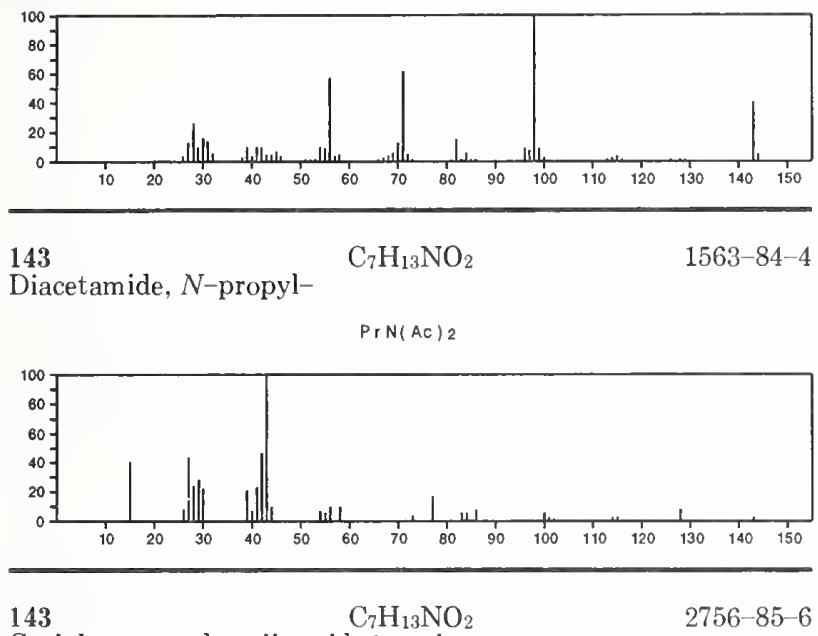

Cyclohexanecarboxylic acid, 1-amino-
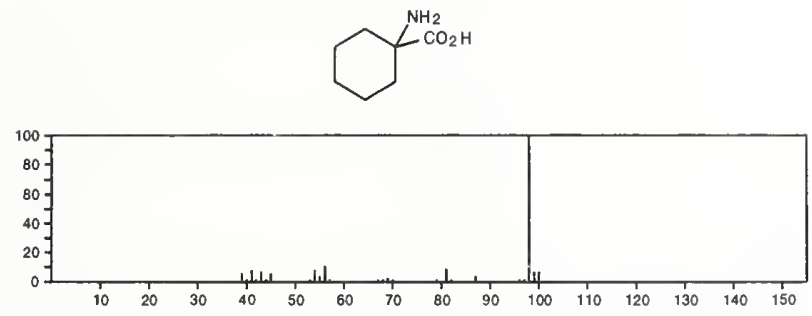

143

L-Proline, ethyl ester

$\mathrm{C}_{7} \mathrm{H}_{13} \mathrm{NO}_{2}$

$5817-26-5$
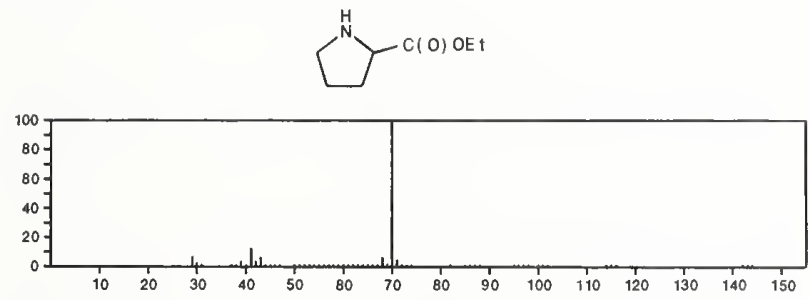

143

$\mathrm{C}_{7} \mathrm{H}_{13} \mathrm{NO}_{2}$

2-Propenal, 3-(dimethylamino)-3-ethoxy-

$26387-77-9$

$\mathrm{OCHCH}=\mathrm{C}(\mathrm{OE} \mathrm{I}) \mathrm{NME} 2$

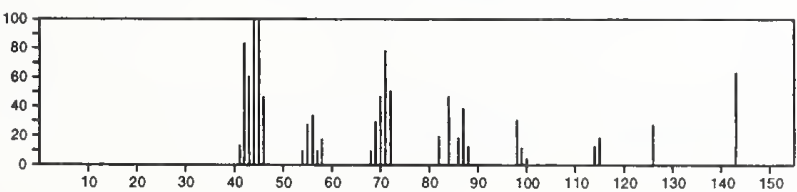

143

$\mathrm{C}_{7} \mathrm{H}_{13} \mathrm{NO}_{2}$

$27957-91-1$

L-Proline, 1-methyl-, methyl ester

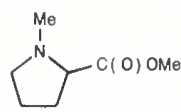

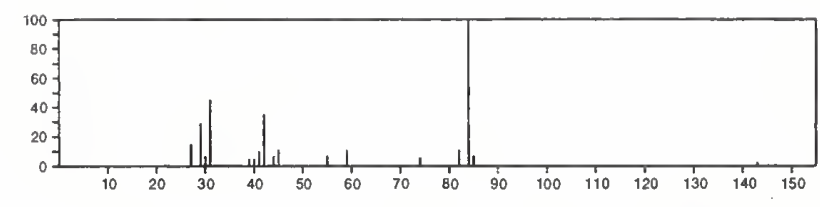

$143 \quad \mathrm{C}_{7} \mathrm{H}_{13} \mathrm{NO}_{2}$

Butyramide, $N$-propionyl-

Pr CONHCOE

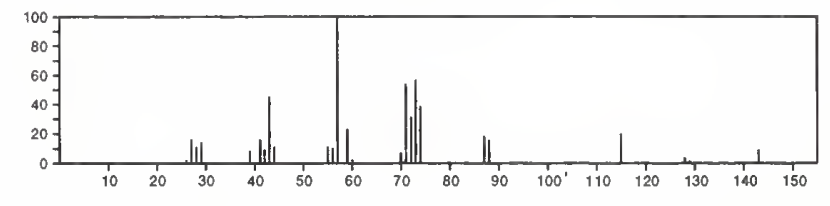

143

$\mathrm{C}_{7} \mathrm{H}_{13} \mathrm{NO}_{2}$

$35633-52-4$

Propanenitrile, 3-(2-methoxy-1-methylethoxy)-

$\mathrm{MeOCH} 2 \mathrm{CHMe} \mathrm{OCH}_{2} \mathrm{CH}_{2} \mathrm{CN}$

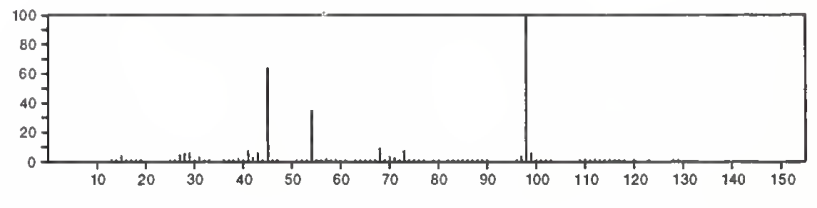

143

$\mathrm{C}_{7} \mathrm{H}_{13} \mathrm{NO}_{2}$

$49582-68-5$

3-Buten-2-one, 4-(dimethylamino)-4-methoxy-

$\mathrm{Me}{ }_{2} \mathrm{NC}(\mathrm{OMe})=\mathrm{CHCOMe}$

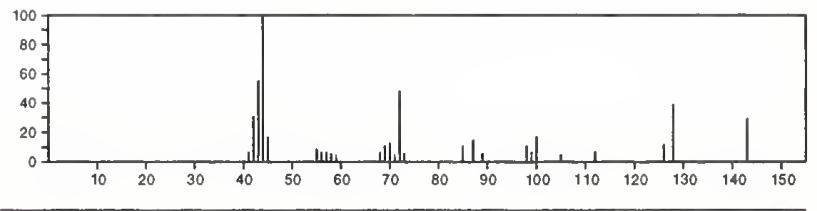

143

$\mathrm{C}_{7} \mathrm{H}_{13} \mathrm{NO}_{2}$

$51052-78-9$

4-Piperidineacetic acid<smiles>O=C(O)CC1CCNCC1</smiles>

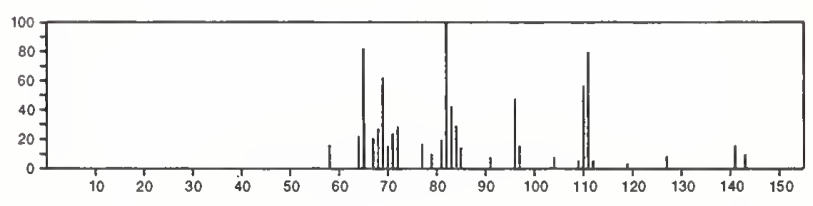

143

$\mathrm{C}_{7} \mathrm{H}_{13} \mathrm{NO}_{2}$

Cyclohexane, (methyl-aci-nitro)-

$55937-97-8$
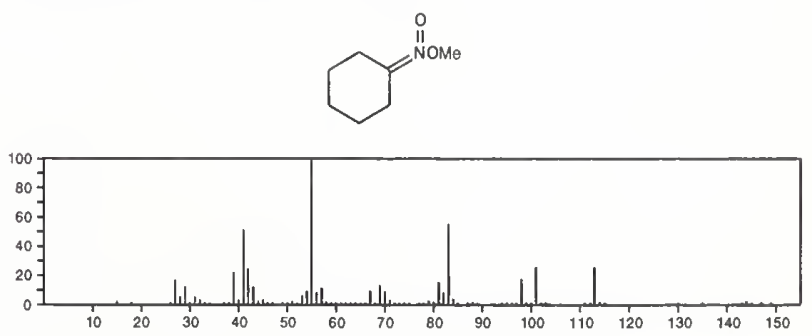
143

Hexane, 1-isothiocyanato-

$\mathrm{C}_{7} \mathrm{H}_{13} \mathrm{NS}$

$\mathrm{SCN}\left(\mathrm{CH}_{2}\right)_{5} \mathrm{Me}$

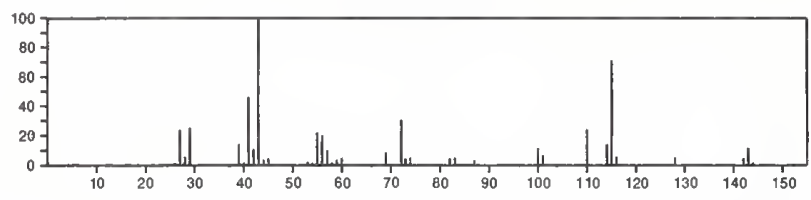

143

3,5-Pyridinedicarbonitrile, 2

$\mathrm{C}_{8} \mathrm{H}_{5} \mathrm{~N}_{3}$<smiles></smiles>

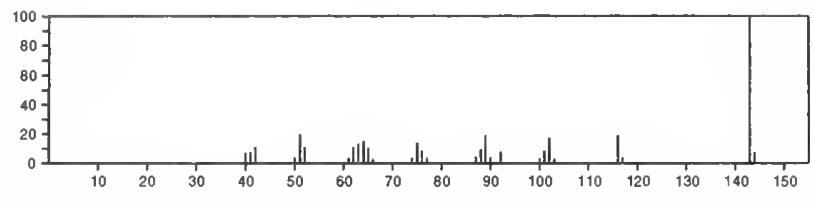

$143 \quad \mathrm{C}_{8} \mathrm{H}_{5} \mathrm{~N}_{3}$

3,5-Pyridinedicarbonitrile, 4-methyl-<smiles>Nc1cncc(O)c1N</smiles>
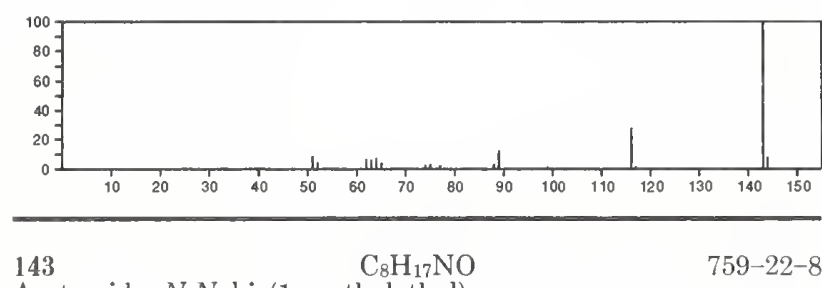

Acetamide, $N, N$-bis(1-methylethyl)-

$759-22-8$

i-Pr 2 NAC

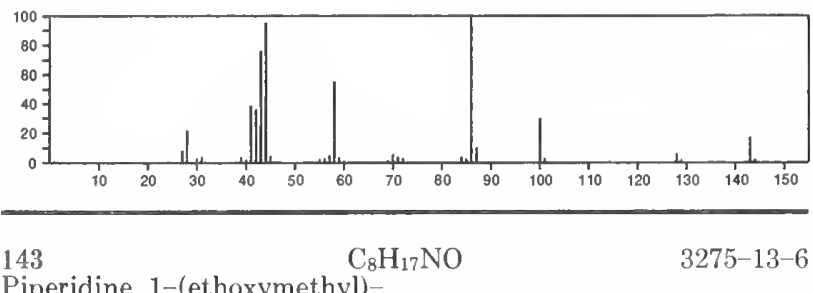

Piperidine, 1-(ethoxymethyl)-

$\overbrace{N^{-}}^{-\mathrm{CH}_{2} \mathrm{OEt}}$

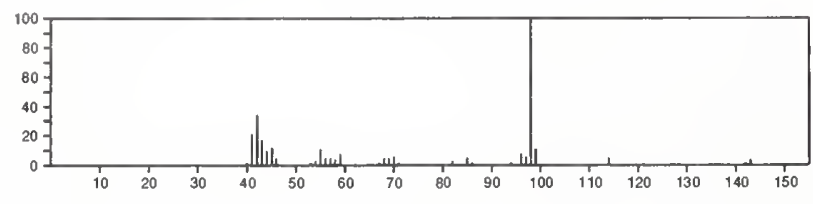

$143 \quad \mathrm{C}_{8} \mathrm{H}_{17} \mathrm{NO}$

2-Heptanone, $\mathrm{O}$-methyloxime

4098-77-5

$\mathrm{MeON}=\mathrm{CMe}_{e}\left(\mathrm{CH}_{2}\right){ }_{4} \mathrm{Me}$

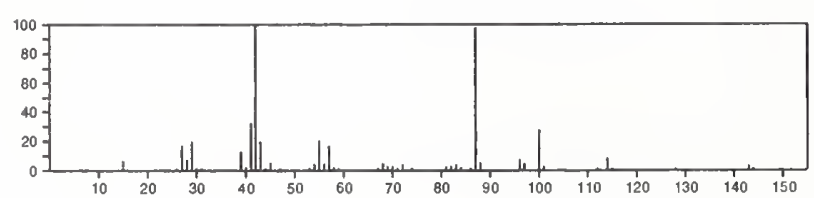

143

Acetamide, $N$-hexyl-

$\mathrm{C}_{8} \mathrm{H}_{17} \mathrm{NO}$

7501-79-3

$\mathrm{Me}\left(\mathrm{CH}_{2}\right) 5 \mathrm{NHAC}$

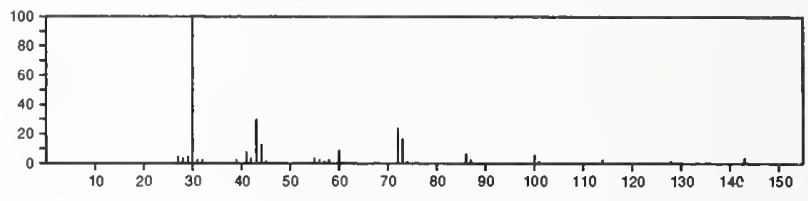

143

3-Pentanone, 2,4-dimethyl-, $\mathrm{O}$-methyloxime

$15754-23-1$

CHMe 2

$\mathrm{Me} \mathrm{ON}=\mathrm{CCHMe}$

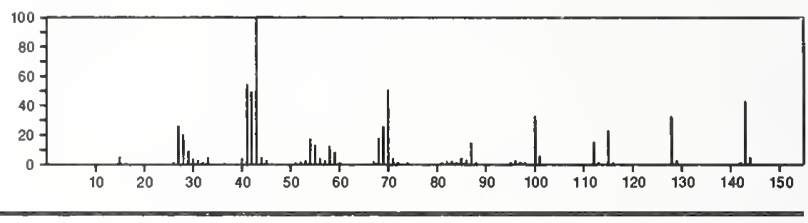

143

$\mathrm{C}_{8} \mathrm{H}_{17} \mathrm{NO}$

Cyclohexanol, 2-(dimethylamino)-, cis $^{-}$

20431-82-7<smiles>CN(C)C1CCCCC1O</smiles>

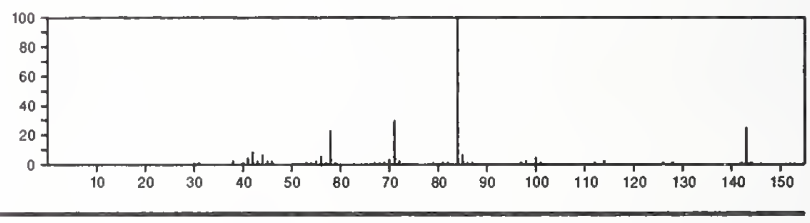

143

$\mathrm{C}_{8} \mathrm{H}_{17} \mathrm{NO}$

20734-31-0

4-Piperidinol, 4-ethyl-1-methyl-
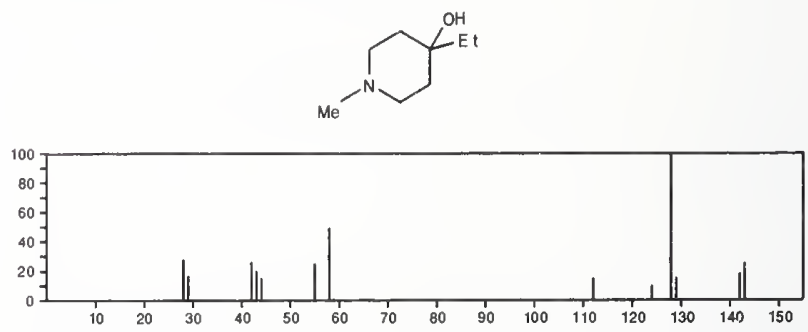

143

2-Pentanone, $\mathrm{O}$-propyloxime

$\mathrm{C}_{8} \mathrm{H}_{17} \mathrm{NO}$

$54004-39-6$

$\operatorname{PrON}=\mathrm{CP} r \mathrm{Me}$

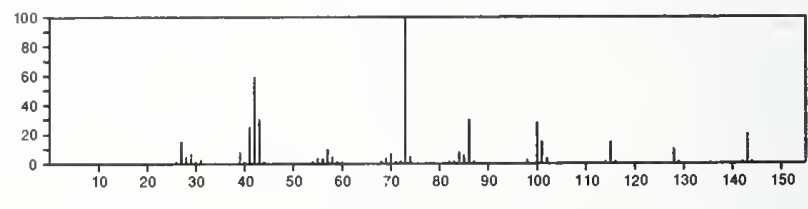

143

3-Piperidinol, 1-ethyl-6-methyl-

54751-98-3
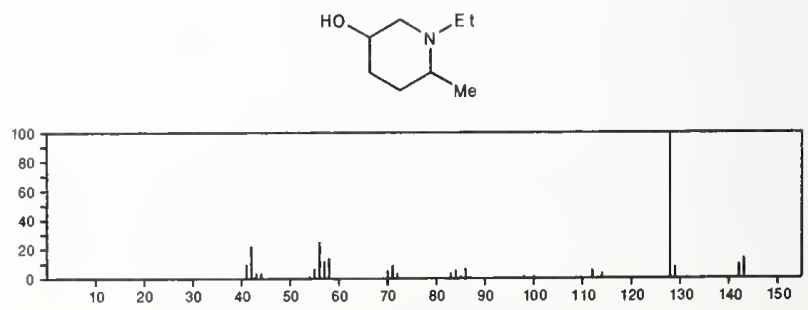
$143 \quad \mathrm{C}_{8} \mathrm{H}_{17} \mathrm{NO}$

Formamide, $N$-butyl- $N$-(1-methylethyl)-

$\mathrm{Me}\left(\mathrm{CH}_{2}\right)_{3} \mathrm{~N}(\mathrm{Pr}-\mathrm{H}) \mathrm{CH}=\mathrm{O}$

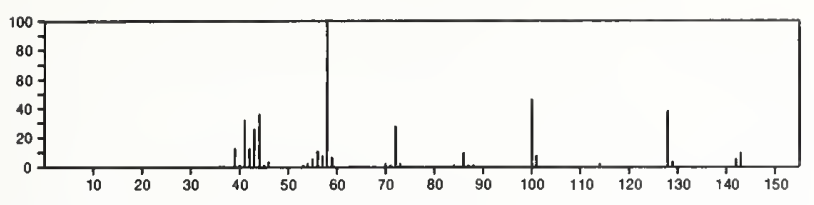

$143 \quad \mathrm{C}_{8} \mathrm{H}_{17} \mathrm{NO}$

$54966-01-7$

Butanamide, $N$-methyl-N-(1-methylethyl)-

$\mathrm{MeN}(\mathrm{Pr}-\mathrm{i}) \mathrm{COPr}$

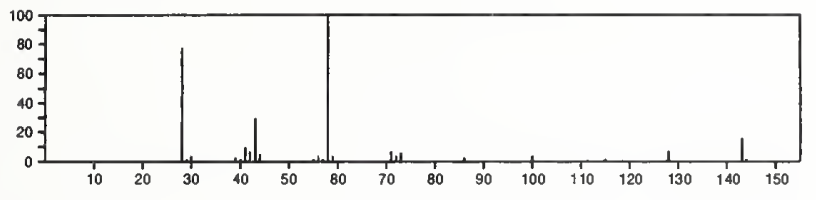

$143 \quad \mathrm{C}_{9} \mathrm{H}_{21} \mathrm{~N}$

1-Propanamine, $N, N$-dipropyl-

$\mathrm{NPr}_{3}$

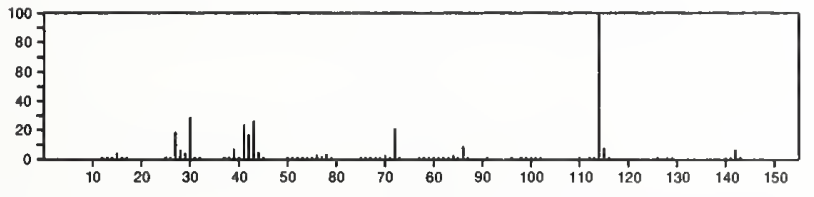

143

1-Nonanamine

$\mathrm{C}_{9} \mathrm{H}_{21} \mathrm{~N}$

$112-20-9$

$\mathrm{Me}\left(\mathrm{CH}_{2}\right)_{8} \mathrm{NH}_{2}$

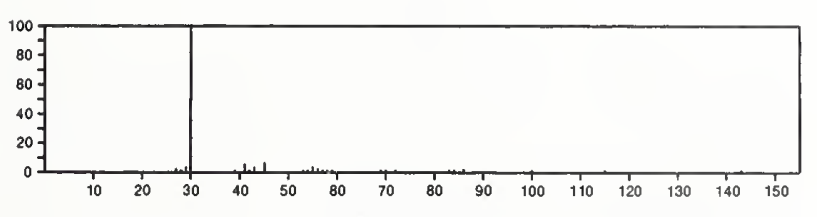

143

$\mathrm{C}_{9} \mathrm{H}_{21} \mathrm{~N}$

3378-63-0

Hexylamine, 3,5,5-trimethyl-

$\mathrm{H}_{2} \mathrm{NCH}_{2} \mathrm{CH}_{2} \mathrm{CHM}_{0} \mathrm{CH}_{2} \mathrm{CMe}_{3}$

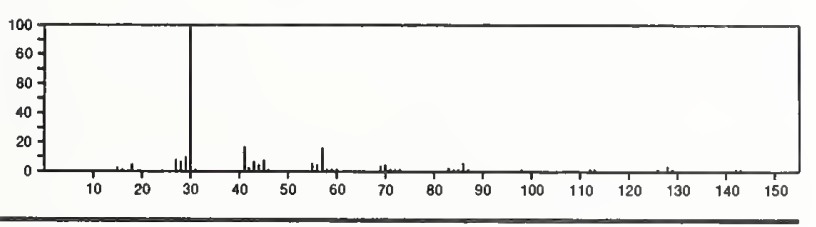

143

$\mathrm{C}_{9} \mathrm{H}_{21} \mathrm{~N}$

1-Butanamine, $N$-butyl- $N$-methyl-

3405-45-6

$\mathrm{Me}\left(\mathrm{CH}_{2}\right)_{3} \mathrm{NMe}\left(\mathrm{CH}_{2}\right)_{3} \mathrm{Me}$

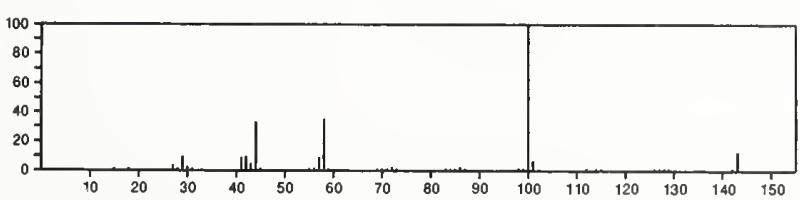

143

$\mathrm{C}_{9} \mathrm{H}_{21} \mathrm{~N}$

$5756-49-0$

1-Pentanamine, $N$-methyl-N-(1-methylethyl)-

$\operatorname{MeN}(\mathrm{Pr}-\mathrm{i})\left(\mathrm{CH}_{2}\right){ }_{4} \mathrm{Me}$

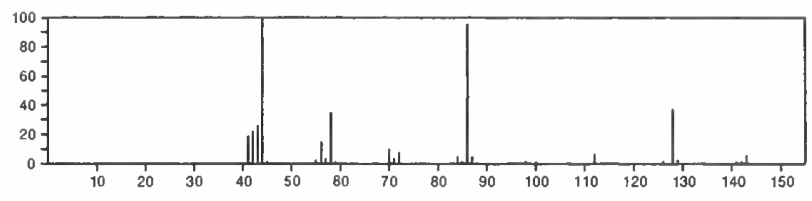

143

$\mathrm{C}_{9} \mathrm{H}_{21} \mathrm{~N}$

20193-23-1

1-Hexanamine, $N$-propyl-

$\mathrm{Me}\left\{\mathrm{CH}_{2}\right\} 5 \mathrm{NHPr}$

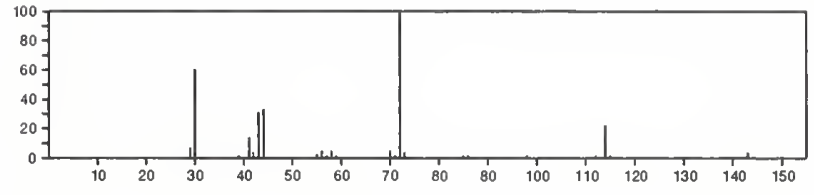

143

1- Hexanamine, 3,5,5-trimethyl-

$36551-19-6$

$\mathrm{Me}_{3} \mathrm{C}\left(\mathrm{CH}_{2}\right)_{5} \mathrm{NH}_{2}$

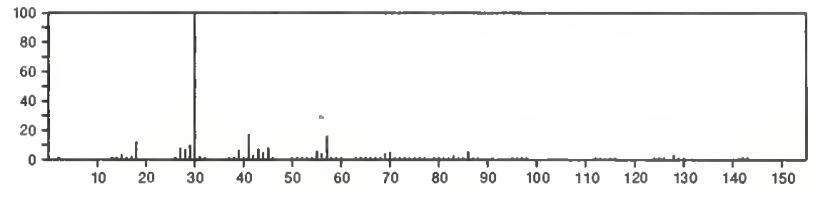

143

2-Naphthalenamine

$\mathrm{C}_{10} \mathrm{H}_{9} \mathrm{~N}$

$91-59-8$
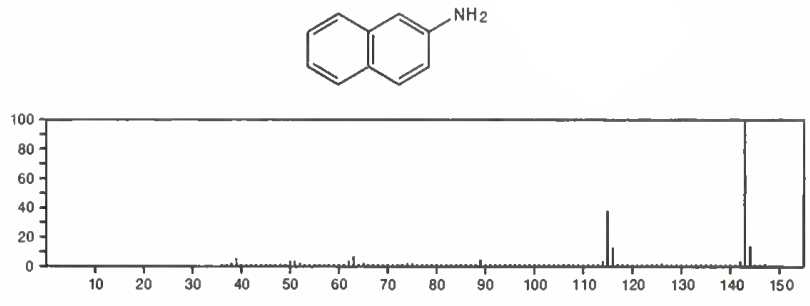

143

Quinoline, 6-methyl-

$\mathrm{C}_{10} \mathrm{H}_{9} \mathrm{~N}$

$91-62-3$
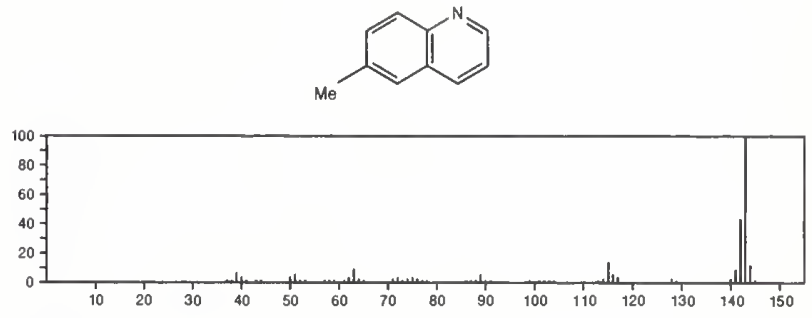

143

Quinoline, 2-methyl-

$\mathrm{C}_{10} \mathrm{H}_{9} \mathrm{~N}$

$91-63-4$
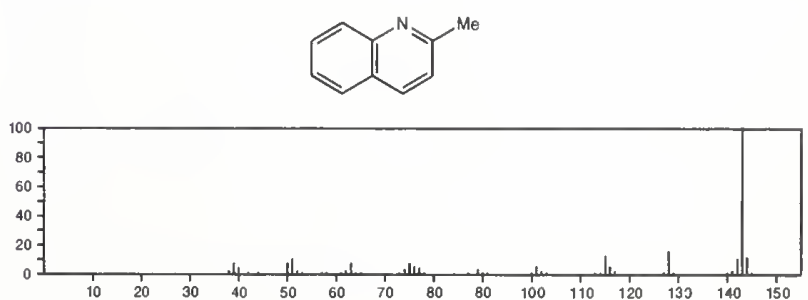
143

Quinoline, 4-methyl-

\section{$\mathrm{C}_{10} \mathrm{H}_{9} \mathrm{~N}$}
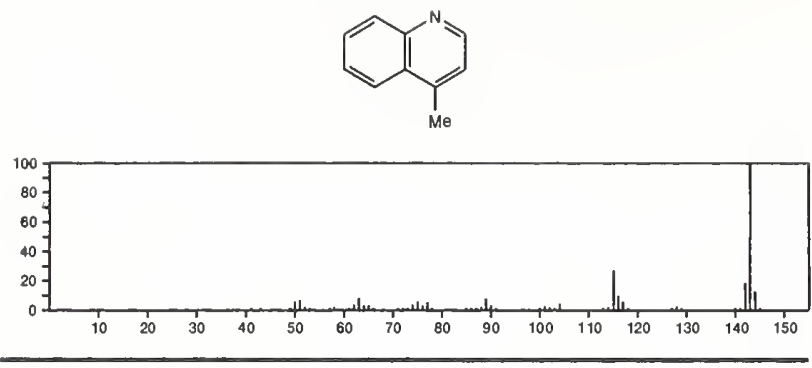

143

Quinoline, 8-methyl-

$\mathrm{C}_{10} \mathrm{H}_{9} \mathrm{~N}$

$611-32-5$
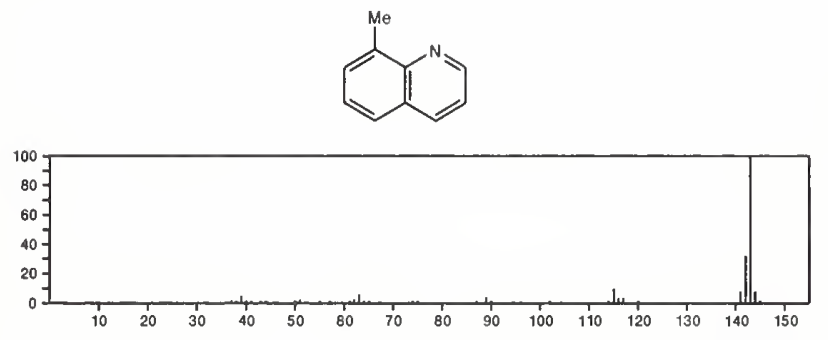

143

$\mathrm{C}_{10} \mathrm{H}_{9} \mathrm{~N}$

$612-58-8$

Quinoline, 3-methyl-
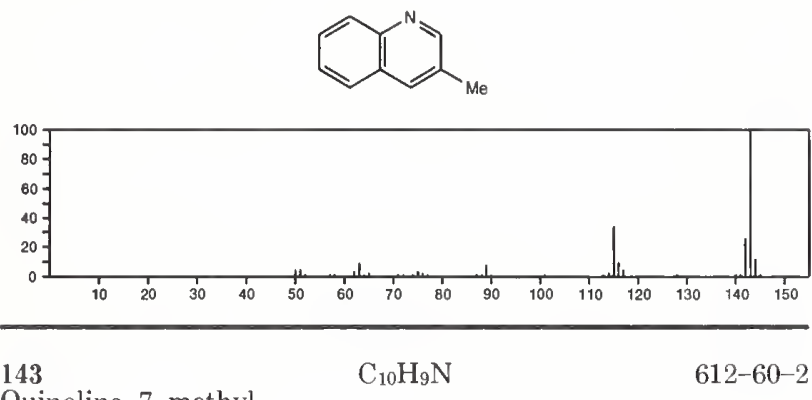

Quinoline, 7-methyl-
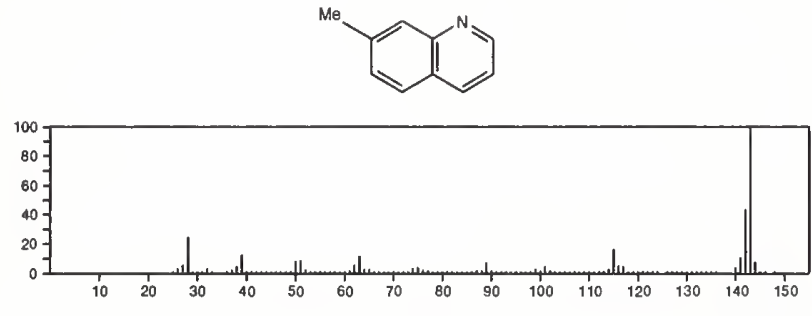

$143 \quad \mathrm{C}_{10} \mathrm{H}_{9} \mathrm{~N}$

1H-Pyrrole, 1-phenyl-

$635-90-5$
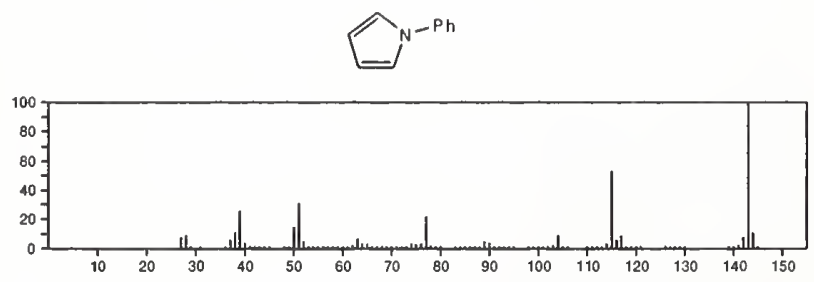

143

Isoquinoline, 3-methyl-

$\mathrm{C}_{10} \mathrm{H}_{9} \mathrm{~N}$

$1125-80-0$
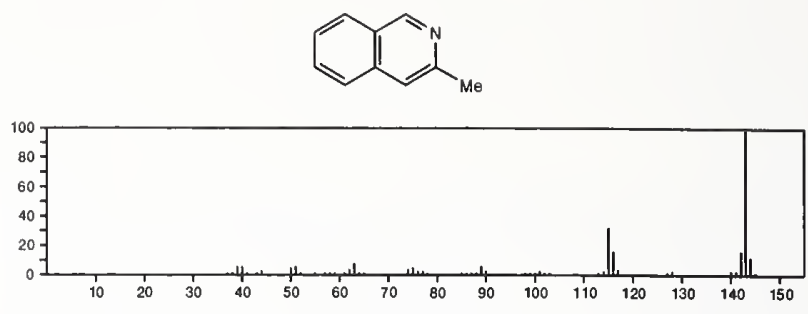

143

$\mathrm{C}_{10} \mathrm{H}_{9} \mathrm{~N}$

$1721-93-3$

Isoquinoline, 1-methyl-
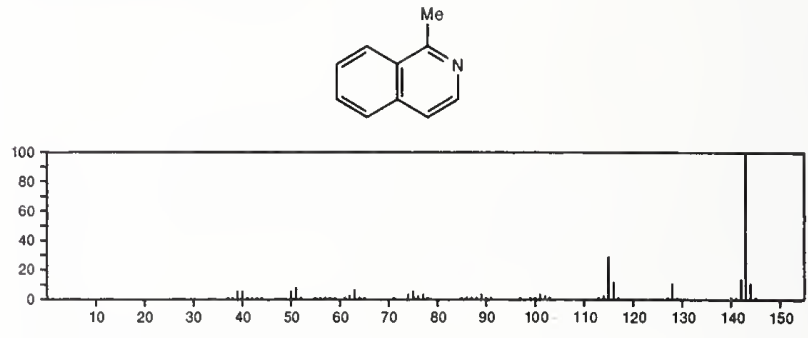

143

$\mathrm{C}_{10} \mathrm{H}_{9} \mathrm{~N}$

$7661-55-4$

Quinoline, 5-methyl-
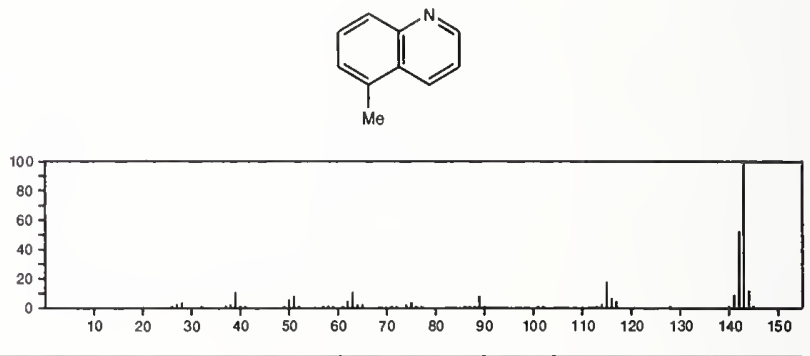

143

$\mathrm{C}_{10} \mathrm{H}_{9} \mathrm{~N}$

Benzenepropanenitrile, $\alpha$-methylene-

28769-48-4

$\mathrm{H}_{2} \mathrm{C}=\mathrm{C}(\mathrm{CN}) \mathrm{CH}_{2} \mathrm{Ph}$

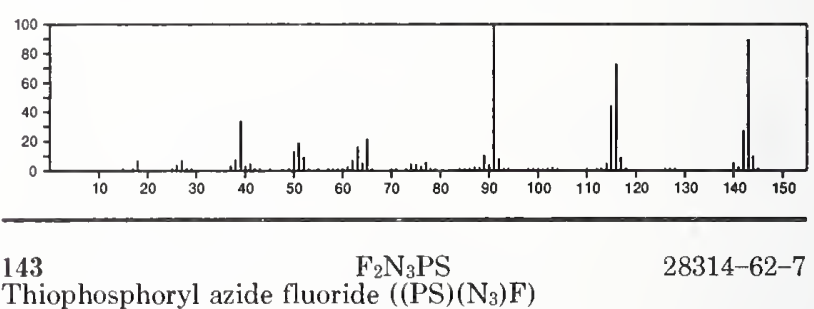

$\mathrm{N}_{3} \mathrm{PF}_{2}=\mathrm{S}$

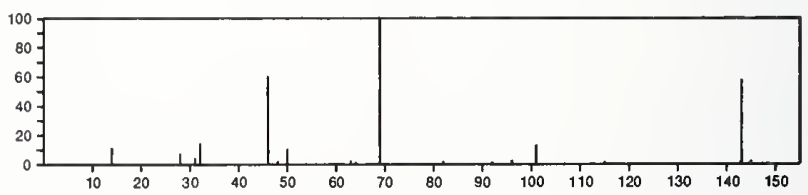


143

$\mathrm{F}_{5} \mathrm{H}_{2} \mathrm{NS}$

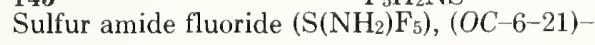

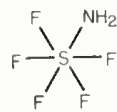

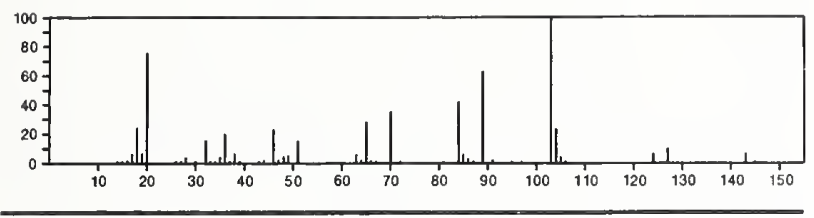

144

$\mathrm{C}_{2} \mathrm{H}_{6} \mathrm{ClO}_{3} \mathrm{P}$

Phosphorochloridic acid, dimethyl ester

$813-77-4$
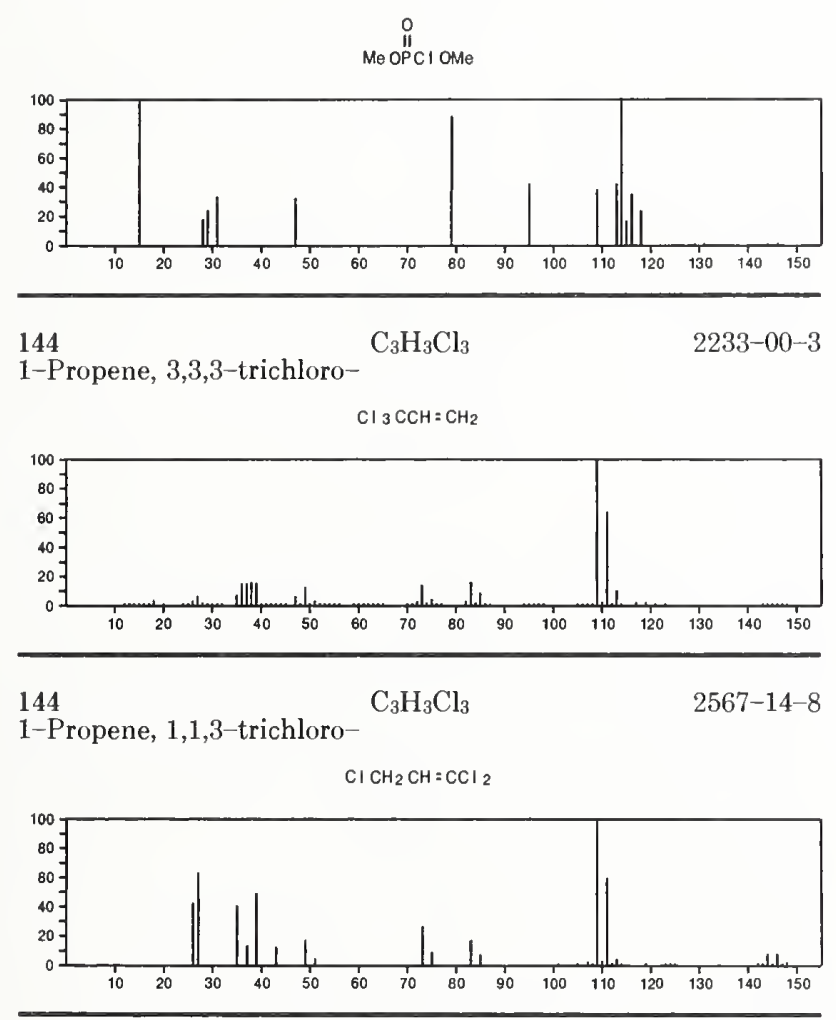

\section{4}

1-Propene, 1,1,2-trichloro

$\mathrm{C}_{3} \mathrm{H}_{3} \mathrm{Cl}_{3}$

$\mathrm{Cl}_{2} \mathrm{C}=\mathrm{CC} / \mathrm{Me}$
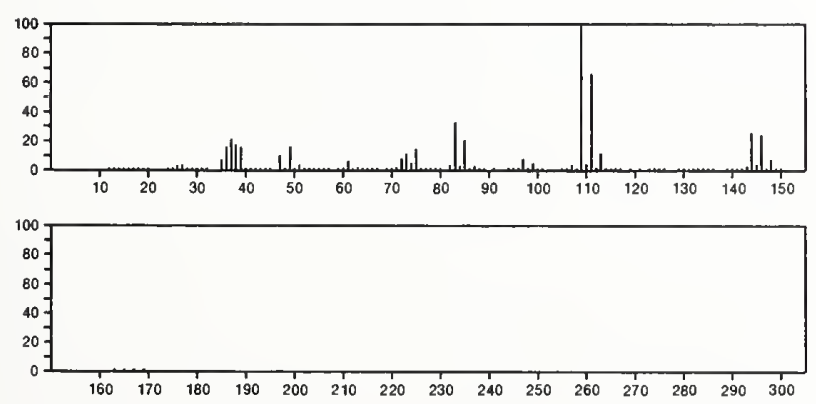

144

1,2,3-Thiadiazole-4-carboxylic acid, 5-methyl-

$22097-10-5$<smiles>Nc1snnc1C(=O)O</smiles>

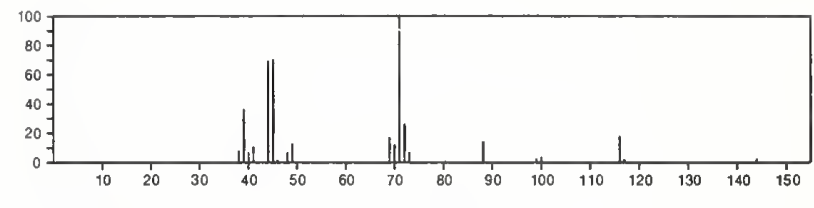

144

Sydnone, 3-(carboxymethyl)-

$\mathrm{C}_{4} \mathrm{H}_{4} \mathrm{~N}_{2} \mathrm{O}_{4}$

26537-53-1

$\sum_{-0}^{0-N}={ }_{N}^{-C_{2}-\mathrm{CO}_{2} \mathrm{H}}$

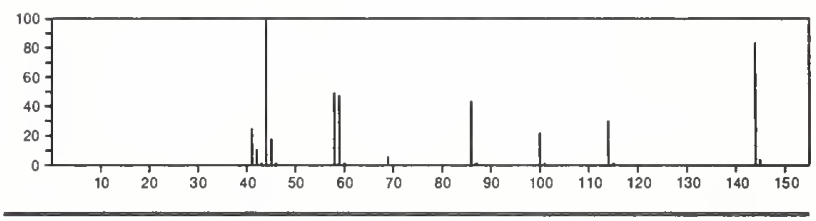

144

4,5-Pyrimidinediamine, 2-chloro-

$14631-08-4$<smiles>Nc1cnc(Cl)nc1N</smiles>

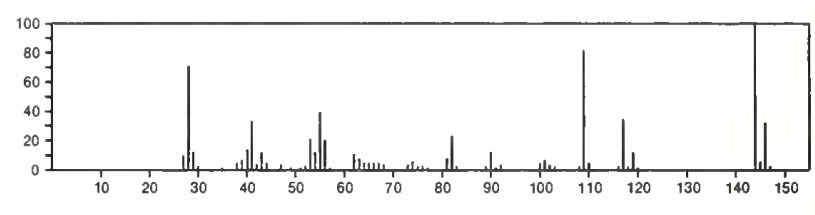

144

Piperazine, 1,4-dinitroso-

$\mathrm{C}_{4} \mathrm{H}_{8} \mathrm{~N}_{4} \mathrm{O}_{2}$

$140-79-4$
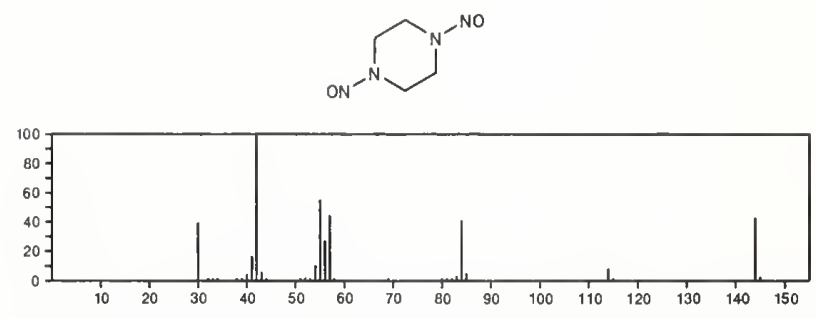

${ }_{2,6}^{144}$-Piperazinedione, dioxime $\mathrm{C}_{4} \mathrm{H}_{8} \mathrm{~N}_{4} \mathrm{O}_{2}$

$35975-29-2$<smiles>N=C1CNCC(=O)N1</smiles>

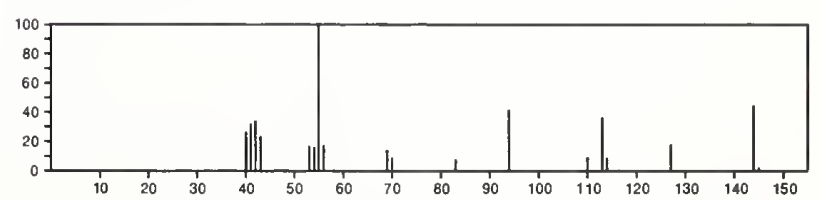


144 $\mathrm{C}_{4} \mathrm{H}_{8} \mathrm{~N}_{4} \mathrm{~S}$

3-Thiazolidinecarboxamidine, 2-imino-<smiles>N=C(N)N1CCSC1=N</smiles>

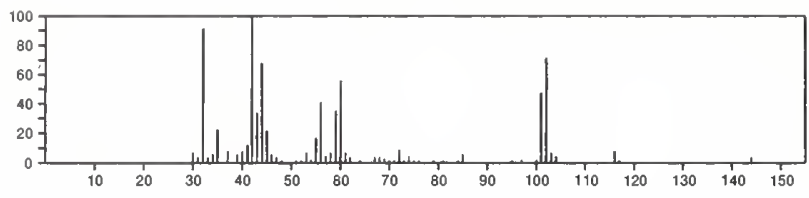

144

$\mathrm{C}_{5} \mathrm{H}_{4} \mathrm{OS}_{2}$

$5694-59-7$

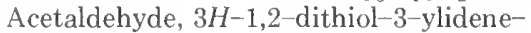
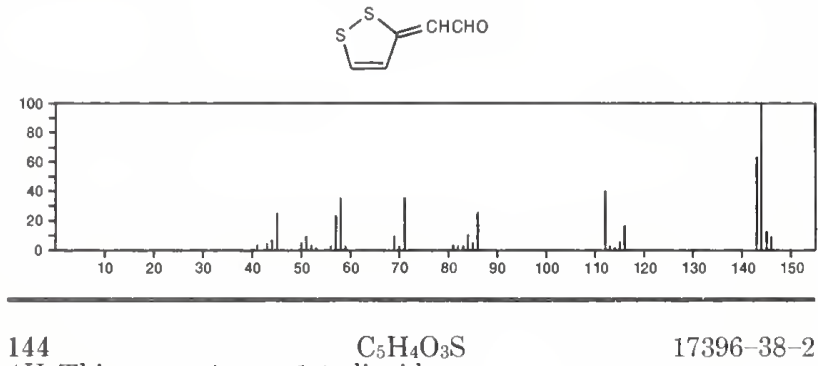

$17396-38-2$

4H-Thiopyran-4-one, 1,1-dioxide
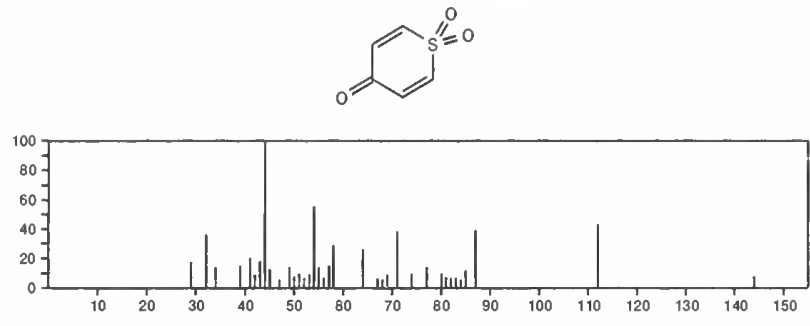

$144 \quad \mathrm{C}_{5} \mathrm{H}_{5} \mathrm{ClN}_{2} \mathrm{O}$

Pyridazine, 3-chloro-6-methoxy-

$1722-10-7$
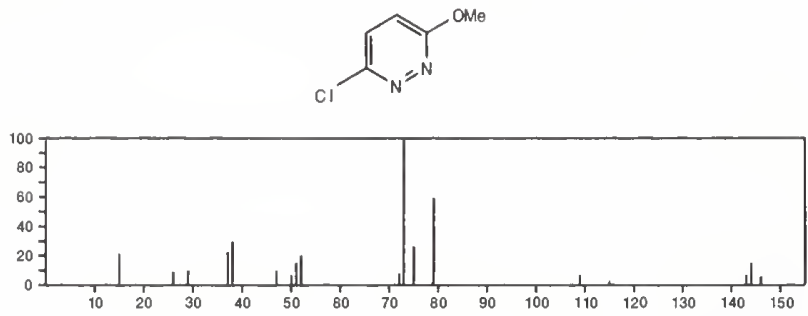

144

$\mathrm{C}_{5} \mathrm{H}_{8} \mathrm{~N}_{2} \mathrm{O}_{3}$

Acetamide, $N, N^{\prime}$-carbonylbis-

AC NHCONHAC

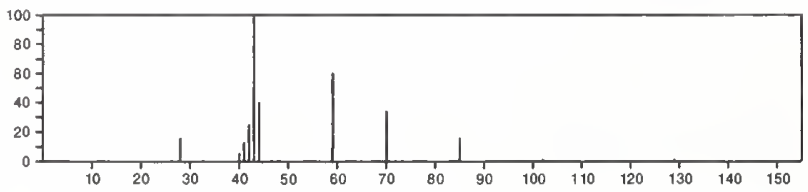

144

$\mathrm{C}_{5} \mathrm{H}_{8} \mathrm{~N}_{2} \mathrm{O}_{3}$

1123-21-3

2,4(1H,3H)-Pyrimidinedione, dihydro-5-hydroxy-5-methyl-
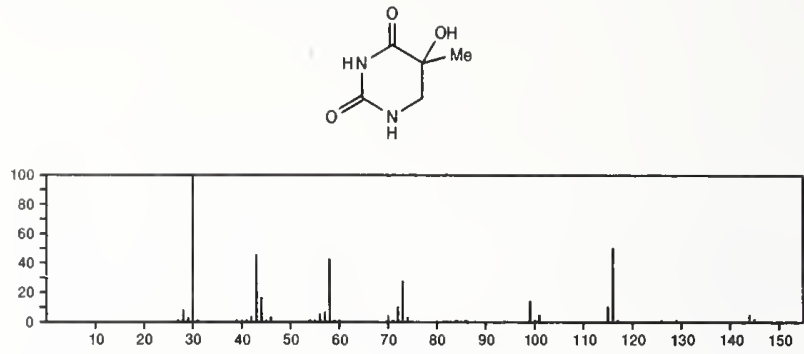

144

$\mathrm{C}_{5} \mathrm{H}_{8} \mathrm{~N}_{2} \mathrm{O}_{3}$

7519-36-0

L-Proline, 1-nitroso-
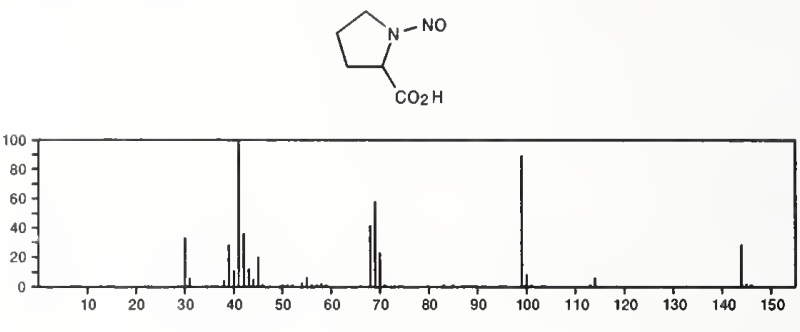

144

$\mathrm{C}_{6} \mathrm{H}_{8} \mathrm{O}_{4}$

1,4-Dioxane-2,5-dione, 3,6-dimethyl-

$95-96-5$<smiles>CC1OC(=O)C([N+](=O)[O-])OC1=O</smiles>

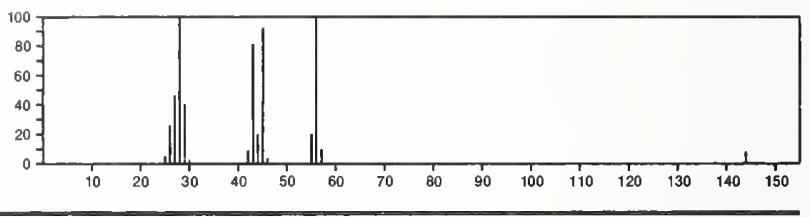

144

$\mathrm{C}_{6} \mathrm{H}_{8} \mathrm{O}_{4}$

$624-48-6$

2-Butenedioic acid $(Z)$-, dimethyl ester

$\left.\mathrm{MeOC}_{\mathrm{O}} \mathrm{O}\right) \mathrm{CH}=\mathrm{CHC}(\mathrm{O}) \mathrm{OM}$

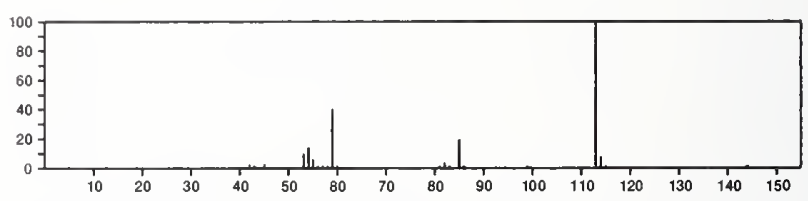

144

$\mathrm{C}_{6} \mathrm{H}_{8} \mathrm{O}_{4}$

2-Butenedioic acid $(E)$-, dimethyl ester

$624-49-7$

$\mathrm{MeOC}(\mathrm{O}) \mathrm{CH}: \mathrm{CHC}(\mathrm{O}) \mathrm{OMe}$

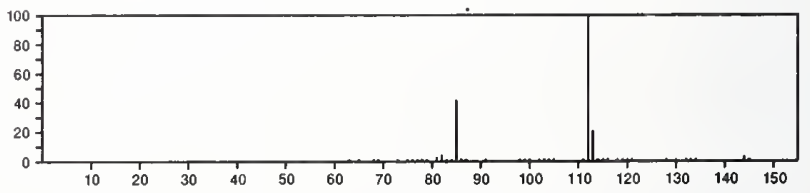


144 $1,2-$ Cyclobutanedicarboxylic acid, trans

$1124-13-6$
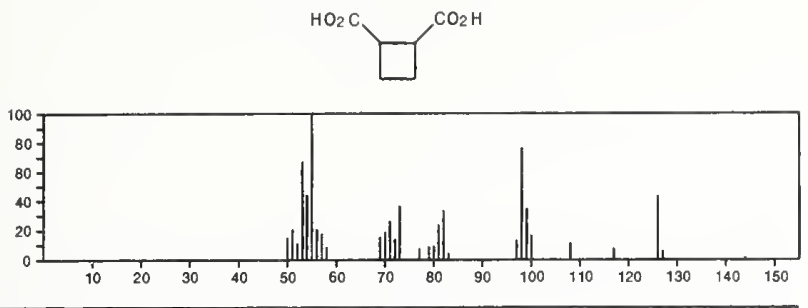

$144 \quad \mathrm{C}_{6} \mathrm{H}_{8} \mathrm{O}_{4}$

1,2-Cyclobutanedicarboxylic acid, cis

$1461-94-5$
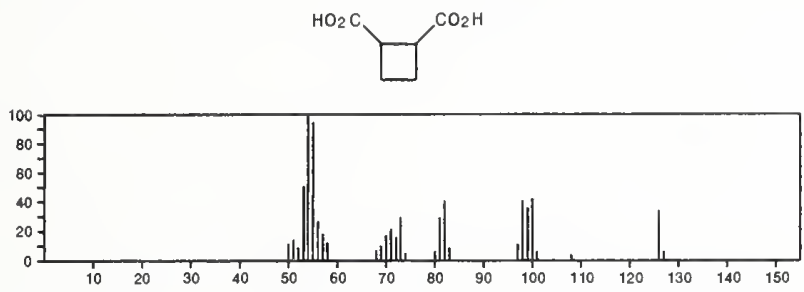

$144 \quad \mathrm{C}_{6} \mathrm{H}_{8} \mathrm{O}_{4} \quad 28564-83-2$ 4H-Pyran-4-one, 2,3-dihydro-3,5-dihydroxy-6-methyl-<smiles>CC1=C(O)C(=O)C(O)CO1</smiles>

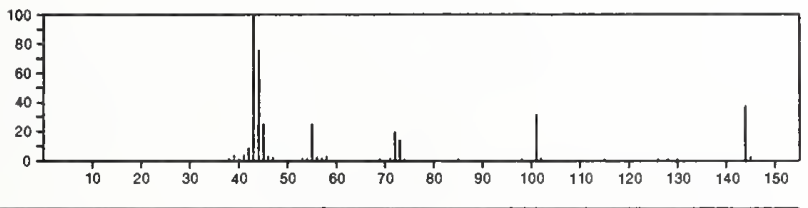

144

2-Butene-1,4-diol, diformate

$\mathrm{C}_{6} \mathrm{H}_{8} \mathrm{O}_{4}$

$29619-56-5$

$\mathrm{O}: \mathrm{CHOCH}_{2} \mathrm{CH}: \mathrm{CHCH}_{2} \mathrm{OCH}=\mathrm{O}$
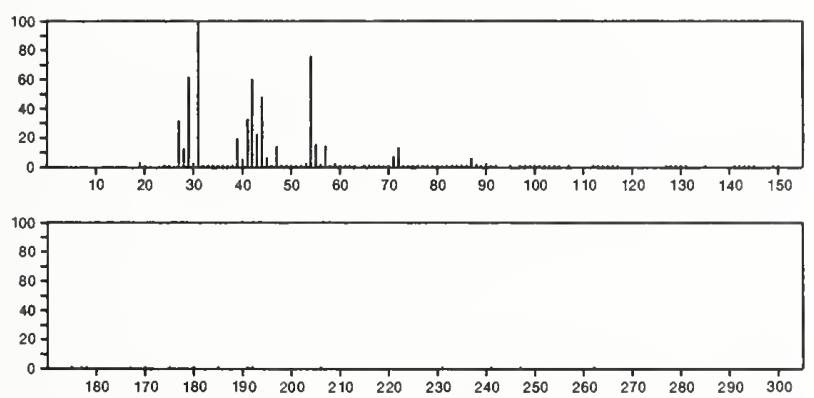

\section{4}

$\begin{array}{lllllllllllllll}180 & 170 & 180 & 190 & 200 & 210 & 220 & 230 & 240 & 250 & 260 & 270 & 280 & 290 & 300\end{array}$

$36568-10-2$

Pentanoic acid, 3,5-dioxo-, methyl ester

$\mathrm{OCHCH}_{2} \mathrm{COCH}_{2} \mathrm{C}(\mathrm{O}) \mathrm{OMe}$

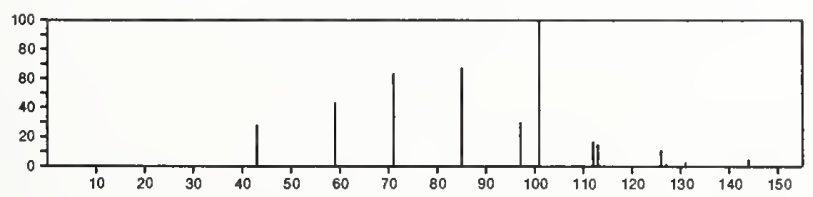

$144 \quad \mathrm{C}_{6} \mathrm{H}_{9} \mathrm{~N}_{2} . \mathrm{Cl}$

Pyridinium, 1-amino-4-methyl-, chloride

$34061-83-1$

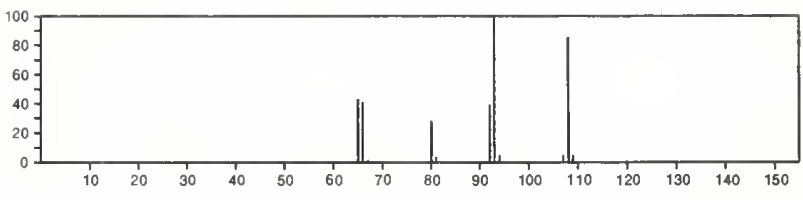

144

$\mathrm{C}_{6} \mathrm{H}_{9} \mathrm{~N}_{2} \mathrm{Cl}$

34061-84-2

Pyridinium, 1-amino-2-methyl-, chloride
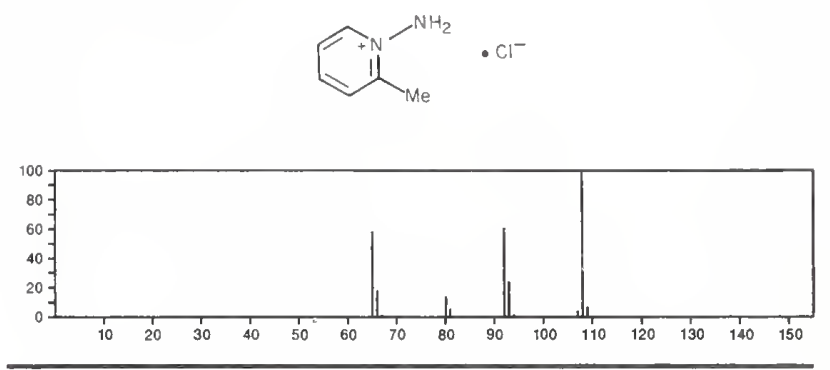

144

$\mathrm{C}_{6} \mathrm{H}_{12} \mathrm{~N}_{2} \mathrm{O}_{2}$

$55401-87-1$

Hydrazinecarboxylic acid, butylidene--, methyl ester

$\mathrm{MeOC}(0) \mathrm{NHN}=\mathrm{CHPr}$

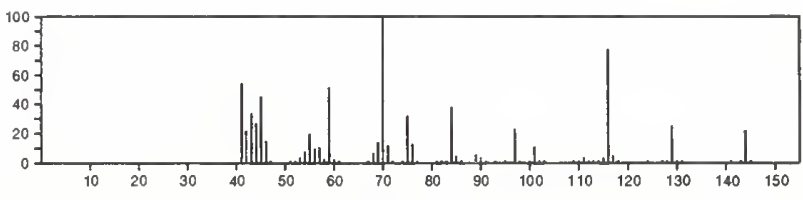

144

$\mathrm{C}_{6} \mathrm{H}_{12} \mathrm{~N}_{2} \mathrm{O}_{2}$

$55556-87-1$

Morpholine, 3,5-dimethyl-4-nitroso-<smiles>O=[N+]([O-])C1COC[CH]N1[N+](=O)[O-]</smiles>

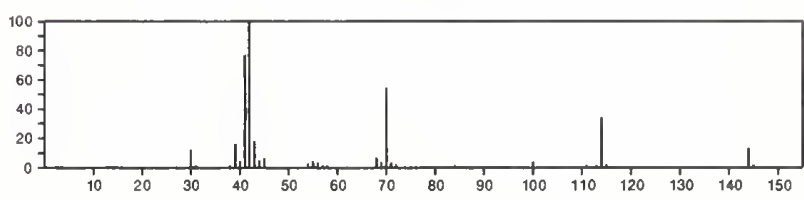

144

$\mathrm{C}_{6} \mathrm{H}_{12} \mathrm{O}_{2} \mathrm{Si}$

2-Propenoic acid, trimethylsilyl ester

$13688-55-6$

$\mathrm{Me} 3 \mathrm{SiOC}(\mathrm{O}) \mathrm{CH}=\mathrm{CH}_{2}$

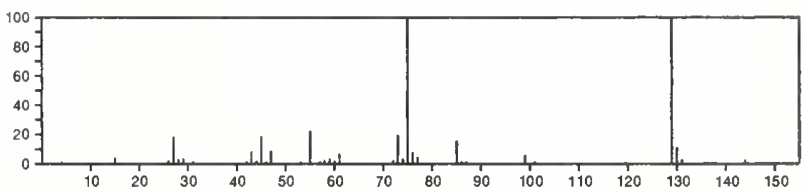


144 1,2,4,5-Tetrazine, 1,4-diethylhexahydro-<smiles>CCN1CNN(CC)CN1</smiles>

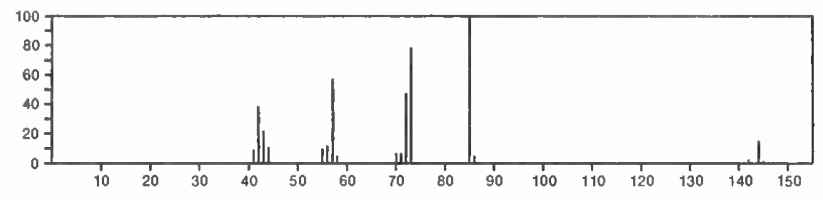

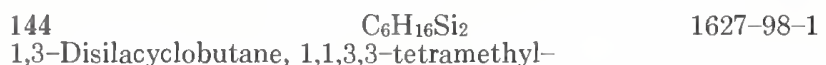
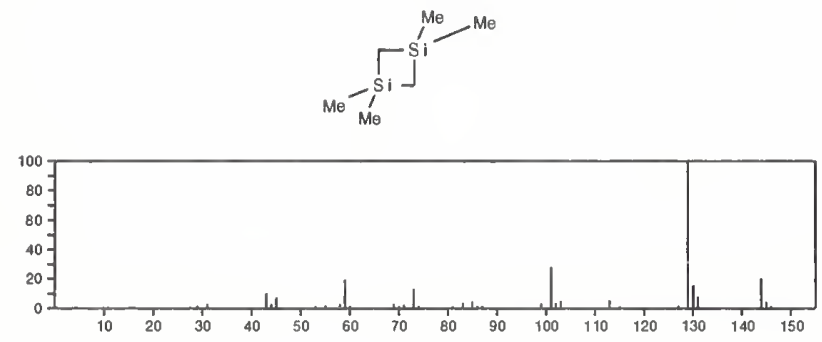

144

$\mathrm{C}_{7} \mathrm{H}_{9} \mathrm{ClO}$

1-Penten-4-yn-3-ol, 1-chloro-3-ethyl-

$113-18-8$

$\mathrm{Cl} C H=C H C E+(\mathrm{OH}) \mathrm{C} \equiv \mathrm{CH}$

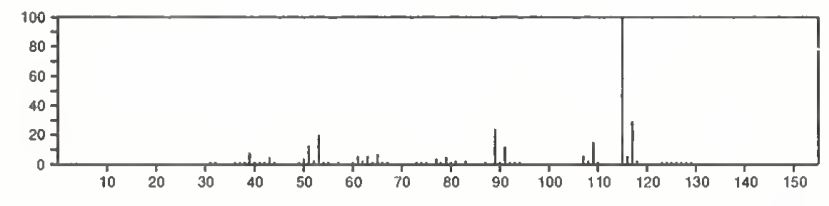

$144 \quad \mathrm{C}_{7} \mathrm{H}_{12} \mathrm{OS}$

1-Oxa-4-thiaspiro[4.4]nonane

176-38-5
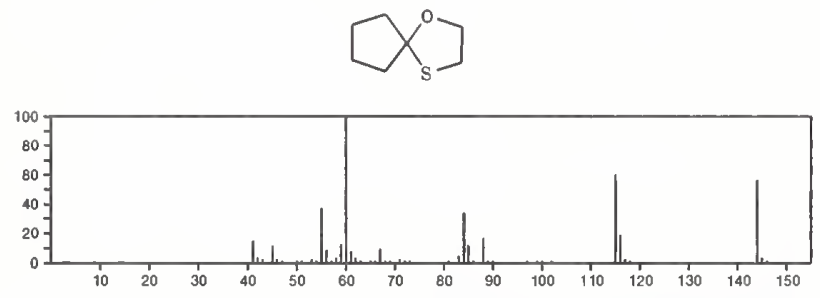

$144 \quad \mathrm{C}_{7} \mathrm{H}_{12} \mathrm{OS}$

$23510-98-7$

Cyclohexanone, 4-(methylthio)-
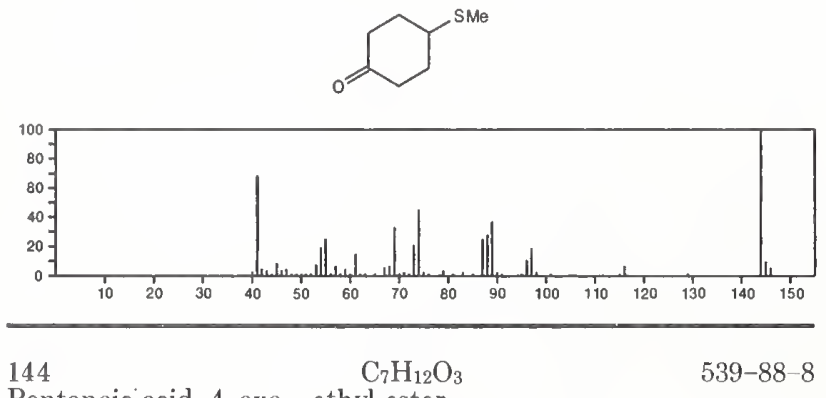

Pentanoic acid, 4-oxo-, ethyl ester

Et OC(O) $\mathrm{CH}_{2} \mathrm{CH}_{2}$ COMe

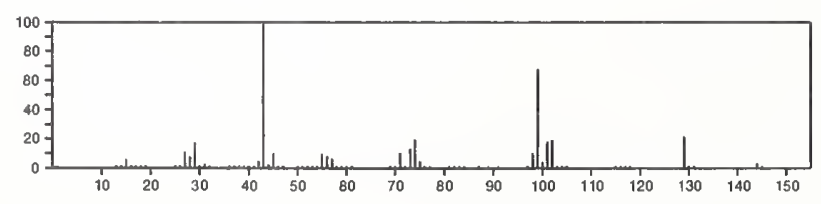

144

Cyclohexanecarboxylic acid, 2-hydroxy-

609-69-8<smiles>O=C(O)C1CCCCC1O</smiles>

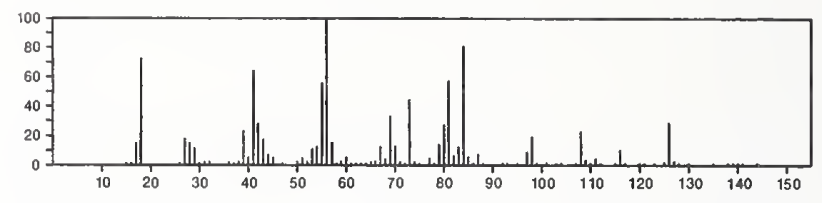

144

$\mathrm{C}_{7} \mathrm{H}_{12} \mathrm{O}_{3}$

637-64-9

2-Furanmethanol, tetrahydro-, acetate

$\mathrm{C}^{\mathrm{O} \mathrm{CH}_{2} \mathrm{OAC}}$

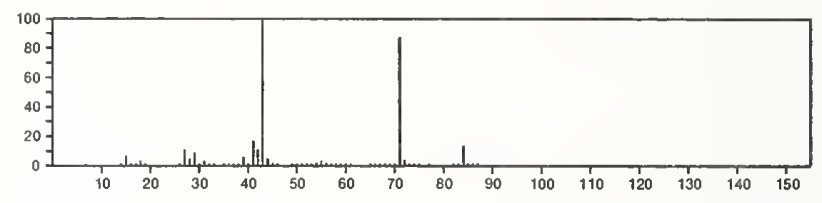

144

$\mathrm{C}_{7} \mathrm{H}_{12} \mathrm{O}_{3}$

$3682-42-6$

Valeric acid, 3-methyl-2-oxo-, methyl ester

$\mathrm{Me}_{2} \mathrm{CH}_{2} \mathrm{CHMe} \mathrm{COC}(\mathrm{O}) \mathrm{OMe}$

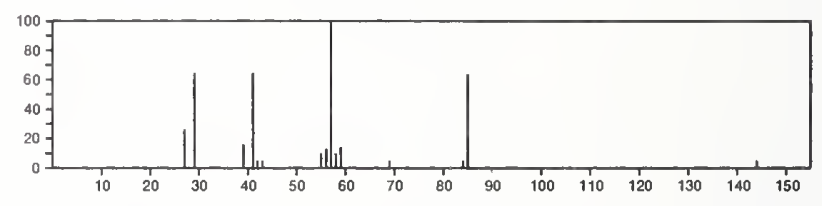

144

$\mathrm{C}_{7} \mathrm{H}_{12} \mathrm{O}_{3}$

$3682-43-7$

Pentanoic acid, 4-methyl-2-0xo-, methyl ester

$\mathrm{Me} \mathrm{OC}(0) \mathrm{COCH}_{2} \mathrm{CHMe}_{2}$

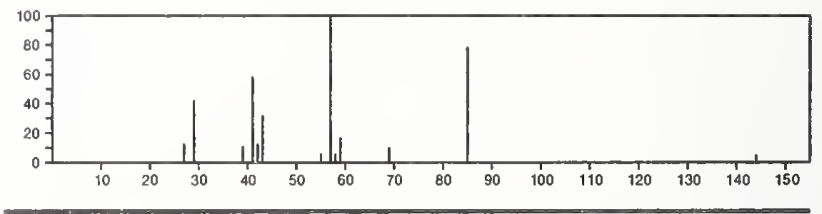

144

2-Pentanone, 5-(acetyloxy)-

$\mathrm{C}_{7} \mathrm{H}_{12} \mathrm{O}_{3}$

$5185-97-7$

$\mathrm{AcO}\left(\mathrm{CH}_{2}\right)_{3} \mathrm{COMe}$

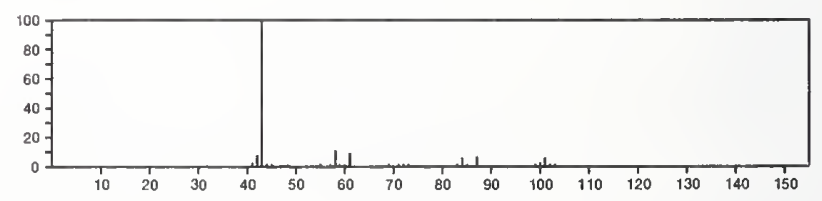

144

$\mathrm{C}_{7} \mathrm{H}_{12} \mathrm{O}_{3}$

1,3-Dioxolan-2-one, 4,4,5,5-tetramethyl-
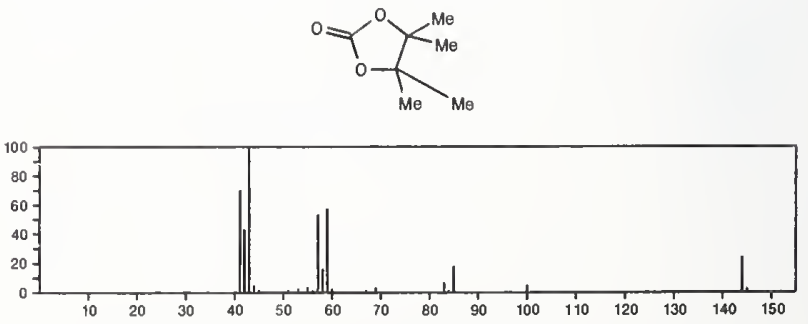
144

$$
\mathrm{C}_{7} \mathrm{H}_{12} \mathrm{O}_{3}
$$

1,3-Dioxolane-2-propanal, 2-methyl-

24108-29-0
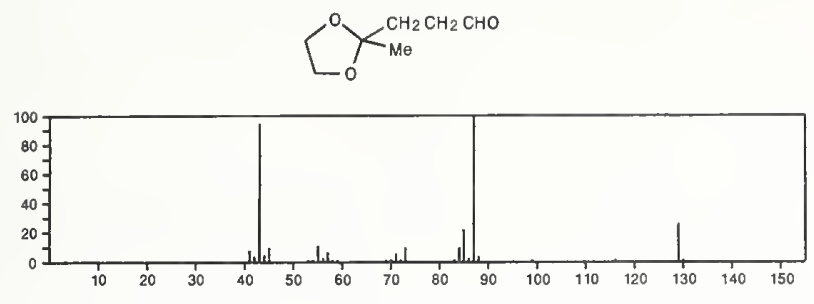

144

$\mathrm{C}_{7} \mathrm{H}_{12} \mathrm{O}_{3}$

Butanoic acid, 2-ethyl-3-oxo-, methyl ester

$51756-08-2$

Me OC ( O) CHEt COME

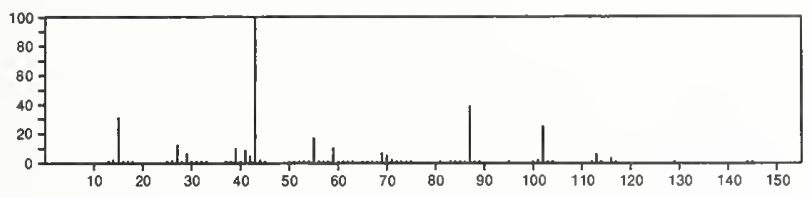

144

$\mathrm{C}_{7} \mathrm{H}_{12} \mathrm{O}_{3}$

56009-32-6

2-Butenoic acid, 2-methoxy-3-methyl-, methyl ester

$\mathrm{Me}_{2} \mathrm{C}=\mathrm{C}(\mathrm{OMO}) \mathrm{C}(\mathrm{O}) \mathrm{OMe}$

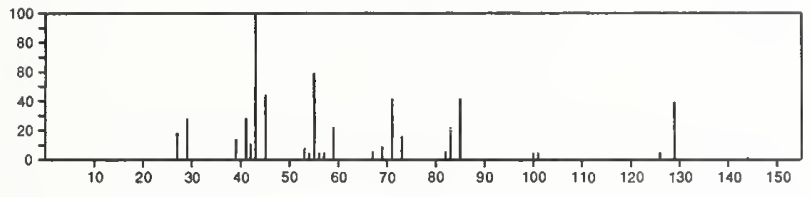

$144 \quad \mathrm{C}_{7} \mathrm{H}_{16} \mathrm{~N}_{2} \mathrm{O}$

4-Morpholinepropanamine

$123-00-2$
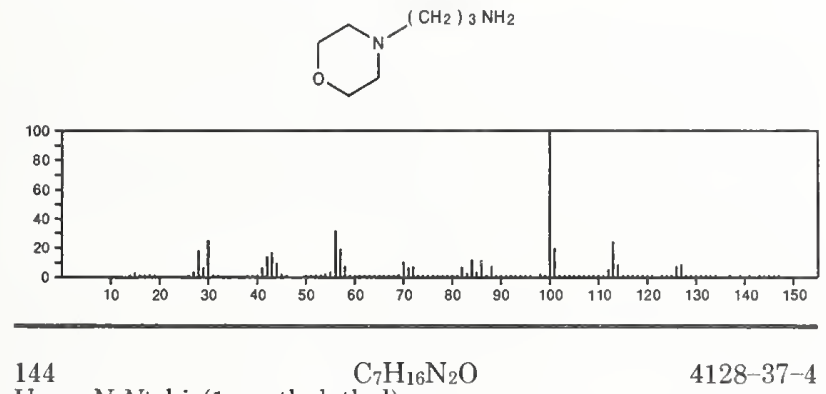

$4128-37-4$

Urea, $N, N^{\prime}$-bis(1-methylethyl)-

i-PrNHCONHPr-i
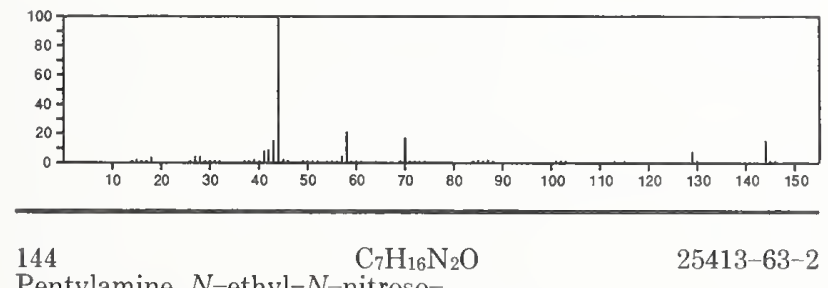

25413-63-2

Pentylamine, $N$-ethyl- $N$-nitroso-

$\mathrm{EtN}(\mathrm{NO})\left(\mathrm{CH}_{2}\right) 4 \mathrm{Me}$

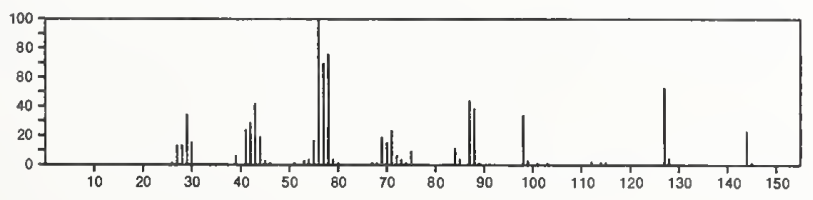

$144 \quad \mathrm{C}_{7} \mathrm{H}_{16} \mathrm{~N}_{2} \mathrm{O}$

1-Butanamine, $N$-nitroso- $N$-propyl-

$25413-64-3$

$\operatorname{PrN}(\mathrm{NO})\left(\mathrm{CH}_{2}\right)_{3} \mathrm{MO}_{0}$

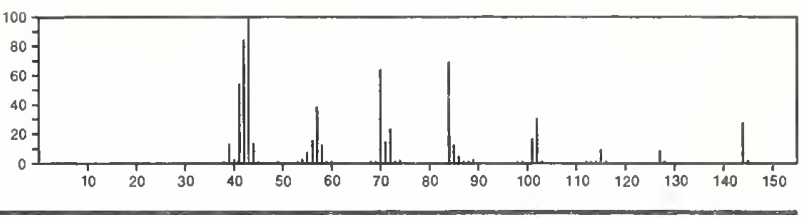

144

$\mathrm{C}_{8} \mathrm{H}_{13} \mathrm{Cl}$

$823-83-6$

Cyclohexane, 1-(chloromethyl)-4-methylene-
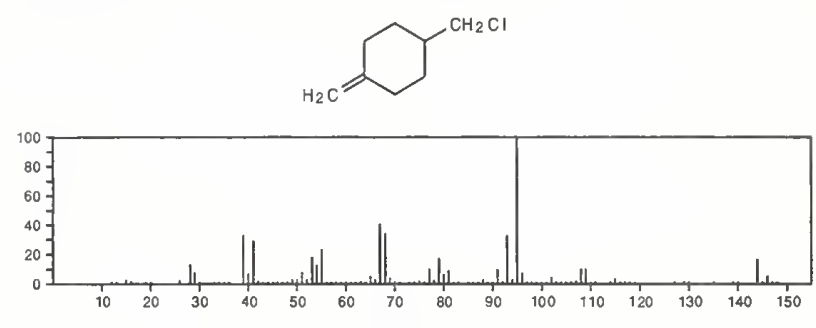

$144 \quad \mathrm{C}_{8} \mathrm{H}_{13} \mathrm{Cl}$

2064-03-1

Bicyclo[2.2.2]octane, 1-chloro-
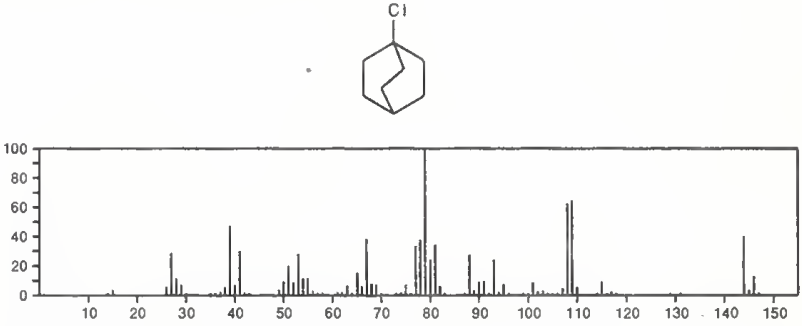

144

Cyclohexane, (2-chloroethenyl)-

15963-69-6

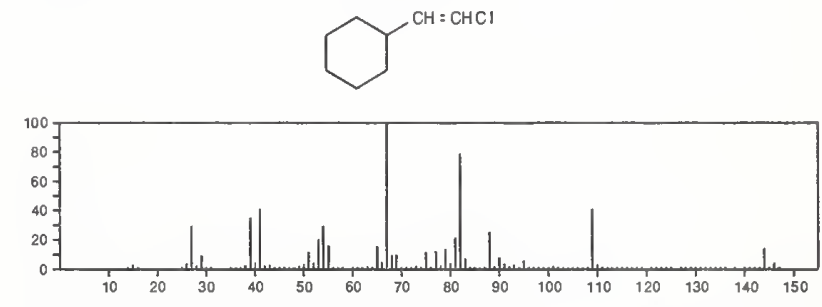

144

$\mathrm{C}_{8} \mathrm{H}_{13} \mathrm{Cl}$

$19138-54-6$

Bicyclo[2.2.1] heptane, 2-chloro-2-methyl-, exo-
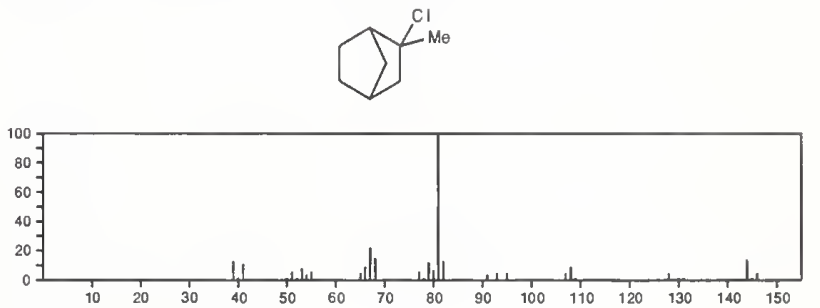
144

$\mathrm{C}_{8} \mathrm{H}_{13} \mathrm{Cl}$

$22768-96-3$

Bicyclo[2.2.1]heptane, 2-chloro-1-methyl-, exo-
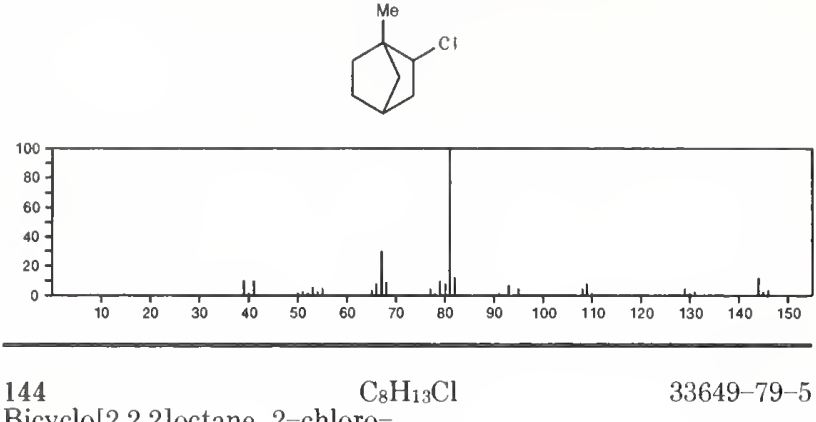

Bicyclo[2.2.2]octane, 2-chloro-
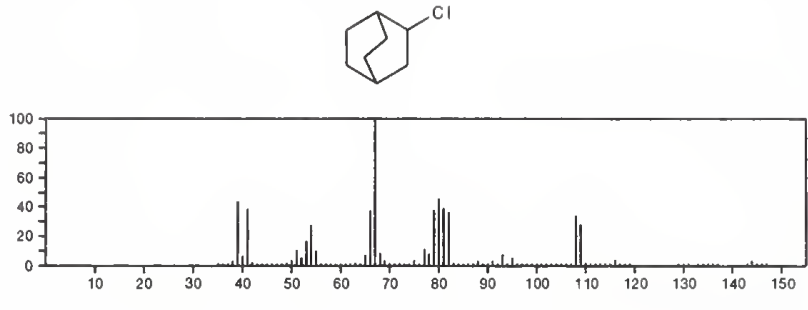

$144 \quad \mathrm{C}_{8} \mathrm{H}_{16} \mathrm{O}_{2} \quad 97-85-8$

Propanoic acid, 2-methyl-, 2-methylpropyl ester

i-Bu OC( 0 ) CHMe 2

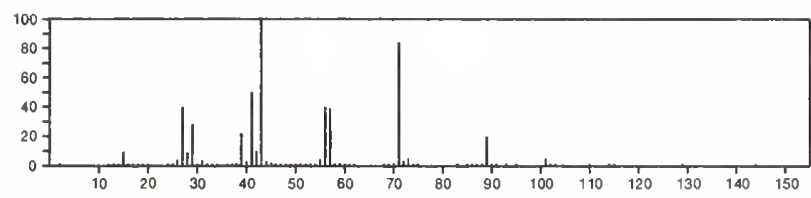

144

$\mathrm{C}_{8} \mathrm{H}_{16} \mathrm{O}_{2}$

Propanoic acid, 2-methyl-, butyl ester

$97-87-0$

$\mathrm{Me} \mathrm{CHC}_{2}(\mathrm{O}) \mathrm{O}\left(\mathrm{CH}_{2}\right)_{3} \mathrm{Me}$

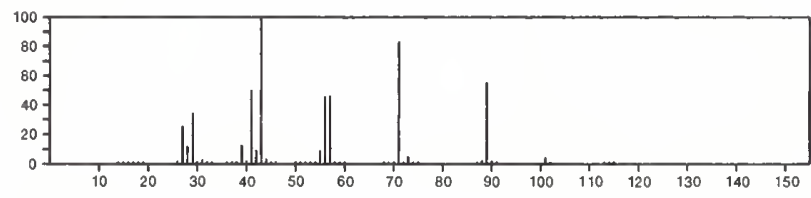

$144 \quad \mathrm{C}_{8} \mathrm{H}_{16} \mathrm{O}_{2}$

105-68-0

1-Butanol, 3-methyl-, propanoate

$\mathrm{Me}_{2} \mathrm{CHCH}_{2} \mathrm{CH}_{2} \mathrm{OC}(\mathrm{O}) \mathrm{Et}$

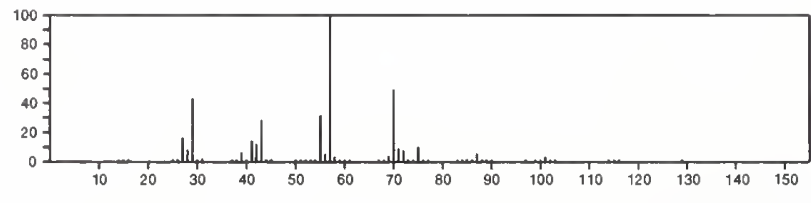

144

$\mathrm{C}_{8} \mathrm{H}_{16} \mathrm{O}_{2}$

106-73-0

Heptanoic acid, methyl ester

$\mathrm{Me}\left(\mathrm{CH}_{2}\right){ }_{5} \mathrm{C}(\mathrm{O}) \mathrm{OMe}$

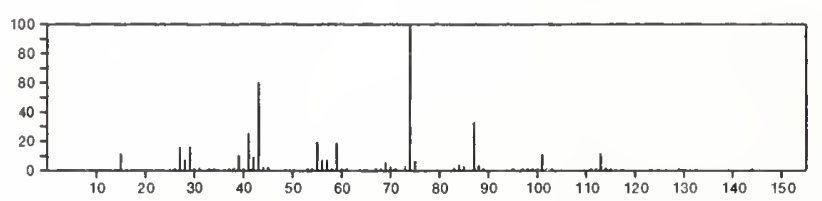

144

$\mathrm{C}_{8} \mathrm{H}_{16} \mathrm{O}_{2}$

$\operatorname{PrC}(\mathrm{O}) \mathrm{O}\left(\mathrm{CH}_{2}\right)_{3} \mathrm{Me}$

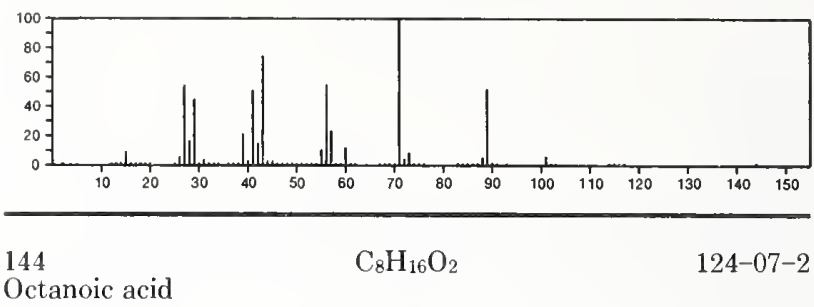

$\mathrm{HO}_{2} \mathrm{C}\left(\mathrm{CH}_{2}\right)_{6} \mathrm{Me}$

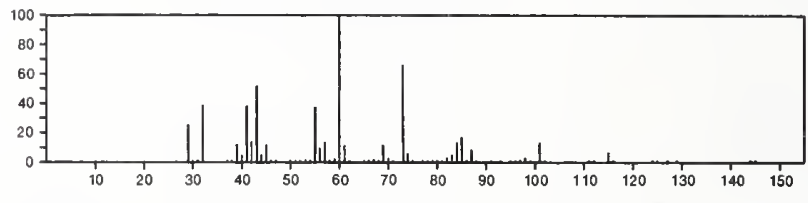

144

$\mathrm{C}_{8} \mathrm{H}_{16} \mathrm{O}_{2}$

$142-92-7$

Acetic acid, hexyl ester

$\mathrm{Me}\left(\mathrm{CH}_{2}\right) 5 \mathrm{OAC}$

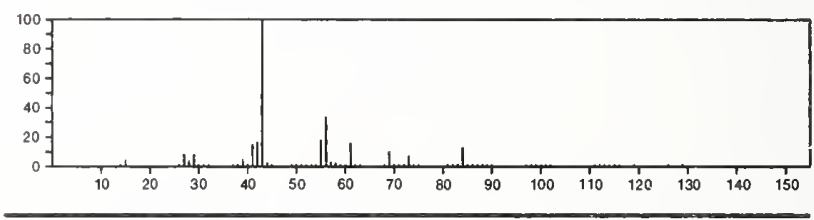

144

$\mathrm{C}_{8} \mathrm{H}_{16} \mathrm{O}_{2}$

$149-57-5$

Hexanoic acid, 2-ethyl-

$\mathrm{HO}_{2} \mathrm{CCHE} I\left(\mathrm{CH}_{2}\right)_{3} \mathrm{Me}$

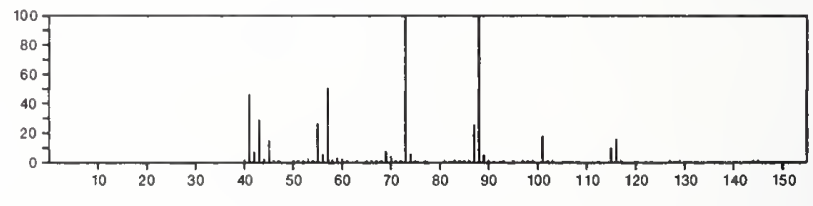

144

Propanoic acid, pentyl ester

$\mathrm{C}_{8} \mathrm{H}_{16} \mathrm{O}_{2}$

624-54-4

$\mathrm{EtC}(\mathrm{O}) \mathrm{O}\left(\mathrm{CH}_{2}\right) 4 \mathrm{Me}$

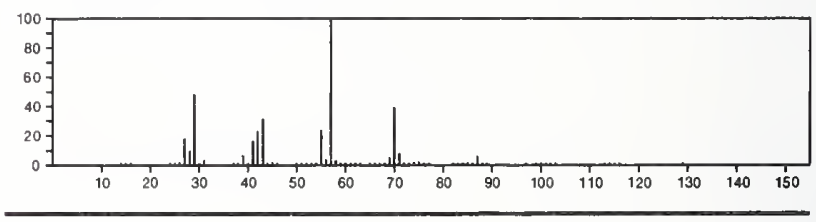

144

$\mathrm{C}_{8} \mathrm{H}_{16} \mathrm{O}_{2}$

Butanoic acid, 1-methylpropyl ester

819-97-6

$\operatorname{Pr} C(0) 0 B u-s$

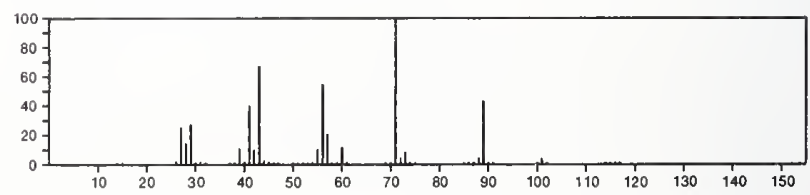


144

Cyclohexane, 1,1-dimethoxy-

$\mathrm{C}_{8} \mathrm{H}_{16} \mathrm{O}_{2}$

$933-40-4$
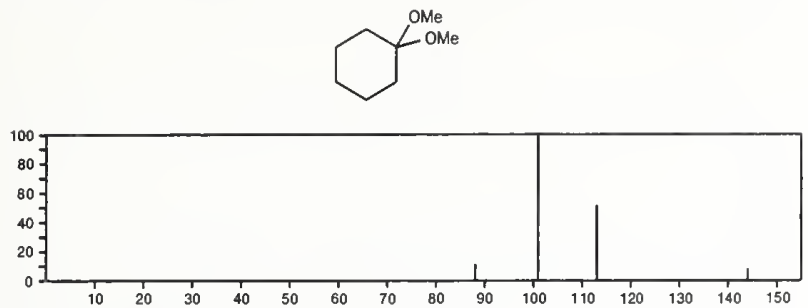

144

$\mathrm{C}_{8} \mathrm{H}_{16} \mathrm{O}_{2}$

Ethanol, 2-(cyclohexyloxy)-
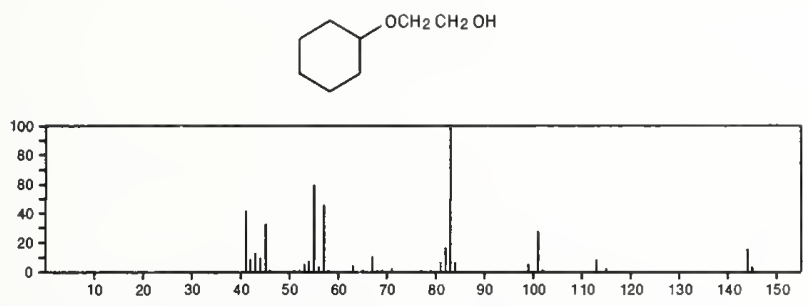

144

$\mathrm{C}_{8} \mathrm{H}_{16} \mathrm{O}_{2}$

$2 \mathrm{H}$-Pyran, tetrahydro-2-(1-methylethoxy)-
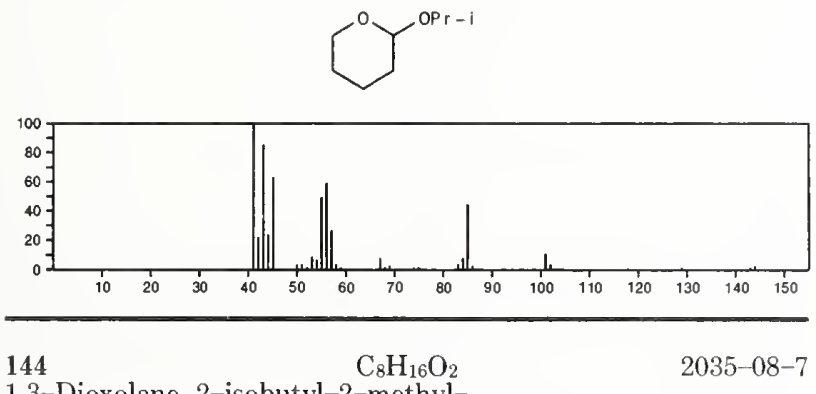

1,3-Dioxolane, 2-isobutyl-2-methyl-
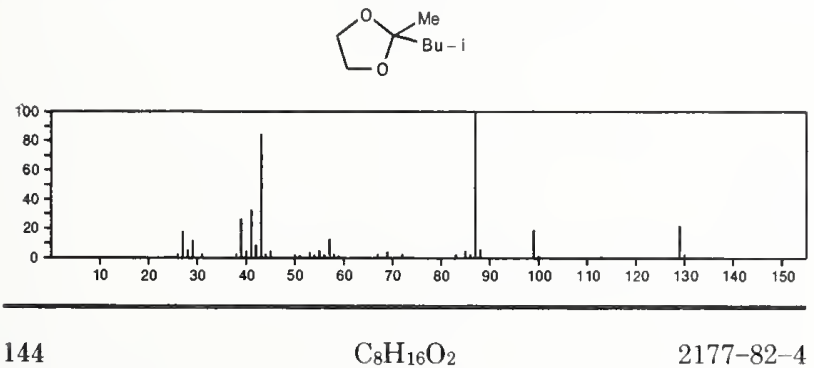

Hexanoic acid, 4-methyl-, methyl ester

$2177-82-4$

$\mathrm{MeOC}(\mathrm{O}) \mathrm{CH}_{2} \mathrm{CH}_{2} \mathrm{CHMeCH}_{2} \mathrm{Me}$

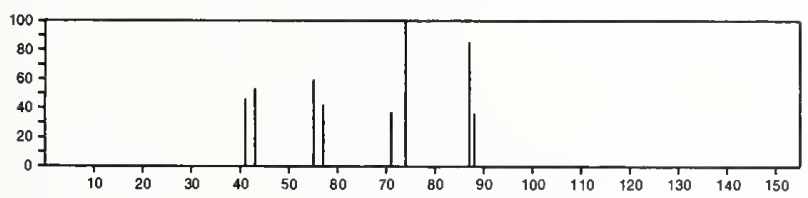

144

$\mathrm{C}_{8} \mathrm{H}_{16} \mathrm{O}_{2}$

Hexanoic acid, 5-methyl-, methyl ester

$2177-83-5$

$\mathrm{Me}_{2} \mathrm{CH}\left(\mathrm{CH}_{2}\right)_{3} \mathrm{C}(\mathrm{O}) \mathrm{OMe}$

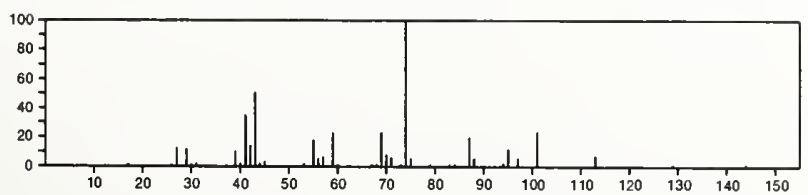

$144 \quad \mathrm{C}_{8} \mathrm{H}_{16} \mathrm{O}_{2}$

1-Propanol, 2,2-dimethyl-, propionate

$3581-69-9$

$\mathrm{EtC}(\mathrm{O}) \mathrm{OCH}_{2} \mathrm{CMe}_{3}$

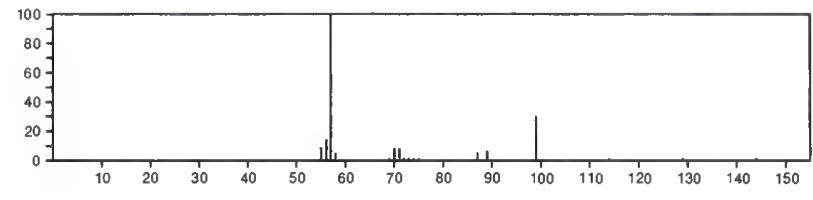

144

$\mathrm{C}_{8} \mathrm{H}_{16} \mathrm{O}_{2}$

$3611-76-5$

3-Furanol, tetrahydro-2,2,4,4-tetramethyl-
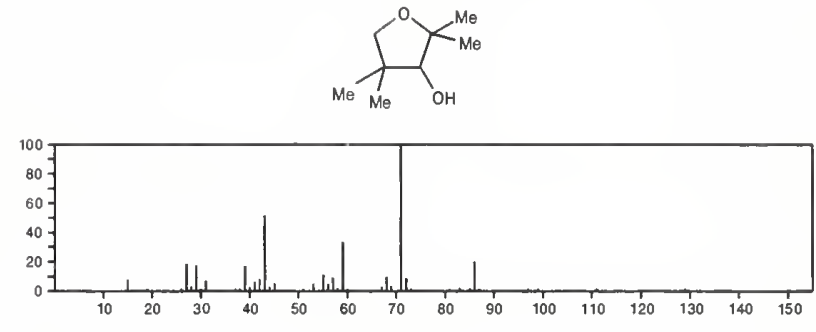

144

$\mathrm{C}_{8} \mathrm{H}_{16} \mathrm{O}_{2}$

$m$-Dioxane, 2,4,4,6-tetramethyl-

$5182-37-6$

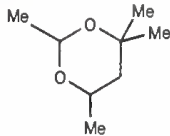

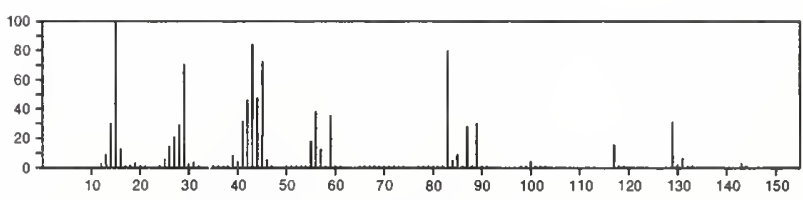

144

$\mathrm{C}_{8} \mathrm{H}_{16} \mathrm{O}_{2}$

$6135-54-2$

1,3-Dioxolane, 2-(1,1-dimethylethyl)-2-methyl-

$\sum_{0}^{0} \gamma_{\mathrm{Bu}-\mathrm{t}}^{\mathrm{Me}}$

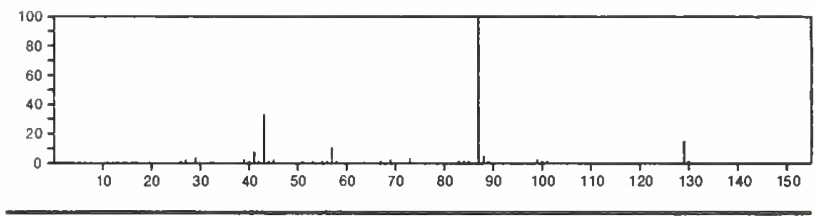

144

$\mathrm{C}_{8} \mathrm{H}_{16} \mathrm{O}_{2}$

$6321-14-8$

2-Hexanone, 3-hydroxy-3,5-dimethyl-

$\mathrm{Me}_{2} \mathrm{CHCH}_{2} \mathrm{CMe}(\mathrm{OH}) \mathrm{COMe}_{\mathrm{O}}$

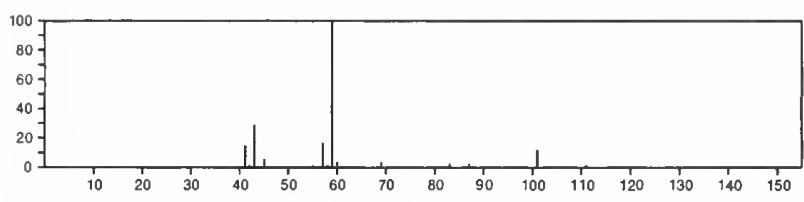

144

$\mathrm{C}_{8} \mathrm{H}_{16} \mathrm{O}_{2}$

7250-85-3

2-Butene, 1,4-diethoxy-

$\mathrm{E} t \mathrm{OCH}_{2} \mathrm{CH}=\mathrm{CHCH}_{2} \mathrm{OE}$ :

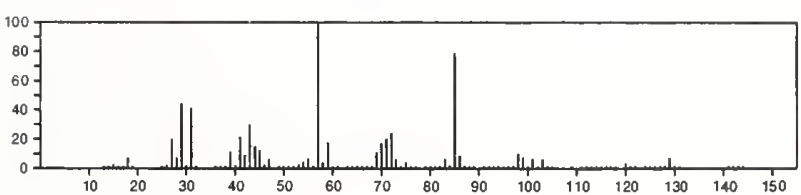


$144 \quad \mathrm{C}_{8} \mathrm{H}_{16} \mathrm{O}_{2}$

2-Heptanone, 3-hydroxy-3-methyl-

$\mathrm{MeCOCMe}(\mathrm{OH})\left(\mathrm{CH}_{2}\right)_{3} \mathrm{Me}$

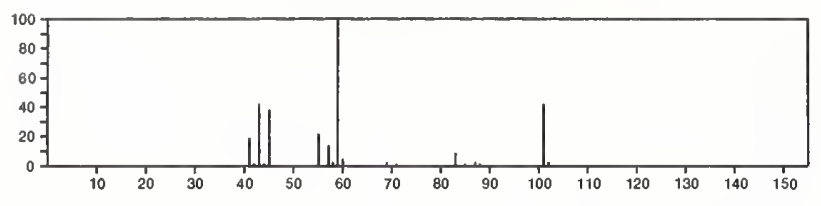

$144 \quad \mathrm{C}_{8} \mathrm{H}_{16} \mathrm{O}_{2}$

1,3-Dioxolane, 2-butyl-2-methyl-

$\sum_{0}^{0}<_{M \theta}^{\left(\mathrm{CH}_{2}\right)_{3} \mathrm{Me}}$
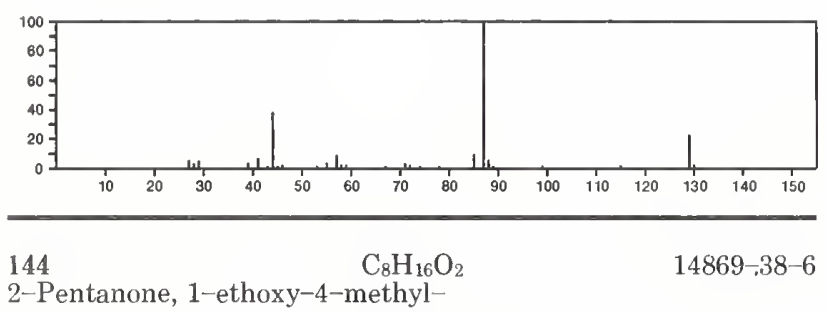

$\mathrm{E}: \mathrm{OCH}_{2} \mathrm{COCH}_{2} \mathrm{CHMe}_{2}$
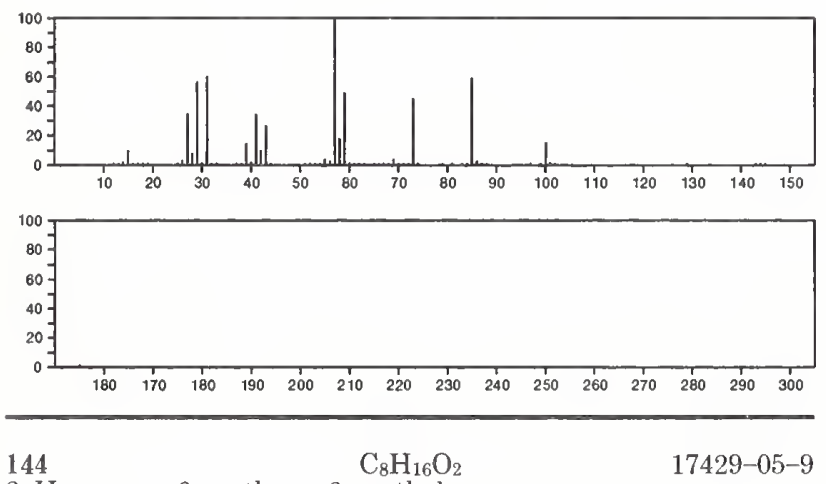

3-Hexanone, 6-methoxy-2-methyl-

$\mathrm{Me} 2 \mathrm{CHCO}\left(\mathrm{CH}_{2}\right)_{3} \mathrm{OM}_{0}$

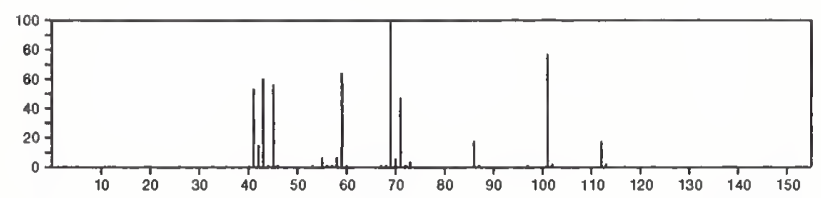

$144 \quad \mathrm{C}_{8} \mathrm{H}_{16} \mathrm{O}_{2}$

1,3-Dioxane, 2,2,4,6-tetramethyl-, trans
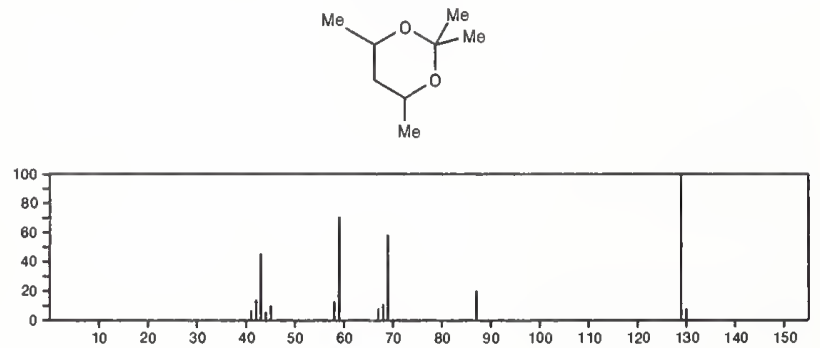

$144 \quad \mathrm{C}_{8} \mathrm{H}_{16} \mathrm{O}_{2}$

$28046-68-6$

Cyclohexane, 1,4-dimethoxy-, cis-
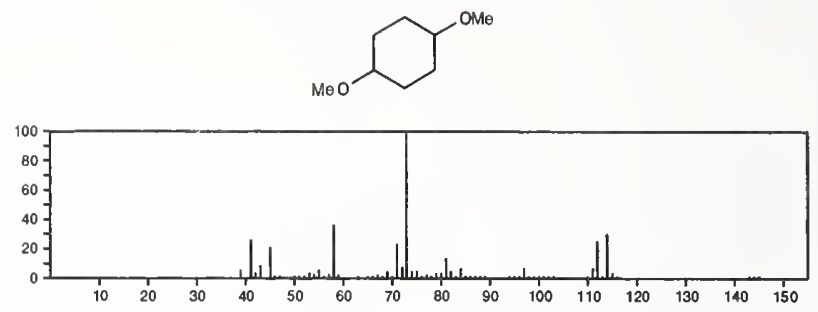

144

$\mathrm{C}_{8} \mathrm{H}_{16} \mathrm{O}_{2}$

28046-69-7

Cyclohexane, 1,4-dimethoxy-, trans-
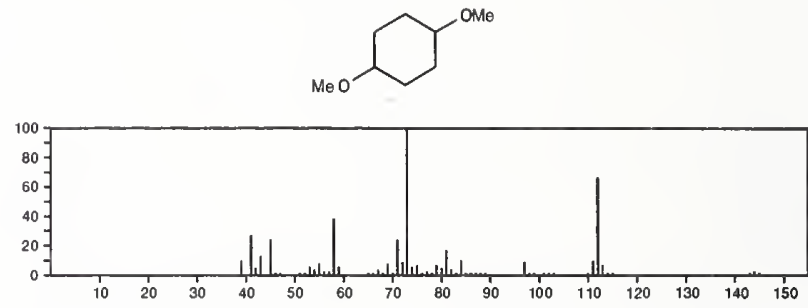

144

$\mathrm{C}_{8} \mathrm{H}_{16} \mathrm{O}_{2}$

$29887-60-3$

Cyclohexane, 1,2-dimethoxy-, trans-
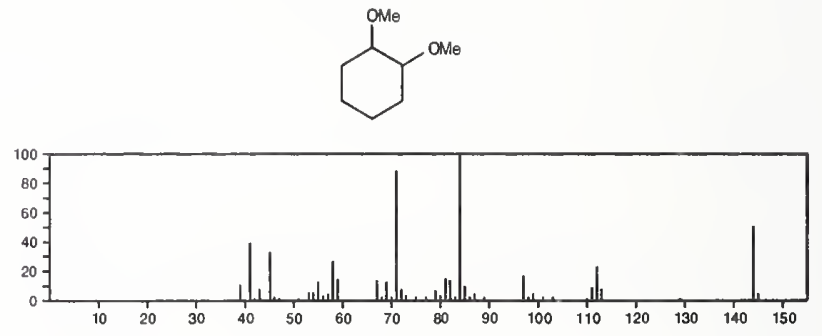

144

$\mathrm{C}_{8} \mathrm{H}_{16} \mathrm{O}_{2}$

Cyclohexane, 1,3-dimethoxy-, trans-

$29887-61-4$
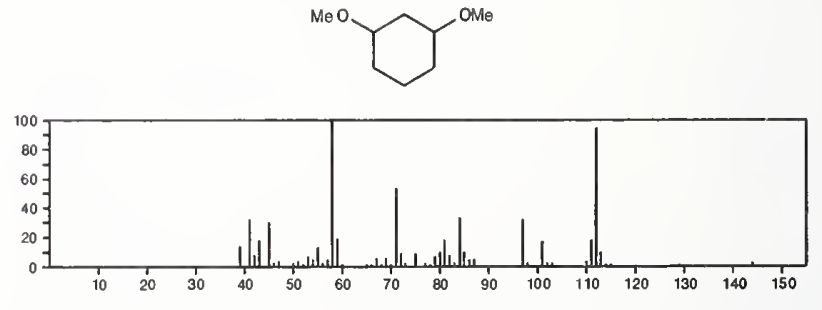

$144 \quad \mathrm{C}_{8} \mathrm{H}_{16} \mathrm{O}_{2}$

$30363-80-5$

Cyclohexane, 1,2-dimethoxy-, cis-
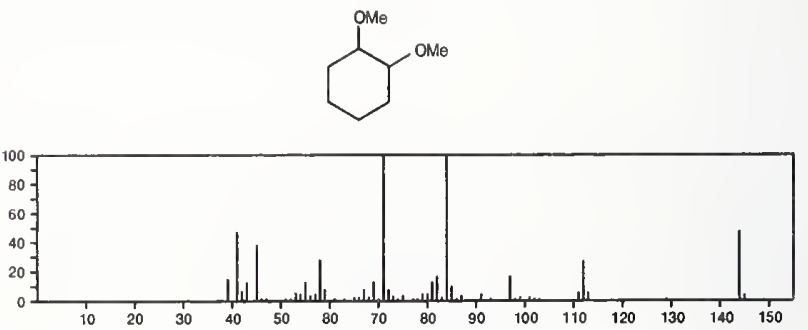
$144 \quad \mathrm{C}_{8} \mathrm{H}_{16} \mathrm{O}_{2}$

$30363-81-6$

Cyclohexane, 1,3-dimethoxy-, cis-
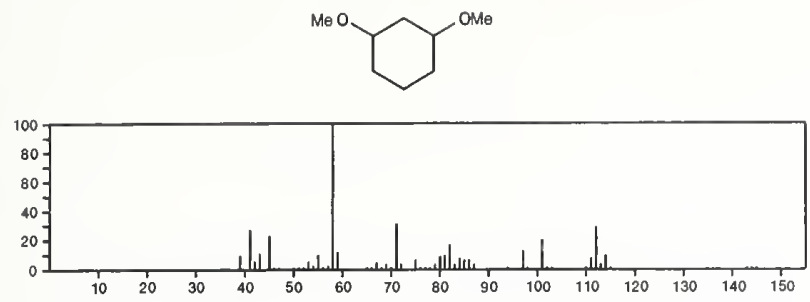

$144 \quad \mathrm{C}_{8} \mathrm{H}_{16} \mathrm{O}_{2} \quad 54004-45-4$ 1-Propanol, 2-methyl-2-[(2-methyl-2-propenyl)oxy]-

$\mathrm{HOCH}_{2} \mathrm{CM}_{2} \mathrm{OCH}_{2} \mathrm{CMe}_{2}=\mathrm{CH}_{2}$

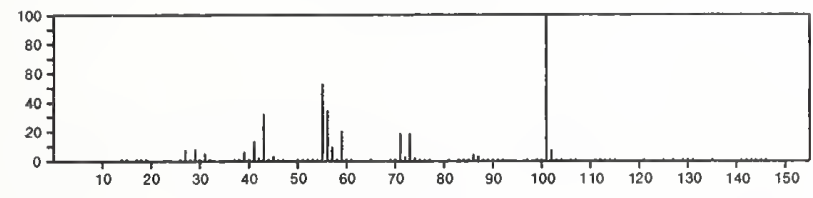

$144 \quad \mathrm{C}_{8} \mathrm{H}_{16} \mathrm{O}_{2} \quad 54004-46-5$ $2 H$-Pyranmethanol, tetrahydro-2,5-dimethyl-
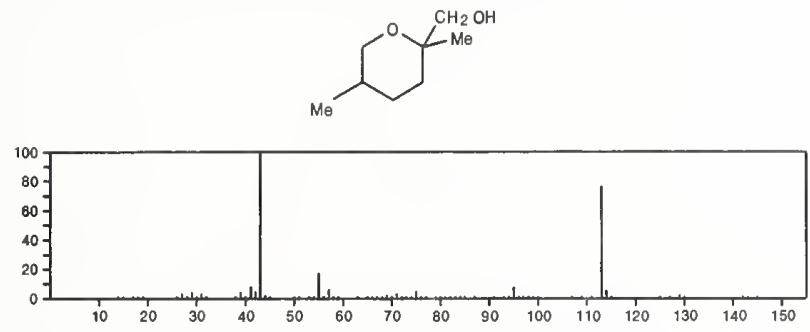

$144 \quad \mathrm{C}_{8} \mathrm{H}_{16} \mathrm{O}_{2}$

1,2-Cyclopentanediol, 1-(1-methylethyl)-, trans-

$56335-92-3$
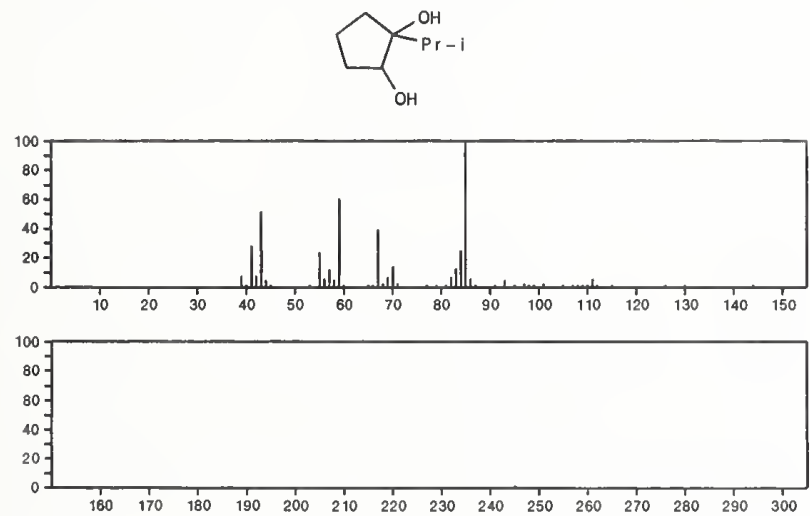

$144 \quad \mathrm{C}_{8} \mathrm{H}_{16} \mathrm{O}_{2}$

2-Hexanone, 3-methoxy-5-methyl-

$56667-04-0$

$\mathrm{Me}_{2} \mathrm{CHCH}_{2} \mathrm{CH}$ ( $\mathrm{OMe}$ ) COMe

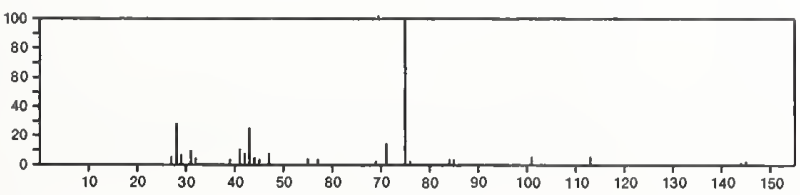

144

$\mathrm{C}_{8} \mathrm{H}_{16} \mathrm{O}_{2}$

$56805-30-2$

Hexanal, 3-(hydroxymethyl)-4-methyl-

$\mathrm{CH}_{2} \mathrm{OH}$

$\mathrm{Me} \mathrm{CH}_{2} \mathrm{CHM}_{8}{ }_{\mathrm{CH}} \mathrm{CH}_{2} \mathrm{CHO}$

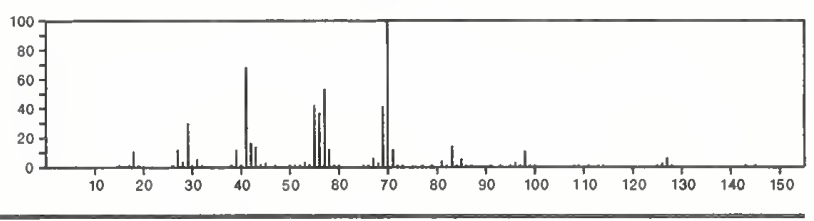

144

$\mathrm{C}_{8} \mathrm{H}_{16} \mathrm{O}_{2}$

$56805-31-3$

Pentanal, 3-(hydroxymethyl)-4,4-dimethyl-

$\mathrm{CM} 3$

$\mathrm{OCHCH}_{2} \mathrm{CHCH}_{2} \mathrm{OH}$
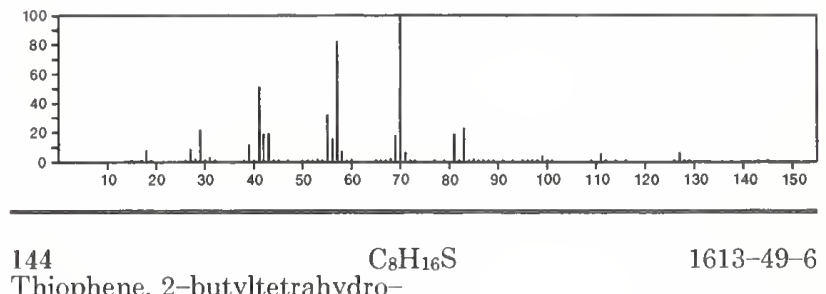

Thiophene, 2-butyltetrahydro-
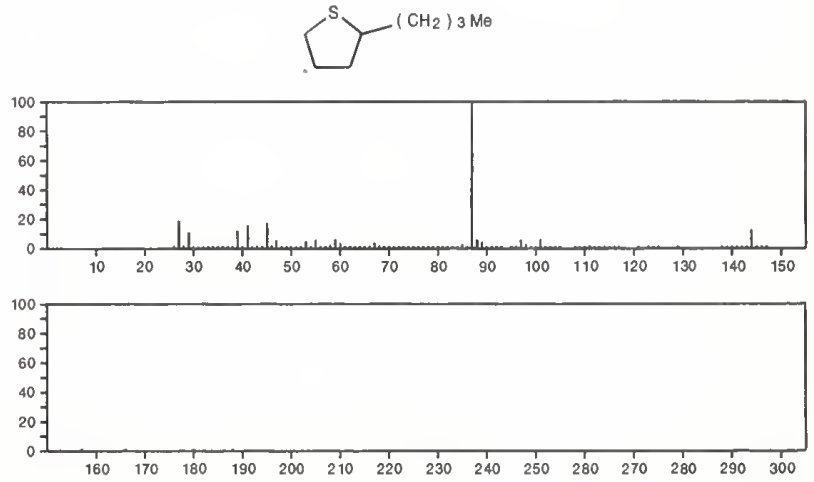

144

$\begin{array}{lllllllllllllll}160 & 170 & 180 & 190 & 200 & 210 & 220 & 230 & 240 & 250 & 280 & 270 & 280 & 290 & 300\end{array}$

Sulfide, cyclopentyl propyl

$\mathrm{C}_{8} \mathrm{H}_{16} \mathrm{~S}$

$7133-14-4$
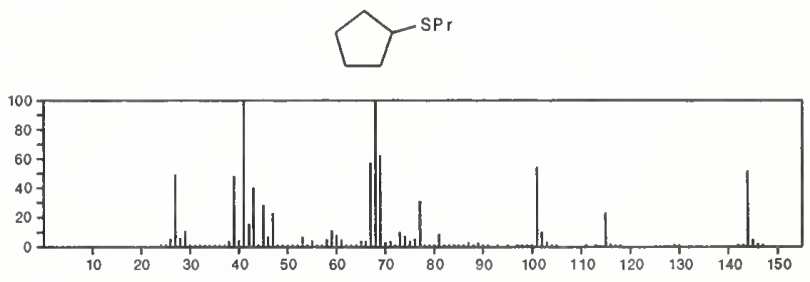

144

$\mathrm{C}_{8} \mathrm{H}_{16} \mathrm{~S}$

$7133-15-5$

Sulfide, cyclopentyl isopropyl
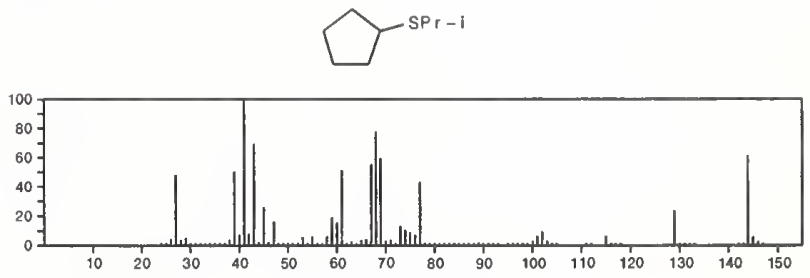
144

Cyclohexane, (ethylthio)-

$\mathrm{C}_{8} \mathrm{H}_{16} \mathrm{~S}$
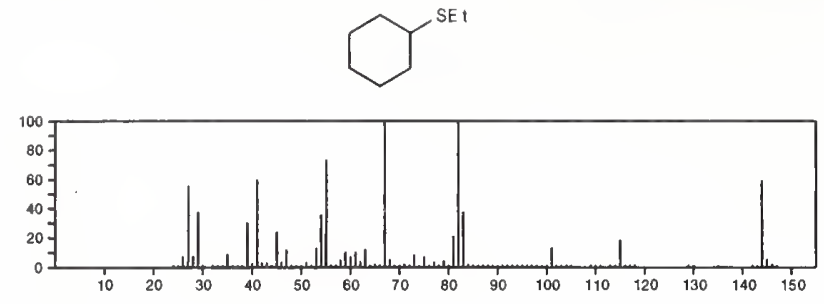

144

Sulfide, hexyl vinyl

\section{$\mathrm{C}_{8} \mathrm{H}_{16} \mathrm{~S}$}

$18888-20-5$

$\mathrm{Me}\left(\mathrm{CH}_{2}\right)_{5} \mathrm{SCH}=\mathrm{CH}_{2}$

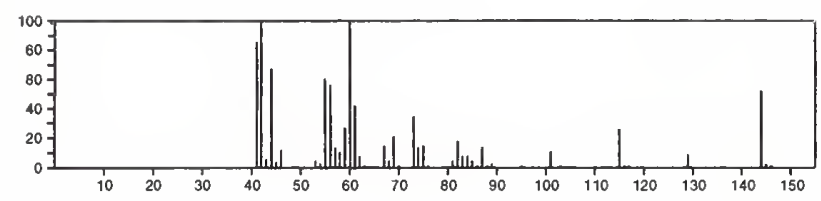

144

Silane, tetraethyl-

$\mathrm{C}_{8} \mathrm{H}_{20} \mathrm{Si}$

$631-36-7$
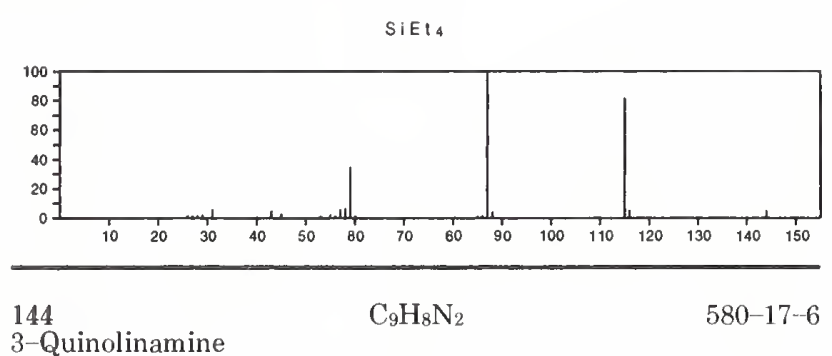

3-Quinolinamine
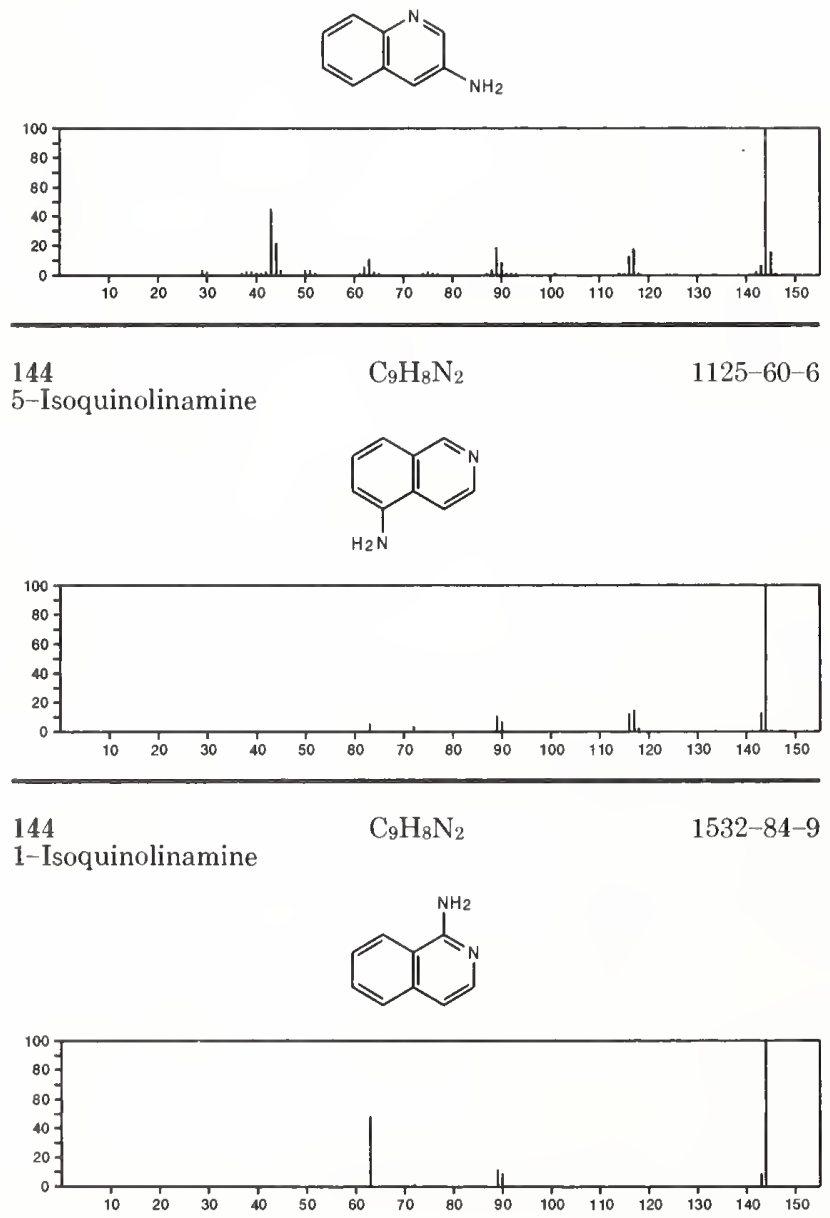

${ }_{144} \mathrm{C}_{9} \mathrm{H}_{8} \mathrm{~N}_{2}$

$1569-16-0$

e, 2-methyl-
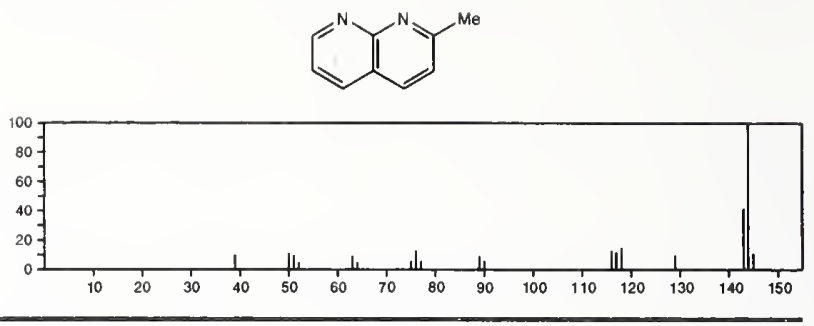

144

1,8-Naphthyridine, 4-methyl-

$\mathrm{C}_{9} \mathrm{H}_{8} \mathrm{~N}_{2}$

1569-17-1<smiles>Nc1ccnc2ncccc12</smiles>

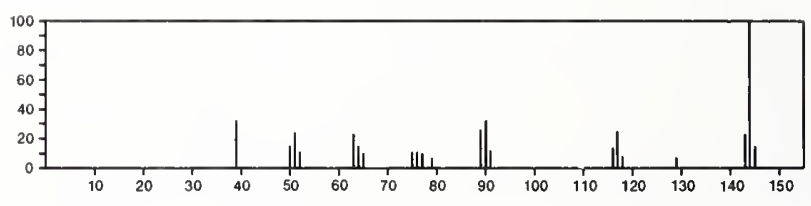

144

Quinoxaline, 2-methyl-

$\mathrm{C}_{9} \mathrm{H}_{8} \mathrm{~N}_{2}$

$7251-61-8$
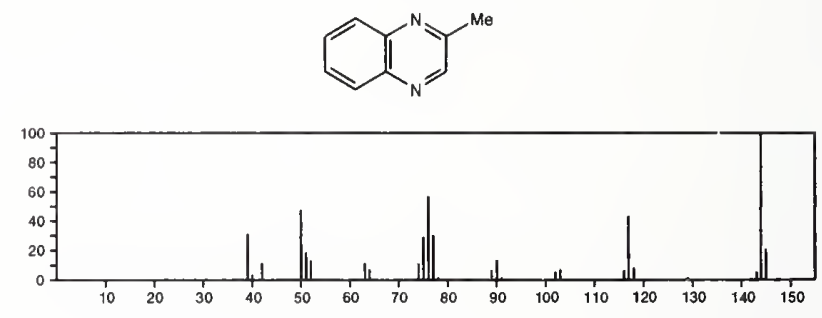

$144 \quad \mathrm{C}_{9} \mathrm{H}_{8} \mathrm{~N}_{2}$

$7675-30-1$

1,6-Naphthyridine, 4-methyl-
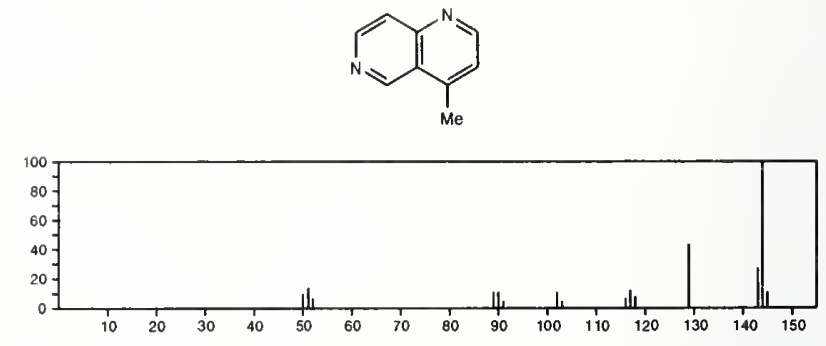

144

1,6-Naphthyridine, 2-methyl-

$\mathrm{C}_{9} \mathrm{H}_{8} \mathrm{~N}_{2}$

7675-31-2
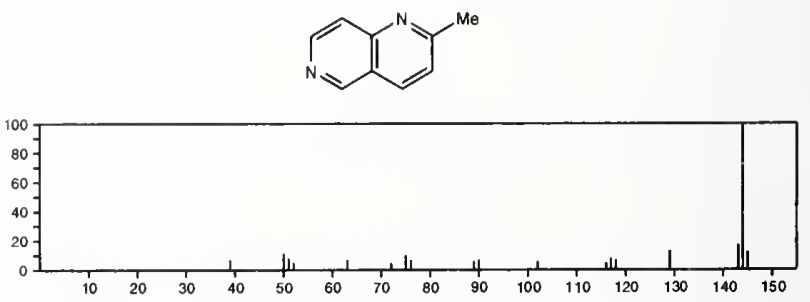
144

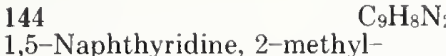
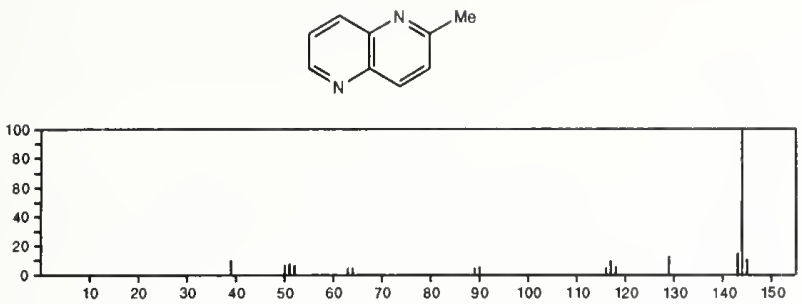

$144 \quad \mathrm{C}_{9} \mathrm{H}_{8} \mathrm{~N}_{2}$

1,5-Naphthyridine, 4-methyl-<smiles>Nc1ccnc2cccnc12</smiles>
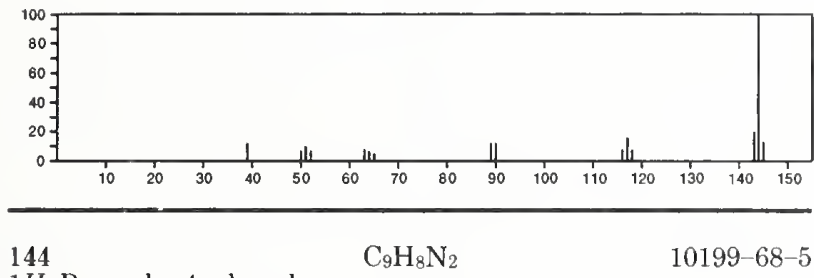

$1 H$-Pyrazole, 4-phenyl-
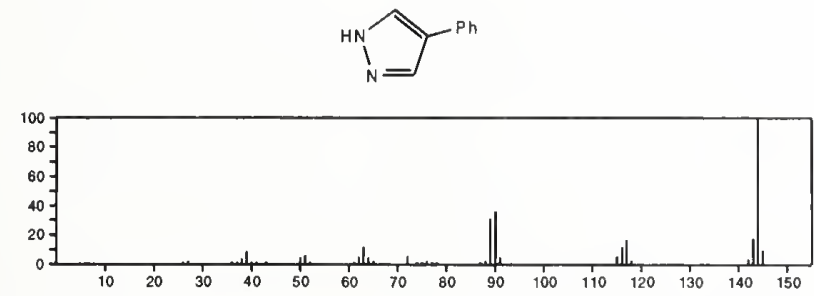

144

1,6-Naphthyridine, 3-methyl-

$\mathrm{C}_{9} \mathrm{H}_{8} \mathrm{~N}_{2}$
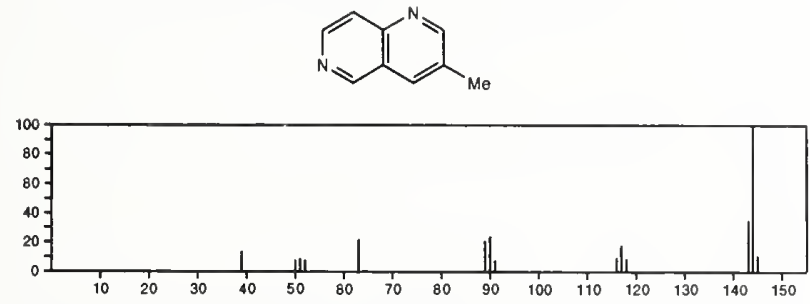

144

1,8-Naphthyridine, 3-methyl-

$\mathrm{C}_{9} \mathrm{H}_{8} \mathrm{~N}_{2}$
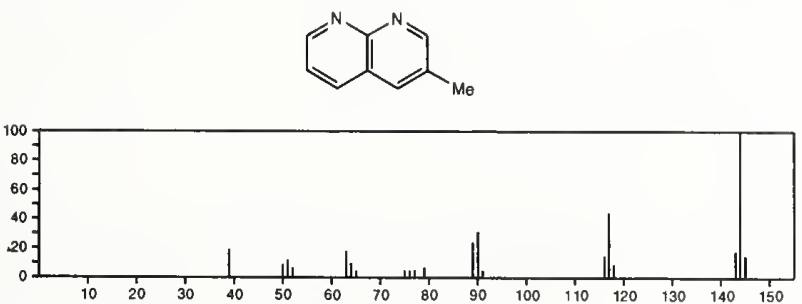

144

Cinnoline, 3-methyl

$\mathrm{C}_{9} \mathrm{H}_{8} \mathrm{~N}_{2}$

$17372-78-0$
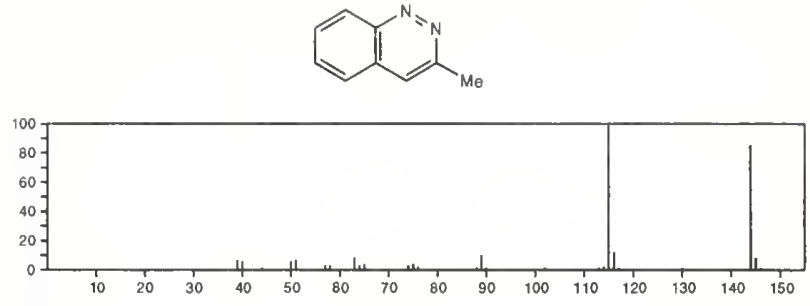

144

1,5-Naphthyridine, 3-methyl

$\mathrm{C}_{9} \mathrm{H}_{8} \mathrm{~N}_{2}$

18937-71-8
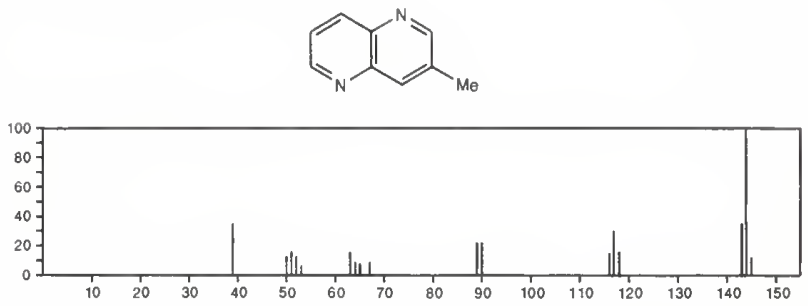

144

$\mathrm{C}_{9} \mathrm{H}_{8} \mathrm{~N}_{2}$

23687-25-4

4-Isoquinolinamine
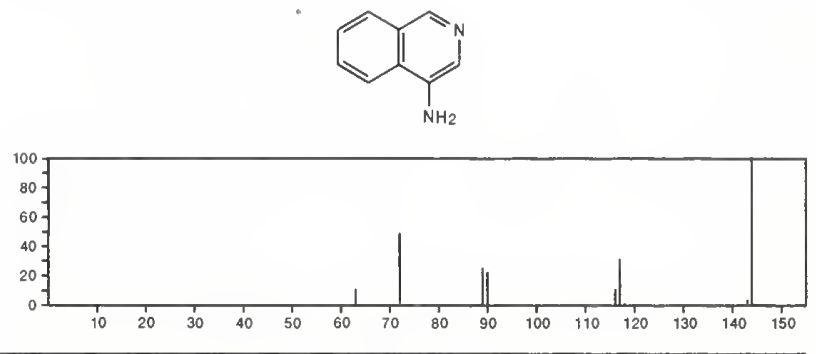

144

$\mathrm{C}_{9} \mathrm{H}_{8} \mathrm{~N}_{2}$

$23687-26-5$

6-Isoquinolinamine
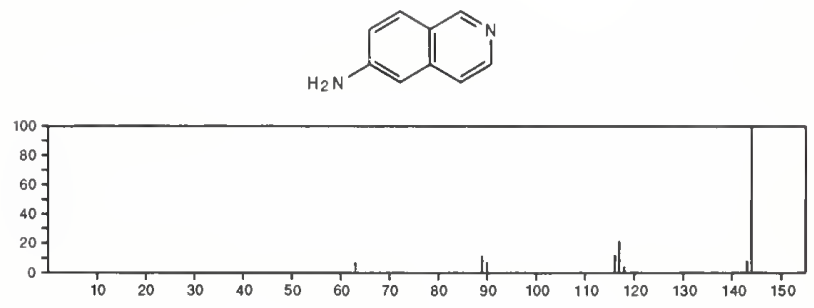

144

8-Isoquinolinamine

$\mathrm{C}_{9} \mathrm{H}_{8} \mathrm{~N}_{2}$

$23687-27-6$
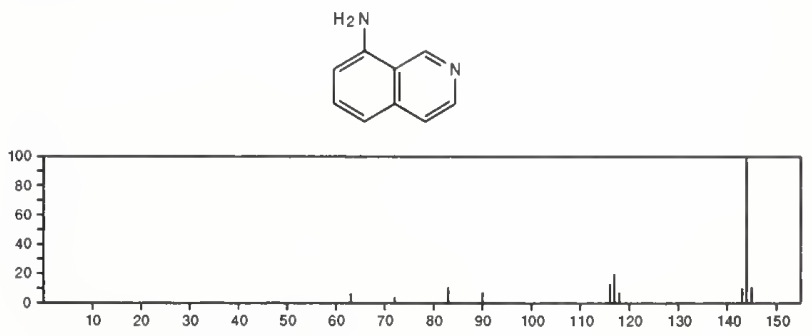
144 7-Isoquinolinamine

$\mathrm{C}_{9} \mathrm{H}_{8} \mathrm{~N}_{2}$

$23707-37-1$
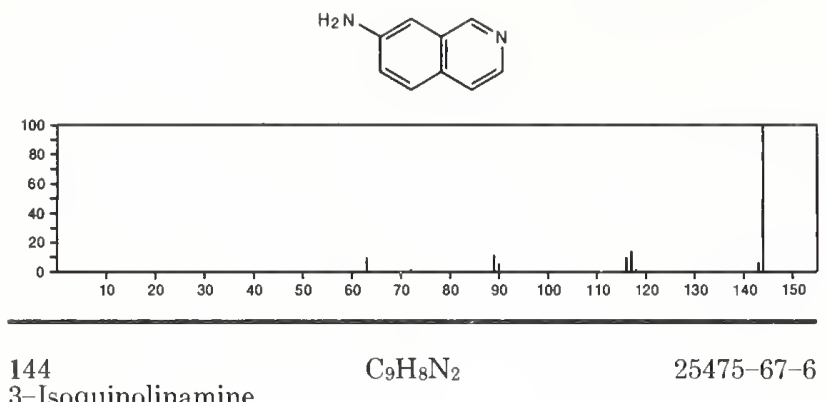

3-Isoquinolinamine
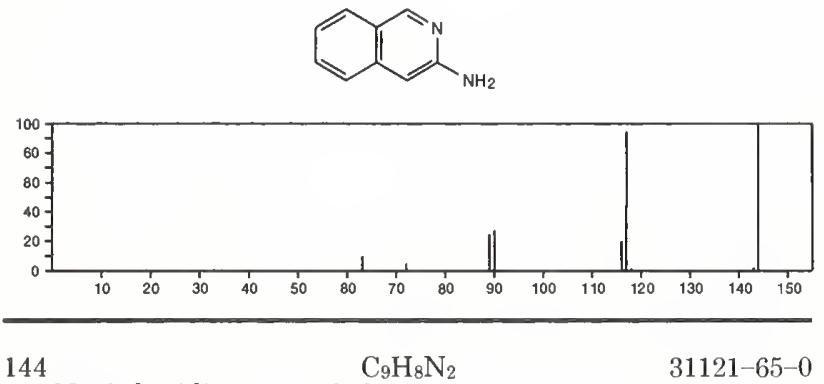

$31121-65-0$ 2,6-Naphthyridine, 4-methyl-<smiles>Nc1cncc2ccncc12</smiles>

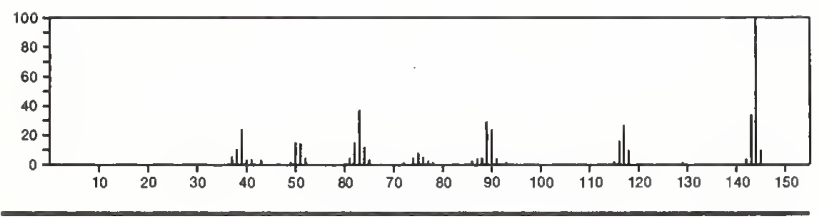

144

4-Heptanol, 2,6-dimethyl-

$\mathrm{C}_{9} \mathrm{H}_{20} \mathrm{O}$

$108-82-7$

$\mathrm{Me}_{2} \mathrm{CHCH}_{2} \mathrm{CH}$ (OH) $\mathrm{CH}_{2} \mathrm{CHM}_{2}$

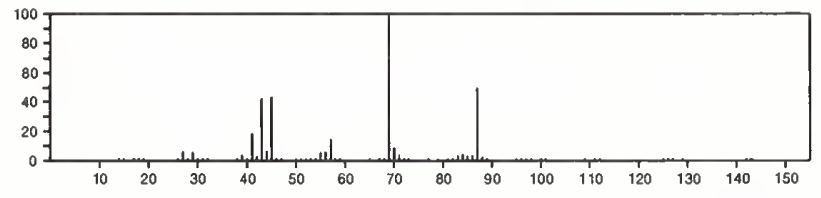

144

1-Nonanol

$\mathrm{C}_{9} \mathrm{H}_{20} \mathrm{O}$

$143-08-8$
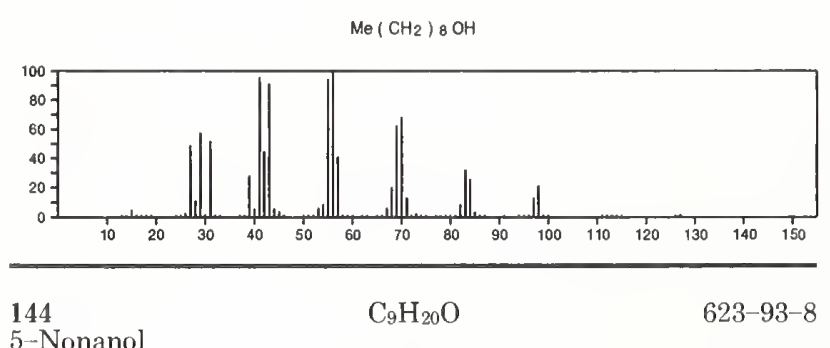

5--Nonanol

$\mathrm{Me}\left(\mathrm{CH}_{2}\right)_{3} \mathrm{CH}(\mathrm{OH})\left(\mathrm{CH}_{2}\right)_{3} \mathrm{Me}$

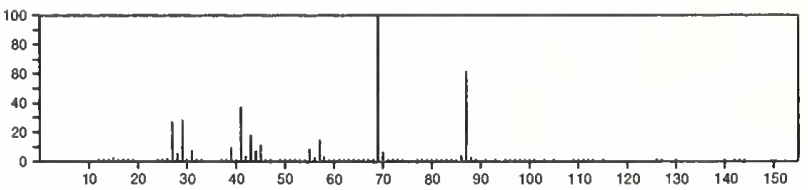

144

2-Nonanol

$\mathrm{C}_{9} \mathrm{H}_{20} \mathrm{O}$

628-99-9

$\mathrm{MeCH}(\mathrm{OH})\left(\mathrm{CH}_{2}\right)_{8} \mathrm{Me}$

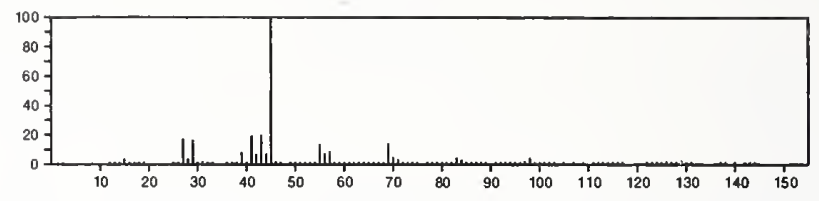

144

3-Heptanol, 3,6-dimethyl-

$\mathrm{C}_{9} \mathrm{H}_{20} \mathrm{O}$

$1573-28-0$

$\mathrm{Me}_{2} \mathrm{CHCH}_{2} \mathrm{CH}_{2} \mathrm{CE}(\mathrm{OH}) \mathrm{Me}$

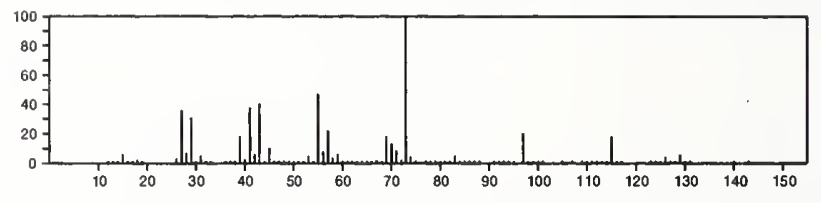

144

Heptane, 1-ethoxy

$\mathrm{C}_{9} \mathrm{H}_{20} \mathrm{O}$

1969-43-3

$\mathrm{Me}\left(\mathrm{CH}_{2}\right)_{8} \mathrm{OEI}$

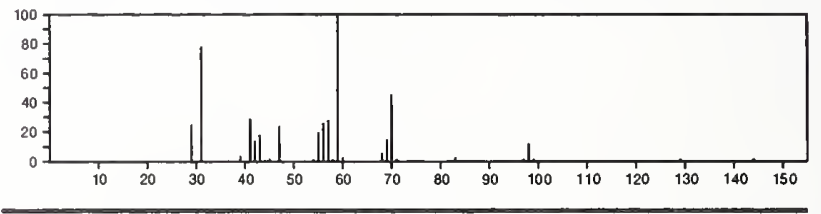

144

$\mathrm{C}_{9} \mathrm{H}_{20} \mathrm{O}$

$3452-97-9$

1-Hexanol, 3,5,5-trimethyl-

$\mathrm{HOCH}_{2} \mathrm{CH}_{2} \mathrm{CHMe} \mathrm{CH}_{2} \mathrm{CMe}$

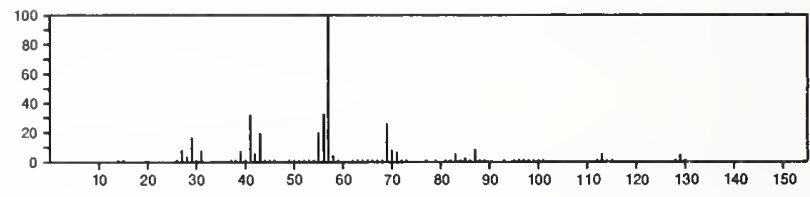

144

$\mathrm{C}_{9} \mathrm{H}_{20} \mathrm{O}$

$5340-36-3$

3-Octanol, 3-methyl-

$\mathrm{EtCMe}(\mathrm{OH})\left(\mathrm{CH}_{2}\right){ }_{4} \mathrm{Me}$

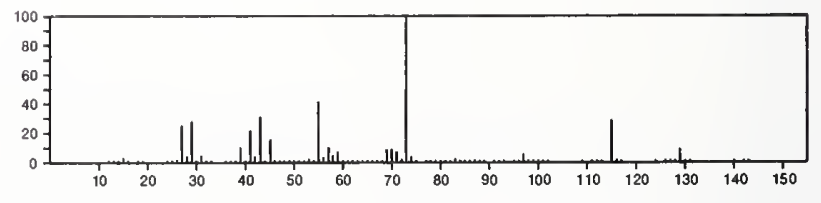

144

144-Heptanol, 3,4-dimethyl-

$\mathrm{C}_{9} \mathrm{H}_{20} \mathrm{O}$

5406-10-0

$\mathrm{MeCH} 2 \mathrm{CHMeCPr}(\mathrm{OH}) \mathrm{Me}$

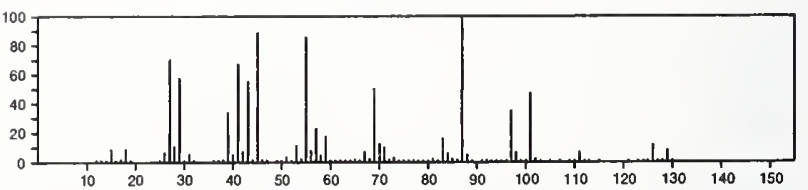


144

4-Nonanol

$\mathrm{C}_{9} \mathrm{H}_{20} \mathrm{O}$

$\operatorname{PrCH}(\mathrm{OH})\left(\mathrm{CH}_{2}\right)_{4} \mathrm{Me}$

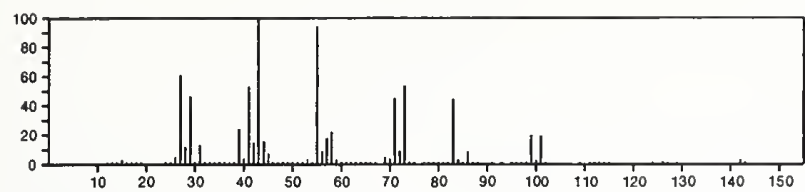

144

Ether, hexyl isopropyl

$\mathrm{C}_{9} \mathrm{H}_{20} \mathrm{O}$

$\mathrm{Me}\left(\mathrm{CH}_{2}\right)$ ) $\mathrm{OPr}-\mathbf{i}$

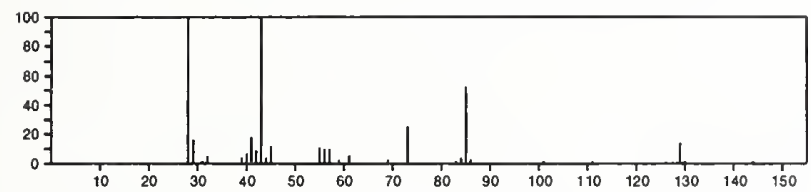

144

Ether, butyl pentyl

$\mathrm{C}_{9} \mathrm{H}_{20} \mathrm{O}$

$\mathrm{Me}\left\langle\mathrm{CH}_{2}\right)_{4} \mathrm{O}\left(\mathrm{CH}_{2}\right){ }_{3} \mathrm{Me}$

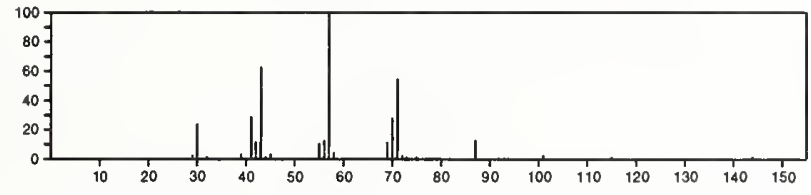

$144 \quad \mathrm{C}_{9} \mathrm{H}_{20} \mathrm{O}$

3-Heptanol, 2,4-dimethyl-

$\mathrm{PrCHMO} \mathrm{CH}(\mathrm{OH}) \mathrm{CHMe}_{2}$

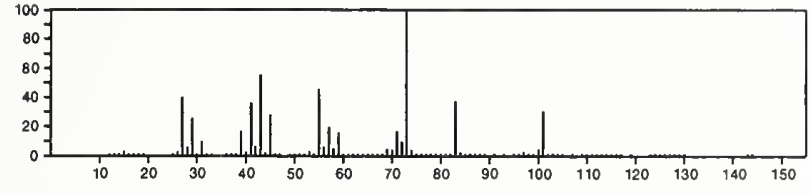

144

3-Heptanol, 2,6-dimethyl-

$\mathrm{C}_{9} \mathrm{H}_{20} \mathrm{O}$

19549-73-6

$\mathrm{Me}_{2} \mathrm{CHCH}(\mathrm{OH}) \mathrm{CH}_{2} \mathrm{CH}_{2} \mathrm{CHMe} 2$

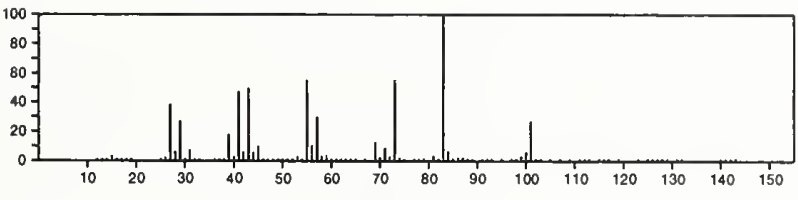

144

4-Heptanol, 2,4-dimethyl-

$\mathrm{C}_{9} \mathrm{H}_{20} \mathrm{O}$

$19549-77-0$

$\mathrm{PrCMe}(\mathrm{OH}) \mathrm{CH}_{2} \mathrm{CHMe}$

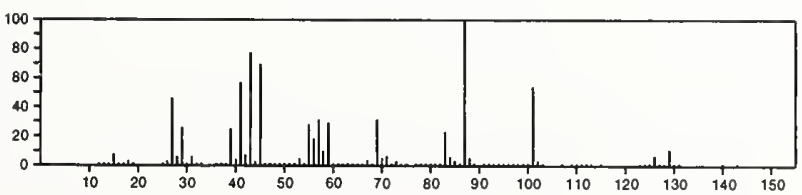

144

2-Heptanol, 5-ethyl-

$\mathrm{C}_{9} \mathrm{H}_{20} \mathrm{O}$

19780-40-6

$\mathrm{MeCH}(\mathrm{OH}) \mathrm{CH}_{2} \mathrm{CH}_{2} \mathrm{CHE}_{2}$

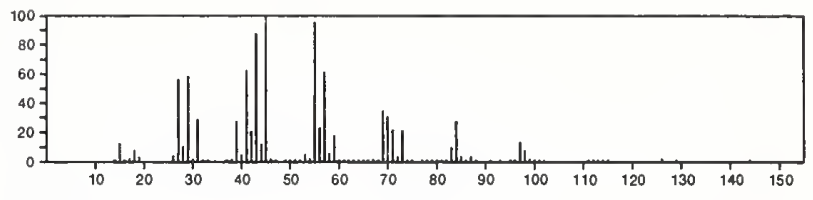

144

4-Octanol, 4-methyl-

$\mathrm{C}_{9} \mathrm{H}_{20} \mathrm{O}$

23418-37-3

$\operatorname{PrCMe}(\mathrm{OH})\left(\mathrm{CH}_{2}\right)_{3} \mathrm{Me}$

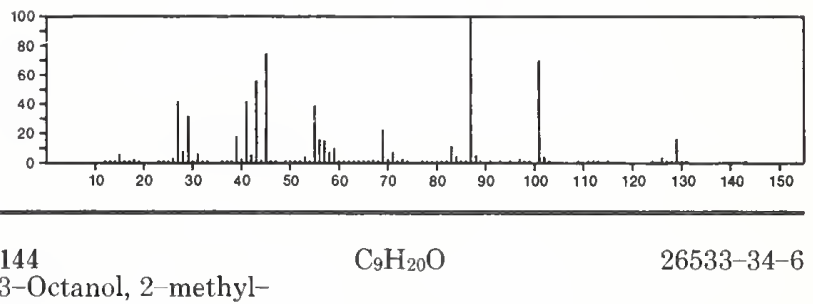

$\mathrm{Me}\left(\mathrm{CH}_{2}\right)_{4} \mathrm{CH}(\mathrm{OH}) \mathrm{CHMe}_{2}$

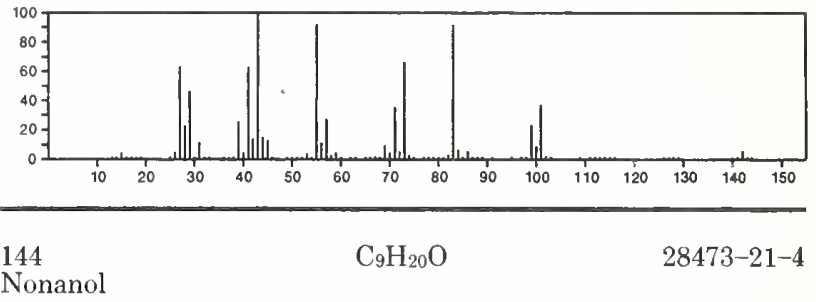

$\mathrm{Me}\left(\mathrm{CH}_{2}\right)_{7} \mathrm{Me}+\mathrm{OH}$

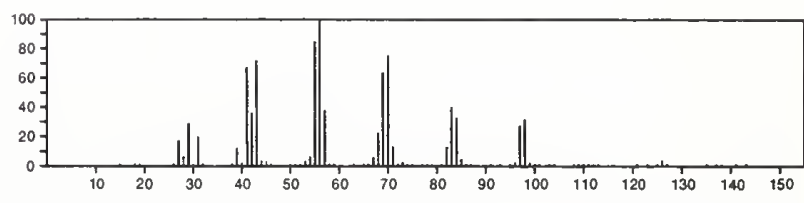

144

$\mathrm{C}_{9} \mathrm{H}_{20} \mathrm{O}$

53685-78-2

Hexane, 1-propoxy-

$\mathrm{Me}\left(\mathrm{CH}_{2}\right) 5 \mathrm{OP} \mathrm{r}$

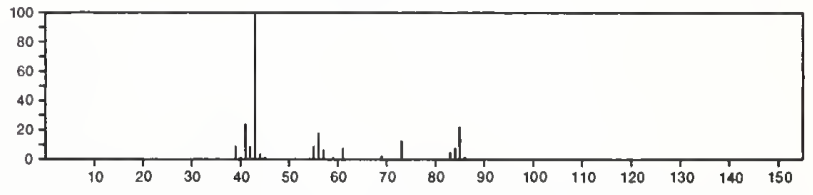

144

1-Pentanol, 3-methyl-2-propyl-

54004-40-9

$\mathrm{MeCH}_{2} \mathrm{CHMe} \mathrm{CHP} \mathrm{r} \mathrm{CH}_{2} \mathrm{OH}$

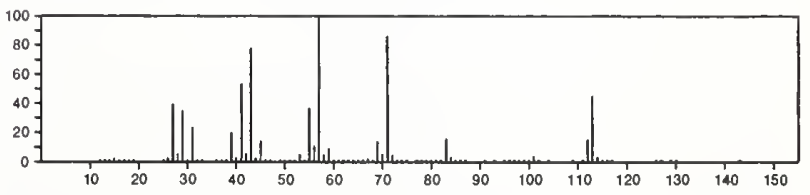


402

EPA/NIH MASS SPECTRAL DATA BASE

144

144

$\mathrm{C}_{9} \mathrm{H}_{20} \mathrm{O}$

1-Pentanol, 4-methyl-2-propyl-

$54004-41-0$

$\mathrm{Me}_{2} \mathrm{CHCH}_{2} \mathrm{CHPr} \mathrm{CH}_{2} \mathrm{OH}$

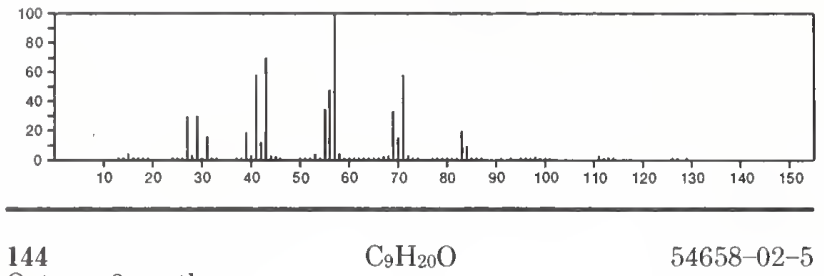

Octane, 3 methoxy-

$\mathrm{EtCH}(\mathrm{OMe})\left(\mathrm{CH}_{2}\right){ }_{4} \mathrm{Me}$

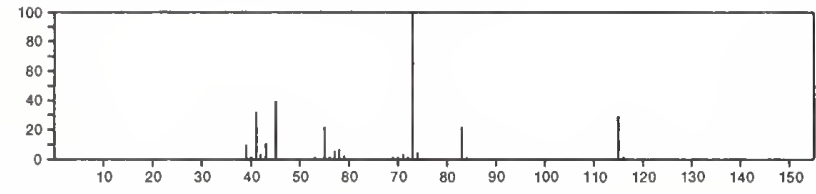

144

$\mathrm{C}_{10} \mathrm{H}_{8} \mathrm{O}$

$90-15-3$
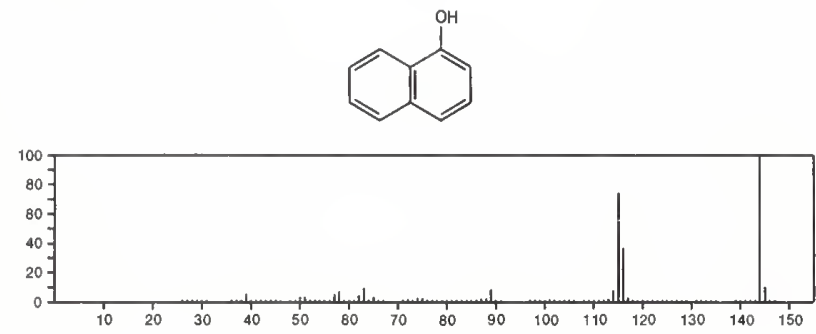

144

$\mathrm{C}_{10} \mathrm{H}_{8} \mathrm{O} \quad 135-19-3$
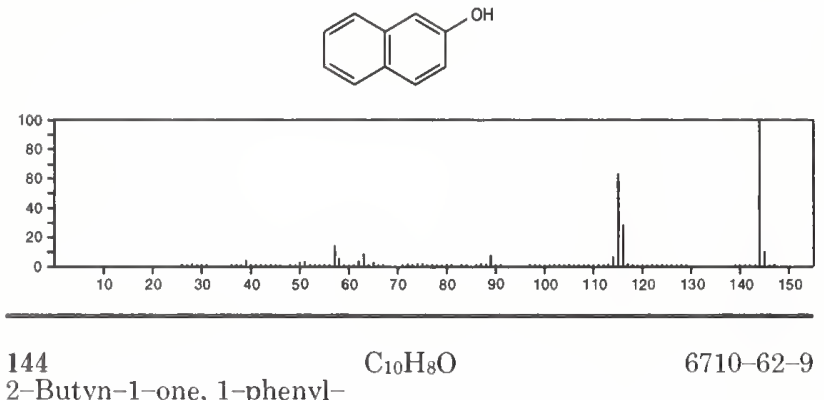

$\mathrm{PnCOC} \equiv \mathrm{CMO}$

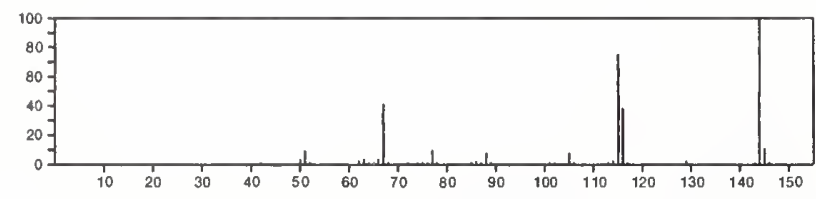

$144 \quad \mathrm{C}_{11} \mathrm{H}_{12} \quad$ 2717-44-4

Naphthalene, 1,2-dihydro-3-methyl-
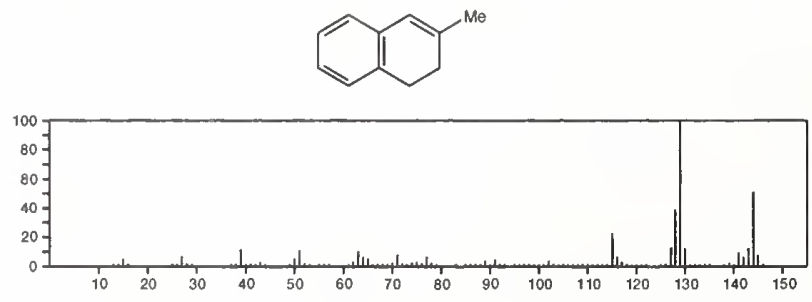

144
Naphthalene, 1,2-dihydro-6-methyl

$2717-47-7$
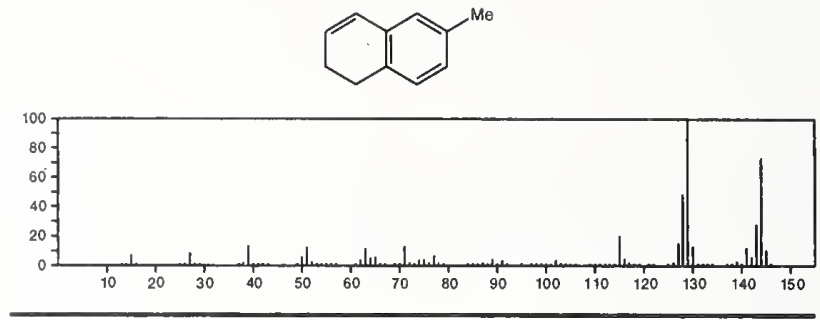

144

$\mathrm{C}_{11} \mathrm{H}_{12}$

$4486-29-7$

1,4-Methanonaphthalene, 1,2,3,4-tetrahydro-
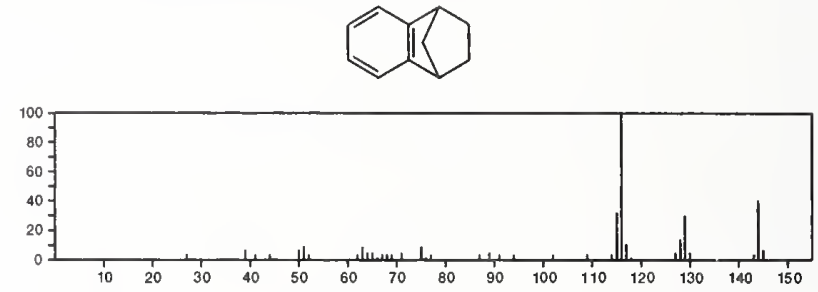

144

$\mathrm{C}_{11} \mathrm{H}_{12}$

6571
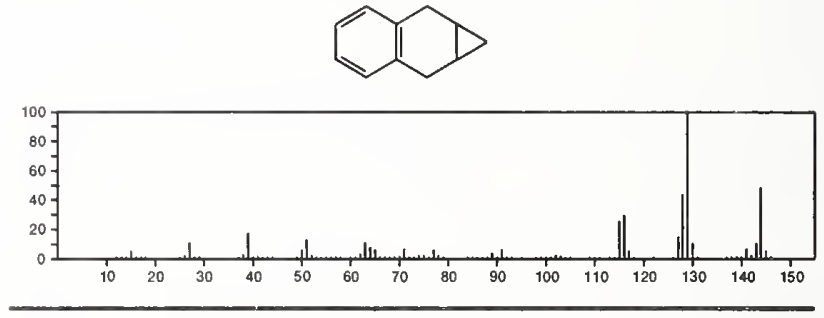

$144 \quad \mathrm{C}_{11} \mathrm{H}_{12}$

$7125-62-4$

5H-Benzocycloheptene, 6,7-dihydro-
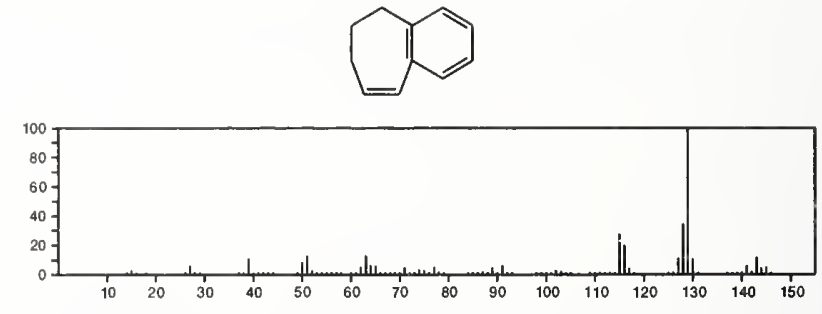

$144 \quad \mathrm{C}_{11} \mathrm{H}_{12} \quad$ 13912-97-5 $1 \mathrm{H}$-Cyclobut $[\mathrm{a}]$ indene, 2,2a,7,7a-tetrahydro-
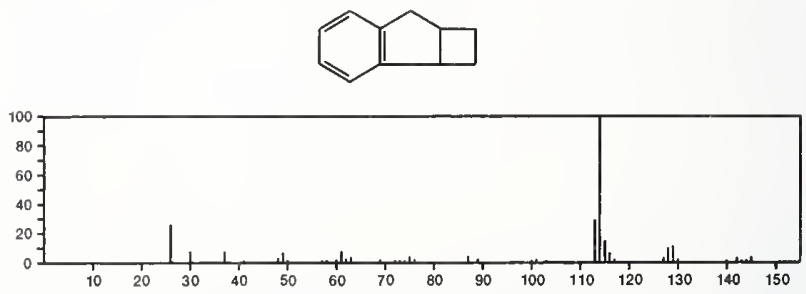
144 -Indene, 1,1-dimethyl-

$\mathrm{C}_{11} \mathrm{H}_{12}$

18636-55-0
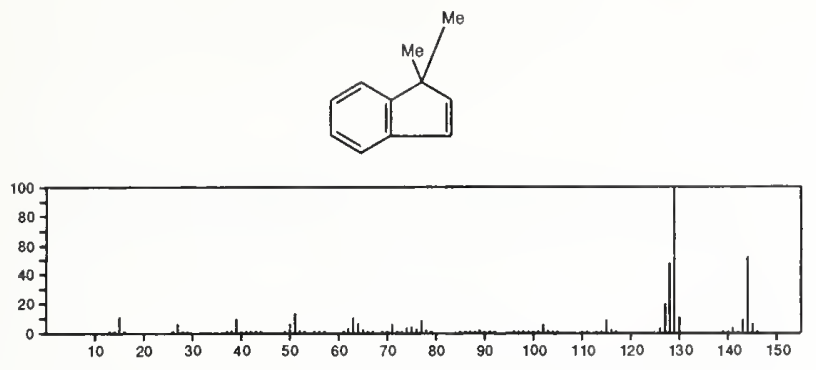

\section{4}

$\mathrm{C}_{11} \mathrm{H}_{12}$
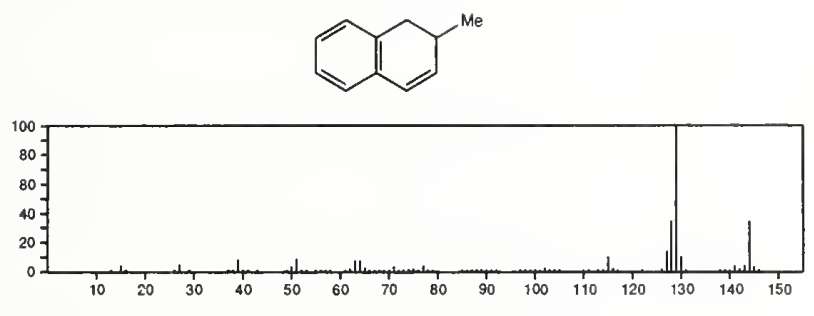

145

$\mathrm{C}_{2} \mathrm{H}_{6} \mathrm{Cl}_{2} \mathrm{NP}$

Phosphoramidous dichloride, dimethyl-

683-85-2

$\mathrm{Cl}_{2} \mathrm{PNMe}_{2}$

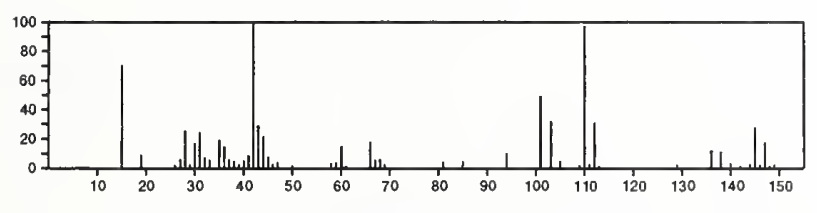

145

2-Thiazolamine, 5-nitro-

$\mathrm{C}_{3} \mathrm{H}_{3} \mathrm{~N}_{3} \mathrm{O}_{2} \mathrm{~S}$

$121-66-4$
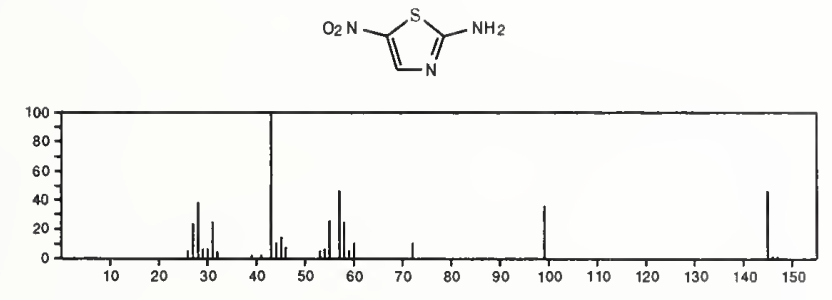

145

1,3,5-Triazine-2,4-diamine,

$\mathrm{C}_{3} \mathrm{H}_{4} \mathrm{ClN}_{5}$<smiles>Nc1nc(N)nc(Cl)n1</smiles>

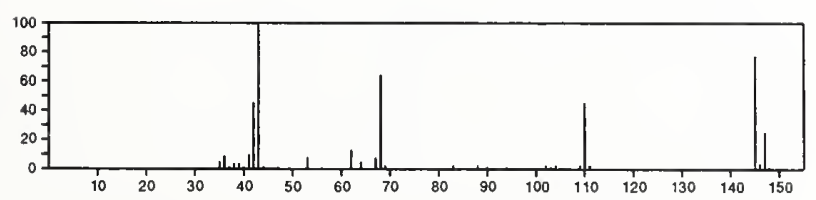

145

Urea, $N$-ethyl- $N^{\prime}, N^{\prime}$-dimethyl- $N$-nitroso-

$50285-71-7$

$E T N(N O)$ CONME 2

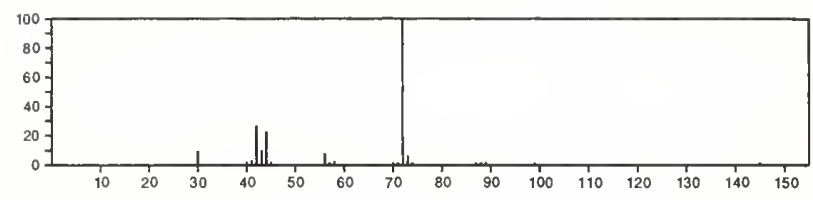

145

$\mathrm{C}_{5} \mathrm{H}_{11} \mathrm{~N}_{3} \mathrm{~S}$

Hydrazinecarbothioamide, 2-butylidene-

20812-04-8

H2NCSNHN $=$ CHP r

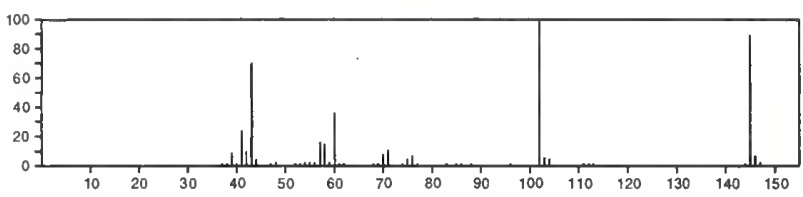

145

$\mathrm{C}_{6} \mathrm{H}_{8} \mathrm{ClNO}$

19788-37-5

Isoxazole, 4-(chloromethyl)-3,5-dimethyl-
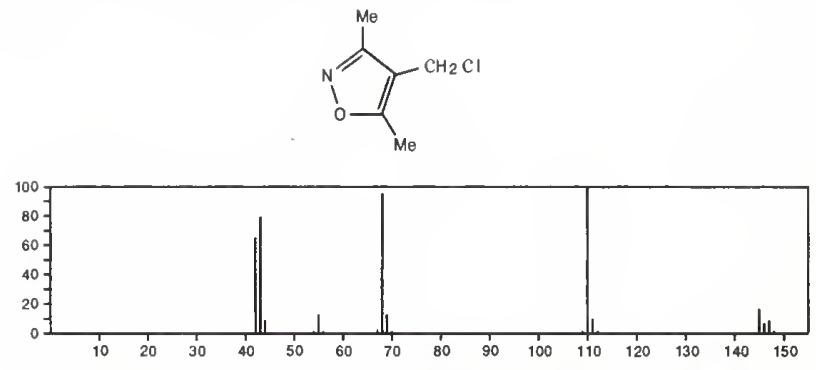

145

$\mathrm{C}_{6} \mathrm{H}_{11} \mathrm{NO}_{3}$

Glycine, $N$-acetyl-, ethyl ester

1906-82-7

$\mathrm{ACNHCH}_{2} \mathrm{C}(\mathrm{O}) \mathrm{OEt}$

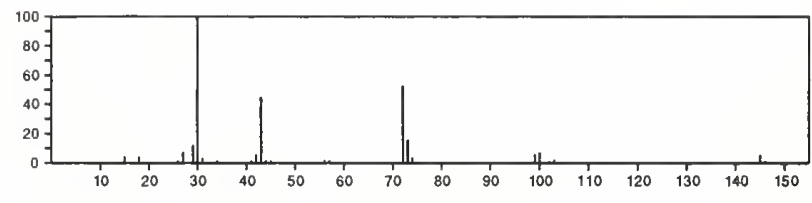

145

$\mathrm{C}_{6} \mathrm{H}_{11} \mathrm{NO}_{3}$

$7211-57-6$

Butanoic acid, 2-(acetylamino)-

$\mathrm{ACNHCHE}+\mathrm{CO}_{2} \mathrm{H}$

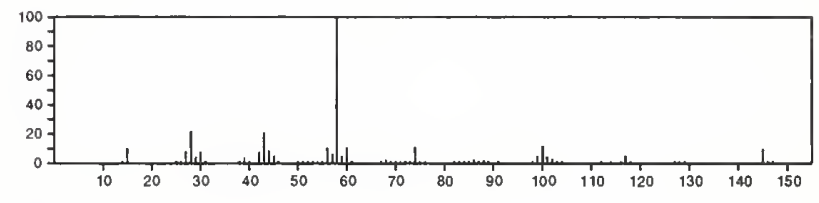

145

$\mathrm{C}_{6} \mathrm{H}_{11} \mathrm{NO}_{3}$

15166-66-2

5-Isoxazolidinecarboxylic acid, 5-methyl-, methyl ester
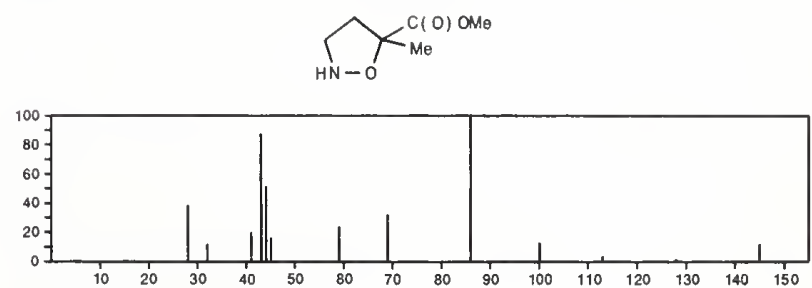
$145-\mathrm{C}_{6} \mathrm{H}_{11} \mathrm{NO}_{3}$

DL-Alanine, $N$-acetyl-, methyl ester

Me OC ( O) CHMENHAC

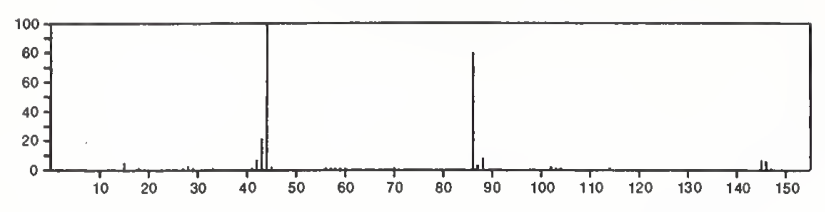

$145 \quad \mathrm{C}_{6} \mathrm{H}_{11} \mathrm{NO}_{3}$

2-Isoxazolidinecarboxylic acid, ethyl ester

$\sum_{0}-C(0), O E t$

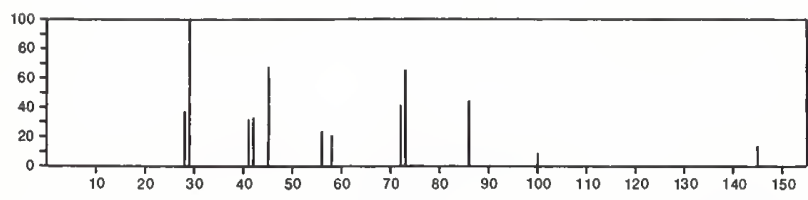

145

$\mathrm{C}_{6} \mathrm{H}_{11} \mathrm{NO}_{3}$

Carbamic acid, 2-propenyl-, 2-hydroxyethyl ester

$55956-17-7$

$\mathrm{H}_{2} \mathrm{C}=\mathrm{CHCH}_{2} \mathrm{NHC}(\mathrm{O}) \mathrm{OCH}_{2} \mathrm{CH}_{2} \mathrm{OH}$

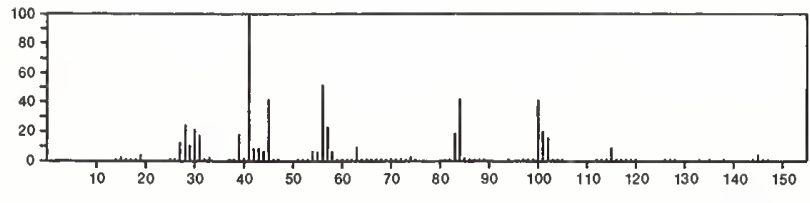

$145 \quad \mathrm{C}_{6} \mathrm{H}_{13} \mathrm{BClN}$ 51783-28-9

Boranamine, 1-chloro- $N, N$-dimethyl-1-(1-methyl-2-propenyl)-

$\mathrm{Me}_{2} \mathrm{NBCl} \mathrm{CHMeCH}=\mathrm{CH}_{2}$

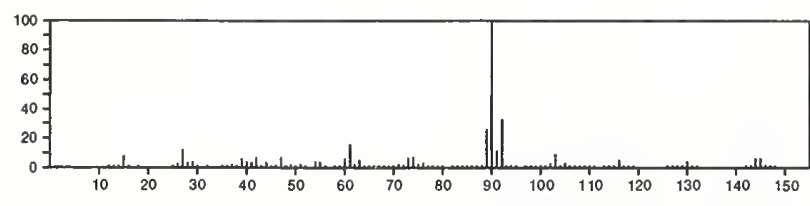

145

Pentane, 2,4-dimethyl-2-nitro-

$597-45-5$

$\mathrm{Me}_{2} \mathrm{CNO}_{2} \mathrm{CH}_{2} \mathrm{CHM}_{2}$

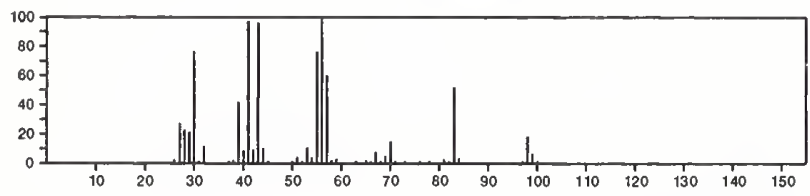

145

Heptane, 1-nitro-

$\mathrm{C}_{7} \mathrm{H}_{15} \mathrm{NO}_{2}$

693-39-0

$\mathrm{O}_{2} \mathrm{~N}\left(\mathrm{CH}_{2}\right){ }_{6} \mathrm{Me}$

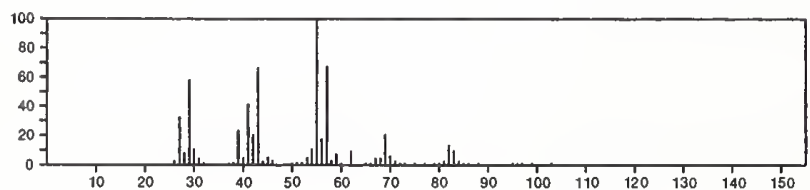

145

L-Leucine, methyl ester

$\mathrm{C}_{7} \mathrm{H}_{15} \mathrm{NO}_{2}$

$2666-93-5$

$\mathrm{MeOC}(\mathrm{O}) \mathrm{CH}\left(\mathrm{NH}_{2}\right) \mathrm{CH}_{2} \mathrm{CHMe}_{2}$
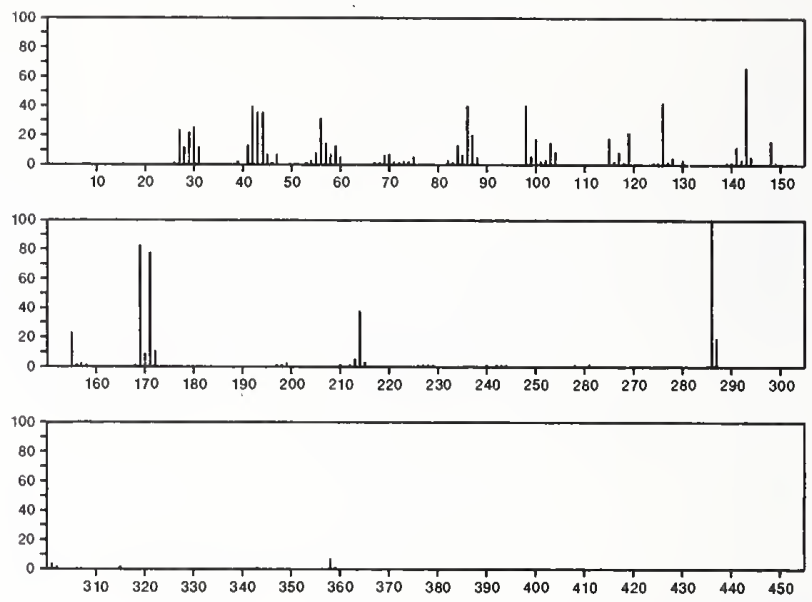

$145 \quad \mathrm{C}_{7} \mathrm{H}_{15} \mathrm{NO}_{2}$

1-Propanol, 3-(dimethylamino)-, acetate (ester)

4339-94-0

$\mathrm{ACO}\left(\mathrm{CH}_{2}\right)_{3} \mathrm{NME}_{2}$

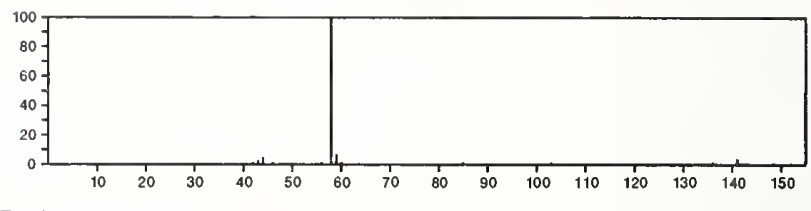

145

DL-Norvaline, ethyl ester

$\mathrm{C}_{7} \mathrm{H}_{15} \mathrm{NO}_{2}$

$13893-43-1$

$\mathrm{E}: \mathrm{OC}(\mathrm{O}) \mathrm{CH}\left(\mathrm{NH}_{2}\right) \mathrm{Pr}$

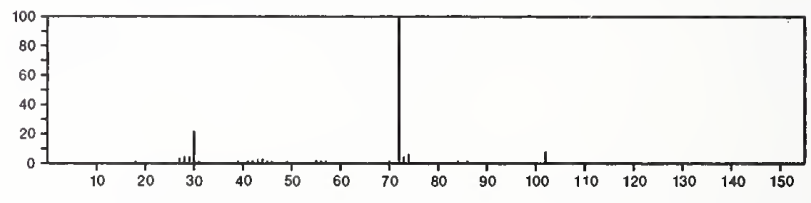

145

L-Valine, ethyl ester

$\mathrm{C}_{7} \mathrm{H}_{15} \mathrm{NO}_{2}$

17431-03-7

$\mathrm{Me} 2 \mathrm{CHCH}\left(\mathrm{NH}_{2}\right) \mathrm{C}(\mathrm{O}) \mathrm{OE}$ :

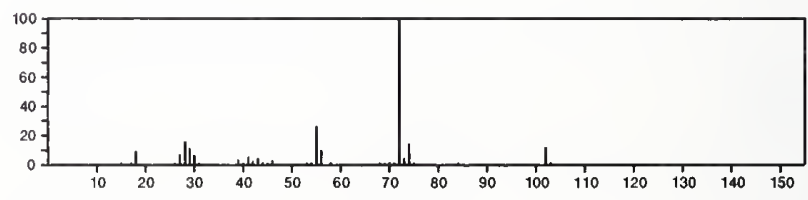

145

L-Norleucine, methyl ester

$\mathrm{C}_{7} \mathrm{H}_{15} \mathrm{NO}_{2}$

$21754-55-2$

$\mathrm{MeOC}(\mathrm{O}) \mathrm{CH}\left(\mathrm{NH}_{2}\right)\left(\mathrm{CH}_{2}\right)$ 3 $\mathrm{Me}$

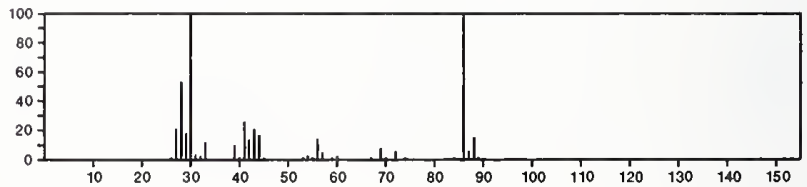


145

EPA/NIH MASS SPECTRAL DATA BASE

405

145

$\mathrm{C}_{7} \mathrm{H}_{15} \mathrm{NO}_{2}$

$\mathrm{MeOC}(\mathrm{O}) \mathrm{CH}\left(\mathrm{NH}_{2}\right)\left(\mathrm{CH}_{2}\right)_{3} \mathrm{Me}$

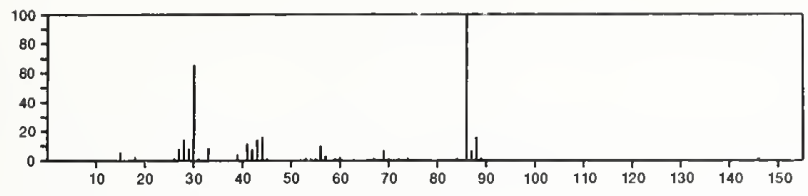

145

$\mathrm{C}_{7} \mathrm{H}_{15} \mathrm{NO}_{2}$

$54644-60-9$

Carbamic acid, butylmethyl-, methyl ester

$\mathrm{MeOC}(0) \mathrm{NMe}\left(\mathrm{CH}_{2}\right)_{3} \mathrm{Me}$

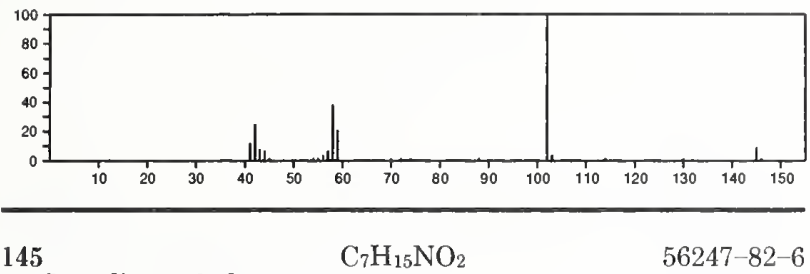

DL-Isovaline, ethyl ester

Et OC ( O) CE t $\left(\mathrm{NH}_{2}\right) \mathrm{Me}$

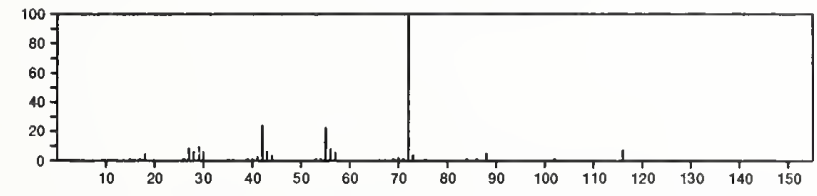

145

$\mathrm{C}_{8} \mathrm{H}_{7} \mathrm{~N}_{3}$

$2764-84-3$

$1 H$-Benzotriazole, 1-ethenyl-
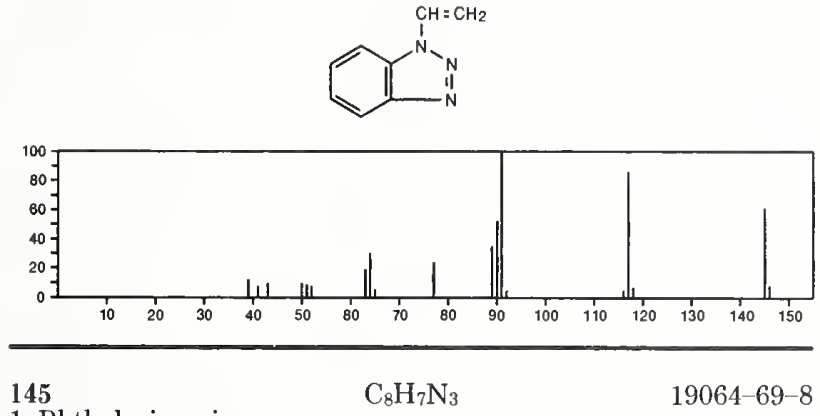

1-Phthalazinamine
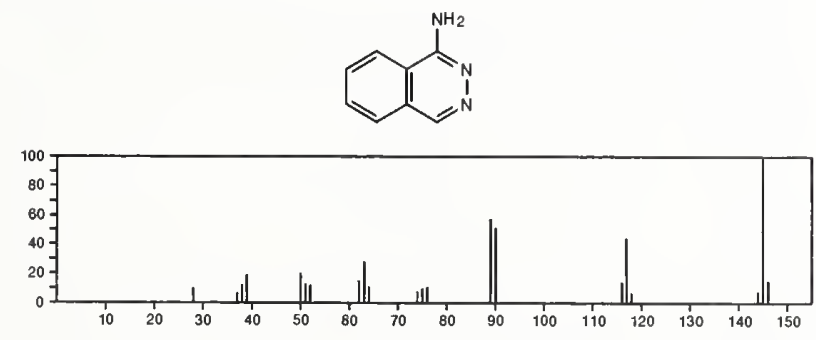

$145 \quad \mathrm{C}_{8} \mathrm{H}_{7} \mathrm{~N}_{3} \quad 28732-71-0$

Pyrido[2,3- $d$ ]pyrimidine, 4-methyl-
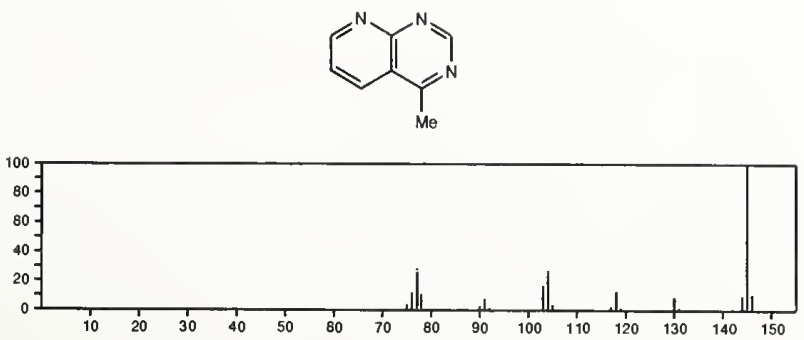

145

Ethanamine, $N$-ethyl-N-[(1-methylethoxy)methyl $]-$

i $-\mathrm{PrOCH}_{2} \mathrm{NE} t_{2}$
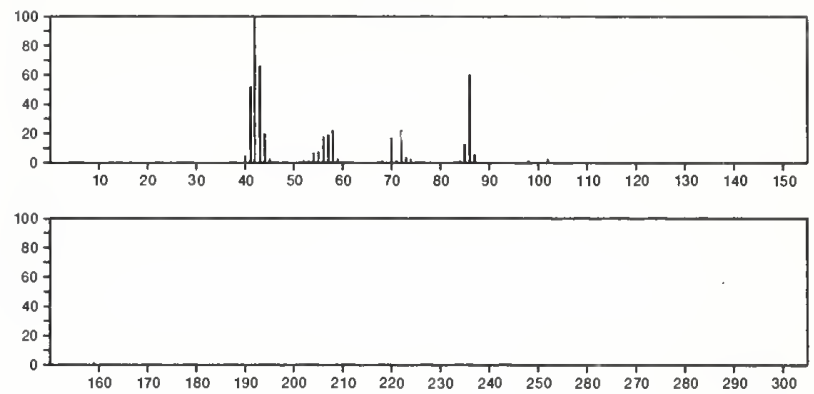

$145 \quad \mathrm{C}_{9} \mathrm{H}_{7} \mathrm{NO} \quad 59-31-4$
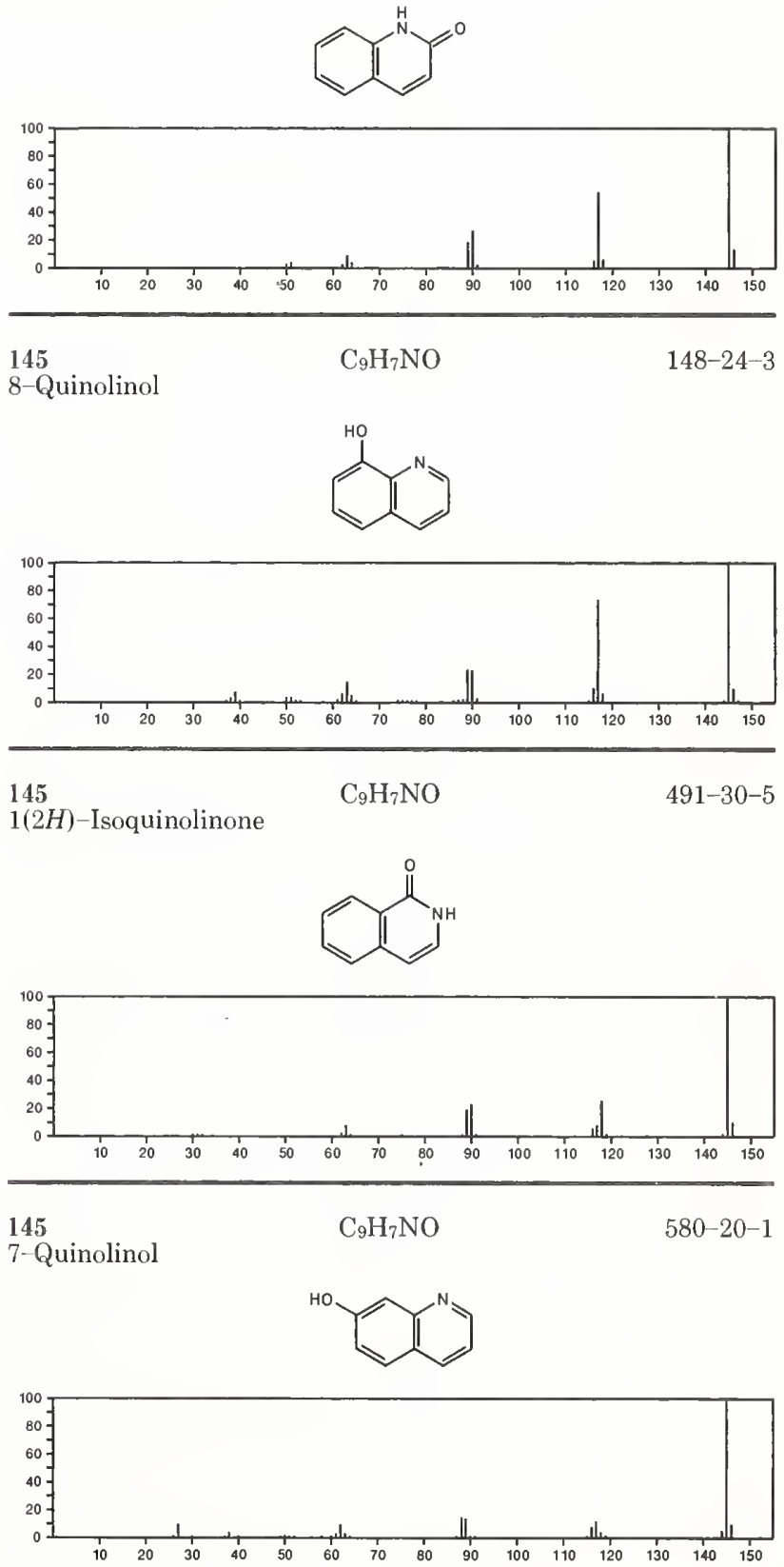
Isoquinoline, 2-oxide
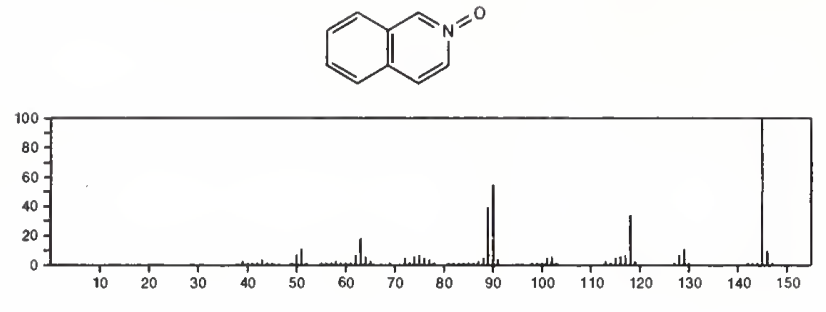

145

Quinoline, 1-oxide

$\mathrm{C}_{9} \mathrm{H}_{7} \mathrm{NO}$

$1613-37-2$
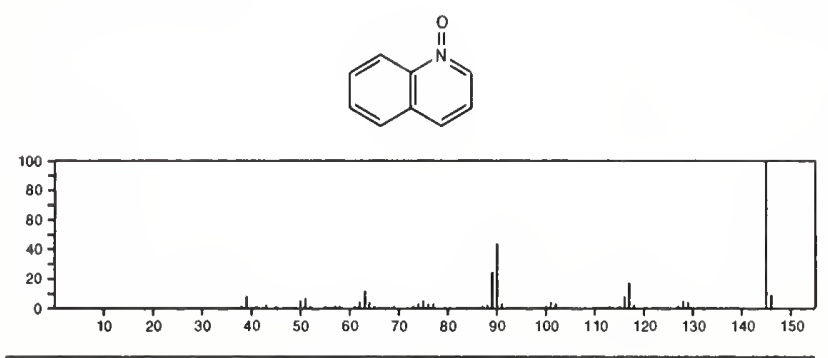

145

Oxazole, 2-phenyl

$\mathrm{C}_{9} \mathrm{H}_{7} \mathrm{NO}$

20662-88-8
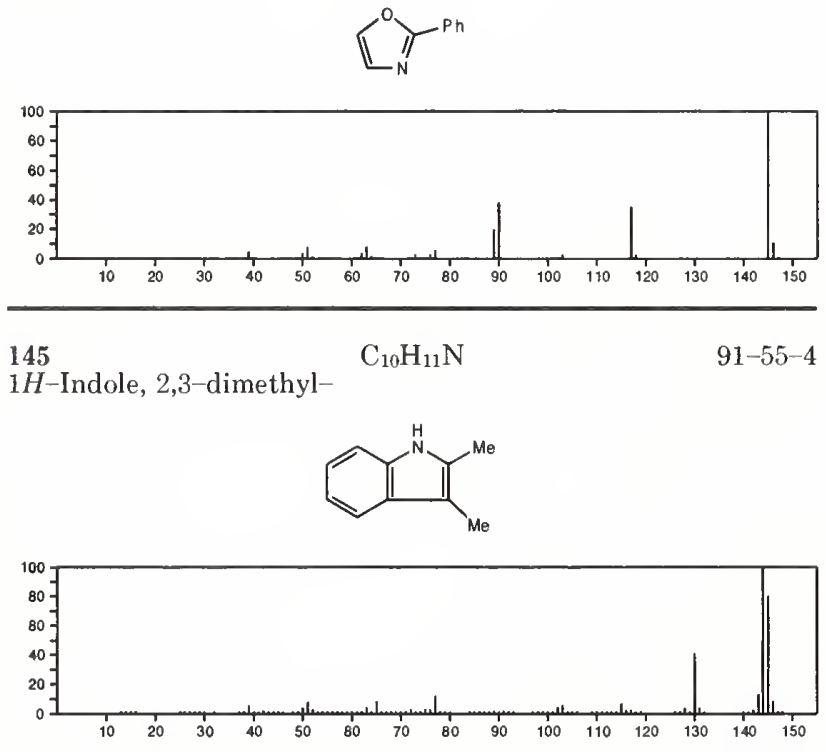

145
Indolizine, 2,3-dimethyl-

$769-65-3$
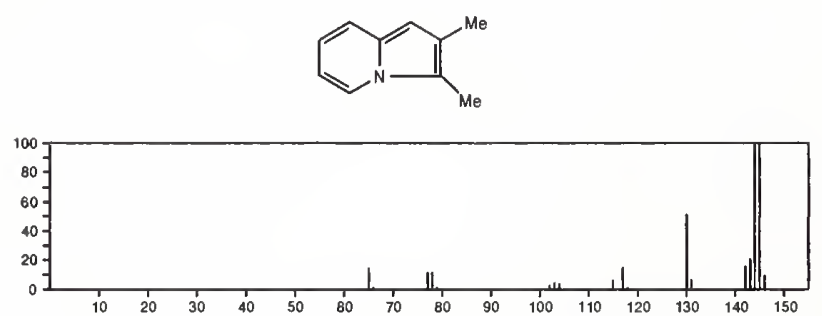

$\mathrm{PhCHE},\{\mathrm{CN}\}$

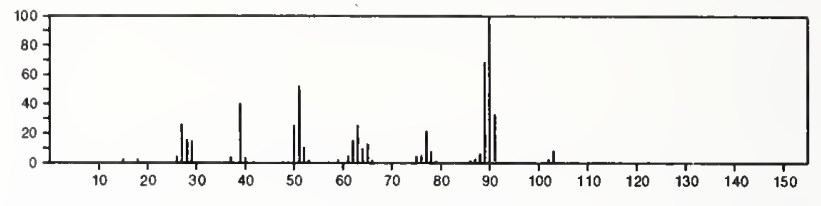

145

Indolizine, 2,5-dimethyl-

$\mathrm{C}_{10} \mathrm{H}_{11} \mathrm{~N}$

$769-83-5$
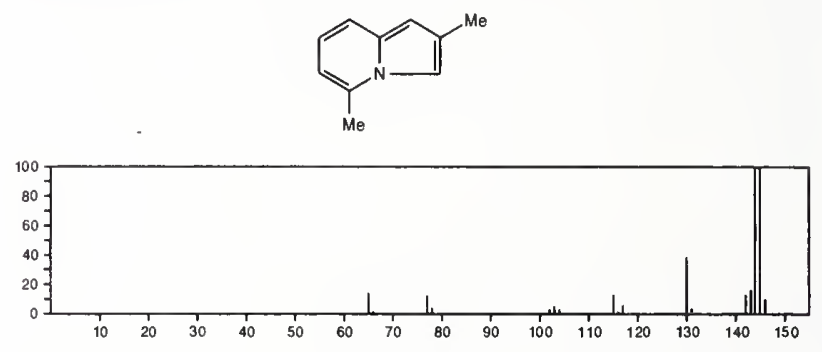

145

$\mathrm{C}_{10} \mathrm{H}_{11} \mathrm{~N}$

$769-88-0$

Indolizine, 2,6-dimethyl-
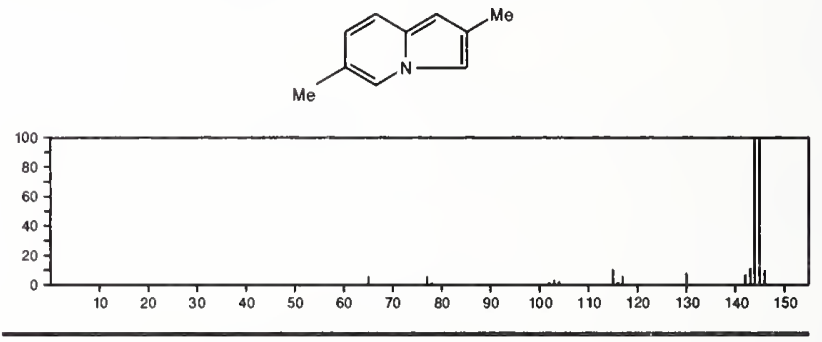

145

$\mathrm{C}_{10} \mathrm{H}_{11} \mathrm{~N}$

769-89-1

Indolizine, 2,7-dimethyl-
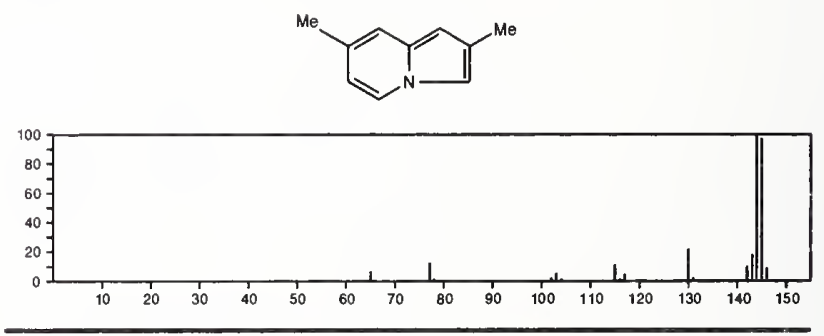

145

$\mathrm{C}_{10} \mathrm{H}_{11} \mathrm{~N}$

$875-30-9$

1H-Indole, 1,3-dimethyl-
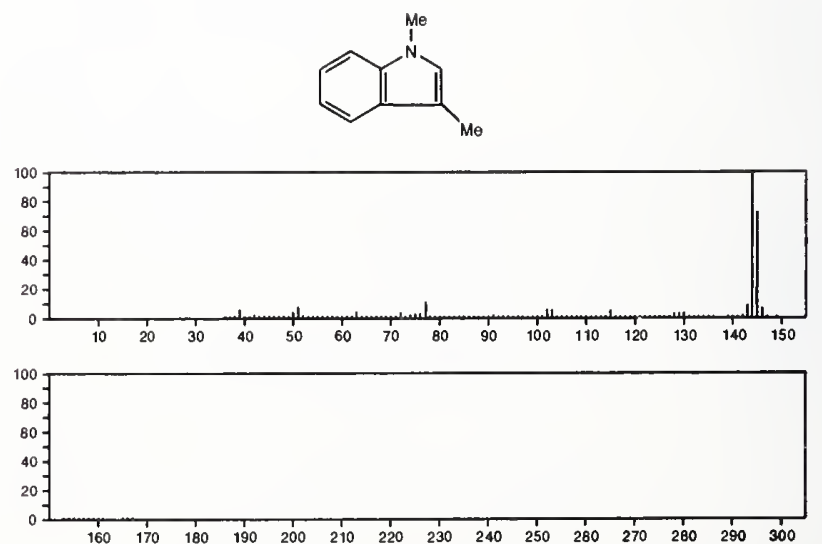
145 $\mathrm{C}_{10} \mathrm{H}_{11} \mathrm{~N}$

1125-77-5

145

Indole, 1,7-dimethyl-

$\mathrm{C}_{10} \mathrm{H}_{11} \mathrm{~N}$

Indolizine, 1,2-dimethyl-
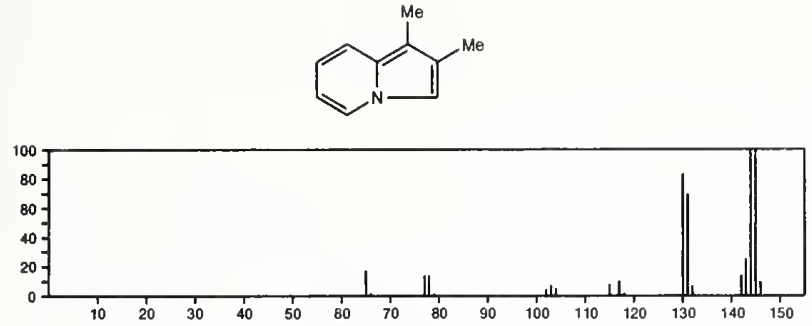

$145 \quad \mathrm{C}_{10} \mathrm{H}_{11} \mathrm{~N} \quad 1196-79-8$

$1 H$-Indole, 2,5-dimethyl-
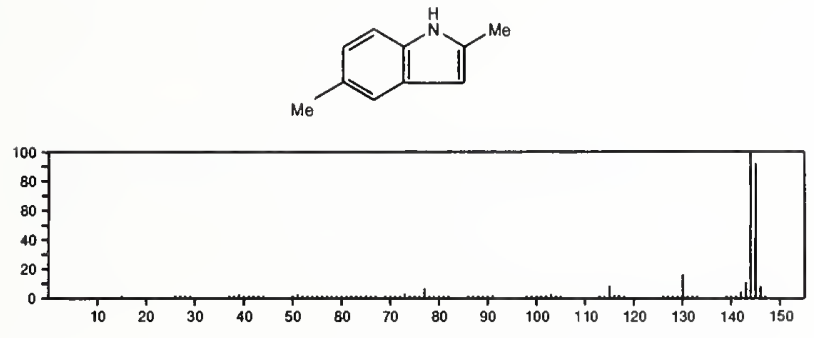

145

$\mathrm{C}_{10} \mathrm{H}_{11} \mathrm{~N}$

$1761-13-3$

Indolizine, 3,5-dimethyl-
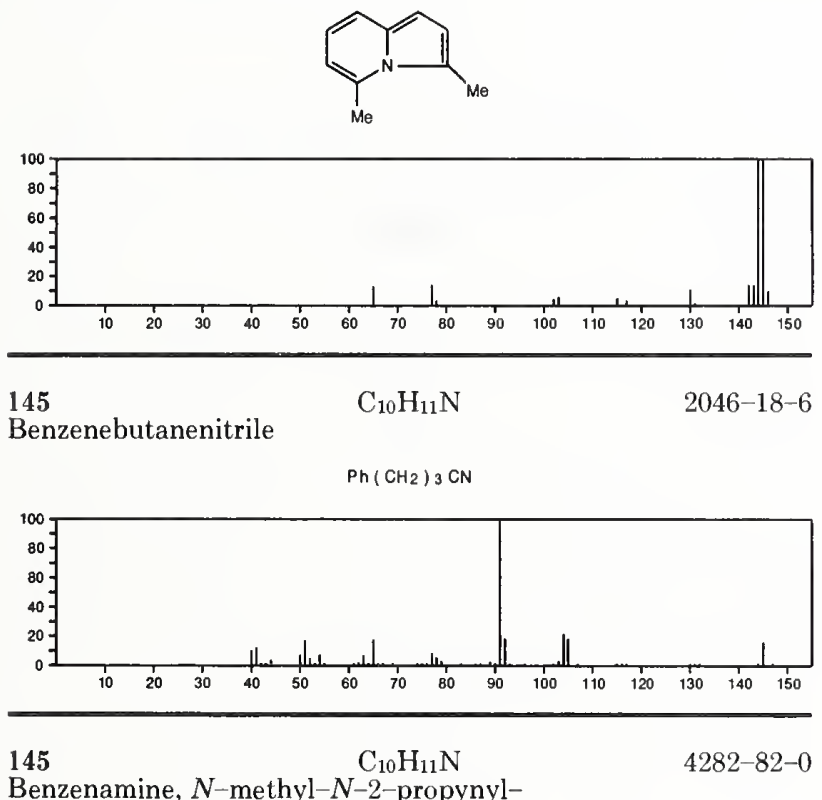

Benzenamine, $N$-methyl- $N$-2-propynyl-

$\mathrm{HC} \equiv \mathrm{CCH}_{2} \mathrm{NMePh}$

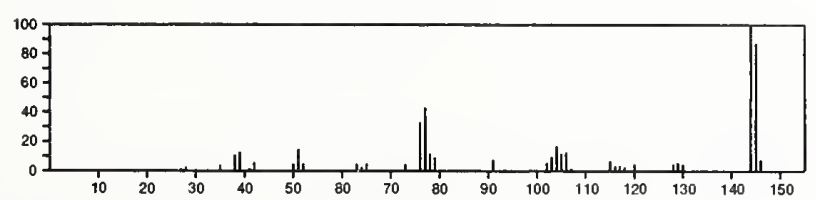

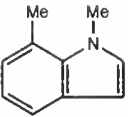
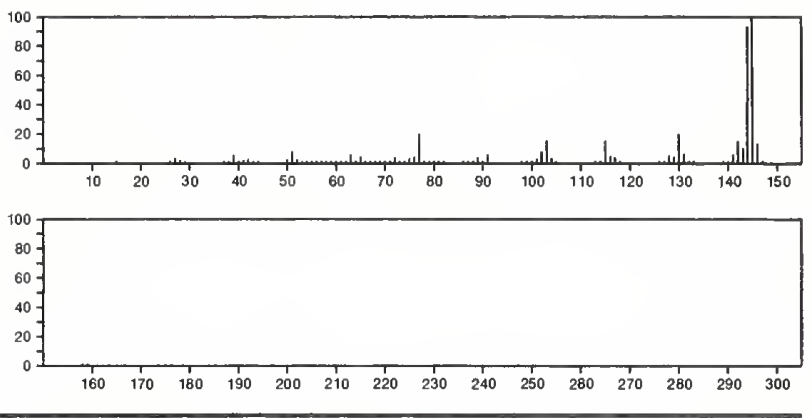

145

$1 H$-Indole, 2,6-dimethyl-

$\mathrm{C}_{10} \mathrm{H}_{11} \mathrm{~N}$

$5649-36-5$
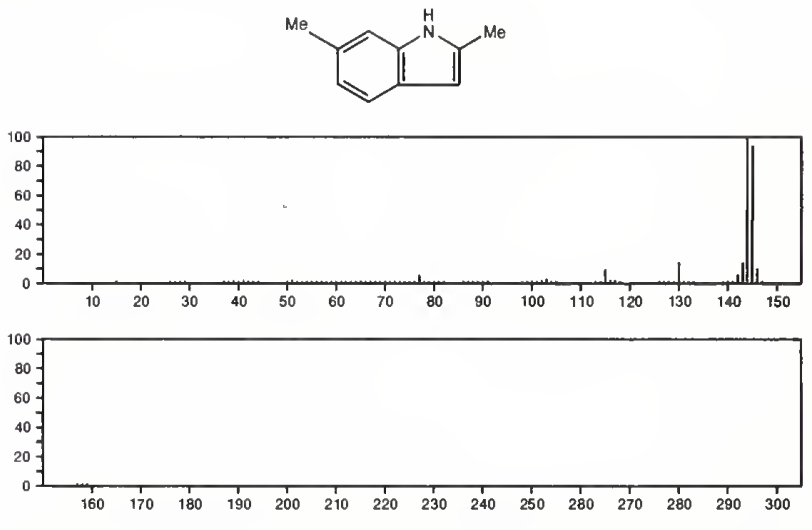

145 Indolizine, 2,8-dimethyl--

$\mathrm{C}_{10} \mathrm{H}_{11} \mathrm{~N}$

$31108-59-5$
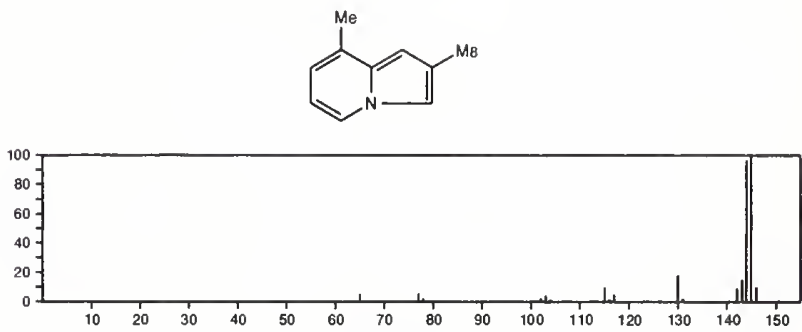

145 -Indole, 5,7-dimethyl- $\mathrm{C}_{10} \mathrm{H}_{11} \mathrm{~N}$

54020-53-0
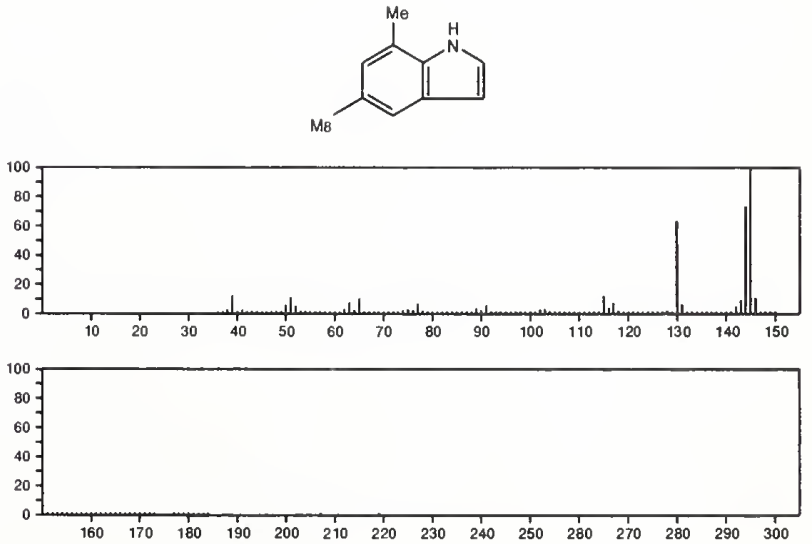
146

Methane, bromochlorofluoro-

$\mathrm{BrCHCl}(\mathrm{F})$

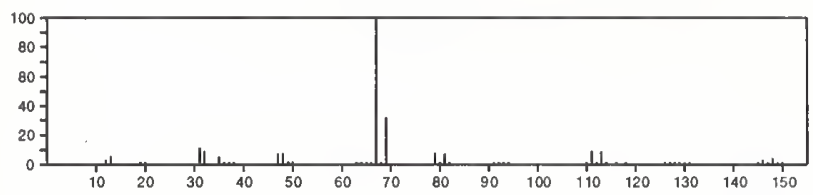

146

Arsine, (trifluoromethyl)-
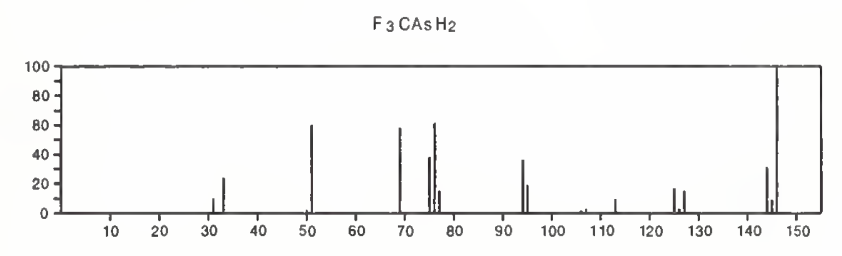

146

Acetic acid, dichlorofluoro-

$$
\mathrm{C}_{2} \mathrm{HCl}_{2} \mathrm{FO}_{2}
$$

$\mathrm{Cl}_{2} \mathrm{CF}\left(\mathrm{CO}_{2} \mathrm{H}\right)$
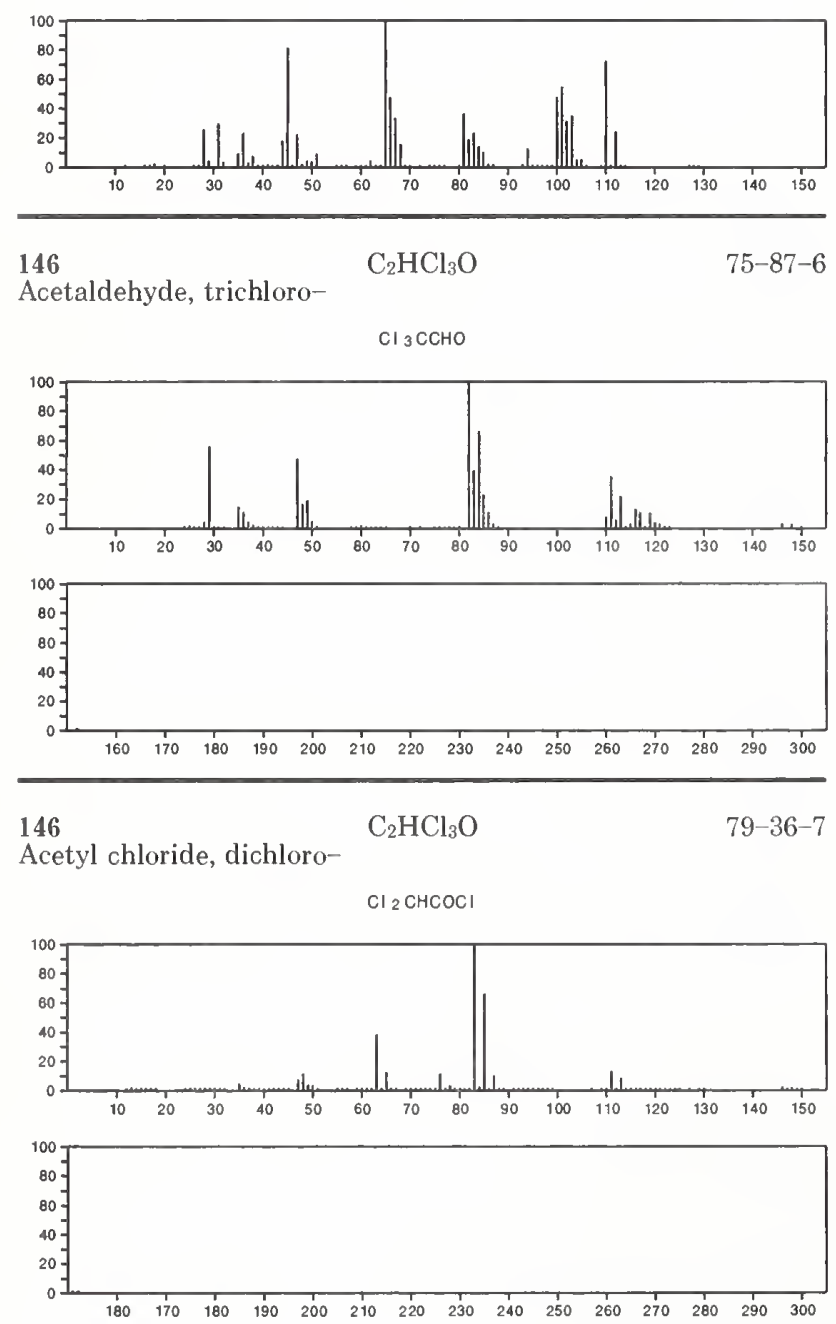

146 Acetic acid, trifluorodithio-

$\mathrm{C}_{2} \mathrm{HF}_{3} \mathrm{~S}_{2}$

20570-36-9
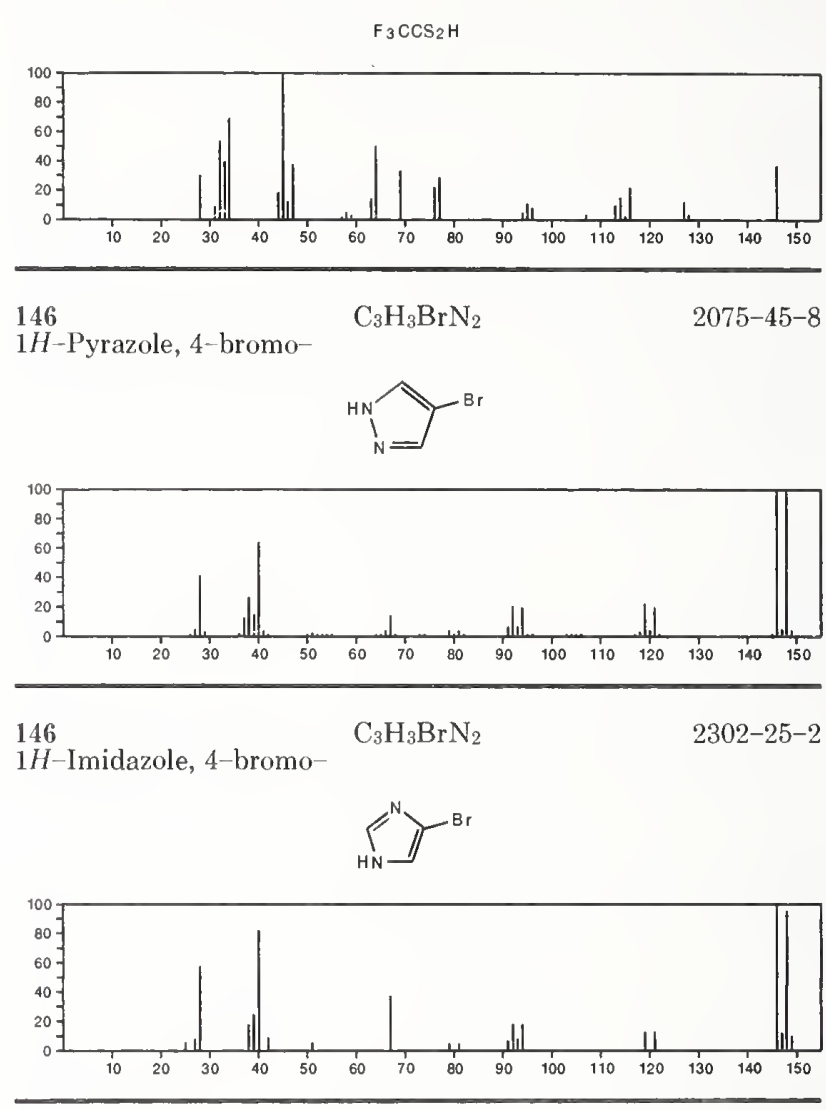

146

$\mathrm{C}_{3} \mathrm{H}_{5} \mathrm{Cl}_{3}$

$96-18-4$

Propane, 1,2,3-trichloro-

$\mathrm{Cl} \mathrm{CH}_{2} \mathrm{CHCl} \mathrm{CH}_{2} \mathrm{Cl}$

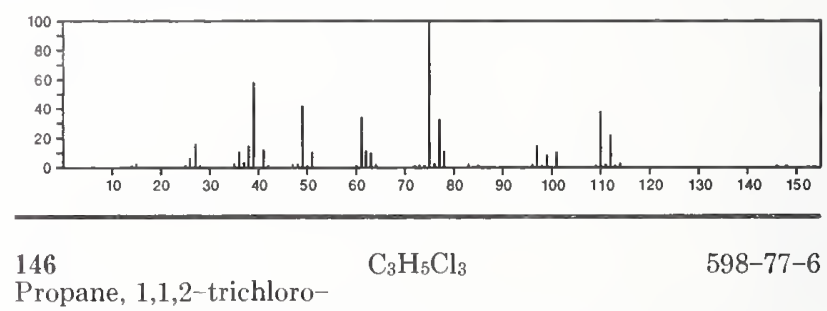

$\mathrm{Cl}_{2} \mathrm{CHCHCl} \mathrm{Me}_{\mathrm{M}}$
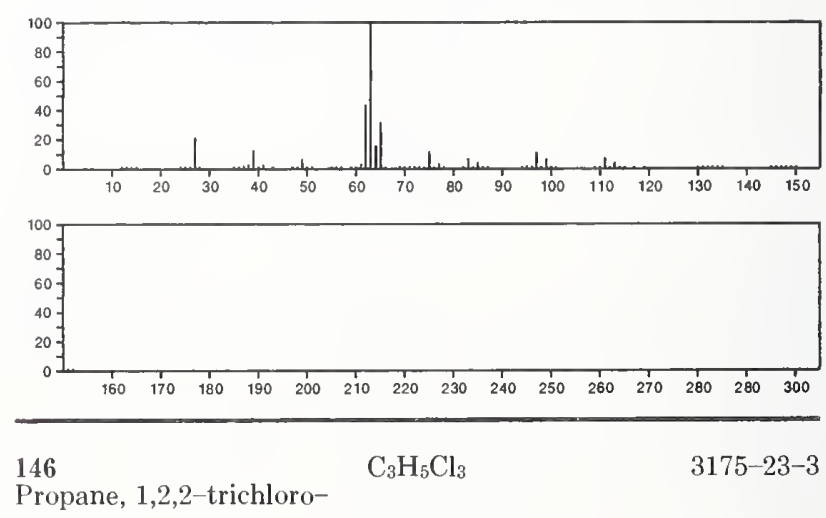

Propane, 1,2,2-trichloro-

$\mathrm{Cl} \mathrm{CH}_{2} \mathrm{CCl}_{2} \mathrm{Me}$

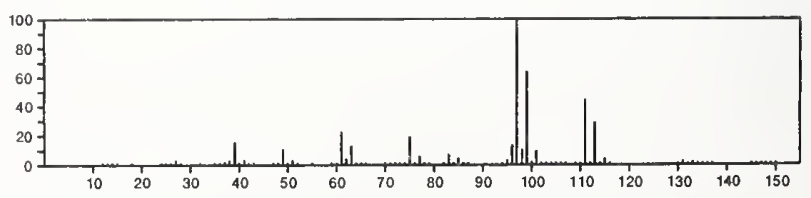


146

Propane, 1,1,1-trichloro-

$\mathrm{C}_{3} \mathrm{H}_{5} \mathrm{Cl}_{3}$

CI 3 CE t

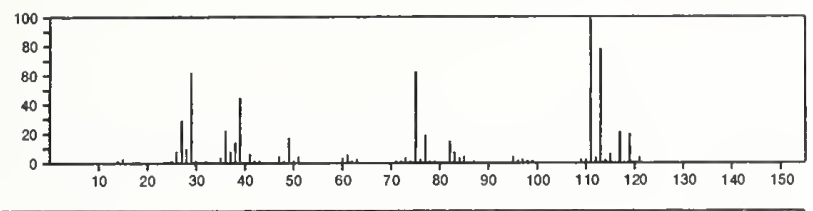

$146 \quad \mathrm{C}_{3} \mathrm{H}_{6} \mathrm{~F}_{3} \mathrm{OP}$

Phosphine oxide, dimethyl(trifluoromethyl)-

$26348-91-4$

$\mathrm{F}_{3} \mathrm{CPMe}_{2}=0$

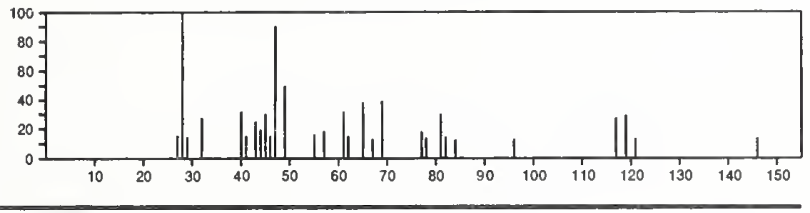

146

$\mathrm{C}_{4} \mathrm{H}_{3} \mathrm{ClN}_{2} \mathrm{O}_{2}$

2,4 $(1 H, 3 H)$-Pyrimidinedione, 5-chloro-

$1820-81-1$<smiles>O=c1[nH]cc(Cl)c(=O)[nH]1</smiles>

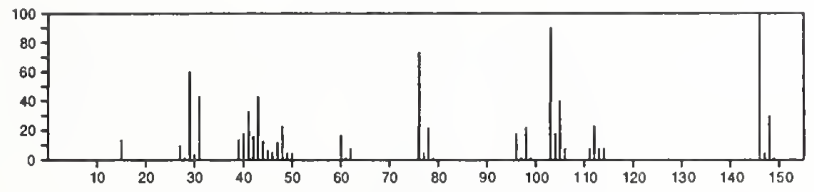

\section{6}

$\mathrm{C}_{4} \mathrm{H}_{3} \mathrm{ClN}_{2} \mathrm{~S}$

3(2H)-Pyridazinethione, 6-chloro-<smiles>S=c1ccc(Cl)n[nH]1</smiles>
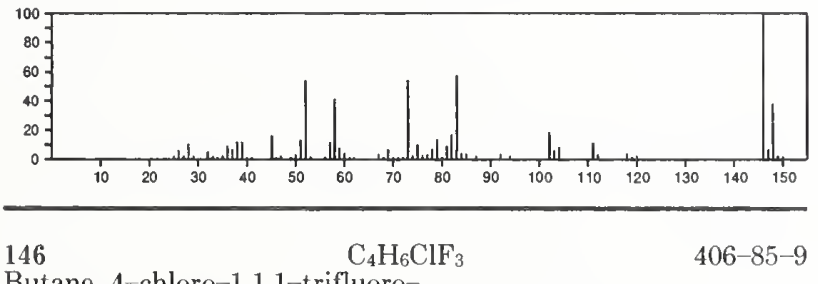

Butane, 4-chloro-1,1,1-trifluoro-

$\mathrm{F}_{3} \mathrm{C}\left(\mathrm{CH}_{2}\right)_{3} \mathrm{Cl}$
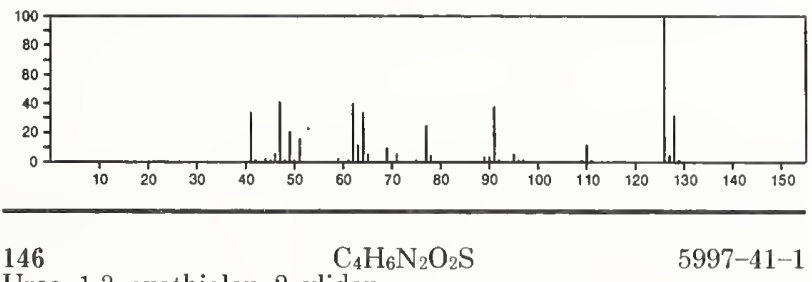

Urea, 1,3-oxathiolan-2-ylidene-
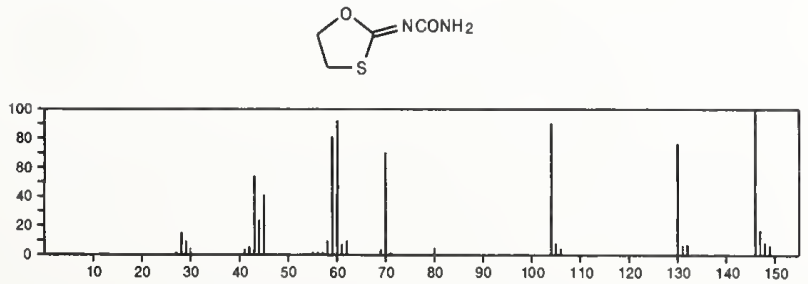

$146 \quad \mathrm{C}_{4} \mathrm{H}_{14} \mathrm{Si}_{3}$

1,3,5-Trisilacyclohexane, 1-methyl-

$18148-11-3$<smiles>N[SiH]1C[SiH2]C[SiH2]C1</smiles>

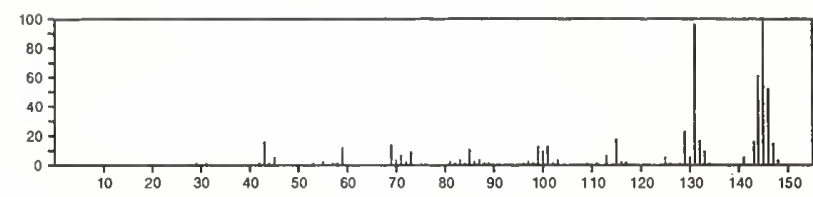

$146 \quad \mathrm{C}_{5} \mathrm{H}_{10} \mathrm{~N}_{2} \mathrm{O}_{3}$

Carbamic acid, ethylnitroso-, ethyl ester

$614-95-9$

EIOCIO\}N(NO)EI

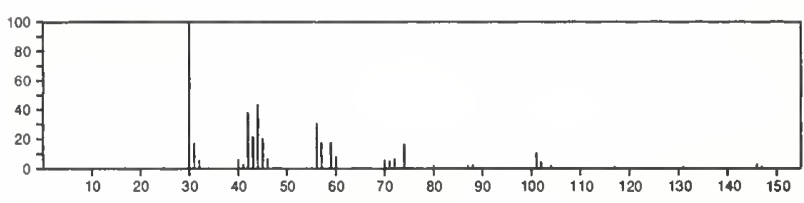

146

$\mathrm{C}_{5} \mathrm{H}_{12} \mathrm{Ge}$

Germacyclobutane, 1,1-dimethyl-

21961-74-0
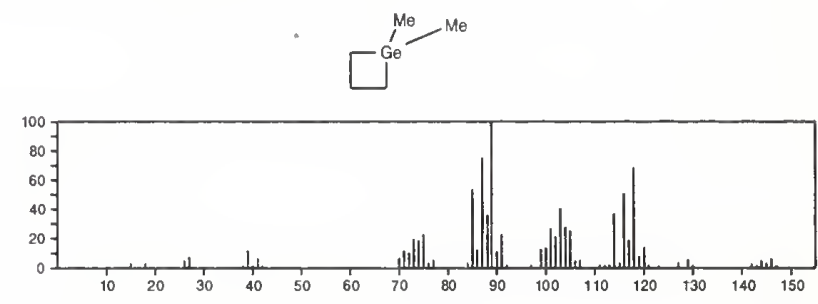

146

Benzene, 1,2-dichloro

$\mathrm{C}_{6} \mathrm{H}_{4} \mathrm{Cl}_{2}$

$95-50-1$
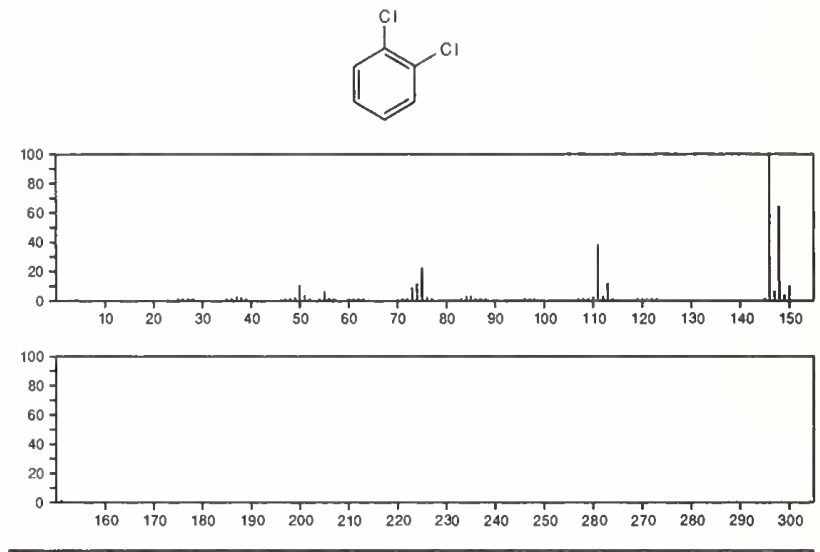

146

$\mathrm{C}_{6} \mathrm{H}_{4} \mathrm{Cl}_{2}$

$106-46-7$

Benzene, 1,4-dichloro-
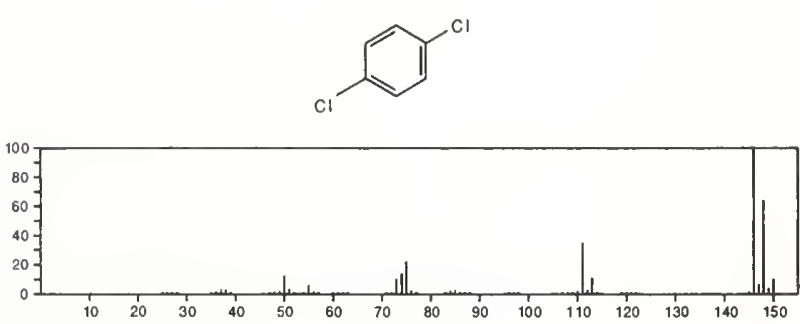


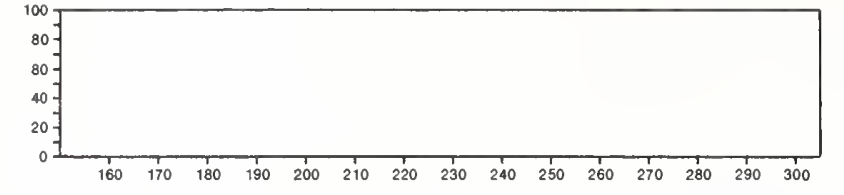

146

$\mathrm{C}_{6} \mathrm{H}_{4} \mathrm{Cl}_{2}$

541-73-1

Benzene, 1,3-dichloro-
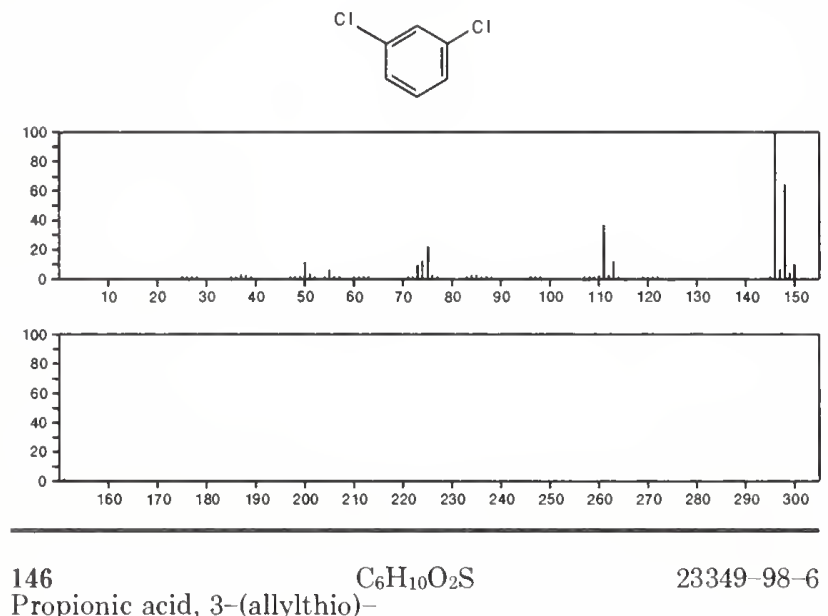

Propionic acid, 3-(allylthio)

$\mathrm{HO}_{2} \mathrm{CCH}_{2} \mathrm{CH}_{2} \mathrm{SCH}_{2} \mathrm{CH}=\mathrm{CH}_{2}$

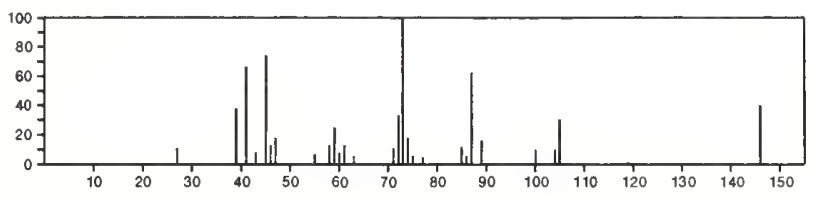

146

$\mathrm{C}_{6} \mathrm{H}_{10} \mathrm{O}_{2} \mathrm{~S}$

33266-06--7

Ketone, methyl 2-methyl-1,3-oxothiolan-2-yl

$\sum_{S}^{0} \gamma_{A C}^{M e}$

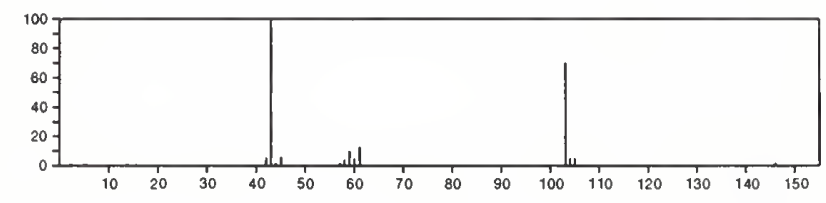

146

$\mathrm{C}_{6} \mathrm{H}_{10} \mathrm{O}_{4}$

95-92-1

Ethanedioic acid, diethyl ester

EtOC (O) C(O) OE :
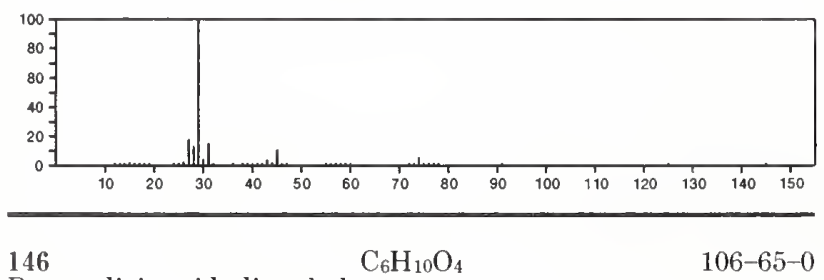

$106-65-0$

Butanedioic acid, dimethyl ester

$\mathrm{MeOC}(\mathrm{O}) \mathrm{CH}_{2} \mathrm{CH}_{2} \mathrm{C}(\mathrm{O}) \mathrm{OMe}$

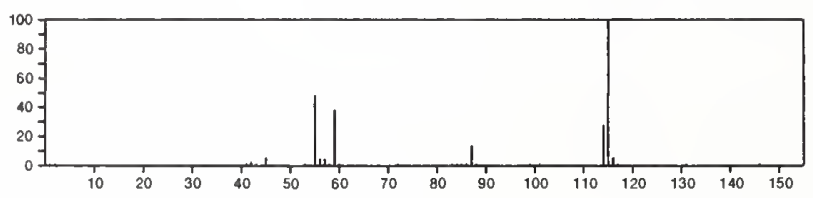

146

1,2-Ethanediol, diacetate

$\mathrm{C}_{6} \mathrm{H}_{10} \mathrm{O}_{4}$

$111-55-7$

$\mathrm{ACOCH} 2 \mathrm{CH}_{2} \mathrm{OAC}$

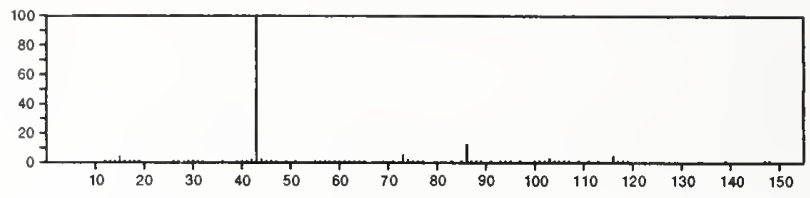

146

Hexanedioic acid

$\mathrm{C}_{6} \mathrm{H}_{10} \mathrm{O}_{4}$

124-04-9
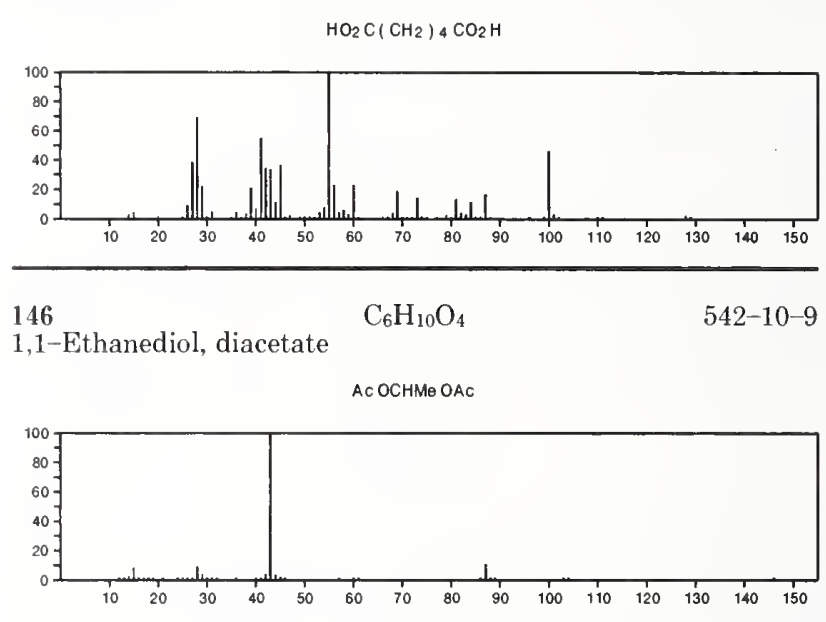

$146 \quad \mathrm{C}_{6} \mathrm{H}_{10} \mathrm{O}_{4}$

609-02-9

Propanedioic acid, methyl-, dimethyl ester

$\mathrm{MeOC}(\mathrm{O}) \mathrm{CHMeC}(\mathrm{O}) \mathrm{OM}_{\mathrm{N}}$

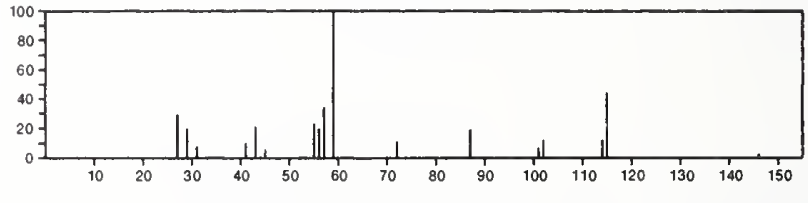

146

$\mathrm{C}_{6} \mathrm{H}_{10} \mathrm{O}_{4}$

Pentanedioic acid, monomethyl ester

$1501-27-5$

$\mathrm{HO}_{2} \mathrm{C}\left(\mathrm{CH}_{2}\right)_{3} \mathrm{C}(\mathrm{O}) \mathrm{OMe}$

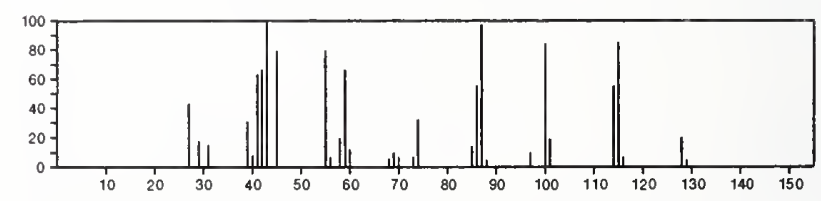

146

2,2'-Bi-1,3-dioxolane

$\mathrm{C}_{6} \mathrm{H}_{10} \mathrm{O}_{4}$

6705-89-1
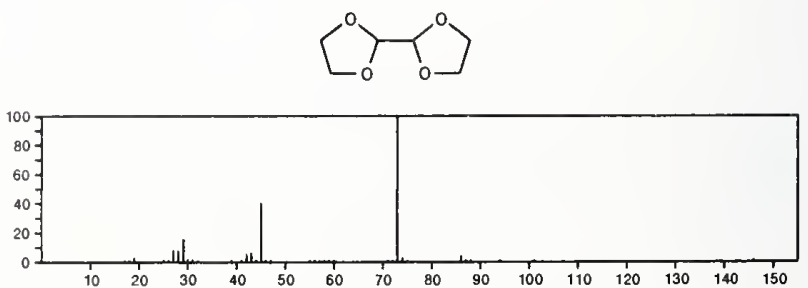
146 $\mathrm{C}_{6} \mathrm{H}_{10} \mathrm{O}_{4}$

arabino-Hex-1-enitol, 1,5-anhydro-2-deoxy-

26566-29-0
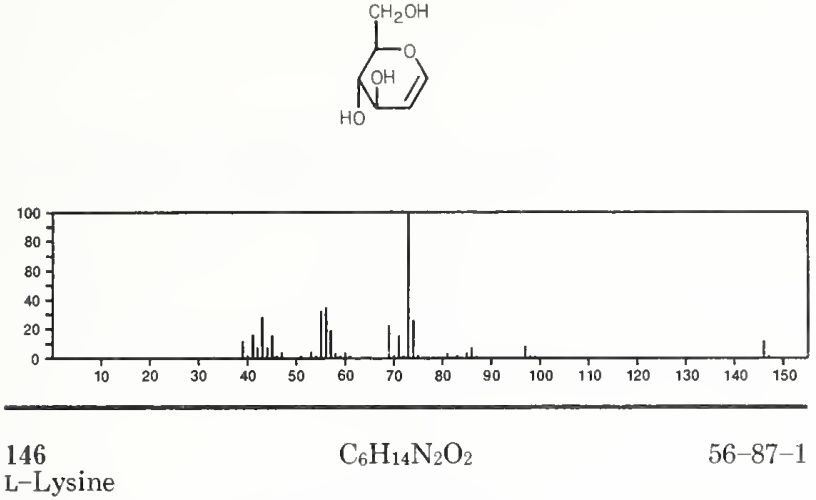

L-Lysine

$\mathrm{HO}_{2} \mathrm{CCH}\left(\mathrm{NH}_{2}\right)\left(\mathrm{CH}_{2}\right) \mathrm{NH}_{2}$

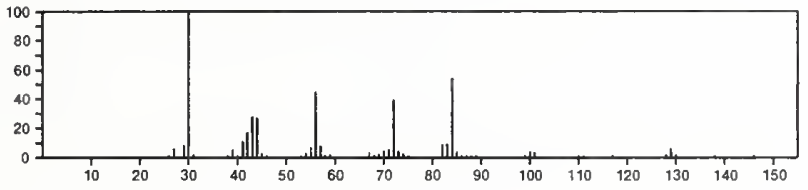

$146 \quad \mathrm{C}_{6} \mathrm{H}_{14} \mathrm{~N}_{2} \mathrm{O}_{2}$

1-Propanamine, $N$-nitro- $N$-propyl-

4164-29-8

$\mathrm{Pr}_{2} \mathrm{NNO}_{2}$

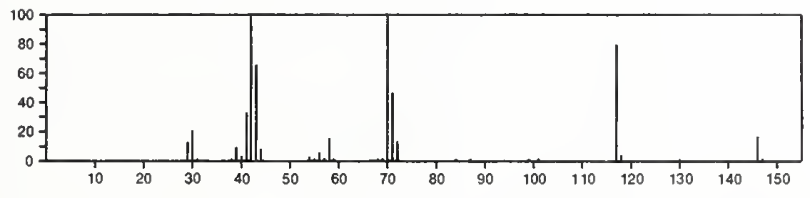

$146 \quad \mathrm{C}_{6} \mathrm{H}_{14} \mathrm{~N}_{2} \mathrm{O}_{2}$

Diethylamine, 1,1'-dimethyl- $N$-nitro-

4164-30-1

$\mathrm{i}-\mathrm{Pr}_{2} \mathrm{NNO}_{2}$

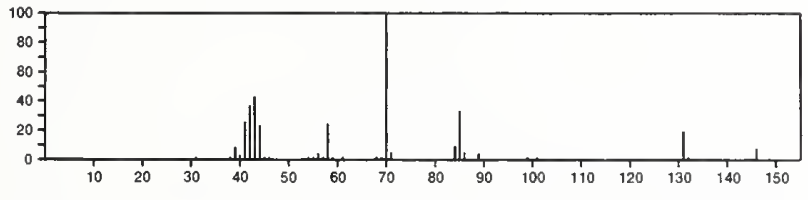

$146 \quad \mathrm{C}_{6} \mathrm{H}_{14} \mathrm{~N}_{2} \mathrm{O}_{2}$

1-Butanamine, $N$-ethyl- $N$-nitro-

$52330-08-2$

$\mathrm{EtN}\left(\mathrm{NO}_{2}\right)\left(\mathrm{CH}_{2}\right) 3 \mathrm{Me}$

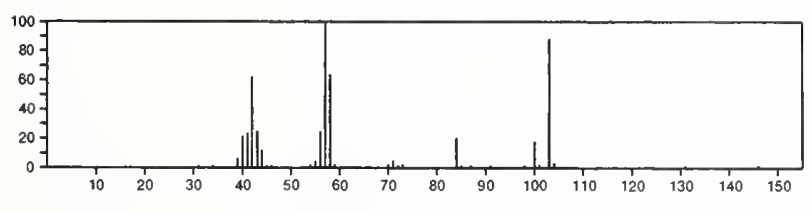

146

$\mathrm{C}_{6} \mathrm{H}_{14} \mathrm{O}_{2} \mathrm{Si}$

Methanol, (trimethylsilyl)-, acetate

$2917-65-9$

$\mathrm{ACOCH}_{2} \mathrm{SiMe}_{3}$

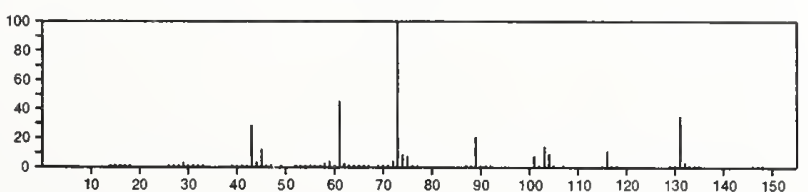

146

$\mathrm{C}_{6} \mathrm{H}_{14} \mathrm{O}_{2} \mathrm{Si}$

$16844-98-7$

Silanol, trimethyl-, propanoate

ElC(O) OS I Me 3

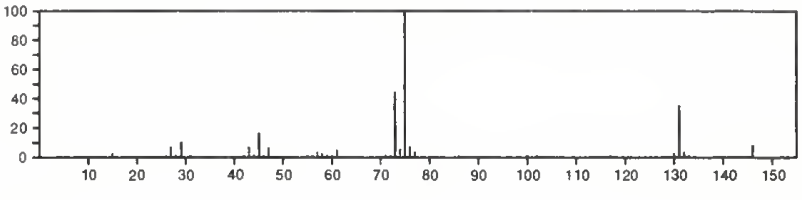

146

Boric acid $\left(\mathrm{H}_{3} \mathrm{BO}_{3}\right)$, triethyl ester

$150-46-9$

\section{$\mathrm{C}_{6} \mathrm{H}_{15} \mathrm{BO}_{3}$}

OE t

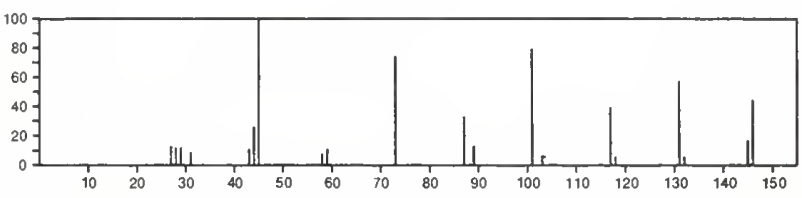

$146 \quad \mathrm{C}_{6} \mathrm{H}_{18} \mathrm{Si}_{2}$

1189-75-9

Silane, [(dimethylsilyl)methyl] trimethyl-

$\mathrm{Me}_{3} \mathrm{Si} \mathrm{CH}_{2} \mathrm{SiHMe}$

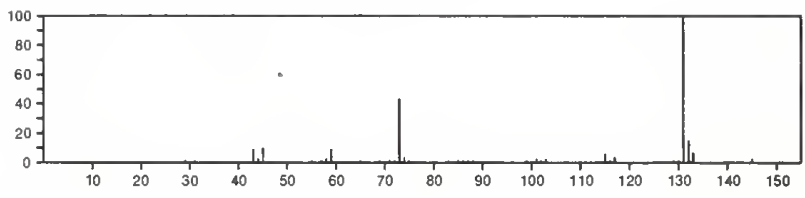

146

Disilane, hexamethyl-

$\mathrm{C}_{6} \mathrm{H}_{18} \mathrm{Si}_{2}$

$1450-14-2$

MezSiSiMe 3

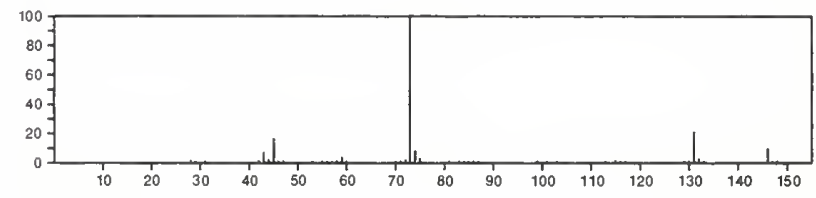

$146 \quad \mathrm{C}_{7} \mathrm{H}_{5} \mathrm{~F}_{3}$

Benzene, (trifluoromethyl)-

98- $08-8$

$\mathrm{F}_{3} \mathrm{CPn}$
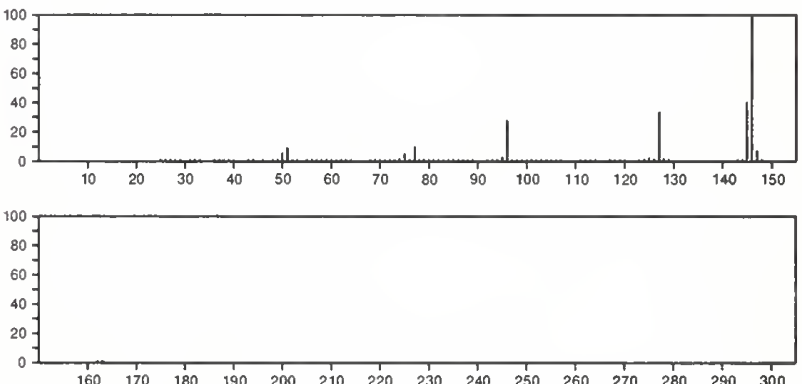
146

$\mathrm{C}_{7} \mathrm{H}_{5} \mathrm{~F}_{3}$

Benzene, methyl-, trifluoro deriv.

$\mathrm{PhMe}+3 \mathrm{~F}$

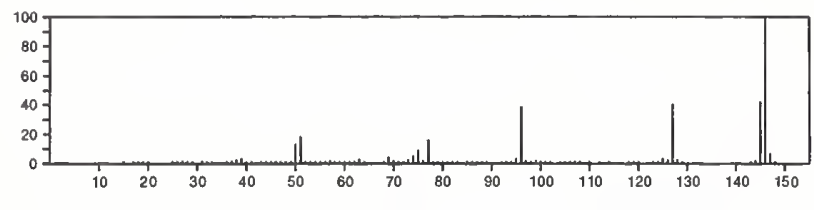

$146 \quad \mathrm{C}_{7} \mathrm{H}_{6} \mathrm{~N}_{4} \quad 936-40-3$

Pteridine, 7-methyl-
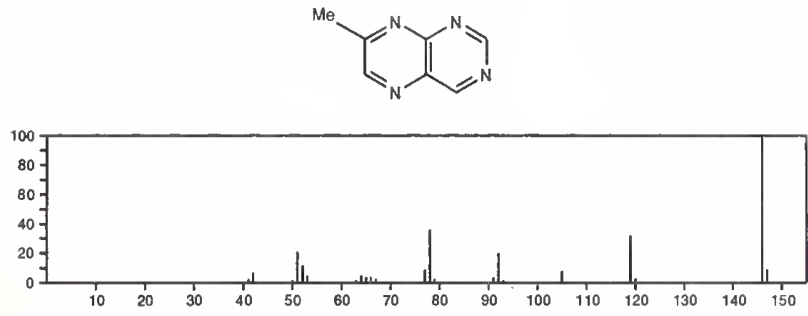

146

Pteridine, 2-methyl-

$\mathrm{C}_{7} \mathrm{H}_{6} \mathrm{~N}_{4}$

$2432-20-4$
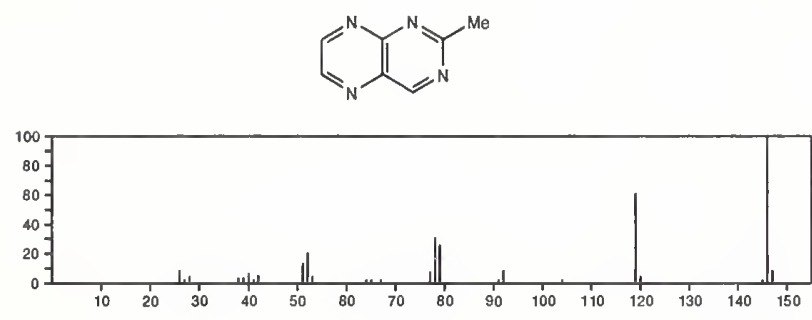

146

$\mathrm{C}_{7} \mathrm{H}_{6} \mathrm{~N}_{4}$

$2432-21-5$

Pteridine, 4-methyl-<smiles>Nc1ncnc2nccnc12</smiles>

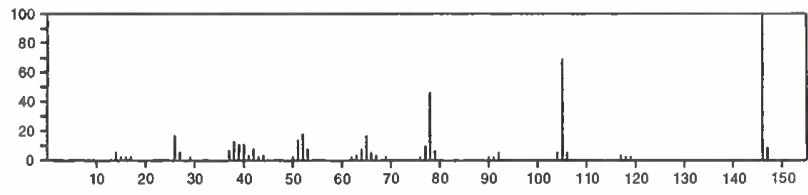

146

$\mathrm{C}_{7} \mathrm{H}_{11} \mathrm{ClO}$

Bicyclo[2.2.1]heptan-2-ol, 3-chloro-<smiles>OC1C2CCC(C2)C1Cl</smiles>

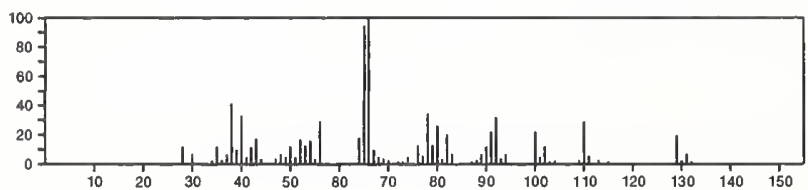

146 $\mathrm{C}_{7} \mathrm{H}_{14} \mathrm{OS}$

$2432-32-8$

$\mathrm{Me}\left(\mathrm{CH}_{2}\right)_{4} \mathrm{SAC}$

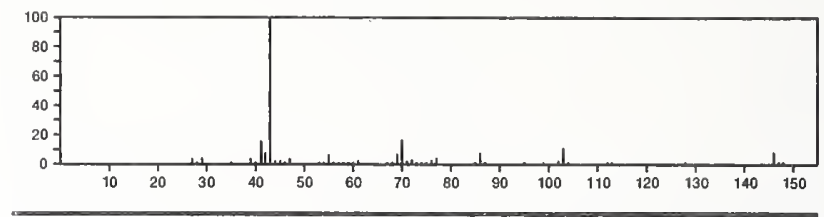

146

$\mathrm{C}_{7} \mathrm{H}_{14} \mathrm{OS}$

Acetic acid, thio-, $S$-isopentyl ester

$2432-38-4$

$\mathrm{Me}_{2} \mathrm{CHCH}_{2} \mathrm{CH}_{2} \mathrm{SAC}$

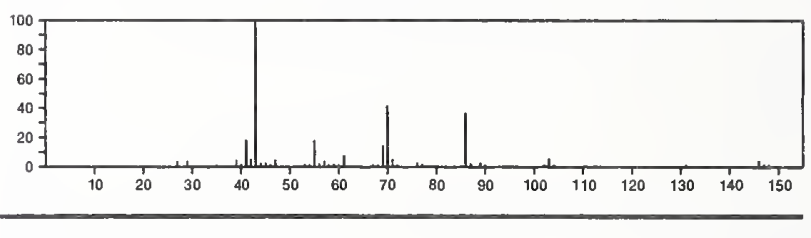

146

$\mathrm{C}_{7} \mathrm{H}_{14} \mathrm{OS}$

$2432-40-8$

Acetic acid, thio-, S-1-methylbutyl ester

PrCHMESAC

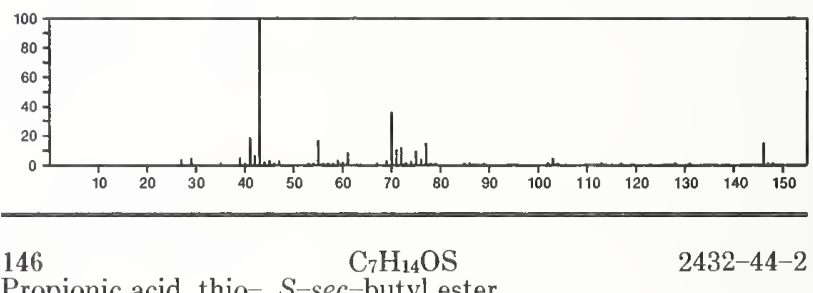

Propionic acid, thio-, $S$-sec-butyl ester

$\mathrm{E}\left\{\mathrm{C}(\mathrm{O}) \mathrm{S}\left(\mathrm{CH}_{2}\right)_{3} \mathrm{Me}\right.$

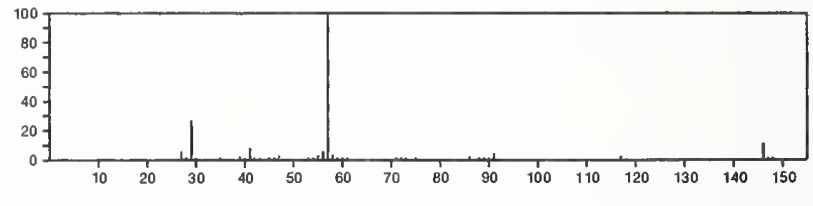

146

$\mathrm{C}_{7} \mathrm{H}_{14} \mathrm{OS}$

Propionic acid, thio-, $S$-isobutyl ester

2432-48-6

$\mathrm{i}-\mathrm{BuSC}(\mathrm{O}) \mathrm{Et}$

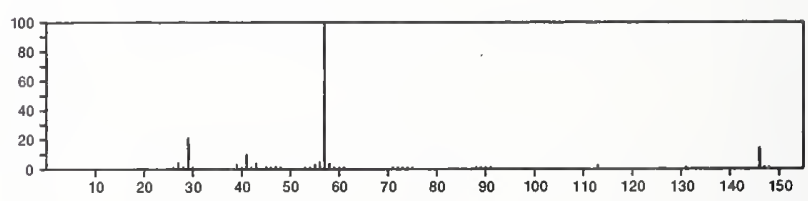

146

$\mathrm{C}_{7} \mathrm{H}_{14} \mathrm{OS}$

$2432-57-7$

Butanethioic acid, 3-methyl-, $S$-ethyl ester

$\mathrm{Me}_{2} \mathrm{CHCH}_{2} \mathrm{Cl}(\mathrm{O}) \mathrm{SEt}$

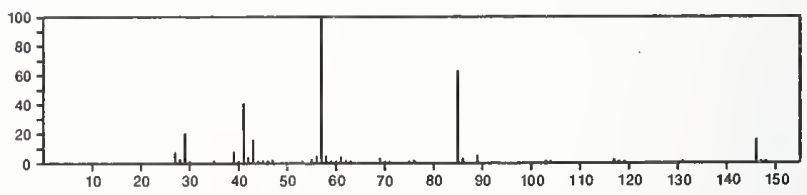


146

$\mathrm{C}_{7} \mathrm{H}_{14} \mathrm{OS}$

Hexanethioic acid, $S$-methyl ester

$\mathrm{Me}\left(\mathrm{CH}_{2}\right)_{4} \mathrm{C}(\mathrm{O}) \mathrm{SMe}$

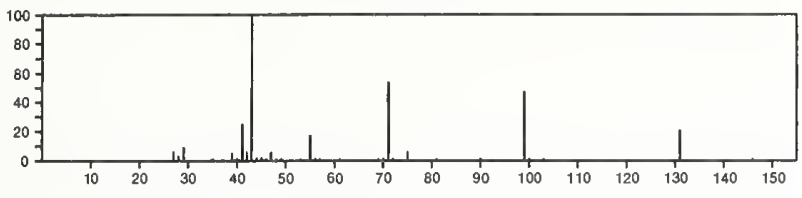

146

Pentanethioic acid, $S$-ethyl ester

2432-92-0

$\mathrm{Me}\left(\mathrm{CH}_{2}\right)_{3} \mathrm{C}(\mathrm{O}) \mathrm{SEt}$

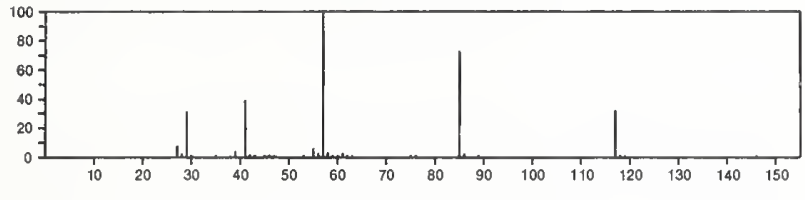

146

$\mathrm{C}_{7} \mathrm{H}_{14} \mathrm{OS}$

2H-Pyran, 2-(ethylthio) tetrahydro-

$16315-51-8$
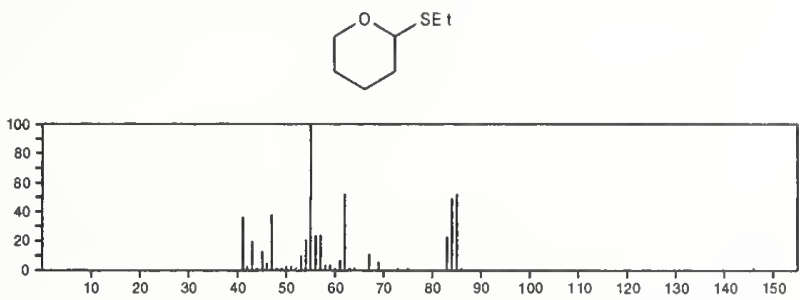

146

$\mathrm{C}_{7} \mathrm{H}_{14} \mathrm{OS}$

1,3-Oxathiane, 2,4,6-trimethyl-, $(2 \alpha, 4 \beta, 6 \alpha)-$

22425-90-7
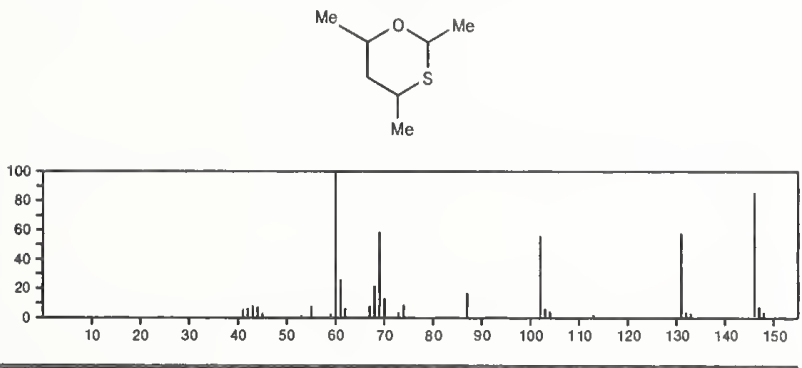

146

$\mathrm{C}_{7} \mathrm{H}_{14} \mathrm{OS}$

1,3-Oxathiane, 2,4,6-trimethyl-, $(2 \alpha, 4 \alpha, 6 \beta)$ -

22425-91-8<smiles>CC1CC([N+](=O)[O-])SC(C)O1</smiles>

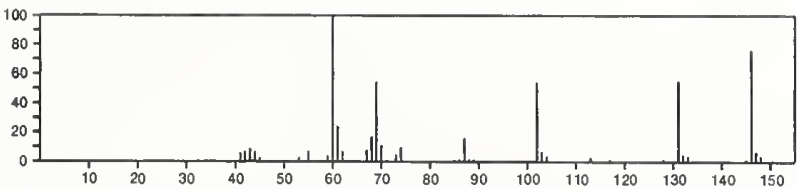

146

$\mathrm{C}_{7} \mathrm{H}_{14} \mathrm{OS}$

1,3-Oxathiane, 2,4,6-trimethyl-, $(2 \alpha, 4 \alpha, 6 \alpha)$ -
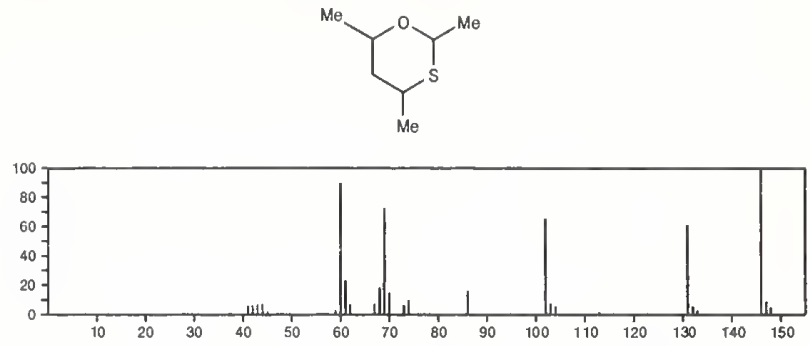

${ }_{1,3}^{146}$-Oxathiane, 2-isopropyl-

24699-59-0
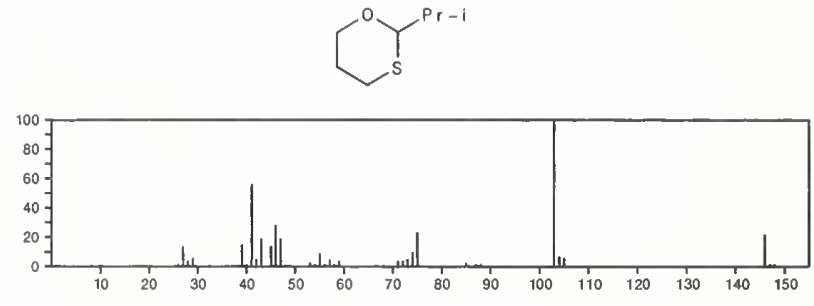

146-Oxathiane, 2-ethyl-2-methyl-
1,3-O

30098-80-7<smiles>CCC1([N+](=O)[O-])OCCCS1</smiles>

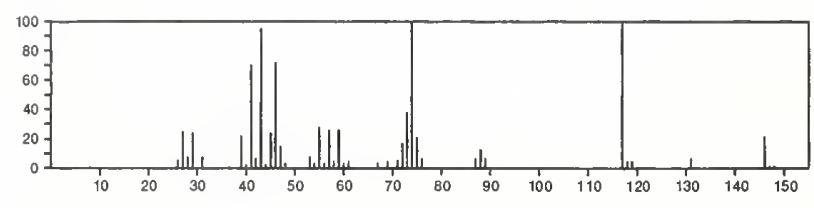

$146 \quad \mathrm{C}_{7} \mathrm{H}_{14} \mathrm{OS}$

30253-09-9

1,3-Oxathiane, 2,2,6-trimethyl-<smiles>CC1CCSC(C)([N+](=O)[O-])O1</smiles>

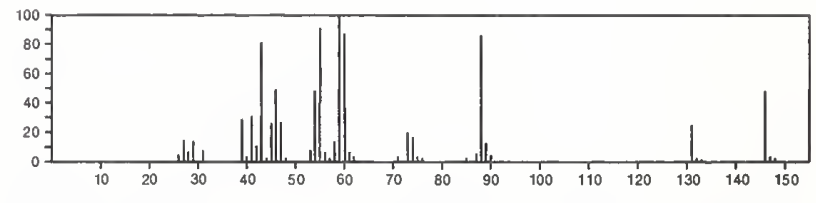

146

$\mathrm{C}_{7} \mathrm{H}_{14} \mathrm{OS}$

$33709-59-0$

1,3-Oxathiane, 2-ethyl-6-methyl-<smiles>CCC1OC([N])CCS1</smiles>

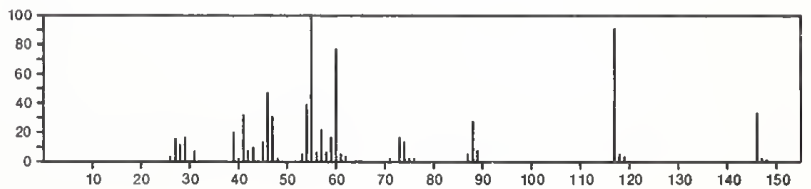


146 Carbonic acid, dipropyl ester

$\mathrm{C}_{7} \mathrm{H}_{14} \mathrm{O}_{3}$

$623-96-1$

$\operatorname{PrOC}(0)$ OP

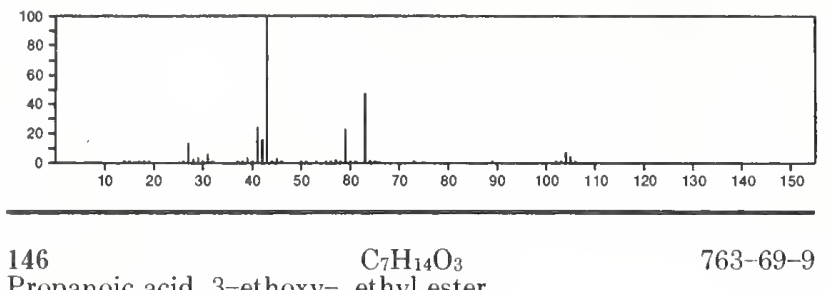

Propanoic acid, 3-ethoxy-, ethyl ester

$\mathrm{EtOC}(\mathrm{O}) \mathrm{CH}_{2} \mathrm{CH}_{2} \mathrm{OEt}$

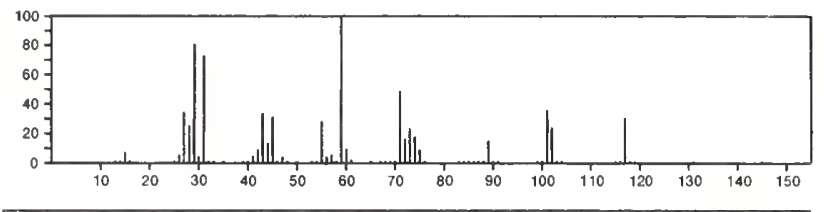

$146 \quad \mathrm{C}_{7} \mathrm{H}_{14} \mathrm{O}_{3}$

2441-06-7

Butanoic acid, 2-hydroxy-3-methyl-, ethyl ester

$\mathrm{Me}{ }_{2} \mathrm{CHCH}(\mathrm{OH}) \mathrm{C}(\mathrm{O}) \mathrm{OE}$ t

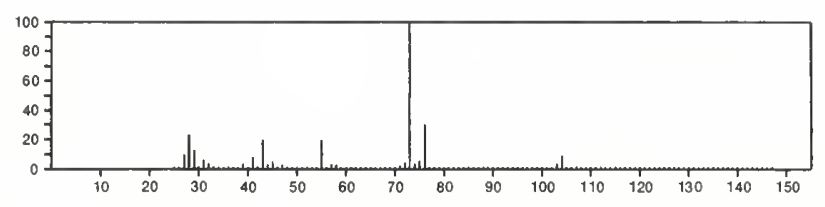

146

2-Propanone, 1,1-diethoxy-

$\mathrm{C}_{7} \mathrm{H}_{14} \mathrm{O}_{3}$

$5774-26-5$

(EtO) ${ }_{2} \mathrm{CHCOM}$

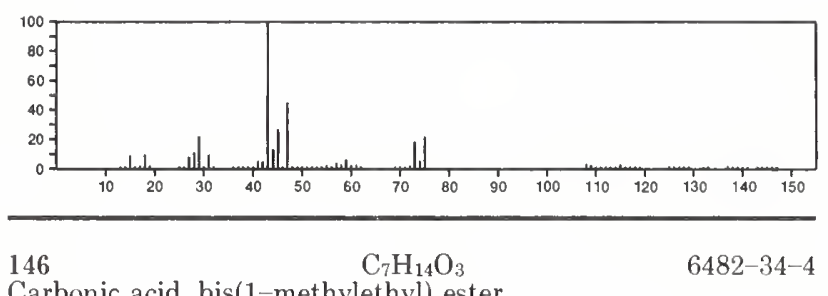

Carbonic acid, bis(1-methylethyl) ester

$\mathrm{i}-\operatorname{PrOC}(0) \mathrm{OPr}-1$

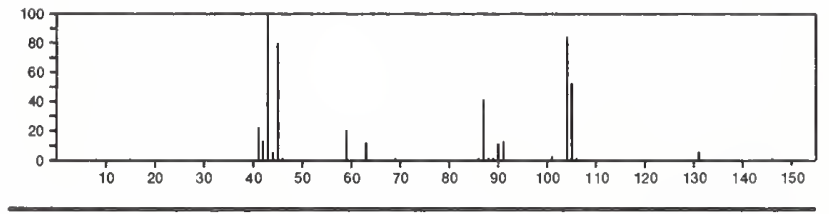

$146 \quad \mathrm{C}_{7} \mathrm{H}_{14} \mathrm{O}_{3}$

6938-26-7

Pentanoic acid, 2-hydroxy-, ethyl ester

$\mathrm{E}+\mathrm{OC}(\mathrm{O}) \mathrm{CH}(\mathrm{OH}) \mathrm{Pr}$

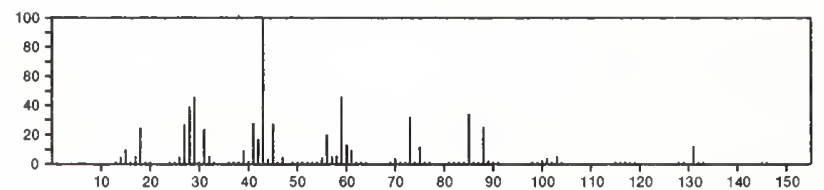

146

$\mathrm{C}_{7} \mathrm{H}_{14} \mathrm{O}_{3}$

$21317-50-0$

$2 H$-Pyran-3-ol, tetrahydro-6-methoxy-2-methyl-, $[2 R-(2 \alpha, 3 \beta, 6 \beta)]-$
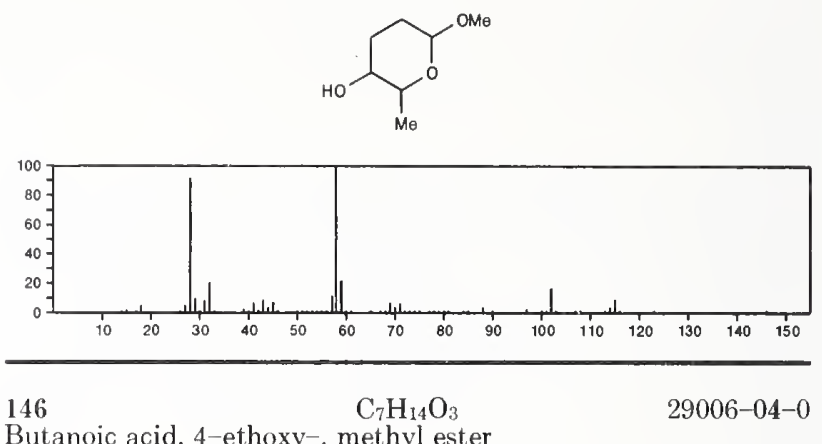

Butanoic acid, 4-ethoxy-, methyl ester

$\mathrm{EtO}\left(\mathrm{CH}_{2}\right)_{3} \mathrm{C}(\mathrm{O}) \mathrm{OM}_{\theta}$

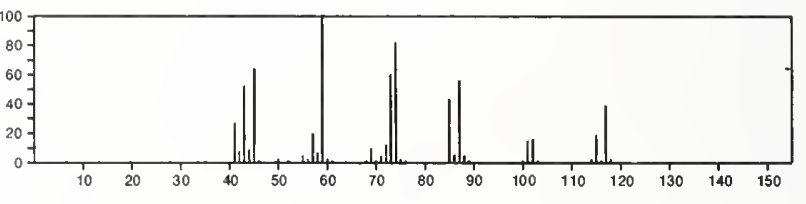

146

$\mathrm{C}_{7} \mathrm{H}_{14} \mathrm{O}_{3}$

29021-98-5

1,3-Dioxolane-2-propanol, 2-methyl-
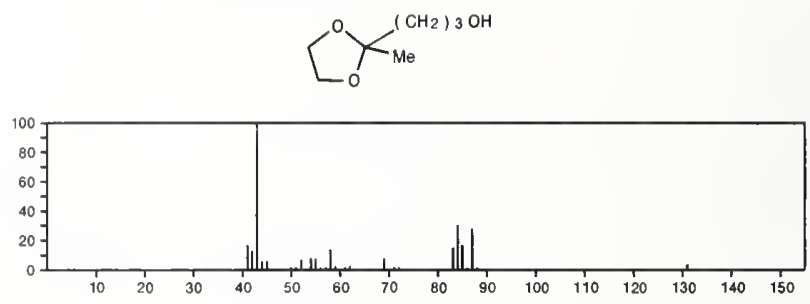

$146 \quad \mathrm{C}_{7} \mathrm{H}_{14} \mathrm{O}_{3}$

Pentanoic acid, 2-hydroxy-4-methyl-, methyl ester

$40348-72-9$

$\mathrm{MeOC}(\mathrm{O}) \mathrm{CH}(\mathrm{OH}) \mathrm{CH}_{2} \mathrm{CHMe}_{2}$

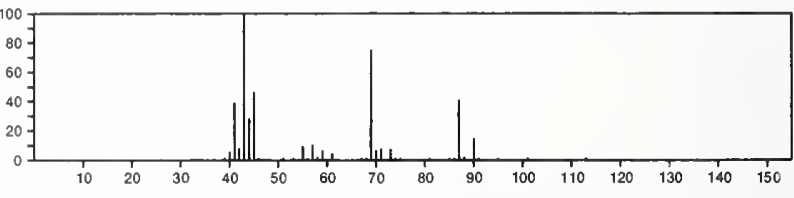

146

$\mathrm{C}_{7} \mathrm{H}_{14} \mathrm{O}_{3}$

$41654-19-7$

Pentanoic acid, 2-hydroxy-3-methyl-, methyl ester

$\left.{ }_{\theta} \mathrm{CH}_{2} \mathrm{CHM} \mathrm{CH}_{\theta} \mathrm{OH}\right) \mathrm{C}(\mathrm{O}) \mathrm{OM}$

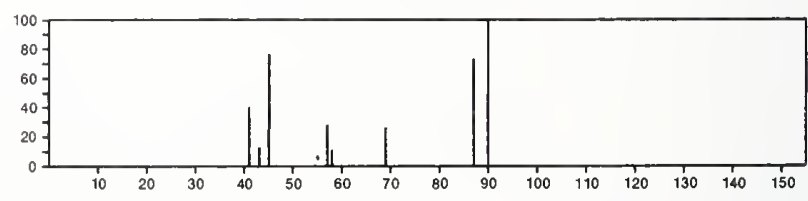

146

$\mathrm{C}_{7} \mathrm{H}_{14} \mathrm{O}_{3}$

42415-64-5

Acetic acid, (1-methylethoxy)--, ethyl ester

$\left.\mathrm{I}-\mathrm{PrOCH} \mathrm{OC}_{2} \mathrm{O}\right) \mathrm{OE}$

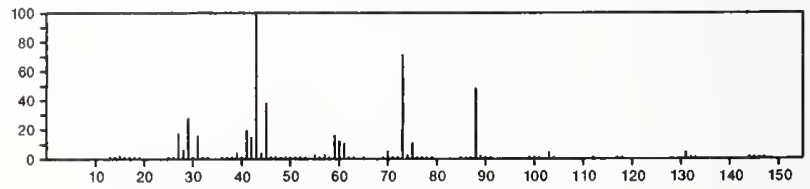


146

$\mathrm{C}_{7} \mathrm{H}_{14} \mathrm{O}_{3}$

Pentanoic acid, 5-methoxy-, methyl ester

$52546-36-8$

$\mathrm{MeO}\left(\mathrm{CH}_{2}\right)_{4} \mathrm{C}(\mathrm{O}) \mathrm{OMe}$

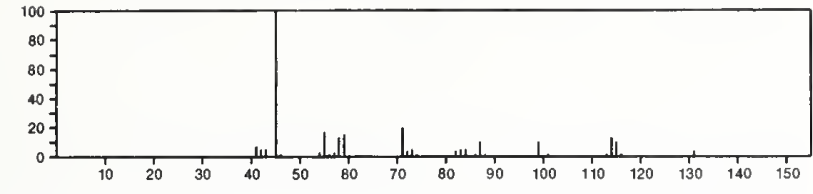

146

3-Pentanone, 1,5-dimethoxy-

$\mathrm{C}_{7} \mathrm{H}_{14} \mathrm{O}_{3}$

$\mathrm{Me} \mathrm{OCH}_{2} \mathrm{CH}_{2} \mathrm{COCH}_{2} \mathrm{CH}_{2} \mathrm{OMe}_{\mathrm{N}}$

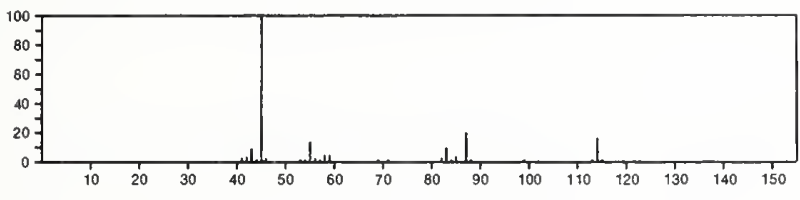

146

$\mathrm{C}_{7} \mathrm{H}_{14} \mathrm{O}_{3}$

$54063-13-7$

Acetic acid, ethoxy-, 1-methylethyl ester

$\mathrm{E}_{1} \mathrm{OCH}_{2} \mathrm{C}(\mathrm{O}) \mathrm{OPr}_{-} \mathrm{i}$

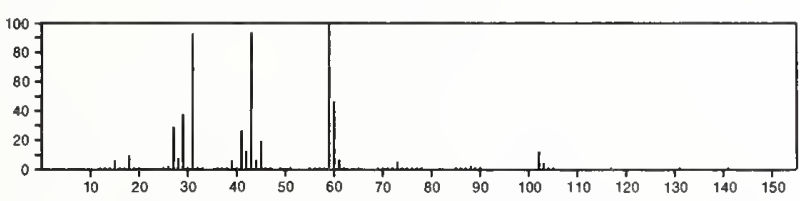

146

$\mathrm{C}_{7} \mathrm{H}_{14} \mathrm{O}_{3}$

Ethene, (2-ethoxy-1-methoxyethoxy)-

54063-18-2

$\mathrm{E}$ t OCH $\mathrm{H}_{2} \mathrm{CH}(\mathrm{OMe}) \mathrm{OCH}=\mathrm{CH}_{2}$

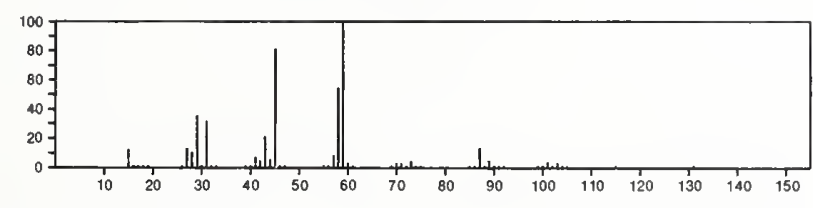

146

$\mathrm{C}_{7} \mathrm{H}_{18} \mathrm{~N}_{2} \mathrm{O}$

2-Propanol, 1,3-bis(dimethylamino)

$5966-51-8$

$\mathrm{Me}_{2} \mathrm{NCH}_{2} \mathrm{CH}(\mathrm{OH}) \mathrm{CH}_{2} \mathrm{NMe}_{2}$

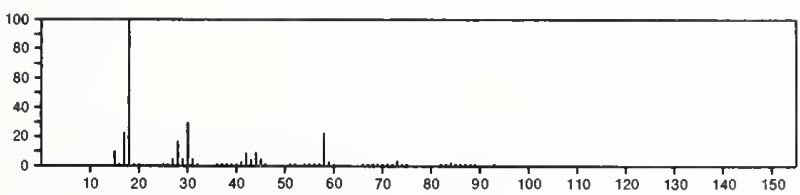

146

Silane, butoxytrimethyl-

$\mathrm{C}_{7} \mathrm{H}_{18} \mathrm{OSi}$

$1825-65-6$

$\mathrm{Me}\left(\mathrm{CH}_{2}\right)_{3} \mathrm{OSIMO}$

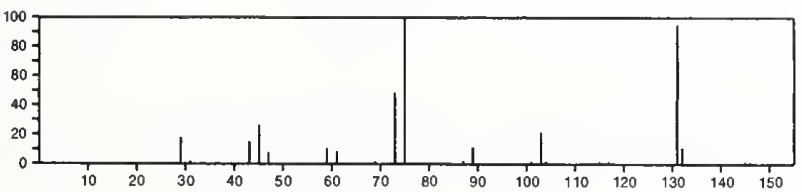

146

$\mathrm{C}_{7} \mathrm{H}_{18} \mathrm{OSi}$

Silane, trimethyl(1-methylpropoxy)-

$\mathrm{Me} 3 \mathrm{Si} \mathrm{OBu}-\mathrm{s}$

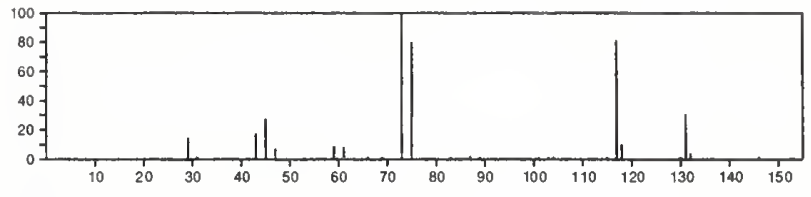

146

Silane, (1,1-dimethylethoxy)trimethyl

13058-24-7

t-BuOSi Me 3

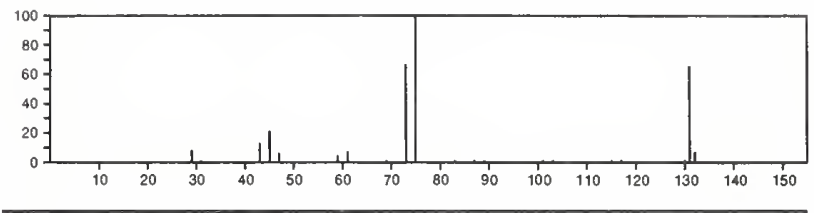

146

$\mathrm{C}_{7} \mathrm{H}_{18} \mathrm{OSi}$

Silane, trimethyl(propoxymethyl)-

$17348-62-8$

$\mathrm{PrOCH}_{2} \mathrm{SiMe}_{3}$

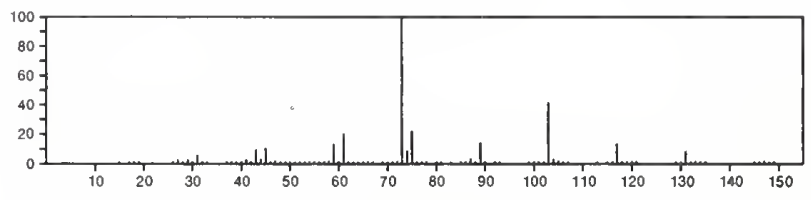

146

$\mathrm{C}_{7} \mathrm{H}_{18} \mathrm{OSi}$

Silane, trimethyl(2-methylpropoxy)

$18269-50-6$

$\mathrm{Me} 3 \mathrm{Si} \mathrm{OBu}$ -

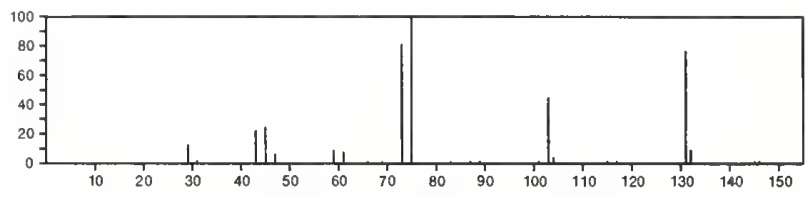

146

$\mathrm{C}_{8} \mathrm{H}_{6} \mathrm{~N}_{2} \mathrm{O}$

1125-61-7

Cinnoline, 1-oxide
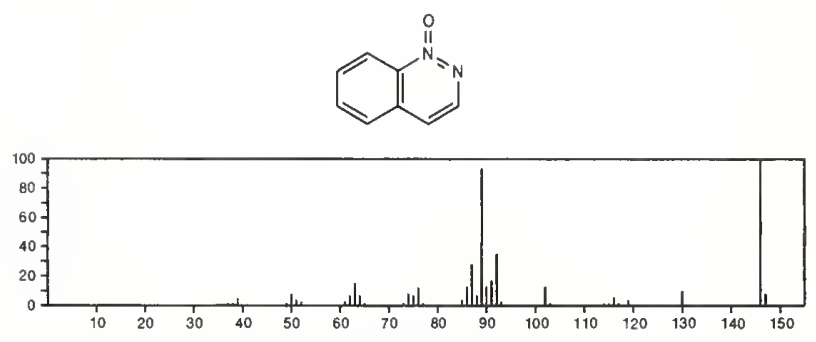

146

2(1H)-Quinoxalinone

$\mathrm{C}_{8} \mathrm{H}_{6} \mathrm{~N}_{2} \mathrm{O}$

$1196-57-2$<smiles>O=c1cnc2ccccc2[nH]1</smiles>

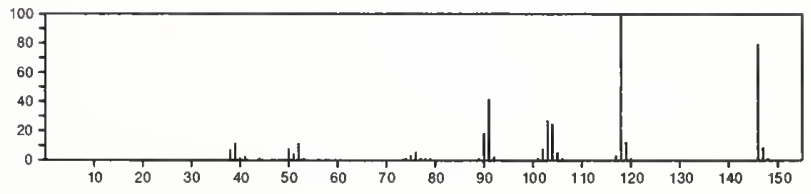


$146 \quad \mathrm{C}_{8} \mathrm{H}_{6} \mathrm{~N}_{2} \mathrm{O}$

$1 H$-Benzimidazole-2-carboxaldehyde
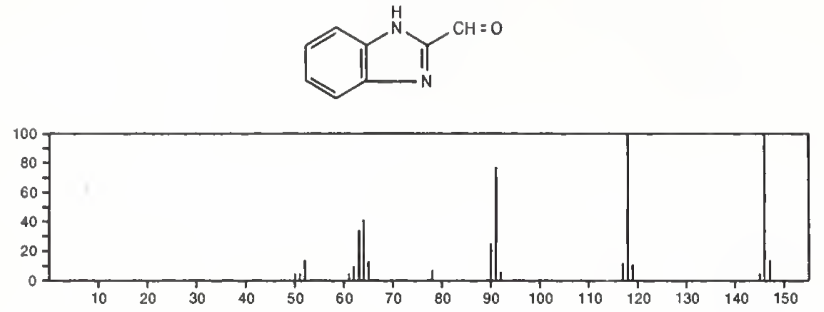

146

Cinnoline, 2-oxide

$\mathrm{C}_{8} \mathrm{H}_{6} \mathrm{~N}_{2} \mathrm{O}$

$4215-44-5$
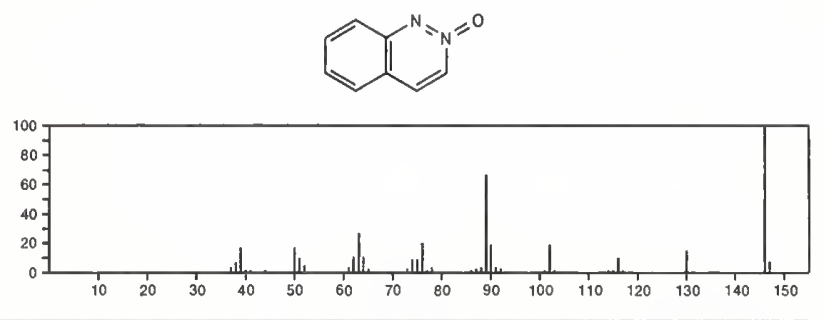

146

Quinoxaline, 1-oxide

$\mathrm{C}_{8} \mathrm{H}_{6} \mathrm{~N}_{2} \mathrm{O}$

6935-29-1
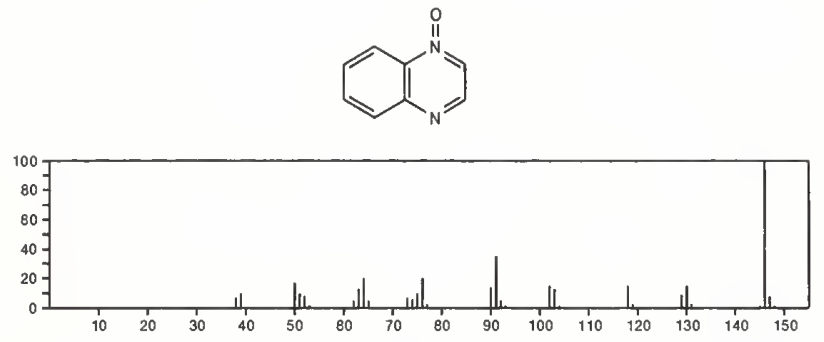

146

$\mathrm{C}_{8} \mathrm{H}_{6} \mathrm{~N}_{2} \mathrm{O}$

$18636-89-0$

Phthalazine, 2-oxide
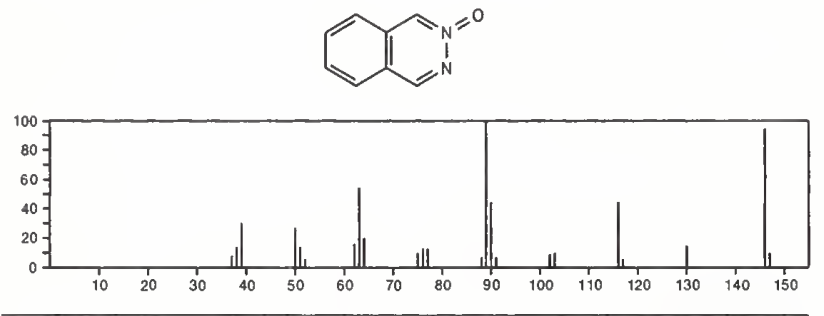

146

Quinazoline, 3-oxide

$\mathrm{C}_{8} \mathrm{H}_{6} \mathrm{~N}_{2} \mathrm{O}$

32907-43-0
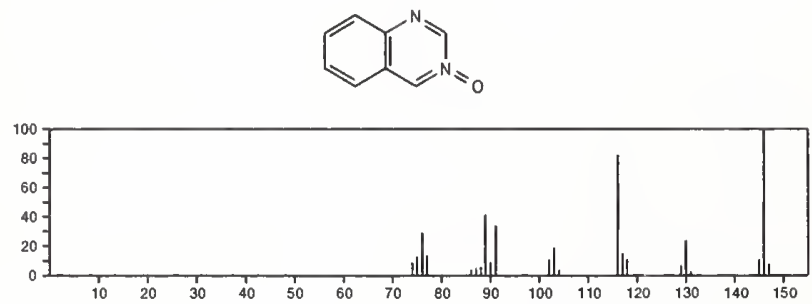

$146 \quad \mathrm{C}_{8} \mathrm{H}_{12} \mathrm{~F}_{2}$

20277-40-1

Bicyclo[2.2.2]octane, 1,4-difluoro-
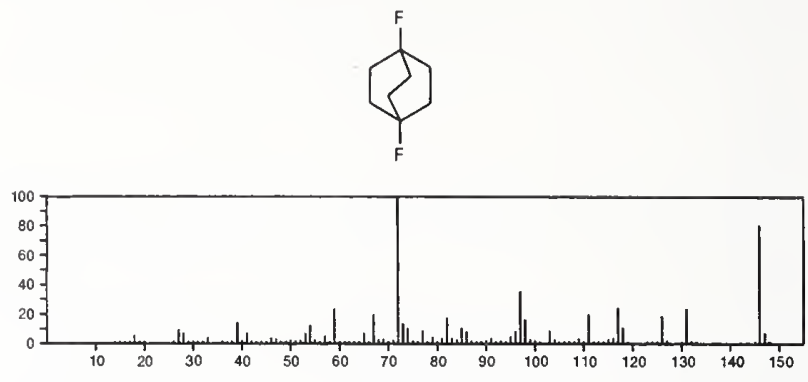

146

1,3-Hexanediol, 2-ethyl-

$\mathrm{HOCH}_{2} \mathrm{CHE} t \mathrm{CH}(\mathrm{OH}) \mathrm{P}$

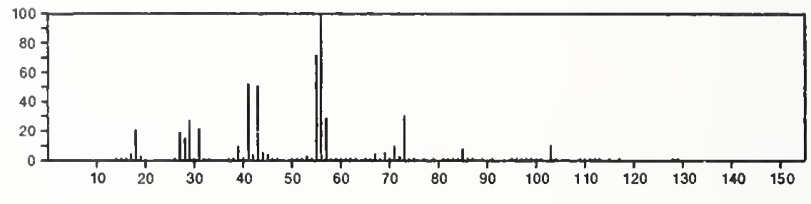

146

$\mathrm{C}_{8} \mathrm{H}_{18} \mathrm{O}_{2}$

Propane, 1,1'-[ethylidenebis(oxy)]bis-

$105-82-8$

$\mathrm{MeCH}(\mathrm{OPr})_{2}$

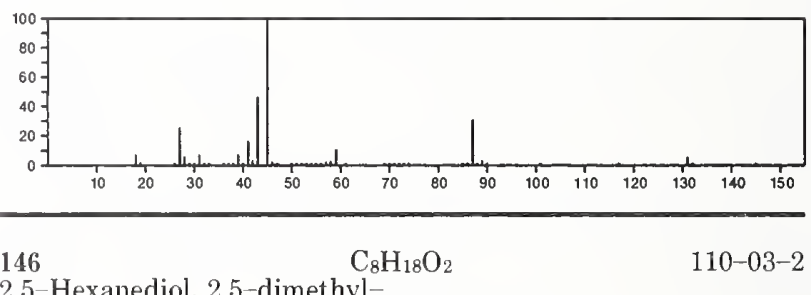

$\mathrm{Me}_{2} \mathrm{COHCH}_{2} \mathrm{CH}_{2} \mathrm{CM}_{2} \mathrm{OH}$

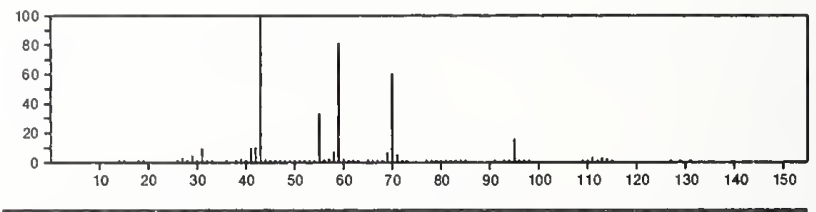

146

$\mathrm{C}_{8} \mathrm{H}_{18} \mathrm{O}_{2}$

Peroxide, bis(1,1-dimethylethyl)

$110-05-4$

$t-B$ OOOBu-

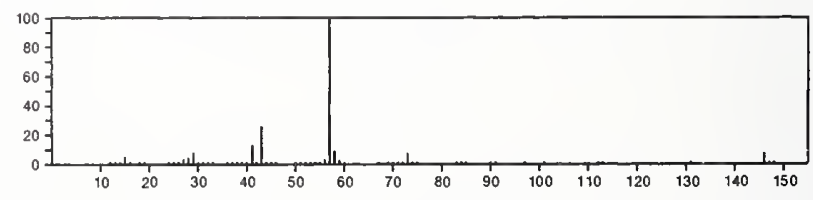

146

$\mathrm{C}_{8} \mathrm{H}_{18} \mathrm{O}_{2}$

$112-25-4$

Ethanol, 2-(hexyloxy)-

$\mathrm{HOCH}_{2} \mathrm{CH}_{2} \mathrm{O}\left(\mathrm{CH}_{2}\right) 5 \mathrm{M}$

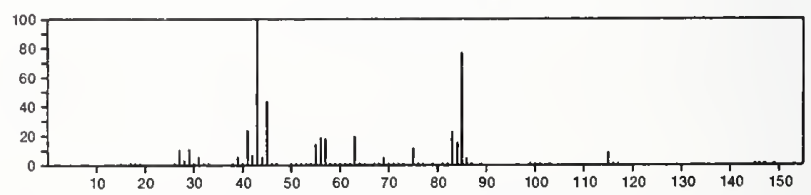


${ }_{1,3}^{146}$-Pentanediol, 2,2,4-trimethyl-

$\mathrm{Me}_{2} \mathrm{CHCH}$ ( $\mathrm{OH}$ ) $\mathrm{CMe}_{2} \mathrm{CH}_{2} \mathrm{OH}$

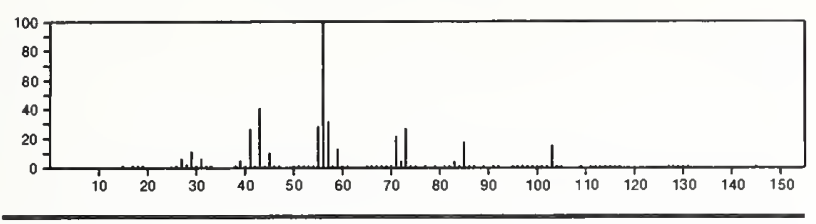

146

1,2-Octanediol

$\mathrm{C}_{8} \mathrm{H}_{18} \mathrm{O}_{2}$

$1117-86-8$

$\mathrm{Me}$ ( $\mathrm{CH}_{2}$ ) $5 \mathrm{CH}$ ( $\mathrm{OH}$ ) $\mathrm{CH}_{2} \mathrm{OH}$

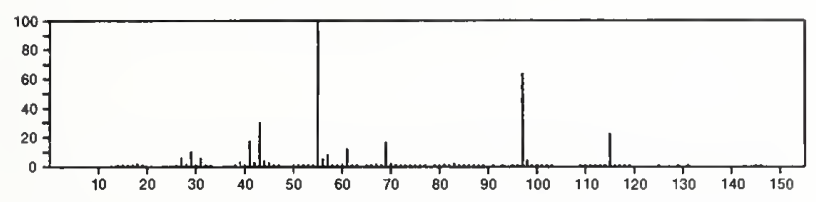

146

3,4-Hexanediol, 3,4-dimethyl-

$\mathrm{C}_{8} \mathrm{H}_{18} \mathrm{O}_{2}$

$1185-02-0$

EtCMe (OH) CEt ( OH) Me

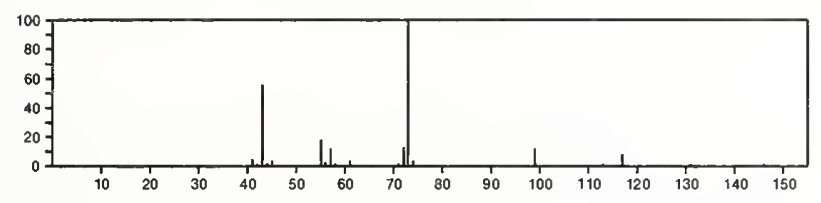

146

Peroxide, dibutyl

$\mathrm{C}_{8} \mathrm{H}_{18} \mathrm{O}_{2}$

$\mathrm{Me}\left(\mathrm{CH}_{2}\right)_{3} \mathrm{OO}\left(\mathrm{CH}_{2}\right)_{3} \mathrm{Me}$
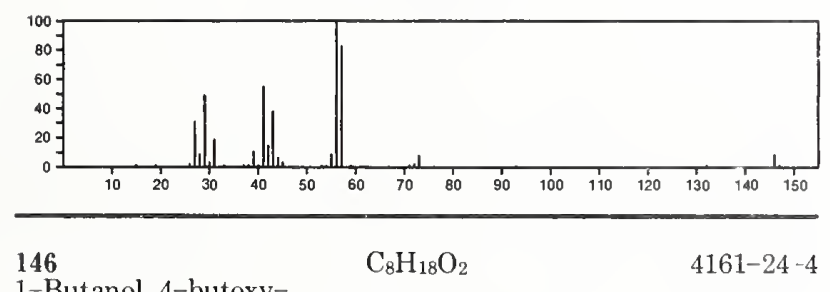

1-Butanol, 4-butoxy-

$\mathrm{HO}\left(\mathrm{CH}_{2}\right)_{4} \mathrm{O}\left(\mathrm{CH}_{2}\right)_{3} \mathrm{Me}$
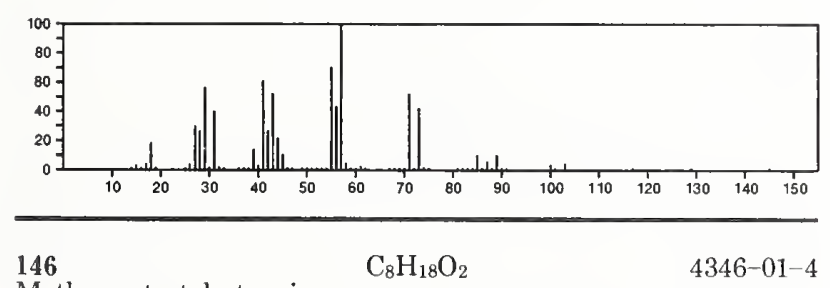

Methane, tert-butoxyisopropoxy-

$\mathrm{t}-\mathrm{Bu} \mathrm{OCH}_{2} \mathrm{OPr}_{-} \mathrm{i}$

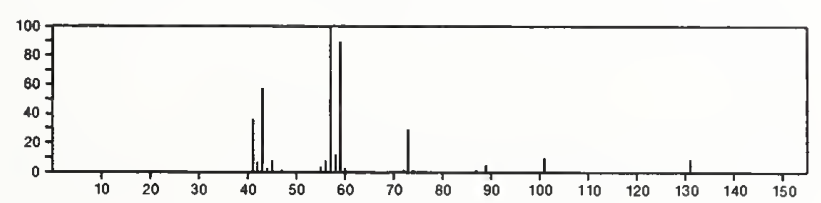

$146 \quad \mathrm{C}_{8} \mathrm{H}_{18} \mathrm{O}_{2}$

Peroxide, bis(1-methylpropyl)

$4715-28-0$

$s-8 u 00 B u-s$

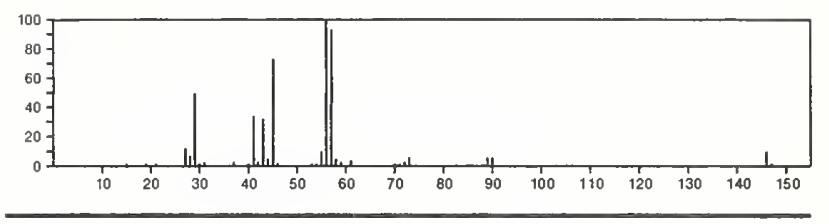

146

$\mathrm{C}_{8} \mathrm{H}_{18} \mathrm{O}_{2}$

$13179-98-1$

Hexane, 1,6-dimethoxy-

$\mathrm{MeO}\left(\mathrm{CH}_{2}\right) 6 \mathrm{OMe}$
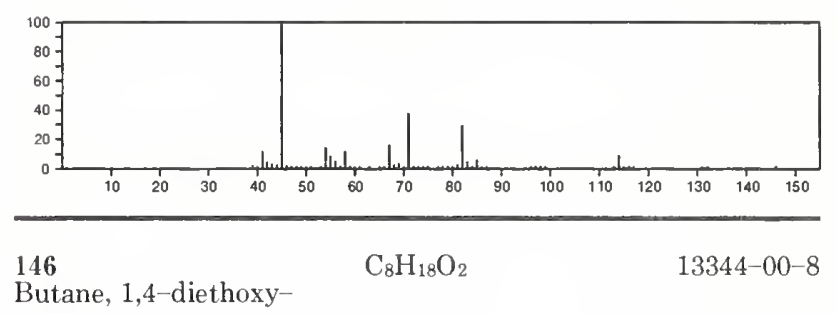

$\mathrm{EtO}\left(\mathrm{CH}_{2}\right){ }_{4} \mathrm{OEt}$
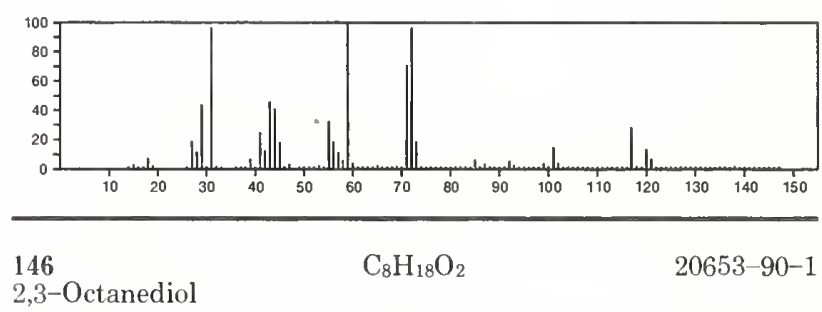

2,3-Octanediol

$\mathrm{Me}\left(\mathrm{CH}_{2}\right)_{4} \mathrm{CH}(\mathrm{OH}) \mathrm{CH}(\mathrm{OH}) \mathrm{Me}$
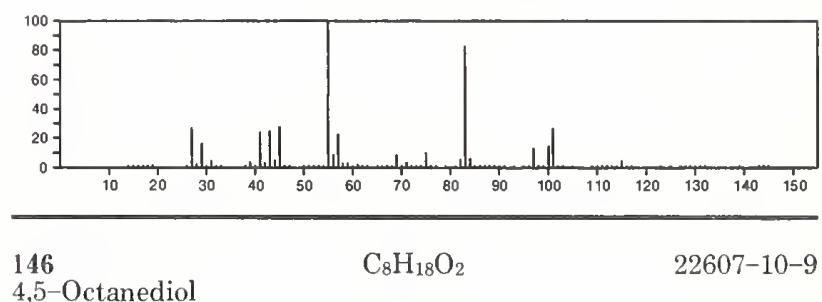

4,5 -Octanediol

$\mathrm{PrCH}(\mathrm{OH}) \mathrm{CH}(\mathrm{OH}) \mathrm{Pr}$

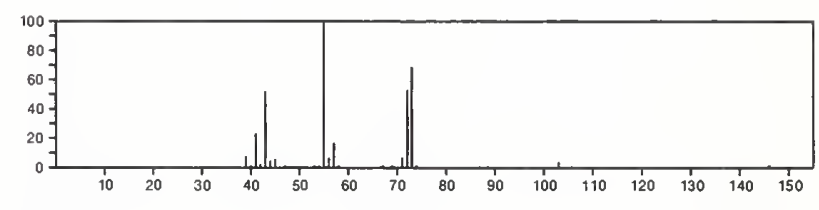

$146 \quad \mathrm{C}_{8} \mathrm{H}_{18} \mathrm{O}_{2} \quad 22607-11-0$

3,4-Hexanediol, 2,5-dimethyl-

$\mathrm{Me} 2 \mathrm{CHCH}(\mathrm{OH}) \mathrm{CH}(\mathrm{OH}) \mathrm{CHMe}_{2}$

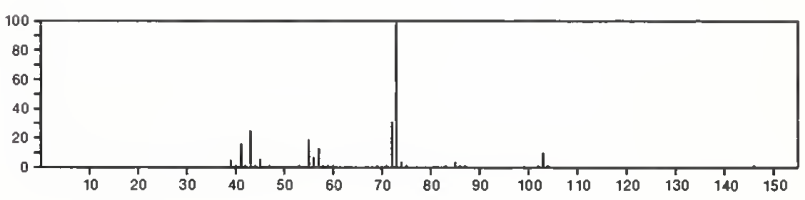


146

1,3-Octanediol

$\mathrm{C}_{8} \mathrm{H}_{18} \mathrm{O}_{2}$

$\mathrm{HOCH}_{2} \mathrm{CH}_{2} \mathrm{CH}(\mathrm{OH})\left(\mathrm{CH}_{2}\right) 4 \mathrm{Me}$

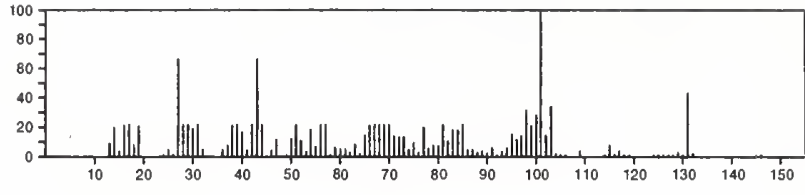

146

$\mathrm{C}_{8} \mathrm{H}_{18} \mathrm{~S}$

Propane, 2,2'-thiobis [2-methyl-

$S(B u-t) 2$

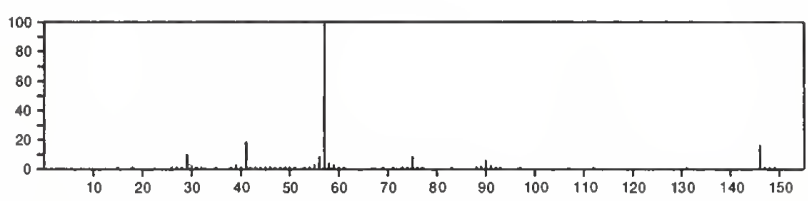

146

1-Octanethiol

$\mathrm{C}_{8} \mathrm{H}_{18} \mathrm{~S}$

$\mathrm{Me}\left(\mathrm{CH}_{2}\right)_{7} \mathrm{SH}$
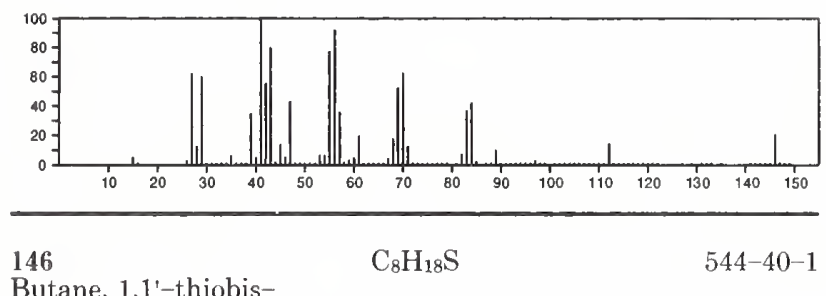

Butane, 1,1'-thiobis-

$\mathrm{Me}\left(\mathrm{CH}_{2}\right)_{3} \mathrm{~S}\left(\mathrm{CH}_{2}\right)_{3} \mathrm{Me}$

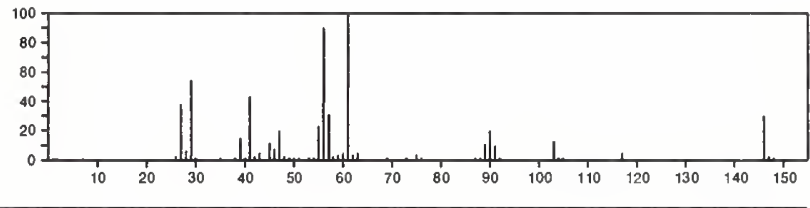

146

$\mathrm{C}_{8} \mathrm{H}_{18} \mathrm{~S}$

Propane, 1,1'-thiobis[2-methyl-

$592-65-4$

$S(B u-i)_{2}$

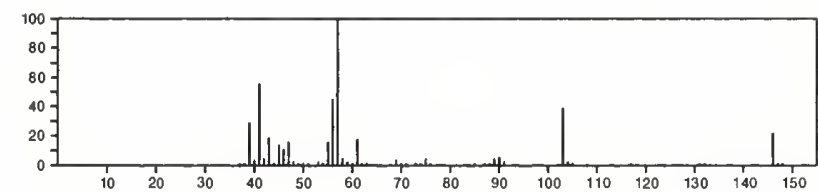

146

Butane, 2,2'-thiobis-

$\mathrm{C}_{8} \mathrm{H}_{18} \mathrm{~S}$

626-26-6

$S(B u-s)_{2}$

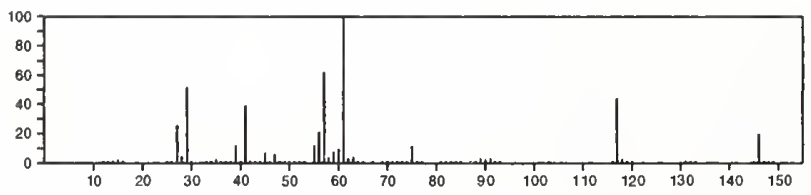

146

2-Heptanethiol, 2-methyl-

$\mathrm{C}_{8} \mathrm{H}_{18} \mathrm{~S}$

763-20-2

$\mathrm{Me}_{2} \mathrm{CSH}\left(\mathrm{CH}_{2}\right)_{4} \mathrm{Me}$

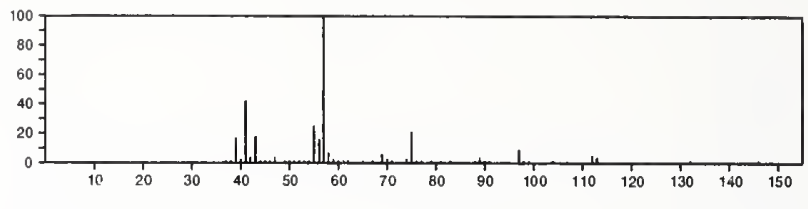

146

Hexane, 1-(ethylthio)-

$\mathrm{C}_{8} \mathrm{H}_{18} \mathrm{~S}$

$7309-44-6$

$\mathrm{Me}\left(\mathrm{CH}_{2}\right) 5 \mathrm{SE}$

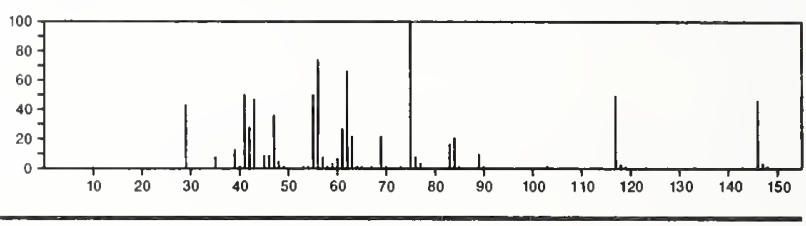

146

1-Hexanethiol, 2-ethyl-

$\mathrm{C}_{8} \mathrm{H}_{18} \mathrm{~S}$

7341-17-5

$\mathrm{Me}\left(\mathrm{CH}_{2}\right)_{3} \mathrm{CHE}_{\mathrm{CH}} \mathrm{CH}_{2} \mathrm{SH}$

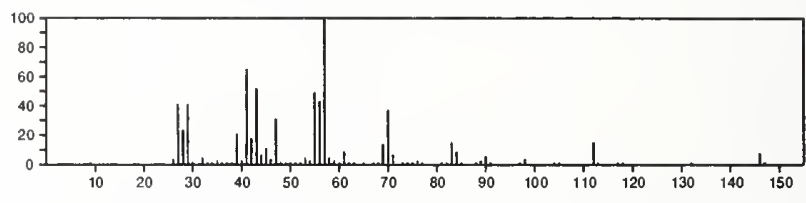

$146 \quad \mathrm{C}_{8} \mathrm{H}_{18} \mathrm{~S}$

Sulfide, isopropyl pentyl

$\mathrm{Me}\left(\mathrm{CH}_{2}\right)_{4} \mathrm{SPr}_{-1} \mathrm{i}$

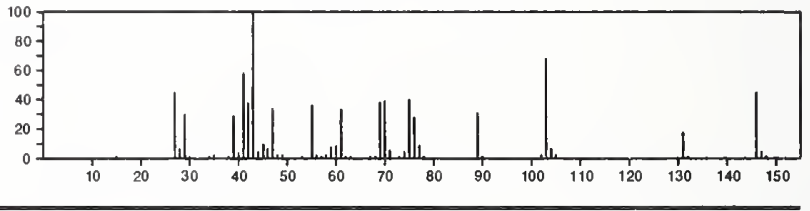

146

Heptane, 1-(methylthio)-

$\mathrm{C}_{8} \mathrm{H}_{18} \mathrm{~S}$

20291-61-6

$\mathrm{MeS}\left(\mathrm{CH}_{2}\right) \& \mathrm{Me}$

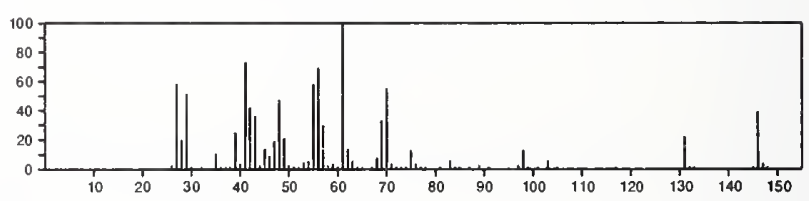

146

$\mathrm{C}_{8} \mathrm{H}_{18} \mathrm{~S}$

$42841-80-5$

Pentane, 1-(propylthio)-

$\mathrm{Me}\left(\mathrm{CH}_{2}\right)_{4} \mathrm{SPr}_{\mathrm{Pr}}$

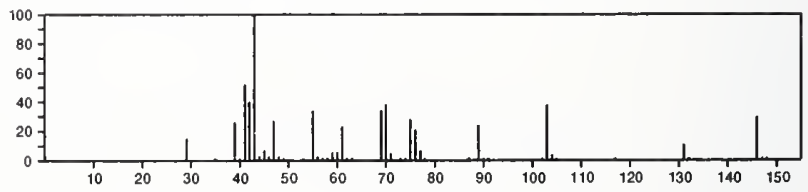


146

Pentane, 2-[(1-methylethyl)thio $]^{-}$

$\operatorname{PrCHMe}\left(\mathrm{SPr}_{-}-\mathrm{i}\right)$

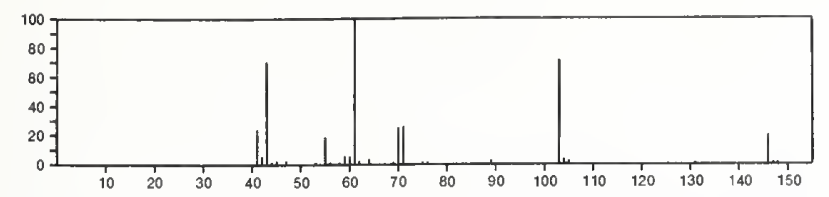

146

3-Hexanethiol, 3-ethyl-

$\mathrm{C}_{8} \mathrm{H}_{18} \mathrm{~S}$

$55956-00-8$

$\operatorname{PrCEt} 2(\mathrm{SH})$

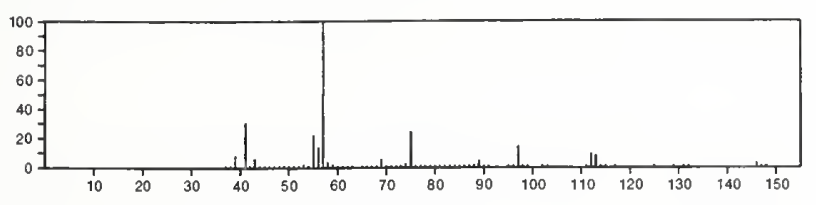

146

$\mathrm{C}_{8} \mathrm{H}_{19} \mathrm{P}$

819-19-2

Phosphine, bis(1,1-dimethylethyl)-

$\mathrm{PH}(\mathrm{Bu}-1) 2$
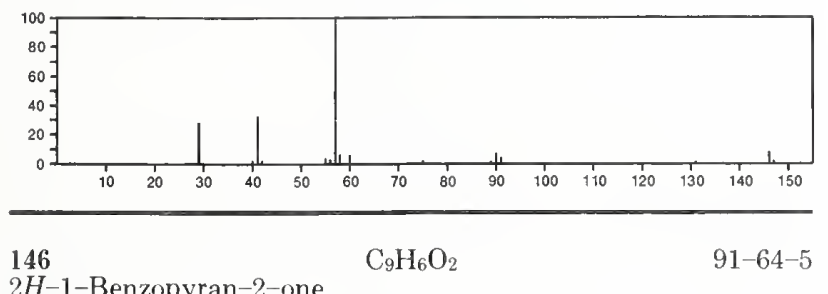

2H-1-Benzopyran-2-one
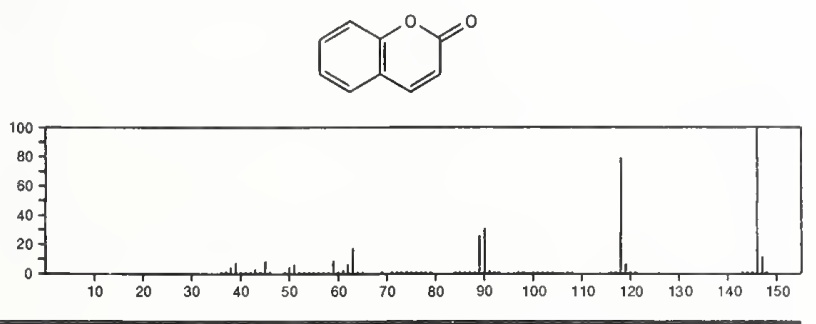

146

$\mathrm{C}_{9} \mathrm{H}_{6} \mathrm{O}_{2}$

491-38-3

4H-1-Benzopyran-4-one
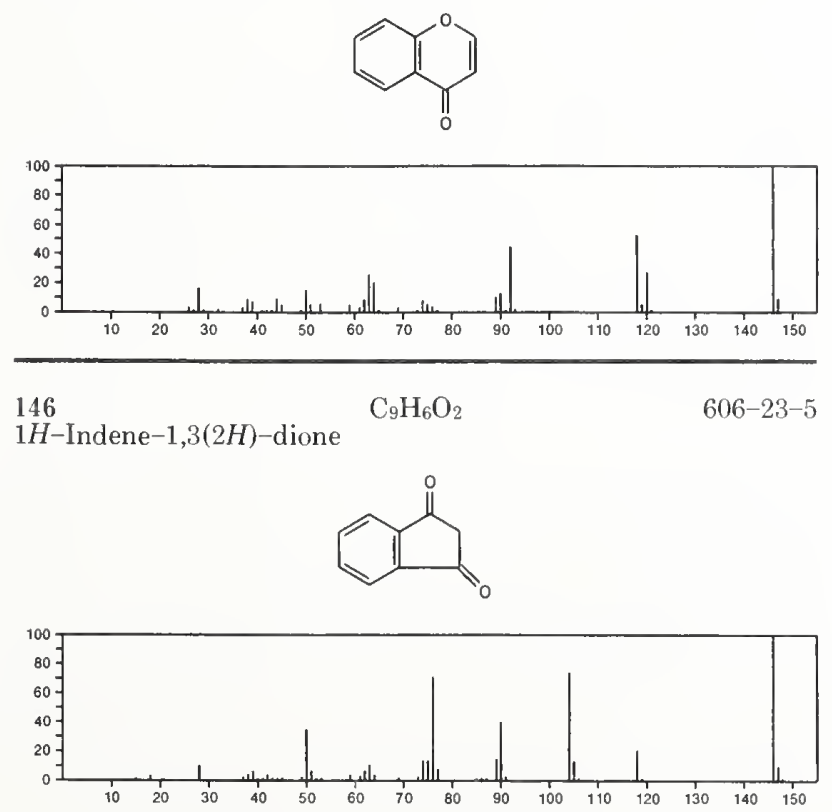

$146 \quad \mathrm{C}_{9} \mathrm{H}_{10} \mathrm{~N}_{2}$

$532-12-7$

Pyridine, 3-(3,4-dihydro-2H-pyrrol-5-yl)
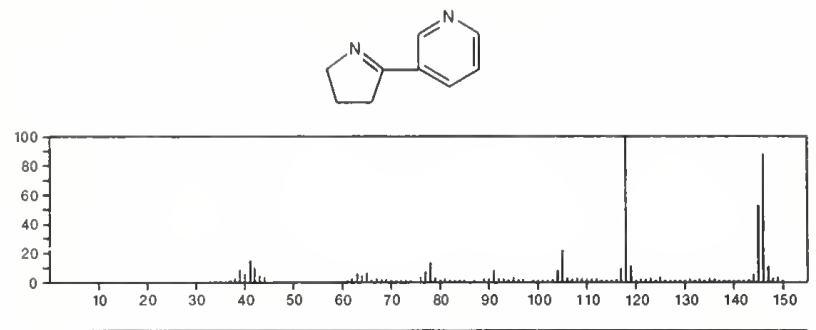

146

$\mathrm{C}_{9} \mathrm{H}_{10} \mathrm{~N}_{2}$

$1 \mathrm{H}$-Benzimidazole, 5,6-dimethyl-

582-60-5
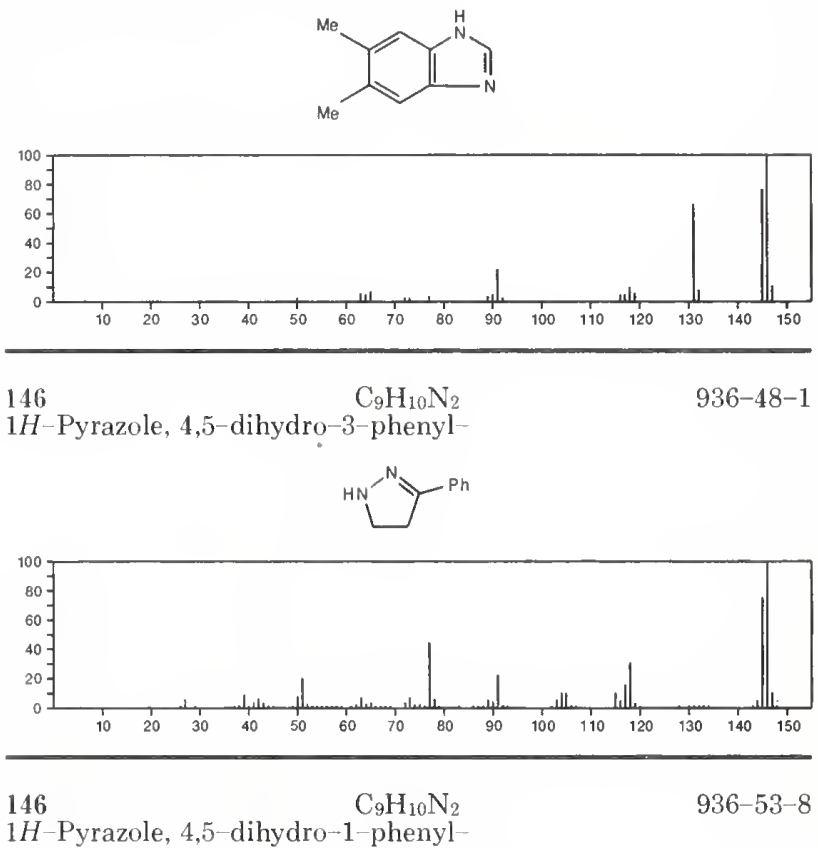

$1 H$-Pyrazole, 4,5-dihydro-1-phenyl-
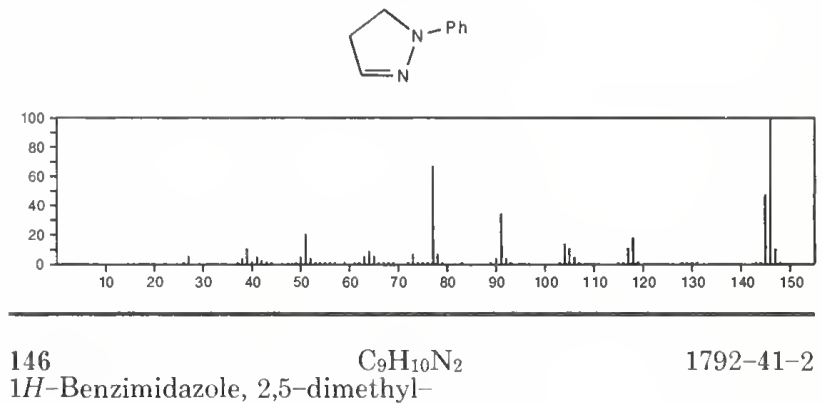

$1 H$-Benzimidazole, 2,5-dimethyl-
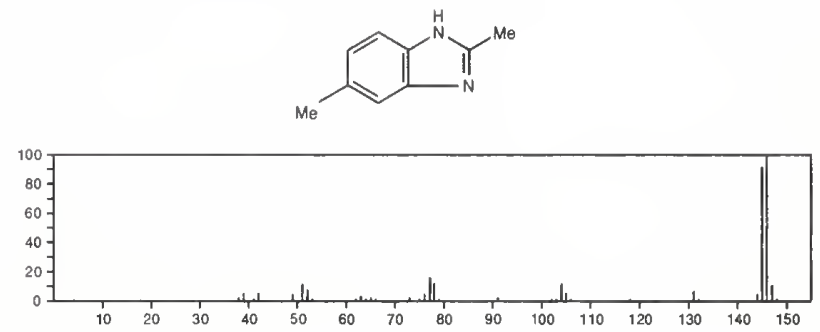
146

$1 H$-Benzimidazole, 2-ethyl-

$\mathrm{C}_{9} \mathrm{H}_{10} \mathrm{~N}_{2}$
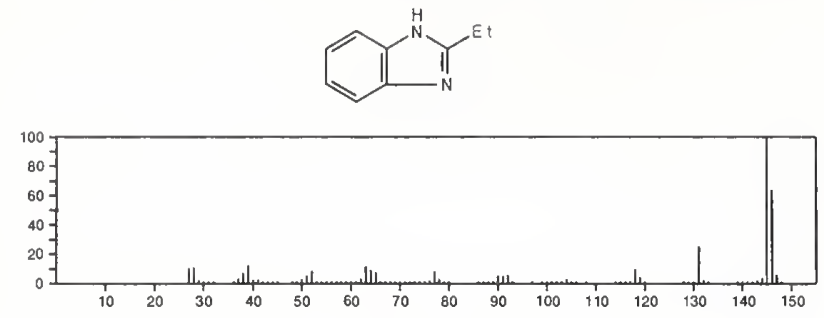

146

1H-Pyrrolo[2,3-b]pyridine, 2-ethyl-
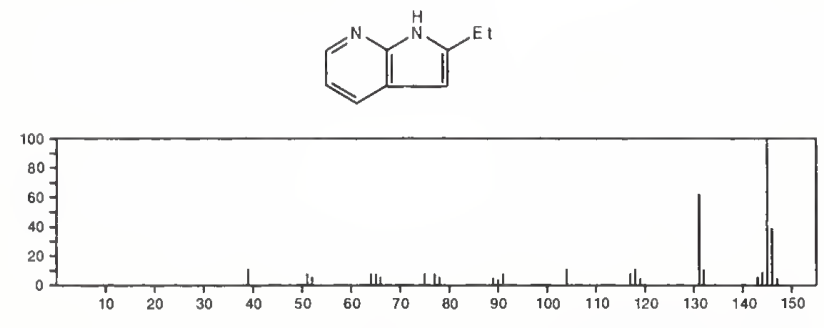

$146 \quad \mathrm{C}_{9} \mathrm{H}_{10} \mathrm{~N}_{2}$

$1 H$-Pyrrolo[2,3-b]pyridine, 3,4-dimethyl-
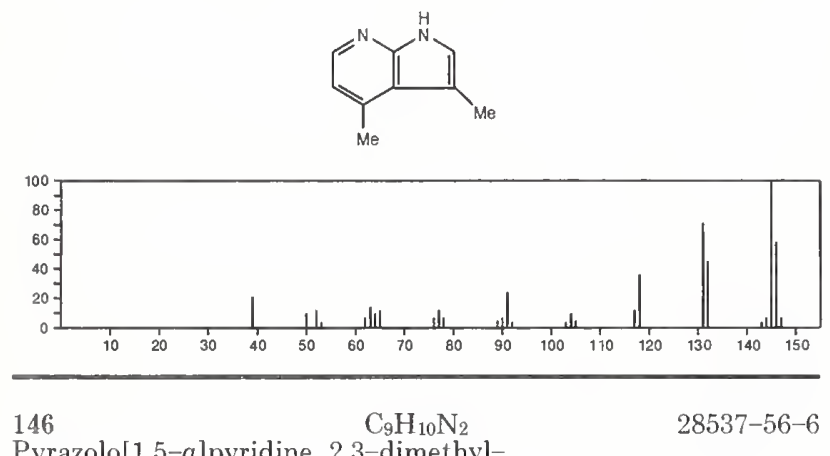

Pyrazolo[1,5-a]pyridine, 2,3-dimethyl-
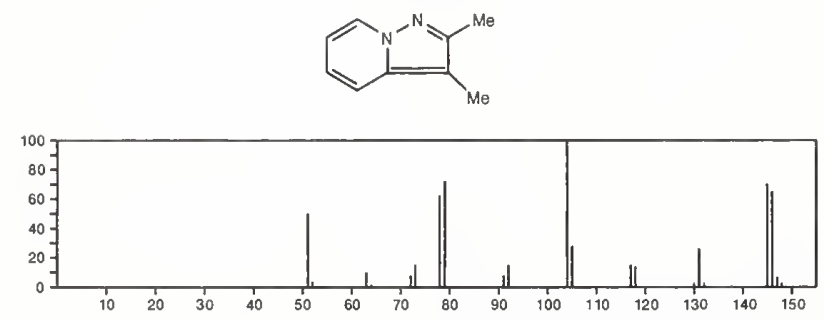

$146 \quad \mathrm{C}_{9} \mathrm{H}_{10} \mathrm{~N}_{2}$

$54063-11-5$

$1 H$-Pyrrole, 1,1'-methylenebis-

$\mathrm{N}^{\mathrm{CH}}-\mathrm{N}$
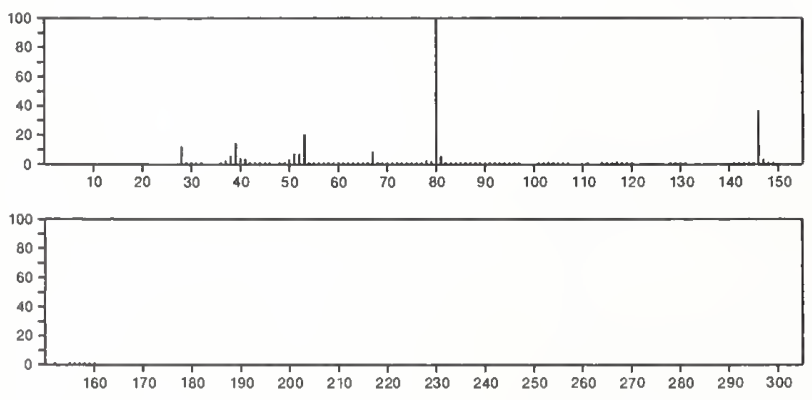

146

Naphthalene, 1-fluoro-

$\mathrm{C}_{10} \mathrm{H}_{7} \mathrm{~F}$

$321-38-0$
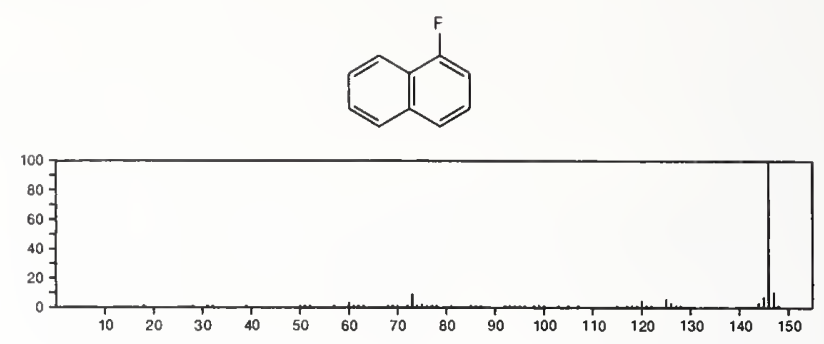

146
Naphthalene, 2-fluoro-

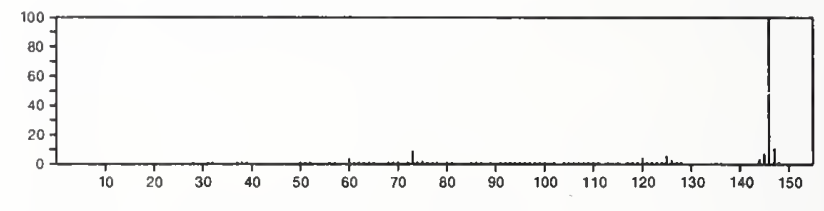

\begin{tabular}{ll}
\hline 146 & $\mathrm{C}_{10} \mathrm{H}_{10} \mathrm{O}$ \\
$3-$ Buten-2-one, 4-phenyl- & $122-57-6$
\end{tabular}

PhCH: $\mathrm{CHCOM}$
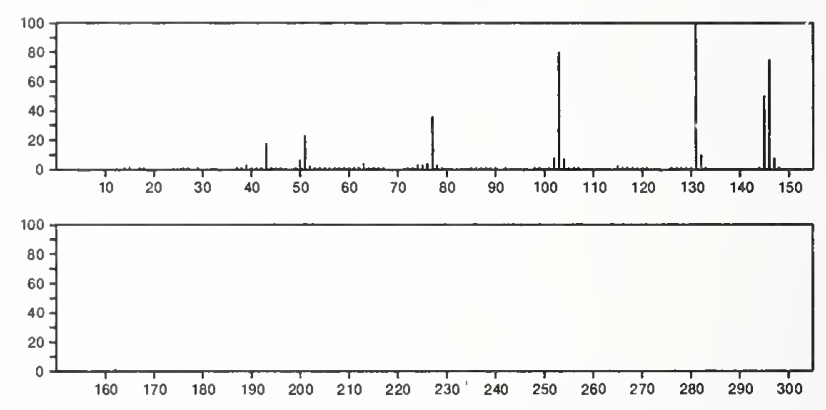

146

1(2H)-Naphthalenone, 3,4-dihydro-

$529-34-0$<smiles>O=C1CCCc2ccccc21</smiles>

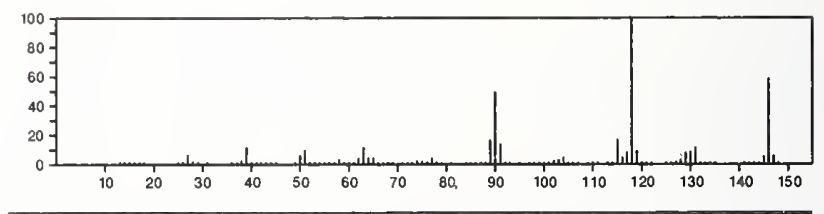

146

$\mathrm{C}_{10} \mathrm{H}_{10} \mathrm{O}$

$530-93-8$

2(1H)-Naphthalenone, 3,4-dihydro-
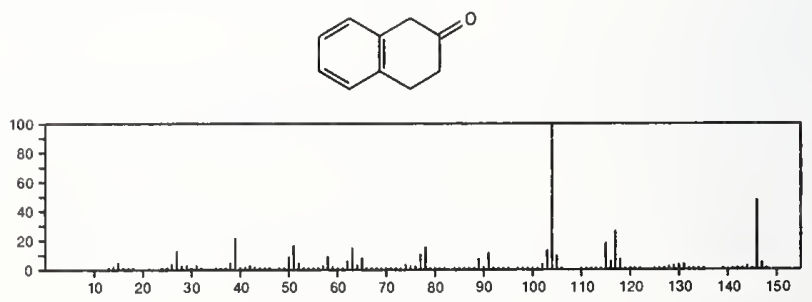
$\mathrm{C}_{10} \mathrm{H}_{10} \mathrm{O}$

Naphth $[1,2-b$ \}oxirene, $1 \mathrm{a}, 2,3,7 \mathrm{~b}$-tetrahydro
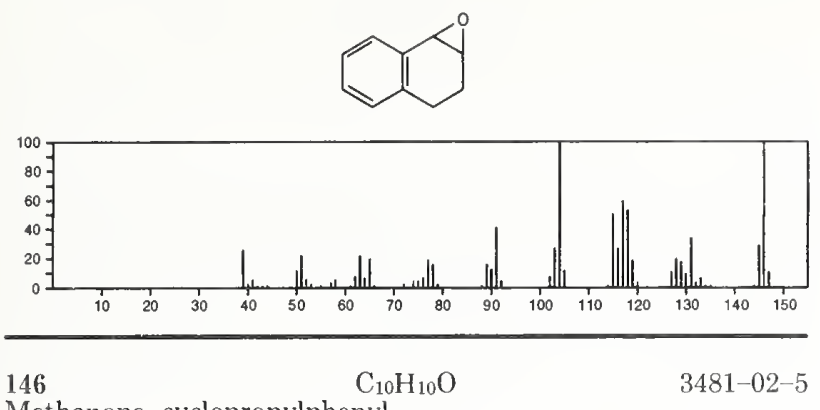

Methanone, cyclopropylphenyl
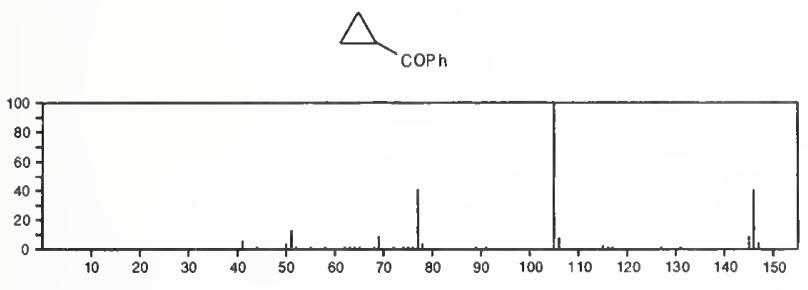

$146 \quad \mathrm{C}_{10} \mathrm{H}_{10} \mathrm{O}$

$1 H$-Inden-1-one, 2,3-dihydro-3-methyl-
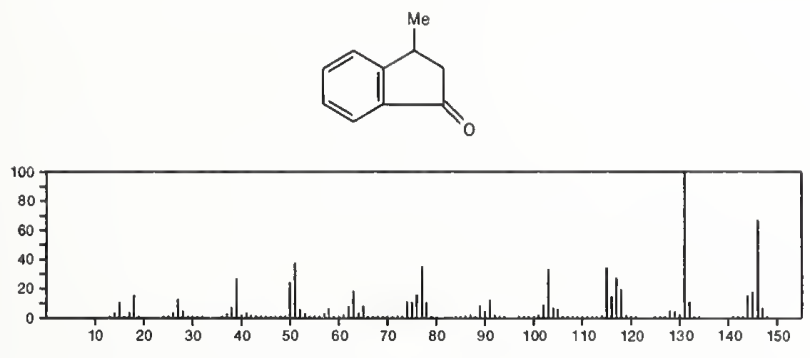

146
$2-$ Propyn-1-ol, $3-p-$ tolyl-

$\mathrm{C}_{10} \mathrm{H}_{10} \mathrm{O}$

$16017-24-6$
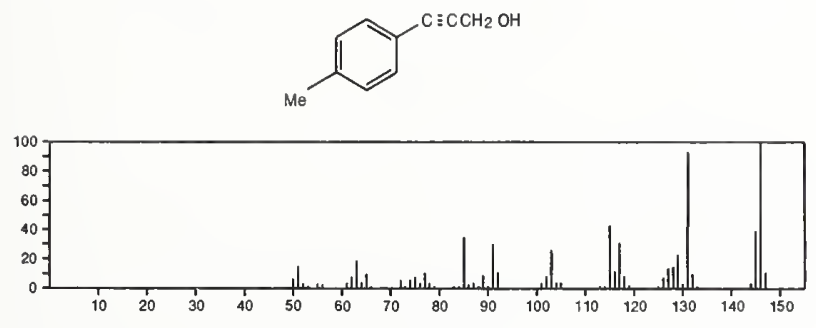

\section{6}

$\mathrm{C}_{10} \mathrm{H}_{10} \mathrm{O}$

Cycloprop $[a]$ inden-6-ol, 1,1a,6,6a-tetrahydro-
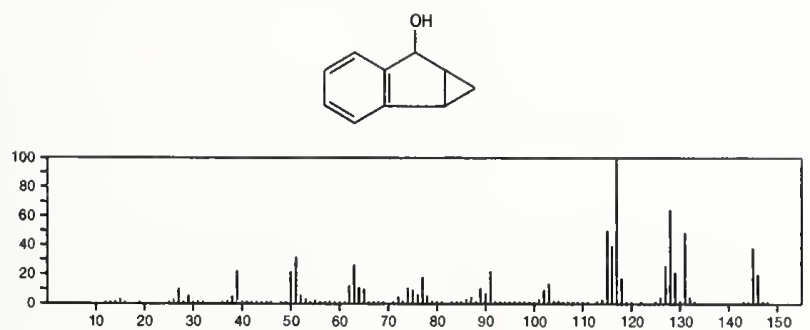

146

Benzufuran, 4,7-dimethyl-

$\mathrm{C}_{10} \mathrm{H}_{10} \mathrm{O}$

$28715-26-6$
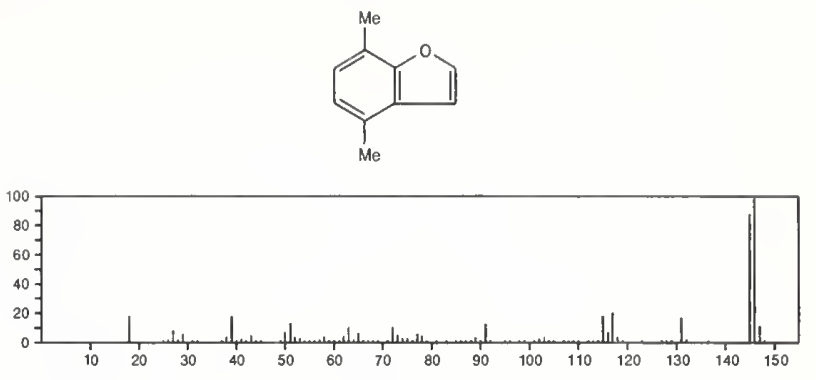

146

$\mathrm{C}_{11} \mathrm{H}_{14}$

$700-88-9$

Benzene, cyclopentyl-
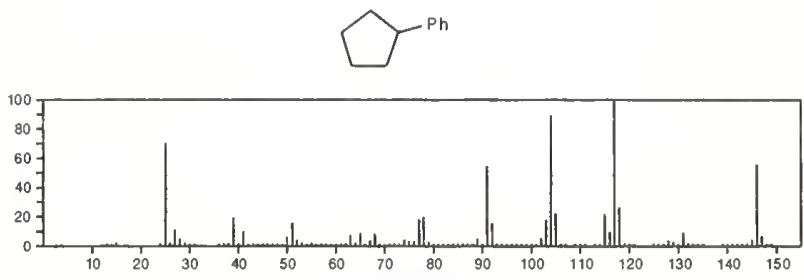

146

Indan, 5,6-dimethyl-

$\mathrm{C}_{11} \mathrm{H}_{14}$

$1075-22-5$
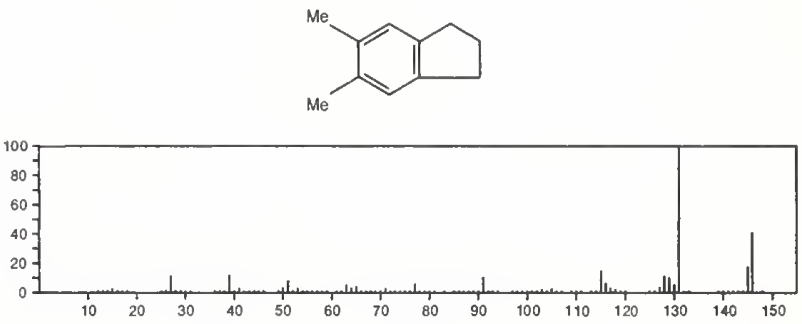

146

$\mathrm{C}_{11} \mathrm{H}_{14}$

$1559-81-5$

Naphthalene, 1,2,3,4-tetrahydro-1-methyl-
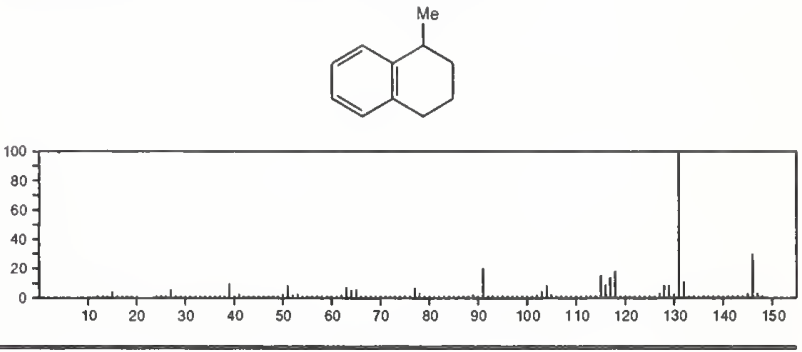

146

$\mathrm{C}_{11} \mathrm{H}_{14}$

$1647-06-9$

Benzene, (2-methyl-3-butenyl)-

$\mathrm{PhCH}_{2} \mathrm{CHMe} \mathrm{CH}=\mathrm{CH}_{2}$

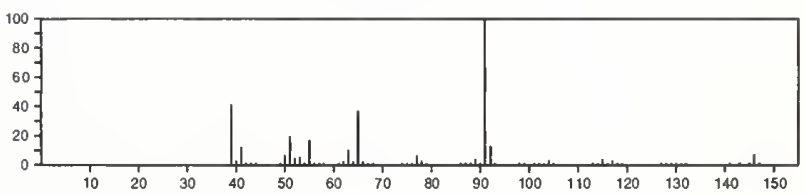


146

$\mathrm{C}_{11} \mathrm{H}_{14}$

Naphthalene, 1,2,3,4-tetrahydro-6-methyl-

$1680-51-9$
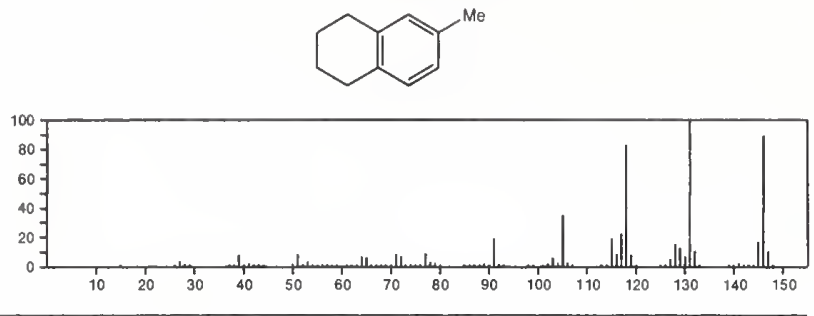

146

$$
\mathrm{C}_{11} \mathrm{H}_{14}
$$

$1685-82-1$

$1 H$-Indene, 2,3-dihydro-4,6-dimethyl-
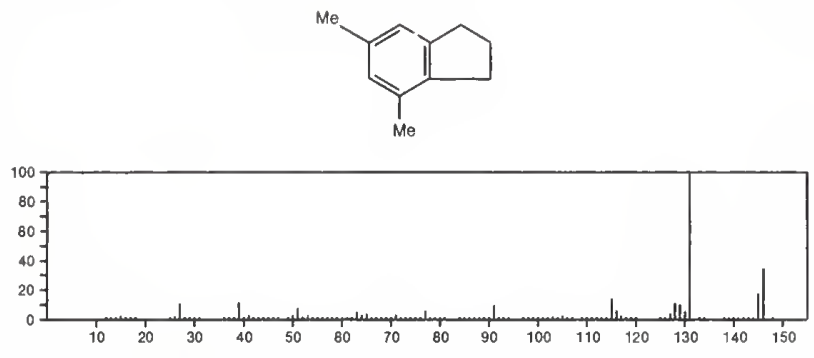

146

$\mathrm{C}_{11} \mathrm{H}_{14}$

Naphthalene, 1,2,3,4-tetrahydro-5-methyl-
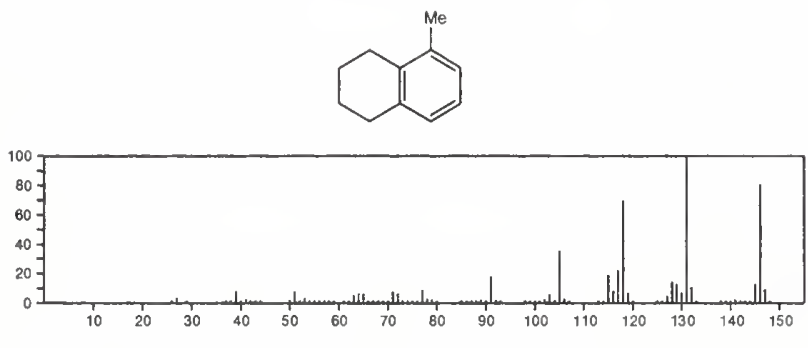

146

$\mathrm{C}_{11} \mathrm{H}_{14}$

Naphthalene, 1,2,3,4-tetrahydro-2-methyl-
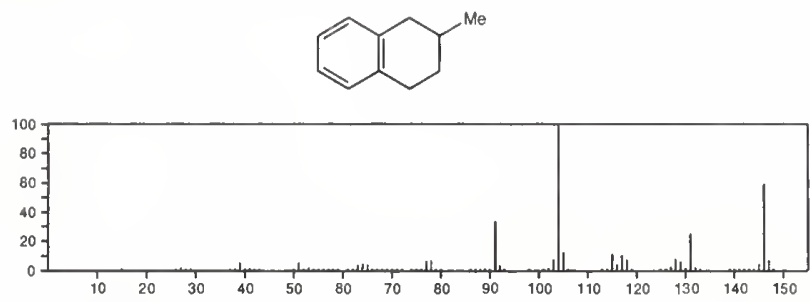

$146 \quad \mathrm{C}_{11} \mathrm{H}_{14}$

$1 H$-Indene, 2,3-dihydro-1,3-dimethyl-

$4175-53-5$
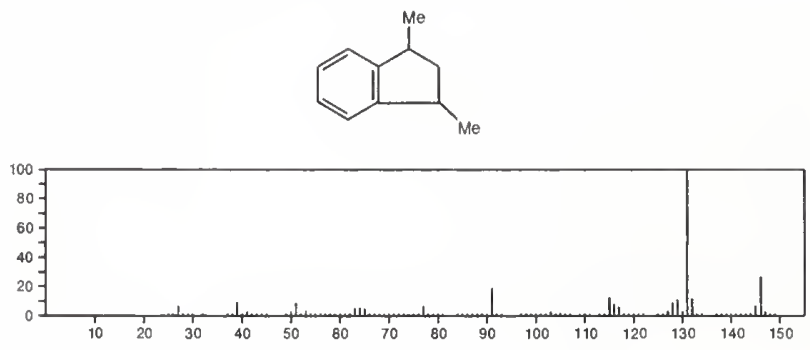

146 $\mathrm{C}_{11} \mathrm{H}_{14}$

$4489-84-3$

Benzene, (3-methyl-2-butenyl)

$\mathrm{Me}{ }_{2} \mathrm{C}=\mathrm{CHCH}_{2} \mathrm{Ph}$

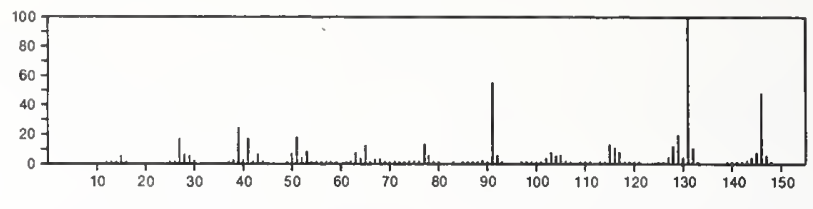

146 $\mathrm{C}_{11} \mathrm{H}_{14}$

4830-99-3

1H-Indene, 1-ethyl-2,3-dihydro-
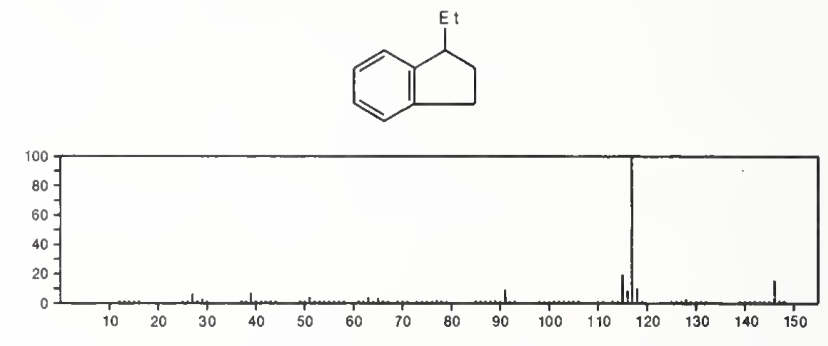

$146 \quad \mathrm{C}_{11} \mathrm{H}_{14}$

1H-Indene, 2,3-dihydro-1,1-dimethyl-

4912-92-9
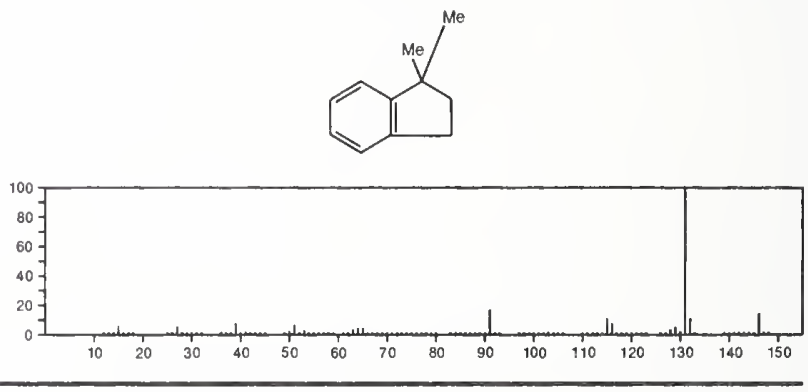

146

$\mathrm{C}_{11} \mathrm{H}_{14}$

1H-Indene, 2,3-dihydro-4,7-dimethyl

$6682-71-9$
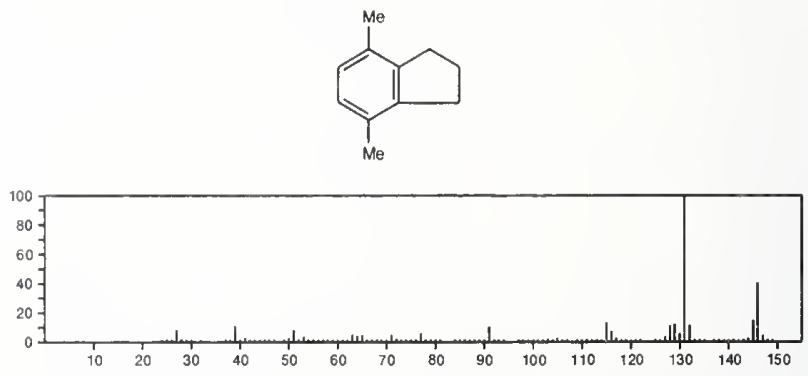

146

$\mathrm{C}_{11} \mathrm{H}_{14}$

$6683-51-8$

Benzene, (3-methy]-3-butenyl)-

$\mathrm{PhCH}_{2} \mathrm{CH}_{2} \mathrm{CMe}=\mathrm{CH}_{2}$

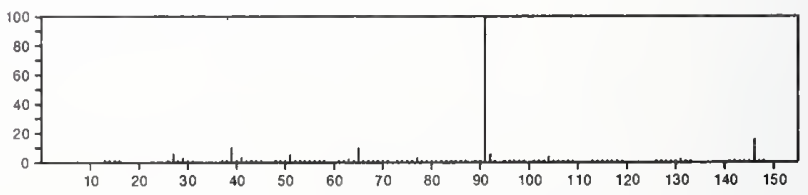


146

Benzene, 3-pentenyl-, $(E)$ -

$\mathrm{C}_{11} \mathrm{H}_{14}$

$16091-23-9$

$\mathrm{MeCH} \equiv \mathrm{CHCH}_{2} \mathrm{CH}_{2} \mathrm{Ph}$

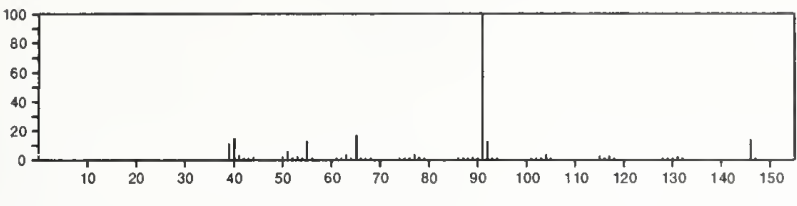

146

Benzene, 3-pentenyl-, $(Z)-$

$\mathrm{C}_{11} \mathrm{H}_{14}$

$16487-65-3$

$\mathrm{Me} \mathrm{CH}=\mathrm{CHCH}_{2} \mathrm{CH}_{2} \mathrm{Ph}$

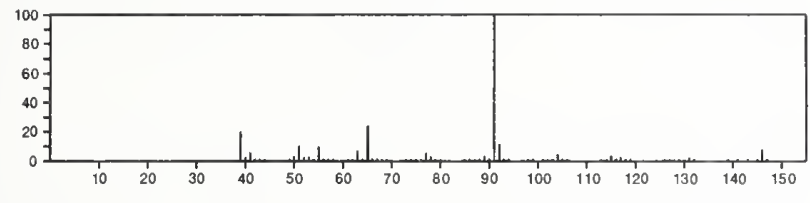

146

$\mathrm{C}_{11} \mathrm{H}_{14}$

1H-Indene, 2,3-dihydro-1,2-dimethyl-
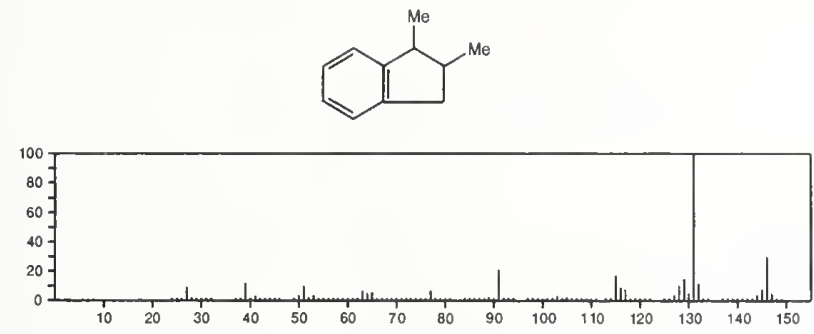

$146 \quad \mathrm{C}_{11} \mathrm{H}_{14}$

1H-Indene, 2,3-dihydro-1,6-dimethyl-
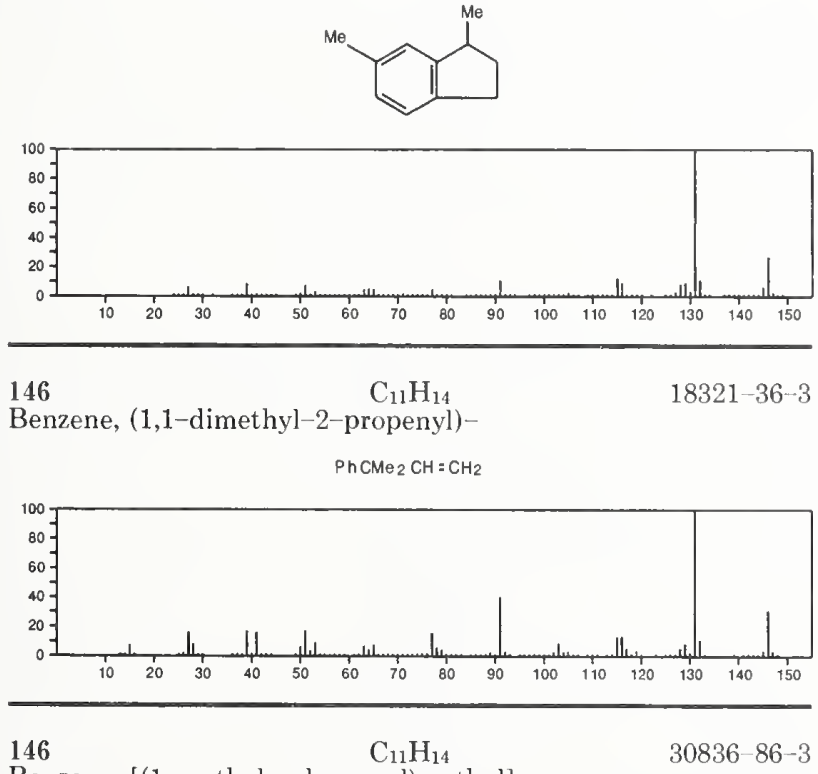

Benzene, [(1-methylcyclopropyl)methyl]--
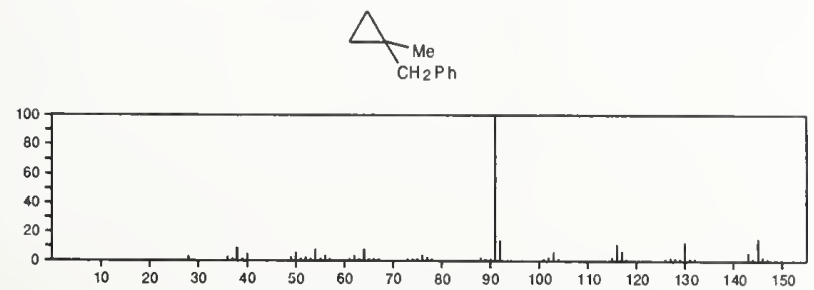

146

$\mathrm{F}_{6} \mathrm{~S}$

Sulfur fluoride $\left(\mathrm{SF}_{6}\right),(\mathrm{OC}-6-11)$ -

$2551-62-4$

$\mathrm{SF}_{6}$

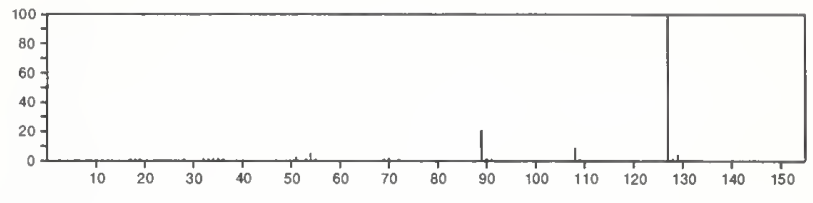

147

$\mathrm{C}_{2} \mathrm{H}_{4} \mathrm{~F}_{3} \mathrm{NOS}$

$51735-82-1$

Methanesulfinamide, $1,1,1$-trifluoro- $N$-methyl-

$\mathrm{MeNHS}(\mathrm{O}) \mathrm{CF}_{3}$

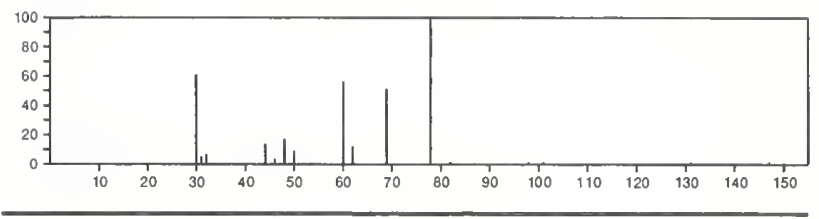

147

$\mathrm{C}_{3} \mathrm{H}_{5} \mathrm{~N}_{3} \mathrm{~S}_{2}$

$5319-77-7$

1,3,4-Thiadiazol-2-amine, 5-(methylthio)-
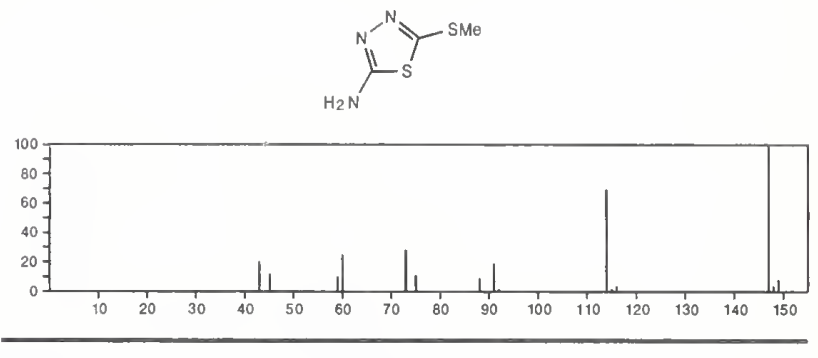

147

$\mathrm{C}_{5} \mathrm{H}_{6} \mathrm{ClNO}_{2}$

6702-21-2

Lactonitrile, 3-chloro-, acetate

$\mathrm{ACOCH}(\mathrm{CN}) \mathrm{CH}_{2} \mathrm{Cl}$

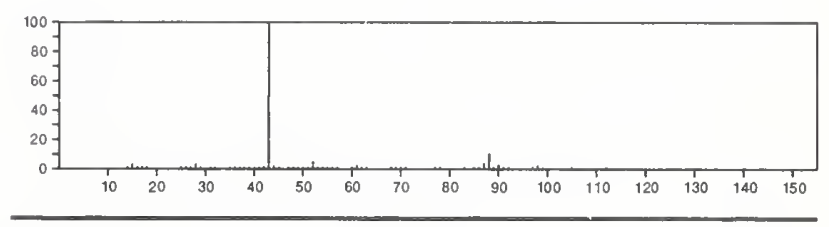

147

$\mathrm{C}_{5} \mathrm{H}_{9} \mathrm{NO}_{4}$

$56-86-0$

L-Glutamic acid

$\mathrm{HO}_{2} \mathrm{CCH}_{2} \mathrm{CH}_{2} \mathrm{CH}\left(\mathrm{NH}_{2}\right) \mathrm{CO}_{2} \mathrm{H}$

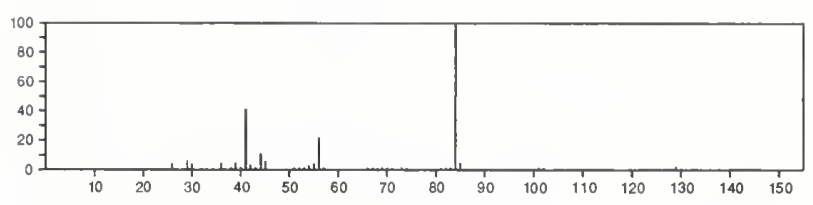

147

$\mathrm{C}_{5} \mathrm{H}_{9} \mathrm{NO}_{4}$

$16354-58-8$

L-Serine, $N$-acetyl-

$\mathrm{ACNHCH}\left(\mathrm{CO}_{2} \mathrm{H}\right) \mathrm{CH}_{2} \mathrm{OH}$

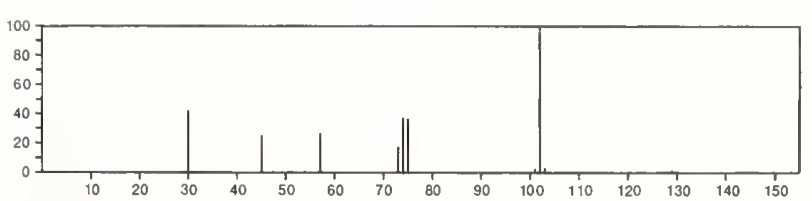


147

$\mathrm{C}_{6} \mathrm{H}_{10} \mathrm{CINO}$

Cyclohexane, 1-chloro-2-nitroso-
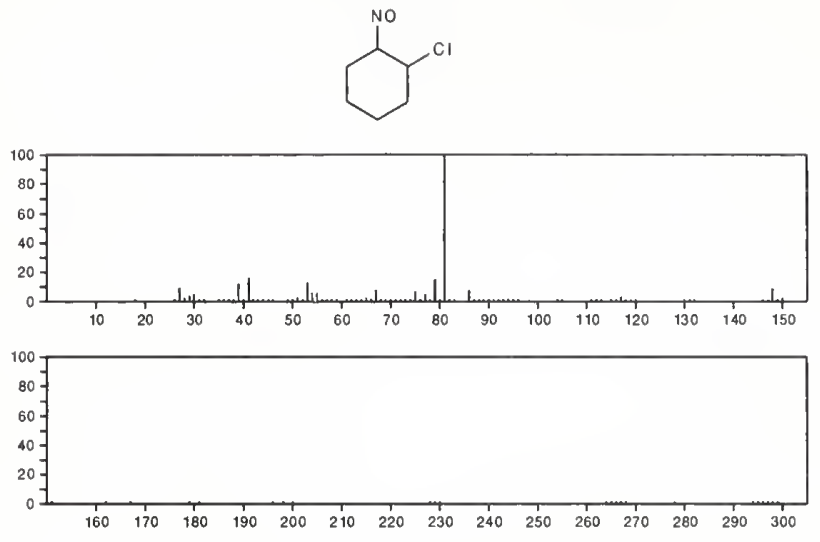

$147 \quad \mathrm{C}_{6} \mathrm{H}_{13} \mathrm{NOS} \quad 32805-46-2$ Sulfonium, (acetylamino) diethyl-, hydroxide, inner salt

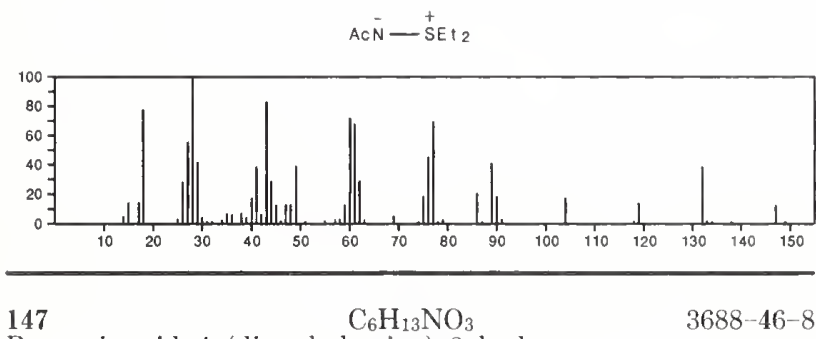

Butanoic acid, 4-(dimethylamino) -3 -hydroxy-

$\mathrm{HO}_{2} \mathrm{CCH}_{2} \mathrm{CH}(\mathrm{OH}) \mathrm{CH}_{2} \mathrm{NMe}_{2}$
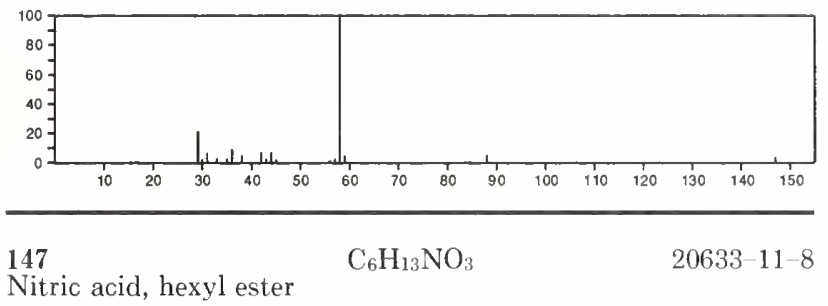

Nitric acid, hexyl este

$\mathrm{Me}\left(\mathrm{CH}_{2}\right)_{5} \mathrm{ONO}_{2}$

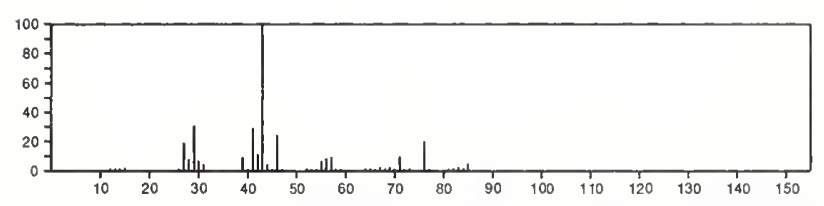

147

$\mathrm{C}_{6} \mathrm{H}_{13} \mathrm{NO}_{3}$

Acetamide, 2-methoxy-N-(2-methoxyethyl)

$55956-18-8$

$\mathrm{Me} \mathrm{OCH} 2 \mathrm{CONHCH}_{2} \mathrm{CH}_{2} \mathrm{OMe}$

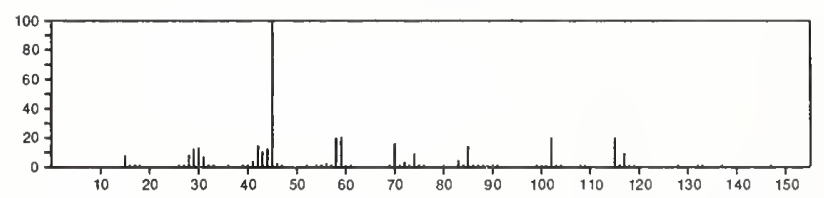

147

$1,2,3-$ Benzotriazin-4(1H)-one

$\mathrm{C}_{7} \mathrm{H}_{5} \mathrm{~N}_{3} \mathrm{O}$

$90-16-4$
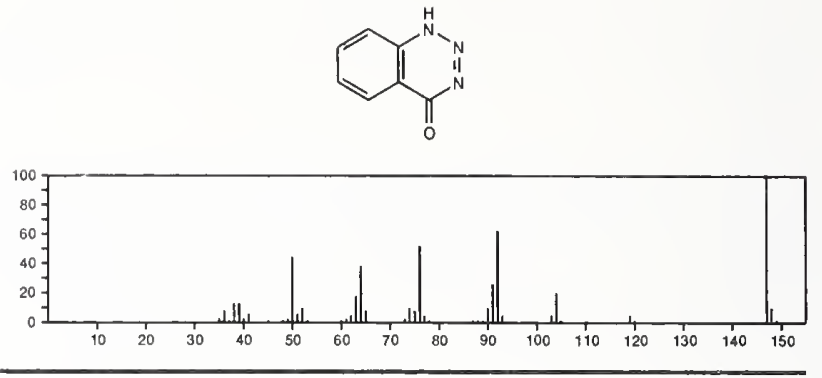

147

$\mathrm{C}_{7} \mathrm{H}_{5} \mathrm{~N}_{3} \mathrm{O}$

$582-61-6$

Benzoyl azide

$\mathrm{N}_{3} \mathrm{COPh}$

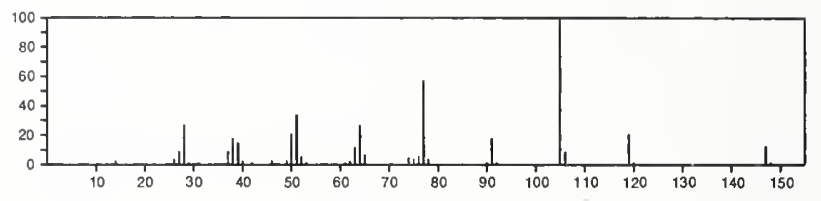

147

$\mathrm{C}_{7} \mathrm{H}_{5} \mathrm{~N}_{3} \mathrm{O}$

Pyridine, 2-(1,2,4-oxadiazol-3-yl)-

$13389-59-8$
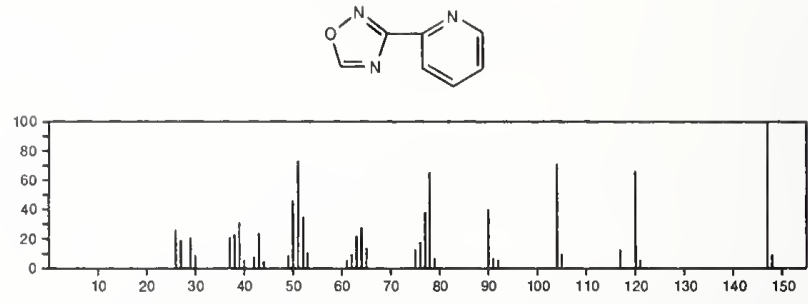

147

$\mathrm{C}_{7} \mathrm{H}_{5} \mathrm{~N}_{3} \mathrm{O}$

$13428-22-3$

Pyridine, 2-(1,3,4-oxadiazol-2-yl)-
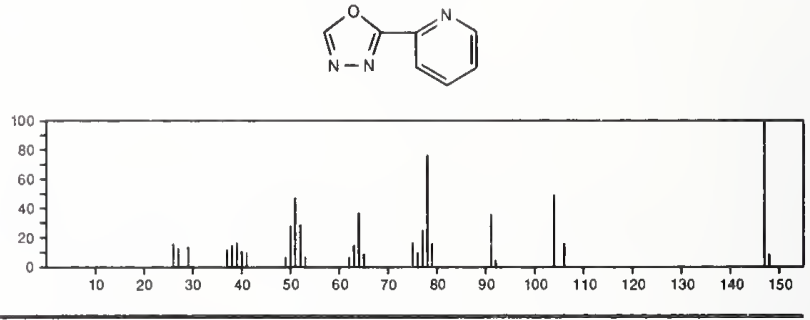

147

$\mathrm{C}_{7} \mathrm{H}_{5} \mathrm{~N}_{3} \mathrm{O}$

16952-64-0

Pyrido $[4,3-d]$ pyrimidin-4(3H)-one<smiles>O=c1nc[nH]c2ccncc12</smiles>

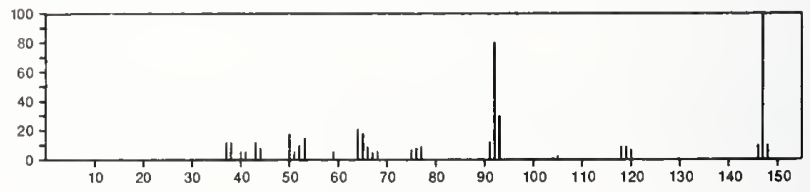


147

$\mathrm{C}_{7} \mathrm{H}_{5} \mathrm{~N}_{3} \mathrm{O}$

Pyrido $[3,4-d]$ pyrimidin-4(3H)-one<smiles>O=c1nc[nH]c2cnccc12</smiles>

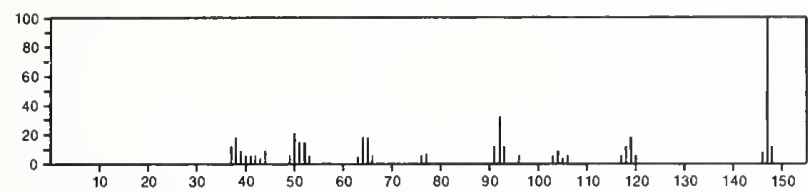

147

$\mathrm{C}_{7} \mathrm{H}_{5} \mathrm{~N}_{3} \mathrm{O}$

Pyrido[2,3-d]pyrimidin-4(1H)-one<smiles>O=c1nc[nH]c2ncccc12</smiles>

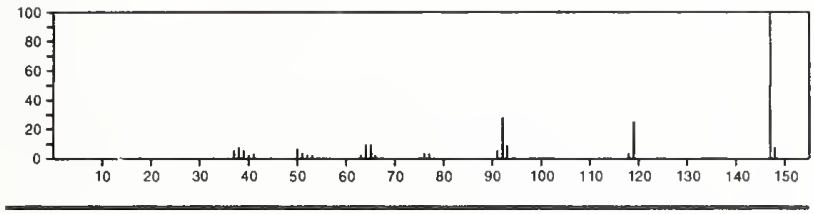

147

$\mathrm{C}_{7} \mathrm{H}_{5} \mathrm{~N}_{3} \mathrm{O}$

$37538-67-3$

Pyrido[3,2-d]pyrimidin-4-ol<smiles>O=c1nc[nH]c2cccnc12</smiles>

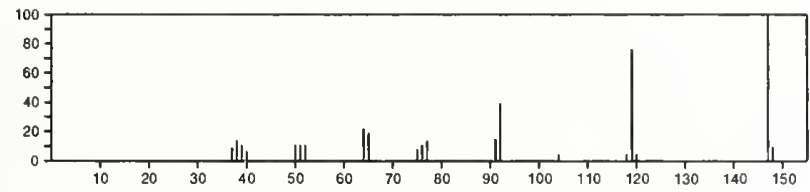

147

$\mathrm{C}_{7} \mathrm{H}_{5} \mathrm{~N}_{3} \mathrm{O}$

$56805-24-4$

$1 H$-Imidazo $[4,5-b]$ pyridine-2-carboxaldehyde
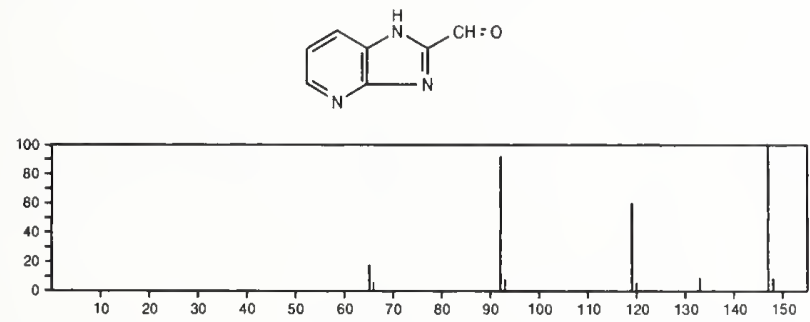

147

$\mathrm{C}_{7} \mathrm{H}_{5} \mathrm{~N}_{3} \mathrm{O}$

$56805-25-5$

$1 H$-Imidazo[4,5-c]pyridine-2-carboxaldehyde
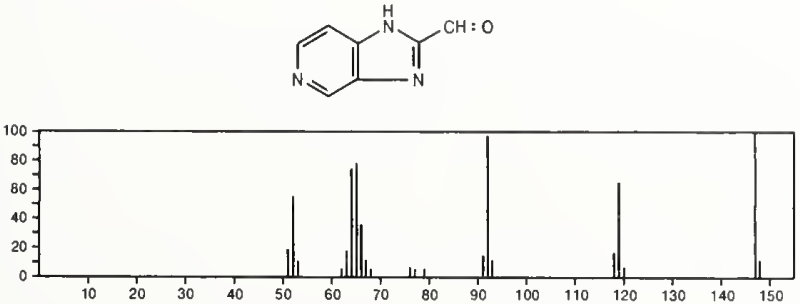

147

Piperidine, 3-chloro-1-ethyl-

$\mathrm{C}_{7} \mathrm{H}_{14} \mathrm{ClN}$

$2167-11-5$
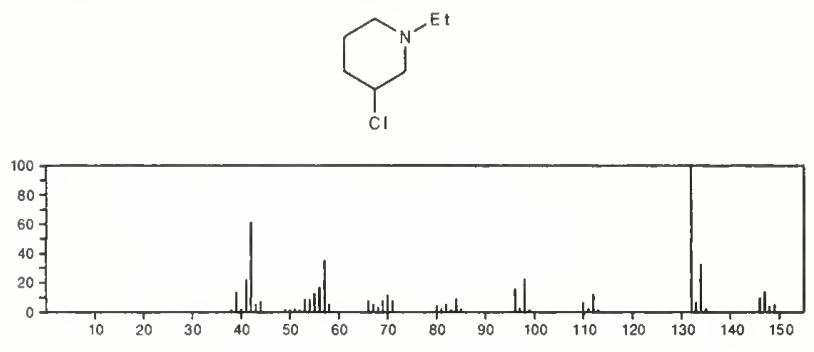

147

$\mathrm{C}_{7} \mathrm{H}_{14} \mathrm{ClN}$

Allylamine, 3 -chloro-N-isopropyl-2-methyl-, (Z)

$23240-43-9$

$-\mathrm{Pr} \mathrm{NHCH}_{2} \mathrm{CMe}=\mathrm{CHCl}$

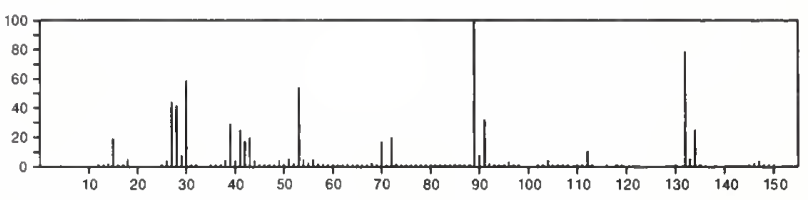

147

$\mathrm{C}_{7} \mathrm{H}_{14} \mathrm{ClN}$

23240-44-0

Allylamine, 3-chloro- $N$-isopropyl-2-methyl-, $(E)$

$i-\mathrm{Pr} \mathrm{NHCH} 2 \mathrm{CMe}=\mathrm{CHCl}$

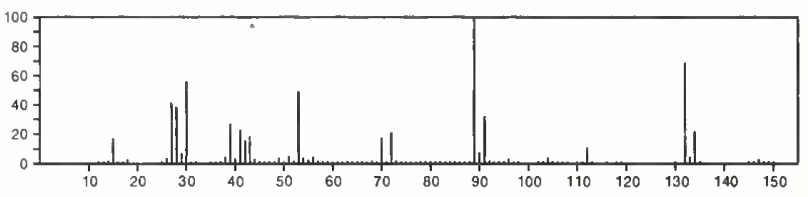

147

$\mathrm{C}_{7} \mathrm{H}_{17} \mathrm{NO}_{2}$

$55759-85-8$

1-Propanamine, 3-(2-methoxy-1-methylethoxy)-

$\mathrm{H}_{2} \mathrm{~N}\left(\mathrm{CH}_{2}\right)_{3} \mathrm{OCHMeCH}_{2} \mathrm{OMe}$

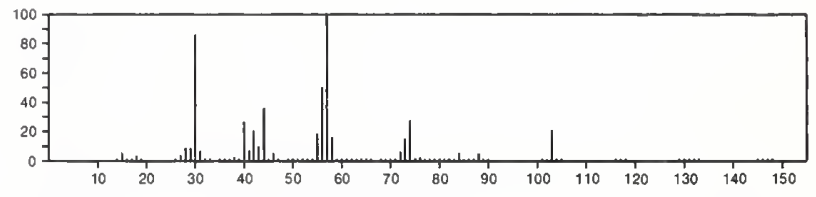

147

$\mathrm{C}_{7} \mathrm{H}_{17} \mathrm{NS}$

3492-79-3

Ethanamine, $N$-ethyl- $N$-[(ethylthio)methyl]-

$\mathrm{EtSCH} 2 \mathrm{NE}$ : 2
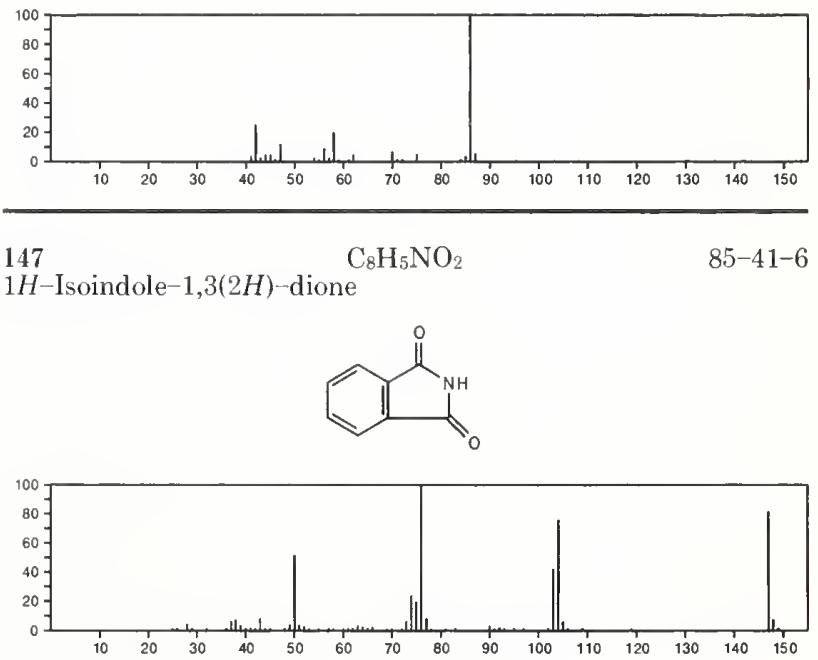
147

$1 H$-Indole-2,3-dione

$\mathrm{C}_{8} \mathrm{H}_{5} \mathrm{NO}_{2}$
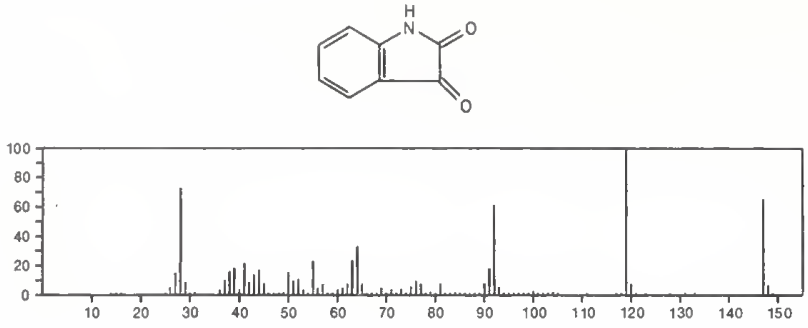

147

$\mathrm{C}_{8} \mathrm{H}_{5} \mathrm{NO}_{2}$

Benzoic acid, 4-cyano-

619-65-8
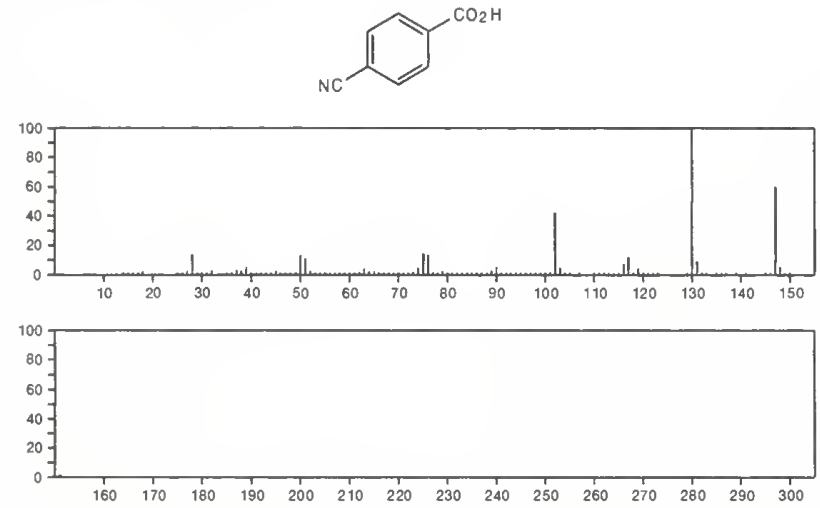

147

$\mathrm{C}_{8} \mathrm{H}_{9} \mathrm{~N}_{3}$

$s^{-T r i a z o l o}[4,3-a]$ pyridine, 3,5-dimethyl-
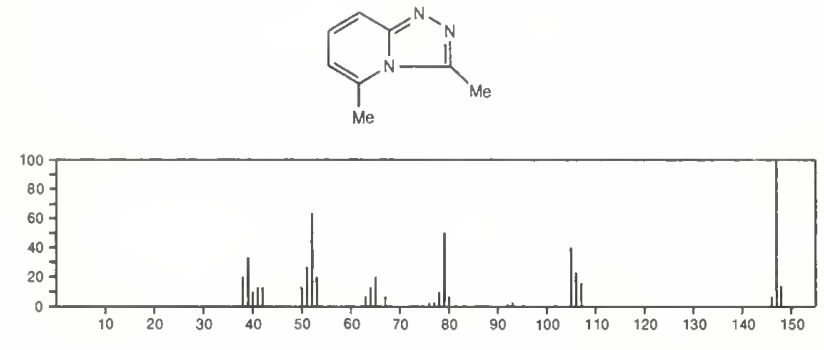

$147 \quad \mathrm{C}_{8} \mathrm{H}_{9} \mathrm{~N}_{3}$

$s$-Triazolo[4,3-a]pyridine, 3-ethyl-

4919-17-9
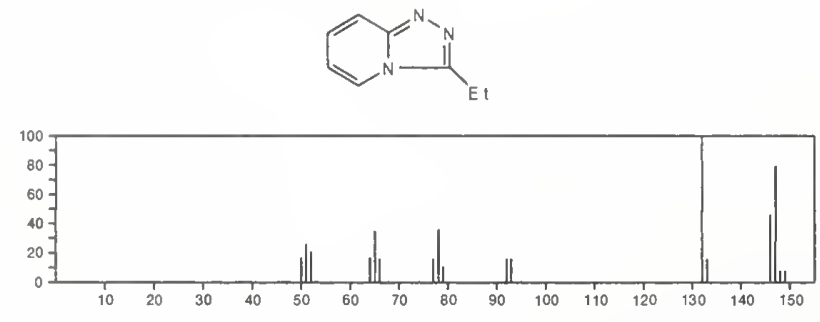

$147 \quad \mathrm{C}_{8} \mathrm{H}_{9} \mathrm{~N}_{3} \quad 4931-22-0$

$[1,2,4]$ Triazolo $[1,5-a]$ pyridine, 2,7 -dimethyl-<smiles>Nc1ccn2nc(N)nc2c1</smiles>

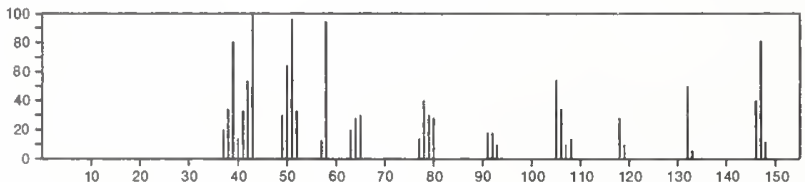

$147 \quad \mathrm{C}_{8} \mathrm{H}_{9} \mathrm{~N}_{3}$

$s$-Triazolo $[4,3-a]$ pyridine, 3,8-dimethyl-

13936-48-6
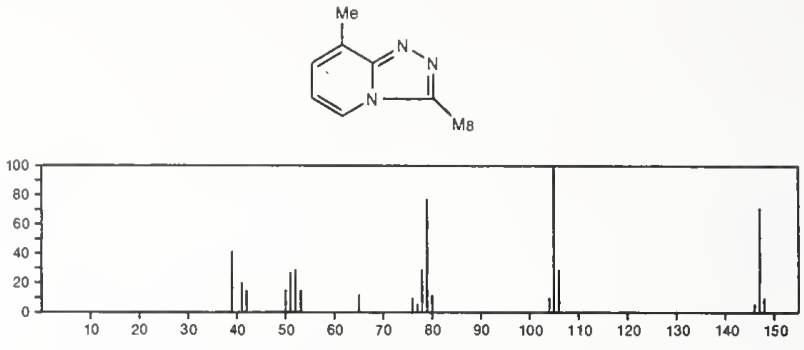

147 -Benzotriazole, 2-ethyl-

$\mathrm{C}_{8} \mathrm{H}_{9} \mathrm{~N}_{3}$

16584-04-6
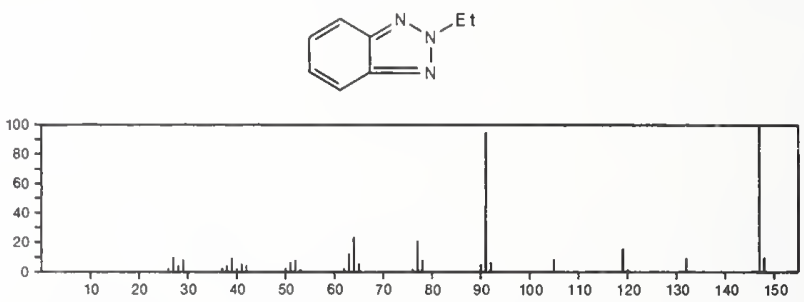

147

Benzene, 2-azido-1,3-dimethyl-

$\mathrm{C}_{8} \mathrm{H}_{9} \mathrm{~N}_{3}$

$26334-20-3$
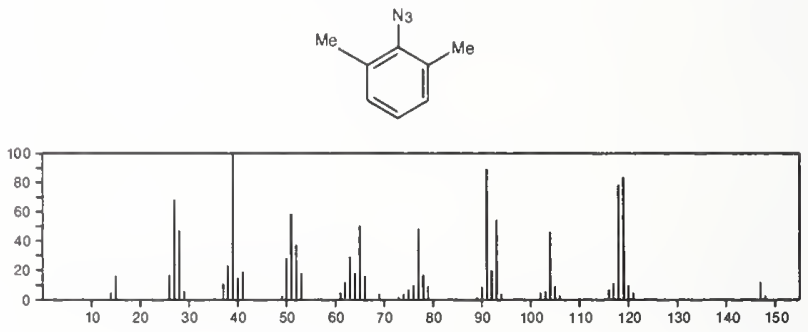

147

$\mathrm{C}_{8} \mathrm{H}_{9} \mathrm{~N}_{3}$

32366-25-9

Benzene, (1-azidoethyl)-

$\mathrm{PhCHMe}\left(\mathrm{N}_{3}\right)$

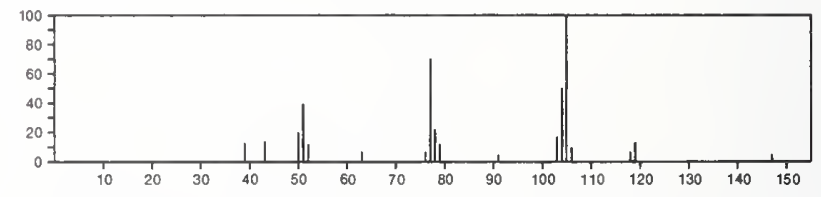

147

$\mathrm{C}_{9} \mathrm{H}_{9} \mathrm{NO}$

Cyanic acid, 2,4-dimethylphenyl ester

1126-16-5
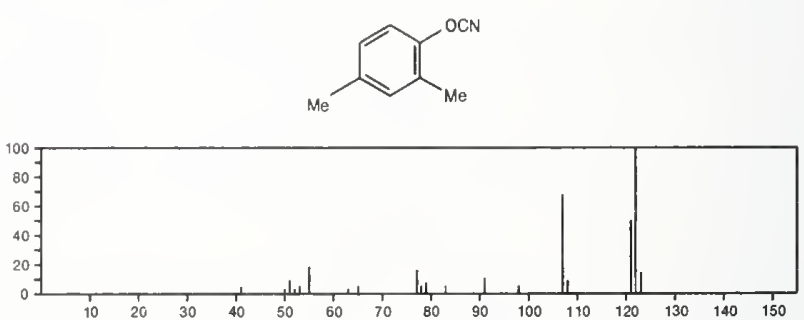
$\mathrm{C}_{9} \mathrm{H}_{9} \mathrm{NO}$
$1 \mathrm{H}-$ Indole-1-carboxaldehyde, $2,3-$ dihydro-
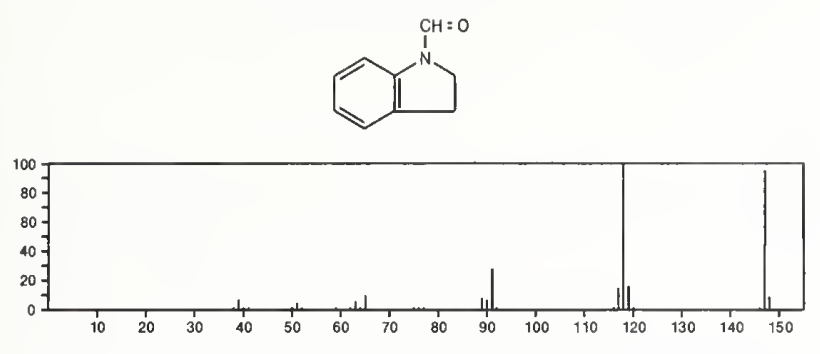

147

$\mathrm{C}_{9} \mathrm{H}_{9} \mathrm{NO}$

Benzenepropanenitrile, $\beta$-hydroxy-

$17190-29-3$

$\mathrm{NCCH}_{2} \mathrm{CH}(\mathrm{OH}) \mathrm{Ph}$

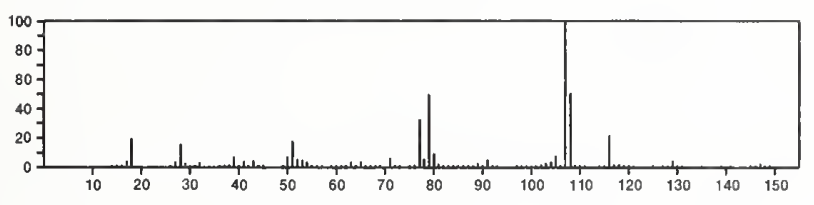

147

$\mathrm{C}_{9} \mathrm{H}_{9} \mathrm{NO}$

$22320-21-4$

2-Indolizinemethanol
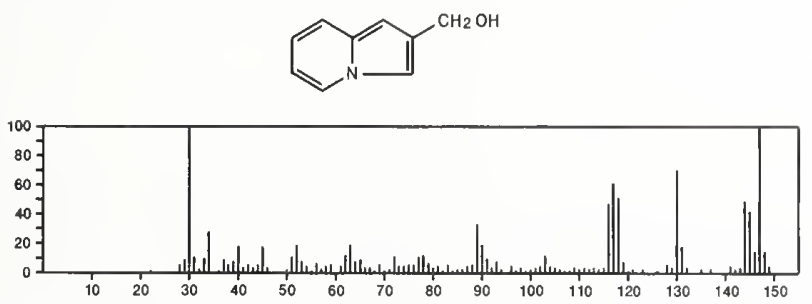

147

$\mathrm{C}_{9} \mathrm{H}_{14} \mathrm{BN}$

Boranamine, $N, N, 1$-trimethyl-1-phenyl-

3519-71-9

Me 2 NBMePh

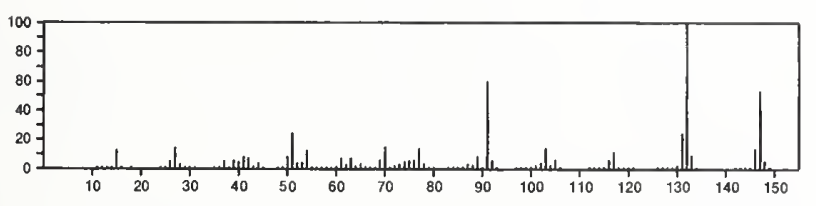

147

$\mathrm{C}_{10} \mathrm{H}_{13} \mathrm{~N}$

936-43-6

Aziridine, 1,2-dimethyl-3-phenyl-, trans-
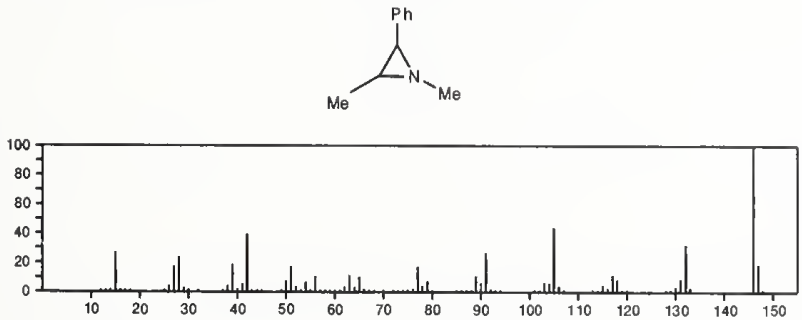

147

1-Naphthalenamine, 5,6,7,8-tetrahydro-

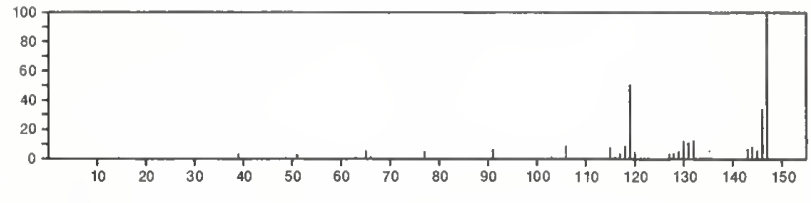

$147 \quad \mathrm{C}_{10} \mathrm{H}_{13} \mathrm{~N}$

2-Naphthalenamine, 5,6,7,8-tetrahydro-

$2217-43-8$
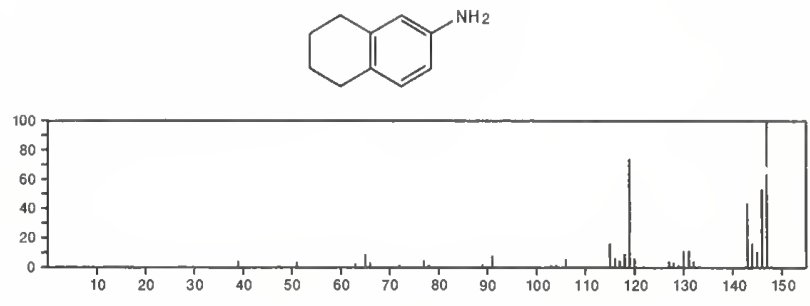

147

Aziridine, 1-(2-phenylethyl)-

$3164-46-3$

$\widehat{\triangle}_{\mathrm{N}_{\mathrm{CH}_{2} \mathrm{CH}_{2} \mathrm{Ph}}}$

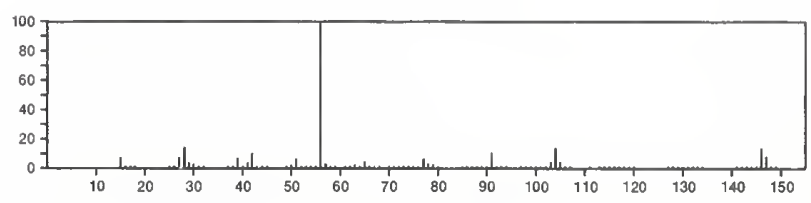

147

$\mathrm{C}_{10} \mathrm{H}_{13} \mathrm{~N}$

4965-09-7

Isoquinoline, 1,2,3,4-tetrahydro-1-methyl-
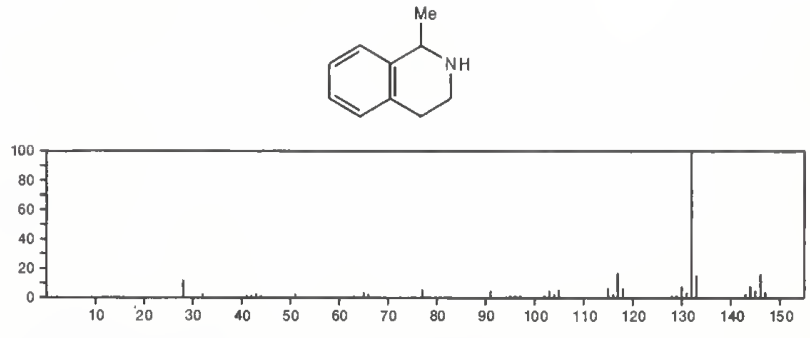

147

$\mathrm{C}_{10} \mathrm{H}_{13} \mathrm{~N}$

$6852-55-7$

1-Propanamine, $N$-(phenylmethylene)-

$\operatorname{PrN}=\mathrm{CHPh}$

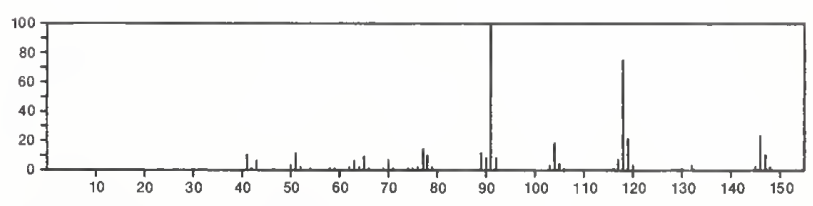

147

$\mathrm{C}_{10} \mathrm{H}_{13} \mathrm{~N}$

$6852-56-8$

2-Propanamine, $N$-(phenylmethylene)-

i-PrN $:$ CHPh

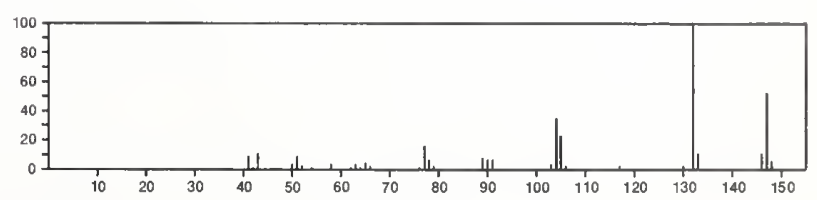


$\mathrm{C}_{10} \mathrm{H}_{13} \mathrm{~N}$

1H-Indole, 2,3-dihydro-1,2-dimethyl-
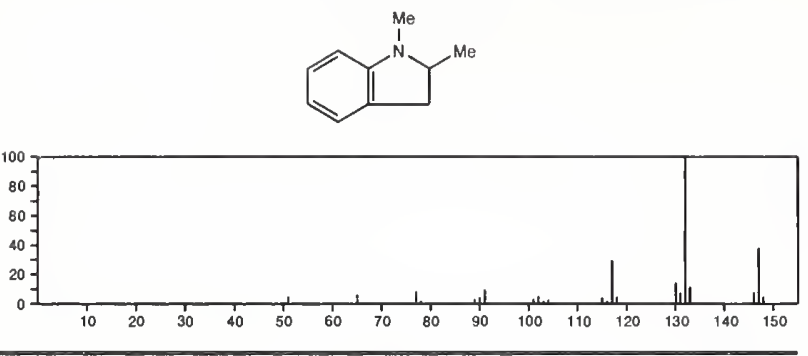

$147 \quad \mathrm{C}_{10} \mathrm{H}_{13} \mathrm{~N}$

Isoquinoline, 1,2,3,4-tetrahydro-3-methyl-

29726-60-1
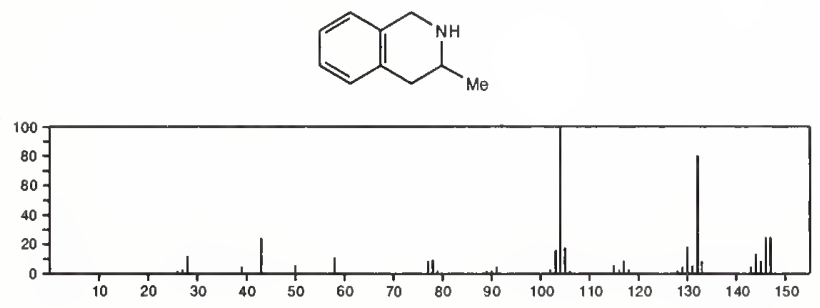

$147 \quad \mathrm{C}_{10} \mathrm{H}_{13} \mathrm{~N}$

$55702-57-3$

Azetidine, 2-methyl-1-phenyl-
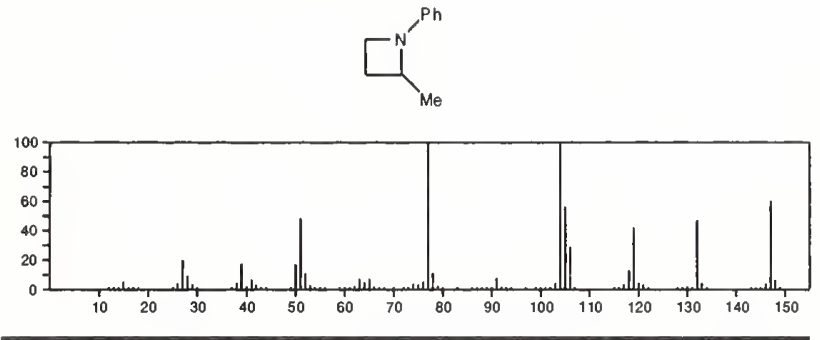

$147 \quad \mathrm{C}_{10} \mathrm{H}_{13} \mathrm{~N}$

$55702-58-4$

Azetidine, 1-methyl-2-phenyl-
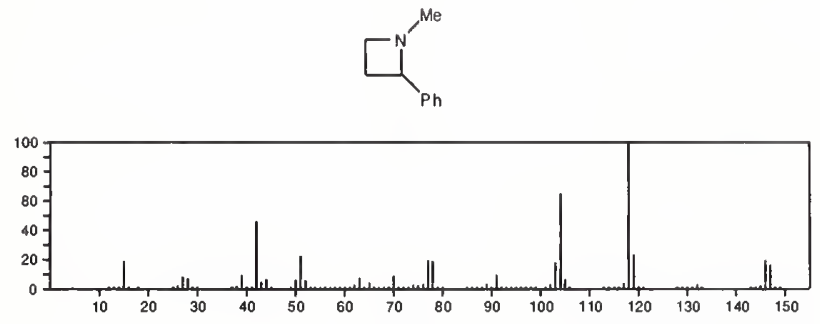

147

$\mathrm{C}_{10} \mathrm{H}_{13} \mathrm{~N}$

Cyclopropanamine, $N$-methyl-1-phenyl-

$56771-48-3$

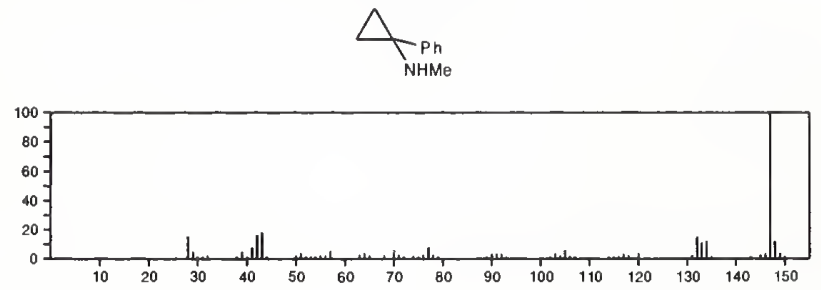

148

$\mathrm{CBrF}_{3}$

$75-63-8$

Methane, bromotrifluoro-

$\mathrm{BrCF}_{3}$
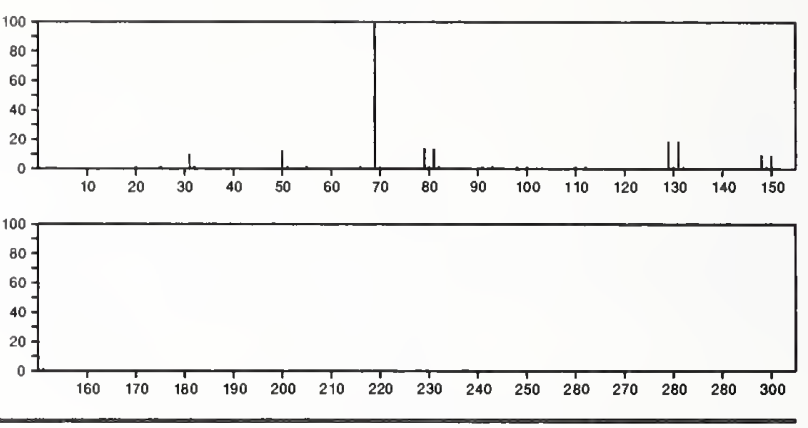

148

$\mathrm{C}_{2} \mathrm{Cl}_{3} \mathrm{~F}$

$359-29-5$

Ethene, trichlorofluoro-

$\mathrm{FCCl}=\mathrm{CCl}_{2}$
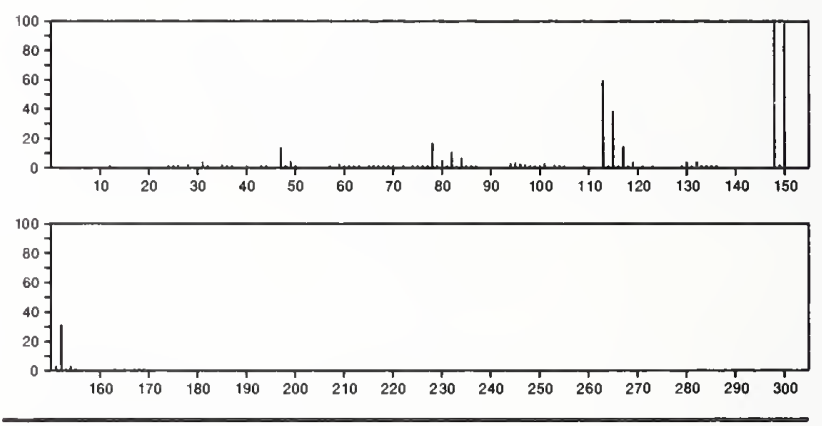

148

$\mathrm{C}_{2} \mathrm{H}_{3} \mathrm{Cl}_{3} \mathrm{O}$

$115-20-8$

Ethanol, 2,2,2-trichloro-

$\mathrm{HOCH}_{2} \mathrm{CCl}_{3}$
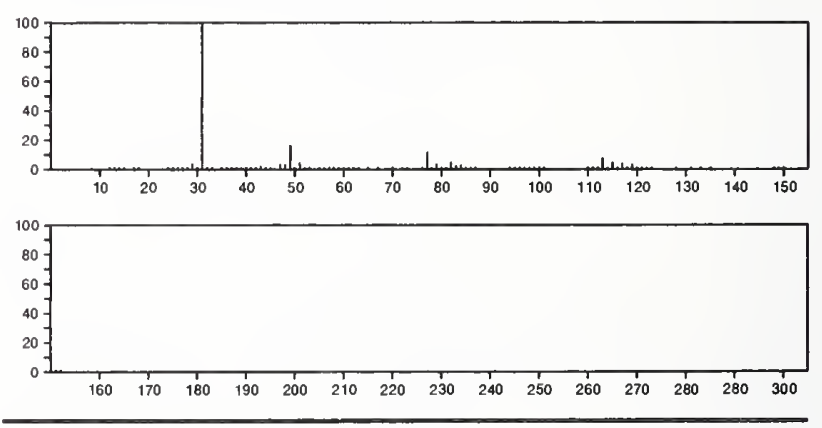

148

$\mathrm{C}_{2} \mathrm{H}_{3} \mathrm{Cl}_{3} \mathrm{O}$

Ether, chloromethyl dichloromethyl

$2799-32-8$

$\mathrm{Cl} \mathrm{CH}_{2} \mathrm{OCHCl}_{2}$
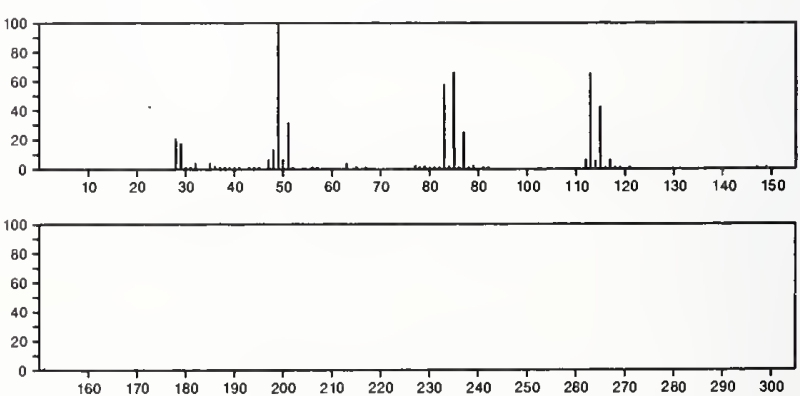
148

Propene, 3-chloro-1,1,3,3-tetrafluoro-

$\mathrm{ClCF}_{2} \mathrm{CH}_{2}=\mathrm{CF}_{2}$
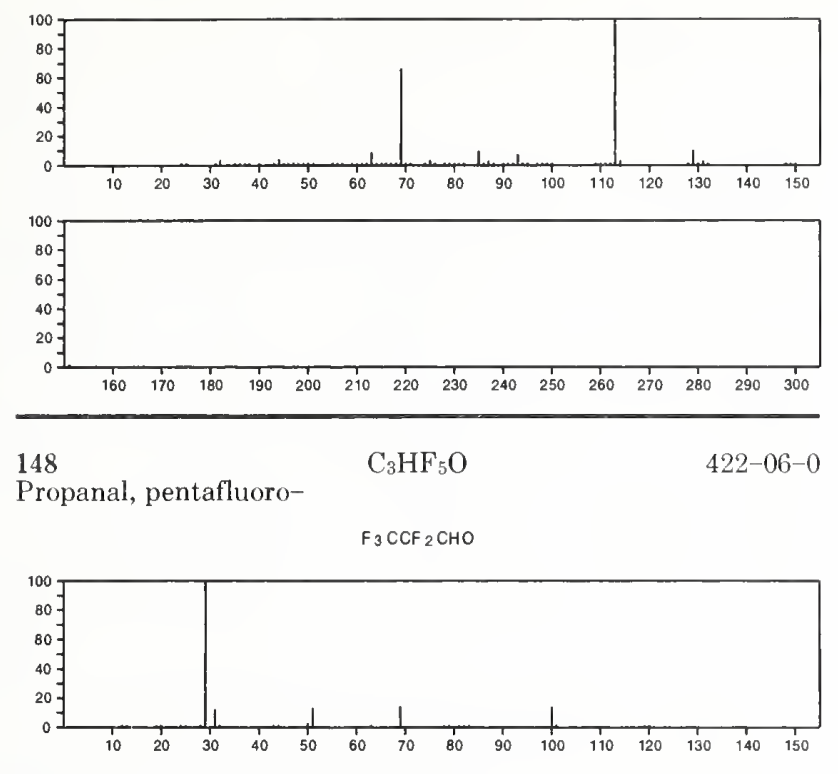

148

$\mathrm{C}_{3} \mathrm{HF}_{5} \mathrm{O}$

431-71-0

2-Propanone, 1,1,1,3,3-pentafluoro-

$\mathrm{F}_{3} \mathrm{CCOCHF}_{2}$

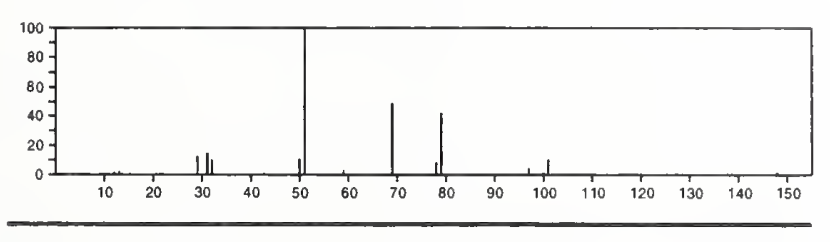

148

$\mathrm{C}_{3} \mathrm{H}_{4} \mathrm{ClF}_{3} \mathrm{O}$

$425-87-6$

Ethane, 2-chloro-1,1,2-trifluoro-1-methoxy-

$\mathrm{FCHCl} \mathrm{CF}_{2} \mathrm{OMe}$

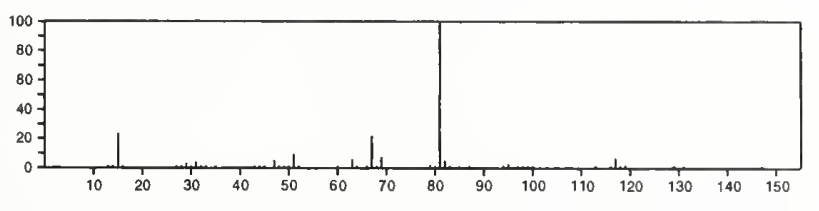

148

$\mathrm{C}_{4} \mathrm{H}_{4} \mathrm{~S}_{3}$

3H-1,2-Dithiole-3-thione, 5-methyl-
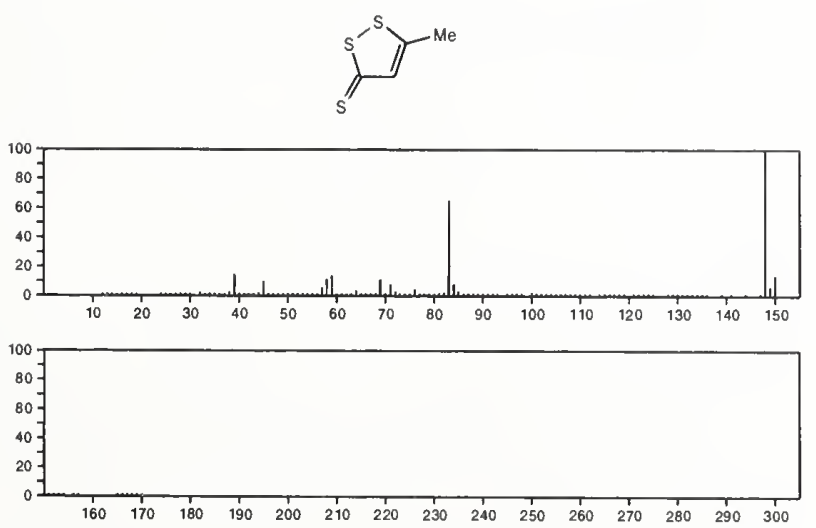

148

$\mathrm{C}_{4} \mathrm{H}_{5} \mathrm{ClN}_{2} \mathrm{~S}$

Thiazole, 2-amino-4-(chloromethyl)-
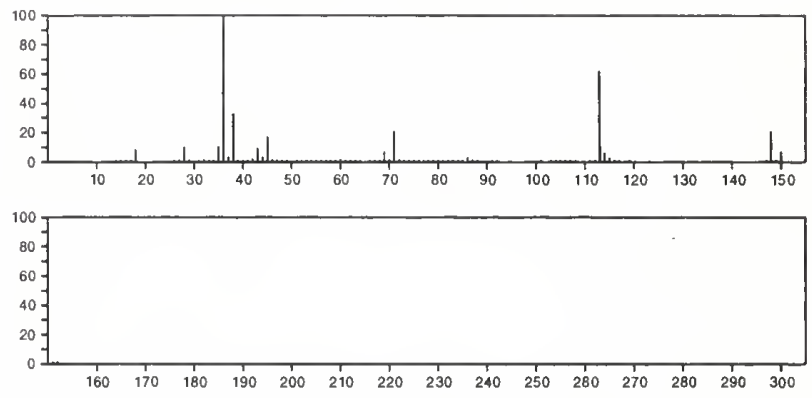

148

$\mathrm{C}_{4} \mathrm{H}_{8} \mathrm{~N}_{2} \mathrm{O}_{2} \mathrm{~S}$

Acetic acid, 2-(thiocarboxy)hydrazide, $O$-methyl ester

ACNHNHC (S) OME
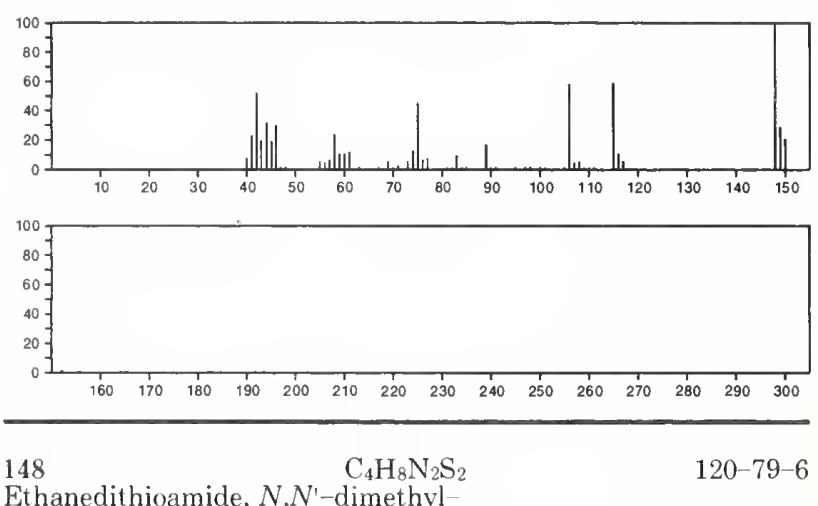

Ethanedithioamide, $N, N^{\prime}$-dimethyl

MeNHCSCSNHME

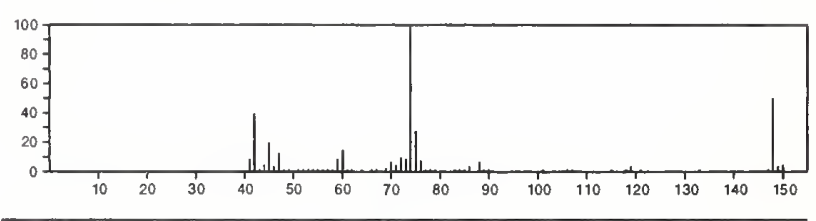

148

1,3,5-Trisilahexane, 5-methyl-

$\mathrm{C}_{4} \mathrm{H}_{16} \mathrm{Si}_{3}$

$18827-17-3$

$\mathrm{Me}_{2} \mathrm{Si} \mathrm{HCH}_{2} \mathrm{SiH}_{2} \mathrm{CH}_{2} \mathrm{Si} \mathrm{H}_{3}$

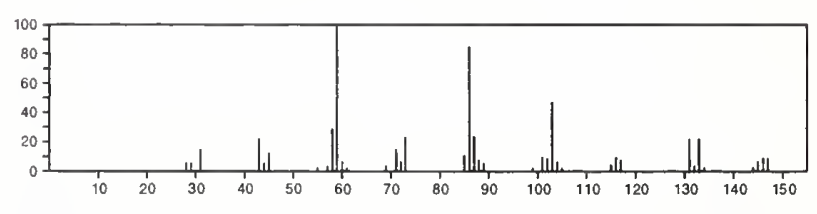

148

$\mathrm{C}_{5} \mathrm{H}_{8} \mathrm{O}_{3} \mathrm{~S}$

$583-92-6$

Butanoic acid, 4-(methylthio)-2-oxo-

$\mathrm{MeSCH}_{2} \mathrm{CH}_{2} \mathrm{COCO}_{2} \mathrm{H}$

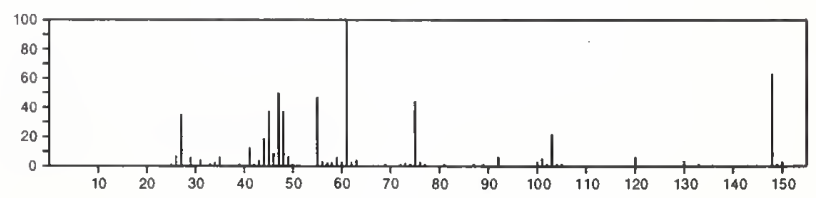


148 $\mathrm{C}_{5} \mathrm{H}_{8} \mathrm{O}_{3} \mathrm{~S}$

$17396-35-9$

4H-Thiopyran-4-one, tetrahydro-, 1,1-dioxide
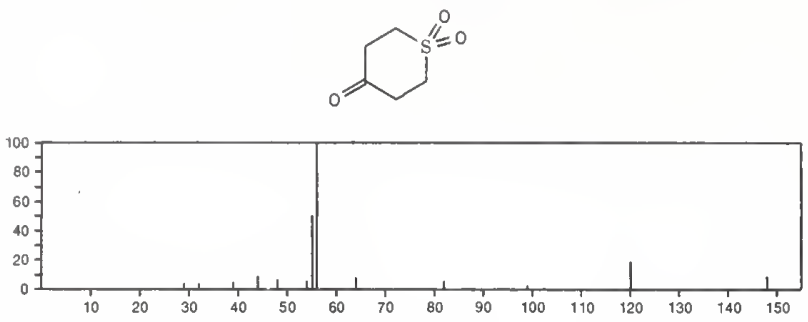

148

Cyclopentane, bromo-

$\mathrm{C}_{5} \mathrm{H}_{9} \mathrm{Br}$

$137-43-9$
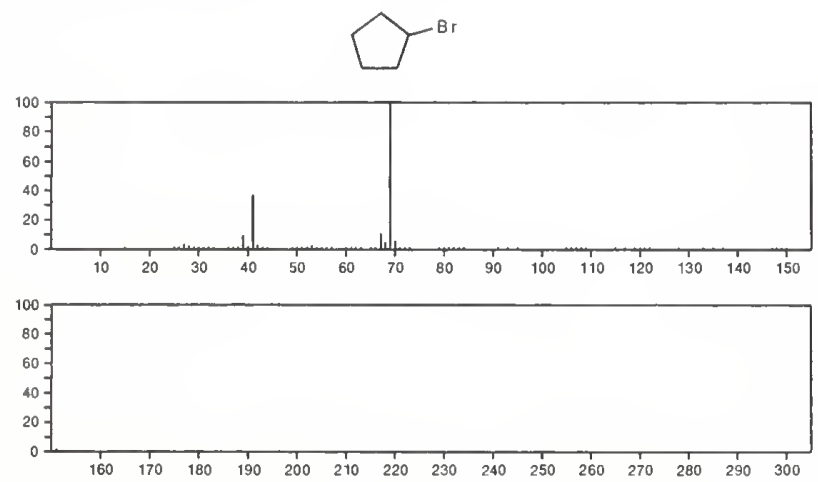

148

$\mathrm{C}_{5} \mathrm{H}_{9} \mathrm{O}_{3} \mathrm{P}$

2,6,7-Trioxa-1-phosphabicyclo[2.2.2] octane, 4-methyl-
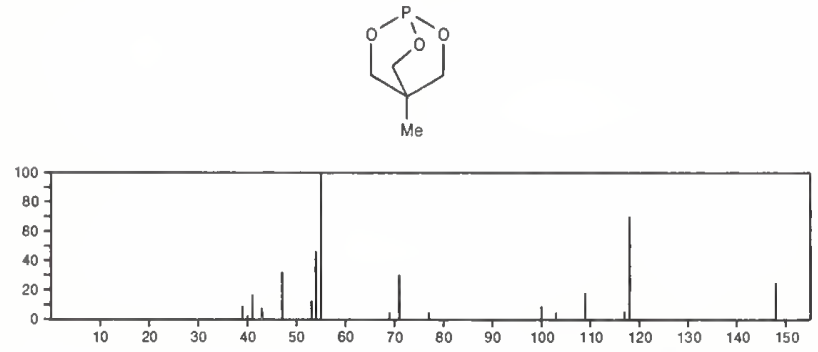

148

$\mathrm{C}_{5} \mathrm{H}_{12} \mathrm{~N}_{2} \mathrm{O}_{3}$

$15438-70-7$

Urea, $N, N^{\prime}$-bis (2-hydroxyethyl)-

$4 \mathrm{CCH}_{2} \mathrm{CH}_{2} \mathrm{NHCONHCH}_{2} \mathrm{CH}_{2} \mathrm{OH}$
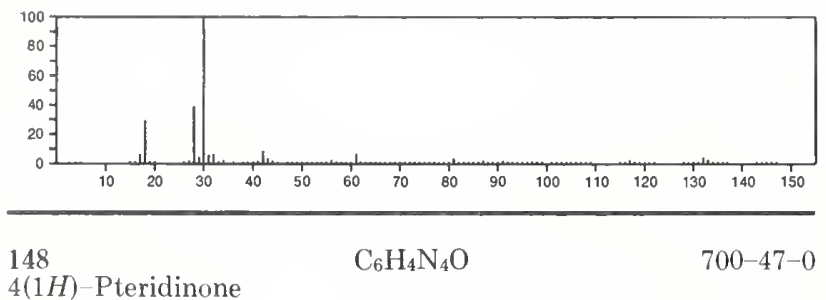<smiles>O=c1nc[nH]c2nccnc12</smiles>

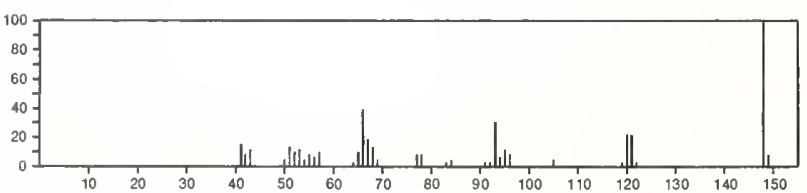

148

2(1H)-Pteridinone

$\mathrm{C}_{6} \mathrm{H}_{4} \mathrm{~N}_{4} \mathrm{O}$

$2432-24-8$<smiles>O=c1ncc2nccnc2[nH]1</smiles>

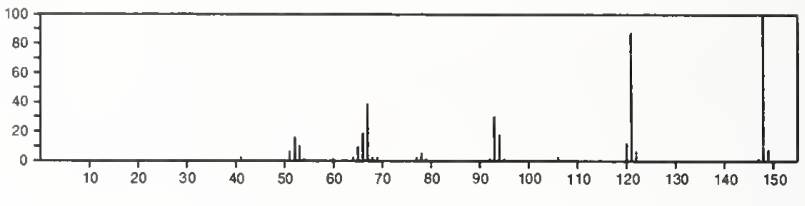

148

$6(5 H)$-Pteridinone

$\mathrm{C}_{6} \mathrm{H}_{4} \mathrm{~N}_{4} \mathrm{O}$

$2432-26-0$<smiles>O=c1cnc2ncncc2[nH]1</smiles>

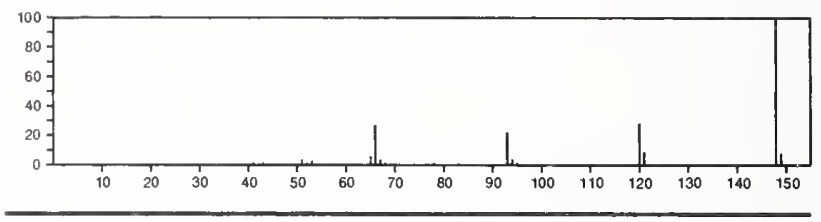

148

$7(1 H)$-Pteridinone

$\mathrm{C}_{6} \mathrm{H}_{4} \mathrm{~N}_{4} \mathrm{O}$

2432-27-1
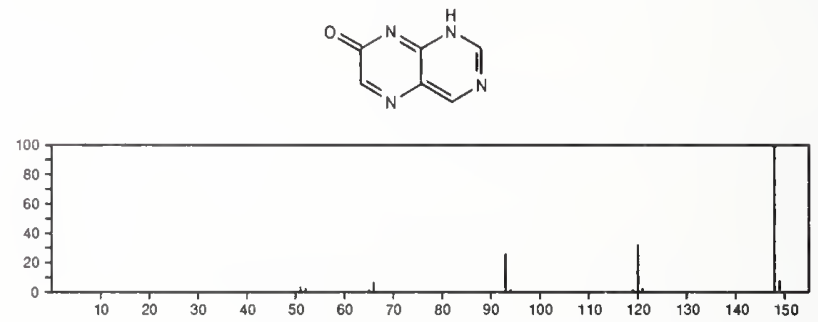

$148 \quad \mathrm{C}_{6} \mathrm{H}_{4} \mathrm{~N}_{4} \mathrm{O}$

$56805-26-6$

1H-Purine-8-carboxaldehyde
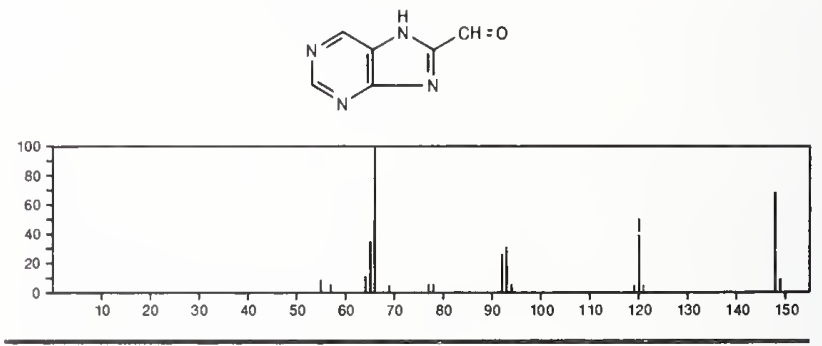

148

$\mathrm{C}_{6} \mathrm{H}_{12} \mathrm{O}_{2} \mathrm{~S}$

$6251-33-8$

Thiepane, 1,1-dioxide
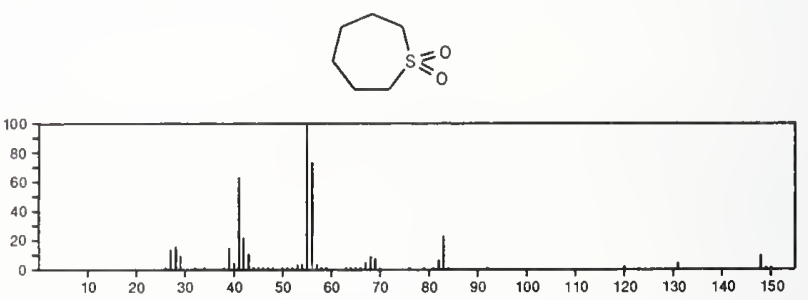
148

$\mathrm{C}_{6} \mathrm{H}_{12} \mathrm{O}_{2} \mathrm{~S}$

Propanoic acid, 2-mercapto-, 1-methylethyl ester

- PrOC(O) $\mathrm{CH}(\mathrm{SH}) \mathrm{M}$

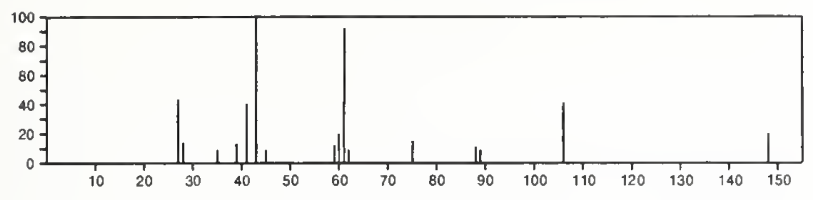

148

$\mathrm{C}_{6} \mathrm{H}_{12} \mathrm{O}_{2} \mathrm{~S}$

Acetic acid, mercapto-, sec-butyl ester

$16849-96-0$

$s-\mathrm{BuOC}(\mathrm{O}) \mathrm{CH}_{2} \mathrm{SH}$

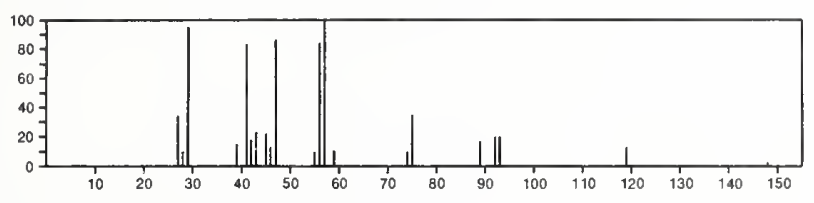

148

$\mathrm{C}_{6} \mathrm{H}_{12} \mathrm{O}_{2} \mathrm{~S}$

$18673-13-7$

Propanoic acid, 3-(ethylthio)-, methyl ester

$\mathrm{Me} \mathrm{OC}(\mathrm{O}) \mathrm{CH}_{2} \mathrm{CH}_{2} \mathrm{SE}$ t

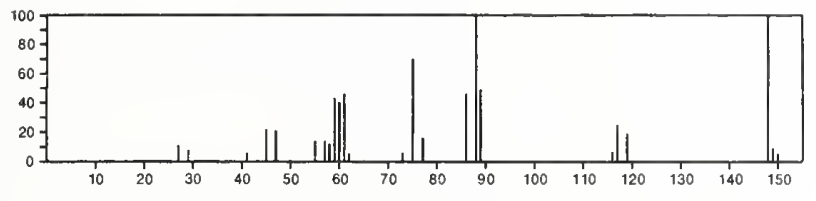

\section{8}

$\mathrm{C}_{6} \mathrm{H}_{12} \mathrm{O}_{2} \mathrm{~S}$

Propionic acid, 2-mercapto--, propyl ester

$19788-50-2$

$\mathrm{PrOC}(\mathrm{O}) \mathrm{CH}(\mathrm{SH}) \mathrm{Me}$

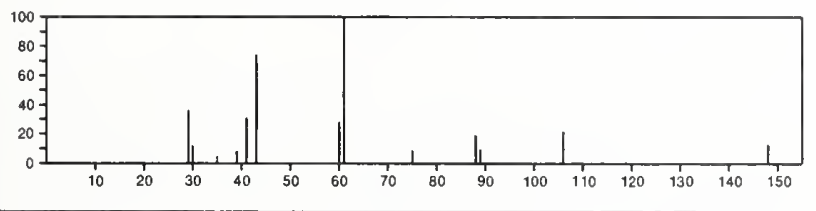

148

Acetic acid, (butylthio)-

\section{$\mathrm{C}_{6} \mathrm{H}_{12} \mathrm{O}_{2} \mathrm{~S}$}

20600-61-7

$\mathrm{HO}_{2} \mathrm{CCH}_{2} \mathrm{~S}\left(\mathrm{CH}_{2}\right)_{3} \mathrm{Me}$

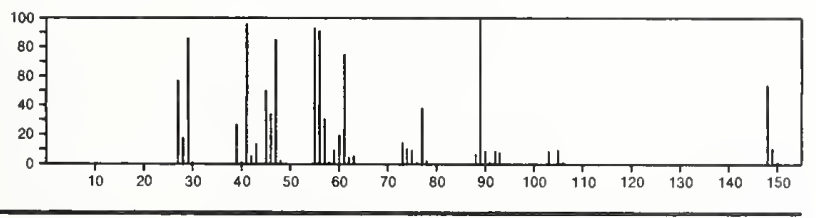

148

$\mathrm{C}_{6} \mathrm{H}_{12} \mathrm{O}_{2} \mathrm{~S}$

Acetic acid, (propylthio)-, methyl ester

$20600-65-1$

$\mathrm{PrSCH}_{2} \mathrm{C}(\mathrm{O})$ OMe

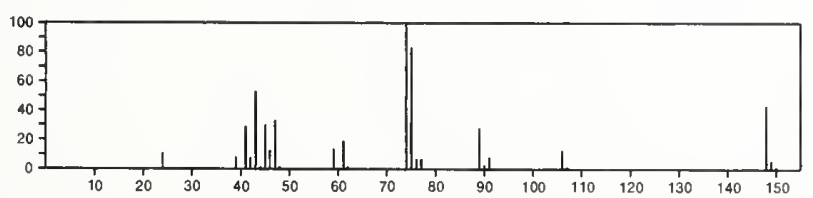

148

$\mathrm{C}_{6} \mathrm{H}_{12} \mathrm{O}_{2} \mathrm{~S}$

Acetic acid, [(1,1-dimethylethyl)thio]-

$24310-22-3$

$\mathrm{HO}_{2} \mathrm{CCH}_{2} \mathrm{SBu}-\mathrm{t}$

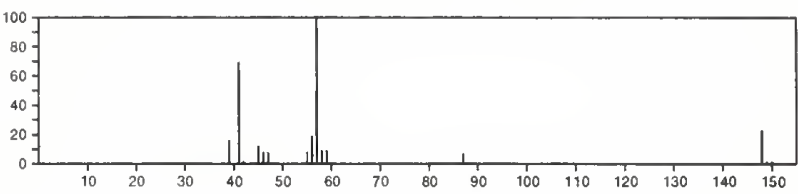

148

p-Dioxane-2,5-dimethanol

$\mathrm{C}_{6} \mathrm{H}_{12} \mathrm{O}_{4}$

$14236-12-5$<smiles>O=CC1COC(CO)CO1</smiles>
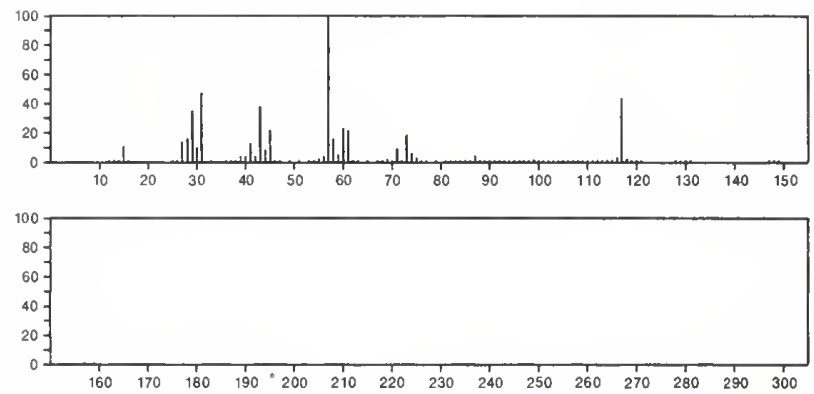

148

$\mathrm{C}_{6} \mathrm{H}_{12} \mathrm{O}_{4}$

$29749-76-6$

Propionic acid, 2,3-dimethoxy-, methyl ester

$\mathrm{MeOC}(\mathrm{O}) \mathrm{CH}$ ( OMe ) $\mathrm{CH}_{2} \mathrm{OMe}$

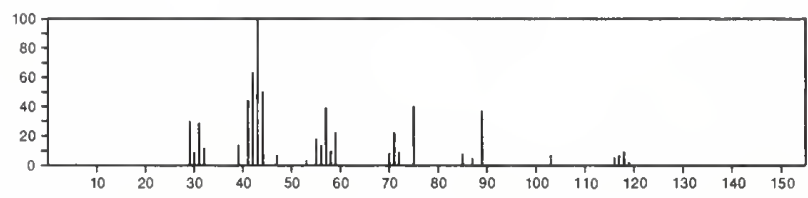

148

1,4-Dioxane-2,6-dimethanol

$\mathrm{C}_{6} \mathrm{H}_{12} \mathrm{O}_{4}$

54120-69-3
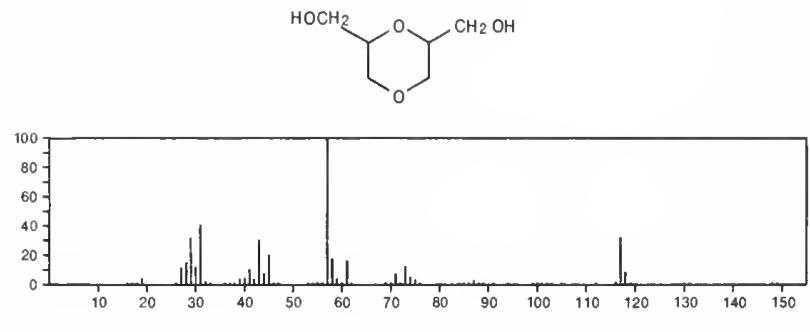

148

1,3-Dithiane, 2,2-dimethyl-

$\mathrm{C}_{6} \mathrm{H}_{12} \mathrm{~S}_{2}$

6007-22-3
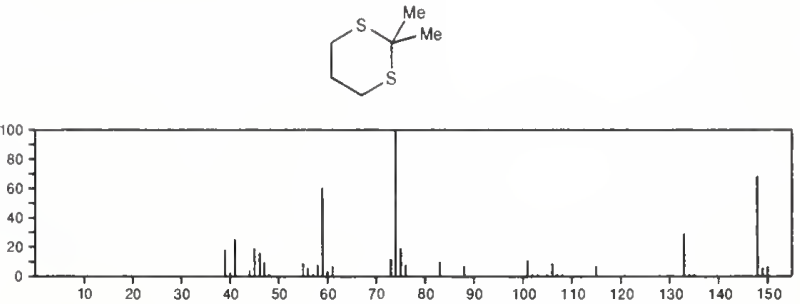
148

Ethene, 1,2-bis(ethylthio)-

$\mathrm{C}_{6} \mathrm{H}_{12} \mathrm{~S}_{2}$

$E t S C H=C H S E$ t
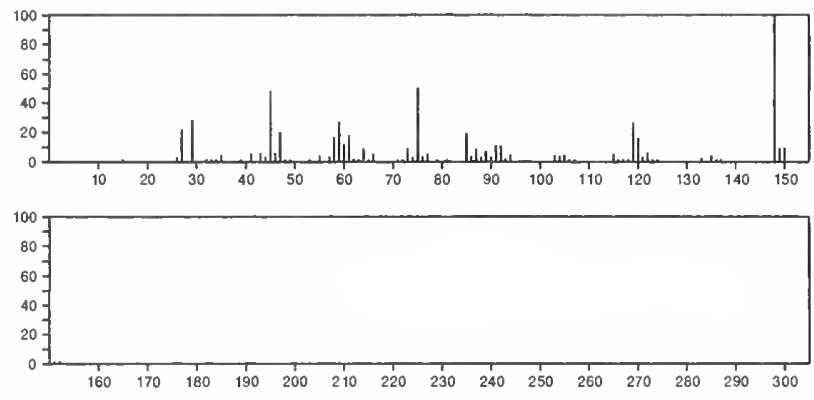

148

Ethanol, 2,2'-(1,2-ethanediyldiimino)bis-

$\mathrm{HOCH}_{2} \mathrm{CH}_{2} \mathrm{NHCH}_{2} \mathrm{CH}_{2} \mathrm{NHCH}_{2} \mathrm{CH}_{2} \mathrm{OH}$

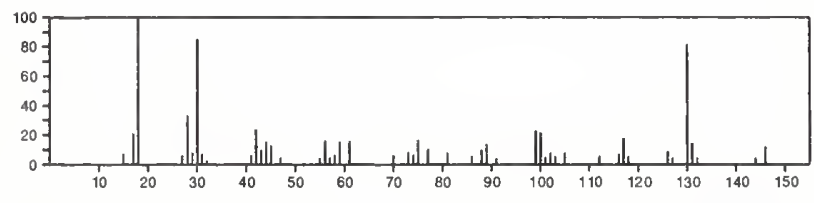

$148 \quad \mathrm{C}_{6} \mathrm{H}_{16} \mathrm{O}_{2} \mathrm{Si}$

Silane, (2-methoxyethoxy)trimethyl-

$18173-74-5$

$\mathrm{MeOCH} 2 \mathrm{CH}_{2}$ OSi Mes

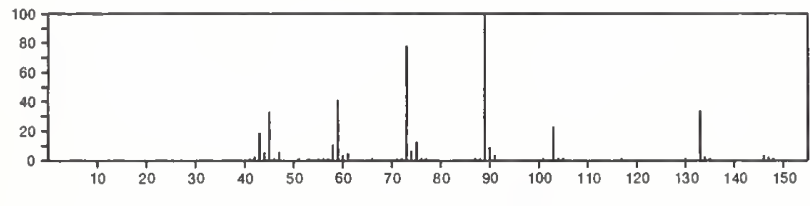

148

$\mathrm{C}_{7} \mathrm{H}_{8} \mathrm{~N}_{4}$

$5006-56-4$

1,2,4-Triazolo[4,3-a]pyridin-3-amine, 7-methyl-
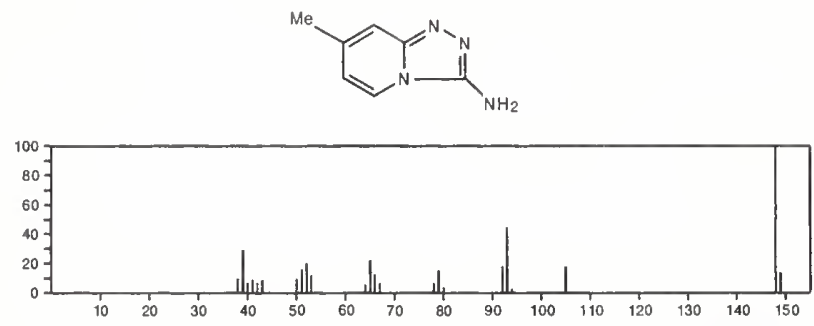

148

$\mathrm{C}_{7} \mathrm{H}_{8} \mathrm{~N}_{4}$

$5528-60-9$

$s$-Triazolo[4,3-a]pyridine, 3-amino-6-methyl-
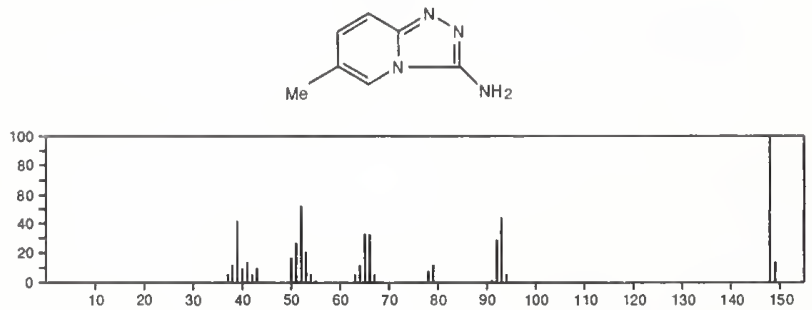

148

$\mathrm{C}_{7} \mathrm{H}_{8} \mathrm{~N}_{4}$

$5595-15-3$

$s$-Triazolo[4,3-a]pyridine, 3-amino-5-methyl-<smiles>Nc1cccc2nnc(N)n12</smiles>

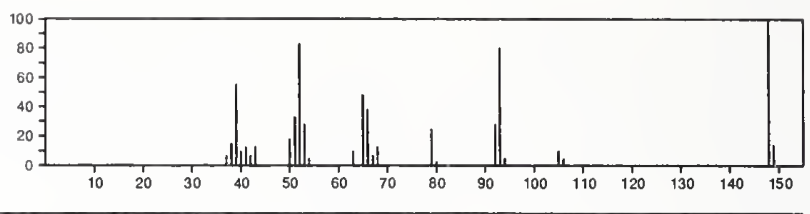

148

$\mathrm{C}_{7} \mathrm{H}_{8} \mathrm{~N}_{4}$

Pyrazolo[5,1-c][1,2,4]triazine, 3,4-dimethyl-

$6726-49-4$
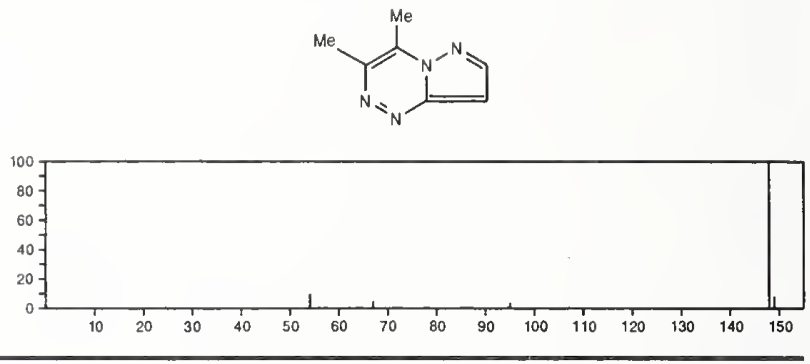

148

$\mathrm{C}_{7} \mathrm{H}_{8} \mathrm{~N}_{4}$

1H-Benzotriazole, 7-amino-1-methyl-

$13183-01-2$
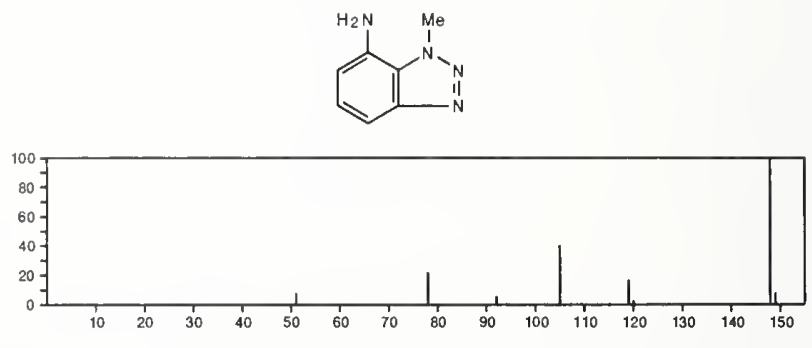

148

$\mathrm{C}_{7} \mathrm{H}_{8} \mathrm{~N}_{4}$

$19848-77-2$

s-Triazolo[4,3-a]pyrazine, 5,8-dimethyl-
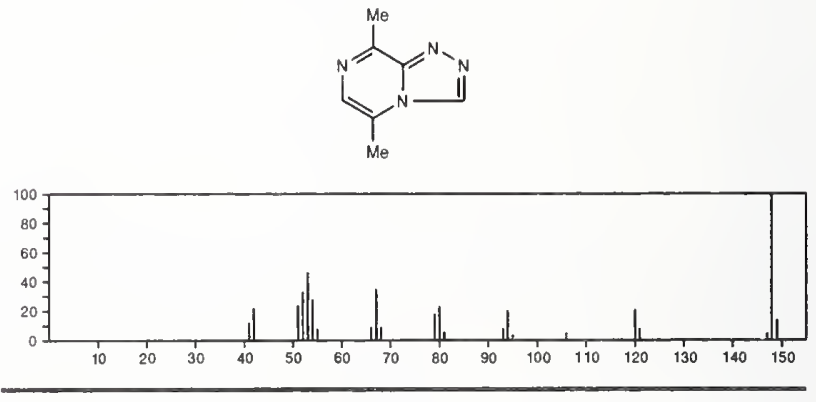

148

$\mathrm{C}_{7} \mathrm{H}_{8} \mathrm{~N}_{4}$

$19848-78-3$

$s$-Triazolo[4,3-a]pyrazine, 3,8-dimethyl-
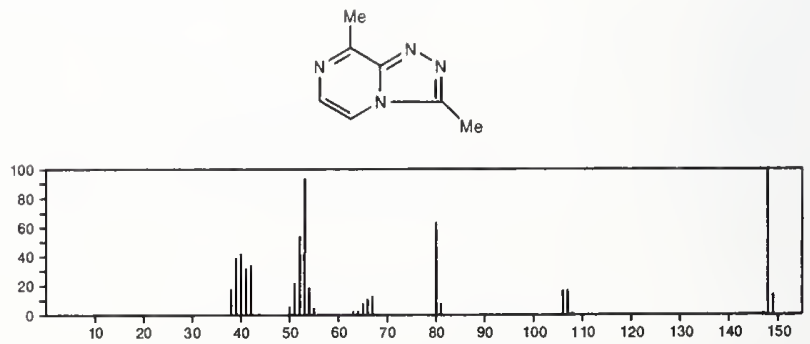
$\mathrm{C}_{7} \mathrm{H}_{8} \mathrm{~N}_{4}$

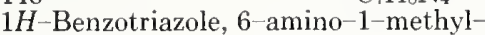
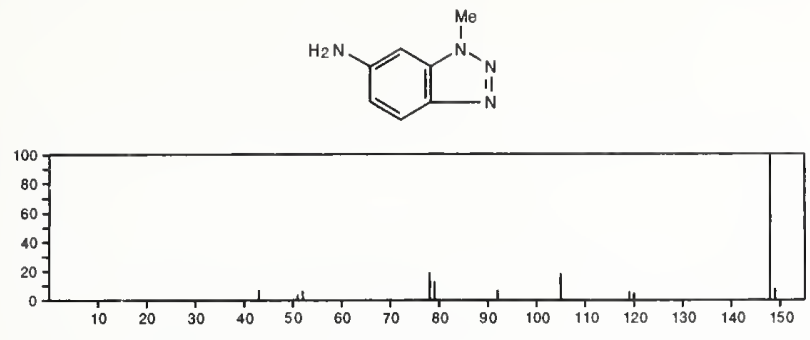

$148 \quad \mathrm{C}_{7} \mathrm{H}_{8} \mathrm{~N}_{4}$

1H-Benzotriazole, 4-amino-1-methyl-
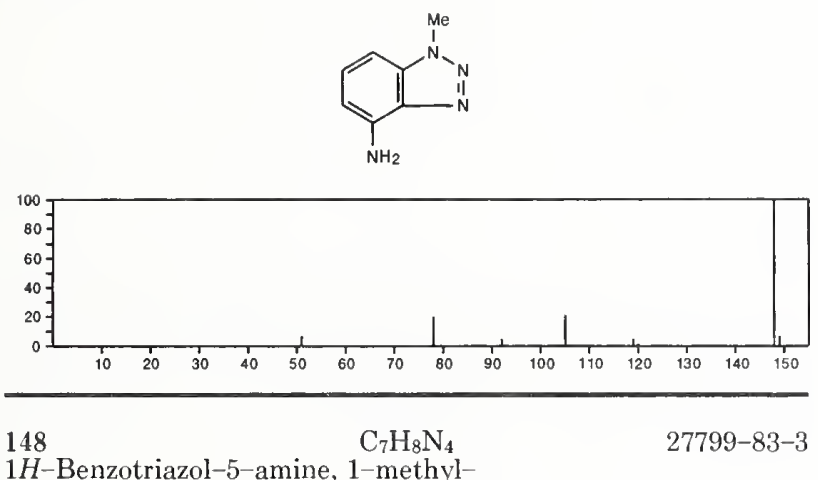

1H-Benzotriazol-5-amine, 1-methyl-
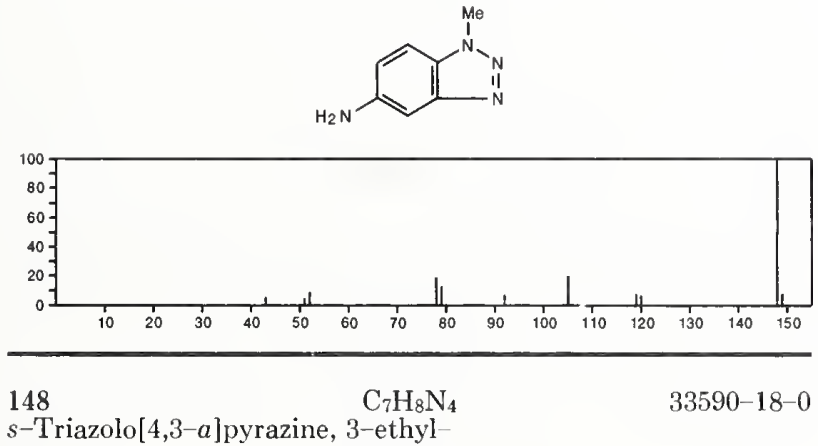

$s$-Triazolo[4,3-a]pyrazine, 3-ethyl-
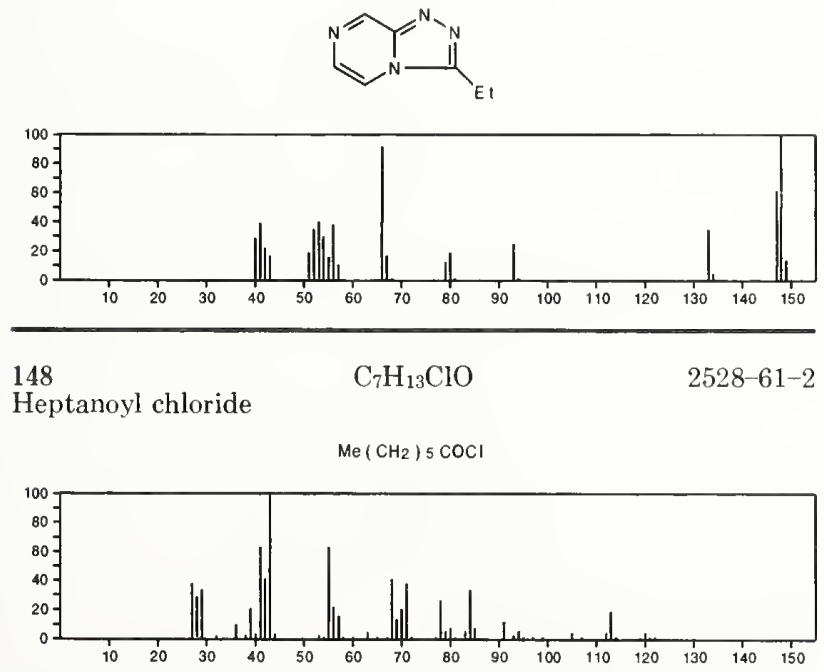

148

Sulfoxide, butyl propyl

$\mathrm{C}_{7} \mathrm{H}_{16} \mathrm{OS}$

2977-02-8

$\mathrm{Me}\left(\mathrm{CH}_{2}\right)_{3} \mathrm{~S}(\mathrm{O}) \mathrm{Pr}$

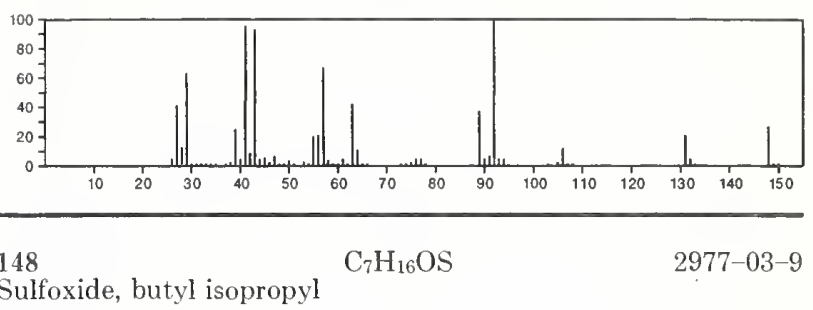

$\mathrm{Me}\left(\mathrm{CH}_{2}\right)_{3} \mathrm{~S}(\mathrm{O}) \mathrm{Pr}-\mathrm{i}$

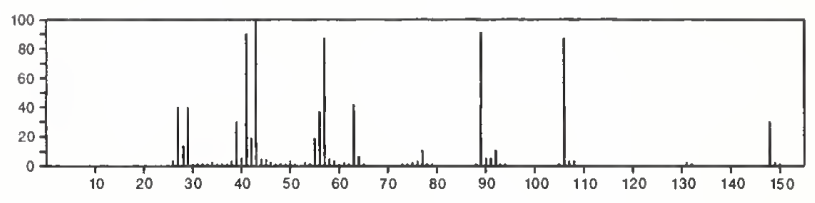

148 $\mathrm{C}_{7} \mathrm{H}_{16} \mathrm{O}_{3}$

$122-51-0$

Ethane, 1,1',1"-[methylidynetris(oxy)]tris

$\mathrm{HC}(\mathrm{OE} 1)_{3}$

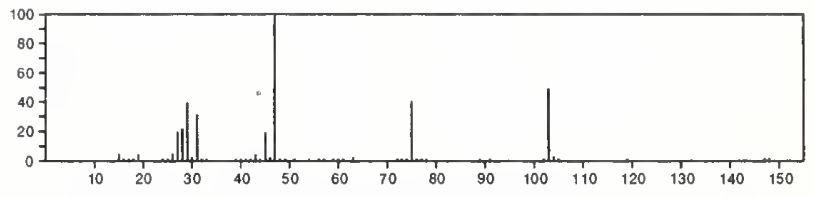

148

$\mathrm{C}_{7} \mathrm{H}_{16} \mathrm{O}_{3}$

2-Propanol, 1-(2-methoxypropoxy)-

13429-07-7

$\mathrm{MeCH}$ ( OMe ) $\mathrm{CH}_{2} \mathrm{OCH}_{2} \mathrm{CH}(\mathrm{OH}) \mathrm{Me}$

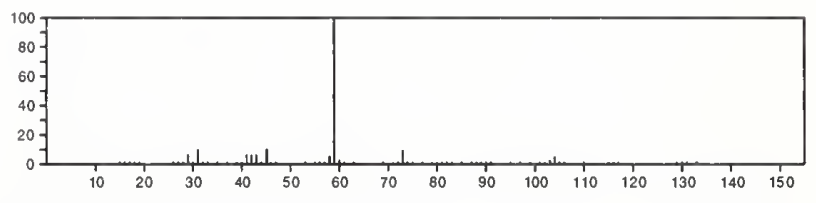

$148 \quad \mathrm{C}_{7} \mathrm{H}_{16} \mathrm{O}_{3}$

1-Propanol, 2-(2-methoxypropoxy)-

$13588-28-8$

$\mathrm{HOCH}_{2} \mathrm{CHMeOCH}_{2} \mathrm{CH}(\mathrm{OMe}) \mathrm{Me}$

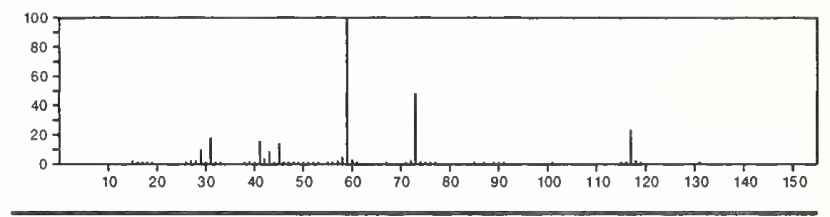

148

$\mathrm{C}_{7} \mathrm{H}_{16} \mathrm{O}_{3}$

$20324-32-7$

2-Propanol, 1-(2-methoxy-1-methylethoxy)-

$\mathrm{MeCH}(\mathrm{OH}) \mathrm{CH}_{2} \mathrm{OCHMe} \mathrm{CH}_{2} \mathrm{OMe}$

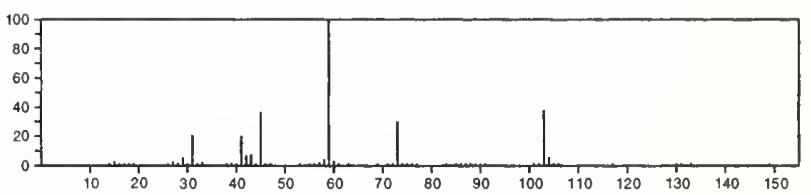


$148 \quad \mathrm{C}_{7} \mathrm{H}_{16} \mathrm{O}_{3}$

20637-34-7

1-Propanol, 3-methoxy-2-(methoxymethyl)-2-methyl-

$\mathrm{CH}_{2} \mathrm{OH}$

Me $\mathrm{OCH}_{2} \stackrel{\mathrm{C}}{\mathrm{CM}} \mathrm{CH}_{2} \mathrm{OM}_{0}$

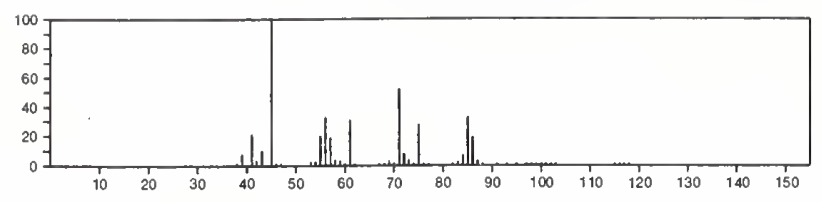

148

Butane, 1,2,4-trimethoxy-

$\mathrm{C}_{7} \mathrm{H}_{16} \mathrm{O}_{3}$

$20637-48-3$

$\mathrm{M}_{\theta} \mathrm{OCH}_{2} \mathrm{CH}_{2} \mathrm{CH}$ ( OMe) $\mathrm{CH}_{2} \mathrm{OM}_{\theta}$

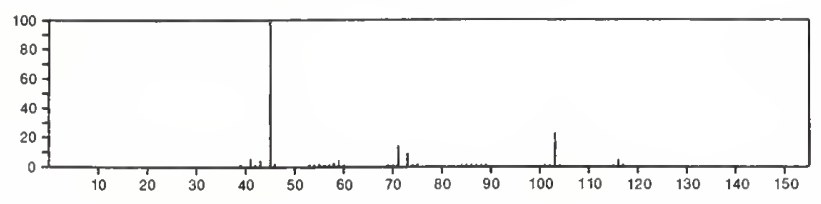

148

$\mathrm{C}_{7} \mathrm{H}_{16} \mathrm{O}_{3}$

$55956-21-3$

1-Propanol, 2-(2-methoxy-1-methylethoxy)-

$\mathrm{MeOCH}_{2} \mathrm{CHMeOCHMe} \mathrm{CH}_{2} \mathrm{OH}$

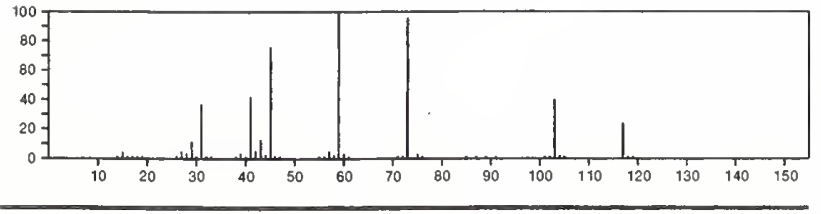

148

$\mathrm{C}_{8} \mathrm{H}_{4} \mathrm{O}_{3}$

$85-44-9$

1,3-Isobenzofurandione
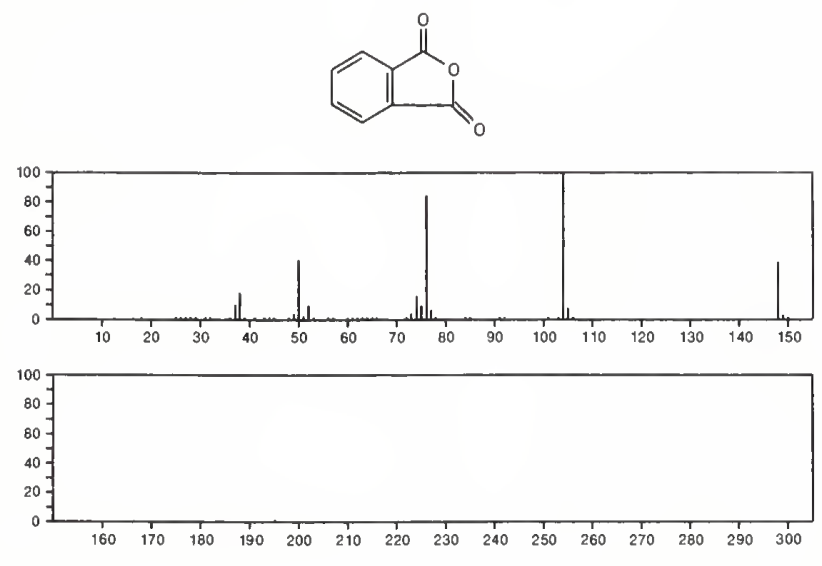

$148 \quad \mathrm{C}_{8} \mathrm{H}_{8} \mathrm{~N}_{2} \mathrm{O} \quad 769-28-8$

3-Pyridinecarbonitrile, 1,2-dihydro-4,6-dimethyl-2-oxo-
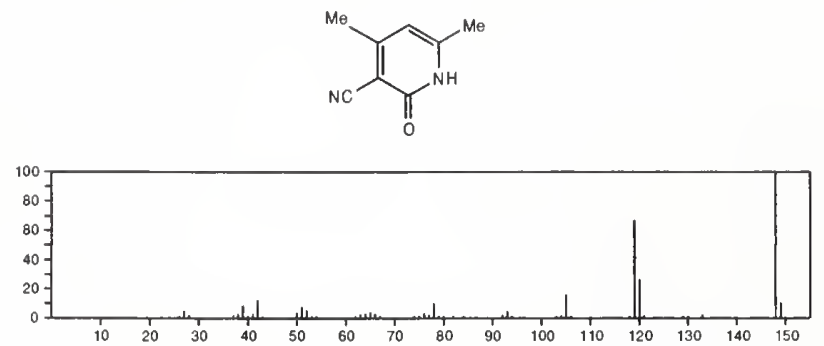

$148 \quad \mathrm{C}_{8} \mathrm{H}_{8} \mathrm{~N}_{2} \mathrm{O}$

$1006-19-5$

3H-Indazol-3-one, 1,2-dihydro-1-methyl-
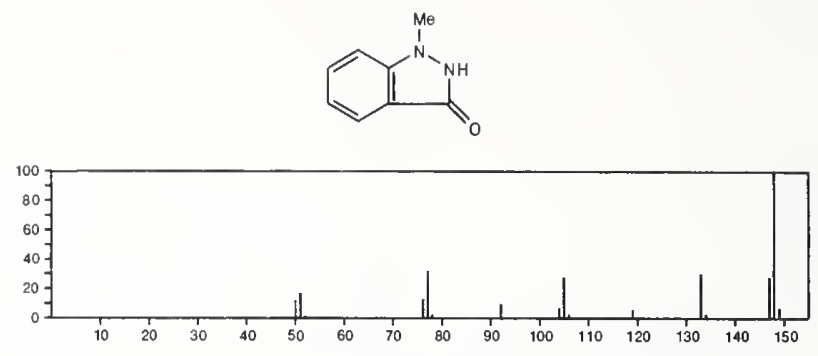

3-Indazolinone, 2-methyl-
$\mathrm{C}_{8} \mathrm{H}_{8} \mathrm{~N}_{2} \mathrm{O} \quad 1848-40-4$
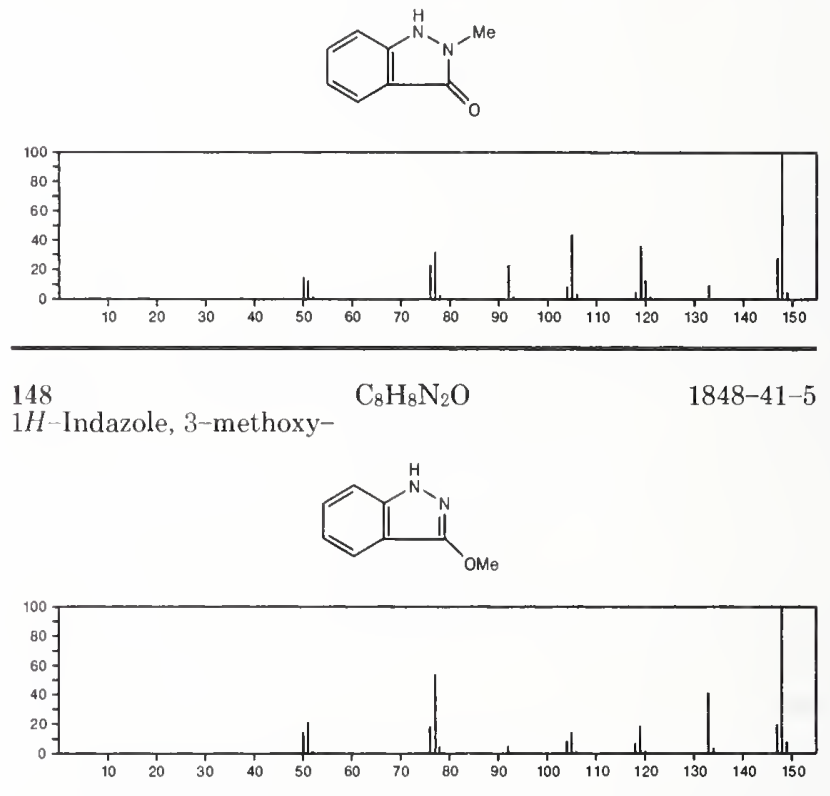

148

$\mathrm{C}_{8} \mathrm{H}_{8} \mathrm{~N}_{2} \mathrm{O}$

$5400-75-9$

2H-Benzimidazol-2-one, 1,3-dihydro-5-methyl-
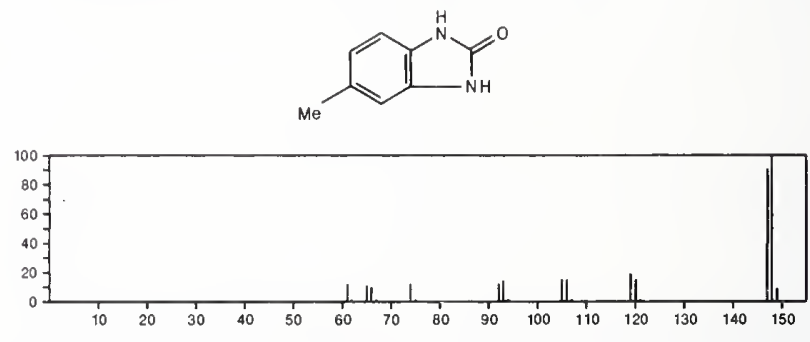

$148 \quad \mathrm{C}_{8} \mathrm{H}_{8} \mathrm{~N}_{2} \mathrm{O}$

Benzimidazole, 2-methyl-, 3-oxide

$16007-52-6$
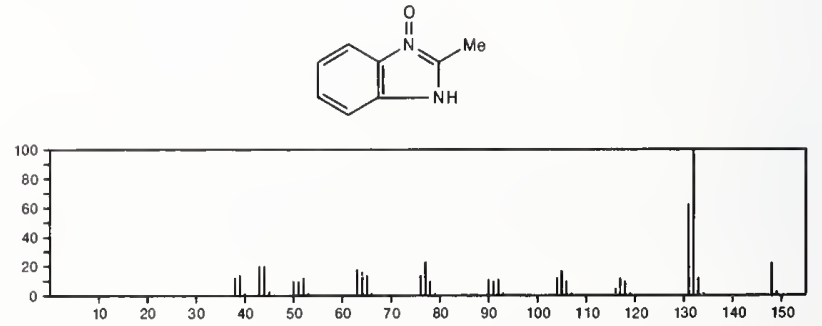
148 2(3H)-Benzoxazolimine, 3-methyl-
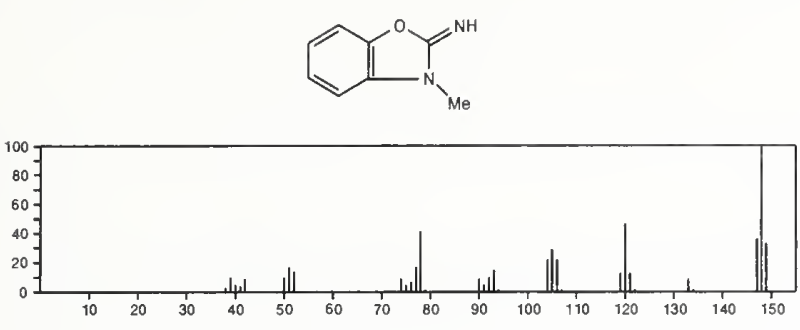

148

Benzoxazole, 2-(methylamino)-

\section{$\mathrm{C}_{8} \mathrm{H}_{8} \mathrm{~N}_{2} \mathrm{O}$}
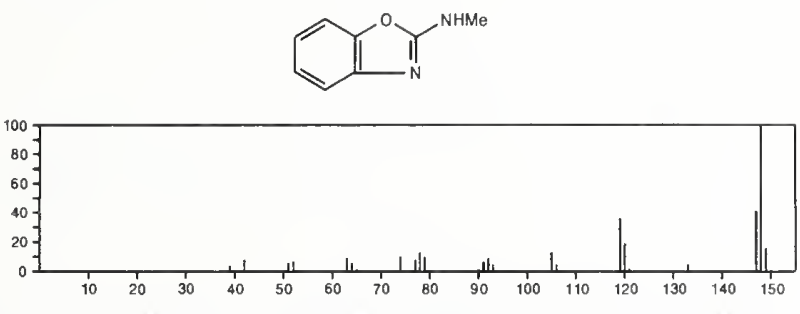

148

\section{$\mathrm{C}_{8} \mathrm{H}_{8} \mathrm{~N}_{2} \mathrm{O}$}

Pyridine, 4-(4,5-dihydro-2-oxazolyl)-
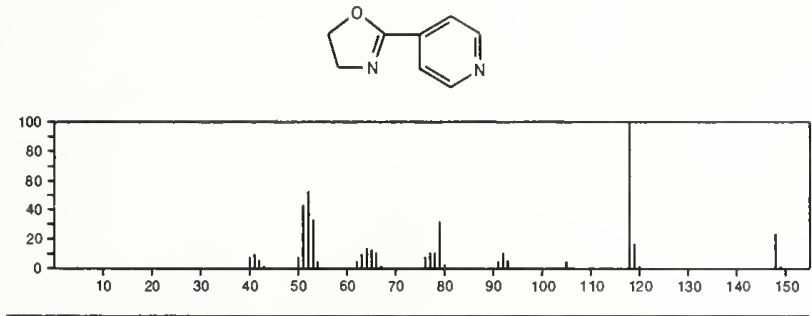

148

Octane, 1-chloro-

\section{$\mathrm{C}_{8} \mathrm{H}_{17} \mathrm{Cl}$}

111-85-3

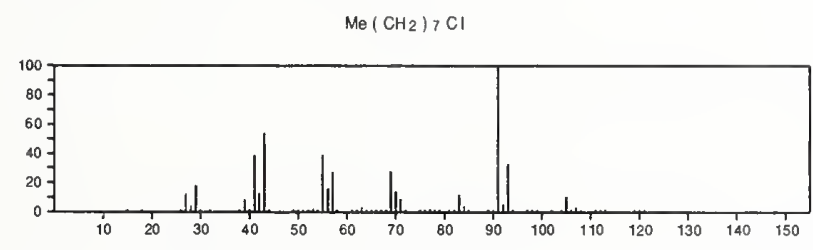

148

Heptane, 3-(chloromethyl)-

$\mathrm{C}_{8} \mathrm{H}_{17} \mathrm{Cl}$

123-04-6

$\mathrm{Me}\left\{\mathrm{CH}_{2}\right)_{3} \mathrm{CHE}\left\{\mathrm{CH}_{2} \mathrm{Cl}\right.$

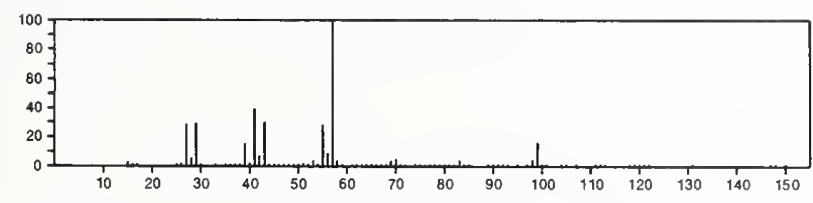

148

Octane, 2-chloro-

$\mathrm{C}_{8} \mathrm{H}_{17} \mathrm{Cl}$

628-61-5

$\mathrm{MeCHCl}\left(\mathrm{CH}_{2}\right) 5 \mathrm{Me}$

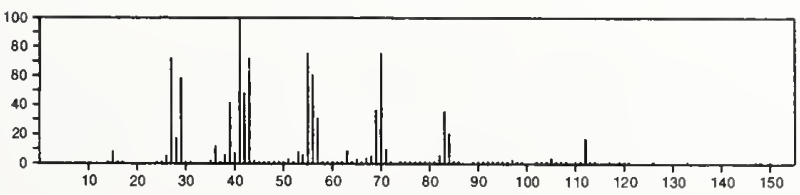

148

2H-1-Benzopyran-2 one, 3,4-dihydro

119-84-6
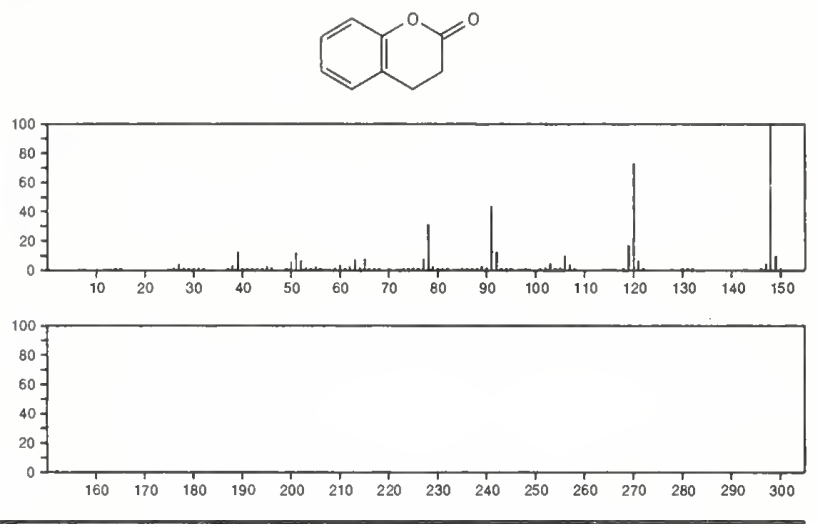

148

2-Propenoic acid, 3-phenyl-, $(E)-$

$140-10-3$

$\mathrm{HO}_{2} \mathrm{CCH}=\mathrm{CHPh}$

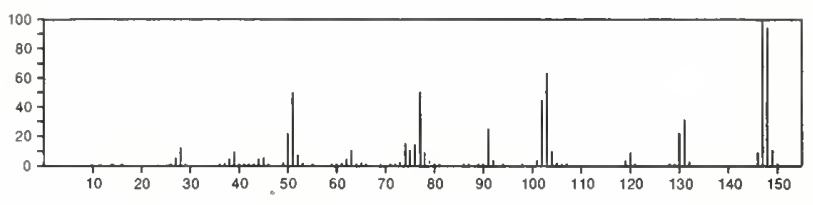

148

$\mathrm{C}_{9} \mathrm{H}_{8} \mathrm{O}_{2}$

491-37-2

4H-1-Benzopyran-4-one, 2,3-dihydro-
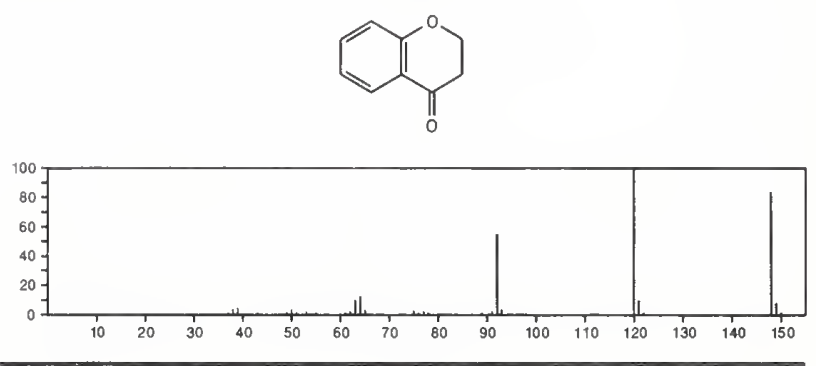

148

1,2-Propanedione, 1-phenyl-

$\mathrm{C}_{9} \mathrm{H}_{8} \mathrm{O}_{2}$

579-07-7

Me COCOPh

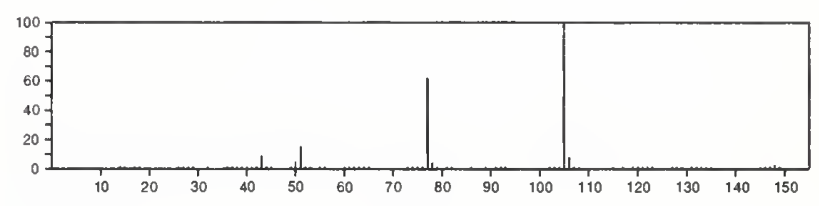

148

$\mathrm{C}_{9} \mathrm{H}_{8} \mathrm{O}_{2}$

2-Propenoic acid, 3-phenyl-

$621-82-9$

$\mathrm{HO}_{2} \mathrm{CCH}=\mathrm{CHPh}$

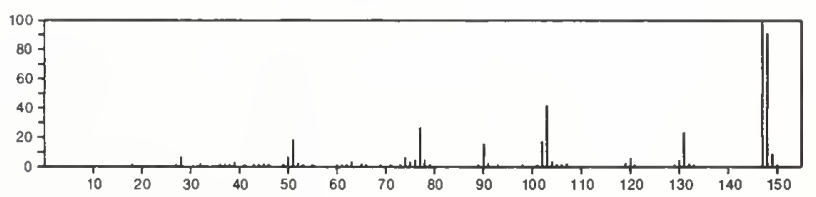


148

$\mathrm{C}_{9} \mathrm{H}_{8} \mathrm{O}_{2}$

$3(2 \mathrm{H})$-Benzofuranone, 7-methyl-

669-04-5
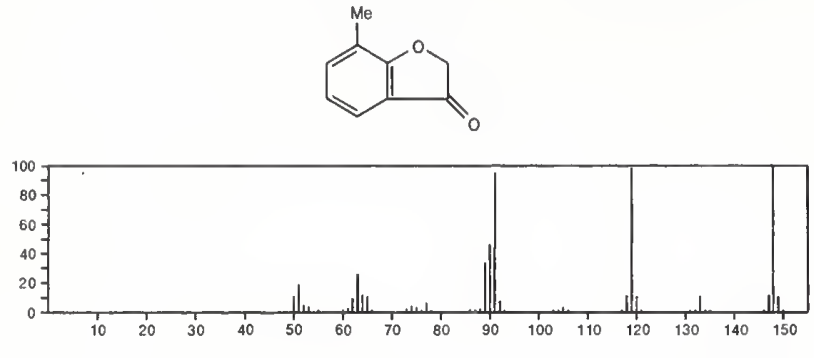

148

Furan, 2,2'-methylenebis-

$\mathrm{C}_{9} \mathrm{H}_{8} \mathrm{O}_{2}$

$1197-40-6$<smiles>c1coc(CCc2ccco2)c1</smiles>

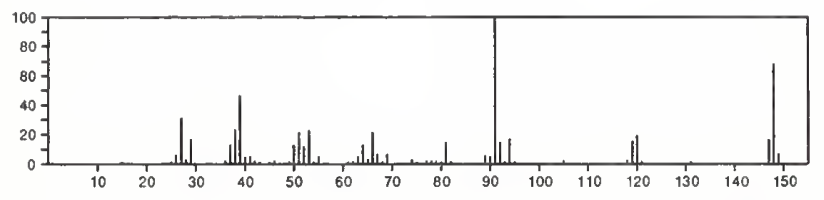

148

$\mathrm{C}_{9} \mathrm{H}_{8} \mathrm{O}_{2}$

$3(2 H)$-Benzofuranone, 6-methyl-
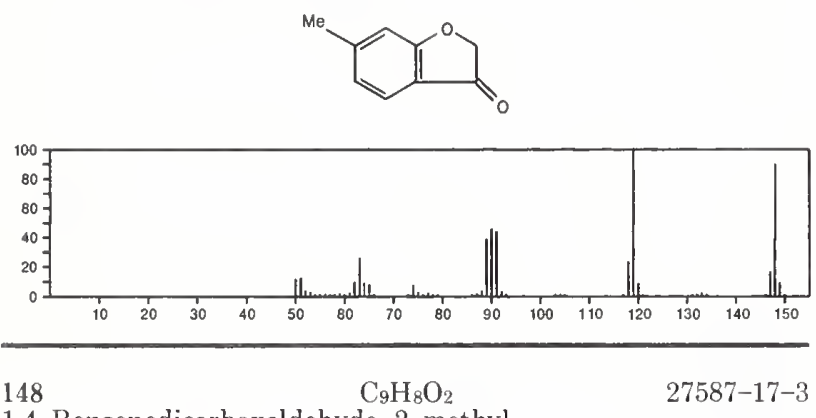

1,4-Benzenedicarboxaldehyde, 2-methyl-
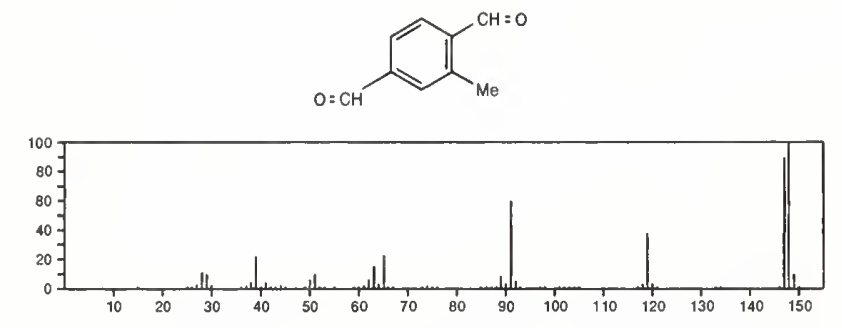

148

2(3H)-Benzofuranone, $3-\mathrm{methy}_{8} \mathrm{O}_{2}$
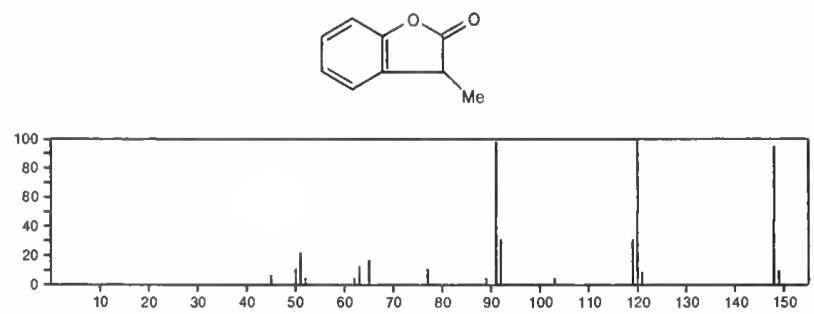

148

$\mathrm{C}_{9} \mathrm{H}_{8} \mathrm{O}_{2}$

3(2H)-Benzofuranone, 2-methyl-

$35567-59-0$
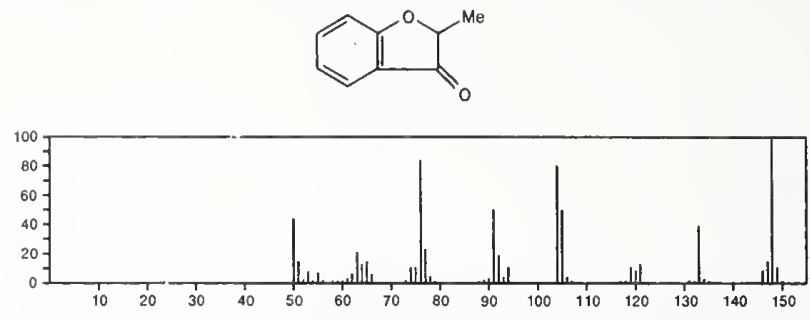

148

$\mathrm{C}_{9} \mathrm{H}_{8} \mathrm{O}_{2}$

1(3H)-Isobenzofuranone, 5-methyl

$54120-64-8$
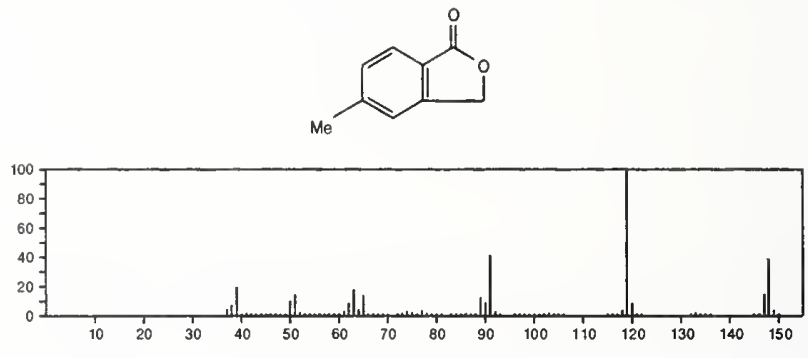

$148 \quad \mathrm{C}_{9} \mathrm{H}_{8} \mathrm{O}_{2}$

3(2H)-Benzofuranone, 4-methyl-

54120-65-9
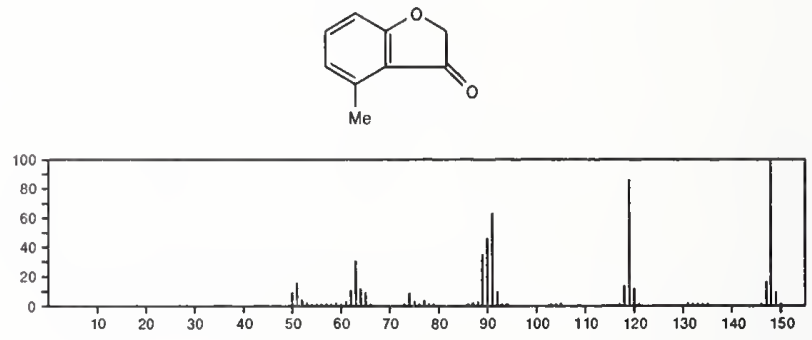

148

$\mathrm{C}_{9} \mathrm{H}_{8} \mathrm{O}_{2}$

$54120-66-0$

$3(2 H)$-Benzofuranone, 5-methyl-
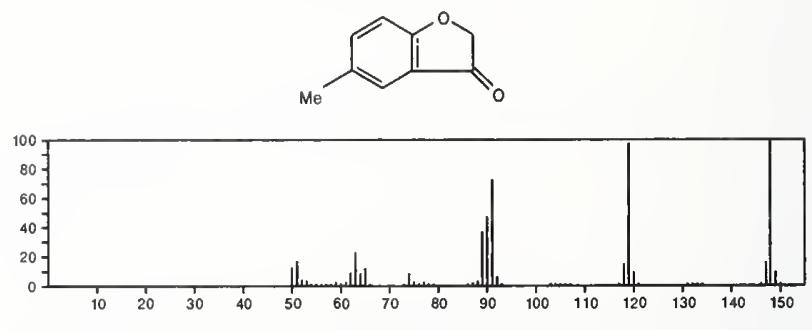

148

$\mathrm{C}_{9} \mathrm{H}_{8} \mathrm{~S}$

$14315-11-8$

Benzo[b]thiophene, 4-methyl-
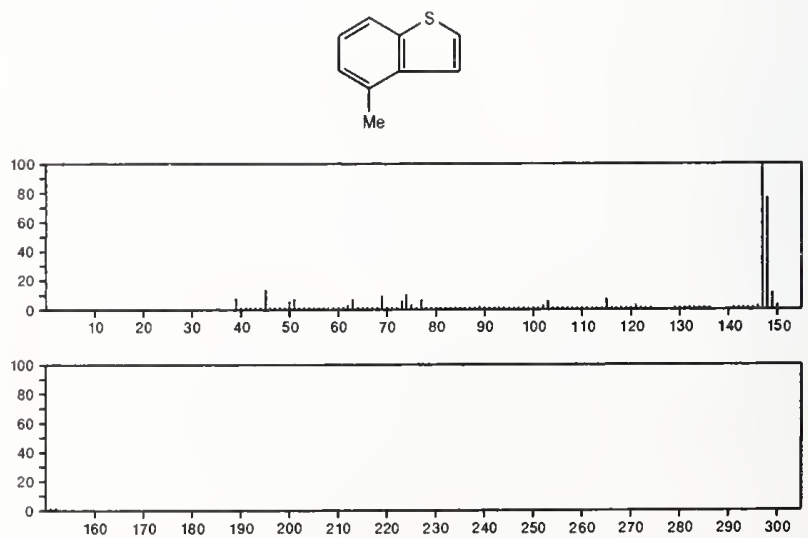
148 $\mathrm{C}_{9} \mathrm{H}_{8} \mathrm{~S}$

$14315-14-1$

Benzo[b]thiophene, 5-methyl-
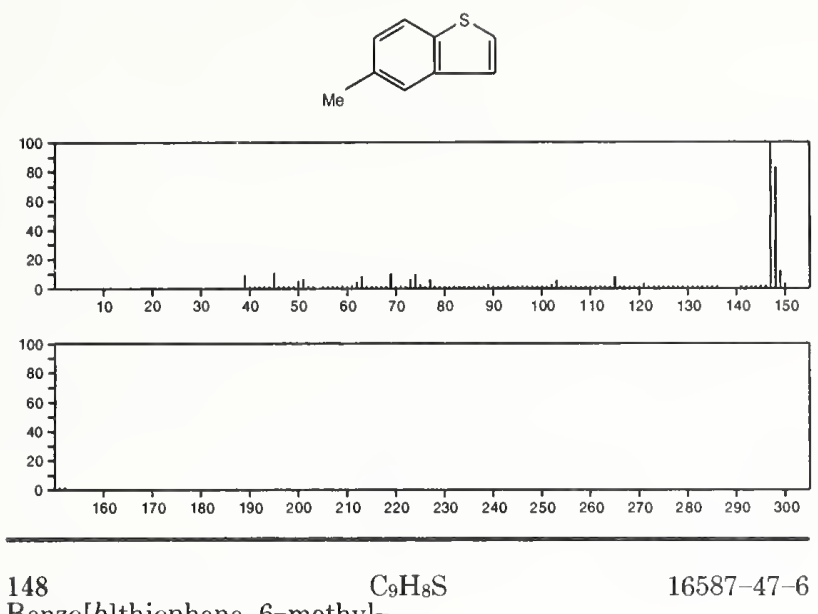

Benzo[b]thiophene, 6-methyl-
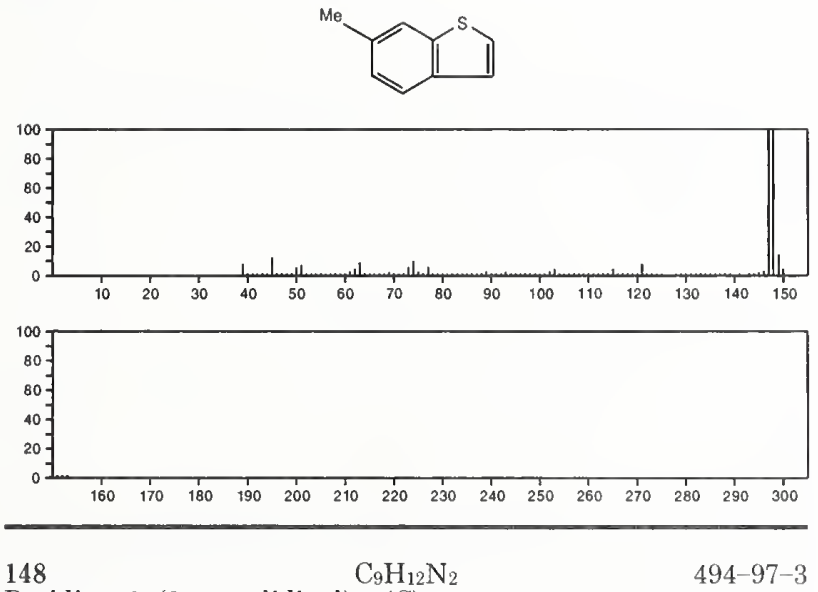

Pyridine, 3-(2-pyrrolidinyl)-, $(S)-$
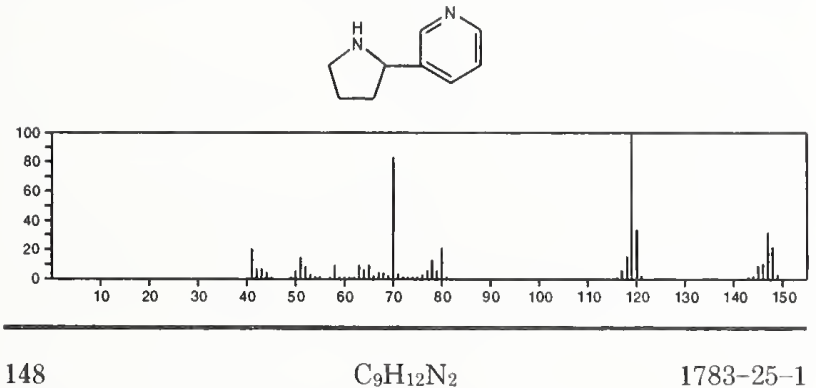

Methanimidamide, $N, N$-dimethyl- $N^{\prime}$-phenyl

$1783-25-1$ $\mathrm{Me}_{2} \mathrm{NCH}=\mathrm{NPh}$

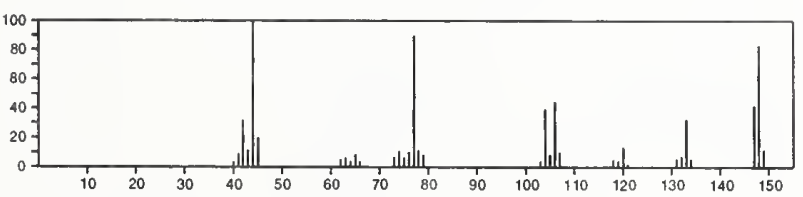

$148 \quad \mathrm{C}_{9} \mathrm{H}_{12} \mathrm{~N}_{2}$

1,1-Cyclopropanedicarbonitrile, 2-methyl-2-propyl-

$16738-88-8$
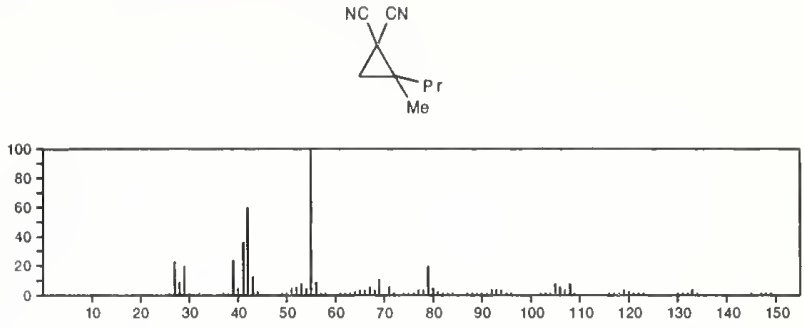

148

Ethanone, 1-(2,4-dimethylpheny)

89-74-7
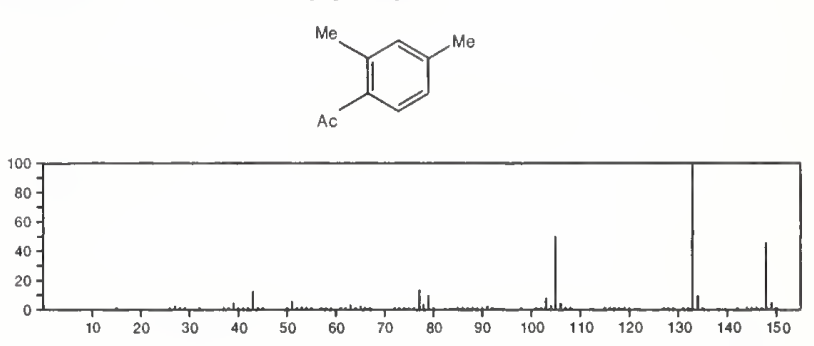

148

$\mathrm{C}_{10} \mathrm{H}_{12} \mathrm{O}$

$104-46-1$

Benzene, 1-methoxy-4-(1-propenyl)-<smiles>CCOc1ccc(OC)cc1</smiles>

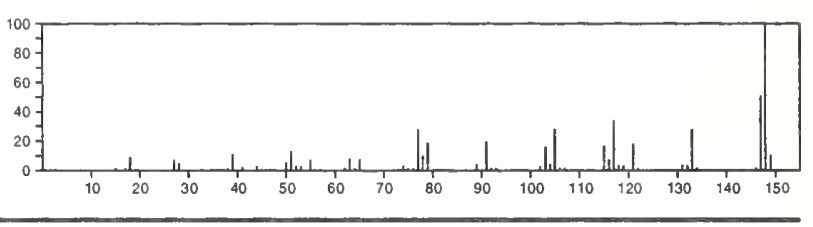

148 $\mathrm{C}_{10} \mathrm{H}_{12} \mathrm{O}$

$122-03-2$

Benzaldehyde, 4-(1-methylethyl)
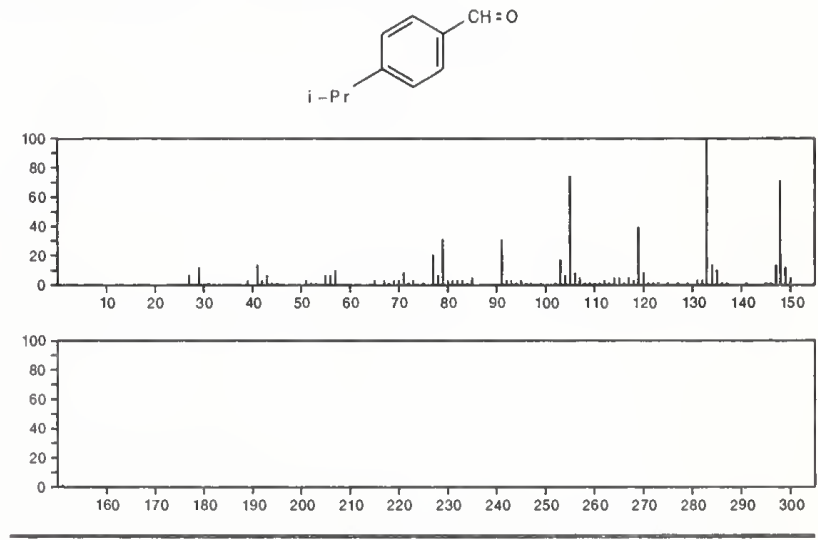

148

$\mathrm{C}_{10} \mathrm{H}_{12} \mathrm{O}$

Benzene, 1-methoxy-4-(2-propenyl)-

140-67-0<smiles>CCc1ccc(OC)cc1</smiles>

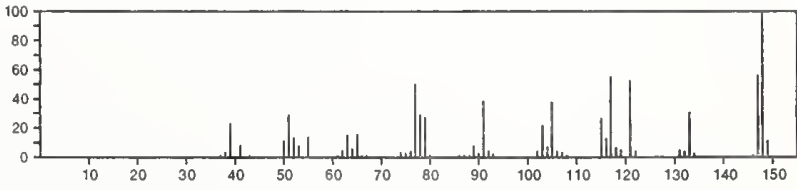


148

C $\mathrm{C}_{10} \mathrm{H}_{12} \mathrm{O}$

$\mathrm{C}_{10}$
thyl-<smiles>Cc1cc(C)c(C=O)c([N+](=O)[O-])c1</smiles>
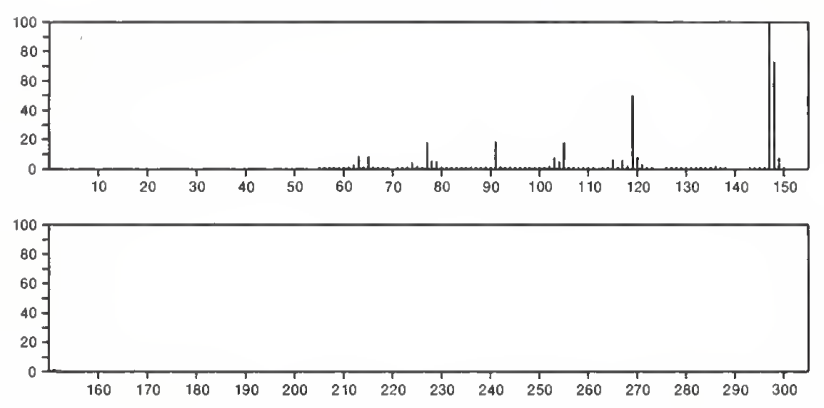

148

1-Butanone, 1-phenyl-

$$
\mathrm{C}_{10} \mathrm{H}_{12} \mathrm{O}
$$

$495-40-9$

PrCOPh

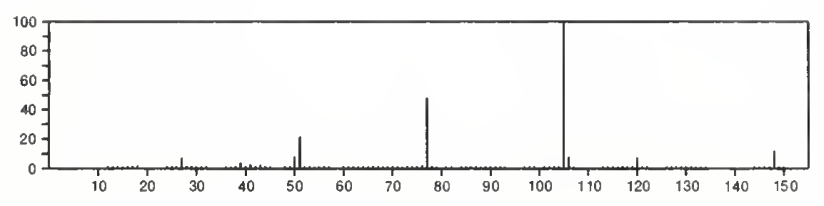

$148 \quad \mathrm{C}_{10} \mathrm{H}_{12} \mathrm{O}$

1-Naphthalenol, 1,2,3,4-tetrahydro-
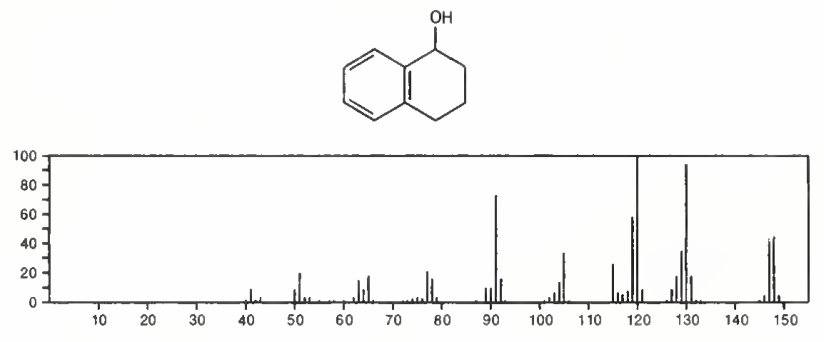

$148 \quad \mathrm{C}_{10} \mathrm{H}_{12} \mathrm{O}$

1-Naphthalenol, 5,6,7,8-tetrahydro-
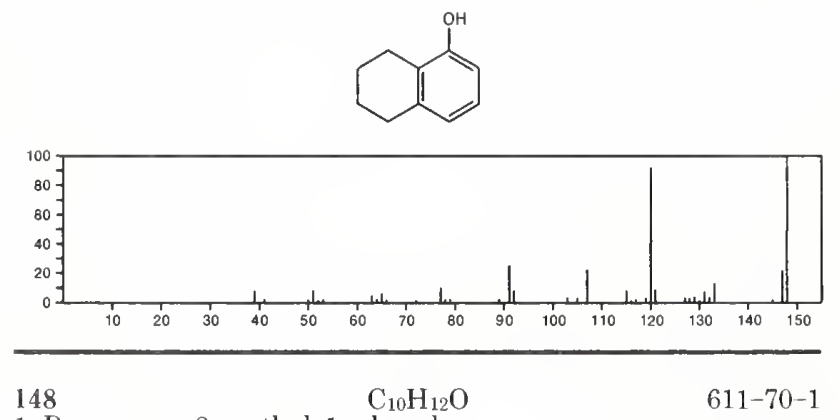

$611-70-1$

1-Propanone, 2-methyl-1-phenyl-

$\mathrm{Me} 2 \mathrm{CHCOPh}$

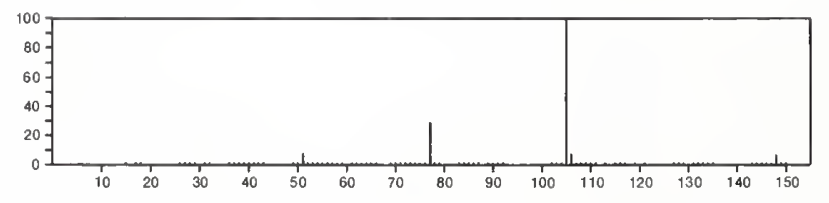

$148 \quad \mathrm{C}_{10} \mathrm{H}_{12} \mathrm{O}$

Ethanone, 1-(4-ethylphenyl)-
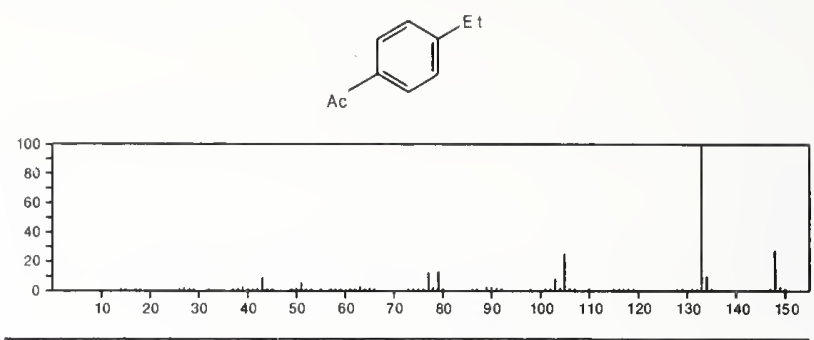

148

2-Naphthalenol, 5,6,7,8-tetrahydro-

$$
\underset{\mathrm{C}_{10} \mathrm{H}_{12} \mathrm{O}}{\mathrm{C}^{-}}
$$

$1125-78-6$
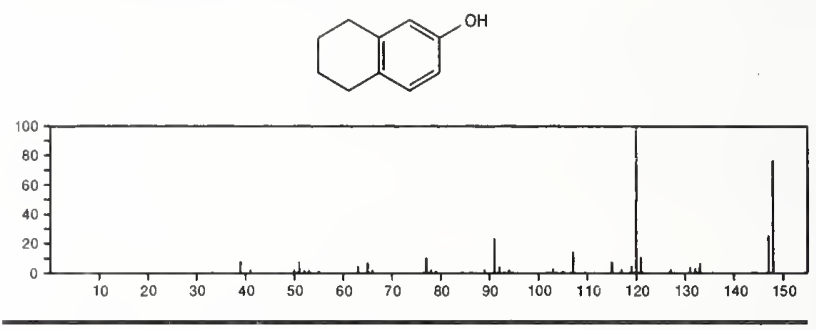

148

Benzaldehyde, 2,4,5-trimethyl

$$
\mathrm{C}_{10} \mathrm{H}_{12} \mathrm{O}
$$

5779-72-6<smiles>Cc1cc(C)c(C=O)cc1C</smiles>

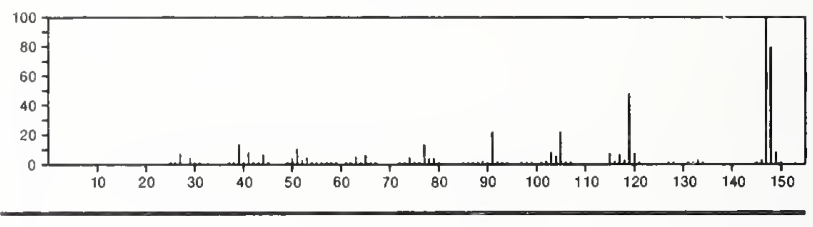

148
Benzene, $[(2-$ methyl-2-propenyl)oxy $]-$

5820-22-4

$\mathrm{PhOCH} 2 \mathrm{CMe}=\mathrm{CH}_{2}$
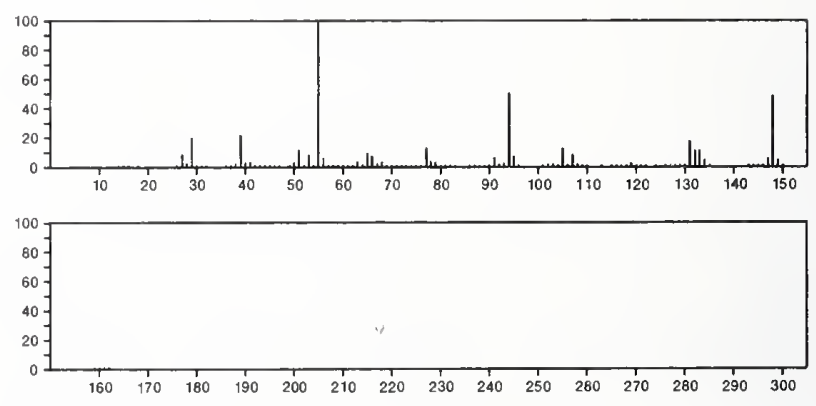

148

$\mathrm{C}_{10} \mathrm{H}_{12} \mathrm{O}$

$6169-78-4$

1-Benzoxepin, 2,3,4,5-tetrahydro
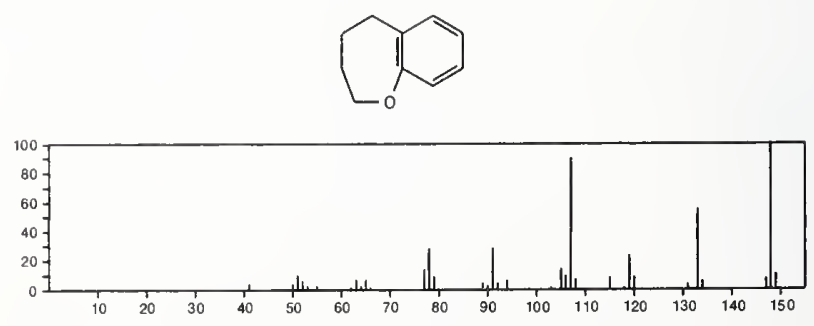
148

$\mathrm{C}_{10} \mathrm{H}_{12} \mathrm{O}$

$13030-26-7$

2H-1-Benzopyran, 3,4-dihydro-2-methyl
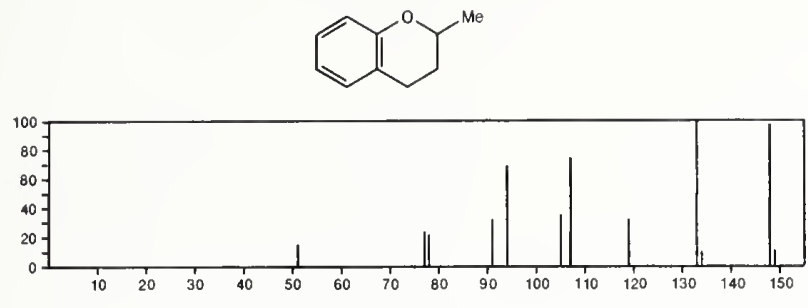

$148 \quad \mathrm{C}_{10} \mathrm{H}_{12} \mathrm{O}$

$13351-15-0$

1,2,4-Metheno- $1 H$-cyclobuta[cd]pentalen-3-ol, octahydro-, $\left(1 \alpha, 1 \mathrm{a} \beta, 2 \alpha, 3 \alpha, 3 \mathrm{a} \beta, 4 \alpha, 4 \mathrm{a} \beta, 5 \mathrm{~b} \beta, 6 S^{*}\right)$
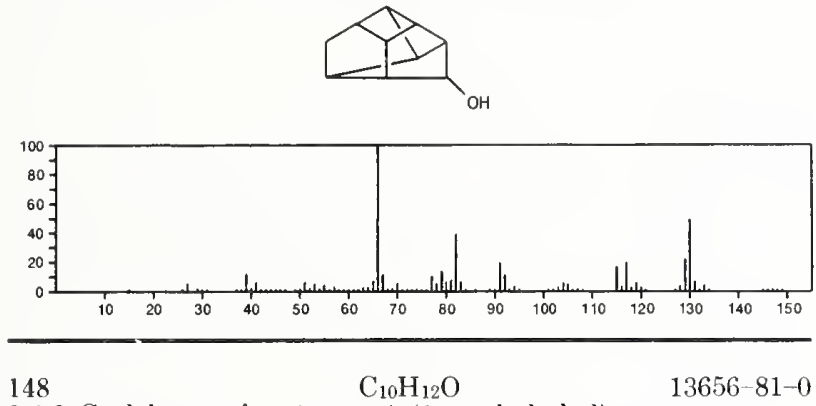

2,4,6-Cycloheptatrien-1-one, 4-(1-methylethyl)-
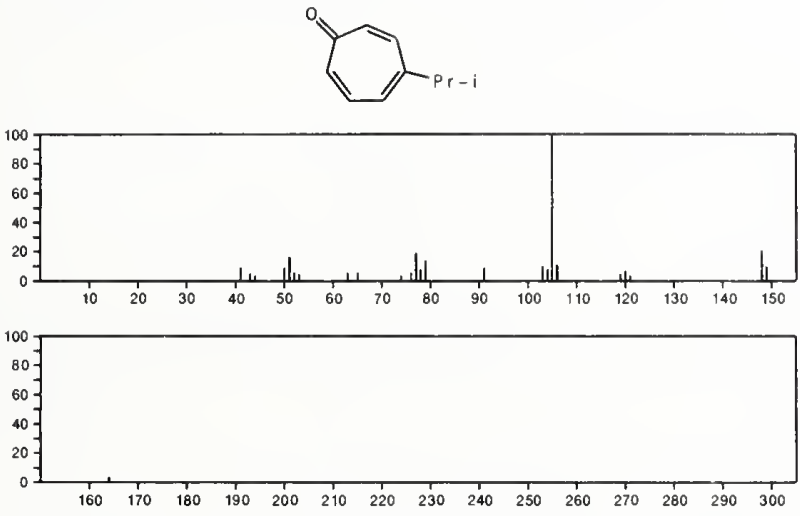

148

$\mathrm{C}_{10} \mathrm{H}_{12} \mathrm{O}$

Benzene, [(2-propenyloxy)methyl]-

$14593-43-2$

$\mathrm{H}_{2} \mathrm{C}=\mathrm{CHCH}_{2} \mathrm{OCH}_{2} \mathrm{Ph}$

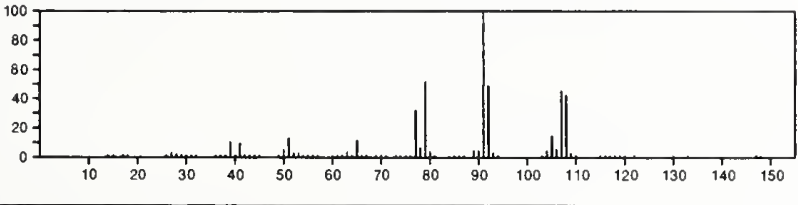

$148 \quad \mathrm{C}_{10} \mathrm{H}_{12} \mathrm{O}$

$15776-05-3$

1,2,4-Metheno-1H-cyclobuta[cd]pentalen-3-ol, octahydro-, $\left(1 \alpha, 1 \mathrm{a} \beta, 2 \alpha, 3 \beta, 3 \mathrm{a} \beta, 4 \alpha, 5 \mathrm{a} \beta, 5 \mathrm{~b} \beta, 6 S^{*}\right)$
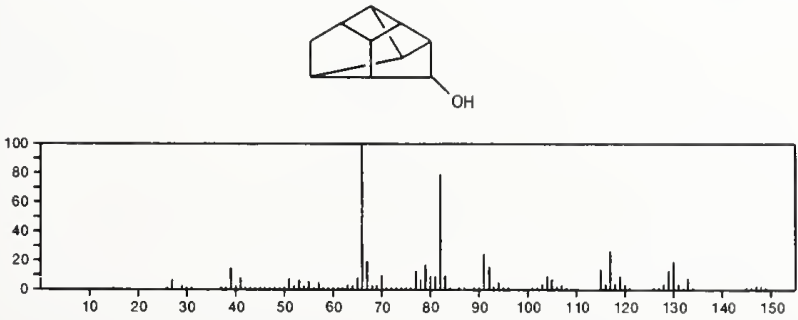

148

$\mathrm{C}_{10} \mathrm{H}_{12} \mathrm{O}$

Benzene, (3-methoxy-1 propenyl)-

$16277-67-1$

$\mathrm{Me} \mathrm{OCH}_{2} \mathrm{CH}=\mathrm{CHPh}$
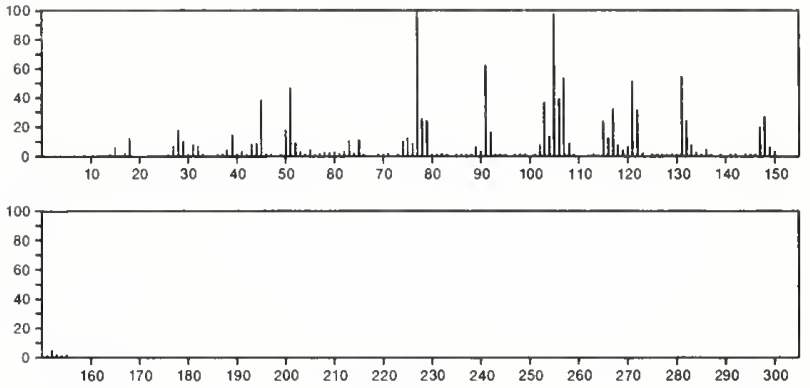

148

$\mathrm{C}_{10} \mathrm{H}_{12} \mathrm{O}$

$18328-11-5$

Benzenebutanal

$\mathrm{Ph}\left(\mathrm{CH}_{2}\right)_{3} \mathrm{CHO}$

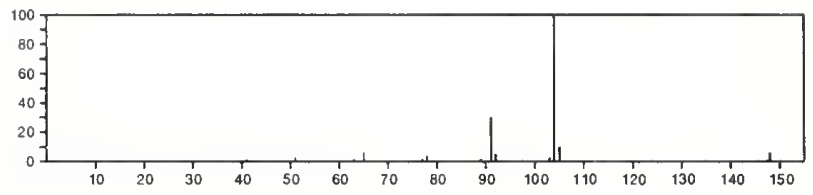

148

$\mathrm{C}_{10} \mathrm{H}_{12} \mathrm{O}$

20944-88-1

Phenol, 2-(2-methyl-2-propenyl)-
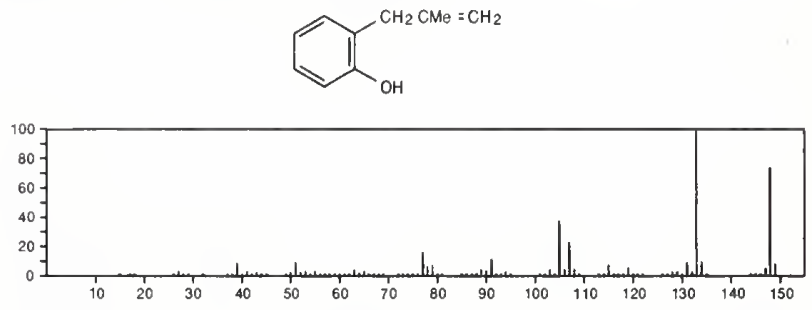

148

$\mathrm{C}_{10} \mathrm{H}_{12} \mathrm{O}$

$30844-13-4$

1,3,5,7-Cyclooctatetraene, 1-(methoxymethyl)-
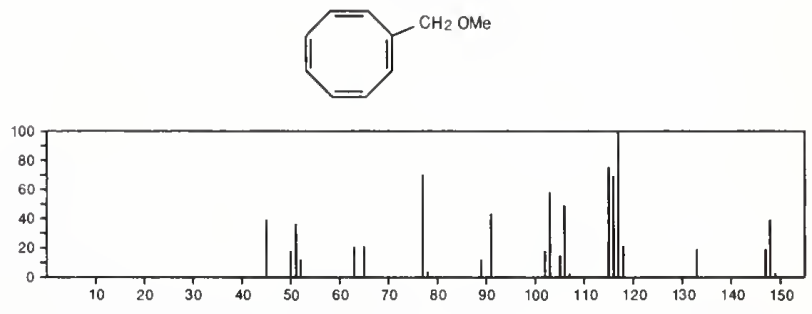

148

$\mathrm{C}_{10} \mathrm{H}_{12} \mathrm{O}$

$33641-78-0$

Phenol, $p-(2-$ methylallyl) -
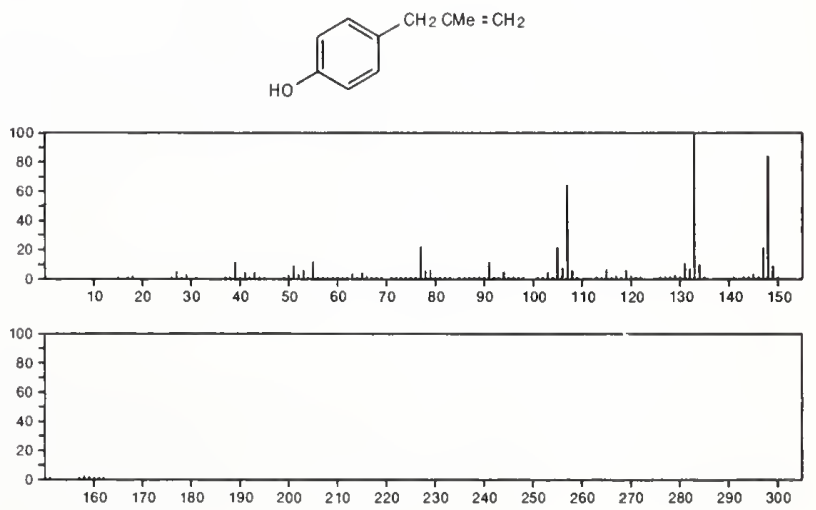
148

$\mathrm{C}_{10} \mathrm{H}_{12} \mathrm{O}$

Benzene, ethenyl(methoxymethyl)-
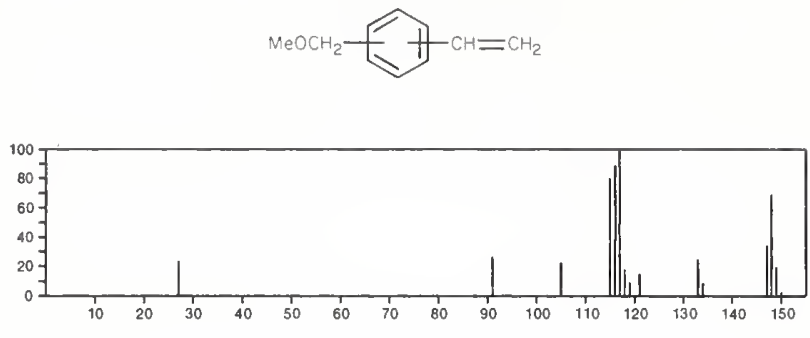

148

$\mathrm{C}_{11} \mathrm{H}_{16}$

$98-51-1$

Benzene, 1-(1,1-dimethylethyl)-4-methyl-
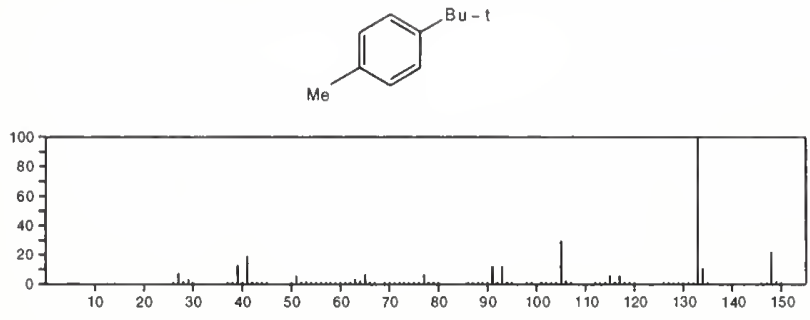

148

Benzene, pentyl-

$\mathrm{C}_{11} \mathrm{H}_{16}$

538-68-1

$\mathrm{Ph}\left(\mathrm{CH}_{2}\right){ }_{4} \mathrm{Me}$

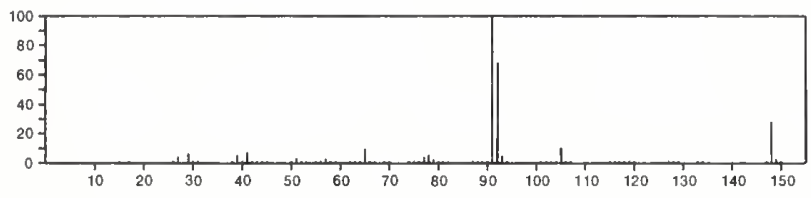

148

$\mathrm{C}_{11} \mathrm{H}_{16}$

$700-12-9$

Benzene, pentamethyl-
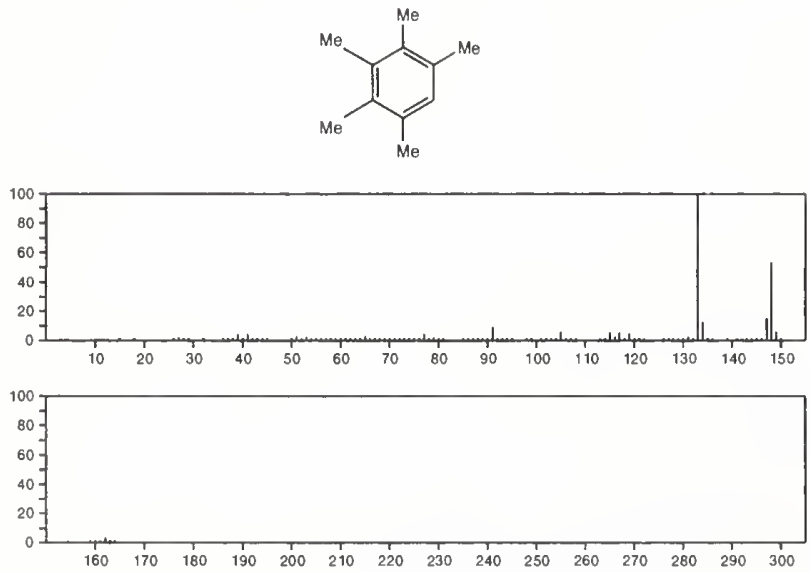

148

$\mathrm{C}_{11} \mathrm{H}_{16}$

Benzene, (2,2-dimethylpropyl)-

$1007-26-7$

$\mathrm{Me}_{3} \mathrm{CCH}_{2} \mathrm{Ph}$

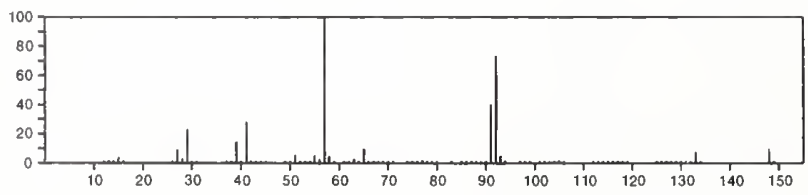

48

$\mathrm{C}_{11} \mathrm{H}_{16}$

1075-38-3

Benzene, 1-(1,1-dimethylethyl)-3-methyl-
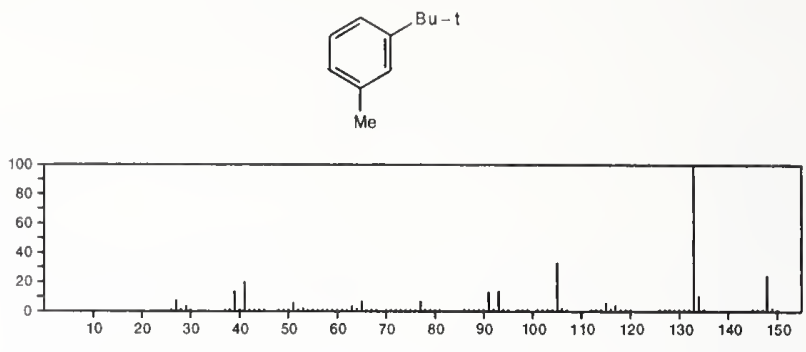

148

$\mathrm{C}_{11} \mathrm{H}_{16}$

$1196-58-3$

Benzene, (1-ethylpropyl)-

Et 2 CHPh
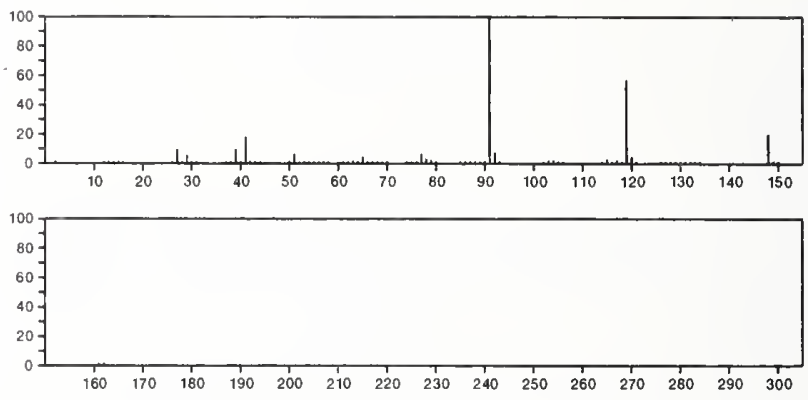

148

$\mathrm{C}_{11} \mathrm{H}_{16}$

2049-94-7

Benzene, (3-methylbutyl)-

$\mathrm{Me}_{2} \mathrm{CHCH}_{2} \mathrm{CH}_{2} \mathrm{Ph}$

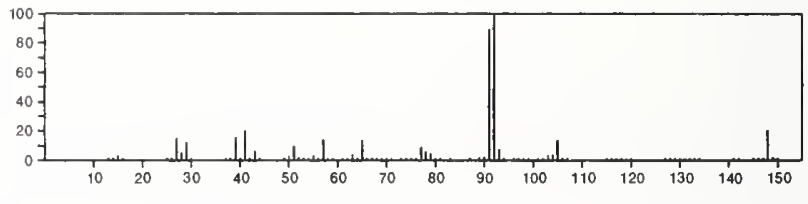

148

$\mathrm{C}_{11} \mathrm{H}_{16}$

2049-95-8

Benzene, (1,1-dimethylpropyl)-

$\mathrm{PhCE} t(\mathrm{Ph})$

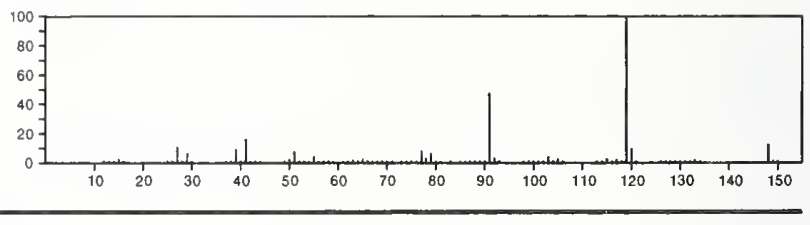

148

$\mathrm{C}_{11} \mathrm{H}_{16}$

$2719-52-0$

Benzene, (1-methylbutyl)-

$\mathrm{PnCHP} ₹(\mathrm{Ph})$

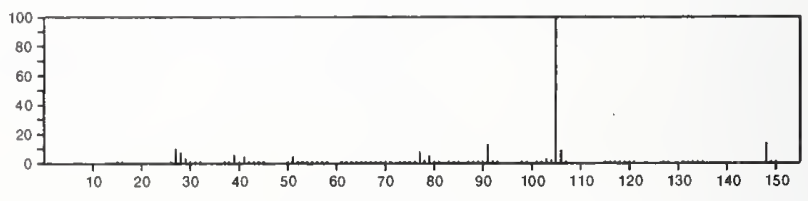

148

Benzene, (2-methylbutyl)-

$\mathrm{C}_{11} \mathrm{H}_{16}$

$3968-85-2$

$\mathrm{PhCH}_{2} \mathrm{CHM}_{\mathrm{CH}} \mathrm{CH}_{2} \mathrm{Me}$

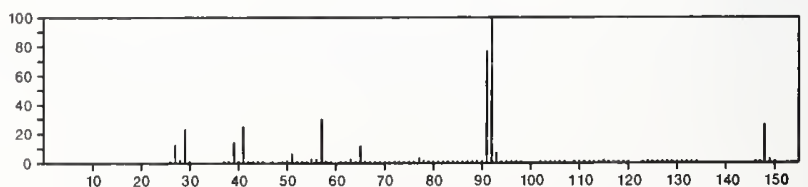



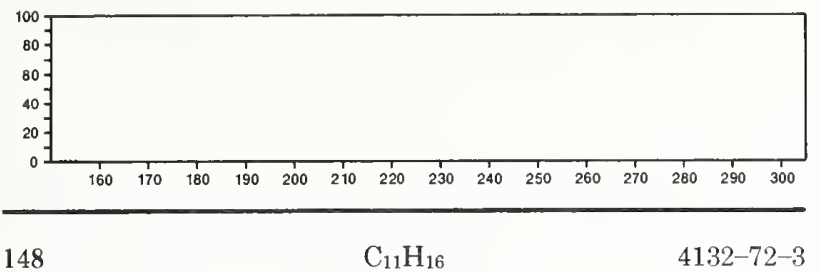

Benzene, 1,4-dimethyl-2-(1-methylethyl)-
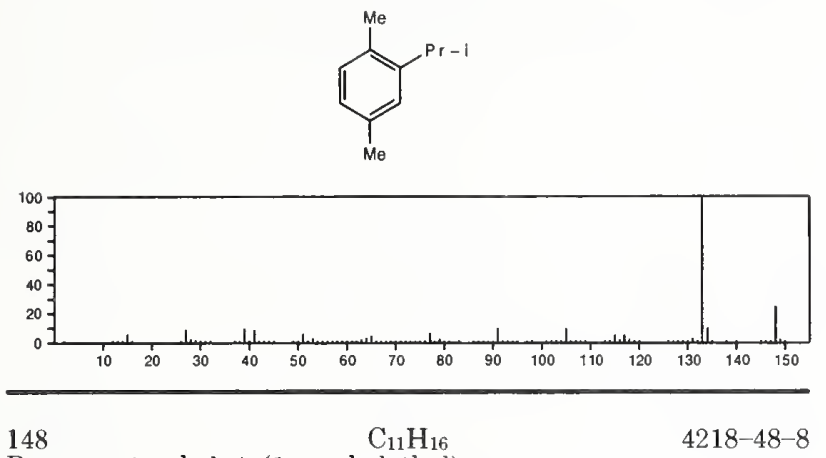

Benzene, 1-ethyl-4-(1-methylethyl)-
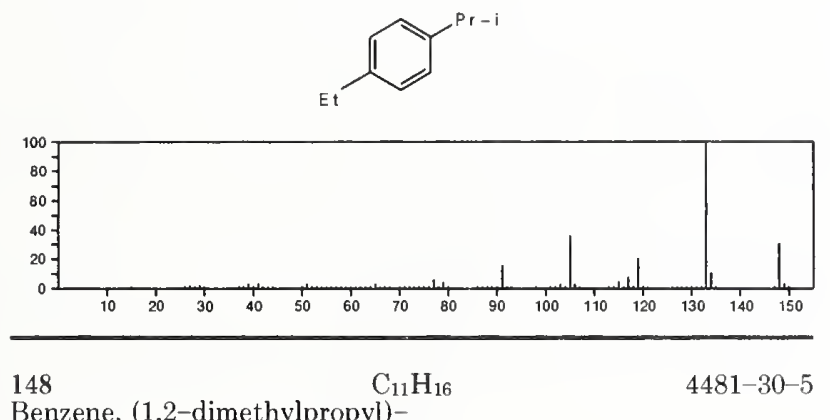

Benzene, (1,2-dimethylpropyl)-

$\mathrm{Me}_{2} \mathrm{CHCHMePh}_{\mathrm{C}}$

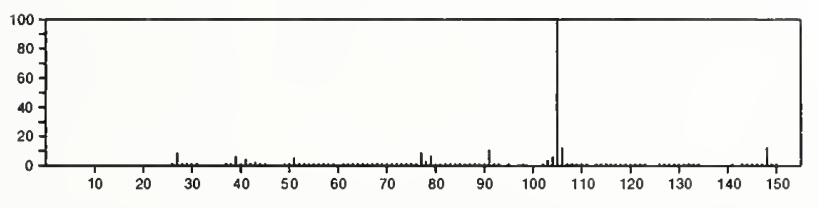

148

$\mathrm{C}_{11} \mathrm{H}_{16}$

$4706-89-2$

Benzene, 2,4-dimethyl-1-(1-methylethyl)-
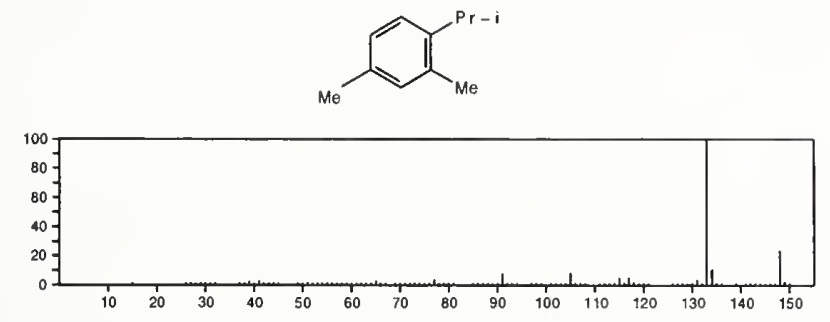

148

$\mathrm{C}_{11} \mathrm{H}_{16}$

Benzene, 1,3-dimethyl-5-(1-methylethyl)-
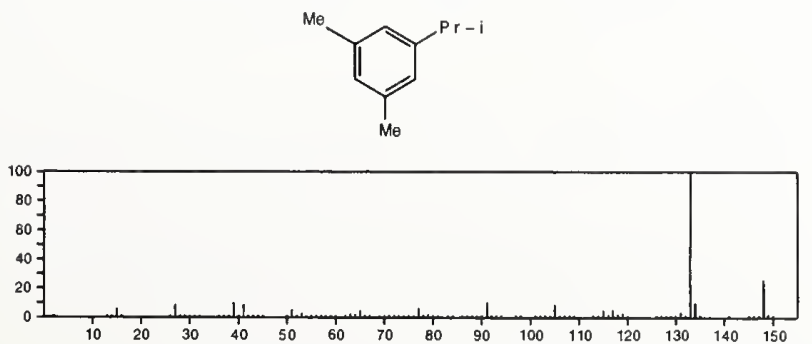

$4706-90-5$
148

$\mathrm{C}_{11} \mathrm{H}_{16}$

$4920-99-4$

Benzene, 1-ethyl-3-(1-methylethyl)-
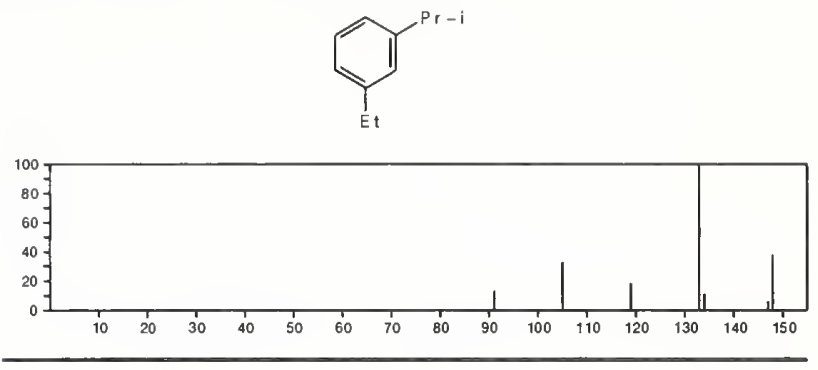

148

Toluene, $p$-isobutyl-

$\mathrm{C}_{11} \mathrm{H}_{16}$

5161-04-6
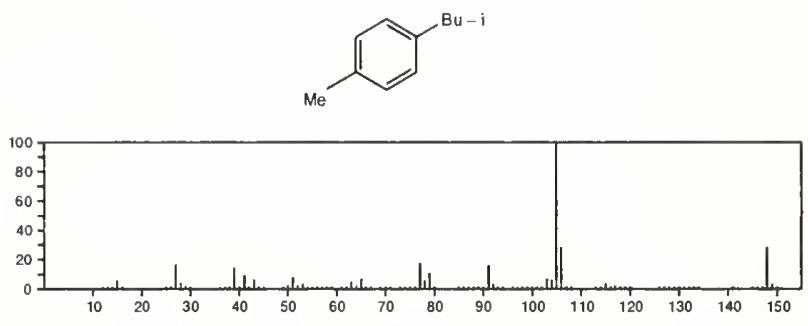

148

$\mathrm{C}_{11} \mathrm{H}_{16}$

Benzene, 1-ethyl-2,4,5-trimethyl-

$17851-27-3$<smiles>CCc1cc([N+](=O)[O-])c([N+](=O)[O-])cc1[N+](=O)[O-]</smiles>

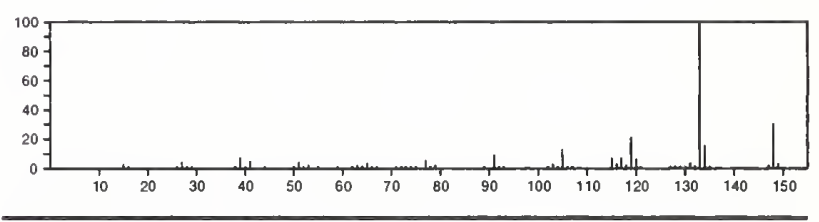

148

Benzene, diethylmethyl-

$\mathrm{C}_{11} \mathrm{H}_{16}$

$25550-13-4$
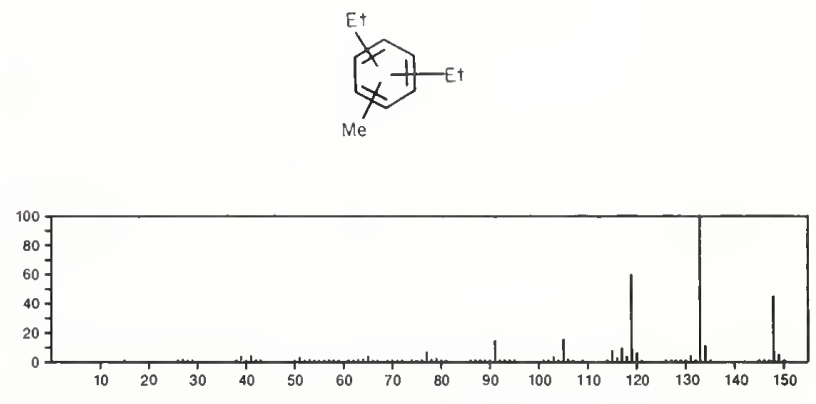

148

$\mathrm{C}_{11} \mathrm{H}_{16}$

Benzene, (1,1-dimethylethyl) methyl-

$27138-21-2$
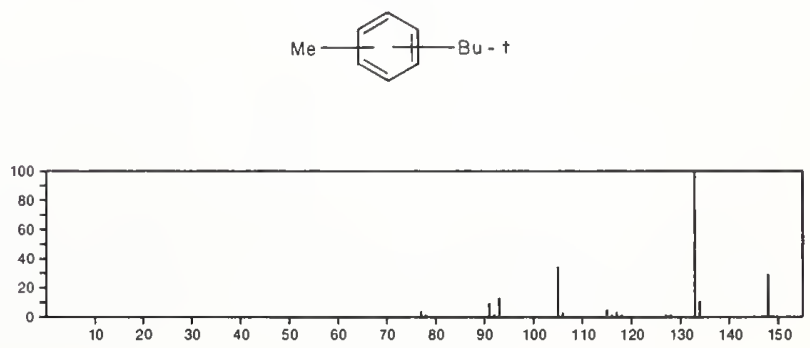
148

1,4-Cycloheptadiene, 6-(1-butenyl)-, [S-(Z)]

$33156-92-2$
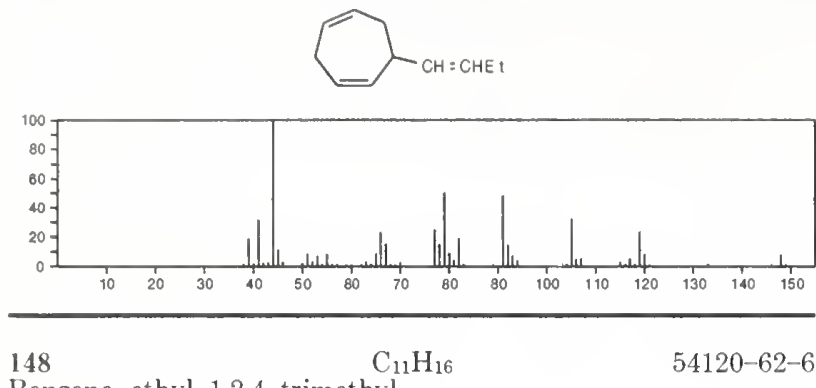

$54120-62-6$

Benzene, ethyl-1,2,4-trimethyl-
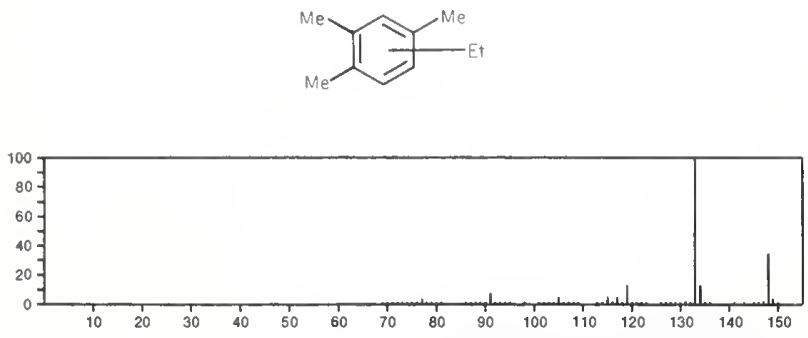

149

$\mathrm{CF}_{5} \mathrm{~N}_{3}$

Diaziridine, 3-(difluoroamino)trifluoro<smiles></smiles>

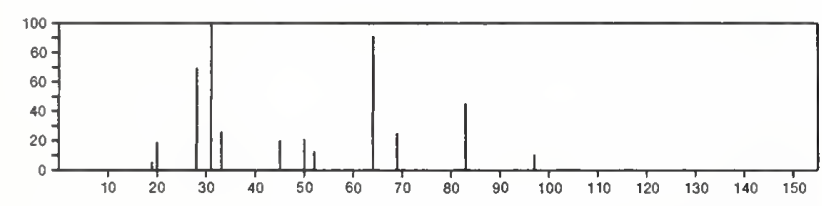

149

Carbamic acid, acetyldithio-, methyl ester

$16696-88-1$

ACNHC(S) SMe
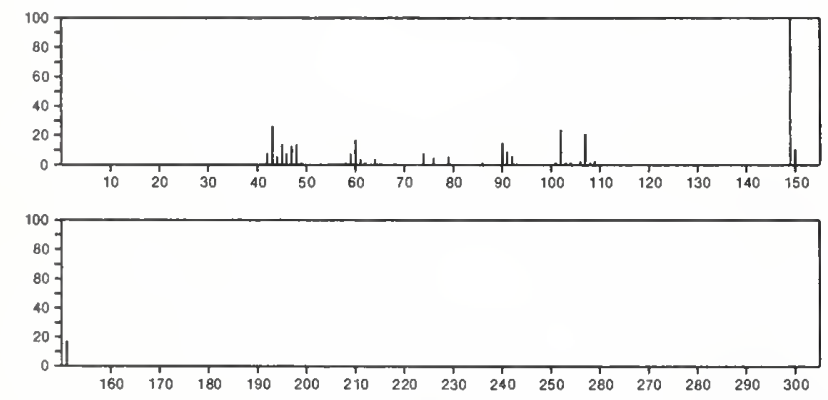

49

Azetidine, 1-bromo-2-methyl-

$\mathrm{C}_{4} \mathrm{H}_{8} \mathrm{BrN}$

$38455-32-2$

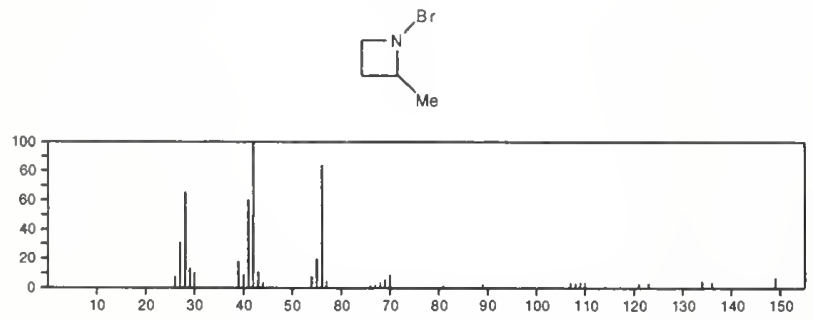

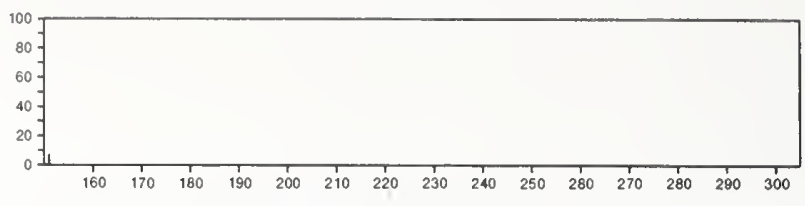

149

L-Methionine

$\mathrm{C}_{5} \mathrm{H}_{11} \mathrm{NO}_{2} \mathrm{~S}$

63-68-3

$\mathrm{HO}_{2} \mathrm{CCH}\left(\mathrm{NH}_{2}\right) \mathrm{CH}_{2} \mathrm{CH}_{2} \mathrm{SMe}$

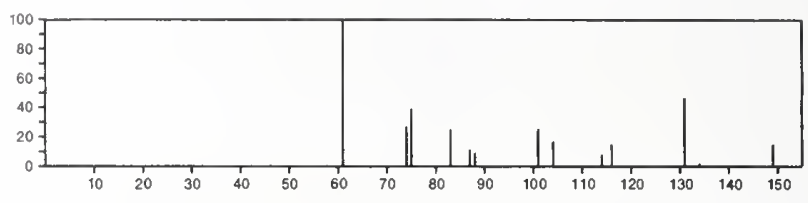

$149 \quad \mathrm{C}_{5} \mathrm{H}_{11} \mathrm{NS}_{2}$

Carbamodithioic acid, dimethyl-, ethyl ester

617-38-9

EISC ( S) NMe2

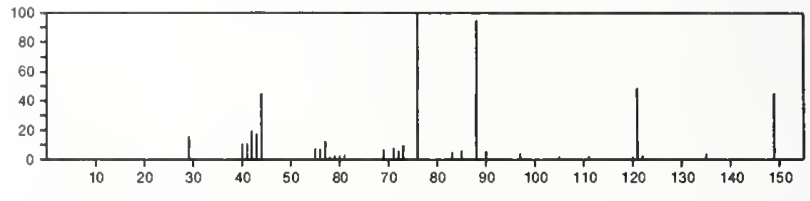

149

$\mathrm{C}_{6} \mathrm{H}_{7} \mathrm{~N}_{5}$

$443-72-1$

$1 H$-Purin-6-amine, $N$-methyl-
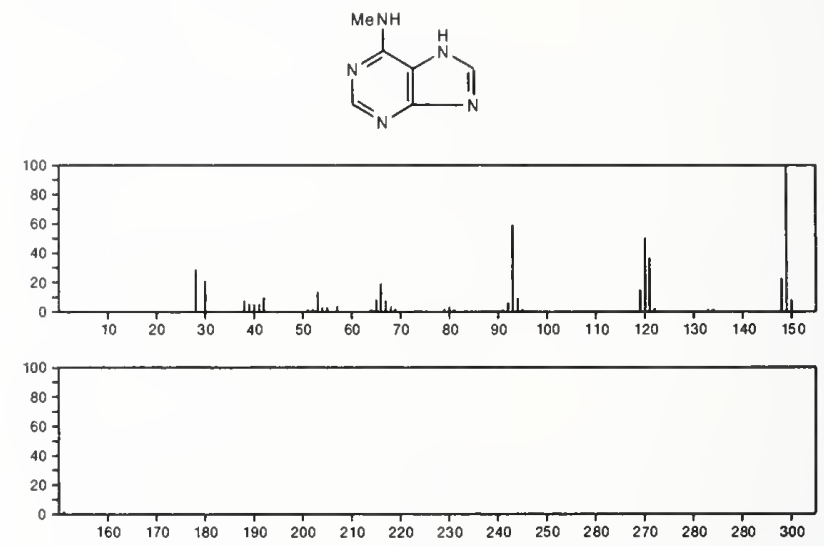

149

7H-Purin-6-amine, 7-methyl

$\mathrm{C}_{6} \mathrm{H}_{7} \mathrm{~N}_{5}$

$935-69-3$
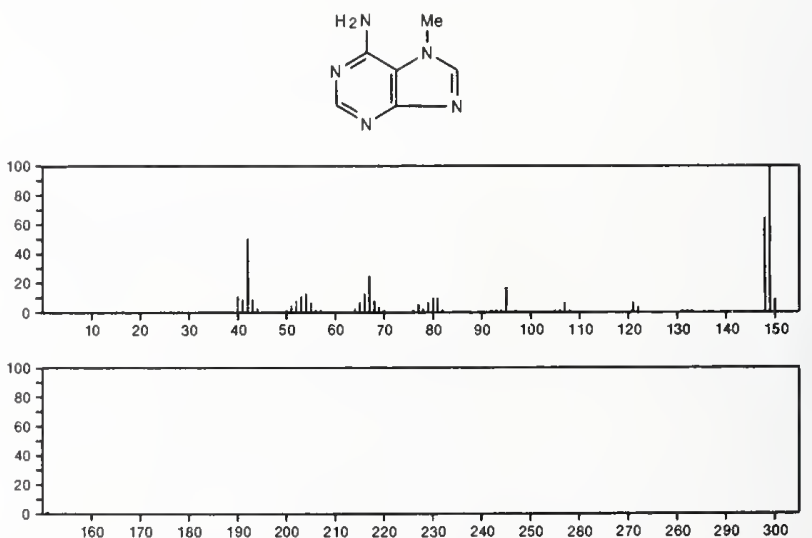
149

$\mathrm{C}_{7} \mathrm{H}_{7} \mathrm{~N}_{3} \mathrm{O}$

Benzene, 1-azido-4-methoxy-
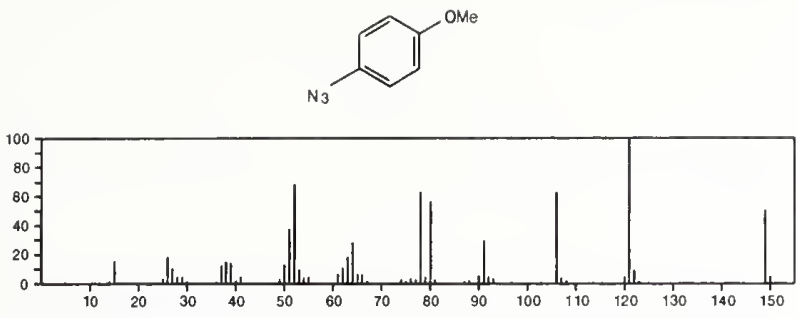

$149 \quad \mathrm{C}_{7} \mathrm{H}_{7} \mathrm{~N}_{3} \mathrm{O} \quad 13980-64-8$

$1 H-s$-Triazolo[1,5-a]pyridin-4-ium, 2-hydroxy-1-methyl-, hy= droxide, inner salt
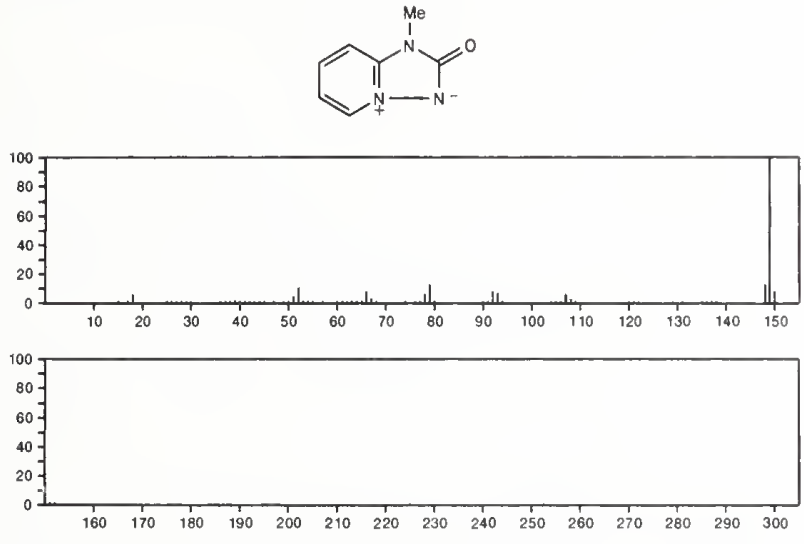

149

$\mathrm{C}_{7} \mathrm{H}_{7} \mathrm{~N}_{3} \mathrm{O}$

20442-97-1

Benzene, 1-azido-2-methoxy-
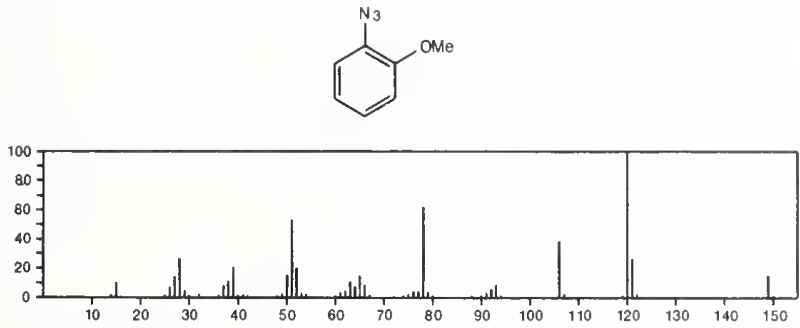

$149 \quad \mathrm{C}_{7} \mathrm{H}_{7} \mathrm{~N}_{3} \mathrm{O}$

27799-90-2

$1 H$-Benzotriazole, 4-methoxy-
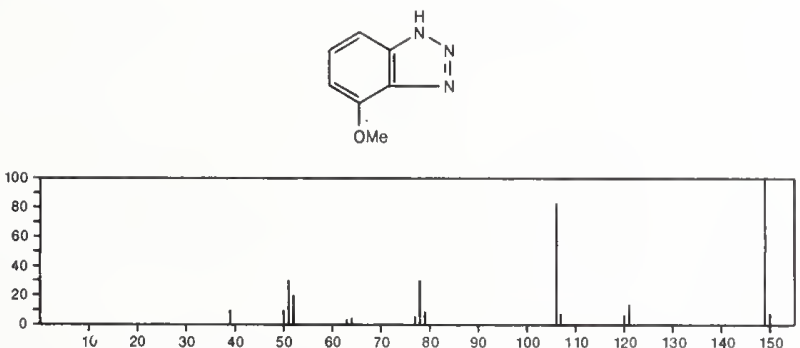

$149 \quad \mathrm{C}_{7} \mathrm{H}_{7} \mathrm{~N}_{3} \mathrm{O}$

$1 H$-Benzotriazole, 5-methoxy-<smiles>COc1ccc2[nH]nc(CNc3ccccc3)c2c1</smiles>

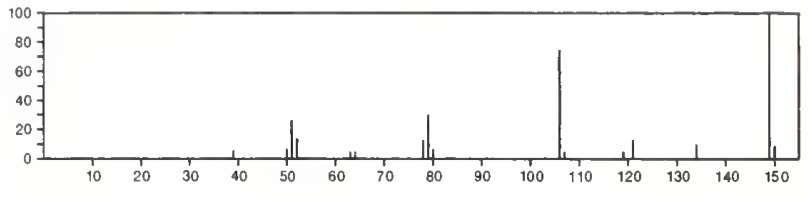

149

$\mathrm{C}_{8} \mathrm{H}_{7} \mathrm{NO}_{2}$

5466-88-6

2H-1,4-Benzoxazin-3(4H)-one<smiles>O=C1COc2ccccc2N1</smiles>

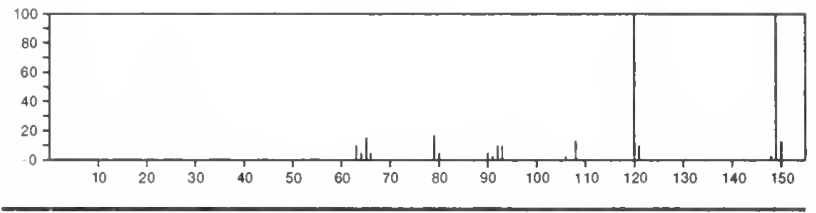

$149 \quad \mathrm{C}_{8} \mathrm{H}_{7} \mathrm{NO}_{2}$

1,3-Oxazetidin-2-one, 3-phenyl-

$16877-22-8$
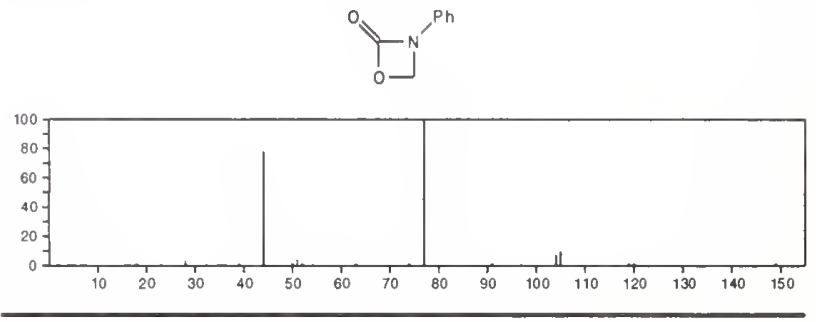

149

$\mathrm{C}_{8} \mathrm{H}_{7} \mathrm{NS}$

$120-75-2$

Benzothiazole, 2-methy]
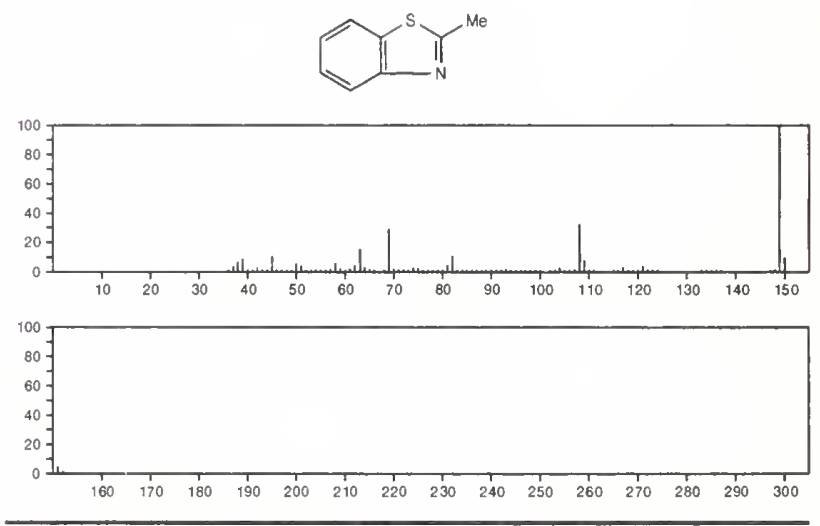

149

$\mathrm{C}_{8} \mathrm{H}_{7} \mathrm{NS}$

$6187-89-9$

1,2-Benzisothiazole, 3-methyl-
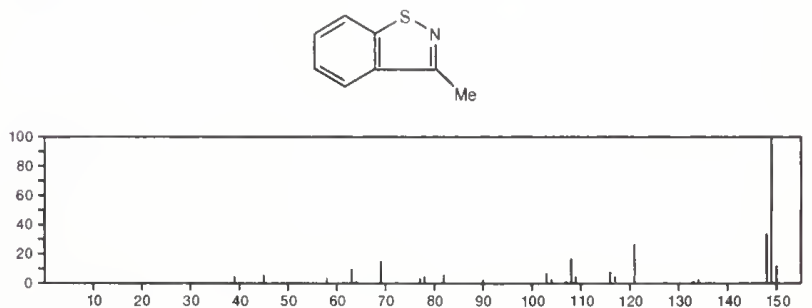

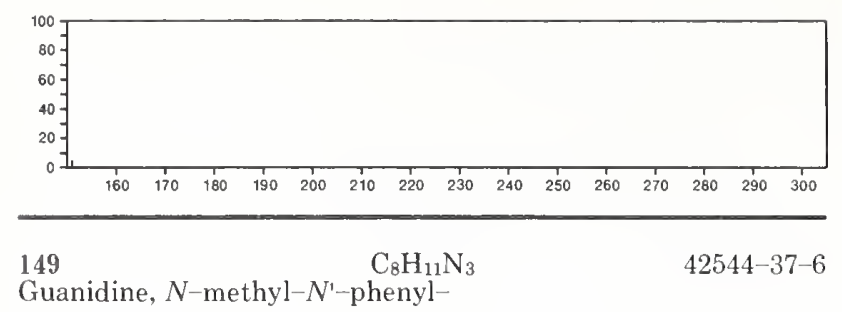

Guanidine, $N$-methyl- $N$ '- phenyl-

$H N=C(N H M e) N H P h$

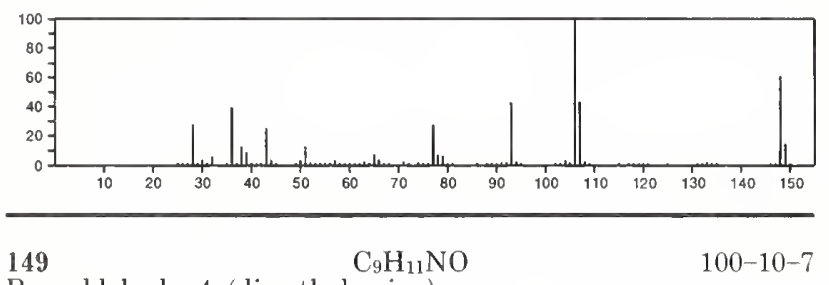

Benzaldehyde, 4-(dimethylamino)
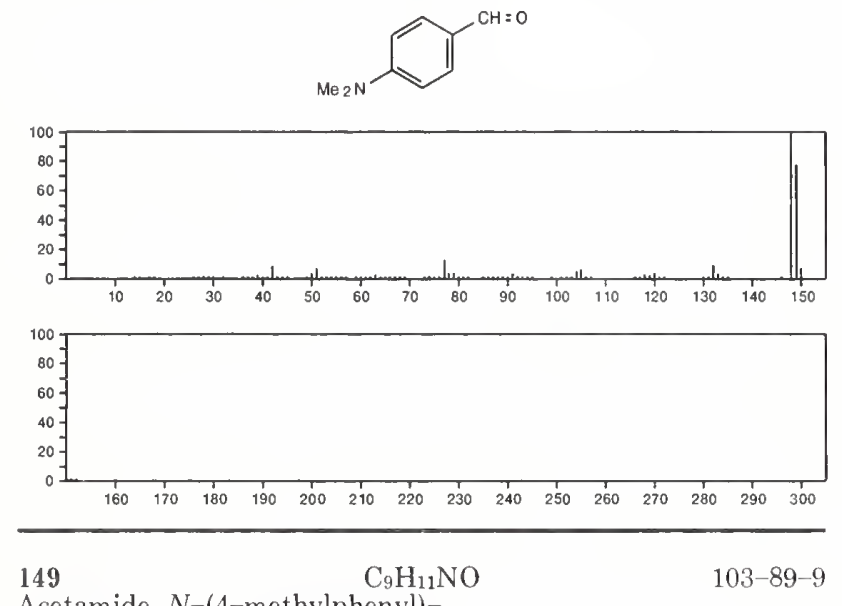

Acetamide, $N$-(4-methylphenyl)-
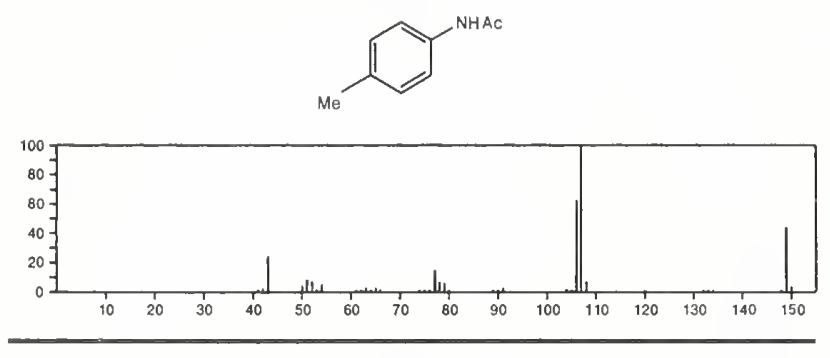

$149 \quad \mathrm{C}_{9} \mathrm{H}_{11} \mathrm{NO}$

$120-66-1$

Acetamide, $\mathrm{N}-(2-$ methylphenyl $)$ -
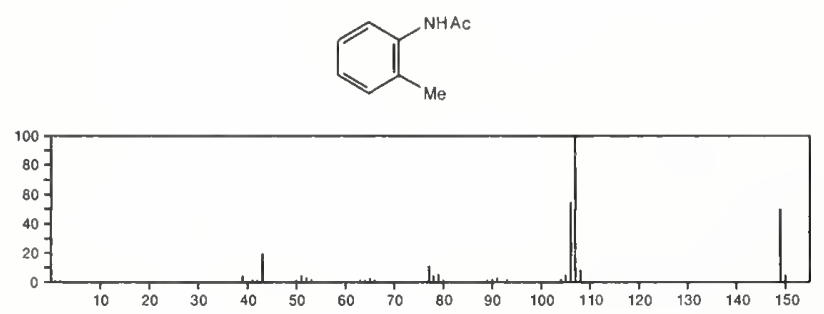

149

$\mathrm{C}_{9} \mathrm{H}_{11} \mathrm{NO}$

$537-92-8$

Acetamide, $N$-(3-methylphenyl)
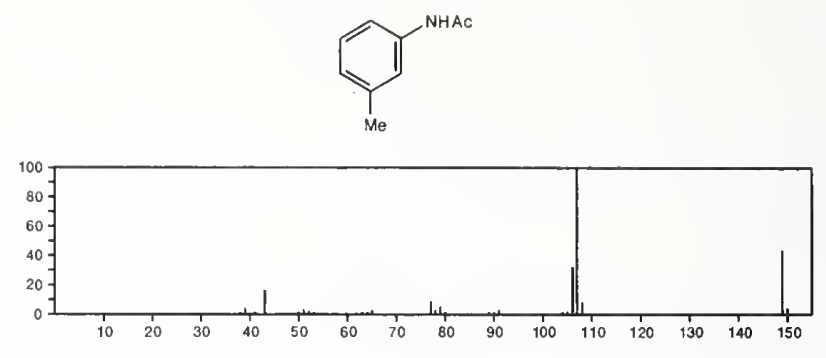

149

$\mathrm{C}_{9} \mathrm{H}_{11} \mathrm{NO}$

$579-10-2$

Acetamide, $N$-methyl- $N$-phenyl-

$\operatorname{PhNMe}(A C)$

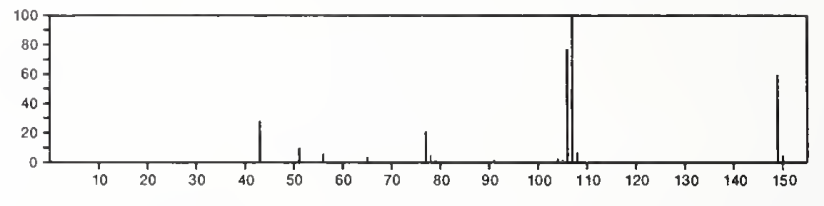

149

$\mathrm{C}_{9} \mathrm{H}_{11} \mathrm{NO}$

$588-46-5$

Acetamide, $N$-(phenylmethyl)-

$\mathrm{ACNHCH}_{2} \mathrm{Ph}$
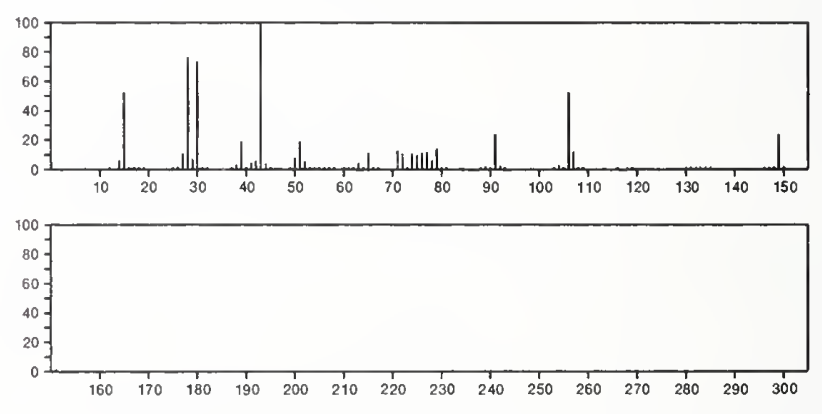

$149 \quad \mathrm{C}_{9} \mathrm{H}_{11} \mathrm{NO}$ 611-74-5

Benzamide, $N, N$-dimethyl-

$\mathrm{Me}_{2} \mathrm{NCOPh}$

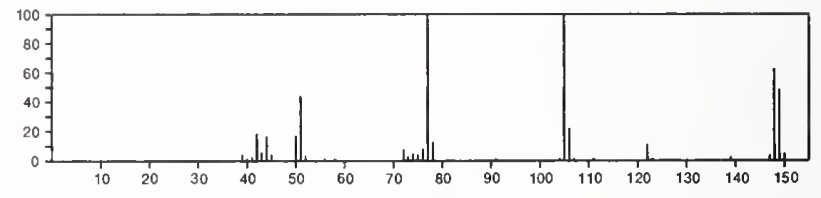

149

$\mathrm{C}_{9} \mathrm{H}_{11} \mathrm{NO}$

$614-17-5$

Benzamide, $N$-ethyl-

EtNHCOPh

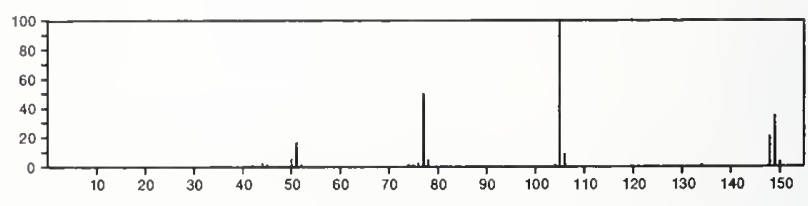

$149 \quad \mathrm{C}_{9} \mathrm{H}_{11} \mathrm{NO}$

Benzenecarboximidic acid, ethyl ester

825-60-5

$P h C(O E t)=N H$

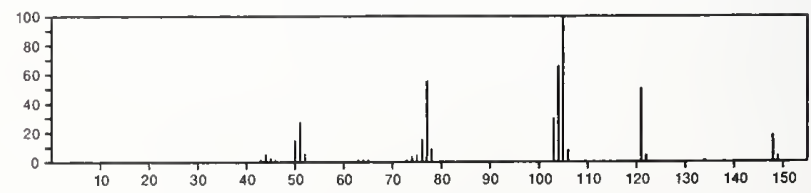


149

1-Butanone, 1-(3-pyridinyl)-

$\mathrm{C}_{9} \mathrm{H}_{11} \mathrm{NO}$
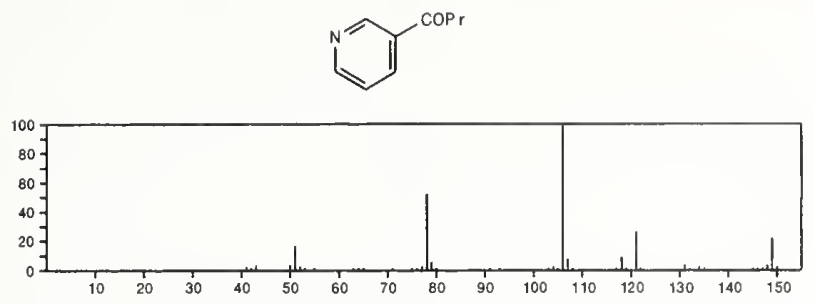

149

$\mathrm{C}_{9} \mathrm{H}_{11} \mathrm{NO}$

$1701-71-9$

1-Butanone, 1-(4-pyridinyl)-
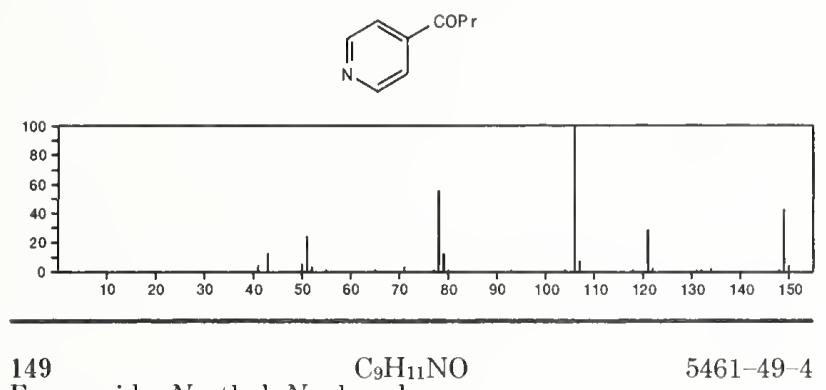

Formamide, $N$-ethyl- $N$-phenyl-

$5461-49-4$

$\mathrm{PhNE} T \mathrm{CH}=\mathrm{O}$
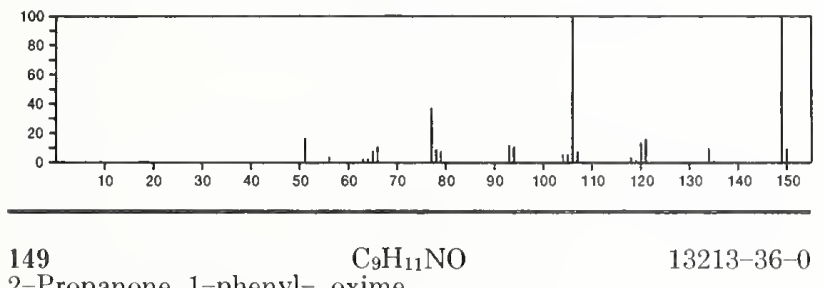

13213-36-0

2-Propanone, 1-phenyl-, oxime

$\mathrm{PhCH}_{2} \mathrm{CMe}=\mathrm{NOH}$

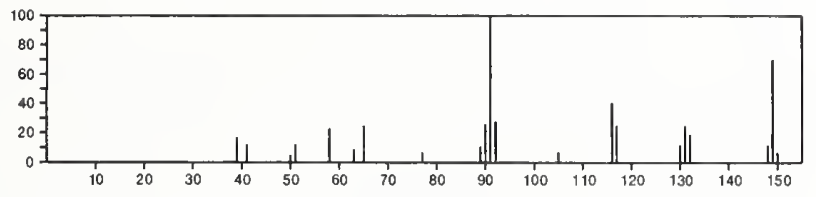

149

Benzaldehyde, $O$-ethyloxime

$\mathrm{C}_{9} \mathrm{H}_{11} \mathrm{NO}$

$13858-87-2$

$\mathrm{Ph} C \mathrm{CH}=\mathrm{NOE}$ :

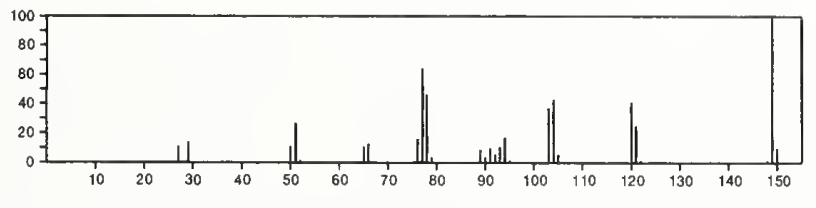

149
Oxazolidine, 3-phenyl-

$\mathrm{C}_{9} \mathrm{H}_{11} \mathrm{NO}$

20503-92-8
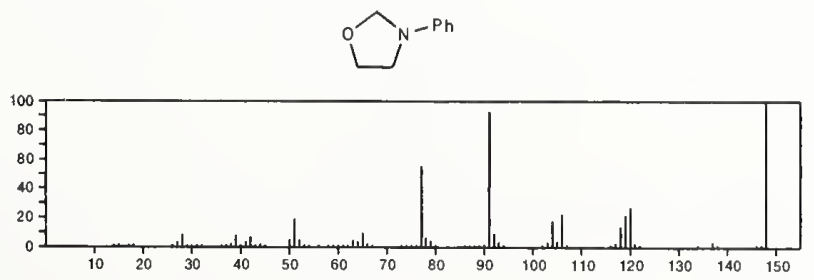

149

$\mathrm{C}_{9} \mathrm{H}_{11} \mathrm{NO}$

$22971-32-0$

1-Butanone, 1-(2-pyridinyl)-
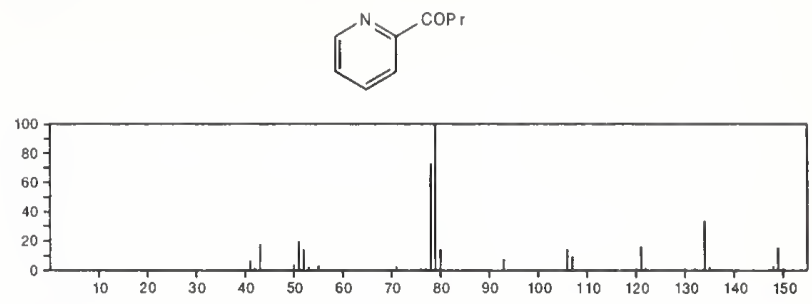

149

$\mathrm{C}_{9} \mathrm{H}_{11} \mathrm{NO}$

$33499-39-7$

Benzaldehyde, 4-methyl-, $\mathrm{O}$-methyloxime<smiles>CC(=O)c1ccc(C)cc1</smiles>

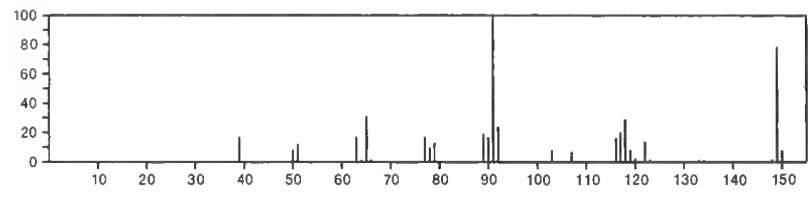

$149 \quad \mathrm{C}_{9} \mathrm{H}_{11} \mathrm{NO}$

1,3,5-Cycloheptatriene-1-carboxamide, 7-methyl-

$56771-82-5$
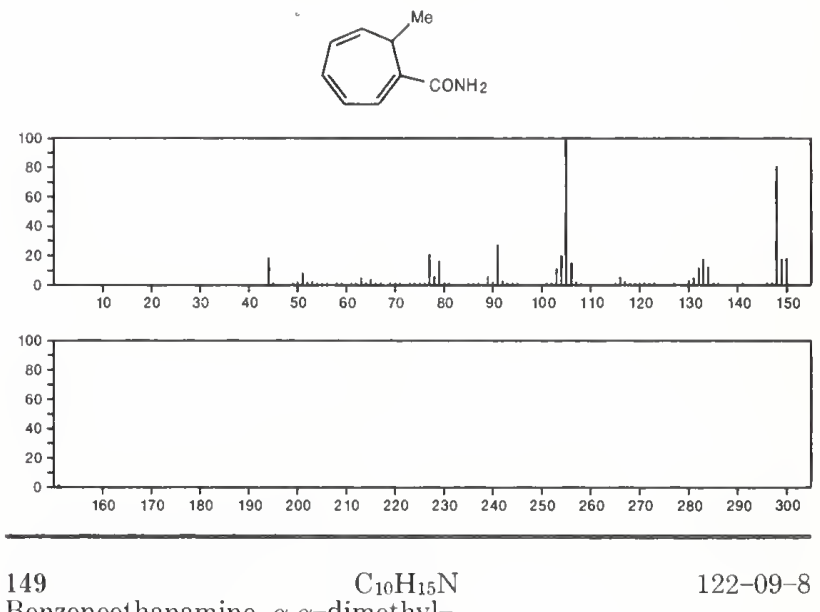

Benzeneethanamine, $\alpha, \alpha$-dimethyl-

$\mathrm{Me}_{2} \mathrm{CNH}_{2} \mathrm{CH}_{2} \mathrm{Ph}$

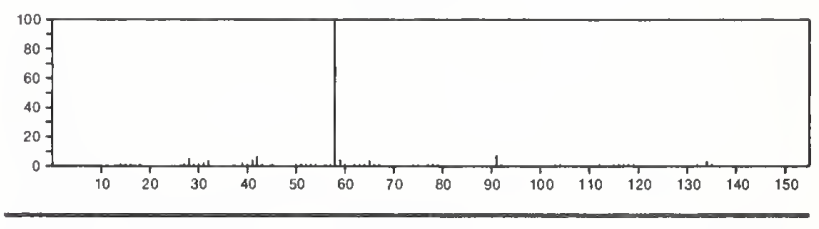

$149 \quad \mathrm{C}_{10} \mathrm{H}_{15} \mathrm{~N}$

Benzeneethanamine, $N, \alpha$-dimethyl-, $(S)$ -

$537-46-2$

$\mathrm{MeCH}$ ( NHMe) $\mathrm{CH}_{2} \mathrm{Ph}$

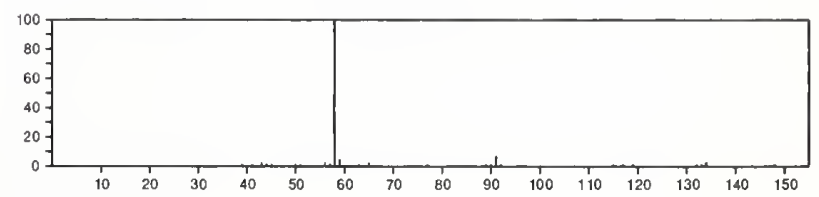


149

Benzeneethanamine, $N, N$-dimethyl-

$1126-71-2$

$\mathrm{Me} 2 \mathrm{NCH}_{2} \mathrm{CH}_{2} \mathrm{Ph}$

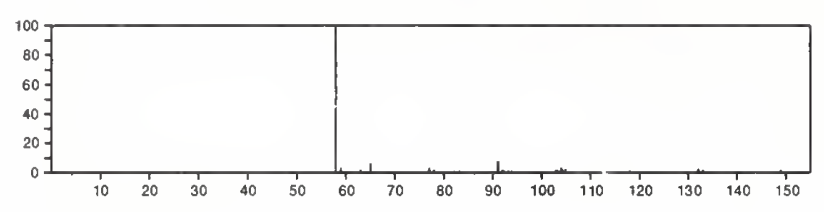

149

$\mathrm{C}_{10} \mathrm{H}_{15} \mathrm{~N}$

$4052-88-4$
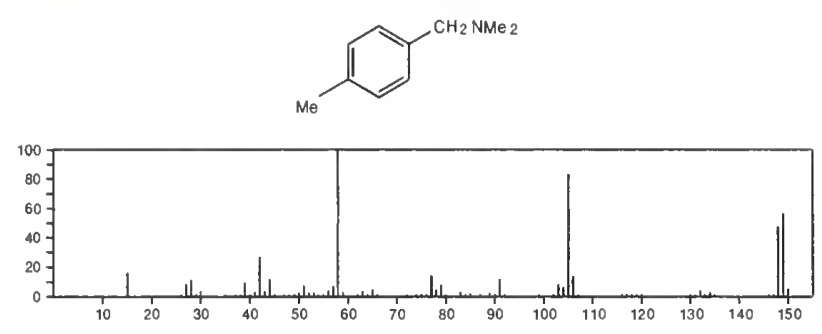

149

Benzeneethanamine, $\mathrm{N}, \mathrm{C}_{10} \mathrm{H}_{15} \mathrm{~N}$

dimethyl-

$\mathrm{MeCH}$ ( NHMe $) \mathrm{CH}_{2} \mathrm{Ph}$

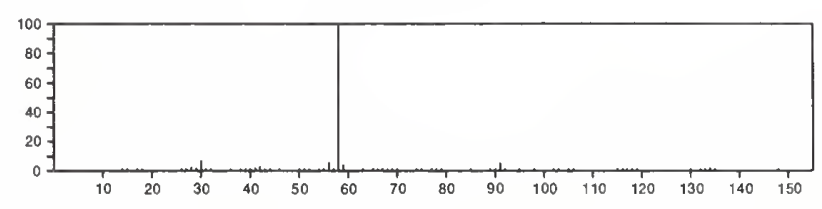

149

Pyridine, 2-neopentyl-

$\mathrm{C}_{10} \mathrm{H}_{15} \mathrm{~N}$

$31590-84-8$
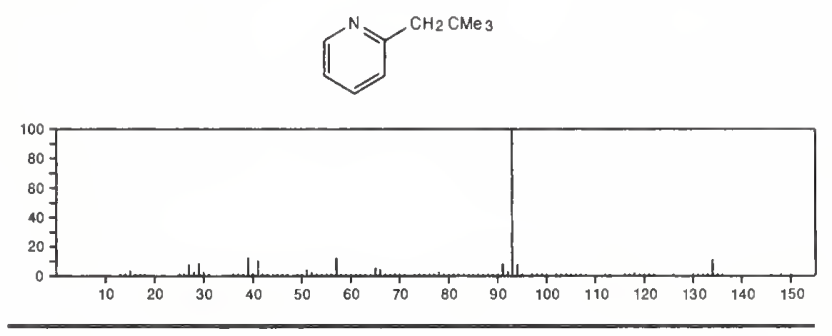

$149 \quad \mathrm{C}_{10} \mathrm{H}_{15} \mathrm{~N}$

Benzeneethanamine, $N, \alpha$-dimethyl-, $(R)-$

$\mathrm{MeCH}$ ( NHMe) $\mathrm{CH}_{2} \mathrm{Ph}$

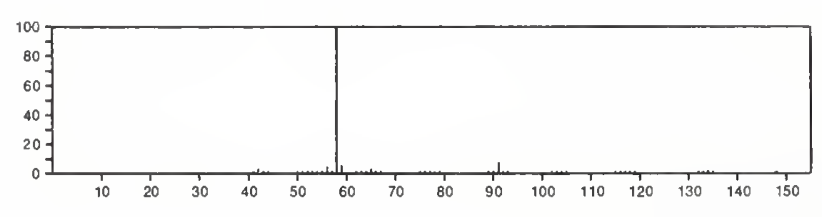

149

$\mathrm{C}_{10} \mathrm{H}_{15} \mathrm{~N}$

$55760-14-0$

Cyclobutaneacetonitrile, 1-methyl-2-(1-methylethylidene $)$ -
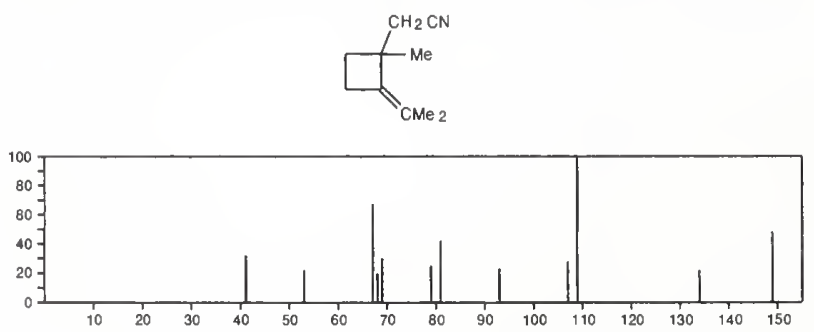

149

$\mathrm{C}_{10} \mathrm{H}_{15} \mathrm{~N}$

$55760-15-1$

Cyclobutaneacetonitrile, 1-methyl-2-(1-methylethenyl)-
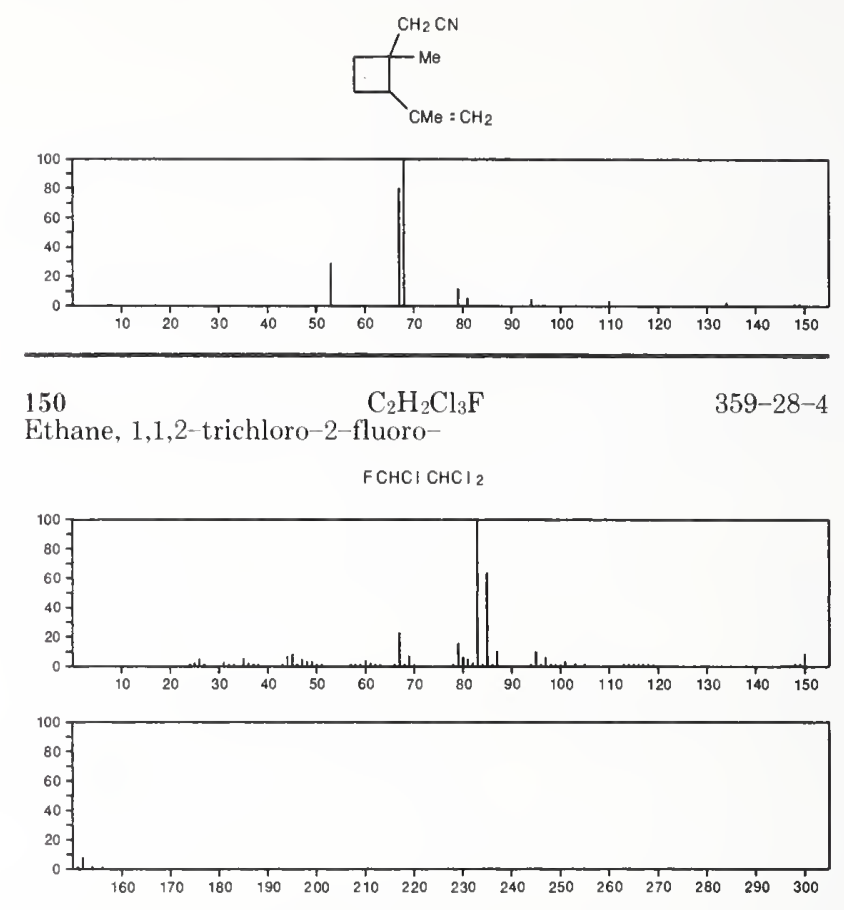

$150 \quad \mathrm{C}_{2} \mathrm{H}_{8} \mathrm{~N}_{2} \cdot \mathrm{C}_{2} \mathrm{H}_{2} \mathrm{O}_{4}$

Hydrazine, ethyl-, ethanedioate (1:1)

6629-60-3

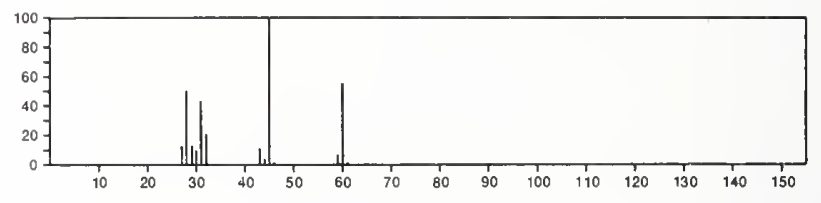

150

$\mathrm{C}_{3} \mathrm{~F}_{6}$

1-Propene, 1,1,2,3,3,3-hexafluoro

$116-15-4$

$\mathrm{F}_{3} \mathrm{CCF}=\mathrm{CF}_{2}$
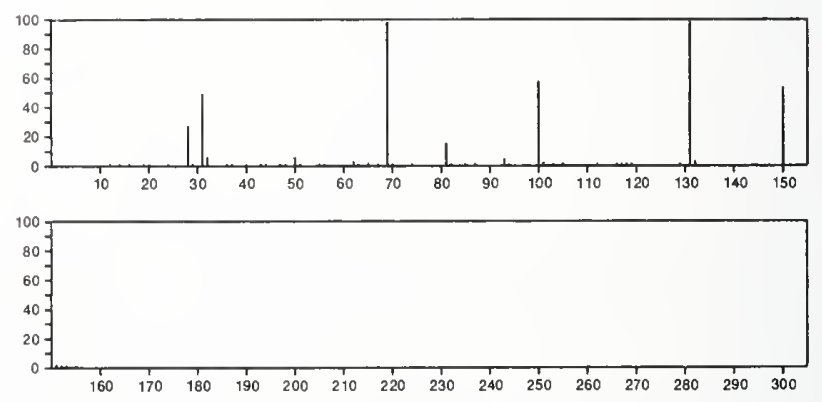

150

1,2 -Dithiolane-3-carboxylic acid

$6629-12-5$
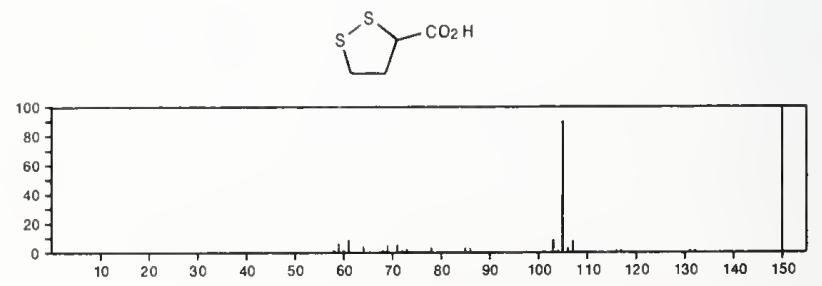


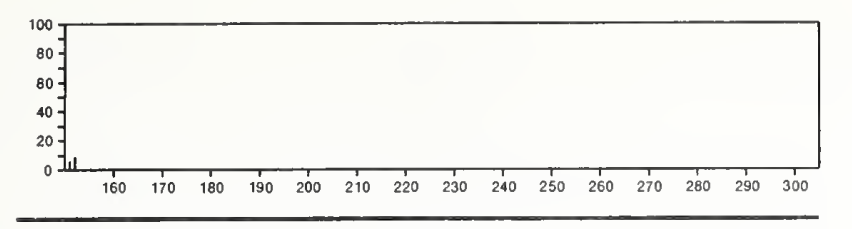

$150 \quad \mathrm{C}_{5} \mathrm{H}_{5} \mathrm{~F}_{3} \mathrm{~N}_{2} \quad 10010-93-2$

$1 H$-Pyrazole, 3-methyl-5-(trifluoromethyl)-
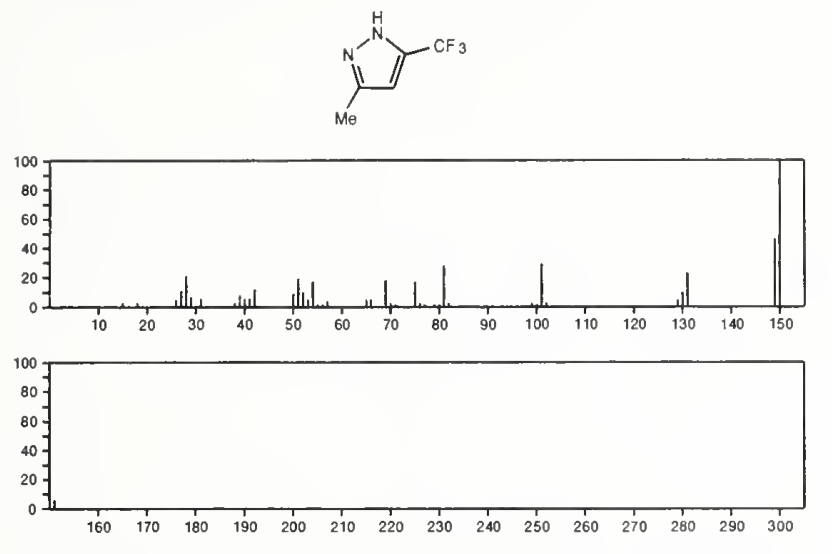

$150 \quad \mathrm{C}_{5} \mathrm{H}_{6} \mathrm{~N}_{6} \quad 51292-20-7$

Imidazo[5,1-f][1,2,4] triazine-2,7-diamine
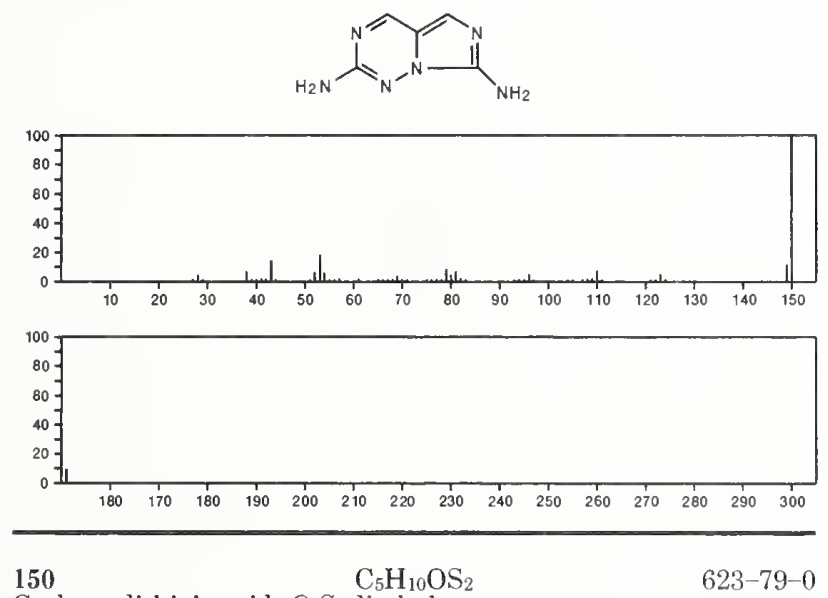

Carbonodithioic acid, $O, S$-diethyl ester

623-79-0

EtOC(S) SEt
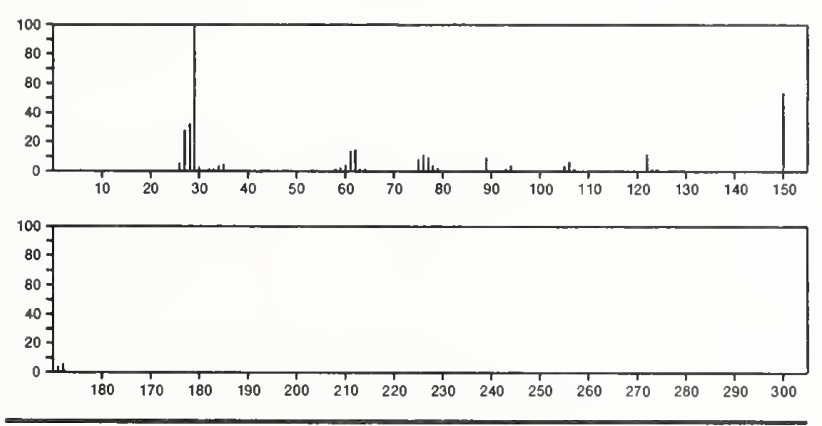

$150 \quad \mathrm{C}_{5} \mathrm{H}_{10} \mathrm{OS}_{2}$

Carbonodithioic acid, $S, S$-diethyl ester

$623-80-3$

EtSC(O) SEt

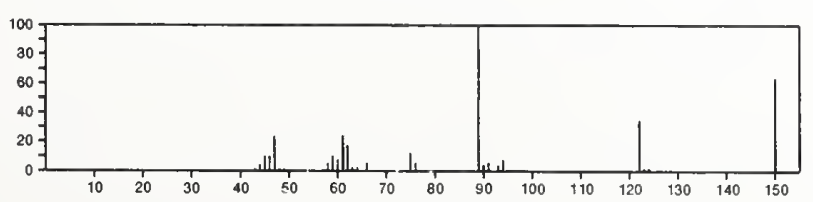

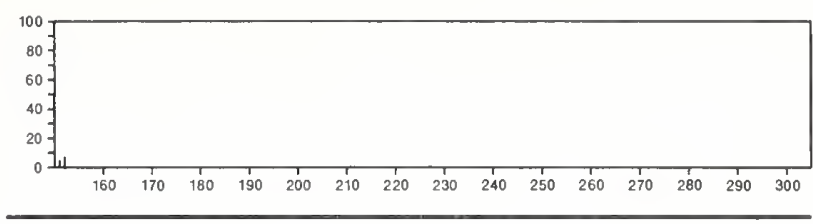

150

$\mathrm{C}_{5} \mathrm{H}_{10} \mathrm{O}_{3} \mathrm{~S}$

$19788-48-8$

Acetic acid, mercapto-, 2-methoxyethyl ester

$\mathrm{MeOCH}_{2} \mathrm{CH}_{2} \mathrm{OC}(\mathrm{O}) \mathrm{CH}_{2} \mathrm{SH}$

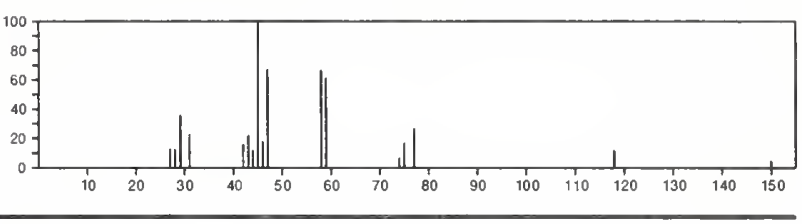

150

D-Ribose

$\mathrm{C}_{5} \mathrm{H}_{10} \mathrm{O}_{5}$

50-69-1

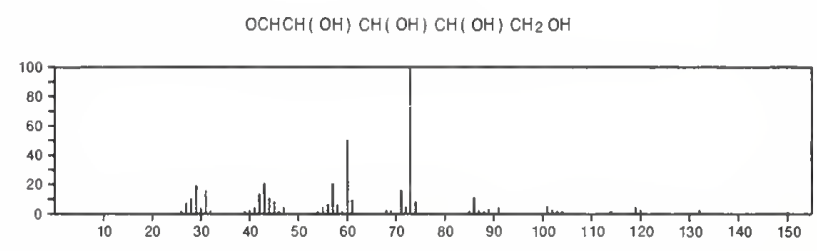

150

1,2,3,4,5-Cyclopentanepentol

$\mathrm{C}_{5} \mathrm{H}_{10} \mathrm{O}_{5}$

56772-25-9<smiles>OC1C(O)C(O)C(O)C1O</smiles>

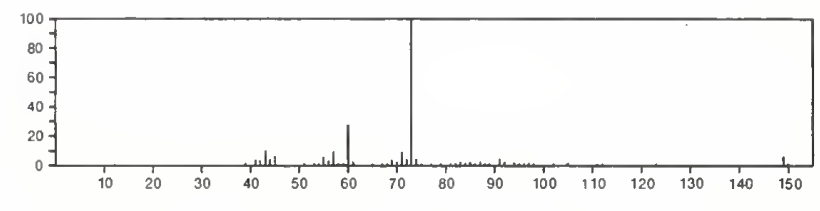

150

$\mathrm{C}_{5} \mathrm{H}_{11} \mathrm{Br}$

107-81-3

Pentane, 2-bromo-

$\operatorname{PrCHBr}$ (Me)

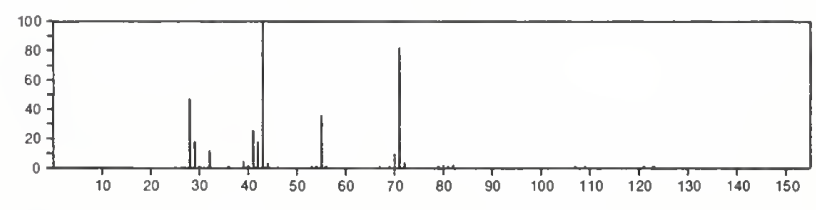

150

$\mathrm{C}_{5} \mathrm{H}_{11} \mathrm{Br}$

107-82-4

Butane, 1-bromo-3-methyl-

$\mathrm{Br} \mathrm{CH}_{2} \mathrm{CH}_{2} \mathrm{CHMe}_{2}$
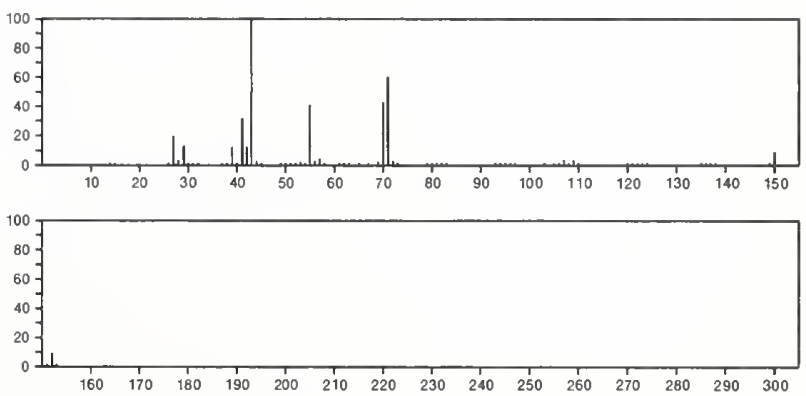
150

Pentane, 1-bromo-

$\mathrm{C}_{5} \mathrm{H}_{11} \mathrm{Br}$

$110-53-2$

$\mathrm{Br}\left(\mathrm{CH}_{2}\right) 4 \mathrm{Me}$
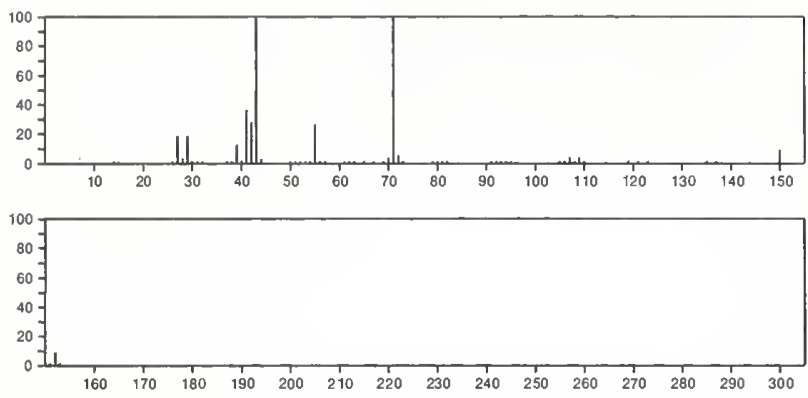

150

Butane, 2-bromo-2-methyl-

$\mathrm{C}_{5} \mathrm{H}_{11} \mathrm{Br}$

$507-36-8$

$\mathrm{E} t \mathrm{CBr}(\mathrm{Me}) 2$
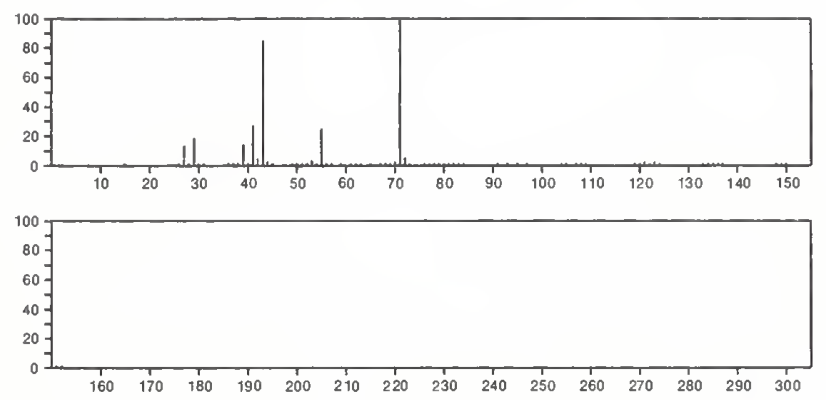

150

Propane, 1-bromo-2,2-dimethyl-

$630-17-1$

$\mathrm{BrCH}_{2} \mathrm{CMe}_{3}$
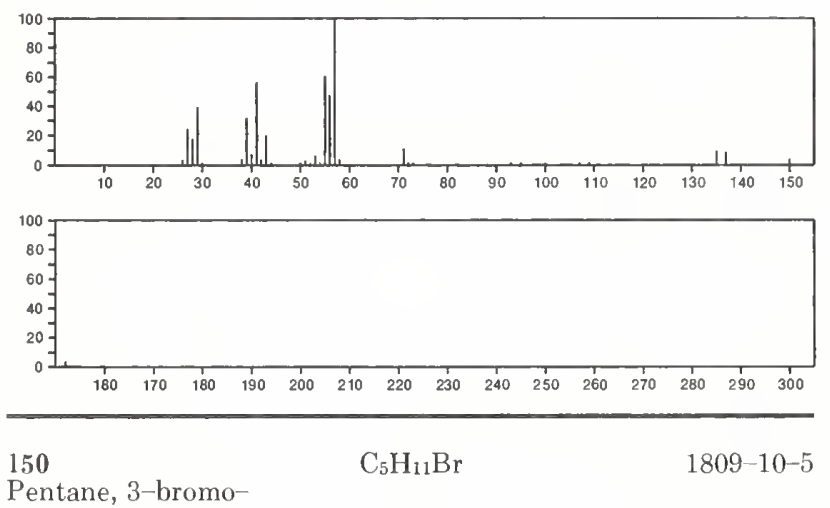

Pentane, 3-bromo-

$\mathrm{Et}_{2} \mathrm{CHBr}$
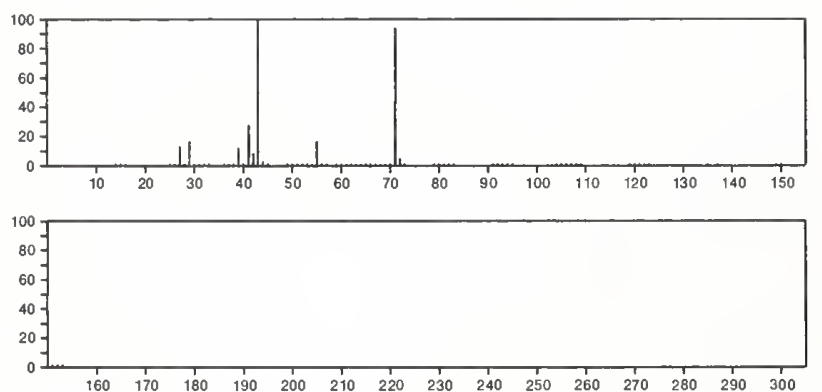

150

Butane, 1-bromo-2-methyl-

$\mathrm{C}_{5} \mathrm{H}{ }_{11} \mathrm{Br}$

10422-35-2

$\mathrm{BrCH}_{2} \mathrm{CHMe} \mathrm{CH}_{2} \mathrm{M}$
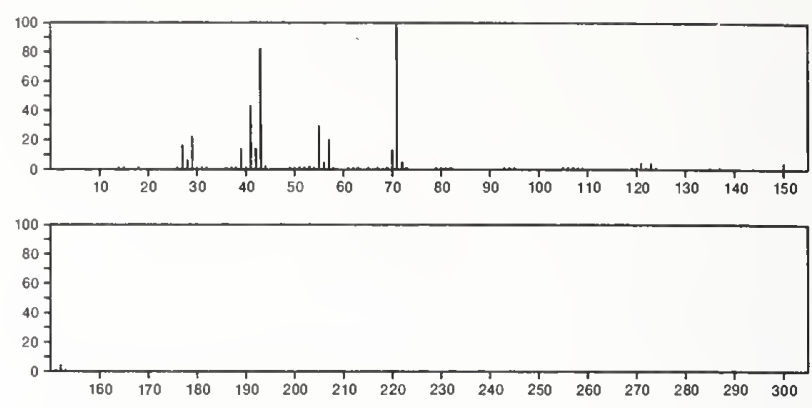

150

$\mathrm{C}_{6} \mathrm{H}_{2} \mathrm{~F}_{4}$

$327-54-8$

Benzene, 1,2,4,5-tetrafluoro-
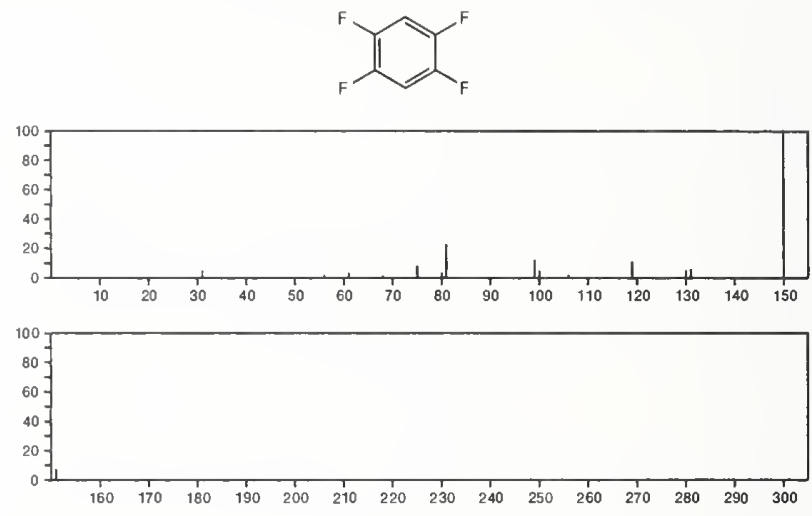

150

Benzene, 1,2,3,4-tetrafluoro

$\mathrm{C}_{6} \mathrm{H}_{2} \mathrm{~F}_{4}$

$551-62-2$
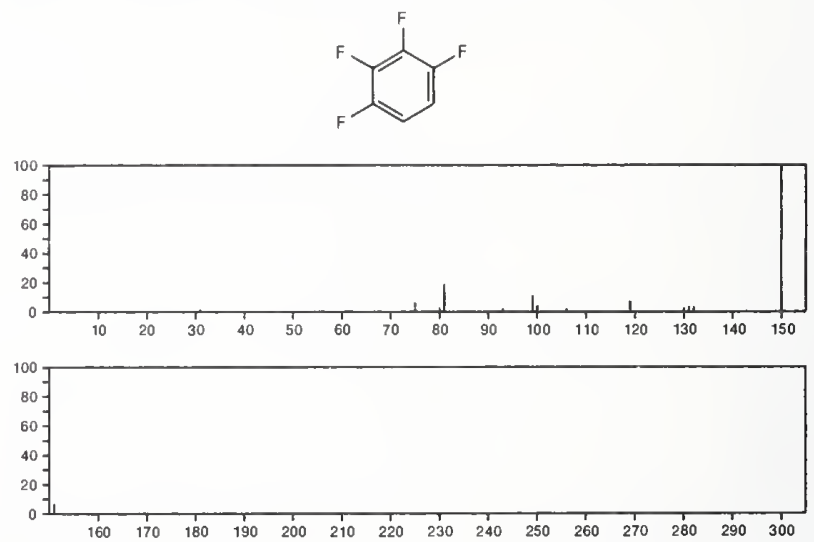

150

$\mathrm{C}_{6} \mathrm{H}_{2} \mathrm{~F}_{4}$

$2367-82-0$

Benzene, 1,2,3,5-tetrafluoro-
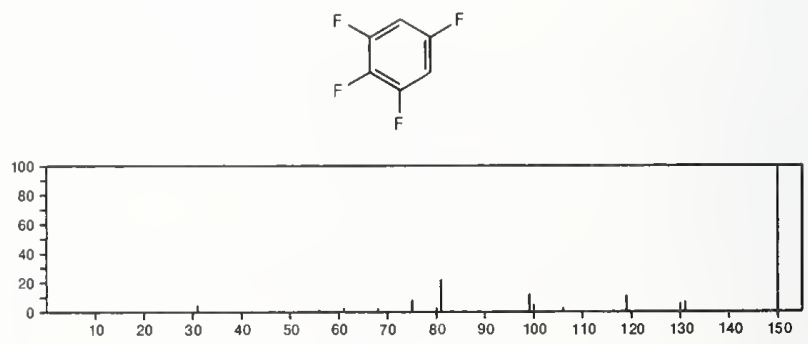


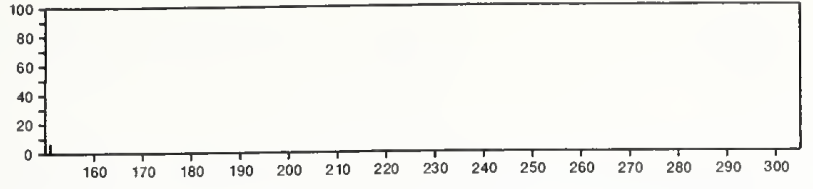

$150 \quad \mathrm{C}_{6} \mathrm{H}_{6} \mathrm{~N}_{4} \mathrm{O}$

6H-Purin-6-one, 1,7-dihydro-7-methyl-
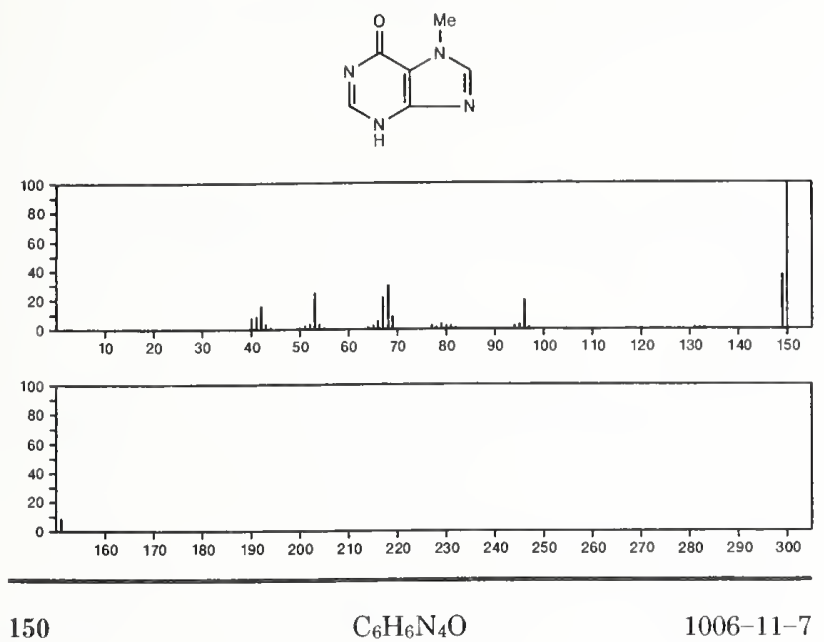

6H-Purin-6-one, 3,7-dihydro-3-methyl-

$1006-11-7$
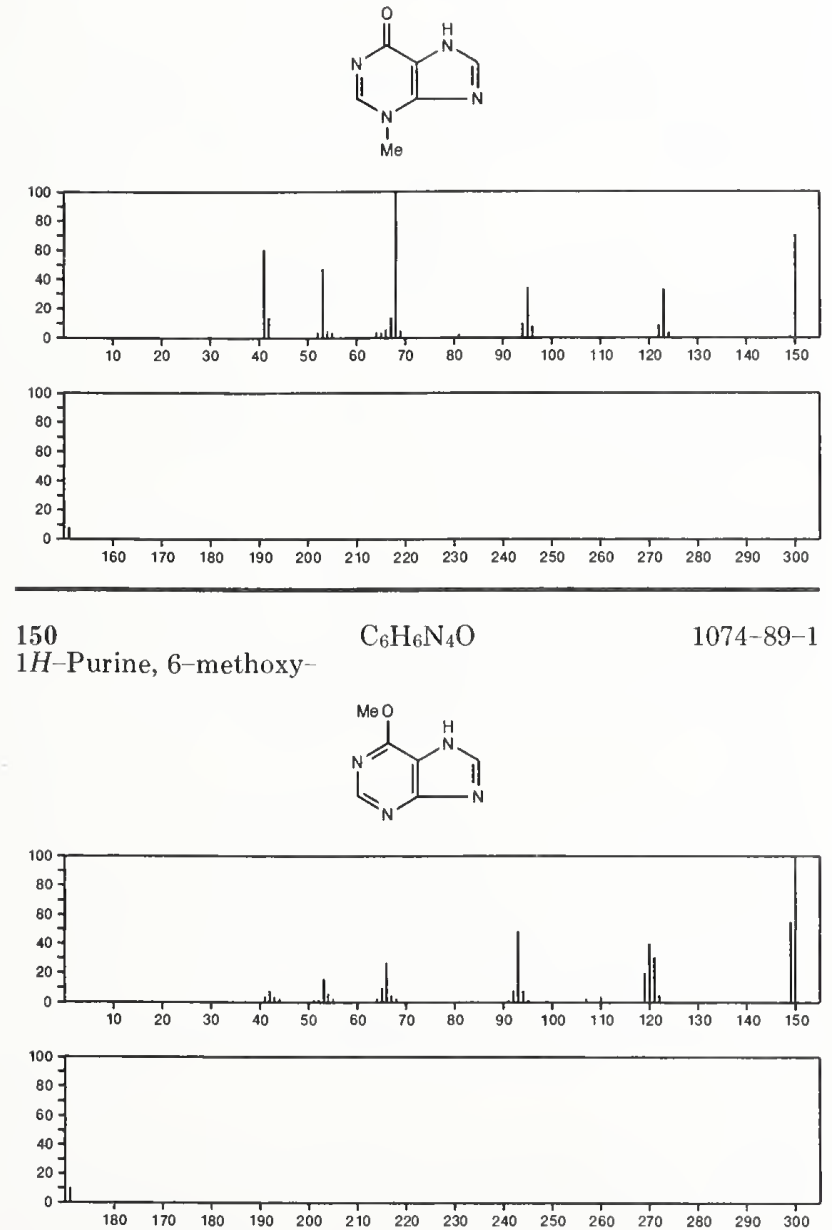

150

$\mathrm{C}_{6} \mathrm{H}_{6} \mathrm{~N}_{4} \mathrm{O}$

6H-Purin-6-one, 1,7-dihydro-1-methyl-
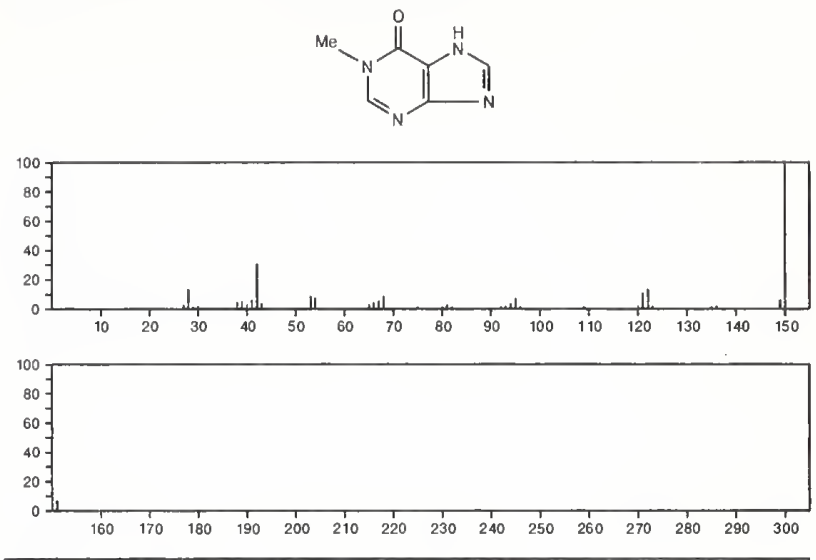

$150 \quad \mathrm{C}_{6} \mathrm{H}_{11} \mathrm{ClO}_{2}$

Acetic acid, chloro-, butyl ester

$590-02-3$

$\mathrm{Me}\left(\mathrm{CH}_{2}\right)_{3} \mathrm{OC}(\mathrm{O}) \mathrm{CH}_{2} \mathrm{C}$

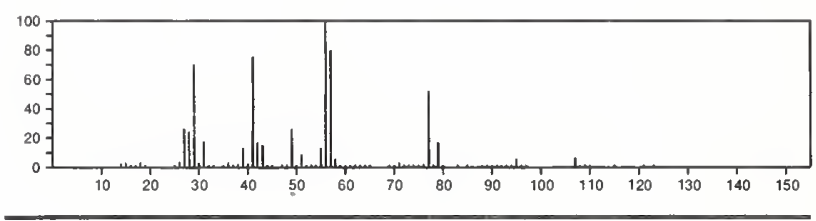

150

$\mathrm{C}_{6} \mathrm{H}_{11} \mathrm{ClO}_{2}$

Carbonochloridic acid, pentyl ester

$638-41-5$

$\mathrm{Me}\left(\mathrm{CH}_{2}\right){ }_{4} \mathrm{OC}(\mathrm{O}) \mathrm{Cl}$
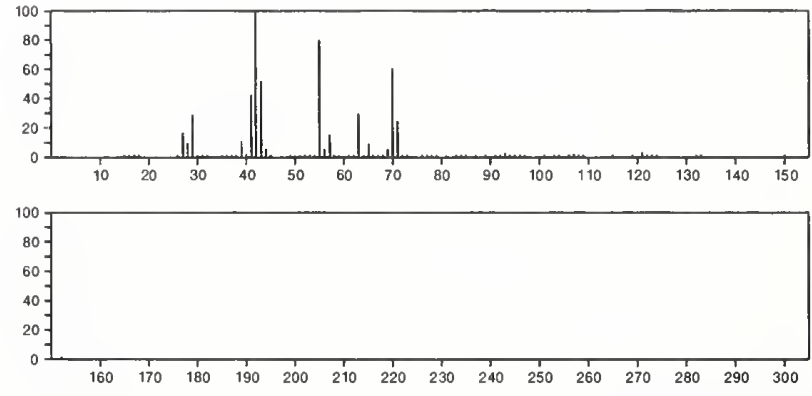

150

$\mathrm{C}_{6} \mathrm{H}_{11} \mathrm{ClO}_{2}$

691-93-0

Propanoic acid, 3-chloro-, 1-methylethyl ester

$\mathrm{Cl} \mathrm{CH}_{2} \mathrm{CH}_{2} \mathrm{ClO}$ OP $\mathrm{Or}$
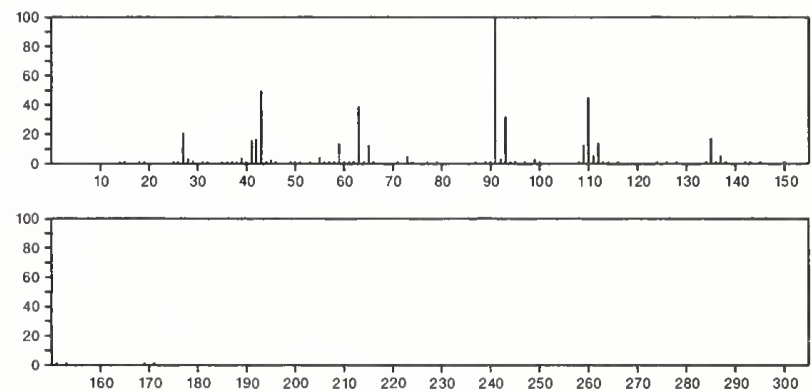
150

$\mathrm{C}_{6} \mathrm{H}_{11} \mathrm{ClO}_{2}$

$3153-36-4$

Butanoic acid, 4-chloro-, ethyl ester

$\mathrm{Cl}\left(\mathrm{CH}_{2}\right)_{3} \mathrm{C}(\mathrm{O}) \mathrm{OEt}$

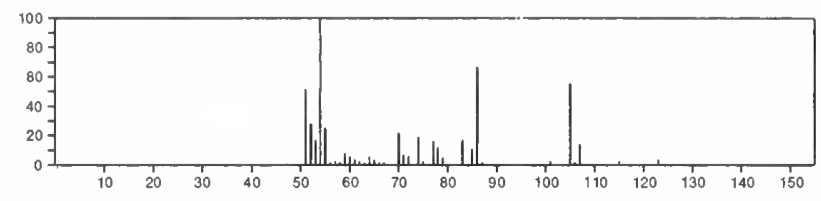

$150 \quad \mathrm{C}_{6} \mathrm{H}_{11} \mathrm{ClO}_{2} \quad 21491-96-3$

Propanoic acid, 3-chloro-2,2-dimethyl-, methyl ester

$\mathrm{MeOC}(\mathrm{O}) \mathrm{CMe}_{2} \mathrm{CH}_{2} \mathrm{Cl}$
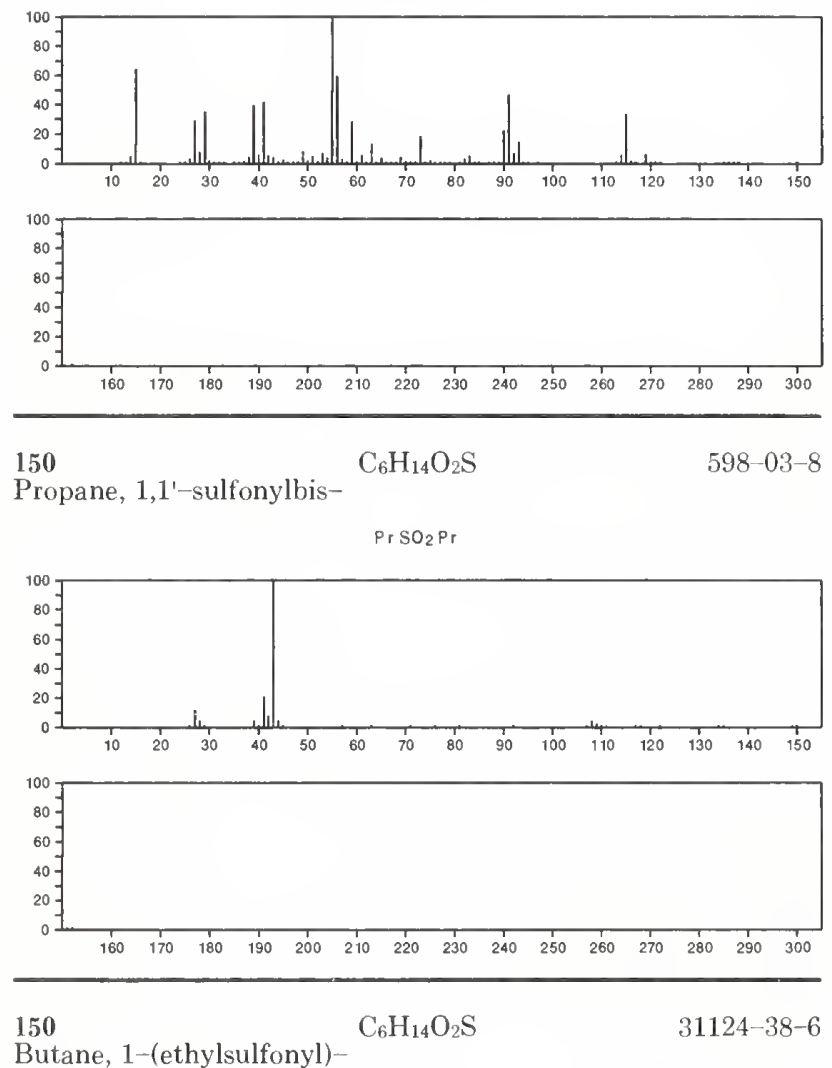

Butane, 1-(ethylsulfonyl)-

$\mathrm{Me}\left(\mathrm{CH}_{2}\right)_{3} \mathrm{SO}_{2} \mathrm{Et}$
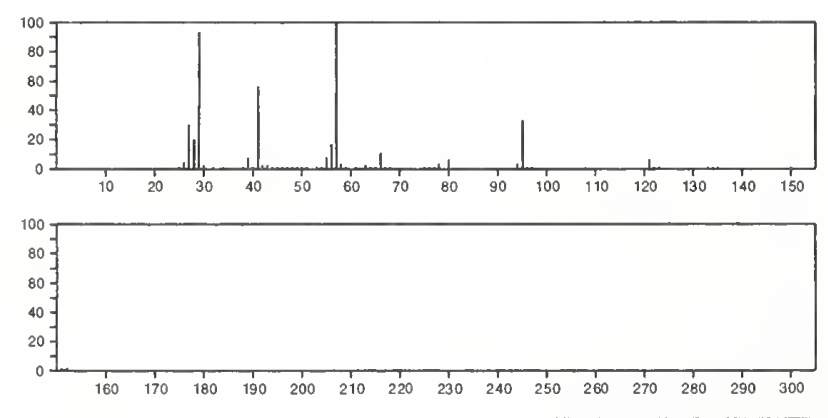

$150 \quad \mathrm{C}_{6} \mathrm{H}_{14} \mathrm{O}_{4}$

Ethanol, 2,2'-[1,2-ethanediylbis $($ oxy $)]$ bis-

$112-27-6$

$\mathrm{HOCH}_{2} \mathrm{CH}_{2} \mathrm{OCH}_{2} \mathrm{CH}_{2} \mathrm{OCH}_{2} \mathrm{CH}_{2} \mathrm{OH}$

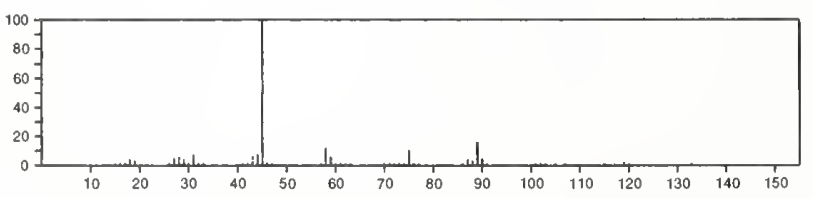

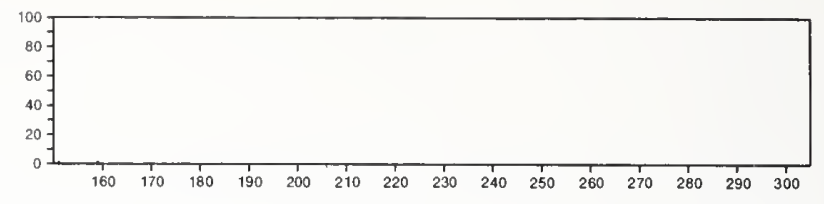

150

Disulfide, dipropyl

$\mathrm{C}_{6} \mathrm{H}_{14} \mathrm{~S}_{2}$

$629-19-6$

prsspr
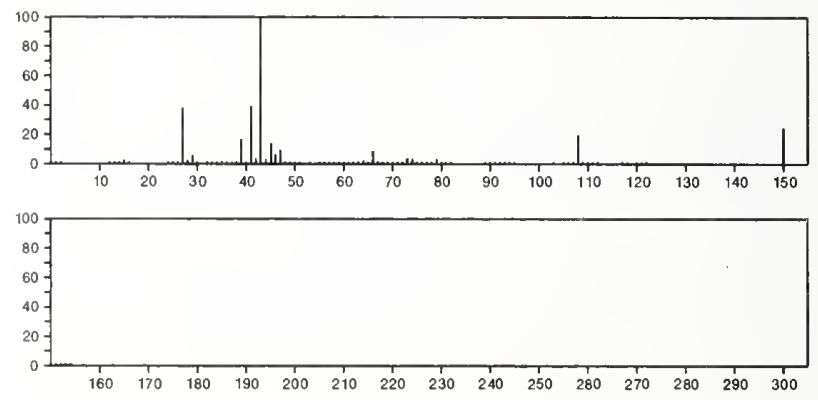

150

$\mathrm{C}_{6} \mathrm{H}_{14} \mathrm{~S}_{2}$

Disulfide, 1,1-dimethylethyl ethyl

4151-69-3

EtSSBu-t
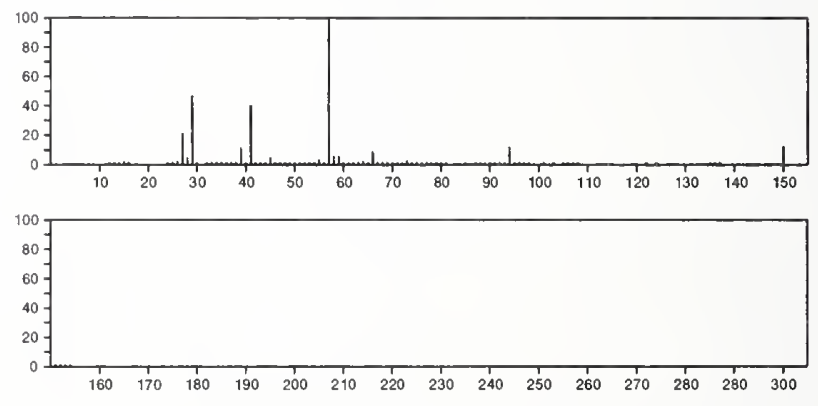

150

$\mathrm{C}_{6} \mathrm{H}_{14} \mathrm{~S}_{2}$

Disulfide, bis(1-methylethyl)

$i-\operatorname{Pr} S S P r-i$
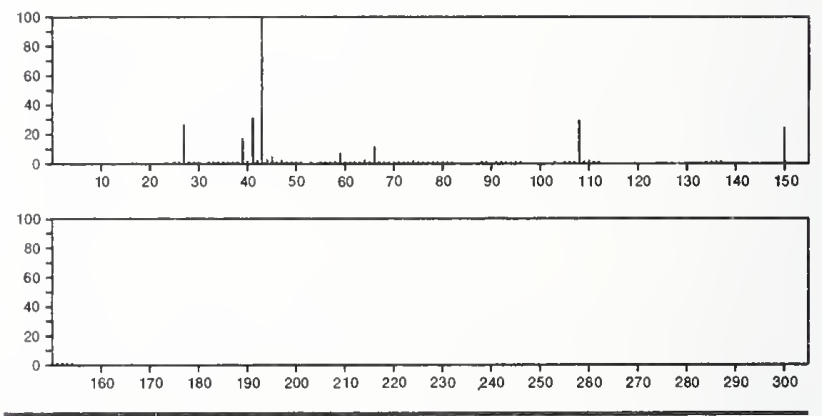

150

$\mathrm{C}_{6} \mathrm{H}_{14} \mathrm{~S}_{2}$

$5395-75-5$

Ethane, 1,2-bis(ethylthio)-

$\mathrm{E}$ ! $\mathrm{SCH}_{2} \mathrm{CH}_{2} \mathrm{SE}$
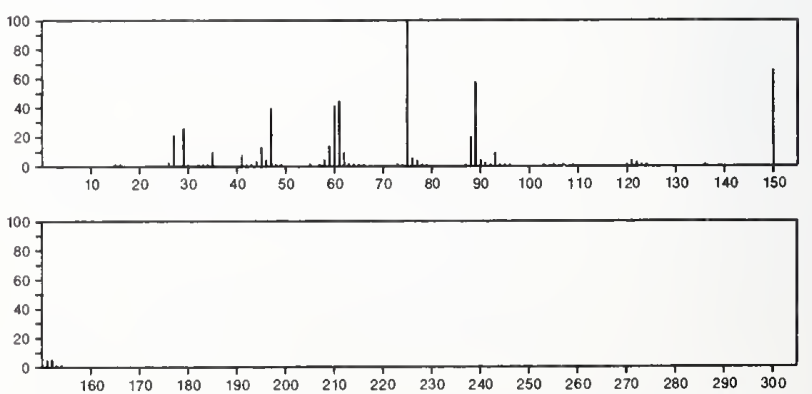
150

Ethane, 1,1-bis(ethylthio)-

$\mathrm{C}_{6} \mathrm{H}_{14} \mathrm{~S}_{2}$

$\mathrm{MeCH}\left(S \mathrm{SE}_{1}\right)_{2}$
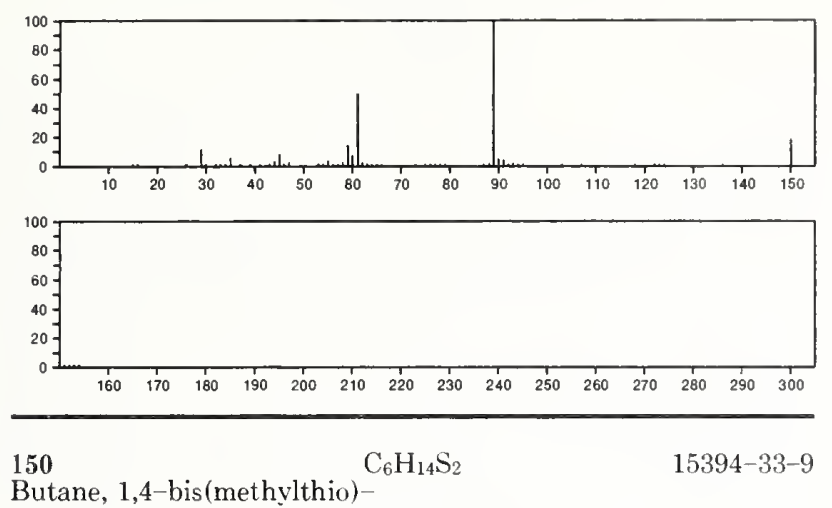

Butane, 1,4-bis(methylthio)-
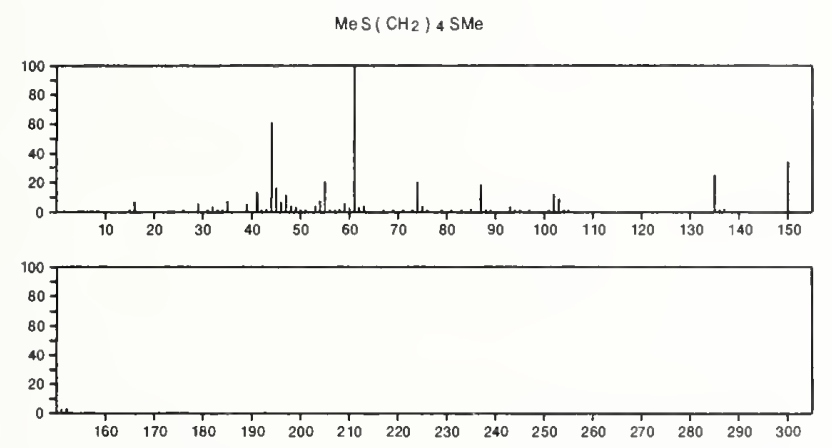

150

Disulfide, isopropyl propyl

$\mathrm{C}_{6} \mathrm{H}_{14} \mathrm{~S}_{2}$

PrSSPr-i
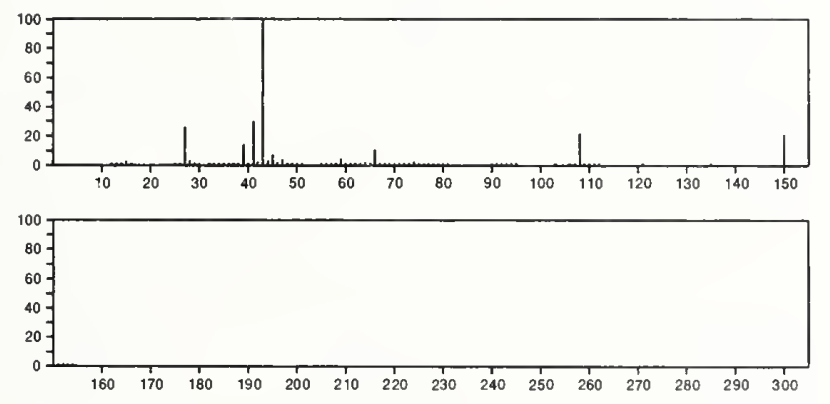

150

Disulfide, ethyl 2-methylpropyl

\section{$\mathrm{C}_{6} \mathrm{H}_{14} \mathrm{~S}_{2}$}

Et SSBu-i
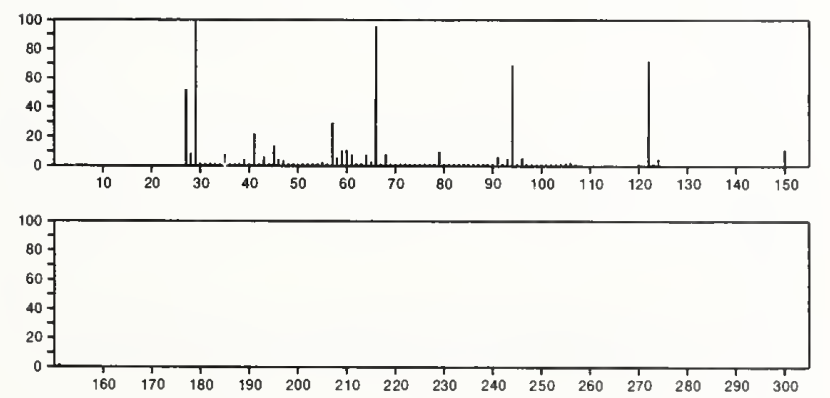

150

Disulfide, ethyl(

$\mathrm{C}_{6} \mathrm{H}_{14} \mathrm{~S}_{2}$

E:SSBu-S
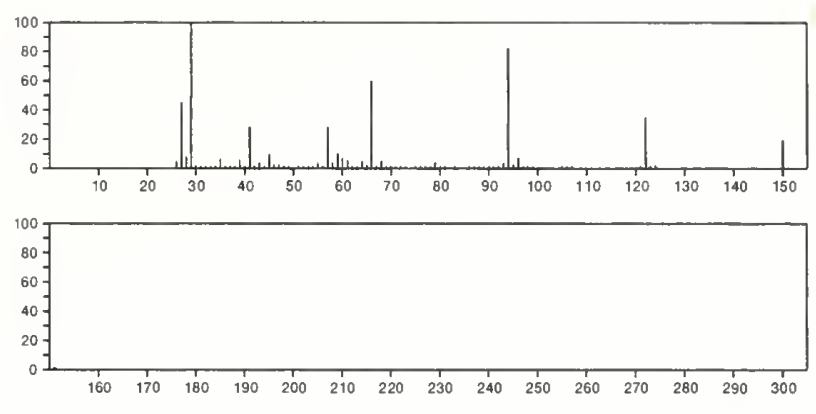

150

2-Benzothiazolamine

$\mathrm{C}_{7} \mathrm{H}_{6} \mathrm{~N}_{2} \mathrm{~S}$

$136-95-8$
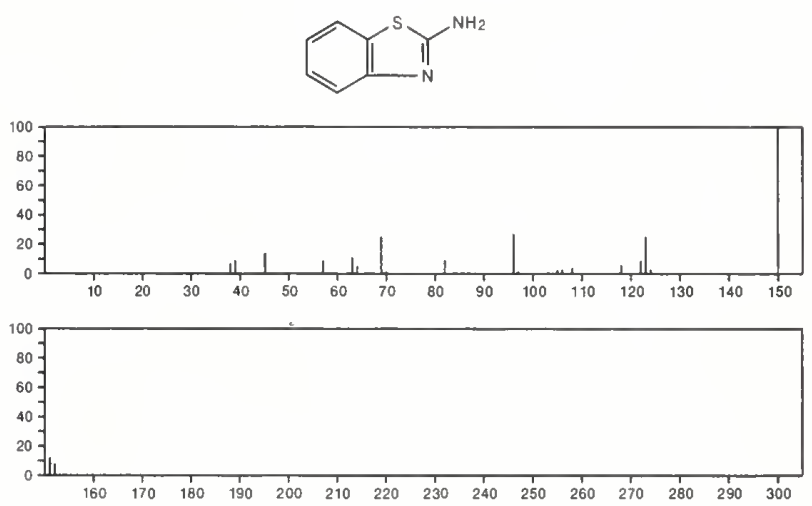

150

$\mathrm{C}_{7} \mathrm{H}_{10} \mathrm{~N}_{4}$

$6726-50-7$

Pyrazolo[5,1-c]-as-triazine, 4,6-dihydro-3,4-dimethyl-
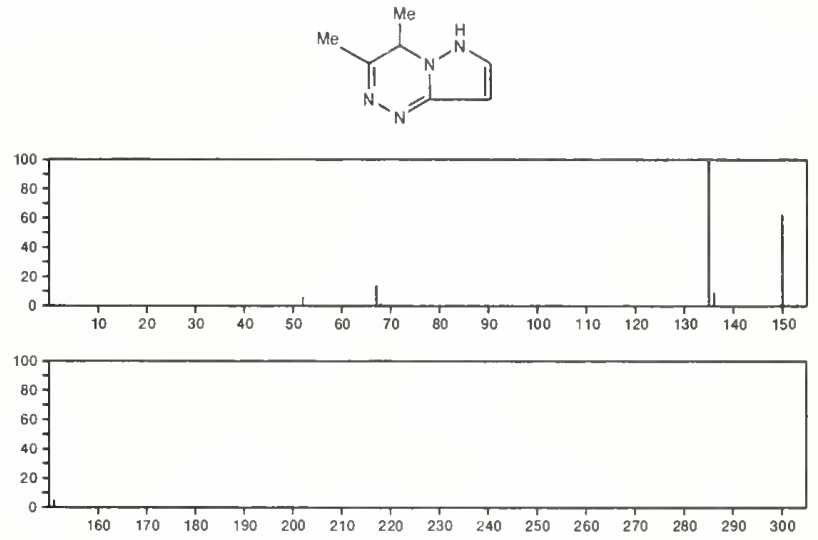

$\mathrm{C}_{7} \mathrm{H}_{10} \mathrm{Si}_{2}$

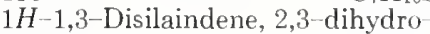

$4361-65-3$
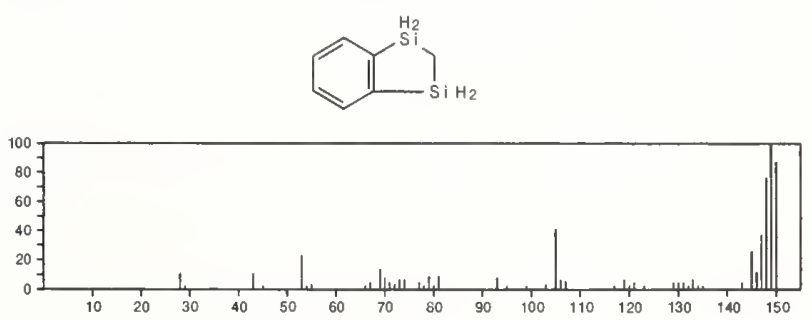


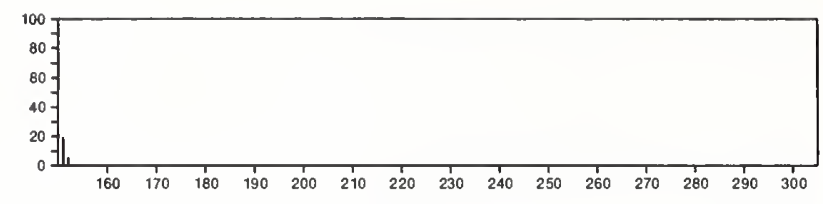

150

$\mathrm{C}_{8} \mathrm{H}_{6} \mathrm{O}_{3}$

$119-67-5$

Benzoic acid, 2-formyl-
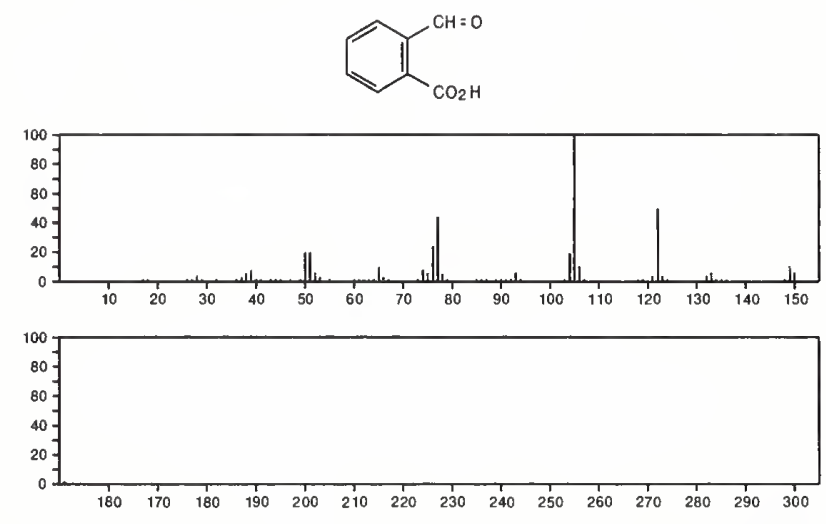

150

$\mathrm{C}_{8} \mathrm{H}_{6} \mathrm{O}_{3}$

1,3-Benzodioxole-5-carboxaldehyde

$120-57-0$
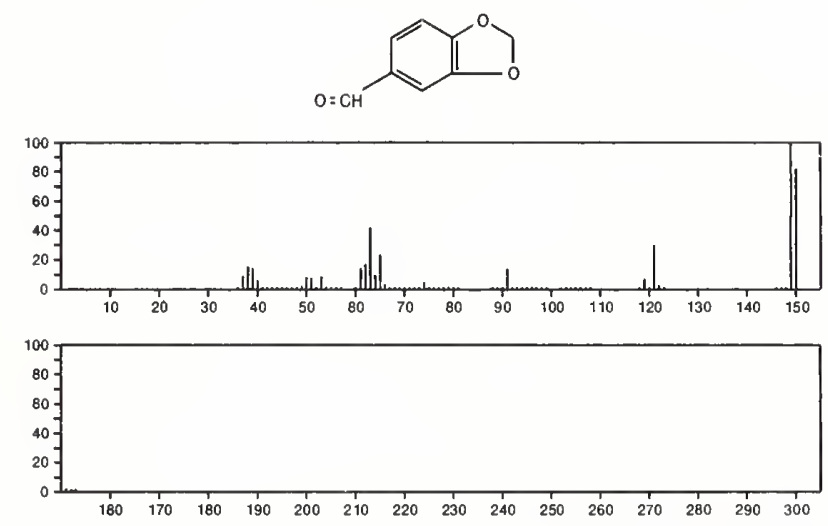

150

Benzoic acid, 4-formyl-

$\mathrm{C}_{8} \mathrm{H}_{6} \mathrm{O}_{3}$

619-66-9
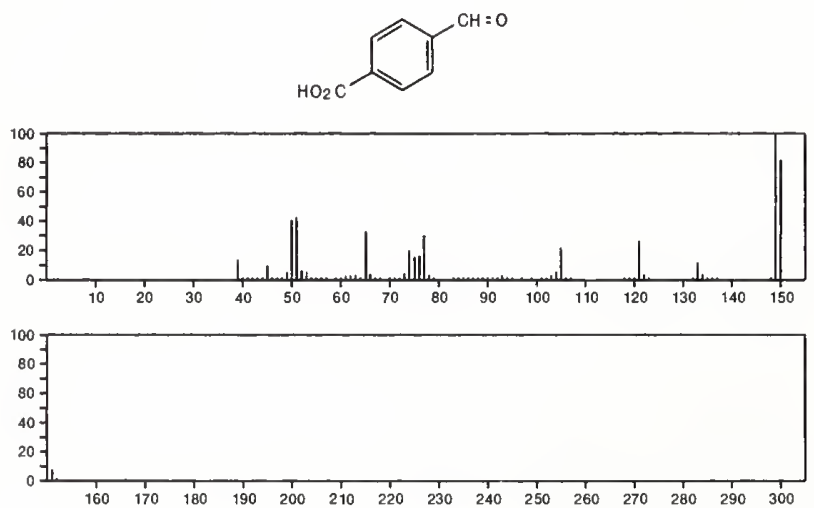

150

$\mathrm{C}_{8} \mathrm{H}_{10} \mathrm{~N}_{2} \mathrm{O}$

$138-89-6$

Benzenamine, $N, N$-dimethyl-4-nitroso-
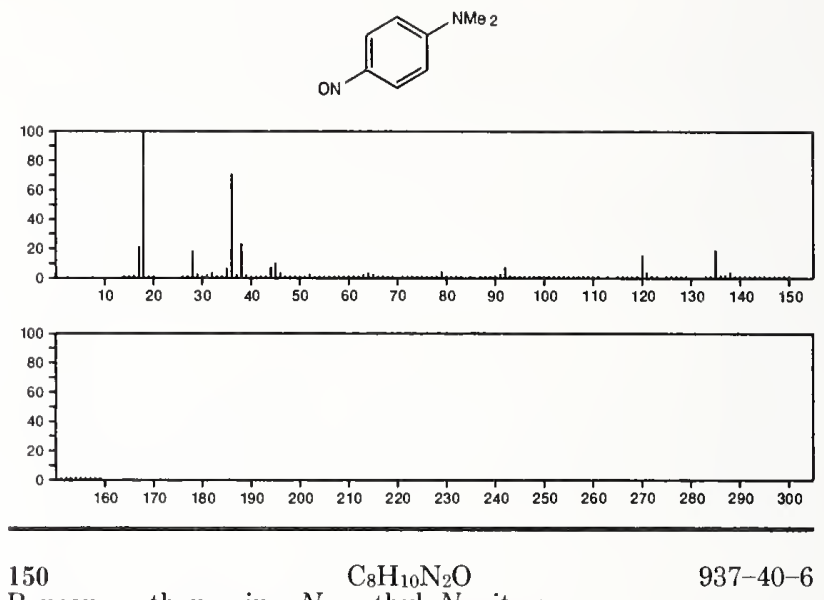

Benzenemethanamine, $N$-methyl- $N$-nitroso-

$\mathrm{MeN}$ (NO) $\mathrm{CH}_{2} \mathrm{Ph}$
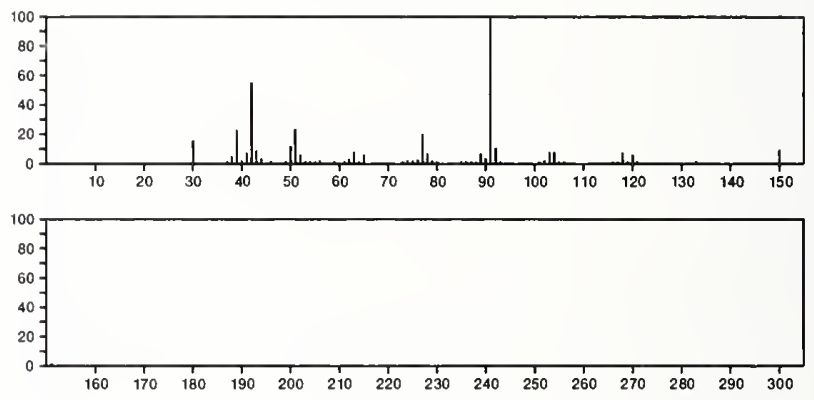

150
Benzoic acid, 2-methylhydrazide

1660-24-8

PhCONHNHME

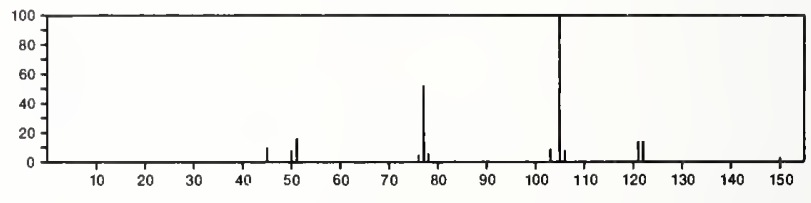

150

$\mathrm{C}_{8} \mathrm{H}_{10} \mathrm{~N}_{2} \mathrm{O}$

7584-27-2

Pyridinium, 1-(acetylamino)-2-methyl-, hydroxide, inner salt
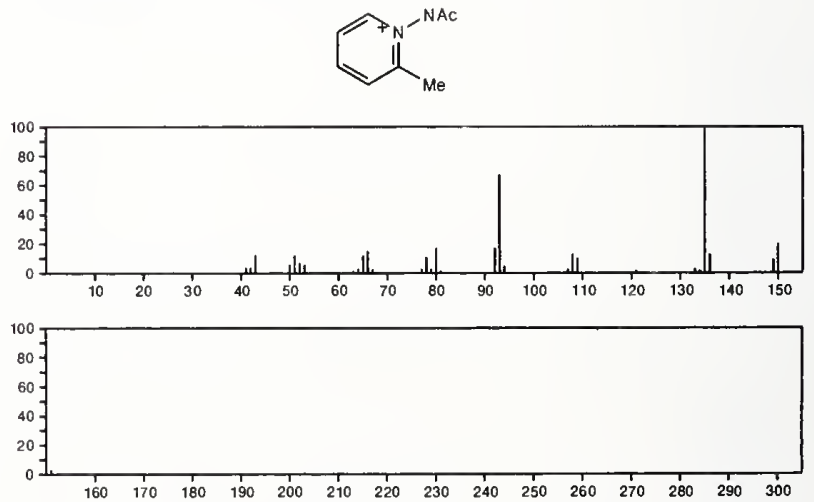
150

$\mathrm{C}_{8} \mathrm{H}_{10} \mathrm{~N}_{2} \mathrm{O}$

$7584-29-4$

4-Picolinium, 1-acetamido-, hydroxide, inner salt
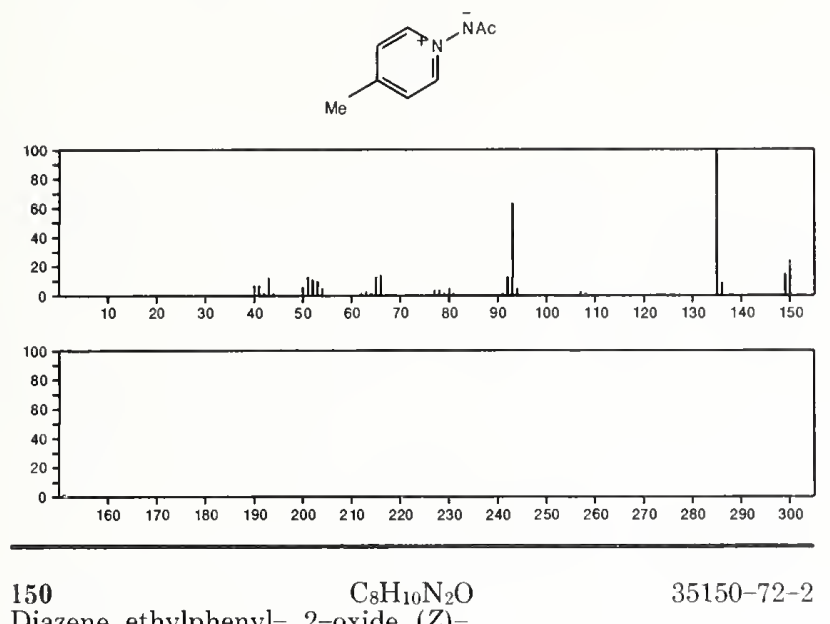

Diazene, ethylphenyl-, 2-oxide, $(Z)-$

$E \backslash N=N P h=0$

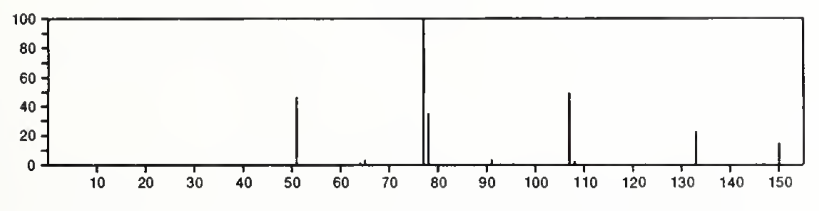

$150 \quad \mathrm{C}_{8} \mathrm{H}_{10} \mathrm{~N}_{2} \mathrm{O}$

Diazene, ethylphenyl-, 2-oxide, $(E)-$

$E \backslash N: N P h=0$

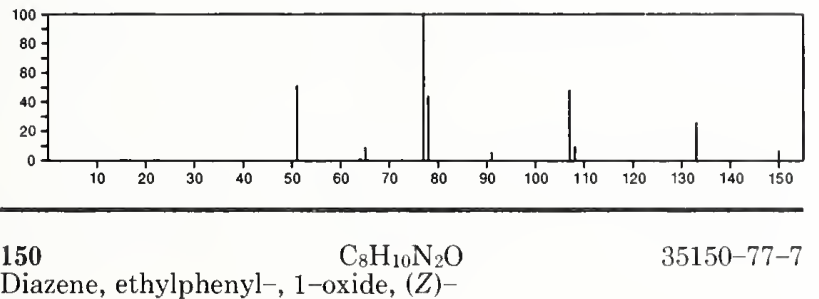

Diazene, ethylphenyl-, 1-oxide, (Z)-

$O=N E:=N P h$

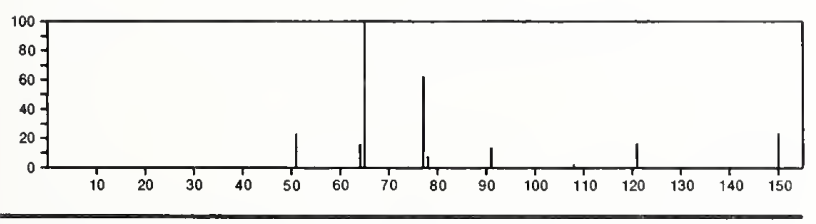

150

$\mathrm{C}_{8} \mathrm{H}_{10} \mathrm{~N}_{2} \mathrm{O}$

Diazene, ethylphenyl-, 1-oxide, $(E)$ -

$35150-78-8$

$O=N E t=N P h$

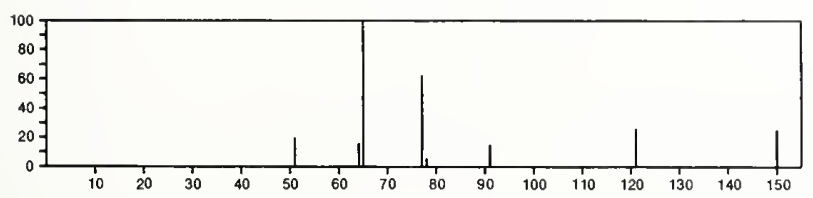

150

$\mathrm{C}_{9} \mathrm{H}_{10} \mathrm{O}_{2}$

Benzoic acid, 2-methyl-, methyl ester

89-71-4<smiles>COC(=O)c1ccccc1N</smiles>
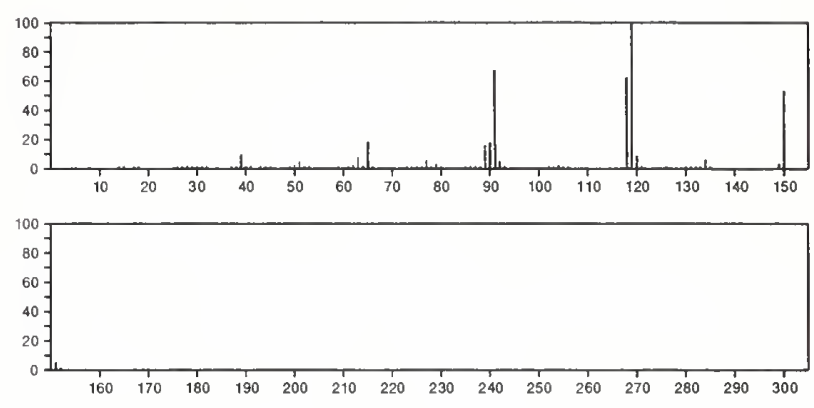

150

Benzoic acid, ethyl ester

$\mathrm{C}_{9} \mathrm{H}_{10} \mathrm{O}_{2}$

93-89-0

Etoc(O) Ph
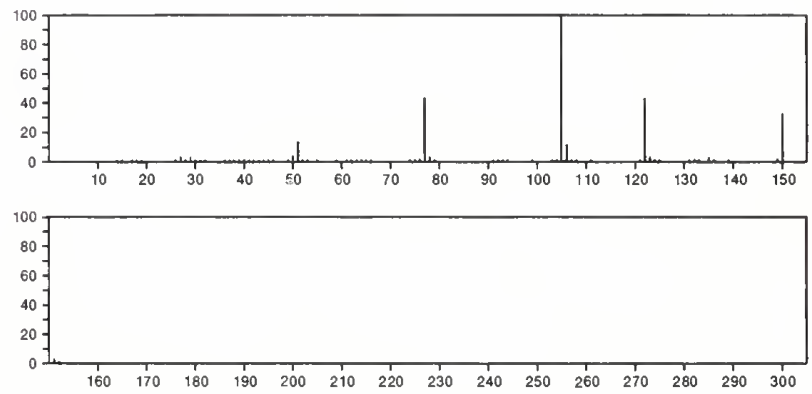

150

$\mathrm{C}_{9} \mathrm{H}_{10} \mathrm{O}_{2}$

Benzoic acid, 3-methyl-, methyl ester

99-36-5
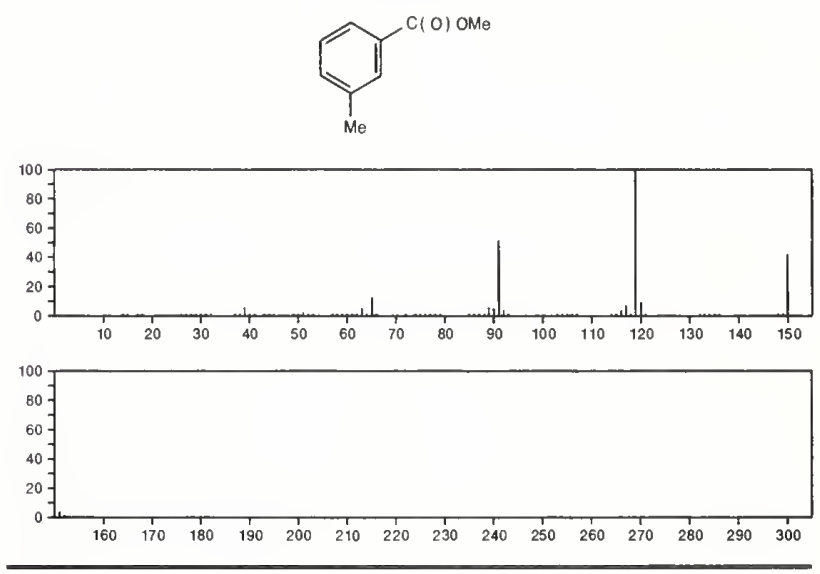

150

$\mathrm{C}_{9} \mathrm{H}_{10} \mathrm{O}_{2}$

Benzoic acid, 4-methyl-, methyl ester

$99-75-2$
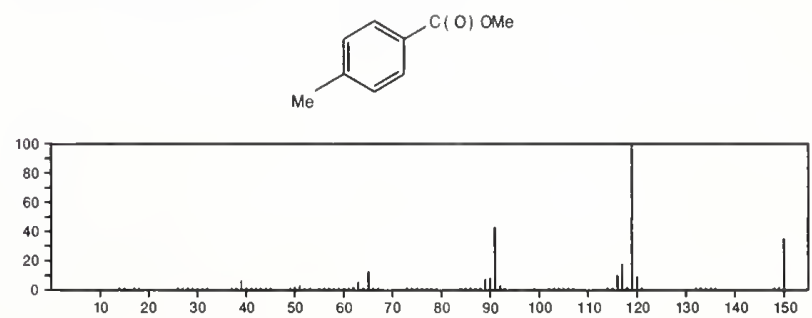


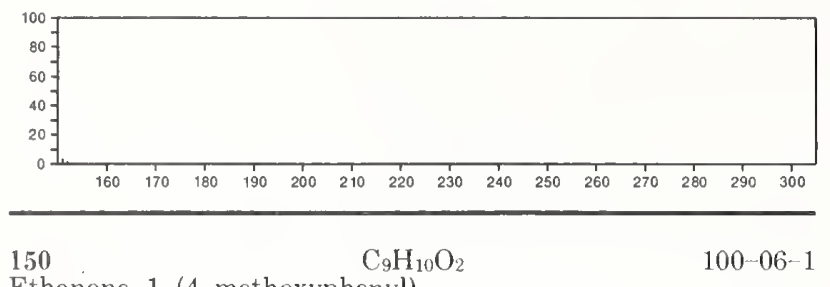

150

Acetic acid, phenylmethyl ester

$\mathrm{C}_{9} \mathrm{H}_{10} \mathrm{O}_{2}$

$\mathrm{ACOCH} \mathrm{Ph}_{2}$
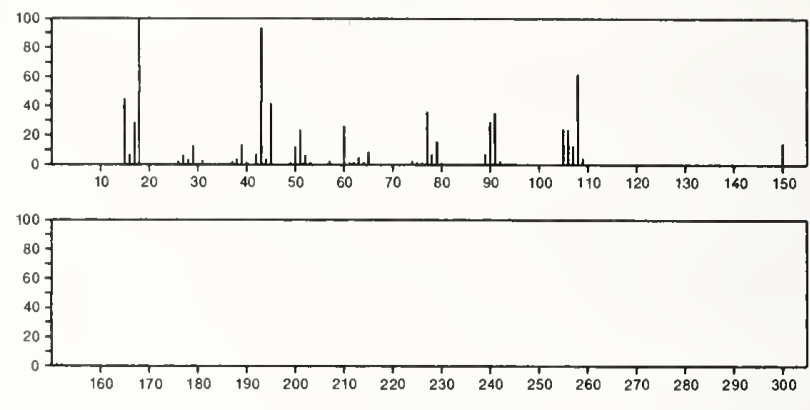

150

Benzoic acid, 3,5-dimethyl-

$\mathrm{C}_{9} \mathrm{H}_{10} \mathrm{O}_{2}$

499-06-9
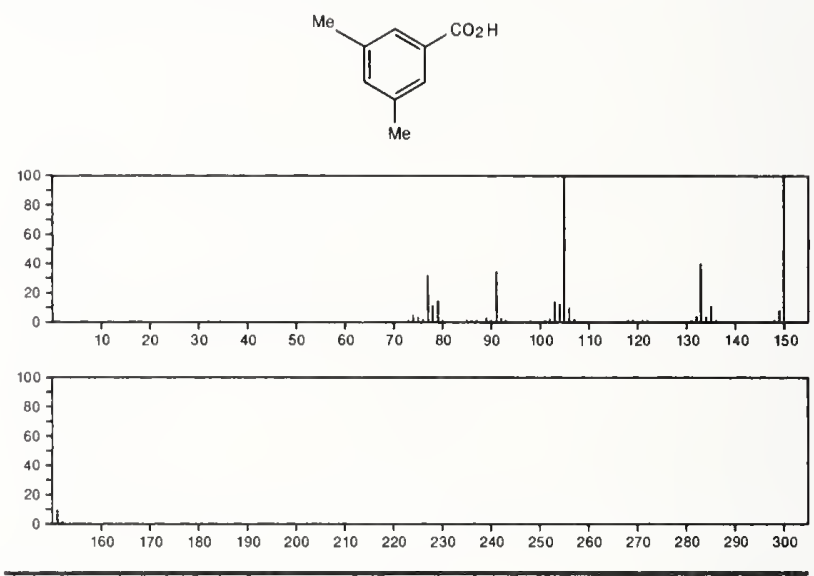

150

$\mathrm{C}_{9} \mathrm{H}_{10} \mathrm{O}_{2}$

$501-52-0$

Benzenepropanoic acid

$\mathrm{HO}_{2} \mathrm{CCH}_{2} \mathrm{CH}_{2} \mathrm{Ph}$
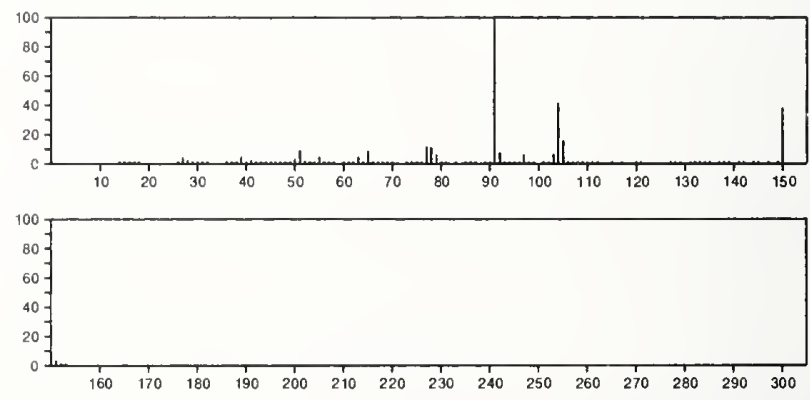

150

$\mathrm{C}_{9} \mathrm{H}_{10} \mathrm{O}_{2}$

Acetic acid, 2-methylphenyl ester

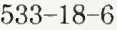

150
Oxirane, (phenoxymethyl)-

$122-60-1$
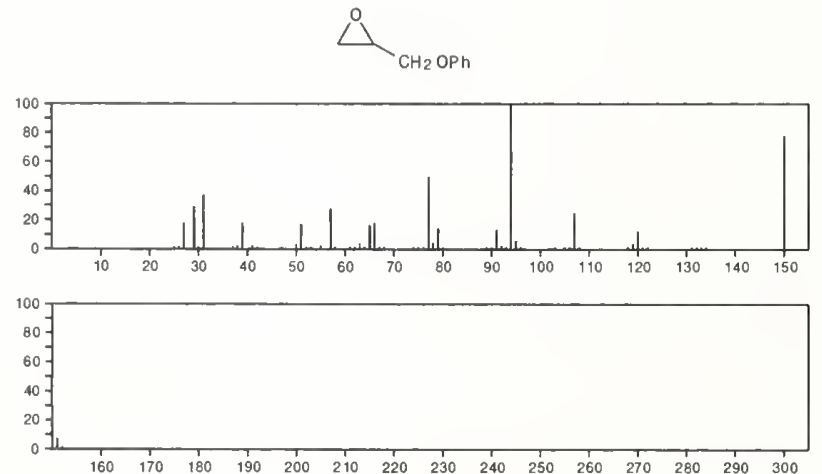
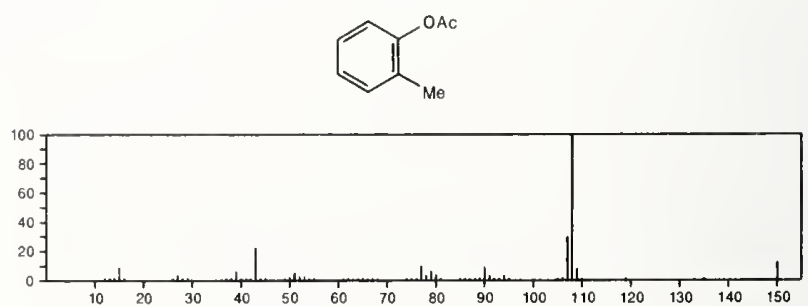
150

Benzoic acid, 2,3-dimethyl-
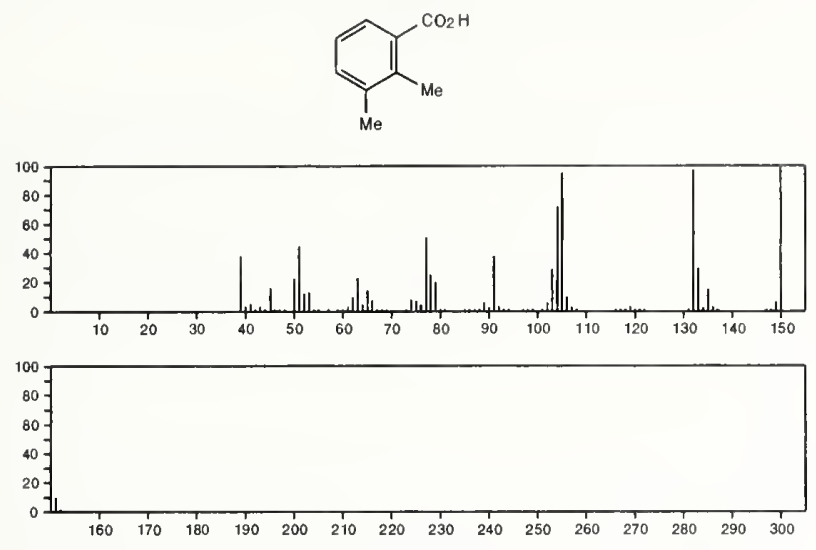

150

Benzoic acid, 2,5-dimethyl-

$\mathrm{C}_{9} \mathrm{H}_{10} \mathrm{O}_{2}$

610-72-0
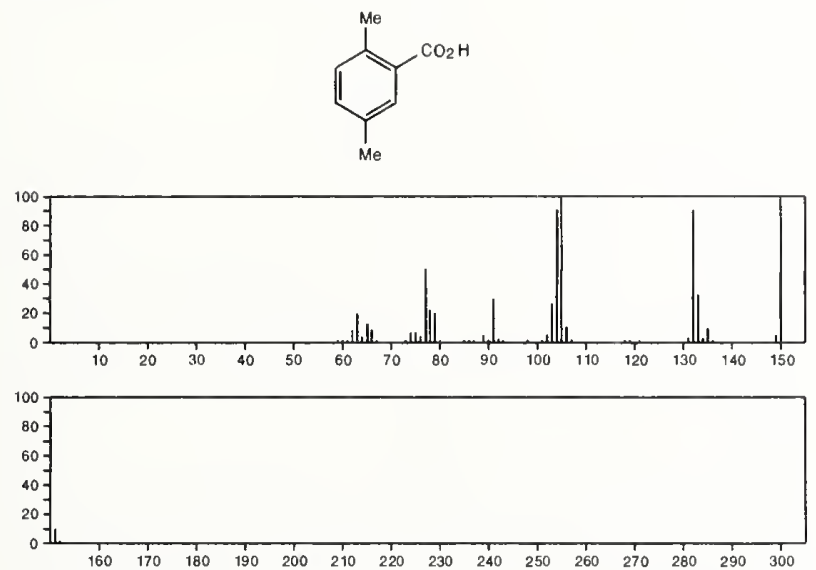

\section{0}

Benzoic acid, 2,4-dimethyl-

$\mathrm{C}_{9} \mathrm{H}_{10} \mathrm{O}_{2}$

$611-01-8$<smiles>Cc1ccc(C(=O)O)c(C)c1</smiles>
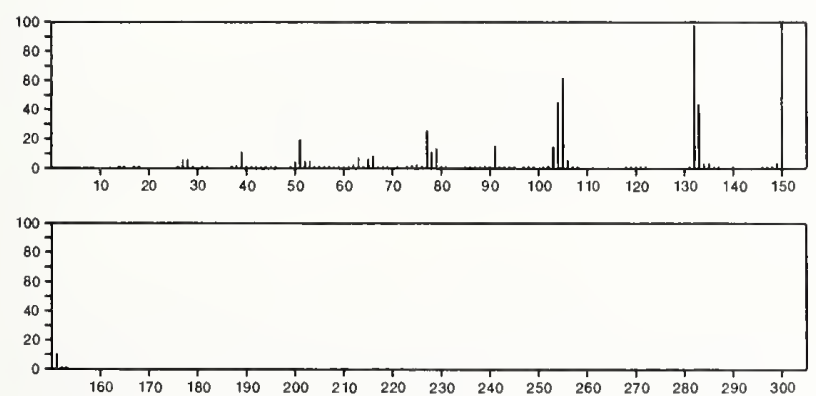

150

150

Benzoic acid, 3,4-dimethyl-

\section{$\mathrm{C}_{9} \mathrm{H}_{10} \mathrm{O}_{2}$}
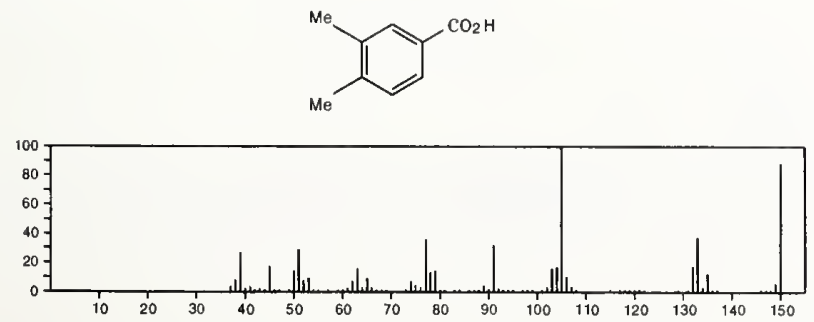

619-04-5
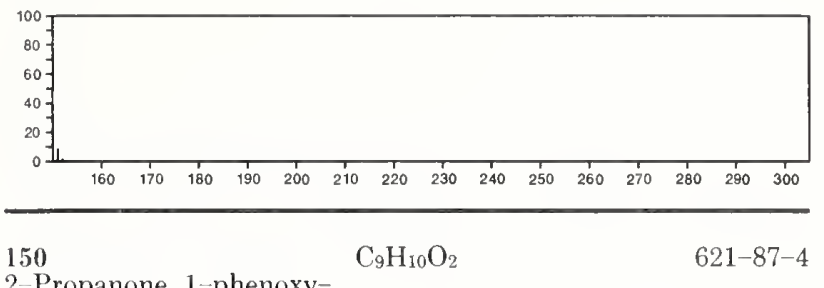

2-Propanone, 1-phenoxy-

$\mathrm{PhOCH}_{2} \mathrm{COMe}_{\mathrm{O}}$
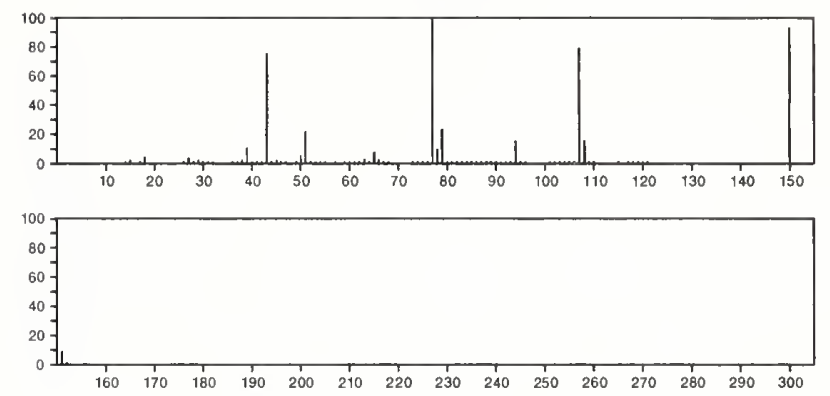

150

Benzoic acid, 2,6-dimethyl-

$\mathrm{C}_{9} \mathrm{H}_{10} \mathrm{O}_{2}$

632-46-2
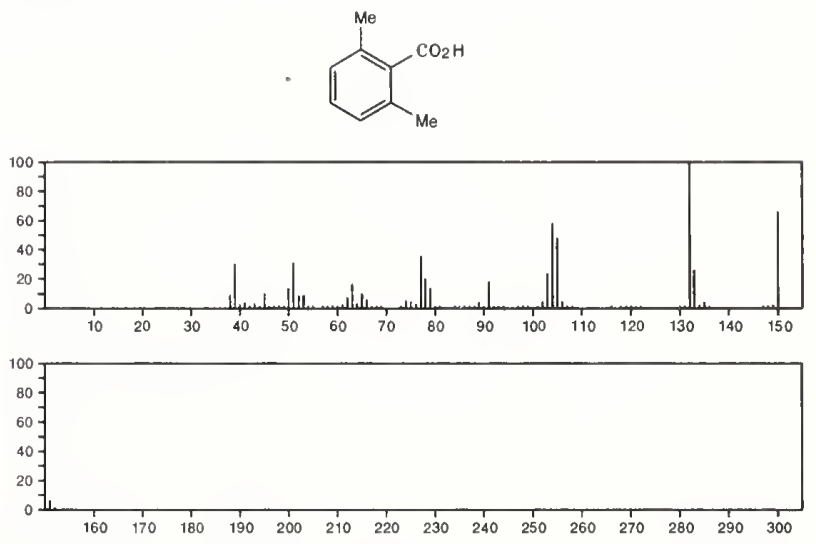

150

Propanoic acid, phenyl ester

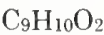

$637-27-4$

EtC(O) OPh
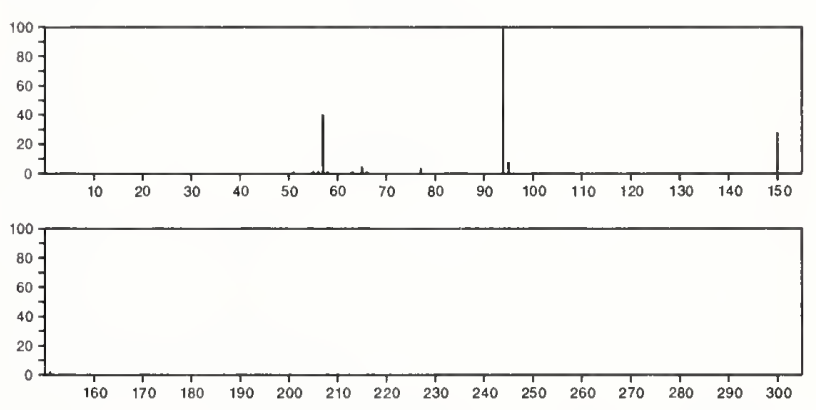

150

1,3-Dioxolane, 2-phenyl-

$\mathrm{C}_{9} \mathrm{H}_{10} \mathrm{O}_{2}$

936-51-6
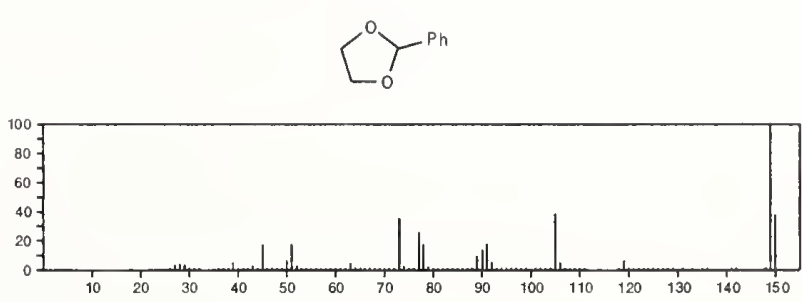


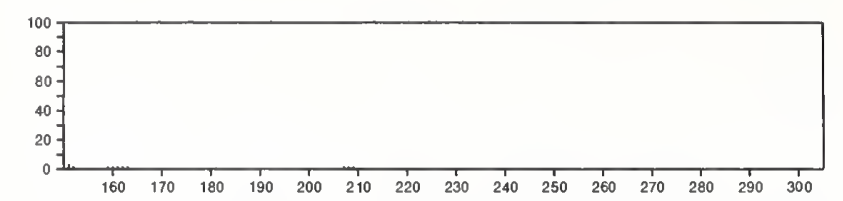

$150 \quad \mathrm{C}_{9} \mathrm{H}_{10} \mathrm{O}_{2}$

Phenol, 4-(3-hydroxy-1-propenyl)-
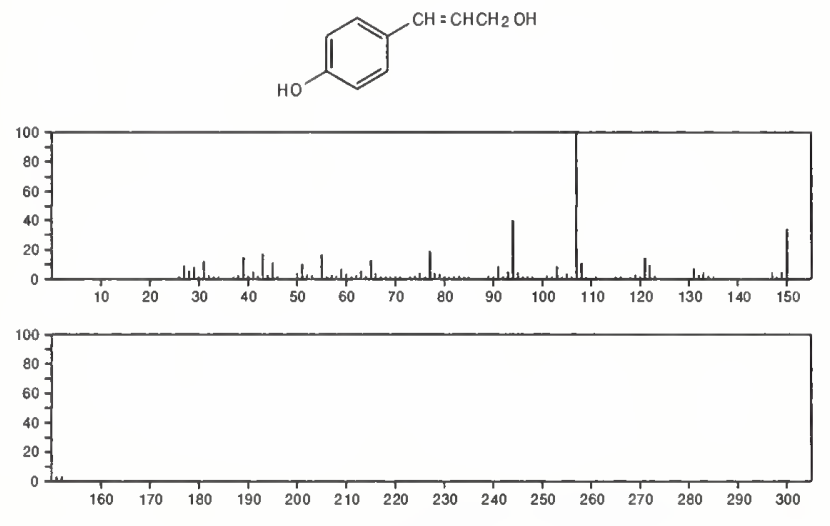

150

$1 H_{-}$-Indene-1,2-diol, 2,3-dihydro-, cis-

$4647-42-1$
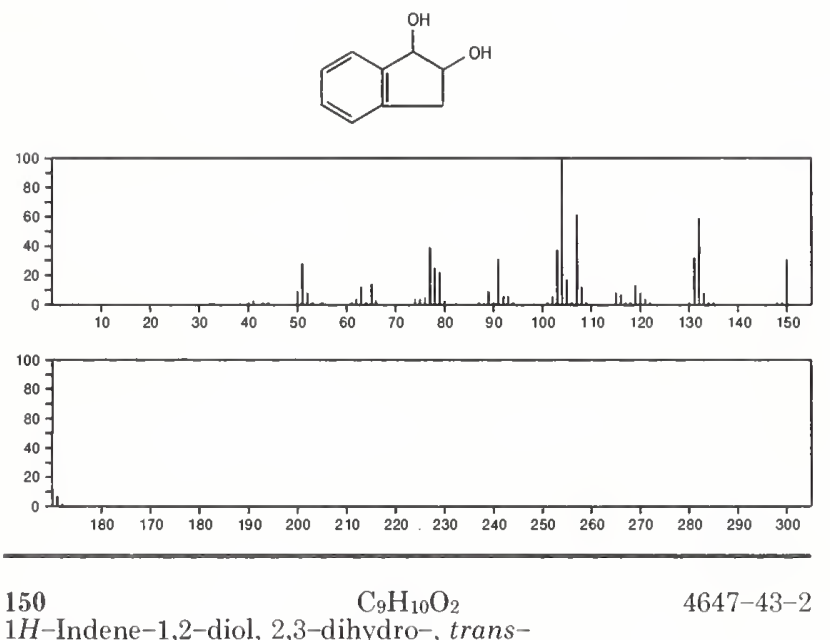

1H-Indene-1,2-diol, 2,3-dihydro-, trans-
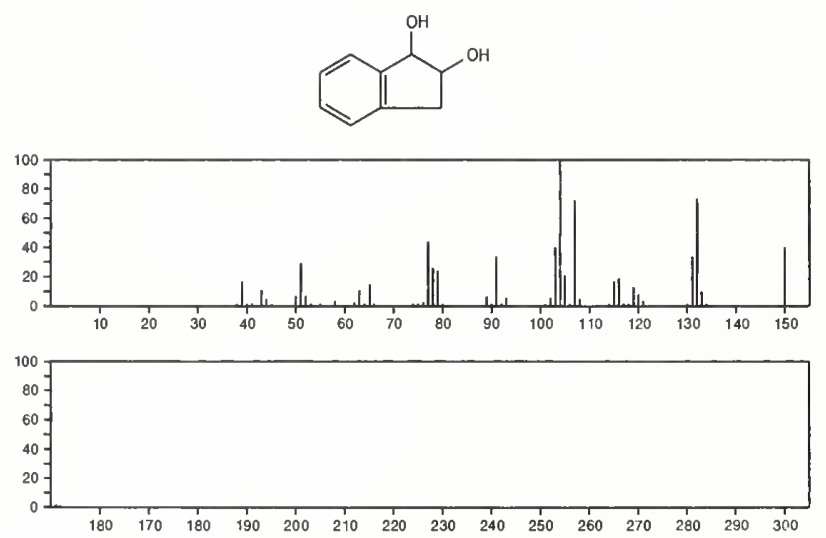

150

$\mathrm{C}_{9} \mathrm{H}_{10} \mathrm{O}_{2}$

$2 H$-1,5-Benzodioxepin, 3,4-dihydro-

7216-18-4
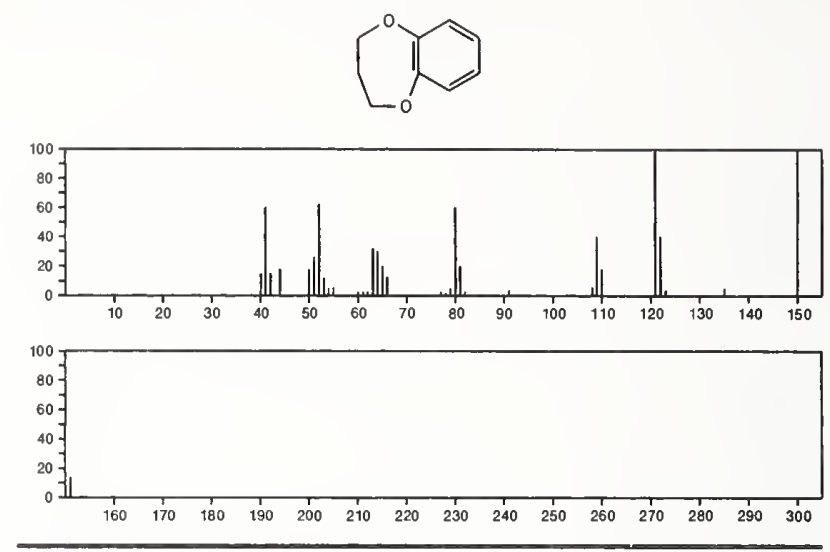

150

Benzoic acid, ethyl-

$\mathrm{C}_{9} \mathrm{H}_{10} \mathrm{O}_{2}$

$28134-31-8$
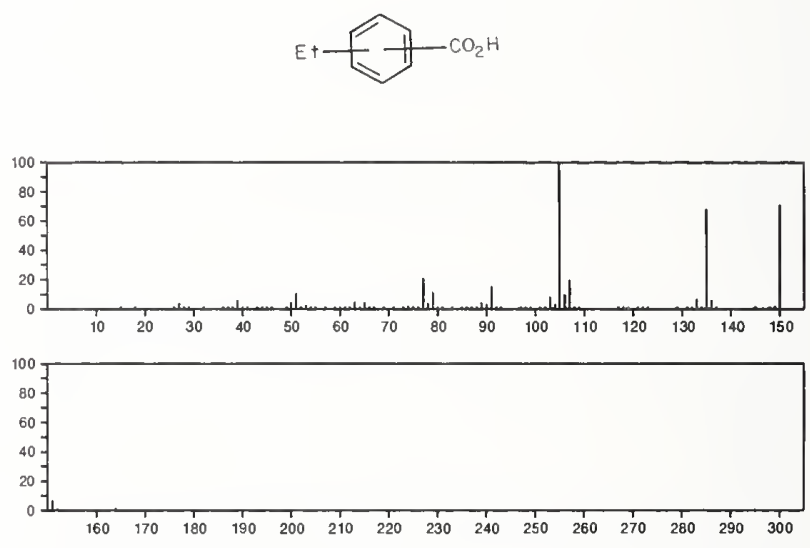

150

2-Furanacetaldehyde, $\alpha$-isopropylidene-

$31681-28-4$

\section{$\mathrm{C}_{9} \mathrm{H}_{10} \mathrm{O}_{2}$}

O $\mathrm{C}(\mathrm{CHO})=\mathrm{CMe}_{2}$
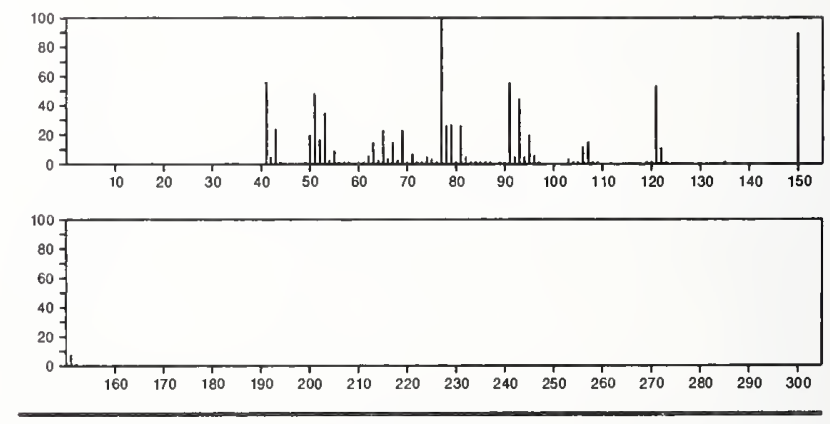

150

$\mathrm{C}_{9} \mathrm{H}_{10} \mathrm{O}_{2}$

31776-28-0

2-Furanacetaldehyde, $\alpha$-methyl- $\alpha$-vinyl-

$$
\text { OMe ( } \mathrm{CHO}) \mathrm{CH}=\mathrm{CH}_{2}
$$

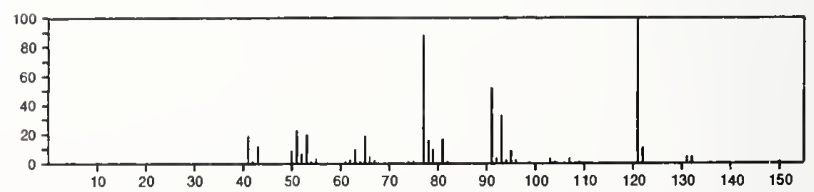


150 3-Penten-2-one, 3-(2-furanyl)-

$\mathrm{C}_{9} \mathrm{H}_{10} \mathrm{O}_{2}$
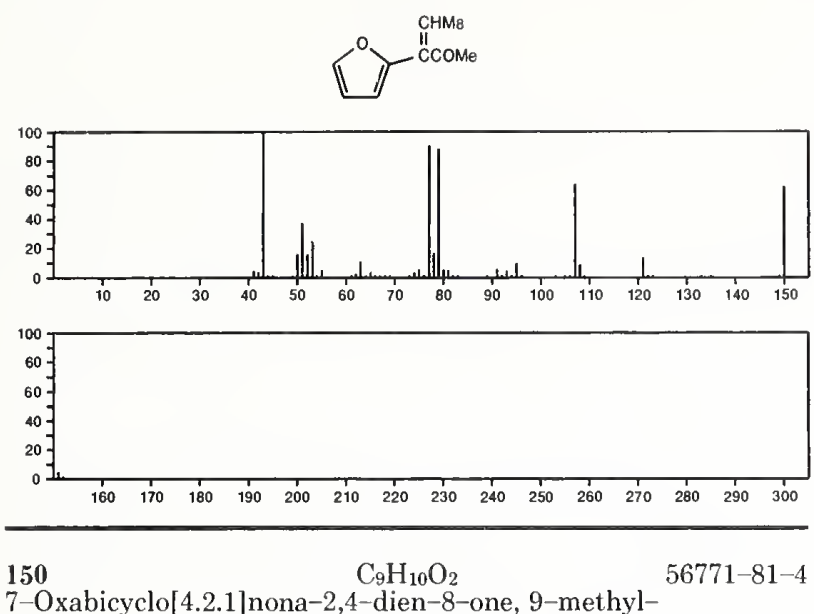

7-Oxabicyclo[4.2.1]nona-2,4-dien-8-one, 9-methyl-
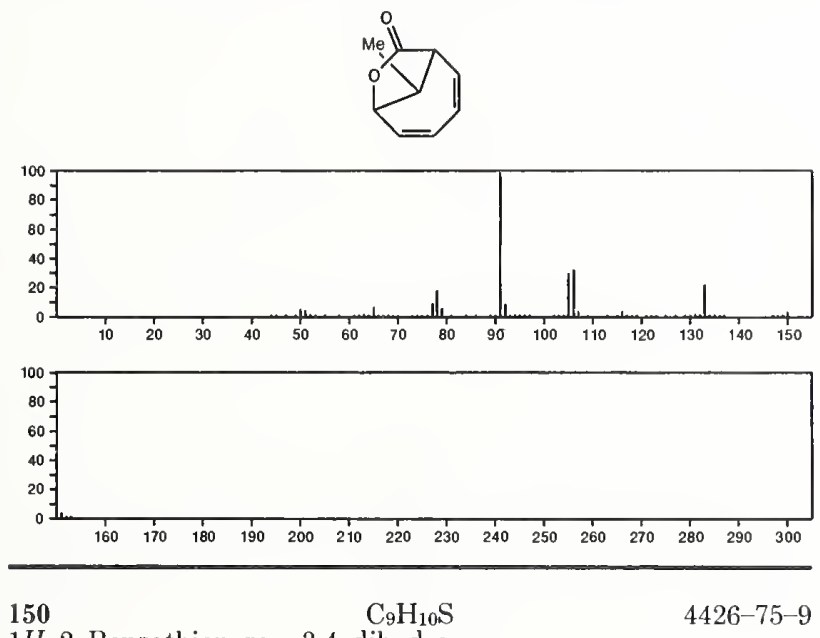

1H-2-Benzothiopyran, 3,4-dihydro-
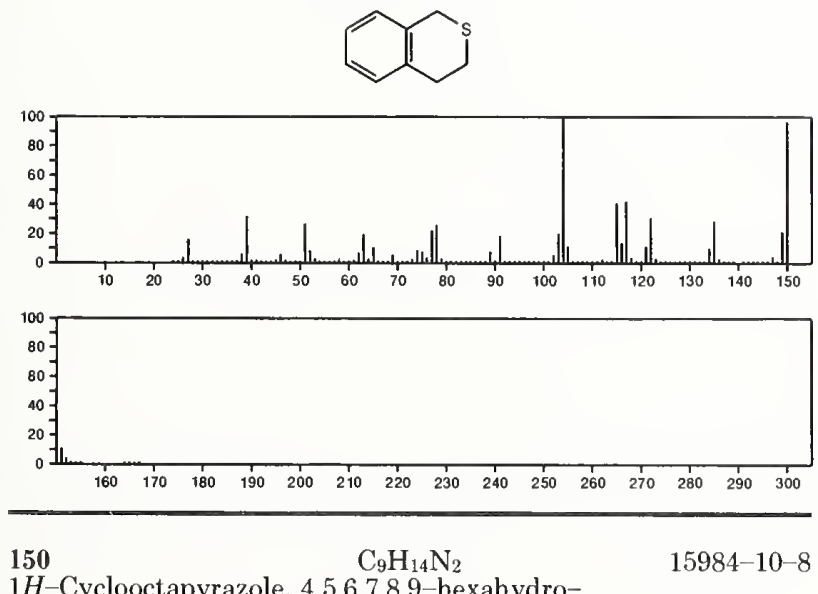

$1 H$-Cyclooctapyrazole, 4,5,6,7,8,9-hexahydro-
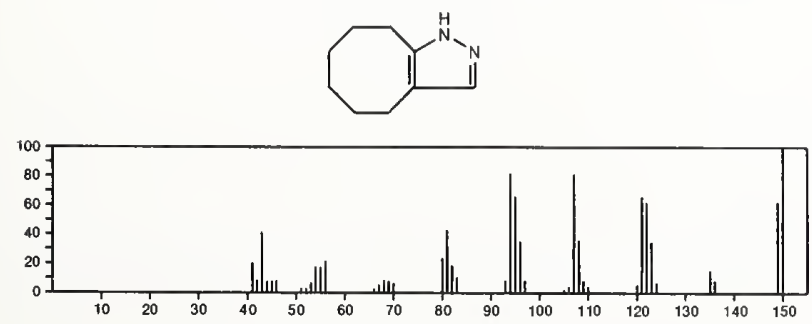

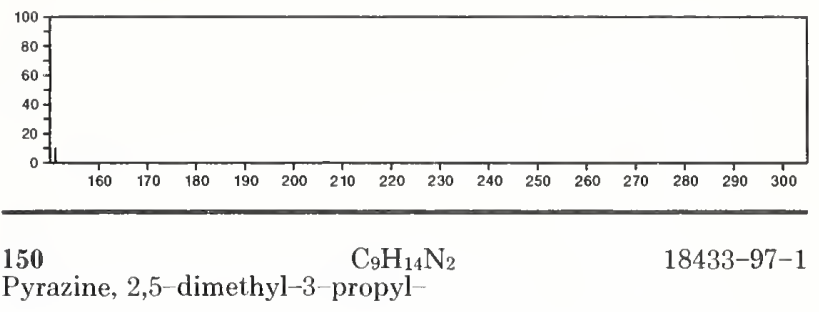<smiles>CCCc1nc(C)cnc1C</smiles>
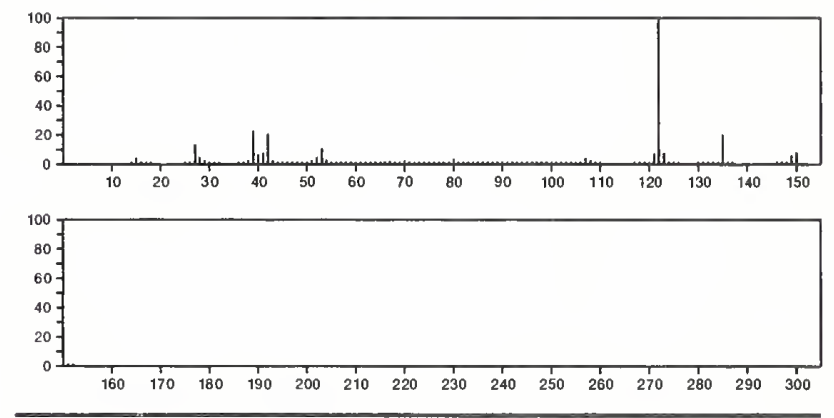

150

Piperidine, 2-(1H-pyrrol-2-yl)-

$54966-12-0$
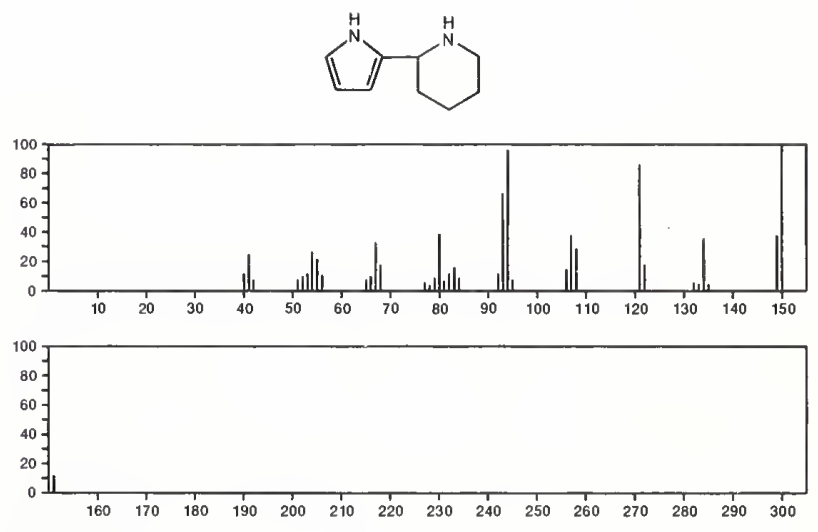

150

Silane, trimethylphenyl-

$\mathrm{C}_{9} \mathrm{H}_{14} \mathrm{Si}$

$768-32-1$

M83 Siph
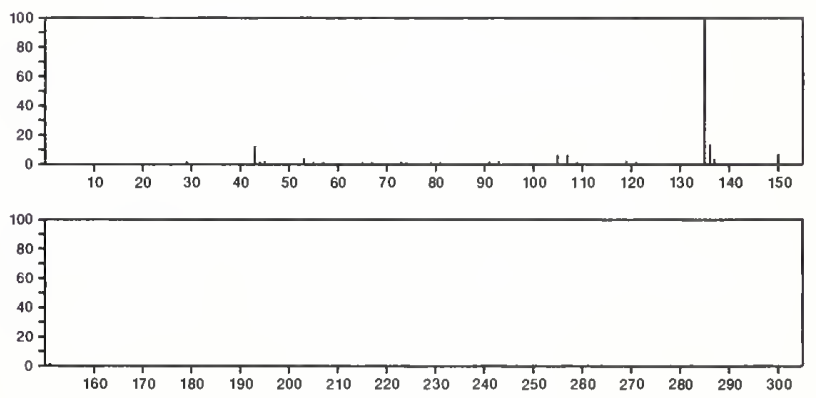
150

$\mathrm{C}_{10} \mathrm{H}_{11} \mathrm{~F}$

Naphthalene, 5-fluoro-1,2,3,4-tetrahydro-

$700-45-8$
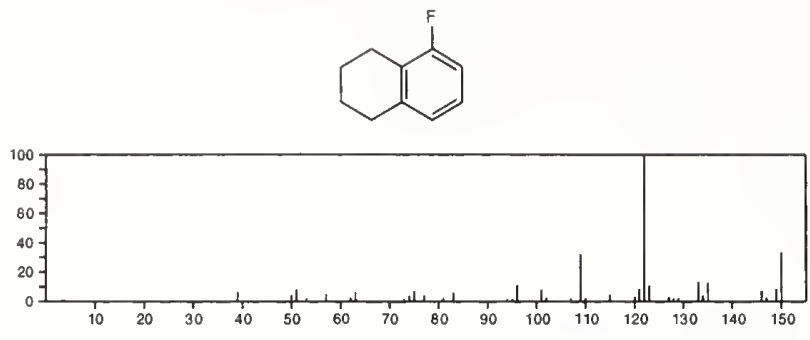

$\mathrm{C}_{10} \mathrm{H}_{11} \mathrm{~F}$
Naphthalene, 6-fluoro-1,2,3,4-tetrahydro-
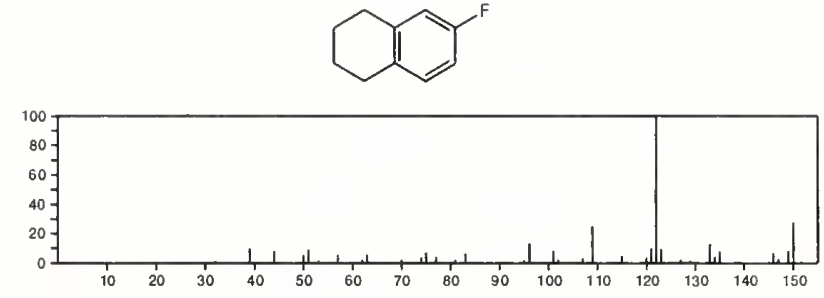

150

Phenol, 2-(1,1-dimethylethyl)

$\mathrm{C}_{10} \mathrm{H}_{14} \mathrm{O}$

88-18-6
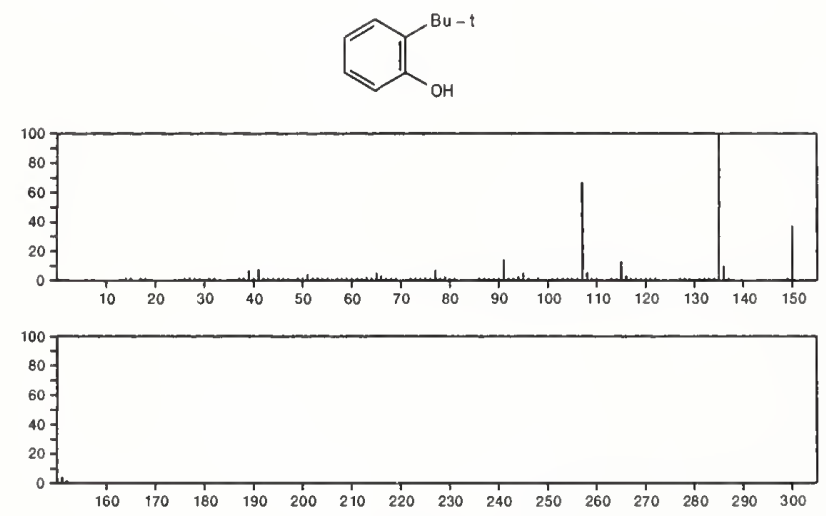

150

$$
\mathrm{C}_{10} \mathrm{H}_{14} \mathrm{O}
$$

$89-72-5$

Phenol, 2-(1-methylpropyl)-
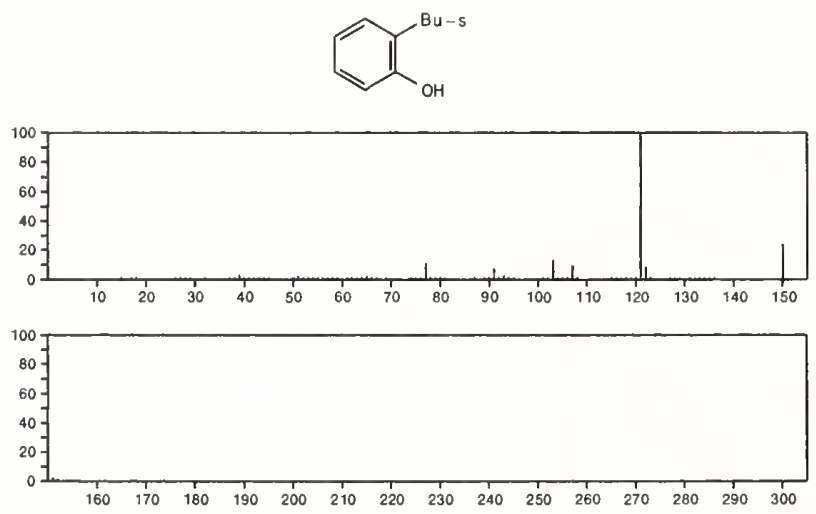

$150 \quad \mathrm{C}_{10} \mathrm{H}_{14} \mathrm{O}$

Phenol, 5-methyl--2-(1-methylethyl)-

89-83-8
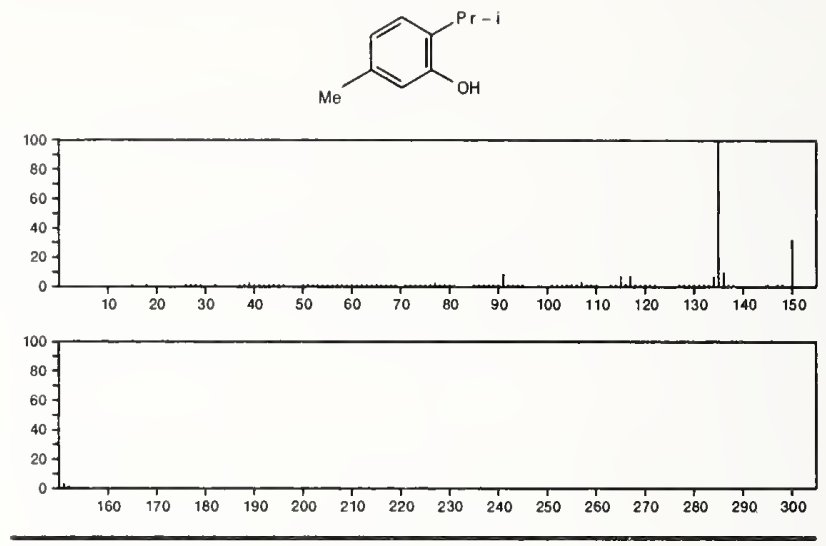

150

Phenol, 4-(1,1-dimethylethyl)

$\mathrm{C}_{10} \mathrm{H}_{14} \mathrm{O}$

98-54-4
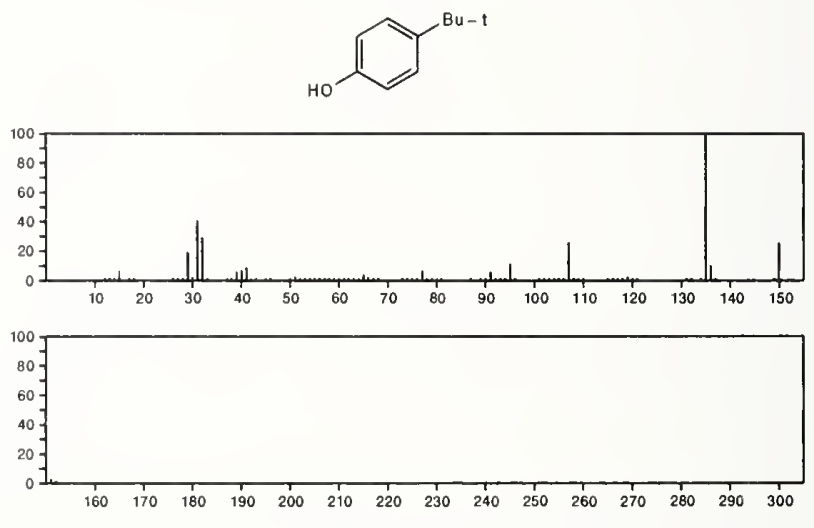

150

$\mathrm{C}_{10} \mathrm{H}_{14} \mathrm{O}$

$99-49-0$

2-Cyclohexen-1-one, 2-methyl-5-(1-methylethenyl)-
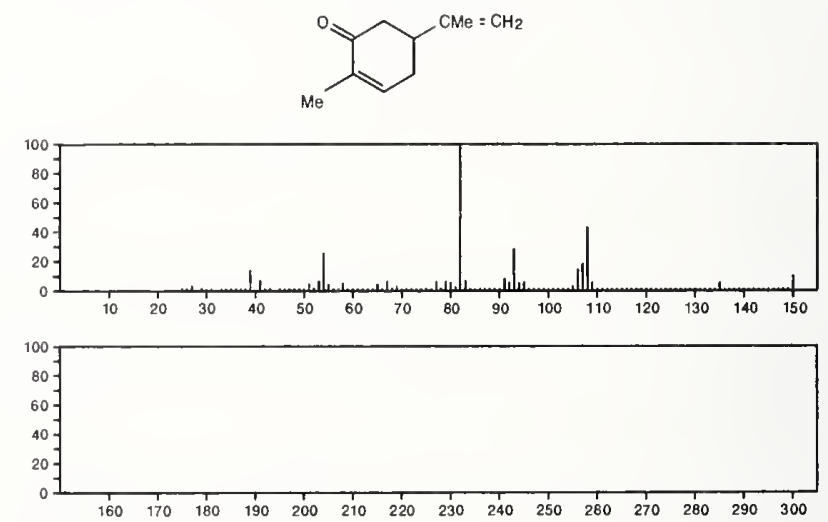

150

Phenol, 4-(1-methylpropyl)-

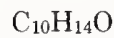

$99-71-8$
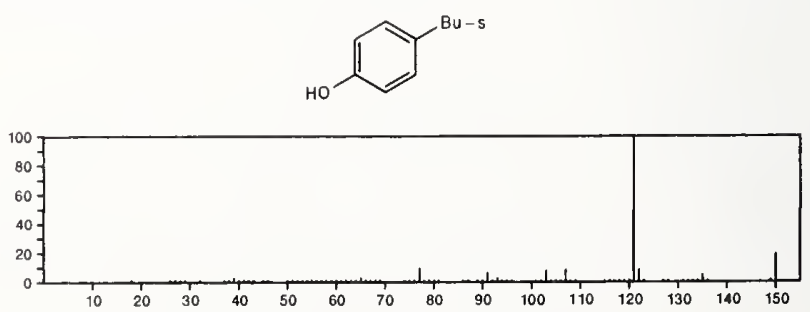


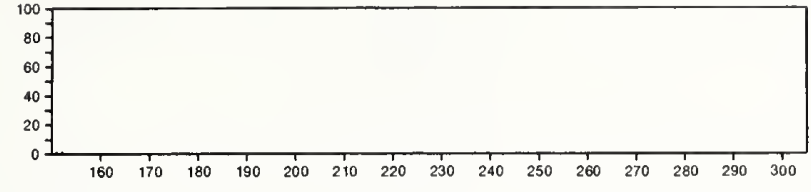

150

$\mathrm{C}_{10} \mathrm{H}_{14} \mathrm{O}$

$100-86-7$

Benzeneethanol, $\alpha, \alpha$-dimethyl

$\mathrm{Me}_{2} \mathrm{COHCH}_{2} \mathrm{Ph}$

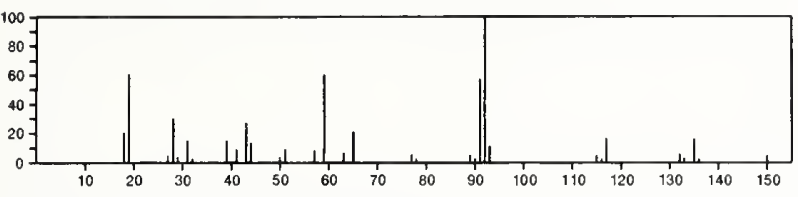

150

$\mathrm{C}_{10} \mathrm{H}_{14} \mathrm{O}$

$104-45-0$

Benzene, 1-methoxy-4-propyl-
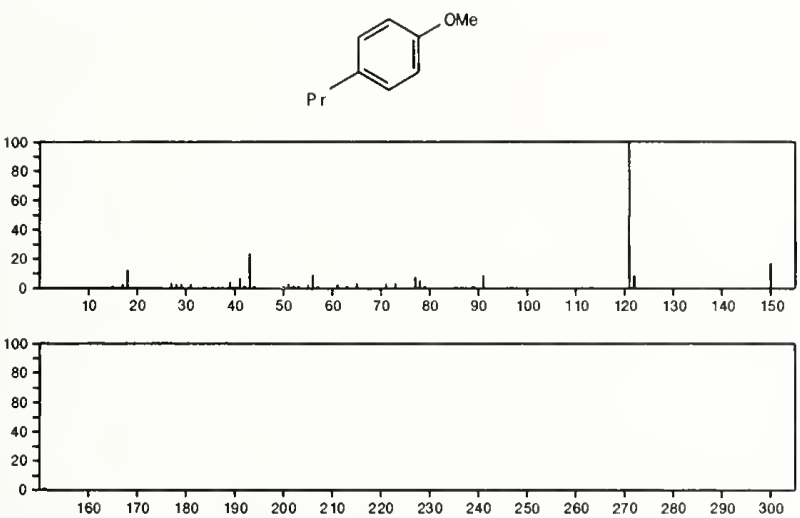

$\begin{array}{lllllllllllllll}160 & 170 & 180 & 190 & 1 & 1 & 1 & 1 & 1 & 1 & 1 & 1 & 1 & 1 & 1 \\ 1\end{array}$

150

$\mathrm{C}_{10} \mathrm{H}_{14} \mathrm{O}$

$491-09-8$

2-Cyclohexen-1-one, 3-methyl-6-(1-methylethylidene)-
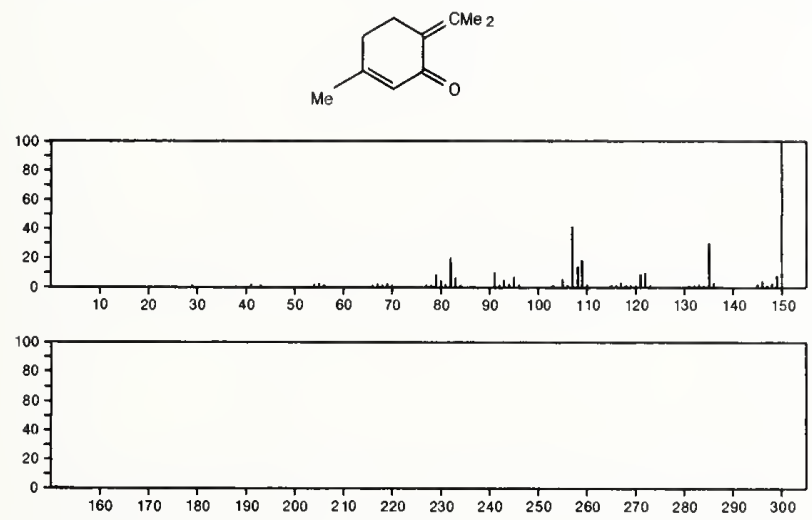

150

$\mathrm{C}_{10} \mathrm{H}_{14} \mathrm{O}$

Benzofuran, 4,5,6,7-tetrahydro-3,6-dimethyl-

494-90-6
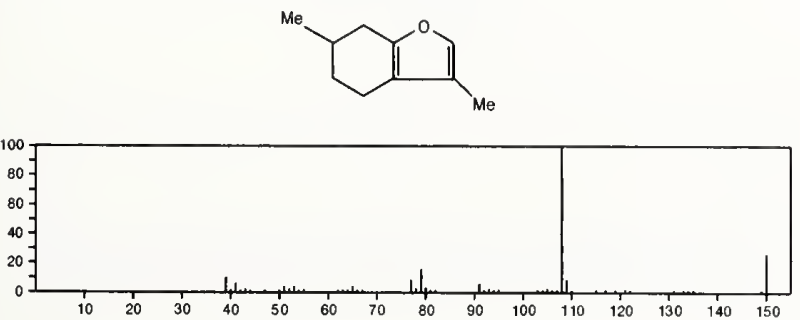

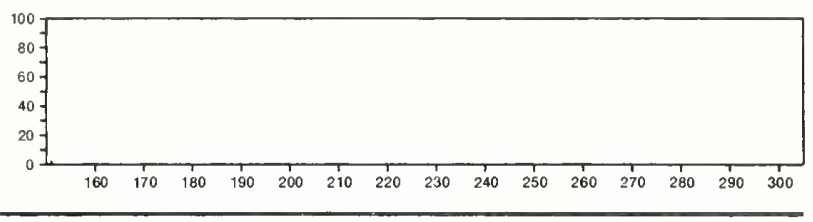

150

$\mathrm{C}_{10} \mathrm{H}_{14} \mathrm{O}$

$499-75-2$

Phenol, 2-methyl-5-(1-methylethyl)-
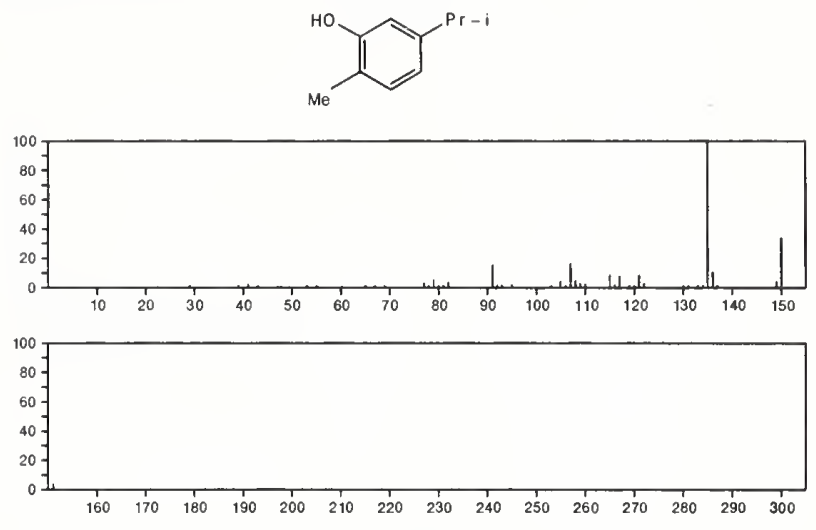

150

$\mathrm{C}_{10} \mathrm{H}_{14} \mathrm{O}$

$539-52-6$

Furan, 3-(4-methyl-3-pentenyl)-

$\mathrm{CH}_{2} \mathrm{CH}_{2} \mathrm{CH}=\mathrm{CMe}_{2}$

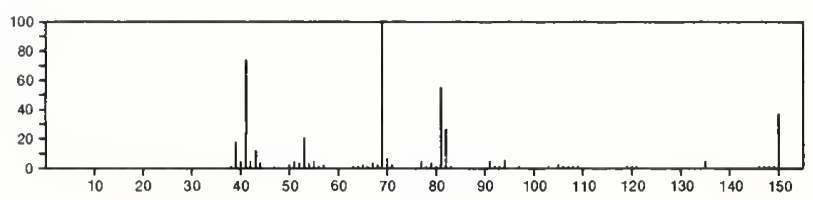

Phenol, 3-(1,1-dimethylethyl)

$\mathrm{C}_{10} \mathrm{H}_{14} \mathrm{O}$

$585-34-2$
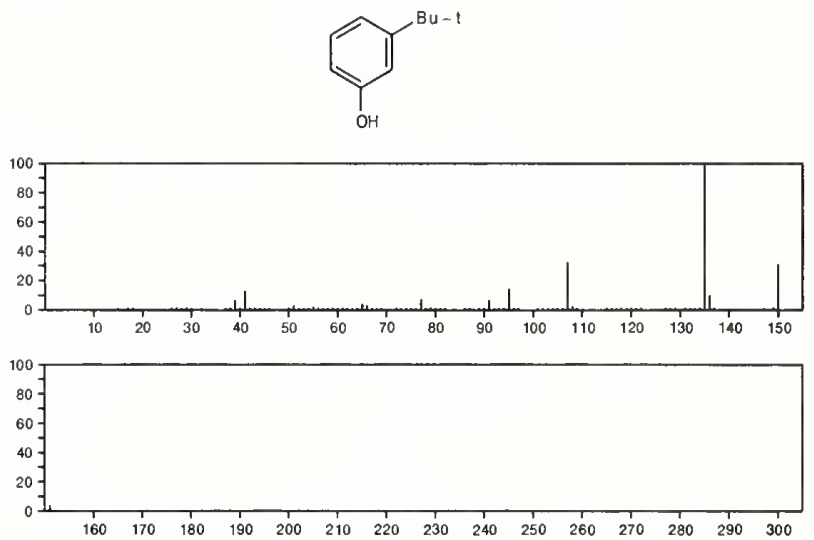

150

$\mathrm{Ci}_{0} \mathrm{H}_{14} \mathrm{O}$

$700-58-3$

Tricyclo[3.3.1.13,7]decanone
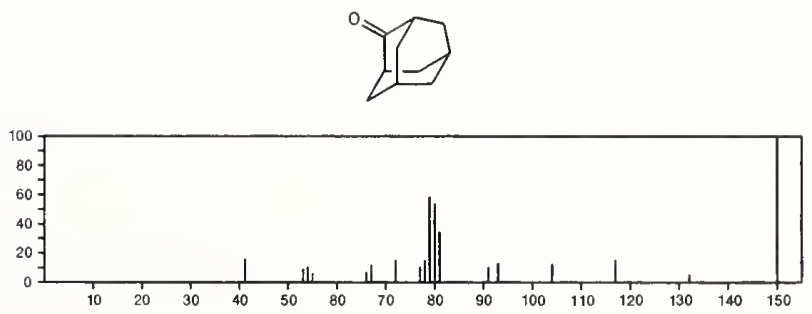


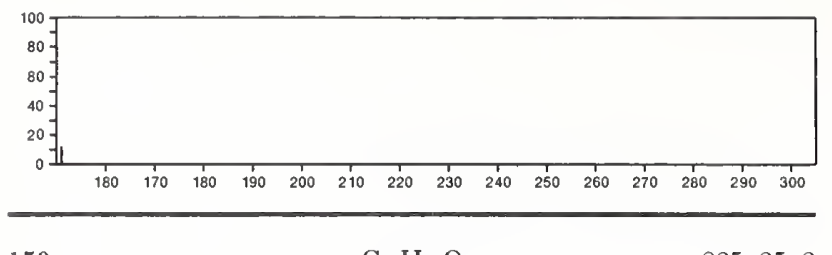

$150 \quad \mathrm{C}_{10} \mathrm{H}_{14} \mathrm{O} \quad 825-25-2$ Cyclopentanone, 2-cyclopentylidene-
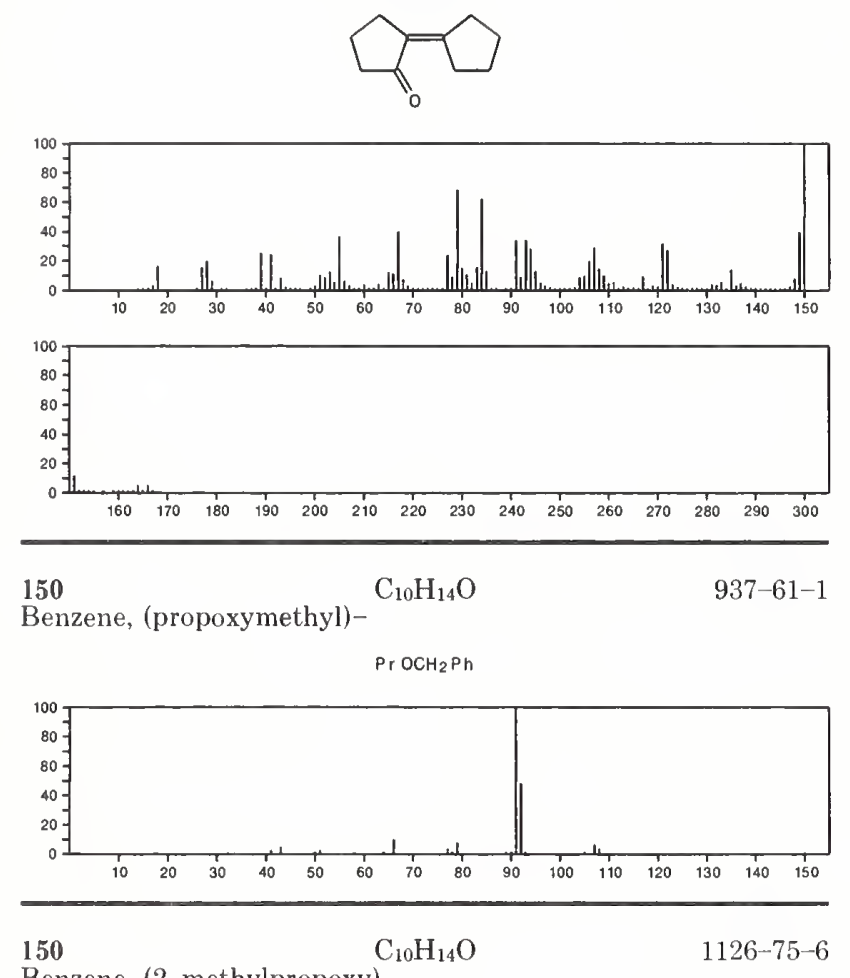

Benzene, (2-methylpropoxy)-

PhOBu-i
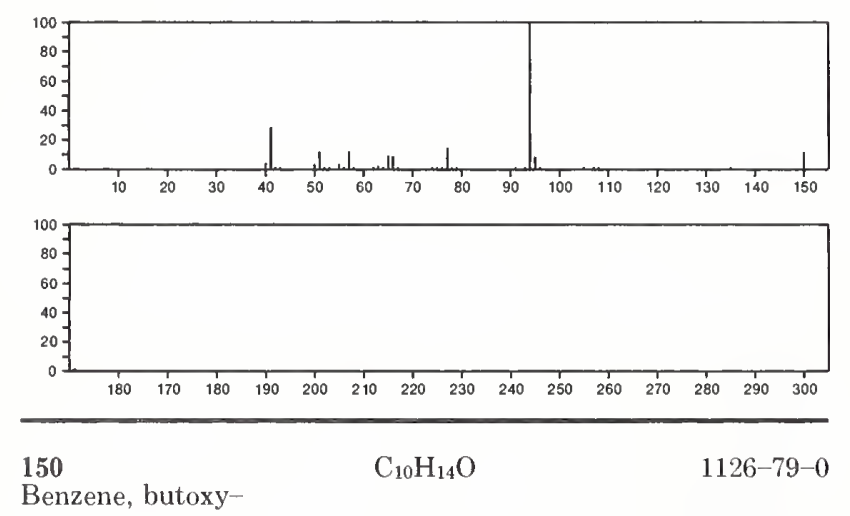

Benzene, butoxy-

$\mathrm{Me}\left(\mathrm{CH}_{2}\right)_{3} \mathrm{OPh}$
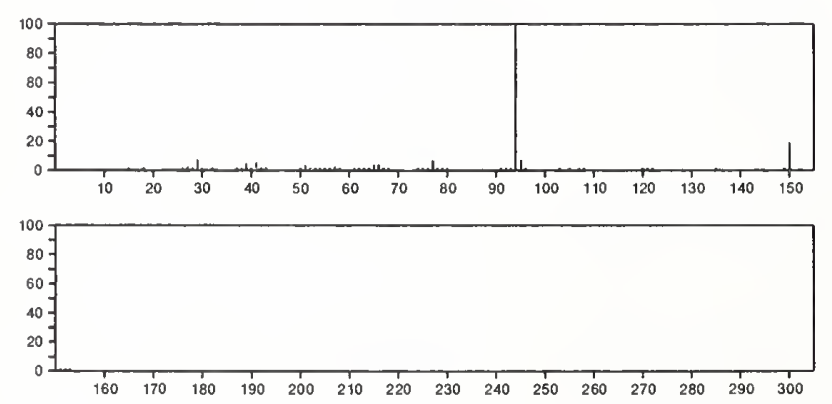

150

2(3H)-Naphthalenone, 4,4a,5,6,7,8-hexahydro-

$1196-55-0$
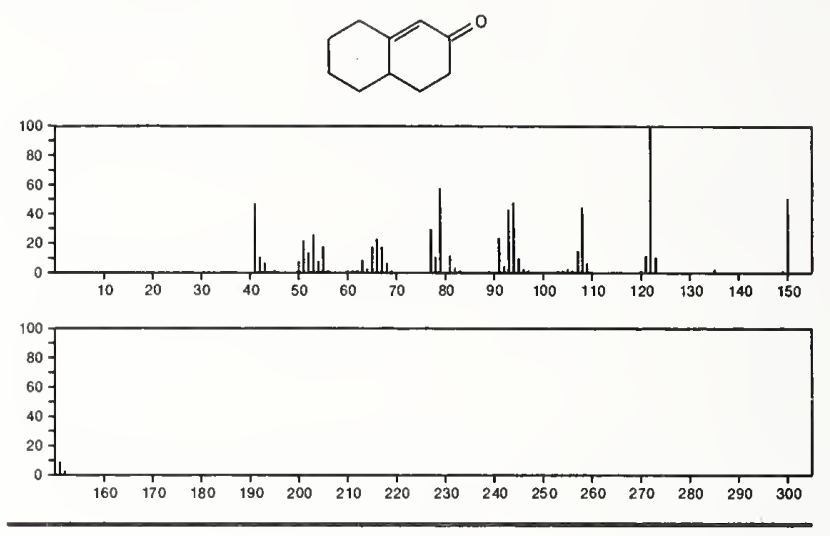

150

Benzenemethanol, $\alpha, \alpha, 4$-trimethyl-

$1197-01-9$<smiles>Cc1ccc(C(=O)O)cc1</smiles>
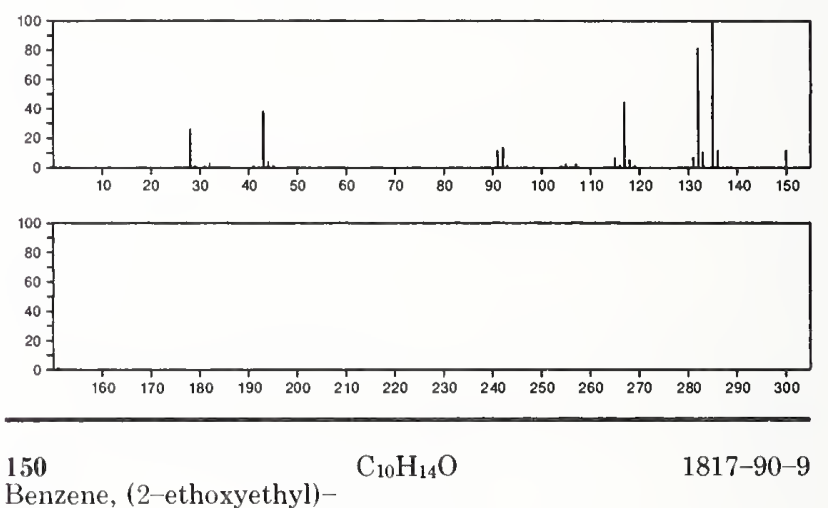

Benzene, (2-ethoxyethyl)-

$\mathrm{PhCH}_{2} \mathrm{CH}_{2} \mathrm{OE}$ t
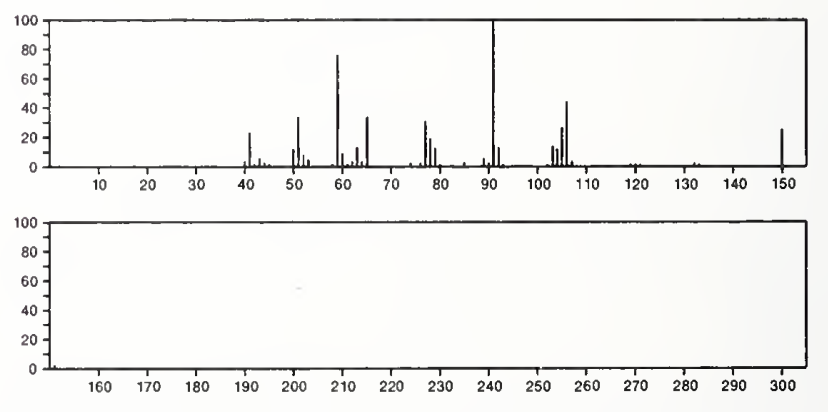

$150 \quad \mathrm{C}_{10} \mathrm{H}_{14} \mathrm{O}$ 2244-16-8

2-Cyclohexen-1-one, 2-methyl-5-(1-methylethenyl)-, $(S)-$
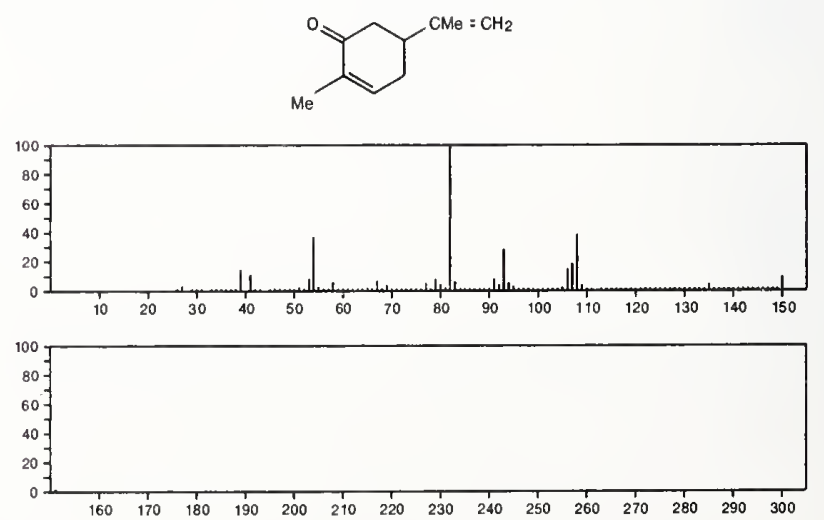
150

$\mathrm{C}_{10} \mathrm{H}_{14} \mathrm{O}$

3-Buten-2-one, 4-(3-cyclohexen-1-yl)
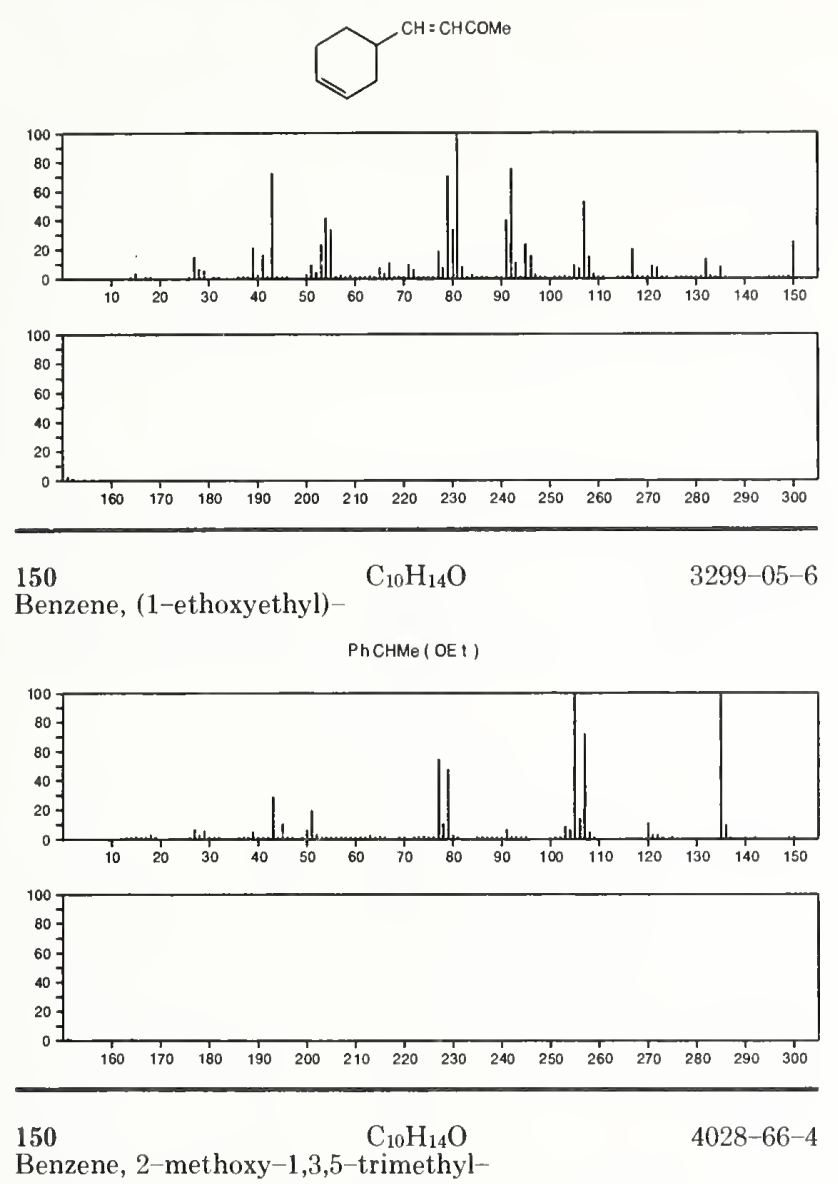

Benzene, 2-methoxy-1,3,5-trimethyl-
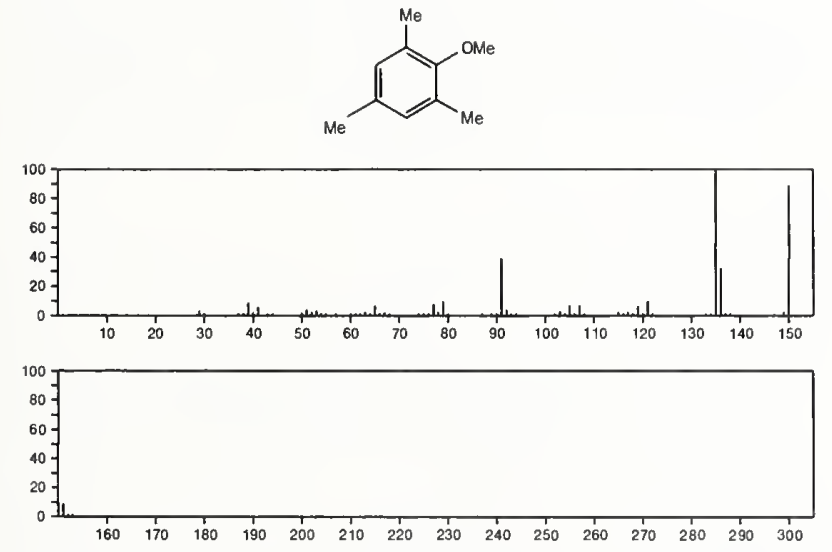

150

$\mathrm{C}_{10} \mathrm{H}_{14} \mathrm{O}$

Benzene, 1-methoxy-4-(1-methylethyl)-

$4132-48-3$
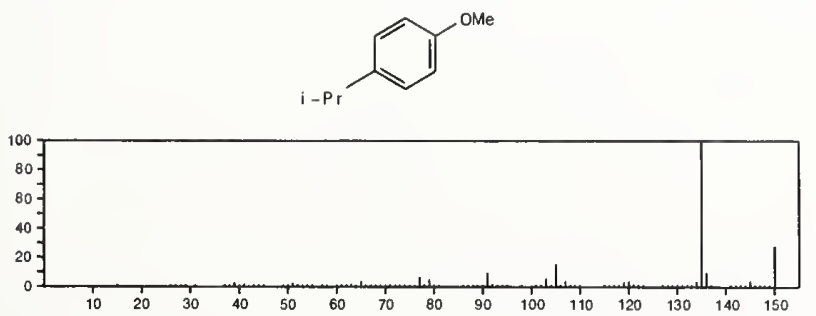

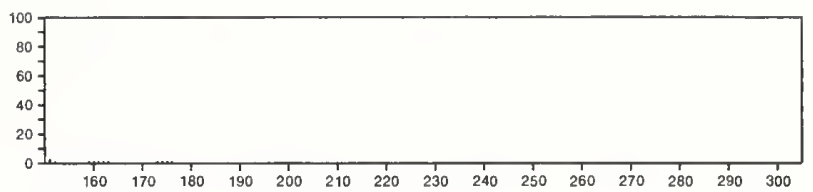

150

Benzeneethanol, $\beta, 4$-dimethyl-

$$
\mathrm{C}_{10} \mathrm{H}_{14} \mathrm{O}
$$

$4371-50-0$<smiles>Cc1ccc(CCO)cc1</smiles>
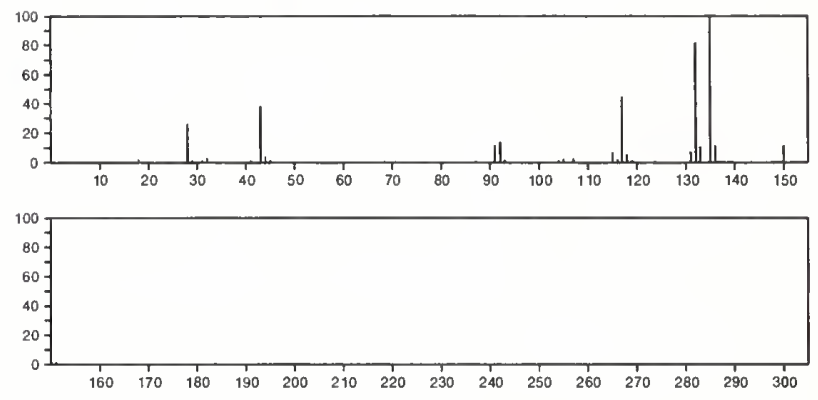

150

$\mathrm{C}_{10} \mathrm{H}_{14} \mathrm{O}$

Benzenemethanol, 2,4,5-trimethyl-

$4393-05-9$<smiles>Cc1cc(C)c(C)cc1C</smiles>
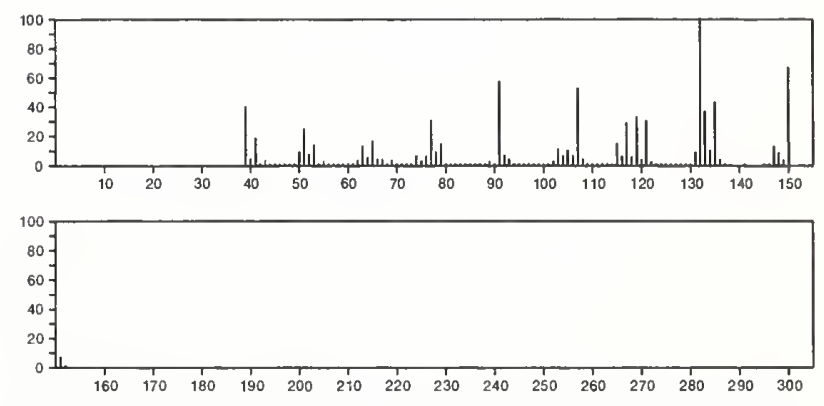

$150 \quad \mathrm{C}_{10} \mathrm{H}_{14} \mathrm{O} \quad 6485-40-1$

2-Cyclohexen-1-one, 2-methyl-5-(1-methylethenyl)-, $(R)$ -
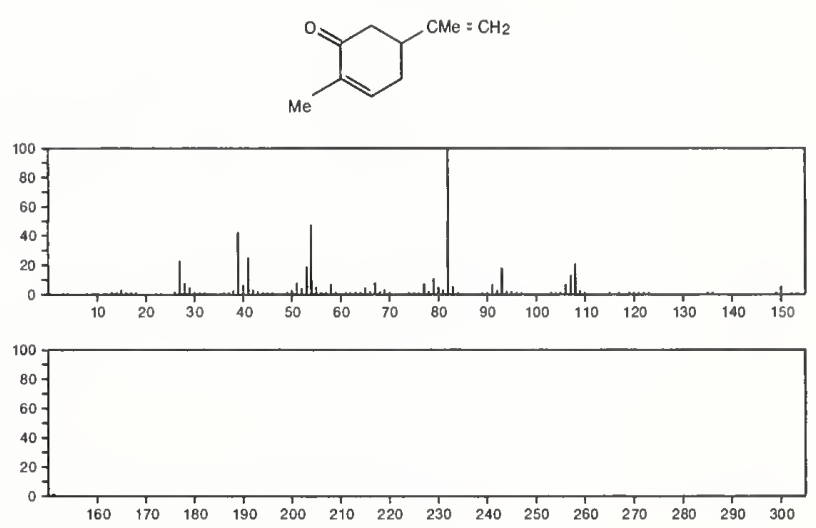
150
Benzene, (1,1-dimethylethoxy)-

$\mathrm{C}_{10} \mathrm{H}_{14} \mathrm{O}$

PhOBu- $t$

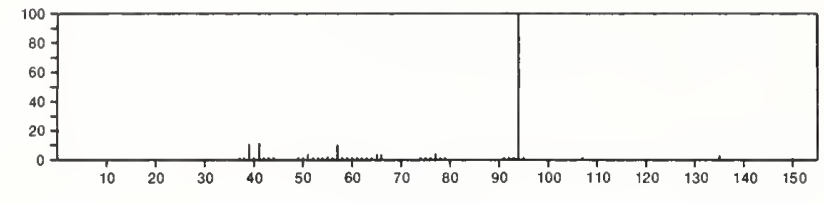

150

$\mathrm{C}_{10} \mathrm{H}_{14} \mathrm{O}$

2-Cyclopenten-1-one, 2-(2-butenyl)-3-methyl-, $(Z)$ -
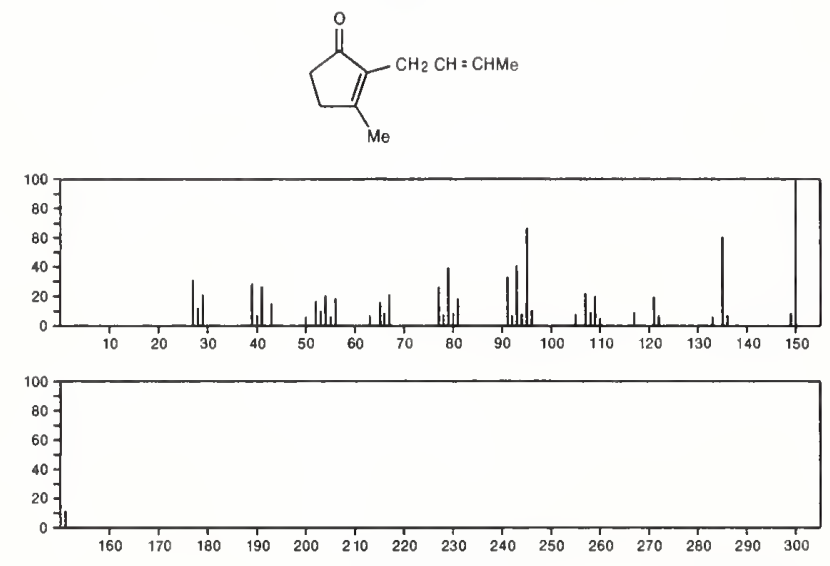

$150 \quad \mathrm{C}_{10} \mathrm{H}_{14} \mathrm{O} \quad 17428-89-6$

1-Indanone, 3a,4,7,7a-tetrahydro-7a-methyl-, cis-
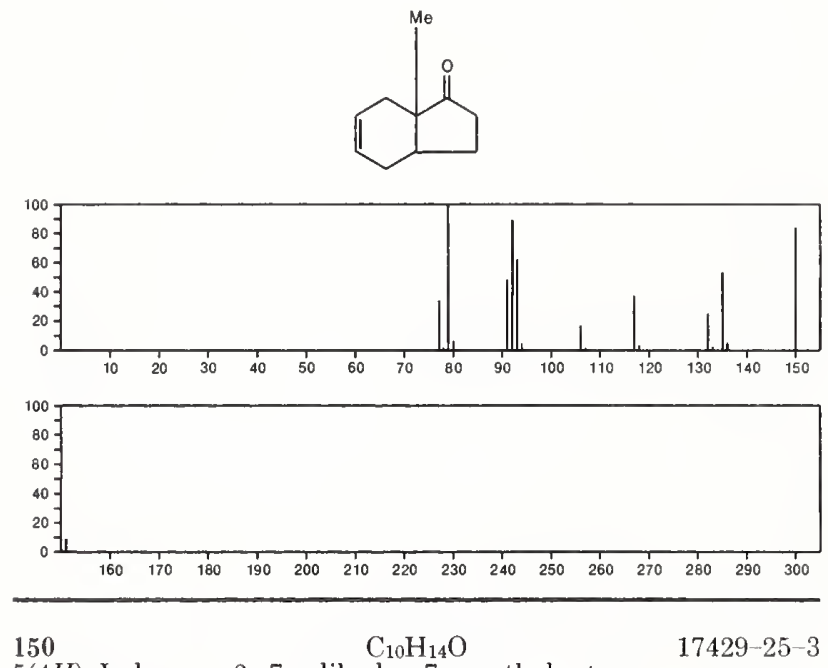

5(4H)-Indanone, 3a,7a-dihydro-7a-methyl-, trans-
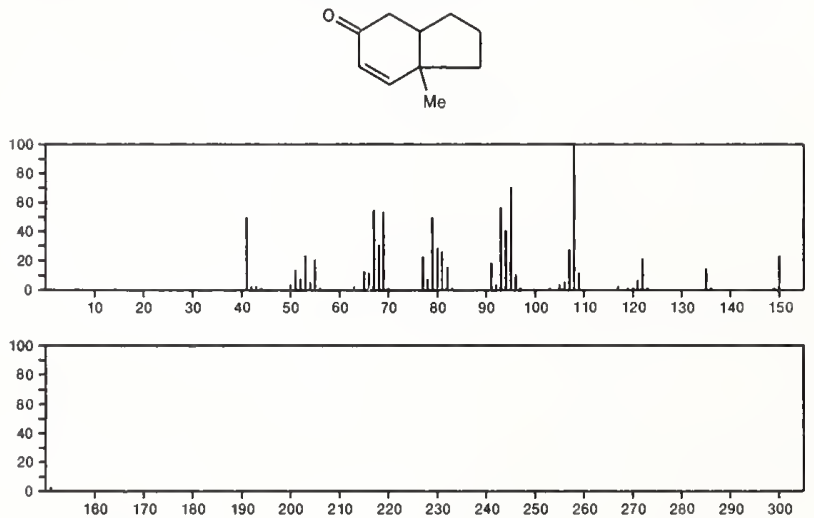

150

2,5-Cyclohexadien-1-one, 4-ethyl-3,4-dimethyl-

$17429-35-5$
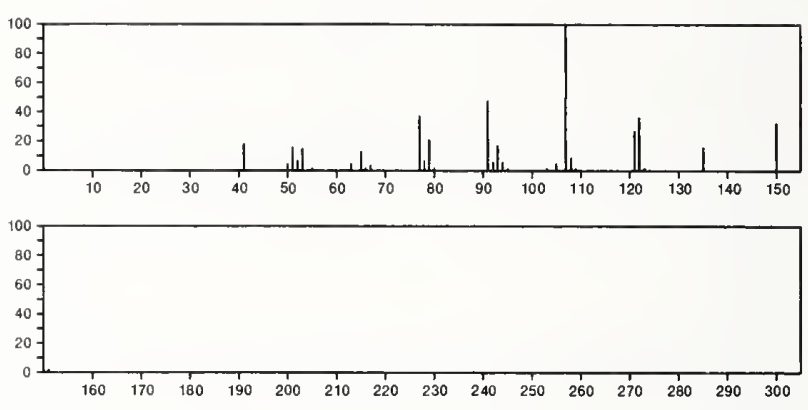

150

$\mathrm{C}_{10} \mathrm{H}_{14} \mathrm{O}$

$18031-40-8$

1-Cyclohexene-1-carboxaldehyde, 4-(1-methylethenyl)-, (S)-
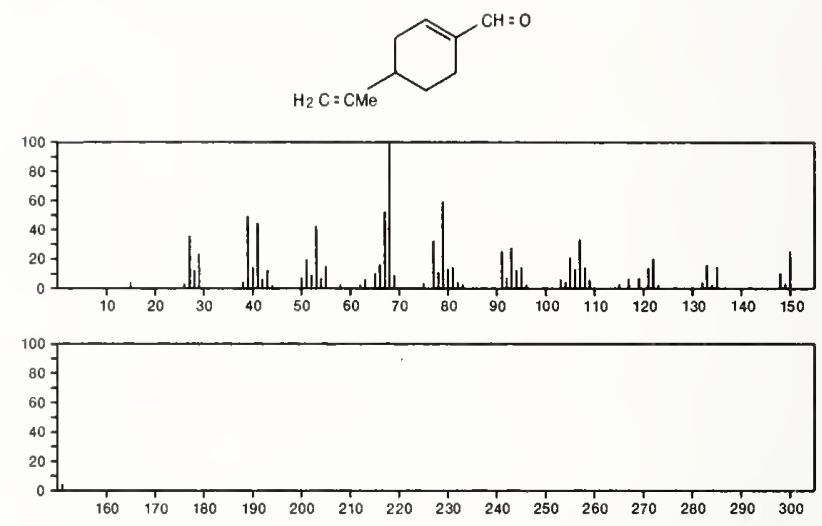

150

$\mathrm{C}_{10} \mathrm{H}_{14} \mathrm{O}$

18309-32-5

Bicyclo[3.1,1]hept-3-en-2-one, 4,6,6-trimethyl-, $(1 R$-cis)-
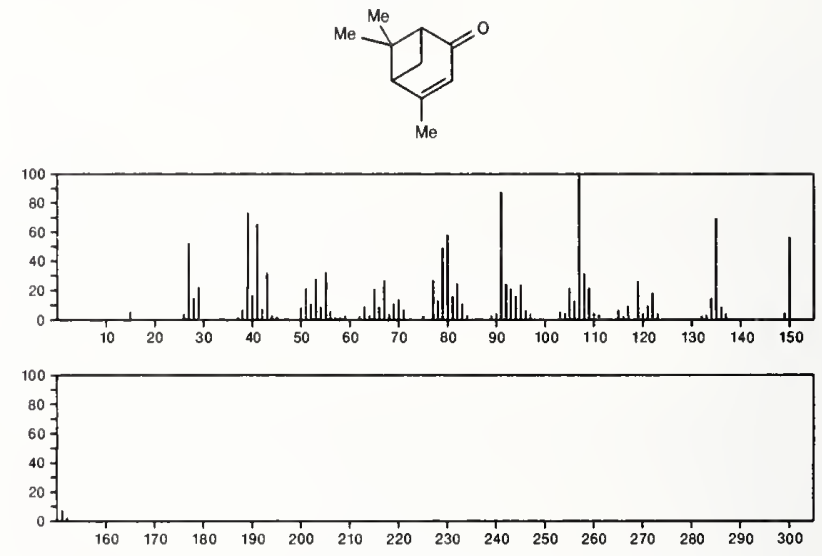

150

Anisole, 2,3,6-trimethyl-

$\mathrm{C}_{10} \mathrm{H}_{14} \mathrm{O}$

$21573-36-4$
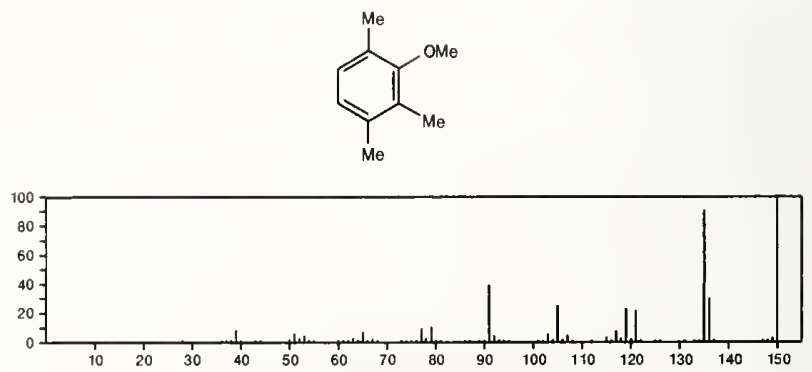

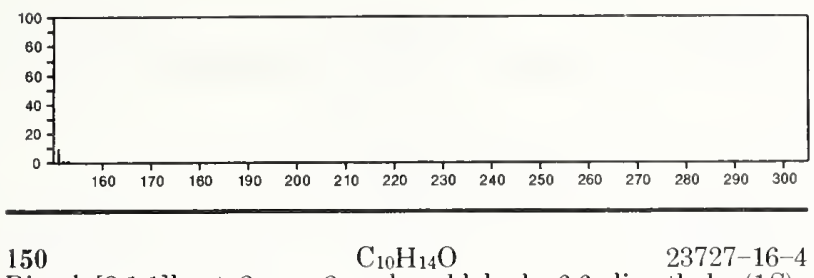

Bicyclo[3.1.1]hept-2-ene-2-carboxaldehyde, 6,6-dimethyl-, (1S)-
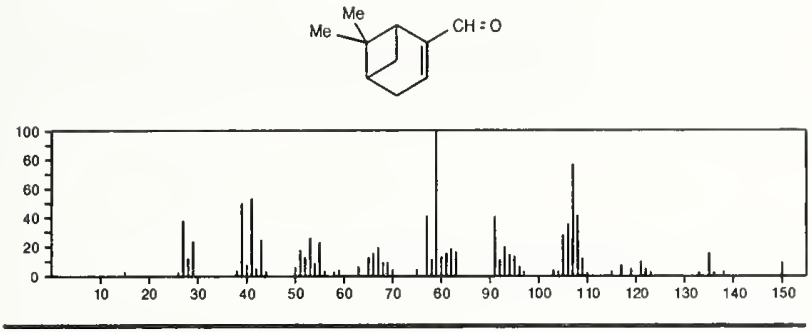

150

$\mathrm{C}_{10} \mathrm{H}_{14} \mathrm{O}$

$24545-81-1$

Bicyclo[3.1.0]hex-3-en-2-one, 4-methyl-1-(1-methylethyl)
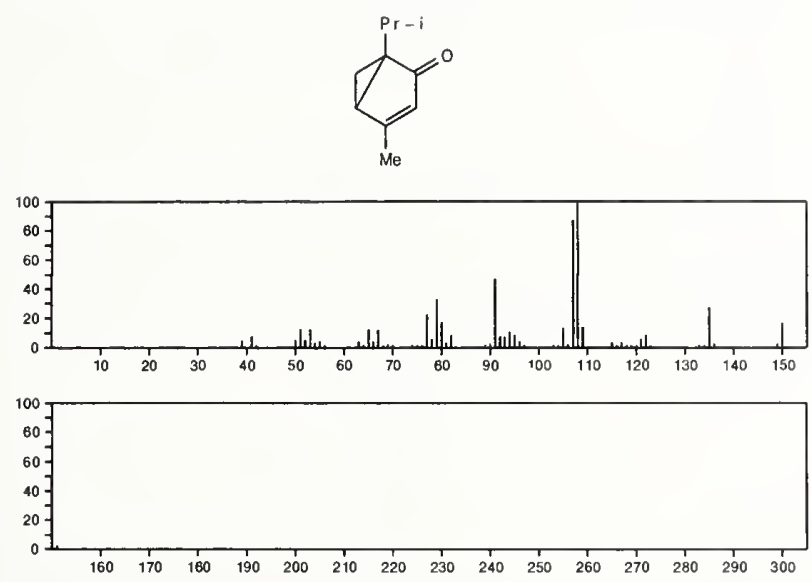

150

Phenol, diethyl-

$\mathrm{C}_{10} \mathrm{H}_{14} \mathrm{O}$

$26967-65-7$
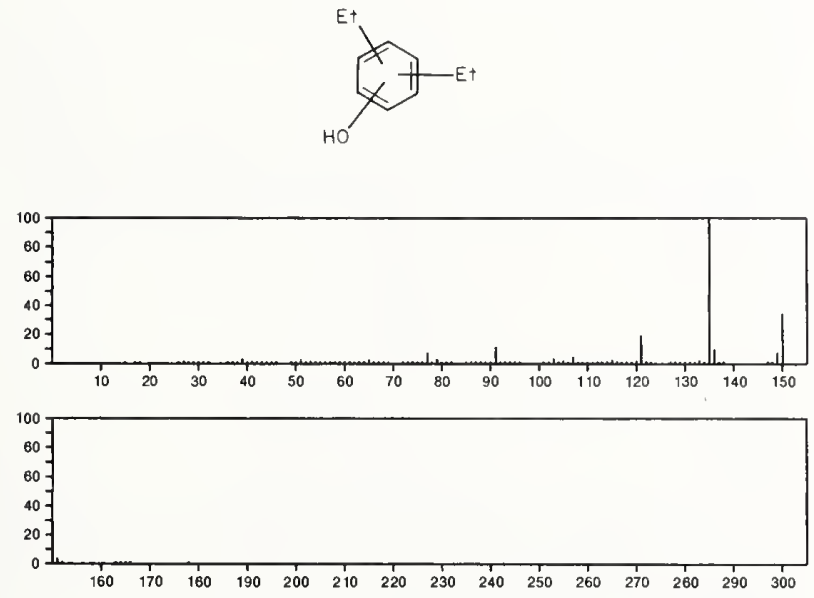

150

$\mathrm{C}_{10} \mathrm{H}_{14} \mathrm{O}$

$27567-85-7$

2,5-Methano $1 H$-inden-7(4H)-cne, hexahyd $0^{-}$
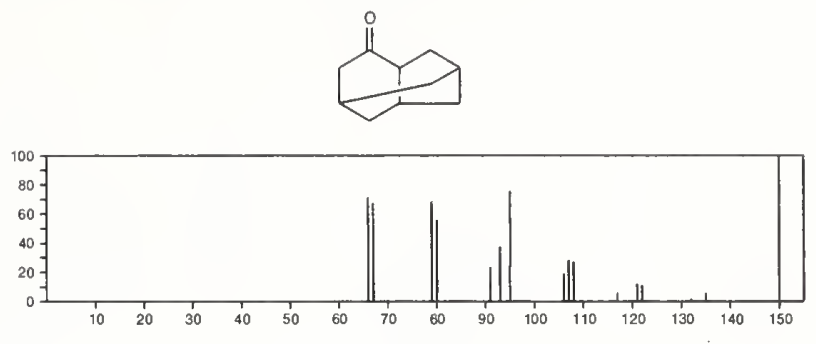

150

Ethanol, 2-xylyl

$\mathrm{C}_{10} \mathrm{H}_{14} \mathrm{O}$

$27577-96-4$
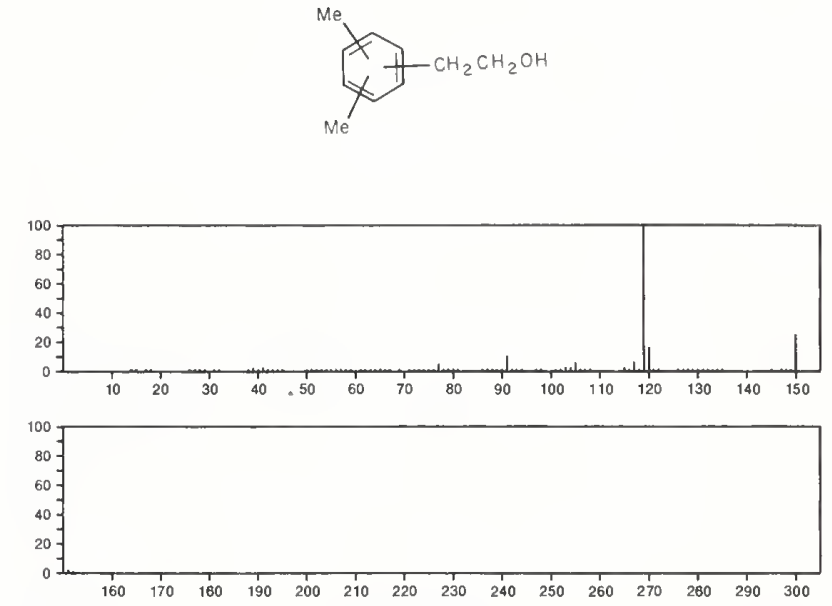

150

$\mathrm{C}_{10} \mathrm{H}_{14} \mathrm{O}$

$41673-72-7$

Benzeneethanol, ar-ethyl-
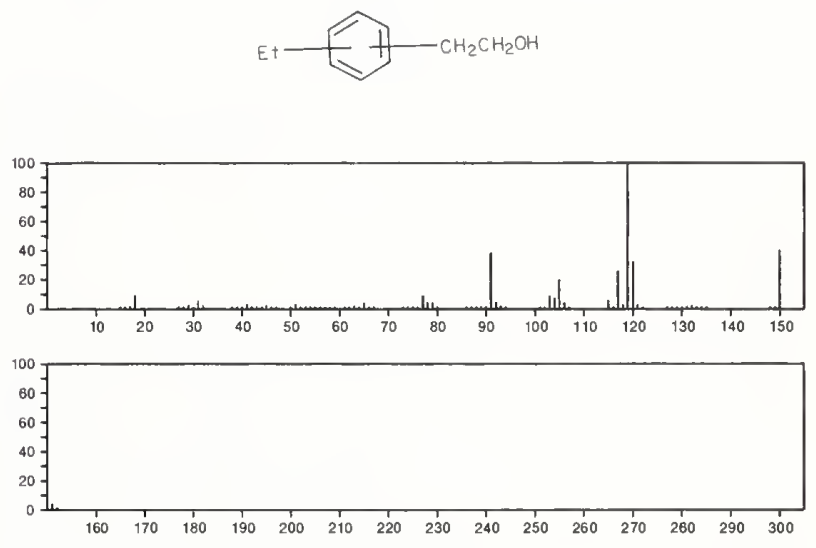

150

$\mathrm{C}_{10} \mathrm{H}_{14} \mathrm{O}$

$41702-60-7$

1,7-Octadien-3-one, 2-methyl-6-methylene-

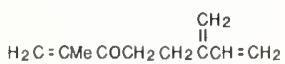

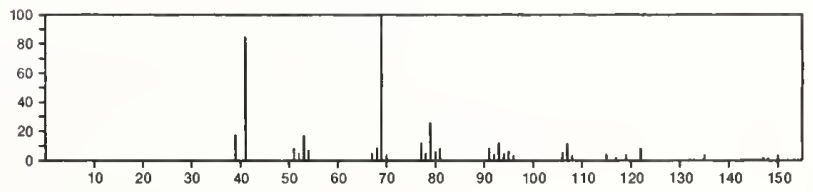


150

Benzeneethanol, $\alpha, \beta$-dimethyl-

$\mathrm{C}_{10} \mathrm{H}_{14} \mathrm{O}$

$52089-32-4$

$\mathrm{Me} C H(\mathrm{OH}) \mathrm{CHM}$ Ph

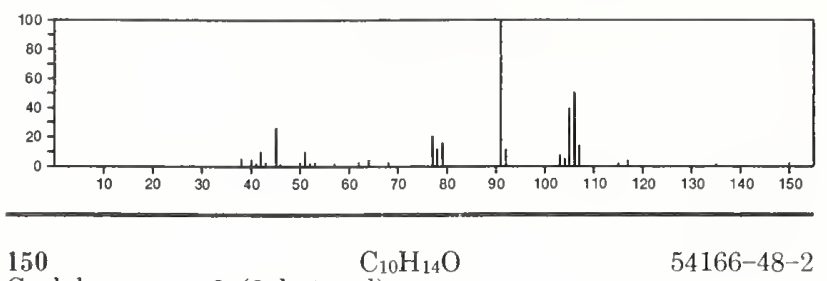

Cyclohexanone, 2-(2-butynyl)-
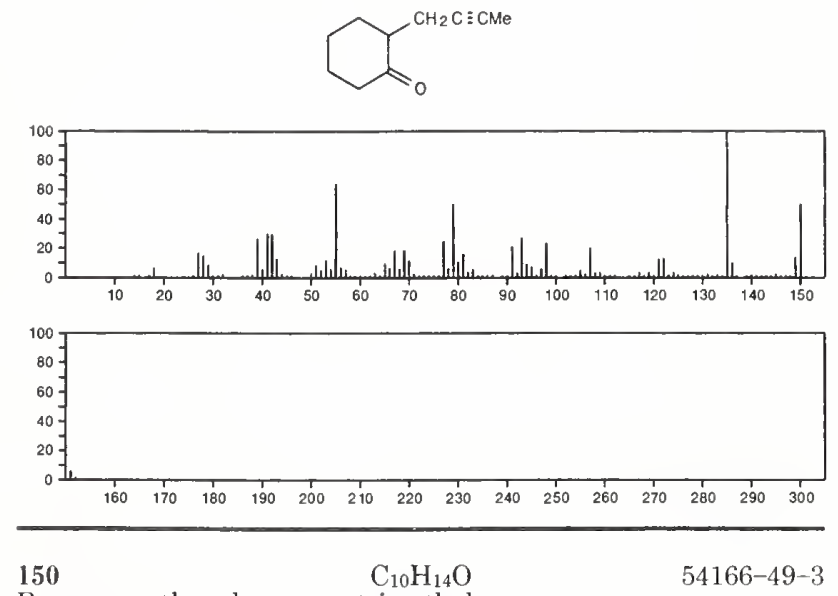

Benzenemethanol, ar,ar, $\alpha$-trimethyl-
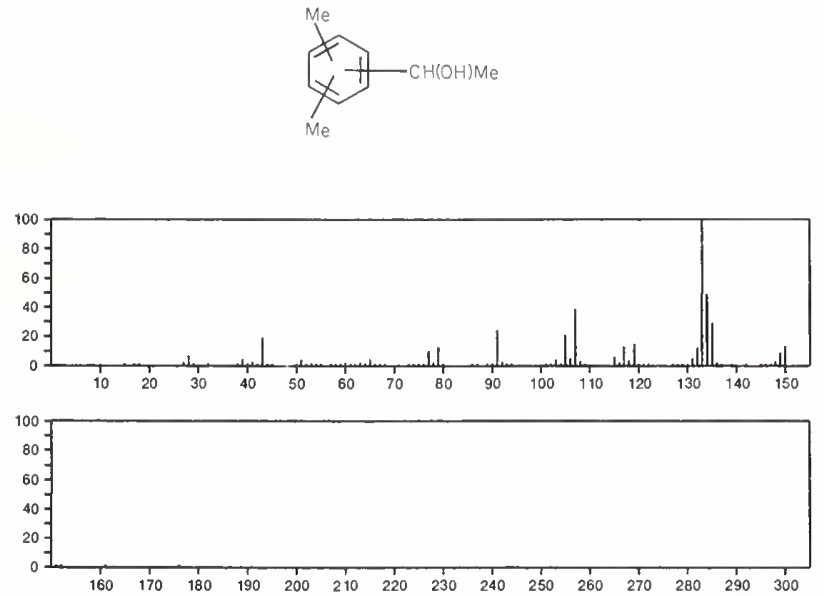

150

$\mathrm{C}_{10} \mathrm{H}_{14} \mathrm{O}$

1-Oxaspiro[2.5]oct-5-ene, 8,8-dimethy]-4-methylene--
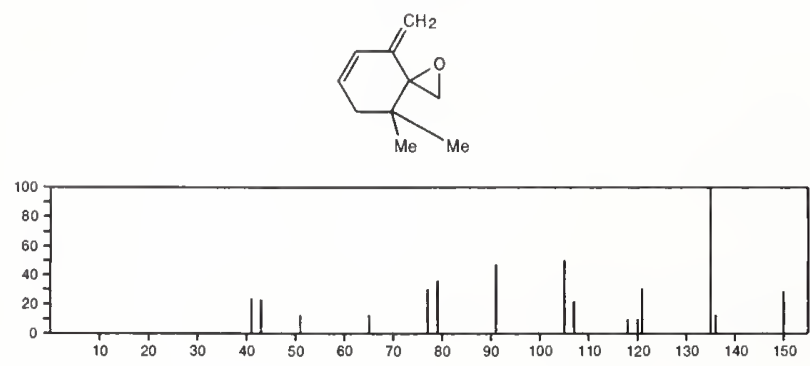

150

$\mathrm{C}_{10} \mathrm{H}_{14} \mathrm{O}$

$54725-16-5$

$2 H$-Inden-2-one, 1,4,5,6,7,7a-hexahydro-7a-methyl-, $(S)$ -
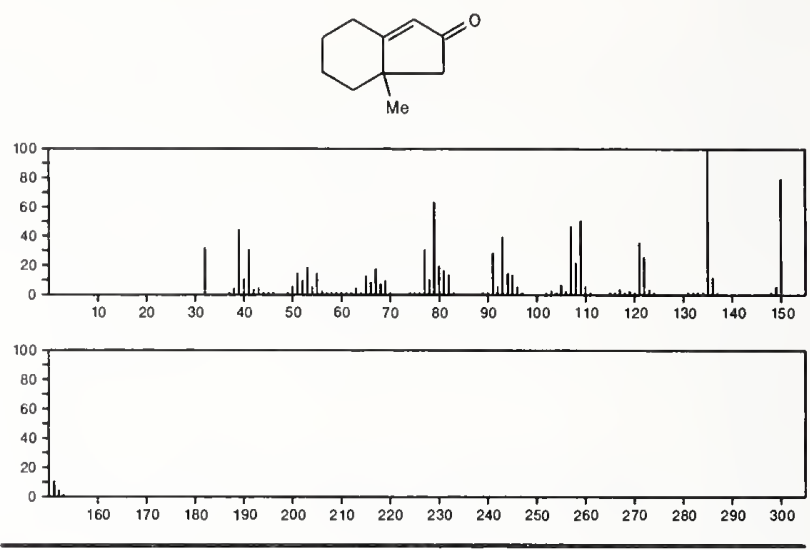

150

1,5,7-Octatrien-3-one, 2,6-dimethyl-, (E)

$55712-51-1$

$\mathrm{H}_{2} \mathrm{C}=\mathrm{CHCMe}=\mathrm{CHCH}_{2} \mathrm{COCM}=\mathrm{CH}_{2}$

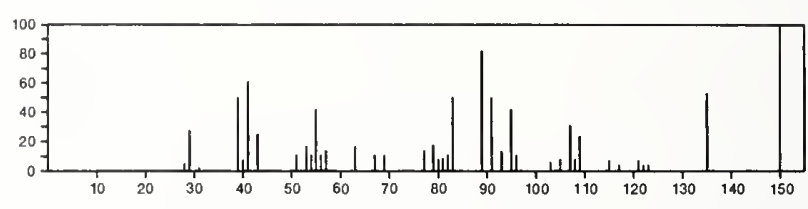

150

$\mathrm{C}_{11} \mathrm{H}_{18}$

$281-46-9$

Tricyclo[4.3.1.13,8]undecane
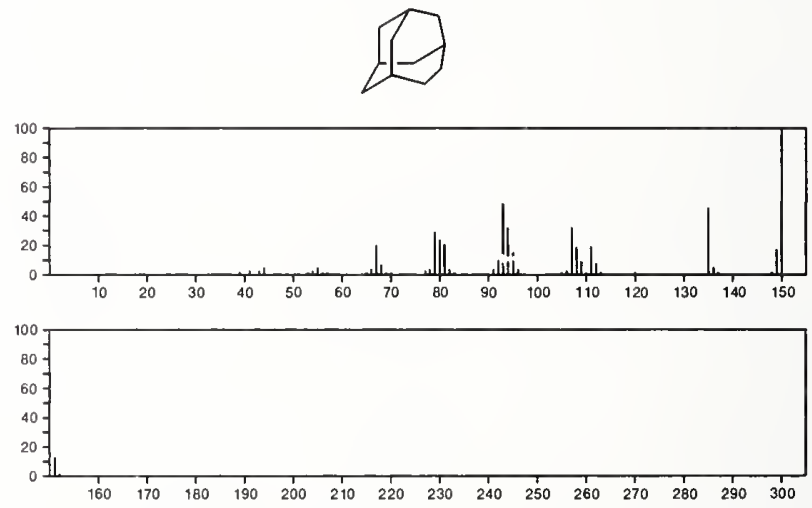

150
Naphthalene,
$\mathrm{C}_{11} \mathrm{H}_{18}$
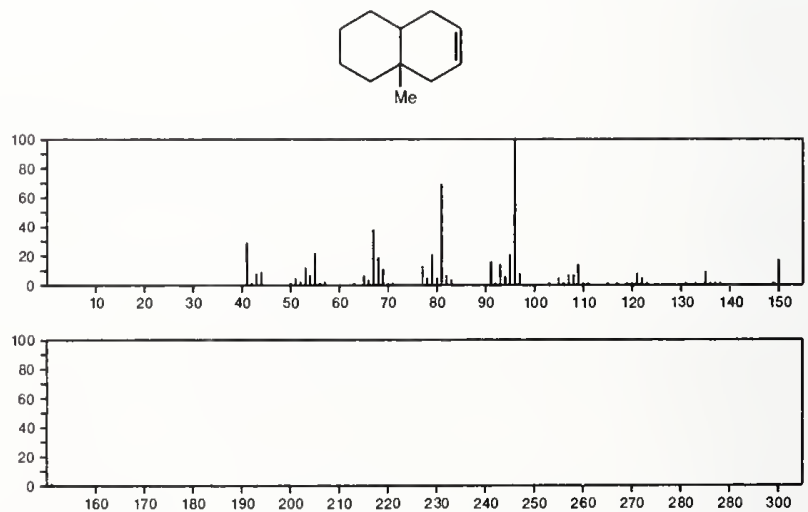
150 $\mathrm{C}_{11} \mathrm{H}_{18}$

22822-99-7
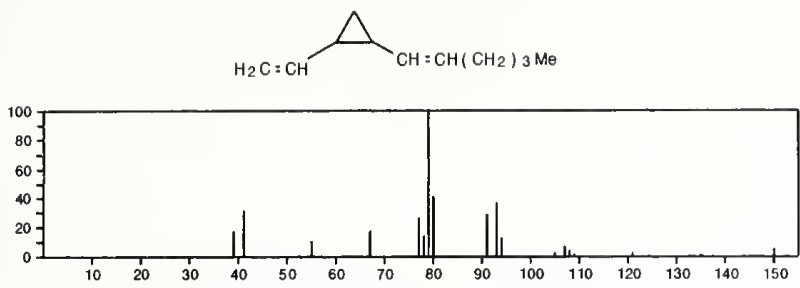

150

$\mathrm{C}_{11} \mathrm{H}_{18}$

$54166-47-1$

Bicyclo[5.1.0]octane, 8-(1-methylethylidene)-
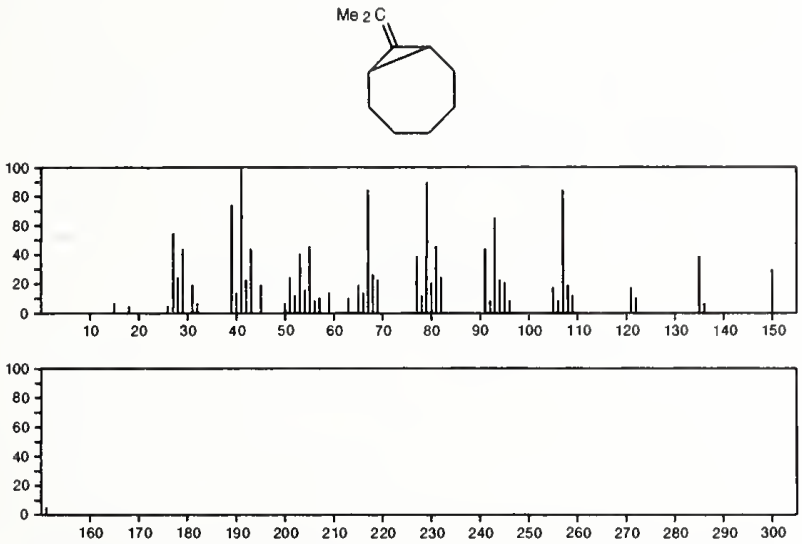

150

$\mathrm{C}_{11} \mathrm{H}_{18}$

$56030-49-0$

Cyclohexene, 3-(3-methyl-1-butenyl)-, (E)-
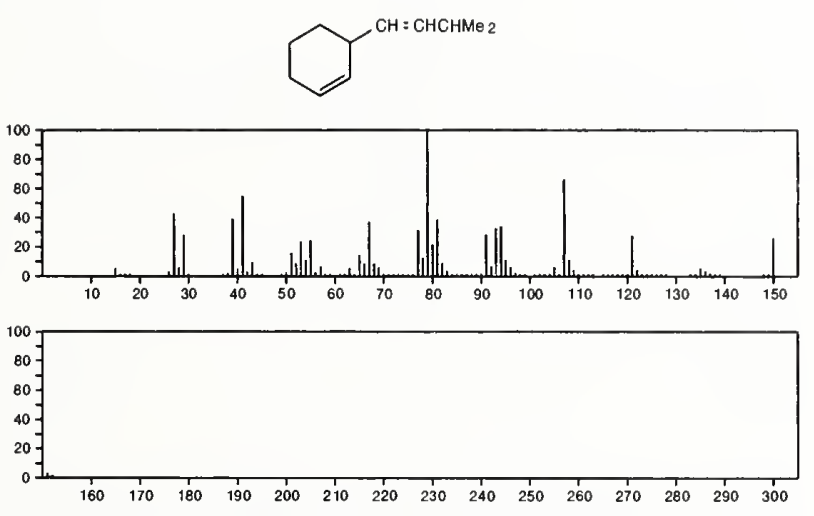

$150 \quad \mathrm{C}_{11} \mathrm{H}_{18} \quad 56324-70-0$

$1 H^{-}$-Indene, 1-ethylideneoctahydro-, trans $^{-}$
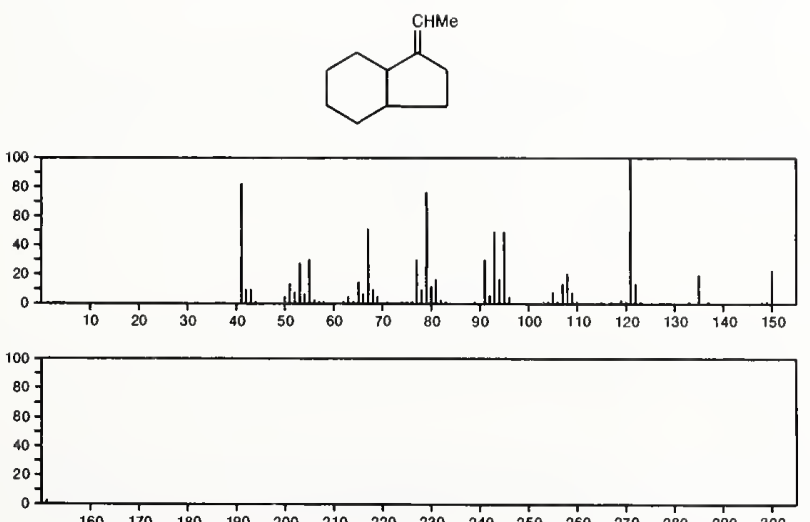

151

Methane, trinitro

$\mathrm{CHN}_{3} \mathrm{O}_{6}$

$517-25-9$

$\mathrm{HC}\left(\mathrm{NO}_{2}\right)_{3}$

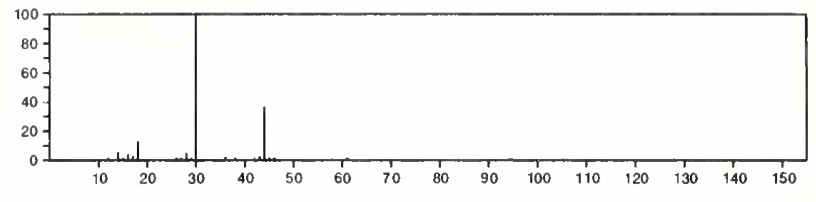

$151 \quad \mathrm{C}_{4} \mathrm{H}_{9} \mathrm{NO}_{5}$

Ethanol, 2,2'-oxybis-, mononitrate

20633-16-3

$\mathrm{HOCH}_{2} \mathrm{CH}_{2} \mathrm{OCH}_{2} \mathrm{CH}_{2} \mathrm{ONO}_{2}$

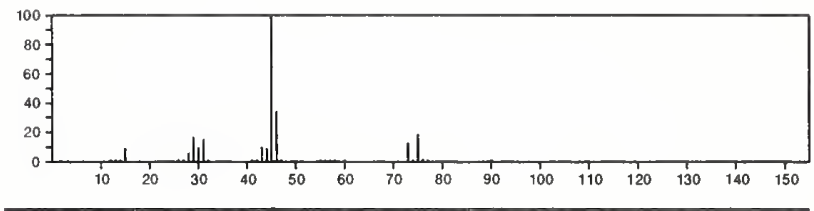

151

Pyridine, 2,3,5,6-tetrafluoro

$\mathrm{C}_{5} \mathrm{HF}_{4} \mathrm{~N}$

$2875-18-5$<smiles>Fc1cc(F)c(F)nc1F</smiles>
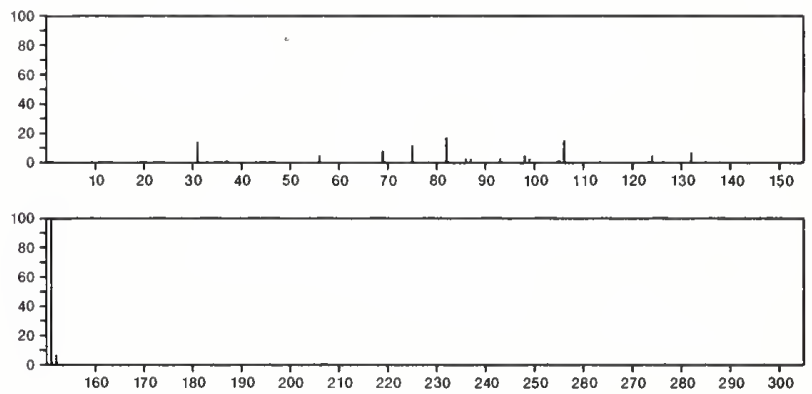

151

$\mathrm{C}_{5} \mathrm{H}_{5} \mathrm{~N}_{5} \mathrm{O}$

6H-Purin-6-one, 2-amino-1,7-dihydro-

$73-40-5$<smiles>Nc1nc(=O)c2[nH]cnc2[nH]1</smiles>
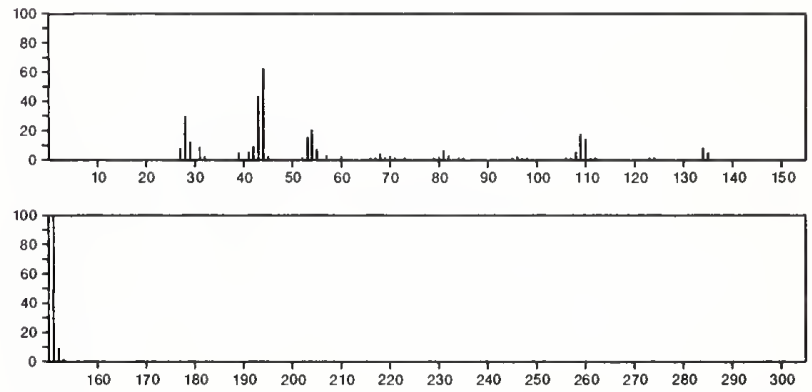

151

$\mathrm{C}_{6} \mathrm{H}_{5} \mathrm{~N}_{3} \mathrm{~S}$

$6952-68-7$

1,2,4-Triazolo[4,3-a]pyridine-3(2H)-thione
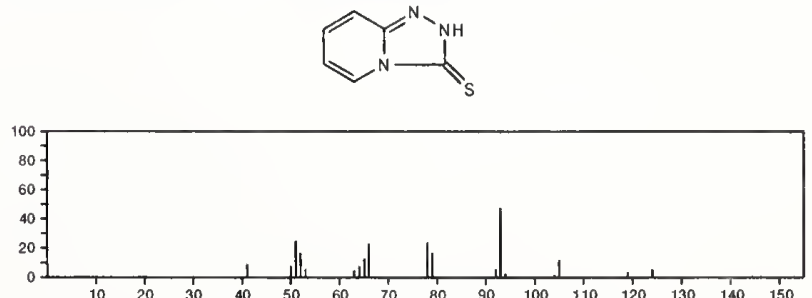


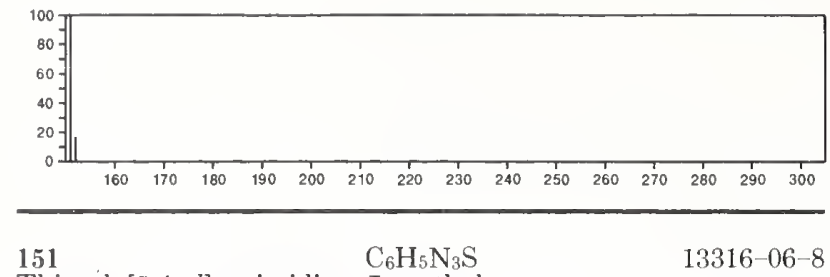

Thiazolo $[5,4-d]$ pyrimidine, $7-$ methyl-
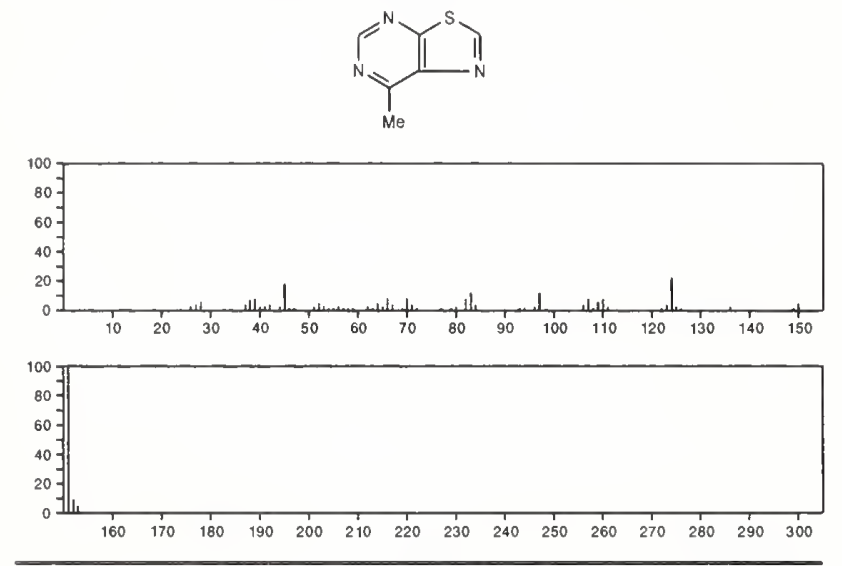

$151 \quad \mathrm{C}_{6} \mathrm{H}_{5} \mathrm{~N}_{3} \mathrm{~S} \quad 13554-88-6$

Thiazolo[5,4-d]pyrimidine, 2-methyl-
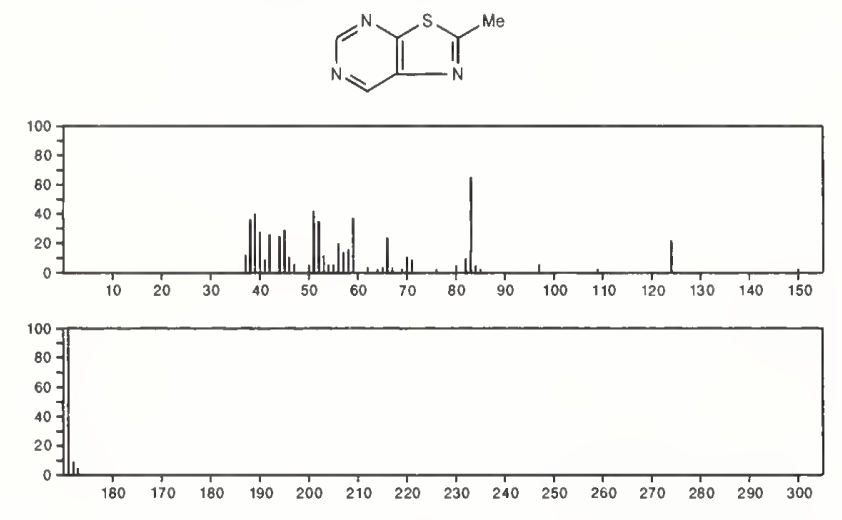

151

Thiazolo[ $[5,4-d]$ pyrimidine, $5-$ methyl
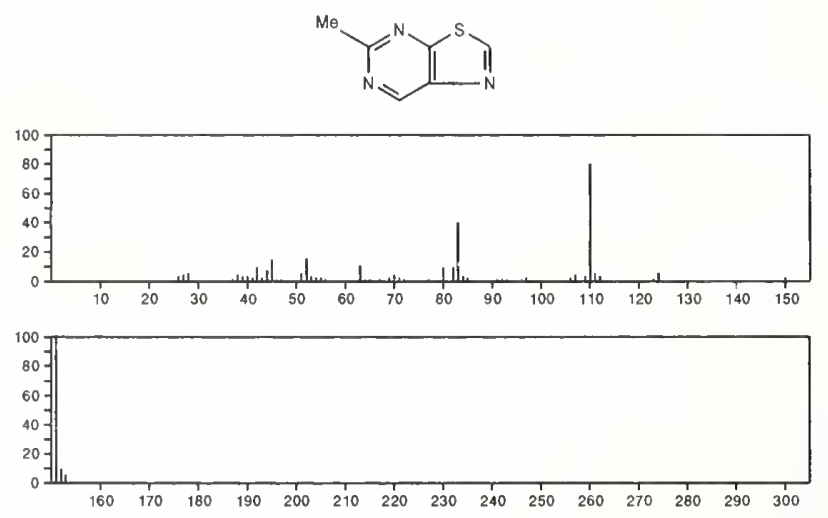

151

$\mathrm{C}_{6} \mathrm{H}_{9} \mathrm{~N}_{5}$

$35975-34-9$

1(2H)-Pyrazineacetonitrile, 5-amino-3,6-dihydro-3-imino-
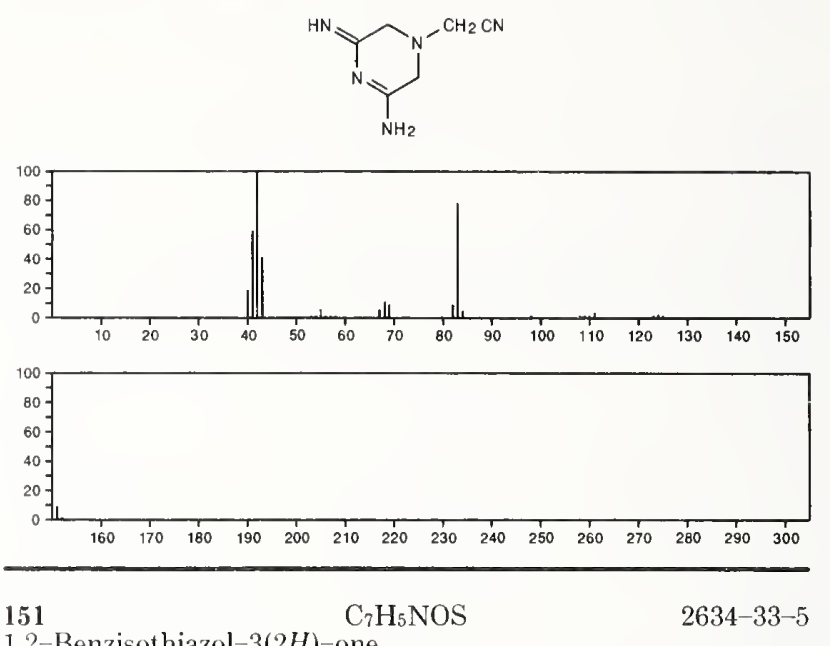

1,2-Benzisothiazol-3(2H)-one
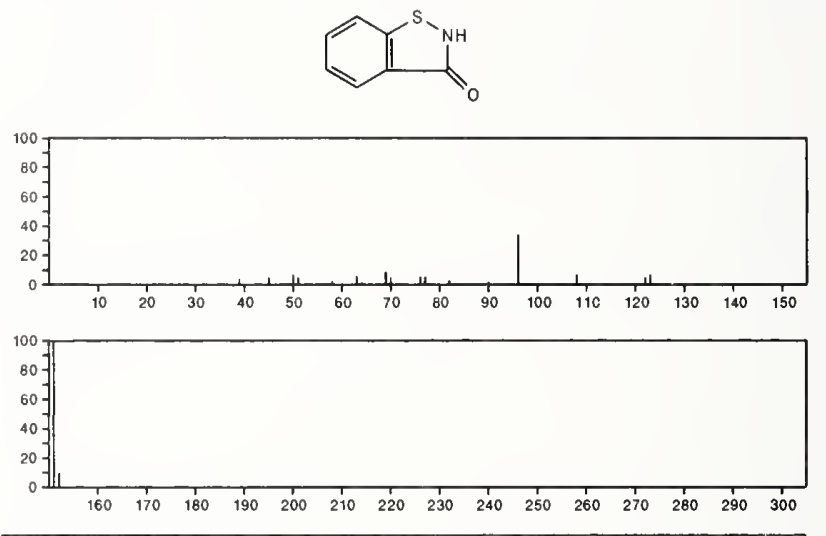

151

Benzaldehyde, 3-nitro-

$\mathrm{C}_{7} \mathrm{H}_{5} \mathrm{NO}_{3}$

$99-61-6$
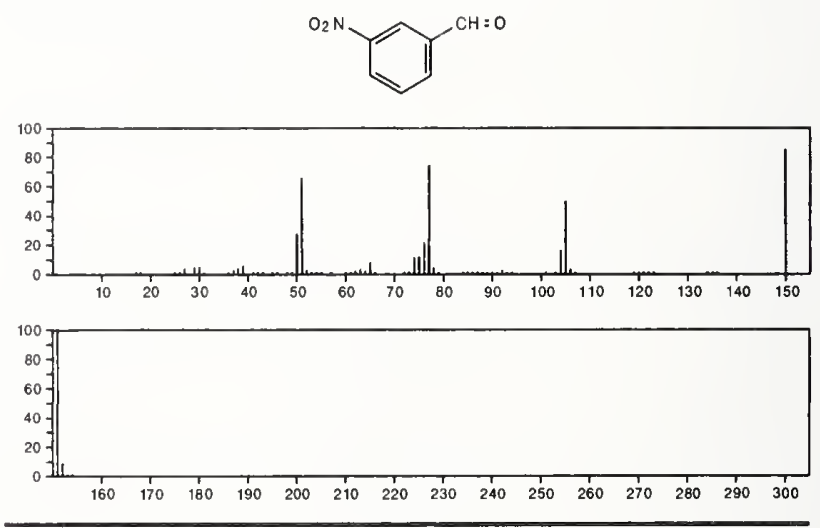

151

$\mathrm{C}_{7} \mathrm{H}_{5} \mathrm{NO}_{3}$

$552-89-6$

Benzaldehyde, 2-nitro-
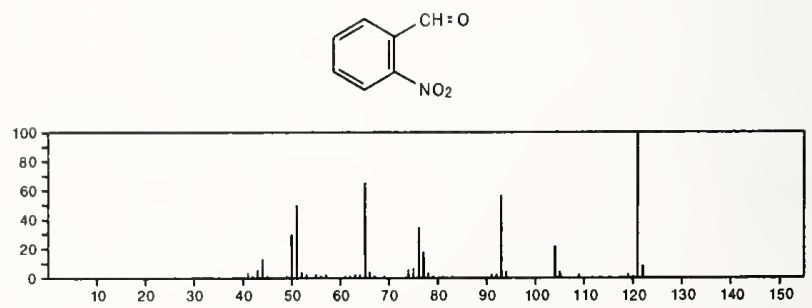
151

Benzaldehyde, 4-nitro-

$\mathrm{C}_{7} \mathrm{H}_{5} \mathrm{NO}_{3}$

$555-16-8$
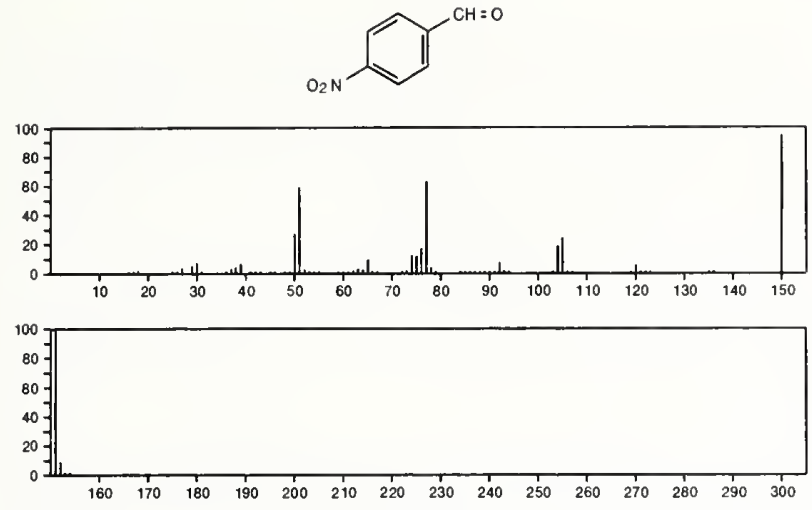

151

$\mathrm{C}_{7} \mathrm{H}_{5} \mathrm{NO}_{3}$

$612-27-1$

Benzoic acid, 2-nitroso-
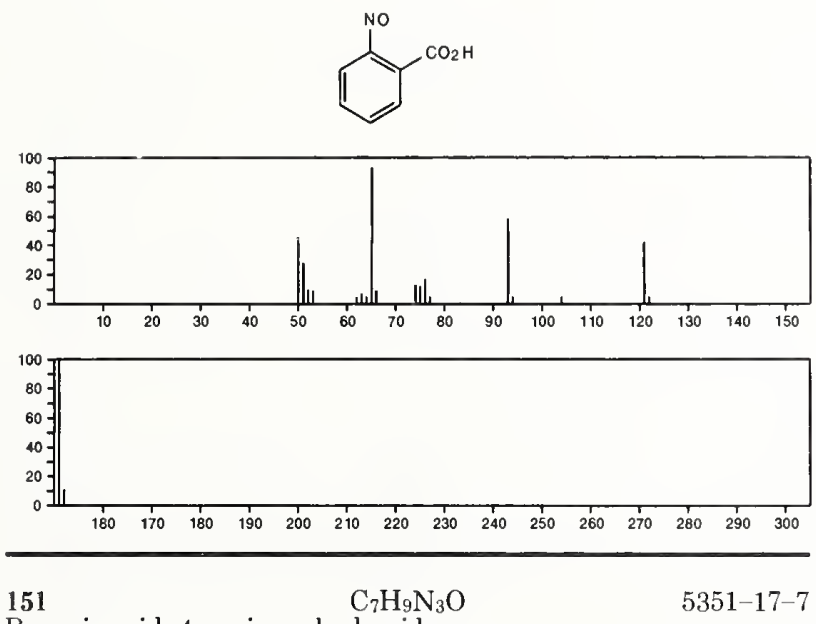

Benzoic acid, 4-amino-, hydrazide
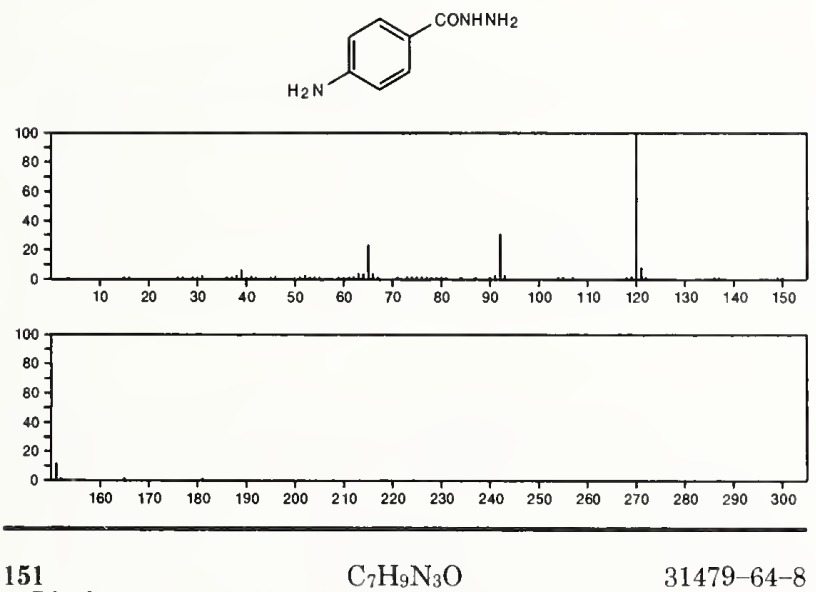

3-Picolinium, 1-ureido-, hydroxide, inner salt
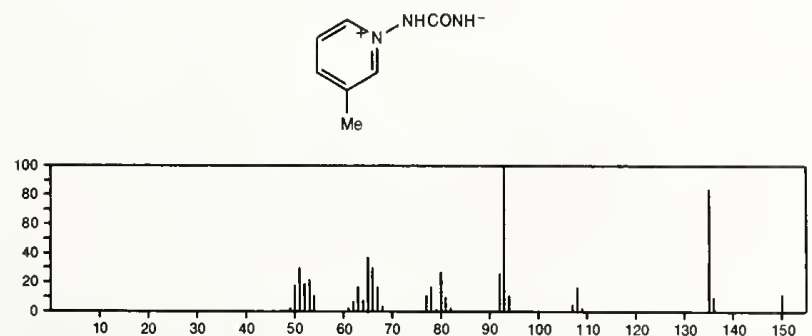

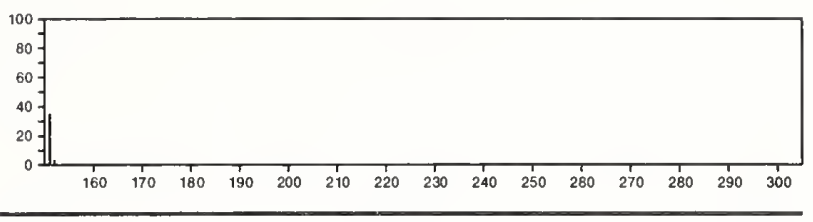

151

$\mathrm{C}_{8} \mathrm{H}_{9} \mathrm{NO}_{2}$

$100-12-9$

Benzene, 1-ethyl-4-nitro-<smiles>CCc1ccc([N+](=O)[O-])cc1</smiles>
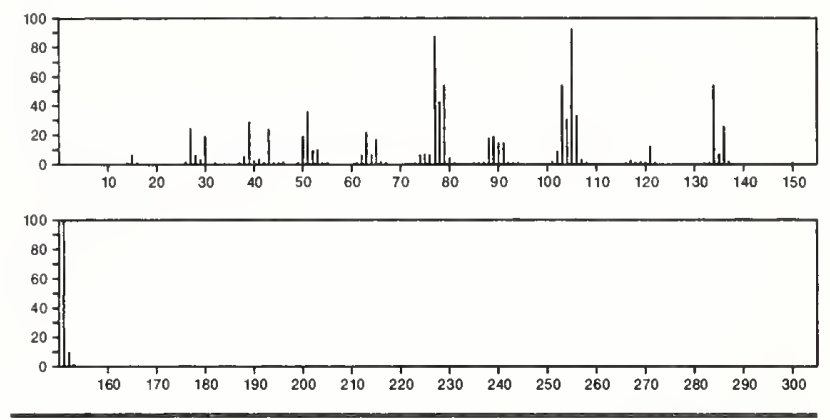

151

$\mathrm{C}_{8} \mathrm{H}_{9} \mathrm{NO}_{2}$

Acetamide, $N$-(4-hydroxyphenyl)-

$103-90-2$
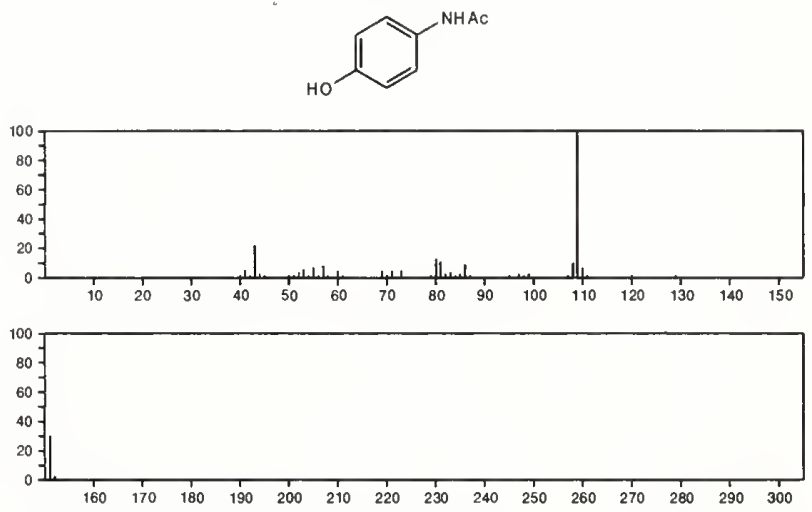

151

$\mathrm{C}_{8} \mathrm{H}_{9} \mathrm{NO}_{2}$

Benzoic acid, 2-amino-, methyl ester

134-20-3
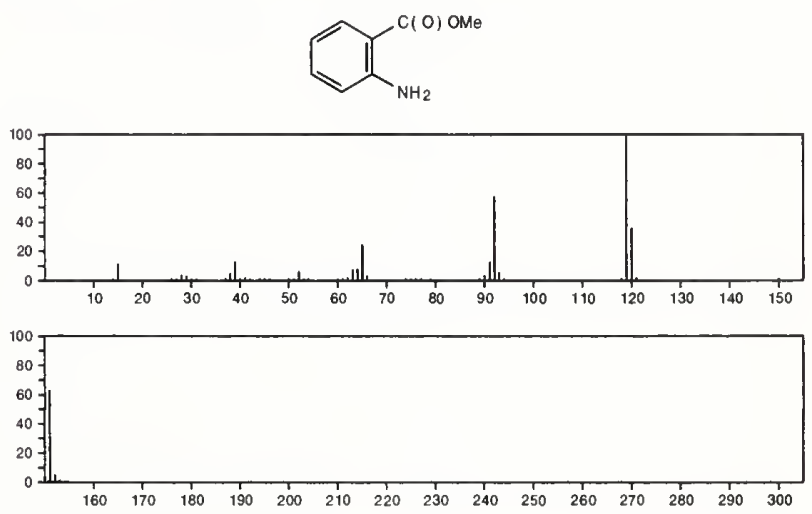
$151 \quad \mathrm{C}_{8} \mathrm{H}_{9} \mathrm{NO}_{2}$

Acetamide, $N$-(2-hydroxyphenyl)-
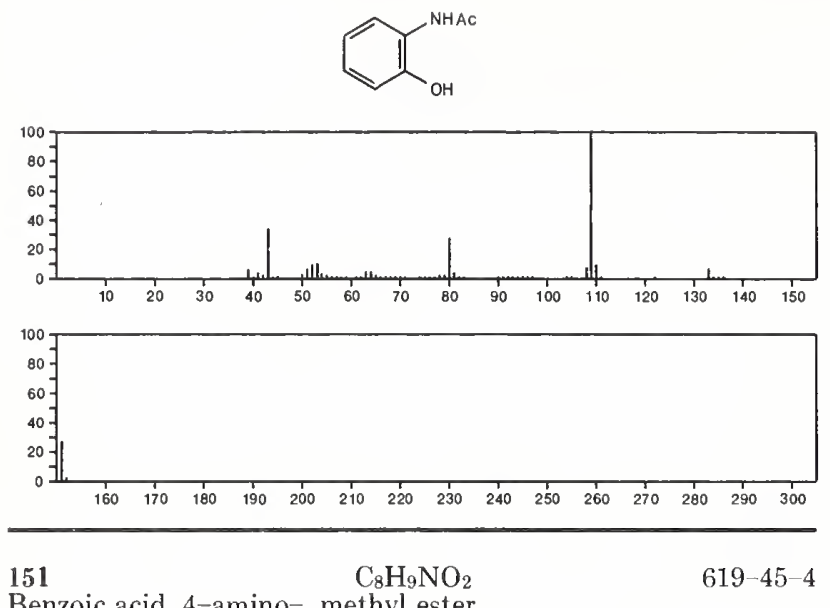

Benzoic acid, 4-amino-, methyl ester
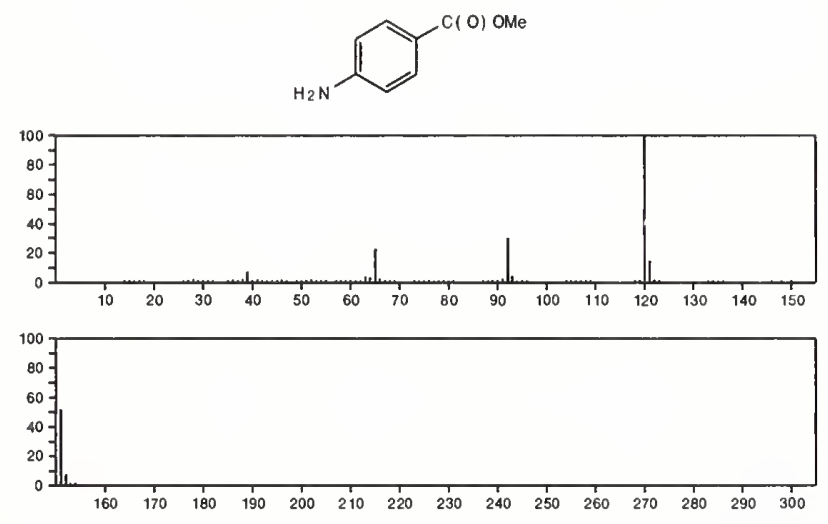

151

3-Pyridinol, 4-methyl-, acetate (ester)
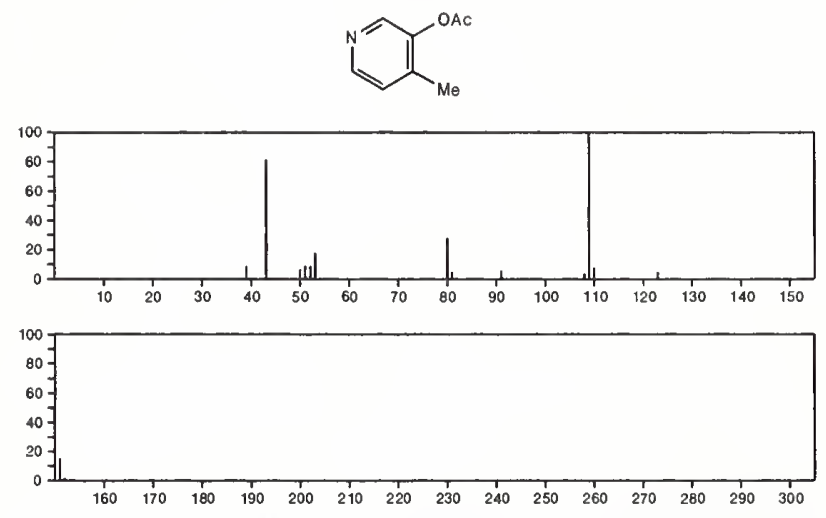

151

4-Pyridinemethanol, acetate (ester)

$1007-48-3$
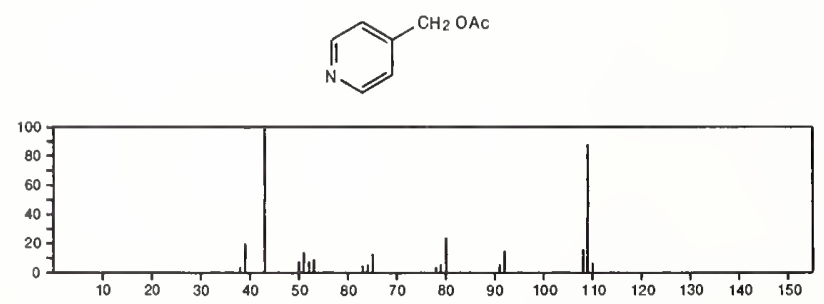

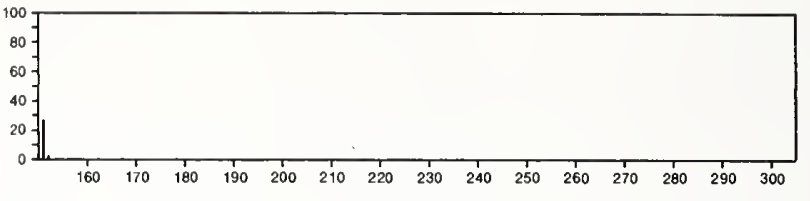

151

$\mathrm{C}_{8} \mathrm{H}_{9} \mathrm{NO}_{2}$

2-Pyridinemethanol, acetate (ester)

$1007-49-4$
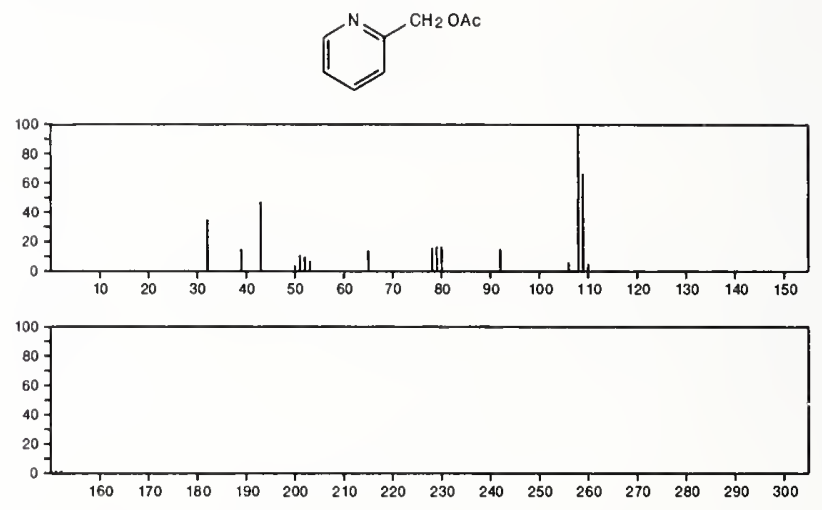

151

$\mathrm{C}_{8} \mathrm{H}_{9} \mathrm{NO}_{2}$

1469-48-3

$1 \mathrm{H}$-Isoindole-1,3(2H)-dione, 3a,4,7,7a-tetrahydro-, cis-
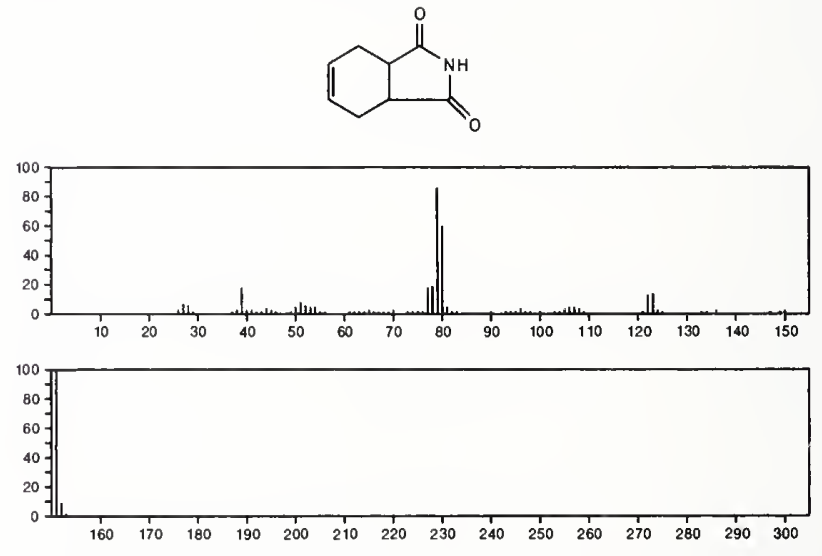

151

$\mathrm{C}_{8} \mathrm{H}_{9} \mathrm{NO}_{2}$

Carbamic acid, methyl-, phenyl ester

1943-79-9

PhOC(O) NHME

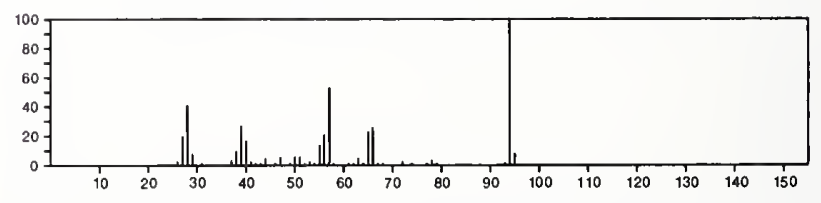

151

$\mathrm{C}_{8} \mathrm{H}_{9} \mathrm{NO}_{2}$

Carbamic acid, phenyl-, methyl ester

2603-10-3

$\mathrm{PhNHC}(\mathrm{O}) \mathrm{OMe}$

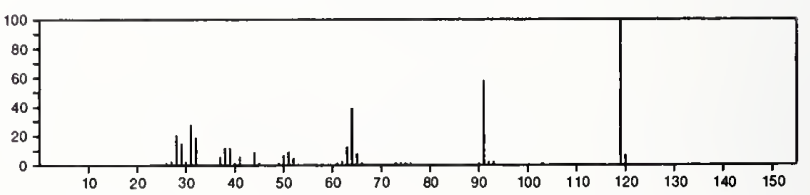


151

$\mathrm{C}_{8} \mathrm{H}_{9} \mathrm{NO}_{2}$

Benzaldehyde, 4-methoxy-, oxime
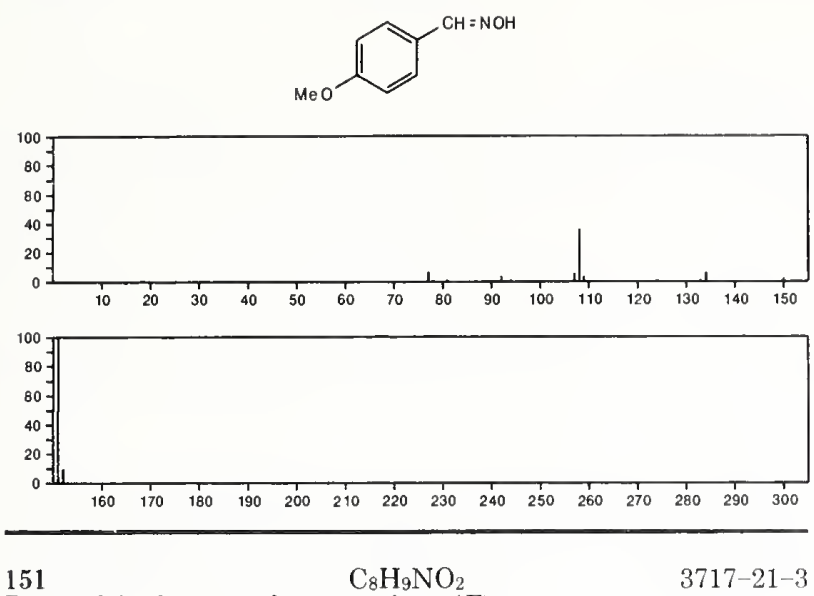

Benzaldehyde, 4-methoxy-, oxime, $(E)-$
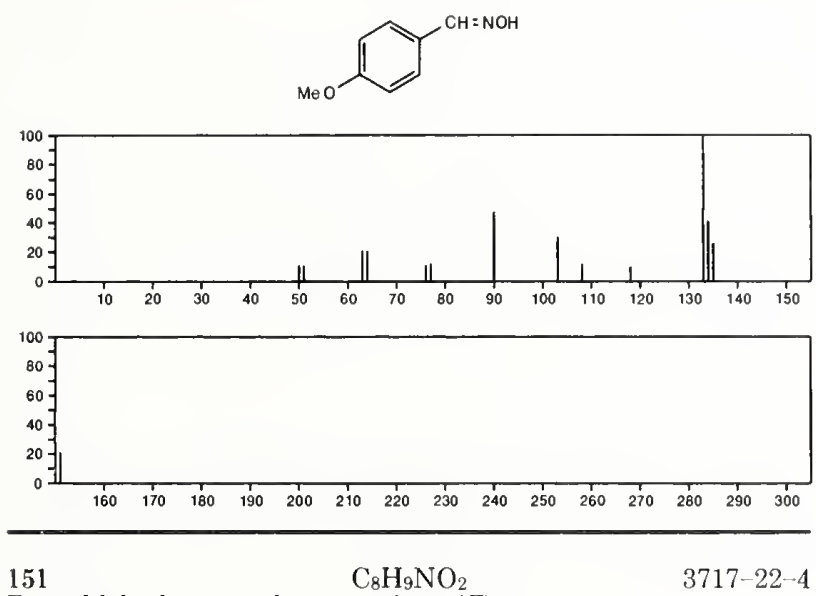

Benzaldehyde, 4-methoxy-, oxime, (Z)-
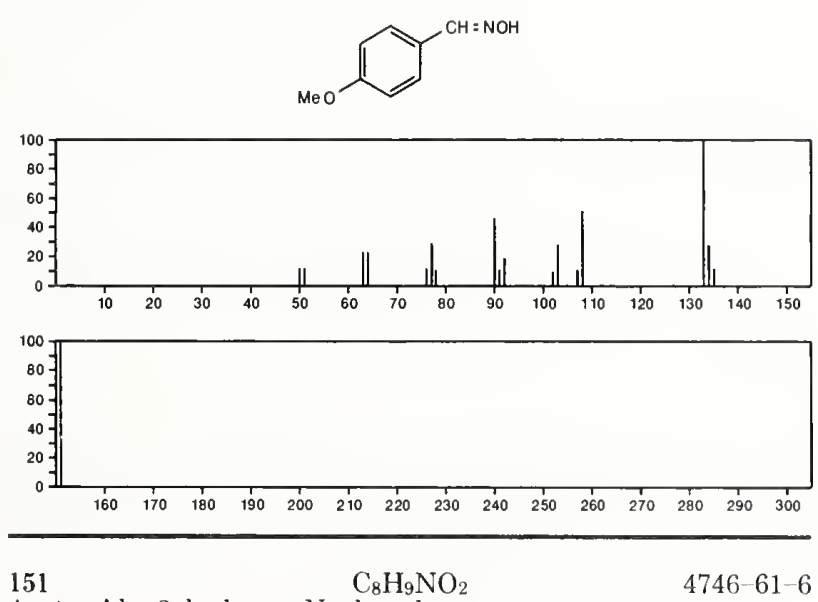

Acetamide, 2-hydroxy- $N$-phenyl-

$\mathrm{PhNHCOCH} 2 \mathrm{OH}$
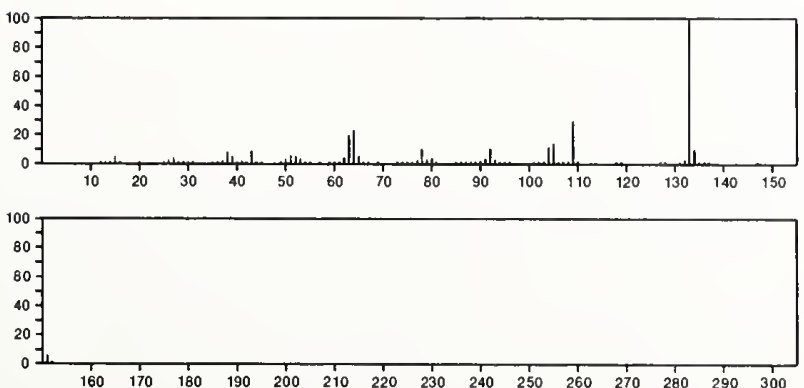

$151 \quad \mathrm{C}_{8} \mathrm{H}_{9} \mathrm{NO}_{2}$

3-Pyridinol, 6-methyl-, acetate (ester)

4842-89-1<smiles>CC(=O)Oc1ccc(C)nc1</smiles>
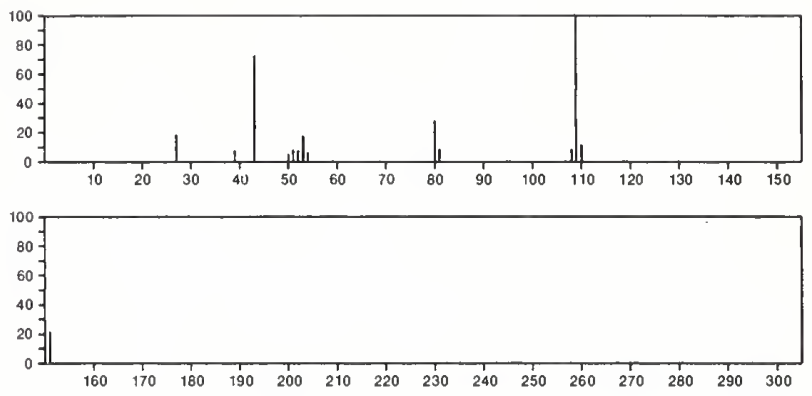

151

Benzene, (1-nitroethyl)-

$\mathrm{C}_{8} \mathrm{H}_{9} \mathrm{NO}_{2}$

7214-61-1

$\mathrm{PhCHMe}\left\langle\mathrm{NO}_{2}\right\}$

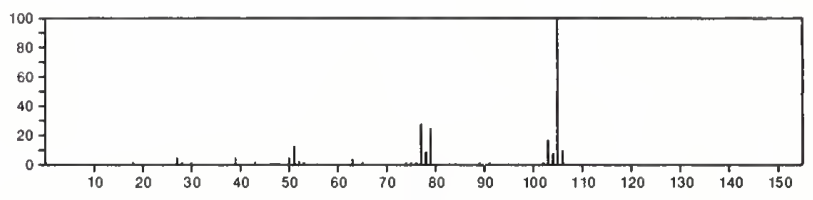

151

$\mathrm{C}_{8} \mathrm{H}_{9} \mathrm{NO}_{2}$

$19628-76-3$

Phenol, 3,5-dimethyl-4-nitroso
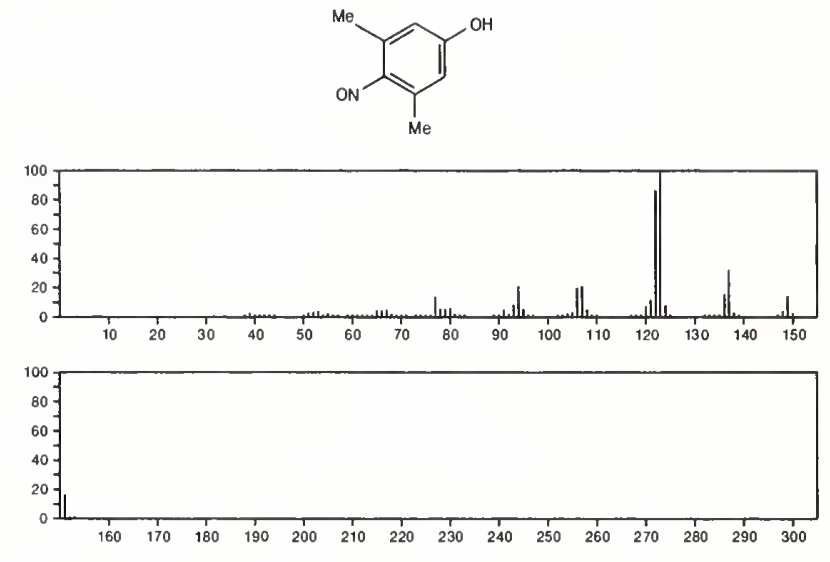

151

$\mathrm{C}_{8} \mathrm{H}_{9} \mathrm{NO}_{2}$

24935-26-0

Pyridinium, 1-(2-carboxyethyl)-, hydroxide, inner salt
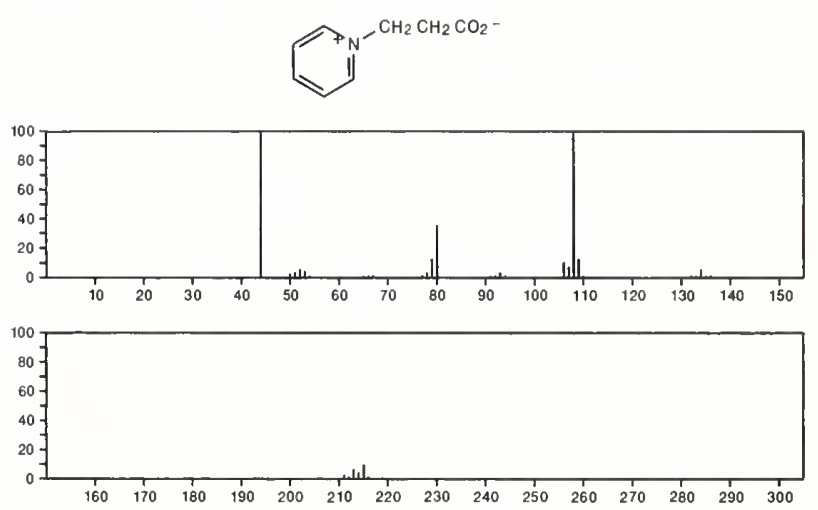
151

Benzene, 1-methyl-4-(nitro

$\mathrm{C}_{8} \mathrm{H}_{9} \mathrm{NO}_{2}$<smiles>Cc1ccc(C=O)cc1</smiles>
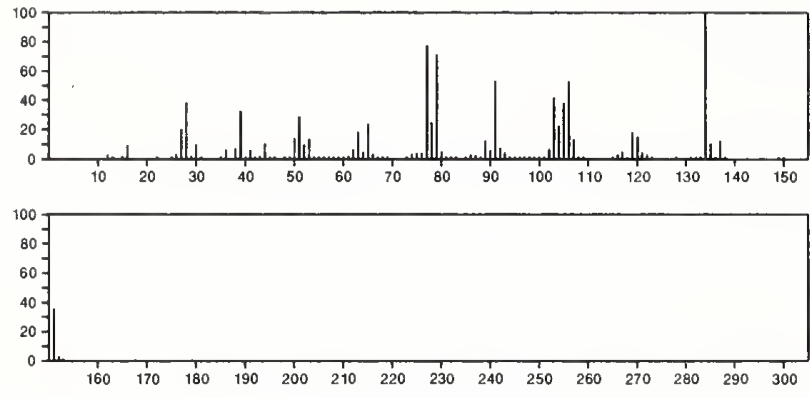

$151 \quad \mathrm{C}_{8} \mathrm{H}_{9} \mathrm{NO}_{2} \quad 34600-54-9$ $1 H$-Pyrrole-2-carboxylic acid, 1-(1-propenyl)-, (E)-
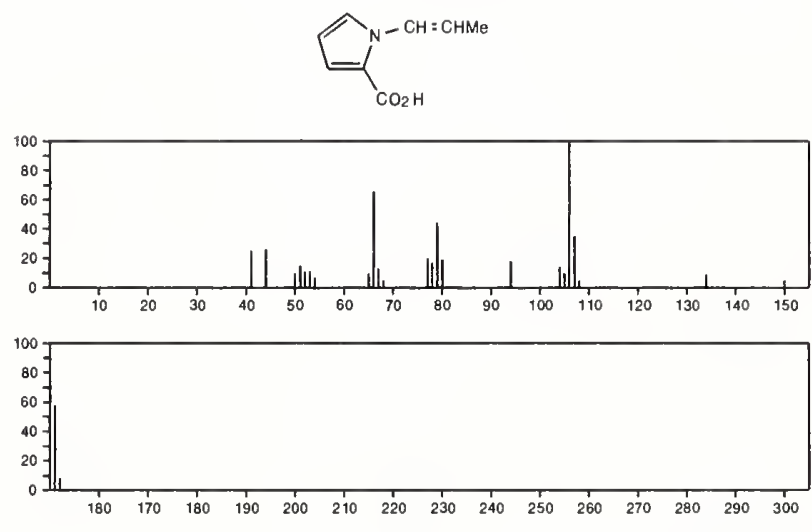

151

$\mathrm{C}_{8} \mathrm{H}_{9} \mathrm{NO}_{2}$

$36880-54-3$

Pyridinium, 1-(1-carboxyethyl)-, hydroxide, inner salt
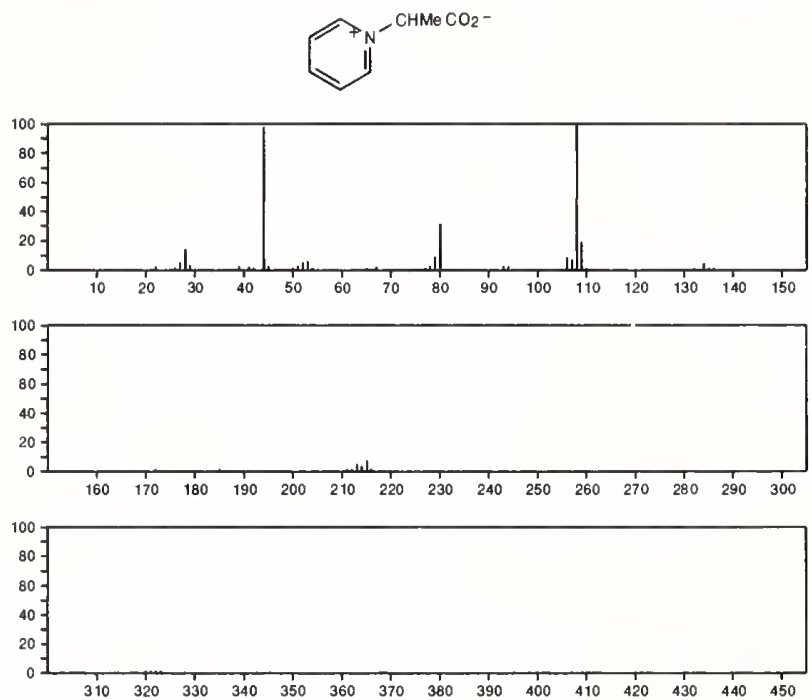

151

$\mathrm{C}_{8} \mathrm{H}_{9} \mathrm{~N}$

38489-80-4
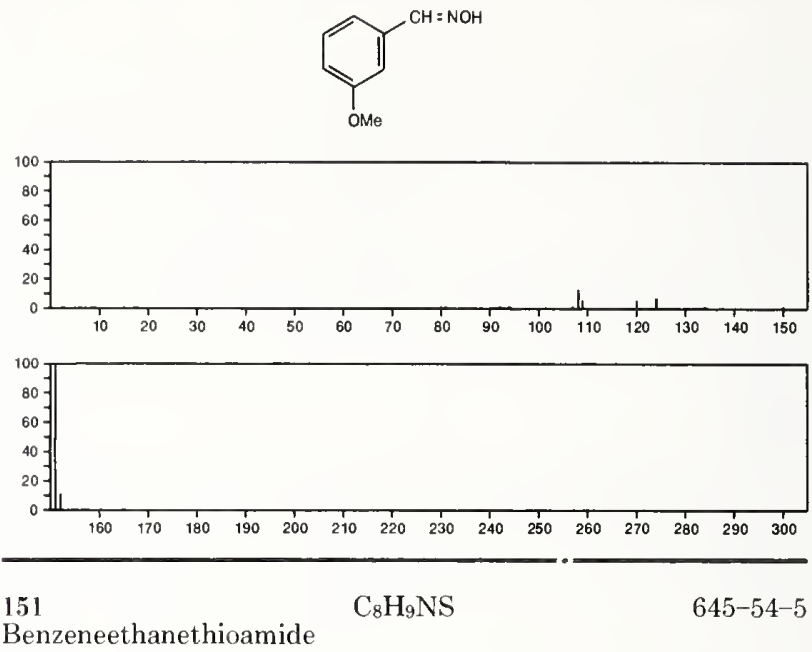

$\mathrm{H}_{2} \mathrm{NCSCH}_{2} \mathrm{Ph}$
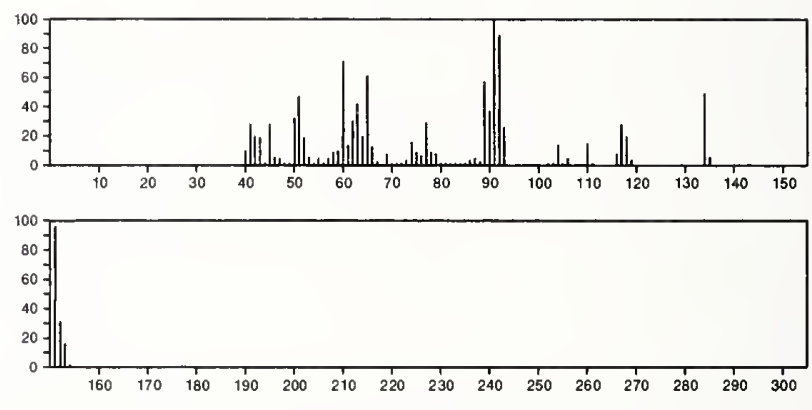

151

$\mathrm{C}_{9} \mathrm{H}_{13} \mathrm{NO}$

Benzeneethanamine, 4-methoxy-

$55-81-2$
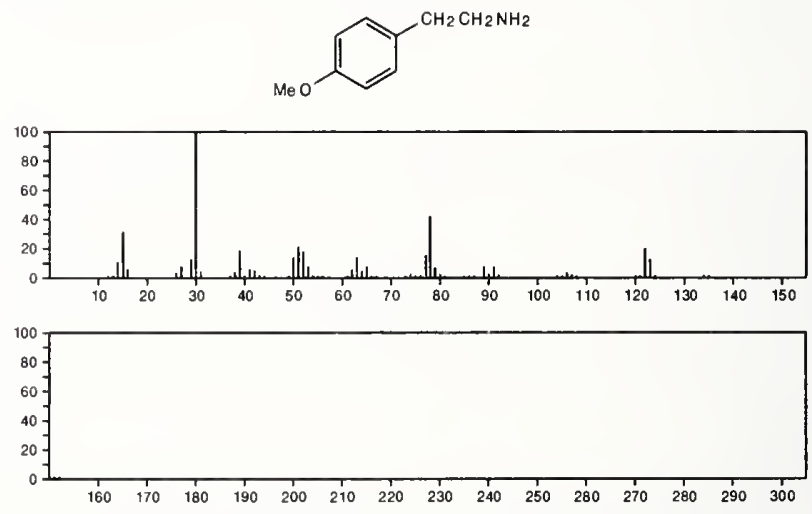

151

$\mathrm{C}_{9} \mathrm{H}_{13} \mathrm{NO}$

Ethanol, 2-[(3-methylphenyl)amino]-

$102-41-0$
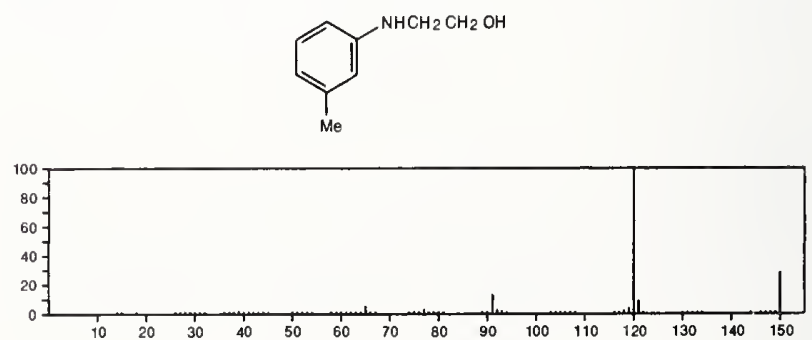


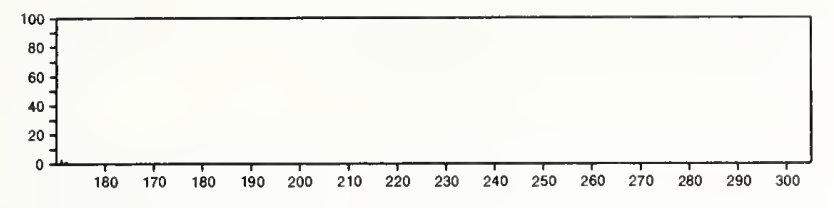

$151 \quad \mathrm{C}_{9} \mathrm{H}_{13} \mathrm{NO}$

Phenol, 4-[2-(methylamino)ethyl] -

$370-98-9$
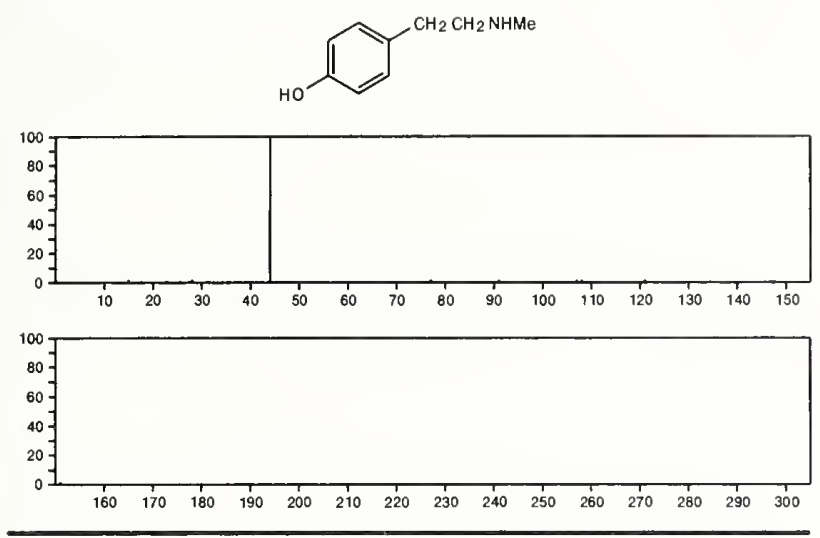

$151 \quad \mathrm{C}_{9} \mathrm{H}_{13} \mathrm{NO}$

Cyclohexanepropanenitrile, 2-oxo-
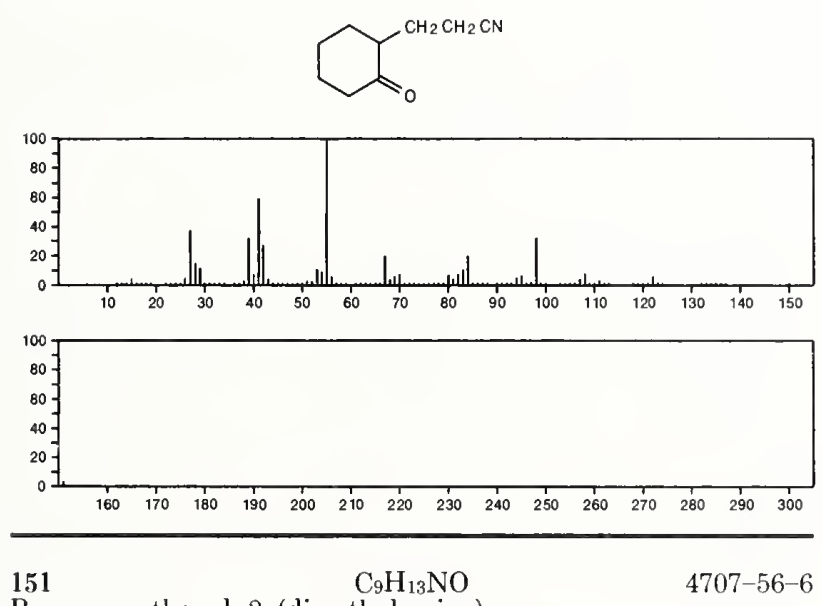

Benzenemethanol, 2-(dimethylamino)-
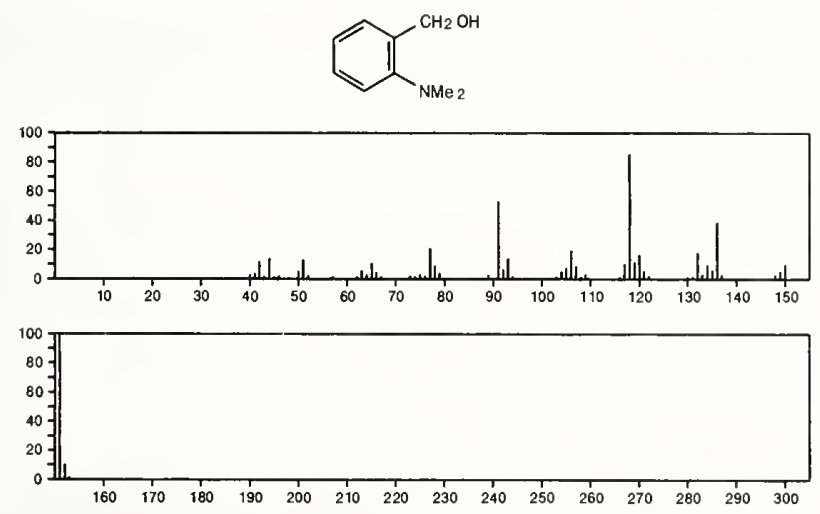

151

$\mathrm{C}_{9} \mathrm{H}_{13} \mathrm{NO}$

Acetamide, $N$-bicyclo[2.2.1]hept-2-en-7-yl-, anti-

$14098-17-0$
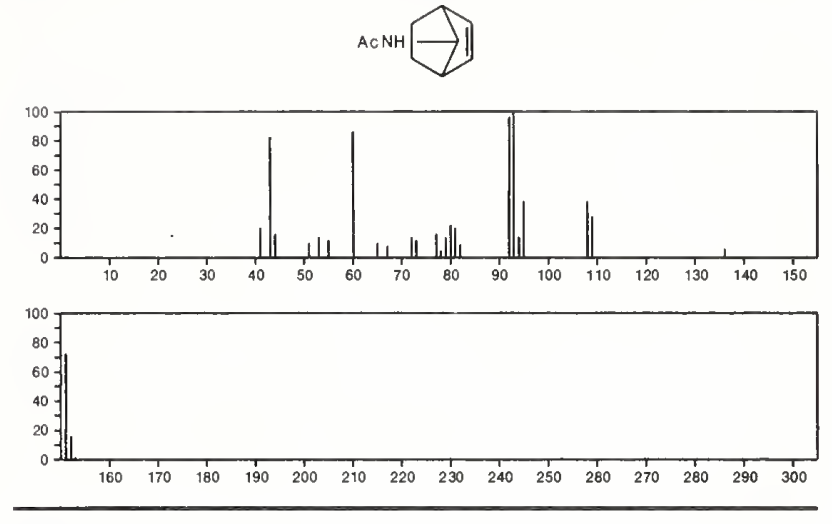

151

$\mathrm{C}_{9} \mathrm{H}_{13} \mathrm{NO}$

14174-01-7

Acetamide, $N-2-$ norbornen-7-yl-, syn-
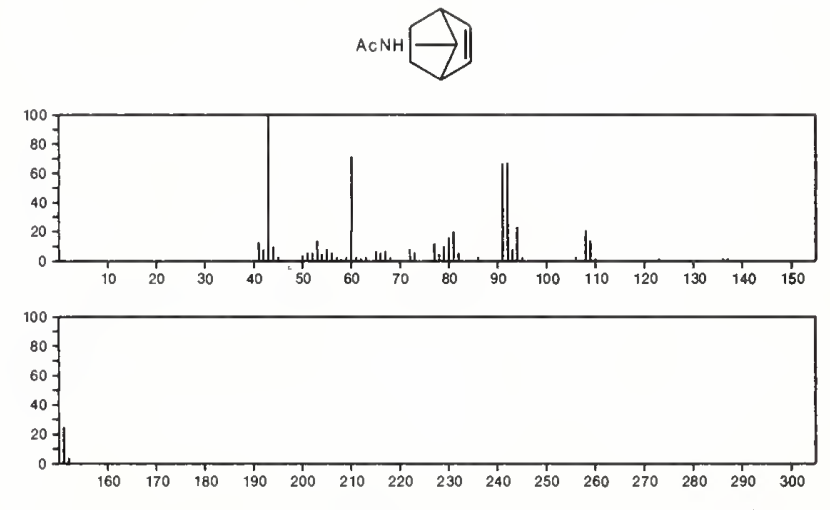

151

$\mathrm{C}_{9} \mathrm{H}_{13} \mathrm{NO}$

23501-93-1

Benzenemethanol, 3-(dimethylamino)-
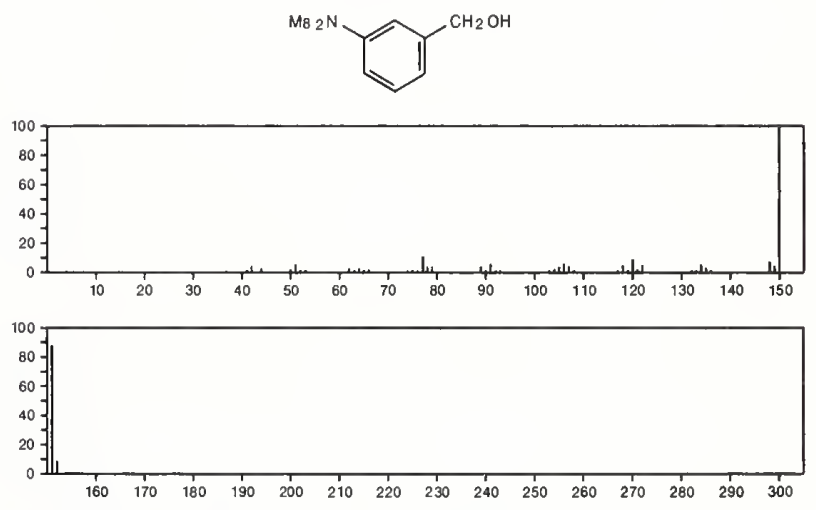

$151 \quad \mathrm{C}_{9} \mathrm{H}_{13} \mathrm{NO} 31061-58-2$

Benzenaminium, 2-hydroxy- $N, N, N$-trimethyl-, hydroxide, inner salt
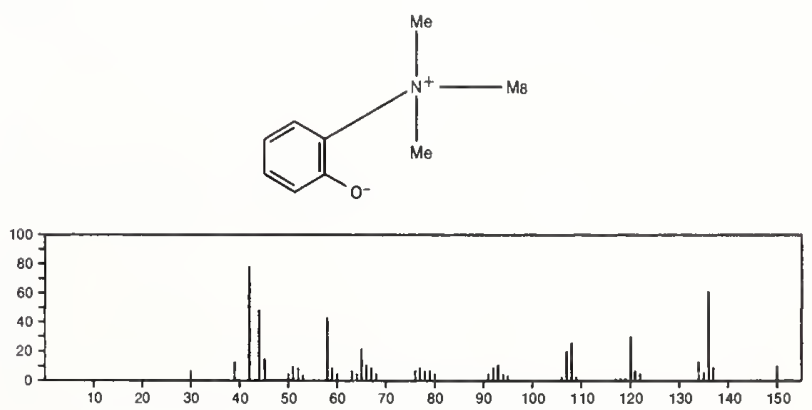


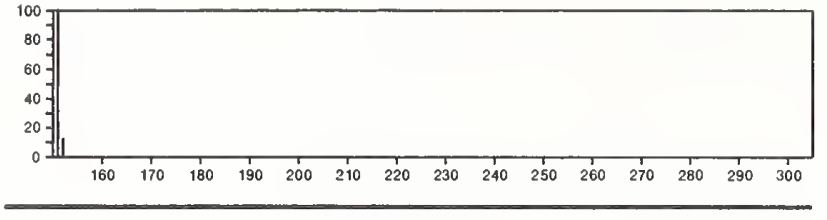

$151 \quad \mathrm{C}_{9} \mathrm{H}_{13} \mathrm{NO} 31061-59-3$

Benzenaminium, 3-hydroxy- $N, N, N$-trimethyl-, hydroxide, inner salt
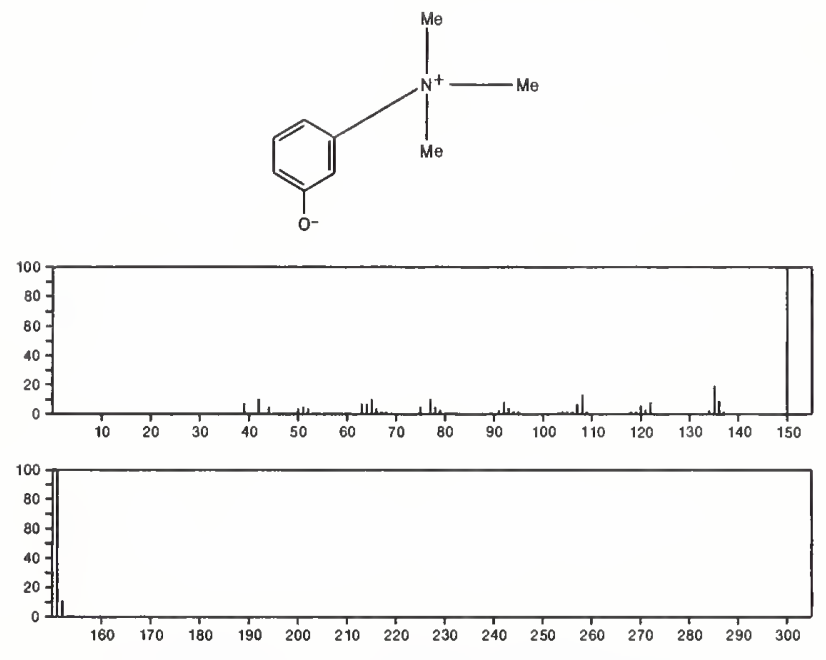

151

$\mathrm{C}_{9} \mathrm{H}_{13} \mathrm{NO}$

$31061-60-6$

Ammonium, ( $p$-hydroxyphenyl)trimethyl-, hydroxide, inner salt
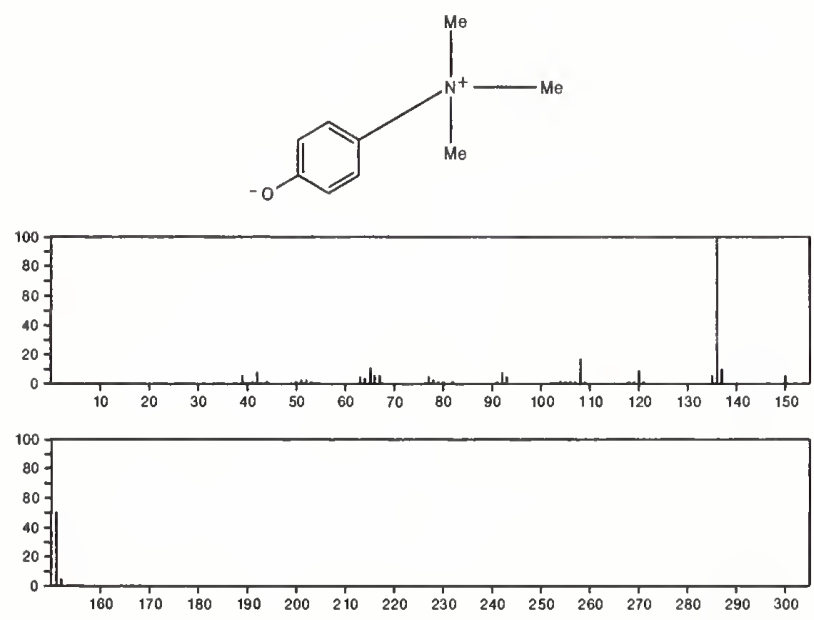

151

Pyridine, 2-butyl-, 1-oxide

$\mathrm{C}_{9} \mathrm{H}_{13} \mathrm{NO}$

$31396-32-4$
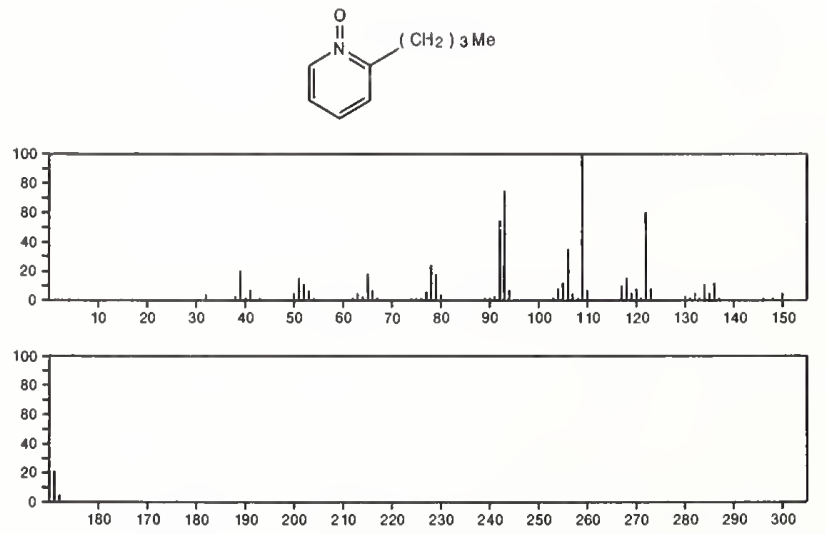

151

$\mathrm{C}_{9} \mathrm{H}_{13} \mathrm{NO}$

$31396-33-5$

Pyridine, 3-butyl-, 1-oxide
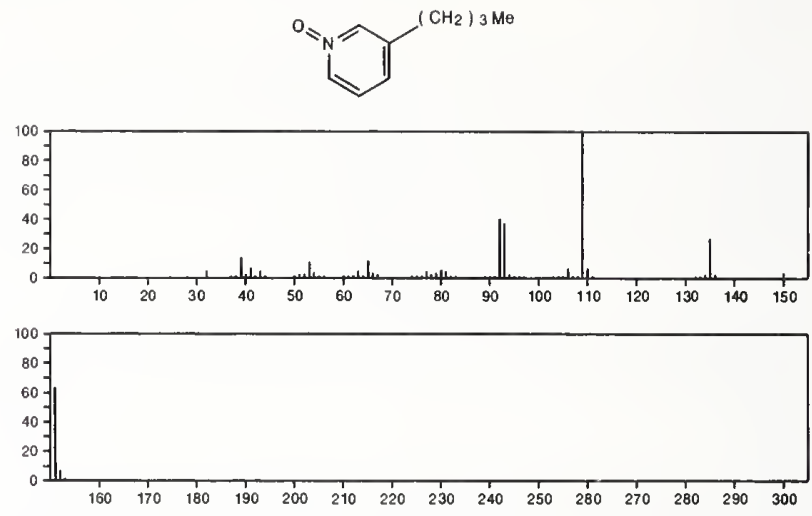

151

$\mathrm{C}_{9} \mathrm{H}_{13} \mathrm{NO}$

31396-34-6

Pyridine, 4-butyl-, 1-oxide
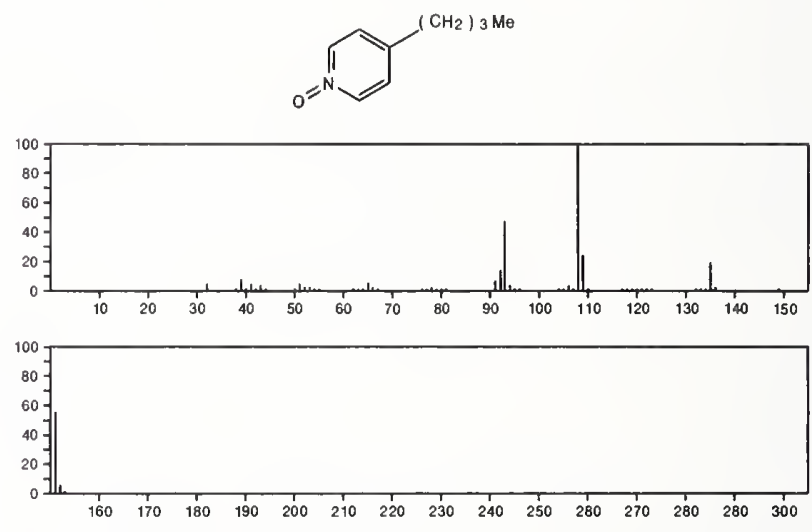

151

$\mathrm{C}_{10} \mathrm{H}_{17} \mathrm{~N}$

Pyrrolidine, 1-(1-cyclohexen-1-yl)-

1125-99-1
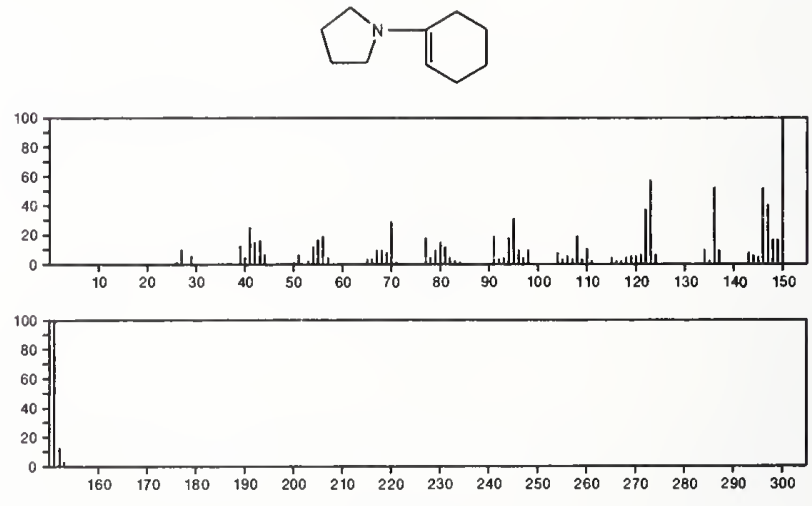

$151 \quad \mathrm{C}_{10} \mathrm{H}_{17} \mathrm{~N}$

Piperidine, 1-(1-cyclopenten-1-yl)-

1614-92-2
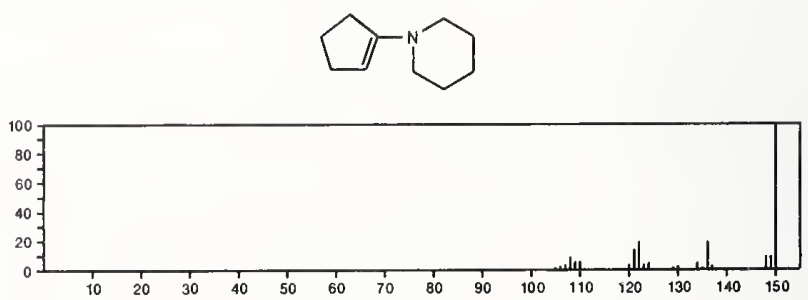


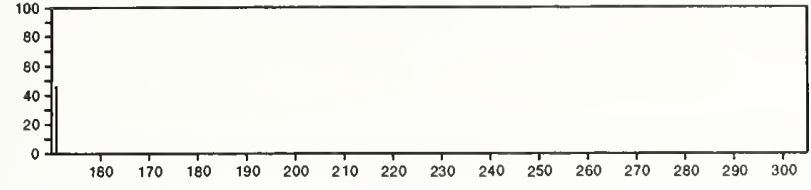

$151 \quad \mathrm{C}_{10} \mathrm{H}_{17} \mathrm{~N}$

Naphthalen-4a,8a-imine, octahydro-
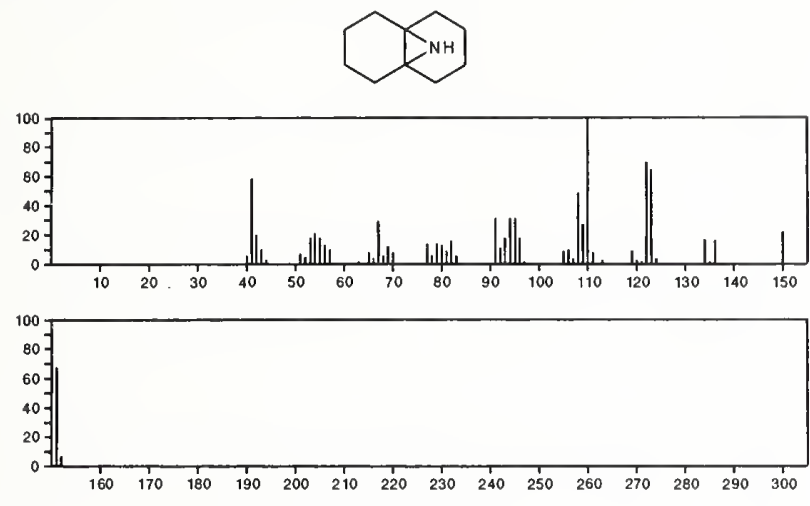

152

Methane, tetrachloro-

$\mathrm{CCl}_{4}$

$56-23-5$

$\mathrm{CCl}_{4}$

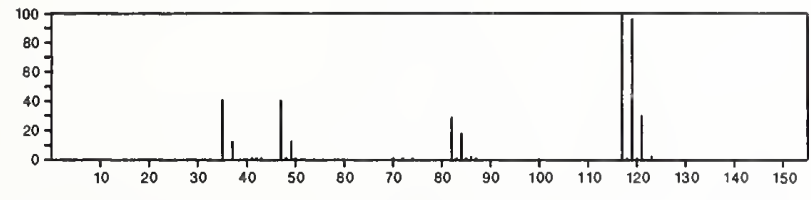

152

$\mathrm{C}_{2} \mathrm{HCl}_{2} \mathrm{~F}_{3}$

Ethane, 2,2-dichloro-1,1,1-trifluoro-

306-83-2

$\mathrm{Cl}_{2} \mathrm{CHCF}_{3}$
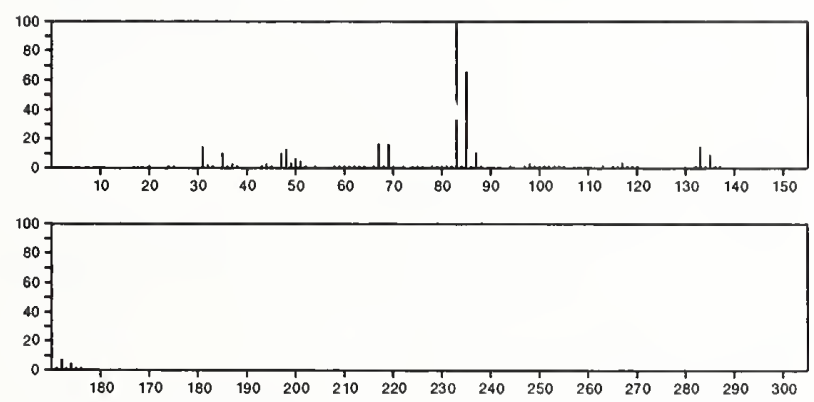

152

$\mathrm{C}_{2} \mathrm{HCl}_{2} \mathrm{~F}_{3}$

$354-23-4$

Ethane, 1,2-dichloro-1,1,2-trifluoro-

$\mathrm{FCHCl} \mathrm{CClF} 2$
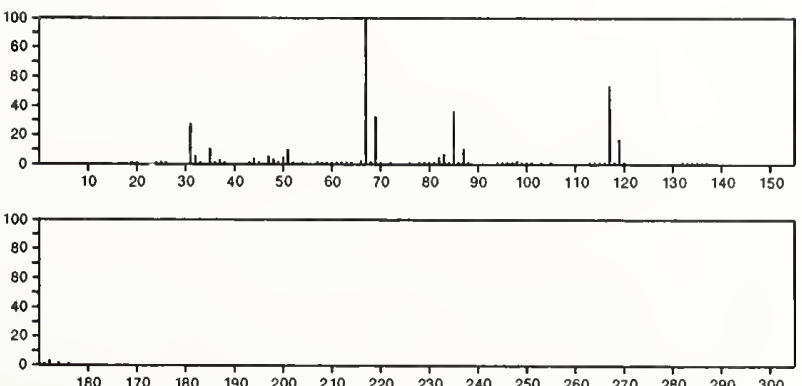

152

1,2-Ethanediol, dinitrate

$\mathrm{C}_{2} \mathrm{H}_{4} \mathrm{~N}_{2} \mathrm{O}_{6}$

628-96-6

$\mathrm{O}_{2} \mathrm{NOCH}_{2} \mathrm{CH}_{2} \mathrm{ONO}_{2}$

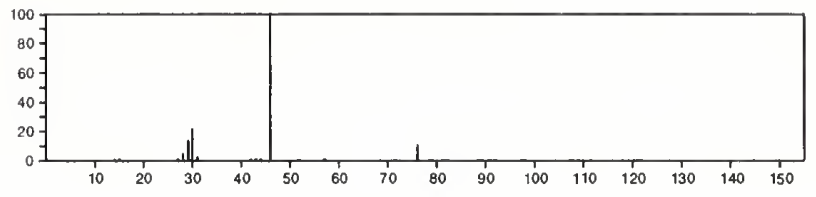

152

$\mathrm{C}_{3} \mathrm{H}_{3} \mathrm{~F}_{3} \mathrm{~N}_{4}$

$697-94-9$

1H-Tetrazole, 1-methyl-5-(trifluoromethyl)-
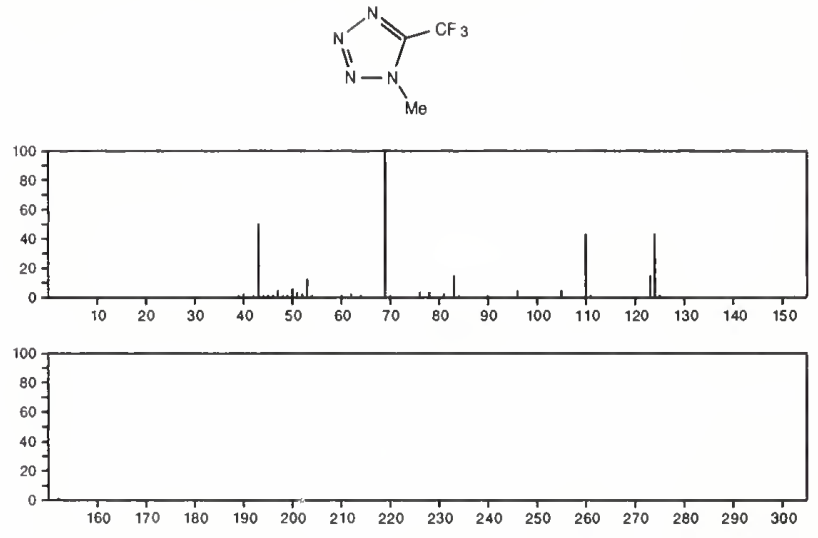

152

$\mathrm{C}_{3} \mathrm{H}_{3} \mathrm{~F}_{3} \mathrm{~N}_{4}$

$768-27-4$

$2 \mathrm{H}$-Tetrazole, 2-methyl-5-(trifluoromethyl)-
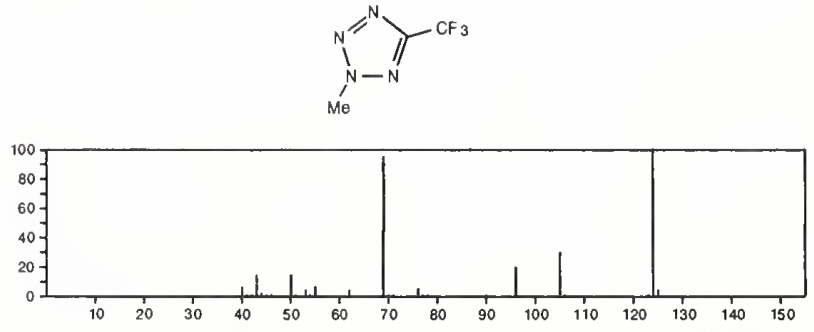

152

$\mathrm{C}_{3} \mathrm{H}_{5} \mathrm{BrO}_{2}$

Acetic acid, bromo-, methyl ester

$96-32-2$

$\mathrm{BrCH}_{2} \mathrm{C}(\mathrm{O}) \mathrm{OMe}$
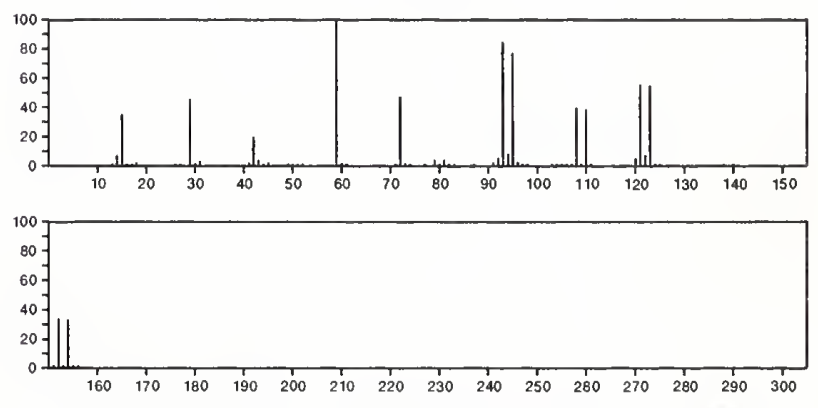

152

Propanoic acid, 3-bromo-

\section{$\mathrm{C}_{3} \mathrm{H}_{5} \mathrm{BrO}_{2}$}

$590-92-1$

$\mathrm{BrCH}_{2} \mathrm{CH}_{2} \mathrm{CO}_{2} \mathrm{H}$

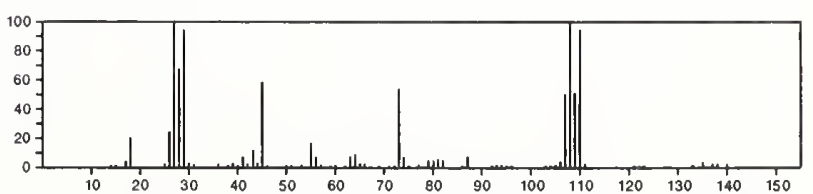




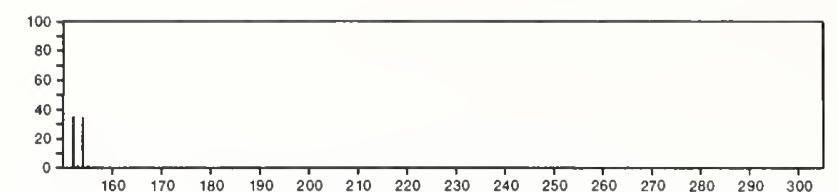

$152 \quad \mathrm{C}_{3} \mathrm{H}_{9} \mathrm{BS}_{3}$

Thioboric acid $\left(\mathrm{H}_{3} \mathrm{BS}_{3}\right)$, trimethyl ester

997-49-9
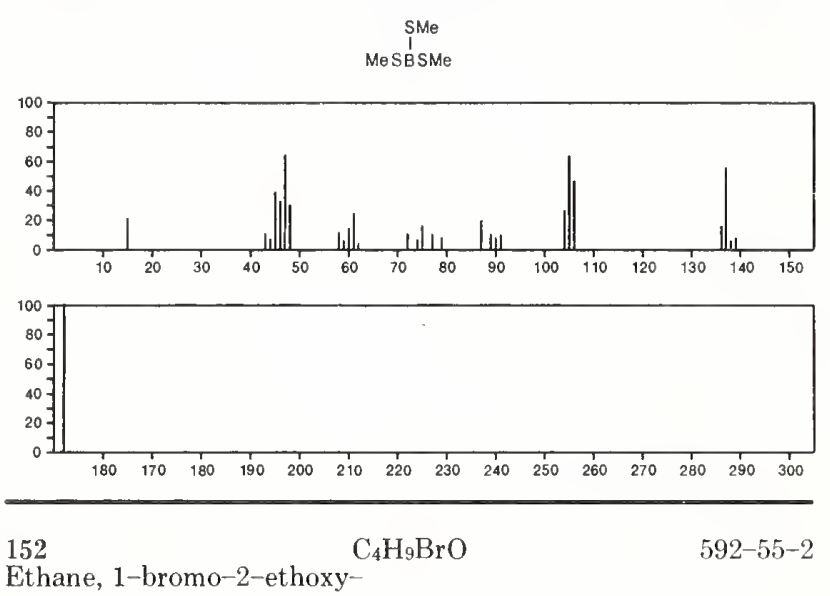

Ethane, 1-bromo-2-ethoxy-

$\mathrm{E} t \mathrm{OCH}_{2} \mathrm{CH}_{2} \mathrm{Br}$
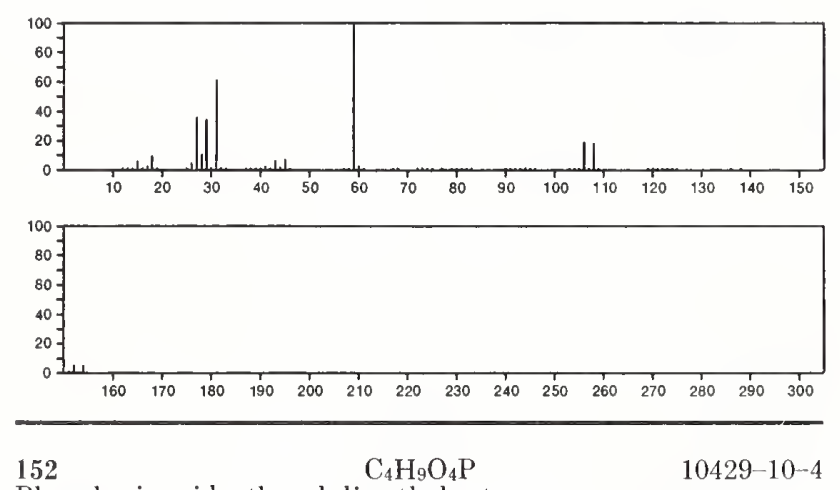

Phosphoric acid, ethenyl dimethyl ester
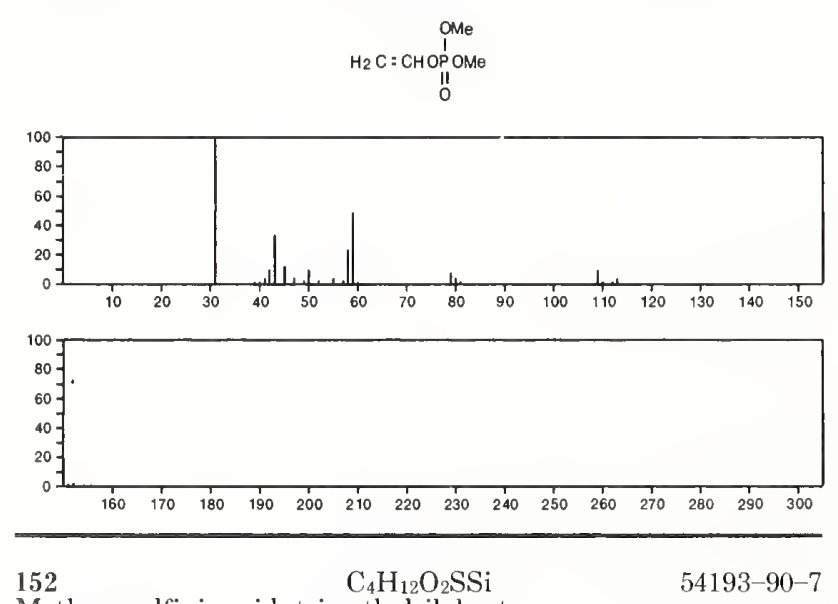

Methanesulfinic acid, trimethylsilyl ester

MeS(O) OSiMe 3

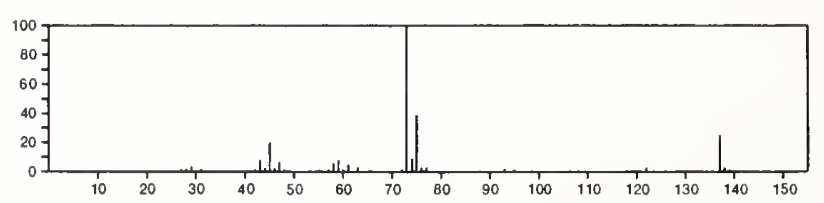

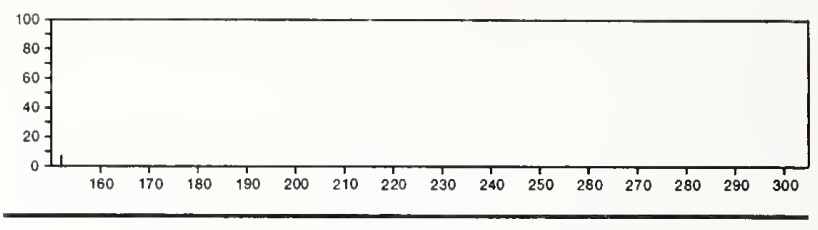

152

$\mathrm{C}_{4} \mathrm{H}_{12} \mathrm{O}_{4} \mathrm{Si}$

Silicic acid $\left(\mathrm{H}_{4} \mathrm{SiO}_{4}\right)$, tetramethyl ester

$681-84-5$
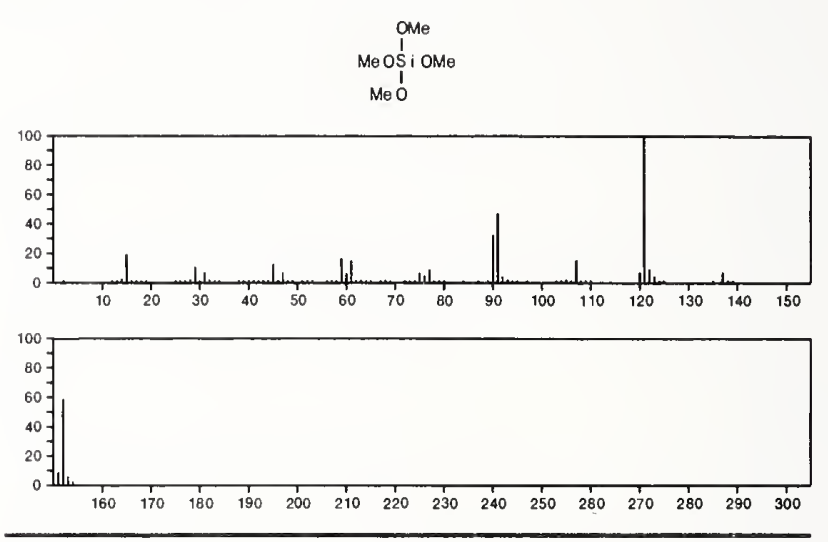

152

$\mathrm{C}_{4} \mathrm{H}_{16} \mathrm{~B}_{8}$

31566-09-3

9,10-Dicarbadecaborane(12), 9,10-dimethyl-
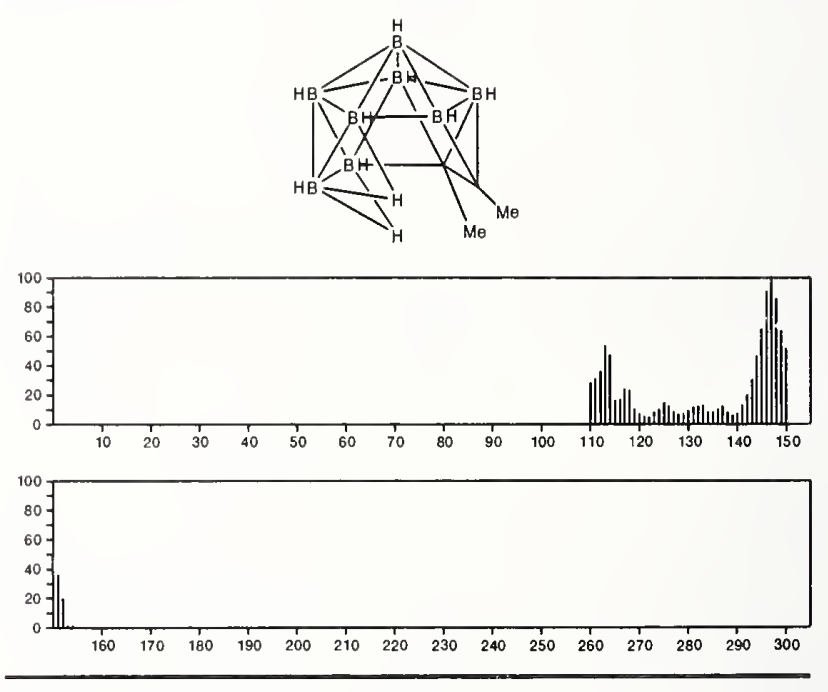

152

$\mathrm{C}_{5} \mathrm{H}_{4} \mathrm{~N}_{4} \mathrm{O}_{2}$

69-89-6

1 H-Purine-2,6-dione, 3,7-dihydro-
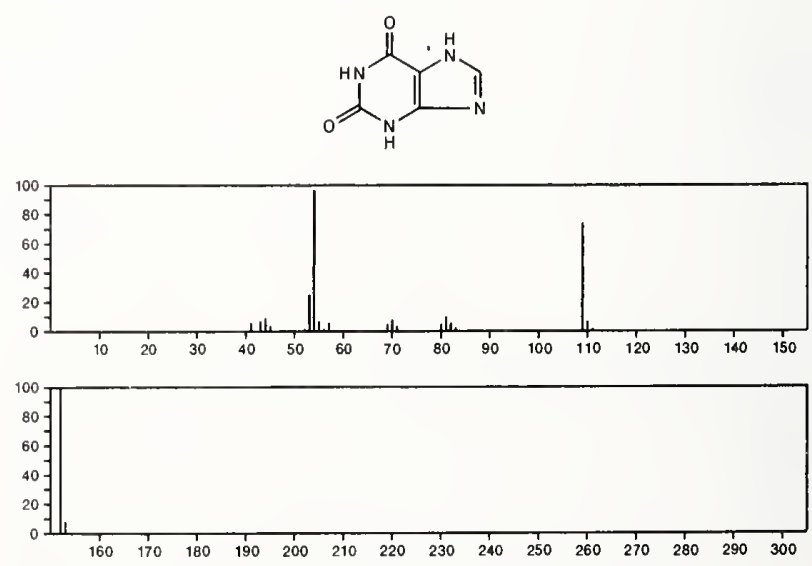
152

$\mathrm{C}_{5} \mathrm{H}_{4} \mathrm{~N}_{4} \mathrm{O}_{2}$

$1 \mathrm{H}$-Pyrazolo[3,4-d]pyrimidine-4,6 $(5 \mathrm{H}, 7 \mathrm{H})$-dione
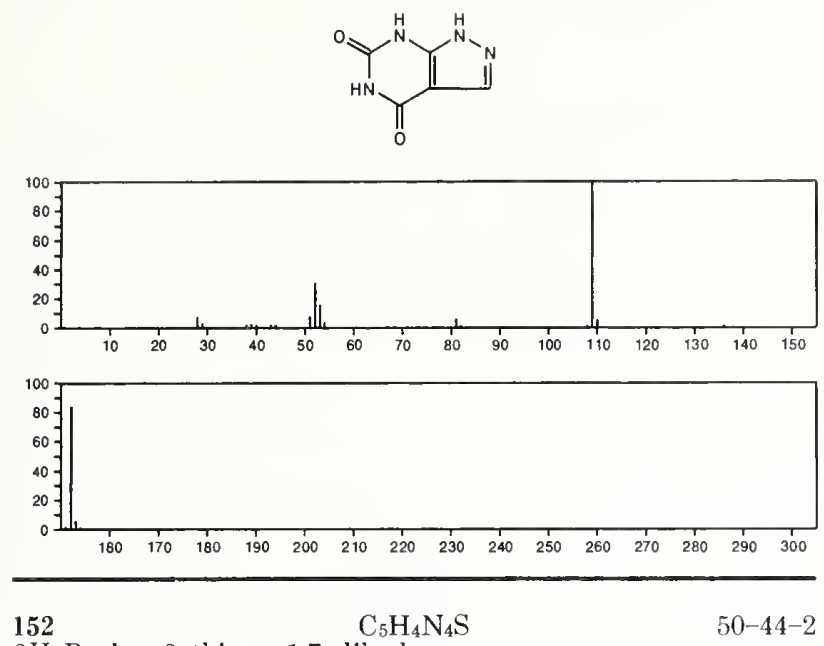

6H-Purine-6-thione, 1,7-dihydro-
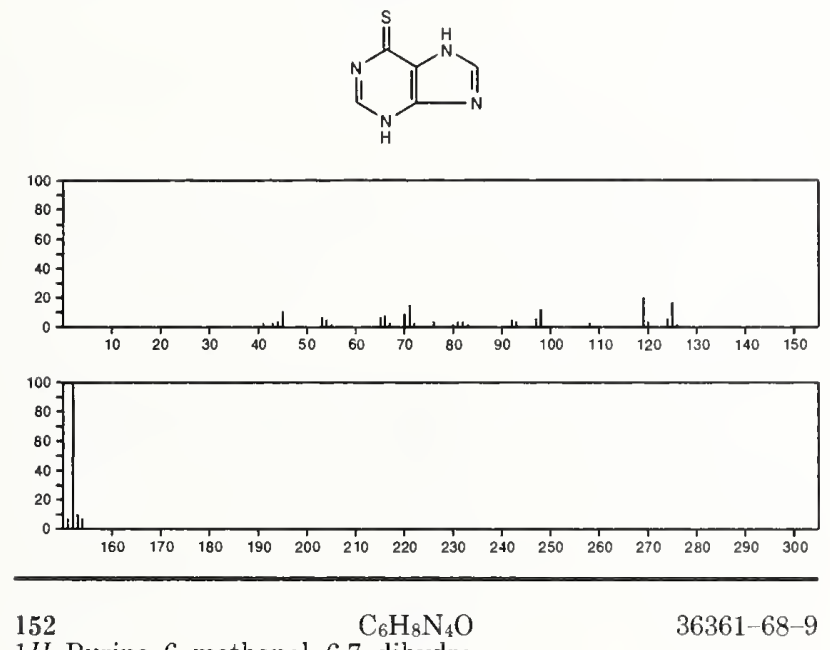

1 H-Purine-6-methanol, 6,7-dihydro-
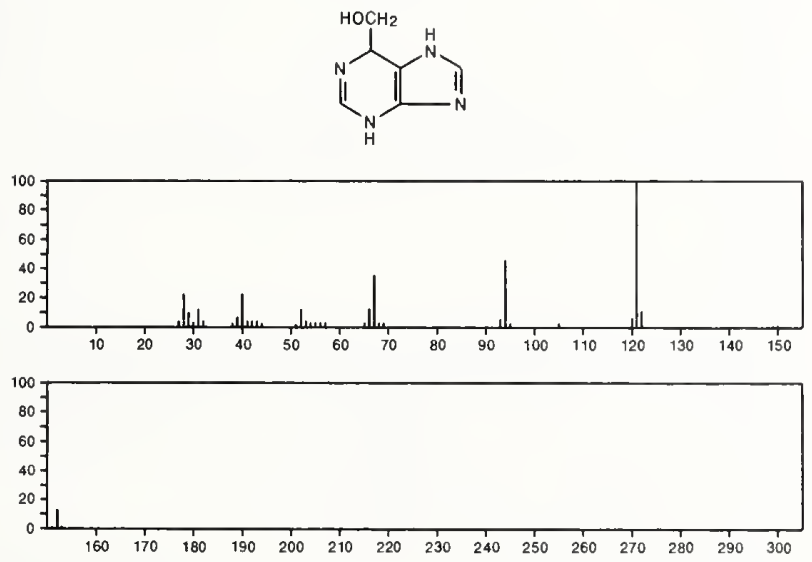

152

$\mathrm{C}_{6} \mathrm{H}_{10} \mathrm{Cl}_{2}$

$822-86-6$

Cyclohexane, 1,2-dichloro-, trans-
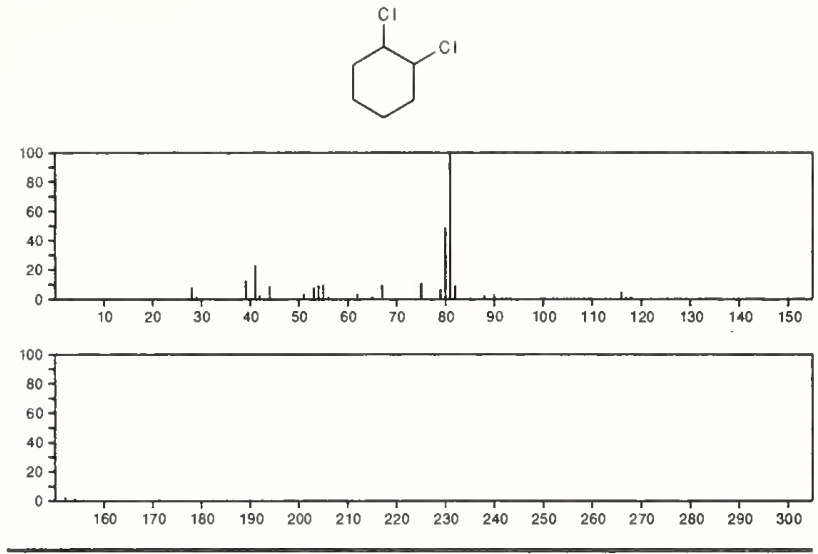

152

$\mathrm{C}_{6} \mathrm{H}_{10} \mathrm{Cl}_{2}$

$1121-21-7$

Cyclohexane, 1,2-dichloro-
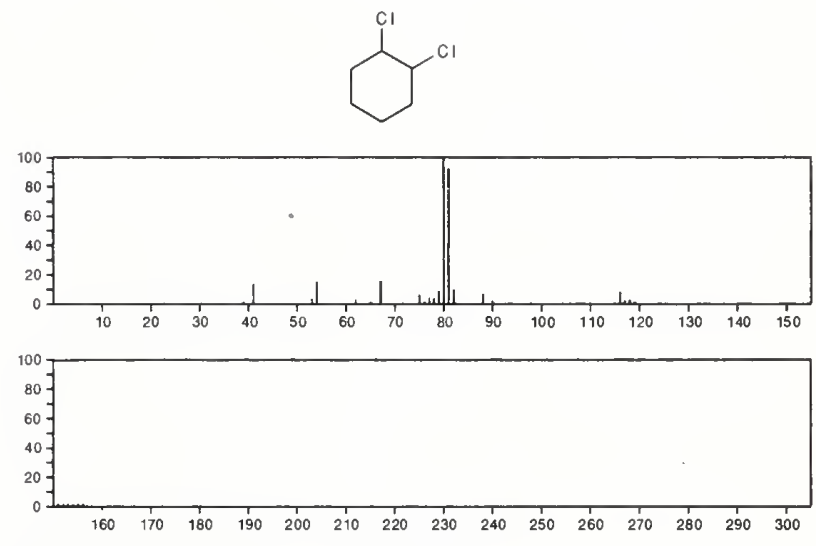

152

$\mathrm{C}_{6} \mathrm{H}_{10} \mathrm{Cl}_{2}$

2108-92-1

Cyclohexane, 1,1-dichloro-
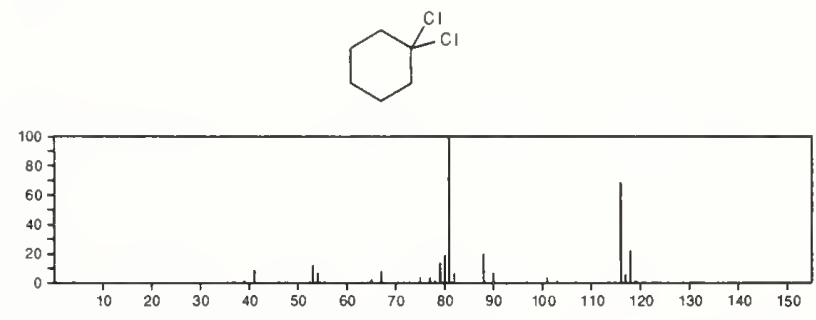

152

$\mathrm{C}_{6} \mathrm{H}_{10} \mathrm{Cl}_{2}$

$10498-35-8$

Cyclohexane, 1,2-dichloro-, cis-
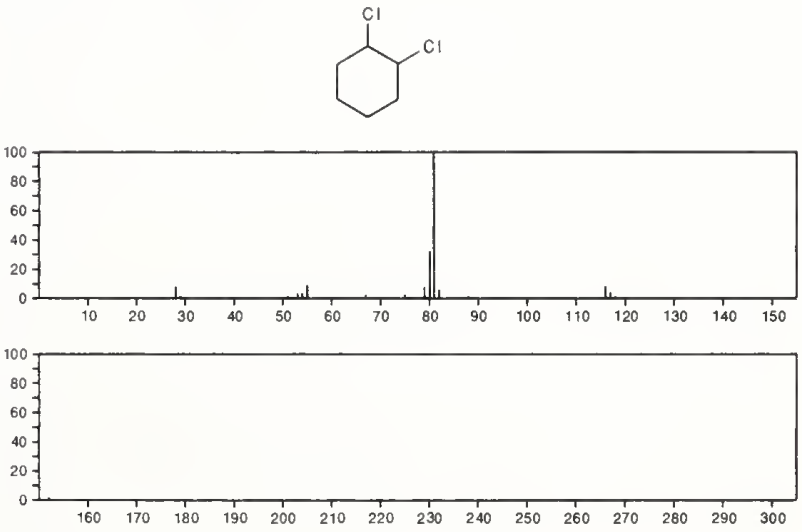
Cyclohexane, 1,4-dichloro-, cis-<smiles>ClC1CCC(Cl)CC1</smiles>
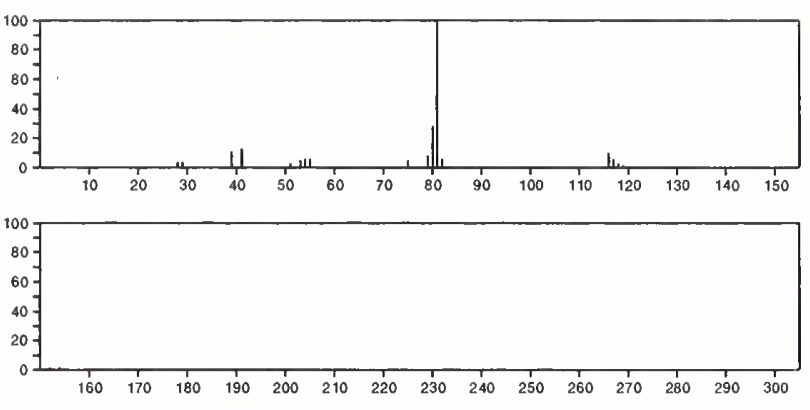

152

$\mathrm{C}_{6} \mathrm{H}_{10} \mathrm{Cl}_{2}$

Cyclohexane, 1,4-dichloro-, trans-
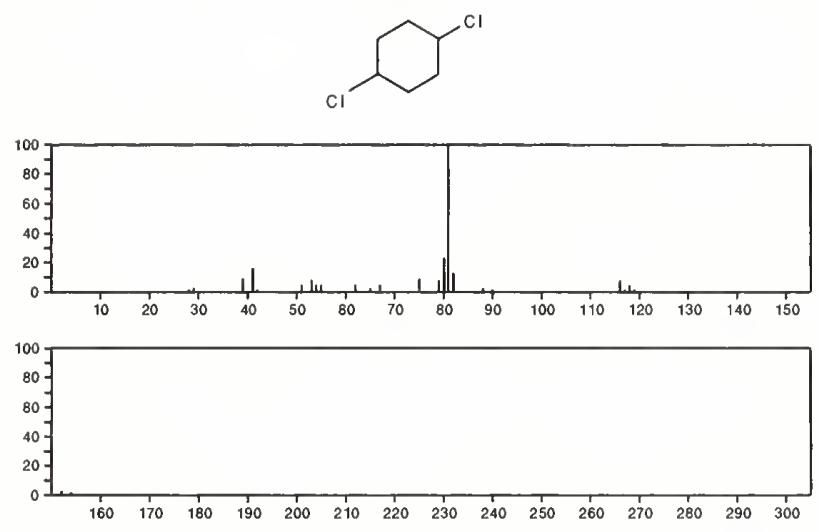

152

$\mathrm{C}_{6} \mathrm{H}_{10} \mathrm{Cl}_{2}$

$19398-57-3$

Cyclohexane, 1,4-dichloro-
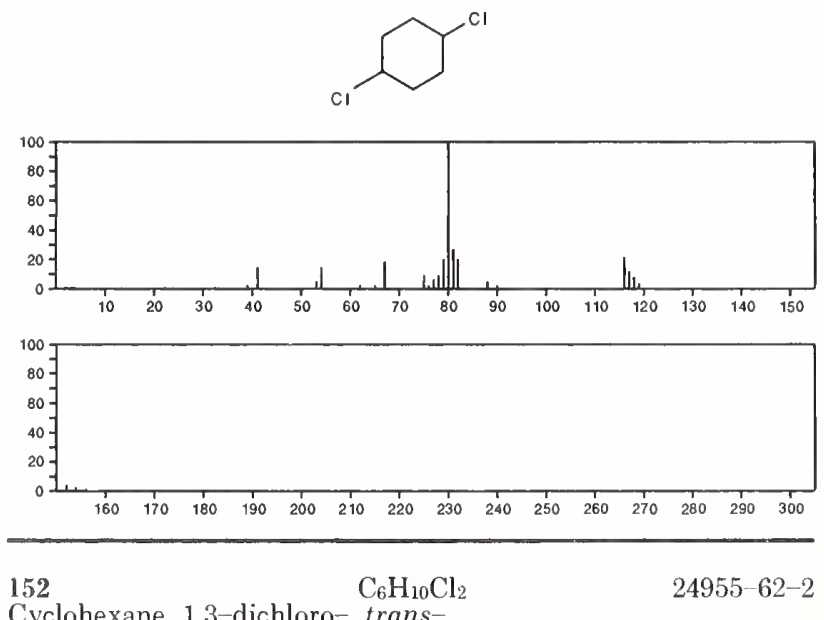

Cyclohexane, 1,3-dichloro-, trans-
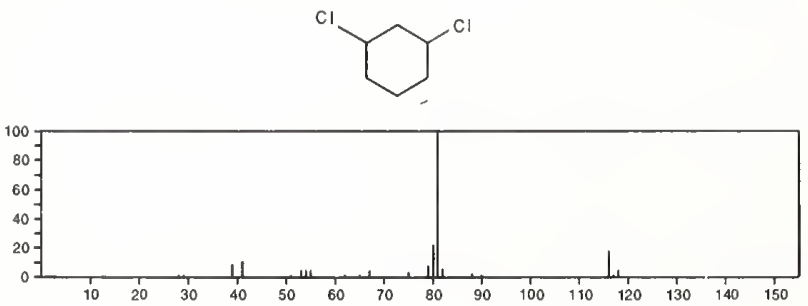
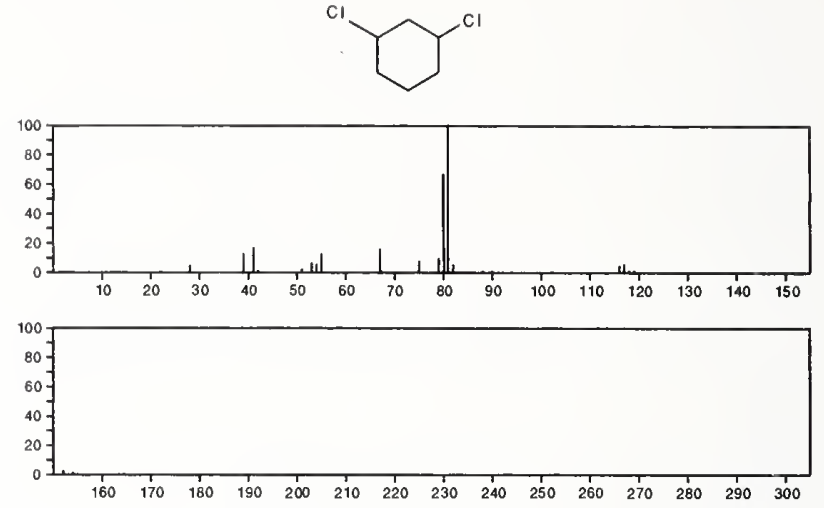

152

1-Pentene, 5-chloro-4-(chlorome

$\mathrm{C}_{6} \mathrm{H}_{10} \mathrm{Cl}_{2}$

$27990-74-5$

$\mathrm{CH}_{2} \mathrm{Cl}$

$\mathrm{H}_{2} \mathrm{C}=\mathrm{CHCH}_{2} \mathrm{CHCH}_{2} \mathrm{Cl}$
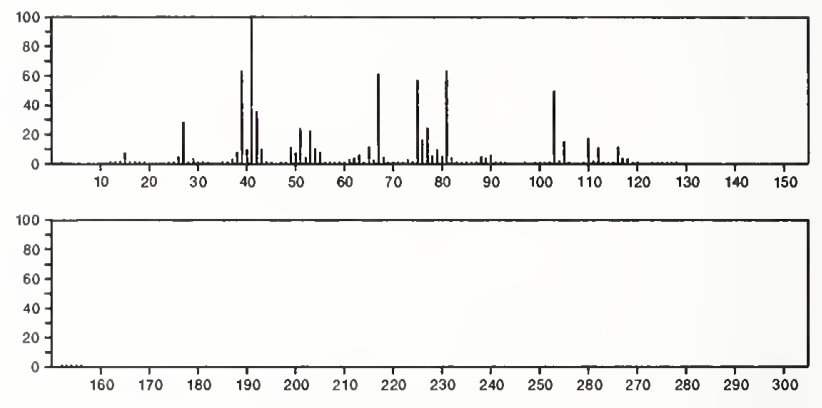

152

Cyclohexane, 1,3-dichloro-

$\mathrm{C}_{6} \mathrm{H}_{10} \mathrm{Cl}_{2}$

$55887-78-0$
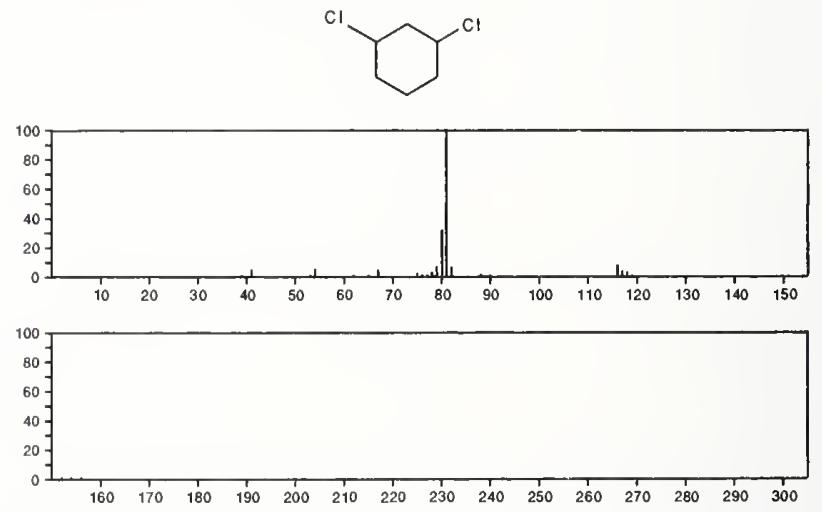

152

$\mathrm{C}_{6} \mathrm{H}_{14} \mathrm{ClP}$

40244-90-4

Phosphinous chloride, bis(1-methylethyl)-

$\mathrm{CIP}(\mathrm{Pr}-\mathrm{i})_{2}$
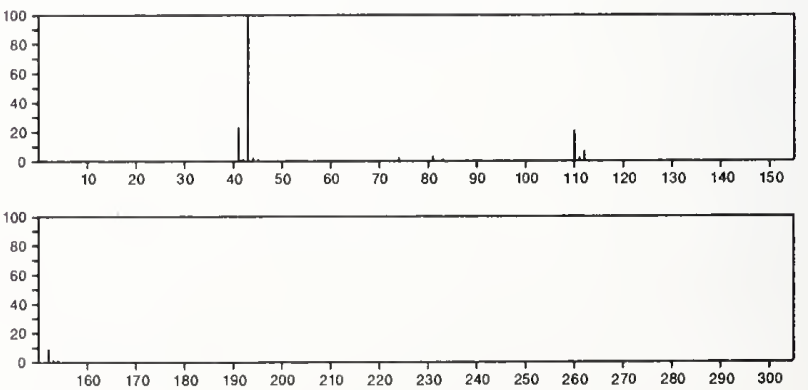
152

$\mathrm{C}_{7} \mathrm{H}_{8} \mathrm{~N}_{2} \mathrm{O}_{2}$

$99-52-5$

152

$\mathrm{C}_{8} \mathrm{H}_{8} \mathrm{OS}$

$5873-86-9$

Benzenamine, 2-methyl-4-nitro-<smiles>Cc1cc([N+](=O)[O-])ccc1N</smiles>
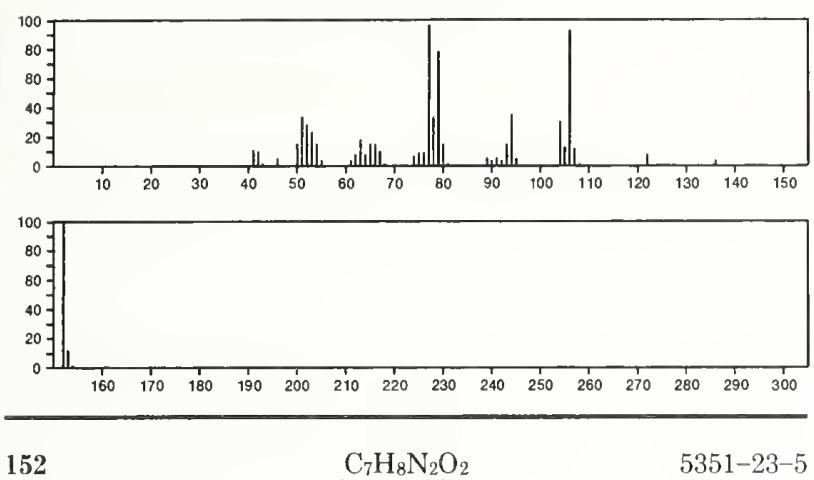

Benzoic acid, 4-hydroxy-, hydrazide
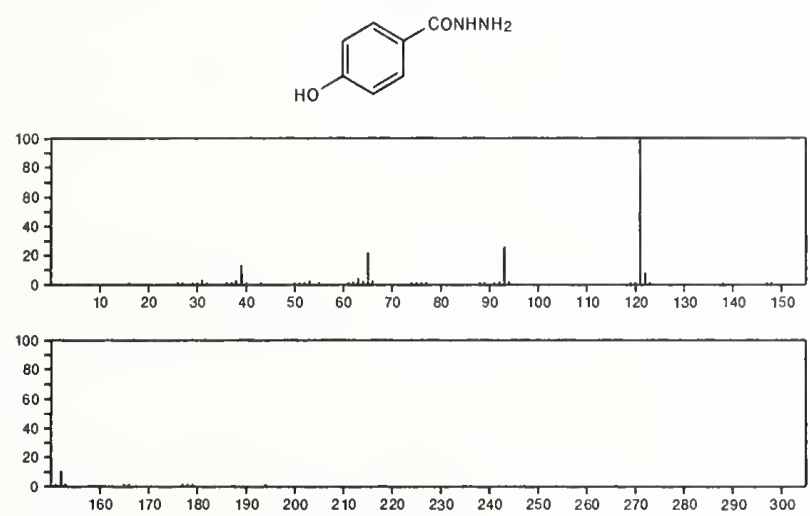

152

Thiourea, phenyl-

$\mathrm{C}_{7} \mathrm{H}_{8} \mathrm{~N}_{2} \mathrm{~S}$

103-85-5

$\mathrm{H}_{2}$ NCSNHPh
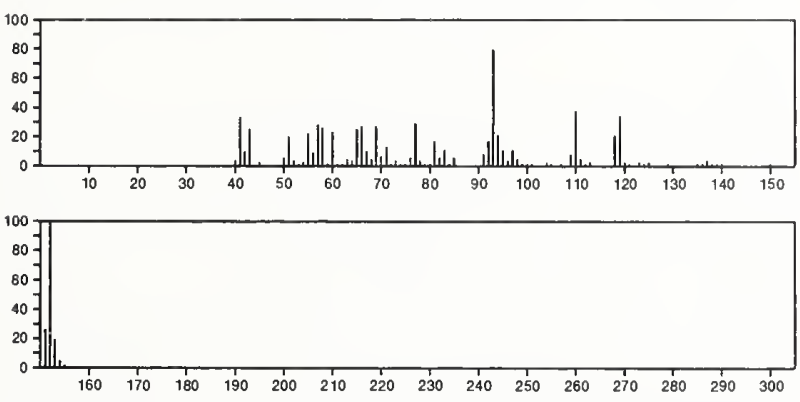

152

$\mathrm{C}_{7} \mathrm{H}_{8} \mathrm{~N}_{2} \mathrm{~S}$

Benzenecarbothioic acid, hydrazide

$20605-40-7$

$\mathrm{H}_{2}$ NNHCSPh
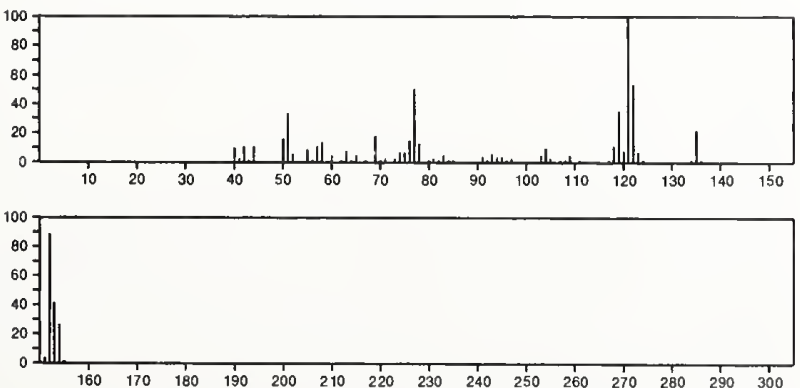

Benzenecarbothioic acid, $O$-methyl ester

$\mathrm{MeOC}(\mathrm{S}) \mathrm{Ph}$
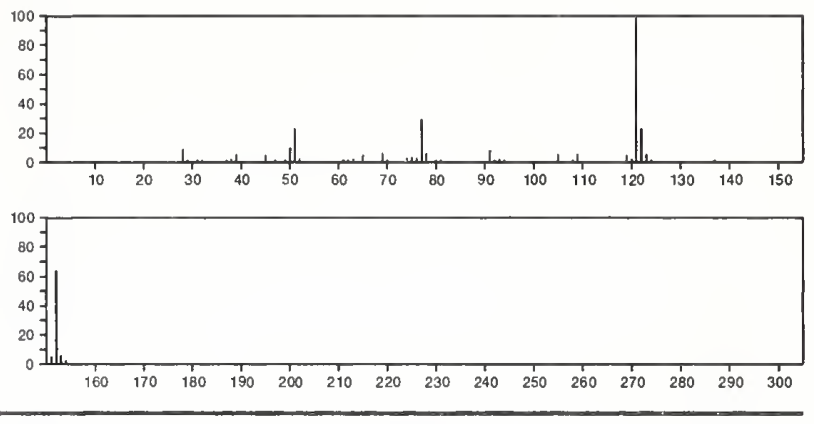

152

$\mathrm{C}_{8} \mathrm{H}_{8} \mathrm{OS}$

$5925-68-8$

Benzenecarbothioic acid, $S$-methyl ester

$\mathrm{MeSc}(\mathrm{O}) \mathrm{Ph}$
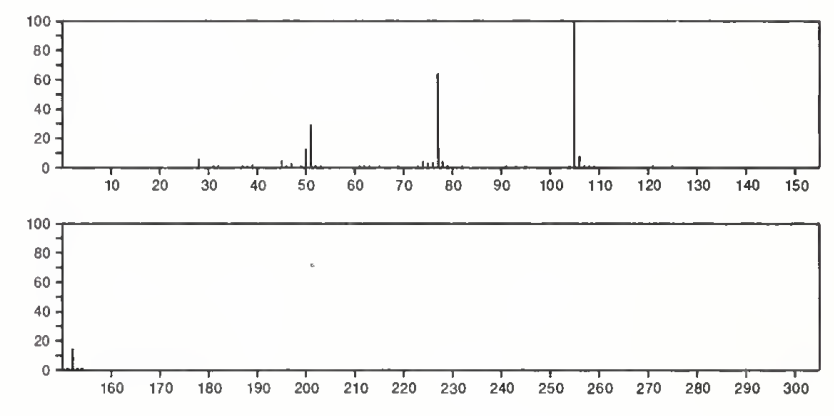

152

$\mathrm{C}_{8} \mathrm{H}_{8} \mathrm{O}_{3}$

Benzoic acid, 2-hydroxy-3-methyl-

83-40-9
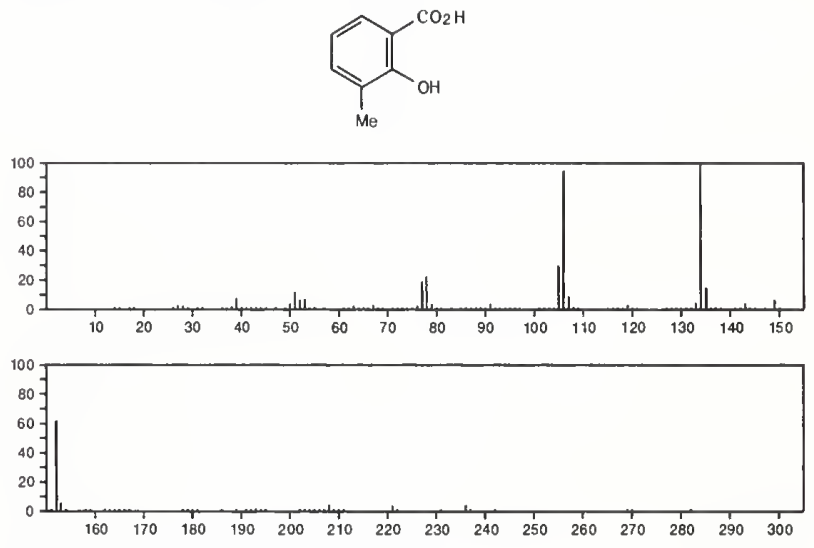

152

$\mathrm{C}_{8} \mathrm{H}_{8} \mathrm{O}_{3}$

85-43-8

1,3-Isobenzofurandione, 3a,4,7,7a-tetrahydro-
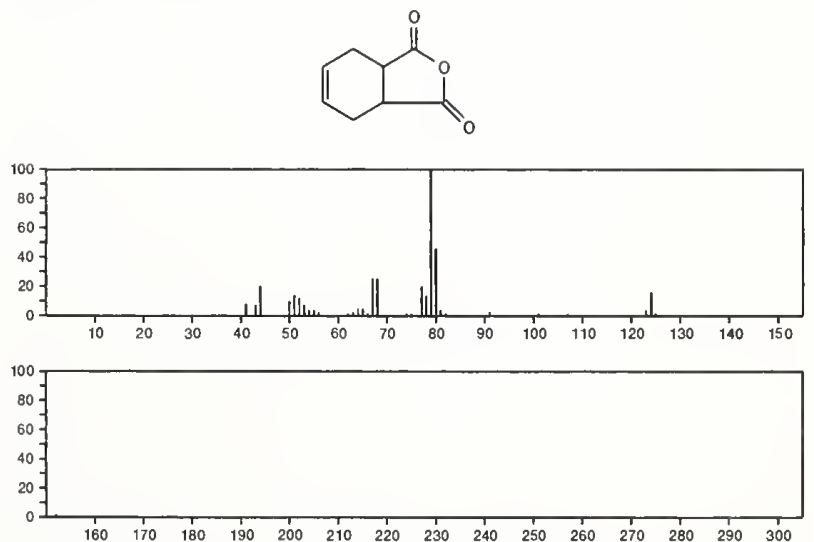
152

$\mathrm{C}_{8} \mathrm{H}_{8} \mathrm{O}_{3}$

Ethanone, 1-(2,4-dihydroxyphenyl)
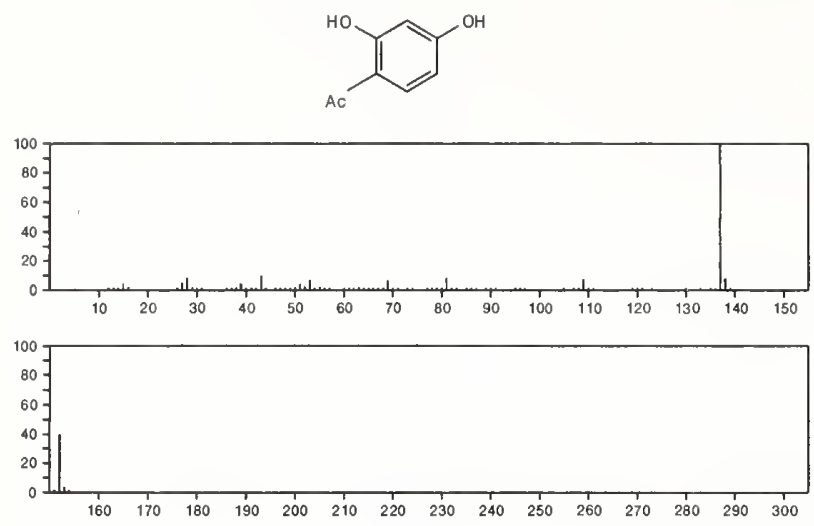

152

Benzeneacetic acid, $\alpha$-hydroxy-

$\mathrm{C}_{8} \mathrm{H}_{8} \mathrm{O}_{3}$

$90-64-2$

$\mathrm{PhCH}(\mathrm{OH}) \mathrm{CO}_{2} \mathrm{H}$
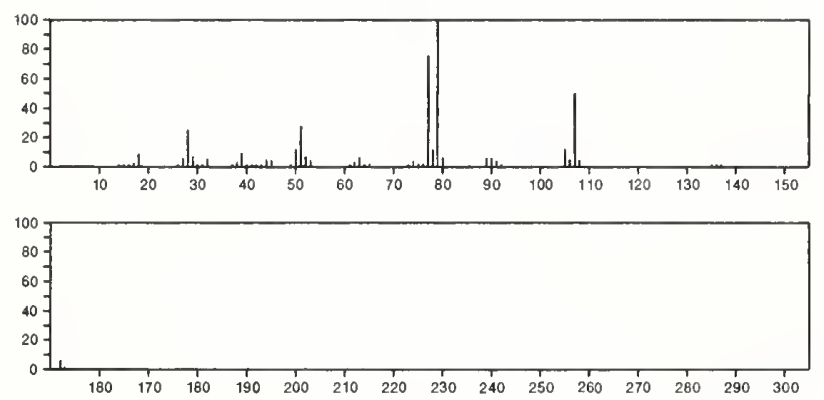

152

$\mathrm{C}_{8} \mathrm{H}_{8} \mathrm{O}_{3}$

$99-76-3$

Benzoic acid, 4-hydroxy-, methyl ester
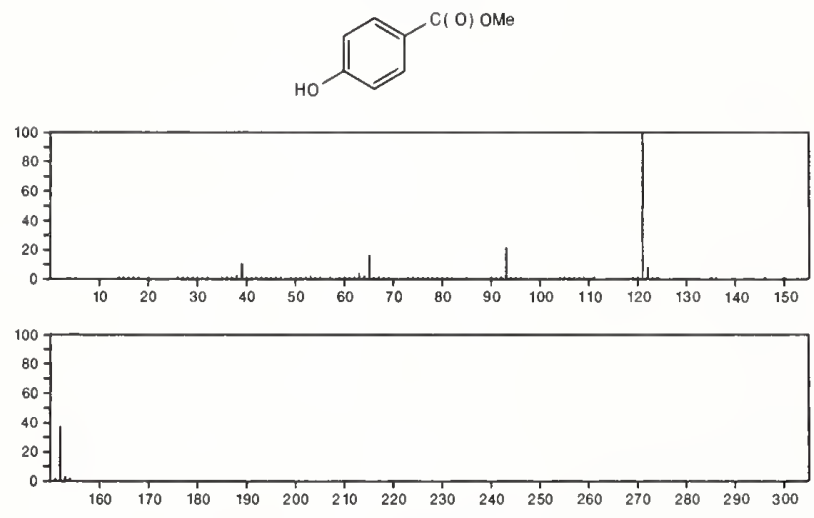

152

$\mathrm{C}_{8} \mathrm{H}_{8} \mathrm{O}_{3}$

100-09-4

Benzoic acid, 4-methoxy-
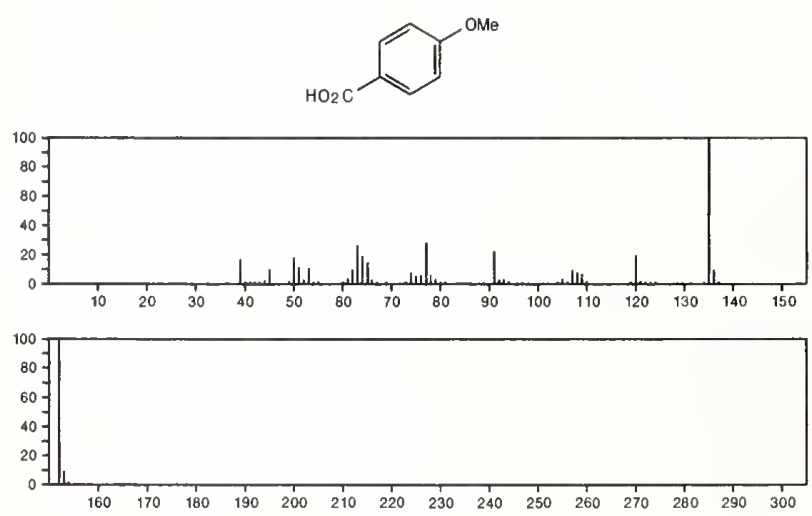

$152 \quad \mathrm{C}_{8} \mathrm{H}_{8} \mathrm{O}_{3}$

Benzoic acid, 2-hydroxy-, methyl ester

119-36-8<smiles>O=C(O[Na])c1ccccc1O</smiles>
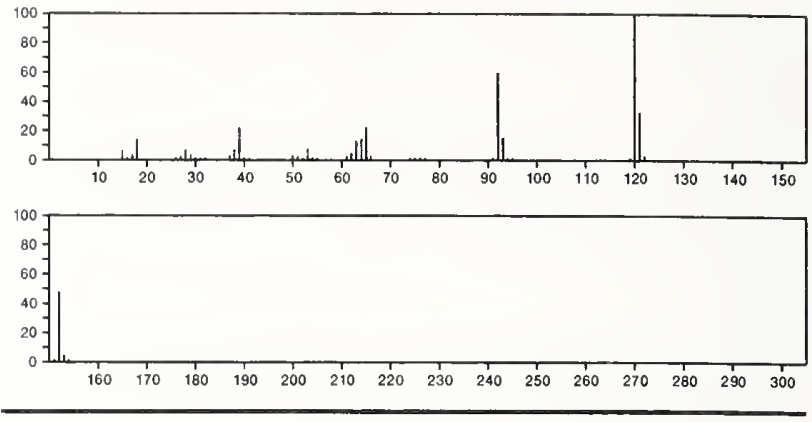

152

$\mathrm{C}_{8} \mathrm{H}_{8} \mathrm{O}_{3}$

121-33-5

Benzaldehyde, 4-hydroxy-3-methoxy-
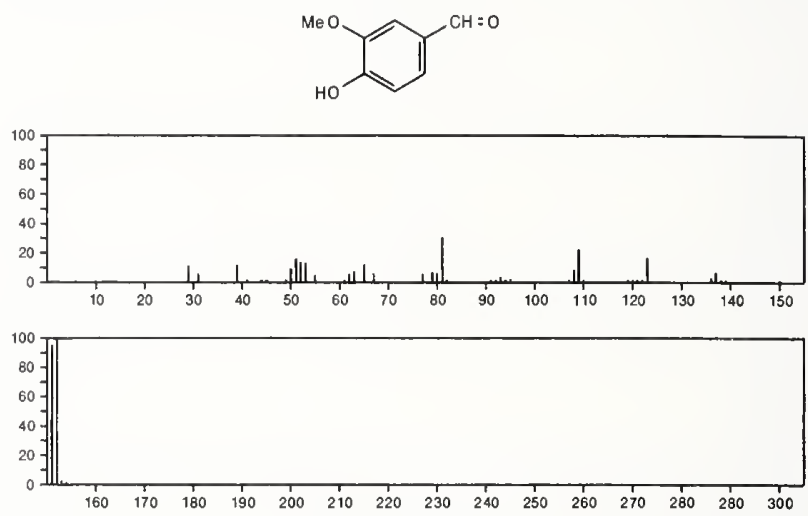

152

Acetic acid, phenoxy-

$\mathrm{C}_{8} \mathrm{H}_{8} \mathrm{O}_{3}$

$122-59-8$

$\mathrm{HO}_{2} \mathrm{CCH}_{2} \mathrm{OPh}$
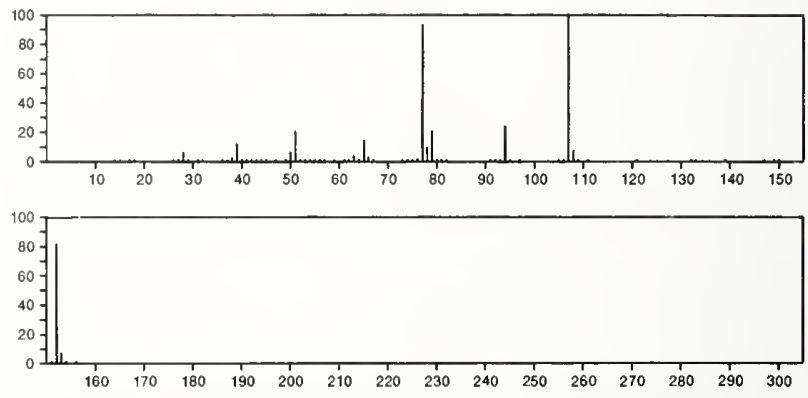

152

$\mathrm{C}_{8} \mathrm{H}_{8} \mathrm{O}_{3}$

$156-38-7$

Benzeneacetic acid, 4-hydroxy-
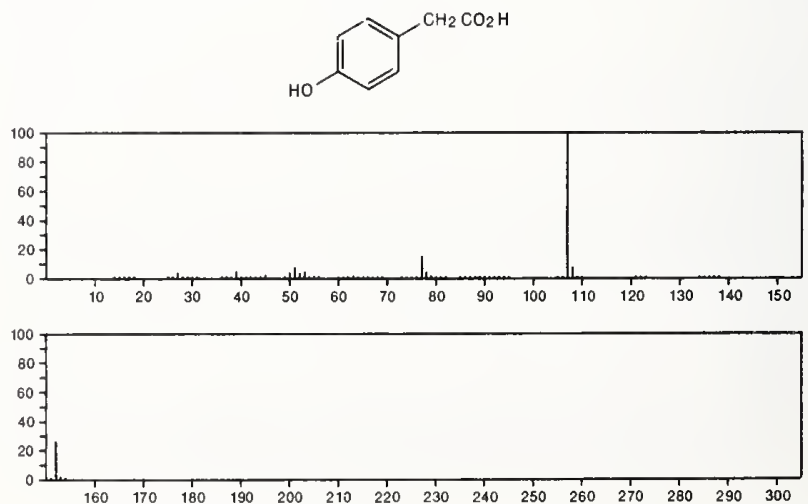
152

$\mathrm{C}_{8} \mathrm{H}_{8} \mathrm{O}_{3}$

Benzaldehyde, 2,4-dihydroxy-6-methyl
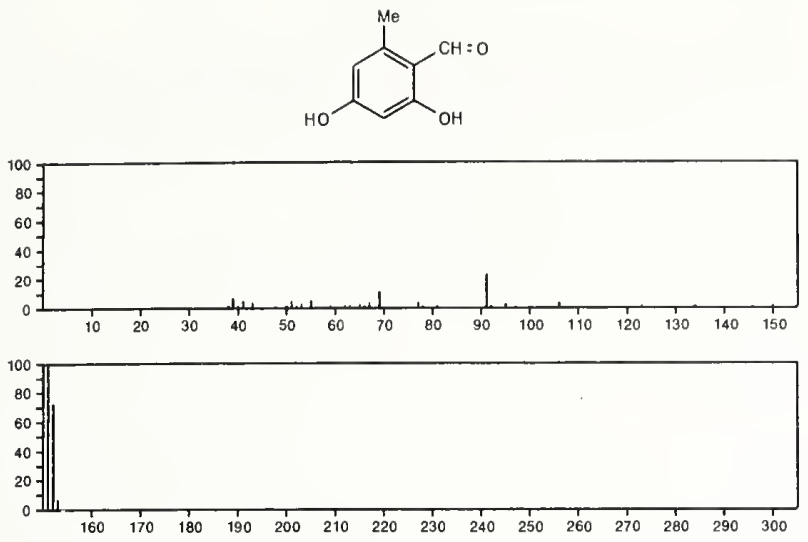

152

Benzoic acid, 2-hydroxy-6-methyl-

$567-61-3$
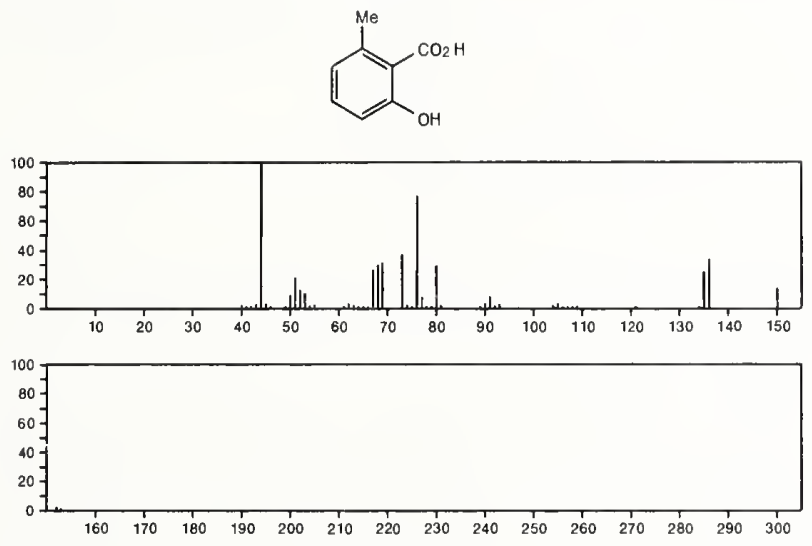

\section{2}

Benzoic acid, 2-methoxy-

$$
\mathrm{C}_{8} \mathrm{H}_{8} \mathrm{O}_{3}
$$

$579-75-9$
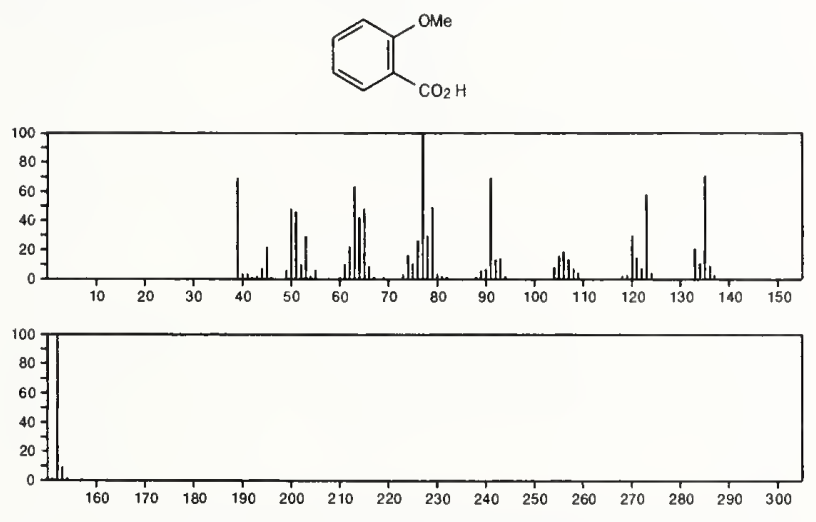

152

Benzoic acid, 3-methoxy-

$$
\mathrm{C}_{8} \mathrm{H}_{8} \mathrm{O}_{3}
$$

$586-38-9$
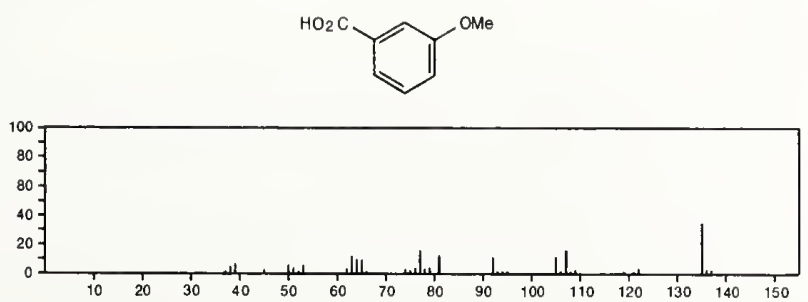

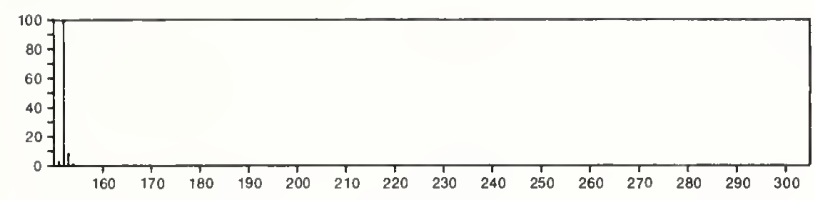

152

$\mathrm{C}_{8} \mathrm{H}_{8} \mathrm{O}_{3}$

Benzoic acid, 2-(hydroxymethyl)-
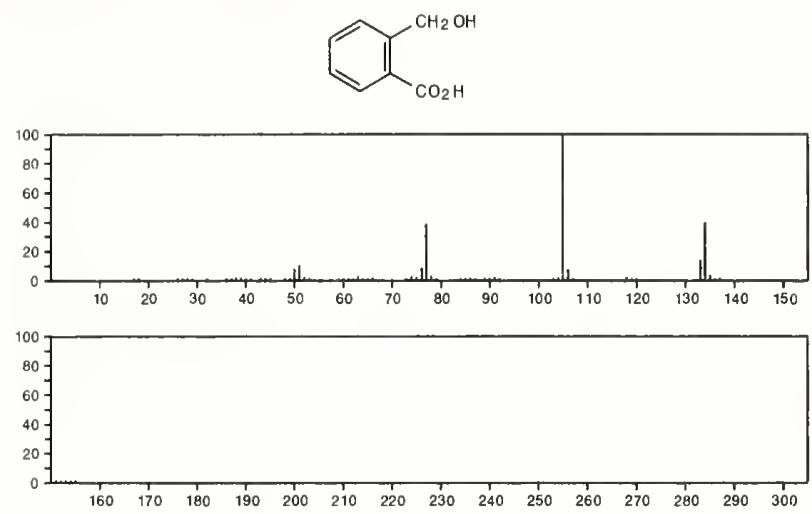

$152 \quad \mathrm{C}_{8} \mathrm{H}_{8} \mathrm{O}_{3}$

$614-13-1$

2,5-Cyclohexadiene-1,4-dione, 2-methoxy-5-methyl-
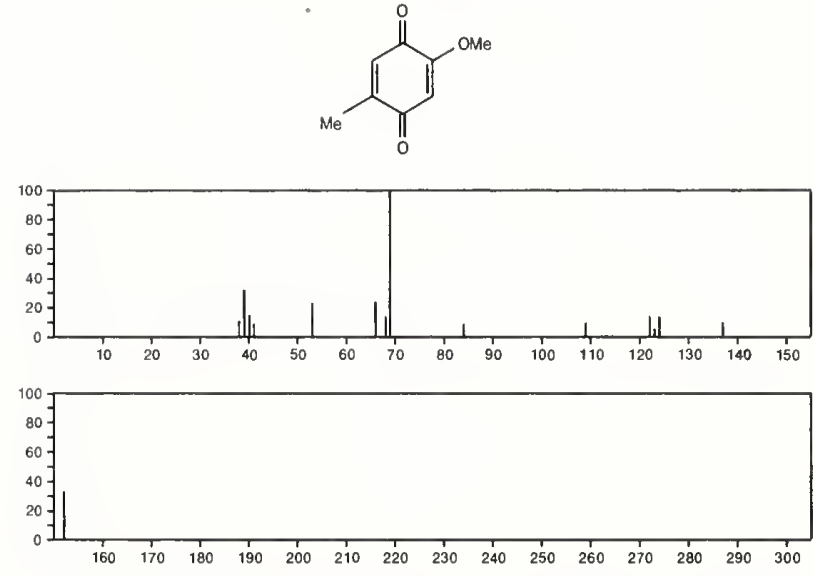

152

Benzeneacetic acid, 2-hydroxy

$\mathrm{C}_{8} \mathrm{H}_{8} \mathrm{O}_{3}$

614-75-5
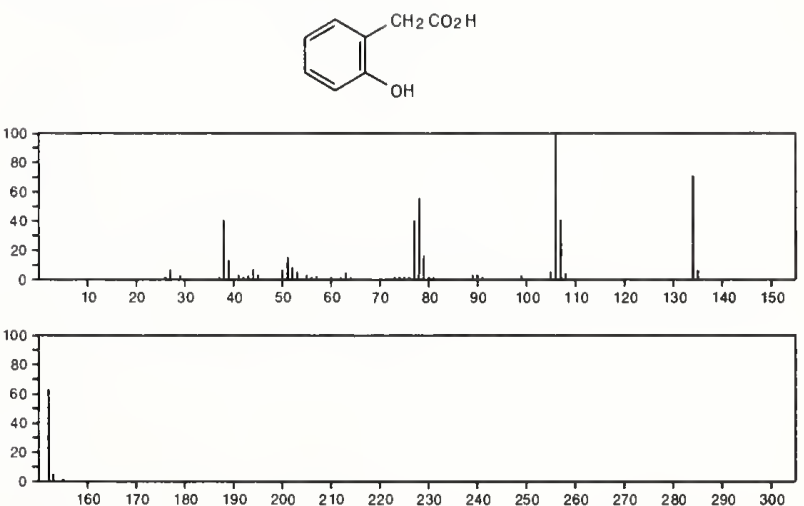
152

$\mathrm{C}_{8} \mathrm{H}_{8} \mathrm{O}_{3}$

Benzeneacetic acid, 3-hydroxy-

$621-37-4$
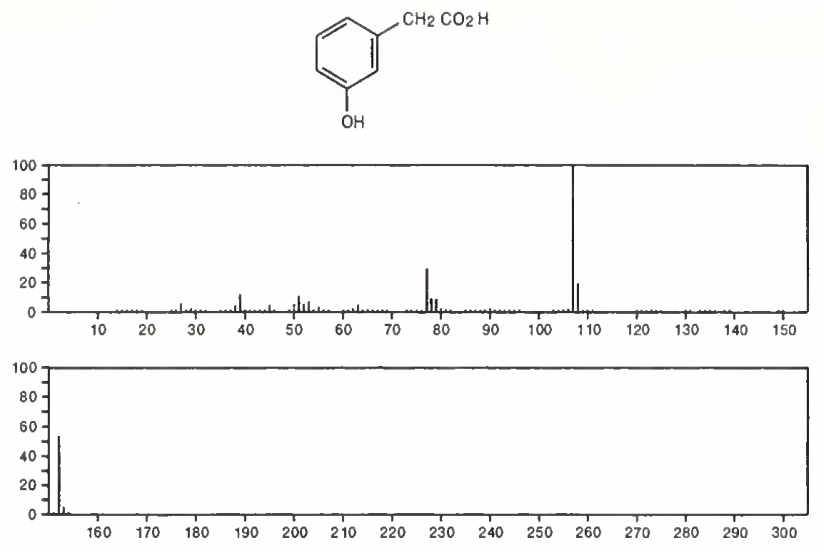

152

$\mathrm{C}_{8} \mathrm{H}_{8} \mathrm{O}_{3}$

2-Furancarboxylic acid, 2-propenyl ester

$4208-49-5$

$\triangle \mathrm{C}(\mathrm{O}) \mathrm{OCH}_{2} \mathrm{CH}=\mathrm{CH}_{2}$
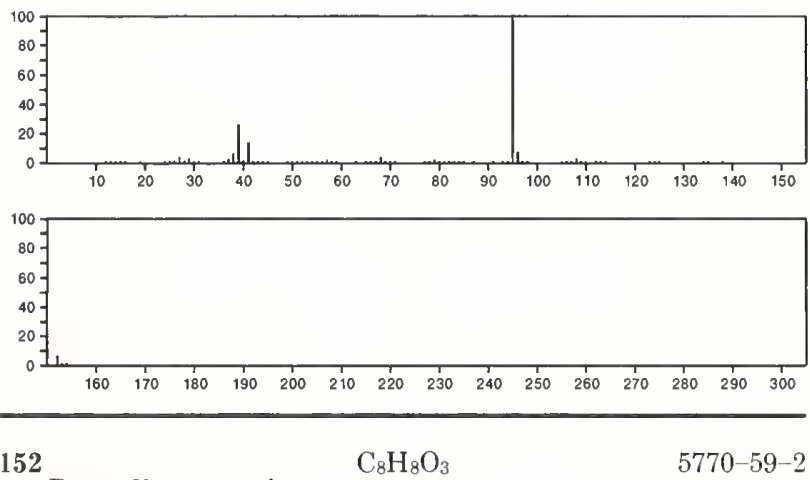

1,4-Benzodioxan-2-ol<smiles>OC1COc2ccccc2O1</smiles>
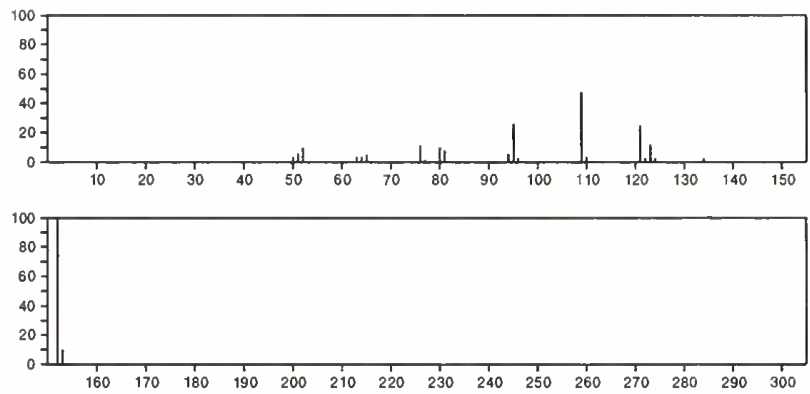

$152 \quad \mathrm{C}_{8} \mathrm{H}_{8} \mathrm{O}_{3}$

$13149-03-6$

1,3-Isobenzofurandione, 3a,4,7,7a-tetrahydro-, trans-
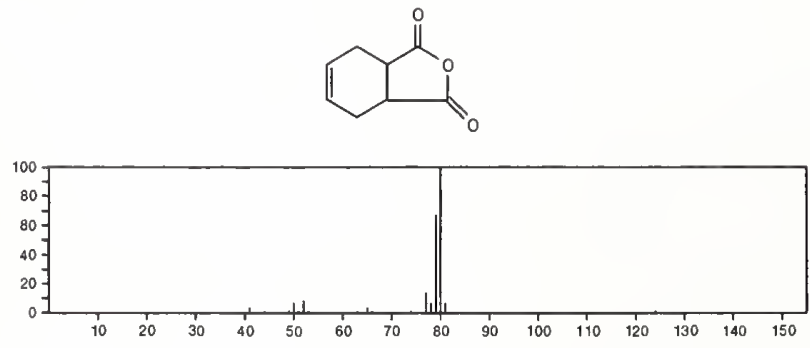

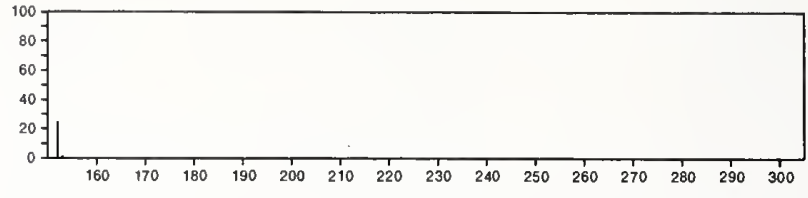

152

$\mathrm{C}_{8} \mathrm{H}_{8} \mathrm{O}_{3}$

Carbonic acid, methyl phenyl ester

$13509-27-8$

Phoc (o) OMe
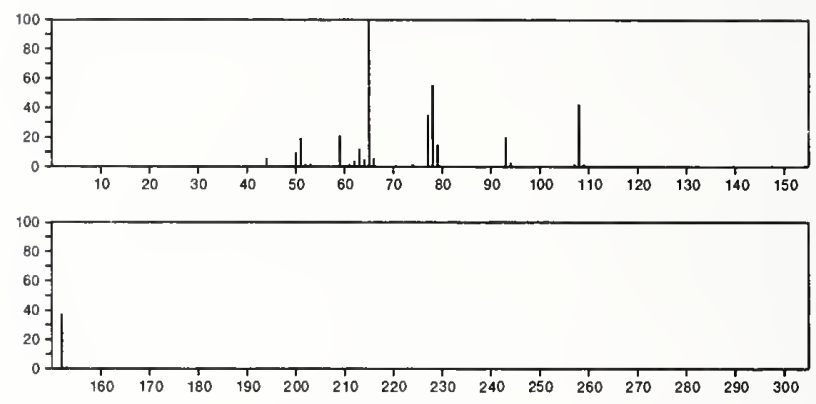

152

$\mathrm{C}_{8} \mathrm{H}_{8} \mathrm{O}_{3}$

Benzoic acid, 3-hydroxy-, methyl ester

$19438-10-9$
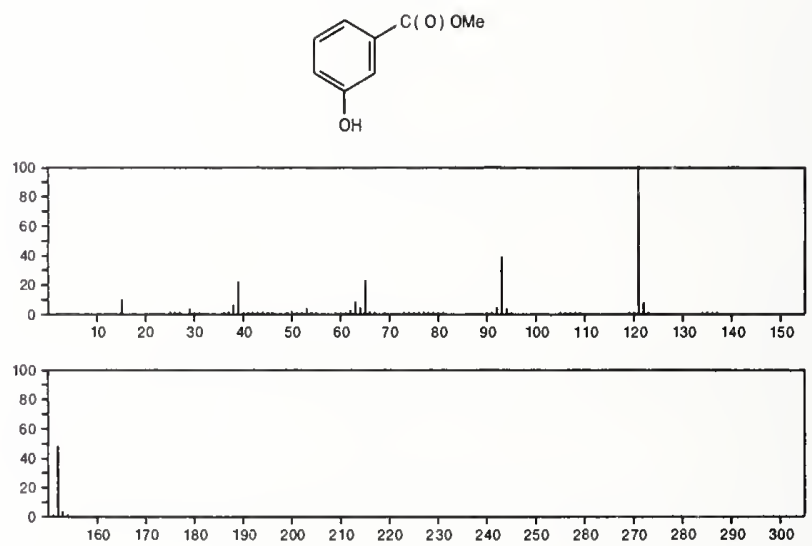

152

$\mathrm{C}_{8} \mathrm{H}_{8} \mathrm{O}_{3}$

1,3-Isobenzofurandione, tetrahydro-

$26266-63-7$
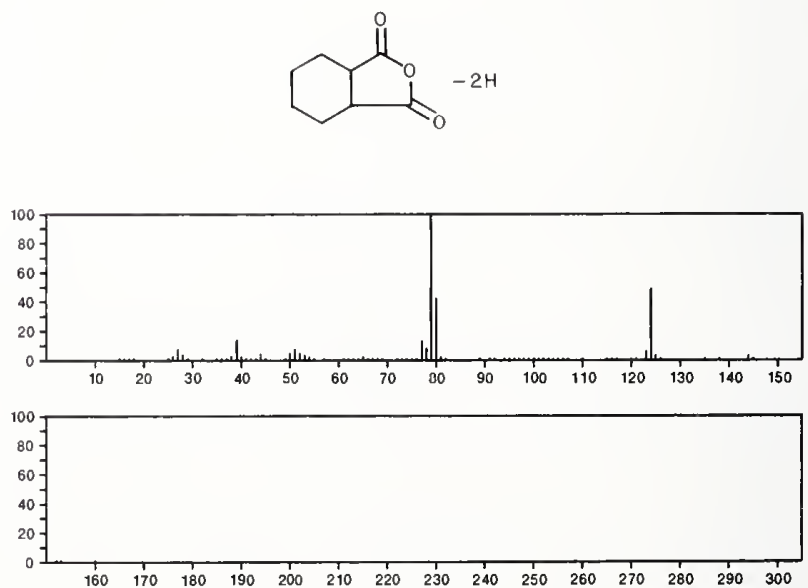
152

$\mathrm{C}_{8} \mathrm{H}_{12} \mathrm{~N}_{2} \mathrm{O}$

4(1H)-Pyrimidinone, 6 -methyl-2-(1-methylethyl)
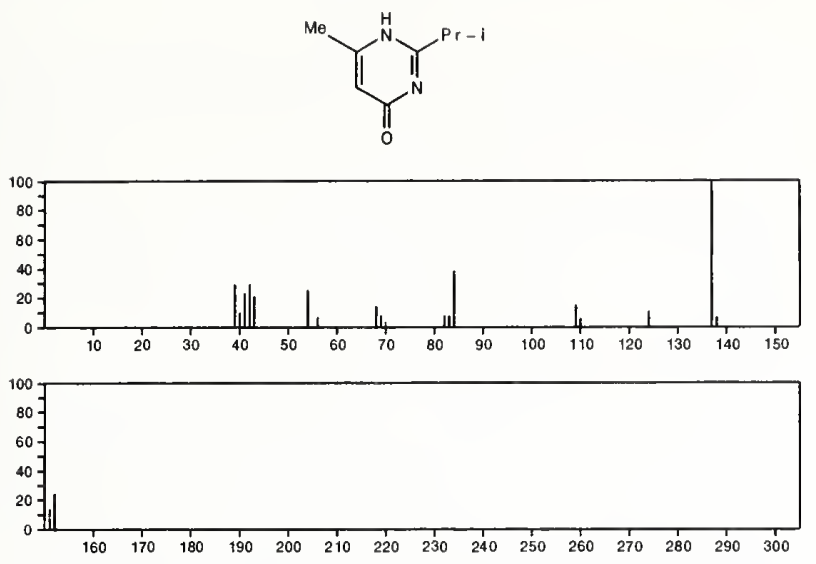

152

$\mathrm{C}_{8} \mathrm{H}_{12} \mathrm{~N}_{2} \mathrm{O}$

Pyrimidine, 2-ethoxy-4,6-dimethyl-
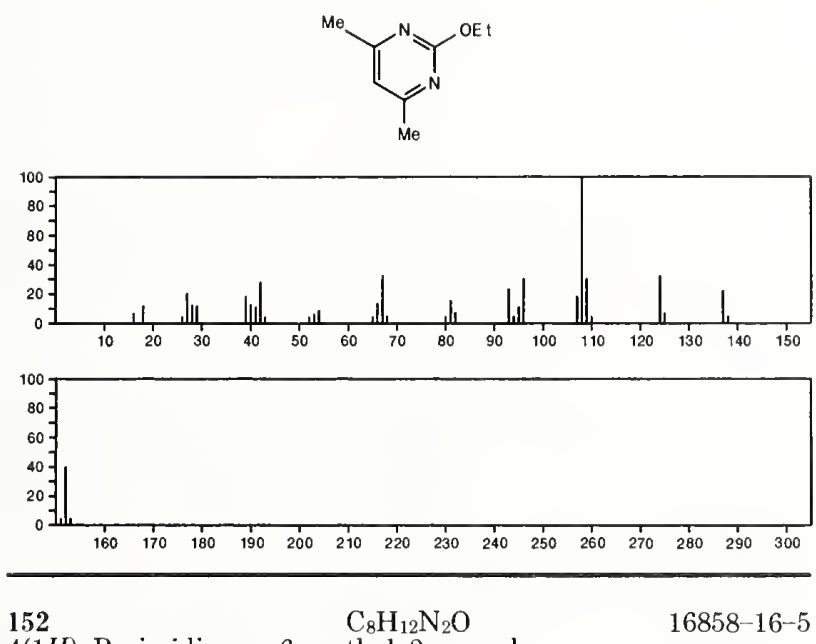

4(1H)-Pyrimidinone, 6-methyl-2-propyl-
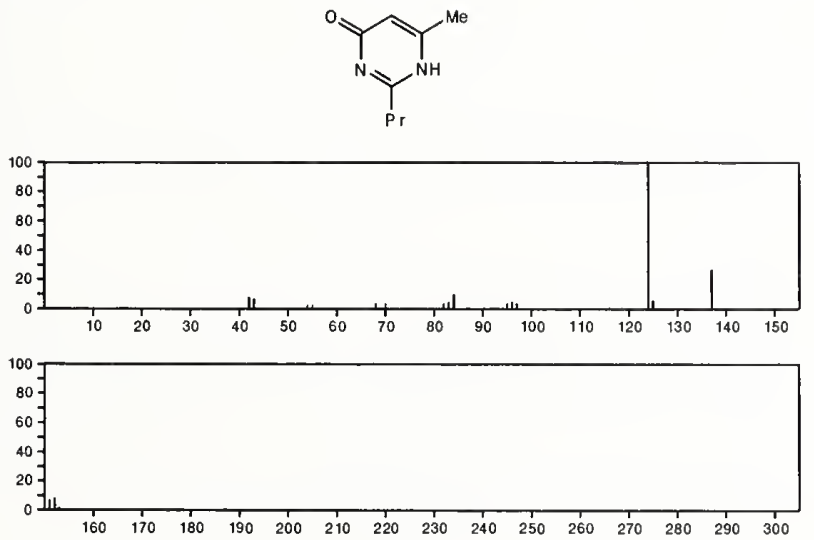

152

$\mathrm{C}_{8} \mathrm{H}_{12} \mathrm{~N}_{2} \mathrm{O}$

4(3H)-Primidinone, 3-ethyl-2,6-dimethyl-<smiles>CCn1c(N)nc(C)cc1=O</smiles>
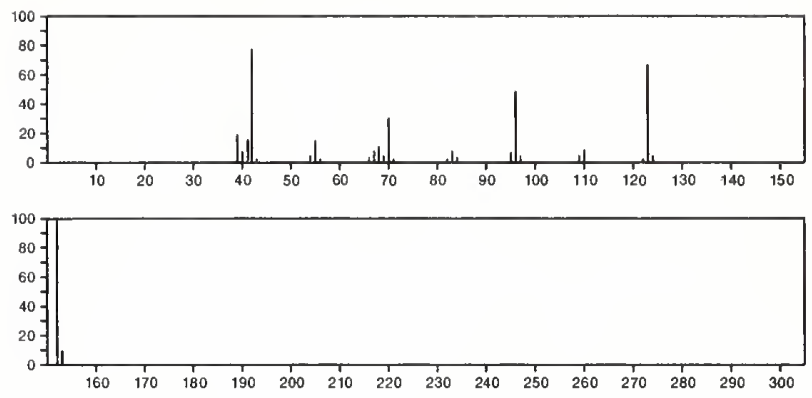

152

$\mathrm{C}_{8} \mathrm{H}_{12} \mathrm{~N}_{2} \mathrm{O}$

$32363-54-5$

4(3H)-Pyrimidinone, 2-ethyl-3,6-dimethyl-<smiles>CCc1nc(C)cc(=O)n1C</smiles>
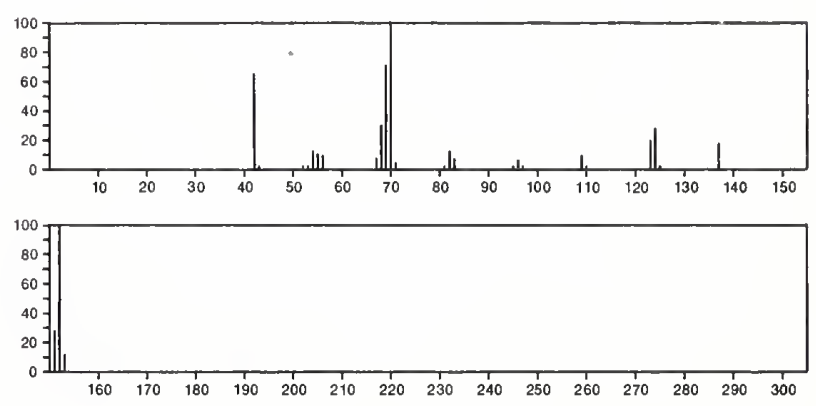

$152 \quad \mathrm{C}_{8} \mathrm{H}_{12} \mathrm{~N}_{2} \mathrm{O}$

Ethanol, 2-(1-phenylhydrazino)-

$49540-59-2$

$\mathrm{HOCH}_{2} \mathrm{CH}_{2} \mathrm{~N}\left(\mathrm{NH}_{2}\right) \mathrm{Ph}$
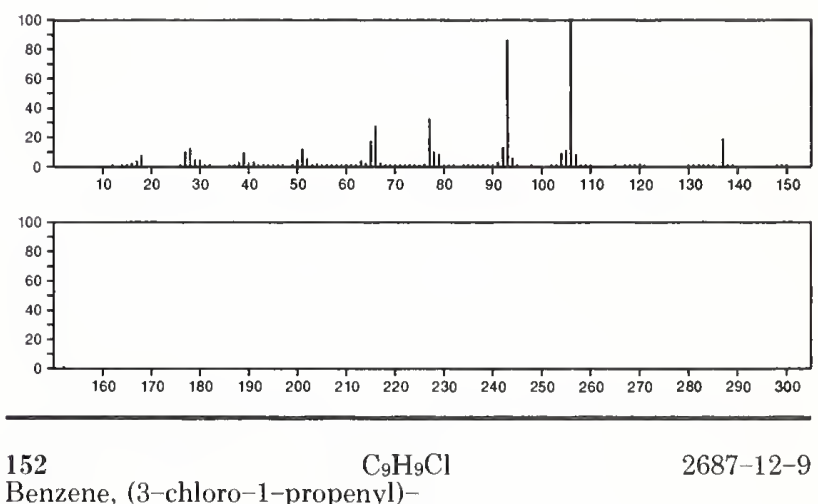

Benzene, (3-chloro-1-propenyl)-

$\mathrm{PhCH}=\mathrm{CHCH}_{2} \mathrm{Cl}$
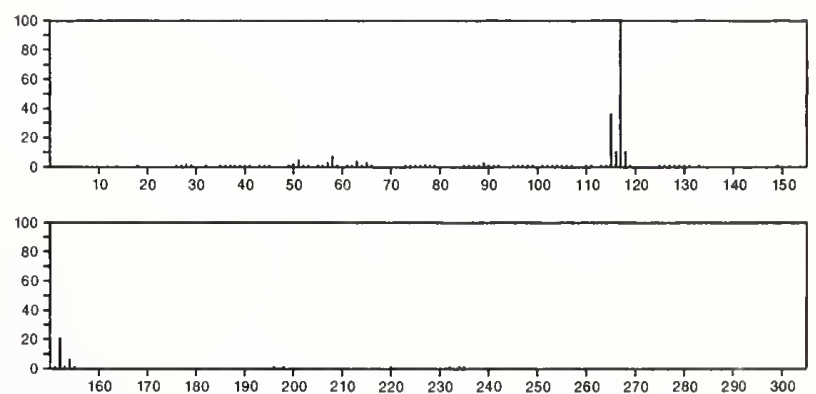
152

Benzene, (3-chloroallyl)-

$\mathrm{C}_{9} \mathrm{H}_{9} \mathrm{Cl}$

6268-37-7

$\mathrm{PhCH}_{2} \mathrm{CH}=\mathrm{CHCl}$
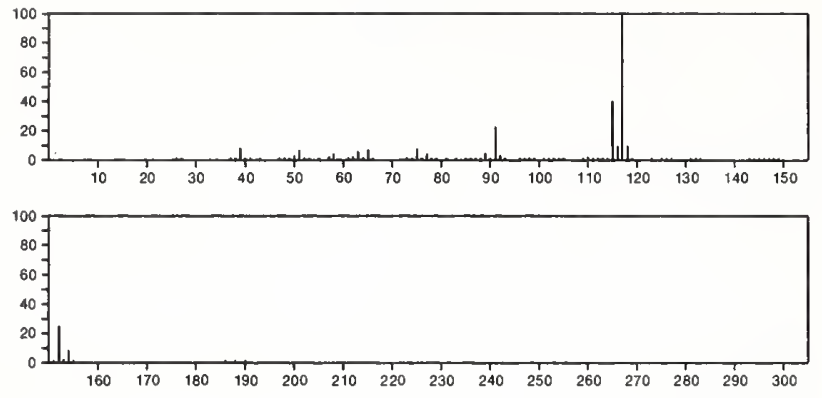

152

Benzene, (chloromethyl)ethenyl
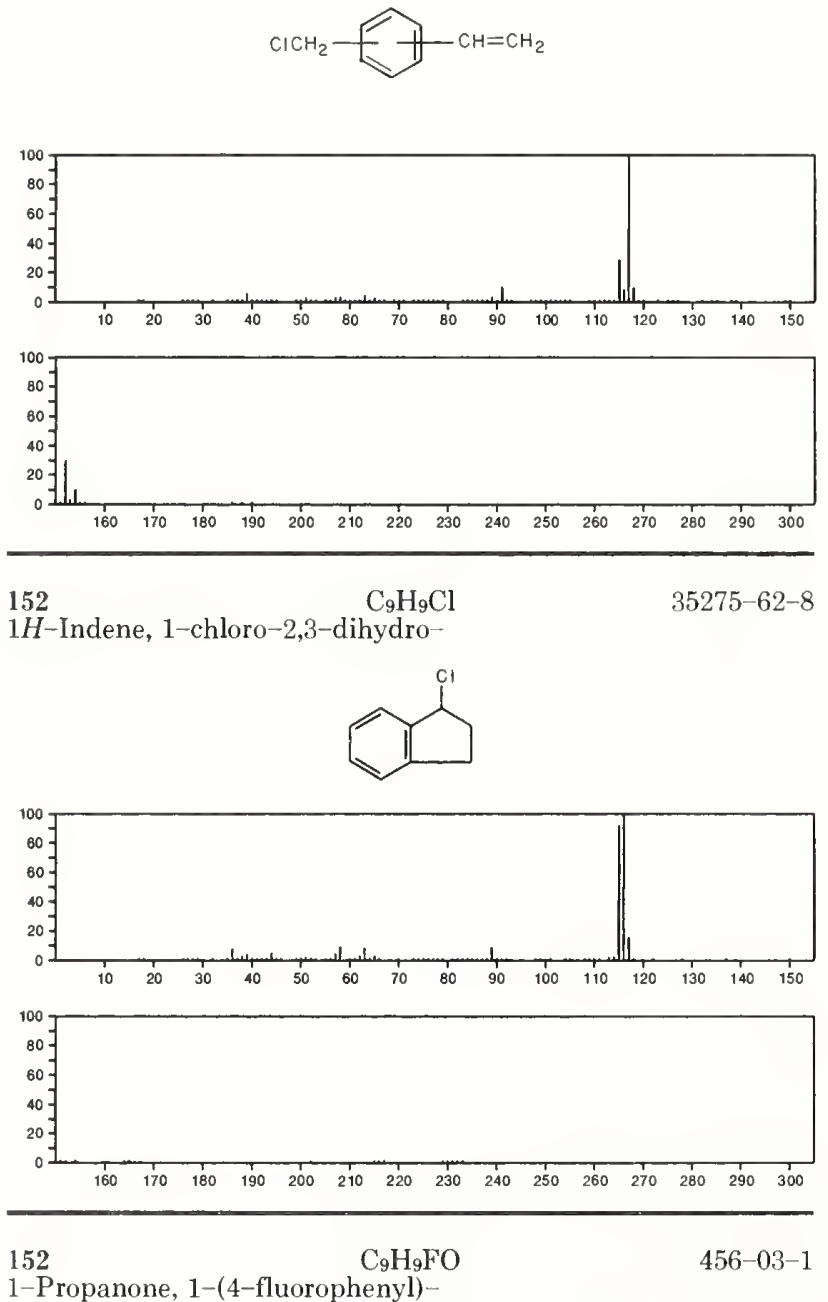

1-Propanone, 1-(4-fluorophenyl)-
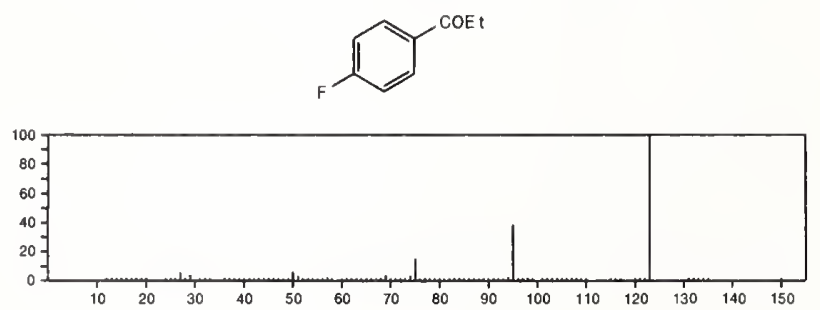

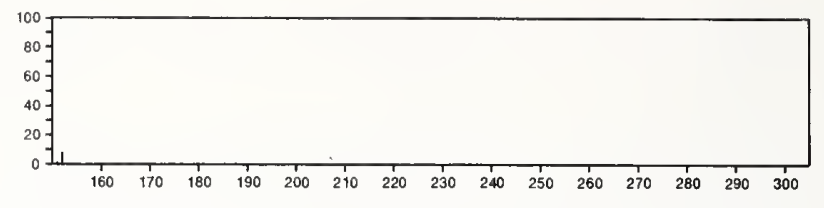

152

$\mathrm{C}_{9} \mathrm{H}_{12} \mathrm{O}_{2}$

Hydroperoxide, 1-methyl-1-phenylethyl

$80-15-9$

$\mathrm{HOOCM}_{2} \mathrm{Ph}$

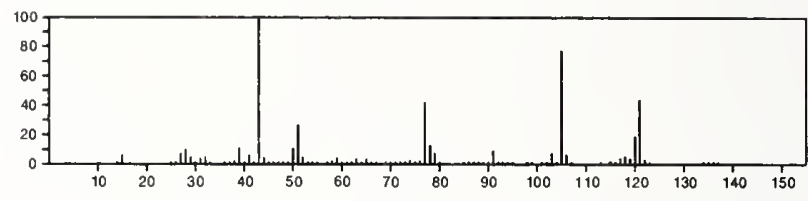

$152 \quad \mathrm{C}_{9} \mathrm{H}_{12} \mathrm{O}_{2}$

$551-45-1$

2-Cyclopenten-1-one, 4-hydroxy-3-methyl-2-(2-propenyl)-
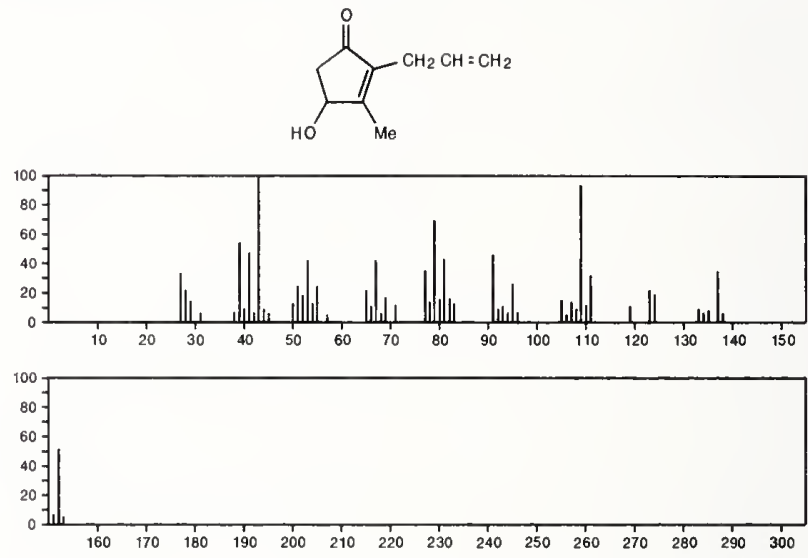

152

Ethanol, 2-(phenylmethoxy)-

$\mathrm{C}_{9} \mathrm{H}_{12} \mathrm{O}_{2}$

$622-08-2$

$\mathrm{HOCH}_{2} \mathrm{CH}_{2} \mathrm{OCH}_{2} \mathrm{Ph}$
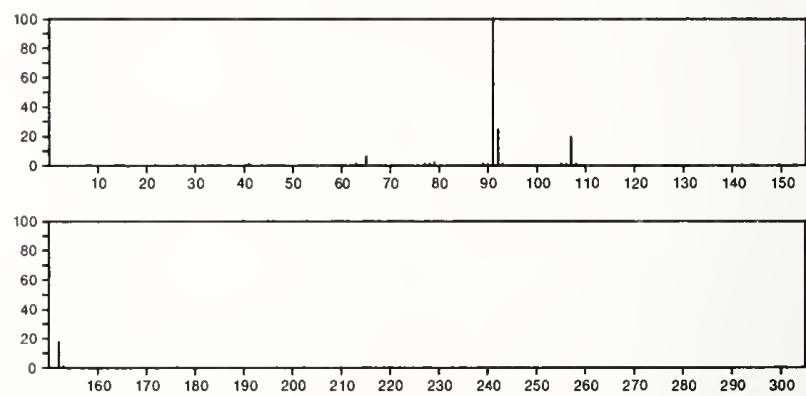

152

Benzenepropanol, 2-hydroxy

$\mathrm{C}_{9} \mathrm{H}_{12} \mathrm{O}_{2}$

$1481-92-1$<smiles>OCCc1ccccc1O</smiles>

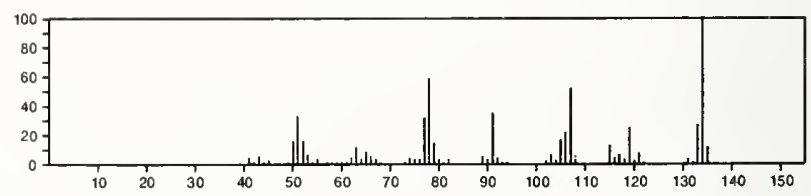


152

$\mathrm{C}_{9} \mathrm{H}_{12} \mathrm{O}_{2}$

4169-04-4

1-Propanol, 2-phenoxy-

$\mathrm{PhOCHMe} \mathrm{CH}_{2} \mathrm{OH}$
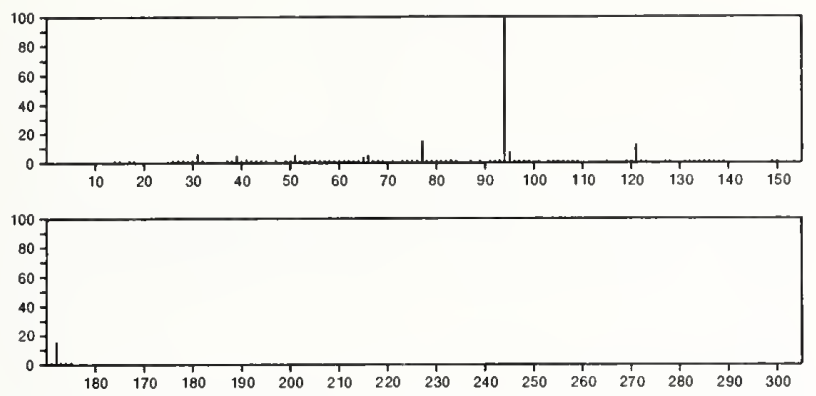

$152 \quad \mathrm{C}_{9} \mathrm{H}_{12} \mathrm{O}_{2}$

Benzeneethanol, 3-methoxy-
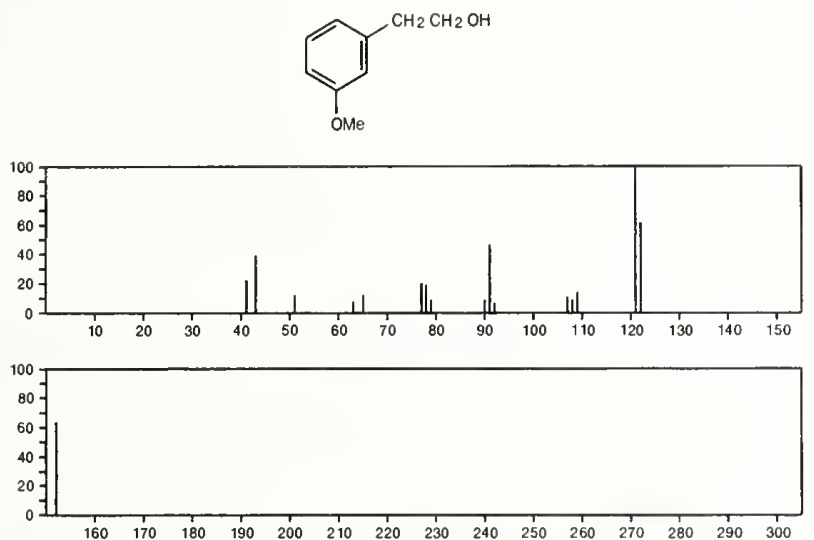

$\begin{array}{lllllllllllllll}160 & 170 & 180 & 190 & 200 & 210 & 220 & 230 & 240 & 250 & 260 & 270 & 280 & 290 & 300\end{array}$

152

$\mathrm{C}_{9} \mathrm{H}_{12} \mathrm{O}_{2}$

$6555-48-2$

Tricyclo[2.2.1.02,6]heptan-3-ol, acetate
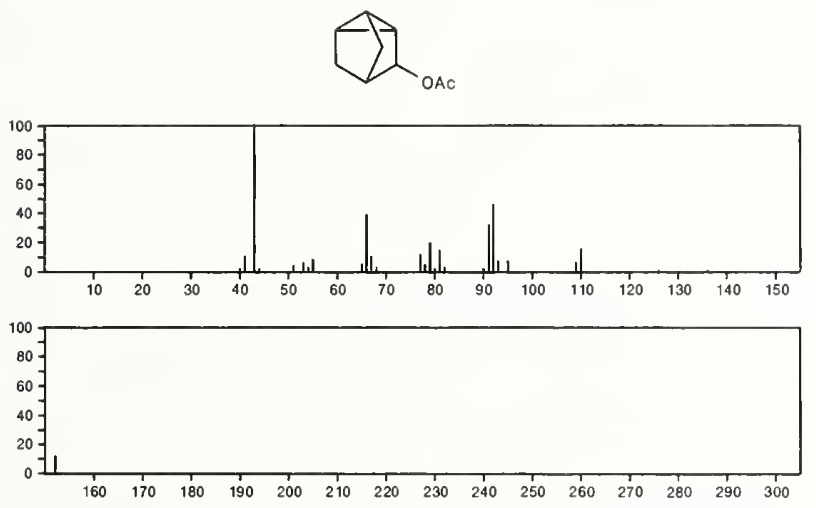

152

Ethanol, 2-(3-methylphenoxy)
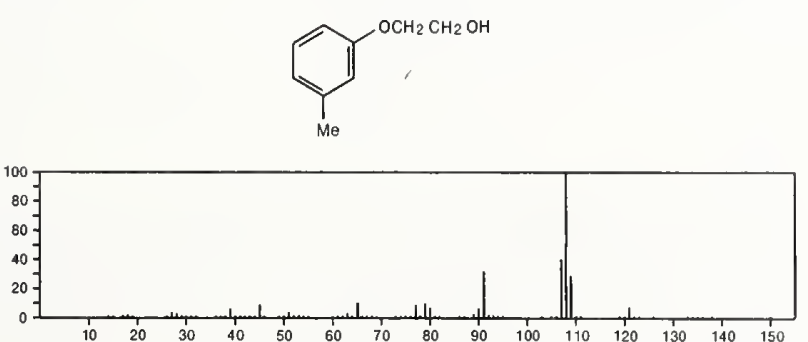

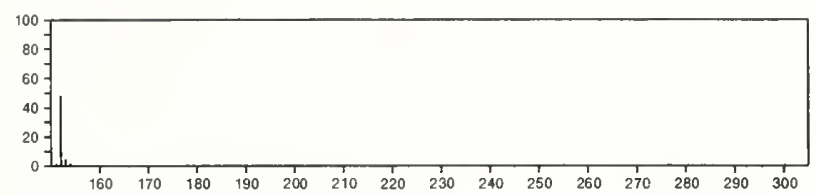

152

Ethanol, 2-(4-methylphenoxy)

$\mathrm{C}_{9} \mathrm{H}_{12} \mathrm{O}_{2}$

15149-10-7
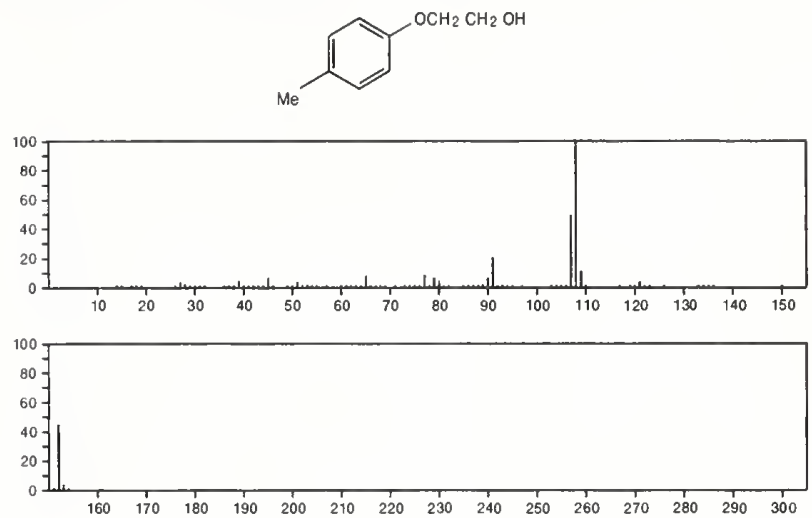

152

$\mathrm{C}_{9} \mathrm{H}_{12} \mathrm{O}_{2}$

$18979-50-5$

Phenol, 4-propoxy-
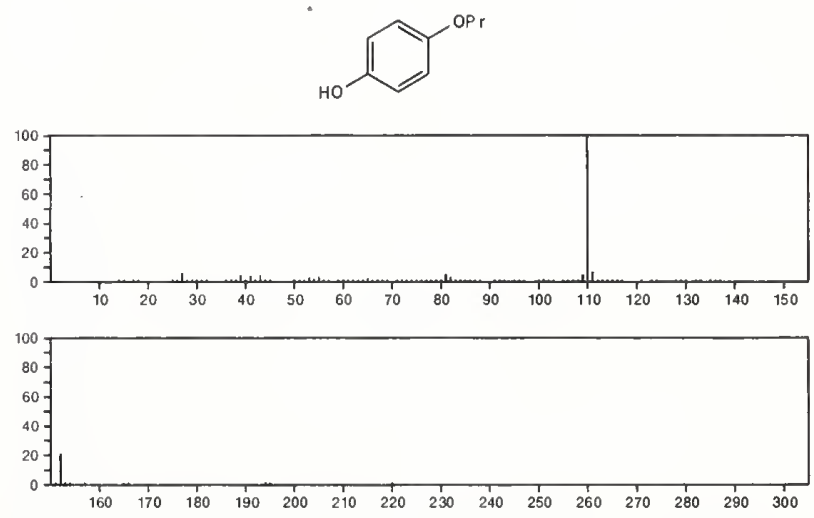

152

$\mathrm{C}_{9} \mathrm{H}_{12} \mathrm{O}_{2}$

$20907-03-3$

2-Pentanone, 1-(2-furanyl)
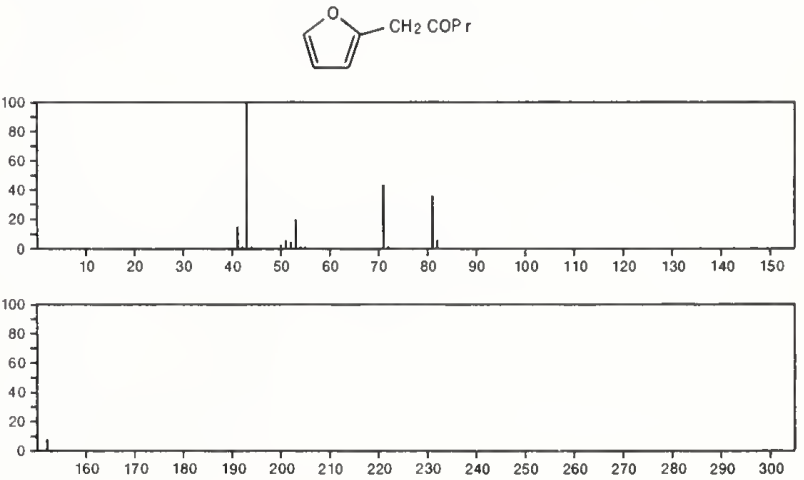
152

$\mathrm{C}_{9} \mathrm{H}_{12} \mathrm{O}_{2}$

2-Butanone, 1-(2-furanyl)-3-methyl-

¿ $\mathrm{CH}_{2} \mathrm{COCHMe}_{2}$
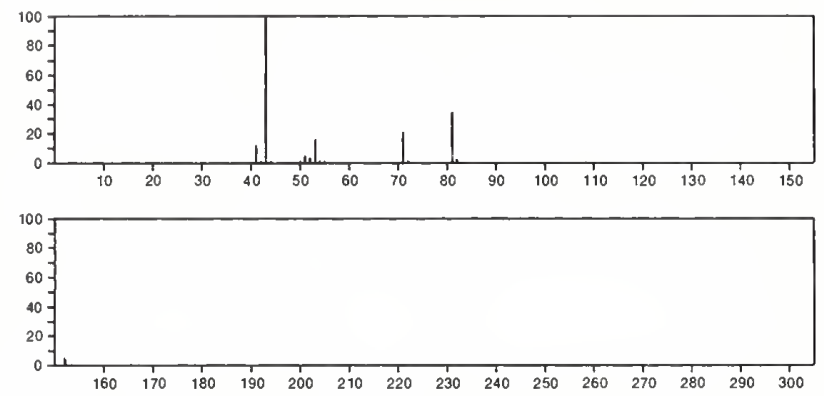

152

Benzene, 1-methoxy-2-(methoxymethyl)
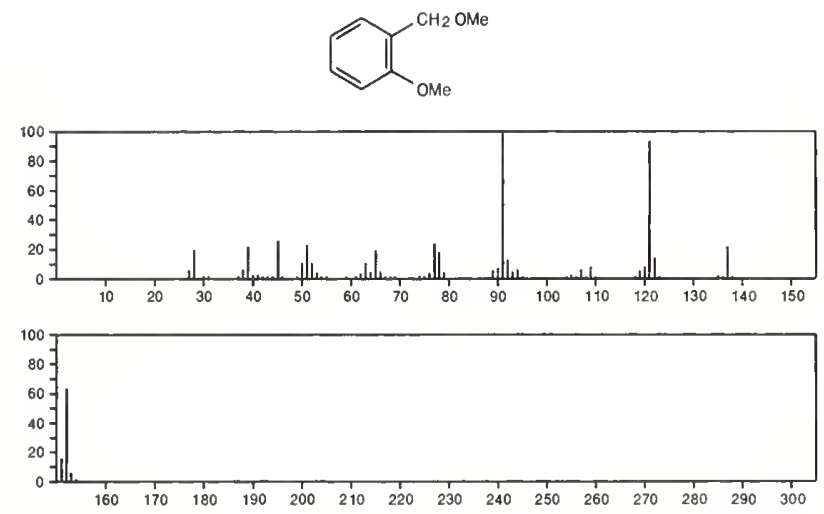

152

Benzenemethanol, $\alpha$-ethyl-4-hydroxy-
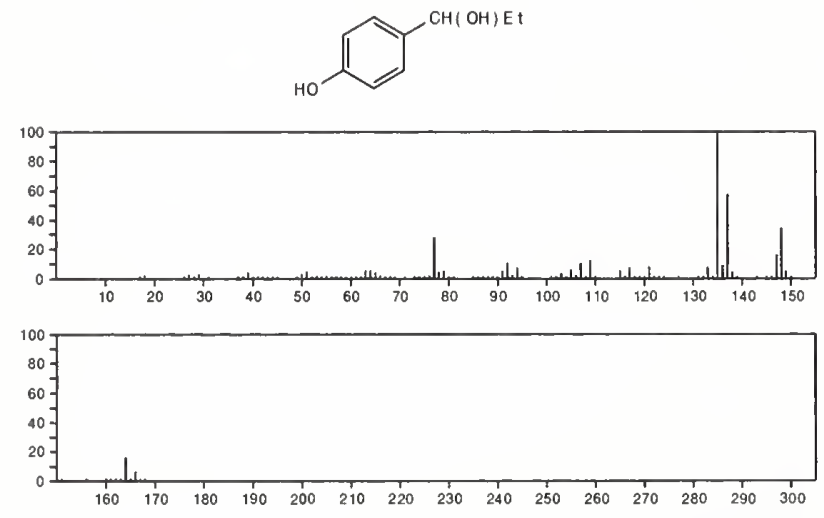

152

$\mathrm{C}_{9} \mathrm{H}_{12} \mathrm{O}_{2}$

Benzene, [(methoxymethoxy)methyl]-

$31600-55-2$

$\mathrm{MeOCH} \mathrm{OCH}_{2} \mathrm{Ph}$
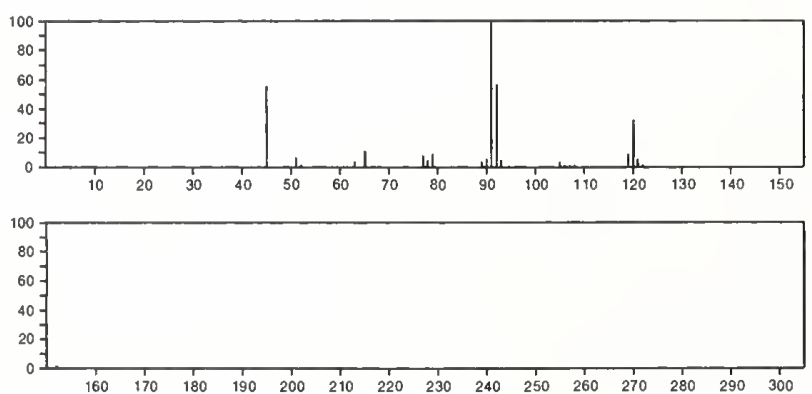

152

2- Furanacetaldehyde, $\alpha$-propyl-

$31681-26-2$

¿о
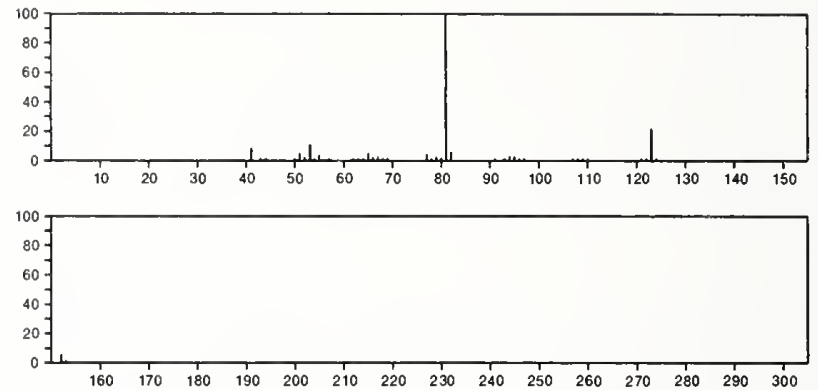

152

2-Furanacetaldehyde, $\alpha$-isopropyl-

$31681-30-8$

(1) $\mathrm{CH}(\mathrm{CHO}) \mathrm{CHMe}_{2}$
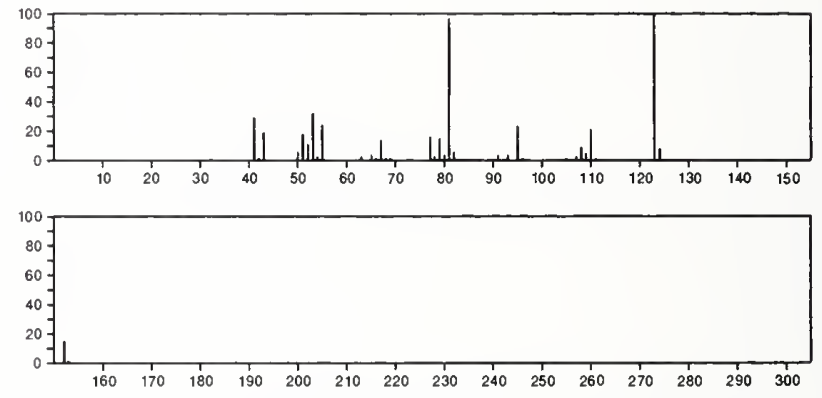

$152 \quad \mathrm{C}_{9} \mathrm{H}_{12} \mathrm{O}_{2}$

34883-01-7

Phenol, 5-methoxy-2,3-dimethyl-
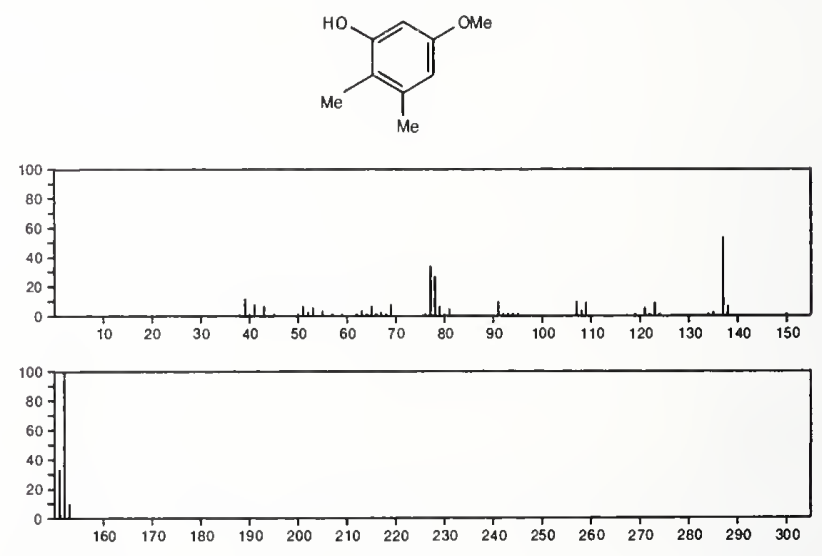

$152 \quad \mathrm{C}_{9} \mathrm{H}_{12} \mathrm{O}_{2}$

$41532-81-4$

Benzene, (2-methoxyethoxy)-

$\mathrm{Me} \mathrm{OCH}_{2} \mathrm{CH}_{2} \mathrm{OPh}$
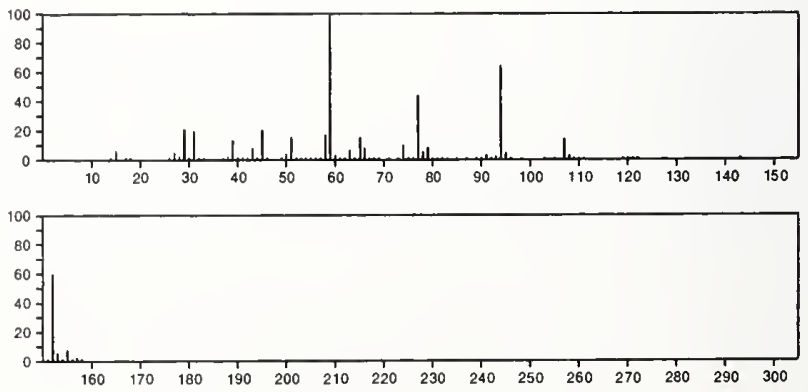
152 2(3H)-Benzofuranone, hexahydro-3-methylene-

$\mathrm{C}_{9} \mathrm{H}_{12} \mathrm{O}_{2}$
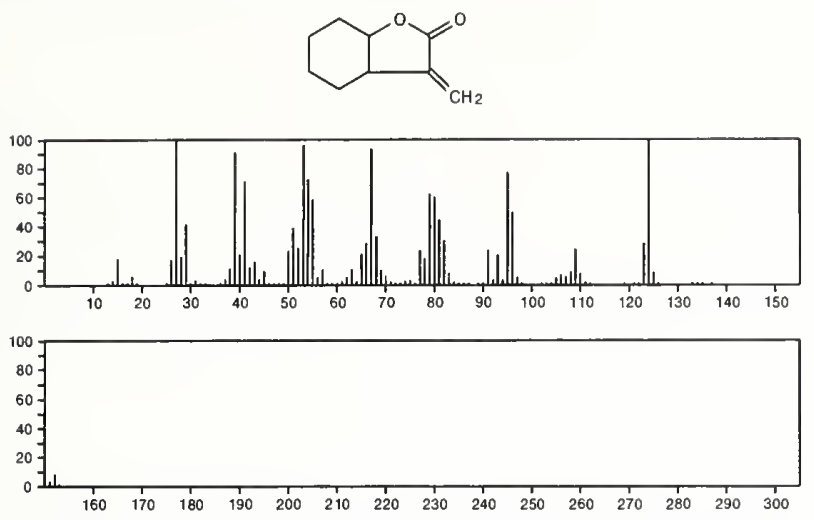

152

2-Cyclohexen-1-one, 4-(2-oxopropyl)-
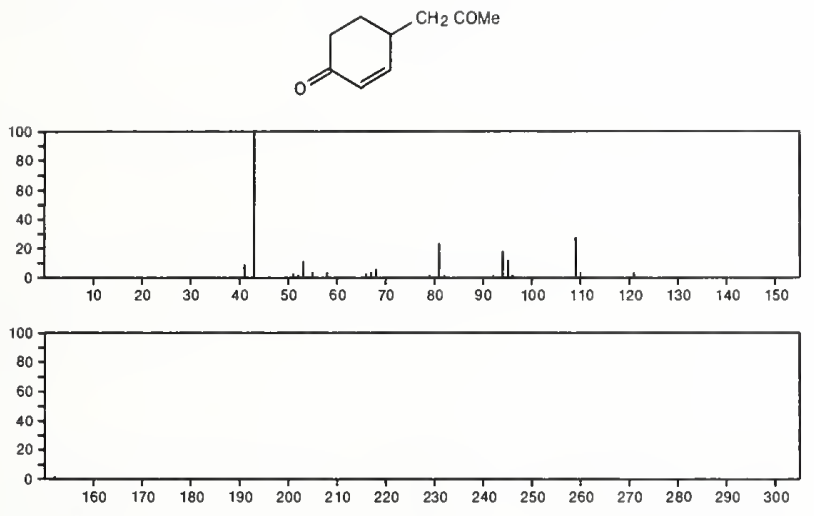

$152 \quad \mathrm{C}_{9} \mathrm{H}_{12} \mathrm{O}_{2} \quad 56701-05-4$

Tricyclo[3.2.0.02,7]heptane-3-carboxylic acid, methyl ester, $(1 \alpha, 2 \alpha, 3 \alpha, 5 \beta, 7 \alpha)$
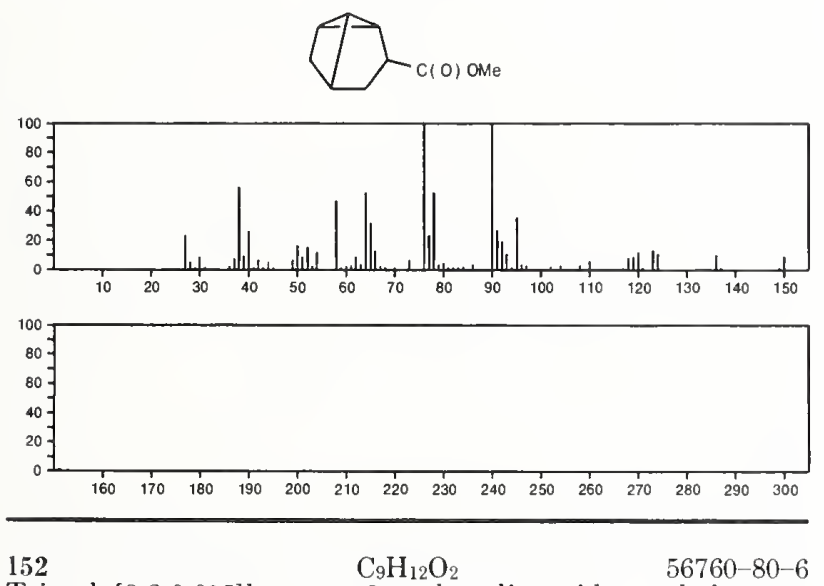

Tricyclo[3.2.0.02,7]heptane-3-carboxylic acid, methyl ester, $(1 \alpha, 2 \alpha, 3 \beta, 5 \beta, 7 \alpha)-$
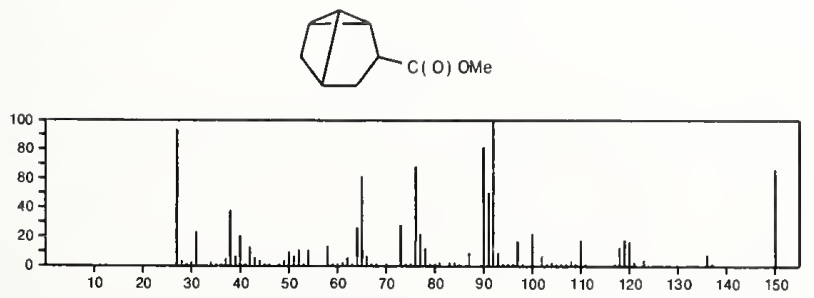
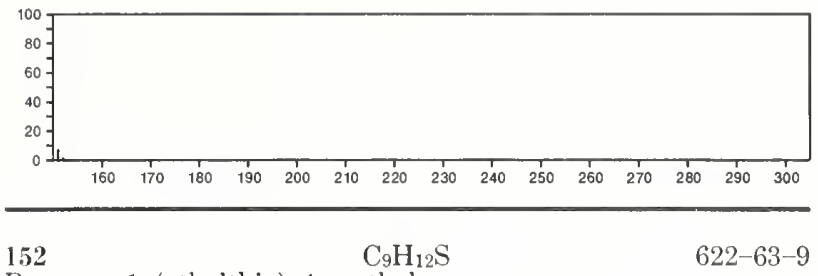

Benzene, 1-(ethylthio)-4-methyl-

$622-63-9$
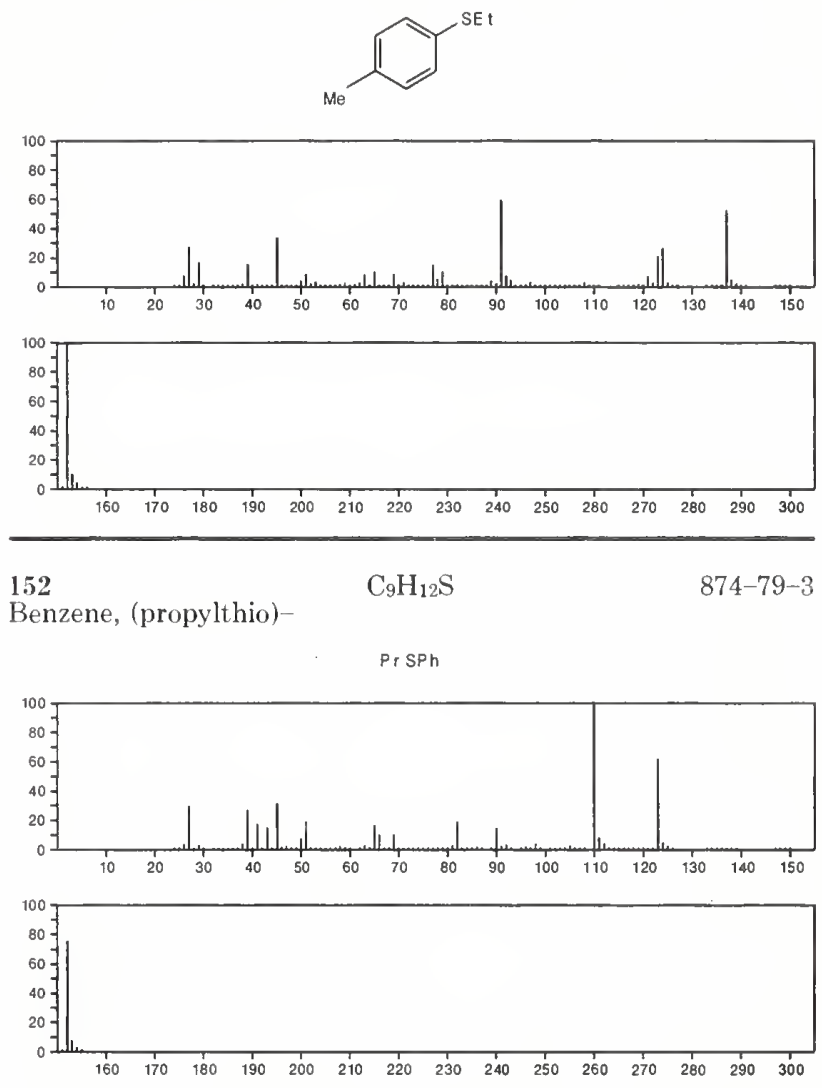

152

$\mathrm{C}_{9} \mathrm{H}_{12} \mathrm{~S}$

$3695-36-1$

Benzene, 1-(ethylthio)-2-methyl-
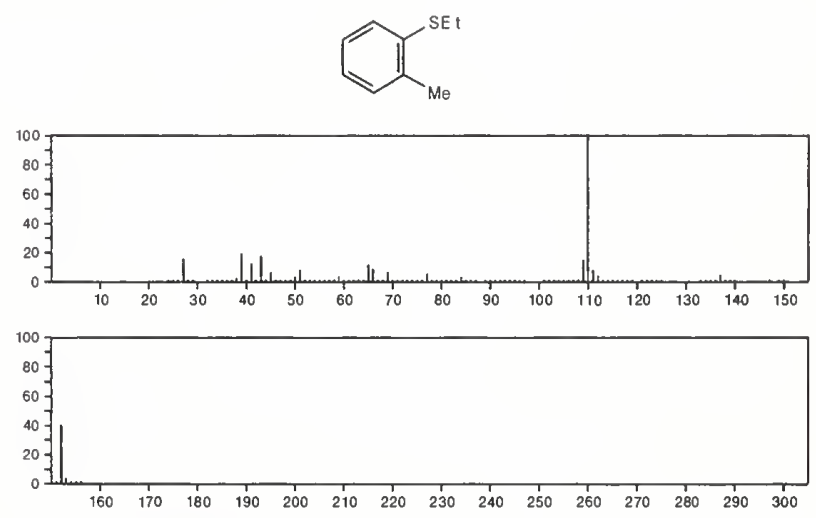

$152 \quad \mathrm{C}_{9} \mathrm{H}_{12} \mathrm{~S}$

$6263-62-3$

Benzene, [(ethylthio)methyl].

$\mathrm{EtSCH} \mathrm{Ph}_{2}$

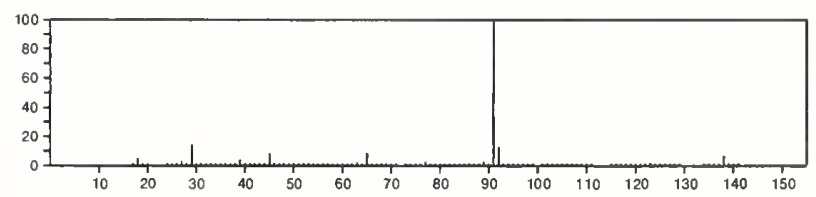




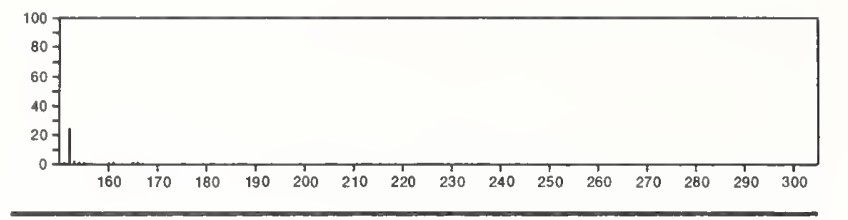

152

Benzene, 1-(ethylthio)-3-methyl-

$34786-24-8$
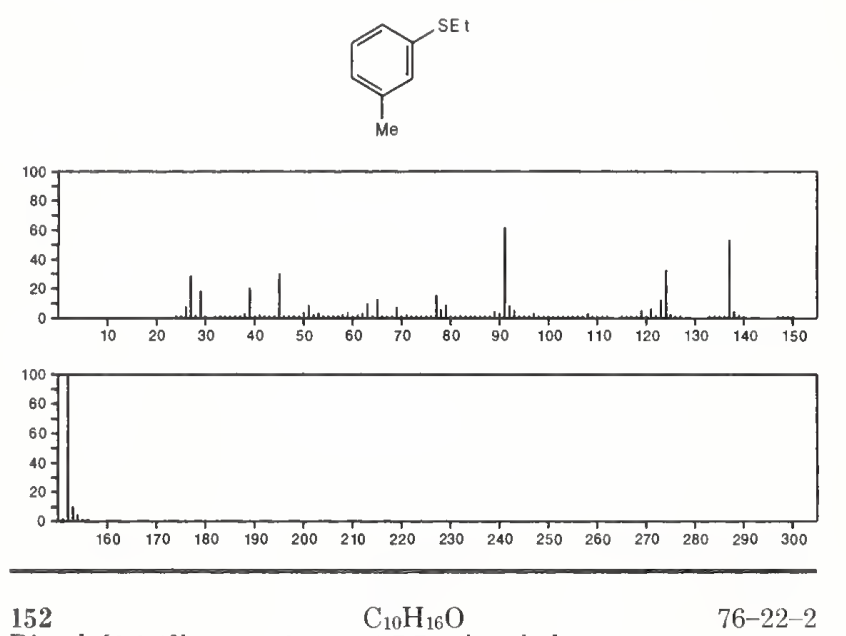

Bicyclo[2.2.1] heptan-2-one, 1,7,7-trimethyl-
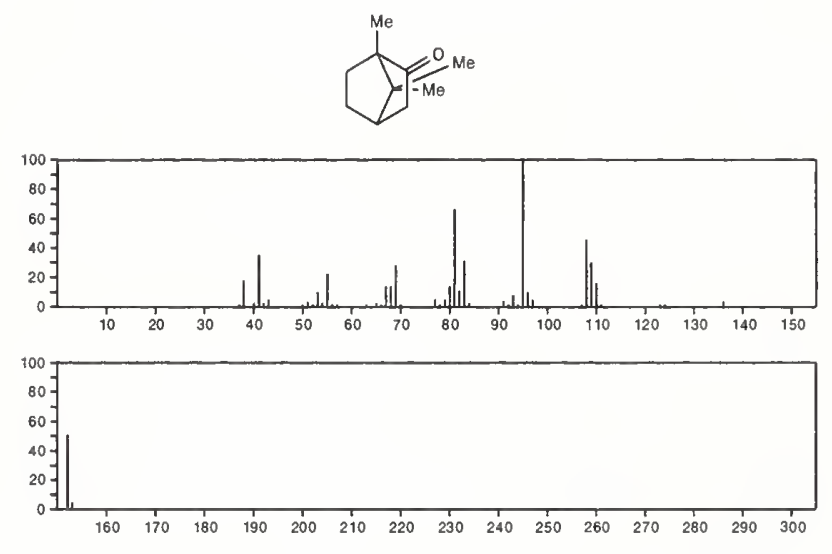

152

$\mathrm{C}_{10} \mathrm{H}_{16} \mathrm{O}$

2-Cyclohexen-1-one, 3-methyl-6-(1-methylethyl)-

$89-81-6$<smiles>CC1=CC(=O)C(PI)CC1</smiles>
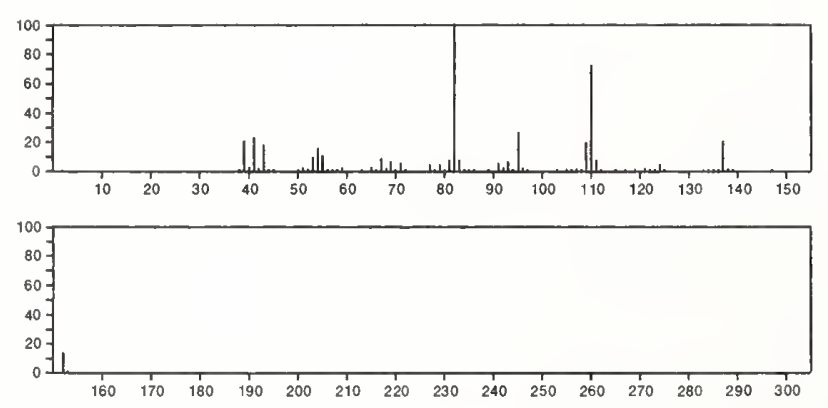

152

$\mathrm{C}_{10} \mathrm{H}_{16} \mathrm{O}$

$89-82-7$

Cyclohexanone, 5-methyl-2-(1-methylethylidene)-, $(R)-$<smiles>CC(C)=C1CCC(C)CC1=O</smiles>
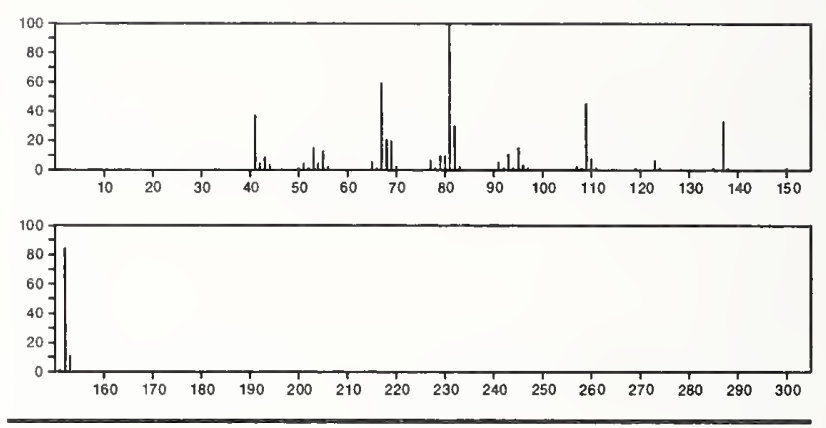

152

$\mathrm{C}_{10} \mathrm{H}_{16} \mathrm{O}$

2-Cyclohexen-1-ol, 2-methyl-5-(1-methylethenyl)

$99-48-9$
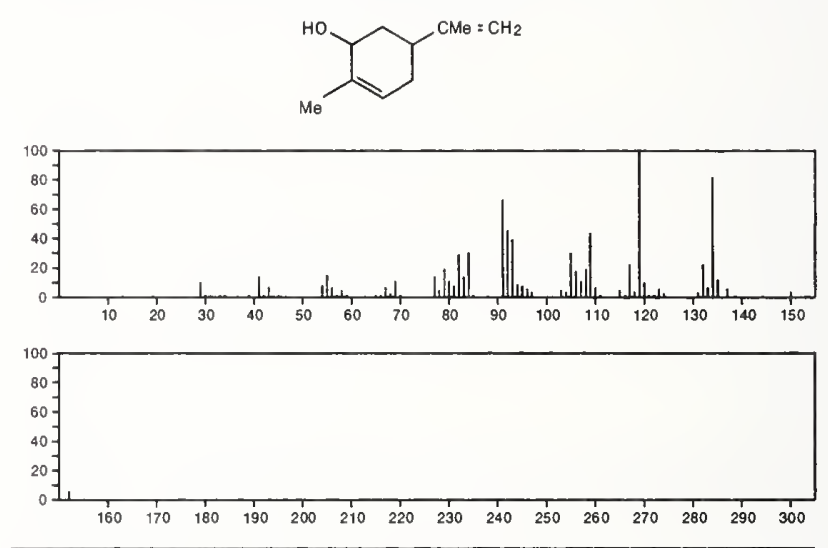

$152 \quad \mathrm{C}_{10} \mathrm{H}_{16} \mathrm{O}$

$106-26-3$

2,6-Octadienal, 3,7-dimethyl-, (Z)-

$\mathrm{OCHCH}=\mathrm{CMeCH}_{2} \mathrm{CH}_{2} \mathrm{CH}=\mathrm{CMe}_{2}$

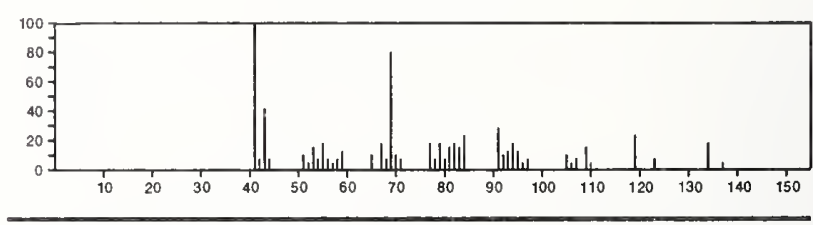

152

2,6-Octadienal, 3,7-dimethyl-, $(E)$ -

$141-27-5$

$\mathrm{OCHCH}=\mathrm{CMeCH}_{2} \mathrm{CH}_{2} \mathrm{CH}=\mathrm{CMe} 2$
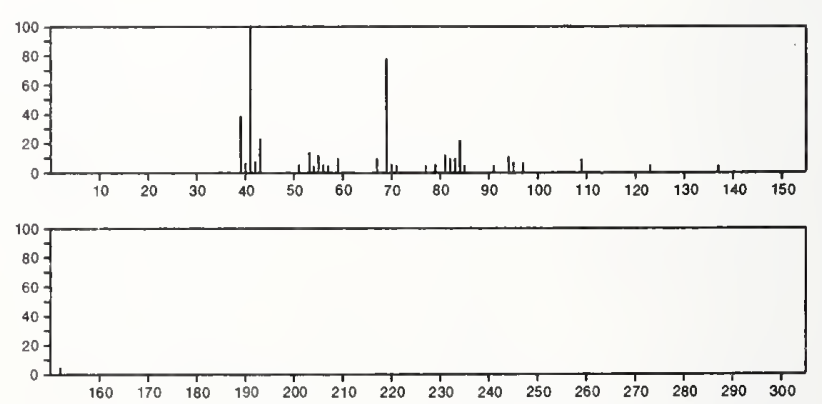
152

$\mathrm{C}_{10} \mathrm{H}_{16} \mathrm{O}$

$432-25-7$

1-Cyclohexene-1-carboxaldehyde, 2,6,6-trimethyl-
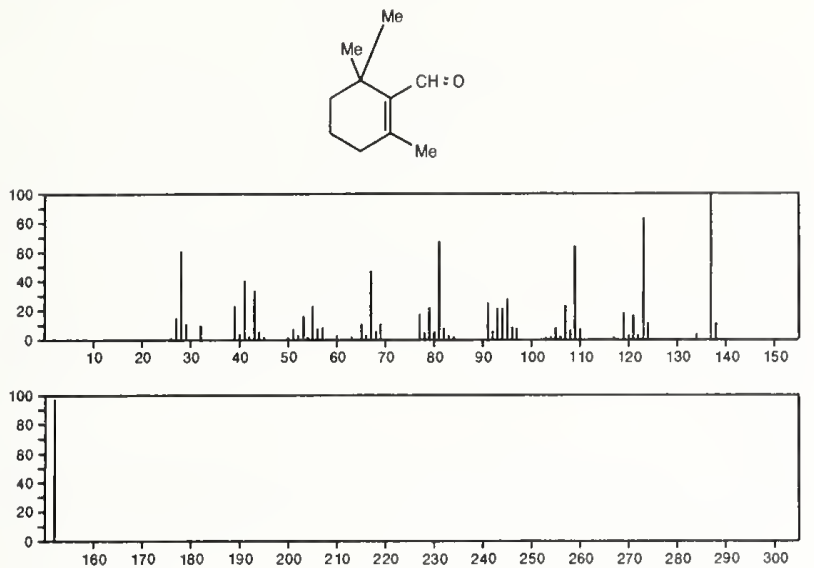

$152 \quad \mathrm{C}_{10} \mathrm{H}_{16} \mathrm{O}$ 471-15-8

Bicyclo[3.1.0] hexan-3-one, 4-methyl-1-(1-methylethyl)-, [1S$(1 \alpha, 4 \beta, 5 \alpha)]-$
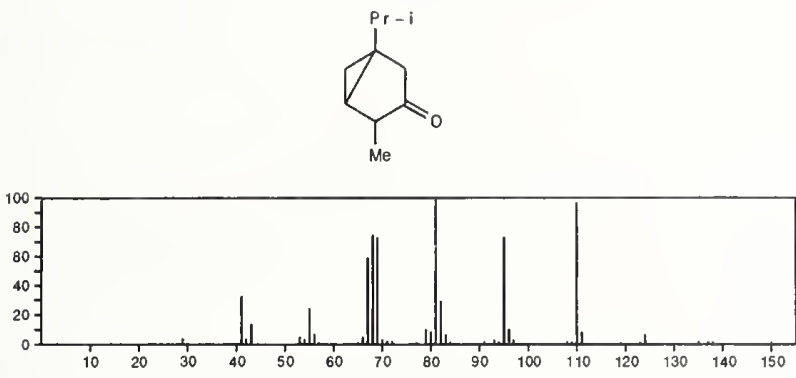

152

$\mathrm{C}_{10} \mathrm{H}_{16} \mathrm{O}$

$471-16-9$

Bicyclo[3.1.0]hexan-3-ol, 4-methylene-1-(1-methylethyl)$[1 S-(1 \alpha, 3 \beta, 5 \alpha)]-$
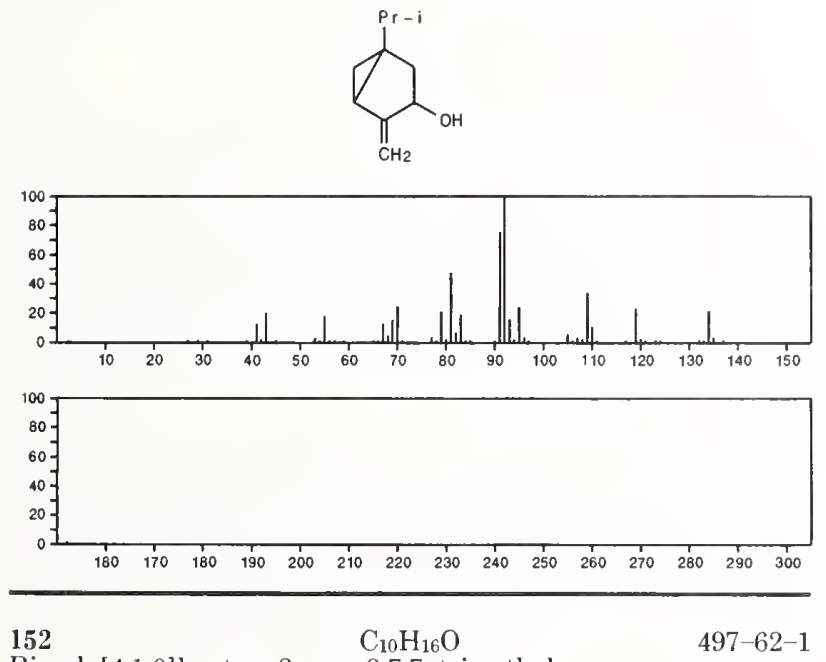

Bicyclo[4.1.0]heptan-2-one, 3,7,7-trimethyl-
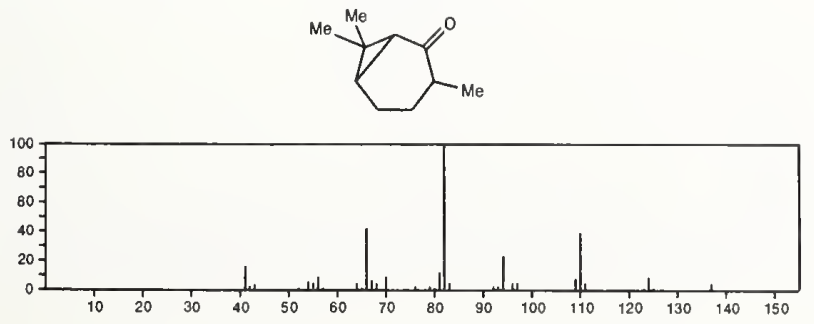

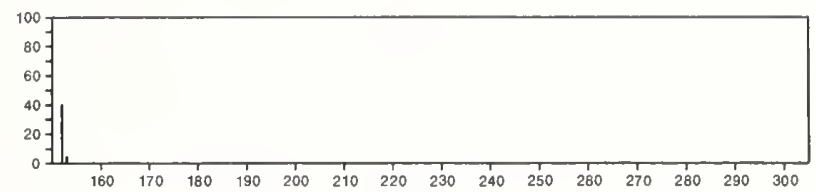

$\mathrm{C}_{10} \mathrm{H}_{16} \mathrm{O}$

152

Bicyclo[3.1.1]hept-2-ene-2-methanol, 6,6-dimethyl-
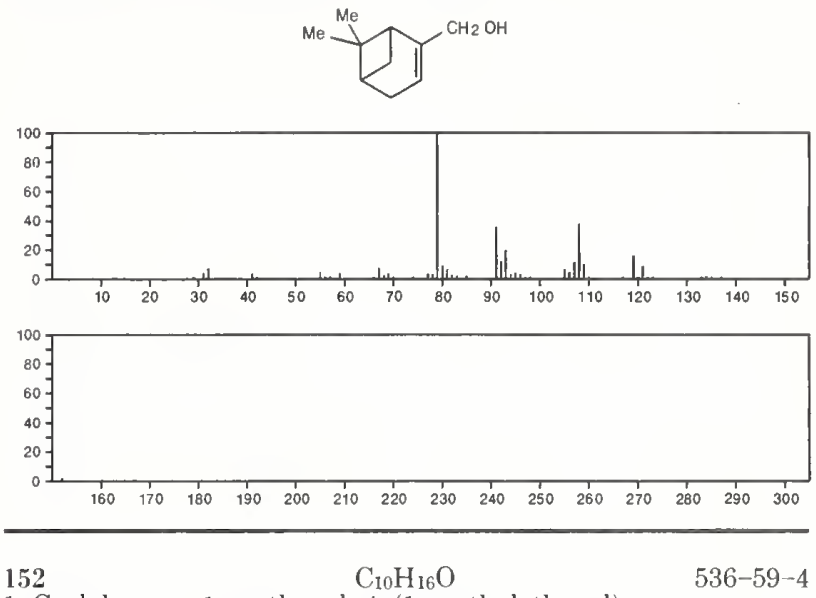

1-Cyclohexene-1-methanol, 4-(1-methylethenyl)
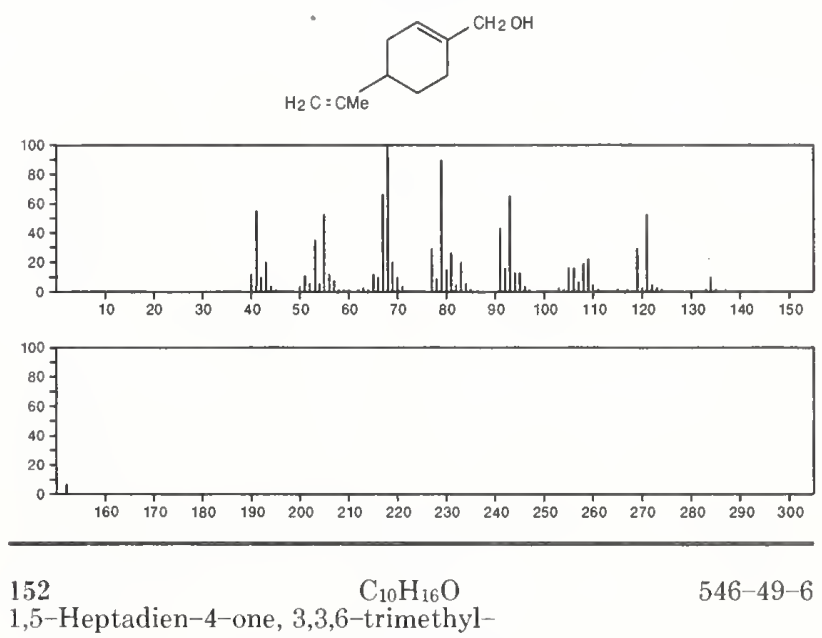

$\mathrm{Me} 2 \mathrm{C}=\mathrm{CHCOCMe} 2 \mathrm{CH}=\mathrm{CH}_{2}$
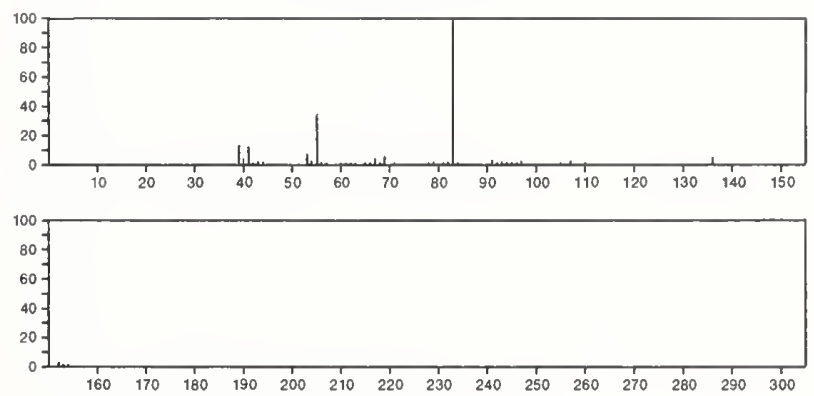
152

$\mathrm{C}_{10} \mathrm{H}_{16} \mathrm{O}$

$546-80-5$

Bicyclo[3.1.0]hexan-3-one, 4-methyl-1-(1-methylethyl)-, [1S

$(1 \alpha, 4 \alpha, 5 \alpha)]-$
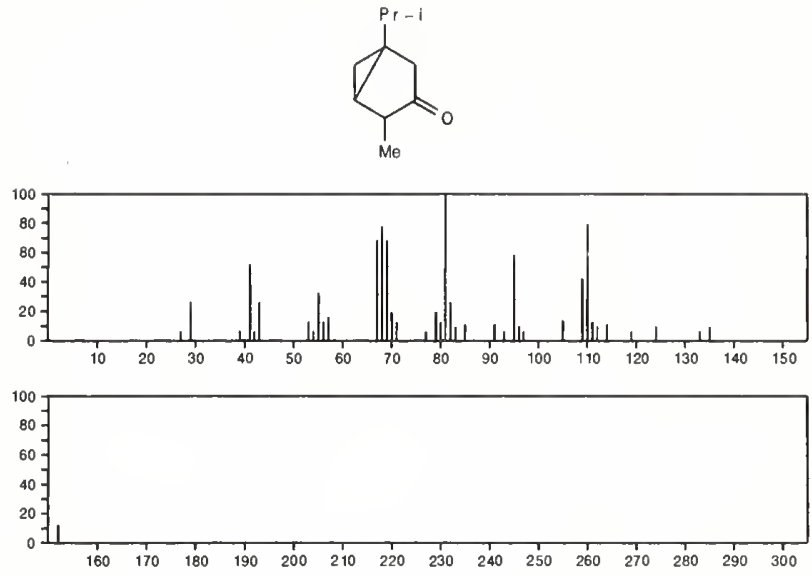

152

$\mathrm{C}_{10} \mathrm{H}_{16} \mathrm{O}$

1195-79-5

Bicyclo[2.2.1]heptan-2-one, 1,3,3-trimethyl-
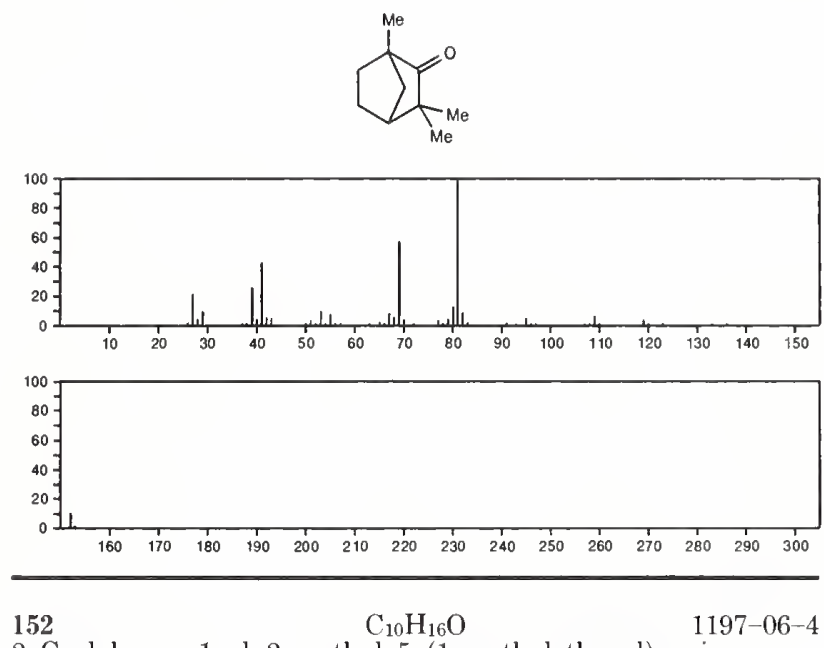

2-Cyclohexen-1-ol, 2-methyl-5-(1-methylethenyl)-, cis-
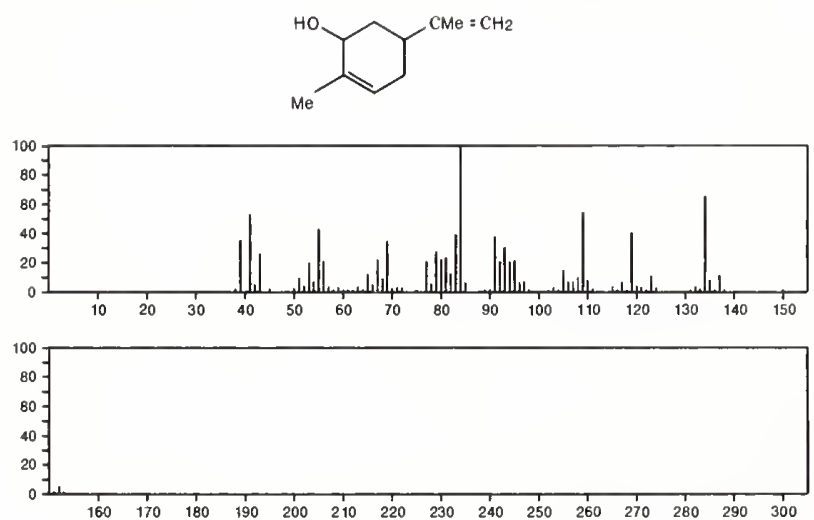

152

$\mathrm{C}_{10} \mathrm{H}_{16} \mathrm{O}$

$1197-07-5$

2-Cyclohexen-1-ol, 2-methyl-5-(1-methylethenyl)-, trans-
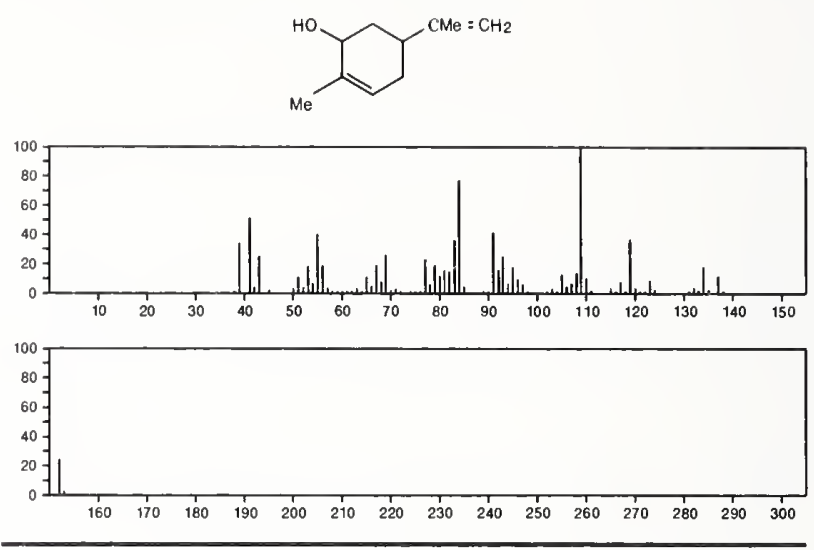

152

$\mathrm{C}_{10} \mathrm{H}_{16} \mathrm{O}$

4696-15-5

Bicyclo[5.2.1\}decan-10-one
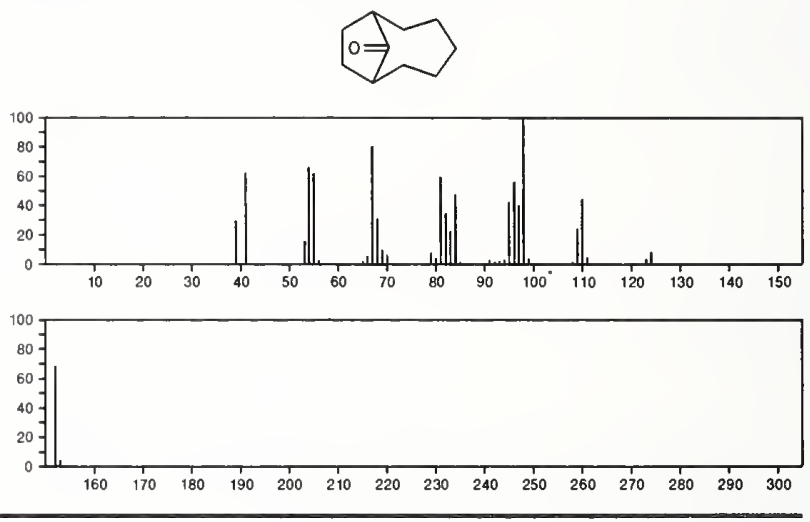

${ }_{\left[1,1^{\prime}-\text { Bicyclopentyl }\right]-2-\text { one }} \mathrm{C}_{10} \mathrm{H}_{16} \mathrm{O}$

4884-24-6
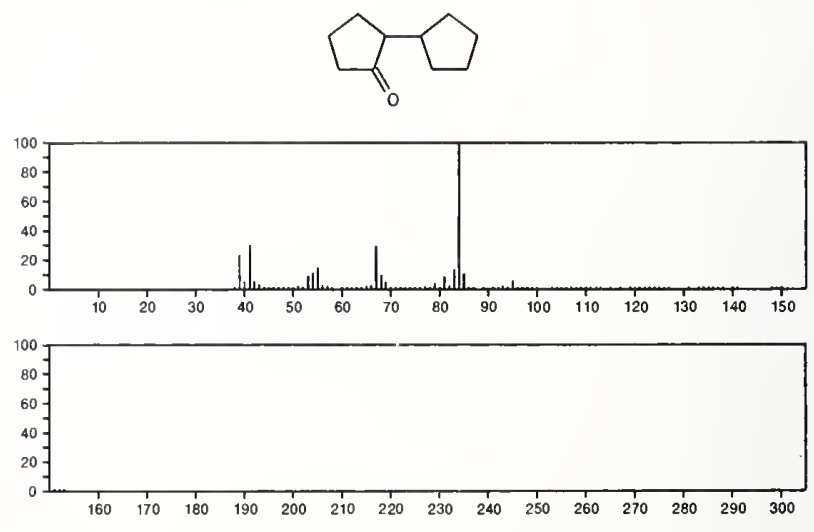

152

$\mathrm{C}_{10} \mathrm{H}_{16} \mathrm{O}$

5113-66-6

2-Cyclohexen-1-one, 5-methyl-2-(1-methylethyl)-
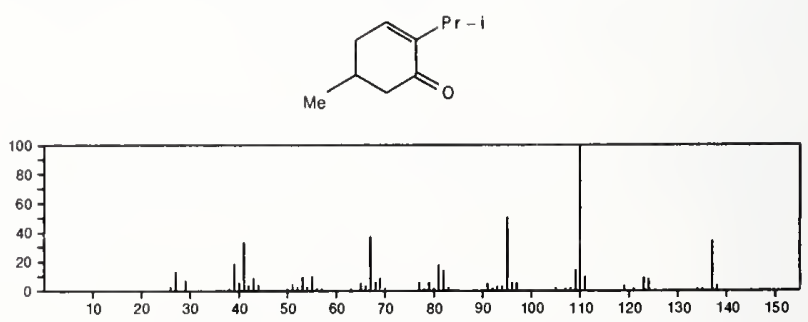


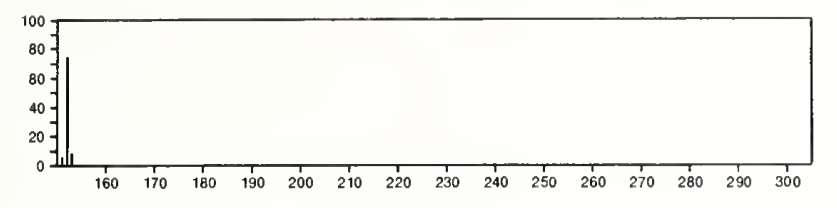

152

2,6-Octadienal, 3,7-dimethyl-

$\mathrm{C}_{10} \mathrm{H}_{16} \mathrm{O}$

$5392-40-5$

$\mathrm{OCHCH}=\mathrm{CMeCH}_{2} \mathrm{CH}_{2} \mathrm{CH}=\mathrm{CMe}_{2}$
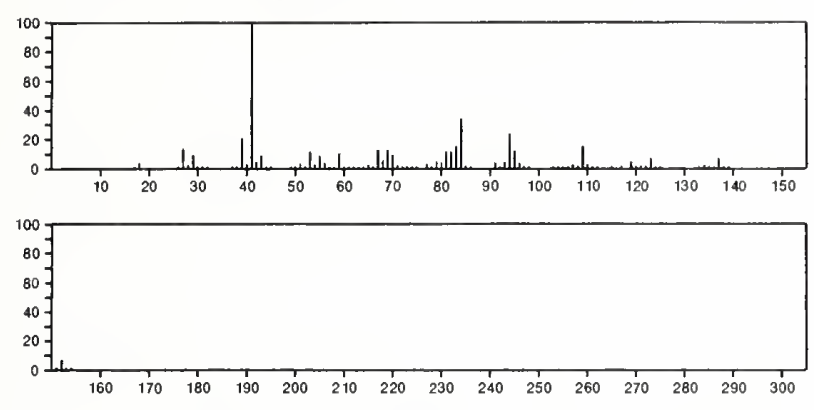

152

$\mathrm{C}_{10} \mathrm{H}_{16} \mathrm{O}$

$6508-22-1$

2-Oxatricyclo[3.3.1.1 $\left.1^{3,7}\right]$ decane, 1-methyl-
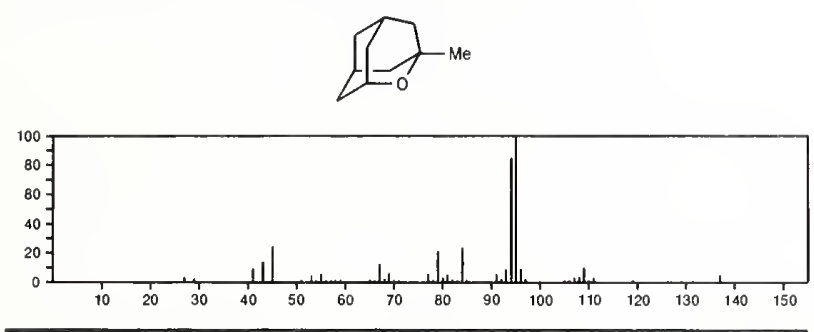

152

$\mathrm{C}_{10} \mathrm{H}_{16} \mathrm{O}$

$7764-50-3$

Cyclohexanone, 2-methyl-5-(1-methylethenyl)-
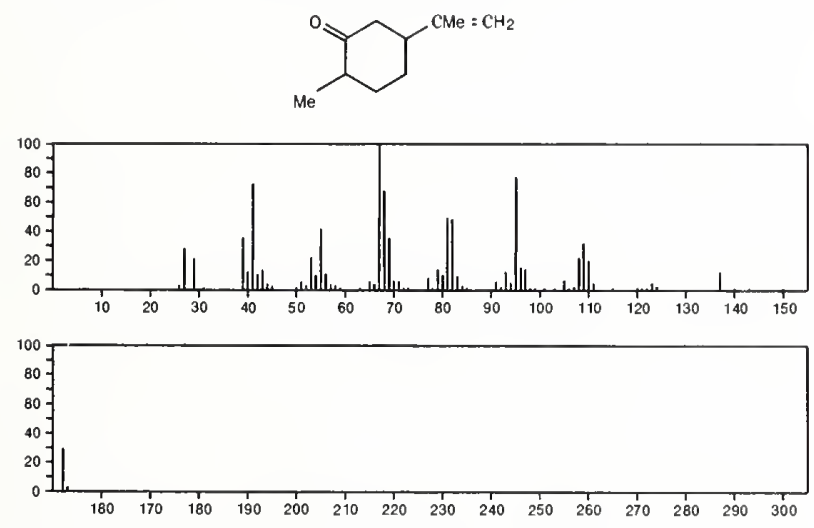

$152 \quad \mathrm{C}_{10} \mathrm{H}_{16} \mathrm{O} \quad 10292-98-5$

Bicyclo[2.2.1]heptan-2-one, 4,7,7-trimethyl-, (1S)-
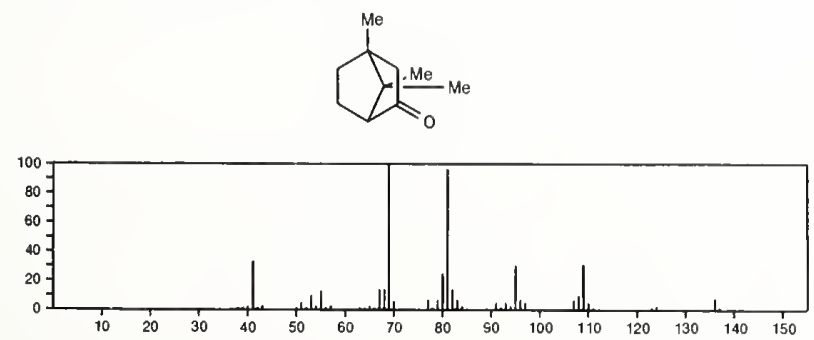

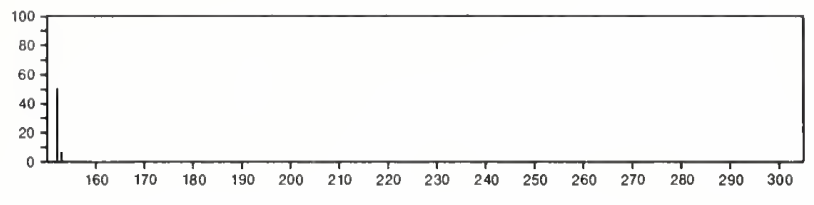

$152 \quad \mathrm{C}_{10} \mathrm{H}_{16} \mathrm{O} \quad 13025-91-7$

1H-Inden-1-one, octahydro-7a-methyl-, cis-- $^{-}$
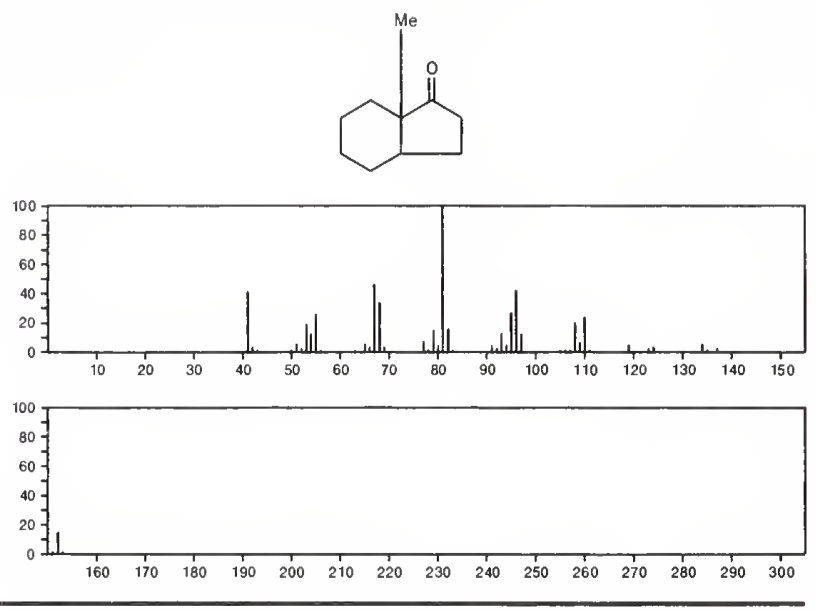

152

2H-Inden-2-one, octahydro-3a-methyl-, cis-

13351-29-6
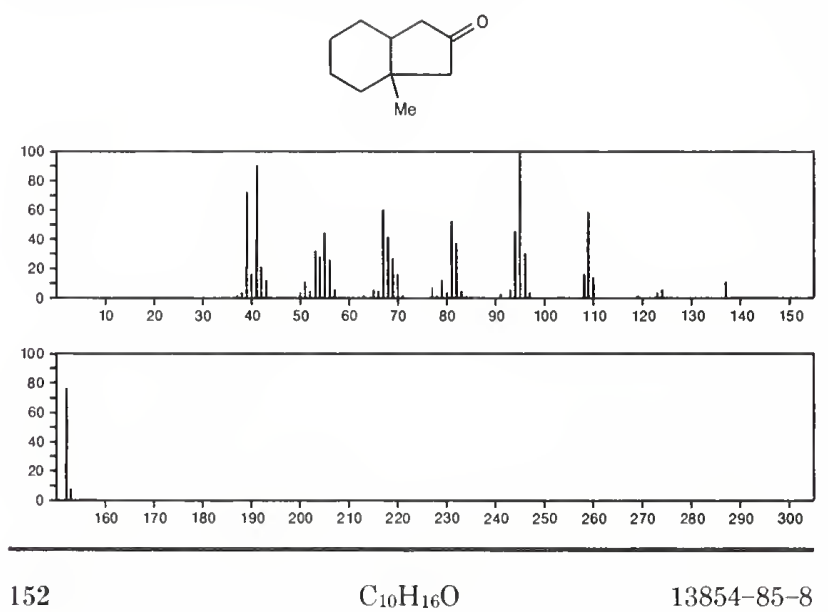

Bicyclo[2.2.1]heptan-2-one, 4,7,7-trimethyl-, (1R)-
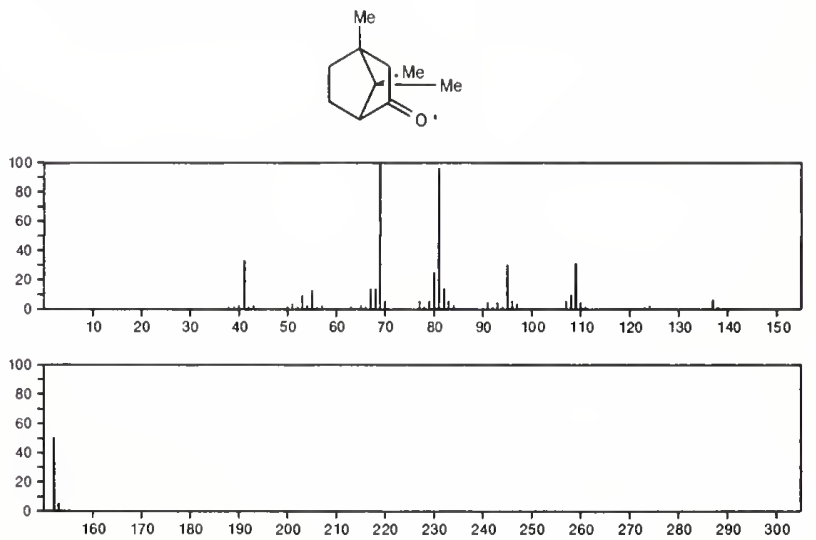
152

$\mathrm{C}_{10} \mathrm{H}_{16} \mathrm{O}$

$15358-88-0$

Bicyclo[3.1.1]heptan-3-one, 2,6,6-trimethyl-, $(1 \alpha, 2 \beta, 5 \alpha)$ -
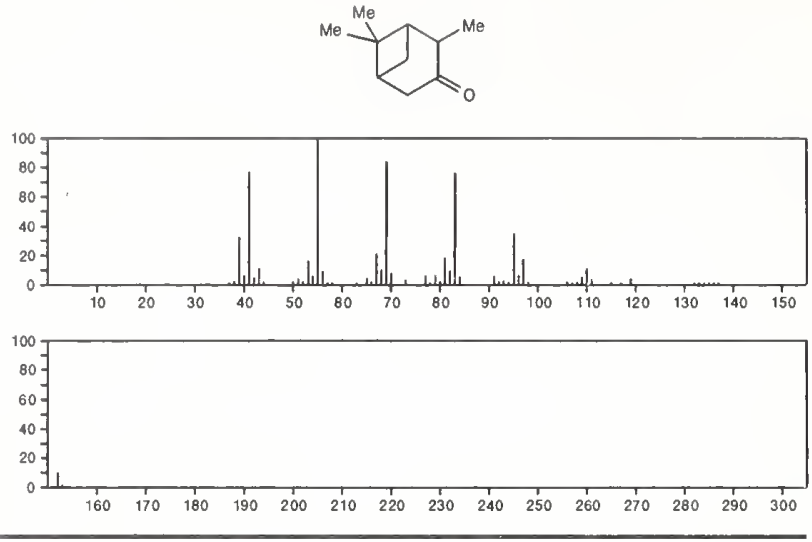

$152 \quad \mathrm{C}_{10} \mathrm{H}_{16} \mathrm{O} \quad 15932-80-6$

Cyclohexanone, 5-methyl-2-(1-methylethylidene)-
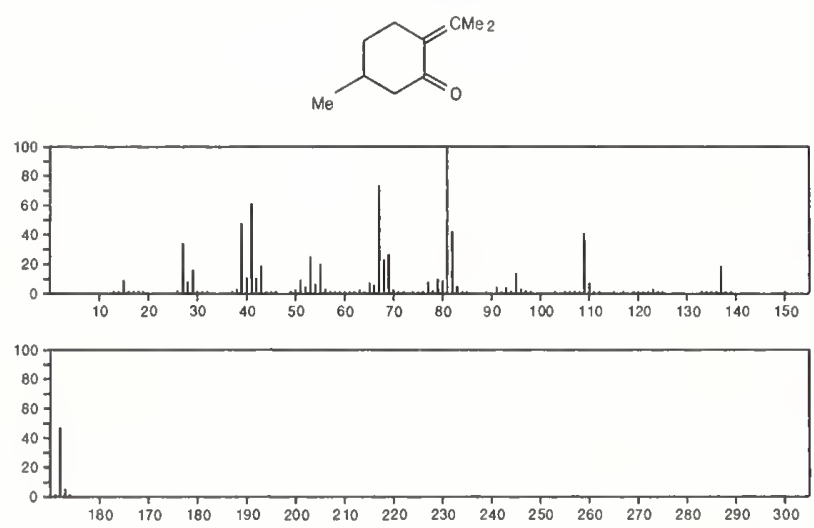

152

2(1H)-Naphthalenone, octahydro-, trans-
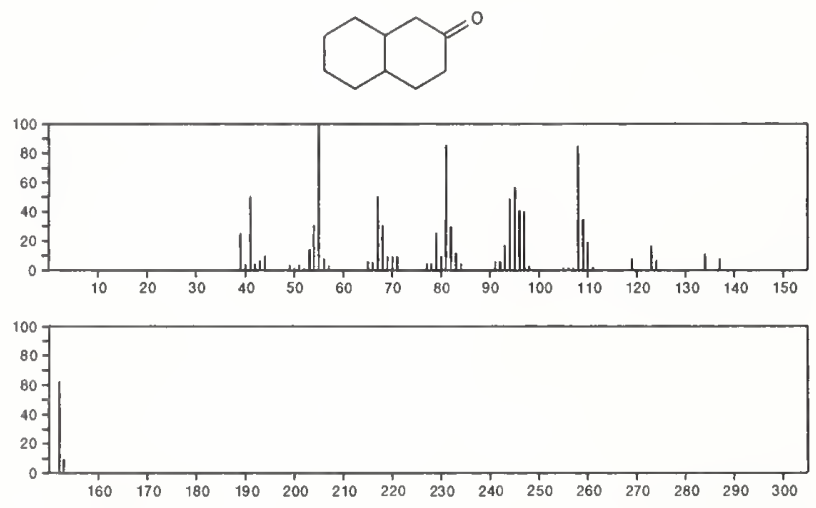

152

$\mathrm{C}_{10} \mathrm{H}_{16} \mathrm{O}$

$17428-83-0$

1H-Inden-1-one, octahydro-7a-methyl-, trans-
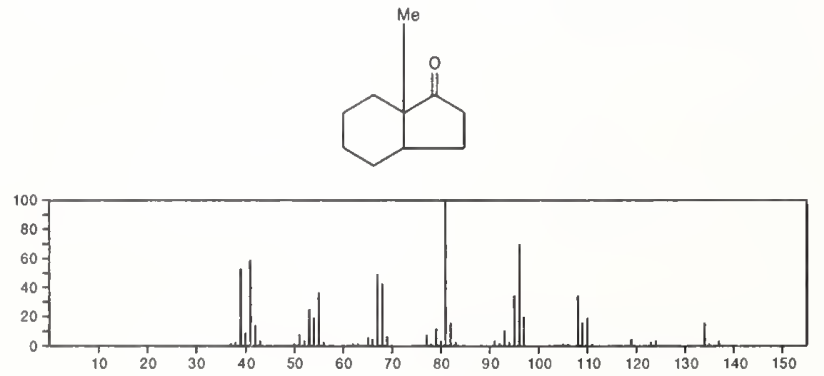

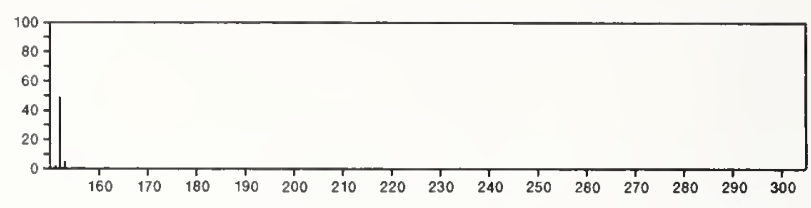

152

$\mathrm{C}_{10} \mathrm{H}_{16} \mathrm{O}$

$17429-33-3$

2-Cyclohexen-1-one, 4-ethyl-4,5-dimethyl-<smiles>CCC1(C)C=CC(=O)CC1C</smiles>
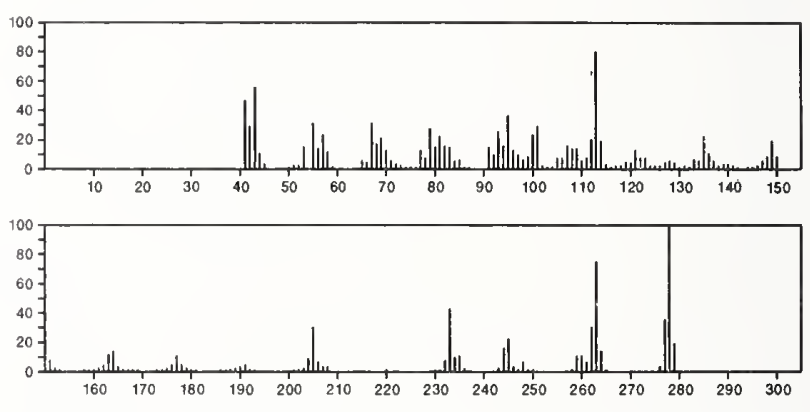

152

$\mathrm{C}_{10} \mathrm{H}_{16} \mathrm{O}$

2-Cyclohexen-1-one, 4-ethyl-3,4-dimethyl-

$17622-46-7$
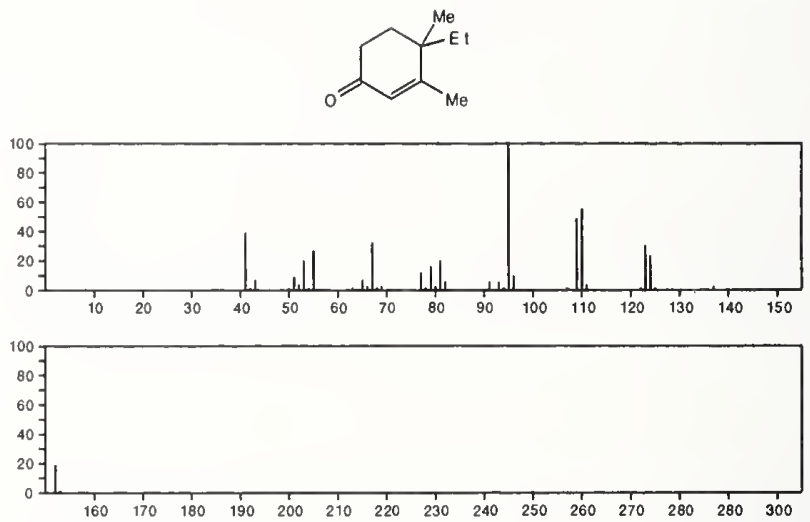

152

$\mathrm{C}_{10} \mathrm{H}_{16} \mathrm{O}$

20379-99-1

2-Indanone, hexahydro-3a-methyl-, trans-
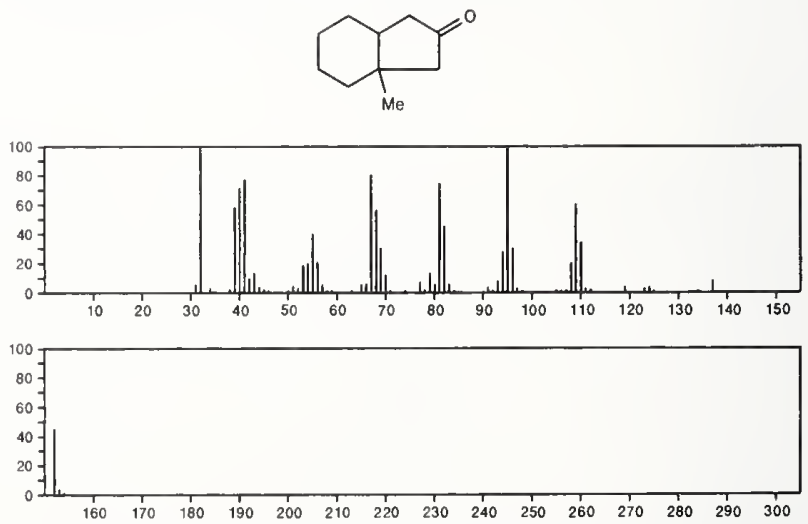
152

Bicyclo[4.3.1]decan-10-one $\mathrm{C}_{10} \mathrm{H}_{16} \mathrm{O}$

$20440-21-5$
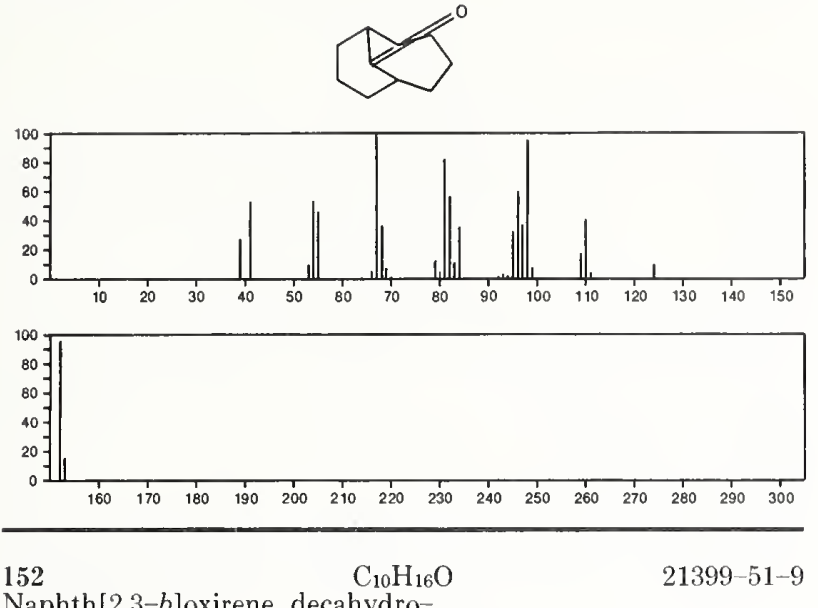

Naphth $[2,3-b]$ oxirene, decahydro-
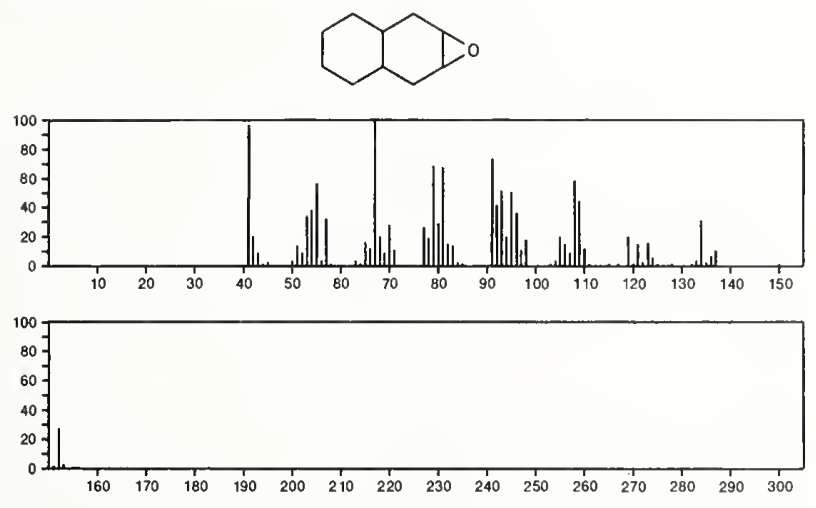

$152 \quad \mathrm{C}_{10} \mathrm{H}_{16} \mathrm{O} \quad 26532-24-1$ Acetaldehyde, (3,3-dimethylcyclohexylidene)-, $(Z)-$
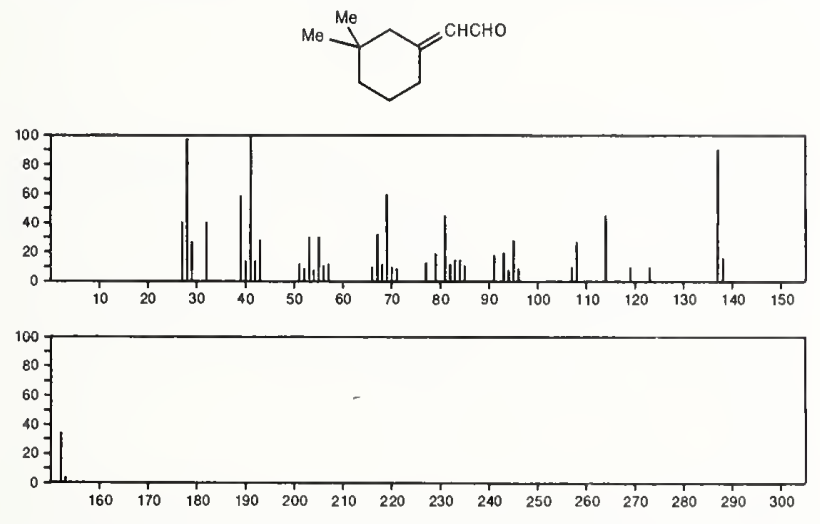

$152 \quad \mathrm{C}_{10} \mathrm{H}_{16} \mathrm{O}$ 26532-25-2

Acetaldehyde, (3,3-dimethylcyclohexylidene)-, (E)-
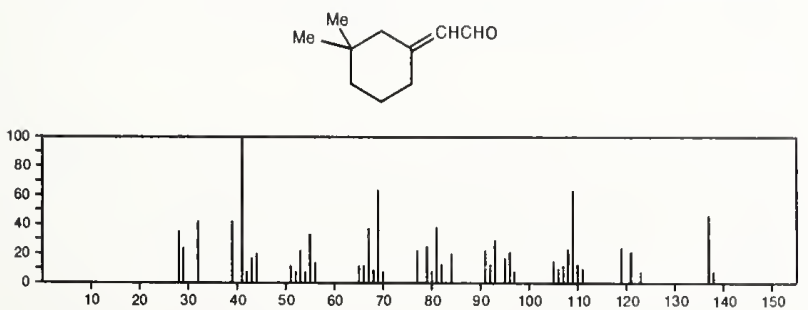

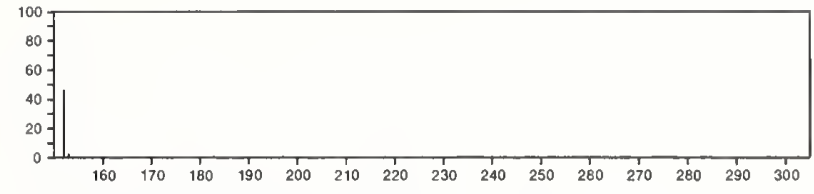

$\mathrm{C}_{10} \mathrm{H}_{16} \mathrm{O}$

$28840-87-1$

2,5-Methano-1H-inden-7-ol, octahydro-, $(2 \alpha, 3 \mathrm{a} \beta, 5 \alpha, 7 \alpha, 7 \mathrm{a} \beta)$
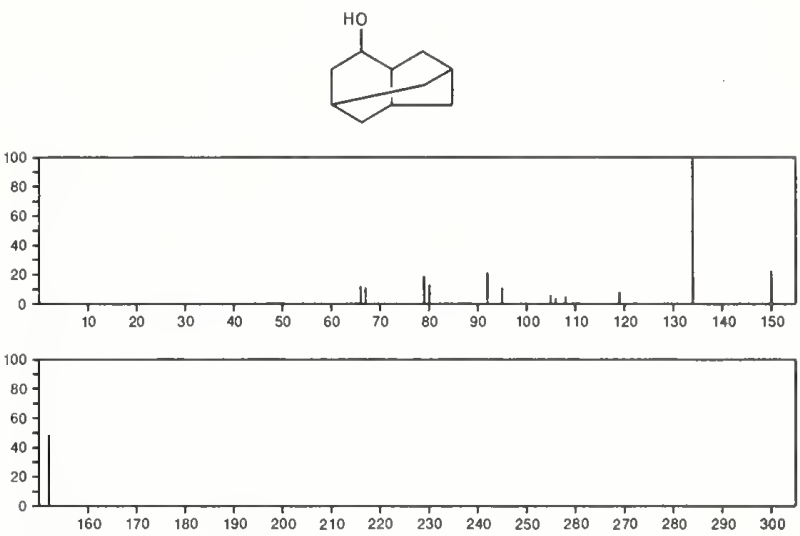

152

$\mathrm{C}_{10} \mathrm{H}_{16} \mathrm{O}$

$28840-88-2$

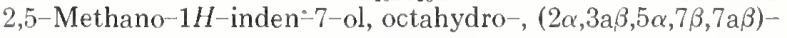
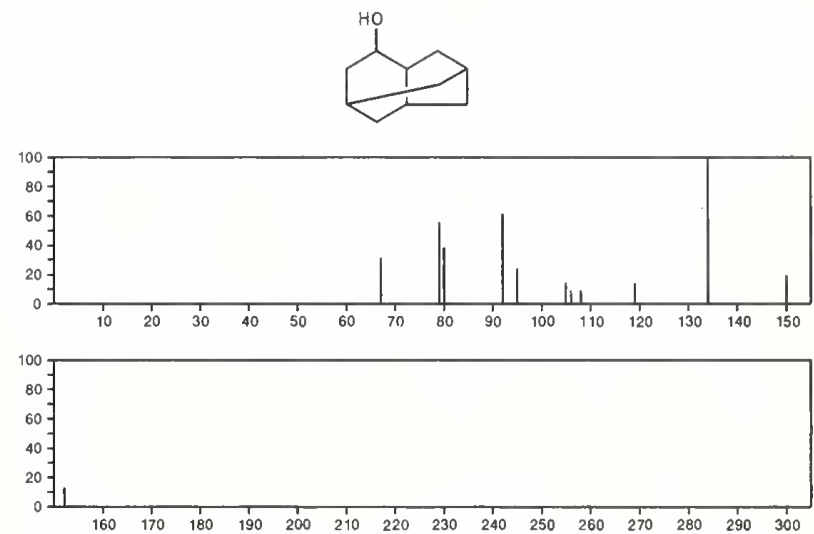

152

5-Octyn-4-one, 2,7-dimethyl-

$\mathrm{C}_{10} \mathrm{H}_{16} \mathrm{O}$

$29030-74-8$

$\mathrm{Me}_{2} \mathrm{CHC}: \mathrm{CCOCH}_{2} \mathrm{CHMe}_{2}$
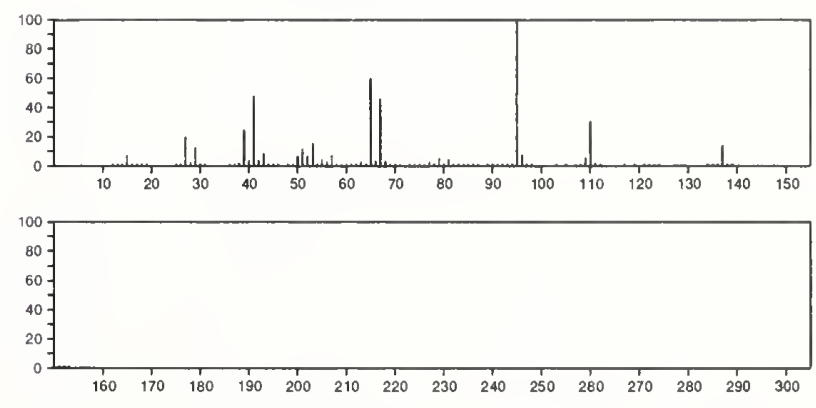

152
$1,5,7-$ Octatrien-3-ol, $2,6-$ dimethyl-

$29414-56-0$

$\mathrm{H}_{2} \mathrm{C}: \mathrm{CHCMe}_{\mathrm{C}}=\mathrm{CHCH}_{2} \mathrm{CH}(\mathrm{OH}) \mathrm{CMe}: \mathrm{CH}_{2}$

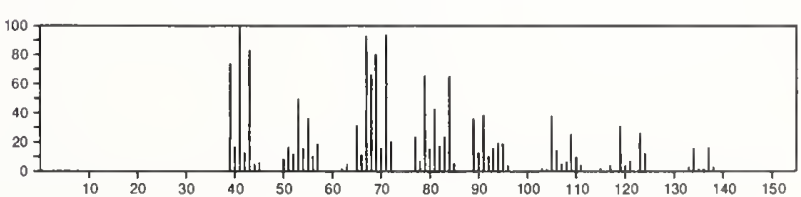




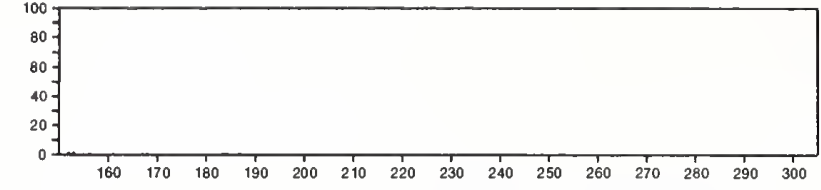

\begin{tabular}{ll}
\hline $\mathrm{C}_{10} \mathrm{H}_{16} \mathrm{O}$ & $29548-13-8$ \\
$p$-Mentha-1(7),8(10)-dien-9-ol
\end{tabular}

p-Mentha-1(7),8(10)-dien-9-ol
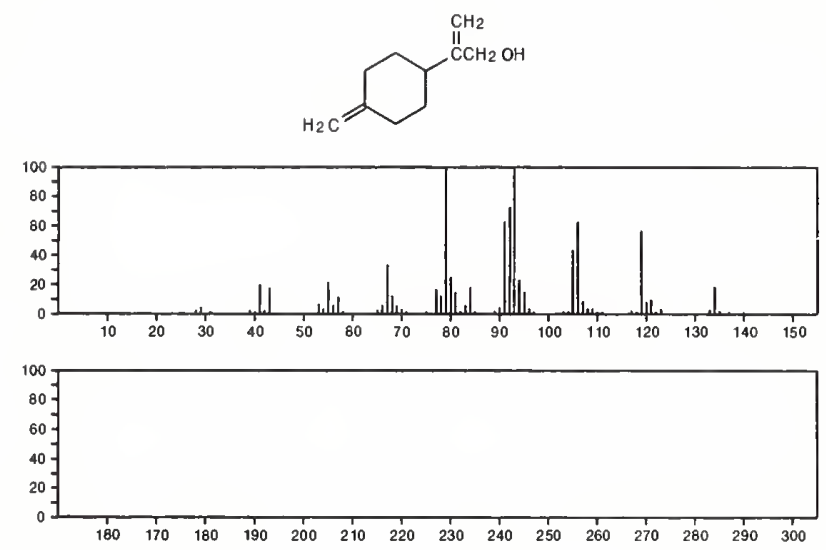

152

$\mathrm{C}_{10} \mathrm{H}_{16} \mathrm{O}$

$29550-55-8$

Tricyclo[2.2.1.02,6]heptane-3-methanol, 2,3-dimethyl-
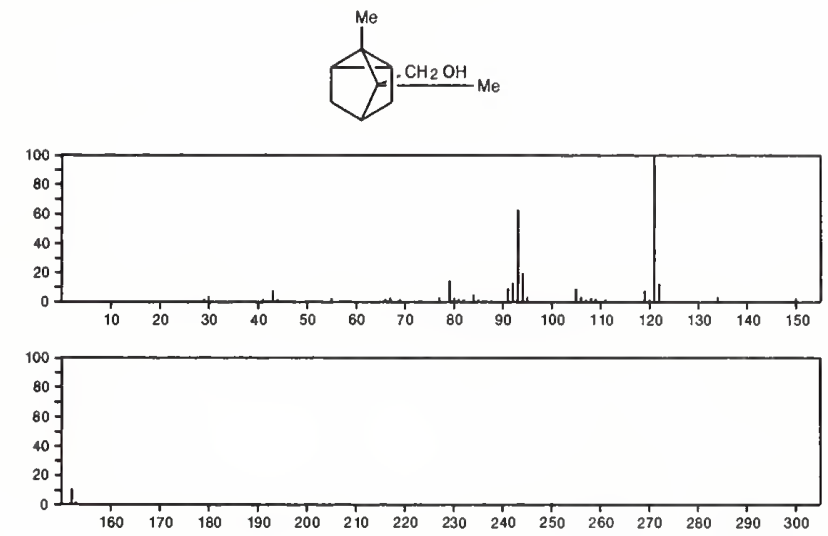

$152 \quad \mathrm{C}_{10} \mathrm{H}_{16} \mathrm{O} \quad 29606-79-9$

Cyclohexanone, 5-methyl-2-(1-methylethenyl)-, trans-
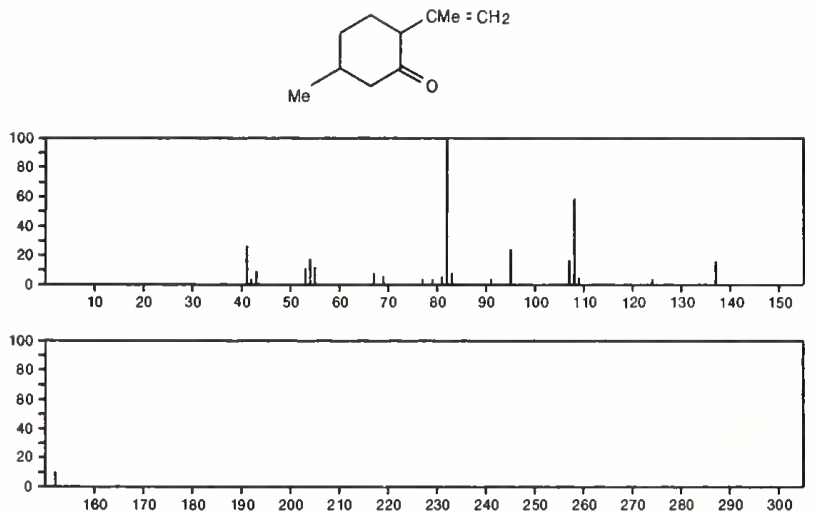

152

$\mathrm{C}_{10} \mathrm{H}_{16} \mathrm{O}$

$29750-24-1$

Bicyclo[4.1.0]heptan-2-one, 3,5,5-trimethyl-
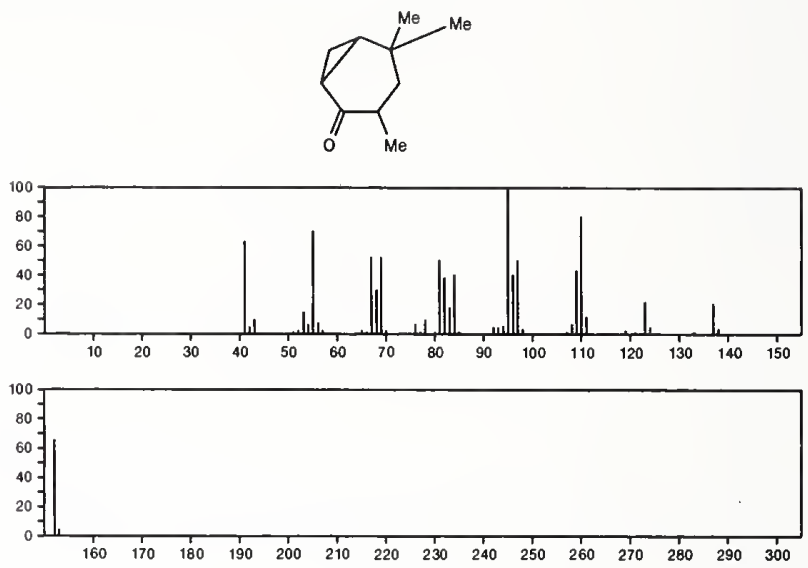

$152 \quad \mathrm{C}_{10} \mathrm{H}_{16} \mathrm{O}$

3,7-Nonadien-2-one, 8-methyl-, $(E)$ -

$35408-14-1$

$\mathrm{Me} \mathrm{COCH}=\mathrm{CHCH}_{2} \mathrm{CH}_{2} \mathrm{CH}=\mathrm{CMe} 2$
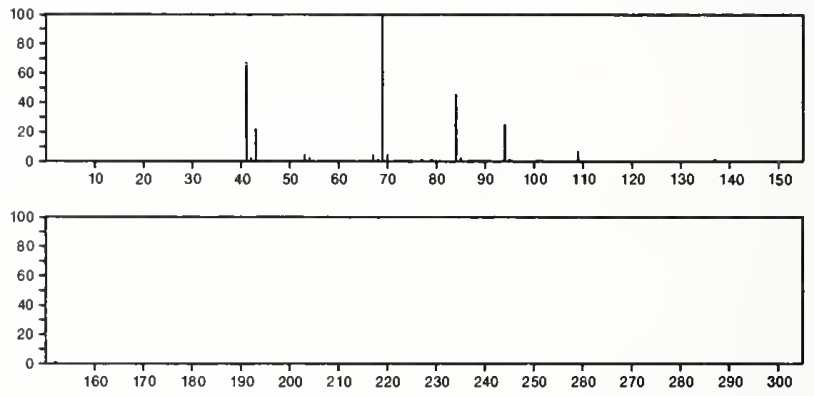

$152 \quad \mathrm{C}_{10} \mathrm{H}_{16} \mathrm{O} \quad 40702-26-9$ 3-Cyclohexene-1-carboxaldehyde, 1,3,4-trimethyl-
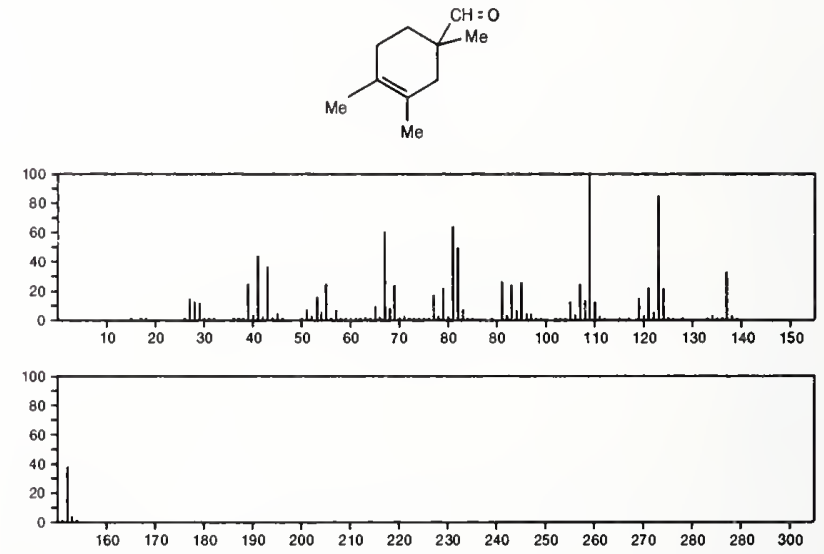

152

$\mathrm{C}_{10} \mathrm{H}_{16} \mathrm{O}$

Ethanone, 1-(1,4-dimethyl-3-cyclohexen-1-yl)-

$43219-68-7$
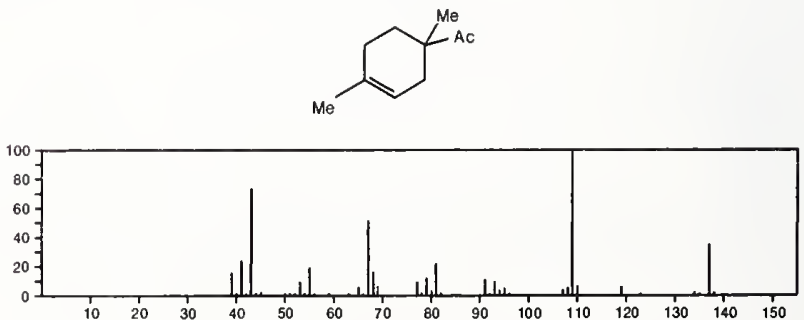

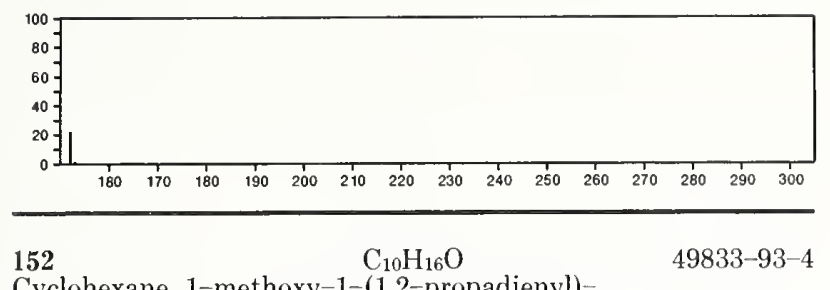

Cyclohexane, 1-methoxy-1-(1,2-propadienyl)-
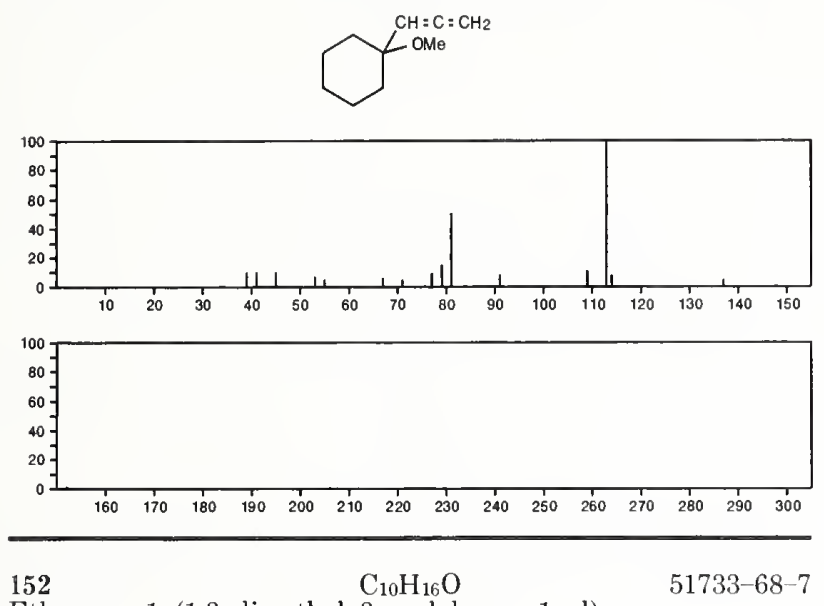

Ethanone, 1-(1,3-dimethyl-3-cyclohexen-1-yl)-
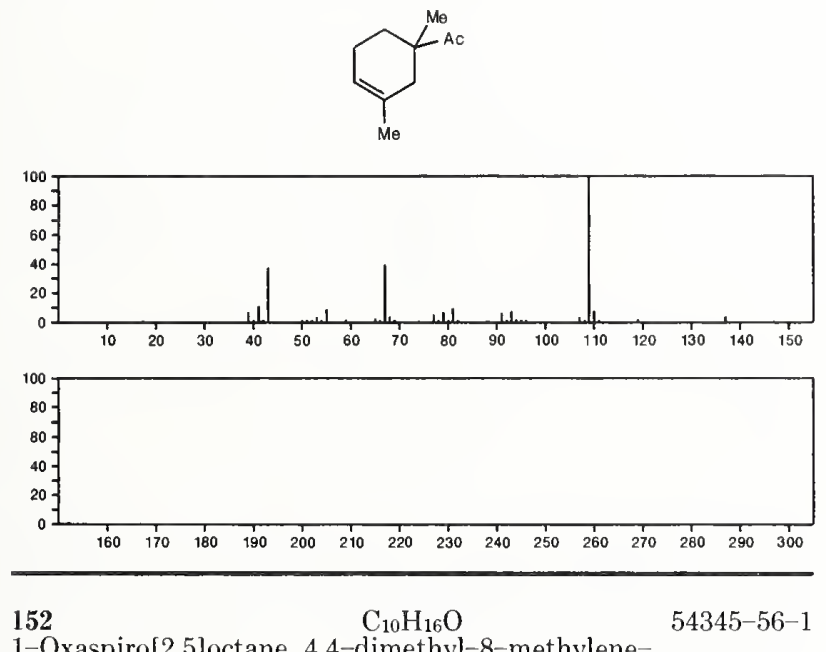

1-Oxaspiro[2.5]octane, 4,4-dimethyl-8-methylene
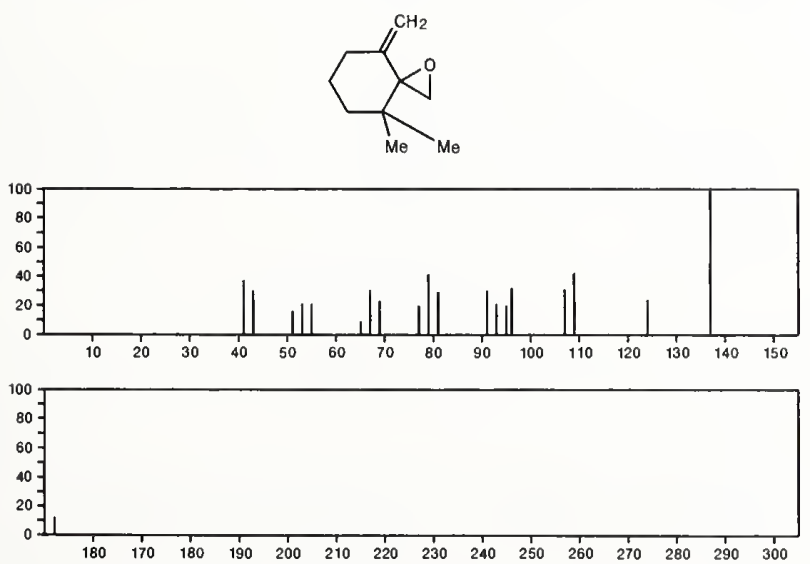

152

$\mathrm{C}_{10} \mathrm{H}_{16} \mathrm{O}$

$55759-84-7$

Bicyclo\{3.2.0]heptan-2-one, 1,4,4-trimethyl-
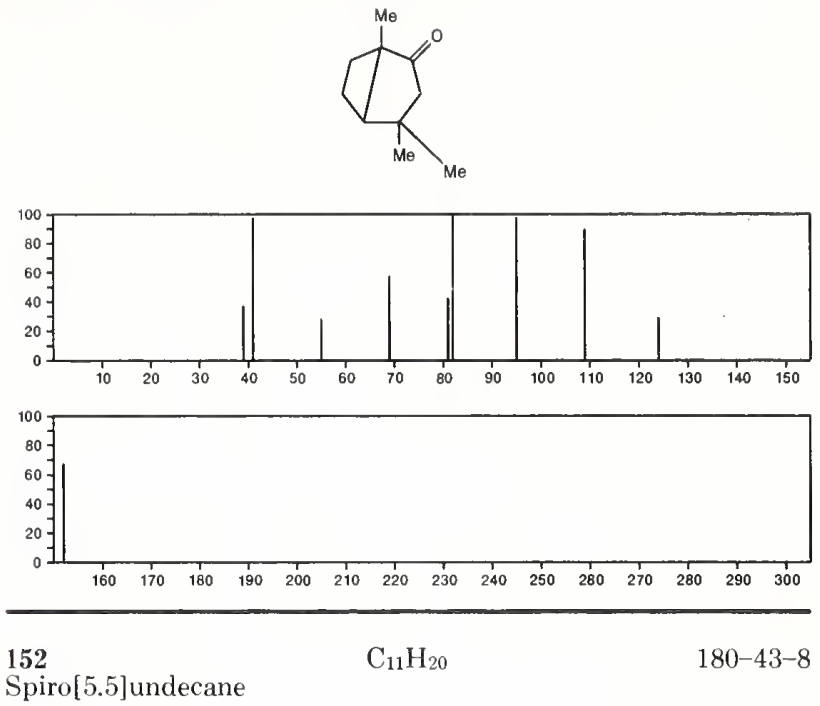

Spiro[5.5]undecane
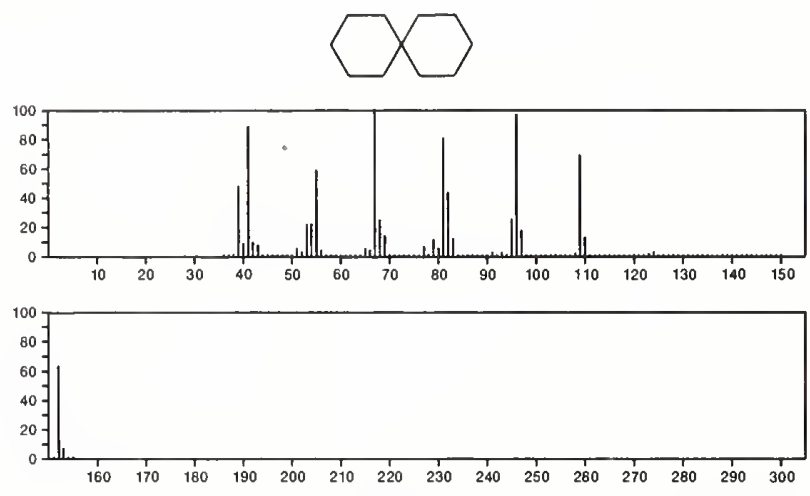

152

1-Undecyne

$\mathrm{C}_{11} \mathrm{H}_{20}$

2243-98-3

$\mathrm{HC} \equiv \mathrm{C}\left(\mathrm{CH}_{2}\right)_{8} \mathrm{Me}$

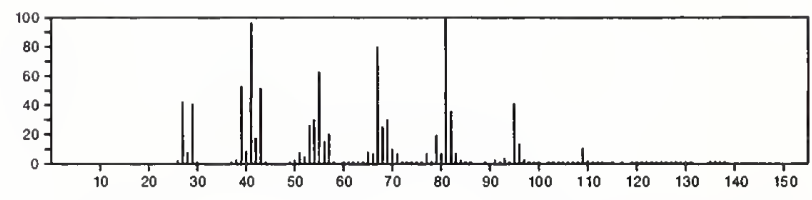

152

$\mathrm{C}_{11} \mathrm{H}_{20}$

Naphthalene, decahydro-2-methyl-

2958-76-1
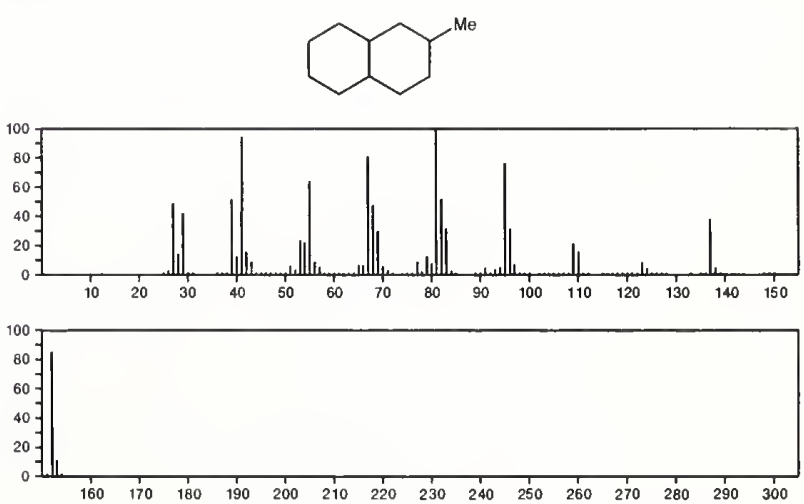
152

Cyclohexene, 1-isopentyl-

$$
\mathrm{C}_{11} \mathrm{H}_{20}
$$
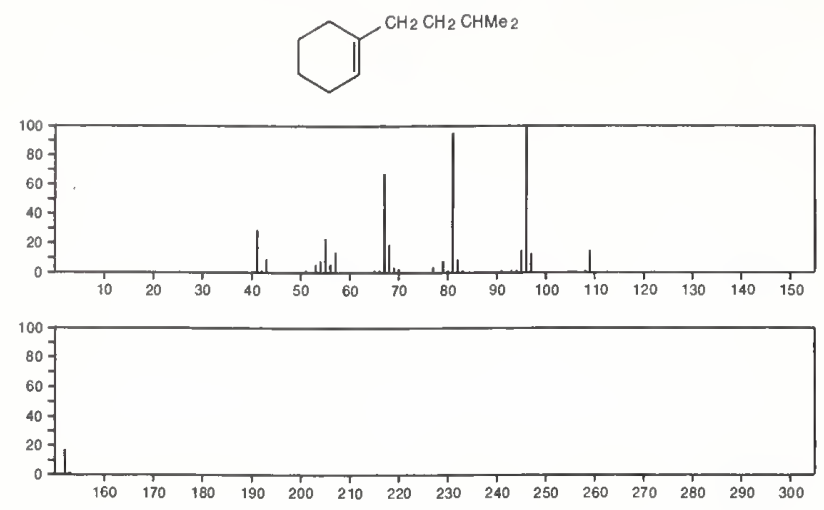

152

Cyclohexene, 1-pentyl-

$\mathrm{C}_{11} \mathrm{H}_{20}$

15232-85-6
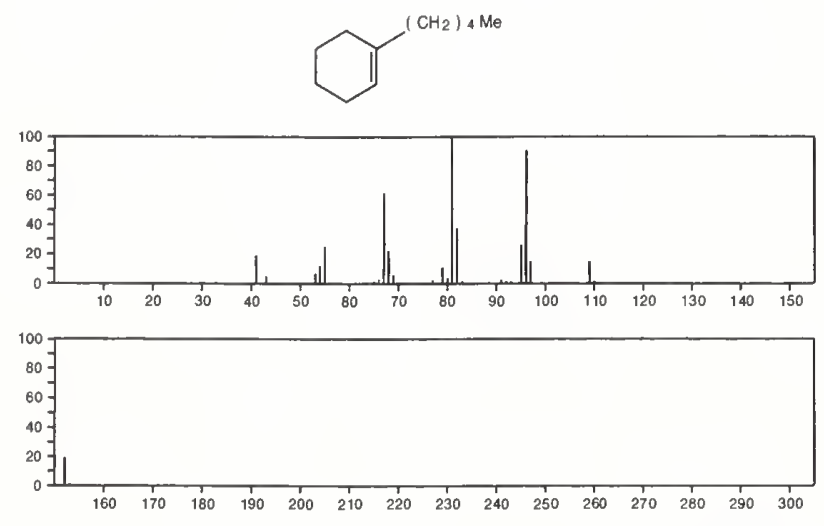

152

Bicyclo[4.1.0] heptane, 7-butyl-

$\mathrm{C}_{11} \mathrm{H}_{20}$

18645-10-8

$\mathrm{Me}\left(\mathrm{CH}_{2}\right)_{3}$
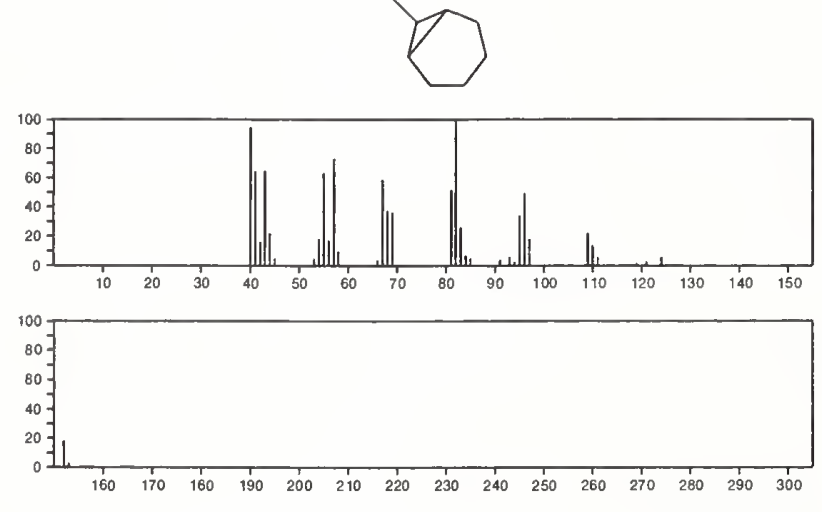

152

3-Octyne, 2,2,7-trimethyl-

$\mathrm{C}_{11} \mathrm{H}_{20}$

55402-13-6

$\mathrm{Me}_{2} \mathrm{CHCH}_{2} \mathrm{CH}_{2} \mathrm{C} \equiv \mathrm{CCMe}_{3}$
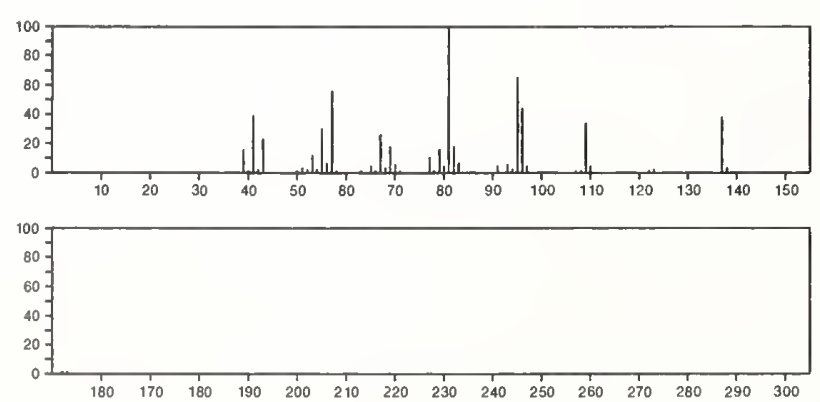

152

1,4 -Undecadiene, $(E)$

$\mathrm{C}_{11} \mathrm{H}_{20}$

$55976-13-1$

$\mathrm{Me}\left(\mathrm{CH}_{2}\right){ }_{5} \mathrm{CH}=\mathrm{CHCH}_{2} \mathrm{CH}=\mathrm{CH}_{2}$
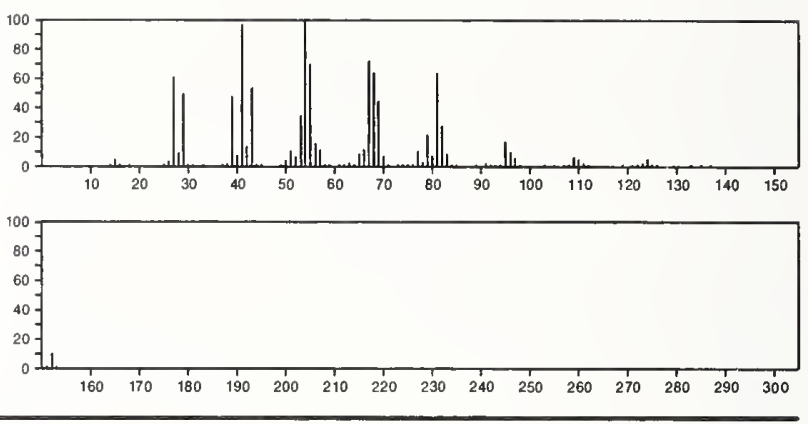

152

$\mathrm{C}_{11} \mathrm{H}_{20}$

$55976-14-2$

1,4-Undecadiene, $(Z)$ -

$\mathrm{Me}\left(\mathrm{CH}_{2}\right)_{5} \mathrm{CH}=\mathrm{CHCH}_{2} \mathrm{CH}=\mathrm{CH}_{2}$
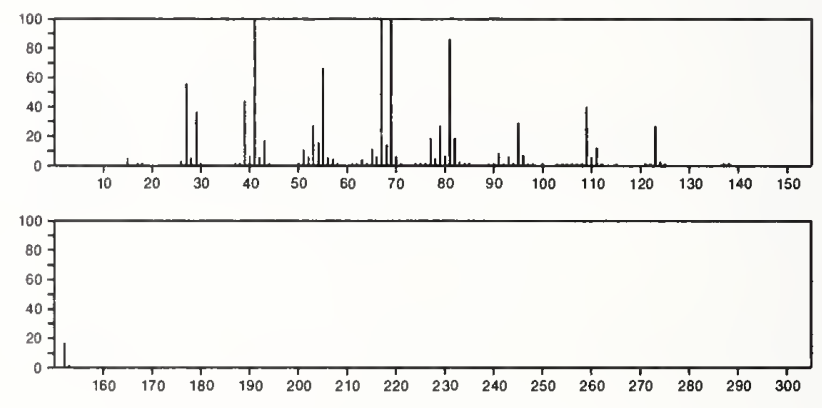

152

$\mathrm{C}_{11} \mathrm{H}_{20}$

56259-17-7

Cyclopropane, 1-(1-methylethyl)-2-(2-methyl-1-methylenepropyl)-
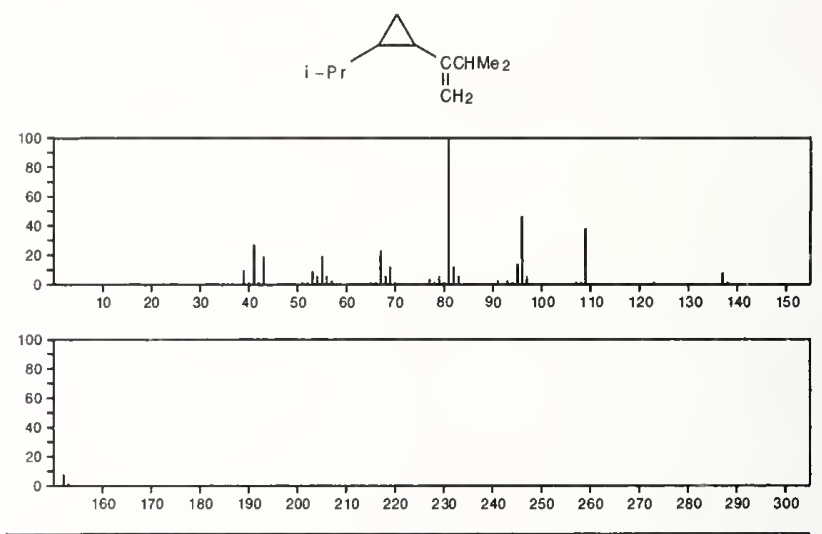

152

$\mathrm{C}_{11} \mathrm{H}_{20}$

$56701-50-9$

Cyclopropane, 1,1-dimethyl-2-(1-methylethyl)-3-(1-methyl= ethylidene)-, ( $( \pm)-$<smiles>C=C1C(C)C1(C)C</smiles>

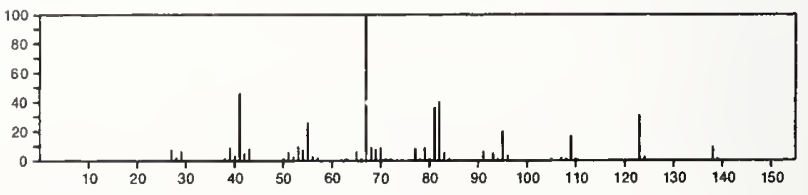


152

Acenaphthylene

$\mathrm{C}_{12} \mathrm{H}_{8}$

208-96-8
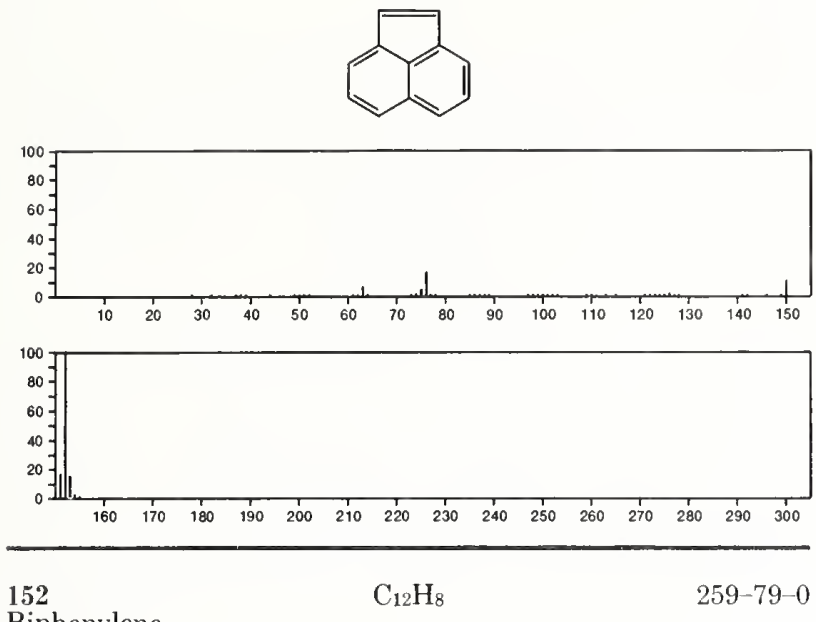

Biphenylene
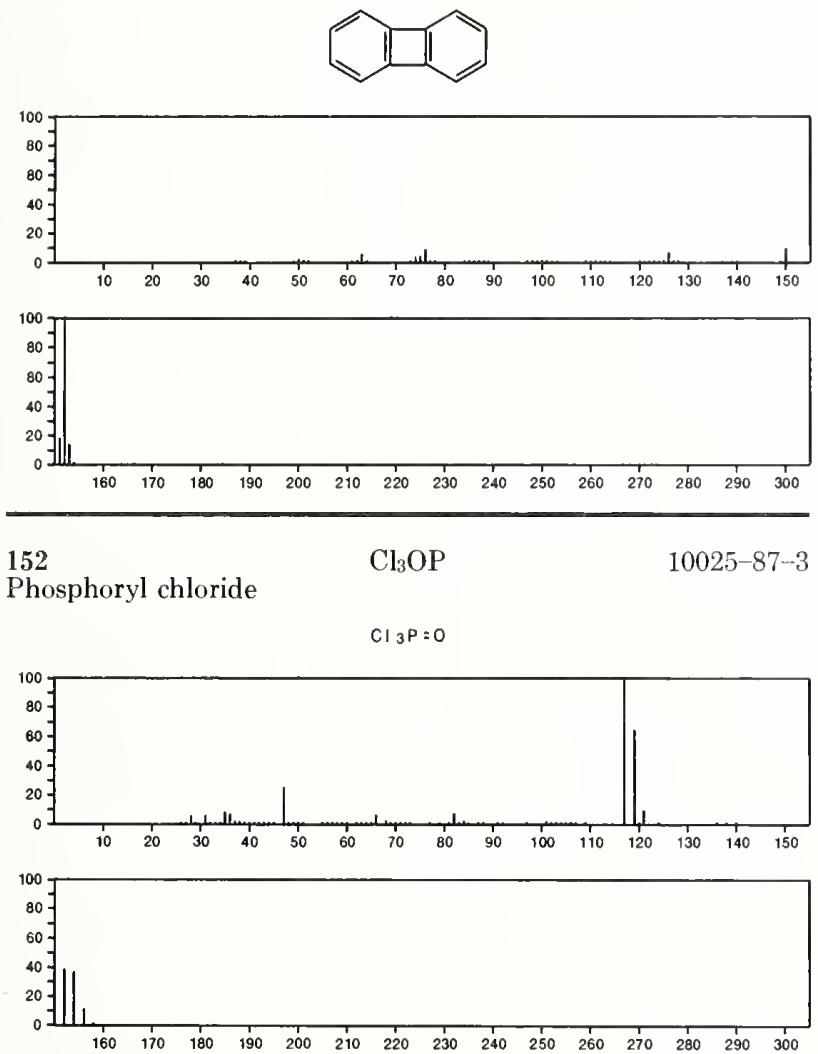

\section{3}

$153 \quad \mathrm{CF}_{5} \mathrm{NS}$

$\mathrm{CF}_{5} \mathrm{NS}$

$\mathrm{F}_{3} \mathrm{CN}=\mathrm{SF}_{2}$
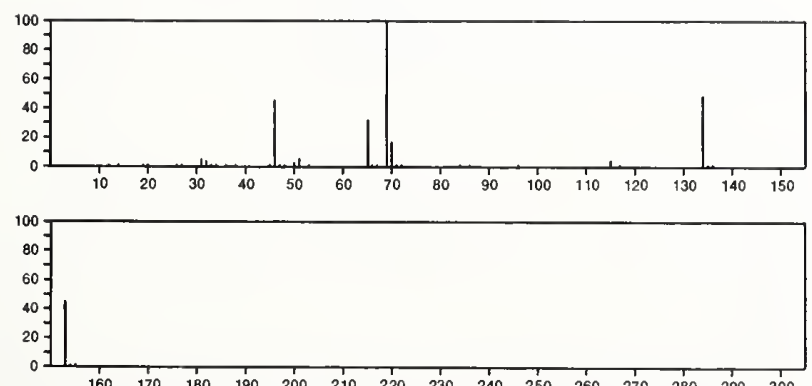

153

Sulfonium, [(chloroacetyl)amino] dimethyl-, hydroxide, inner salt

$\stackrel{+}{\mathrm{Me}} 2 \stackrel{-}{\mathrm{S}} \mathrm{N} \mathrm{COCH}_{2} \mathrm{Cl}$
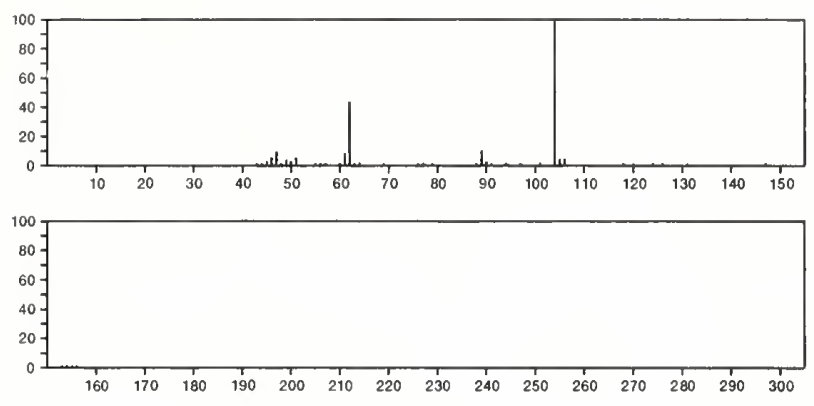

$153 \quad \mathrm{C}_{4} \mathrm{H}_{12} \mathrm{NO}_{3} \mathrm{P}$

Phosphoramidic acid, diethyl ester

1068-21-9

$\stackrel{\circ}{\text { II }}$ (NH2) OEI
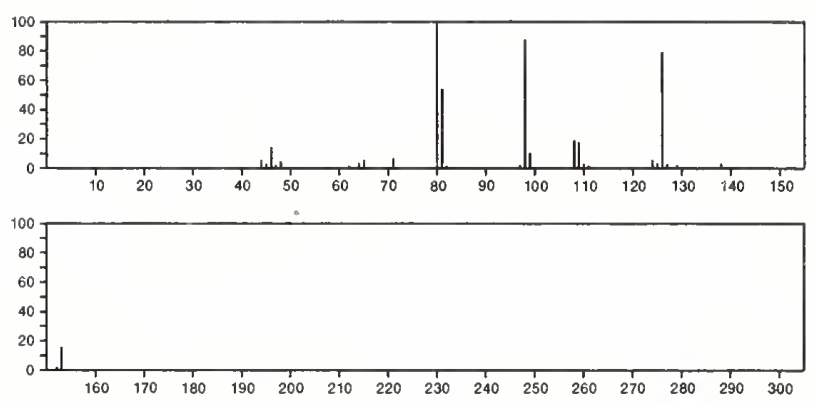

153

$\mathrm{C}_{5} \mathrm{H}_{3} \mathrm{~N}_{3} \mathrm{OS}$

26271-18-1

$[1,2,5]$ Thiadiazolo $[3,4-c]$ pyridin-4(5H)-one
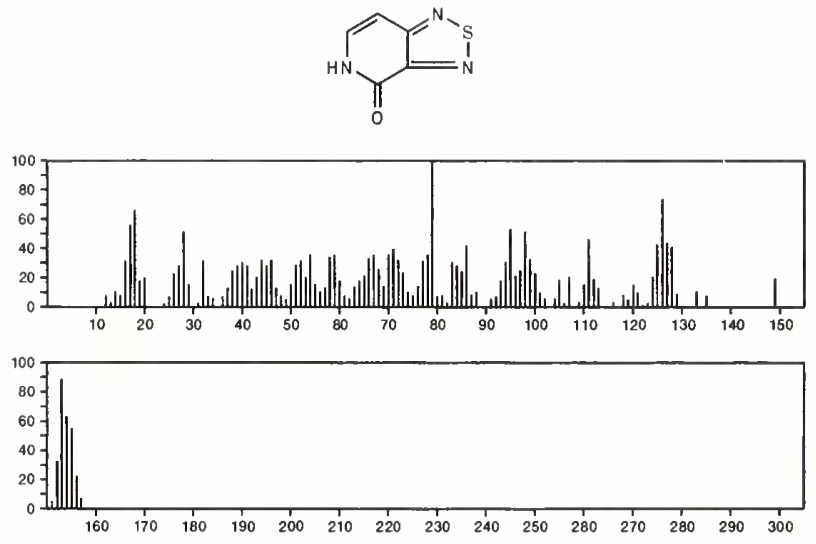

153

$\mathrm{C}_{5} \mathrm{H}_{7} \mathrm{~N}_{5} \mathrm{O}$

33925-00-7

Purin-8-ol, 6-amino-8,9-dihydro-
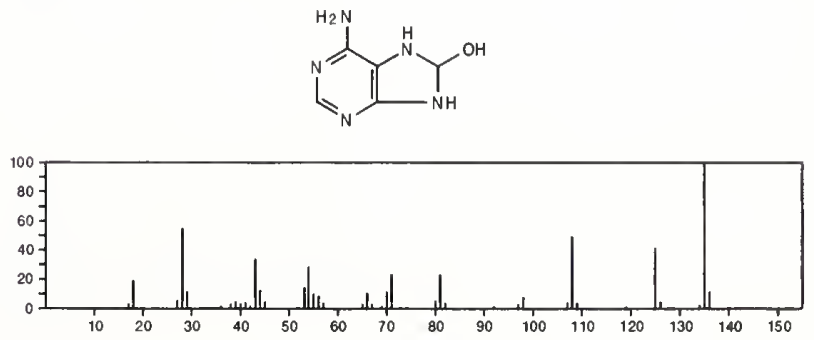

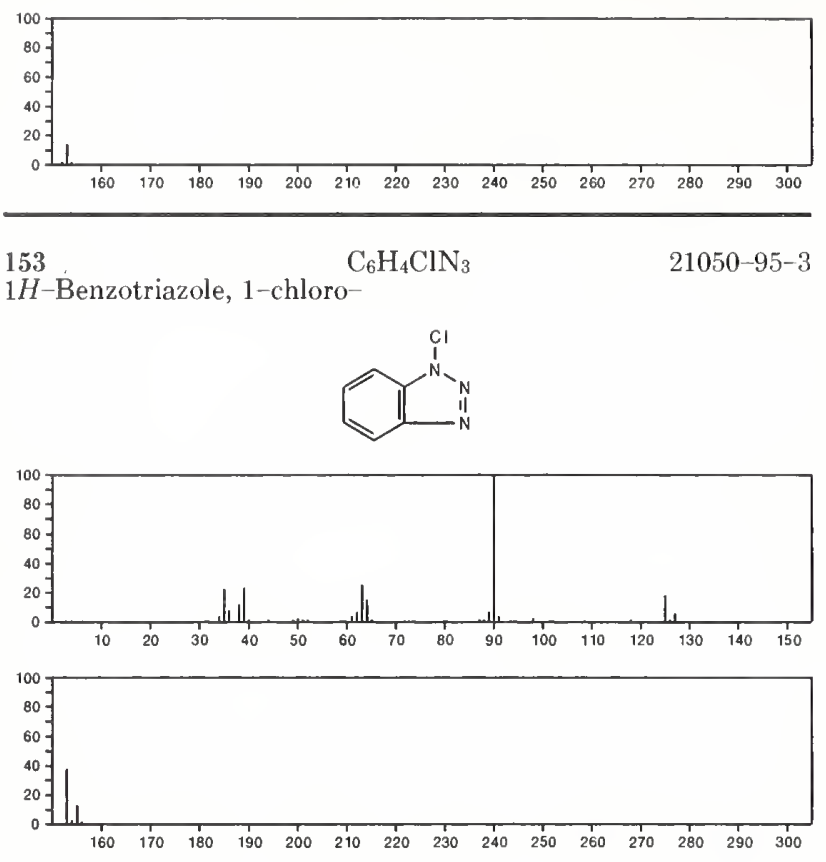

153

Hydrazine, (4-nitrophenyl)-

\section{$\mathrm{C}_{6} \mathrm{H}_{7} \mathrm{~N}_{3} \mathrm{O}_{2}$}

$100-16-3$
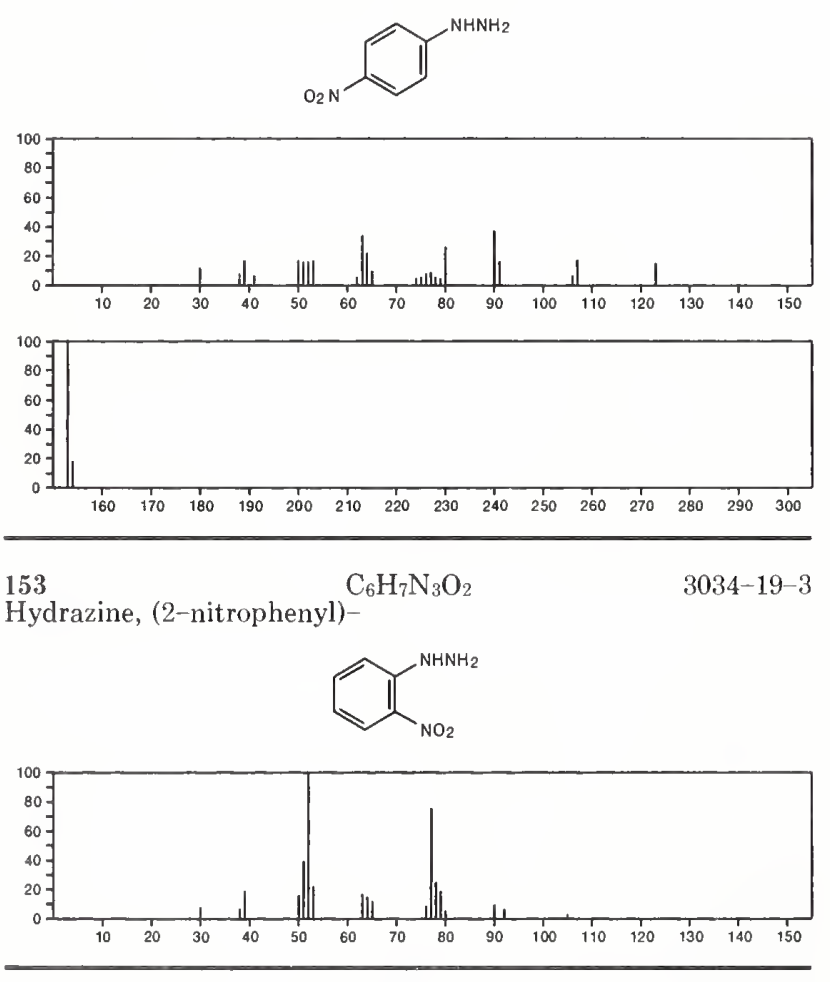

$153 \quad \mathrm{C}_{6} \mathrm{H}_{7} \mathrm{~N}_{3} \mathrm{O}_{2}$

1,2-Benzenediamine, 3-nitro-
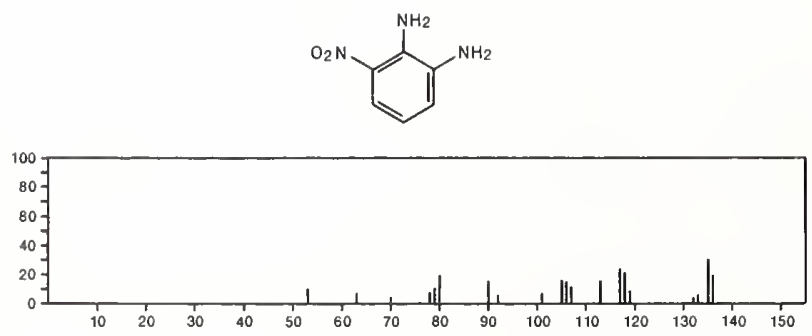

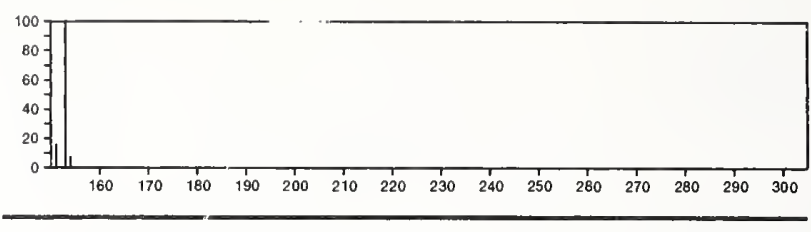

153

$\mathrm{C}_{6} \mathrm{H}_{7} \mathrm{~N}_{3} \mathrm{O}_{2}$

2-Pyridinamine, 3 - methyl- $N$-nitro-

$18344-53-1$
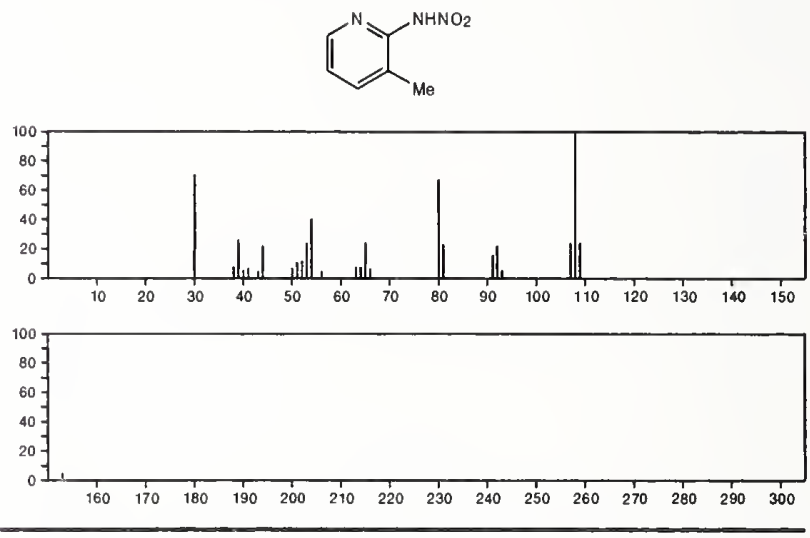

153

$\mathrm{C}_{6} \mathrm{H}_{7} \mathrm{~N}_{3} \mathrm{O}_{2}$

2(1H)-Pyridinimine, 1 -methyl- $N$-nitro-

$31396-29-9$
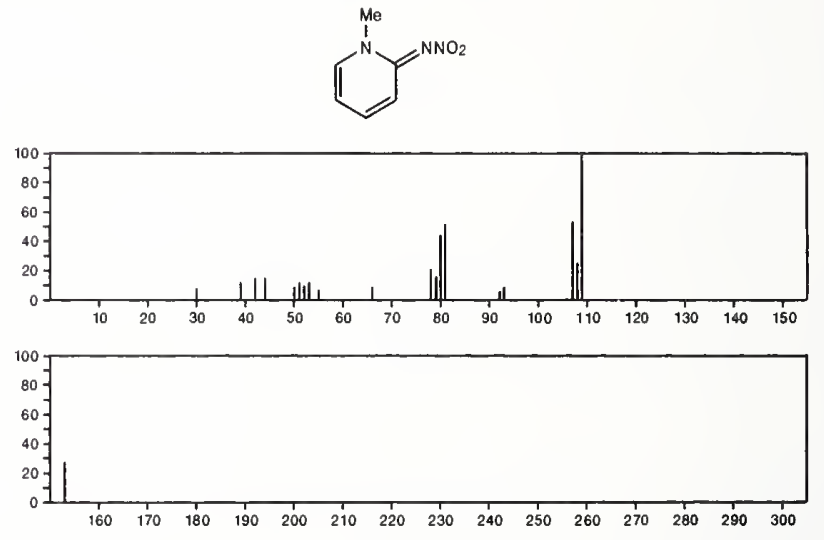

$153 \quad \mathrm{C}_{6} \mathrm{H}_{7} \mathrm{~N}_{3} \mathrm{O}_{2}$

$55760-13-9$

3H-Pyrazolo[4,3-b]pyridine-3,3-diol, 1,2-dihydro-
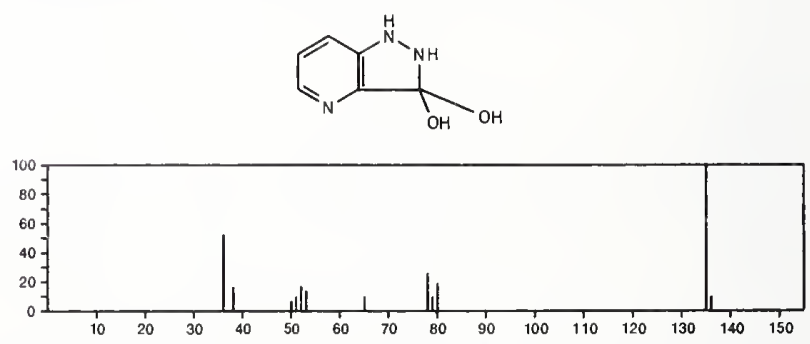

153

$\mathrm{C}_{6} \mathrm{H}_{15} \mathrm{NO} . \mathrm{ClH}$

14426-20-1

Ethanol, 2-(diethylamino)-, hydrochloride

$\mathrm{HOCH}_{2} \mathrm{CH}_{2} \mathrm{NET}_{2}$ - $\mathrm{HCl}$

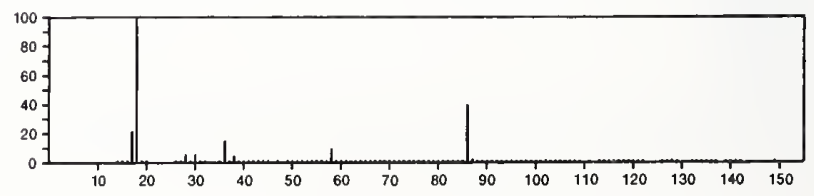




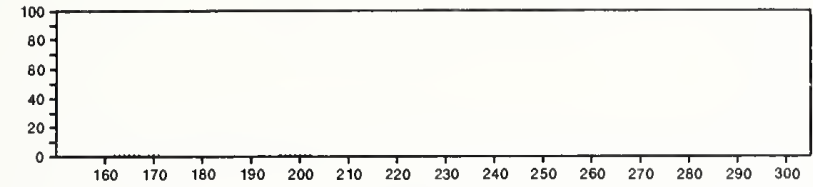

$\begin{array}{lllllllllllllll}160 & 170 & 180 & 190 & 200 & 210 & 220 & 230 & 240 & 250 & 260 & 270 & 280 & 290 & 300\end{array}$

153

$\mathrm{C}_{7} \mathrm{H}_{4} \mathrm{ClNO}$

$104-12-1$

Benzene, 1-chloro-4-isocyanato-
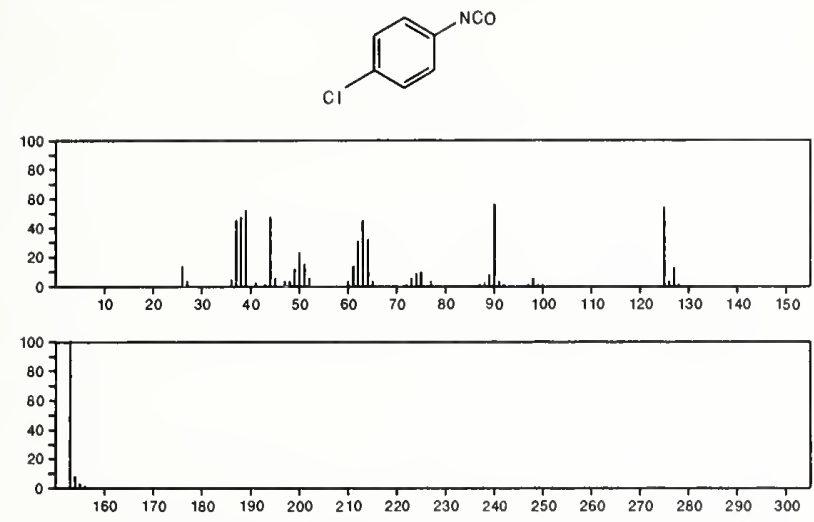

153

$\mathrm{C}_{7} \mathrm{H}_{4} \mathrm{ClNO}$

$51134-03-3$

Benzene, chloroisocyanato-
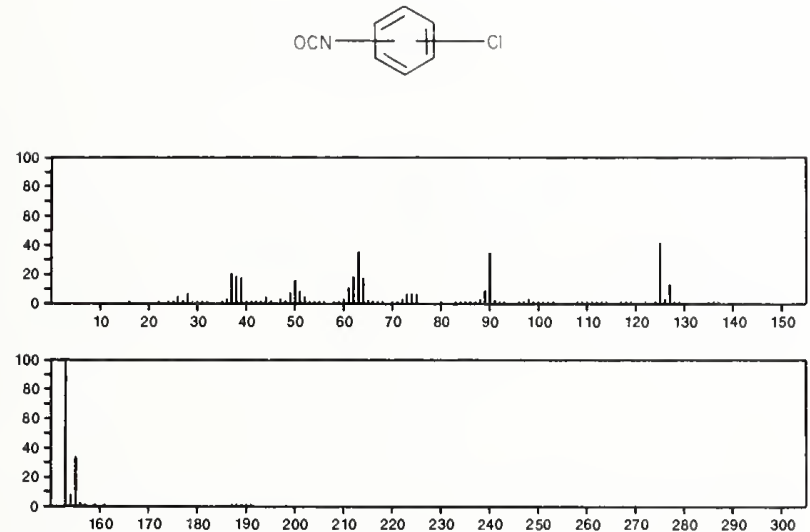

$153 \quad \mathrm{C}_{7} \mathrm{H}_{7} \mathrm{NOS}$

$15795-43-4$

Benzenamine, 3-methyl- $N$-sulfinyl-
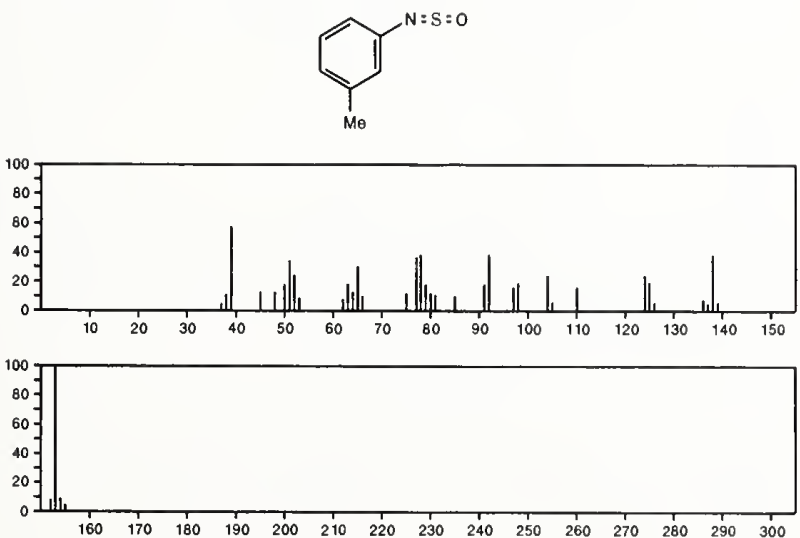

153

$\mathrm{C}_{7} \mathrm{H}_{7} \mathrm{NOS}$

$23003-45-4$

'Thiazolo[3,2-a]pyridinium, 2,3-dihydro-8-hydroxy-, hydroxide, inner salt
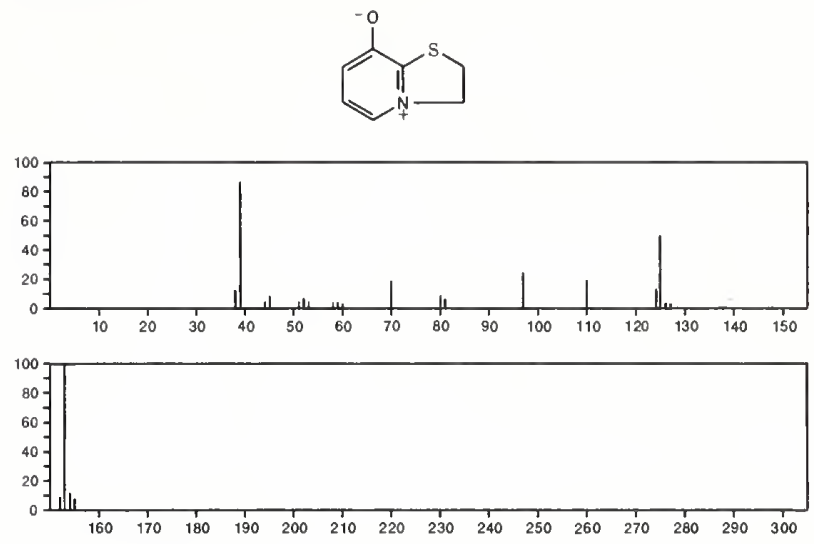

153

$\mathrm{C}_{7} \mathrm{H}_{7} \mathrm{NO}_{3}$

91-23-6

Benzene, 1-methoxy-2-nitro-
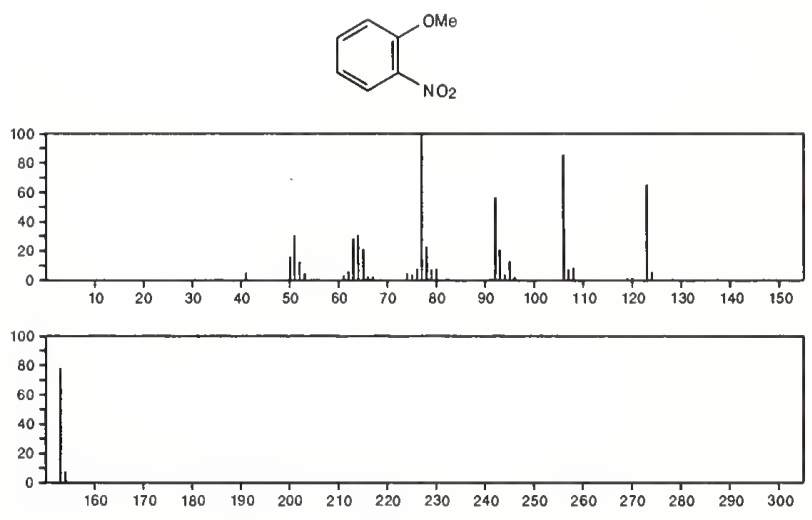

153

$\mathrm{C}_{7} \mathrm{H}_{7} \mathrm{NO}_{3}$

$100-17-4$

Benzene, 1-methoxy-4-nitro-
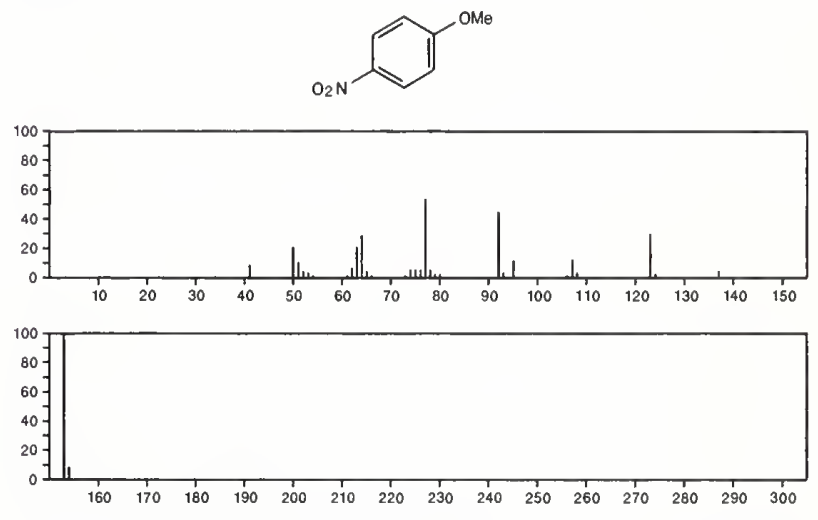

153

Phenol, 4-methyl-2-nitro-

$$
\mathrm{C}_{7} \mathrm{H}_{7} \mathrm{NO}_{3}
$$

$119-33-5$
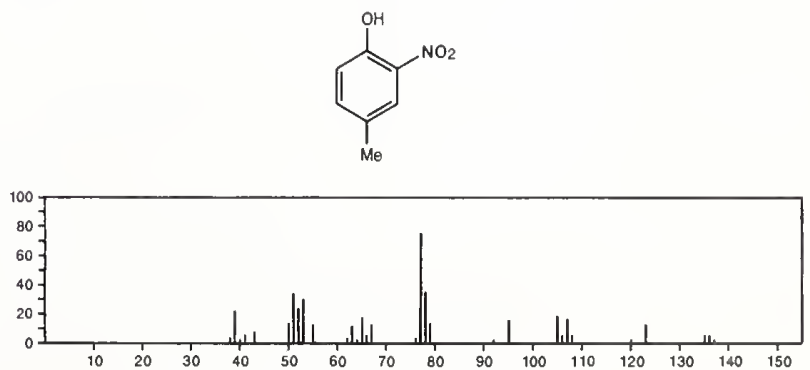


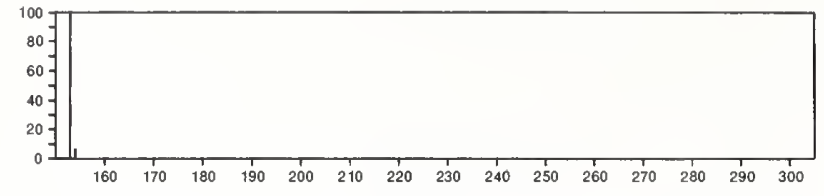

153

Benzoic acid, 2-amino-3-hydroxy-
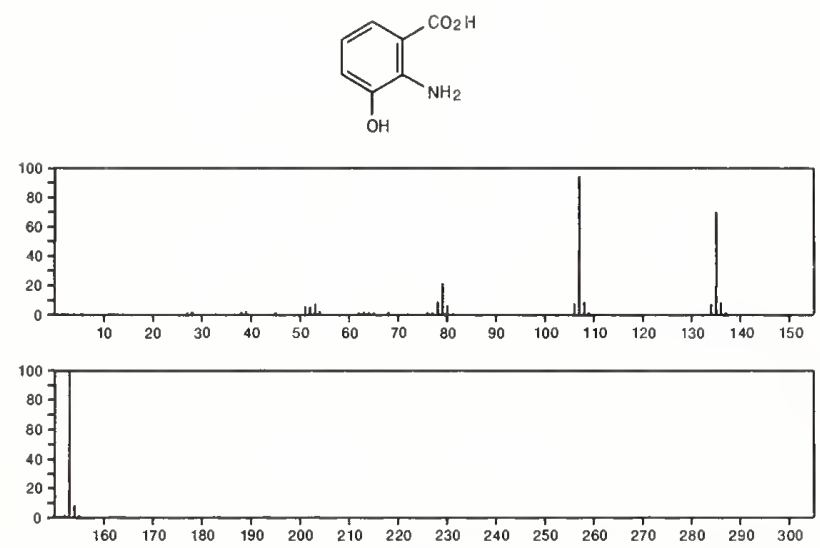

153

$\mathrm{C}_{7} \mathrm{H}_{7} \mathrm{NO}_{3}$

Benzene, 1-methoxy-3-nitro-
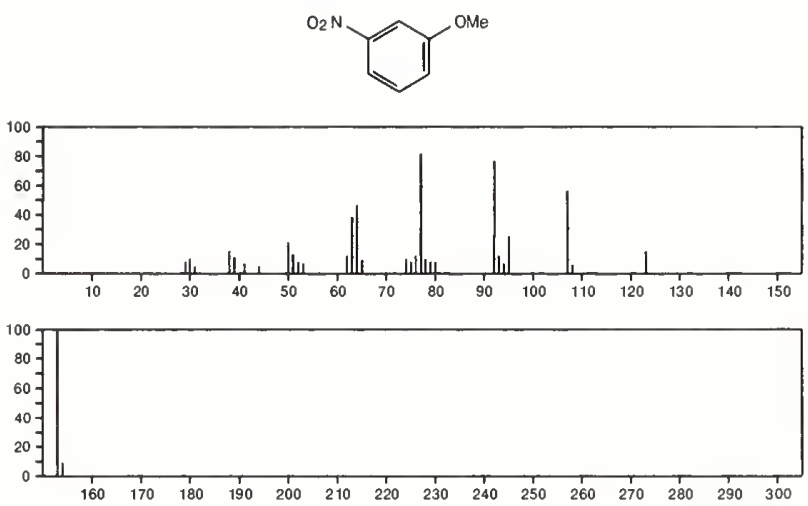

153

$\mathrm{C}_{7} \mathrm{H}_{7} \mathrm{NO}_{3}$

$612-25-9$

Benzenemethanol, 2-nitro-<smiles>O=Cc1ccccc1[N+](=O)[O-]</smiles>
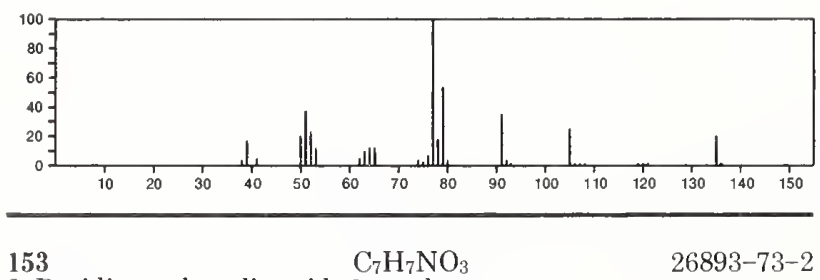

2-Pyridinecarboxylic acid, 6-methoxy-

$26893-73-2$
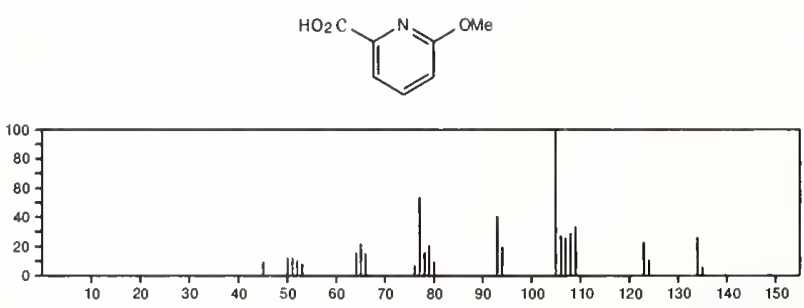

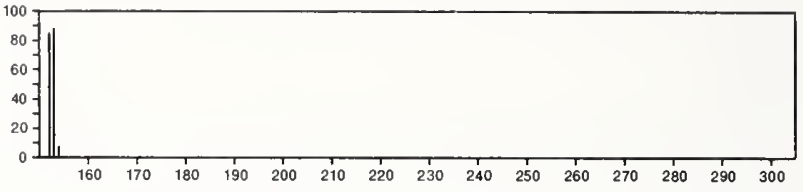

${ }_{2-\text { Pyridinecarboxylic acid, }}^{153} \mathrm{C}_{7} \mathrm{H}_{7}$-methoxy-

$29082-92-6$<smiles>COc1ccc(C(=O)O)nc1</smiles>
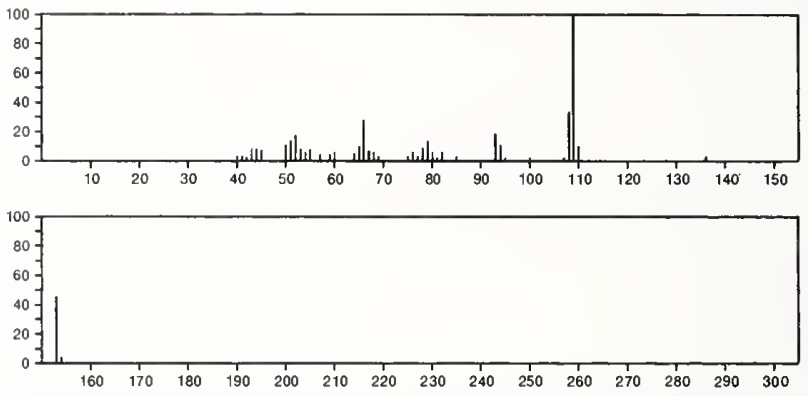

$153 \quad \mathrm{C}_{7} \mathrm{H}_{7} \mathrm{NO}_{3}$

Tricyclo[2.2.1.01,4 heptan-2-one, 6-nitro-

$56666-50-3$
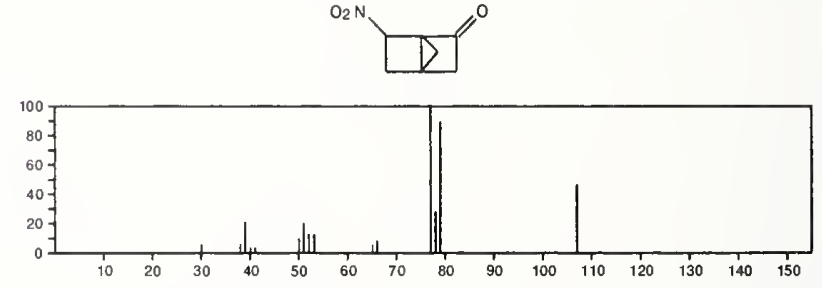

153

$\mathrm{C}_{7} \mathrm{H}_{11} \mathrm{~N}_{3} \mathrm{O}$

7749-48-6

2 -Pyrimidinamine, 4-ethoxy-6-methyl-
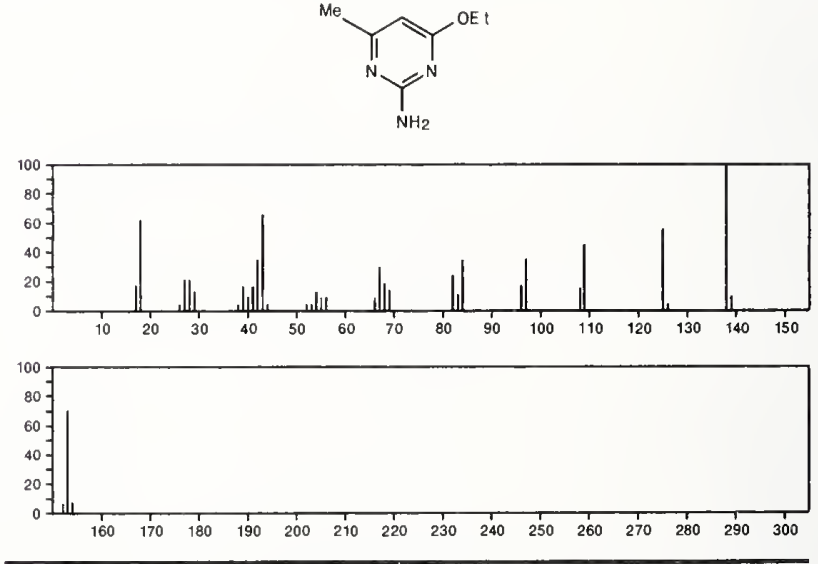

153

$\mathrm{C}_{8} \mathrm{H}_{11} \mathrm{NO}_{2}$

$51-61-6$

1,2-Benzenediol, 4-(2-aminoethyl)-
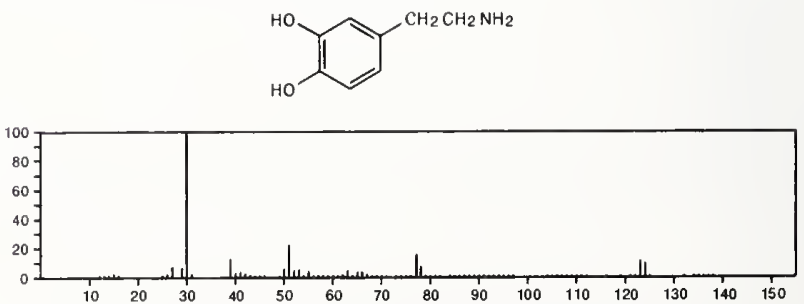

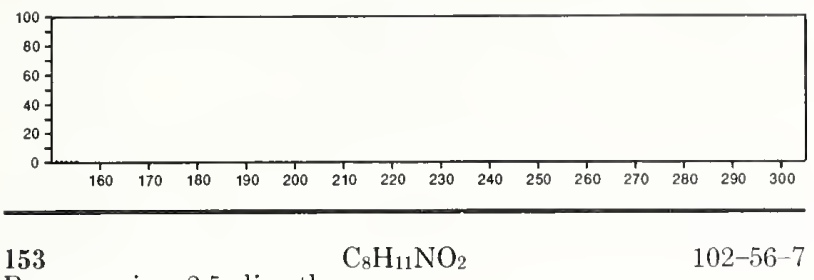

Benzenamine, 2,5-dimethoxy-
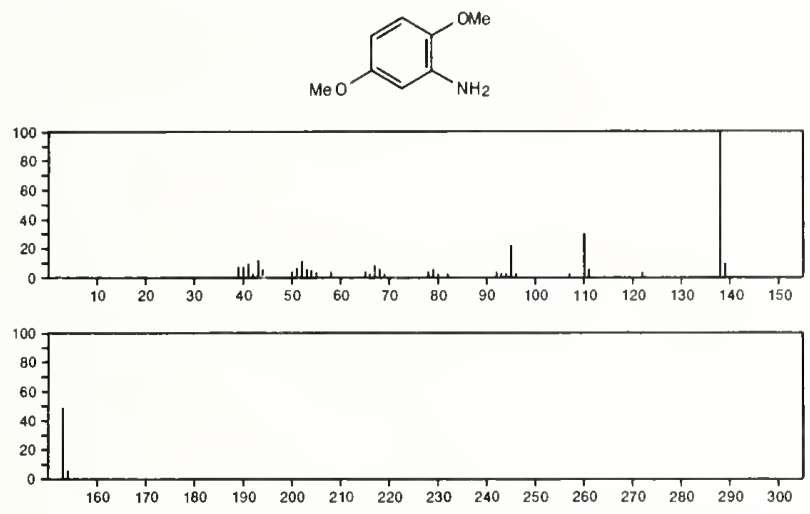

153

$\mathrm{C}_{8} \mathrm{H}_{11} \mathrm{NO}_{2}$

$1196-92-5$

Phenol, 4-(aminomethyl)-2-methoxy-
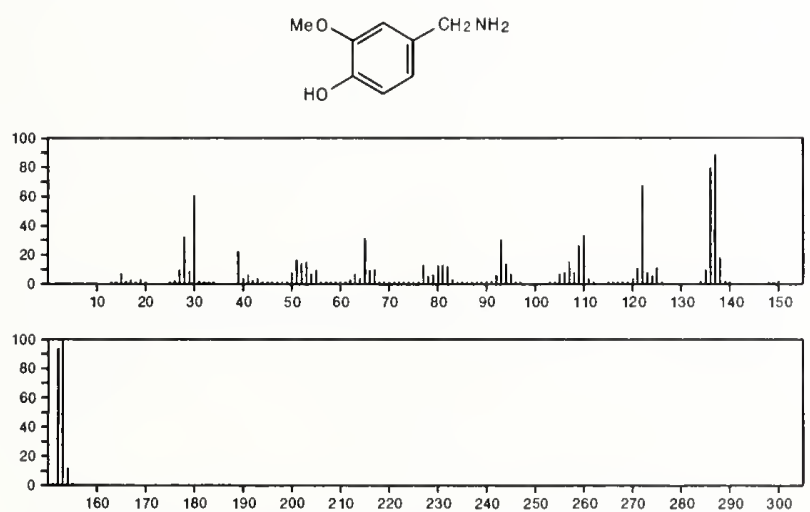

\section{3}

$\mathrm{C}_{8} \mathrm{H}_{11} \mathrm{NO}_{2}$

$1 H$-Isoindole-1,3(2H)-dione, hexahydro

$1444-94-6$
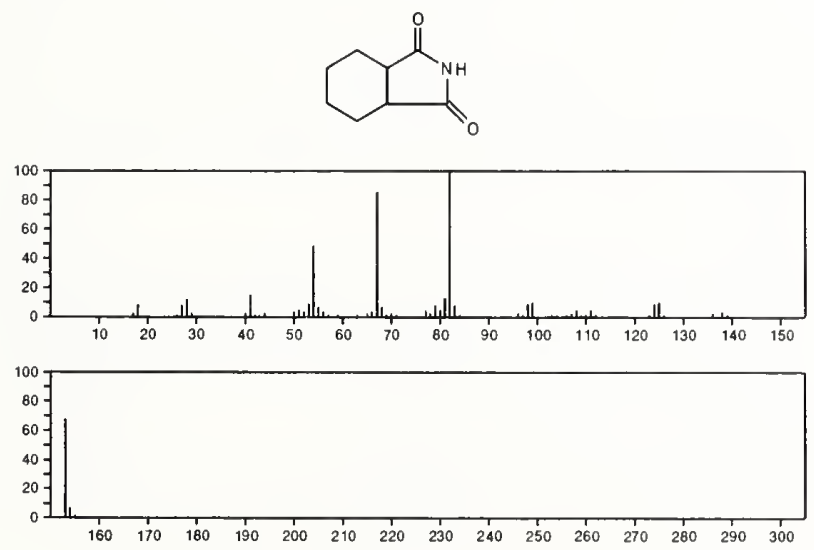

153

$\mathrm{C}_{8} \mathrm{H}_{11} \mathrm{NO}_{2}$

Benzenemethanol, $\alpha$-(aminomethyl)-4-hydroxy-, $( \pm)-$

$1915-83-9$
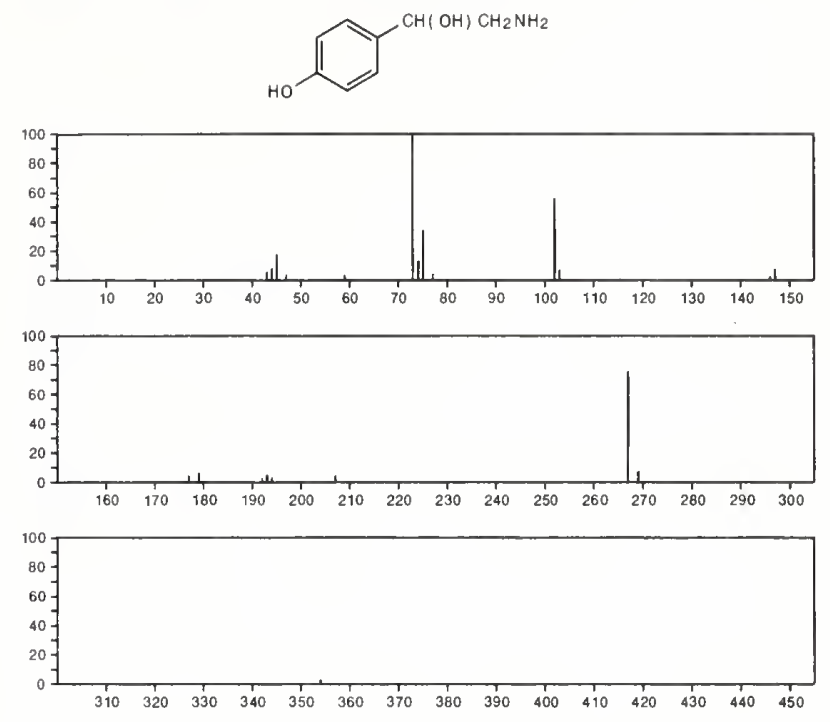

15.3

$1 H$-Pyrrole-2,5-dione, 1-butyl-
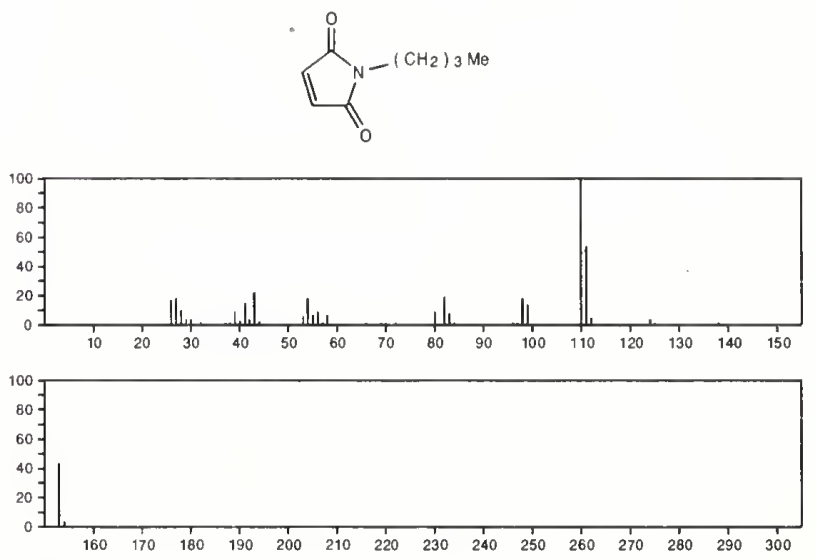

$153 \quad \mathrm{C}_{8} \mathrm{H}_{11} \mathrm{NO}_{2} \quad 25471-69-6$

Furo[2,3,4-gh]pyrrolizin-2(2aH)-one, hexahydro-, $(2 \mathrm{a} \alpha, 7 \mathrm{a} \alpha, 7 \mathrm{~b} \alpha)-$
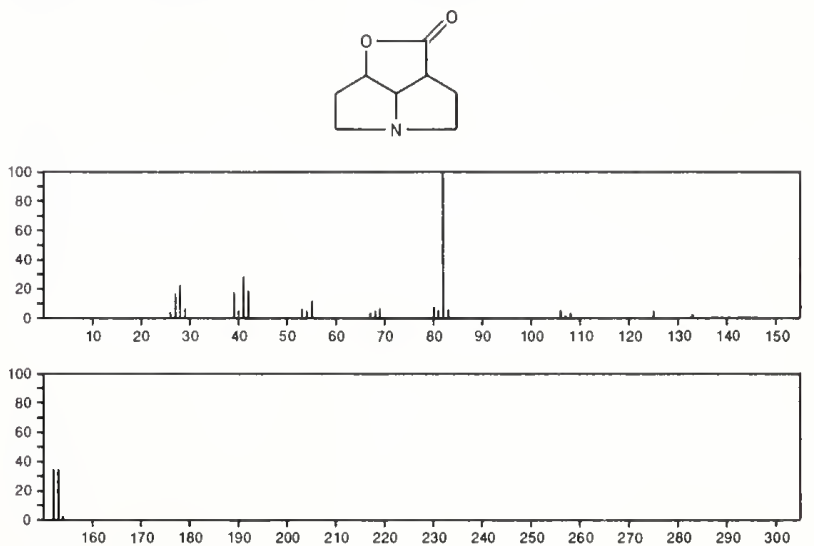
153 $\mathrm{C}_{8} \mathrm{H}_{11} \mathrm{NO}_{2}$

2(5H)-Furanone, 5-(butylimino)-
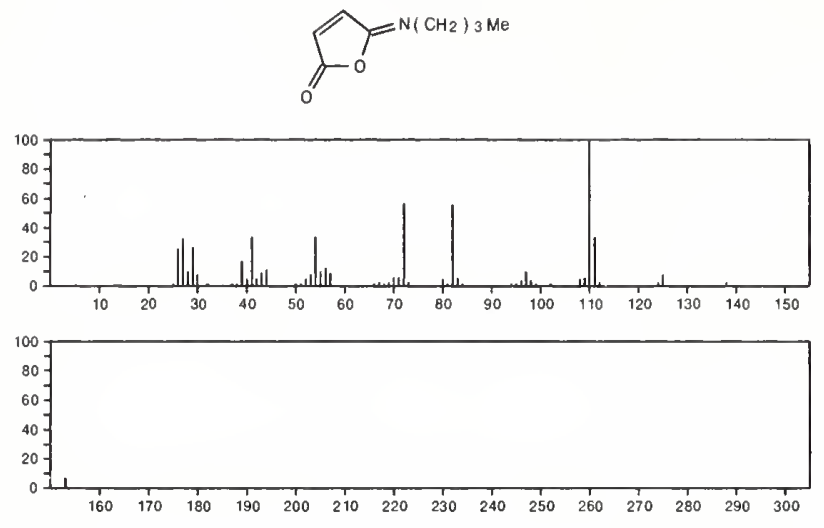

$153 \quad \mathrm{C}_{8} \mathrm{H}_{11} \mathrm{NO}_{2} \quad 54244-77-8$

2-Butenoic acid, 2-(eyanomethyl)-, ethyl ester

CHMe
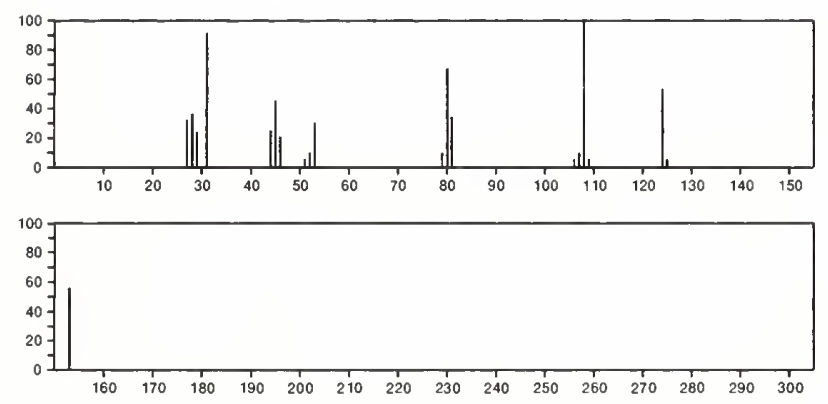

153

$\mathrm{C}_{8} \mathrm{H}_{11} \mathrm{NO}_{2}$

Carbamic acid, 1,3,5-hexatrienyl-, methyl ester

$56701-03-2$

$\mathrm{H}_{2} \mathrm{C}=\mathrm{CHCH}=\mathrm{CHCH}=\mathrm{CHNHC}(\mathrm{O}) \mathrm{OMe}$
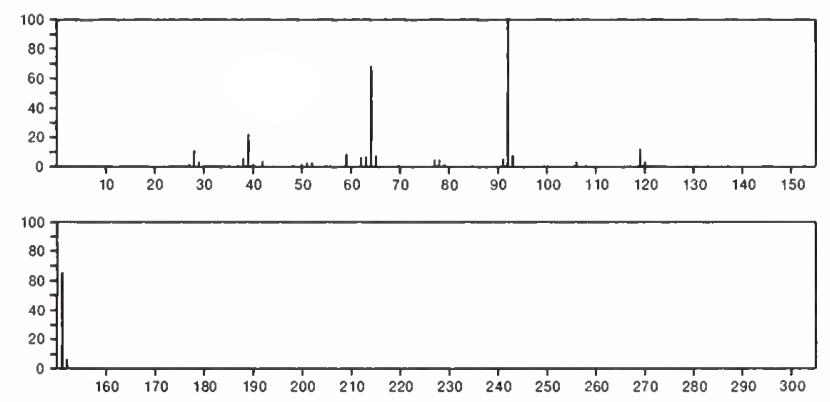

$153 \quad \mathrm{C}_{8} \mathrm{H}_{11} \mathrm{NS}$

2(1 H)-Pyridinethione, 1,4,6-trimethyl-
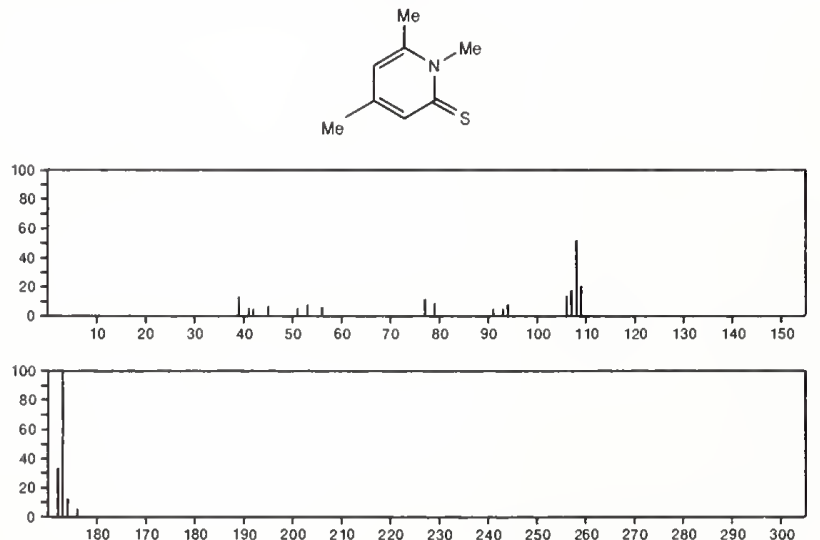

153

$\mathrm{C}_{8} \mathrm{H}_{11} \mathrm{NS}$

$19006-72-5$

2(1H)-Pyridinethione, 1-ethyl-4-methyl-
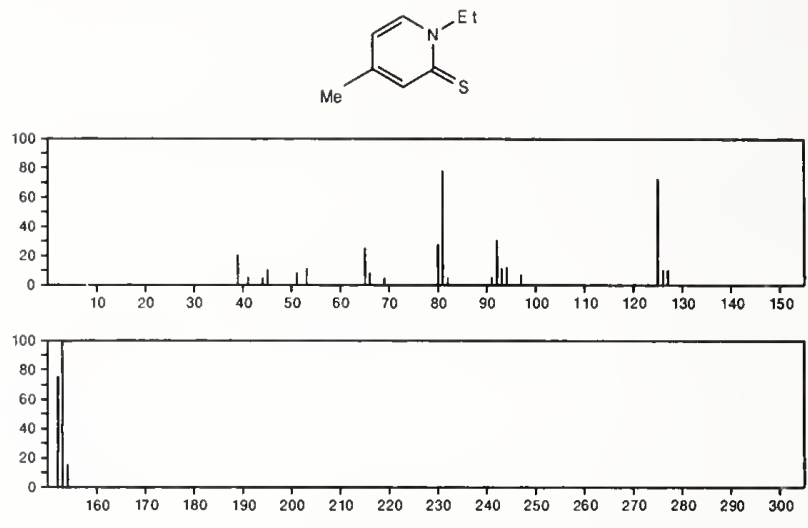

153

2(1H)-Pyridinethione, 1-ethyl-6-methyl-

$19006-73-6$
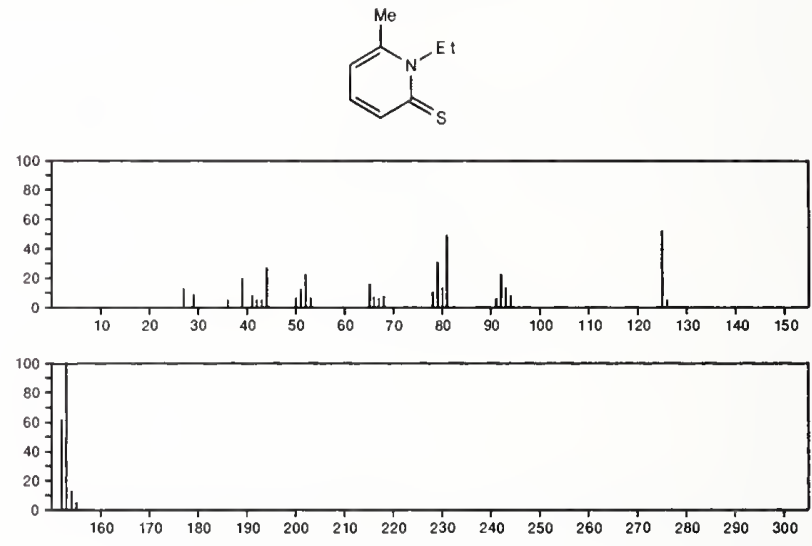

153

$\mathrm{C}_{8} \mathrm{H}_{11} \mathrm{NS}$

$19006-74-7$

2(1H)-Pyridinethione, 1-propyl
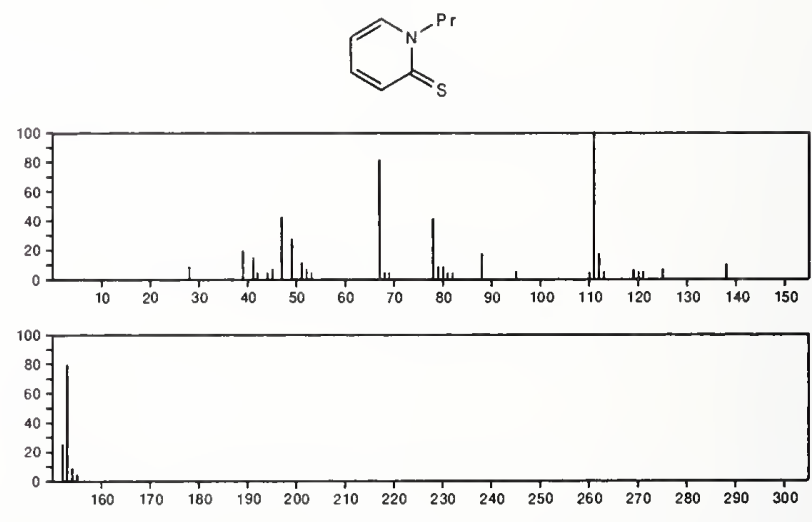

153

$\mathrm{C}_{8} \mathrm{H}_{11} \mathrm{NS}$

$19006-78-1$

4-Picoline, 2-(ethylthio)-
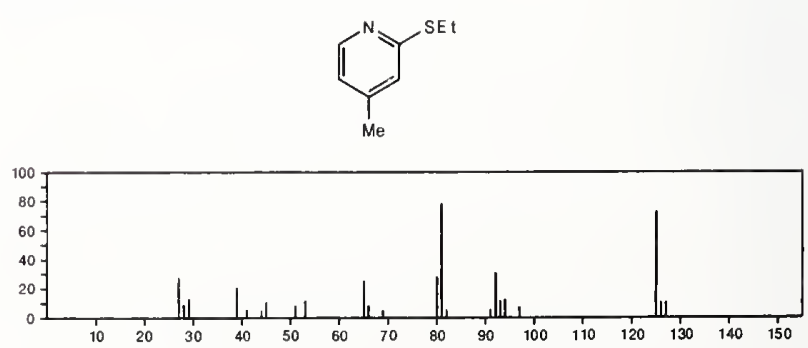


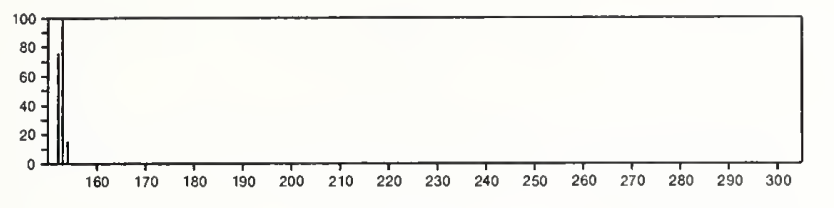

$\mathbf{1 5 3}$
$2-$ Picoline, 6-(ethylthio)-
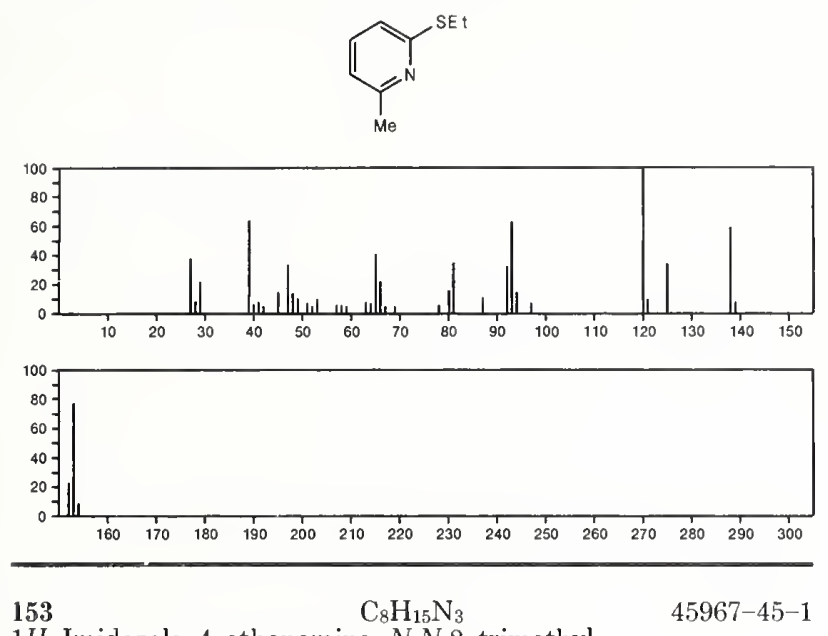

$1 H$-Imidazole-4-ethanamine, $N, N, 2$-trimethyl-

$$
\mathrm{Me}
$$
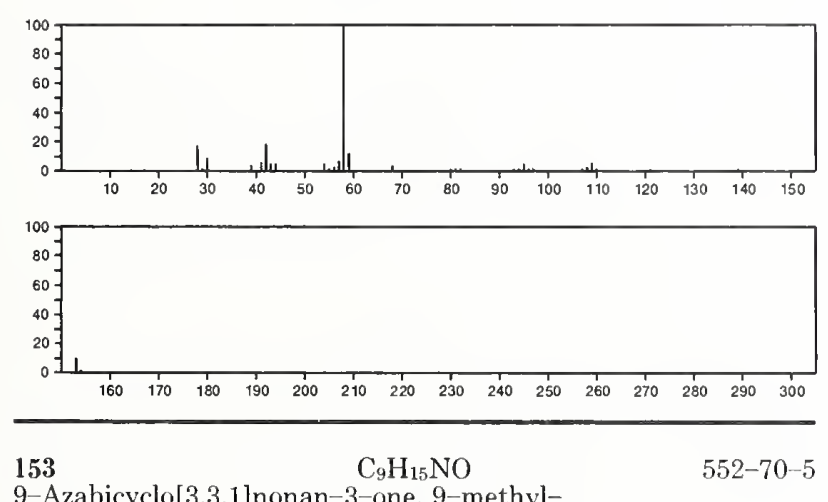

9-Azabicyclo[3.3.1]nonan-3-one, 9-methyl-
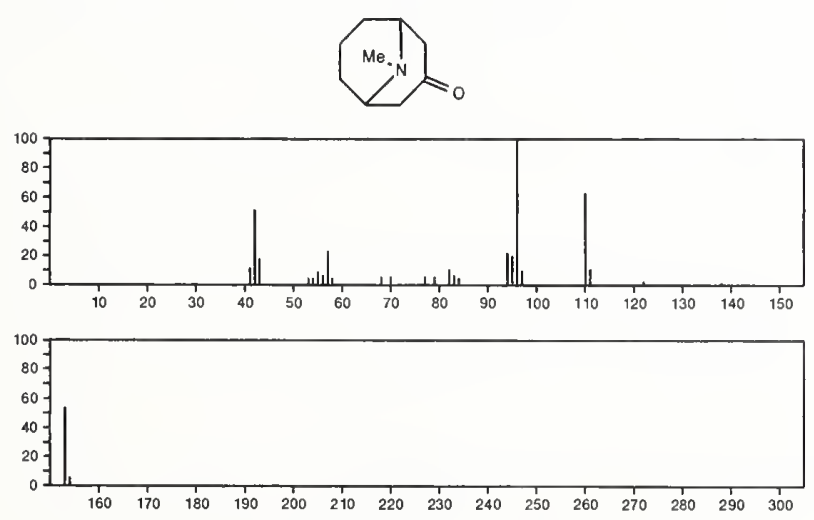

153

$\mathrm{C}_{9} \mathrm{H}_{15} \mathrm{NO}$

8-Azabicyclo[3.2.1]octane, 8-acetyl-

$769-04-0$
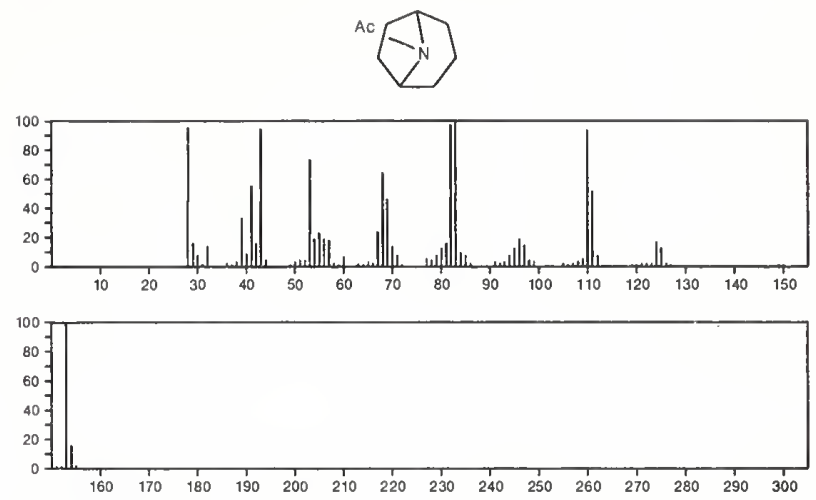

153

$\mathrm{C}_{9} \mathrm{H}_{15} \mathrm{NO}$

Morpholine, 4-(1-cyclopenten-1-yl)-

$936-52-7$
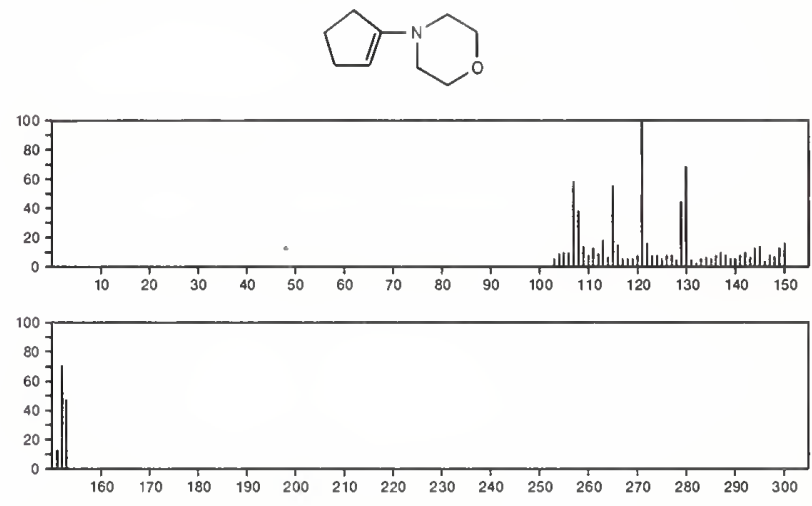

153

$\mathrm{C}_{9} \mathrm{H}_{15} \mathrm{NO}$

3-Buten-2-one, 4-(1-piperidinyl)-

$1809-57-0$
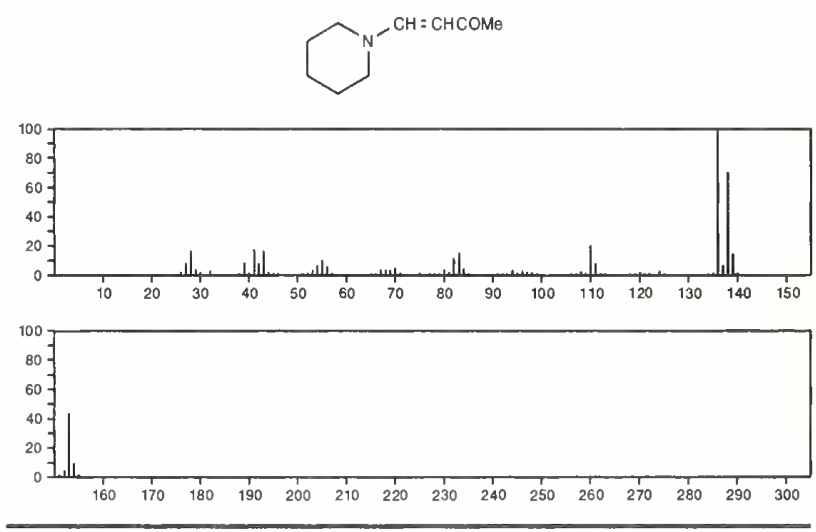

153

$\mathrm{C}_{9} \mathrm{H}_{15} \mathrm{NO}$

4146-35-4

3-Azabicyclo[3.3.1]nonan-9-one, 3-methyl-
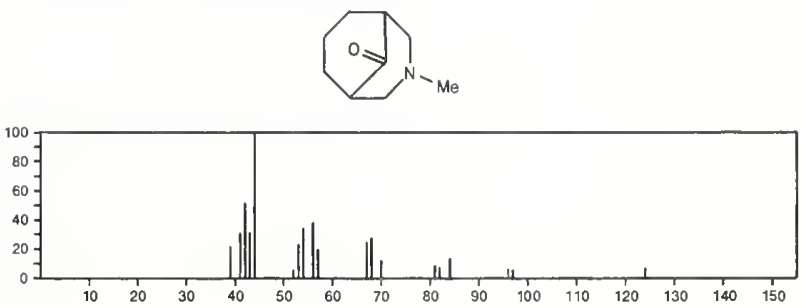

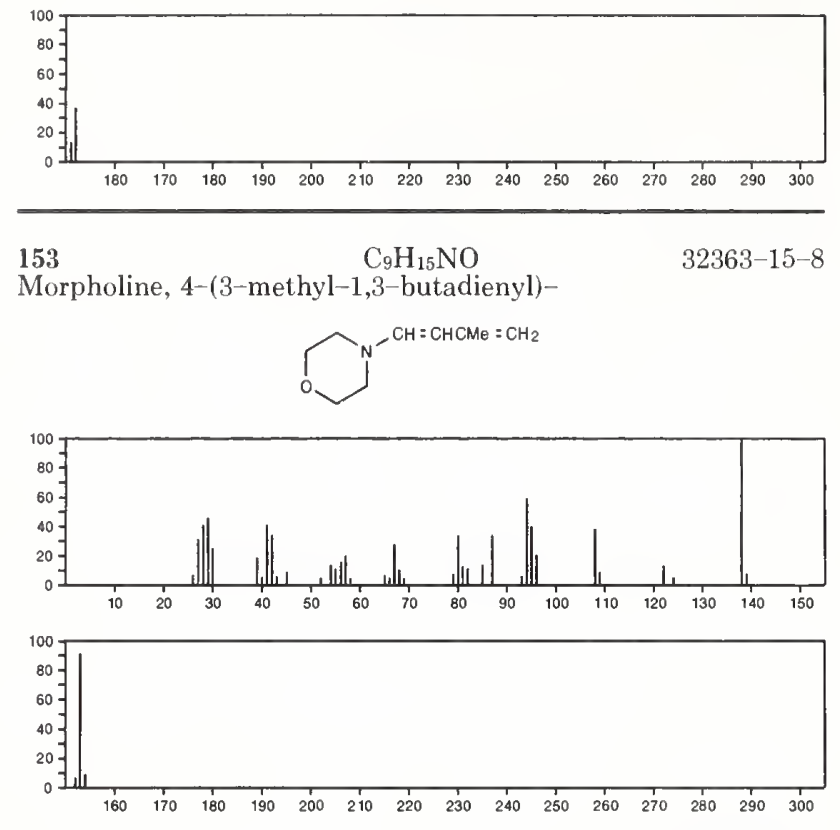

$153 \quad \mathrm{C}_{9} \mathrm{H}_{15} \mathrm{NO} 49656-54-4$ 9-Azabicyclo[3.3.1]non-6-en-2-ol, 9-methyl-, endo-
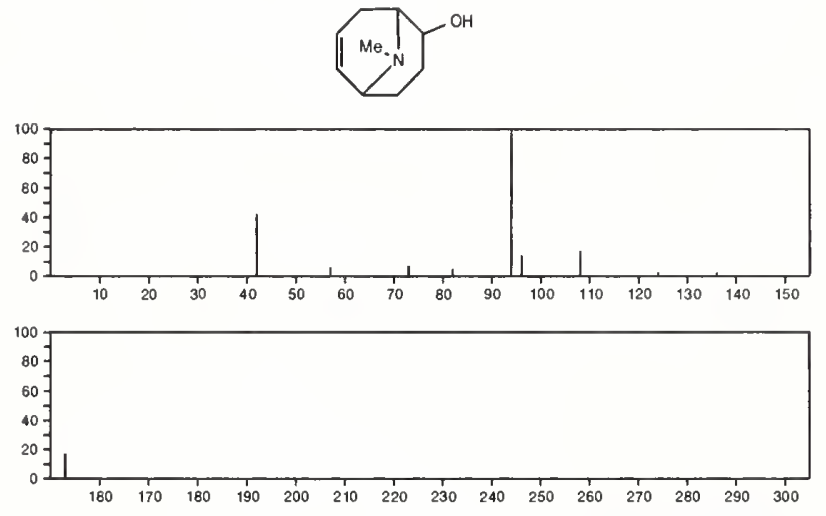

$153 \quad \mathrm{C}_{9} \mathrm{H}_{15} \mathrm{NO} 50483-91-5$

2-Azetidinone, 1,3,3-trimethyl-4-(1-methylethylidene)-
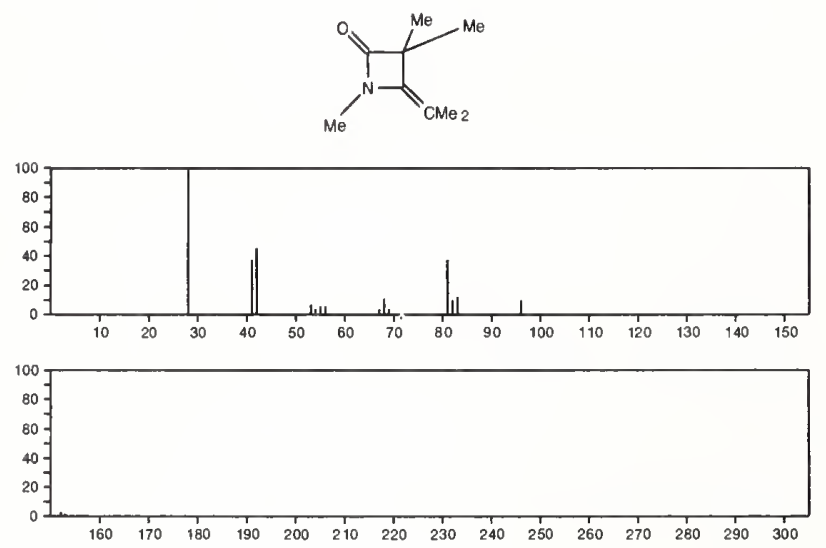

153

Heptanenitrile, 4-acetyl-

$\mathrm{C}_{9} \mathrm{H}_{15} \mathrm{NO}$

$55320-41-7$
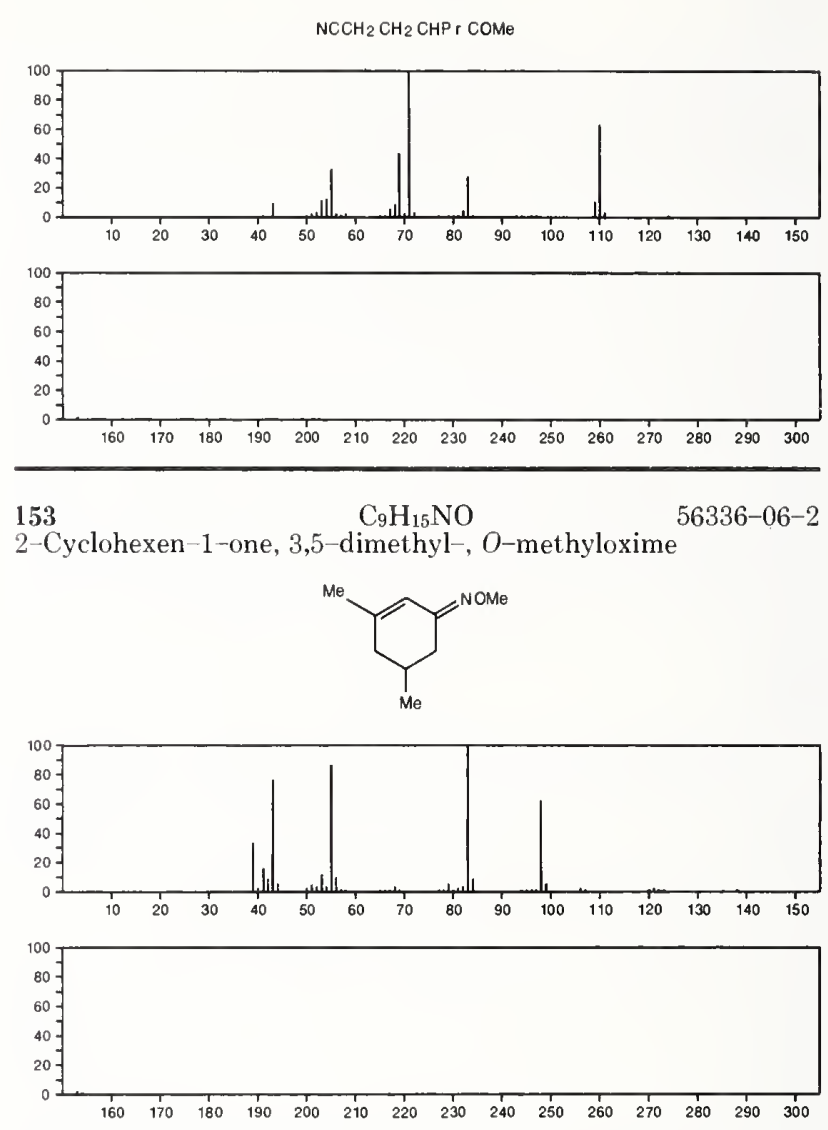

153

$\mathrm{C}_{10} \mathrm{H}_{19} \mathrm{~N}$

$464-42-6$

Bicyclo[2.2.1]heptan-2-amine, 1,7,7-trimethyl--, endo-
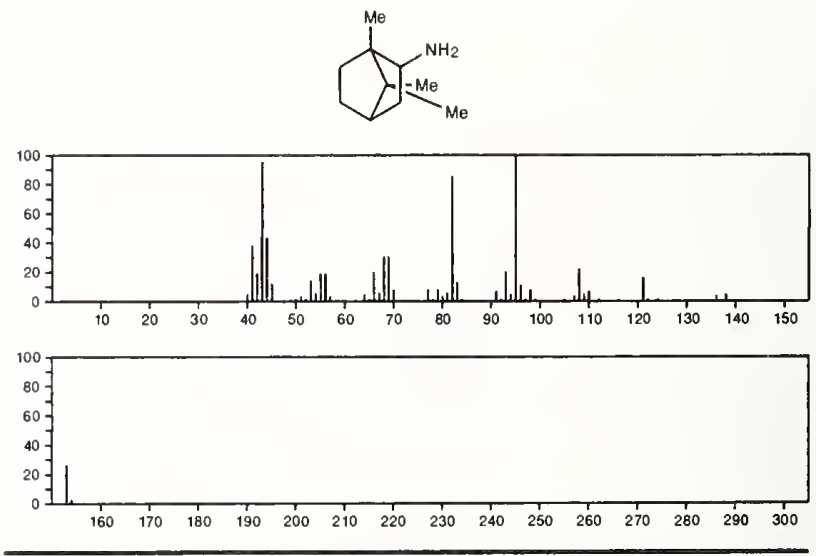

153

3-Azabicyclo[3.2.1] octane, 1,8,8-trimethyl-, (1R)

$465-49-6$
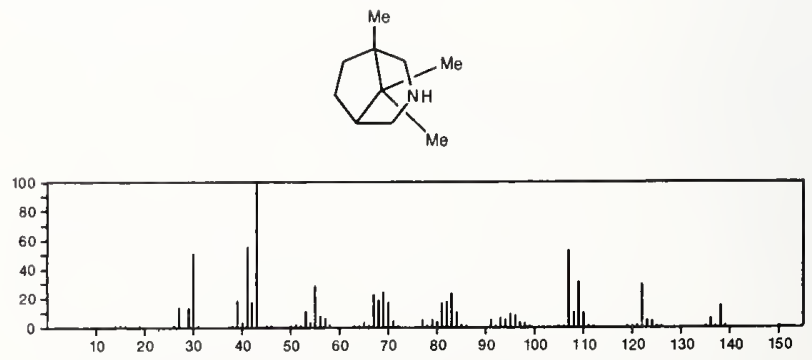


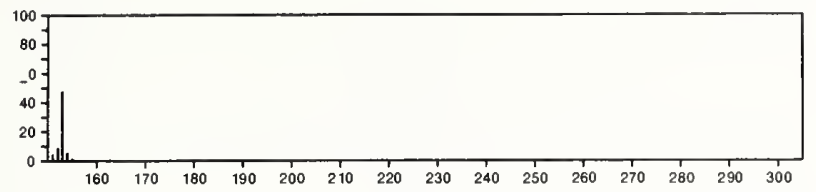

\section{$153 \quad \mathrm{C}_{10} \mathrm{H}_{19} \mathrm{~N}$}

Quinoline, decahydro-1-methyl-, trans-
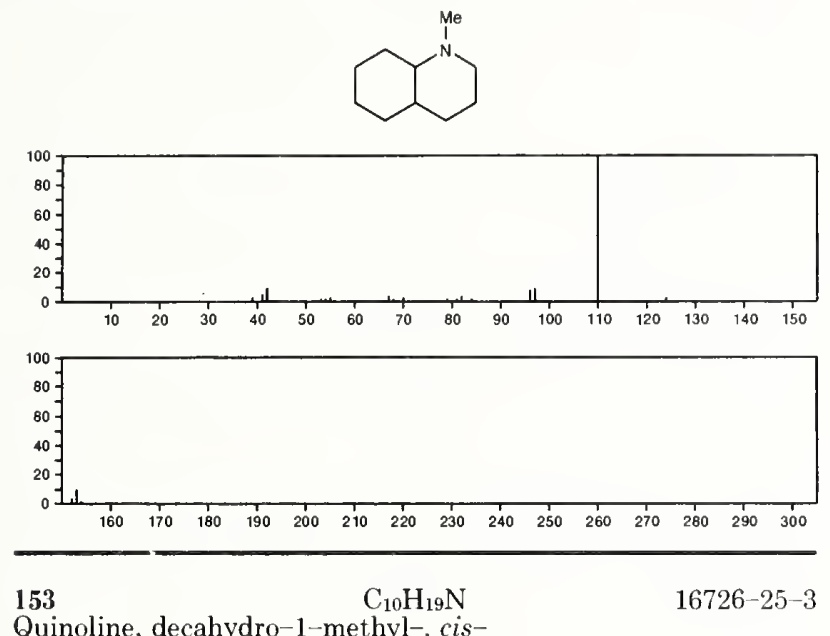

Quinoline, decahydro-1-methyl-, cis-
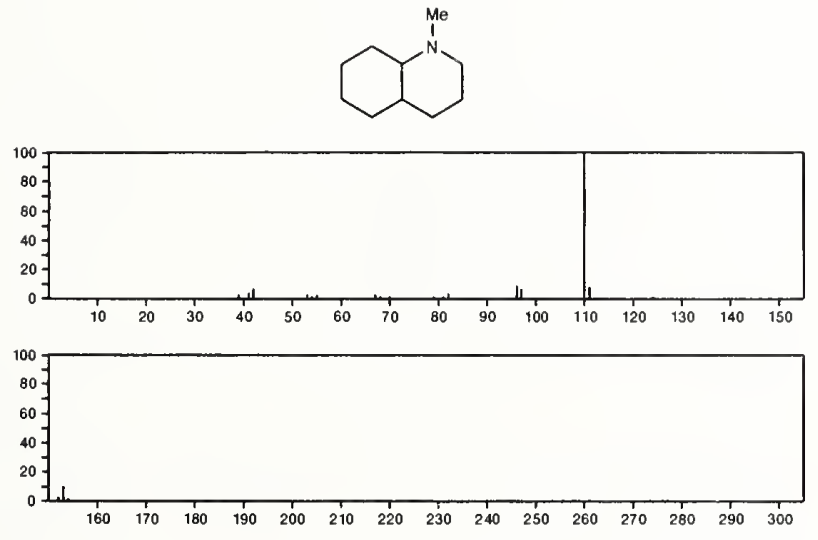

153

$\mathrm{C}_{10} \mathrm{H}_{19} \mathrm{~N}$

Piperidine, 1-(2-methyl-1-butenyl)-

$35155-43-2$
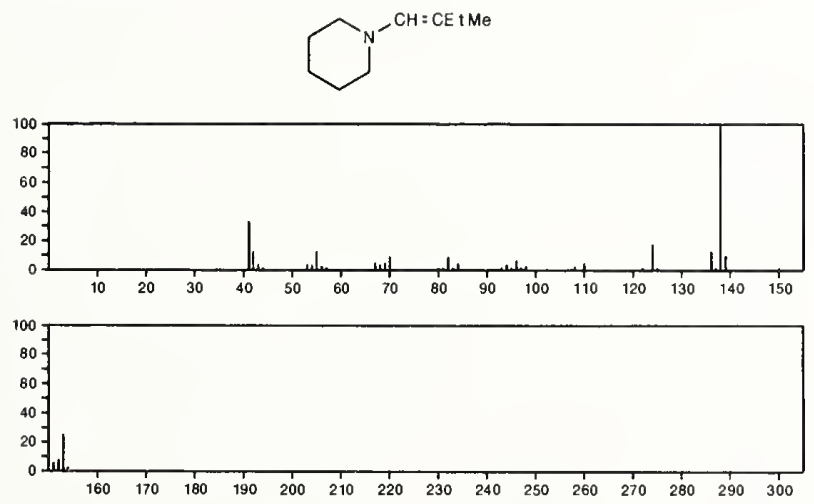

153

Piperidine, 1-(1-pentenyl)-

$\mathrm{C}_{10} \mathrm{H}_{19} \mathrm{~N}$

$49845-25-2$
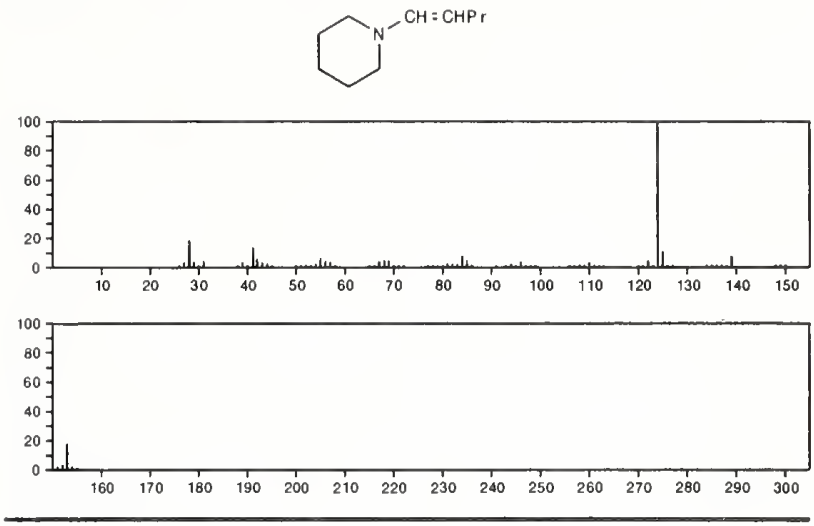

153

$\mathrm{C}_{10} \mathrm{H}_{19} \mathrm{~N}$

$55669-80-2$

Aziridine, 2-(1,1-dimethylethyl)-3-methyl-1-(2-propenyl)-, trans-<smiles>[10BH2]C1C(C)N1CCC</smiles>
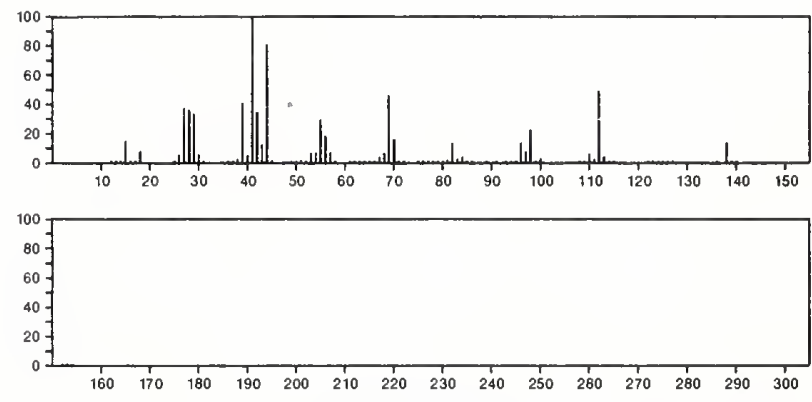

153

$\mathrm{C}_{11} \mathrm{H}_{7} \mathrm{~N}$

$86-53-3$

1-Naphthalenecarbonitrile
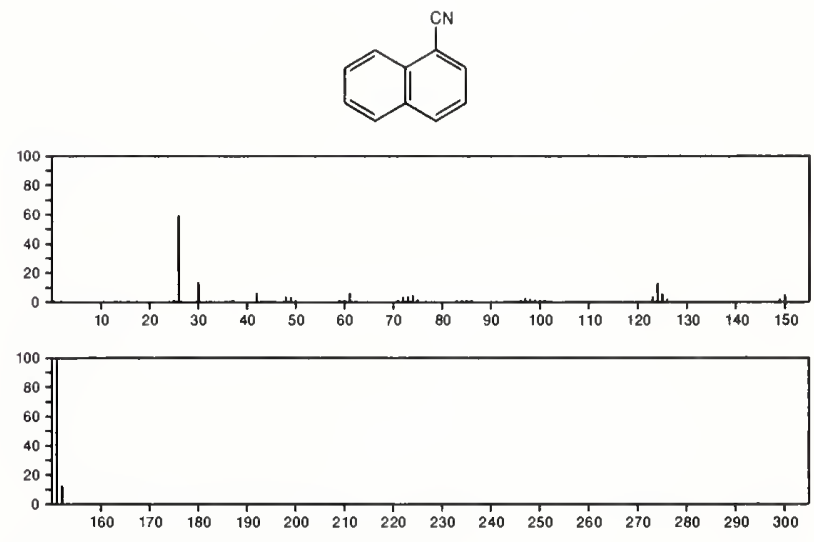

154

$\mathrm{C}_{2} \mathrm{ClF}_{5}$

$76-15-3$

$\mathrm{F}_{3} \mathrm{CCCIF}_{2}$

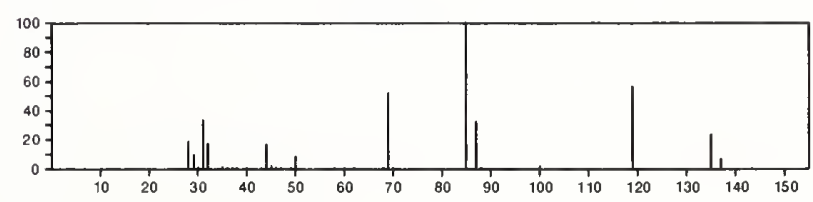



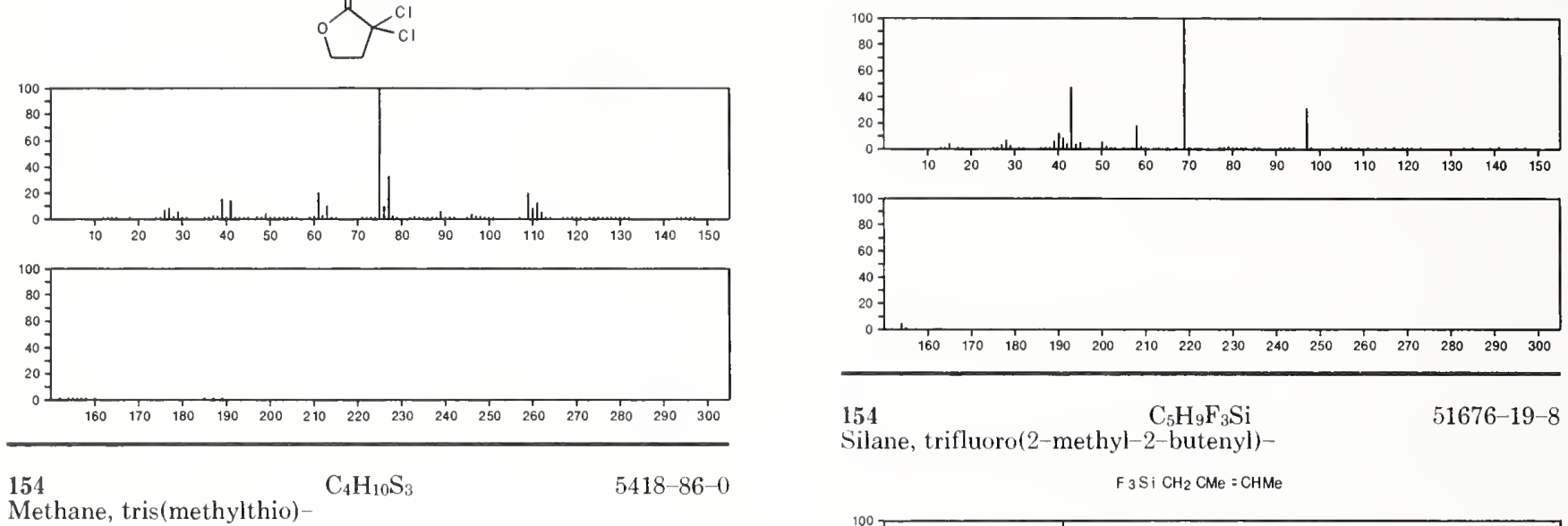

$\mathrm{HC}$ (SMe) 3
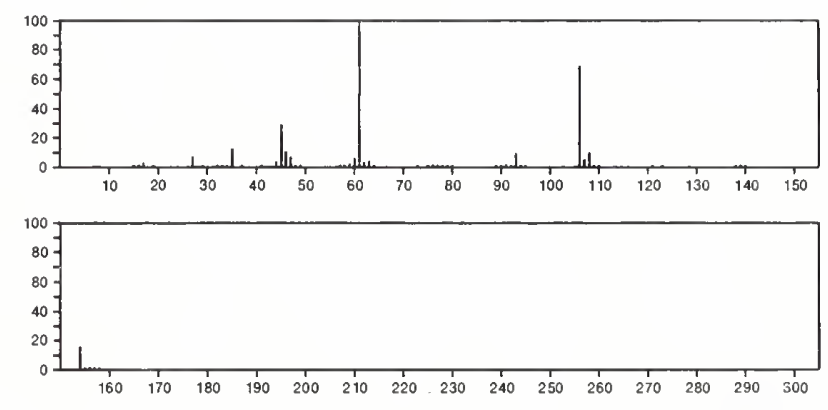

$154 \quad \mathrm{C}_{4} \mathrm{H}_{12} \mathrm{ClN}_{2} \mathrm{P} \quad 3348-44-5$

Phosphorodiamidous chloride, tetramethyl-

$\mathrm{Me} 2 \mathrm{NPCl}$ NMe 2
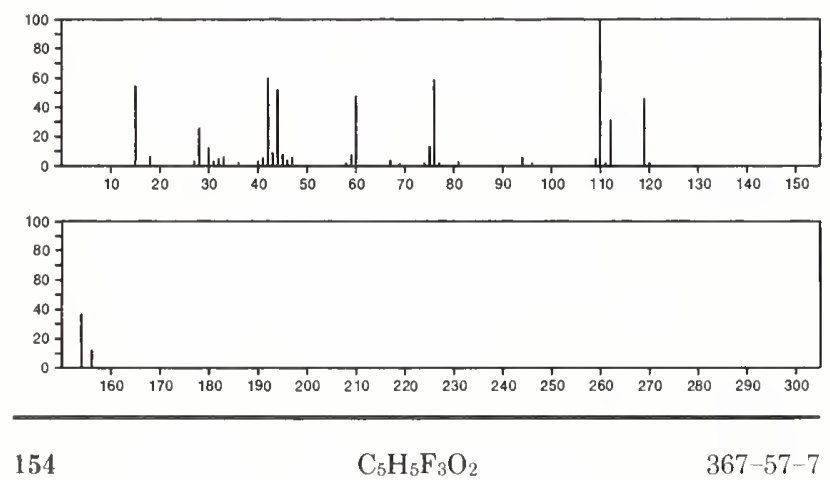

2,4-Pentanedione, 1,1,1-trifluoro-
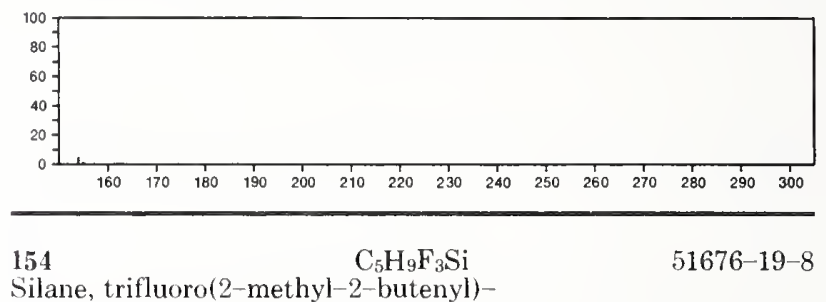

Silane, trifluoro(2-methyl-2-butenyl)-

$\mathrm{F}_{3} \mathrm{Si} \mathrm{CH}_{2} \mathrm{CMe}=\mathrm{CHMe}$
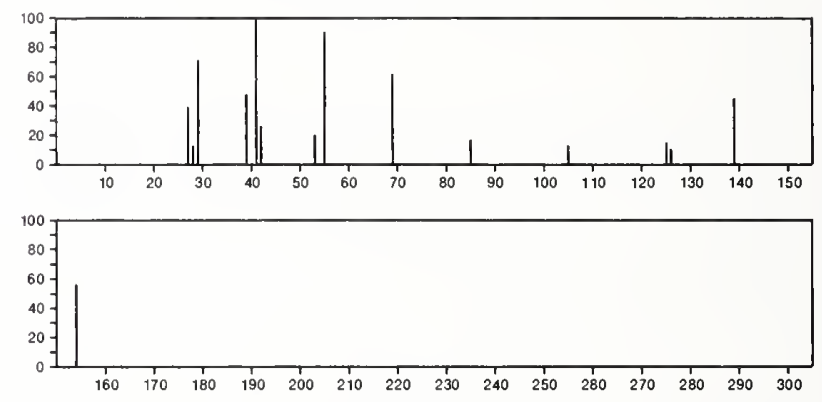

154

1,5-Hexadiene, 3,3,4,4-tetrafluoro

$1763-21-9$

$\mathrm{H}_{2} \mathrm{C}=\mathrm{CHCF}_{2} \mathrm{CF}_{2} \mathrm{CH}=\mathrm{CH}_{2}$
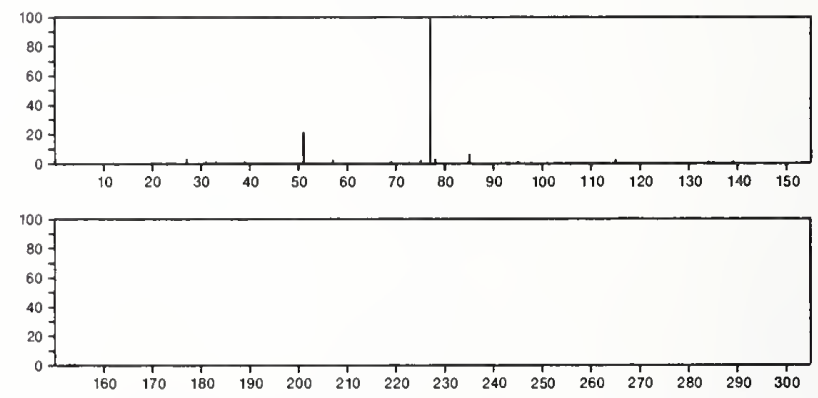

$154 \quad \mathrm{C}_{6} \mathrm{H}_{6} \mathrm{~N}_{2} \mathrm{OS}$

$17420-03-0$

Hydrazine, phenylsulfinyl-

$P h N H N=S: 0$
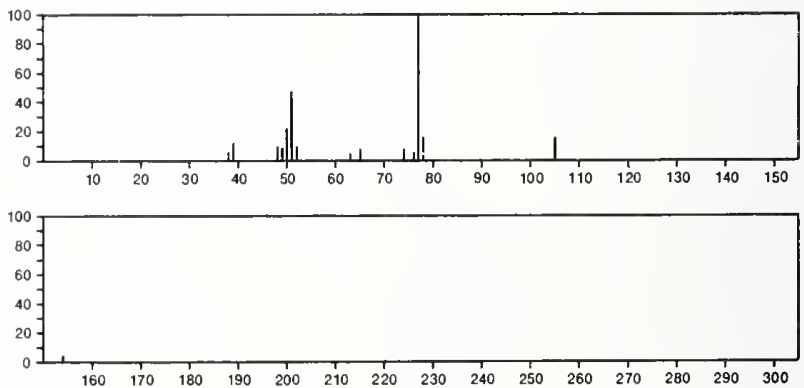
154

$\mathrm{C}_{6} \mathrm{H}_{6} \mathrm{~N}_{2} \mathrm{OS}$

$56196-65-7$

Acetonitrile, (3-methyl-4-oxo-2-thiazolidinylidene)-
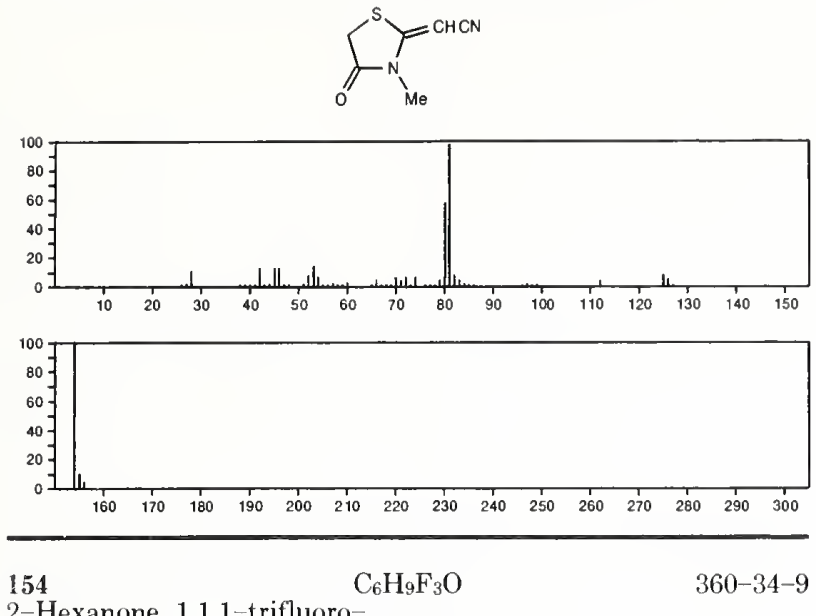

2-Hexanone, 1,1,1-trifluoro-

$\mathrm{Me}\left(\mathrm{CH}_{2}\right)_{3} \mathrm{COCF}_{3}$
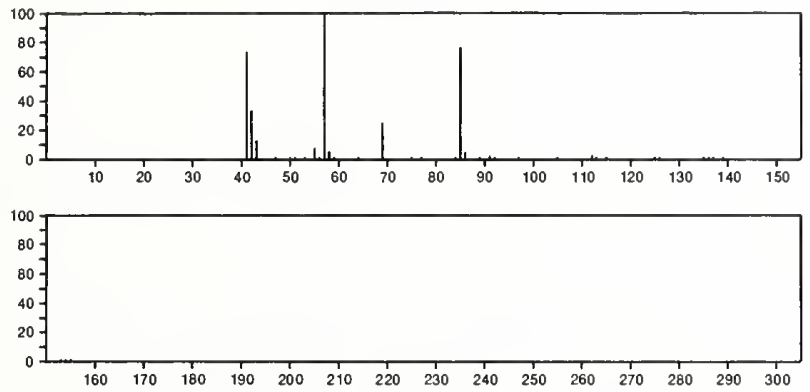

154

1,3,5-Triazin-2-amine, $N$-ethyl-4-methoxy-

$37034-43-8$
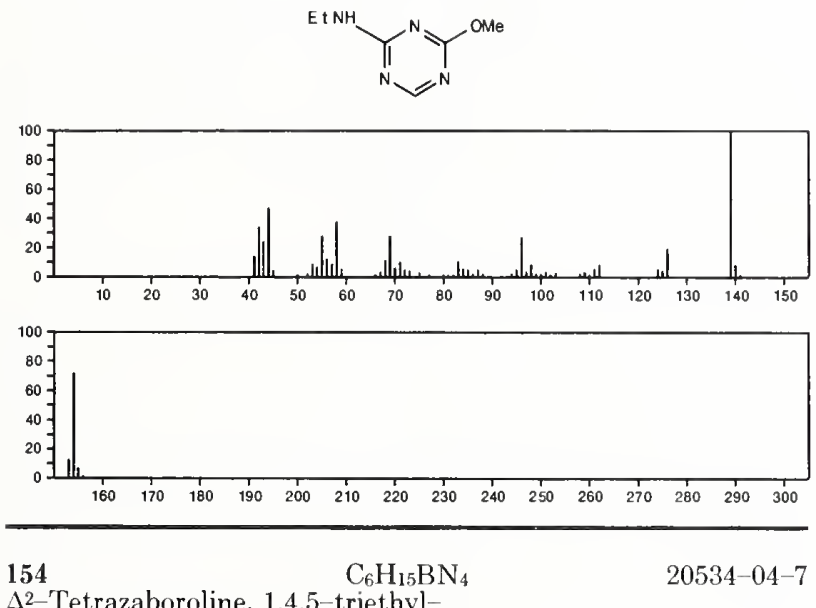

$\Delta^{2}$-Tetrazaboroline, 1,4,5-triethyl-
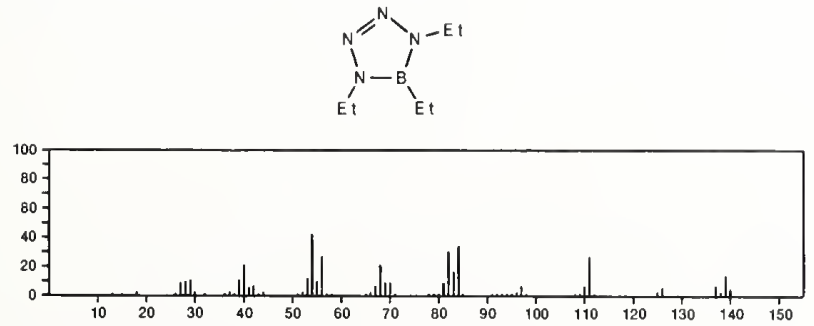

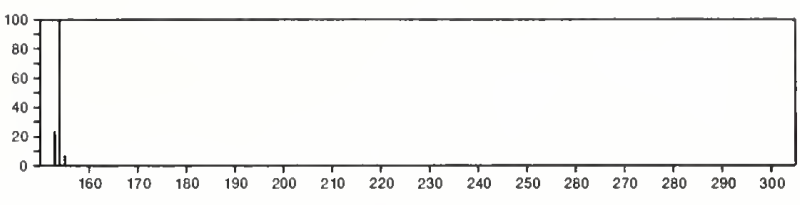

154

$\mathrm{C}_{7} \mathrm{H}_{6} \mathrm{O}_{2} \mathrm{~S}$

$147-93-3$

Benzoic acid, 2-mercapto<smiles>O=C(O)c1ccccc1S</smiles>
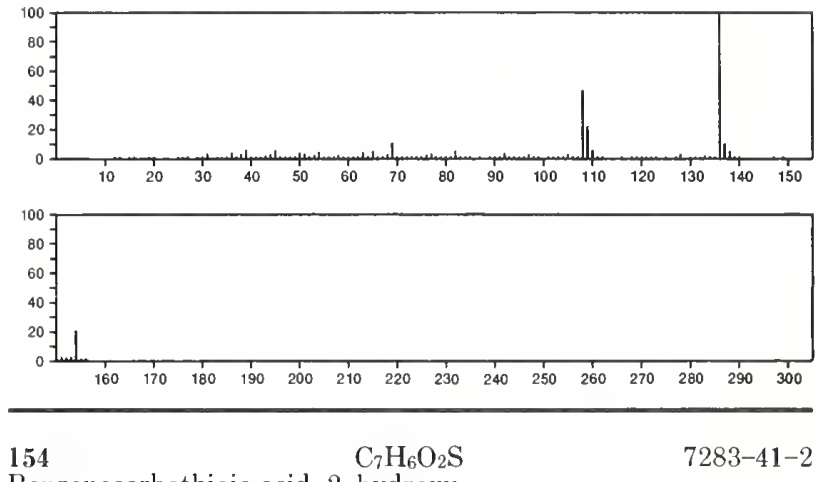

7283-41-2

Benzenecarbothioic acid, 2-hydroxy-
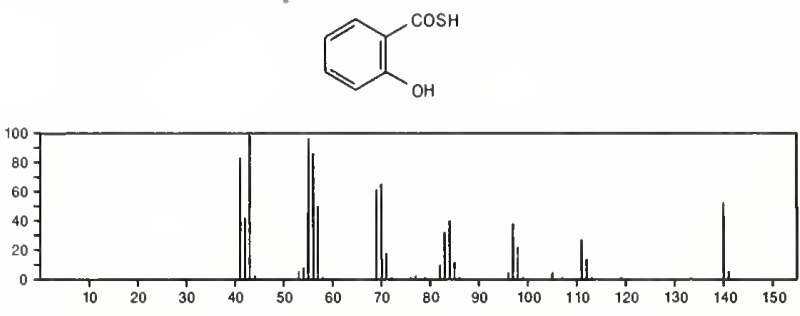

154

$\mathrm{C}_{7} \mathrm{H}_{6} \mathrm{O}_{4}$

89-86-1

Benzoic acid, 2,4-dihydroxy-
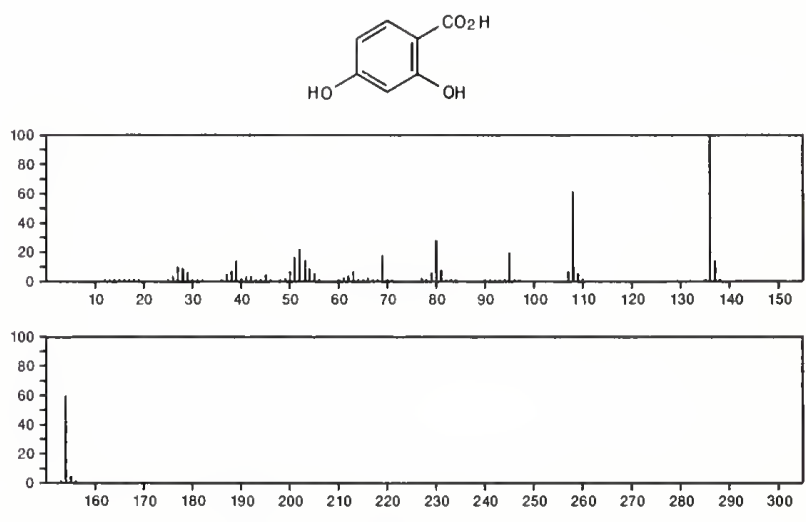

154

$\mathrm{C}_{7} \mathrm{H}_{6} \mathrm{O}_{4}$

99-10-5

Benzoic acid, 3,5-dihydroxy-
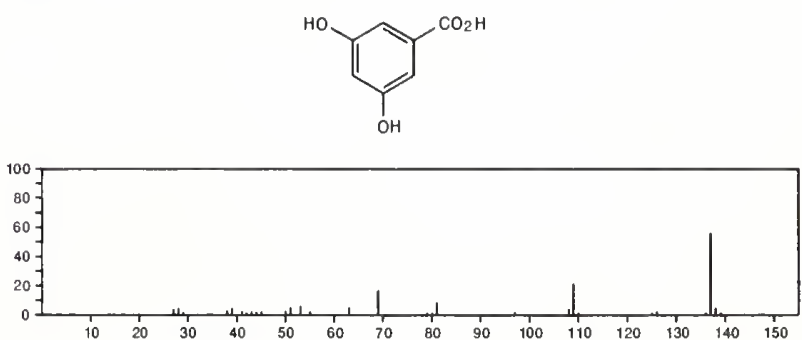


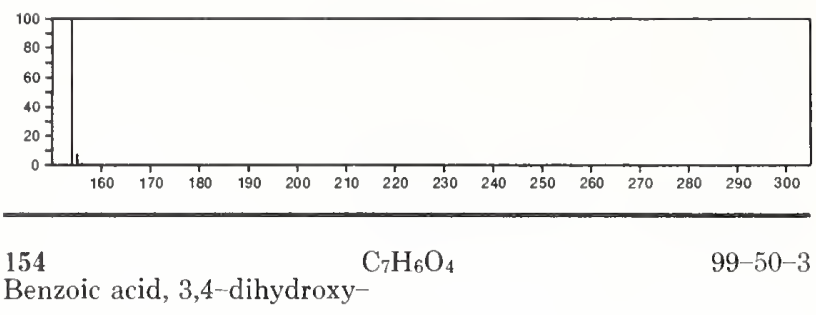

Benzoic acid, 3,4-dihydroxy-
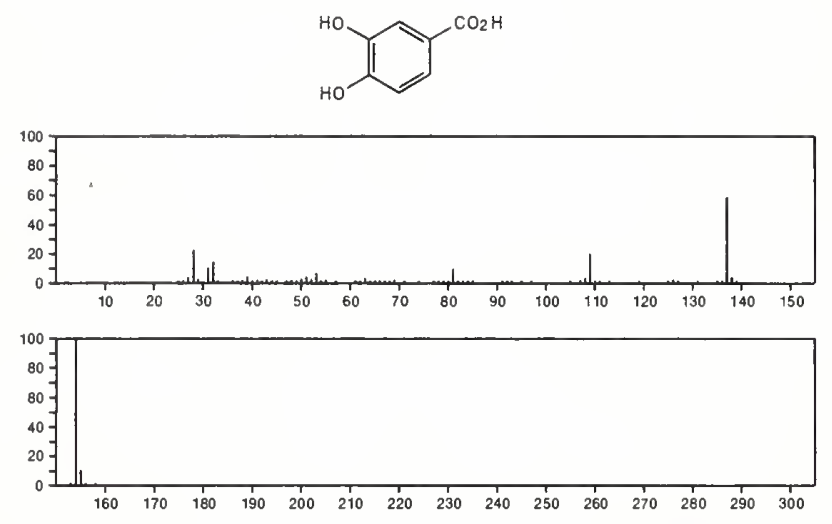

$154 \quad \mathrm{C}_{7} \mathrm{H}_{6} \mathrm{O}_{4} \quad 303-07-1$

Benzoic acid, 2,6-dihydroxy-
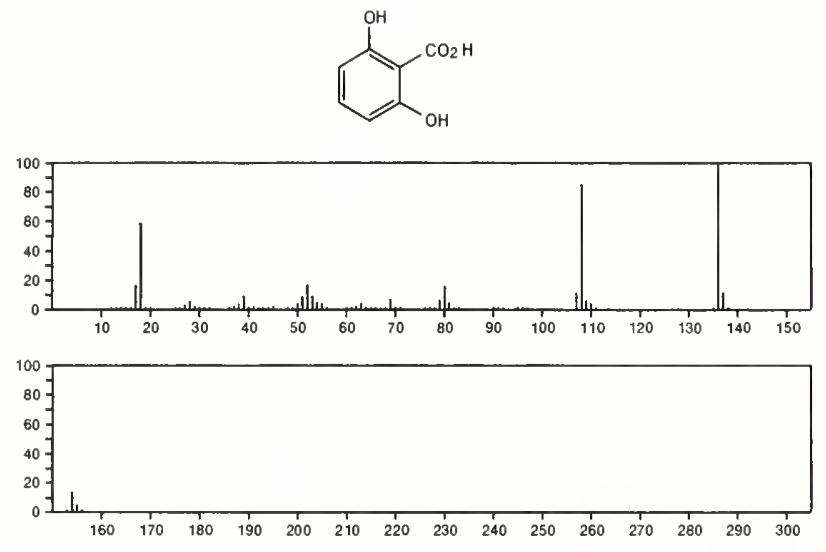

$\begin{aligned} & \mathbf{1 5 4} \\ & \text { Benzoic acid, 2,3-dihydroxy- }\end{aligned} \mathrm{C}_{7} \mathrm{H}_{6} \mathrm{O}_{4} \quad 303-38-8$
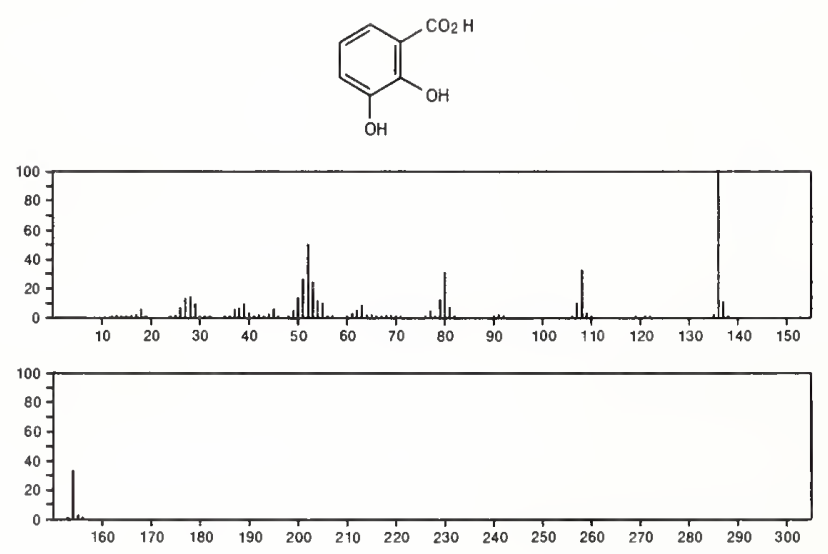

154

Benzoic acid, 2,5-dihydroxy

$\mathrm{C}_{7} \mathrm{H}_{6} \mathrm{O}_{4}$

$490-79-9$
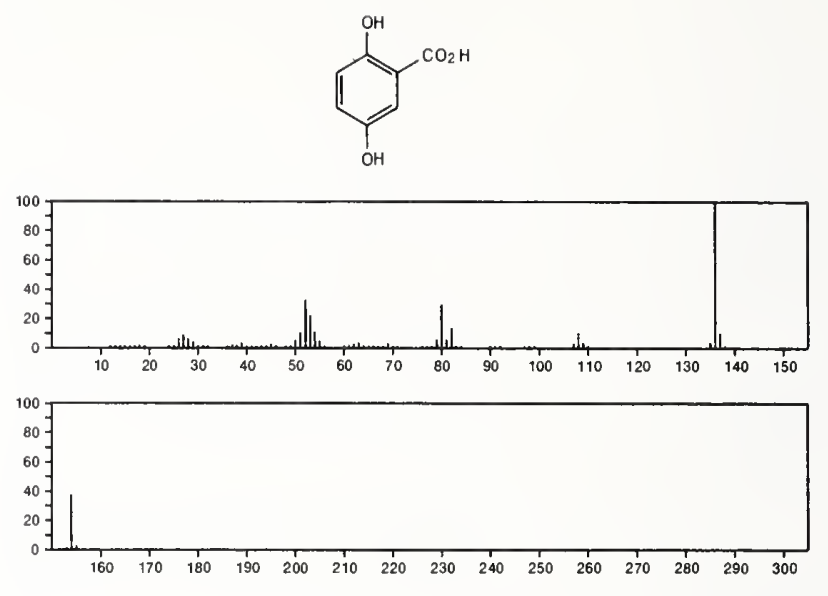

154

$\mathrm{C}_{7} \mathrm{H}_{6} \mathrm{O}_{4}$

32180-43-1

7-Oxabicyclo[4.1.0]hept-3-ene-2,5-dione, 3-(hydroxymethyl)-, $( \pm)$ -
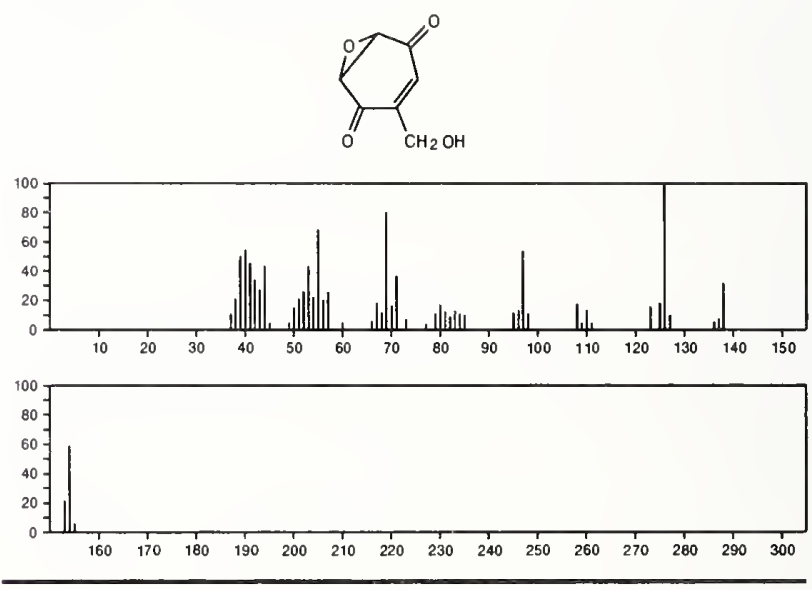

154

$\mathrm{C}_{7} \mathrm{H}_{6} \mathrm{~S}_{2}$

$21505-25-9$

2,4,6-Cycloheptatriene-1-thione, 2-mercapto-
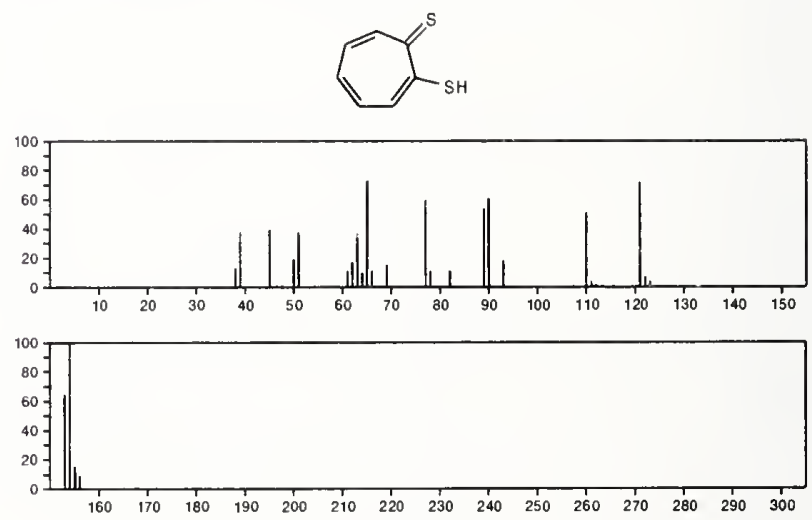
154

$\mathrm{C}_{7} \mathrm{H}_{10} \mathrm{~N}_{2} \mathrm{O}_{2}$

2,4(1H,3H)-Pyrimidinedione, 3-ethyl-6-methyl-

1006-24-2<smiles>CCn1c(=O)cc([N+](=O)[O-])[nH]c1=O</smiles>
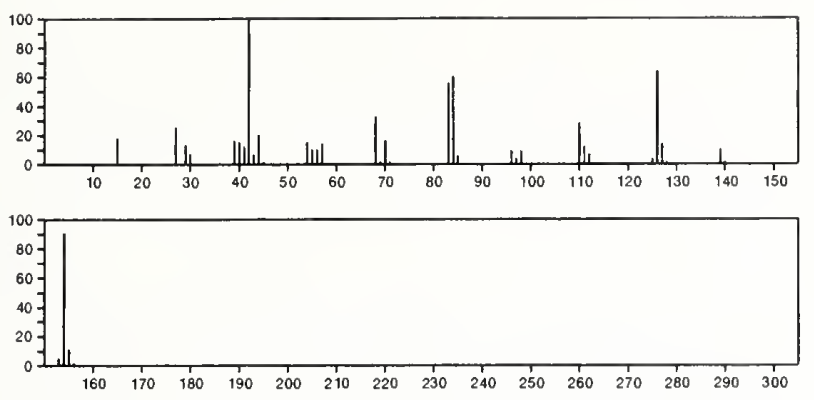

154

$\mathrm{C}_{7} \mathrm{H}_{10} \mathrm{~N}_{2} \mathrm{O}_{2}$

13509-52-9

2,4(1H,3H)-Pyrimidinedione, $1,3,6$-trimethyl-<smiles>Cc1cc(=O)n(C)c(=O)n1C</smiles>
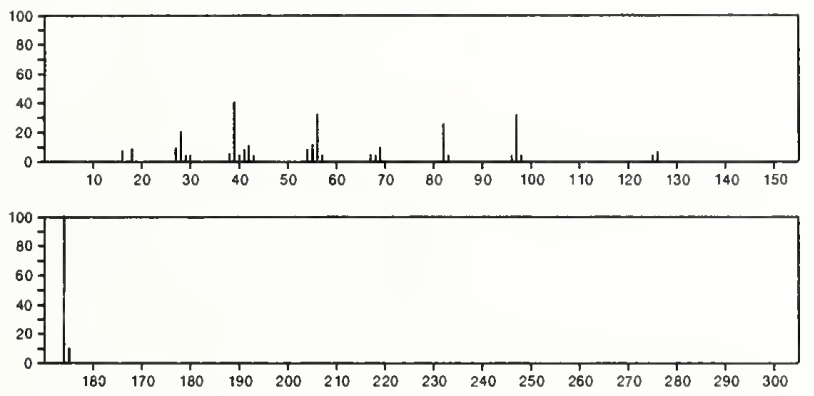

4(1H)-Pyrimidinone, 5-ethoxy-2-methyl-<smiles>CCOc1c[nH]c(N)nc1=O</smiles>
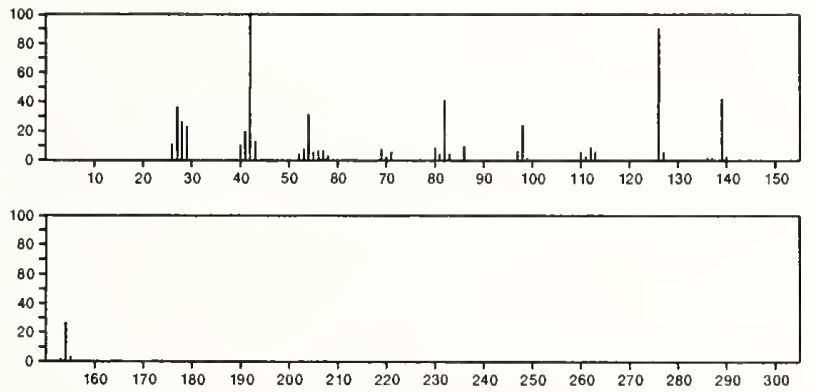

154 4(1H)-Pyrimidinone, 6-ethoxy-2-methyl

$38249-34-2$<smiles>CCOc1cc(=O)nc(N)[nH]1</smiles>
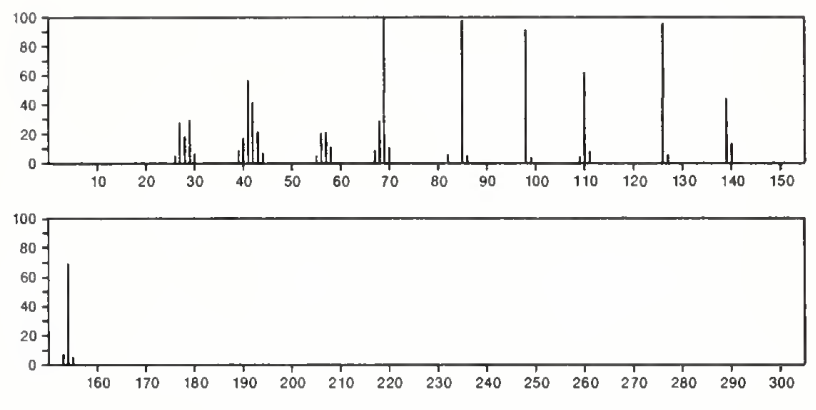

154

$\mathrm{C}_{8} \mathrm{H}_{7} \mathrm{ClO}$

$99-02-5$

Ethanone, 1-(3-chlorophenyl)
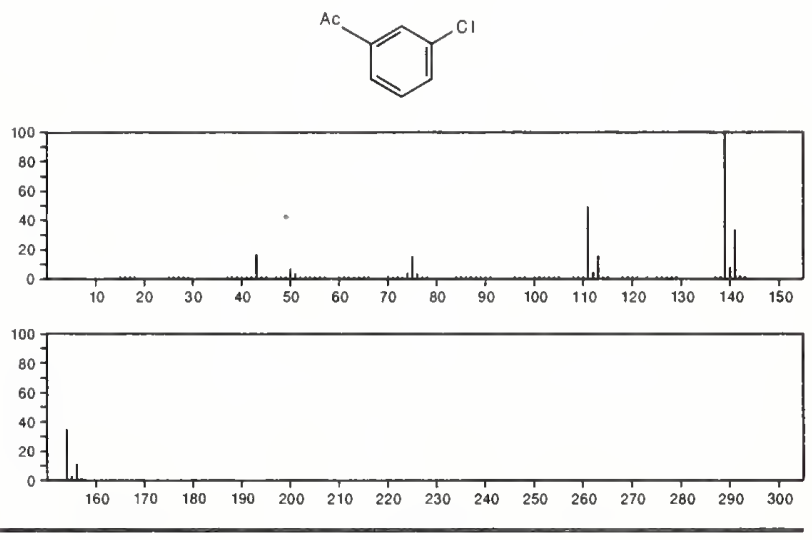

154

$\mathrm{C}_{8} \mathrm{H}_{7} \mathrm{ClO}$

99-91-2

Ethanone, 1-(4-chlorophenyl)-
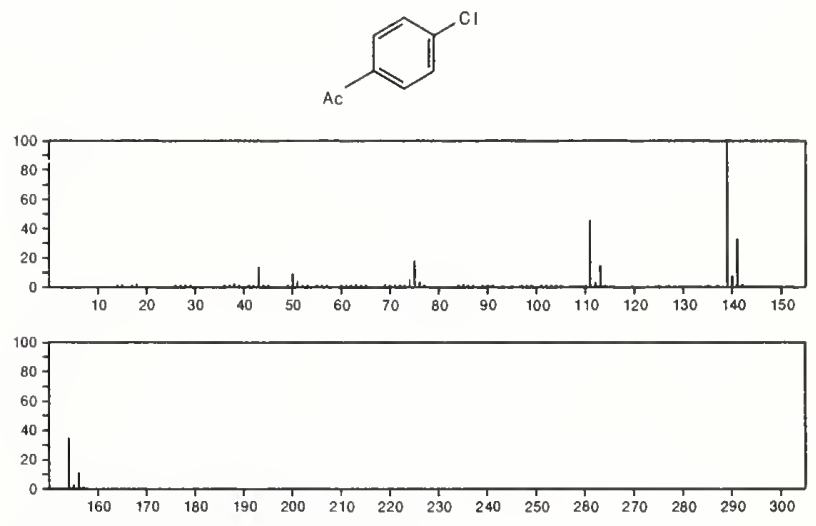

154

Ethanone, 2-chloro-1-phenyl-

$532-27-4$

$\mathrm{Cl} \mathrm{CH}_{2} \mathrm{COPh}$

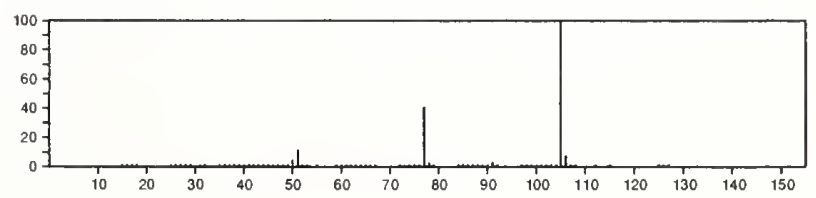




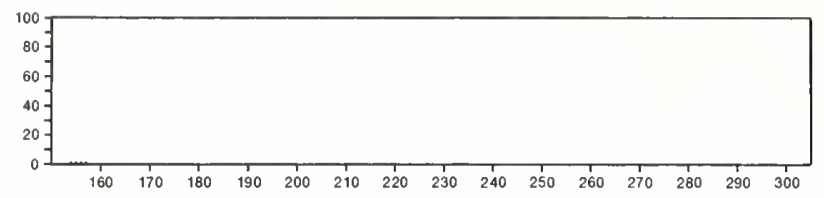

154

Benzoyl chloride, 2-methyl-

$\mathrm{C}_{8} \mathrm{H}_{7} \mathrm{ClO}$

$933-88-0$
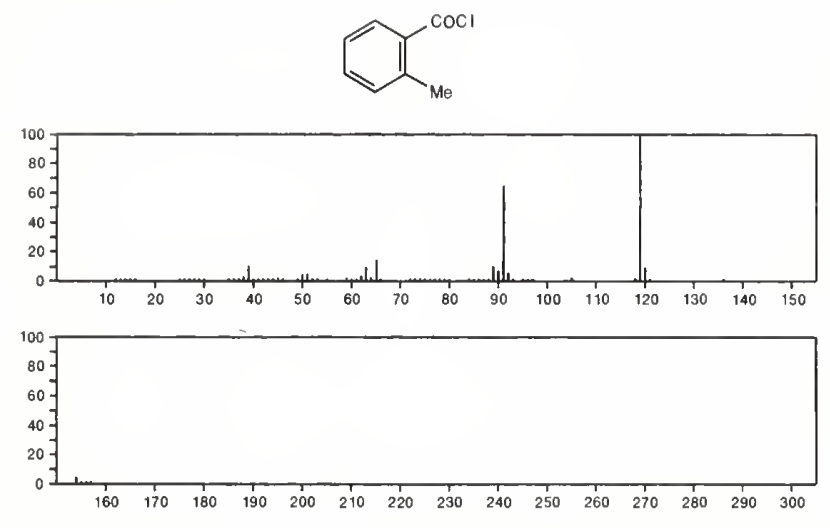

154

Ethanone, 1-(2-chlorophenyl)-

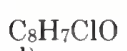

$2142-68-9$
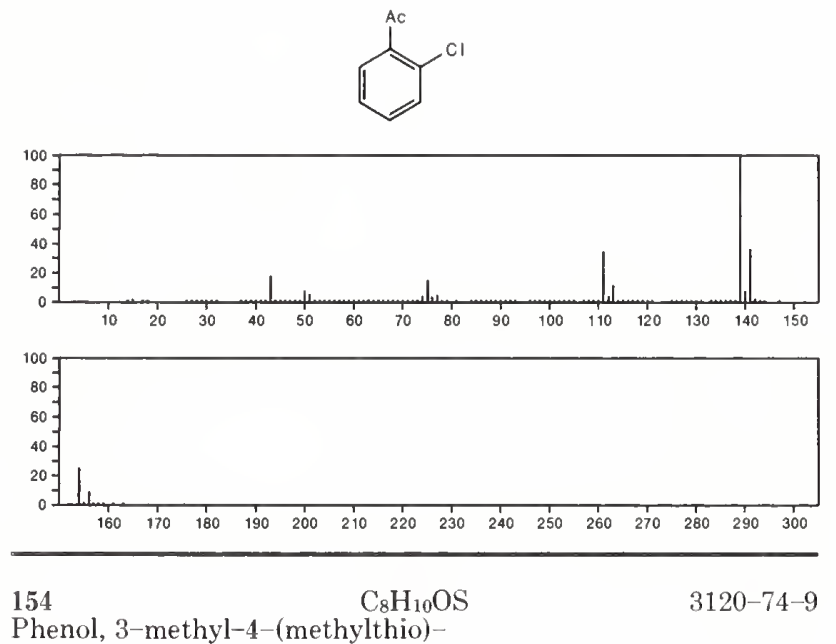

Phenol, 3-methyl-4-(methylthio)-
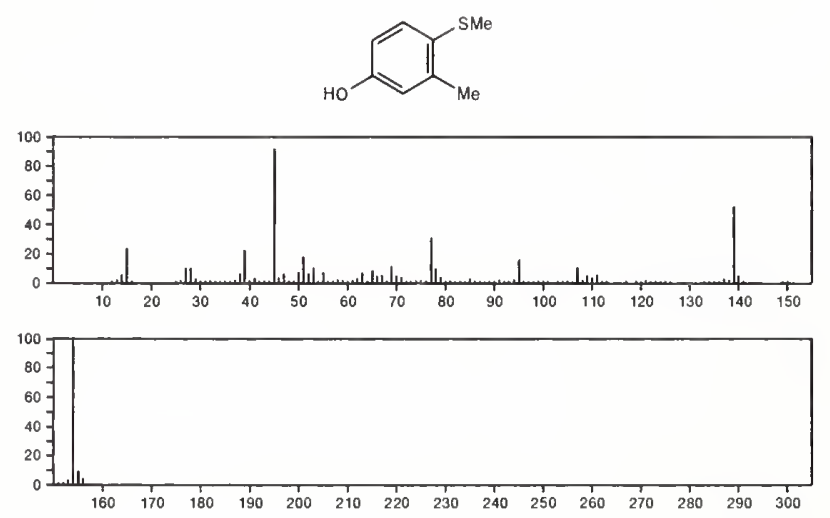

154

1-Butanone, 1-(2-thienyl)-

$\mathrm{C}_{8} \mathrm{H}_{10} \mathrm{OS}$

$5333-83-5$
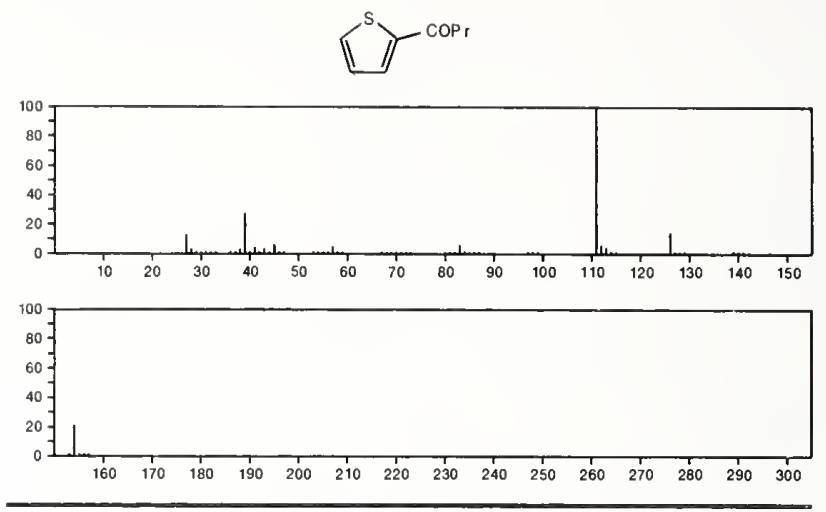

154

Ethanethiol, 2 -phenoxy-

$\mathrm{C}_{8} \mathrm{H}_{10} \mathrm{OS}$

$6338-63-2$

$\mathrm{PhOCH}_{2} \mathrm{CH}_{2} \mathrm{SH}$
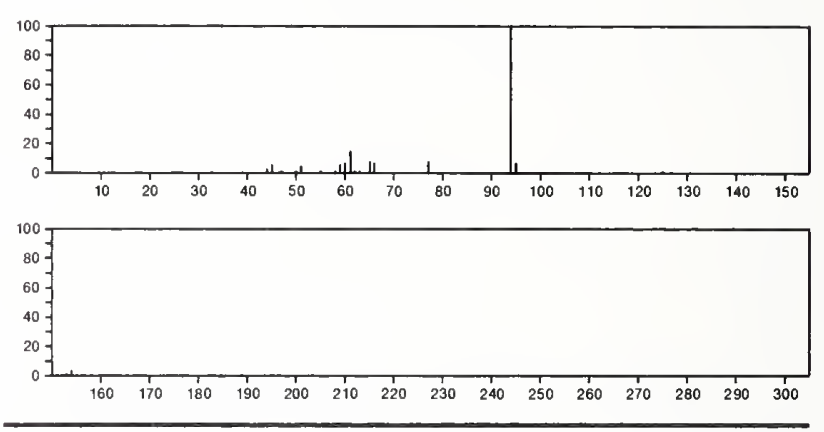

154

Phenol, 2-(ethylthio)

$\mathrm{C}_{8} \mathrm{H}_{10} \mathrm{OS}$

$29549-60-8$<smiles>CCc1ccccc1O</smiles>
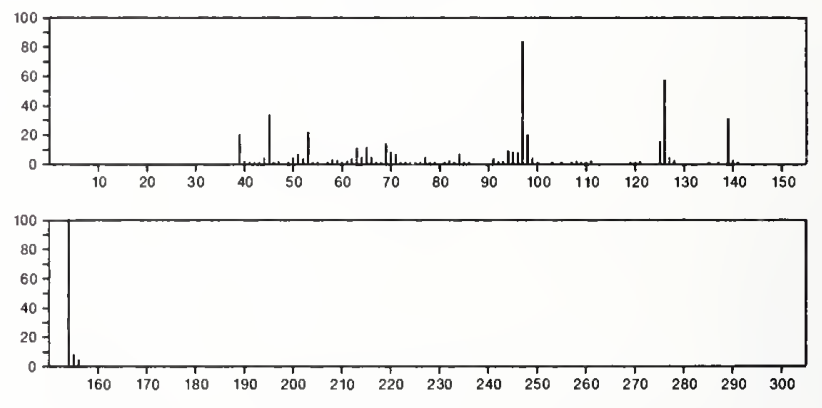

154

$\mathrm{C}_{8} \mathrm{H}_{10} \mathrm{O}_{3}$

$85-42-7$

1,3-Isobenzofurandione, hexahydro-
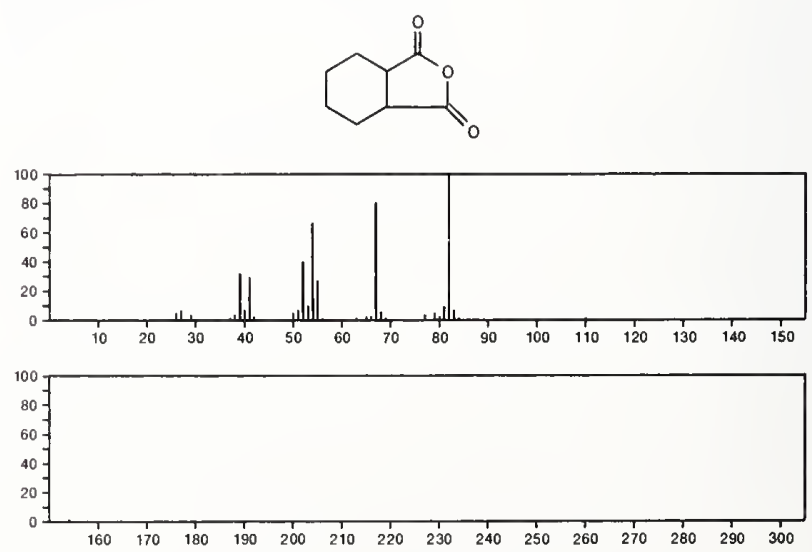
154

Phenol, 3,5-dimethoxy-

$\mathrm{C}_{8} \mathrm{H}_{10} \mathrm{O}_{3}$
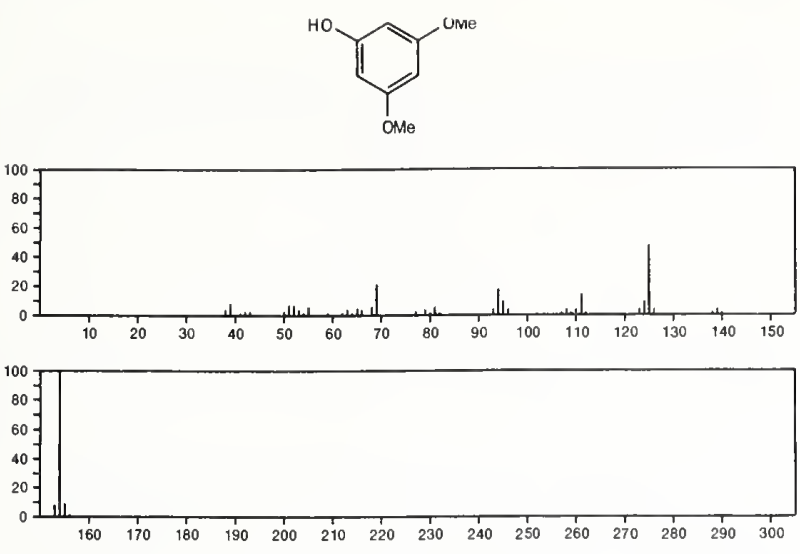

154

$\mathrm{C}_{8} \mathrm{H}_{10} \mathrm{O}_{3}$

2 -Furancarboxylic acid, propyl ester
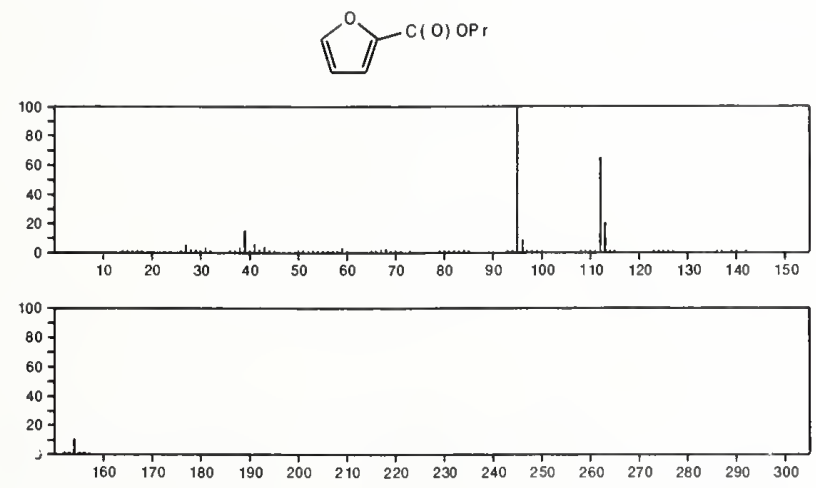

154

2-Furanmethanol, propanoate

$\mathrm{C}_{8} \mathrm{H}_{10} \mathrm{O}_{3}$

$623-19-8$
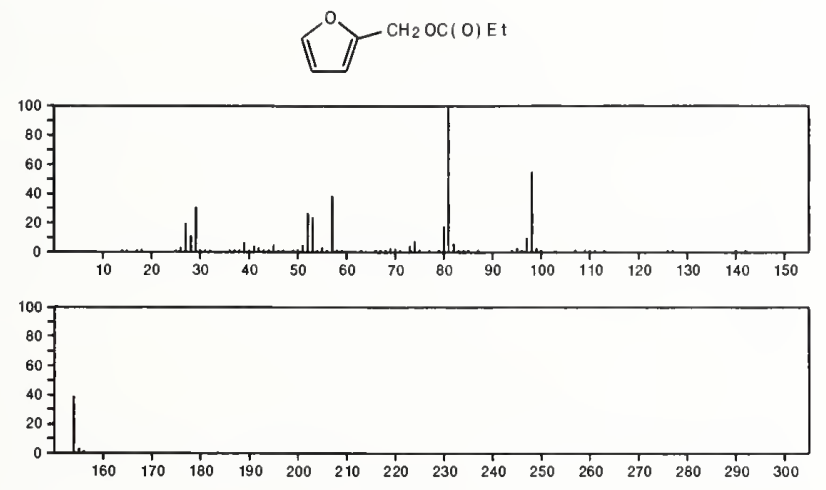

154

Phenol, 3,4-dimethoxy-

$\mathrm{C}_{8} \mathrm{H}_{10} \mathrm{O}_{3}$

2033-89-8<smiles>COc1ccc(O)cc1O</smiles>

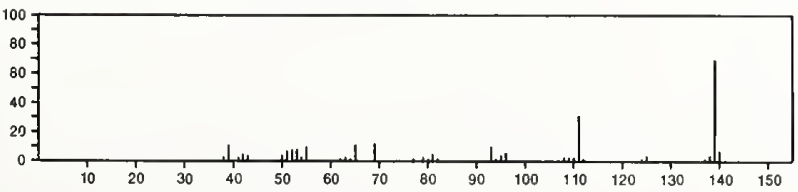

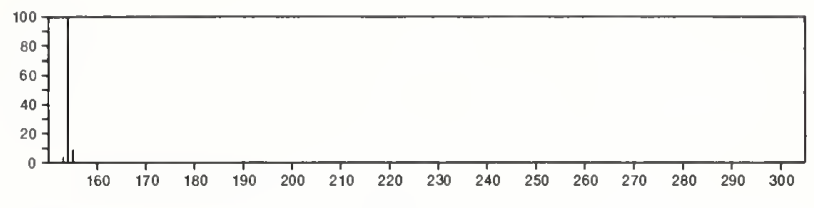

154

$\mathrm{C}_{8} \mathrm{H}_{10} \mathrm{O}_{3}$

4056-69-3

1,3-Cyclopentanedione, 2-acetyl-4-methyl-
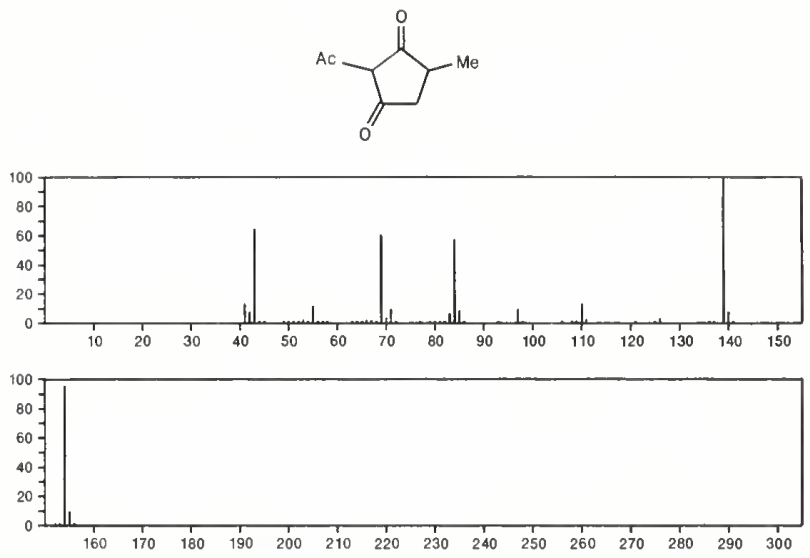

154

$\mathrm{C}_{8} \mathrm{H}_{10} \mathrm{O}_{3}$

1,2-Benzenediol, 4-(2-hydroxyethyl)-

10597-60-1
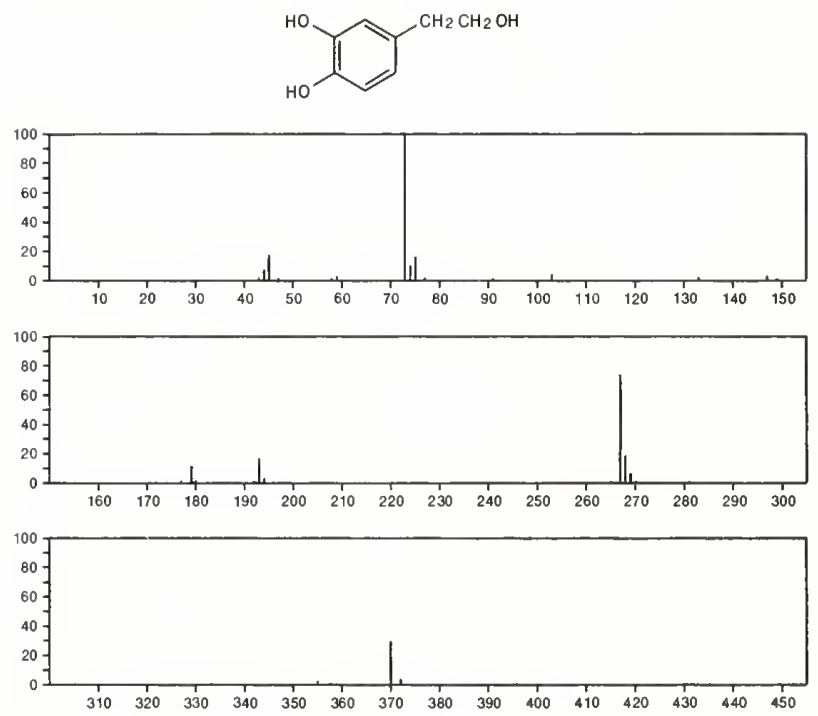

154

3-Butene-1,2-diol, 1-(2-furanyl)-

19261-13-3
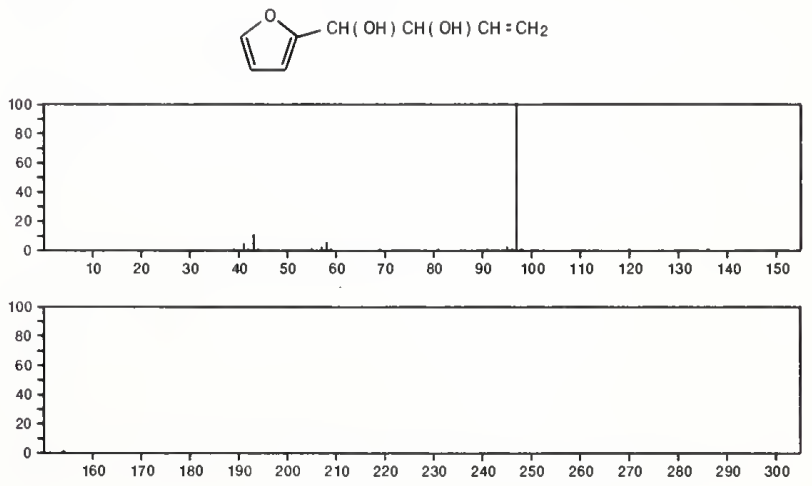
154

$\mathrm{C}_{8} \mathrm{H}_{10} \mathrm{O}_{3}$

$50267-11-3$

$3,8,11$-Trioxatetracyclo[4.4.1.02,4.07,9]undecane, $(1 \alpha, 2 \alpha, 4 \alpha, 6 \alpha, 7 \beta, 9 \beta)$ -
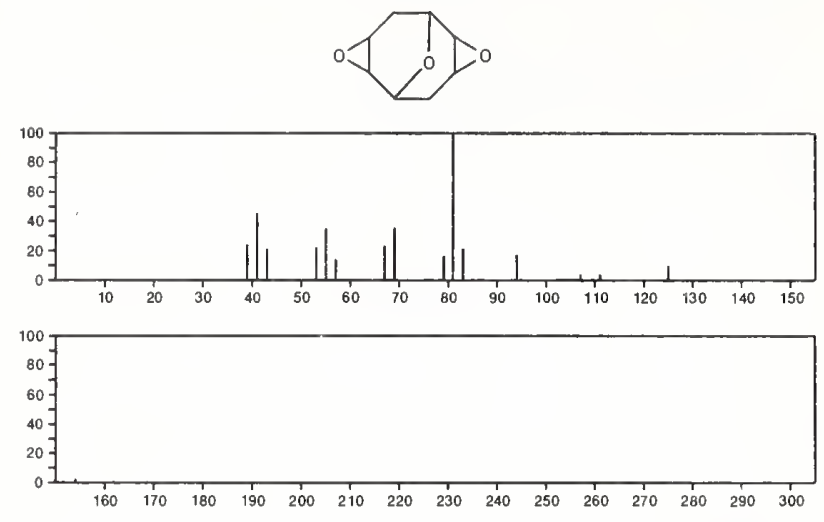

154

$3,8,11$-Trioxatetracyclo[4.4.1.02,4.07,9] undecane, $(1 \alpha, 2 \beta, 4 \beta, 6 \alpha, 7 \beta, 9 \beta)-$
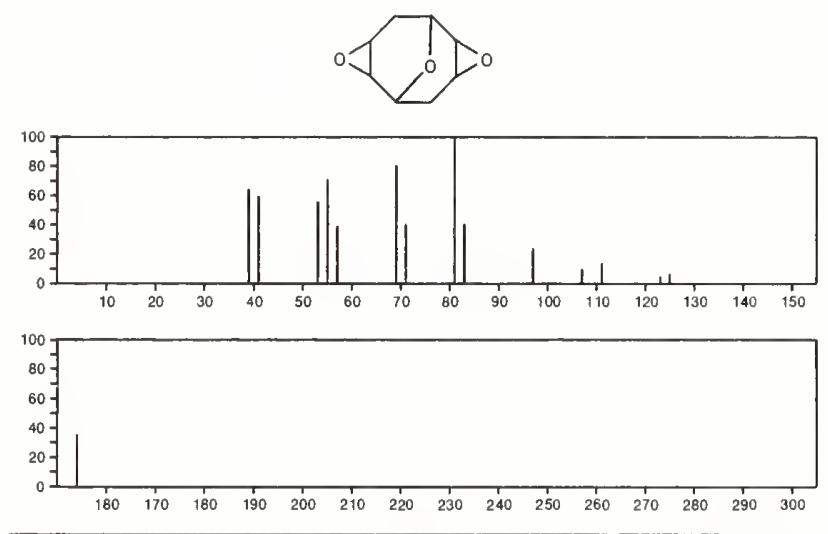

$154 \quad \mathrm{C}_{8} \mathrm{H}_{10} \mathrm{O}_{3} \quad 50607-35-7$

2H-Pyran-2-one, 3-ethyl-4-hydroxy-6-methyl-
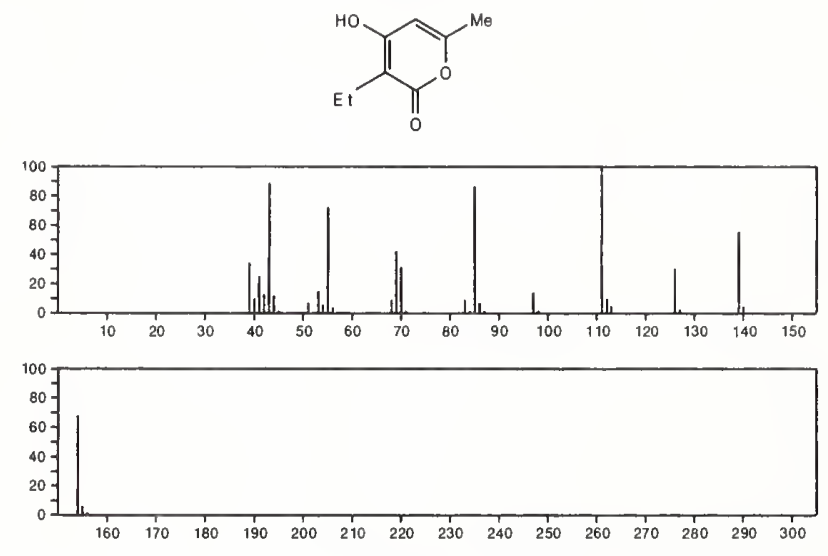

154

1,4-Dioxane, 2-(2-furanyl)

$\mathrm{C}_{8} \mathrm{H}_{10} \mathrm{O}_{3}$

$56666-97-8$
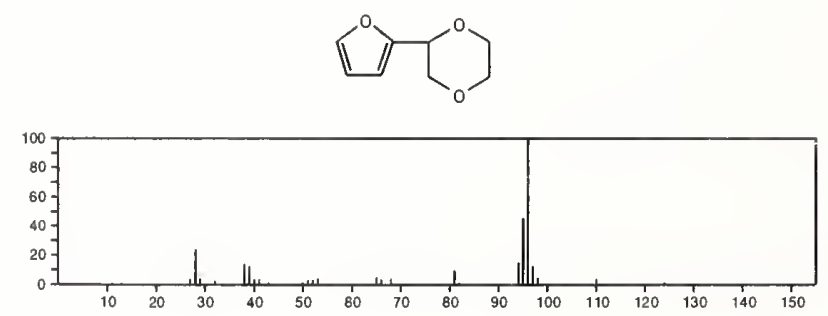
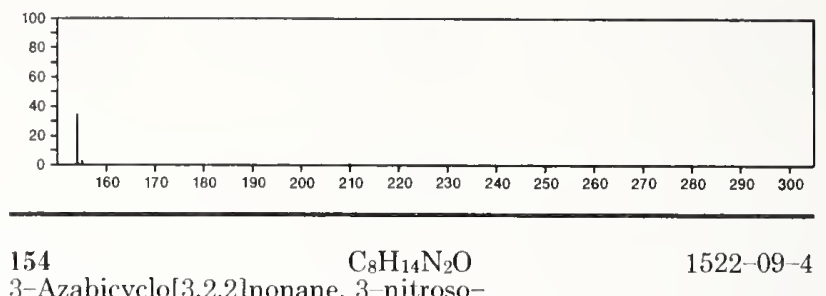

3-Azabicyclo[3.2.2]nonane, 3-nitroso-
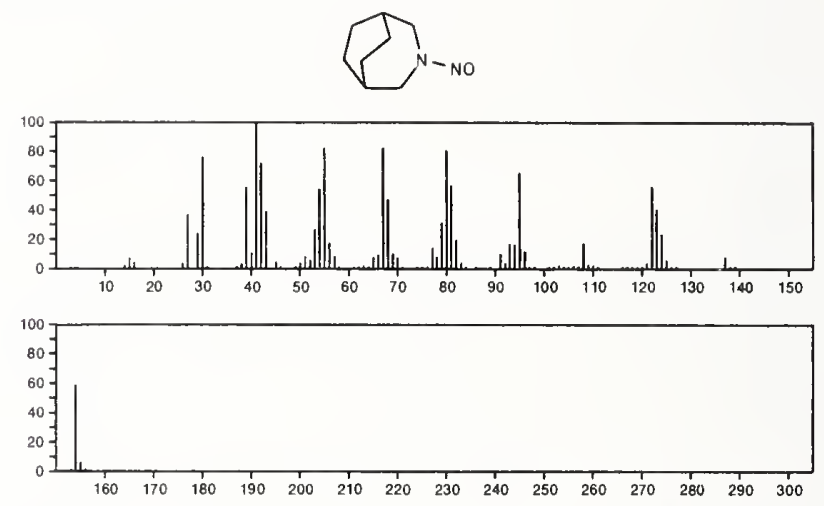

154

$\mathrm{C}_{8} \mathrm{H}_{14} \mathrm{~N}_{2} \mathrm{O}$

3-Buten-2-one, 4-(1-aziridinyl)-4-(dimethylamino)-

$49582-43-6$
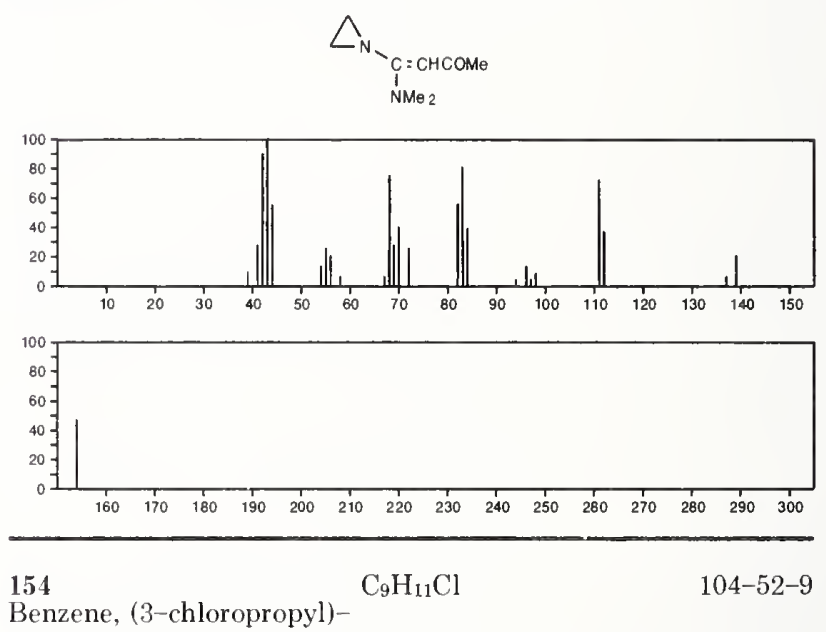

Benzene, (3-chloropropyl)-

$\mathrm{Ph}\left(\mathrm{CH}_{2}\right)_{3} \mathrm{Cl}$
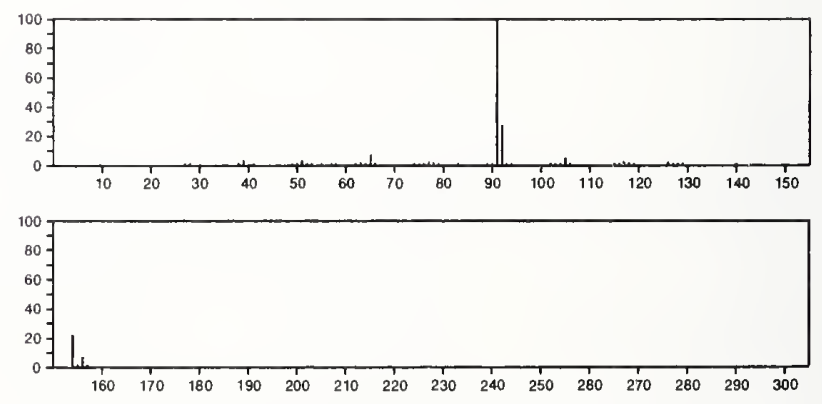

154

$\mathrm{C}_{9} \mathrm{H}_{11} \mathrm{Cl}$

Benzene, (2-chloro-1-methylethyl)-

$824-47-5$

$\mathrm{Cl} \mathrm{CH}_{2} \mathrm{CHMePh}$

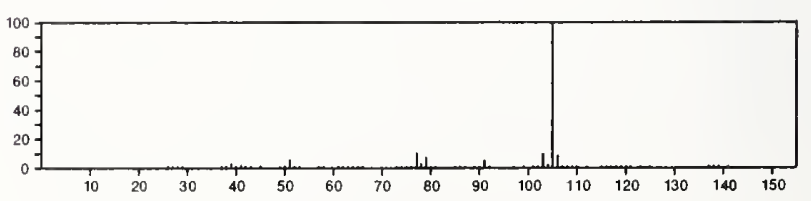



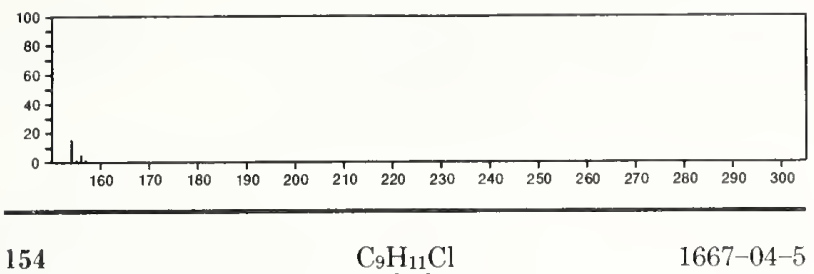

Benzene, 2-chloro-1,3,5-trimethyl-
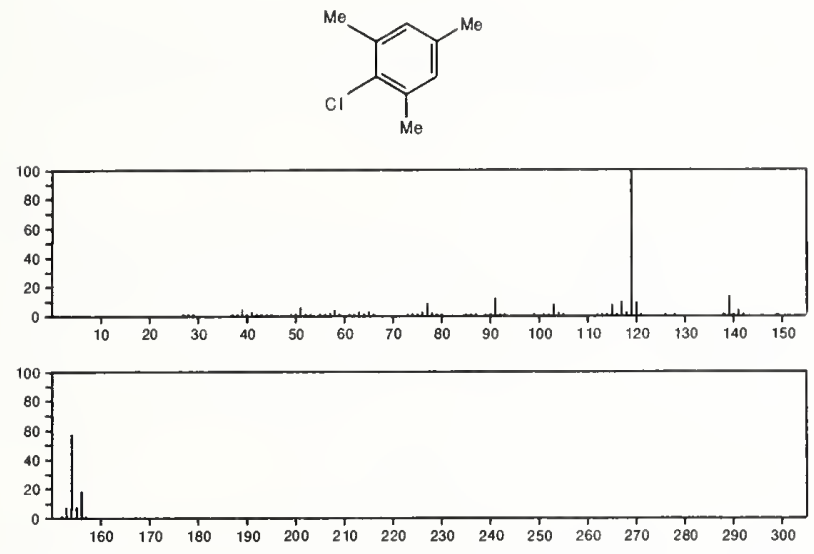

\section{4}

Benzene, 1-chloro-2-propyl-

$$
\mathrm{C}_{9} \mathrm{H}_{11} \mathrm{Cl}
$$

$1730-86-5$
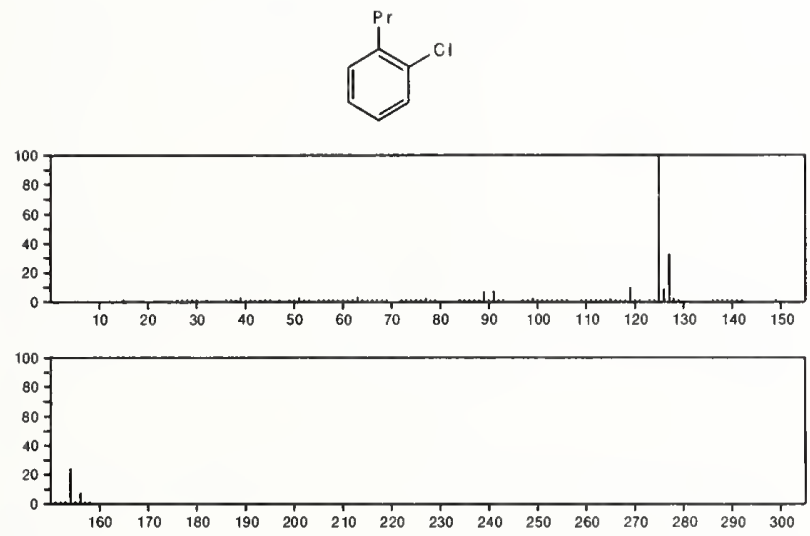

154

$\mathrm{C}_{9} \mathrm{H}_{11} \mathrm{Cl}$

Benzene, 1-chloro-2-(1-methylethyl)-
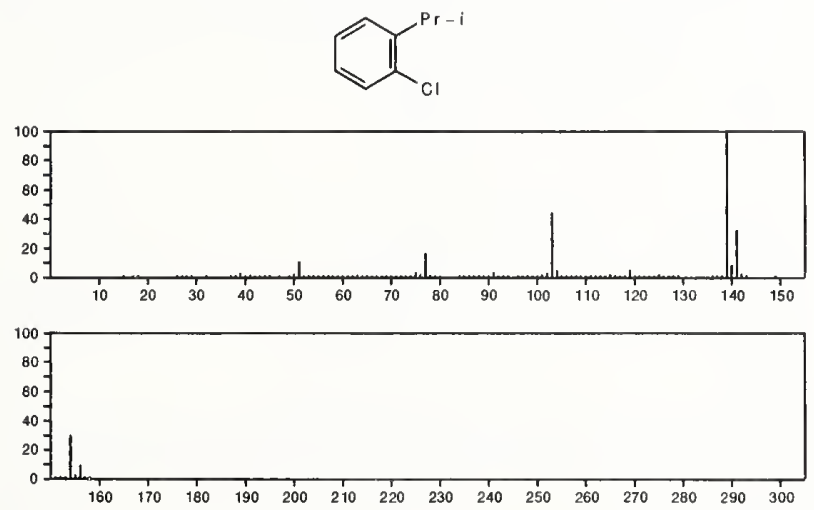

154

$\mathrm{C}_{9} \mathrm{H}_{11} \mathrm{Cl}$

Benzene, 1-chloro-4-(1-methylethyl)-
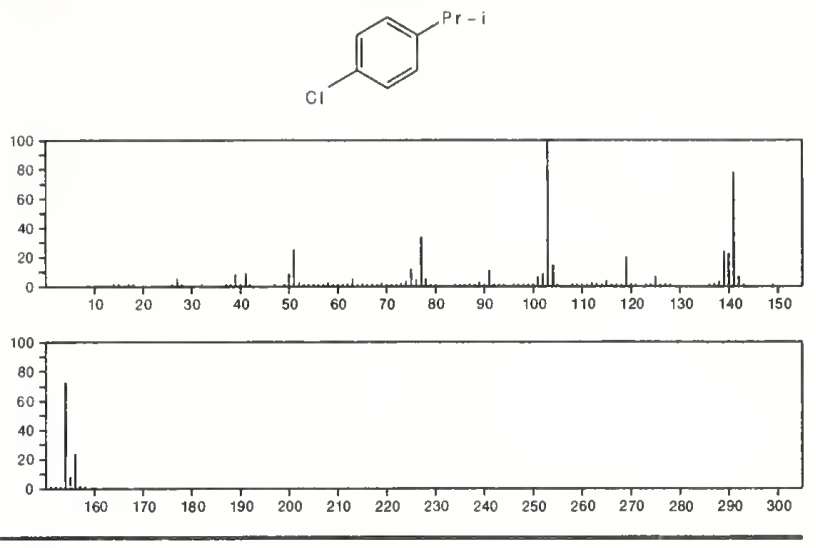

154

Benzene, (2-chloropropyl)-

$\mathrm{C}_{9} \mathrm{H}_{11} \mathrm{Cl}$

$10304-81-1$

$\mathrm{MeCHCl} \mathrm{CH}_{2} \mathrm{Ph}$
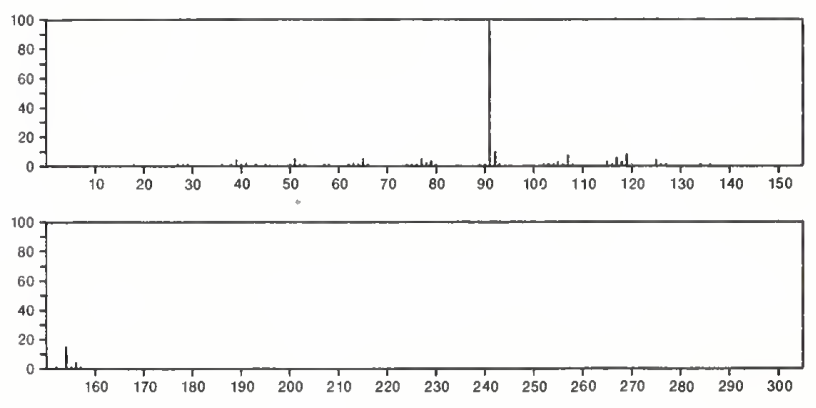

154

$\mathrm{C}_{9} \mathrm{H}_{11} \mathrm{Cl}$

26968-58-1

Benzene, (chloromethyl)ethyl-
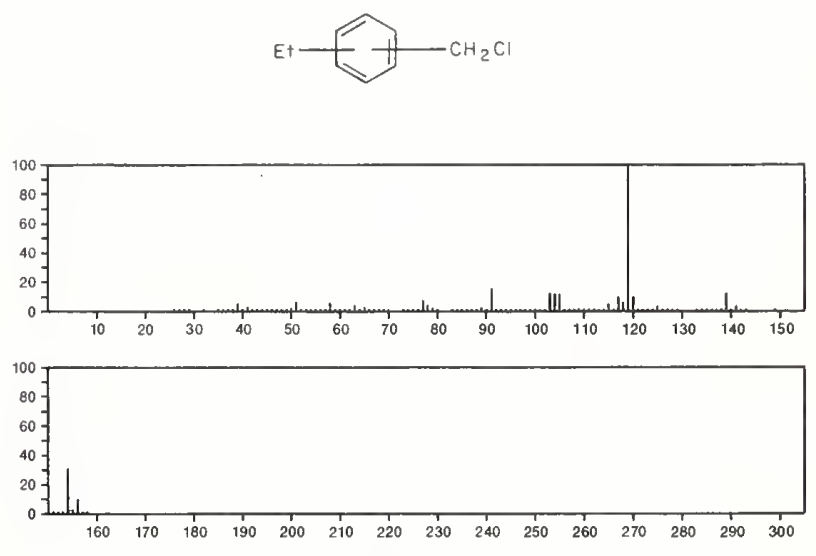

154

$\mathrm{C}_{9} \mathrm{H}_{14} \mathrm{O}_{2}$

Bicyclo[2.2.2] octane-1-carboxylic acid

699-55-8
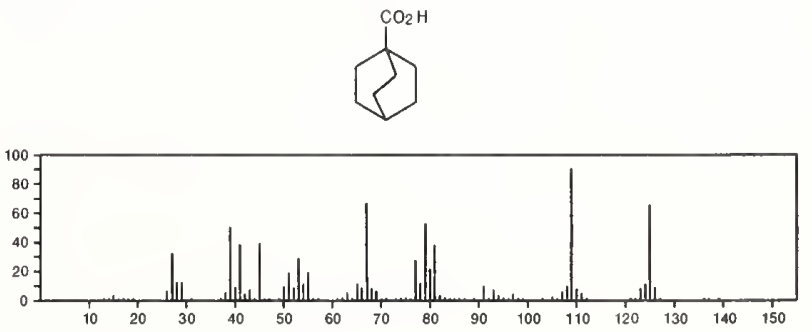


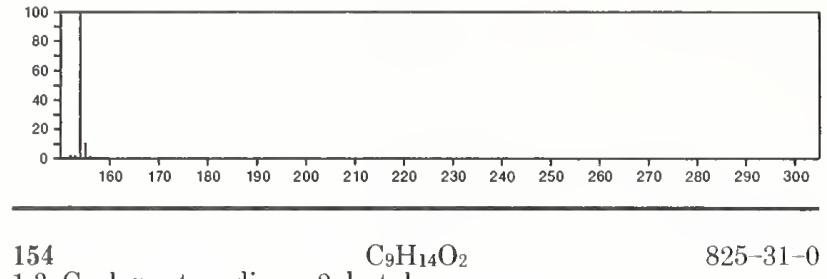

1,3-Cyclopentanedione, 2-butyl-
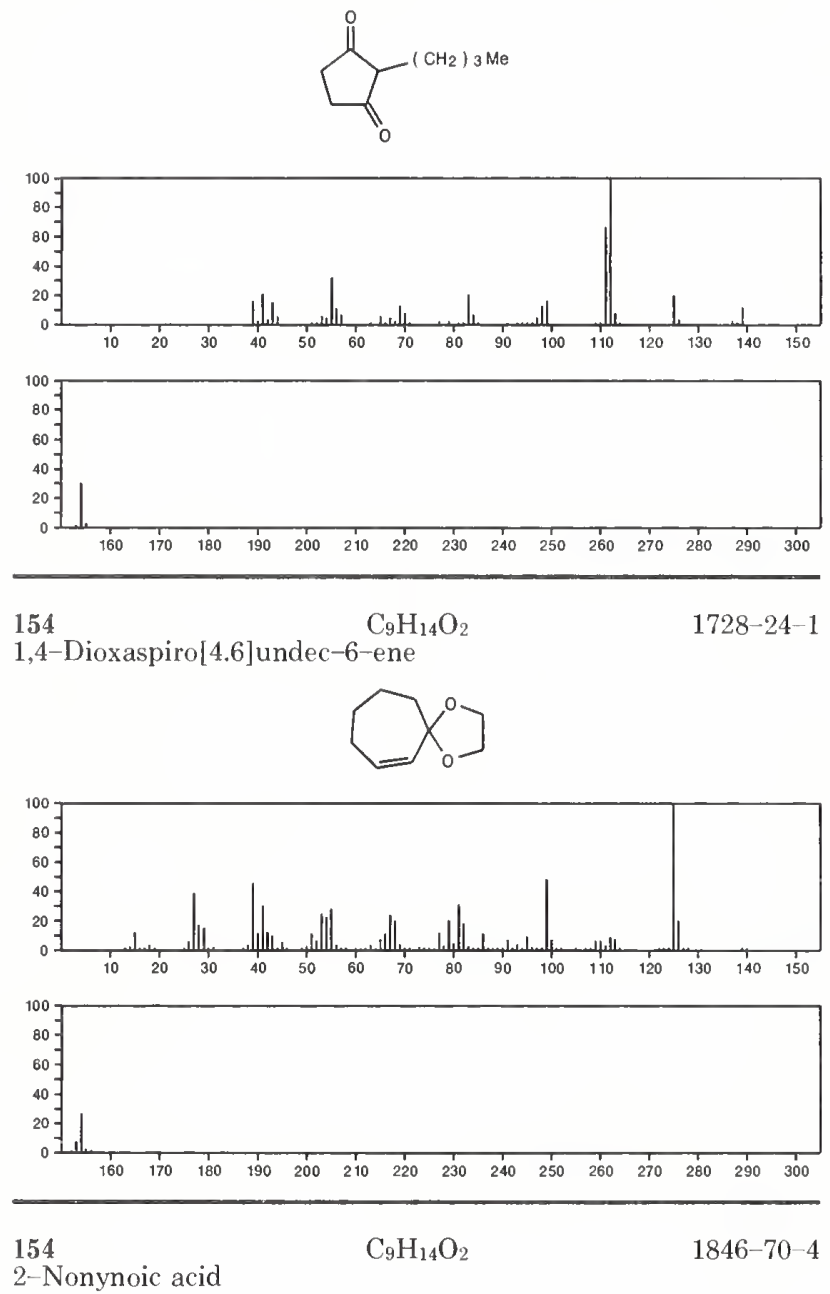

$\mathrm{Me}\left(\mathrm{CH}_{2}\right)_{5} \mathrm{C} \equiv \mathrm{CCO}_{2} \mathrm{H}$
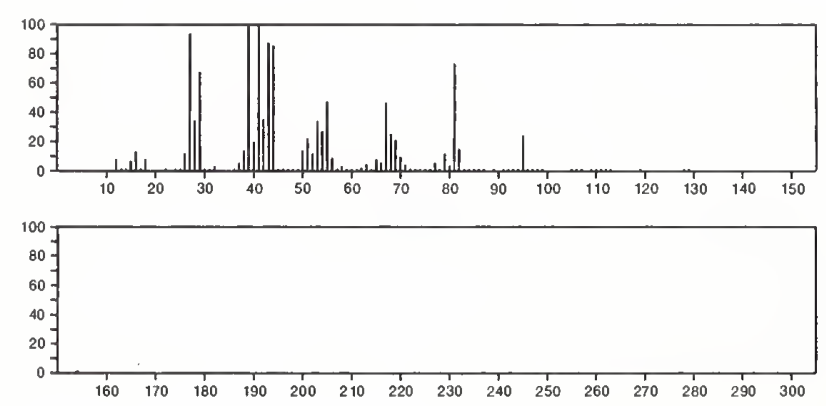

154

2-Propenoic acid, cyct

$3066-71-5$
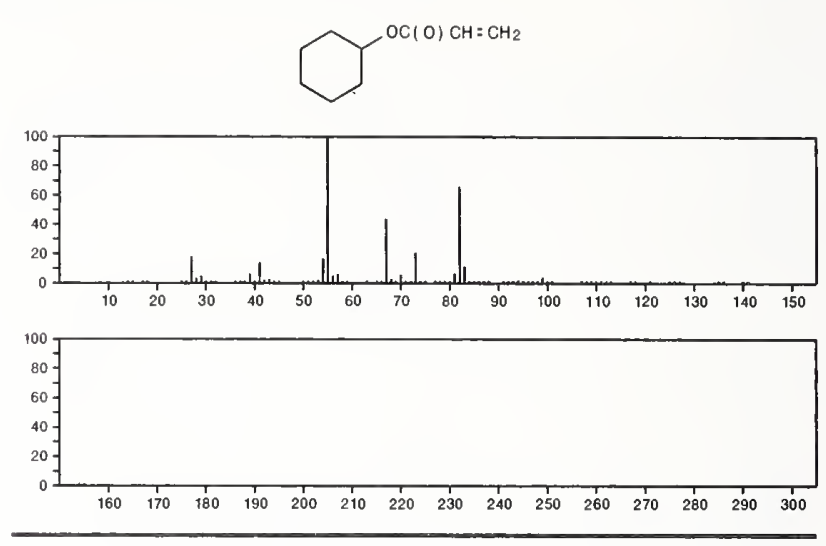

154

$\mathrm{C}_{9} \mathrm{H}_{14} \mathrm{O}_{2}$

$4362-67-8$

1,3-Dioxolane, 4,5-diethenyl-2,2-dimethyl-
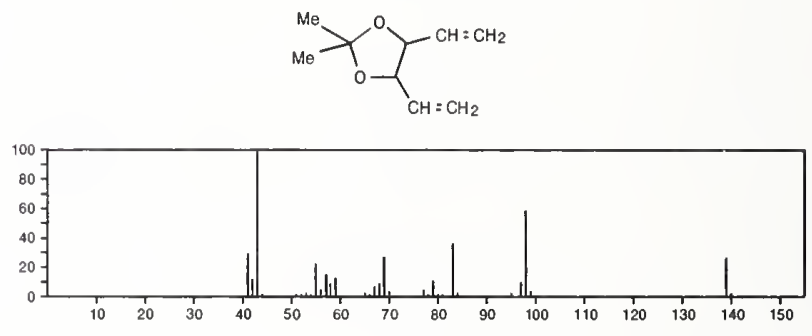

$154 \quad \mathrm{C}_{9} \mathrm{H}_{14} \mathrm{O}_{2}$

Cyclohexanecarboxylic acid, ethenyl ester

$4840-76-0$
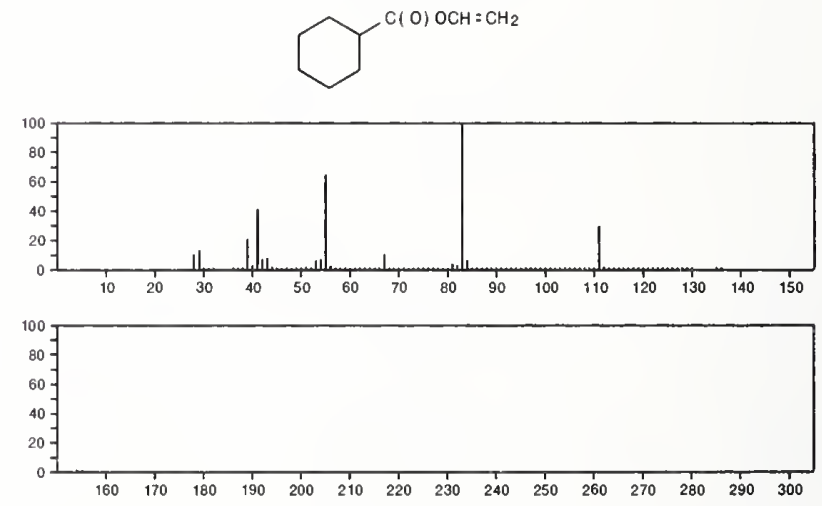

154

Bicyclo[2.2.2]octanone, 4-methoxy-

4893-16-7
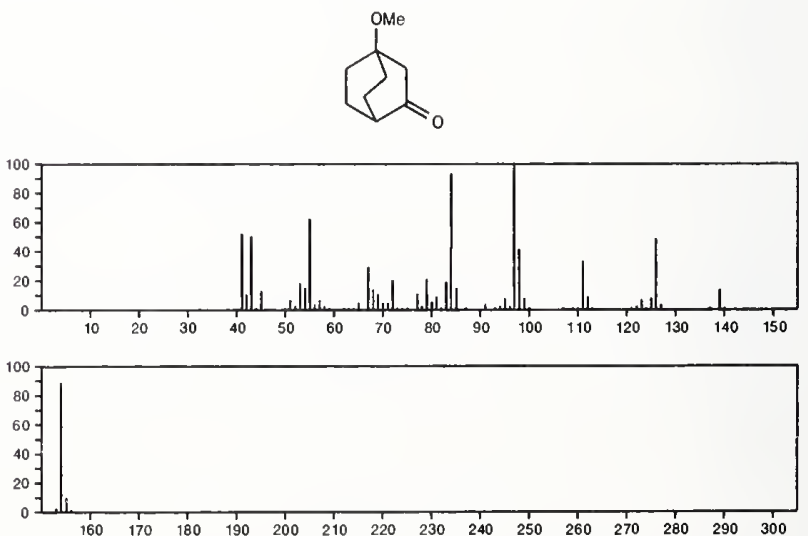
$154 \quad \mathrm{C}_{9} \mathrm{H}_{14} \mathrm{O}_{2} \quad 6493-79-4$ 3-Cyclohexene-1-carboxylic acid, 4-methyl-, methyl ester
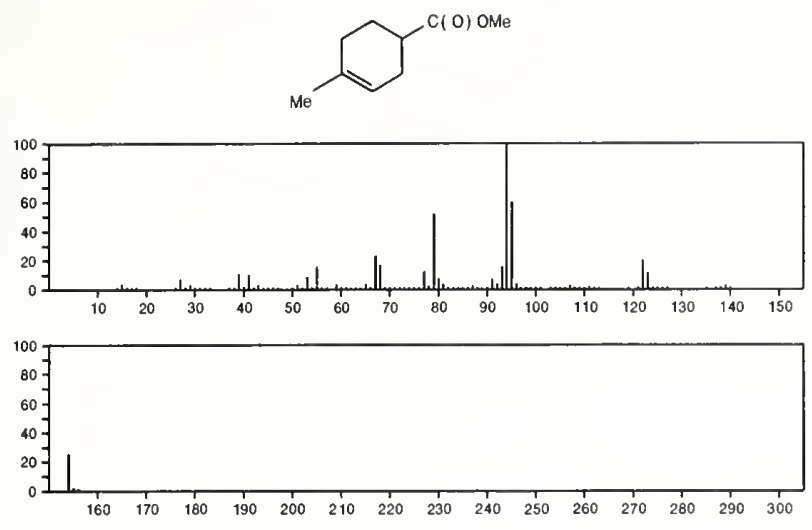

$154 \quad \mathrm{C}_{9} \mathrm{H}_{14} \mathrm{O}_{2}$

1,4-Dioxaspiro[4.6]undec-7-ene
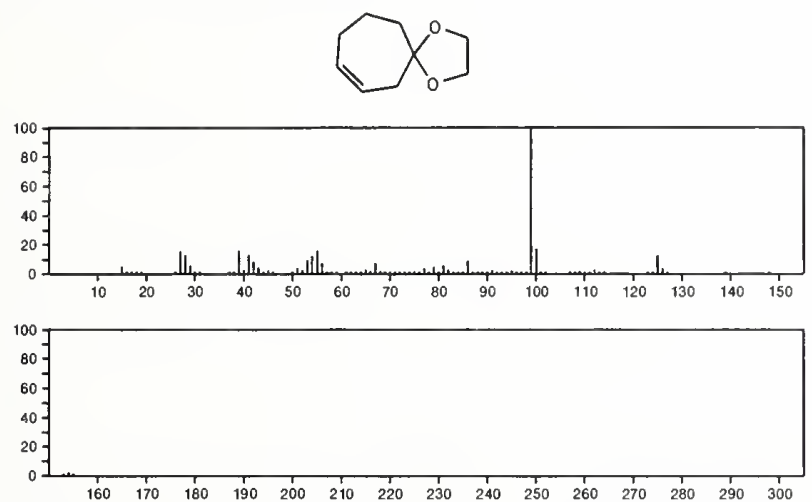

154

$\mathrm{C}_{9} \mathrm{H}_{14} \mathrm{O}_{2}$

$7196^{-96-5}$

1,4-Benzodioxin, 4a,5,6,7,8,8a-hexahydro-2-methyl-, trans-
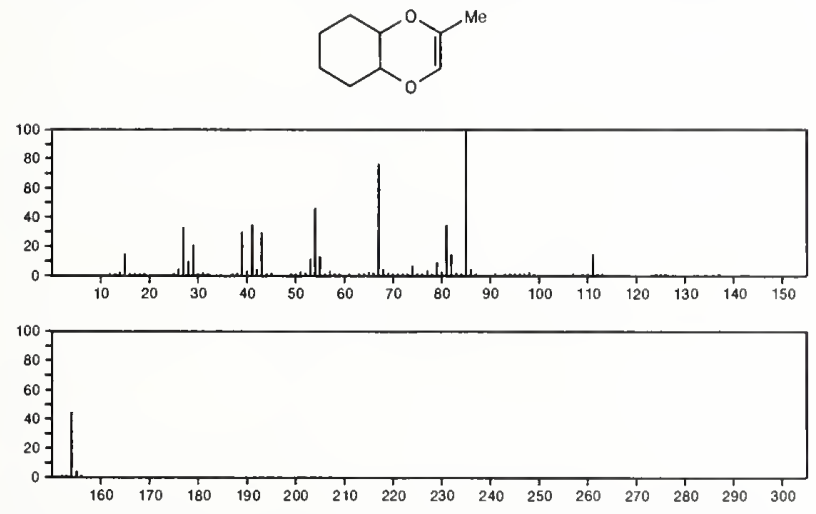

154

$\mathrm{C}_{9} \mathrm{H}_{14} \mathrm{O}_{2}$

$7229-32-5$

Cyclohexanol, 2-(2-propynyloxy)-, trans-
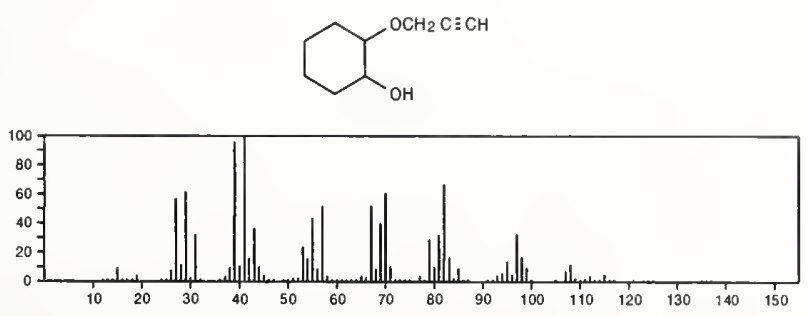

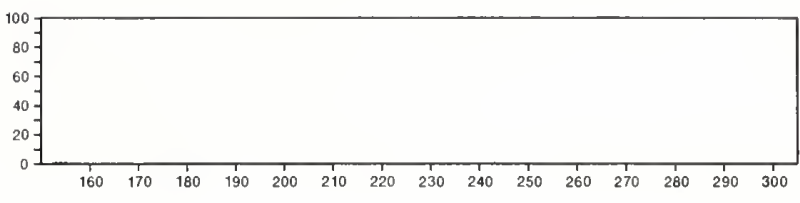

154

$\mathrm{C}_{9} \mathrm{H}_{14} \mathrm{O}_{2}$

$10276-21-8$

7-Oxabicyclo[4.1.0]heptan-2-one, 4,4,6-trimethyl
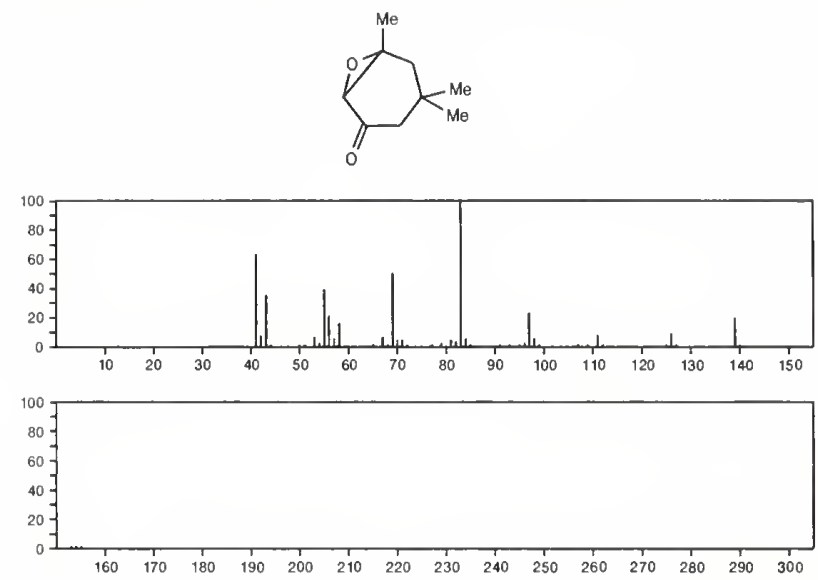

154

7-Octynoic acid, methyl ester

18458-50-9

$\mathrm{HC}=\mathrm{C}\left(\mathrm{CH}_{2}\right) 5 \mathrm{C}(\mathrm{O}) \mathrm{OM}$
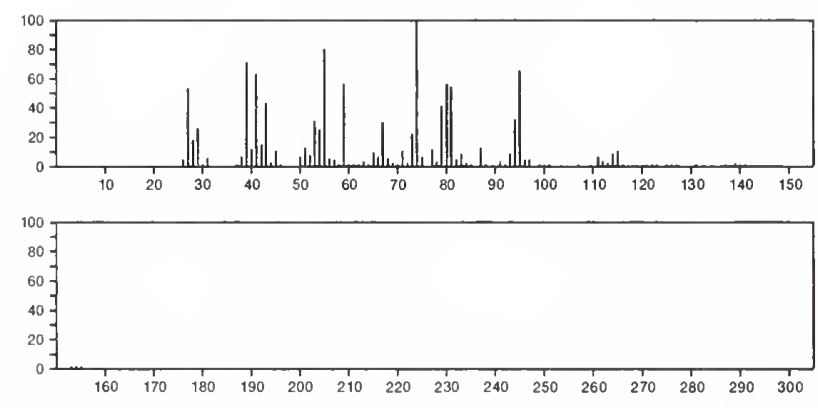

154

$\mathrm{C}_{9} \mathrm{H}_{14} \mathrm{O}_{2}$

1,4-Cyclohexanedione, 2,2,6-trimethyl-

20547-99-3
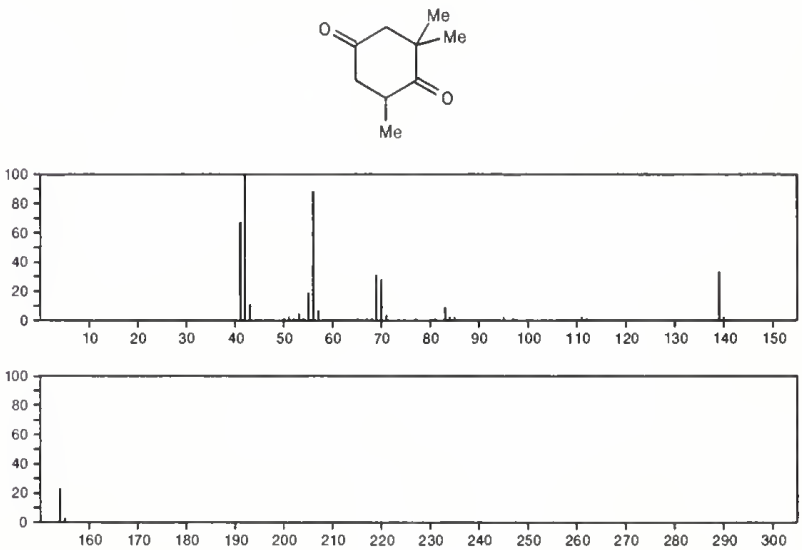
154

$\mathrm{C}_{9} \mathrm{H}_{14} \mathrm{O}_{2}$

1,4-Dioxaspiro[4.5]decane, 6-methylene-
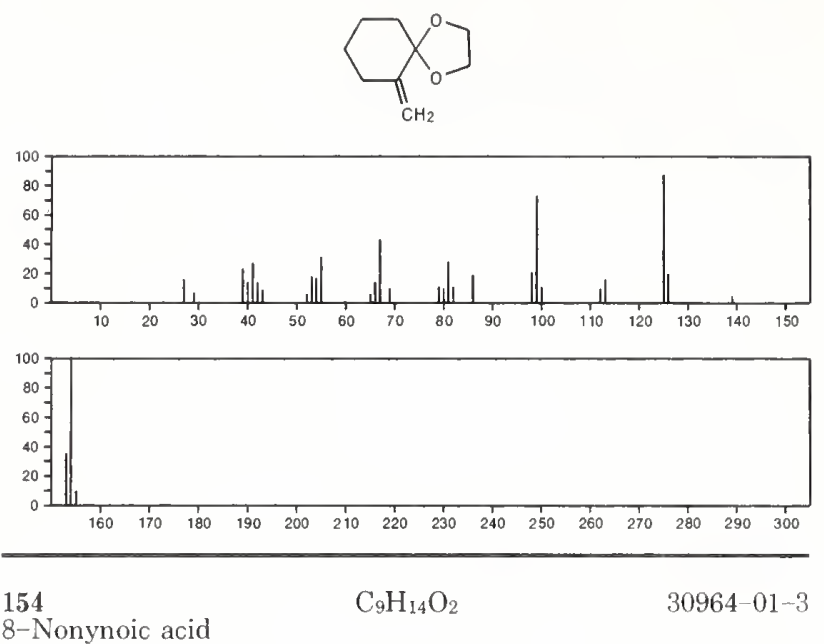

8-Nonynoic acid

$\mathrm{HC} \equiv \mathrm{C}\left(\mathrm{CH}_{2}\right)_{6} \mathrm{CO}_{2} \mathrm{H}$
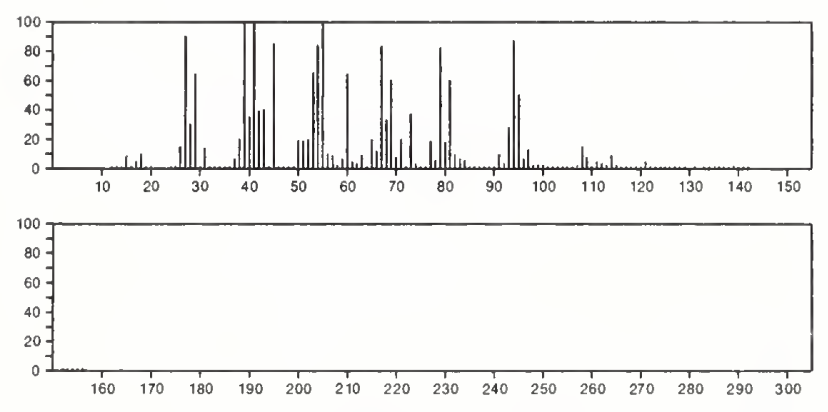

154
$\mathrm{C}_{9} \mathrm{H}_{14} \mathrm{O}_{2}$

Bicyclo[2.2.1] heptan-2-ol, acetate
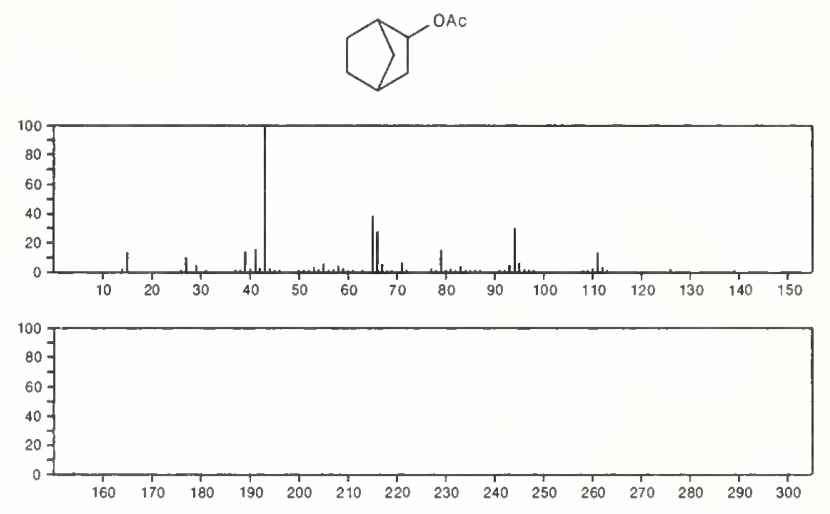

$154 \quad \mathrm{C}_{9} \mathrm{H}_{14} \mathrm{O}_{2}$

1,4-Benzodioxin, octahydro-2-methylene-, trans-

$38653-34-8$<smiles>C=C1COC2CCCCC2O1</smiles>
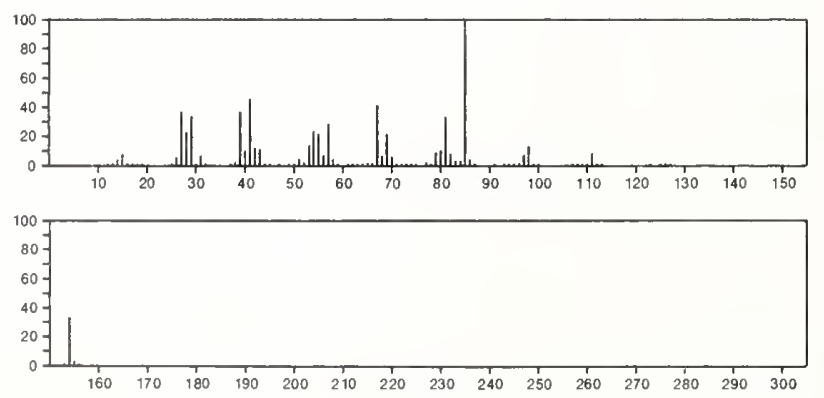

154

$\mathrm{C}_{9} \mathrm{H}_{14} \mathrm{O}_{2}$

$40365-61-5$

2H-Pyran, 2-(3-butynyloxy)tetrahydro-
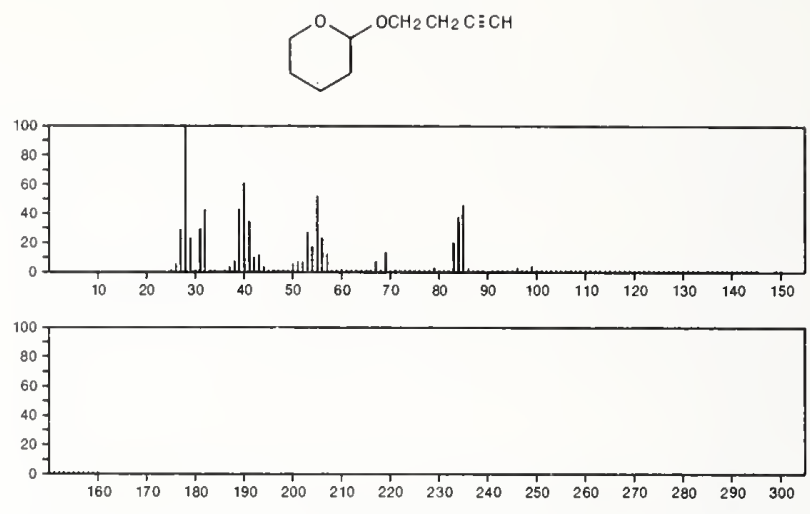

$154 \quad \mathrm{C}_{9} \mathrm{H}_{14} \mathrm{O}_{2} \quad 41977-59-7$

Cyclopropanecarboxylic acid, 3-ethenyl-2,2-dimethyl-, methyl ester, trans-
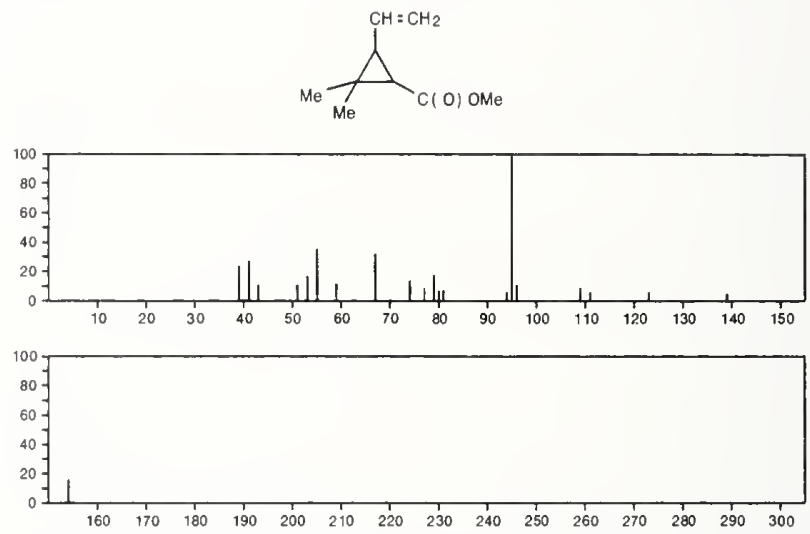

$154 \quad \mathrm{C}_{9} \mathrm{H}_{14} \mathrm{O}_{2}$

Cyclopentaneacetic acid, ethenyl ester

$45955-66-6$
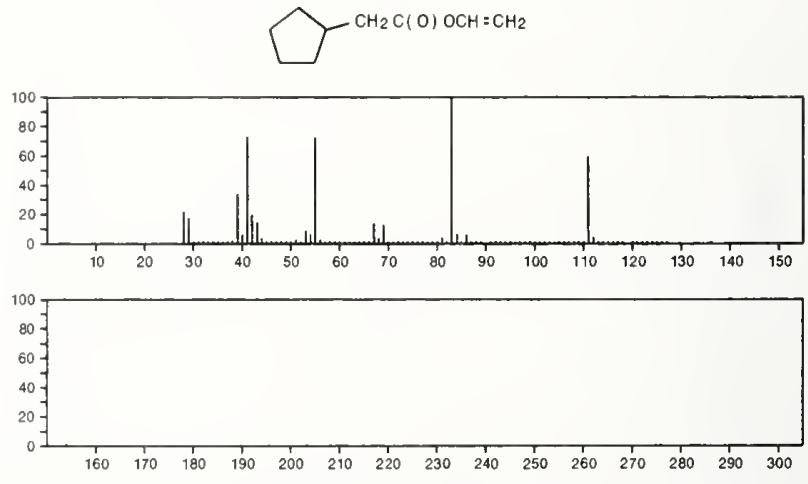

154

$\mathrm{C}_{9} \mathrm{H}_{14} \mathrm{O}_{2}$

50786-09-9

1-Oxaspiro[2.5] octan-4-one, 2,2-dimethyl-
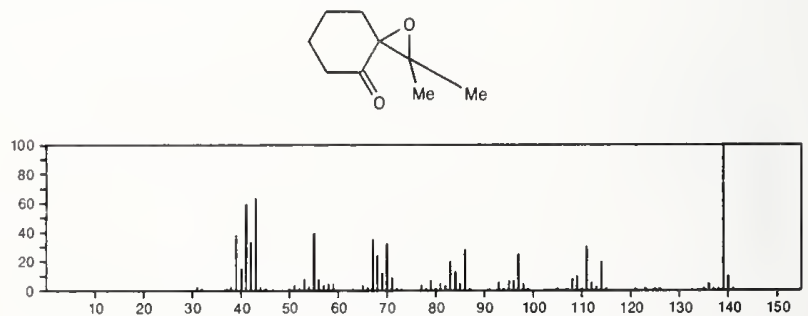


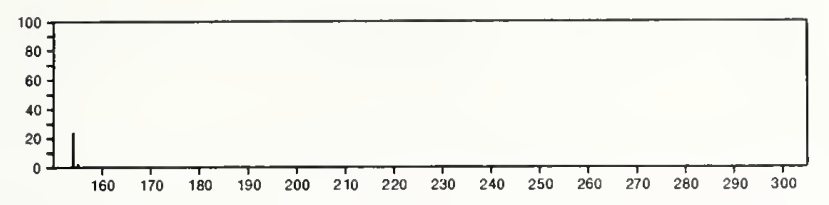

154 1,3-Cyclopentanedione, 4-butyl-
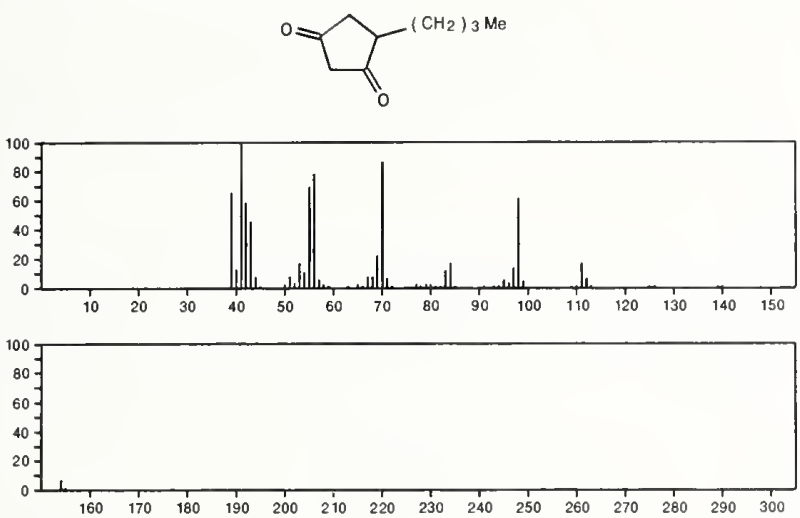

154

1,3-Benzodioxole, 2 ethenylhexahydro-
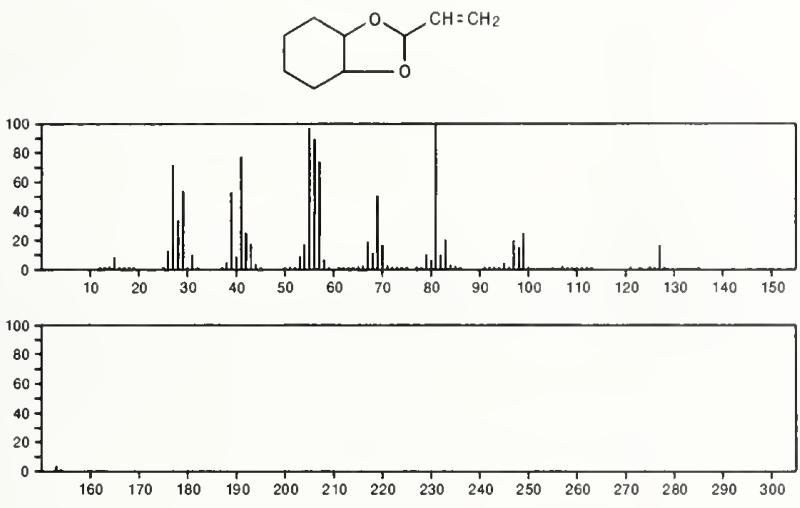

$154 \quad \mathrm{C}_{9} \mathrm{H}_{14} \mathrm{O}_{2} \quad 55956-38-2$

5 H-Cyclohepta-1,4-dioxin, 2,3,6,7,8,9-hexahydro-
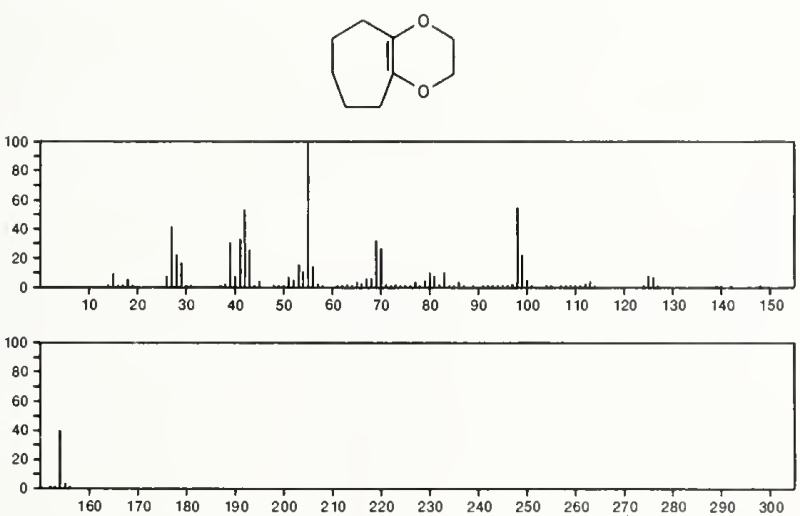

154

$\mathrm{C}_{9} \mathrm{H}_{14} \mathrm{O}_{2}$

$55956-39-3$

5H-Cyclohepta-1,4-dioxin, 2,3,4a,6,7,9a-hexahydro-, cis-
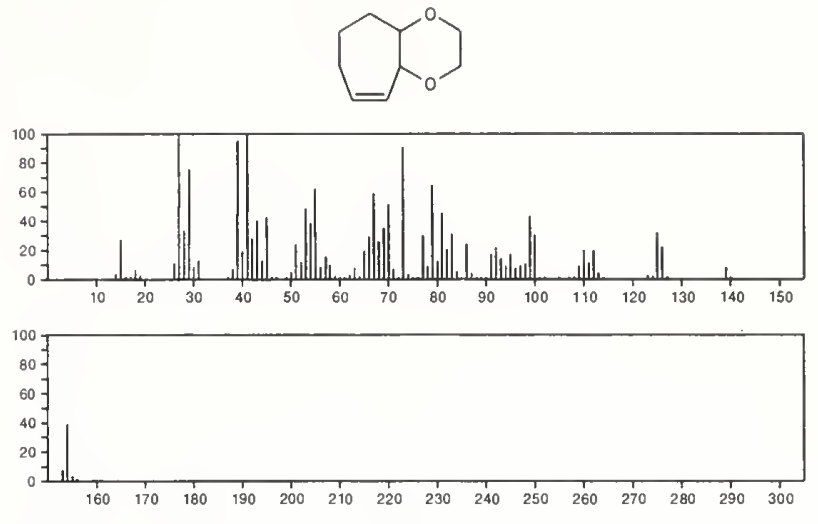

154

$\mathrm{C}_{9} \mathrm{H}_{14} \mathrm{O}_{2}$

5-Hexen-2-one, 3-ethylidene-1-methoxy-

$55956-40-6$

$\mathrm{MeOCH} 2 \mathrm{COCCH}_{2} \mathrm{CH}=\mathrm{CH}_{2}$
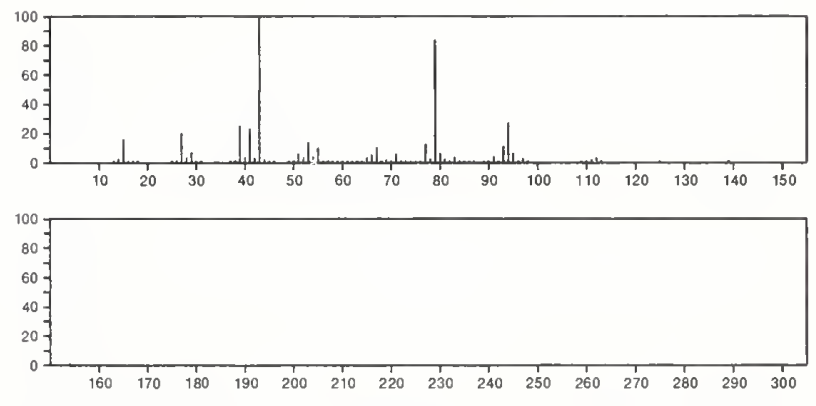

154 $\mathrm{C}_{9} \mathrm{H}_{14} \mathrm{O}_{2}$

55975-33-2

5H-Cyclohepta-1,4-dioxin, 2,3,4a,6,7,9a-hexahydro-, trans-
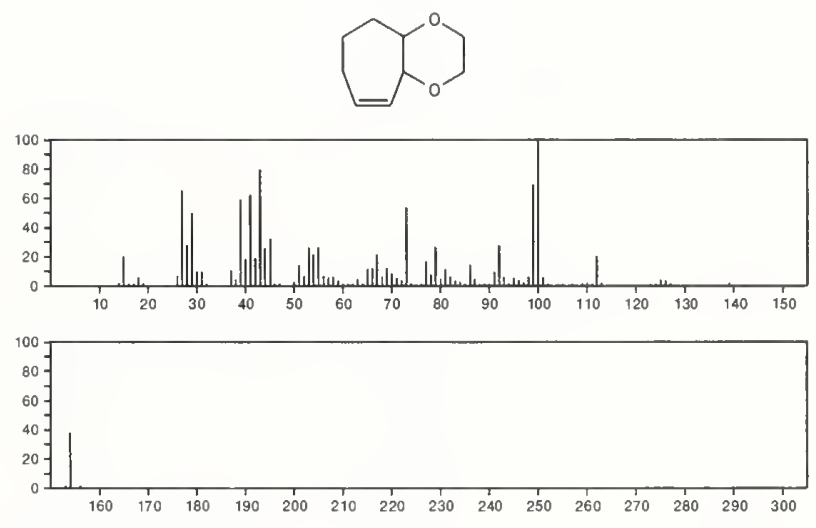

154

6-Nonynoic acid

$\mathrm{C}_{9} \mathrm{H}_{14} \mathrm{O}_{2}$

56630-31-0
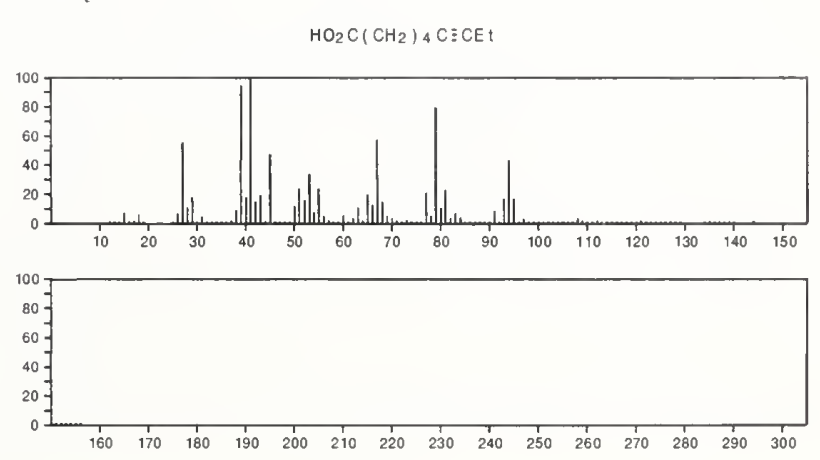
154

$\mathrm{C}_{9} \mathrm{H}_{14} \mathrm{O}_{2}$

$56630-32-1$

$\mathrm{HO}_{2} \mathrm{C}\left(\mathrm{CH}_{2}\right){ }_{5} \mathrm{C} \equiv \mathrm{CMe}$
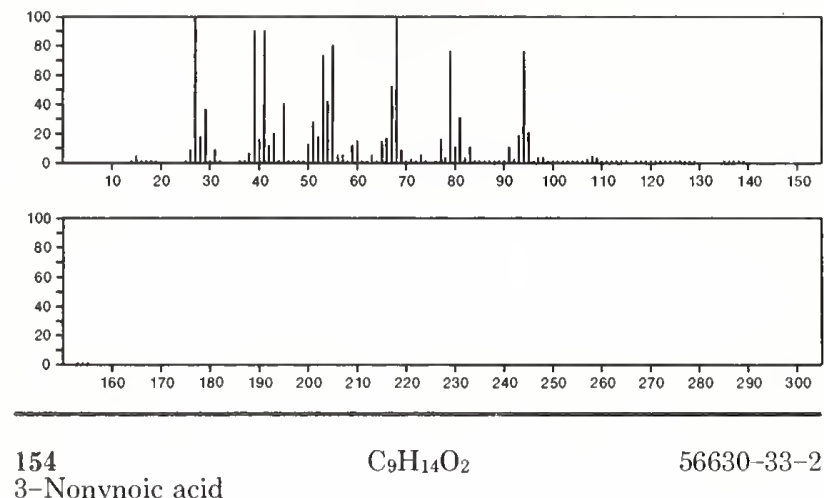

3-Nonynoic acid

$\mathrm{HO}_{2} \mathrm{CCH}_{2} \mathrm{C} \equiv \mathrm{C}\left(\mathrm{CH}_{2}\right)_{4} \mathrm{Me}$
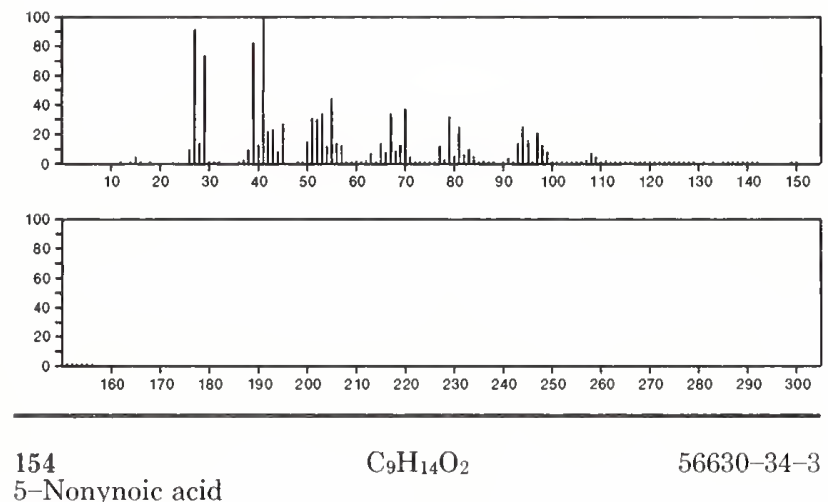

5-Nonynoic acid

$\mathrm{HO}_{2} \mathrm{C}\left(\mathrm{CH}_{2}\right)_{3} \mathrm{C} \equiv \mathrm{CPr}$
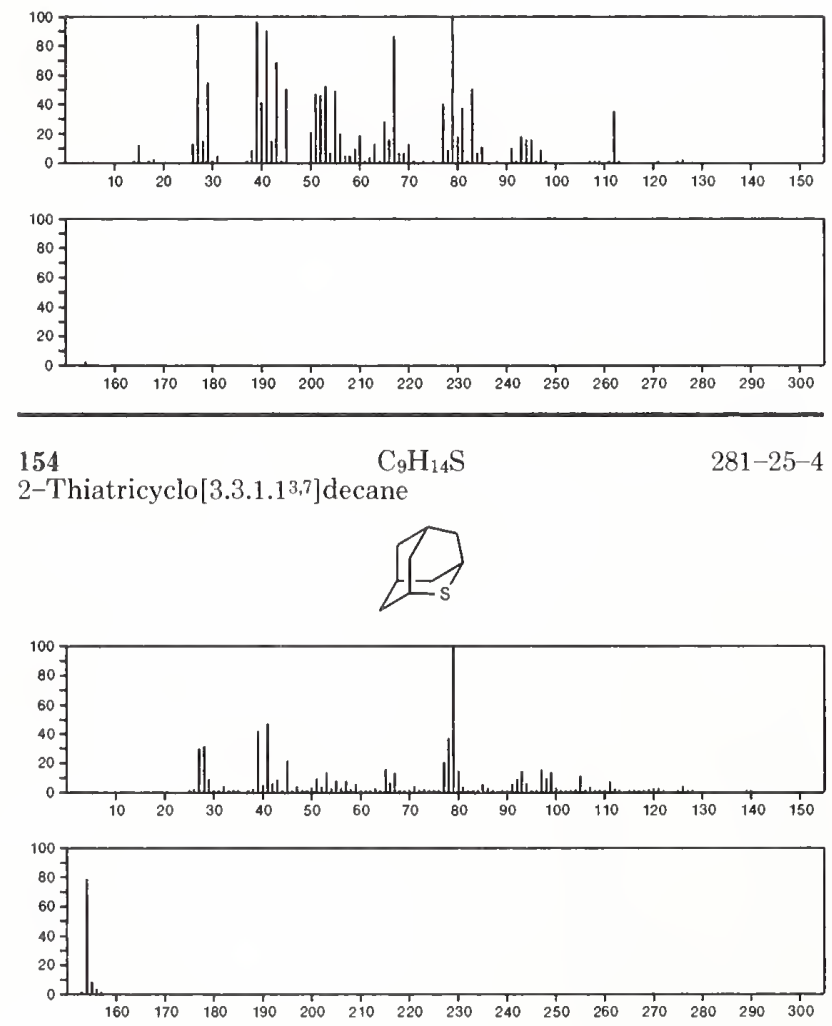

154

$\mathrm{C}_{9} \mathrm{H}_{14} \mathrm{~S}$

$30221-54-6$

2-Cyclopentene-1-thione, 2,3,4,4-tetramethyl-
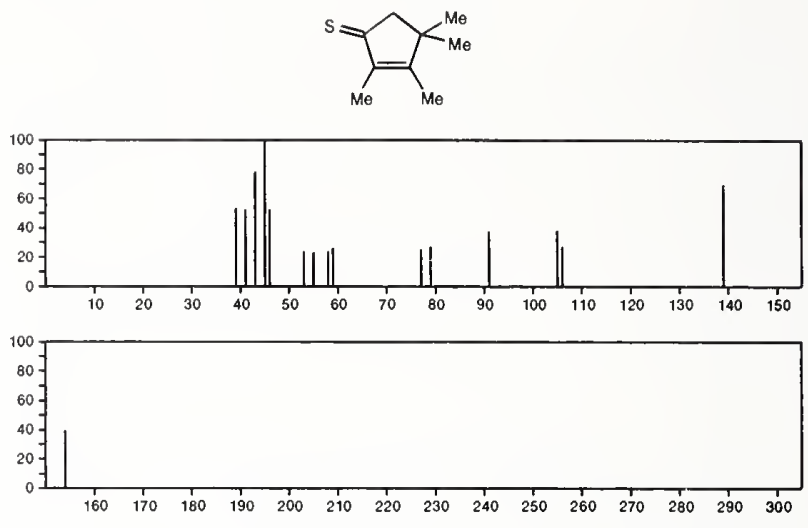

154

$\mathrm{C}_{9} \mathrm{H}_{14} \mathrm{~S}$

$30221-55-7$

2-Cyclohexene-1-thione, 3,5,5-trimethyl-
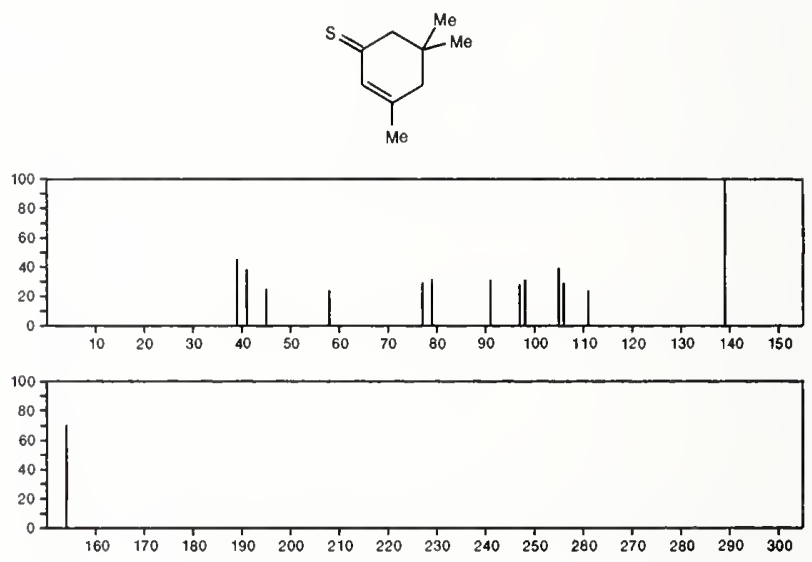

154

$\mathrm{C}_{9} \mathrm{H}_{14} \mathrm{~S}$

$33312-98-0$

Bicyclo[2.2.1] heptane-2-thione, 3,3-dimethyl-
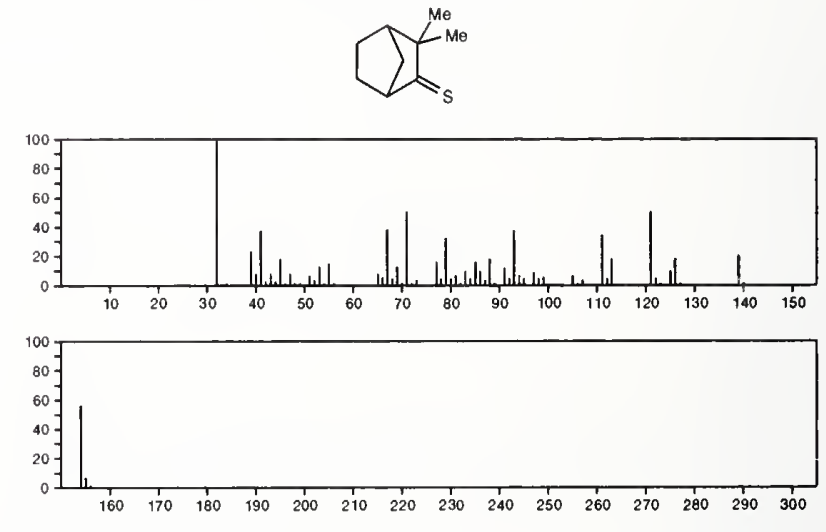

154

$\mathrm{C}_{9} \mathrm{H}_{14} \mathrm{~S}$

38693-71-9

2-Cyclohexene-1-thione, 3,6,6-trimethyl-
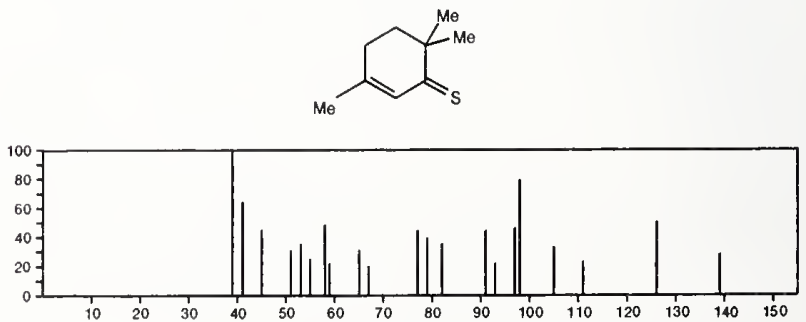


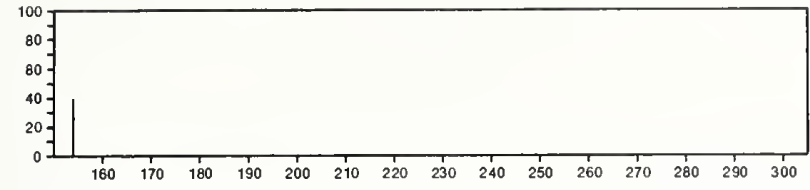

154

Pyrrolidine, 1,1'-methylenebis-

$\mathrm{C}_{9} \mathrm{H}_{18} \mathrm{~N}_{2}$

$7309-47-9$
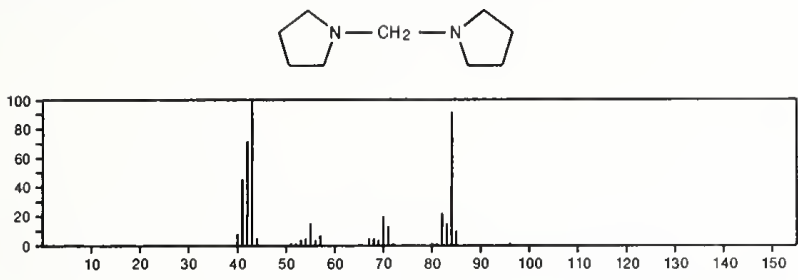

154

$\mathrm{C}_{9} \mathrm{H}_{18} \mathrm{~N}_{2}$

Azetidine, 1,1'-methylenebis[2-methyl-

$38455-30-0$
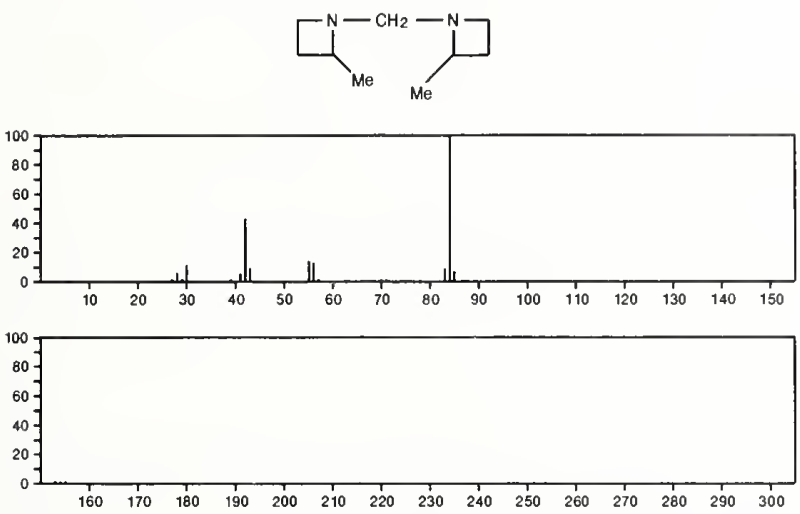

\section{4}

Silane, 1-hexynyltrimethyl-

$\mathrm{C}_{9} \mathrm{H}_{88} \mathrm{Si}$

$3844-94-8$

$\mathrm{Me}_{3} \mathrm{Si} \mathrm{C} \equiv \mathrm{C}\left(\mathrm{CH}_{2}\right)_{3} \mathrm{Me}$
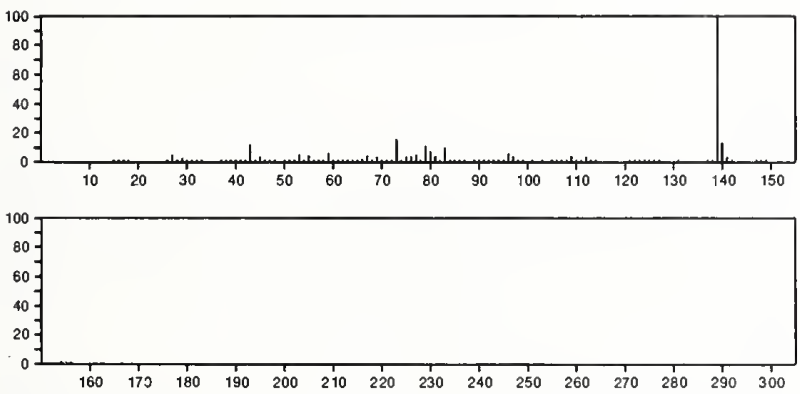

154

$\mathrm{C}_{9} \mathrm{H}_{18} \mathrm{Si}$

Silane, 1-cyclohexen-1-yltrimethyl-
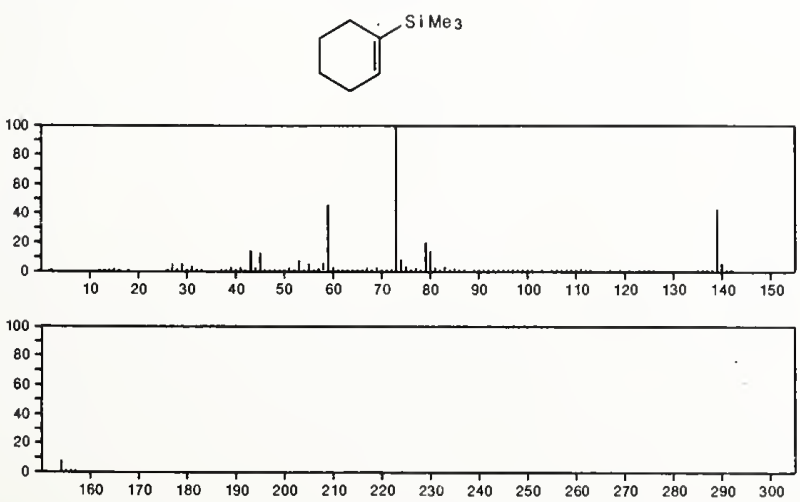

154 $\mathrm{C}_{9} \mathrm{H}_{18} \mathrm{Si}$

Silane, 2-cyclohexen-1-yltrimethyl-
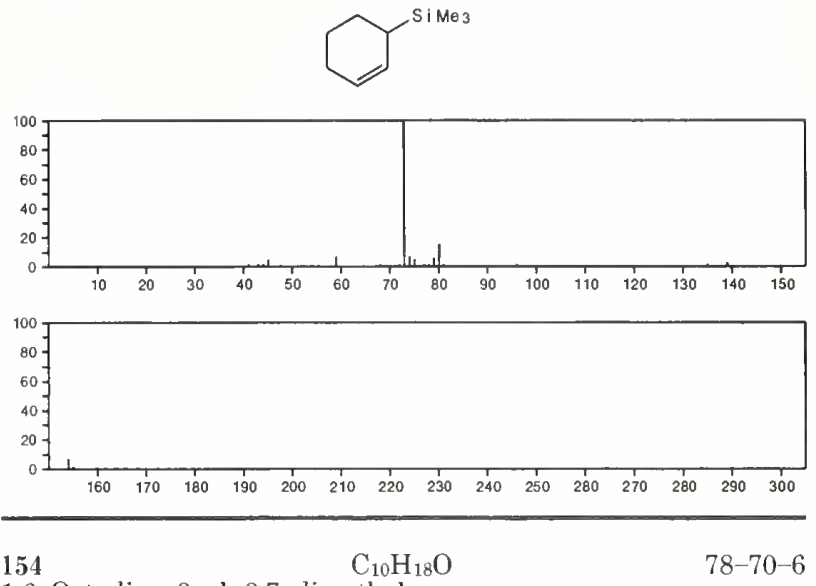

1,6-Octadien-3-ol, 3,7-dimethyl-

$\mathrm{H}_{2} \mathrm{C}=\mathrm{CHCMe}(\mathrm{OH}) \mathrm{CH}_{2} \mathrm{CH}_{2} \mathrm{CH}=\mathrm{CMe} 2$

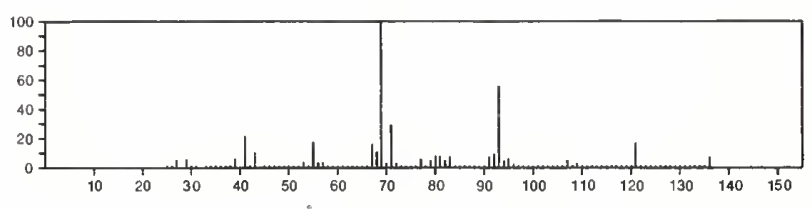

154

$\mathrm{C}_{10} \mathrm{H}_{18} \mathrm{O}$

89-79-2

Cyclohexanol, 5-methyl-2-(1-methylethenyl)-, $[1 R-(1 \alpha, 2 \beta, 5 \alpha)]-$<smiles>COC1CCC(C)CC1O</smiles>
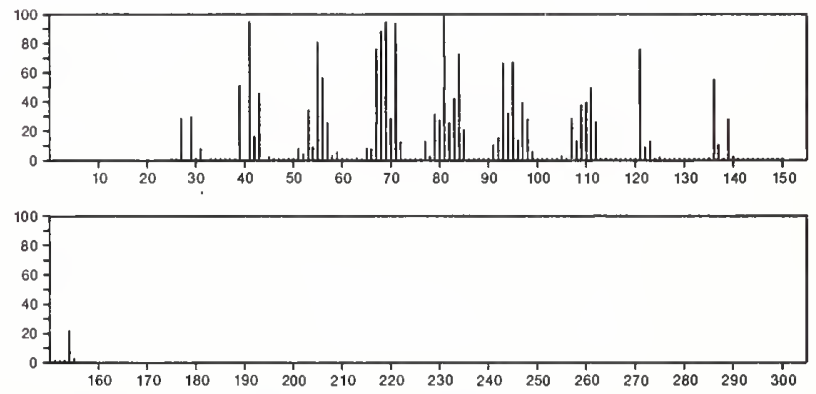

154

$\mathrm{C}_{10} \mathrm{H}_{18} \mathrm{O}$

$89-80-5$

Cyclohexanone, 5-methyl-2-(1-methylethyl)-, trans-<smiles>CC1CCC(Br)C(=O)C1</smiles>
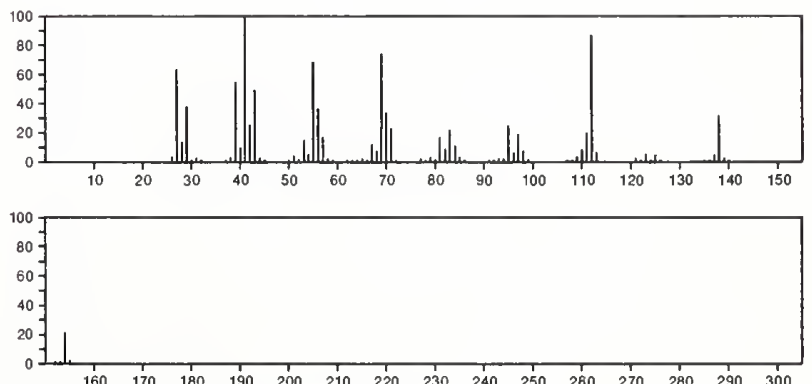
154

Cyclohexanone, 4-(1,1-dimethylethyl)-
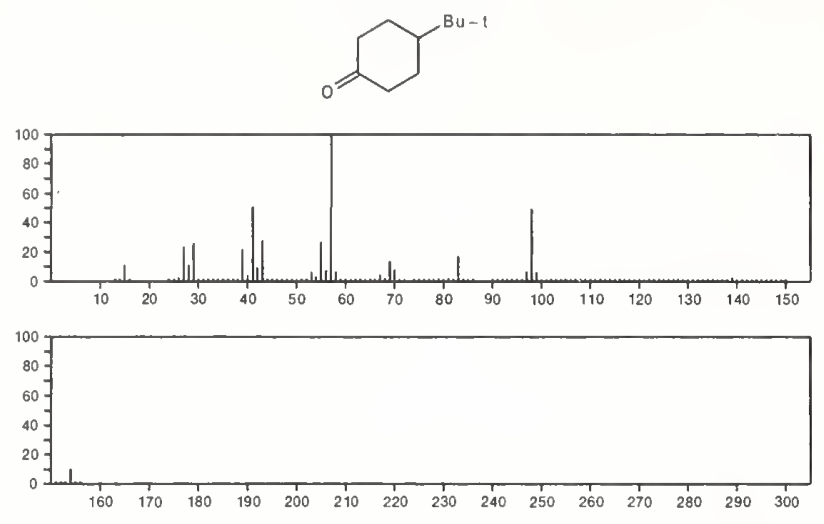

154

$\mathrm{C}_{10} \mathrm{H}_{18} \mathrm{O}$

98-55-5

3-Cyclohexene-1-methanol, $\alpha, \alpha, 4$-trimethyl-
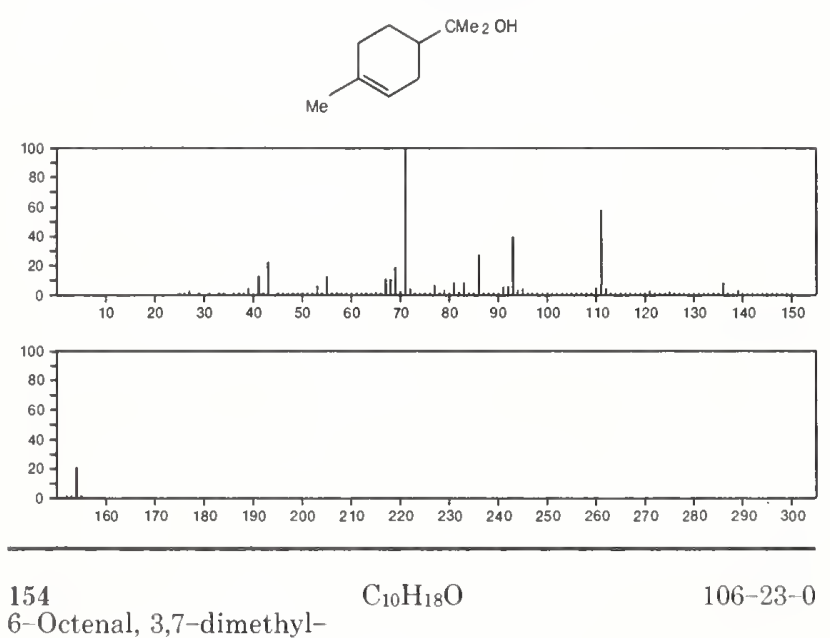

6-Octenal, 3,7-dimethyl-

$\mathrm{OCHCH}_{2} \mathrm{CHMe} \mathrm{CH}_{2} \mathrm{CH}_{2} \mathrm{CH}=\mathrm{CMe}_{2}$
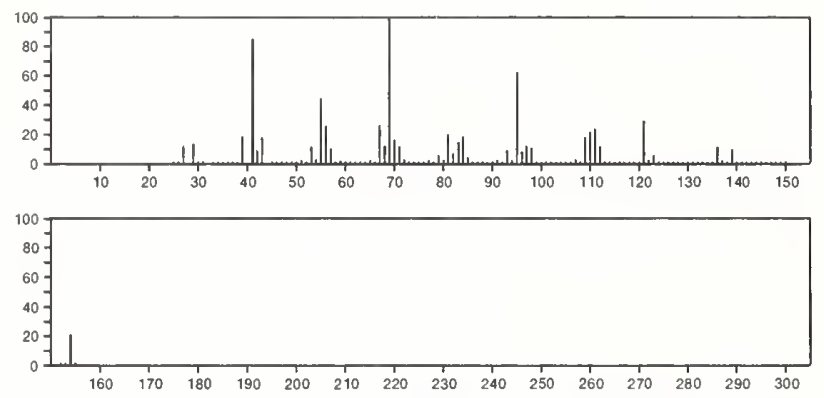

154

2,6-Octadien-1-ol, 3,7-dimethyl-,

$\mathrm{Me}_{2} \mathrm{C}=\mathrm{CHCH}_{2} \mathrm{CH}_{2} \mathrm{CMe}=\mathrm{CHCH}_{2} \mathrm{OH}$
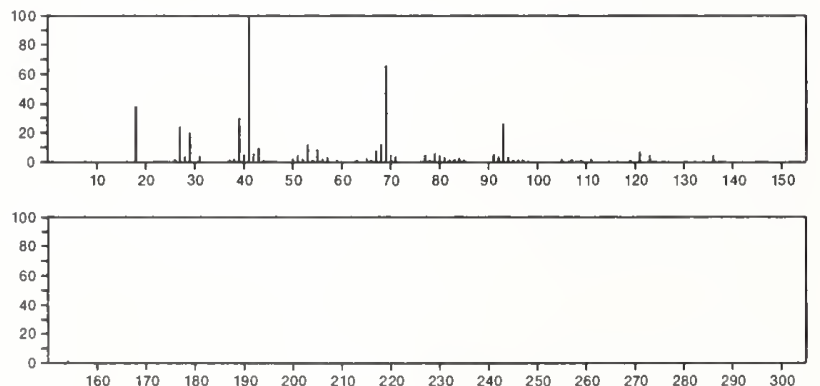

154

2,6-Octadien-1-ol, 3,7-dimethyl-, (Z)-

$106-25-2$

$\mathrm{Me}_{2} \mathrm{C}=\mathrm{CHCH}_{2} \mathrm{CH}_{2} \mathrm{CMe}_{2}=\mathrm{CHCH}_{2} \mathrm{OH}$
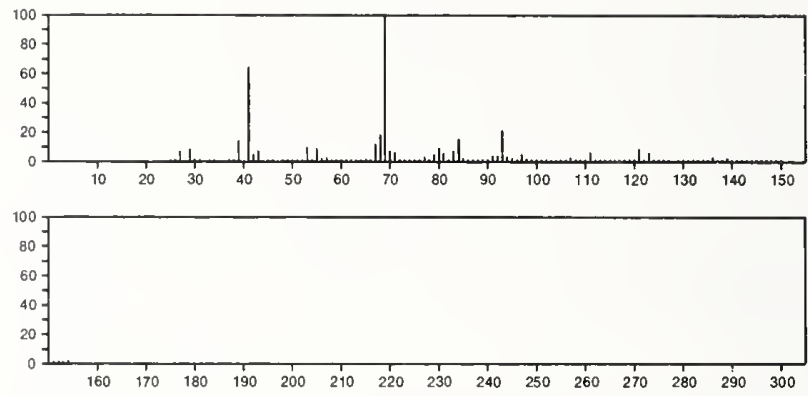

154

$\mathrm{C}_{10} \mathrm{H}_{18} \mathrm{O}$

$124-76-5$

Bicyclo[2.2.1\}heptan-2-ol, 1,7,7-trimethyl-, exo-
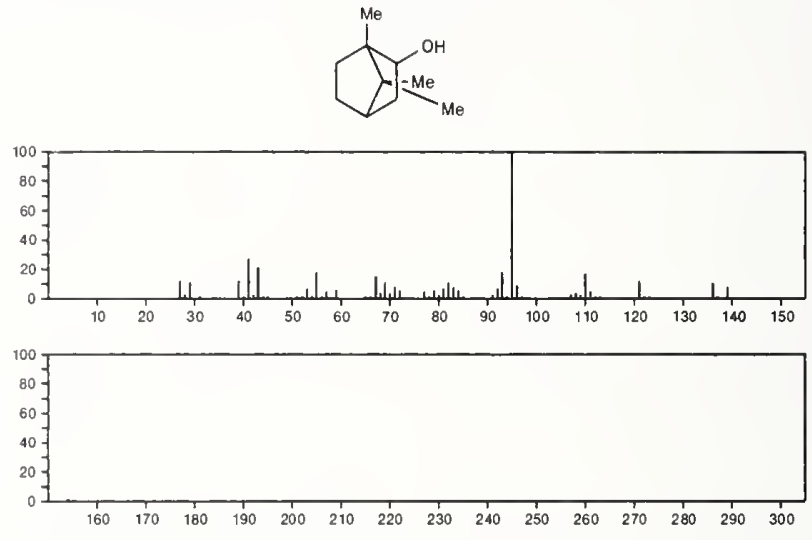

$154 \quad \mathrm{C}_{10} \mathrm{H}_{18} \mathrm{O}$

$138-87-4$

Cyclohexanol, 1-methyl-4-(1-methylethenyl)-
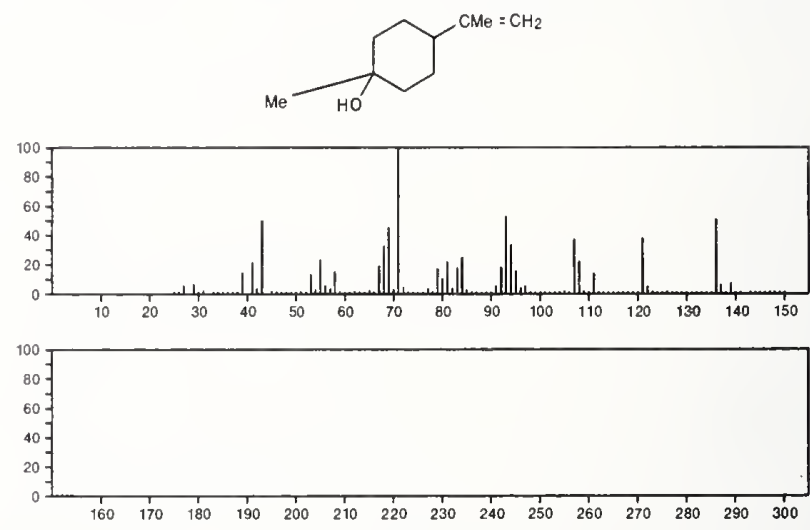

154

$\mathrm{C}_{10} \mathrm{H}_{18} \mathrm{O}$

$464-45-9$

Bicyclo[2.2.1] heptan-2-ol, 1,7,7-trimethyl-, (1S-endo)-
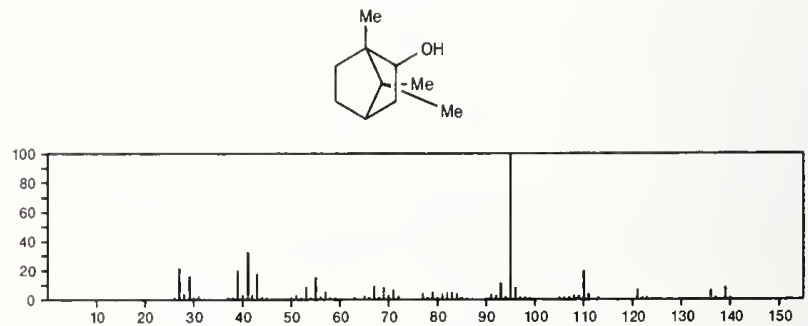


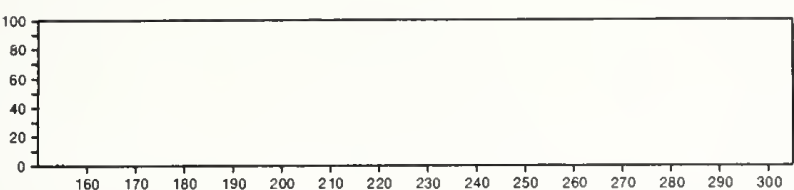

154

$\mathrm{C}_{10} \mathrm{H}_{18} \mathrm{O}$

$470-67-7$

7-Oxabicyclo[2.2.1]heptane, 1-methyl-4-(1-methylethyl)-
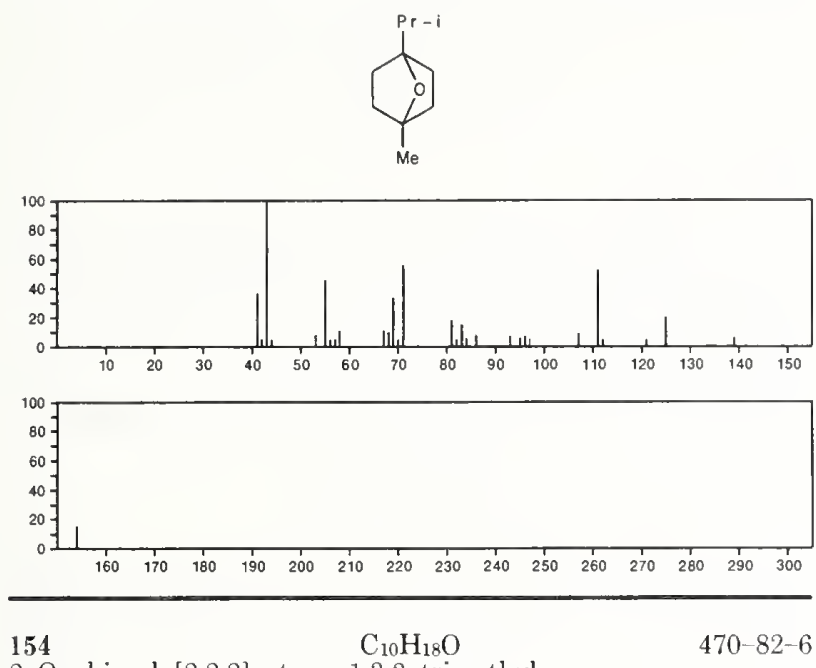

2-Oxabicyclo[2.2.2] octane, 1,3,3-trimethyl-
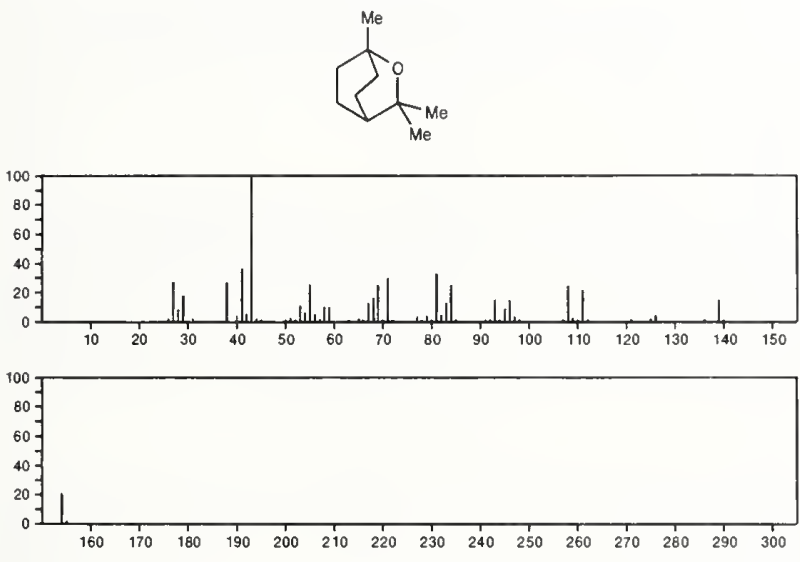

$154 \quad \mathrm{C}_{10} \mathrm{H}_{18} \mathrm{O} \quad 491-07-6$

Cyclohexanone, 5-methyl-2-(1-methylethyl)-, cis-
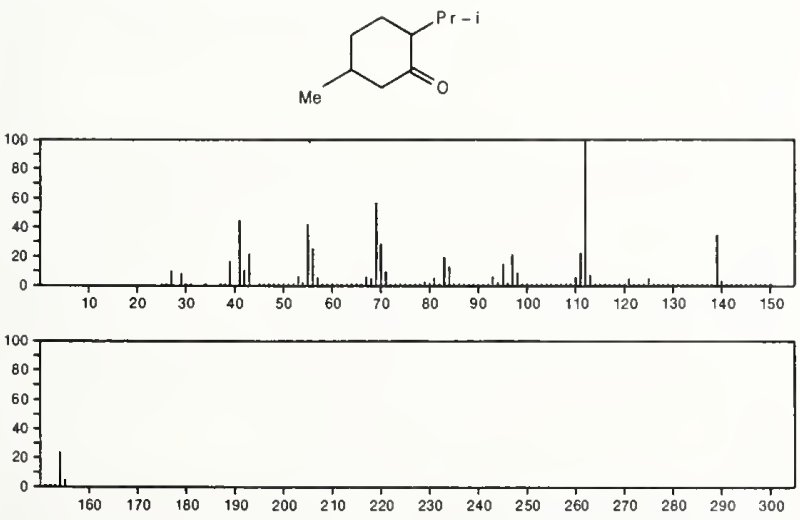

154

4-Hexen-1-ol, 5-methyl-2-(1-methylethenyl)-, $(R)-$

$498-16-8$ $\mathrm{CH}_{2} \mathrm{OH}$

$\mathrm{Me}_{2} \mathrm{C}: \mathrm{CHCH}_{2} \mathrm{CHCMe}=\mathrm{CH}_{2}$

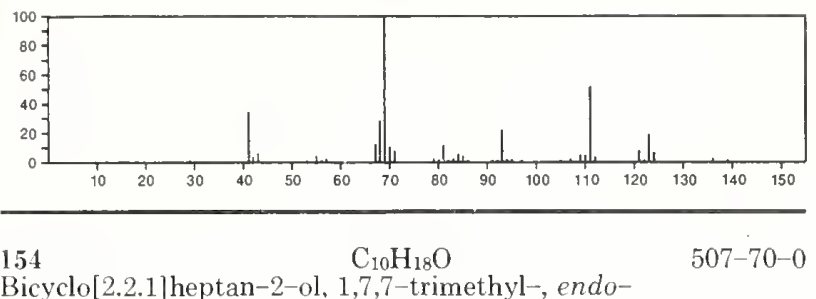

154
Bicyclo[2.2.1]heptan-2-ol,
$\mathrm{C}_{10} \mathrm{H}_{18} \mathrm{O}$
1,7-trimethyl-, endo-
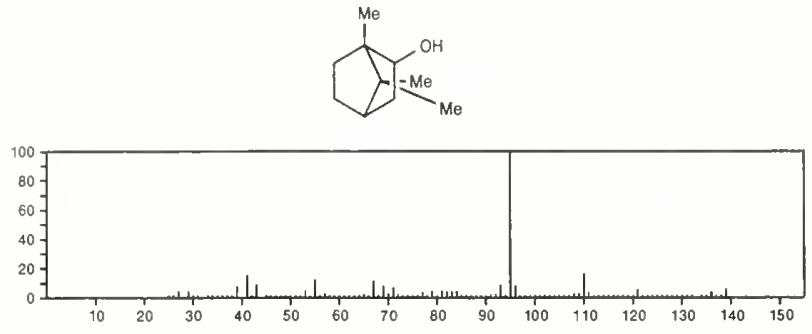

154

$\mathrm{C}_{10} \mathrm{H}_{18} \mathrm{O}$

$513-23-5$

Bicyclo[3.1.0]hexan-3-ol, 4-methyl-1-(1-methylethyl)-<smiles>CC1C2CC3(Br)CC1C3C2O</smiles>

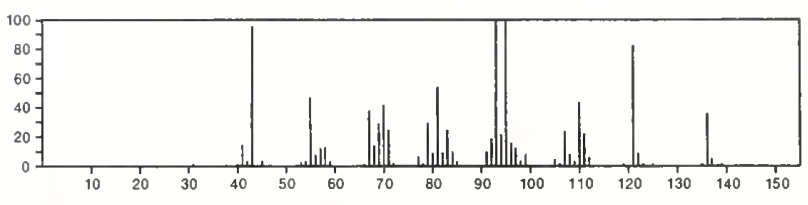

154

$\mathrm{C}_{10} \mathrm{H}_{18} \mathrm{O}$

536-30-1

2-Cyclohexen-1-ol, 2-methyl-5-(1-methylethyl)-, (1S-cis)-<smiles>CC1=CCC(PI)CC1O</smiles>
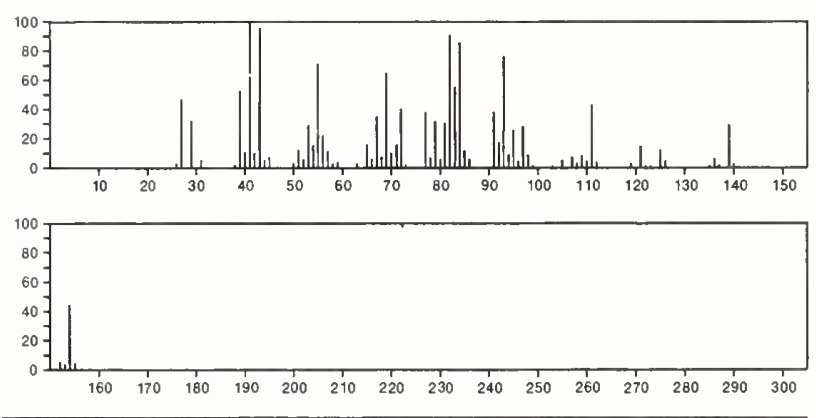

154

$\mathrm{C}_{10} \mathrm{H}_{18} \mathrm{O}$

7-Octen-2-ol, 2-methyl-6-methylene-

543-39-5

$\mathrm{Me}_{2} \mathrm{COH}\left(\mathrm{CH}_{2}\right)_{3} \mathrm{CCH}=\mathrm{CH}_{2}$

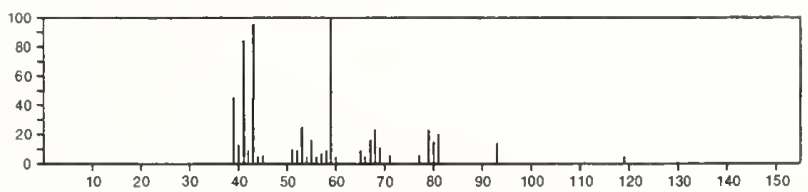


<smiles>CC12CCC(C1)C(C)(O)CC2</smiles>

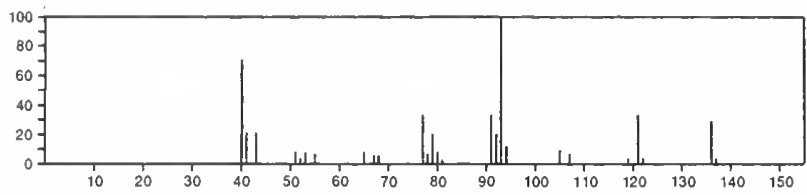

154

$\mathrm{C}_{10} \mathrm{H}_{18} \mathrm{O}$

3-Cyclohexen-1-ol, 4-methyl-1-(1-methylethyl)-

$562-74-3$
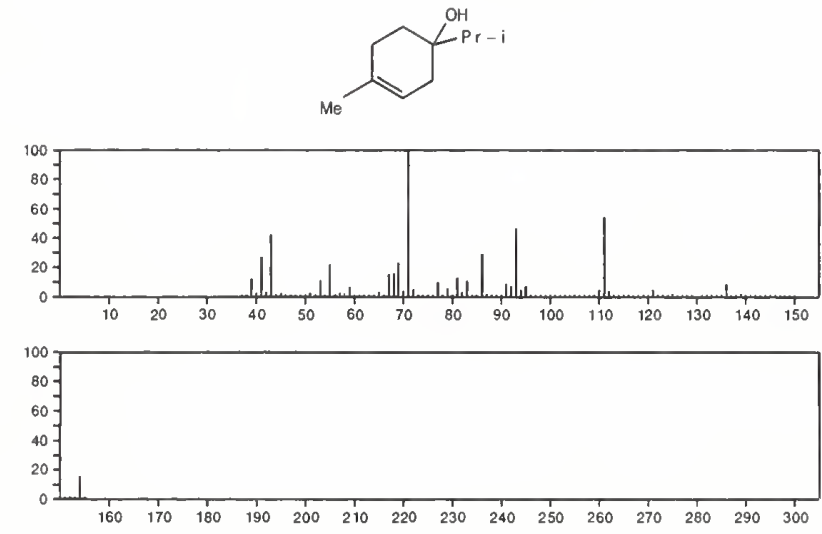

154

$\mathrm{C}_{10} \mathrm{H}_{18} \mathrm{O}$

2,6-Octadien-1-ol, 3,7-dimethyl-

$\mathrm{Me}_{2} \mathrm{C}: \mathrm{CHCH}_{2} \mathrm{CH}_{2} \mathrm{CMe}: \mathrm{CHCH}_{2} \mathrm{OH}$
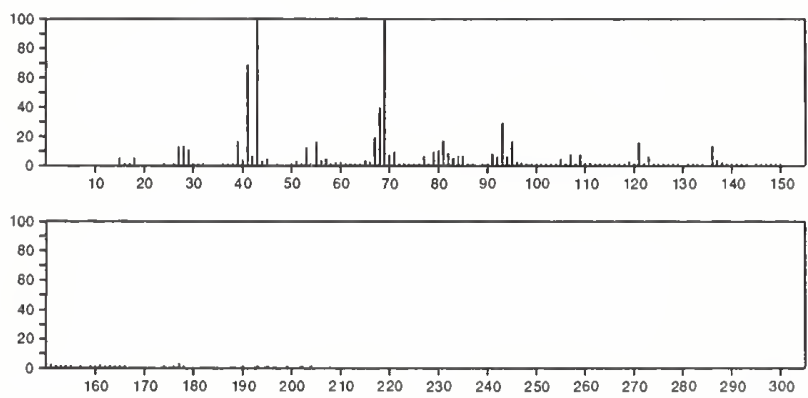

$\begin{array}{lllllllllllllll}160 & 170 & 180 & 190 & 200 & 210 & 220 & 230 & 240 & 250 & 260 & 270 & 280 & 290 & 300\end{array}$

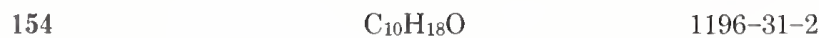

Cyclohexanone, 5-methyl-2-(1-methylethyl)-, (2R-cis)-<smiles>CC1CCC(Br)C(=O)C1</smiles>
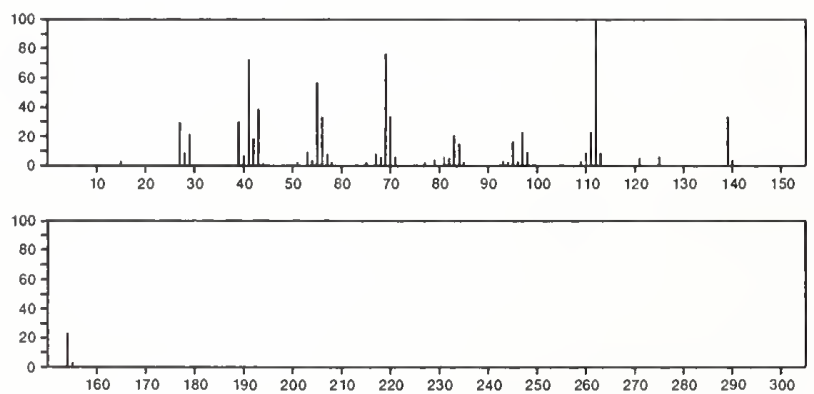

154

Cyclodecanone

$\mathrm{C}_{10} \mathrm{H}_{18} \mathrm{O}$

$1502-06-3$
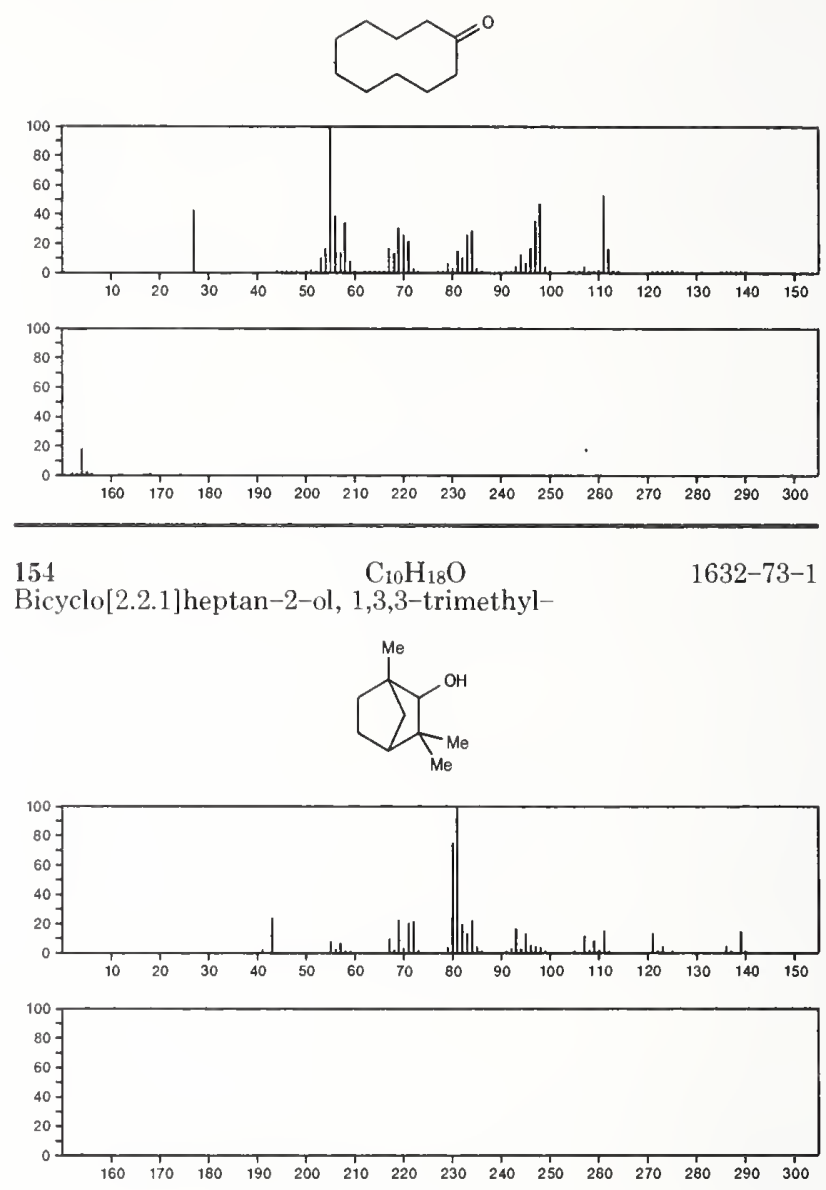

154

2-Butanone, 4-cyclohexyl-

$\mathrm{C}_{10} \mathrm{H}_{18} \mathrm{O}$

$2316-85-0$
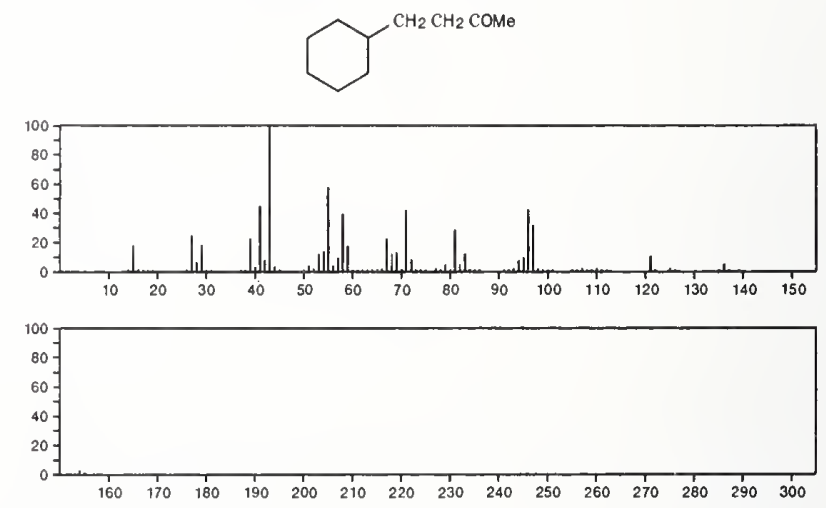

154

2-Nonen-4-one, 2-methyl

\section{$\mathrm{C}_{10} \mathrm{H}_{18} \mathrm{O}$}

2903-23-3

$\mathrm{Me}\left(\mathrm{CH}_{2}\right)_{4} \mathrm{COCH}=\mathrm{CMe}$

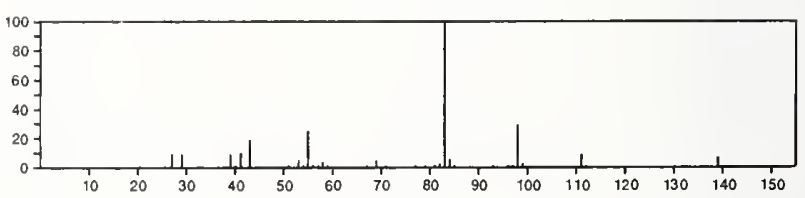




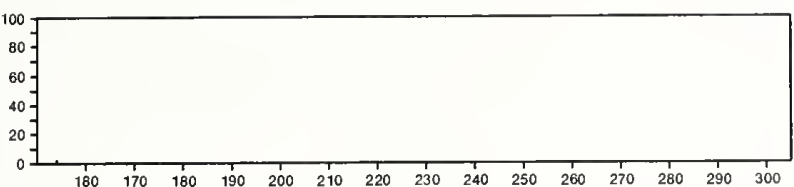

154

$\mathrm{C}_{10} \mathrm{H}_{18} \mathrm{O}$

4028-58-4

Cyclopentanol, 1,2-dimethyl-3-(1-methylethenyl)-, $[1 R-(1 \alpha, 2 \beta, 3 \beta)]-$
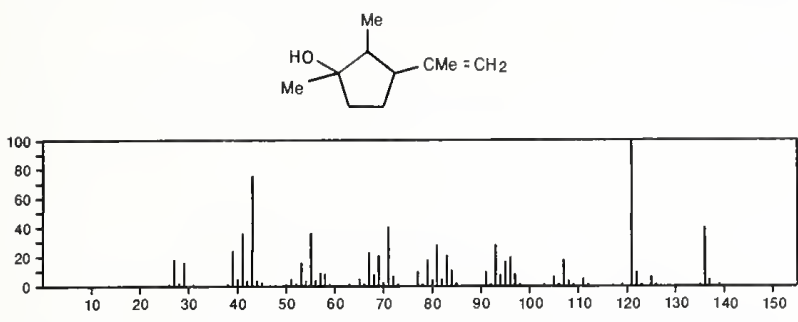

$154 \quad \mathrm{C}_{10} \mathrm{H}_{18} \mathrm{O} \quad 4028-59-5$ Cyclopentanol, 1,2-dimethyl-3-(1-methylethenyl)-, [1R-(1 $2,2 \alpha, 3 \beta)]$
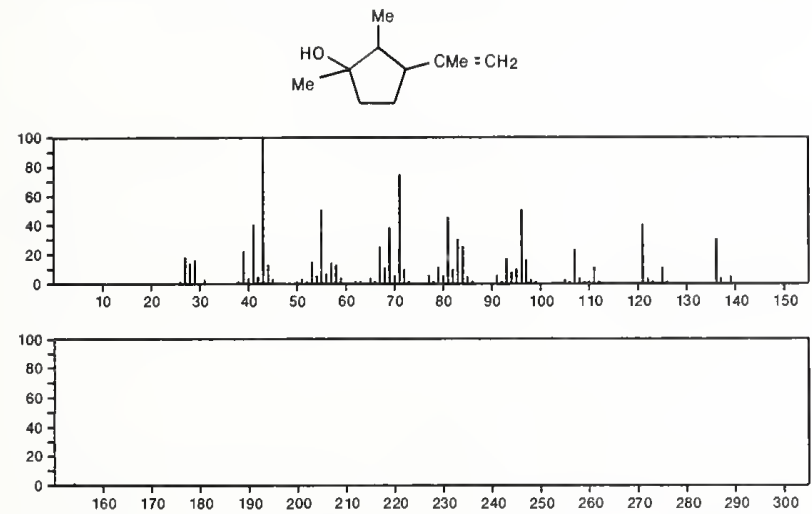

$\mathbf{1 5 4} \mathrm{C}_{10} \mathrm{H}_{18} \mathrm{O} \quad 4028-60-8$ Cyclopentanol, 1,2-dimethyl-3-(1-methylethenyl)-, [1R-(1 $1 \alpha, 2 \alpha, 3 \alpha)]-$
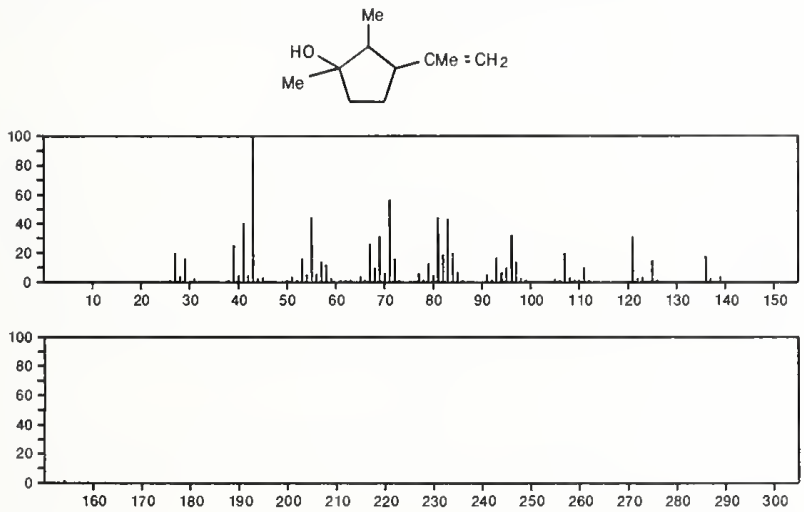

$\overline{154} \quad \mathrm{C}_{10} \mathrm{H}_{18} \mathrm{O} \quad 4099-07-4$

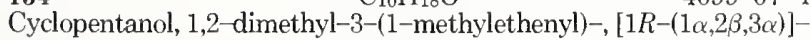
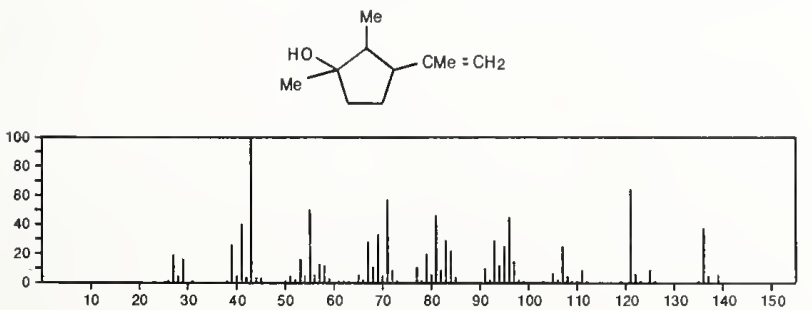

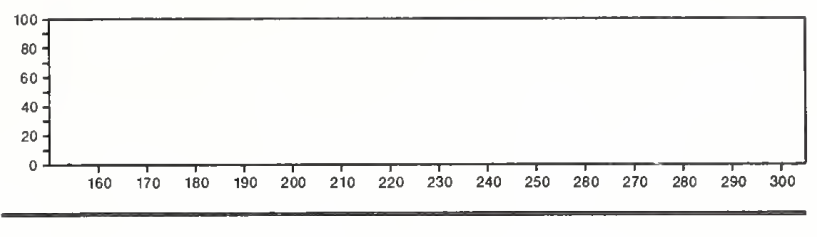

154

$\left[1,1^{\prime}-\right.$ Bicyclopentyl $]-2-o l$

$\mathrm{C}_{10} \mathrm{H}_{18} \mathrm{O}$

$4884-25-7$<smiles>OC1CCCC1C1CCCC1</smiles>
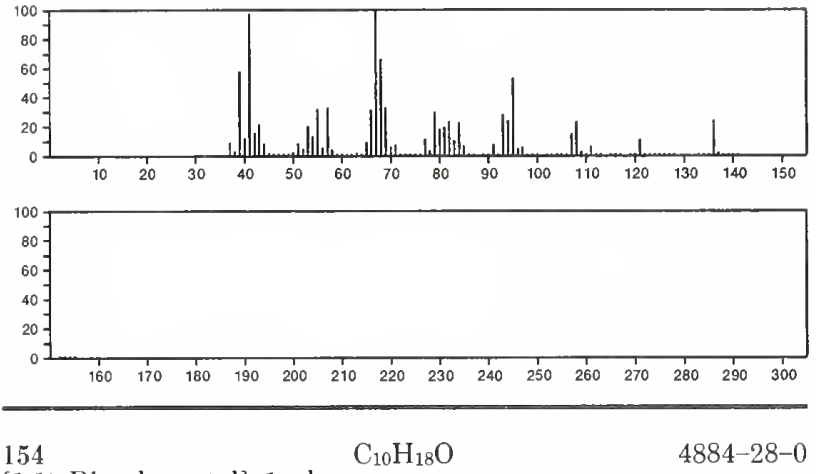

$4884-28-0$

[1,1'-Bicyclopentyl]-1-ol
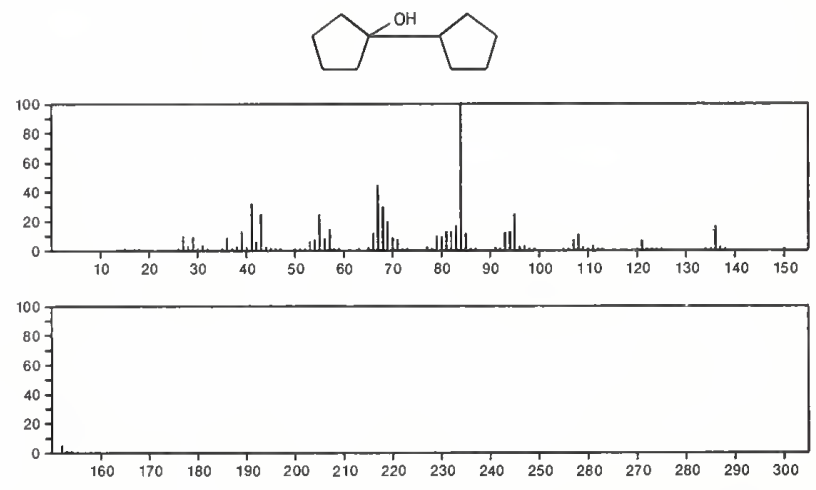

154

$\mathrm{C}_{10} \mathrm{H}_{18} \mathrm{O}$

5502-99-8

Cyclohexaneethanol, 4-methyl- $\beta$-methylene-
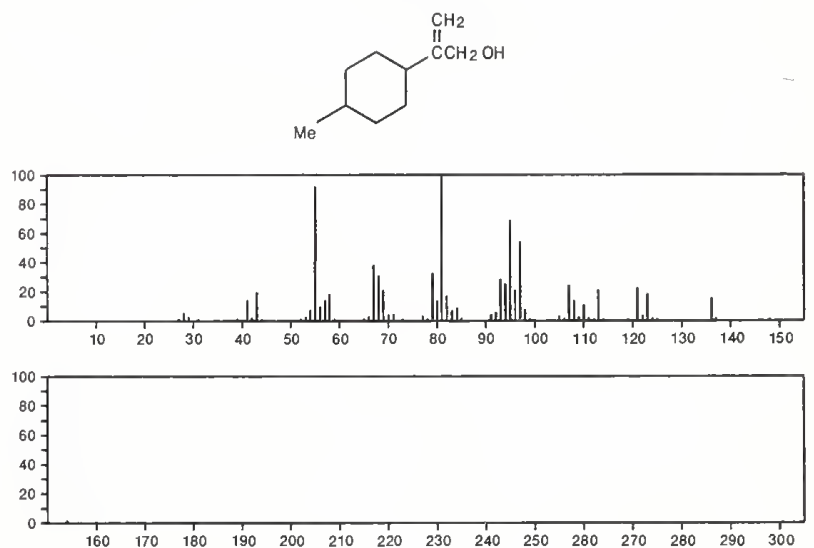
154

1-Octyn-3-ol, 4-ethyl-

$\mathrm{C}_{10} \mathrm{H}_{18} \mathrm{O}$

$\mathrm{HC} \equiv \mathrm{CCH}(\mathrm{OH}) \mathrm{CHE}+\left(\mathrm{CH}_{2}\right)_{3} \mathrm{Me}$

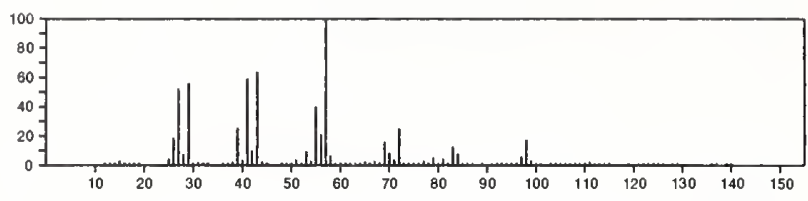

154

$\mathrm{C}_{10} \mathrm{H}_{18} \mathrm{O}$

$6555-95-9$

Bicyclo[2.2.2]octane, 1-methoxy-4-methyl-
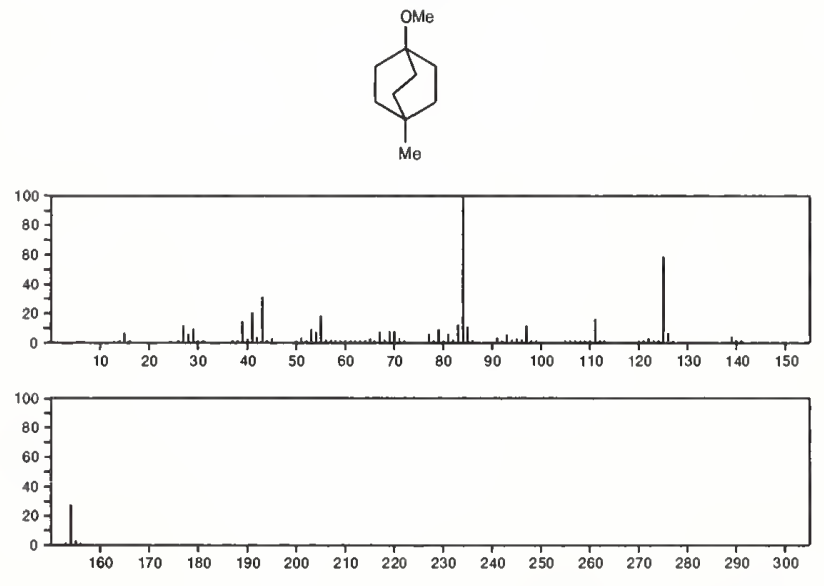

154

5-Nonen-4-one, 6-methyl-

$\mathrm{C}_{10} \mathrm{H}_{18} \mathrm{O}$

$7036-98-8$

$P_{r} \mathrm{COCH}=\mathrm{CP} P_{r} \mathrm{Me}$
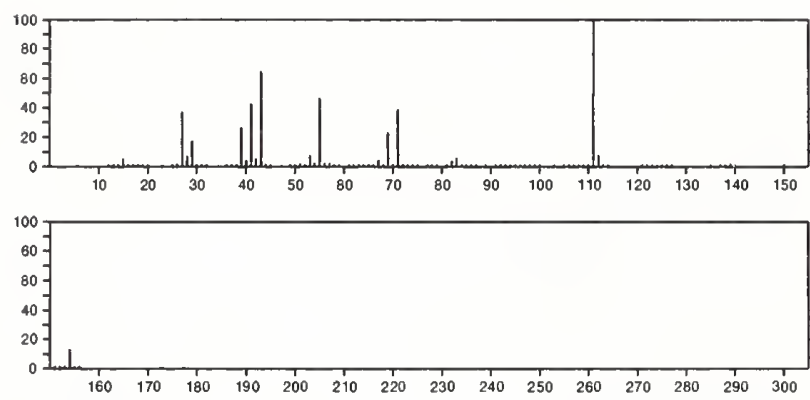

154

Cyclohexanone, 5-methyl-2-(1-methylethyl)-

$10458-14-7$<smiles>C[C@H]1CC[C@@H](Br)C(=O)C1</smiles>
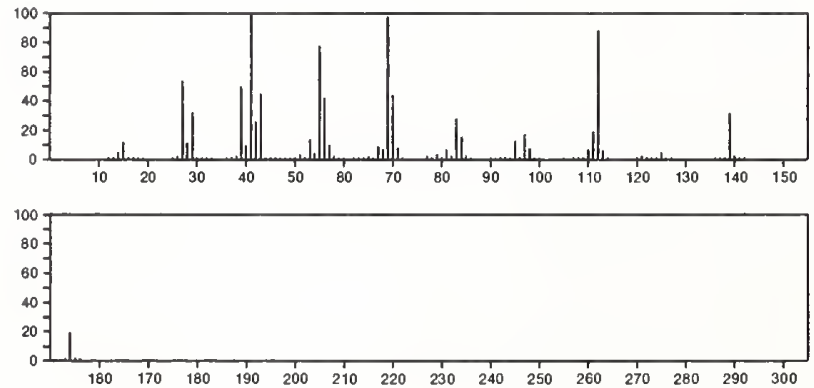

154 3-Cyclohexene-1-methanol, $\alpha, \alpha, 4$-trimethyl-, $(S)$ -

$10482-56-1$
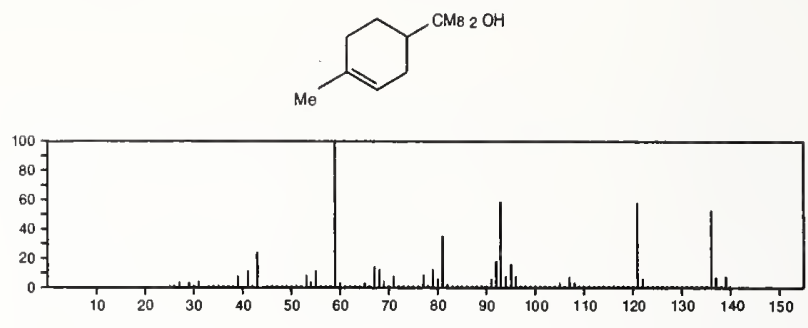

154

3-Decen-2-one

$\mathrm{C}_{10} \mathrm{H}_{18} \mathrm{O}$

$10519-33-2$

$\mathrm{Me} \mathrm{COCH}=\mathrm{CH}\left(\mathrm{CH}_{2}\right) 5 \mathrm{Me}$
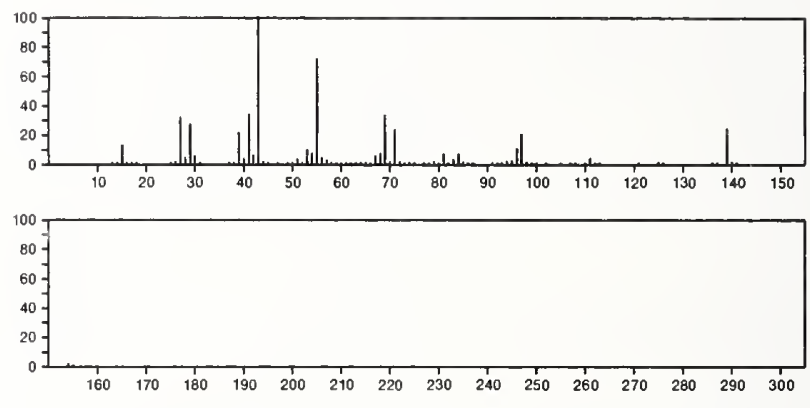

154

$\mathrm{C}_{10} \mathrm{H}_{18} \mathrm{O}$

$13835-30-8$

3-Cyclohexene-1-ethanol, $\beta, 4$-dimethyl-, $\left[R-\left(R^{*}, R^{*}\right)\right]-$
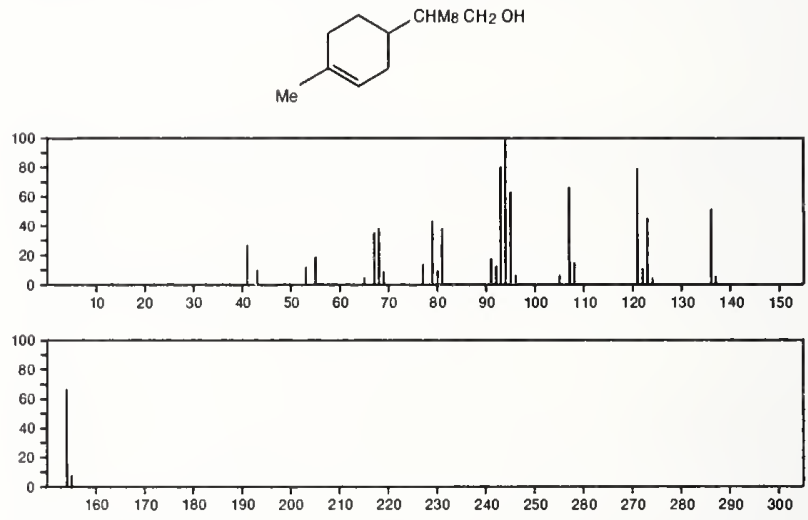

154

$\mathrm{C}_{10} \mathrm{H}_{18} \mathrm{O}$

$15404-56-5$

2-Oxabicyclo[2.2.1] heptane, 1,3,3,7-tetramethyl-, $(1 R, 4 S, 7 R)-(+)-$
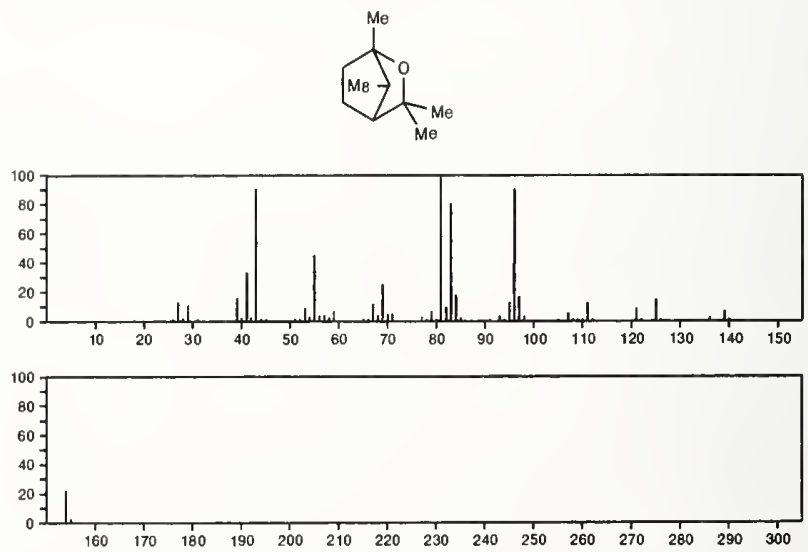
154

$\mathrm{C}_{10} \mathrm{H}_{18} \mathrm{O}$

$15404-57-6$

2-Oxabicyclo[2.2.1]heptane, 1,3,3,7-tetramethyl-, $(1 R, 4 S, 7 S)-(+)-$
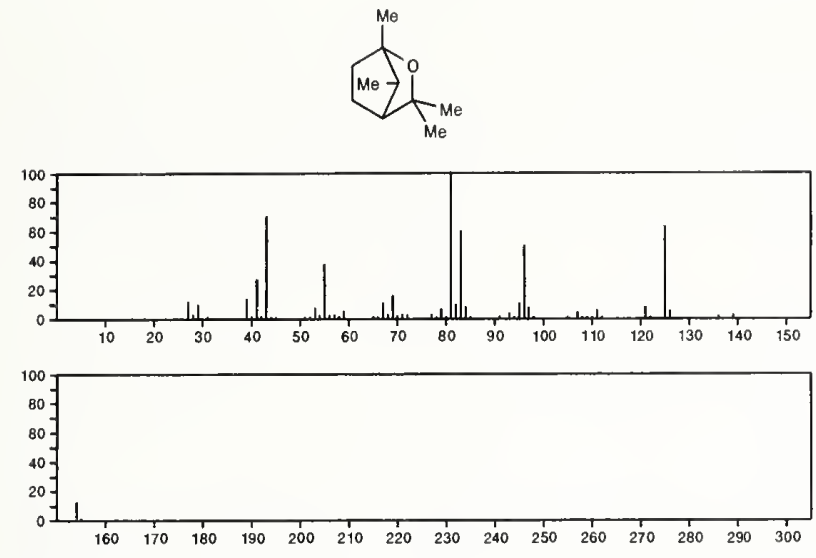

154 $\mathrm{C}_{10} \mathrm{H}_{18} \mathrm{O}$

$16409-43-1$

$2 H$-Pyran, tetrahydro-4-methyl-2-(2-methyl-1-propenyl)-
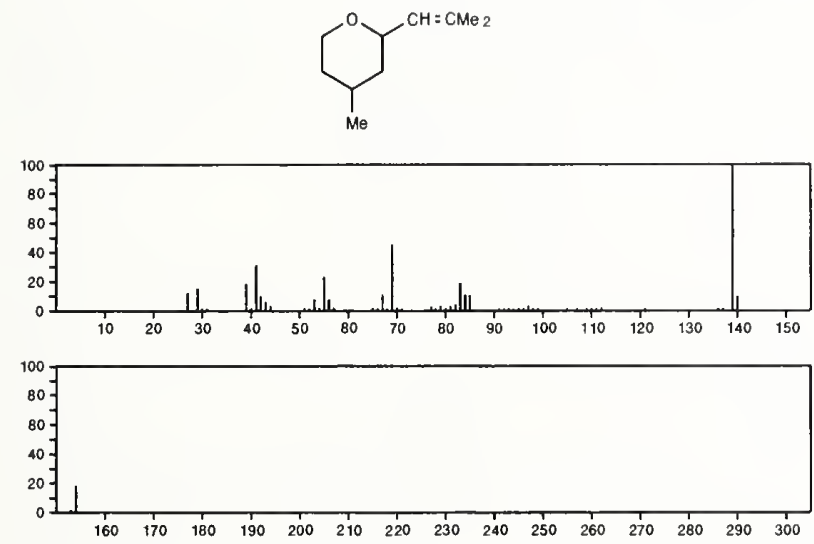

154

Cyclohexanone, 2,2-diethyl-

$\mathrm{C}_{10} \mathrm{H}_{18} \mathrm{O}$

$16519-67-8$
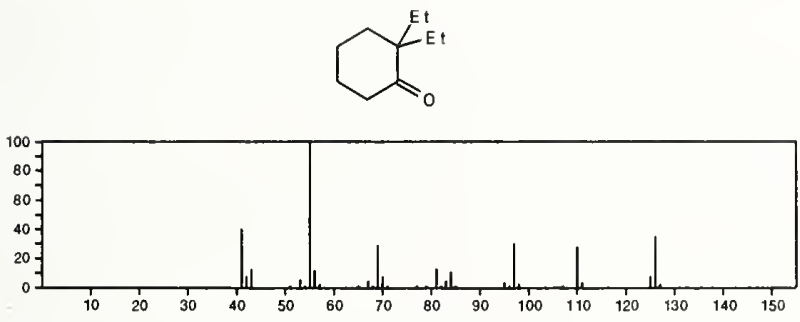

154

Cyclohexanone, 2,6-diethyl-

$\mathrm{C}_{10} \mathrm{H}_{18} \mathrm{O}$

16519-68-9
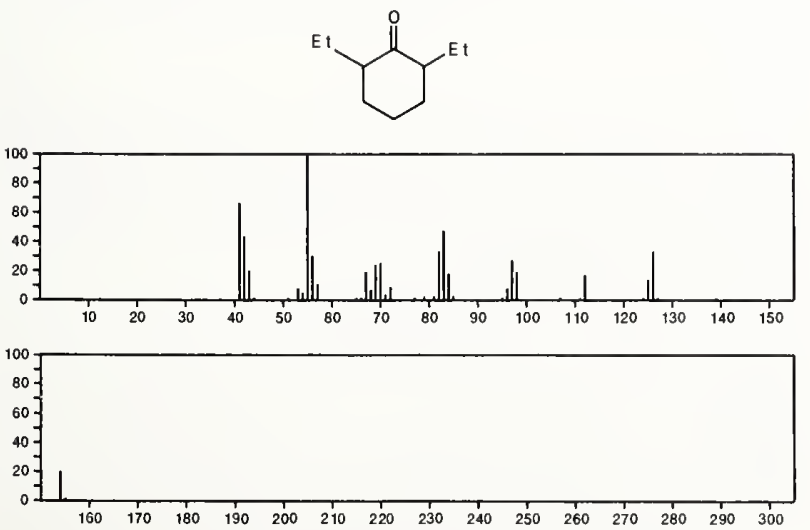

$154 \quad \mathrm{C}_{10} \mathrm{H}_{18} \mathrm{O}$

Cyclohexanone, 4-ethyl-3,4-dimethyl-

17429-42-4<smiles>C[C@@H]1CC(=O)CCC1(C)N</smiles>
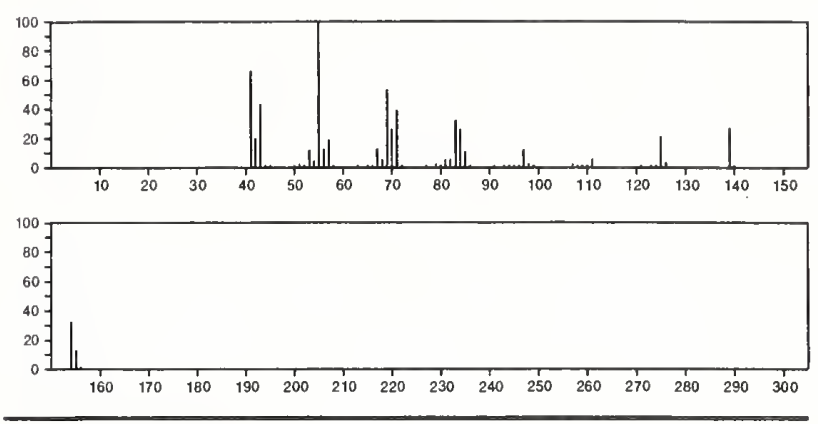

154

$\mathrm{C}_{10} \mathrm{H}_{18} \mathrm{O}$

Ketone, methyl 2,2,3-trimethylcyclopentyl

17983-22-1
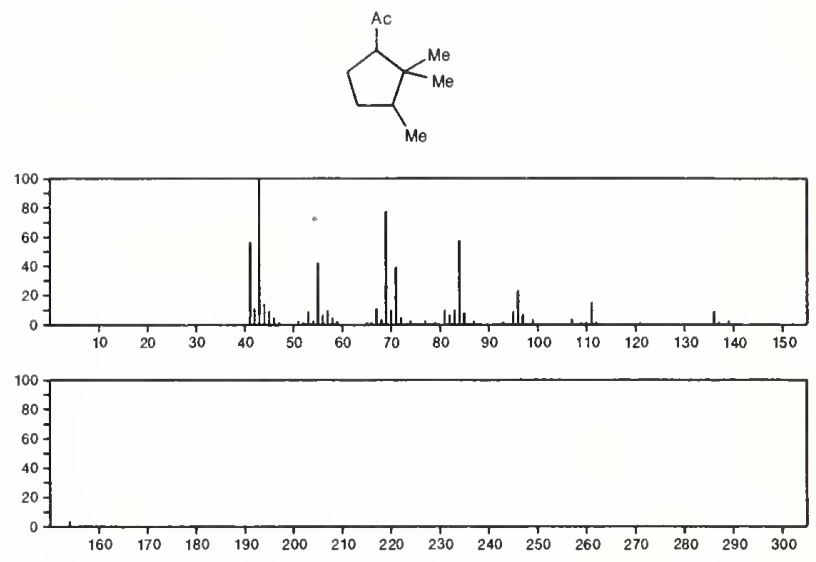

154

$\mathrm{C}_{10} \mathrm{H}_{18} \mathrm{O}$

Ketone, 2,2-dimethylcyclohexyl methyl

17983-26-5<smiles>CC1CCCCC1(C)C</smiles>
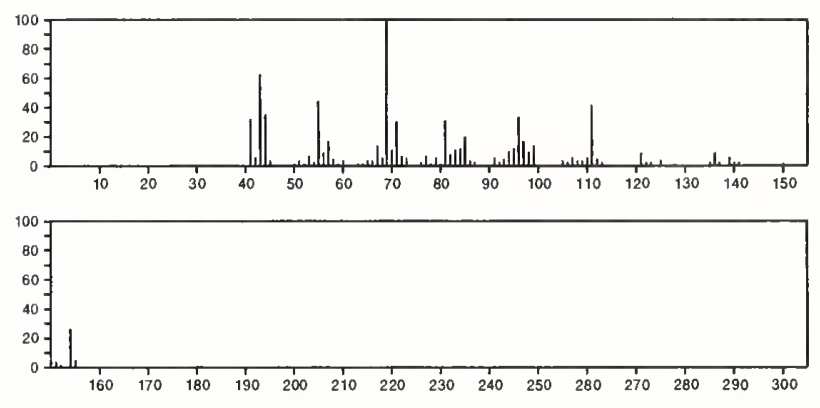

154

$\mathrm{C}_{10} \mathrm{H}_{18} \mathrm{O}$

3-Cyclohexene-1-ethanol, $\beta, 4$-dimethyl-

18479-68-0
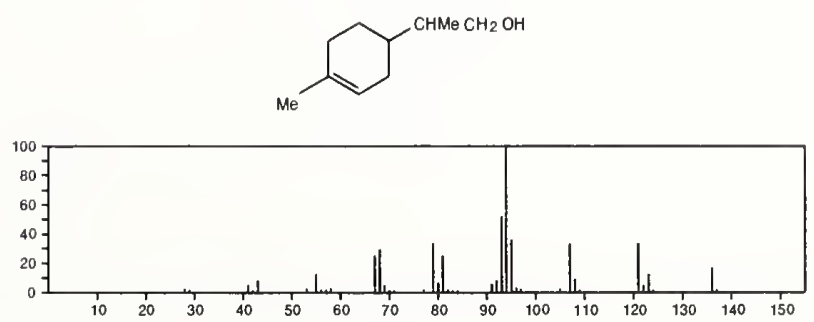


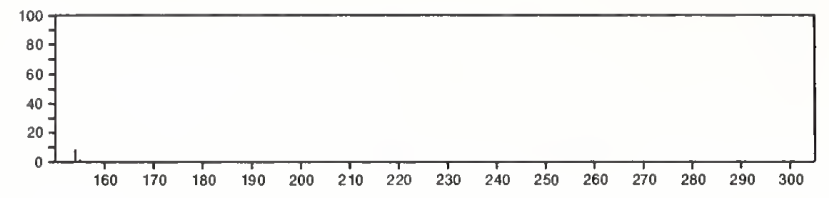

$154 \quad \mathrm{C}_{10} \mathrm{H}_{18} \mathrm{O} \quad 18675-33-7$ Cyclohexanol, 2-methyl-5-(1-methylethenyl)-, $(1 \alpha, 2 \alpha, 5 \beta)-$
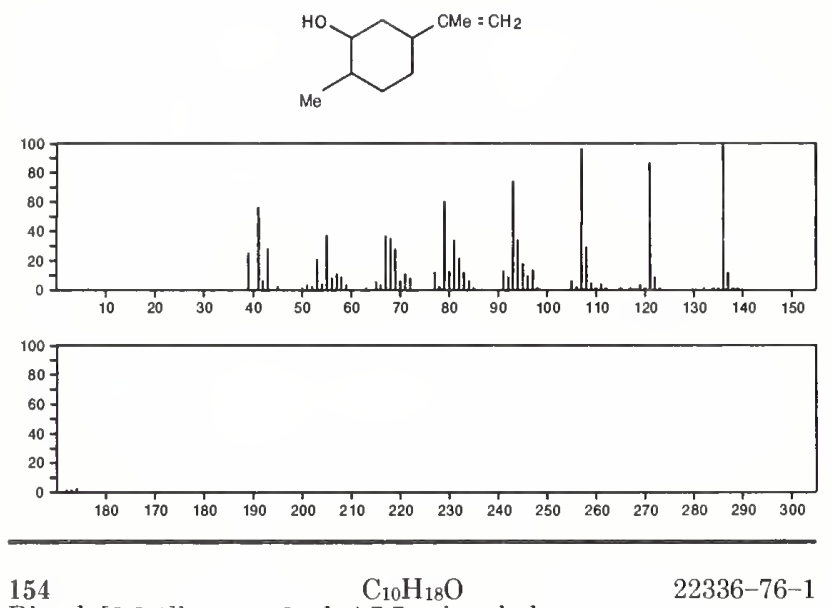

Bicyclo[2.2.1]heptan-2-ol, 4,7,7-trimethyl-
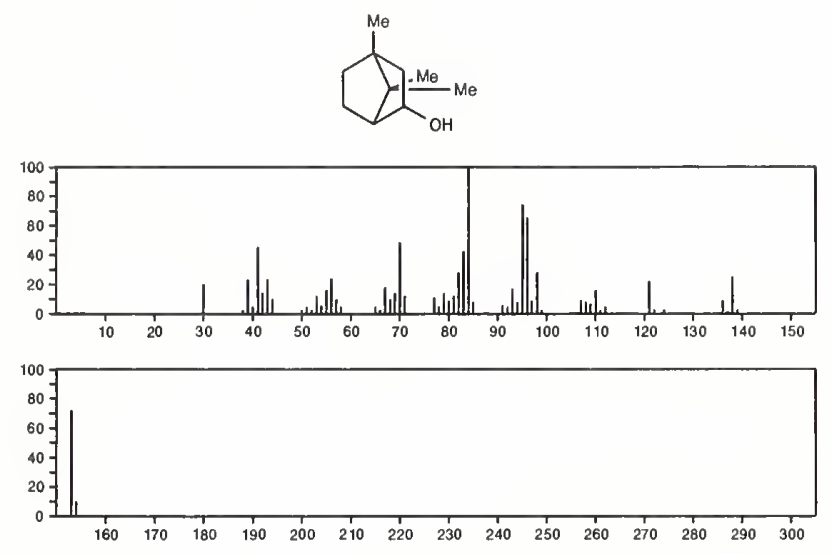

154

Ether, tert-butyl isopropylidenecyclopropyl

$24524-56-9$
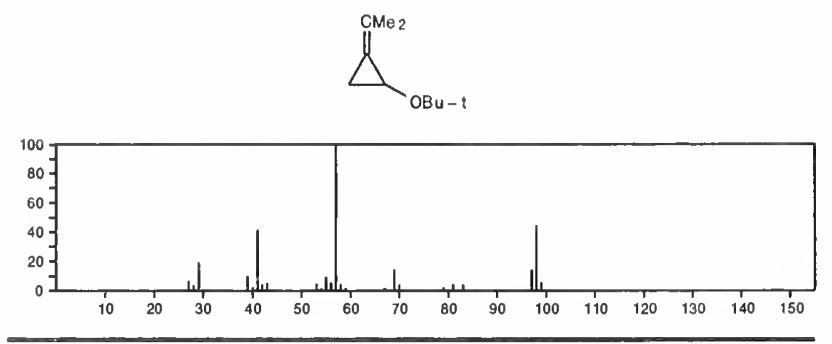

$154 \quad \mathrm{C}_{10} \mathrm{H}_{18} \mathrm{O} \quad 26532-22-9$

Cyclobutaneethanol, 1-methyl-2-(1-methylethenyl)-, (1R-cis)-

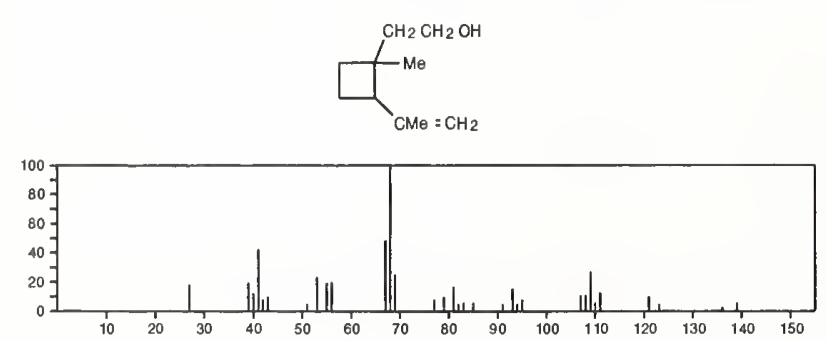

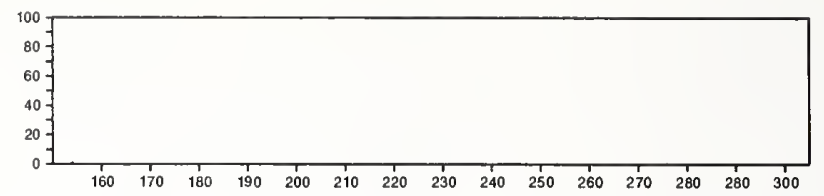

$154 \quad \mathrm{C}_{10} \mathrm{H}_{18} \mathrm{O} \quad 30346-21-5$ Cyclobutaneethanol, 1-methyl-2-(1-methylethenyl)-, trans-
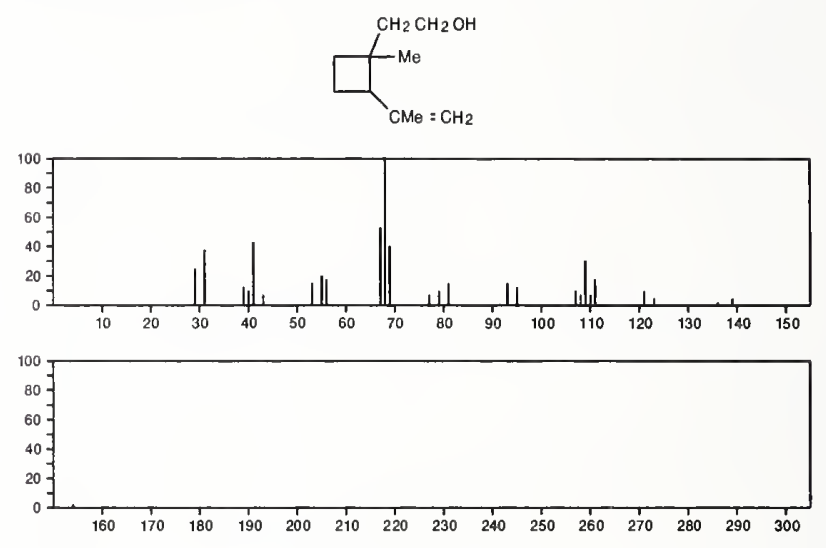

154

$\mathrm{C}_{10} \mathrm{H}_{18} \mathrm{O}$

Cyclohexene, 1-(1,1-dimethylethoxy)-

$31053-82-4$
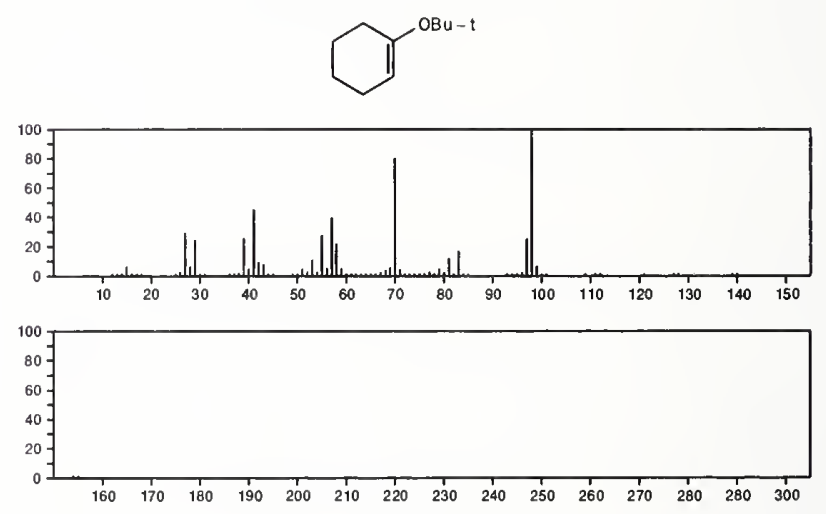

154

3-Hepten-2-one, 3-propyl- $\mathrm{C}_{10} \mathrm{H}_{18} \mathrm{O}$

$32064-69-0$

$\operatorname{Pr} \mathrm{CH}=\mathrm{CPr} \mathrm{COM}$
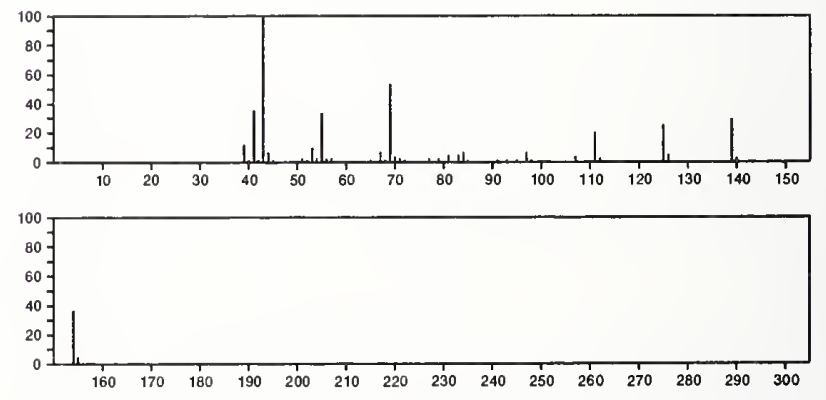

$154 \quad \mathrm{C}_{10} \mathrm{H}_{18} \mathrm{O} \quad 32064-70-3$

2-Heptanone, 3-propylidene--

$\left(\mathrm{CH}_{2}\right)_{3} \mathrm{Me}$

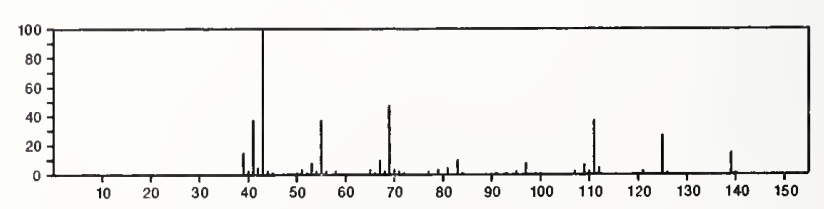



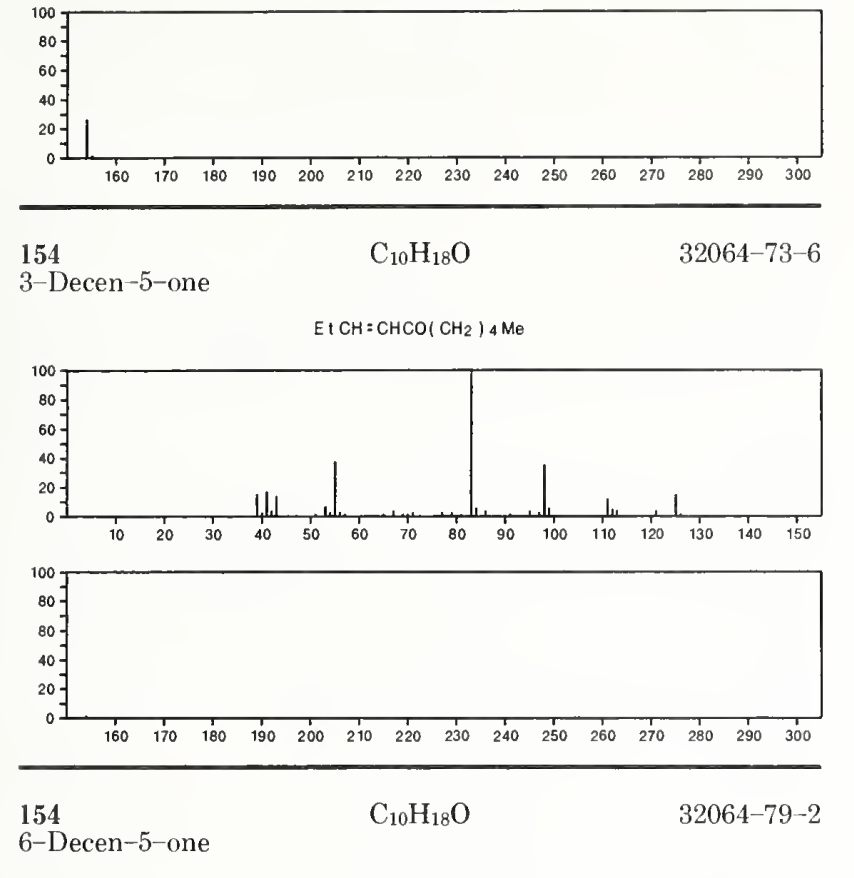

$\mathrm{Me}\left(\mathrm{CH}_{2}\right){ }_{3} \mathrm{COCH}=\mathrm{CHP} \mathrm{r}$

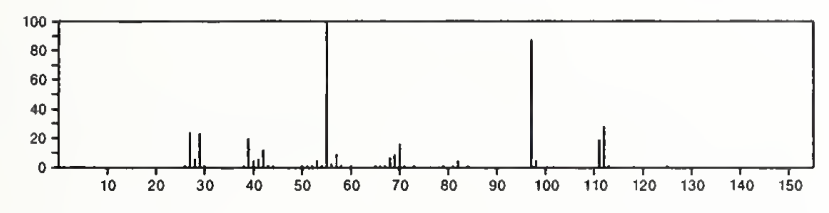

$154 \quad \mathrm{C}_{10} \mathrm{H}_{18} \mathrm{O}$

$32730-40-8$

Cyclohexene, 3-(2-methylpropoxy)-
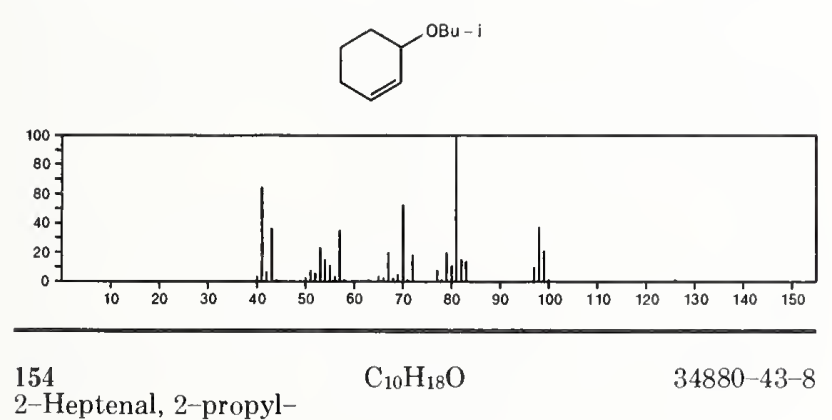

2-Heptenal, 2-propyl-

$\mathrm{Me}\left(\mathrm{CH}_{2}\right){ }_{3} \mathrm{CH}=\mathrm{CPr} \mathrm{CHO}$
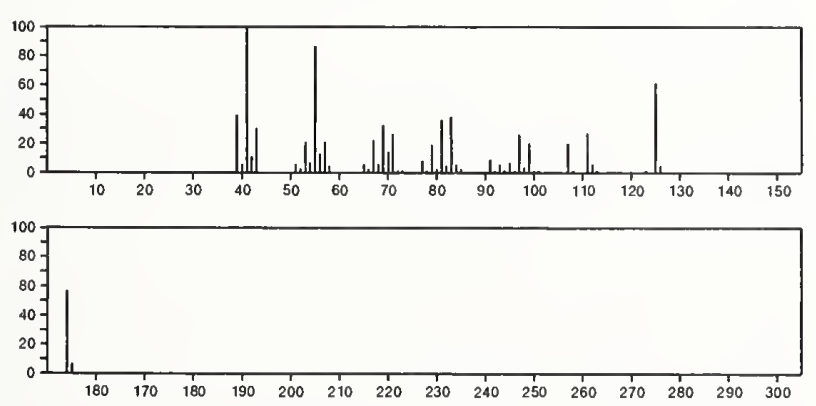

154

9 -Decen-2-one

$\mathrm{C}_{10} \mathrm{H}_{18} \mathrm{O}$

35194-30-0

$\mathrm{MeCO}\left(\mathrm{CH}_{2}\right)_{6} \mathrm{CH}=\mathrm{CH}_{2}$
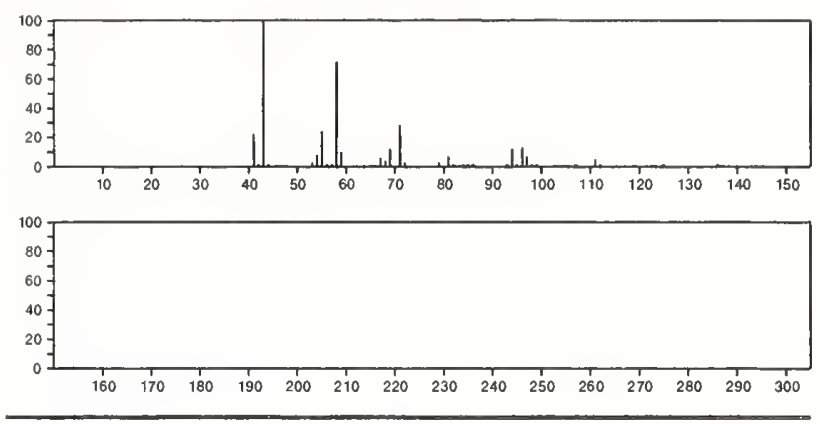

154

7-Decen-2-one

$\mathrm{C}_{10} \mathrm{H}_{18} \mathrm{O}$

$35194-33-3$
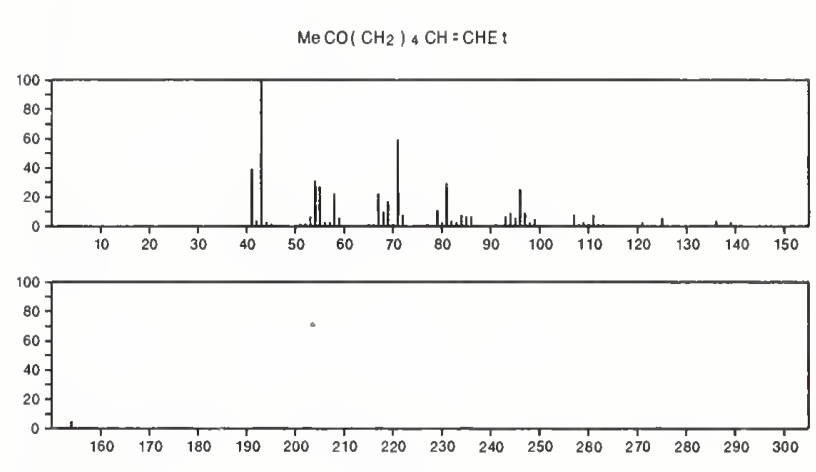

$154 \quad \mathrm{C}_{10} \mathrm{H}_{18} \mathrm{O} \quad 38049-26-2$

Cyclohexanol, 2-methyl-5-(1-methylethenyl)-, $(1 \alpha, 2 \beta, 5 \alpha)-$
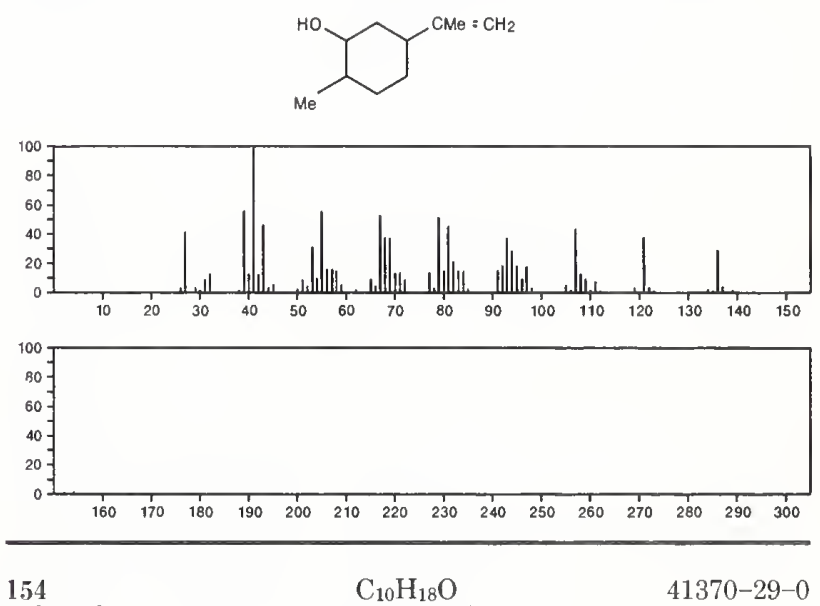

Ethanol, 2-(3,3-dimethylcyclohexylidene)-
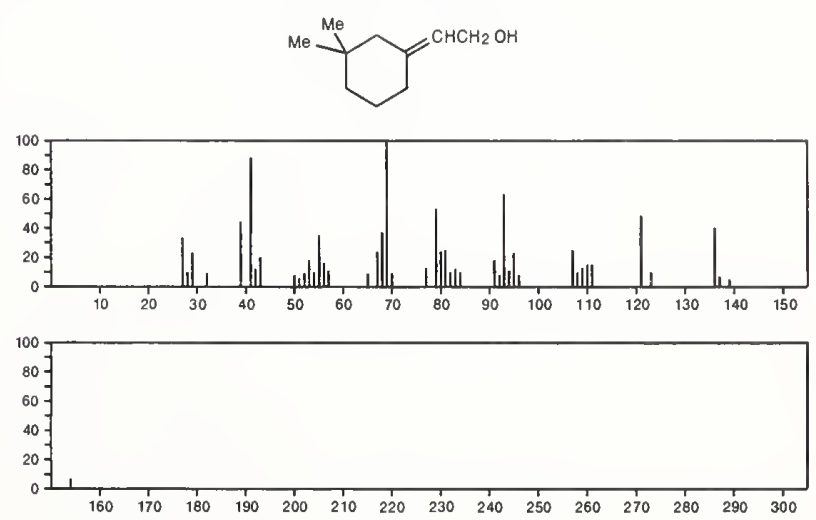
154 4-Hepten-3-one, 5-ethyl-2-methyl-

$\mathrm{Me} 2 \mathrm{CHCOCH}=\mathrm{CE}{ }_{2}$
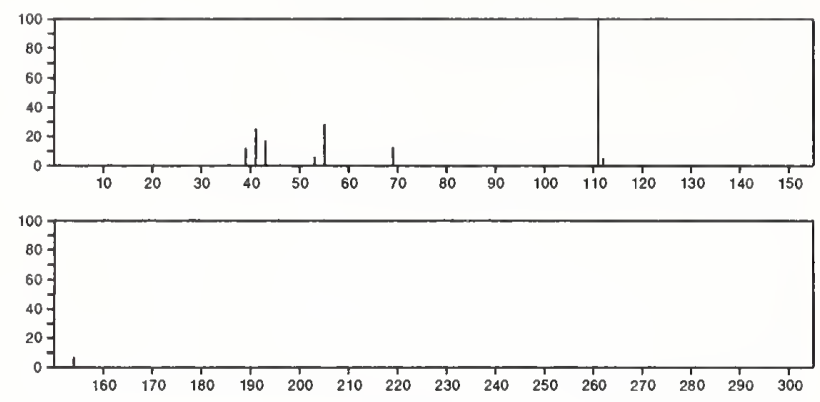

154

5-Hepten-3-one, 5-ethyl-2-methyl-

$\mathrm{Me}_{2} \mathrm{CHCOCH}_{2} \mathrm{CEt}=\mathrm{CHMe}$
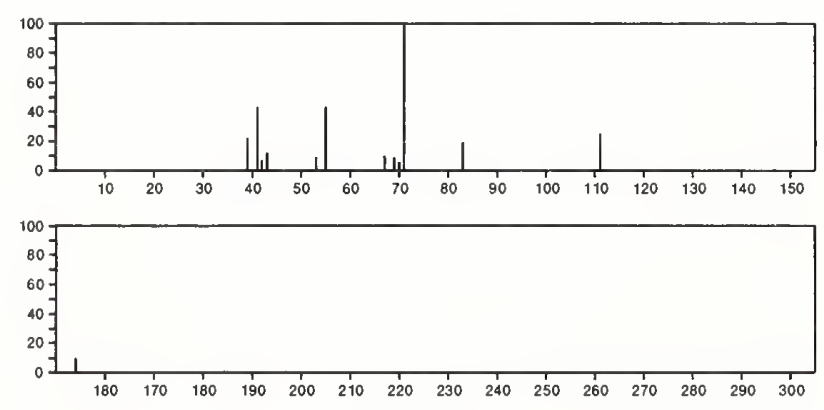

154

5-Octen-2-one, 6-ethyl-

$\mathrm{C}_{10} \mathrm{H}_{18} \mathrm{O}$

$51298-28-3$

$\mathrm{MeCOCH} \mathrm{CH}_{2} \mathrm{CH}=\mathrm{CET} 2$
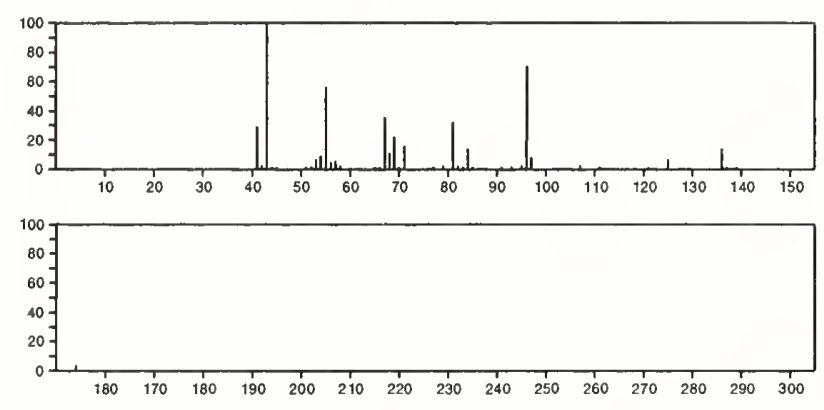

154

1-Nonen-3-one, 2-methyl-

$\mathrm{C}_{10} \mathrm{H}_{18} \mathrm{O}$

$51756-19-5$

$\mathrm{Me}\left(\mathrm{CH}_{2}\right){ }_{5} \mathrm{COCM}=\mathrm{CH}_{2}$
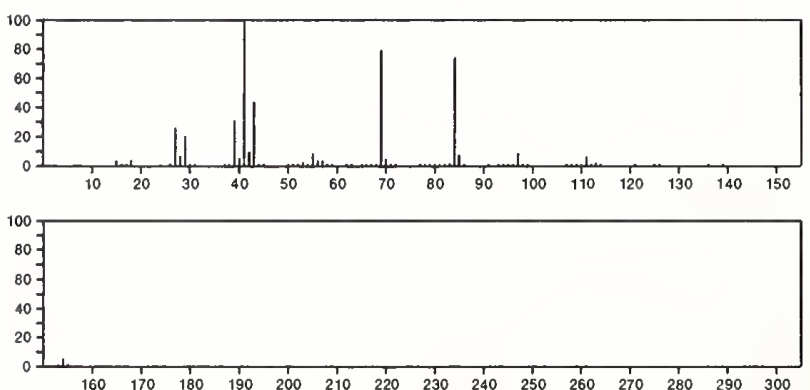

154

$\mathrm{C}_{10} \mathrm{H}_{18} \mathrm{O}$

Cyclohexane, 1-(ethoxymethyl)-4-methylene-

$54244-88-1$
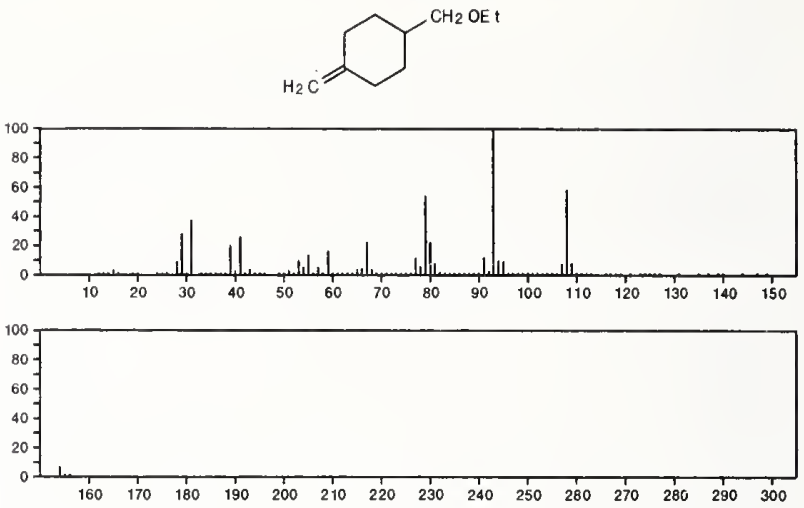

154

$\mathrm{C}_{10} \mathrm{H}_{18} \mathrm{O}$

$54244-89-2$

Furan, 4,5-diethyl-2,3-dihydro-2,3-dimethyl-
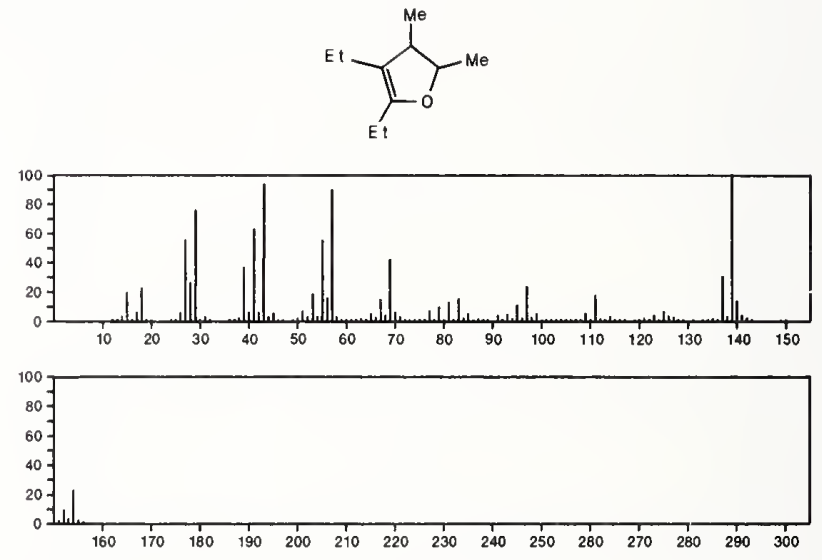

154

3-Hepten-2-one, 3-ethyl-4-methyl-

54244-90-5

$\mathrm{C}_{10} \mathrm{H}_{18} \mathrm{O}$

Me COCE $t=$ CPrME
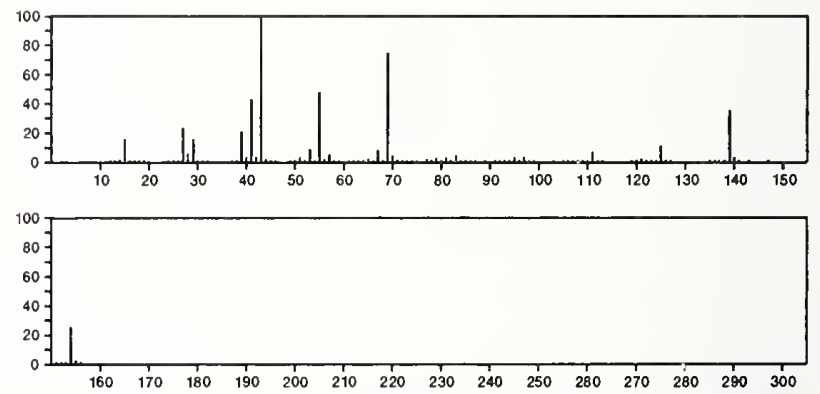

154

1-Hexyne, 3-ethoxy-3,4-dimethyl-

$54244-91-6$

$\mathrm{MeCH}_{2} \mathrm{CHM}_{e} \mathrm{CMe}$ ( $\mathrm{OE}$ ?) $\mathrm{C} \equiv \mathrm{CH}$
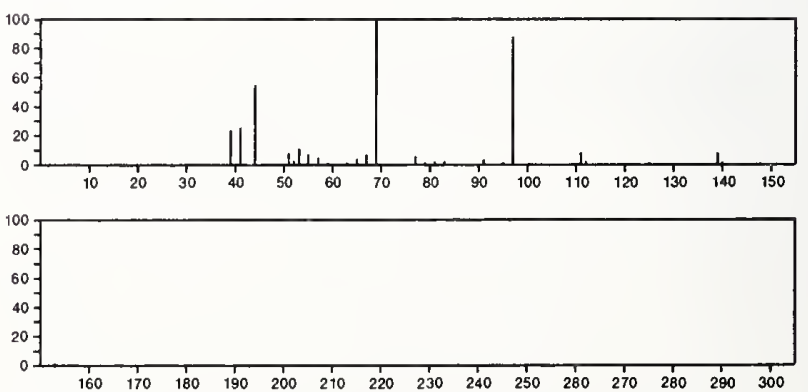
$154 \quad \mathrm{C}_{10} \mathrm{H}_{18} \mathrm{O}$

1-Heptyne, 3-methoxy-3,4-dimethyl-

$54244-92-7$

$\mathrm{HC} \equiv \mathrm{CCM}_{\theta}\{\mathrm{OMe}\} \mathrm{CHP}_{2} \mathrm{Me}$
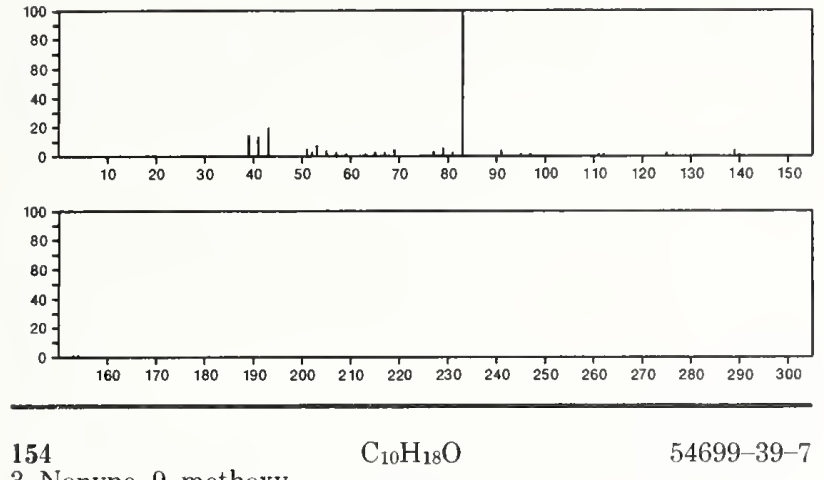

3-Nonyne, 9-methoxy-

$\mathrm{MeO}\left\langle\mathrm{CH}_{2}\right)_{5} \mathrm{C} \equiv \mathrm{CEt}$

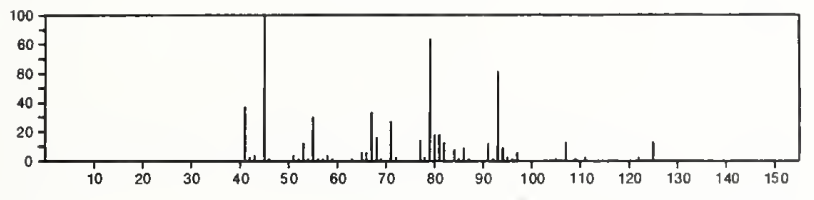

154

2-Cyclohexen-1-ol, 4-ethyl-1,4-dimethyl-

$55162-55-5$
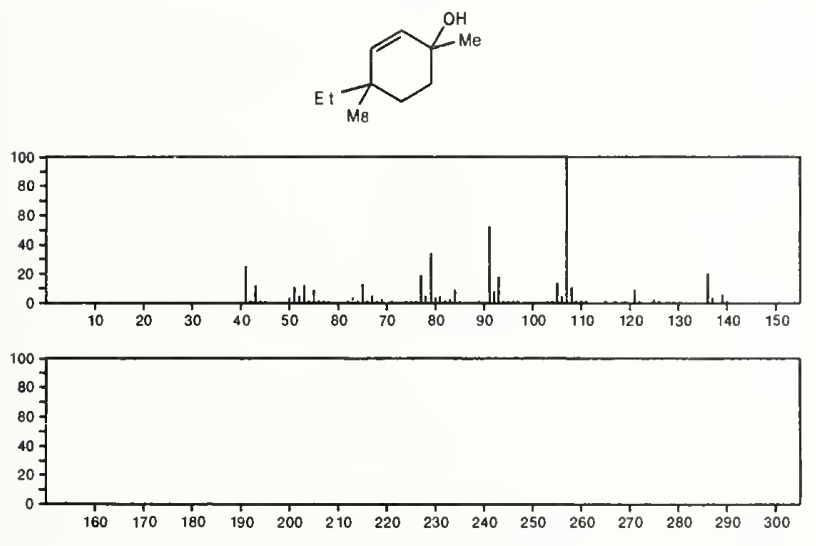

154

$\mathrm{C}_{10} \mathrm{H}_{18} \mathrm{O}$

$56259-15-5$

1-Propanone, 2-methyl-1-[2-(1-methylethyl)cyclopropyl]-
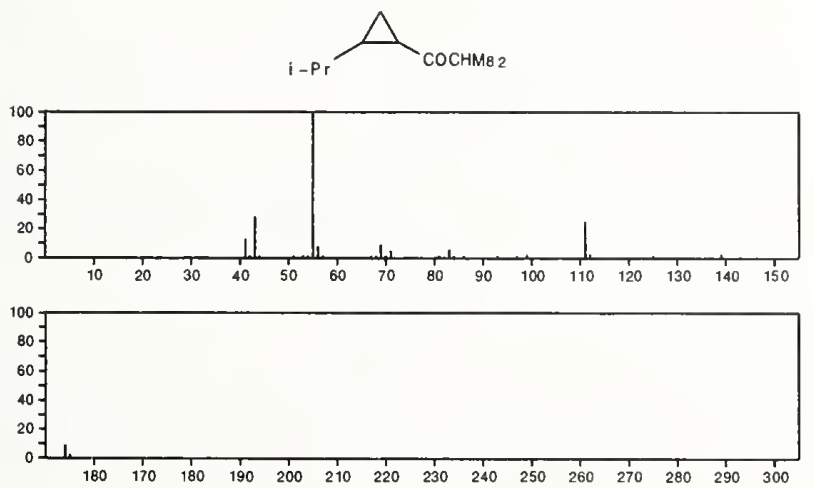

$154 \quad \mathrm{C}_{10} \mathrm{H}_{18} \mathrm{O}$ $56666-68-3$ 1-Cyclopentene-1-methanol, $\alpha, \alpha, 4,5$-tetramethyl-, cis-
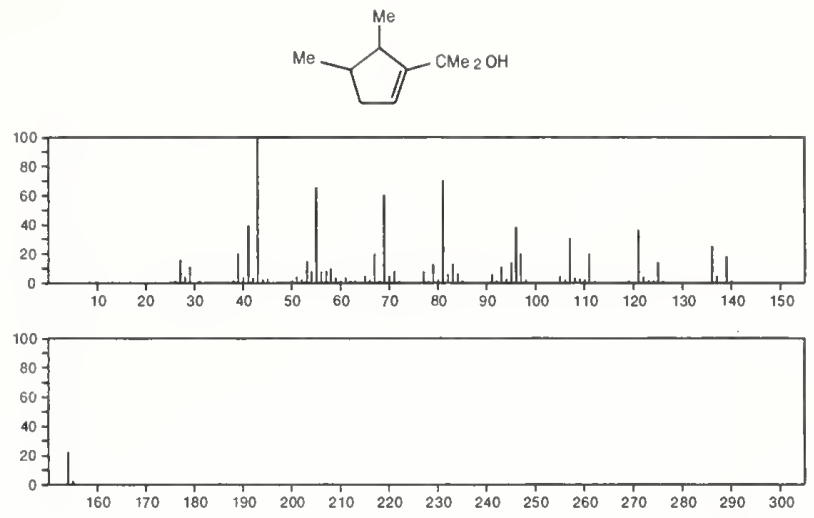
$\mathrm{C}_{10} \mathrm{H}_{18} \mathrm{O}$
1-Cyclopentene-1-methanol, $\alpha, \alpha, 4,5$-tetramethyl-, trans-
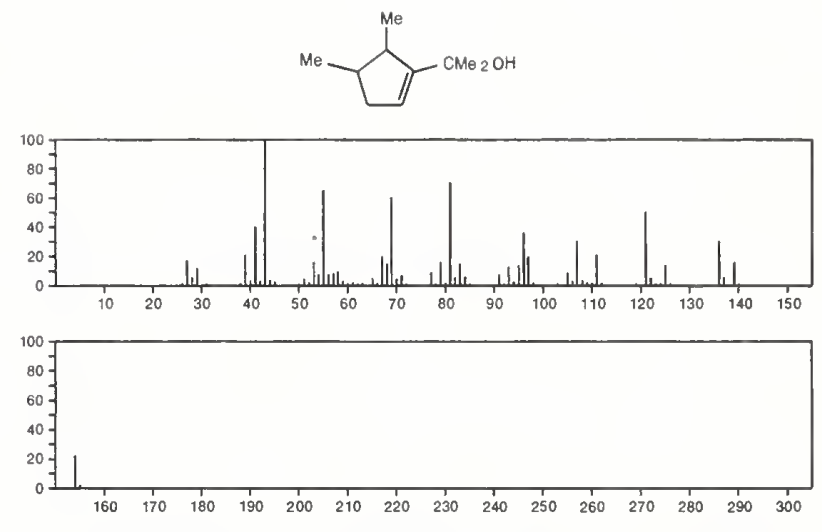

154
Cyclopropane, (1,1-dimethylethoxy)(1-methylethylidene)-
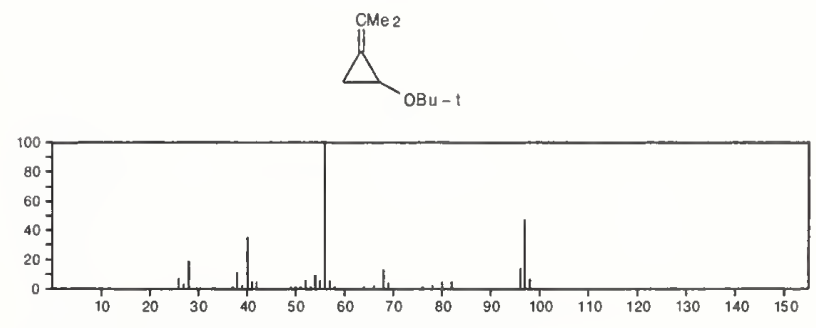

154

$\mathrm{C}_{11} \mathrm{H}_{6} \mathrm{O}$

$277-96-3$

$2 H$-Cyclopropa[3,4]naphth $[1,2-b]$ oxirene
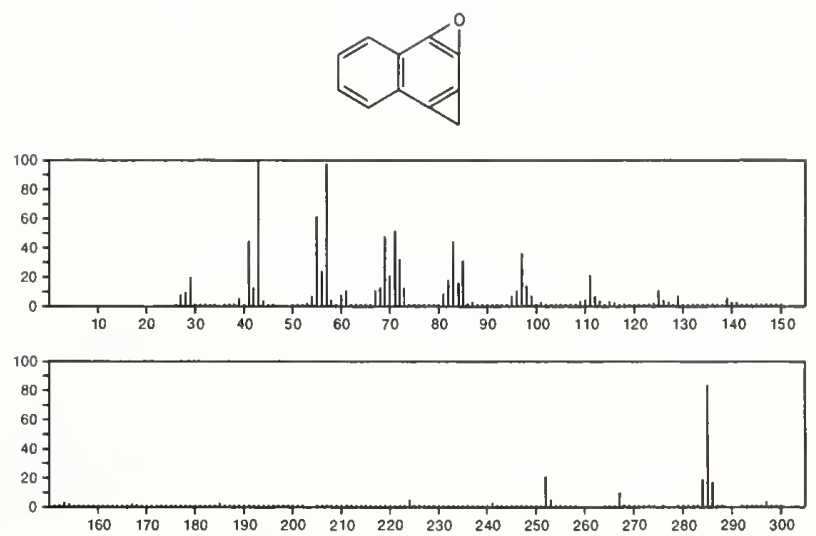

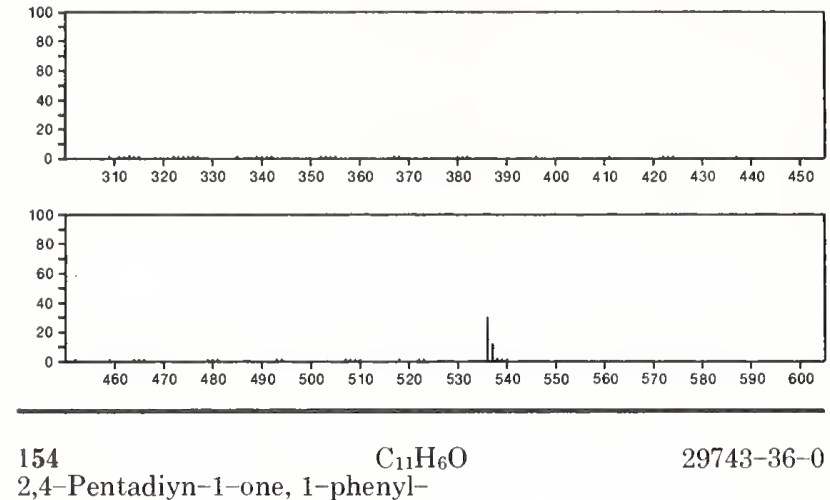

2,4-Pentadiyn-1-one, 1-phenyl-

$\mathrm{HC} \equiv \mathrm{CC} \equiv \mathrm{CCOPh}$
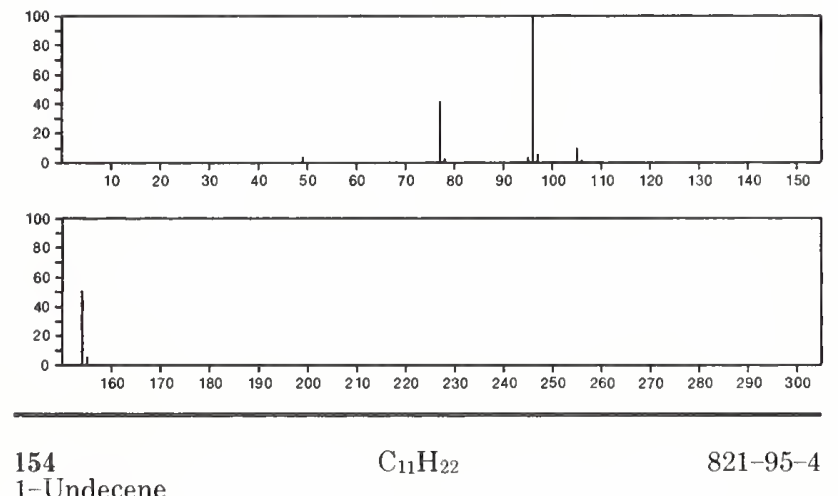

1-Undecene

$\mathrm{H}_{2} \mathrm{C}=\mathrm{CH}\left(\mathrm{CH}_{2}\right)_{8} \mathrm{Me}$
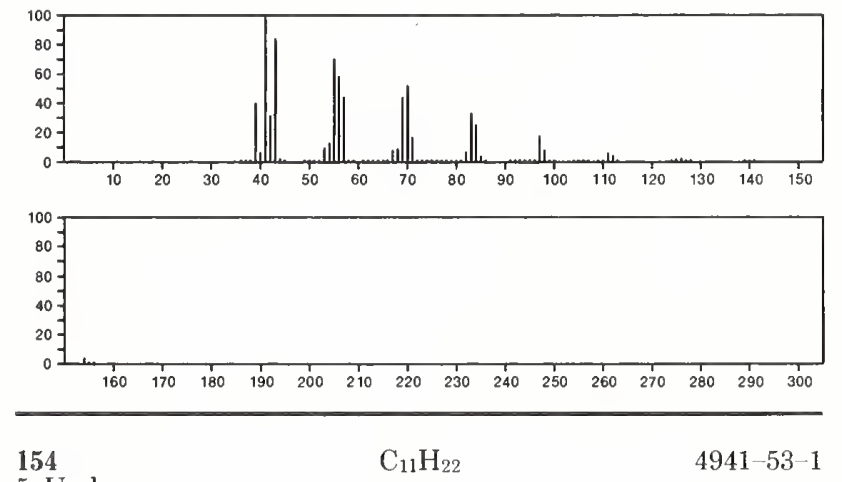

5-Undecene

$\mathrm{Me}\left(\mathrm{CH}_{2}\right)_{3} \mathrm{CH}=\mathrm{CH}\left(\mathrm{CH}_{2}\right)_{4} \mathrm{Me}$
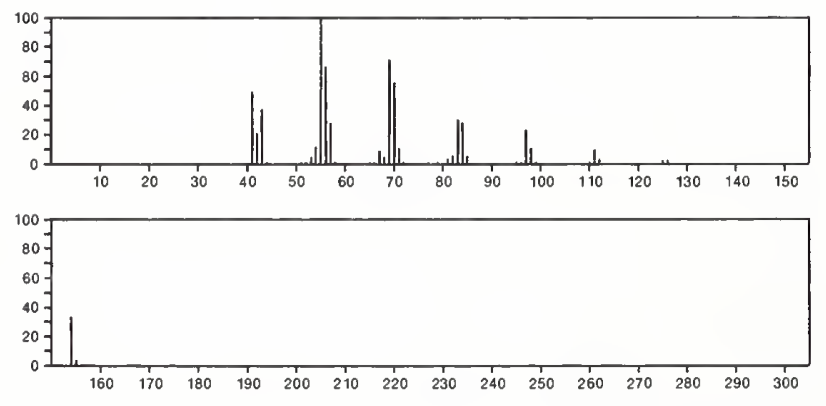

154

1-Octene, 2-propyl-

$\mathrm{C}_{11} \mathrm{H}_{22}$

$\mathrm{Me}\left(\mathrm{CH}_{2}\right){ }_{5} \mathrm{CPr}=\mathrm{CH}_{2}$

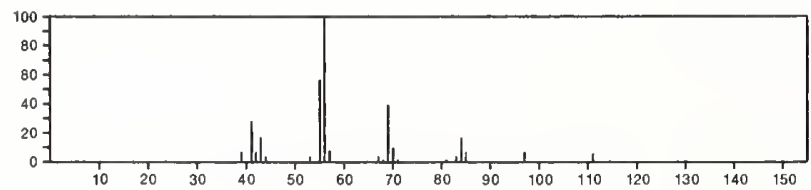

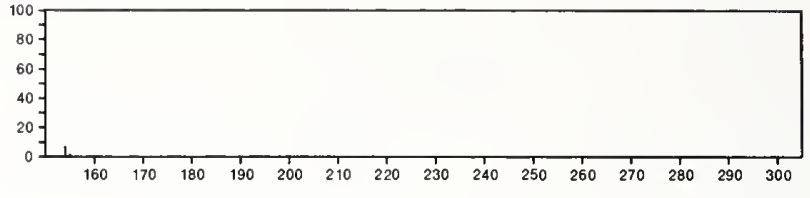

154

Cyclohexane, (1,1-dimethylpropyl)-

$31797-64-5$
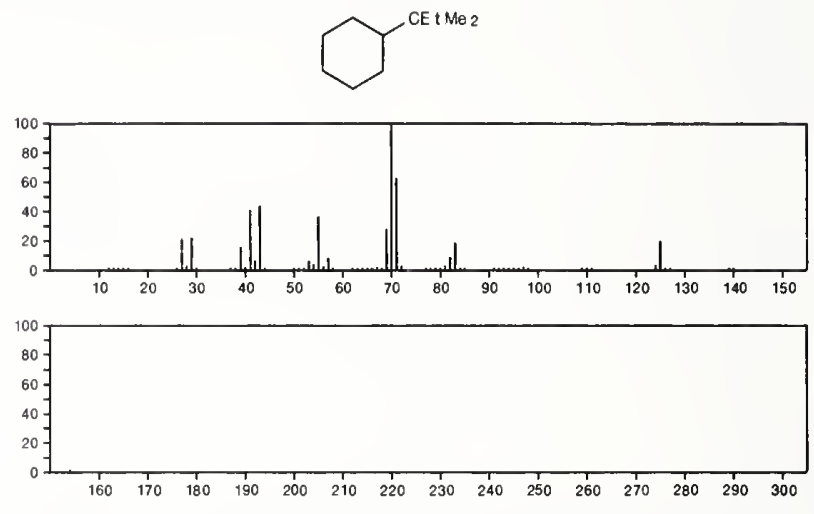

154

Cyclopropane, 1,2-dibutyl-

$\mathrm{C}_{11} \mathrm{H}_{22}$

41977-32-6
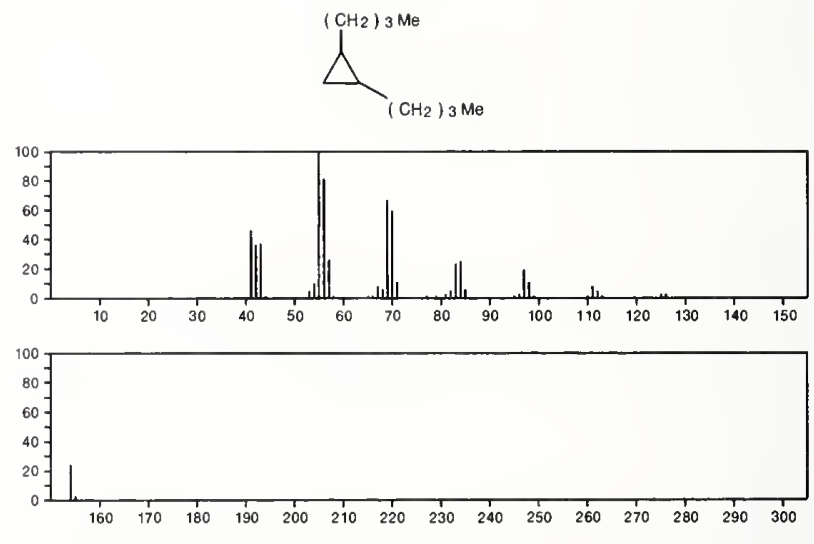

154

$\mathrm{C}_{11} \mathrm{H}_{22}$

Cyclopropane, 1-pentyl-2-propyl-

$41977-33-7$
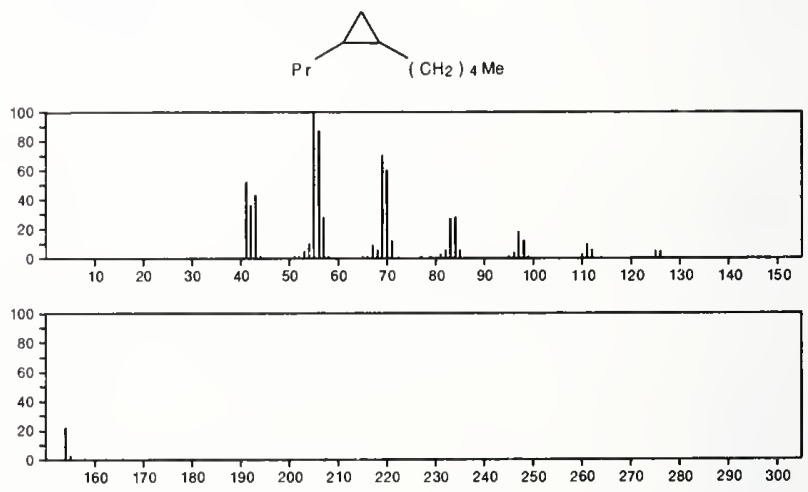
$154 \quad \mathrm{C}_{11} \mathrm{H}_{22}$

Cyclopropane, 1-butyl-1-methyl-2-propyl
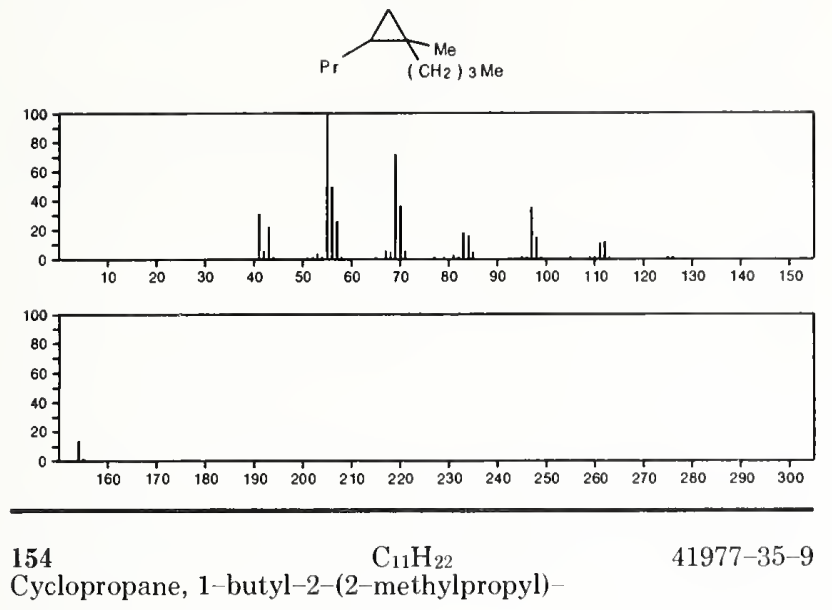

Cyclopropane, 1-butyl-2-(2-methylpropyl)
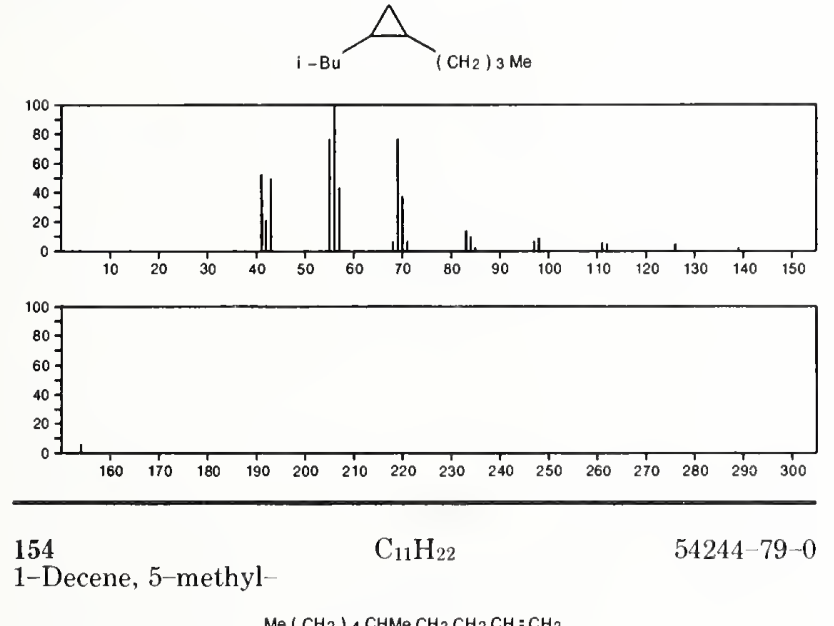

$\mathrm{Me}\left(\mathrm{CH}_{2}\right)_{4} \mathrm{CHMe} \mathrm{CH}_{2} \mathrm{CH}_{2} \mathrm{CH}=\mathrm{CH}_{2}$
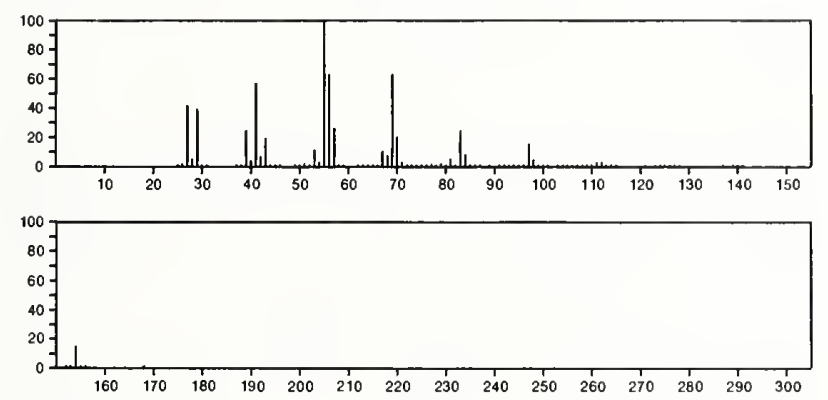

154

Acenaphthylene, 1,2-dihydro-

$\mathrm{C}_{12} \mathrm{H}_{10}$

$83-32-9$
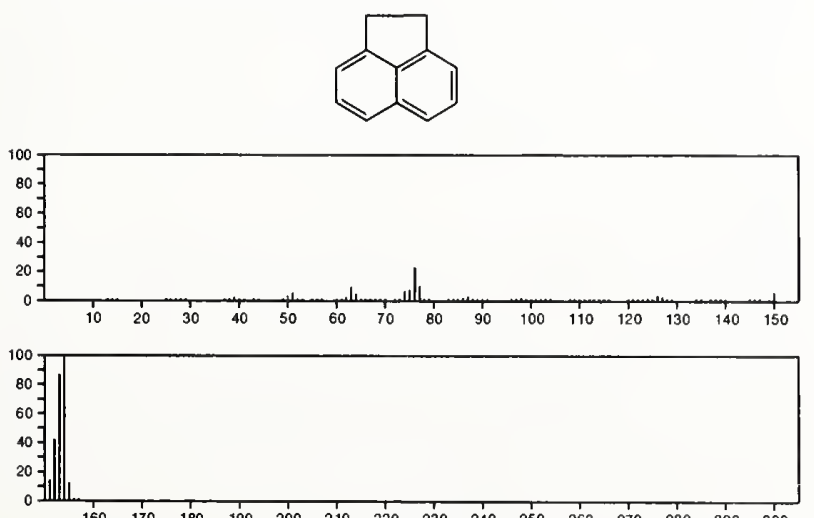

154

1,1'-Biphenyl

$\mathrm{C}_{12} \mathrm{H}_{10}$

$92-52-4$
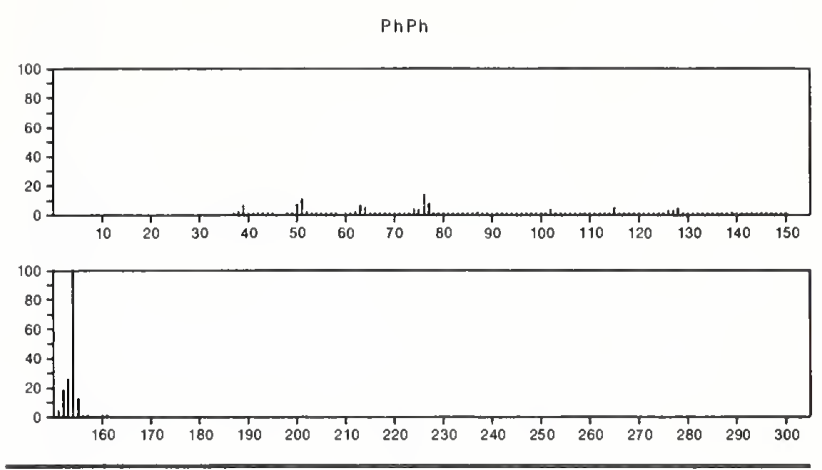

154

1,4-Ethenonaphthalene, 1,4-dihydro-

$7322-47-6$
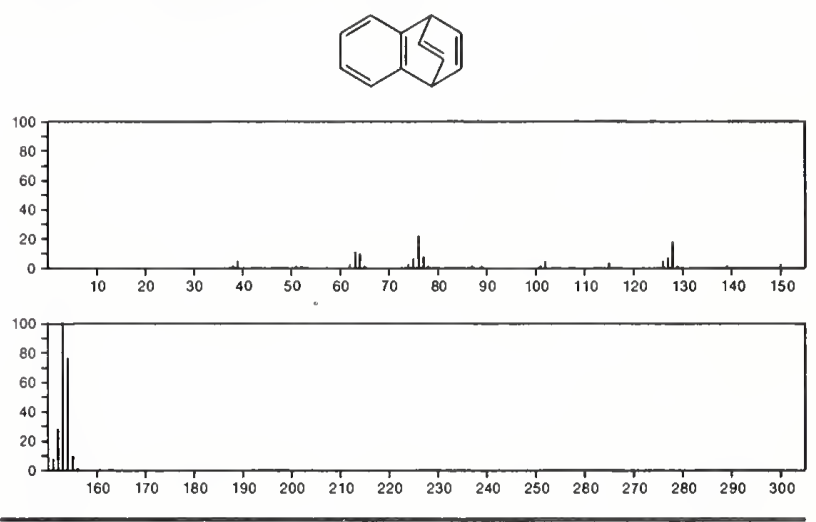

155

$\mathrm{C}_{3} \mathrm{H}_{9} \mathrm{NO}_{2} \mathrm{~S}_{2}$

$55649-95-1$

Sulfonium, dimethyl[(methylsulfonyl)amino]-, hydroxide, inner salt

$\mathrm{MeSO}_{2} \stackrel{-+}{\mathrm{NS}} \mathrm{NMe}_{2}$
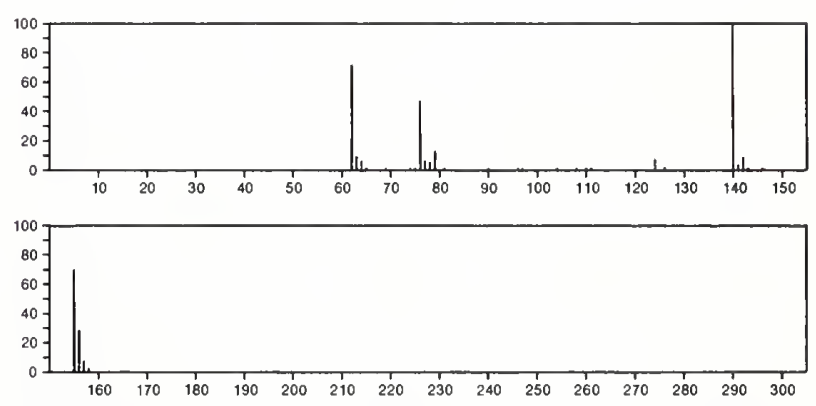

155

$\mathrm{C}_{3} \mathrm{H}_{10} \mathrm{NO}_{2} \mathrm{PS}$

Phosphoramidothioic acid, methyl-, $O, O$-dimethyl ester

31464-99-0
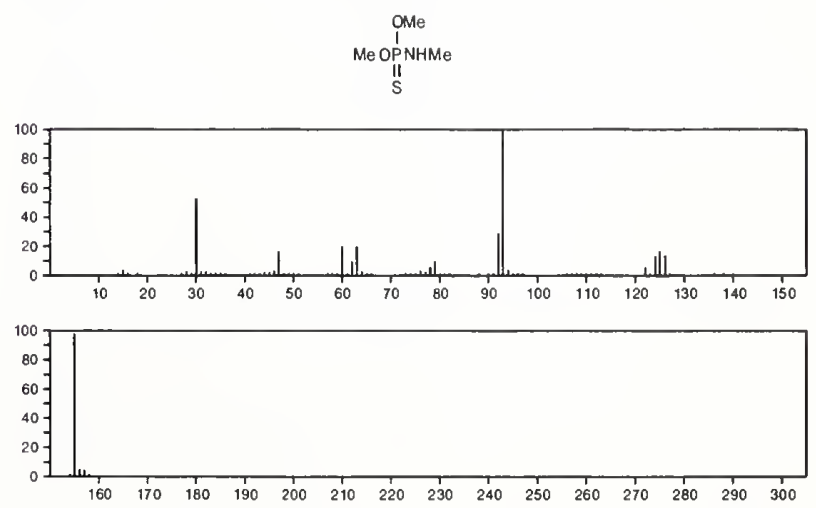
155

$\mathrm{C}_{5} \mathrm{H}_{8} \mathrm{~F}_{3} \mathrm{NO}$

Acetamide, 2,2,2-trifluoro- $N$-propyl-

PrNHCOCF 3
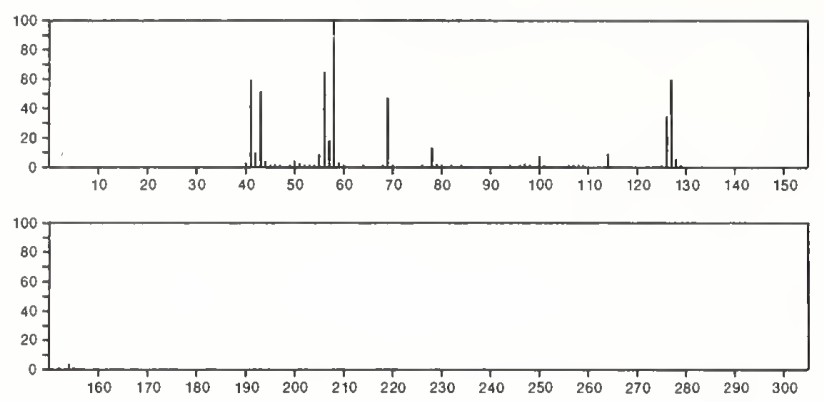

155

1,3,5-Triazin-2(1H)-one, 4-amino-6-(ethylamino)

$7313-54-4$<smiles>CCNc1nc(=O)nc(N)[nH]1</smiles>
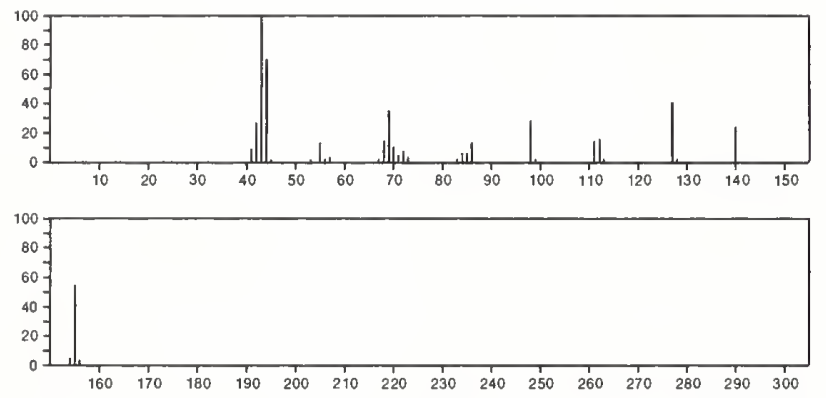

155

$\mathrm{C}_{5} \mathrm{H}_{9} \mathrm{~N}_{5} \mathrm{O}$

$55702-52-8$

1,3,5-Triazin-2(1H)-one, 4,6-bis(methylamino)-
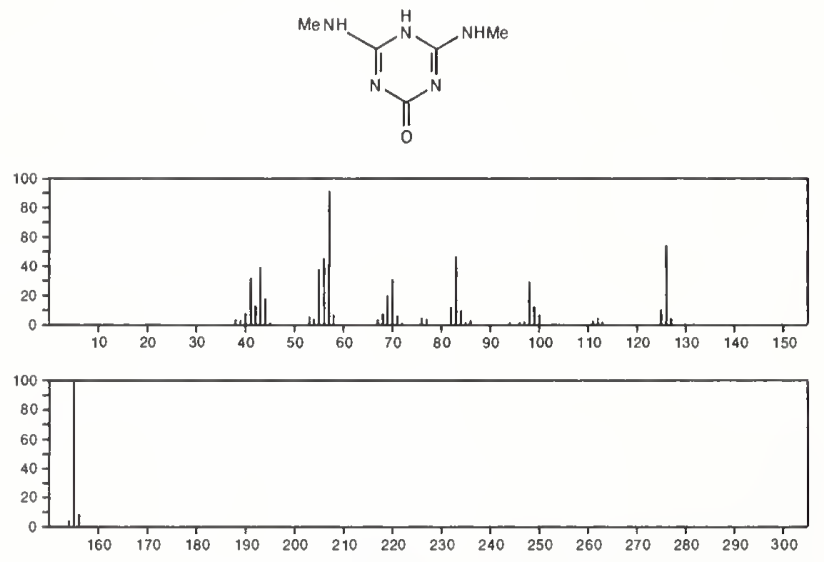

155

L-Histidine

$\mathrm{C}_{6} \mathrm{H}_{9} \mathrm{~N}_{3} \mathrm{O}_{2}$

$71-00-1$
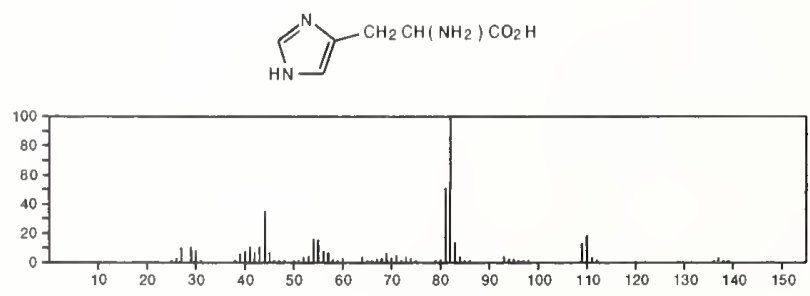

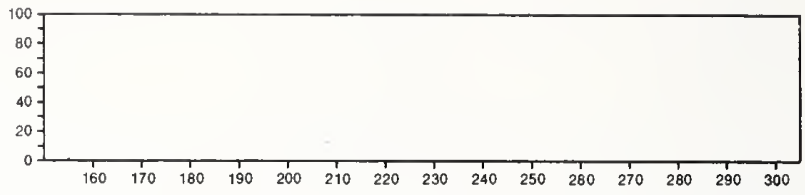

155

$\mathrm{C}_{6} \mathrm{H}_{9} \mathrm{~N}_{3} \mathrm{O}_{2}$

$4(1 H)$-Pyrimidinone, 2-amino-6-ethoxy-

$42956-82-1$
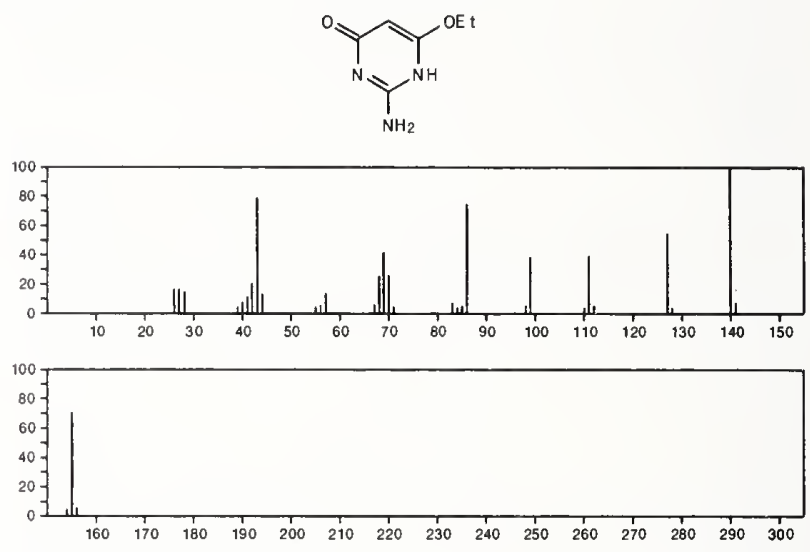

155

$\mathrm{C}_{6} \mathrm{H}_{9} \mathrm{~N}_{3} \mathrm{~S}$

4-Pyrimidinamine, 2-(ethylthio)-

$54308-63-3$
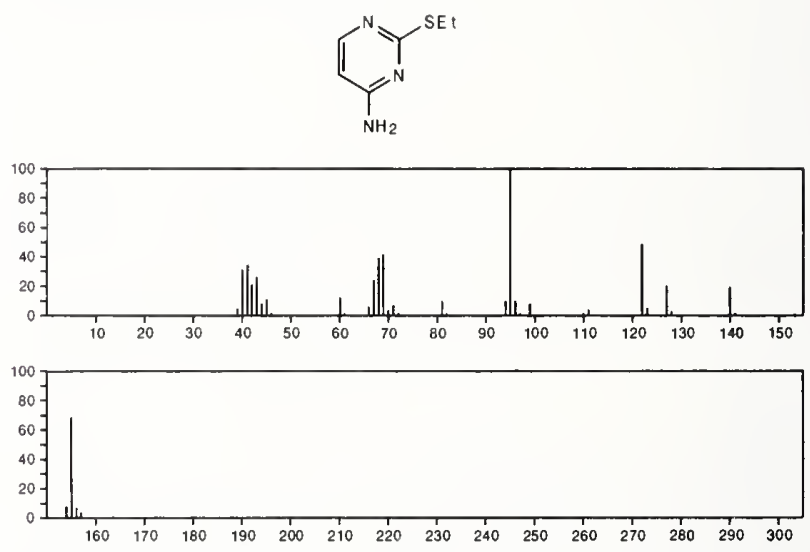

155

$\mathrm{C}_{6} \mathrm{H}_{9} \mathrm{~N}_{3} \mathrm{~S}$

$54308-64-4$

4 -Pyrimidinamine, 5-methyl-2-(methylthio) -
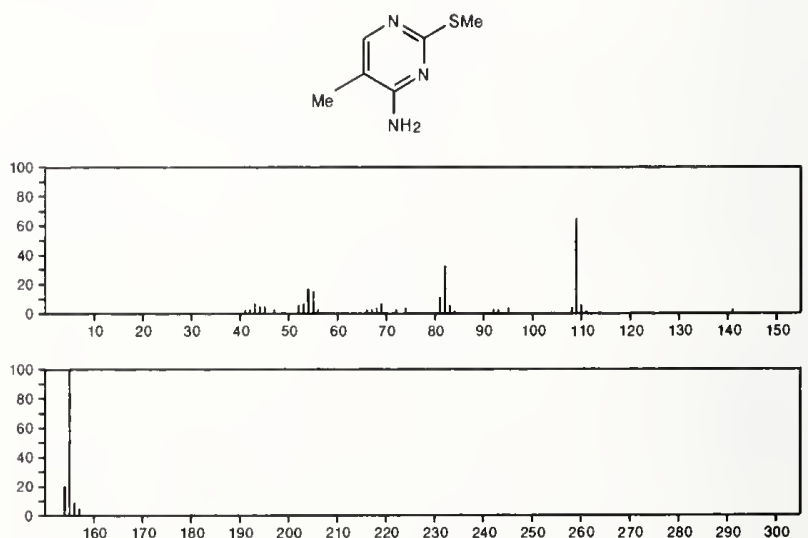
155

Benzamide, 4-chloro-

$\mathrm{C}_{7} \mathrm{H}_{6} \mathrm{CINO}$

619-56-7
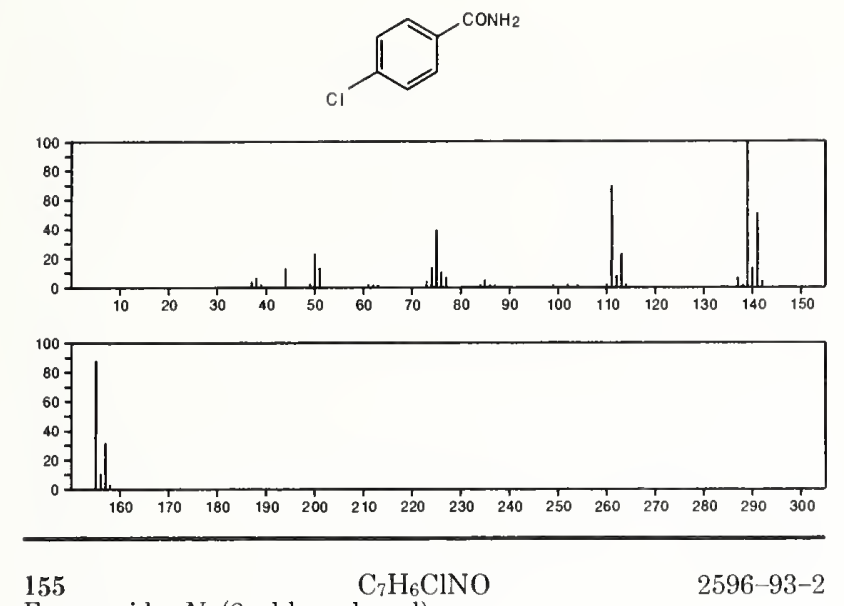

Formamide, $N$-(2-chlorophenyl)-
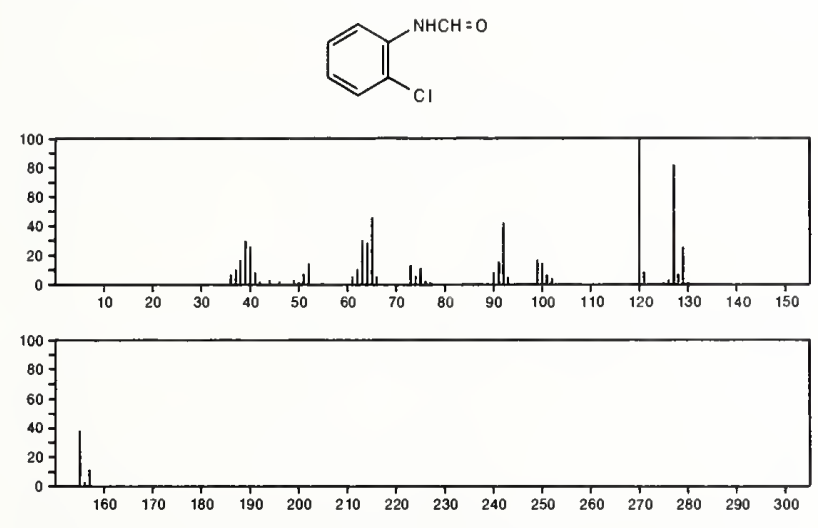

$155 \quad \mathrm{C}_{7} \mathrm{H}_{6} \mathrm{ClNO}$

Benzaldehyde, 4-chloro-, oxime, $(Z)$ -
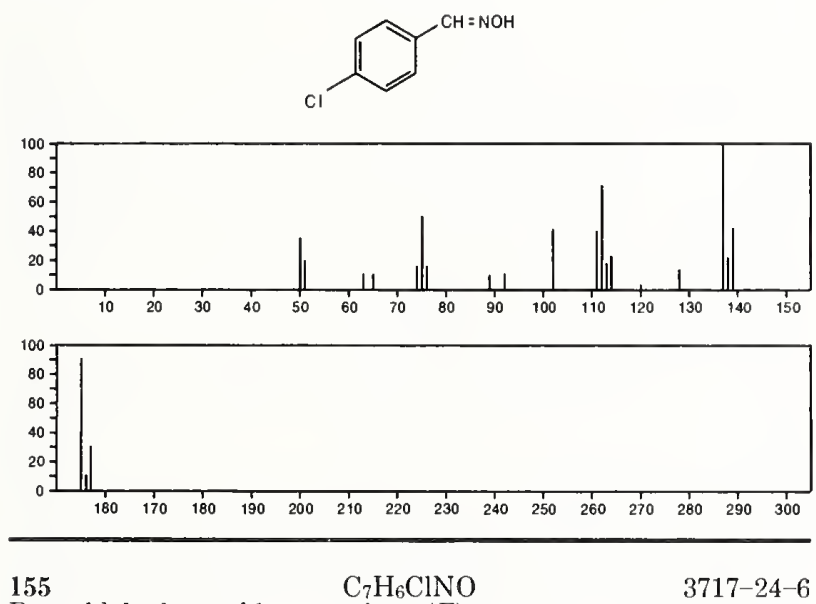

Benzaldehyde, 4-chloro-, oxime, $(E)$

$3717-24-6$
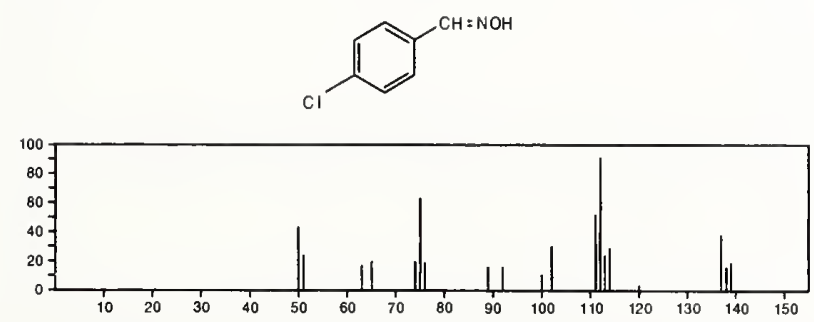

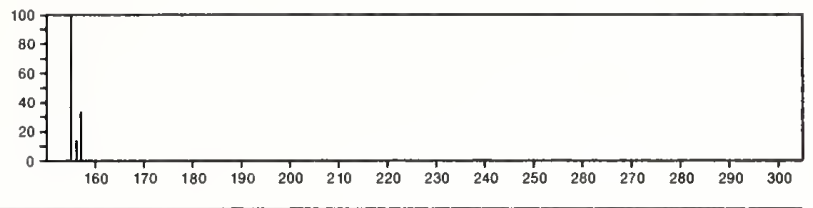

155

$\mathrm{C}_{7} \mathrm{H}_{6} \mathrm{ClNO}$

Benzaldehyde, 3-chloro-, oxime, $(Z)$ -

3717-33-7
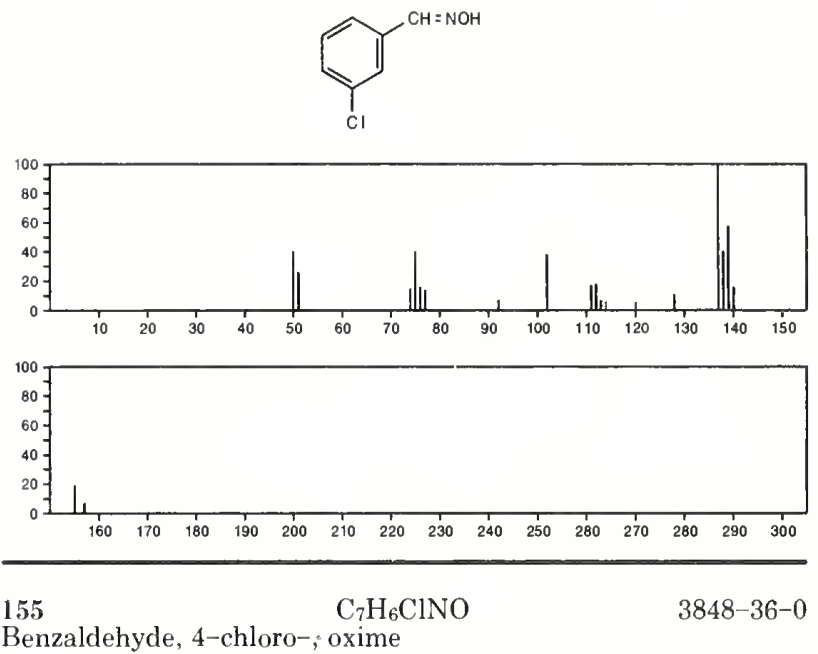

Benzaldehyde, 4-chloro-; oxime
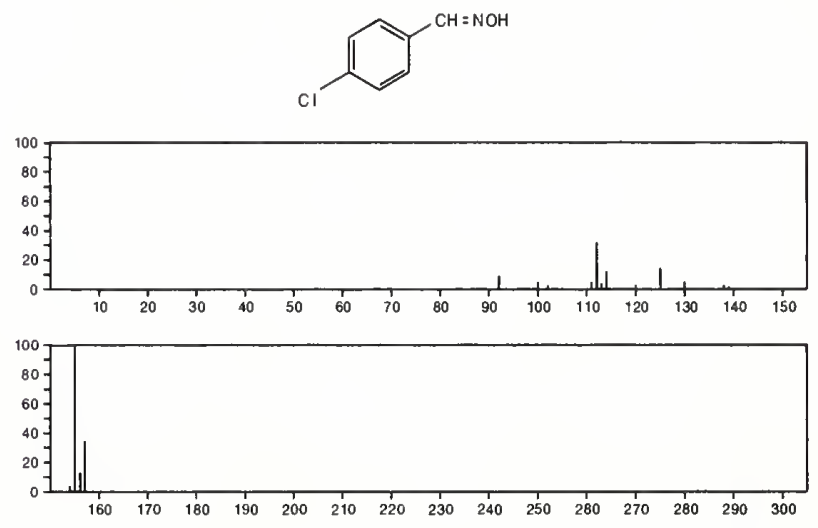

155

$\mathrm{C}_{7} \mathrm{H}_{6} \mathrm{ClNO}$

Benzaldehyde, 3-chloro-, oxime, $(E)^{-}$

$4006-79-5$
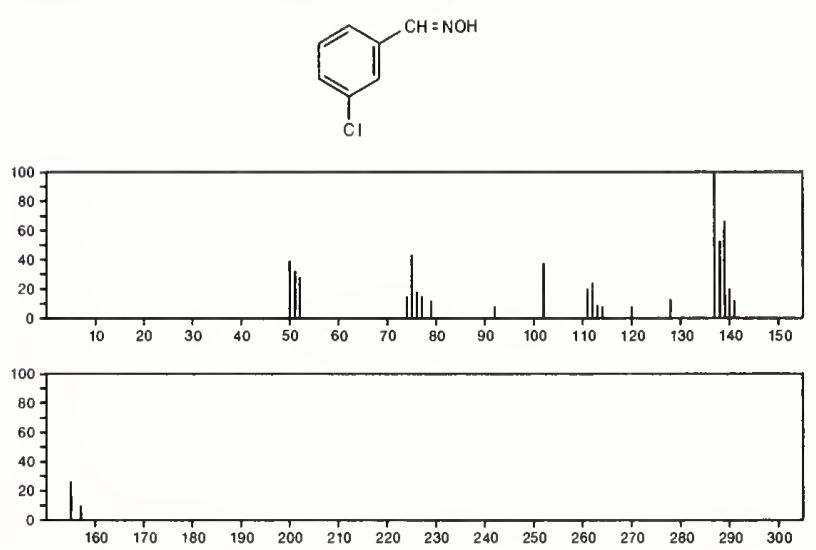
155

$\mathrm{C}_{7} \mathrm{H}_{6} \mathrm{CINO}$

Benzaldehyde, 3-chloro-, oxime
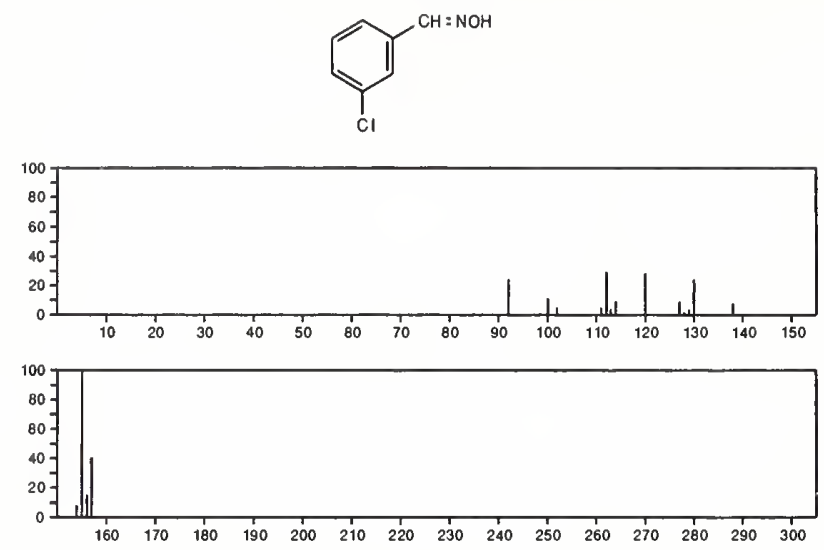

155

Sulfoximine, $S$-methyl-S-phenyl-

$\mathrm{HN}=\mathrm{SPhMB}=0$
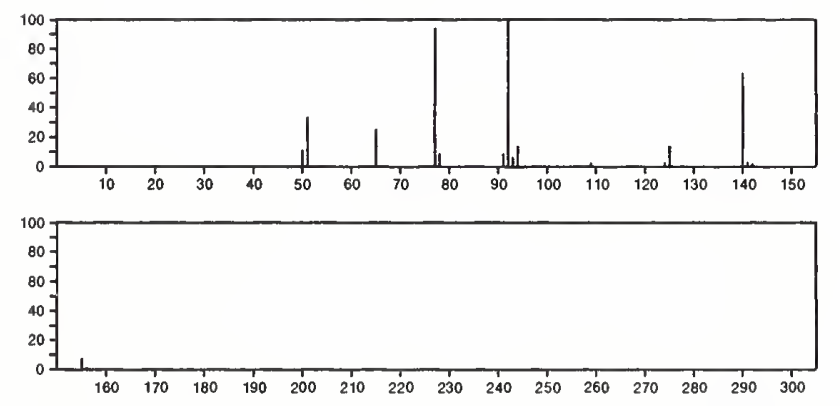

155

3-Pyridinol, 6-methyl-2-(methylthio)

\section{$\mathrm{C}_{7} \mathrm{H}_{9} \mathrm{NOS}$}
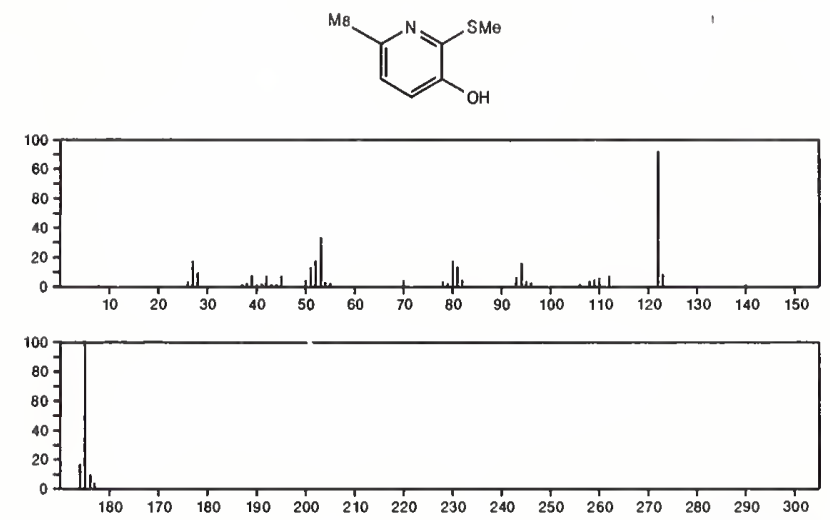

155

Hydrazinecarboxamide, 2-cyclohexylidene-

1589-61-3

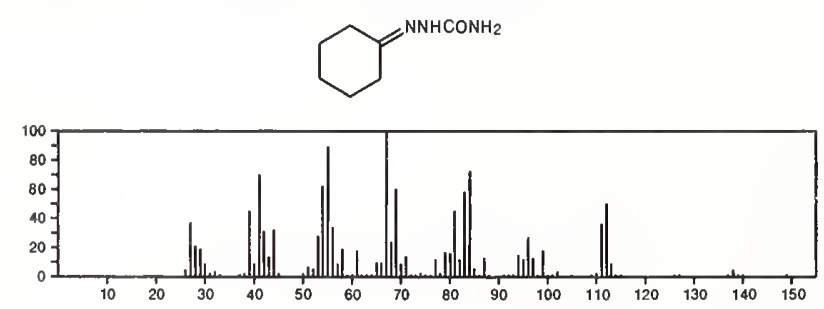

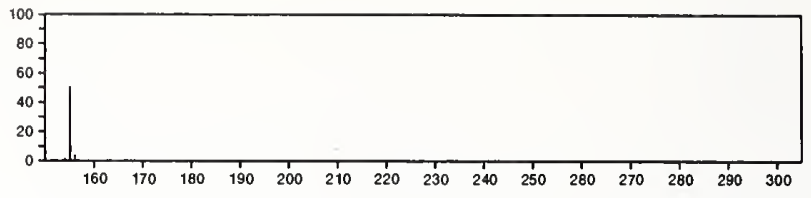

155

Benzenamine, 2-chloro- $N$-ethyl

\section{$\mathrm{C}_{8} \mathrm{H}_{10} \mathrm{ClN}$}

$\overbrace{\mathrm{Cl}}^{\mathrm{NHEt}}$
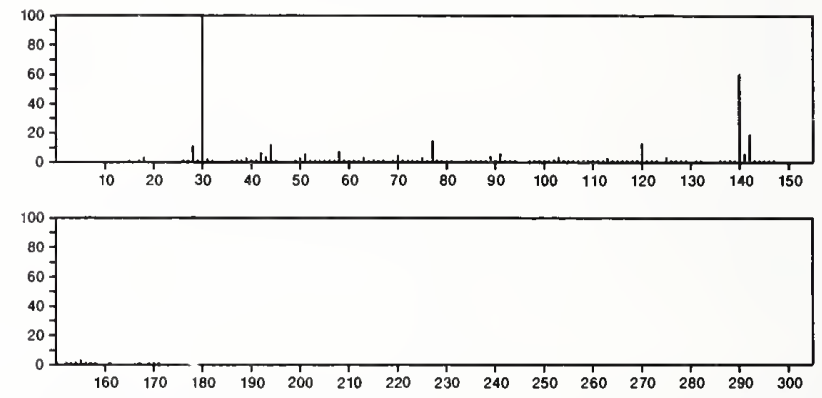

155

$\mathrm{C}_{8} \mathrm{H}_{13} \mathrm{NO}_{2}$

63-75-2

3-Pyridinecarboxylic acid, 1,2,5,6-tetrahydro-1-methyl-, methyl ester
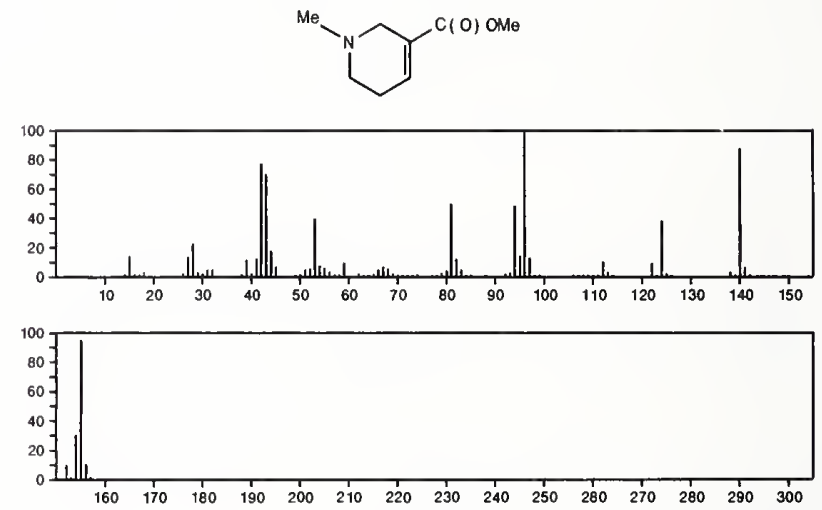

155

$\mathrm{C}_{8} \mathrm{H}_{13} \mathrm{NO}_{2}$

$520-63-8$

1H-Pyrrolizine-7-methanol, 2,3,5,7a-tetrahydro-1-hydroxy-, $(1 S-c i s)$ -
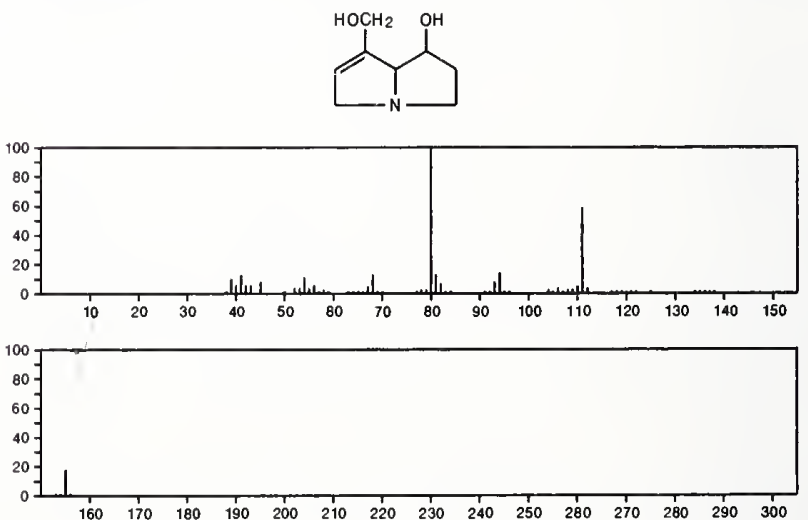
$155 \quad \mathrm{C}_{8} \mathrm{H}_{13} \mathrm{NO}_{2}$

Butanoic acid, 2-cyano-3-methyl-, ethyl ester

$3213-49-8$

$\mathrm{Me} 2 \mathrm{CHCH}(\mathrm{CN}) \mathrm{C}(0) \mathrm{OE}$
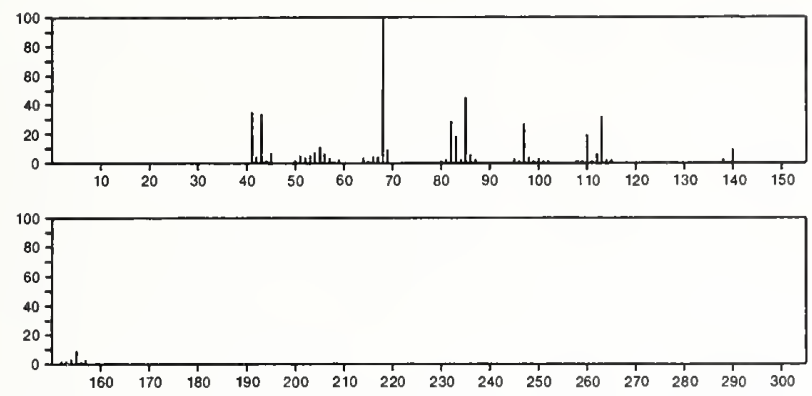

155

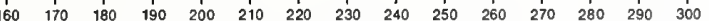

$\mathrm{C}_{8} \mathrm{H}_{13} \mathrm{NO}_{2}$

Hexanoic acid, 2-cyano-, methyl ester

$7309-46-8$

$\mathrm{MeOC}(\mathrm{O}) \mathrm{CH}(\mathrm{CN})\left(\mathrm{CH}_{2}\right)_{3} \mathrm{Me}$
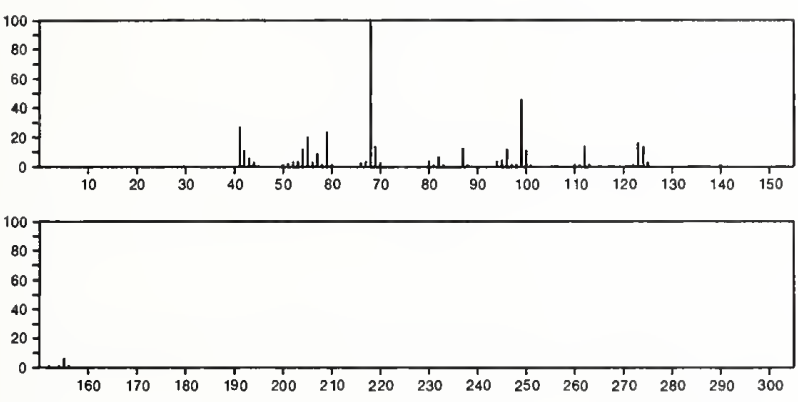

$155 \quad \mathrm{C}_{8} \mathrm{H}_{13} \mathrm{NO}_{2}$

Succinimide, 2-ethyl- $N, 2$-dimethyl-

$13861-99-9$
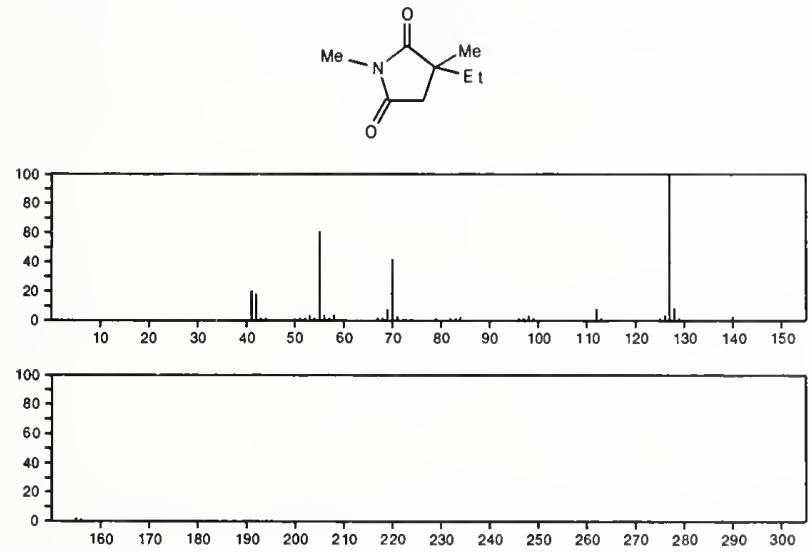

155

$\mathrm{C}_{8} \mathrm{H}_{13} \mathrm{NO}_{2}$

19822-83-4

Cyclopropanepropionic acid, $\alpha$-amino- $\beta$-methyl-2-methylene-
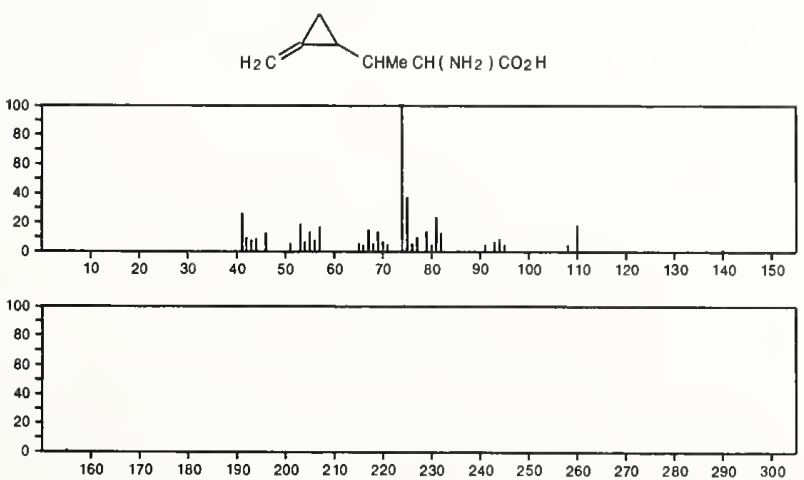

155

$\mathrm{C}_{8} \mathrm{H}_{13} \mathrm{NO}_{2}$

$25115-67-7$

Glutarimide, $N, 3,3$-trimethyl-<smiles>CN1C(=O)CC(C)(N)CC1=O</smiles>
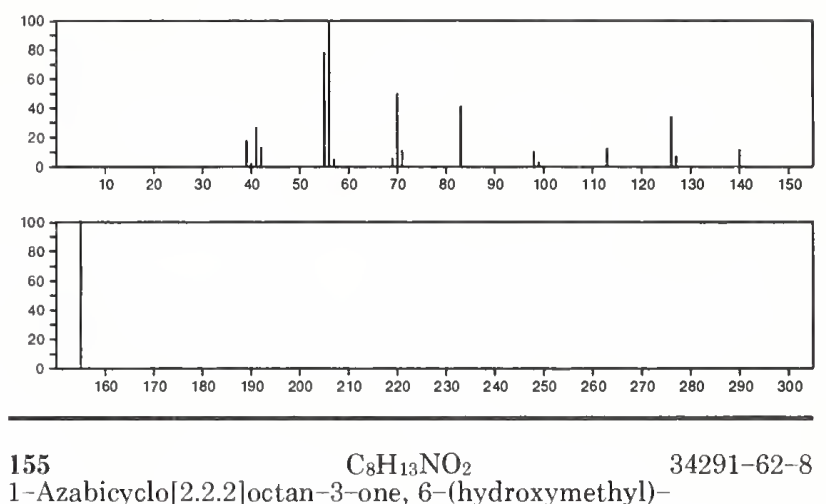

1-Azabicyclo[2.2.2] octan-3-one, 6-(hydroxymethyl)-
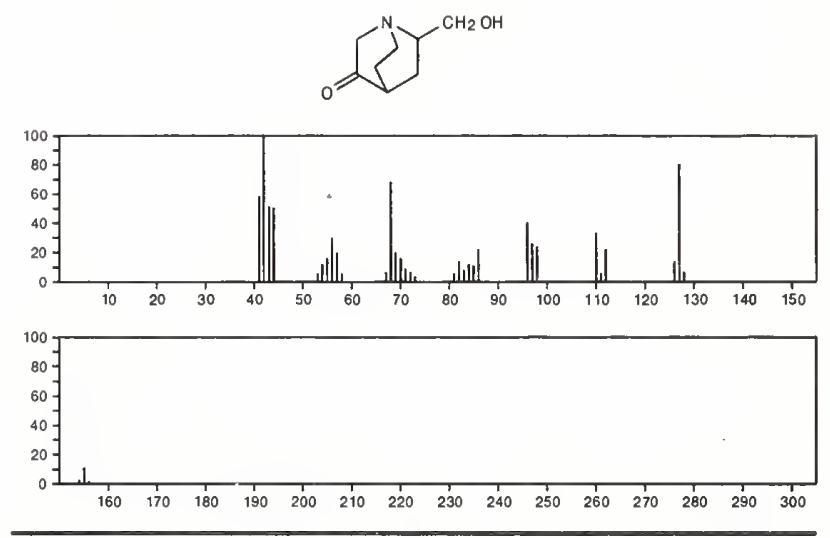

155

$\mathrm{C}_{8} \mathrm{H}_{13} \mathrm{NO}_{2}$

3-Piperidinone, 1-acetyl-6-methyl-

$54751-97-2$<smiles>CC1CCC(=O)CN1C</smiles>
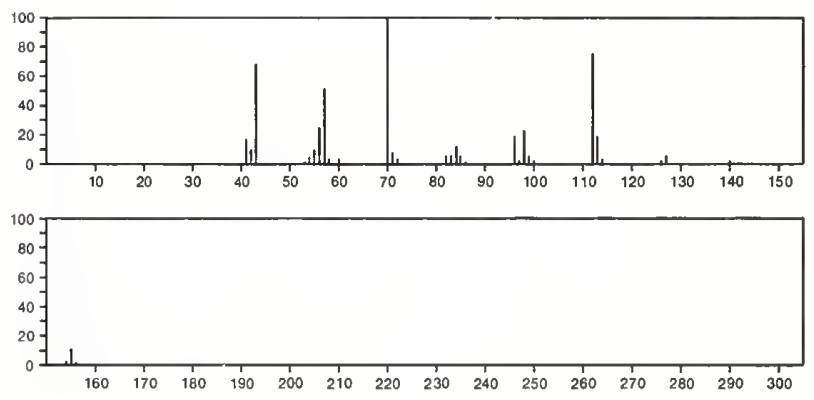

155

$\mathrm{C}_{8} \mathrm{H}_{13} \mathrm{NS}$

$15679-14-8$

Thiazole, 2-(1,1-dimethylethyl)-4-methyl-
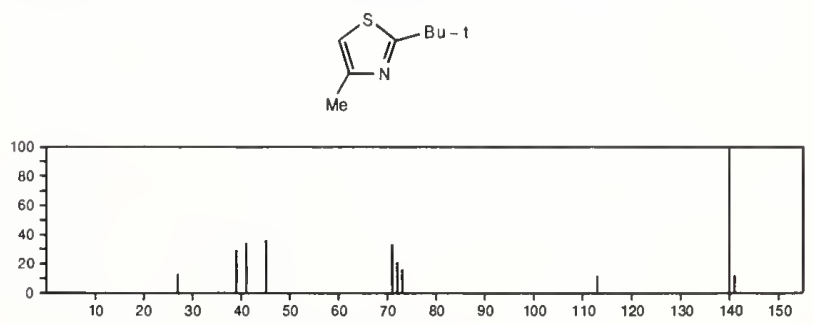


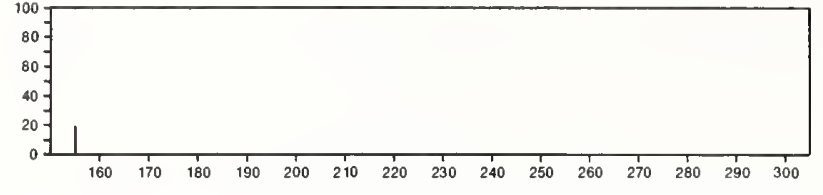

155

Thiazole, 2-ethyl-5-propyl-

\section{$\mathrm{C}_{8} \mathrm{H}_{13} \mathrm{NS}$}

$27149-25-3$
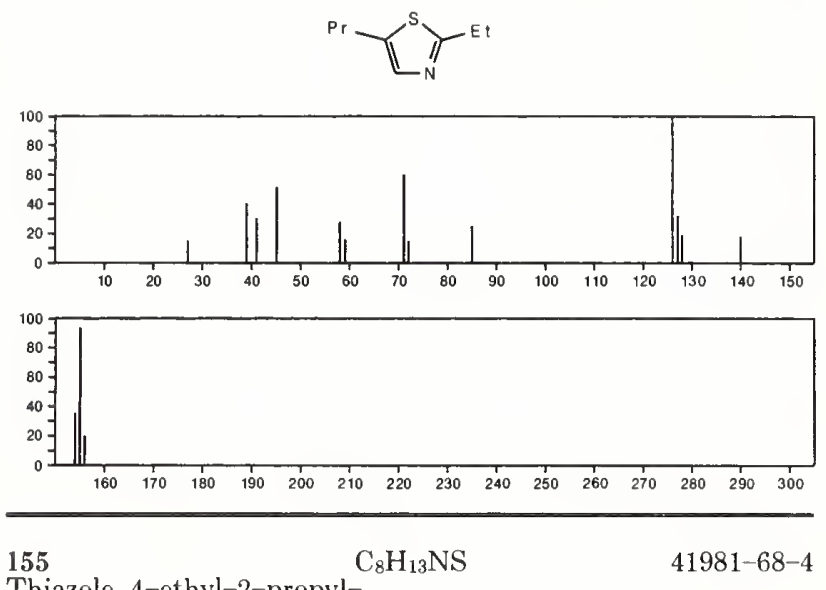

Thiazole, 4-ethyl-2-propyl-
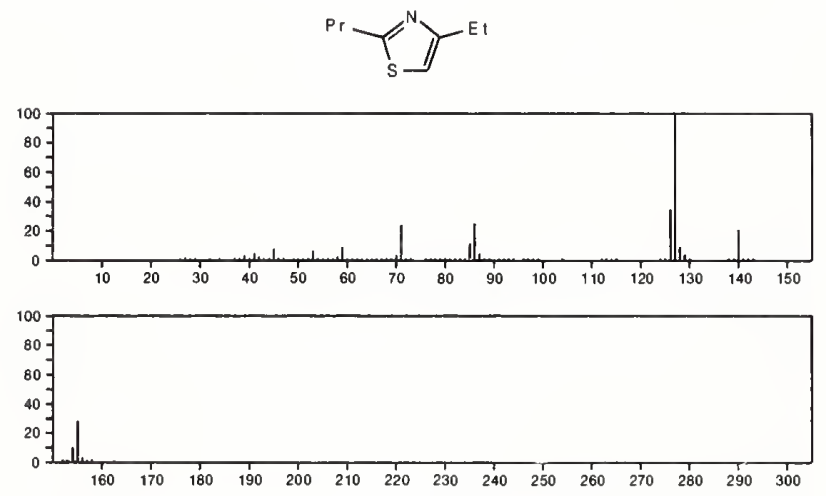

155

Thiazole, 4-butyl-2-methyl-

$\mathrm{C}_{8} \mathrm{H}_{13} \mathrm{NS}$

$41981-69-5$
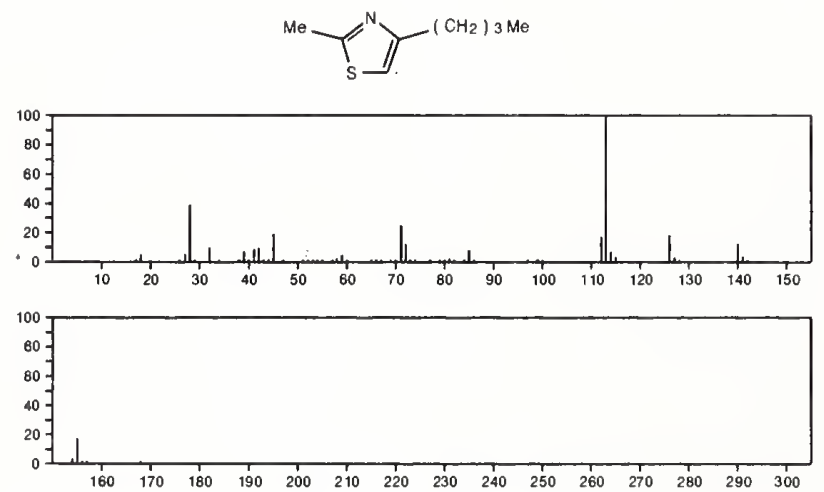

155

$\mathrm{C}_{8} \mathrm{H}_{13} \mathrm{NS}$

$41981-70-8$

Thiazole, 2,4-dimethyl-5-propyl-<smiles>CCCc1sc(N)nc1N</smiles>
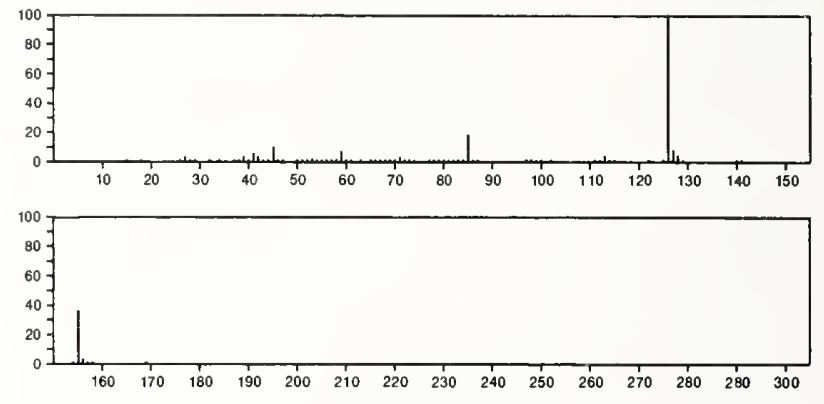

155

Thiazole, 2,5-diethyl-4-methyl-

$41981-71-9$<smiles>CCc1nc(CC)c(N)s1</smiles>
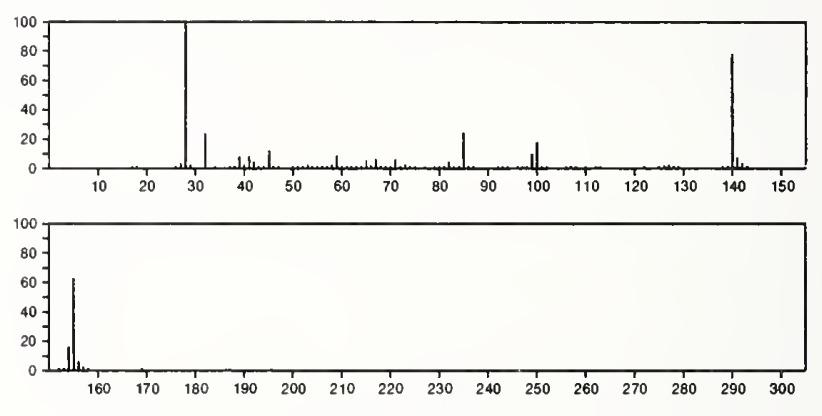

155

$\mathrm{C}_{8} \mathrm{H}_{13} \mathrm{NS}$

$41981-72-0$

Thiazole, 4,5-dimethyl-2-propyl
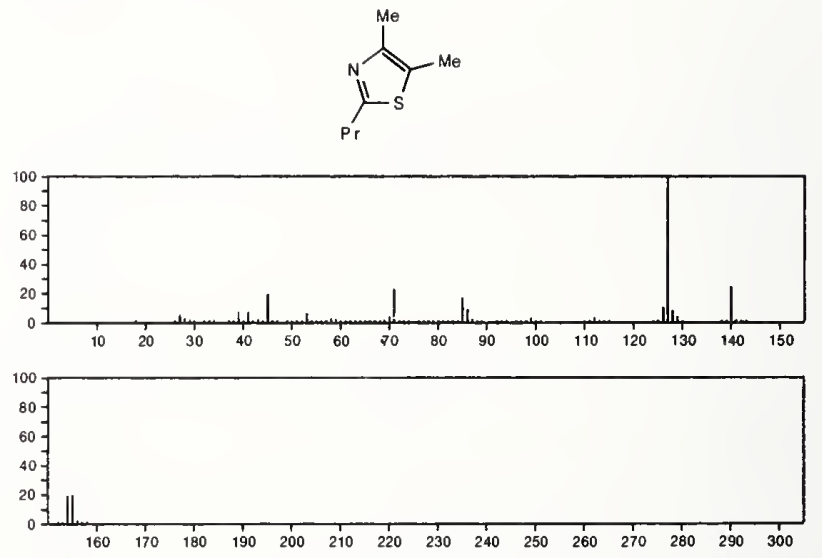

155

$\mathrm{C}_{8} \mathrm{H}_{1}: \mathrm{NS}$

$52414-85-4$

Thiazole, 2-butyl-5-methyl-
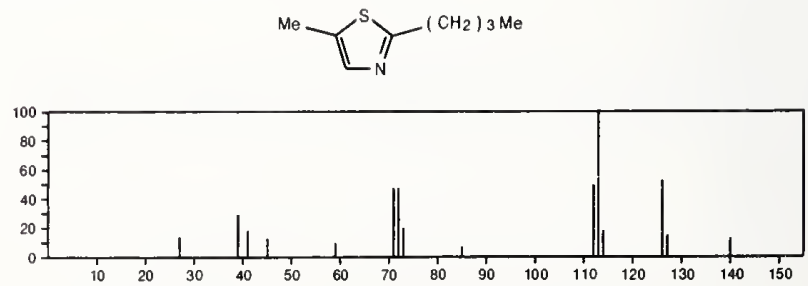


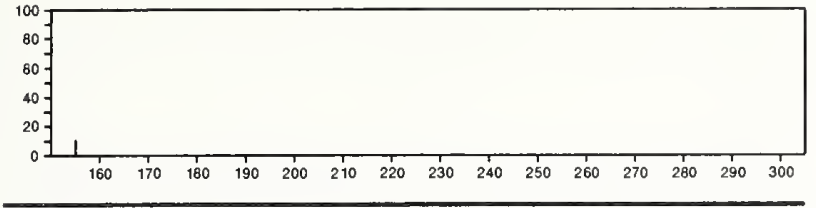

155

Thiazole, 2,4-diethyl-5-methyl-

\section{$\mathrm{C}_{8} \mathrm{H}_{13} \mathrm{NS}$}

$52414-89-8$<smiles>CCc1nc(CC)c(C)s1</smiles>
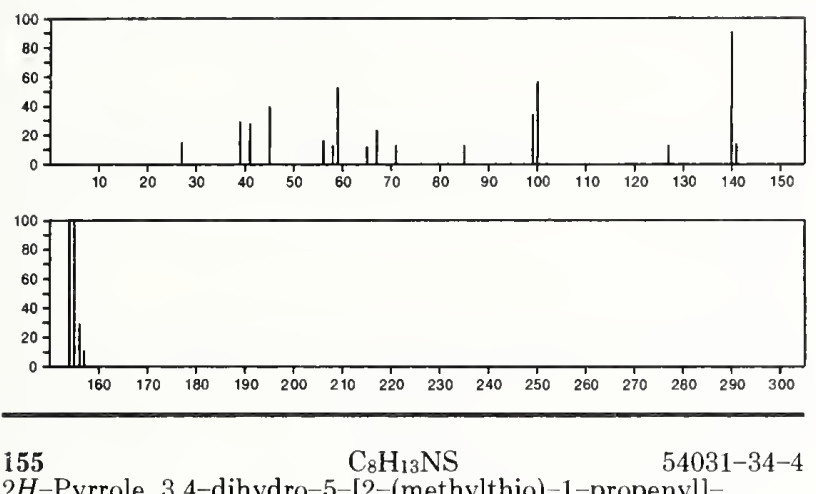

$2 H$-Pyrrole, 3,4-dihydro-5-[2-(methylthio)-1-propenyl]-
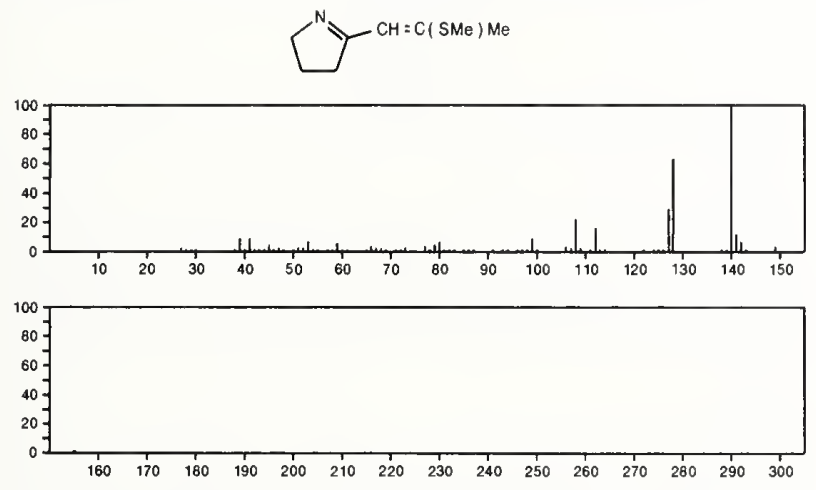

155

2-Propanone, 1-(1-methyl-2-piperidinyl)-

$553-77-5$
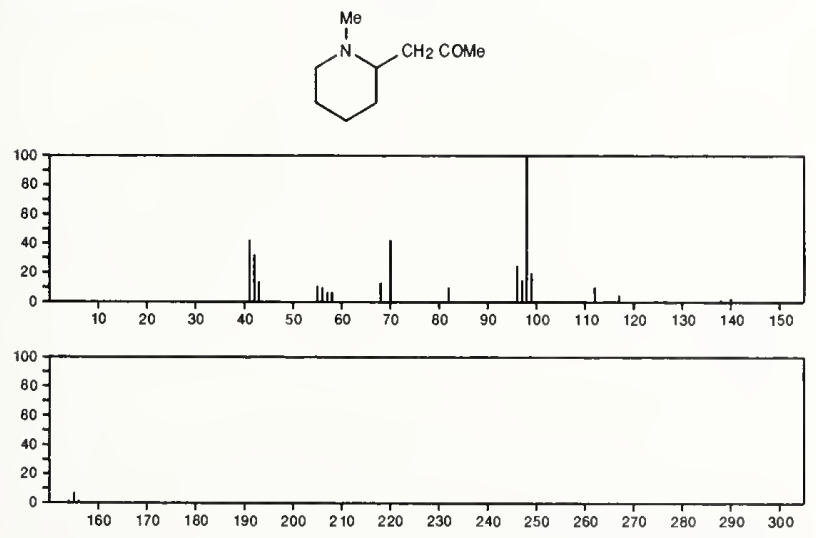

155

Cyclononanone, oxime

$\mathrm{C}_{9} \mathrm{H}_{17} \mathrm{NO}$

$2972-02-3$
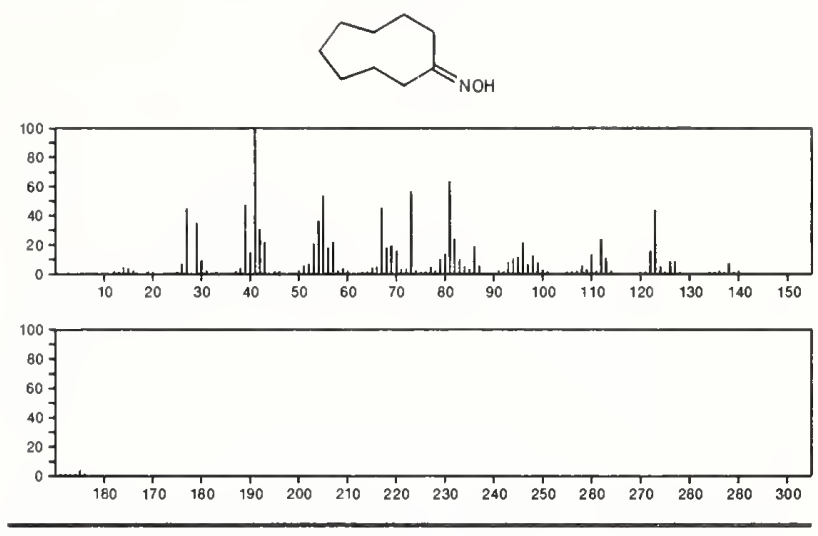

155

Pyrrolidine, 1-valeryl-

$\mathrm{C}_{9} \mathrm{H}_{17} \mathrm{NO}$

$4419-57-2$

$\mathrm{N}^{-\mathrm{CO}\left(\mathrm{CH}_{2}\right)_{3} \mathrm{Me}}$
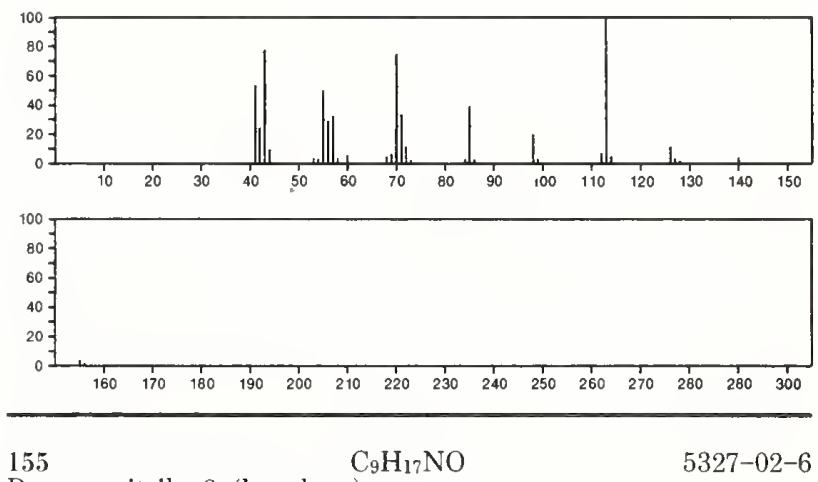

Propanenitrile, 3-(hexyloxy)-

$\mathrm{NCCH}_{2} \mathrm{CH}_{2} \mathrm{O}\left(\mathrm{CH}_{2}\right) 5 \mathrm{Me}$
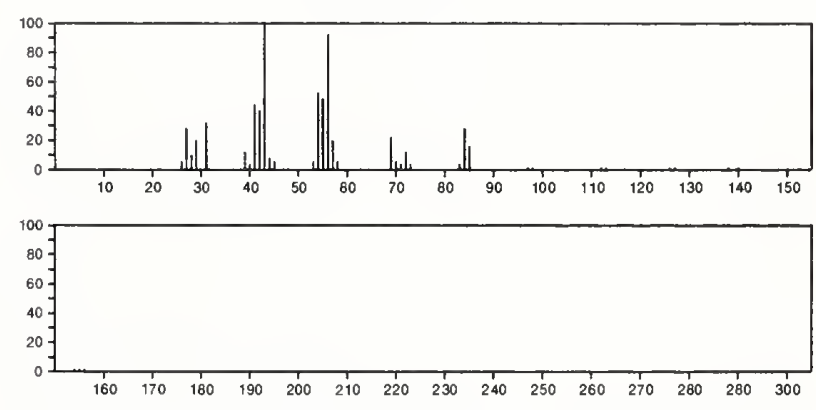

155

$\mathrm{C}_{9} \mathrm{H}_{17} \mathrm{NO}$

$2 \mathrm{H}$-Quinolizin-1-ol, octahydro-, cis-

$10447-19-5$
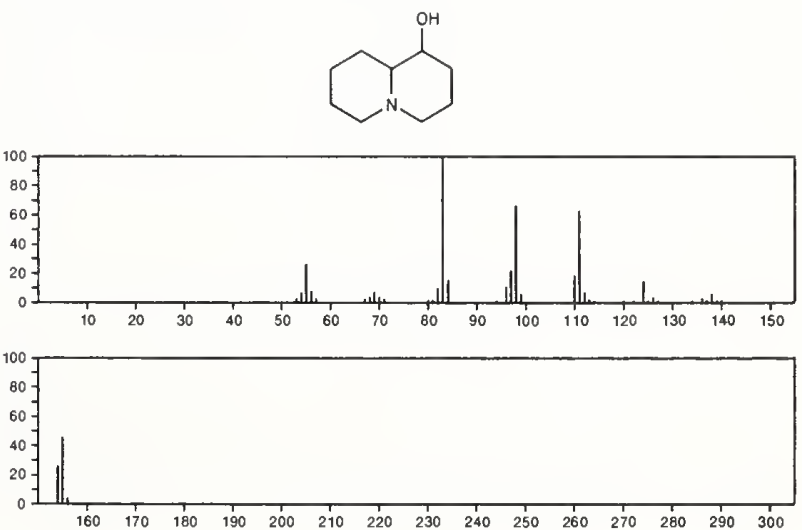
155 $\mathrm{C}_{9} \mathrm{H}_{17} \mathrm{NO}$

$2 \mathrm{H}^{-}$Quinolizin-1-ol, octahydro-, trans-

$10447-20-8$
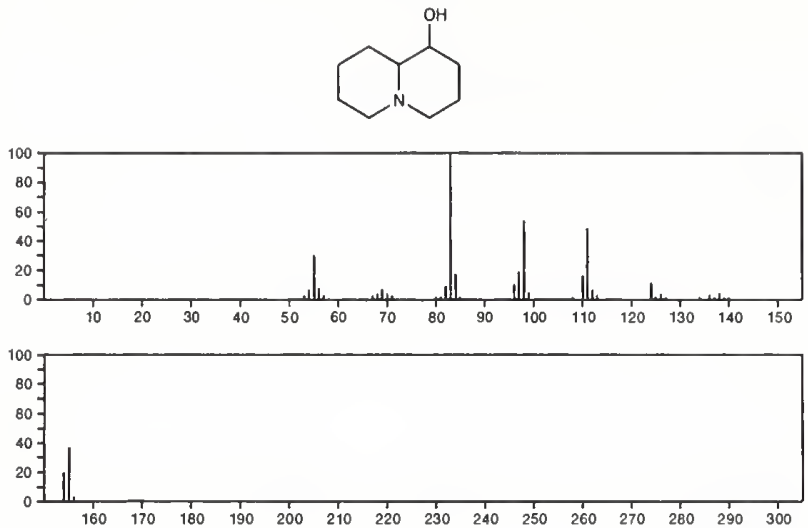

$\begin{array}{lllllllllllllll}160 & 170 & 180 & 190 & 200 & 210 & 220 & 230 & 240 & 250 & 260 & 270 & 280 & 290 & 100\end{array}$

155

3-Azabicyclo[3.3.1]nonan-9-ol, 3-methyl-, syn-
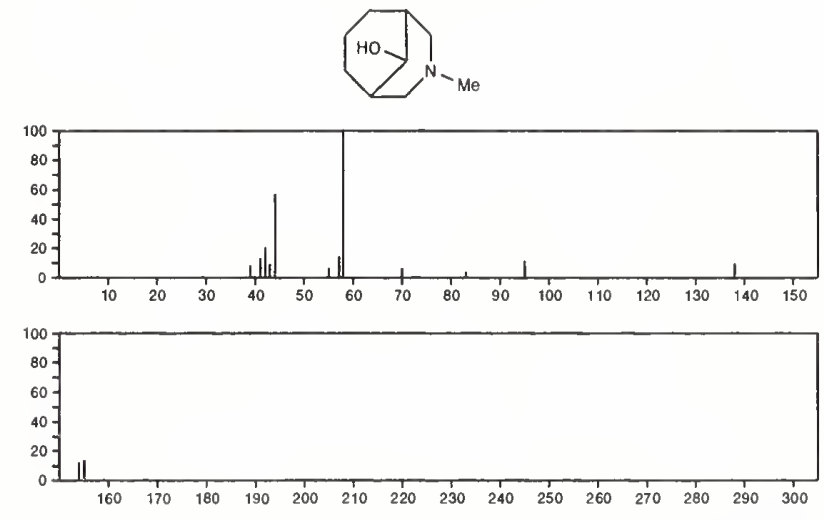

155

$\mathrm{C}_{9} \mathrm{H}_{17} \mathrm{NO}$

$13962-79-3$

3-Azabicyclo[3.3.1]nonan-9-ol, 3-methyl-, anti-
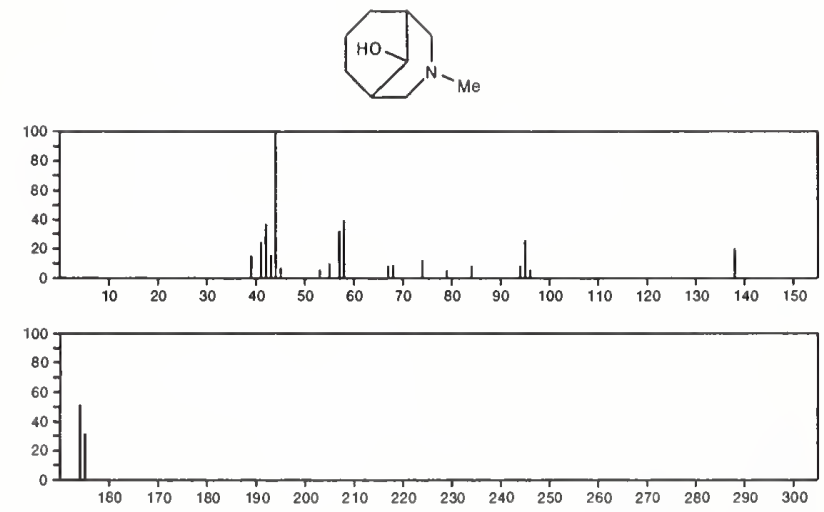

$155 \quad \mathrm{C}_{9} \mathrm{H}_{17} \mathrm{NO} \quad 15409-60-6$

Cyclohexanone, 2-[(dimethylamino)methyl]
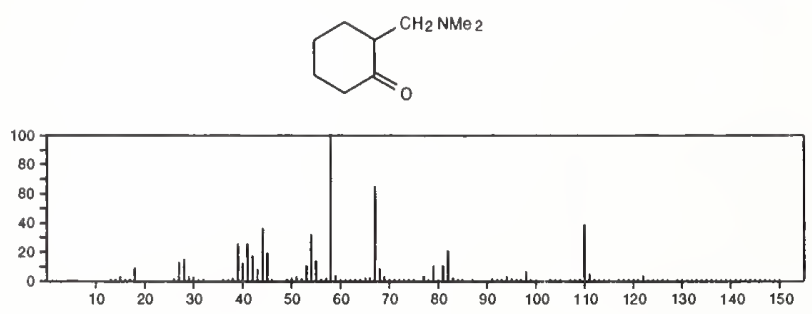

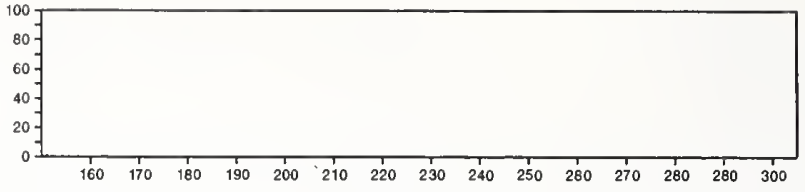

155

$\mathrm{C}_{9} \mathrm{H}_{17} \mathrm{NO}$

2H-Quinolizin-3-ol, octahydro-, trans-

15769-36-5
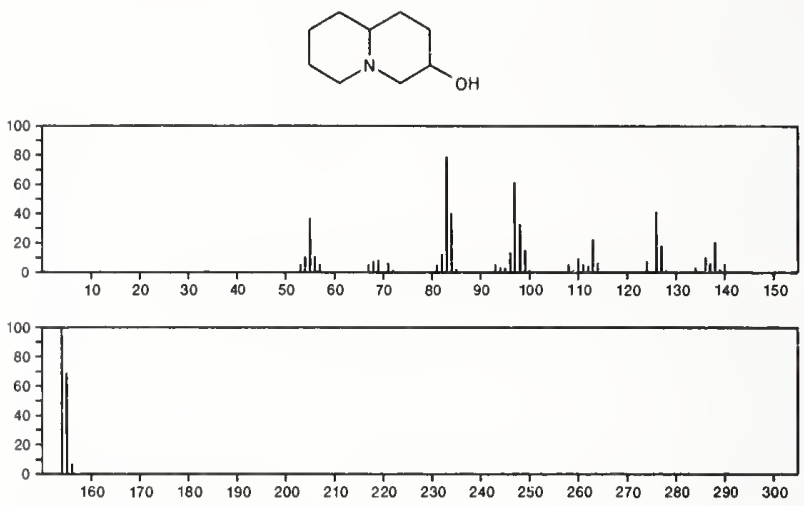

155

$\mathrm{C}_{9} \mathrm{H}_{17} \mathrm{NO}$

$22525-60-6$

$2 H$-Quinolizin-1-ol, octahydro-<smiles>OC1CCCN2CCCCC12</smiles>
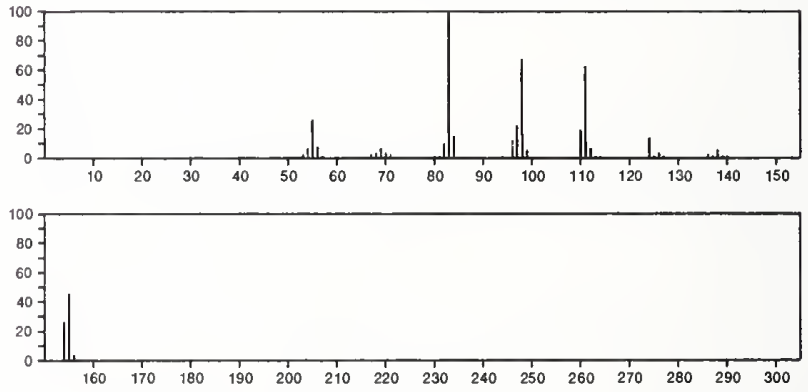

155

$\mathrm{C}_{9} \mathrm{H}_{17} \mathrm{NO}$

$24985-57-7$

2-Octen-4-one, 2-(methylamino)

$\mathrm{MeC}(\mathrm{NHMe})=\mathrm{CHCO}\left(\mathrm{CH}_{2}\right)_{3} \mathrm{Me}$
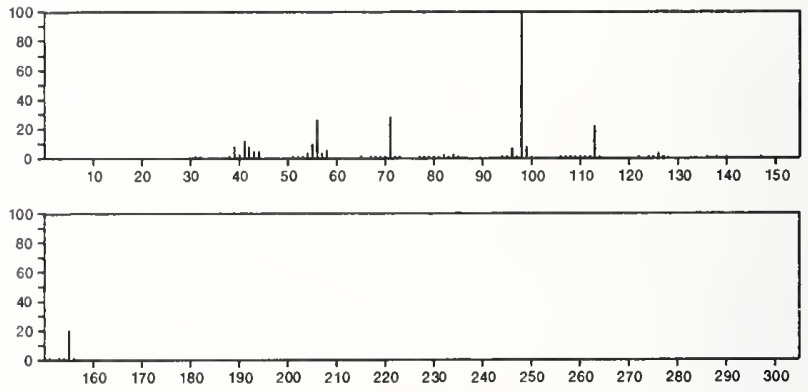

155

$\mathrm{C}_{9} \mathrm{H}_{17} \mathrm{NO}$

24985-58-8

3-Octen-2-one, 4-(methylamino)

$\mathrm{Me} \mathrm{COCH}: \mathrm{C}(\mathrm{NHMe})\left(\mathrm{CH}_{2}\right){ }_{3} \mathrm{Me}$

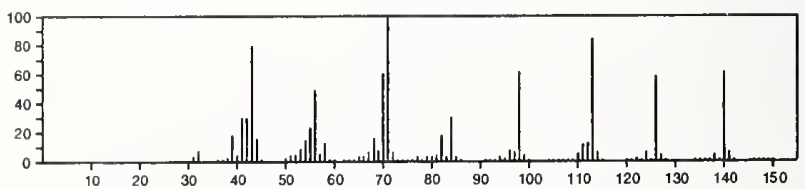




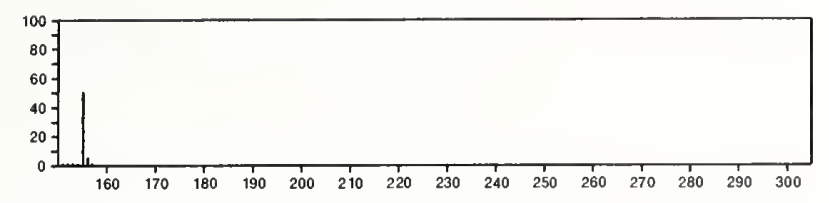

155

$\mathrm{C}_{9} \mathrm{H}_{17} \mathrm{NO}$

2H-Quinolizin-2-ol, octahydro-, trans-

$31172-60-8$
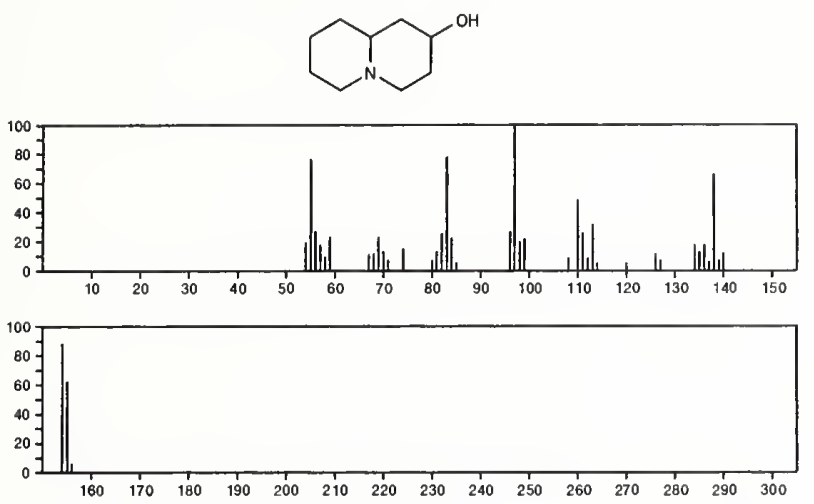

155

$\mathrm{C}_{9} \mathrm{H}_{17} \mathrm{NO}$

$35790-99-9$

6-Azabicyclo[3.2.1]octane, 5-methoxy-6-methyl-
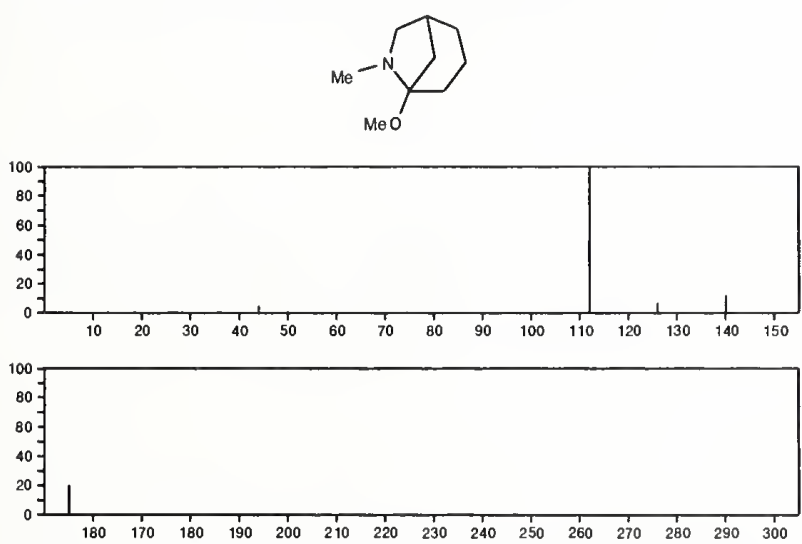

$\begin{array}{lllllllllllllll}180 & 170 & 180 & 190 & 200 & 210 & 220 & 230 & 240 & 250 & 260 & 270 & 280 & 290 & 300\end{array}$

155

$\mathrm{C}_{9} \mathrm{H}_{17} \mathrm{NO}$

$37835-57-7$

4-Pyridinemethanol, 1-ethyl-1,2,3,6-tetrahydro- $\alpha$-methyl-
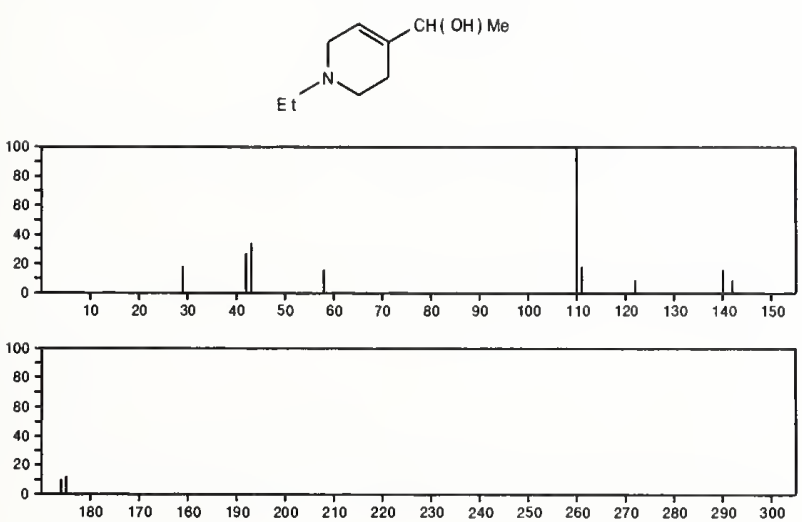

155

3-Octen-2-one, $O$ methyloxime

$\mathrm{C}_{9} \mathrm{H}_{17} \mathrm{NO}$

39209-05-7

$\mathrm{Me}\left(\mathrm{CH}_{2}\right)_{3} \mathrm{CH}=\mathrm{CHCMe}=\mathrm{NOMe}$
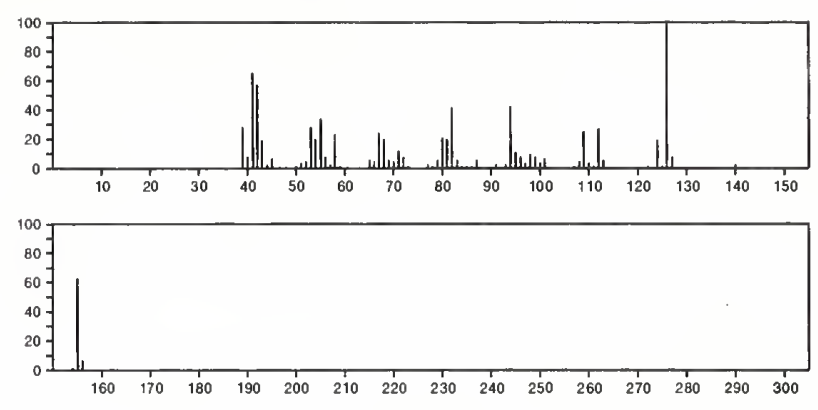

$155 \quad \mathrm{C}_{9} \mathrm{H}_{17} \mathrm{NO}$

Acetamide, $N$-cyclopentyl- $N$-ethyl-

$54244-76-7$
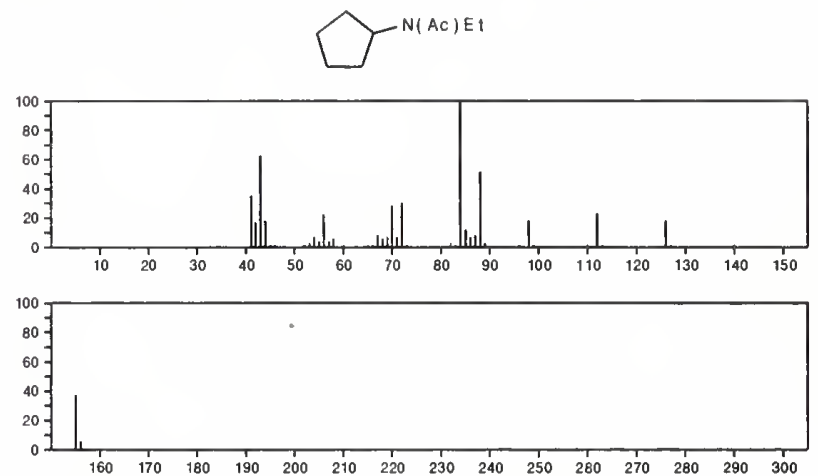

155
$2 \mathrm{H}^{-}$Quinolizin-3-ol, octahydro-
$\mathrm{C}_{9} \mathrm{H}_{17} \mathrm{NO}$

$54308-61-1$
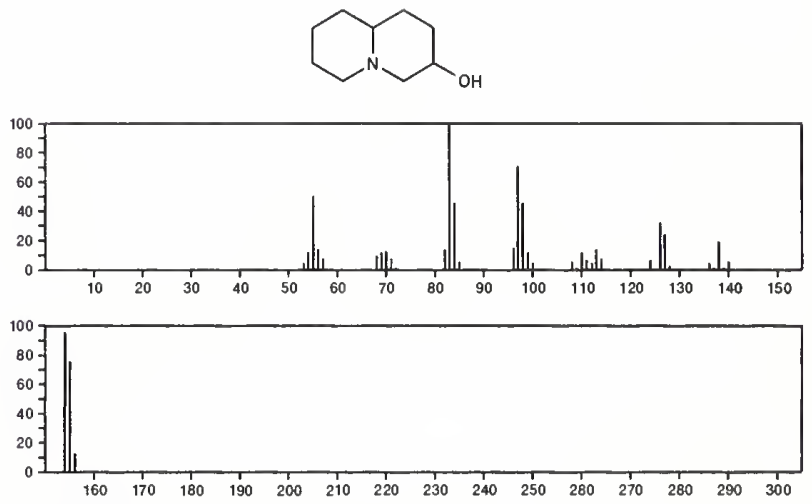

155

2H-Quinolizin-2-ol, octahydro-

\section{$\mathrm{C}_{9} \mathrm{H}_{17} \mathrm{NO}$}

54308-62-2
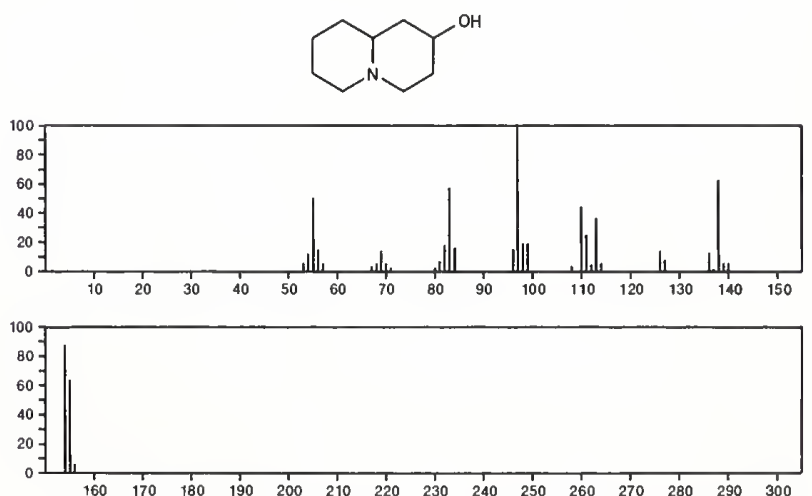
155 Cyclohexaneethanamine, $N, \alpha$-dimethyl-

$101-40-6$
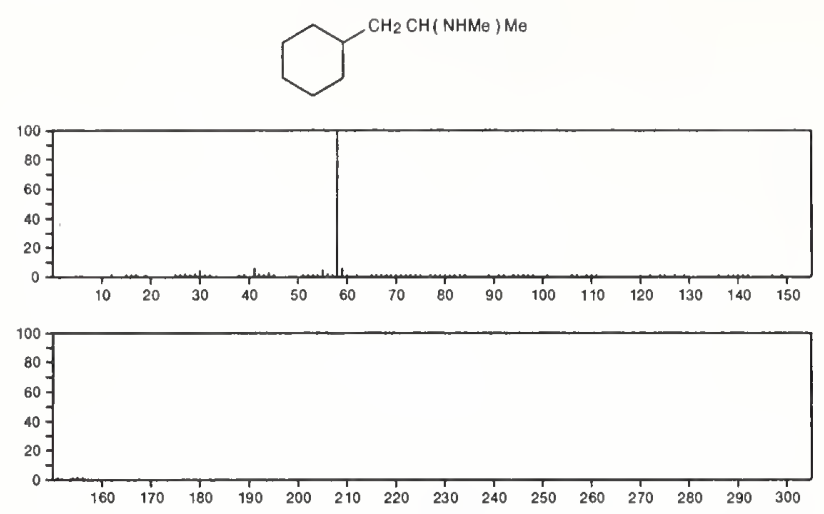

155

Piperidine, 1-pentyl-

$\mathrm{C}_{10} \mathrm{H}_{21} \mathrm{~N}$

$10324-58-0$
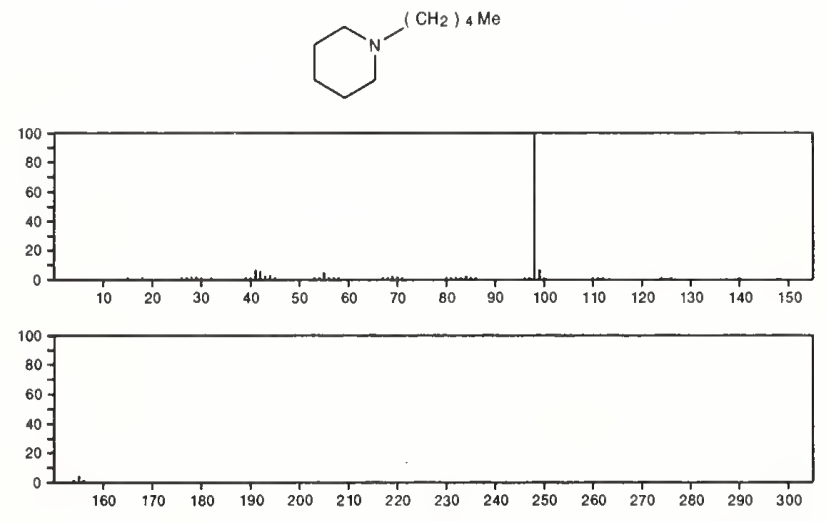

155

Methylamine, $N-$ (1-butylpentylidene)

$10599-81-2$

$\left(\mathrm{CH}_{2}\right)_{3} \mathrm{Me}$

$\mathrm{Me}\left(\mathrm{CH}_{2}\right)_{3} \mathrm{C}=\mathrm{NM}$
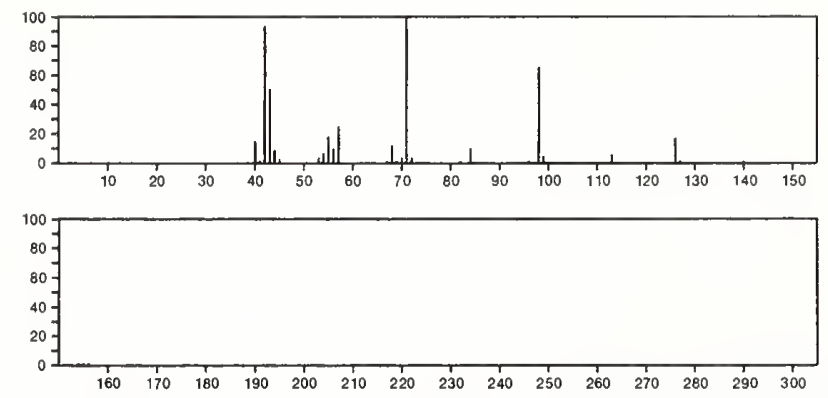

$155 \quad \mathrm{C}_{10} \mathrm{H}_{21} \mathrm{~N}$

Methylamine, $N$-(1-isopropylhexylidene)-

$\mathrm{CHMe} 2$

$\mathrm{Me}\left(\mathrm{CH}_{2}\right){ }_{4} \mathrm{C}=\mathrm{NMe}$

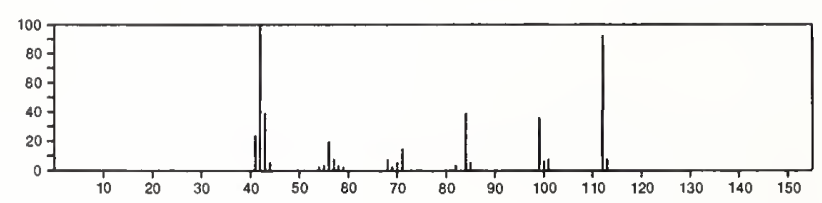

155

$\mathrm{C}_{10} \mathrm{H}_{21} \mathrm{~N}$

$23399-21-5$

Cyclohexanamine, 5-methyl-2-(1-methylethyl)-, $(1 \alpha, 2 \alpha, 5 \beta)-$<smiles>CC1CCC(PI)C(N)C1</smiles>
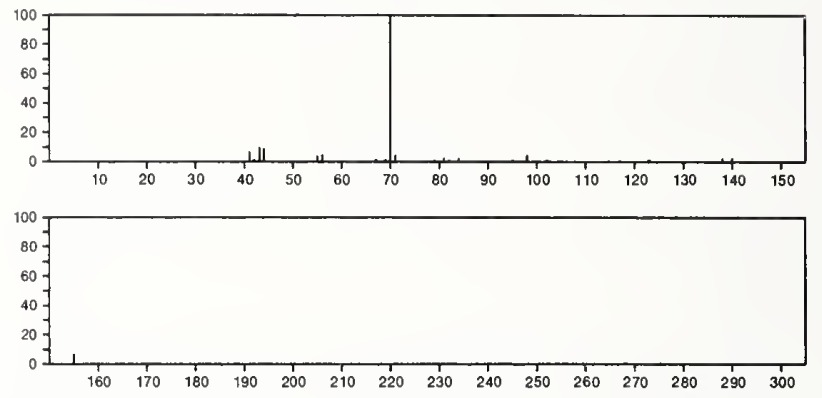

155

$\mathrm{C}_{10} \mathrm{H}_{21} \mathrm{~N}$

1-Butanamine, 2-methyl- $N$-(2-methylbutylidene)-

$54518-97-7$

$\mathrm{Me} \mathrm{CH}_{2} \mathrm{CHMe} \mathrm{CH}_{2} \mathrm{~N}=\mathrm{CHCHMe}_{2} \mathrm{CH}_{2} \mathrm{Me}$
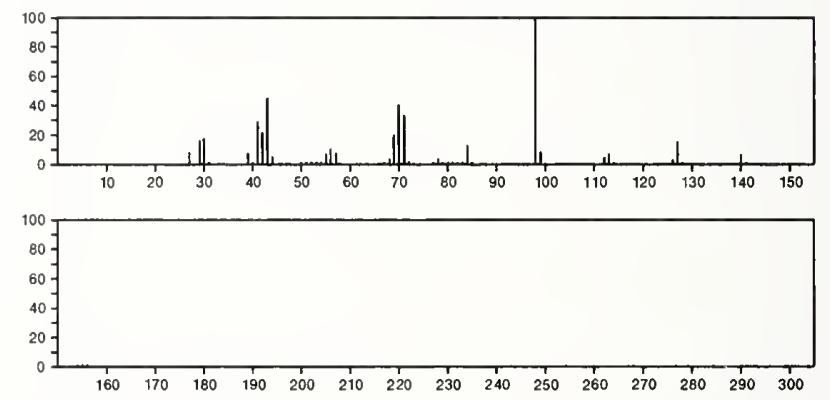

155

$\mathrm{C}_{10} \mathrm{H}_{21} \mathrm{~N}$

3-Octen-2-amine, $N, N$-dimethyl-, $(E)$

$55956-31-5$

$\mathrm{Me}\left(\mathrm{CH}_{2}\right)_{3} \mathrm{CH}=\mathrm{CHCHMeNMe} 2$
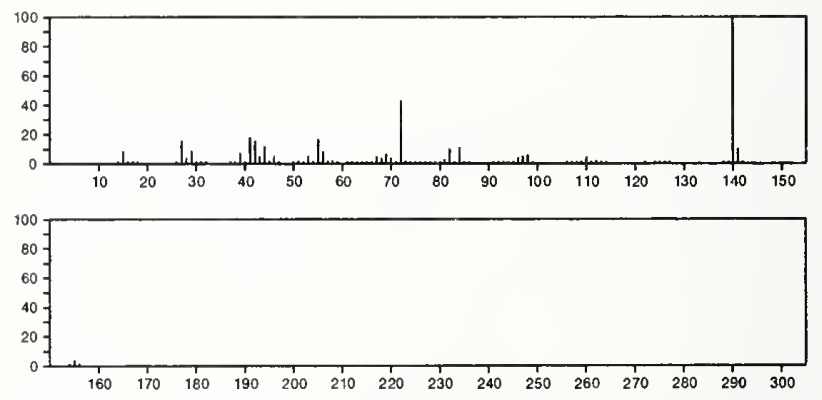

156

$\mathrm{C}_{2} \mathrm{H}_{5} \mathrm{I}$

75-03-6

Ethane, iodo-

Et l
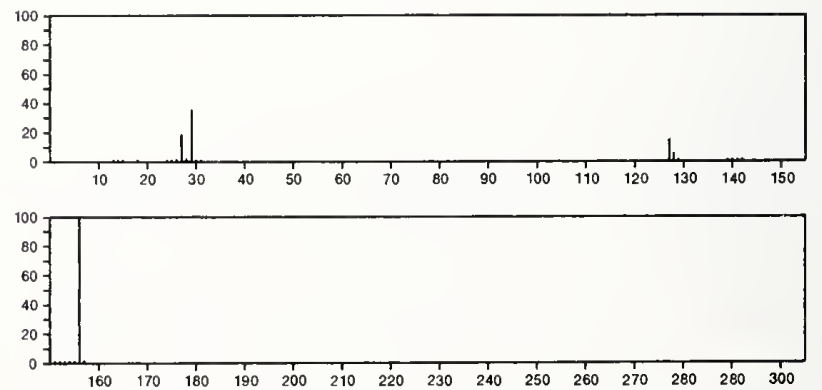
156 $\mathrm{C}_{3} \mathrm{H}_{3} \mathrm{BrF}_{2}$

Propene, 3-bromo-3,3-difluoro-

$420-90-6$

$\mathrm{F}_{2} \mathrm{CBrCH}: \mathrm{CH}_{2}$

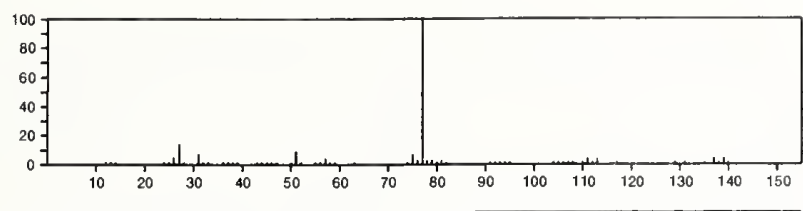

156 $\mathrm{C}_{3} \mathrm{H}_{6} \mathrm{BrCl}$

$109-70-6$

Propane, 1-bromo-3-chloro-

$\mathrm{Br}\left(\mathrm{CH}_{2}\right)_{3} \mathrm{Cl}$
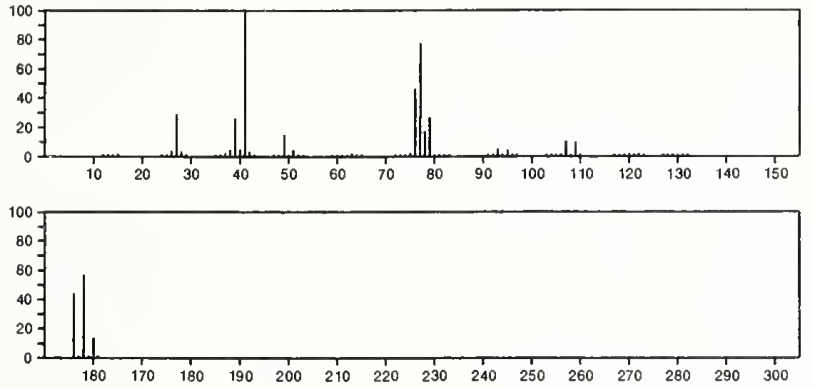

156

$\mathrm{C}_{3} \mathrm{H}_{6} \mathrm{BrCl}$

$3017-95-6$

Propane, 2-bromo-1-chloro-

$\mathrm{Cl} \mathrm{CH}_{2} \mathrm{CHBrMe}_{\mathrm{Me}}$
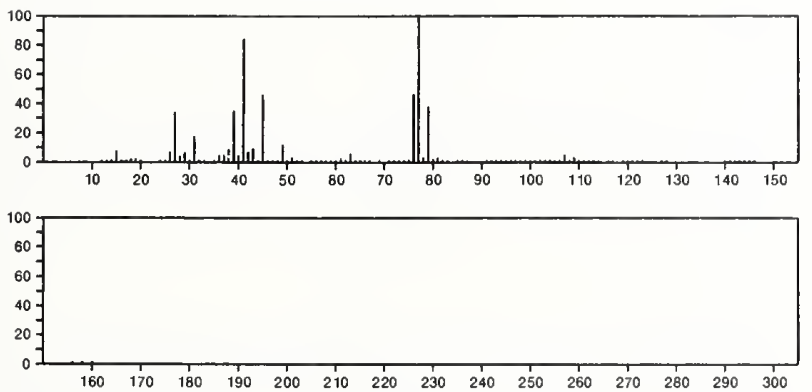

156

$\mathrm{C}_{3} \mathrm{H}_{9} \mathrm{O}_{3} \mathrm{PS}$

$152-18-1$

Phosphorothioic acid, $O, O, O$-trimethyl ester
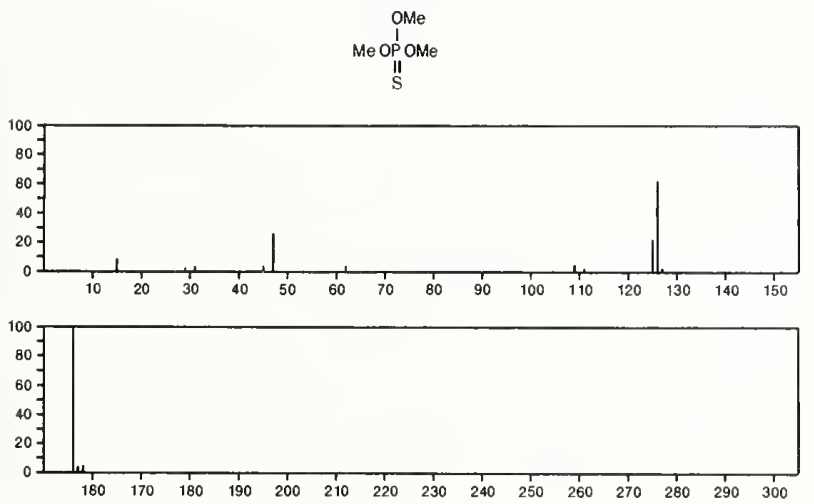

$156 \quad \mathrm{C}_{3} \mathrm{H}_{9} \mathrm{O}_{3} \mathrm{PS}$

Phosphorothioic acid, $O, O, S$-trimethyl ester

$152-20-5$
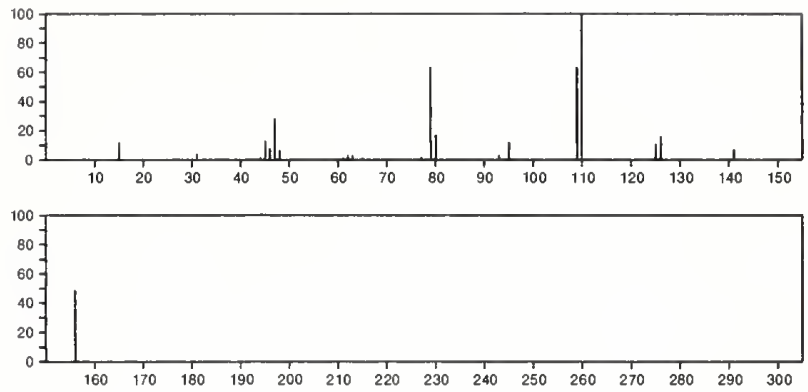

156

$\mathrm{C}_{3} \mathrm{H}_{10} \mathrm{FN}_{2} \mathrm{PS}$

$36267-52-4$

Phosphonofluoridothioic hydrazide, $P, 2,2$-trimethyl-

$\mathrm{S}: \mathrm{PF}$ (Me) NHNME 2
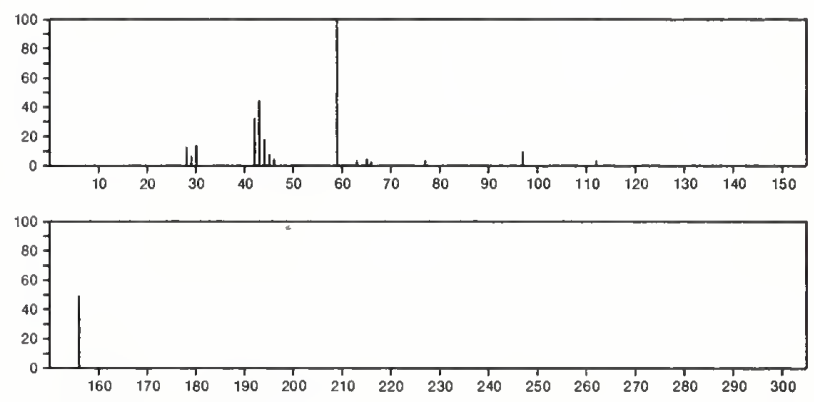

156

1,4-Dioxane, 2,3-dichloro-

$\mathrm{C}_{4} \mathrm{H}_{6} \mathrm{Cl}_{2} \mathrm{O}_{2}$

$95-59-0$<smiles>ClC1OCCOC1Cl</smiles>
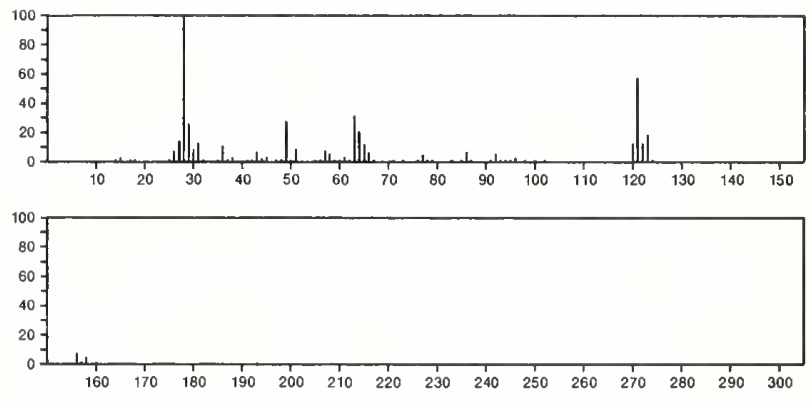

156

$\mathrm{C}_{4} \mathrm{H}_{6} \mathrm{Cl}_{2} \mathrm{O}_{2}$

Acetic acid, dichloro-, ethyl ester

$\mathrm{E}+\mathrm{OC}(\mathrm{O}) \mathrm{CHCl}_{2}$
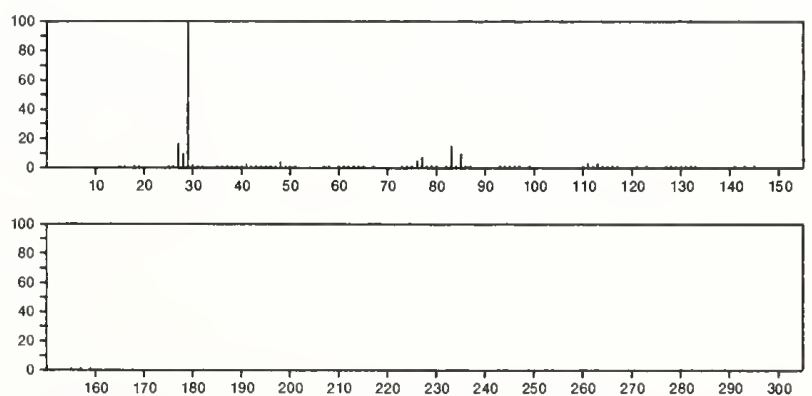
156

Butyric acid, 2,3-dichloro-

$\mathrm{C}_{4} \mathrm{H}_{6} \mathrm{Cl}_{2} \mathrm{O}_{2}$

$600-32-8$

$\mathrm{MeCHCl} \mathrm{CHCl} \mathrm{CO}_{2} \mathrm{H}$
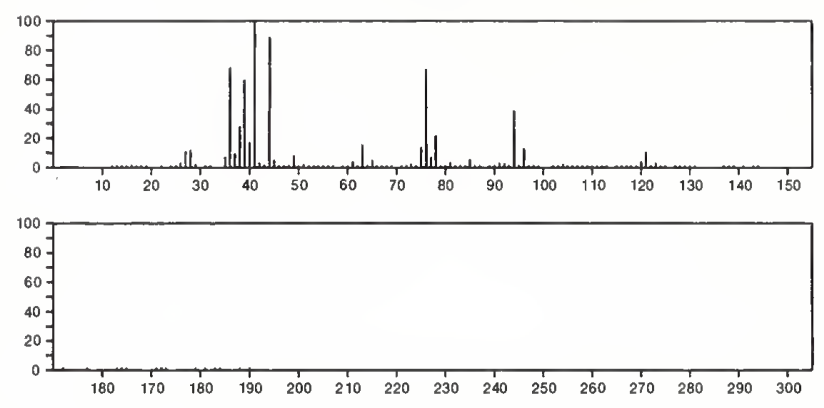

156

Carbonochloridic acid, 2-chloro-1-methylethyl ester

$\mathrm{ClC}(\mathrm{O}) \mathrm{OCHMeCH}_{2} \mathrm{Cl}$

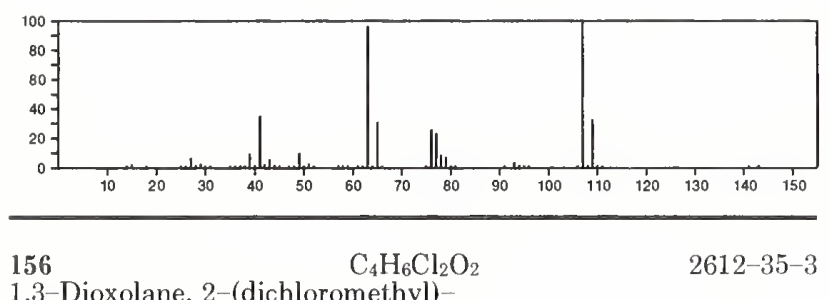

1,3-Dioxolane, 2-(dichloromethyl)-
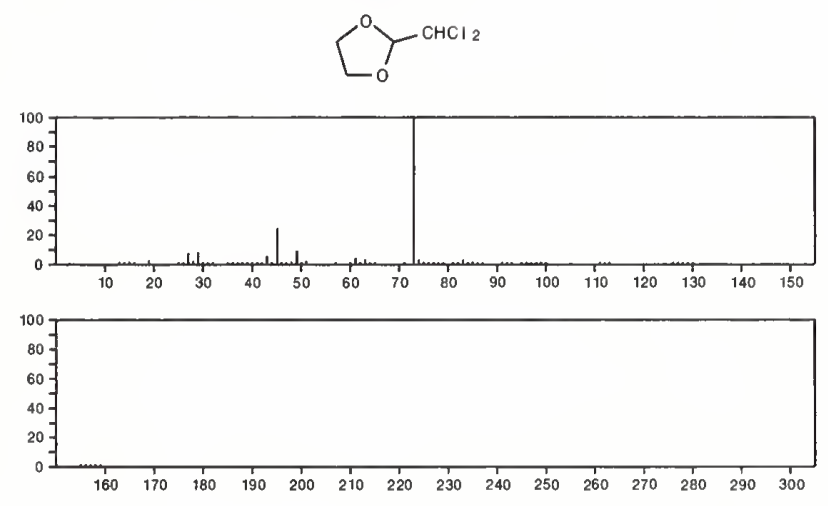

156

Propanoic acid, 2,3-dichloro-, methyl ester

$3674-09-7$
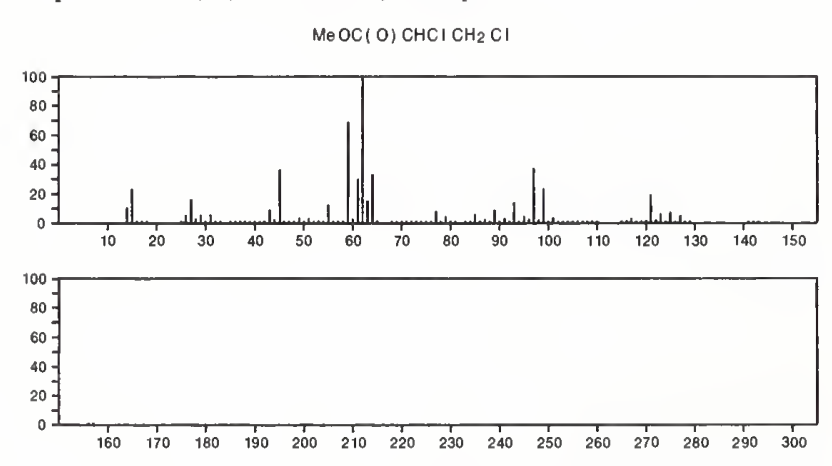

156

Butyric acid, 2,2-dichloro-

$\mathrm{C}_{4} \mathrm{H}_{6} \mathrm{Cl}_{2} \mathrm{O}_{2}$

$\mathrm{E}\left(\mathrm{CCl}_{2}\left(\mathrm{CO}_{2} \mathrm{H}\right)\right.$

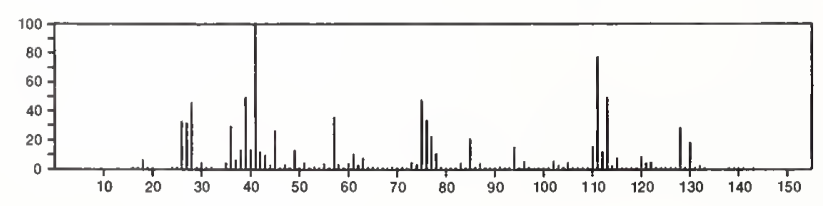

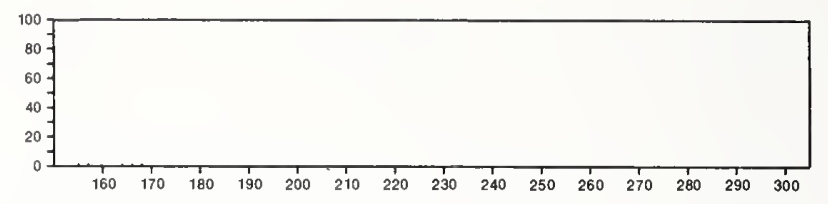

156

$\mathrm{C}_{4} \mathrm{H}_{6} \mathrm{Cl}_{2} \mathrm{O}_{2}$

Propanoic acid, 2,2-dichloro-, methyl ester

$17640-02-7$

$\mathrm{MeOC}(\mathrm{O}) \mathrm{CCl}_{2} \mathrm{Me}$
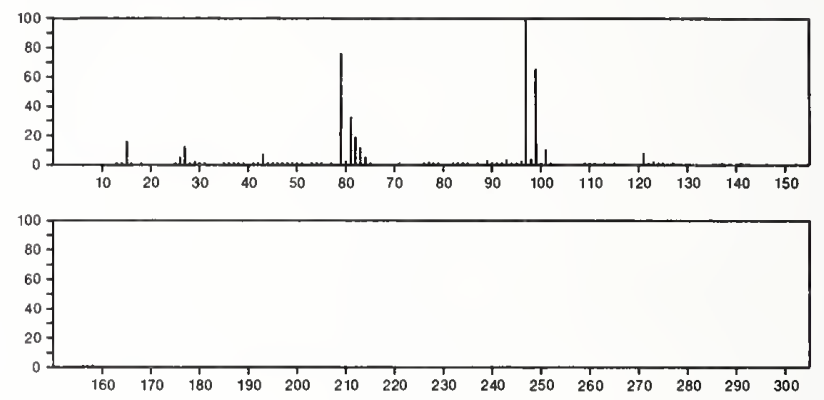

$156 \quad \mathrm{C}_{5} \mathrm{H}_{4} \mathrm{~N}_{2} \mathrm{O}_{4}$

$65-86-1$

4-Pyrimidinecarboxylic acid, 1,2,3,6-tetrahydro-2,6-dioxo-
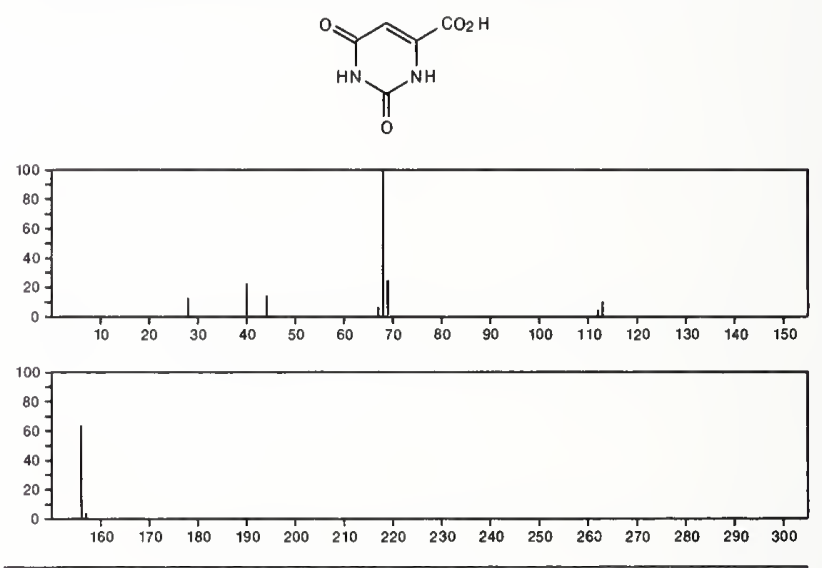

156

2,5-Furandicarboxylic acid

$\mathrm{C}_{6} \mathrm{H}_{4} \mathrm{O}_{5}$

$3238-40-2$
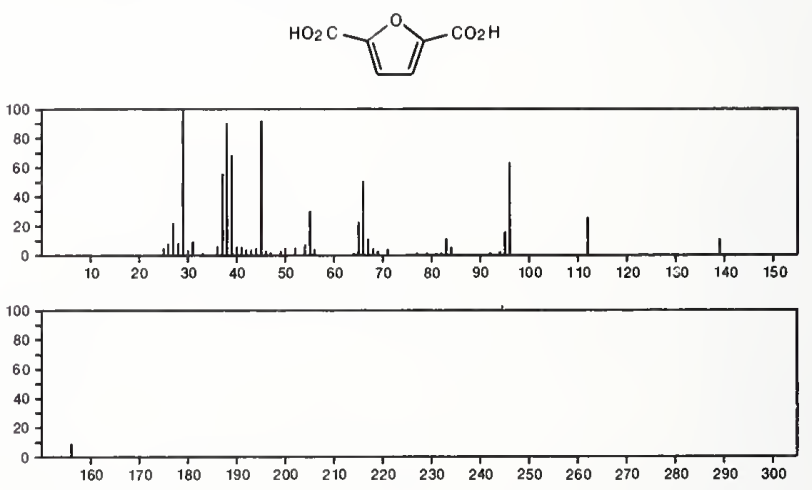
156

3,4-Furandicarboxylic acid

$\mathrm{C}_{6} \mathrm{H}_{4} \mathrm{O}_{5}$
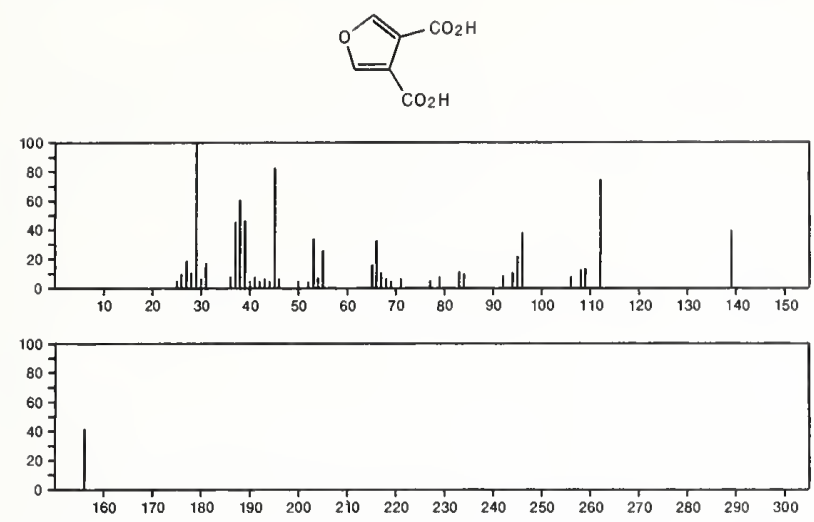

156

Benzene, bromo-

$\mathrm{C}_{6} \mathrm{H}_{5} \mathrm{Br}$

$108-86-1$
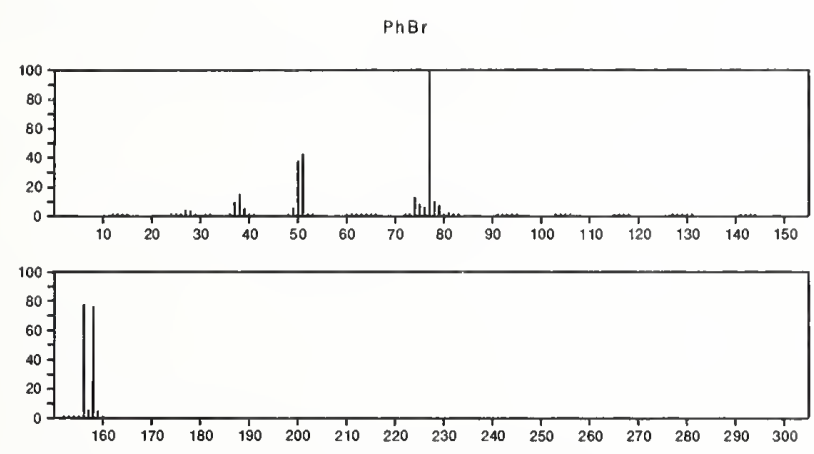

156

$\mathrm{C}_{6} \mathrm{H}_{8} \mathrm{~N}_{2} \mathrm{OS}$

4(1H)-Pyrimidinone, 2-(ethylthio)-
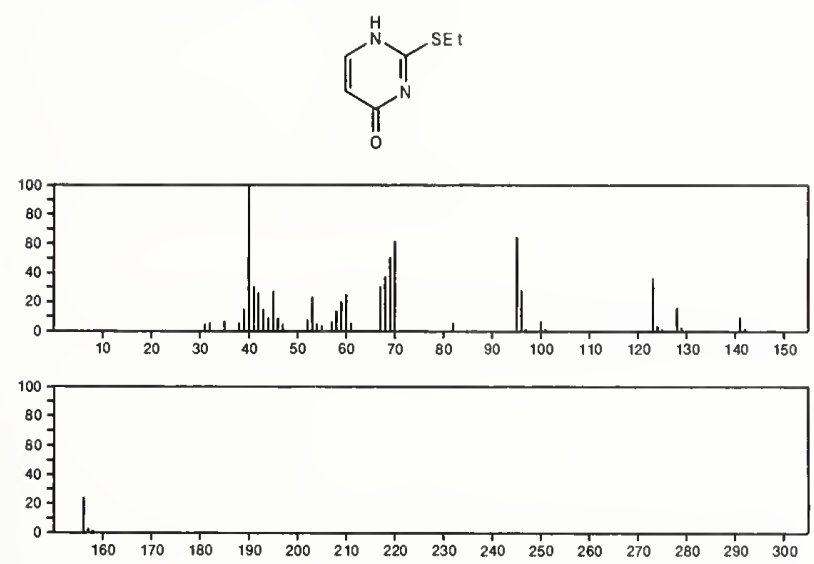

156

4(1H)-Pyrimidinone, 5-methyl-2-(methylthio)-
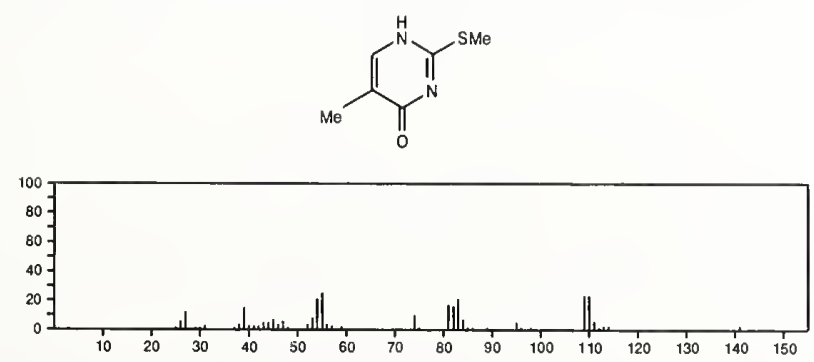

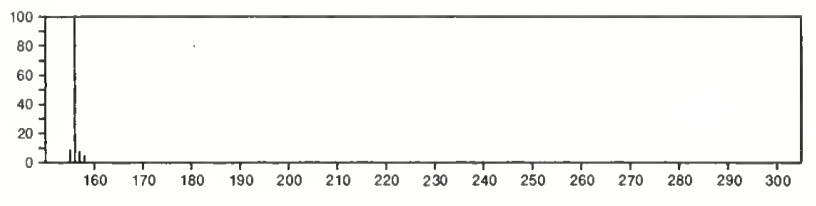

156

$\mathrm{C}_{6} \mathrm{H}_{8} \mathrm{~N}_{2} \mathrm{OS}$

35231-61-9

5-Pyrimidinol, 2-methyl-4-(methylthio)-
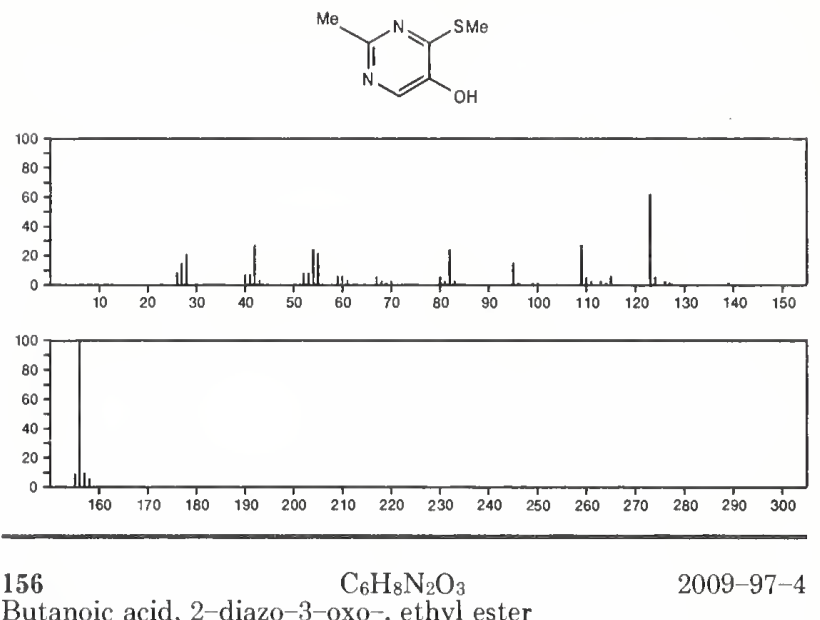

Butanoic acid, 2-diazo-3-0xo-, ethyl ester

EtoC(O) $\stackrel{\mathrm{N}^{\mathrm{N}}}{\mathrm{CCOM}}$
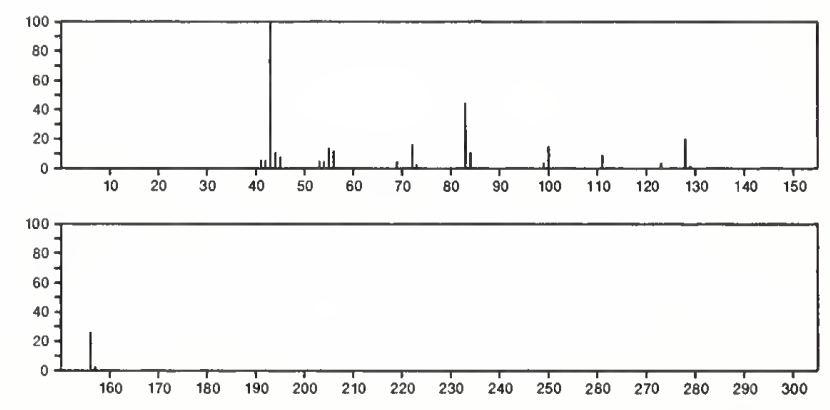

156

$\mathrm{C}_{6} \mathrm{H}_{8} \mathrm{~N}_{2} \mathrm{O}_{3}$

$55557-01-2$

3-Pyridinecarboxylic acid, 1,2,5,6-tetrahydro-1-nitroso-
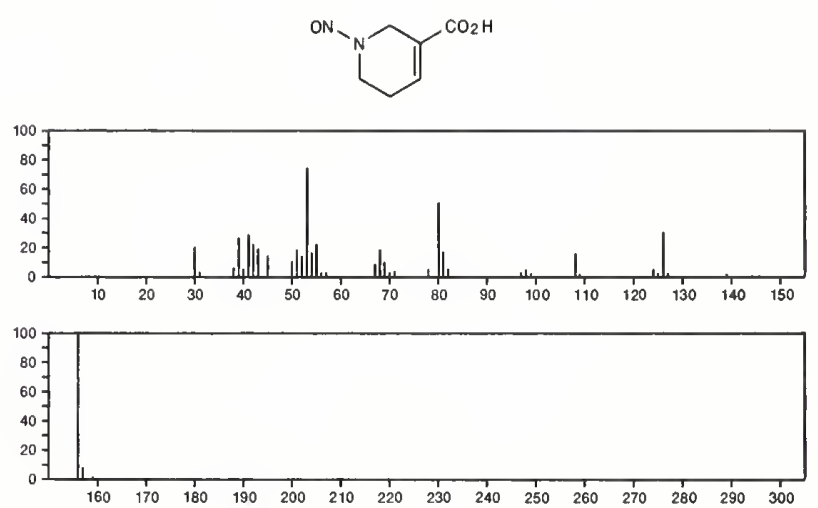
156

Benzoic acid, 4-chloro-

$\mathrm{C}_{7} \mathrm{H}_{5} \mathrm{ClO}_{2}$

$74-11-3$
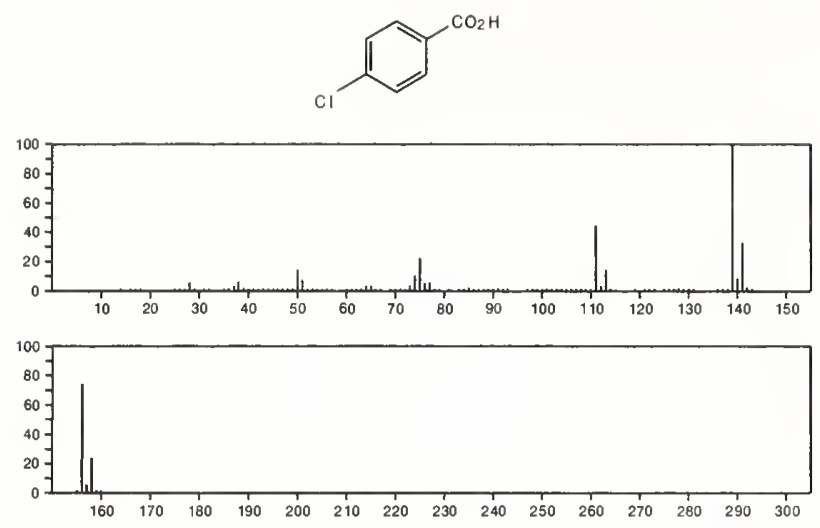

156

Benzoic acid, 2-chloro-

$\mathrm{C}_{7} \mathrm{H}_{5} \mathrm{ClO}_{2}$

$118-91-2$
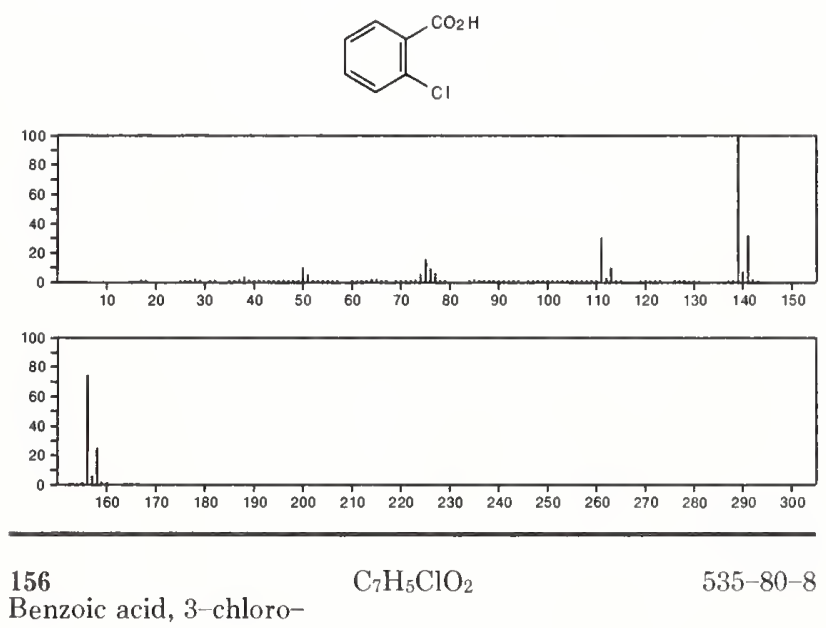

Benzoic acid, 3-chloro-
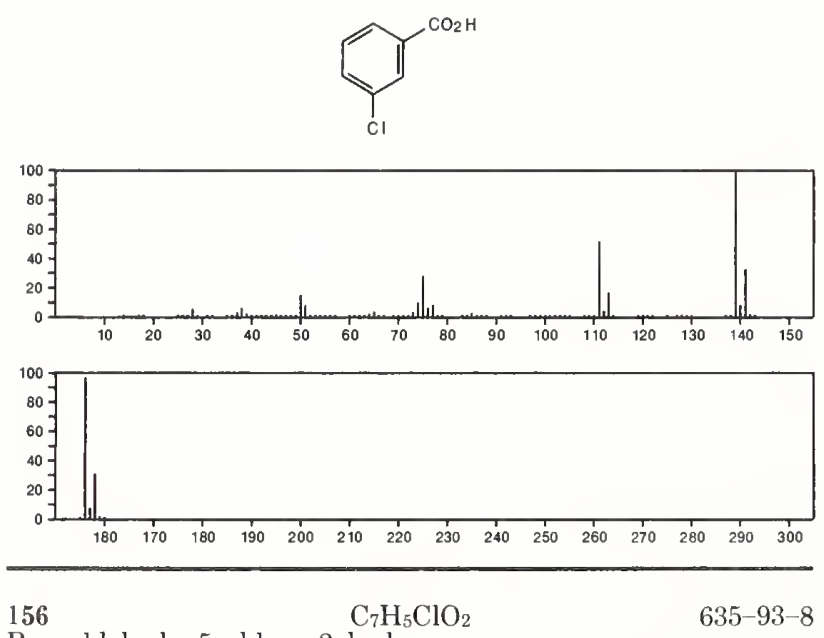

Benzaldehyde, 5-chloro-2-hydroxy-
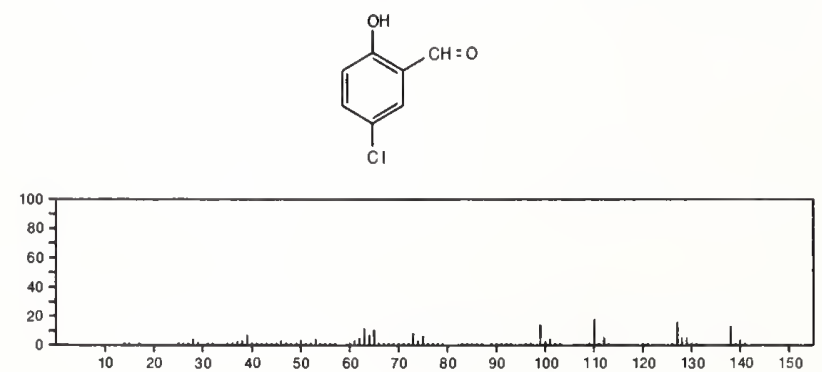

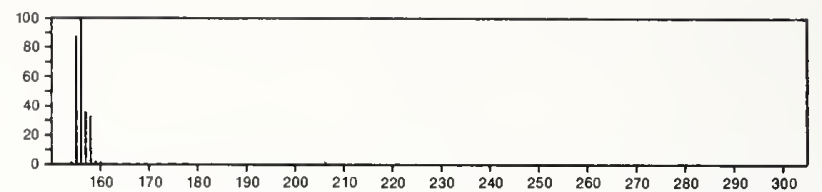

$156 \quad \mathrm{C}_{7} \mathrm{H}_{5} \mathrm{ClO}_{2}$

$1885-14-9$

Carbonochloridic acid, phenyl ester

$\mathrm{CIC}(\mathrm{O}) \mathrm{OPh}$
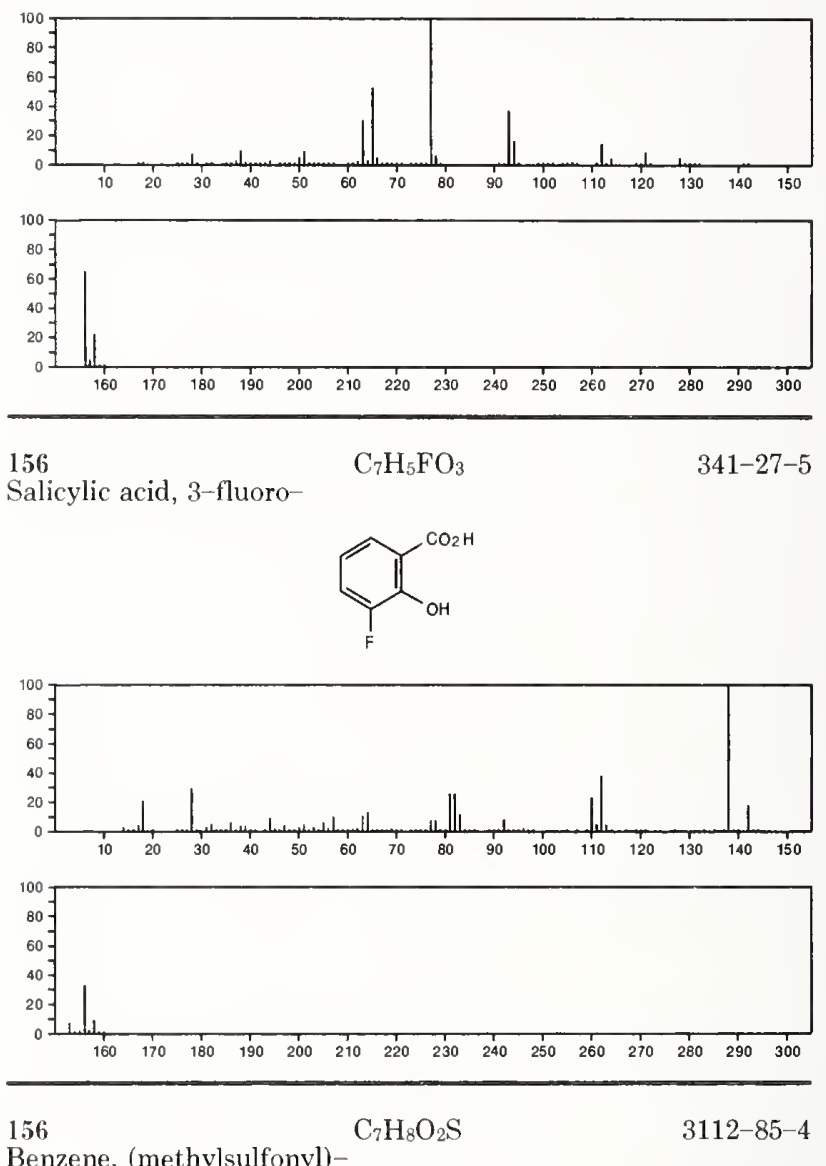

Benzene, (methylsulfonyl)-

$\mathrm{MeSO}_{2} \mathrm{Ph}$
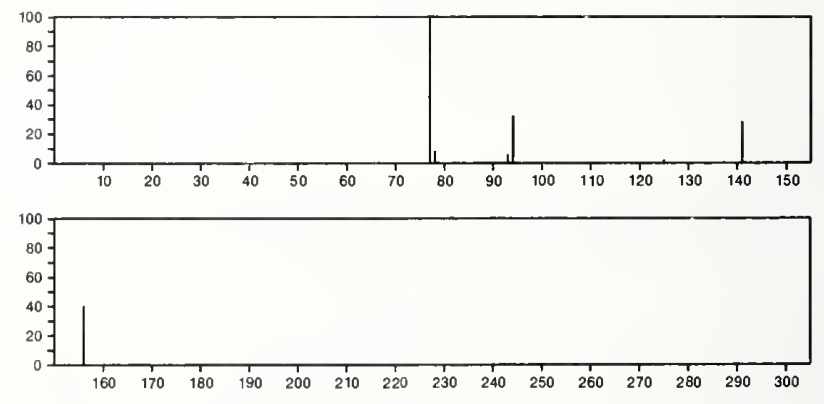

156

$\mathrm{C}_{7} \mathrm{H}_{8} \mathrm{O}_{2} \mathrm{~S}$

56666-83-2

2-Thiabicyclo[3.1.0]hex-3-ene-3-carboxylic acid, methyl ester
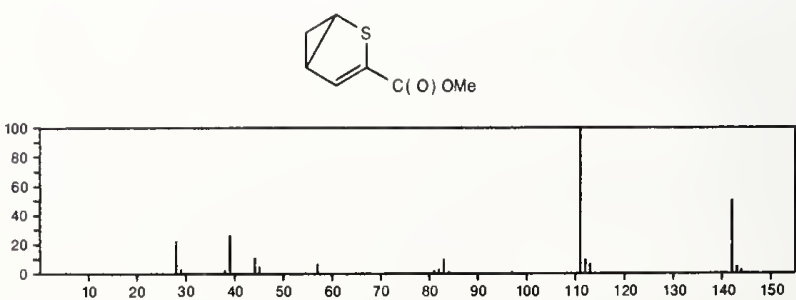


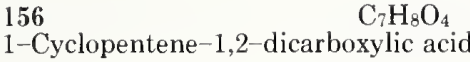
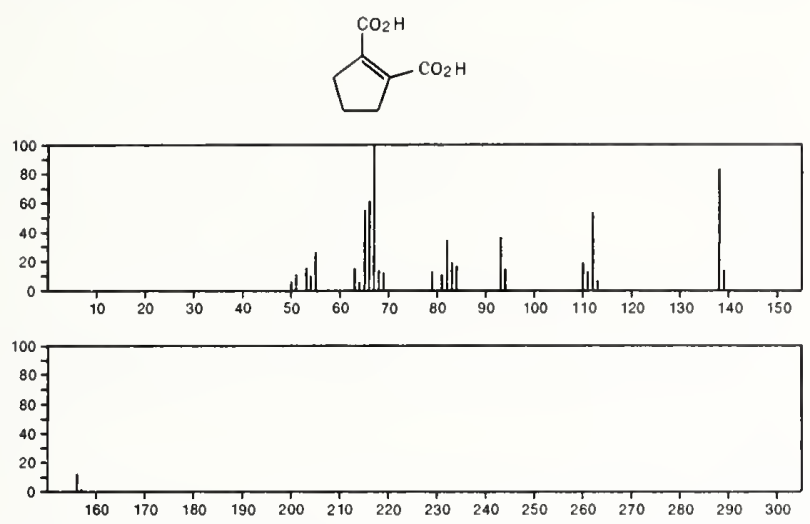

156

1,5-Cyclohexadiene-1-carboxylic acid, 3,4-dihydroxy-
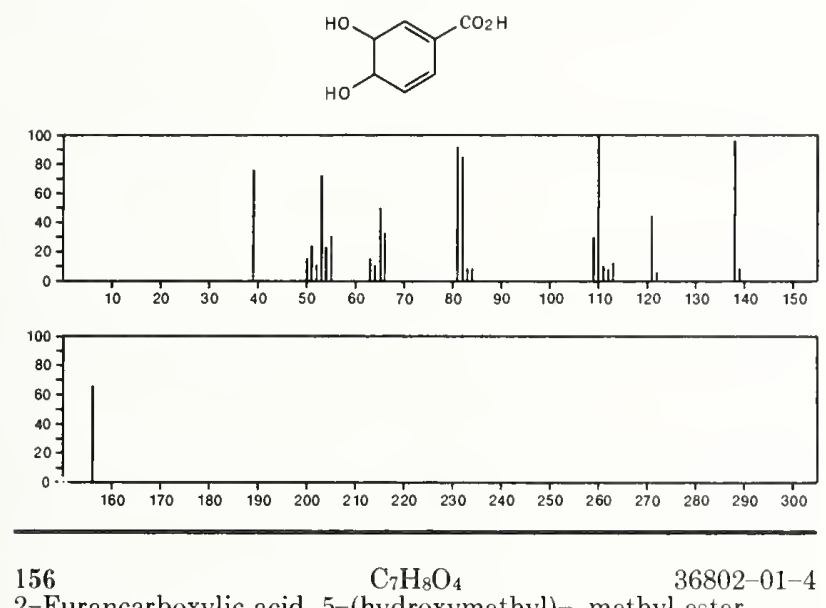

2-Furancarboxylic acid, 5-(hydroxymethyl)-, methyl ester
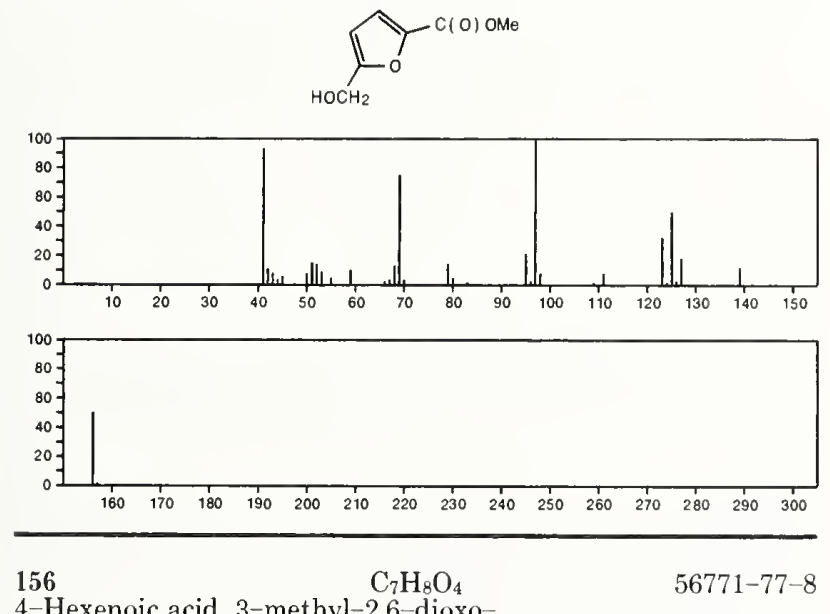

4-Hexenoic acid, 3-methyl-2,6-dioxo-

$\mathrm{OCHCH}=\mathrm{CHCHMe} \mathrm{COCO}_{2} \mathrm{H}$
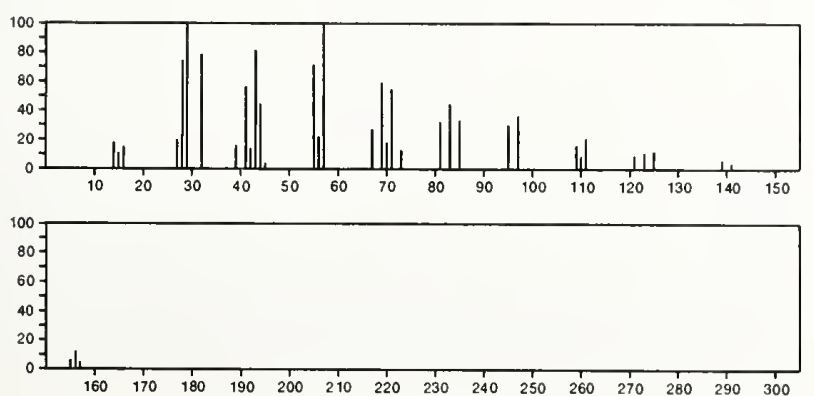

$156 \quad \mathrm{C}_{7} \mathrm{H}_{12} \mathrm{~N}_{2} \mathrm{O}_{2}$

2,4-Imidazolidinedione, 5,5-diethyl-
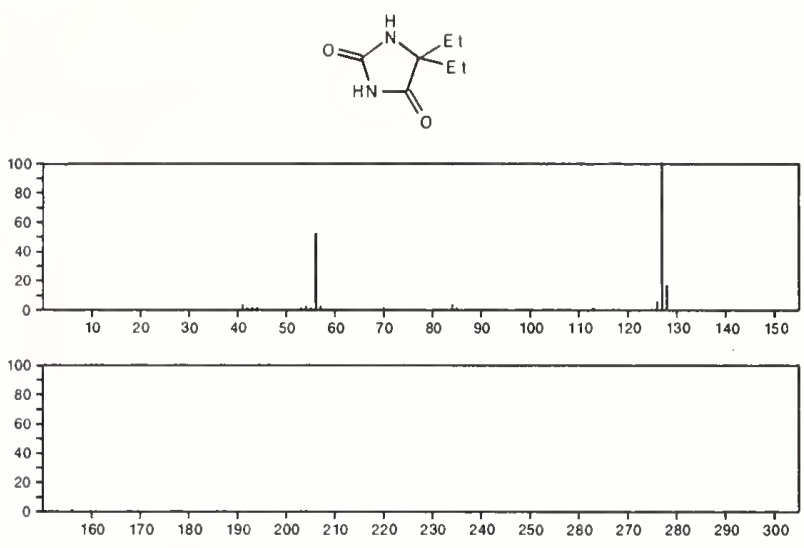

156

$\mathrm{C}_{7} \mathrm{H}_{12} \mathrm{~N}_{2} \mathrm{O}_{2}$

Carbazic acid, 3-cyclopentylidene-, methyl ester

$14702-41-1$
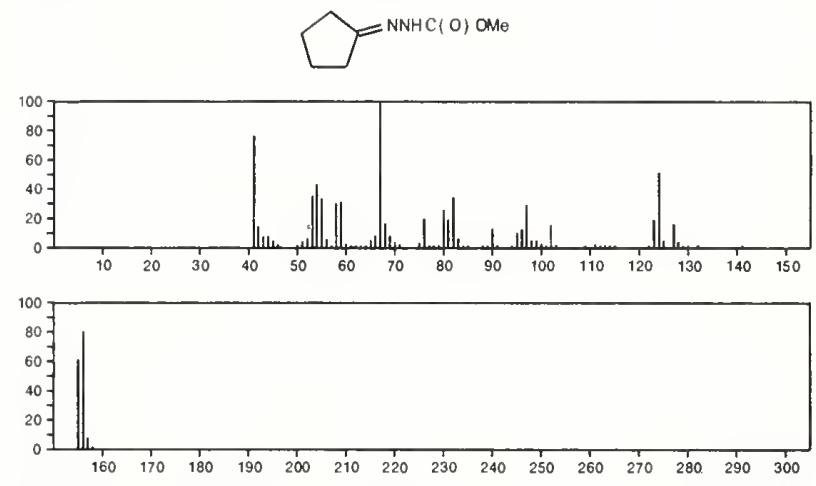

156

Sydnone, 3-neopentyl-

$$
\mathrm{C}_{7} \mathrm{H}_{12} \mathrm{~N}_{2} \mathrm{O}_{2}
$$

$26537-48-4$
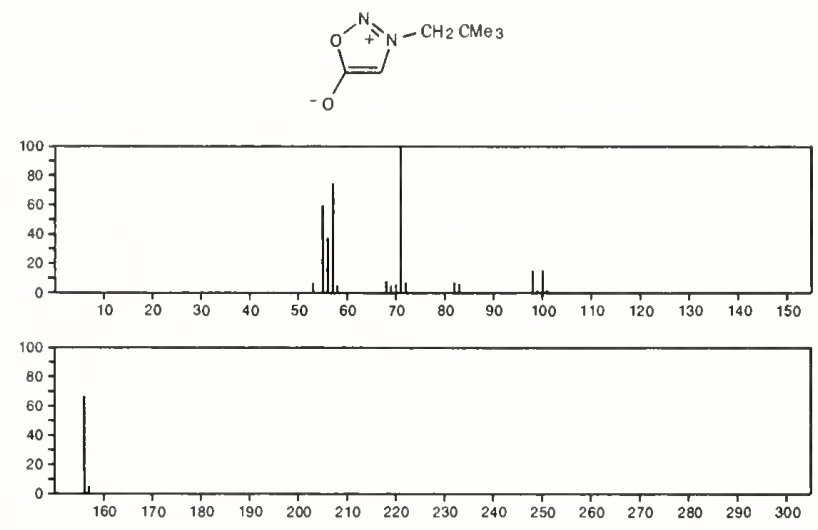

156

Sydnone, 3-isopentyl-

$\mathrm{C}_{7} \mathrm{H}_{12} \mathrm{~N}_{2} \mathrm{O}_{2}$

$26537-51-9$
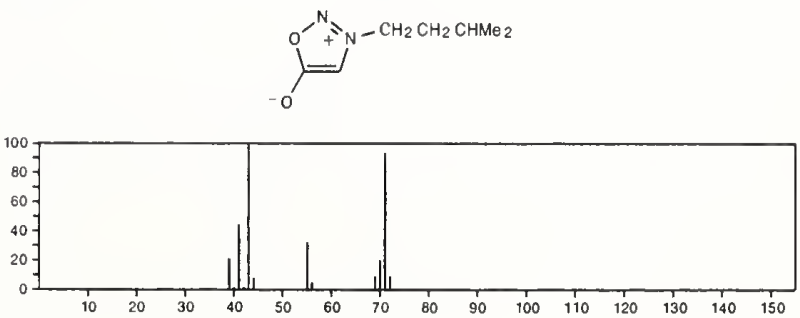


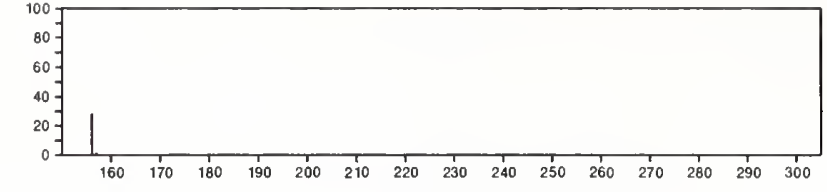

156

Hydantoin, 3-butyl-

$\mathrm{C}_{7} \mathrm{H}_{12} \mathrm{~N}_{2} \mathrm{O}_{2}$

$33599-31-4$
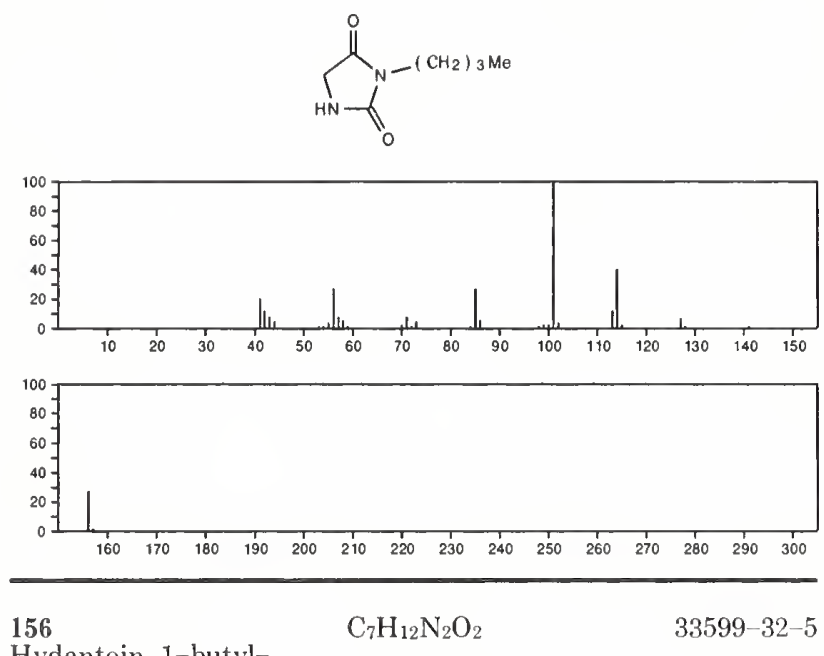

Hydantoin, 1-butyl-
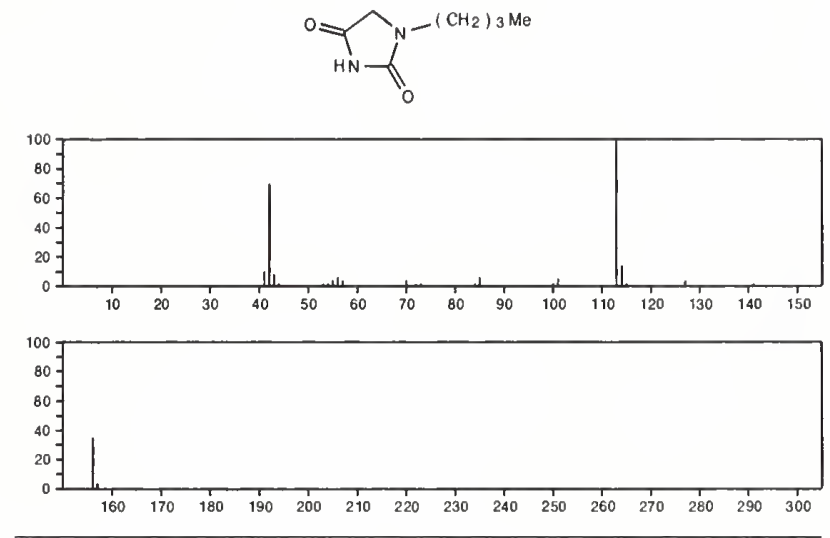

156

$\mathrm{C}_{7} \mathrm{H}_{13} \mathrm{BO}_{3}$

24372-01-8

Lactic acid, monoanhydride with 1 -butaneboronic acid, cyclic ester
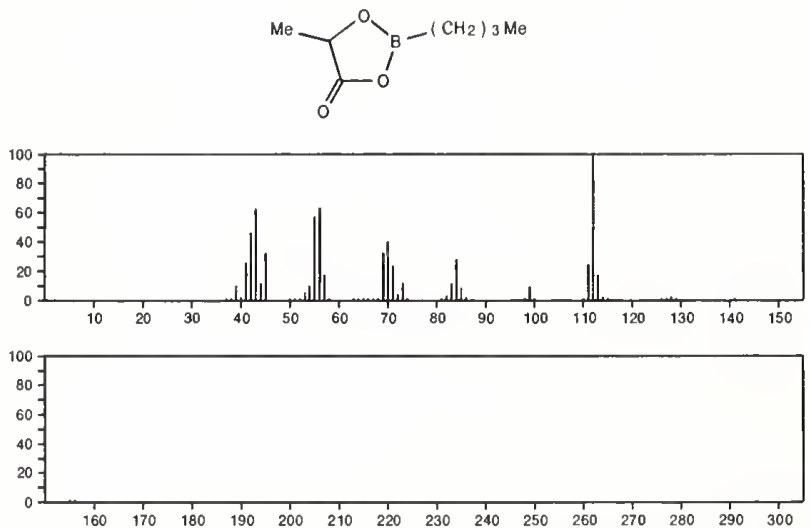

156 $\mathrm{C}_{7} \mathrm{H}_{13} \mathrm{BO}_{3}$

$33823-94-8$

Hydracrylic acid, monoanhydride with 1-butaneboronic acid, cyclic ester
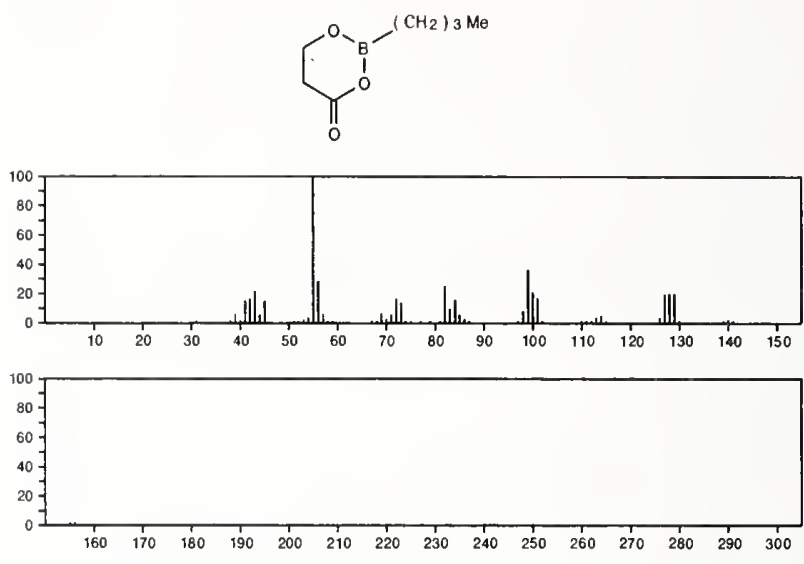

156

$\mathrm{C}_{7} \mathrm{H}_{16} \mathrm{Si}_{2}$

$5927-28-6$

1,3-Disilacyclopent-4-ene, 1,1,3,3-tetramethyl-
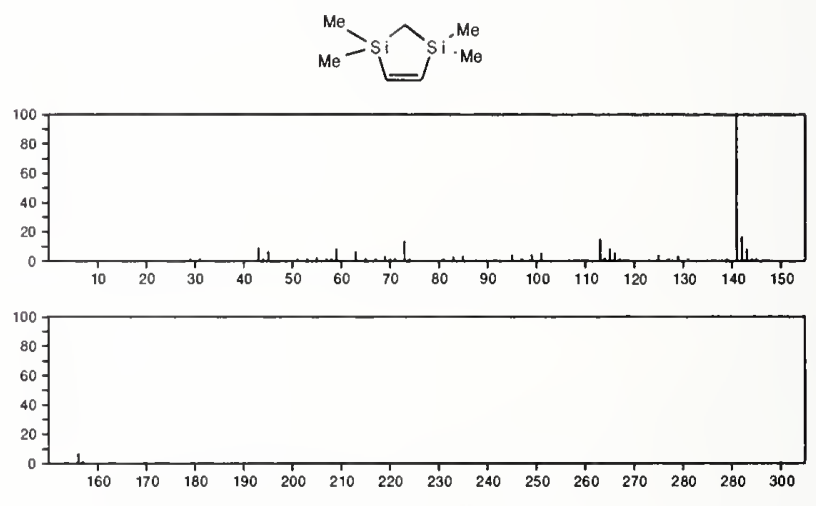

156

$\mathrm{C}_{8} \mathrm{H}_{4} \mathrm{~N}$

Pyrido[2,3-d]pyrimidine-4-carbonitrile

$29482-47-1$<smiles>N#Cc1ncnc2ncccc12</smiles>
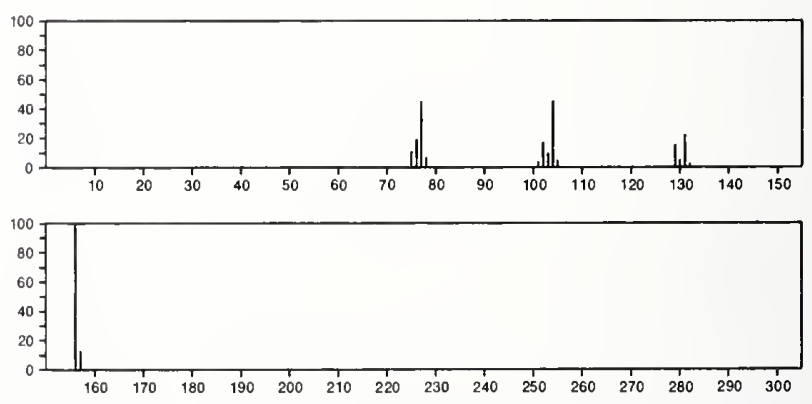

156

$\mathrm{C}_{8} \mathrm{H}_{9} \mathrm{ClO}$

614-72-2

Benzene, 1-chloro-2-ethoxy-
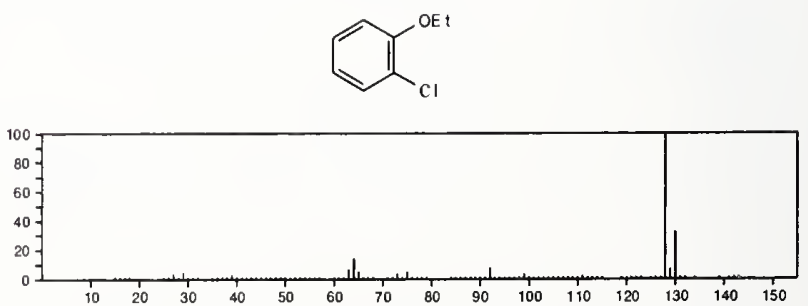

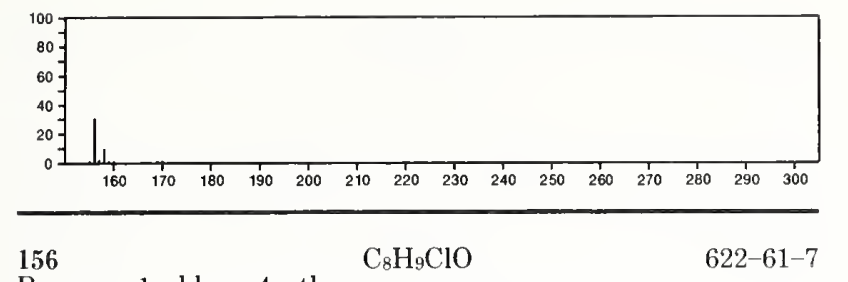

Benzene, 1-chloro-4-ethoxy-
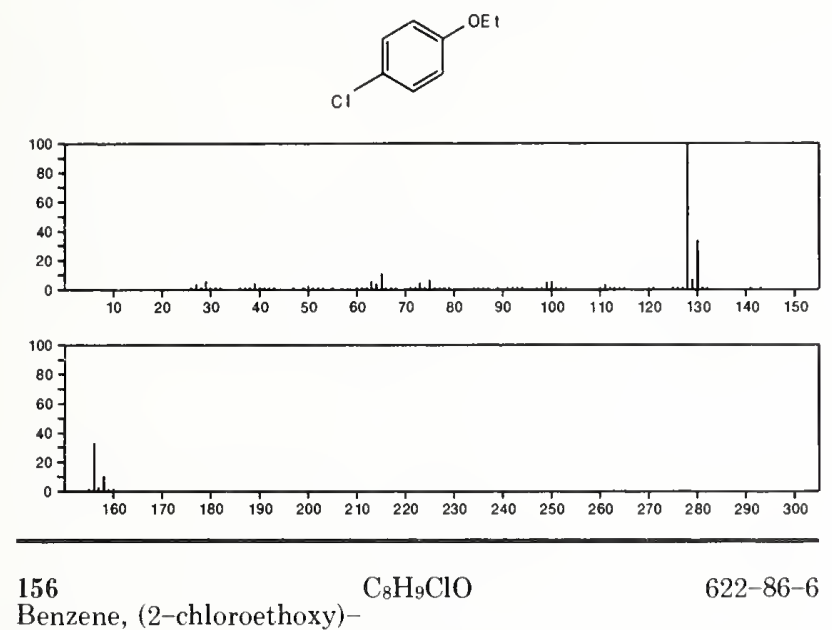

Benzene, (2-chloroethoxy)-
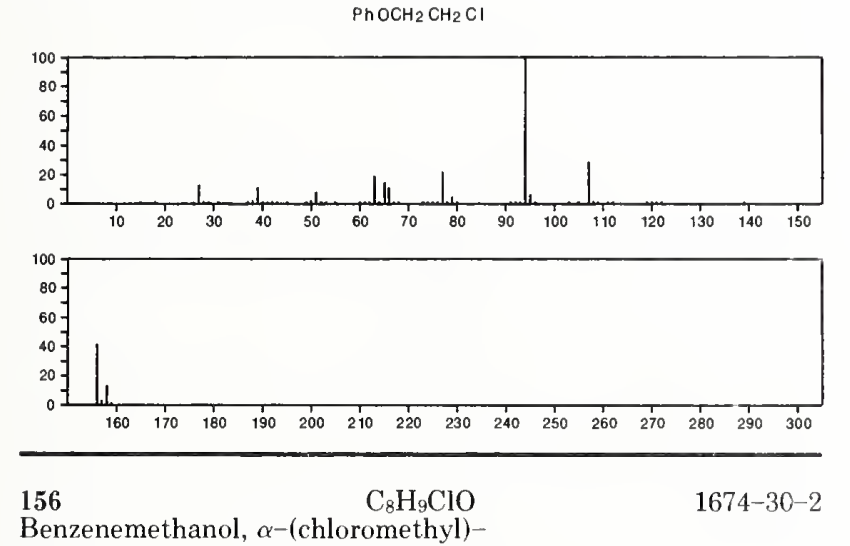

$\mathrm{ClCH}_{2} \mathrm{CH}(\mathrm{OH}) \mathrm{Ph}$
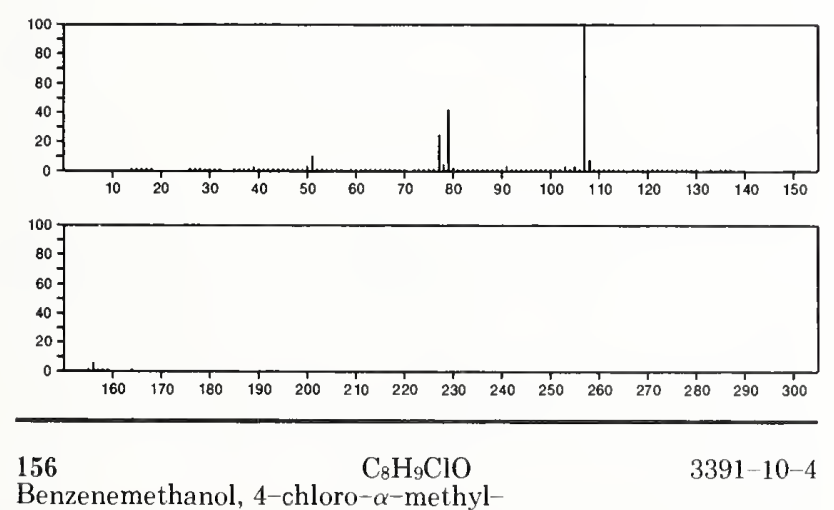

Benzenemethanol, 4-chloro- $\alpha$-methyl-
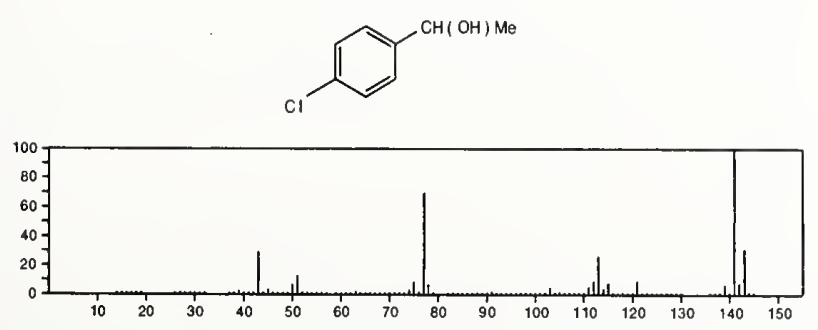

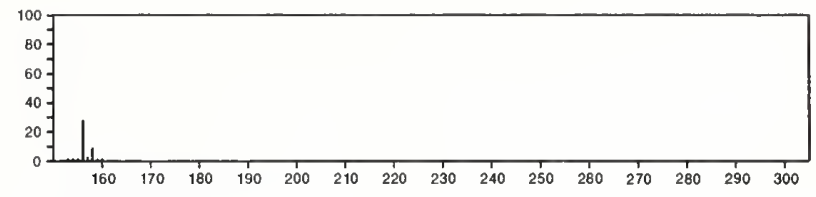

156
Benzeneethanol, 3-chloro-
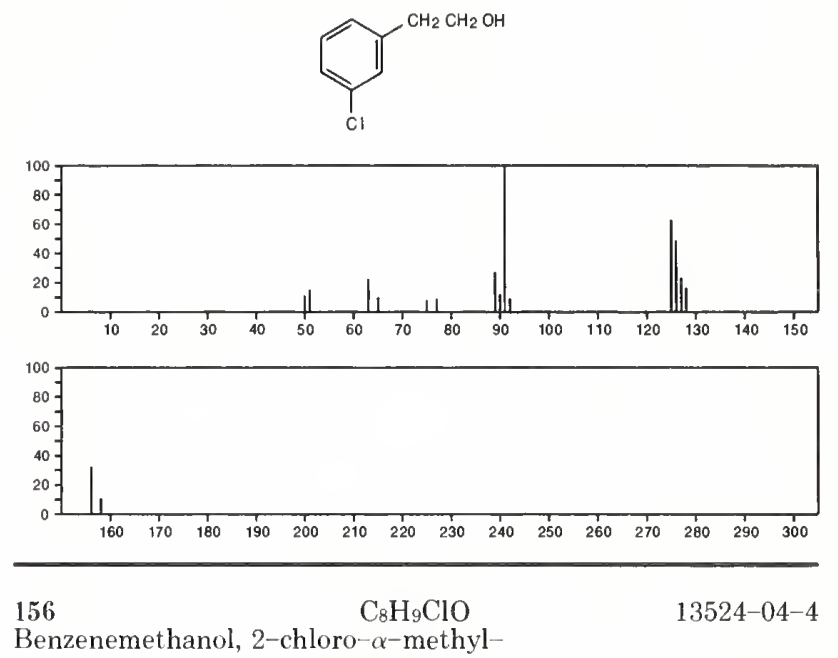

Benzenemethanol, 2-chloro- $\alpha$-methyl
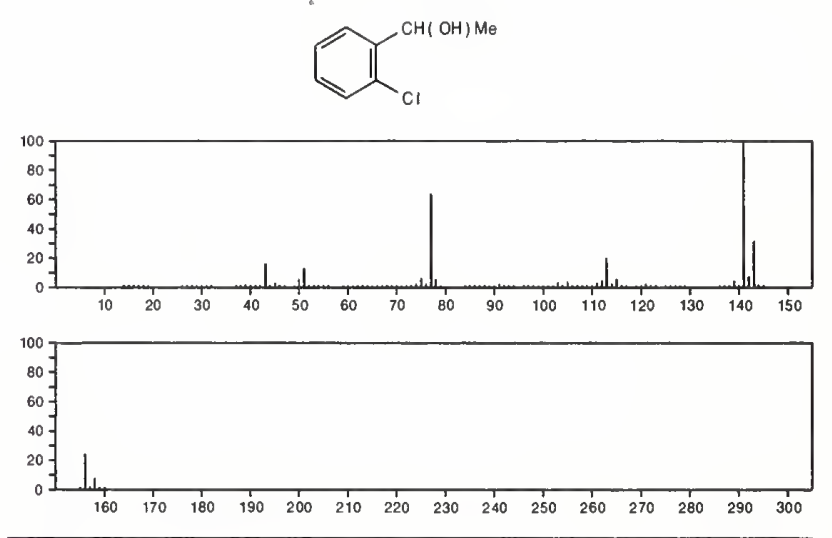

$156 \quad \mathrm{C}_{8} \mathrm{H}_{12} \mathrm{O}_{3}$

Cyclopentanecarboxylic acid, 2-oxo-, ethyl ester

$611-10-9$
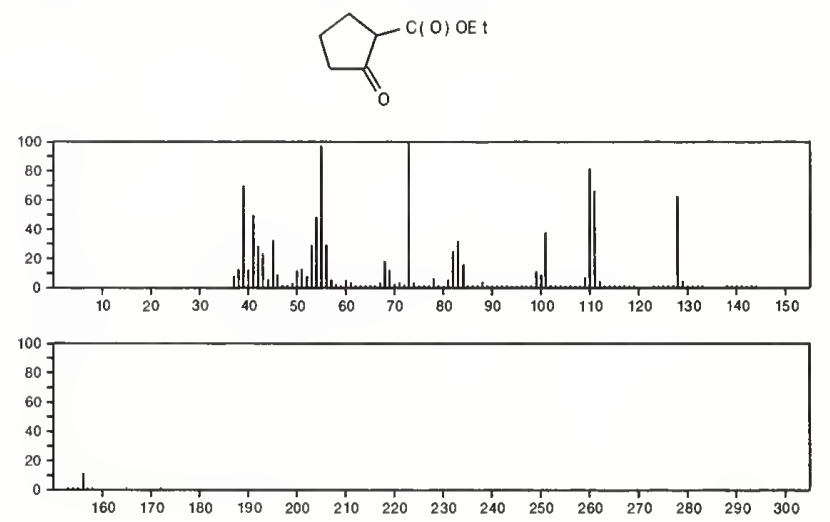
156

1,2-Butanediol, 1-(2-furyl)-

$\mathrm{C}_{8} \mathrm{H}_{12} \mathrm{O}_{3}$

$\overbrace{}^{\mathrm{CH}} \mathrm{OH}) \mathrm{CH}(\mathrm{OH}) \mathrm{EI}$
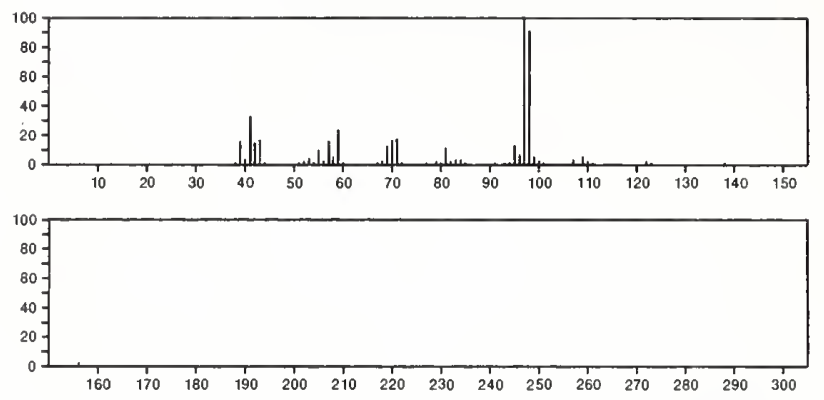

156

1,4-Dioxaspiro[4.5]decan-8-one

$\mathrm{C}_{8} \mathrm{H}_{12} \mathrm{O}_{3}$

$4746-97-8$
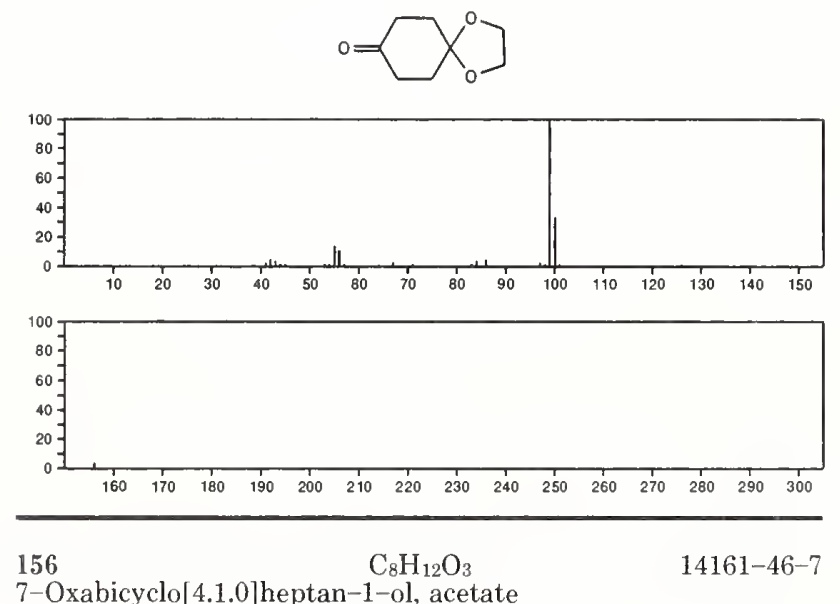

7-Oxabicyclo[4.1.0]heptan-1-ol, acetate
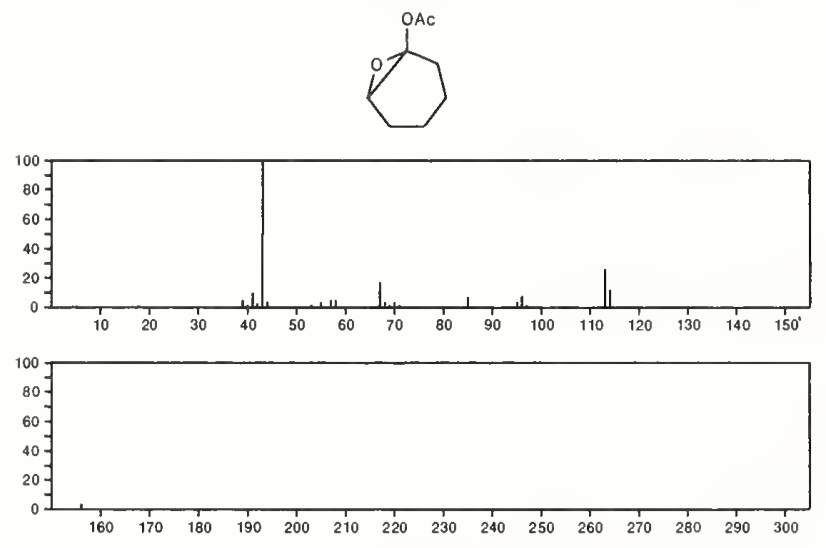

156

$3,4(2 H, 5 H)$-Furandione, 2,2,5,5-tetramethyl-

$14744-18-4$
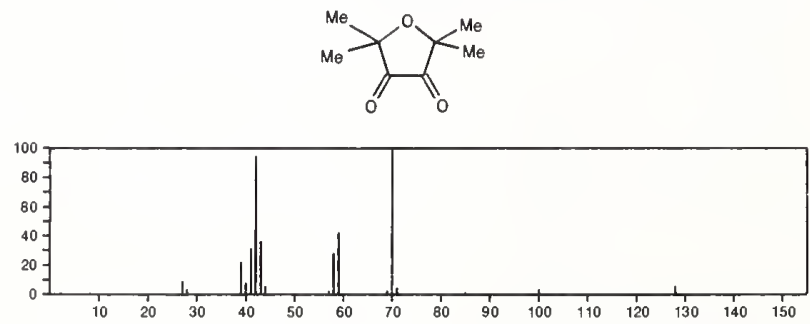

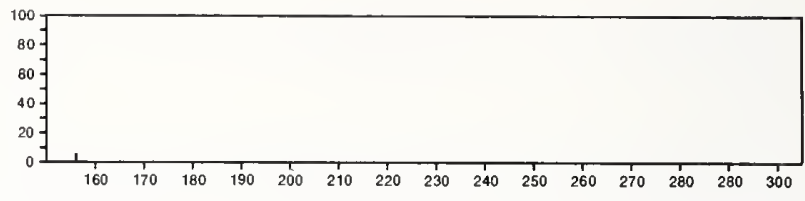

156

$\mathrm{C}_{8} \mathrm{H}_{12} \mathrm{O}_{3}$

Propanoic acid, 3-(2-propynyloxy)-, ethyl ester

$55702-68-6$

$\mathrm{Et} \mathrm{OC}(\mathrm{O}) \mathrm{CH}_{2} \mathrm{CH}_{2} \mathrm{OCH}_{2} \mathrm{C} \equiv \mathrm{CH}$

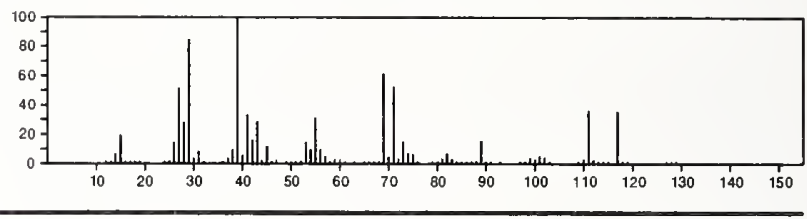

156

$\mathrm{C}_{8} \mathrm{H}_{14} \mathrm{NO}_{2}$

$2154-34-9$

1-Pyrrolidinyloxy, 2,2,5,5-tetramethyl-3-oxo-<smiles>CC1(C)CC(=O)C([N+](=O)[O-])N1O</smiles>
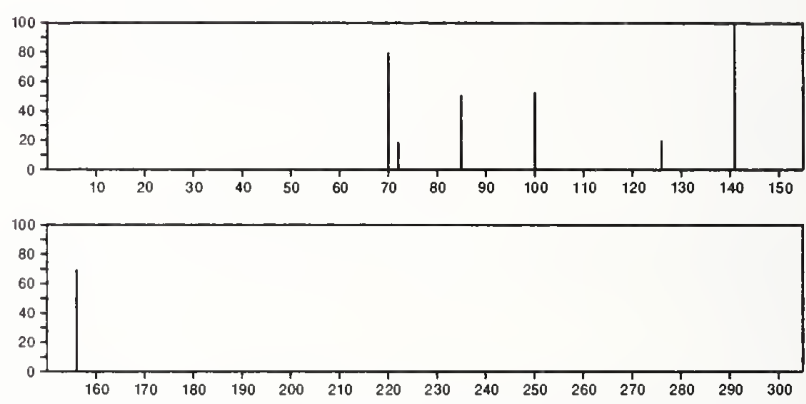

$156 \quad \mathrm{C}_{8} \mathrm{H}_{16} \mathrm{~N}_{2} \mathrm{O}$

$20917-50-4$

1H-Azonine, octahydro-1-nitroso-
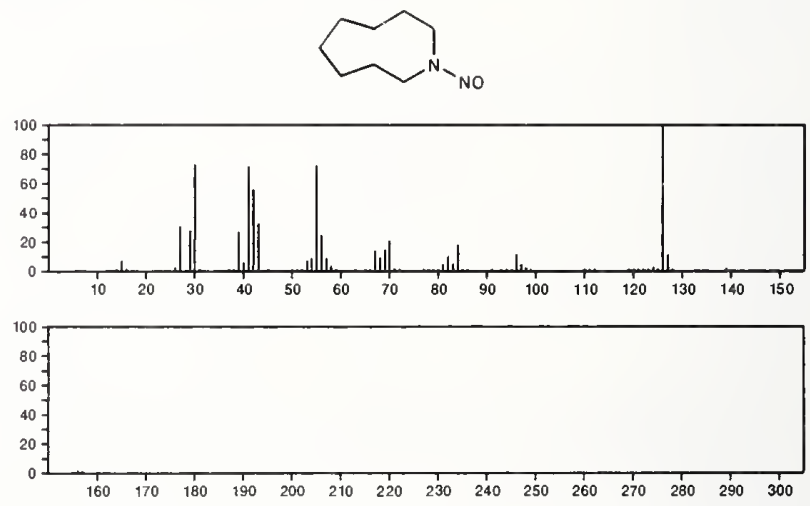

156

$\mathrm{C}_{8} \mathrm{H}_{16} \mathrm{~N}_{2} \mathrm{O}$

42801-00-3

2-Propenal, 3-(dimethylamino)-3-[(1-methylethyl)amino]-

$\mathrm{OCHCH}=\mathrm{C}(\mathrm{NHPr}-\mathrm{i}) \mathrm{NME} 2$
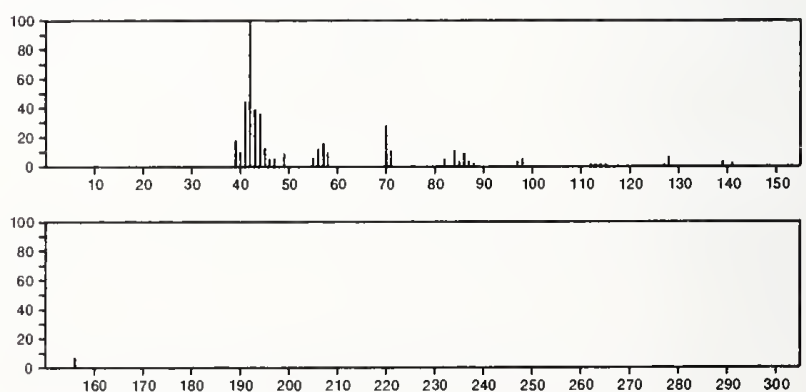
$\mathrm{C}_{8} \mathrm{H}_{16} \mathrm{~N}_{2} \mathrm{O}$

42801-01-4

2-Propenal, 3-(dimethylamino) $-2-[(1-$ methylethyl)amino $]$

$\mathrm{OCHC}(\mathrm{NHPr}-\mathbf{i})=\mathrm{CHNME}_{2}$
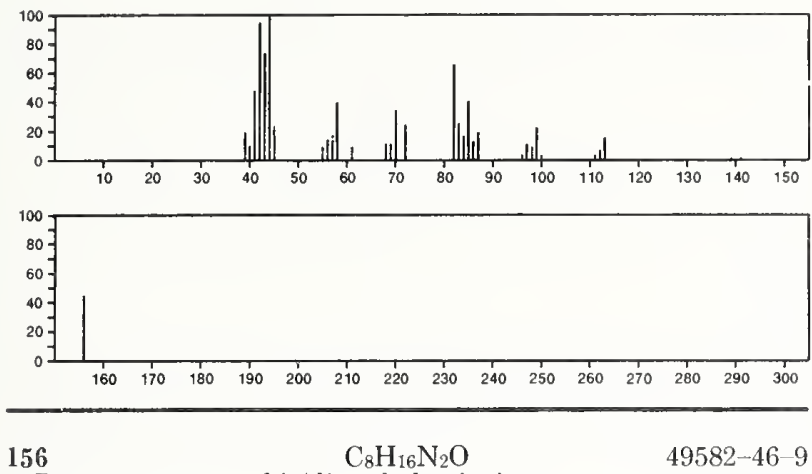

3-Buten-2-one, 4,4-bis(dimethylamino)-

$$
\text { NMe } 2
$$

$\mathrm{MeCOCH}: \mathrm{CNME}_{2}$
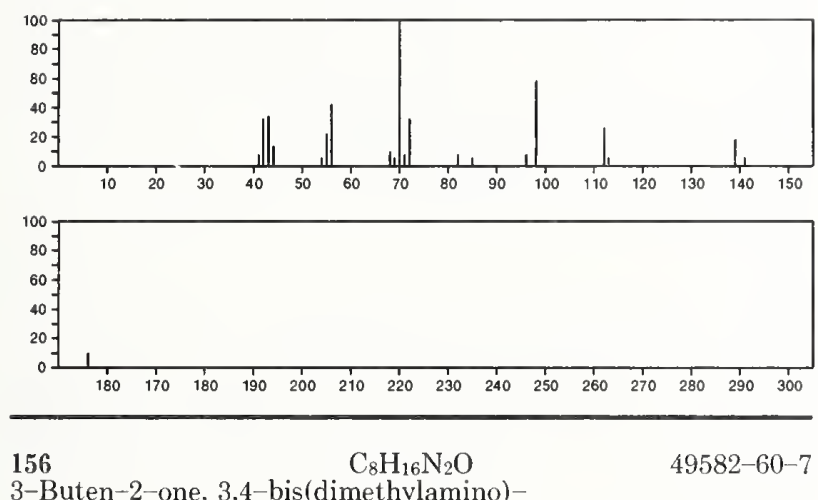

3-Buten-2-one, 3,4-bis(dimethylamino)-

$$
\mathrm{NM}=2
$$

$\mathrm{Me}_{2} \mathrm{NCH}=\mathrm{CCOMe}$
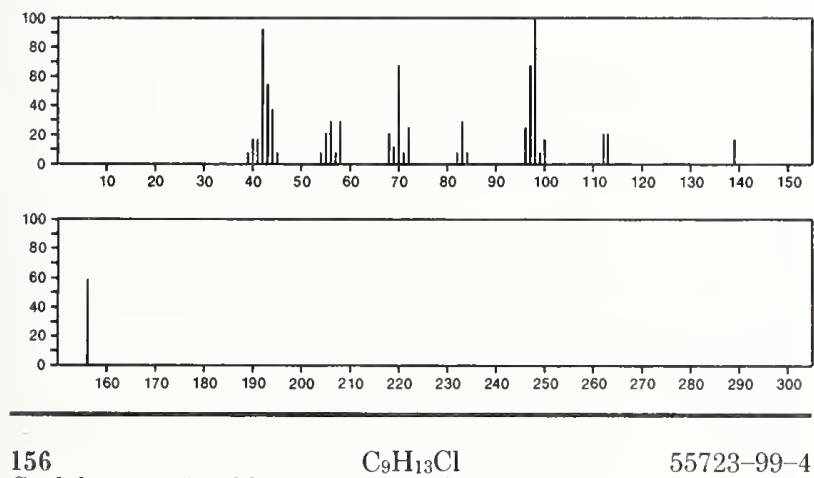

Cyclohexane, (3-chloro-1-propynyl)-
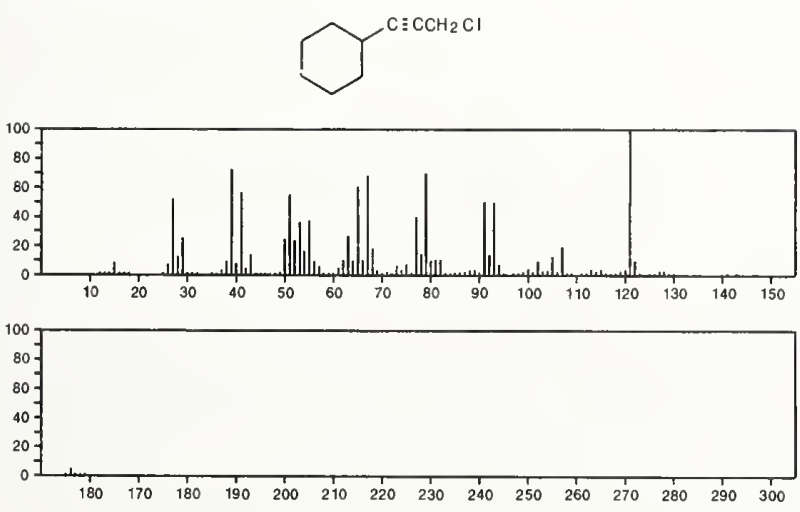

$156 \quad \mathrm{C}_{9} \mathrm{H}_{16} \mathrm{O}_{2}$

$123-68-2$

Hexanoic acid, 2-propenyl ester

$\left.\mathrm{Me}\left(\mathrm{CH}_{2}\right)_{4} \mathrm{ClO}\right) \mathrm{OCH}_{2} \mathrm{CH}=\mathrm{CH}_{2}$

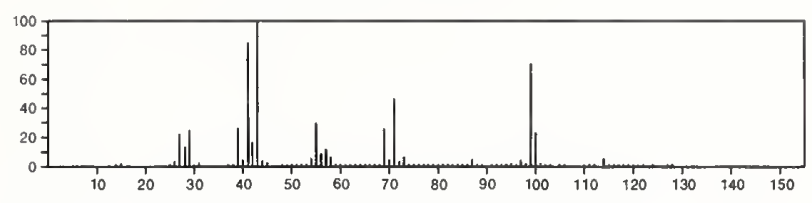

156

$\mathrm{C}_{9} \mathrm{H}_{16} \mathrm{O}_{2}$

$701-97-3$

Cyclohexanepropanoic acid
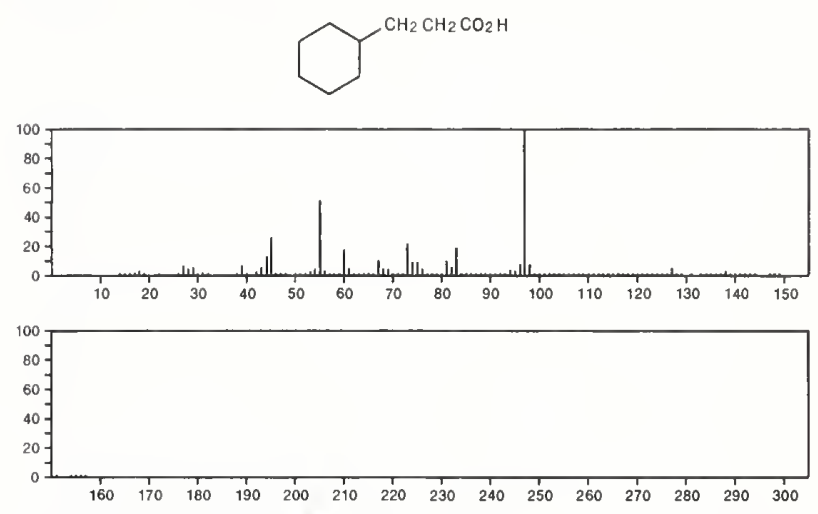

156

$\mathrm{C}_{9} \mathrm{H}_{16} \mathrm{O}_{2}$

1,4-Dioxaspiro[4.5]decane, 8-methyl-

$935-51-3$
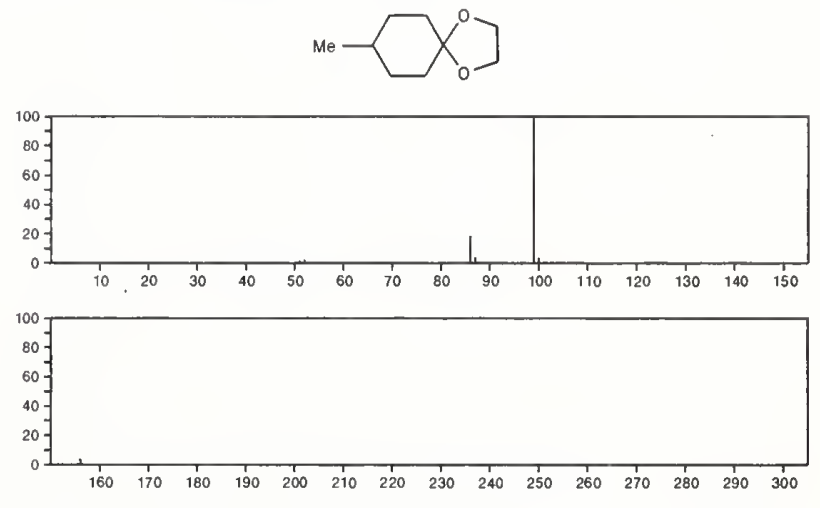

156

$\mathrm{C}_{9} \mathrm{H}_{16} \mathrm{O}_{2}$

2849-98-1

2-Propenoic acid, 2-methyl-, pentyl ester

$\mathrm{Me}\left(\mathrm{CH}_{2}\right){ }_{4} \mathrm{OC}(\mathrm{O}) \mathrm{CMe}=\mathrm{CH}_{2}$
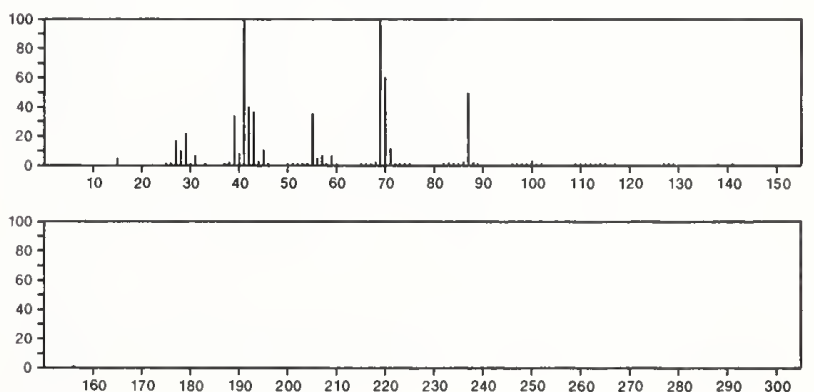
156

$\mathrm{C}_{9} \mathrm{H}_{16} \mathrm{O}_{2}$

$3431-87-6$

3-Penten-2-one, 4-butoxy-

$\mathrm{Me}\left(\mathrm{CH}_{2}\right)_{3} \mathrm{OCMe}: \mathrm{CHCOMe}$
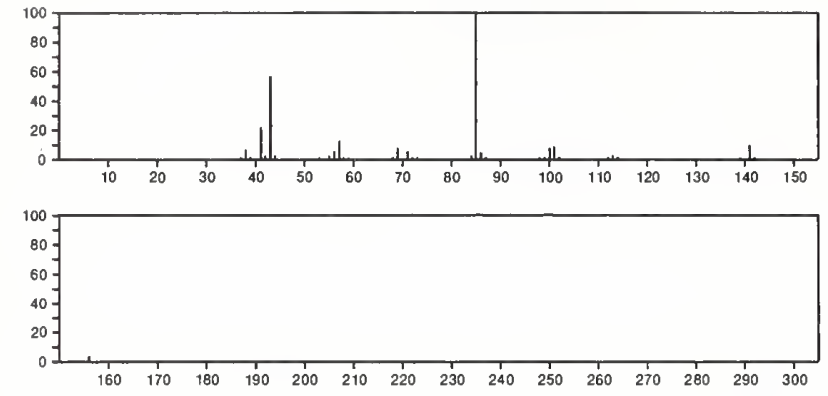

$156 \quad \mathrm{C}_{9} \mathrm{H}_{16} \mathrm{O}_{2}$

Cyclohexene, 4-(dimethoxymethyl)
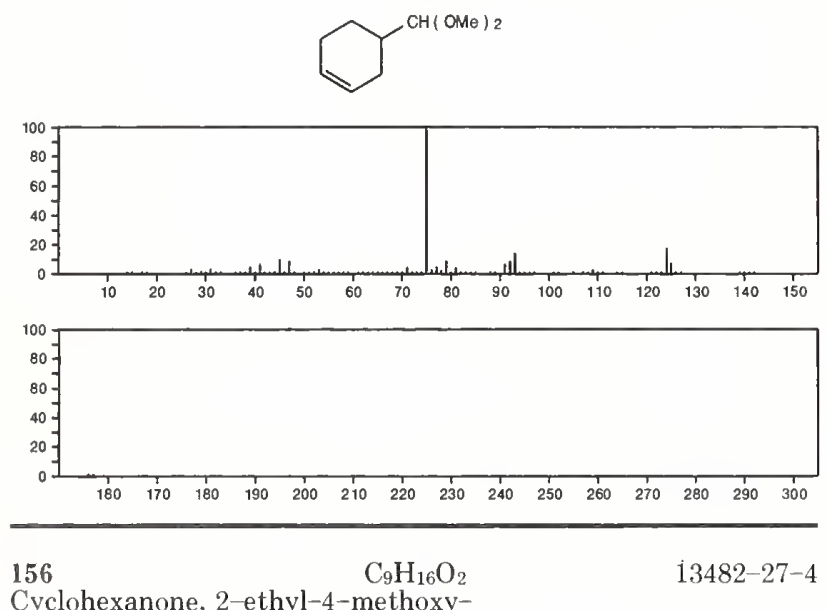

Cyclohexanone, 2-ethyl-4-methoxy-
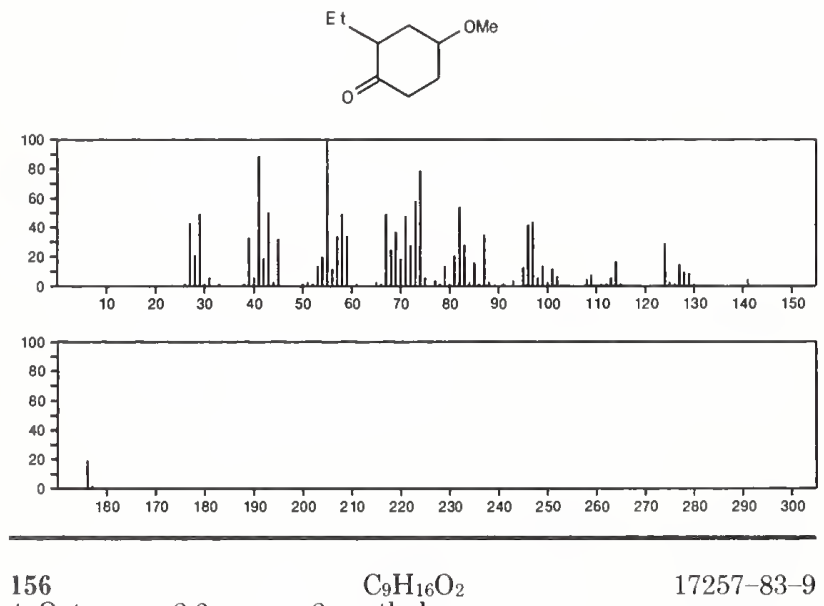

4-Octanone, 2,3-epoxy-2-methyl-

$17257-83-9$
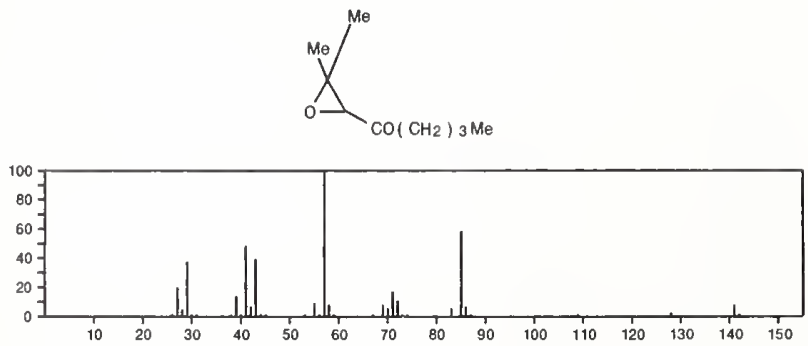

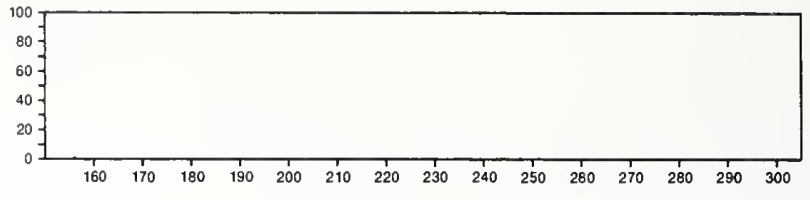

156

$\mathrm{C}_{9} \mathrm{H}_{16} \mathrm{O}_{2}$

4-Octenoic acid, methyl ester, $(Z)$ -

$21063-71-8$

$\mathrm{MeOC}(\mathrm{O}) \mathrm{CH}_{2} \mathrm{CH}_{2} \mathrm{CH}=\mathrm{CHP}$ r
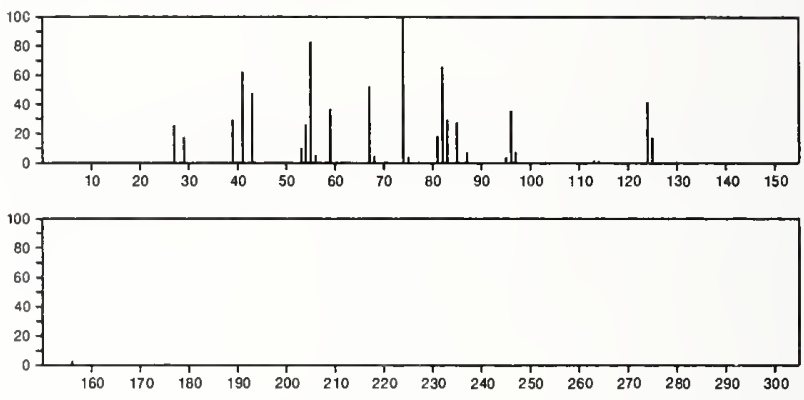

156

$\mathrm{C}_{9} \mathrm{H}_{16} \mathrm{O}$

1,5-Heptadiene-3,4-diol, 2,5-dimethyl-

$22607-16-5$

$\mathrm{H}_{2} \mathrm{C}=\mathrm{CMe} \mathrm{CH}(\mathrm{OH}) \mathrm{CH}(\mathrm{OH}) \mathrm{CMe}=\mathrm{CHMe}$
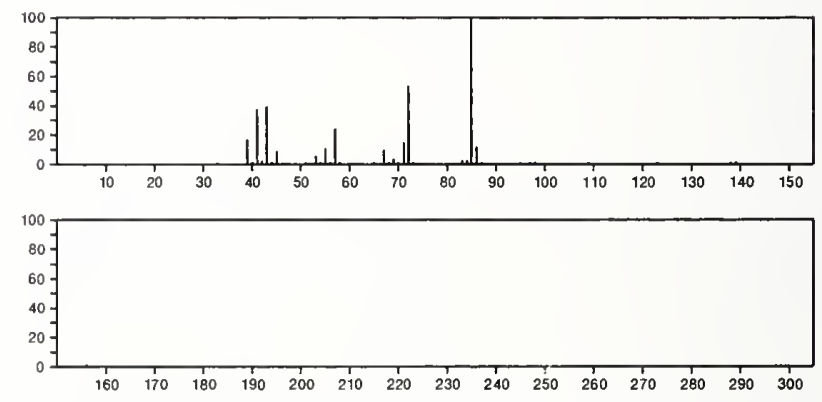

156

2-Octen-4-one, 2-methoxy

$$
\mathrm{C}_{9} \mathrm{H}_{16} \mathrm{O}_{2}
$$

$24985-48-6$

$\mathrm{MeC}(\mathrm{OMe})=\mathrm{CHCO}\left(\mathrm{CH}_{2}\right)_{3} \mathrm{Me}$
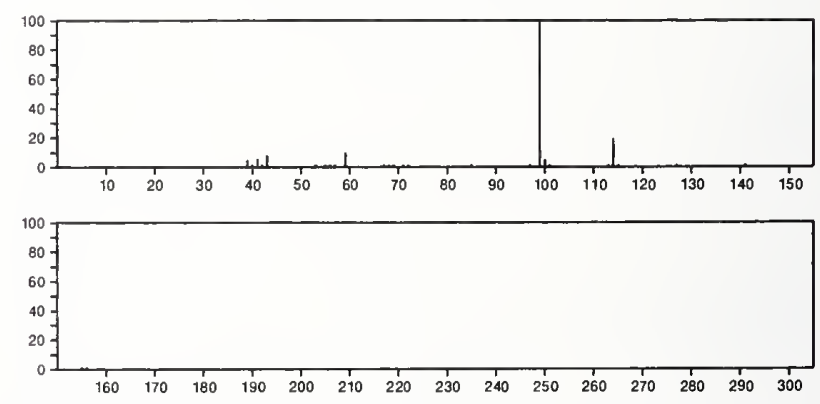

156

3-Octen-2-one, 4-methoxy-

$$
\mathrm{C}_{9} \mathrm{H}_{16} \mathrm{O}_{2}
$$

24985-52-2

$\mathrm{Me} \mathrm{COCH}=\mathrm{C}(\mathrm{OMe})\left(\mathrm{CH}_{2}\right)_{3} \mathrm{Me}$
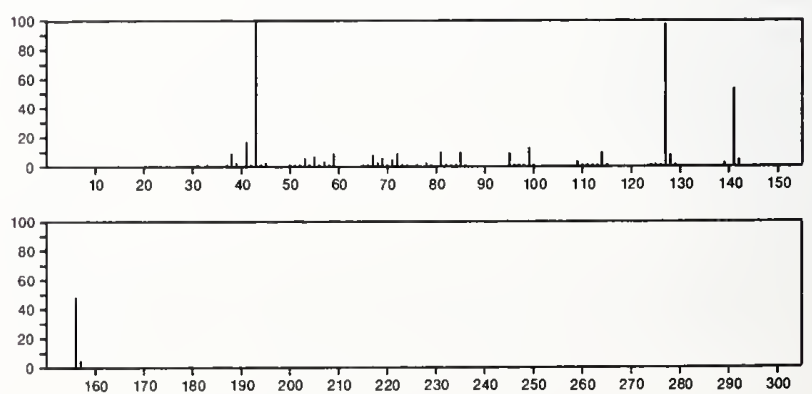
156

6-Heptenoic acid, ethyl ester

$\mathrm{C}_{9} \mathrm{H}_{16} \mathrm{O}_{2}$

$\mathrm{H}_{2} \mathrm{C}=\mathrm{CH}\left(\mathrm{CH}_{2}\right\}_{4} \mathrm{C}(\mathrm{O}) \mathrm{OE}$
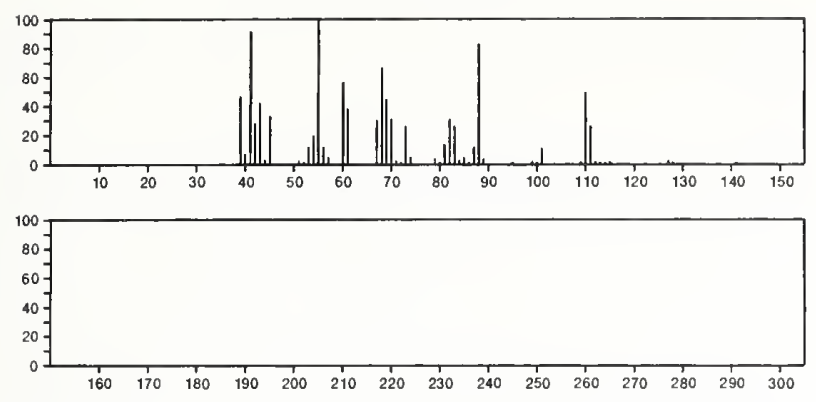

156

8-Nonenoic acid

$\mathrm{C}_{9} \mathrm{H}_{16} \mathrm{O}_{2}$

$\mathrm{H}_{2} \mathrm{C}=\mathrm{CH}\left(\mathrm{CH}_{2}\right)_{6} \mathrm{CO}_{2} \mathrm{H}$
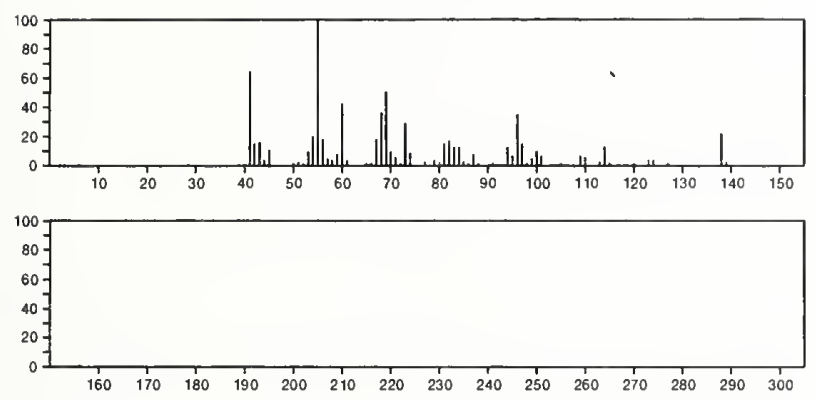

156

$\mathrm{C}_{9} \mathrm{H}_{16} \mathrm{O}_{2}$

3-Octenoic acid, methyl ester, $(E)_{-}$

$35234-16-3$

$\mathrm{MeOC}(\mathrm{O}) \mathrm{CH}_{2} \mathrm{CH}=\mathrm{CH}\left(\mathrm{CH}_{2}\right)_{3} \mathrm{Me}$
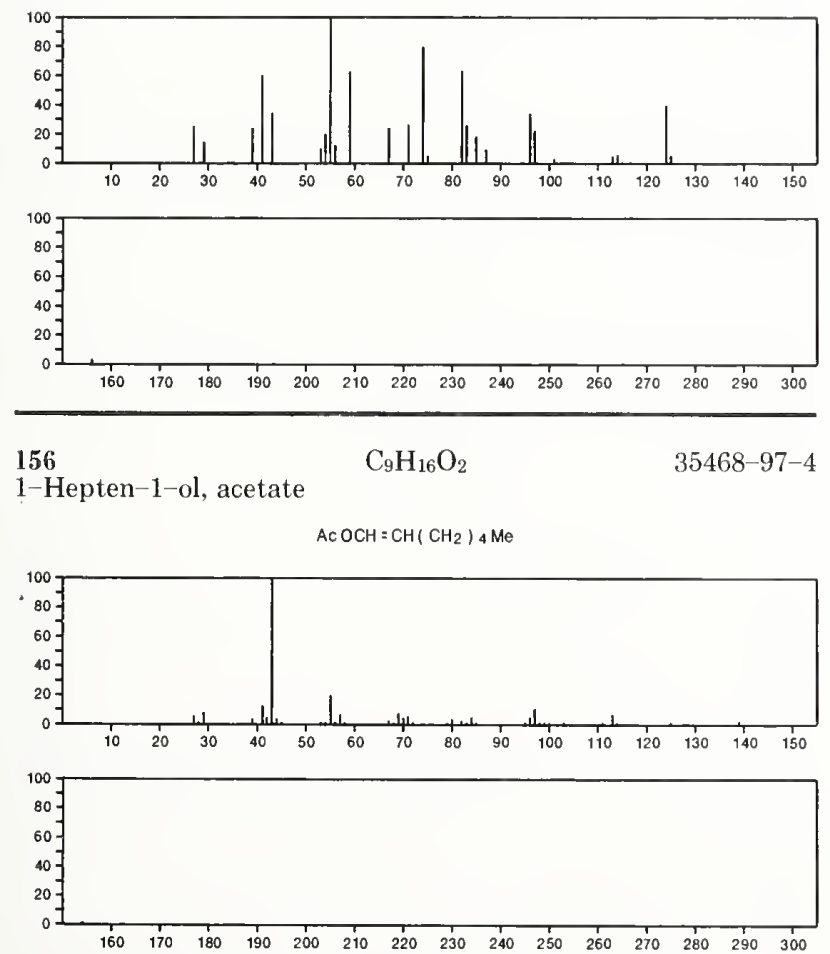

156

$\mathrm{C}_{9} \mathrm{H}_{16} \mathrm{O}_{2}$

$38477-06-4$

$\mathrm{HO}_{2} \mathrm{CCE}_{2} \mathrm{CMe}_{\mathrm{CH}} \mathrm{CH}_{2}$
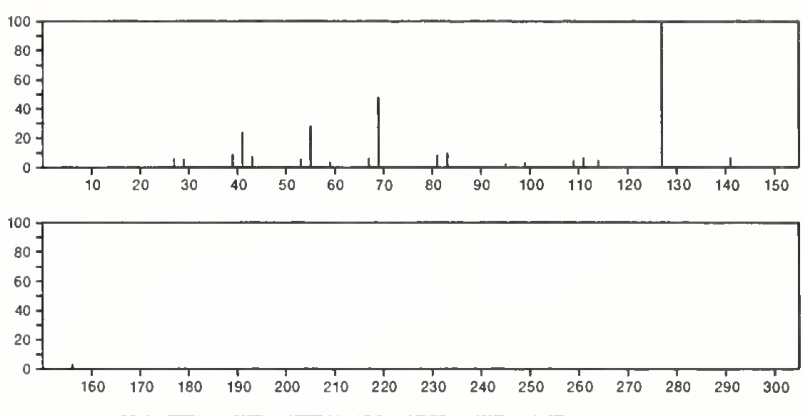

156

3-Pentenoic acid, 2,2-diethyl-

$\mathrm{C}_{9} \mathrm{H}_{16} \mathrm{O}_{2}$

$38477-07-5$

$\mathrm{MeCH}=\mathrm{CHCE} t_{2} \mathrm{CO}_{2} \mathrm{H}$
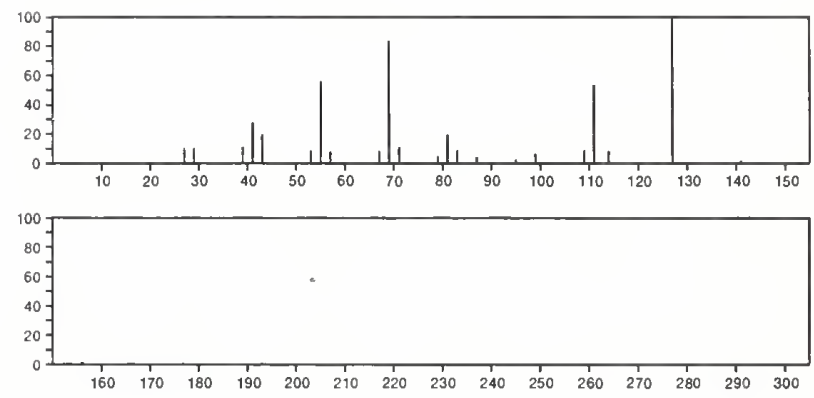

156

$\mathrm{C}_{9} \mathrm{H}_{16} \mathrm{O}_{2}$

$44970-05-0$

Pentanoic acid, 2,2-dimethyl-, ethenyl ester

$\operatorname{PrCMe} 2 \mathrm{C}(\mathrm{O}) \mathrm{OCH}=\mathrm{CH}_{2}$
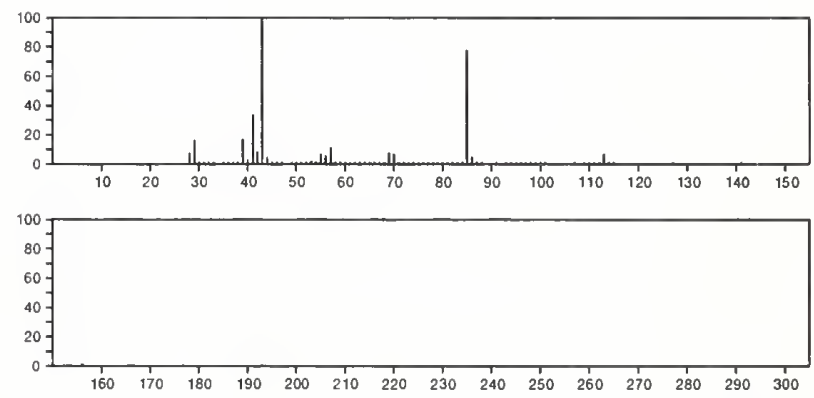

156

$\mathrm{C}_{9} \mathrm{H}_{16} \mathrm{O}_{2}$

2-Heptenoic acid, 3-methyl-, methyl ester

$50652-81-8$

$\mathrm{Me}\left(\mathrm{CH}_{2}\right)_{3} \mathrm{CMe}=\mathrm{CHC}(\mathrm{O}) \mathrm{OMe}$
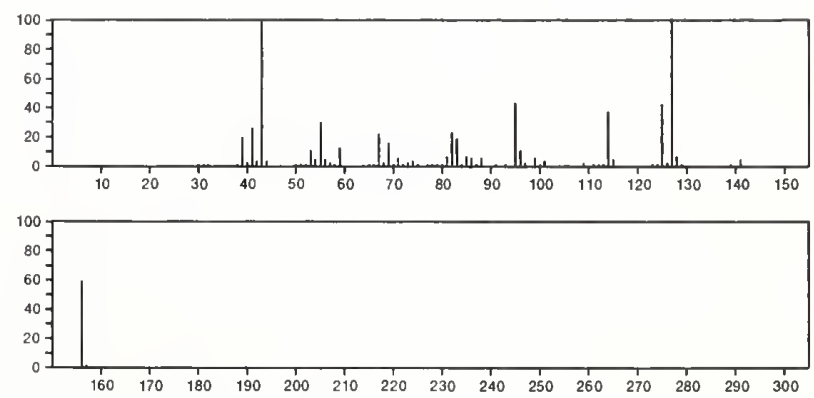
156

$\mathrm{C}_{9} \mathrm{H}_{16} \mathrm{O}_{2}$

$51181-40-9$

Cyclohexanecarboxylic acid, 4-methyl-, methyl ester
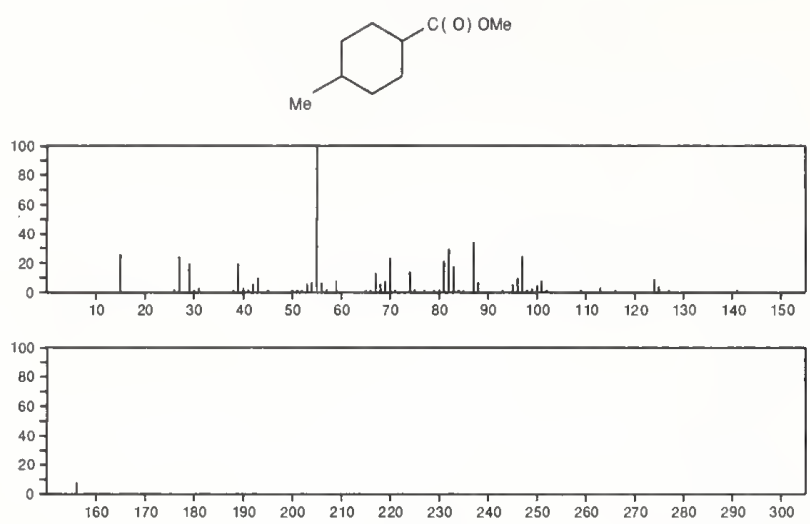

156

$\mathrm{C}_{9} \mathrm{H}_{16} \mathrm{O}_{2}$

$54340-69-1$

5-Heptenoic acid, ethyl ester, $(E)$ -

$\mathrm{EtOC}(\mathrm{O})\left(\mathrm{CH}_{2}\right)_{3} \mathrm{CH}=\mathrm{CHMe}$
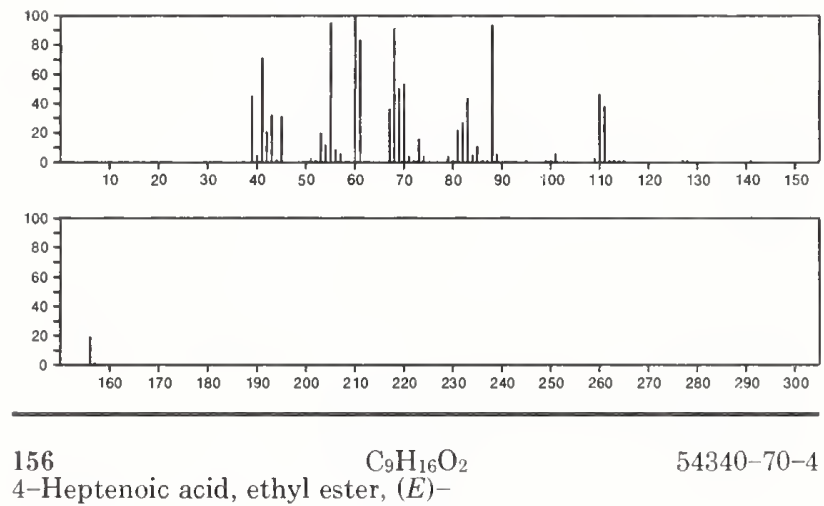

$\mathrm{Et} \mathrm{CH}=\mathrm{CHCH}_{2} \mathrm{CH}_{2} \mathrm{C}(\mathrm{O}) \mathrm{OE}$ t
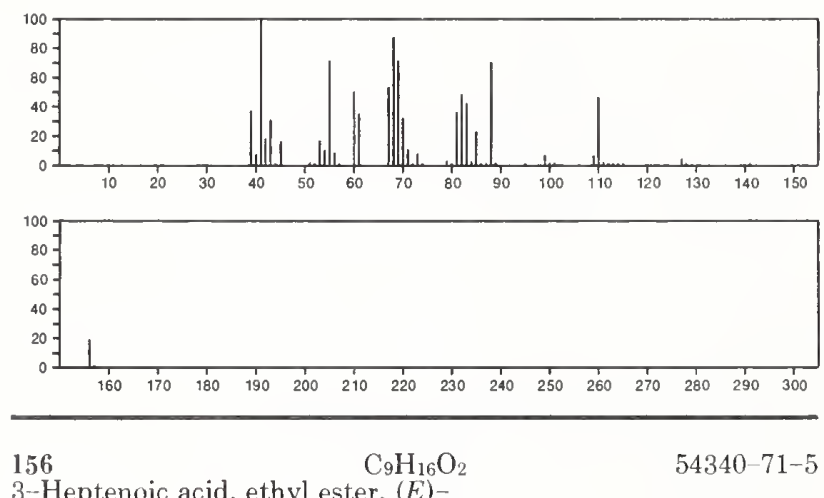

3-Heptenoic acid, ethyl ester, $(E)$ -

$\mathrm{EtOC}(\mathrm{O}) \mathrm{CH}_{2} \mathrm{CH}=\mathrm{CHPr}$
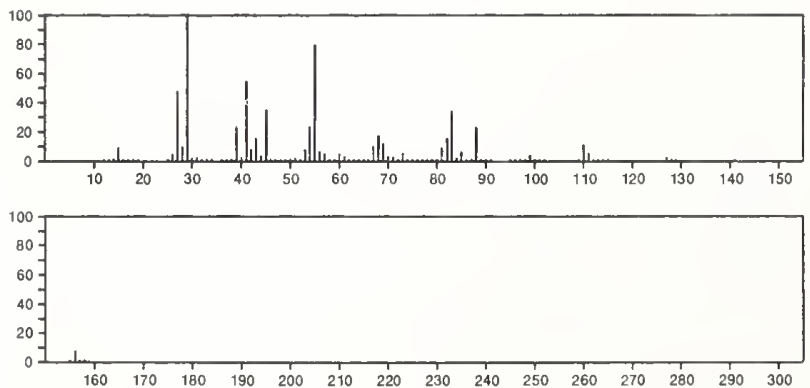

$56 \quad \mathrm{C}_{9} \mathrm{H}_{16} \mathrm{O}_{2}$

2-Heptenoic acid, ethyl ester, $(E)-$

$54340-72-6$

$\mathrm{E}+\mathrm{OC}(\mathrm{O}) \mathrm{CH}=\mathrm{CH}\left(\mathrm{CH}_{2}\right)_{3} \mathrm{Me}$
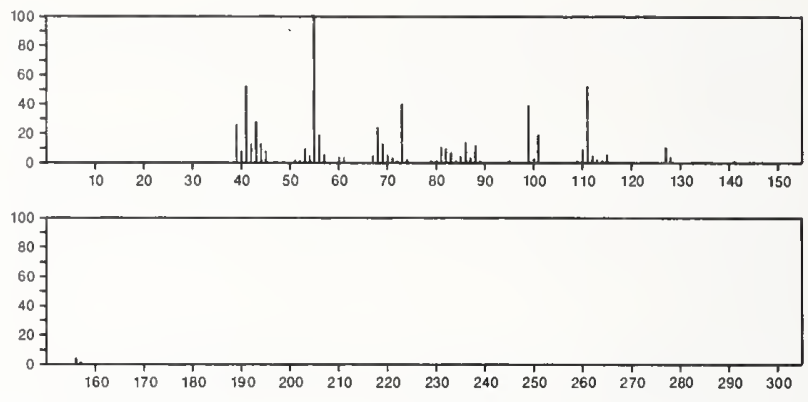

156

$\mathrm{C}_{9} \mathrm{H}_{16} \mathrm{O}_{2}$

Cyclohexanol, 2-methyl-, acetate, cis-

$54714-33-9$
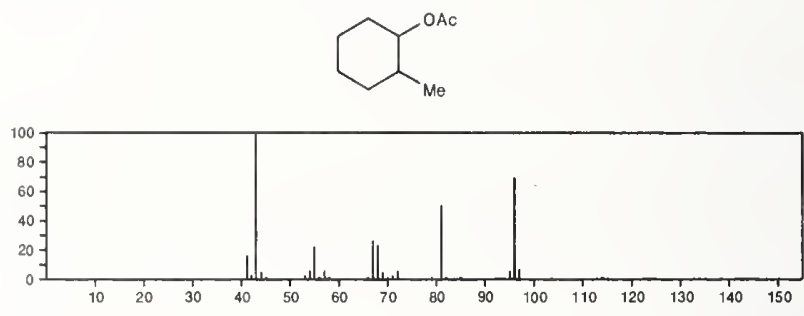

156

$\mathrm{C}_{9} \mathrm{H}_{16} \mathrm{O}_{2}$

Cyclohexanol, 2-methyl-, acetate, trans-

$54714-34-0$
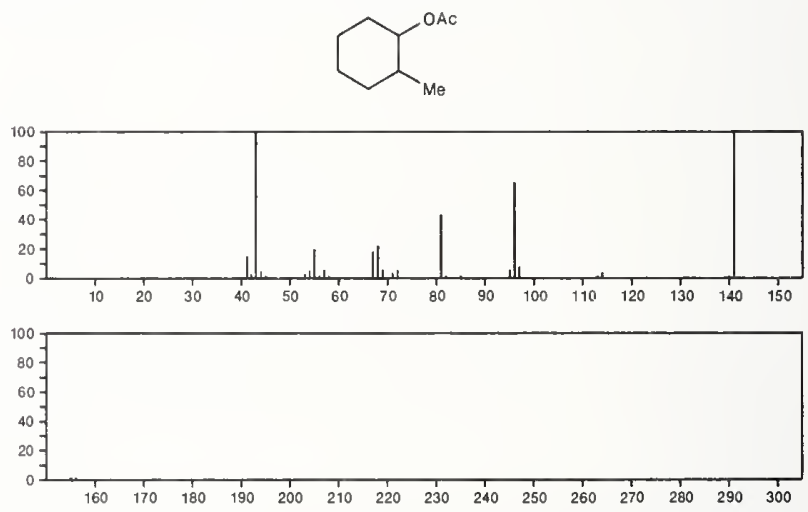

156

$\mathrm{C}_{9} \mathrm{H}_{16} \mathrm{O}_{2}$

$55013-32-6$

2(3H)-Furanone, 5-butyldihydro-4-methyl-, cis
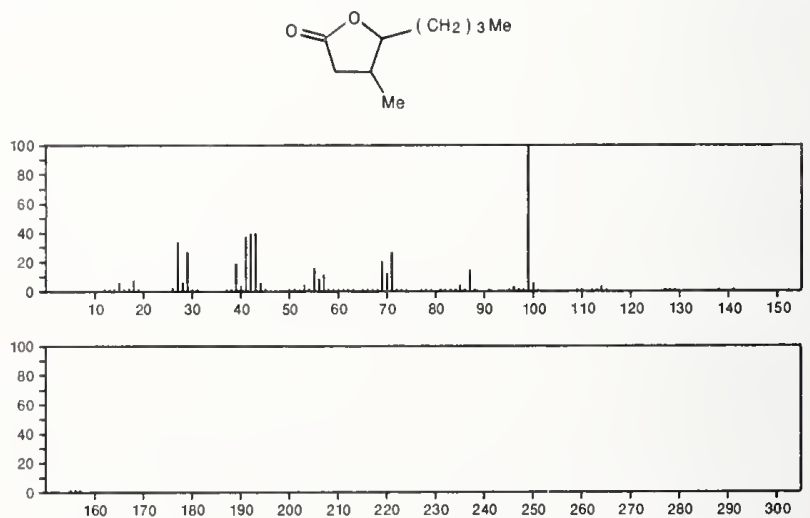
156

2,6-Octadiene-4,5-diol, 4-methyl-

$\mathrm{Me} C \mathrm{CH}=\mathrm{CHCH}(\mathrm{OH}) \mathrm{CMe}(\mathrm{OH}) \mathrm{CH}=\mathrm{CHM}$

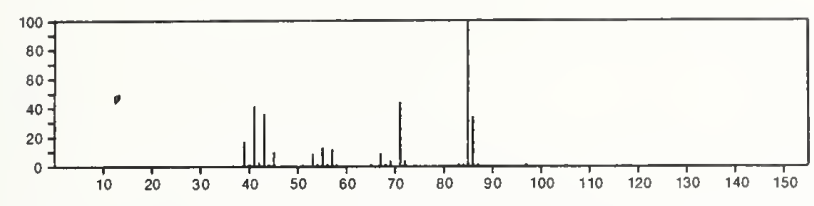

156

$\mathrm{C}_{9} \mathrm{H}_{16} \mathrm{O}_{2}$

56943-71-6

Ethanone, 1-(hexahydro-2H-oxocin-3-yl)-
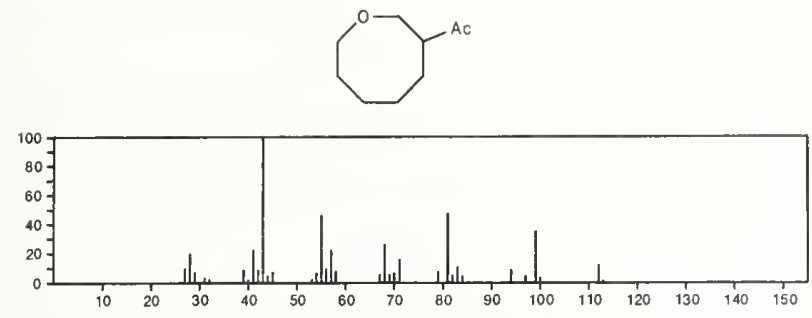

156

$\mathrm{C}_{9} \mathrm{H}_{16} \mathrm{~S}$

$39825-77-9$

Bicyclo[2.2.2]octane-1-thiol, 4-methyl-
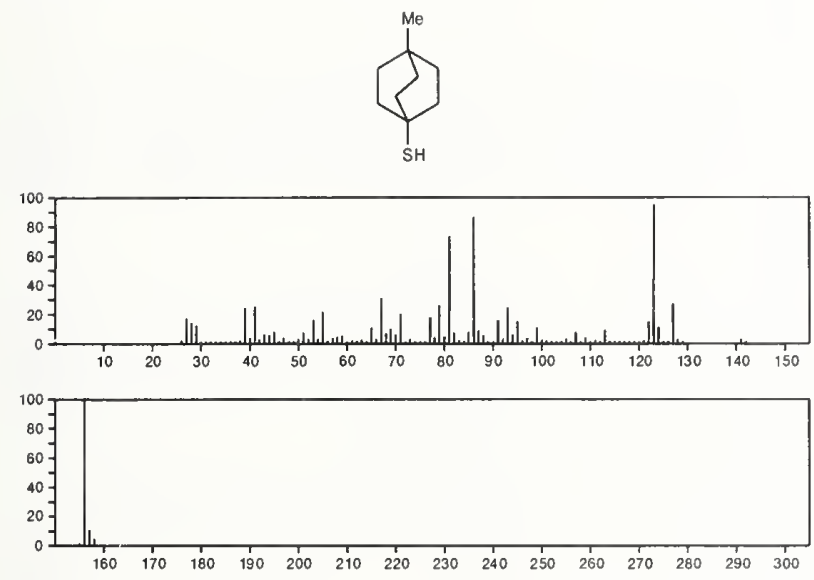

\section{$156 \quad \mathrm{C}_{9} \mathrm{H}_{16} \mathrm{~S}$}

2H-1-Benzothiopyran, octahydro-, trans-

$54340-73-7$
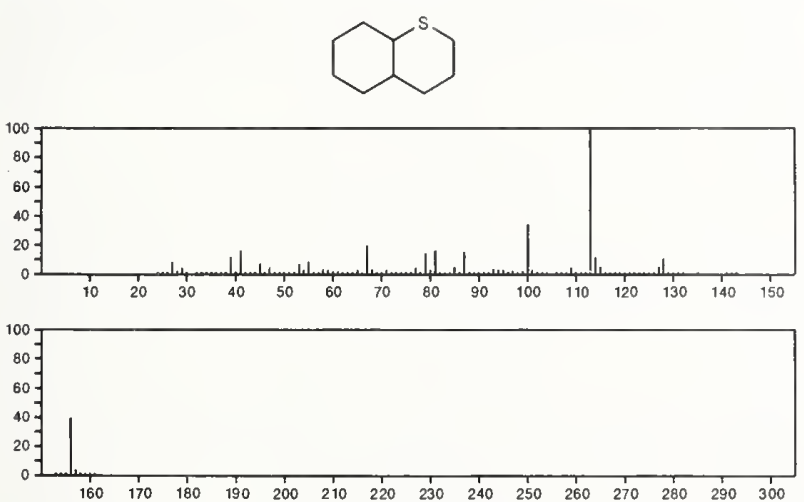

156

$\mathrm{C}_{9} \mathrm{H}_{16} \mathrm{~S}$

$54340-74-8$

1H-2-Benzothiopyran, octahydro-, cis-
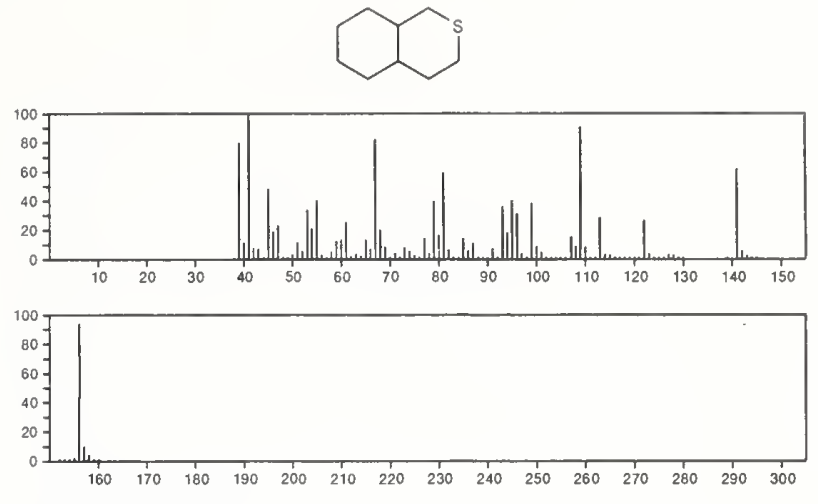

156

$\mathrm{C}_{9} \mathrm{H}_{18} \mathrm{NO}$

1-Piperidinyloxy, 2,2,6,6-tetramethyl-

2564-83-2
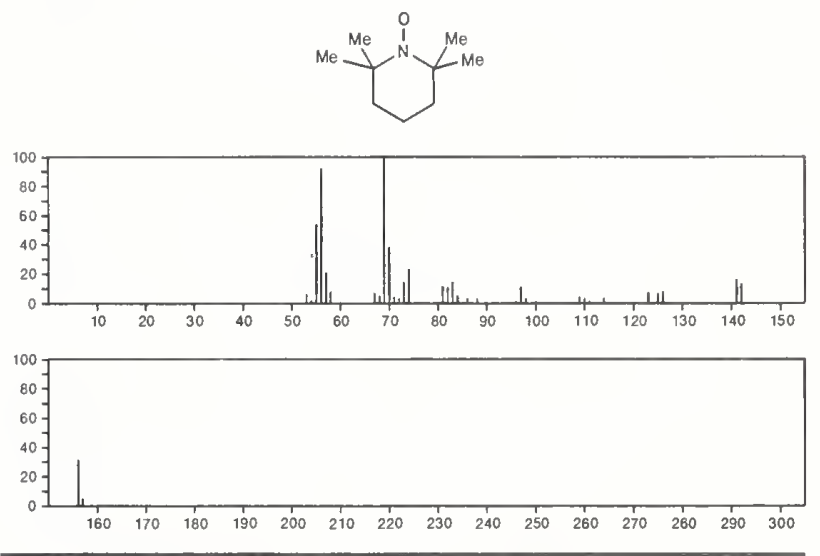

$156 \quad \mathrm{C}_{9} \mathrm{H}_{20} \mathrm{~N}_{2}$

4-Heptanone, dimethylhydrazone

14090-58-5

$\mathrm{P}{ }_{2} \mathrm{C}=\mathrm{NNM}_{2}$
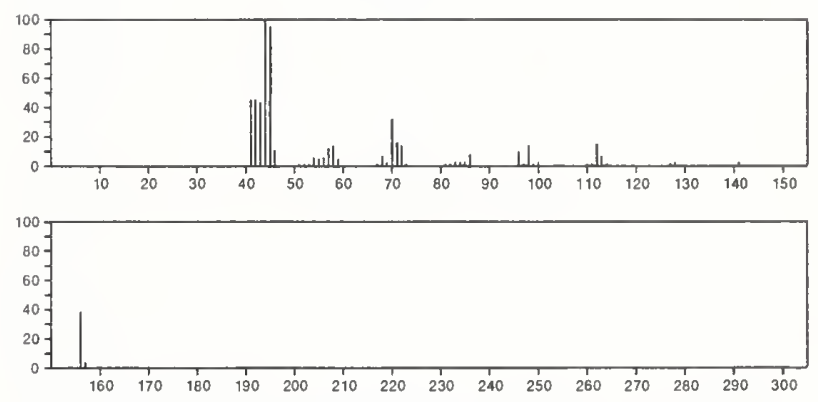

156

$\mathrm{C}_{9} \mathrm{H}_{20} \mathrm{~N}_{2}$

Piperazine, 2,5-dimethyl-3-propyl-

$54365-81-0$<smiles>CCCC1NC(N)CNC1C</smiles>

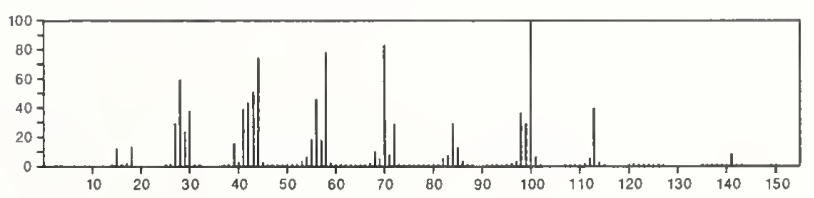




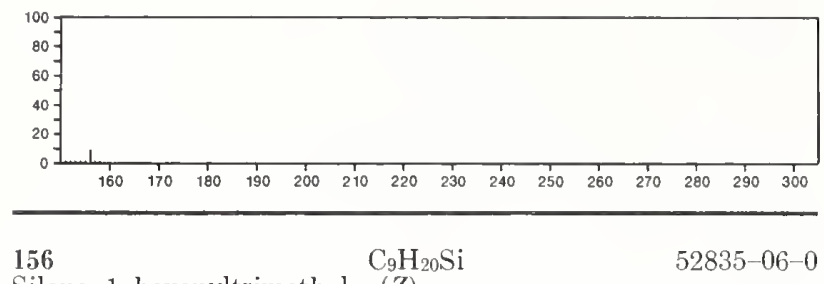

Silane, 1-hexenyltrimethyl-, $(Z)-$
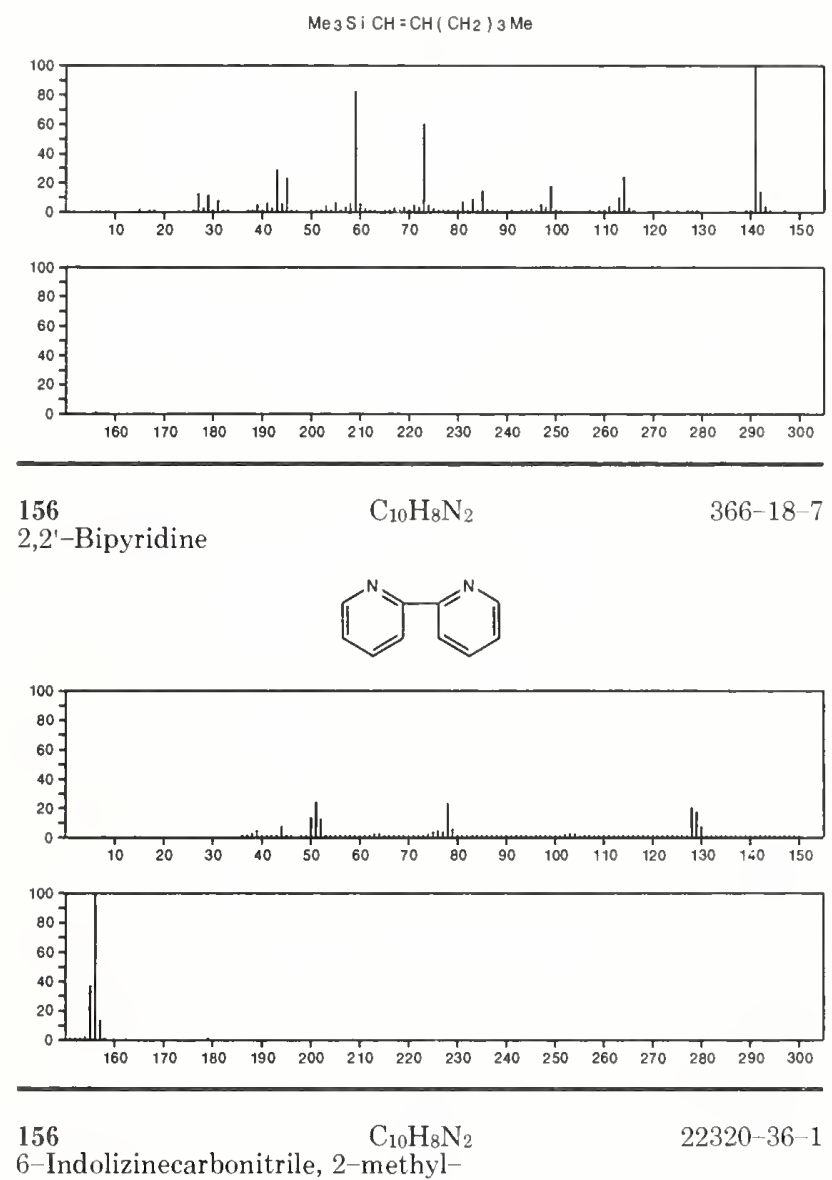

6-Indolizinecarbonitrile, 2-methyl-
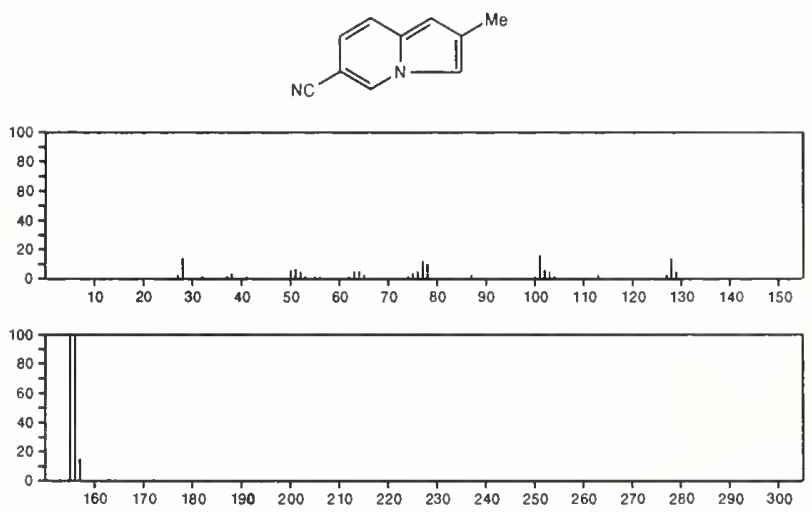

$156 \quad \mathrm{C}_{10} \mathrm{H}_{20} \mathrm{O}$

Cyclohexanol, 5-methyl -2-(1-methylethyl)-, (1 $\alpha, 2 \beta, 5 \alpha)-$

89-78-1<smiles>CC1CCC(I)C(O)C1</smiles>
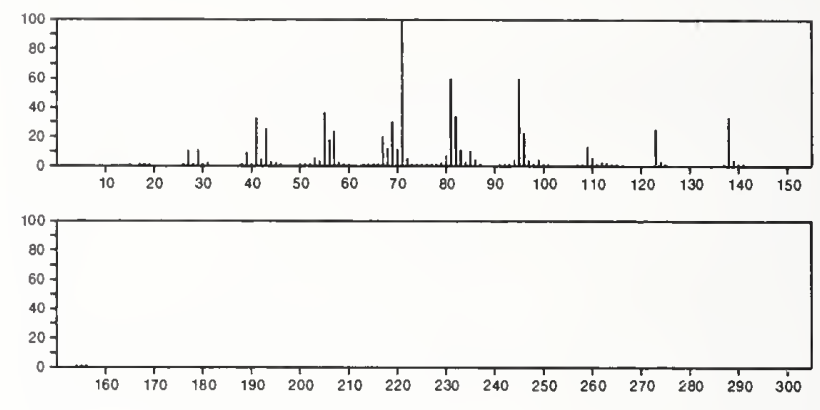

156

$\mathrm{C}_{10} \mathrm{H}_{20} \mathrm{O}$

Cyclohexanol, 4-(1,1-dimethylethyl)-

$98-52-2$
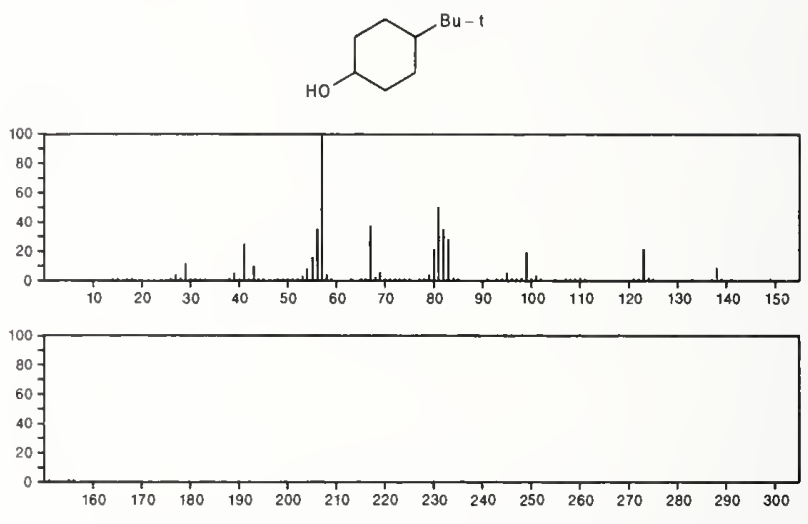

156

$\mathrm{C}_{10} \mathrm{H}_{20} \mathrm{O}$

$103-44-6$

Heptane, 3-[(ethenyloxy)methyl]-

$\mathrm{Me}\left(\mathrm{CH}_{2}\right)$ 3 $\mathrm{CHE}+\mathrm{CH}_{2} \mathrm{OCH}=\mathrm{CH}_{2}$
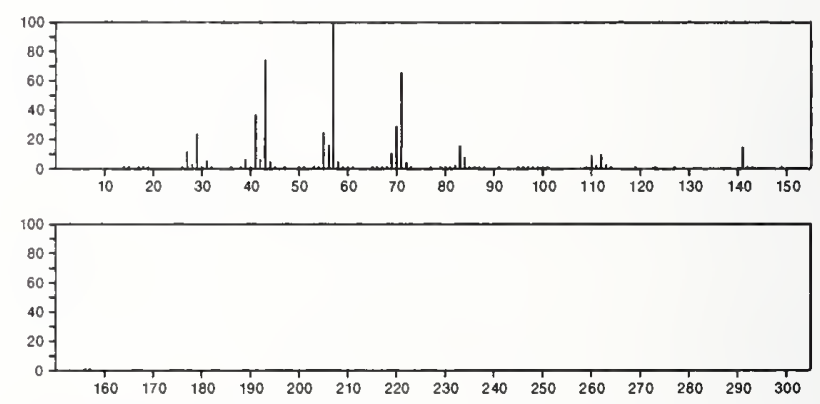

156

$\mathrm{C}_{10} \mathrm{H}_{20} \mathrm{O}$

$106-22-9$

6-Octen-1-ol, 3,7-dimethyl-

$\mathrm{Me}_{2} \mathrm{C}=\mathrm{CHCH}_{2} \mathrm{CH}_{2} \mathrm{CHM}_{2} \mathrm{CH}_{2} \mathrm{CH}_{2} \mathrm{OH}$
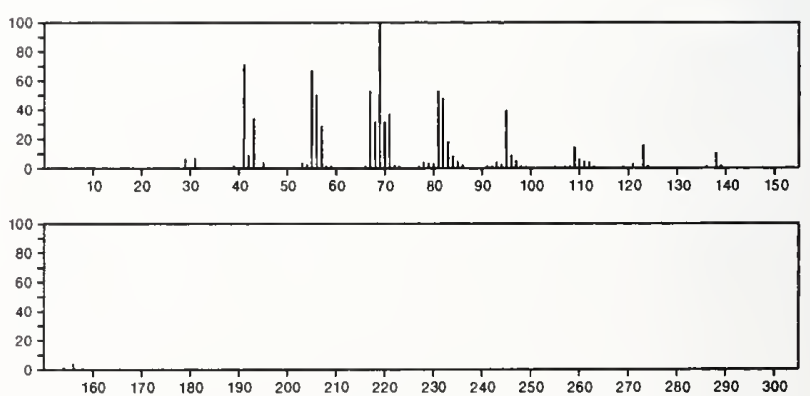
156

$\mathrm{C}_{10} \mathrm{H}_{20} \mathrm{O}$

$\mathrm{OCH}\left(\mathrm{CH}_{2}\right)_{8} \mathrm{Me}$

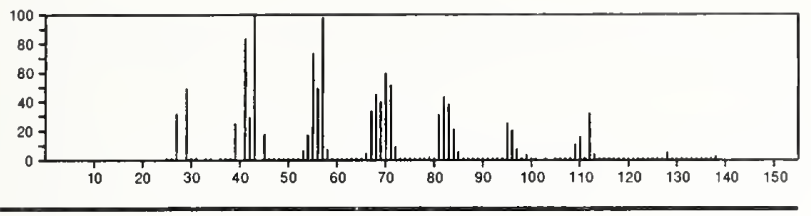

$156 \quad \mathrm{C}_{10} \mathrm{H}_{20} \mathrm{O}$

Cyclohexanol, 5-methyl-2-(1-methylethyl)-, $(1 \alpha, 2 \beta, 5 \beta)-$
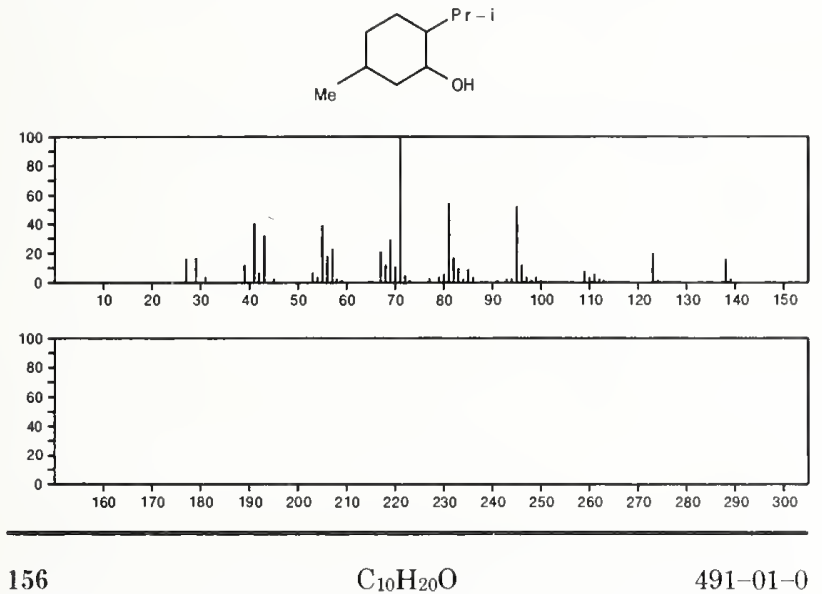

Cyclohexanol, 5-methyl-2-(1-methylethyl)-, $(1 \alpha, 2 \alpha, 5 \beta)-$
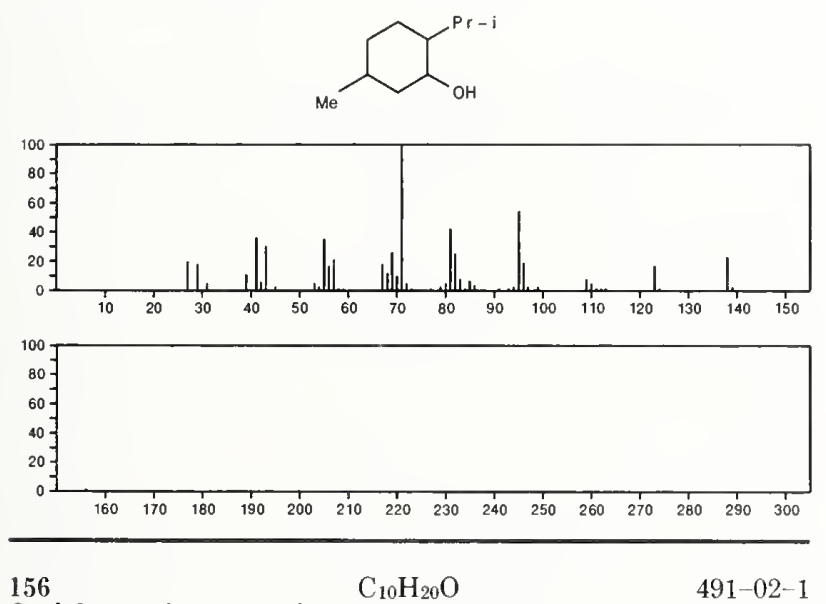

Cyclohexanol, 5-methyl-2-(1-methylethyl)-, $(1 \alpha, 2 \alpha, 5 \alpha)-$
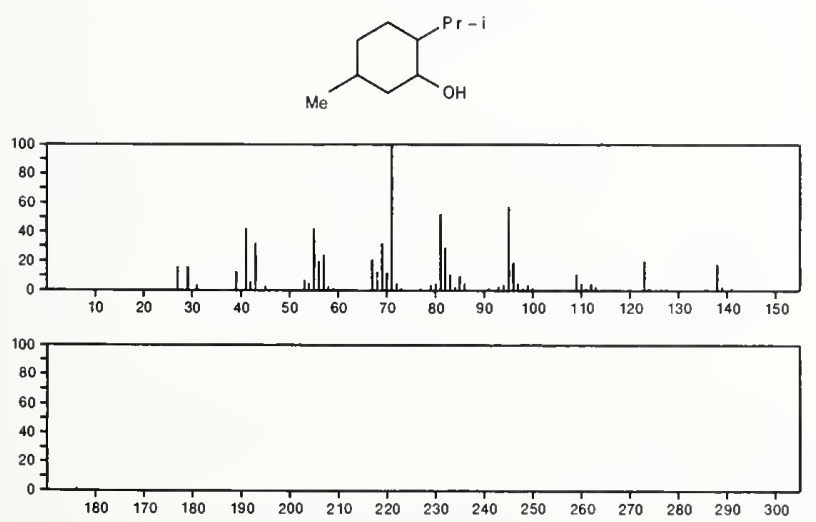

$156 \quad \mathrm{C}_{10} \mathrm{H}_{20} \mathrm{O}$
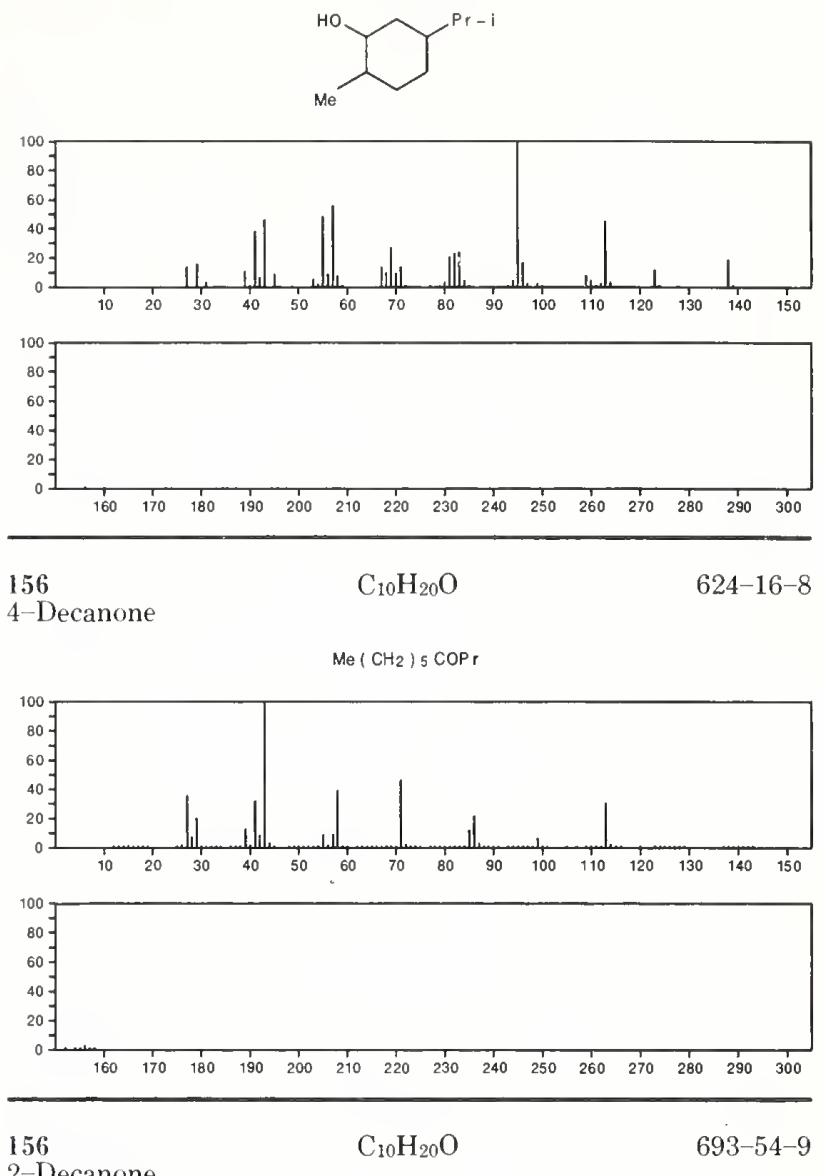

2-Decanone

$\mathrm{Me}\left\{\mathrm{CH}_{2}\right\}$, COMe
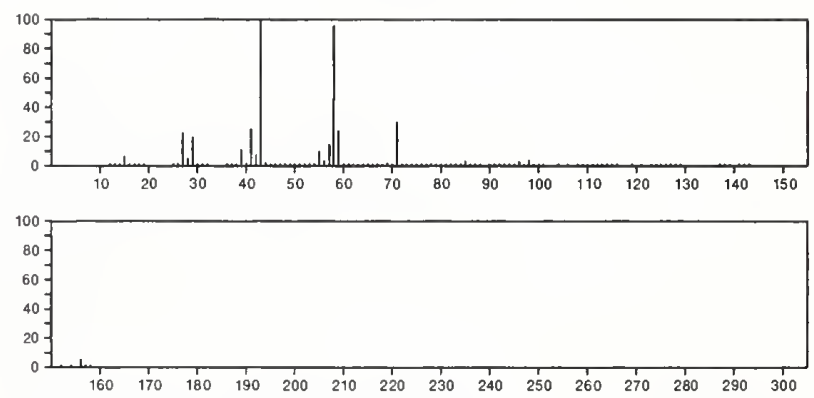

156

5-Decanone

$\mathrm{C}_{10} \mathrm{H}_{20} \mathrm{O}$

$820-29-1$

$\mathrm{Me}\left(\mathrm{CH}_{2}\right)_{4} \mathrm{CO}\left(\mathrm{CH}_{2}\right)_{3} \mathrm{Me}$
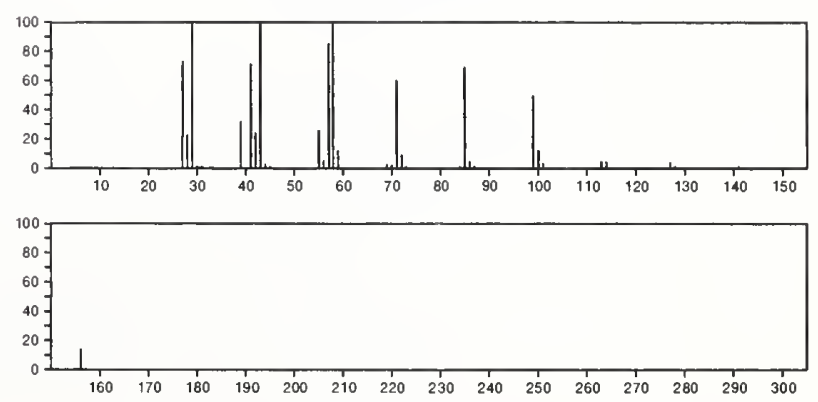
156

3-Decanone

$\mathrm{C}_{10} \mathrm{H}_{20} \mathrm{O}$

$\operatorname{Me}\left(\mathrm{CH}_{2}\right)_{6} \mathrm{COE} \mathrm{I}$
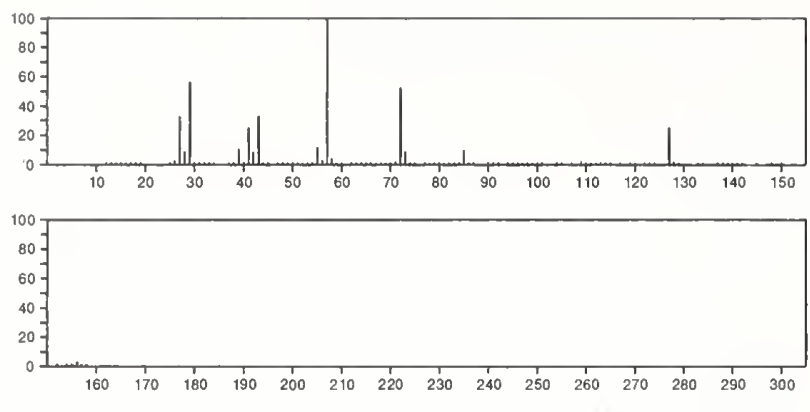

$156 \quad \mathrm{C}_{10} \mathrm{H}_{20} \mathrm{O}$

Cyclohexanol, 4-(1,1-dimethylethyl)-, cis-
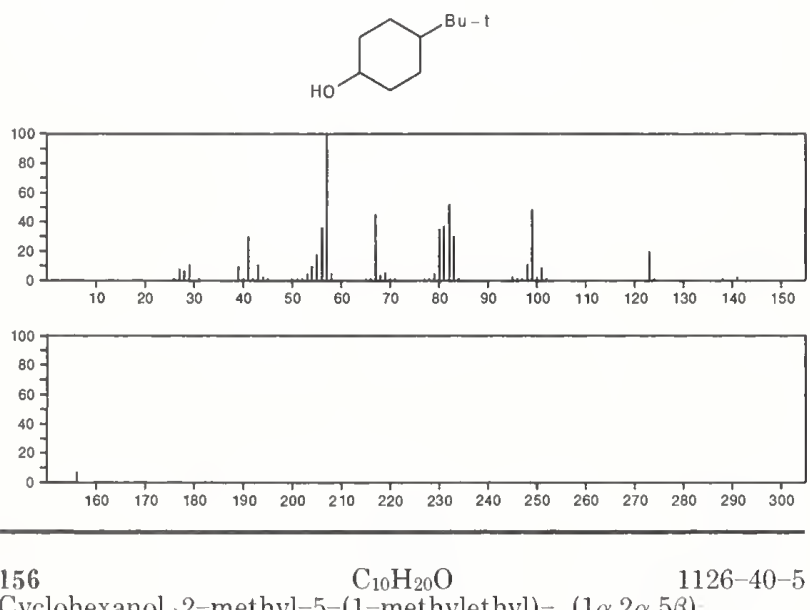

Cyclohexanol, 2-methyl-5-(1-methylethyl)-, $(1 \alpha, 2 \alpha, 5 \beta)$
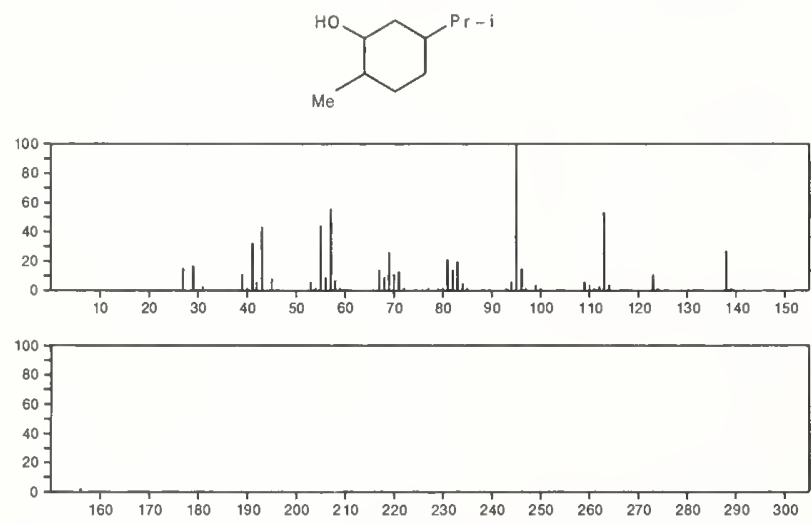

156

Cyclohexanol, 5-methyl-2-(1-methylethyl)-<smiles>C[C@@H]1CC[C@@H](P)[C@H](O)C1</smiles>

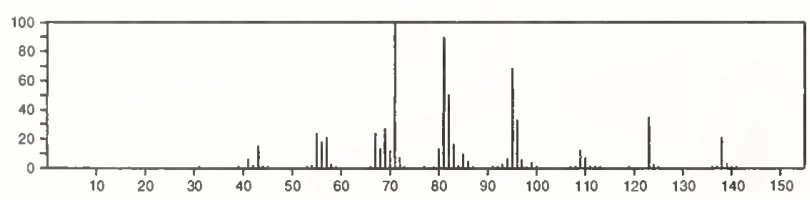

156

Cyclodecanol

$\mathrm{C}_{10} \mathrm{H}_{20} \mathrm{O}$

$1502-05-2$
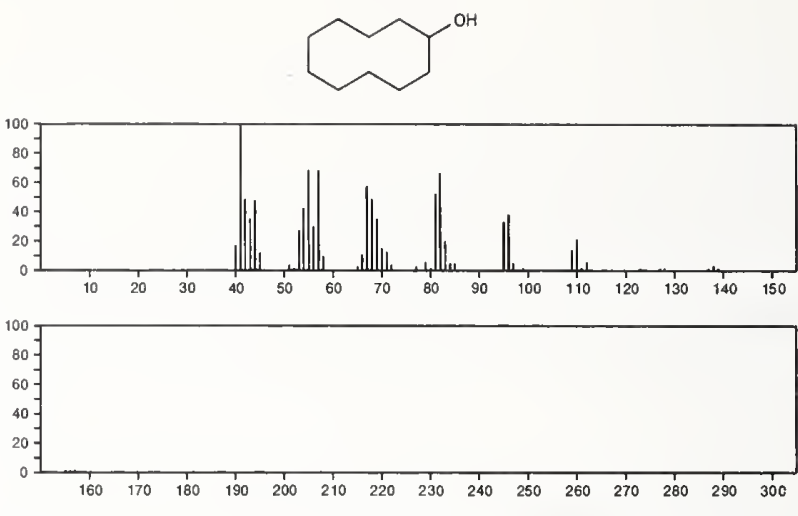

156

$\mathrm{C}_{10} \mathrm{H}_{20} \mathrm{O}$

$3127-80-8$

Cyclohexanol, 2-methyl-5-(1-methylethyl)-, $(1 \alpha, 2 \beta, 5 \beta)$
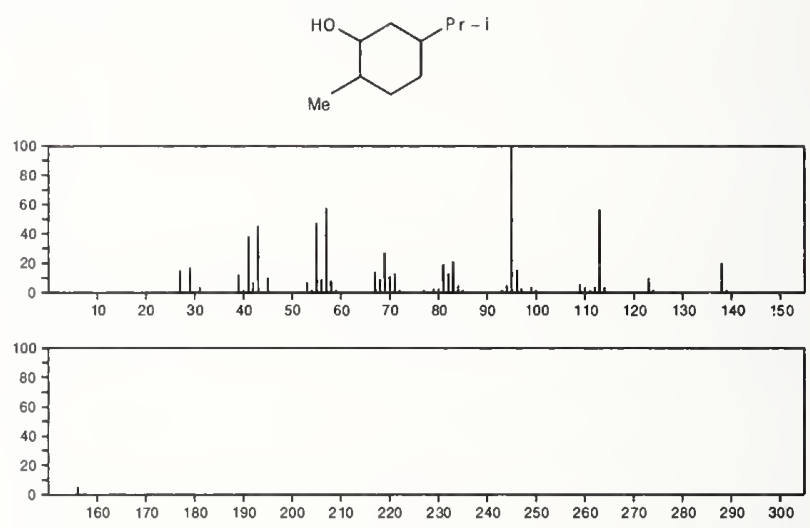

156

$\mathrm{C}_{10} \mathrm{H}_{20} \mathrm{O}$

3239-02-9

p-Menthan-4-ol, cis-
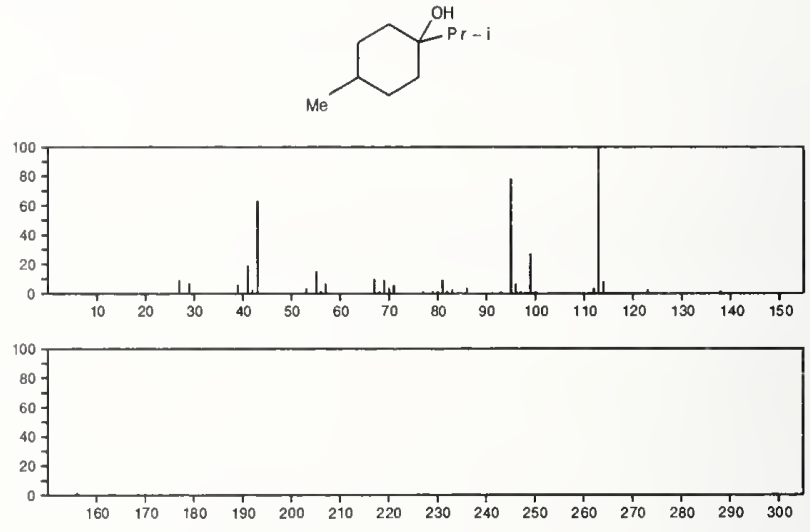

156

$\mathrm{C}_{10} \mathrm{H}_{20} \mathrm{O}$

$3901-93-7$

Cyclohexanol, 1-methyl-4-(1-methylethyl)-, trans-
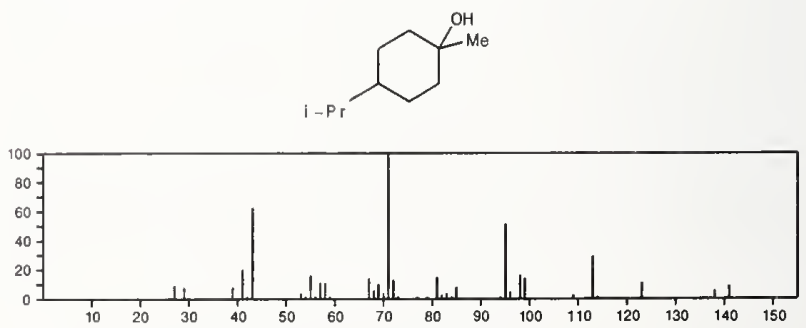


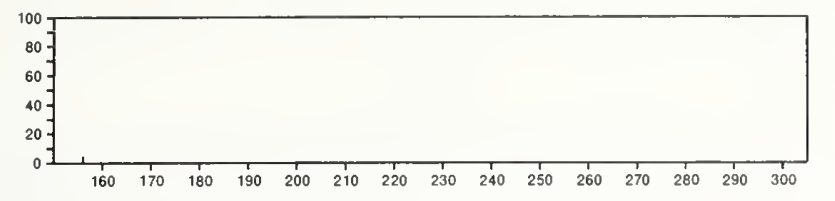

$\mathrm{C}_{10} \mathrm{H}_{20} \mathrm{O}$
$\mathbf{1 5 6}$

Cyclohexanol, 2-(1-methylpropyl)-
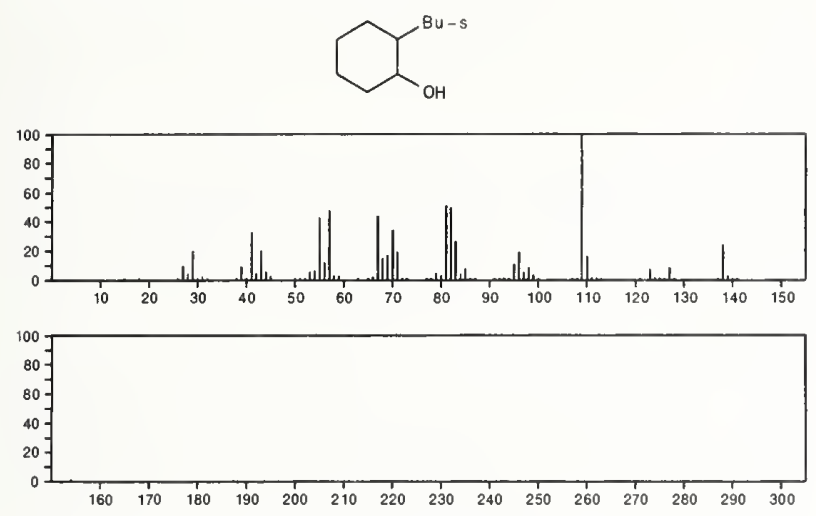

\section{6}

3-Nonanone, 2-methyl-

$\mathrm{C}_{10} \mathrm{H}_{20} \mathrm{O}$

$5445-31-8$

$\mathrm{Me}\left(\mathrm{CH}_{2}\right)_{5} \mathrm{COCHMe} 2$
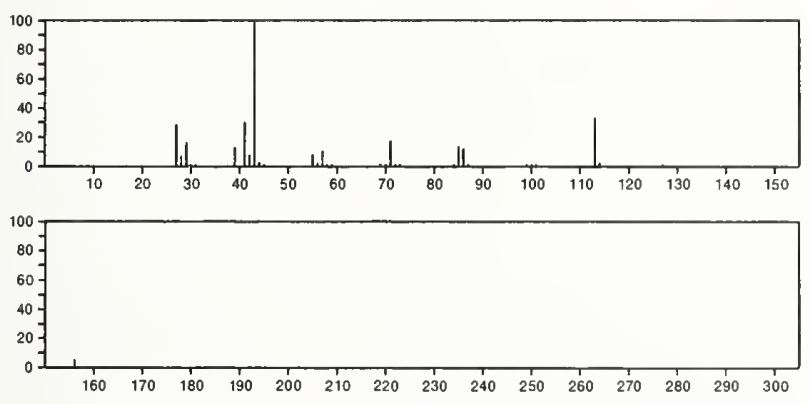

156

4-Nonanone, 8-methyl-

\section{$\mathrm{C}_{10} \mathrm{H}_{20} \mathrm{O}$}

6137-29-7

$\mathrm{Me}_{2} \mathrm{CH}\left(\mathrm{CH}_{2}\right)_{3} \mathrm{COPr}$
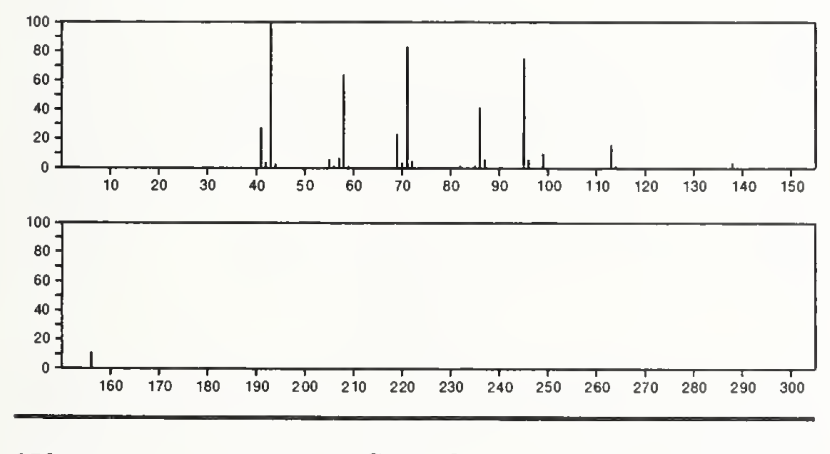

156

Cyclohexanol, 4-sec-butyl-

$\mathrm{C}_{10} \mathrm{H}_{20} \mathrm{O}$

$6292-20-2$
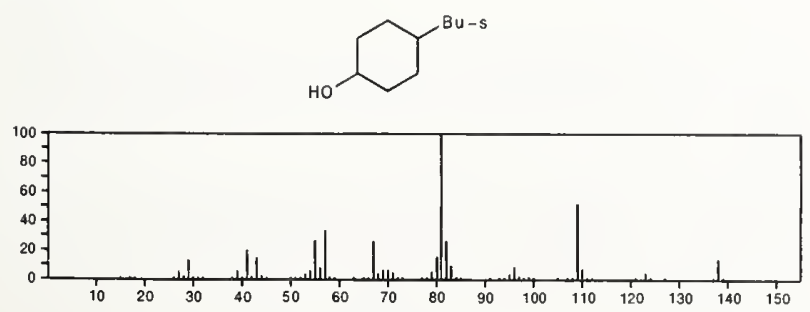

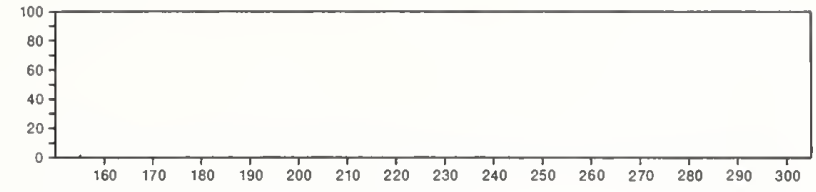

$\mathrm{C}_{10} \mathrm{H}_{20} \mathrm{O}$

156
Cyclohexanepropanol, $\alpha$-methyl-

$10528-67-3$

$\sim^{\mathrm{CH}_{2} \mathrm{CH}_{2} \mathrm{CH}(\mathrm{OH}) \mathrm{Me}}$
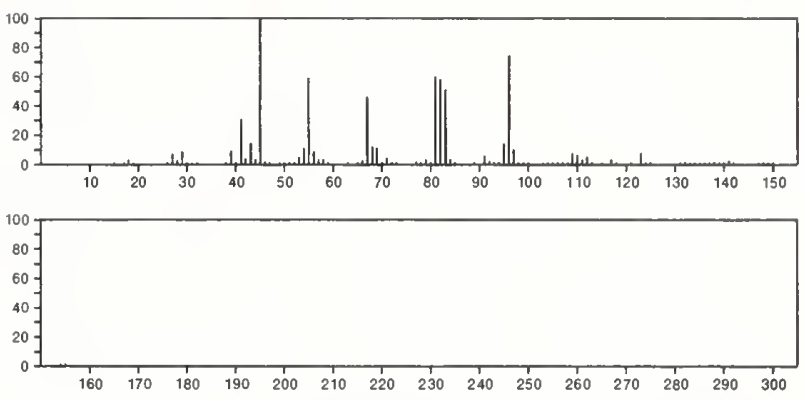

156

$\mathrm{C}_{10} \mathrm{H}_{20} \mathrm{O}$

Cyclohexanol, 2-(1,1-dimethylethyl)-

13491-79-7
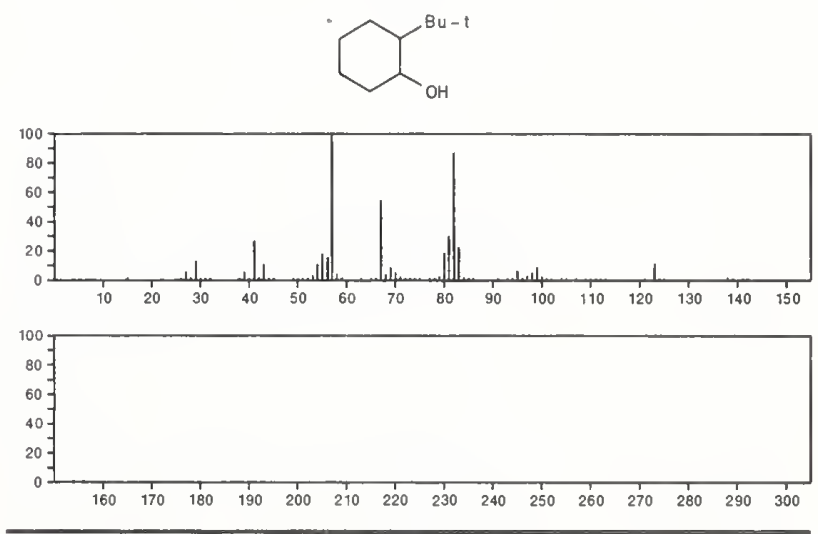

156

Heptane, 1-(2-propenyloxy)-

$\mathrm{C}_{10} \mathrm{H}_{20} \mathrm{O}$

$16519-24-7$

$\mathrm{H}_{2} \mathrm{C}=\mathrm{CHCH}_{2} \mathrm{O}\left(\mathrm{CH}_{2}\right)_{6} \mathrm{Me}$
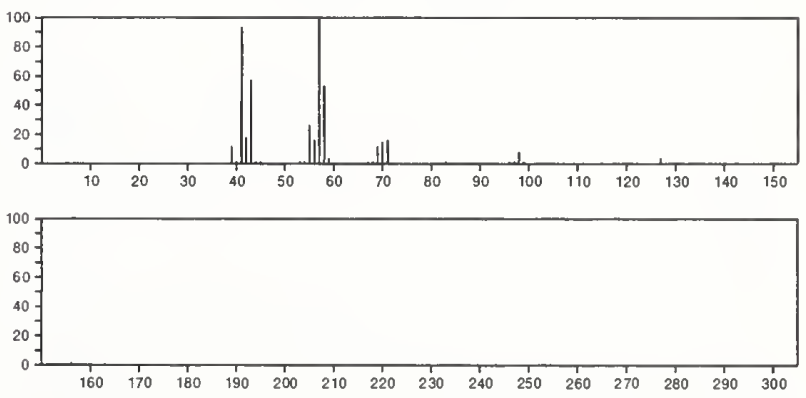

156

$\mathrm{C}_{10} \mathrm{H}_{20} \mathrm{O}$

26489-01-0

6-Octen-1-ol, 3,7-dimethyl-, $( \pm)$

$\mathrm{Me}_{2} \mathrm{C}=\mathrm{CHCH}_{2} \mathrm{CH}_{2} \mathrm{CHMe} \mathrm{CH}_{2} \mathrm{CH}_{2} \mathrm{OH}$

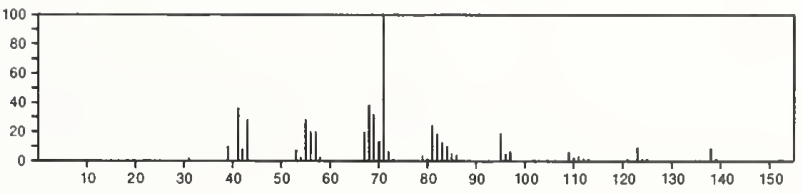




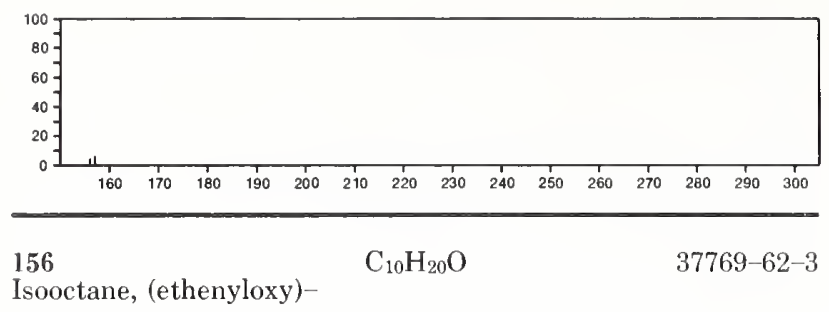

(I SO- $\mathrm{C}_{8} \mathrm{H}_{1} 7$ ) OCH: $\mathrm{CH}_{2}$
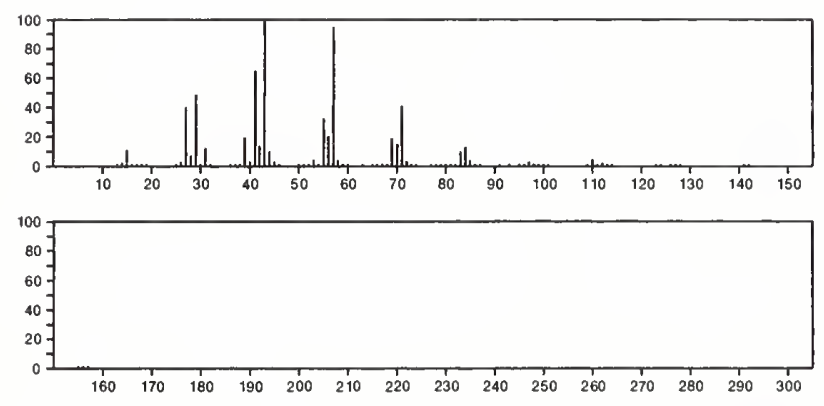

156

$\mathrm{C}_{10} \mathrm{H}_{20} \mathrm{O}$

$42846-32-2$

Cyclohexanol, 2-methyl-5-(1-methylethyl)-, $(1 \alpha, 2 \alpha, 5 \alpha)-$
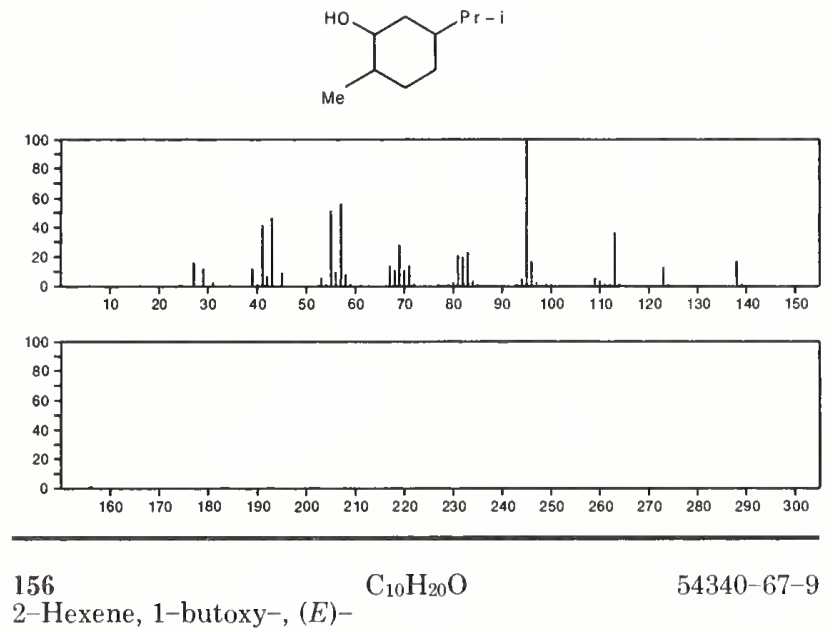

$\mathrm{PrCH}=\mathrm{CHCH}_{2} \mathrm{O}\left(\mathrm{CH}_{2}\right)_{3} \mathrm{Me}$
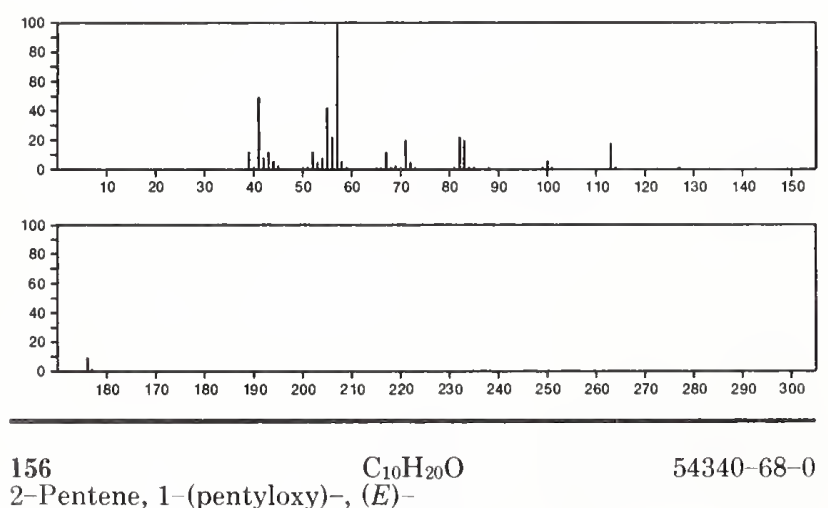

2-Pentene, 1-(pentyloxy)-, $(E)$ -

$\mathrm{Me}\left(\mathrm{CH}_{2}\right)_{4} \mathrm{OCH}_{2} \mathrm{CH}=\mathrm{CHE}$

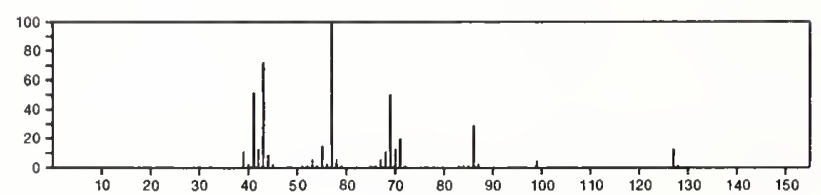

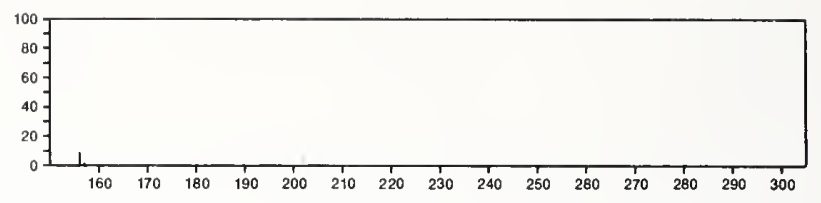

156

2-Pentene, 5-(pentyloxy)-, $(E)$ -

$\mathrm{C}_{10} \mathrm{H}_{20} \mathrm{O}$

$56052-85-8$

$\mathrm{MeCH}=\mathrm{CHCH}_{2} \mathrm{CH}_{2} \mathrm{O}\left(\mathrm{CH}_{2}\right) \& \mathrm{Me}$
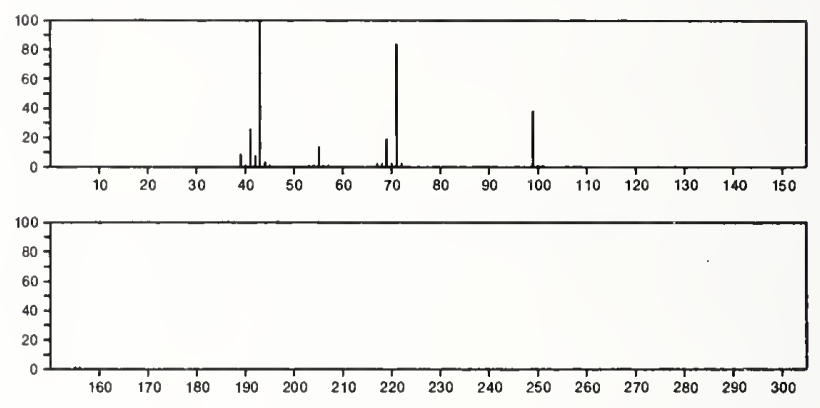

156

1-Pentene, 5-(pentyloxy)-

$\mathrm{C}_{10} \mathrm{H}_{20} \mathrm{O}$

$56052-88-1$

$\mathrm{H}_{2} \mathrm{C}=\mathrm{CH}\left(\mathrm{CH}_{2}\right)_{3} \mathrm{O}\left(\mathrm{CH}_{2}\right)_{4} \mathrm{Me}$
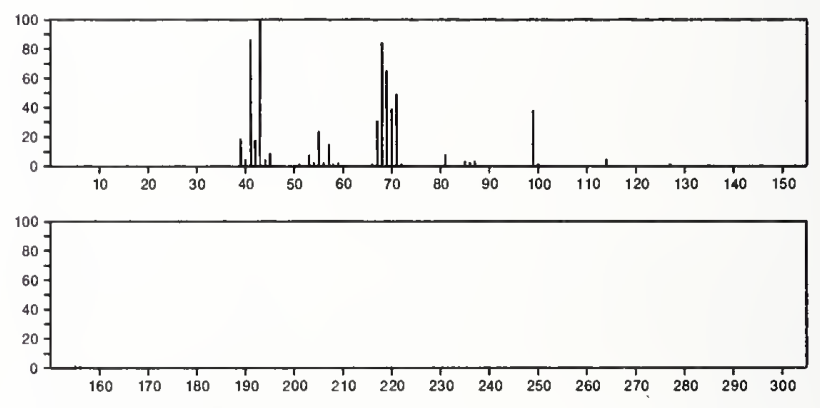

156

$\mathrm{C}_{10} \mathrm{H}_{20} \mathrm{O}$

Cyclopropanemethanol, $\alpha, 2-$ bis( 1 -methylethyl)-

$56259-16-6$
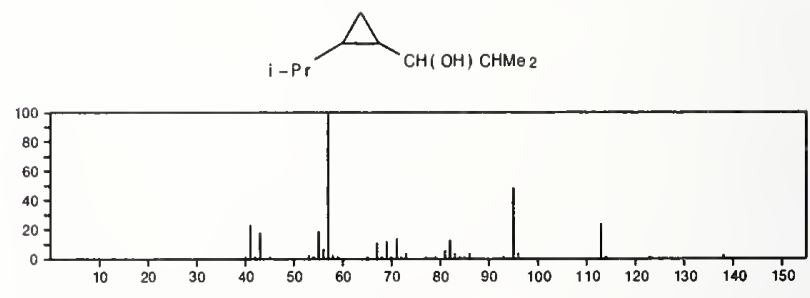

156

$\mathrm{C}_{11} \mathrm{H}_{8} \mathrm{O}$

$36628-80-5$

Bicyclo[4.4.1] undeca-1,3,5,7,9-pentaen-11-one
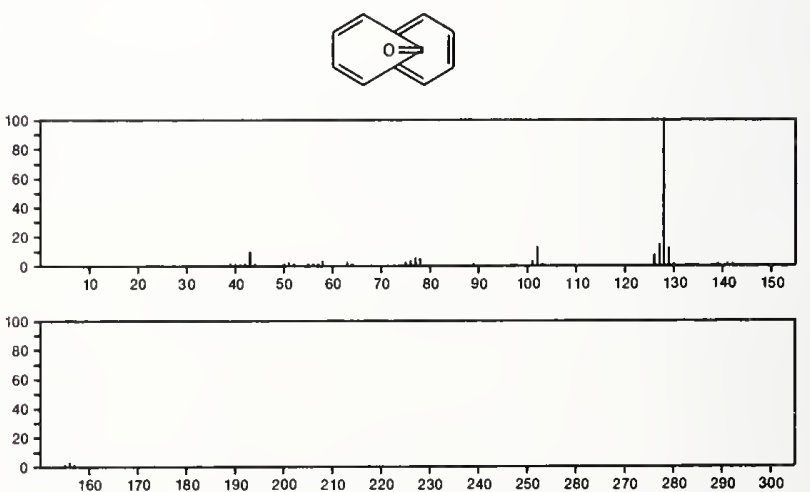
156

Undecane

$$
\mathrm{C}_{11} \mathrm{H}_{24}
$$

$1120-21-4$

$\mathrm{Me}\left(\mathrm{CH}_{2}\right) 9 \mathrm{Me}$
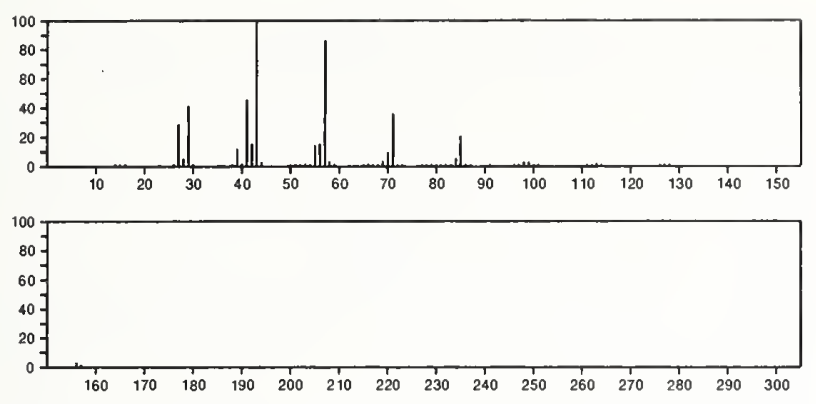

156

Decane, 4-methyl-

$$
\mathrm{C}_{11} \mathrm{H}_{24}
$$

$2847-72-5$

$\operatorname{PrCHMe}\left(\mathrm{CH}_{2}\right) 5 \mathrm{Me}$
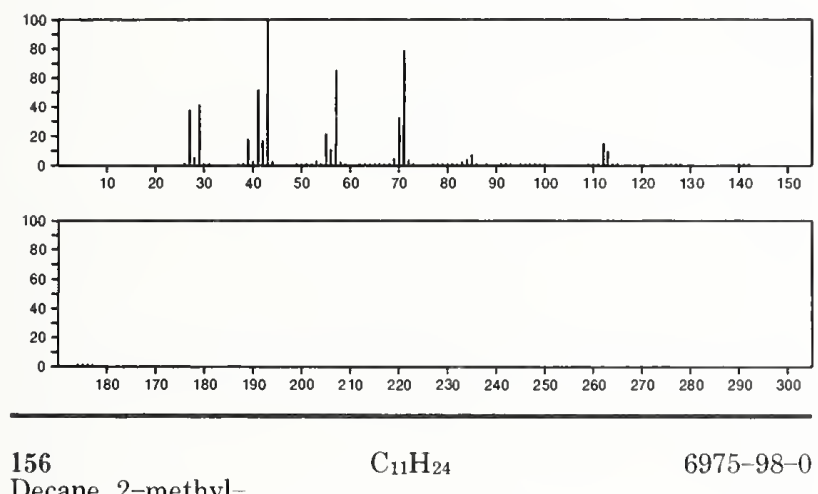

Decane, 2-methyl-

$\mathrm{Me}_{2} \mathrm{CH}\left(\mathrm{CH}_{2}\right) 7 \mathrm{Me}$
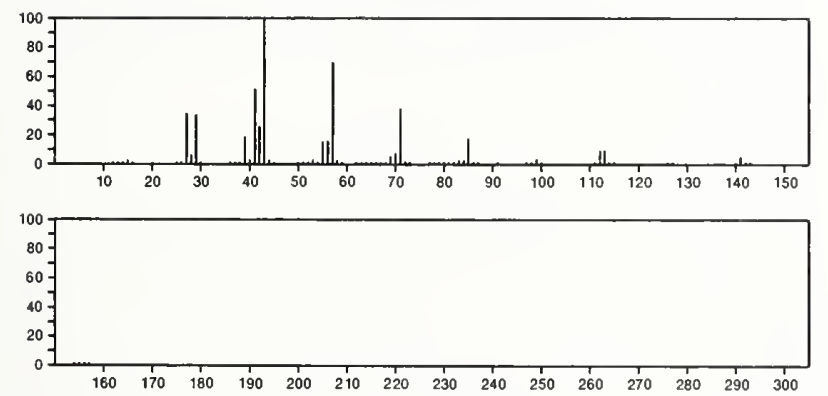

$\begin{array}{lllllllllllllll}160 & 170 & 180 & 190 & 200 & 210 & 220 & 230 & 240 & 250 & 260 & 270 & 280 & 290 & 300\end{array}$

156

Decane, 5-methyl

$\mathrm{C}_{11} \mathrm{H}_{24}$

$\mathrm{Me}\left(\mathrm{CH}_{2}\right)_{4} \mathrm{CHMe}\left(\mathrm{CH}_{2}\right)_{3} \mathrm{Me}$
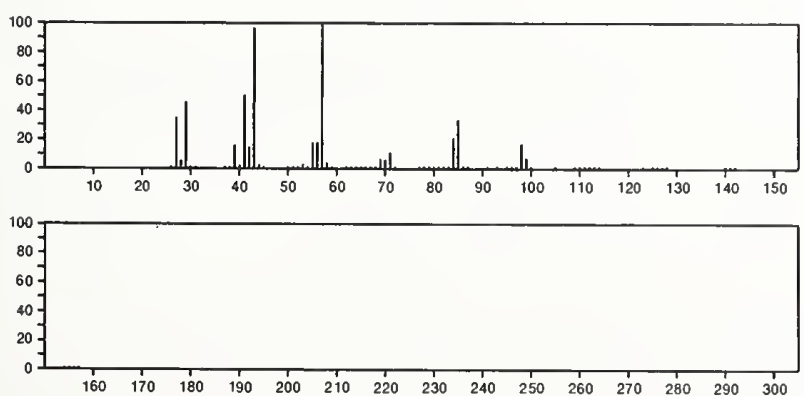

156

Nonane, 2,5-dimethyl-

$\mathrm{C}_{11} \mathrm{H}_{24}$

17302-27-1

$\mathrm{Me}_{2} \mathrm{CHCH}_{2} \mathrm{CH}_{2} \mathrm{CHMe}\left(\mathrm{CH}_{2}\right.$ ) $3 \mathrm{Me}$
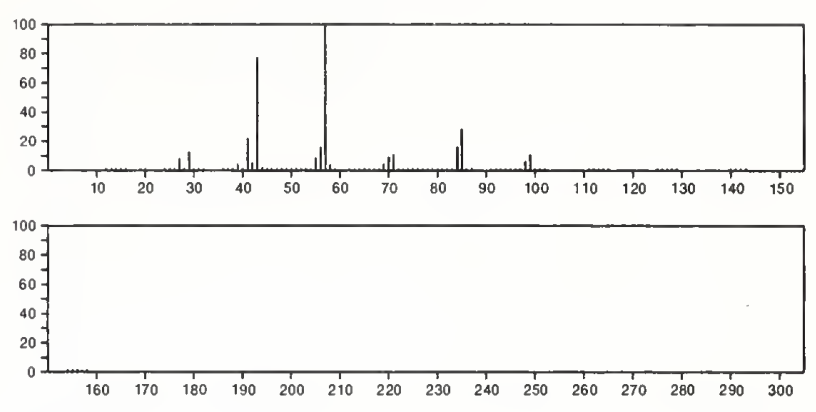

156

Naphthalene, 1,8-dimethyl

$\mathrm{C}_{12} \mathrm{H}_{12}$

569-41-5
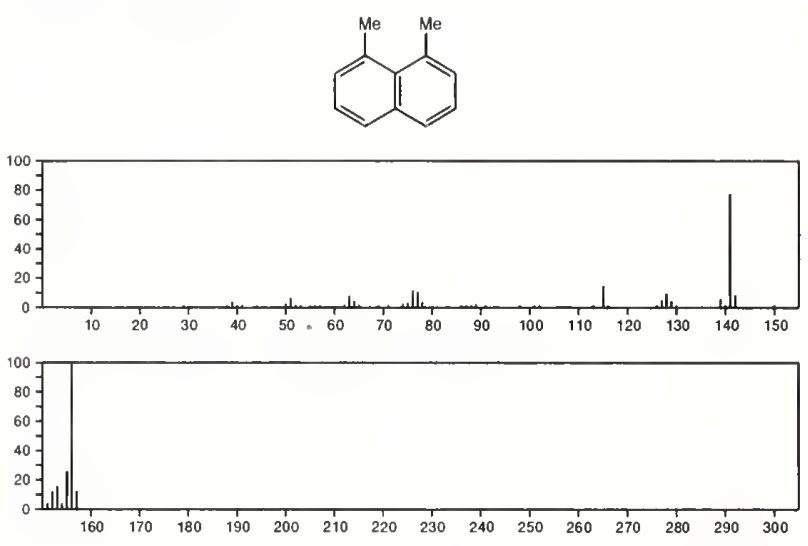

156

Naphthalene, 1,4-dimethyl

$\mathrm{C}_{12} \mathrm{H}_{12}$

571-58-4
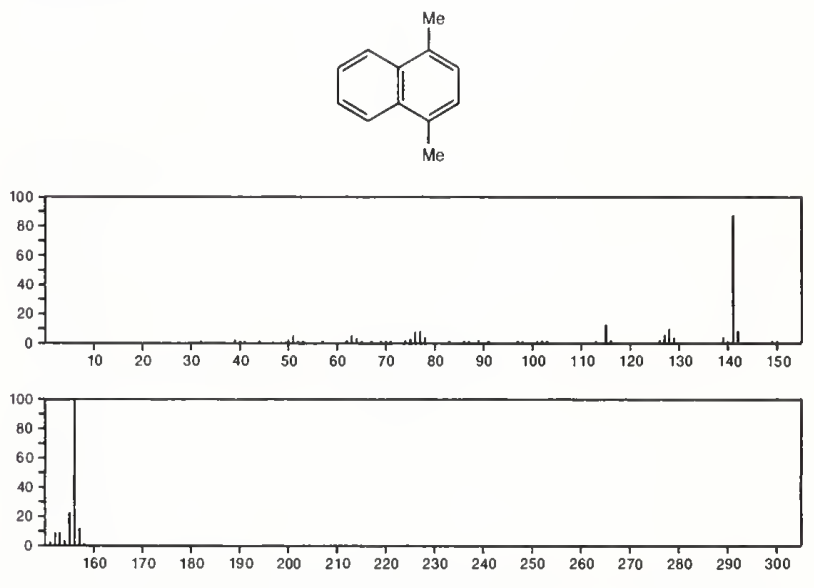

156

Naphthalene, 1,5-dimethyl-

$\mathrm{C}_{12} \mathrm{H}_{12}$

571-61-9
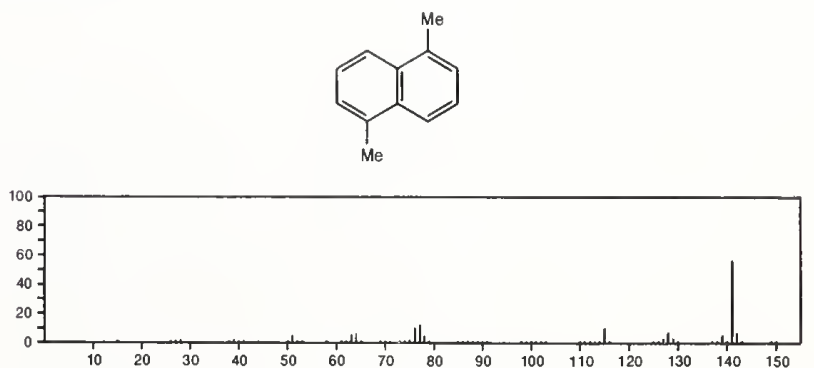
558

EPA/ NIH MASS SPECTRAL DATA BASE

156

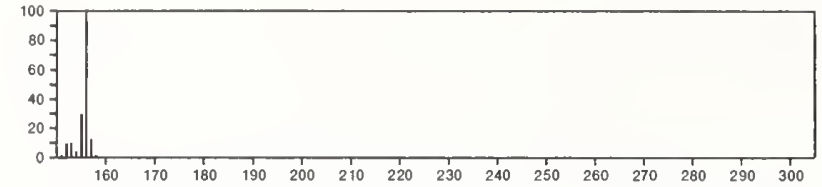

156

Naphthalene, 1,2-dimethyl-
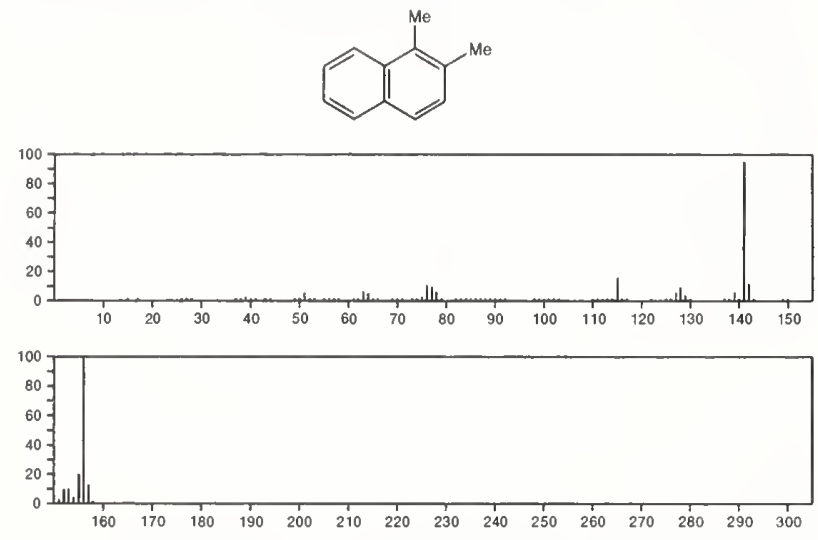

156
Naphthalene, 1,7-dimethyl-
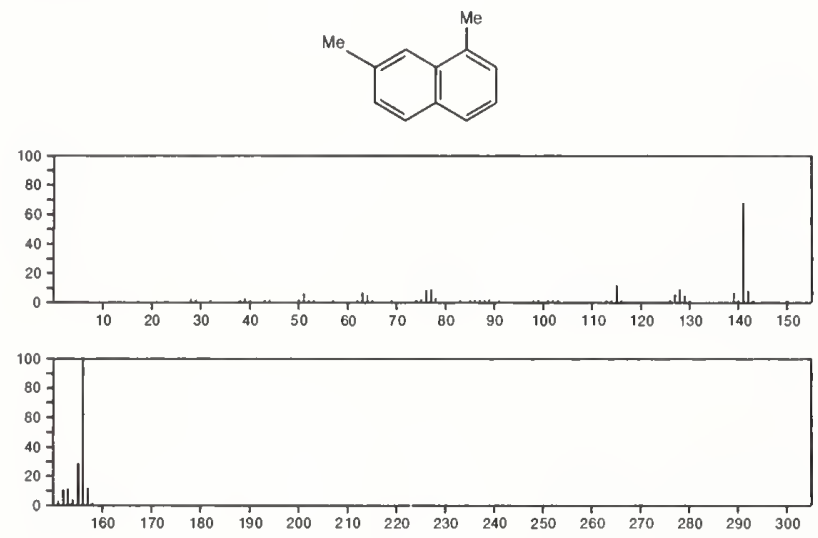

$\mathbf{1 5 6}$
Naphthalene, 1,3-dimethyl-
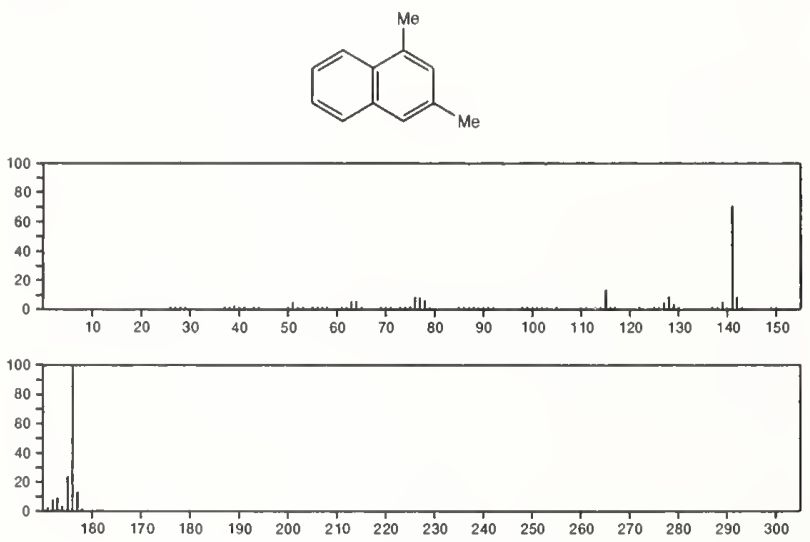

156

Naphthalene, 1,6-dimethyl- ${ }^{-}{ }_{12} \mathrm{H}_{12}$

$575-43-9$
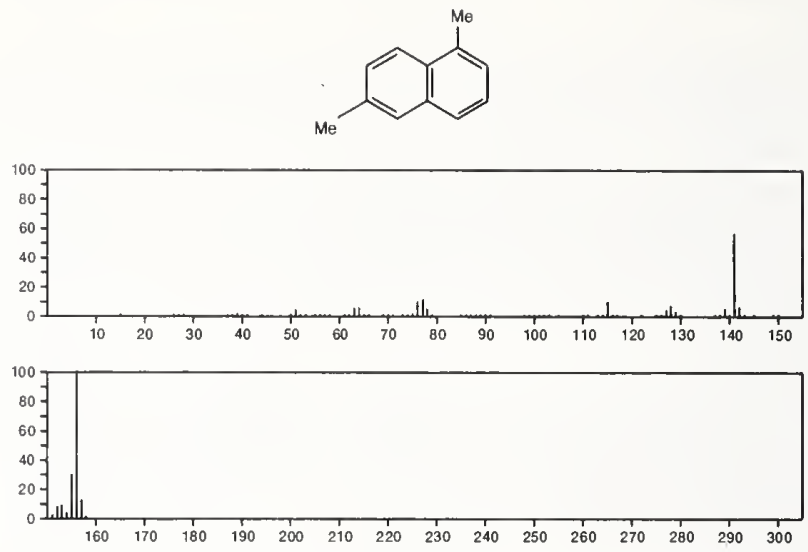

156

Naphthalene, 2,3-dimethyl-
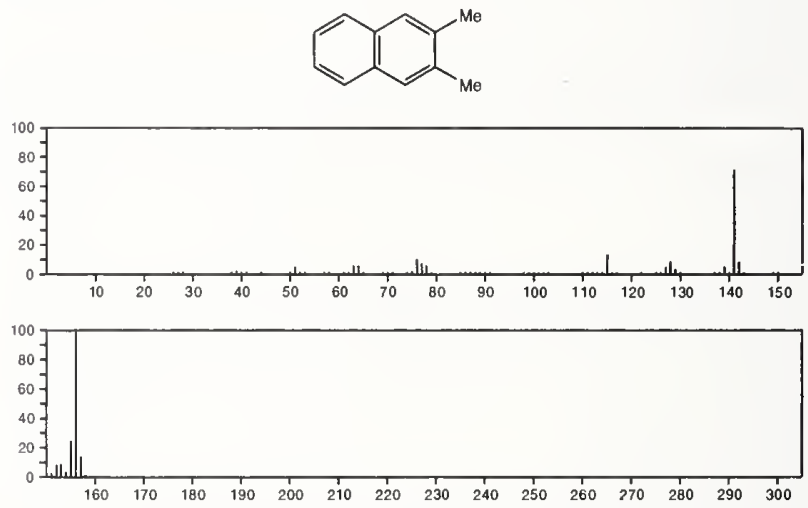

156
Naphthalene, 2,6-dimethyl-
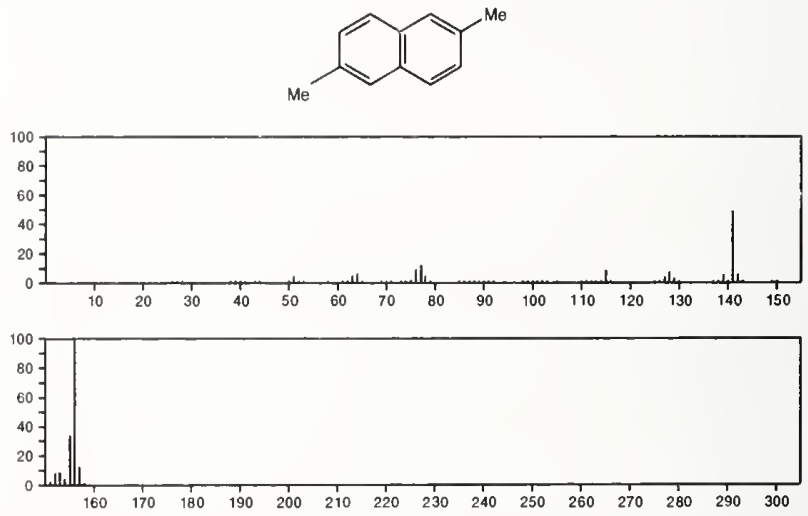

$156 \quad \mathrm{C}_{12} \mathrm{H}_{12} \quad 582-16-1$

Naphthalene, 2,7-dimethyl-
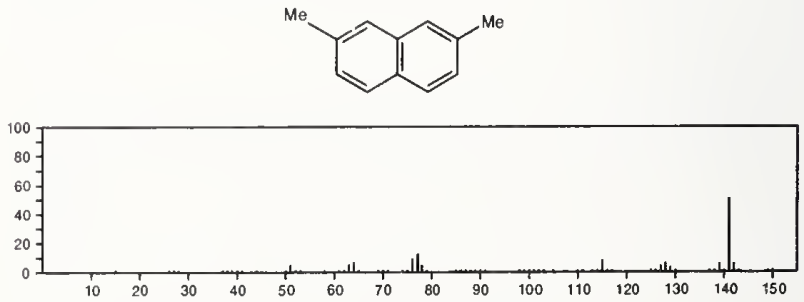
156

EPA/NIH MASS SPECTRAL DATA BASE

559

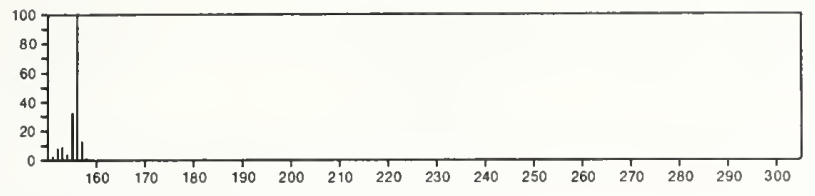

156

Naphthalene, 2-ethyl-
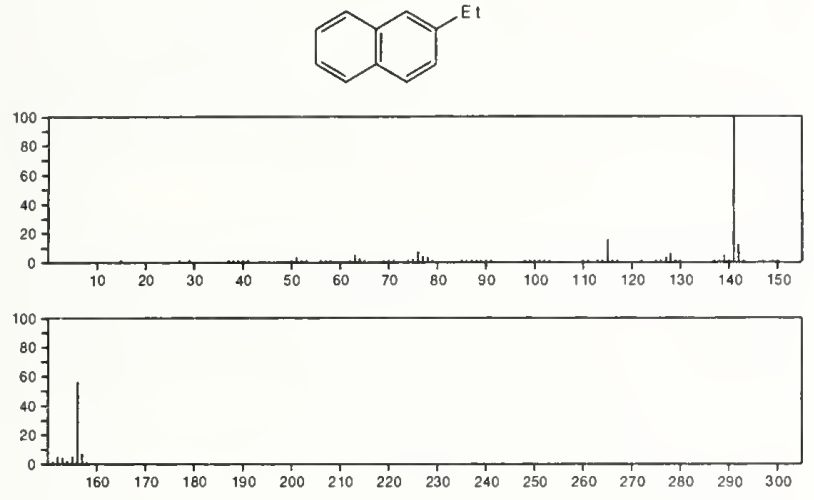

156

Naphthalene, 1-ethyl-
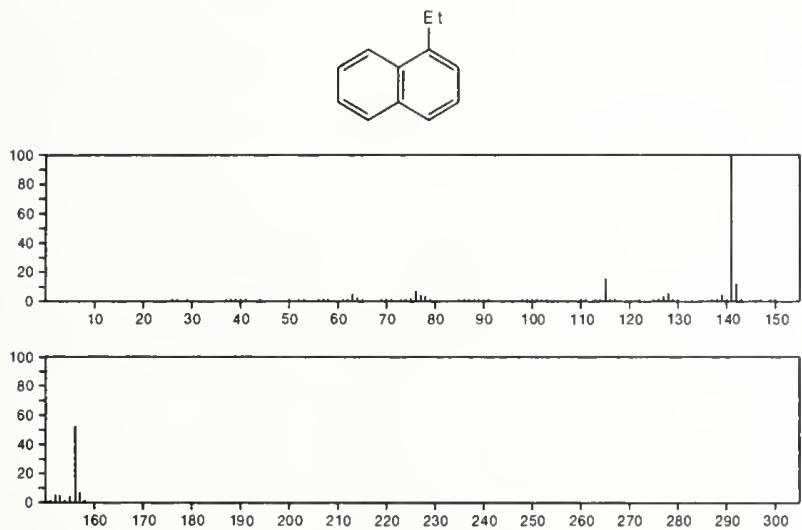

$156 \quad \mathrm{C}_{12} \mathrm{H}_{12}$
Benzene, 2,5-cyclohexadien-1-yl-
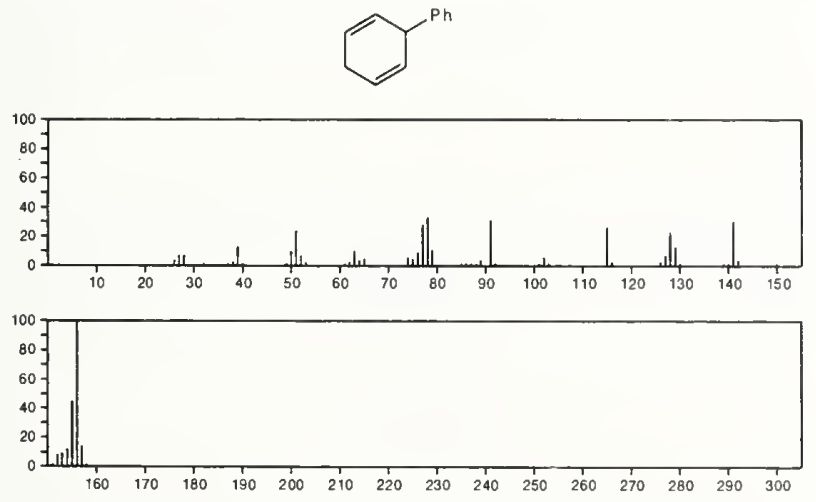

156
Benzene,
$\mathrm{C}_{12} \mathrm{H}_{12}$

$13703-52-1$
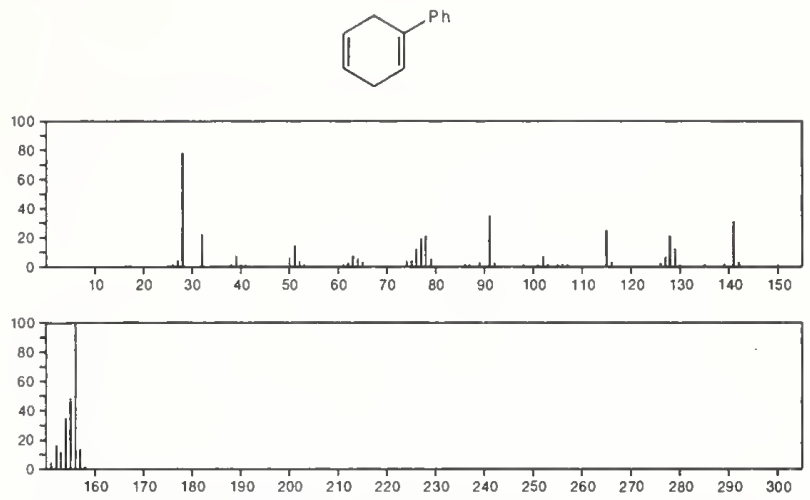

$156 \quad \mathrm{C}_{12} \mathrm{H}_{12} \quad 15619-32-6$

Benzene, 1,3-cyclohexadien-1-yl-
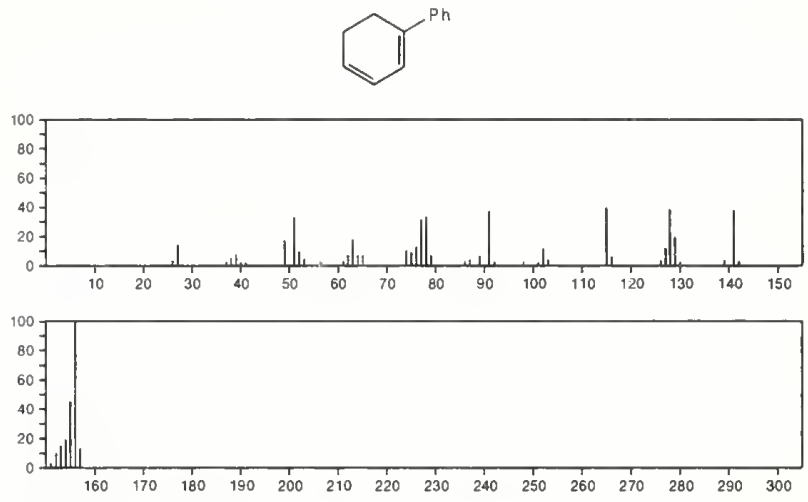

156

$\mathrm{C}_{12} \mathrm{H}_{12}$

$15619-34-8$

Benzene, 1,5-cyclohexadien-1-yl-
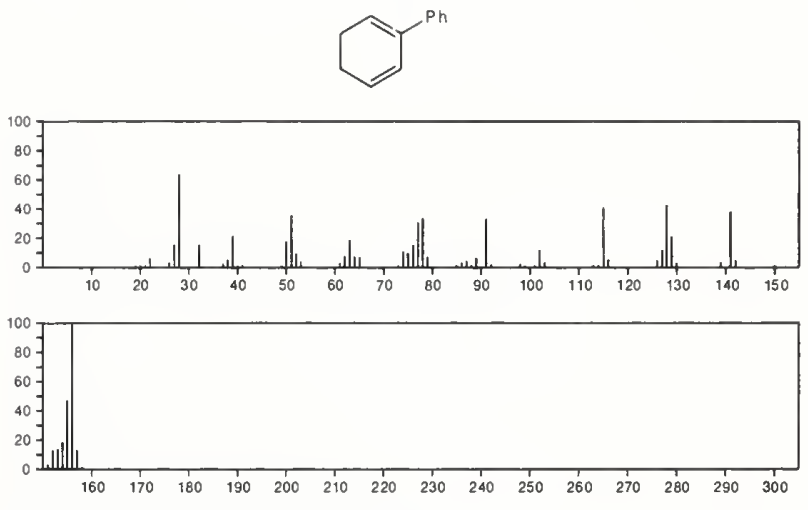

156

$\mathrm{C}_{12} \mathrm{H}_{12}$

1,6-Ethenoazulene, 1,3a,6,8a-tetrahydro-
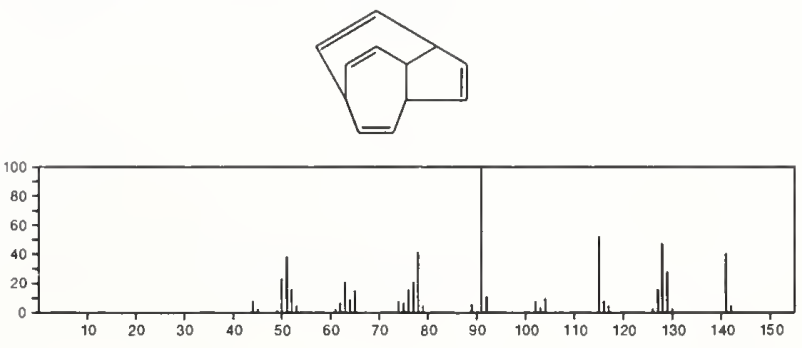


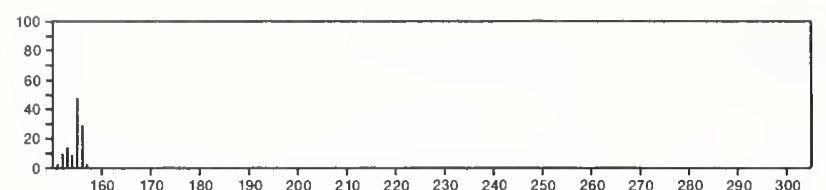

$\begin{array}{lllllllllllllll}160 & 170 & 180 & 190 & 200 & 210 & 220 & 230 & 240 & 250 & 260 & 270 & 280 & 290 & 300\end{array}$

156

$\mathrm{C}_{12} \mathrm{H}_{12}$

Benzene, 2,4-cyclohexadien-1-yl-
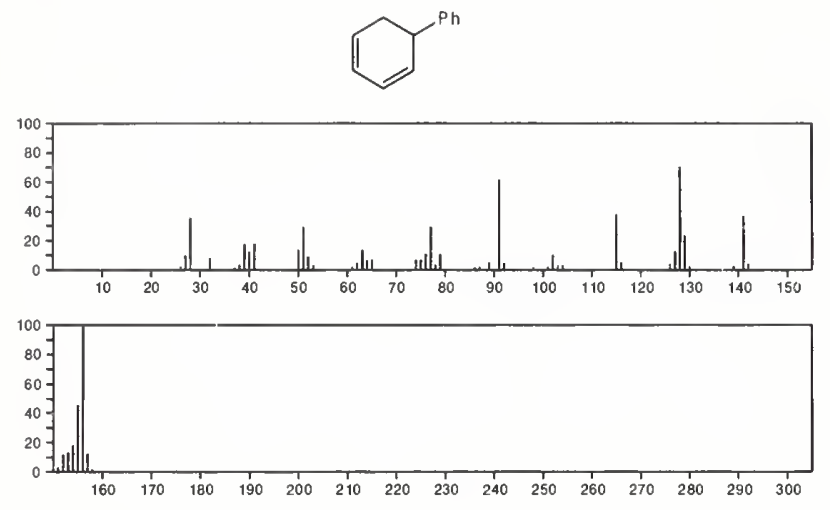

157

Propanenitrile, 2,2,3-trichloro

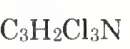

$813-74-1$

$\mathrm{ClCH}_{2} \mathrm{CCl}_{2} \mathrm{CN}$

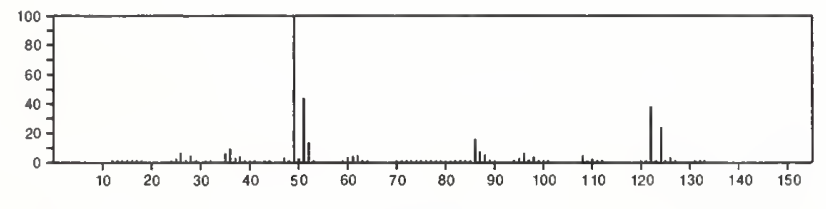

157

Pyridine, 2-bromo-

$\mathrm{C}_{5} \mathrm{H}_{4} \mathrm{BrN}$

109-04-6
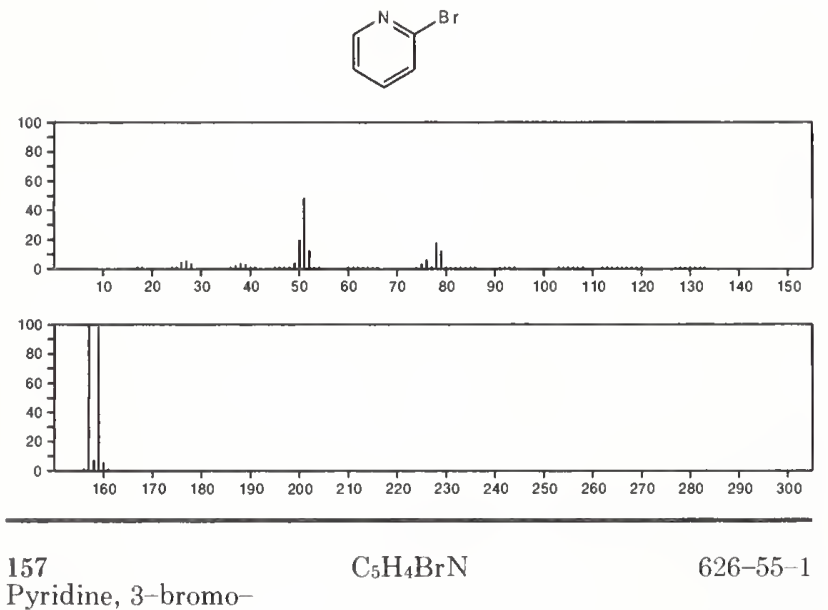

Pyridine, 3-bromo
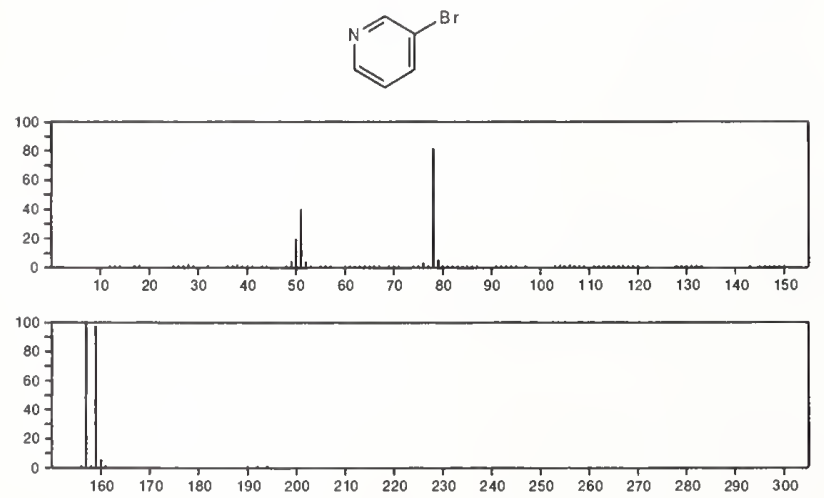

157

$\mathrm{C}_{6} \mathrm{H}_{4} \mathrm{CINO}_{2}$

$121-73-3$

Benzene, 1-chloro-3-nitro-
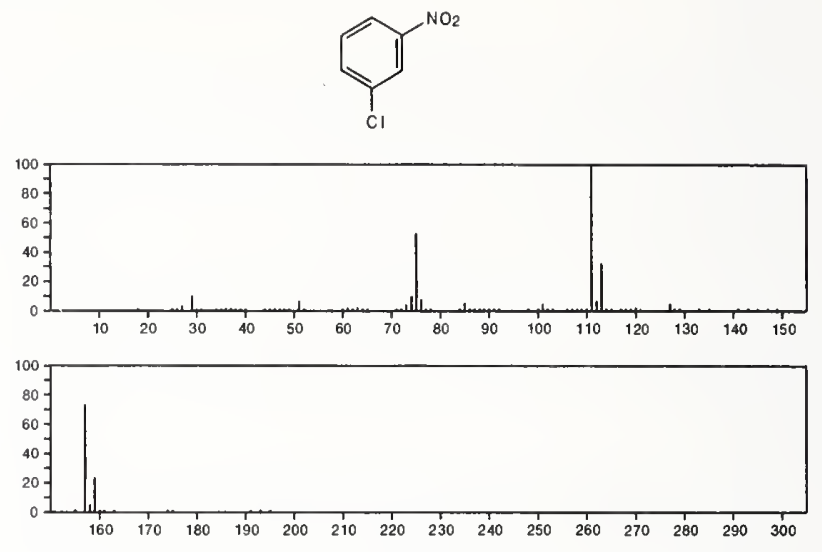

157

$\mathrm{C}_{6} \mathrm{H}_{4} \mathrm{ClNO}_{2}$

2-Pyridinecarboxylic acid, 6-chloro-

$4684-94-0$
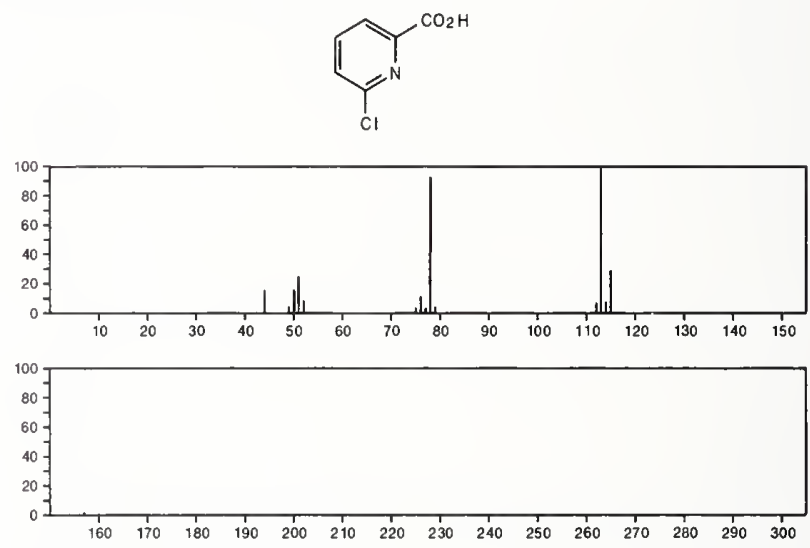

157

Benzenesulfonamide

$\mathrm{C}_{6} \mathrm{H}_{7} \mathrm{NO}_{2} \mathrm{~S}$

$98-10-2$
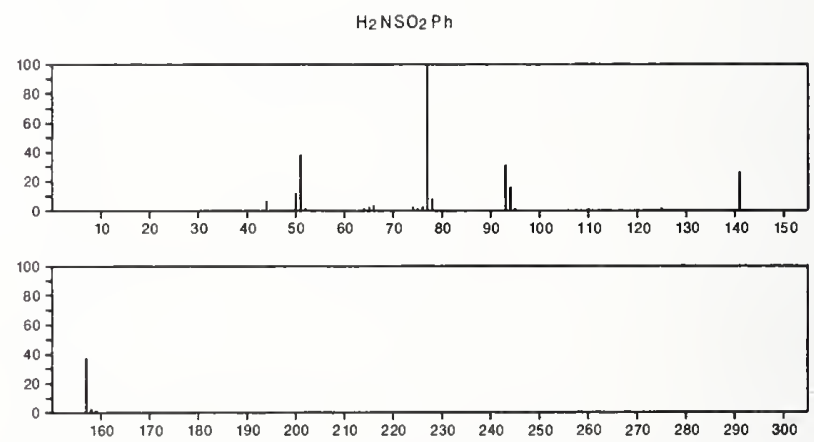

157

5-Thiazoleacetic acid, 4-methyl-

$5255-33-4$
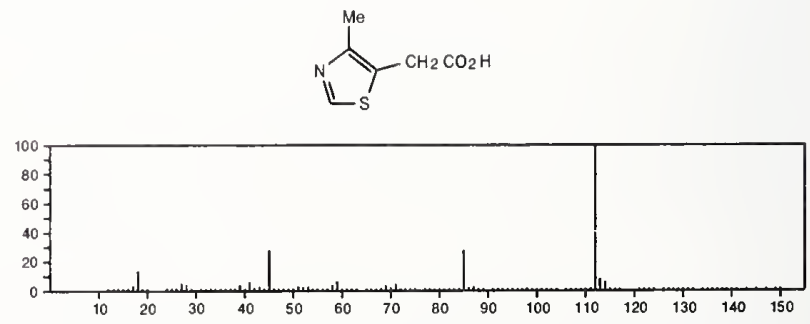


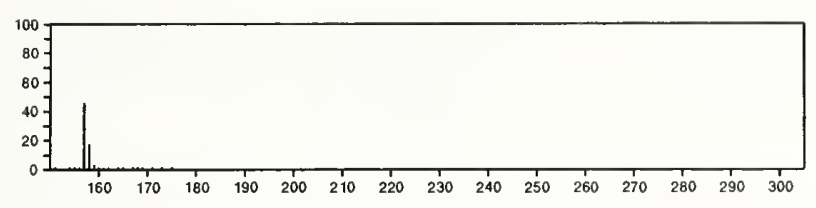

$157 \quad \mathrm{C}_{6} \mathrm{H}_{7} \mathrm{NO}_{2} \mathrm{~S}$

3-Isothiazolecarboxylic acid, ethyl ester

$23244-32-8$
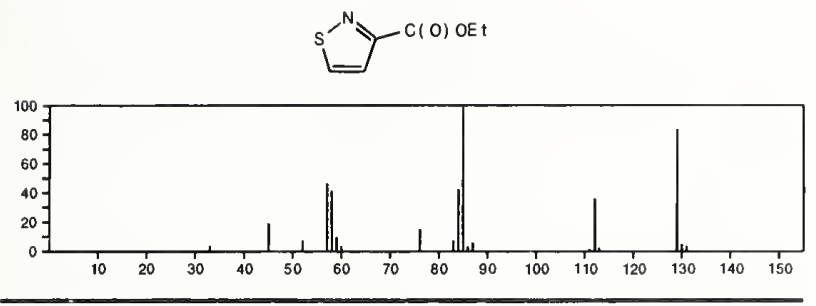

$157 \quad \mathrm{C}_{6} \mathrm{H}_{11} \mathrm{~N}_{3} \mathrm{~S}$

Hydrazinecarbothioamide, 2-cyclopentylidene-

7283-39-8
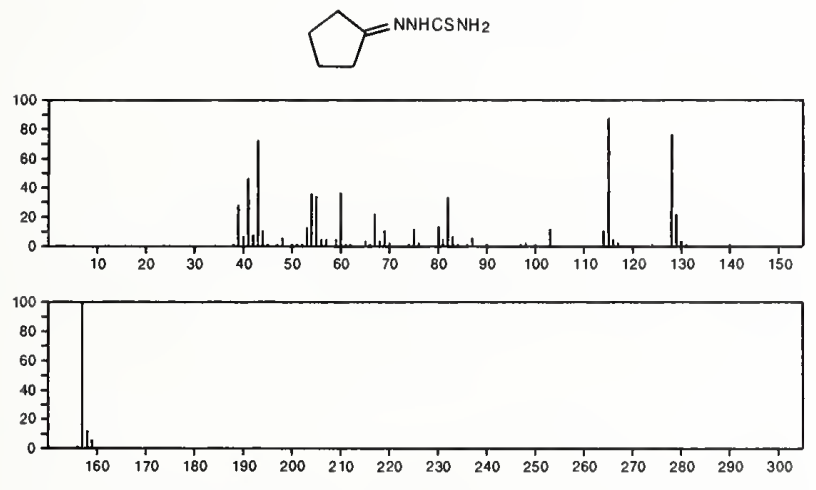

157

L-Proline, 1-acetyl-

$\mathrm{C}_{7} \mathrm{H}_{11} \mathrm{NO}_{3}$

68-95-1
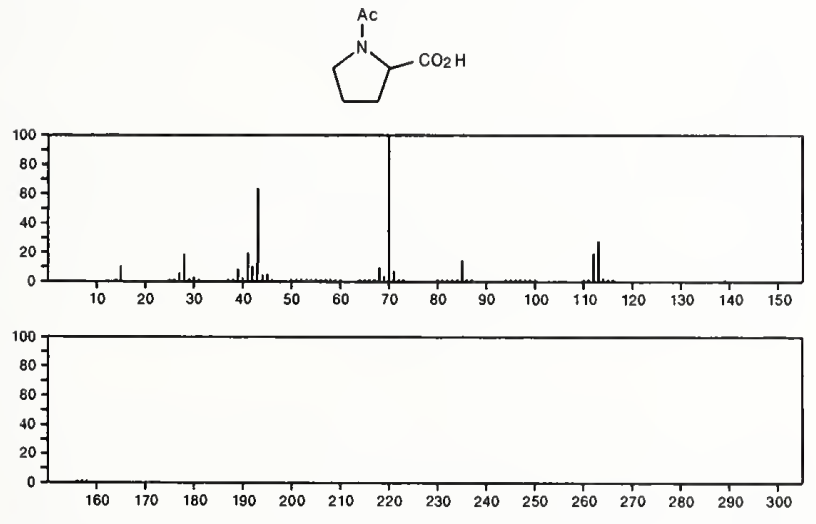

$157 \quad \mathrm{C}_{7} \mathrm{H}_{11} \mathrm{NO}_{3}$

2,4-Oxazolidinedione, 5-ethyl-3,5-dimethyl-

$115-67-3$
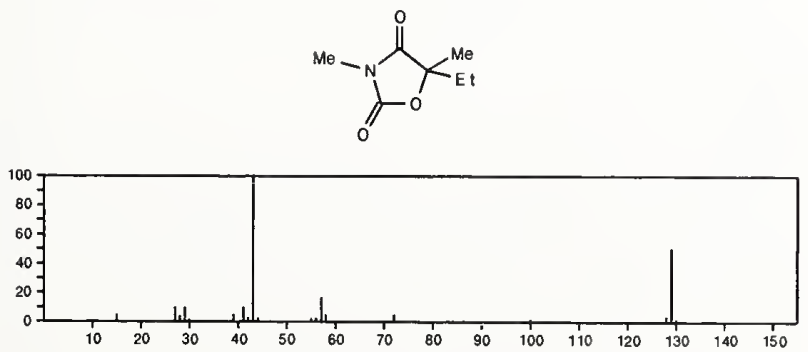

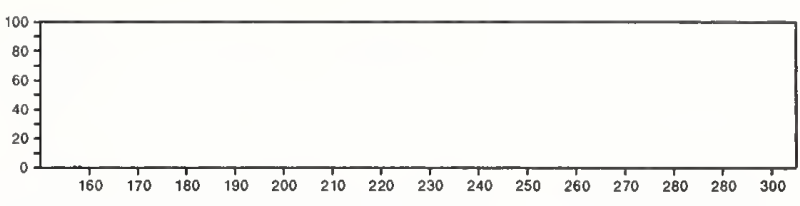

157

$\mathrm{C}_{7} \mathrm{H}_{11} \mathrm{NO}_{3}$

$23840-13-3$

5-Hexynoic acid, 2-amino-4-(hydroxymethyl)-

$\mathrm{CH}_{2} \mathrm{CH}\left(\mathrm{NH}_{2}\right) \mathrm{CO}_{2} \mathrm{H}$

$\mathrm{HC} \equiv \mathrm{CCHCH}_{2} \mathrm{OH}$

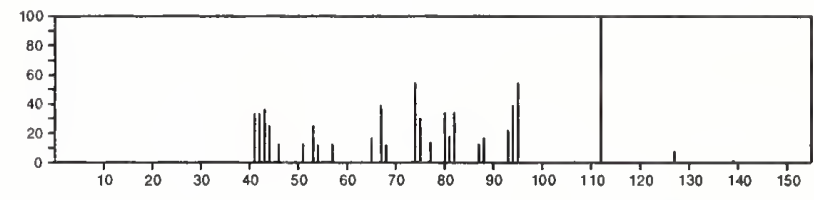

$157 \quad \mathrm{C}_{7} \mathrm{H}_{11} \mathrm{NO}_{3}$

6-Heptynoic acid, 2-amino-4-hydroxy-

$23840-14-4$

$\mathrm{HC} \equiv \mathrm{CCH}_{2} \mathrm{CH}(\mathrm{OH}) \mathrm{CH}_{2} \mathrm{CH}\left(\mathrm{NH}_{2}\right) \mathrm{CO}_{2} \mathrm{H}$

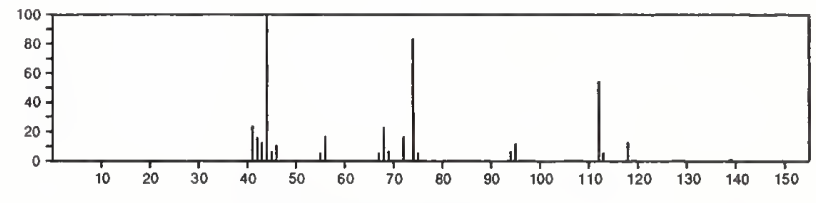

157

L-Proline, 1-methyl $-5-\mathrm{oxo}^{-}$, methyl ester

42435-88-1
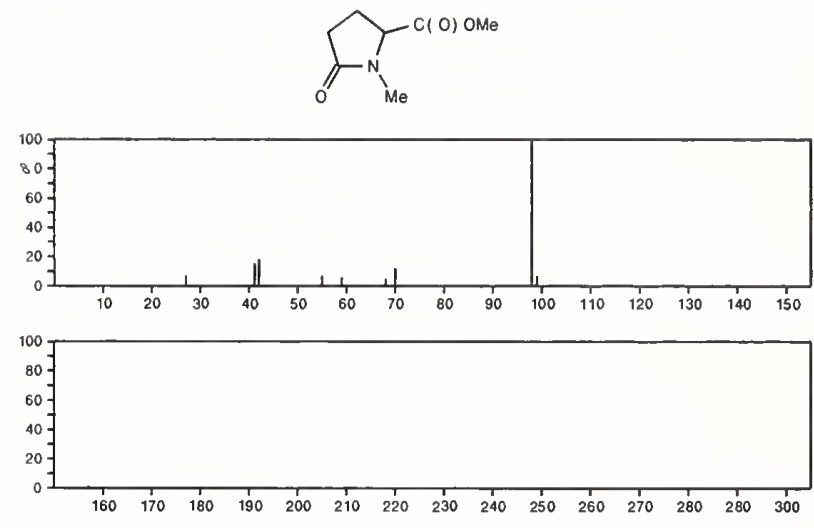

157

$\mathrm{C}_{7} \mathrm{H}_{11} \mathrm{NO}_{3}$

$52812-86-9$

4-Hexenoic acid, 5-amino-3-oxo-, methyl ester

$\mathrm{MeC}\left(\mathrm{NH}_{2}\right)=\mathrm{CHCOCH}_{2} \mathrm{C}(\mathrm{O}) \mathrm{OMe}$
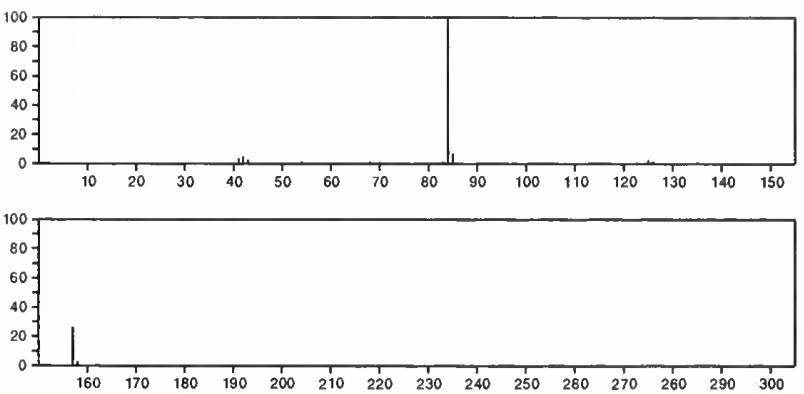
157

$\mathrm{C}_{7} \mathrm{H}_{11} \mathrm{NO}_{3}$

$56145-24-5$

2-Pyrrolidinecarboxylic acid, 2-methyl-5-oxo-, methyl ester
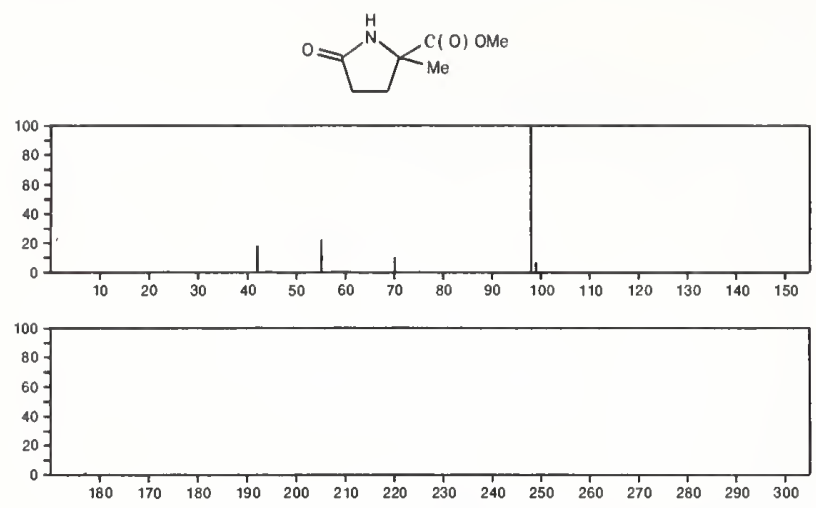

157

Benzeneethanamine, hydrochloride

$156-28-5$

$\mathrm{C}_{8} \mathrm{H}_{11} \mathrm{~N} . \mathrm{ClH}$

$\mathrm{H}_{2} \mathrm{NCH}_{2} \mathrm{CH}_{2} \mathrm{Ph} \cdot \mathrm{HCl}$

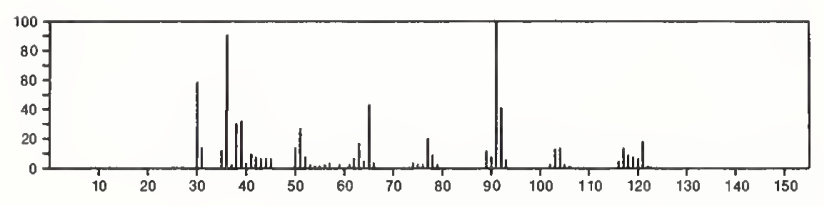

157

$\mathrm{C}_{8} \mathrm{H}_{15} \mathrm{NO}_{2}$

$520-62-7$

$1 H$-Pyrrolizine-1-methanol, hexahydro-7-hydroxy-, $[1 S-(1 \alpha,=$ $7 \alpha, 7 \mathrm{a} \beta)]_{-}^{-}$
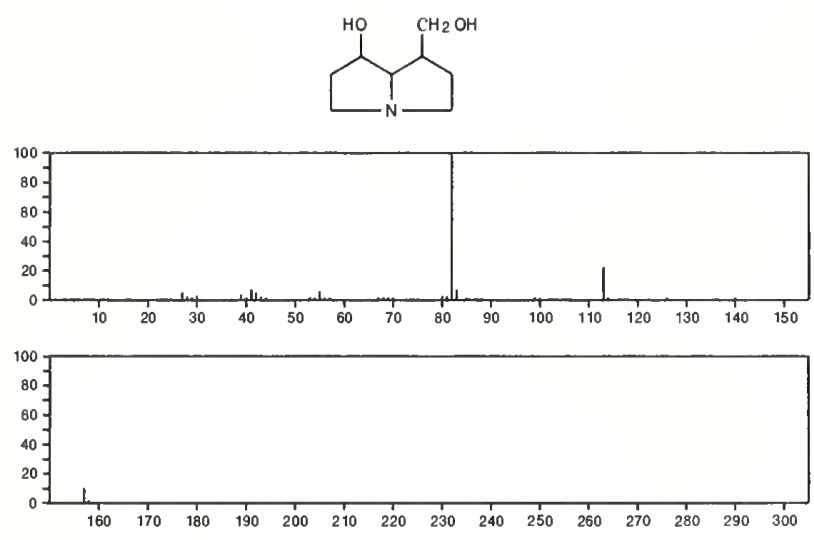

157

Diacetamide, $N$-isobutyl-

$\mathrm{C}_{8} \mathrm{H}_{15} \mathrm{NO}_{2}$

$1787-52-6$

$1-B U N(A C) 2$
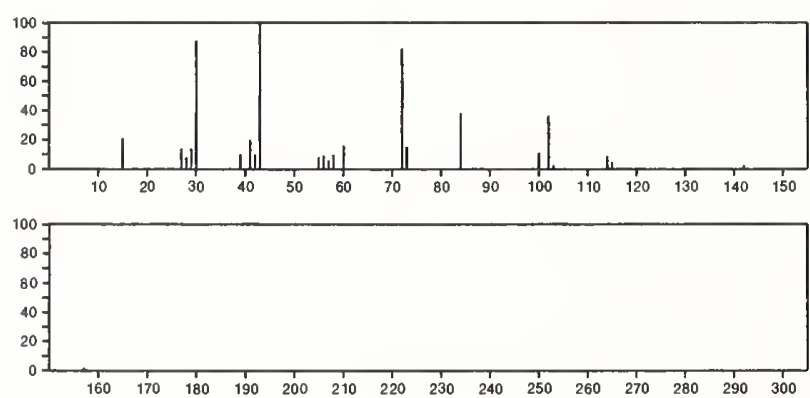

157

Cycloheptanecarboxylic acid, 1-amino-

$6949-77-5$

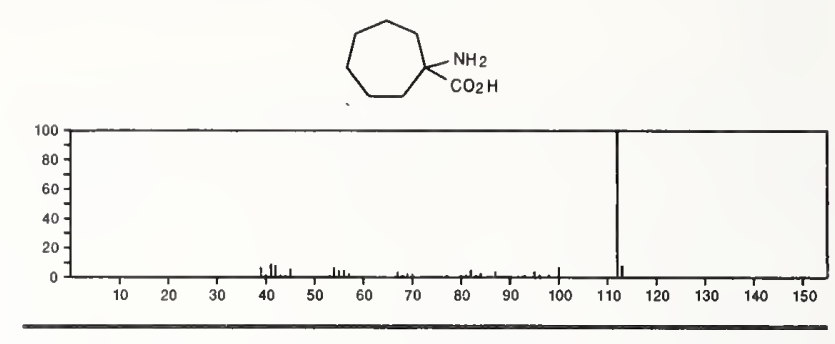

$157 \quad \mathrm{C}_{8} \mathrm{H}_{15} \mathrm{NO}_{2}$

2-Butenoic acid, 3-amino-, 1,1-dimethylethyl ester

$14205-43-7$ $t-\mathrm{BuOC}(\mathrm{O}) \mathrm{CH}=\mathrm{C}\left(\mathrm{NH}_{2}\right) \mathrm{Me}$
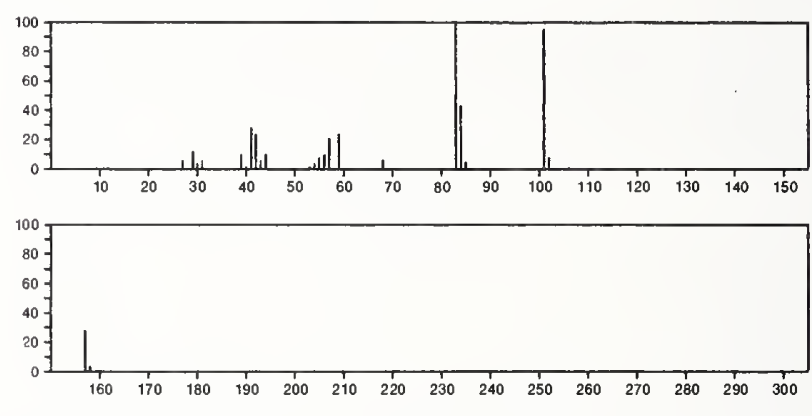

${ }_{\text {Diacetamide, } N \text {-sec-butyl- }} \mathrm{C}_{8} \mathrm{H}_{15} \mathrm{NO}_{2}$

19264-30-3

$S-B u N(A C)_{2}$
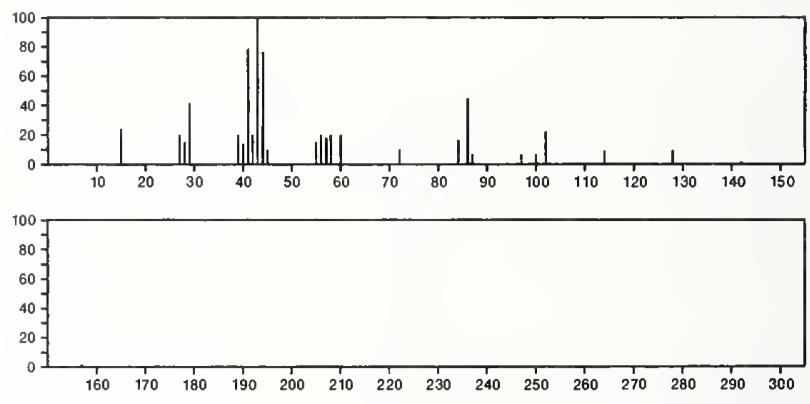

157

$\mathrm{C}_{8} \mathrm{H}_{15} \mathrm{NO}_{2}$

$2 H$-Azonin-2-one, octahydro-6-hydroxy-

23435-07-6
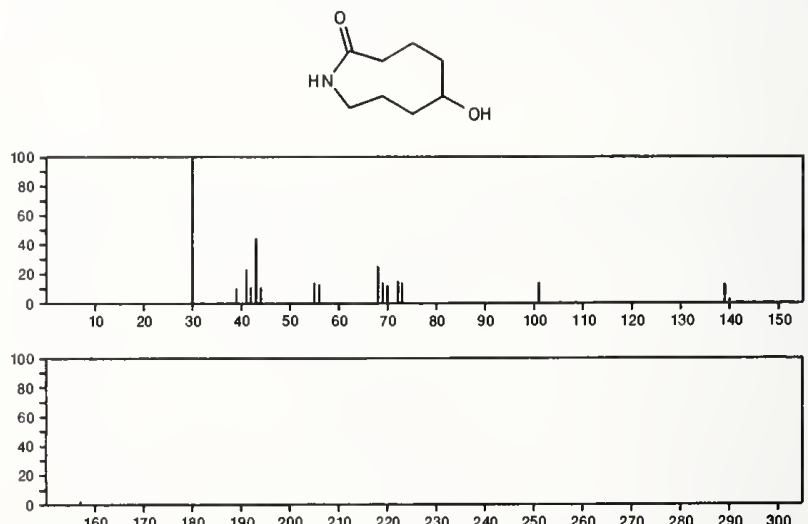
157

$\mathrm{C}_{8} \mathrm{H}_{15} \mathrm{NO}_{2}$

$32663-70-0$

8-Azabicyclo[3.2.1]octan-3-ol, 8-methyl-, 8-oxide, (endo, anti)
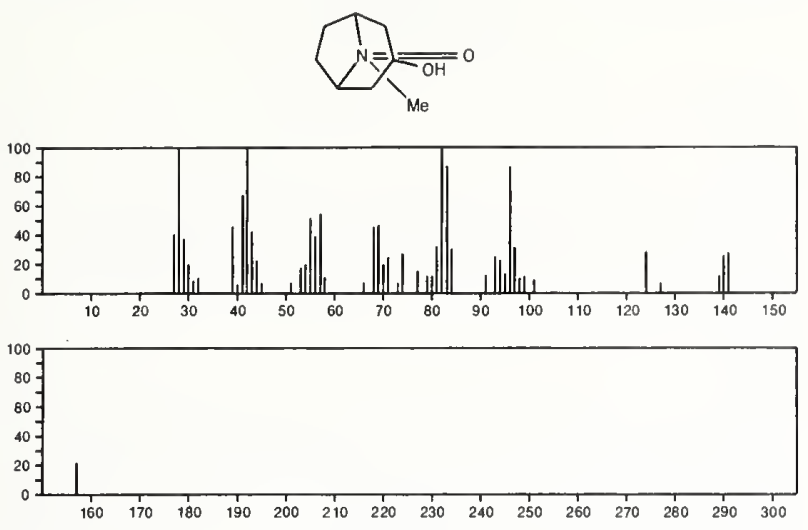

157

$157 \quad \mathrm{C}_{8} \mathrm{H}_{15} \mathrm{NO}_{2} \quad 32663-71-1$

8-Azabicyclo[3.2.1] octan-3-ol, 8-methyl-, 8-oxide, (endo,syn)-
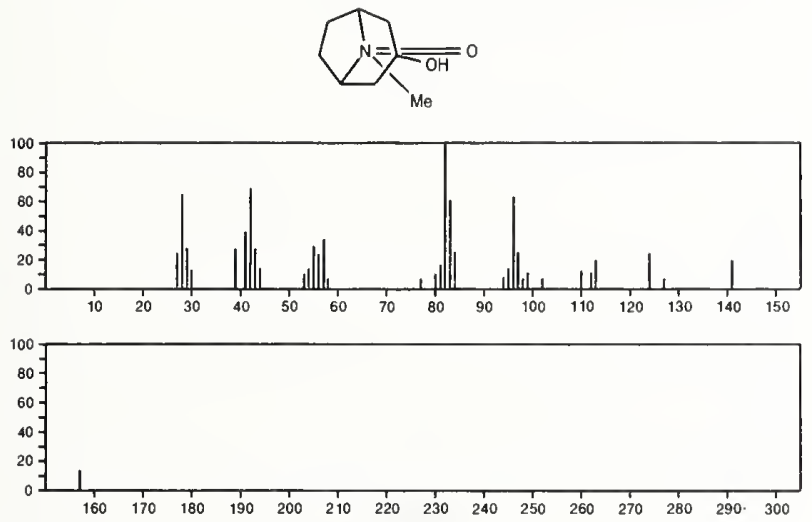

\section{7}

3-Buten-2-one, 4-(dimethylamino)-4-ethoxy-

$49582-71-0$

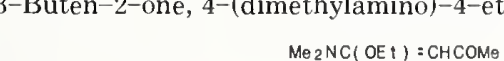
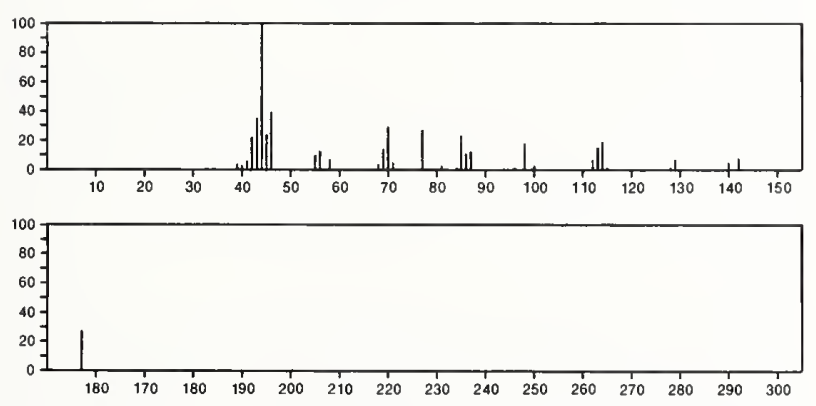

\section{7}

3-Piperidinol, 1-acetyl-6-methyl-
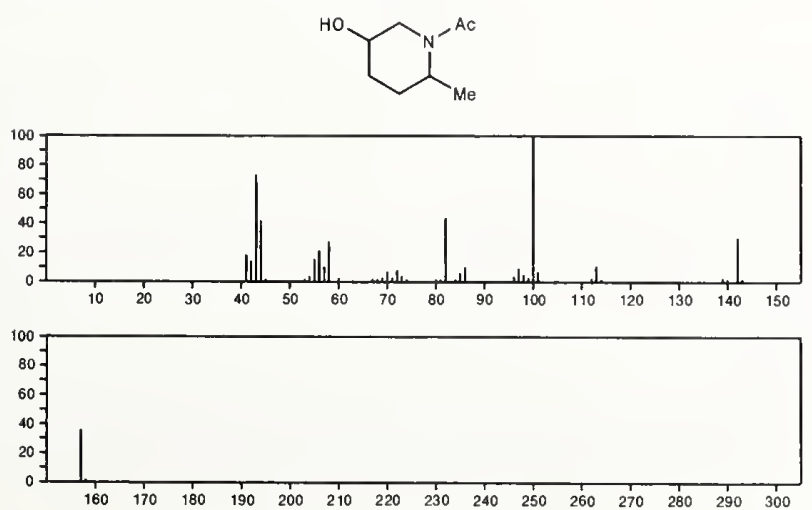

157

$\mathrm{C}_{8} \mathrm{H}_{15} \mathrm{NS}$

$35418-38-3$

2-Pyrrolidinethione, 3,3,5,5-tetramethy]
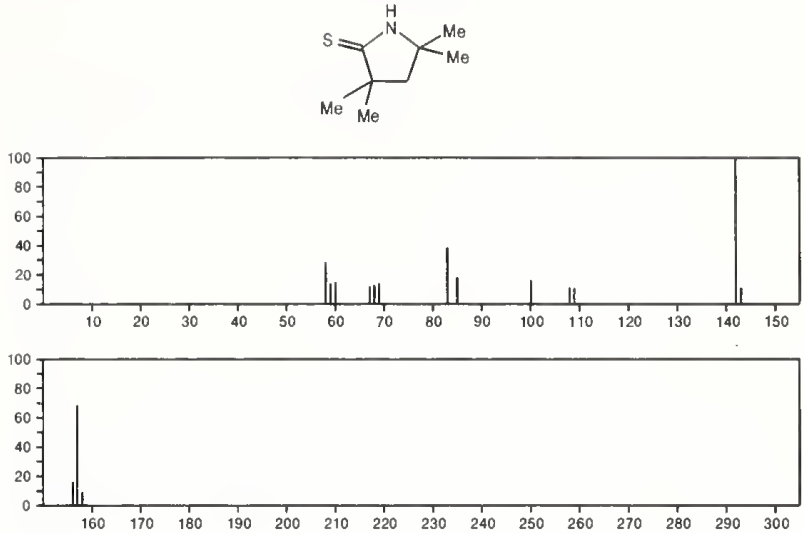

157

$\mathrm{C}_{8} \mathrm{H}_{17} \mathrm{~N}_{2} \mathrm{O}$

$34272-83-8$

1-Pyrrolidinyloxy, 3-amino-2,2,5,5-tetramethyl-
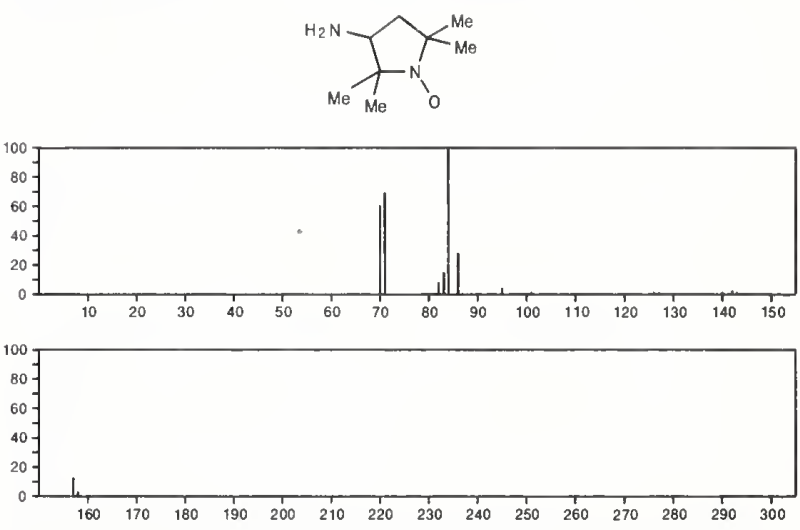

157

$\mathrm{C}_{9} \mathrm{H}_{7} \mathrm{~N}_{3}$

1656-95-7

3,5-Pyridinedicarbonitrile, 2,6-dimethyl-
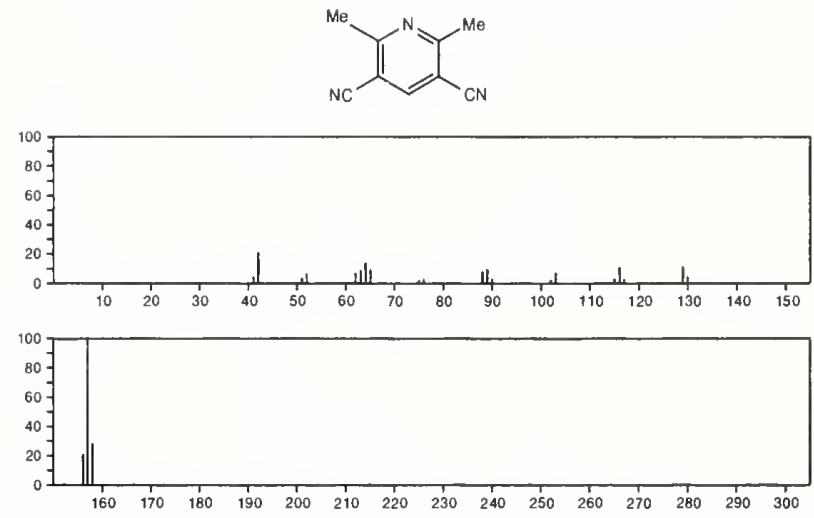

157

$\mathrm{C}_{9} \mathrm{H}_{19} \mathrm{NO}$

Propanamide, $N$-(1,1-dimethylethyl)-2,2-dimethyl-

686-96-4

$\mathrm{t}$-Bu NHCOCMO 3

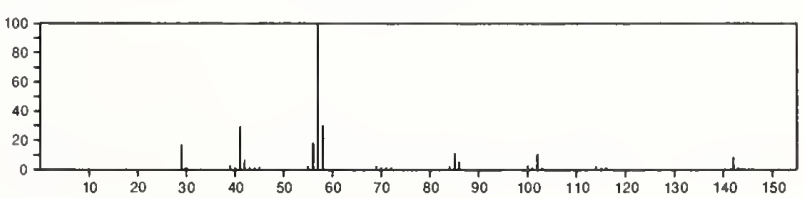




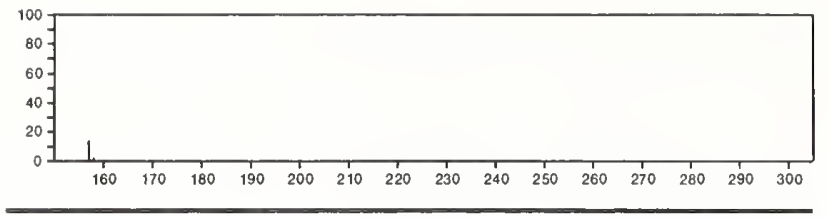

157

Nonanamide

$$
\mathrm{C}_{9} \mathrm{H}_{19} \mathrm{NO}
$$

$1120-07-6$

$\mathrm{Me}\left(\mathrm{CH}_{2}\right)>\mathrm{CONH}_{2}$
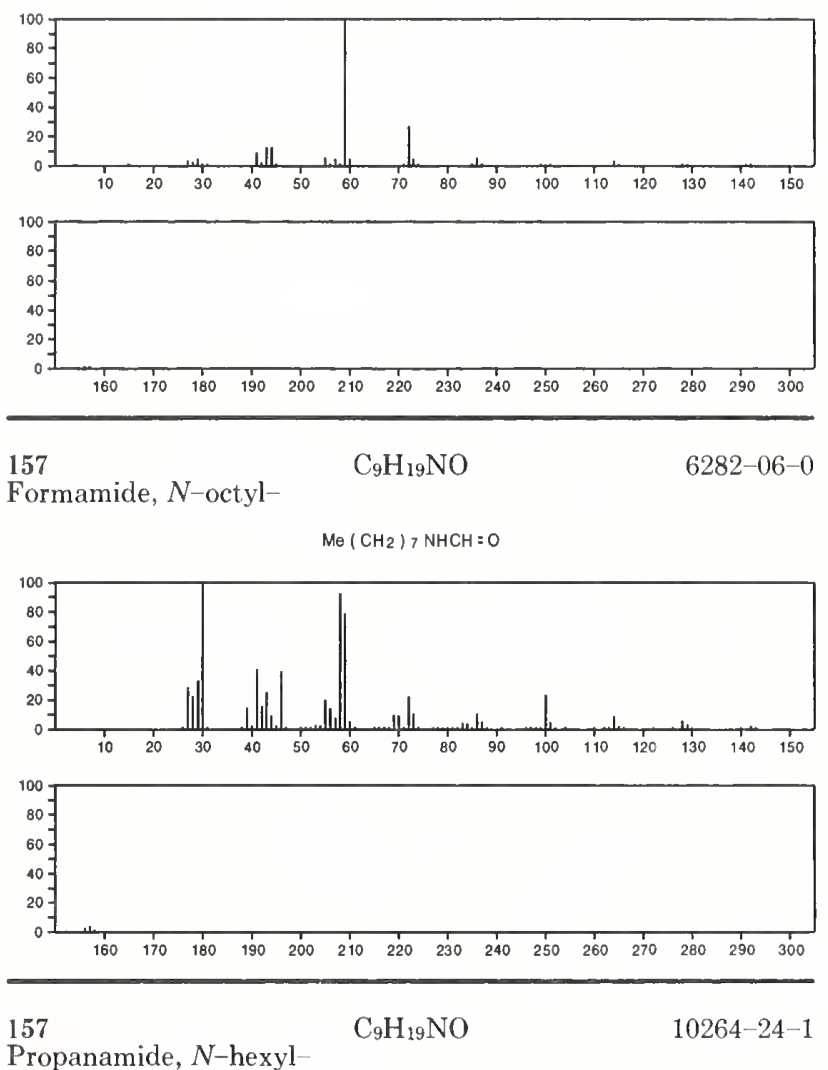

Propanamide, $N$-hexyl-

$\mathrm{Me}\left(\mathrm{CH}_{2}\right){ }_{5} \mathrm{NHCOE}$ t
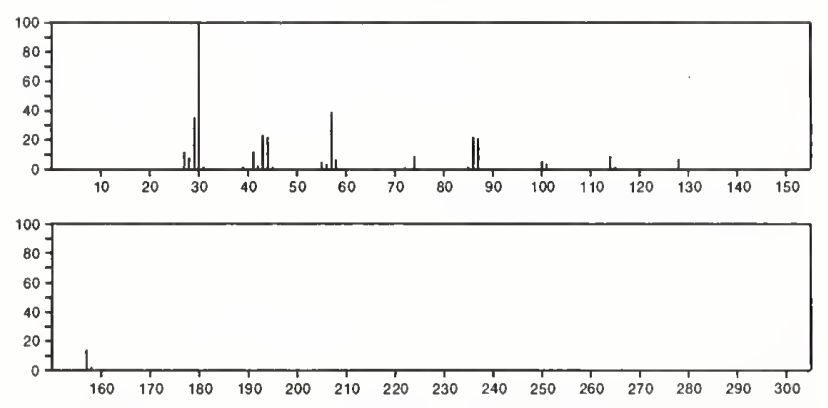

157

5-Nonanone, oxime

$$
\mathrm{C}_{9} \mathrm{H}_{29} \mathrm{NO}
$$

14475-42-4

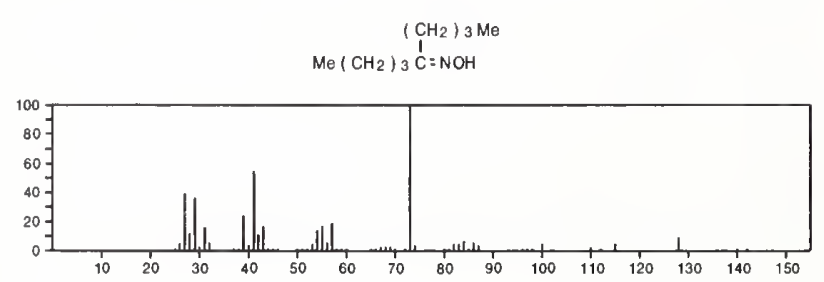

157

$\mathrm{C}_{9} \mathrm{H}_{19} \mathrm{NO}$

2-Heptanone, 6-methyl-, O-methyloxime

$36382-58-8$ $\mathrm{Me}_{2} \mathrm{CH}\left(\mathrm{CH}_{2}\right)_{3} \mathrm{CMe}_{\theta}=\mathrm{NOMN}$
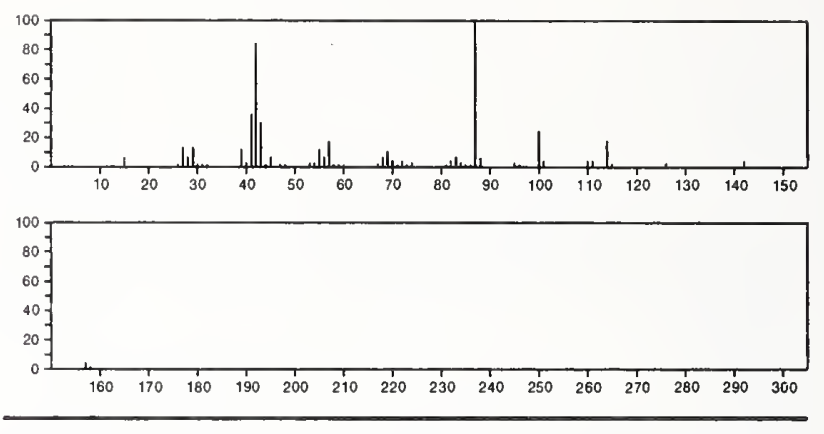

157

2-Octanone, $\mathrm{O}$-methyloxime

$\mathrm{C}_{9} \mathrm{H}_{19} \mathrm{NO}$

$36382-59-9$

$\mathrm{Me}\left(\mathrm{CH}_{2}\right)_{5} \mathrm{CMe}=\mathrm{NOM}$
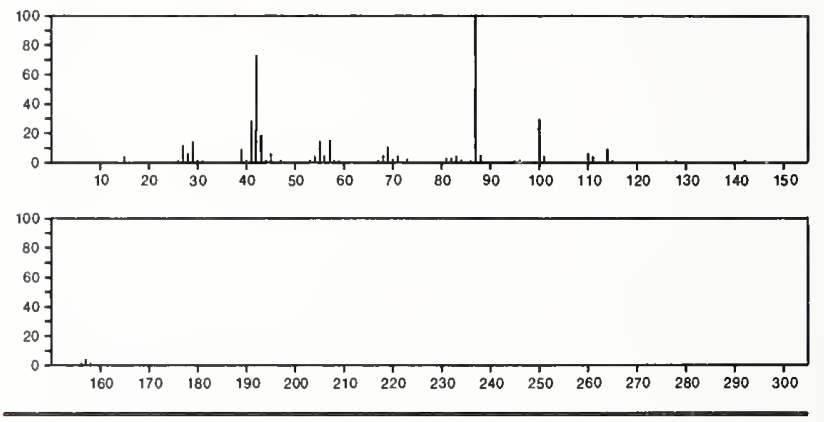

157

4-Piperidinol, 1,4-diethyl-

$\mathrm{C}_{9} \mathrm{H}_{19} \mathrm{NO}$

$37835-53-3$
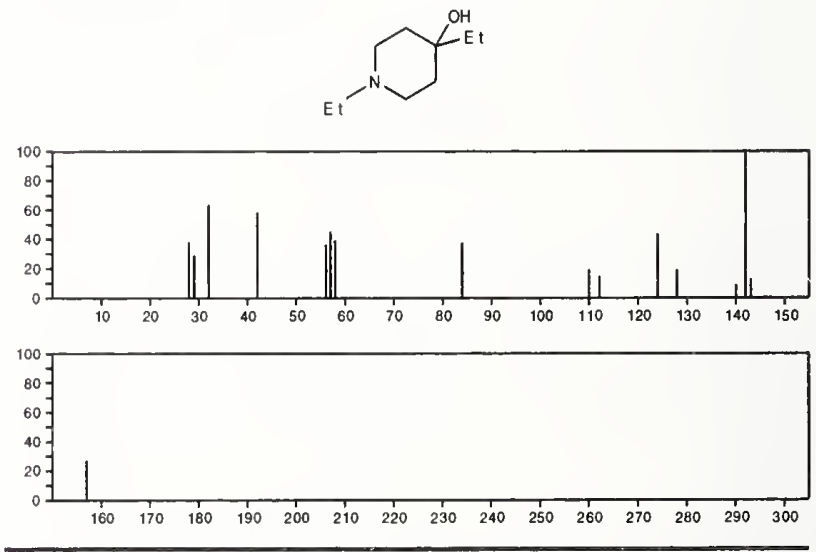

157

$\mathrm{C}_{9} \mathrm{H}_{19} \mathrm{NO}$

4-Piperidinemethanol, 1-ethyl- $\alpha$-methyl-

$37835-58-8$
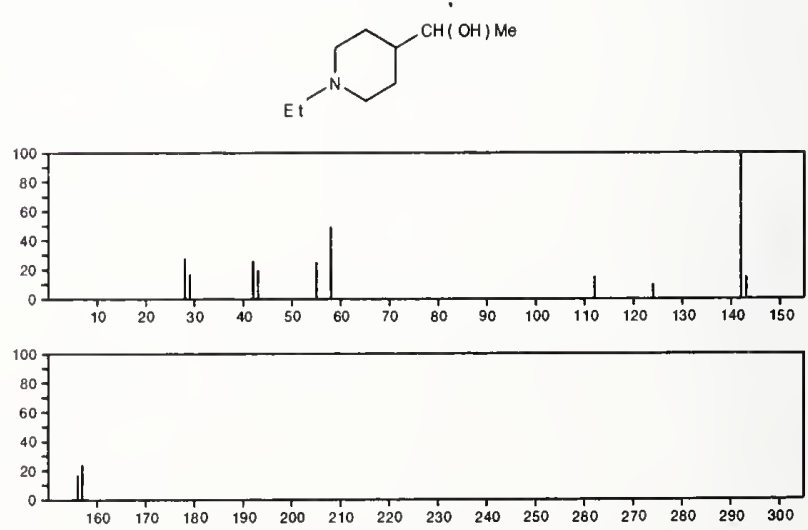
157

Pentanamide, $N$-methyl- $N-(1-$ methylethyl)-

$\mathrm{Me}\left(\mathrm{CH}_{2}\right)_{3} \mathrm{CON}(\mathrm{Pr}-1) \mathrm{Me}$
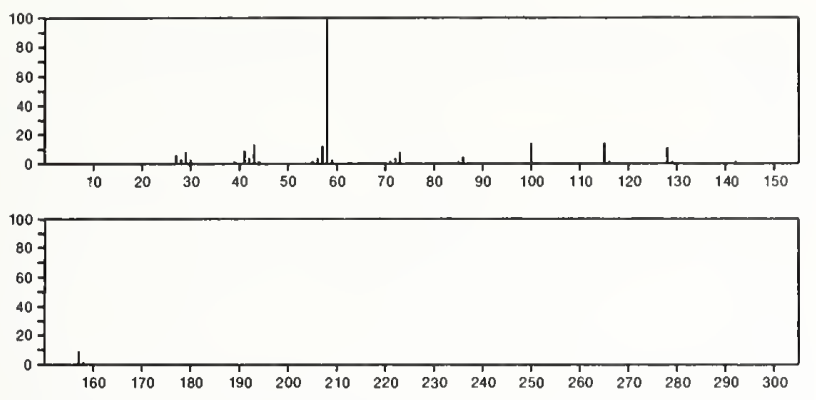

157

$\mathrm{C}_{9} \mathrm{H}_{19} \mathrm{NO}$

55669-83-5

1-Aziridinepropanol, 2-methyl-3-(1-methylethyl)-, trans-<smiles>CC1C([18OH])N1C[18OH]</smiles>
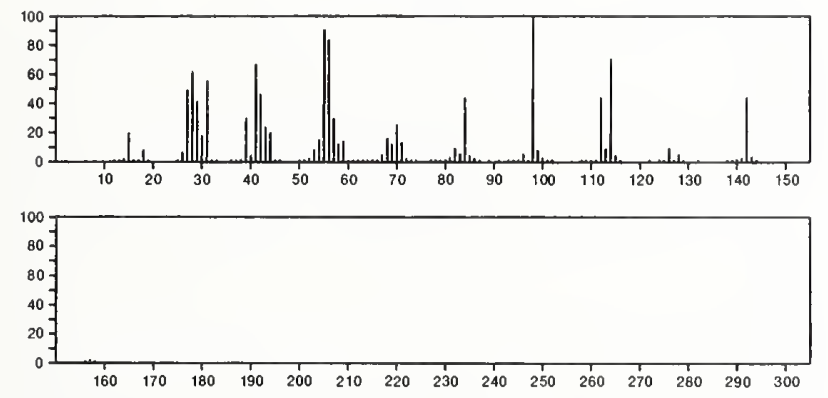

157

$\mathrm{C}_{9} \mathrm{H}_{19} \mathrm{NO}$

Oxazolidine, 2,2,5-trimethyl-3-propyl-
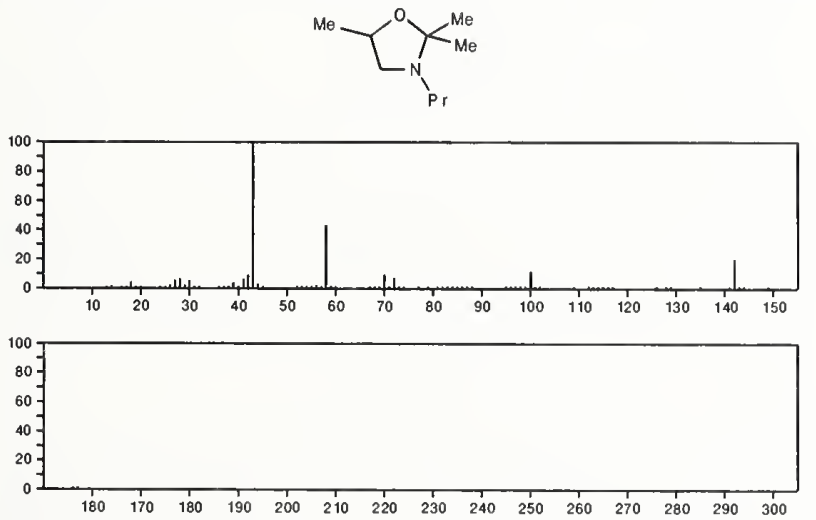

157

$\mathrm{C}_{10} \mathrm{H}_{23} \mathrm{~N}$

1-Butanamine, 3-methyl- $N$-(3-methylbutyl)-

$544-00-3$

$\mathrm{Me}_{2} \mathrm{CHCH}_{2} \mathrm{CH}_{2} \mathrm{NHCH}_{2} \mathrm{CH}_{2} \mathrm{CHMe}_{2}$
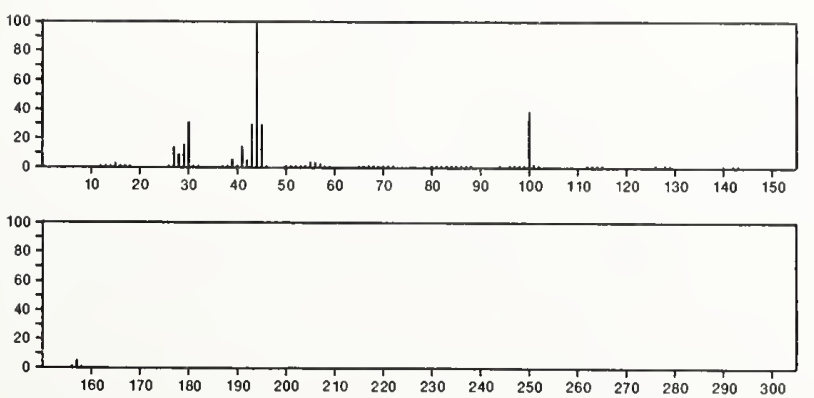

157

1-Decanamine

$\mathrm{C}_{10} \mathrm{H}_{23} \mathrm{~N}$

2016-57-1

$\mathrm{Me}\left(\mathrm{CH}_{2}\right)_{9} \mathrm{NH}_{2}$
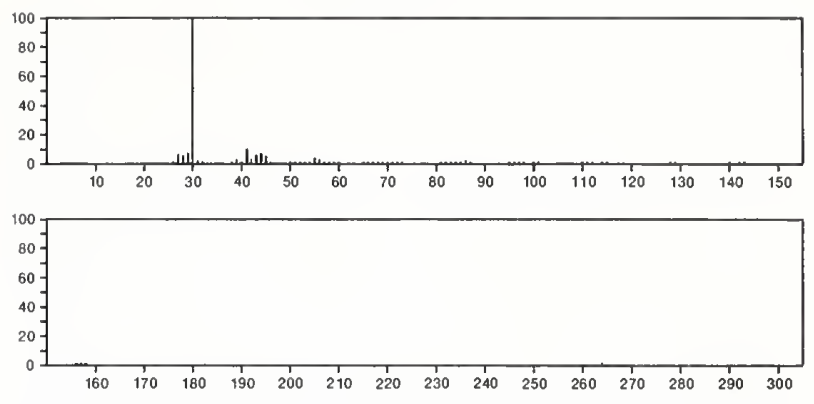

157

1-Pentanamine, $N$-pentyl-

$$
\mathrm{C}_{10} \mathrm{H}_{23} \mathrm{~N}
$$

2050-92-2

$\left.\mathrm{Me}\left(\mathrm{CH}_{2}\right)_{4} \mathrm{NH}_{(} \mathrm{CH}_{2}\right){ }_{4} \mathrm{Me}$
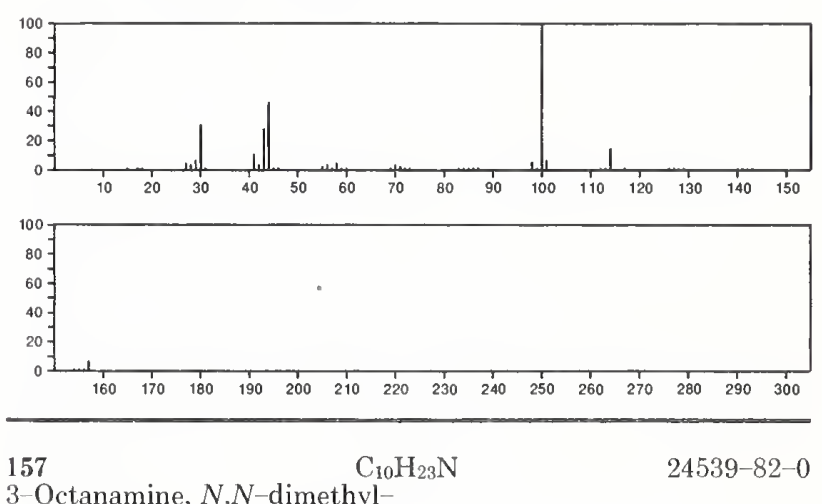

3-Octanamine, $N, N$-dimethyl-

$\mathrm{Me}\left(\mathrm{CH}_{2}\right)_{4} \mathrm{CHE}+\mathrm{NMe}_{2}$
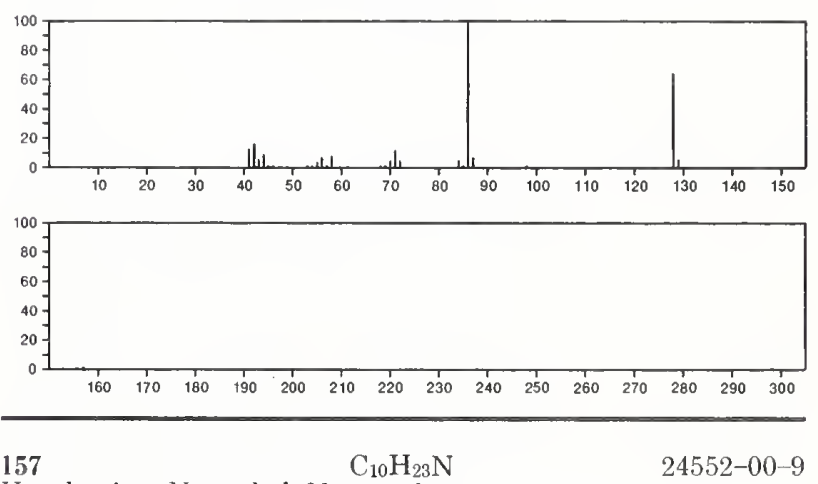

Hexylamine, $N$-methyl- $N$-propyl-

24552-00-9

$\operatorname{PrNMe}\left(\mathrm{CH}_{2}\right) 5 \mathrm{Me}$
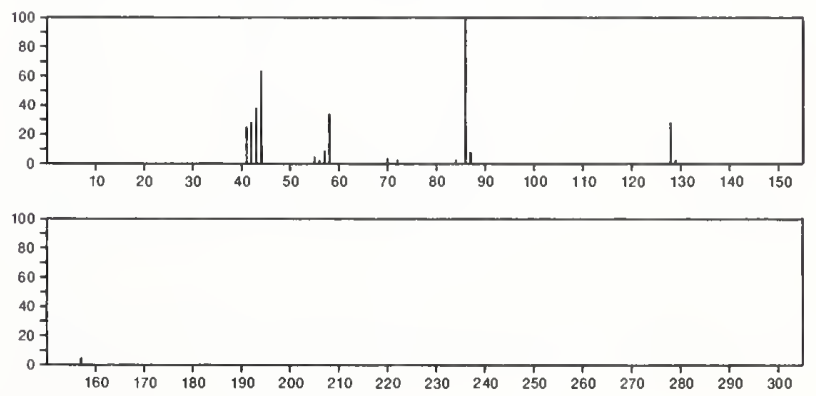
157

$\mathrm{C}_{10} \mathrm{H}_{23} \mathrm{~N}$

1-Hexanamine, 2-ethyl-N,N-dimethyl-

28056-87-3

$\mathrm{Me}\left(\mathrm{CH}_{2}\right)_{3} \mathrm{CHE}_{2} \mathrm{CH}_{2} \mathrm{NMe}_{2}$
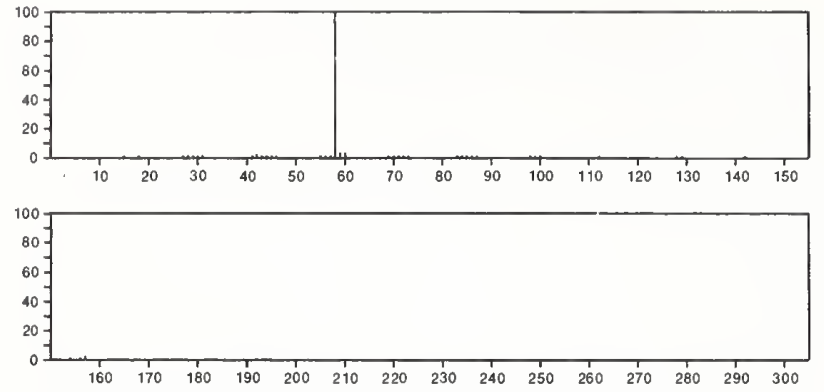

$157 \quad \mathrm{C}_{10} \mathrm{H}_{23} \mathrm{~N} \quad 30278-08-1$ 1-Hexanamine, $N$-butyl-

$\mathrm{Me}\left(\mathrm{CH}_{2}\right) 5 \mathrm{NH}\left(\mathrm{CH}_{2}\right) 3 \mathrm{Me}$
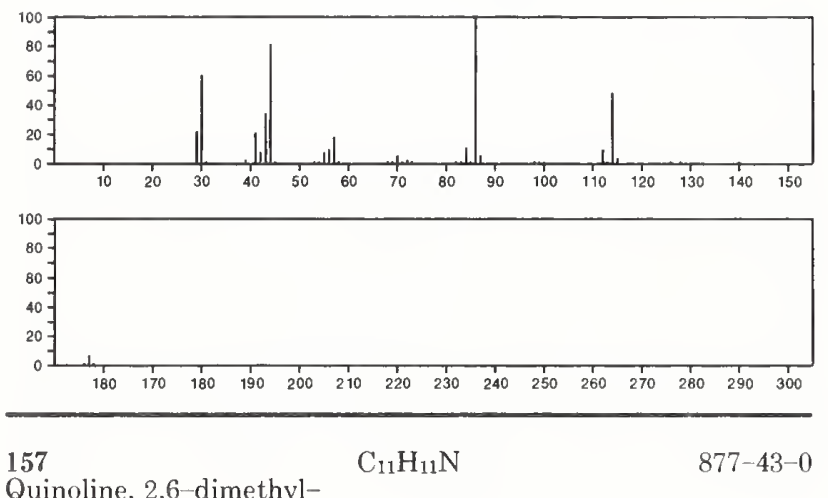

Quinoline, 2,6-dimethyl-
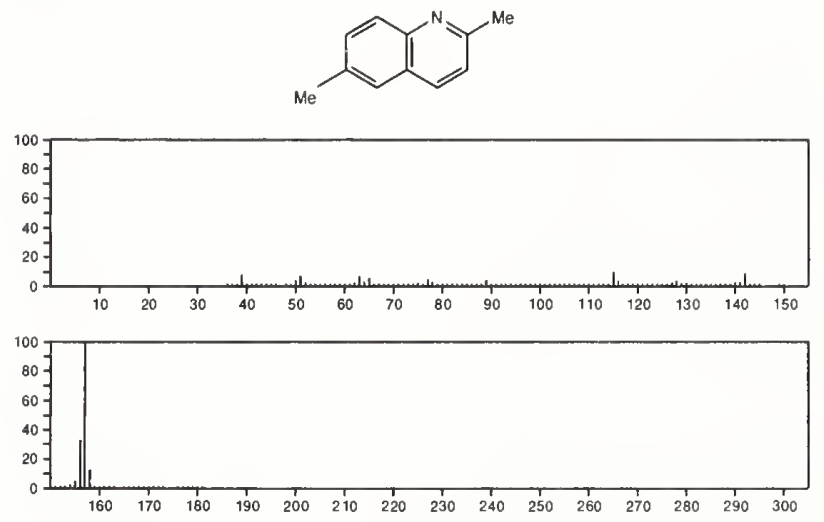

157

Quinoline, 2,4-dimethyl-

$\mathrm{C}_{11} \mathrm{H}_{11} \mathrm{~N}$

$1198-37-4$
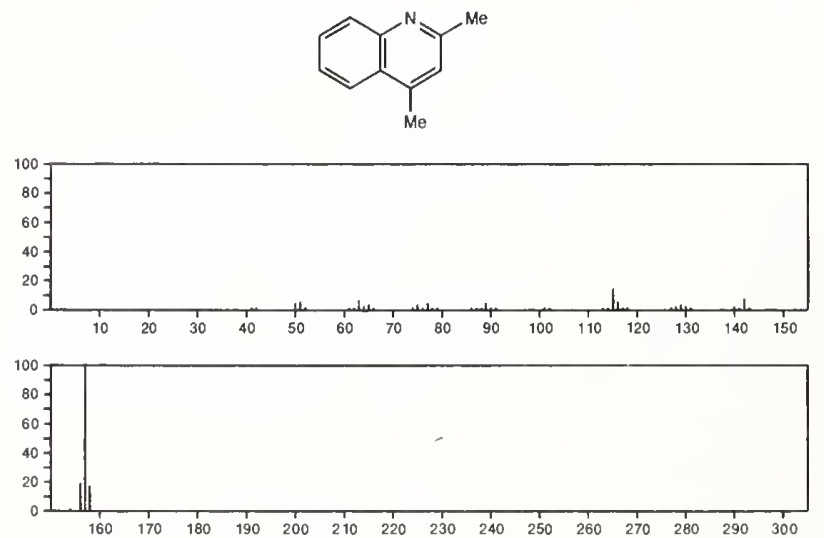

157

Quinoline, 2-ethyl-

$\mathrm{C}_{11} \mathrm{H}_{11} \mathrm{~N}$
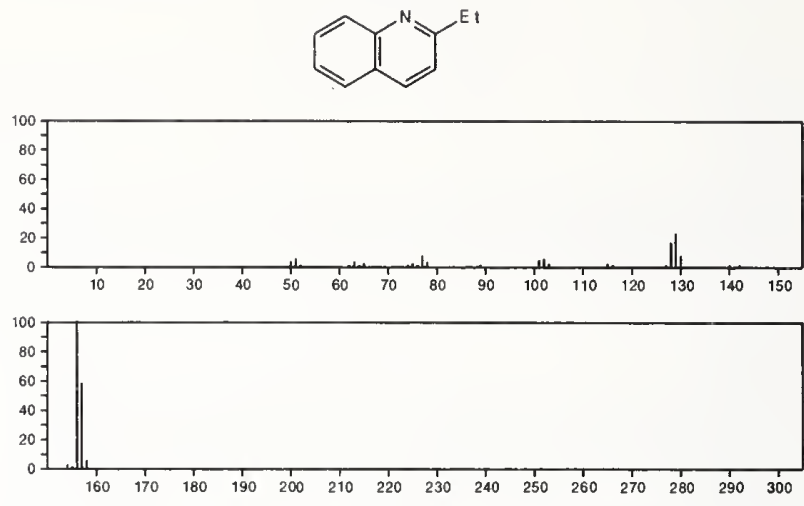

157
Quinoline, 2,3-dimethyl-

$1721-89-7$
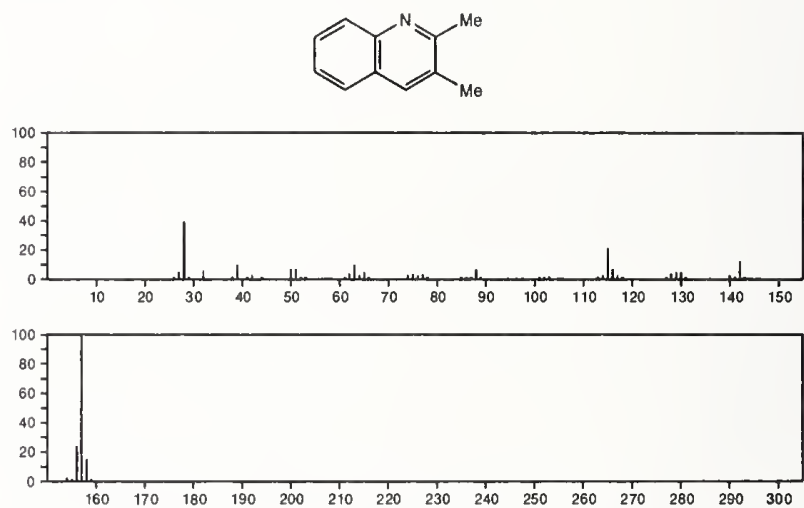

157

$\mathrm{C}_{11} \mathrm{H}_{11} \mathrm{~N}$

2051-97-0

$\mathrm{N}^{-\mathrm{CH}_{2} \mathrm{Ph}}$
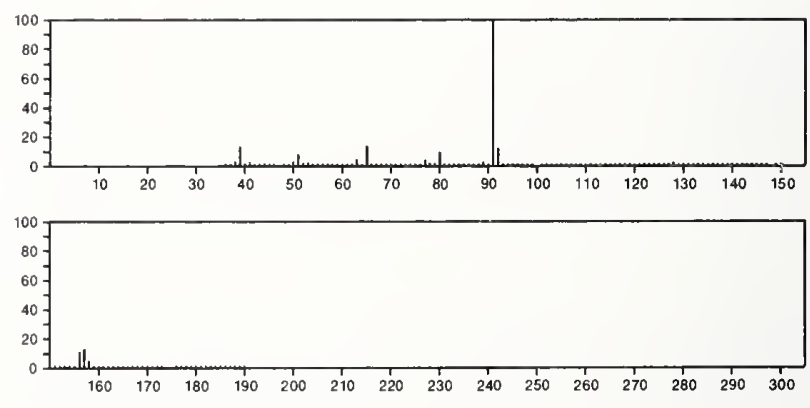

157

Quinoline, 7-ethyl-

$\mathrm{C}_{11} \mathrm{H}_{11} \mathrm{~N}$

7661-47-4
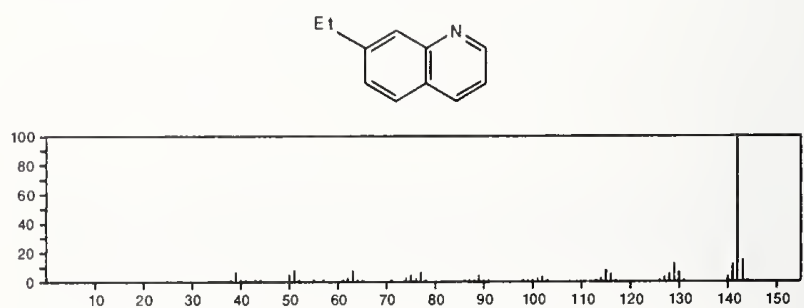


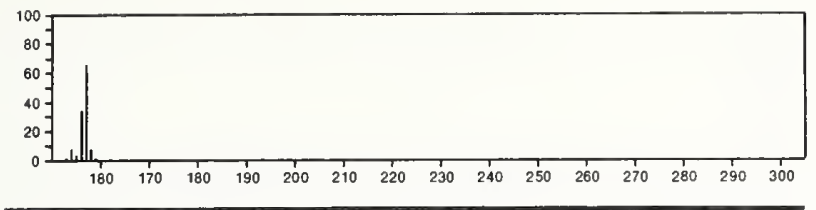

157 Isoquinoline, 1-ethyl-

$$
\mathrm{C}_{11} \mathrm{H}_{11} \mathrm{~N}
$$

7661-60-1
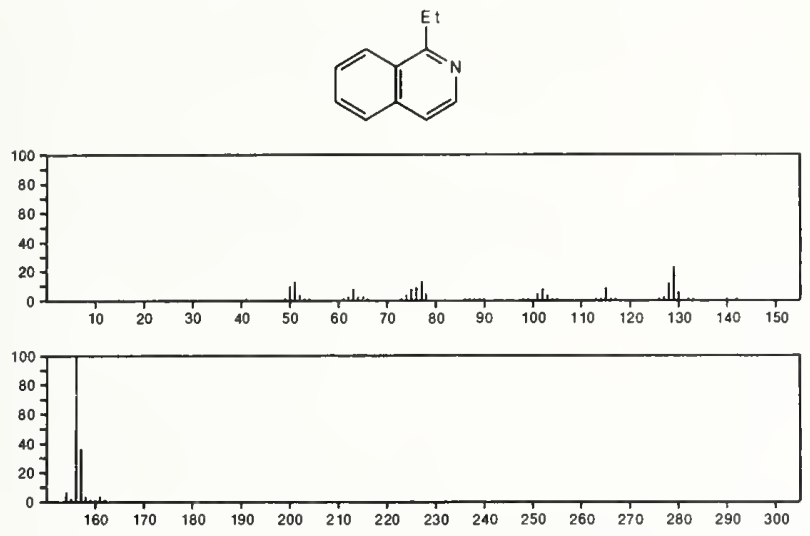

157

$\mathrm{C}_{11} \mathrm{H}_{11} \mathrm{~N}$

2-Naphthonitrile, 5,6,7,8-tetrahydro-
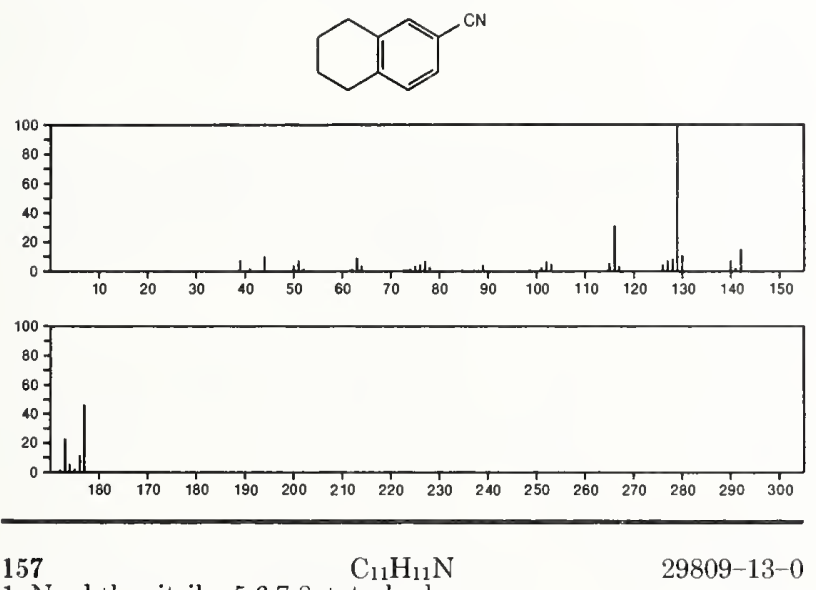

1-Naphthonitrile, 5,6,7,8-tetrahydro-
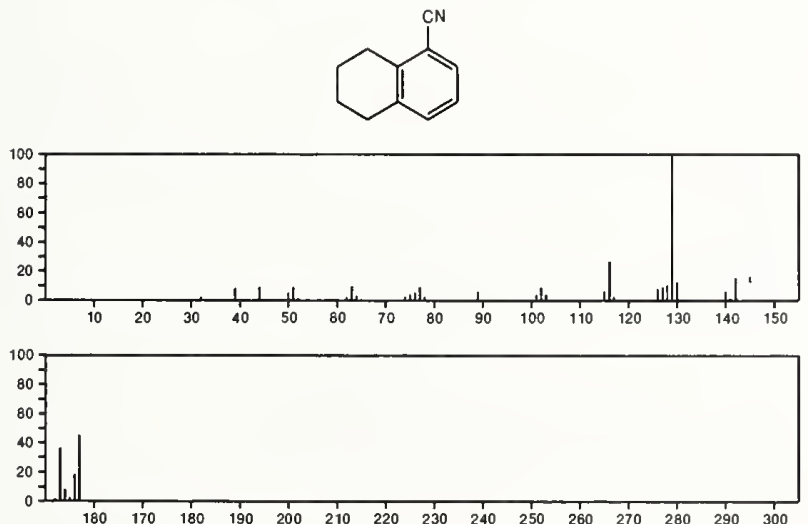

158

$\mathrm{CF}_{6} \mathrm{~S}$

$374-10-7$

Sulfur, trifluoro(trifluoromethyl)-

$\mathrm{F}_{3} \mathrm{SCF}_{3}$
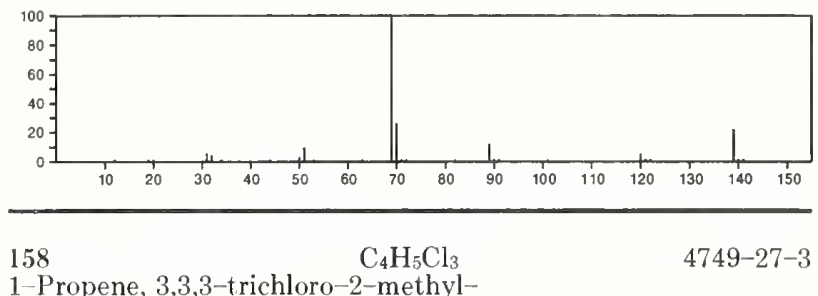

1-Propene, 3,3,3-trichloro-2-methyl-

$\mathrm{Cl}_{3} \mathrm{CCMe}=\mathrm{CH}_{2}$
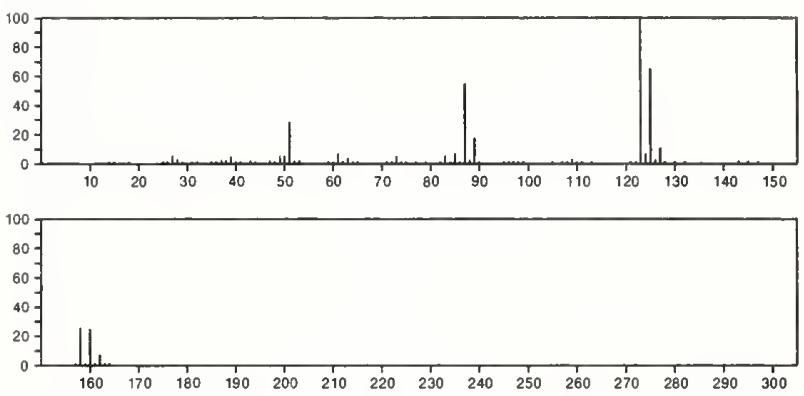

$\begin{array}{lllllllllllllll}160 & 170 & 180 & 190 & 200 & 210 & 220 & 230 & 240 & 250 & 260 & 270 & 280 & 290 & 300\end{array}$

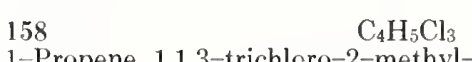

$31702-33-7$

1-Propene, 1,1,3-trichloro-2-methyl-

$\mathrm{Cl} \mathrm{CH}_{2} \mathrm{CMe}=\mathrm{CCl}_{2}$
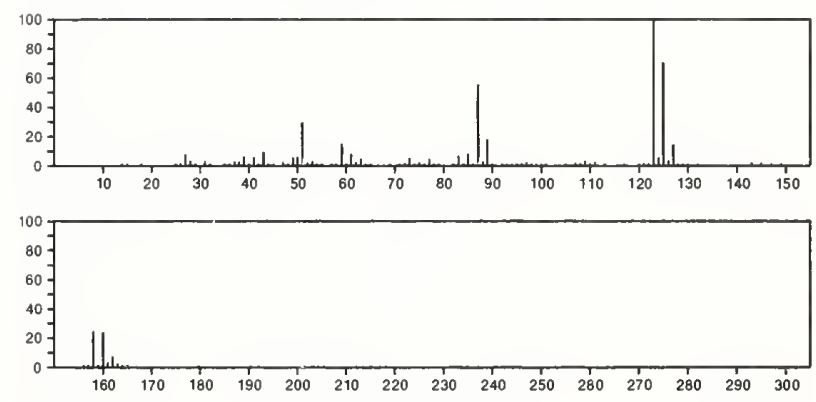

158

$\mathrm{C}_{5} \mathrm{H}_{6} \mathrm{~N}_{2} \mathrm{O}_{2} \mathrm{~S}$

4-Imidazolidinone, 1-acetyl-2-thioxo-
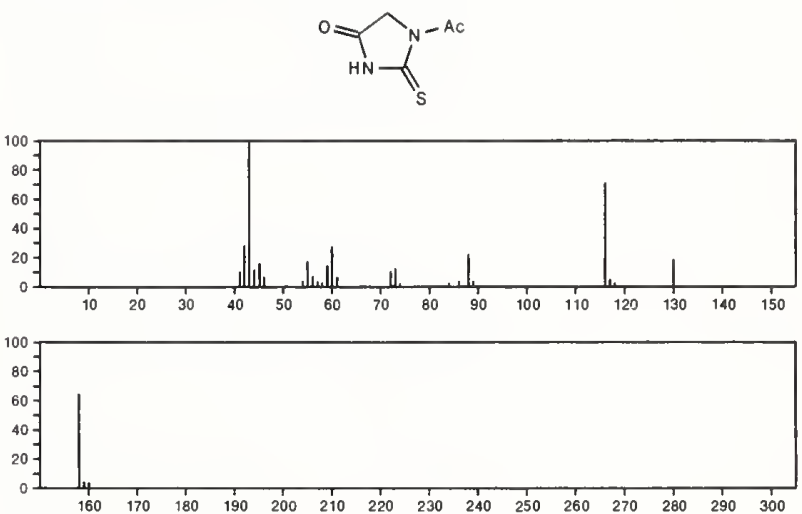
158

$\mathrm{C}_{5} \mathrm{H}_{6} \mathrm{~N}_{2} \mathrm{O}_{4}$

$6773-29-1$

Propanedioic acid, diazo--, dimethyl ester

$\mathrm{MeOC}(0) \stackrel{\mathrm{N}^{2}}{\mathrm{CC}}(0) \mathrm{OMe}$
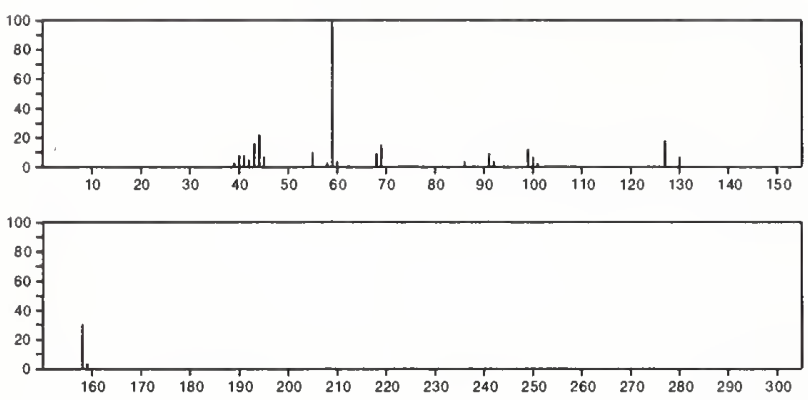

158

$\mathrm{C}_{5} \mathrm{H}_{6} \mathrm{~N}_{2} \mathrm{O}_{4}$

$26574-32-3$

Sydnone, 3-(2-carboxyethyl)-
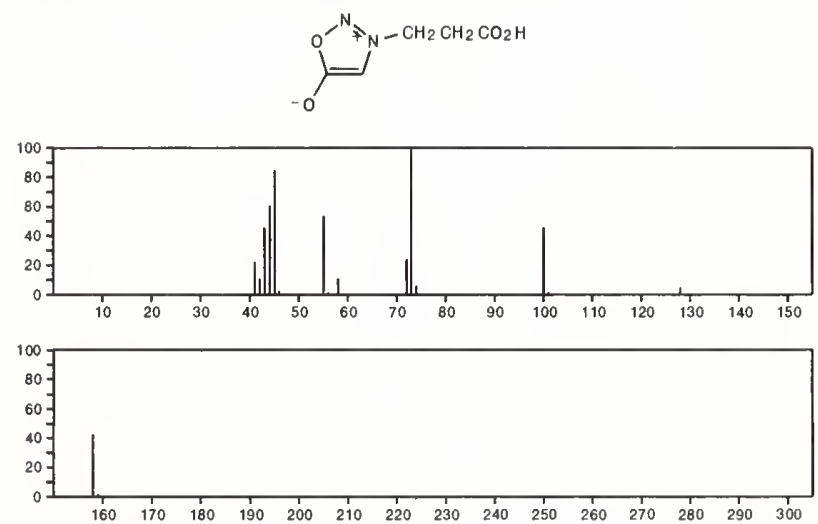

$\begin{array}{lllllllllllllll}160 & 170 & 180 & 190 & 200 & 210 & 220 & 230 & 240 & 250 & 260 & 270 & 280 & 290 & 300\end{array}$

158

$\mathrm{C}_{5} \mathrm{H}_{10} \mathrm{~N}_{4} \mathrm{O}_{2}$

Piperazine, 2-methyl-1,4-dinitroso-<smiles>CC1CN(O)CCN1O</smiles>
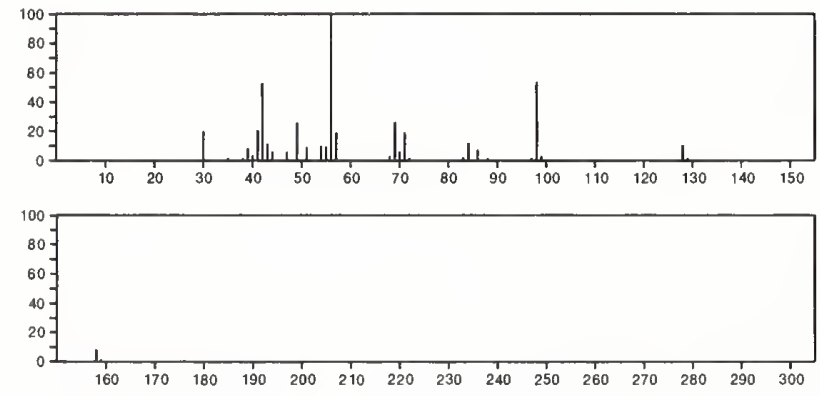

$158 \quad \mathrm{C}_{5} \mathrm{H}_{10} \mathrm{~N}_{4} \mathrm{O}_{2}$

$55557-00-1$

1H-1,4-Diazepine, hexahydro-1,4-dinitroso-
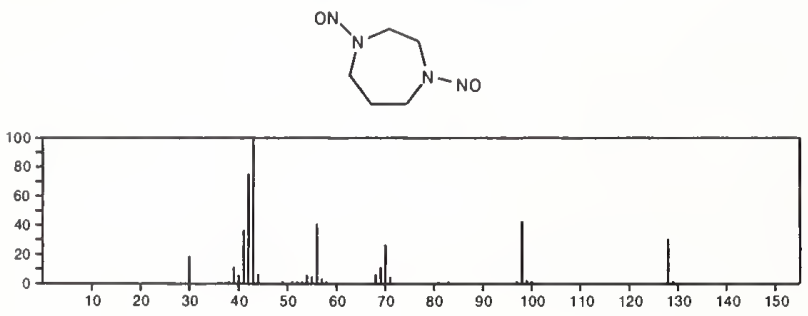

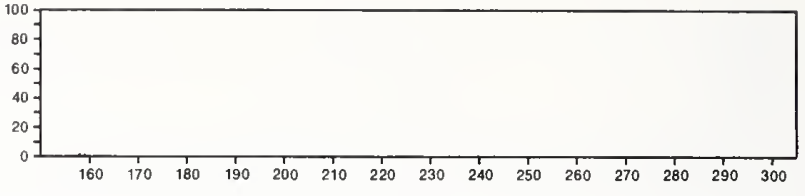

158

Borane, dichlorophenyl

$\mathrm{C}_{6} \mathrm{H}_{5} \mathrm{BCl}_{2}$

$873-51-8$

$\mathrm{Cl}_{2} \mathrm{BPh}$
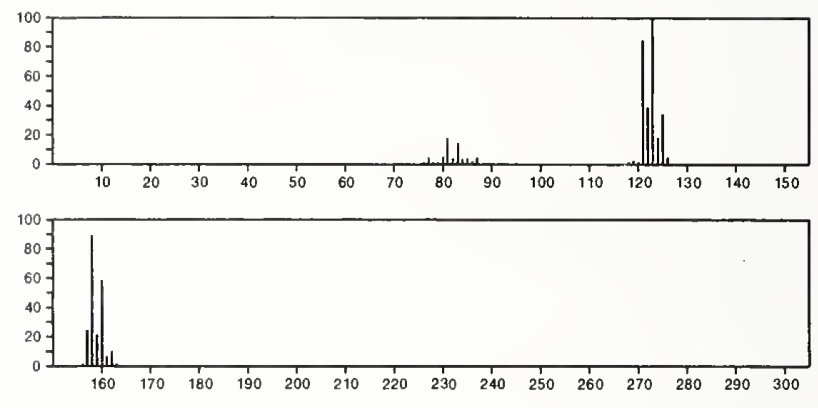

158

$\mathrm{C}_{6} \mathrm{H}_{6} \mathrm{OS}_{2}$

$35972-85-1$

2-Furancarbodithioic acid, methyl ester
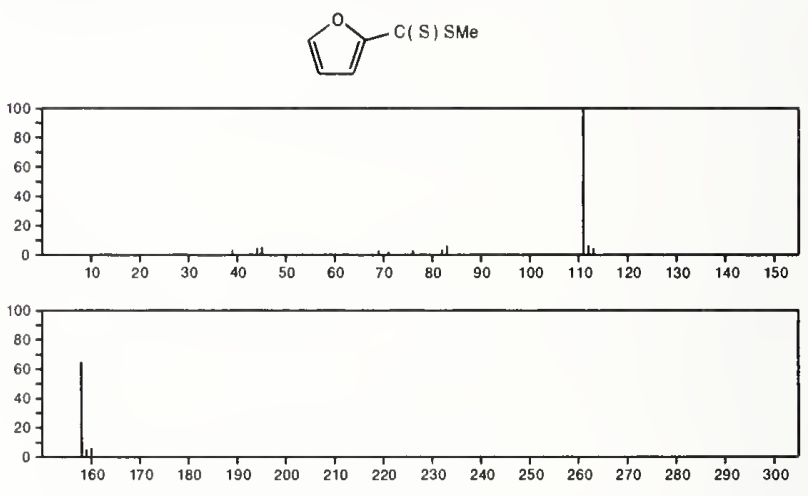

158

$\mathrm{C}_{6} \mathrm{H}_{6} \mathrm{O}_{3} \mathrm{~S}$

98-11-3

Benzenesulfonic acid

$\mathrm{PhSO}_{3} \mathrm{H}$
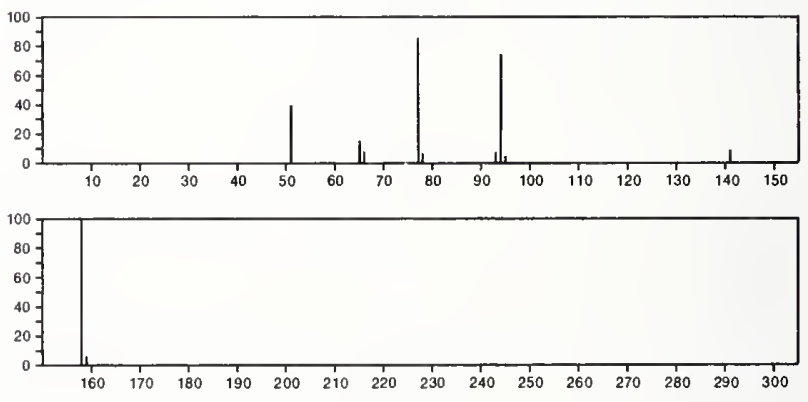

158

$\mathrm{C}_{6} \mathrm{H}_{7} \mathrm{CIN}_{2} \mathrm{O}$

20551-34-2

4(3H)-Pyrimidinone, 5-chloro-2,6-dimethyl-<smiles>[Y6]c1nc(=O)c(Cl)c([N+](=O)[O-])[nH]1</smiles>

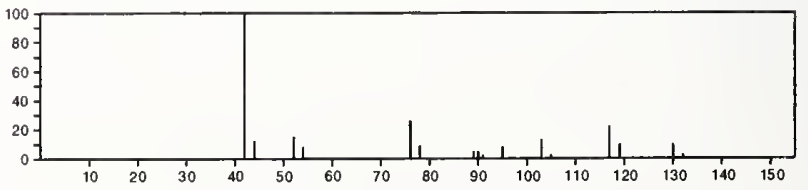



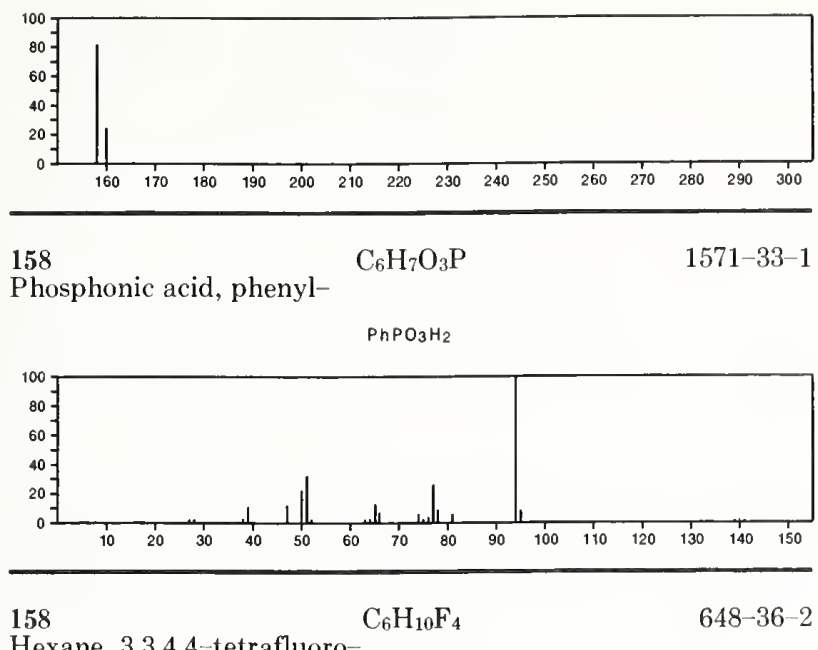

Hexane, 3,3,4,4-tetrafluoro-

$\mathrm{EtCF}_{2} \mathrm{CF}_{2} \mathrm{Et}$
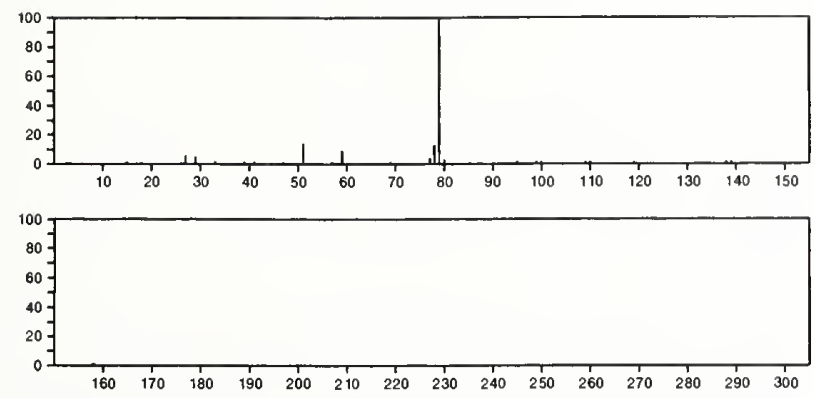

158

4-Imidazolidinone, 5-(1-methylethyl)-2-thioxo-
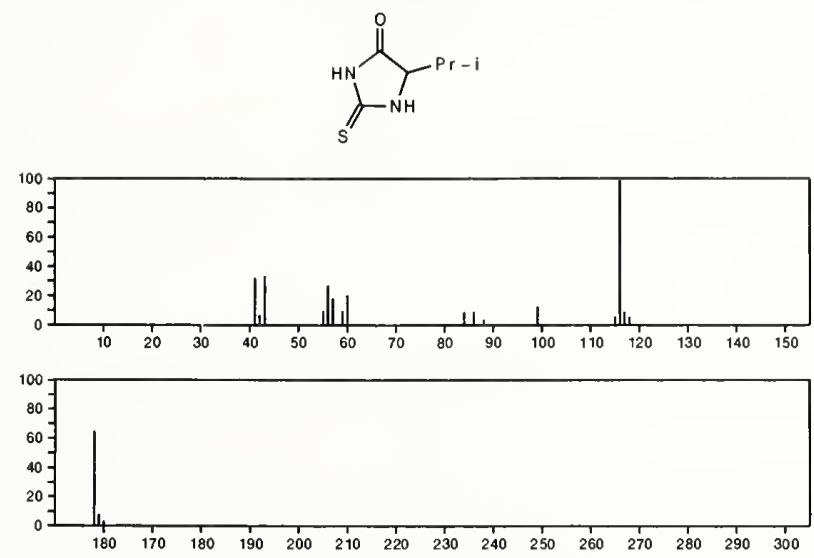

158

$\mathrm{C}_{6} \mathrm{H}_{10} \mathrm{~N}_{2} \mathrm{O}_{3}$

2-Piperidinecarboxylic acid, 1-nitroso
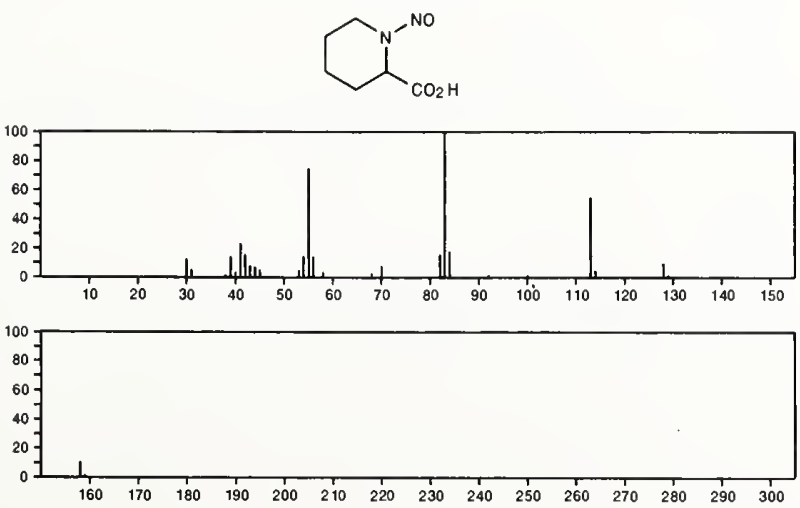

158

$\mathrm{C}_{6} \mathrm{H}_{10} \mathrm{~N}_{2} \mathrm{O}_{3}$

$6238-69-3$

Isonipecotic acid, 1-nitroso-<smiles>O=C(O)C1CCN([N+](=O)[O-])CC1</smiles>
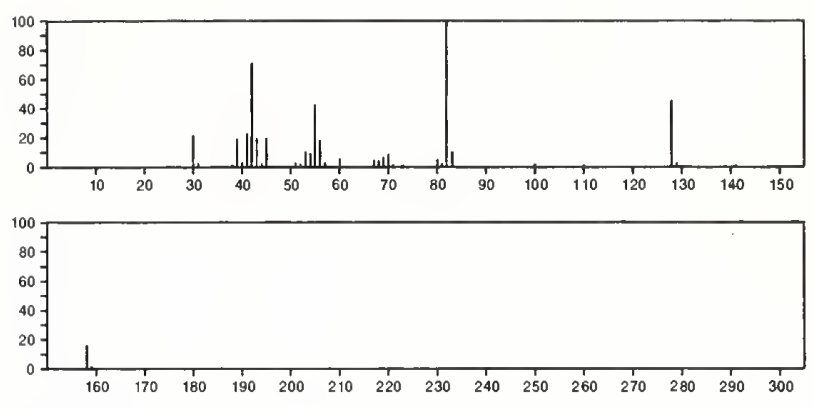

$158 \quad \mathrm{C}_{6} \mathrm{H}_{10} \mathrm{~N}_{2} \mathrm{O}_{3}$

1-Imidazolidinemethanol, 4,4-dimethyl-2,5-dioxo-

$16228-00-5$
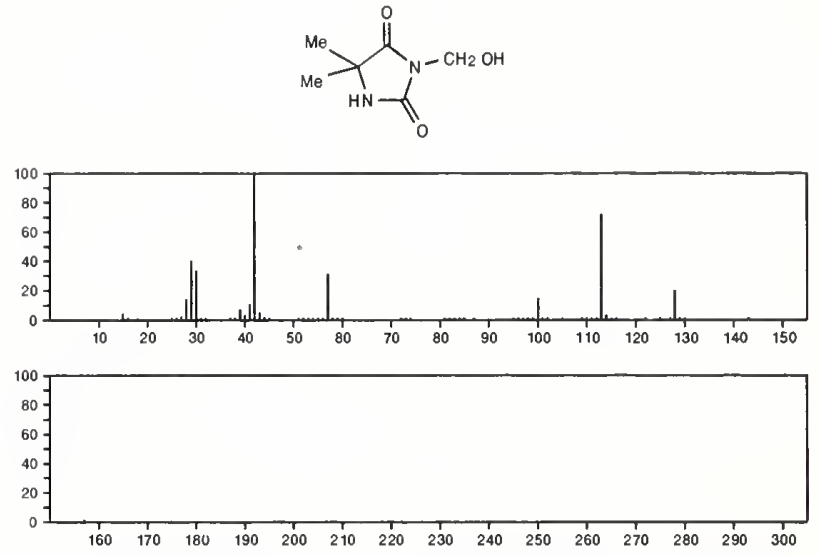

$158 \quad \mathrm{C}_{6} \mathrm{H}_{10} \mathrm{~N}_{2} \mathrm{O}_{3}$

2-Piperidinecarboxylic acid, 1-nitroso-, (S)-

$30310-83-9$
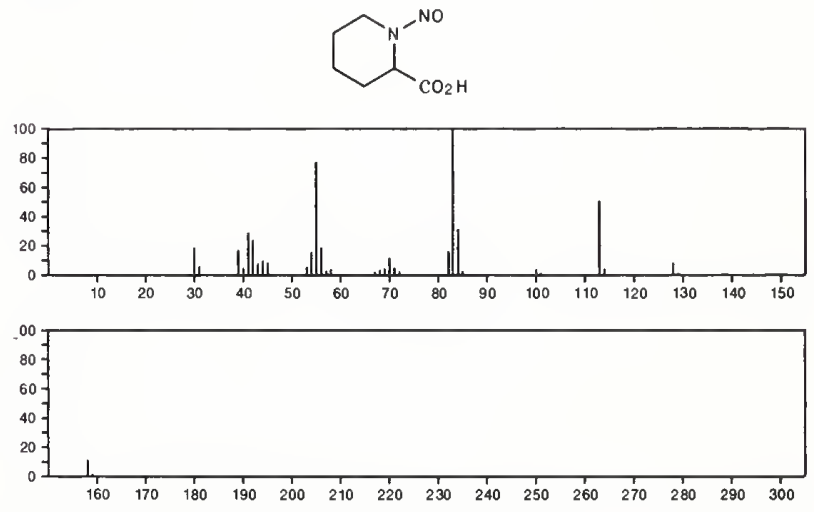

158

$\mathrm{C}_{7} \mathrm{H}_{10} \mathrm{~N}_{2}$. ClH

$637-60-5$

Hydrazine, (4-methylphenyl)-, monohydrochloride
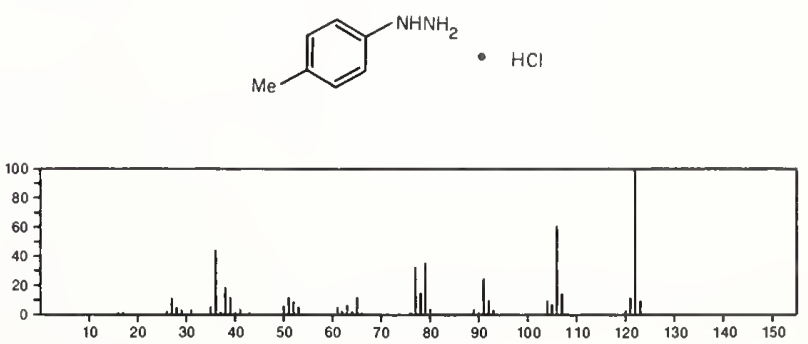


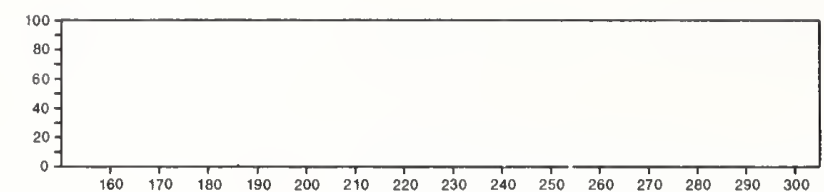

158

$\mathrm{C}_{7} \mathrm{H}_{10} \mathrm{~N}_{2} \mathrm{ClH}$

Hydrazine, (phenylmethyl)-, monohydrochloride

$\mathrm{H}_{2} \mathrm{NNHCH}_{2} \mathrm{Ph} \cdot \mathrm{HCl}$

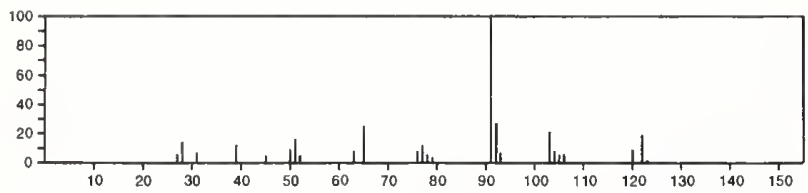

158

2-Propene-1,1-diol, diacetate

$\mathrm{C}_{7} \mathrm{H}_{10} \mathrm{O}_{4}$

$869-29-4$

$\mathrm{OAC}$

$\mathrm{Ac} \mathrm{OCHCH}=\mathrm{CH}_{2}$

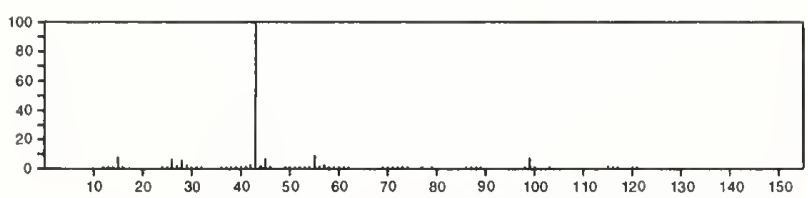

158

$\mathrm{C}_{7} \mathrm{H}_{10} \mathrm{O}_{4}$

Hexanoic acid, 3,5-dioxo-, methyl ester

$\mathrm{MeOC}(\mathrm{O}) \mathrm{CH}_{2} \mathrm{COCH}_{2} \mathrm{COMe}$
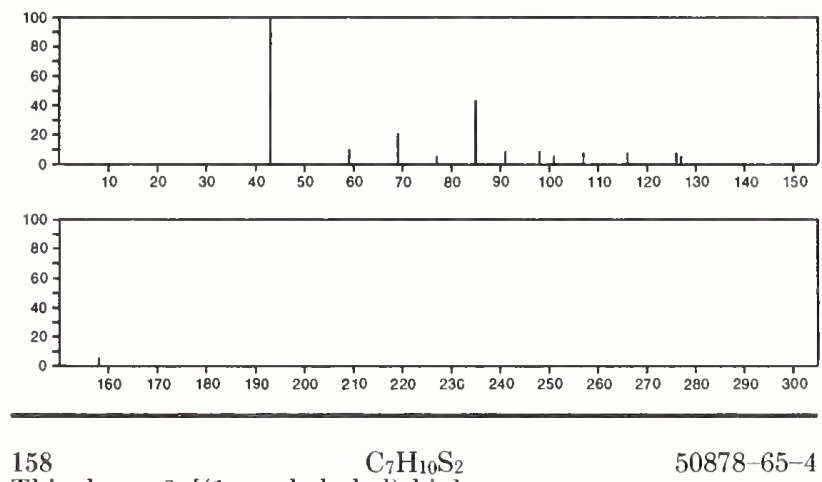

Thiophene, 2-[(1-methylethyl)thio]-

$50878-65-4$
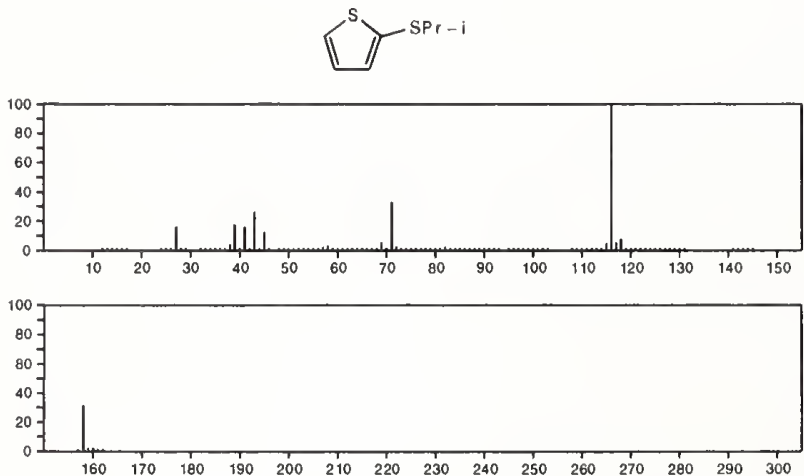

158

$\mathrm{C}_{7} \mathrm{H}_{11} \mathrm{~N}_{2} \mathrm{Cl}$

Pyridinium, 1-amino-2,6-dimethyl-, chloride

$34061-85-3$
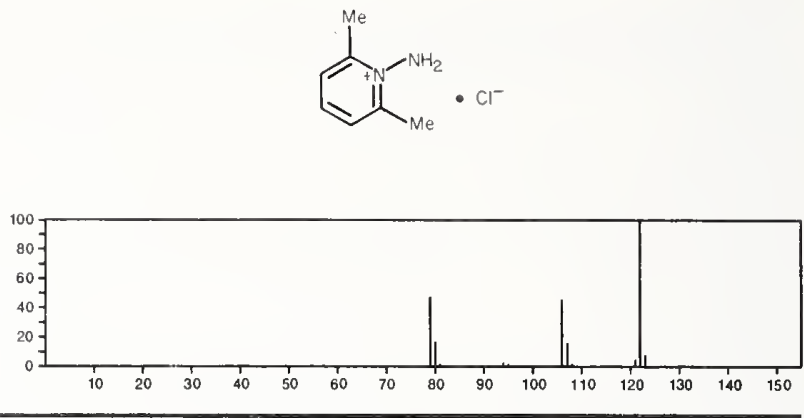

158

$\mathrm{C}_{7} \mathrm{H}_{14} \mathrm{~N}_{2} \mathrm{O}$

$7400-28-4$

Hydrazinecarboxylic acid, butylidene--, ethyl ester

$E: O C(0) N H N=C H P$
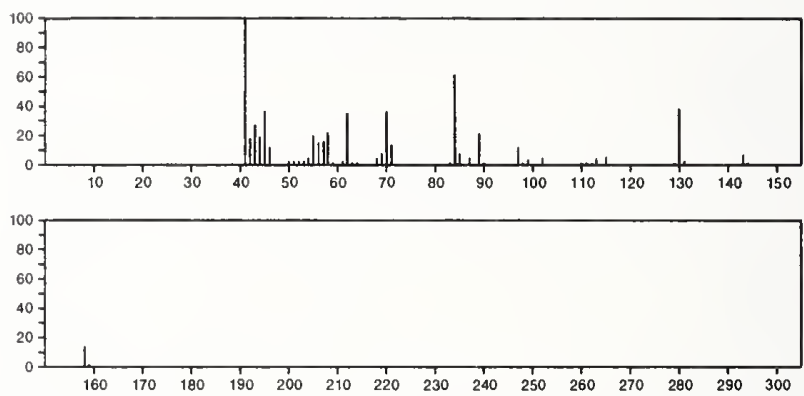

158

$\mathrm{C}_{7} \mathrm{H}_{14} \mathrm{~N}_{2} \mathrm{O}_{2}$

$14702-36-4$

Carbazic acid, 3-pentylidene-, methyl ester

$\mathrm{MeOC}(\mathrm{O}) \mathrm{NHN}=\mathrm{CH}\left(\mathrm{CH}_{2}\right) 3 \mathrm{Me}$
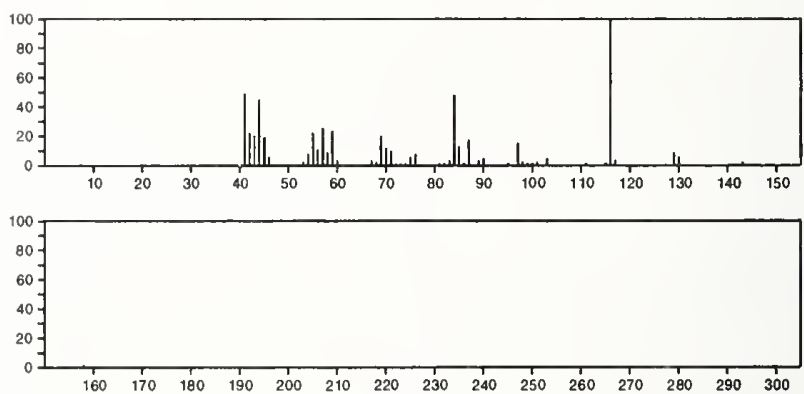

158

$\mathrm{C}_{7} \mathrm{H}_{14} \mathrm{~N}_{2} \mathrm{O}_{2}$

49582-53-8

2-Propenoic acid, 3-(dimethylamino)-3-(methylamino)-, methyl ester

$\mathrm{MeOC}(0) \mathrm{CH}: \mathrm{C}(\mathrm{NHMe}) \mathrm{NME} 2$
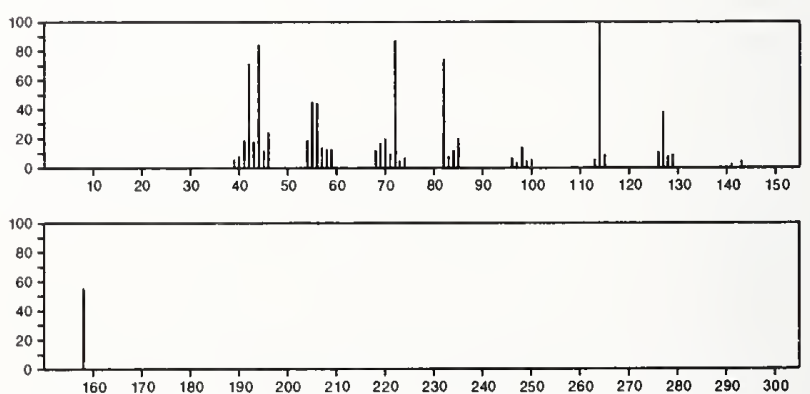
158 $\mathrm{C}_{7} \mathrm{H}_{14} \mathrm{~N}_{2} \mathrm{~S}$

Diethylamine, $N$-isothiocyanato-1,1'-dimethyl-

$17709-98-7$

$$
\text { i-Pr } 2 \text { NNCS }
$$
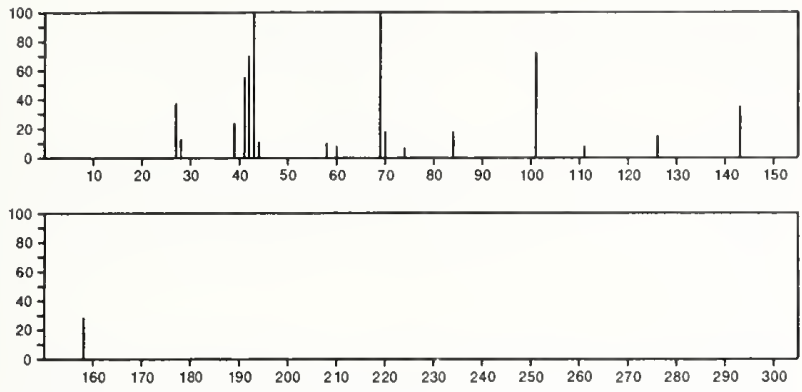

158

$\mathrm{C}_{7} \mathrm{H}_{15} \mathrm{BO}_{3}$

1,3,2-Dioxaborolane, 4-methyl-2-(2-methylpropoxy)-
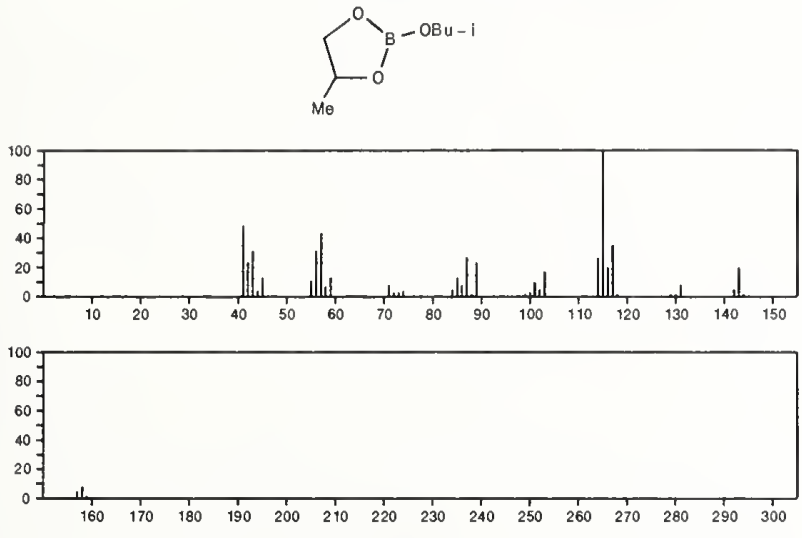

$158 \quad \mathrm{C}_{7} \mathrm{H}_{15} \mathrm{BO}_{3}$

$55162-67-9$

1,3,2-Dioxaborinane, 2-(2-methylpropoxy)-
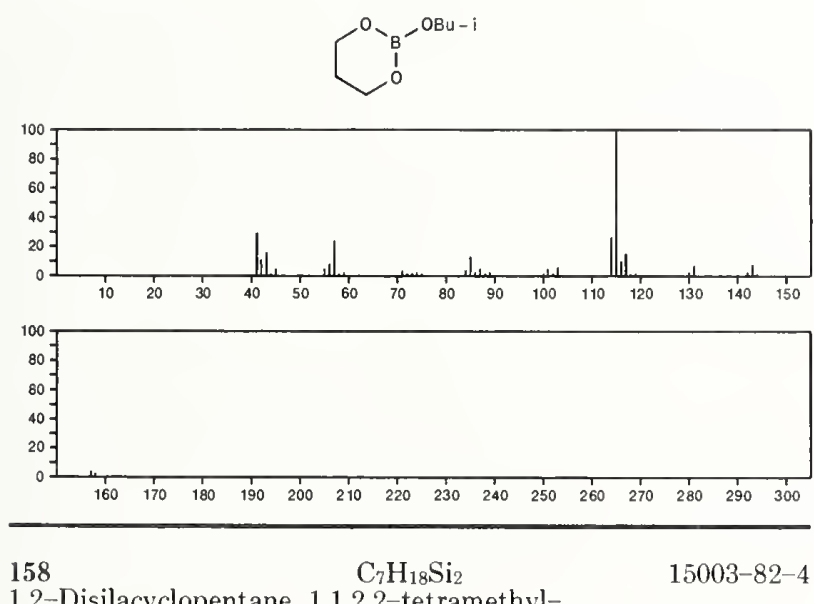

1,2-Disilacyclopentane, 1,1,2,2-tetramethyl-
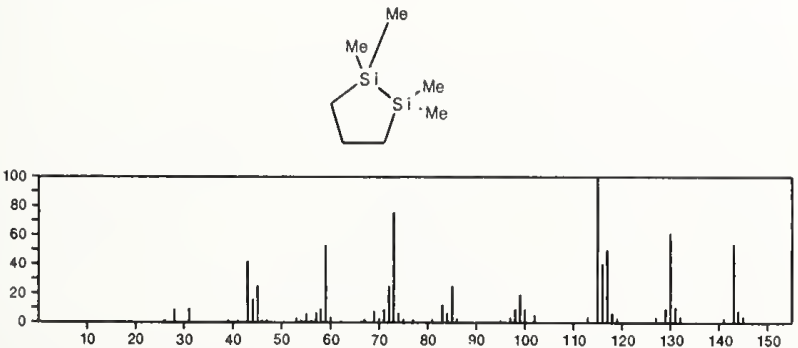

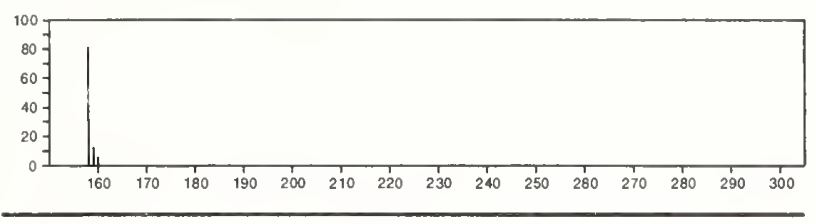

158

Bicyclo[2.2.2]octanone, 4-chloro-

$7697-11-2$
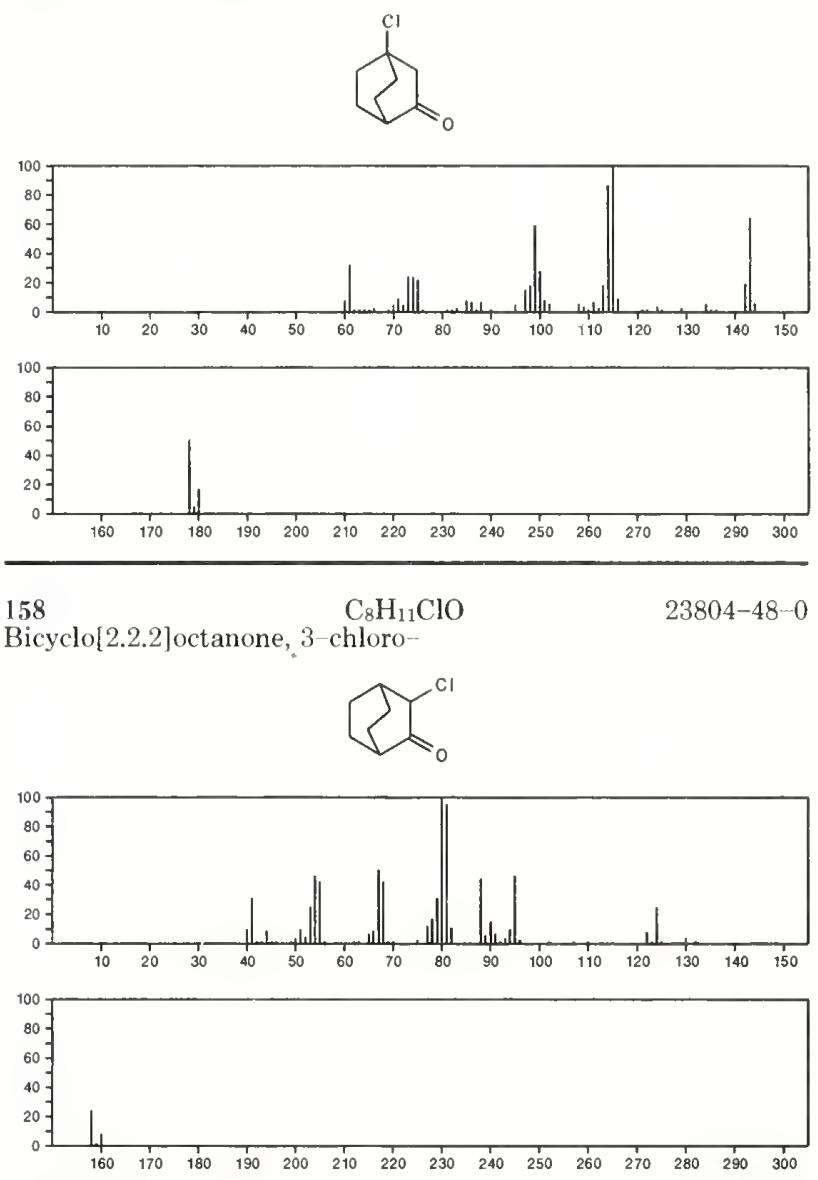

158

$\mathrm{C}_{8} \mathrm{H}_{11} \mathrm{ClO}$

$56324-75-5$

Bicyclo[2.2.2]octan-2-one, 5-chloro-, exo-
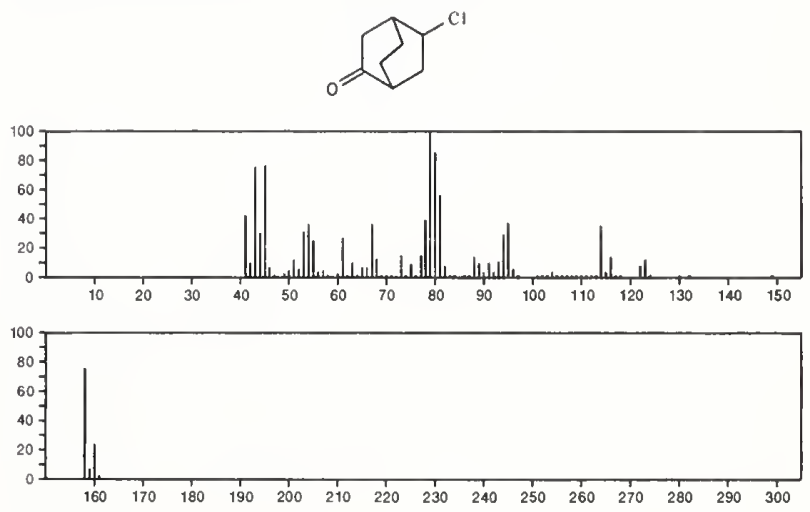
158

$\mathrm{C}_{8} \mathrm{H}_{14} \mathrm{OS}$

1-Oxa-4-thiaspiro[4.5]decane
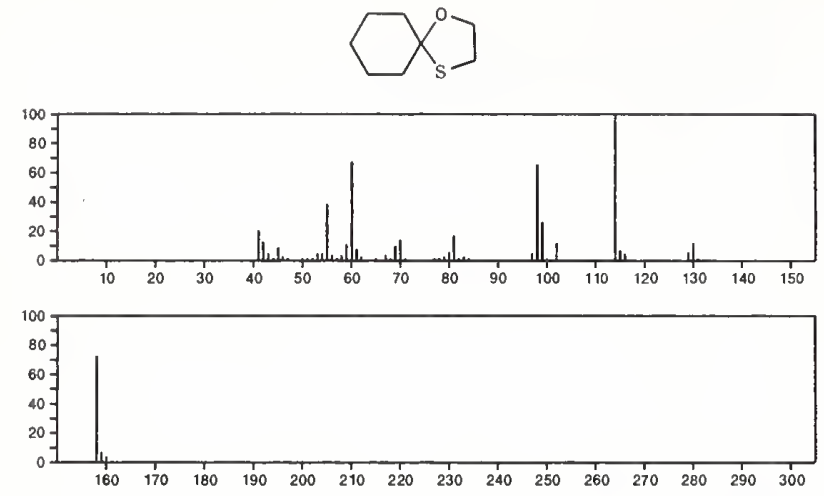

158

$\mathrm{C}_{8} \mathrm{H}_{14} \mathrm{OS}$

9-Thiabicyclo[3.3.1] nonane, 9-oxide
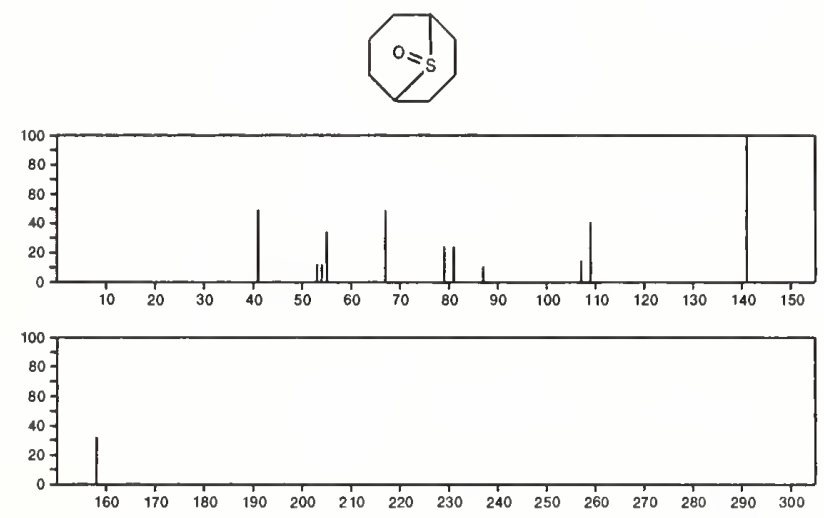

$158 \quad \mathrm{C}_{8} \mathrm{H}_{14} \mathrm{O}_{3}$

Propanoic acid, 2-methyl-, anhydride

$97-72-3$

$\mathrm{Me}_{2} \mathrm{CHC}(0)$ OC( 0$)_{\mathrm{CHMe}_{2}}$

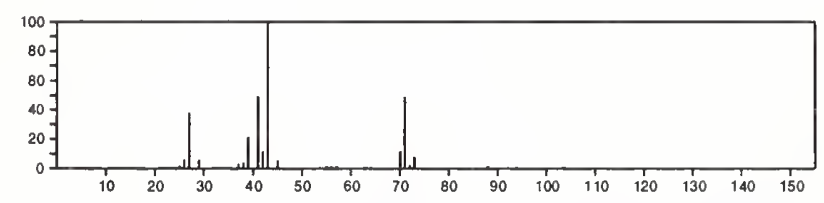

158

Butanoic acid, anhydride

$\mathrm{C}_{8} \mathrm{H}_{14} \mathrm{O}_{3}$

106-31-0

$\operatorname{PrC}(0) O C(0) \operatorname{Pr}$
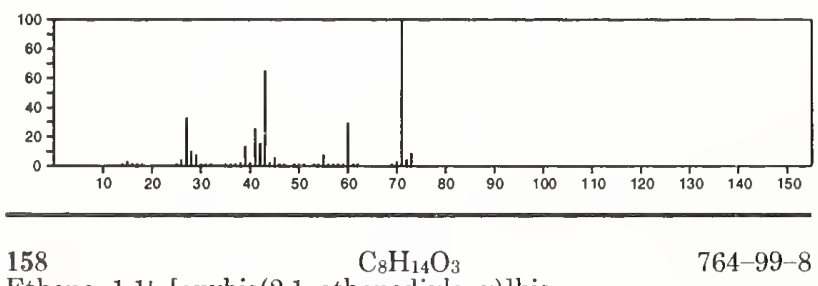

Ethene, 1,1'-[oxybis(2,1-ethanediyloxy) ] bis--

$\mathrm{H}_{2} \mathrm{C}=\mathrm{CHOCH}_{2} \mathrm{CH}_{2} \mathrm{OCH}_{2} \mathrm{CH}_{2} \mathrm{OCH}=\mathrm{CH}_{2}$

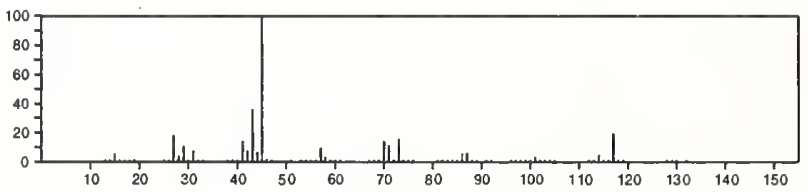

158

2-Butenoic acid, 3-ethoxy-, ethyl ester

998-91-4
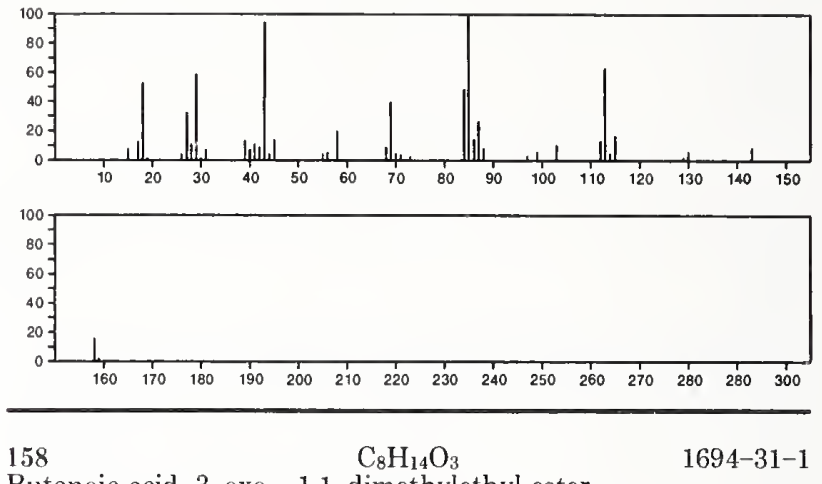

$1694-31-1$

Butanoic acid, 3-0xo-, 1,1-dimethylethyl ester

$\mathrm{Me} \mathrm{COCH}_{2} \mathrm{C}(0) \mathrm{OBu}-1$
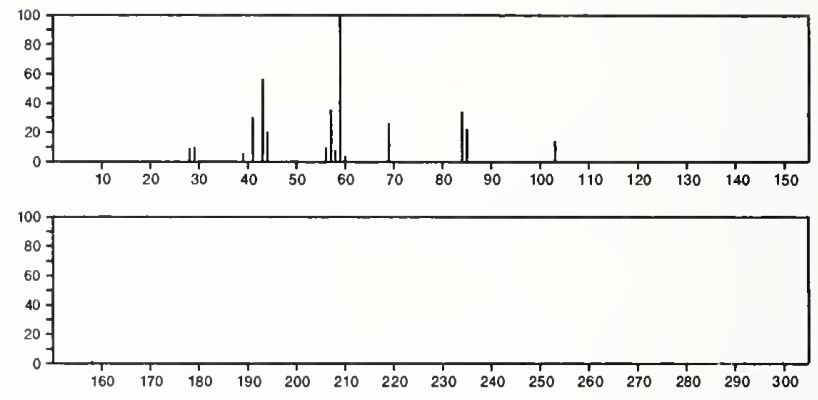

$158 \quad \mathrm{C}_{8} \mathrm{H}_{14} \mathrm{O}_{3}$

$\mathrm{C}_{8} \mathrm{H}_{14} \mathrm{O}_{3} \quad 2236-11-5$

Cyclohexanecarboxylic acid, 2-hydroxy-, methyl ester
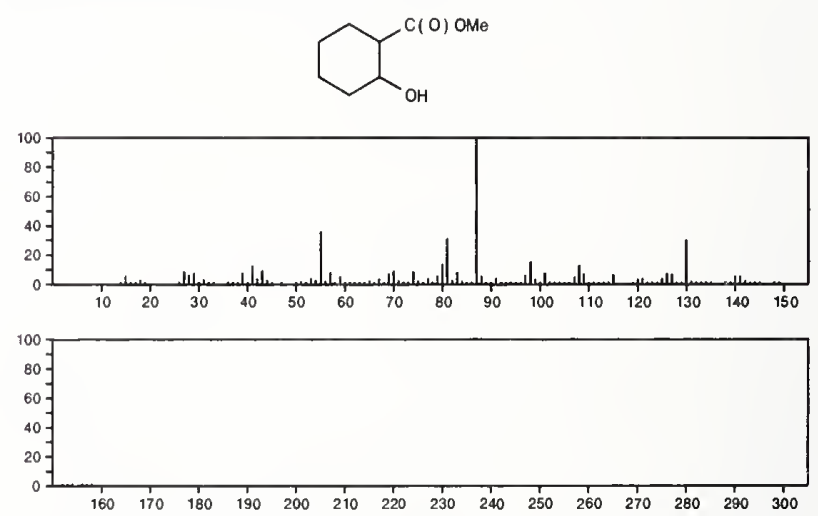

$158 \quad \mathrm{C}_{8} \mathrm{H}_{14} \mathrm{O}_{3}$

2-Hexanone, 6-(acetyloxy)-

$4305-26-4$

$\mathrm{MeCO}\left(\mathrm{CH}_{2}\right)_{4} \mathrm{OAC}$

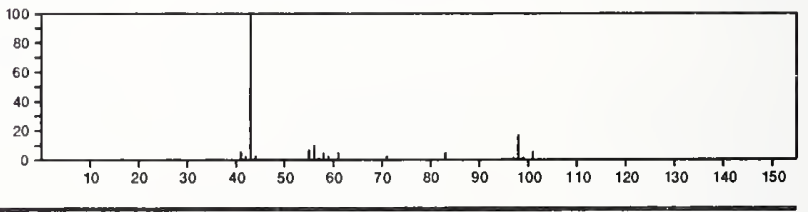

158

$\mathrm{C}_{8} \mathrm{H}_{14} \mathrm{O}_{3}$

Butanoic acid, 3-oxo-', 1-methylpropyl ester

$13562-76-0$

$\mathrm{MeCOCH} 2 \mathrm{C}(\mathrm{O}) \mathrm{OBu}-\mathrm{s}$

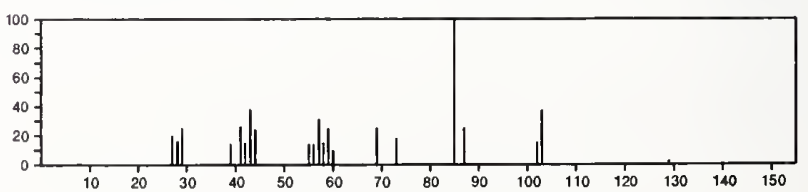




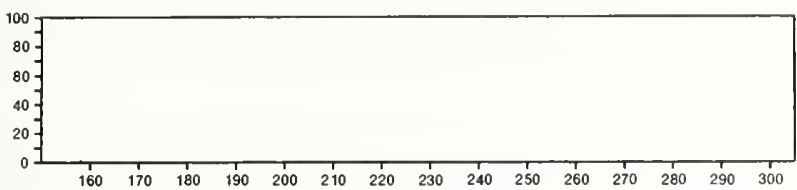

$\begin{array}{lllllllllllllll}160 & 170 & 180 & \$ 90 & 200 & 210 & 220 & 230 & 240 & 250 & 260 & 270 & 280 & 290 & 300\end{array}$

158 $\mathrm{C}_{8} \mathrm{H}_{14} \mathrm{O}_{3}$

Hexanoic acid, 5-oxo-, ethyl ester

$\mathrm{Me} \mathrm{CO}\left(\mathrm{CH}_{2}\right)_{3} \mathrm{C}(\mathrm{O}) \mathrm{OEt}$
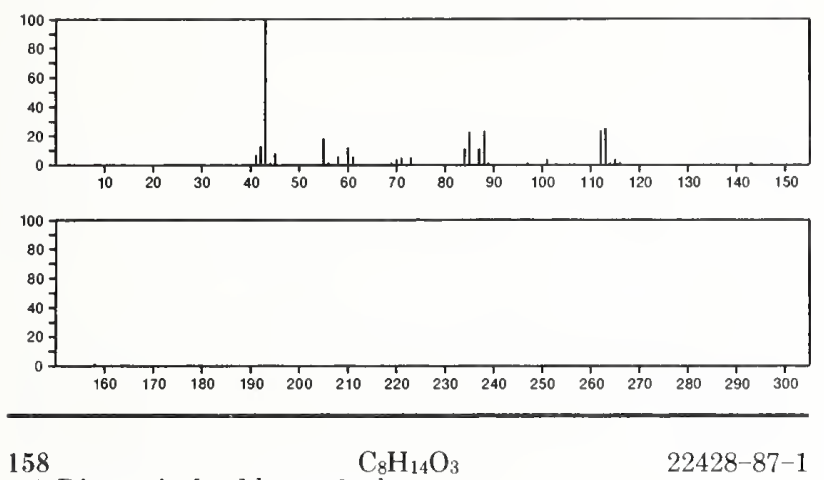

1,4-Dioxaspiro[4.5]decan-8-ol
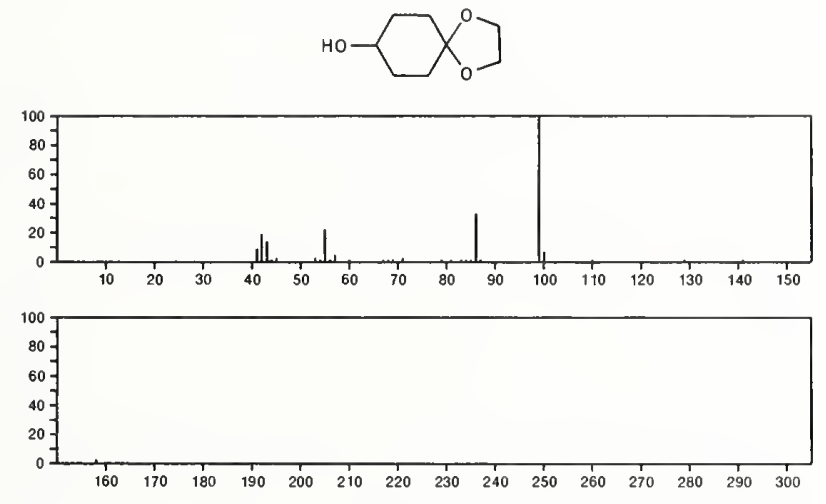

\begin{tabular}{lll}
\hline 158 & $\mathrm{C}_{8} \mathrm{H}_{14} \mathrm{O}_{3}$ & $29887-64-7$
\end{tabular}

Cyclohexanone, 3,5-dimethoxy-, trans
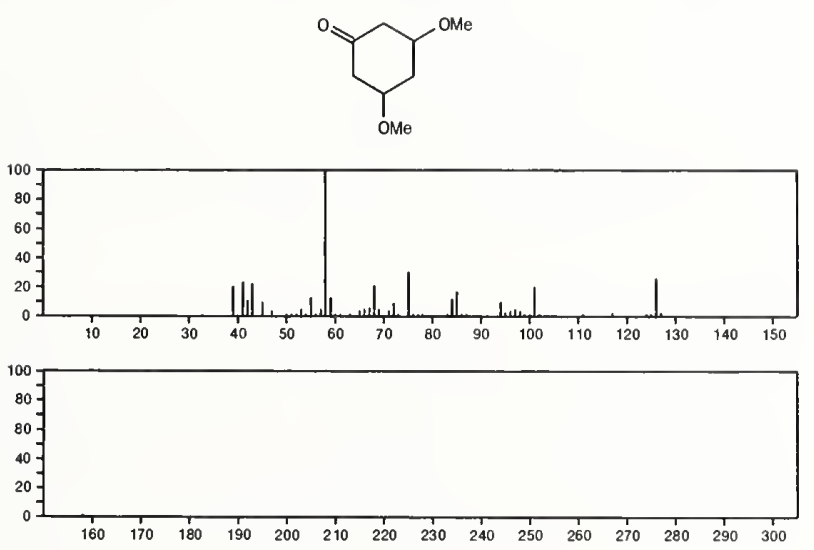

158

$\mathrm{C}_{8} \mathrm{H}_{14} \mathrm{O}_{3}$

Cyclohexanone, 3,5-dimethoxy--, cis- $^{-}$

$30363-85-0$<smiles>COC1CC(=O)CC(O)C1</smiles>
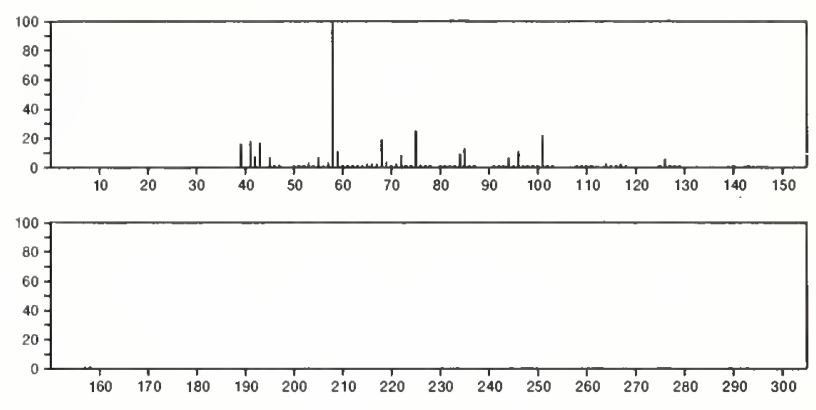

158

$\mathrm{C}_{8} \mathrm{H}_{14} \mathrm{O}_{3}$

$33528-35-7$

2-Butanone, 4-(2-methyl-1,3-dioxolan-2-yl)-
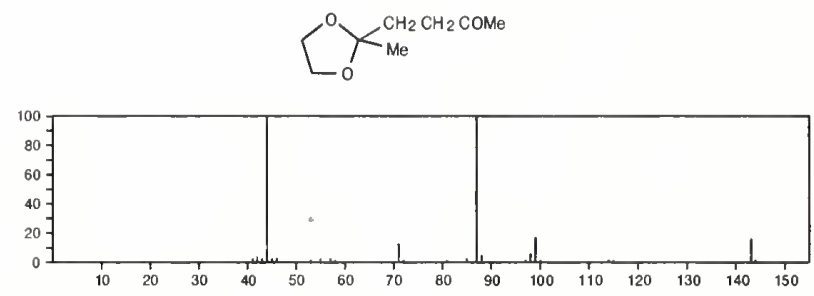

158

$\mathrm{C}_{8} \mathrm{H}_{14} \mathrm{O}_{3}$

34553-37-2

Hexanoic acid, 5-methyl-4-oxo-, methyl ester

$\mathrm{Me}_{2} \mathrm{CHCOCH}_{2} \mathrm{CH}_{2} \mathrm{C}(\mathrm{O}) \mathrm{OMe}_{\mathrm{M}}$
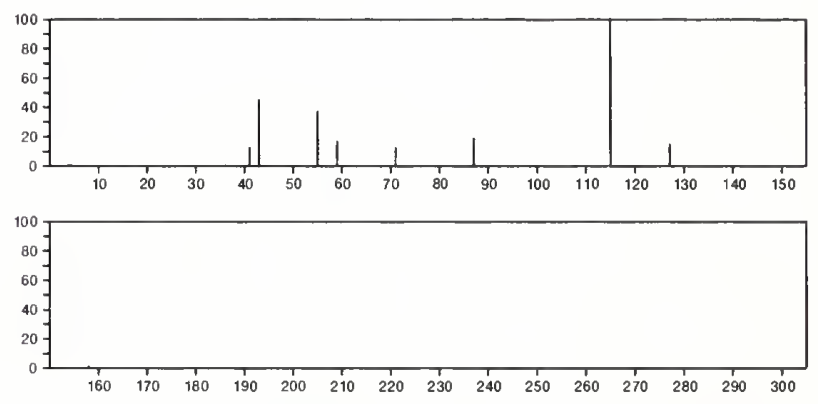

158

$\mathrm{C}_{8} \mathrm{H}_{14} \mathrm{O}_{3}$

51756-10-6

Butanoic acid, 2-acetyl-3-methyl-, methyl ester

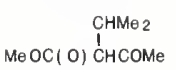
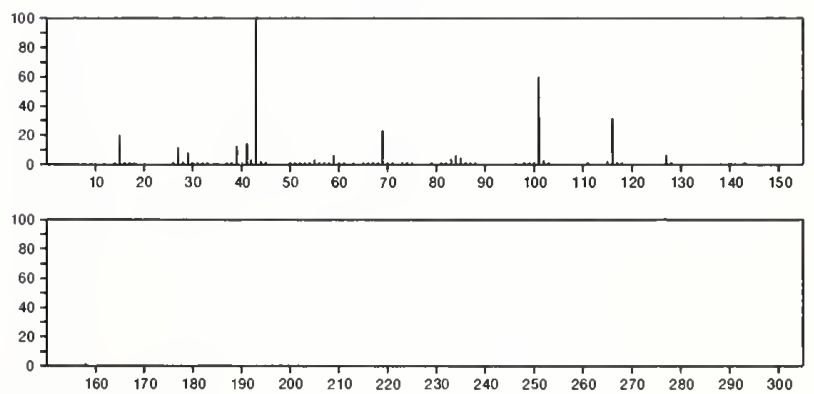
158

$\mathrm{C}_{8} \mathrm{H}_{14} \mathrm{O}_{3}$

$56009-35-9$

2-Pentenoic acid, 2-methoxy-3-methyl-, methyl ester

$\mathrm{MeOC}(\mathrm{O}) \mathrm{C}(\mathrm{OMe})=\mathrm{CE}$ I Me

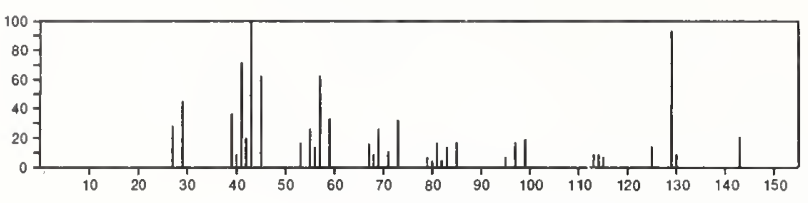

$\mathrm{C}_{8} \mathrm{H}_{14} \mathrm{O}_{3}$

$56009-36-0$

158

2-Pentenoic acid, 2-methoxy-4-methyl-, methyl ester

$\mathrm{MeOC}(0) \mathrm{C}(\mathrm{OM})=\mathrm{CHCHMe}$

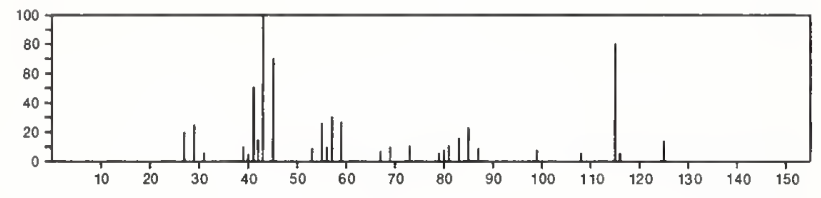

$158 \quad \mathrm{C}_{8} \mathrm{H}_{16} \mathrm{NO}_{2}$

$2154-37-2$

1-Pyrrolidinyloxy, 3-hydroxy-2,2,5,5-tetramethyl-<smiles>[Y6]C1([18O])C(O)CC(C)(C)N1O</smiles>
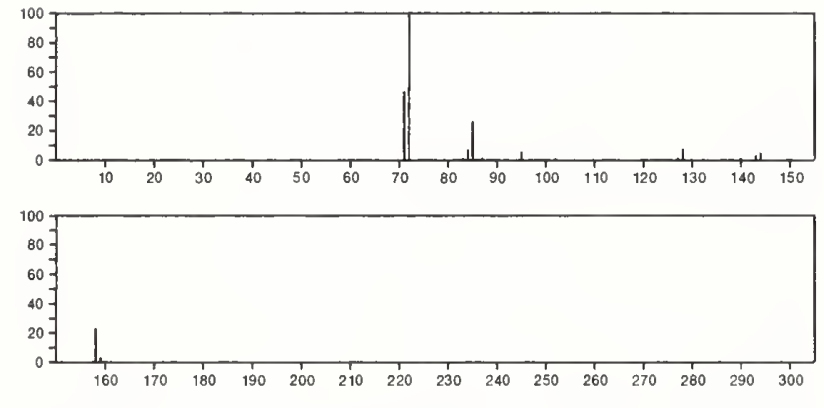

$158 \quad \mathrm{C}_{8} \mathrm{H}_{18} \mathrm{~N}_{2} \mathrm{O}$

$924-16-3$

1 -Butanamine, $N$-butyl- $N$-nitroso-

$\mathrm{Me}\left(\mathrm{CH}_{2}\right)_{3} \mathrm{~N}(\mathrm{NO})\left(\mathrm{CH}_{2}\right)_{3} \mathrm{Me}$
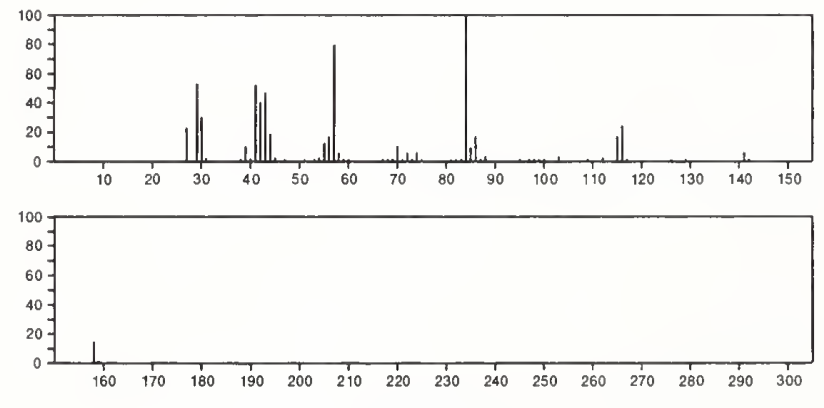

158

$\mathrm{C}_{8} \mathrm{H}_{18} \mathrm{~N}_{2} \mathrm{O}$

$997-95-5$

1-Propanamine, 2-methyl-N-(2-methylpropyl $)-N$-nitroso-

$\mathrm{i}-\mathrm{Bu} \mathrm{N}_{2} \mathrm{NNO}$

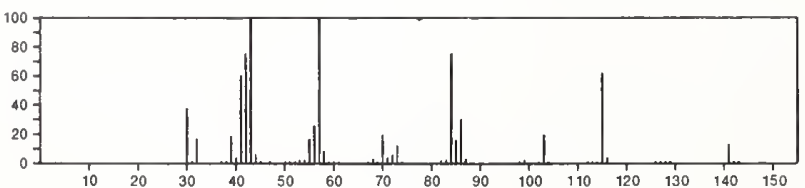

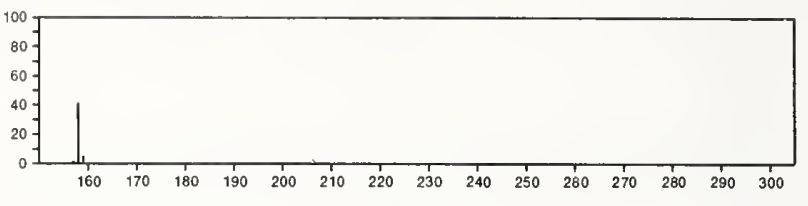

158

$\mathrm{C}_{8} \mathrm{H}_{18} \mathrm{~N}_{2} \mathrm{O}$

1-Pentanamine, $N$-(1-methylethyl $)-N$-nitroso-

$28023-77-0$

$-\operatorname{PrN}(\mathrm{NO})\left(\mathrm{CH}_{2}\right){ }_{4} \mathrm{Me}$
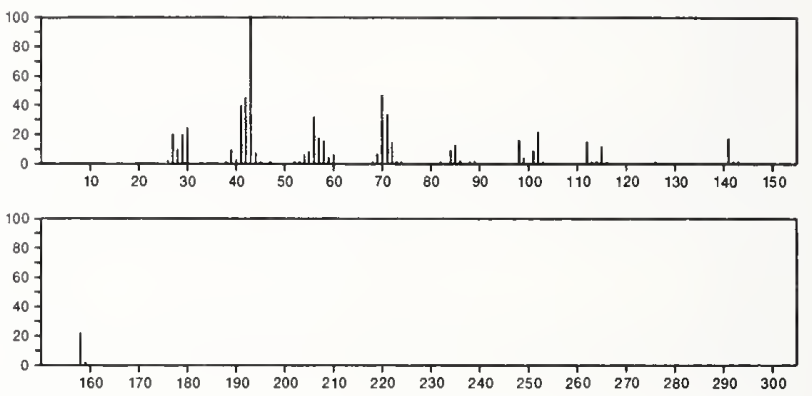

158

$\mathrm{C}_{8} \mathrm{H}_{18} \mathrm{~N}_{2} \mathrm{O}$

1-Pentanamine, $N$-nitroso- $N$-propyl

$28023-78-1$

$\operatorname{PrN}(\mathrm{NO})\left(\mathrm{CH}_{2}\right) 4 \mathrm{Me}$
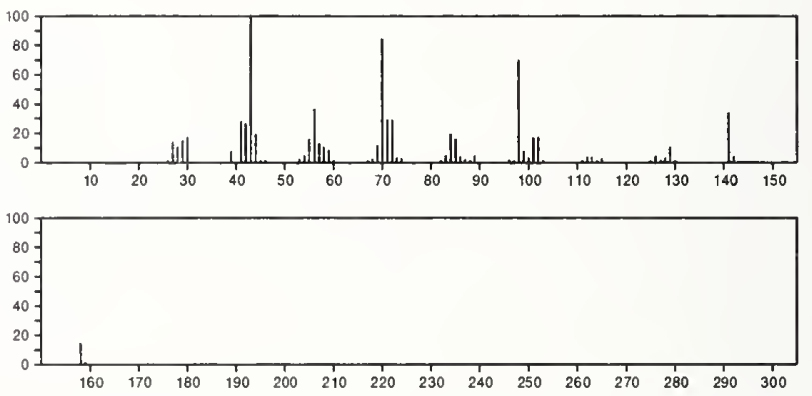

158

$\mathrm{C}_{8} \mathrm{H}_{18} \mathrm{~N}_{2} \mathrm{O}$

1-Butanamine, $N$-(1-methylpropyl)-N-nitroso-

$28023-81-6$

$S-B u N(N O)\left(\mathrm{CH}_{2}\right) 3 \mathrm{Me}$
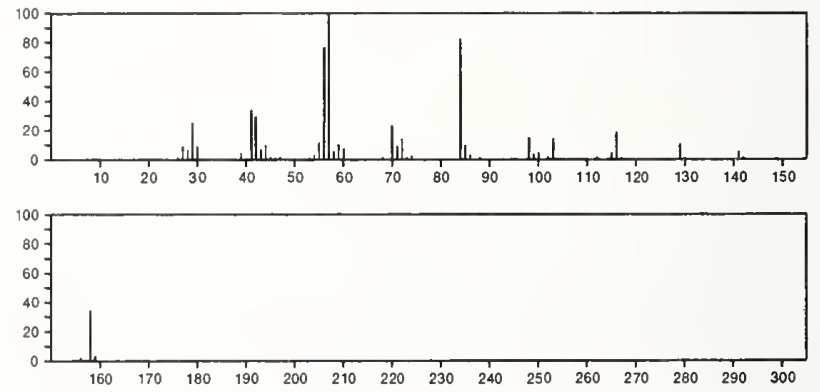

158

$\mathrm{C}_{9} \mathrm{H}_{6} \mathrm{~N}_{2} \mathrm{O}$

$1775-23-1$

$1 \mathrm{H}^{-}$-Inden-1-one, 2-diazo-2,3-dihydro-
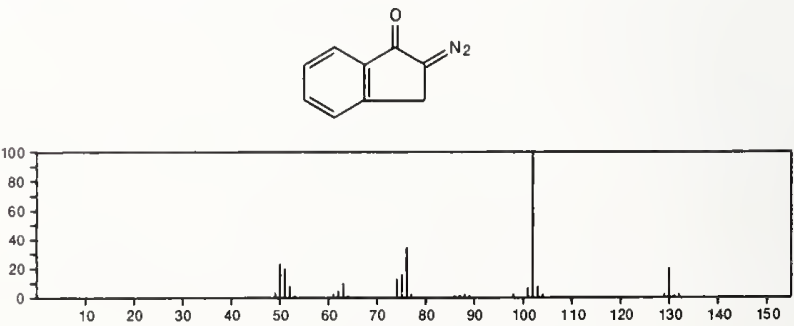


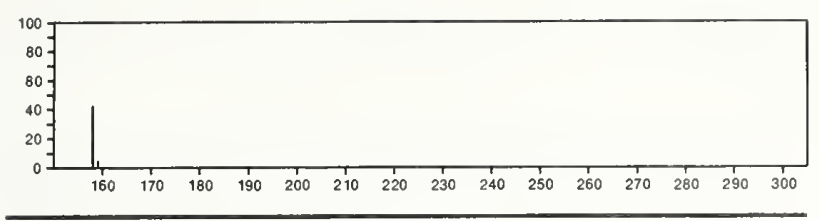

158

\section{$\mathrm{C}_{9} \mathrm{H}_{15} \mathrm{Cl}$}

Bicyclo[2.2.2]octane, 1-chloro-4-methyl-
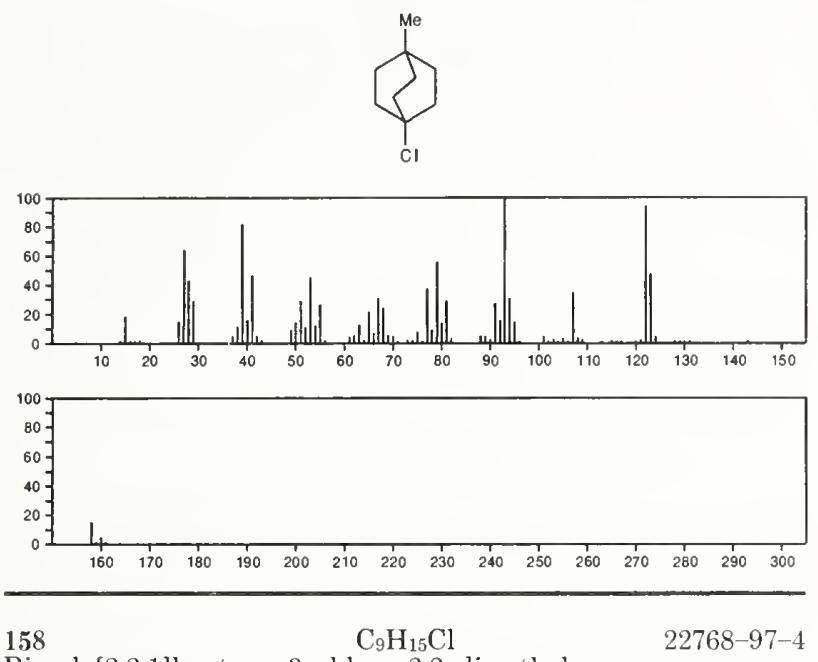

Bicyclo[2.2.1]heptane, 3-chloro-2,2-dimethyl-, exo-
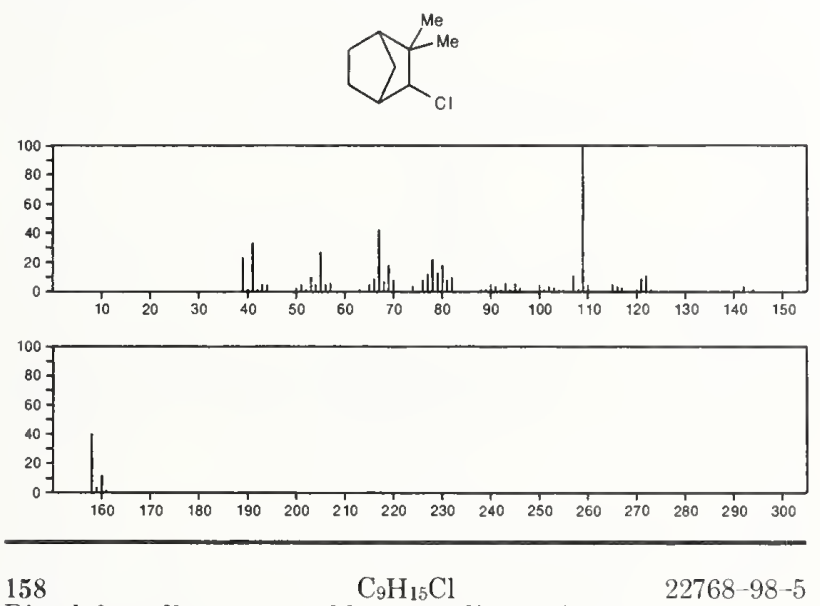

Bicyclo[2.2.1]heptane, 2-chloro-7,7-dimethyl-, exo-
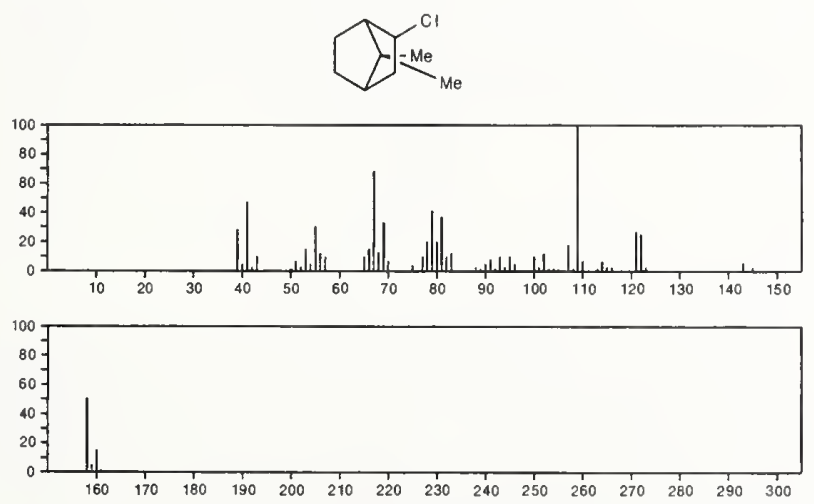

158

3-Heptyne, 7-chloro-2,2-dimethyl-

$55402-10-3$

$\mathrm{Me} 3 \mathrm{CC} \equiv \mathrm{C}\left(\mathrm{CH}_{2}\right)_{3} \mathrm{Cl}$
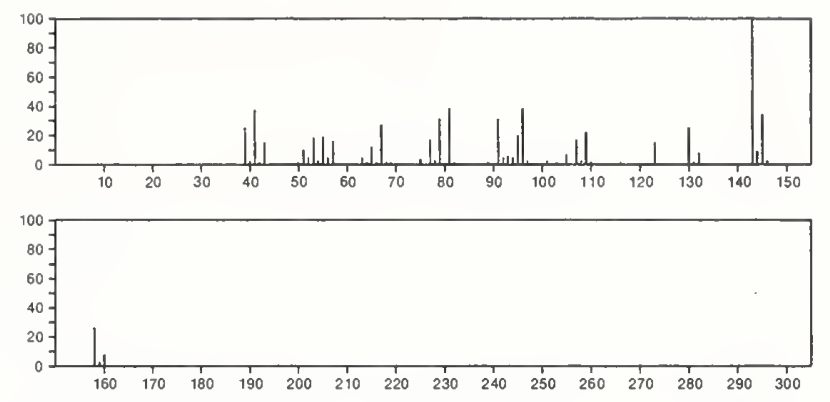

158

Heptanoic acid, ethyl ester

$\mathrm{C}_{9} \mathrm{H}_{18} \mathrm{O}_{2}$

$106-30-9$

$\mathrm{Me}\left(\mathrm{CH}_{2}\right) 5 \mathrm{C}\{\mathrm{O}) \mathrm{OEI}$
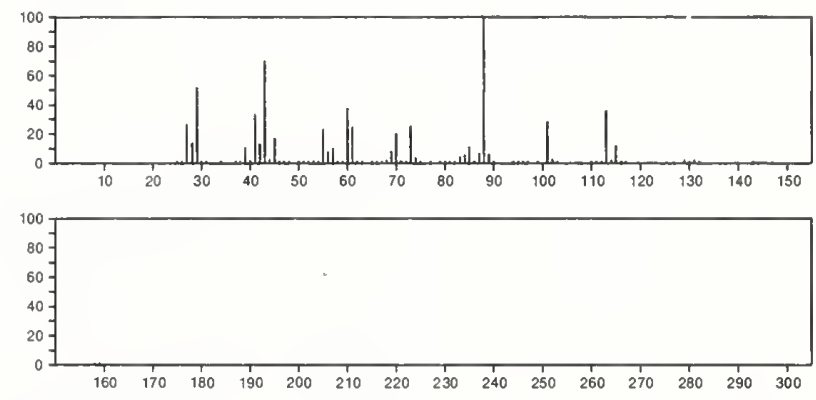

158

$\mathrm{C}_{9} \mathrm{H}_{18} \mathrm{O}_{2}$

Butanoic acid, 3-methyl-, butyl ester

109-19-3

$\mathrm{Me}_{2} \mathrm{CHCH}_{2} \mathrm{C}(\mathrm{O}) \mathrm{O}\left(\mathrm{CH}_{2}\right)_{3} \mathrm{Me}$

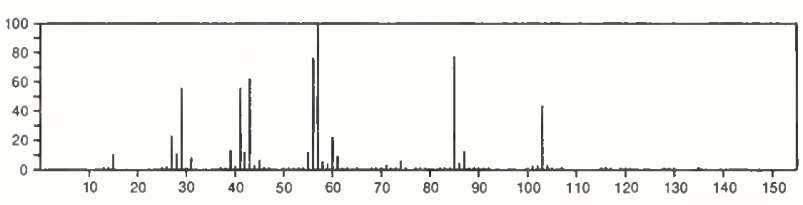

158

$\mathrm{C}_{9} \mathrm{H}_{18} \mathrm{O}_{2}$

$111-11-5$

Octanoic acid, methyl ester
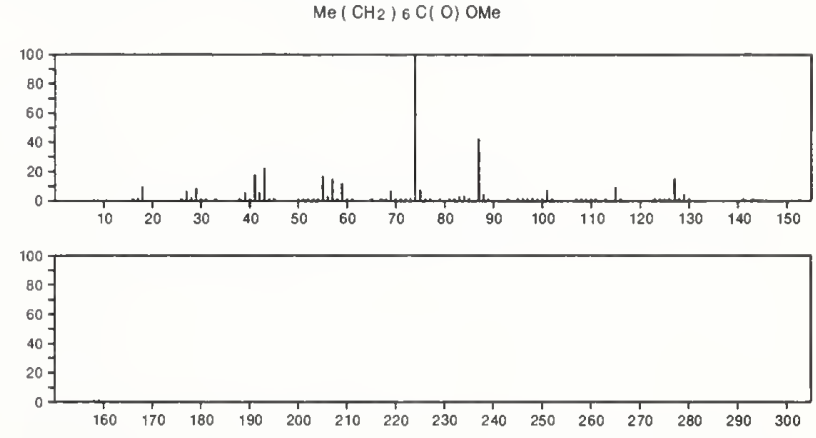

158

Nonanoic acid

$\mathrm{C}_{9} \mathrm{H}_{18} \mathrm{O}_{2}$

$112-05-0$

$\mathrm{HO}_{2} \mathrm{C}\left(\mathrm{CH}_{2}\right)>\mathrm{Me}$

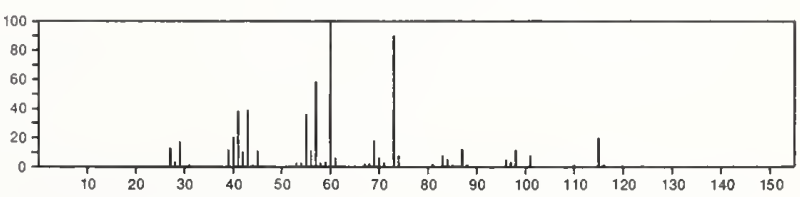




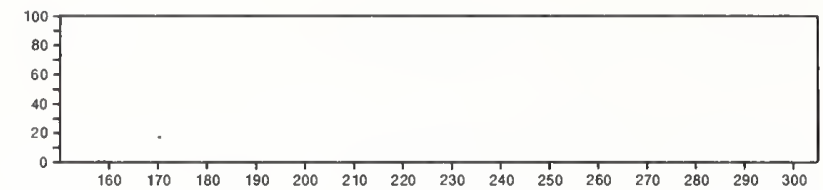

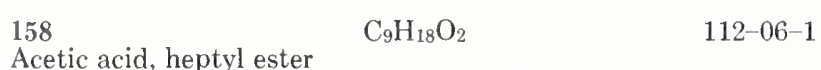

\section{$\mathrm{Me}\left(\mathrm{CH}_{2}\right) 6 \mathrm{OAC}^{\circ}$}

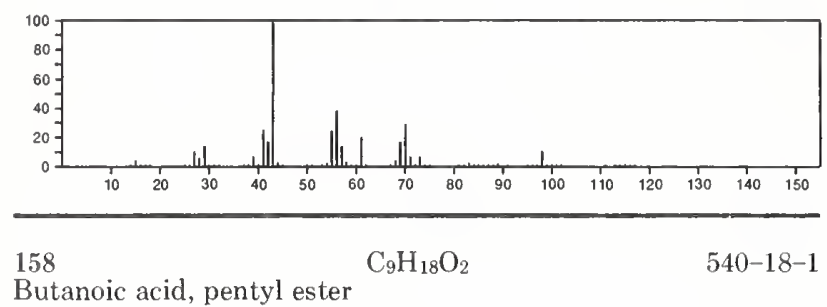

$\operatorname{PrC}(\mathrm{O}) \mathrm{O}\left(\mathrm{CH}_{2}\right){ }_{4} \mathrm{Me}$

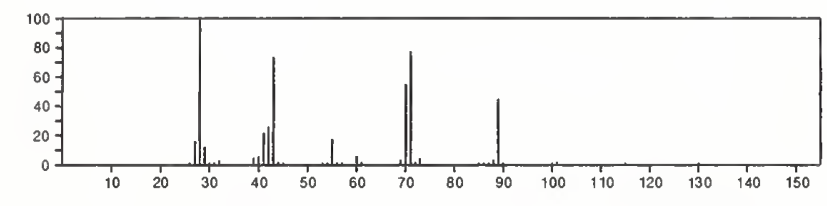

158

$\mathrm{C}_{9} \mathrm{H}_{18} \mathrm{O}_{2}$

Butanoic acid, 3-methyl-, 2-methylpropyl ester

$589-59-3$

i- $\mathrm{BuOC}(\mathrm{O}) \mathrm{CH}_{2} \mathrm{CHMe} 2$
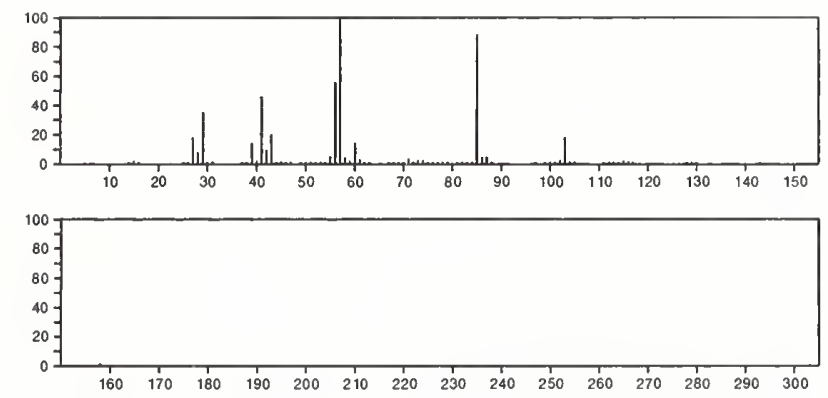

158

$\mathrm{C}_{9} \mathrm{H}_{18} \mathrm{O}_{2}$

Hexanoic acid, 2-ethyl-, methyl ester

816-19-3

MeOC(O) CHE $+\left(\mathrm{CH}_{2}\right)_{3} \mathrm{Me}$
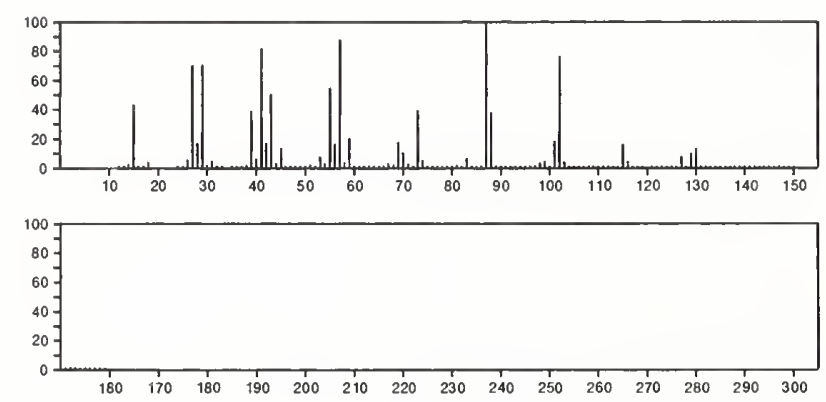

158

$\mathrm{C}_{9} \mathrm{H}_{18} \mathrm{O}_{2}$

Butanoic acid, 2-methyl-, 1-methylpropyl ester

$869-08-9$

$\mathrm{MeCH}_{2} \mathrm{CHMe} \mathrm{C}(\mathrm{O}) \mathrm{OBu}-\mathrm{s}$

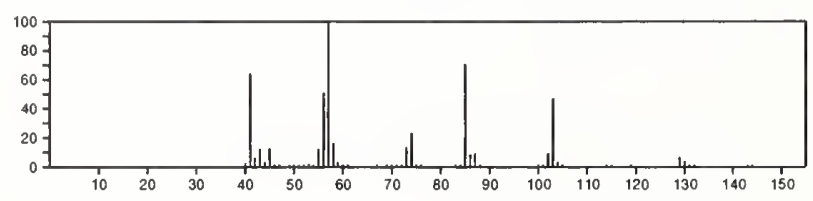

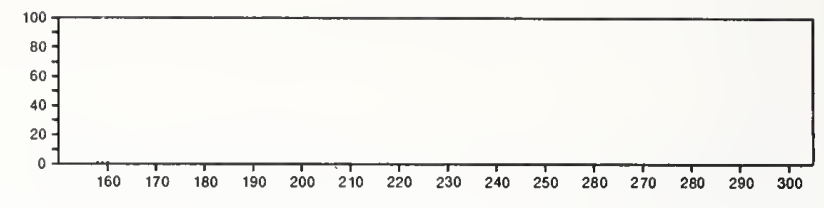

158

1,3-Dioxolane, 2-ethyl-2-isobutyl-

$935-45-5$

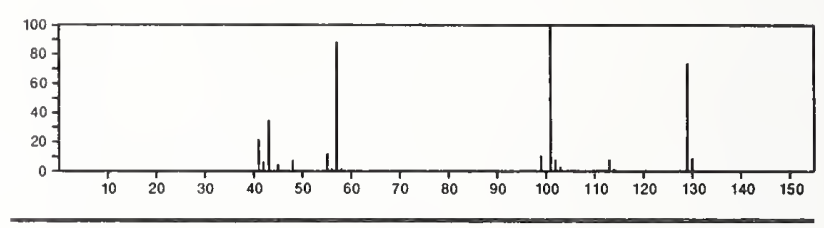

158

1,3-Dioxolane, 2-butyl-2-ethyl-

$935-49-9$

$\sum_{0}^{0}<_{\mathrm{El}}^{\left(\mathrm{CH}_{2}\right)_{3} \mathrm{Me}}$

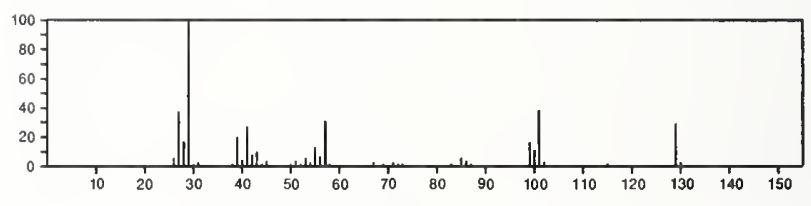

158

$\mathrm{C}_{9} \mathrm{H}_{18} \mathrm{O}_{2}$

$1927-68-0$

2H-Pyran, 2-butoxytetrahydro-
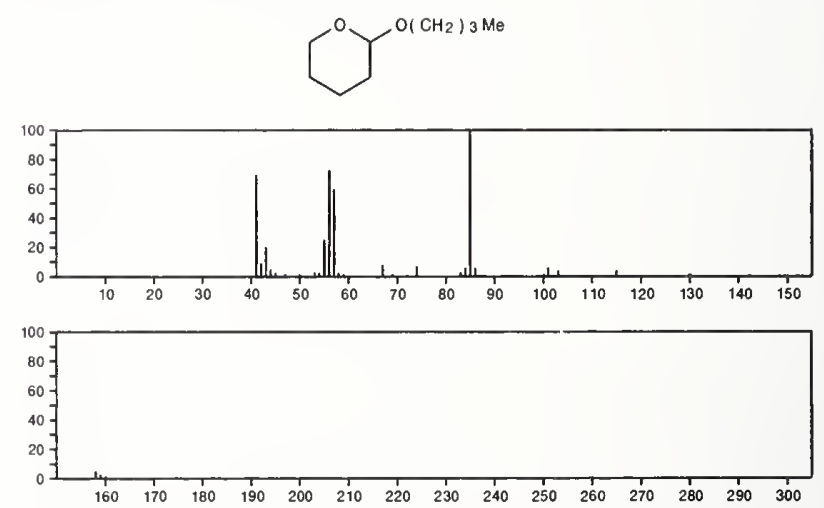

158

$\mathrm{C}_{9} \mathrm{H}_{18} \mathrm{O}_{2}$

$1927-69-1$

2H-Pyran, 2-(1,1-dimethylethoxy)tetrahydro-
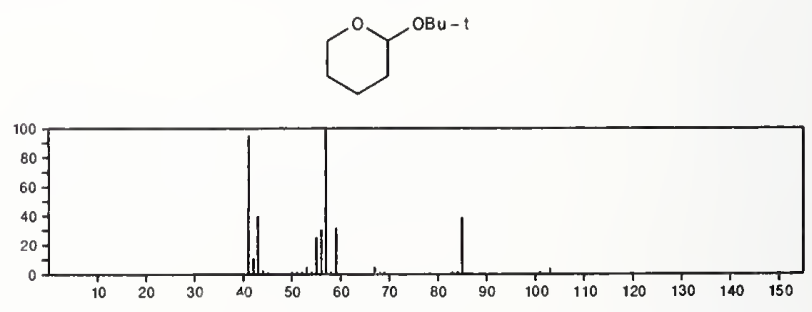

$158 \quad \mathrm{C}_{9} \mathrm{H}_{18} \mathrm{O}_{2}$

Butanoic acid, 2-methyl-, 2-methylpropyl ester

$2445-67-2$

$\mathrm{MeCH}_{2} \mathrm{CHMeC}(\mathrm{O}) \mathrm{OBu}-\mathrm{i}$

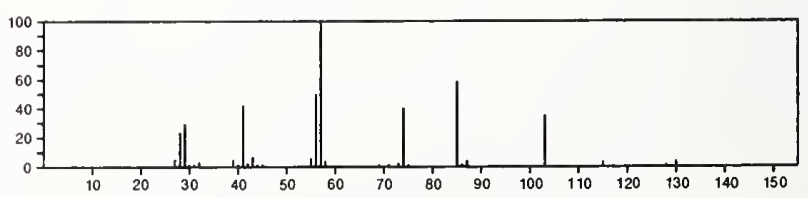


158

$\mathrm{C}_{9} \mathrm{H}_{18} \mathrm{O}_{2}$

2445-76-3

Propanoic acid, hexyl ester

$\mathrm{Me}\left(\mathrm{CH}_{2}\right) 5 \mathrm{OC}(\mathrm{O}) \mathrm{Et}$

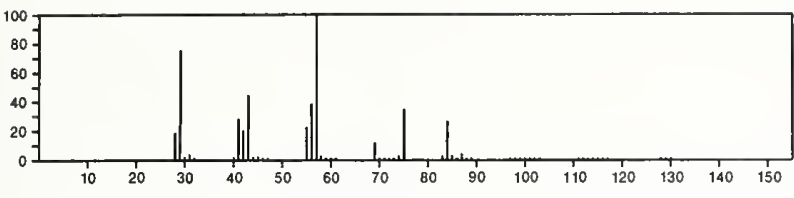

158

Heptanoic acid, 2-ethyl--

$\mathrm{C}_{9} \mathrm{H}_{18} \mathrm{O}_{2}$

$3274-29-1$

$\mathrm{HO}_{2} \mathrm{CCHE} \uparrow\left(\mathrm{CH}_{2}\right) 4 \mathrm{Me}$
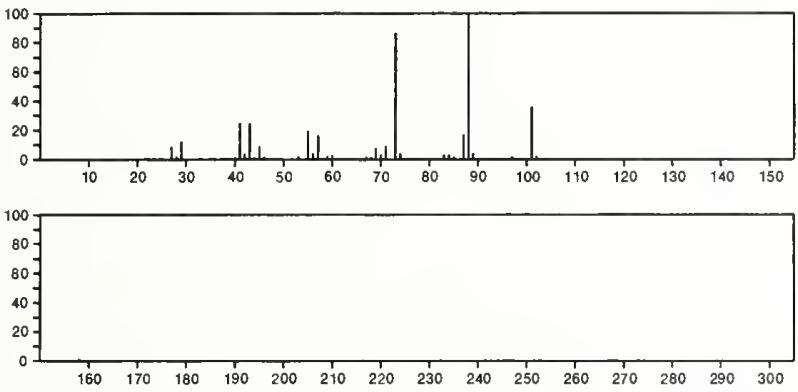

\section{$158 \quad \mathrm{C}_{9} \mathrm{H}_{18} \mathrm{O}_{2}$}

$4352-95-8$

1,3-Dioxolane, 2-methyl-2-pentyl-
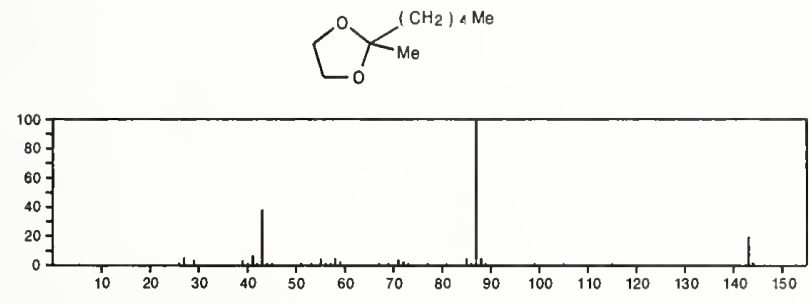

158

$\mathrm{C}_{9} \mathrm{H}_{18} \mathrm{O}_{2}$

$14447-30-4$

1,3-Dioxolane, 2-methyl-2-(3-methylbutyl)-
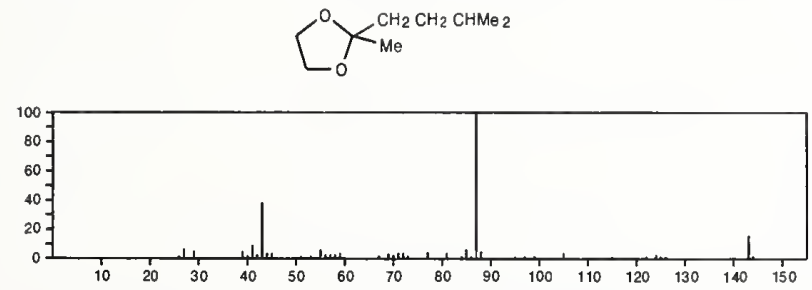

\section{$158 \quad \mathrm{C}_{9} \mathrm{H}_{18} \mathrm{O}_{2}$}

Cyclohexane, 1,1-dimethoxy-3-methyl-
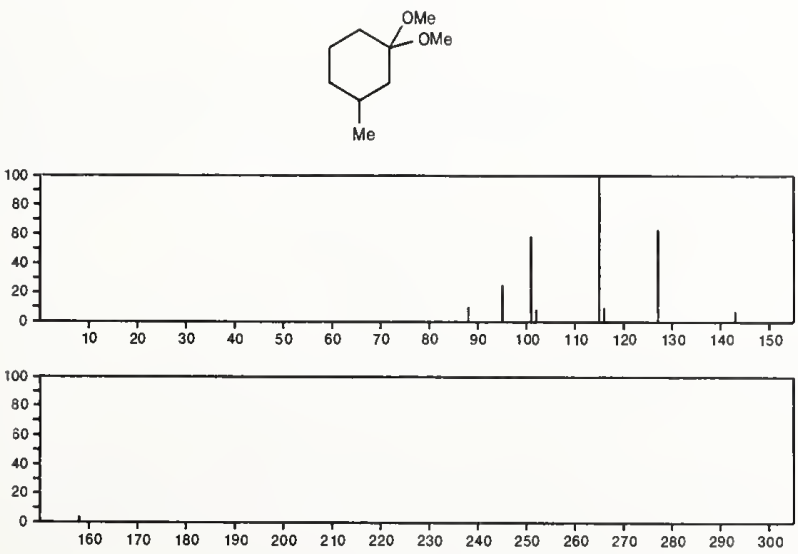

$158 \quad \mathrm{C}_{9} \mathrm{H}_{18} \mathrm{O}_{2}$

Cyclohexane, 1,1-dimethoxy-4-methyl-
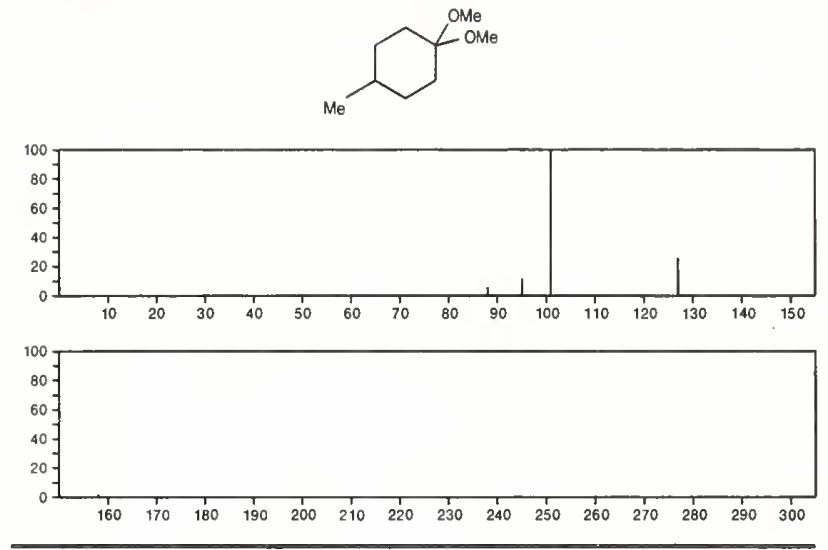

158

$\mathrm{C}_{9} \mathrm{H}_{18} \mathrm{O}_{2}$

$23230-83-3$

Methacrylaldehyde, tert-butyl methyl acetal

( $\mathrm{MeO}$ ) $\mathrm{CHOBU}-1 \mathrm{CMe}=\mathrm{CH}_{2}$
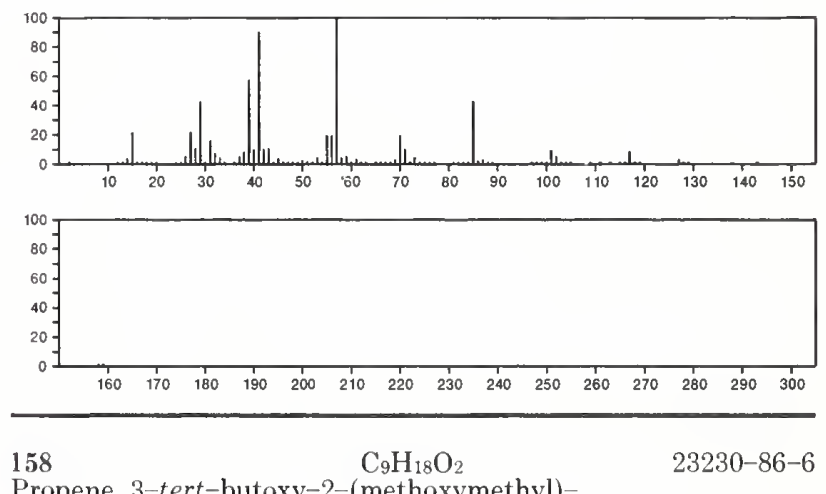

Propene, 3-tert-butoxy-2-(methoxymethyl)-

$\mathrm{CH}_{2}$

$1-\mathrm{BuOCH}_{2} \mathrm{CCH}_{2} \mathrm{OMe}$
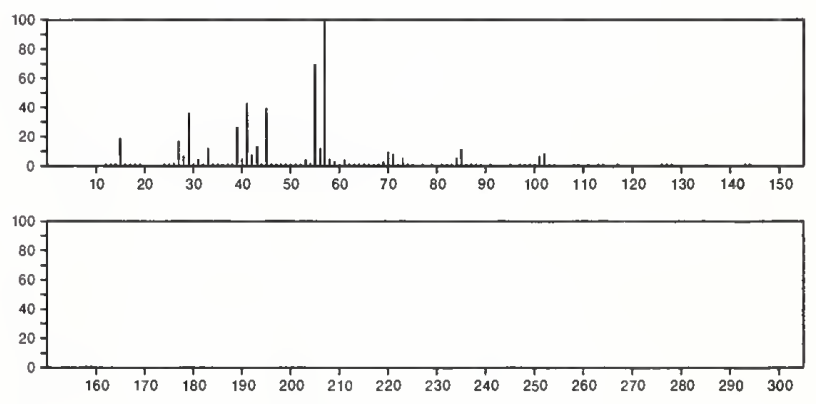

$158 \quad \mathrm{C}_{9} \mathrm{H}_{18} \mathrm{O}_{2} \quad 25368-56-3$

2-Nonanone, 9-hydroxy-

$\mathrm{HO}\left(\mathrm{CH}_{2}\right)>\mathrm{COMe}$

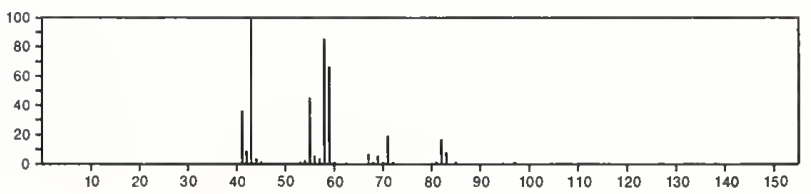


158
Cyclohexane, 1,3-dimethoxy-5-methyl-,
$\mathrm{C}_{9} \mathrm{H}_{18} \mathrm{O}_{2}$<smiles>COC1CC(O)CC(O)C1</smiles>

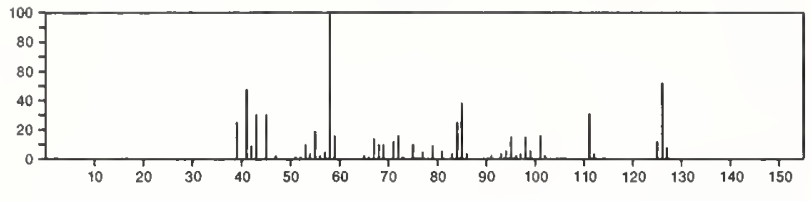

158

$\mathrm{C}_{9} \mathrm{H}_{18} \mathrm{O}_{2}$

29887-66-9

Cyclohexane, 1,4-dimethoxy-2-methyl-, stereoisomer
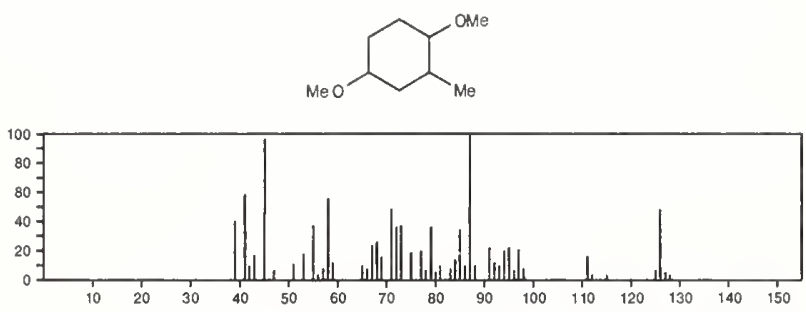

158

$\mathrm{C}_{9} \mathrm{H}_{18} \mathrm{O}_{2}$

Cycloheptane, 1,2-dimethoxy-, trans-

$29887-78-3$
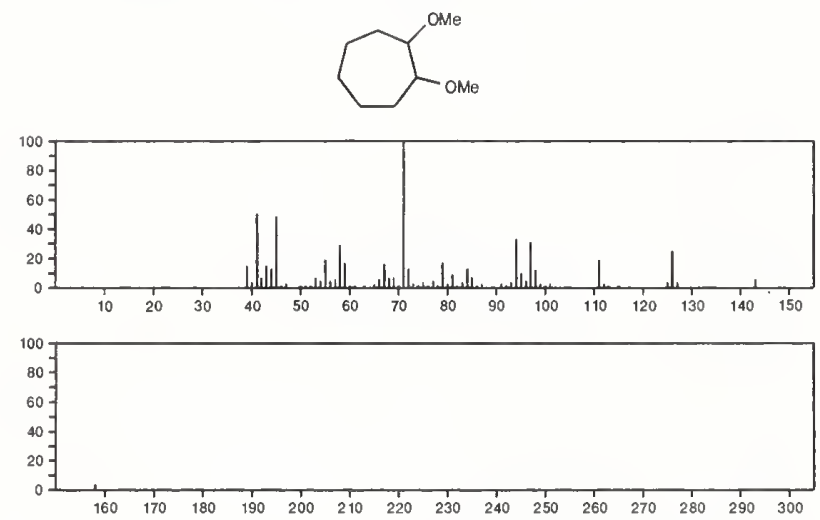

158

$\mathrm{C}_{9} \mathrm{H}_{18} \mathrm{O}_{2}$

Cycloheptane, 1,3-dimethoxy-, trans-

$29887-79-4$
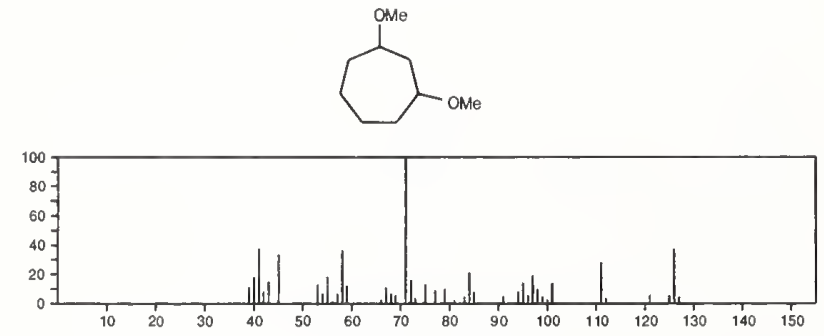

158

Cycloheptane, 1,4-dimethoxy-, trans-

$29887-80-7$
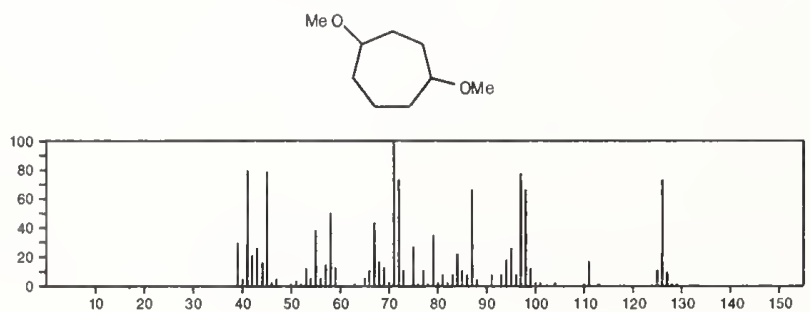

$158 \quad \mathrm{C}_{9} \mathrm{H}_{18} \mathrm{O}_{2}$

$30363-82-7$ Cyclohexane, 1,3-dimethoxy-5-methyl-, stereoisomer<smiles>COC1CC(O)CC(O)C1</smiles>

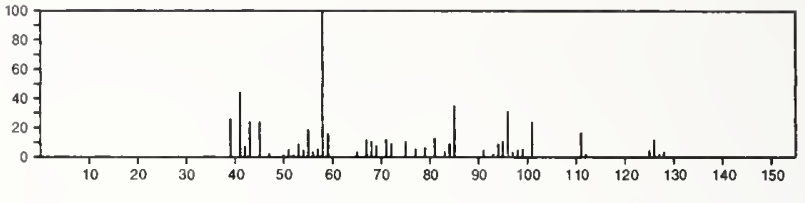

158

$\mathrm{C}_{9} \mathrm{H}_{18} \mathrm{O}_{2}$

$30363-88-3$

Cyclohexane, 1,4-dimethoxy-2-methyl-, stereoisomer
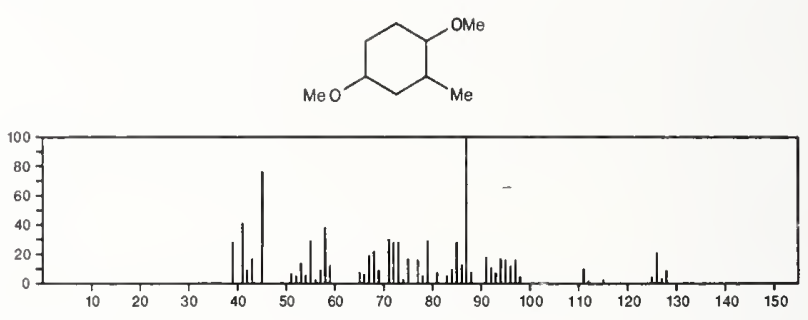

158

$\mathrm{C}_{9} \mathrm{H}_{18} \mathrm{O}_{2}$

Cycloheptane, 1,3-dimethoxy-, cis-

$30363-90-7$
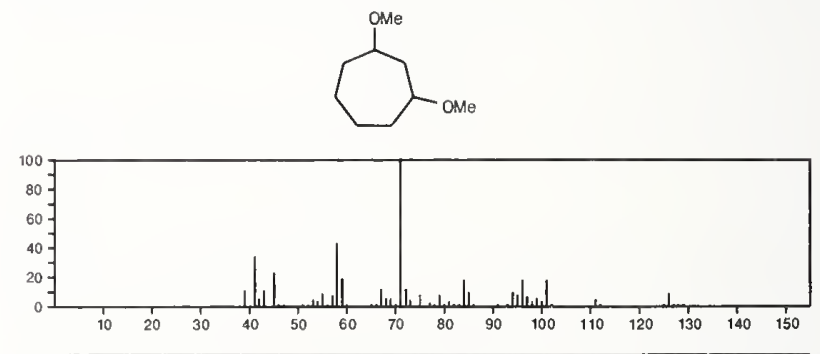

158

$\mathrm{C}_{9} \mathrm{H}_{18} \mathrm{O}_{2}$

$30363-91-8$

Cycloheptane, 1,4-dimethoxy--, cis-
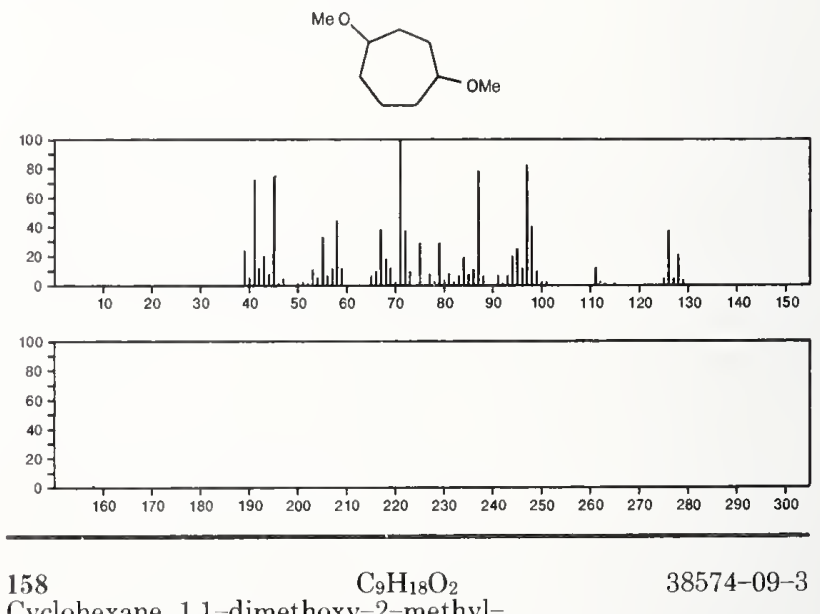

$38574-09-3$

Cyclohexane, 1,1-dimethoxy-2-methyl-
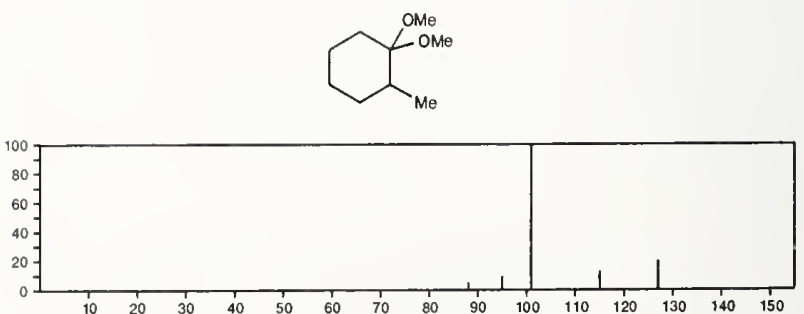


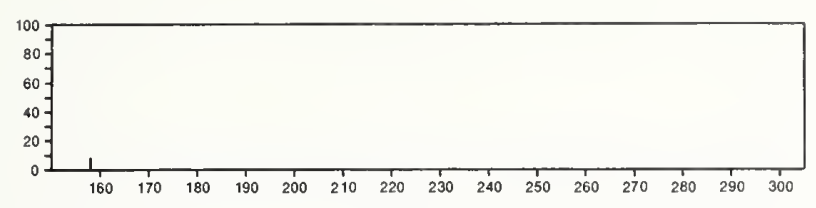

$158 \quad \mathrm{C}_{9} \mathrm{H}_{18} \mathrm{O}_{2}$

Cycloheptane, (methoxymethoxy)-
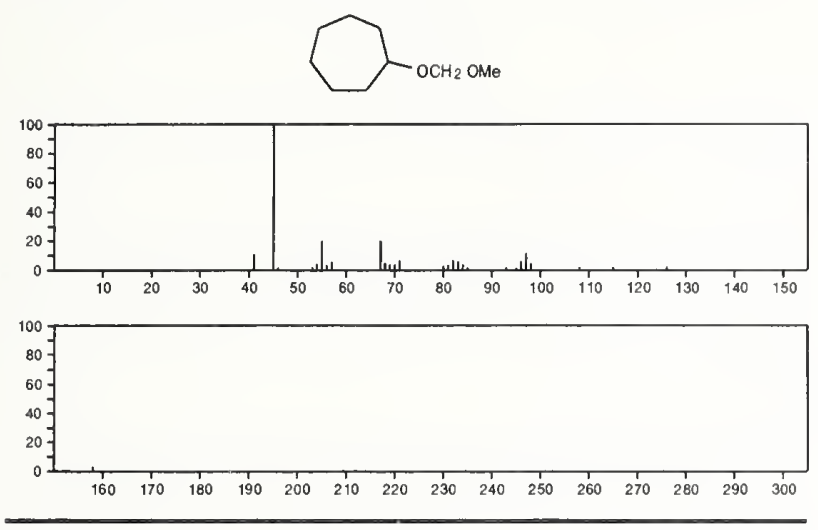

158

2-Heptanone, 1-ethoxy-

$\mathrm{C}_{9} \mathrm{H}_{18} \mathrm{O}_{2}$

51149-70-3

$\mathrm{E}+\mathrm{OCH}_{2} \mathrm{CO}\left(\mathrm{CH}_{2}\right)_{4} \mathrm{Me}$
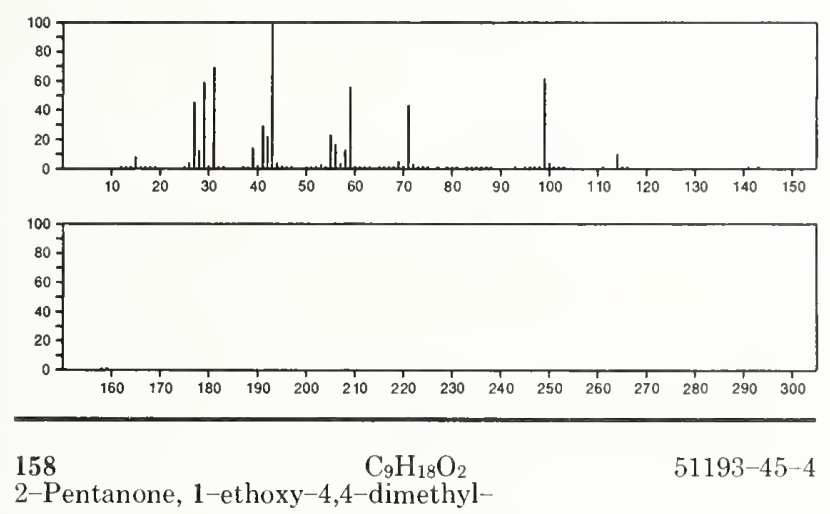

2-Pentanone, 1-ethoxy-4,4-dimethyl-

$\mathrm{E} t \mathrm{OCH}_{2} \mathrm{COCH}_{2} \mathrm{CMe}_{3}$
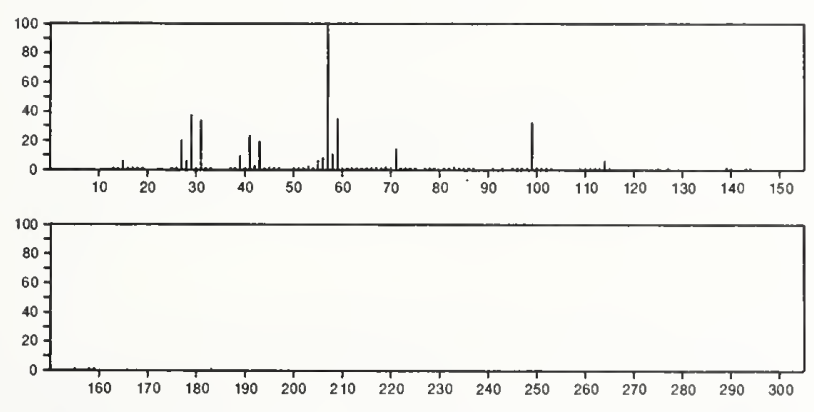

158

$\mathrm{C}_{9} \mathrm{H}_{18} \mathrm{O}_{2}$

2-Butanone, 4-butoxy-3-methyl-

54340-94-2

$\mathrm{Me}$ COCHMe $\mathrm{CH}_{2} \mathrm{O}\left(\mathrm{CH}_{2}\right)_{3} \mathrm{Me}$

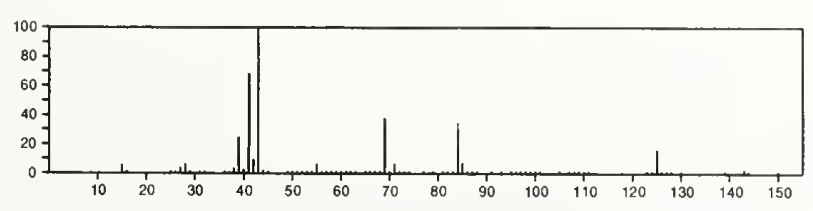

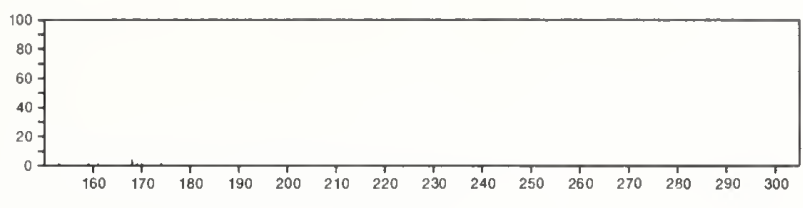

158

$\mathrm{C}_{9} \mathrm{H}_{18} \mathrm{O}$

$54658-03-6$

Me COCE $t(\mathrm{OH})\left(\mathrm{CH}_{2}\right)$ ) Me
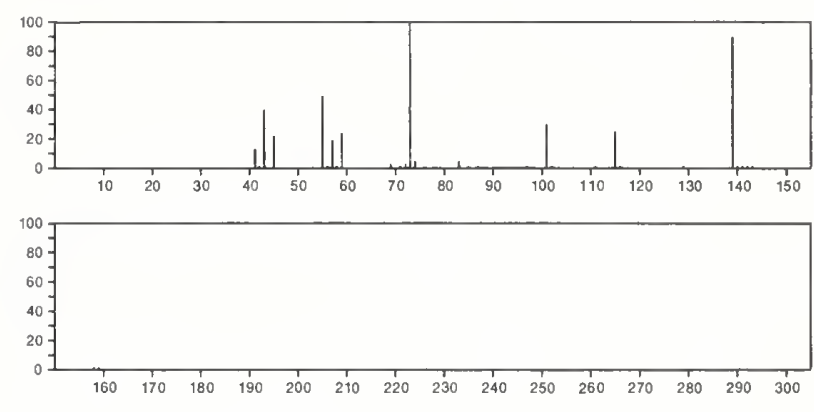

158

Cyclohexane, (ethoxymethoxy)-

$\mathrm{C}_{9} \mathrm{H}_{18} \mathrm{O}_{2}$

54699-29-5
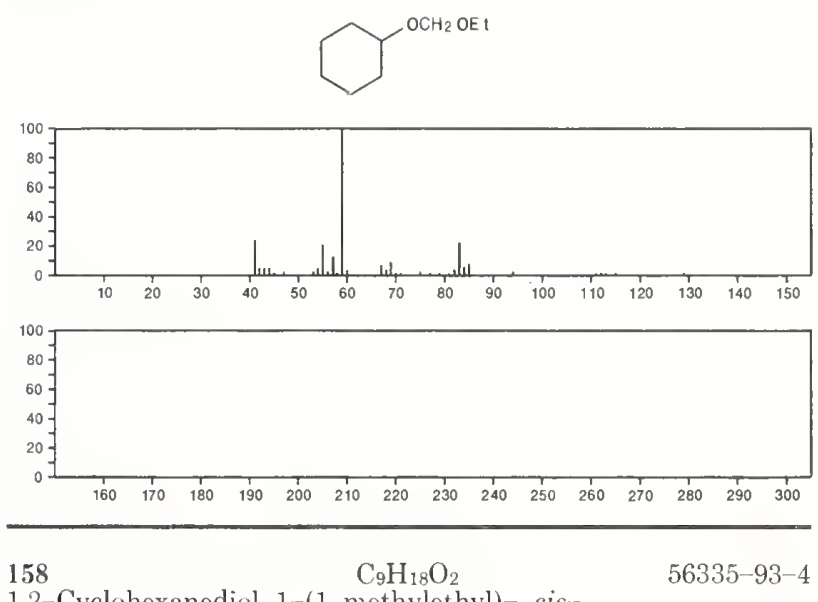

1,2-Cyclohexanediol, 1-(1-methylethyl)-, cis-
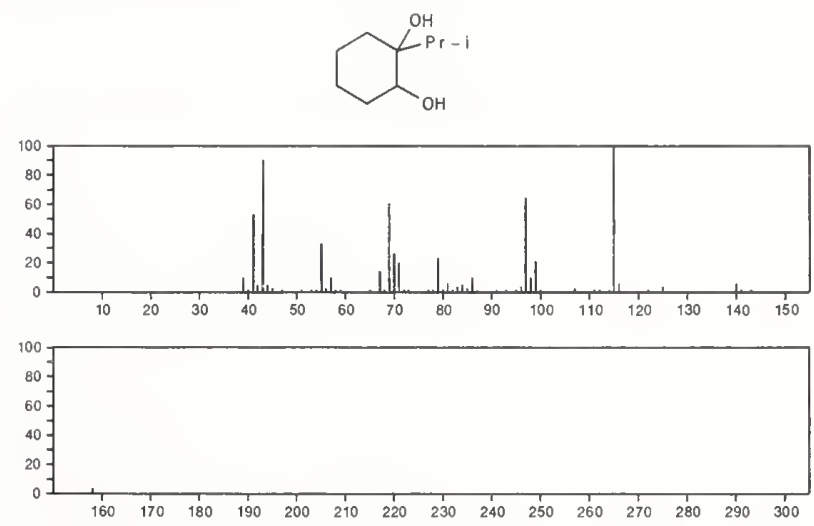

158

Cyclopentane, (butylthio)

$\mathrm{C}_{9} \mathrm{H}_{18} \mathrm{~S}$

$7133-16-6$

$\overbrace{}^{\mathrm{S}}\left(\mathrm{CH}_{2}\right) 3 \mathrm{Me}$

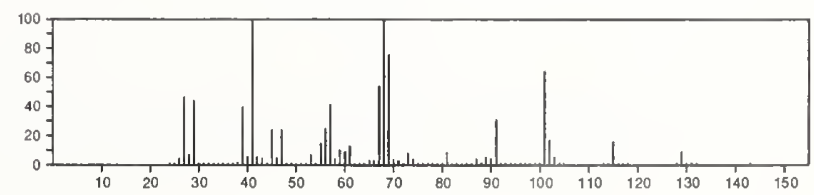



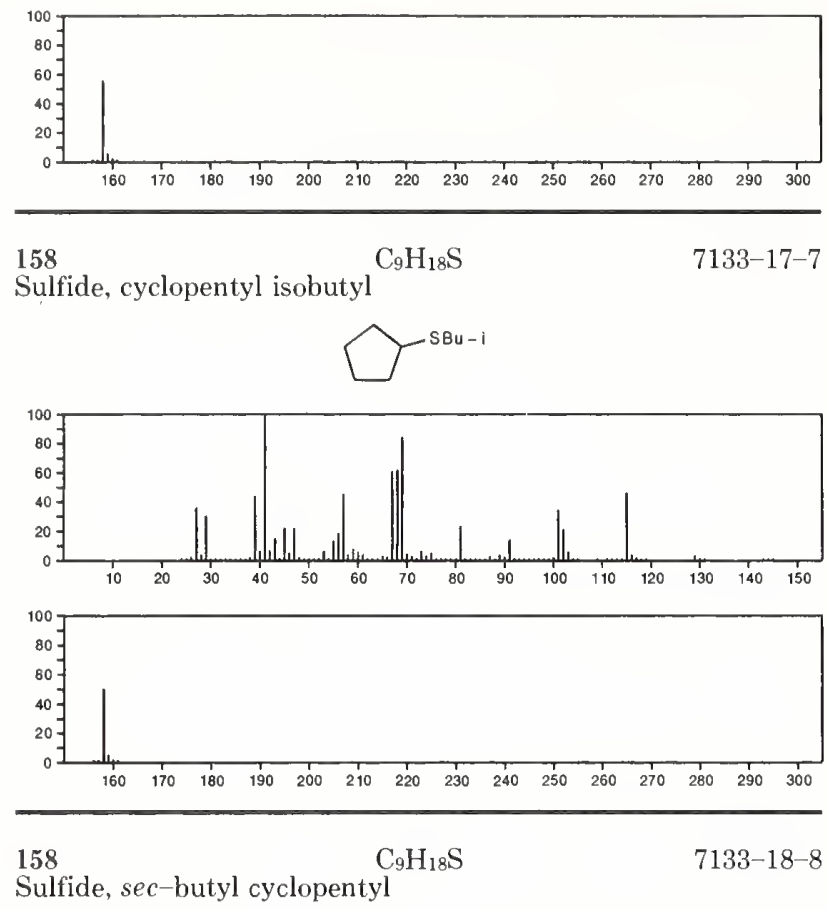

$\Upsilon^{\mathrm{sBu}-\mathrm{s}}$
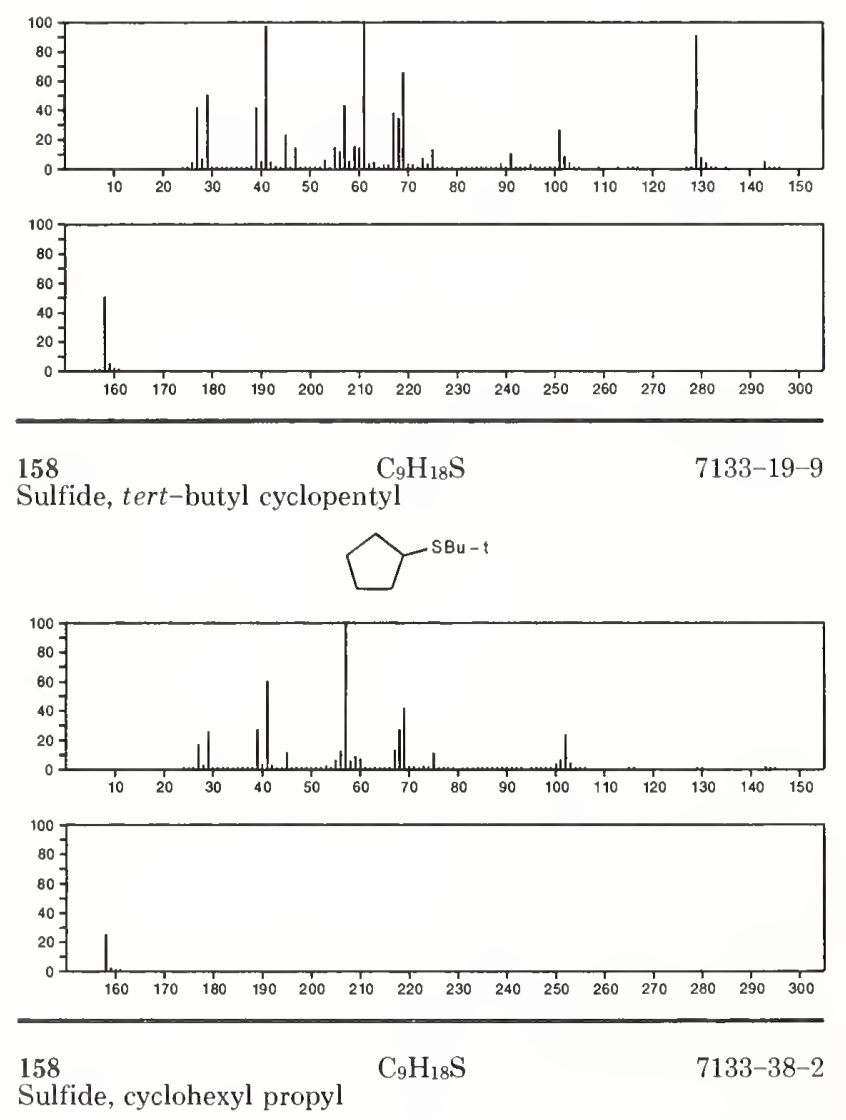

Sulfide, cyclohexyl propyl
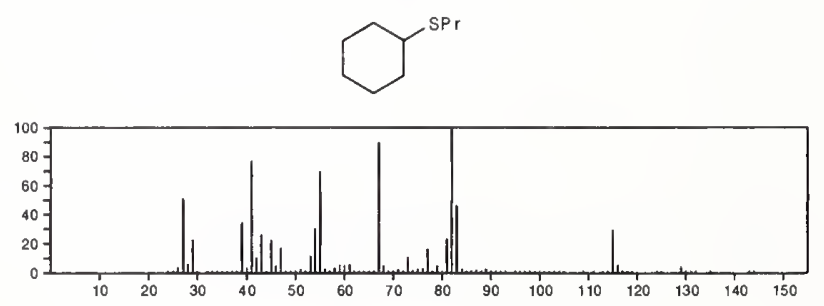

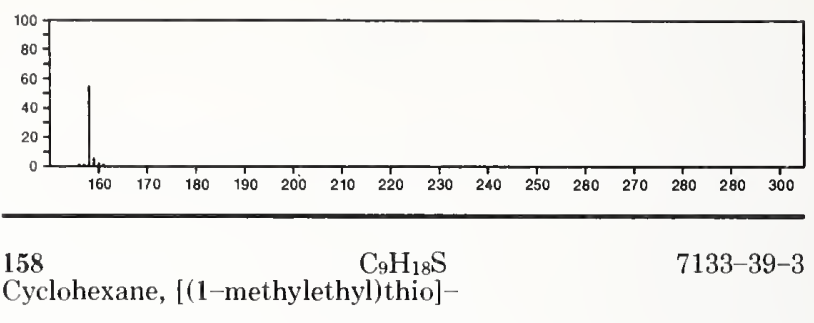

158
Cyclohexane, [(1-methylethyl $)$ thio $]-$
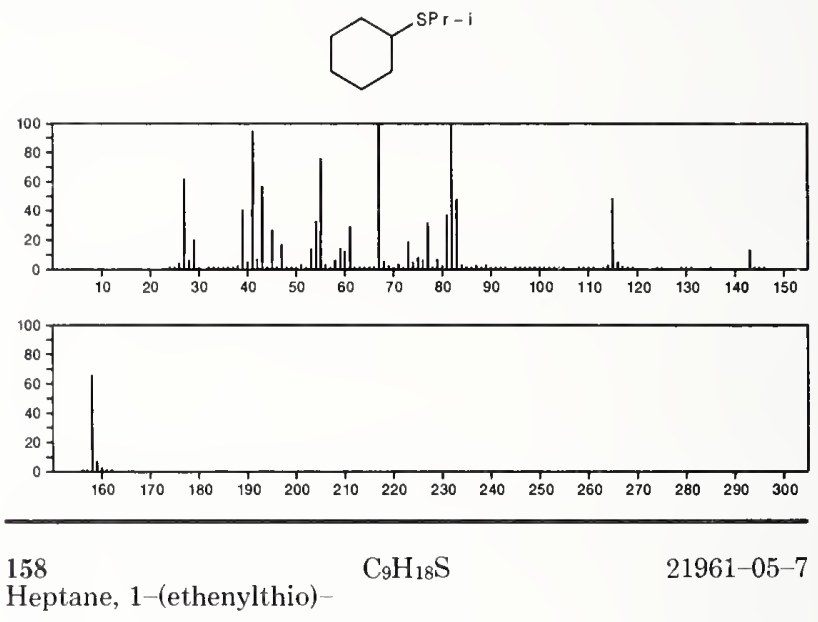

Heptane, 1-(ethenylthio)

$\mathrm{Me}\left(\mathrm{CH}_{2}\right) 6 \mathrm{SCH}=\mathrm{CH}_{2}$
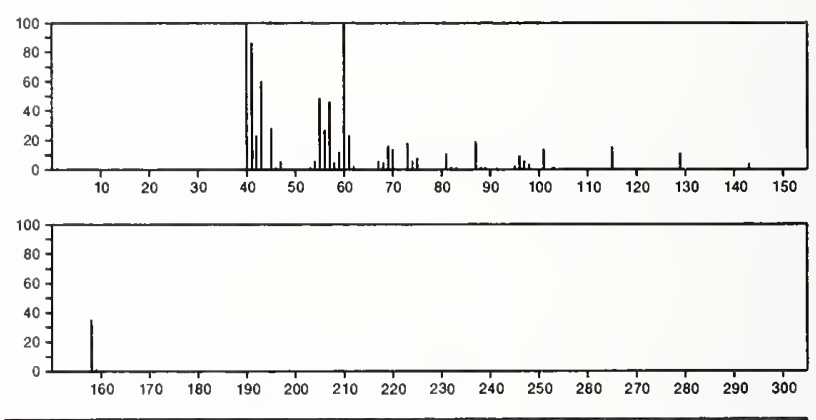

158

3-Heptene, 7-(ethylthio)-

$\mathrm{C}_{9} \mathrm{H}_{18} \mathrm{~S}$

$55320-20-2$

$\mathrm{E} t \mathrm{~S}\left\{\mathrm{CH}_{2}\right\}_{3} \mathrm{CH}=\mathrm{CHE}$ t
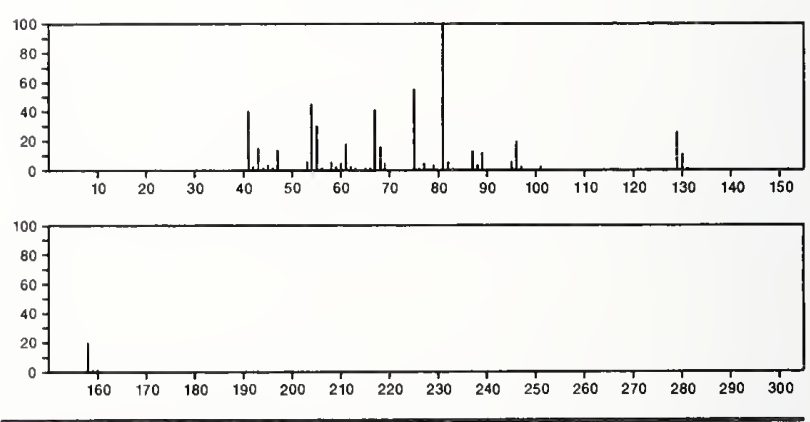

158

$\mathrm{C}_{9} \mathrm{H}_{18} \mathrm{~S}$

Thiophene, 3-butyltetrahydro-2-methyl-

$55320-22-4$
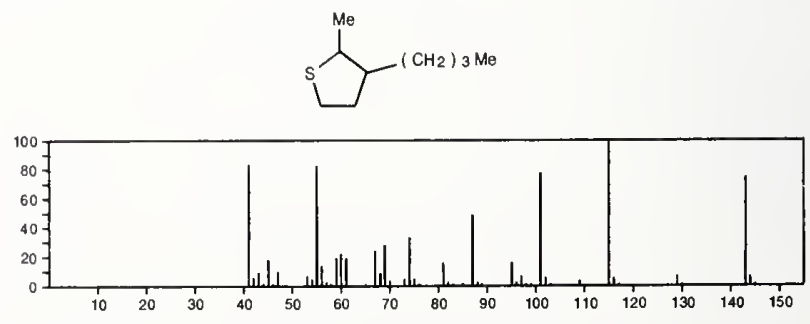

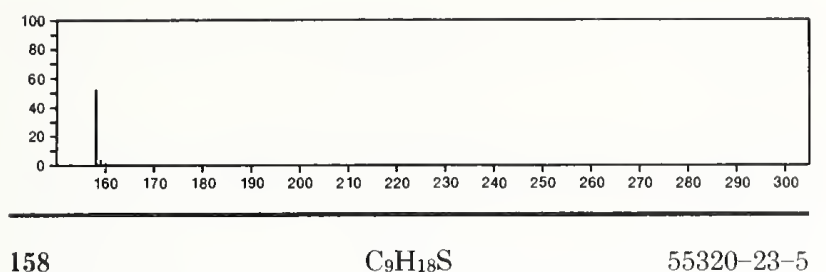

$2 \mathrm{H}$-Thiopyran, tetrahydro-2-methyl-3-propyl-
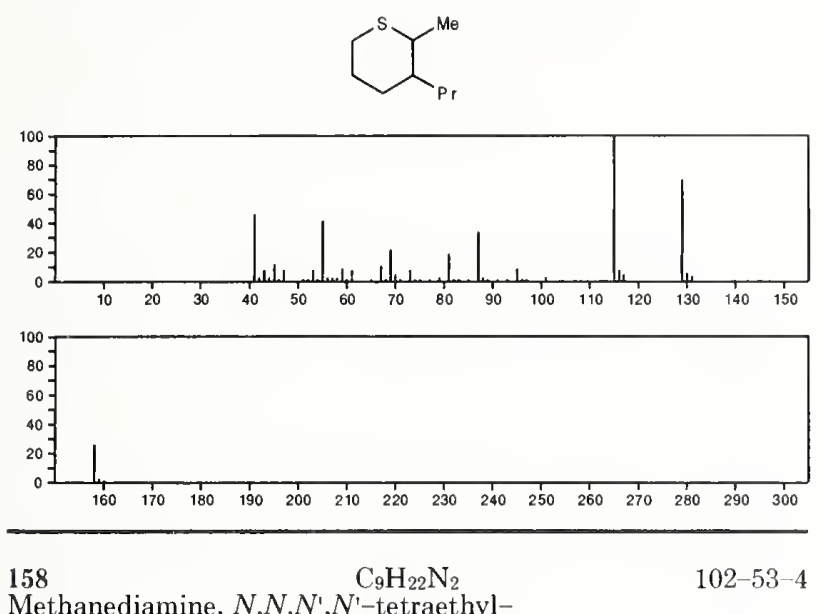

Methanediamine, $N, N, N^{\prime}, N^{\prime}$-tetraethyl-

$\mathrm{Et}_{2} \mathrm{NCH}_{2} \mathrm{NE} \mathrm{I}_{2}$

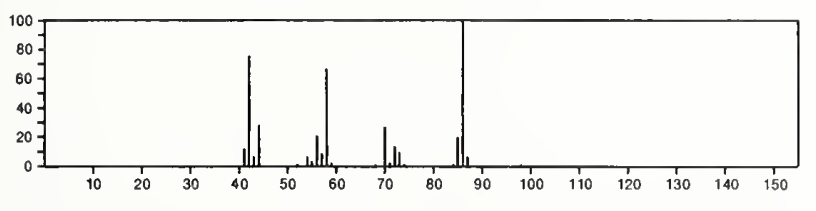

158

1,4-Naphthalenedione

$\mathrm{C}_{10} \mathrm{H}_{6} \mathrm{O}_{2}$

$130-15-4$
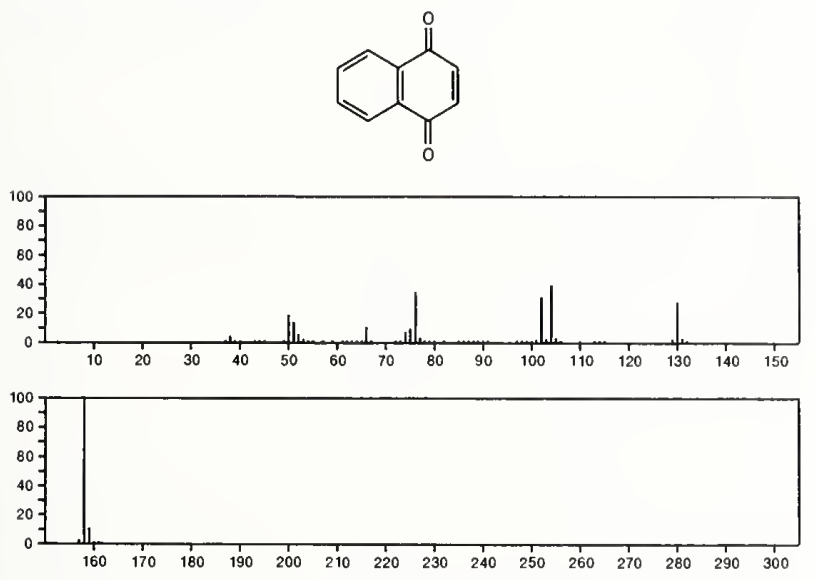

158

1,2-Naphthalenedione

$\mathrm{C}_{10} \mathrm{H}_{6} \mathrm{O}_{2}$

$524-42-5$
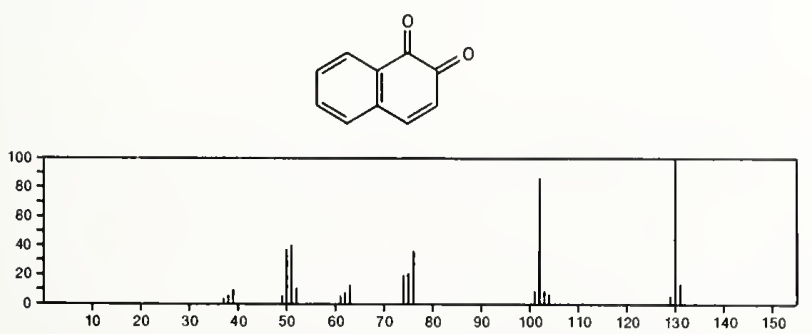

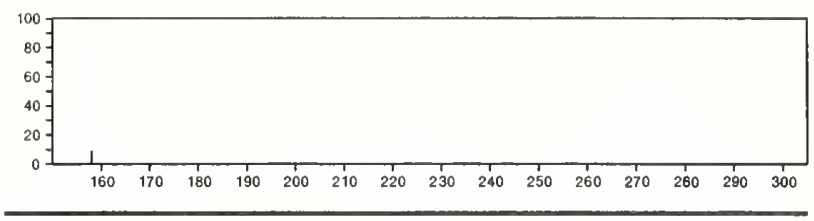

$158 \quad \mathrm{C}_{10} \mathrm{H}_{10} \mathrm{~N}_{2}$

$670-91-7$

1H-Imidazole, 4-(4-methylphenyl)-
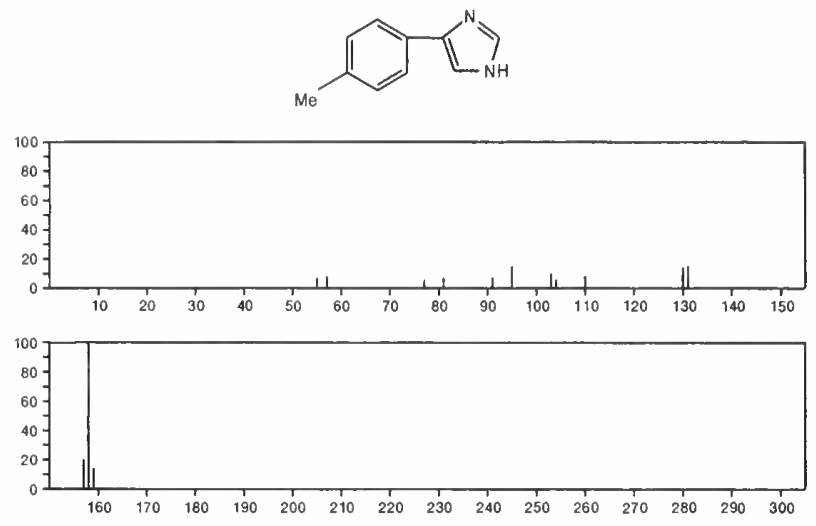

158

$\mathrm{C}_{10} \mathrm{H}_{10} \mathrm{~N}_{2}$

1199-13-9

1,8-Naphthyridine, 3,6-dimethyl-
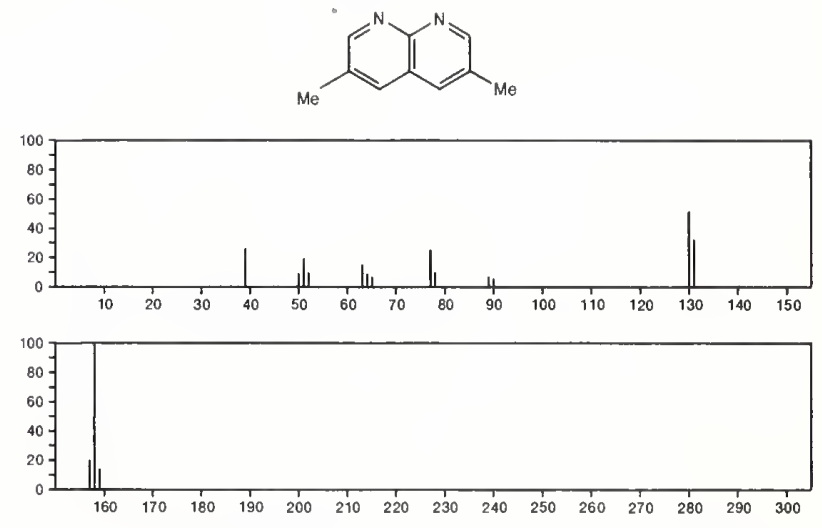

158

Quinoxaline, 2,3-dimethyl-

$$
\mathrm{C}_{10} \mathrm{H}_{10} \mathrm{~N}_{2}
$$

$2379-55-7$<smiles>O=[N+]([O-])c1nc2ccccc2nc1[N+](=O)[O-]</smiles>
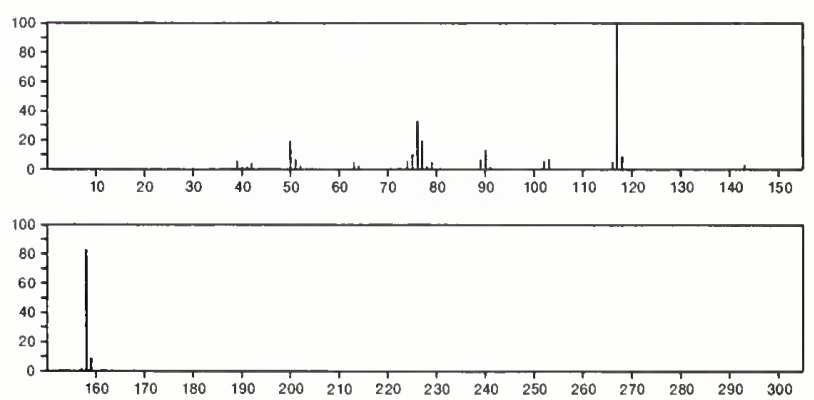
$158 \quad \mathrm{C}_{10} \mathrm{H}_{10} \mathrm{~N}_{2}$

1H-Pyrazole, 3-methyl-5-phenyl-
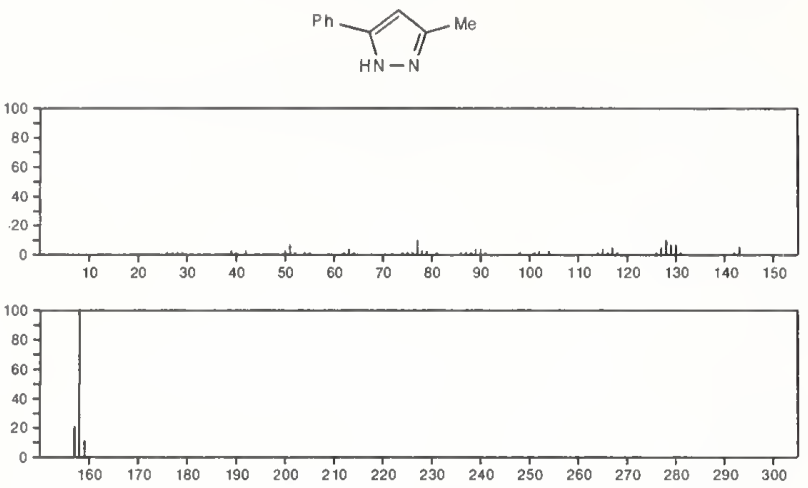

158

Cinnoline, 3,4-dimethyl-

$\mathrm{C}_{10} \mathrm{H}_{10} \mathrm{~N}_{2}$

3929-83-7
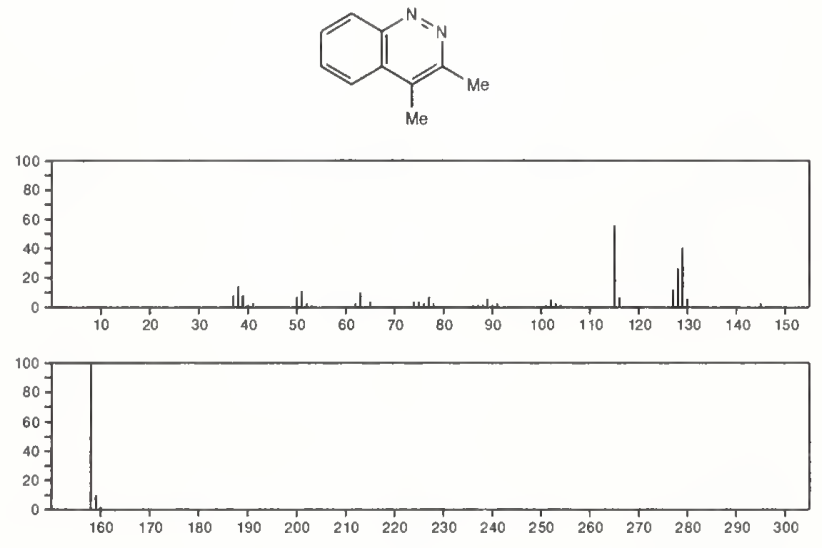

$158 \quad \mathrm{C}_{10} \mathrm{H}_{10} \mathrm{~N}_{2}$

1,8-Naphthyridine, 2,4-dimethyl-

$7544-64-1$
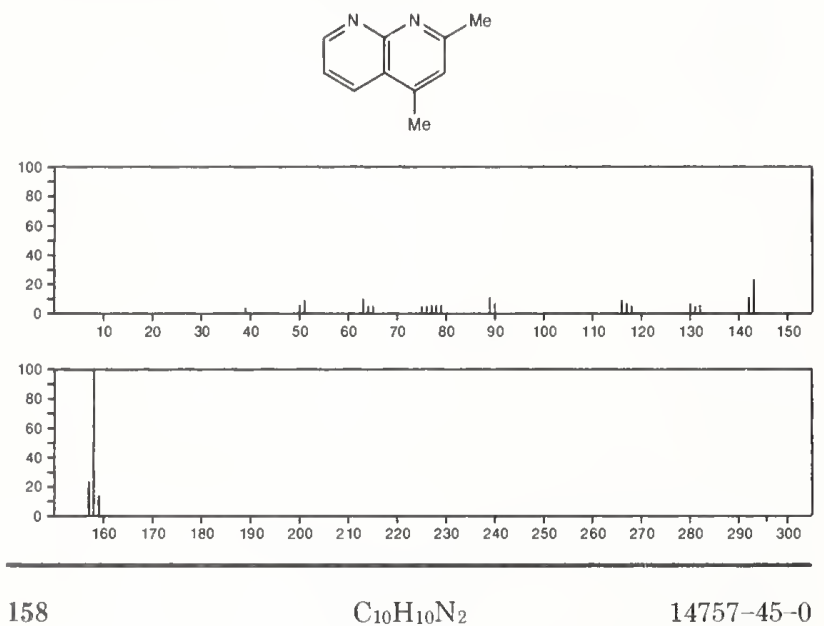

$14757-45-0$

1,8-Naphthyridine, 2,6-dimethyl-
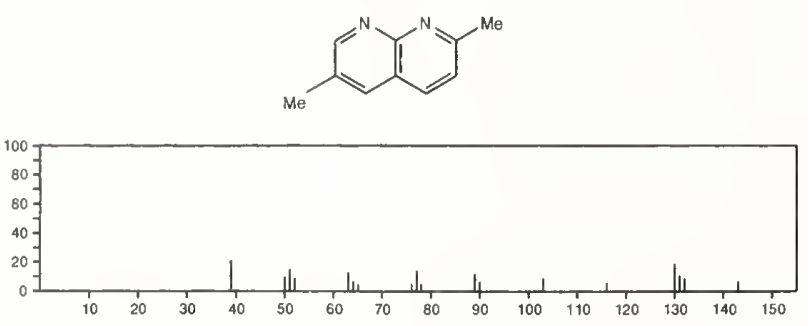

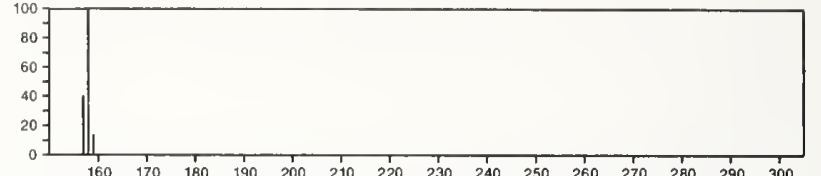

$\begin{array}{lllllllllllllll}160 & 170 & 180 & 190 & 200 & 210 & 220 & 230 & 240 & 250 & 260 & 270 & 280 & 290 & 300\end{array}$

$158 \quad \mathrm{C}_{10} \mathrm{H}_{10} \mathrm{~N}_{2}$

1,8-Naphthyridine, 3,5-dimethyl-

$14757-46-1$<smiles>Cc1cnc2nccc([N+](=O)[O-])c2c1</smiles>
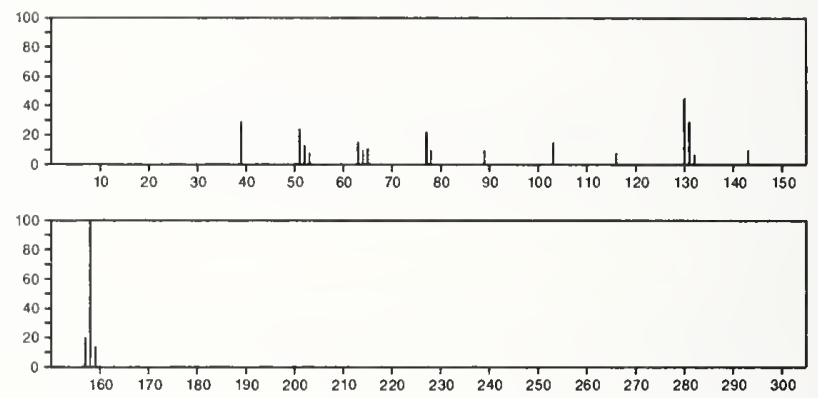

158

1,8-Naphthyridine, 2,5-dimethyl-

$\mathrm{C}_{10} \mathrm{H}_{10} \mathrm{~N}_{2}$

14759-23-0
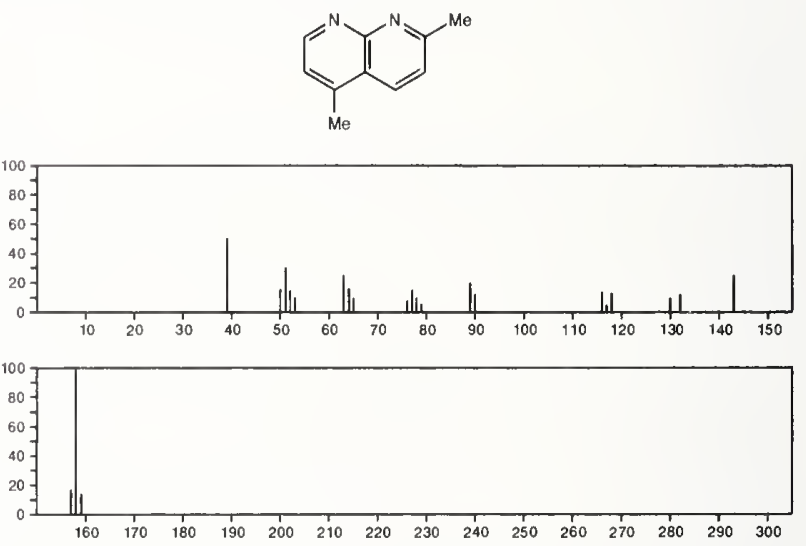

$158 \quad \mathrm{C}_{10} \mathrm{H}_{10} \mathrm{~N}_{2}$

1,8-Naphthyridine, 4,5-dimethyl-

14903-77-6
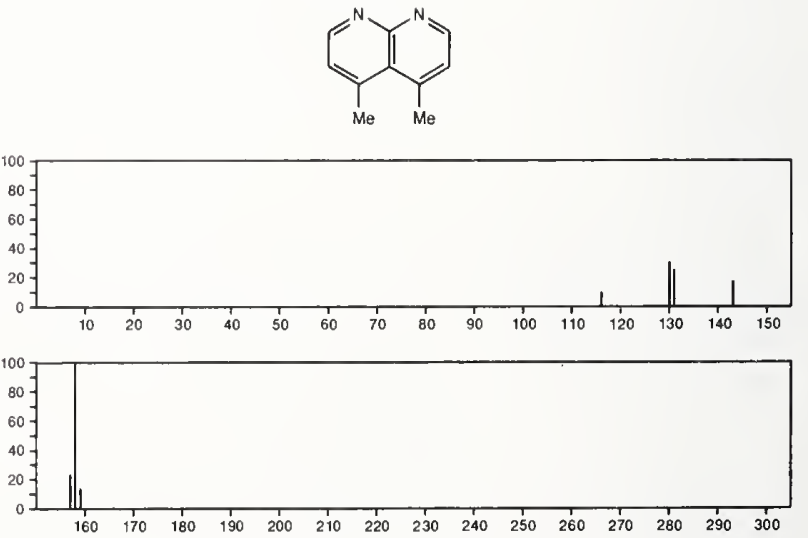
$158 \quad \mathrm{C}_{10} \mathrm{H}_{10} \mathrm{~N}_{2}$

1,8-Naphthyridine, 2,7-dimethyl
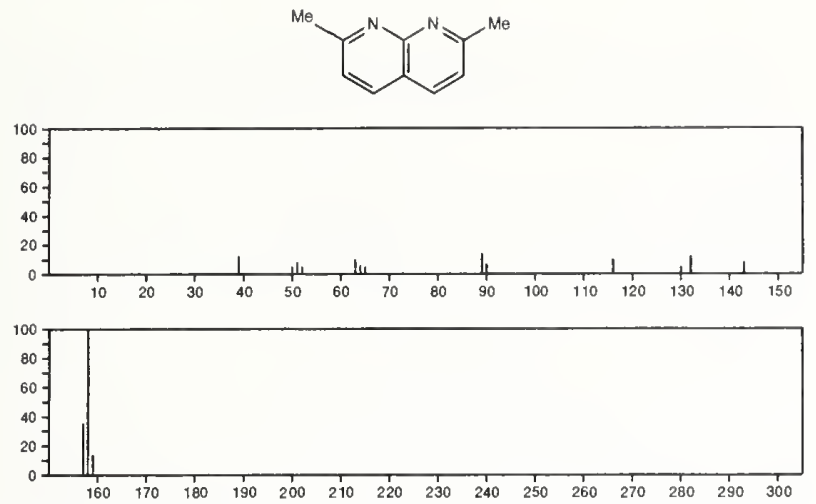

\section{8}

Benzimidazole, 1-allyl-

$\mathrm{C}_{10} \mathrm{H}_{10} \mathrm{~N}_{2}$

$19018-22-5$
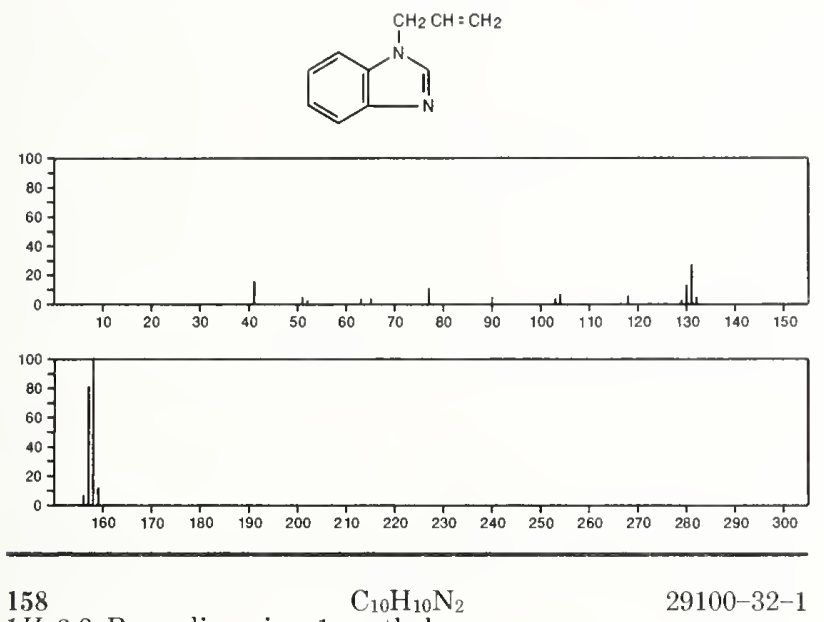

1H-2,3-Benzodiazepine, 1-methyl-
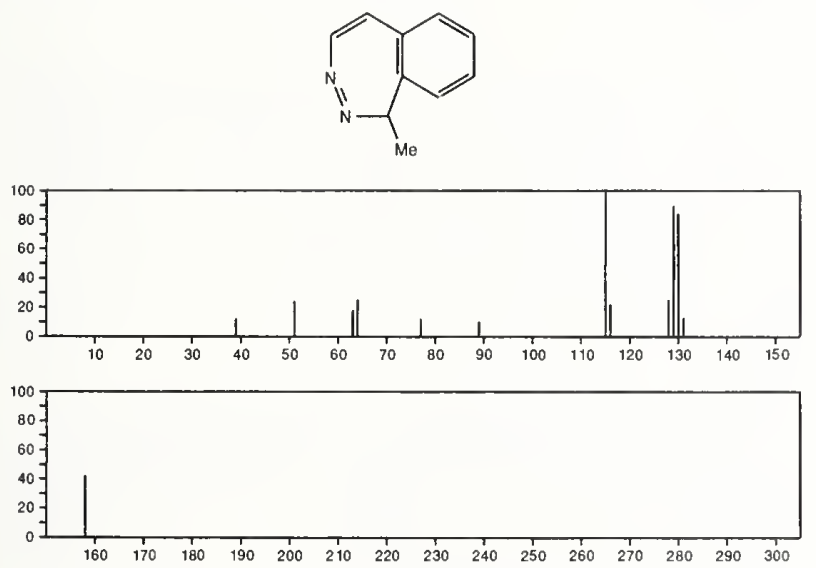

$158 \quad \mathrm{C}_{10} \mathrm{H}_{10} \mathrm{~N}_{2}$

$1 H$-Imidazole, 2-(4-methylphenyl)-

$37122-50-2$
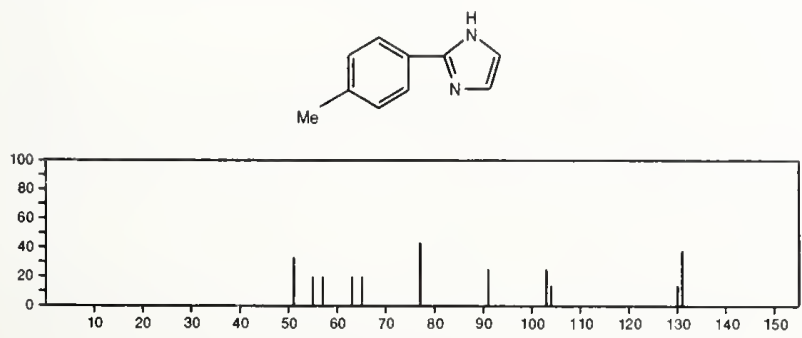
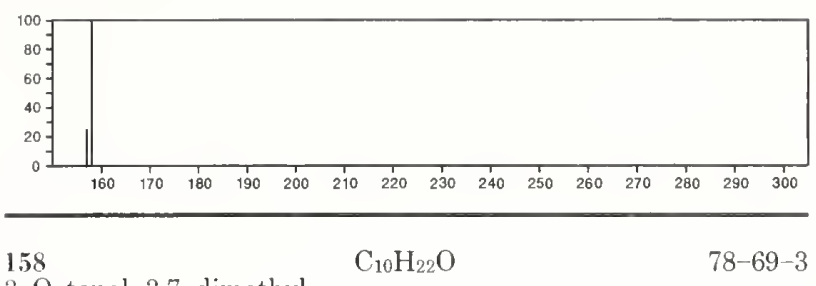

3-Octanol, 3,7-dimethyl-

$\mathrm{EtCMe}(\mathrm{OH})\left(\mathrm{CH}_{2}\right)_{3} \mathrm{CHMe} 2$
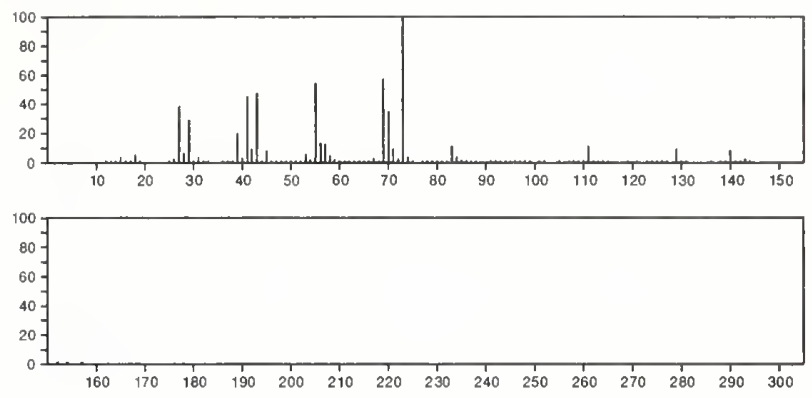

158

1-Octanol, 3,7-dimethyl

$\mathrm{C}_{10} \mathrm{H}_{22} \mathrm{O}$

$106-21-8$
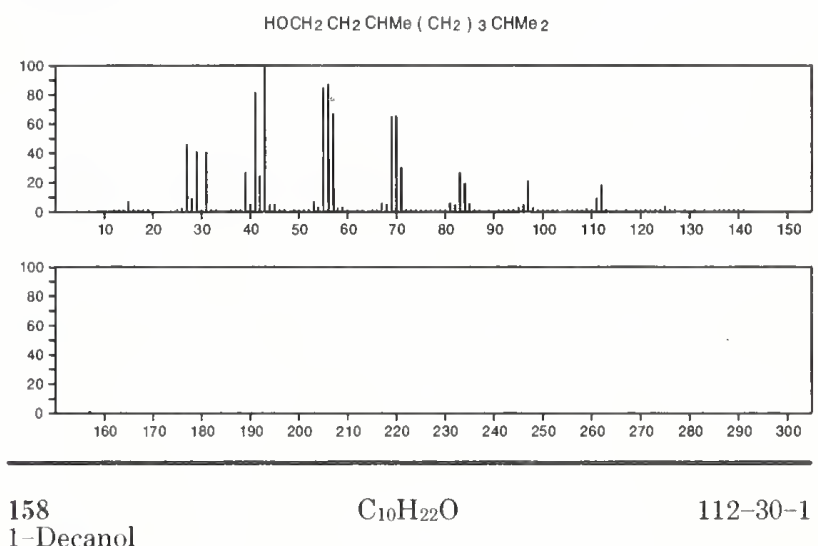

1-Decanol

$\mathrm{Me}\left(\mathrm{CH}_{2}\right)_{9} \mathrm{OH}$
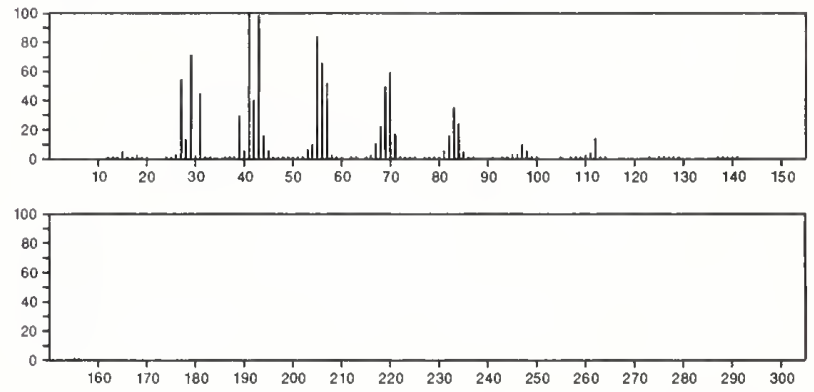

$158 \quad \mathrm{C}_{10} \mathrm{H}_{22} \mathrm{O}$

$151-19-9$

3-Octanol, 3,6-dimethyl

$\mathrm{MeCH}_{2} \mathrm{CHMe} \mathrm{CH}_{2} \mathrm{CH}_{2} \mathrm{CE} t$ ( OH ) Me

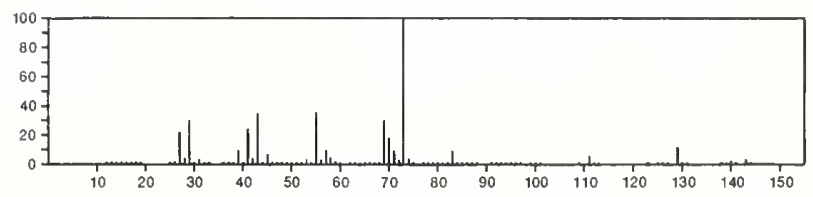


158

Butane, 1,1'-oxybis[3-methyl-

$\mathrm{Me}_{2} \mathrm{CHCH}_{2} \mathrm{CH}_{2} \mathrm{OCH}_{2} \mathrm{CH}_{2} \mathrm{CHMe}_{2}$

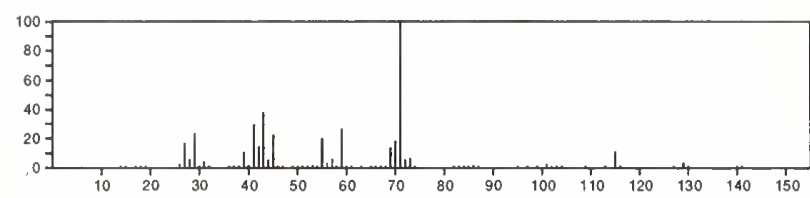

$158 \quad \mathrm{C}_{10} \mathrm{H}_{22} \mathrm{O} \quad 693-65-2$

Pentane, $1,1^{\circ}$-oxybis-

$\mathrm{Me}\left(\mathrm{CH}_{2}\right){ }_{4} \mathrm{O}\left(\mathrm{CH}_{2}\right)_{4} \mathrm{Me}$
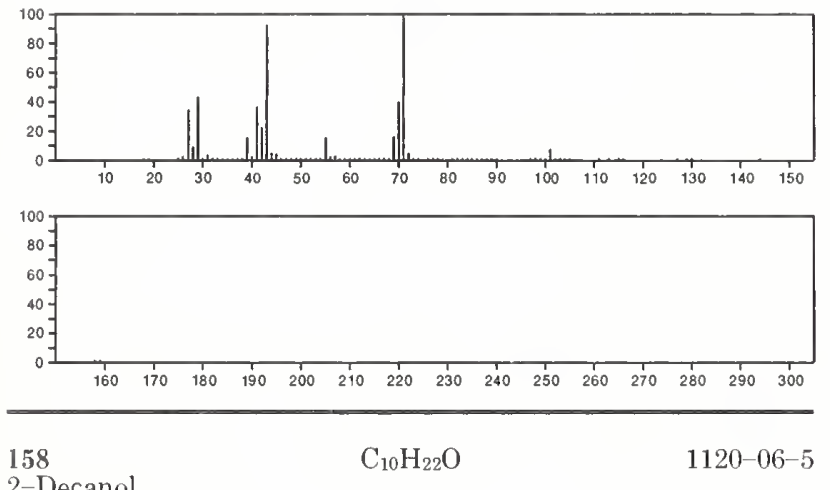

2-Decanol

$\mathrm{MeCH}(\mathrm{OH})\left(\mathrm{CH}_{2}\right)>\mathrm{Me}$
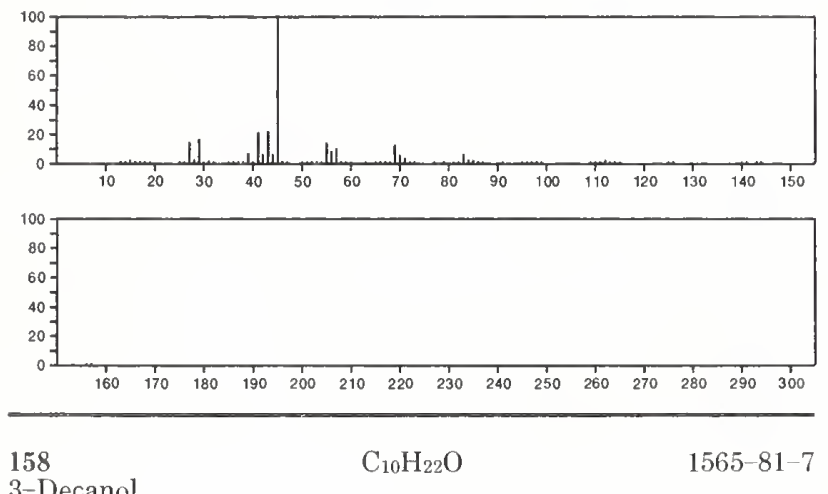

3-Decanol

$\mathrm{EtCH}(\mathrm{OH})\left(\mathrm{CH}_{2}\right)_{6} \mathrm{Me}$
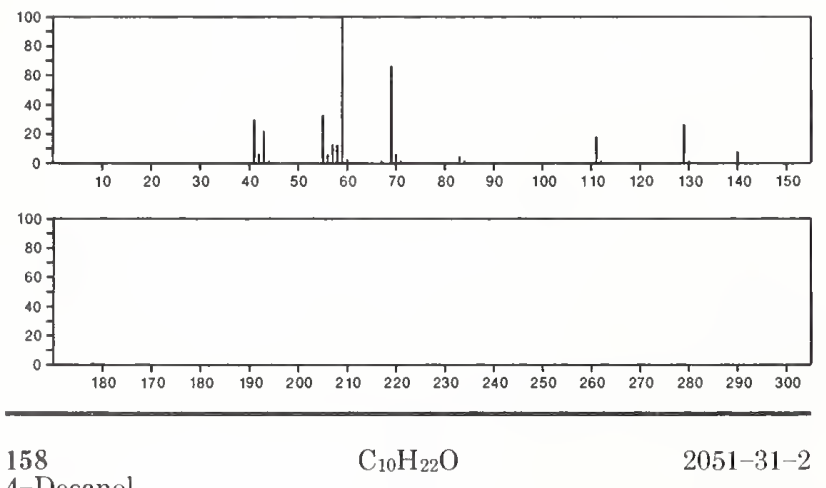

4-Decanol

$\operatorname{PrCH}(\mathrm{OH})\left(\mathrm{CH}_{2}\right) 5 \mathrm{Me}$

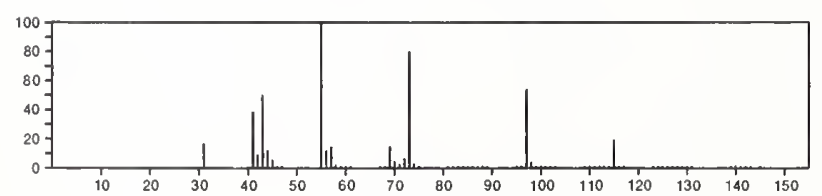

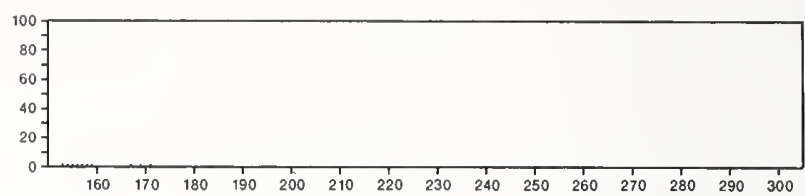

$158 \quad \mathrm{C}_{10} \mathrm{H}_{22} \mathrm{O} \quad 2370-14-1$

1-Octanol, 2,2-dimethyl-

$\mathrm{Me}\left(\mathrm{CH}_{2}\right)_{5} \mathrm{CMe}_{2} \mathrm{CH}_{2} \mathrm{OH}$

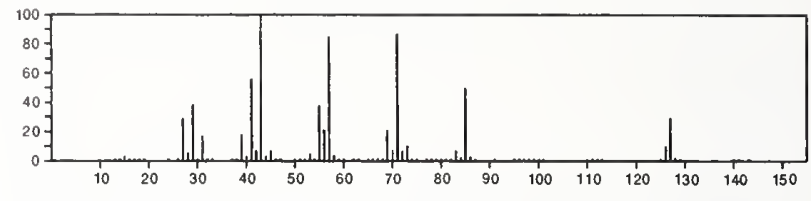

158

$\mathrm{C}_{10} \mathrm{H}_{22} \mathrm{O}$

4419-58-3

Ether, tert-butyl 3,3-dimethylbutyl

$\mathrm{Me}_{3} \mathrm{CCCH}_{2} \mathrm{CH}_{2} \mathrm{OBu}-\mathrm{t}$

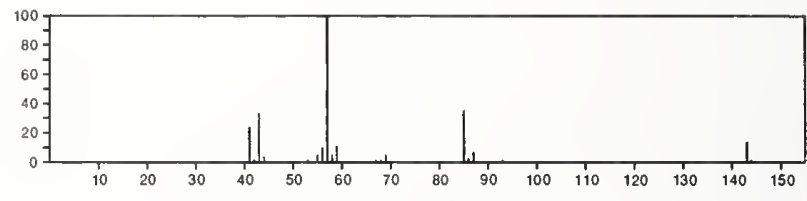

158

5-Decanol

$\mathrm{C}_{10} \mathrm{H}_{22} \mathrm{O}$

$5205-34-5$
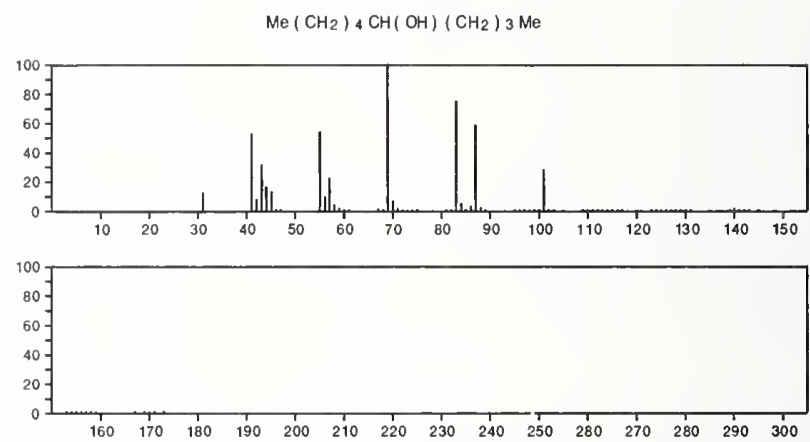

158

1-Heptanol, 2-propyl-

$\mathrm{C}_{10} \mathrm{H}_{22} \mathrm{O}$

$10042-59-8$

$\mathrm{Me}\left(\mathrm{CH}_{2}\right)_{4} \mathrm{CHPrCH}_{2} \mathrm{OH}$

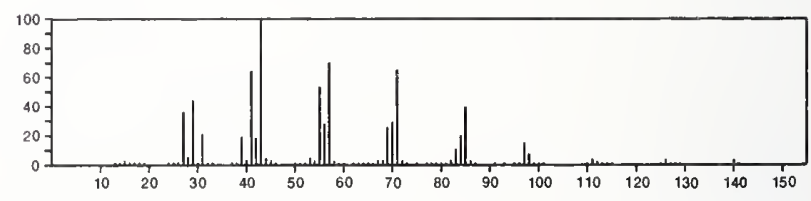

$158 \quad \mathrm{C}_{10} \mathrm{H}_{22} \mathrm{O}$

1-Octanol, 2,7-dimethyl-

$\mathrm{Me}_{2} \mathrm{CH}\left(\mathrm{CH}_{2}\right){ }_{4} \mathrm{CHMe} \mathrm{CH}_{2} \mathrm{OH}$
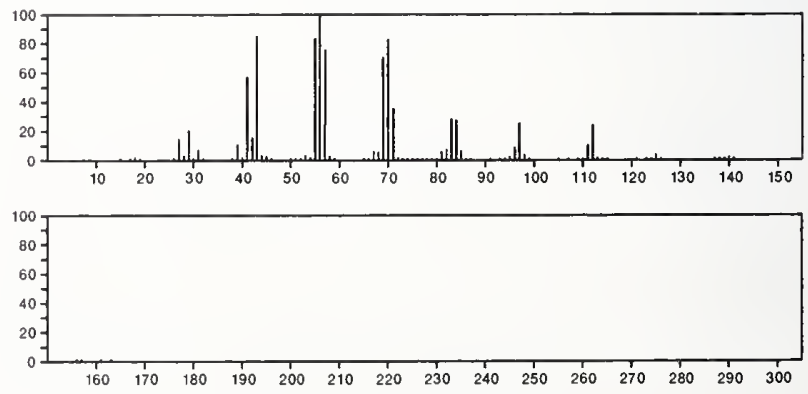
158 -Octanol, 4,7-dimethyl-

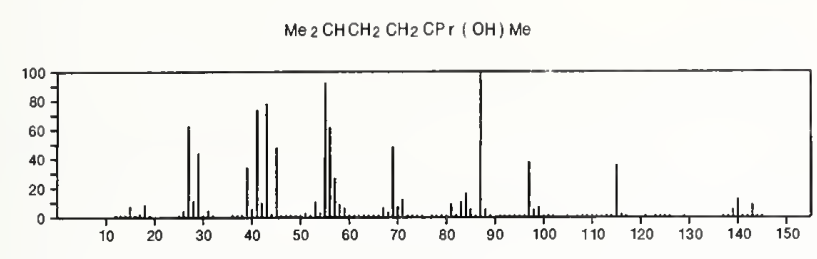

158

3-Octanol, 6-ethyl-

$\mathrm{C}_{10} \mathrm{H}_{22} \mathrm{O}$

$19781-27-2$

$\mathrm{E}$ t $\mathrm{CH}$ ( OH) $\mathrm{CH}_{2} \mathrm{CH}_{2} \mathrm{CHE}$ ?

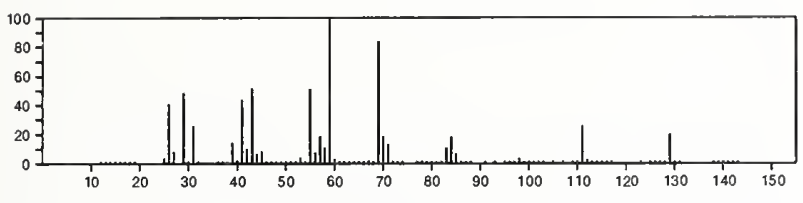

158

$\mathrm{C}_{10} \mathrm{H}_{22} \mathrm{O}$

23418-38-4

4-Nonanol, 4-methyl-

$\operatorname{PrCMe}(\mathrm{OH})\left(\mathrm{CH}_{2}\right)_{4} \mathrm{Me}$
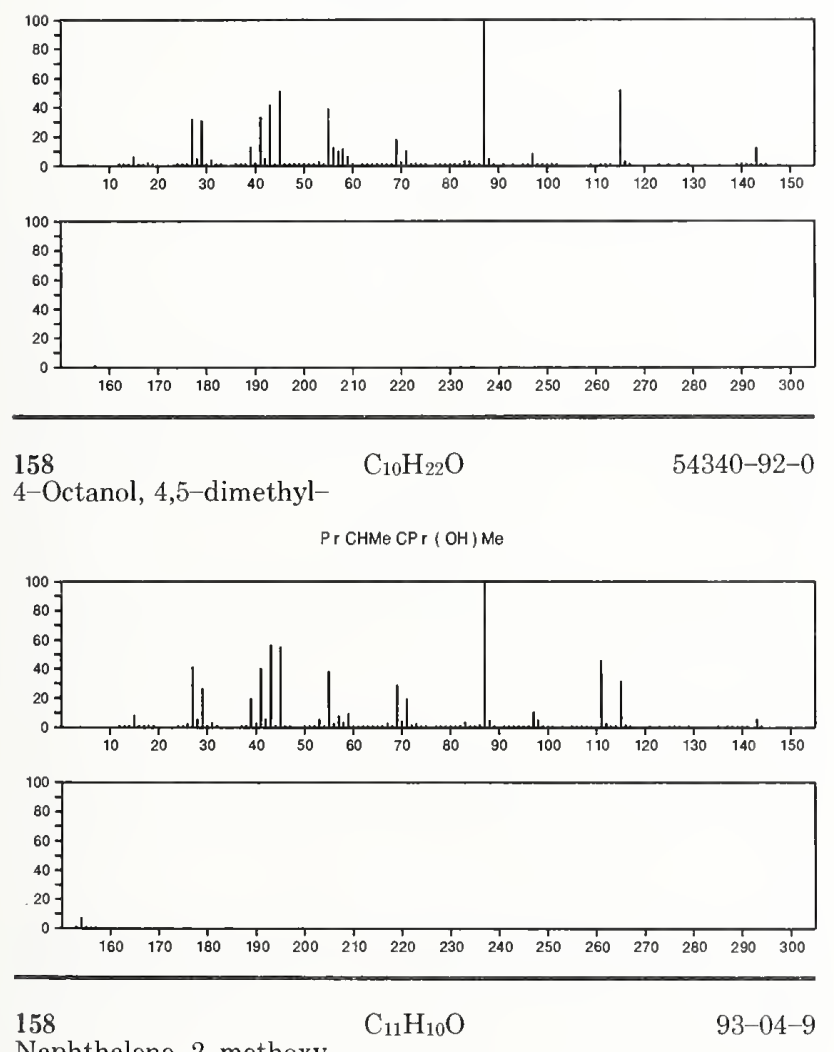

Naphthalene, 2-methoxy-
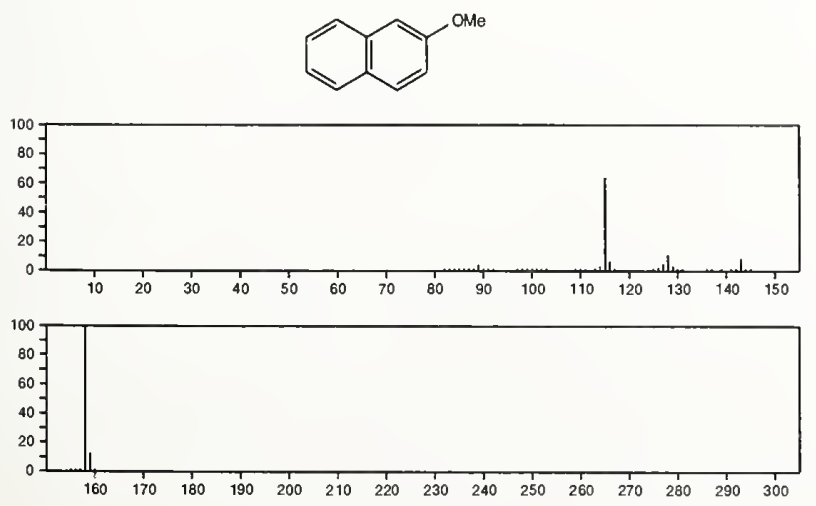

158

Naphthalene, 1-methoxy-

$\mathrm{C}_{11} \mathrm{H}_{10} \mathrm{O}$

$2216-69-5$
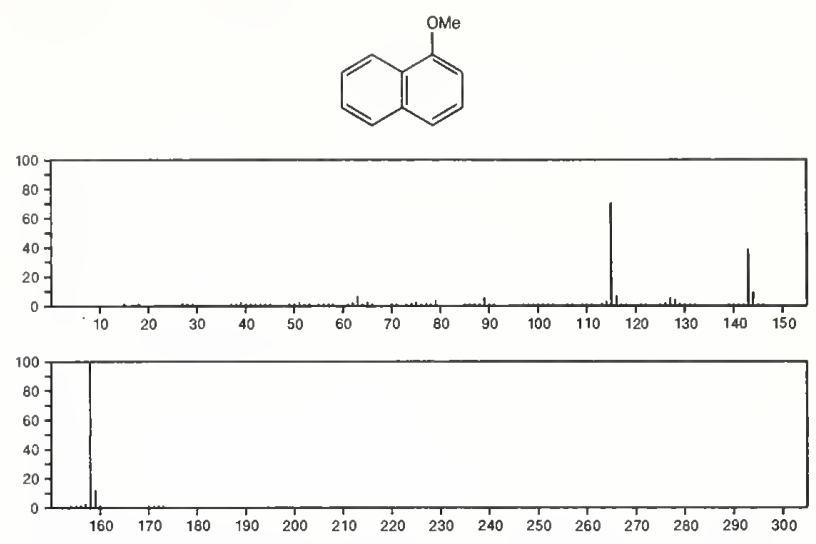

158

$\mathrm{C}_{11} \mathrm{H}_{10} \mathrm{O}$

4796-33-2

1,4-Methanonaphthalen-9-ol, 1,4-dihydro-
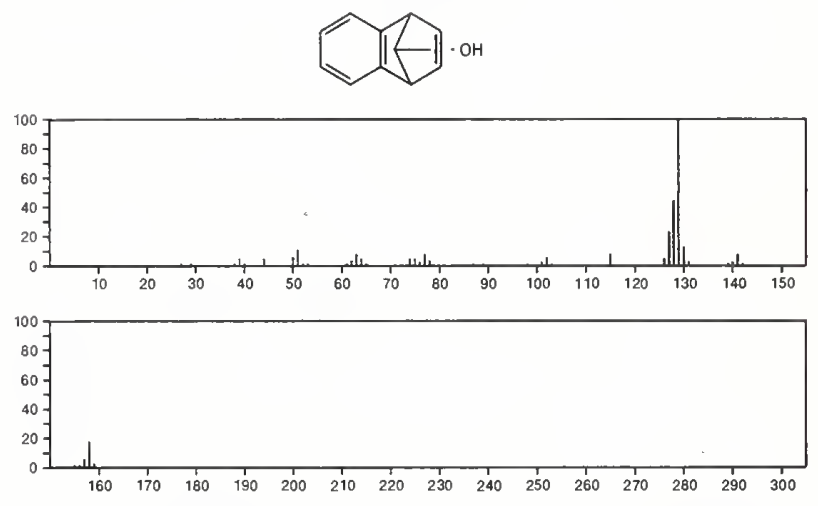

$158 \quad \mathrm{C}_{11} \mathrm{H}_{10} \mathrm{O}$

$\mathrm{C}_{11} \mathrm{H}_{10} \mathrm{O} \quad 6165-88-4$

1,4-Methanonaphthalen-9-one, 1,2,3,4-tetrahydro-
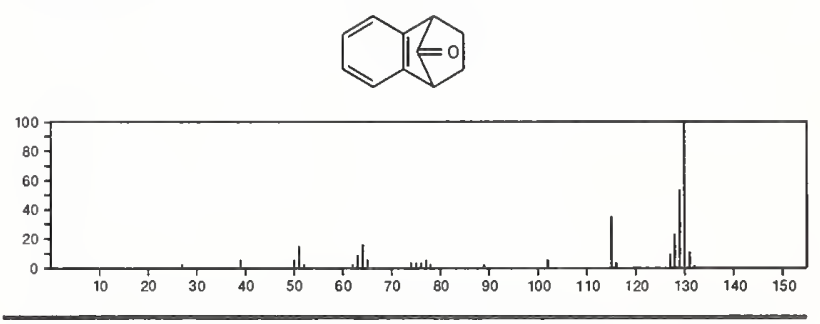

158

$\mathrm{C}_{11} \mathrm{H}_{10} \mathrm{O}$

1,4-Methanonaphthalen-2(1H)-one, 3,4-dihydro-

$7374-90-5$
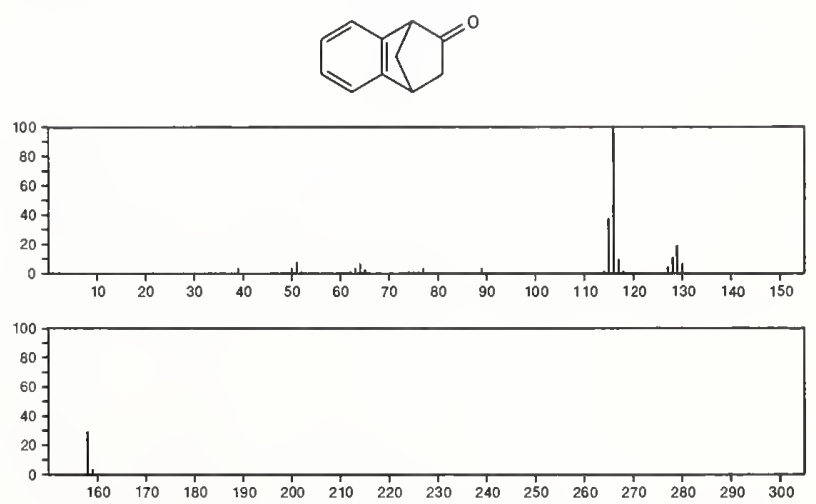
158 $\mathrm{C}_{11} \mathrm{H}_{10} \mathrm{O}$

1-Naphthalenol, 2-methyl-
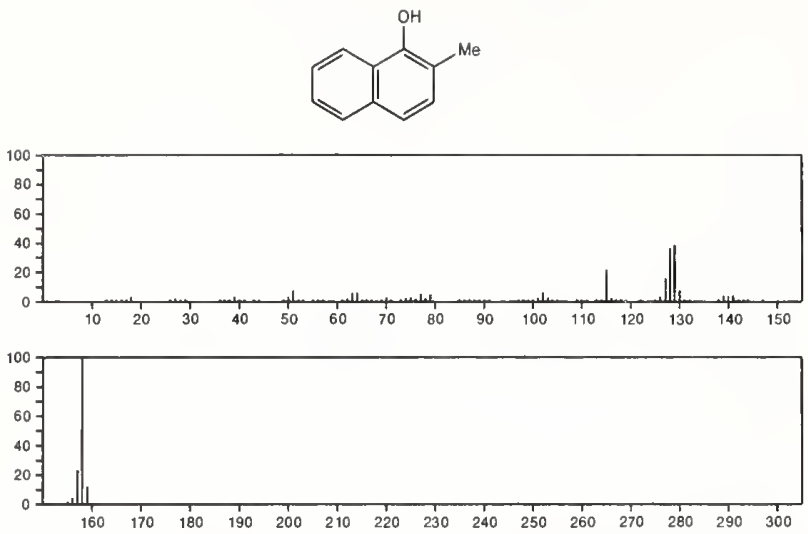

158

$\mathrm{C}_{11} \mathrm{H}_{10} \mathrm{O}$

$10240-08-1$

1-Naphthalenol, 4-methyl-
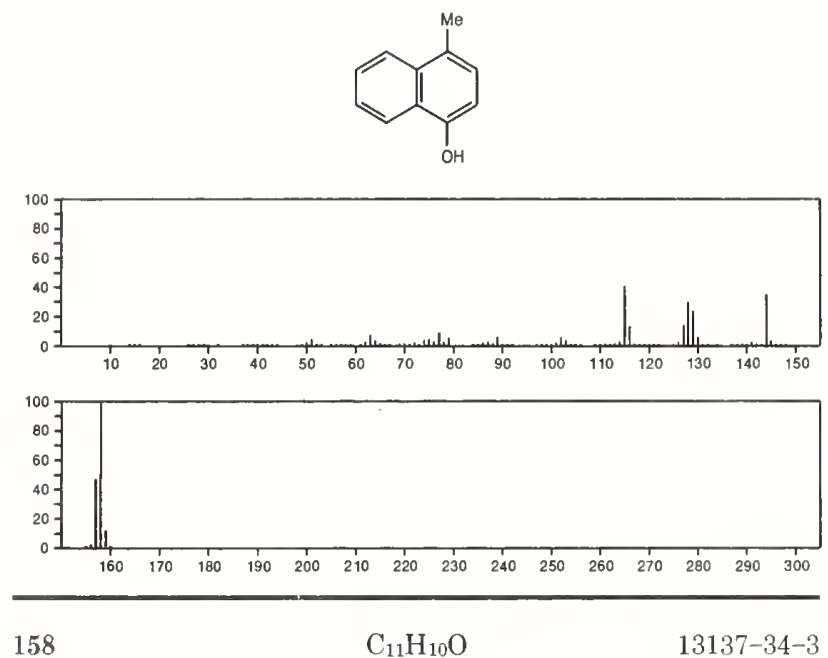

$\begin{array}{cr}\mathrm{C}_{11} \mathrm{H}_{10} \mathrm{O} & 13137-34-3 \\ 2,7-\text { Methanonaphth } & 2,3-b] \text { oxirene, }\end{array}$ $(1 \mathrm{a} \alpha, 2 \beta, 7 \beta, 7 \mathrm{a} \alpha)-$
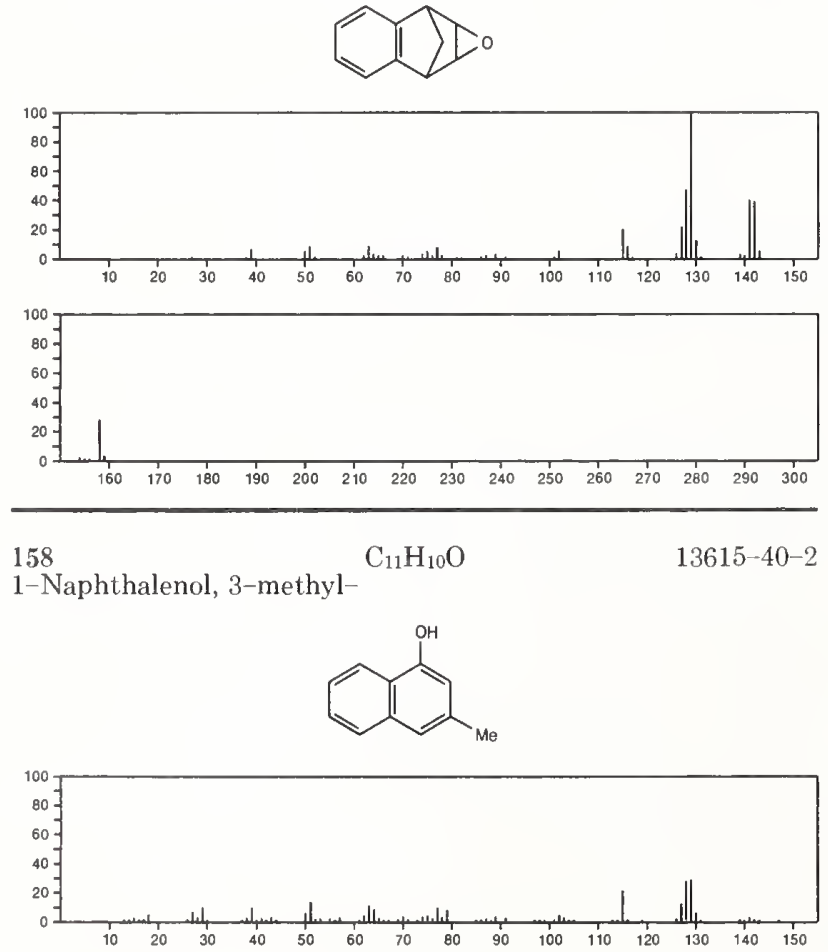

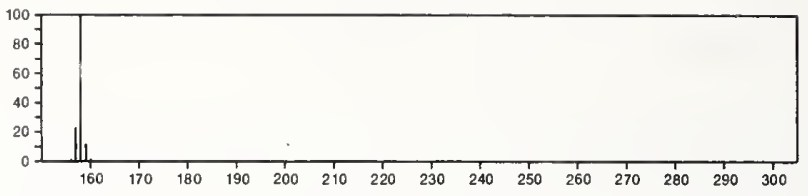

158

$\mathrm{C}_{12} \mathrm{H}_{14}$

$480-72-8$

Acenaphthylene, 1,2,2a,3,4,5-hexahydro-
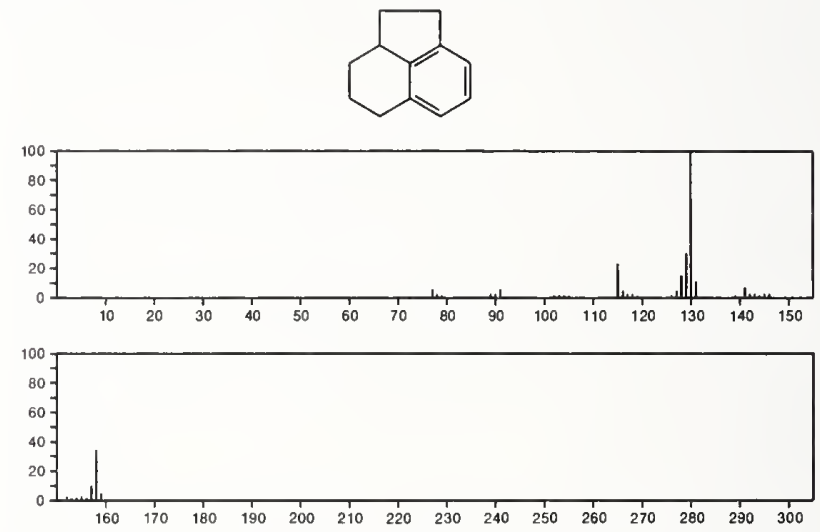

158

$\mathrm{C}_{12} \mathrm{H}_{14}$

771-98-2

Benzene, 1-cyclohexen-1-yl-
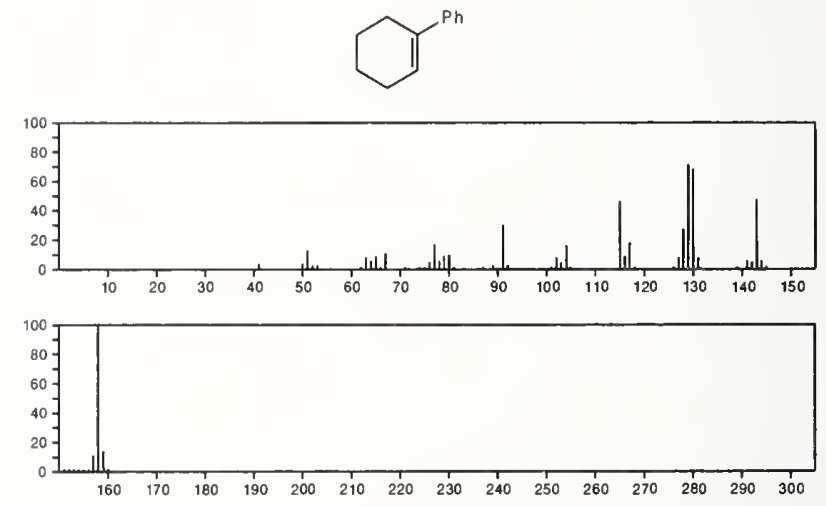

158

$\mathrm{C}_{12} \mathrm{H}_{14}$

1129-65-3

Benzene, 1-hexynyl-

$\mathrm{PhC} \equiv \mathrm{C}\left(\mathrm{CH}_{2}\right)_{3} \mathrm{Me}$
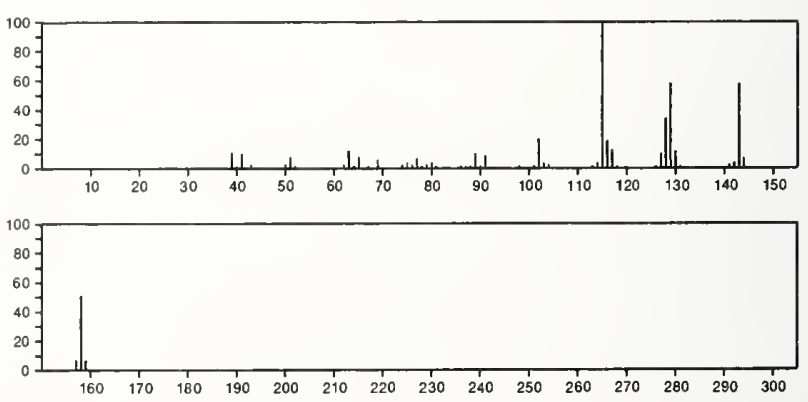
158 $\mathrm{C}_{12} \mathrm{H}_{14}$

Benzene, 1,4-bis(1-methylethenyl)-
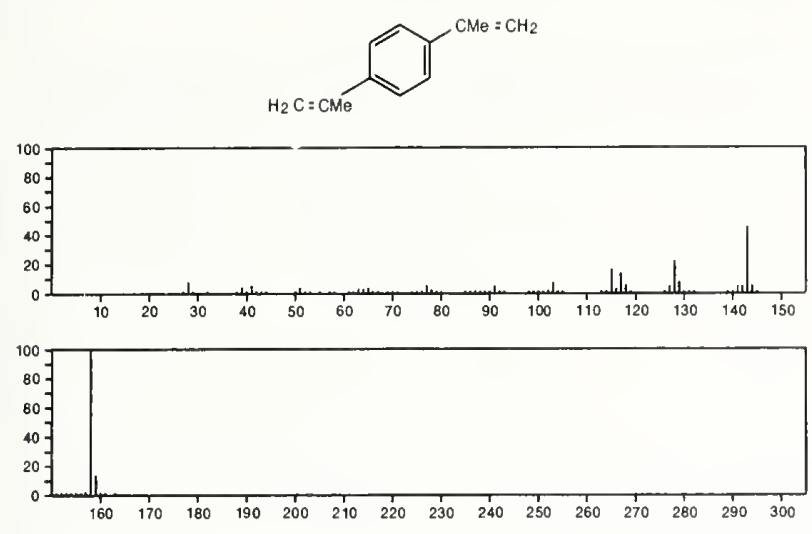

158

$\mathrm{C}_{12} \mathrm{H}_{14}$

Benzene, 1,3-bis(1-methylethenyl)-
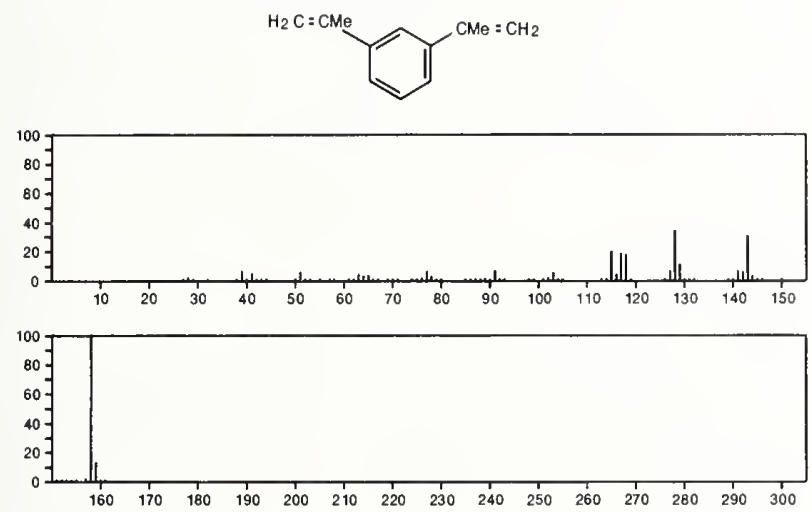

$\begin{array}{lllllllllllllll}160 & 170 & 180 & 190 & 200 & 210 & 220 & 230 & 240 & 250 & 260 & 270 & 280 & 290 & 300\end{array}$

158

1,4-Ethanonaphthalene, 1,2,3,4-tetrahydro-
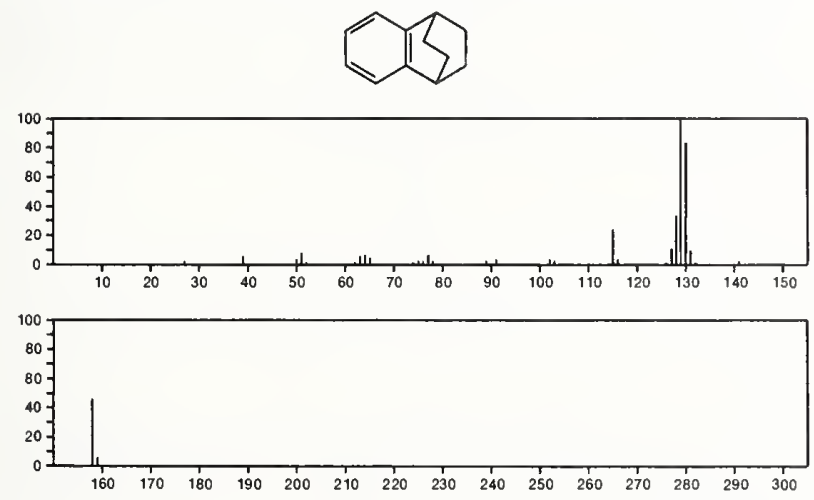

158

158
Benzene, 3-cyclohexen-1-yl-

$\mathrm{C}_{12} \mathrm{H}_{14}$

$4994-16-5$
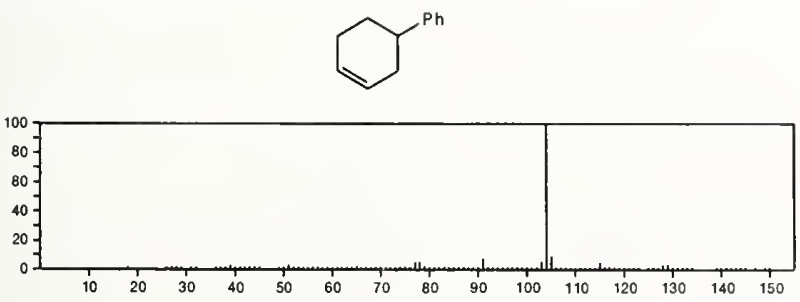

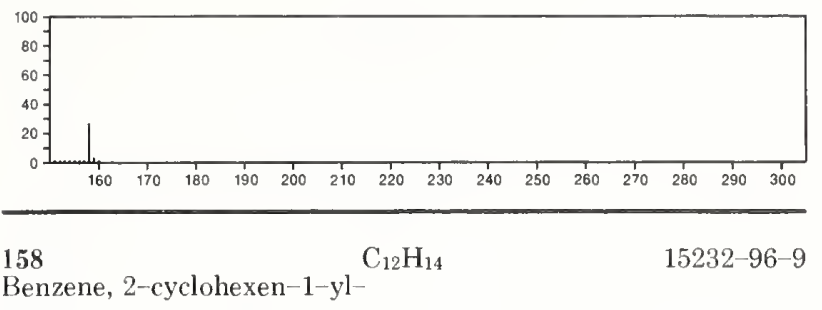

Benzene, $2-c$
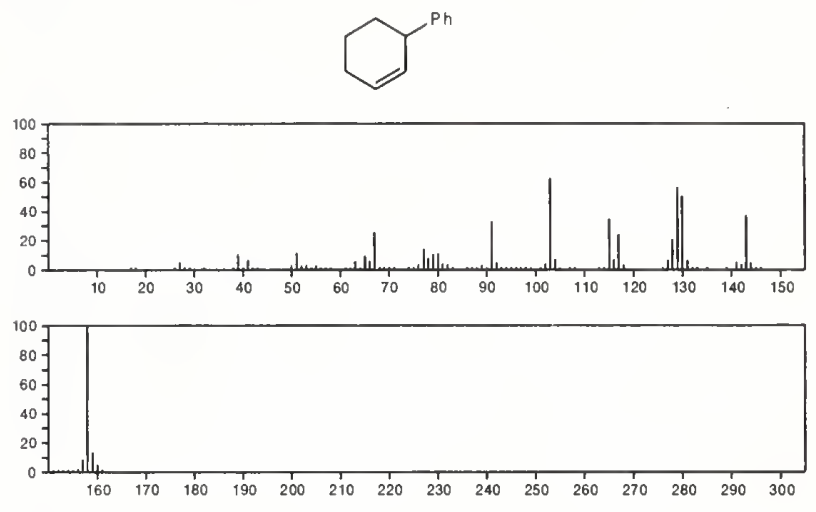

158

$\mathrm{C}_{12} \mathrm{H}_{14}$

20295-17-4

4a,8a-Ethenonaphthalene, 1,4,5,8-tetrahydro-
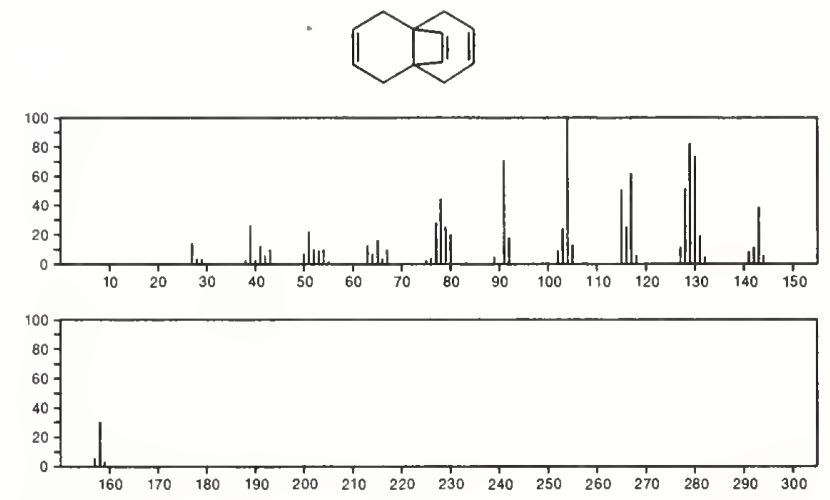

158

$\mathrm{C}_{12} \mathrm{H}_{14}$

24329-97-3

Indan, 2-allyl-
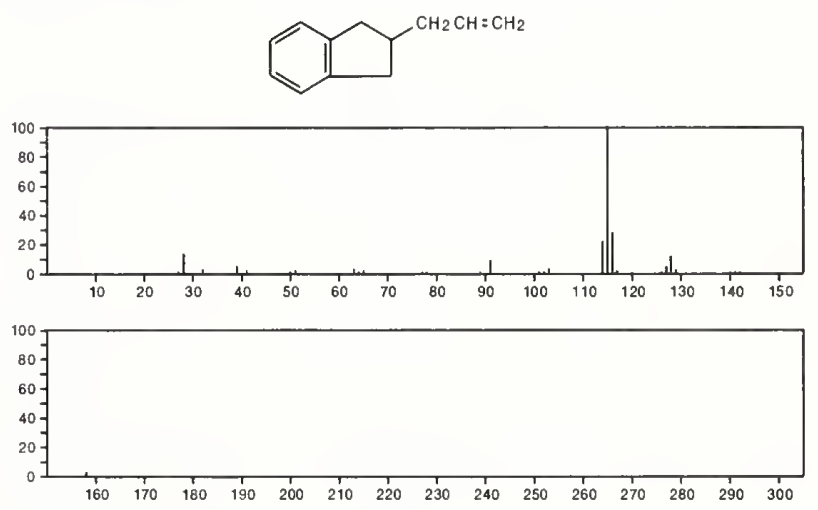
158 $\mathrm{C}_{12} \mathrm{H}_{14}$

Benzene, [(1-methylethylidene)cyclopropyl]-, $(R)$

$24524-55-8$
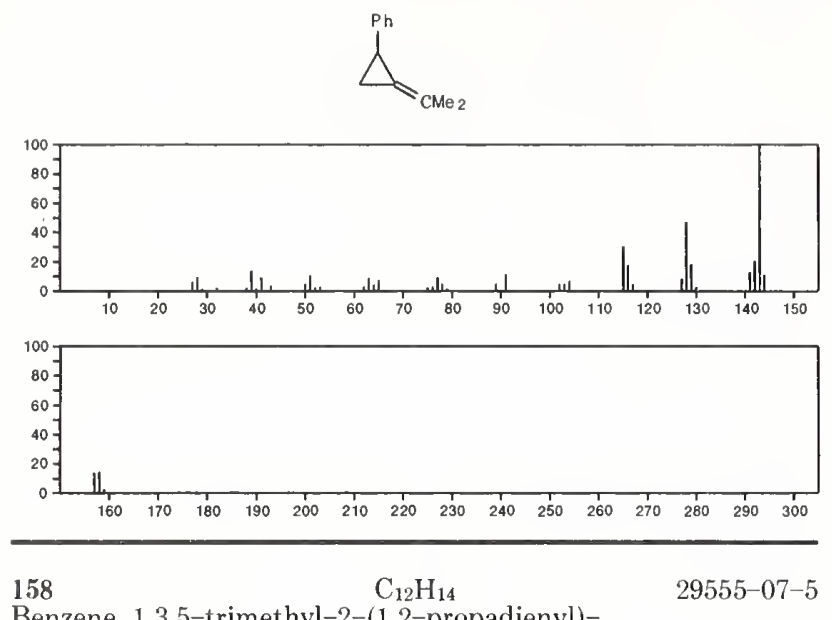

Benzene, 1,3,5-trimethyl-2-(1,2-propadienyl $)-$
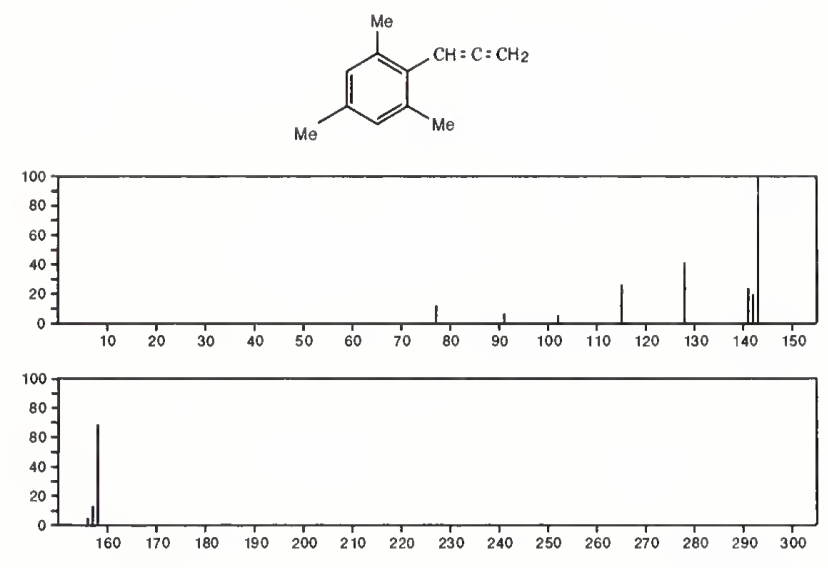

158

Benzene, [(1-methylethylidene)cyclopropyl]-

$\triangle_{\mathrm{CMe}_{2}}^{\mathrm{Ch}}$
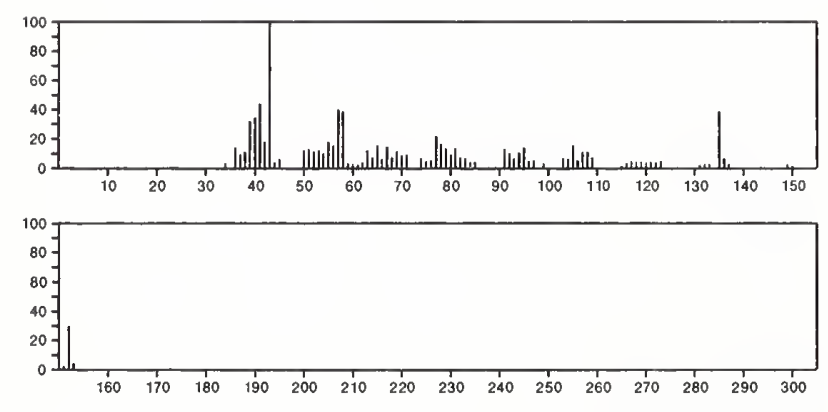

159

Phosphor(isothiocyanatido)thioic difluoride

$14526-12-6$

$\operatorname{SCNPF}_{2}: \mathrm{S}$

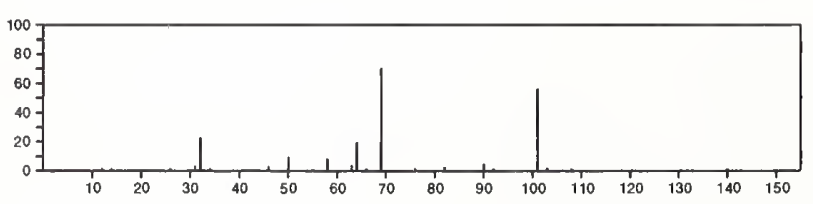

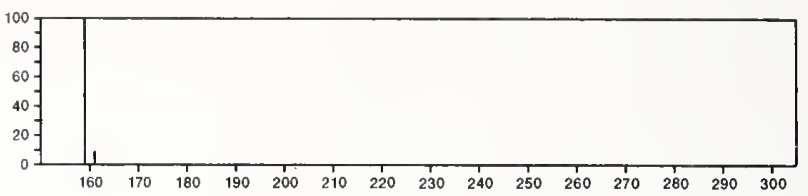

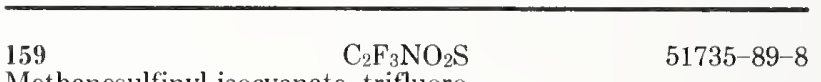

Methanesulfinyl isocyanate, trifluoro-

$\mathrm{F}_{3} \mathrm{CS}(\mathrm{O}) \mathrm{NCO}$
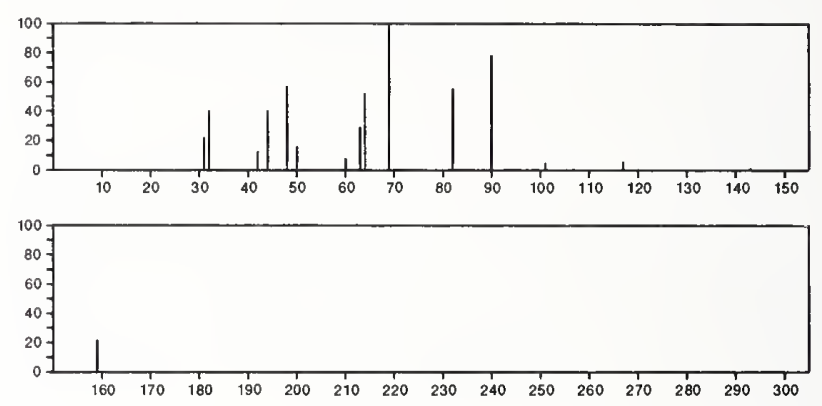

$\begin{array}{lllllllllllllll}160 & 170 & 180 & 190 & 200 & 210 & 220 & 230 & 240 & 250 & 260 & 270 & 280 & 290 & 300\end{array}$

$159 \quad \mathrm{C}_{2} \mathrm{H}_{7}$ ClNOPS

681-04-9

Phosphoramidochloridothioic acid, methyl-, $O$-methyl ester

$\stackrel{\text { II }}{\text { MeNHPCI OMe }}$
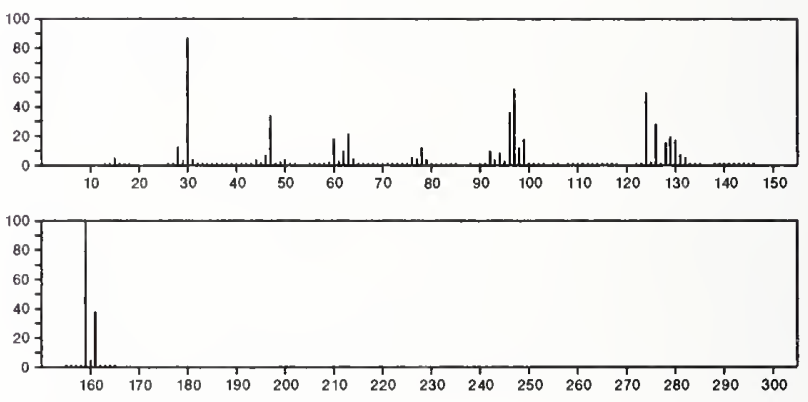

159

$\mathrm{C}_{5} \mathrm{H}_{6} \mathrm{ClN}_{3} \mathrm{O}$

2-Pyrimidinamine, 4-chloro-6-methoxy-

$5734-64-5$<smiles>COc1cc(Cl)nc(N)n1</smiles>
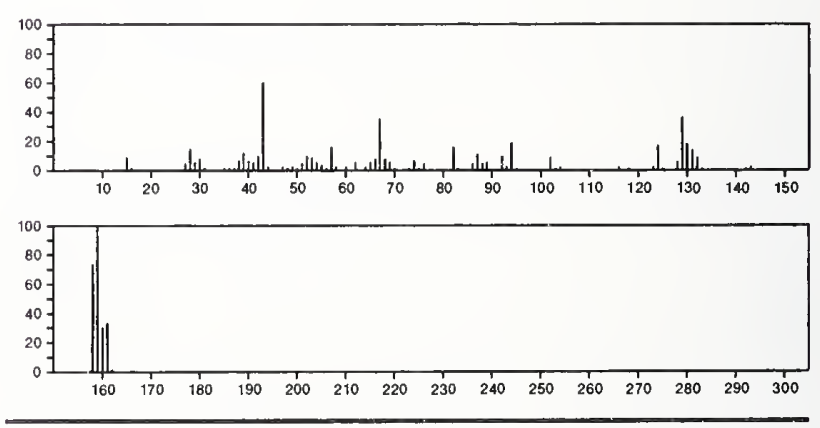

159

$\mathrm{C}_{6} \mathrm{H}_{9} \mathrm{NS}_{2}$

51598-96-0

1-Butene, 4-isothiocyanato-1-(methylthio)-

$\mathrm{SCNCH}_{2} \mathrm{CH}_{2} \mathrm{CH}=\mathrm{CHSMe}$

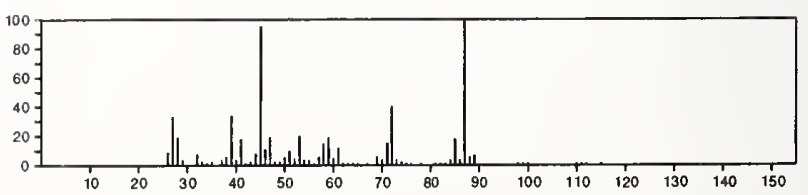




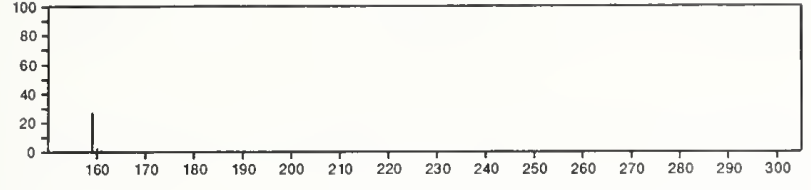

$159 \quad \mathrm{C}_{6} \mathrm{H}_{13} \mathrm{~N}_{3} \mathrm{O}_{2}$

$50285-72-8$

Urea, $N, N$-diethyl- $N^{\prime}$-methyl- $N^{\prime}$-nitroso-

E ${ }_{2} N$ NON $(N O) M e$
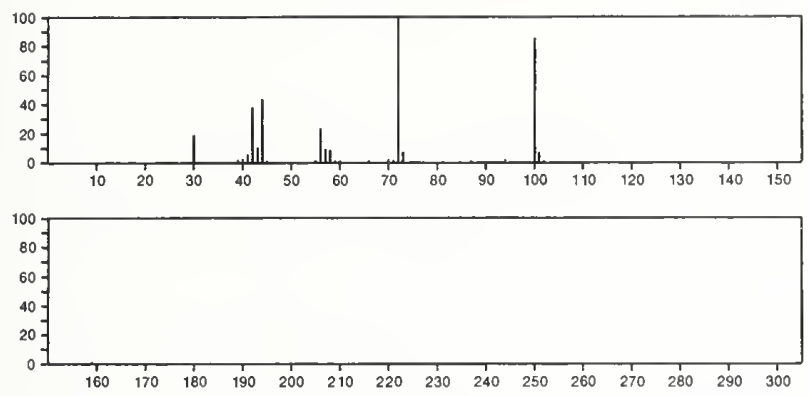

$\mathrm{C}_{6} \mathrm{H}_{13} \mathrm{~N}_{3} \mathrm{~S}$
$159 \quad 1752-39-2$

Hydrazinecarbothioamide, 2-(1-methylbutylidene)

Pr CMe $=\mathrm{NNHCSNH}_{2}$
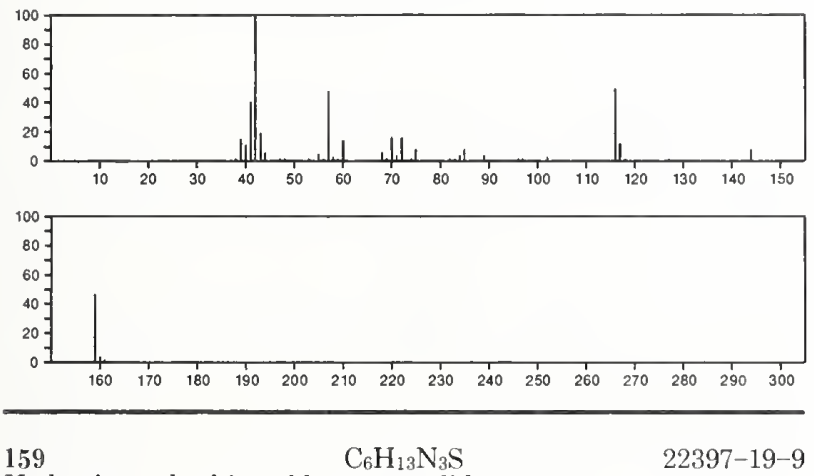

Hydrazinecarbothioamide, 2-pentylidene

$\mathrm{Me}\left(\mathrm{CH}_{2}\right)_{3} \mathrm{CH}: \mathrm{NNHCSNH}$
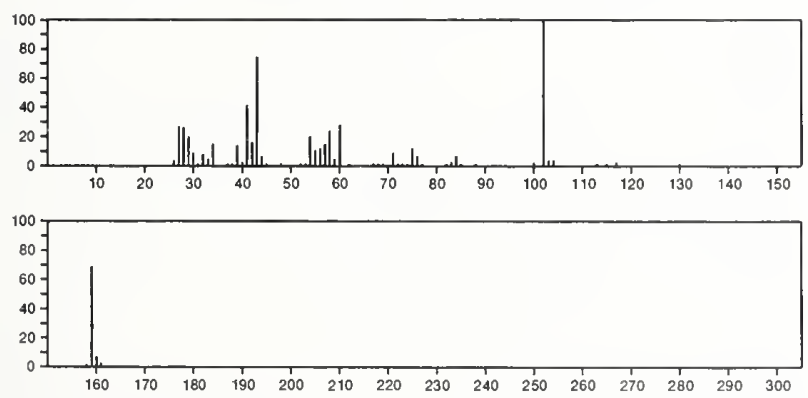

159

L-Valine, $N$-acetyl-

$\mathrm{C}_{7} \mathrm{H}_{13} \mathrm{NO}_{3}$

$96-81-1$

$\mathrm{ACNHCH}\left(\mathrm{CO}_{2} \mathrm{H}\right) \mathrm{CHMe}_{2}$
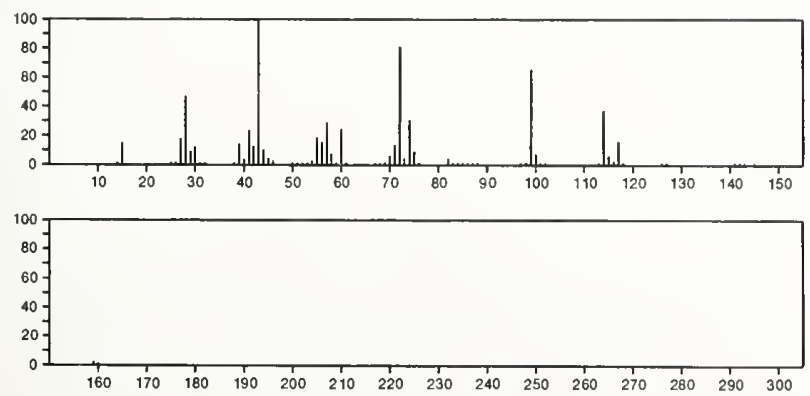

159 $\mathrm{C}_{7} \mathrm{H}_{13} \mathrm{NO}_{3}$

2-Oxazolidinone, 3-(2-hydroxypropyl)-5-methyl-
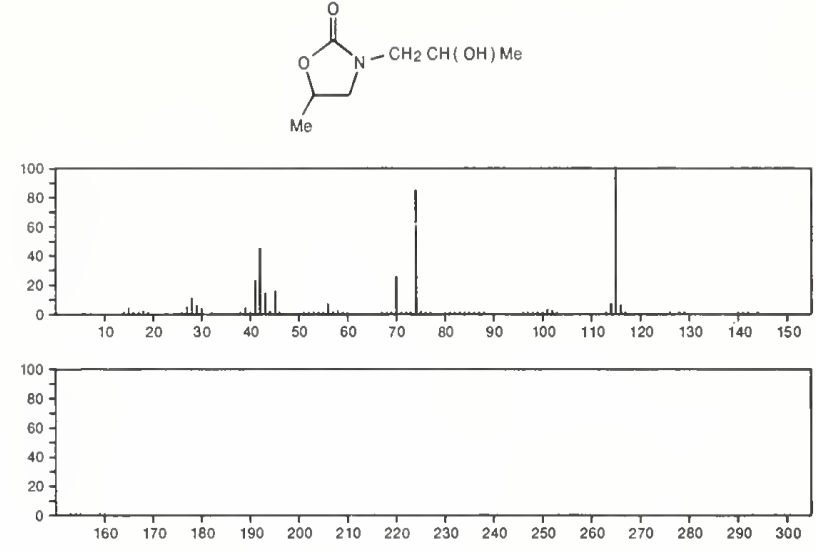

159

$\mathrm{C}_{7} \mathrm{H}_{13} \mathrm{NO}_{3}$

49582-69-6

2-Propenoic acid, 3-(dimethylamino)-3-methoxy-, methyl ester

$\mathrm{MeOC}(\mathrm{O}) \mathrm{CH}=\mathrm{C}(\mathrm{OMe}) \mathrm{NMe}_{2}$
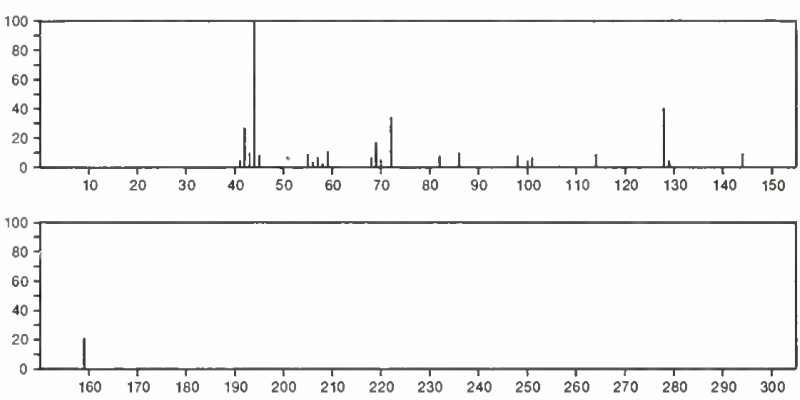

159

$\mathrm{C}_{7} \mathrm{H}_{13} \mathrm{NO}_{3}$

$54340-82-8$

4-Hexenoic acid, 2-amino-6-hydroxy-4-methyl-

$\mathrm{HOCH}_{2} \mathrm{CH}=\mathrm{CMeCH} \mathrm{CH}_{2} \mathrm{CH}\left(\mathrm{NH}_{2}\right) \mathrm{CO}_{2} \mathrm{H}$

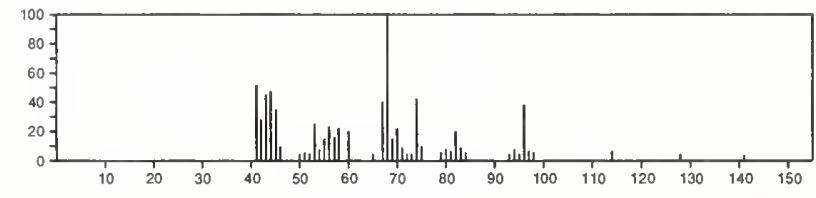

159

$\mathrm{C}_{8} \mathrm{H}_{5} \mathrm{~N}_{3} \mathrm{O}$

$3265-29-0$

2H-Indol-2-one, 3-diazo-1,3-dihydro-
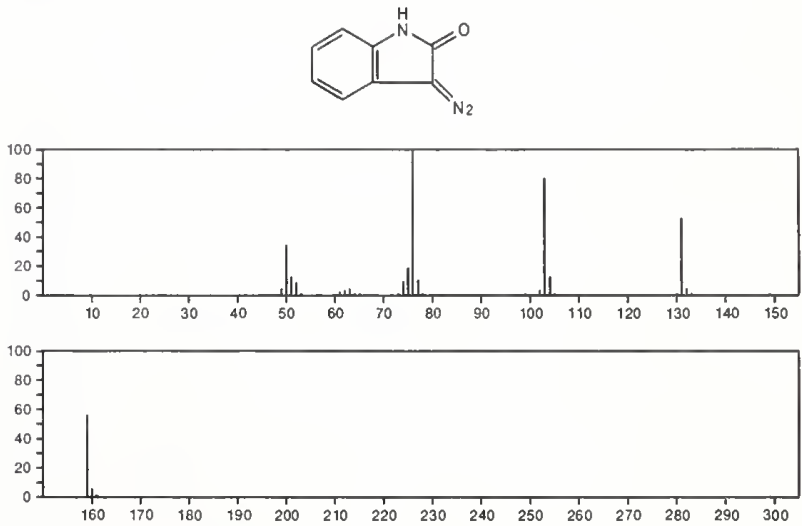
159

L-Isoleucine, ethyl ester

$\mathrm{C}_{8} \mathrm{H}_{17} \mathrm{NO}_{2}$

$921-74-4$

$\mathrm{Et} \mathrm{OC}(\mathrm{O}) \mathrm{CH}\left(\mathrm{NH}_{2}\right) \mathrm{CHMeCH}_{2} \mathrm{Me}$
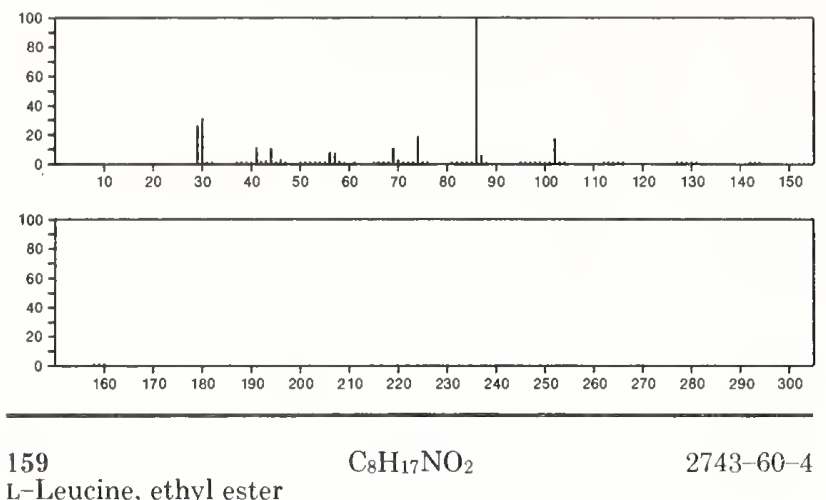

L-Leucine, ethyl ester

$\mathrm{EtOC}(\mathrm{O}) \mathrm{CH}\left(\mathrm{NH}_{2}\right) \mathrm{CH}_{2} \mathrm{CHME}_{2}$
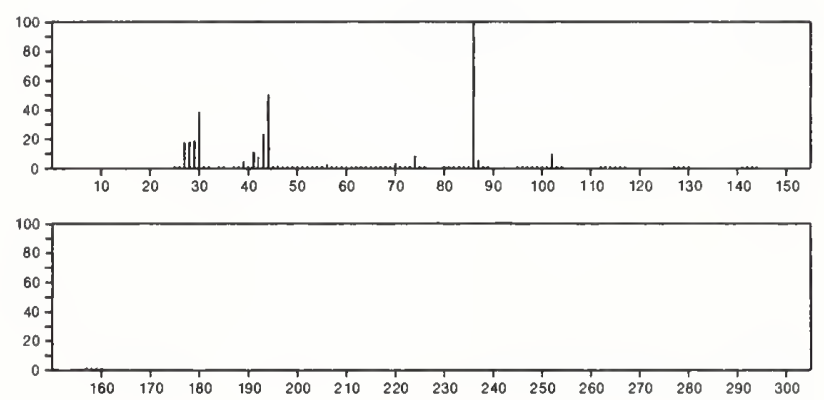

159

DL-Leucine, ethyl ester

$\mathrm{C}_{8} \mathrm{H}_{17} \mathrm{NO}_{2}$

2899--43-6

$\mathrm{EtOC}(\mathrm{O}) \mathrm{CH}\left(\mathrm{NH}_{2}\right) \mathrm{CH}_{2} \mathrm{CHMe} 2$
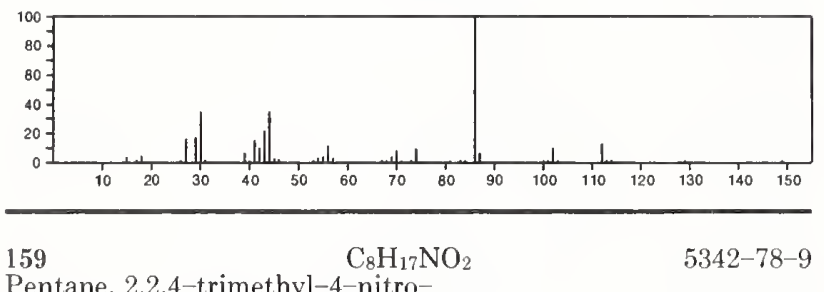

Pentane, 2,2,4-trimethyl-4-nitro-

$\mathrm{Me}_{2} \mathrm{CNO}_{2} \mathrm{CH}_{2} \mathrm{CM}_{3}$

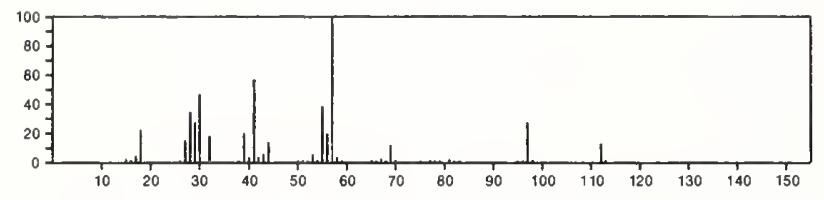

159

$\mathrm{C}_{8} \mathrm{H}_{17} \mathrm{NO}_{2}$

$6141-42-0$

Norleucine, ethyl ester

$\mathrm{EtOC}(\mathrm{O}) \mathrm{CH}\left(\mathrm{NH}_{2}\right)\left(\mathrm{CH}_{2}\right)_{3} \mathrm{Me}$
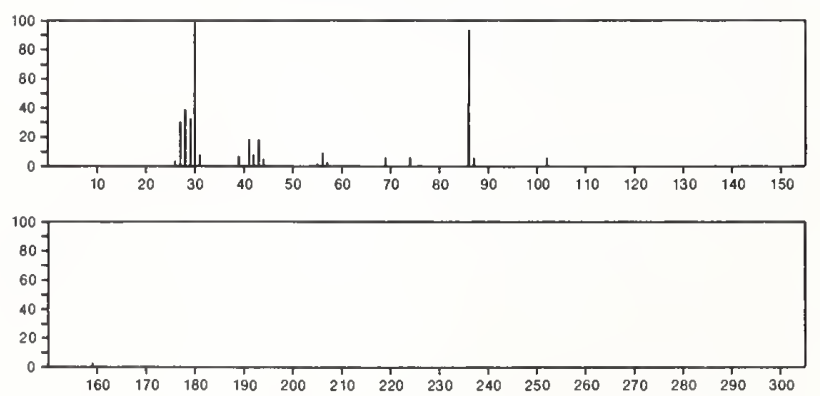

159

Hexanamide, $\mathrm{N}$-(2-hydroxyethyl)-

7726-06-9

$\mathrm{Me}\left(\mathrm{CH}_{2}\right)_{4} \mathrm{CONHCH}_{2} \mathrm{CH}_{2} \mathrm{OH}$
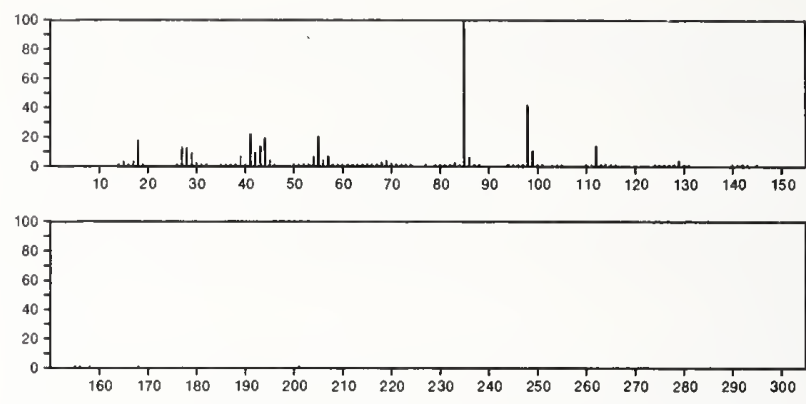

159

L-Norleucine, ethyl ester

$\mathrm{C}_{8} \mathrm{H}_{17} \mathrm{NO}_{2}$

$22628-26-8$

$\mathrm{EtOC}(\mathrm{O}) \mathrm{CH}\left(\mathrm{NH}_{2}\right)\left(\mathrm{CH}_{2}\right)_{3} \mathrm{Me}$
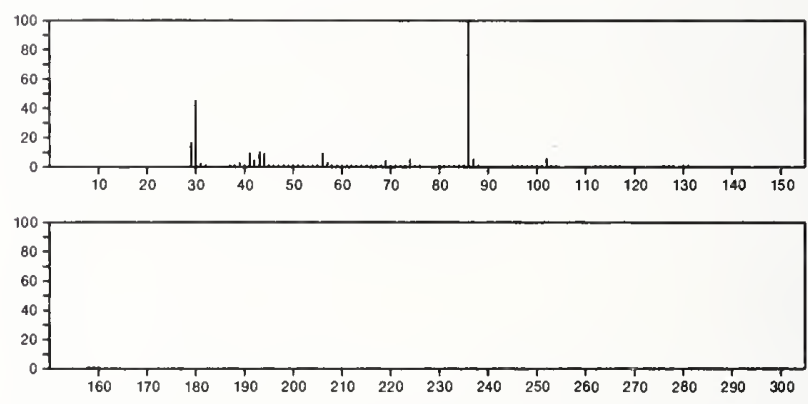

159

DL-Norleucine, ethyl ester

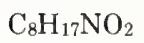

39978-46-6

$\mathrm{EtOC}(\mathrm{O}) \mathrm{CH}\left(\mathrm{NH}_{2}\right)\left(\mathrm{CH}_{2}\right){ }_{3} \mathrm{Me}$
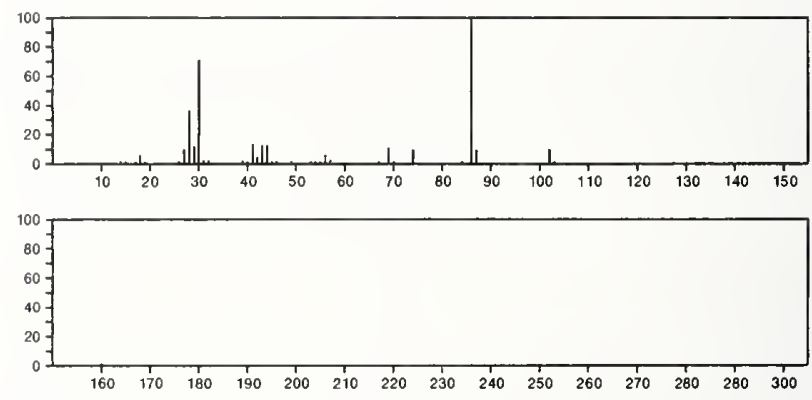

159

DL-Isoleucine, ethyl ester

$\mathrm{C}_{8} \mathrm{H}_{17} \mathrm{NO}_{2}$

$55056-62-7$

$\mathrm{EtOC}(\mathrm{O}) \mathrm{CH}\left(\mathrm{NH}_{2}\right) \mathrm{CHM}_{e} \mathrm{CH}_{2} \mathrm{Me}$

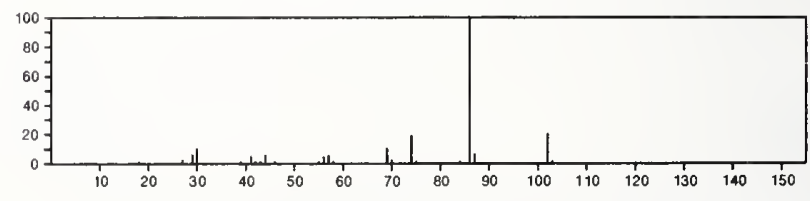

159

$\mathrm{C}_{8} \mathrm{H}_{17} \mathrm{NO}_{2}$

Glycine, $N-(1-$ methylethyl) -, 1-methylethyl ester

$56771-76-7$

$i-\operatorname{PrNHCH} 2 \mathrm{C}(0) O P r-i$

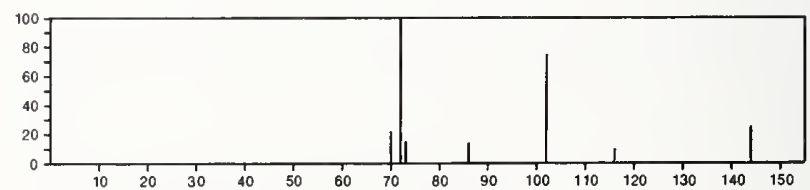




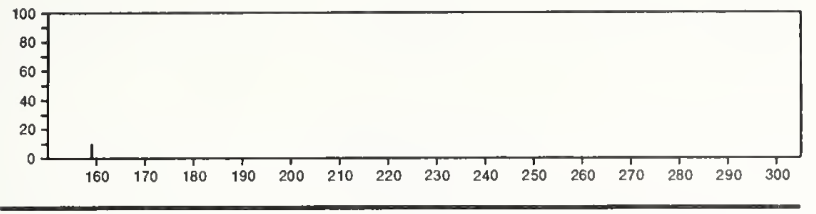

$159 \quad \mathrm{C}_{9} \mathrm{H}_{9} \mathrm{~N}_{3}$

1H-1,2,4-Triazole, 1-(phenylmethyl)
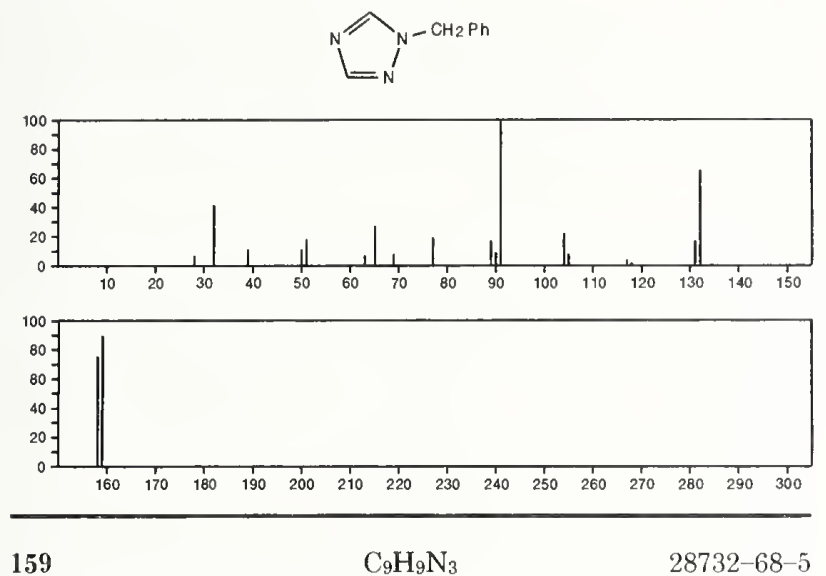

Pyrido[2,3-d]pyrimidine, 4-ethyl-

28732-68-5<smiles>CCc1ncnc2ncccc12</smiles>
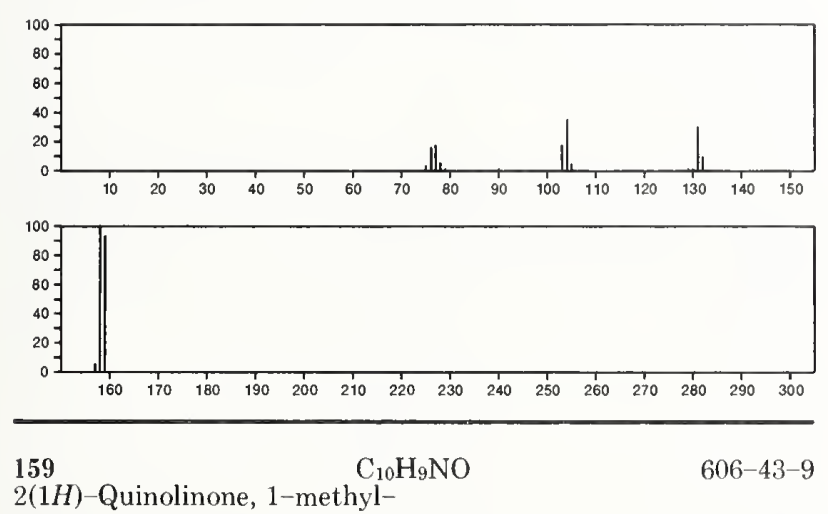

2(1H)-Quinolinone, 1-methyl-
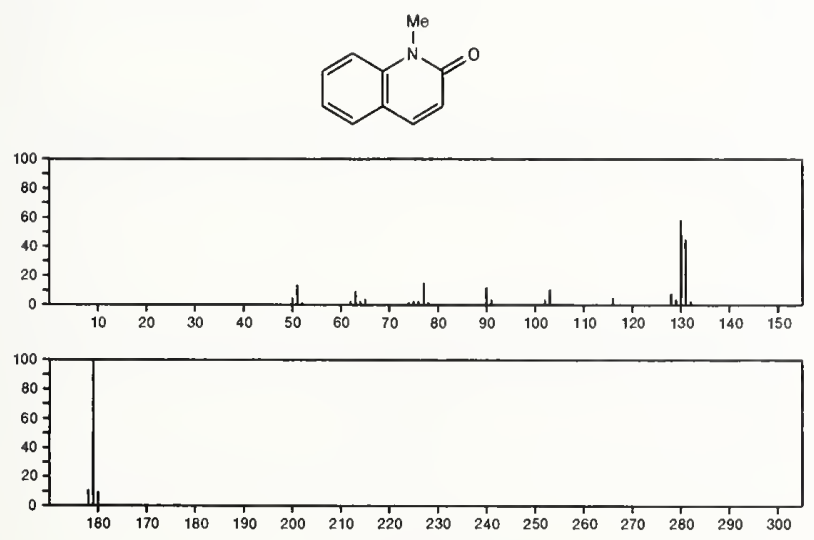

159

2(1H)-Quinolinone, 4-methyl-

$\mathrm{C}_{10} \mathrm{H}_{9} \mathrm{NO}$

$607-66-9$
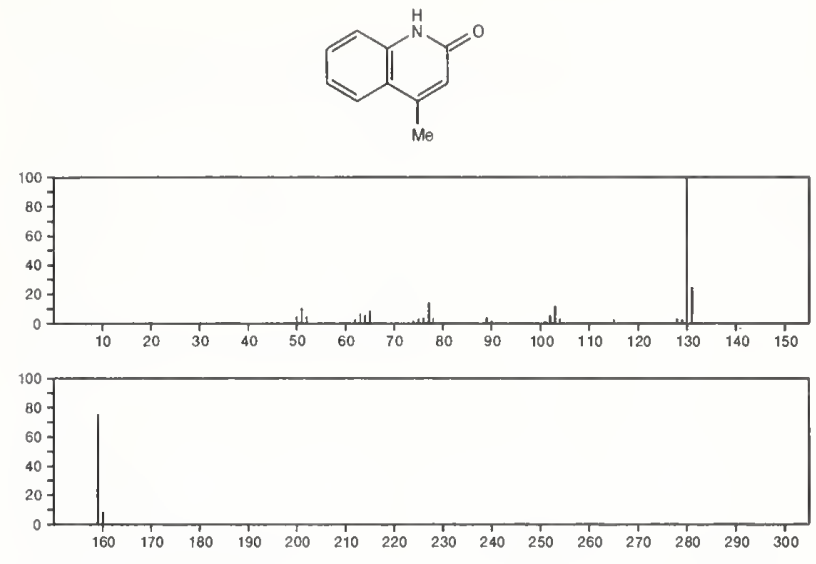

\begin{tabular}{ll}
\hline 159 Quinolinol, 2-methyl- & $\mathrm{C}_{10} \mathrm{H}_{9} \mathrm{NO}$ \\
4-
\end{tabular}
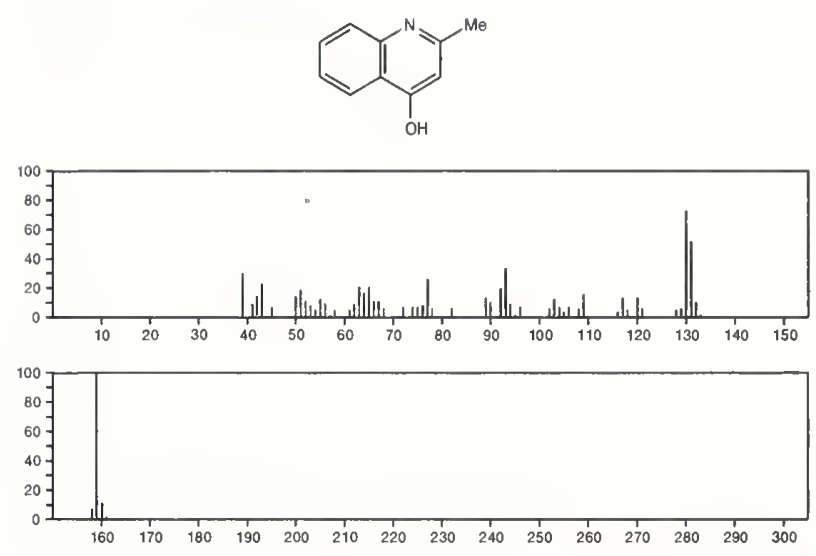

159

Ethanone, 1-(1H-indol-3-yl)-

$\mathrm{C}_{10} \mathrm{H}_{9} \mathrm{NO}$

$703-80-0$
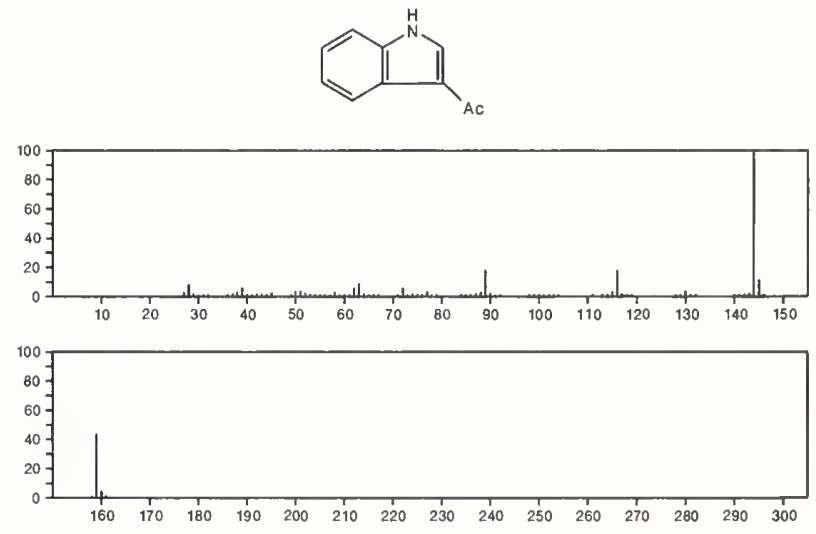

159

8-Quinolinol, 2-methyl-

$\mathrm{C}_{10} \mathrm{H}_{9} \mathrm{NO}$

826-81-3
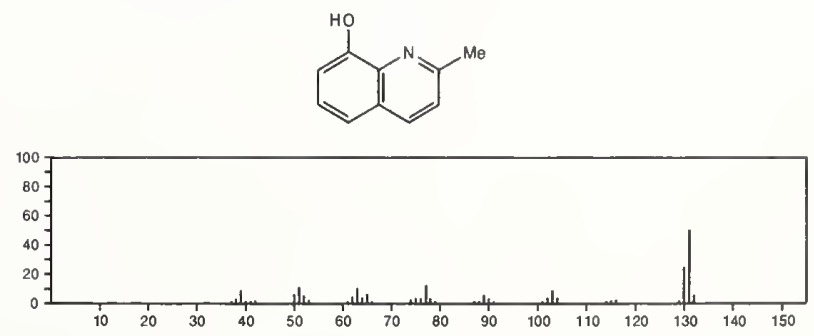


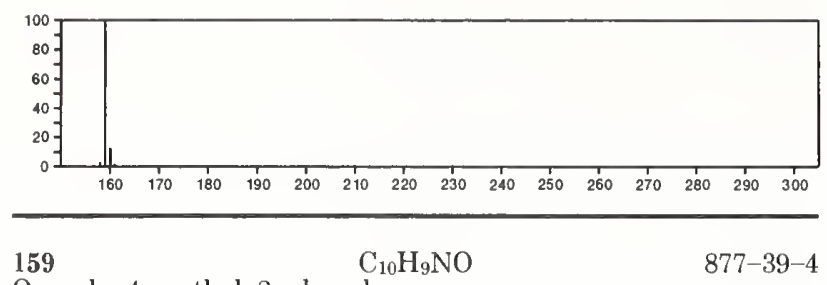

Oxazole, 4-methyl-2-phenyl-
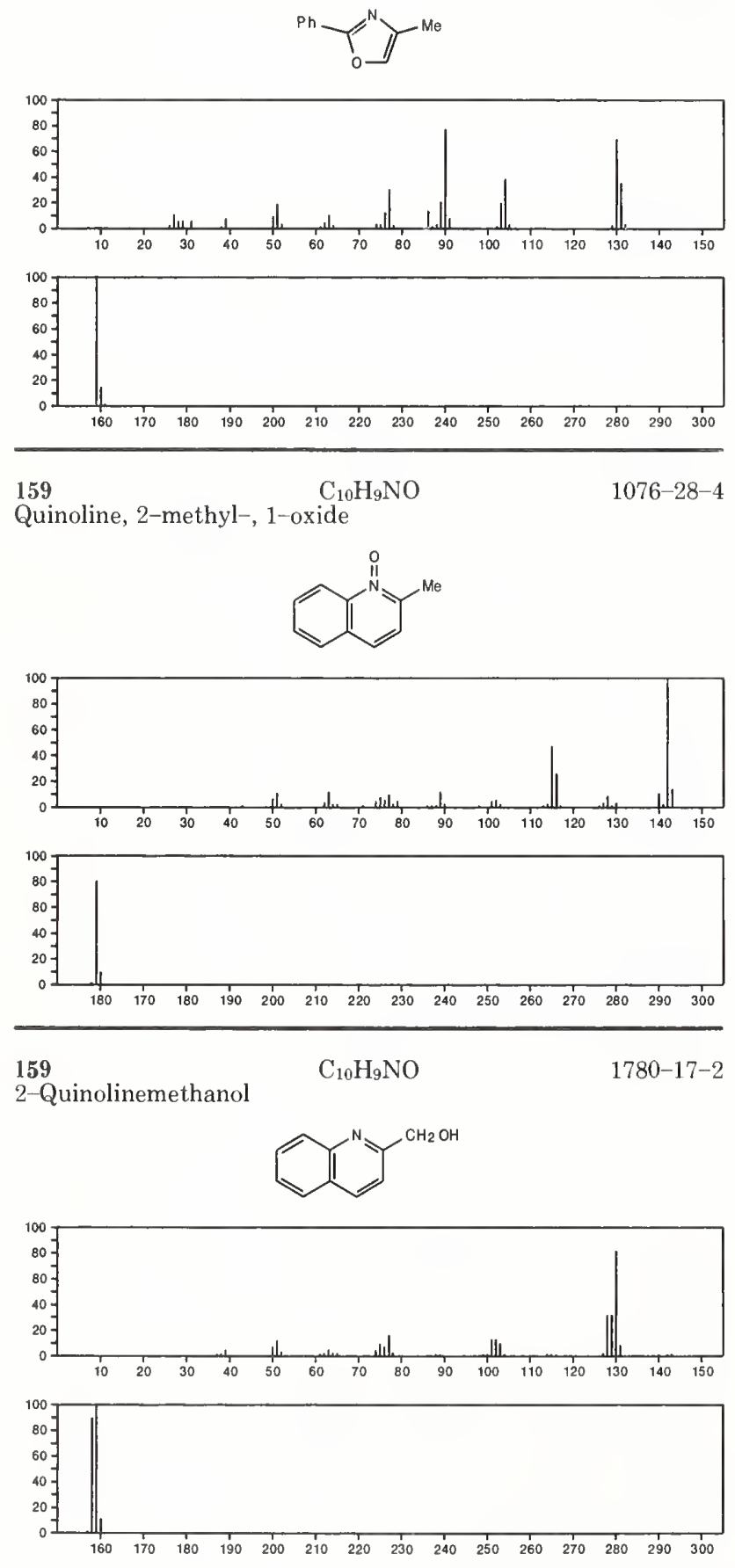

159 2(1H)-Quinolinone, 3-methyl-

$\mathrm{C}_{10} \mathrm{H}_{9} \mathrm{NO}$

2721-59-7
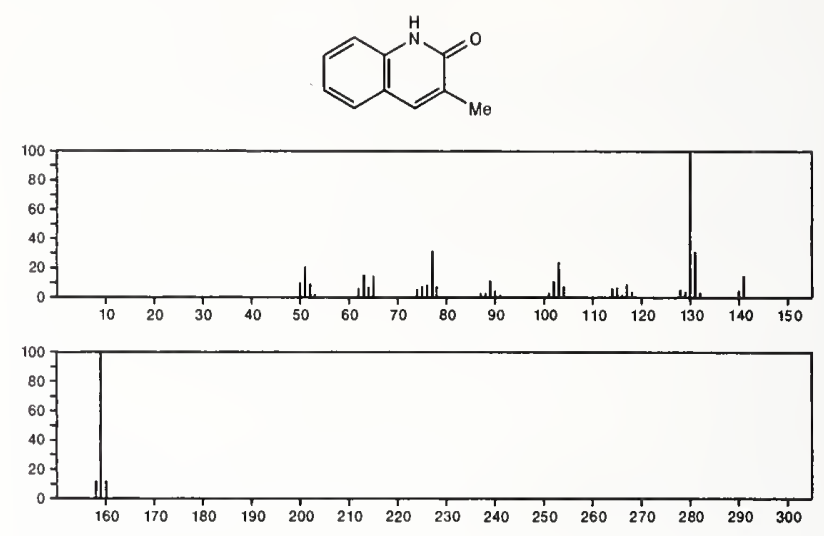

159

$\mathrm{C}_{10} \mathrm{H}_{9} \mathrm{NO}$

Isoquinoline, 1-methyl-, 2-oxide

$3222-65-9$
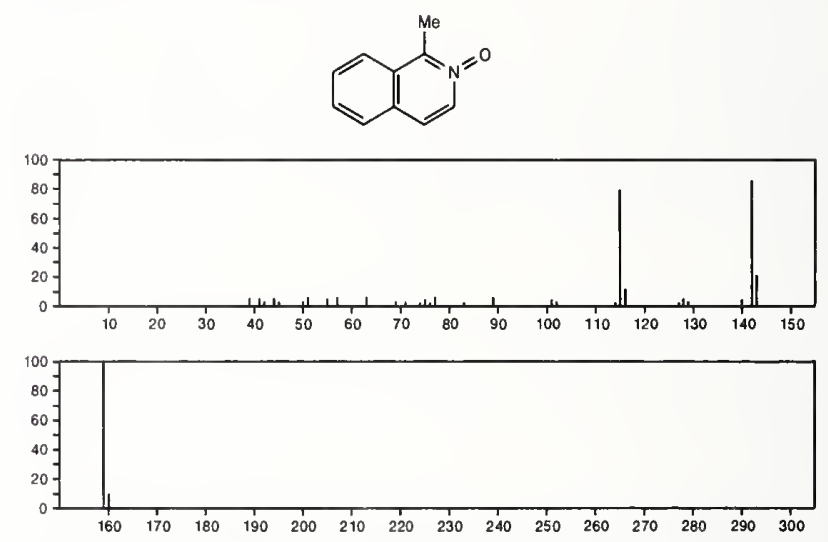

159

8-Quinolinol, 4-methyl-

$\mathrm{C}_{10} \mathrm{H}_{9} \mathrm{NO}$

3846-73-9
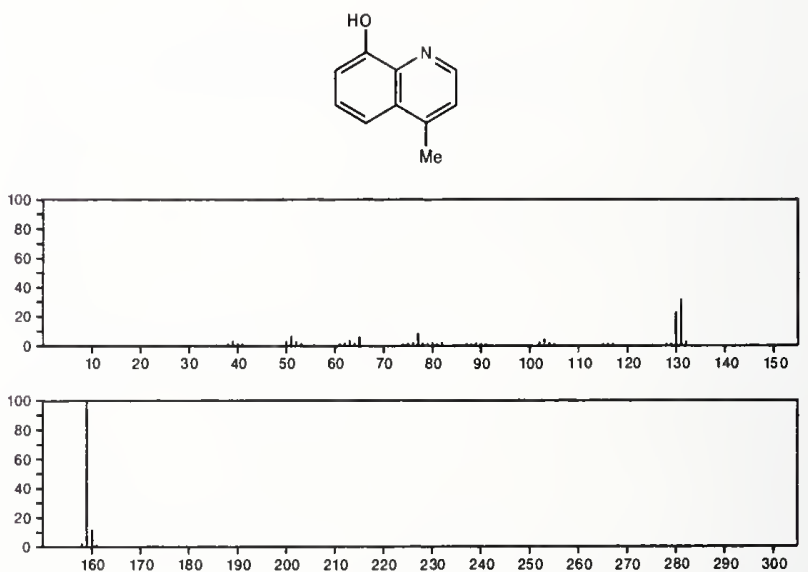
159 $\mathrm{C}_{10} \mathrm{H}_{9} \mathrm{NO}$

Quinoline, 4-methyl-, 1-oxide<smiles>Nc1cc[n+]([O-])c2ccccc12</smiles>
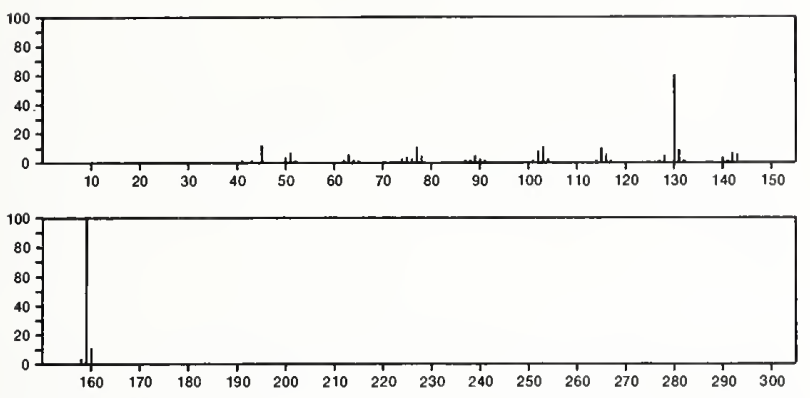

159

Quinoline, 6-methyl-, 1-oxide

$\mathrm{C}_{10} \mathrm{H}_{9} \mathrm{NO}$
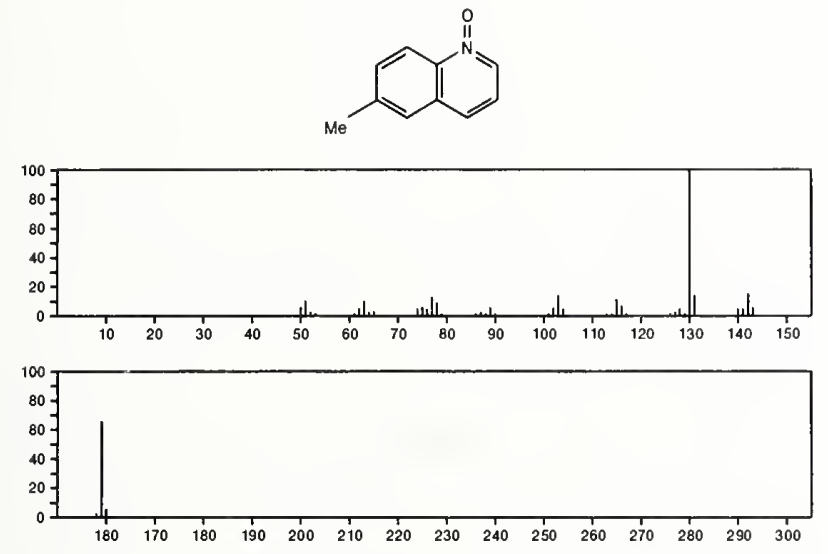

159

Oxazole, 5-methyl-2-phenyl-

$\mathrm{C}_{10} \mathrm{H}_{9} \mathrm{NO}$

$5221-67-0$
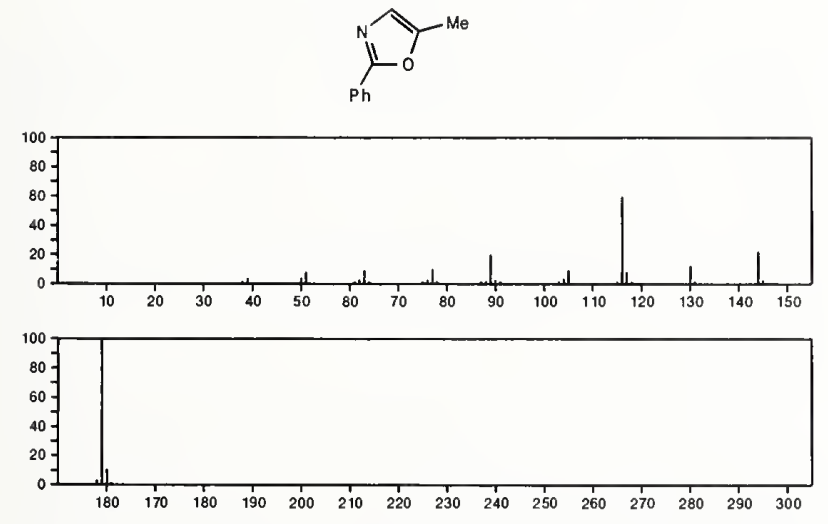

$\stackrel{159}{8-Q u i n o l i n o l, ~ 7-m e t h y l-~}$

$\mathrm{C}_{10} \mathrm{H}_{9} \mathrm{NO}$
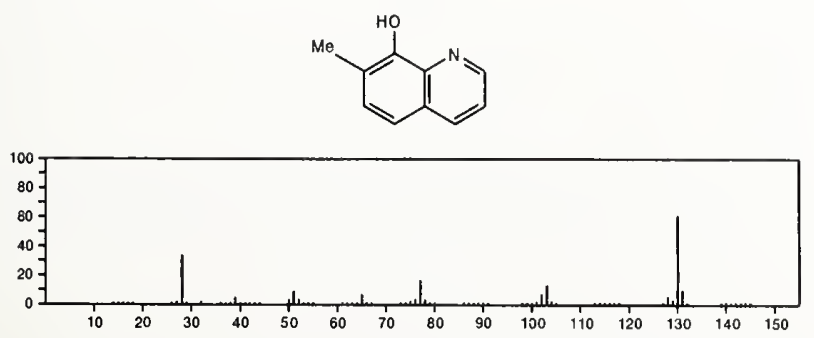

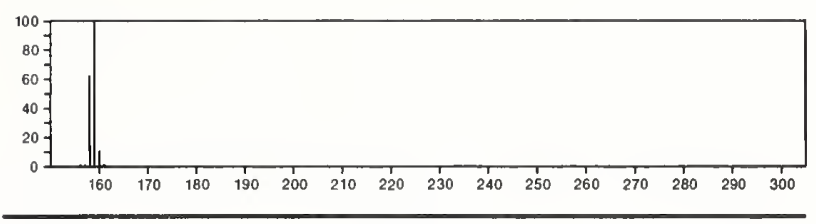

159

$\mathrm{C}_{10} \mathrm{H}_{9} \mathrm{NO}$

6931-16-4

Quinoline, 2-methoxy-
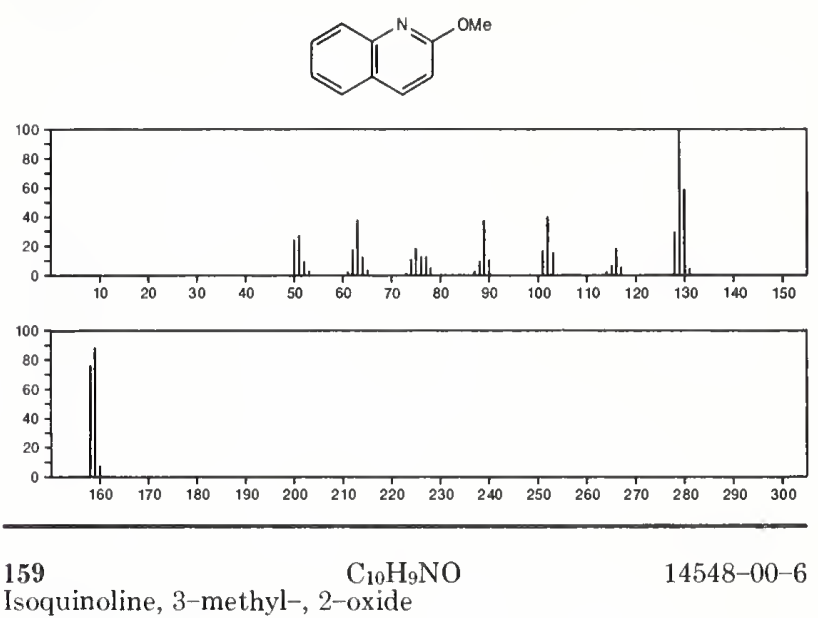

Isoquinoline, 3-methyl-, 2-oxide
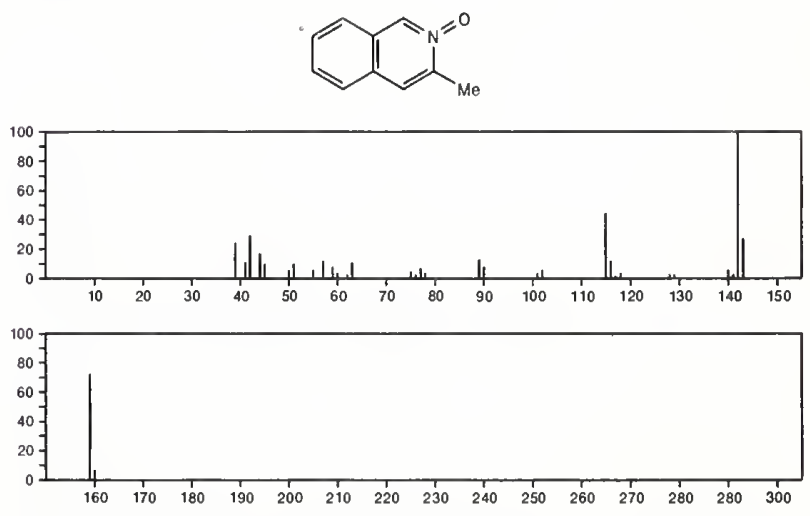

159

$\mathrm{C}_{10} \mathrm{H}_{9} \mathrm{NO}$

16032-35-2

8-Quinolinemethanol
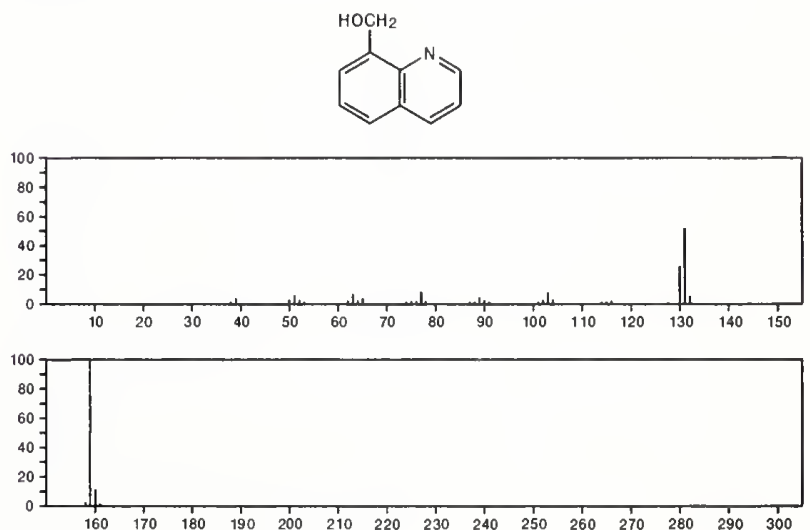
159 $\mathrm{C}_{10} \mathrm{H}_{9} \mathrm{NO}$

Ethanone, 1-(3-indolizinyl)-
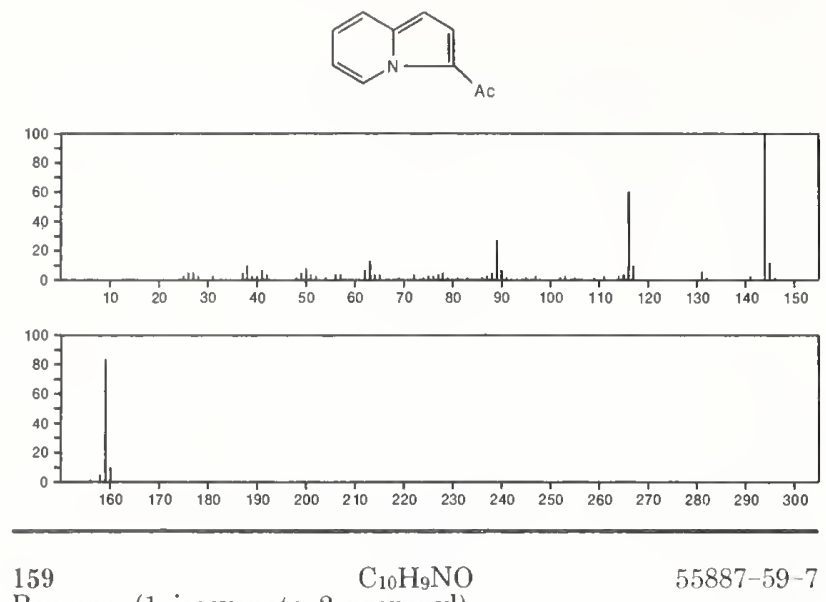

Benzene, (1-isocyanato-2-propenyl)-

$\mathrm{PhCH}(\mathrm{NCO}) \mathrm{CH}=\mathrm{CH}_{2}$
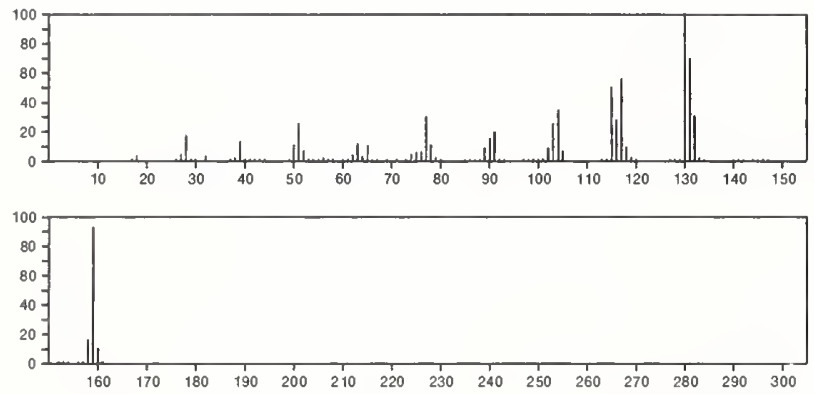

159

$\mathrm{C}_{11} \mathrm{H}_{13} \mathrm{~N}$

Benzenemethanamine, $N$-methyl- $N$-2-propynyl

$555-57-7$

$\mathrm{HC} \equiv \mathrm{CCH}_{2} \mathrm{NMeCH}_{2} \mathrm{Ph}$
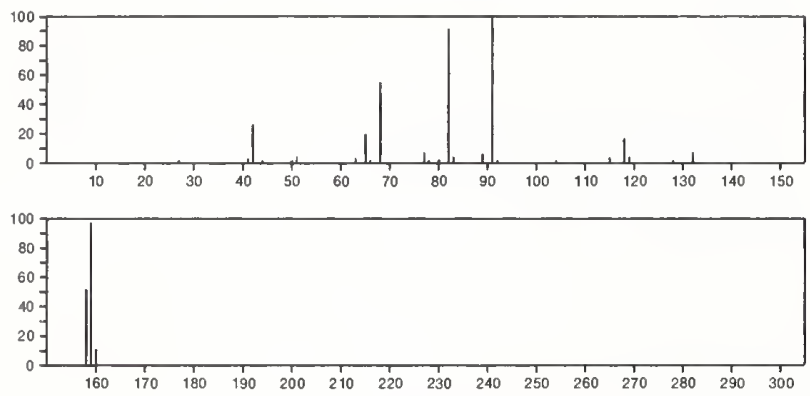

159
$3 H$-Indole, 2,3,3-trimethyl-
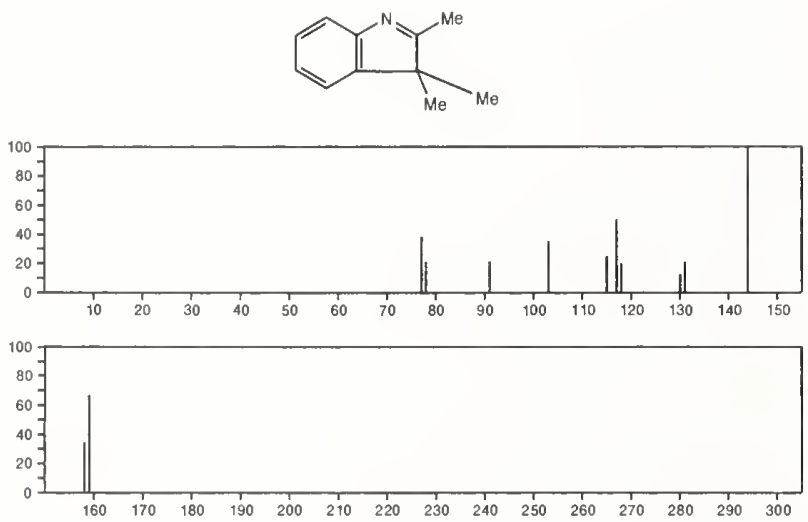

159

$1 \mathrm{H}$-Indole, 1,2,3-trimethyl-

$\mathrm{C}_{11} \mathrm{H}_{13} \mathrm{~N}$

$1971-46-6$
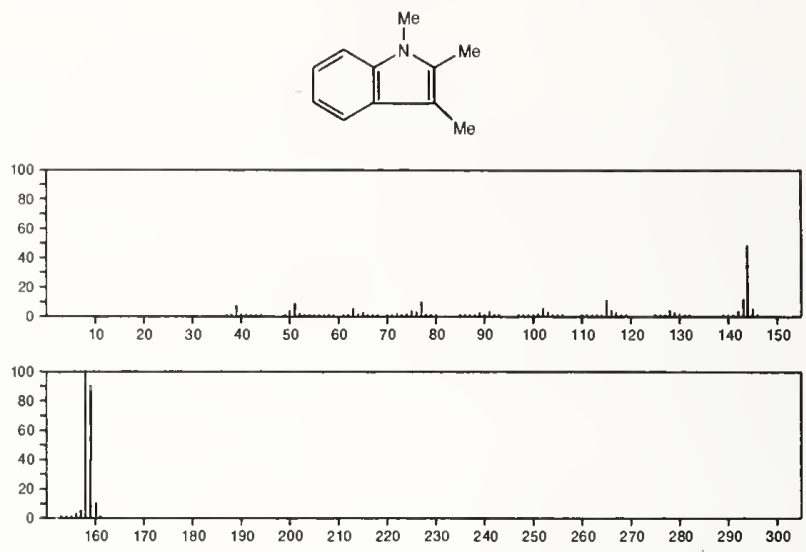

H-1,4-Ethanoquinoline, $3,4-\mathrm{C}_{13} \mathrm{~N}$

$4363-25-1$

2H-1,4-Ethanoquinoline, 3,4-dihydro-
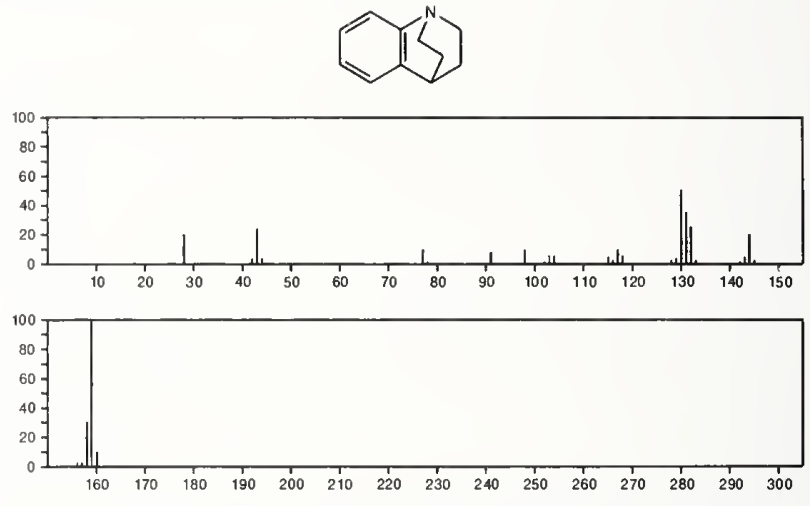

159 -Indole, 5,6,7-trimethyl- $\mathrm{C}_{11} \mathrm{H}_{13} \mathrm{~N}$

$54340-99-7$
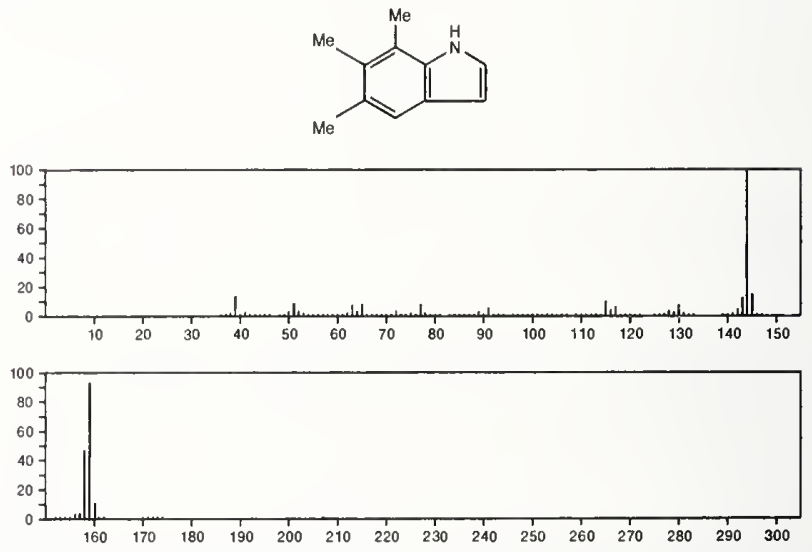

$160 \quad \mathrm{C}_{2} \mathrm{H}_{6} \mathrm{ClO}_{2} \mathrm{PS}$

Phosphorochloridothioic acid, $\mathrm{O}, \mathrm{O}$-dimethyl ester

$2524-03-0$

$\stackrel{\text { II }}{\mathrm{MeOP} C \mathrm{OM}}$

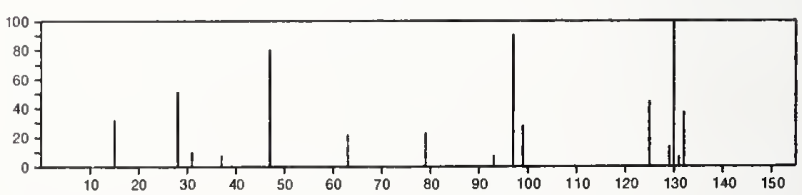




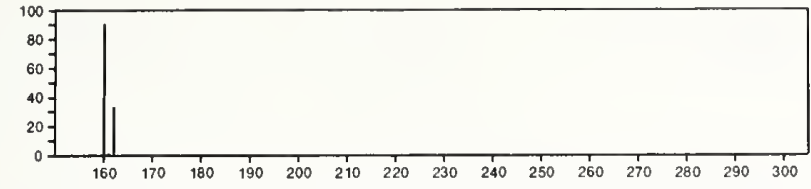

$160 \quad \mathrm{C}_{2} \mathrm{H}_{7} \mathrm{~F}_{2} \mathrm{~N}_{2} \mathrm{PS} \quad 36267-50-2$

Phosphorodifluoridothioic hydrazide, 2,2-dimethyl

$S=\mathrm{PF}_{2} \mathrm{NHNME}_{2}$
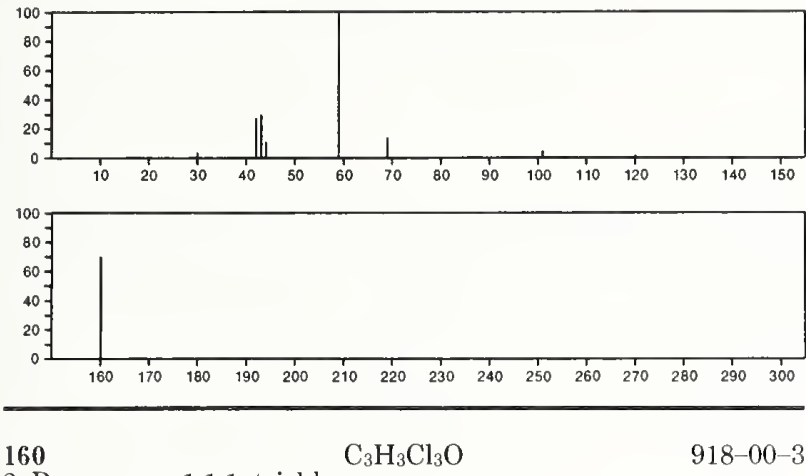

$918-00-3$

2-Propanone, 1,1,1-trichloro-

$\mathrm{Cl}_{3} \mathrm{CCOMe}$

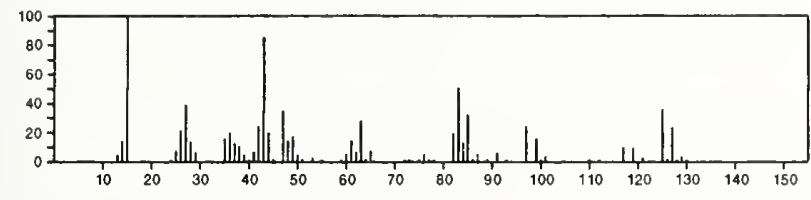

160

Propanoyl chloride, 2,2-dichloro

$\mathrm{C}_{3} \mathrm{H}_{3} \mathrm{Cl}_{3} \mathrm{O}$

$\mathrm{MeCCl} 2 \mathrm{COCl}$
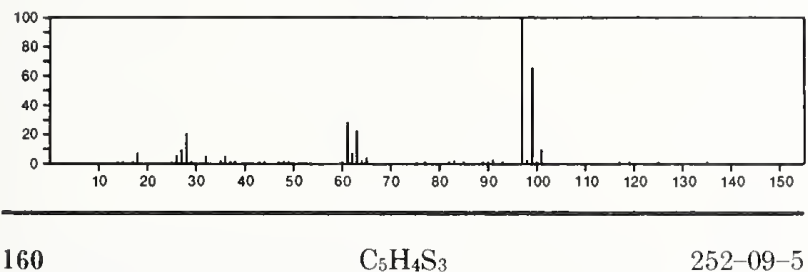

$[1,2]$ Dithiolo[1,5-b][1,2]dithiole-7-SIV

252-09-5
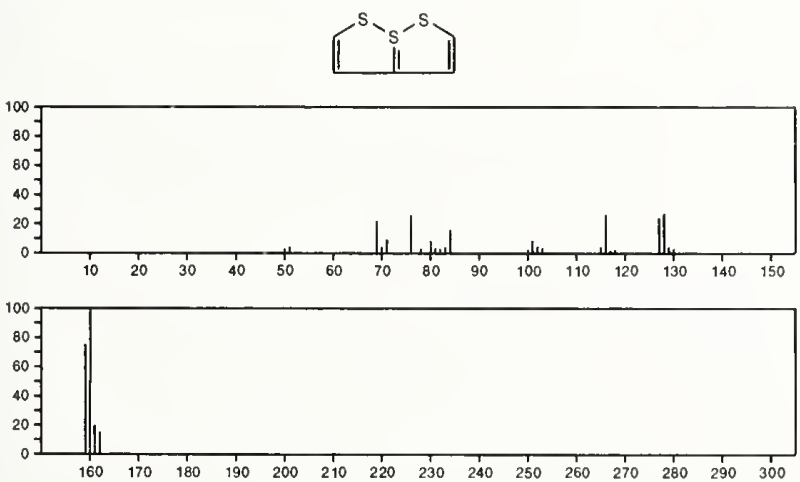

160

$\mathrm{C}_{5} \mathrm{H}_{5} \mathrm{ClN}_{2} \mathrm{~S}$

Pyridazine, 3-chloro-6-(methylthio)-<smiles>CS(=O)(=O)c1ccc(Cl)nn1</smiles>
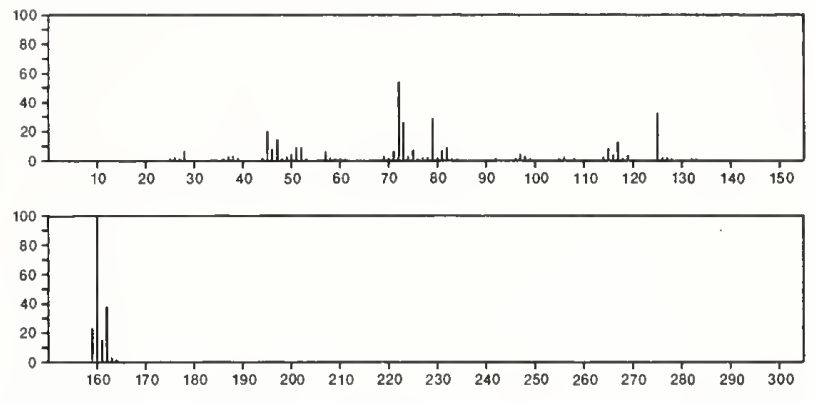

160

$\mathrm{C}_{5} \mathrm{H}_{8} \mathrm{~N}_{2} \mathrm{O}_{4}$

2943-56-8

$2,4(1 H, 3 H)$-Pyrimidinedione, dihydro-5,6-dihydroxy-5-methyl-<smiles>CC1(O)C(=O)NC(=O)NC1O</smiles>
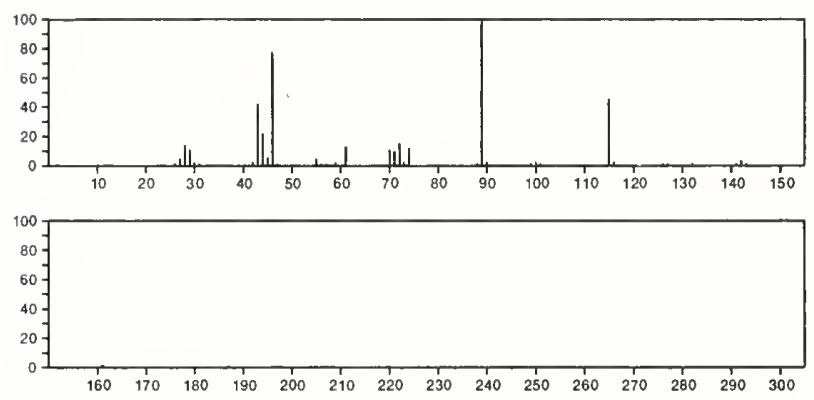

160

$\mathrm{C}_{5} \mathrm{H}_{8} \mathrm{~N}_{2} \mathrm{O}_{4}$

$30310-80-6$

L-Proline, 4-hydroxy-1-nitroso-, trans
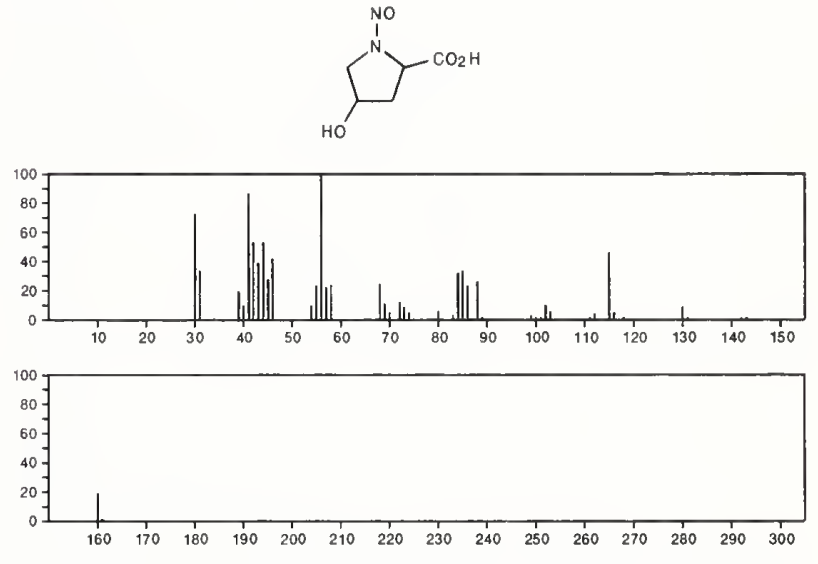

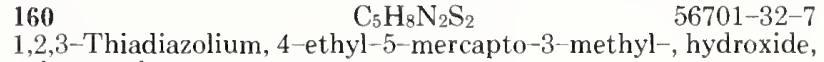

$\mathrm{C}_{5} \mathrm{H}_{8} \mathrm{~N}_{2} \mathrm{~S}_{2}$

$56701-32-7$ inner salt
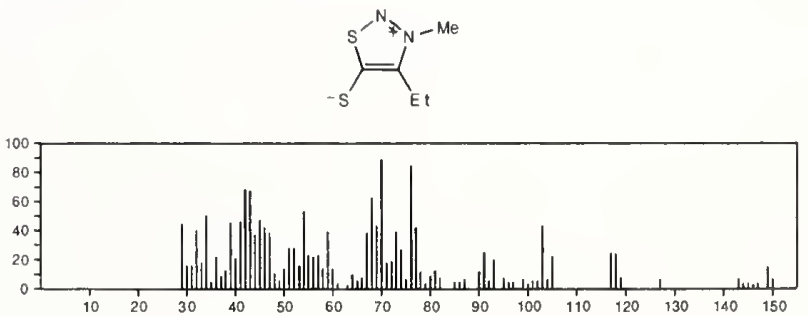


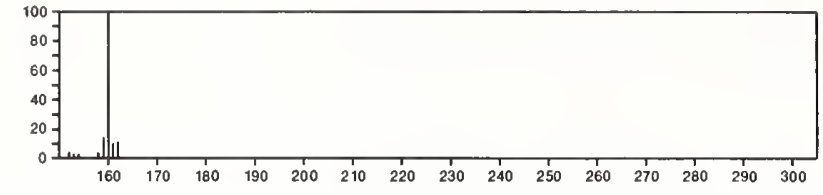

$160 \quad \mathrm{C}_{5} \mathrm{H}_{16} \mathrm{Si}_{3}$

1,3,5-Trisilacyclohexane, 1,1-dimethyl-
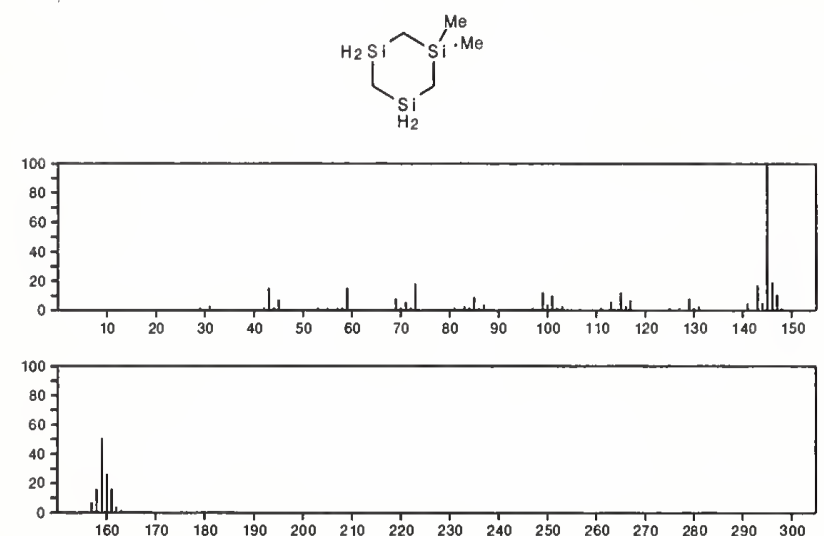

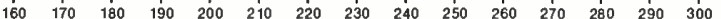

160

$\mathrm{C}_{6} \mathrm{H}_{5} \mathrm{ClO}_{3}$

$7559-81-1$

4H-Pyran-4-one, 2-(chloromethyl)-5-hydroxy-
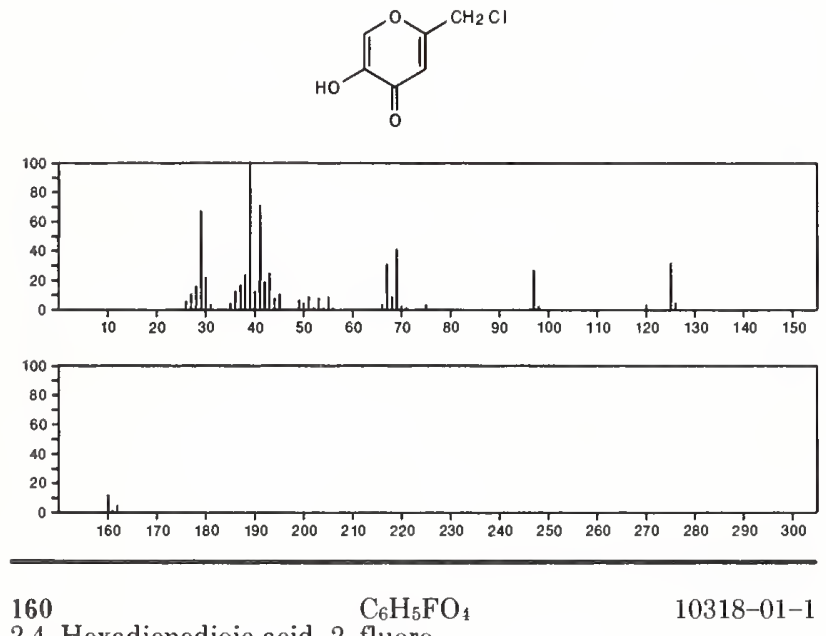

2,4-Hexadienedioic acid, 2-fluoro-

$\mathrm{HO}_{2} \mathrm{CCF}=\mathrm{CHCH}=\mathrm{CHCO}_{2} \mathrm{H}$
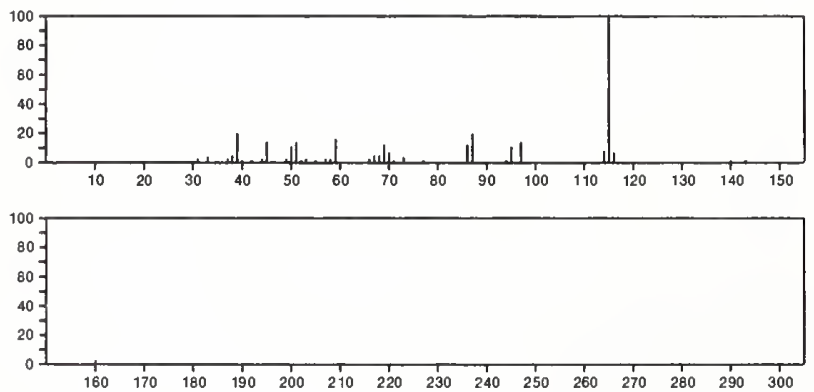

160

Cyclohexene, 3-bromo-

$\mathrm{C}_{6} \mathrm{H}_{9} \mathrm{Br}$

$1521-51-3$
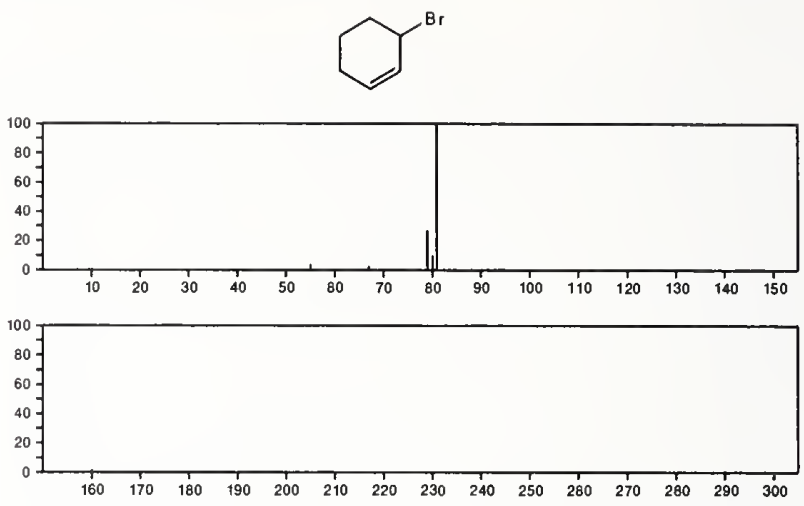

160

$\mathrm{C}_{6} \mathrm{H}_{9} \mathrm{Br}$

Cyclopentene, 3-(bromomethyl)-

$17645-61-3$
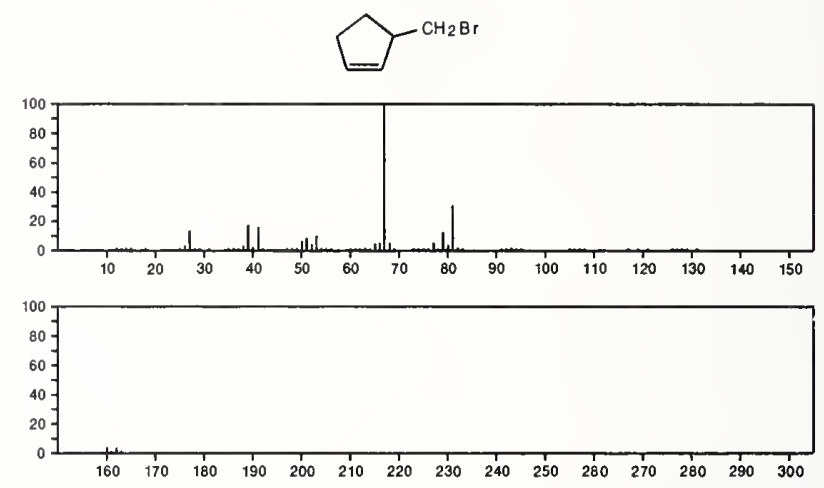

160

2-Hexyne, 6-bromo-

$\mathrm{C}_{6} \mathrm{H}_{9} \mathrm{Br}$

$55402-12-5$

$\mathrm{Br}\left(\mathrm{CH}_{2}\right)_{3} \mathrm{C} \equiv \mathrm{CMe}$
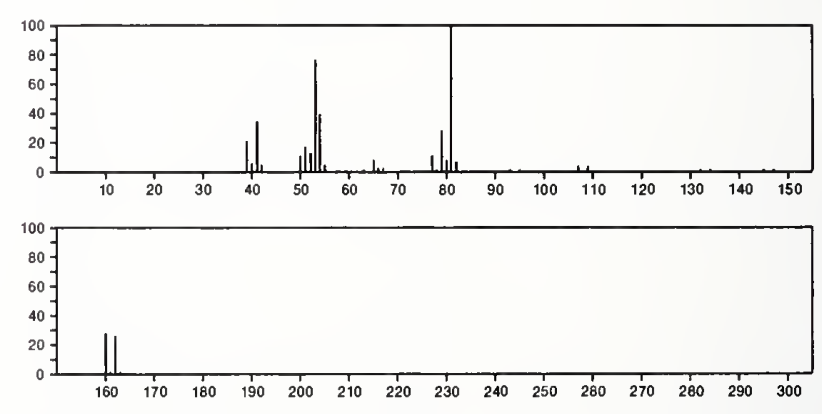

160

L-Alanine, $N$-L-alanyl-

$\mathrm{C}_{6} \mathrm{H}_{12} \mathrm{~N}_{2} \mathrm{O}_{3}$

1948-31-8

$\mathrm{MeCH}\left(\mathrm{NH}_{2}\right)$ CONHCHMe $\mathrm{CO}_{2} \mathrm{H}$

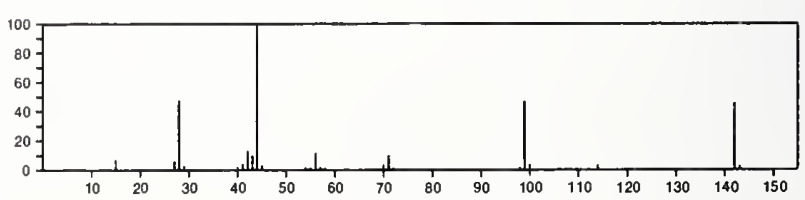


160

$\mathrm{C}_{7} \mathrm{H}_{6} \mathrm{ClFO}$

$452-09-5$

Benzene, 4-chloro-2-fluoro-1-methoxy-
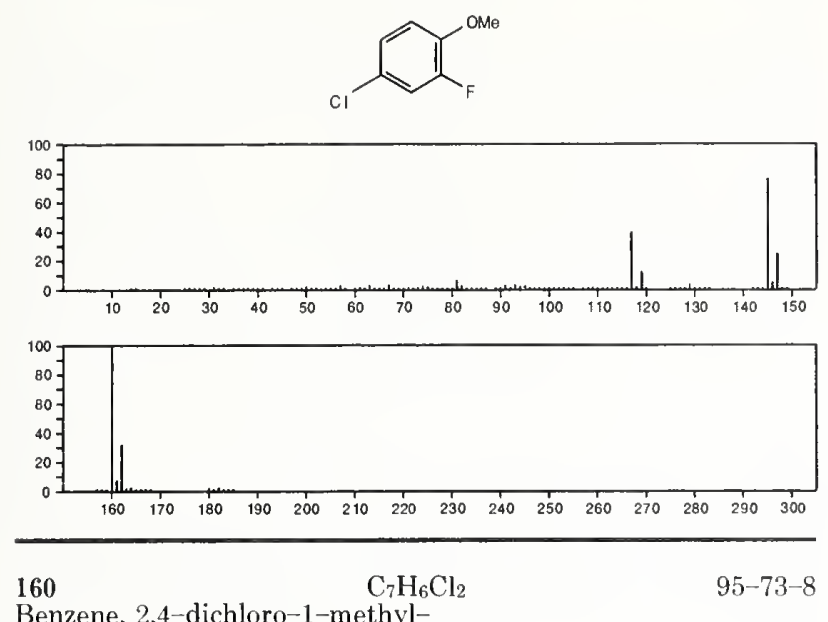

Benzene, 2,4-dichloro-1-methyl-
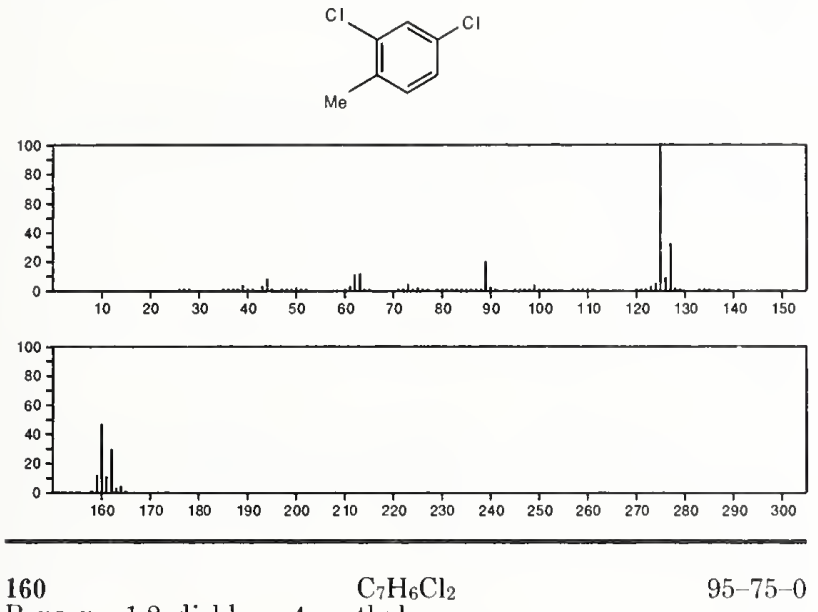

Benzene, 1,2-dichloro-4-methyl-
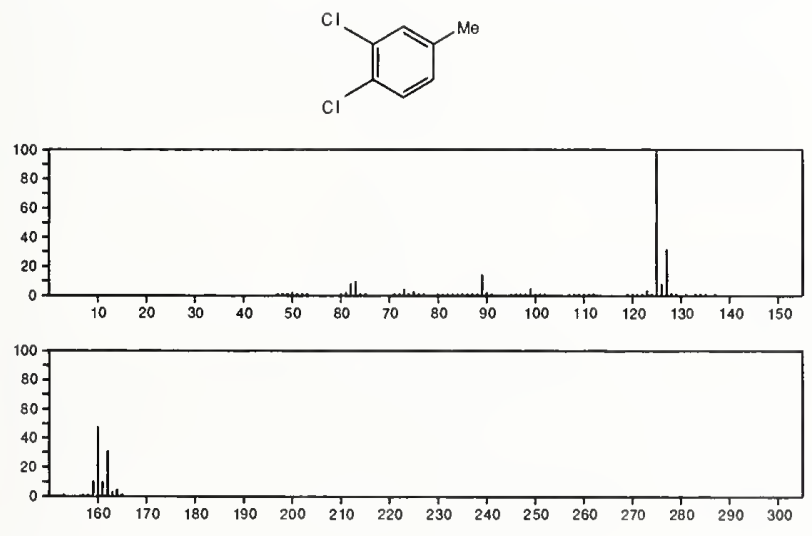

160

$\mathrm{C}_{7} \mathrm{H}_{6} \mathrm{Cl}_{2}$

$98-87-3$

Benzene, (dichloromethyl)-

$\mathrm{Cl}_{2} \mathrm{CHPh}$

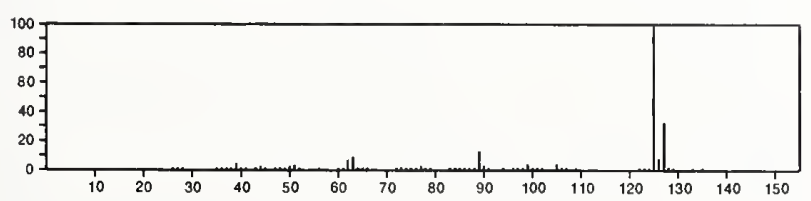

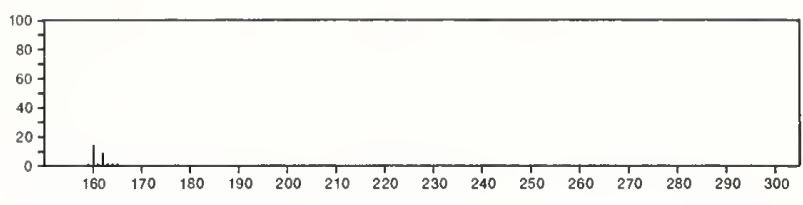

160

$\mathrm{C}_{7} \mathrm{H}_{6} \mathrm{Cl}_{2}$

Benzene, 1,3-dichloro-2-methyl-

$118-69-4$
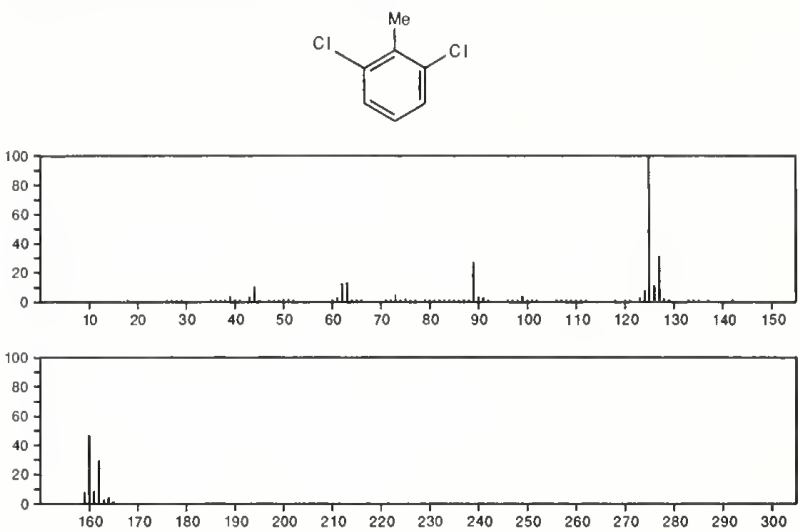

160

$\mathrm{C}_{7} \mathrm{H}_{6} \mathrm{Cl}_{2}$

Benzene, 1-chloro-2-(chloromethyl)-

$611-19-8$<smiles>ClCc1ccccc1Cl</smiles>
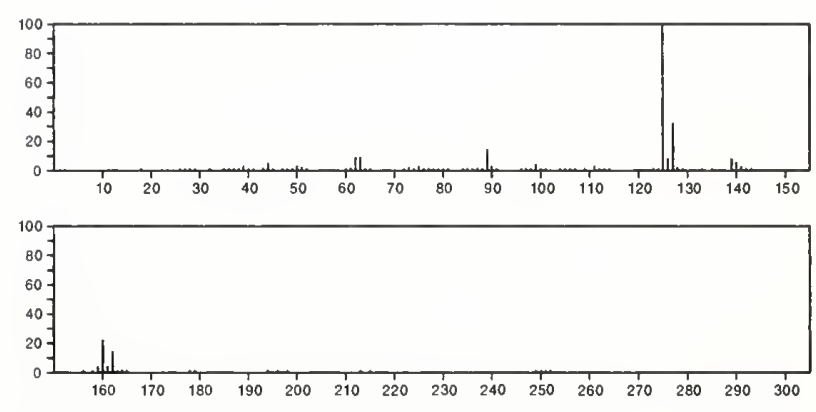

160

$\mathrm{C}_{7} \mathrm{H}_{6} \mathrm{Cl}_{2}$

Benzene, 1-chloro-3-(chloromethyl)-

$620-20-2$
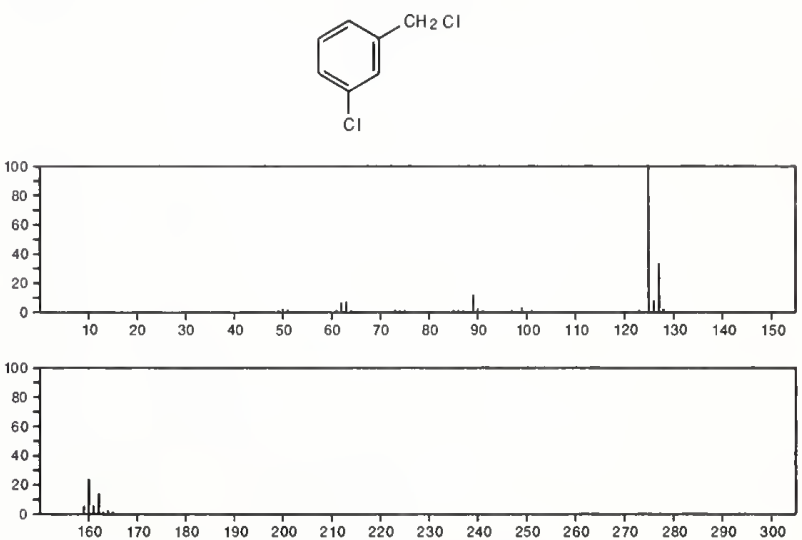
160

$\mathrm{C}_{7} \mathrm{H}_{6} \mathrm{Cl}_{2}$

Benzene, 1,4-dichloro-2-methyl-
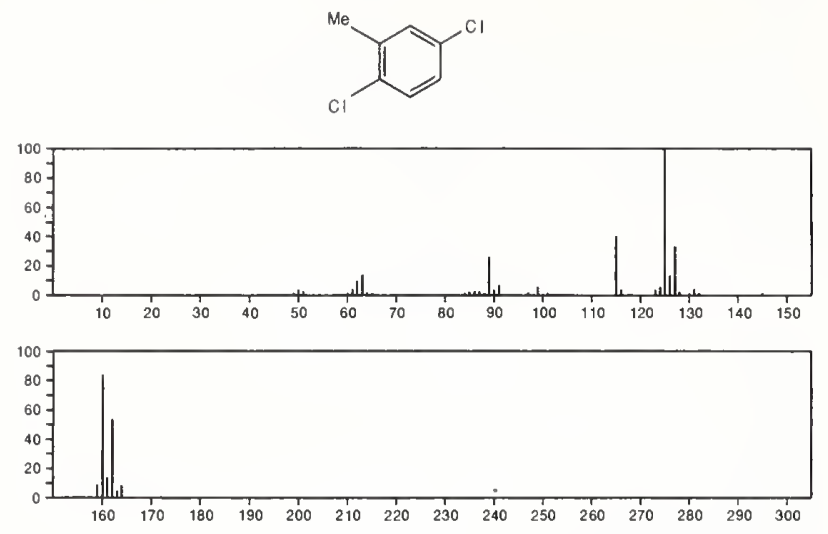

160

$\mathrm{C}_{7} \mathrm{H}_{6} \mathrm{Cl}_{2}$

29797-40-8

Benzene, dichloromethyl-
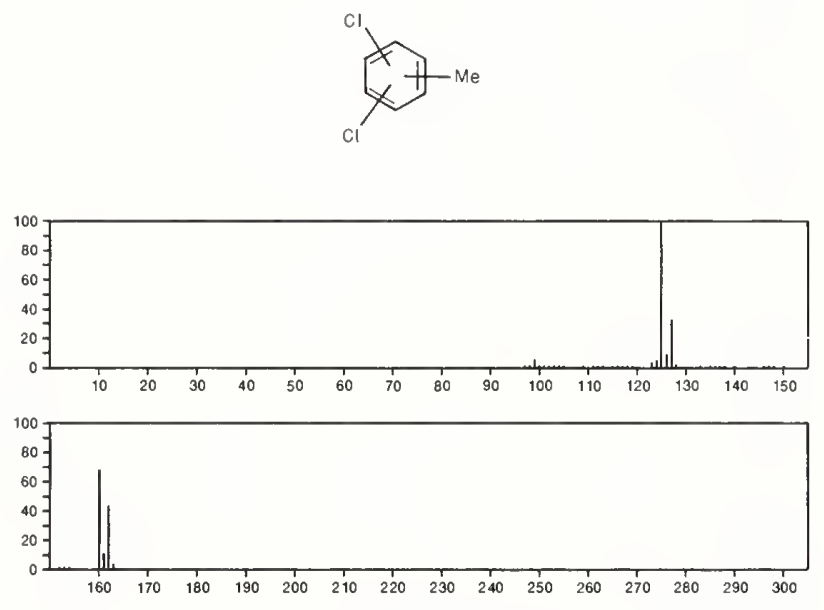

$160 \quad \mathrm{C}_{7} \mathrm{H}_{9} \mathrm{BN}_{4}$

$\Delta^{2-T e t r a z a b o r o l i n e, ~ 1-m e t h y l-4-p h e n y l-~}$
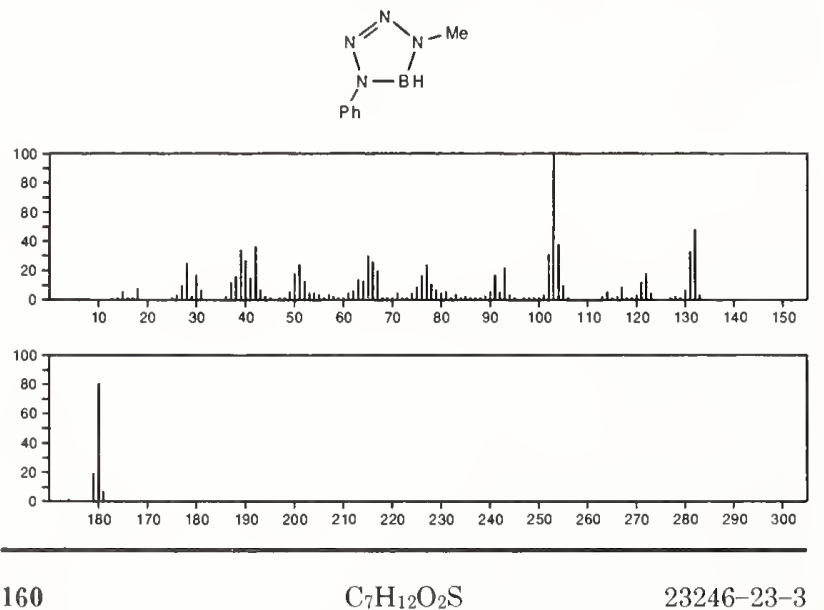

Propionic acid, 3-(allylthio)-, methyl ester

$23246-23-3$

$\mathrm{MeOC}(\mathrm{O}) \mathrm{CH}_{2} \mathrm{CH}_{2} \mathrm{SCH}_{2} \mathrm{CH}=\mathrm{CH}_{2}$

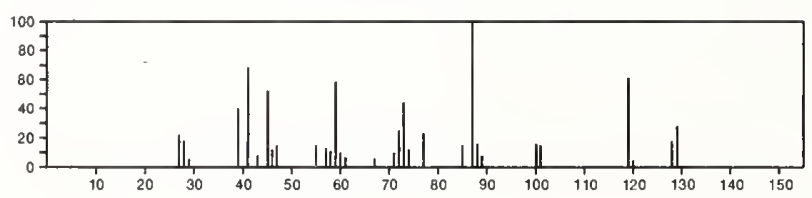

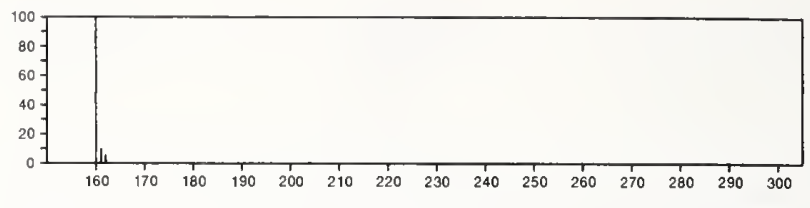

160

$\mathrm{C}_{7} \mathrm{H}_{12} \mathrm{O}_{2} \mathrm{~S}$

1,4-Oxathiepan-2-one, 3,3-dimethyl-

$35562-79-9$
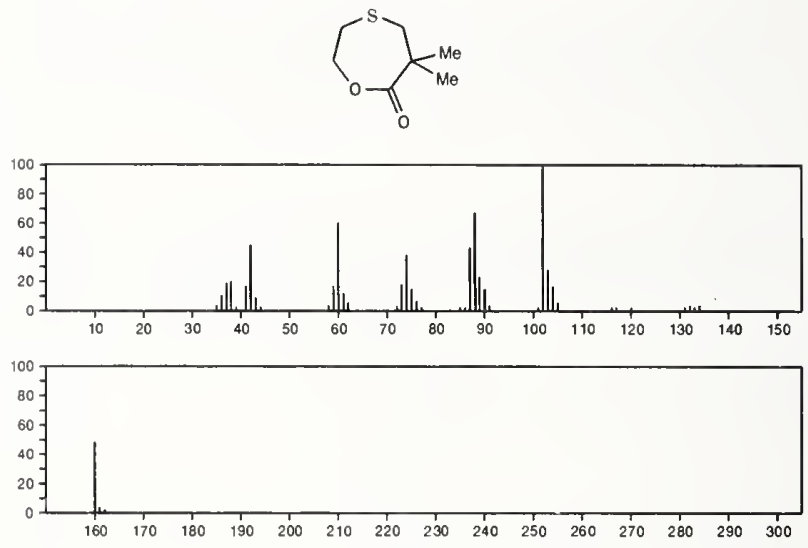

160

$\mathrm{C}_{7} \mathrm{H}_{12} \mathrm{O}_{4}$

$105-53-3$

Propanedioic acid, diethyl ester

$\mathrm{E}$ I OC (O) $\mathrm{CH}_{2} \mathrm{C}(\mathrm{O}) \mathrm{OE}$ :
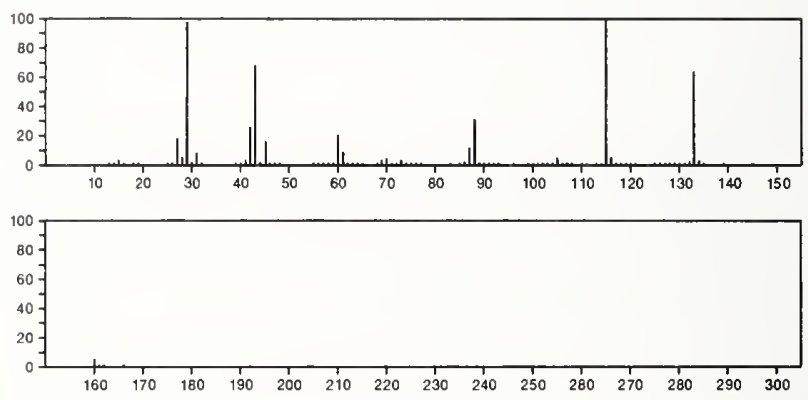

160

Heptanedioic acid

$\mathrm{C}_{7} \mathrm{H}_{12} \mathrm{O}_{4}$

111-16-0

$\mathrm{HO}_{2} \mathrm{C}\left(\mathrm{CH}_{2}\right)_{5} \mathrm{CO}_{2} \mathrm{H}$

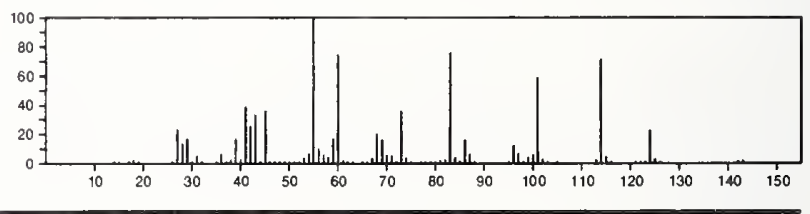

160

1,3-Propanediol, diacetate

$\mathrm{C}_{7} \mathrm{H}_{12} \mathrm{O}_{4}$

628-66-0

$\mathrm{ACO}\left(\mathrm{CH}_{2}\right)_{3} \mathrm{OAC}$
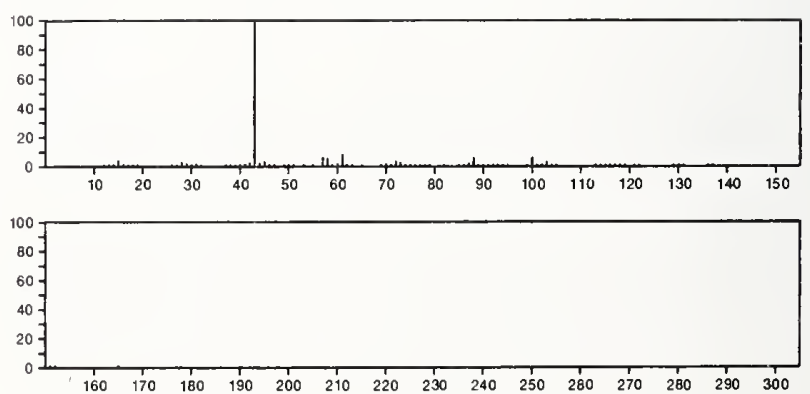
160 $\mathrm{C}_{7} \mathrm{H}_{12} \mathrm{O}_{4}$

$1119-40-0$

Pentanedioic acid, dimethyl ester

$\mathrm{MeOC}(\mathrm{O})\left(\mathrm{CH}_{2}\right)_{3} \mathrm{C}(\mathrm{O}) \mathrm{OMe}$

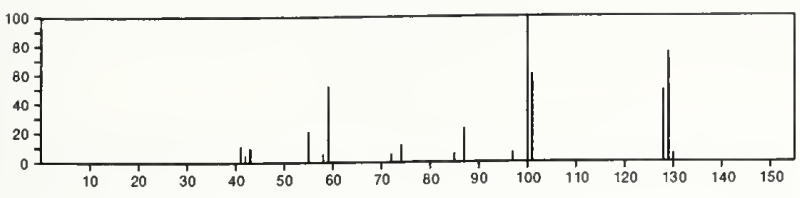

160

$\mathrm{C}_{7} \mathrm{H}_{12} \mathrm{O}_{4}$

$1604-11-1$

Butanedioic acid, methyl--, dimethyl ester

$\mathrm{MeOC}(0) \mathrm{CH}_{2} \mathrm{CHMe} C(\mathrm{O}) \mathrm{OMe}$
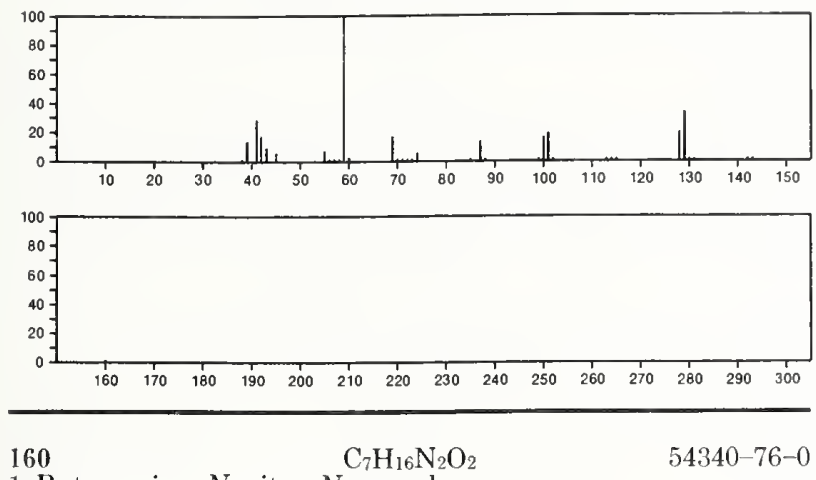

1-Butanamine, $N$-nitro- $N$-propyl-

$\operatorname{PrN}\left(\mathrm{NO}_{2}\right)\left(\mathrm{CH}_{2}\right) 3 \mathrm{Me}$
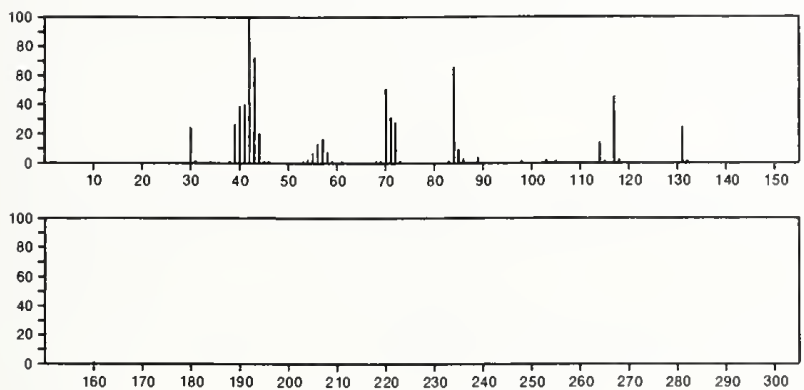

160

160

$\mathrm{C}_{7} \mathrm{H}_{16} \mathrm{~N}_{2} \mathrm{~S}$

$26536-60-7$

PrNHCSNHPT
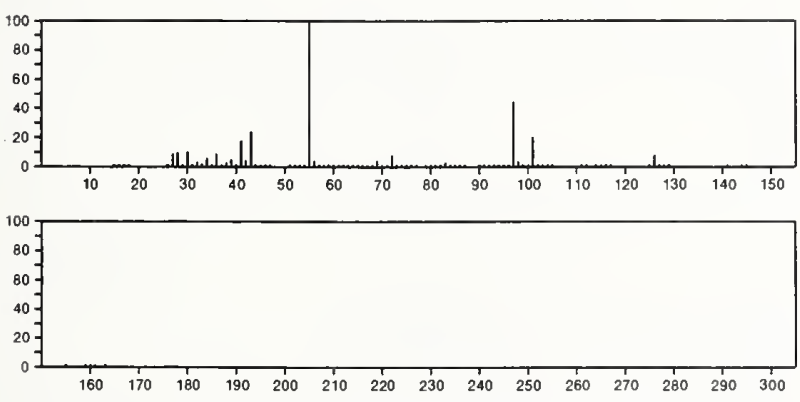

160

$\mathrm{C}_{7} \mathrm{H}_{16} \mathrm{O}_{2} \mathrm{Si}$

$16844-99-8$

Butanoic acid, trimethylsilyl ester

$\mathrm{Me} 3 \mathrm{SiOC}(0) \mathrm{Pr}$

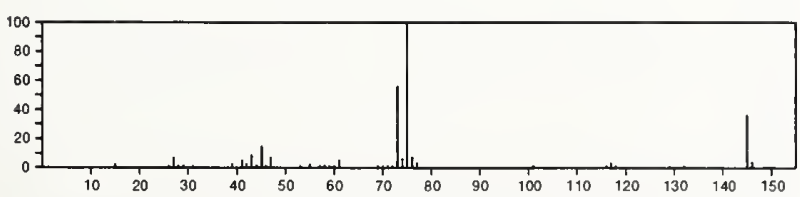

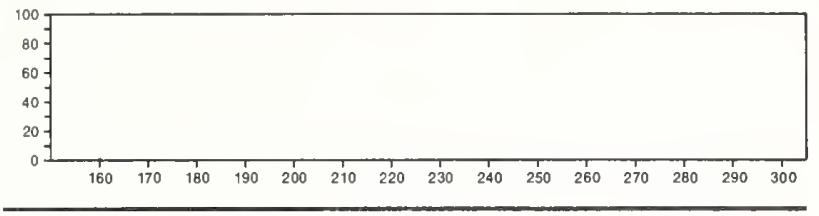

160

$\mathrm{C}_{7} \mathrm{H}_{16} \mathrm{O}_{2} \mathrm{Si}$

$16883-61-7$

Propanoic acid, 2-methyl--, trimethylsilyl ester

$\mathrm{Me}_{3} \mathrm{Si} \mathrm{OC}(\mathrm{O}) \mathrm{CHMe}_{2}$
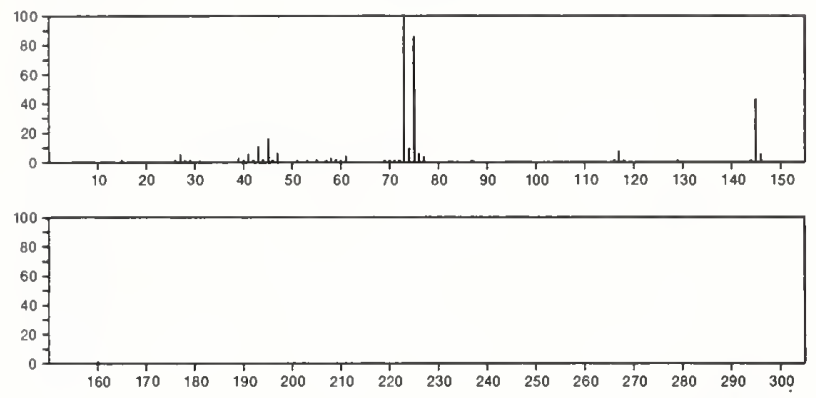

160

$\mathrm{C}_{7} \mathrm{H}_{20} \mathrm{Si}_{2}$

2117-28-4

Silane, methylenebis[trimethyl-

$\mathrm{Me}_{3} \mathrm{Si} \mathrm{CH}_{2} \mathrm{SiMe}_{3}$
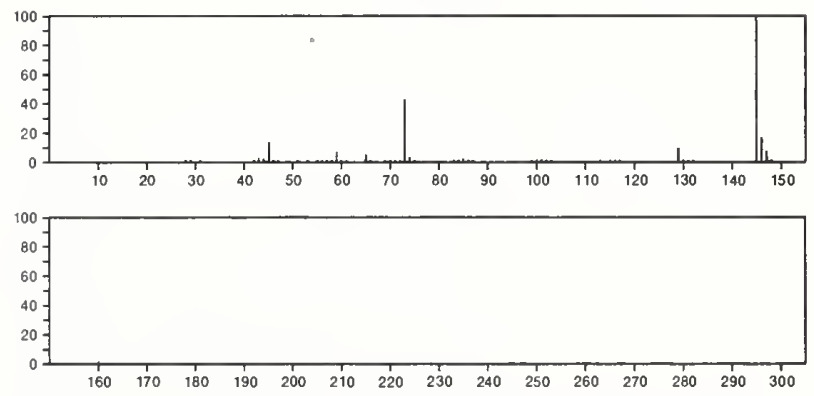

160

Disilane, ethylpentamethyl-

$\mathrm{C}_{7} \mathrm{H}_{20} \mathrm{Si}_{2}$

$15063-64-6$

Me 3 SISIE:Me2
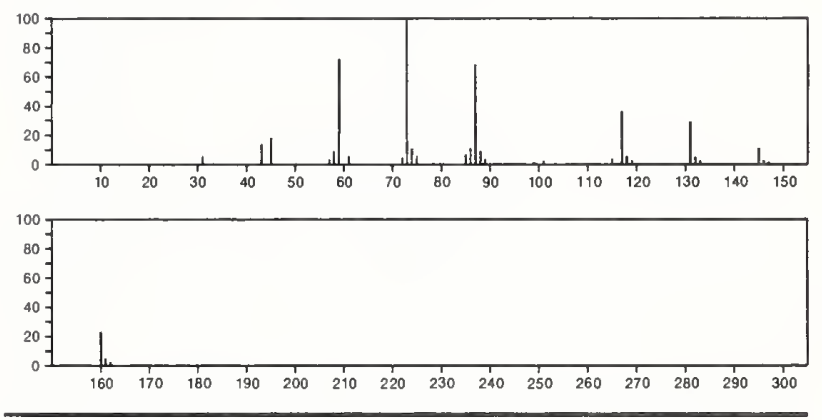

160

$\mathrm{C}_{8} \mathrm{H}_{4} \mathrm{~N}_{2} \mathrm{O}_{2}$

$104-49-4$

Benzene, 1,4 diisocyanato-
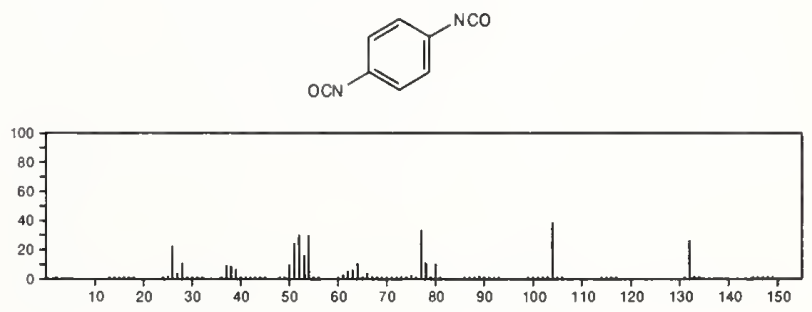


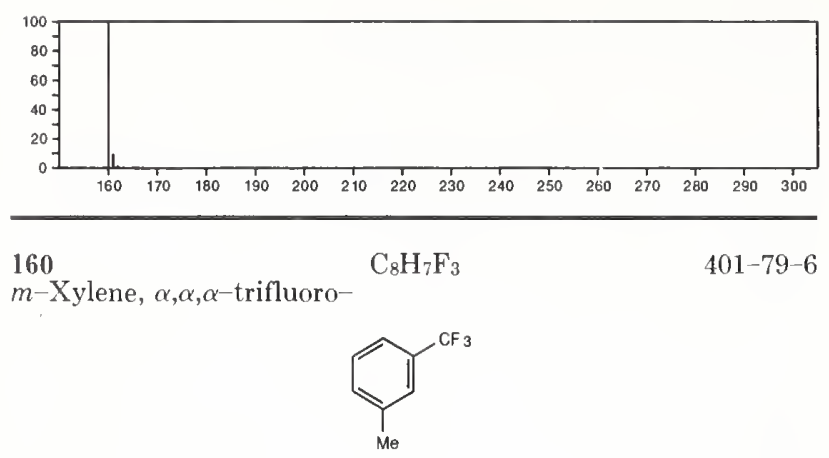

160

1,4-Phthalazinediamine

$\mathrm{C}_{8} \mathrm{H}_{8} \mathrm{~N}_{4}$

$17987-70-1$
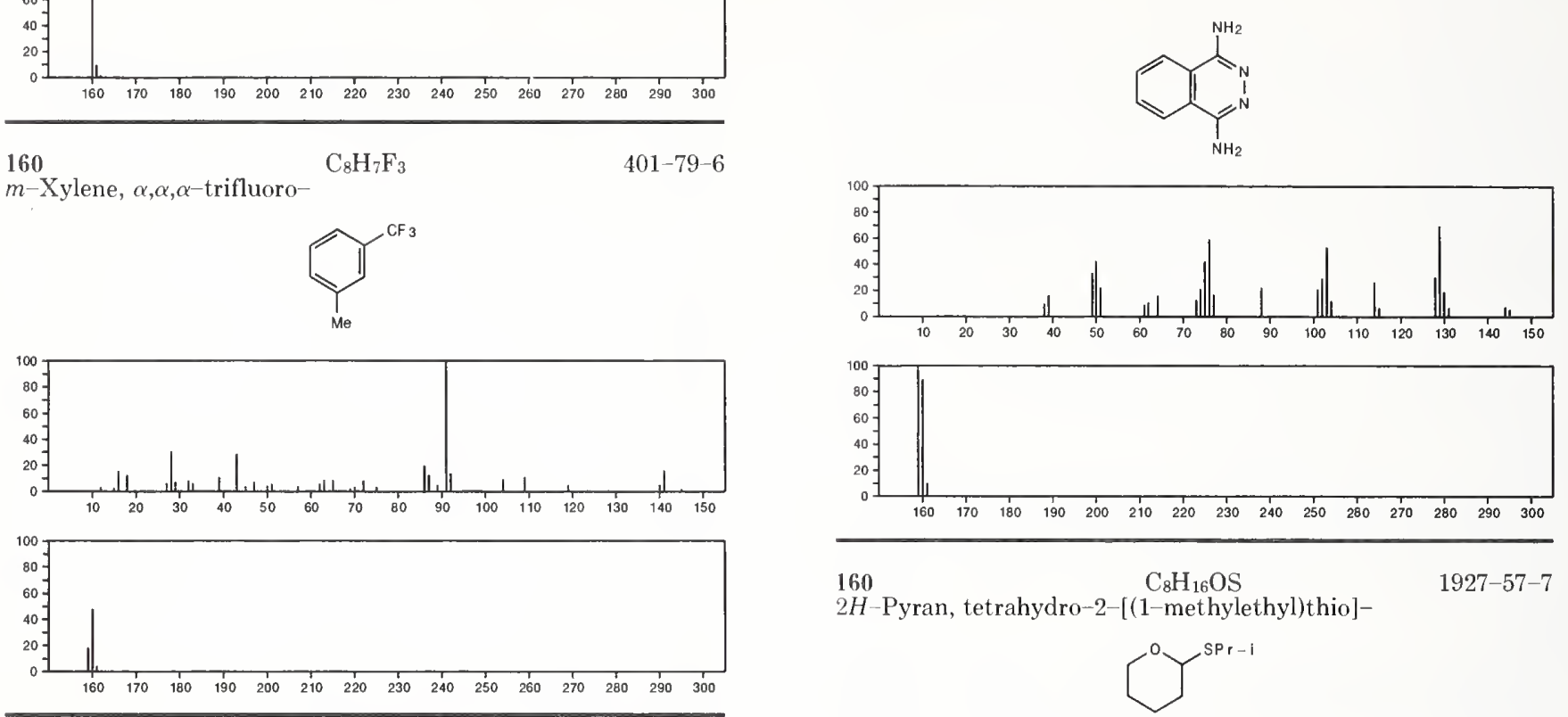

160

$\mathrm{C}_{8} \mathrm{H}_{7} \mathrm{~F}_{3}$

6140-17-6

Benzene, 1-methyl-4-(trifluoromethyl)-
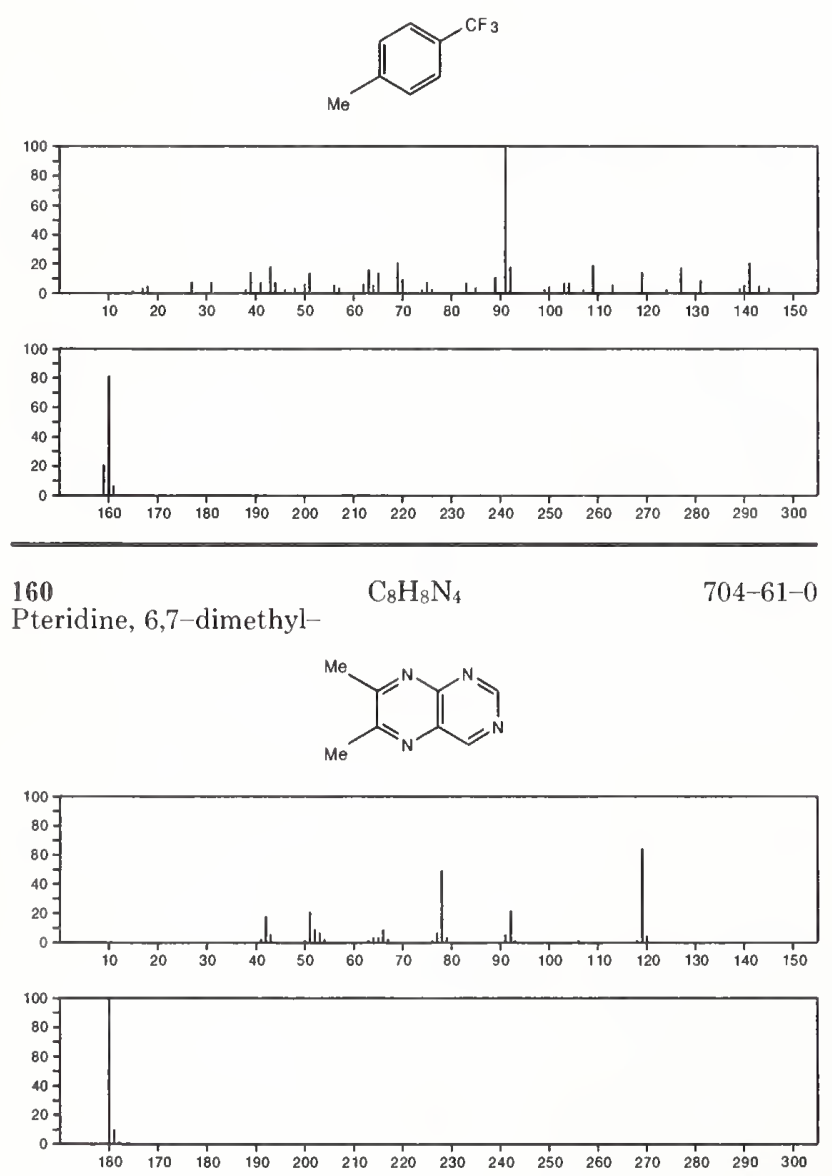

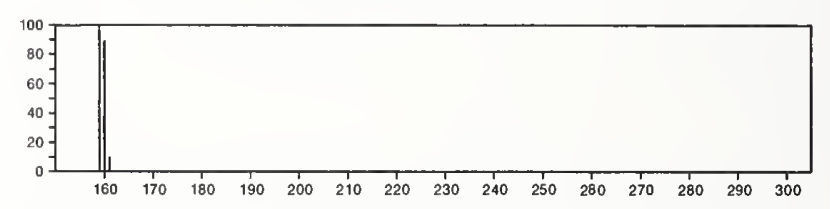

2H-Pyran, tetrahydro-2-[(1-methylethyl)thio]-
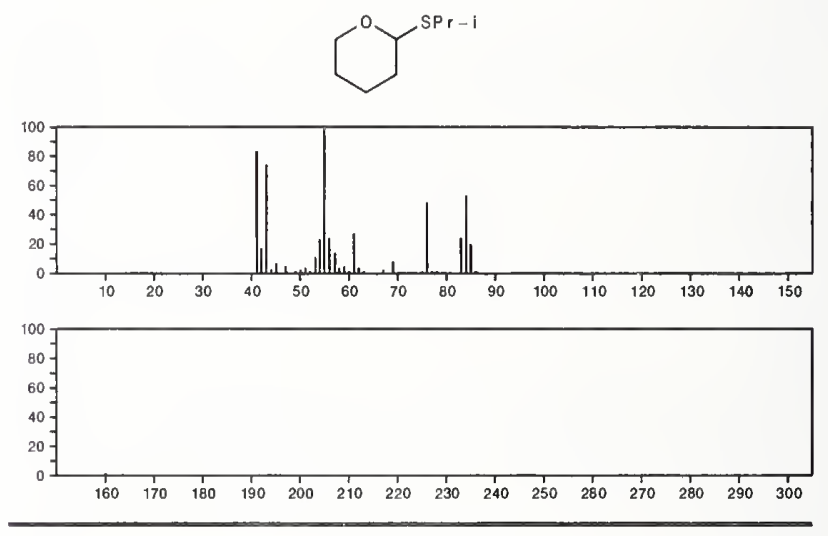

160

Acetic acid, thio-, $S$-hexyl ester

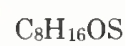

2307-12-2

$\mathrm{Me}\left(\mathrm{CH}_{2}\right) 5 \mathrm{SAC}$
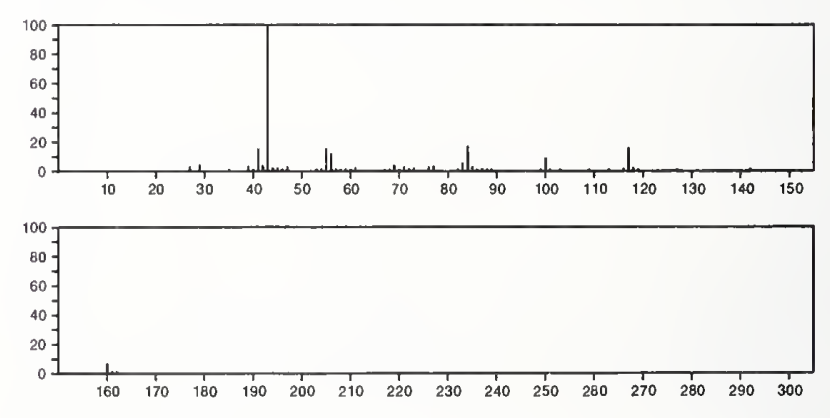

160

$\mathrm{C}_{8} \mathrm{H}_{16} \mathrm{OS}$

Propionic acid, thio-, $S$-isopentyl ester

$2432-49-7$

$\mathrm{Me}_{2} \mathrm{CHCH}_{2} \mathrm{CH}_{2} \mathrm{SC}(\mathrm{O}) \mathrm{Et}$
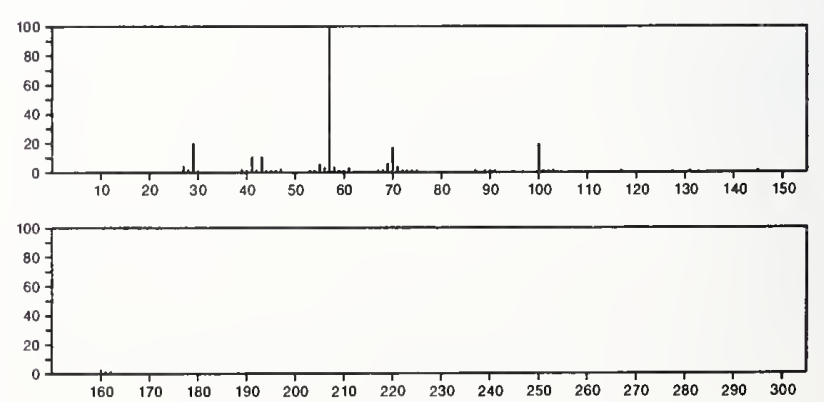

$160 \quad \mathrm{C}_{8} \mathrm{H}_{16} \mathrm{OS} \quad 1927-57-7$ 
160

$\mathrm{C}_{8} \mathrm{H}_{16} \mathrm{OS}$

Butyric acid, thio--, $S$-sec-butyl ester

$\operatorname{PrCl}(\mathrm{O}) \mathrm{S}\left(\mathrm{CH}_{2}\right)_{3} \mathrm{Me}$
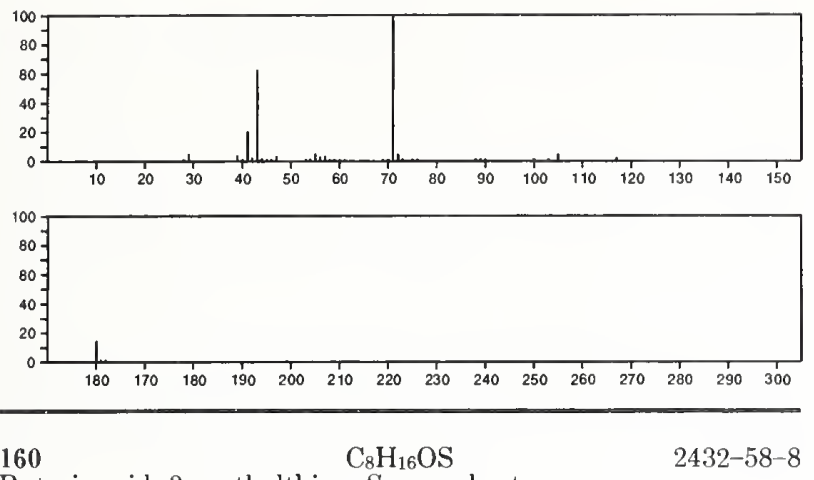

Butyric acid, 3-methylthio-, $S$-propyl ester

$\mathrm{Me}_{2} \mathrm{CHCH}_{2} \mathrm{C}(\mathrm{O}) \mathrm{SPr}$
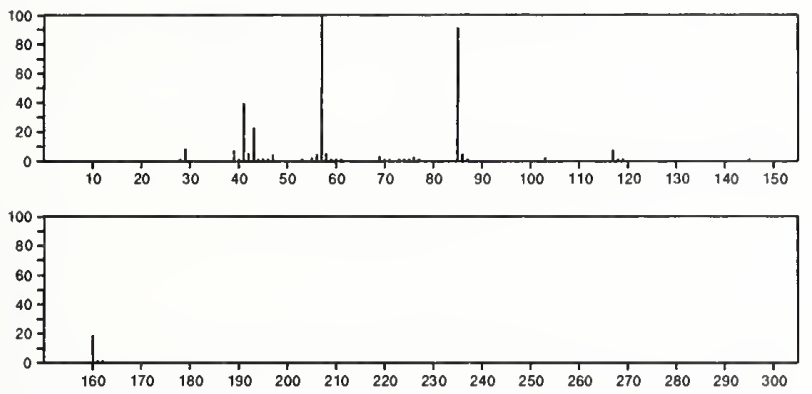

160

Pentanethioic acid, $S$-propyl ester

$\mathrm{Me}\left(\mathrm{CH}_{2}\right)_{3} \mathrm{C}(\mathrm{O}) \mathrm{SPr}$
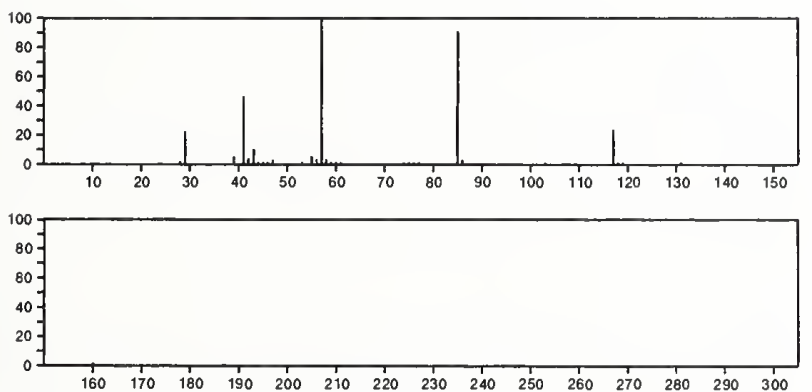

$\begin{array}{lllllllllllllll}160 & 170 & 180 & 190 & 200 & 210 & 220 & 230 & 240 & 250 & 260 & 270 & 280 & 290 & 300\end{array}$

160

$\mathrm{C}_{8} \mathrm{H}_{16} \mathrm{OS}$

$2432-82-8$

Heptanethioic acid, $S$-methyl ester

$\mathrm{Me}\left(\mathrm{CH}_{2}\right){ }_{5} \mathrm{C}(\mathrm{O}) \mathrm{SMe}$
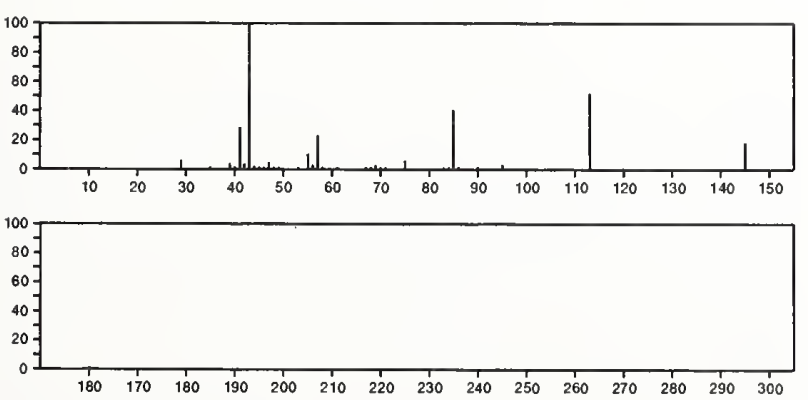

160

$\mathrm{C}_{8} \mathrm{H}_{16} \mathrm{OS}$

$2450-12-6$

Hexanethioic acid, $S$-ethyl ester

$\mathrm{M}\left\langle\mathrm{CH}_{2}\right){ }_{4} \mathrm{C}(\mathrm{O}) \mathrm{SE}$
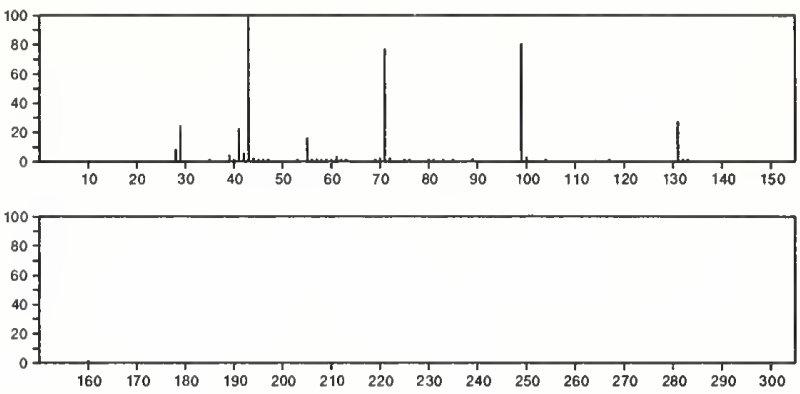

$160 \quad \mathrm{C}_{8} \mathrm{H}_{16} \mathrm{OS}$

Propanethioic acid, $S$-pentyl ester

$2602-64-4$

$\mathrm{E} t \mathrm{C}(\mathrm{O}) \mathrm{S}\left(\mathrm{CH}_{2}\right)_{4} \mathrm{Me}$
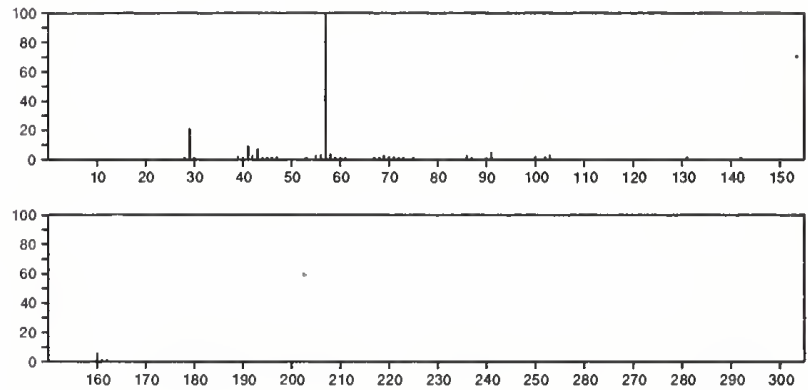

160

$\mathrm{C}_{8} \mathrm{H}_{16} \mathrm{OS}$

$6330-43-4$

Butanethioic acid, $S$-(1,1-dimethylethyl) ester

t-Busc(0) Pr
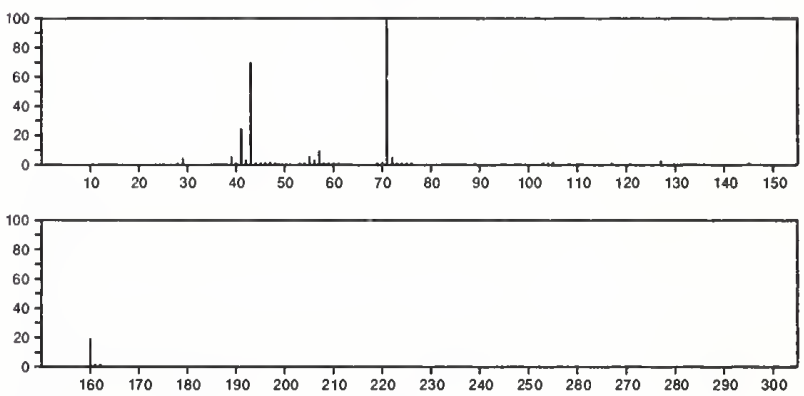

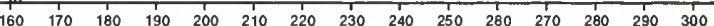

$160 \quad \mathrm{C}_{8} \mathrm{H}_{16} \mathrm{OS}$

1,3-Oxathiane, 2-ethyl-2,6-dimethyl-, cis-

$30032-10-1$
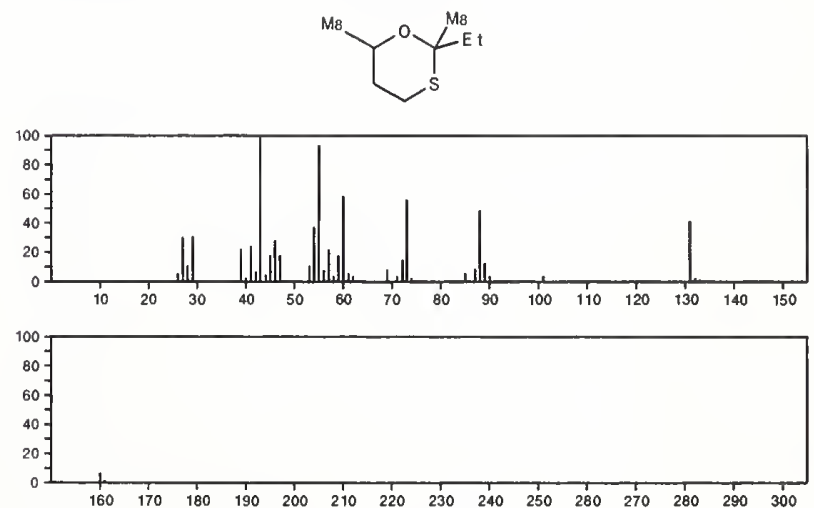
160

$\mathrm{C}_{8} \mathrm{H}_{16} \mathrm{OS}$

$30032-11-2$

1,3-Oxathiane, 2-ethyl-2,6-dimethyl-, trans-
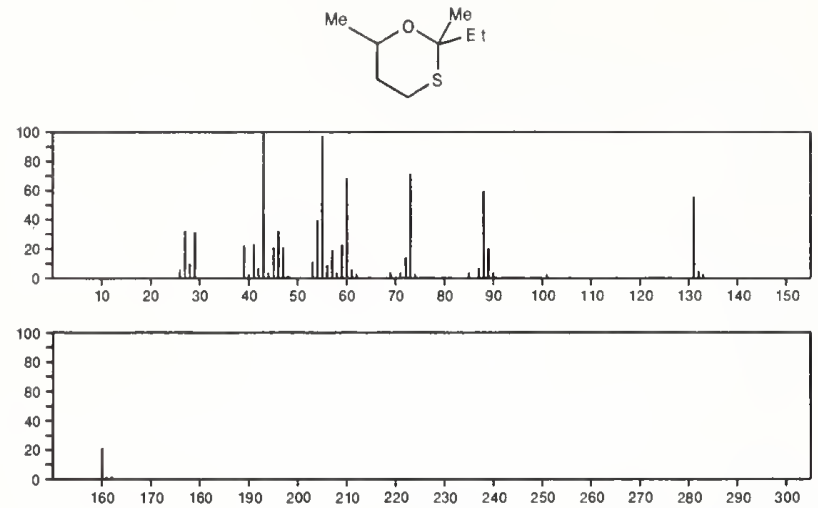

160

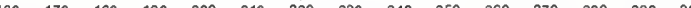

1,3-Oxathiane, 2-methyl-2-(1-methylethyl)
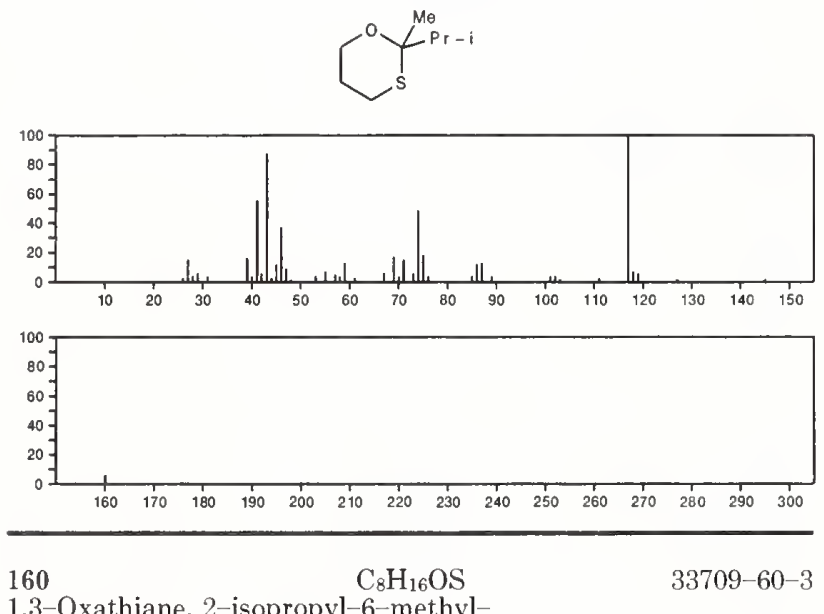

1,3-Oxathiane, 2-isopropyl-6-methyl-
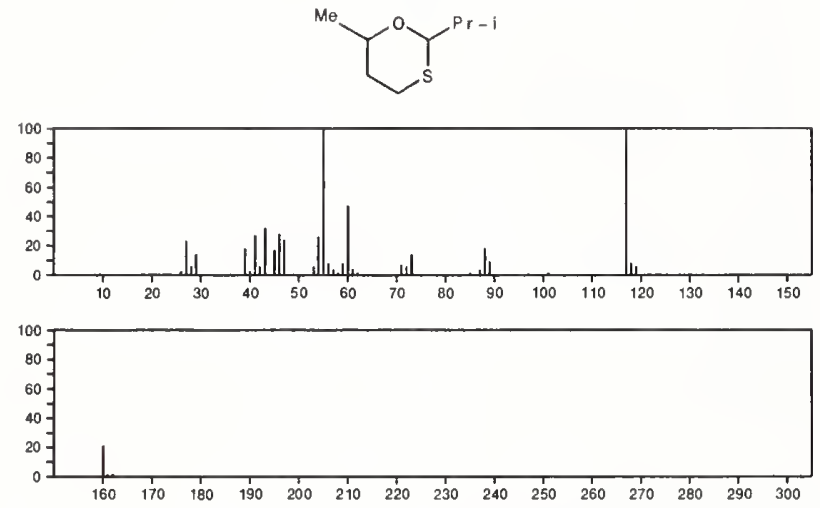

$160 \quad \mathrm{C}_{8} \mathrm{H}_{16} \mathrm{OS}$

1,3-Oxathiane, 2,2,4,6-tetramethyl-, cis-

$34560-79-7$<smiles>CC1CC([N])OC(C)(N)S1</smiles>

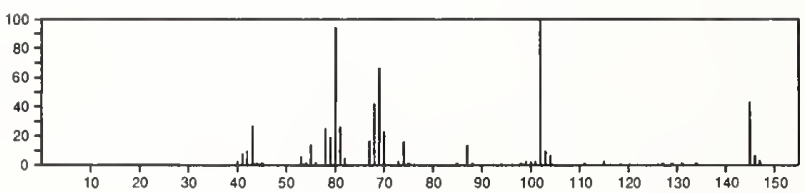

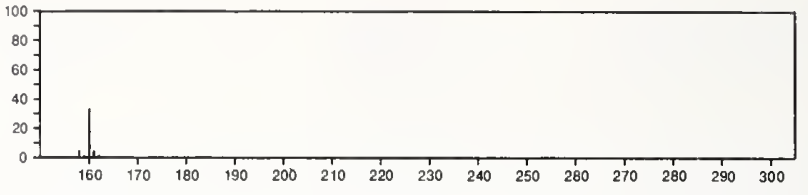

$\mathrm{C}_{8} \mathrm{H}_{16} \mathrm{OS}$

$55590-84-6$

Ethanethioic acid, $S$-(1-ethylbutyl) ester

ACSCHPrE
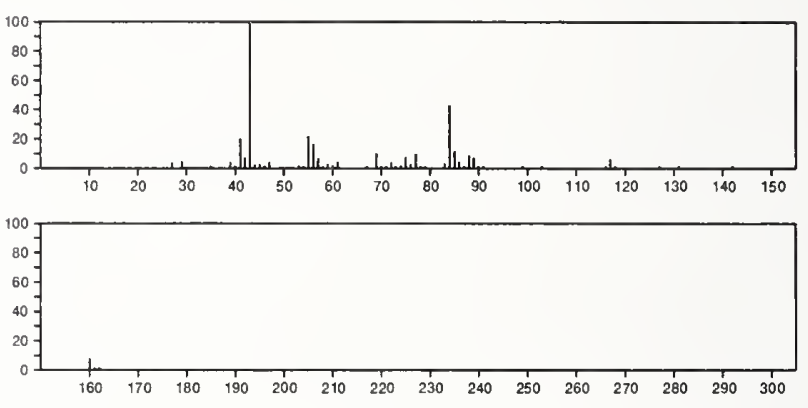

160

$\mathrm{C}_{8} \mathrm{H}_{16} \mathrm{OS}$

$56052-25-6$

2-Propanone, 1-(pentylthio)-

$\mathrm{MeCOCH}_{2} \mathrm{~S}\left(\mathrm{CH}_{2}\right)_{4} \mathrm{Me}$
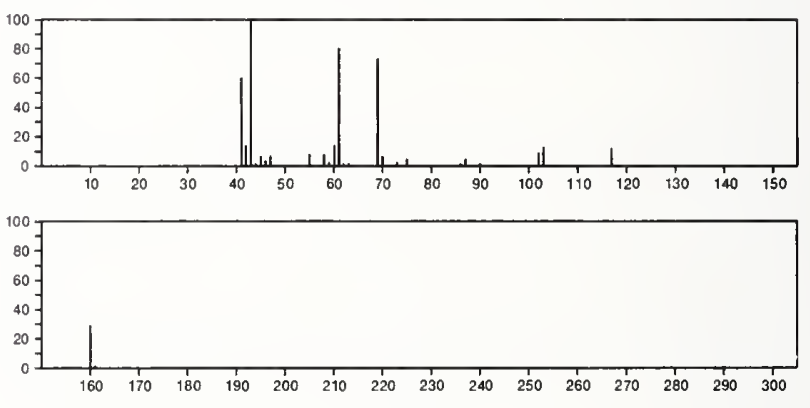

160

$\mathrm{C}_{8} \mathrm{H}_{16} \mathrm{O}_{3}$

764-89-6

Octanoic acid, 8-hydroxy-

$\mathrm{HO}_{2} \mathrm{C}\left(\mathrm{CH}_{2}\right)>\mathrm{OH}$

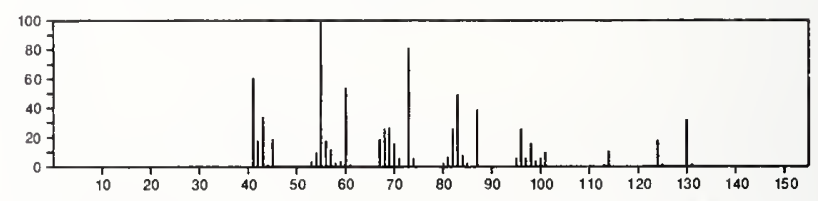

160

$\mathrm{C}_{8} \mathrm{H}_{16} \mathrm{O}_{3}$

$3320-90-9$

Furan, 2,5-diethoxytetrahydro-
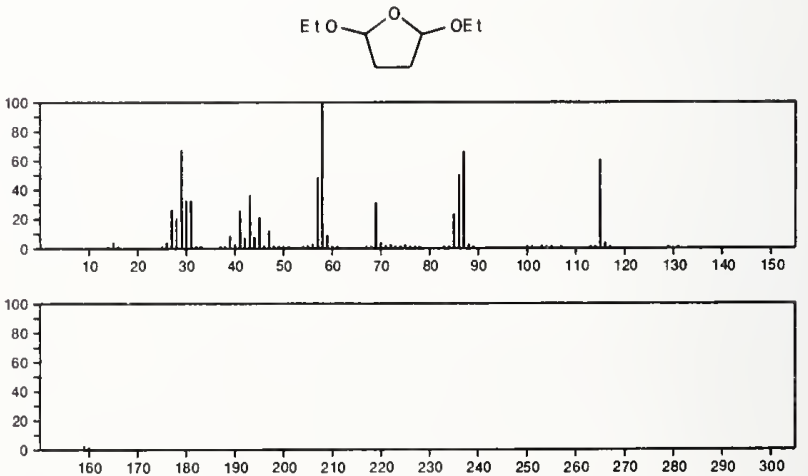
160

$\mathrm{C}_{8} \mathrm{H}_{16} \mathrm{O}_{3}$

1,3-Dioxolane-2-butanol, 2-methyl-

$5745-75-5$<smiles>CC1(CO)OCCO1</smiles>

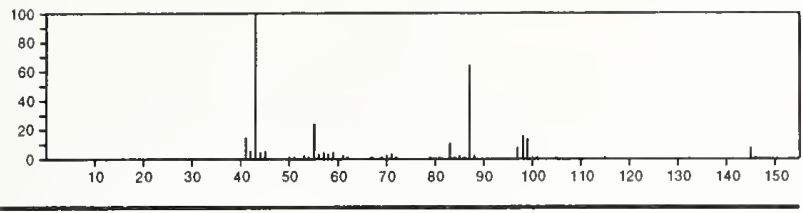

160

$\mathrm{C}_{8} \mathrm{H}_{16} \mathrm{O}_{3}$

17639-74-6

Acetic acid, (1-methylethoxy)-, 1-methylethyl ester

$\mathrm{i}-8 \mathrm{rOCH}_{2} \mathrm{C}(\mathrm{O}) \mathrm{OPr}-$
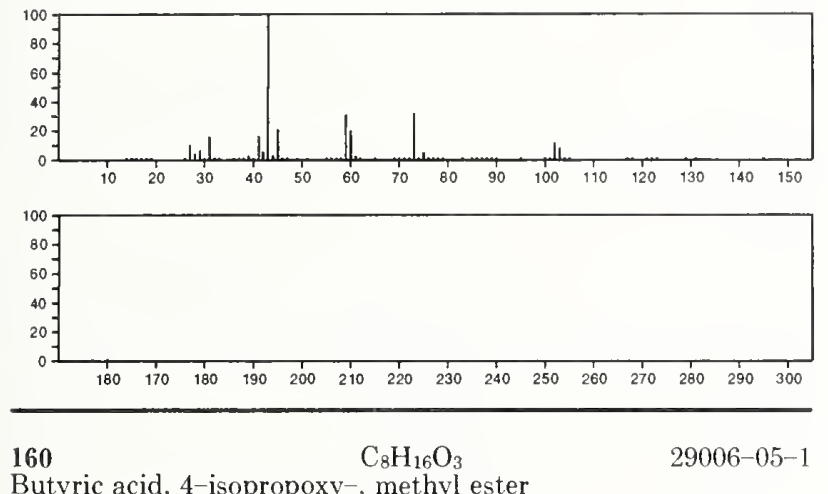

Butyric acid, 4-isopropoxy-, methyl ester

$$
\text { i }-\mathrm{PrO}\left(\mathrm{CH}_{2}\right)_{3} \mathrm{C}(\mathrm{O}) \mathrm{OMe}
$$

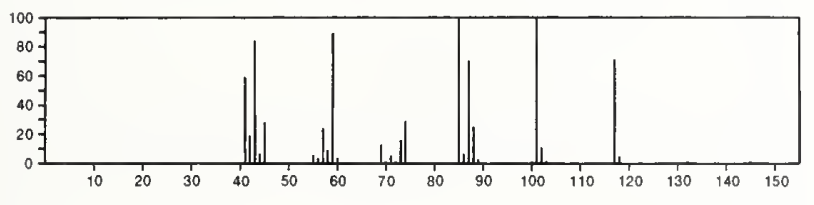

160

$\mathrm{C}_{8} \mathrm{H}_{16} \mathrm{O}_{3}$

$29887-58-9$

Cyclopentane, 1,2,3-trimethoxy-, stereoisomer
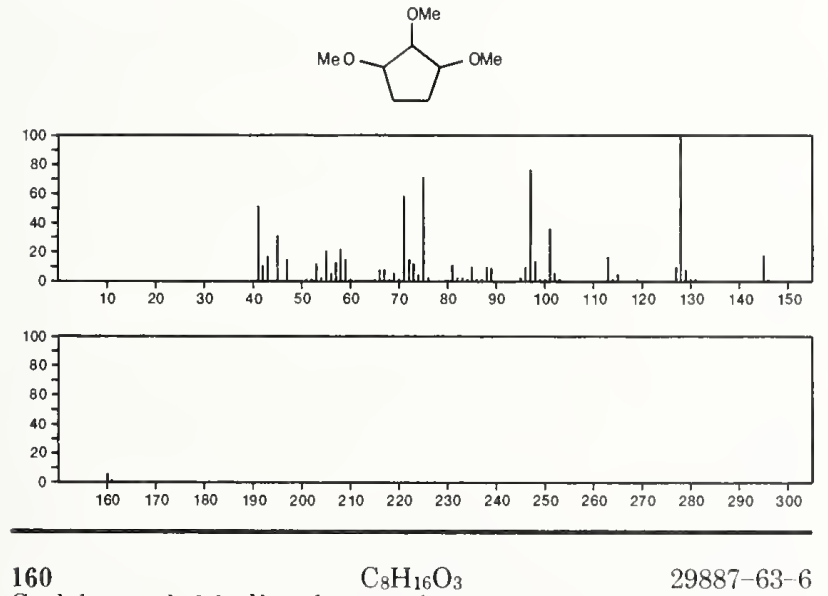

Cyclohexanol, 3,5-dimethoxy-, cis-1,3,trans-1,5-
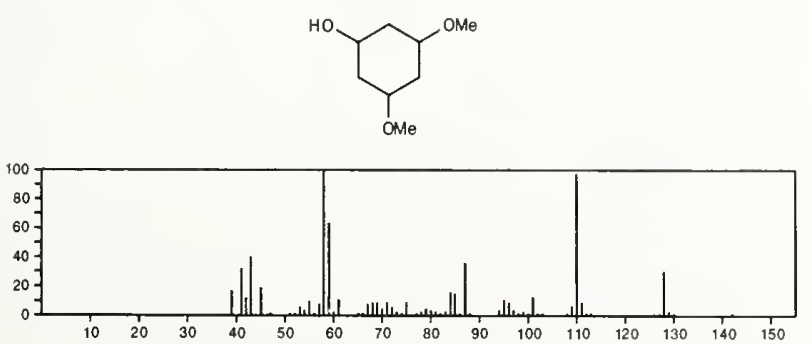

160

$\mathrm{C}_{8} \mathrm{H}_{16} \mathrm{O}_{3}$

$30363-64-5$

Cyclohexanol, 3.5-dimethoxy-, stereoisomer<smiles>COC1CC(O)CC(O)C1</smiles>

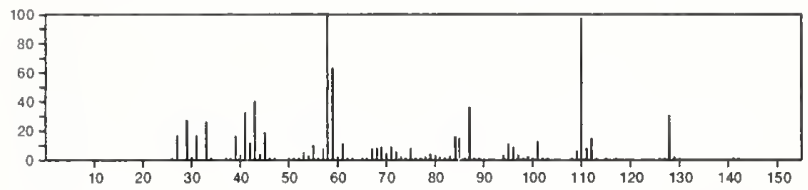

160

$\mathrm{C}_{8} \mathrm{H}_{16} \mathrm{O}_{3}$

$30363-83-8$

Cyclohexanol, 3,5-dimethoxy-, stereoisomer<smiles>COC1CC(O)CC(O)C1</smiles>
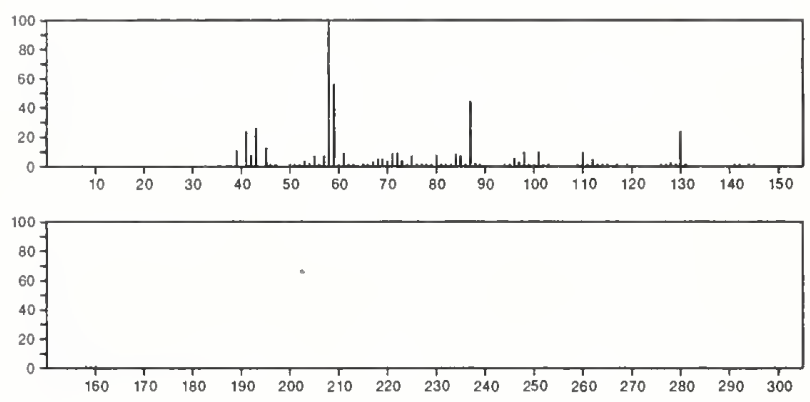

$160 \quad \mathrm{C}_{8} \mathrm{H}_{16} \mathrm{O}_{3} \quad 30517-18-1$ Cyclohexanol, 3,5-dimethoxy-, stereoisomer<smiles>COC1CC(O)CC(O)C1</smiles>
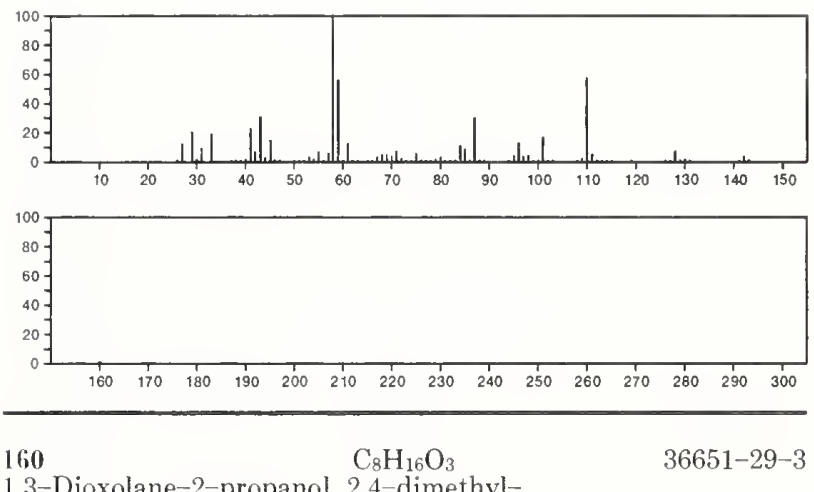

1,3-Dioxolane-2-propanol, 2,4-dimethyl-
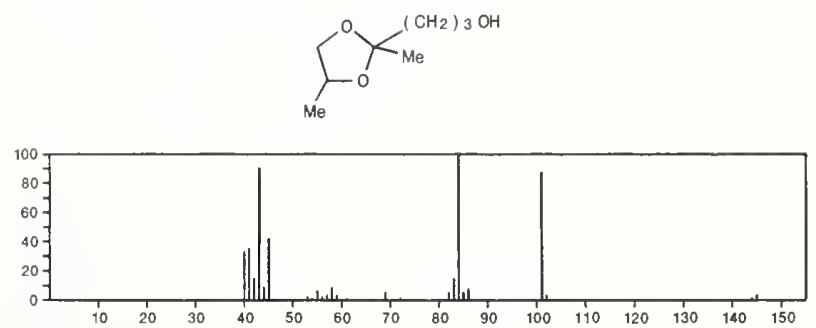
160

$\mathrm{C}_{8} \mathrm{H}_{16} \mathrm{O}_{3}$

1,3-Dioxane-2-propanol, 2-methyl-
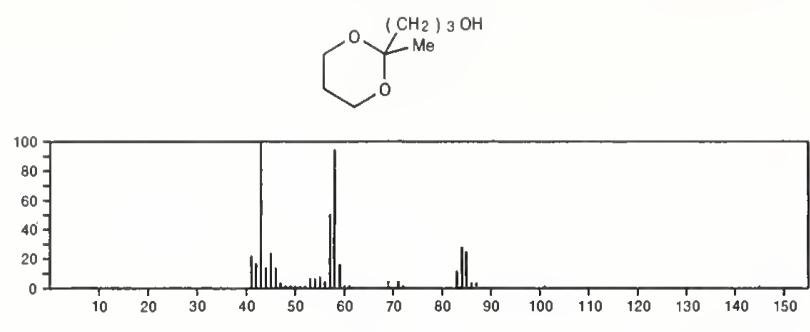

$160 \quad \mathrm{C}_{8} \mathrm{H}_{16} \mathrm{O}$

1,3-Dioxolane-2-propanol, $\alpha, 2$-dimethyl-

$54632-67-6$

$$
\sum_{0}^{\mathrm{O}} \mathrm{CH}_{\mathrm{Me}}^{\mathrm{CH}_{2} \mathrm{CH}_{2} \mathrm{CH}(\mathrm{OH}) \mathrm{Me}}
$$

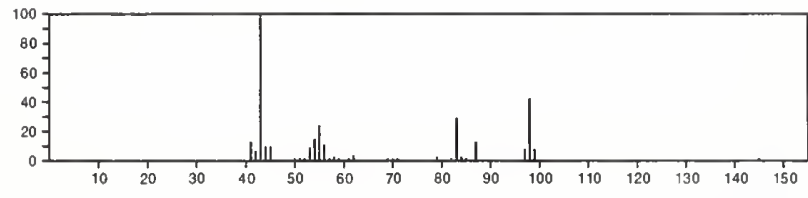

$160 \quad \mathrm{C}_{8} \mathrm{H}_{16} \mathrm{O}_{3} \quad 54751-80-3$

1,3-Dioxolane, 2-(3-methoxypropyl)-2-methyl
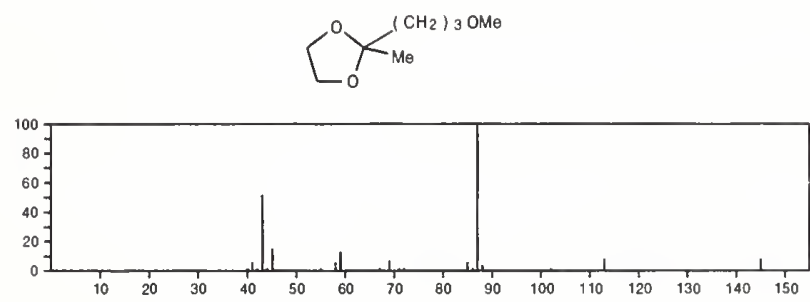

\section{0}

Butanoic acid, 4-butoxy-

$\mathrm{C}_{8} \mathrm{H}_{16} \mathrm{O}_{3}$

$55724-73-7$

$\mathrm{HO}_{2} \mathrm{C}\left(\mathrm{CH}_{2}\right)_{3} \mathrm{O}\left(\mathrm{CH}_{2}\right)_{3} \mathrm{Me}$
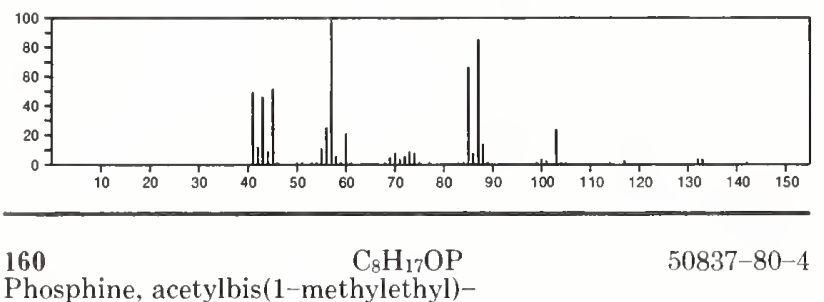

Phosphine, acetylbis(1-methylethyl)-

$-\operatorname{Pr} 2$ PAC
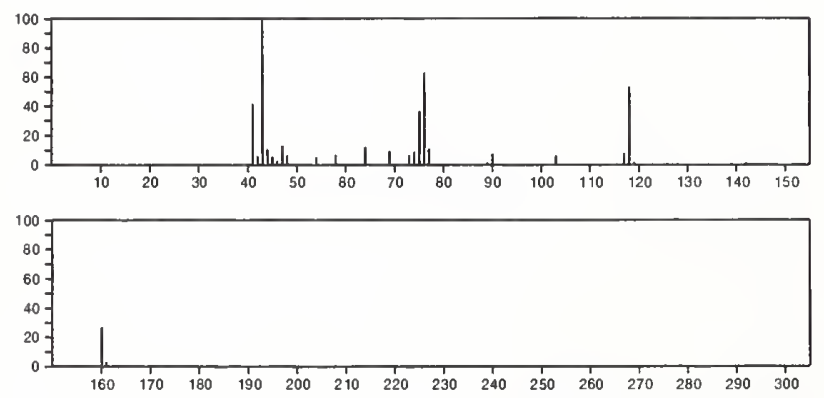

160

$\mathrm{C}_{8} \mathrm{H}_{20} \mathrm{~N}_{2} \mathrm{O}$

Ethanamine, 2,2'-oxybis [ $N, N$-dimethyl-

$3033-62-3$

$\mathrm{Me}_{2} \mathrm{NCH}_{2} \mathrm{CH}_{2} \mathrm{OCH}_{2} \mathrm{CH}_{2} \mathrm{NMe}_{2}$

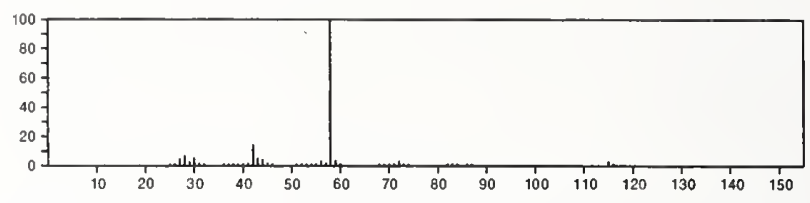

160

$\mathrm{C}_{8} \mathrm{H}_{20} \mathrm{OSi}$

Silane, trimethyl(1-methylbutoxy)

$1825-67-8$

PrCHMe OSIMe 3
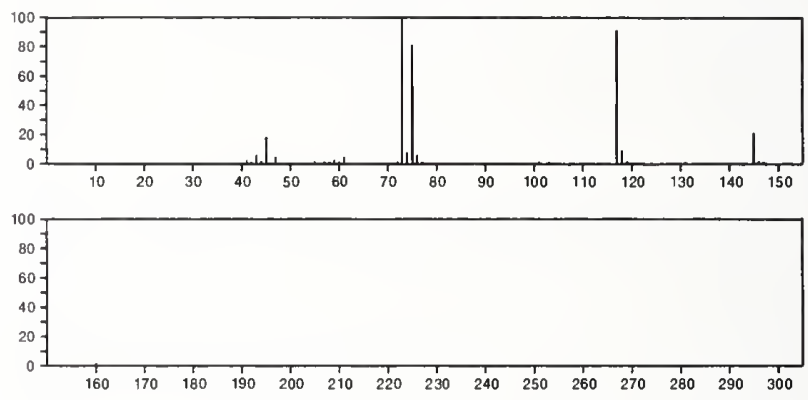

160

$\mathrm{C}_{8} \mathrm{H}_{20} \mathrm{OSi}$

Silane, (1,1-dimethylpropoxy)trimethyl-

6689-16-3

$\mathrm{E}_{\mathrm{C}} \mathrm{CMe}_{2} \mathrm{OSIMe}_{3}$
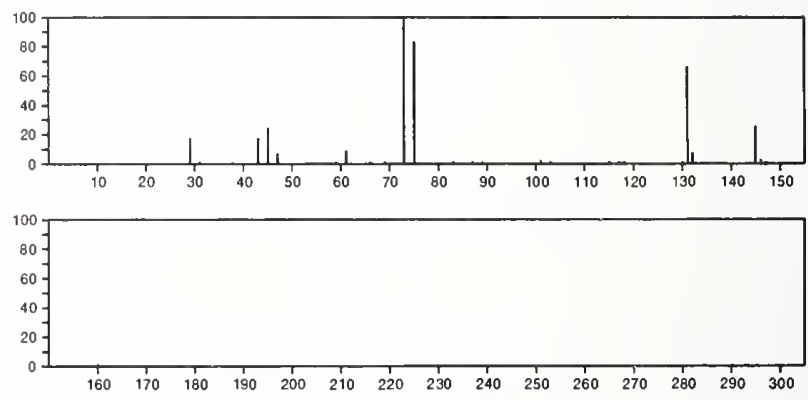

160

$\mathrm{C}_{8} \mathrm{H}_{20} \mathrm{OSi}$

Silane, trimethyl(pentyloxy)-

$14629-45-9$

$\mathrm{Me}\left(\mathrm{CH}_{2}\right)_{4} \mathrm{OSIMe}_{3}$
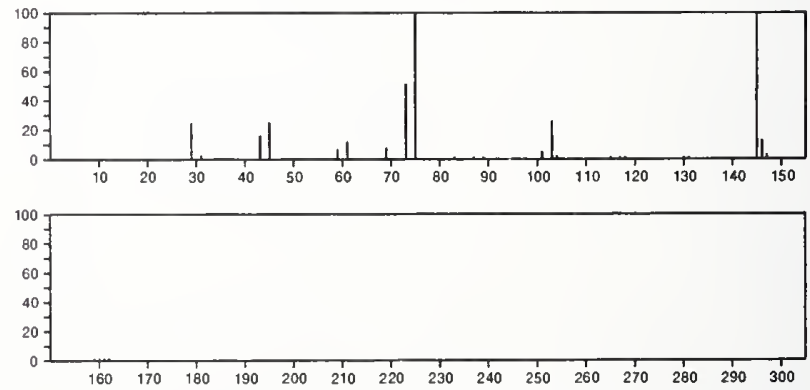

$160 \quad \mathrm{C}_{8} \mathrm{H}_{20} \mathrm{OSi}$

Silane, (sec-butoxymethyl)trimethyl-

17348-64-0

$\mathrm{Me}_{3} \mathrm{Si} \mathrm{CH}_{2} \mathrm{OBu}-\mathrm{s}$

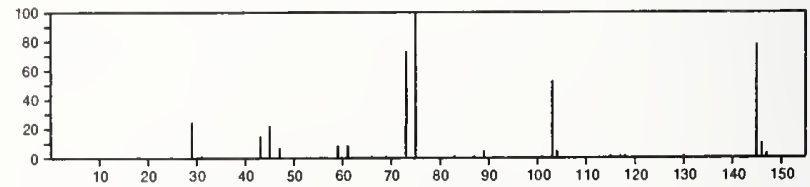




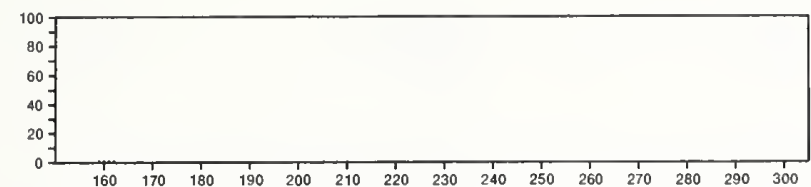

$\begin{array}{lllllllllllllll}160 & 170 & 180 & 190 & 200 & 210 & 220 & 230 & 240 & 250 & 260 & 270 & 280 & 290 & 300\end{array}$

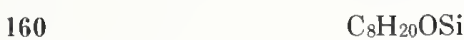

$18246-52-1$

Silane, (butoxymethyl)trimethyl-

$\mathrm{Me}_{3} \mathrm{Si} \mathrm{CH}_{2} \mathrm{O}\left(\mathrm{CH}_{2}\right)_{3} \mathrm{Me}$
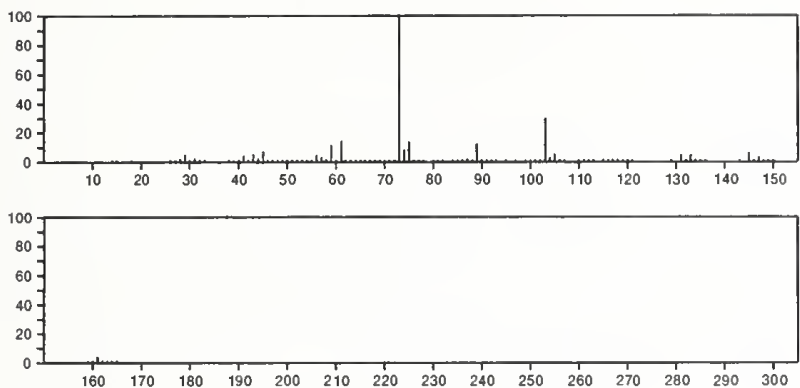

160

$\begin{array}{lllllllllllllll}160 & 170 & 180 & 190 & 200 & 210 & 220 & 230 & 240 & 250 & 260 & 270 & 280 & 290 & 300\end{array}$

$\mathrm{C}_{8} \mathrm{H}_{20} \mathrm{OS}$

$18246-56-5$

$\mathrm{Me}_{3} \mathrm{Si} \mathrm{OCH}_{2} \mathrm{CH}_{2} \mathrm{CHM}_{2}$
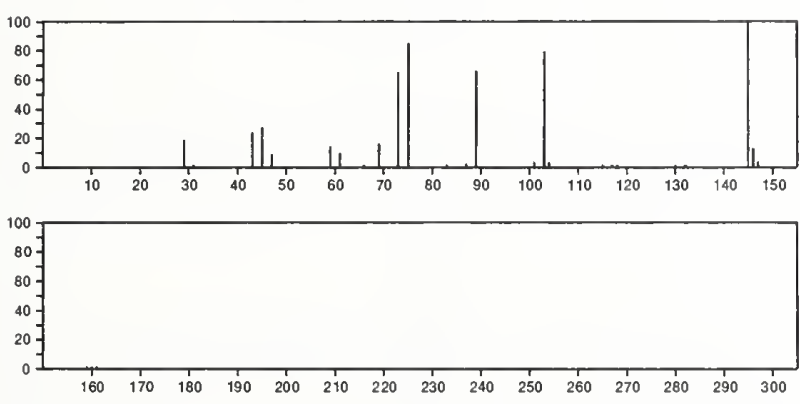

$160 \quad \mathrm{C}_{8} \mathrm{H}_{20} \mathrm{OSi}$

Silane, (2,2-dimethylpropoxy)trimethyl-

$18246-63-4$

$\mathrm{Me}_{3} \mathrm{Si}_{\mathrm{OCH}} \mathrm{CMe}_{3}$
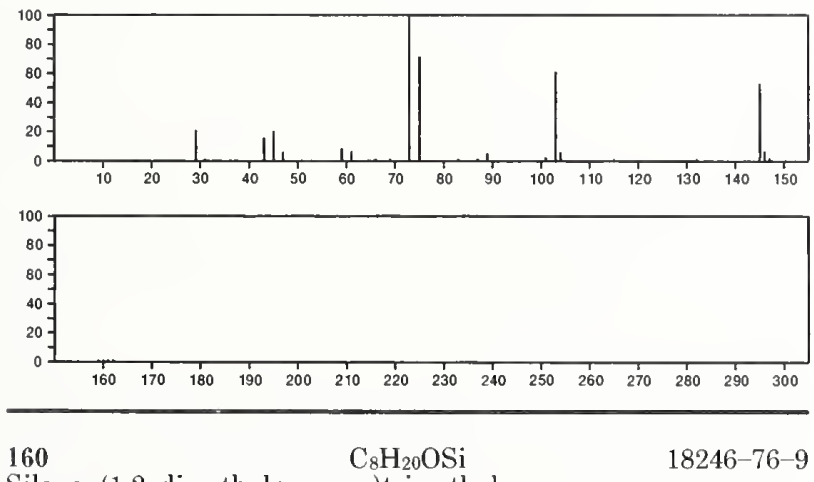

Silane, (1,2-dimethylpropoxy)trimethyl-

$\mathrm{Me} 3 \mathrm{Si}$ OCHMe $\mathrm{CHMe}_{2}$
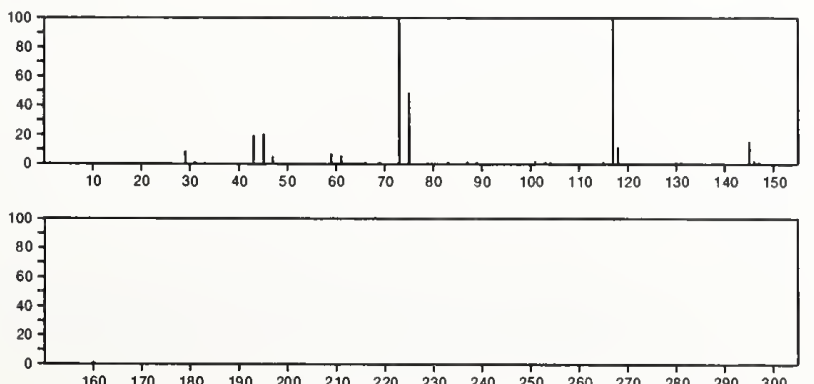

160

$1 H$-Indene-1,2,3-trione

$\mathrm{C}_{9} \mathrm{H}_{4} \mathrm{O}_{3}$

$938-24-9$
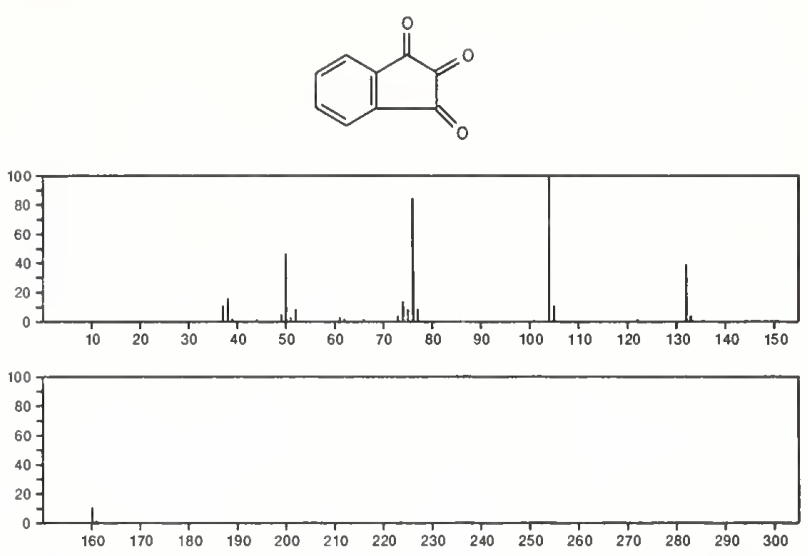

$160 \quad \mathrm{C}_{9} \mathrm{H}_{8} \mathrm{~N}_{2} \mathrm{O}$ 1693-94-3

$4 H$-Pyrido[1,2-a]pyrimidin-4-one, 2-methyl-
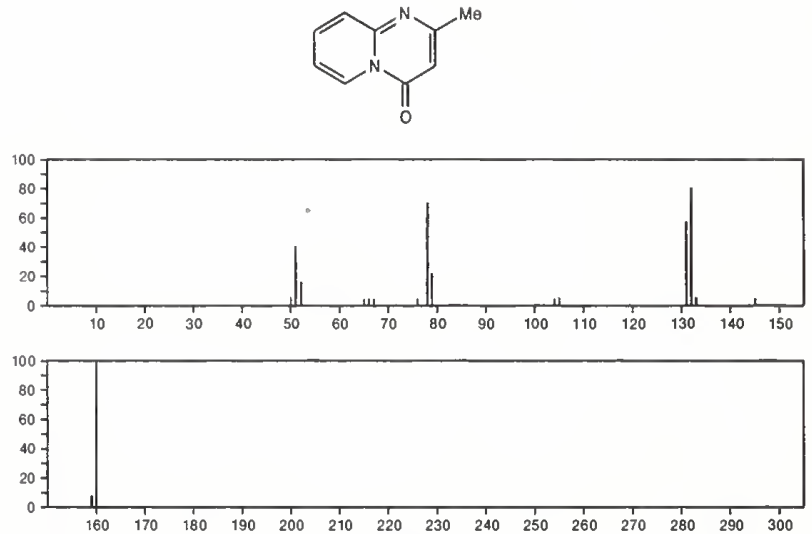

160

$\mathrm{C}_{9} \mathrm{H}_{8} \mathrm{~N}_{2} \mathrm{O}$

4369-55-5
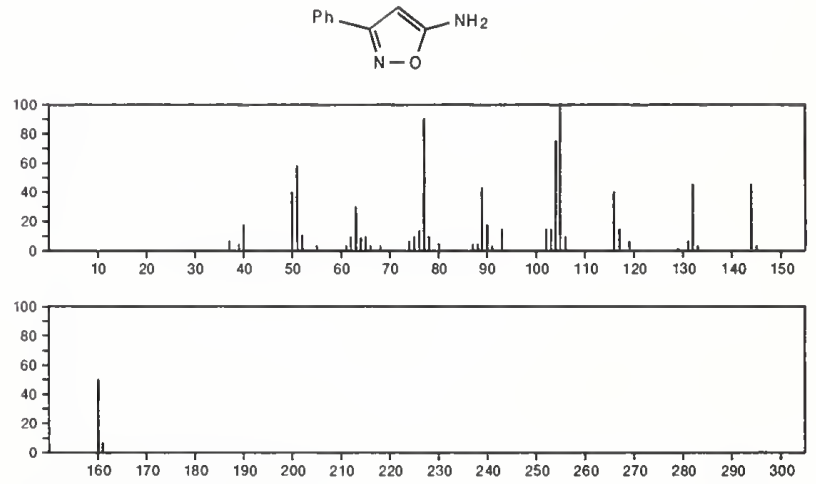

160

$\mathrm{C}_{9} \mathrm{H}_{8} \mathrm{~N}_{2} \mathrm{O}$

$4860-93-9$

3H-Pyrazol-3-one, 2,4-dihydro-5-phenyl-
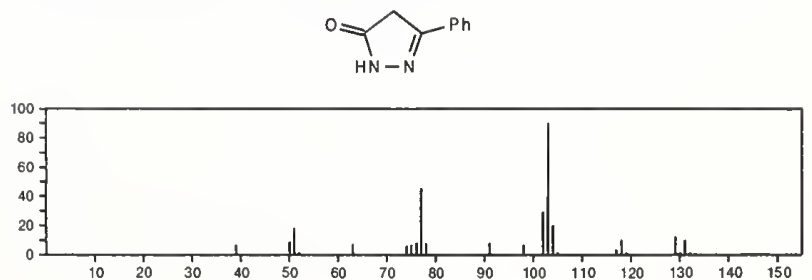


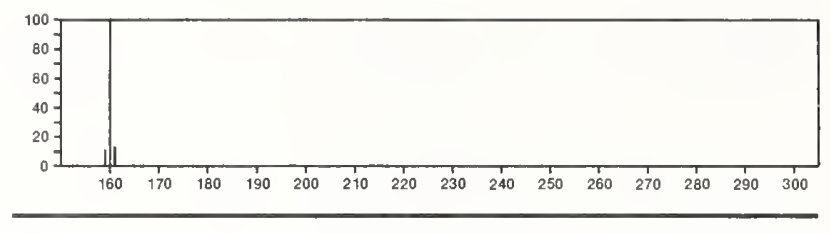

$160 \quad \mathrm{C}_{9} \mathrm{H}_{8} \mathrm{~N}_{2} \mathrm{O} \quad 5004-48-8$

$1(2 H)$-Phthalazinone, 4-methyl-
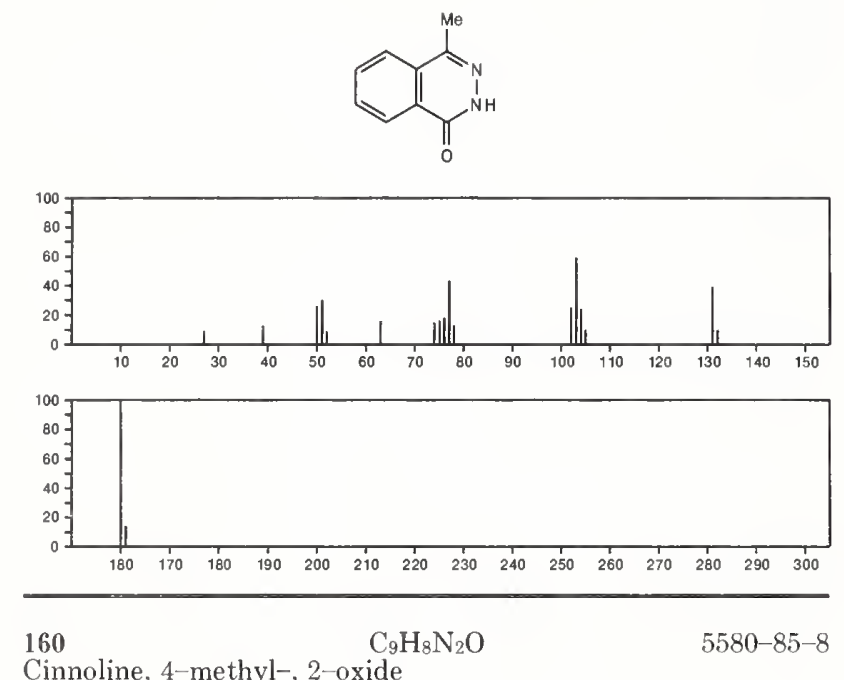

Cinnoline, 4-methyl-, 2-oxide
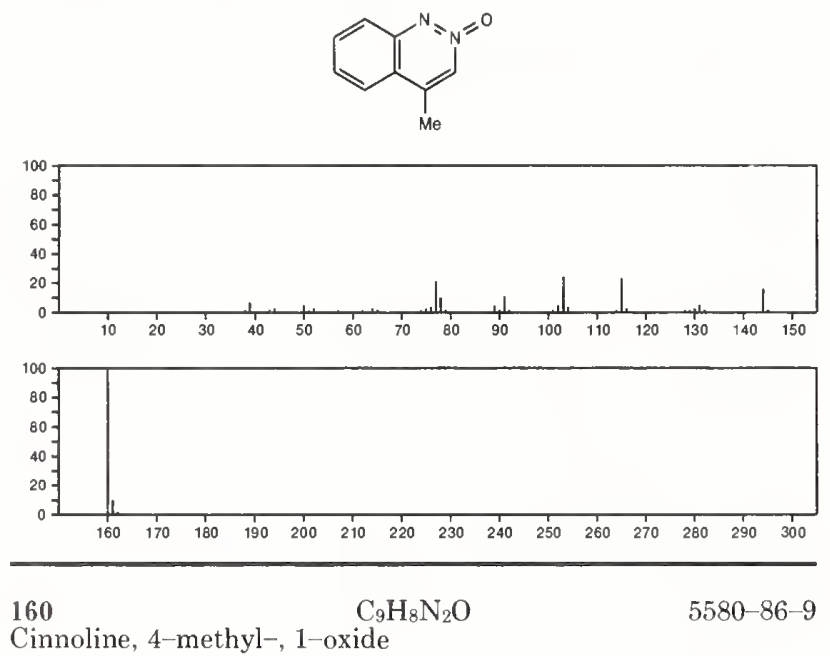

Cinnoline, 4-methyl-, 1-oxide
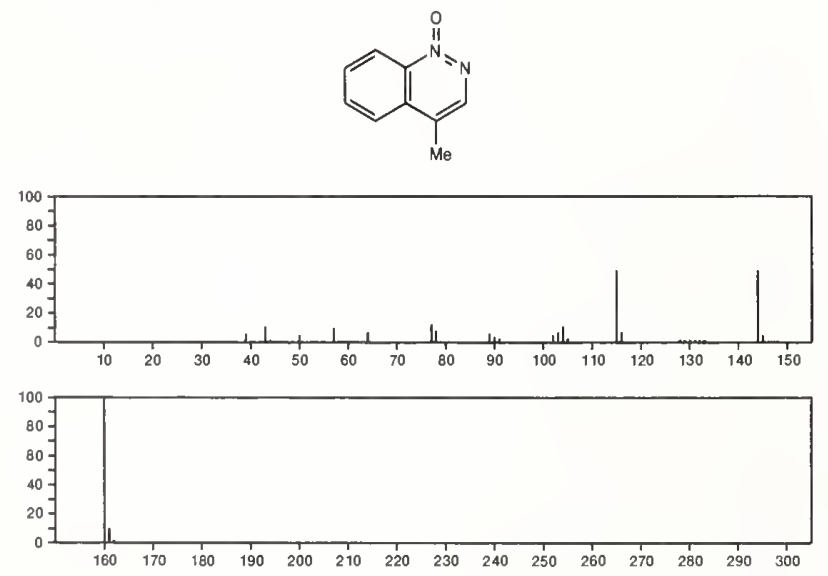

160

$\mathrm{C}_{9} \mathrm{H}_{8} \mathrm{~N}_{2} \mathrm{O}$

$10501-56-1$

Quinazoline, 4-methyl-, 3-oxide
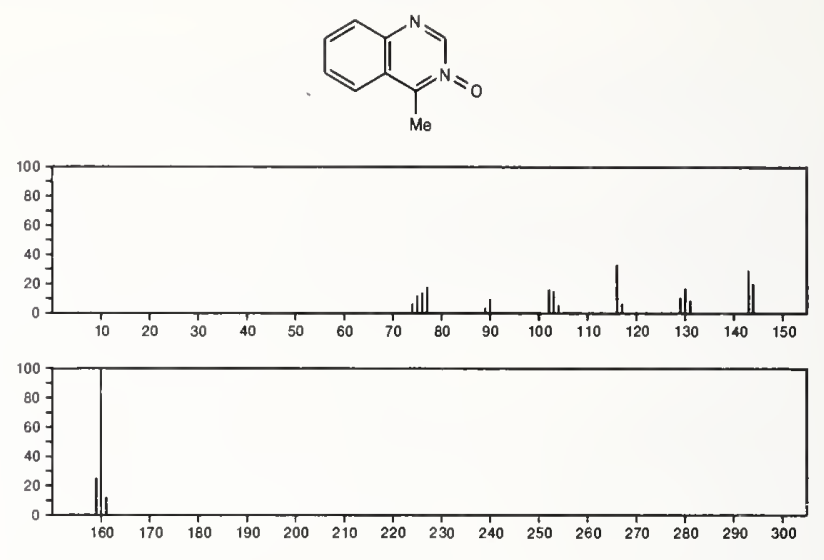

160

$\mathrm{C}_{9} \mathrm{H}_{8} \mathrm{~N}_{2} \mathrm{O}$

Quinoxaline, 2-methyl-, 1-oxide

$18916-44-4$
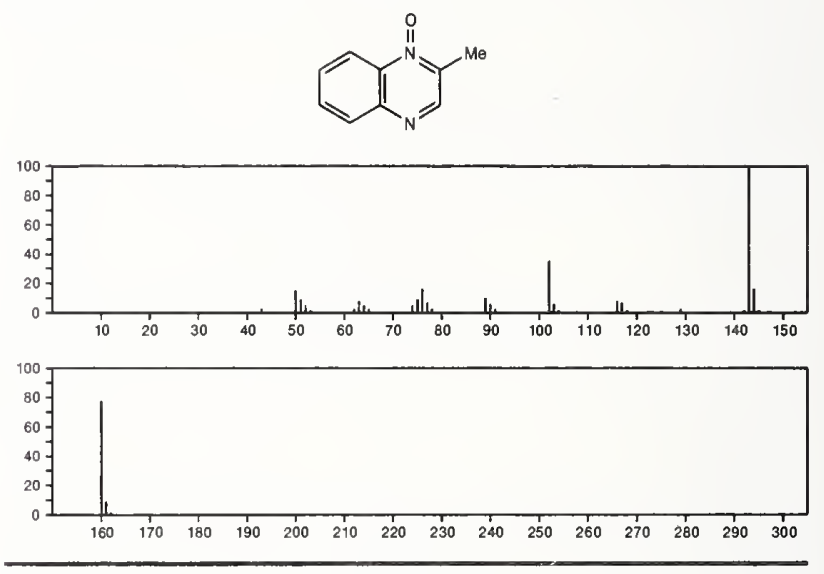

160

$\mathrm{C}_{9} \mathrm{H}_{8} \mathrm{~N}_{2} \mathrm{O}$

$18916-45-5$

Quinoxaline, 2-methyl-, 4-oxide
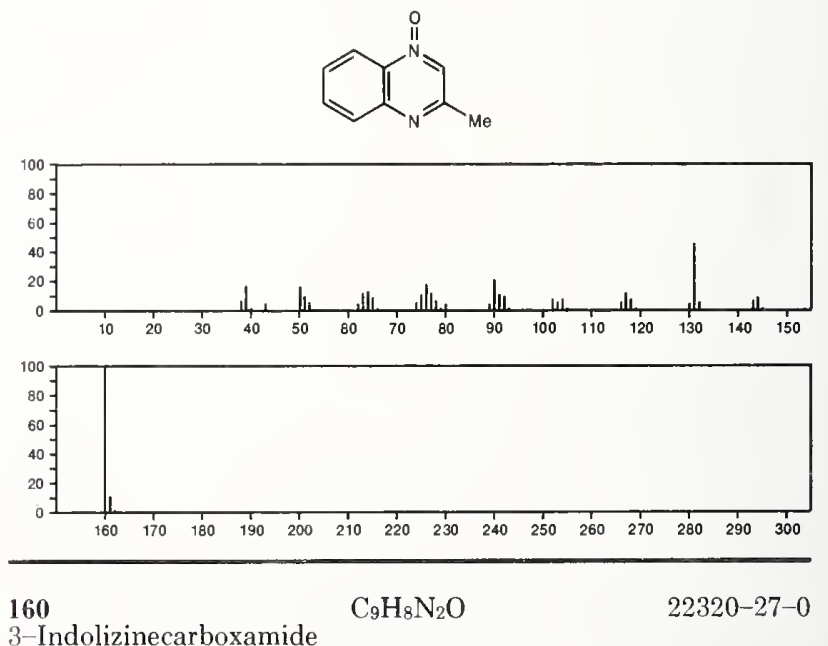

3-Indolizinecarboxamide
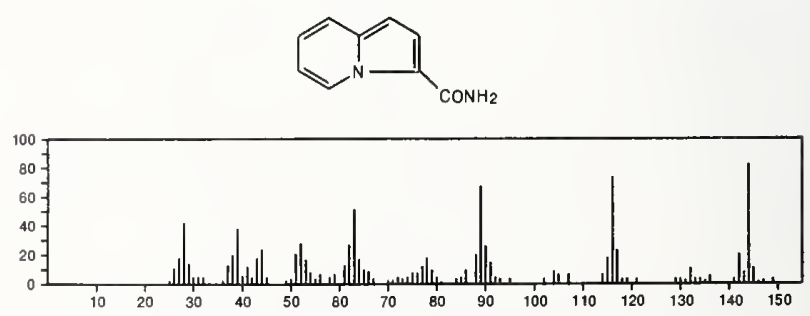

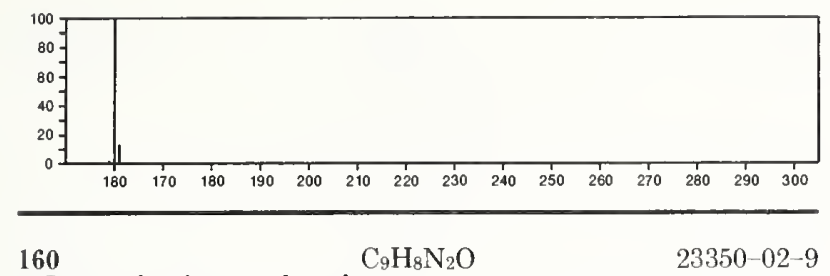

4-Isoxazolamine, 3-phenyl-
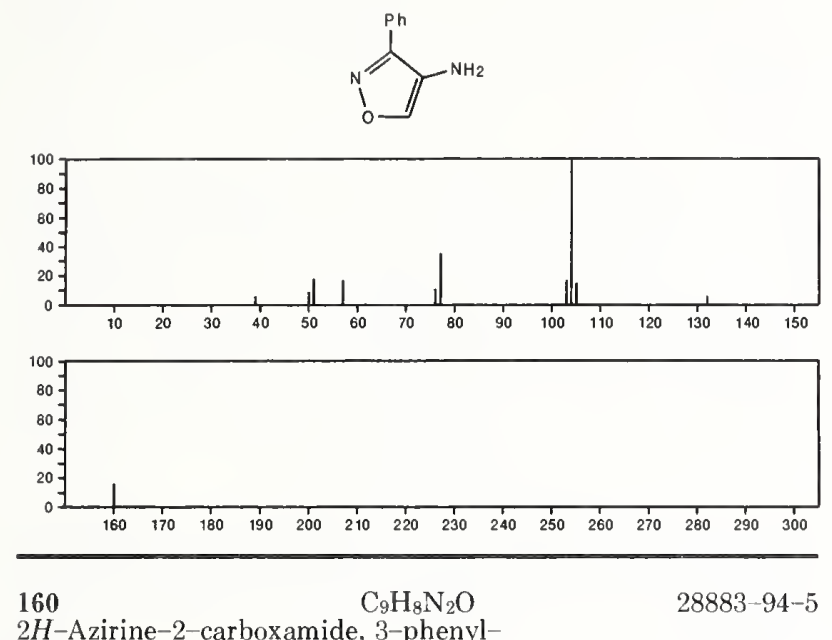

$2 \mathrm{H}$-Azirine-2-carboxamide, 3-phenyl
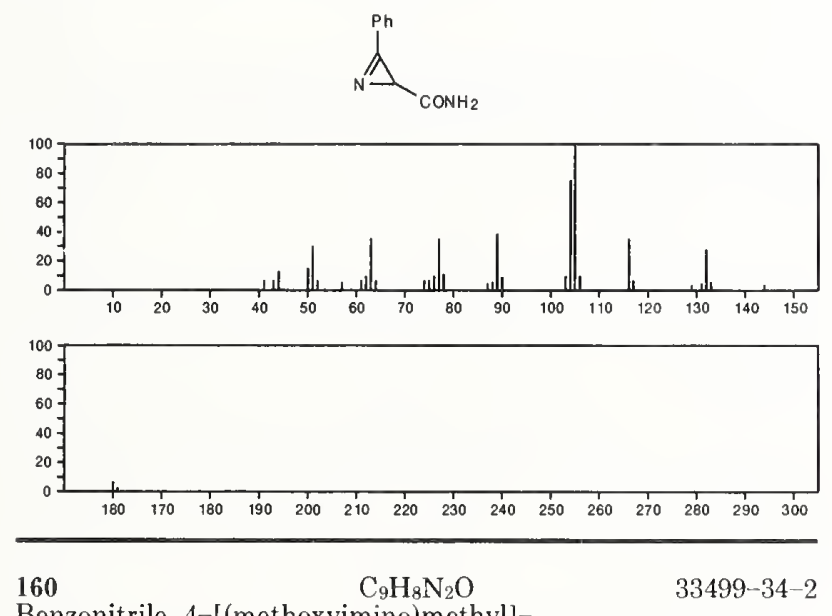

Benzonitrile, 4-[(methoxyimino)methyl]-
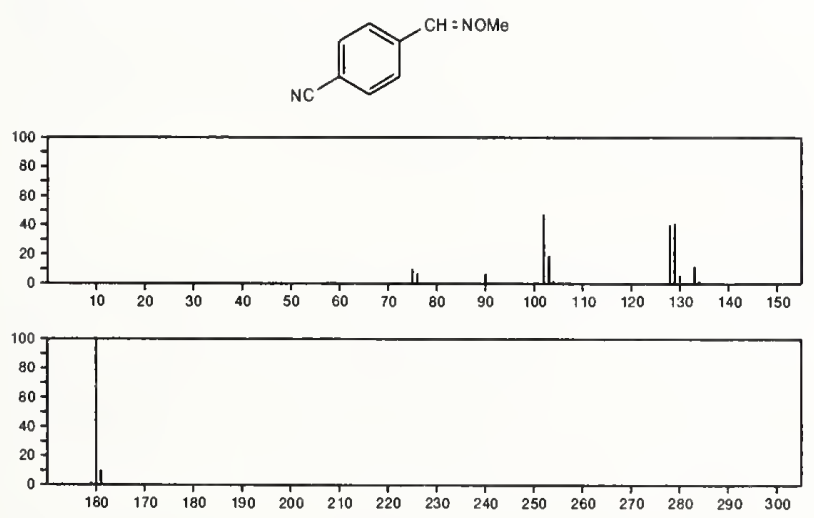

160

2H-Pyrido[1,2-a]pyrimidin-2-one, 4-methyl-
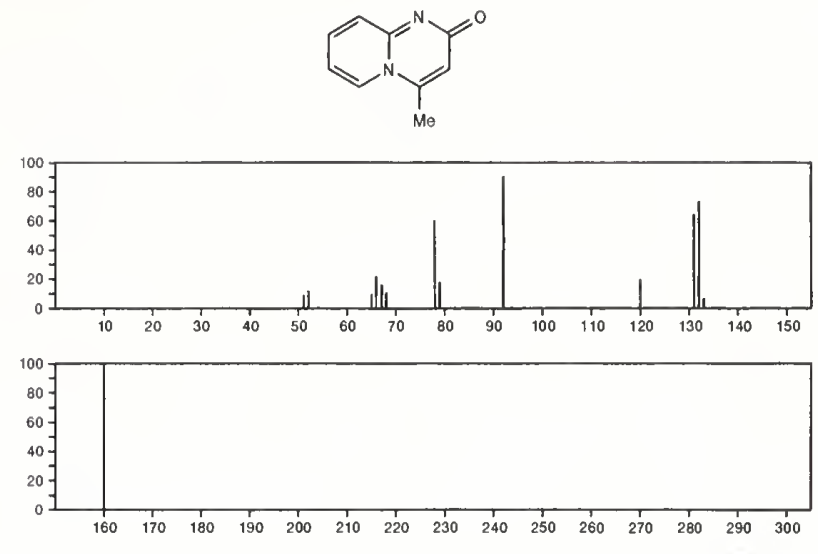

160

$\mathrm{C}_{9} \mathrm{H}_{8} \mathrm{~N}_{2} \mathrm{O}$

Quinazoline, 4-methyl-, 1-oxide

$37920-72-2$<smiles>Nc1nc[n+]([O-])c2ccccc12</smiles>
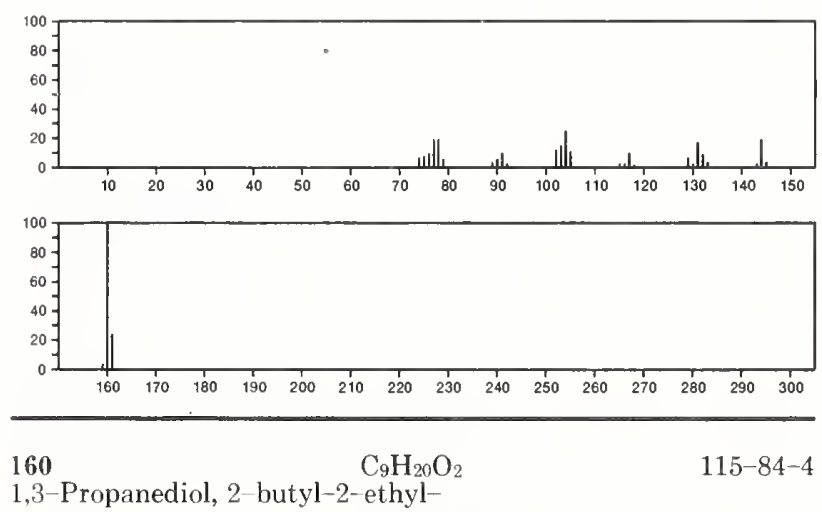

1,3-Propanediol, 2-butyl-2-ethyl-

$\left.(\underset{\mathrm{I}}{\mathrm{C}})_{2}\right)_{3} \mathrm{Me}$
$\mathrm{HOCH}_{2} \mathrm{CE}+\mathrm{CH}_{2} \mathrm{OH}$
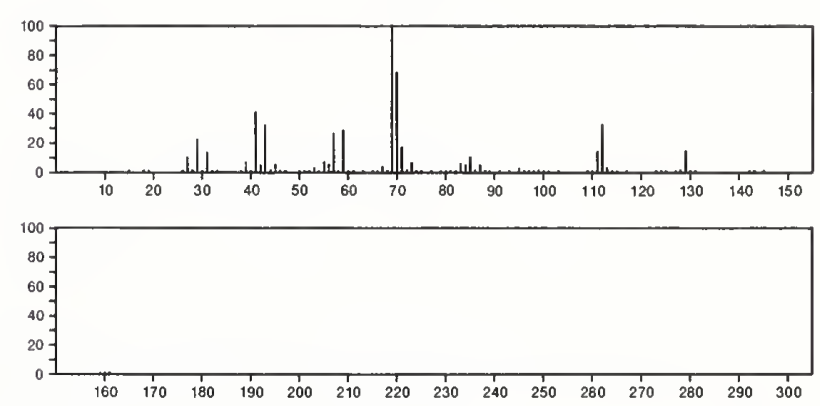

160

$\mathrm{C}_{9} \mathrm{H}_{20} \mathrm{O}_{2}$

Butane, 1,1'-[methylenebis(oxy)] bis-

2568-90-3

$\mathrm{Me}\left(\mathrm{CH}_{2}\right)_{3} \mathrm{OCH}_{2} \mathrm{O}\left(\mathrm{CH}_{2}\right)_{3} \mathrm{Me}$

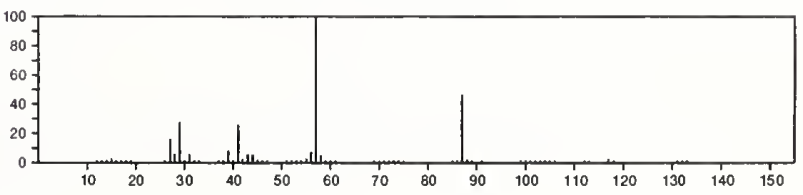




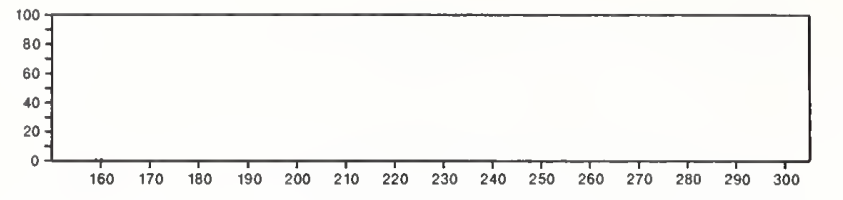

$160 \quad \mathrm{C}_{9} \mathrm{H}_{20} \mathrm{O}_{2} \quad$ 2568-91-4

Methane, diisobutoxy-

$\mathrm{i}-\mathrm{Bu} \mathrm{OCH}_{2} \mathrm{OBu}-\mathrm{i}$
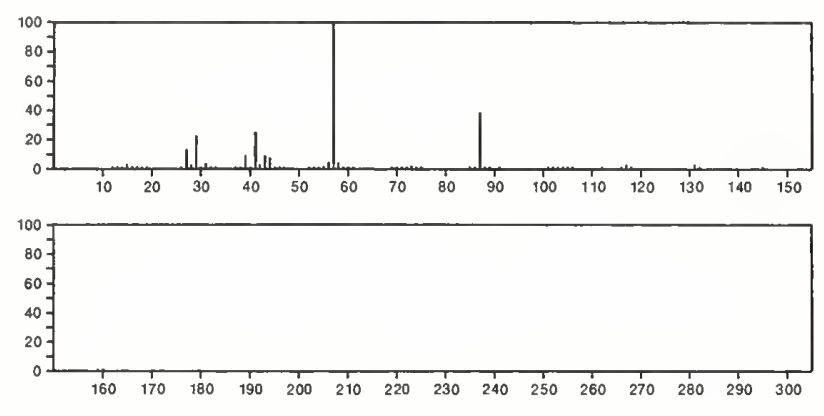

160

Butane, 2,2'-[methylenebis(oxy) $]$ bis-

$2568-92-5$

$s-\mathrm{Bu} \mathrm{OCH}_{2} \mathrm{OBu}-\mathrm{s}$
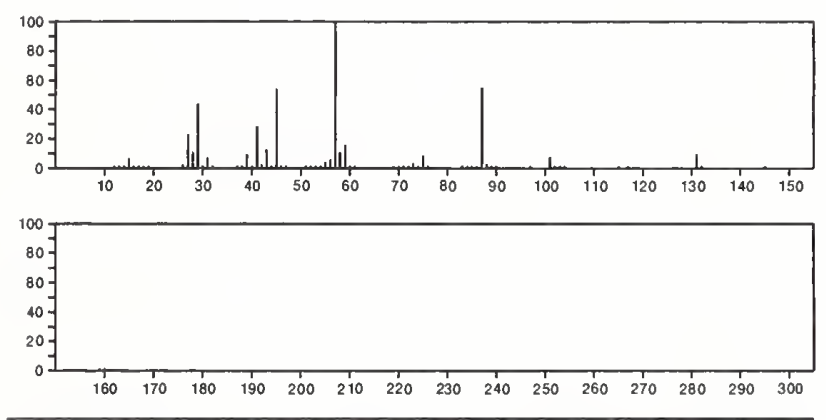

$160 \quad \mathrm{C}_{9} \mathrm{H}_{20} \mathrm{O}_{2}$

$2568-93-6$

Propane, 2,2'-[methylenebis(oxy)]bis[2-methyl-

$\mathrm{t}-\mathrm{Bu} \mathrm{OCH}_{2} \mathrm{OBu}-\mathrm{t}$
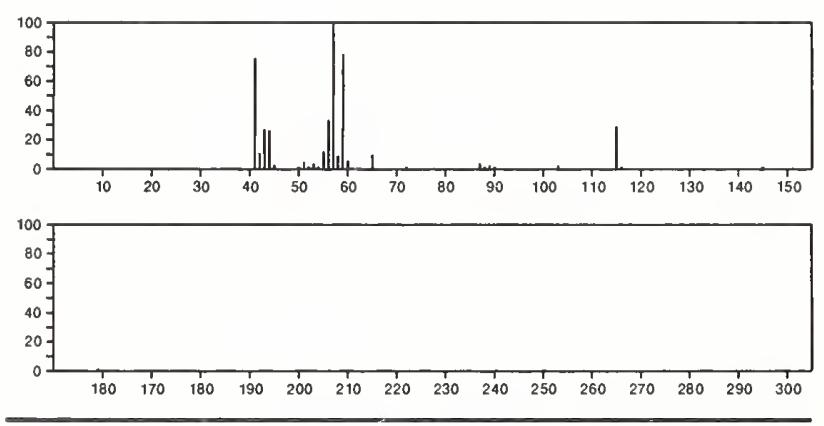

160

1,9-Nonanediol

$\mathrm{C}_{9} \mathrm{H}_{20} \mathrm{O}_{2}$

$3937-56-2$

$\mathrm{HO}\left(\mathrm{CH}_{2}\right) 9 \mathrm{OH}$
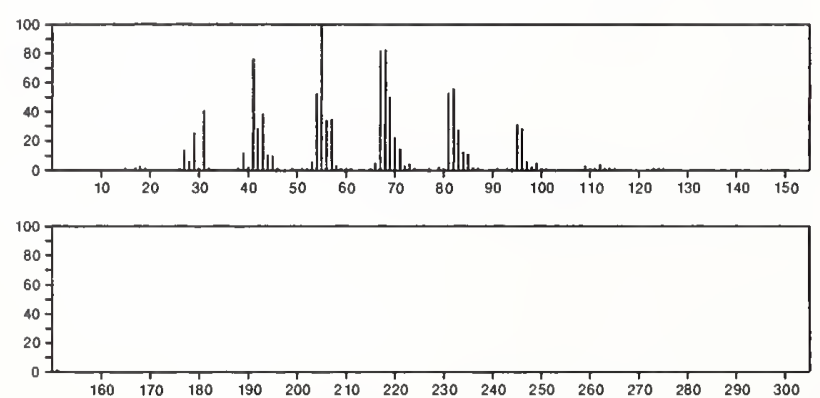

160

Heptane, 1,1-dimethoxy-

$\mathrm{C}_{9} \mathrm{H}_{20} \mathrm{O}_{2}$

$10032-05-0$

$(\mathrm{MeO})_{2} \mathrm{CH}\left(\mathrm{CH}_{2}\right)_{5} \mathrm{Me}$
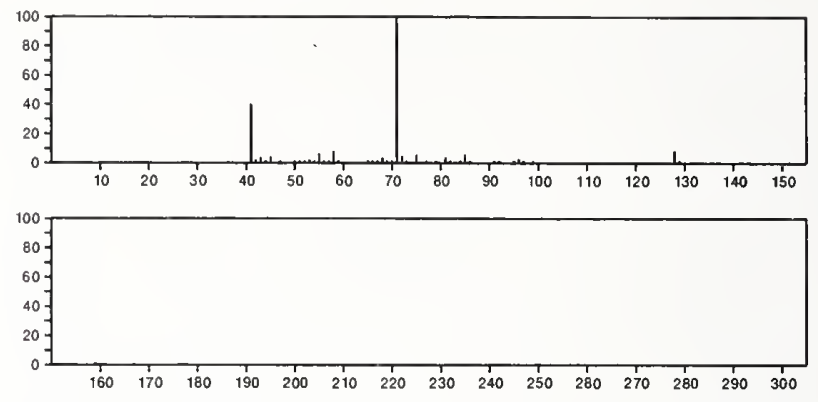

160

$\mathrm{C}_{9} \mathrm{H}_{20} \mathrm{O}_{2}$

2-Propanol, 1-(1,3-dimethylbutoxy)-

54340-89-5

$\mathrm{Me} \mathrm{CH}(\mathrm{OH}) \mathrm{CH}_{2} \mathrm{OCHMe} \mathrm{CH}_{2} \mathrm{CHMe}_{2}$
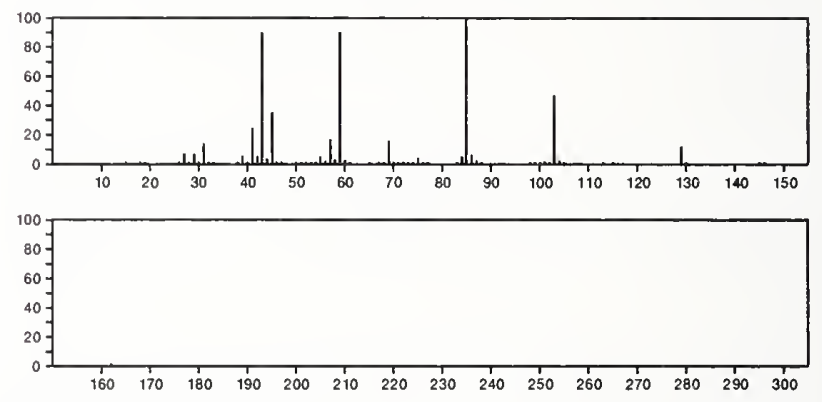

160

1-Nonanethiol

$\mathrm{C}_{9} \mathrm{H}_{20} \mathrm{~S}$

$\mathrm{Me}\left(\mathrm{CH}_{2}\right)_{8} \mathrm{SH}$
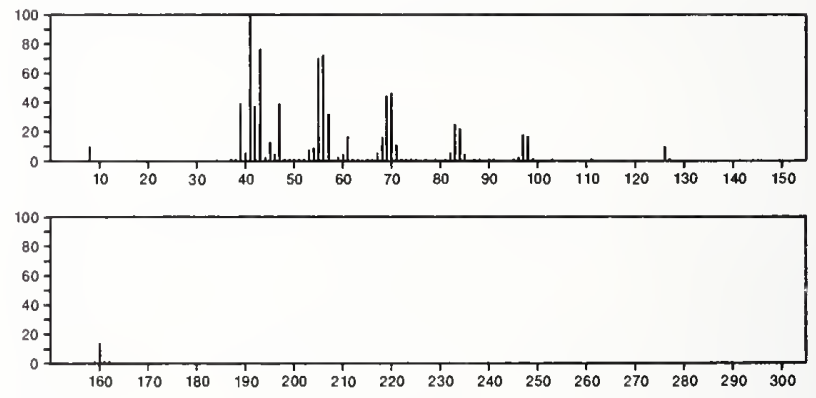

160

$\mathrm{C}_{9} \mathrm{H}_{20} \mathrm{~S}$

Hexane, 1-[(1-methylethyl)thio]-

$56273-33-7$

$\mathrm{Me}\left(\mathrm{CH}_{2}\right) 5 \mathrm{SPr}-\mathrm{i}$
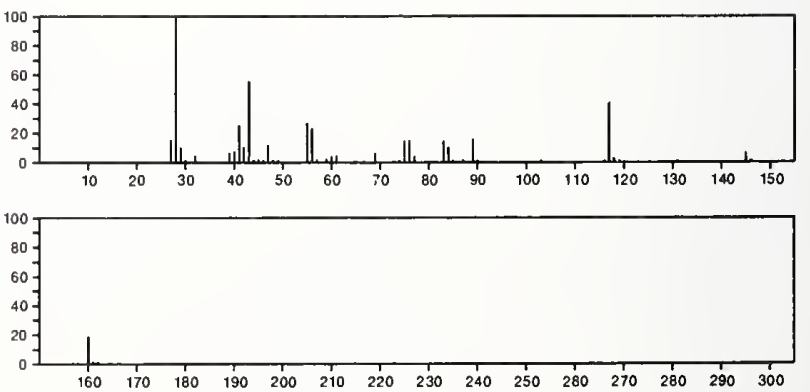
160

$\mathrm{C}_{10} \mathrm{H}_{8} \mathrm{O}_{2}$

2H-1-Benzopyran-2-one, 6-methyl
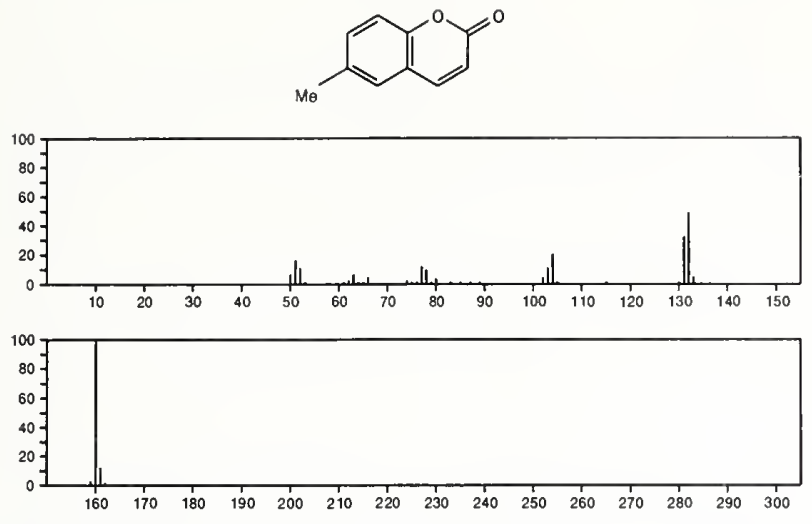

$160 \quad \mathrm{C}_{10} \mathrm{H}_{8} \mathrm{O}_{2}$

$2 \mathrm{H}$-1-Benzopyran-2-one, 4-methyl-
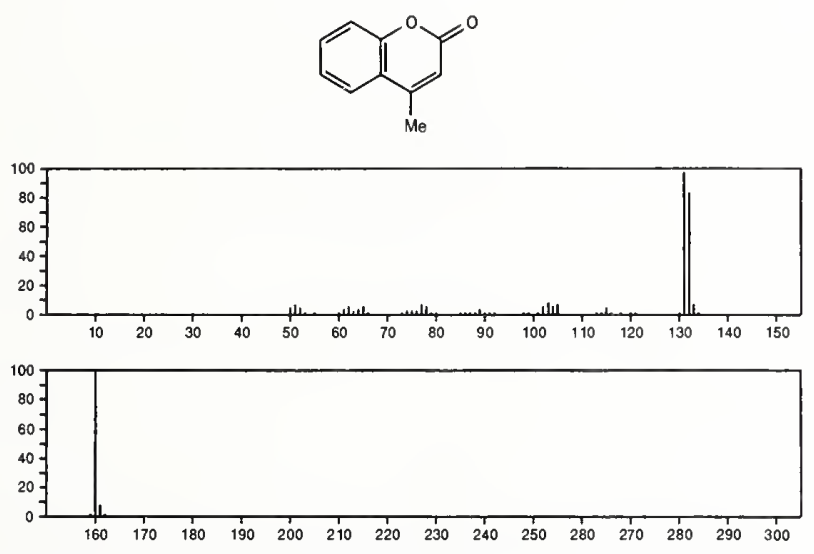

$160 \quad \mathrm{C}_{10} \mathrm{H}_{8} \mathrm{O}_{2}$

2H-1-Benzopyran-2-one, 3-methyl-
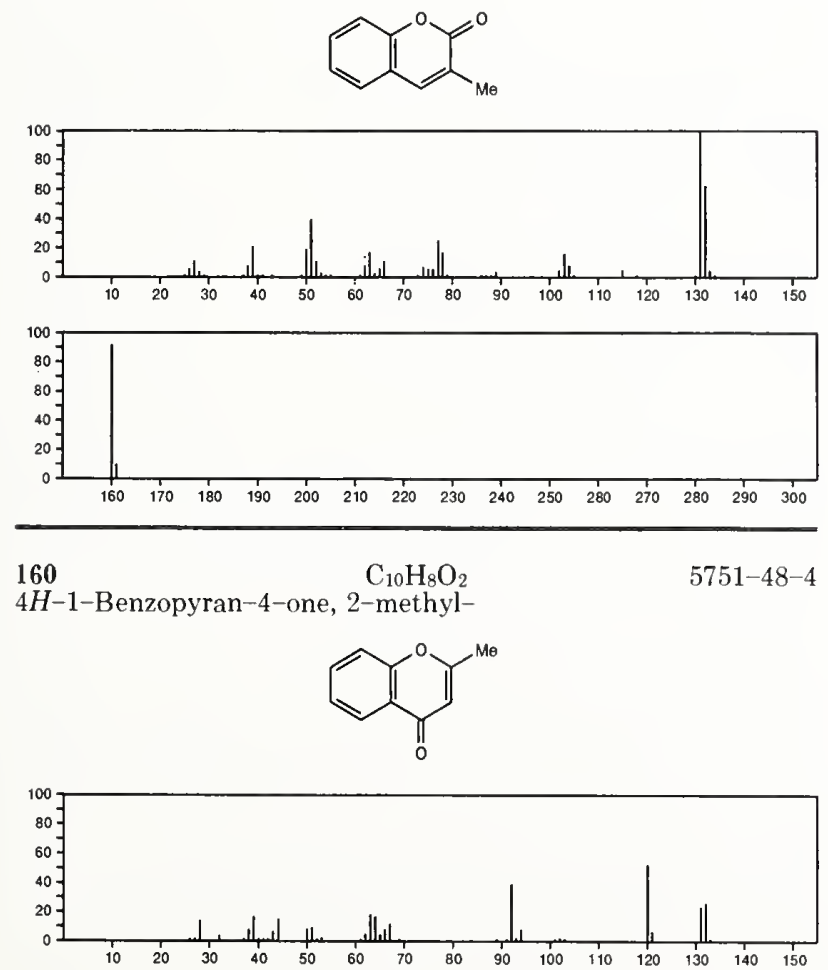

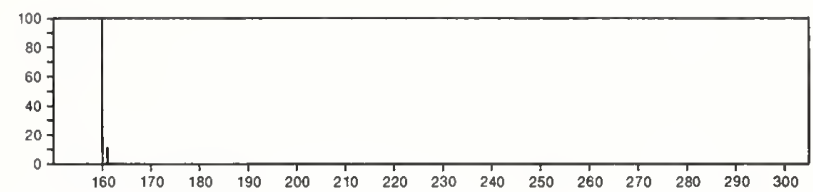

160

2-Naphthalenethiol

$\mathrm{C}_{10} \mathrm{H}_{8} \mathrm{~S}$

$91-60-1$
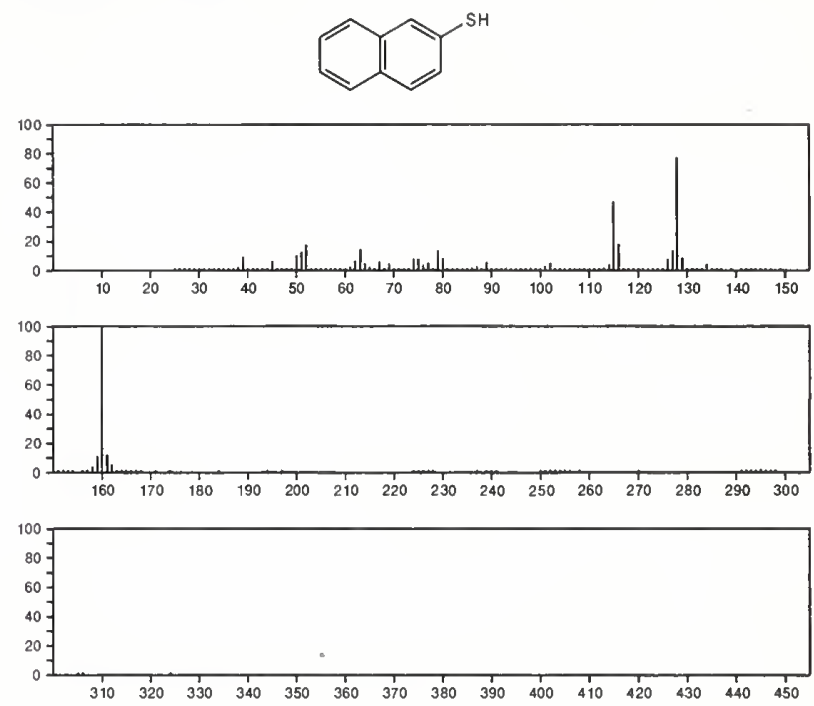

160

$\mathrm{C}_{10} \mathrm{H}_{8} \mathrm{~S}$

$2404-87-7$

Thiophene, 3-phenyl-
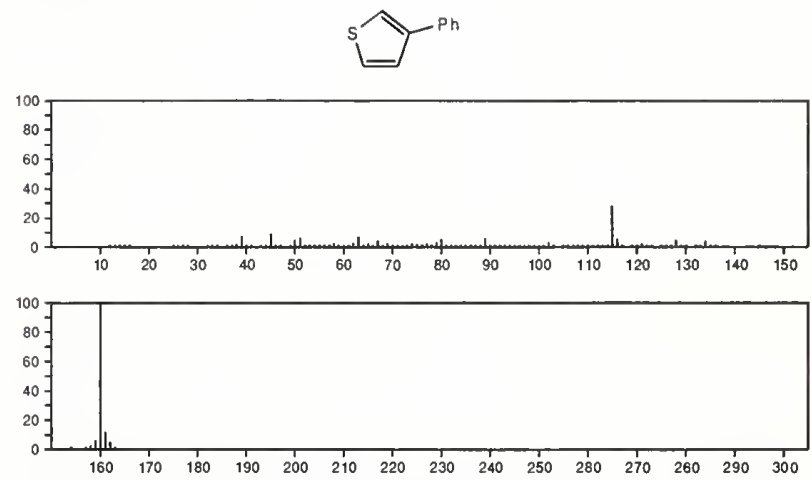

160

$\mathrm{C}_{10} \mathrm{H}_{12} \mathrm{~N}_{2}$

61-54-1

$1 H$-Indole-3-ethanamine
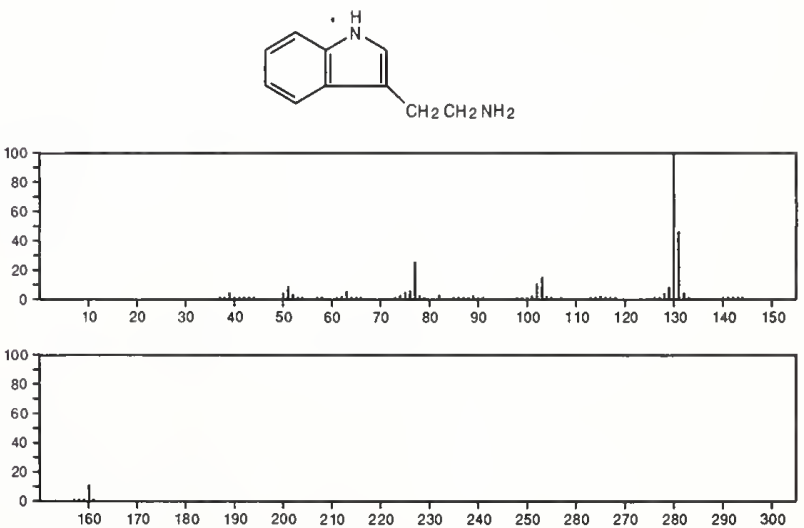
$160 \quad \mathrm{C}_{10} \mathrm{H}_{12} \mathrm{~N}_{2}$

$1 \mathrm{H}$-Imidazole, 4,5-dihydro-4-methyl-2-phenyl-

939-06-0
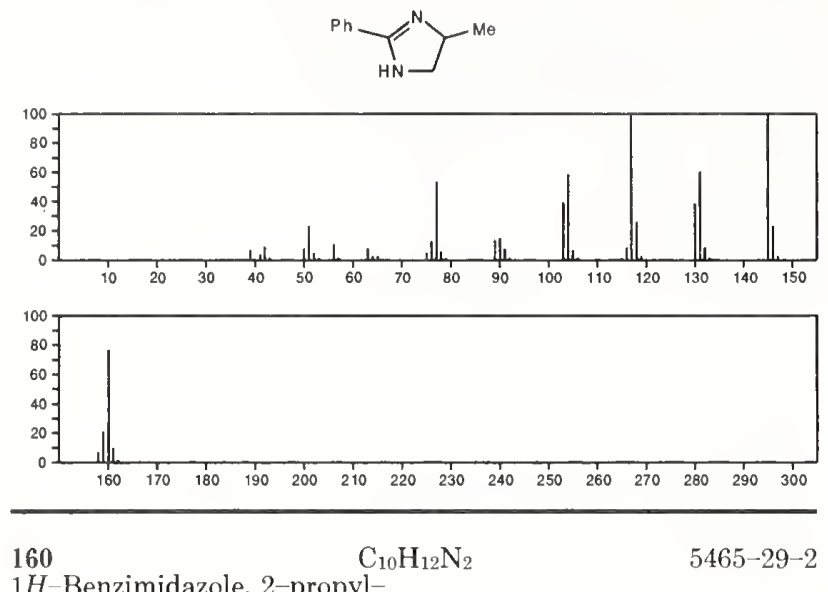

1H-Benzimidazole, 2-propyl-
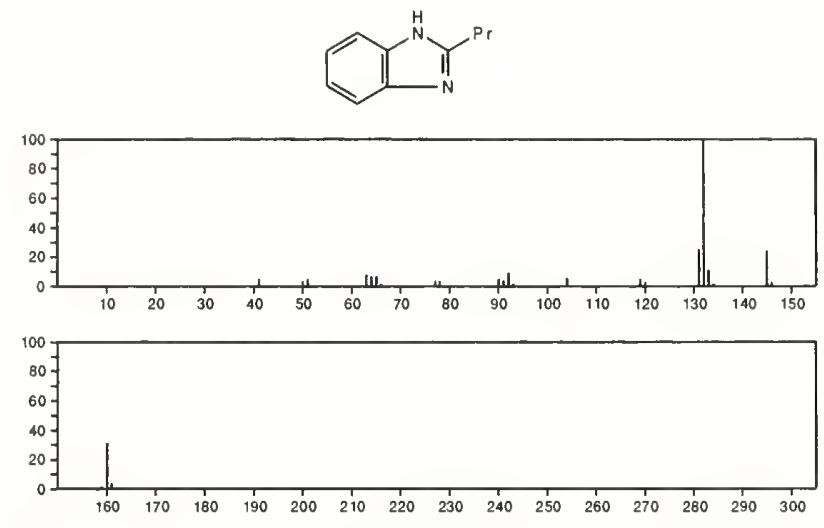

$160 \quad \mathrm{C}_{10} \mathrm{H}_{12} \mathrm{~N}_{2}$

$1 H$-Benzimidazole, 2-(1-methylethyl)-
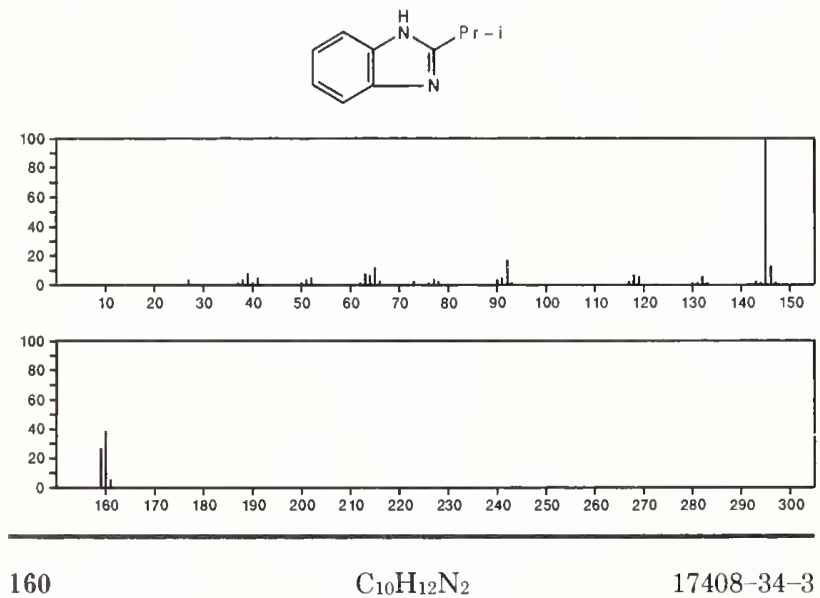

Pyrazolo[1,5-a]pyridine, 2,3,7-trimethyl-

$17408-34-3$
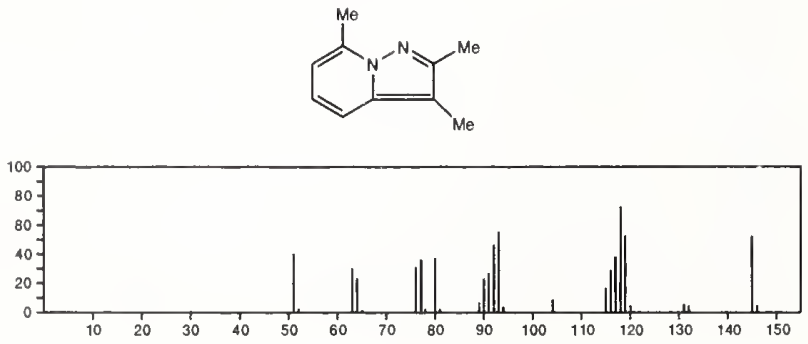

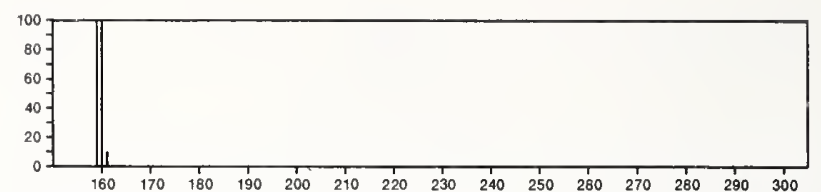

160

$\mathrm{C}_{10} \mathrm{H}_{12} \mathrm{~N}_{2}$

$18233-71-1$

1H-2,4-Benzodiazepine, 2,5-dihydro-3-methyl-
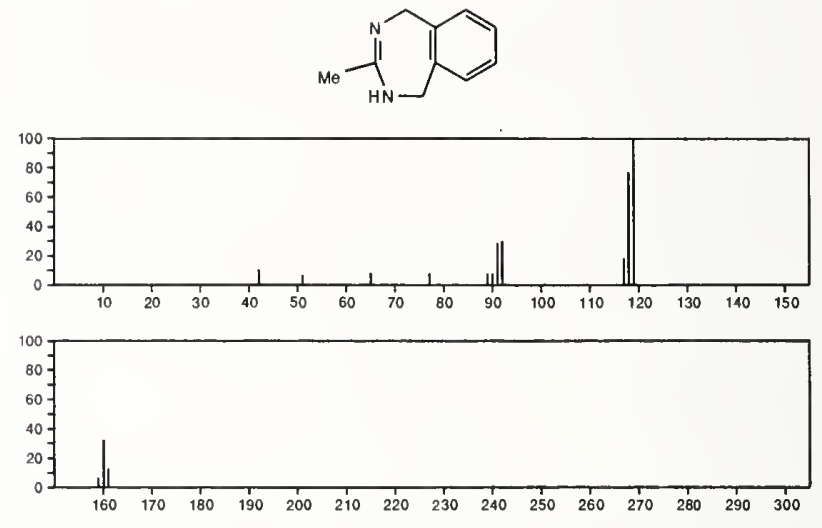

$160 \quad \mathrm{C}_{10} \mathrm{H}_{12} \mathrm{~N}_{2}$

$27257-18-7$

$1 H$-Pyrrolo[2,3-b]pyridine, 2-(1-methylethyl)-
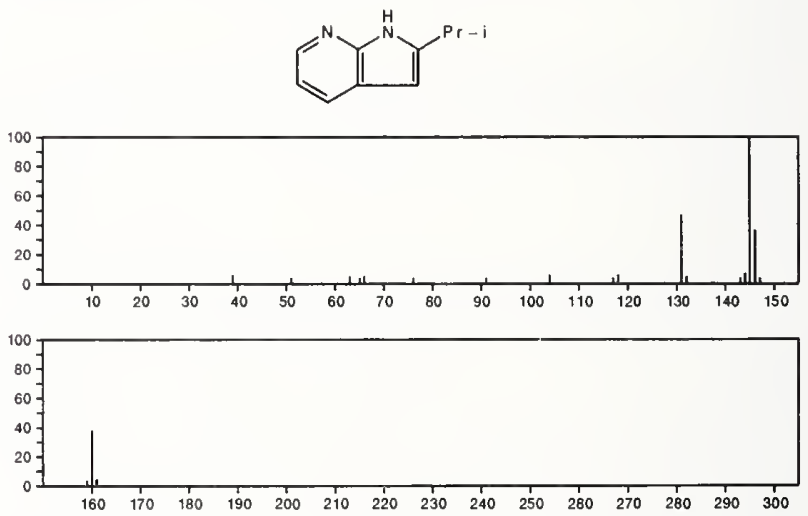

160

$\mathrm{C}_{10} \mathrm{H}_{12} \mathrm{~N}_{2}$

$46035-38-5$

3H-1,3-Benzodiazepine, 4,5-dihydro-2-methyl-
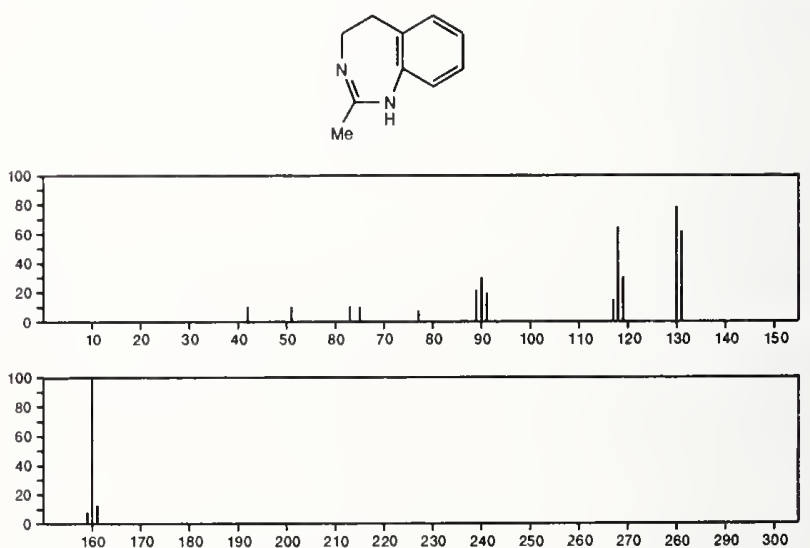
160 $\mathrm{C}_{11} \mathrm{H}_{12} \mathrm{O}$

$1198-20-5$

1,4-Methanonaphthalen-9-ol, 1,2,3,4-tetrahydro-, stereoisomer
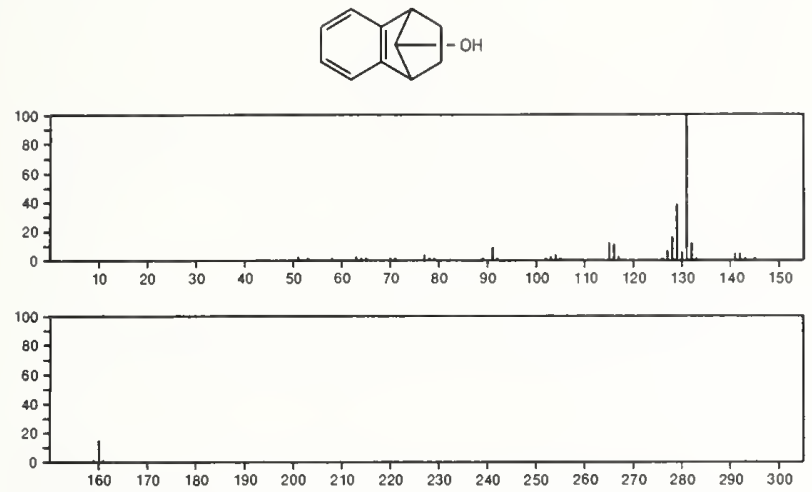

$160 \quad \mathrm{C}_{11} \mathrm{H}_{12} \mathrm{O} \quad 1590-08-5$ 1(2H)-Naphthalenone, 3,4-dihydro-2-methyl-
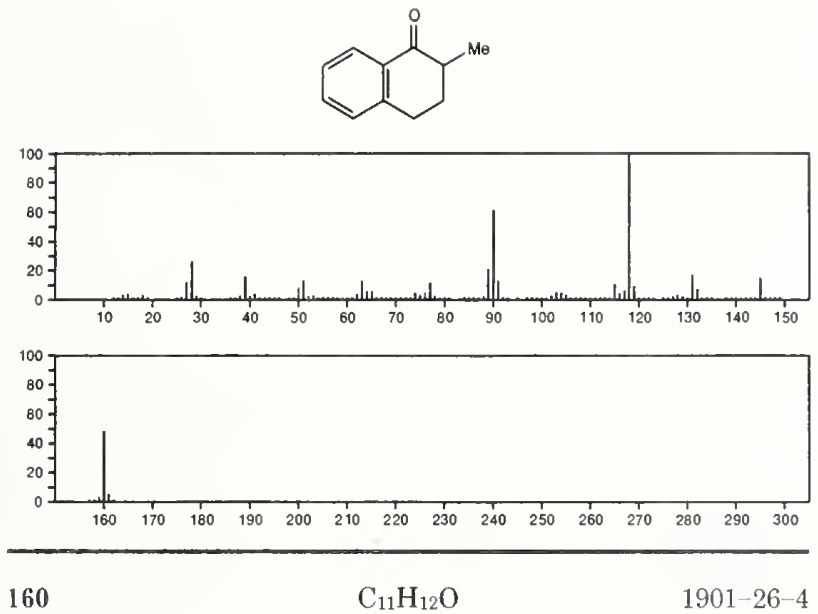

3-Buten-2-one, 3-methyl-4-phenyl-

$\mathrm{PhCH}=\mathrm{CMe} \mathrm{COMe}$
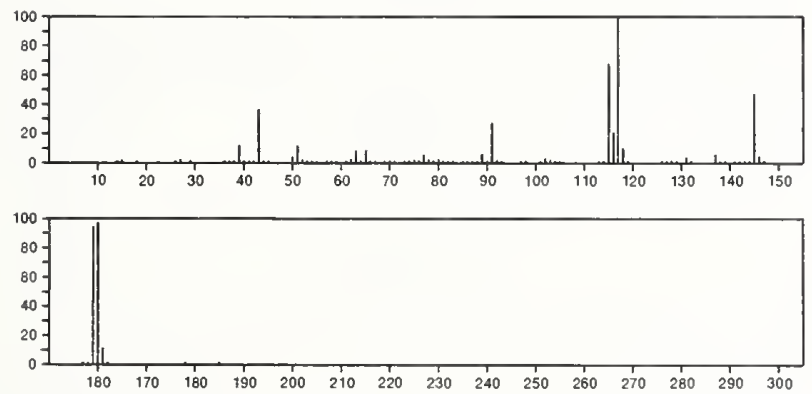

$160 \quad \mathrm{C}_{11} \mathrm{H}_{12} \mathrm{O}$ 5037-60-5

1H-Inden-1-one, 2,3-dihydro-4,7-dimethyl-
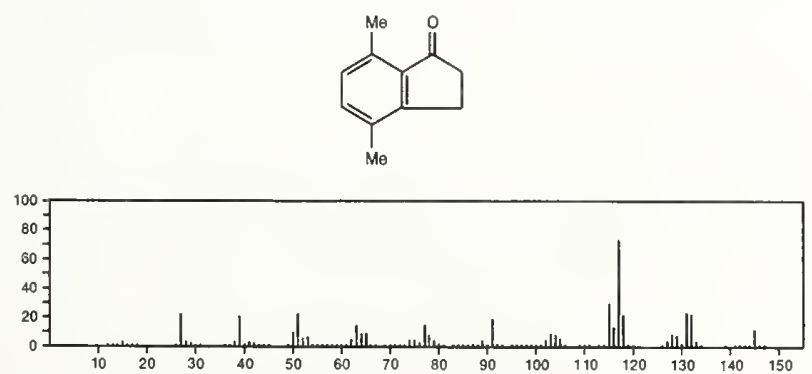
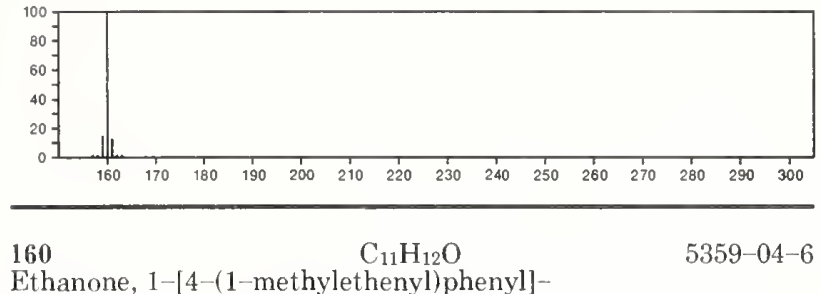

Ethanone, 1-[4-(1-methylethenyl)phenyl]-
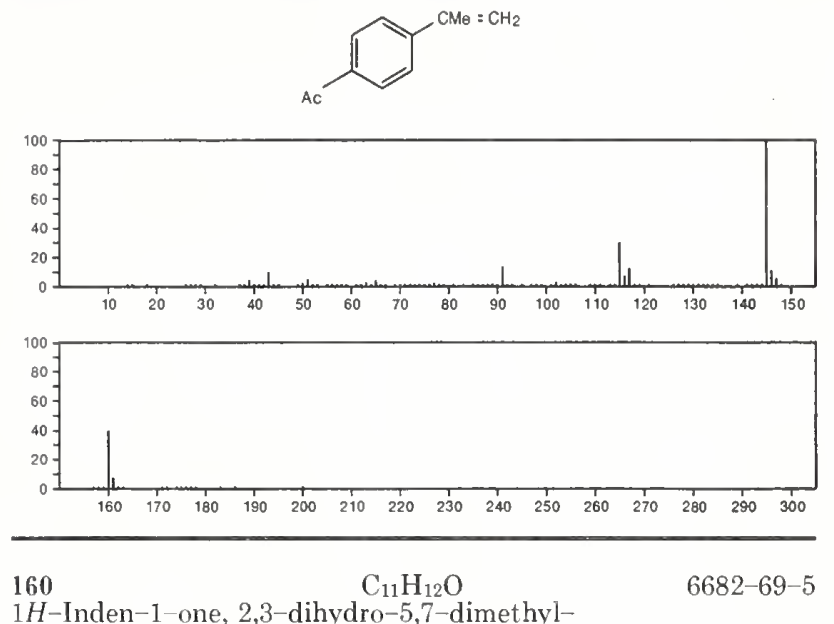

$1 H$-Inden-1-one, 2,3-dihydro-5,7-dimethyl-
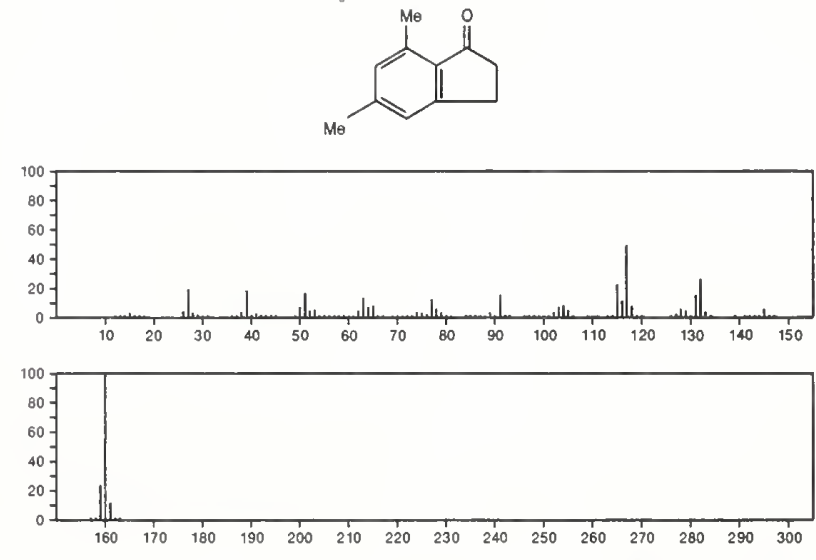

160

$\mathrm{C}_{11} \mathrm{H}_{12} \mathrm{O}$

$6712-35-2$

Benzenemethanol, $\alpha$-methyl- $\alpha-2-$ propynyl-

$\mathrm{HC}: \mathrm{CCH}_{2} \mathrm{CMe}(\mathrm{OH}) \mathrm{Ph}$
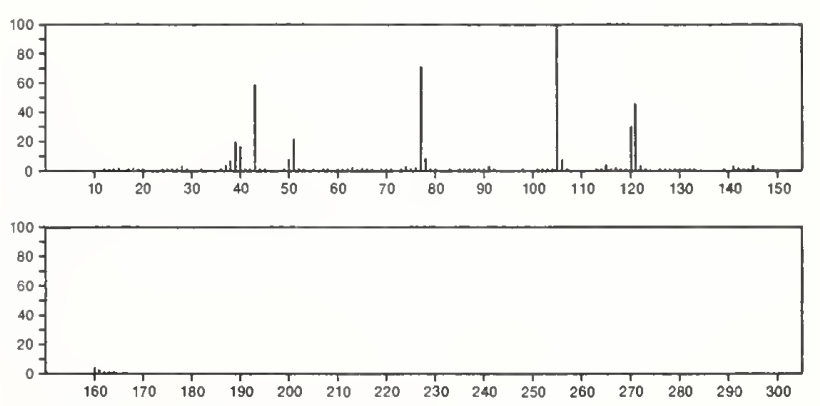
160

1(2H)-Naphthalenone, 3,4-dihydro-5-methyl-

6939-35-1
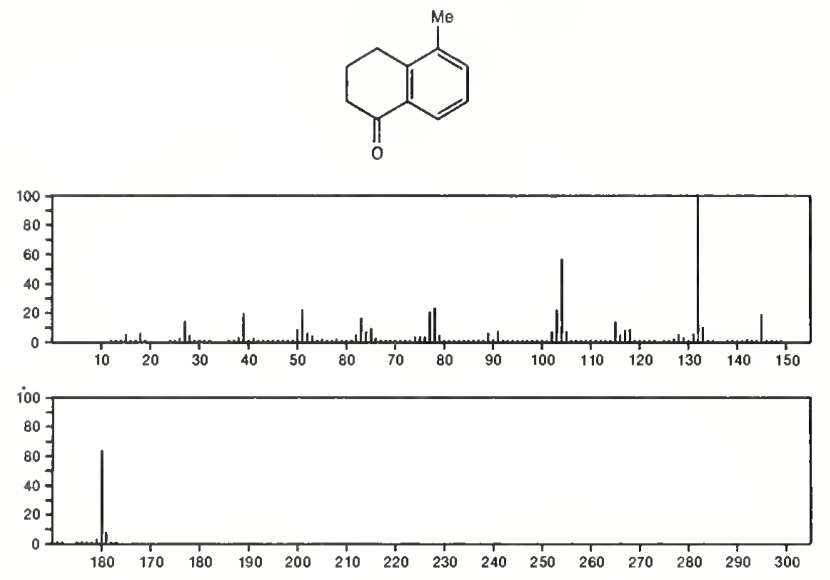

$160 \quad \mathrm{C}_{11} \mathrm{H}_{12} \mathrm{O} \quad 10521-97-8$

3-Penten-2-one, 5-phenyl-

$\mathrm{Me} \mathrm{COCH}=\mathrm{CHCH}_{2} \mathrm{Ph}$
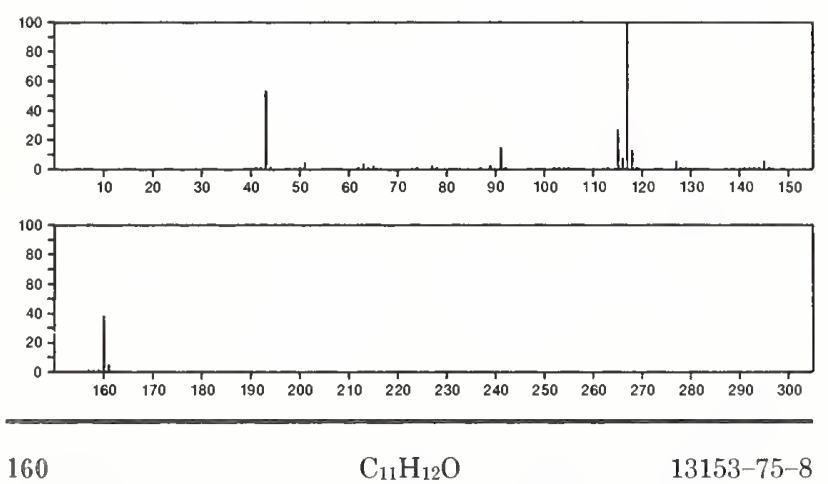

1,4-Methanonaphthalen-2-ol, 1,2,3,4-tetrahydro-, endo-
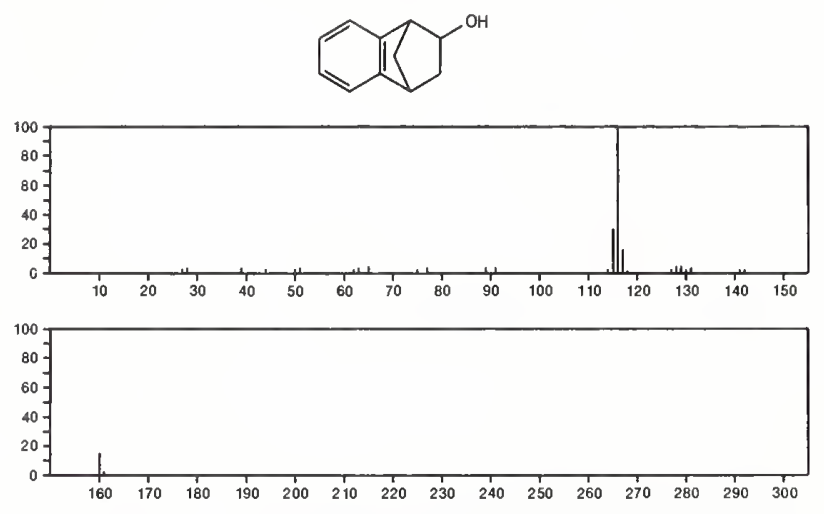

$160 \quad \mathrm{C}_{11} \mathrm{H}_{12} \mathrm{O} \quad 13999-10-5$

1,4-Methanonaphthalen-9-ol, 1,2,3,4-tetrahydro-, syn-
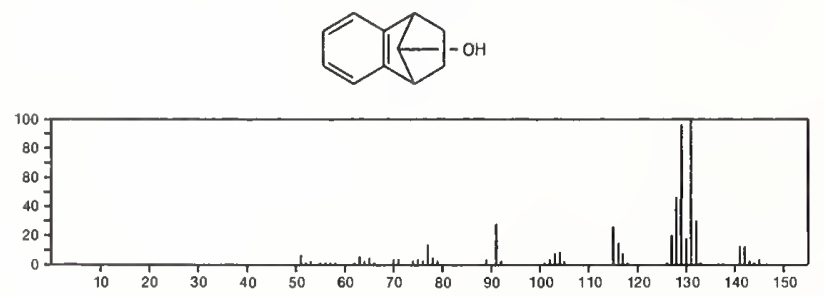

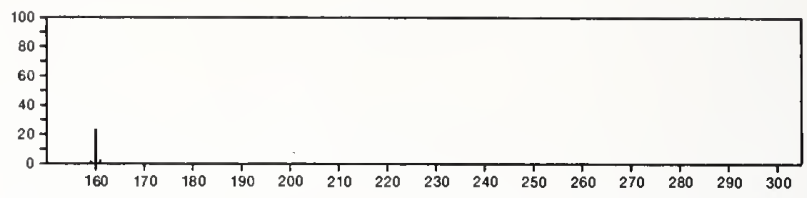

160

$\mathrm{C}_{11} \mathrm{H}_{12} \mathrm{O}$

Ethanone, 1-cyclopropyl-2-phenyl-

14113-94-1
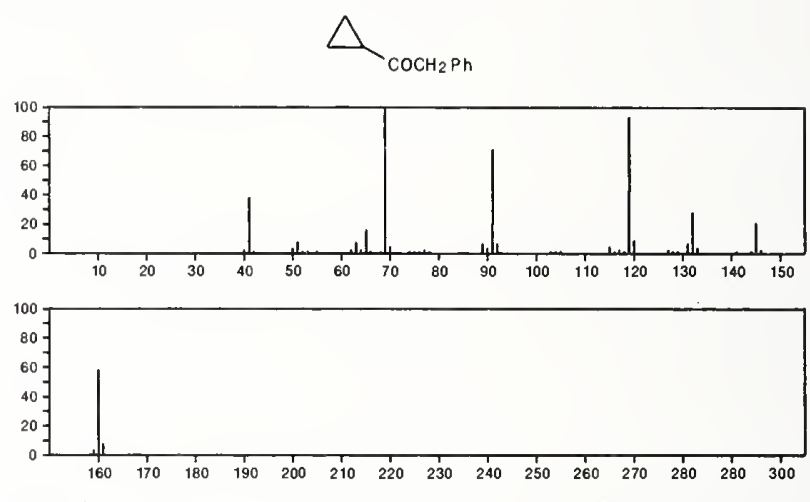

$160 \quad \mathrm{C}_{11} \mathrm{H}_{12} \mathrm{O}$ 14944-23-1

1(2H)-Naphthalenone, 3,4-dihydro-3-methyl-
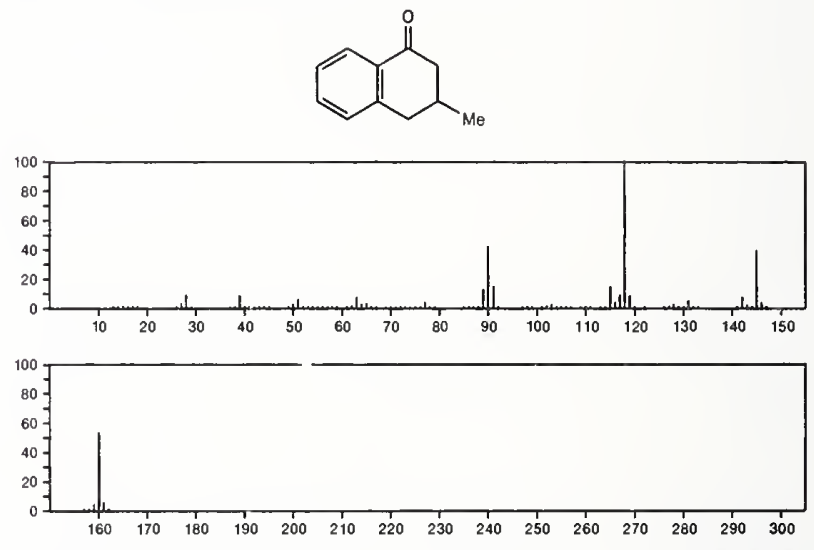

160

$\mathrm{C}_{11} \mathrm{H}_{12} \mathrm{O}$

16440-97-4

1-Indanone, 5,6-dimethyl
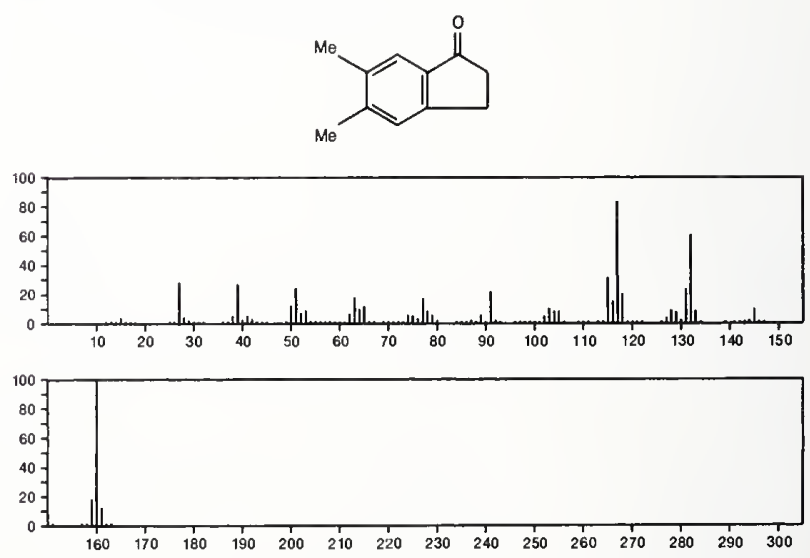
160

1(2H)-Naphthalenone, 3,4-dihydro-4-methyl-
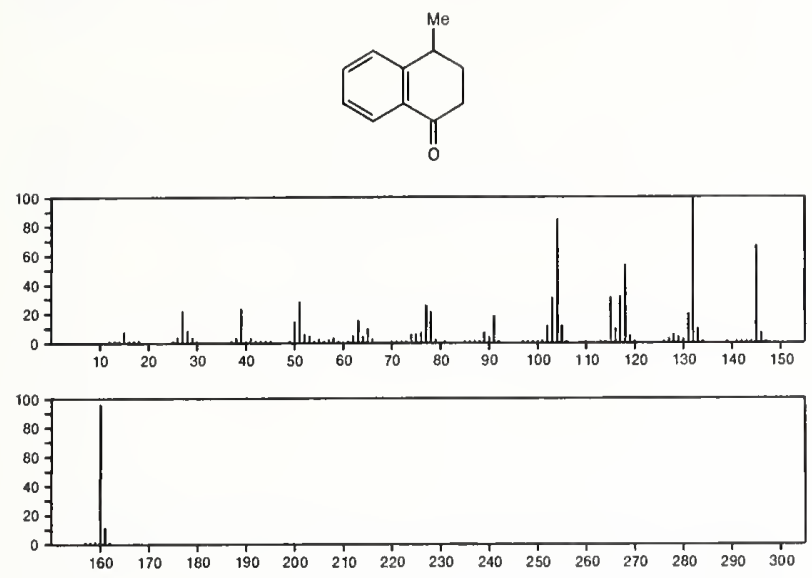

160

$$
\mathrm{C}_{11} \mathrm{H}_{12} \mathrm{O}
$$

1H-Inden-1-one, 2,3-dihydro-3,3- dimethyl-
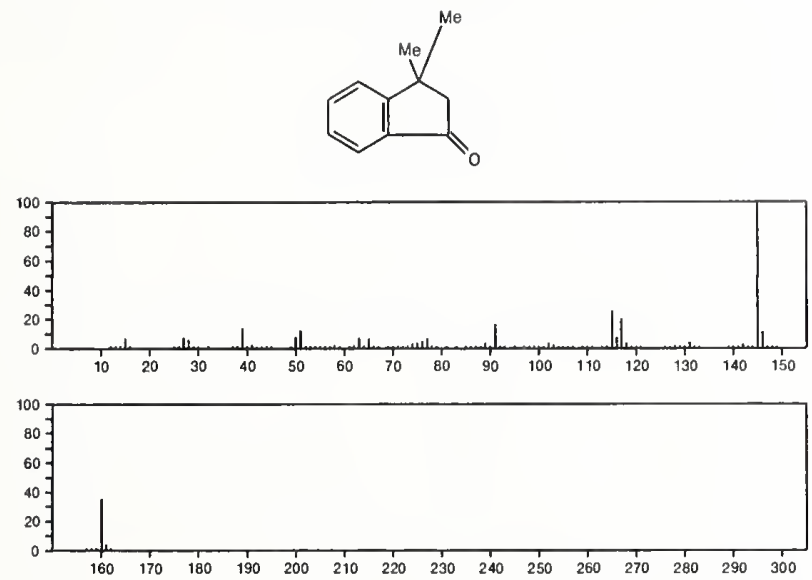

160

2-Pentenal, 5-phenyl-

$\mathrm{C}_{11} \mathrm{H}_{12} \mathrm{O}$

$33046-84-3$

$\mathrm{OCHCH}=\mathrm{CHCH}_{2} \mathrm{CH}_{2} \mathrm{Ph}$
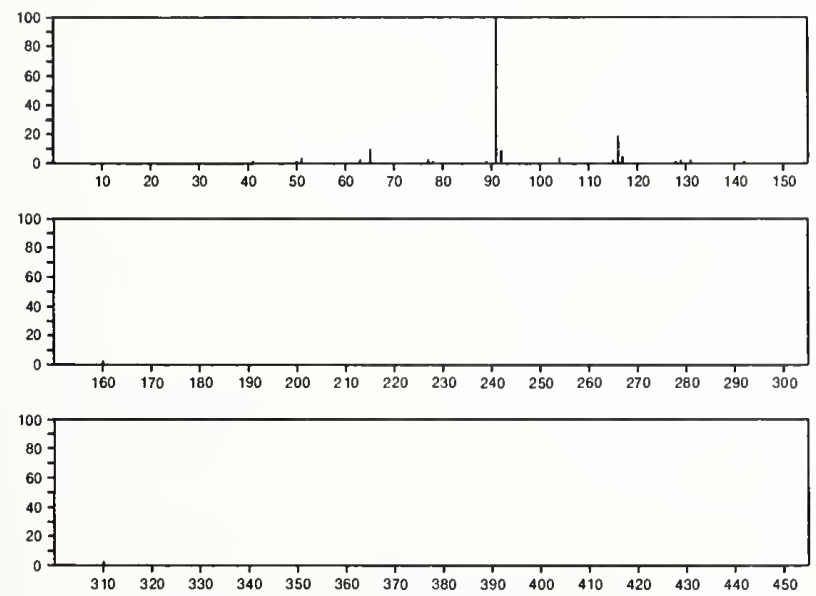

$160 \quad \mathrm{C}_{11} \mathrm{H}_{12} \mathrm{O}$

I(2H)-Naphthalenone, 3,4-dihydro-8-methyl-

$51015-28-2$
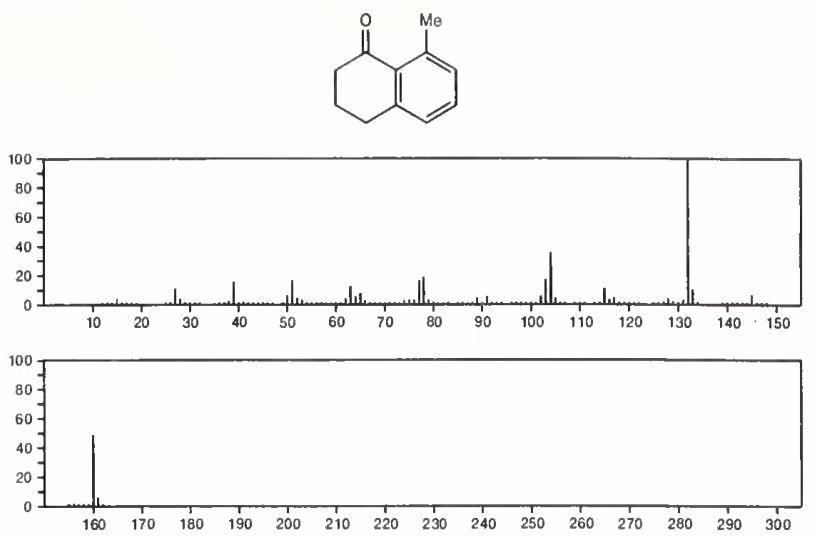

2,4-Cyclohexadien-1-one, 2,6-dimethyl-6-(2-propynyl)-
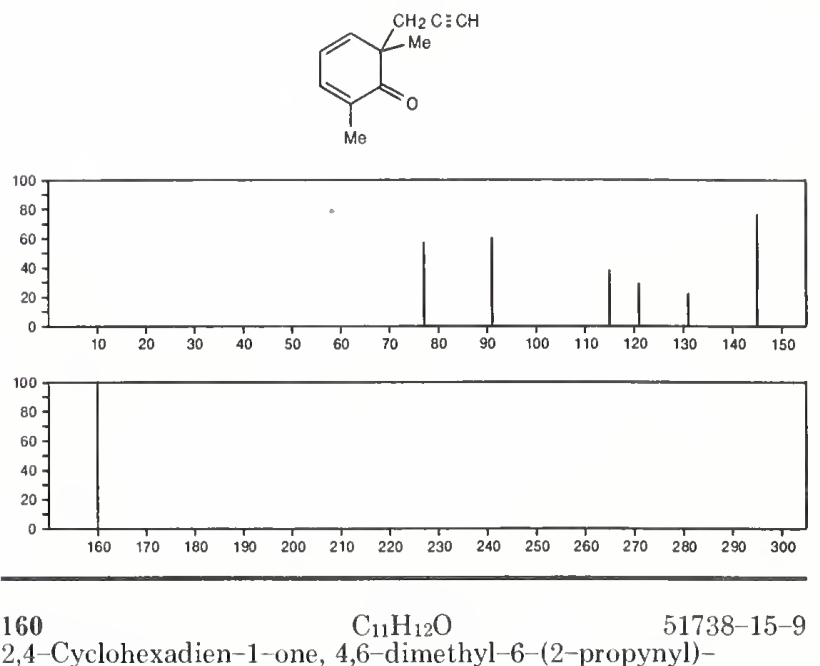

2,4-Cyclohexadien-1-one, 4,6-dimethyl-6-(2-propynyl)-
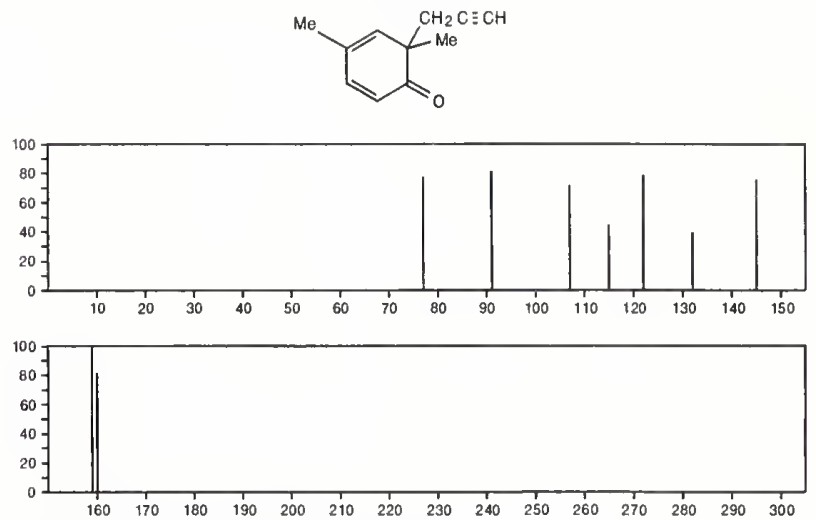

160

$\mathrm{C}_{11} \mathrm{H}_{12} \mathrm{O}$

1,4-Methanonaphthalen-9-ol, 1,2,3,4-tetrahydro-

55255-94-2
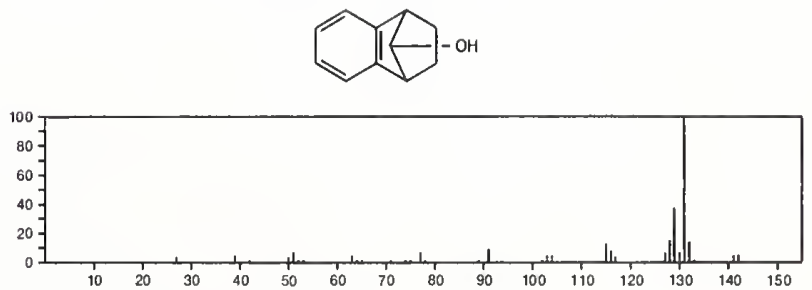

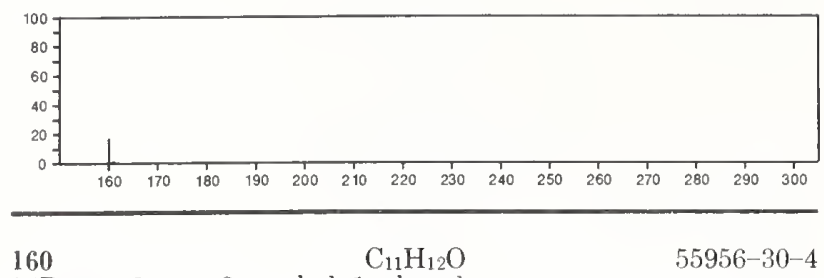

3-Buten-2-one, 3-methyl-1-phenyl-

$\mathrm{PhCH}_{2} \mathrm{COCMe}=\mathrm{CH}_{2}$
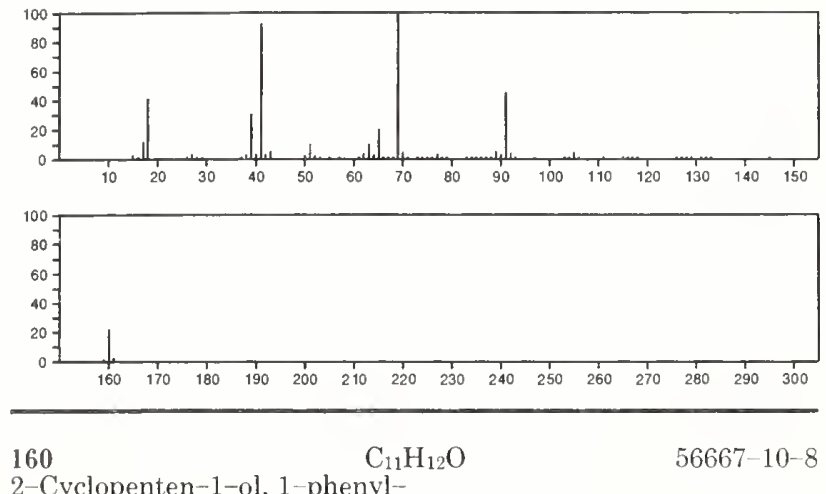

2-Cyclopenten-1-ol, 1-phenyl--

$\mathrm{K}_{\mathrm{OH}}^{\mathrm{Ph}}$
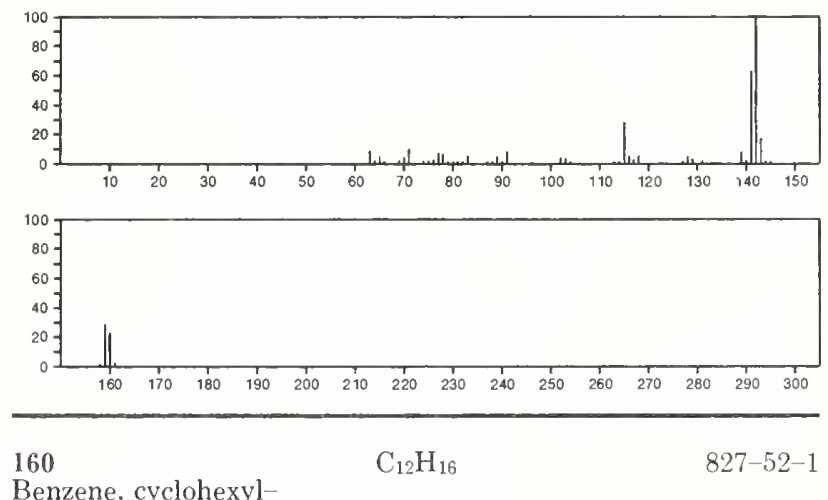

Benzene, cyclohexyl-
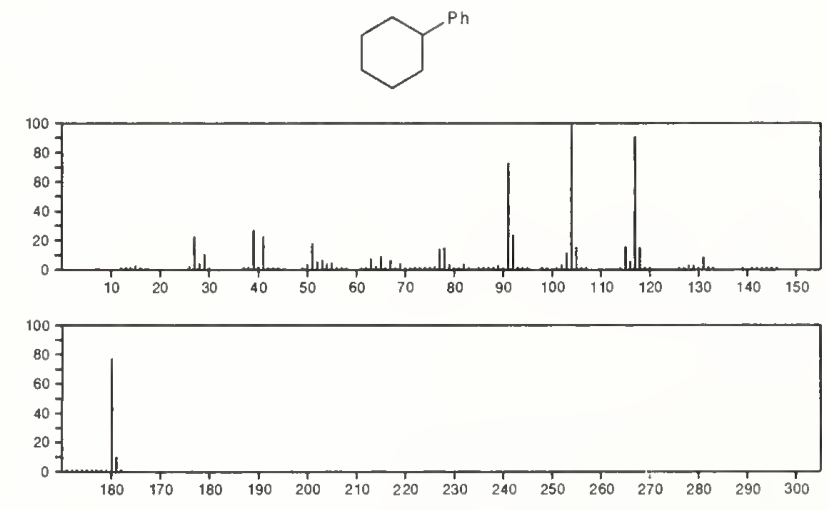

$160 \quad \mathrm{C}_{12} \mathrm{H}_{16} \quad 1076-61-5$

Naphthalene, 1,2,3,4-tetrahydro-6,7-dimethyl-
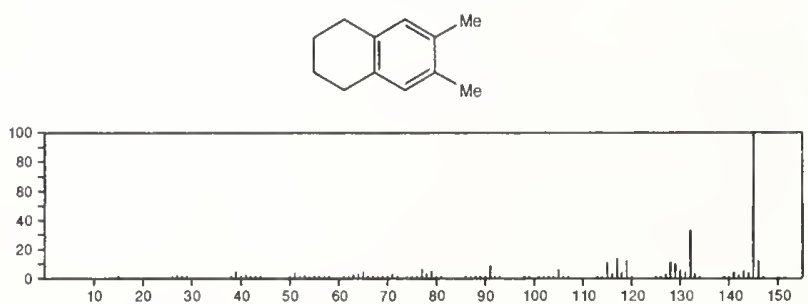

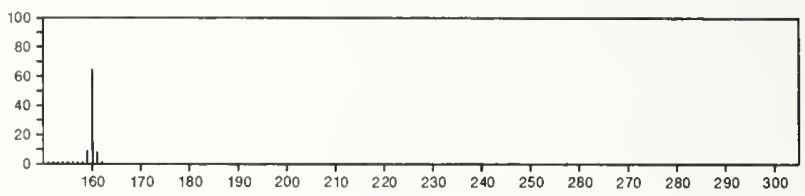

160

$\mathrm{C}_{12} \mathrm{H}_{16}$

Benzene, 1-(1-methylethenyl)-3-(1-methylethyl)-

1129-29-9
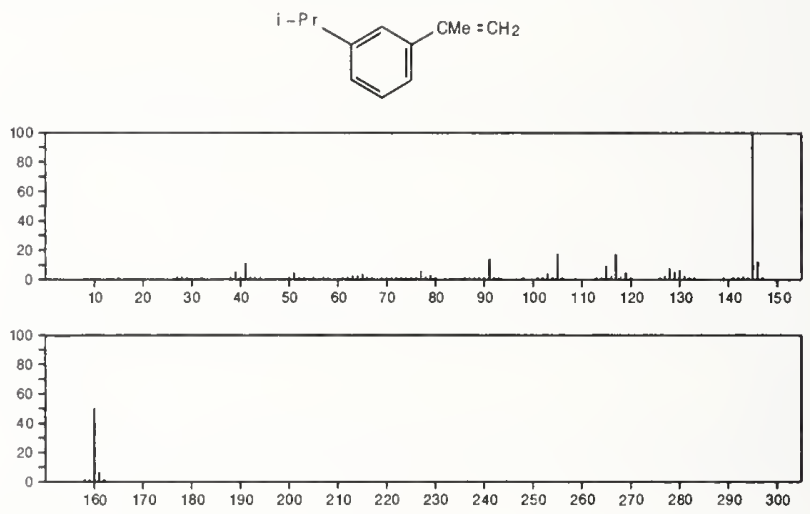

160

$\mathrm{C}_{12} \mathrm{H}_{16}$

$1746-23-2$

Benzene, 1-(1,1-dimethylethyl)-4-ethenyl-
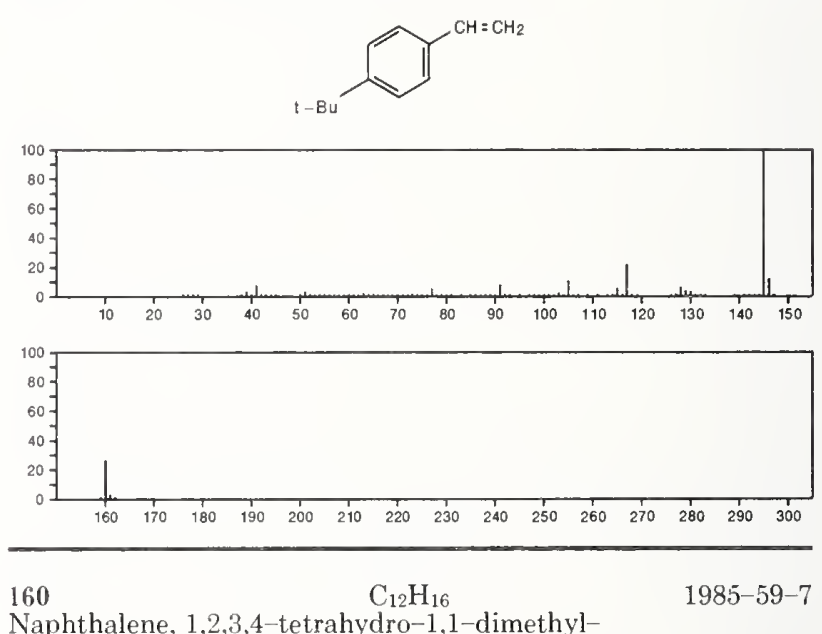

Naphthalene, 1,2,3,4-tetrahydro-1,1-dimethyl-
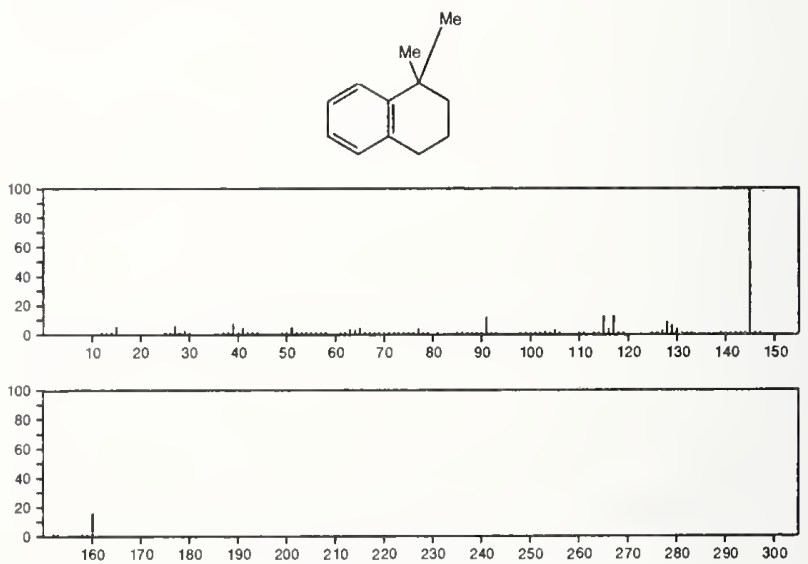
$160 \quad \mathrm{C}_{12} \mathrm{H}_{16} \quad 2388-14-9$

Benzene, 1-(1-methylethenyl)-4-(1-methylethyl)-
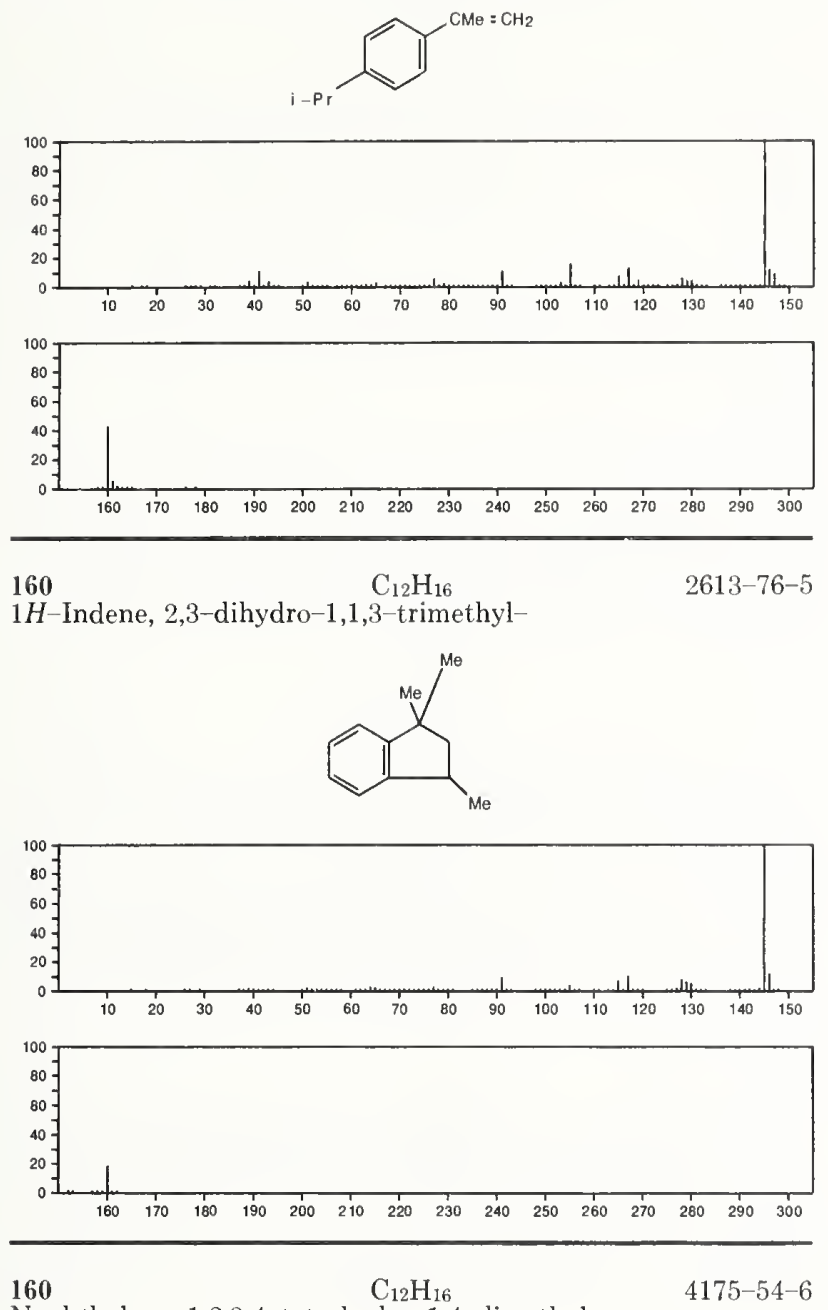

Naph thalene, 1,2,3,4-tetrahydro-1,4-dimethyl-
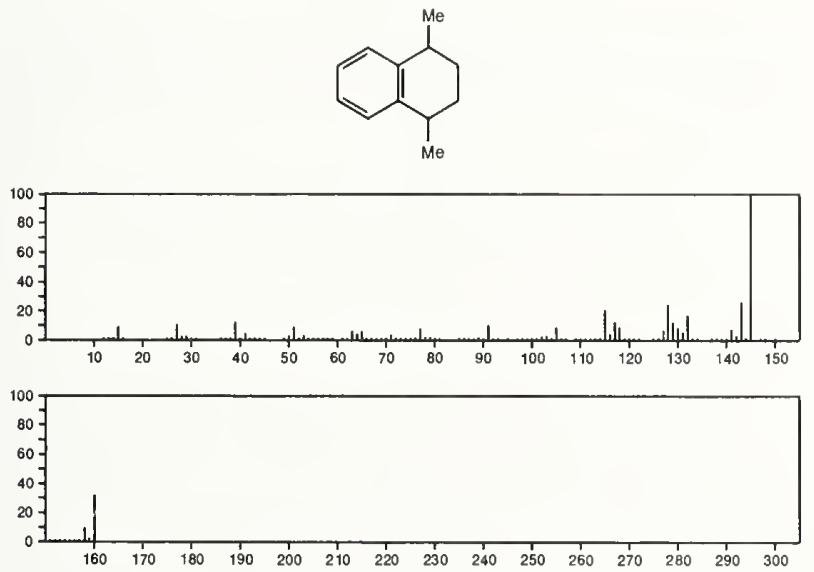

160

Indan, 4,5,7-trimethyl

$\mathrm{C}_{12} \mathrm{H}_{16}$

$6682-06-0$
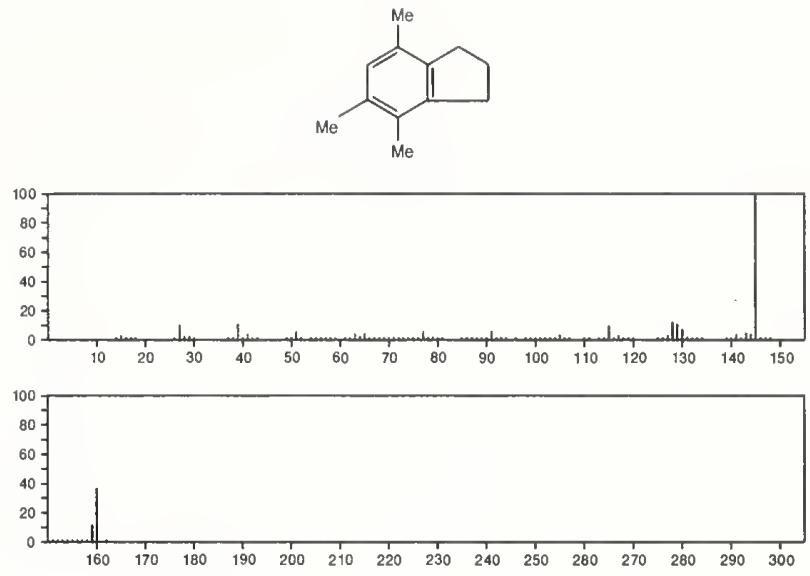

160

$\mathrm{C}_{12} \mathrm{H}_{16}$

$7524-63-2$

Naphthalene, 1,2,3,4-tetrahydro-2,6-dimethyl
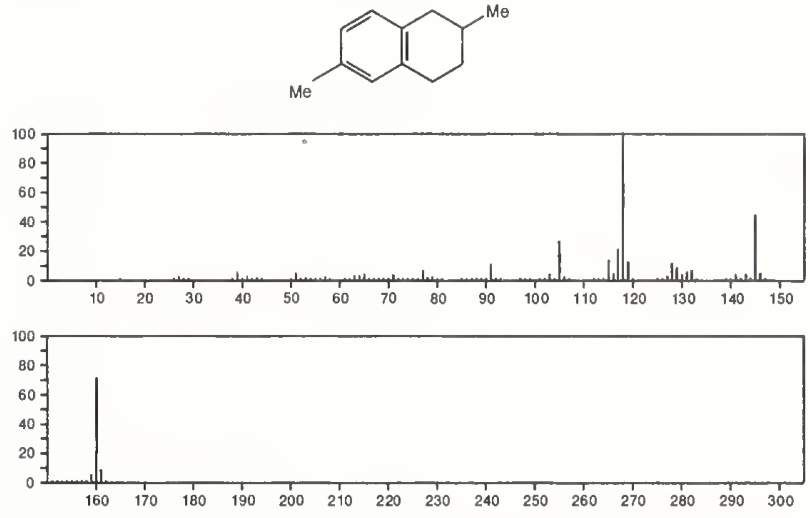

$160 \quad \mathrm{C}_{12} \mathrm{H}_{16} \quad 13065-07-1$ Naphthalene, 1,2,3,4-tetrahydro-2,7-dimethyl-
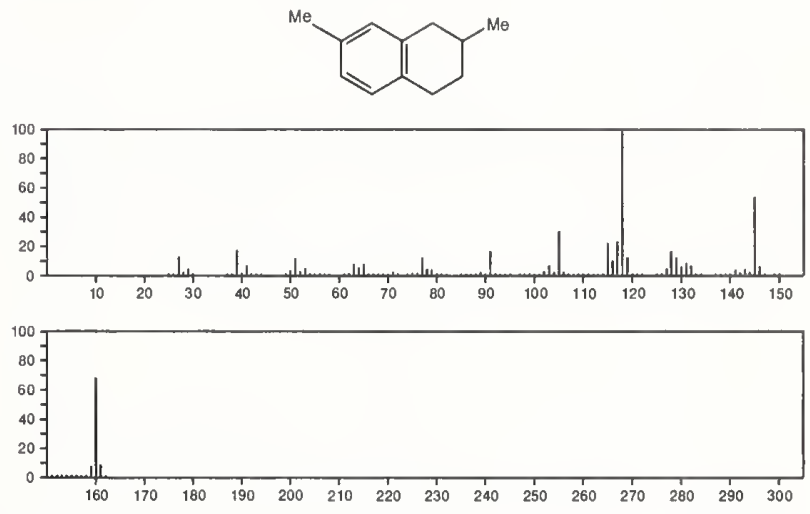

$160 \quad \mathrm{C}_{12} \mathrm{H}_{16}$

$1 H$-Indene, 2,3-dihydro-1,1,6-trimethyl-

$14276-95-0$
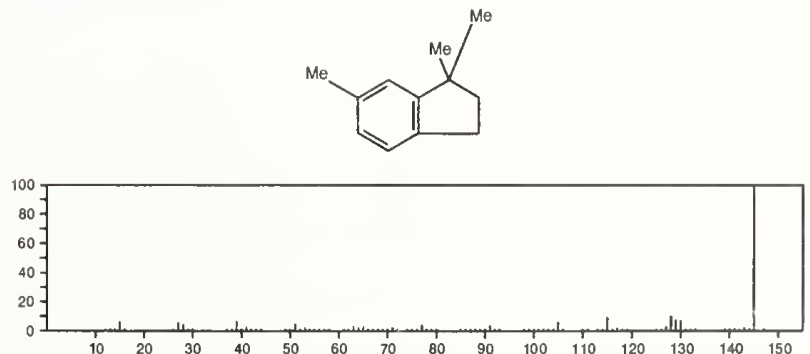

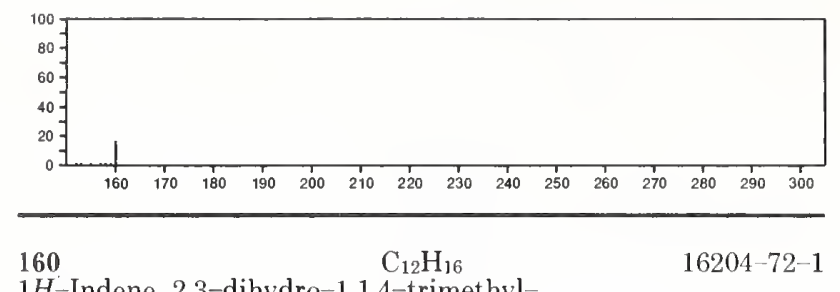

$1 H$-Indene, 2,3-dihydro-1,1,4-trimethyl-
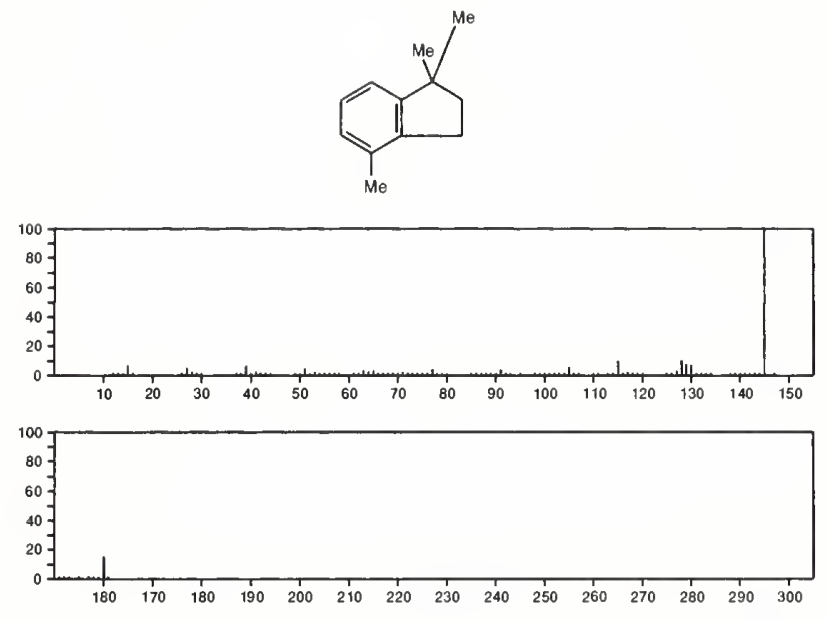

$160 \quad \mathrm{C}_{12} \mathrm{H}_{16} \quad 20027-77-4$ Naphthalene, 1,2,3,4-tetrahydro-5,6-dimethyl-
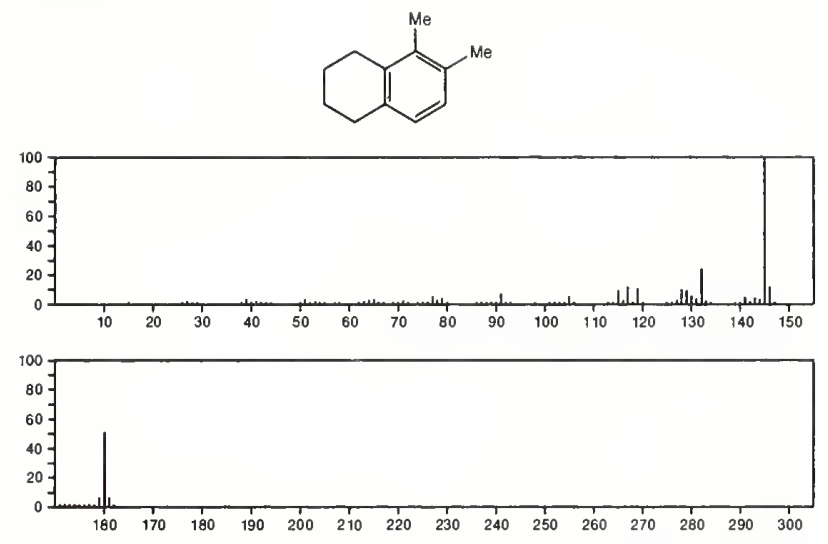

160

Naphthalene, 1,2,3,4-tetrahydro-1,5-dimethyl-

$21564-91-0$
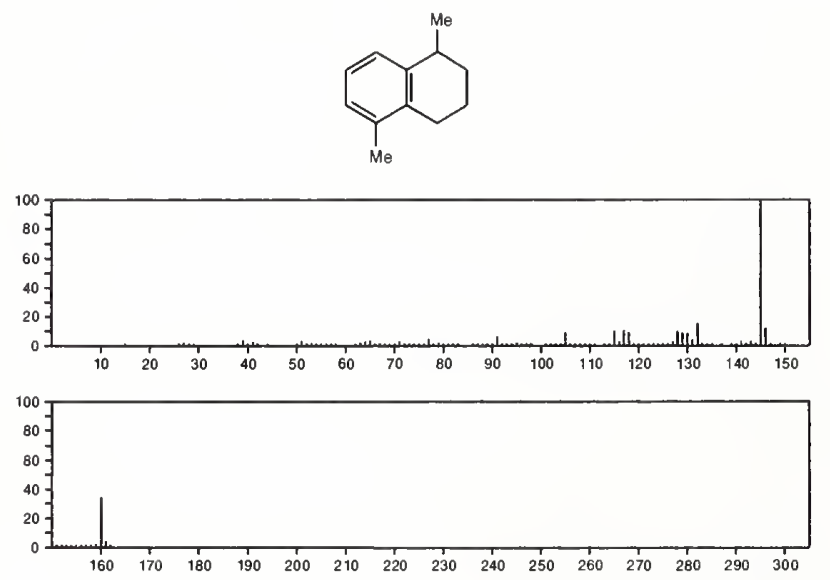

160

Naphthalene, 1,2,3,4-tetrahydro-2,3-dimethyl-

21564-92-1
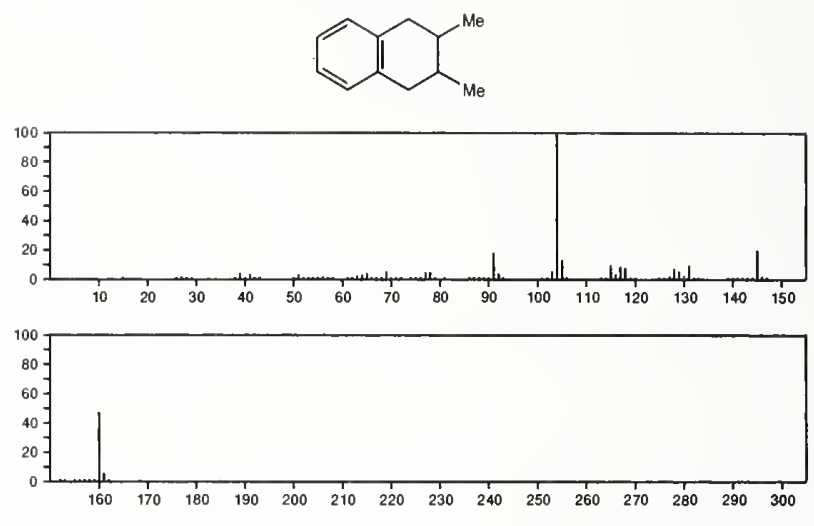

$160 \quad \mathrm{C}_{12} \mathrm{H}_{16}$

$21693-54-9$

Naphthalene, 1,2,3,4-tetrahydro-5,7-dimethyl-
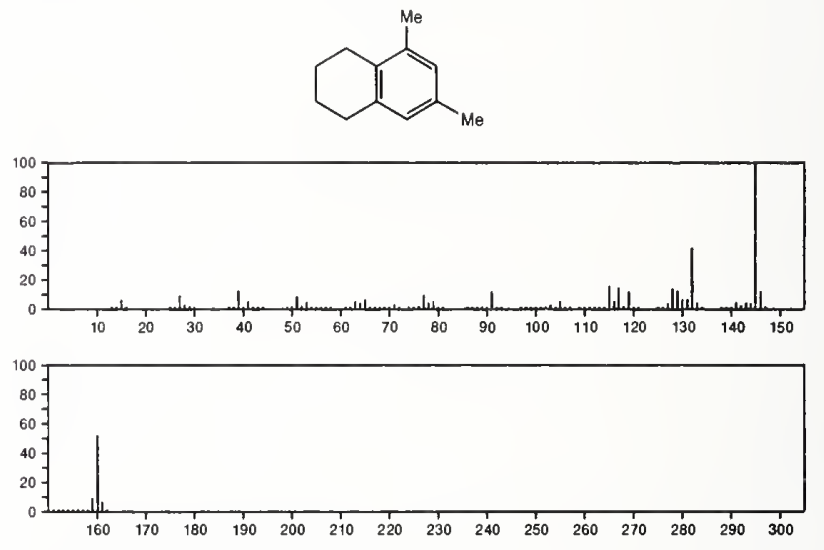

160

$\mathrm{C}_{12} \mathrm{H}_{16}$

$22531-20-0$

Naphthalene, 6-ethyl-1,2,3,4-tetrahydro-
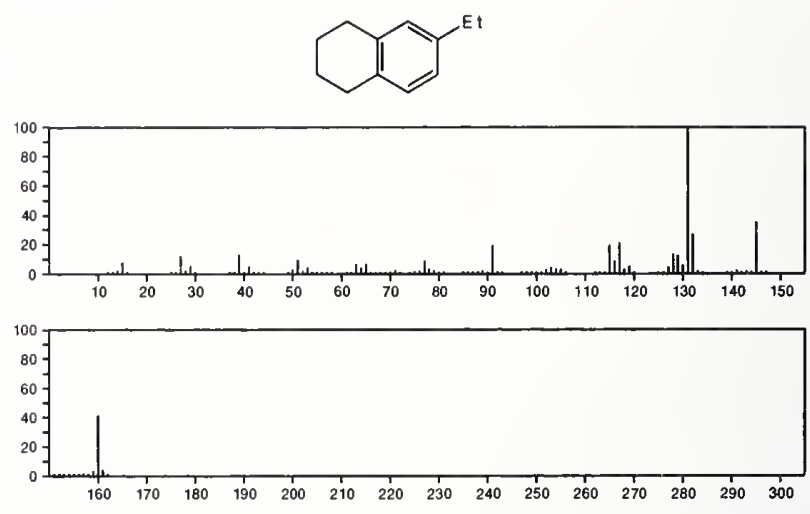

160

$\mathrm{C}_{12} \mathrm{H}_{16}$

25419-33-4

Naphthalene, 1,2,3,4-tetrahydro-1,8-dimethyl-
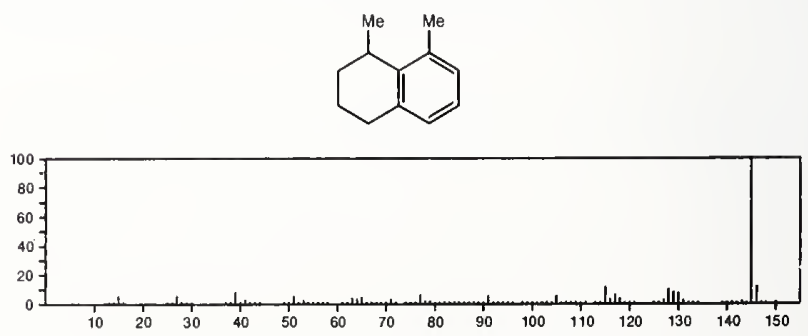


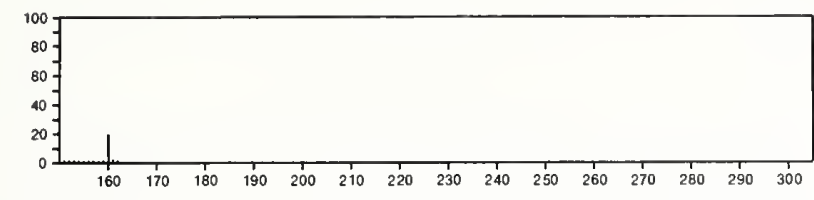

160

$\mathrm{C}_{12} \mathrm{H}_{16}$

27193-71-1

Benzene, (1-methylethenyl)(1-methylethyl)-
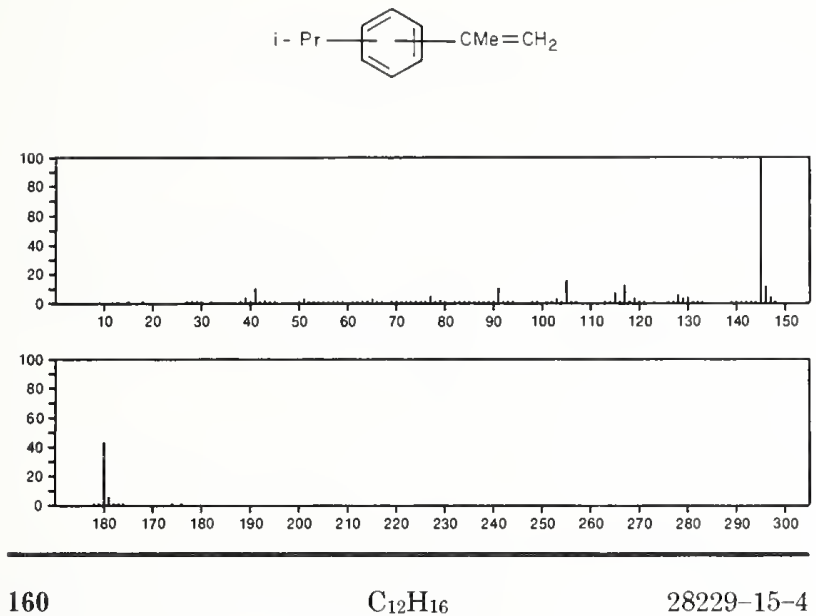

Biphenylene, 1,2,3,6,7,8,8a,8b-octahydro-, trans-
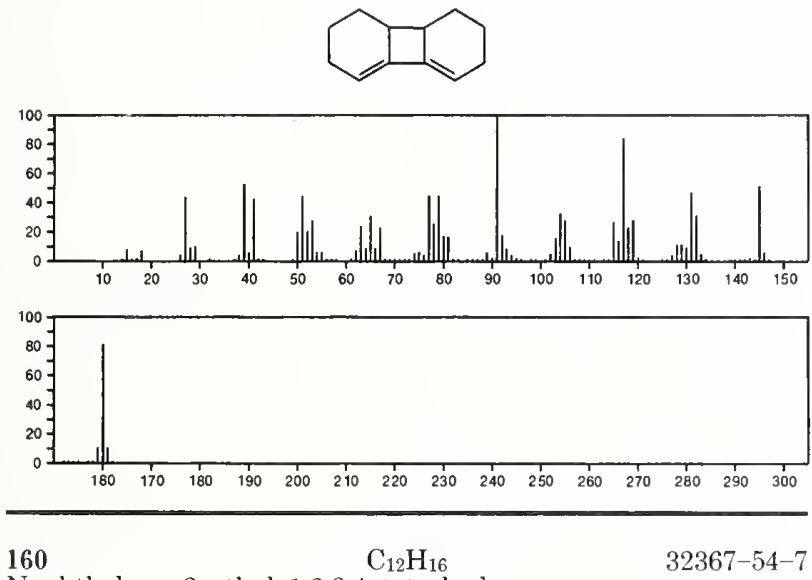

Naphthalene, 2-ethyl-1,2,3,4-tetrahydro-
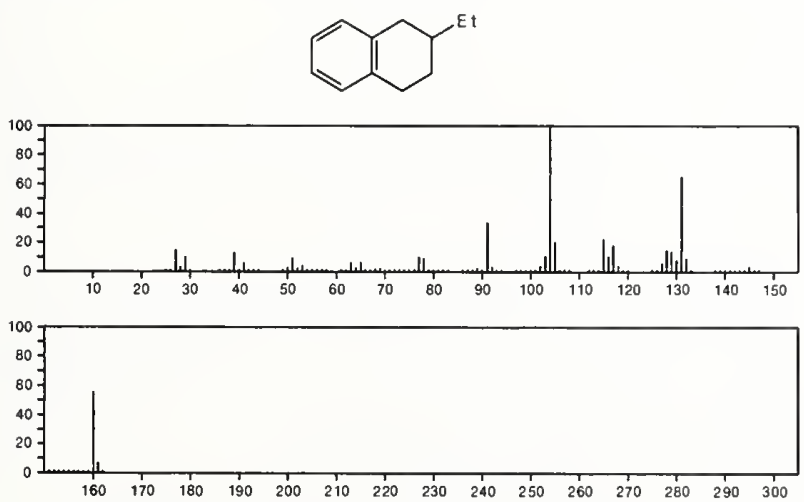

160

$1 H$-Indene, 2,3-dihydro-1,1,5-trimethyl-

$40650-41-7$
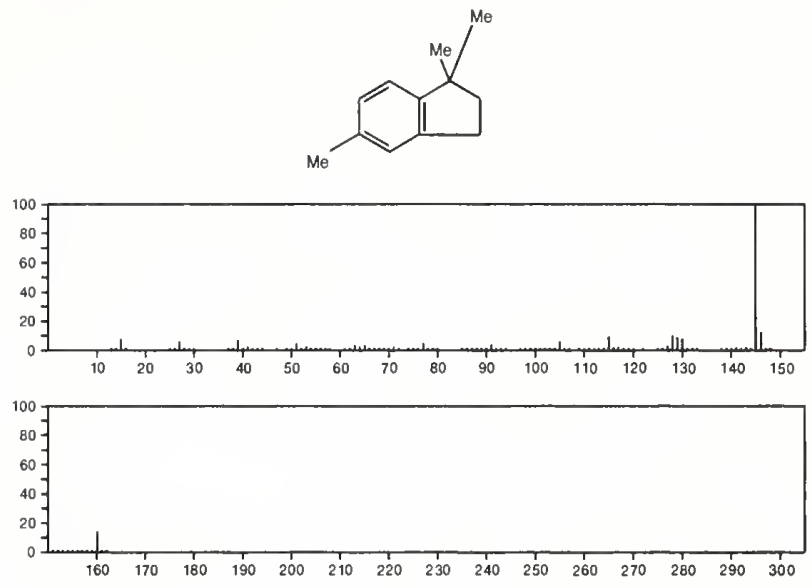

160

$\mathrm{C}_{12} \mathrm{H}_{16}$

Benzene, (3-methyl-4-pentenyl)-

$42524-30-1$

$\mathrm{H}_{2} \mathrm{C}=\mathrm{CHCHMeCH} \mathrm{CH}_{2} \mathrm{Ph}$
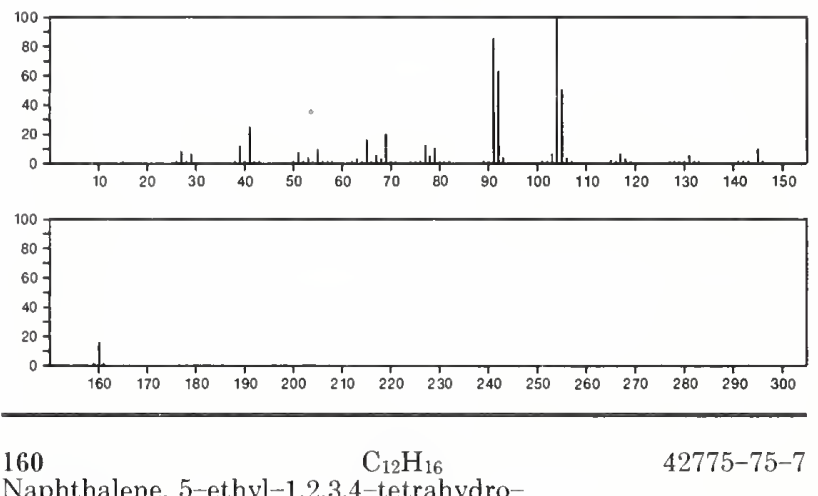

Naphthalene, 5-ethyl-1,2,3,4-tetrahydro-
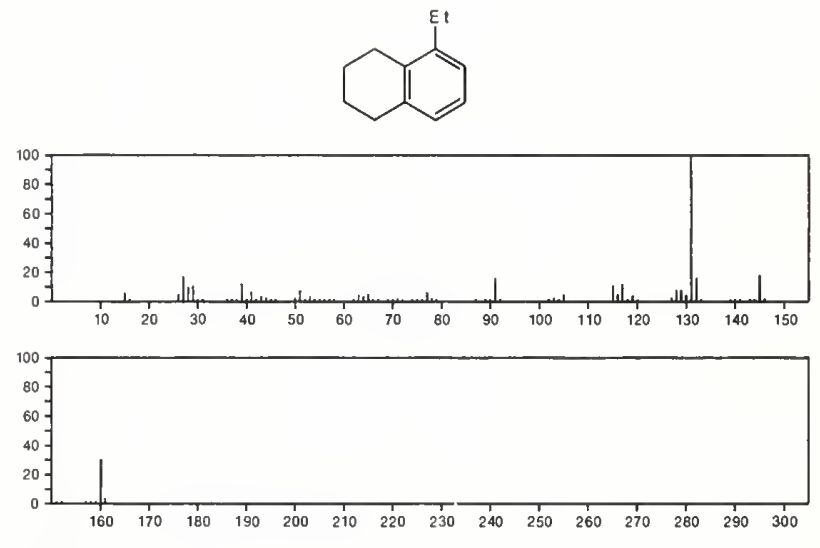

$160 \quad \mathrm{C}_{12} \mathrm{H}_{16}$

Benzene, (1,2-dimethyl-3-butenyl)-

$50871-04-0$

$\mathrm{H}_{2} \mathrm{C}=\mathrm{CHCHM \theta} \mathrm{CHM} \mathrm{P}_{\mathrm{P}}$

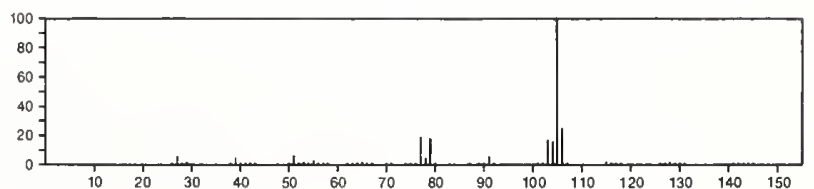




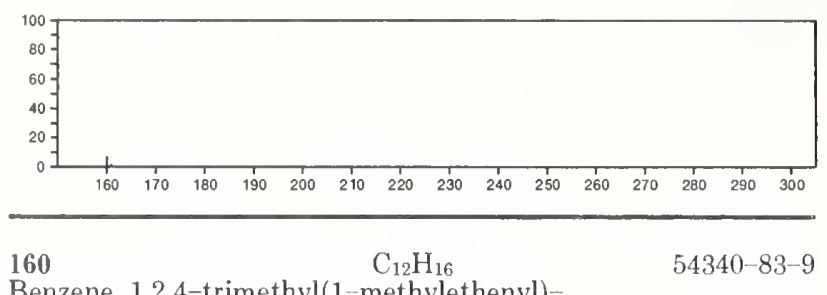

Benzene, 1,2,4-trimethyl(1-methylethenyl)-
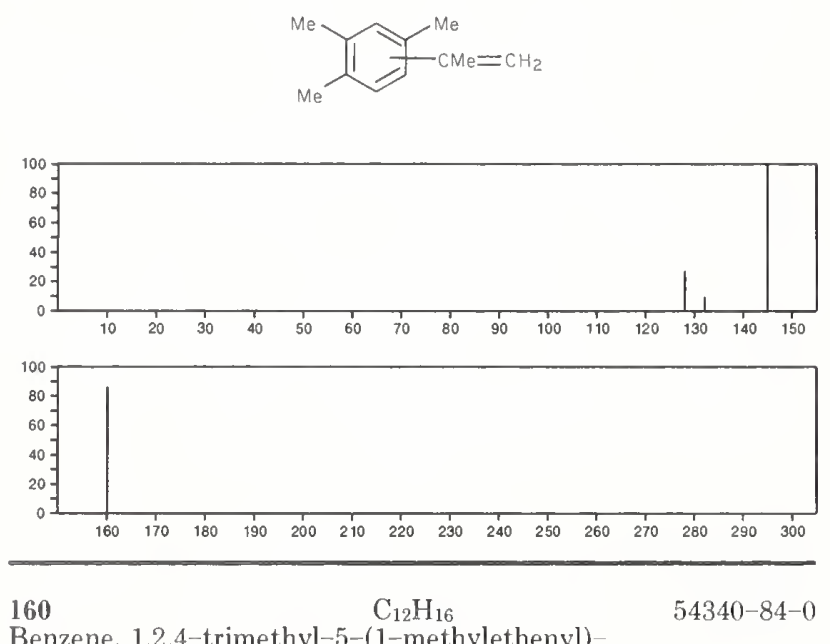

Benzene, 1,2,4-trimethyl-5-(1-methylethenyl)
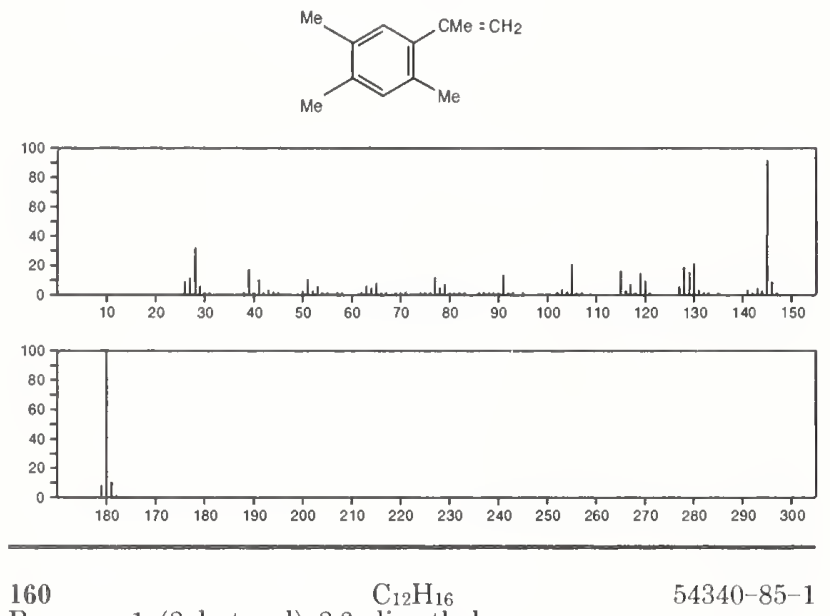

Benzene, 1-(2-butenyl)-2,3-dimethyl-
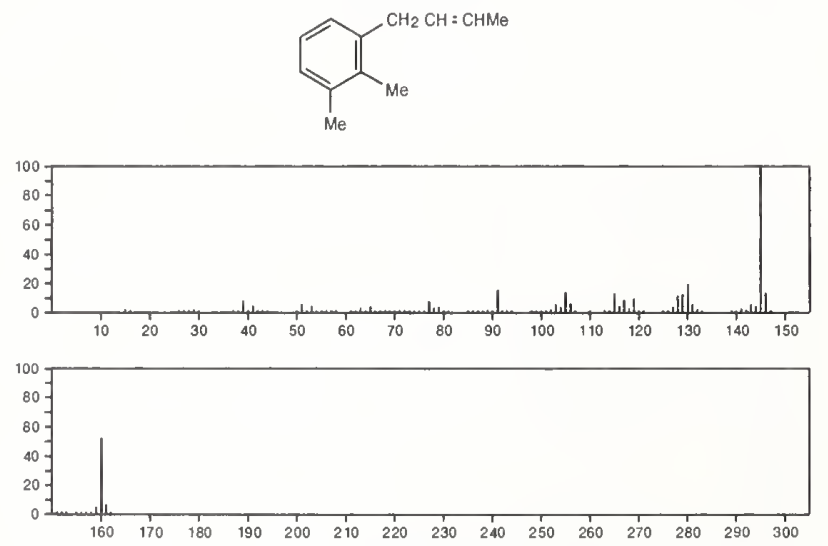

160

$\mathrm{C}_{12} \mathrm{H}_{16}$

$54340-86-2$

Benzene, 4-(2-butenyl)-1,2-dimethyl-, $(E)$
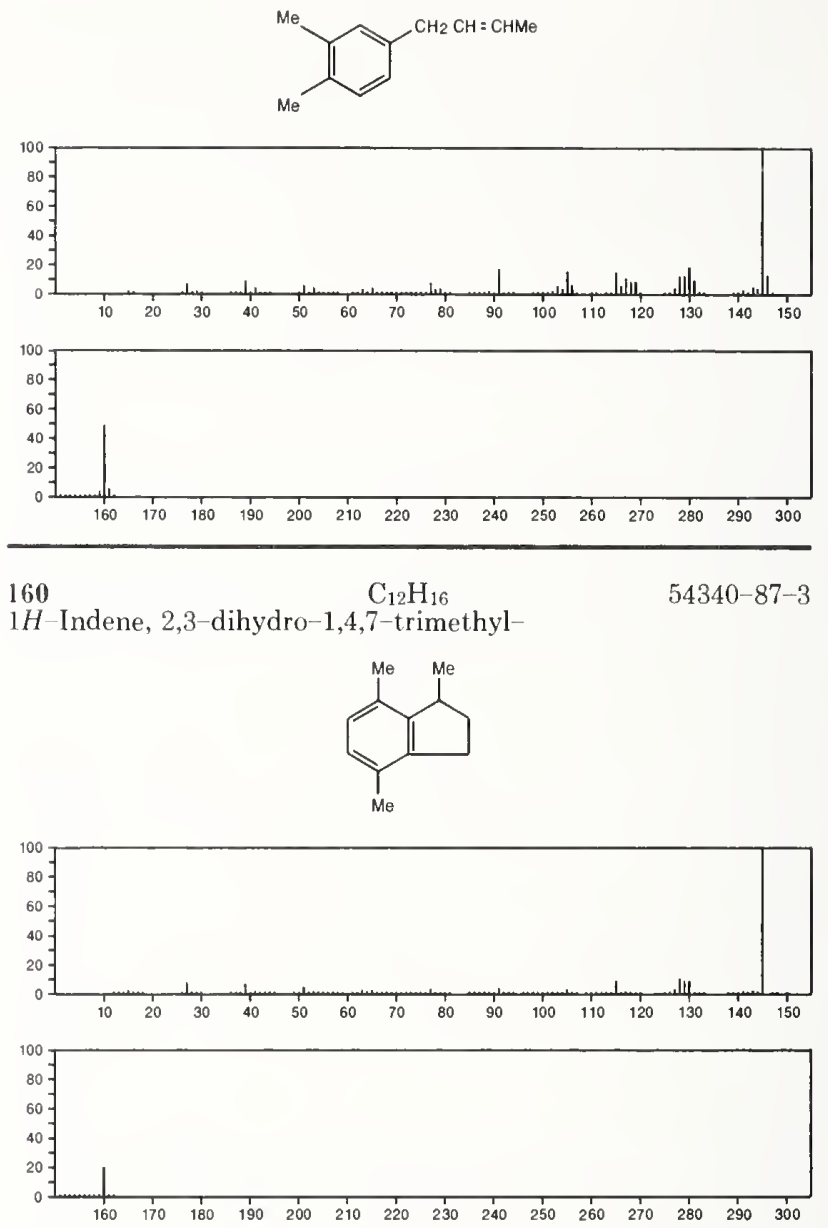

160

$\mathrm{C}_{12} \mathrm{H}_{16}$

$1 H$-Indene, 2,3-dihydro-1,5,7-trimethyl-

$54340-88-4$
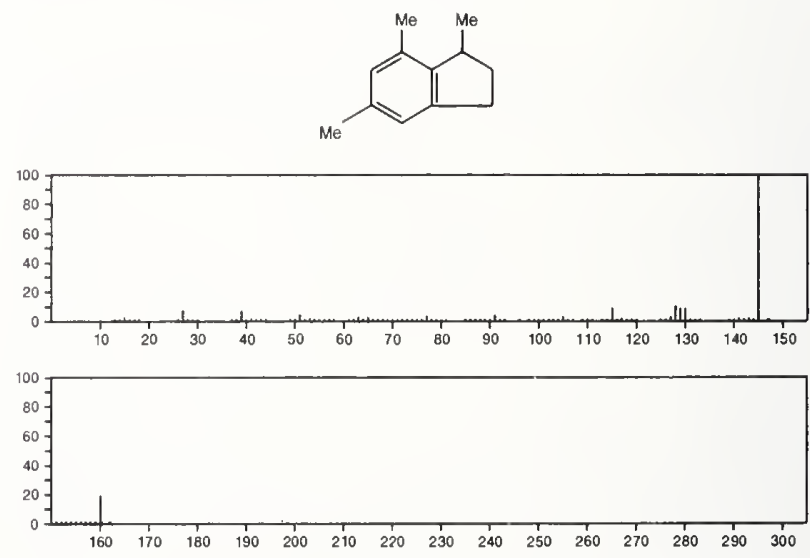

160

$\mathrm{C}_{12} \mathrm{H}_{16}$

Benzene, (1-cyclopropyl-1-methylethyl)-

$56282-43-0$
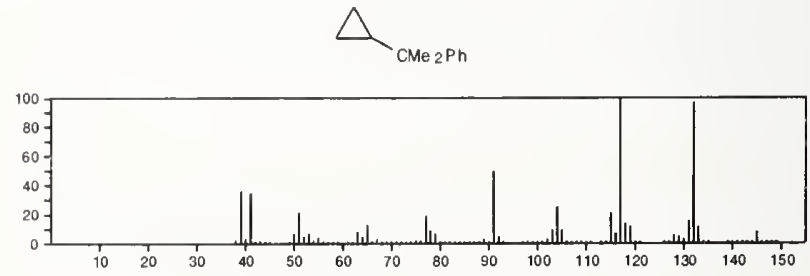


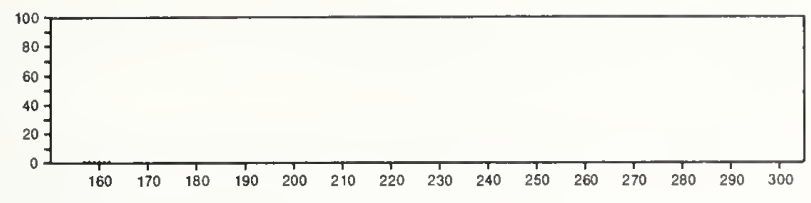

160

$$
\mathrm{C}_{12} \mathrm{H}_{16}
$$

1H-Indene, 1-ethyl-2,3-dihydro-1-methyl-

$56298-75-0$
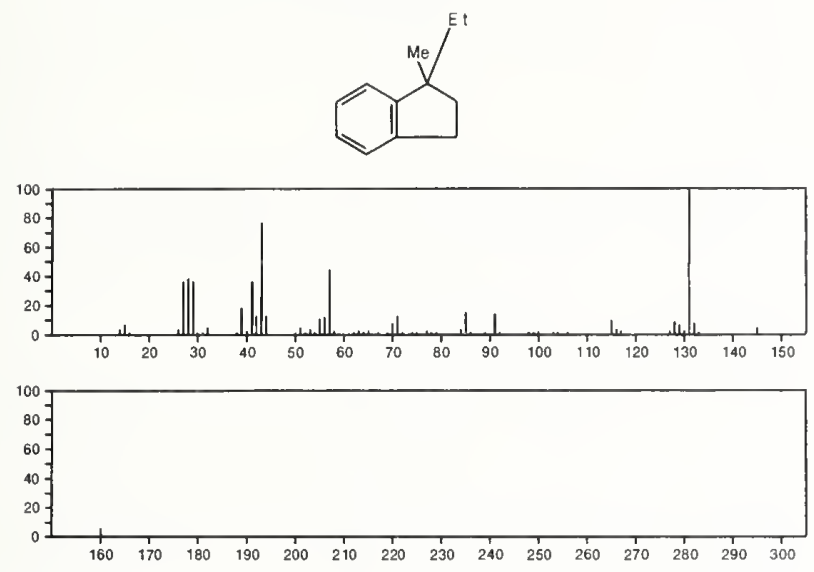

160

$\mathrm{C}_{12} \mathrm{H}_{16}$

$56818-01-0$

Benzene, 1-methyl-4-(3-methyl-3-butenyl)-
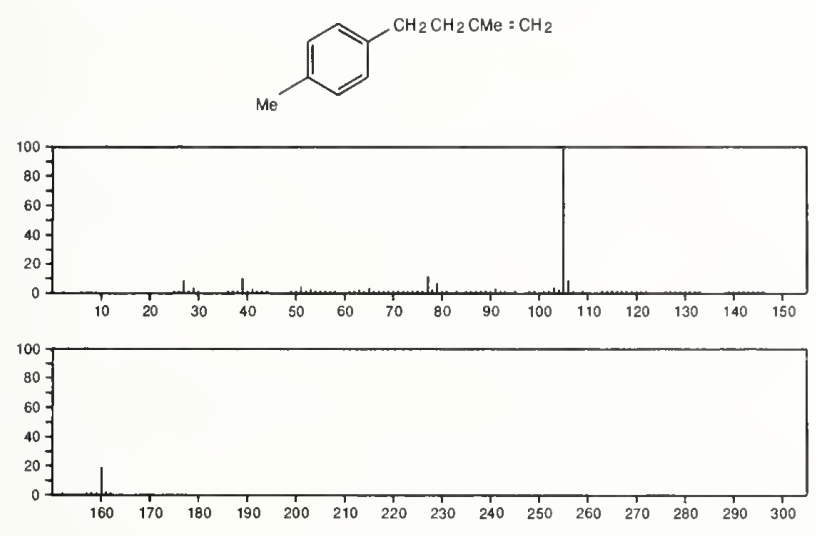

161

$\mathrm{C}_{4} \mathrm{H}_{7} \mathrm{~N}_{3} \mathrm{~S}_{2}$

$25660-70-2$

1,3,4-Thiadiazol-2-amine, 5-(ethylthio)-
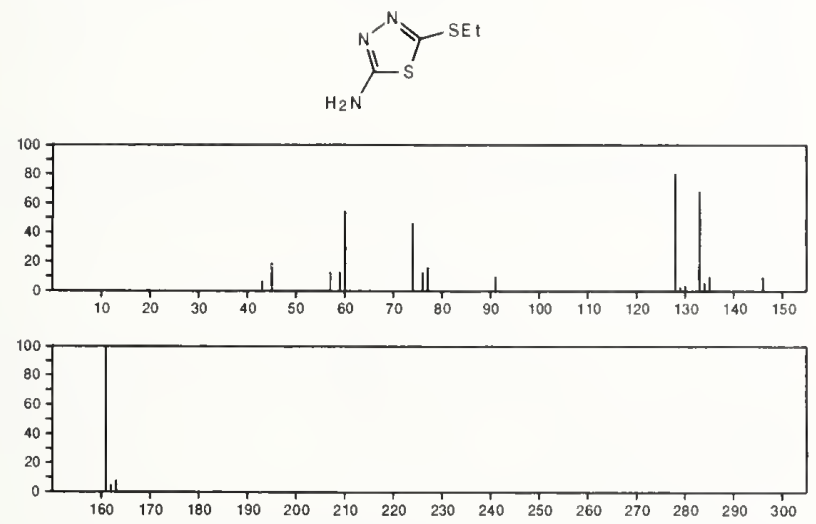

161

$\mathrm{C}_{4} \mathrm{H}_{11} \mathrm{~N}_{5} \mathrm{O}_{2}$

$20004-00-6$

Ethanimidamide, 2,2-iminobis $[N$-hydroxy-

$\underset{\mathrm{HN}}{\mathrm{HN}} \stackrel{\mathrm{NH}}{\|}$
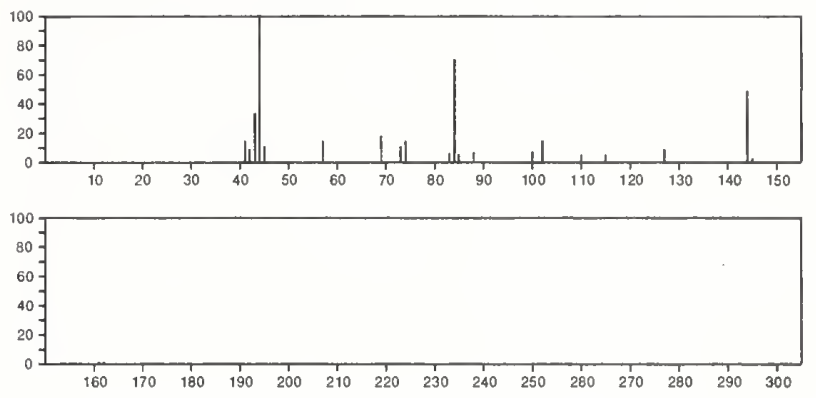

161

$\mathrm{C}_{6} \mathrm{H}_{5} \mathrm{Cl}_{2} \mathrm{~N}$

95-76-1

Benzenamine, 3,4-dichloro-
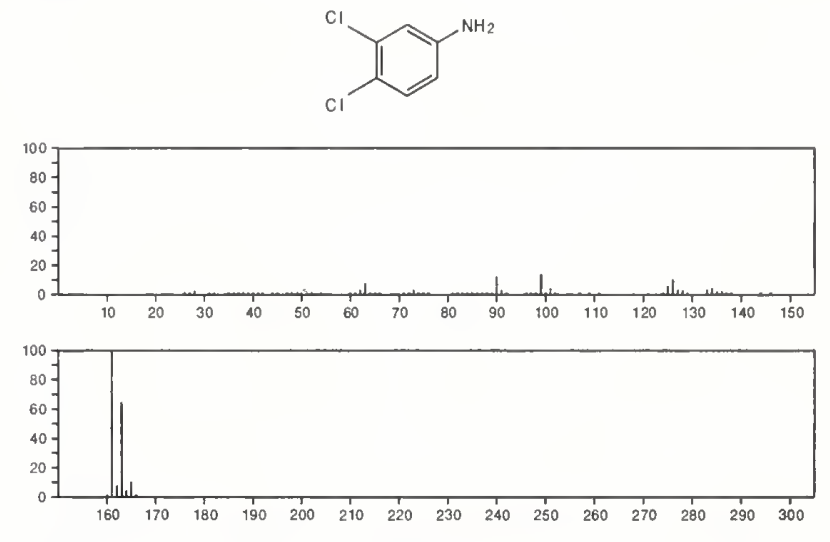

161

$\mathrm{C}_{6} \mathrm{H}_{5} \mathrm{Cl}_{2} \mathrm{~N}$

95-82-9

Benzenamine, 2,5-dichloro-
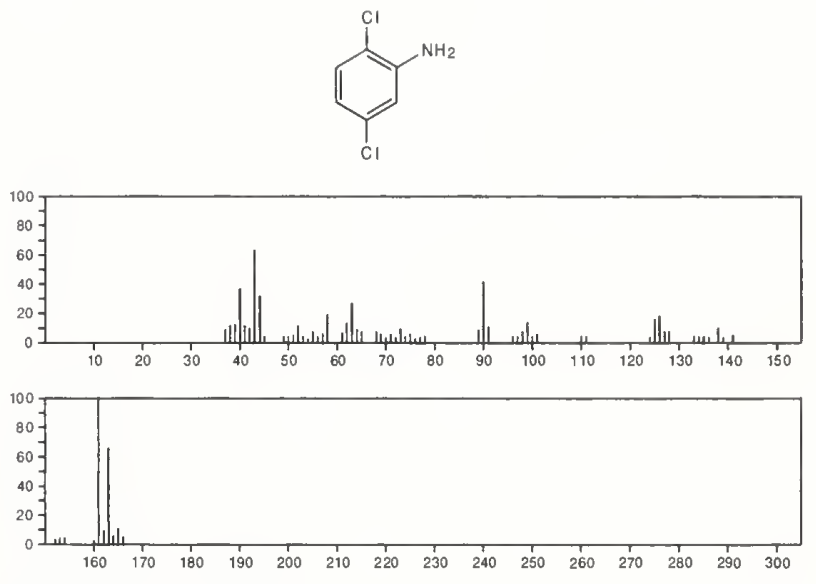

161

$\mathrm{C}_{6} \mathrm{H}_{5} \mathrm{Cl}_{2} \mathrm{~N}$

554-00-7

Benzenamine, 2,4-dichloro-
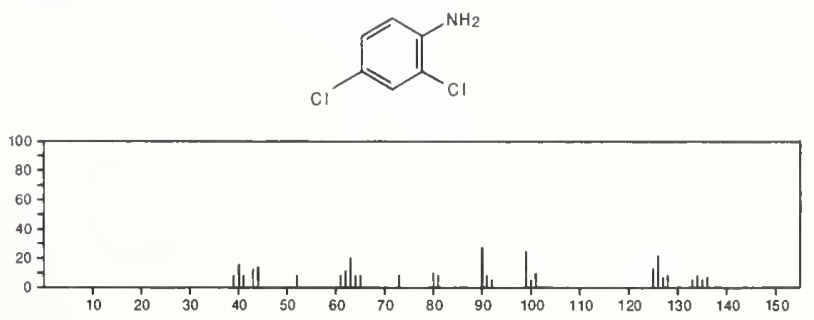


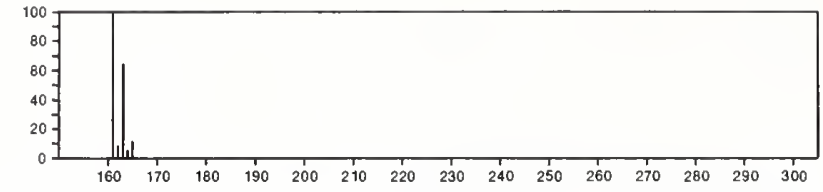

$\begin{array}{ll}161 & \mathrm{C}_{6} \mathrm{H}_{5} \mathrm{Cl}_{2} \mathrm{~N} \\ \text { Benzenamine, 2,3-dichloro- }\end{array}$
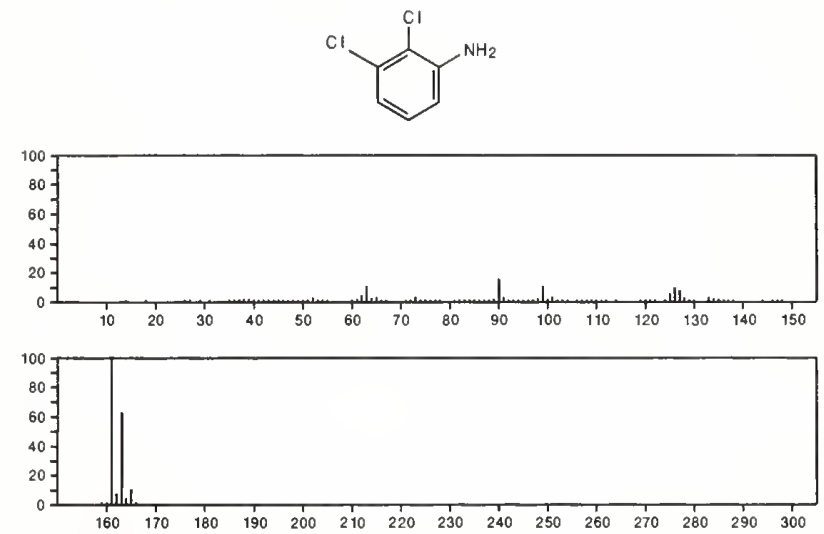

$161 \quad \mathrm{C}_{6} \mathrm{H}_{11} \mathrm{NO}_{2} \mathrm{~S}$

Acetic acid, (dimethylamino) thioxo-, ethyl ester

$16703-48-3$

Me 2 NCSC(O) OE
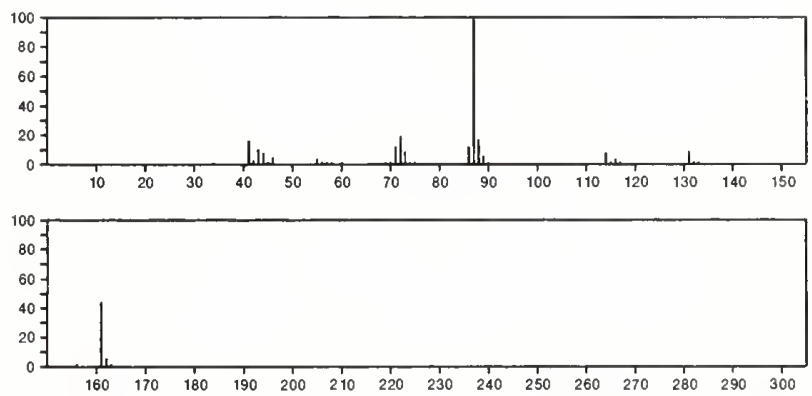

$161 \quad \mathrm{C}_{6} \mathrm{H}_{11} \mathrm{NO}_{4}$

$55299-56-4$

DL-Serine, $N$-acetyl-, methyl ester
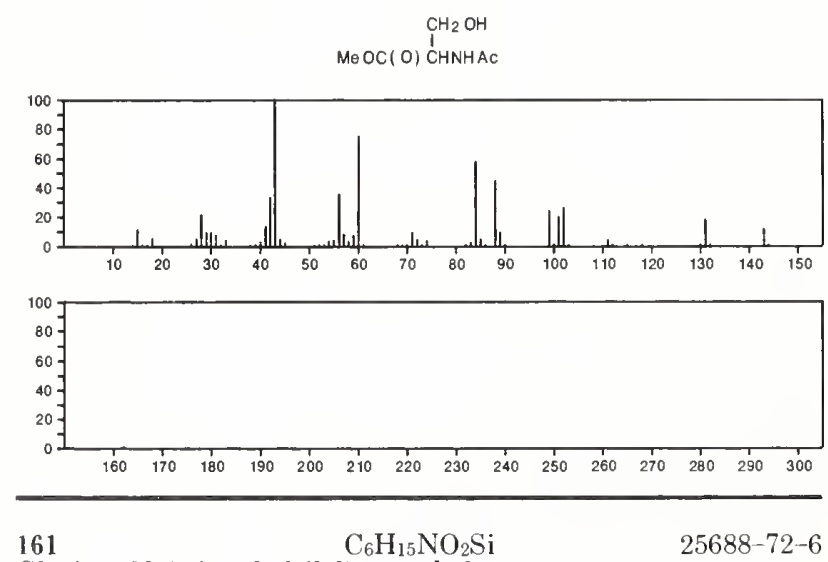

Glycine, $N$-(trimethylsilyl)-, methyl ester

$\mathrm{MeOC}(0) \mathrm{CH}_{2} \mathrm{NHSiMe}_{3}$

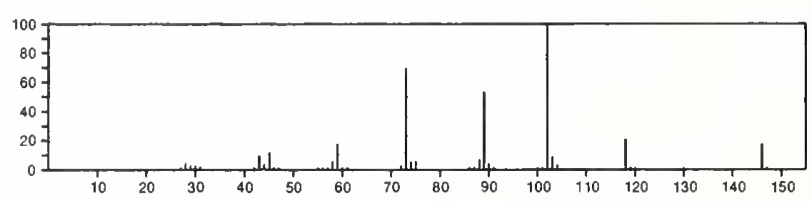

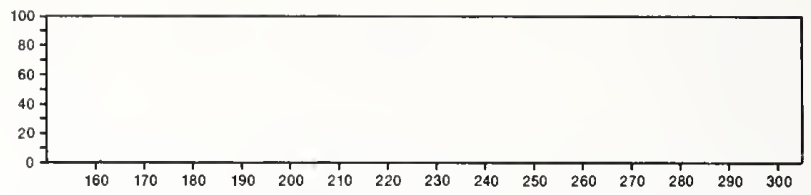

161

$\mathrm{C}_{6} \mathrm{H}_{19} \mathrm{NSi}_{2}$

Silanamine, 1,1,1-trimethyl- $N$-(trimethylsilyl)-

$999-97-3$

$\mathrm{Me}_{3} \mathrm{SiNHSi} \mathrm{Me}_{3}$
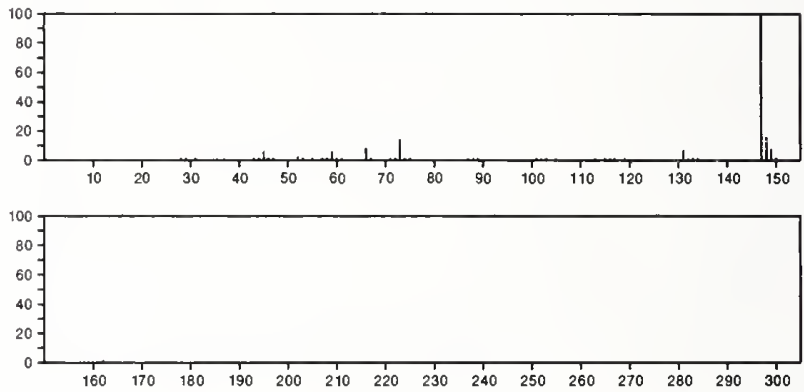

161

$\mathrm{C}_{6} \mathrm{H}_{19} \mathrm{NSi}_{2}$

32713-31-8

Silanamine, $N$-(dimethylsilyl)-1,1,1-trimethyl-, monomethyl deriv.

$\mathrm{NH}\left(\mathrm{SH}_{3}\right)_{2}+6 \mathrm{Me}$
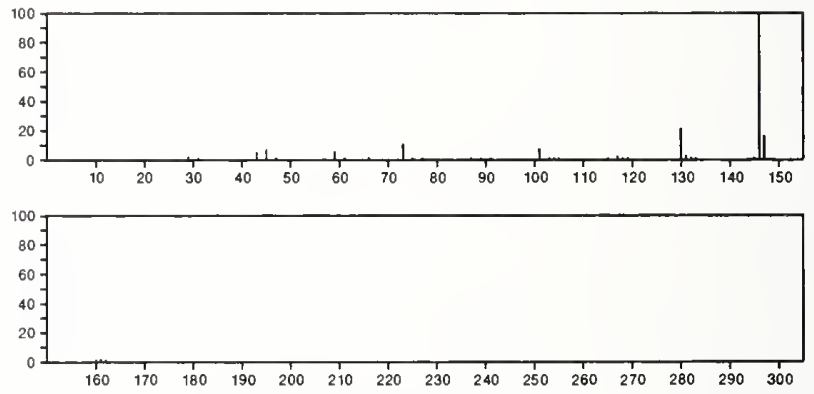

$161 \quad \mathrm{C}_{7} \mathrm{H}_{6} \mathrm{~F}_{3} \mathrm{~N}$

Benzenamine, 3-(trifluoromethyl)-

98-16-8
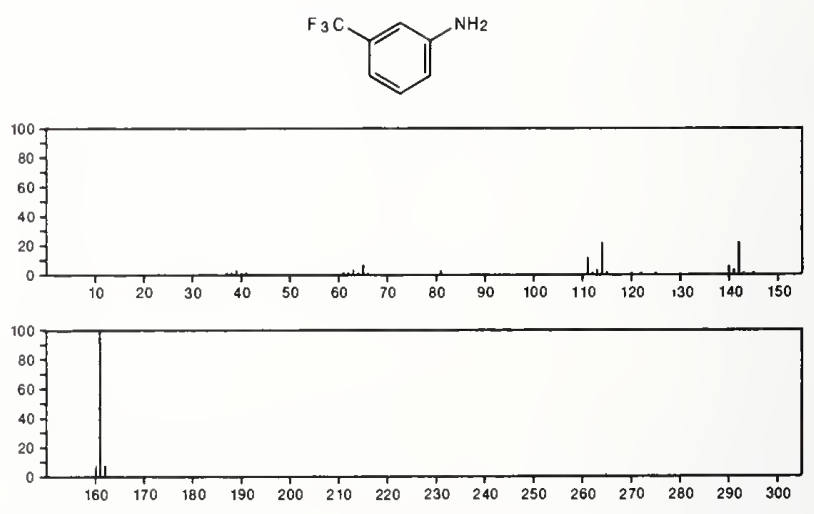

161

$\mathrm{C}_{7} \mathrm{H}_{15} \mathrm{NO}_{3}$

20633-12-9

Nitric acid, heptyl ester

$\mathrm{Me}\left(\mathrm{CH}_{2}\right)_{6} \mathrm{ONO}_{2}$

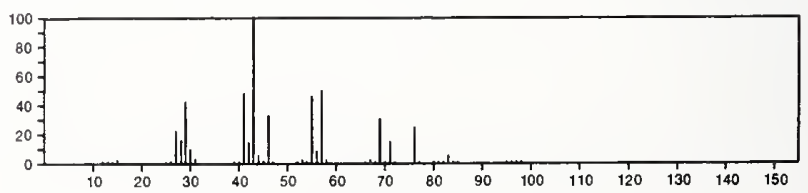


161

$\mathrm{C}_{7} \mathrm{H}_{19 N O S i}$

$16654-64-1$

Ethanamine, $N, N$-dimethyl-2-[(trimethylsilyl)oxy $]$

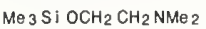
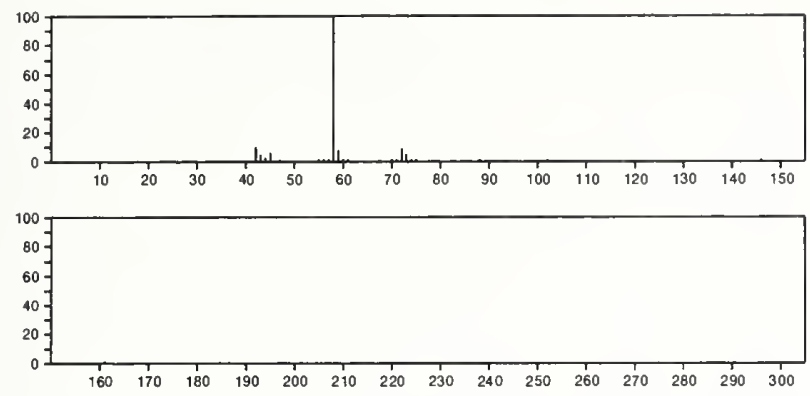

161

$\mathrm{C}_{8} \mathrm{H}_{7} \mathrm{~N}_{3} \mathrm{O}$

Pyrido[3,2-d]pyrimidin-4(3H)-one, 2-methyl-

$3303-26-2$<smiles>Cc1nc(=O)c2ncccc2[nH]1</smiles>
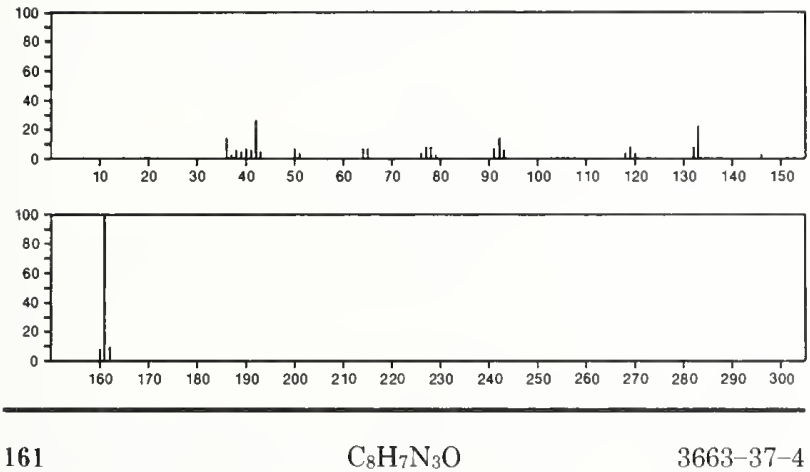

1,2,4-Oxadiazol-5-amine, 3-phenyl-

$3663-37-4$
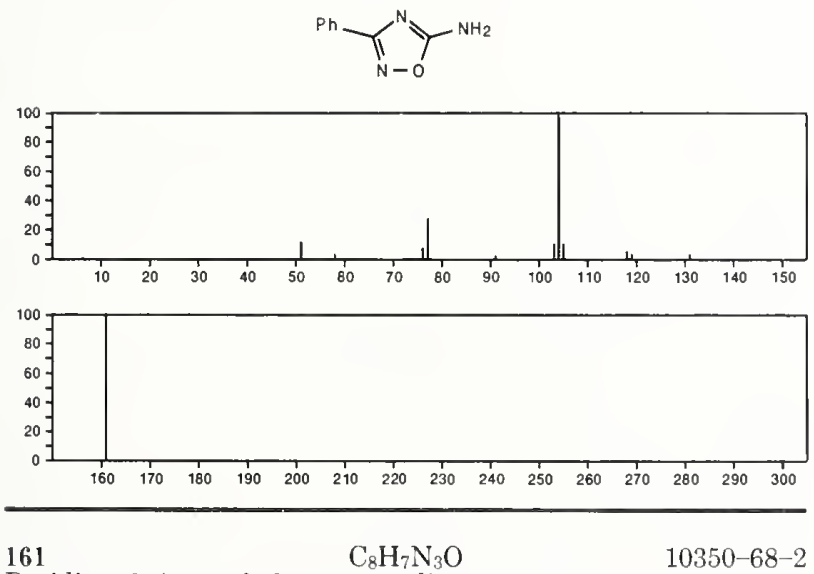

Pyridine, 2-(5-methyl-1,2,4-oxadiazol-3-yl)-
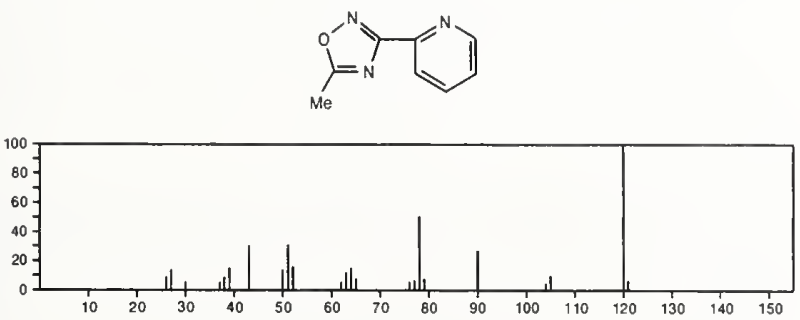

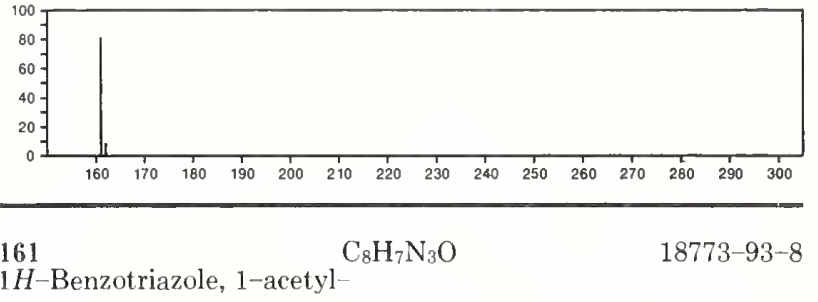

$1 H$-Benzotriazole, 1 -acetyl-
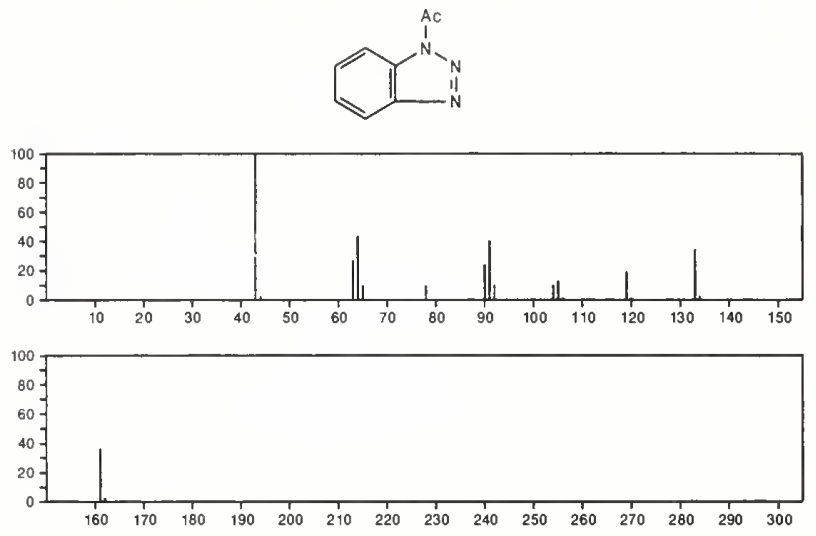

161

$\mathrm{C}_{8} \mathrm{H}_{7} \mathrm{~N}_{3} \mathrm{O}$

21434-16-2

3H-1,2,4-Triazol-3-one, 2,4-dihydro-2-phenyl-
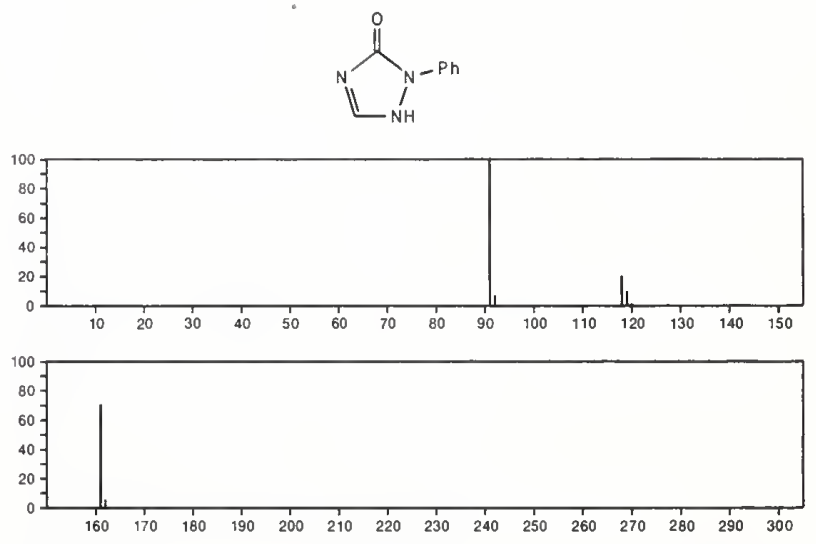

161

$\mathrm{C}_{8} \mathrm{H}_{7} \mathrm{~N}_{3} \mathrm{O}$

22389-82-8

Pyrido[3,4-d]pyrimidin-4(3H)-one, 3-methyl-
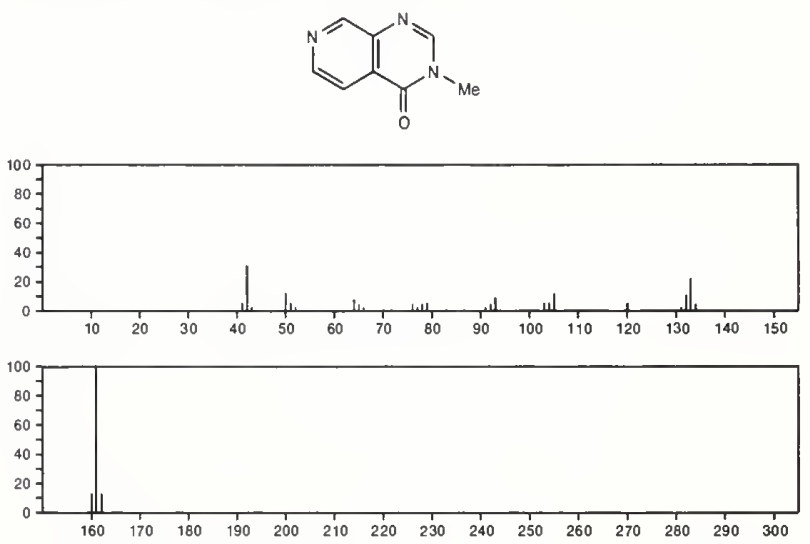
$161 \quad \mathrm{C}_{8} \mathrm{H}_{7} \mathrm{~N}_{3} \mathrm{O}$

Pyrido[2,3-d]pyrimidine, 4-methoxy-
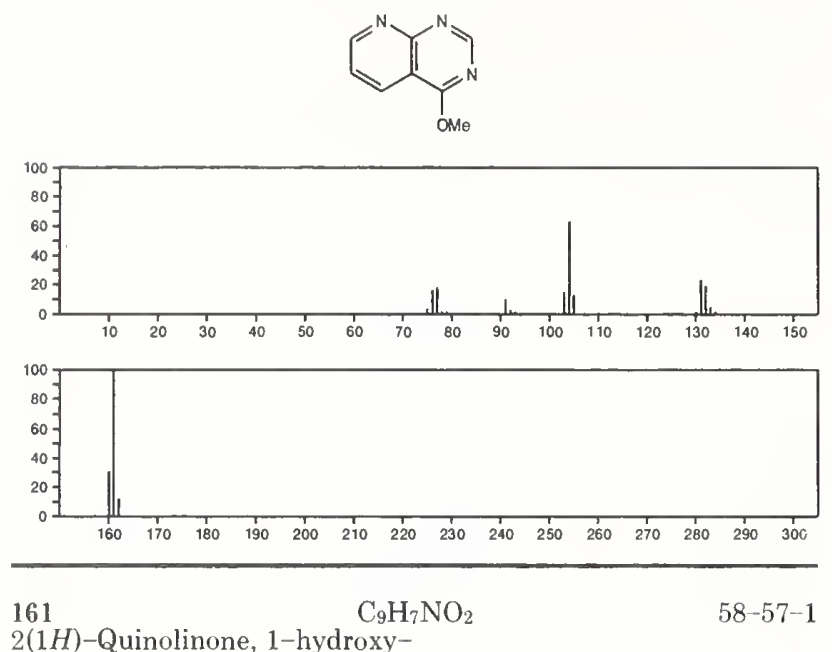

2(1H)-Quinolinone, 1-hydroxy-
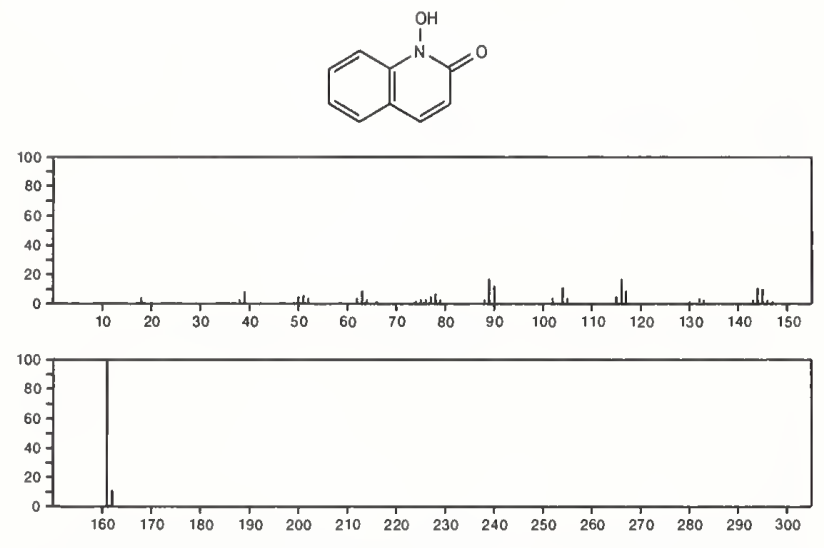

161

608-05-9

1H-Indole-2,3-dione, 5-methyl-
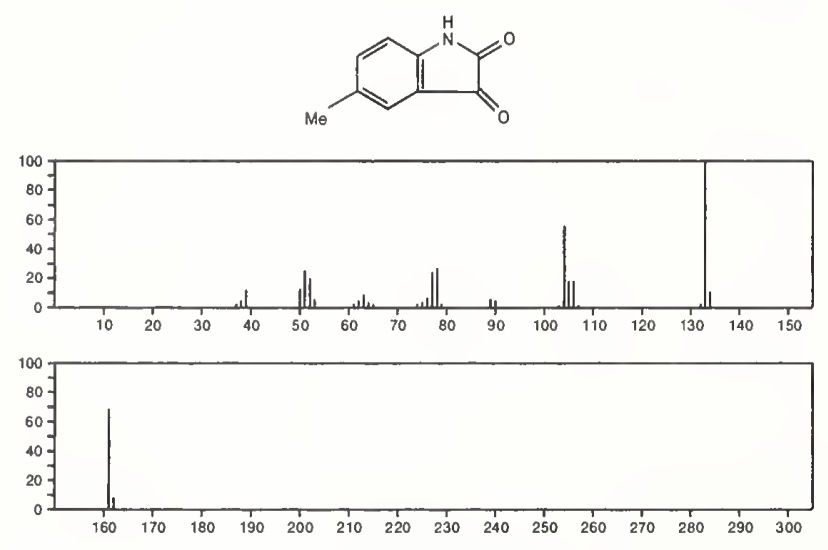

$161 \quad \mathrm{C}_{9} \mathrm{H}_{7} \mathrm{NO}_{2} \quad 771-50-6$

$1 H$-Indole-3-carboxylic acid
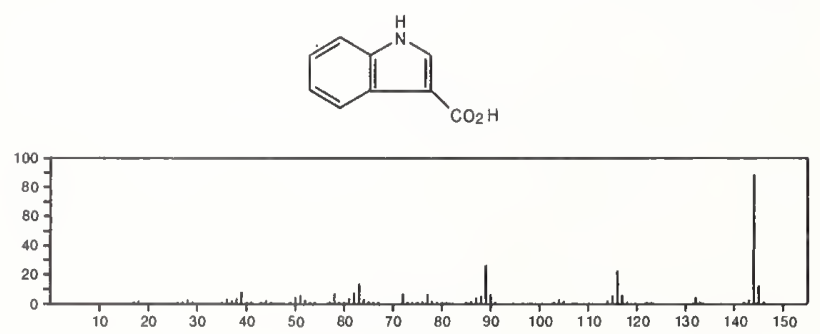

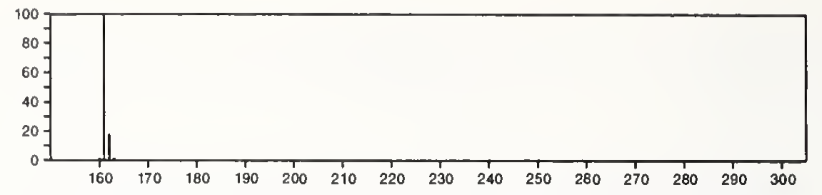

$161 \quad \mathrm{C}_{9} \mathrm{H}_{7} \mathrm{NO}_{2}$

5(4H)-Isoxazolone, 3-phenyl-

1076-59-1
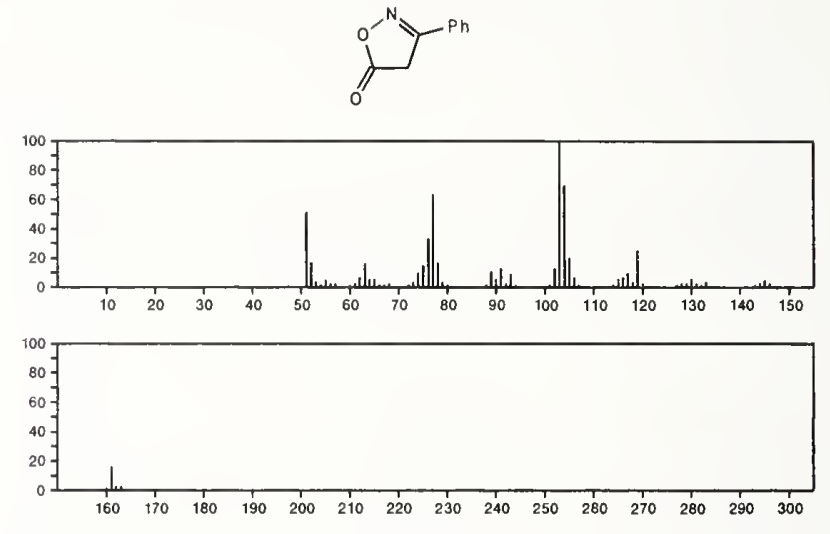

$161 \quad \mathrm{C}_{9} \mathrm{H}_{7} \mathrm{NO}_{2}$

$1 \mathrm{H}$-Indole-2,3-dione, 7-methyl-

$1127-59-9$
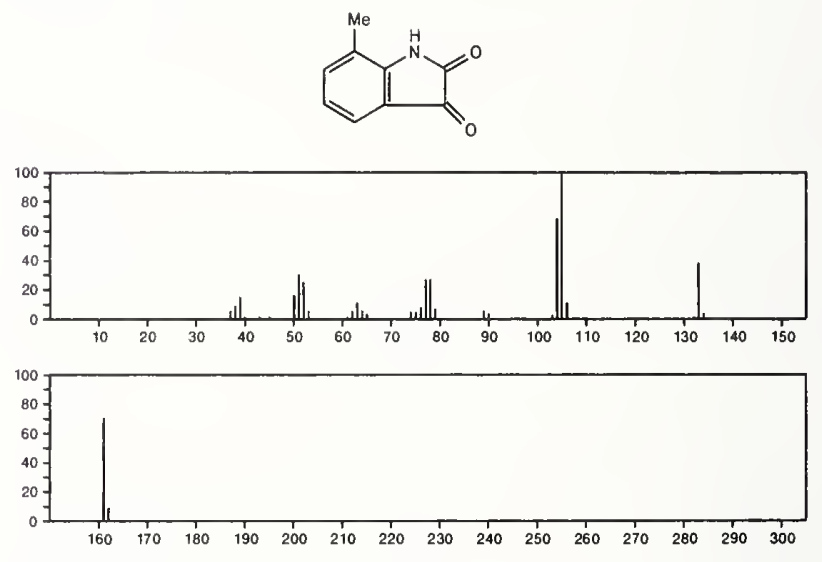

$161 \quad \mathrm{C}_{9} \mathrm{H}_{7} \mathrm{NO}_{2}$

$1 H$-Indole-2,3-dione, 4-methyl-

$1128-44-5$
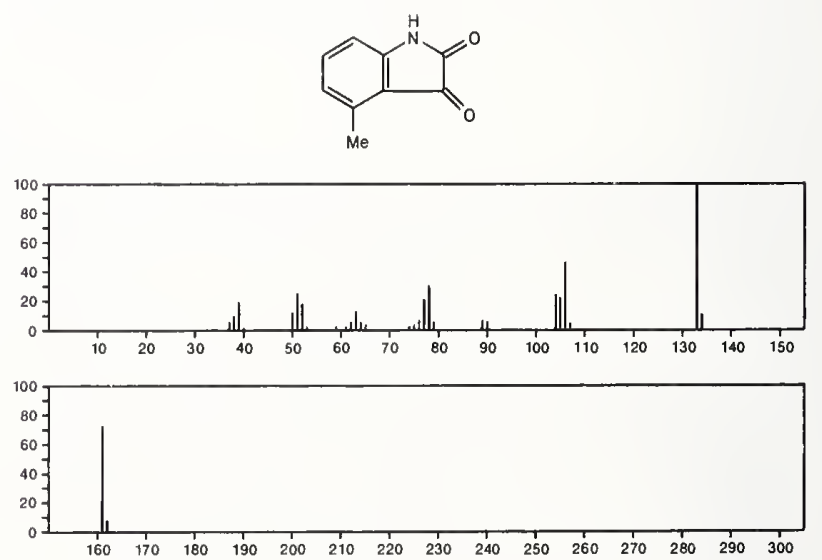
161

$\mathrm{C}_{9} \mathrm{H}_{7} \mathrm{NO}_{2}$

1H-Indole-2,3-dione, 6-methyl-
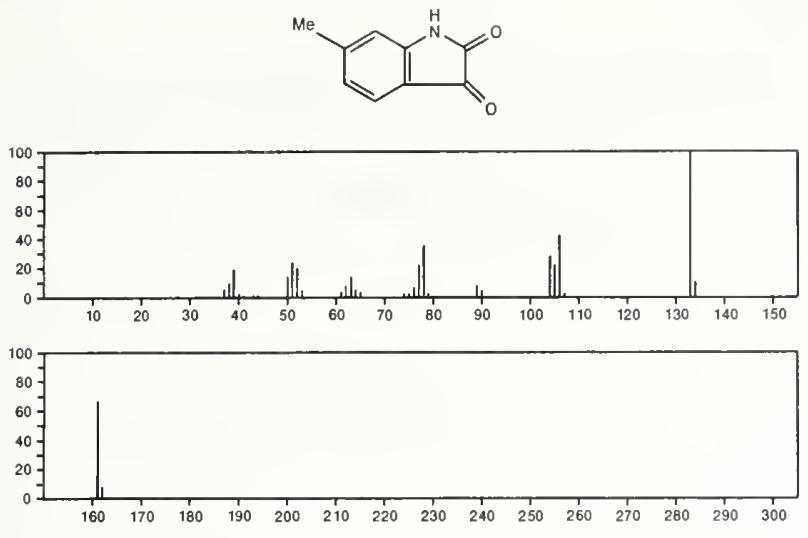

161

2-Quinolinol, 1-oxide

$\mathrm{C}_{9} \mathrm{H}_{7} \mathrm{NO}_{2}$

$10285-97-9$
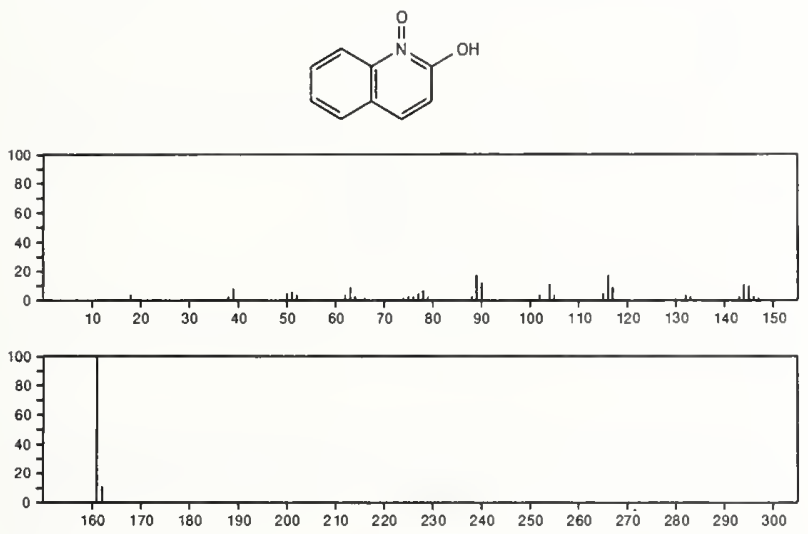

$161 \quad \mathrm{C}_{9} \mathrm{H}_{7} \mathrm{NO}_{2}$

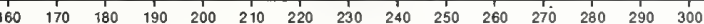

$21201-50-3$

1(2H)-Isoquinolinone, 2-hydroxy-
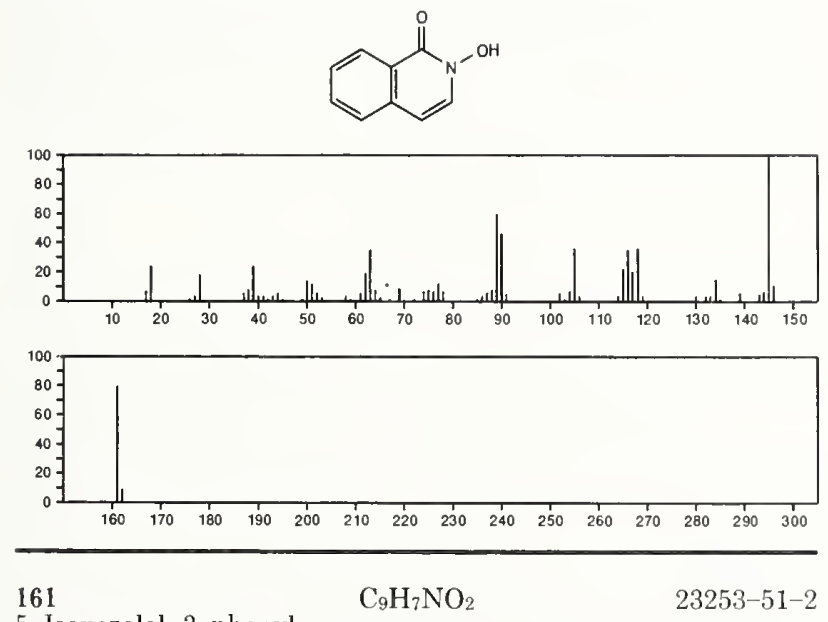

5-Isoxazolol, 3-phenyl-
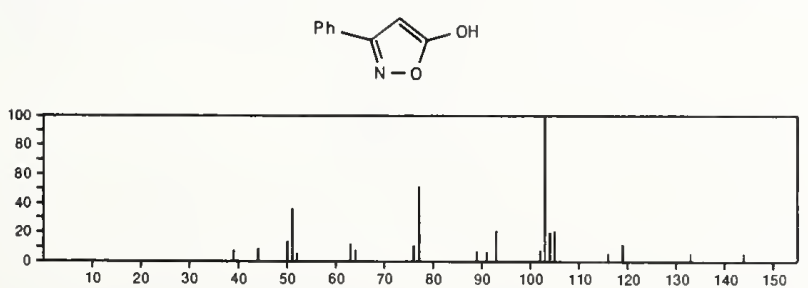

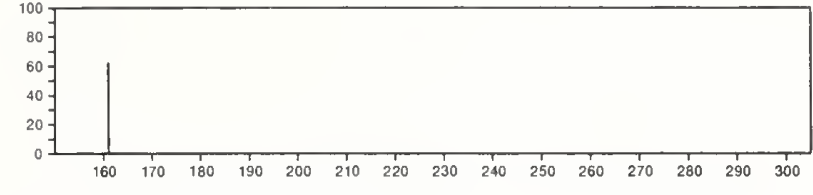

$\mathrm{C}_{9} \mathrm{H}_{7} \mathrm{NO}_{2}$

$41734-55-8$

${ }_{1 H}^{161}$-Indene, 5-nitro
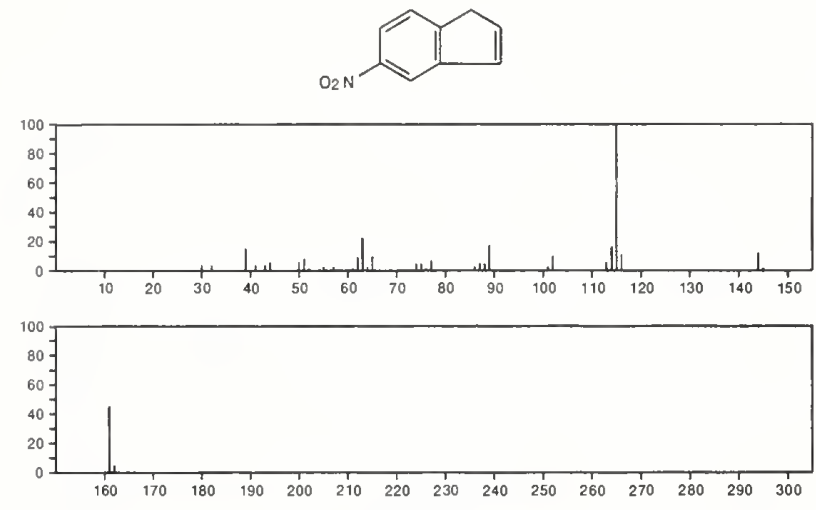

161

4(3H)-Quinolinone, 3-hydroxy-

$55759-82-5$
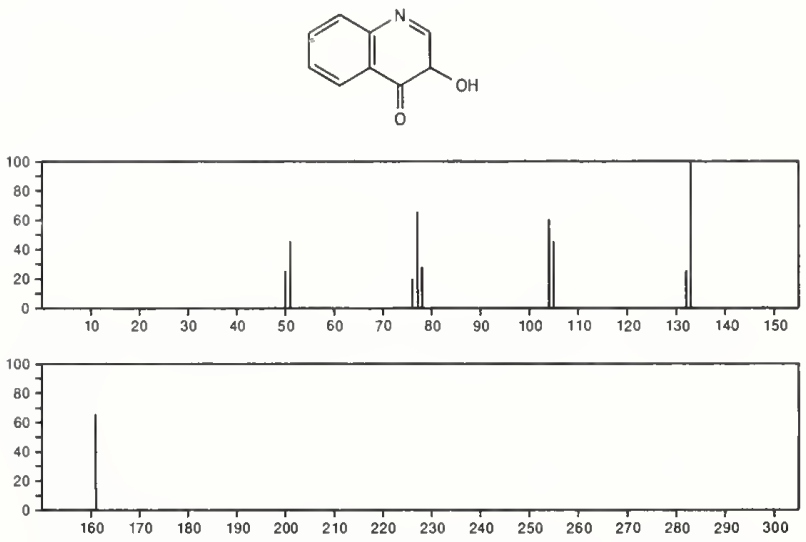

161

Isothiazole, 4-phenyl-

$\mathrm{C}_{9} \mathrm{H}_{7} \mathrm{NS}$

936-46-9
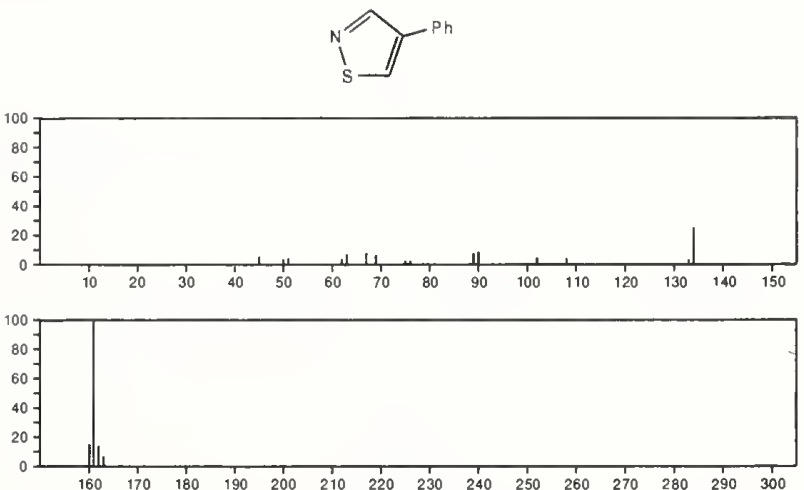
161

$\mathrm{C}_{9} \mathrm{H}_{11} \mathrm{~N}_{3}$

$s$-Triazolo[4,3-a]pyridine, 3,5,7-trimethyl-
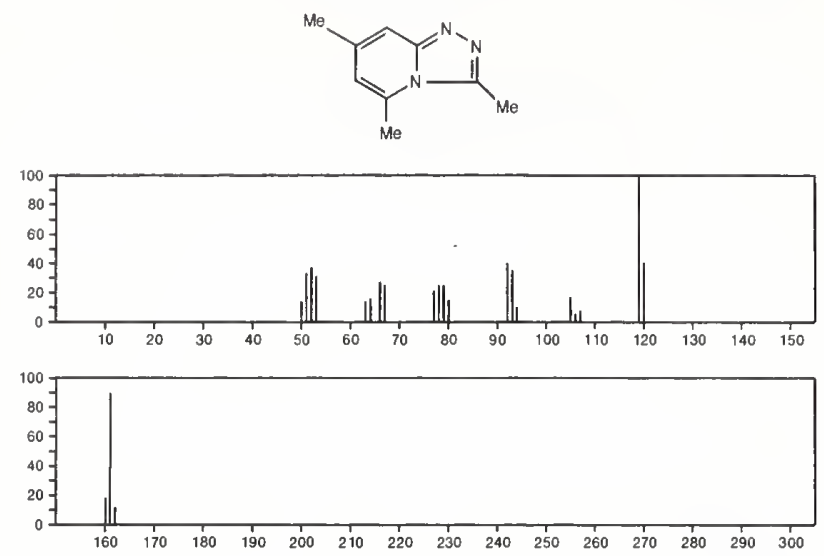

$161 \quad \mathrm{C}_{9} \mathrm{H}_{11} \mathrm{~N}_{3} \quad 4919-18-0$ $s^{-T r i a z o l o}[4,3-a]$ pyridine, 3-ethyl-5-methyl
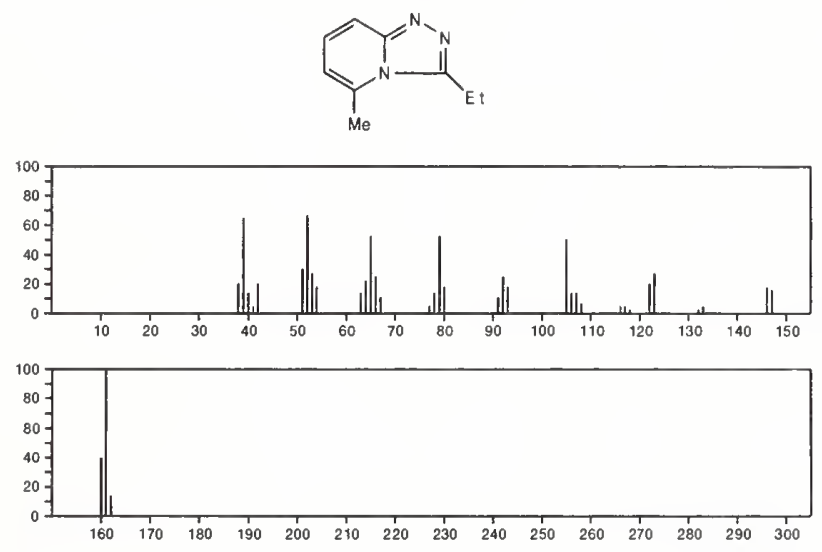

$161 \quad \mathrm{C}_{9} \mathrm{H}_{11} \mathrm{~N}_{3}$

$s$-Triazolo[1,5-a]pyridine, 2,5,7-trimethyl-

$4931-30-0$
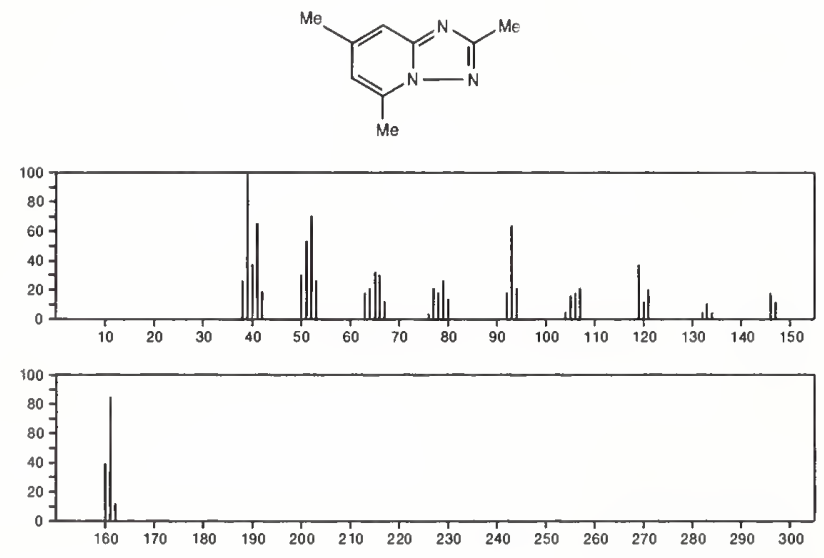

$161 \quad \mathrm{C}_{9} \mathrm{H}_{11} \mathrm{~N}_{3}$

Benzene, (1-azido-1-methylethyl)-

$32366-26-0$

$\mathrm{PhCM}_{2}\left(\mathrm{~N}_{3}\right)$

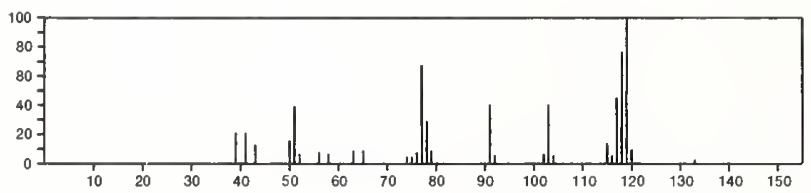

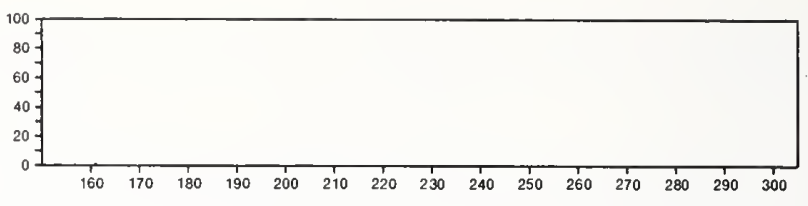

161

$\mathrm{C}_{9} \mathrm{H}_{11} \mathrm{~N}_{3}$

$50872-97-4$

Cyclopenta[4,5]pyrrolo[ $1,2-b][1,2,4]$ triazole, 4a, $5,6,7,7 \mathrm{a}, 8-$ hexa $=$ hydro-8-methylene-
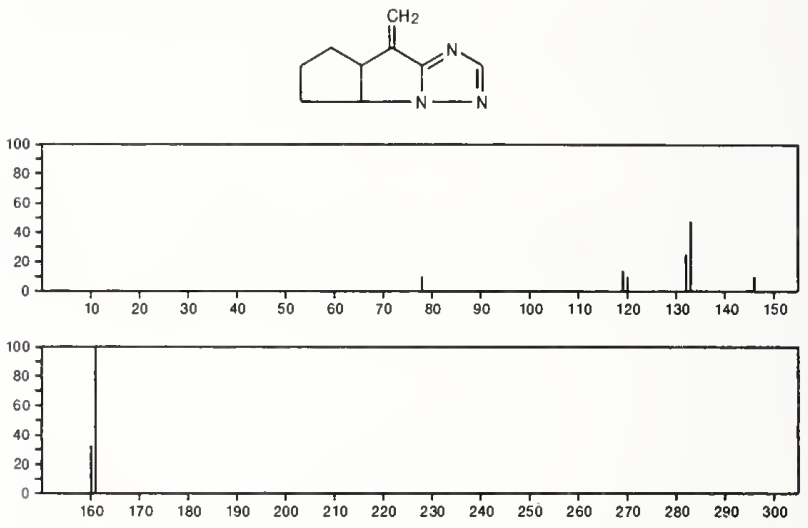

161

$\mathrm{C}_{10} \mathrm{H}_{11} \mathrm{NO}$

2-Buten-1-one, 3-amino-1-phenyl-

1128-85-4

$\mathrm{MeC}\left(\mathrm{NH}_{2}\right)=\mathrm{CHCOPh}$
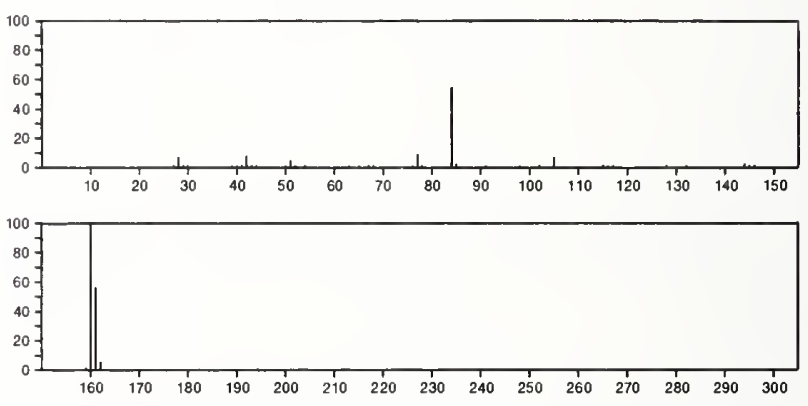

161

2-Pyrrolidinone, 1-phenyl-

$\mathrm{C}_{10} \mathrm{H}_{11} \mathrm{NO}$

4641-57-0
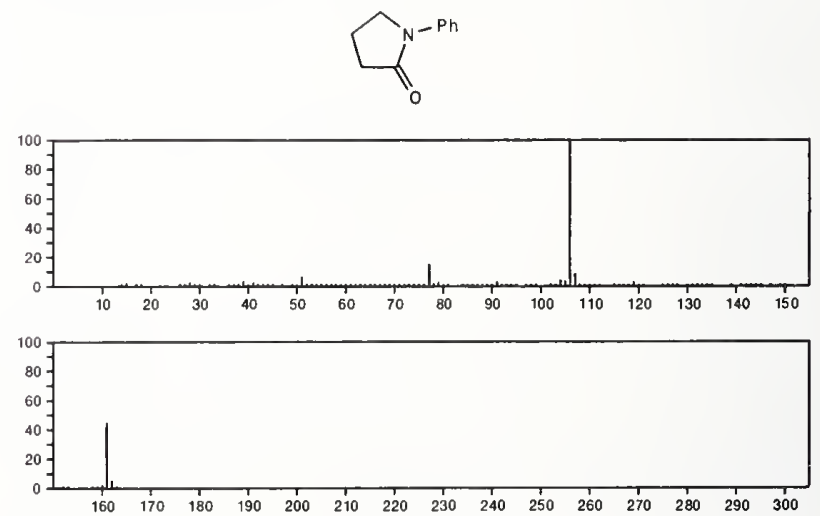

16

$\mathrm{C}_{11} \mathrm{H}_{15} \mathrm{~N}$

1077-18-5

1-Butanamine, $\mathrm{N}$-(phenylmethylene)

$\mathrm{PhCH}=\mathrm{N}\left(\mathrm{CH}_{2}\right)_{3} \mathrm{Me}$

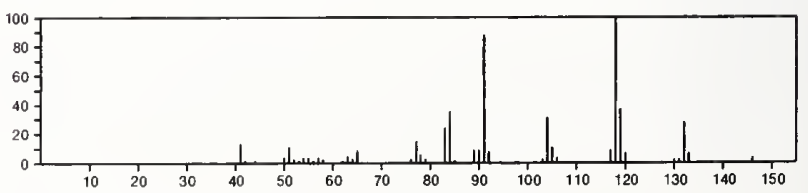




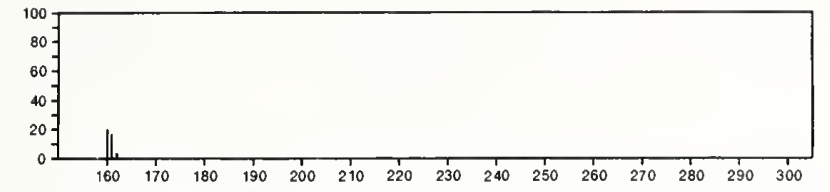

$161 \quad \mathrm{C}_{11} \mathrm{H}_{15} \mathrm{~N}$

2-Propanamine, 2-methyl- $N$-(phenylmethylene)-

$6852-58-0$

$t-B u N=$ CHPh
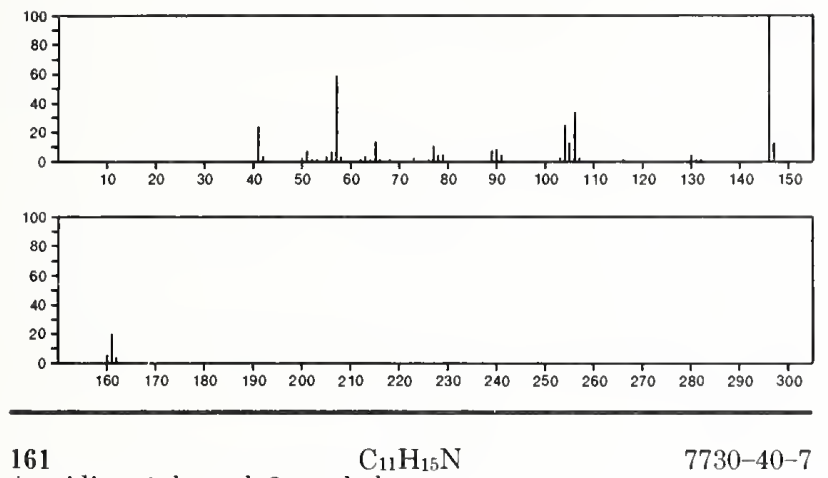

$7730-40-7$

Azetidine, 1-benzyl-2-methyl-
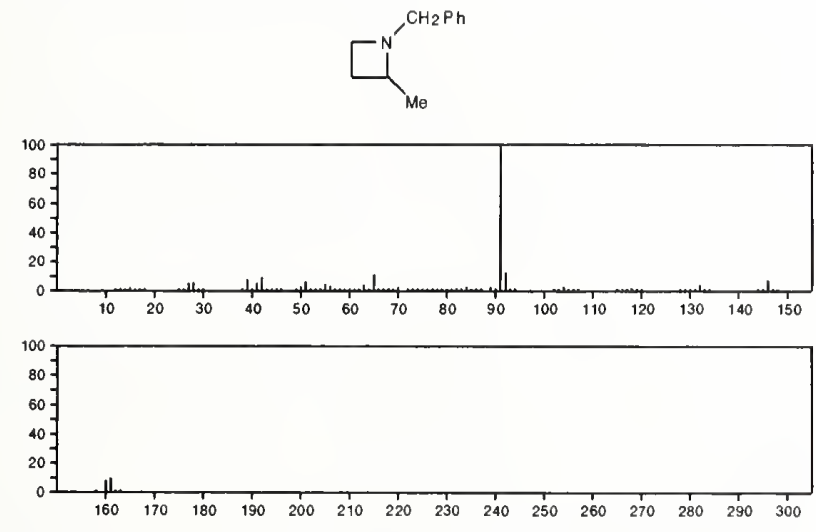

161

$$
\mathrm{C}_{11} \mathrm{H}_{15} \mathrm{~N}
$$

$10433-34-8$

Benzeneethanamine, $N$-(1-methylethylidene)-

$\mathrm{PhCH}_{2} \mathrm{CH}_{2} \mathrm{~N}=\mathrm{CMe}_{2}$
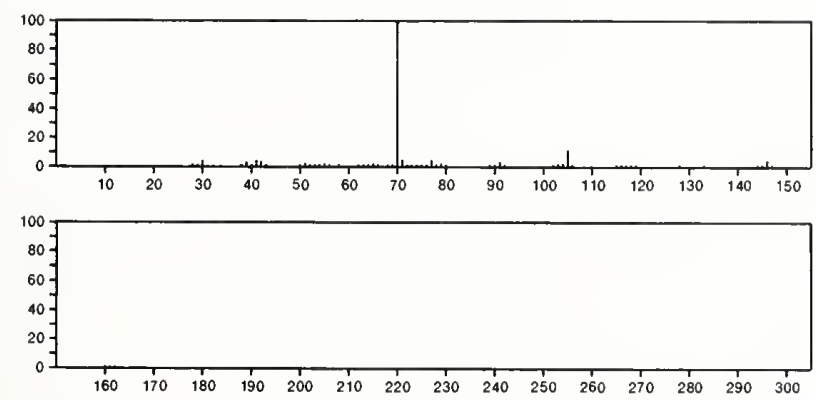

161

$\mathrm{C}_{11} \mathrm{H}_{15} \mathrm{~N}$

Isoquinoline, 1,2,3,4-tetrahydro-1,2-dimethyl-

14429-09-5
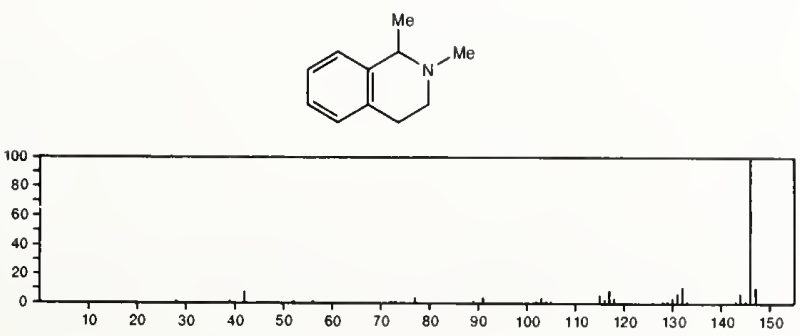

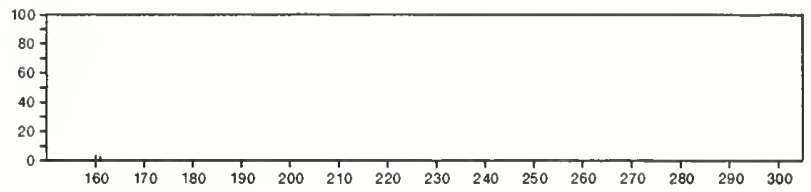

$161 \quad \mathrm{C}_{11} \mathrm{H}_{15} \mathrm{~N}$

1H-Indole, 2,3-dihydro-2,3,3-trimethyl-

18781-58-3
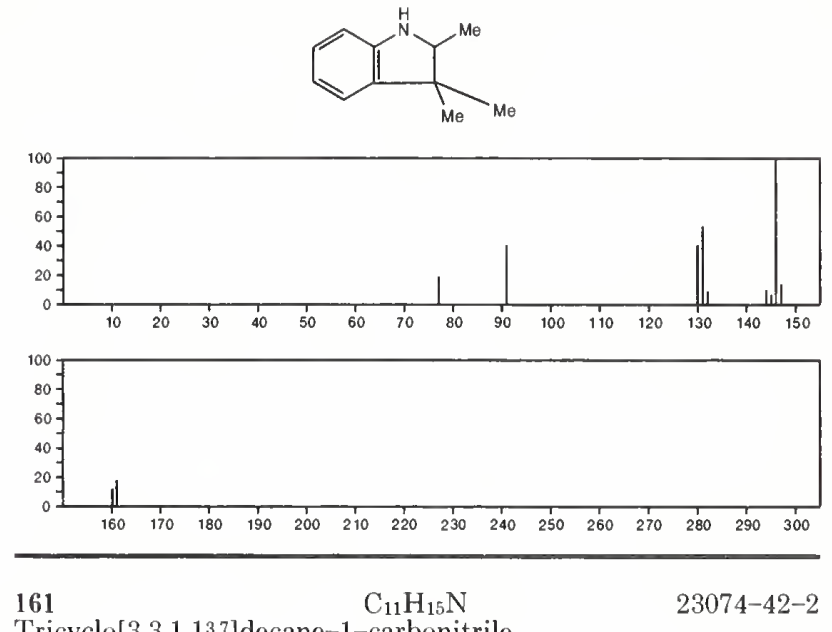

Tricyclo[3.3.1.13,7]decane-1-carbonitrile

23074-42-2
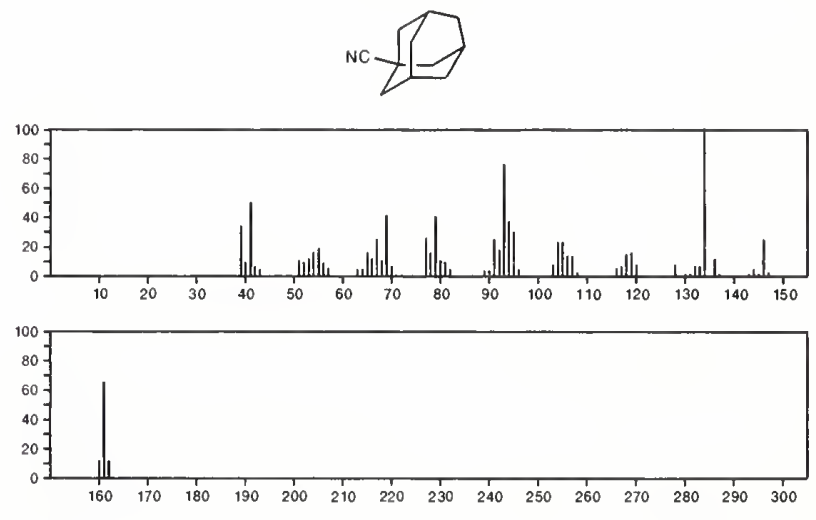

161

$\mathrm{C}_{11} \mathrm{H}_{15} \mathrm{~N}$

24432-52-8

Aziridine, 2,3-dimethyl-1-(phenylmethyl)-, trans-
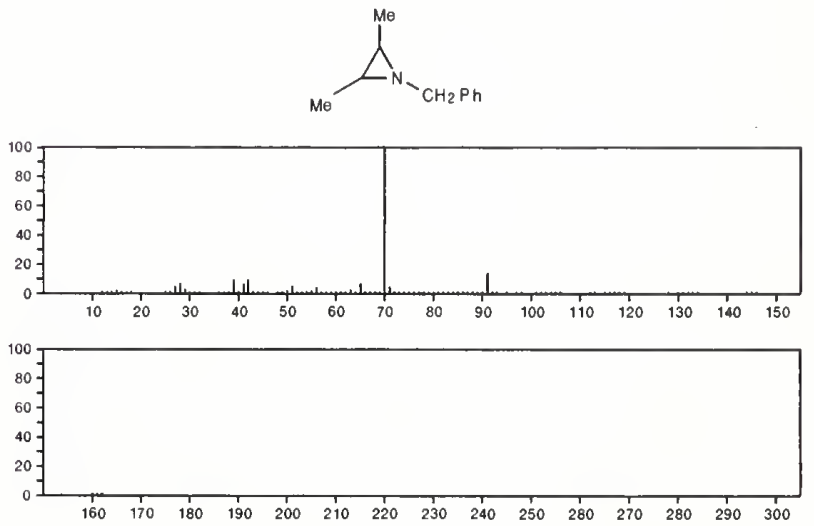
161

$\mathrm{C}_{11} \mathrm{H}_{15} \mathrm{~N}$

$29666-60-2$

Methanamine, $N$-(1-methyl-3-phenylpropylidene)-

$\mathrm{MeN}=\mathrm{CMeCH}_{2} \mathrm{CH}_{2} \mathrm{Ph}$
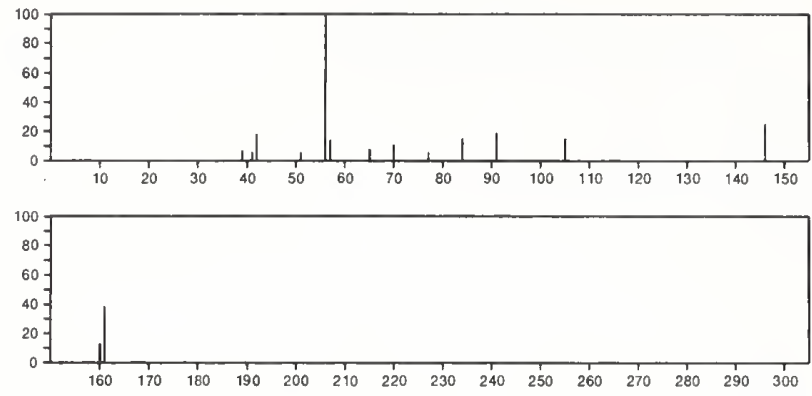
161
Benzenemethanimine, $\alpha-(1,1-$ dimethylethyl $)-$

$\mathrm{Me} 3 \mathrm{CCPh}=\mathrm{NH}$
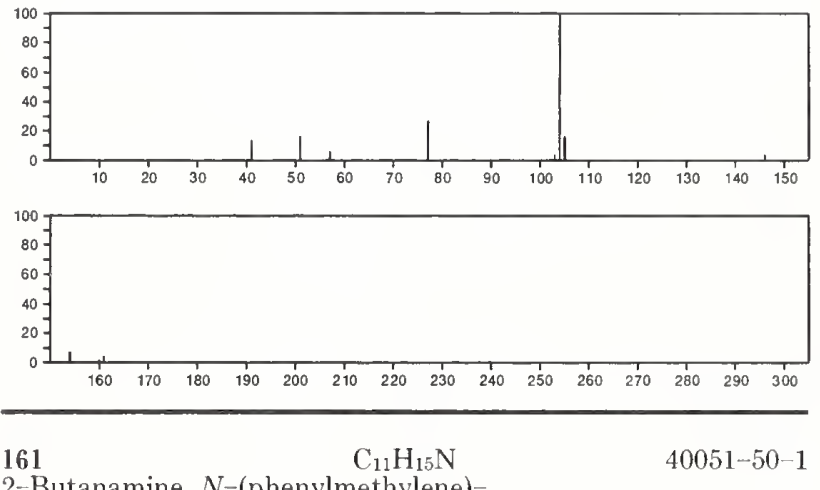

2-Butanamine, $\mathrm{N}$-(phenylmethylene)

$s-B \cup N=C H P h$
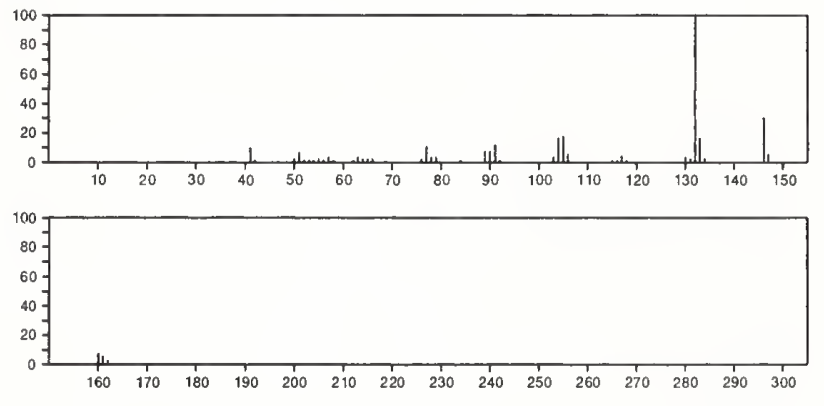

$161 \quad \mathrm{C}_{11} \mathrm{H}_{15} \mathrm{~N} \quad 54365-72-9$

Isoquinoline, 1,2,3,4-tetrahydro-2,3-dimethyl
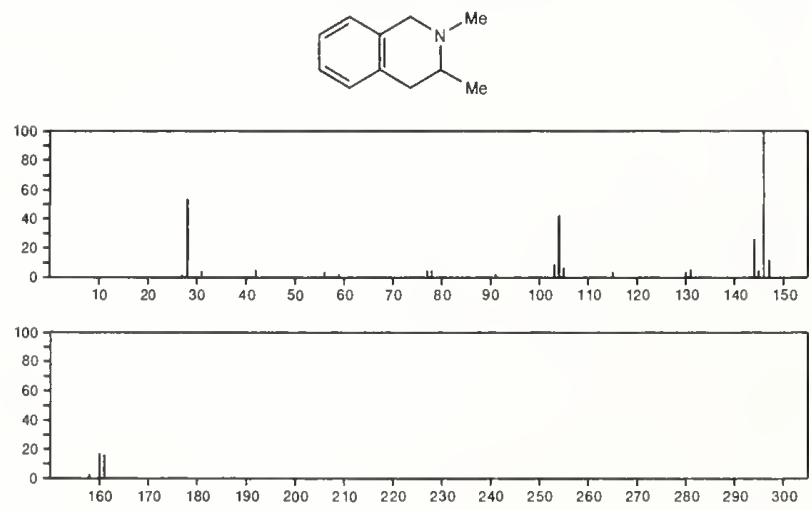

161

$\mathrm{C}_{11} \mathrm{H}_{15} \mathrm{~N}$

$55702-31-3$

Azetidine, 3-methyl-1-(phenylmethyl)-
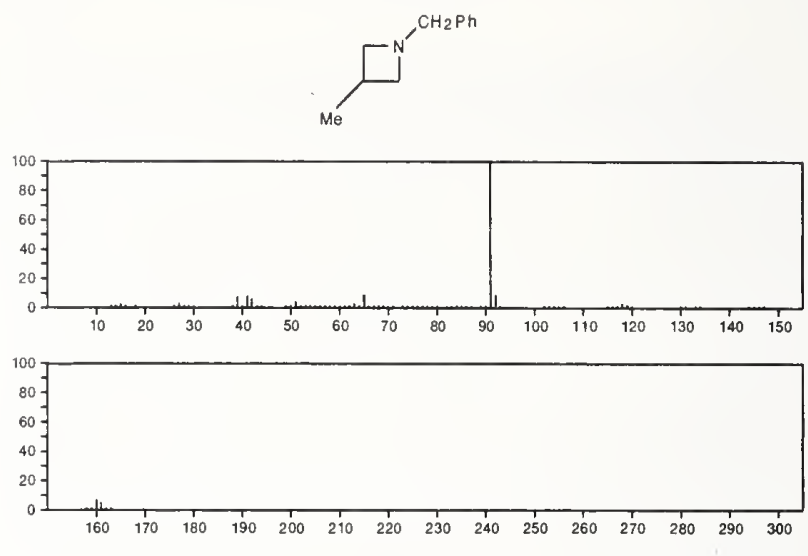

161

$\mathrm{C}_{11} \mathrm{H}_{15} \mathrm{~N}$

Cyclopropanamine, $N$-methyl-1-(4-methylphenyl)-

56701-44-1
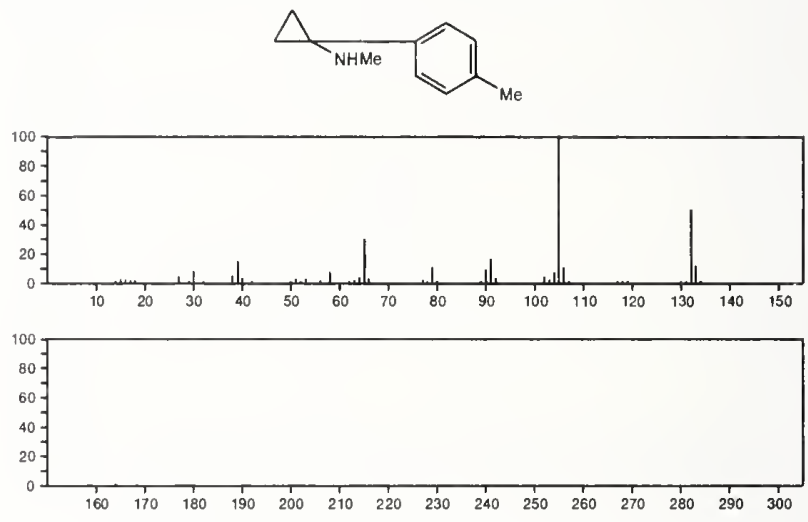

162

Methane, bromodichloro-

$\mathrm{CHBrCl}_{2}$

75-27-4

$\mathrm{Br} \mathrm{CHCl}_{2}$
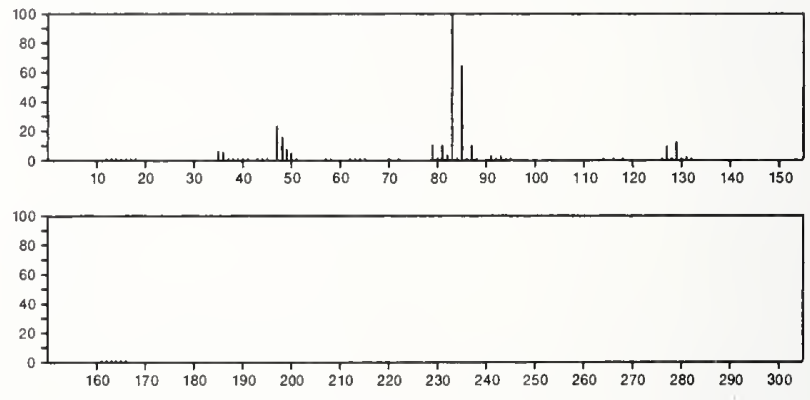

162

Acetic acid, trichloro-

$\mathrm{C}_{2} \mathrm{HCl}_{3} \mathrm{O}_{2}$

76-03-9

$\mathrm{Cl}_{3} \mathrm{CCO}_{2} \mathrm{H}$
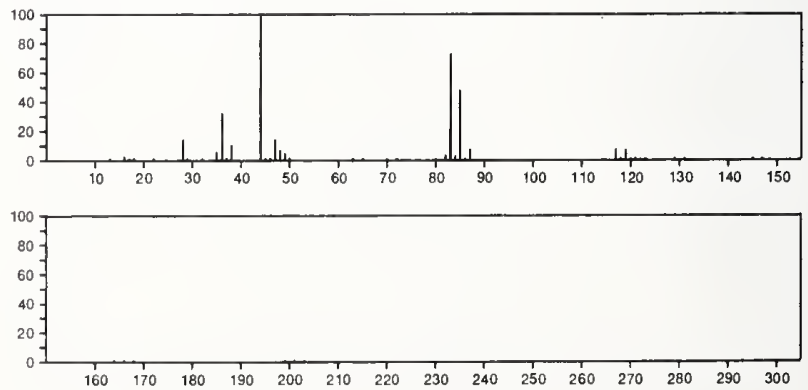
162

$\mathrm{C}_{4} \mathrm{~F}_{6}$

1,3-Butadiene, 1,1,2,3,4,4-hexafluoro-

$\mathrm{F}_{2} \mathrm{C}=\mathrm{CF} \mathrm{CF}=\mathrm{CF}_{2}$
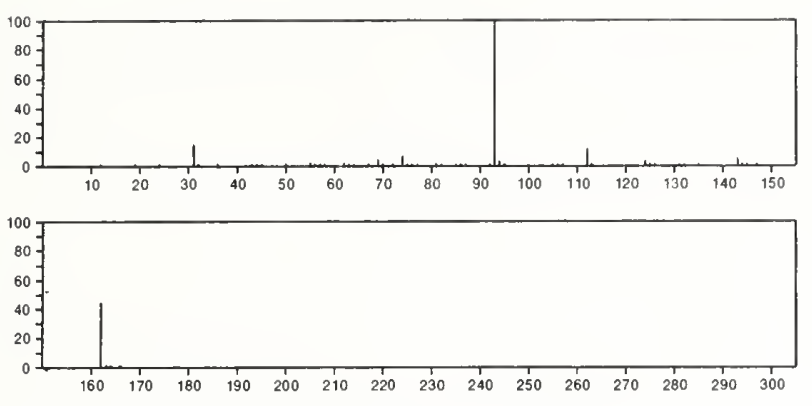

162

2-Butyne, 1,1,1,4,4,4-hexafluoro-

$692-50-2$

$\mathrm{F}_{3} \mathrm{CC} \equiv \mathrm{CCF} 3$
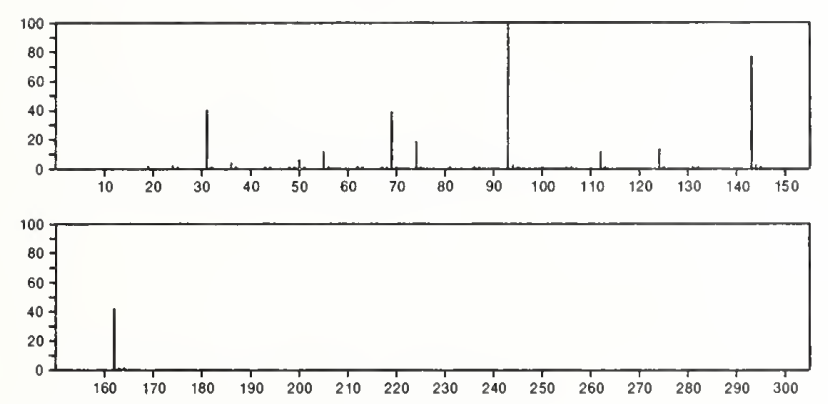

162

Cyclobutene, hexafluoro-

$\mathrm{C}_{4} \mathrm{~F}_{6}$

697-11-0
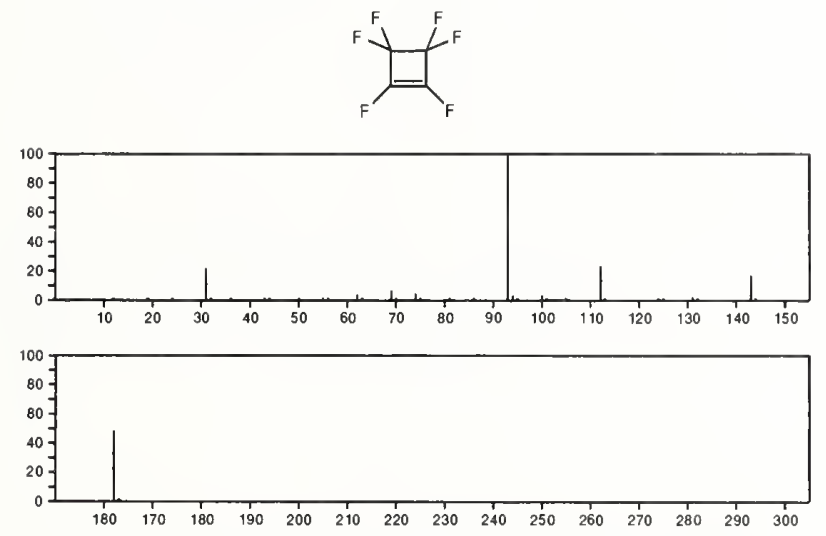

162

$\mathrm{C}_{4} \mathrm{H}_{6} \mathrm{~N}_{2} \mathrm{O}_{5}$

Glycine, $N$-(carboxymethyl)-N-nitroso-

$\mathrm{HO}_{2} \mathrm{CCH}_{2} \mathrm{~N}$ ( NO) $\mathrm{CH}_{2} \mathrm{CO}_{2} \mathrm{H}$
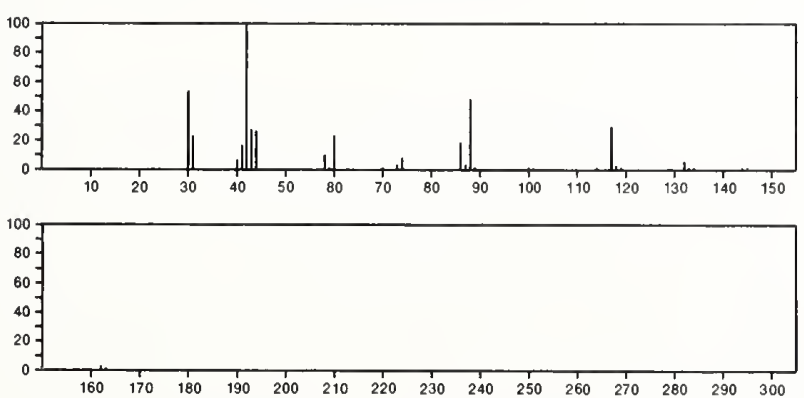

162

$\mathrm{C}_{5} \mathrm{H}_{4} \mathrm{Cl}_{2} \mathrm{~N}_{2}$

19064-64-3

Pyridazine, 3,6-dichloro-4-methyl-
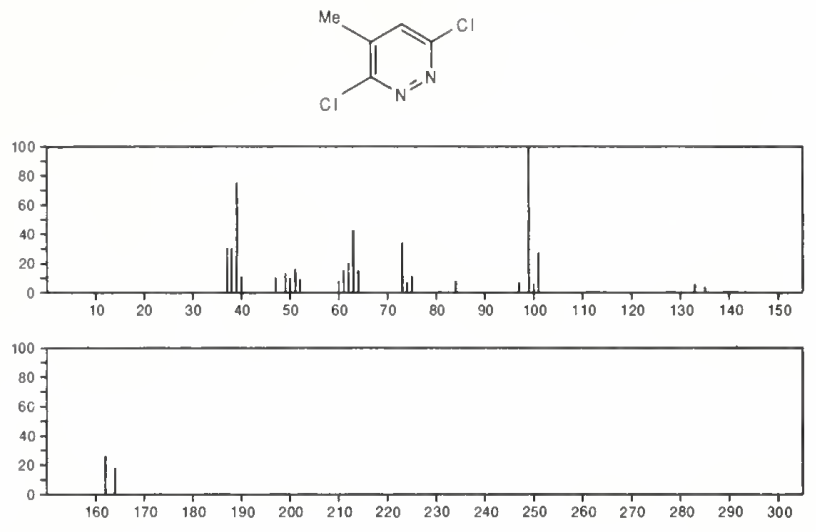

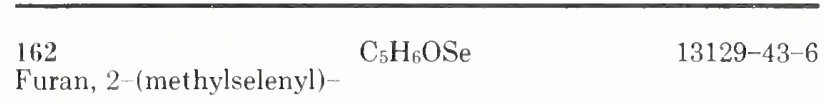
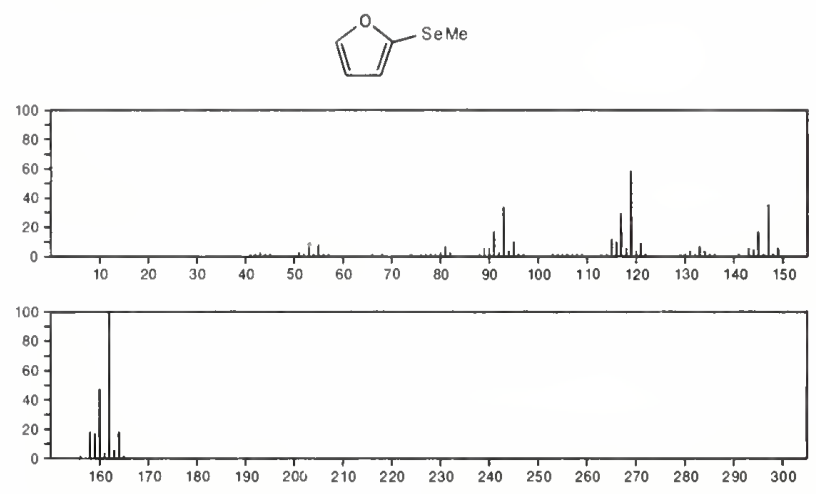

162

1-Propyne, 3-(2-bromoethoxy)-

$\mathrm{C}_{5} \mathrm{H}_{7} \mathrm{BrO}$

18668-74-1

$\mathrm{Br} \mathrm{CH}_{2} \mathrm{CH}_{2} \mathrm{OCH}_{2} \mathrm{C}: \mathrm{CH}$
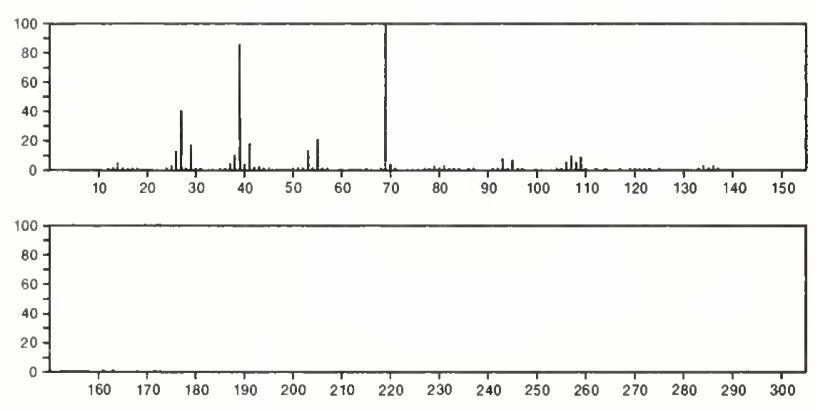

162

$\mathrm{C}_{5} \mathrm{H}_{18} \mathrm{Si}_{3}$

$55836-80-1$

Silane, (silylmethyl)[(trimethylsilyl)methyl]-

$\mathrm{Me}_{3} \mathrm{Si} \mathrm{CH}_{2} \mathrm{~S}_{\mathrm{H}} \mathrm{H}_{2} \mathrm{CH}_{2} \mathrm{SiH}_{3}$
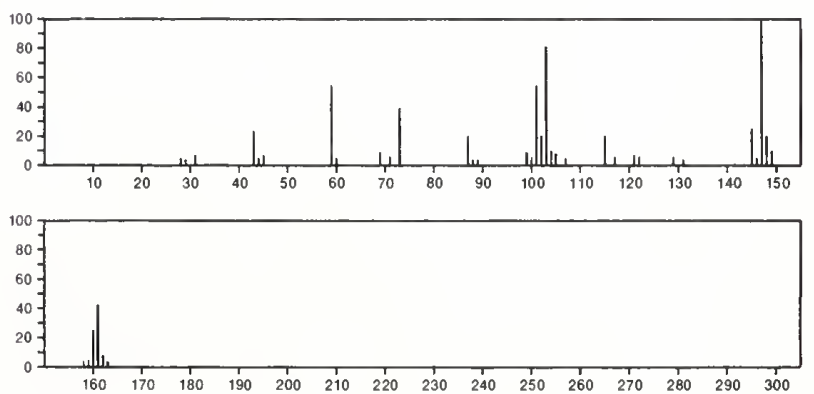
162

Phenol, 2,6-dichloro-

$\mathrm{C}_{6} \mathrm{H}_{4} \mathrm{Cl}_{2} \mathrm{O}$

$87-65-0$
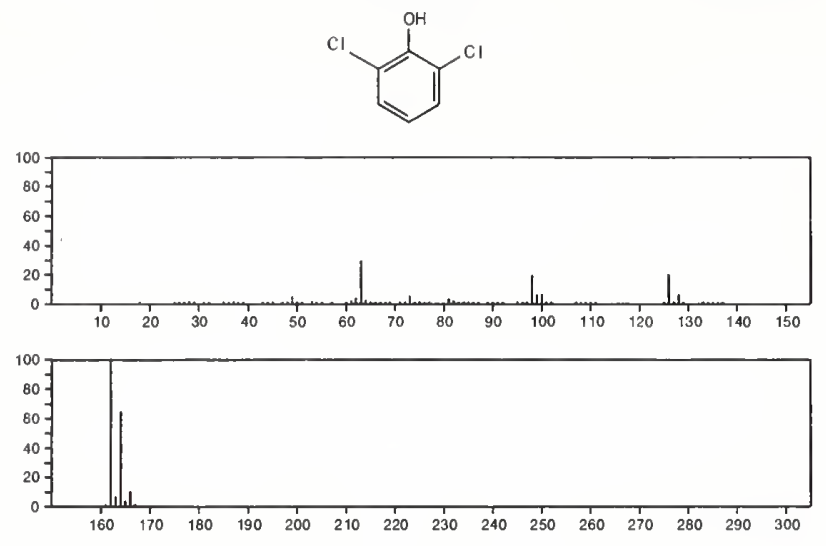

162

Phenol, 3,4-dichloro-

$\mathrm{C}_{6} \mathrm{H}_{4} \mathrm{Cl}_{2} \mathrm{O}$

$95-77-2$
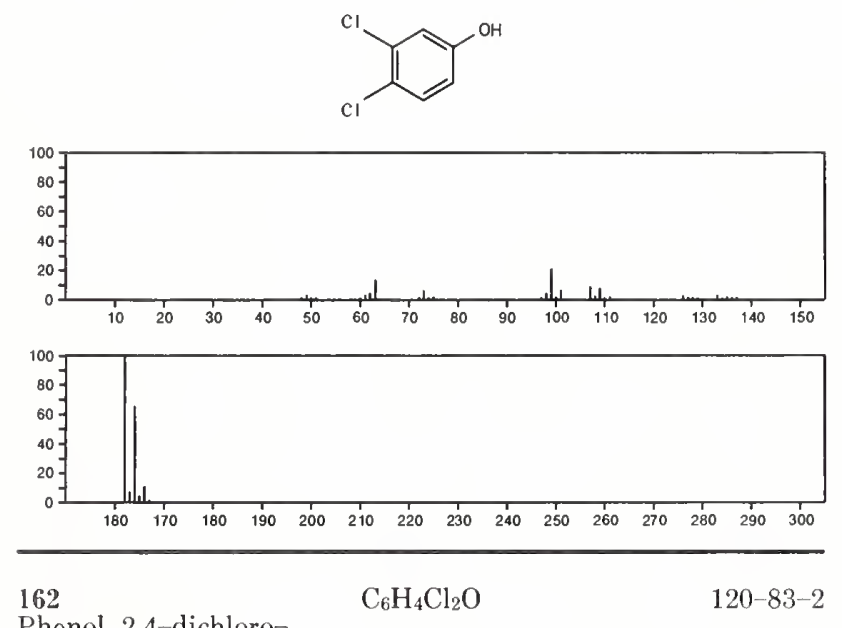

Phenol, 2,4-dichloro-
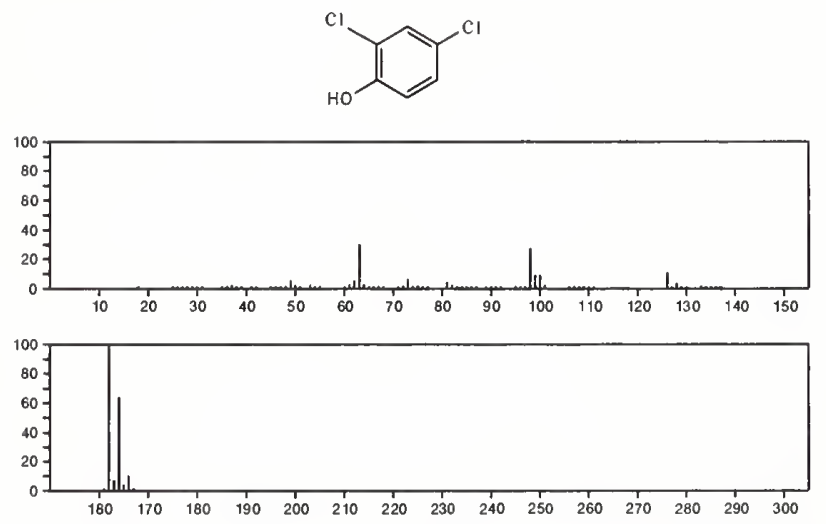

162

Phenol, 2,3-dichloro-

\section{$\mathrm{C}_{6} \mathrm{H}_{4} \mathrm{Cl}_{2} \mathrm{O}$}

576-24-9
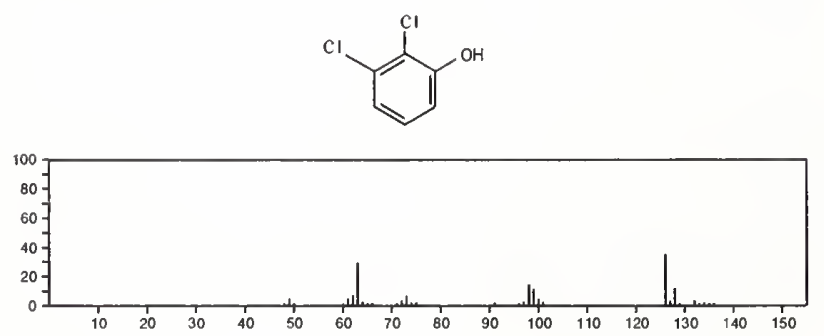

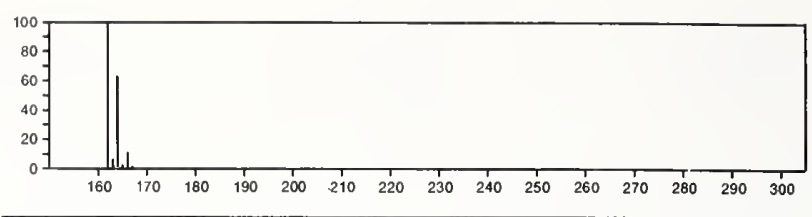

162

Phenol, 2,5-dichloro-

$\mathrm{C}_{6} \mathrm{H}_{4} \mathrm{Cl}_{2} \mathrm{O}$

$583-78-8$<smiles>Oc1cc(Cl)ccc1Cl</smiles>
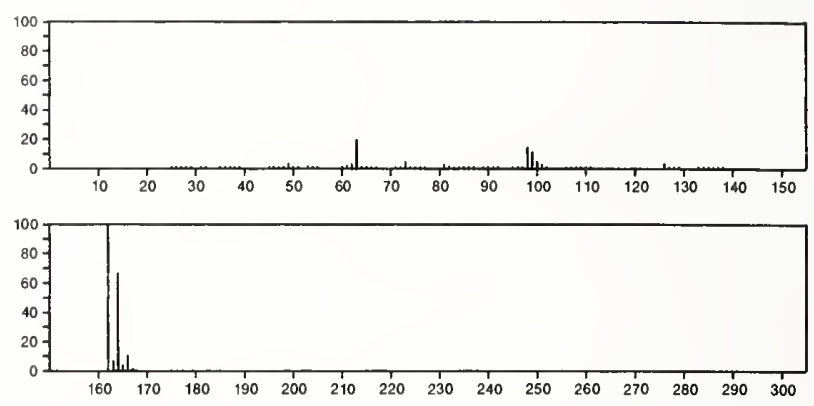

162

Phenol, 3,5-dichloro-

$\mathrm{C}_{6} \mathrm{H}_{4} \mathrm{Cl}_{2} \mathrm{O}$

$591-35-5$
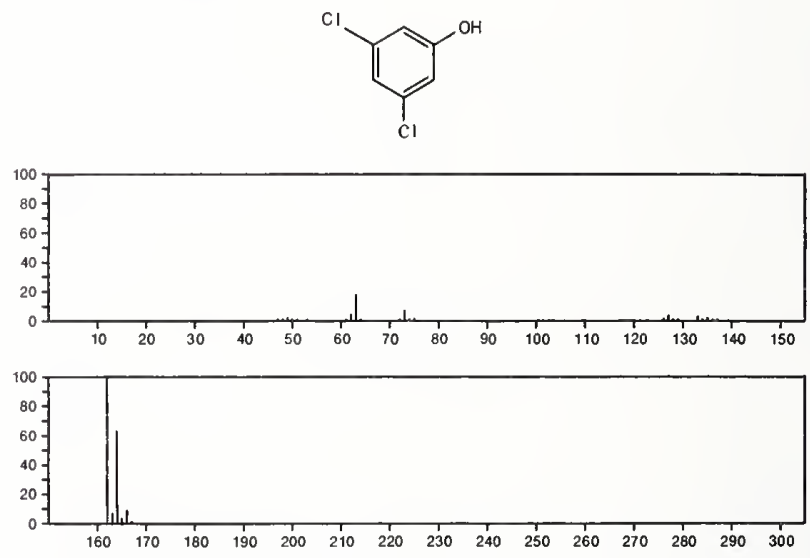

162

$\mathrm{C}_{6} \mathrm{H}_{7} \mathrm{FN}_{2} . \mathrm{ClH}$

Hydrazine, (3-fluorophenyl)-, monohydrochloride

$2924-16-5$
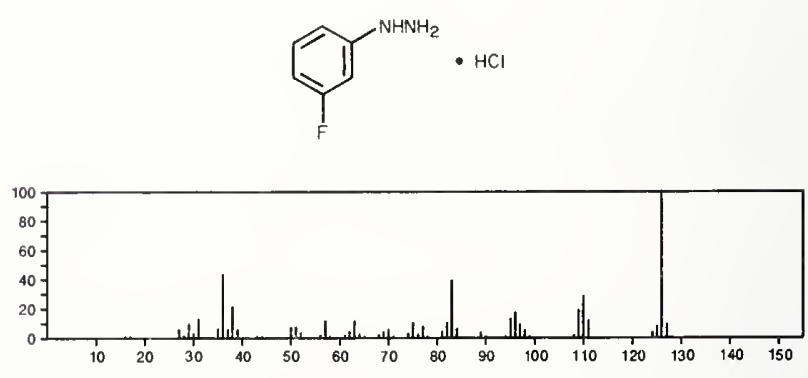

162

$162 \quad \mathrm{C}_{6} \mathrm{H}_{10} \mathrm{OS}_{2}$

$\mathrm{C}_{6} \mathrm{H}_{10} \mathrm{OS}_{2}$

20383-01-1

$\mathrm{EtSC}(\mathrm{O}) \mathrm{CH}_{2} \mathrm{CSM}$

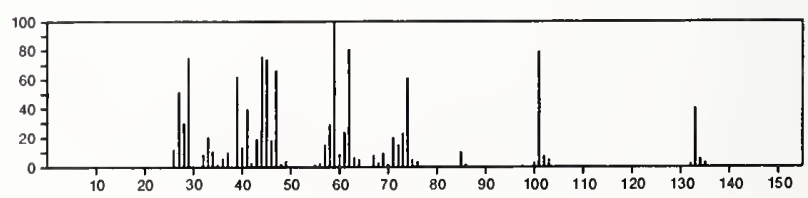




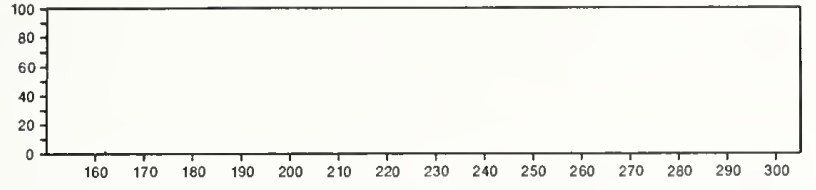

$162 \quad \mathrm{C}_{6} \mathrm{H}_{10} \mathrm{OS}_{2} \quad 33266-07-8$

Ethanone, 1-(2-methyl-1,3-dithiolan-2-yl)-
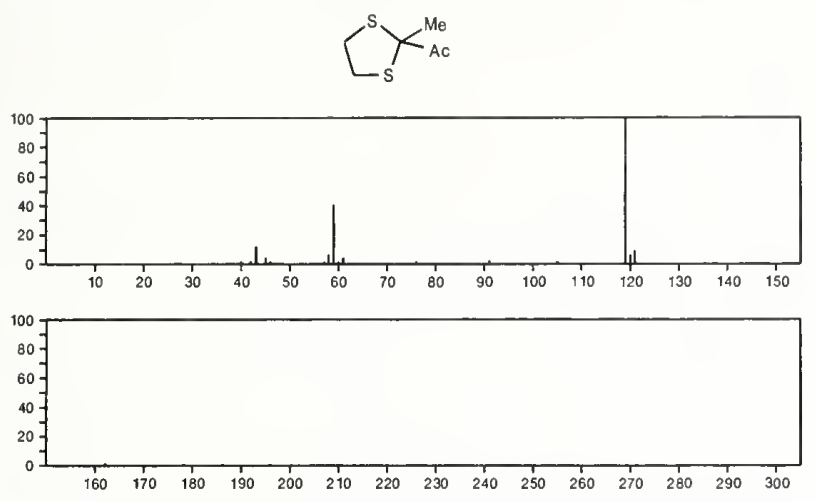

162

$\mathrm{C}_{6} \mathrm{H}_{10} \mathrm{O}_{3} \mathrm{~S}$

1,2-Cyclohexanediol, cyclic sulfite, cis-

19456-18-9
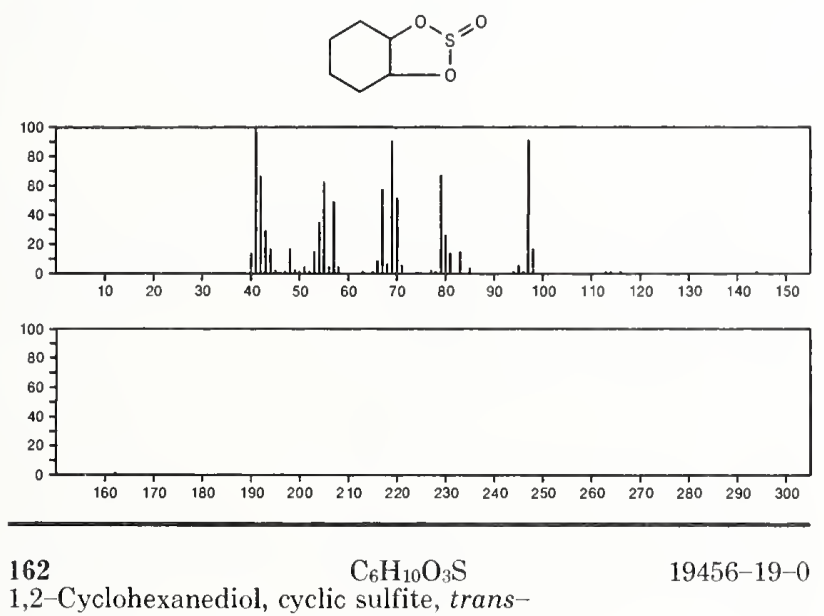

1,2-Cyclohexanediol, cyclic sulfite, trans-
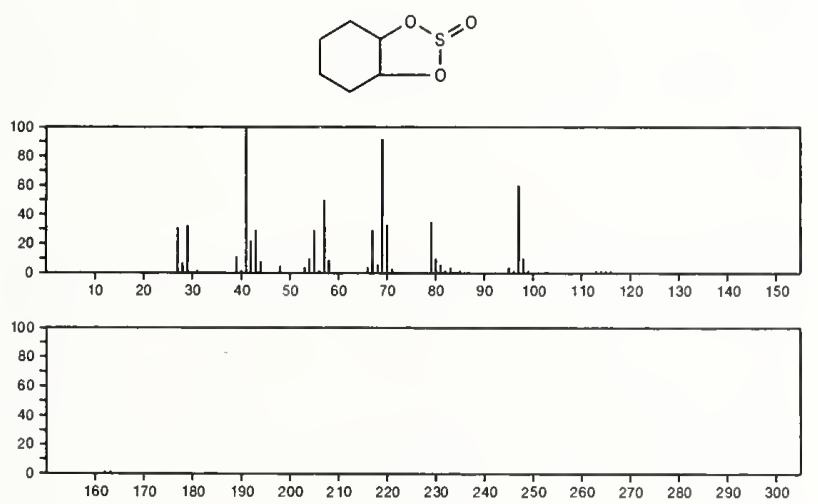

162

$\mathrm{C}_{6} \mathrm{H}_{10} \mathrm{O}_{3} \mathrm{~S}$

D- Fructose, 1,3,6-trideoxy-3,6-epithio-

$55780-98-8$
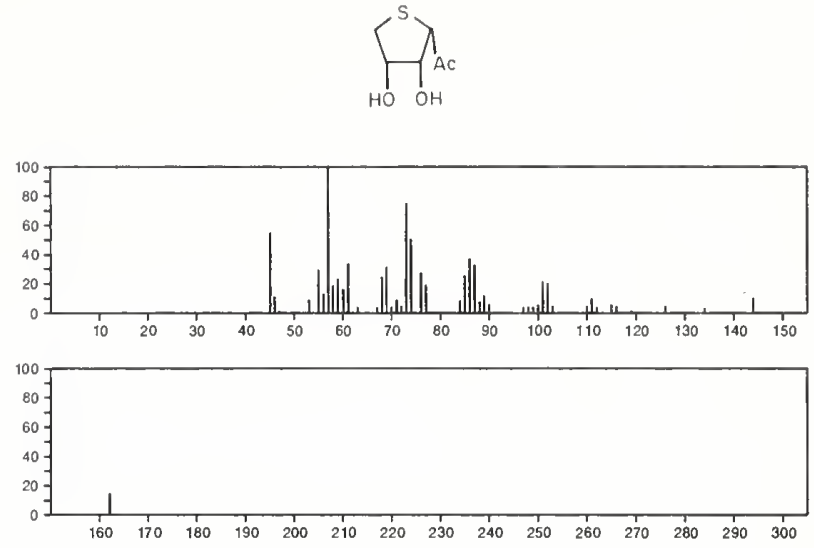

162

$\mathrm{C}_{6} \mathrm{H}_{10} \mathrm{O}_{5}$

Butanedioic acid, hydroxy-, dimethyl ester

$1587-15-1$

$\mathrm{MeOC}(\mathrm{O}) \mathrm{CH}(\mathrm{OH}) \mathrm{CH}_{2} \mathrm{C}(\mathrm{O}) \mathrm{OMe}$

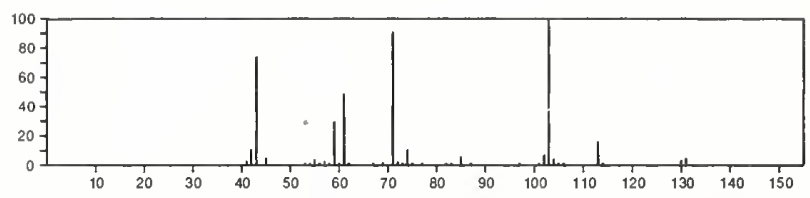

$162 \quad \mathrm{C}_{6} \mathrm{H}_{10} \mathrm{O}_{5}$

$19500-95-9$

Acetic acid, methoxy-, anhydride

$\mathrm{Me} \mathrm{OCH}_{2} \mathrm{C}(\mathrm{O}) \mathrm{OC}(\mathrm{O}) \mathrm{CH}_{2} \mathrm{OMe}$
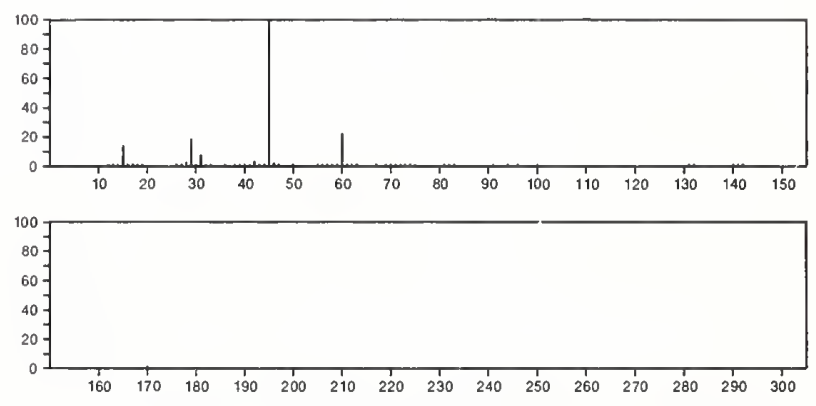

162

$\mathrm{C}_{6} \mathrm{H}_{11} \mathrm{Br}$

108-85-0

Cyclohexane, bromo-
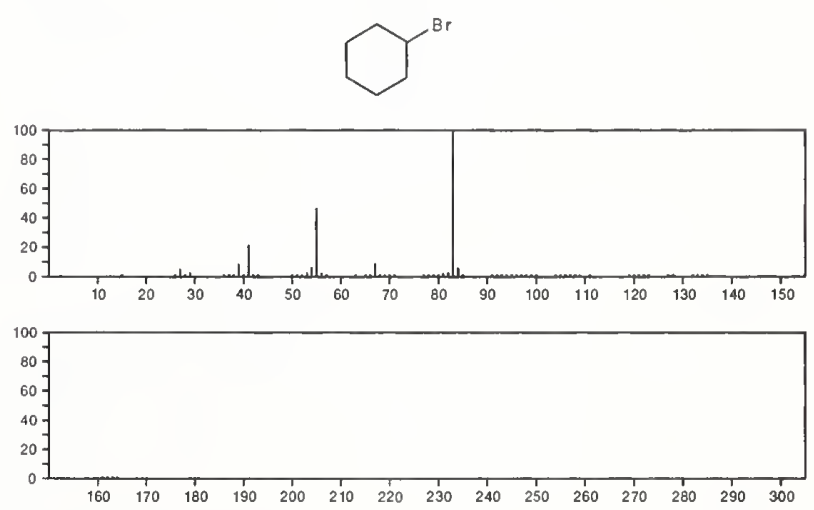
162

1-Hexene, 6-bromo-

$\mathrm{C}_{6} \mathrm{H}_{11} \mathrm{Br}$

$\mathrm{H}_{2} \mathrm{C}=\mathrm{CH}\left(\mathrm{CH}_{2}\right)_{4} \mathrm{Br}$
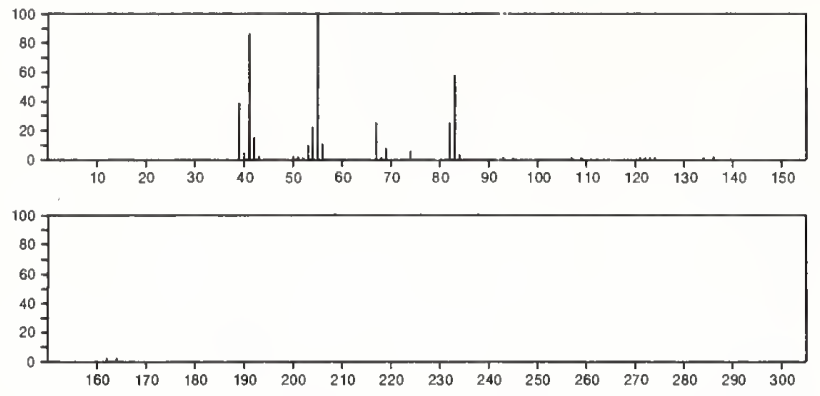

162

1-Hexene, 1-bromo-, $(E)$

$\mathrm{C}_{6} \mathrm{H}_{11} \mathrm{Br}$

$\mathrm{Me}\left(\mathrm{CH}_{2}\right)_{3} \mathrm{CH}=\mathrm{CHBr}$
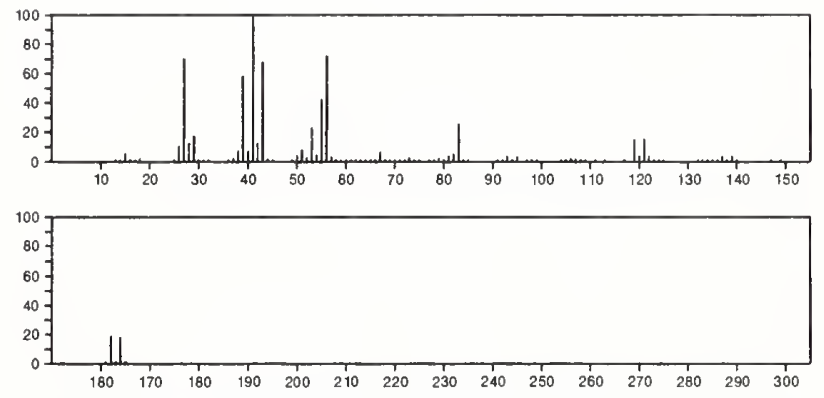

$162 \quad \mathrm{C}_{6} \mathrm{H}_{11} \mathrm{O}_{3} \mathrm{P}$

2,6,7-Trioxa-1-phosphabicyclo[2.2.2]octane, 4-ethyl-

$824-11-3$
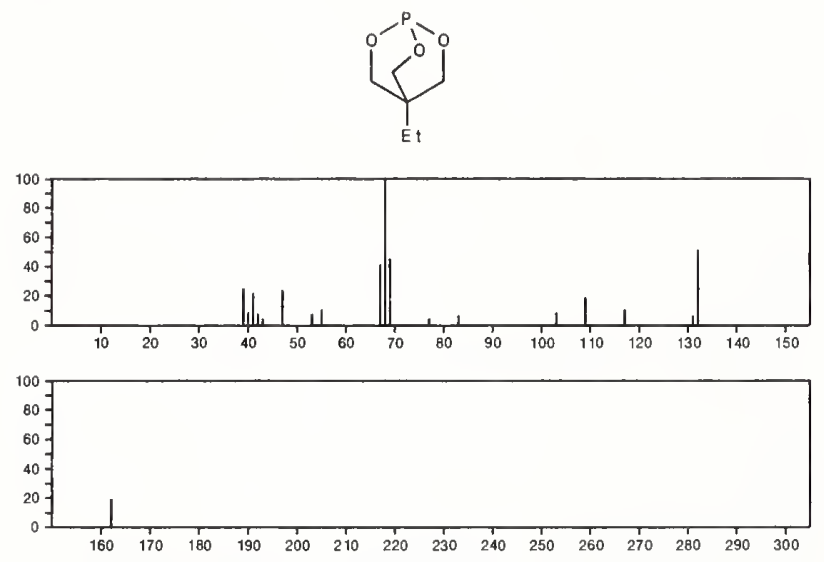

162

Arsine, triethyl-

$\mathrm{C}_{6} \mathrm{H}_{15} \mathrm{As}$

$617-75-4$

AsE:3
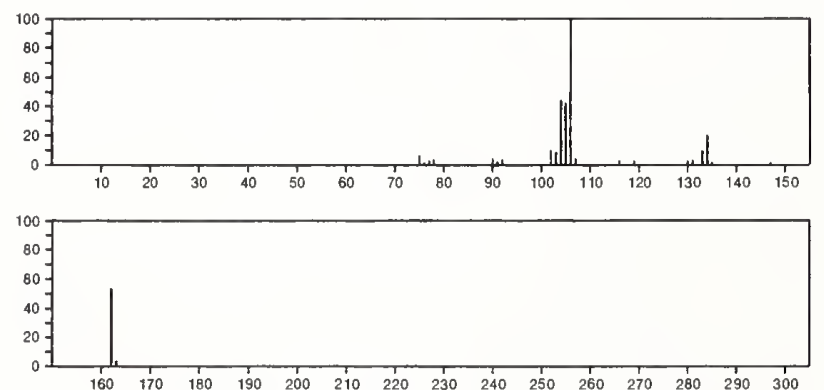

162

Disiloxane, hexamethyl-

$\mathrm{C}_{6} \mathrm{H}_{18} \mathrm{OSi}_{2}$

$107-46-0$

Me3si OSiMe3
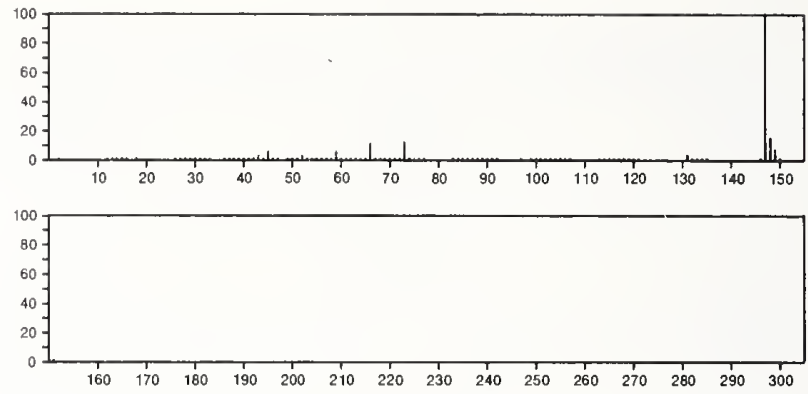

162

2(1H)-Pteridinone, 6-methyl-

$\mathrm{C}_{7} \mathrm{H}_{6} \mathrm{~N}_{4} \mathrm{O}$

$16041-23-9$
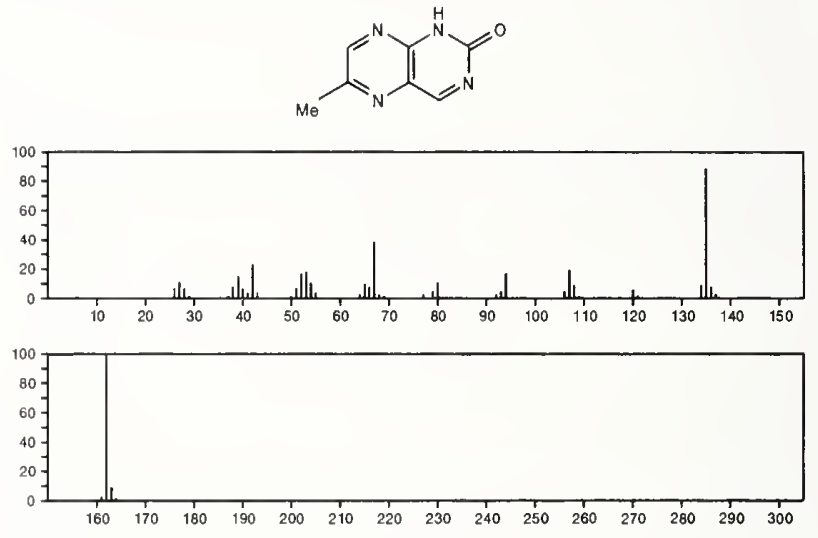

162

$4(1 H)$-Pteridinone, 6-methyl

$\mathrm{C}_{7} \mathrm{H}_{6} \mathrm{~N}_{4} \mathrm{O}$

$16041-24-0$<smiles>Cc1cnc2[nH]cnc(=O)c2n1</smiles>
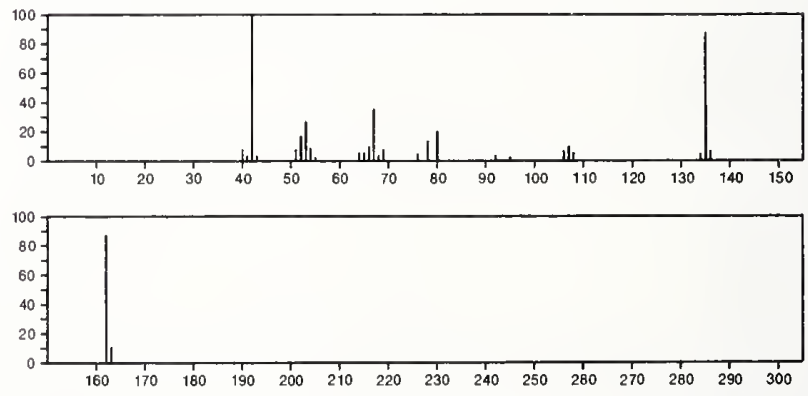

$162 \quad \mathrm{C}_{7} \mathrm{H}_{6} \mathrm{~N}_{4} \mathrm{O}$

6(5H)-Pteridinone, 4-methyl-

16041-28-4
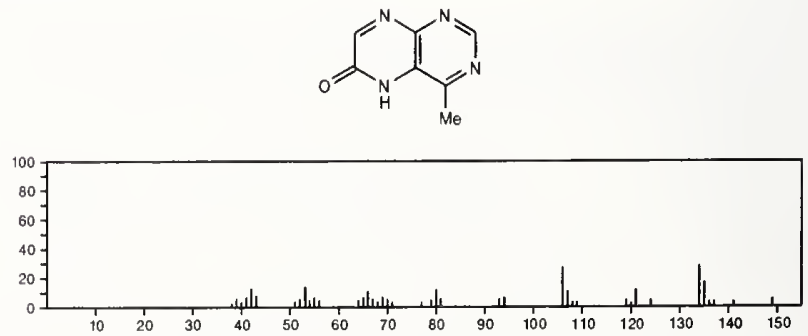


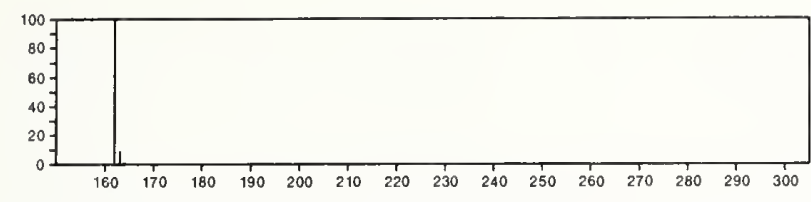

162

$\mathrm{C}_{7} \mathrm{H}_{6} \mathrm{~N}_{4} \mathrm{O}$

$16041-29-5$

7(8H)-Pteridinone, 4-methyl-
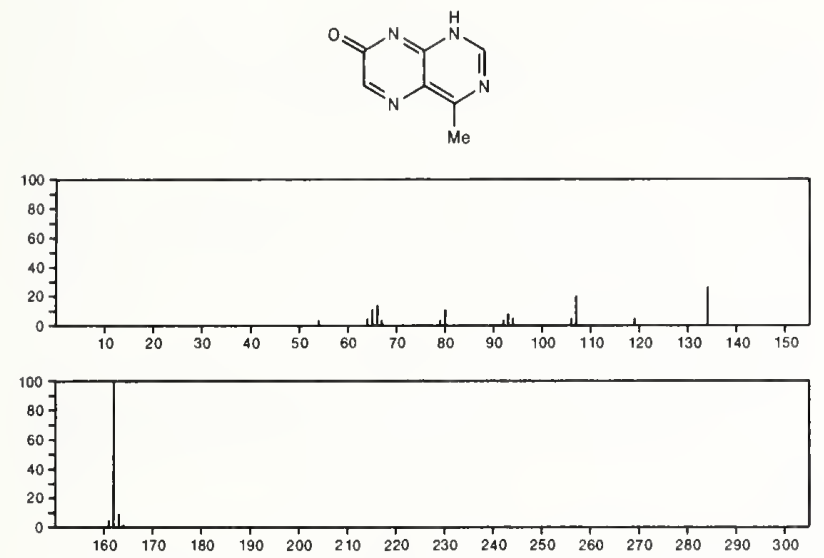

162

7(8H)-Pteridinone, 6-methyl-

$\mathrm{C}_{7} \mathrm{H}_{6} \mathrm{~N}_{4} \mathrm{O}$

$16041-30-8$<smiles>Nc1nc2cnc[nH]c-2nc1=O</smiles>
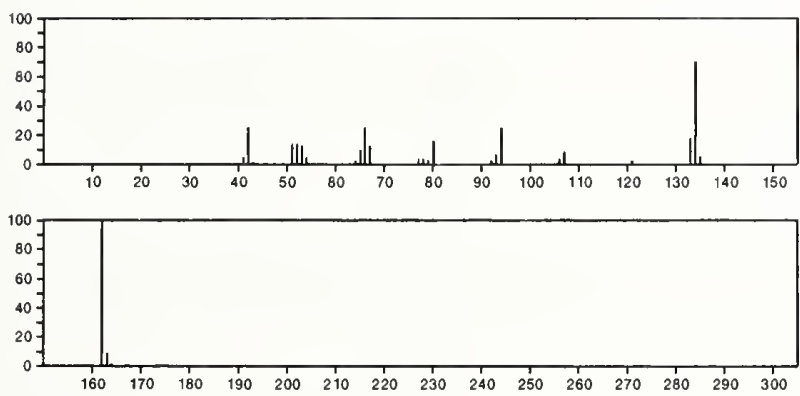

$\begin{array}{rllllllllllllll}160 & 170 & 180 & 190 & 200 & 210 & 220 & 230 & 240 & 250 & 260 & 270 & 280 & 290 & 300\end{array}$

162

$4(1 H)$-Pteridinone, 2-methyl-

$\mathrm{C}_{7} \mathrm{H}_{6} \mathrm{~N}_{4} \mathrm{O}$

$34244-78-5$<smiles>Cc1nc(=O)c2nccnc2[nH]1</smiles>
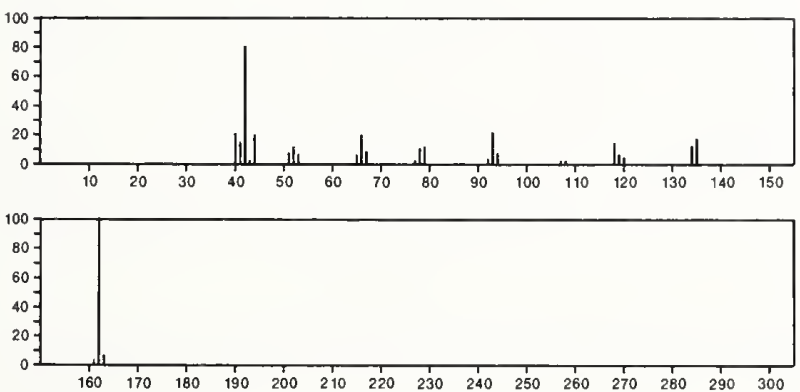

162

$4(1 \mathrm{H})$-Pteridinone, 7 -methyl-

$\mathrm{C}_{7} \mathrm{H}_{6} \mathrm{~N}_{4} \mathrm{O}$

$34244-80-9$
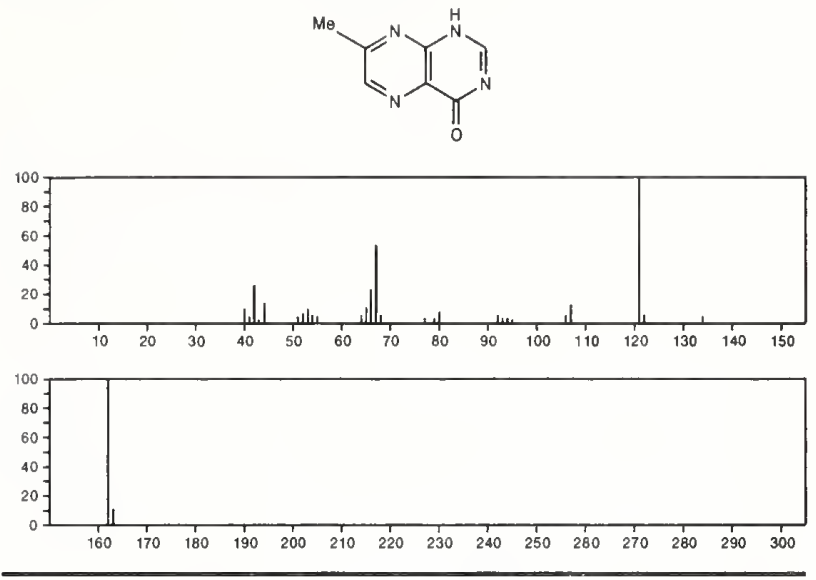

162

Propionic acid, 3-(tert-butylthio)-

927-91-3

t- $\mathrm{Bu} \mathrm{SCH} \mathrm{CH}_{2} \mathrm{CO}_{2} \mathrm{H}$
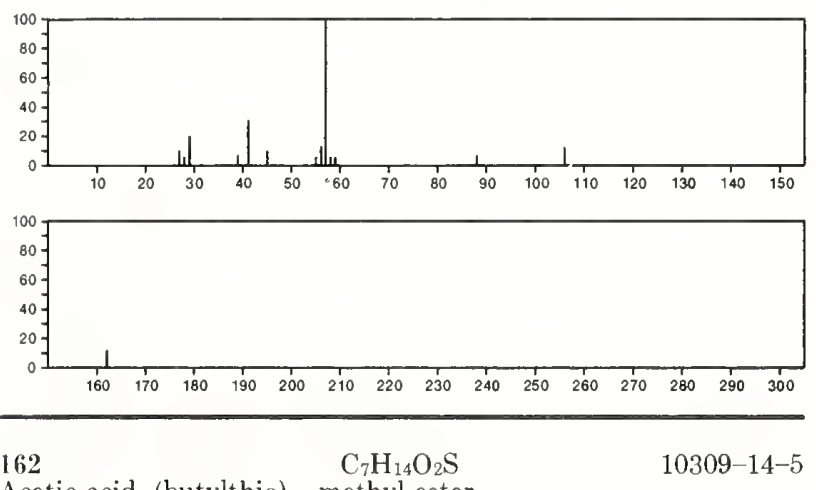

Acetic acid, (butylthio)-, methyl ester

$\mathrm{MeOC}(0) \mathrm{CH}_{2} \mathrm{~S}\left(\mathrm{CH}_{2}\right)_{3} \mathrm{Me}_{\theta}$
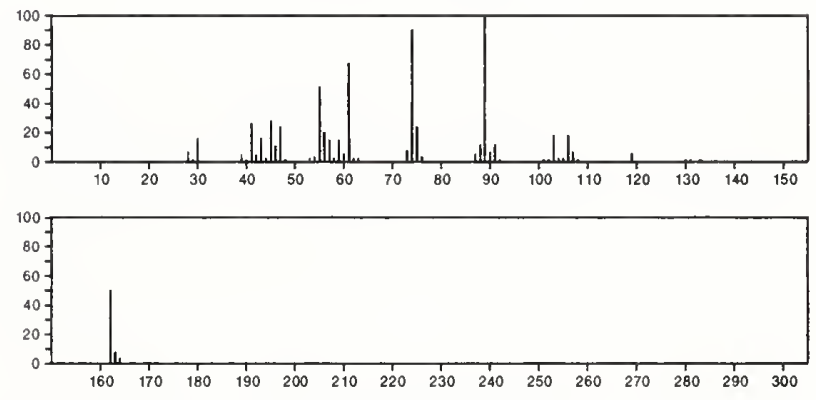

162

$\mathrm{C}_{7} \mathrm{H}_{14} \mathrm{O}_{2} \mathrm{~S}$

Acetic acid, mercapto-, 3-methylbutyl ester

16849-97-1 $\mathrm{HSCH}_{2} \mathrm{C}(\mathrm{O}) \mathrm{OCH}_{2} \mathrm{CH}_{2} \mathrm{CHM}_{2}$
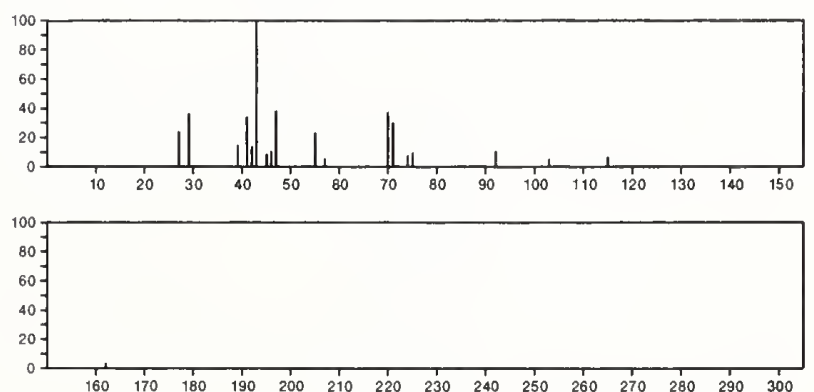
162 Acetic acid, (isobutylthio)-, methyl ester

$\mathrm{i}-\mathrm{BuSCH}_{2} \mathrm{C}(\mathrm{O}) \mathrm{OM}$
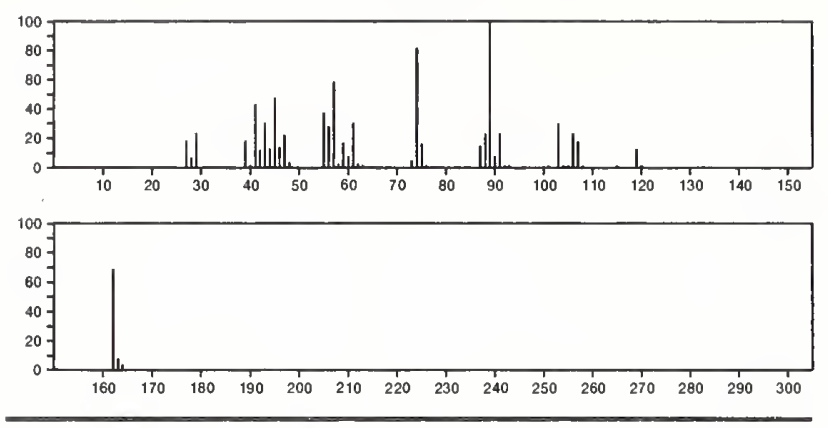

162

Propionic acid, 3-(butylthio)-

$\mathrm{C}_{7} \mathrm{H}_{14} \mathrm{O}_{2} \mathrm{~S}$

22002-73-9

$\mathrm{Me}\left\{\mathrm{CH}_{2}\right\}_{3} \mathrm{SCH}_{2} \mathrm{CH}_{2} \mathrm{CO}_{2} \mathrm{H}$
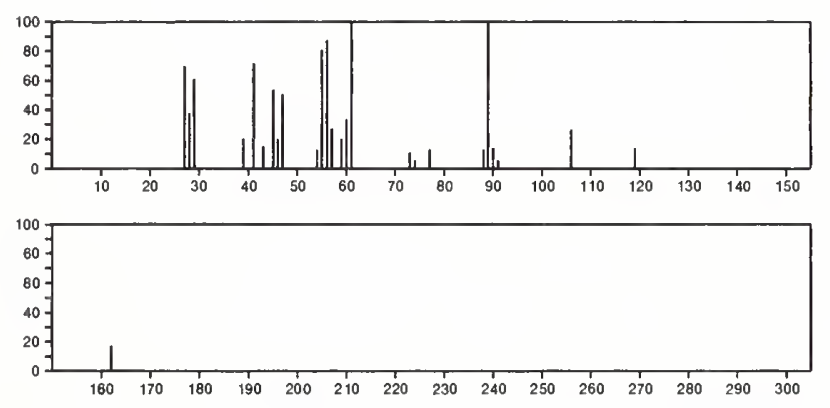

162

1,3-Oxathiolane-2-propanol, 2-methyl-

$36651-30-6$<smiles>CC1(CO)OCCS1</smiles>

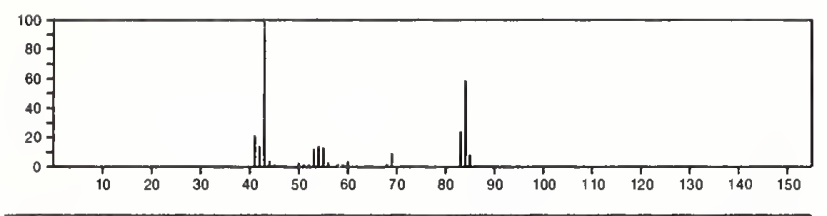

$162 \quad \mathrm{C}_{7} \mathrm{H}_{14} \mathrm{O}_{4}$

D-ribo--Hexose, 2,6-dideoxy-3-O-methyl-

13089-76-4

$\mathrm{Me} \mathrm{CH}(\mathrm{OH}) \mathrm{CH}(\mathrm{OH}) \mathrm{CH}\left(\mathrm{OM}_{\theta}\right) \mathrm{CH}_{2} \mathrm{CHO}$
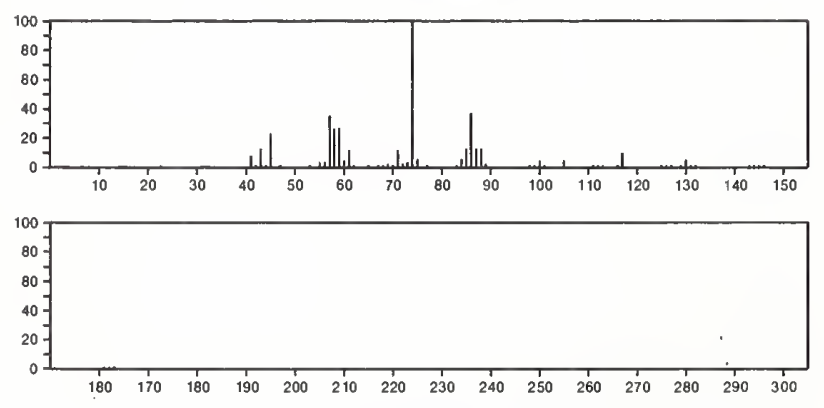

$162 \quad \mathrm{C}_{7} \mathrm{H}_{18} \mathrm{O}_{2} \mathrm{Si} \quad 16654-45-8$

Silane, (2-ethoxyethoxy)trimethyl-

$\mathrm{Et} \mathrm{OCH}_{2} \mathrm{CH}_{2} \mathrm{OSIMe}_{3}$

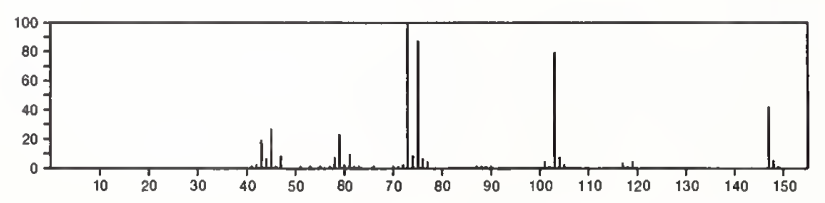

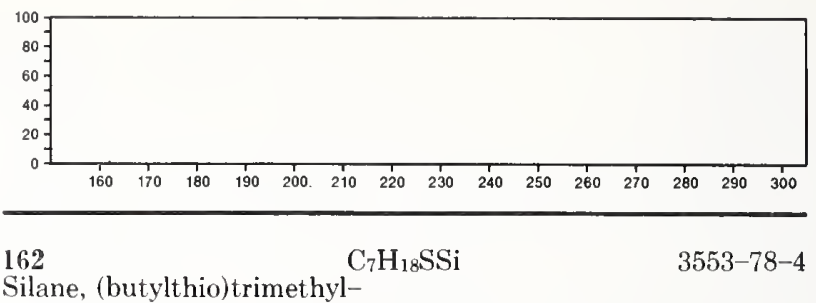

$\mathrm{Me}\left(\mathrm{CH}_{2}\right)_{3}$ SSiMe3
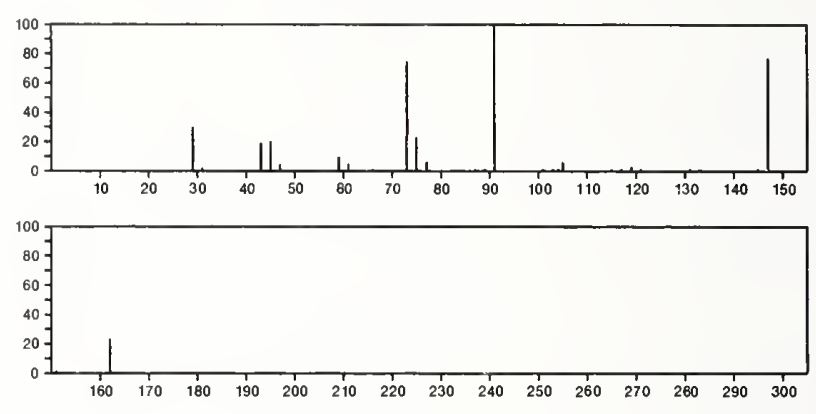

162

Sydnone, 3-phenyl-

$\mathrm{C}_{8} \mathrm{H}_{6} \mathrm{~N}_{2} \mathrm{O}_{2}$

120-06-9
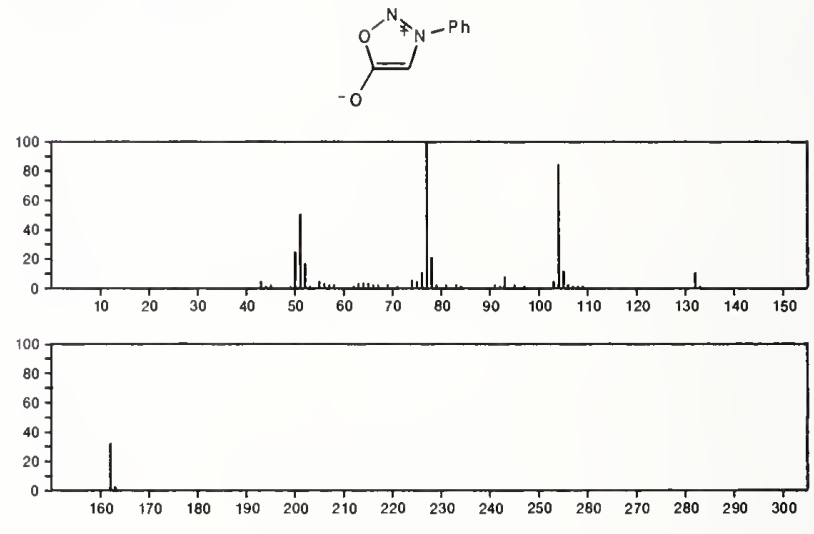

162

Benzeneacetonitrile, 4-nitro-

$\mathrm{C}_{8} \mathrm{H}_{6} \mathrm{~N}_{2} \mathrm{O}_{2}$

$555-21-5$
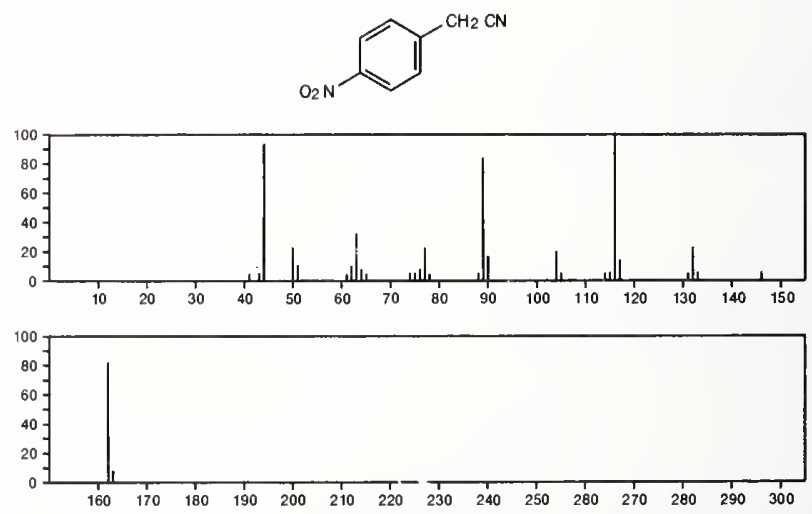
162 $\mathrm{C}_{8} \mathrm{H}_{6} \mathrm{~N}_{2} \mathrm{O}_{2}$

610-66-2

Benzeneacetonitrile, 2-nitro-
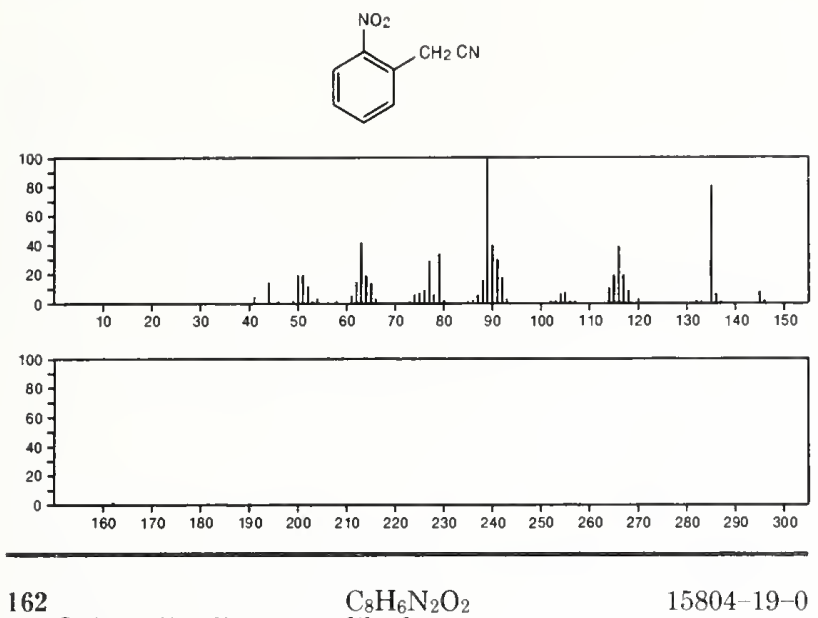

2,3-Quinoxalinedione, 1,4-dihydro-
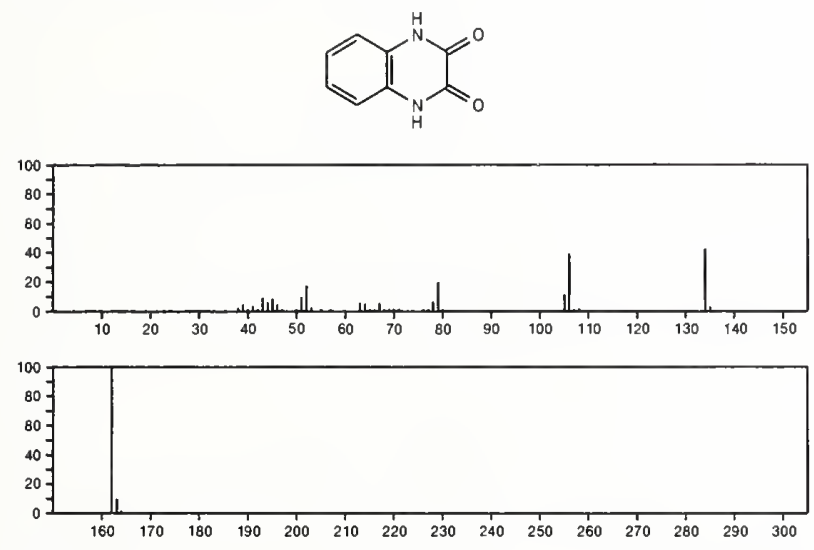

162

$\mathrm{C}_{8} \mathrm{H}_{6} \mathrm{~N}_{2} \mathrm{O}_{2}$

1,2,4-Oxadiazol-3(2H)-one, 5-phenyl-
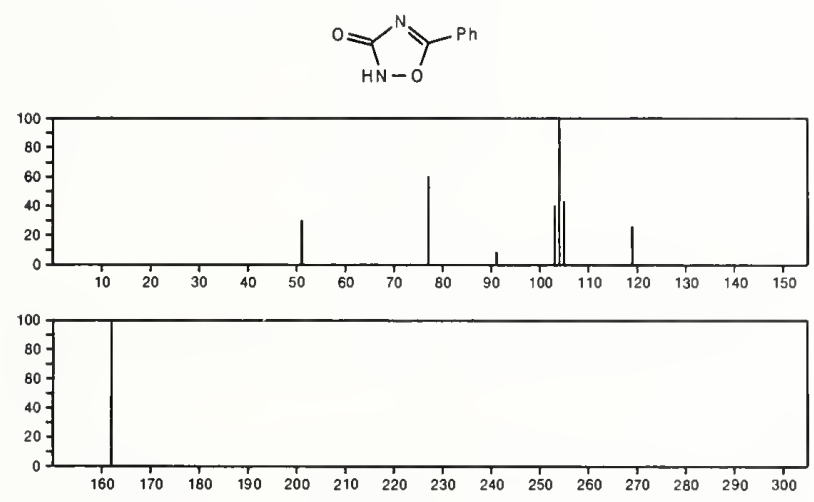

162

1,2,3-Thiadiazole, 4-phenyl-

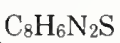

$25445-77-6$
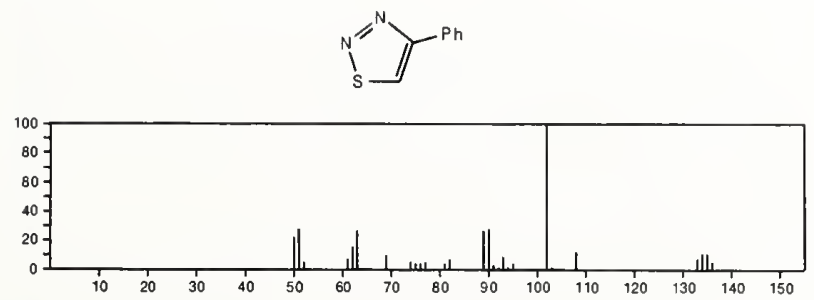
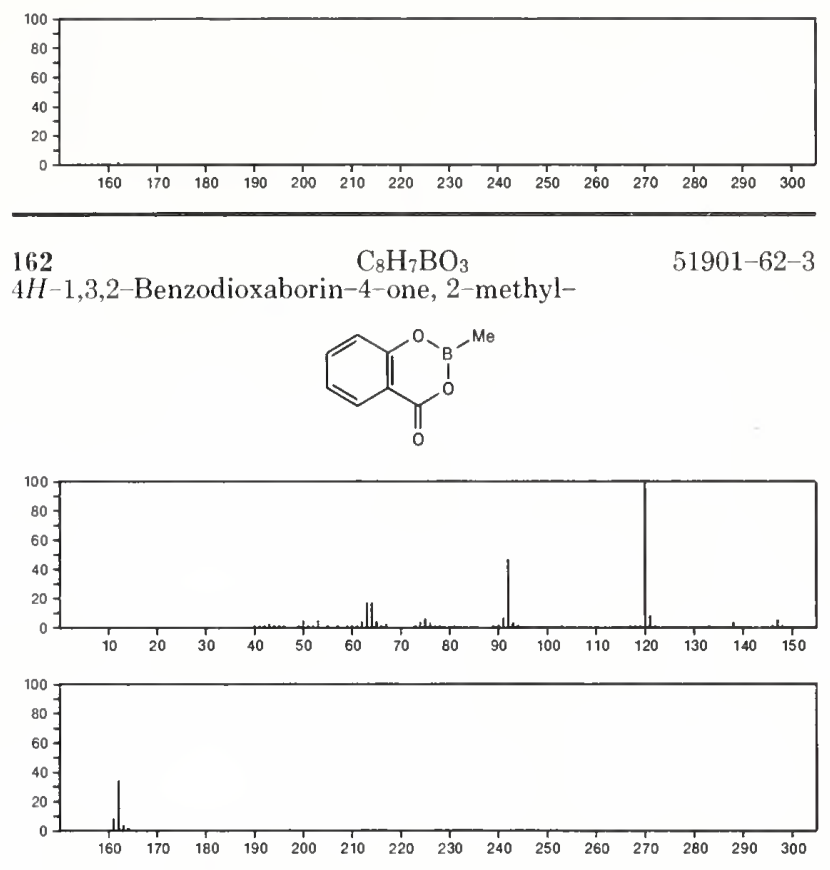

162

$\mathrm{C}_{8} \mathrm{H}_{10} \mathrm{~N}_{4}$

$19848-79-4$

$s$-Triazolo[4,3-a]pyrazine, 3,5,8-trimethyl-
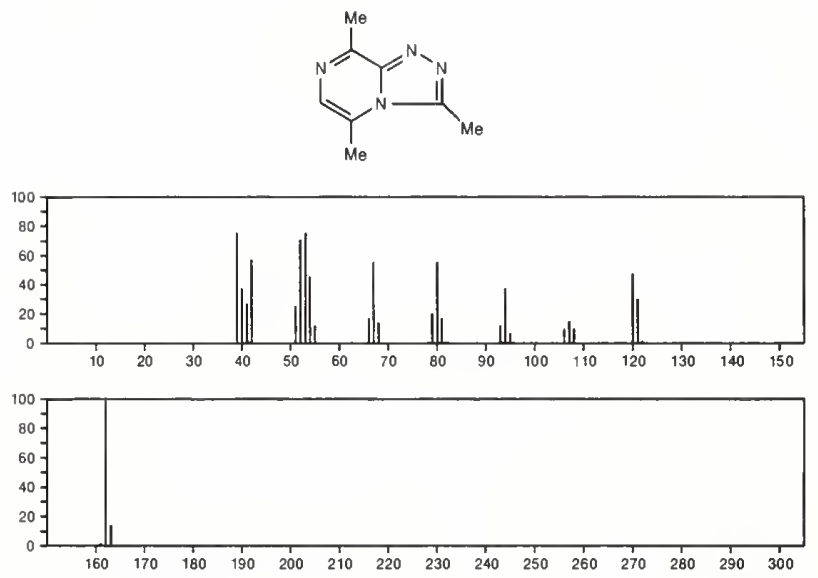

162

$\mathrm{C}_{8} \mathrm{H}_{10} \mathrm{~N}_{4}$

$19848-80-7$

$s$-Triazolo[4,3-a]pyrazine, 3-ethyl-8-methyl-
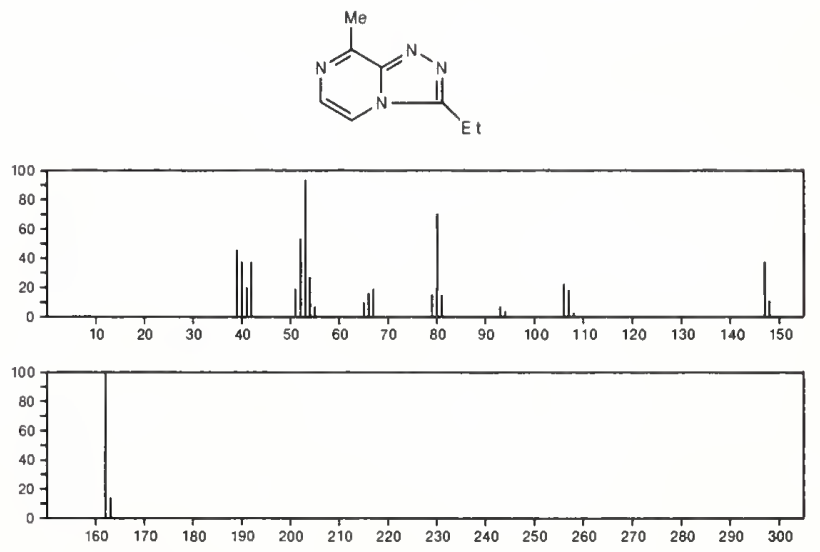
162

$\mathrm{C}_{8} \mathrm{H}_{10} \mathrm{~N}_{4}$

54410-76-3

$[1,2,4]$ Triazolo $[1,5-a]$ pyrazine, 2,5,8-trimethy]-
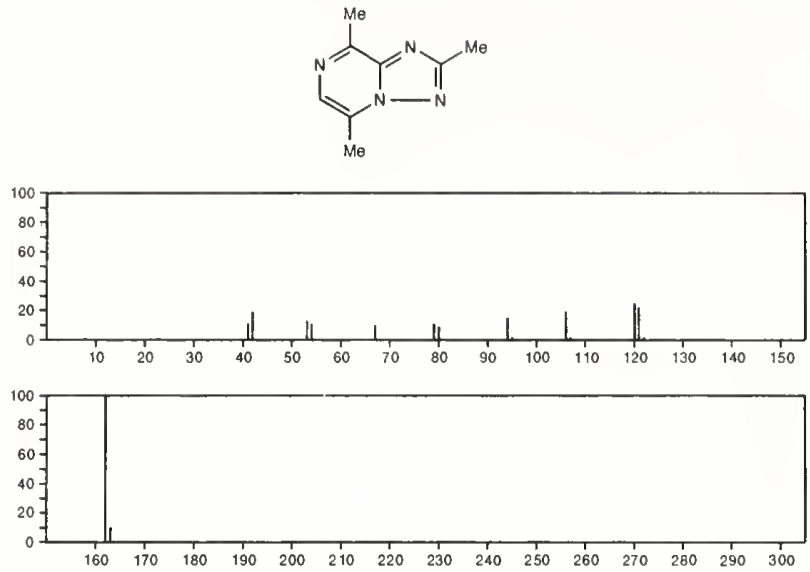

162

Octanoyl chloride

$\mathrm{C}_{8} \mathrm{H}_{15} \mathrm{ClO}$

$111-64-8$

$\mathrm{Me}\left(\mathrm{CH}_{2}\right)_{6} \mathrm{COCl}$

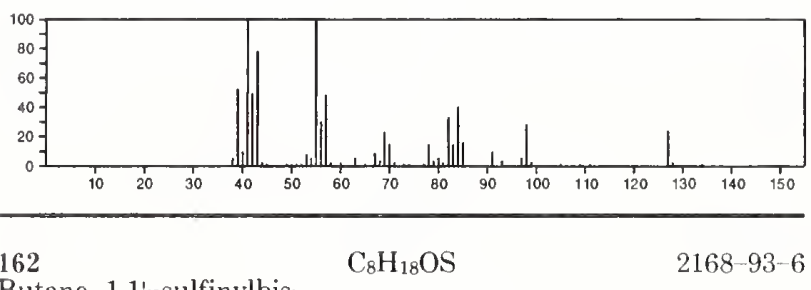

Butane, 1,1'-sulfinylbis-

$\mathrm{Me}\left(\mathrm{CH}_{2}\right)_{3} \mathrm{~S}(\mathrm{O})\left(\mathrm{CH}_{2}\right)_{3} \mathrm{Me}$
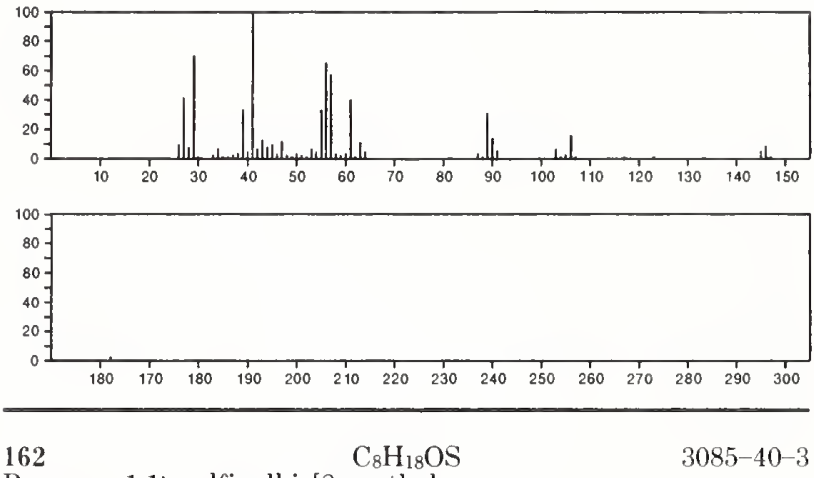

Propane, 1,1'-sulfinylbis[2-methyl-

$i-B u S(O) B u-i$
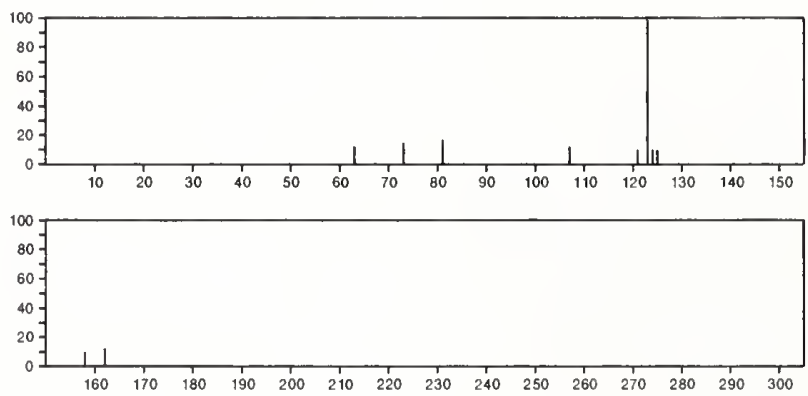

162

$\mathrm{C}_{8} \mathrm{H}_{18} \mathrm{O}_{3}$

78-39-7

$\mathrm{MeC}(\mathrm{OE} 1)_{3}$

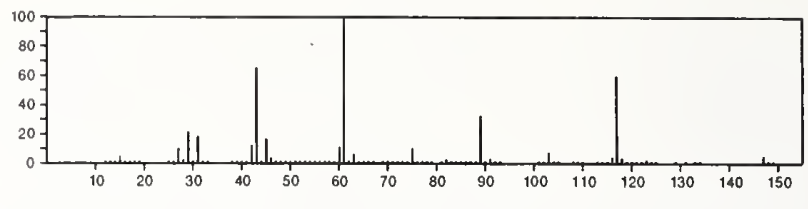

162

Ethanol, 2-(2-butoxyethoxy)-

$\mathrm{C}_{8} \mathrm{H}_{18} \mathrm{O}_{3}$

$112-34-5$

$\mathrm{Me}\left(\mathrm{CH}_{2}\right)_{3} \mathrm{OCH}_{2} \mathrm{CH}_{2} \mathrm{OCH}_{2} \mathrm{CH}_{2} \mathrm{OH}$

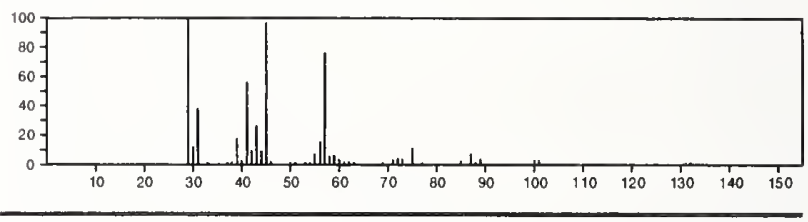

162

$\mathrm{C}_{8} \mathrm{H}_{18} \mathrm{O}_{3}$

$112-36-7$

Ethane, 1,1-oxybis[2-ethoxy-

$\mathrm{E}_{\mathrm{O}} \mathrm{OCH}_{2} \mathrm{CH}_{2} \mathrm{OCH}_{2} \mathrm{CH}_{2} \mathrm{OE}$ t

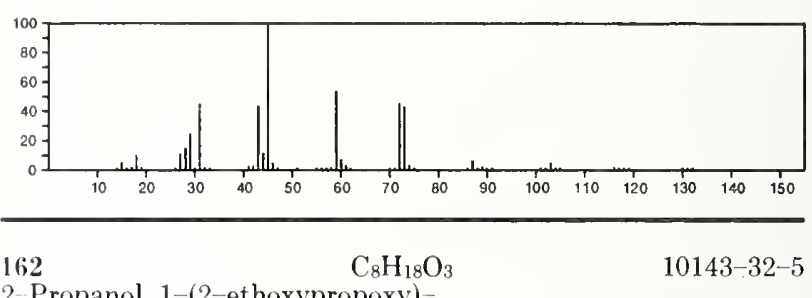

2-Propanol, 1-(2-ethoxypropoxy)-

$\mathrm{Me} \mathrm{CH}(\mathrm{OE} 1) \mathrm{CH}_{2} \mathrm{OCH}_{2} \mathrm{CH}(\mathrm{OH}) \mathrm{Me}$

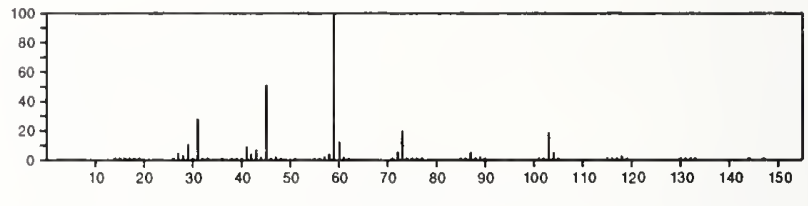

162

$$
\mathrm{C}_{8} \mathrm{H}_{18} \mathrm{O}_{3}
$$

$13820-09-2$

Pentane, 1,1,1-trimethoxy-

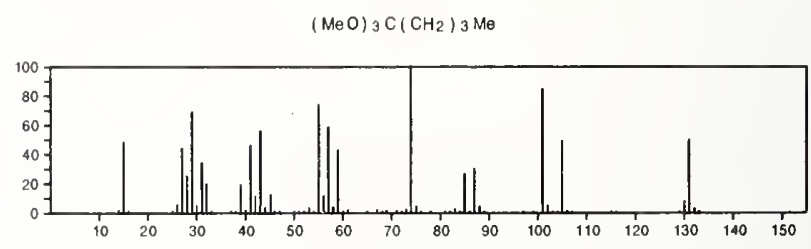

162

$\mathrm{C}_{8} \mathrm{H}_{18} \mathrm{O}_{3}$

15476-20-7

Propane, 1,3-dimethoxy-2-(methoxymethyl)-2-methyl-

$\mathrm{CH}_{2} \mathrm{OMe}_{\mathrm{M}}$

$\mathrm{MeOCH} 2 \stackrel{\mathrm{C}}{\mathrm{C}} \mathrm{Me}_{e} \mathrm{CH}_{2} \mathrm{OMe}_{\mathrm{O}}$

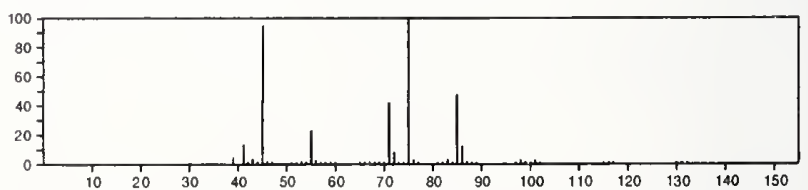


162 $\mathrm{C}_{8} \mathrm{H}_{18} \mathrm{O}_{3}$

Pentane, 1,2,3-trimethoxy-

$\mathrm{Et} \mathrm{CH}$ ( $\mathrm{OMe}$ ) $\mathrm{CH}$ ( $\mathrm{OMe}$ ) $\mathrm{CH}_{2} \mathrm{OMe}$

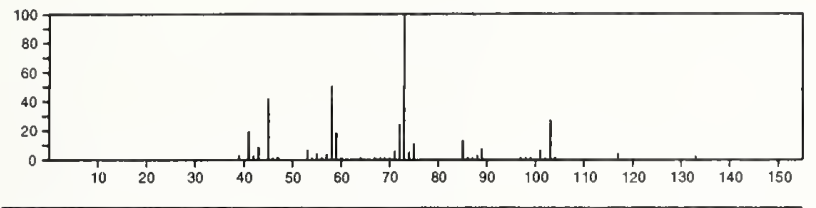

162

$\mathrm{C}_{8} \mathrm{H}_{18} \mathrm{O}_{3}$

54446-78-5

Ethanol, 1-(2-butoxyethoxy)-

$\mathrm{Me}\left(\mathrm{CH}_{2}\right)_{3} \mathrm{OCH}_{2} \mathrm{CH}_{2} \mathrm{OCH}(\mathrm{OH}) \mathrm{Me}$
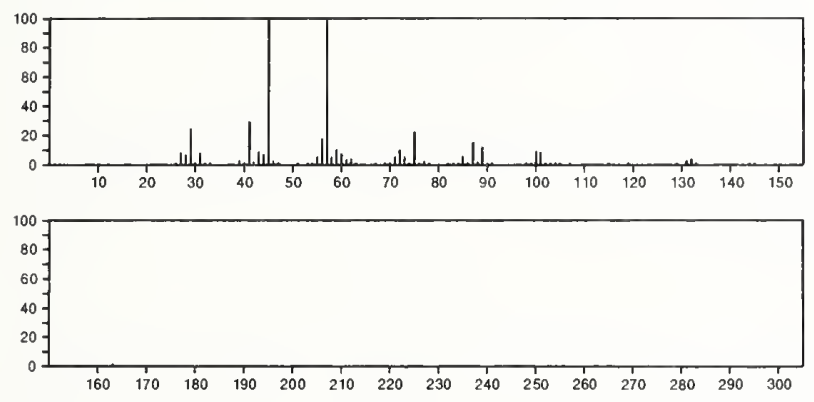

$162 \quad \mathrm{C}_{8} \mathrm{H}_{19} \mathrm{OP}$

Phosphine oxide, bis(1,1-dimethylethyl)-

684-19-5

$(\mathrm{t}-\mathrm{Bu})_{2} \mathrm{PH}=0$
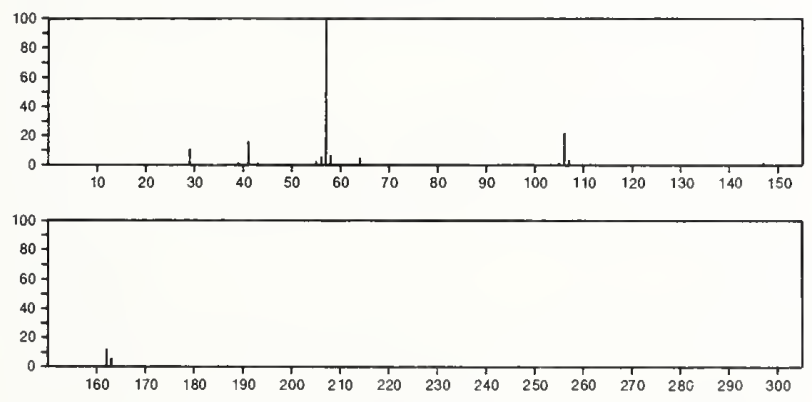

162

2H-1-Benzopyran-2-one, 4-hydroxy-
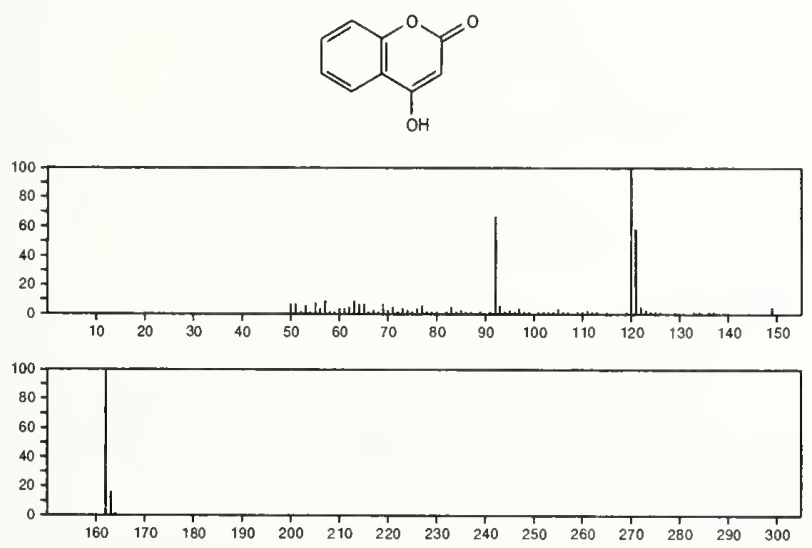

162

2-Imidazolidinone, 1 phenyl

$\mathrm{C}_{9} \mathrm{H}_{10} \mathrm{~N}_{2} \mathrm{O}$

$1848-69-7$
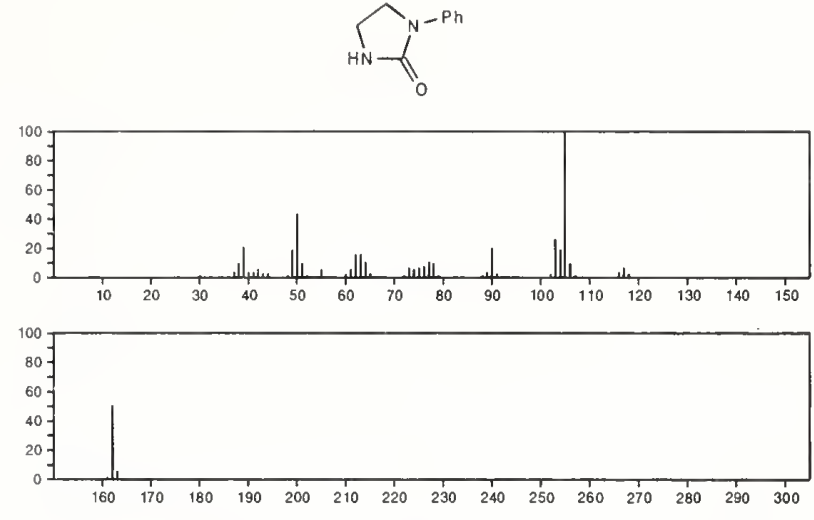

\begin{tabular}{ll}
\hline 162 & $\mathrm{C}_{9} \mathrm{H}_{10} \mathrm{~N}_{2} \mathrm{O}$ \\
$1 \mathrm{H}$-Benzimidazole-2-ethanol
\end{tabular}
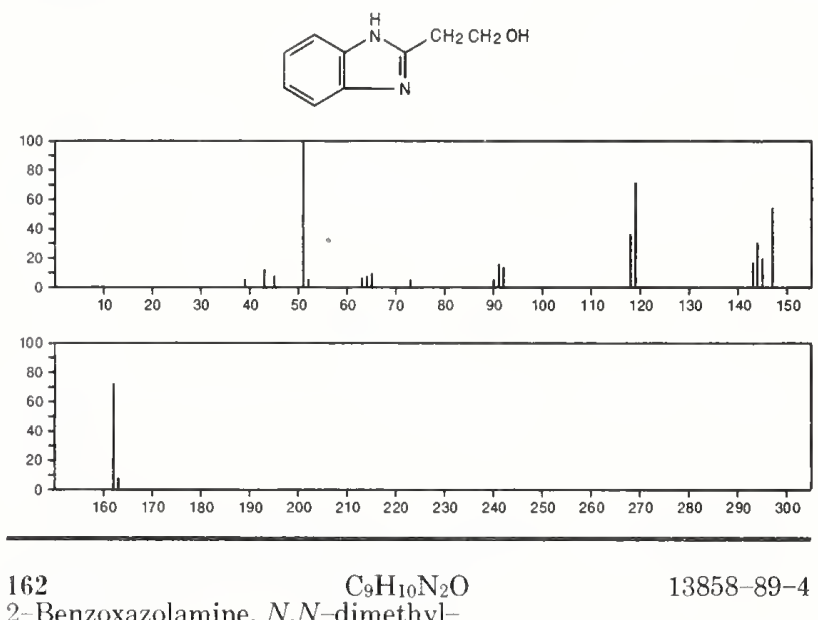

2-Benzoxazolamine, $\mathrm{N}, \mathrm{N}$-dimethyl-
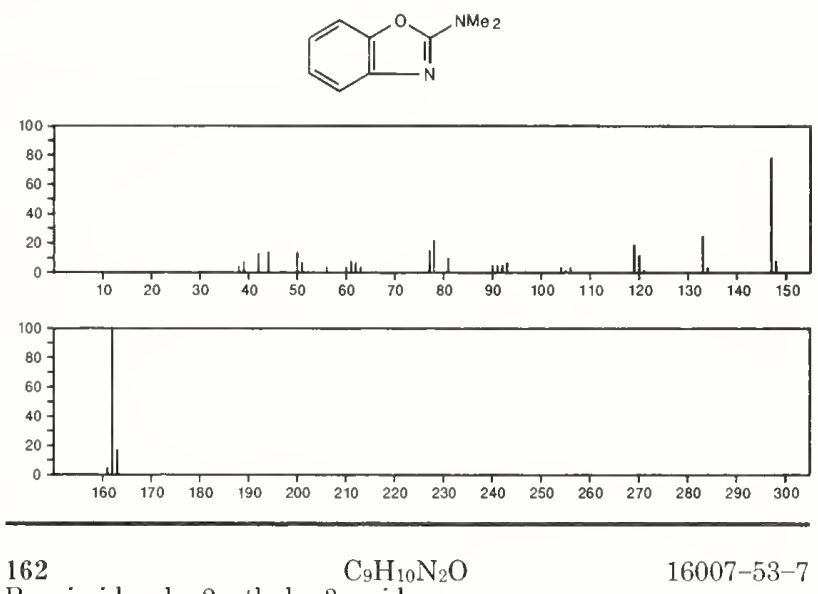

Benzimidazole, 2-ethyl-, 3-oxide
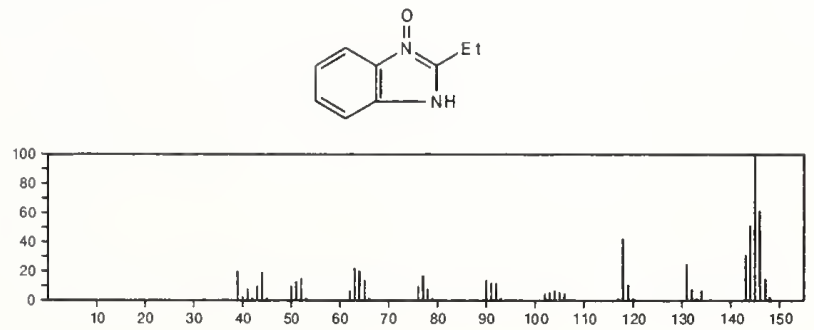


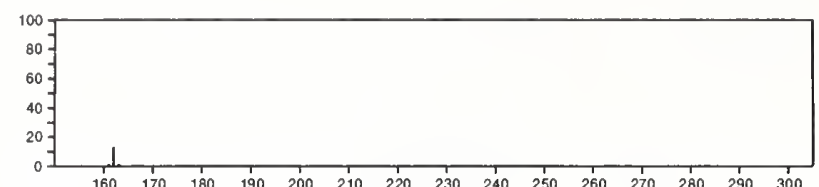

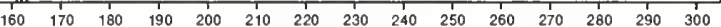

162

Benzoxazole, 2-(ethylamino)-

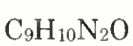

$21326-91-0$
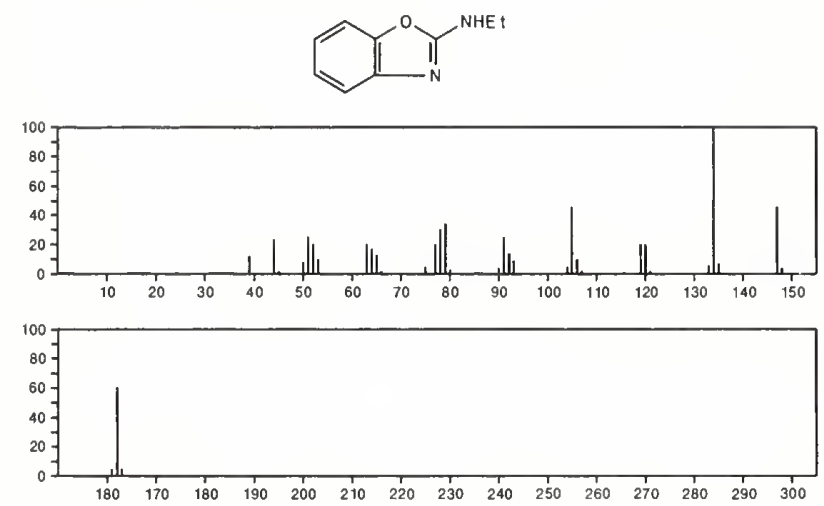

\section{2 \\ $\mathrm{C}_{9} \mathrm{H}_{10} \mathrm{~N}_{2} \mathrm{O}$}

3 H-Indazol-3-one, 1-ethyl-1,2-dihydro-

$54385-62-5$
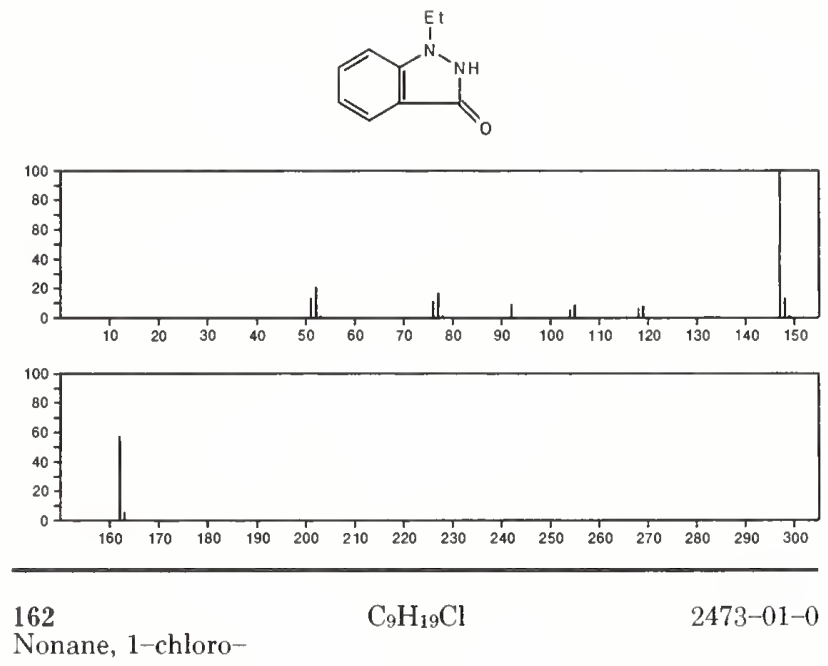

Nonane, 1-chloro-

$\mathrm{Me}\left(\mathrm{CH}_{2}\right)_{8} \mathrm{Cl}$
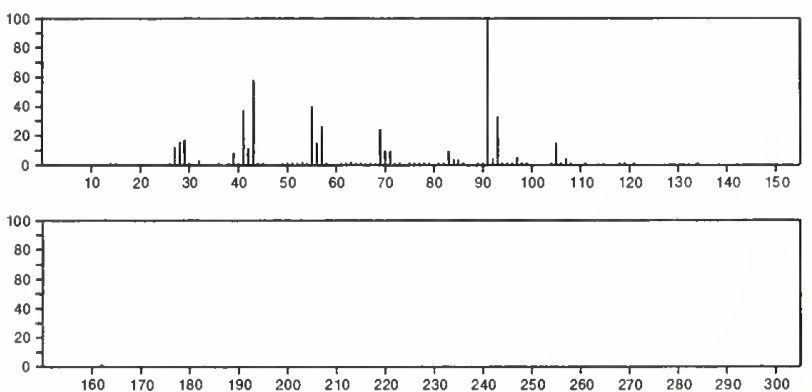

162

Naphthalene, 1-chloro-

$\mathrm{C}_{10} \mathrm{H}_{7} \mathrm{Cl}$

$90-13-1$
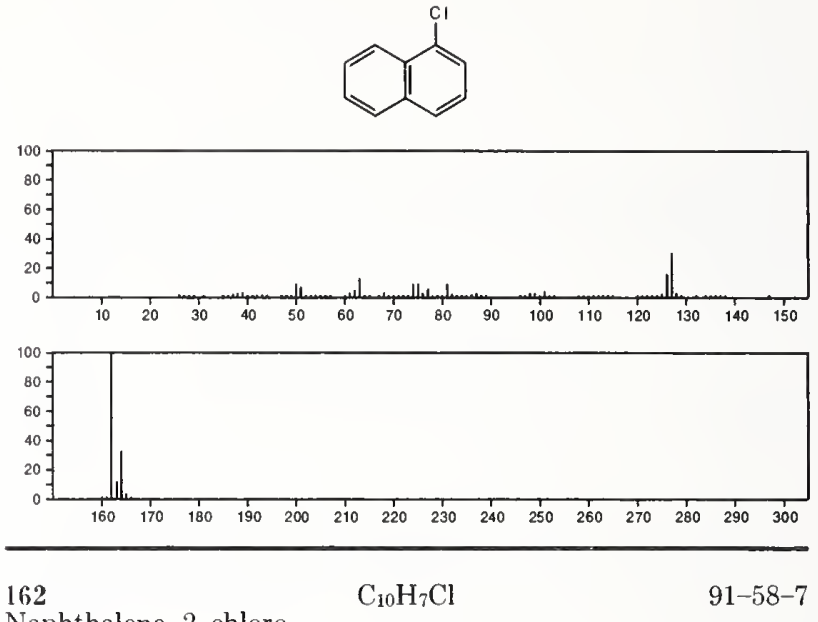

Naphthalene, 2-chloro-
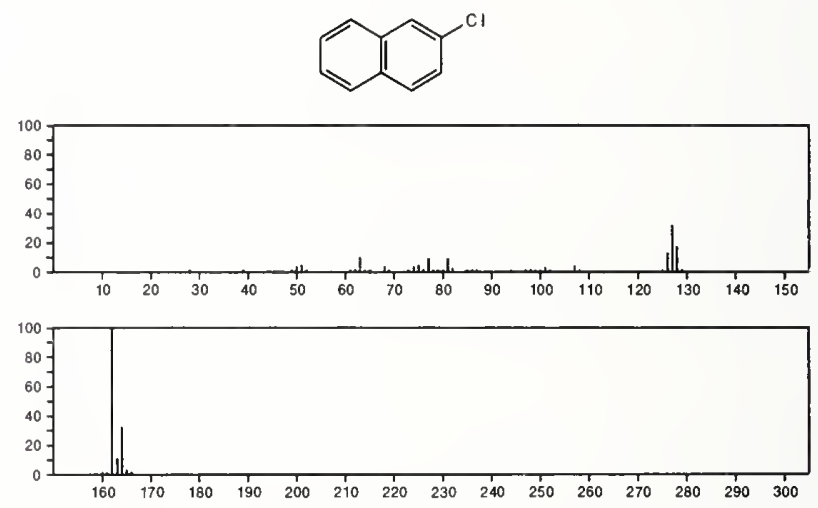

162

$\mathrm{C}_{10} \mathrm{H}_{7} \mathrm{Cl}$

25586-43-0

Naphthalene, chloro-
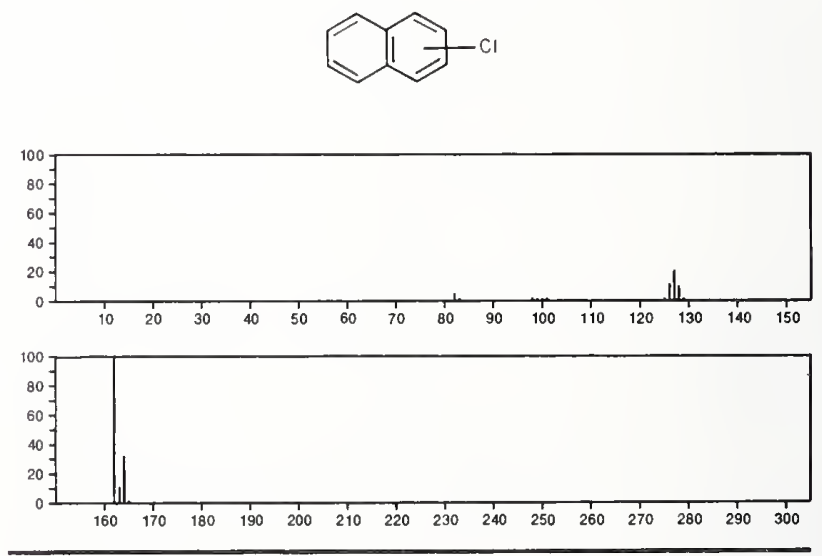

162

1,3-Butanedione, 1-phenyl-

$\mathrm{C}_{10} \mathrm{H}_{10} \mathrm{O}_{2}$

$93-91-4$

$\mathrm{Ph} \mathrm{COCH} 2 \mathrm{COM}_{3}$

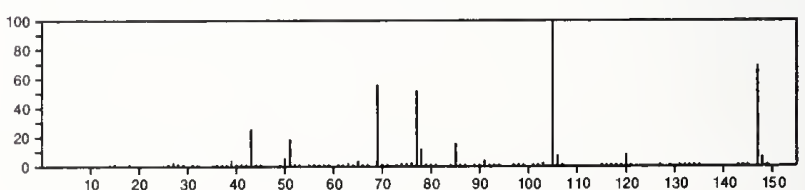



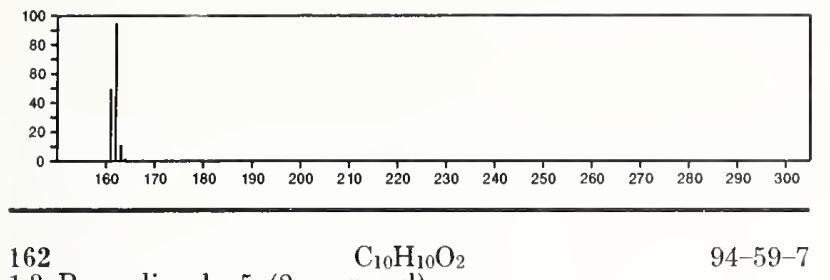

1,3-Benzodioxole, 5-(2-propenyl)-
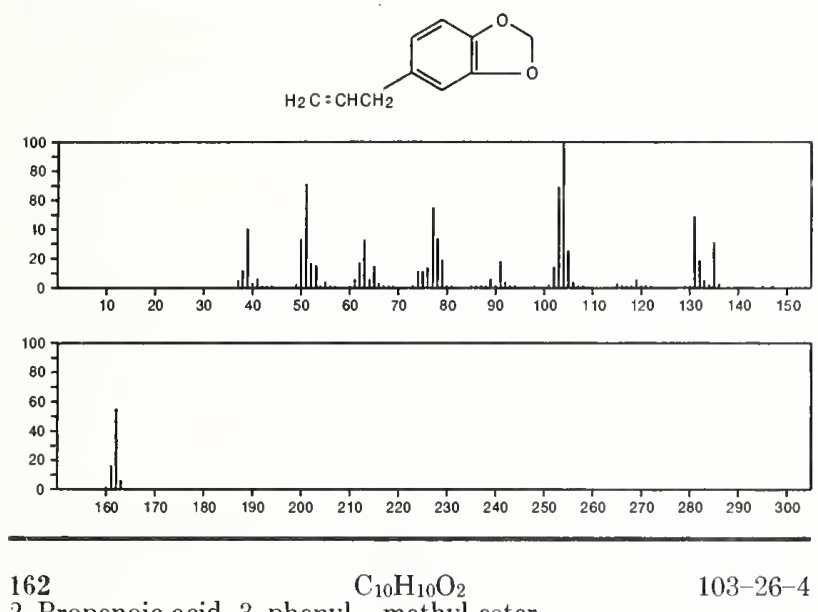

2-Propenoic acid, 3-phenyl-, methyl ester

$\mathrm{MeOC}(\mathrm{O}) \mathrm{CH}=\mathrm{CHPh}$
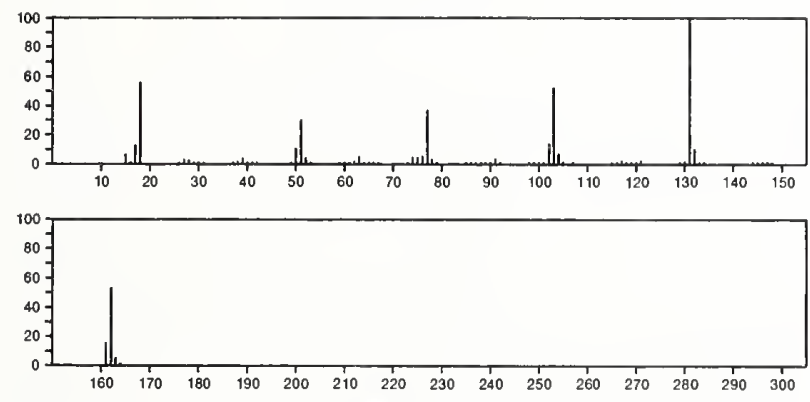

162

1,3-Benzodioxole, 5-(1-propenyl)-

$120-58-1$
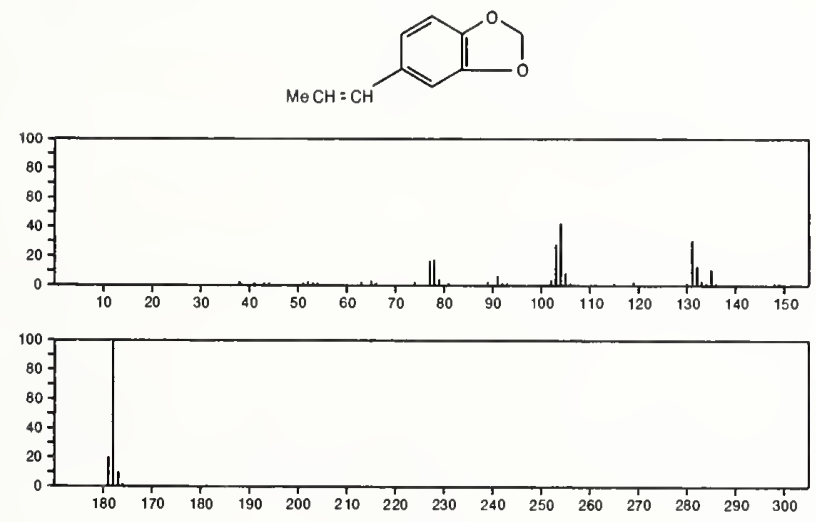

162

$\mathrm{C}_{10} \mathrm{H}_{10} \mathrm{O}_{2}$

Benzoic acid, 2-propenyl ester

$583-04-0$

$\mathrm{H}_{2} \mathrm{C}=\mathrm{CHCH}_{2} \mathrm{OC}(\mathrm{O})$ Ph

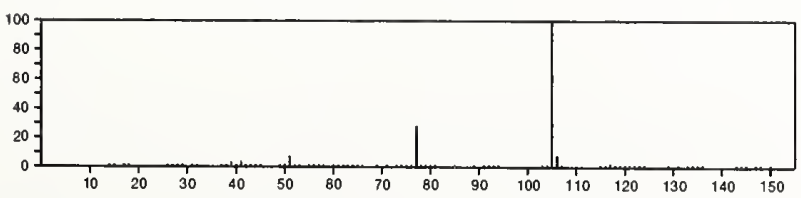

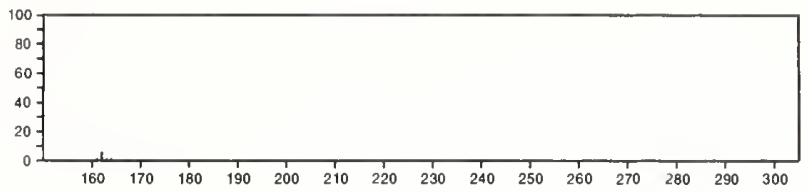

$162 \quad \mathrm{C}_{10} \mathrm{H}_{10} \mathrm{O}_{2}$

$1008-76-0$

2(3H)-Furanone, dihydro-5-phenyl-
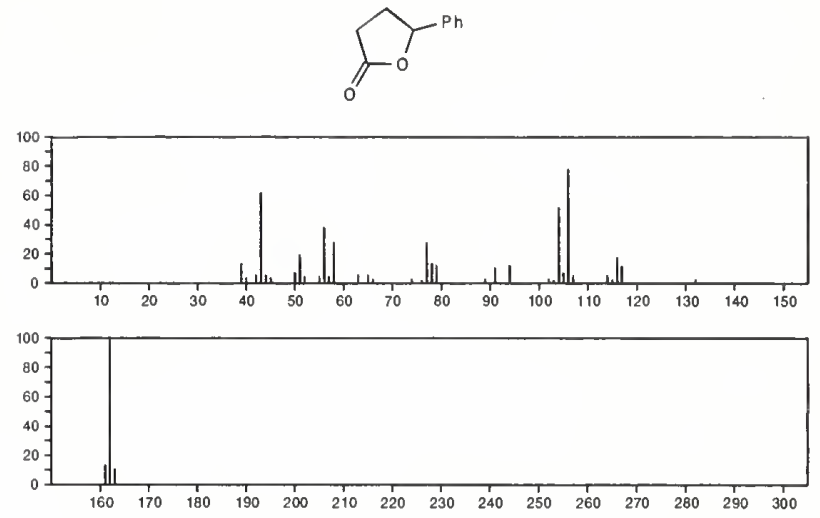

$162 \quad \mathrm{C}_{10} \mathrm{H}_{10} \mathrm{O}_{2}$

$1009-61-6$

Ethanone, 1,1'-(1,4-phenylene)bis-
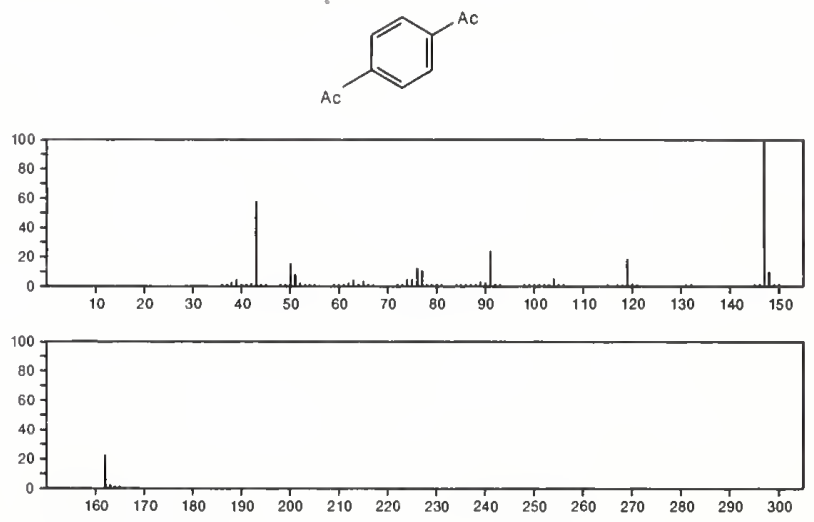

162

$\mathrm{C}_{10} \mathrm{H}_{10} \mathrm{O}_{2}$

Benzoic acid, 4-ethenyl-, methyl ester

$1076-96-6$
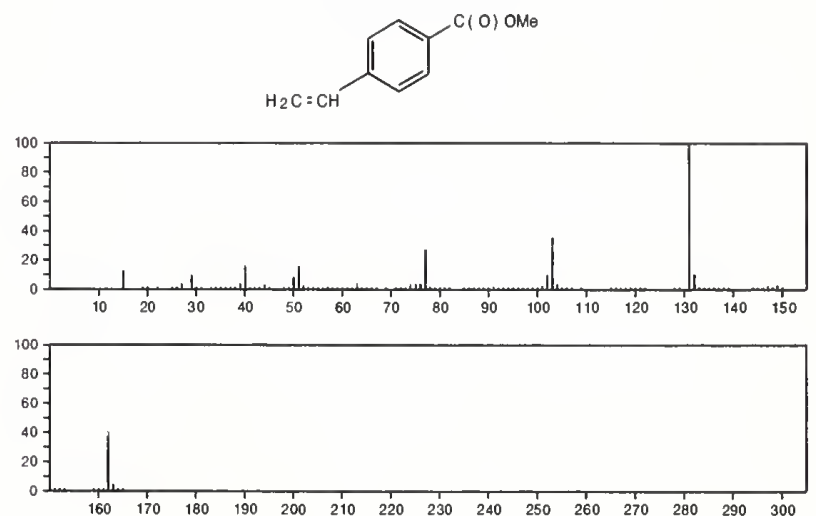
162

$\mathrm{C}_{10} \mathrm{H}_{10} \mathrm{O}_{2}$

2-Propenoic acid, 3-phenyl-, methyl ester, $(E)$ -

$1754-62-7$

$\mathrm{MeOC}(0) \mathrm{CH}=\mathrm{CHPh}$
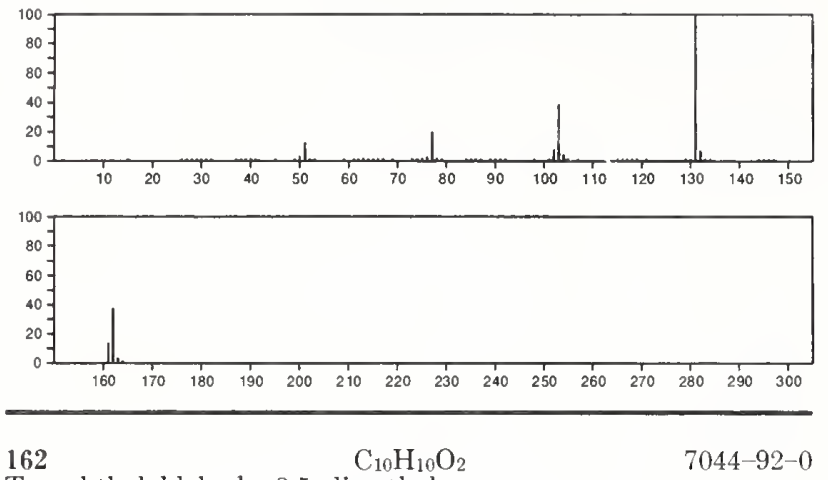

Terephthalaldehyde, 2,5-dimethyl-
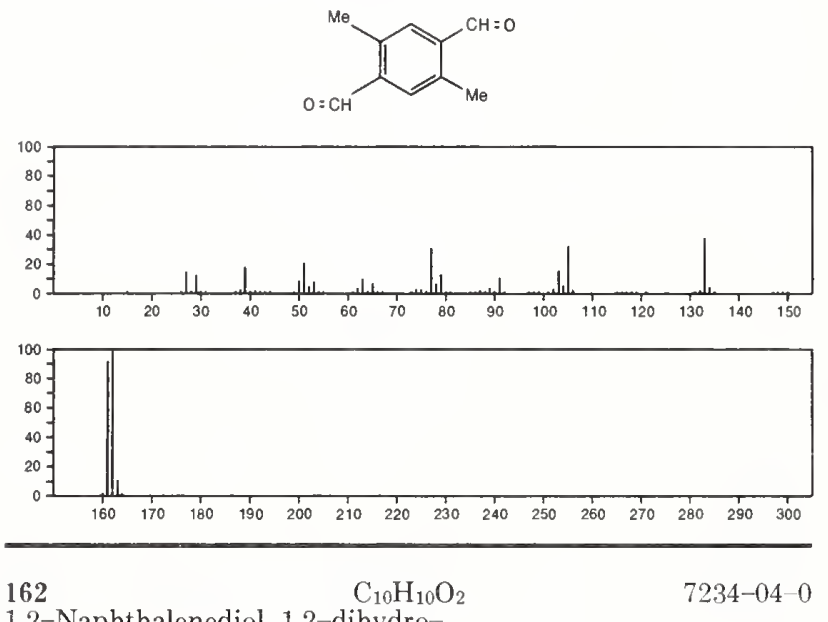

1,2-Naphthalenediol, 1,2-dihydro-
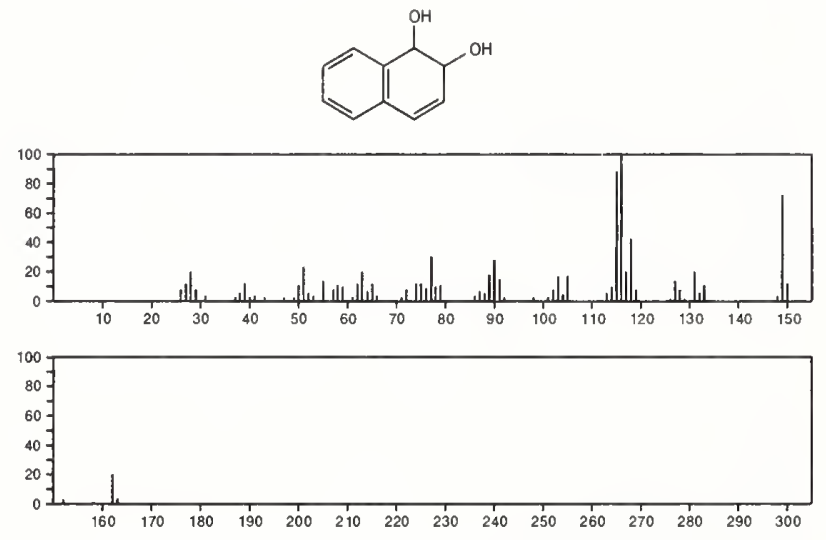

162

$\mathrm{C}_{10} \mathrm{H}_{10} \mathrm{O}_{2}$

2(3H)-Benzofuranone, 3,3-dimethyl-

$13524-76-0$
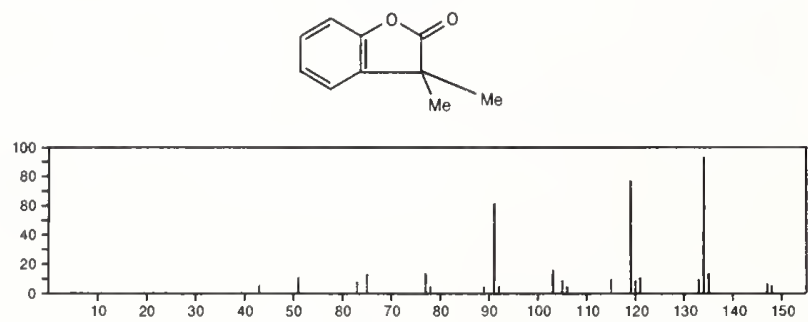

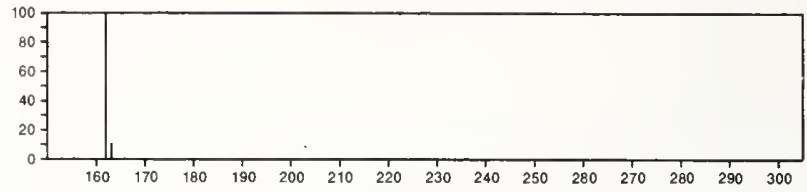

$162 \quad \mathrm{C}_{10} \mathrm{H}_{10} \mathrm{O}_{2} \quad 19560-64-6$ 2H-1,5-Benzodioxepin, 3,4-dihydro-3-methylene-
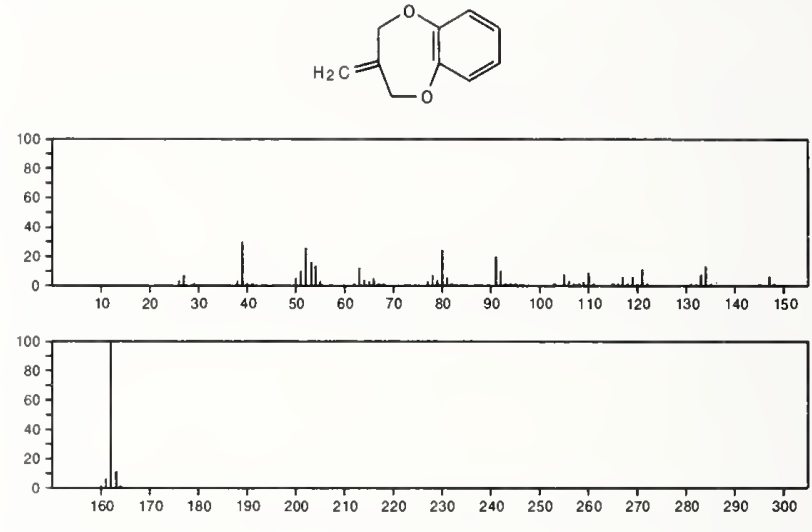

$162 \quad \mathrm{C}_{10} \mathrm{H}_{10} \mathrm{O}_{2}$

$3(2 H)$-Benzofuranone, 4,5-dimethyl-

$20895-42-5$
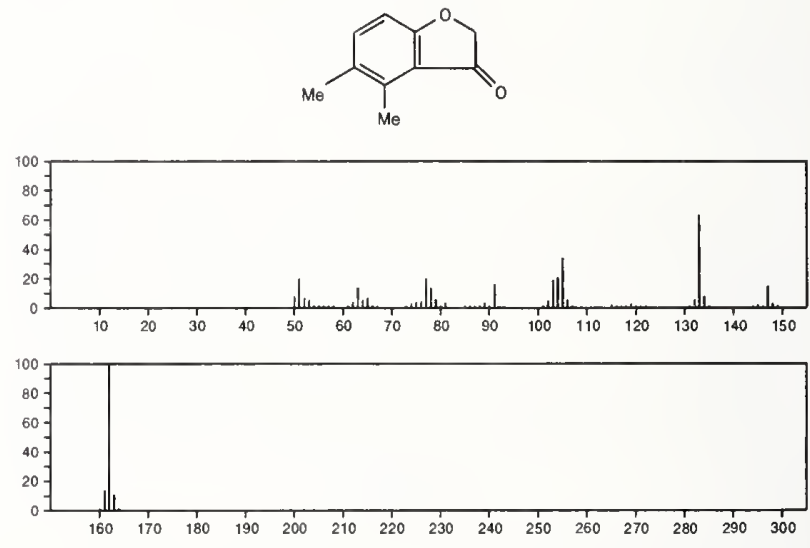

162

$\mathrm{C}_{10} \mathrm{H}_{10} \mathrm{O}_{2}$

$3(2 H)$-Benzofuranone, 5,6-dimethyl-

$20895-43-6$
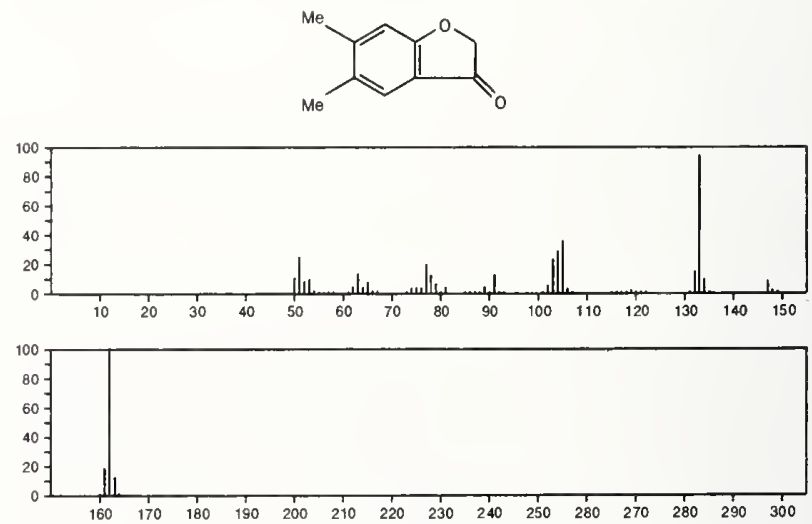
162
$3(2 H)$-Benzofuranone,
$\mathrm{C}_{10} \mathrm{H}_{10} \mathrm{O}_{2}$
4, dimethyl-
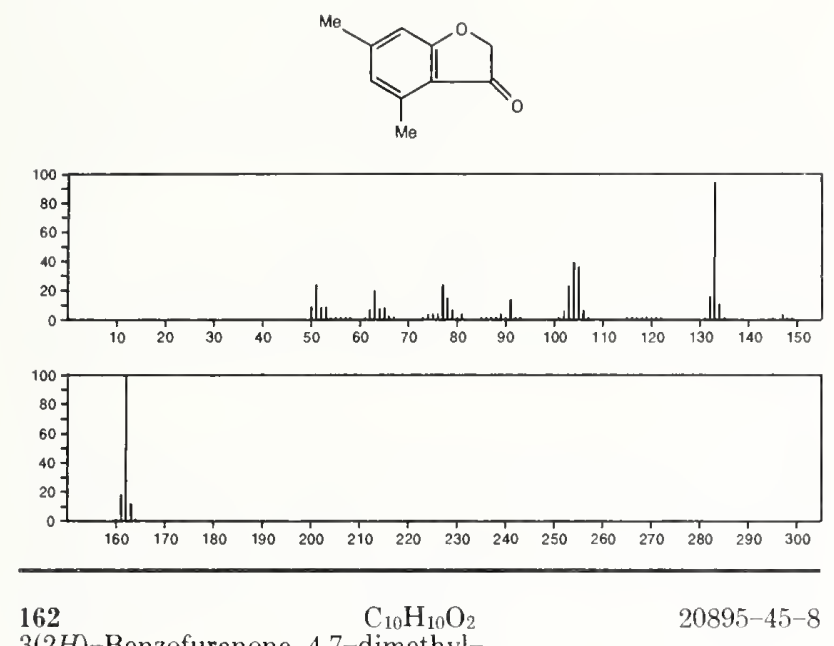

$3(2 \mathrm{H})$-Benzofuranone, 4,7-dimethyl-
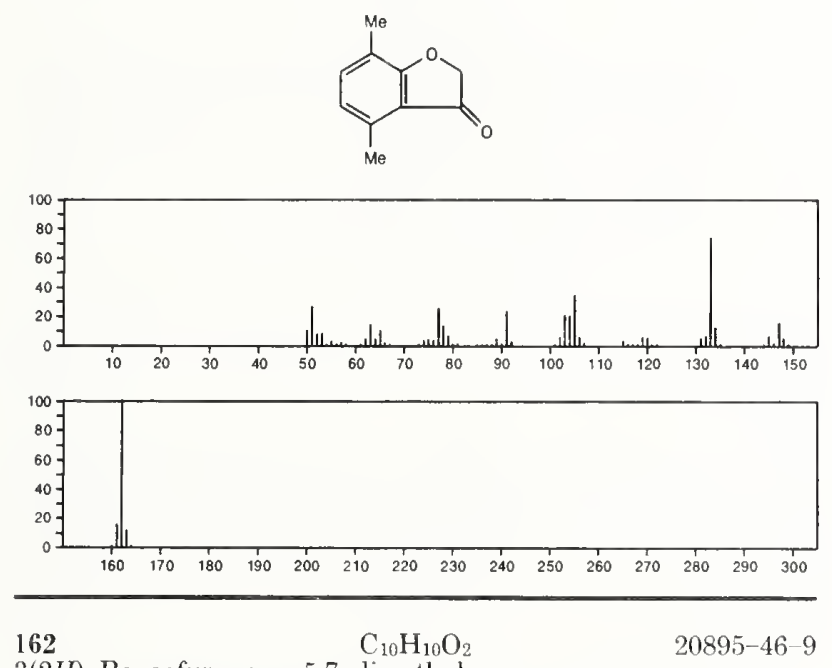

3(2H)-Benzofuranone, 5,7-dimethyl-
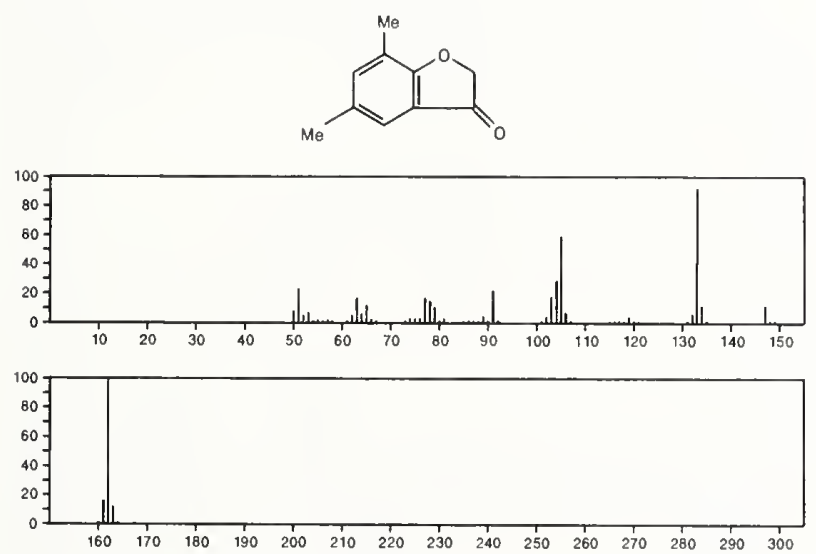

162

$\mathrm{C}_{10} \mathrm{H}_{10} \mathrm{O}_{2}$
dimethyl-

$20895-47-0$
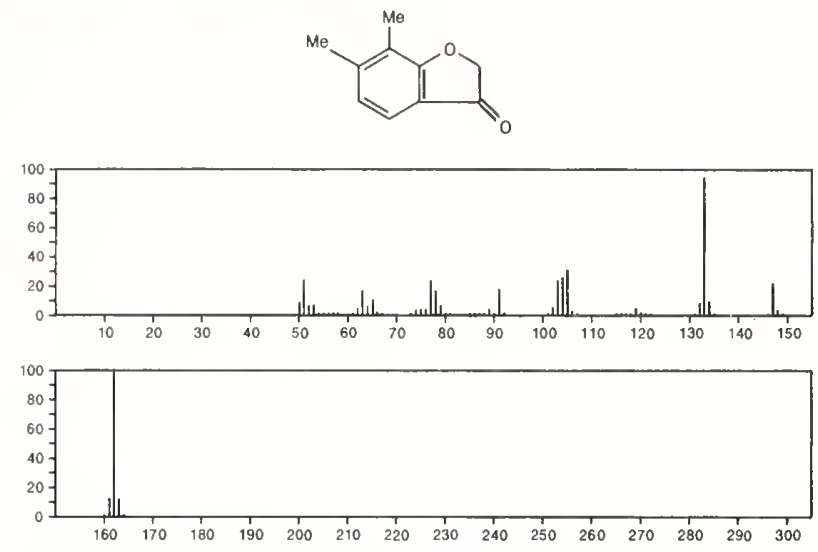

$162 \quad \mathrm{C}_{10} \mathrm{H}_{10} \mathrm{O}_{2}$

2- Cyclopenten-1-one, 2-(4-methyl-2-furyl)-

$21149-13-3$
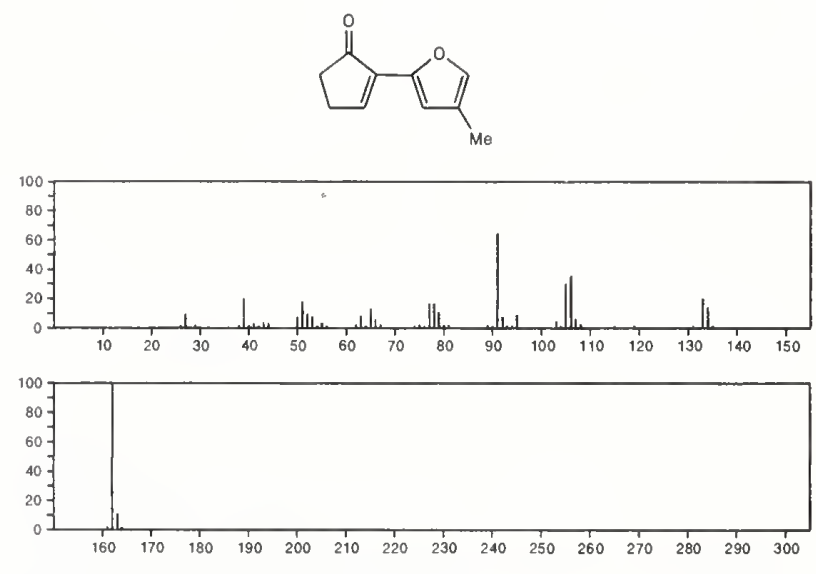

162

$\mathrm{C}_{10} \mathrm{H}_{10} \mathrm{O}_{2}$

21149-14-4

Indene-1,7(4H)-dione, 3a,7a-dihydro-5-methyl-
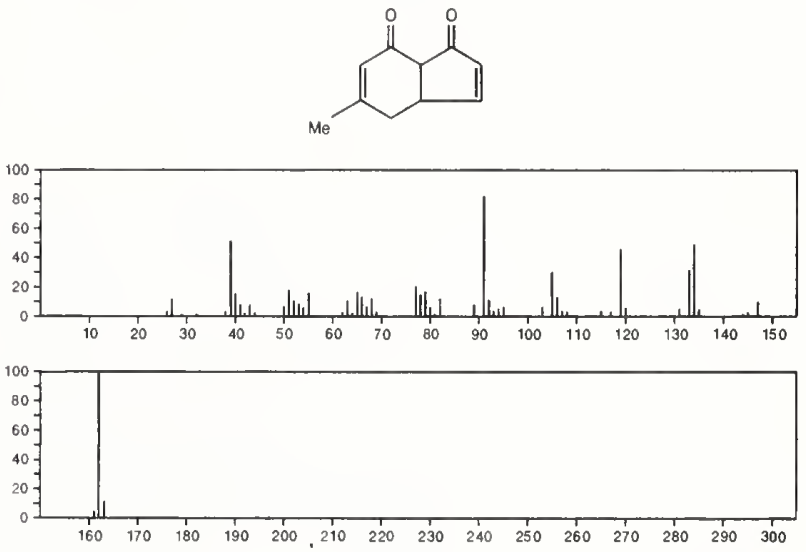
162 $\mathrm{C}_{10} \mathrm{H}_{10} \mathrm{O}_{2}$

Benzaldehyde, 2-hydroxy-3-(2-propenyl)-

$24019-66-7$
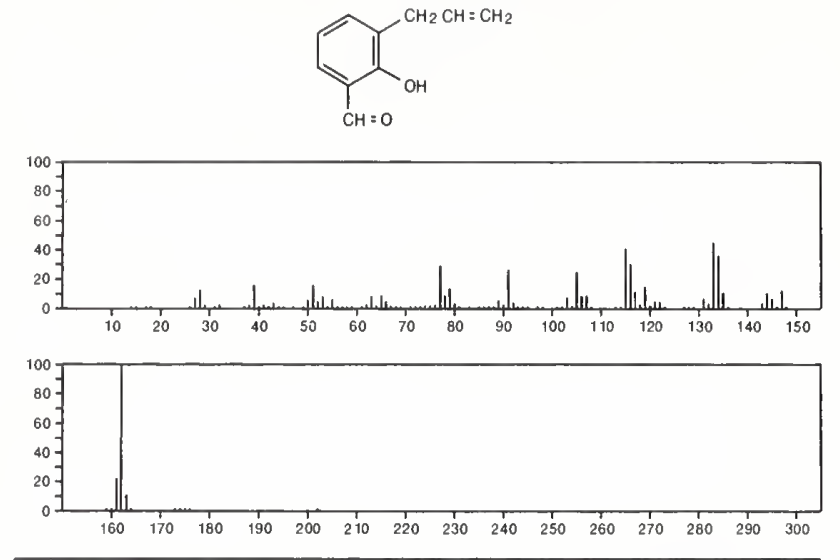

$162 \quad \mathrm{C}_{10} \mathrm{H}_{10} \mathrm{O}_{2}$

Benzaldehyde, 2-(2-propenyloxy)
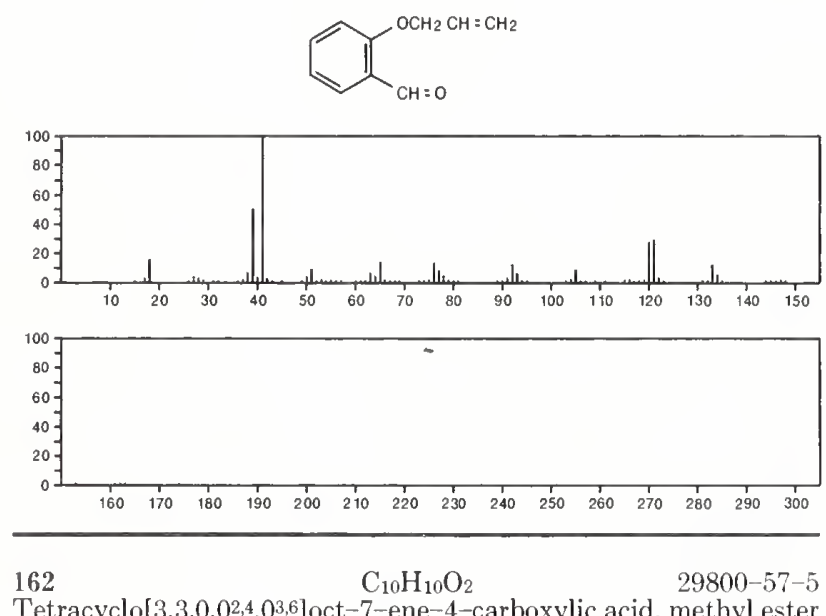

Tetracyclo[3.3.0.02,4,03,6]oct-7-ene-4-carboxylic acid, methyl ester
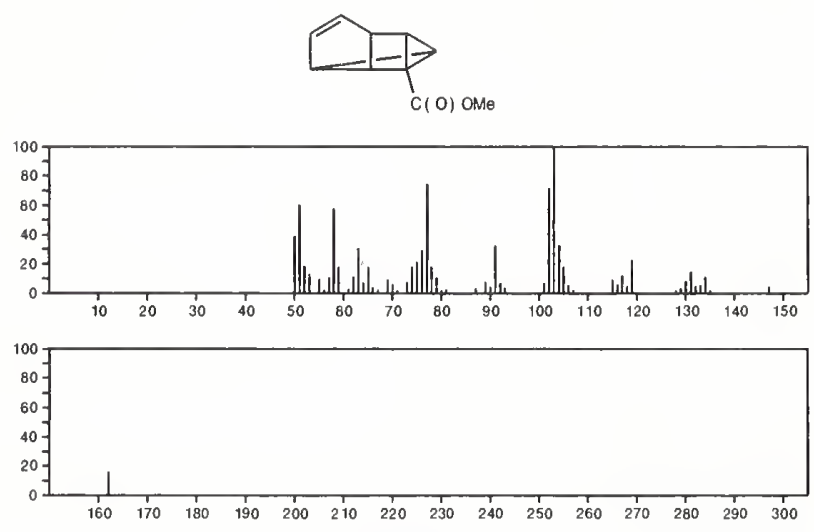

162

Benzeneacetic acid, ar-ethenyl-

$\mathrm{C}_{10} \mathrm{H}_{10} \mathrm{O}_{2}$

$37570-14-2$
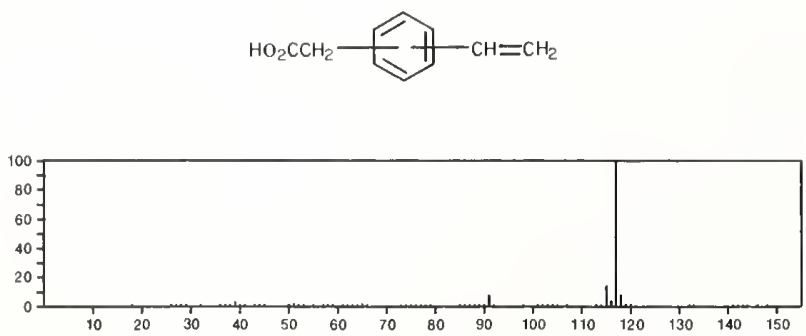

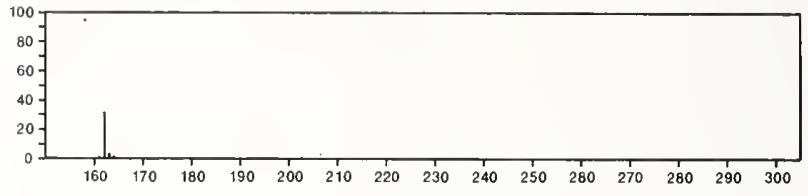

162

$\mathrm{C}_{10} \mathrm{H}_{10} \mathrm{O}_{2}$

Benzaldehyde, 4-(2-propenyloxy)-

$40663-68-1$
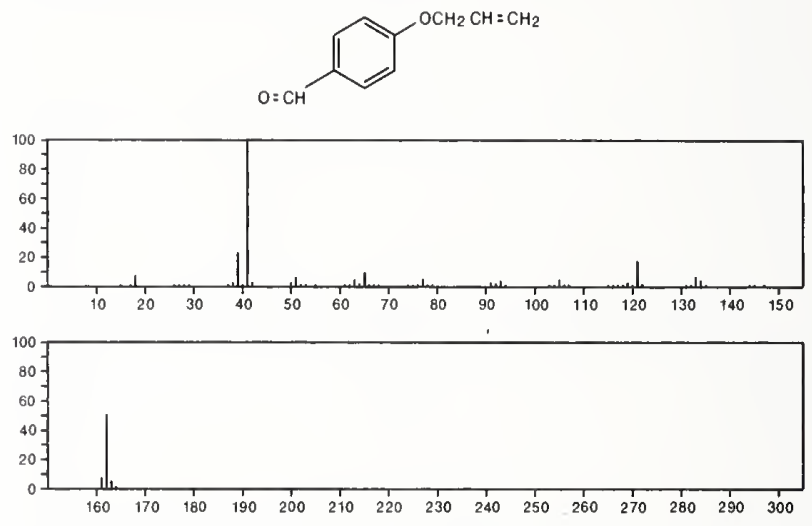

162

$\mathrm{C}_{10} \mathrm{H}_{10} \mathrm{O}_{2}$

$54365-75-2$

5-Benzofurancarboxaldehyde, 2,3-dihydro-2-methyl-
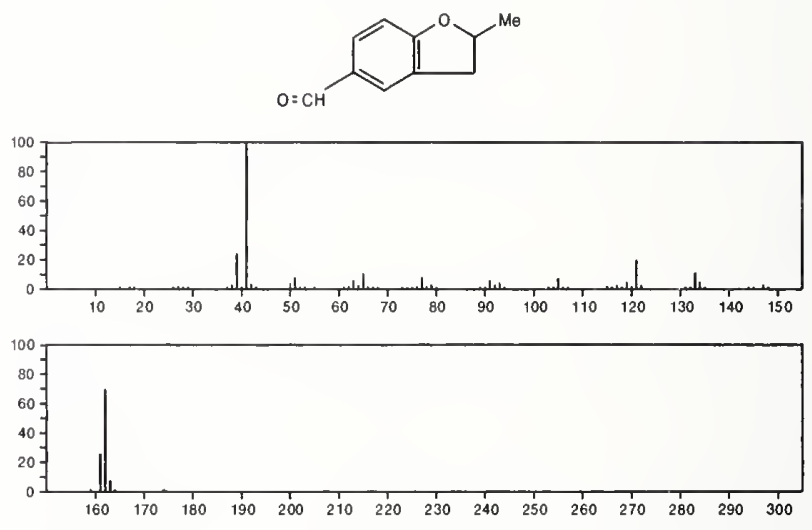

$162 \quad \mathrm{C}_{10} \mathrm{H}_{10} \mathrm{O}_{2}$

3(2H)-Benzofuranone, 2,4-dimethyl-

$54365-76-3$
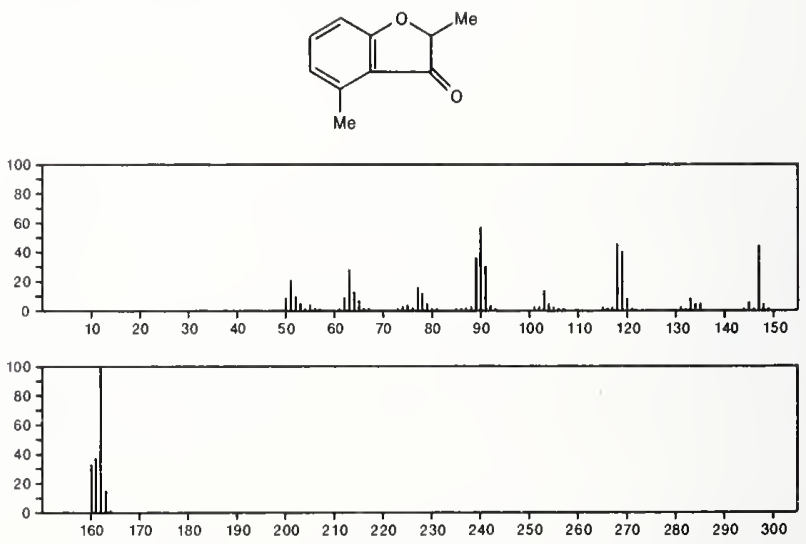
162

$3(2 \mathrm{H})-\mathrm{C}_{10} \mathrm{H}_{10} \mathrm{O}_{2}$
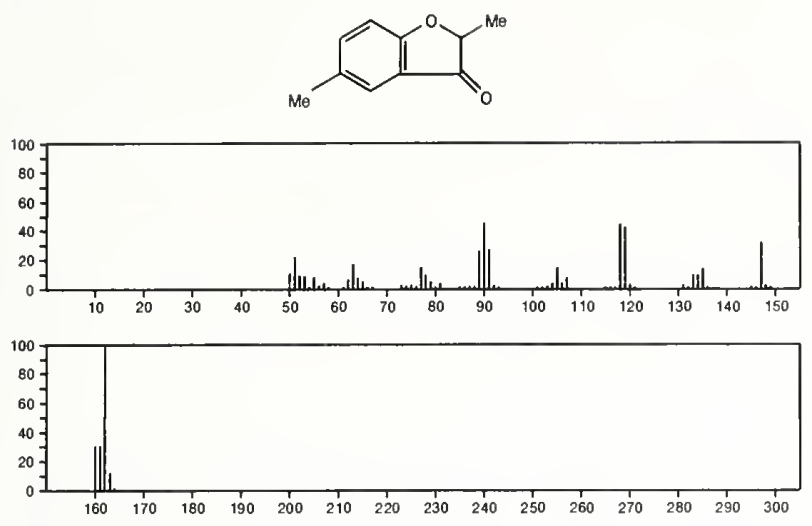

162

$3(2 \mathrm{H})$-Benzofuranone, 2,6-dimeth
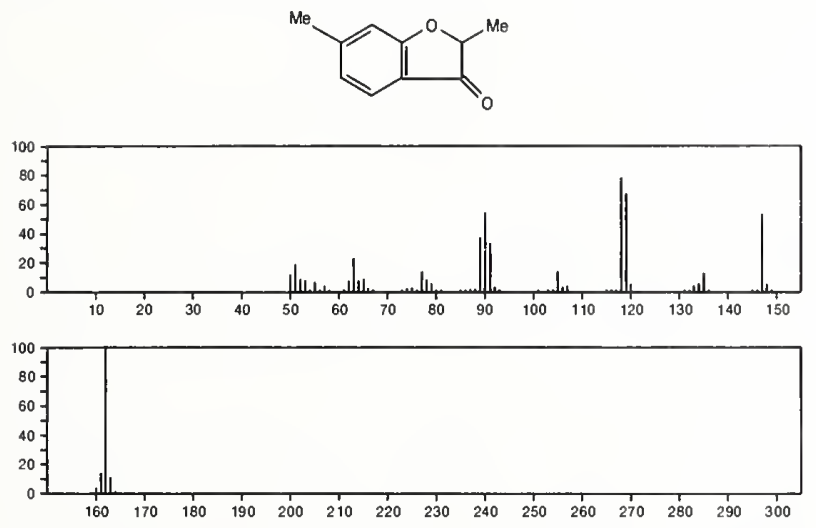

$162 \quad \mathrm{C}_{10} \mathrm{H}_{10} \mathrm{O}_{2}$

3(2H)-Benzofuranone, 2,7-dimethyl-
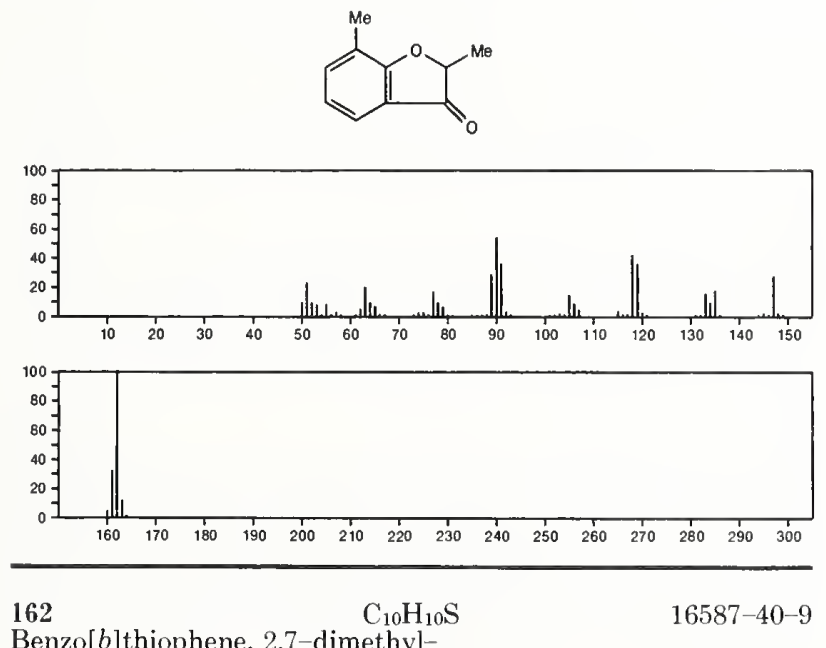

Benzo[ $b]$ thiophene, 2,7-dimethyl-
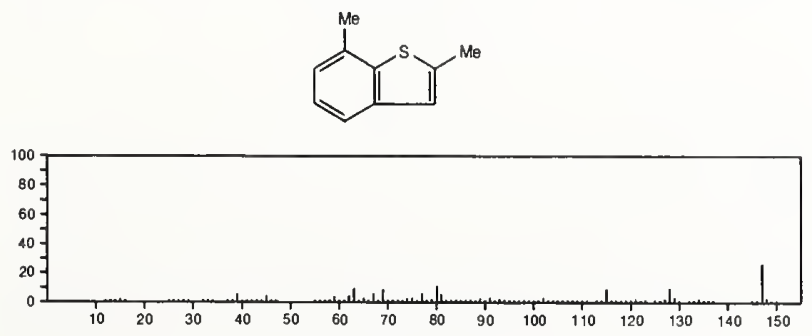
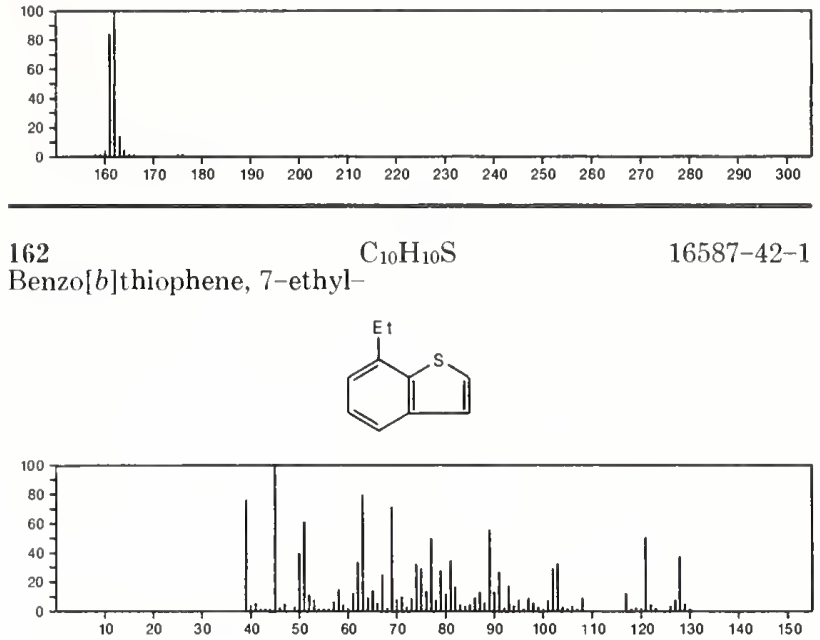

162

$\mathrm{C}_{10} \mathrm{H}_{10} \mathrm{~S}$

Benzo $[b]$ thiophene, 2,5-dimethyl-

$16587-48-7$
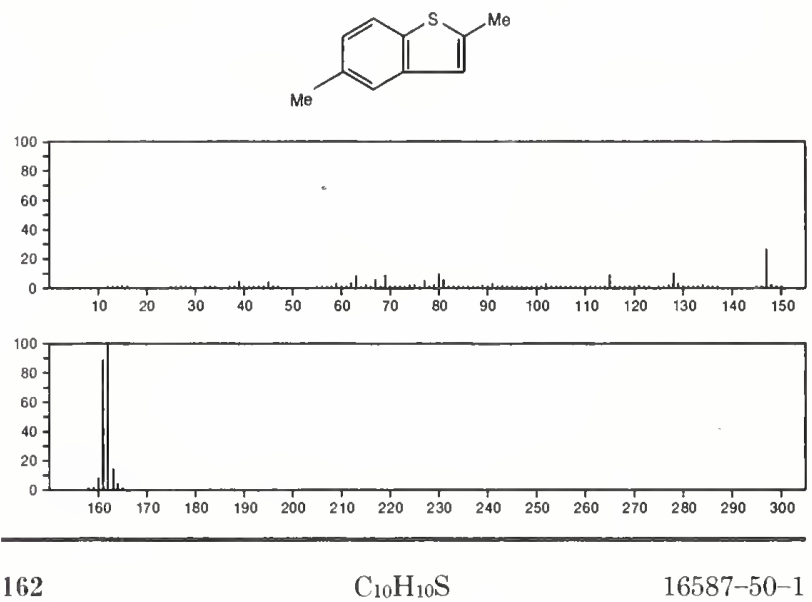

Benzo[ $b]$ thiophene, 3,6-dimethyl-

$16587-50-1$
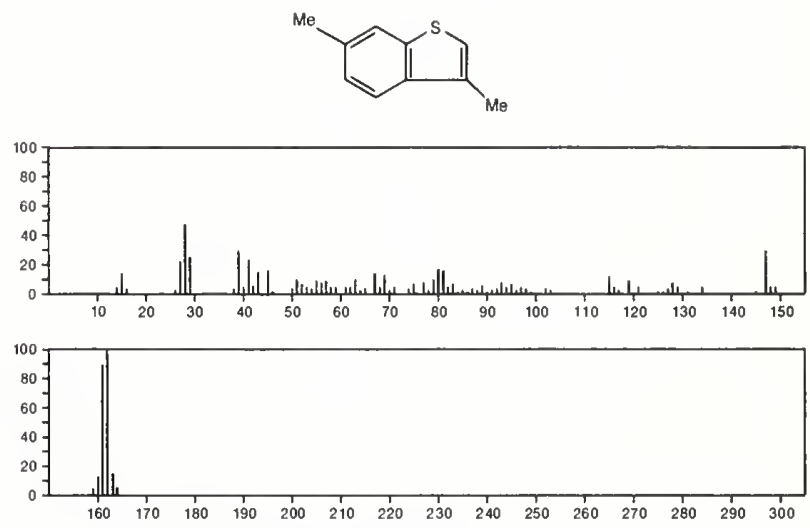

$\begin{array}{ll}162 & \mathrm{C}_{10} \mathrm{H}_{10} \mathrm{~S} \\ \text { Benzo[b]thiophene, ethyl- } & 54385-63-6\end{array}$
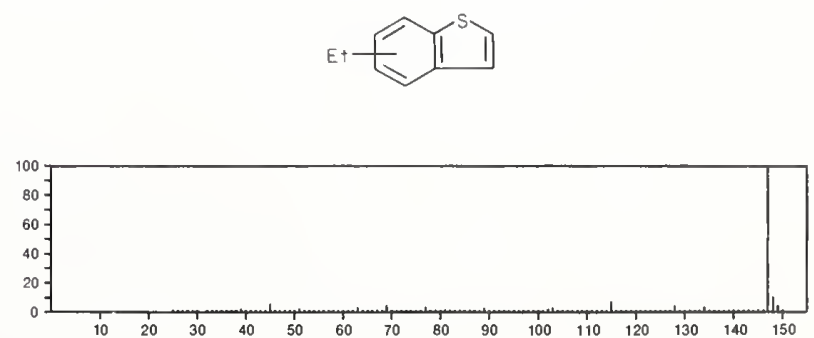

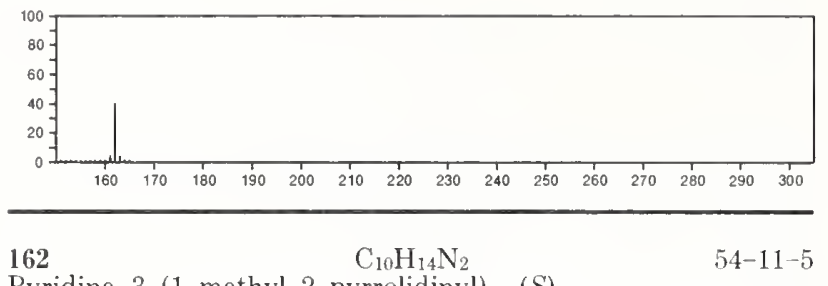

Pyridine, 3-(1-methyl-2-pyrrolidinyl)-, $(S)-$
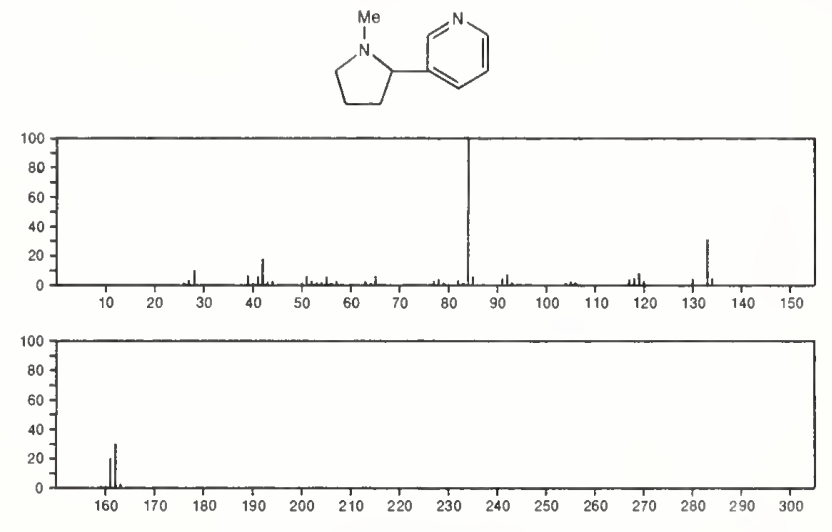

$162 \quad \mathrm{C}_{10} \mathrm{H}_{14} \mathrm{~N}_{2} \quad 494-52-0$

Pyridine, 3-(2-piperidinyl)-, $(S)-$
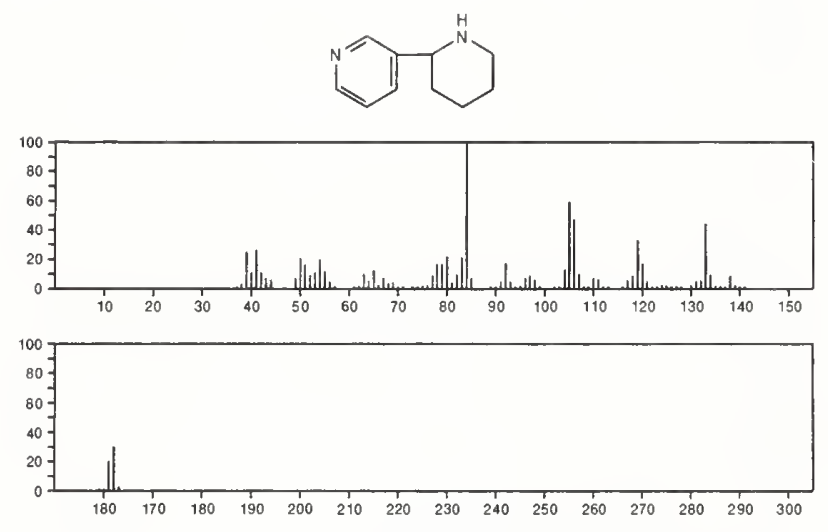

162

$\mathrm{C}_{10} \mathrm{H}_{14} \mathrm{~N}_{2}$

Methanimidamide, $N, N$-dimethyl- $N^{\prime}-(3-$ methylphenyl)
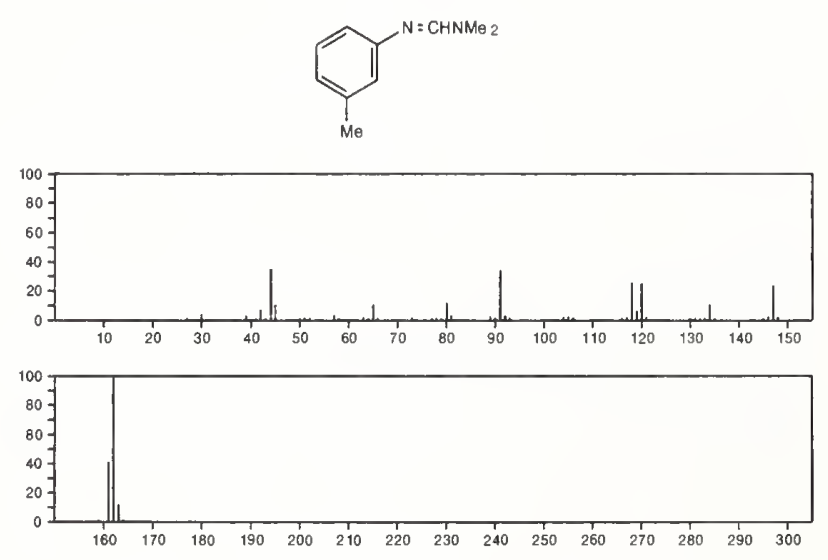

162

$\mathrm{C}_{10} \mathrm{H}_{14} \mathrm{~N}_{2}$

$7549-96-4$ Methanimidamide, $N, N$-dimethyl-N'-(4-methylphenyl)-
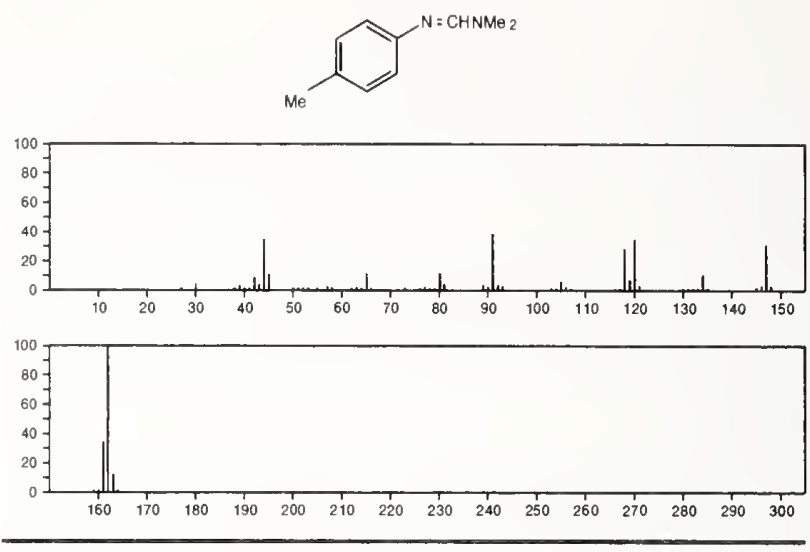

162

$\mathrm{C}_{10} \mathrm{H}_{14} \mathrm{~N}_{2}$

$16738-89-9$

1,1-Cyclopropanedicarbonitrile, 2-butyl-2-methyl-
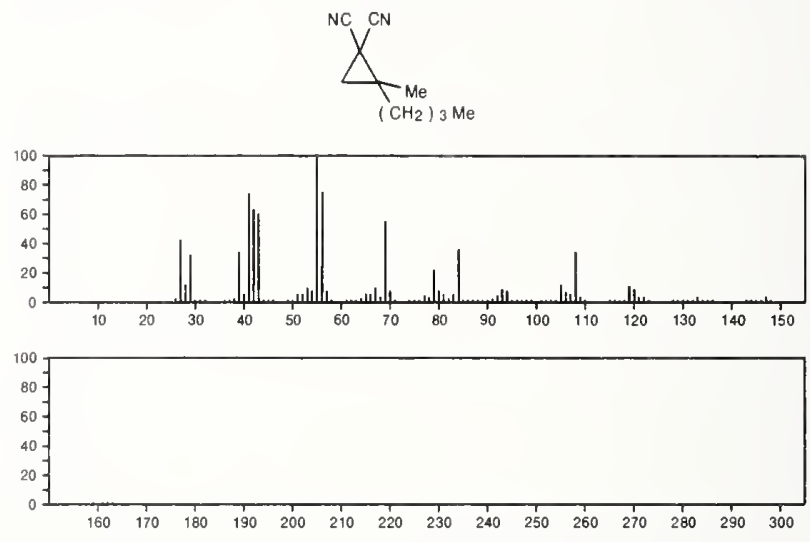

162

Ethanone, 1-[4-(1-methylethyl)phenyl]-

645-13-6
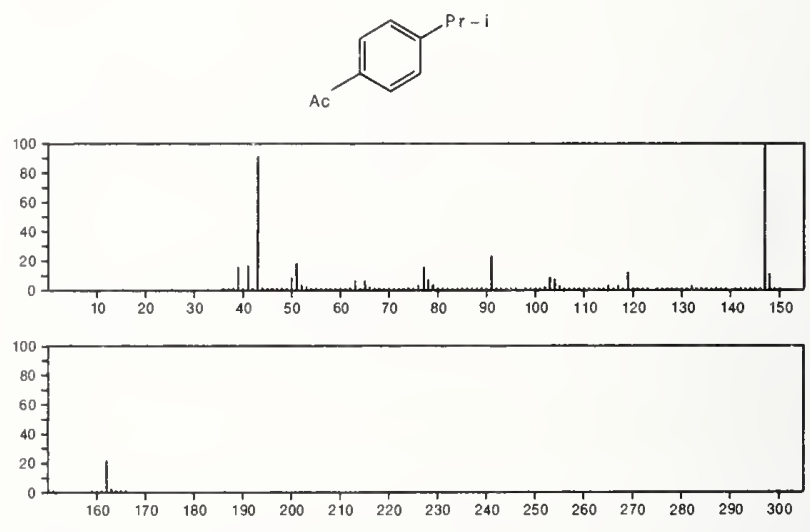

162

$\mathrm{C}_{11} \mathrm{H}_{14} \mathrm{O}$

1008-19-1

Naphthalene, 1,2,3,4-tetrahydro-5-methoxy-
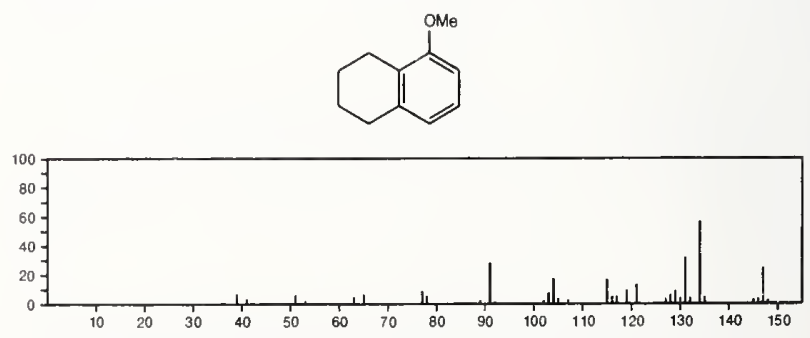

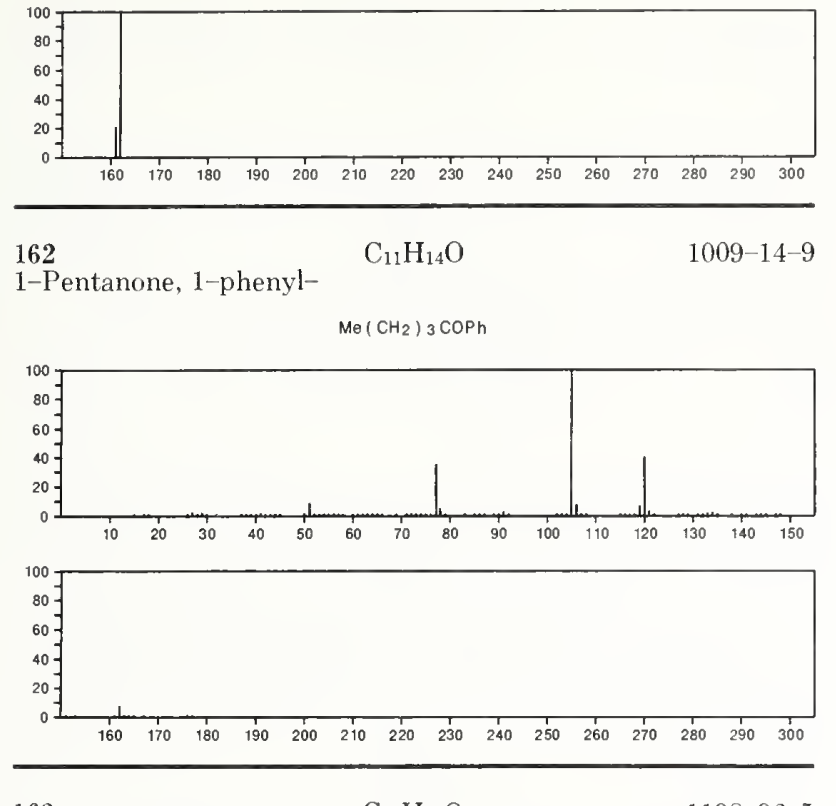

162
Chroman, 2,2-dimethyl-

$\mathrm{C}_{11} \mathrm{H}_{14} \mathrm{O}$

$1198-96-5$
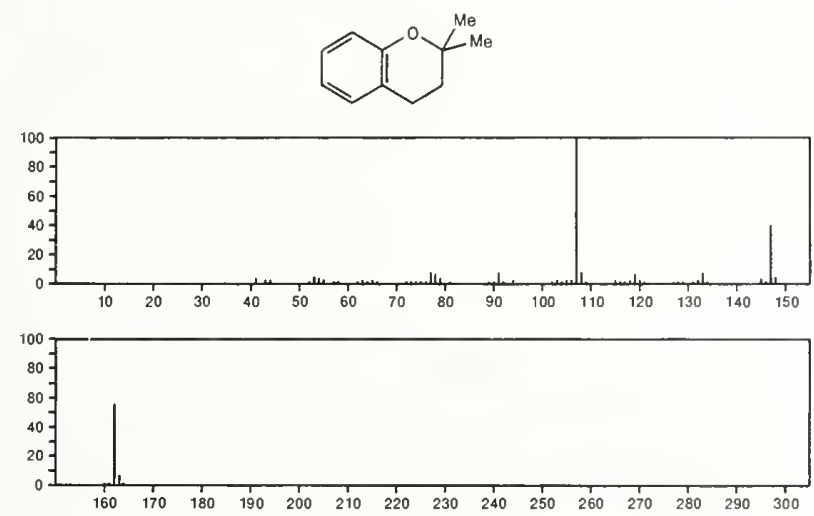

162

$\mathrm{C}_{11} \mathrm{H}_{14} \mathrm{O}$

Benzene, (3-ethoxy-1-propenyl)-

1476-07-9

$\mathrm{E} t \mathrm{OCH}_{2} \mathrm{CH}=\mathrm{CHPh}$
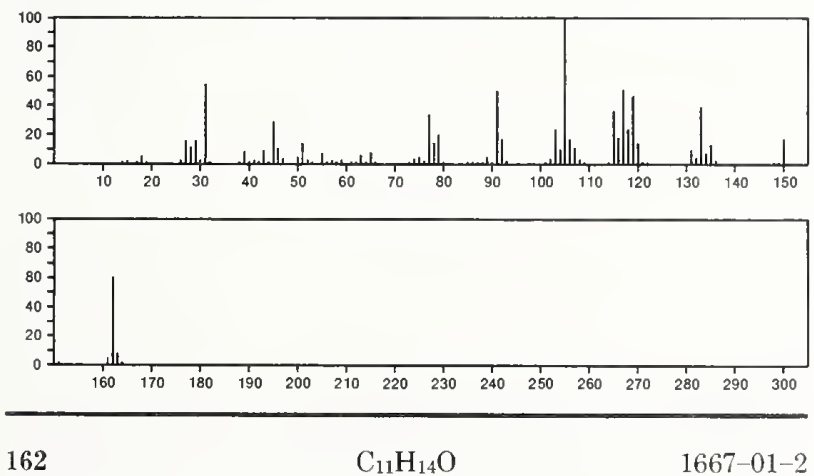

Ethanone, 1-(2,4,6-trimethylphenyl)-
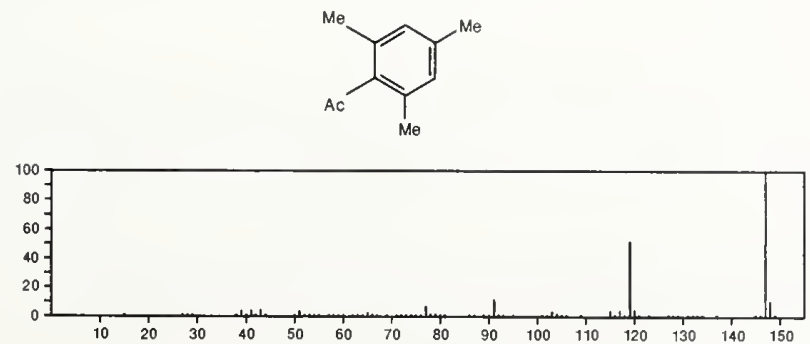

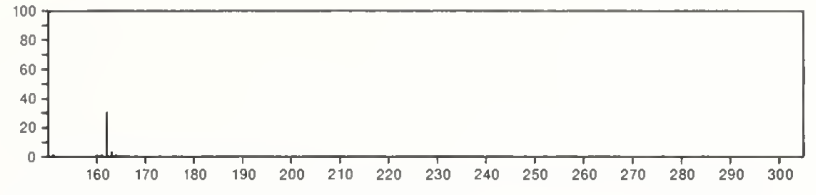

$162 \quad \mathrm{C}_{11} \mathrm{H}_{14} \mathrm{O} \quad 1730-48-9$

Naphthalene, 1,2,3,4 tetrahydro-6-methoxy-
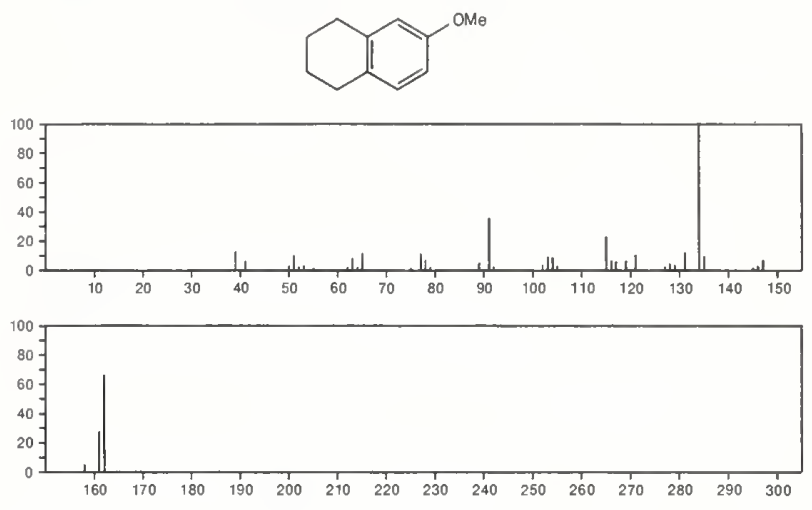

162
$2-$ Pentanone, 5-phenyl-

$2235-83-8$

$\mathrm{Me} \mathrm{CO}\left(\mathrm{CH}_{2}\right)_{3} \mathrm{Ph}$
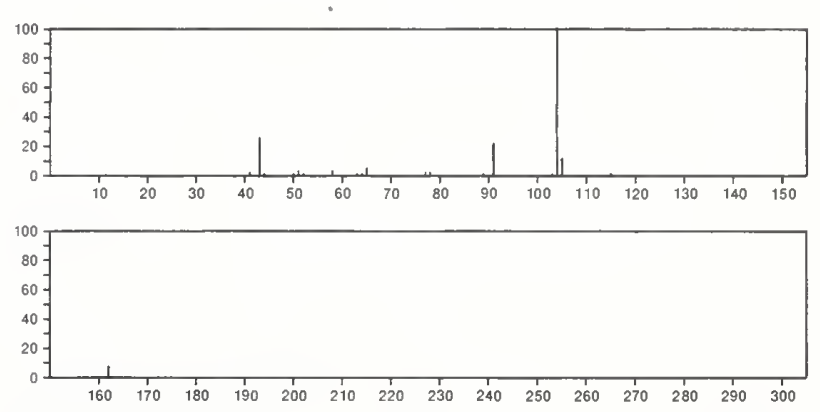

162

2-Butanome, 3-methyl-1-phenyl-

$2893-05-2$

$\mathrm{Me}_{2} \mathrm{CHCOCH}_{2} \mathrm{Ph}$
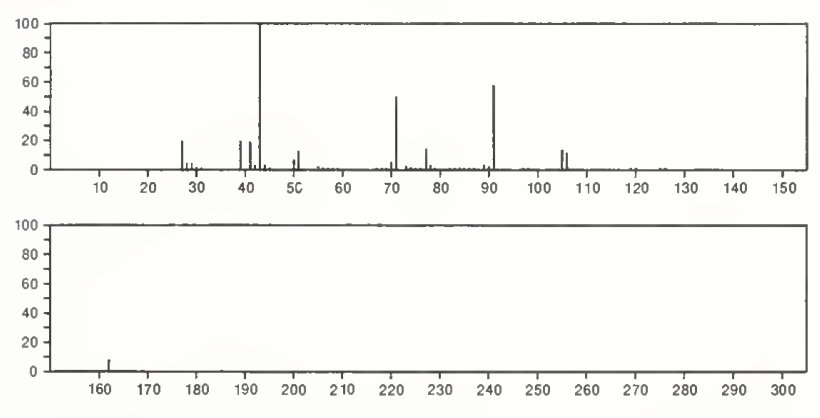

$162 \quad \mathrm{C}_{11} \mathrm{H}_{14} \mathrm{O}$

$3344-45-4$

1-Naphthalenol, 1,2,3,4-tetrahydro-3-methyl-
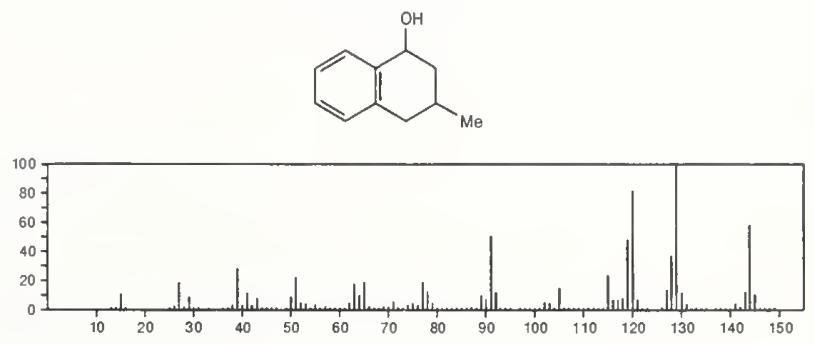


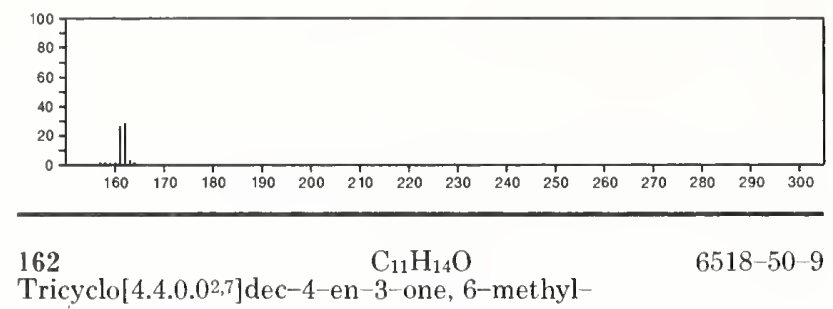

Tricyclo[4,4.0.02,7] dec-4-en-3-one, 6-methyl-
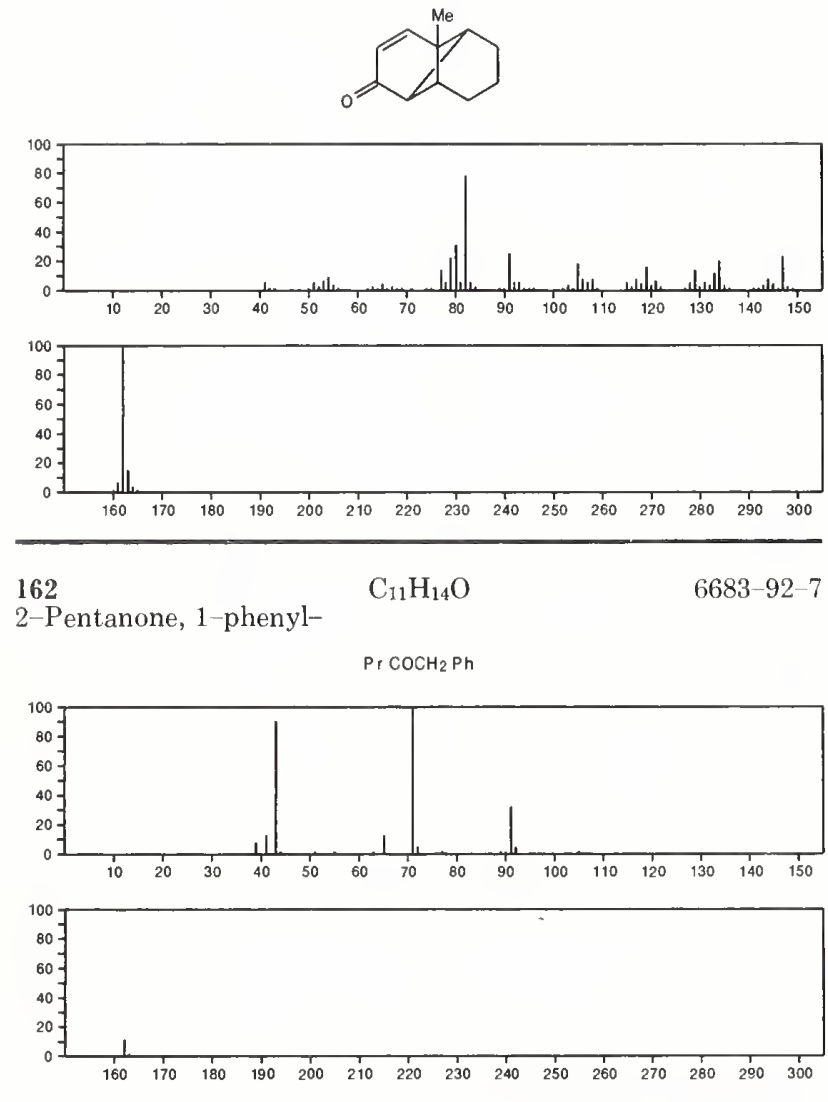

$162 \quad \mathrm{C}_{11} \mathrm{H}_{14} \mathrm{O}$

Benzene, [(3-methyl-2-butenyl)oxy]-

$14309-15-0$

$\mathrm{PhOCH}_{2} \mathrm{CH}=\mathrm{CMe}_{2}$
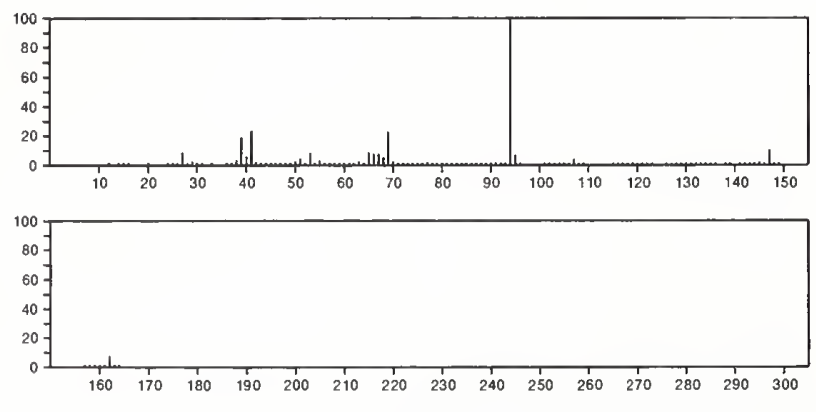

$162 \quad \mathrm{C}_{11} \mathrm{H}_{14} \mathrm{O} \quad 17429-21-9$

2(1H)-Naphthalenone, 4a,5,8,8a-tetrahydro-4a-methyl-, trans-
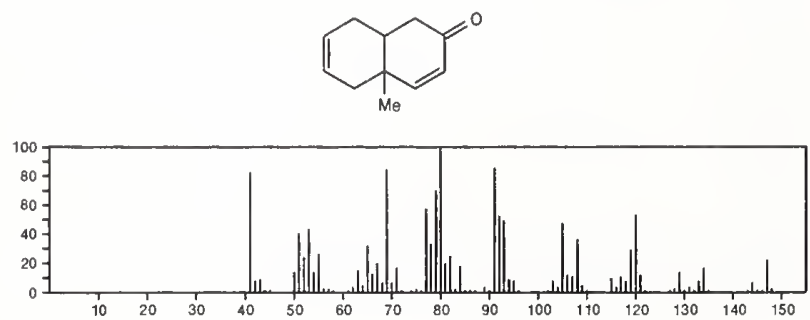

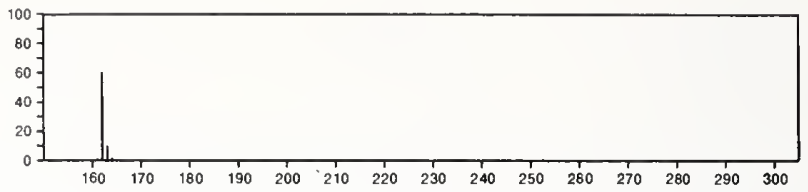

$162 \quad \mathrm{C}_{11} \mathrm{H}_{14} \mathrm{O} \quad 22610-79-3$

2-Cyclopenten-1-one, 3-methyl-2-(2,4-pentadienyl)--, (Z)-
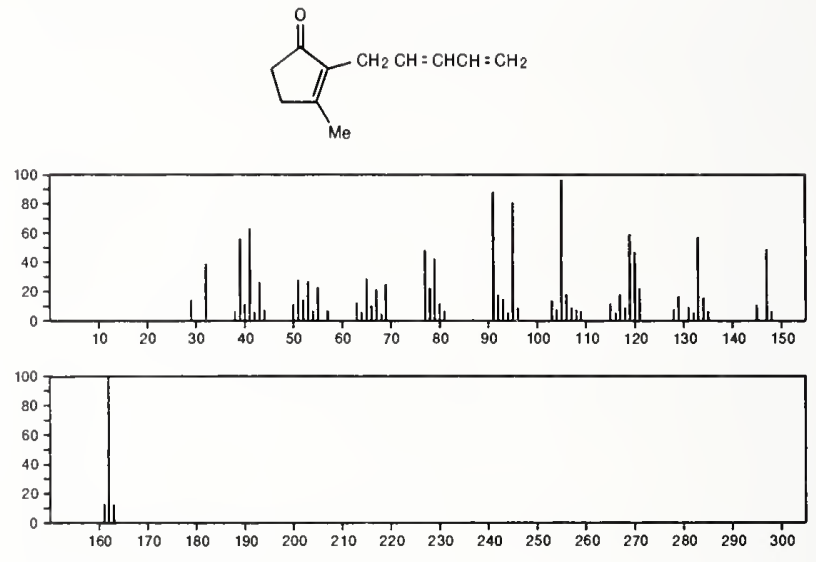

$162 \quad \mathrm{C}_{11} \mathrm{H}_{14} \mathrm{O} \quad 22610-80-6$

2-Cyclopenten-1-one, 3-methyl-2-(1,3-pentadienyl)-, $(E, Z)$ -
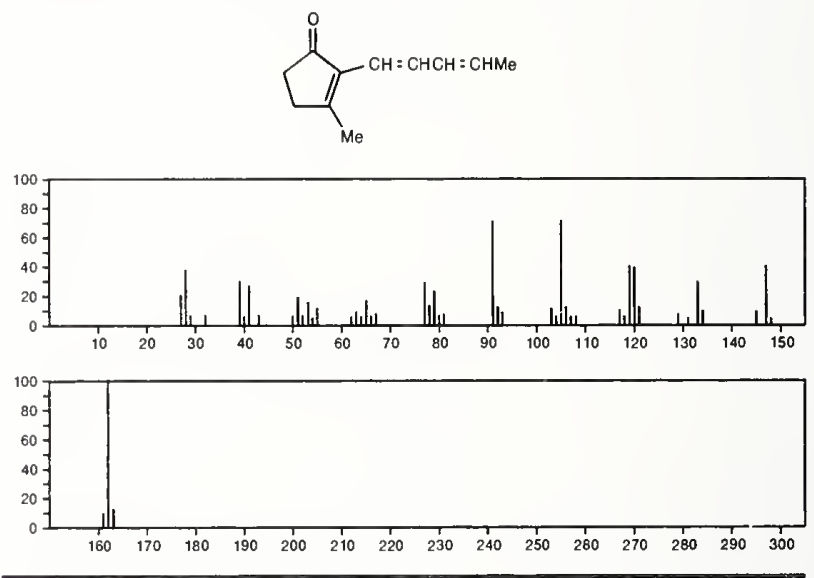

$162 \quad \mathrm{C}_{11} \mathrm{H}_{14} \mathrm{O}$

1-Naphthol, 1,2,3,4-tetrahydro-2-methyl-

$32281-70-2$
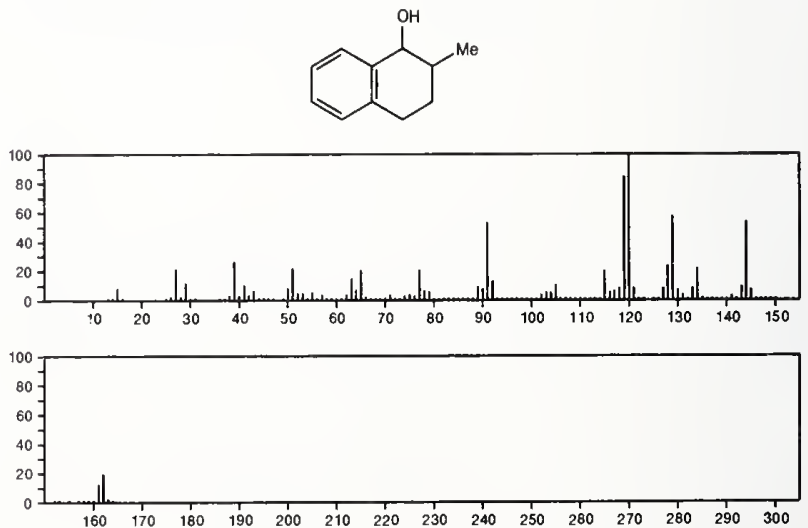
162

$\mathrm{C}_{11} \mathrm{H}_{14} \mathrm{O}$

36884-28-3

Benzenepentanal

$\mathrm{Ph}\left(\mathrm{CH}_{2}\right)_{4} \mathrm{CHO}$
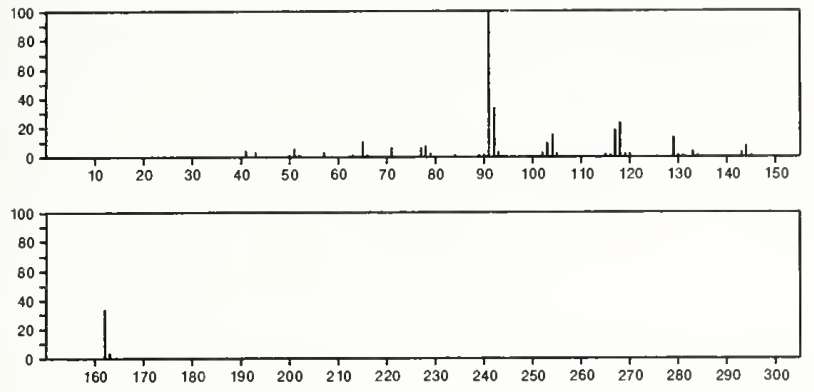

162

$\mathrm{C}_{11} \mathrm{H}_{14} \mathrm{O}$

38393-92-9

$1 H$-Inden-1-ol, 2,3-dihydro-3,3-dimethyl-
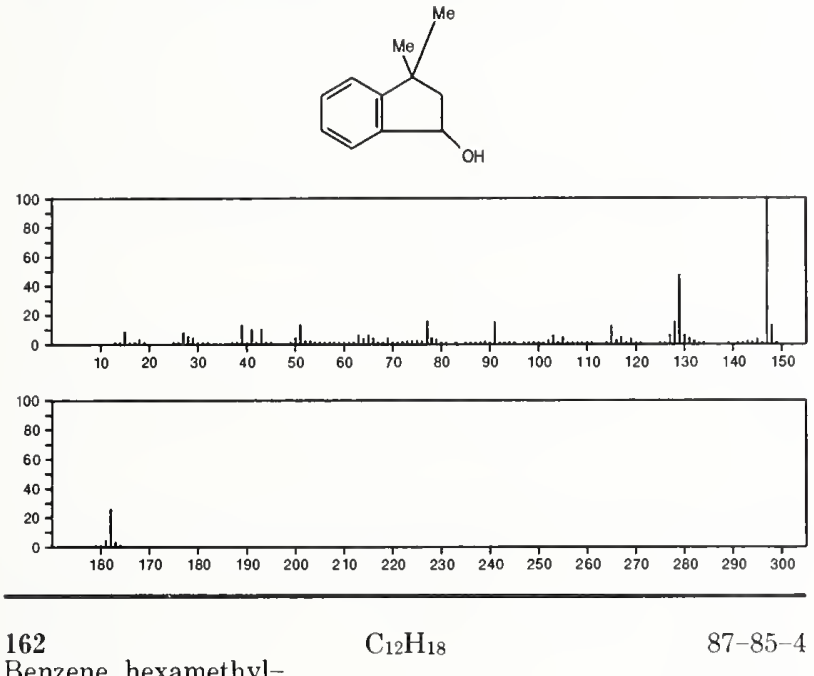

Benzene, hexamethyl-
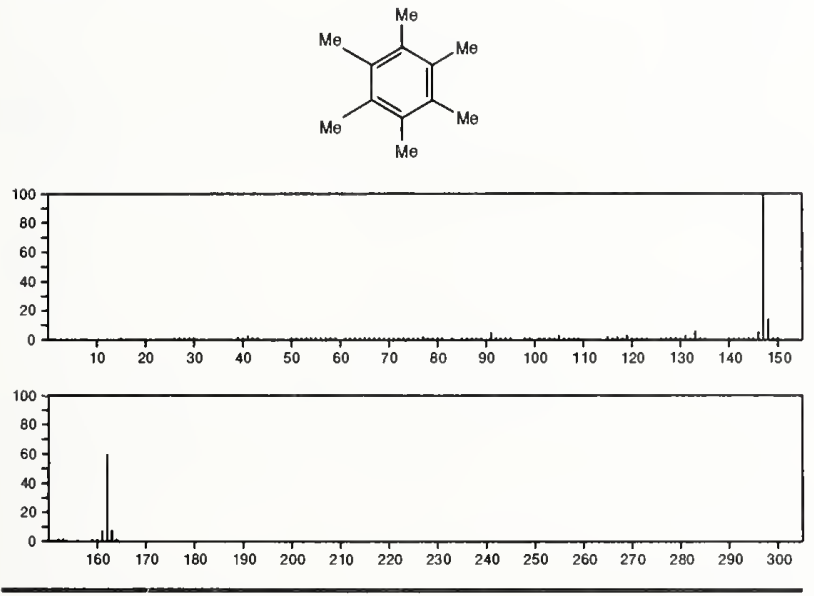

162

$\mathrm{C}_{12} \mathrm{H}_{18}$

Benzene, 1-(1,1-dimethylethyl)-3,5-dimethyl-

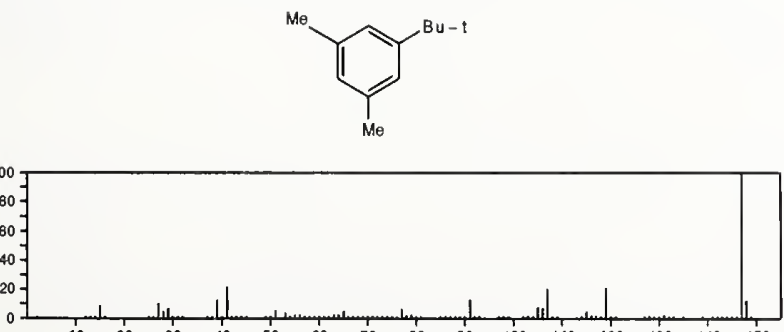

98-19-1

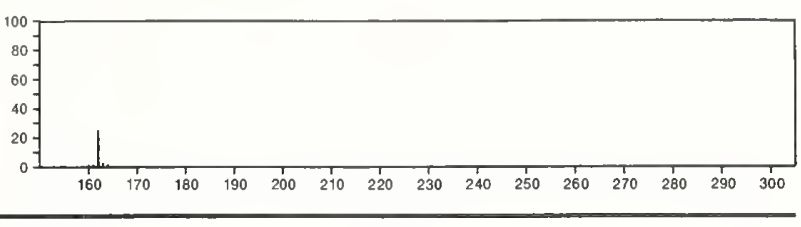

162

Benzene, 1,3-bis(1-methylethyl)-

$99-62-7$
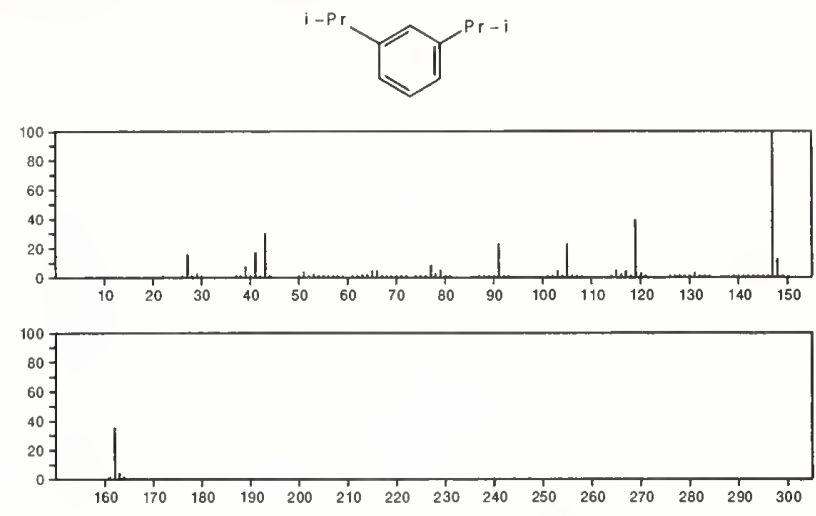

162

$\mathrm{C}_{12} \mathrm{H}_{18}$

$100-18-5$

Benzene, 1,4-bis(1-methylethyl)-
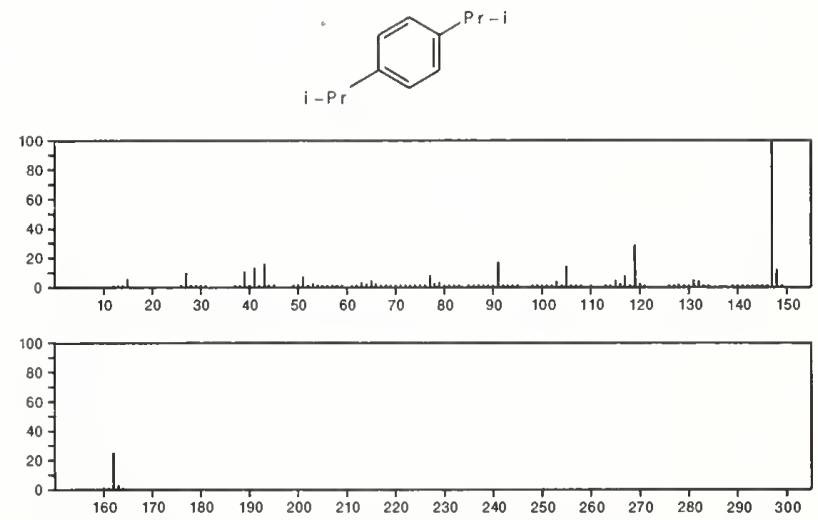

162

$\mathrm{C}_{12} \mathrm{H}_{18}$

102-25-0

Benzene, 1,3,5-triethyl
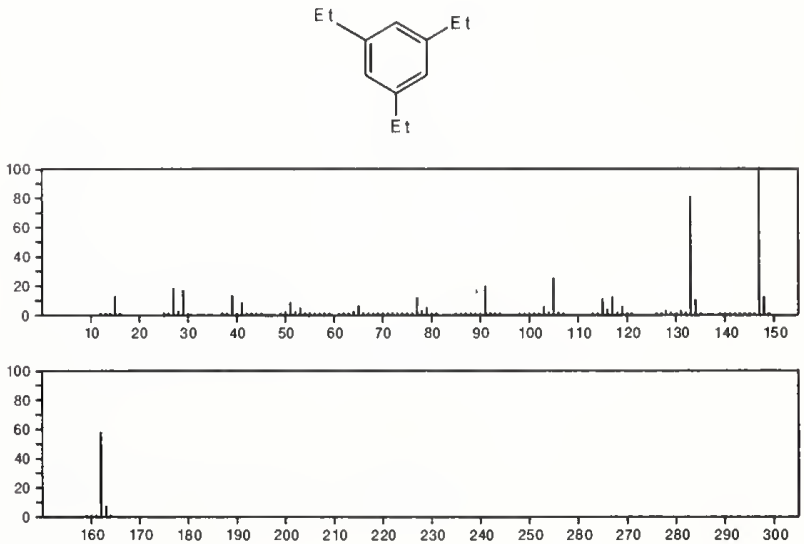
162

Benzene, 1,2-bis(1-methylethyl)

$\mathrm{C}_{12} \mathrm{H}_{18}$

$\overbrace{}^{p r-i}$
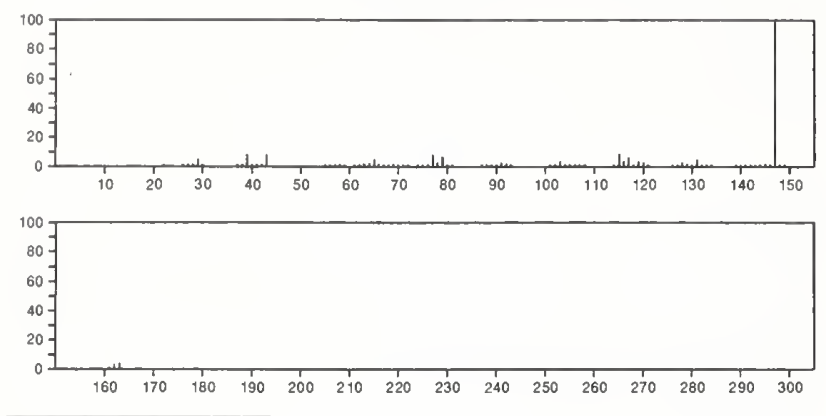

162

1,5,9-Cyclododecatriene, $(E, E, E)-$

$676-22-2$
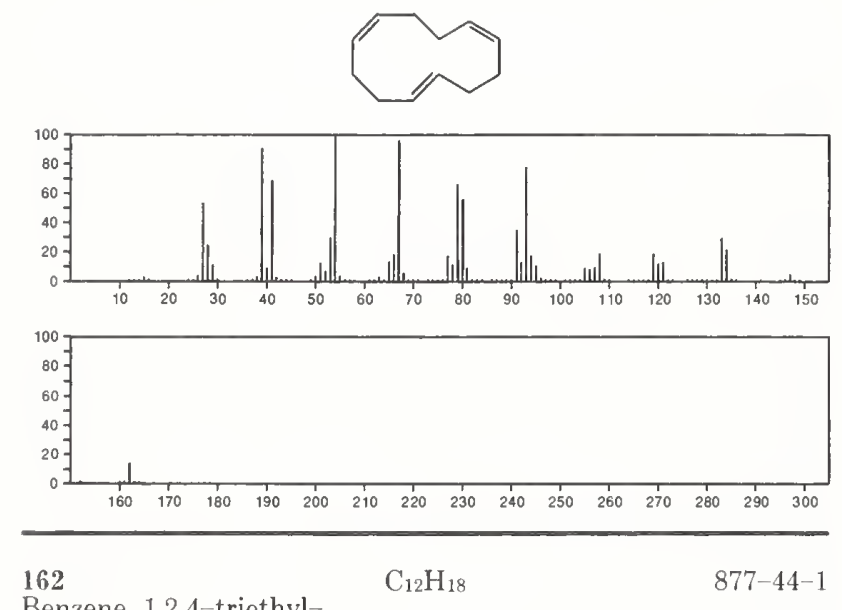

Benzene, 1,2,4-triethyl-
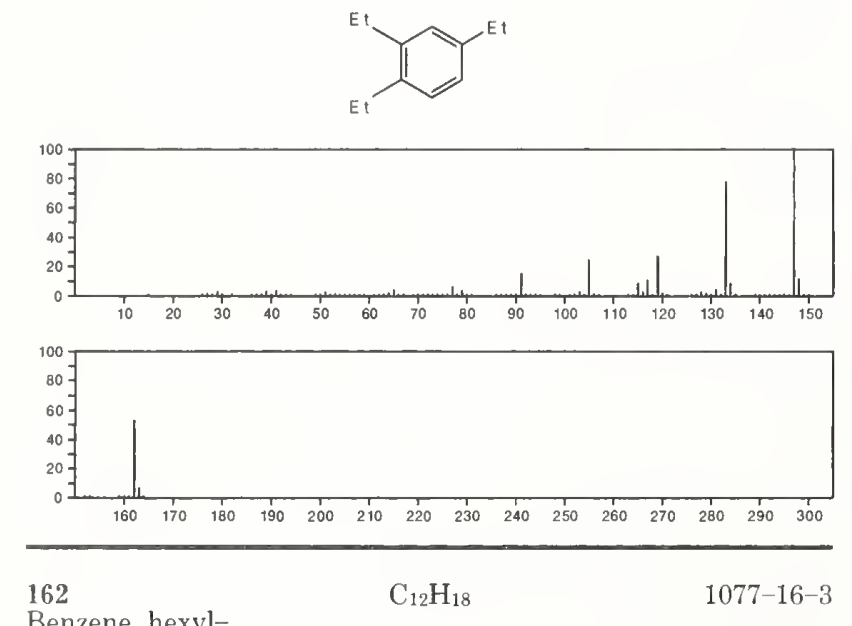

Benzene, hexyl-

$\mathrm{Ph}\left\{\mathrm{CH}_{2}\right) 5 \mathrm{Me}$

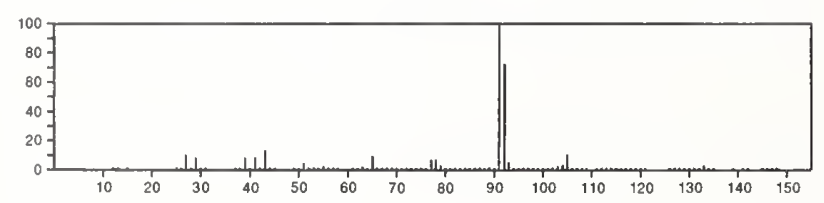

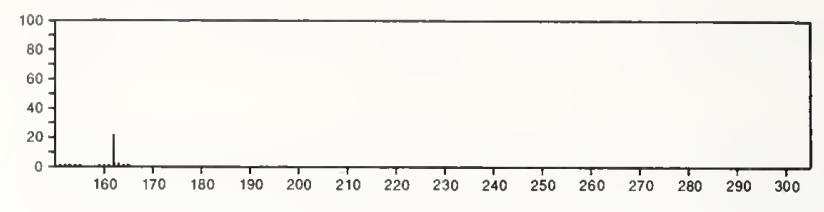

162

$$
\mathrm{C}_{12} \mathrm{H}_{18}
$$

$1483-60-9$

Benzene, 2,4-dimethyl-1-(1-methylpropyl)-
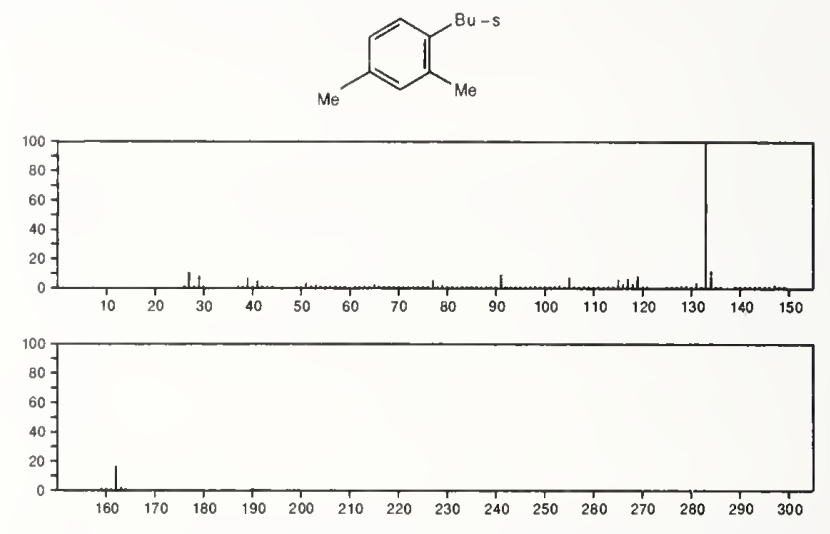

162

Bi-2-cyclohexen-1-yl

$\mathrm{C}_{12} \mathrm{H}_{18}$

1541-20-4
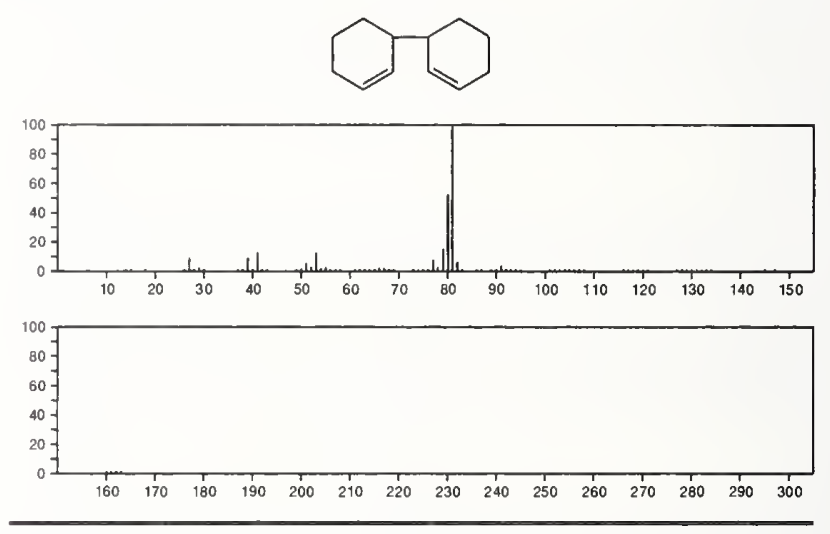

162

Benzene, (1,1-dimethylbutyl)-

$\mathrm{C}_{12} \mathrm{H}_{18}$

$1985-57-5$

$\operatorname{PhCP} r(P h)$
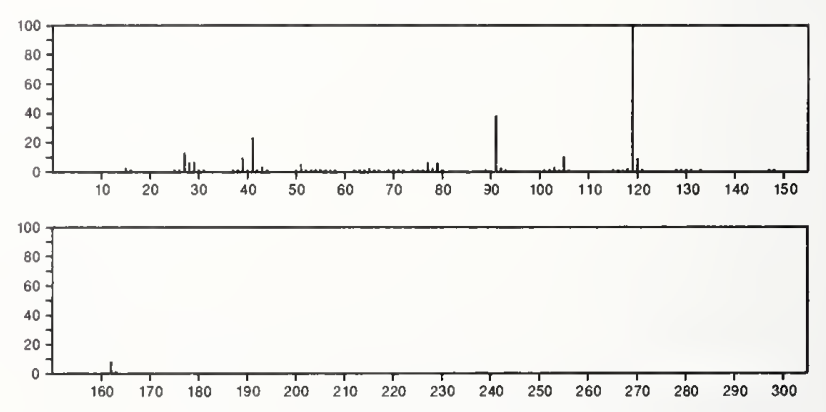

162

$\mathrm{C}_{12} \mathrm{H}_{18}$

Benzene, (1-ethyl-1-methylpropyl)-

$1985-97-3$

$P h C E t_{2}(P h)$

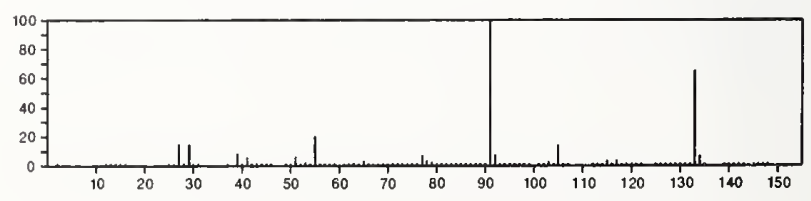




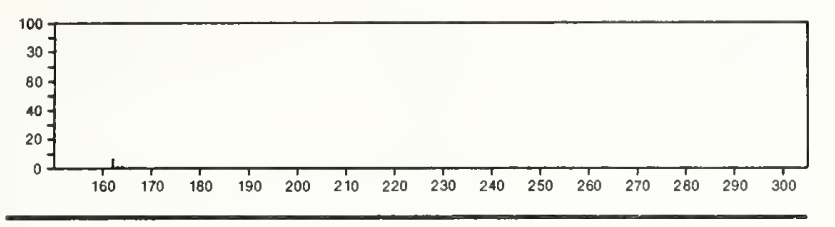

$162 \quad \mathrm{C}_{12} \mathrm{H}_{18} \quad 4468-42-2$

Benzene, (1-ethylbutyl)-

$\operatorname{PhCHPr}(\mathrm{Ph})$
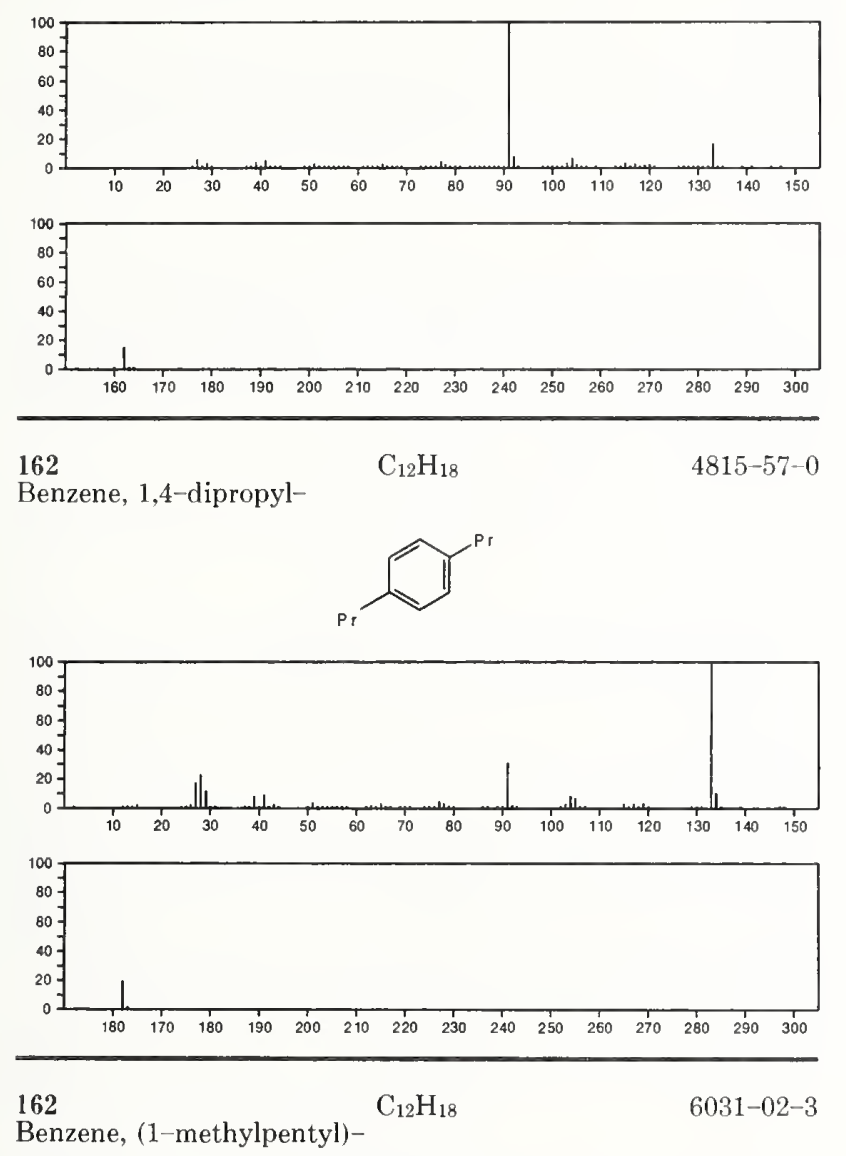

$\mathrm{PhCHMe}\left(\mathrm{CH}_{2}\right)_{3} \mathrm{Me}$
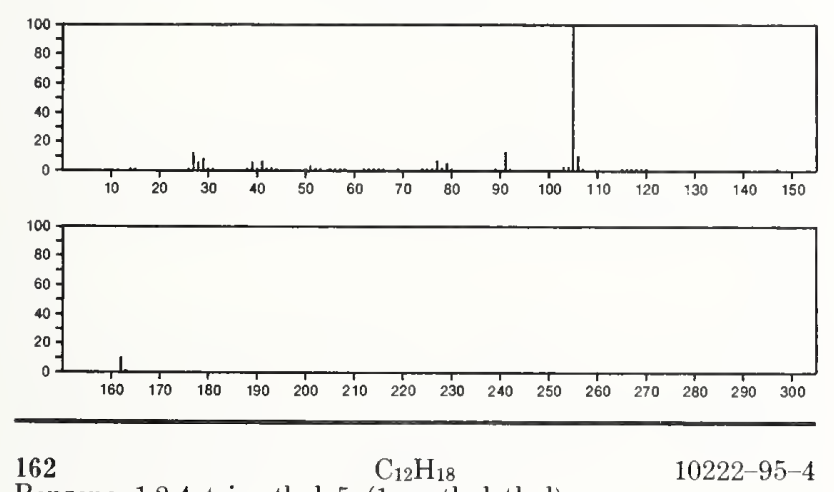

Benzene, 1,2,4-trimethyl-5-(1-methylethyl)-
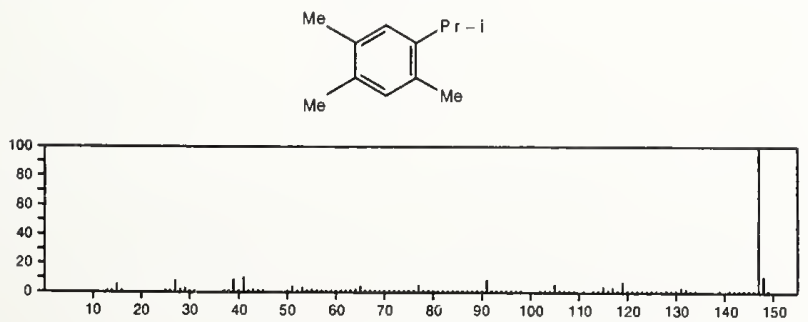

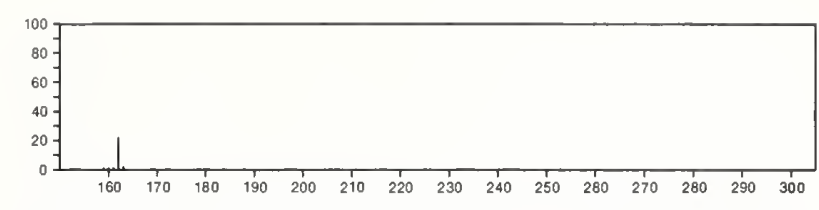

162

Benzene, (3,3-dimethylbutyl)-

$$
\mathrm{C}_{12} \mathrm{H}_{18}
$$

$17314-92-0$

$\mathrm{Me}{ }_{3} \mathrm{CCH}_{2} \mathrm{CH}_{2} \mathrm{Ph}$
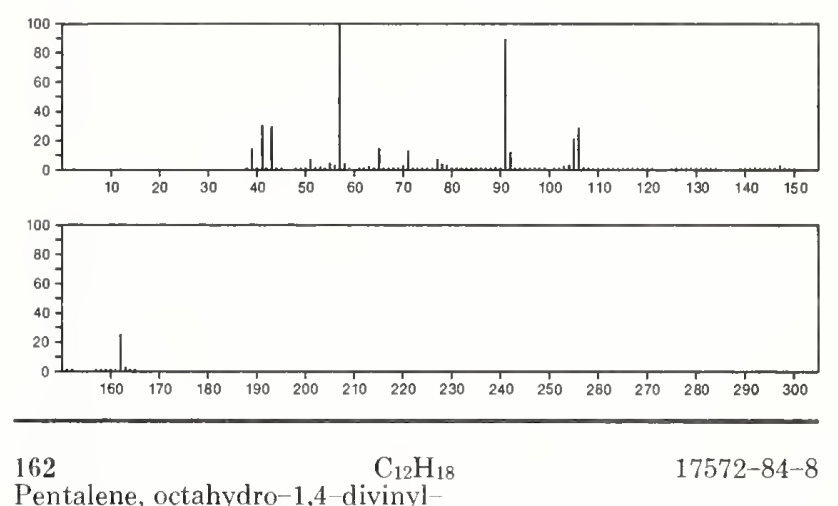

Pentalene, octahydro-1,4-divinyl-

$17572-84-8$
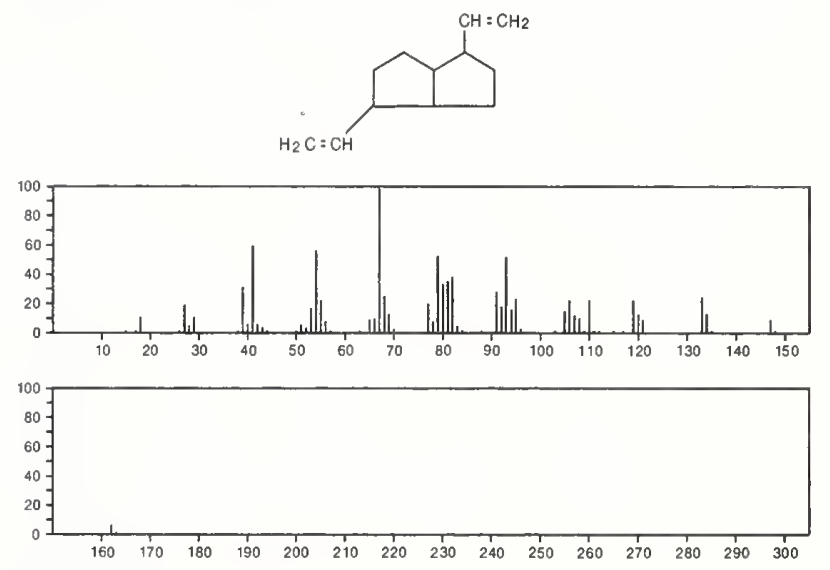

162

Benzene, (2-ethylbutyl)-

$\mathrm{C}_{12} \mathrm{H}_{18}$

$19219-85-3$

$\mathrm{Et} \mathrm{CHCH}_{2} \mathrm{Ph}$
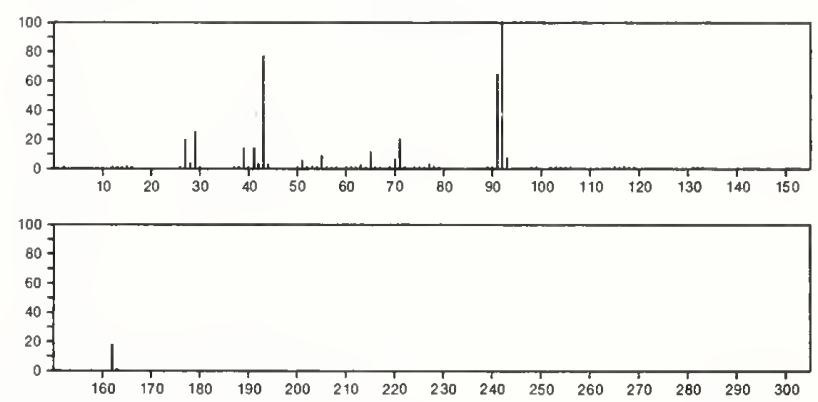

162

Benzene, (1,2,2-trimethylpropyl)-

$19262-20-5$

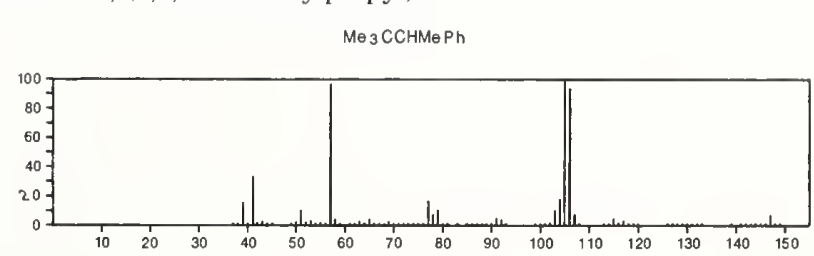



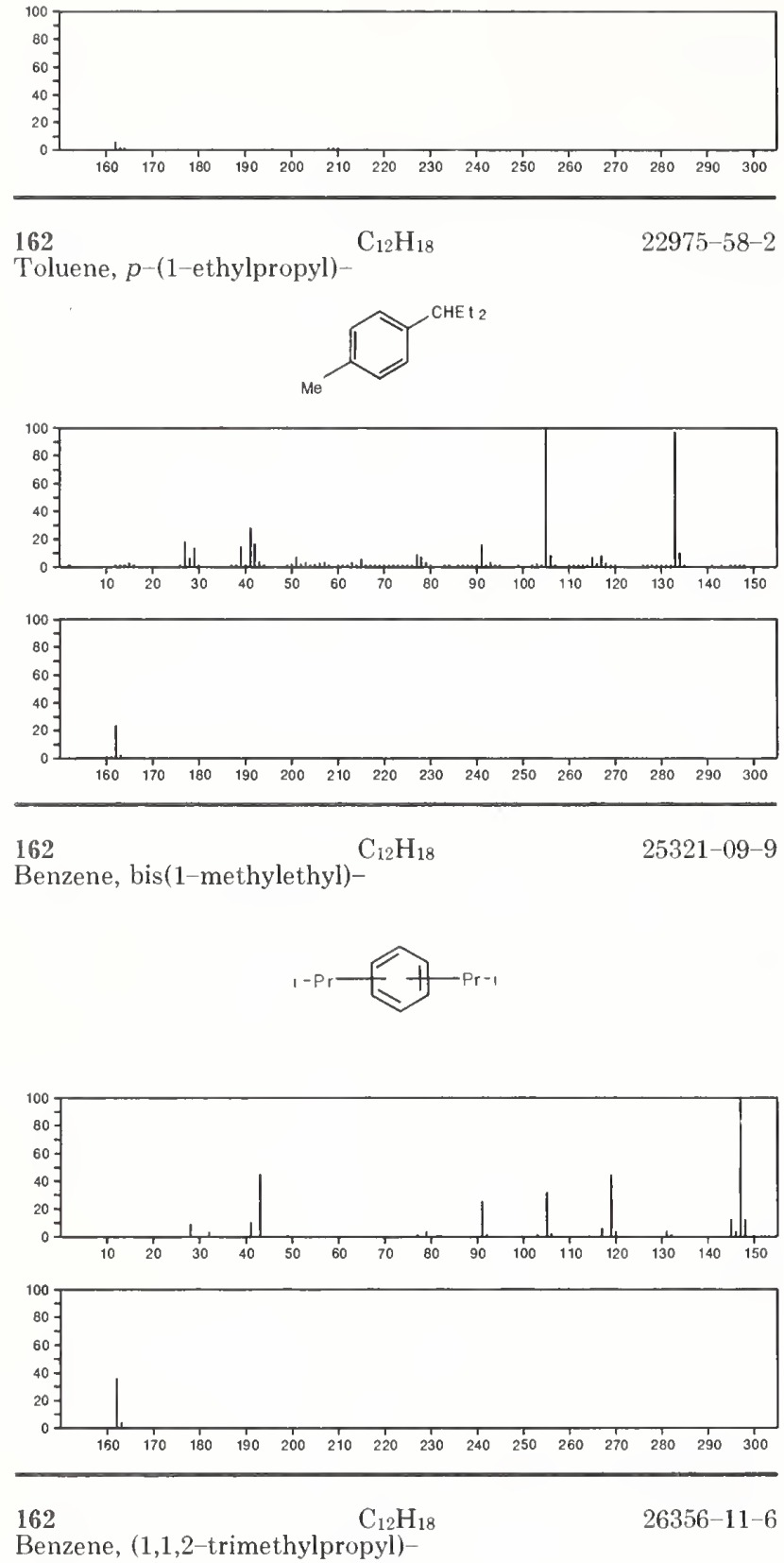

Benzene, (1,1,2-trimethylpropyl)-

$\mathrm{Me}_{2} \mathrm{CHCMe}_{2} \mathrm{Ph}$
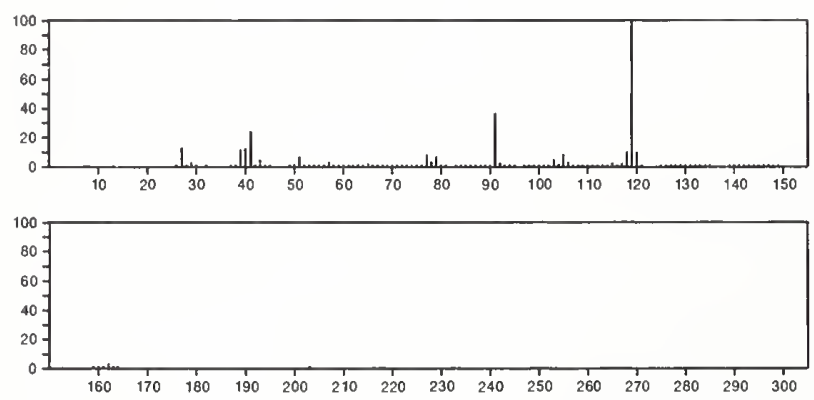

162

Cyclododecatriene

$\mathrm{C}_{12} \mathrm{H}_{18}$

$27070-59-3$
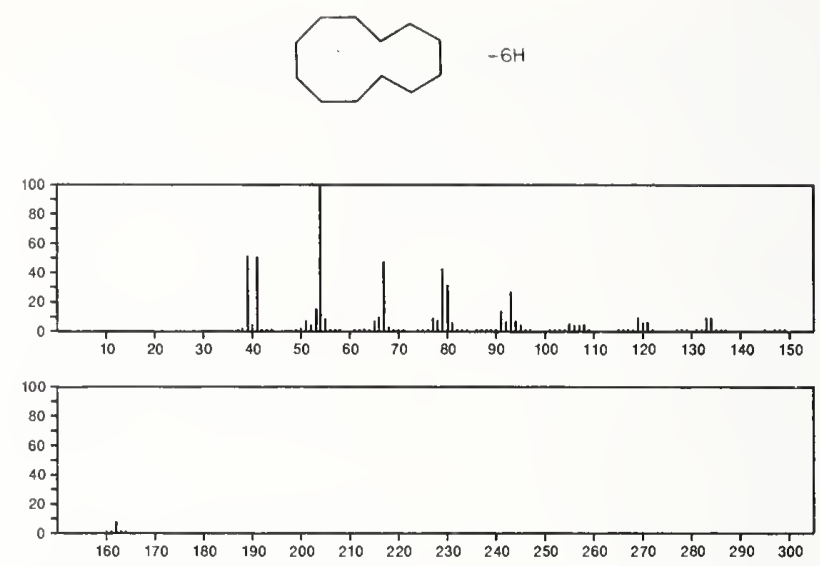

$162 \quad \mathrm{C}_{12} \mathrm{H}_{18}$

$28080-86-6$

$\mathrm{Et}_{\mathrm{CM}} \mathrm{CH}_{2} \mathrm{Ph}$
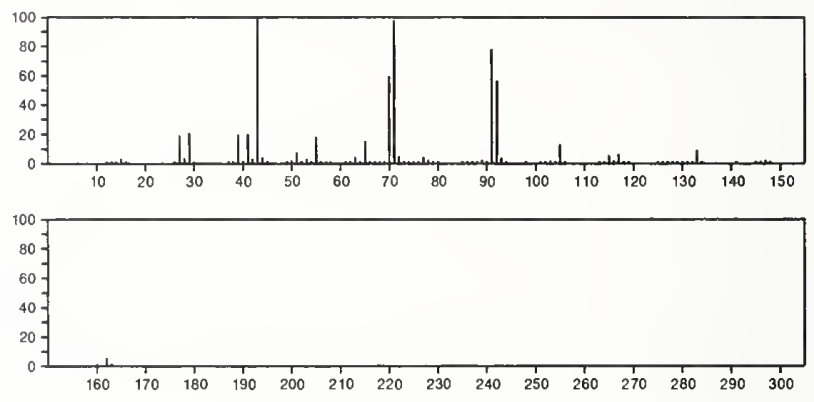

162

$\mathrm{C}_{12} \mathrm{H}_{18}$

$28654-79-7$

Benzene, sec-butylethyl-
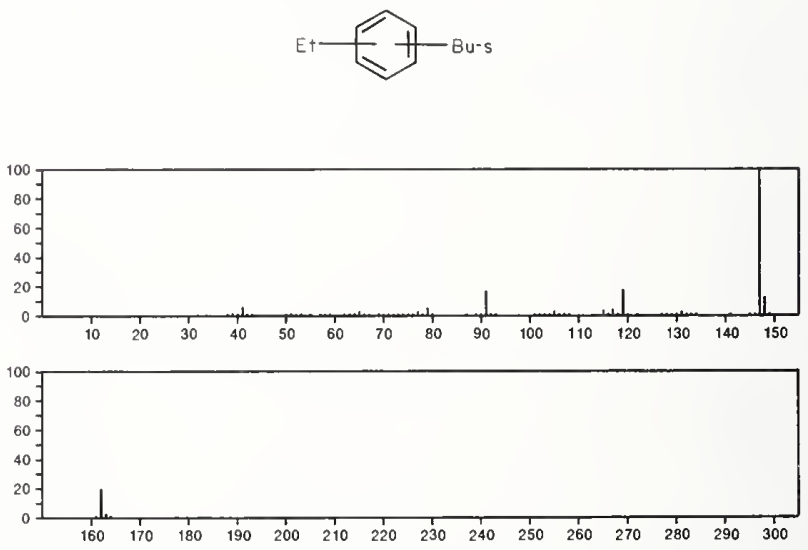
162

$\mathrm{C}_{12} \mathrm{H}_{18}$

Benzene, 3-ethyl-1,2,4,5-tetramethyl-
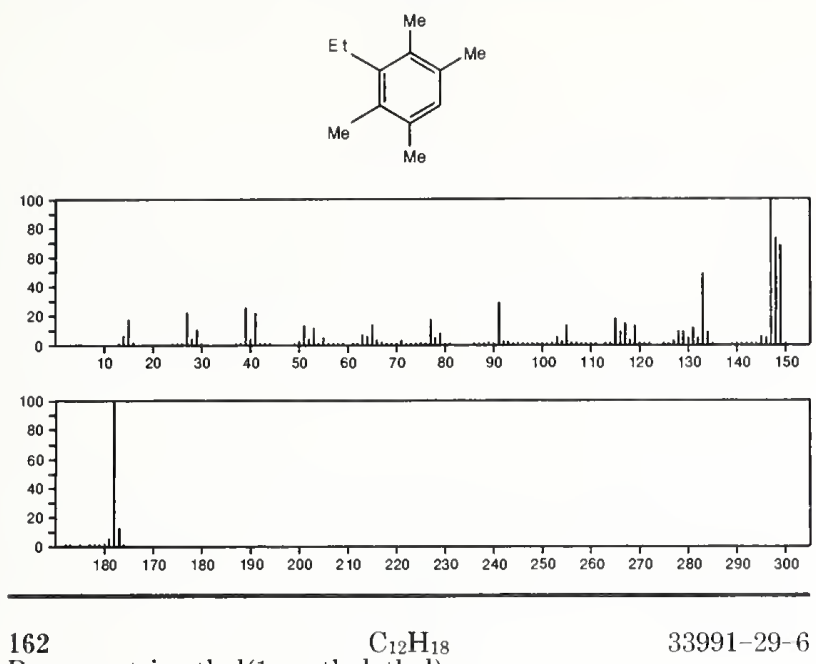

Benzene, trimethyl(1-methylethyl)-
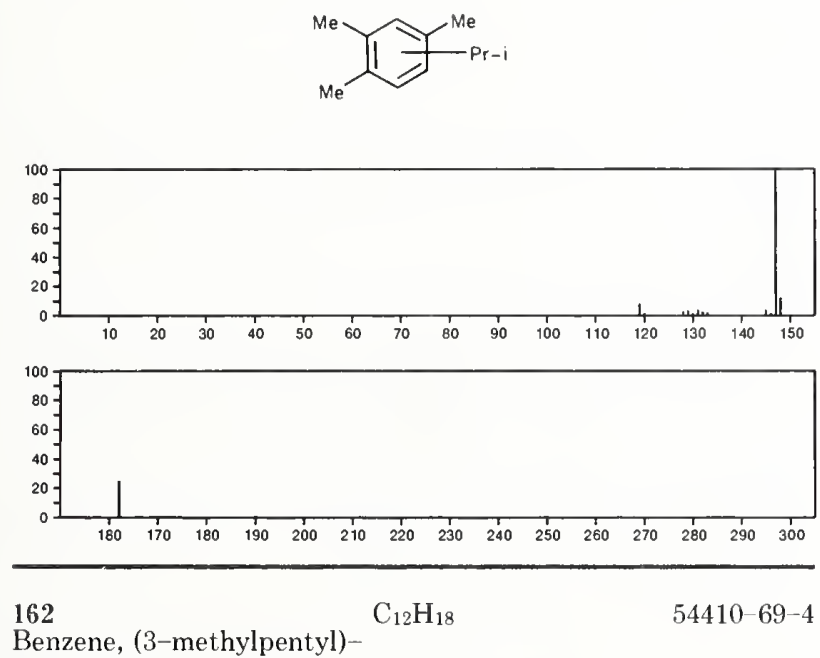

Benzene, (3-methylpentyl)
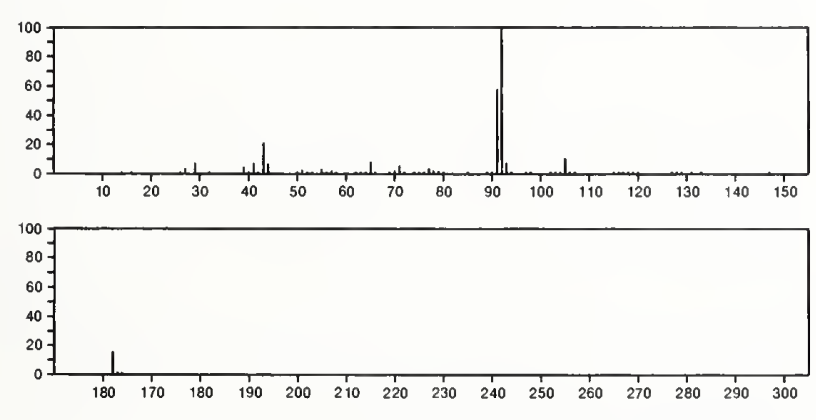

162

$\mathrm{C}_{12} \mathrm{H}_{18}$

Benzene, 1-methyl-2-(1-ethylpropyl)-

$54410-74-1$
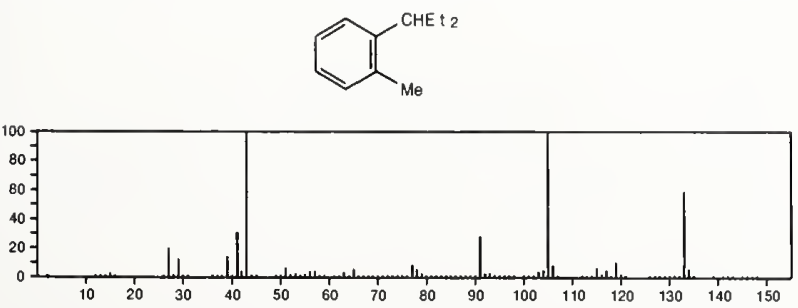

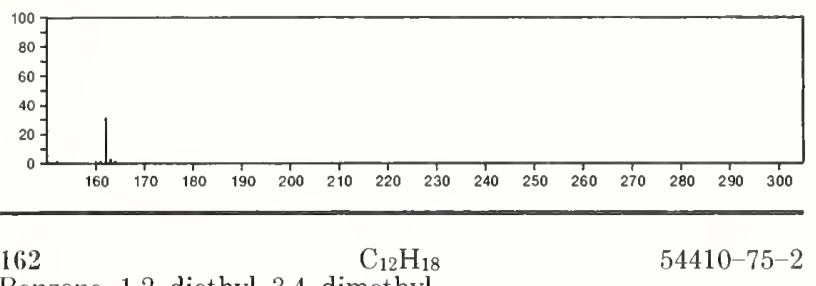

Benzene, 1,2-diethyl-3,4-dimethyl-
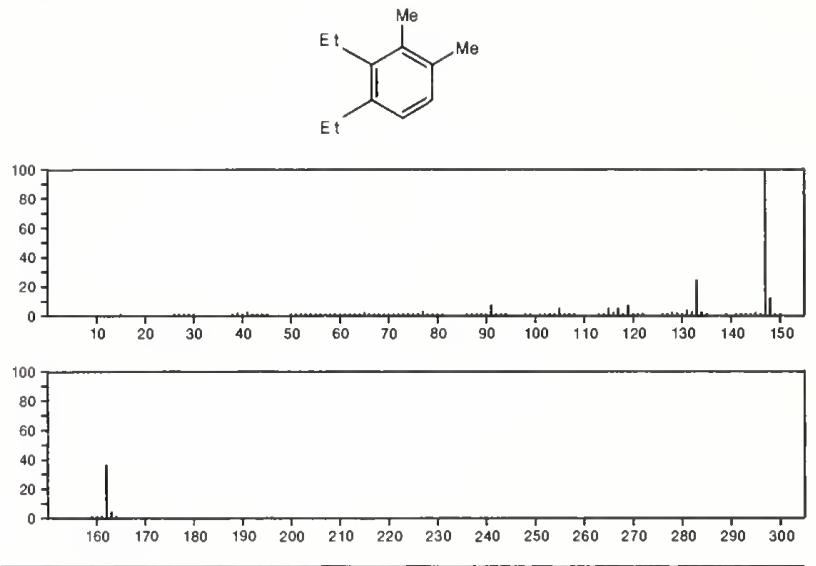

162

$\mathrm{C}_{12} \mathrm{H}_{18}$

55669-88-0

Benzene, 1,4-dimethyl-2-(2-methylpropyl)-
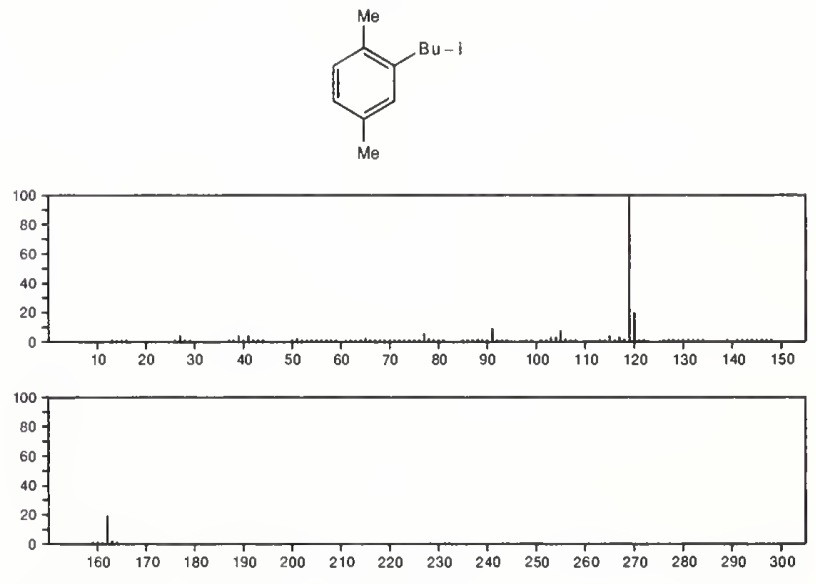

162

3,5-Decadiyne, 2,2-dimethyl-

$$
\mathrm{C}_{12} \mathrm{H}_{18}
$$

55682-73-0

$\mathrm{Me}{ }_{3} \mathrm{CC} \equiv \mathrm{CC} \equiv \mathrm{C}\left(\mathrm{CH}_{2}\right)_{3} \mathrm{Me}$
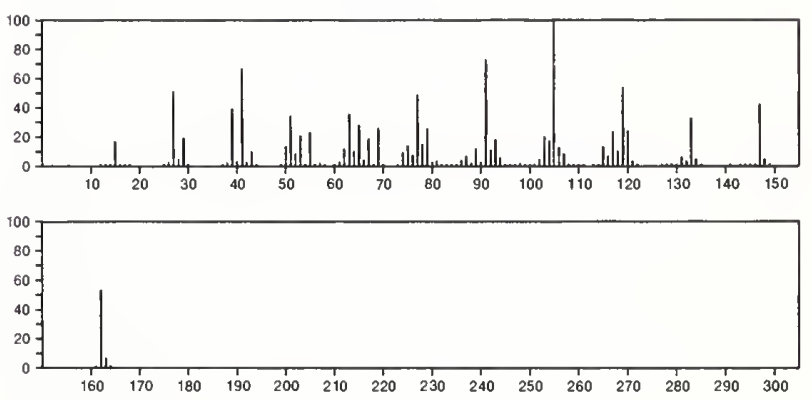
162

$\mathrm{C}_{12} \mathrm{H}_{18}$

$56248-17-0$

Cyclohexene, 1,5,5-trimethyl-6-(2-propenylidene)-
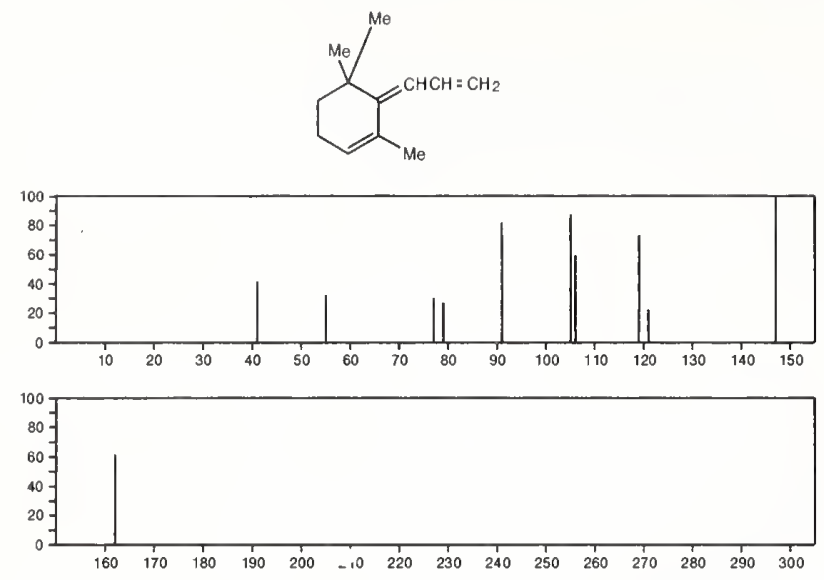

163

Methane, trichloronitro-

$\mathrm{CCl}_{3} \mathrm{NO}_{2}$

$76-06-2$

$\mathrm{Cl}_{3} \mathrm{CNO}_{2}$

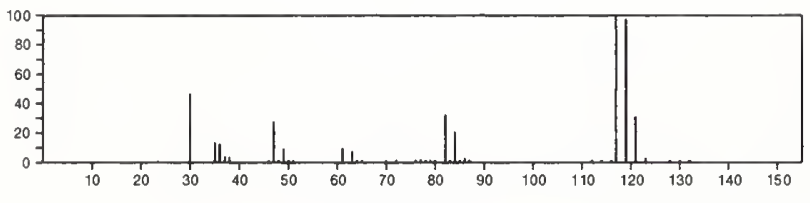

163

$\mathrm{C}_{3} \mathrm{H}_{2} \mathrm{BrNS}$

$3034-55-7$

Thiazole, 5-bromo-
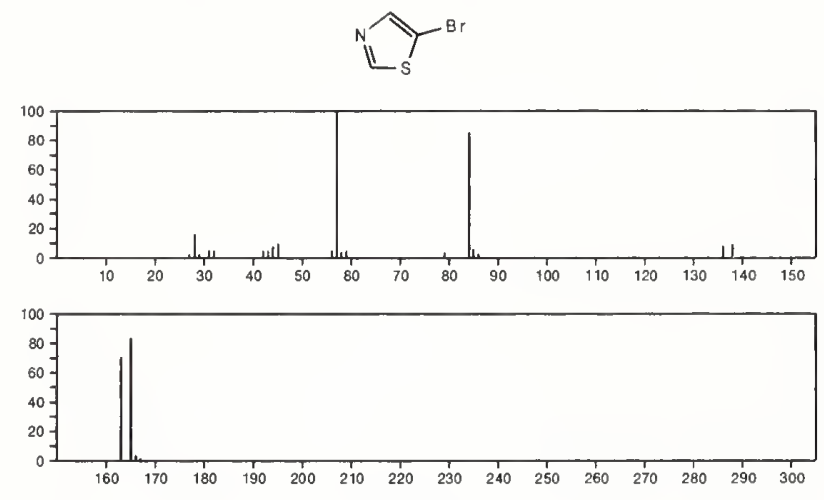

$163 \quad \mathrm{C}_{4} \mathrm{H}_{3} \mathrm{Cl}_{2} \mathrm{~N}_{3} \quad 56-05-3$

2-Pyrimidinamine, 4,6-dichloro-
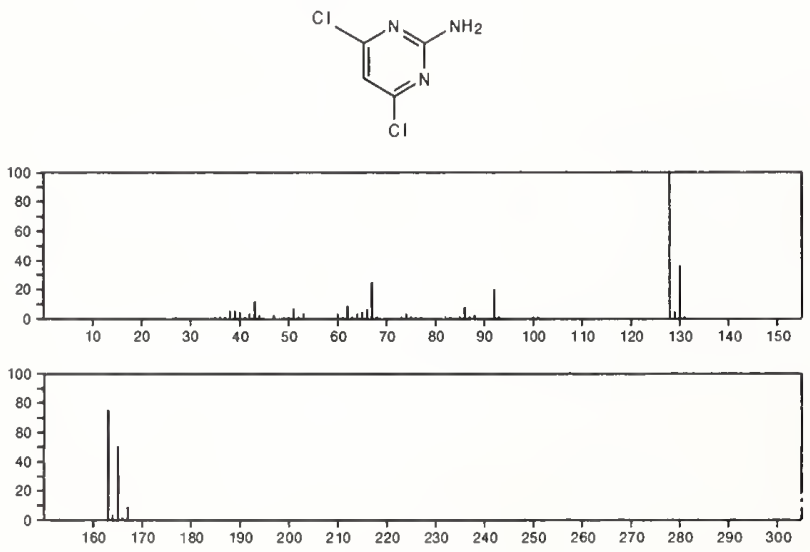

163

$\mathrm{C}_{5} \mathrm{H}_{4} \mathrm{~F}_{3} \mathrm{~N}_{3}$

$16075-42-6$ Pyrimidine, 2-amino-4-(trifluoromethyl)-<smiles>Nc1nccc(C(Cl)(Cl)Cl)n1</smiles>
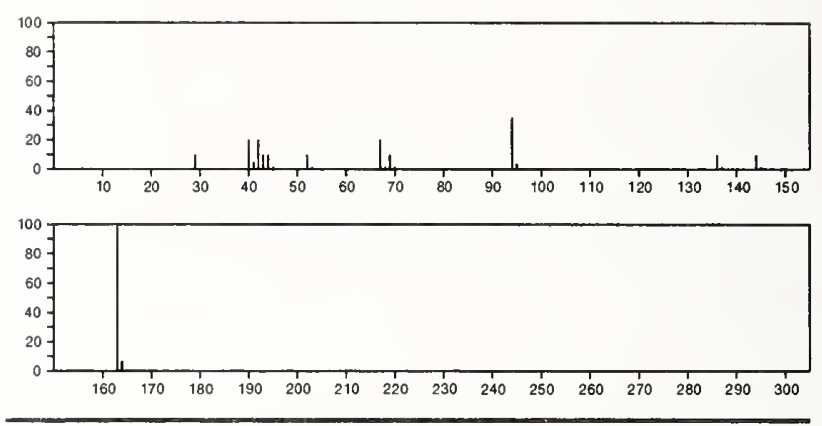

163

$\mathrm{C}_{5} \mathrm{H}_{9} \mathrm{NO}_{3} \mathrm{~S}$

Alanine, $N$-acetyl-2-mercapto-,$( \pm)$

$55956-23-5$

$\mathrm{ACNHCMe}$ ( $\mathrm{SH}$ ) $\mathrm{CO}_{2} \mathrm{H}$
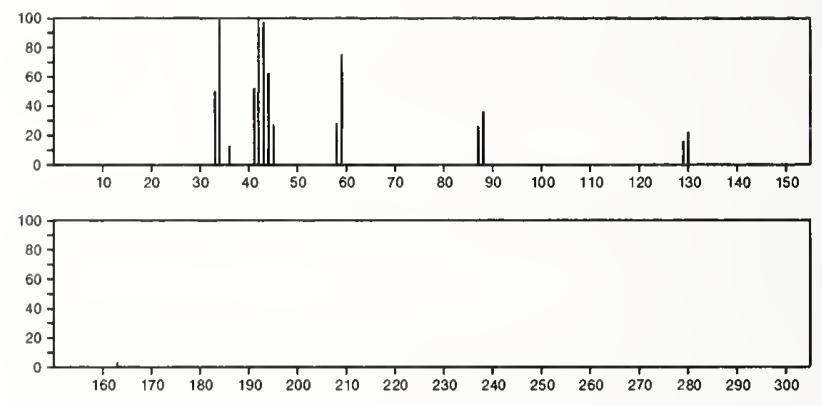

163

4(1H)-Pteridinone, 2-amino-

$\mathrm{C}_{6} \mathrm{H}_{5} \mathrm{~N}_{5} \mathrm{O}$

2236-60-4<smiles>Nc1nc(=O)c2nccnc2[nH]1</smiles>
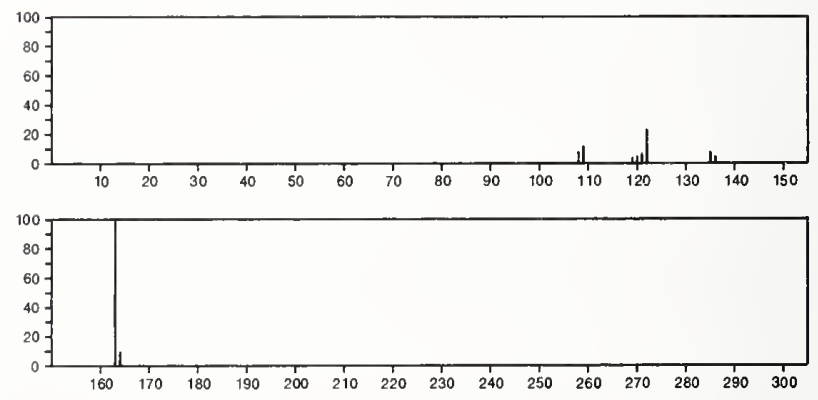

$163 \quad \mathrm{C}_{6} \mathrm{H}_{13} \mathrm{NS}_{2}$

Carbamodithioic acid, diethyl-, methyl ester

$686-07-7$

$\mathrm{MeSC}$ (S) NE $t_{2}$
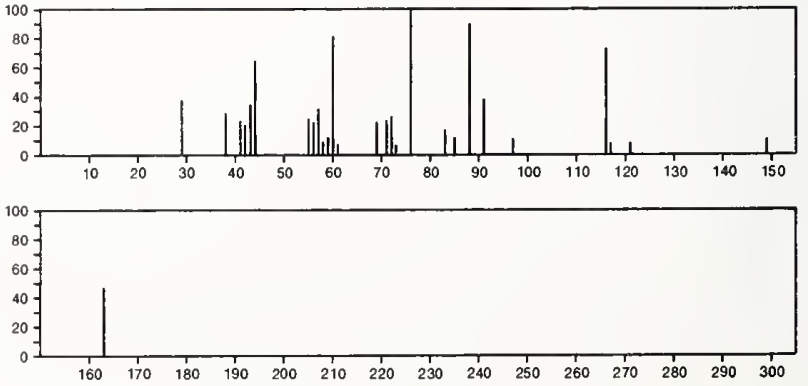
163

$\mathrm{C}_{6} \mathrm{H}_{18} \mathrm{~N}_{3} \mathrm{P}$

Phosphorous triamide, hexamethyl-

$1608-26-0$
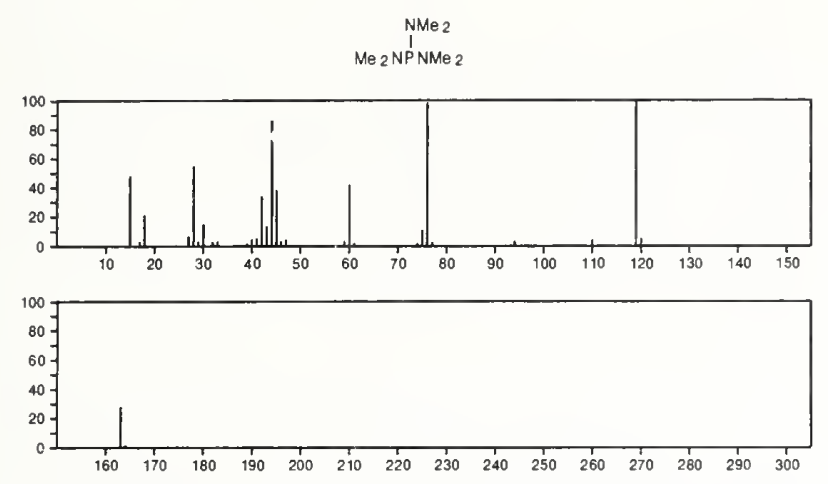

163

$\mathrm{C}_{7} \mathrm{H}_{5} \mathrm{~N}_{3} \mathrm{O}_{2}$

Pyrido[4,3-d]pyrimidine-2,4(1H,3H)-dione
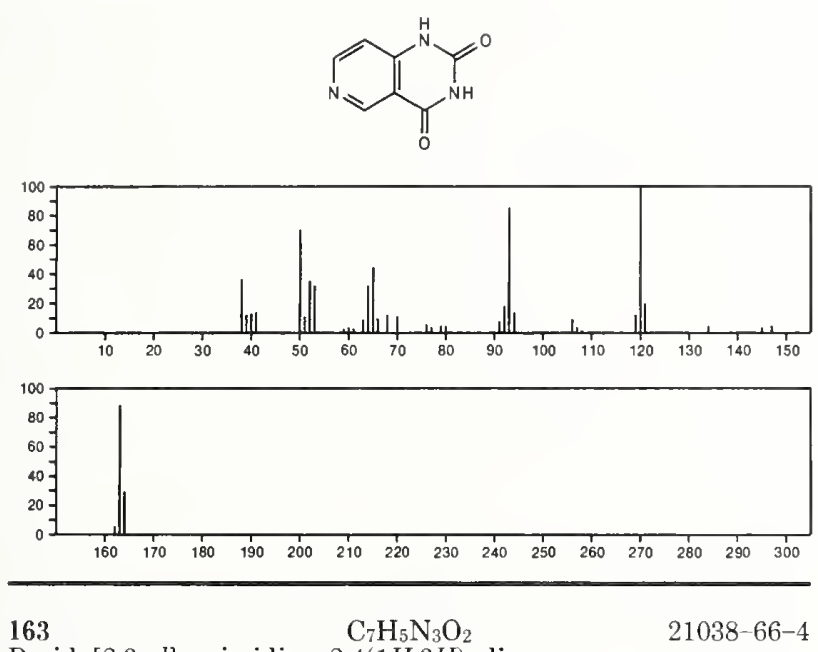

Pyrido[2,3-d]pyrimidine-2,4(1H,3H)-dione
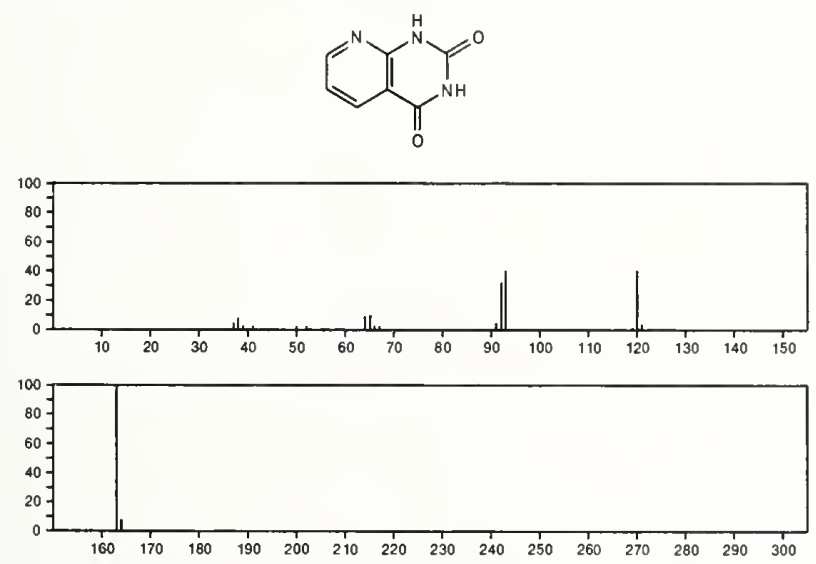

163.

$\mathrm{C}_{7} \mathrm{H}_{5} \mathrm{~N}_{3} \mathrm{O}_{2}$

Pyrido[3,4-d]pyrimidine-2,4(1H,3H)-dione
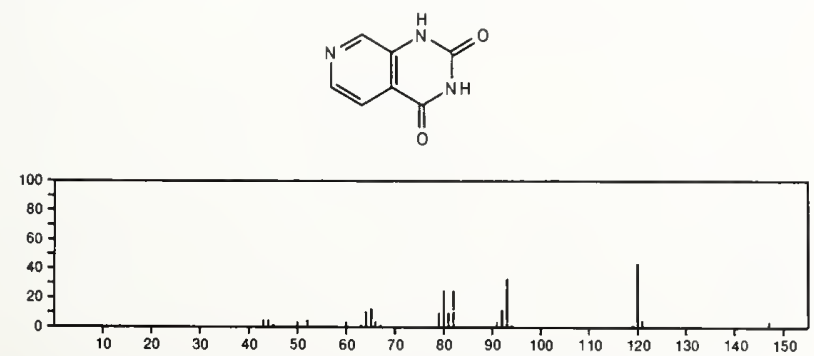

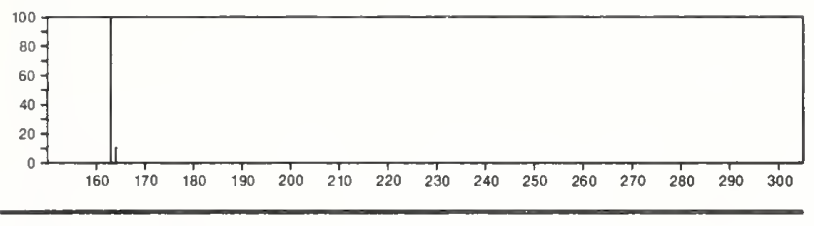

163

$\mathrm{C}_{7} \mathrm{H}_{5} \mathrm{~N}_{3} \mathrm{O}_{2}$

$37538-68-4$

Pyrido[3,2-d]pyrimidine-2,4(1H,3H)-dione<smiles>O=c1[nH]c(=O)c2ncccc2[nH]1</smiles>
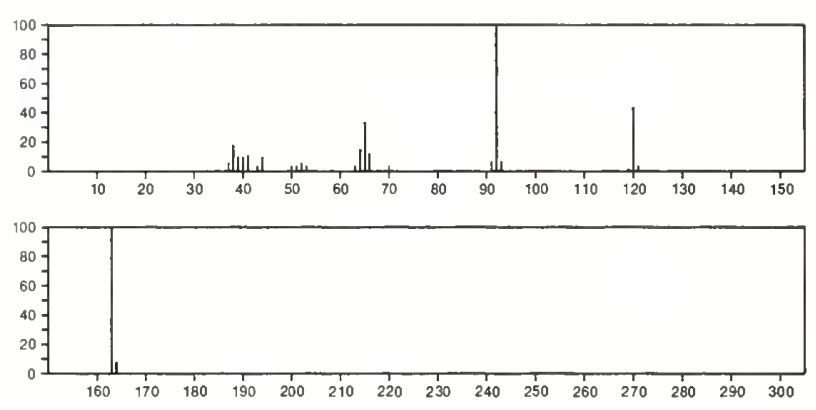

163

$\mathrm{C}_{7} \mathrm{H}_{5} \mathrm{~N}_{3} \mathrm{~S}$

Pyrido $[2,3-d]$ pyridazine-8(7H)-thione

15370-74-8
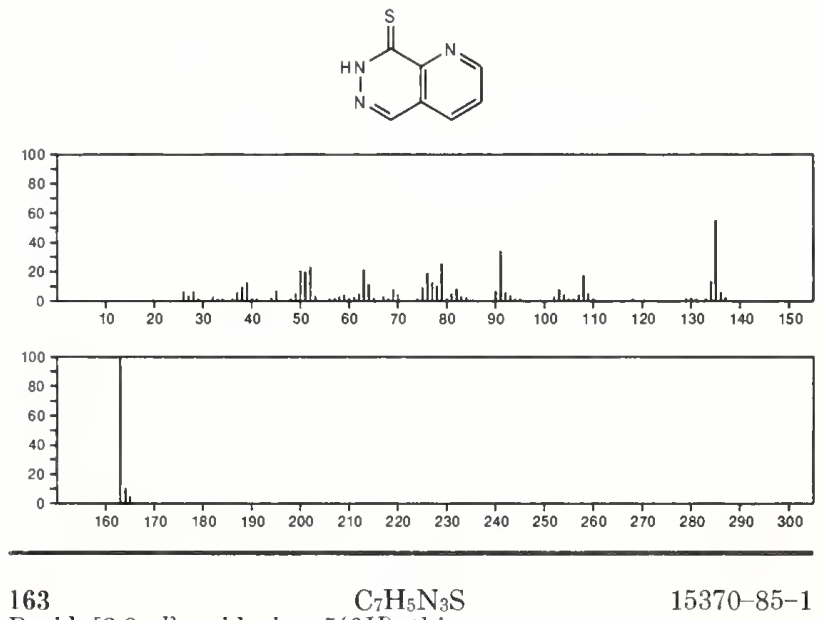

Pyrido[2,3-d]pyridazine-5(6H)-thione
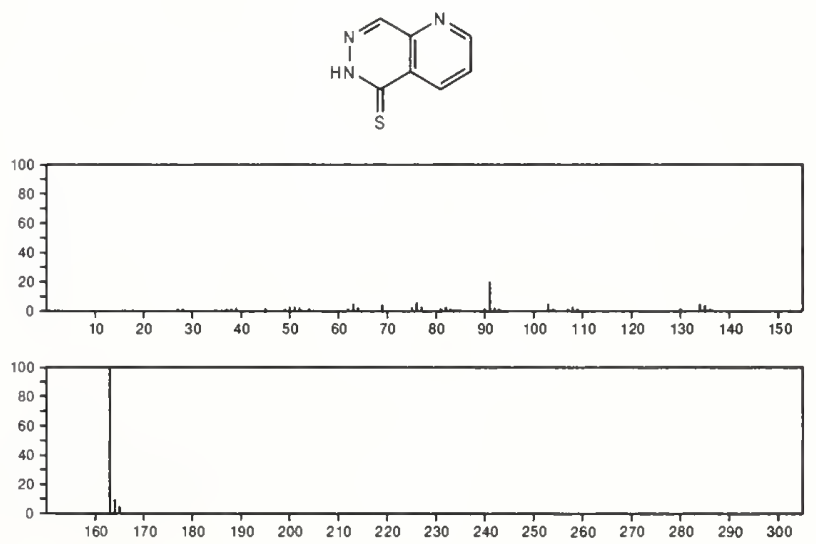
163

$\mathrm{C}_{7} \mathrm{H}_{9} \mathrm{~N}_{5}$

$1 H$-Purin-6-amine, $N, N$-dimethyl-<smiles>Nc1ncnc2nc[nH]c12</smiles>
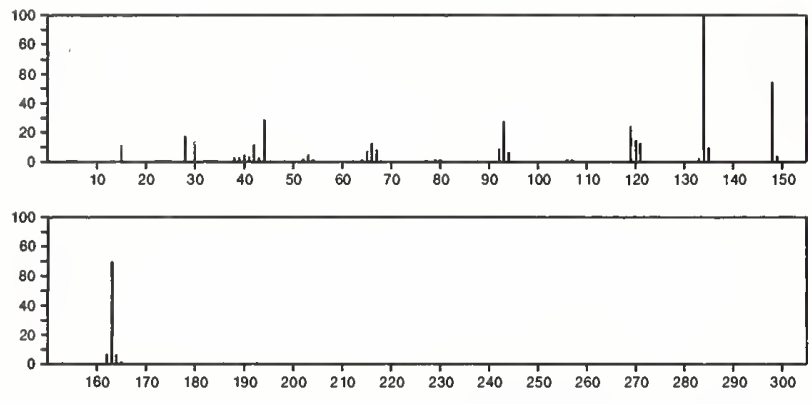

$163 \quad \mathrm{C}_{7} \mathrm{H}_{9} \mathrm{~N}_{5}$

$s$-Triazolo[4,3-a]pyrazine, 3-amino-5,8-dimethyl-

$19855-02-8$
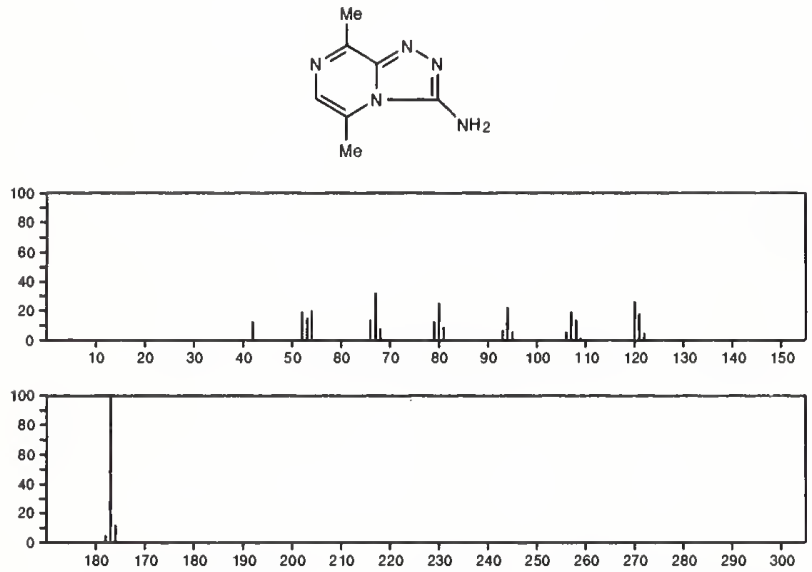

163

Hydrazinecarboxamide, 2-(phenylmethylene)-

$\mathrm{H}_{2} \mathrm{NCONHN}=\mathrm{CHPh}$
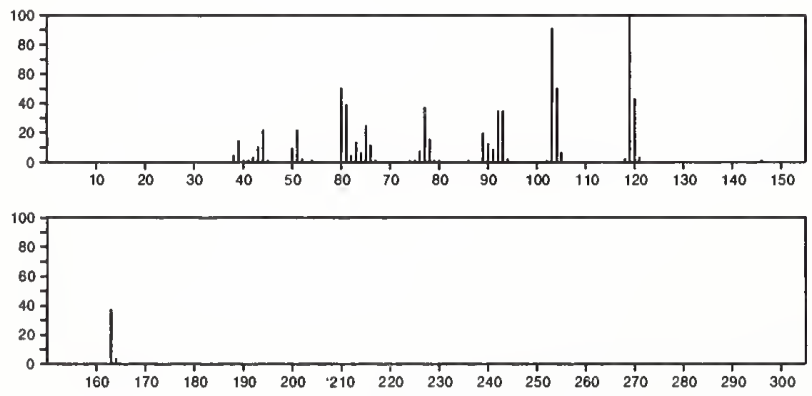

163

Quinoline, 2-chloro-

$\mathrm{C}_{9} \mathrm{H}_{6} \mathrm{CIN}$

$612-62-4$
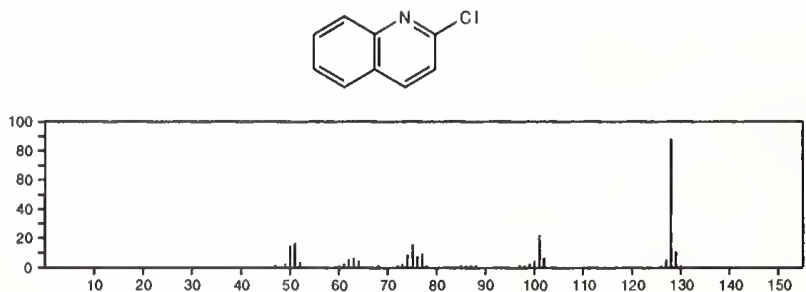

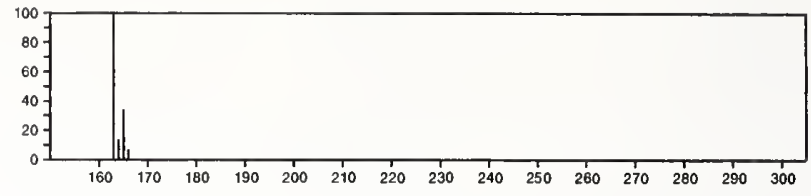

163

$\mathrm{C}_{9} \mathrm{H}_{9} \mathrm{NO}_{2}$

Benzene, (2-nitro-1-propenyl)-

705-60-2

$\mathrm{MeC}\left(\mathrm{NO}_{2}\right)=\mathrm{CHPh}$
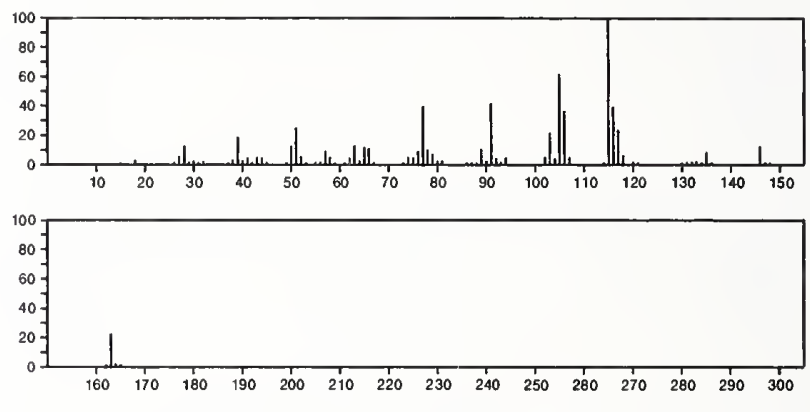

163

$\mathrm{C}_{9} \mathrm{H}_{9} \mathrm{NO}_{2}$

$1575-95-7$

Benzamide, $N$-acetyl

AcNHCOPh
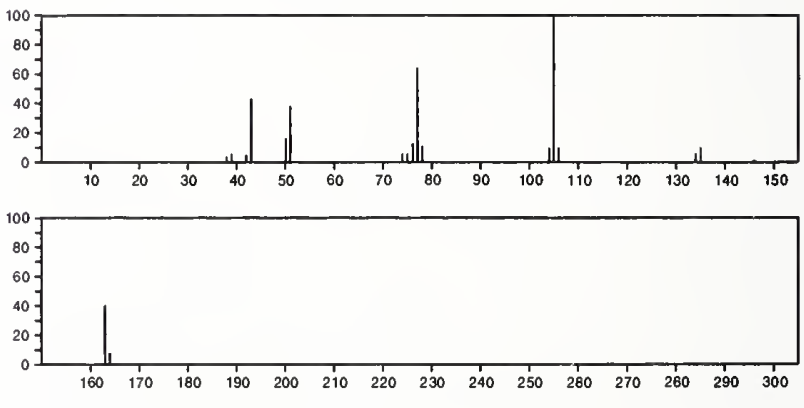

163

$\mathrm{C}_{9} \mathrm{H}_{9} \mathrm{NO}_{2}$

1,3-Butanedione, 1-(3-pyridinyl)-

$3594-37-4$
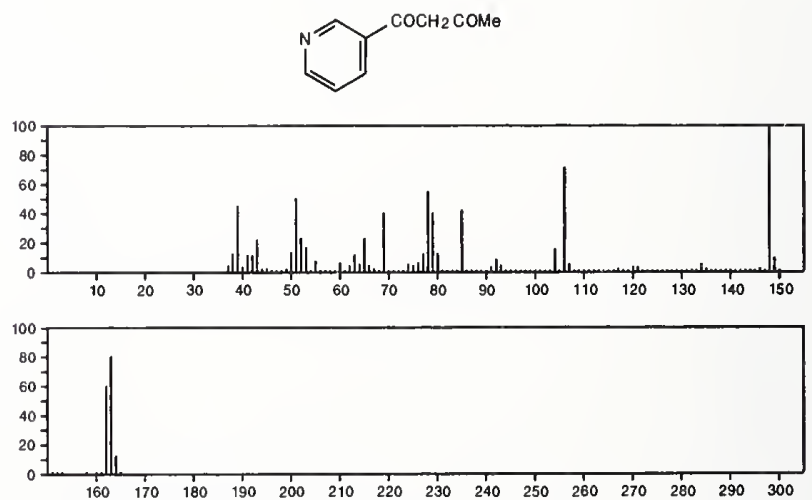

163

$\mathrm{C}_{9} \mathrm{H}_{9} \mathrm{NO}_{2}$

6265-30-1

4,7-Methano- $1 \mathrm{H}$-isoindole-1,3(2H)-dione, 3a,4,7,7a-tetrahydro-, $(3 \mathrm{a} \alpha, 4 \alpha, 7 \alpha, 7 \mathrm{a} \alpha)$
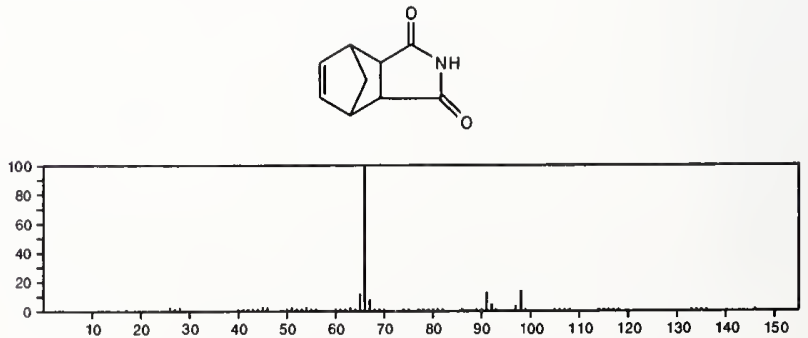


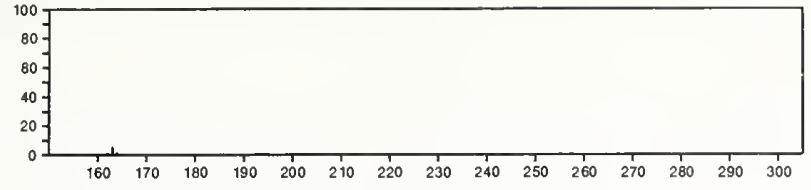

163

$\mathrm{C}_{9} \mathrm{H}_{9} \mathrm{NO}_{2}$

$13303-68-9$

$1 H$-Indole-1-carboxaldehyde, 2,3-dihydro-2-hydroxy-
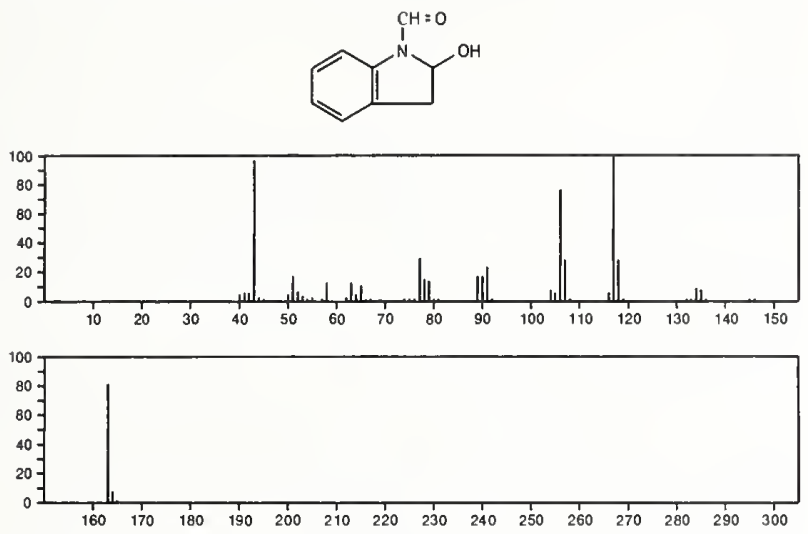

\section{3}

Formamide, $N$-(2-formylphenyl) $-N$-methyl-

$52479-54-6$
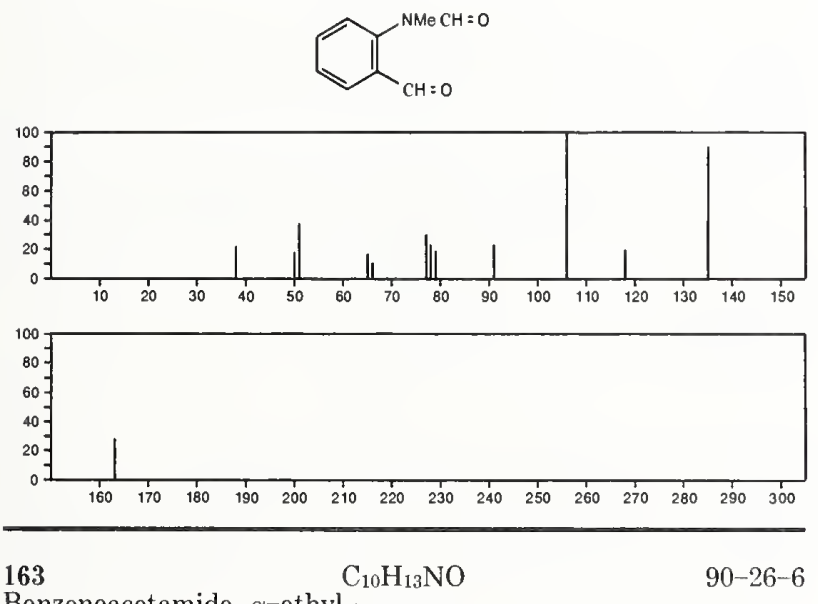

Benzeneacetamide, $\alpha$-ethyl-

$\mathrm{PhCHE}+\mathrm{CONH}_{2}$
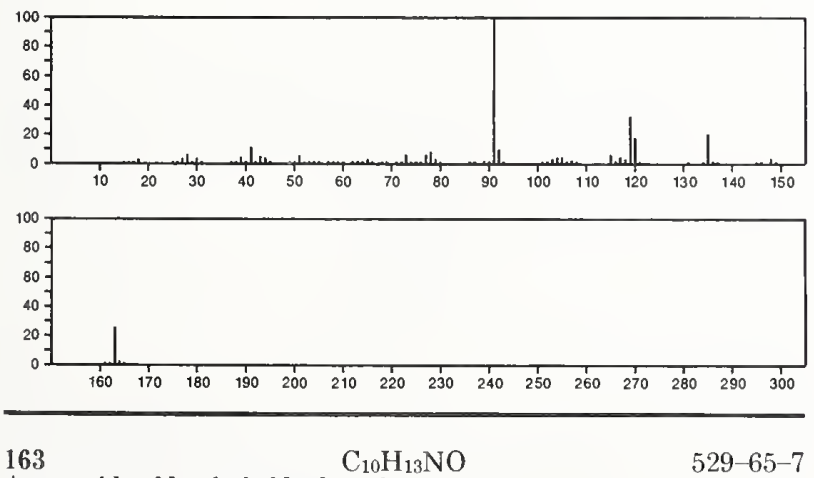

Acetamide, $N$-ethyl- $N$-phenyl-

$529-65-7$

$\operatorname{PhNE} 1(\mathrm{AC})$

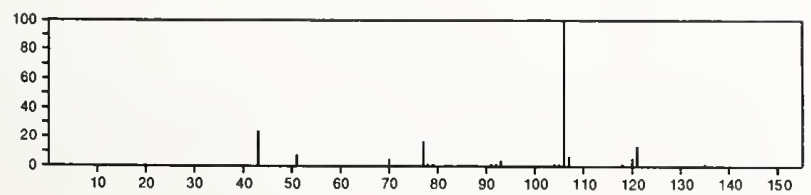

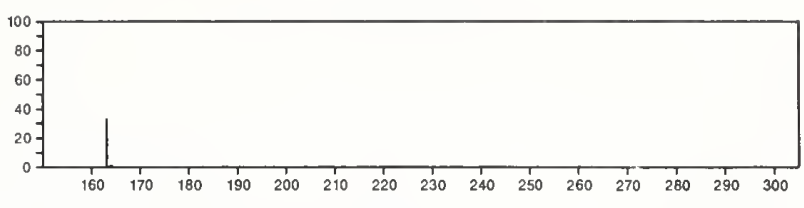

163

$\mathrm{C}_{10} \mathrm{H}_{13} \mathrm{NO}$

612-03-3

Acetamide, $N$-methyl- $N$-(4-methylphenyl)-
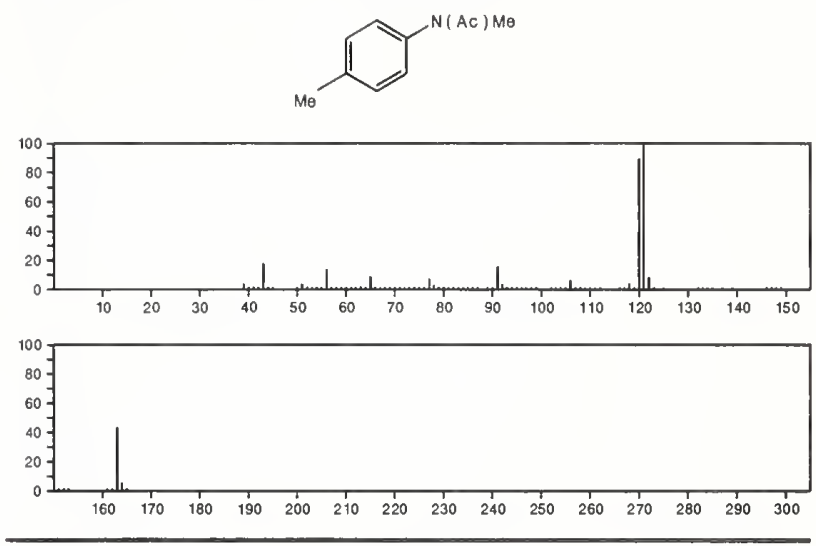

163

$\mathrm{C}_{10} \mathrm{H}_{13} \mathrm{NO}$

$877-95-2$

Acetamide, $N$-(2 phenylethyl)-

$\mathrm{PhCH}_{2} \mathrm{CH}_{2} \mathrm{NHAC}$
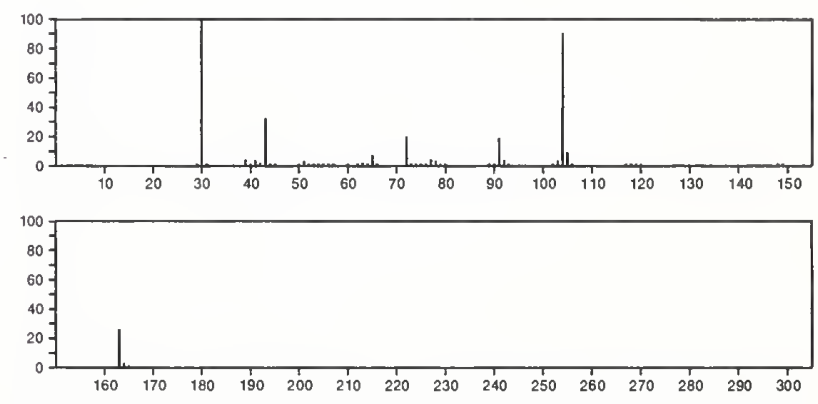

163

$\mathrm{C}_{10} \mathrm{H}_{13} \mathrm{NO}$

Acetamide, $N$-(2,6-dimethylphenyl)-

2198-53-0
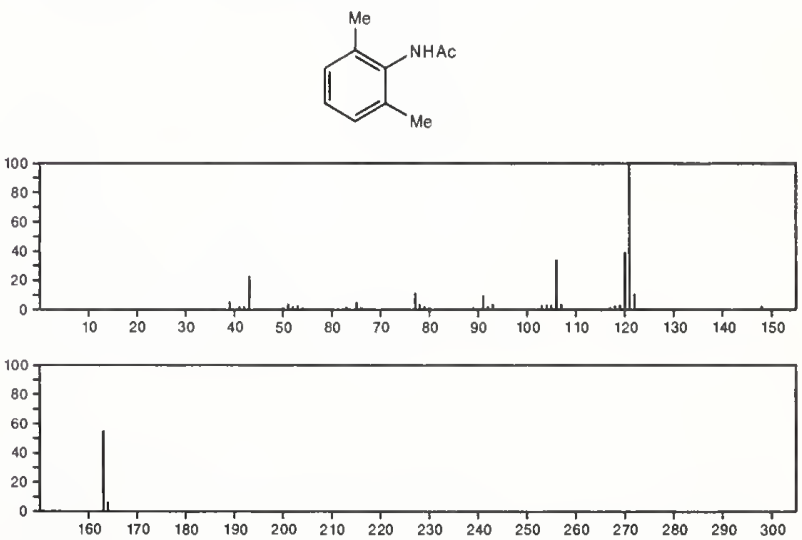

163

$\mathrm{C}_{10} \mathrm{H}_{13} \mathrm{NO}$

3319-03-7

Ethanone, 2-(dimethylamino)-1-phenyl-

$\mathrm{Me}_{2} \mathrm{NCH}_{2} \mathrm{COPh}$

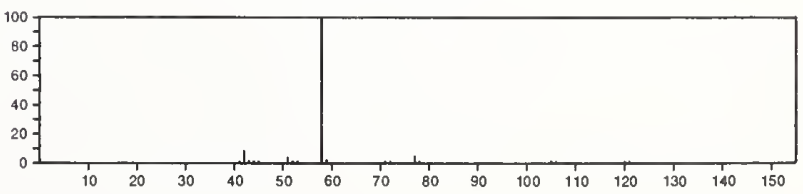




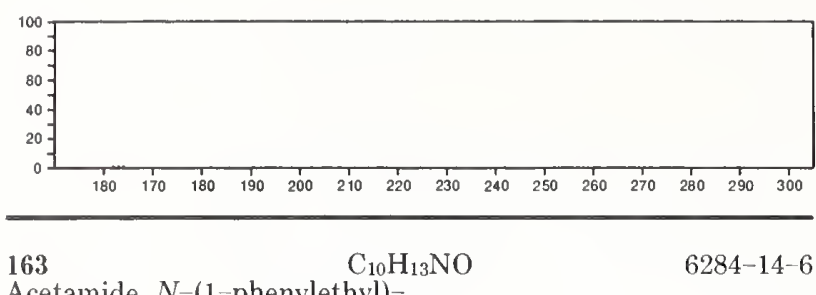

Acetamide, $N-(1-$ phenylethyl $)-$

ACNHCHMePh
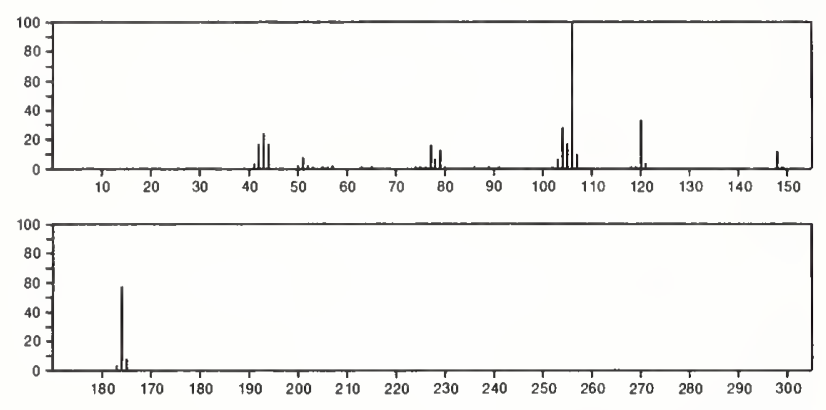

163

$\mathrm{C}_{10} \mathrm{H}_{13} \mathrm{NO}$

1-Pentanone, 1-(2-pyridinyl)-

$7137-97-5$
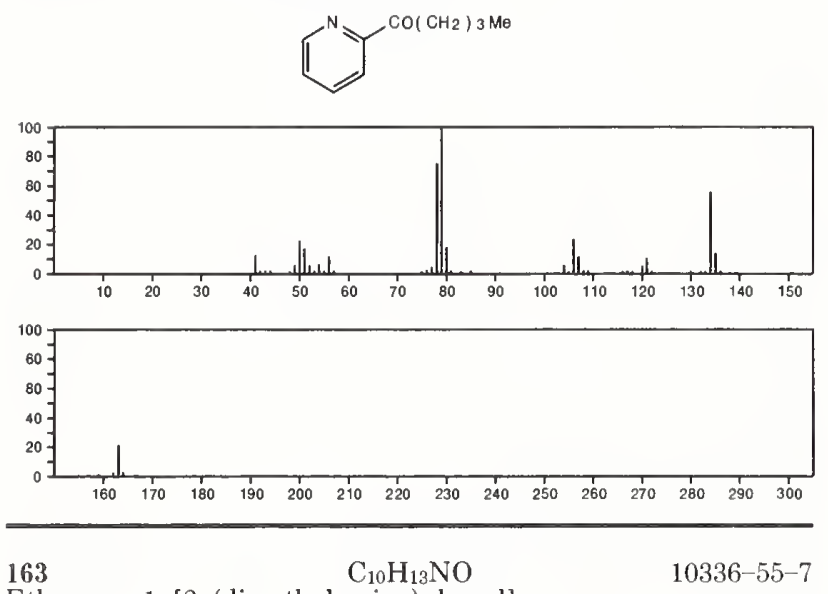

Ethanone, 1-[2-(dimethylamino)phenyl]
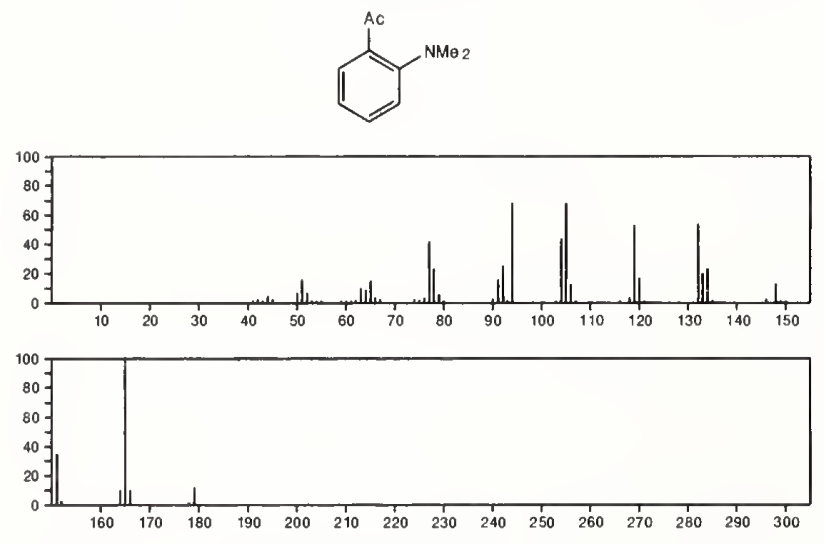

163

Benzamide, $N$-propyl-

$\mathrm{C}_{10} \mathrm{H}_{13} \mathrm{NO}$

$10546-70-0$

PrNHCOPh

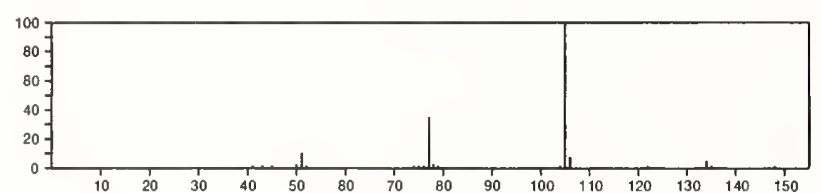

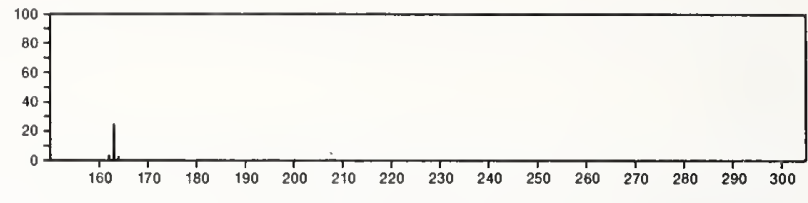

163 $\mathrm{C}_{10} \mathrm{H}_{13} \mathrm{NO}$

18925-69-4

Benzeneacetamide, $N, N$-dimethyl

$\mathrm{Me}_{2} \mathrm{NCOCH}_{2} \mathrm{Ph}$
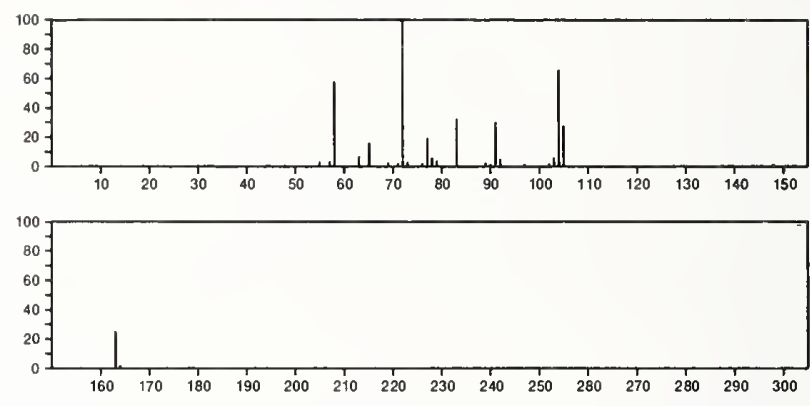

163

$\mathrm{C}_{10} \mathrm{H}_{13} \mathrm{NO}$

Azocine, 2-methoxy-3,8-dimethyl-

$20205-53-2$
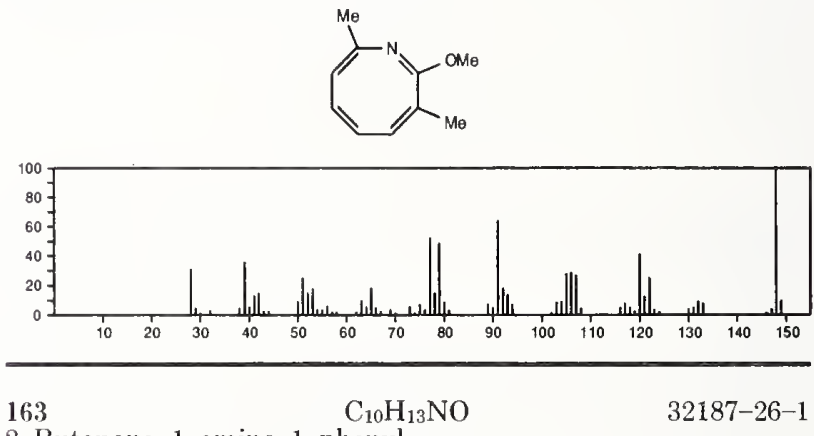

$32187-26-1$

2-Butanone, 1-amino-1-phenyl-

$\mathrm{PhCH}\left(\mathrm{NH}_{2}\right) \mathrm{COE}$
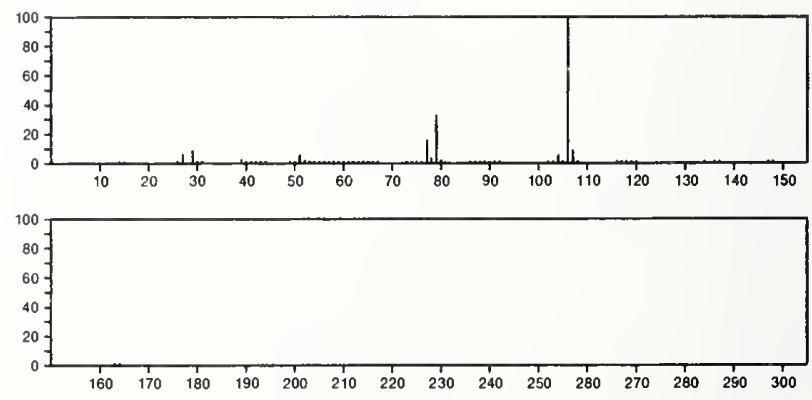

163

$\mathrm{C}_{10} \mathrm{H}_{13} \mathrm{NO}$

Benzaldehyde, $\mathrm{O}$-isopropyloxime

$33499-41-1$

$P h C H=N O P+-i$
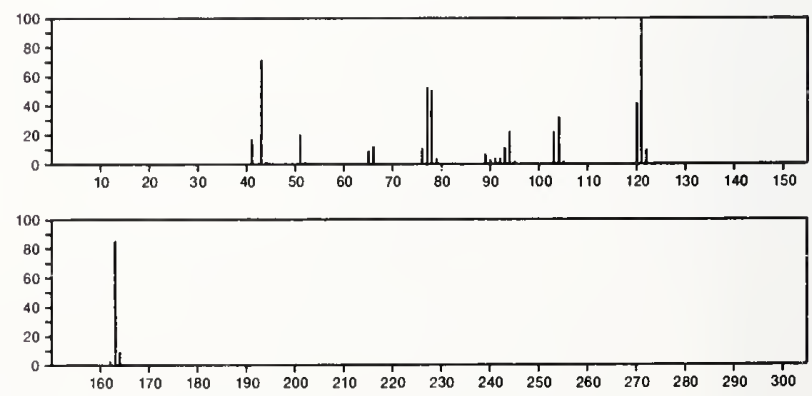
$163 \quad \mathrm{C}_{10} \mathrm{H}_{13} \mathrm{NO}$

Benzaldehyde, $O$-propyloxime

$\mathrm{PhCH}=\mathrm{NOPr}$
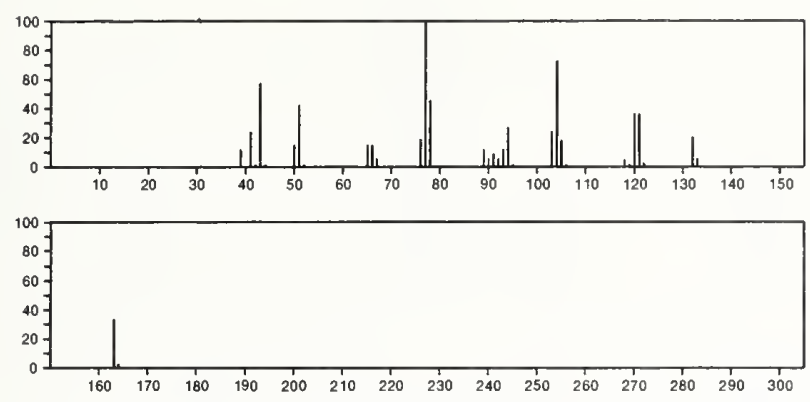

163

$\mathrm{C}_{10} \mathrm{H}_{13} \mathrm{NO}$

2-Butanone, 3-amino-4-phenyl-

40513-35-7

$\mathrm{PhCH} 2 \mathrm{CH}\left(\mathrm{NH}_{2}\right)$ COMe
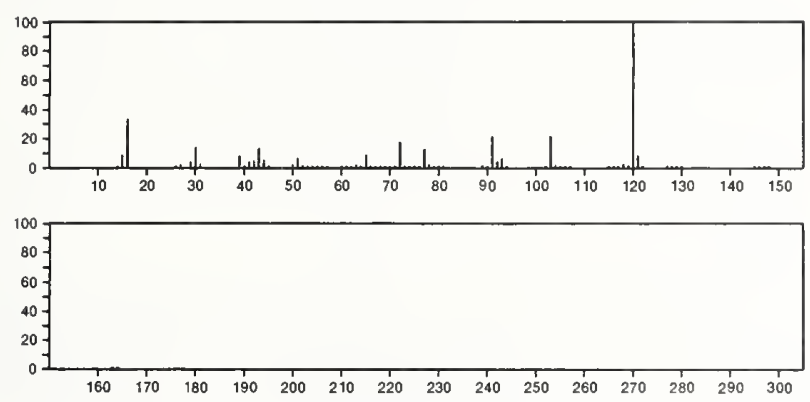

$\overline{\mathrm{C}_{10} \mathrm{H}_{13} \mathrm{NO}} \quad 54410-77-4$

Formamide, $N$-methyl- $N$-[(4-methylphenyl)methyl $]-$
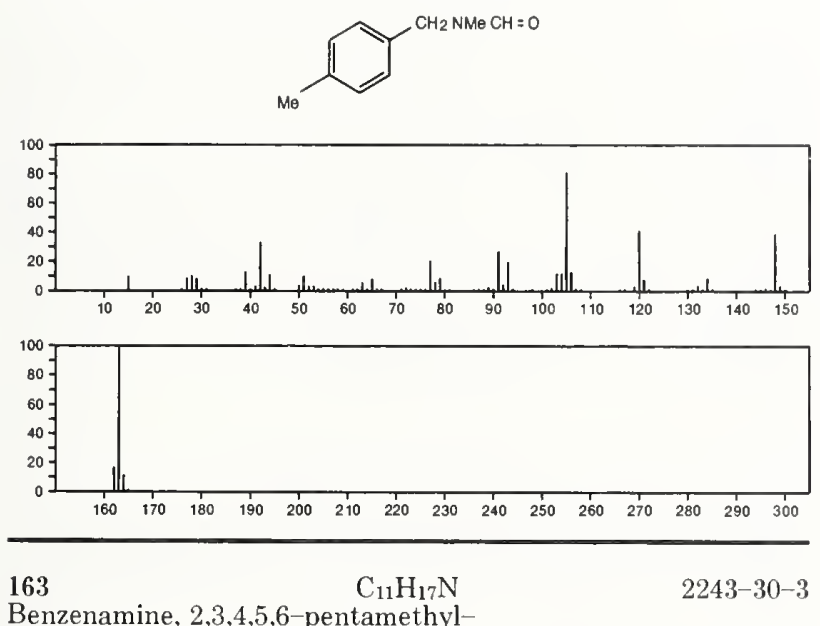

Benzenamine, 2,3,4,5,6-pentamethyl-
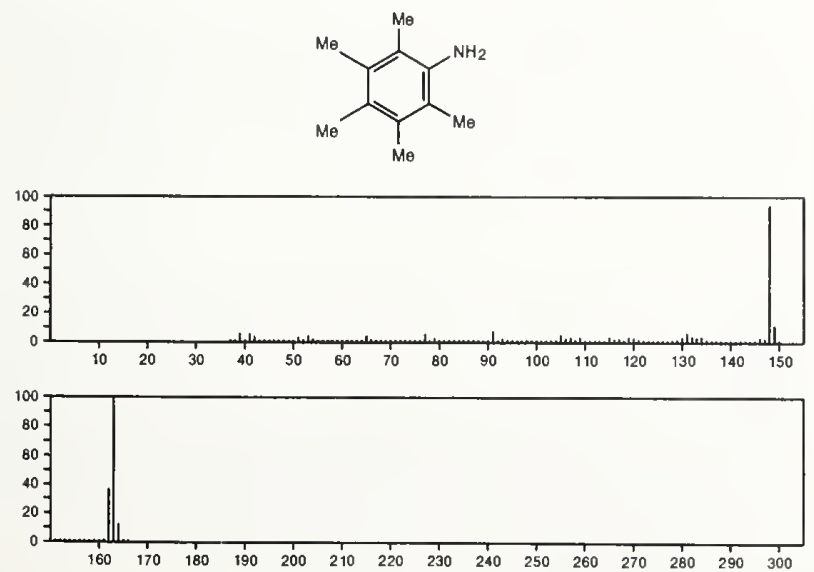

$163 \quad \mathrm{C}_{11} \mathrm{H}_{17} \mathrm{~N}$

Benzenamine, $N$-(2,2-dimethylpropyl)-

$7210-81-3$

$\mathrm{Me} 3 \mathrm{CCH}_{2} \mathrm{NHPh}$
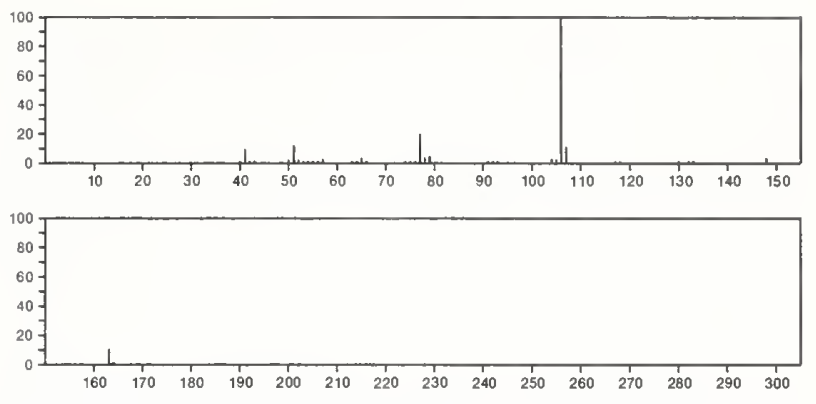

163

$\mathrm{C}_{11} \mathrm{H}_{17} \mathrm{~N}$

$18205-60-2$

Pyrrolidine, 1-(3-cyclohexen $\sim 1$-ylidenemethyl)-
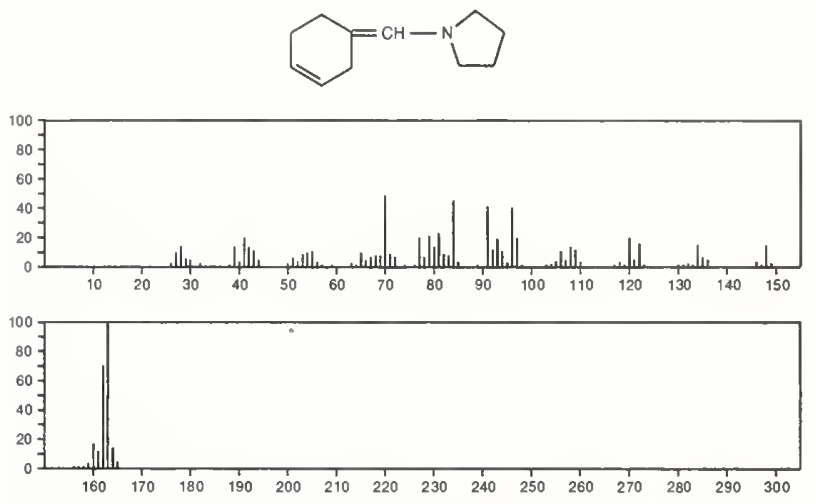

163

$\mathrm{C}_{11} \mathrm{H}_{17} \mathrm{~N}$

p-Menth-1-ene-9-carbonitrile, $(4 R, 8 S)-(+)-$

$26462-76-0$
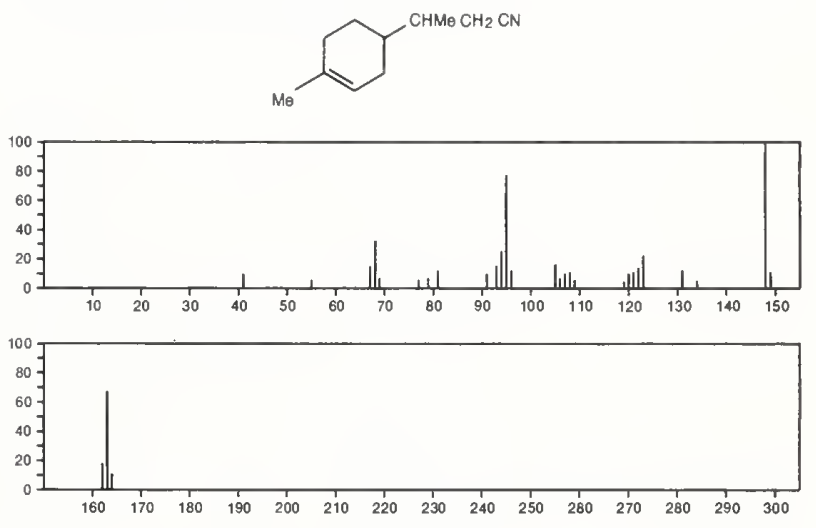

164

$\mathrm{CBrClF}_{2}$

$353-59-3$

Methane, bromochlorodifluoro-

$\mathrm{BrCCl}(F)_{2}$
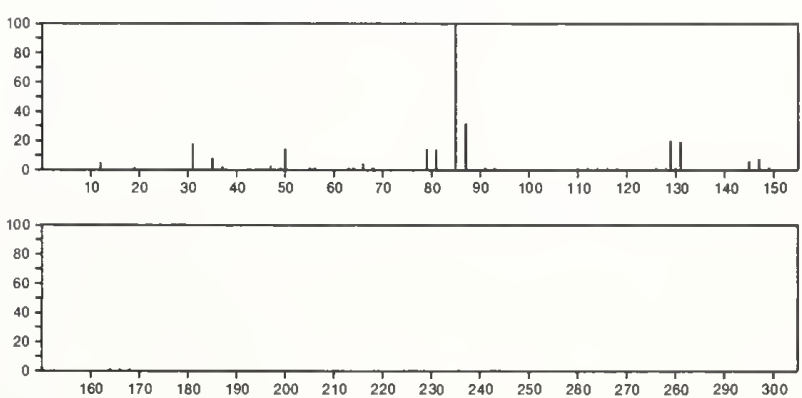
164

Phosphorodichloridothioic acid, $O$-methyl ester

2523-94-6

$\mathrm{MeOPCl}_{2}=\mathrm{S}$
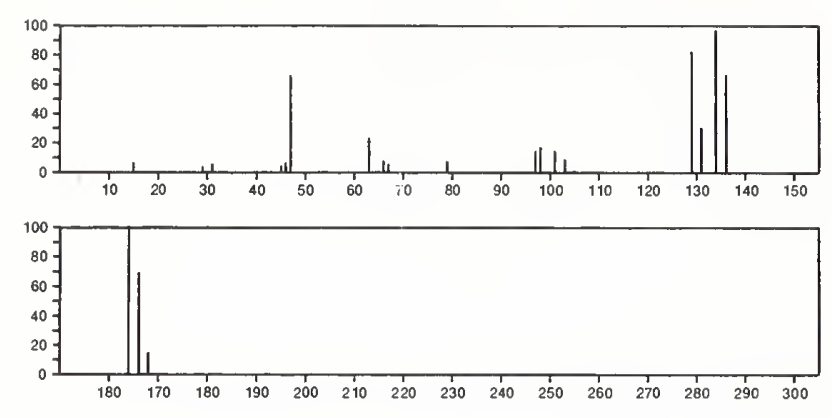

164

Ethene, tetrachloro-

$\mathrm{C}_{2} \mathrm{Cl}_{4}$

127-18-4

$\mathrm{Cl}_{2} \mathrm{C}=\mathrm{CCl}_{2}$
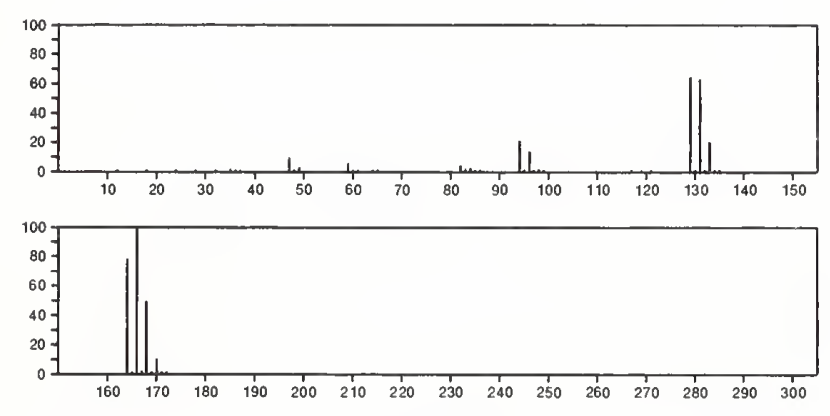

164

1,1-Ethanediol, 2,2,2-trichloro-

$\mathrm{C}_{2} \mathrm{H}_{3} \mathrm{Cl}_{3} \mathrm{O}_{2}$

$(\mathrm{HO})_{2} \mathrm{CHCCl}_{3}$
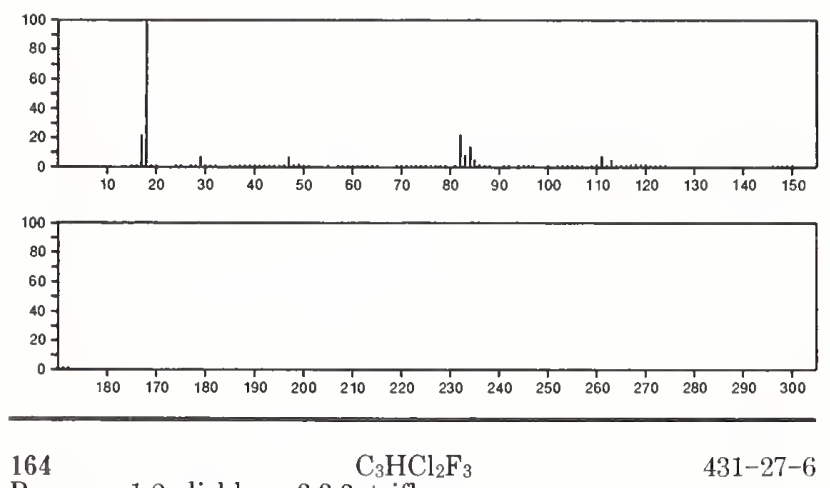

Propene, 1,2-dichloro-3,3,3-trifluoro-

$431-27-6$

$\mathrm{ClCH}=\mathrm{CClCF}_{3}$
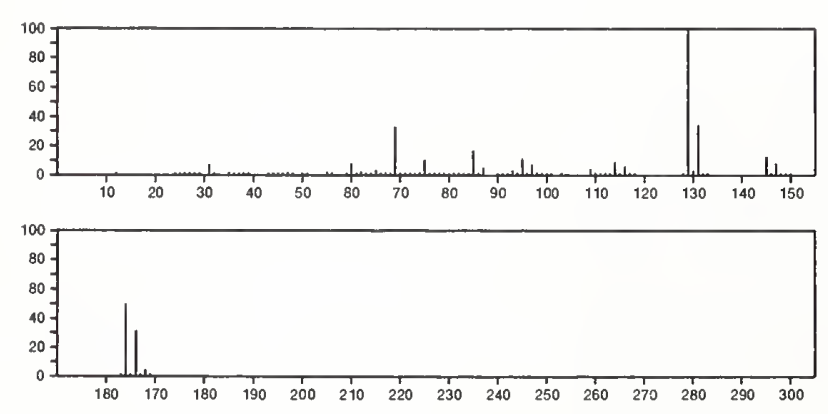

164

$\mathrm{C}_{3} \mathrm{H}_{2} \mathrm{Cl}_{2} \mathrm{~N}_{4}$

$933-20-0$

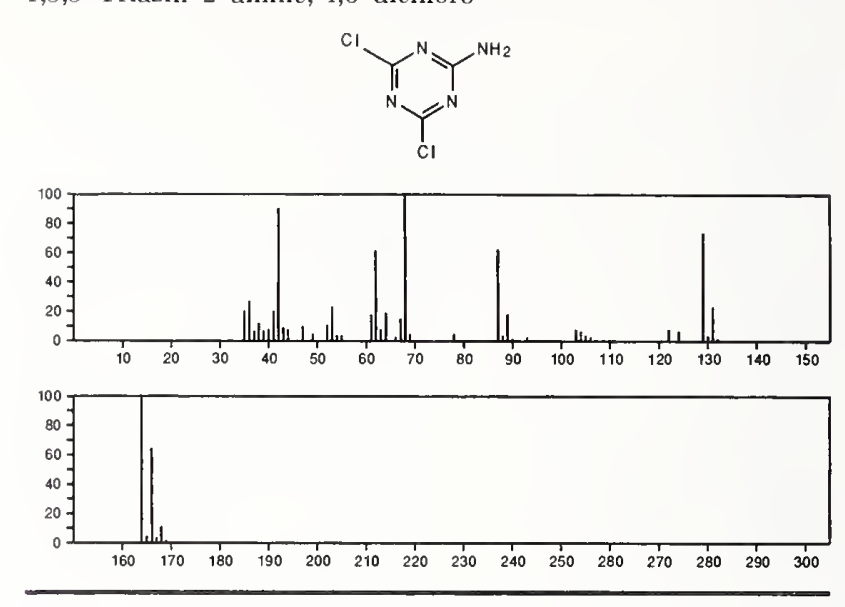

164

$\mathrm{C}_{3} \mathrm{H}_{4} \mathrm{Cl}_{2} \mathrm{~F}_{2} \mathrm{O}$

Ethane, 2,2-dichloro-1,1-difluoro-1-methoxy-

76-38-0

$\mathrm{Cl}_{2} \mathrm{CHCF}_{2} \mathrm{OMO}$

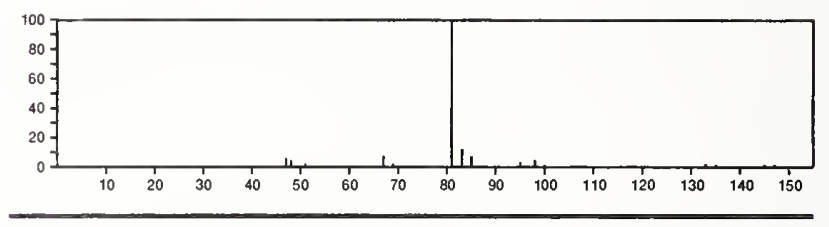

164

$\mathrm{C}_{3} \mathrm{H}_{10} \mathrm{~N}_{2} . \mathrm{C}_{2} \mathrm{H}_{2} \mathrm{O}_{4}$

Hydrazine, propyl-, ethanedioate $(1: 1)$

$6340-91-6$

$\mathrm{MeCH}_{2} \mathrm{CH}_{2} \mathrm{NHNH}_{2} \cdot \mathrm{HO}_{2} \mathrm{CCO}_{2} \mathrm{H}$

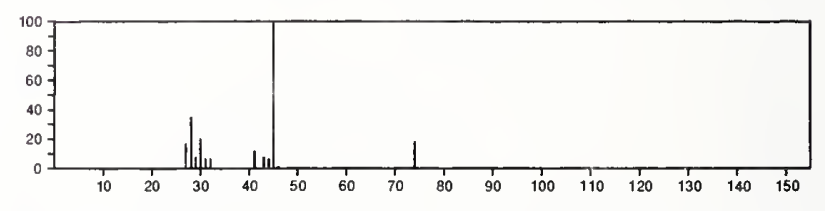

164

$\mathrm{C}_{3} \mathrm{H}_{20} \mathrm{~N}_{2} . \mathrm{C}_{2} \mathrm{H}_{2} \mathrm{O}_{4}$

$6629-61-4$

Hydrazine, (1-methylethyl)-, ethanedioate (1:1)

$\mathrm{Me}_{2} \mathrm{CHNHNH}_{2} \cdot \mathrm{HO}_{2} \mathrm{CCO}_{2} \mathrm{H}$

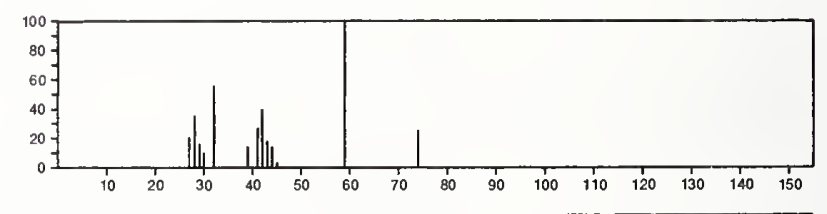

164

1,3,2-Dioxarsenane, 2-methyl-

$\mathrm{C}_{4} \mathrm{H}_{9} \mathrm{AsO}_{2}$

24635-97-0
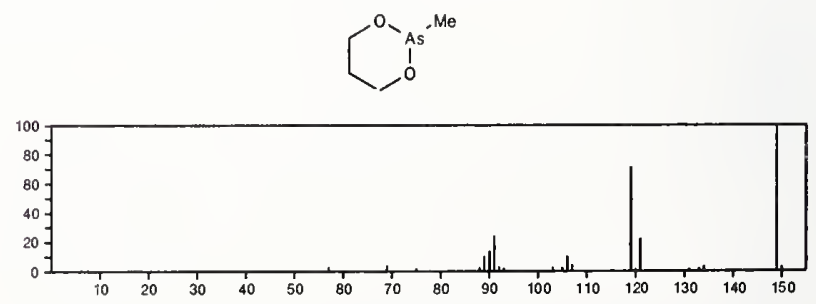


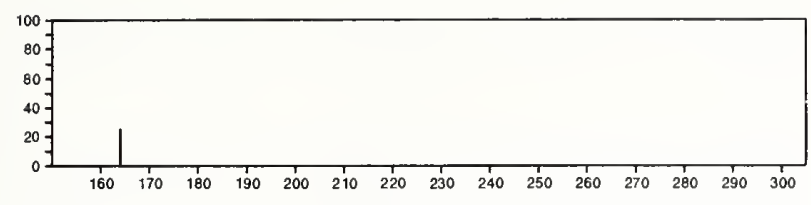

164

3-Pentanone, 2-bromo-

$\mathrm{C}_{5} \mathrm{H}_{9} \mathrm{BrO}$

815-52-1
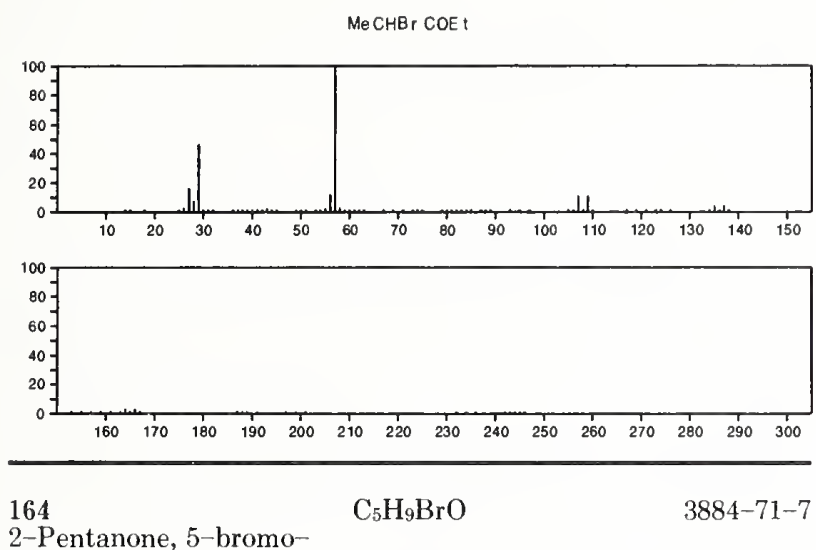

$\mathrm{Br}\left(\mathrm{CH}_{2}\right)_{3} \mathrm{COMe}$
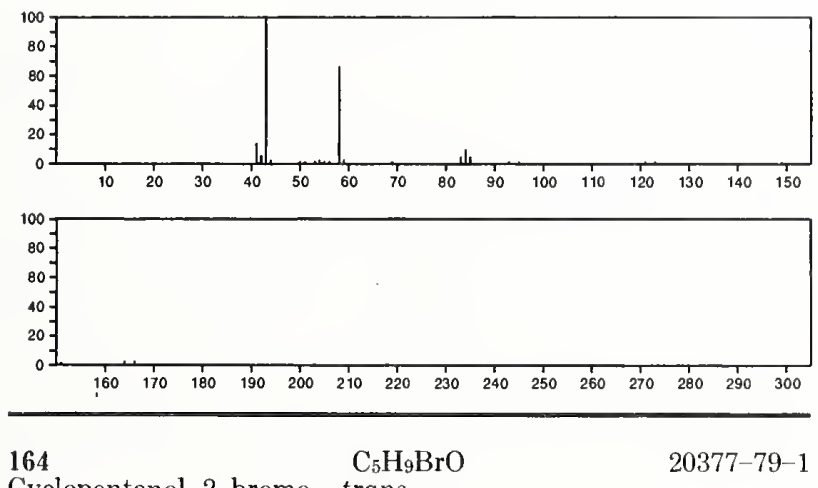

Cyclopentanol, 2-bromo-, trans-
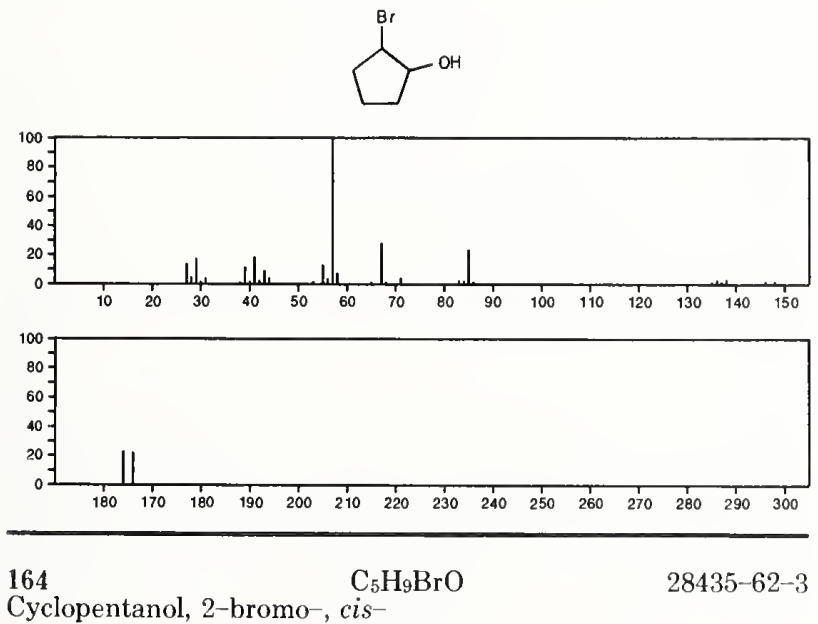

Cyclopentanol, 2-bromo-, cis- $^{-}$
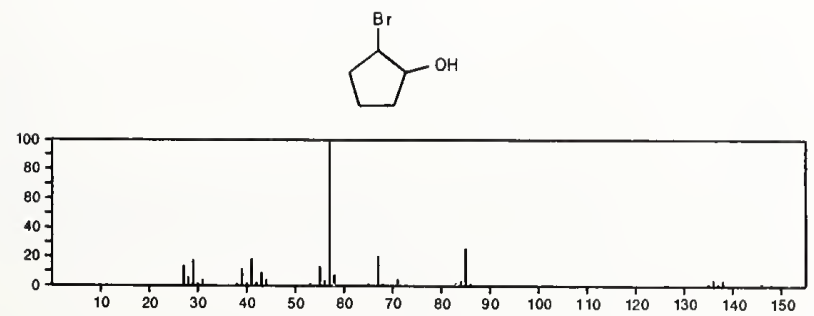
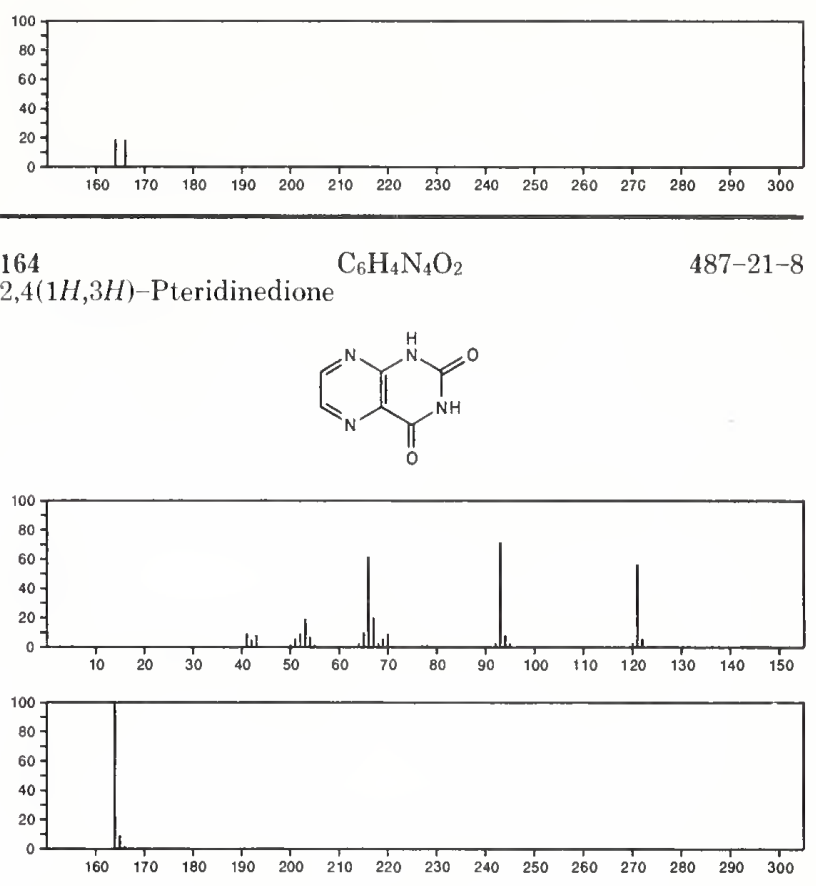

164

$\mathrm{C}_{6} \mathrm{H}_{4} \mathrm{~N}_{4} \mathrm{O}_{2}$

$1516-58-1$

Benzene, 1-azido-2-nitro-<smiles>Nc1ccccc1[N+](=O)[O-]</smiles>
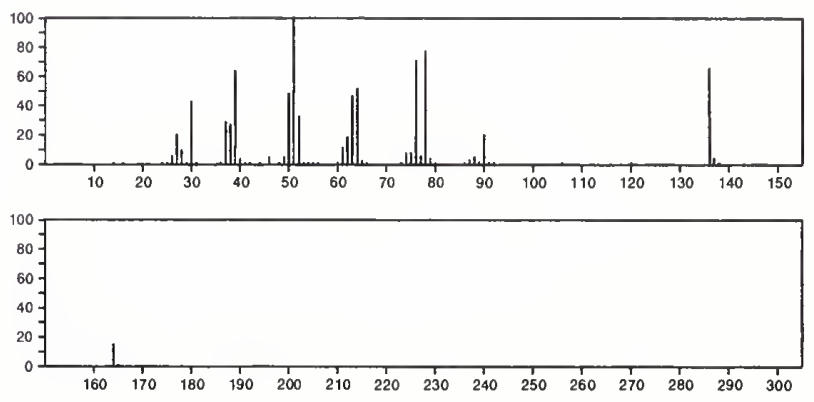

164

$\mathrm{C}_{6} \mathrm{H}_{4} \mathrm{~N}_{4} \mathrm{O}_{2}$

1516-59-2

Benzene, 1-azido-3-nitro-
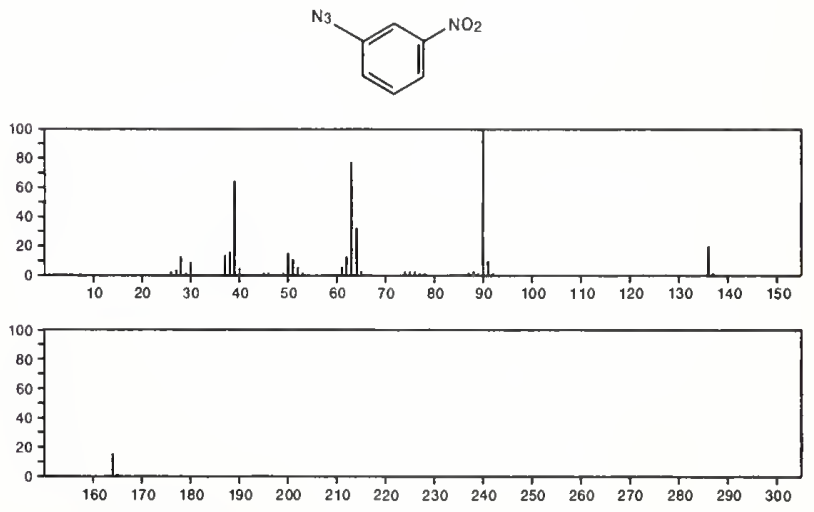
164 $\mathrm{C}_{6} \mathrm{H}_{4} \mathrm{~N}_{4} \mathrm{O}_{2}$

$1516-60-5$

Benzene, 1-azido-4-nitro-
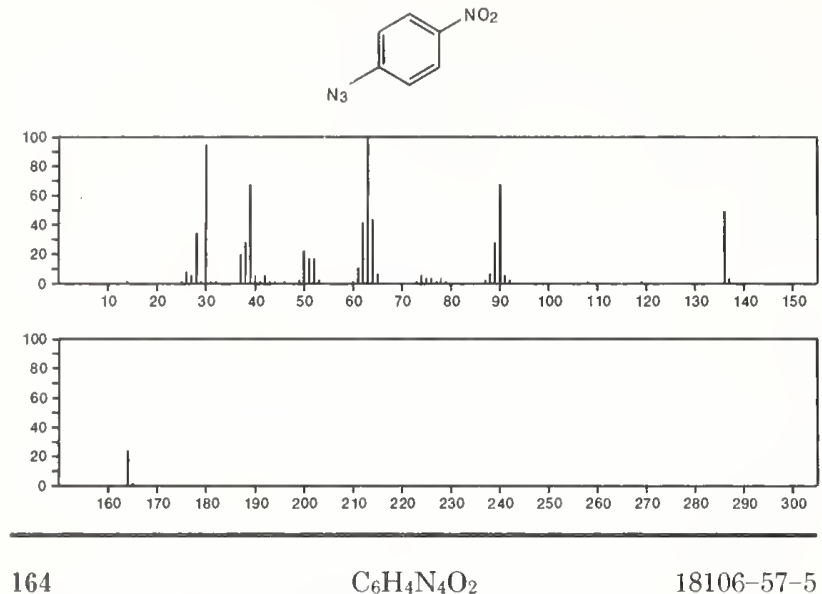

$4(3 H)$-Pteridinone, 3 hydroxy-

$18106-57-5$
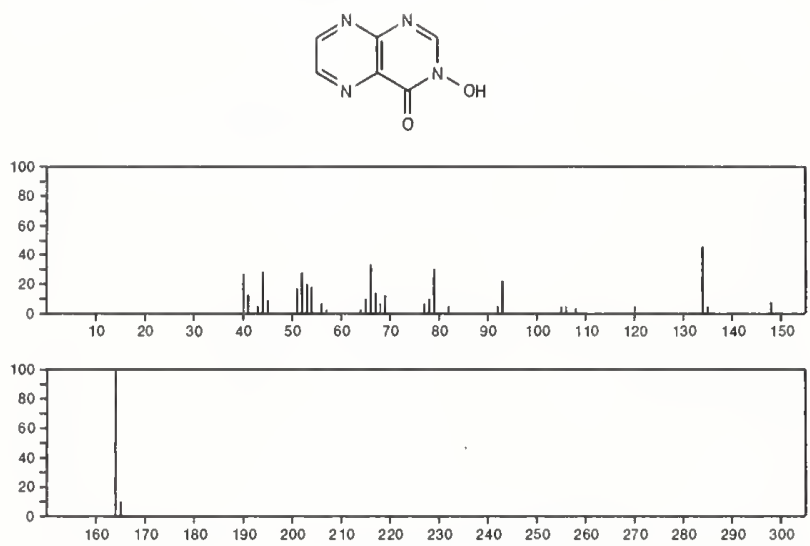

\section{4}

Butanoic acid, 2-chloro-3-0xo-, ethyl ester

609-15-4
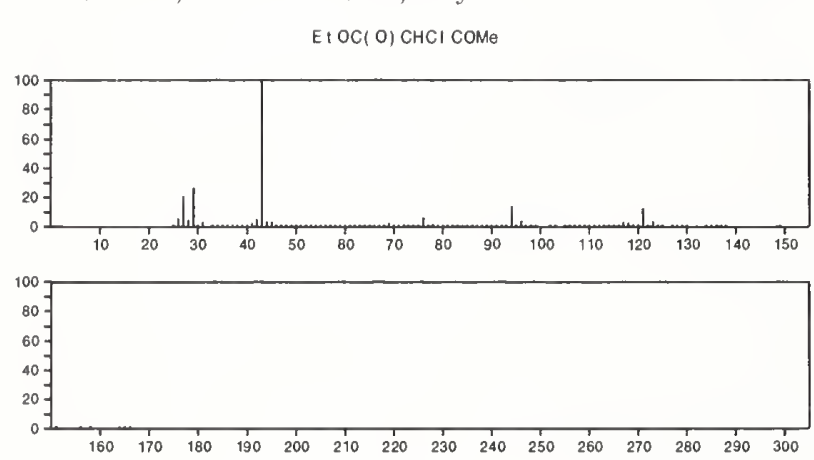

164

Carbonodithioic acid, $S$-ethyl $O$-(1-methylethyl) ester

$38379-93-0$
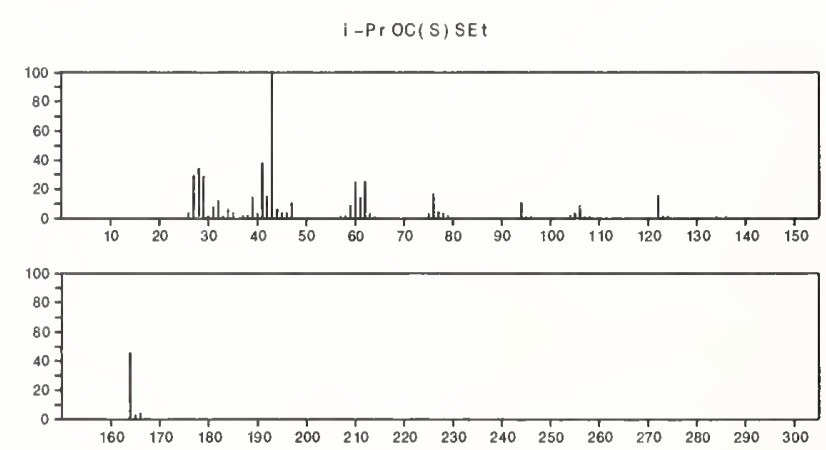

164

$\mathrm{C}_{6} \mathrm{H}_{12} \mathrm{O}_{3} \mathrm{~S}$

$19424-26-1$
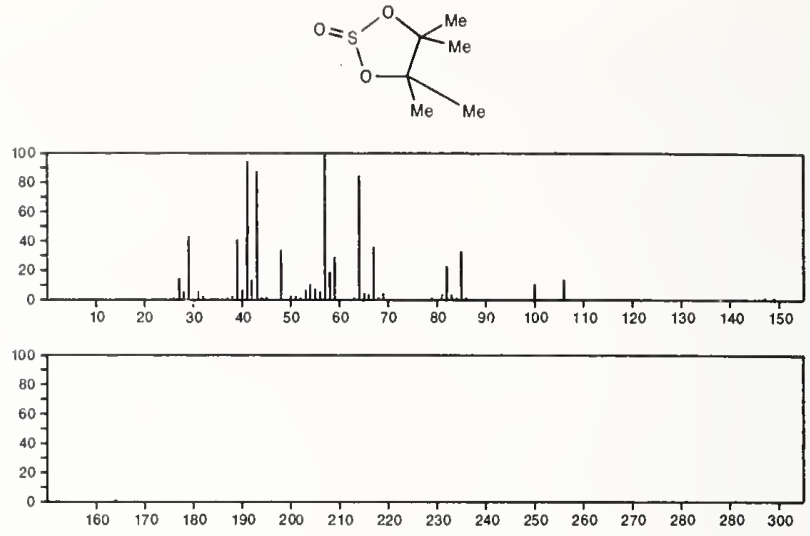

164

$\alpha-\mathrm{D}$-Xylofuranoside, methyl

1824-96-0
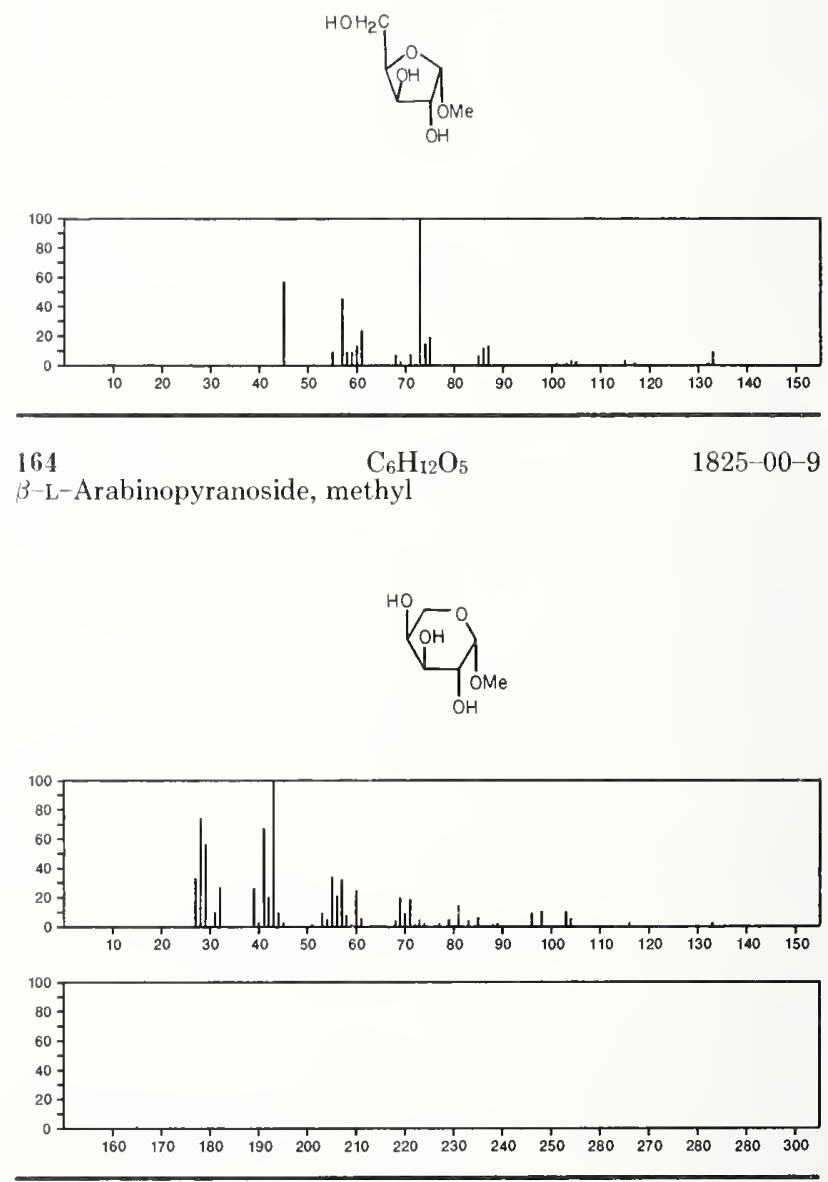

164

$\mathrm{C}_{6} \mathrm{H}_{13} \mathrm{Br}$

$111-25-1$

Hexane, 1-bromo-

$\mathrm{Br}\left(\mathrm{CH}_{2}\right) 5 \mathrm{Me}$

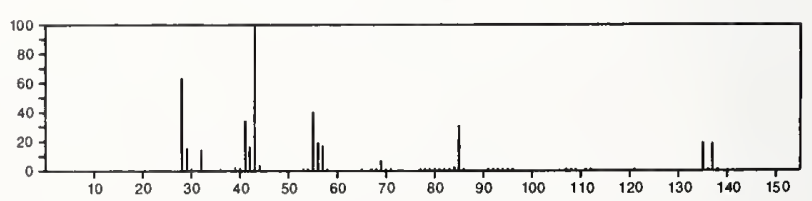



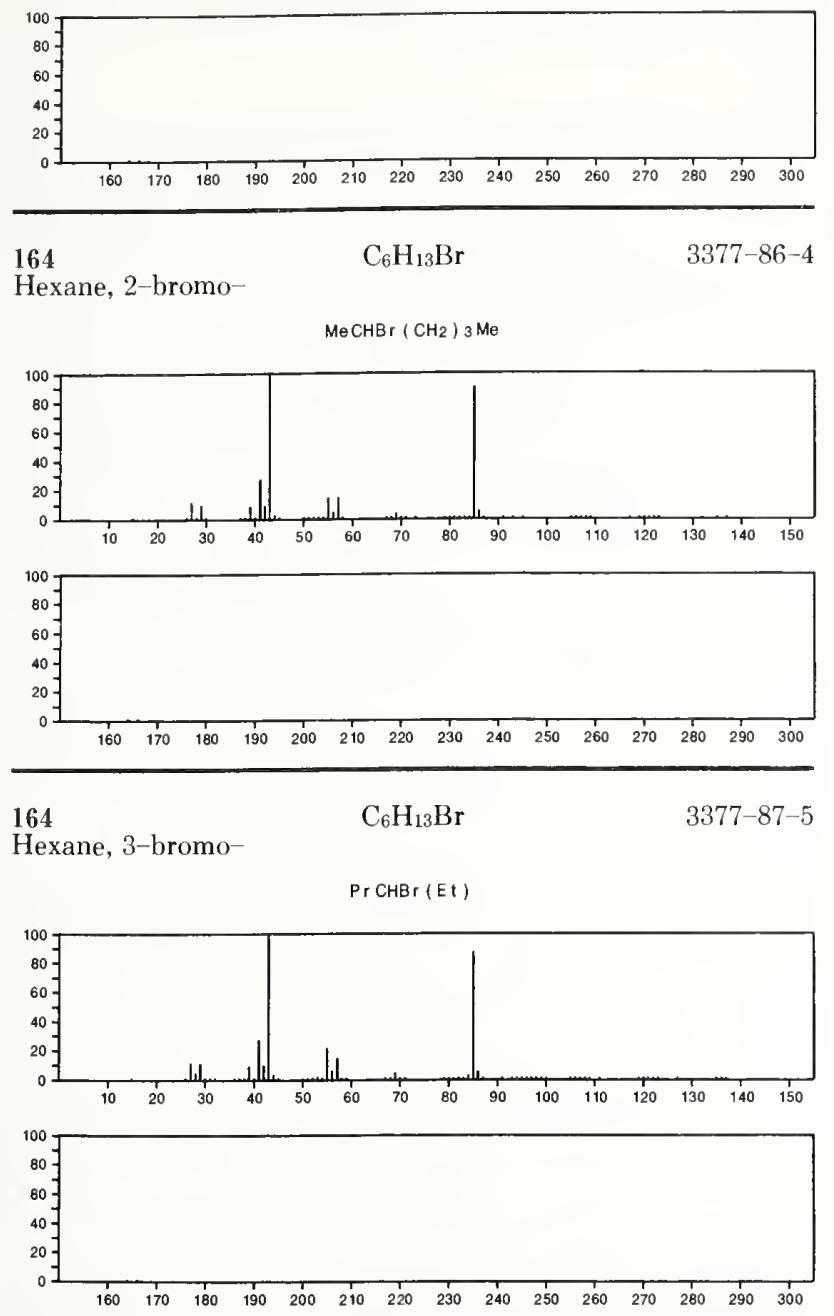

164

Pentane, 1-bromo-3-methyl-

$\mathrm{C}_{6} \mathrm{H}_{13} \mathrm{Br}$

$51116-73-5$

$\mathrm{Br} \mathrm{CH} \mathrm{CH}_{2} \mathrm{CHM}_{e} \mathrm{CH}_{2} \mathrm{Me}$
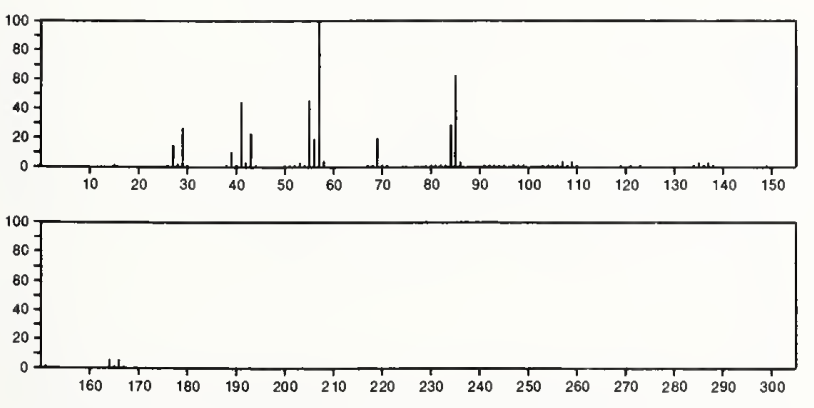

164

Toluene, 2,3,4,5-tetrafluoro-

$$
\mathrm{C}_{7} \mathrm{H}_{4} \mathrm{~F}_{4}
$$

$21622-19-5$
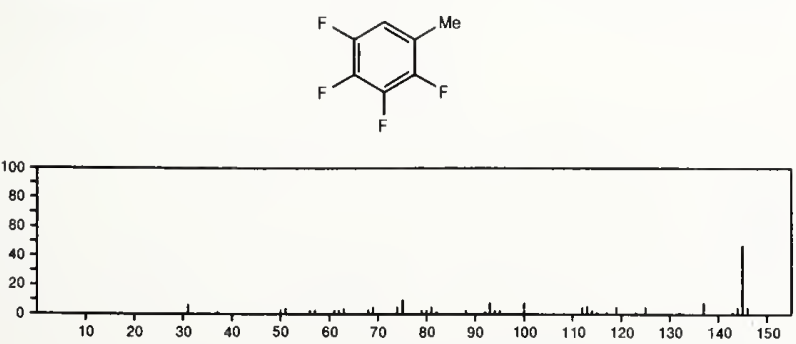

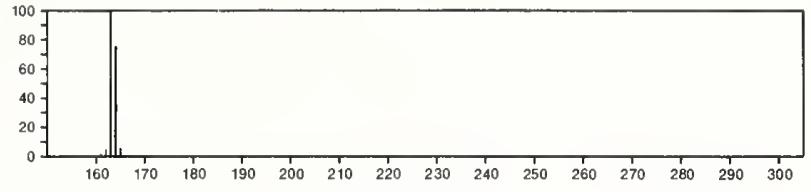

$\mathrm{C}_{7} \mathrm{H}_{4} \mathrm{~N}_{2} \mathrm{O}_{3}$

$100-28-7$

164

Benzene, 1-isocyanato-4-nitro-
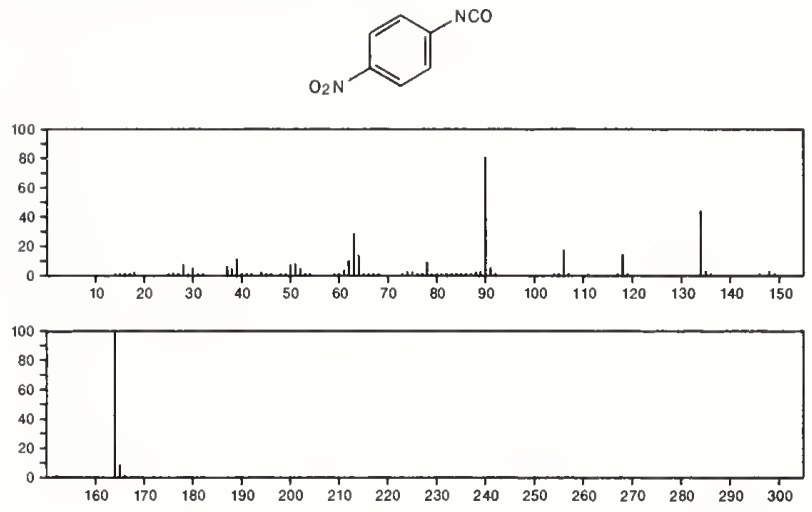

164

$\mathrm{C}_{7} \mathrm{H}_{8} \mathrm{~N}_{4} \mathrm{O}$

$19855-19-7$

$s$-Triazolo[4,3-a]pyrazin-3(2H)-one, 5,8-dimethyl-
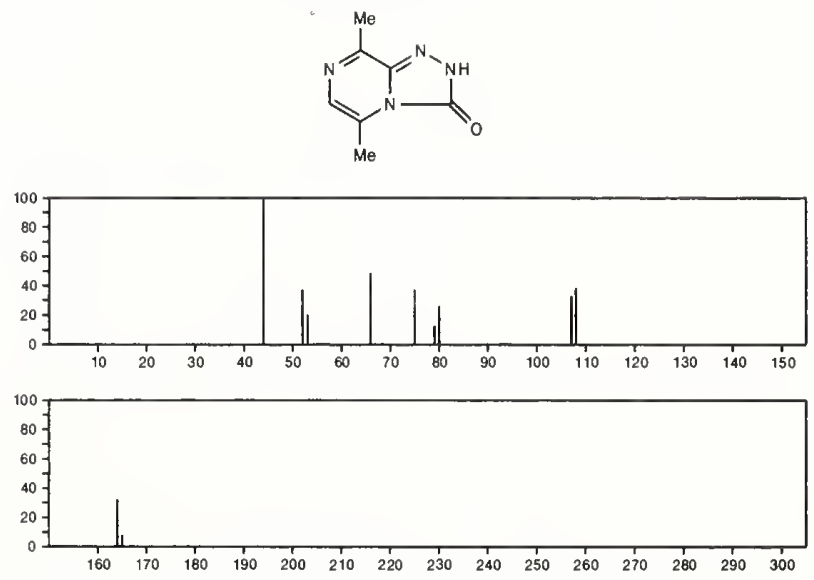

$823-69-8$

Bicyclo[4.1.0]heptane, 7,7-dichloro-
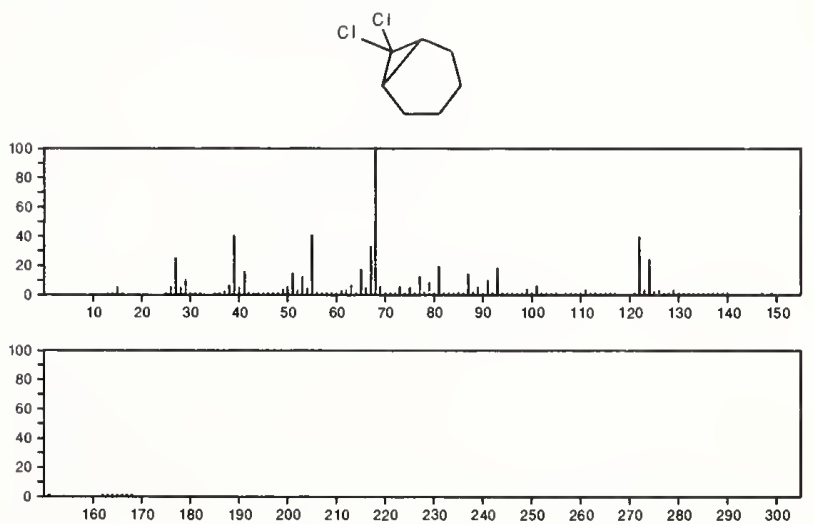
164

$\mathrm{C}_{7} \mathrm{H}_{13} \mathrm{ClO}_{2}$

1,3-Dioxolane, 2-(3-chloropropyl)-2-methyl

$5978-08-5$

$\sum_{0}^{0} Y_{\mathrm{Me}}^{\left(\mathrm{CH}_{2}\right)_{3 \mathrm{Cl}}}$
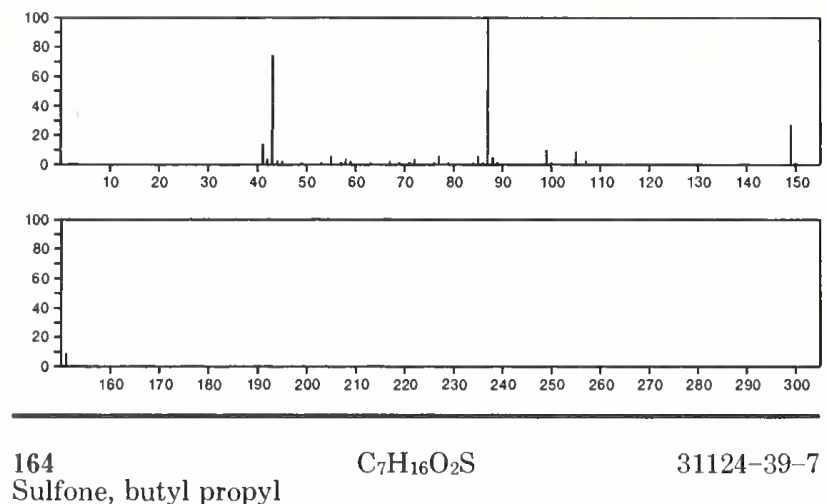

Sulfone, butyl propyl

$\mathrm{Me}\left(\mathrm{CH}_{2}\right)_{3} \mathrm{SO}_{2} \mathrm{Pr}$
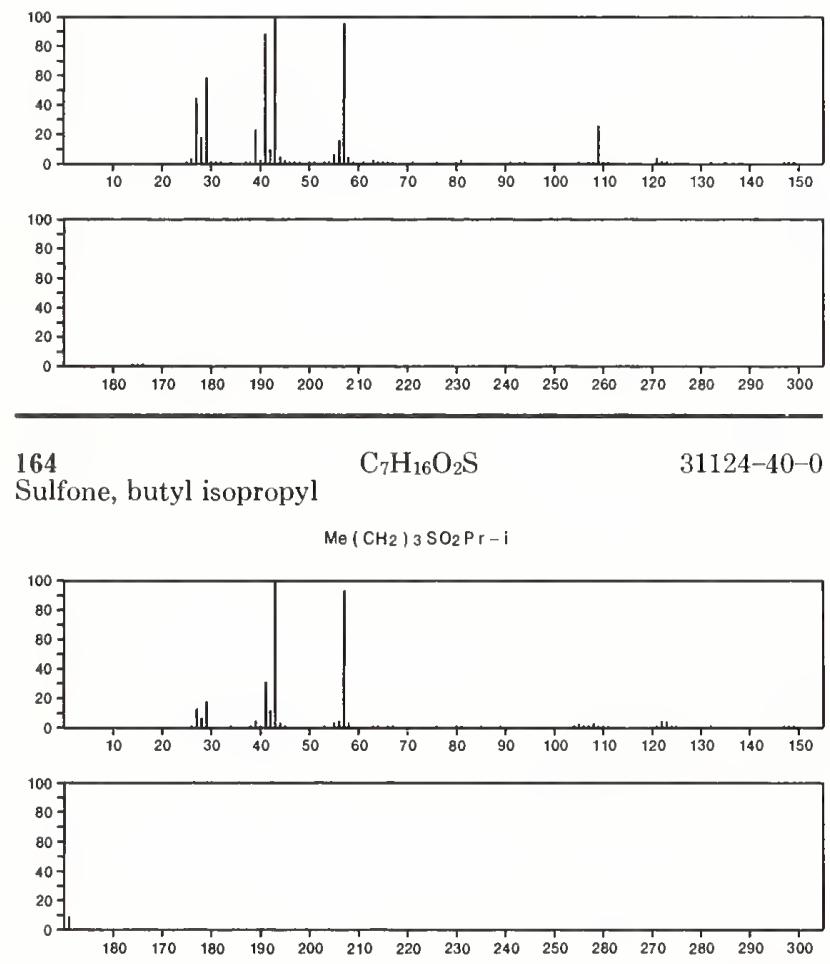

164

$\mathrm{C}_{7} \mathrm{H}_{16} \mathrm{O}_{4}$

Ethanol, 2-[2-(2-methoxyethoxy)ethoxy]

$\mathrm{HOCH}_{2} \mathrm{CH}_{2} \mathrm{OCH}_{2} \mathrm{CH}_{2} \mathrm{OCH}_{2} \mathrm{CH}_{2} \mathrm{OMe}$

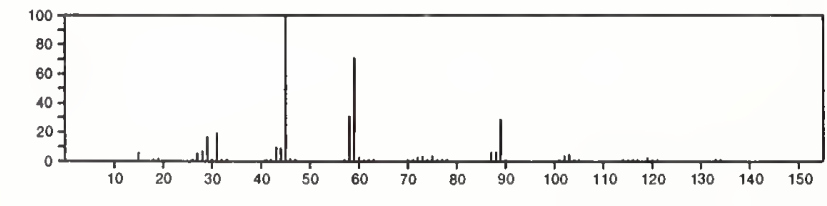

$164 \quad \mathrm{C}_{7} \mathrm{H}_{16} \mathrm{~S}_{2}$

Propane, 2,2-bis(ethylthio)-

$\mathrm{EtS} 2 \mathrm{C}(\mathrm{Me})_{2}$

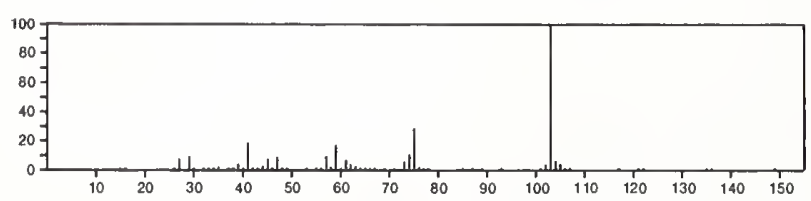

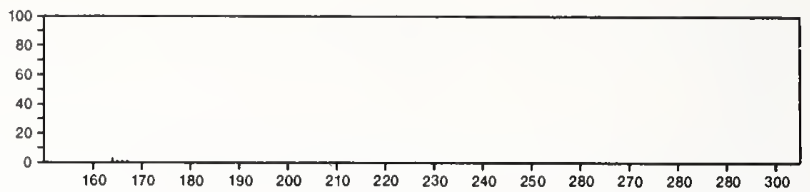

Propane, 1,3-bis(ethylthio)-

$\mathrm{C}_{7} \mathrm{H}_{16} \mathrm{~S}_{2}$

$33672-52-5$

$\mathrm{E}: \mathrm{S}\left(\mathrm{CH}_{2}\right)_{3} \mathrm{SEt}$
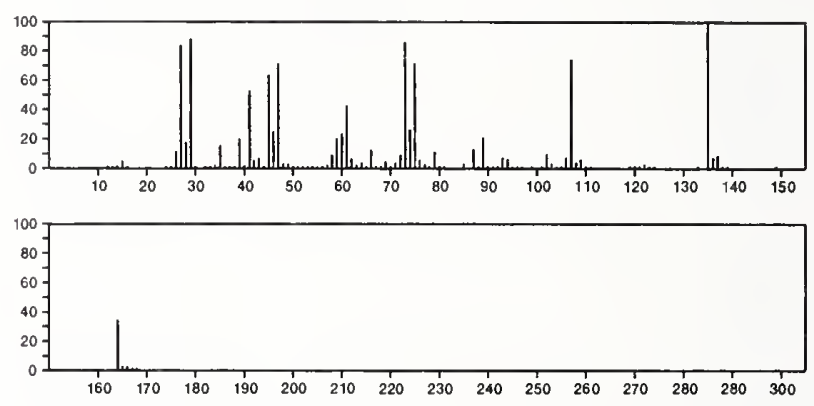

$164 \quad \mathrm{C}_{7} \mathrm{H}_{16} \mathrm{~S}_{2}$

Propane, 1,2-bis(ethylthio)-

$\mathrm{E}$ t SCH $2 \mathrm{CH}$ (SEt) Me
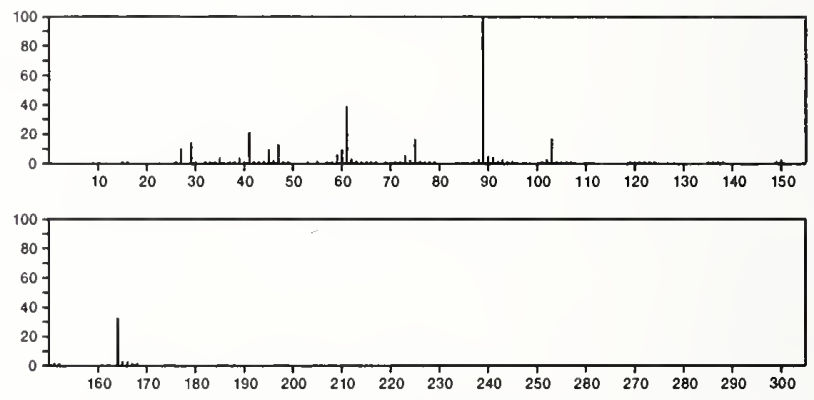

$164 \quad \mathrm{C}_{7} \mathrm{H}_{16} \mathrm{~S}_{2}$

$54410-63-8$

Pentane, 1,5-bis(methylthio)-

$\mathrm{MeS}\left(\mathrm{CH}_{2}\right) 5 \mathrm{SMe}$
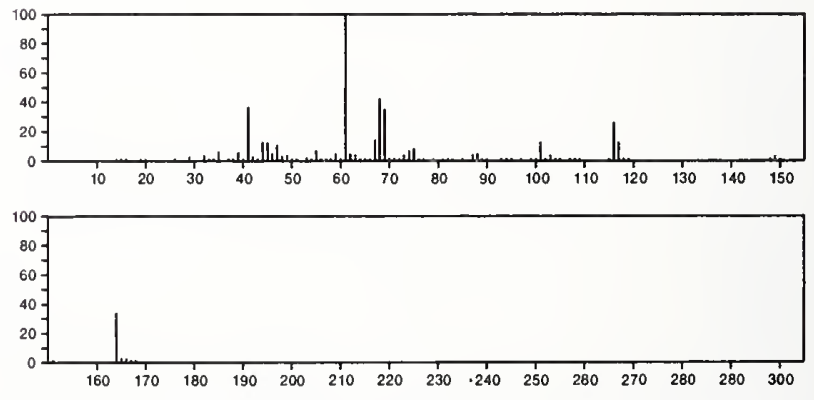

164

$\mathrm{C}_{8} \mathrm{H}_{8} \mathrm{~N}_{2} \mathrm{O}_{2}$

524-40-3

3-Pyridinecarbonitrile, 1,2-dihydro-4-methoxy-1-methyl-2-oxo-
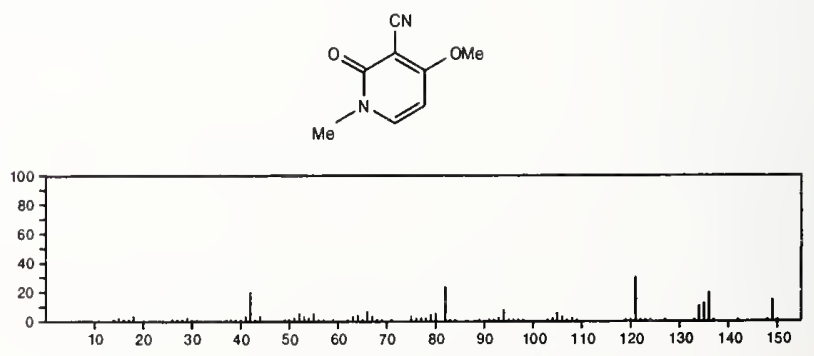


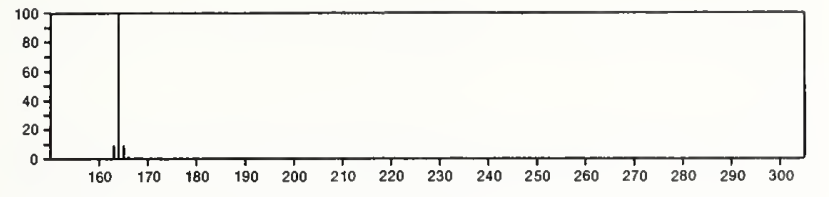

$164 \quad \mathrm{C}_{8} \mathrm{H}_{8} \mathrm{~N}_{2} \mathrm{O}_{2} \quad 2080-75-3$

2H-Benzimidazol-2-one, 1,3-dihydro-5-methoxy-
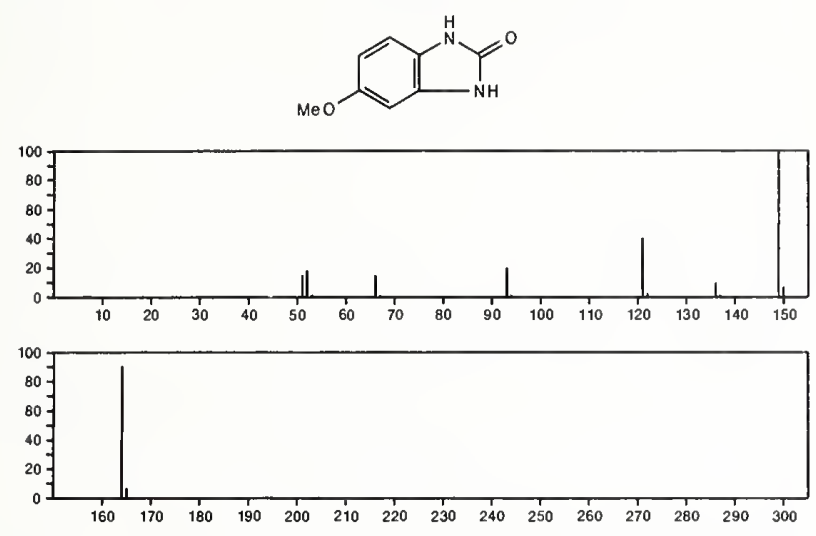

$164 \quad \mathrm{C}_{8} \mathrm{H}_{8} \mathrm{~N}_{2} \mathrm{O}_{2} \quad 16007-56-0$ Benzimidazole, 2-methoxy-, 3-oxide
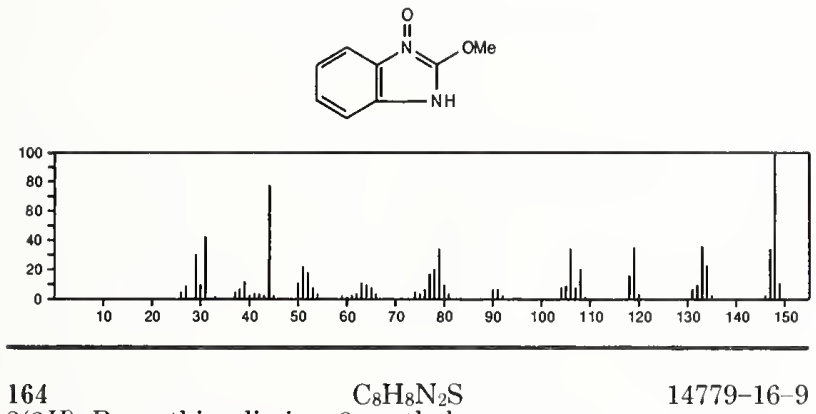

2(3H)-Benzothiazolimine, 3-methyl-
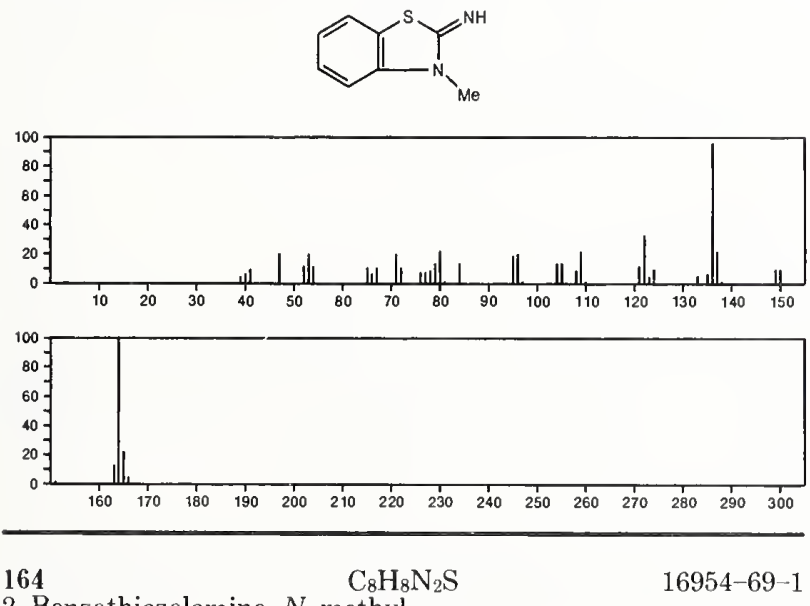

2-Benzothiazolamine, $\mathrm{N}$-methyl-
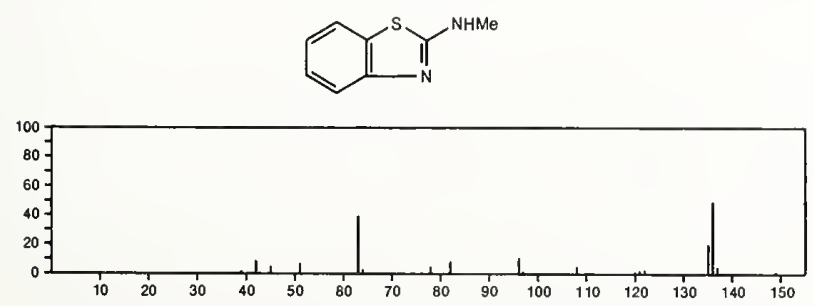

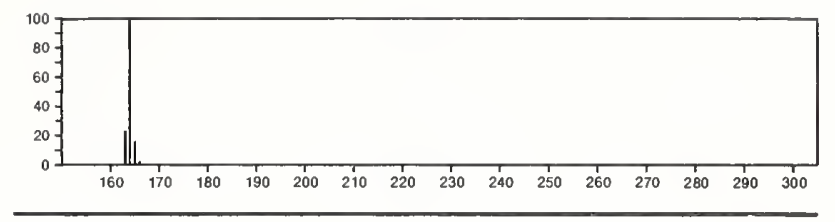

164

$\mathrm{C}_{8} \mathrm{H}_{12} \mathrm{~N}_{4}$

$51659-18-8$

1-Propen-2-amine, $N, N$-dimethyl-1-(1,2,4-triazin-5-yl)-<smiles>CC(C)=Cc1cnncn1</smiles>
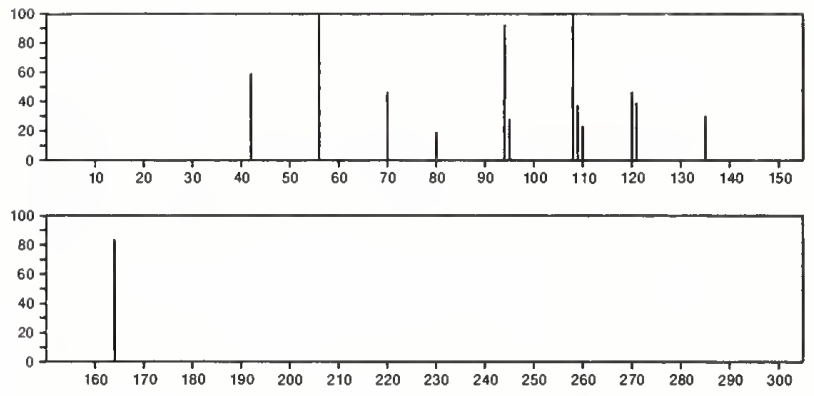

164

1,3-Disilaindan, 1-methyl-

$\mathrm{C}_{8} \mathrm{H}_{12} \mathrm{Si}_{2}$

$18292-03-0$
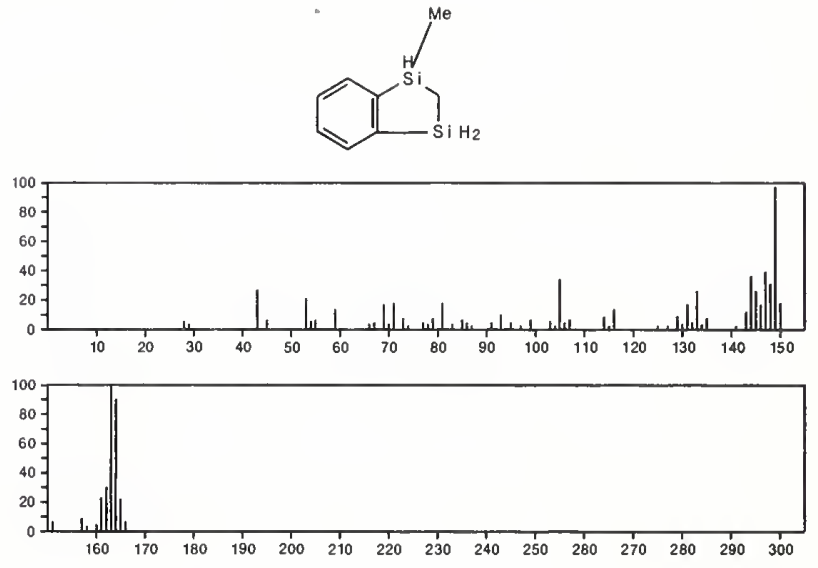

164

$\mathrm{C}_{9} \mathrm{H}_{8} \mathrm{O}_{3}$

156-06-9

Benzenepropanoic acid, $\alpha-\mathrm{oxo}^{-}$

$\mathrm{HO}_{2} \mathrm{CCOCH}_{2} \mathrm{Ph}$
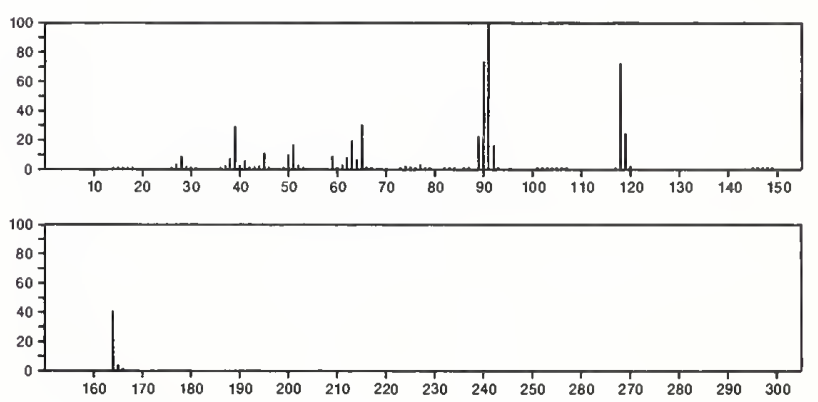
164 $\mathrm{C}_{9} \mathrm{H}_{8} \mathrm{O}_{3}$

2-Propenoic acid, 3-(2-hydroxyphenyl)
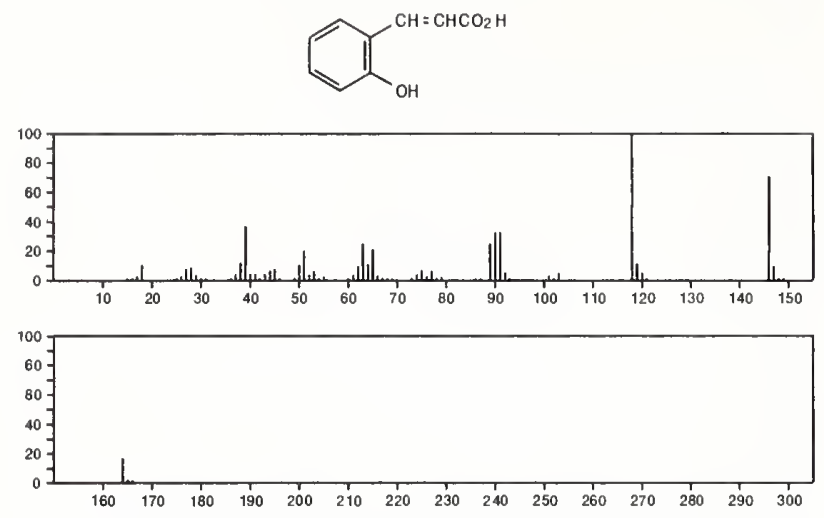

164

$$
\mathrm{C}_{9} \mathrm{H}_{8} \mathrm{O}_{3}
$$

Benzoic acid, 2-formyl-, methyl ester

$4122-56-9$
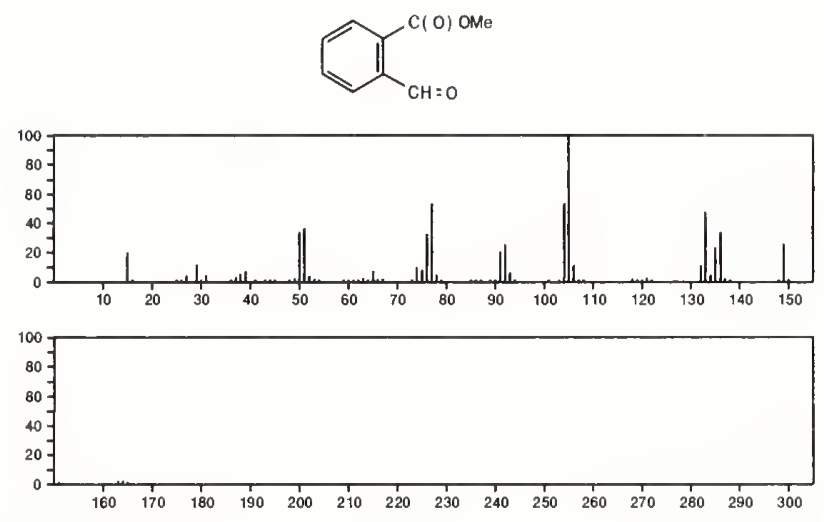

164

1,3-Dioxolan 2-one, 4-phenyl-

$$
\mathrm{C}_{9} \mathrm{H}_{8} \mathrm{O}_{3}
$$

$4427-92-3$
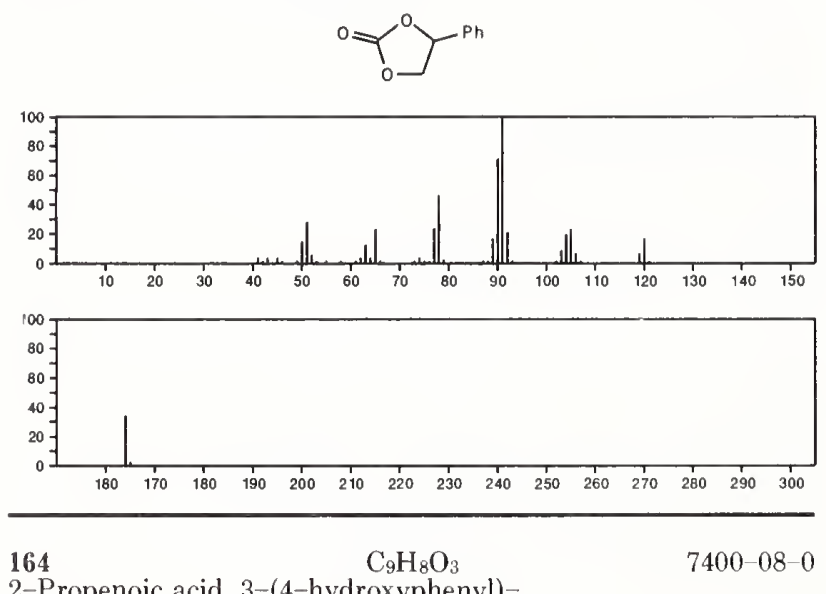

2-Propenoic acid, 3-(4-hydroxyphenyl)-
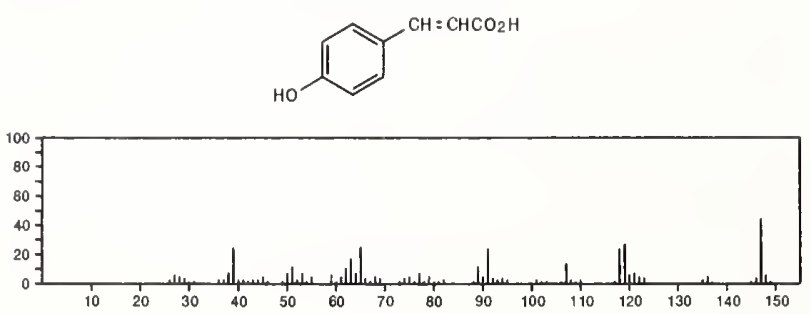

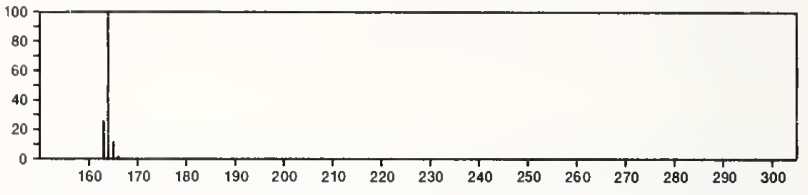

$101-42-8$

164
Urea, $N, N$-dimethyl- $N^{\prime}$-phenyl- $\mathrm{C}_{9} \mathrm{H}_{12} \mathrm{~N}_{2} \mathrm{O}$

$\mathrm{Me} 2 \mathrm{NCONHPh}$
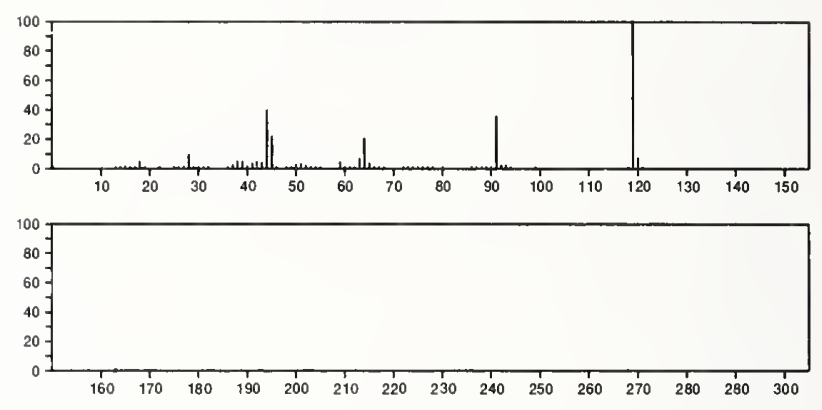

164

$\mathrm{C}_{9} \mathrm{H}_{12} \mathrm{~N}_{2} \mathrm{O}$

Formamidine, $N^{\prime}-(p$-hydroxyphenyl $)-N, N$-dimethyl-

$2350-51-8$
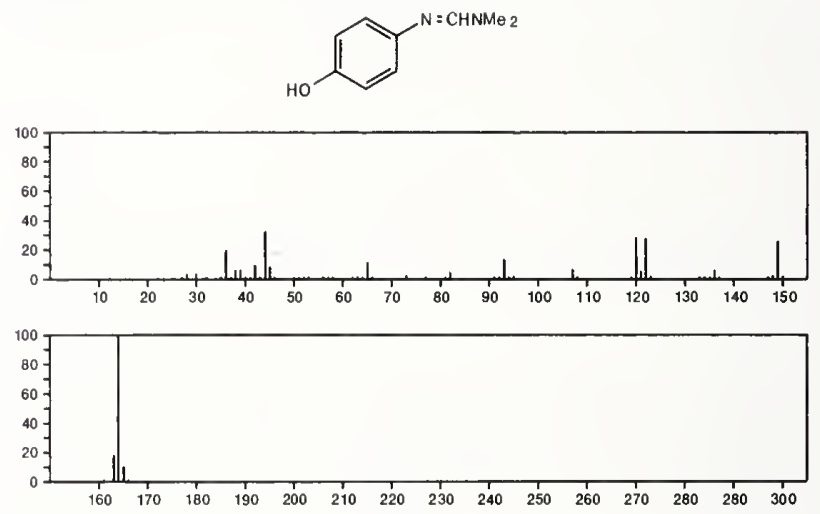

$\mathbf{1 6 4}$
Methanimidamide, $N^{\prime}-(3-$ hydroxyphenyl $)-N, N$-dimethyl-

$\mathrm{C}_{9} \mathrm{H}_{12} \mathrm{~N}_{2} \mathrm{O}$

25635-97-6
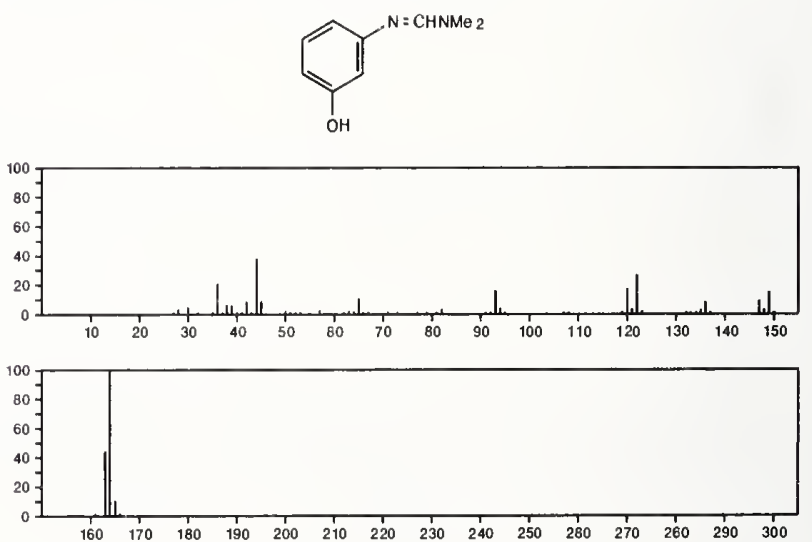
164

$\mathrm{C}_{9} \mathrm{H}_{12} \mathrm{~N}_{2} \mathrm{O}$

31020-35-6

Pyridinium, 1-(acetylamino)-2,6-dimethyl-, hydroxide, inner salt<smiles></smiles>
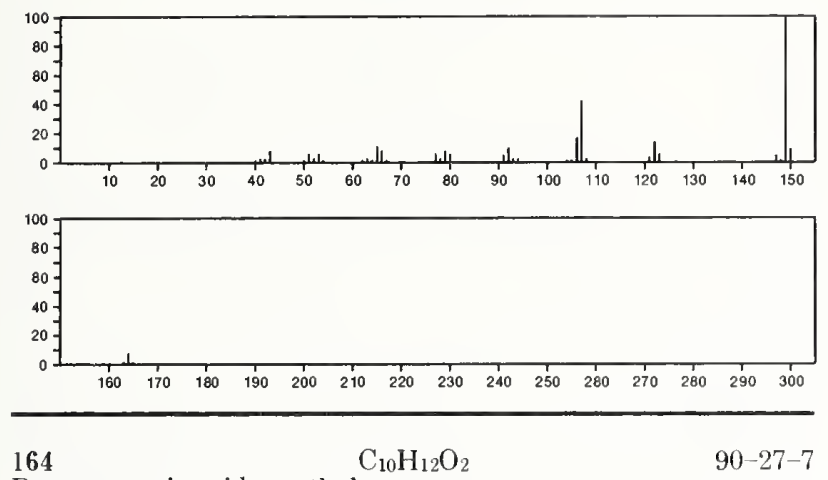

Benzeneacetic acid, $\alpha$-ethyl-

$\mathrm{PhCHE} \uparrow\left(\mathrm{CO}_{2} \mathrm{H}\right)$
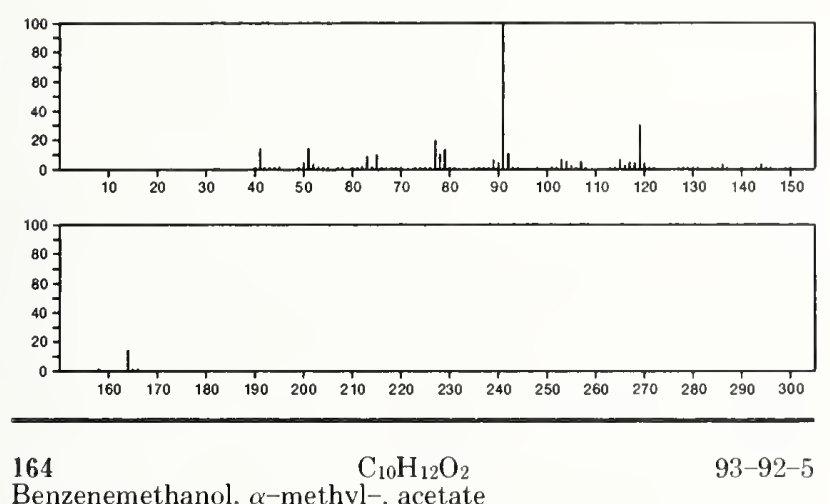

Benzenemethanol, $\alpha$-methyl-, acetate

AC OCHMePh
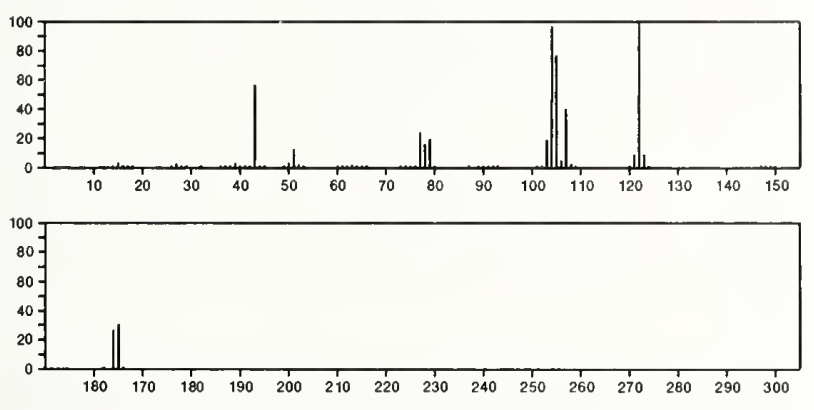

164

$\mathrm{C}_{10} \mathrm{H}_{12} \mathrm{O}_{2}$

Phenol, 2-methoxy-4-(2-propenyl)-
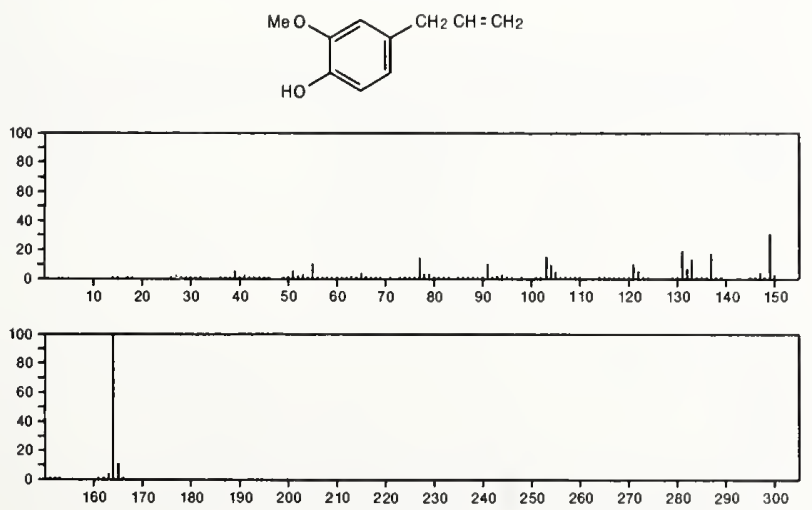

164

$\mathrm{C}_{10} \mathrm{H}_{12} \mathrm{O}_{2}$

$97-54-1$

Phenol, 2-methoxy-4-(1-propenyl)-
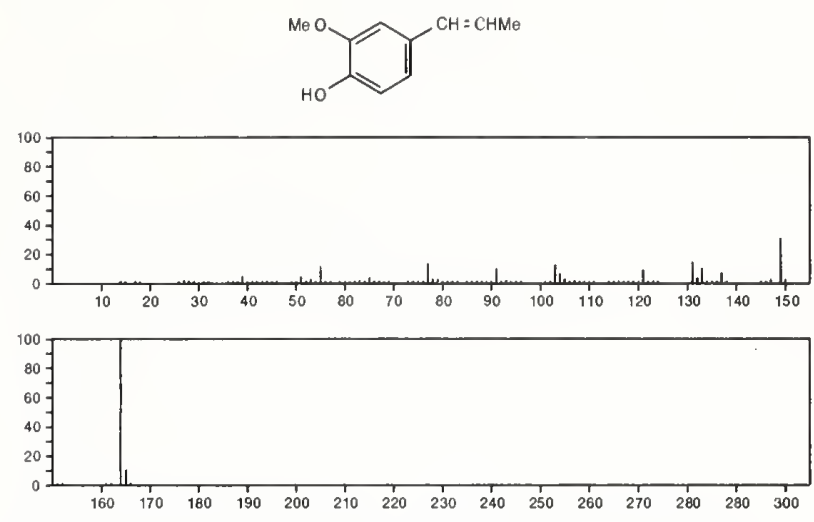

164

1,3-Dioxolane, 2-(phenylmethyl)-

$101-49-5$

$\mathrm{L}_{0}^{\mathrm{O}} \mathrm{CH}^{\mathrm{CH}_{2} \mathrm{Ph}}$
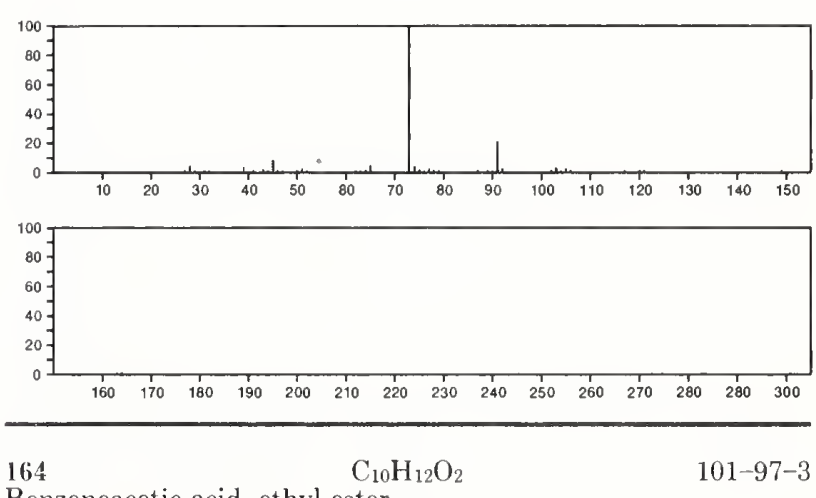

Benzeneacetic acid, ethyl ester

$\mathrm{PhCH}_{2} \mathrm{C}(\mathrm{O}) \mathrm{OEI}$
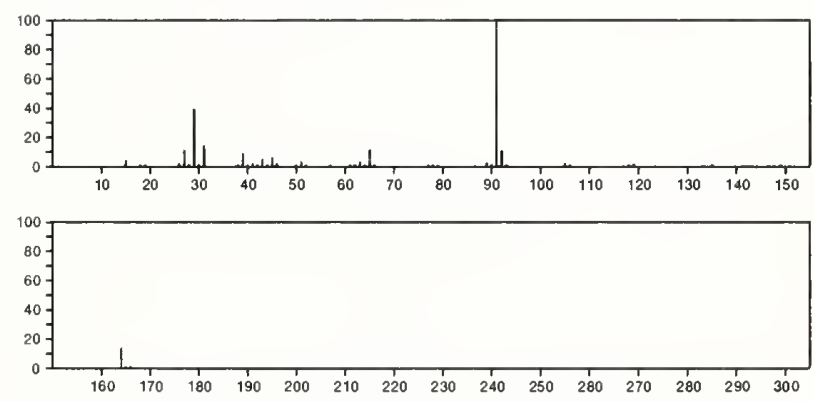

164

$\mathrm{C}_{10} \mathrm{H}_{12} \mathrm{O}_{2}$

Benzenepropanoic acid, methyl ester

103-25-3

$\mathrm{MeOC}(\mathrm{O}) \mathrm{CH}_{2} \mathrm{CH}_{2} \mathrm{Ph}$
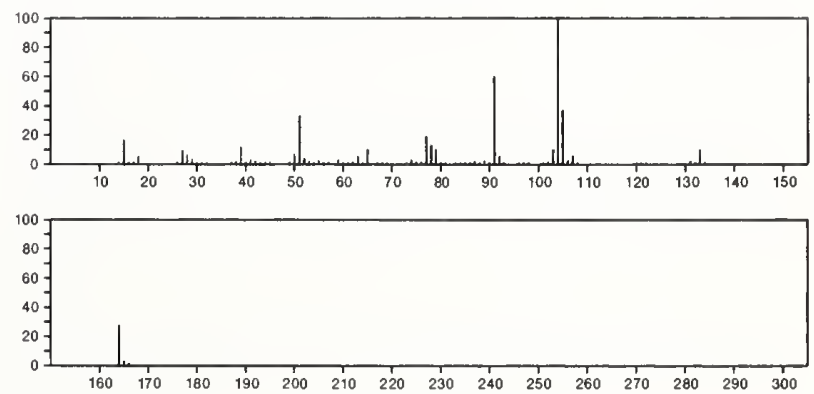
164

$\mathrm{C}_{10} \mathrm{H}_{12} \mathrm{O}_{2}$

Acetic acid, 2-phenylethyl ester

$\mathrm{PhCH}_{2} \mathrm{CH}_{2} \mathrm{OAC}$

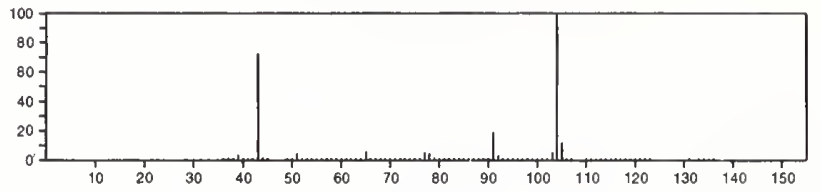

164

$\mathrm{C}_{10} \mathrm{H}_{12} \mathrm{O}_{2}$

1-Propanone, 1-(4-methoxyphenyl)-
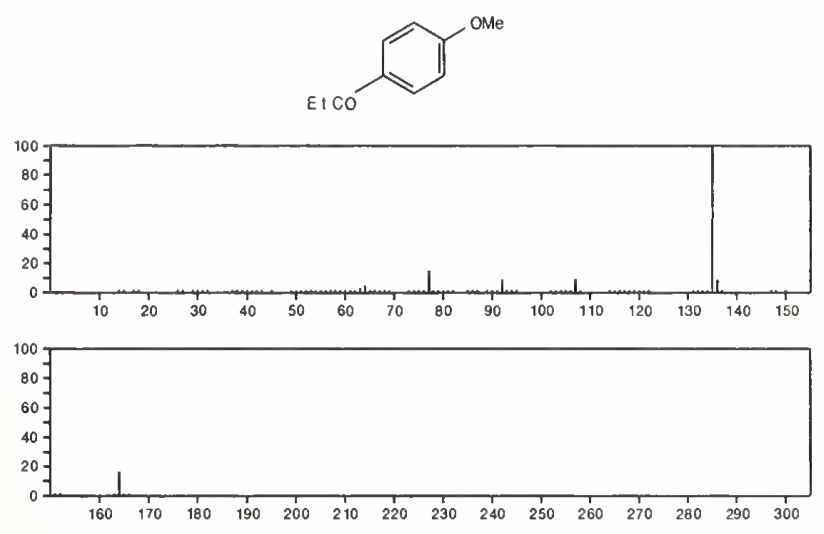

164

$\mathrm{C}_{10} \mathrm{H}_{12} \mathrm{O}_{2}$

$122-84-9$

2-Propanone, 1-(4-methoxyphenyl)-
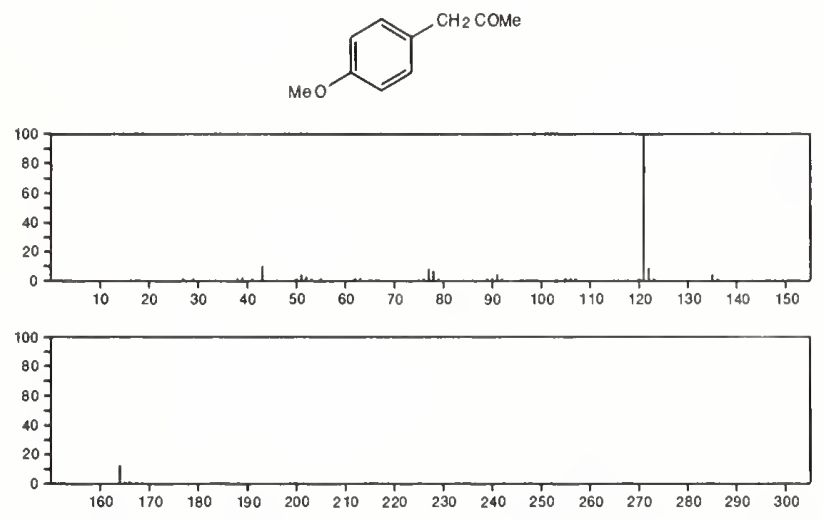

164

$\mathrm{C}_{10} \mathrm{H}_{12} \mathrm{O}_{2}$

$480-63-7$

Benzoic acid, 2,4,6-trimethyl-<smiles>Cc1cc([N+](=O)[O-])c(C(=O)O)c([N+](=O)[O-])c1</smiles>
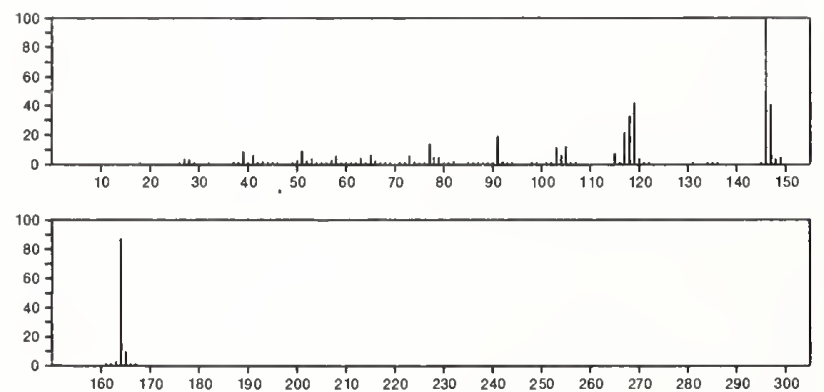

$164 \quad \mathrm{C}_{10} \mathrm{H}_{12} \mathrm{O}_{2}$

2,5-Cyclohexadiene-1,4-dione, 2,3,5,6-tetramethyl-
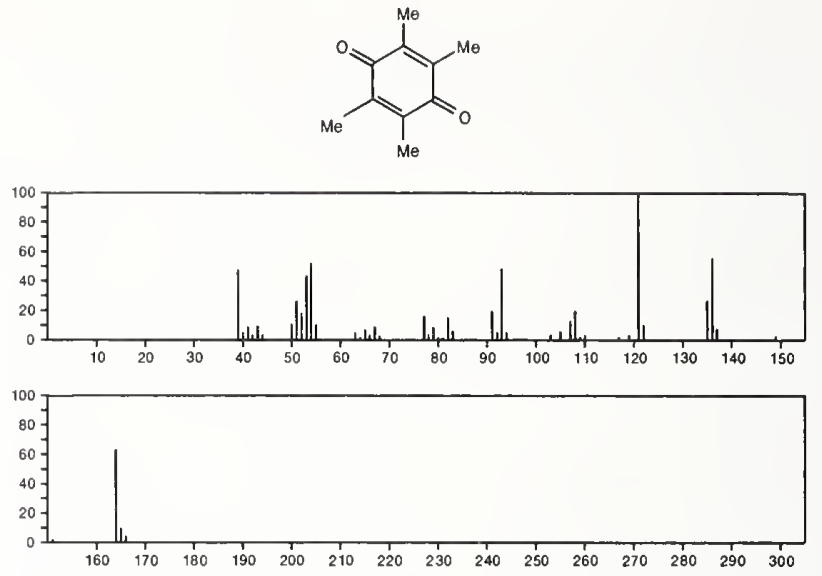

164

$\mathrm{C}_{10} \mathrm{H}_{12} \mathrm{O}_{2}$

$528-90-5$

Benzoic acid, 2,4,5-trimethyl-
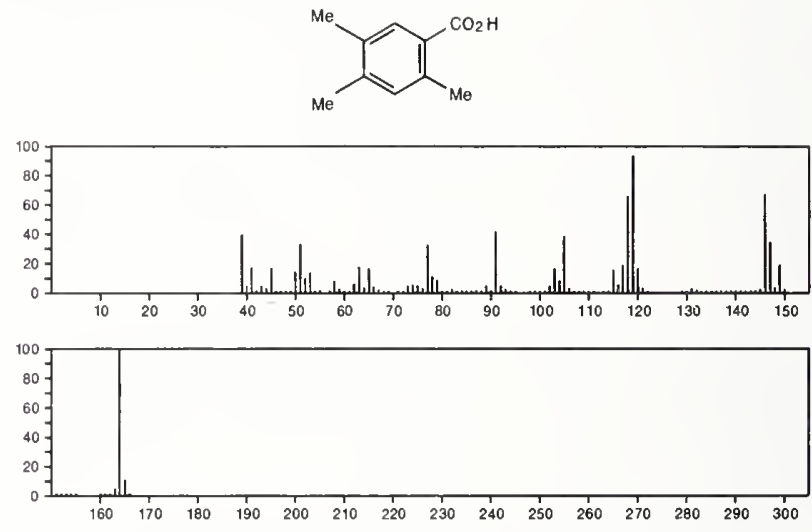

164

$\mathrm{C}_{10} \mathrm{H}_{12} \mathrm{O}_{2}$

Benzoic acid, 4-(1-methylethyl)-
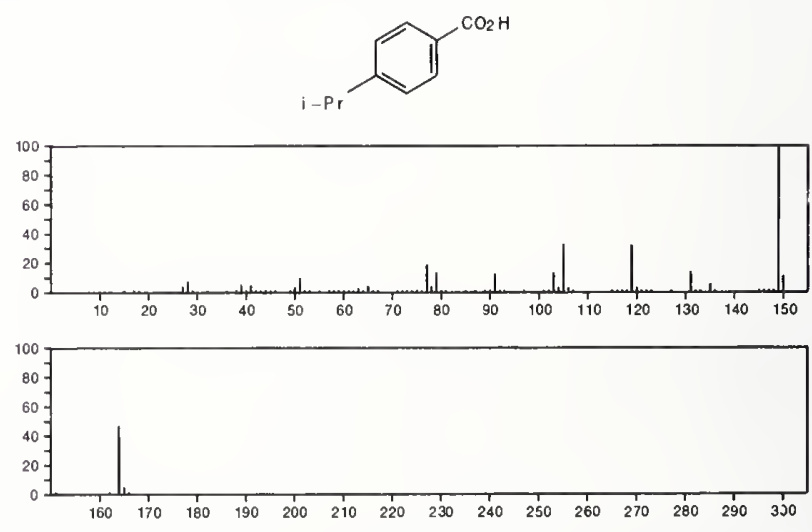

$164 \quad \mathrm{C}_{10} \mathrm{H}_{12} \mathrm{O}_{2} \quad 772-01-0$ 1,3-Dioxane, 2-phenyl-
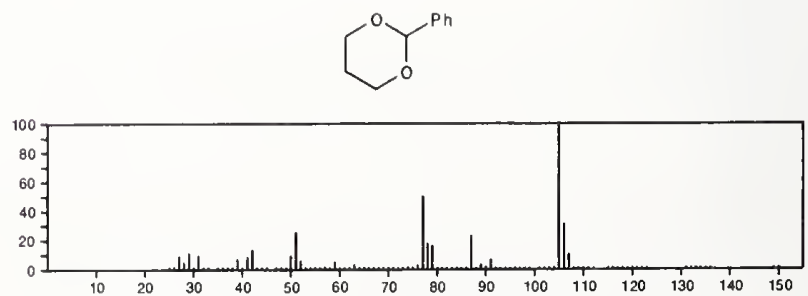


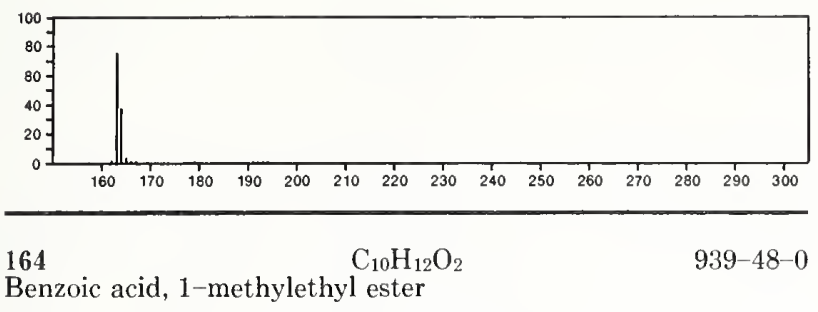

Benzoic acid, 1-methylethyl ester
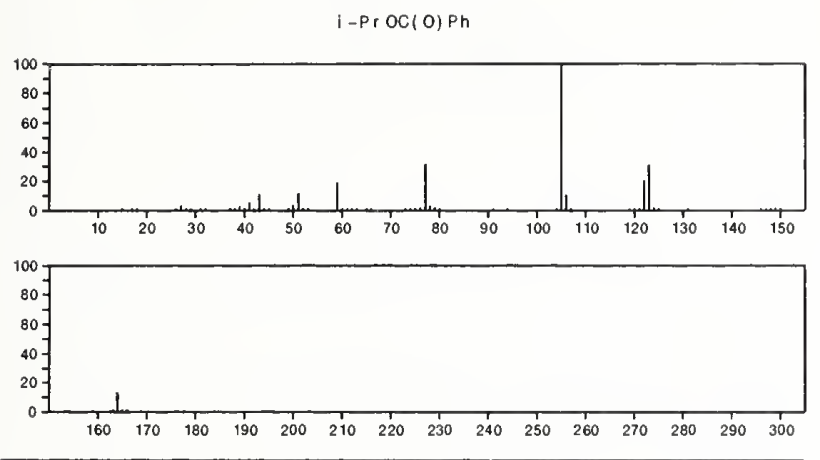

164

Phenol, 2-methoxy-6-(1-propenyl)-

1076-55-7
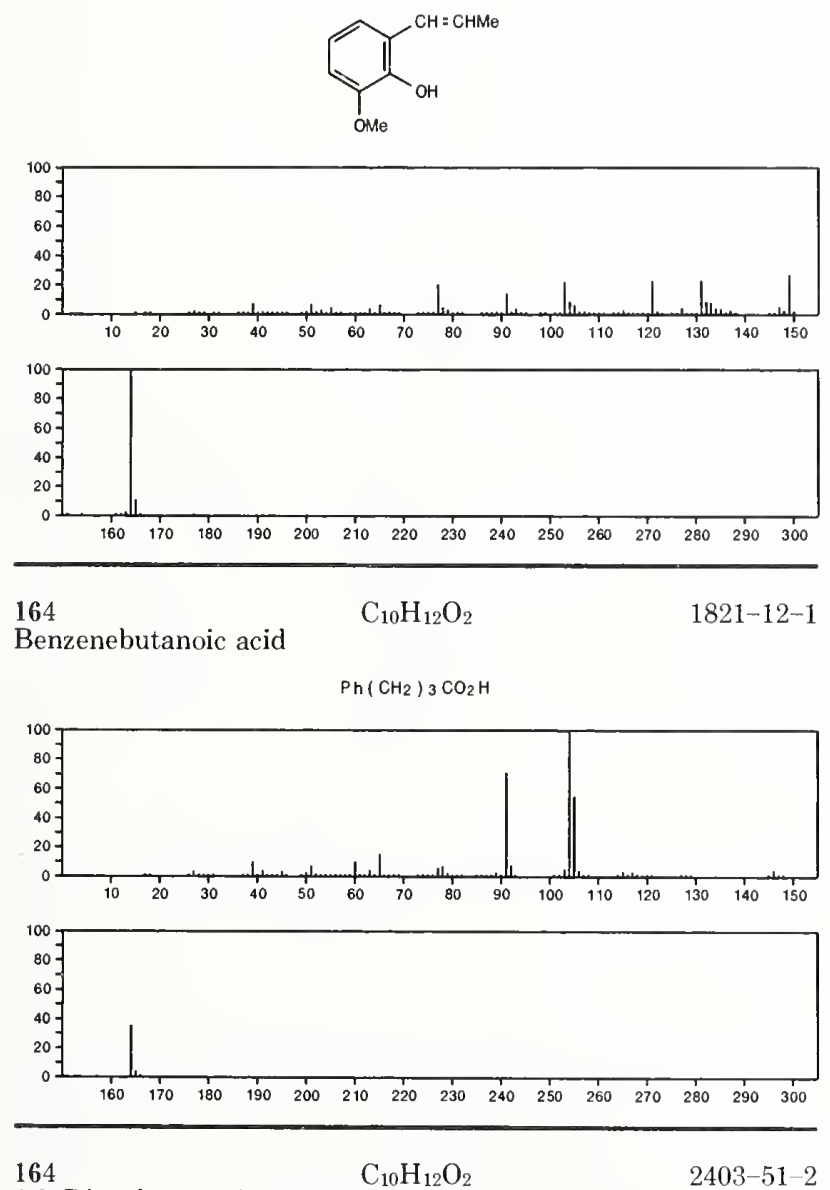

1,3-Dioxolane, 2-(4-methylphenyl)-

$2403-51-2$
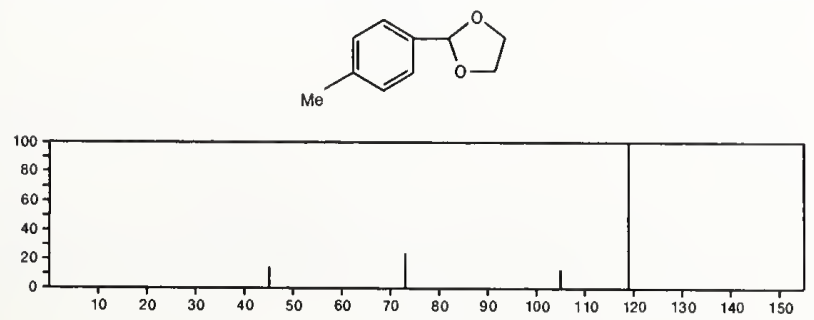

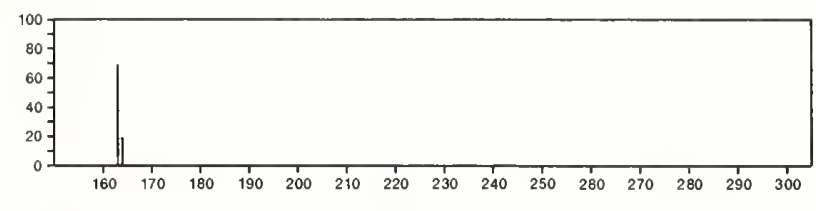

$164 \quad \mathrm{C}_{10} \mathrm{H}_{12} \mathrm{O}_{2}$

1,3-Dioxolane, 4-methyl-2-phenyl-

$2568-25-4$<smiles>CC1COC(c2ccccc2)O1</smiles>
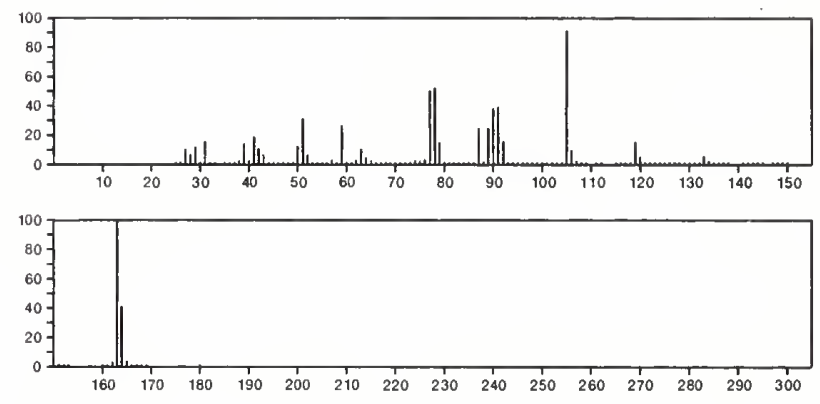

164

Phenol, 3-ethyl-, acetate

$\mathrm{C}_{10} \mathrm{H}_{12} \mathrm{O}_{2}$

$3056-60-8$<smiles>CCc1cccc(OC(C)=O)c1</smiles>
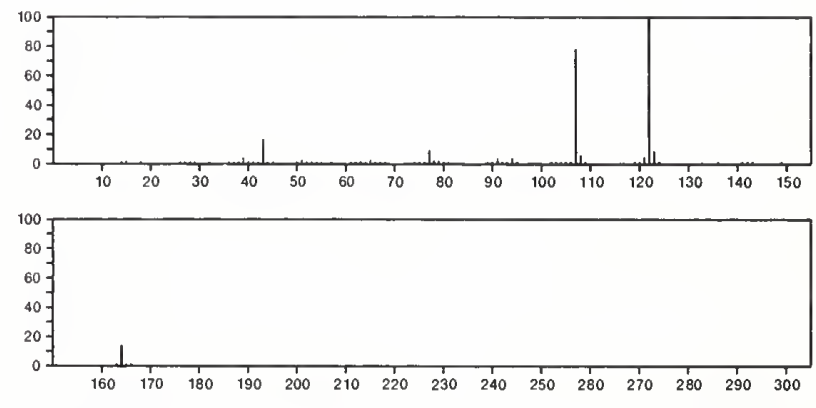

164

$\mathrm{C}_{10} \mathrm{H}_{12} \mathrm{O}_{2}$

$3602-55-9$

2,5-Cyclohexadiene-1,4-dione, 2-(1,1-dimethylethyl)-
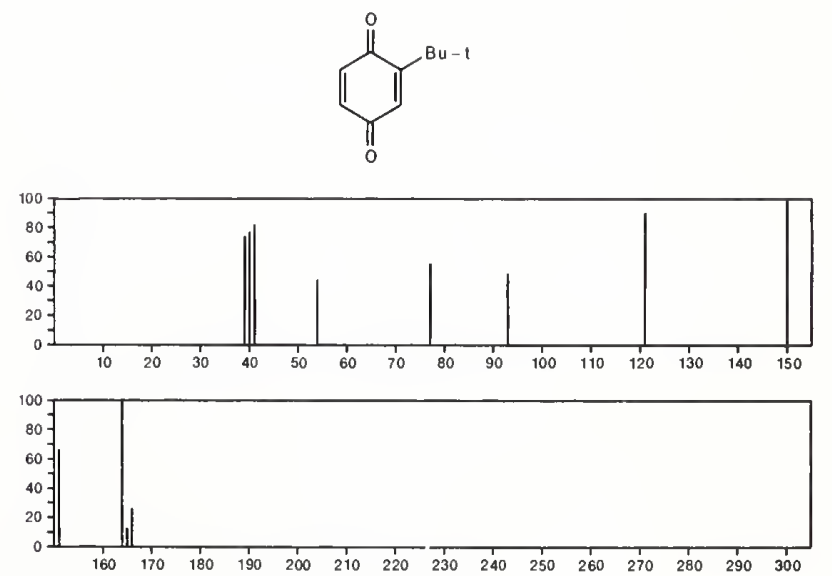
164

$\mathrm{C}_{10} \mathrm{H}_{12} \mathrm{O}_{2}$

1,3-Dioxolane, 2-methyl-2-phenyl-

$3674-77-9$

$L_{0}^{0} \gamma_{M e}^{p h}$
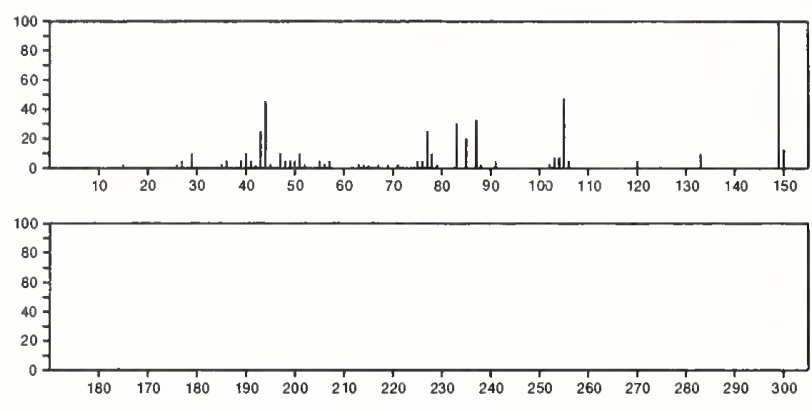

164

Butanoic acid, phenyl ester

$\mathrm{C}_{10} \mathrm{H}_{12} \mathrm{O}_{2}$

$4346-18-3$

$\operatorname{PrC}(0) \mathrm{OPh}$
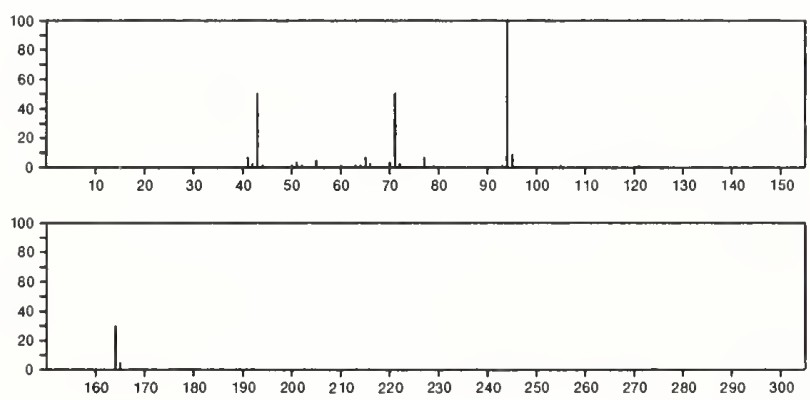

164

$\mathrm{C}_{10} \mathrm{H}_{12} \mathrm{O}_{2}$

2-Butanone, 4-(4-hydroxyphenyl)-

$5471-51-2$
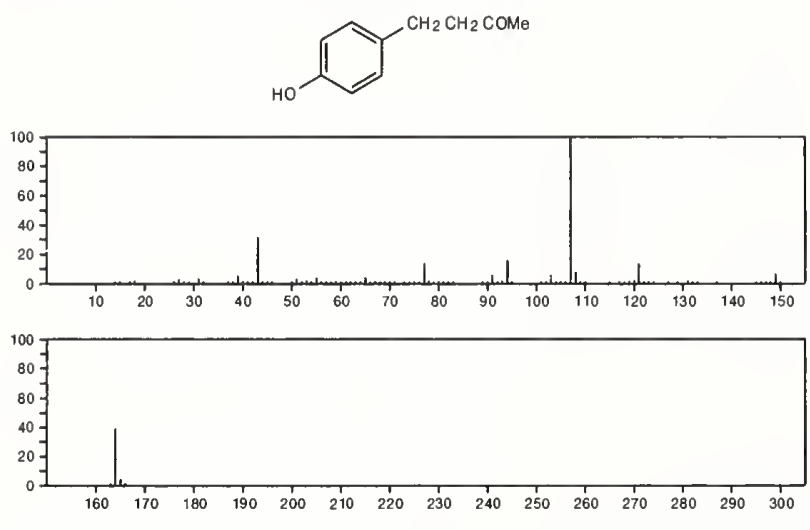

$164 \quad \mathrm{C}_{10} \mathrm{H}_{12} \mathrm{O}_{2} \quad 5932-68-3$

Phenol, 2-methoxy-4-(1-propenyl)-, (E)-
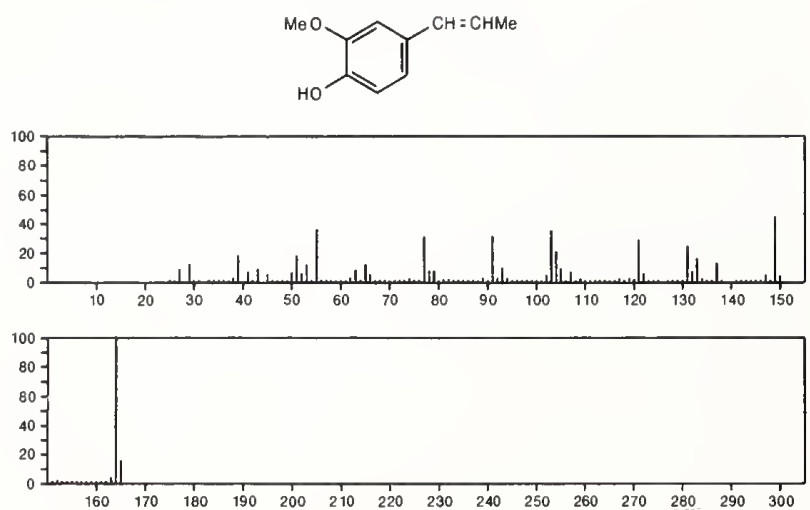

164

$\mathrm{C}_{10} \mathrm{H}_{12} \mathrm{O}_{2}$

$7124-91-6$

1,6-Benzodioxocin, 2,3,4,5-tetrahydro-
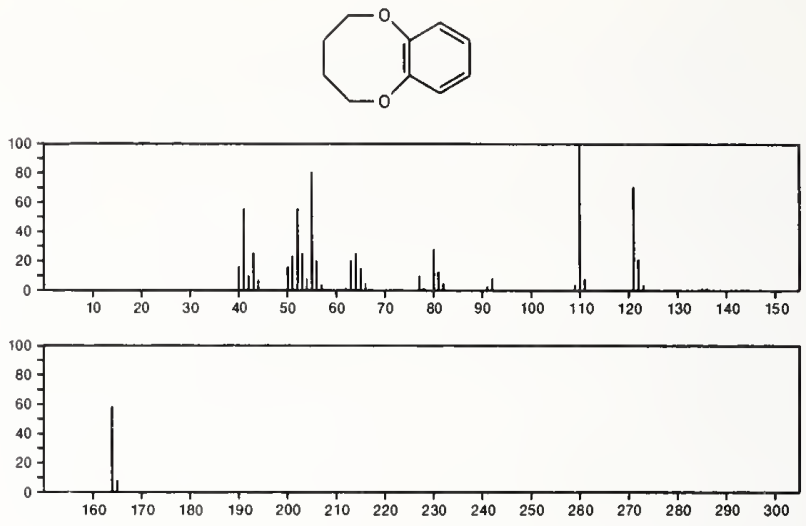

164

$\mathrm{C}_{10} \mathrm{H}_{12} \mathrm{O}_{2}$

$13730-55^{-7}$

Benzoic acid, 2,5-dimethyl-, methyl ester
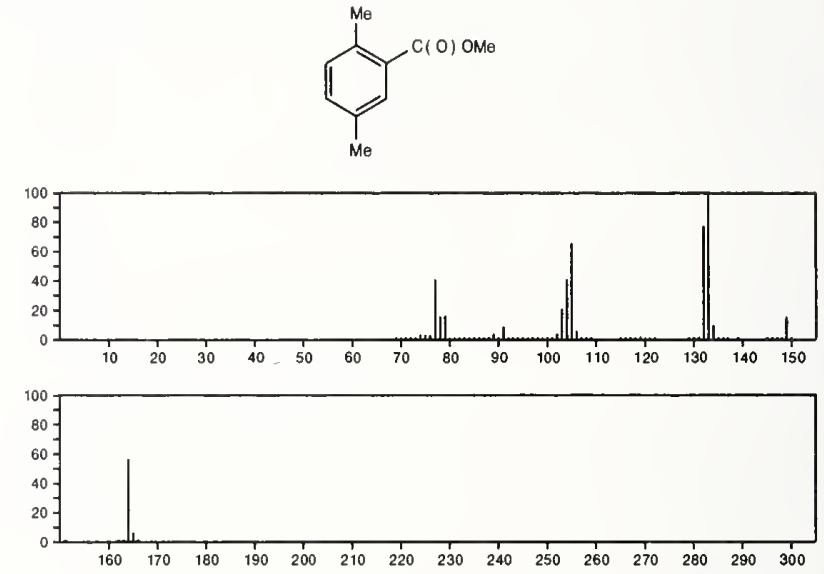

$164 \quad \mathrm{C}_{10} \mathrm{H}_{12} \mathrm{O}_{2}$

1,2-Naphthalenediol, 1,2,3,4-tetrahydro-, trans-

$14211-53-1$
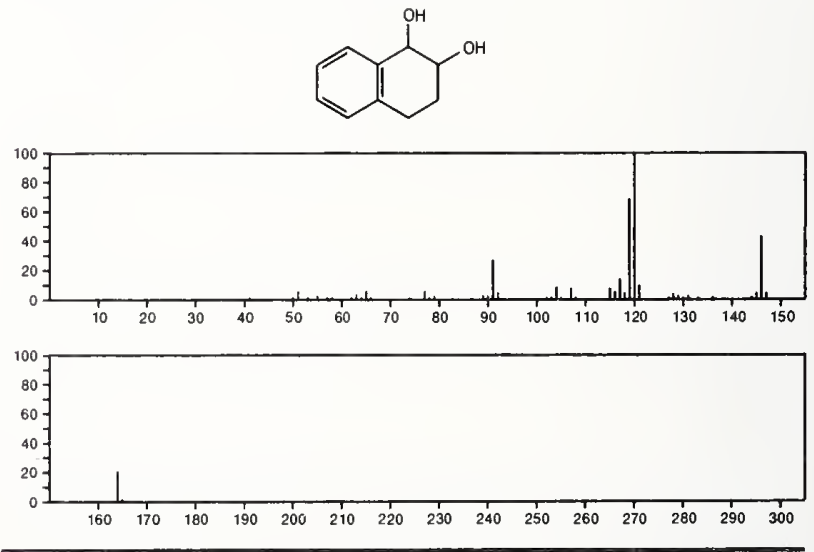

164

$\mathrm{C}_{10} \mathrm{H}_{12} \mathrm{O}_{2}$

Benzenemethanol, 2-methyl-, acetate

17373-93-2
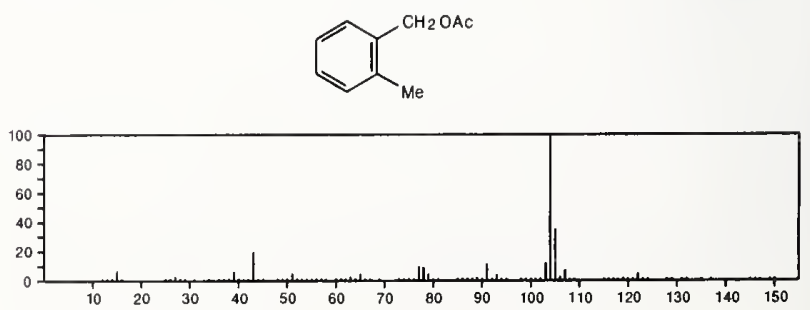


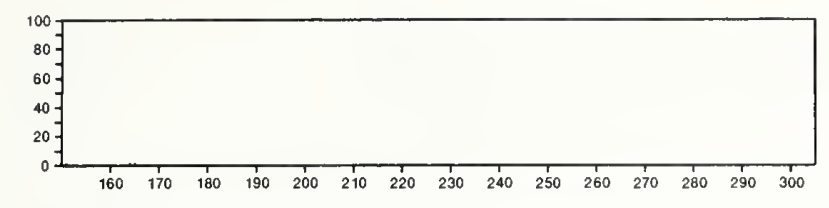

164

$\mathrm{C}_{10} \mathrm{H}_{12} \mathrm{O}_{2}$

Phenol, 2-methoxy-5-(1-propenyl)-, (E)-
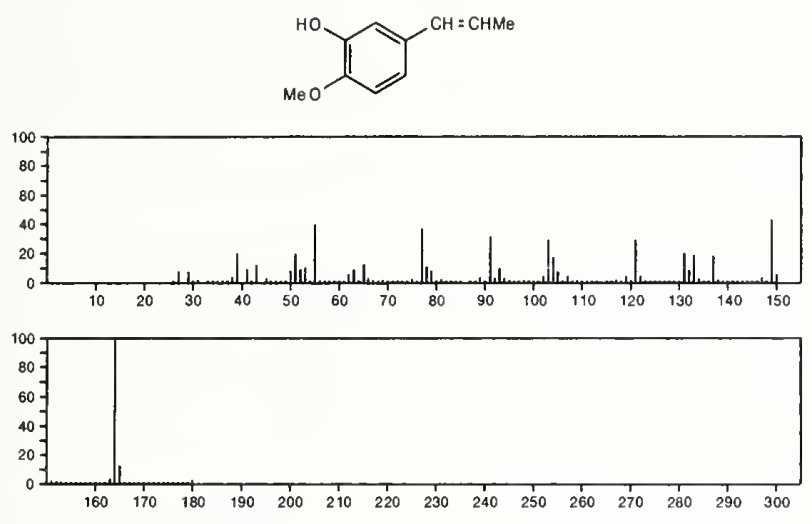

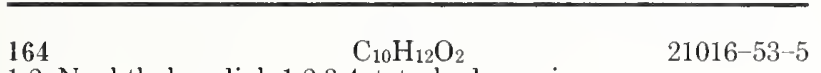

1,2-Naphthalenediol, 1,2,3,4-tetrahydro-, cis-
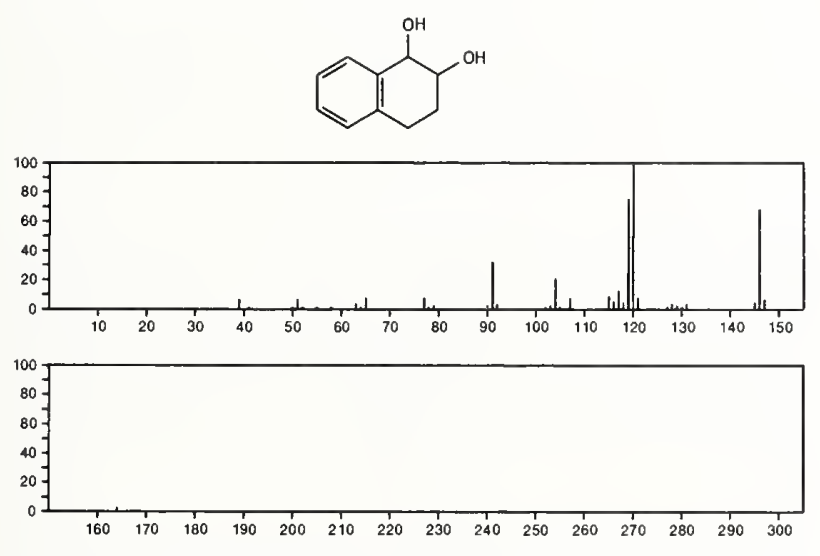

$164 \quad \mathrm{C}_{10} \mathrm{H}_{12} \mathrm{O}_{2} \quad 23617-71-2$

Benzoic acid, 2,4-dimethyl-, methyl ester
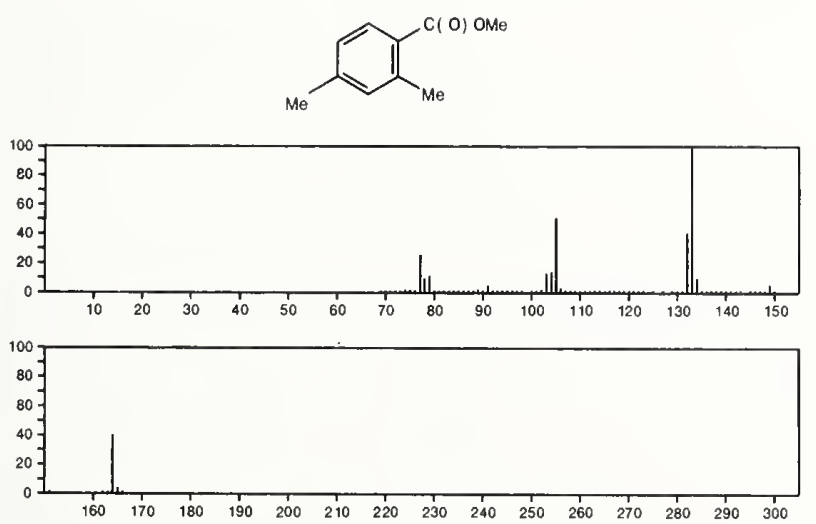

164 Benzoic acid, 3,5-dimethyl-, methyl ester

$25081-39-4$
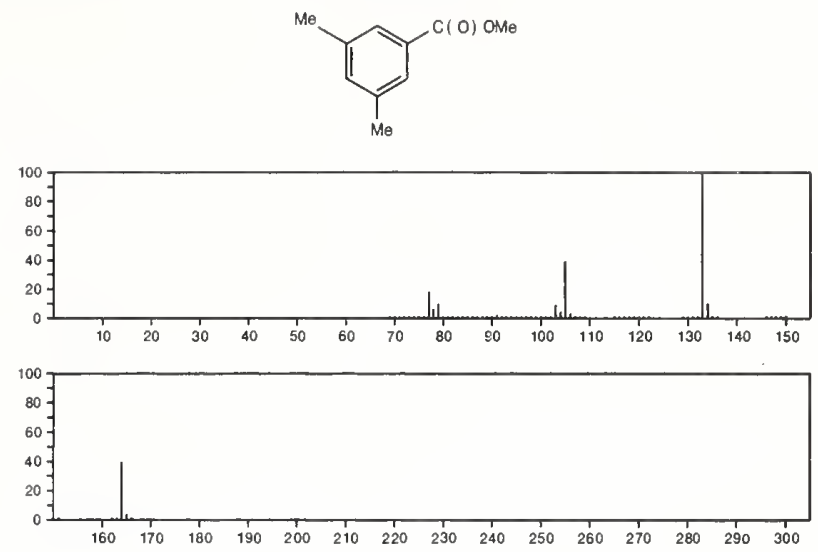

164

Benzene, 1,2-(butylidenedioxy)-

$$
\mathrm{C}_{10} \mathrm{H}_{12} \mathrm{O}_{2}
$$

$30458-34-5$
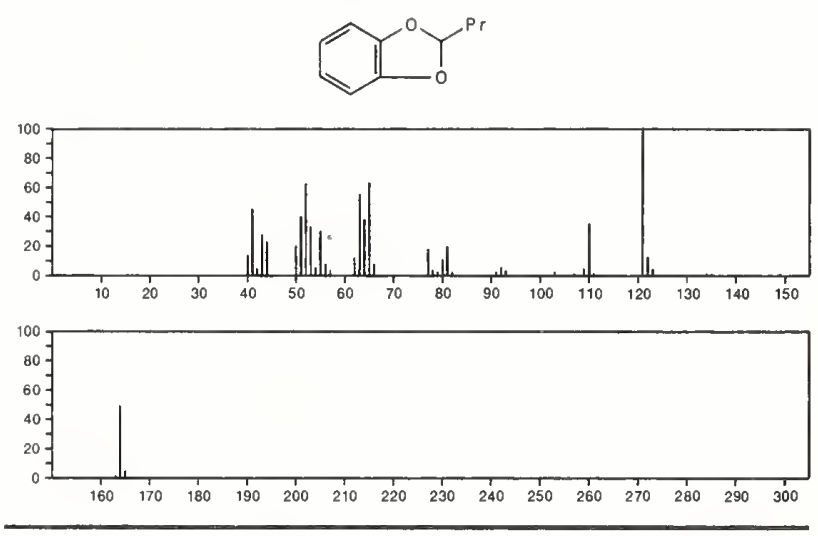

164

1,2-Naphthalenediol, 1,2,3,4-tetrahydro-

$41137-14-8$
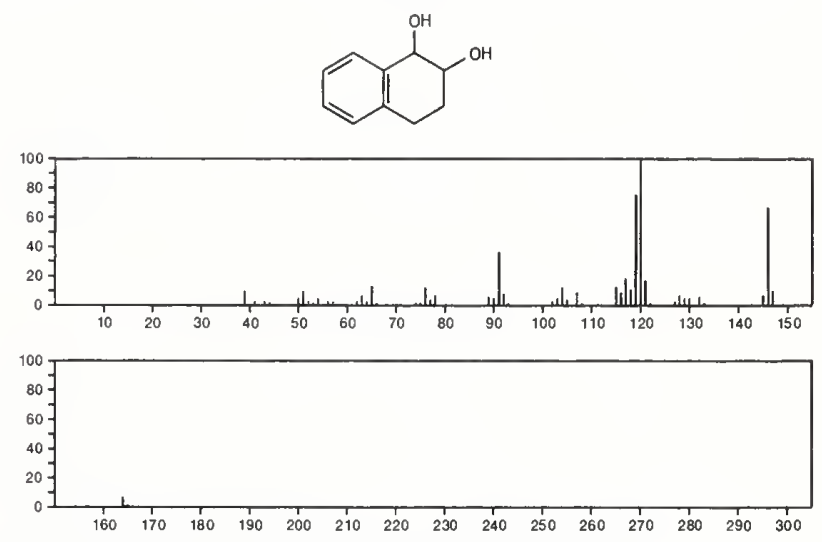

164

$\mathrm{C}_{10} \mathrm{H}_{12} \mathrm{O}_{2}$

$56588-29-5$

1H-Indene-1,2-diol, 2,3-dihydro-1-methyl-, cis-
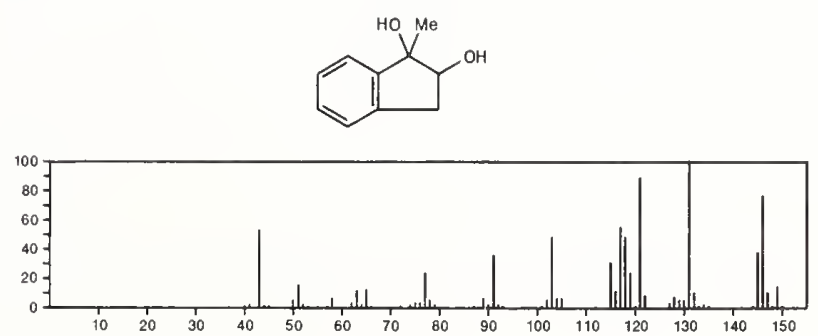


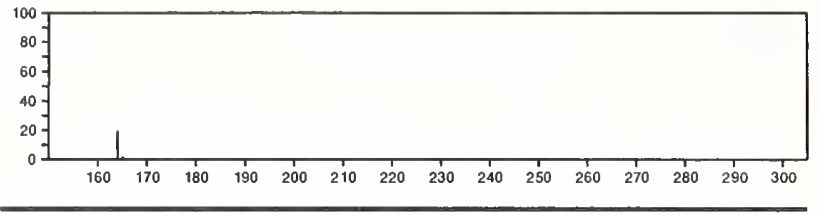

$164 \quad \mathrm{C}_{10} \mathrm{H}_{12} \mathrm{O}_{2}$

$56588-40-0$

1H-Indene-1,2-diol, 2,3-dihydro-2-methyl-, cis-
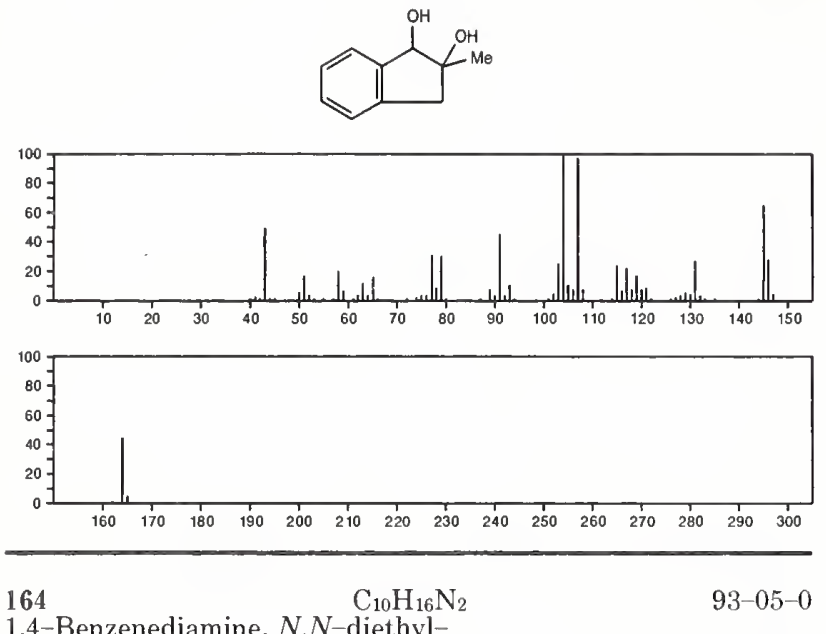

1,4-Benzenediamine, $N, N$-diethyl-
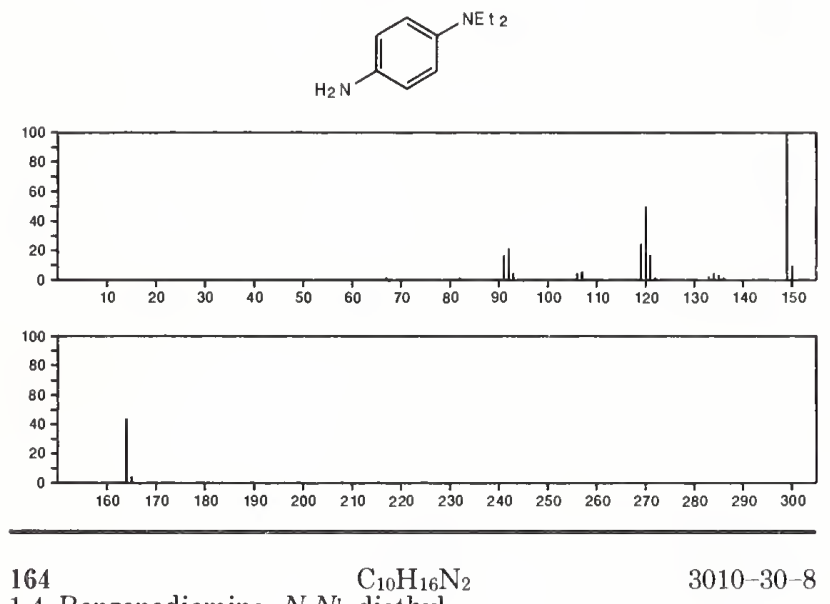

1,4-Benzenediamine, $N, N^{\prime}$-diethyl-
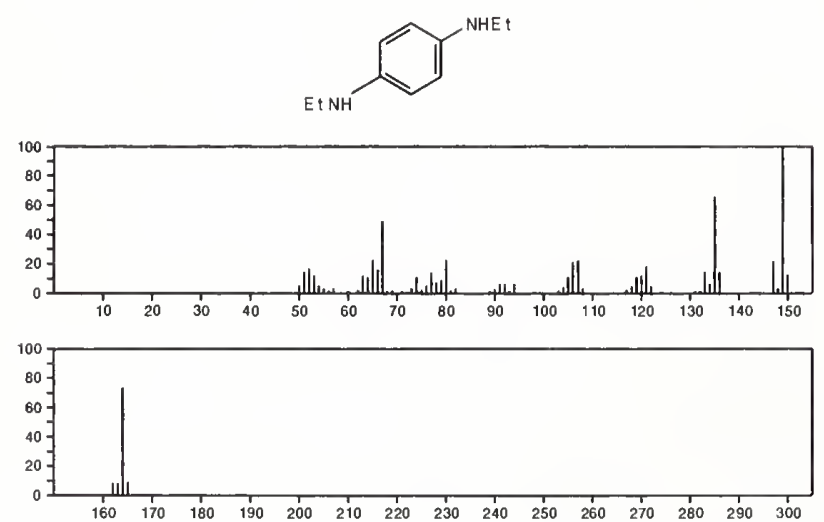

164

$\mathrm{C}_{10} \mathrm{H}_{16} \mathrm{~N}_{2}$

$m$-Phenylenediamine, $N, N^{\prime}$-diethyl-
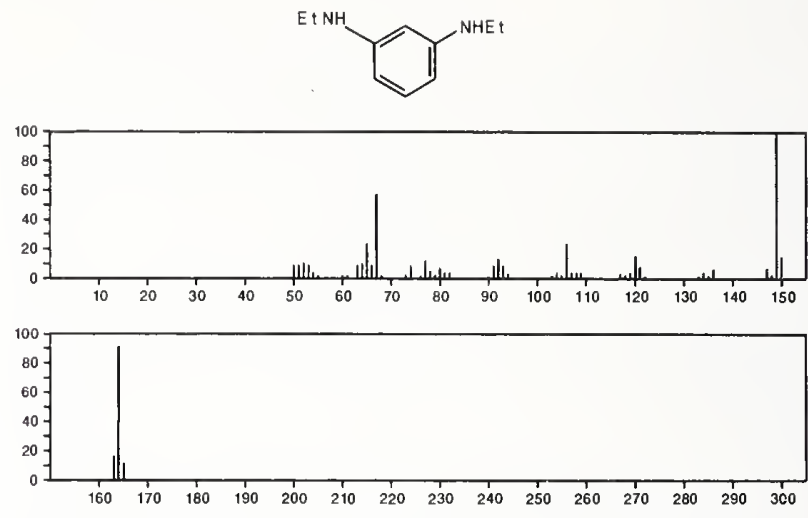

164

Pyrazine, 5-butyl-2,3-dimethyl-

$\mathrm{C}_{10} \mathrm{H}_{16} \mathrm{~N}_{2}$
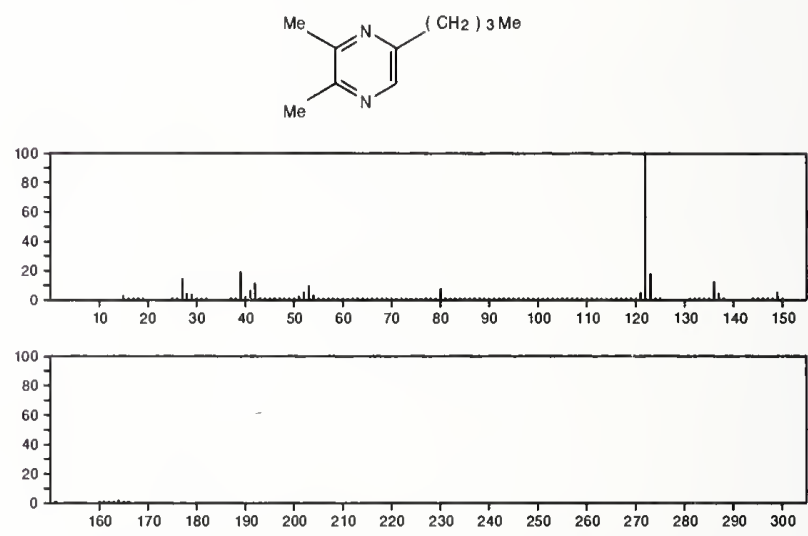

164 o-Phenylenediamine, $N, N^{\prime}$-diethyl-

$24340-87-2$
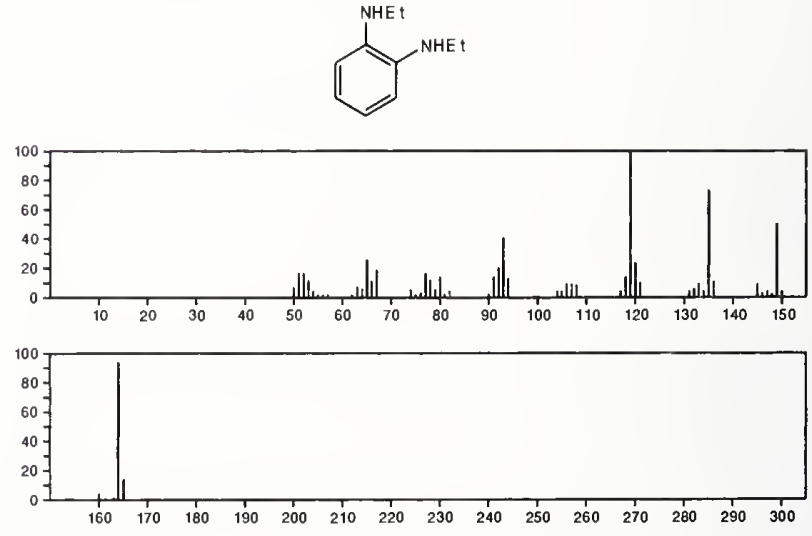

$164 \quad \mathrm{C}_{10} \mathrm{H}_{16} \mathrm{~N}_{2} \quad 24340-88-3$ $p$-Phenylenediamine, $N^{\prime}$-ethyl- $N, N$-dimethyl-
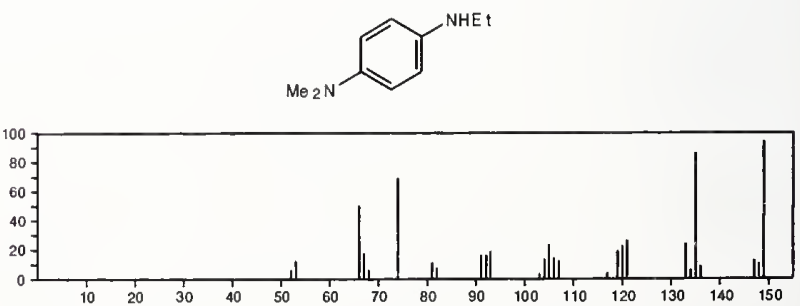

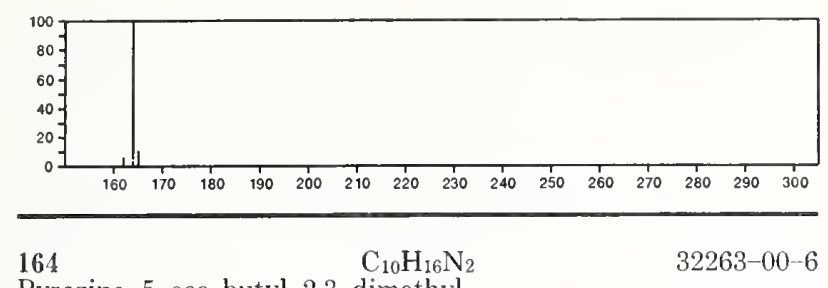

Pyrazine, 5-sec-butyl-2,3-dimethyl-
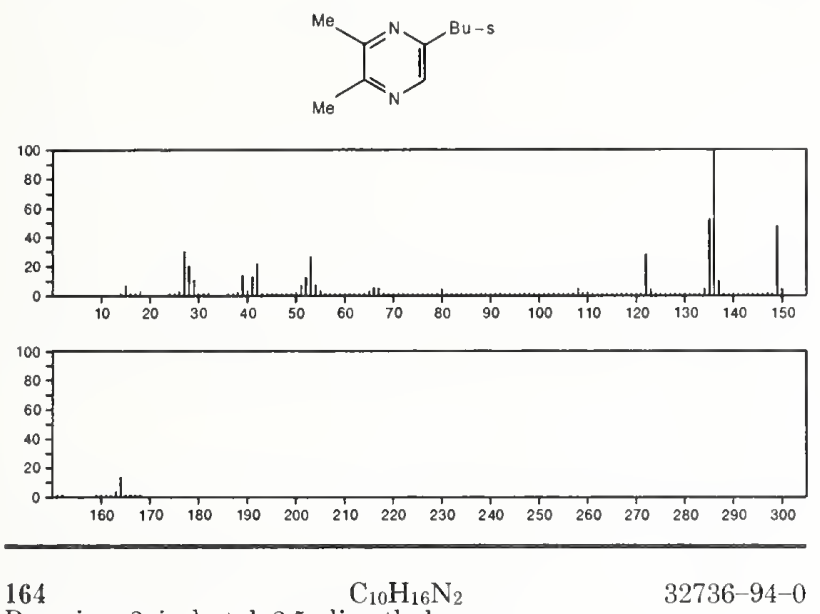

Pyrazine, 3-isobutyl-2,5-dimethyl-
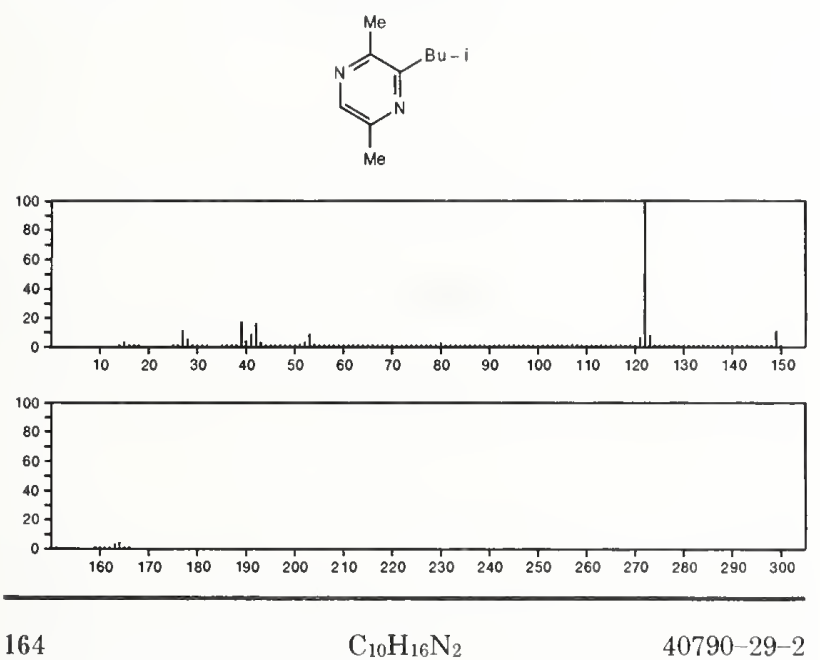

Pyrazine, 3-butyl-2,5-dimethyl-

$40790-29-2$
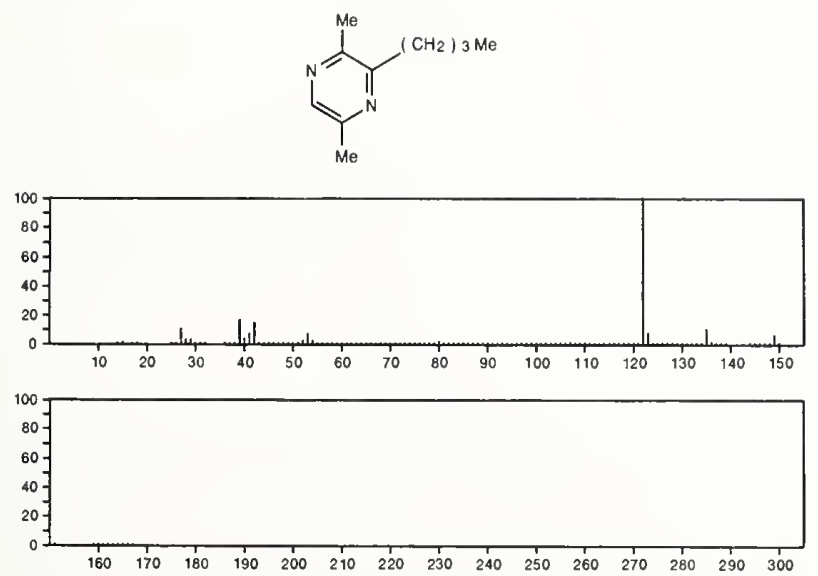

164

Pyrazine, 2-butyl-3,5-dimethyl-

$\mathrm{C}_{10} \mathrm{H}_{16} \mathrm{~N}_{2}$

$50888-63-6$<smiles>CCCCCc1ncc([N+](=O)[O-])nc1[N+](=O)[O-]</smiles>
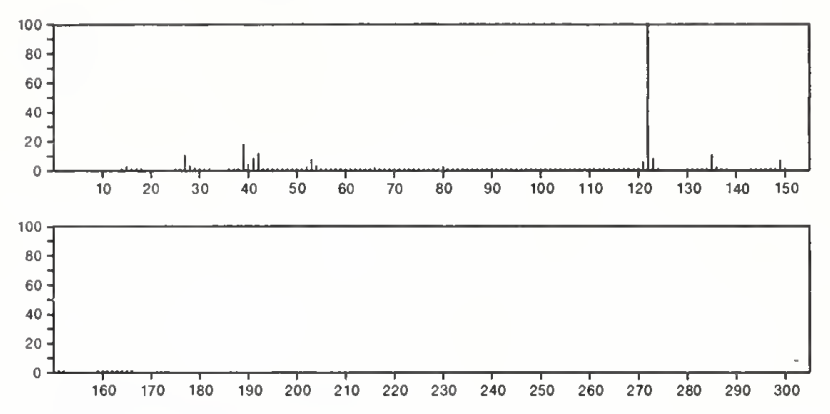

164

$\mathrm{C}_{10} \mathrm{H}_{16} \mathrm{~N}_{2}$

$54410-83-2$

Pyrazine, 2,3-dimethyl-5-(2-methylpropyl)-
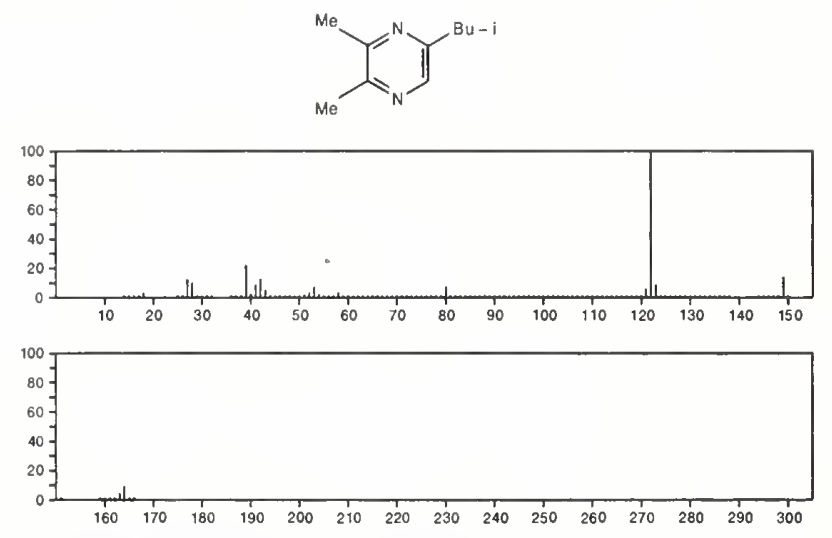

164

Phenol, 4-(1,1-dimethylpropyl)-

$80-46-6$<smiles>CC(C)(C)c1ccc(O)cc1</smiles>
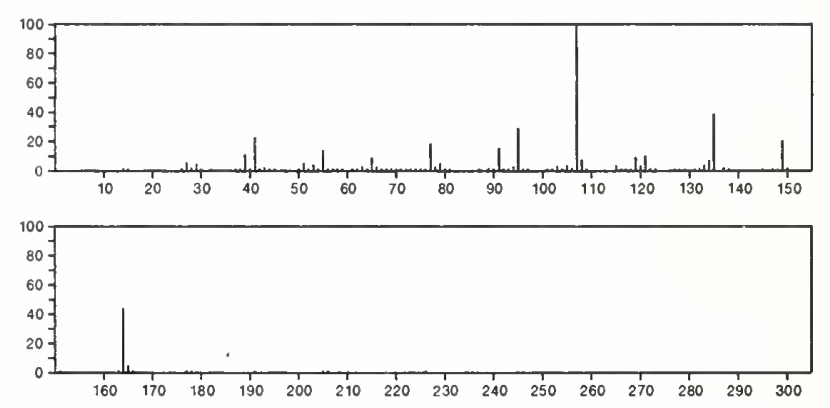

164

$\mathrm{C}_{11} \mathrm{H}_{16} \mathrm{O}$

$98-27-1$

Phenol, 4-(1,1-dimethylethyl)-2-methyl-
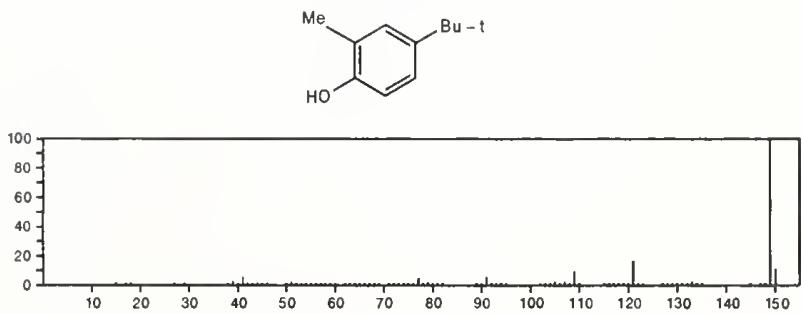


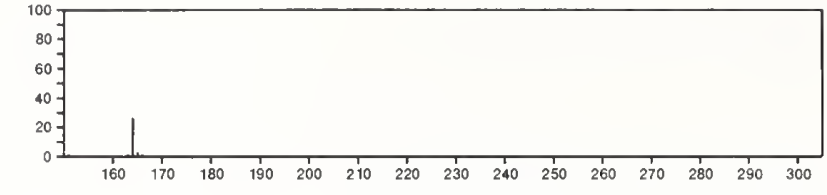

164

Phenol, 2-pentyl-

$\mathrm{C}_{11} \mathrm{H}_{16} \mathrm{O}$

$136-81-2$
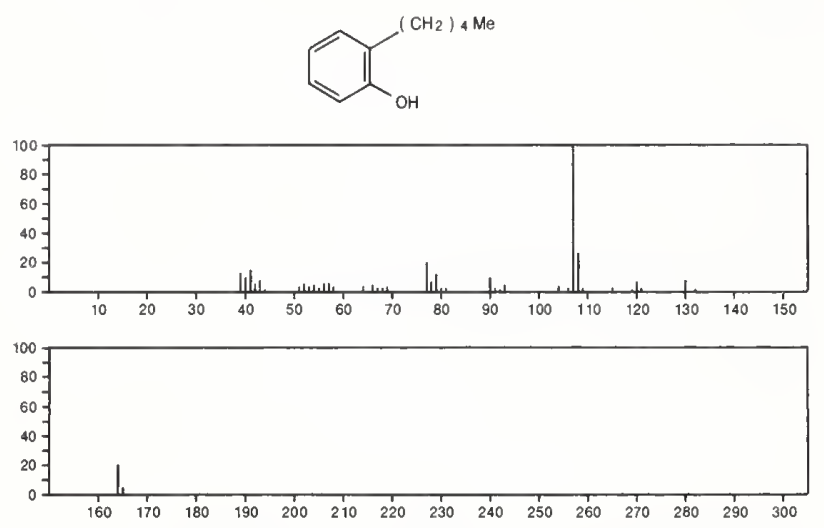

$164 \quad \mathrm{C}_{11} \mathrm{H}_{16} \mathrm{O}$

2-Cyclopenten-1-one, 3-methyl-2-(2-pentenyl)-, $(Z)-$

$488-10-8$
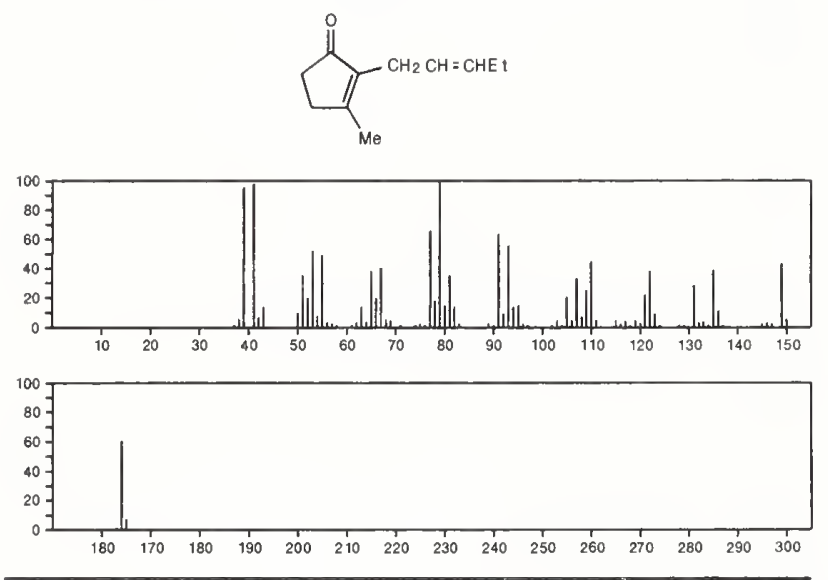

164

Benzene, (butoxymethyl)-

\section{$\mathrm{C}_{11} \mathrm{H}_{16} \mathrm{O}$}

$588-67-0$

$\mathrm{PhCH}_{2} \mathrm{O}\left(\mathrm{CH}_{2}\right)_{3} \mathrm{Me}$
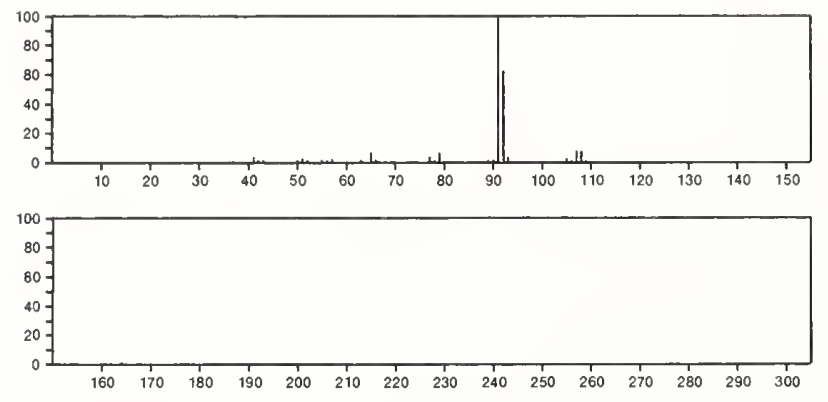

$164 \quad \mathrm{C}_{11} \mathrm{H}_{16} \mathrm{O}$

Benzene, (2,2-dimethylpropoxy)-

$\mathrm{Me}{ }_{3} \mathrm{CCH}_{2} \mathrm{OPh}$

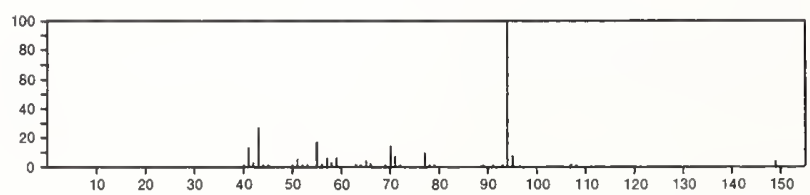

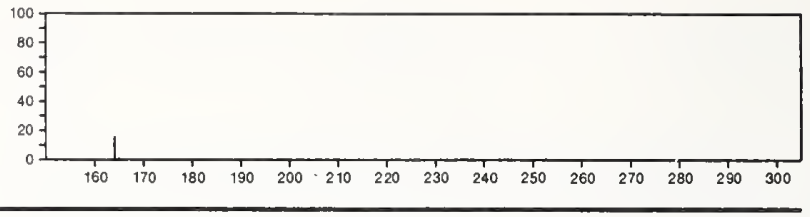

164

$\mathrm{C}_{11} \mathrm{H}_{16} \mathrm{O}$

$2219-82-1$

Phenol, 2-(1,1-dimethylethyl)-6-methyl-
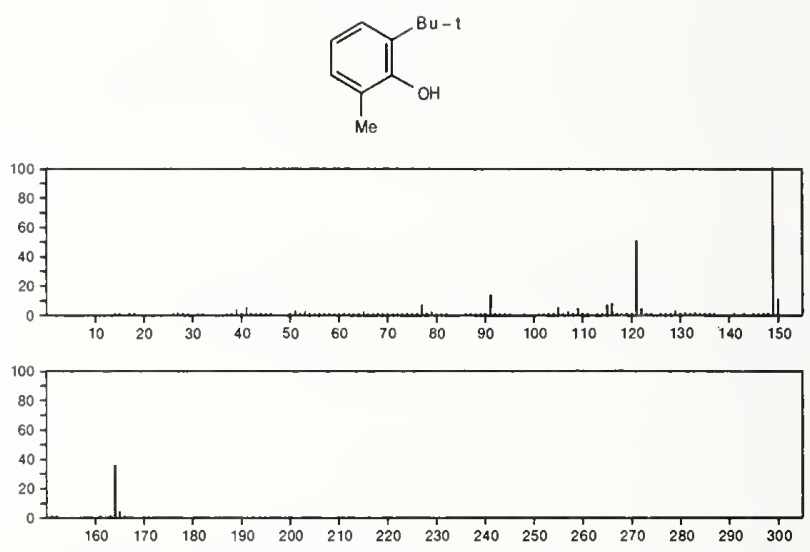

164

$\mathrm{C}_{11} \mathrm{H}_{16} \mathrm{O}$

2409-55-4

Phenol, 2-(1,1-dimethylethyl)-4-methyl-
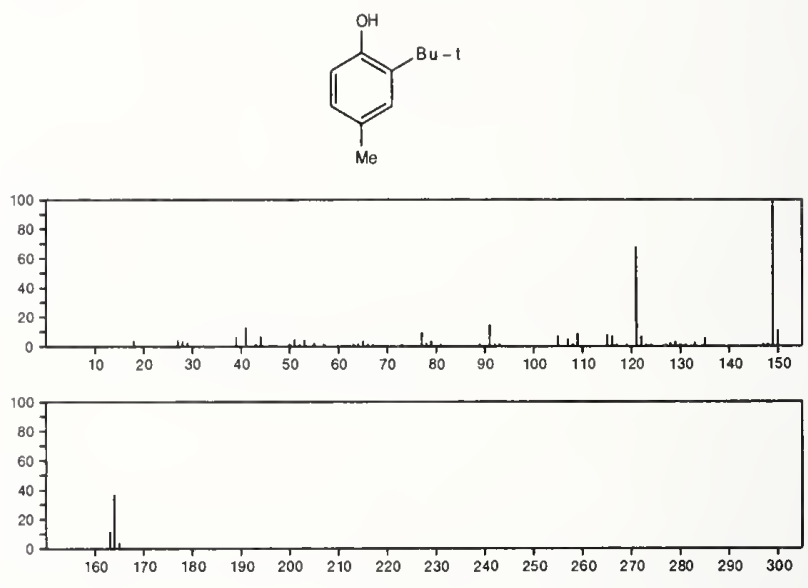

164

Benzeneethanol, $\alpha, \alpha, \beta$-trimethyl-

$\mathrm{C}_{11} \mathrm{H}_{16} \mathrm{O}$

$3280-08-8$

$\mathrm{Me} 2 \mathrm{COHCHMePh}$
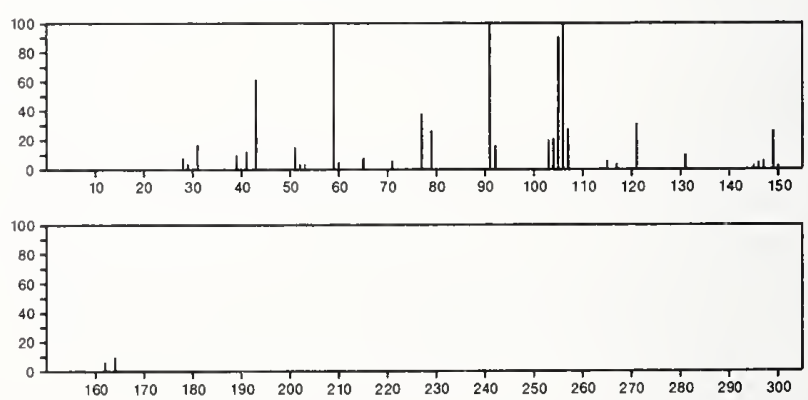
164 $\mathrm{C}_{11} \mathrm{H}_{16} \mathrm{O}$

Benzene, [(1,1-dimethylethoxy)methyl]-

$\mathrm{t}-\mathrm{BuOCH}_{2} \mathrm{Ph}$
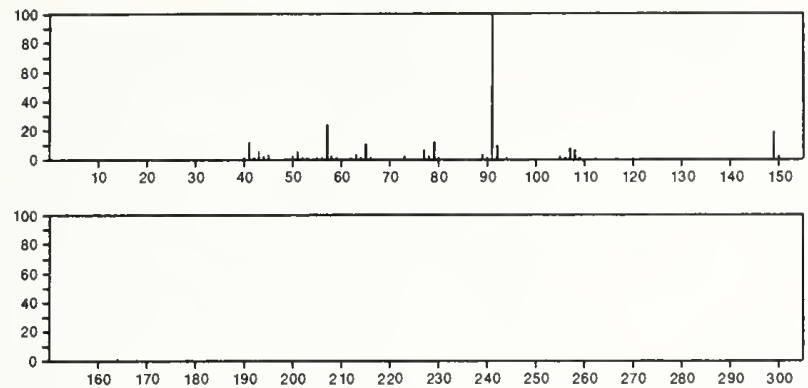

164

$\mathrm{C}_{11} \mathrm{H}_{16} \mathrm{O}$

$4087-39-2$

2(3H)-Naphthalenone, 4,4a,5,6,7,8-hexahydro-4a-methyl-, $(S)$ -
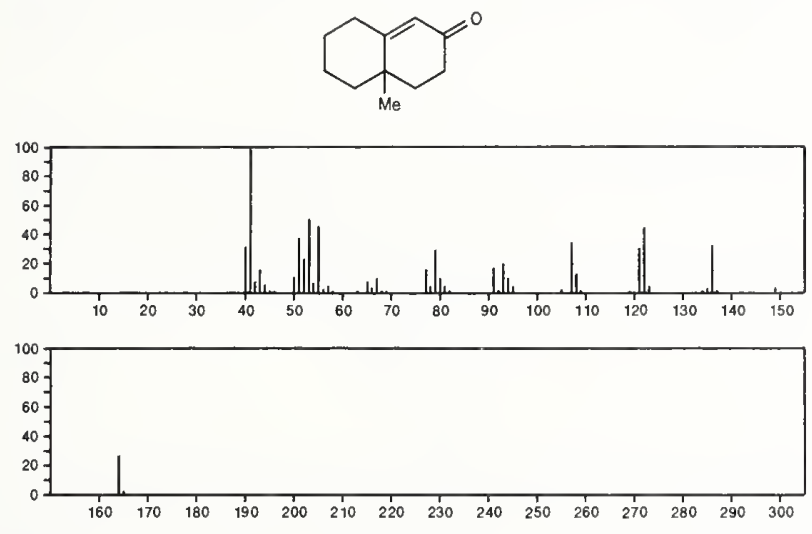

164

$\mathrm{C}_{11} \mathrm{H}_{16} \mathrm{O}$

$5396-38-3$

Benzene, 1-(1,1-dimethylethyl)-4-methoxy-
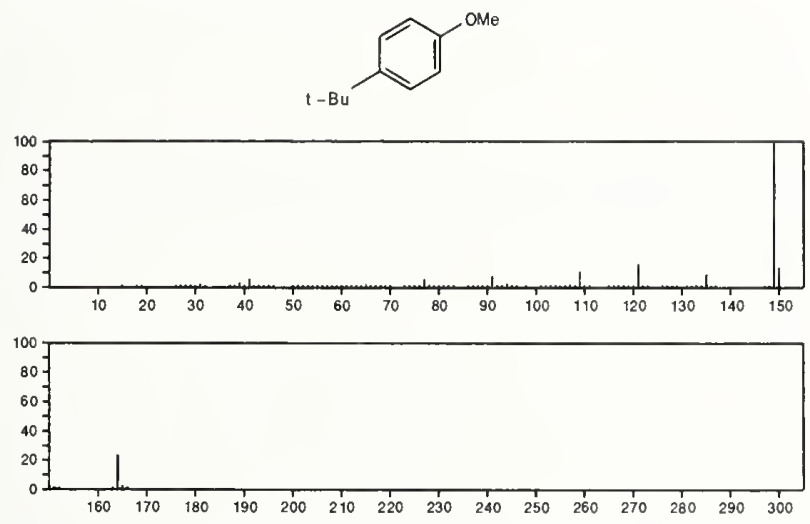

164

m-Cresol, 2-tert-butyl-

$\mathrm{C}_{11} \mathrm{H}_{16} \mathrm{O}$

13037-79-1
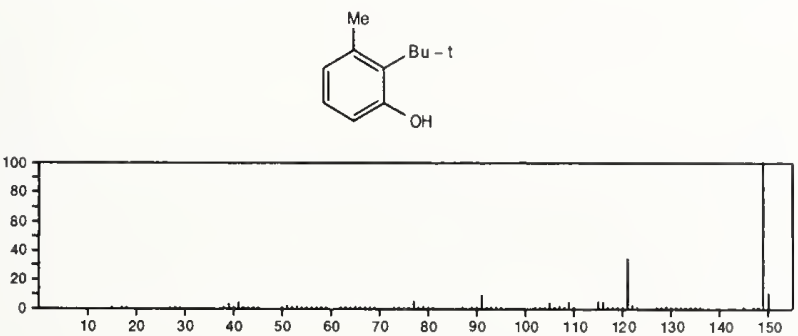

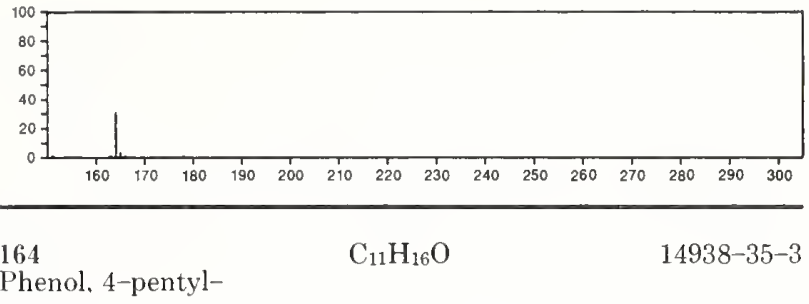

Phenol, 4-pentyl
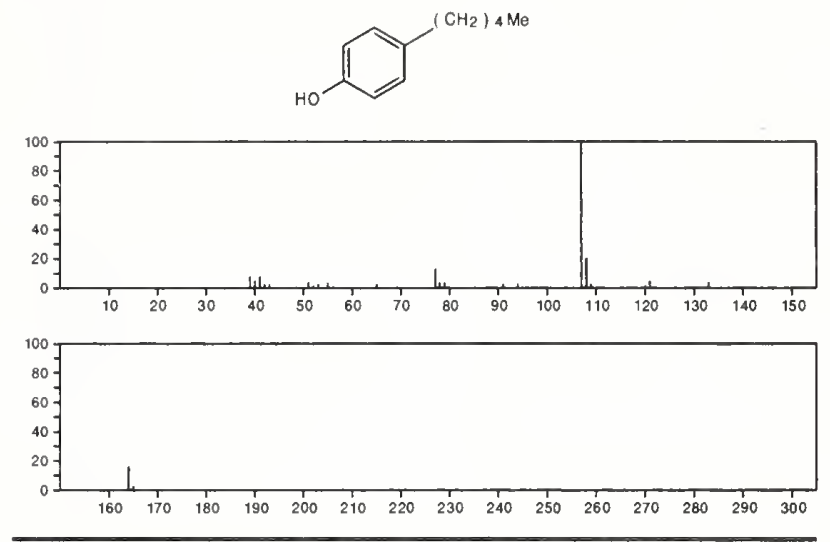

164

$\mathrm{C}_{11} \mathrm{H}_{16} \mathrm{O}$

18366-35-3

Inden-5(4H)-one, 2,6,7,7a-tetrahydro-4,4-dimethyl
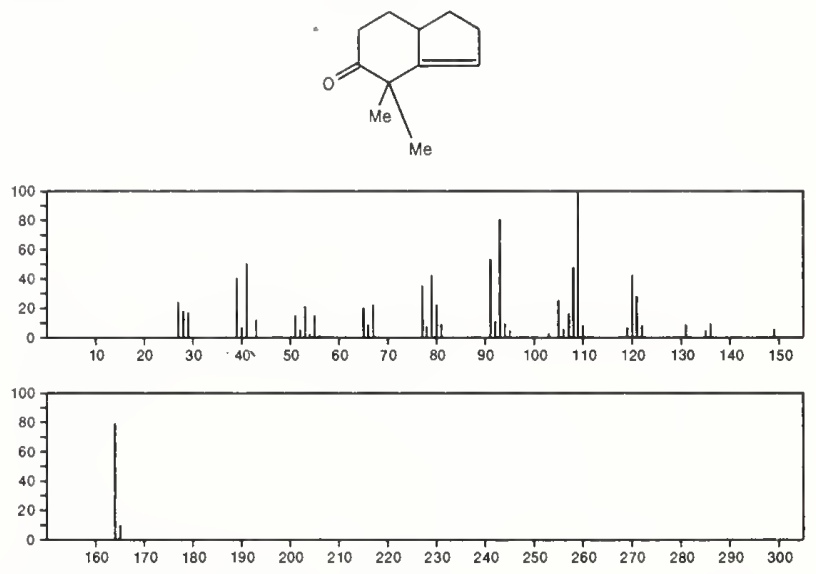

164

$\mathrm{C}_{11} \mathrm{H}_{16} \mathrm{O}$

20056-66-0

Phenol, 3-pentyl-
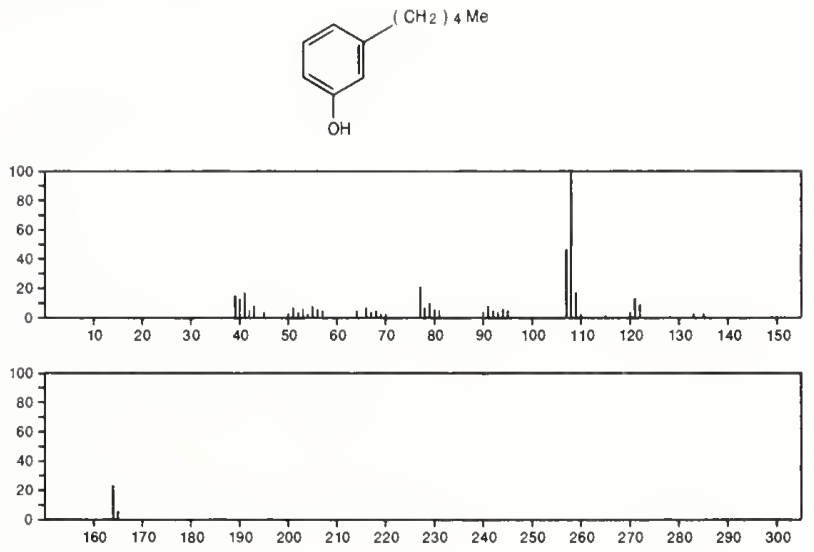
164

Benzeneethanol, $\alpha, \alpha, 4$-trimethyl-
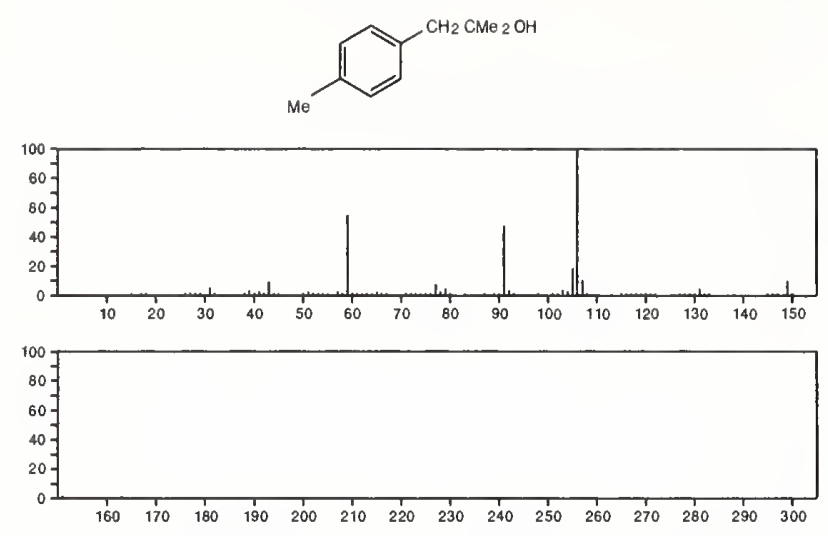

164

$\mathrm{C}_{11} \mathrm{H}_{16} \mathrm{O}$

21841-29-2

1(2H)-Naphthalenone, 3,4,4a,5,8,8a-hexahydro-8a-methyl-, trans-
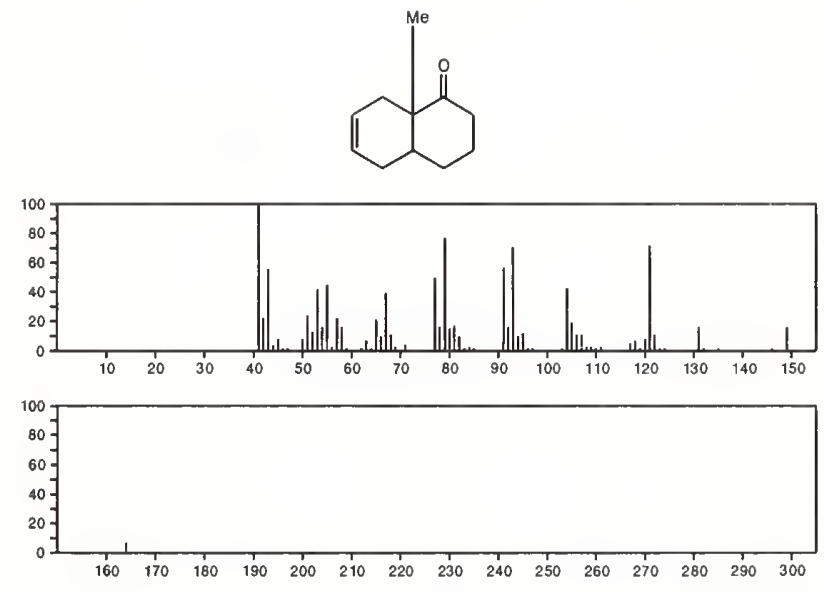

$164 \quad \mathrm{C}_{11} \mathrm{H}_{16} \mathrm{O} \quad 22844-34-4$

2(1H)-Naphthalenone, 4a,5,6,7,8,8a-hexahydro-4a-methyl-, trans-
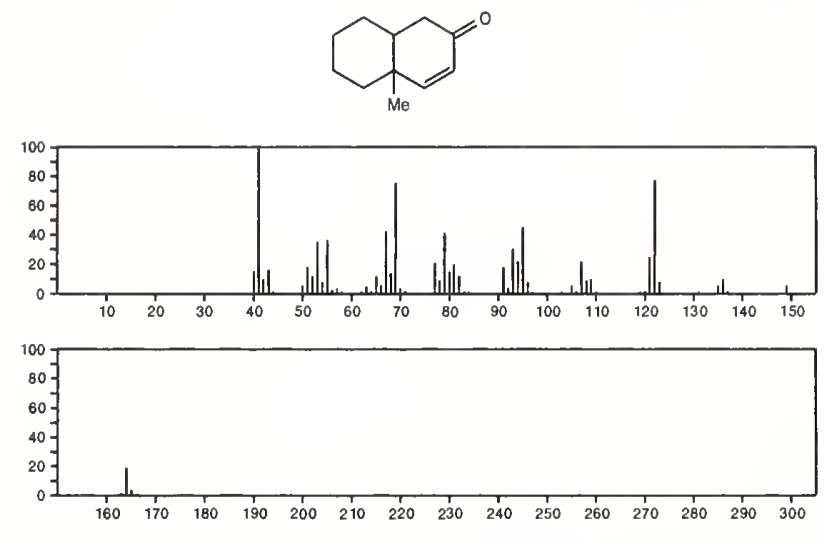

$\begin{array}{cc}\mathrm{C}_{11} \mathrm{H}_{16} \mathrm{O} & 55103-73-6 \\ 2(1 H) \text {-Azulenone, } & 4,5,6,7,8,8 \mathrm{a} \text {-hexahydro- } \\ \text { 8a-methyl-, } & (\mathrm{S}) \text { - }\end{array}$
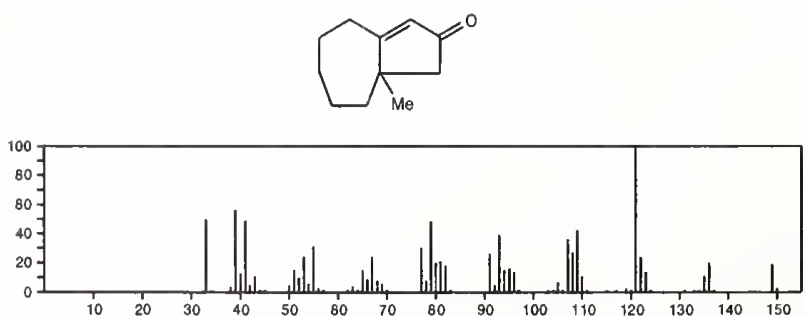
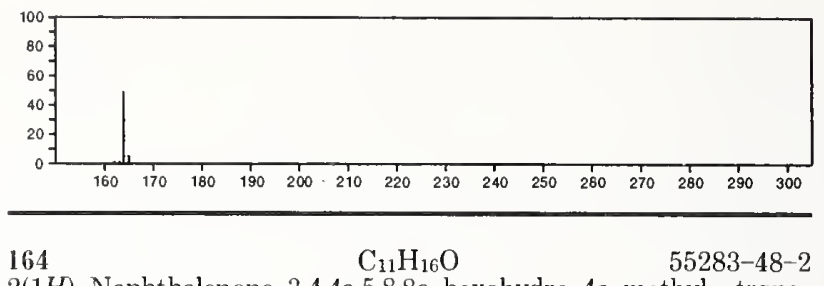

2(1H)-Naphthalenone, 3,4,4a,5,8,8a-hexahydro-4a-methyl-, trans-<smiles>CC12CC=CCC1CC(=O)CC2</smiles>
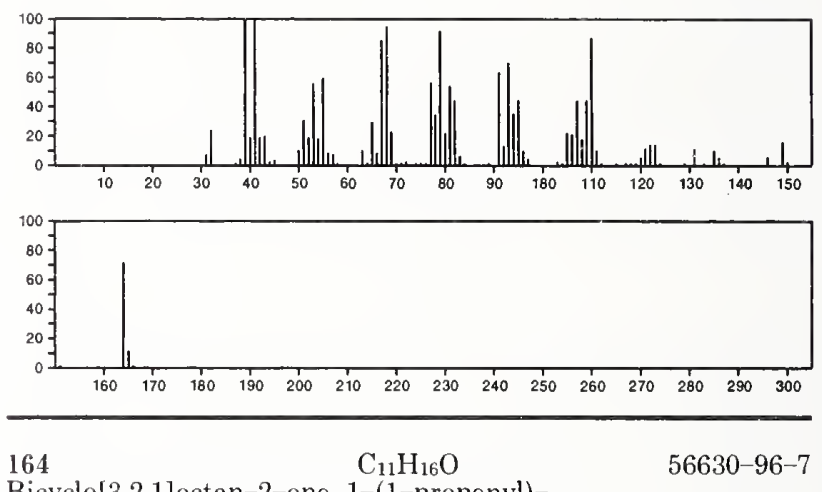

Bicyclo[3.2.1]octan-2-one, 1-(1-propenyl)-
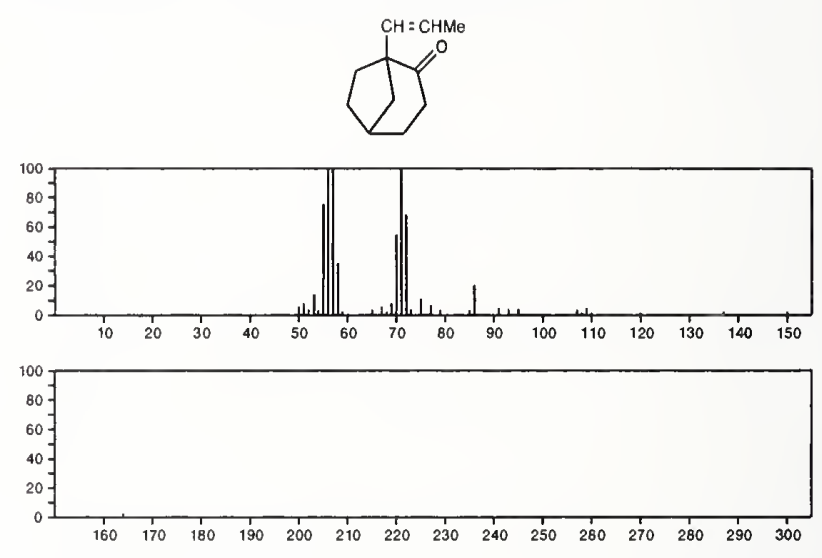

164

$\mathrm{C}_{12} \mathrm{H}_{20}$

$702-79-4$

Tricyclo[3.3.1.1 $\left.{ }^{3,7}\right]$ decane, 1,3-dimethyl-
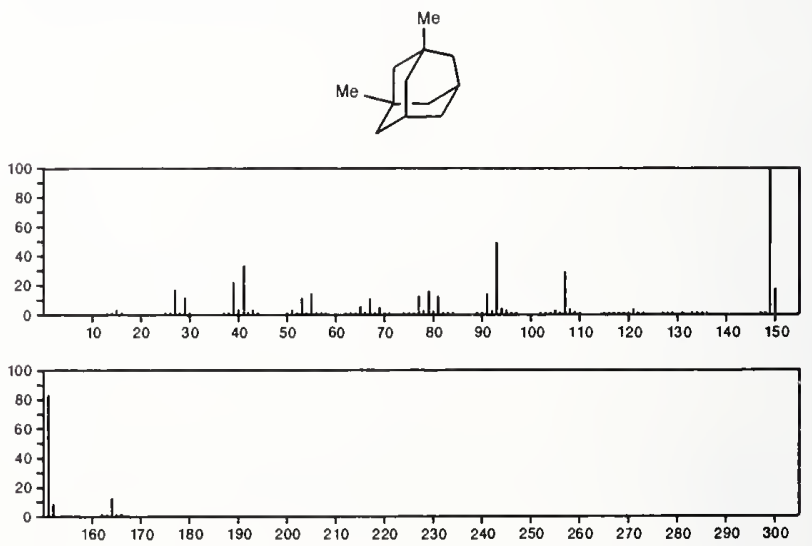
164

1,4-Ethanonaphthalene, decahydro-

W
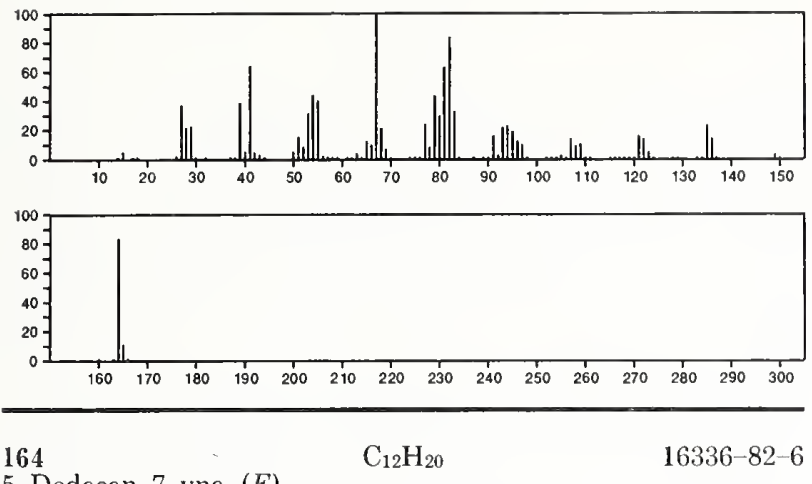

5-Dodecen-7-yne, (E)-

$\mathrm{Me}\left(\mathrm{CH}_{2}\right){ }_{3} \mathrm{C} \equiv \mathrm{CCH}=\mathrm{CH}\left(\mathrm{CH}_{2}\right)_{3} \mathrm{Me}$
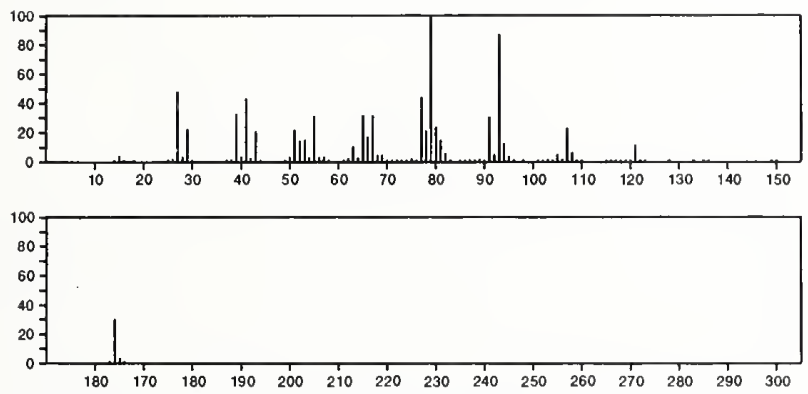

164

5-Dodecen-7-yne, (Z)-

$\mathrm{C}_{12} \mathrm{H}_{20}$

$16336-83-7$

$\mathrm{Me}\left(\mathrm{CH}_{2}\right){ }_{3} \mathrm{C}: \mathrm{CCH}=\mathrm{CH}\left(\mathrm{CH}_{2}\right)_{3} \mathrm{Me}$
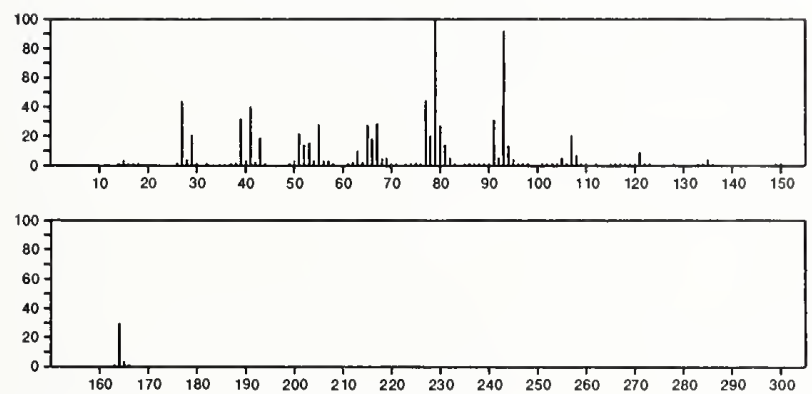

164

$\mathrm{C}_{12} \mathrm{H}_{20}$

$40482-18-6$

Cyclohexane, 1,1,4,4-tetramethyl-2,6-bis(methylene)-
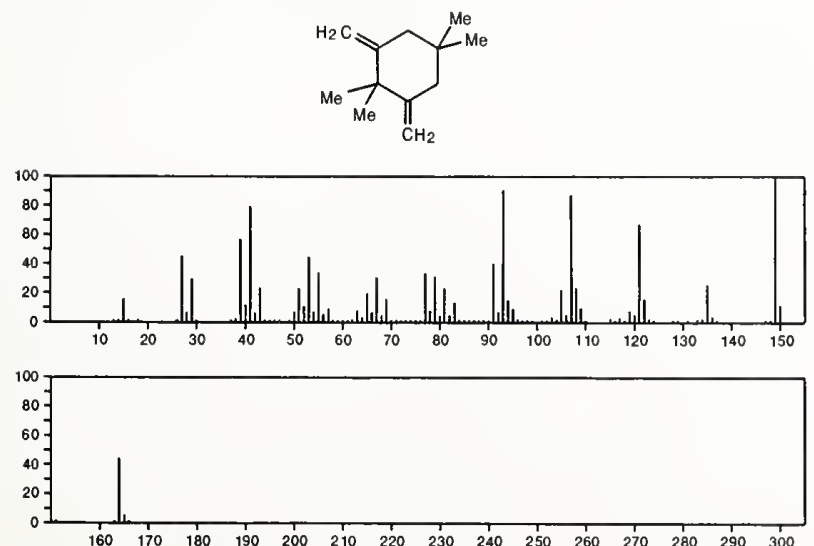

164

$\mathrm{C}_{12} \mathrm{H}_{20}$

$55103-61-2$

$1 H$-Benzocycloheptene, 4,4a,5,6,7,8,9,9a-octahydro-4a-methyl-, trans-
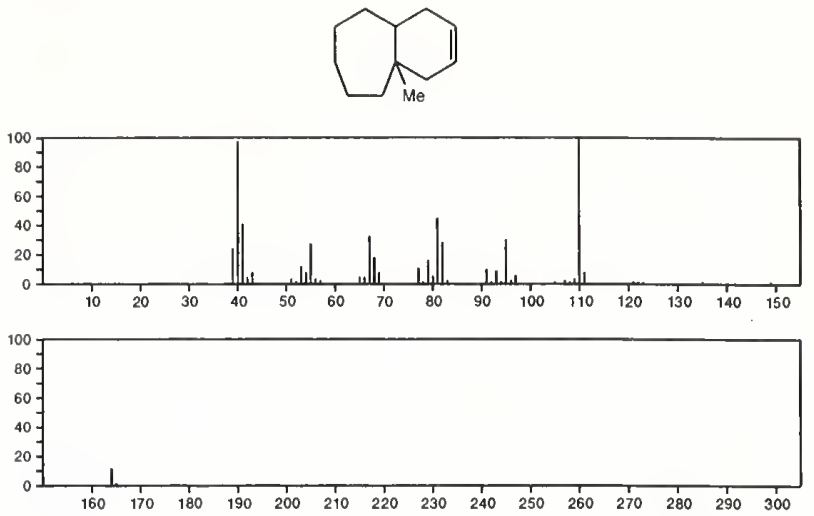

164

3-Decen-5-yne, 2,2-dimethyl- $(Z)$

$55638-49-8$

$\mathrm{Me}_{3} \mathrm{CCH}=\mathrm{CHC} \equiv \mathrm{C}\left(\mathrm{CH}_{2}\right)_{3} \mathrm{Me}$
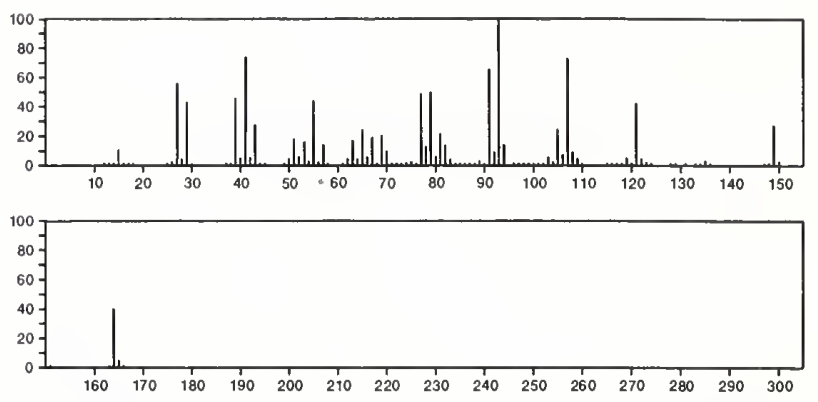

164

$\mathrm{C}_{12} \mathrm{H}_{20}$

5-Decen-3-yne, 2,2-dimethyl-, (Z)-

55669-91-5

$\mathrm{Me}{ }_{3} \mathrm{CC} \equiv \mathrm{CCH}=\mathrm{CH}\left(\mathrm{CH}_{2}\right){ }_{3} \mathrm{Me}$
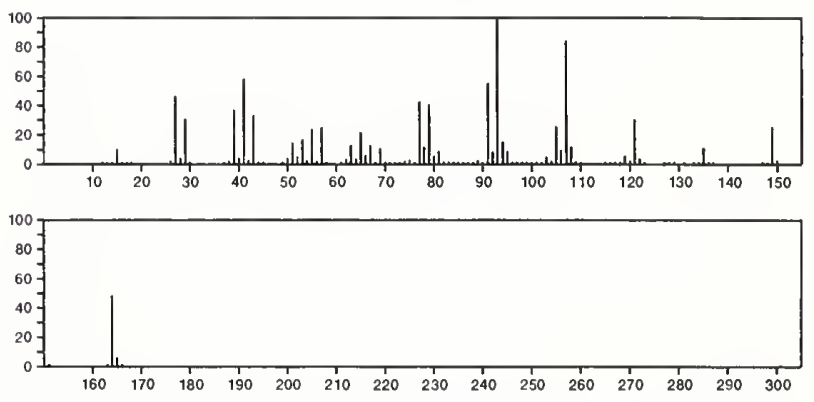

164

$\mathrm{C}_{12} \mathrm{H}_{20}$

3-Octen-5-yne, 2,2,7,7-tetramethyl-

$55682-74-1$

$\mathrm{Me}{ }_{3} \mathrm{CC} \equiv \mathrm{CCH}=\mathrm{CHCMe}$
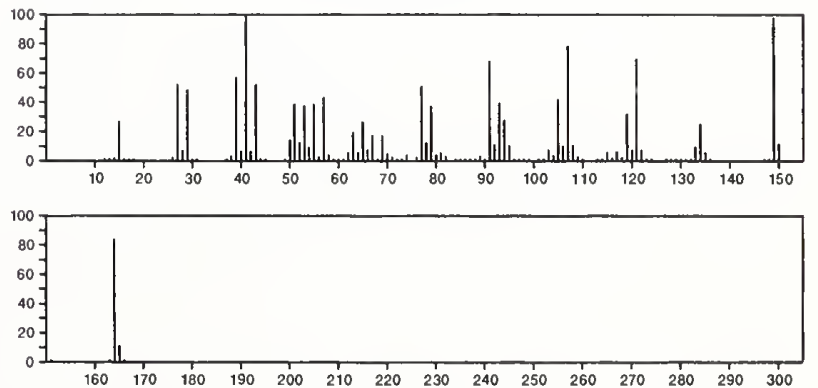
164

$\mathrm{C}_{12} \mathrm{H}_{20}$

55976-09-5

Naphthalene, 1,2,3,4,4a,5,6,8a-octahydro-4a,8-dimethyl-
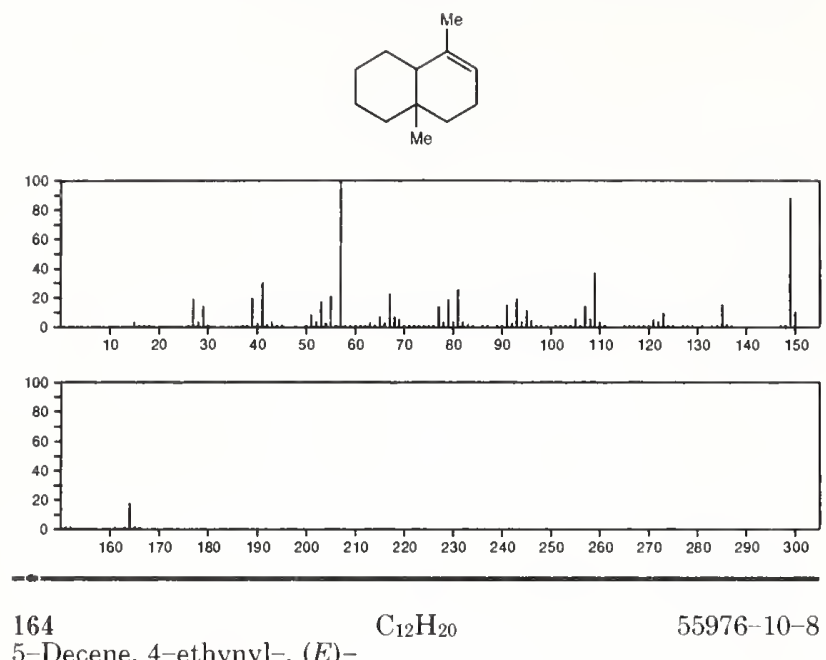

5-Decene, 4-ethynyl-, (E)-

$\mathrm{HC} \equiv \mathrm{CCHPrCH}=\mathrm{CH}\left(\mathrm{CH}_{2}\right)_{3} \mathrm{Me}$
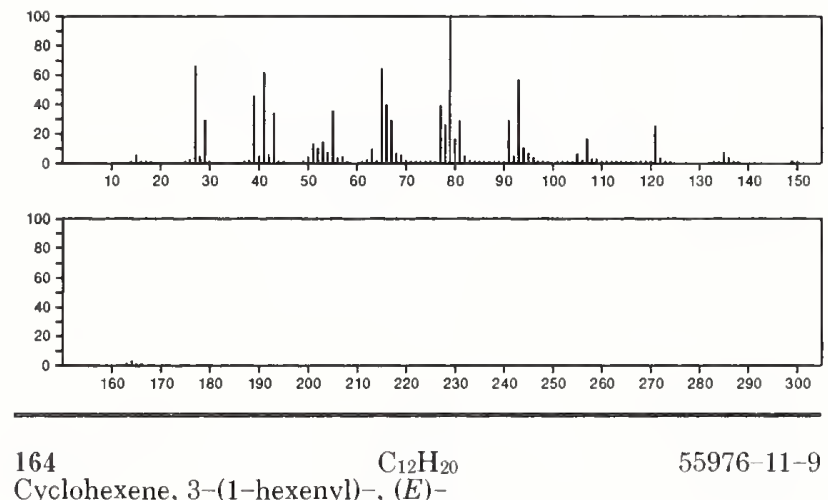

Cyclohexene, 3-(1-hexenyl)-, $(E)-$
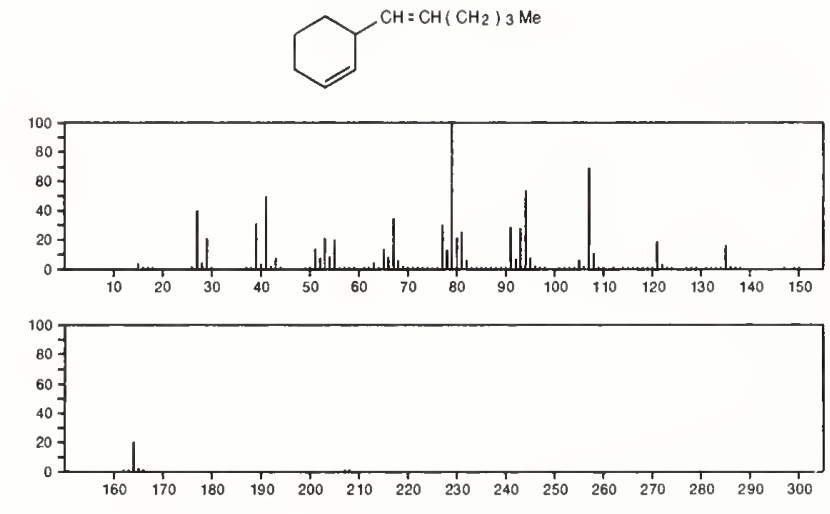

$164 \quad \mathrm{C}_{12} \mathrm{H}_{20} \quad 55976-12-0$

3-Octen-5-yne, 2,2,7,7-tetramethyl-, (E)-

$\mathrm{Me}{ }_{3} \mathrm{CC} \equiv \mathrm{CCH} \equiv \mathrm{CHCMe}_{3}$
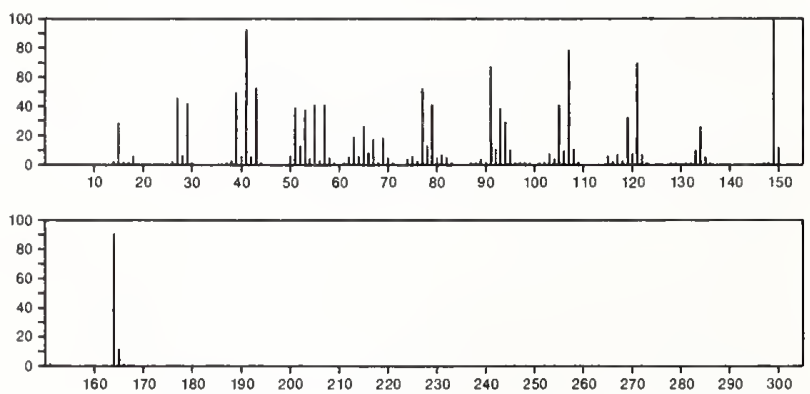

164

$56324-68-6$

$1 H$-Indene, 1-ethylideneoctahydro-7a-methyl-, $(1 E, 3 \mathrm{a} \alpha, 7 \mathrm{a} \beta)$
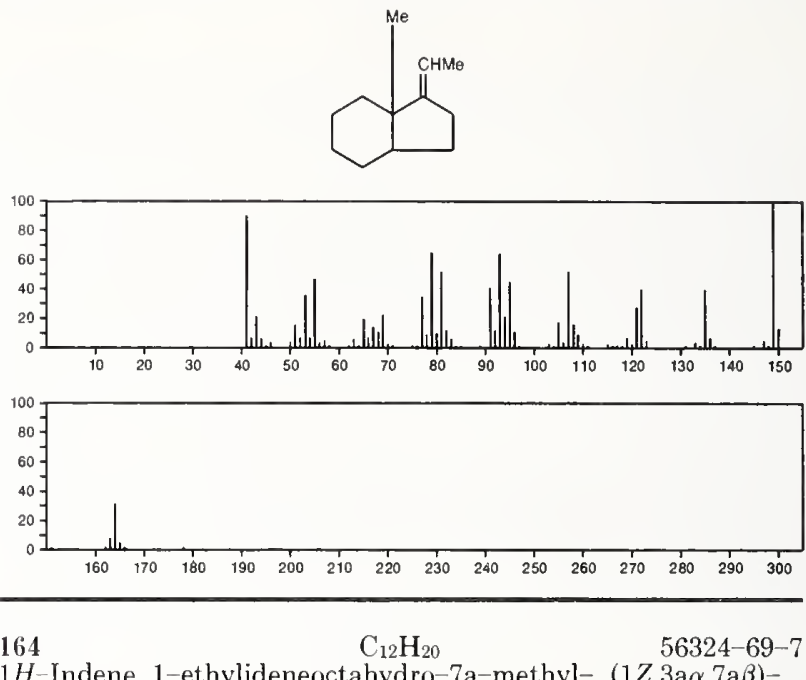

$1 H$-Indene, 1-ethylideneoctahydro-7a-methyl-, $(1 Z, 3 \mathrm{a} \alpha, 7 \mathrm{a} \beta)-$
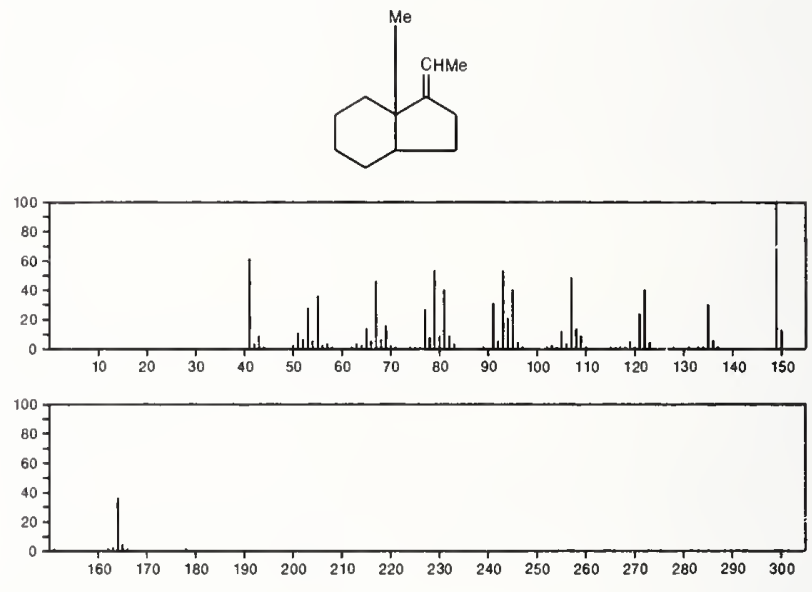

164 -Indene, 1-ethylideneoctahydro-

$56362-87-9$

1H-Indene, 1-ethylideneoctahydro-7a-methyl-, cis-
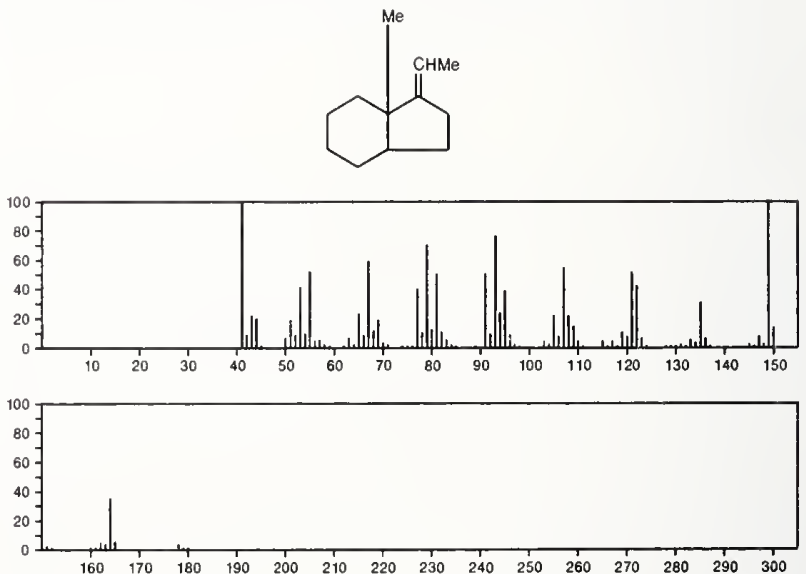
$164 \quad \mathrm{C}_{12} \mathrm{H}_{20}$

Bicyclo[6.1.0]nonane, 9-(1-methylethylidene)-

$56666-90-1$
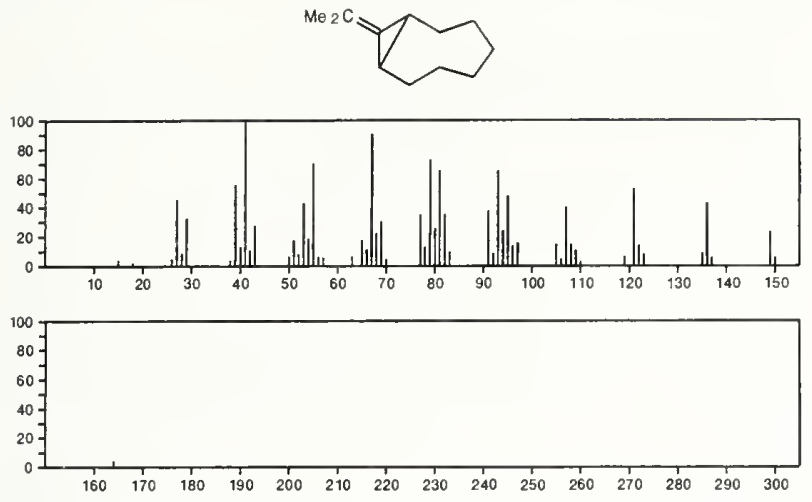

\section{5}

Ethane, 1,1,1-trinitro-

$\mathrm{C}_{2} \mathrm{H}_{3} \mathrm{~N}_{3} \mathrm{O}_{6}$

$595-86-8$

$\mathrm{MeC}\left(\mathrm{NO}_{2}\right)_{3}$

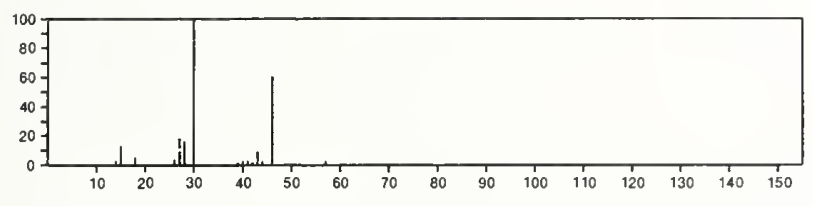

165

$\mathrm{C}_{5} \mathrm{H}_{12} \mathrm{NO}_{3} \mathrm{P}$

29727-88-6

1,3,2-Dioxaphospholan-2-amine, 5,5-dimethyl-, 2-oxide
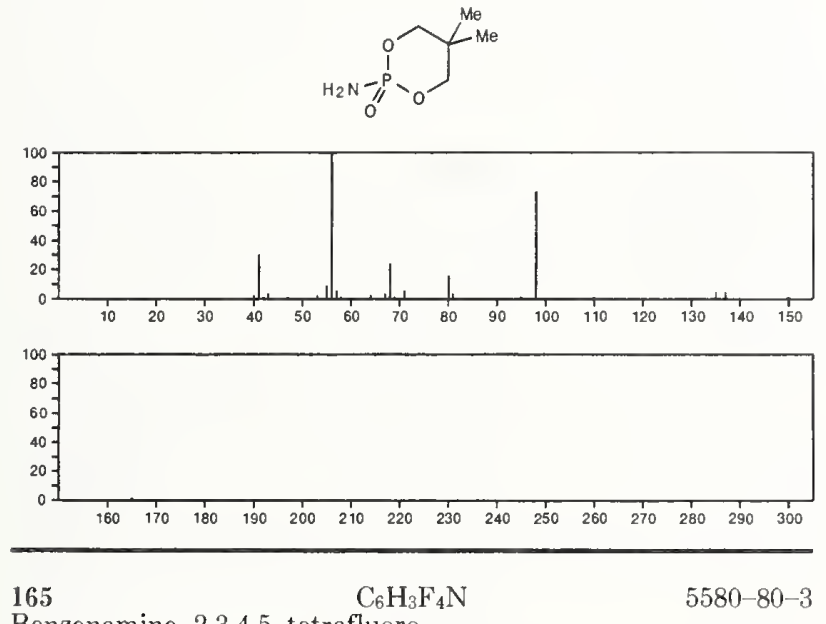

Benzenamine, 2,3,4,5-tetrafluoro-
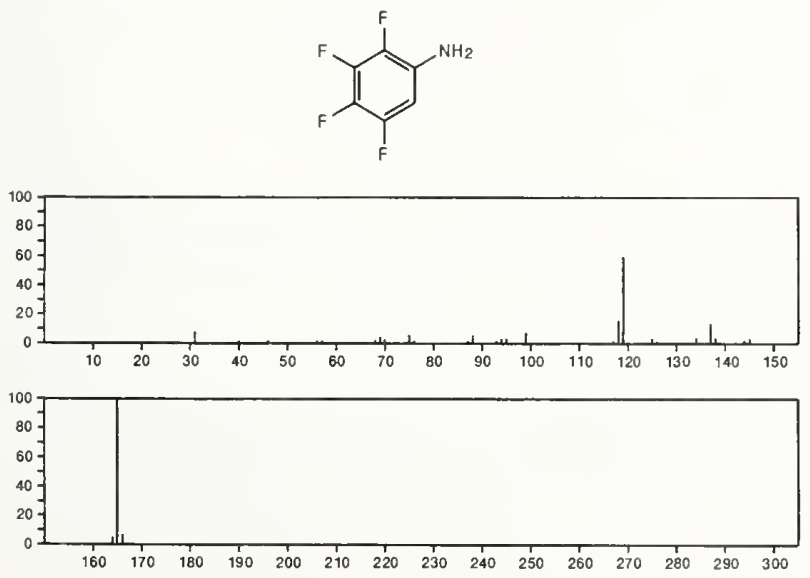

$165 \quad \mathrm{C}_{6} \mathrm{H}_{7} \mathrm{~N}_{5} \mathrm{O}$
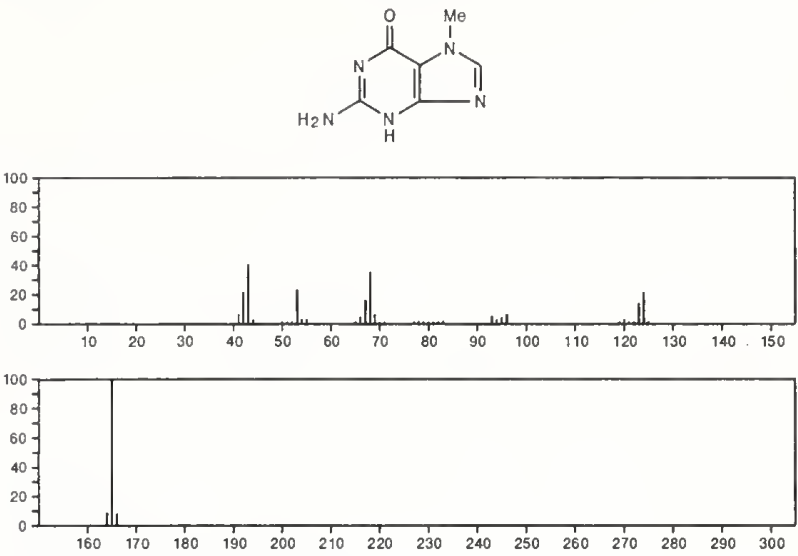

165

6H-Purin-6-one, 2-amino-1,7-dihydro-1-methyl-

938-85-2
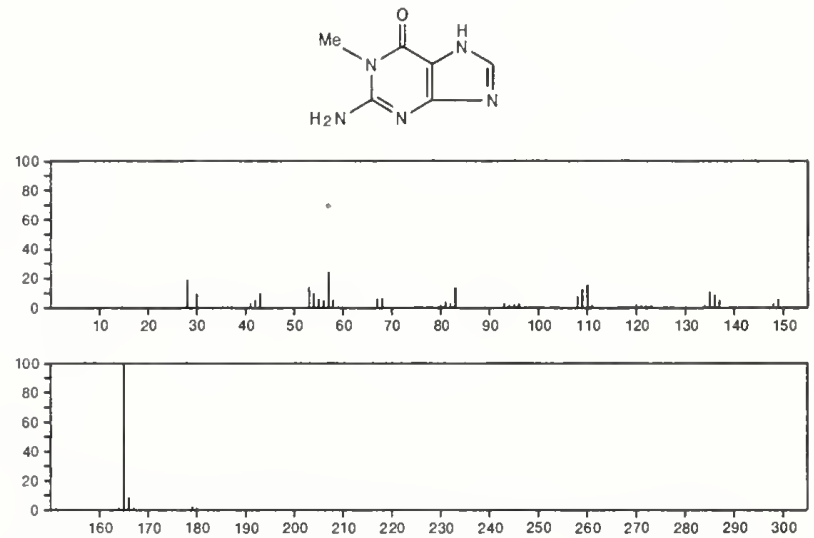

165

$\mathrm{C}_{6} \mathrm{H}_{7} \mathrm{~N}_{5} \mathrm{O}$

$10030-78-1$

6H-Purin-6-one, 1,7-dihydro-2-(methylamino)-
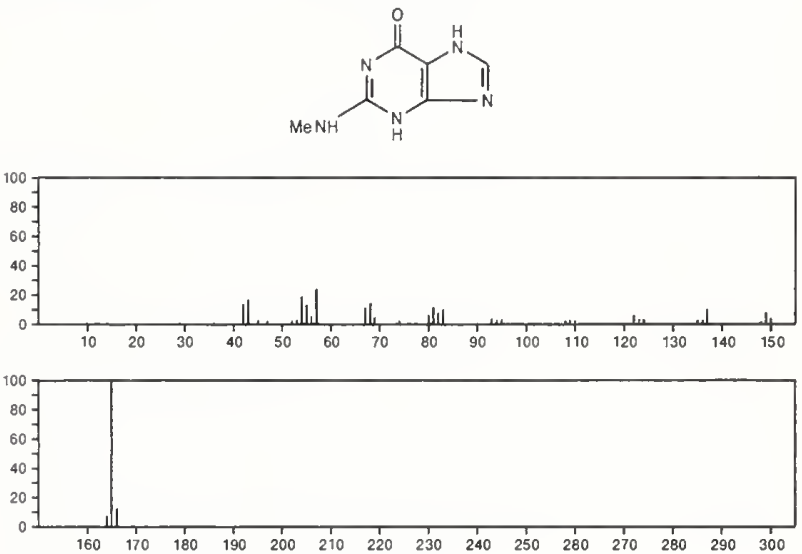
165

$1 H$-Purin-2-amine, 6-methoxy-

$\mathrm{C}_{6} \mathrm{H}_{7} \mathrm{~N}_{5} \mathrm{O}$

$20535-83-5$<smiles>Nc1nc(O[Na])c2[nH]cnc2n1</smiles>
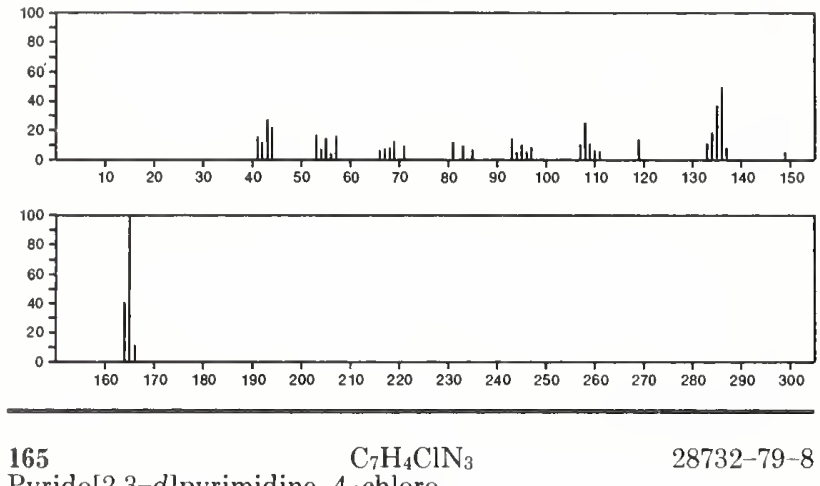

Pyrido[2,3-d]pyrimidine, 4-chloro-
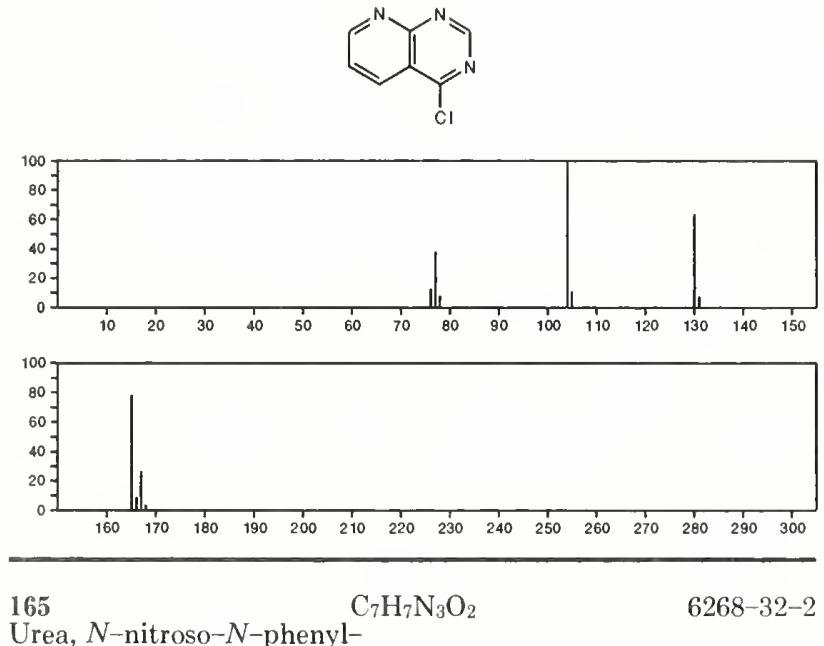

Urea, $N$-nitroso- $N$-phenyl-

$\mathrm{PhN}(\mathrm{NO})$ CONH2
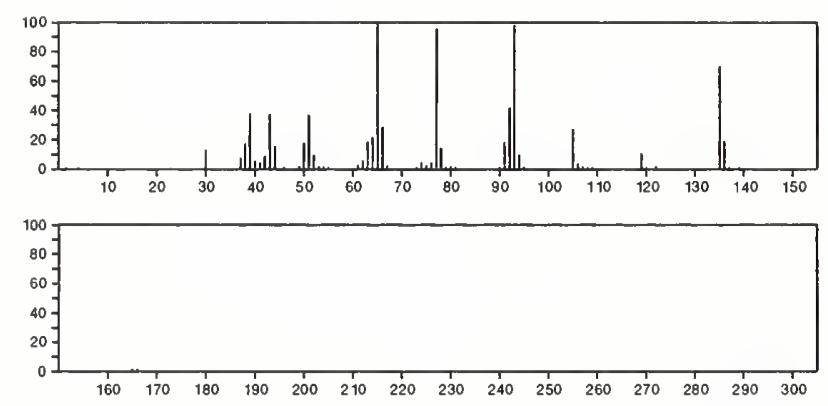

$165 \quad \mathrm{C}_{7} \mathrm{H}_{7} \mathrm{~N}_{3} \mathrm{~S}$

$s$-Triazolo[4,3-a]pyridine-3-thiol, 5-methyl-

$4926-22-1$
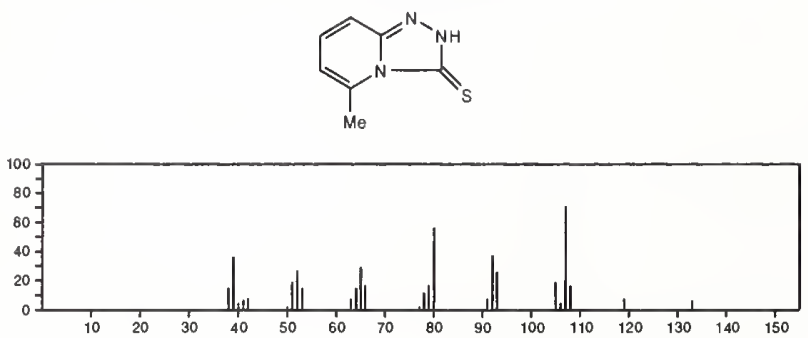

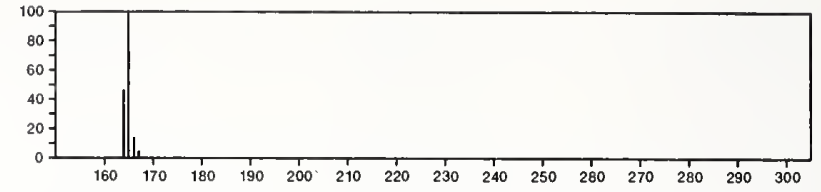

165

$\mathrm{C}_{7} \mathrm{H}_{7} \mathrm{~N}_{3} \mathrm{~S}$

$s$-Triazolo[4,3-a]pyridine-3-thiol, 7-methyl-

4926-23-2
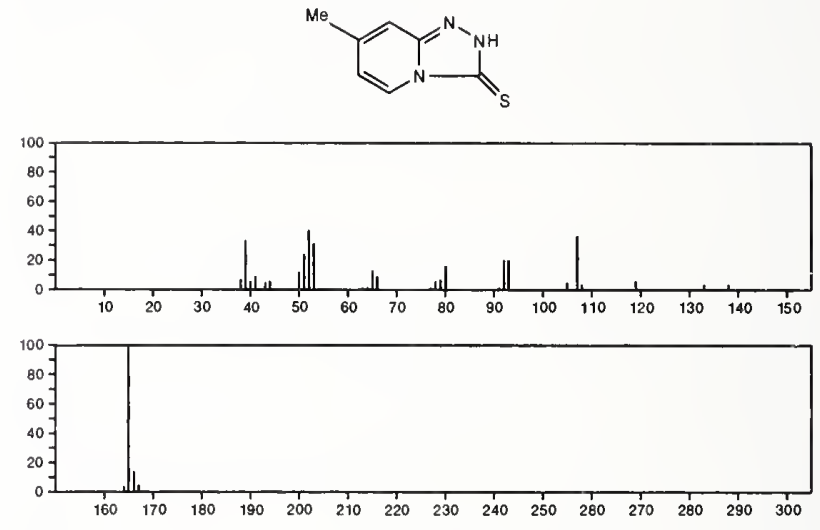

165

$\mathrm{C}_{8} \mathrm{H}_{7} \mathrm{NOS}$

$2 H-1,4$-Benzothiazin-3(4H)-one

$5325-20-2$
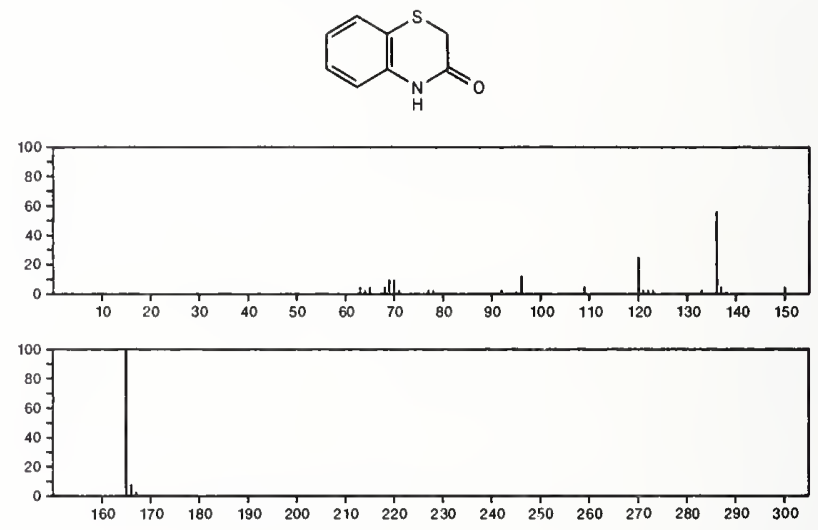

165

$\mathrm{C}_{8} \mathrm{H}_{7} \mathrm{NOS}$

30276-99-4

Thiazolo[3,2-a]pyridinium, 8-hydroxy-3-methyl-, hydroxide, inner
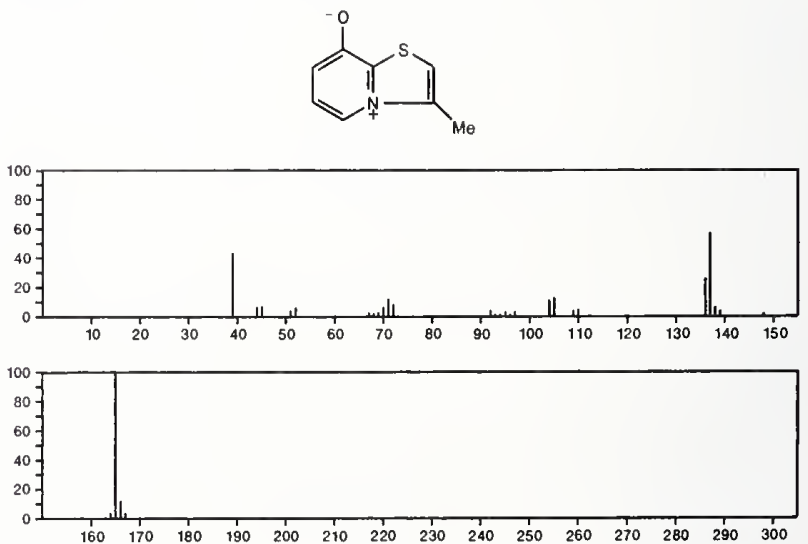
165

$\mathrm{C}_{8} \mathrm{H}_{7} \mathrm{NOS}$

$30277-17-9$

Thiazolo[3,2-a]pyridinium, 8-hydroxy-5-methyl-, hydroxide, inner salt
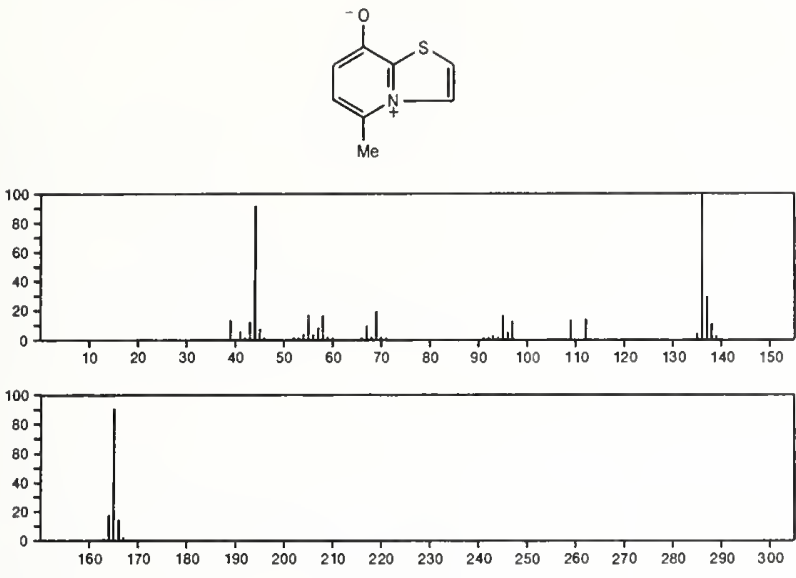

$165 \quad \mathrm{C}_{8} \mathrm{H}_{7} \mathrm{NOS} \quad 40991-38-6$

1,2-Benzisothiazole, 3-methoxy-
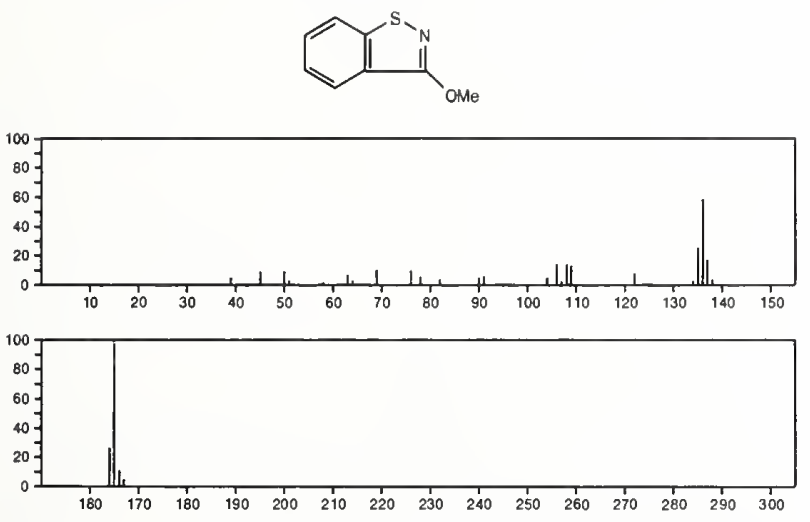

165

$\mathrm{C}_{8} \mathrm{H}_{7} \mathrm{NOS}$

1,4-Oxathiino[3,2-b]pyridine, 6-methyl-
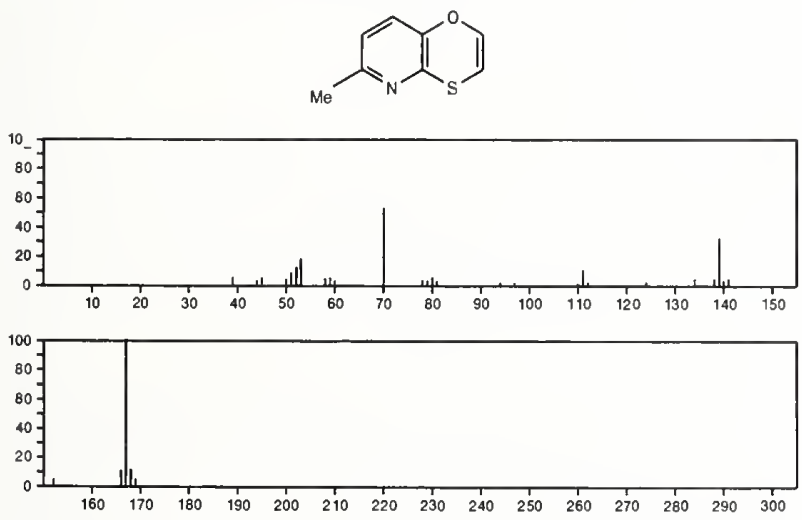

165

$\mathrm{C}_{8} \mathrm{H}_{7} \mathrm{NO}_{3}$

Ethanone, 1-(4-nitrophenyl)-
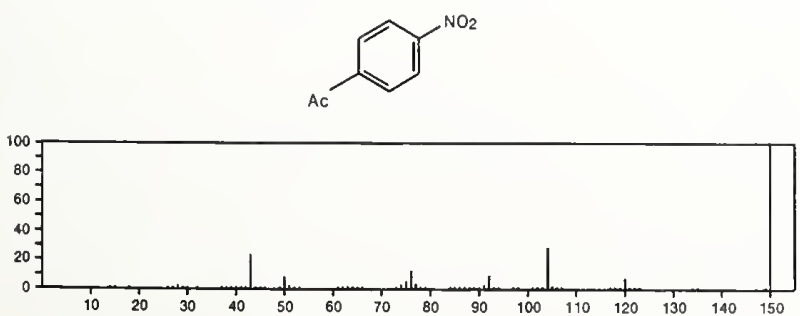

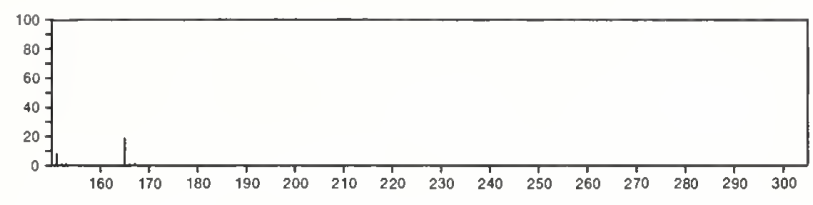

165 $\mathrm{C}_{8} \mathrm{H}_{7} \mathrm{NO}_{3}$

$771-26-6$

2H-1,4-Benzoxazin-3(4H)-one, 4-hydroxy-
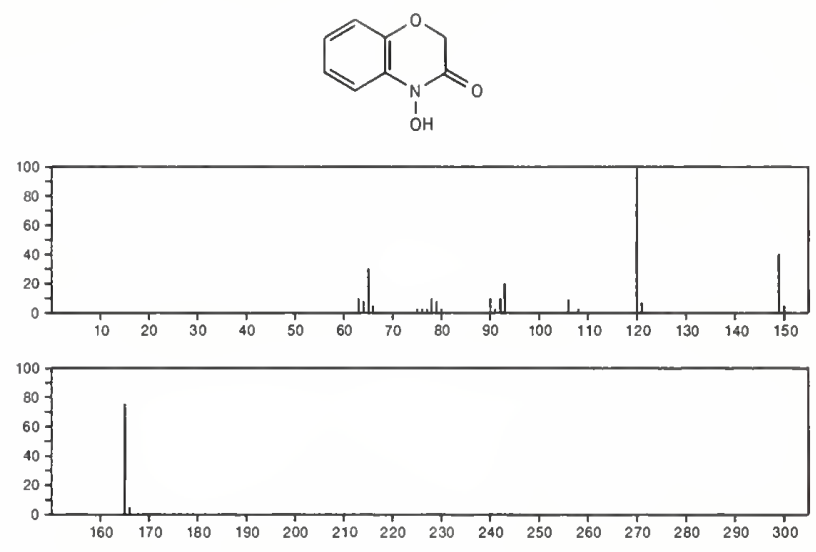

165

Phthalaldehydic acid, oxime

$$
\mathrm{C}_{8} \mathrm{H}_{7} \mathrm{NO}_{3}
$$

$6383-59-1$
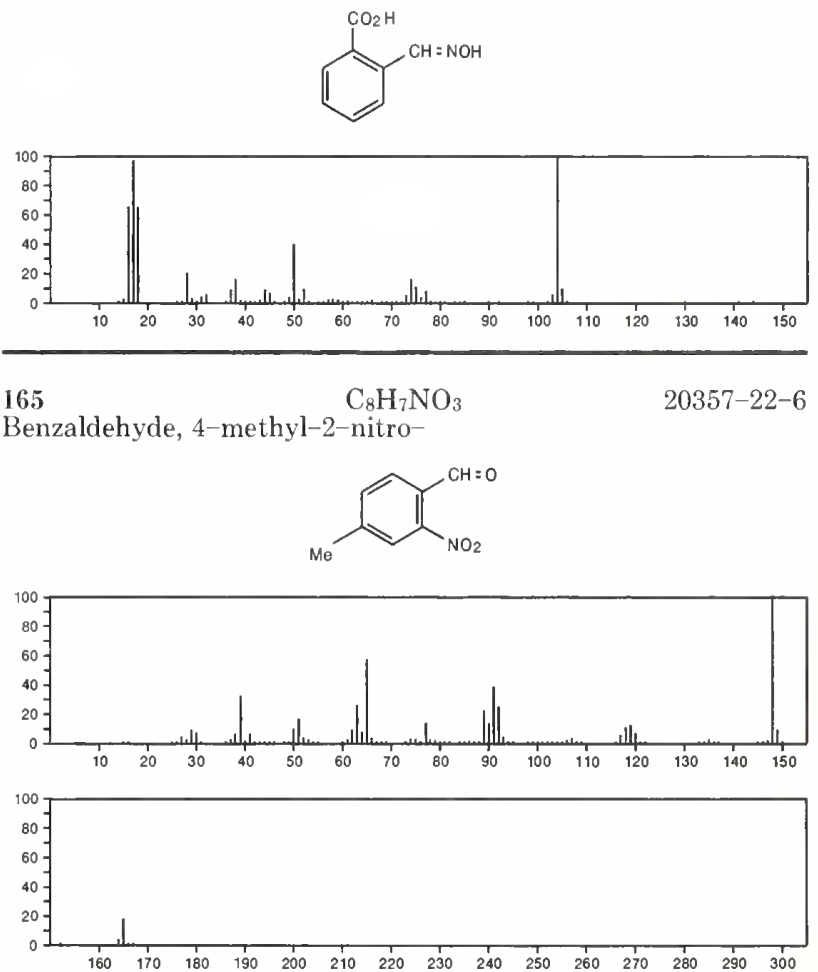

$165 \quad \mathrm{C}_{8} \mathrm{H}_{11} \mathrm{~N}_{3} \mathrm{O} \quad 31382-90-8$ Pyridinium, 3,5-dimethyl-1-ureido-, hydroxide, inner salt
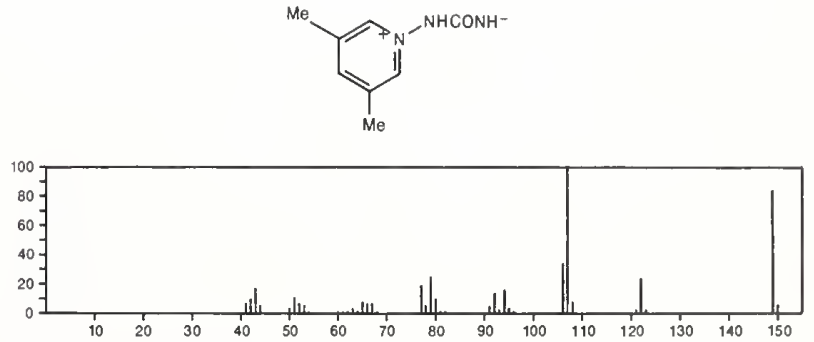


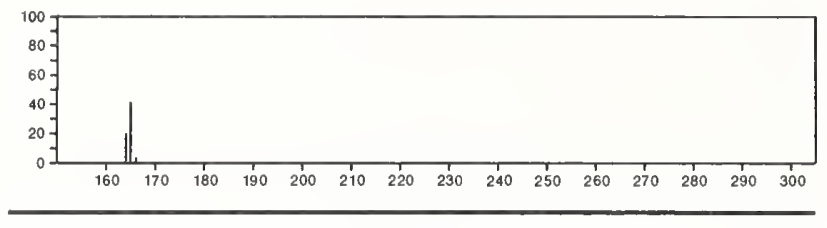

165

$\mathrm{C}_{9} \mathrm{H}_{11} \mathrm{NO}_{2}$

Acetamide, $N$-(4-methoxyphenyl)-
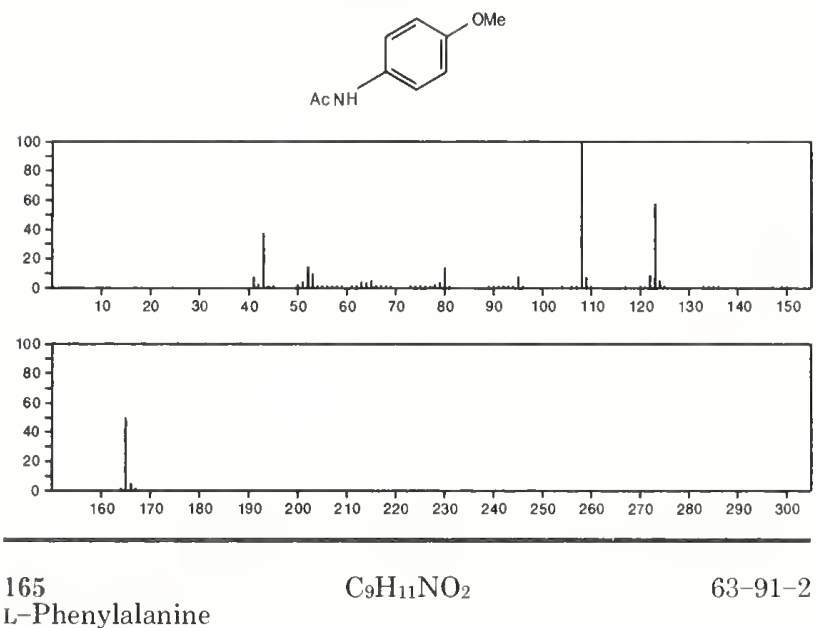

L-Phenylalanine

$\mathrm{HO}_{2} \mathrm{CCH}\left(\mathrm{NH}_{2}\right) \mathrm{CH}_{2} \mathrm{Ph}$
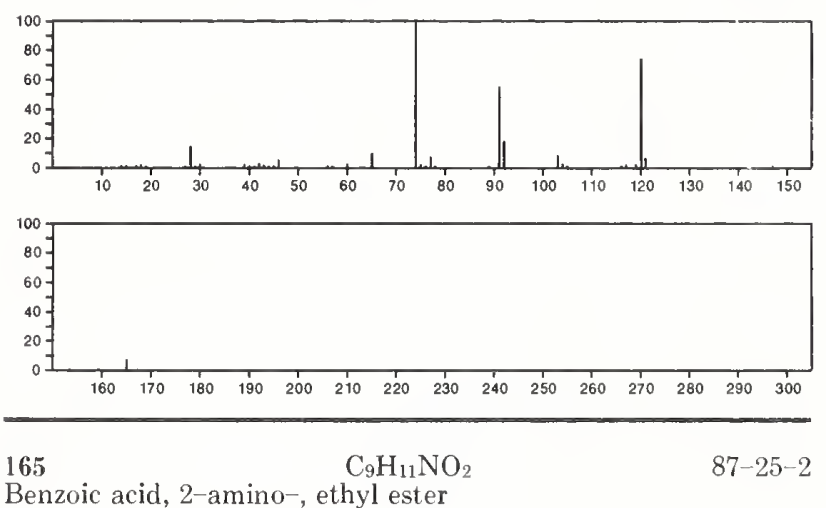

Benzoic acid, 2-amino-, ethyl ester
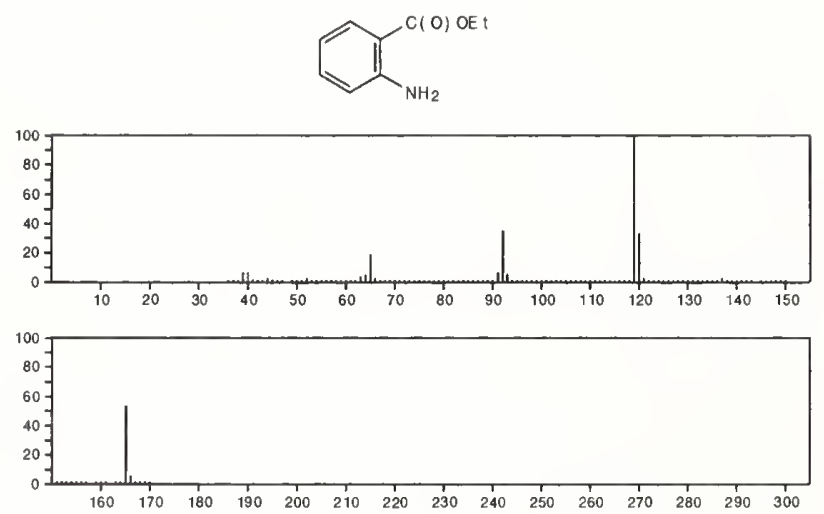

165 Acetamide, $\mathrm{N}-(2-$ methoxyphenyl)-

$93-26-5$
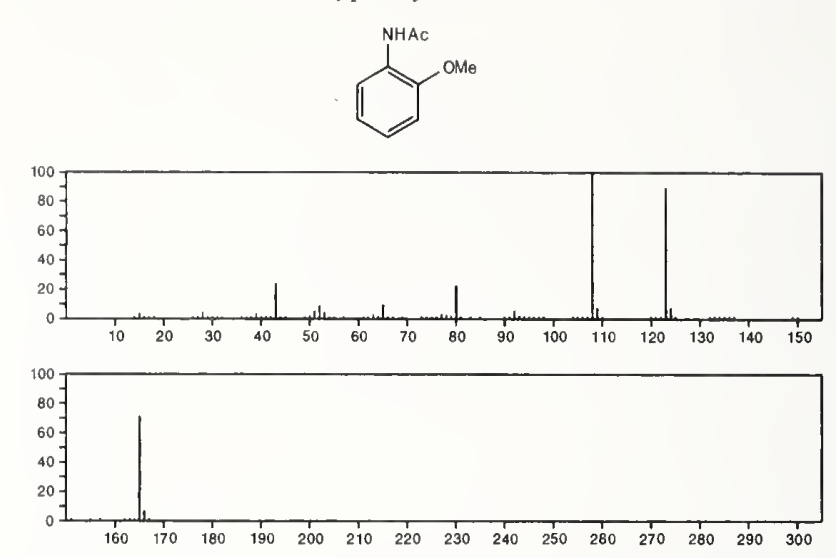

$165 \quad \mathrm{C}_{9} \mathrm{H}_{11} \mathrm{NO}_{2}$

Benzoic acid, 4-amino-, ethyl ester

$94-09-7$
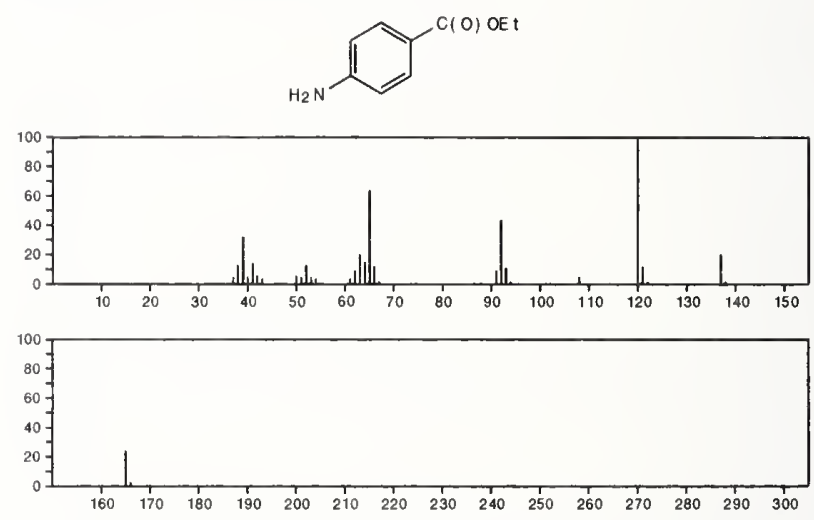

165

Benzoic acid, 3-(dimethylamino)

$99-64-9$
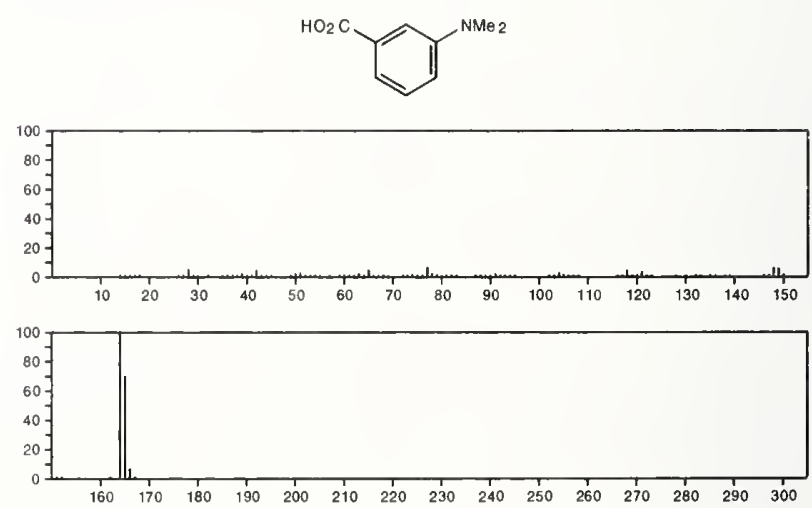

165

Carbamic acid, phenyl-, ethyl $\mathrm{C}_{9} \mathrm{H}_{11} \mathrm{NO}_{2}$

$101-99-5$

PhNHC(O) OE t
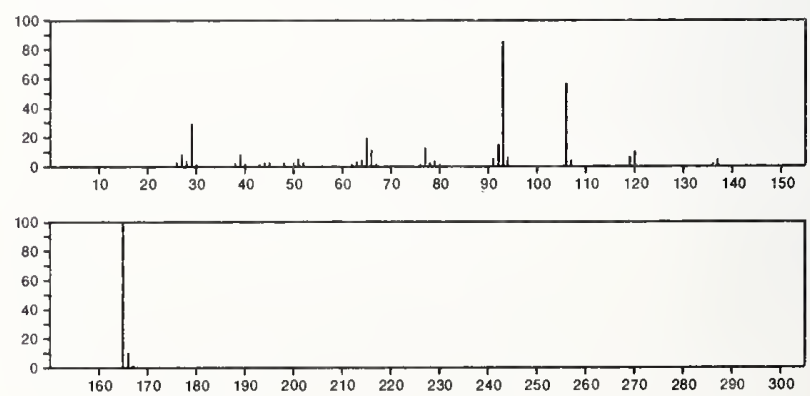
165

$\mathrm{C}_{9} \mathrm{H}_{11} \mathrm{NO}_{2}$

Benzene, 1,3,5-trimethyl-2-nitro-<smiles>Cc1cc([N+](=O)[O-])c([N+](=O)[O-])c([N+](=O)[O-])c1</smiles>
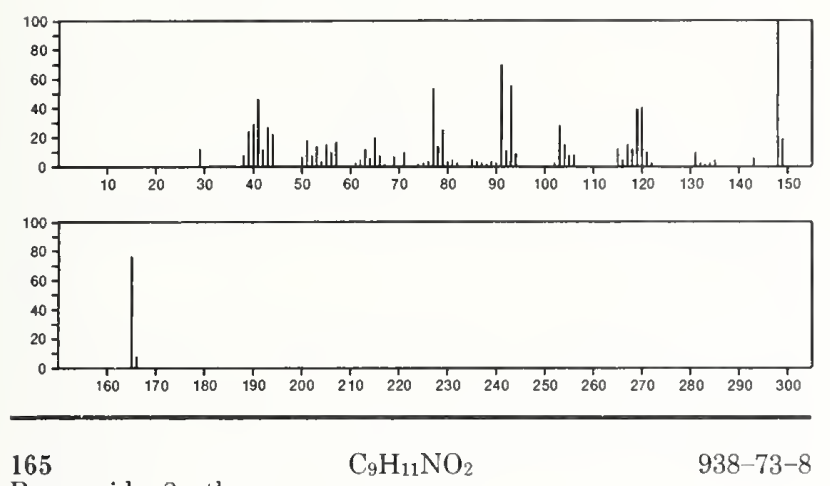

Benzamide, 2-ethoxy-
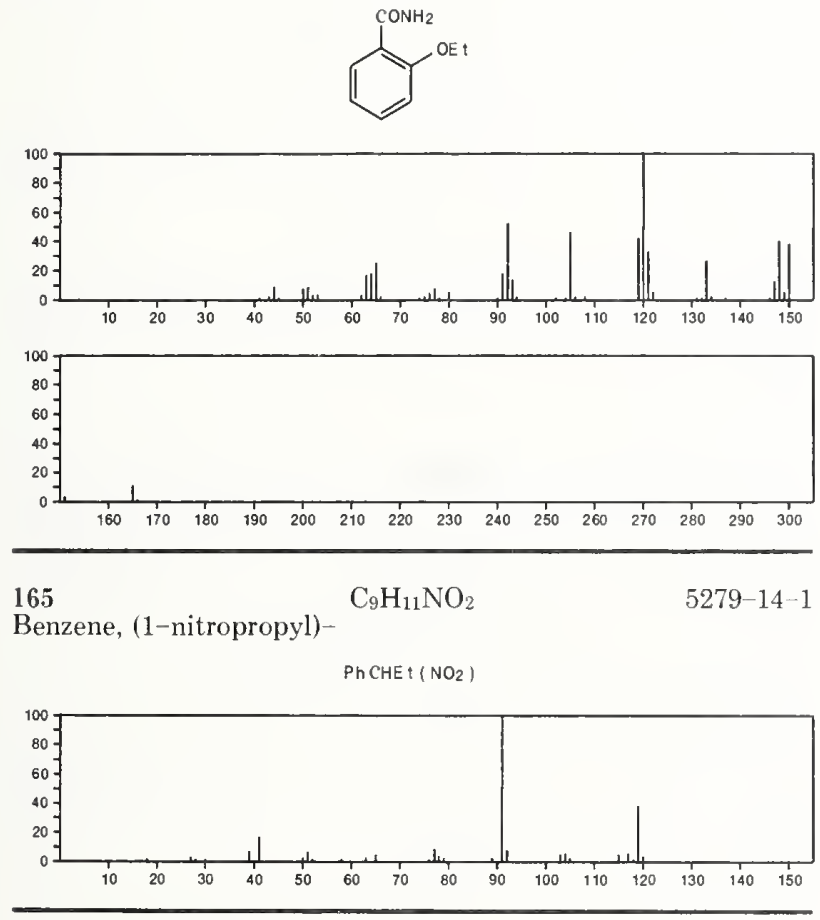

165

$\mathrm{C}_{9} \mathrm{H}_{11} \mathrm{NO}_{2}$

$6318-64-5$

Ethanone, 1-(3-amino-4-methoxyphenyl)-
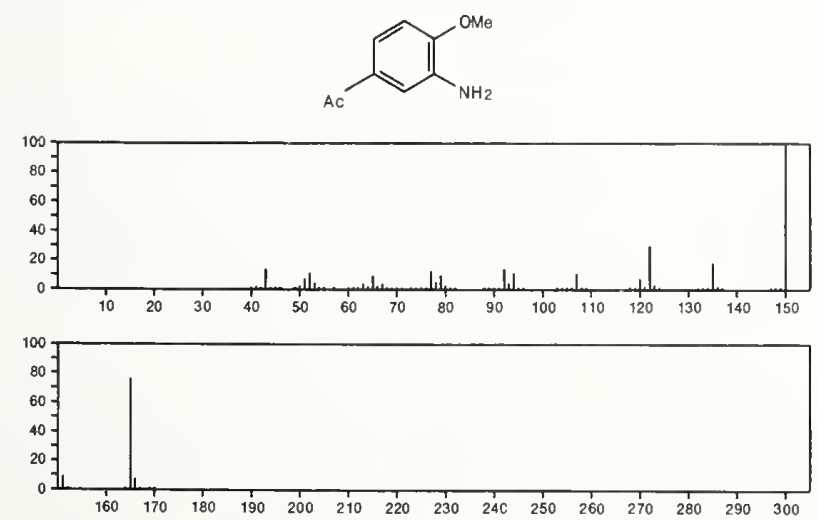

$165 \quad \mathrm{C}_{9} \mathrm{H}_{11} \mathrm{NO}_{2}$

Carbamic acid, (2-methylphenyl)-, methyl ester

$14983-92-7$
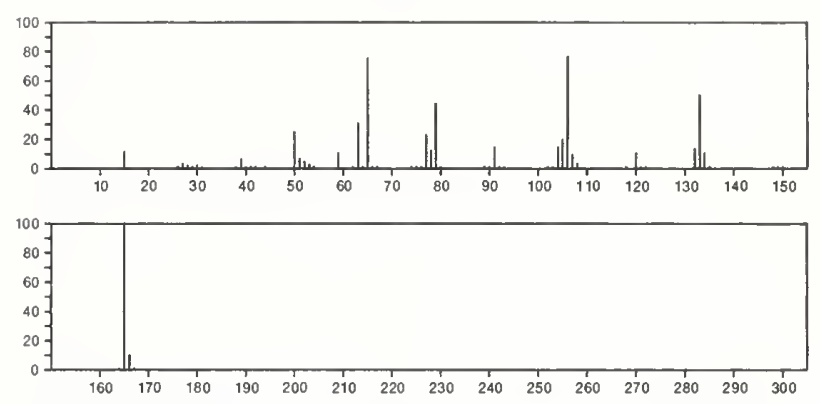

165
Benzene, (2-nitropropyl)- $\mathrm{C}_{9} \mathrm{H}_{11} \mathrm{NO}_{2} \quad 17322-34-8$

$\mathrm{MeCH}\left(\mathrm{NO}_{2}\right) \mathrm{CH}_{2} \mathrm{Ph}$

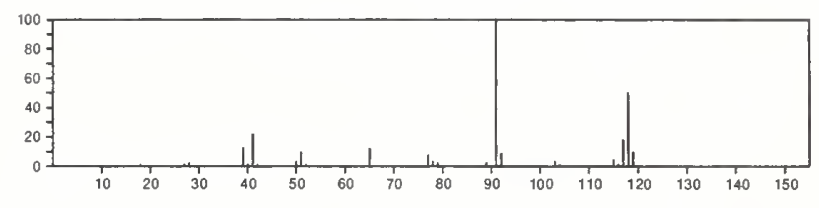

$165 \quad \mathrm{C}_{9} \mathrm{H}_{11} \mathrm{NO}_{2} \quad 18794-49-5$

4-Pyridinemethanol, 3-methyl-, acetate (ester)
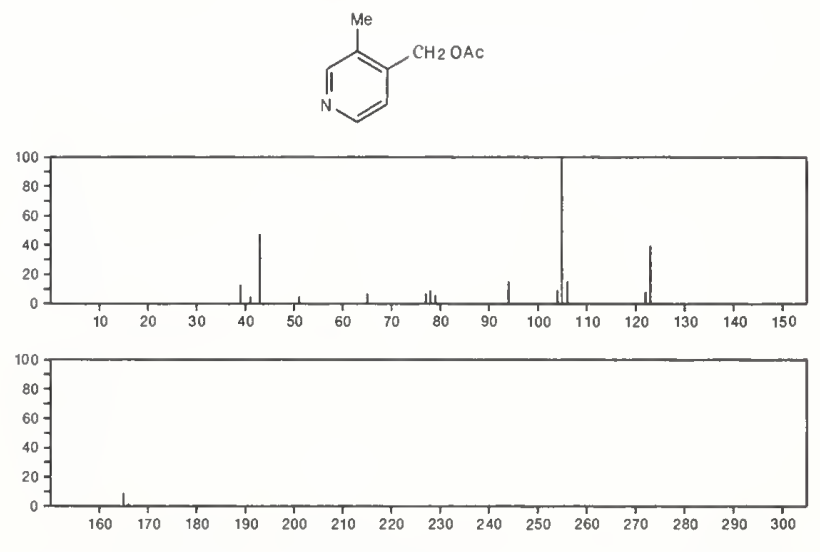

$165 \quad \mathrm{C}_{9} \mathrm{H}_{11} \mathrm{NO}_{2} \quad 20953-81-5$ 4-Azabicyclo[5.1.0]octa-2,5-diene-4-carboxylic acid, methyl ester
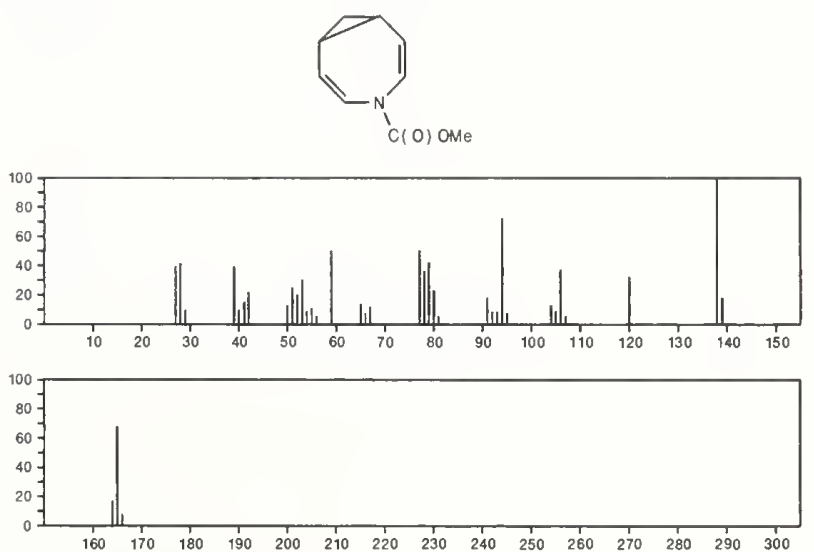
$\mathrm{C}_{9} \mathrm{H}_{11} \mathrm{NO}_{2}$

22139-35-1 5-Azatricyclo[4.2.0.02,4]oct-7-ene-5-carboxylic acid, methyl ester
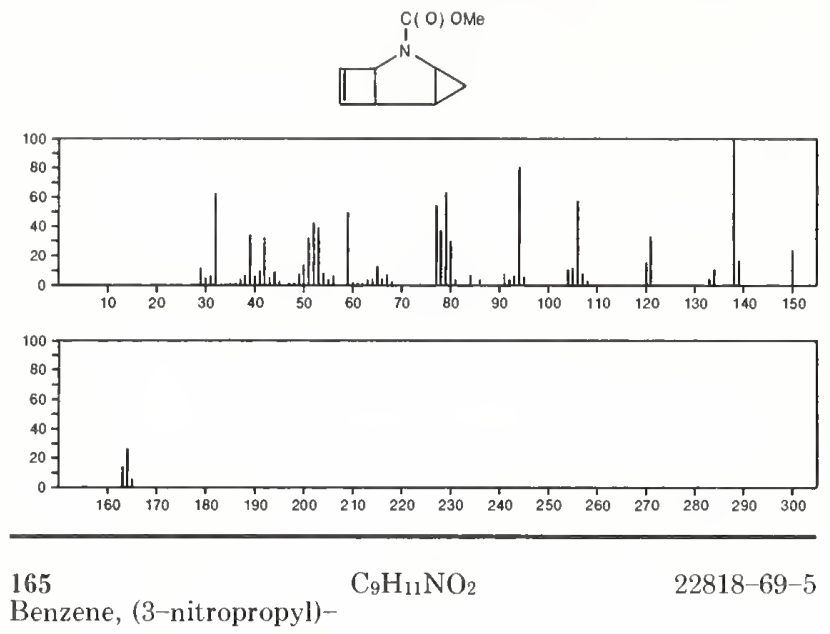

$\mathrm{Ph}\left(\mathrm{CH}_{2}\right)_{3} \mathrm{NO}_{2}$
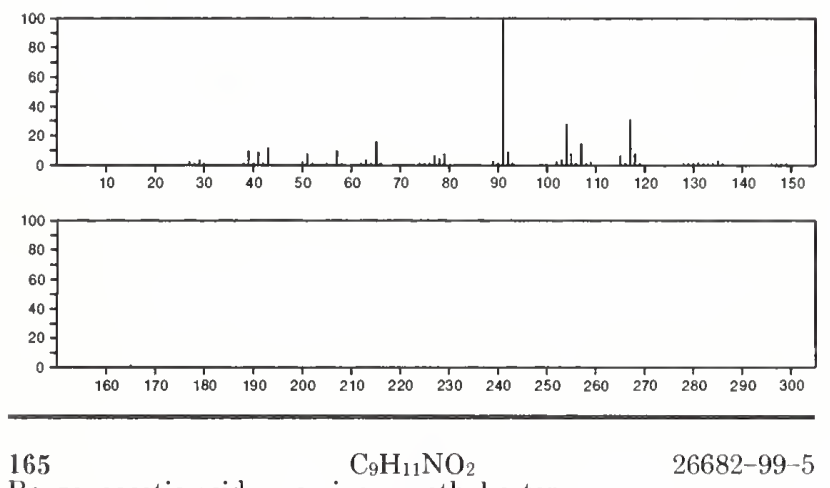

Benzeneacetic acid, $\alpha$-amino-, methyl ester

$\mathrm{MeOC}(\mathrm{O}) \mathrm{CH}\left(\mathrm{NH}_{2}\right) \mathrm{Ph}$
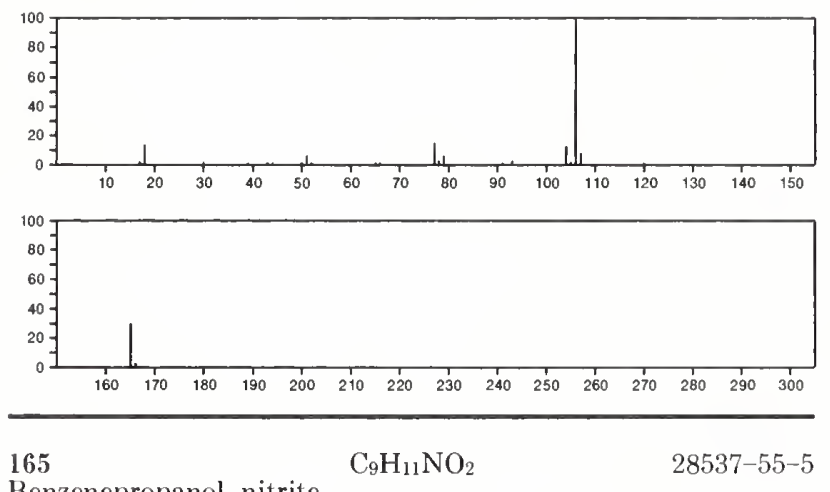

Benzenepropanol, nitrite

$\mathrm{ONO}\left(\mathrm{CH}_{2}\right)_{3} \mathrm{Ph}$

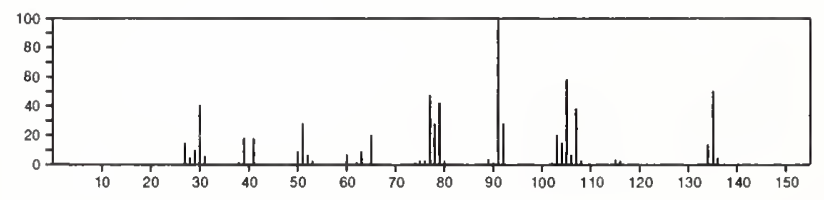

165

$\mathrm{C}_{9} \mathrm{H}_{11} \mathrm{NO}_{2}$

$28839-49-8$

$1 H$-Isoindole-1,3(2H)-dione, 4,5,6,7-tetrahydro-2-methyl-
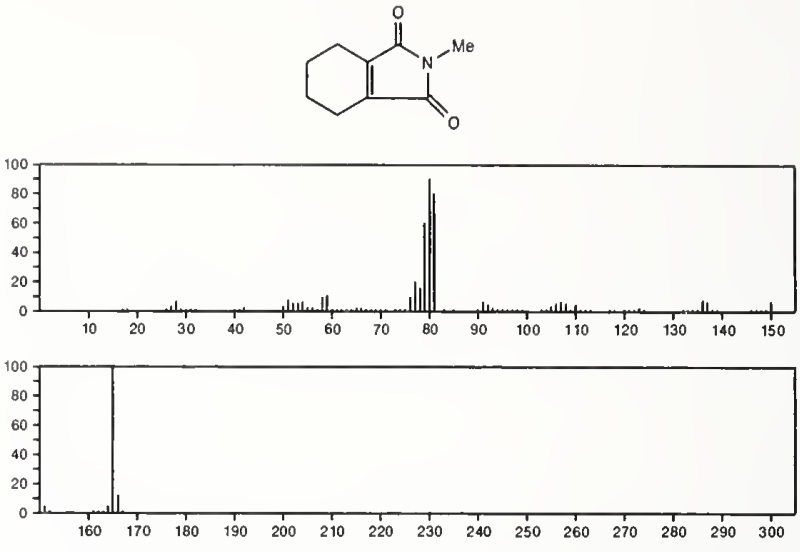

$165 \quad \mathrm{C}_{9} \mathrm{H}_{11} \mathrm{NO}_{2}$

Benzaldehyde, 4-methoxy-, $O$-methyloxime

$33499-40-0$
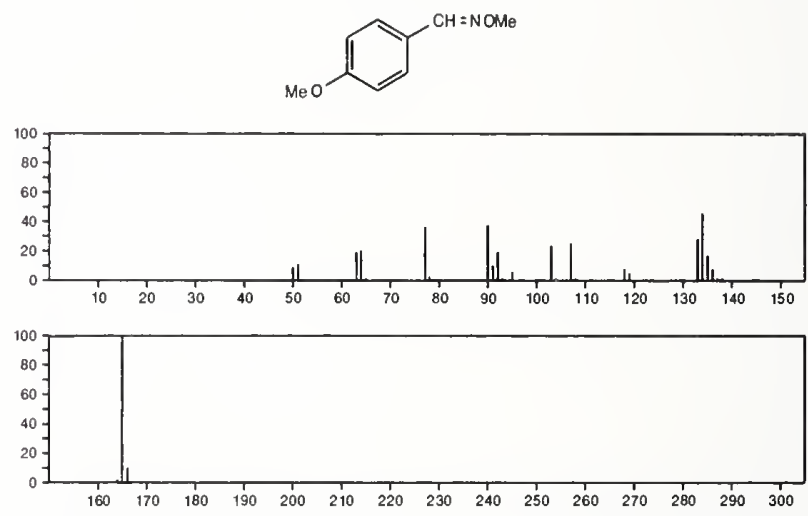

165

$\mathrm{C}_{9} \mathrm{H}_{11} \mathrm{NO}_{2}$

$39076-18-1$

Carbamic acid, (3-methylphenyl)-, methyl ester
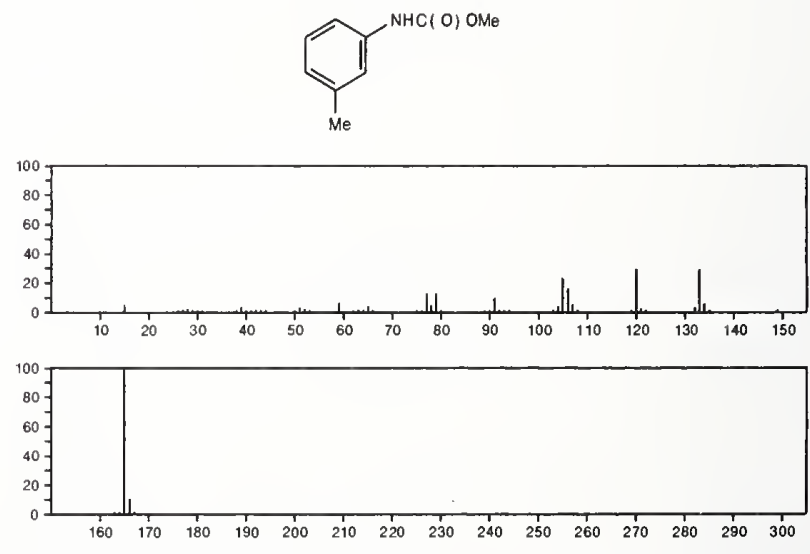

165

$\mathrm{C}_{9} \mathrm{H}_{11} \mathrm{NO}_{2}$

39998-21-5

Acetic acid, (1-methyl-2(1H)-pyridinylidene)-, methyl ester
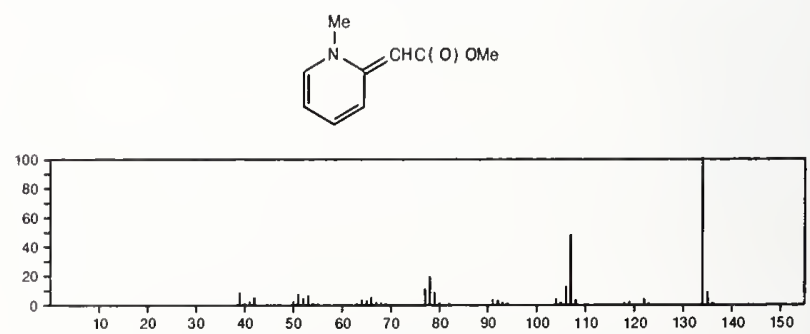


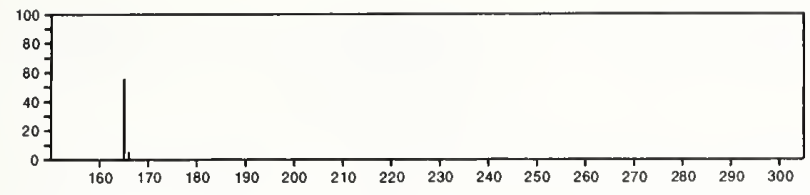

$165 \quad \mathrm{C}_{9} \mathrm{H}_{11} \mathrm{NO}_{2} \quad 39998-22-6$ Acetic acid, (1-methyl-4(1H)-pyridinylidene)-, methyl ester
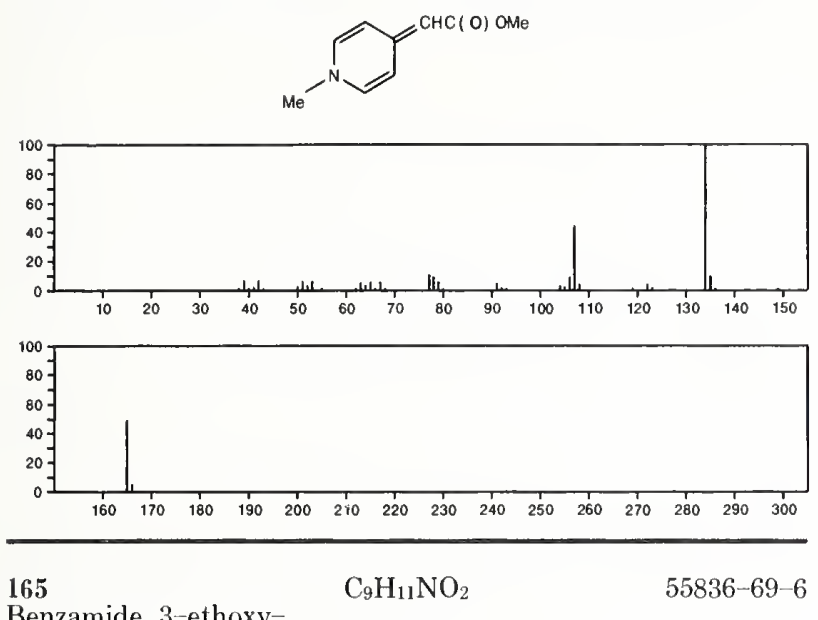

Benzamide, 3-ethoxy-
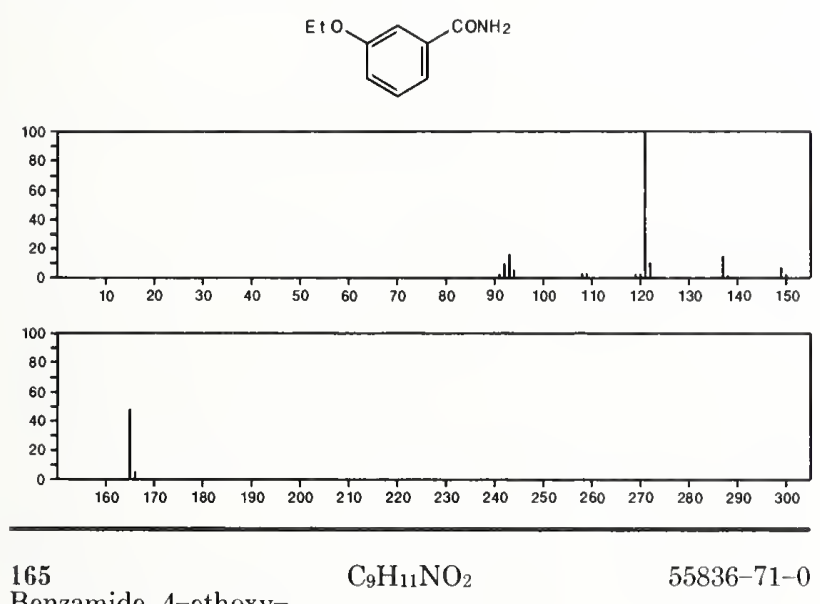

Benzamide, 4-ethoxy-
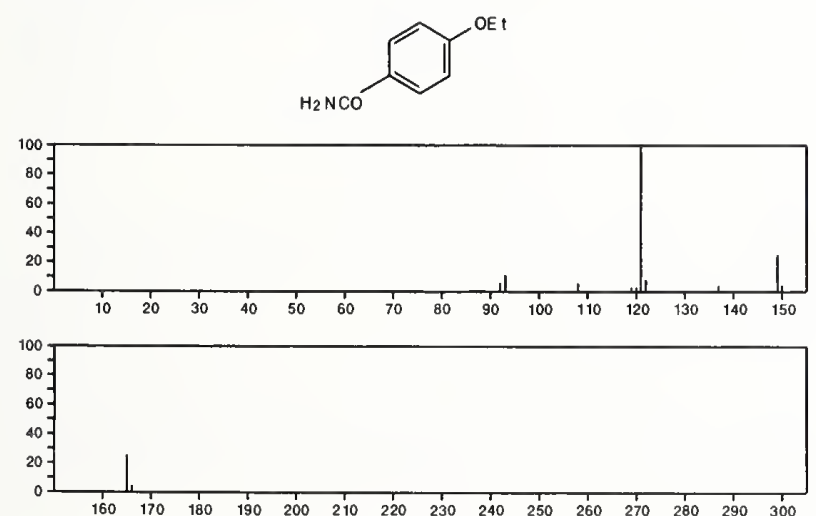

165

$\mathrm{C}_{9} \mathrm{H}_{11} \mathrm{NO}_{2}$

56666-98-9

2-Azabicyclo[3.2.0]hepta-3,6-diene-1-carboxylic acid, 3-methylmethyl ester
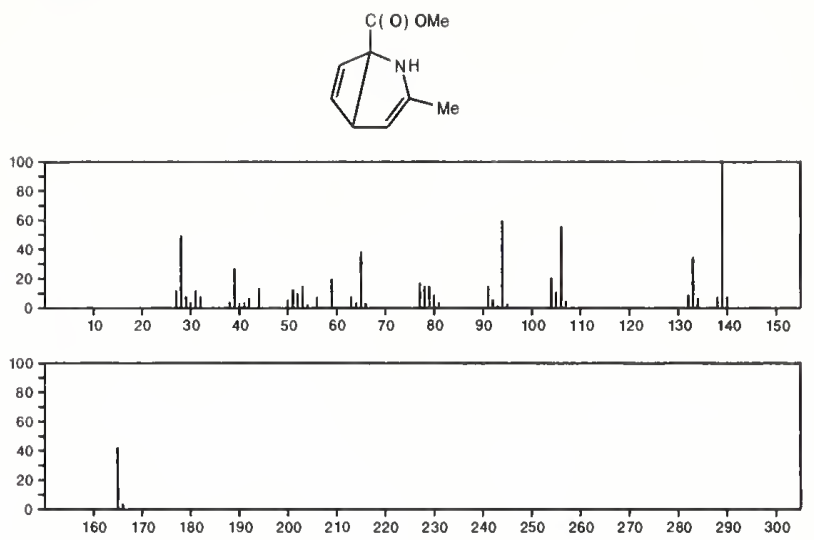

165

$\mathrm{C}_{9} \mathrm{H}_{11} \mathrm{NO}_{2}$

$56666-99-0$

2-Azabicyclo[3.2.0]hepta-3,6-diene-2-carboxylic acid, 5-methylmethyl ester
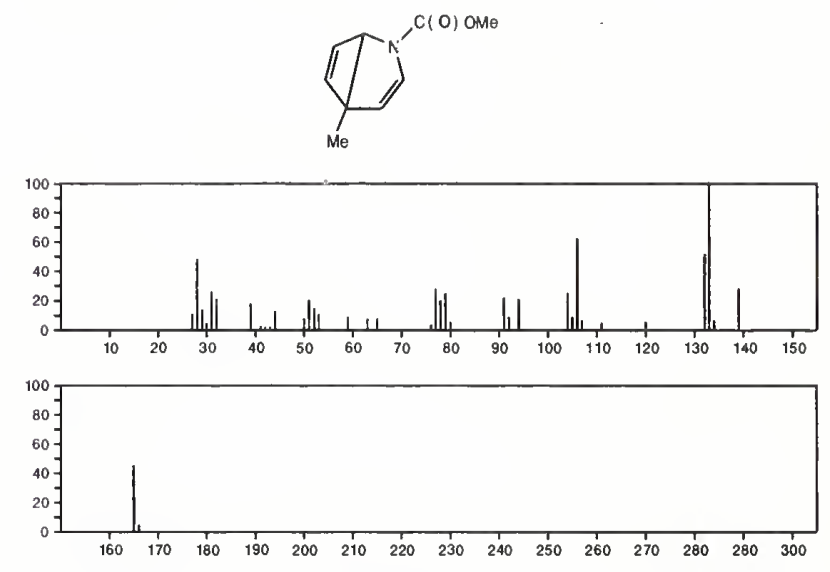

165

$\mathrm{C}_{9} \mathrm{H}_{11} \mathrm{NO}_{2}$

56667-06-2

2-Azabicyclo[3.2.0]hepta-3,6-diene-2-carboxylic acid, 4-methyl-, methyl ester
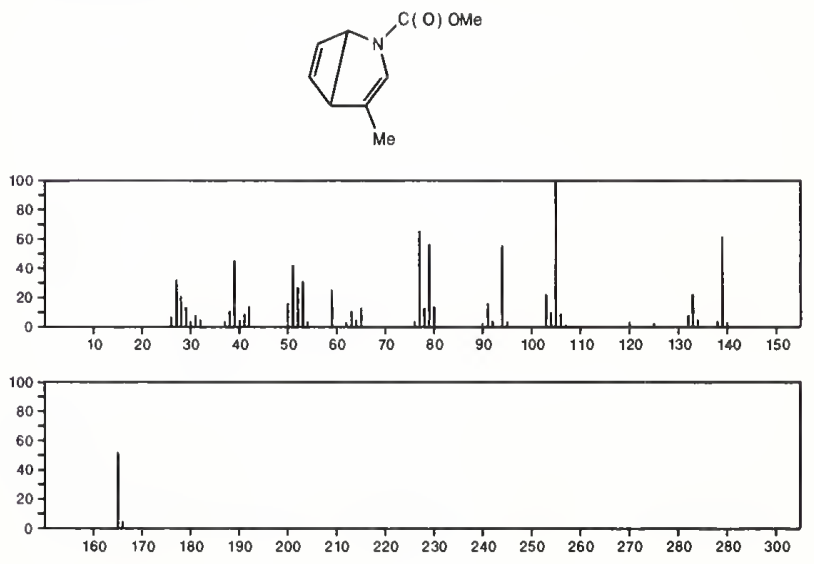
$165 \quad \mathrm{C}_{9} \mathrm{H}_{11} \mathrm{NO}_{2} \quad 56667-07-3$ 2-Azabicyclo[3.2.0]hepta-3,6-diene-2-carboxylic acid, 1-methyl-, methyl ester
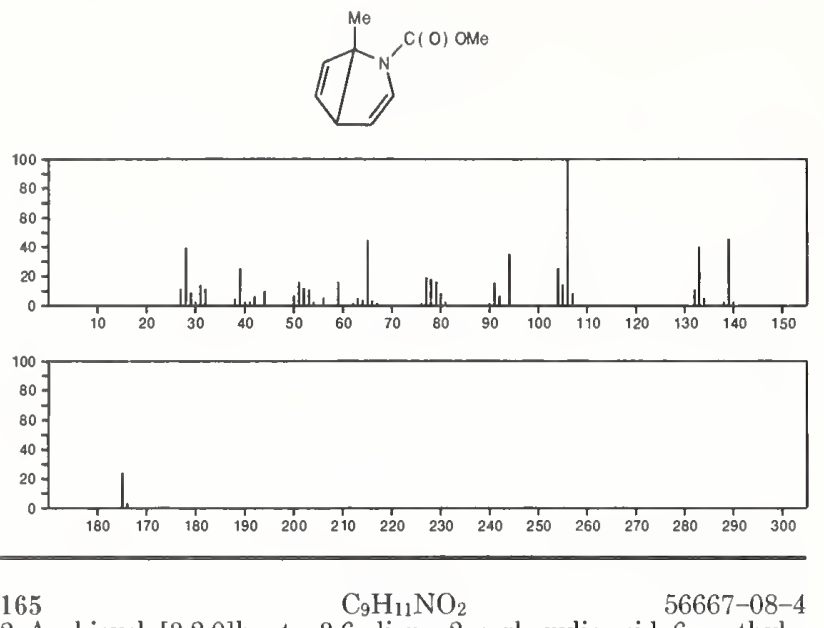

${ }_{2-A 5} \mathrm{C}_{9} \mathrm{H}_{11} \mathrm{NO}_{2} \quad$ 56667-08-4 methyl ester
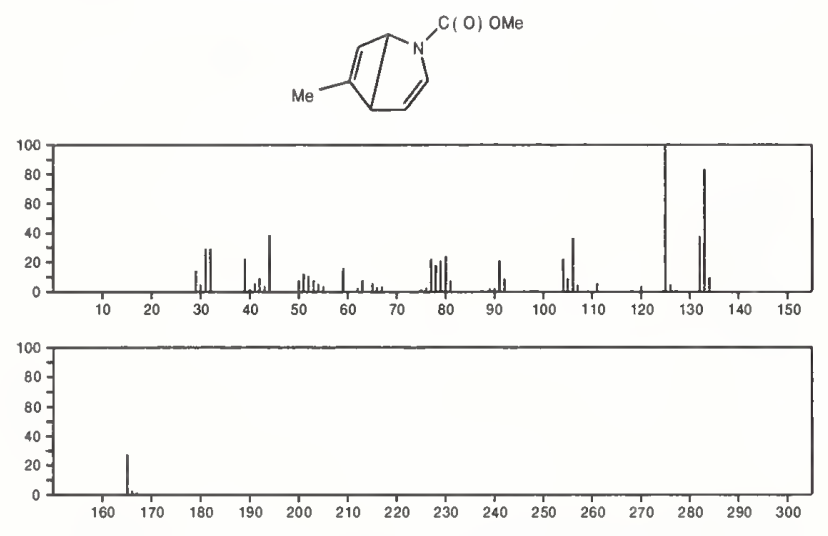

$165 . \mathrm{C}_{9} \mathrm{H}_{15} \mathrm{NSi}$

Pyridine, 2-[(trimethylsilyl)methyl $]-$
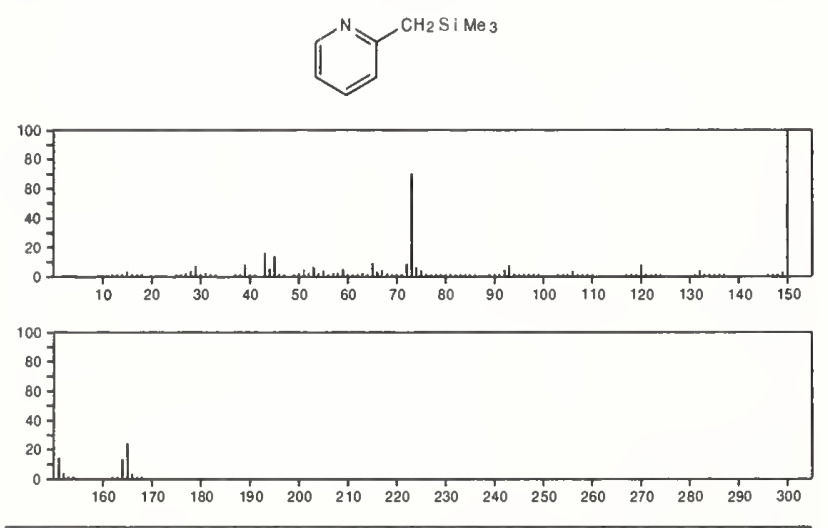

$165 \quad \mathrm{C}_{10} \mathrm{H}_{15} \mathrm{NO} 90-82-4$ Benzenemethanol, $\alpha-[1-$ (methylamino) ethyl $]-,\left[S-\left(R^{*}, R^{*}\right)\right]-$

$\mathrm{MeCH}(\mathrm{NHMe}) \mathrm{CH}(\mathrm{OH}) \mathrm{Ph}$

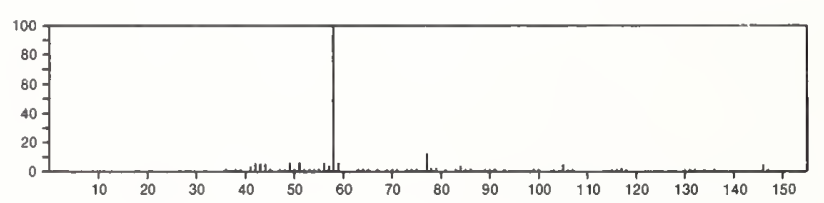

$165 \quad \mathrm{C}_{10} \mathrm{H}_{15} \mathrm{NO} 299-42-3$

Benzenemethanol, $\alpha-\left[1-(\right.$ methylamino)ethyl $]-,\left[R-\left(R^{*}, S^{*}\right)\right]^{-}$

$\mathrm{MeCH}$ ( NHMe) $\mathrm{CH}(\mathrm{OH}) \mathrm{Ph}$
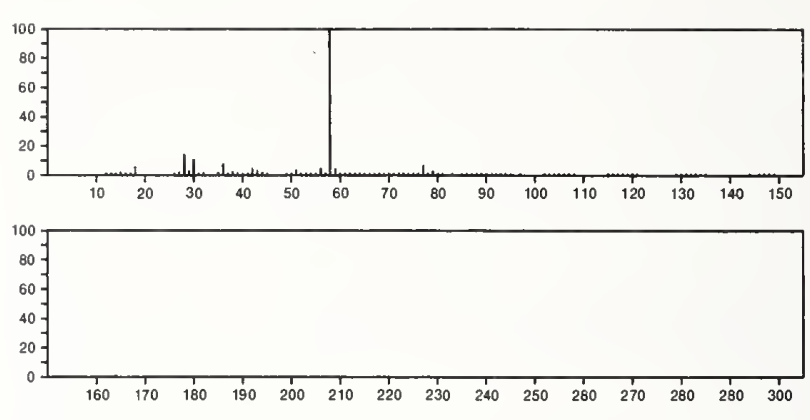

165

$\mathrm{C}_{10} \mathrm{H}_{15} \mathrm{NO}$

$5300-22-1$

Benzenemethanol, $\alpha-[($ ethylamino $)$ methyl $]-$

$\mathrm{E} t \mathrm{NHCH}_{2} \mathrm{CH}(\mathrm{OH}) \mathrm{Ph}$

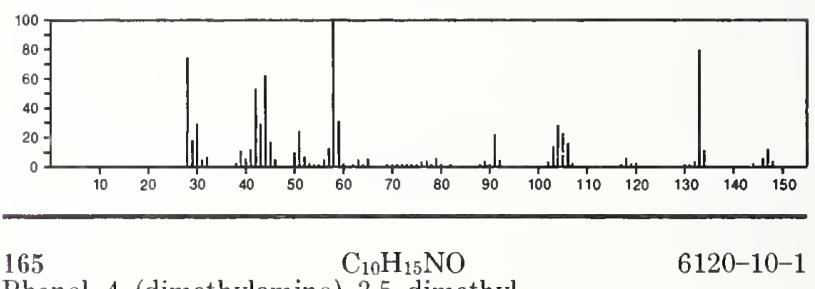

Phenol, 4-(dimethylamino)-3,5-dimethyl-<smiles>Cc1cc(O)cc(C)c1N</smiles>
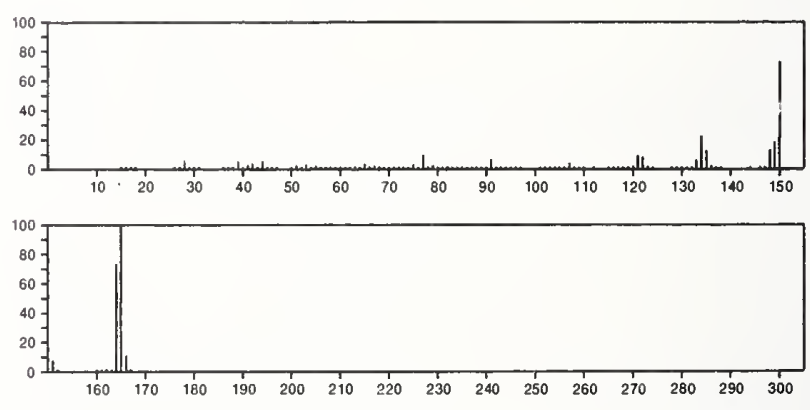

165

$\mathrm{C}_{10} \mathrm{H}_{15} \mathrm{NO}$

Phenol, $p-[3-($ methylamino)propyl] -

$32180-92-0$
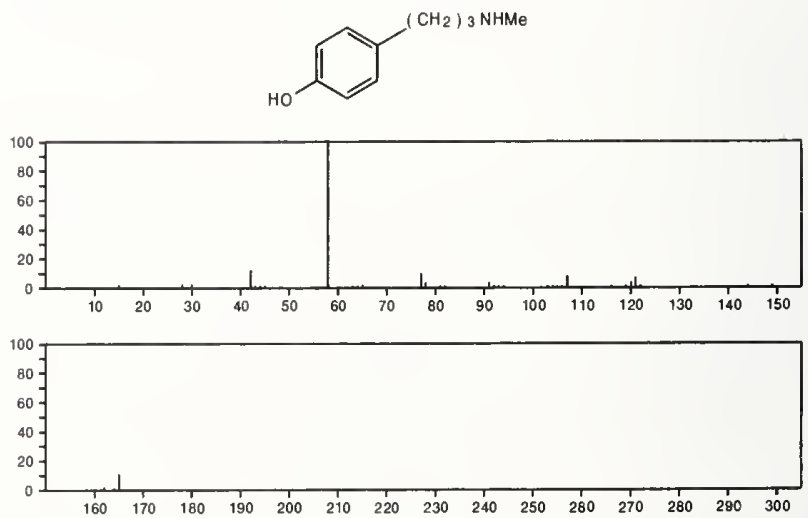
165

$\mathrm{C}_{10} \mathrm{H}_{15} \mathrm{NO}$

Benzenamine, 3-methoxy-2,4,6-trimethyl-
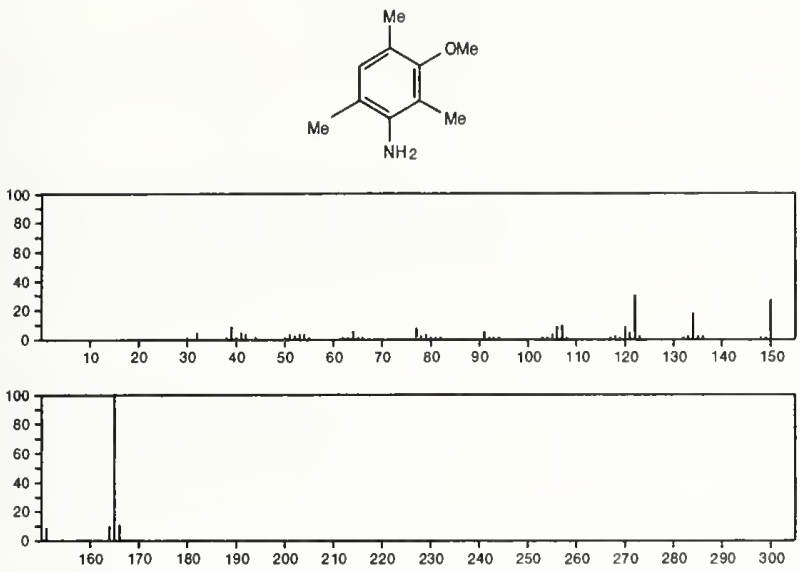

165

$\mathrm{C}_{10} \mathrm{H}_{15} \mathrm{NO}$

$55956-29-1$

Benzenamine, 4-ethoxyethyl-
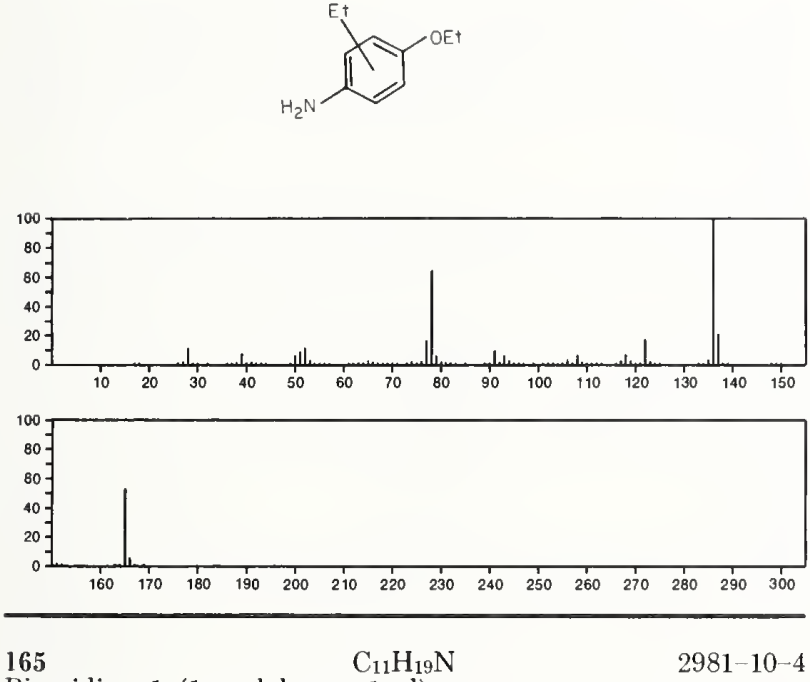

Piperidine, 1-(1-cyclohexen-1-yl)-
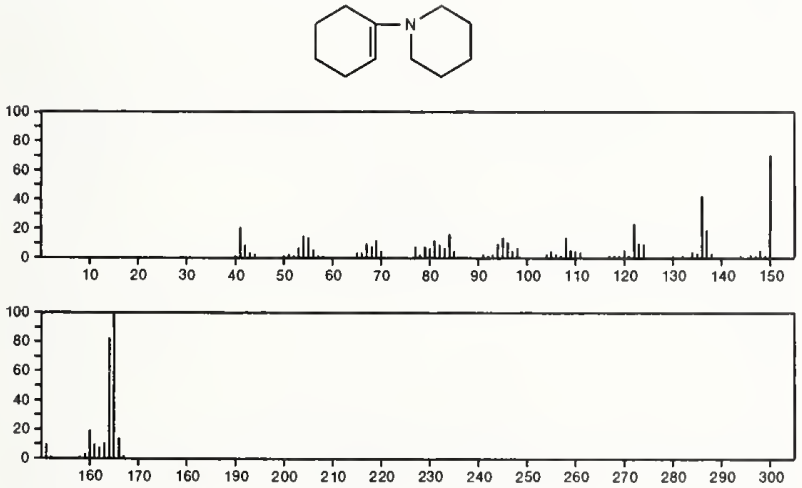

$165 \quad \mathrm{C}_{11} \mathrm{H}_{19} \mathrm{~N}$

Tricyclo[4.3.1.13,8] undecan-3-amine

$3048-63-3$
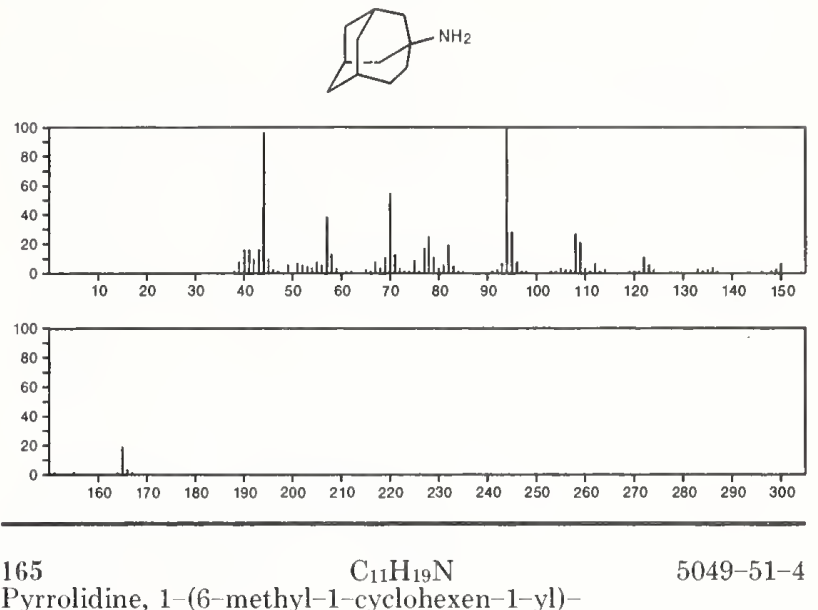

Pyrrolidine, 1-(6-methyl-1-cyclohexen-1-yl)-
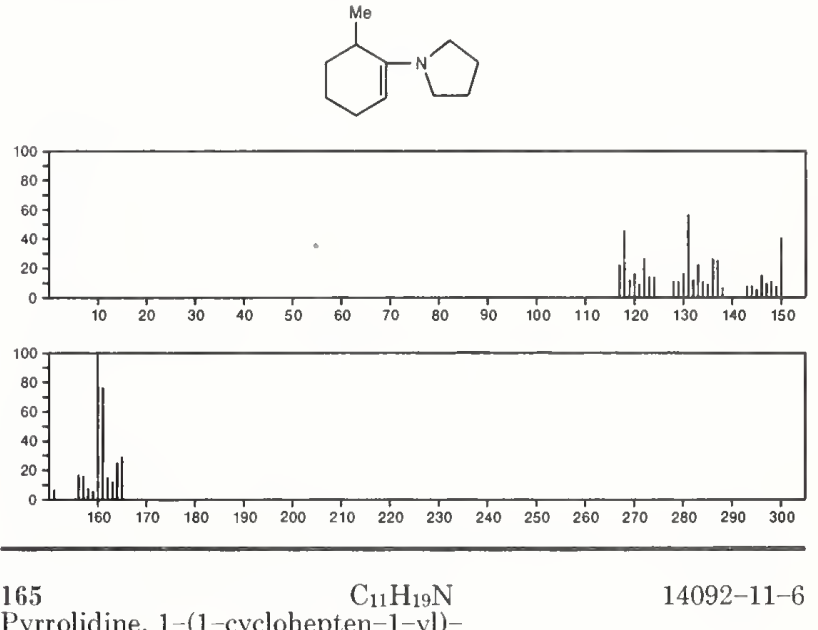

Pyrrolidine, 1-(1-cyclohepten-1-yl $)-$
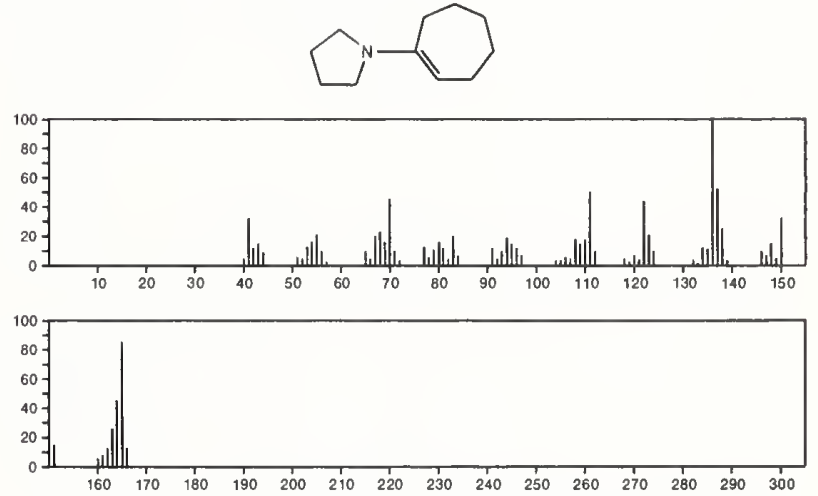

165

$\mathrm{C}_{11} \mathrm{H}_{19} \mathrm{~N}$

31083-61-1

Tricyclo[4.3.1.13,8]undecan-1-amine
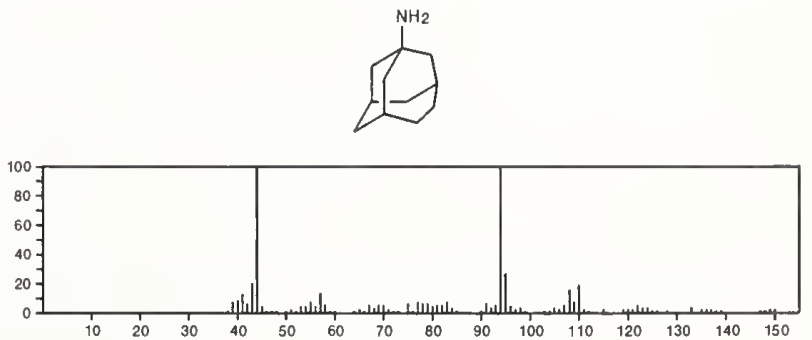


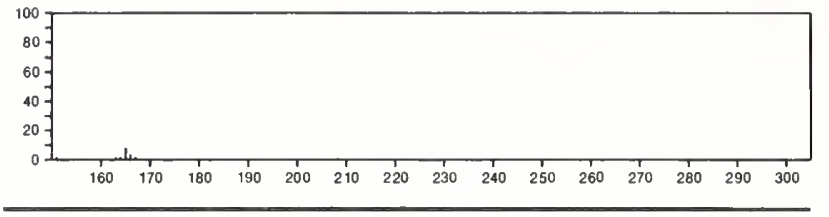

$165 \quad \mathrm{C}_{11} \mathrm{H}_{19} \mathrm{~N} \quad 56053-03-3$ 2-Naphthalenamine, $1,2,4 \mathrm{a}, 5,6,7,8,8 \mathrm{a}-$ octahydro-4a-methyl-
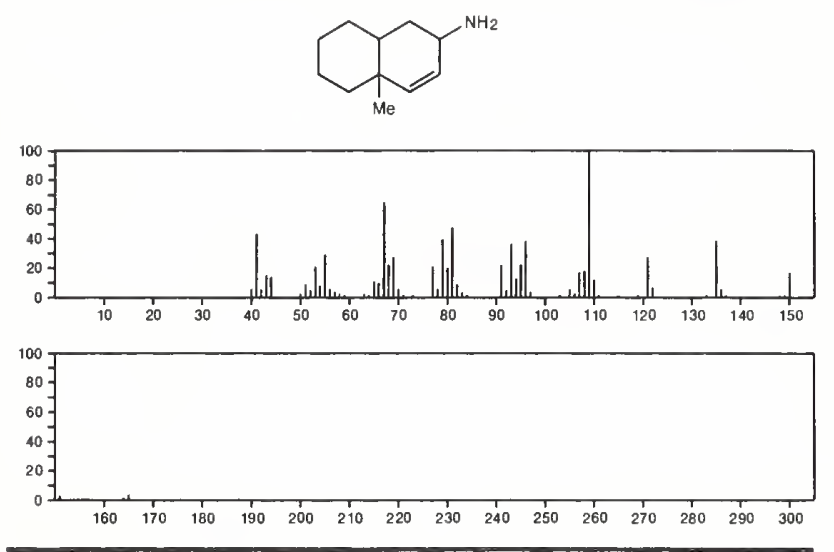

166

$\mathrm{C}_{2} \mathrm{H}_{2} \mathrm{Cl}_{4}$

$79-34-5$

Ethane, 1,1,2,2-tetrachloro-
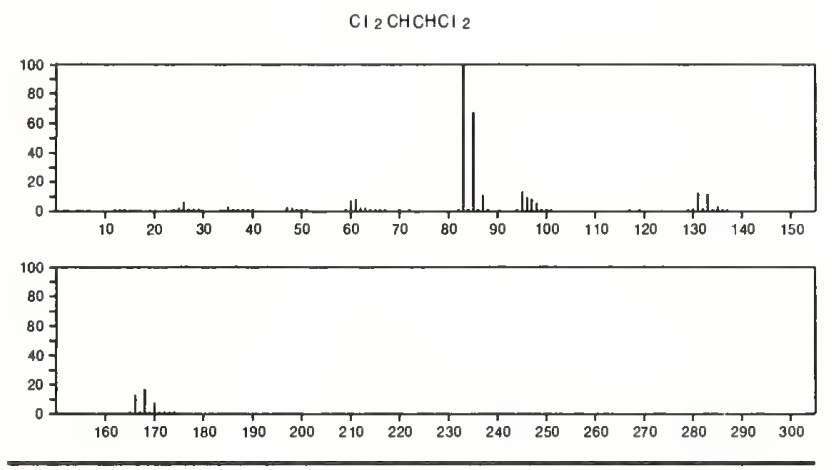

166

$\mathrm{C}_{2} \mathrm{H}_{2} \mathrm{Cl}_{4}$

$630-20-6$

Ethane, 1,1,1,2-tetrachloro-

$\mathrm{Cl} \mathrm{CH}_{2} \mathrm{CCl}_{3}$

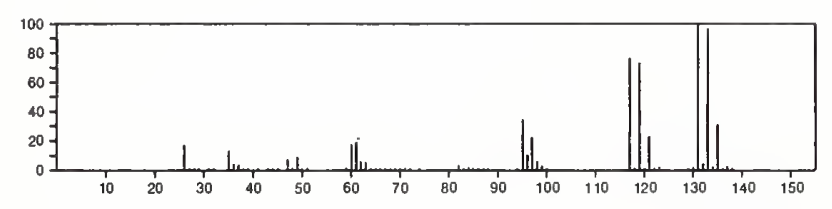

166

$\mathrm{C}_{2} \mathrm{H}_{4} \mathrm{~F}_{4} \mathrm{P}_{2}$

$50966-32-0$

Phosphonous difluoride, 1,2-ethanediylbis-

$\mathrm{F}_{2} \mathrm{PCH}_{2} \mathrm{CH}_{2} \mathrm{PF}_{2}$
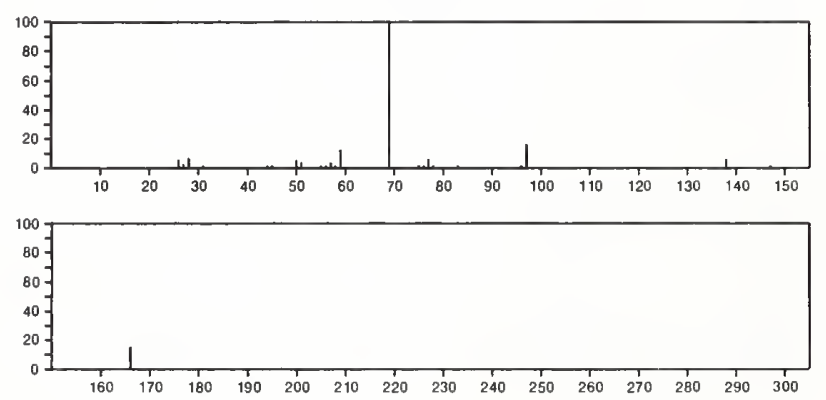

166

$\mathrm{C}_{3} \mathrm{ClF}_{5}$

$79-47-0$

1-Propene, 3-chloro-1,1,2,3,3-pentafluoro-

$\mathrm{F}_{2} \mathrm{CCl} \mathrm{CF}=\mathrm{CF}_{2}$
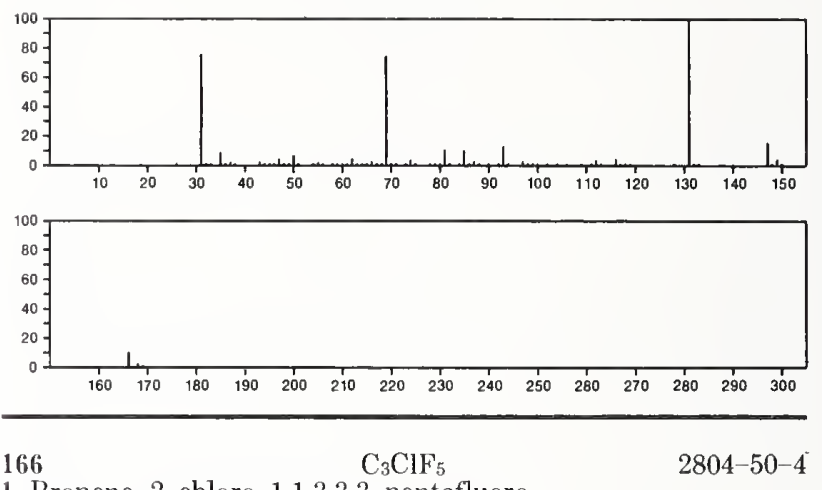

1-Propene, 2-chloro-1,1,3,3,3-pentafluoro-

$\mathrm{F}_{3} \mathrm{CCCl}=\mathrm{CF}_{2}$
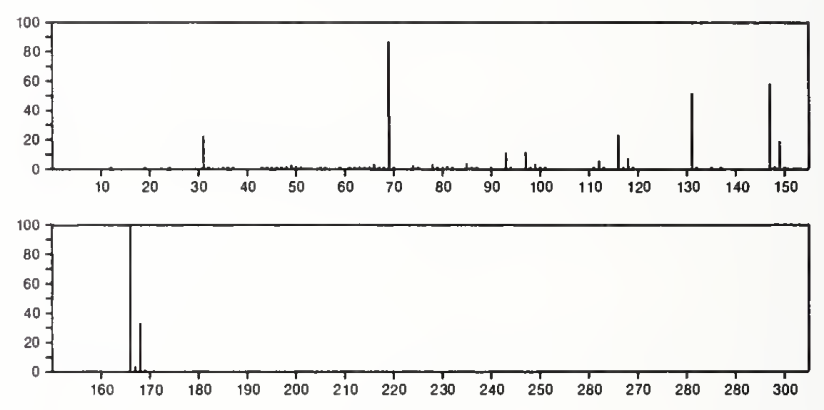

${ }_{2}^{166} \quad \mathrm{C}_{3} \mathrm{~F}_{6} \mathrm{O}$

$684-16-2$

2-Propanone, 1,1,1,3,3,3-hexafluoro-

$\mathrm{F}_{3} \mathrm{CCOCF}_{3}$
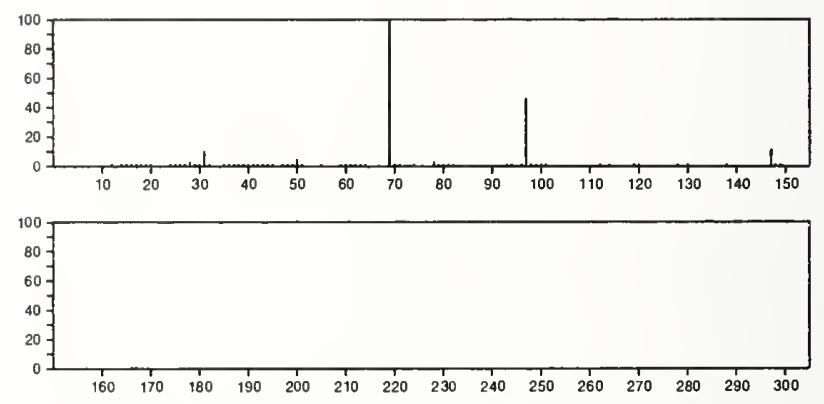

166

$\mathrm{C}_{3} \mathrm{H}_{3} \mathrm{Cl}_{2} \mathrm{~F}_{3}$

Propane, 2,3-dichloro-1,1,1-trifluoro-

$338-75-0$

$\mathrm{Cl} \mathrm{CH}_{2} \mathrm{CHCl} \mathrm{CF}_{3}$
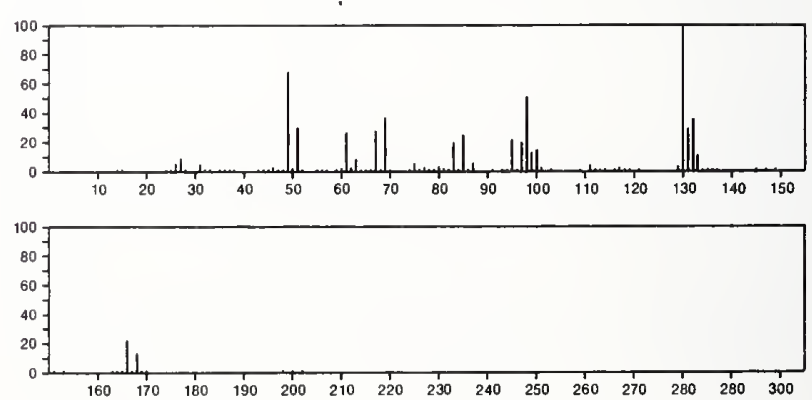
166

$\mathrm{C}_{3} \mathrm{H}_{3} \mathrm{I}$

659-86-9

1-Propyne, 3-iodo-

$\mathrm{I} \mathrm{CH}_{2} \mathrm{C} \equiv \mathrm{CH}$
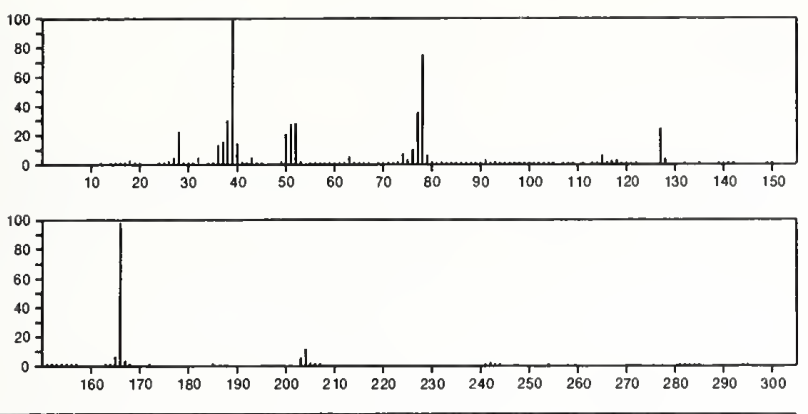

166

1,3-Propanediol, dinitrate

$\mathrm{C}_{3} \mathrm{H}_{6} \mathrm{~N}_{2} \mathrm{O}_{6}$

$3457-90-7$

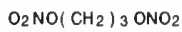

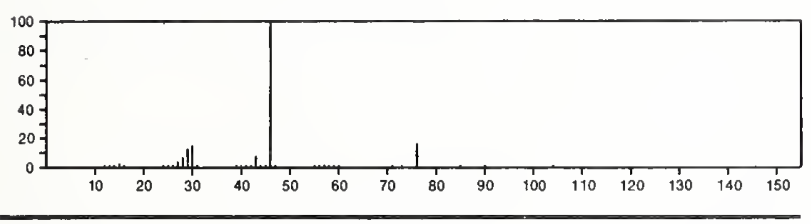

166

$\mathrm{C}_{3} \mathrm{H}_{6} \mathrm{~N}_{2} \mathrm{O}_{6}$

$6423-43-4$

1,2-Propanediol, dinitrate

$\mathrm{O}_{2} \mathrm{NOCH}_{2} \mathrm{CHMeONO}_{2}$

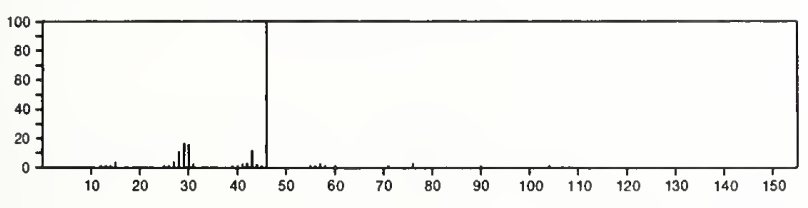

166

$\mathrm{C}_{3} \mathrm{H}_{9} \mathrm{Sb}$

$594-10-5$

Stibine, trimethyl-

SbMe 3
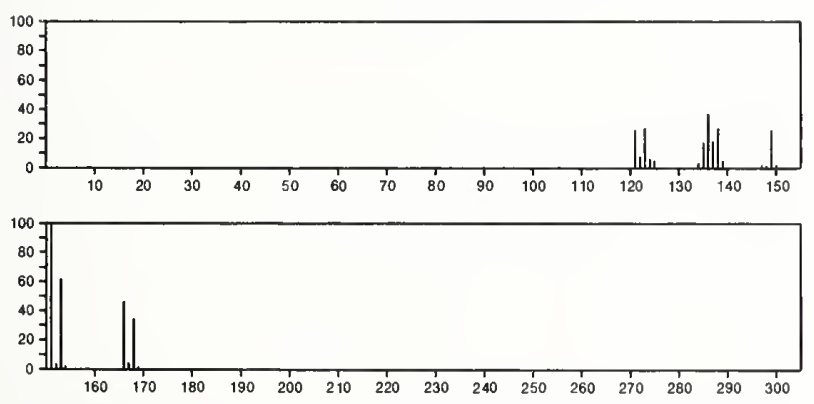

166

2,5-Furandione, 3,4-dichloro-

$\mathrm{C}_{4} \mathrm{Cl}_{2} \mathrm{O}_{3}$

$1122-17-4$
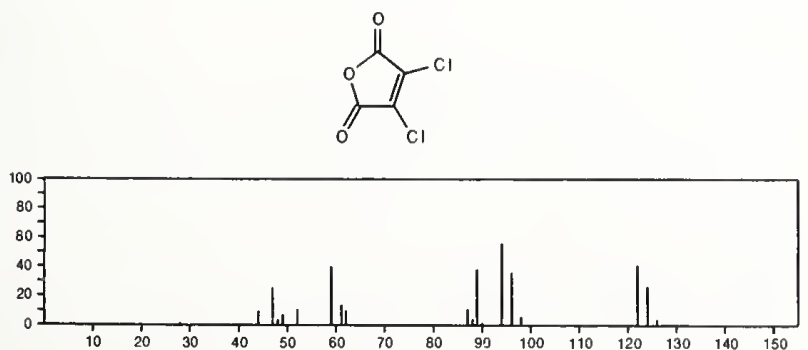

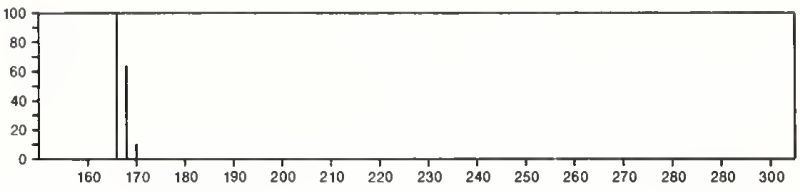

166

Butanoic acid, 2-bromo-

$\mathrm{C}_{4} \mathrm{H}_{7} \mathrm{BrO}_{2}$

$80-58-0$

$\mathrm{Et} \mathrm{CHBr}\left(\mathrm{CO}_{2} \mathrm{H}\right)$
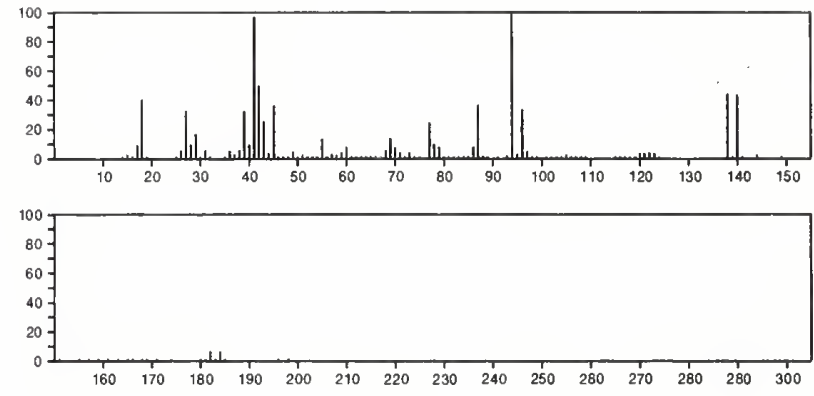

166

Acetic acid, bromo-, ethyl ester

$105-36-2$

$\mathrm{EtOC}(\mathrm{O}) \mathrm{CH}_{2} \mathrm{Br}$
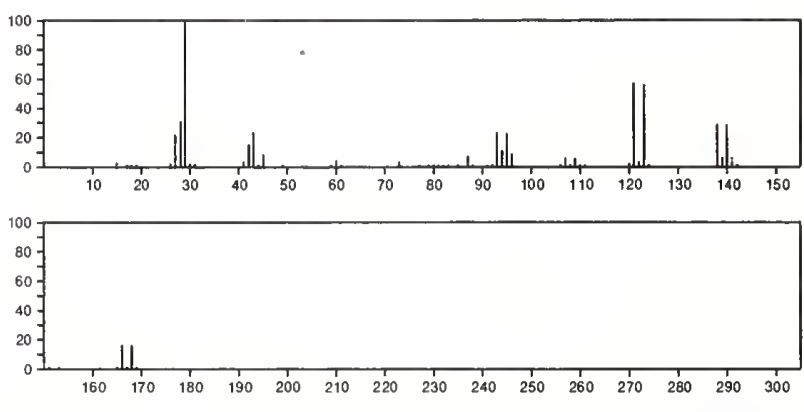

166

Ethanol, 2-bromo-, acetate

$\mathrm{C}_{4} \mathrm{H}_{7} \mathrm{BrO}_{2}$

$927-68-4$

$\mathrm{Ac} \mathrm{OCH}_{2} \mathrm{CH}_{2} \mathrm{Br}$
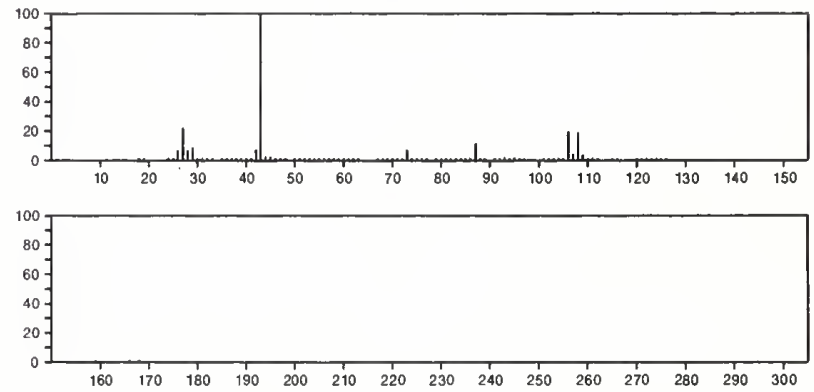

166

Germacyclopentane, 1-chloro-

$\mathrm{C}_{4} \mathrm{H}_{9} \mathrm{ClGe}$

$4554-75-0$

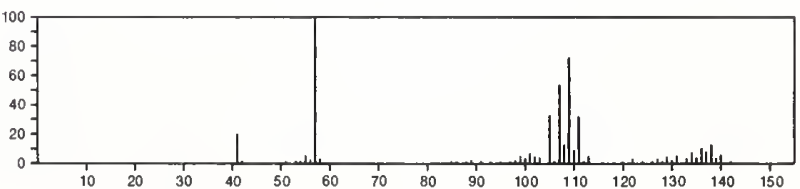




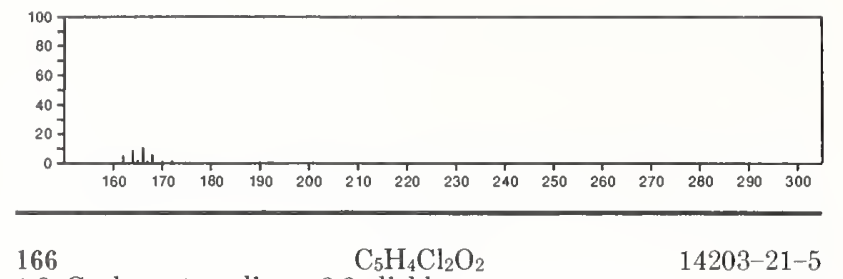

1,3-Cyclopentanedione, 2,2-dichloro-
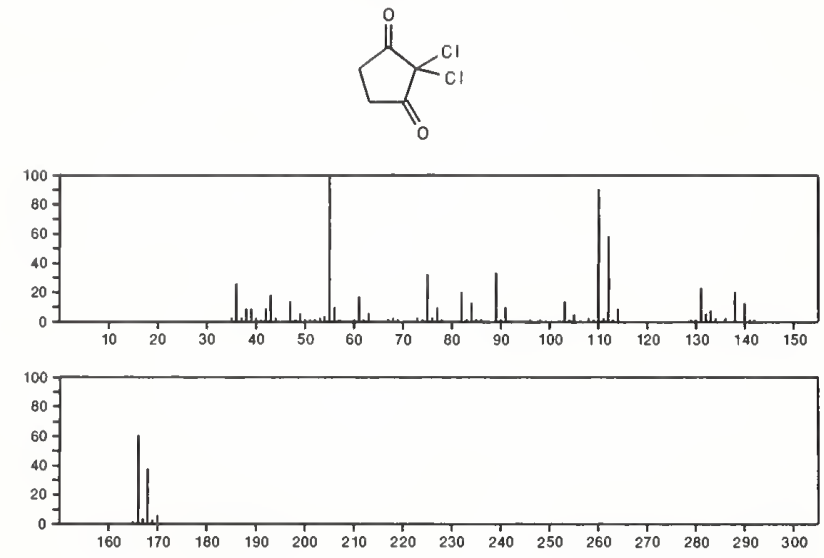

$166 \quad \mathrm{C}_{5} \mathrm{H}_{8} \mathrm{BrF}$

Cyclopentane, 1-bromo-2-fluoro-, cis-

$51422-72-1$
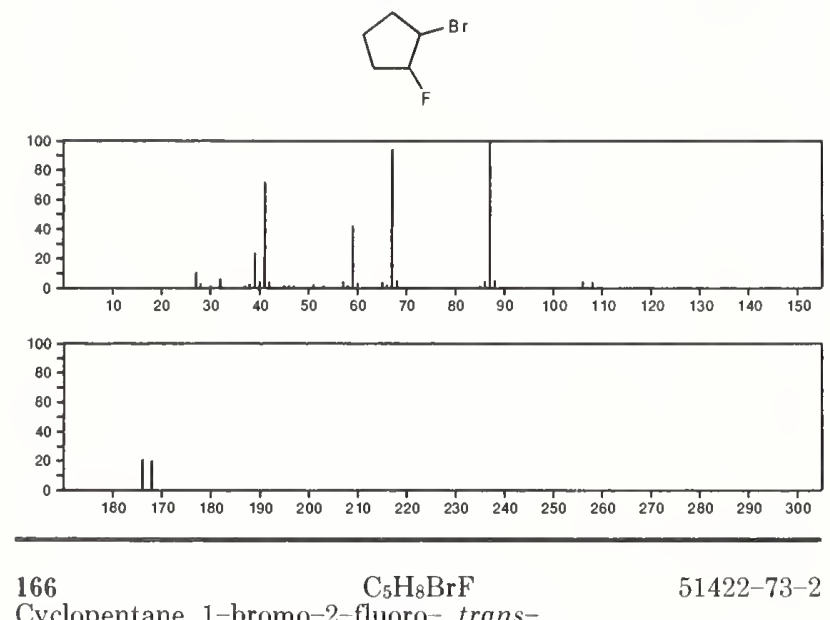

Cyclopentane, 1-bromo-2-fluoro-, trans-
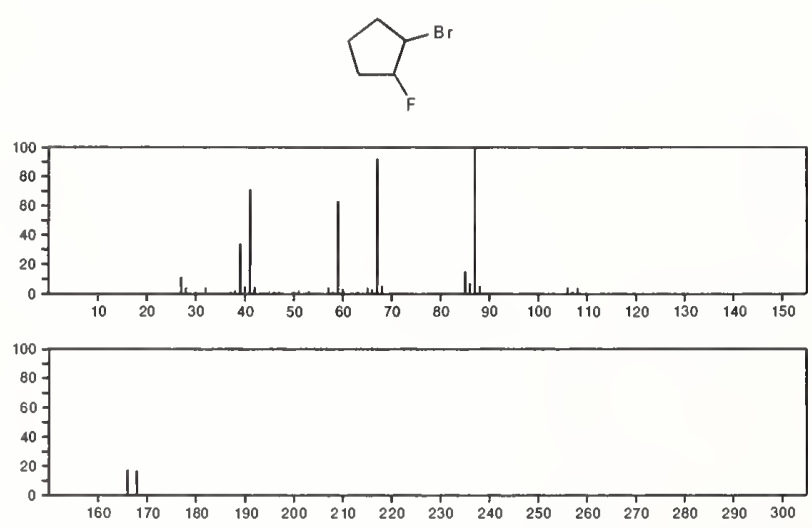

166

Butane, 1-bromo-4-methoxy-

$\mathrm{C}_{5} \mathrm{H}_{11} \mathrm{BrO}$

$4457-67-4$

$\mathrm{MeO}\left(\mathrm{CH}_{2}\right)_{4} \mathrm{Br}$

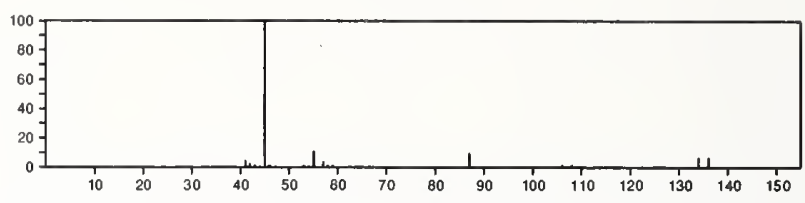

$166 \quad \mathrm{C}_{5} \mathrm{H}_{11} \mathrm{O}_{4} \mathrm{P}$

Phosphoric acid, dimethyl 1-methylethenyl ester

$4185-82-4$
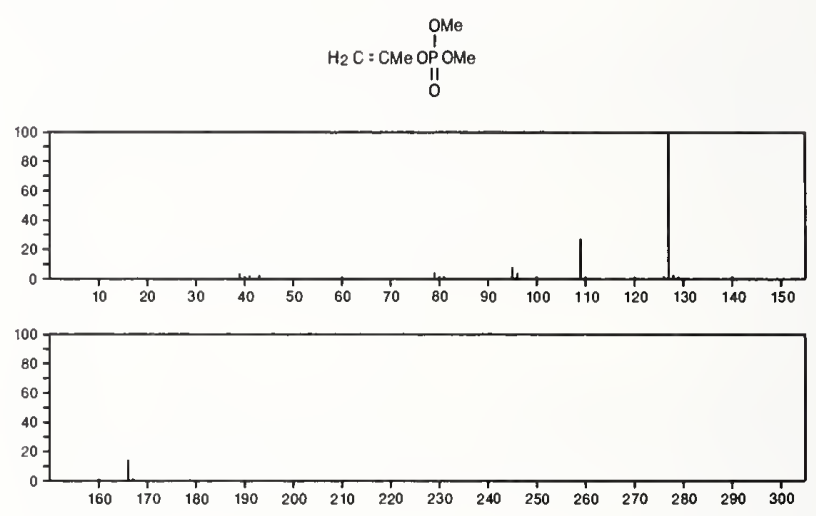

166

$\mathrm{C}_{5} \mathrm{H}_{11} \mathrm{O}_{4} \mathrm{P}$

Phosphoric acid, dimethyl 1 -propenyl ester

$55712-50-0$
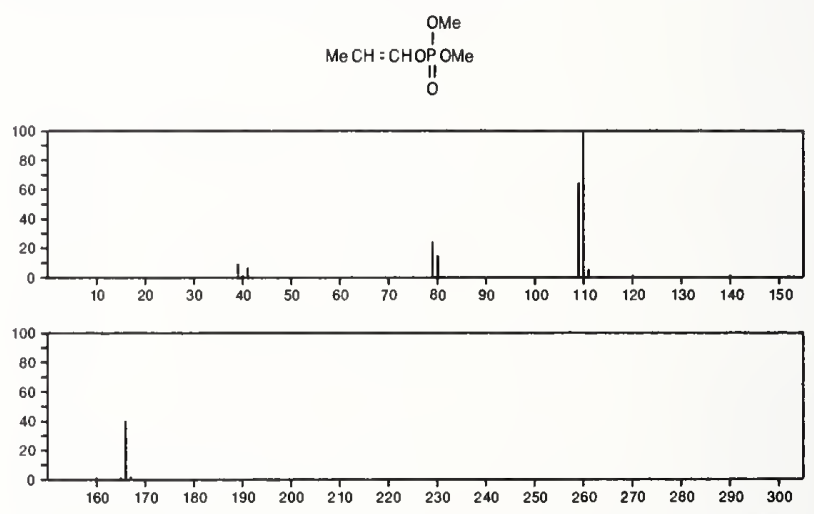

166

$\mathrm{C}_{6} \mathrm{H}_{6} \mathrm{~N}_{4} \mathrm{O}_{2}$

$1076-22-8$

$1 H$-Purine-2,6-dione, 3,7-dihydro-3-methyl-
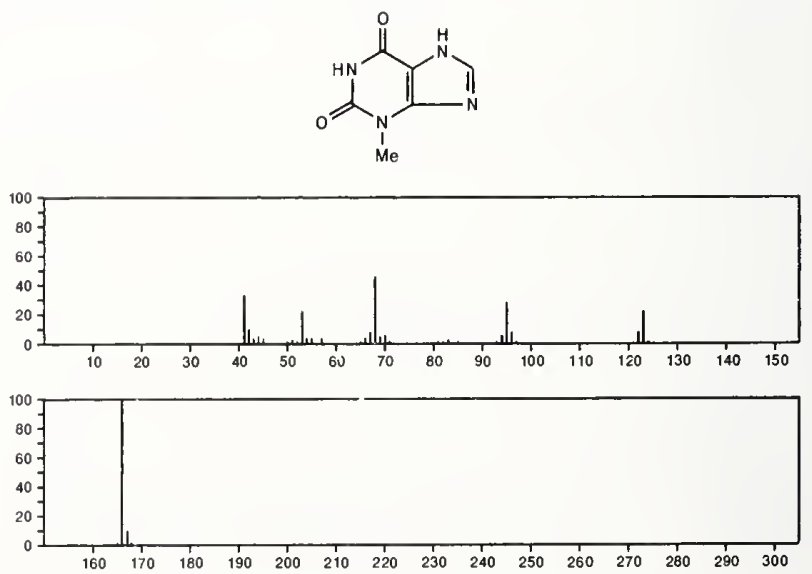
$166 \quad \mathrm{C}_{6} \mathrm{H}_{6} \mathrm{~N}_{4} \mathrm{O}_{2}$

1H-Purine-2,6-dione, 3,7-dihydro-1-methyl-
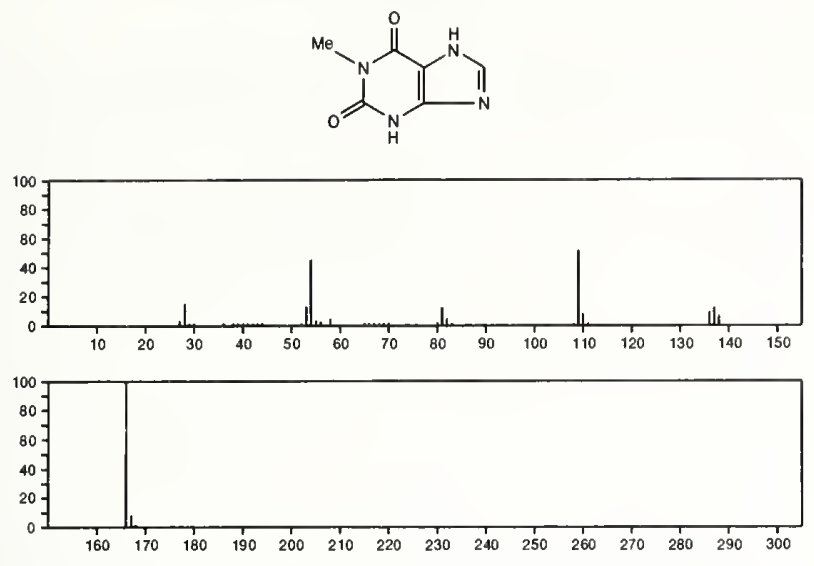

166

$\mathrm{C}_{6} \mathrm{H}_{6} \mathrm{~N}_{4} \mathrm{O}_{2}$

$1 \mathrm{H}$-Purine-2,6-dione, 3,7-dihydromethyl-

28109-92-4<smiles></smiles>
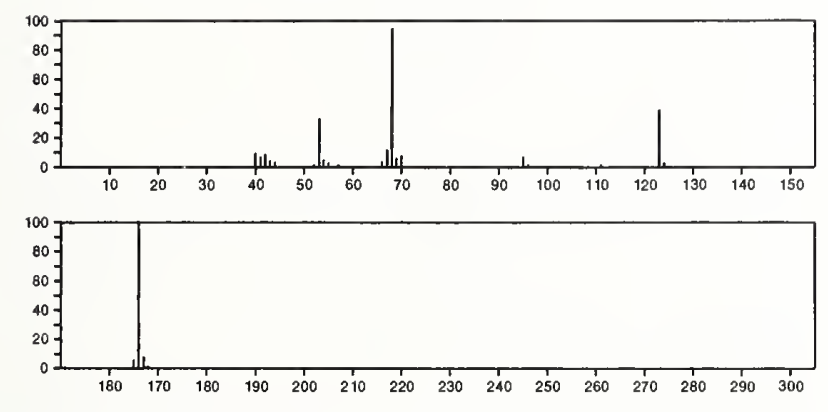

$166 \quad \mathrm{C}_{6} \mathrm{H}_{6} \mathrm{~N}_{4} \mathrm{~S}$

1H-Purine, 6-(methylthio)-
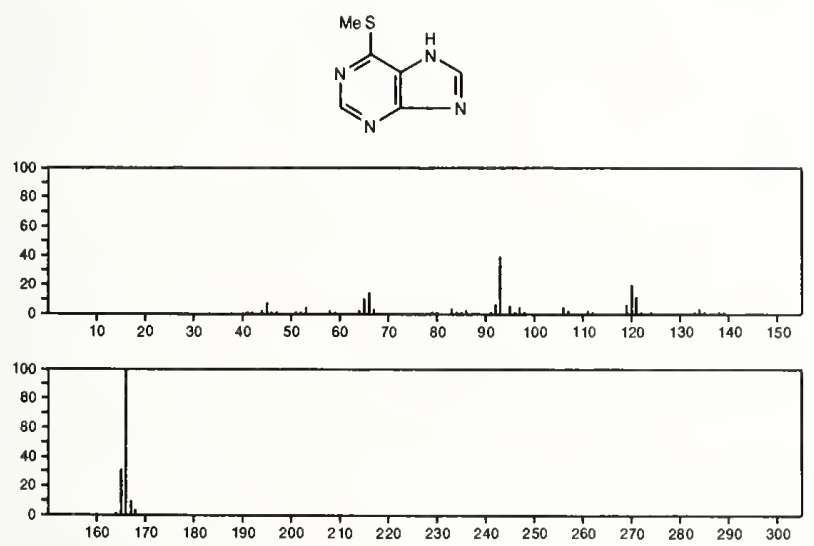

$166 \quad \mathrm{C}_{6} \mathrm{H}_{6} \mathrm{~N}_{4} \mathrm{~S}$

6H-Purine-6-thione, 3,7-dihydro-3-methyl-

$1006-12-8$
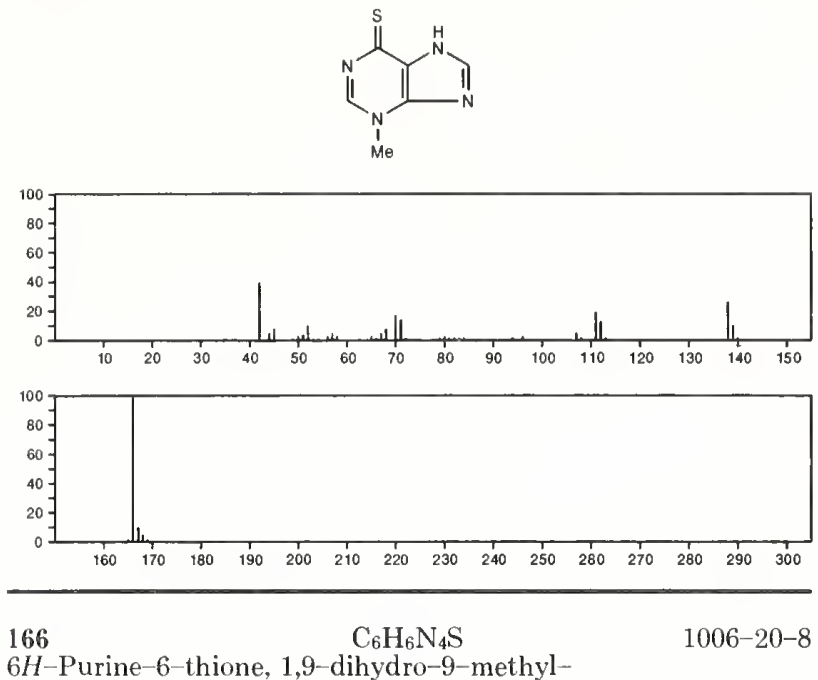

6H-Purine-6-thione, 1,9-dihydro-9-methyl-
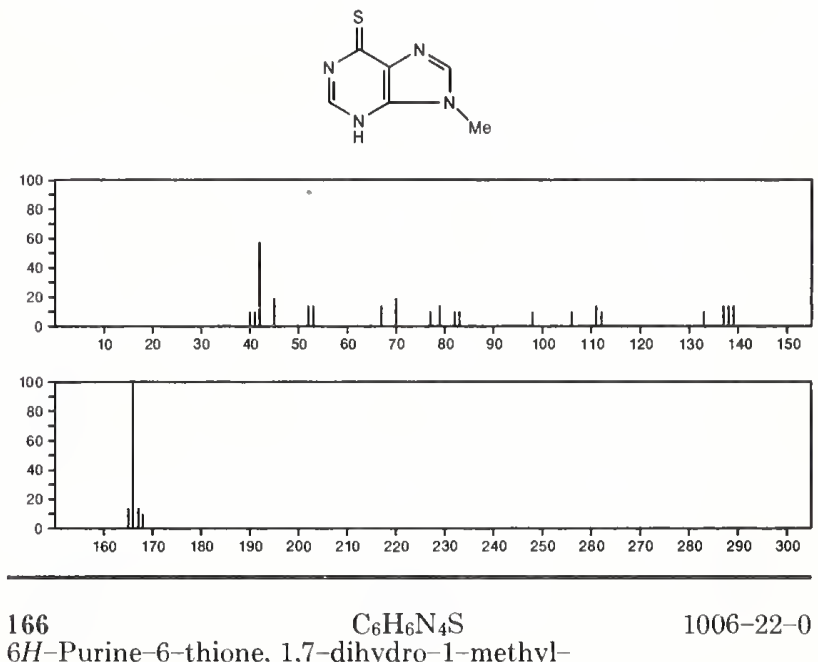

6H-Purine-6-thione, 1,7-dihydro-1-methyl-
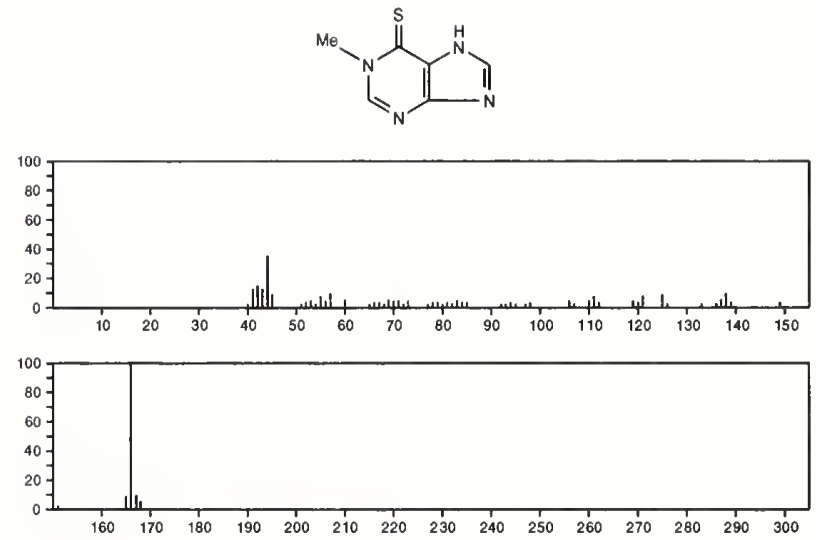
166 $\mathrm{C}_{6} \mathrm{H}_{6} \mathrm{~N}_{4} \mathrm{~S}$

6H-Purine-6-thione, 1,7-dihydro-8-methyl-
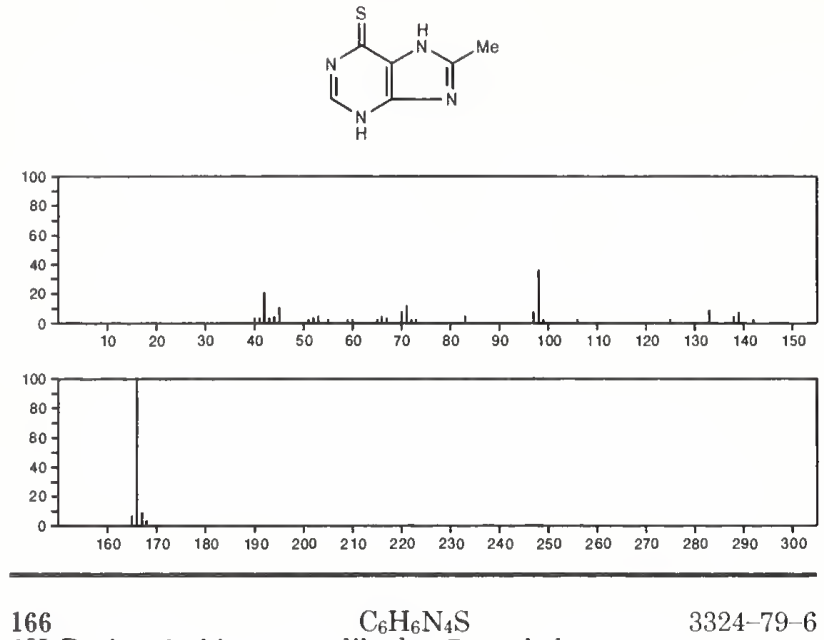

6H-Purine-6-thione, 1,7-dihydro-7-methyl-
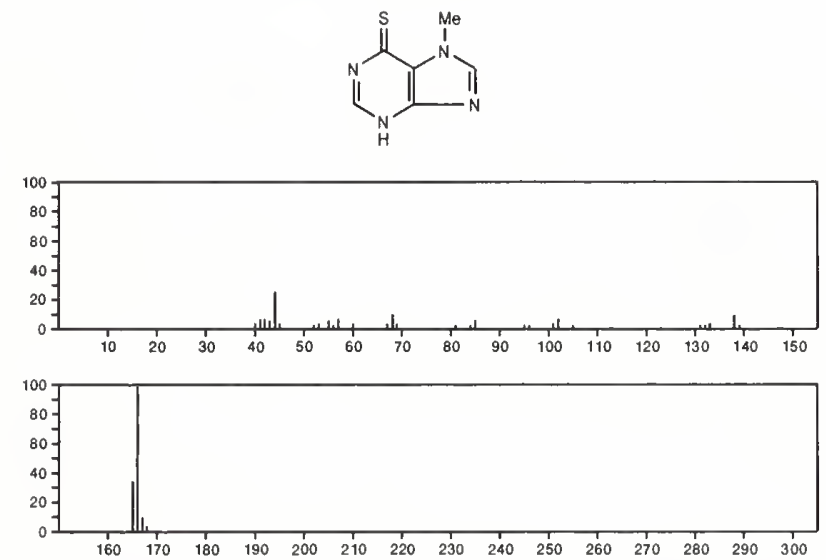

166

$1 H$-Purine, 8 -(methylthio)-

\section{$\mathrm{C}_{6} \mathrm{H}_{6} \mathrm{~N}_{4} \mathrm{~S}$}

$33426-53-8$

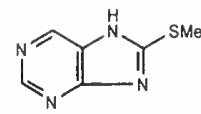
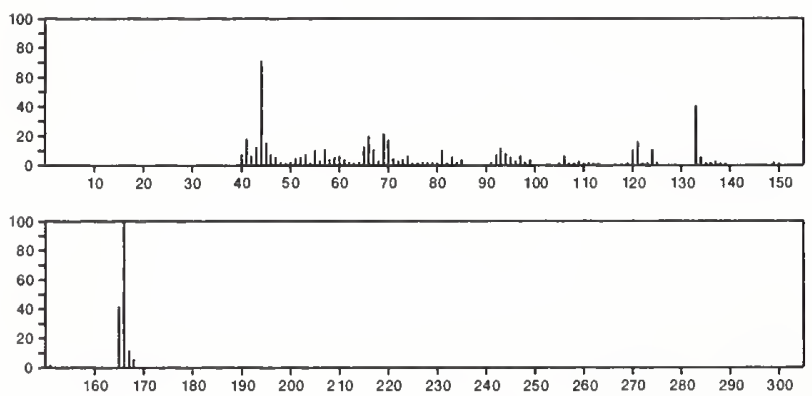

166

$1 H$-Purine, 2-(methylthio)-

$\mathrm{C}_{6} \mathrm{H}_{6} \mathrm{~N}_{4} \mathrm{~S}$

$33512-51-5$
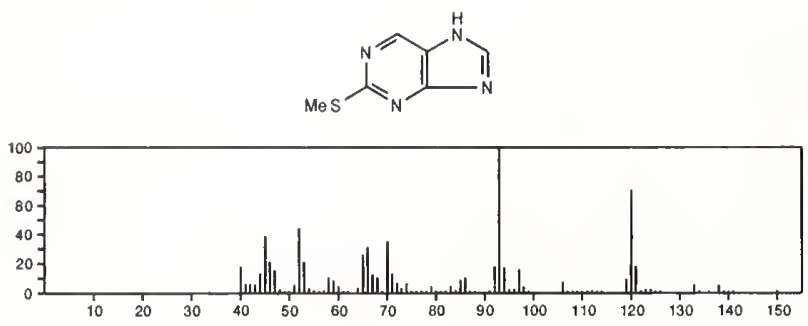

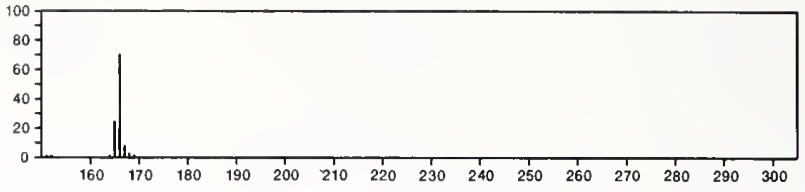

166

$\mathrm{C}_{6} \mathrm{H}_{6} \mathrm{~N}_{4} \mathrm{~S}$

6H-Purine-6-thione, 1,7-dihydro-2-methyl-

$38917-31-6$
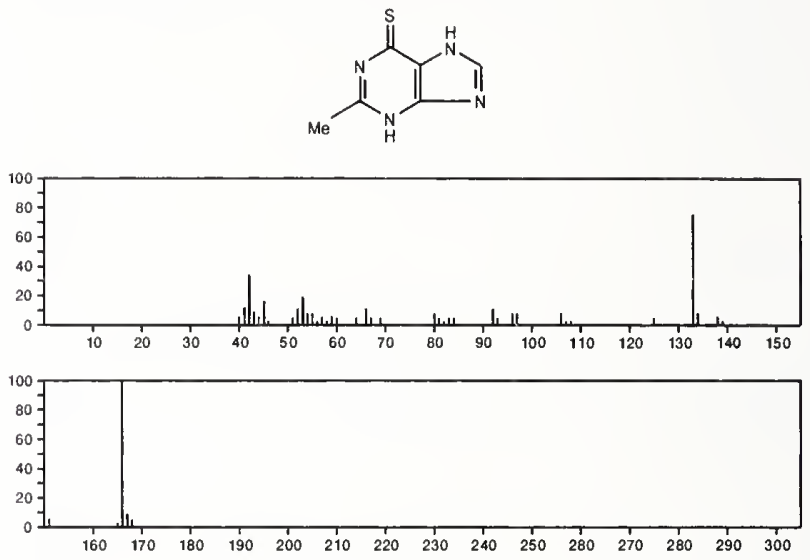

166

Ether, bis(2-chloroallyl)

$\mathrm{C}_{6} \mathrm{H}_{8} \mathrm{Cl}_{2} \mathrm{O}$

$4162-62-3$

$\mathrm{H}_{2} \mathrm{C}=\mathrm{CCl} \mathrm{CH}_{2} \mathrm{OCH}_{2} \mathrm{CCl}=\mathrm{CH}_{2}$

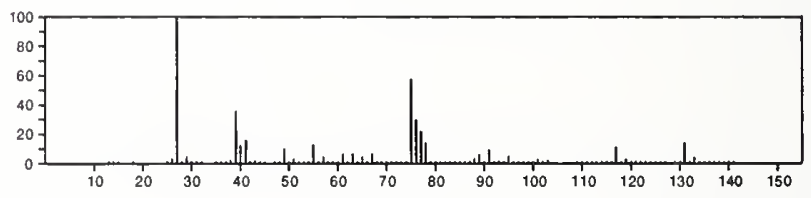

166

$\mathrm{C}_{6} \mathrm{H}_{14} \mathrm{OS}_{2}$

Ethane, 1,1'-[oxybis(methylenethio)]bis-

Et $\mathrm{SCH}_{2} \mathrm{OCH}_{2} \mathrm{SE}$ t
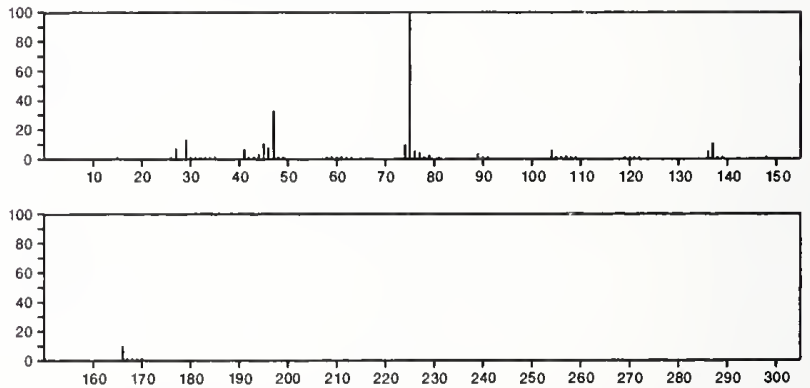

166

Sulfurous acid, dipropyl ester

$\mathrm{C}_{6} \mathrm{H}_{14} \mathrm{O}_{3} \mathrm{~S}$

$623-98-3$

PrOS( O) OPr

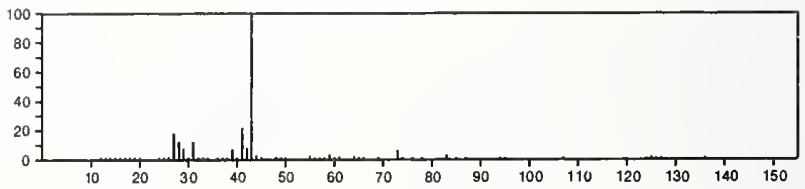


166

$\mathrm{C}_{6} \mathrm{H}_{14} \mathrm{O}_{3} \mathrm{~S}$

Sulfurous acid, bis(1-methylethyl) ester

4773-13-1

$i-\operatorname{PrOS}(0) \mathrm{OPr}_{-\mathrm{i}}$
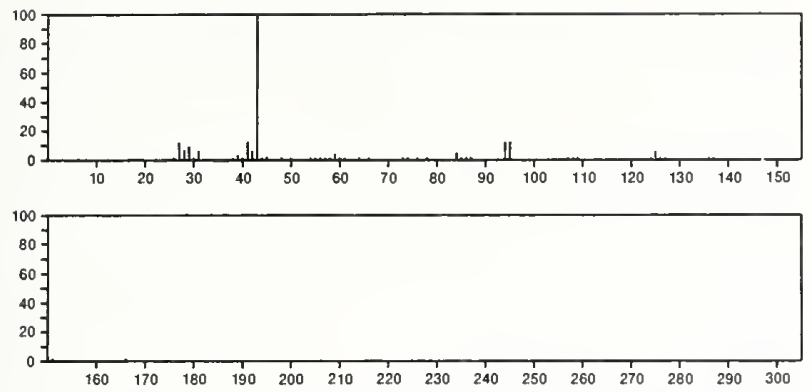

\section{6}

$\mathrm{C}_{6} \mathrm{H}_{14} \mathrm{O}_{3} \mathrm{~S}$

$56282-36-1$

Ethanol, 2-[2-(2-mercaptoethoxy)ethoxy]-

$\mathrm{HSCH}_{2} \mathrm{CH}_{2} \mathrm{OCH}_{2} \mathrm{CH}_{2} \mathrm{OCH}_{2} \mathrm{CH}_{2} \mathrm{OH}$

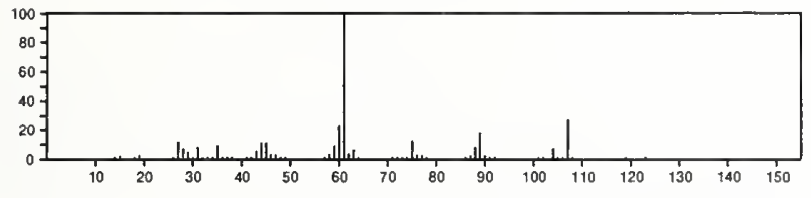

166

Benzamide, 2-nitro-

$\mathrm{C}_{7} \mathrm{H}_{6} \mathrm{~N}_{2} \mathrm{O}_{3}$

610-15-1
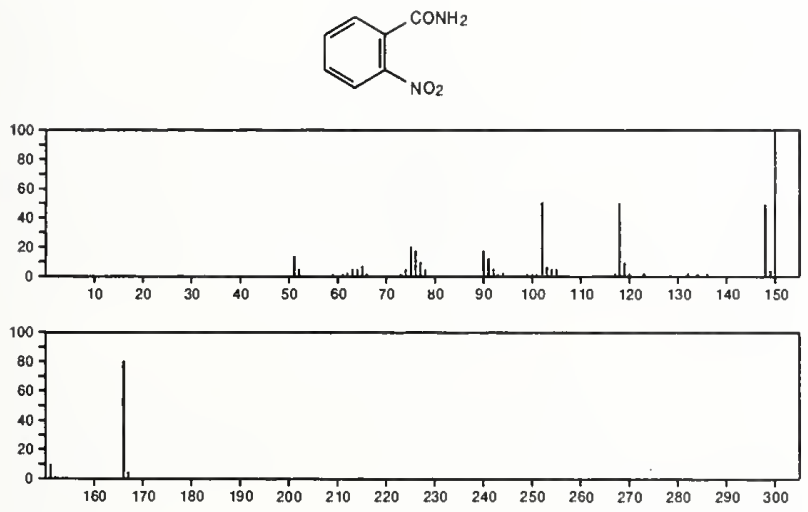

166

$\mathrm{C}_{7} \mathrm{H}_{6} \mathrm{~N}_{2} \mathrm{O}_{3}$

1129-37-9

Benzaldehyde, 4-nitro--, oxime
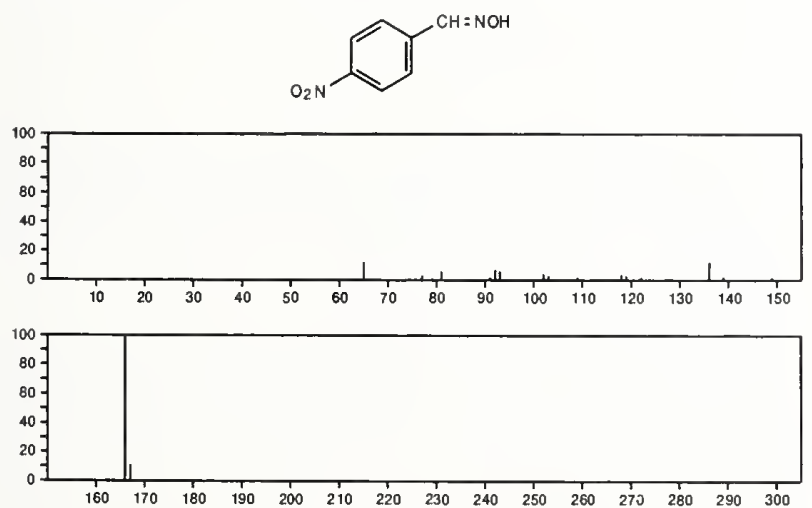

166

$\mathrm{C}_{7} \mathrm{H}_{6} \mathrm{~N}_{2} \mathrm{O}_{3}$

Benzaldehyde, 3-nitro--, oxime

$3431-62-7$
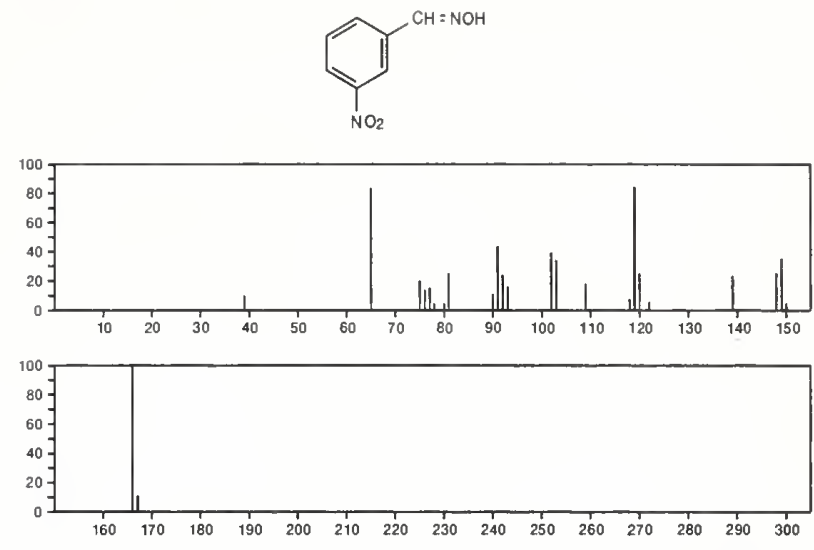

166

$\mathrm{C}_{7} \mathrm{H}_{6} \mathrm{~N}_{2} \mathrm{O}_{3}$

$3717-19-9$

Benzaldehyde, 4-nitro-, oxime, $(E)$ -
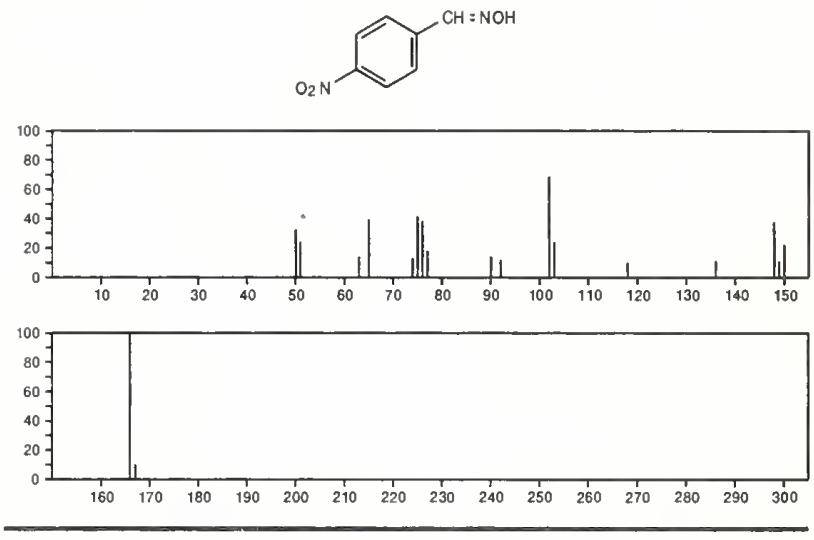

166

$\mathrm{C}_{7} \mathrm{H}_{6} \mathrm{~N}_{2} \mathrm{O}_{3}$

Benzaldehyde, 4-nitro-, oxime, $(Z)-$

$3717-20-2$
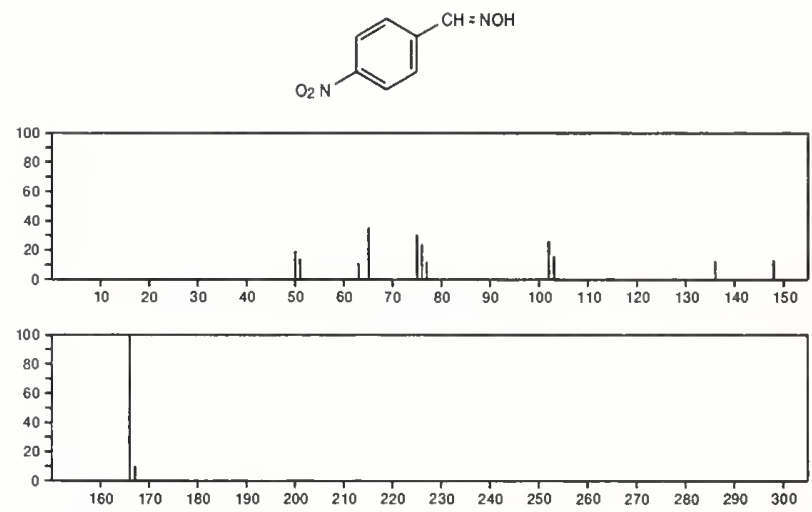

166

$\mathrm{C}_{7} \mathrm{H}_{6} \mathrm{~N}_{2} \mathrm{O}_{3}$

Benzaldehyde, 3-nitro-, oxime, $(E)-$

$3717-29-1$
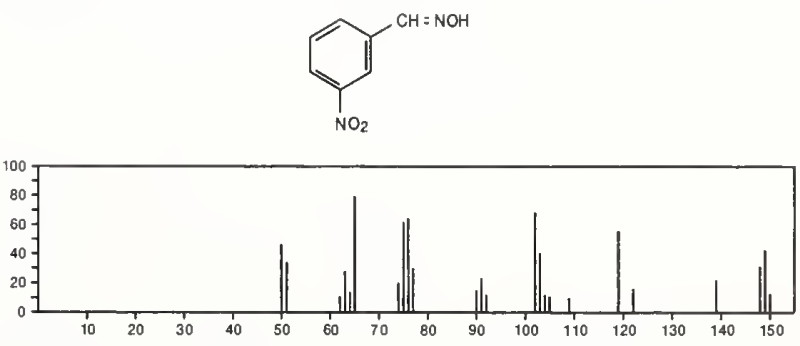

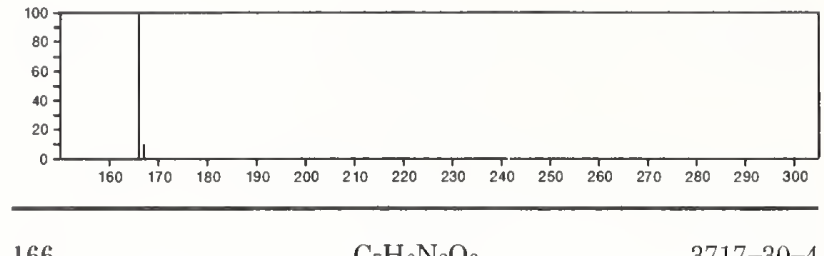

Benzaldehyde, 3-nitro-, oxime, $(Z)-$
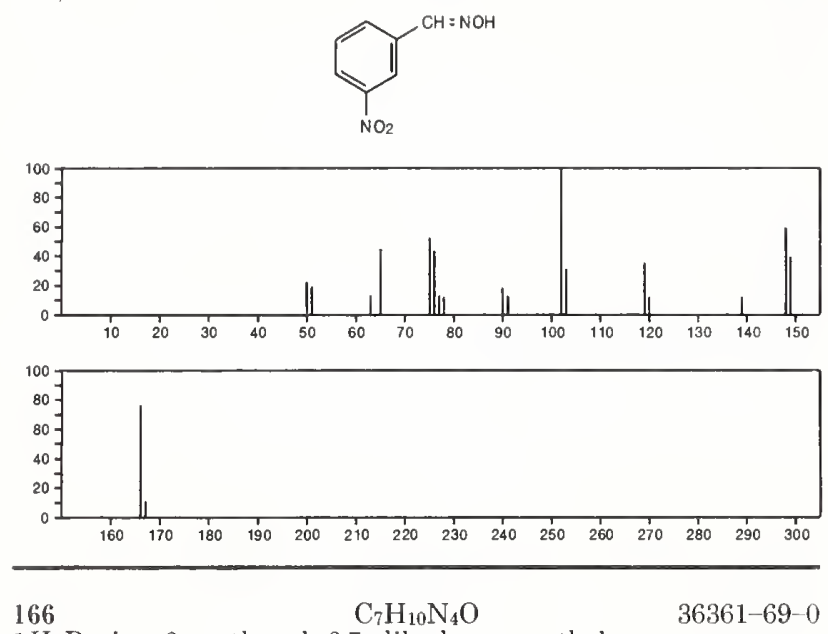

1H-Purine-6-methanol, 6,7-dihydro- $\alpha$-methyl-
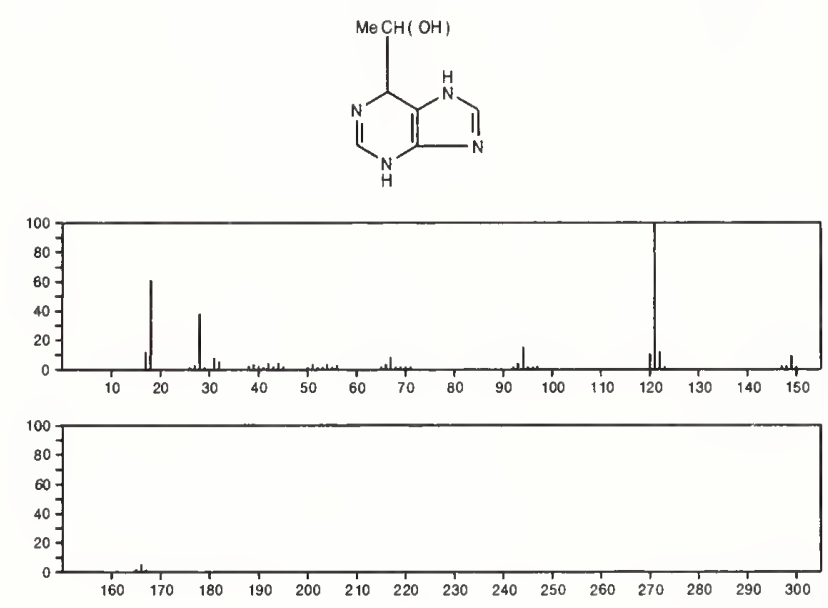

166

$\mathrm{C}_{7} \mathrm{H}_{15} \mathrm{ClO}_{2}$

$20637-37-0$

Propane, 2-(chloromethyl)-1,3-dimethoxy-2-methyl-
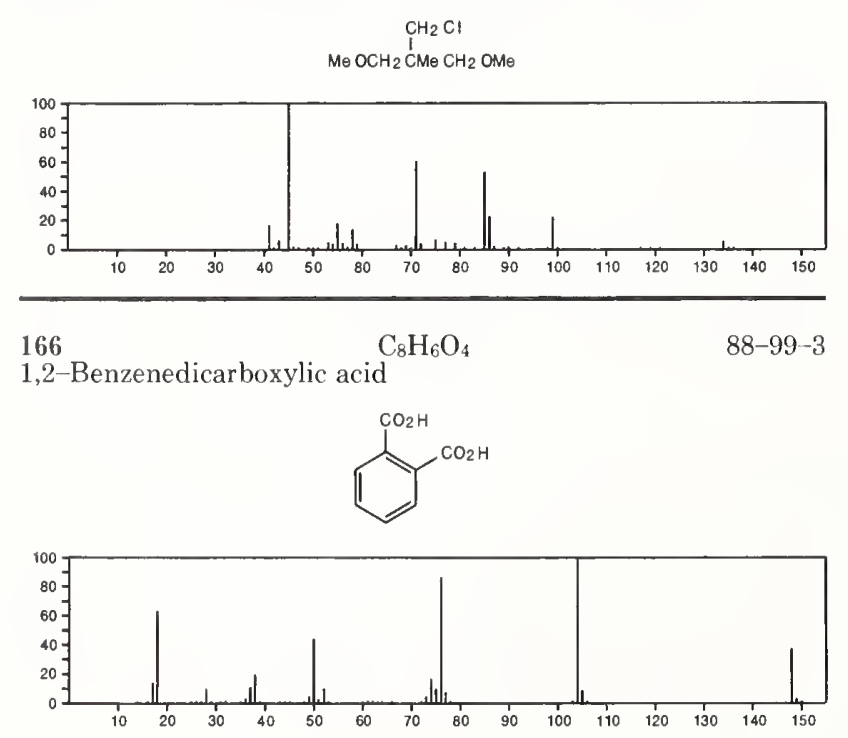

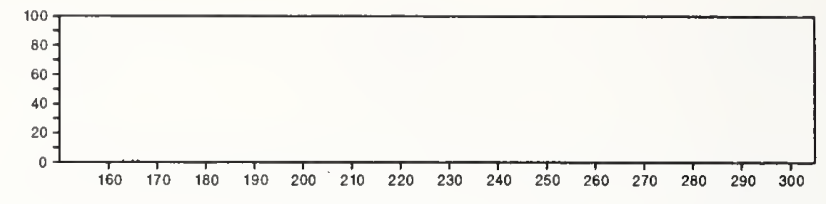

$166 \quad \mathrm{C}_{8} \mathrm{H}_{6} \mathrm{O}_{4}$

1,4-Benzenedicarboxylic acid
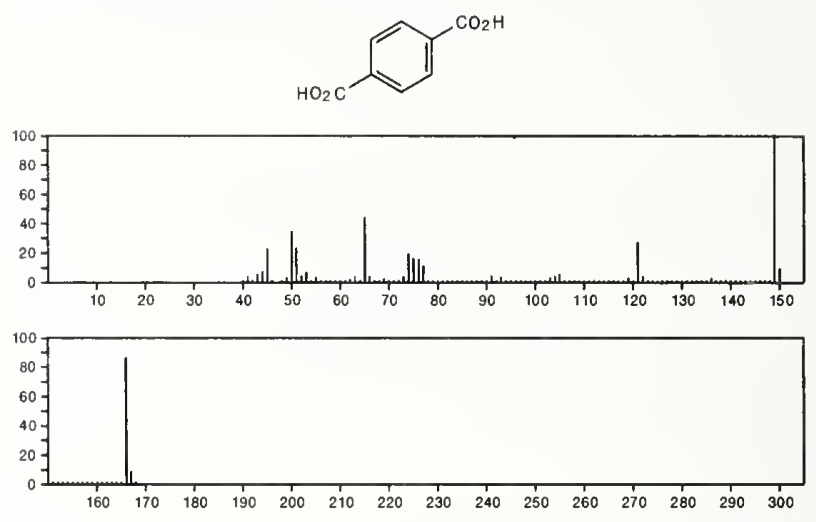

${ }_{1}^{166} 3-$ Benzenedicarboxylic acid $\mathrm{C}_{8} \mathrm{H}_{6} \mathrm{O}_{4}$

$121-91-5$
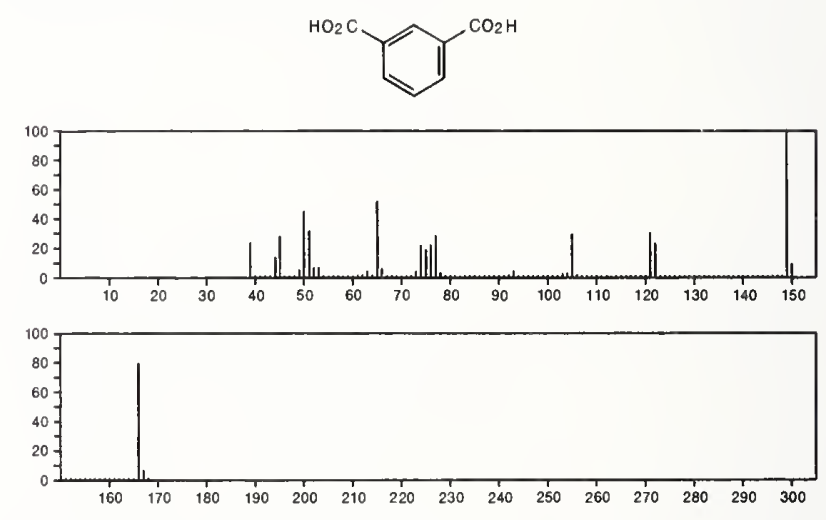

166
$2,2+$-Bithiophene

$\mathrm{C}_{8} \mathrm{H}_{6} \mathrm{~S}_{2}$

492-97-7
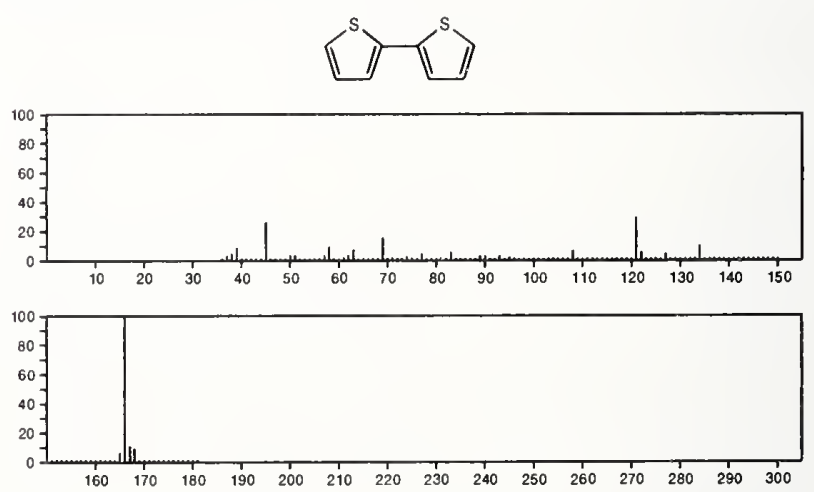
166

2,3'-Bithiophene

$\mathrm{C}_{8} \mathrm{H}_{6} \mathrm{~S}_{2}$

2404-89-9
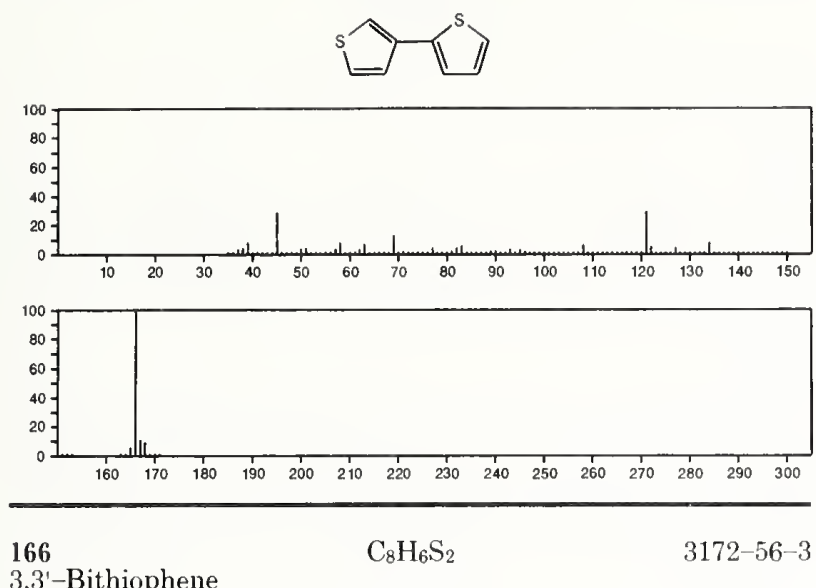

3,3'-Bithiophene
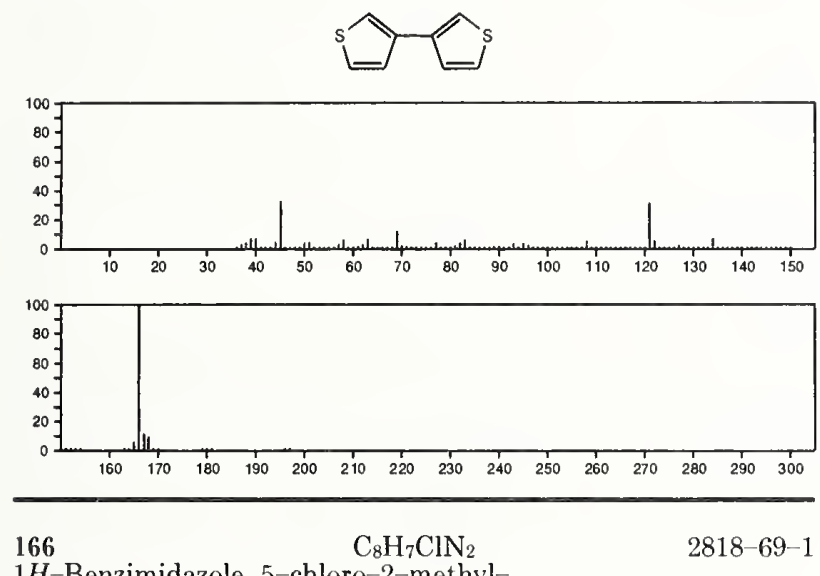

1 H-Benzimidazole, 5-chloro-2-methyl-
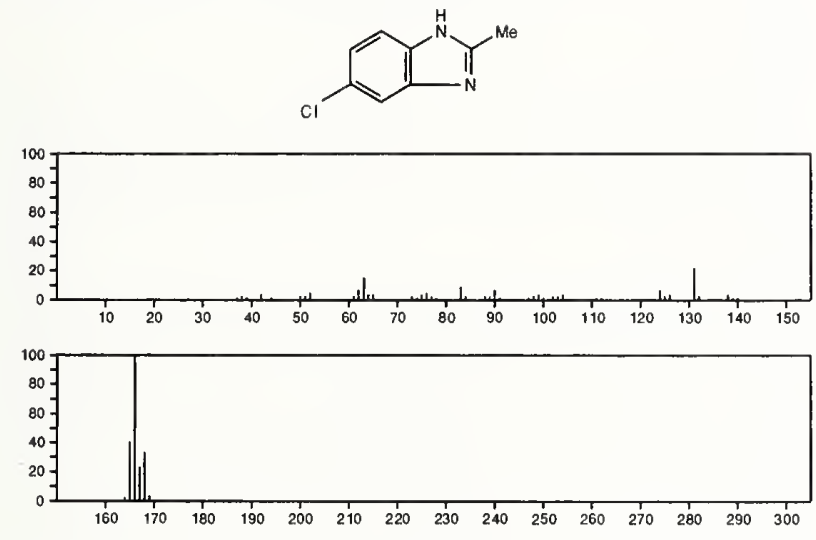

166

$\mathrm{C}_{8} \mathrm{H}_{10} \mathrm{~N}_{2} \mathrm{O}_{2}$

Carbamic acid, (4-aminophenyl)-, methyl ester

6465-03-8
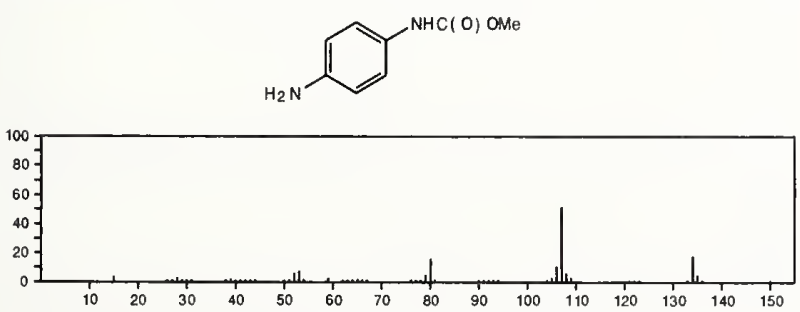

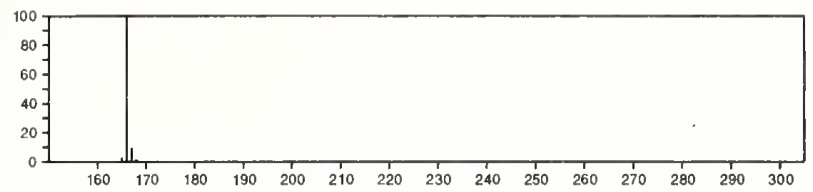

$\mathrm{C}_{8} \mathrm{H}_{10} \mathrm{~N}_{2} \mathrm{O}_{2}$

23025-55-0

166

Pyridinium, 1-[(ethoxycarbonyl)amino]-, hydroxide, inner salt
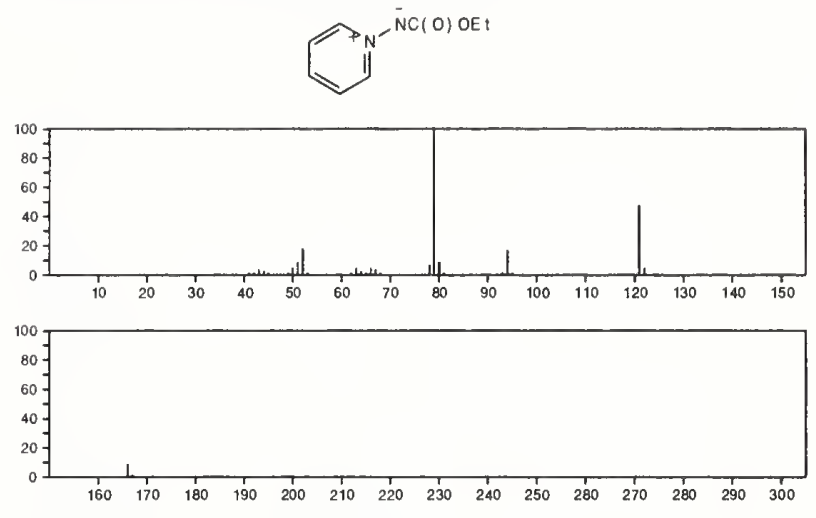

$166 \quad \mathrm{C}_{8} \mathrm{H}_{10} \mathrm{~N}_{2} \mathrm{O}_{2}$
Propanedinitrile, ethyl(1-oxopropoxy)-

54411-13-1

$E+C(0) O C E !(C N)_{2}$
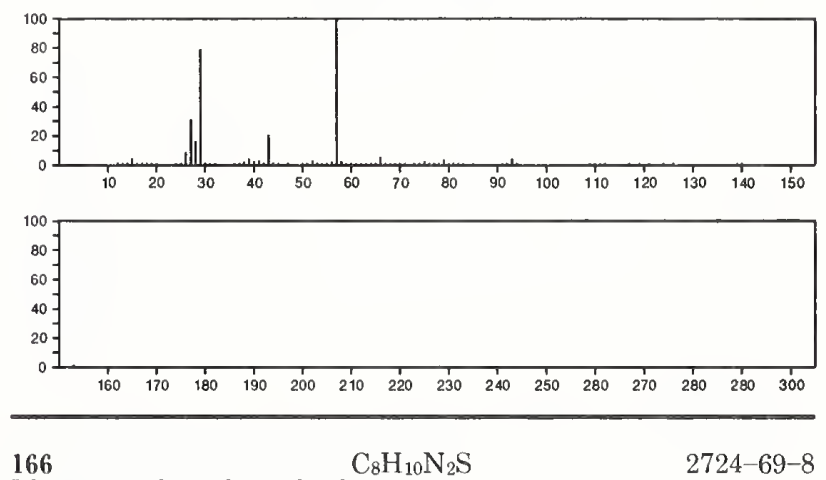

Thiourea, $N$-methyl-N'-phenyl-

2724-69-8

PhNHCSNHMO
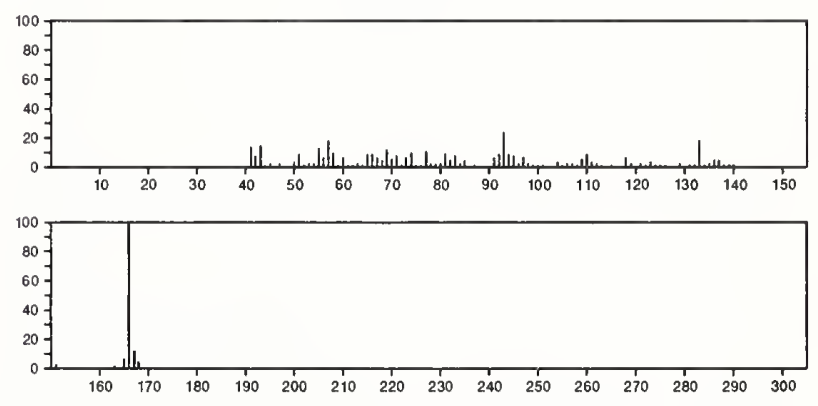

166

1,2,4,5-Tetrazine, 3,6-dipropyì-

$\mathrm{C}_{8} \mathrm{H}_{14} \mathrm{~N}_{4}$

13717-92-5<smiles>CCCc1nnc(CC)nn1</smiles>

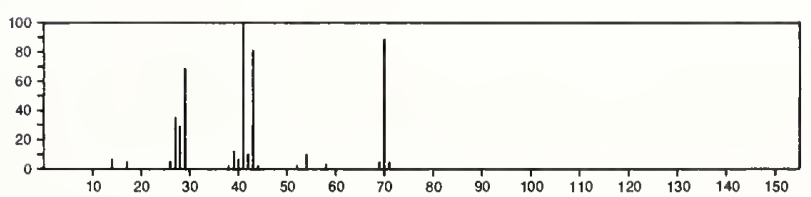




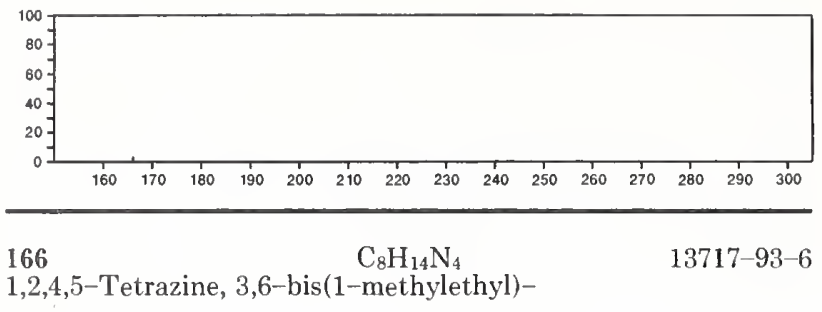

1,2,4,5-Tetrazine, 3,6-bis(1-methylethyl)-
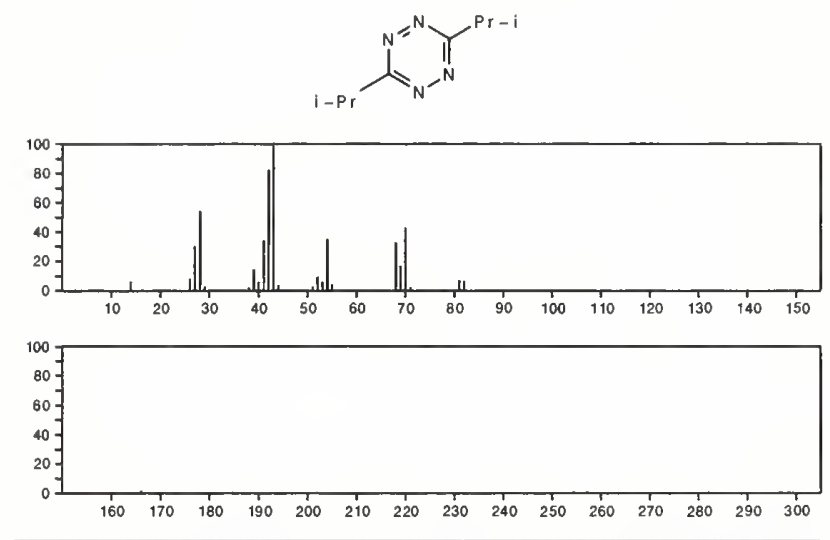

166

$\mathrm{C}_{9} \mathrm{H}_{7} \mathrm{ClO}$

Benzofuran, 5-chloro-2-methyl-
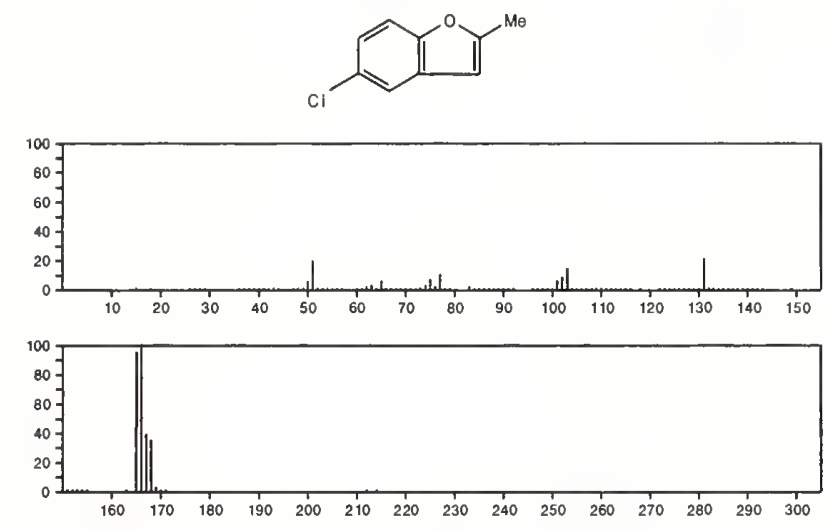

166

2-Propenoic acid, 3-(2-fluorophenyl)-
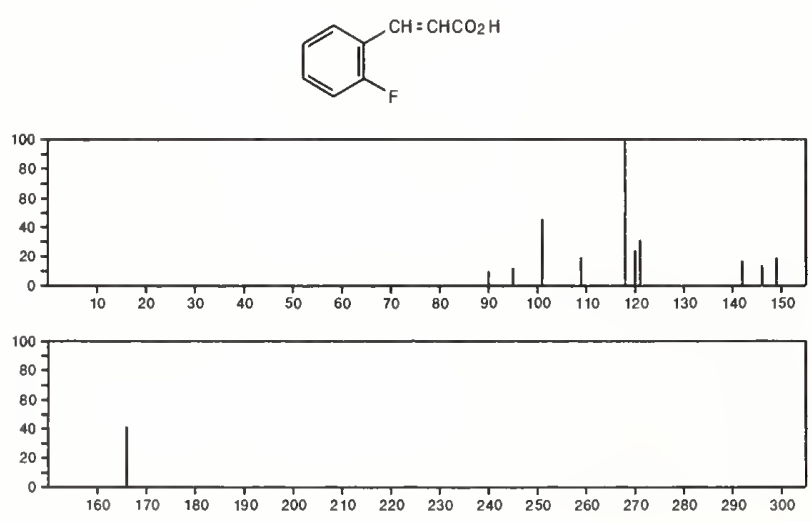

166

Benzenecarbothioic acid, $O$ ethyl ester

$936-61-8$

EtoC(S) Ph
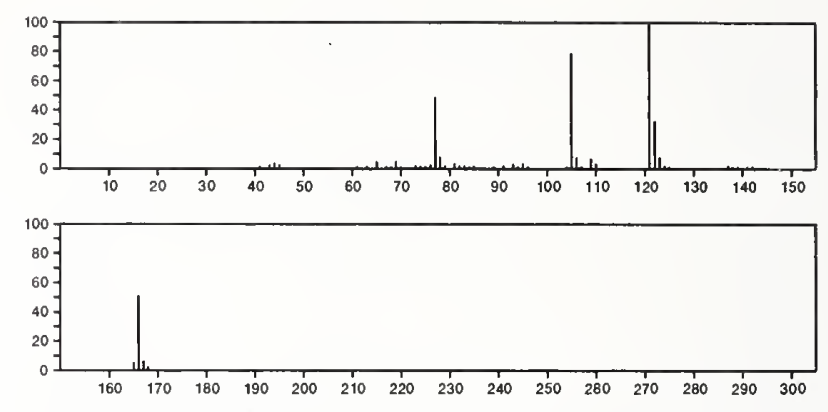

166

$\mathrm{C}_{9} \mathrm{H}_{10} \mathrm{OS}$

Benzenecarbothioic acid, $S$-ethyl ester

1484-17-9

$\mathrm{EtSC}(0) \mathrm{Ph}$
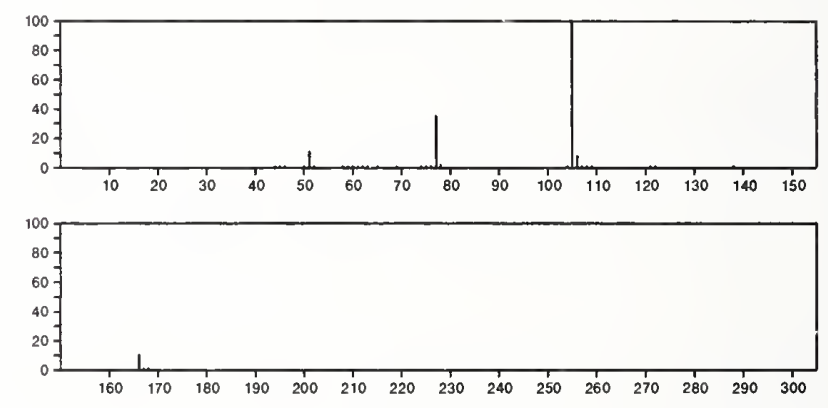

166

$\mathrm{C}_{9} \mathrm{H}_{10} \mathrm{OS}$

$5925-74-6$

Benzeneethanethioic acid, $S$-methyl ester

$\mathrm{PhCH}_{2} \mathrm{C}(\mathrm{O}) \mathrm{SMe}$
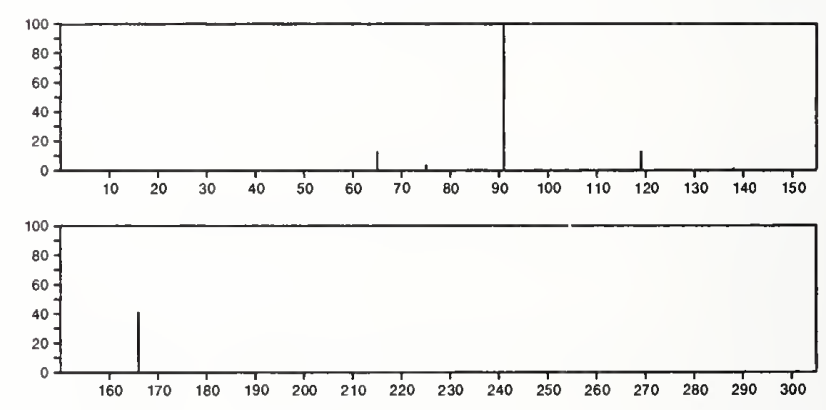

166

$\mathrm{C}_{9} \mathrm{H}_{10} \mathrm{OS}$

$5925-77-9$

Benzenecarbothioic acid, 4-methyl-, S-methyl ester
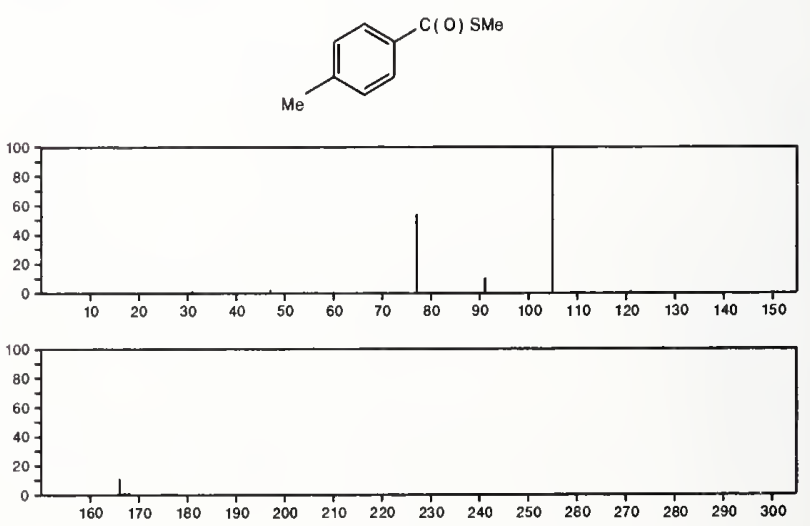
166

$\mathrm{C}_{9} \mathrm{H}_{10} \mathrm{OS}$

Benzenecarbothioic acid, 4-methyl-, $O$-methyl ester
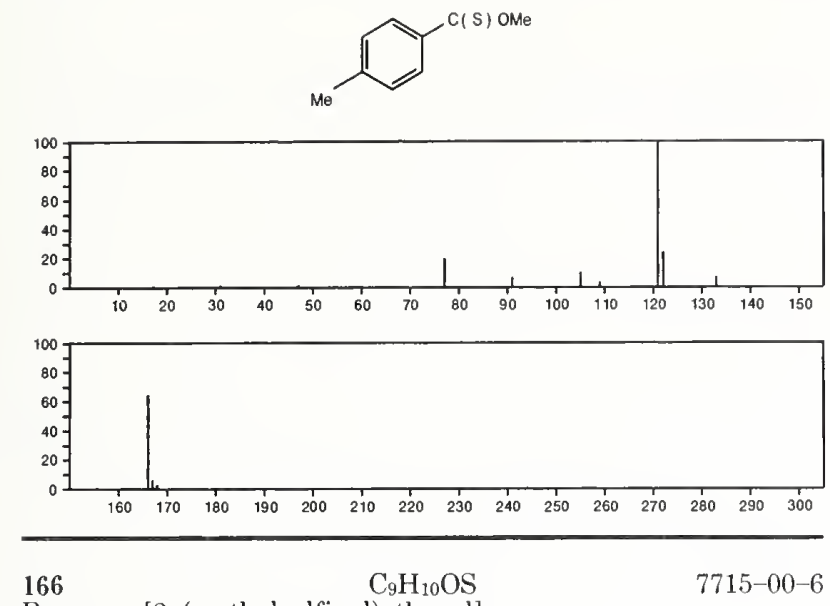

Benzene, [2-(methylsulfinyl)ethenyl]-

$\mathrm{PhCH}=\mathrm{CHS}(\mathrm{O}) \mathrm{Me}$
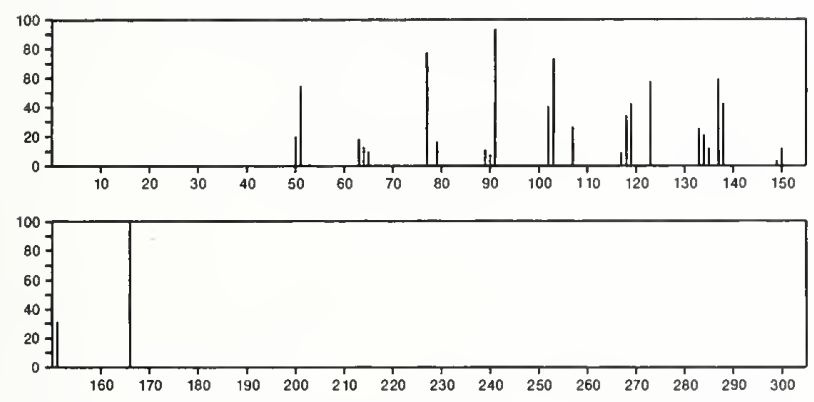

166

$\mathrm{C}_{9} \mathrm{H}_{10} \mathrm{OS}$

Benzenecarbothioic acid, 3-methyl-, $O$-methyl ester
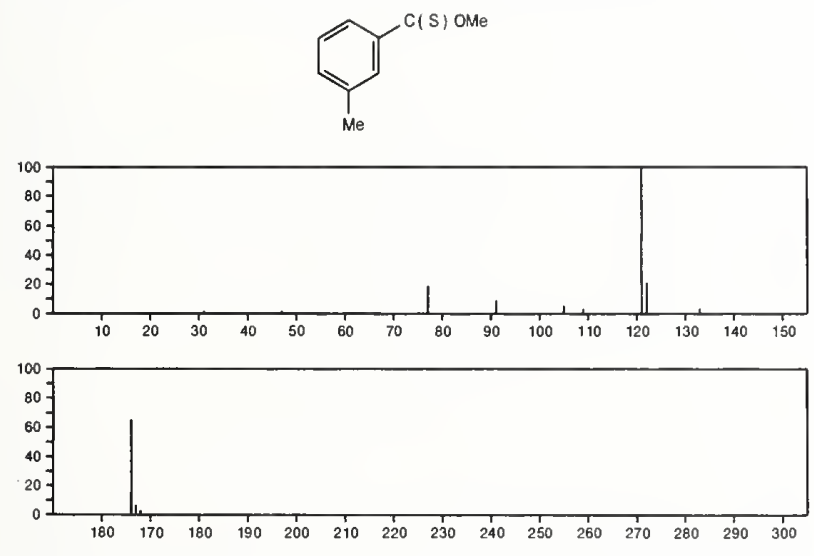

166

$m$-Toluic acid, thio-, $S$-methyl ester
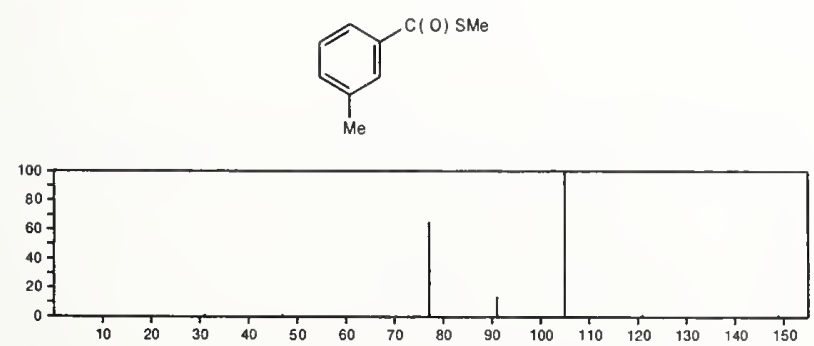

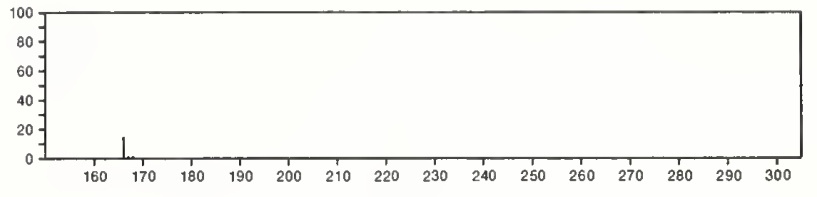

\begin{tabular}{lr}
\hline 166 & $\mathrm{C}_{9} \mathrm{H}_{10} \mathrm{OS}$ \\
Benzenecarbothioic acid, ethyl ester & $56817-89-1$
\end{tabular}

Benzenecarbothioic acid, ethyl ester

PhCOSH $+E+O H$
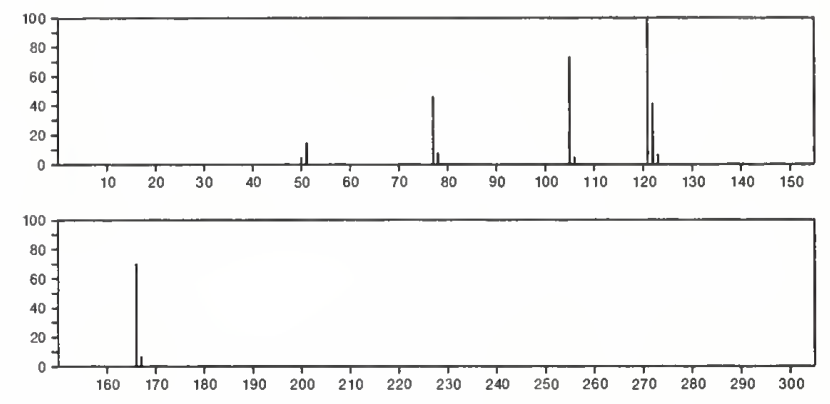

166

$\mathrm{C}_{9} \mathrm{H}_{10} \mathrm{O}_{3}$

$93-02-7$

Benzaldehyde, 2,5-dimethoxy-
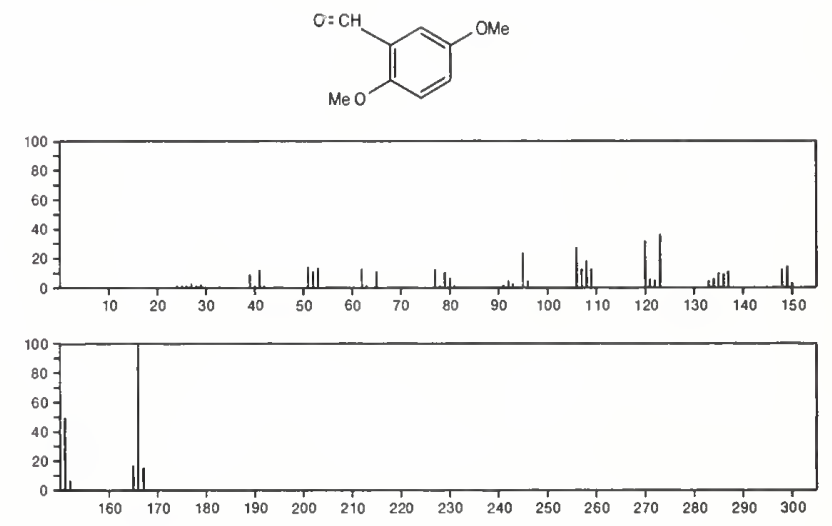

166

$\mathrm{C}_{9} \mathrm{H}_{10} \mathrm{O}_{3}$

$93-25-4$

Benzeneacetic acid, 2-methoxy-
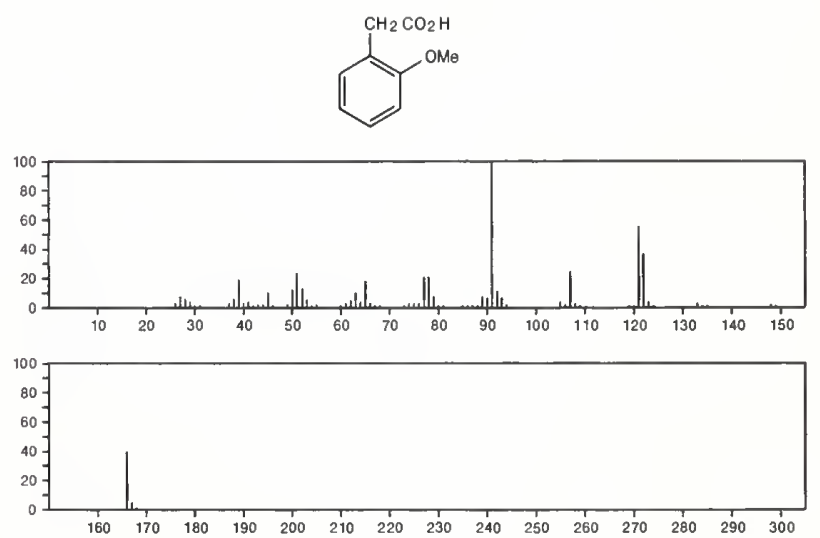
166

$\mathrm{C}_{9} \mathrm{H}_{10} \mathrm{O}_{3}$

Benzeneacetic acid, 4-methoxy-
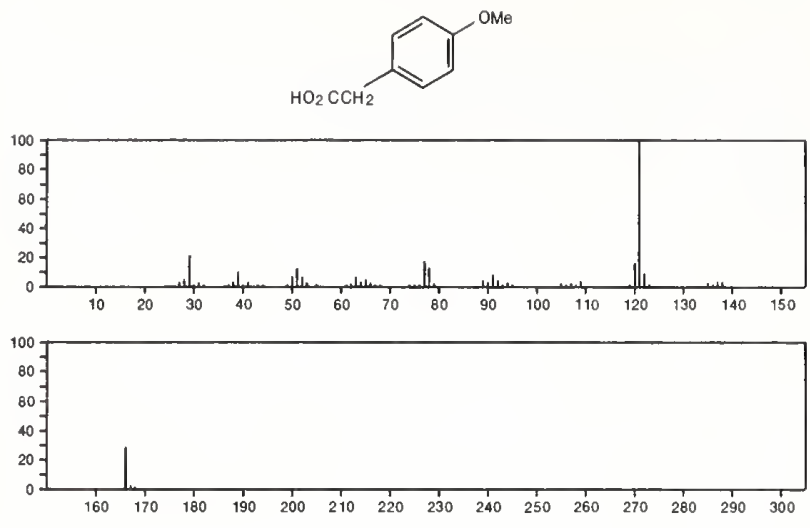

166

$\mathrm{C}_{9} \mathrm{H}_{10} \mathrm{O}_{3}$

120-14-9

Benzaldehyde, 3,4-dimethoxy-
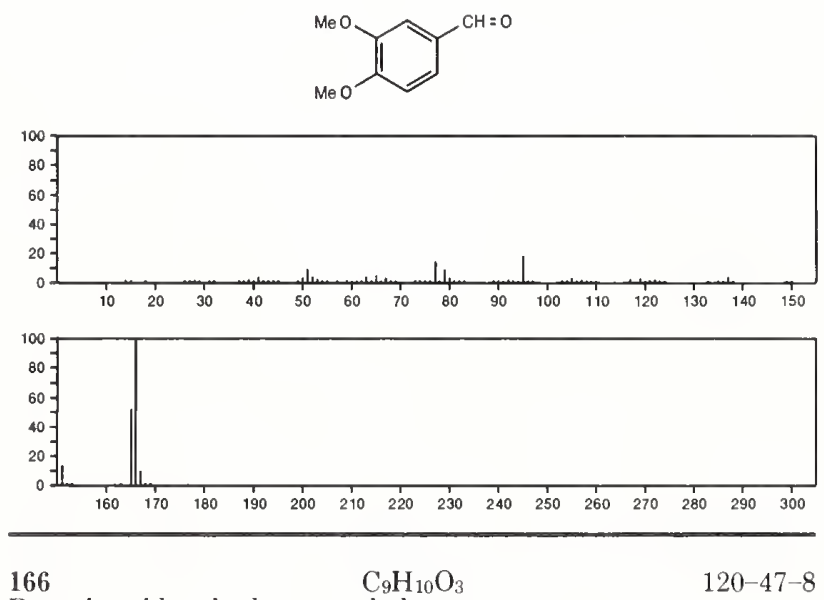

Benzoic acid, 4-hydroxy-, ethyl ester
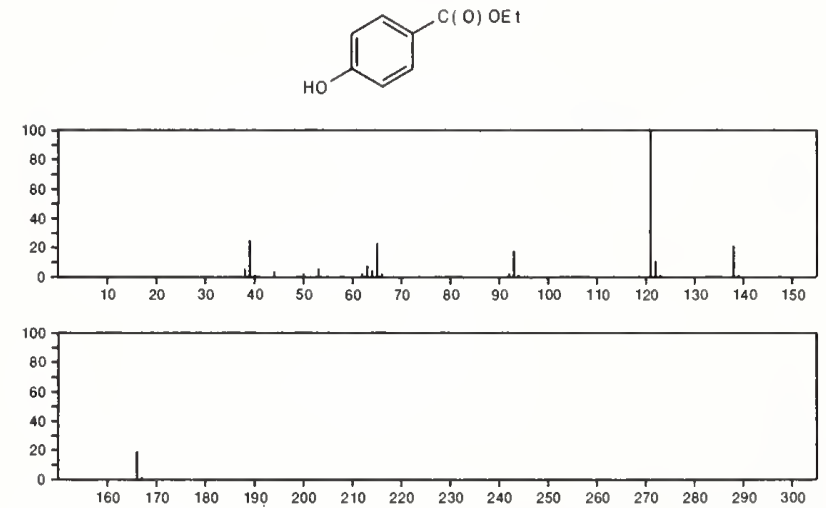

166

Benzoic acid, 4-methoxy-, methyl ester

$121-98-2$
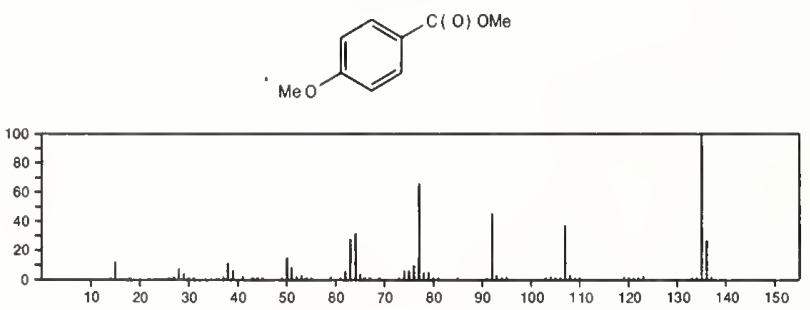

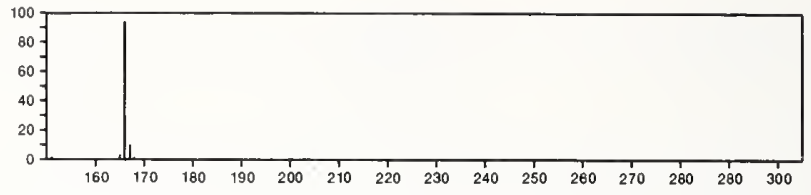

166

$\mathrm{C}_{9} \mathrm{H}_{10} \mathrm{O}_{3}$

Benzenepropanoic acid, $\alpha$-hydroxy-

156-05-8

$\mathrm{HO}_{2} \mathrm{CCH}(\mathrm{OH}) \mathrm{CH}_{2} \mathrm{Ph}$
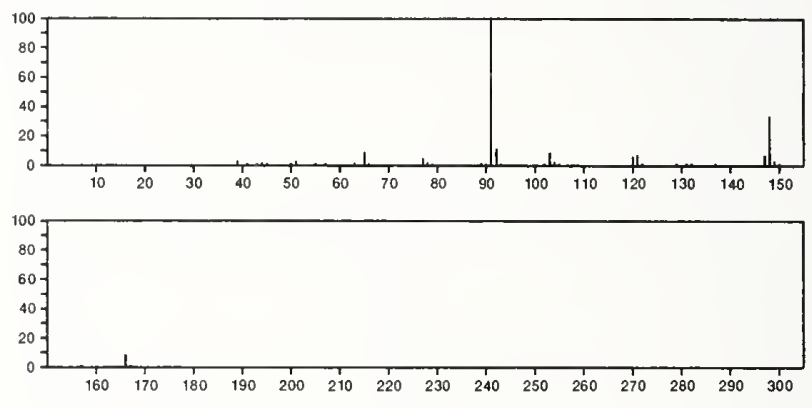

166

$\mathrm{C}_{9} \mathrm{H}_{10} \mathrm{O}_{3}$

498-02-2

Ethanone, 1-(4-hydroxy-3-methoxyphenyl)-
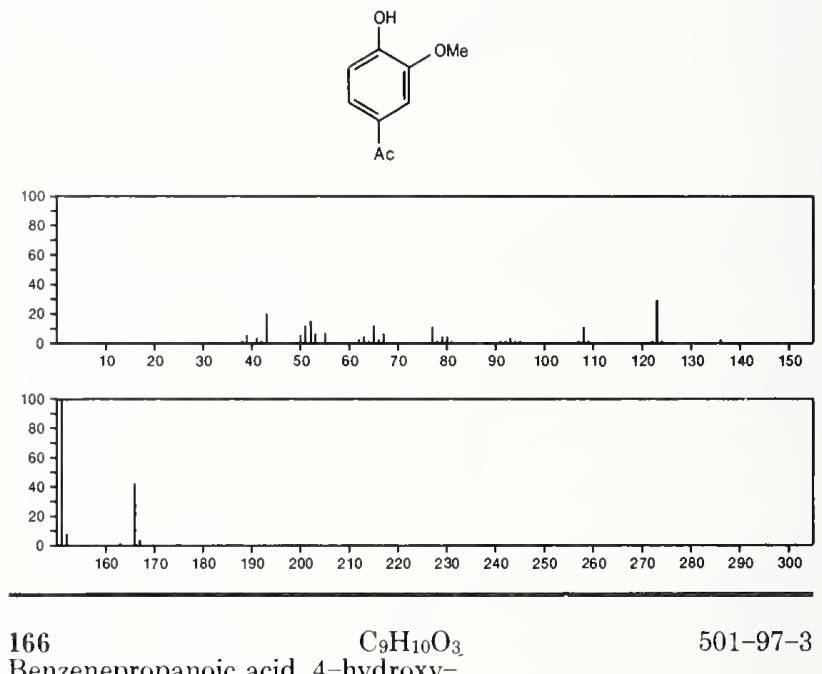

Benzenepropanoic acid, 4-hydroxy-

$501-97-3$
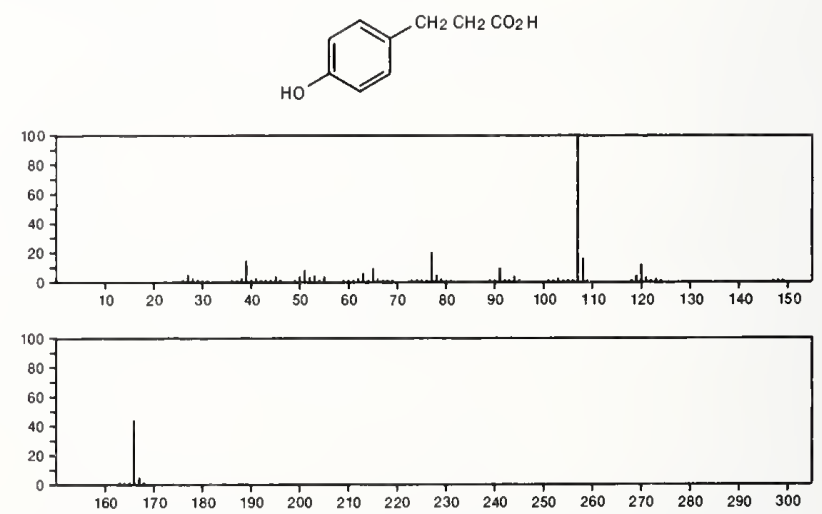

166
Benzeneacetic acid, $\alpha$-hydroxy $-\alpha-$-methyl-

$515-30-0$

$\mathrm{CPhMeMeCO} 2 \mathrm{H}$

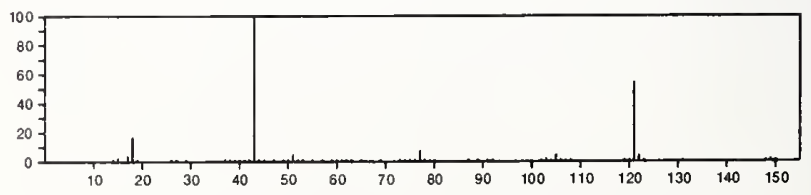




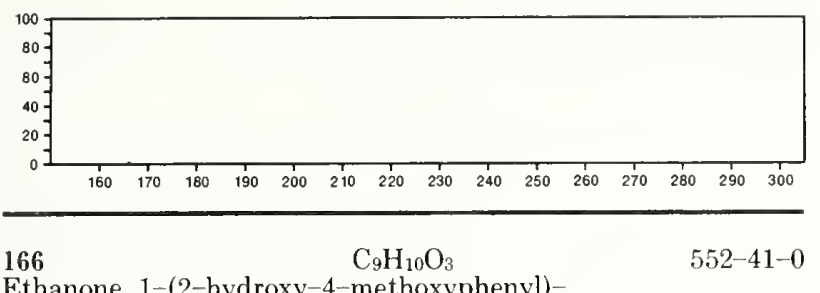

Ethanone, 1-(2-hydroxy-4-methoxyphenyl)-
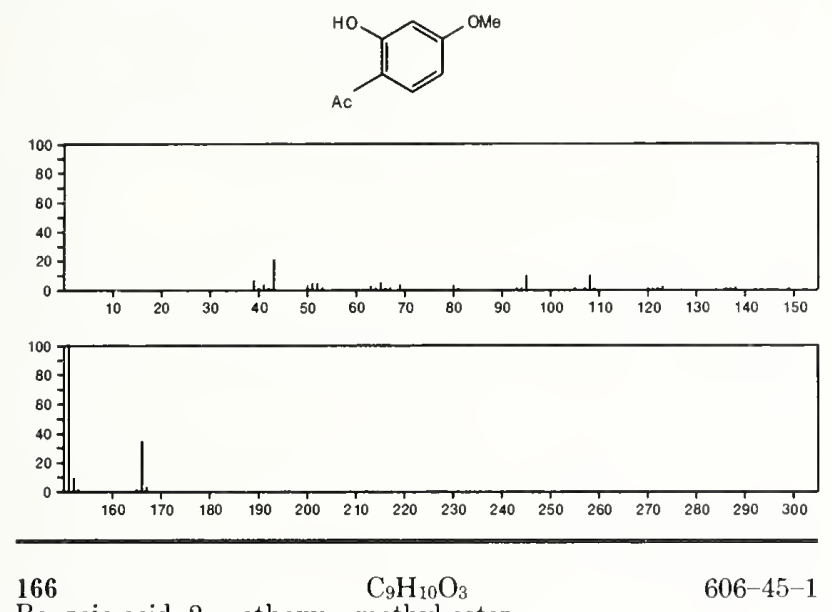

Benzoic acid, 2-methoxy-, methyl ester
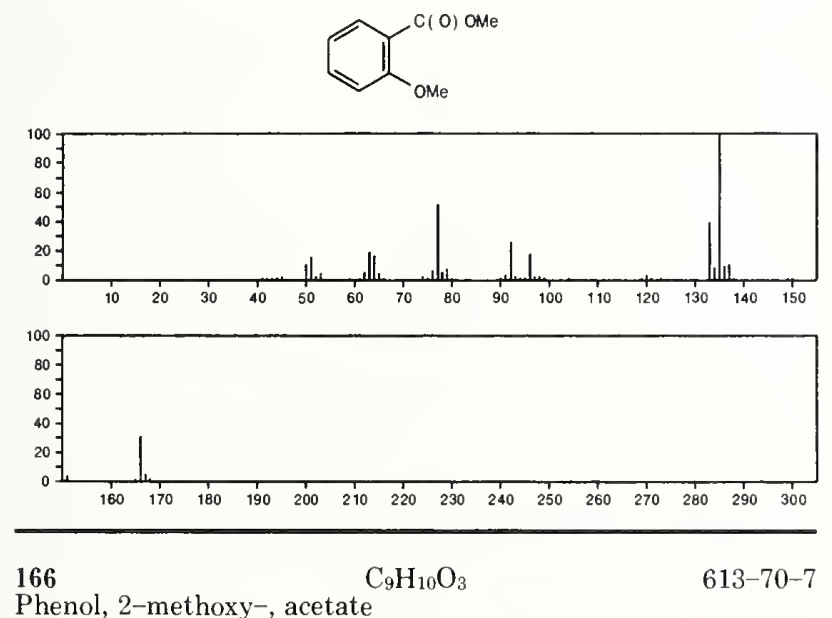

Phenol, 2-methoxy-, acetate
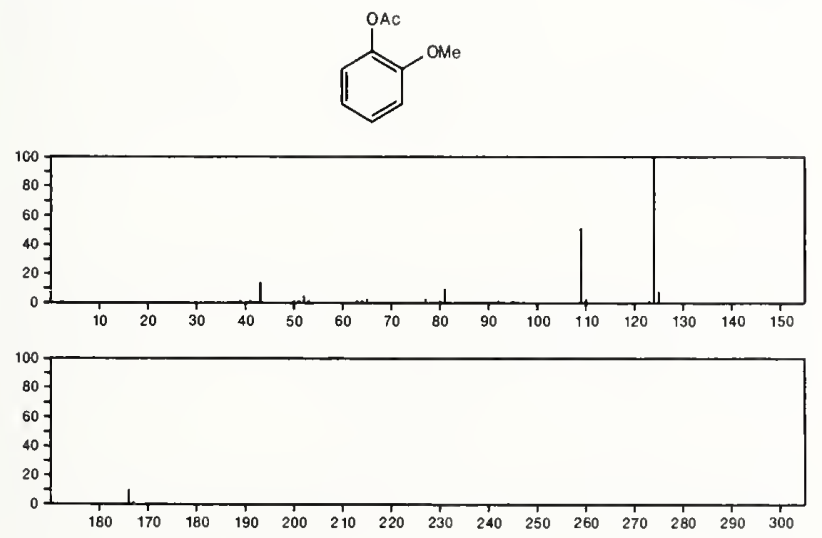

166

2-Propenoic acid, 3-(2-furanyl)-, ethyl ester

$623-20-1$
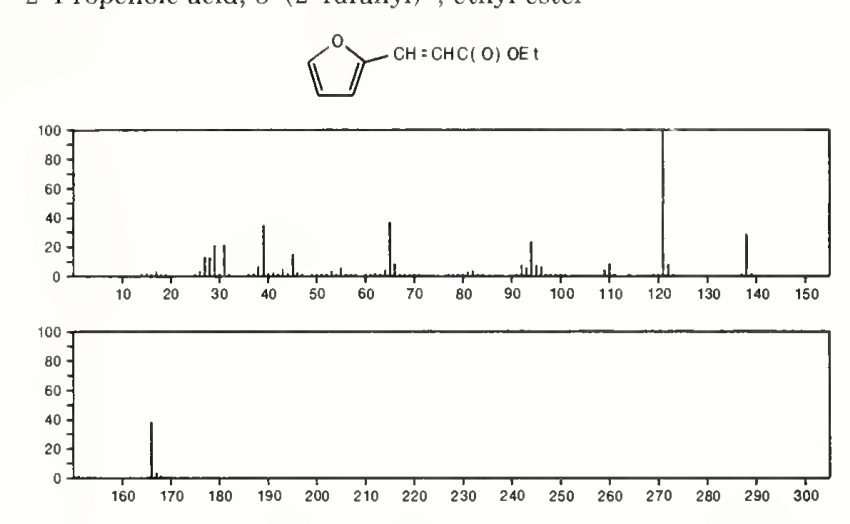

166
Etha

$\mathrm{C}_{9} \mathrm{H}_{10} \mathrm{O}_{3}$

$703-23-1$

Ethanone, 1-(2-hydroxy-6-methoxyphenyl)-
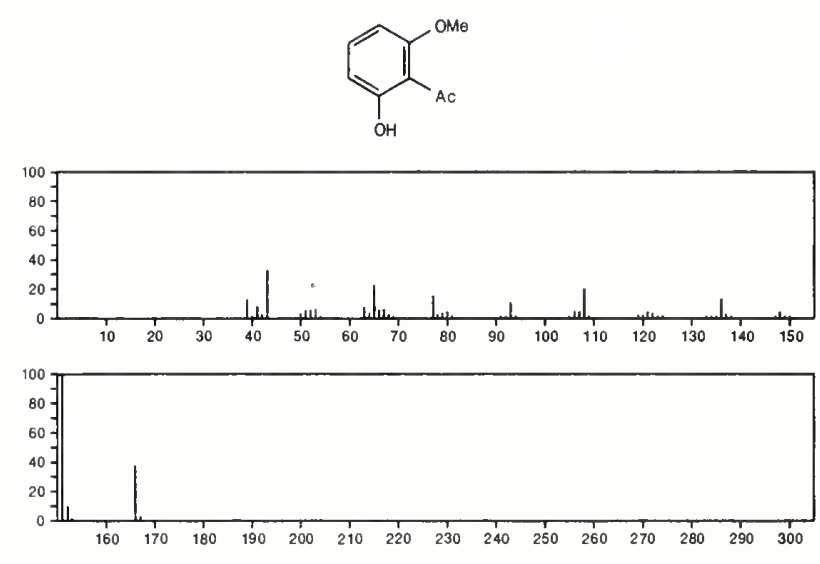

166

$\mathrm{C}_{9} \mathrm{H}_{10} \mathrm{O}_{3}$

$705-15-7$

Ethanone, 1-(2-hydroxy-5-methoxyphenyl)-
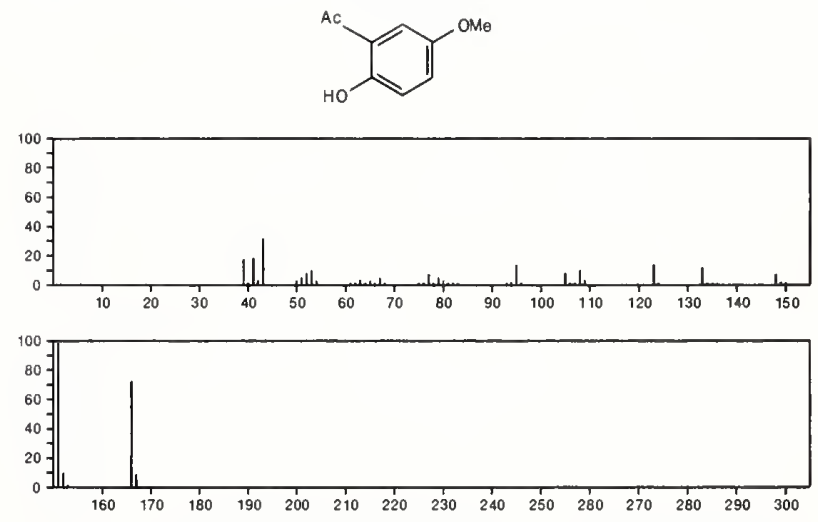

166

$\mathrm{C}_{9} \mathrm{H}_{10} \mathrm{O}_{3}$

$771-90-4$

Benzeneacetic acid, $\alpha$-hydroxy-, methyl ester

$\mathrm{MeOC}(\mathrm{O}) \mathrm{CH}(\mathrm{OH}) \mathrm{Ph}$
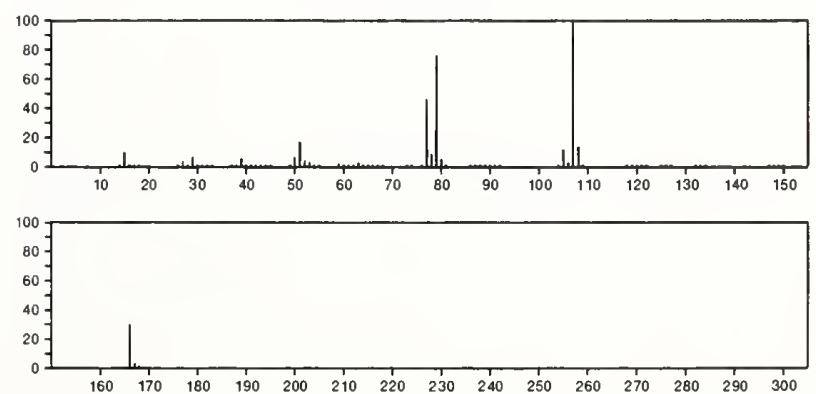
166

$\mathrm{C}_{9} \mathrm{H}_{10} \mathrm{O}_{3}$

Propanoic acid, 2-phenoxy-

$\mathrm{HO}_{2} \mathrm{CCHMeOPh}$
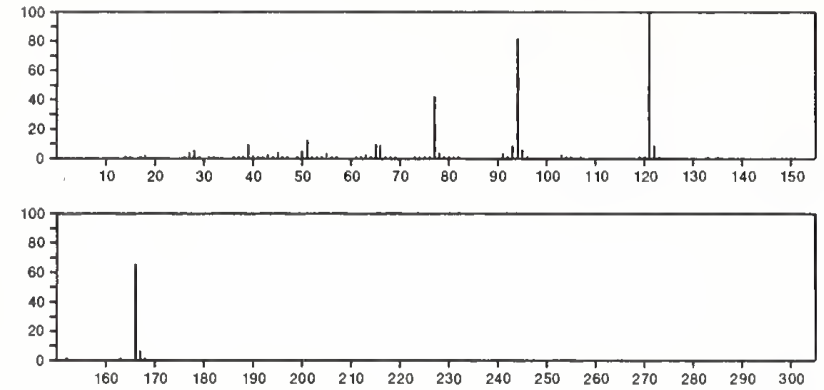

166

Phenol, 4-methoxy-, acetate

$\mathrm{C}_{9} \mathrm{H}_{10} \mathrm{O}_{3}$

$1200-06-2$
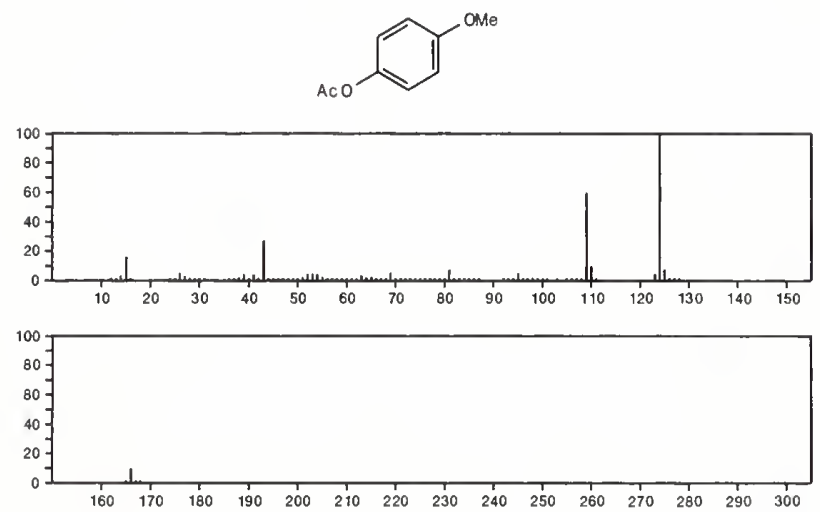

166

Benzeneacetic acid, 3-methoxy-

$\mathrm{C}_{9} \mathrm{H}_{10} \mathrm{O}_{3}$

1798-09-0
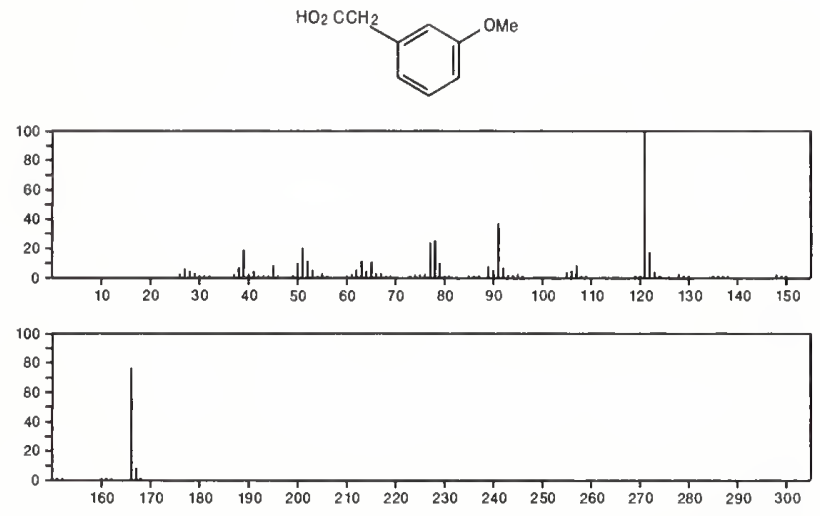

166

$\mathrm{C}_{9} \mathrm{H}_{10} \mathrm{O}_{3}$

1848-01-7

Carbonic acid, methyl 4-methylphenyl ester
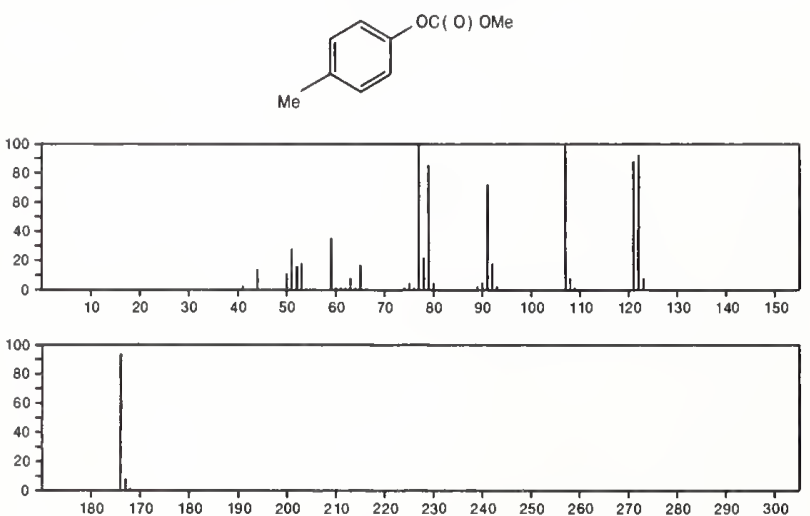

166

$\mathrm{C}_{9} \mathrm{H}_{10} \mathrm{O}_{3}$

Carbonic acid, methyl $m$-tolyl ester

1848-02-8
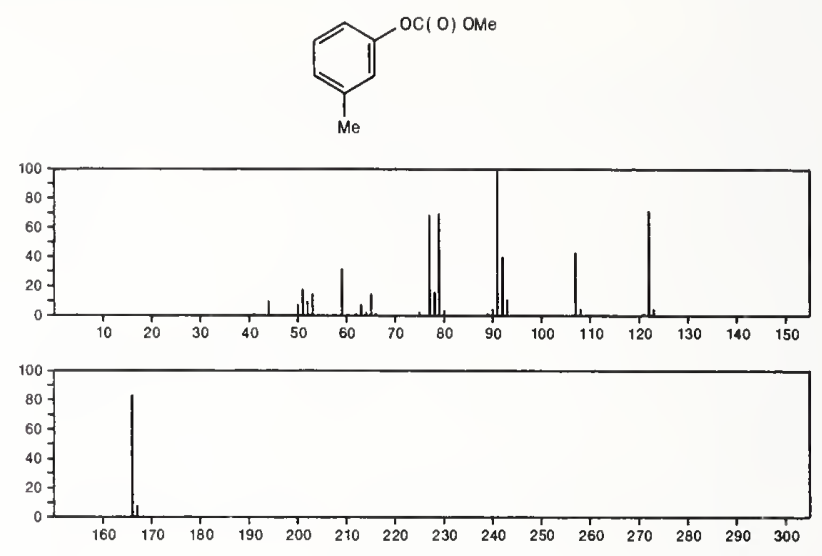

$166 \quad \mathrm{C}_{9} \mathrm{H}_{10} \mathrm{O}_{3}$

Acetic acid, phenoxy-, methyl ester

2065-23-8

$\mathrm{MeOC}(\mathrm{O}) \mathrm{CH}_{2} \mathrm{OPh}$
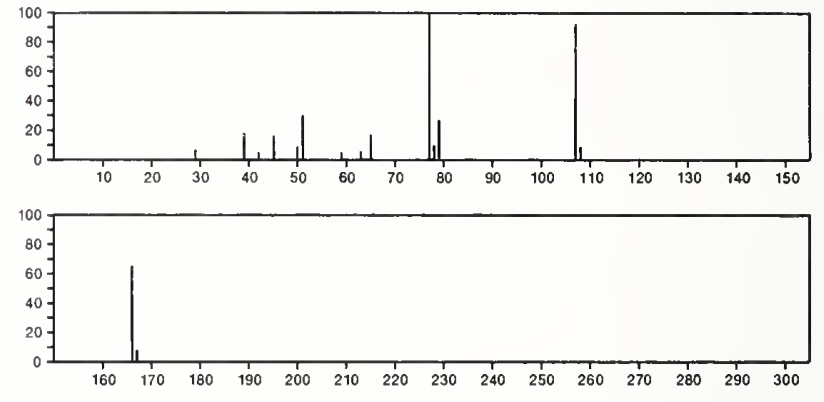

166

$\mathrm{C}_{9} \mathrm{H}_{10} \mathrm{O}_{3}$

$2990-31-0$

Benzaldehyde, 4,6-dihydroxy-2,3-dimethyl-
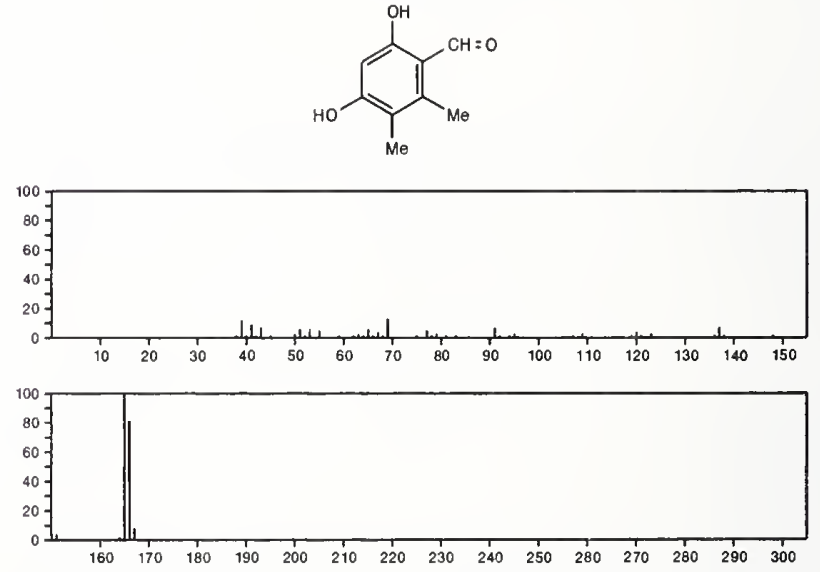

166

$\mathrm{C}_{9} \mathrm{H}_{10} \mathrm{O}_{3}$

$3878-46-4$

Carbonic acid, ethyl phenyl ester

PhOC(O) OE t

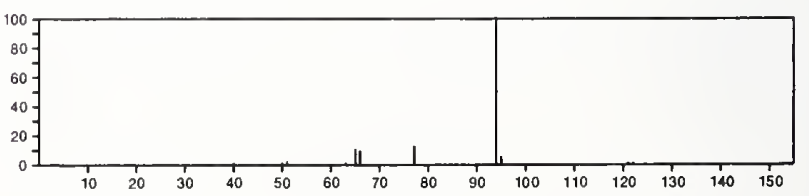




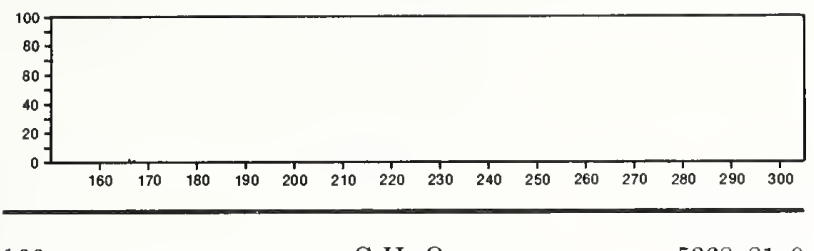

$166 \quad \mathrm{C}_{9} \mathrm{H}_{10} \mathrm{O}_{3}$

5368-81-0

Benzoic acid, 3-methoxy-, methyl ester

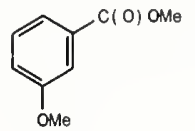

166 $\mathrm{C}_{9} \mathrm{H}_{10} \mathrm{O}_{3}$

Benzeneacetic acid, 4-hydroxy-, methyl ester
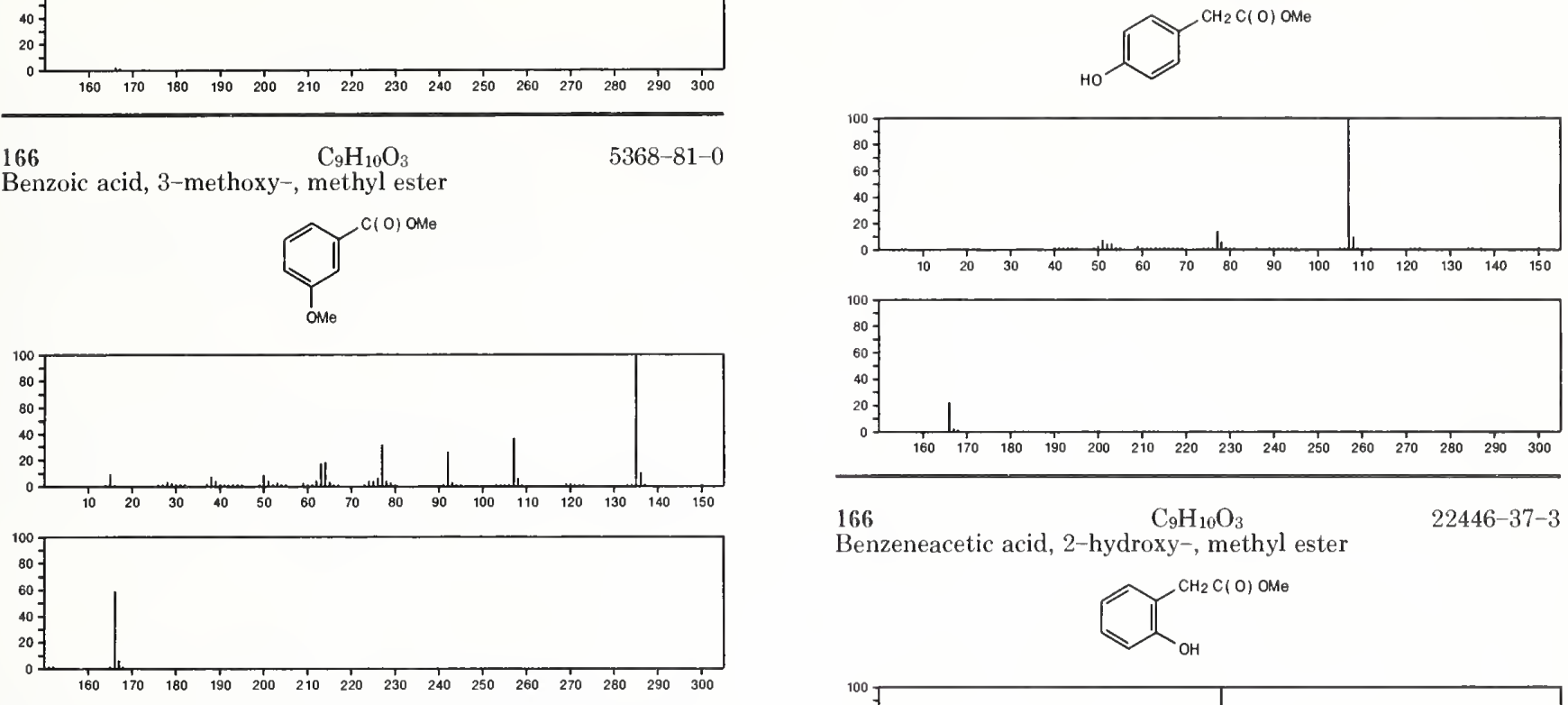

166

$\mathrm{C}_{9} \mathrm{H}_{10} \mathrm{O}_{3}$

22446-37-3

Benzeneacetic acid, 2-hydroxy-, methyl ester
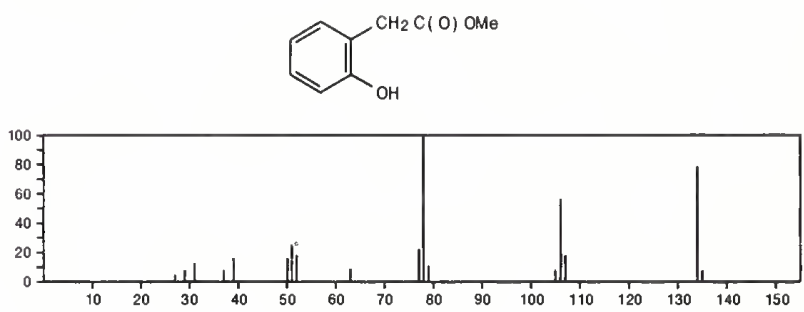

166

$5451-83-2$

Phenol, 3-methoxy-, acetate

$\mathrm{C}_{9} \mathrm{H}_{10} \mathrm{O}_{3}$
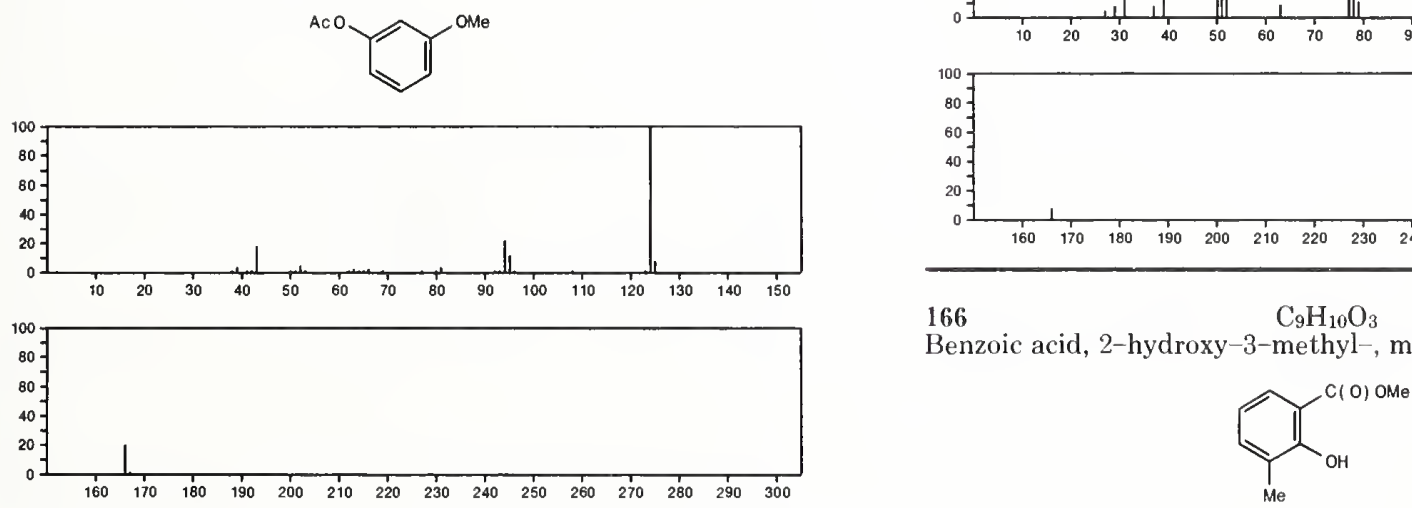

$\begin{array}{lllllllllllllll}160 & 170 & 180 & 190 & 200 & 210 & 220 & 230 & 240 & 250 & 260 & 270 & 280 & 290 & 300\end{array}$

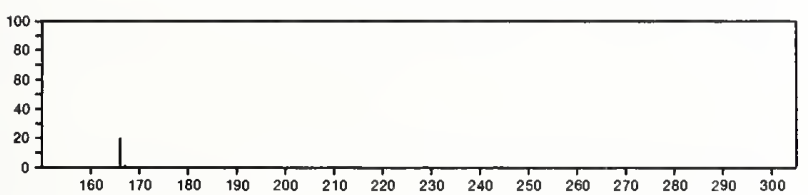

166

$\mathrm{C}_{9} \mathrm{H}_{10} \mathrm{O}_{3}$

$7521-38-2$

4H-Pyran-4-one, 3-acetyl-2,6-dimethyl-
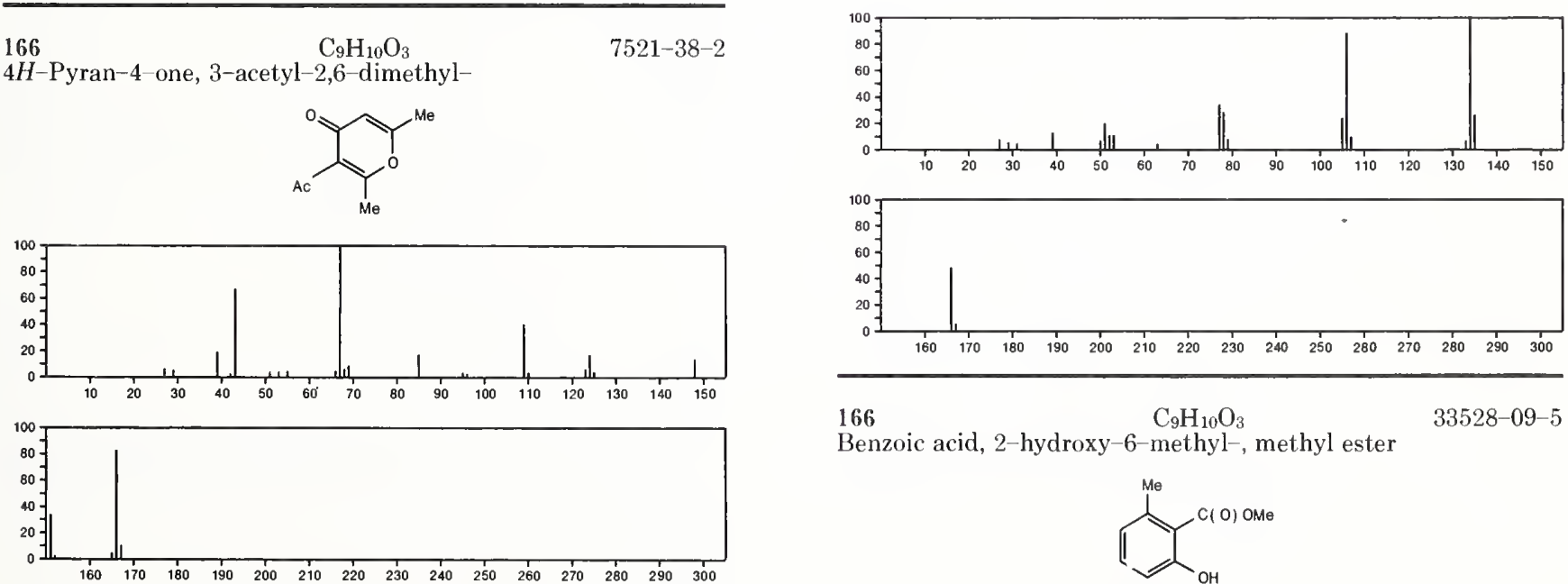

166

$\mathrm{C}_{9} \mathrm{H}_{10} \mathrm{O}_{3}$

33528-09-5

Benzoic acid, 2-hydroxy-6-methyl-, methyl ester
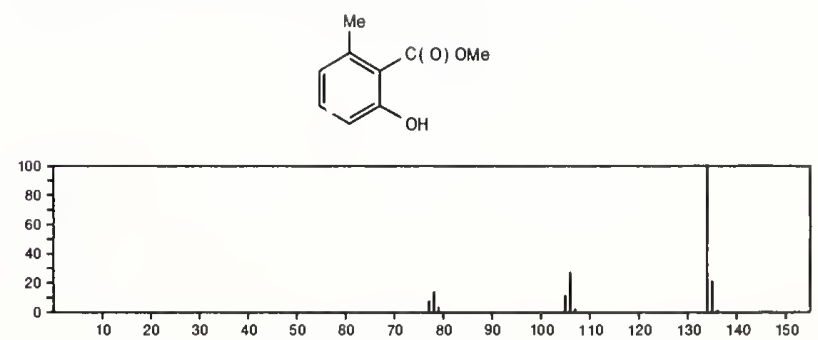


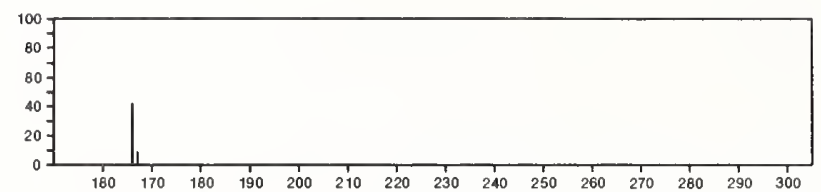

166

$\mathrm{C}_{9} \mathrm{H}_{10} \mathrm{O}_{3}$

$34883-08-4$

Benzaldehyde, 2-hydroxy-4-methoxy-6-methyl-
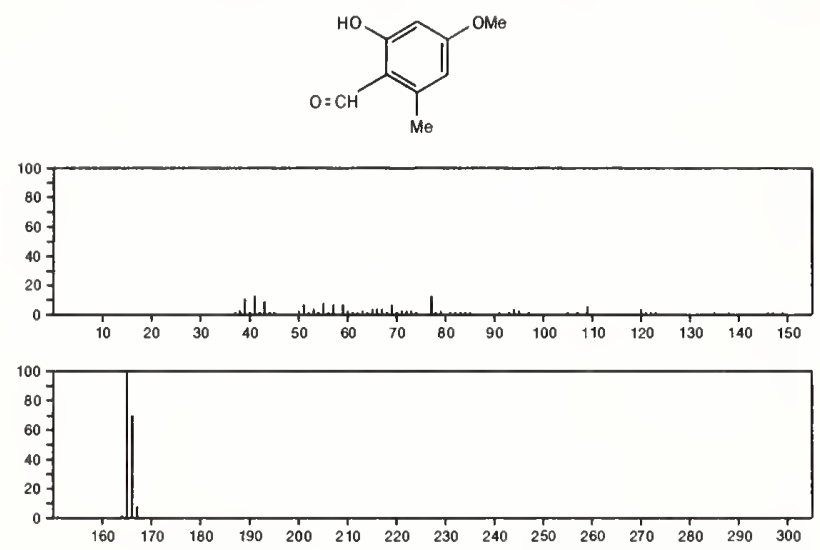

166

$\mathrm{C}_{9} \mathrm{H}_{10} \mathrm{O}_{3}$

$34883-14-2$

Benzaldehyde, 2,4-dihydroxy-3,6-dimethyl
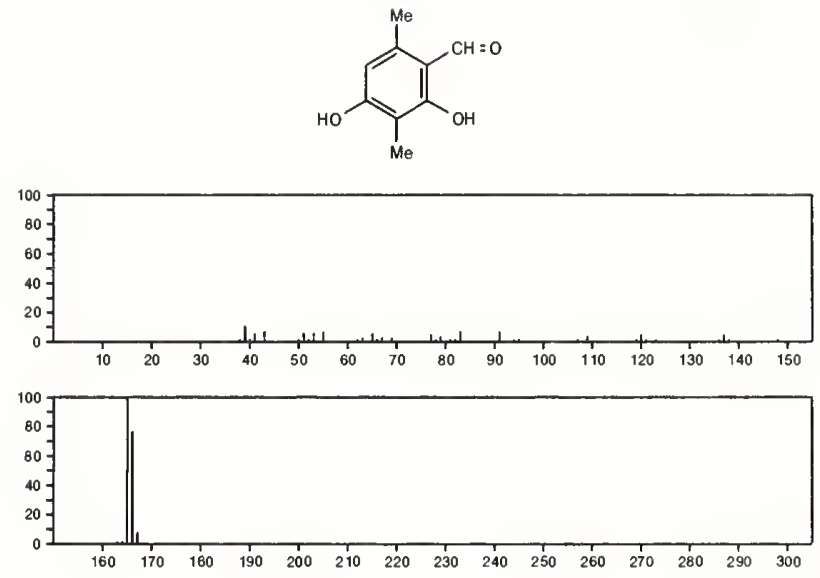

166

$\mathrm{C}_{9} \mathrm{H}_{10} \mathrm{O}_{3}$

$42058-59-3$

Benzeneacetic acid, 3-hydroxy-, methyl ester
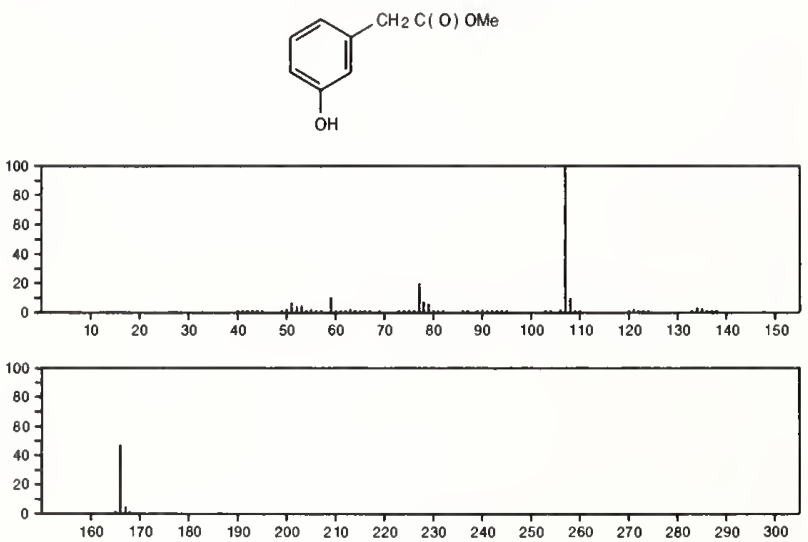

166

$\mathrm{C}_{9} \mathrm{H}_{10} \mathrm{O}_{3}$

$54966-48-2$

2-Butynoic acid, 4-cyclopropyl-4-0xo-, ethyl ester
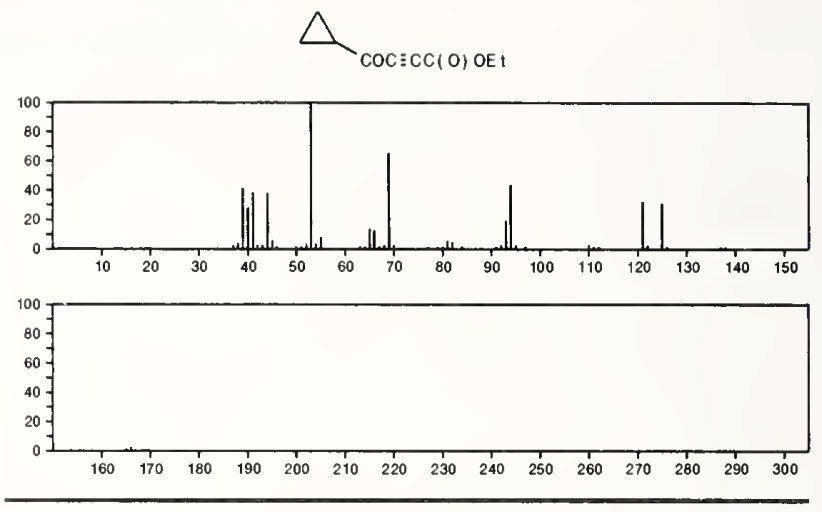

166

$\mathrm{C}_{9} \mathrm{H}_{14} \mathrm{OSi}$

$1529-17-5$

Silane, trimethylphenoxy-

Me3SiOPn
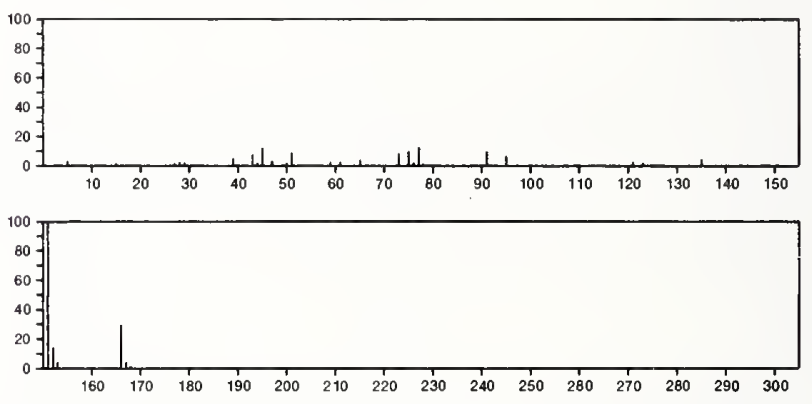

166

$\mathrm{C}_{10} \mathrm{H}_{11} \mathrm{Cl}$

$16608-68-7$

2-Butene, 3-chloro-1-phenyl-, (Z)-

$\mathrm{MeCCl}=\mathrm{CHCH}_{2} \mathrm{Ph}$
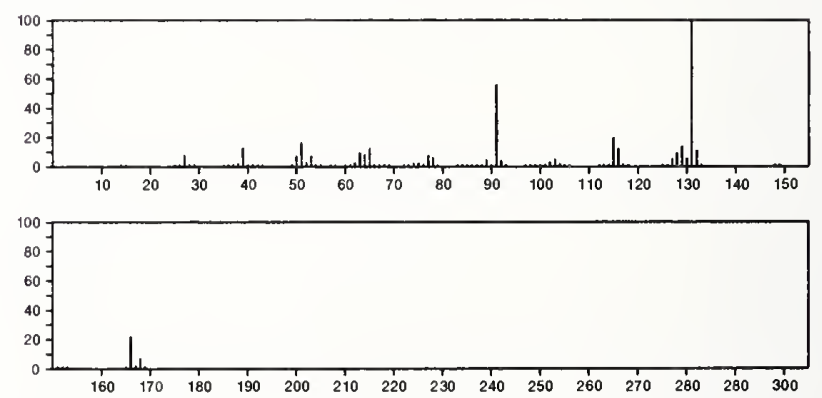

166

$\mathrm{C}_{10} \mathrm{H}_{11} \mathrm{Cl}$

$54411-12-0$

Benzene, (2-chloro-2-butenyl)

$\mathrm{PhCH}_{2} \mathrm{CCl}=\mathrm{CHMO}_{\mathrm{O}}$
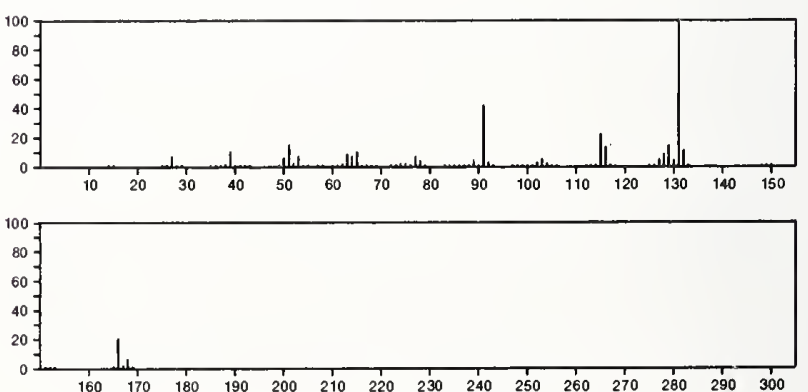
166

1-Butanone, 1-(4-fluorophenyl)-
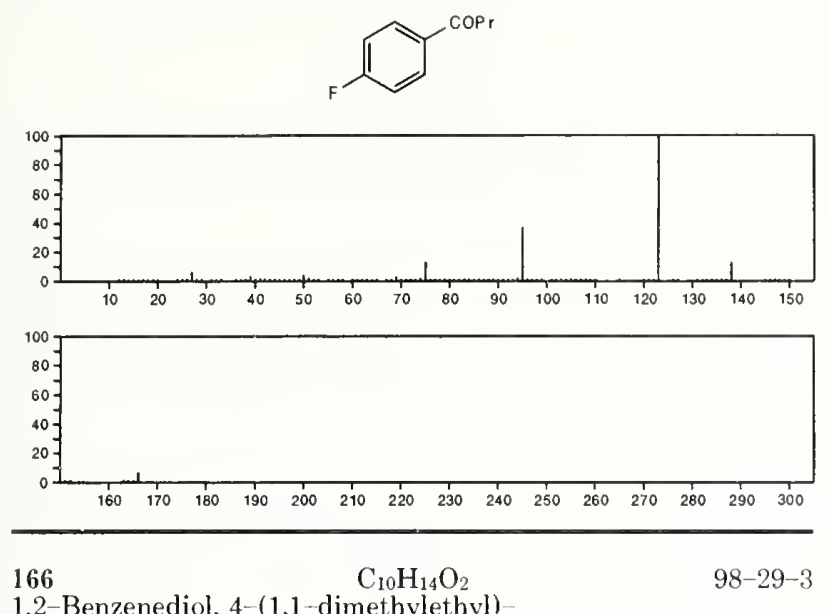

1,2-Benzenediol, 4-(1,1-dimethylethyl)
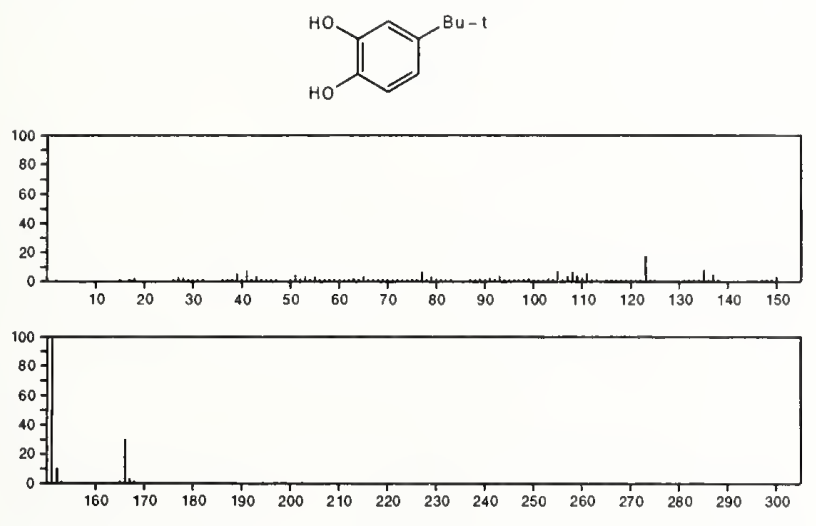

\section{6}

Benzene, (2,2-dimethoxyethyl)-

\section{$\mathrm{C}_{10} \mathrm{H}_{14} \mathrm{O}_{2}$}

101-48-4

(Me O) ${ }_{2} \mathrm{CHCH}_{2} \mathrm{Ph}$

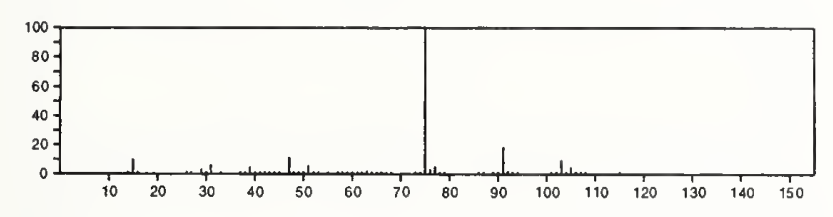

166

Phenol, 4-butoxy-

$\mathrm{C}_{10} \mathrm{H}_{14} \mathrm{O}_{2}$

122-94-1
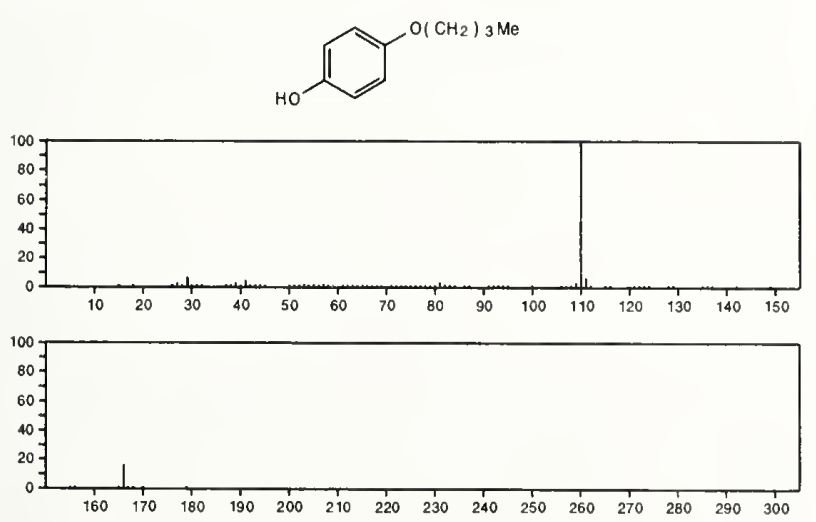

166

Benzene, 1,4-diethoxy-

$\mathrm{C}_{10} \mathrm{H}_{14} \mathrm{O}_{2}$

$122-95-2$
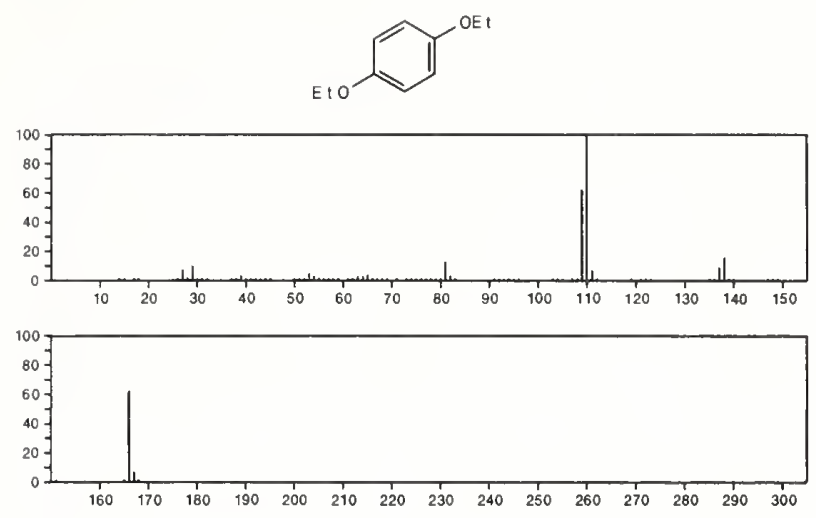

166

$\mathrm{C}_{10} \mathrm{H}_{14} \mathrm{O}_{2}$

Bicyclo[2.2.1] heptane--2,3-dione, 1,7,7-trimethyl-

$465-29-2$
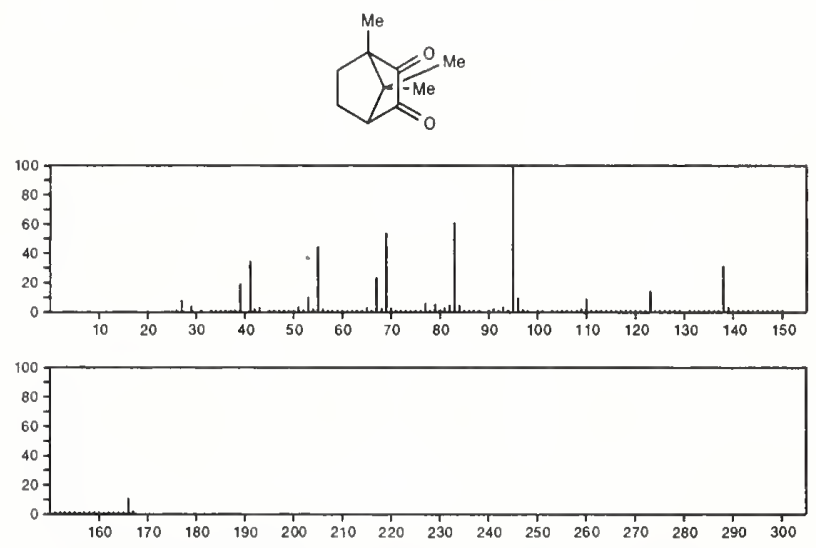

166

$\mathrm{C}_{10} \mathrm{H}_{14} \mathrm{O}_{2}$

490-10-8

Cyclopenta[c]pyran-1(4aH)-one, $5,6,7,7 \mathrm{a}$-tetrahydro-4,7-dimethyl-
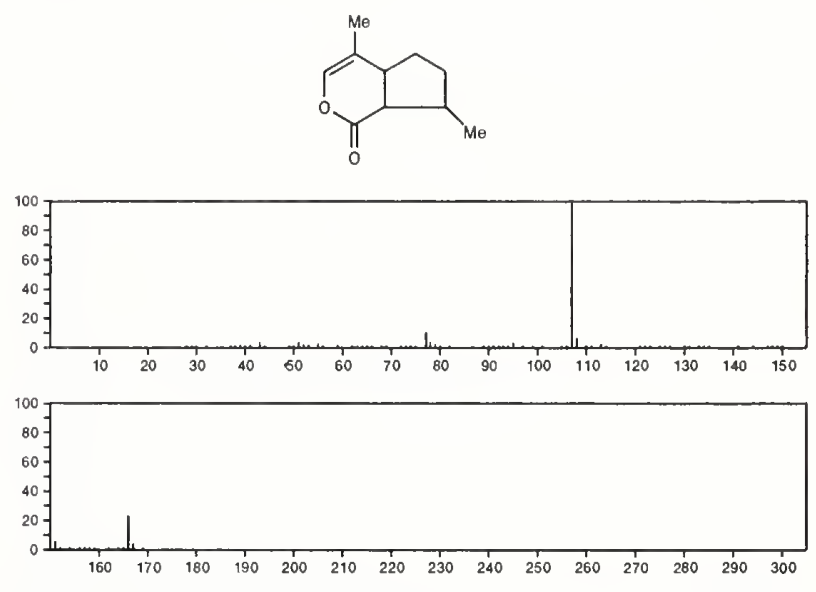

166

$\mathrm{C}_{10} \mathrm{H}_{14} \mathrm{O}_{2}$

$501-96-2$

Benzenepropanol, 4-hydroxy- $\alpha$-methyl-, (-)-
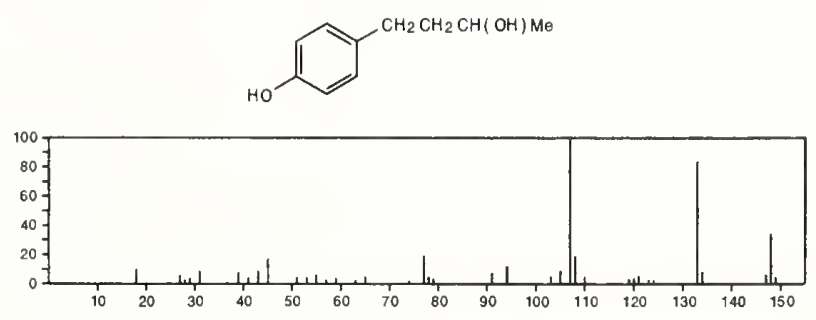


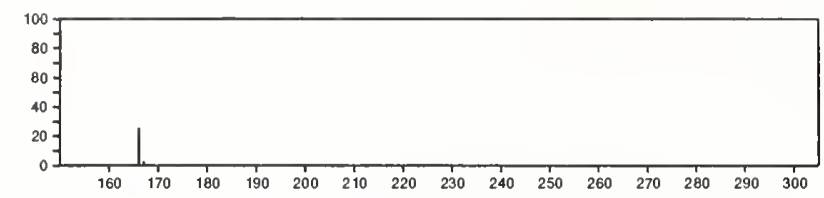

$166 \quad \mathrm{C}_{10} \mathrm{H}_{14} \mathrm{O}_{2}$

$4230-32-4$

Bicyclo[2.2.1]heptane-2,5-dione, 1,7,7-trimethyl-

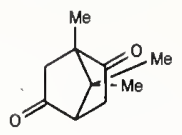

Methane, isopropoxyphenoxy

$\mathrm{PhOCH}_{2} \mathrm{OPr}_{-} \mathrm{I}$
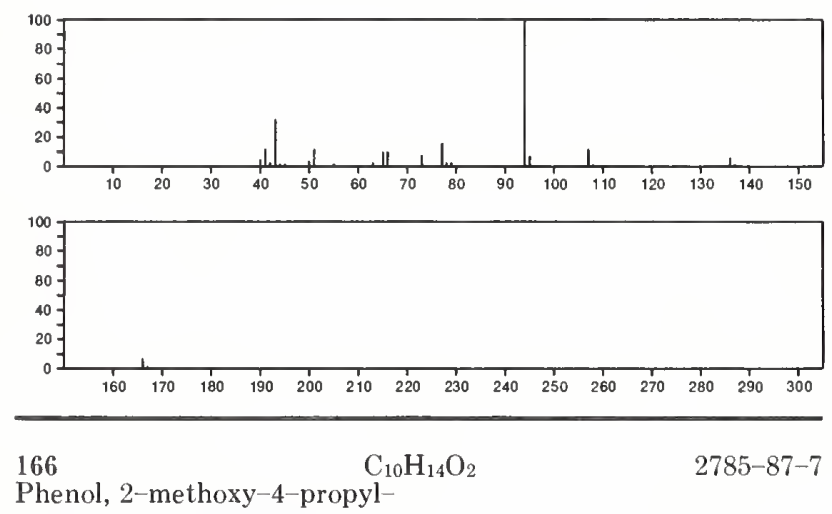

Phenol, 2-methoxy-4-propyl-
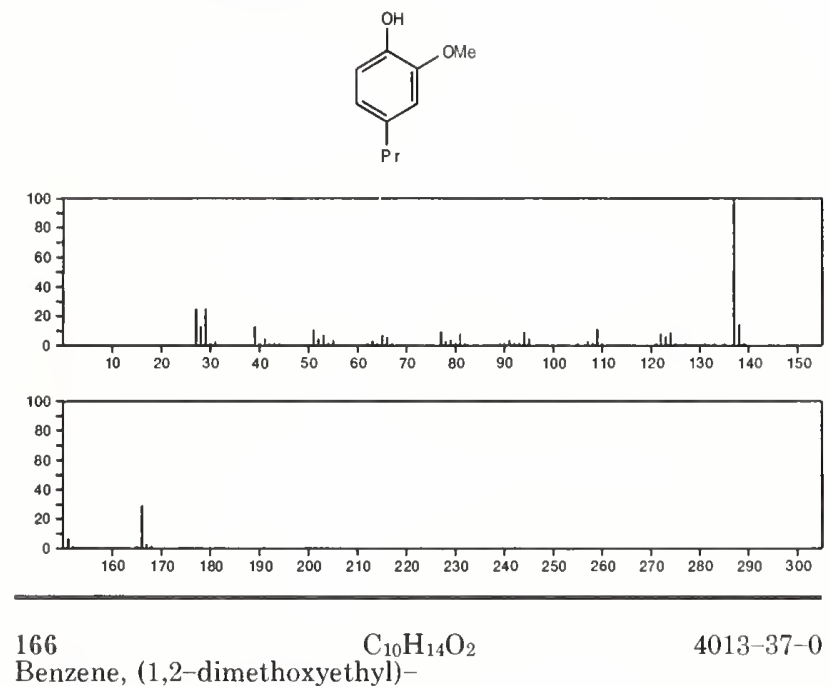

Benzene, (1,2-dimethoxyethyl)-

$\mathrm{MeOCH} 2 \mathrm{CH}$ ( OMe ) Ph
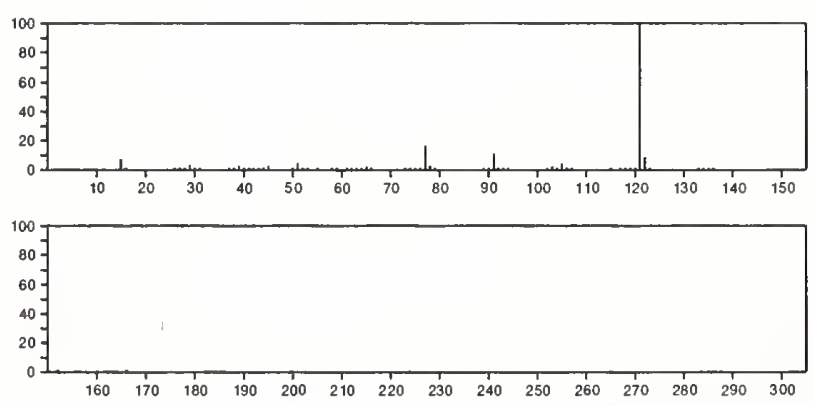

166
1-Propanol, 3-(phenylmethoxy)-- $\mathrm{C}_{10} \mathrm{H}_{14} \mathrm{O}_{2}$
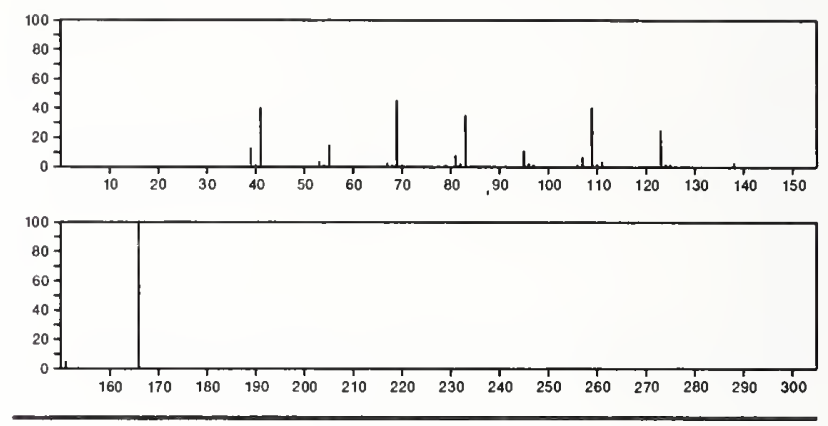

166

Methane, phenoxypropoxy-

$\mathrm{C}_{10} \mathrm{H}_{14} \mathrm{O}_{2}$

4457-16-3

$\mathrm{PhOCH}_{2} \mathrm{OPr}$
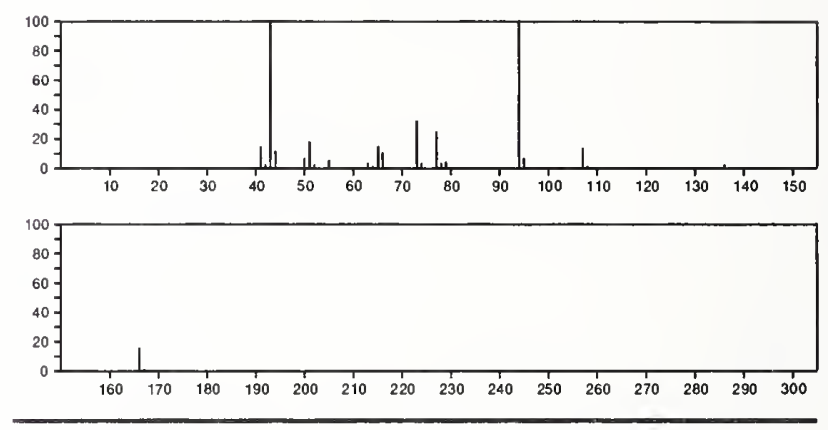

166

$\mathrm{C}_{10} \mathrm{H}_{14} \mathrm{O}_{2}$

4799-66-0

Ethanol, 2-(1-phenylethoxy)-

$\mathrm{PhCHMe} \mathrm{OCH} \mathrm{CH}_{2} \mathrm{OH}$
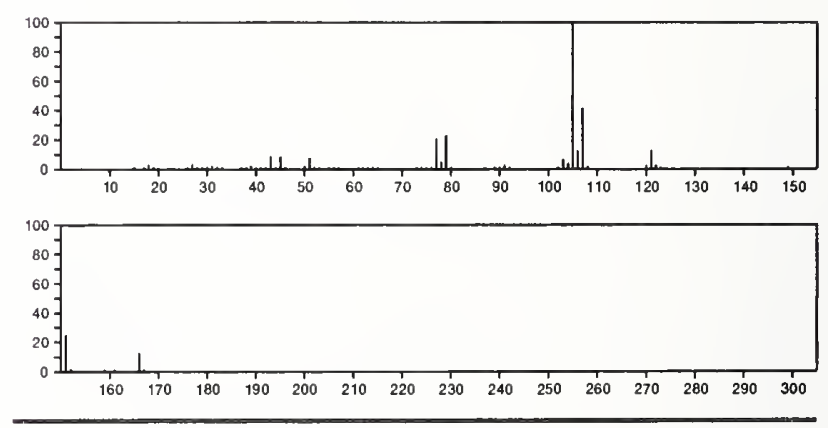

4799-68-2

$\mathrm{PhCH}_{2} \mathrm{O}\left(\mathrm{CH}_{2}\right)_{3} \mathrm{OH}$
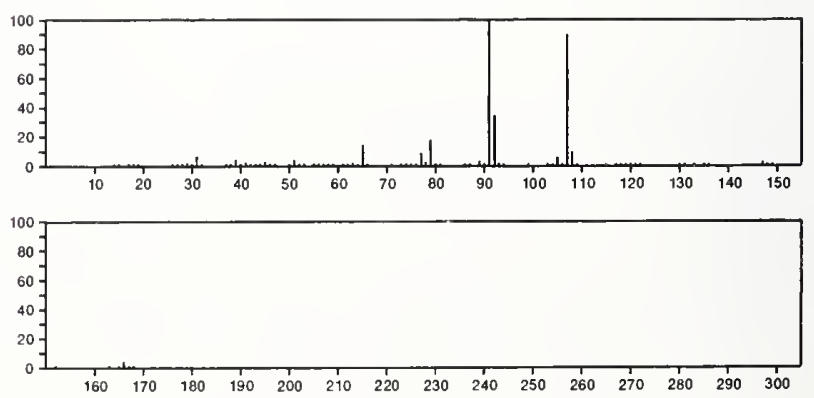
166

$\mathrm{C}_{10} \mathrm{H}_{14} \mathrm{O}_{2}$

Benzenemethanol, $\alpha$-ethyl-4-methoxy-

$5349-60-0$
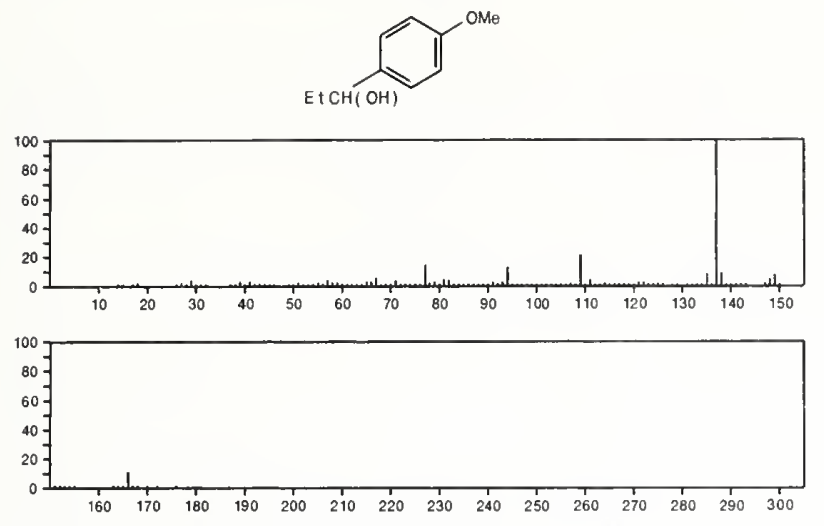

166
Spiro[4.5]decane-6,10-dione
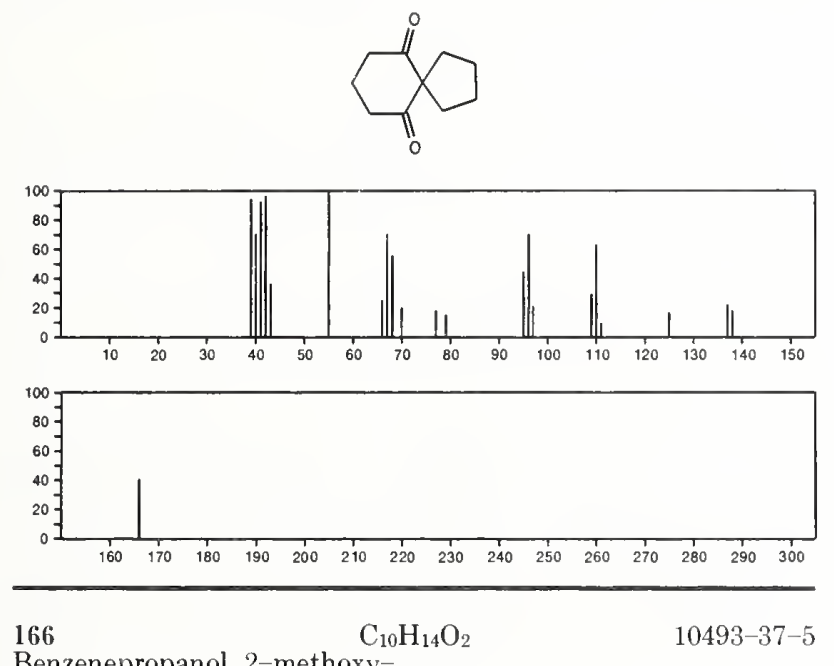

Benzenepropanol, 2-methoxy-
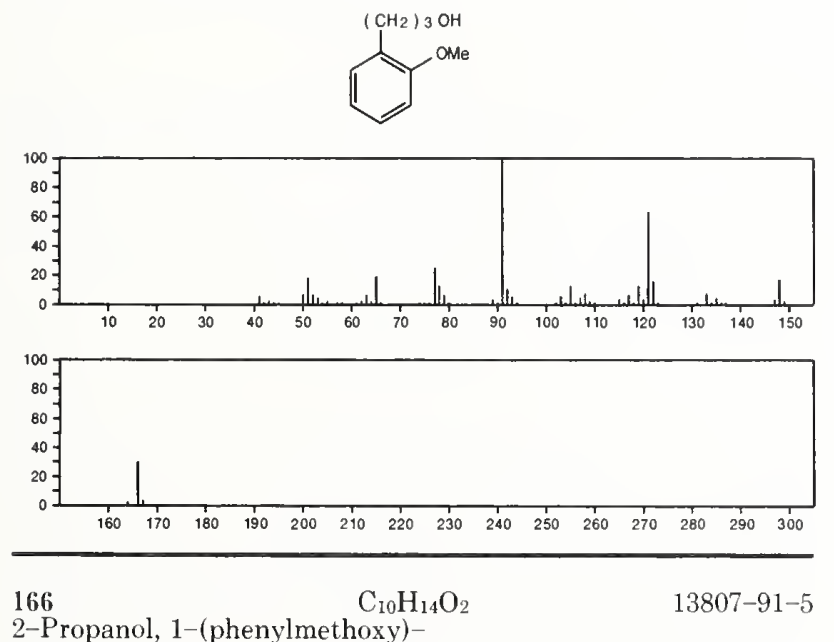

2-Propanol, 1-(phenylmethoxy)-

$\mathrm{PhCH}_{2} \mathrm{OCH}_{2} \mathrm{CH}(\mathrm{OH}) \mathrm{Me}$

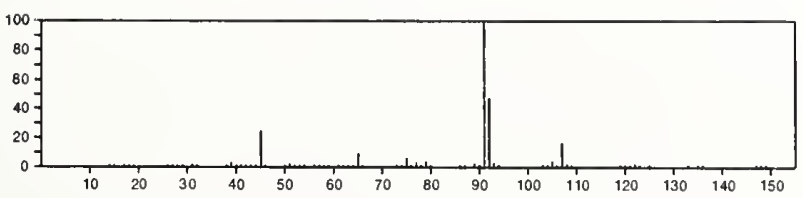

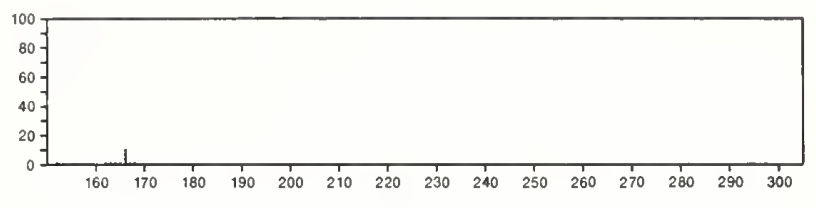

166

$\mathrm{C}_{10} \mathrm{H}_{14} \mathrm{O}_{2}$

17190-74-8

2-Cyclopenten-1-one, 2-(2-butenyl)-4-hydroxy-3-methyl-, (Z)-
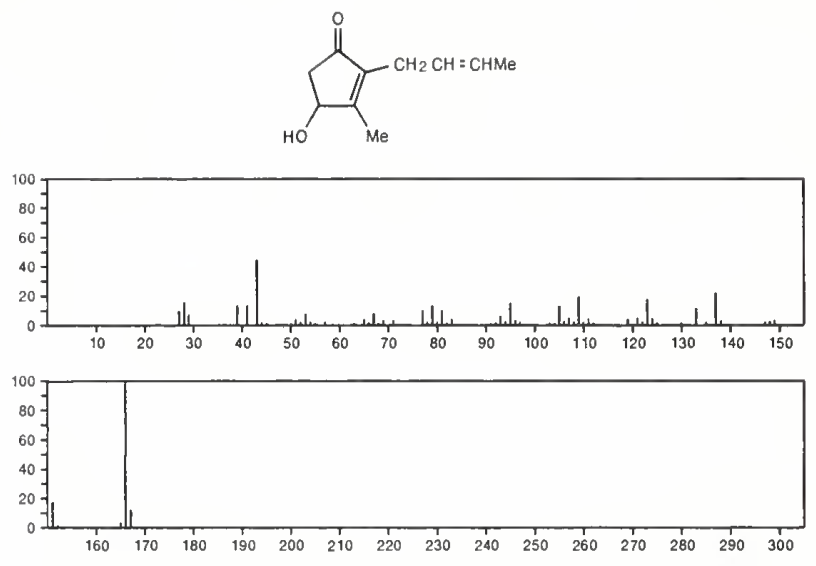

166
Ethane, 1-ethoxy-2-phenoxy-

19594-02-6

$\mathrm{Et} \mathrm{OCH}_{2} \mathrm{CH}_{2} \mathrm{OPh}$
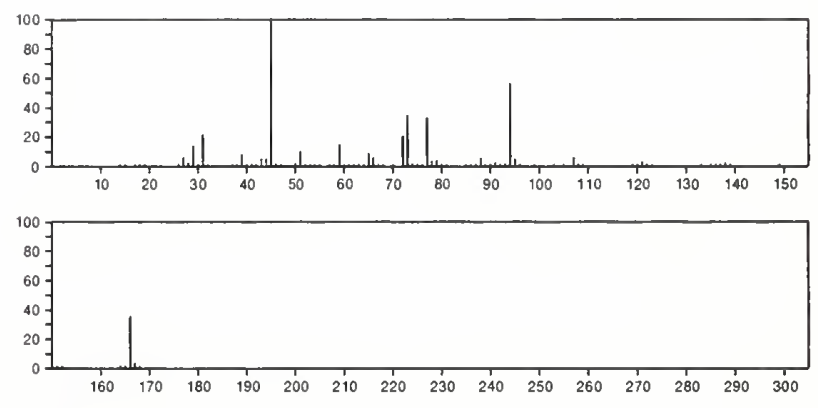

166

1,2-Butanediol, 1-phenyl-

$$
\mathrm{C}_{10} \mathrm{H}_{14} \mathrm{O}_{2}
$$

$22607-13-2$

$\mathrm{E}: \mathrm{CH}(\mathrm{OH}) \mathrm{CH}(\mathrm{OH}) \mathrm{Ph}$
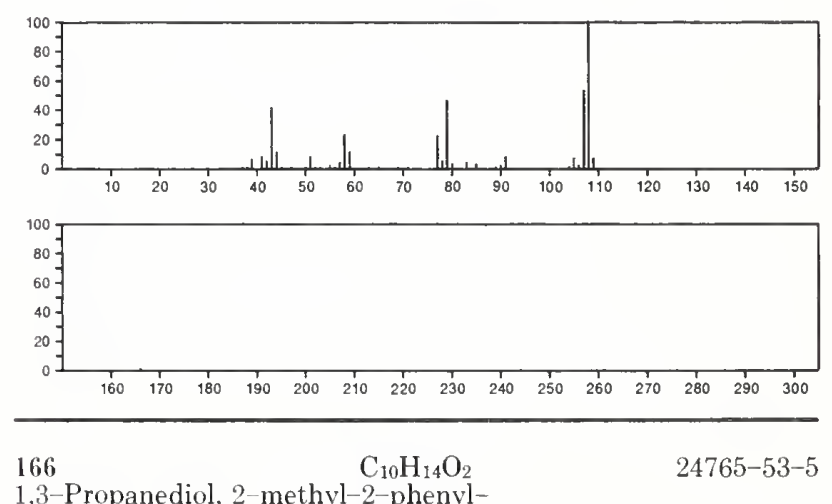

1,3-Propanediol, 2-methyl-2-phenyl-

$\mathrm{HOCH}_{2} \mathrm{CPhM}_{\mathrm{C}} \mathrm{CH}_{2} \mathrm{OH}$

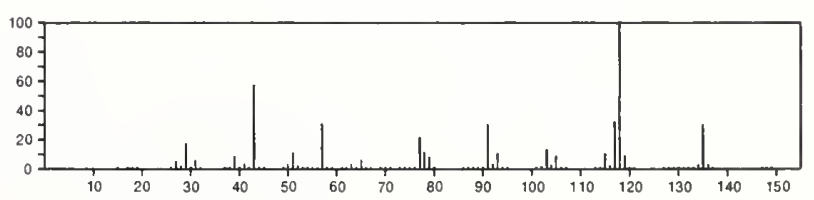


166

Benzene, [(2-methoxyethoxy)methyl $]-$

$\mathrm{PhCH}_{2} \mathrm{OCH}_{2} \mathrm{CH}_{2} \mathrm{OMe}_{\mathrm{O}}$
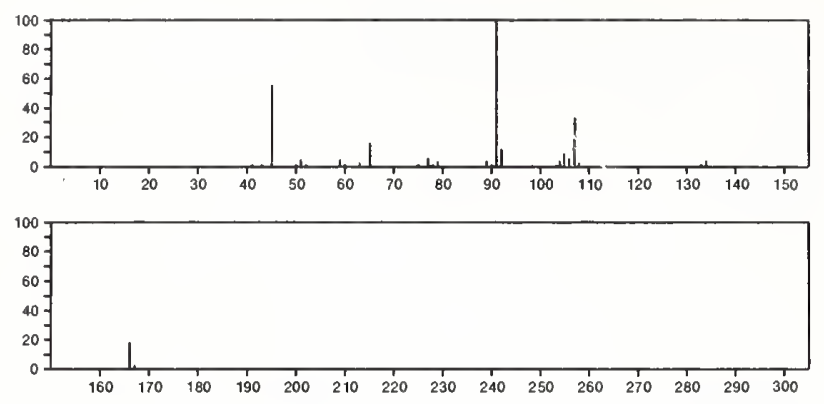

166

Phenol, 5-methoxy-2,3,4-trime

\section{$\mathrm{C}_{10} \mathrm{H}_{14} \mathrm{O}_{2}$}
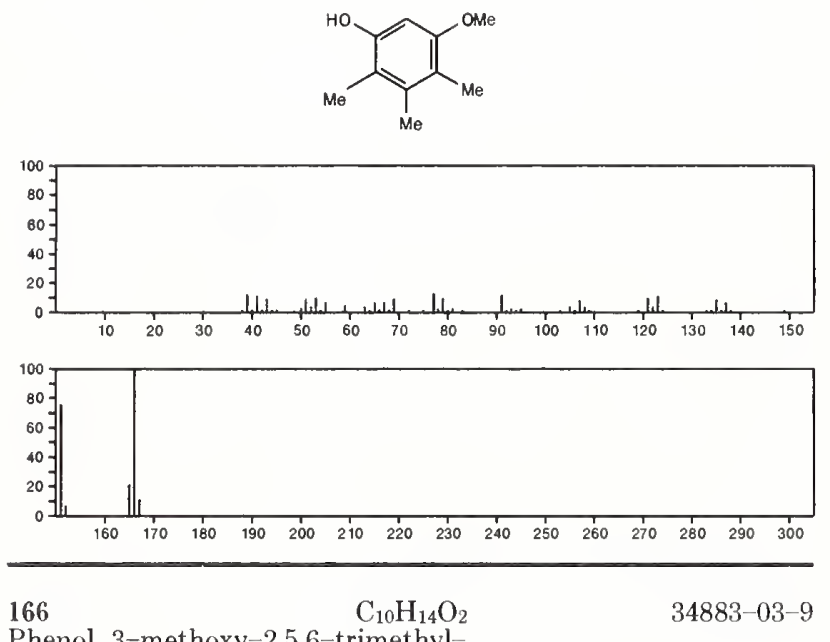

Phenol, 3-methoxy-2,5,6-trimethyl-
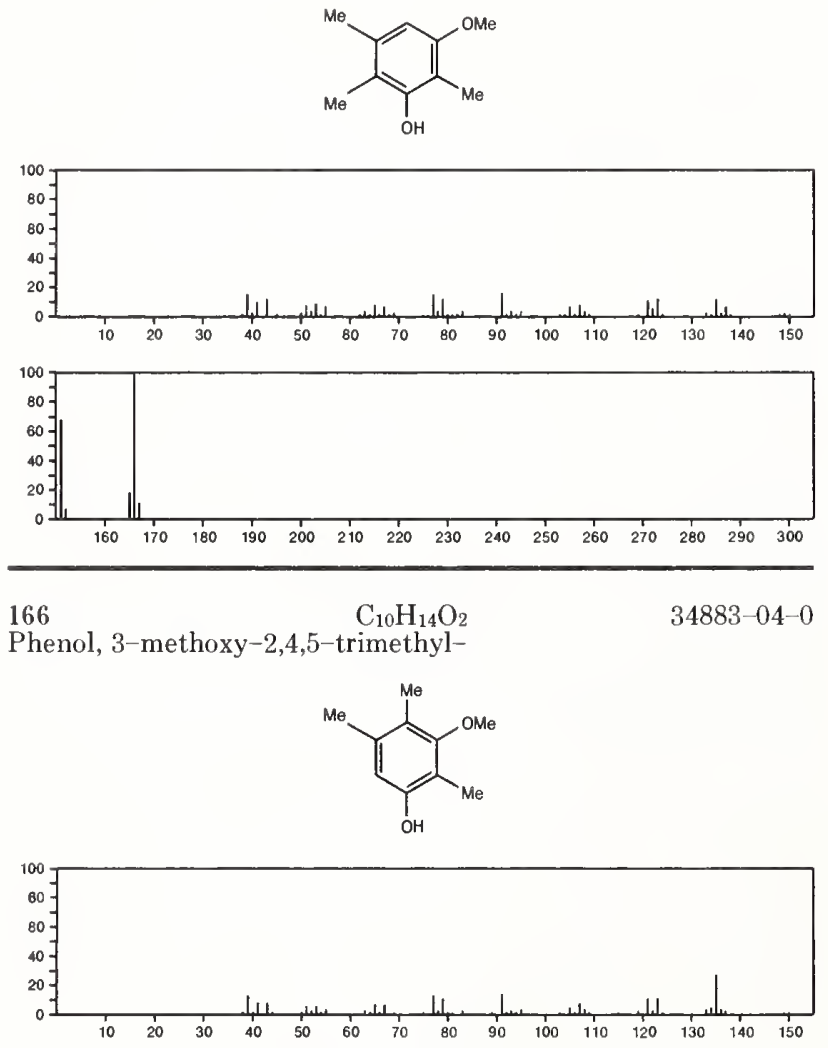

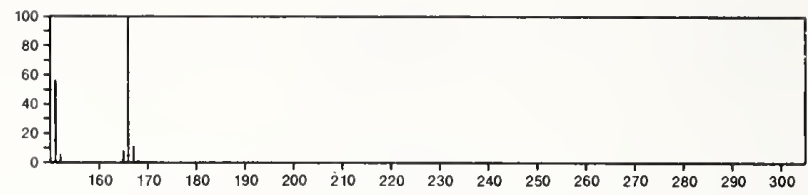

166

$\mathrm{C}_{10} \mathrm{H}_{14} \mathrm{O}_{2}$

Phenol, 3-methoxy-2,4,6-trimethyl-

$34883-05-1$
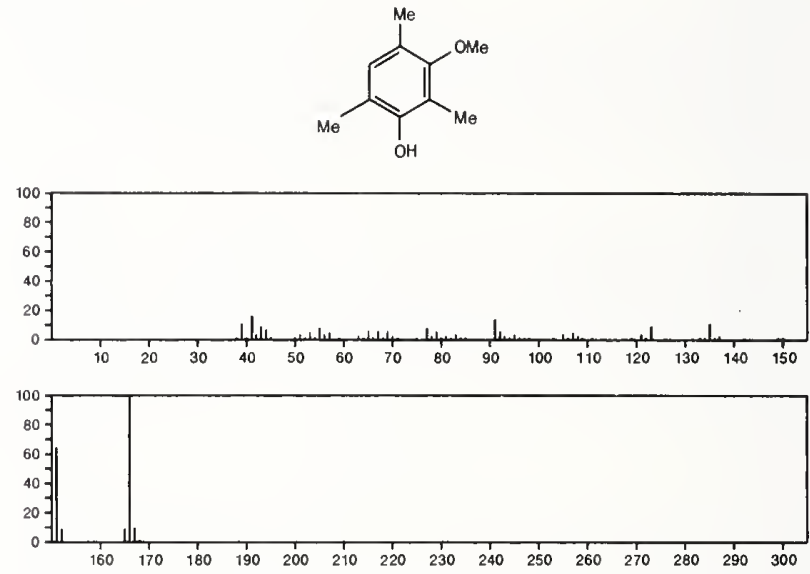

166
Spiro[4.5]decane-1,6-dione

$36803-48-2$
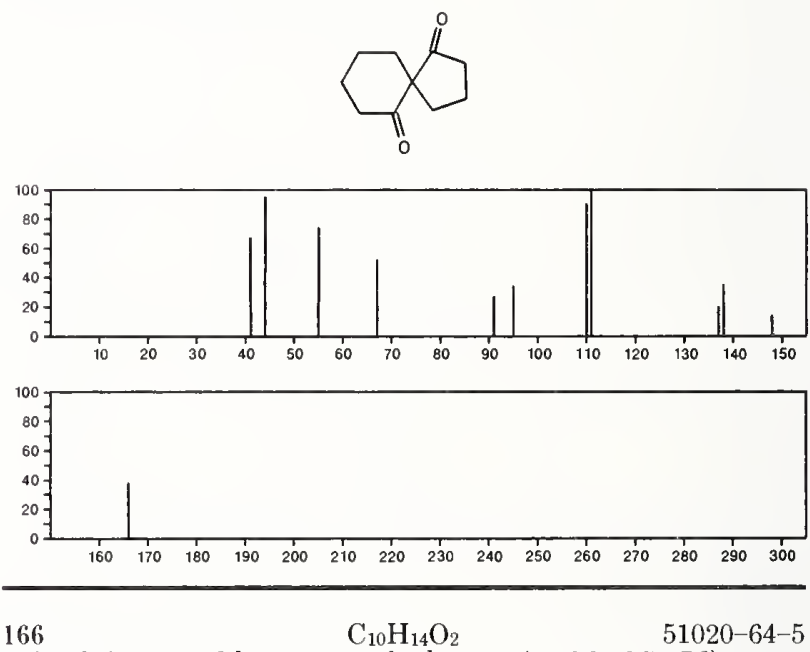

Tricyclo[3.3.1.13,7]decanone, 4 -hydroxy-, $(1 \alpha, 3 \beta, 4 \beta, 5 \alpha, 7 \beta)$ -
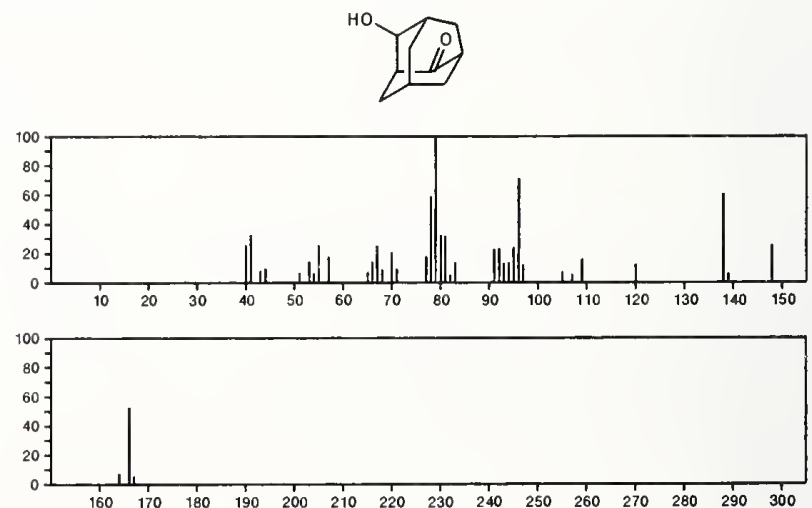
$166 \quad \mathrm{C}_{10} \mathrm{H}_{14} \mathrm{O}_{2} \quad 51020-65-6$

Tricyclo[3.3.1.13,7]decanone, 4-hydroxy-, $(1 \alpha, 3 \beta, 4 \alpha, 5 \alpha, 7 \beta)$ -
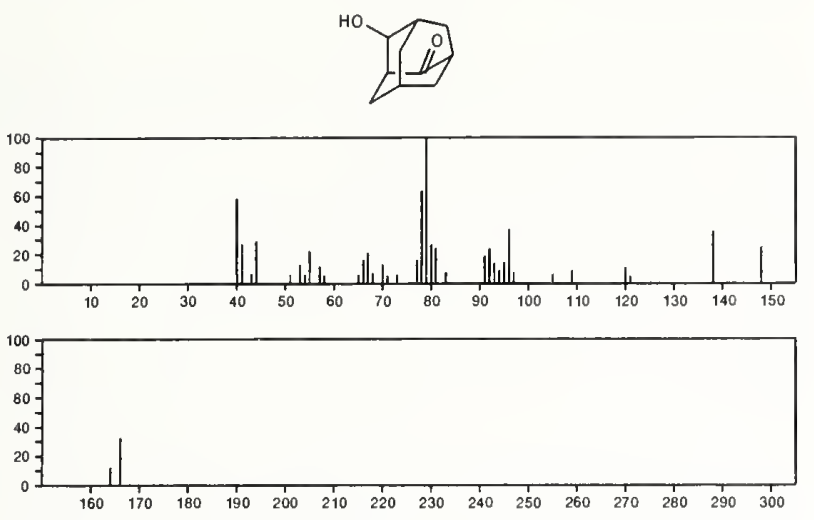

\section{6}

Ethanol, 2-(4-ethylphenoxy)-

\section{$\mathrm{C}_{10} \mathrm{H}_{14} \mathrm{O}_{2}$}
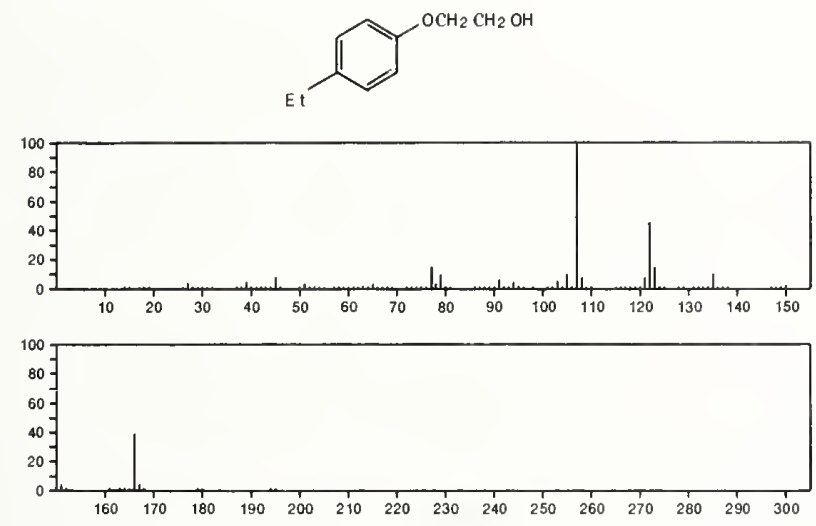

\section{6}

$\mathrm{C}_{10} \mathrm{H}_{14} \mathrm{O}_{2}$

Ethanol, 2-[(3-methylphenyl)methoxy]-

$54411-11-9$
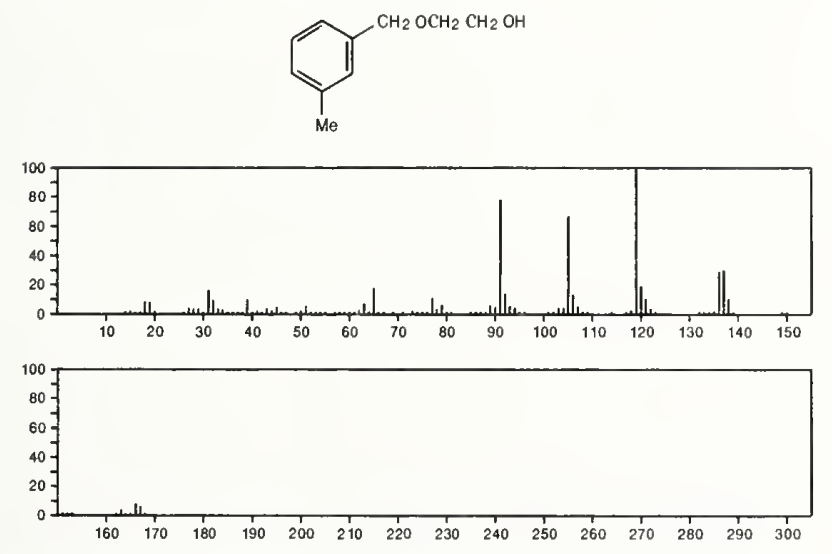

166

Ethanol, 2-(dimethylphenoxy)-

$\mathrm{C}_{10} \mathrm{H}_{14} \mathrm{O}_{2}$

$54411-20-0$
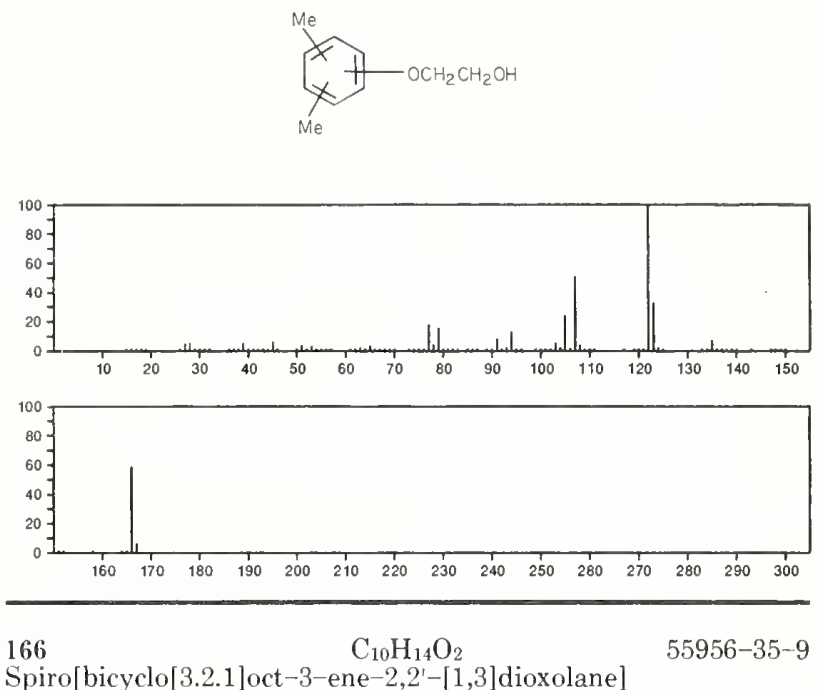

Spiro[bicyclo[3.2.1] oct-3-ene-2,2'-[1,3]dioxolane]
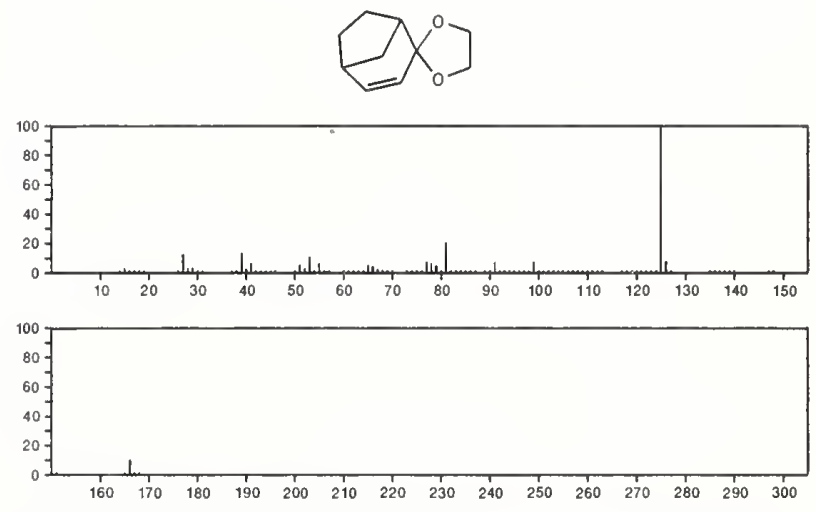

166

$\mathrm{C}_{10} \mathrm{H}_{14} \mathrm{O}_{2}$

$55956-36-0$

5,8-Methano-5H-cyclohepta-1,4-dioxin, 2,3,6,7,8,9-hexahydro-<smiles>C1COC2=C(C1)C1CCC2CC1</smiles>
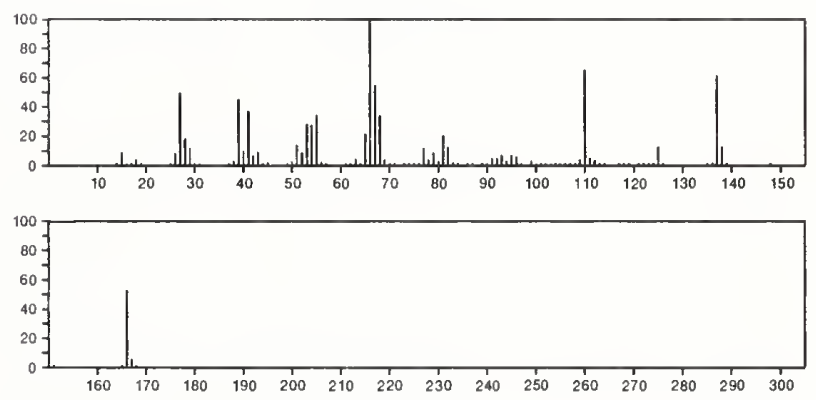

166

Benzene, (butylthio)-

$\mathrm{C}_{10} \mathrm{H}_{14} \mathrm{~S}$

$1126-80-3$

$\mathrm{Me}\left(\mathrm{CH}_{2}\right)_{3} \mathrm{SPh}$

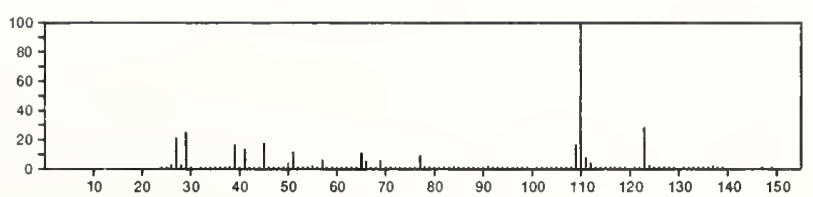




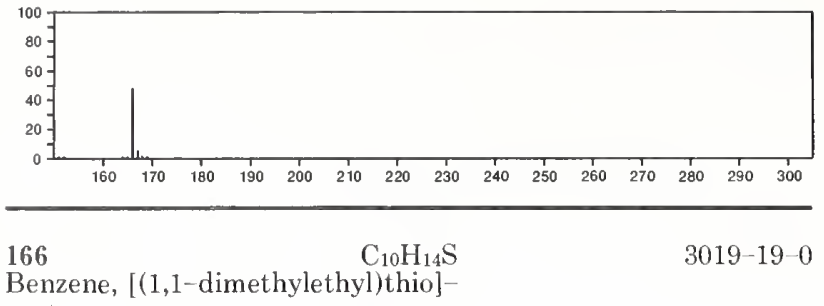

PhSBu-1
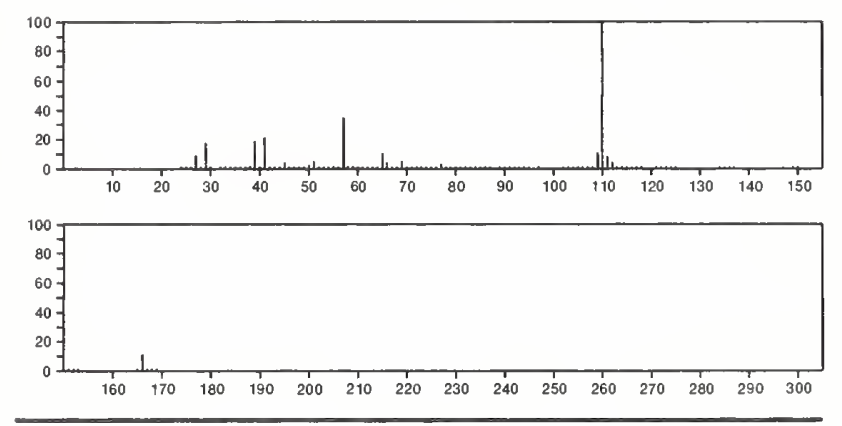

$166 \quad \mathrm{C}_{10} \mathrm{H}_{14} \mathrm{~S}$

Benzene, [(2-methylpropy])thio]-

$13307-61-4$

PhSBu-i
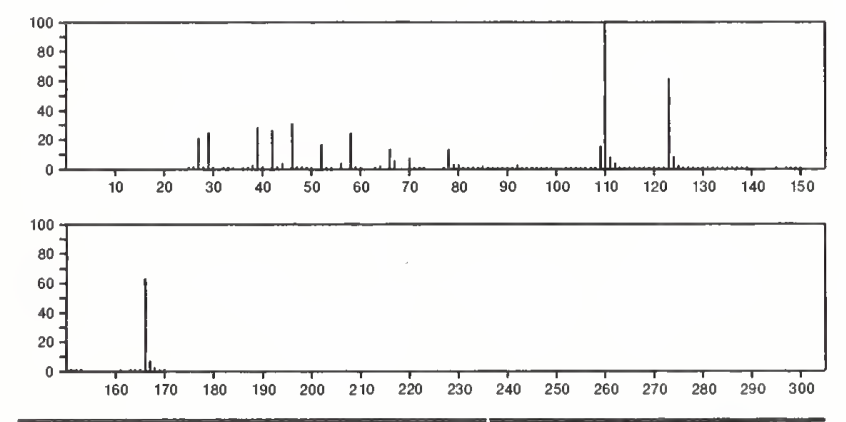

$166 \quad \mathrm{C}_{10} \mathrm{H}_{14} \mathrm{~S}$

Benzene, [(1-methylpropyl)thio]-

$14905-79-4$

PhSBu-s
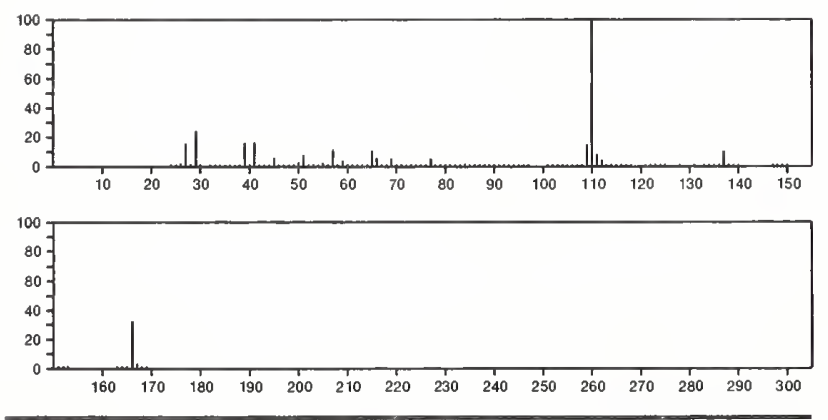

$166 \quad \mathrm{C}_{10} \mathrm{H}_{14} \mathrm{~S} \quad 14905-80-7$

Benzene, 1-methyl-3-[(1-methylethyl)thio]-
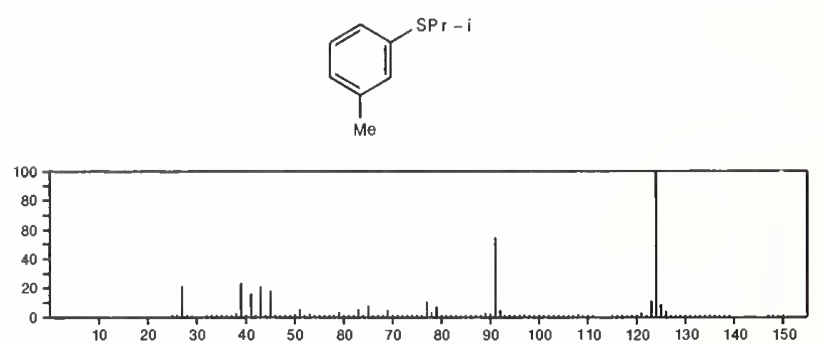

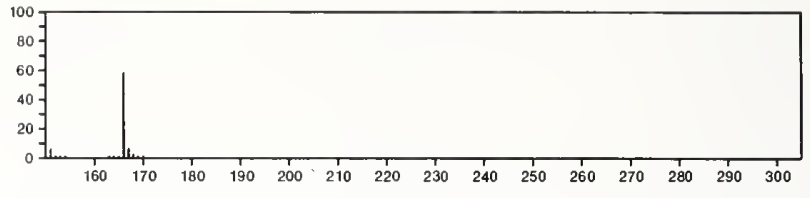

166

$\mathrm{C}_{10} \mathrm{H}_{14} \mathrm{~S}$

Benzene, 1-methyl-4-[(1-methylethyl)thio]-

$14905-81-8$
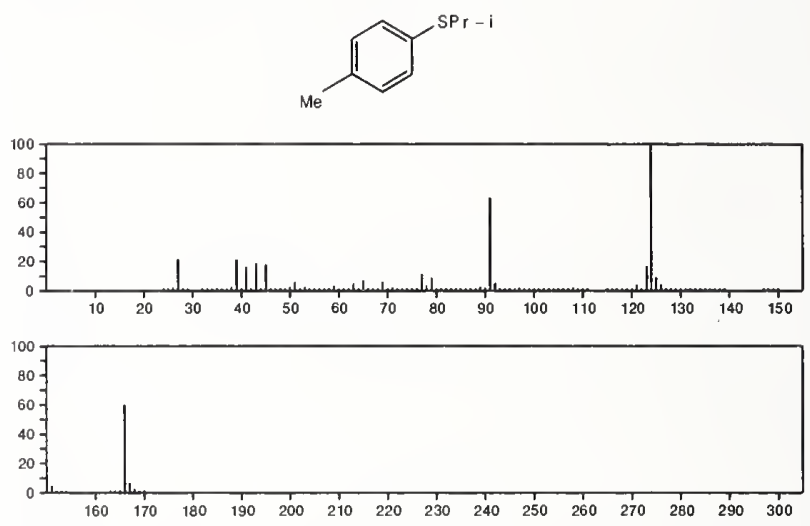

166

$\mathrm{C}_{10} \mathrm{H}_{14 \mathrm{~S}}$

Benzene, 1-methyl-2-(propylthio)-

$15560-97-1$
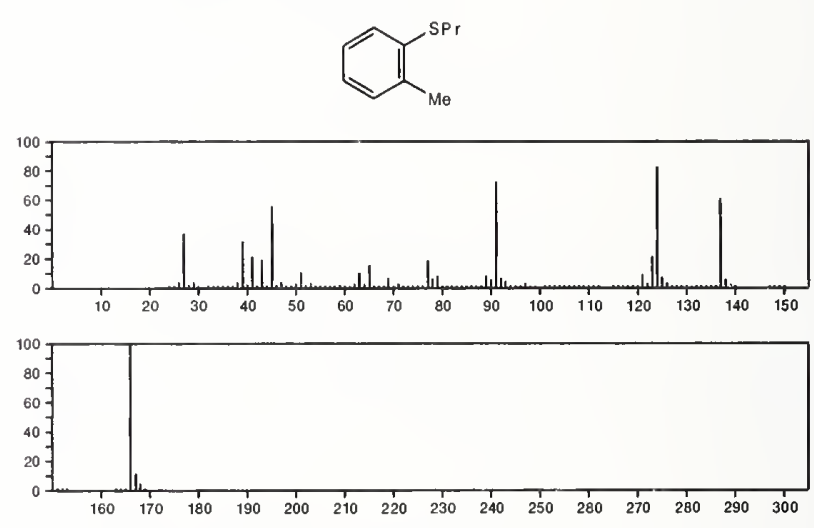

166

$\mathrm{C}_{10} \mathrm{H}_{14} \mathrm{~S}$

$15560-98-2$

Benzene, I-methyl-2-[(1-methylethyl)thio]-
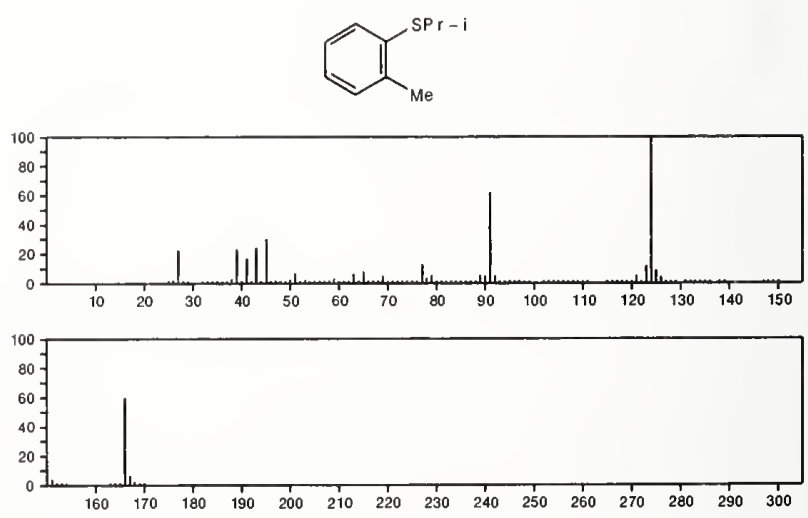
166

Sulfide, ethyl phenethyl

$\mathrm{C}_{10} \mathrm{H}_{14} \mathrm{~S}$

22914-08-5

$\mathrm{PhCH}_{2} \mathrm{CH}_{2} \mathrm{SE}_{1}$
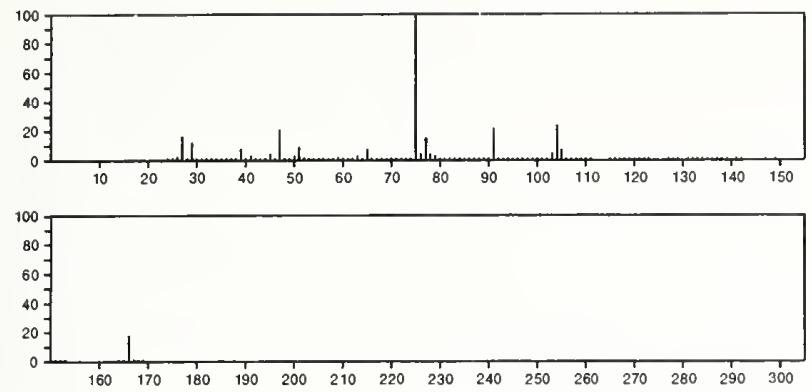

166

$\mathrm{C}_{10} \mathrm{H}_{14} \mathrm{~S}$

Benzene, 1-methyl-4-(propylthio)-

$24599-52-8$
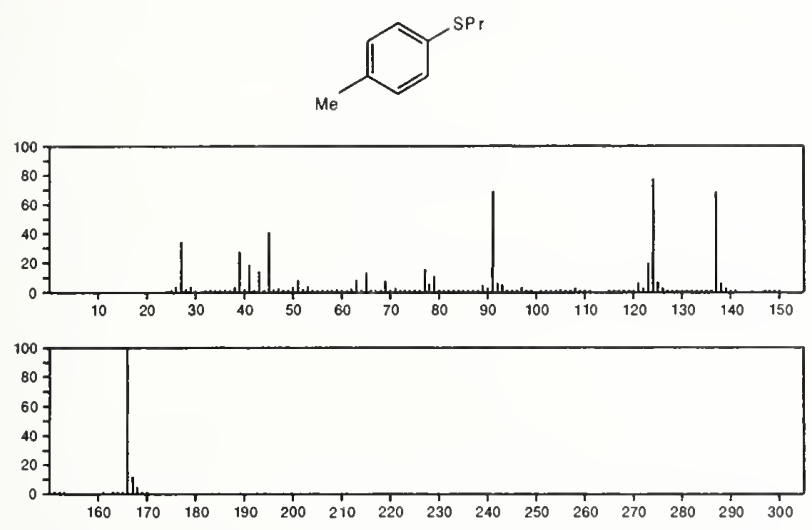

166

$\mathrm{C}_{10} \mathrm{H}_{14} \mathrm{~S}$

24767-95-1

Sulfide, propyl $m$-tolyl
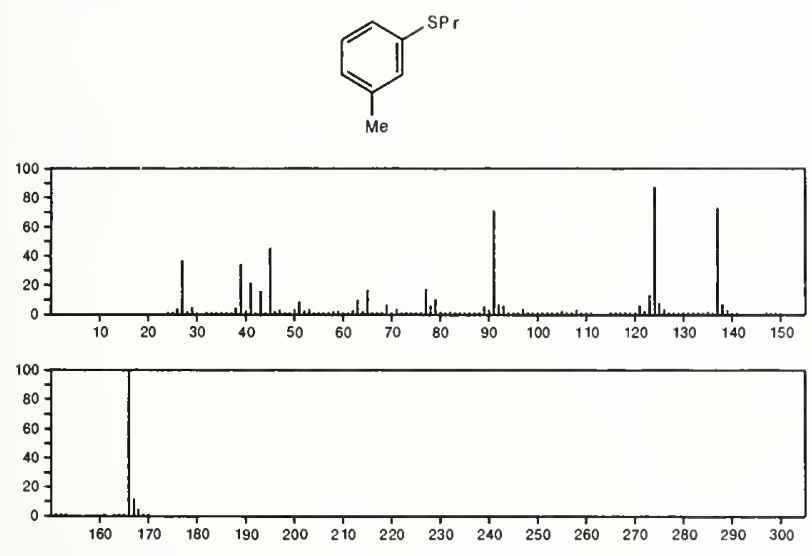

166

$\mathrm{C}_{10} \mathrm{H}_{18} \mathrm{~N}_{2}$

$54966-11-9$

$1 H, 5 H$-Pyrrolo[ $\left[1^{1}, 2^{1}: 3,4\right]$ imidazo[1,5-a]pyridine, octahydro-
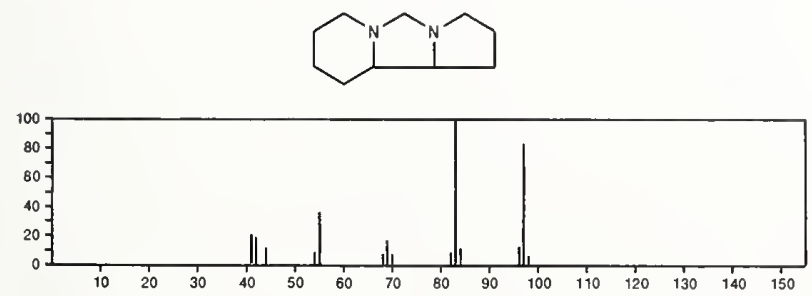

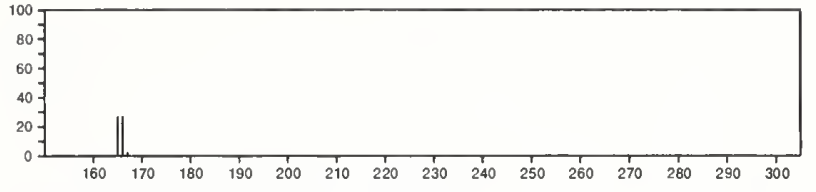

$\mathrm{C}_{11} \mathrm{H}_{18} \mathrm{O}$
Bicyclo[3.1.1]hept-2-ene-2-ethanol, 6,6-dimethyl-

$128-50-7$
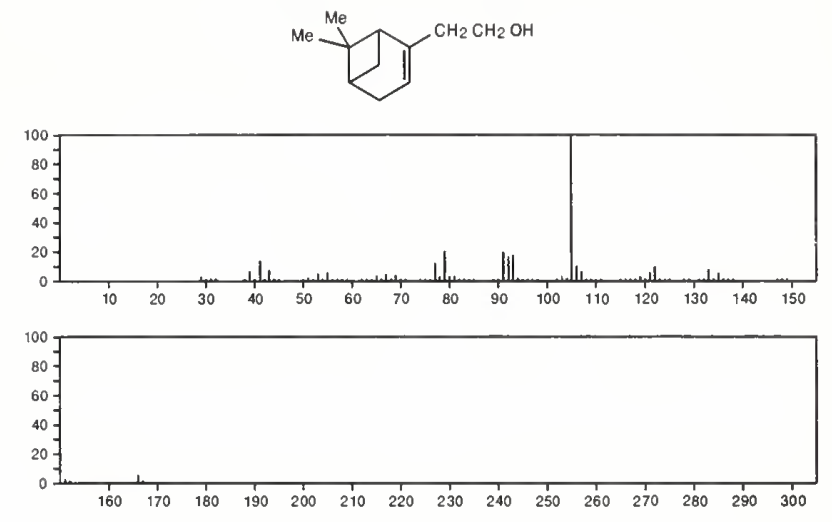

166

$$
\mathrm{C}_{11} \mathrm{H}_{18} \mathrm{O}
$$

$770-62-7$

1(2H)-Naphthalenone, octahydro-8a-methyl-, cis
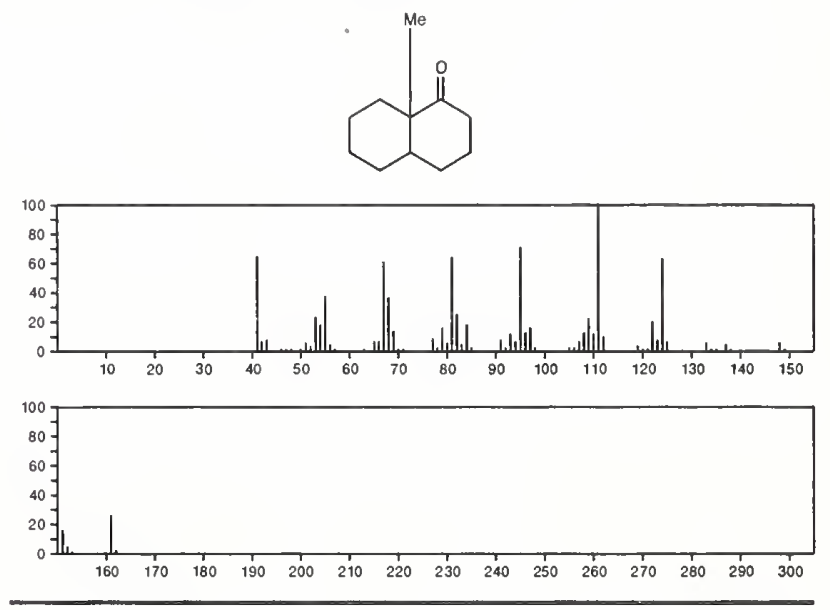

166

$\mathrm{C}_{11} \mathrm{H}_{18} \mathrm{O}$

$937-99-5$

$1(2 \mathrm{H})$-Naphthalenone, octahydro-4a-methyl-, trans-
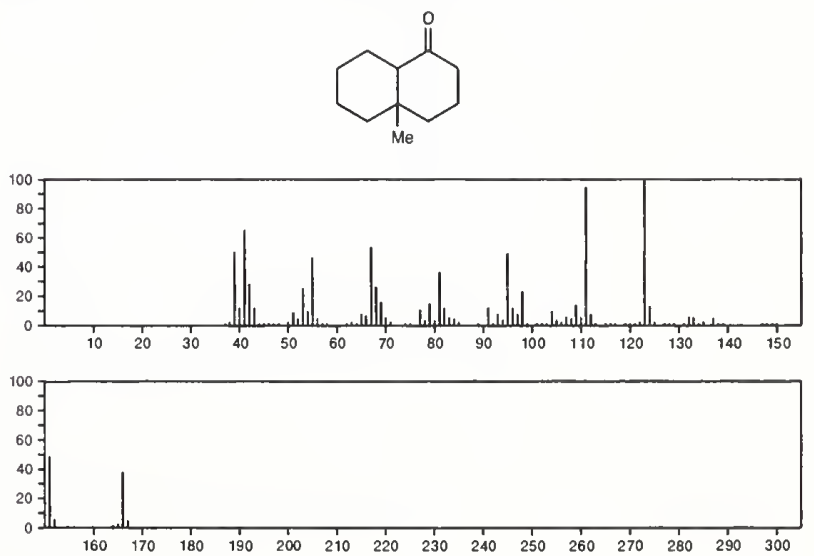
166

$\mathrm{C}_{11} \mathrm{H}_{18} \mathrm{O}$

$938-06-7$

2(1H)-Naphthalenone, octahydro-4a-methyl-, cis-
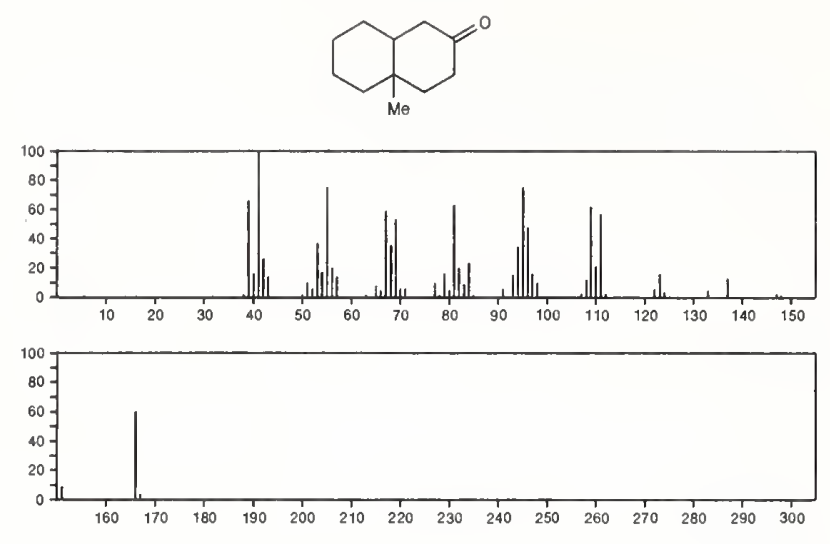

$166 \quad \mathrm{C}_{11} \mathrm{H}_{18} \mathrm{O}$ 938-07-8

2(1H)-Naphthalenone, octahydro-4a-methyl-, trans-
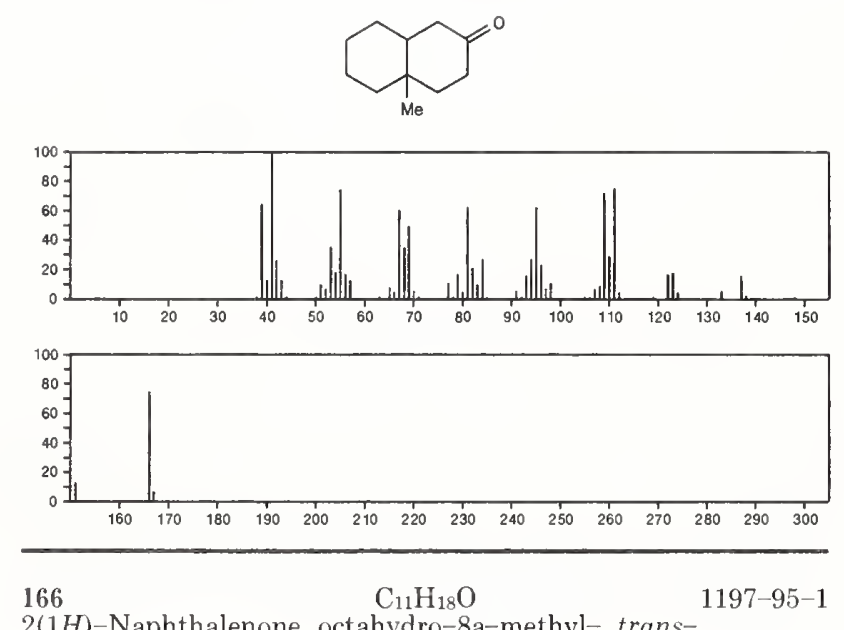

2(1H)-Naphthalenone, octahydro-8a-methyl-, trans-
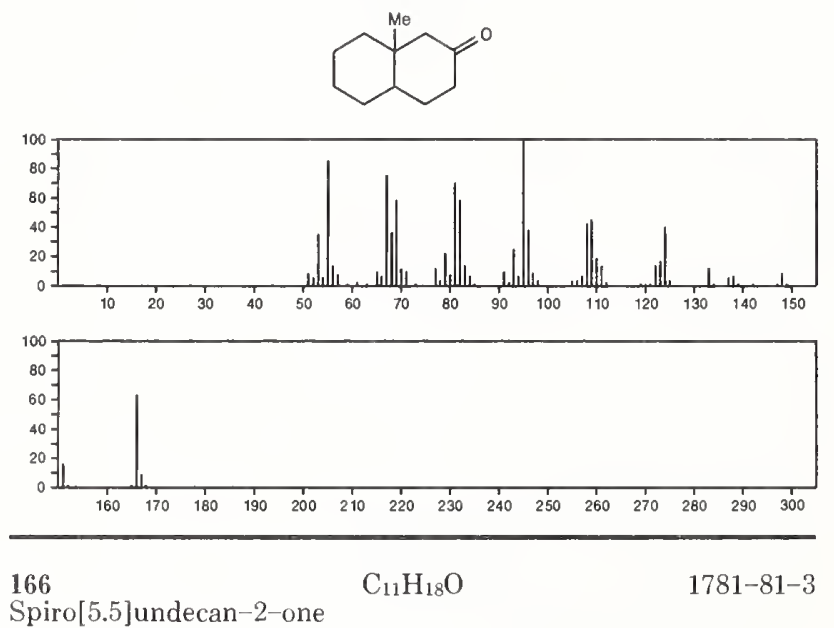

Spiro[5.5]undecan-2-one
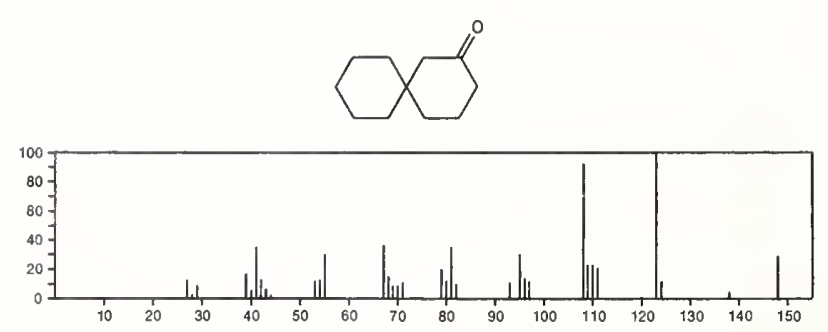
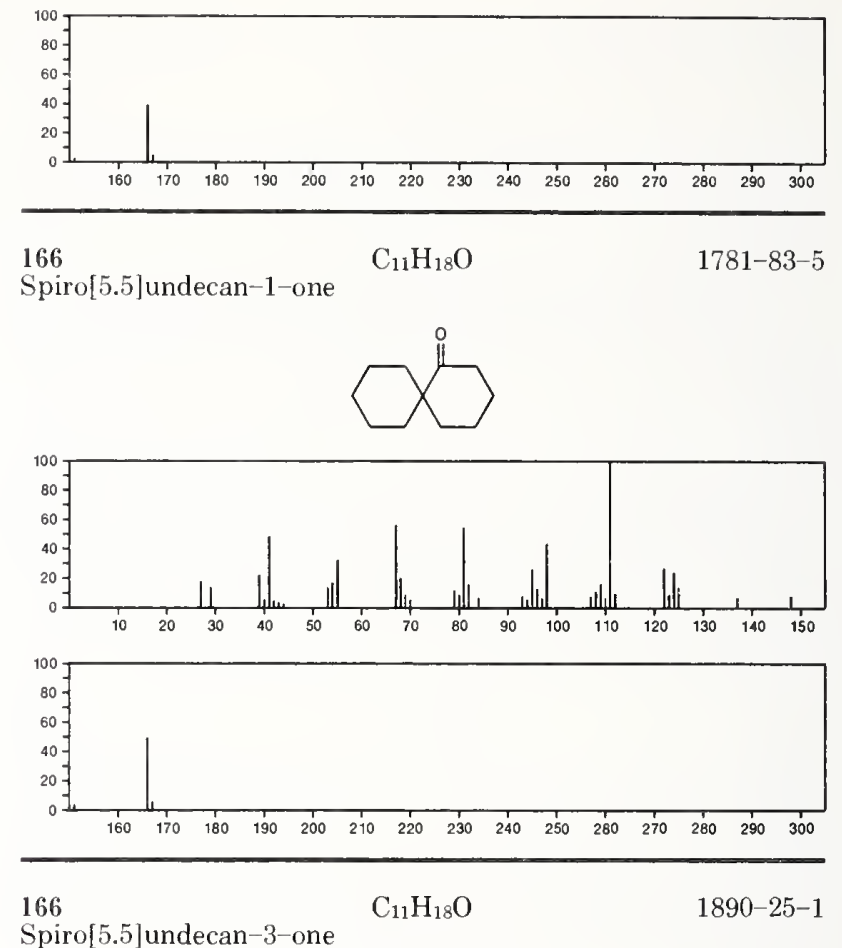

Spiro[5.5] undecan-3-one
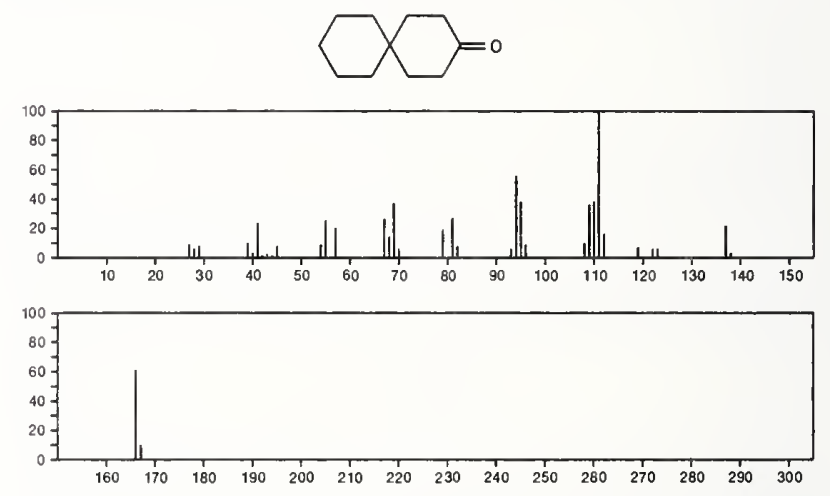

$166 \quad \mathrm{C}_{11} \mathrm{H}_{18} \mathrm{O}$

$2530-17-8$

2(1H)-Naphthalenone, octahydro-8a-methyl-, cis-
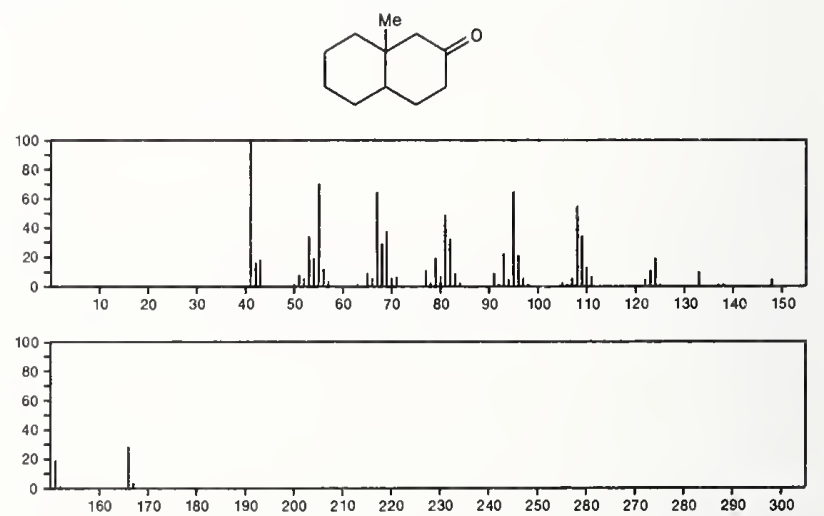
166

Bicyclo[2.2.1]heptan-2-one, 1,3,7,7-tetramethyl
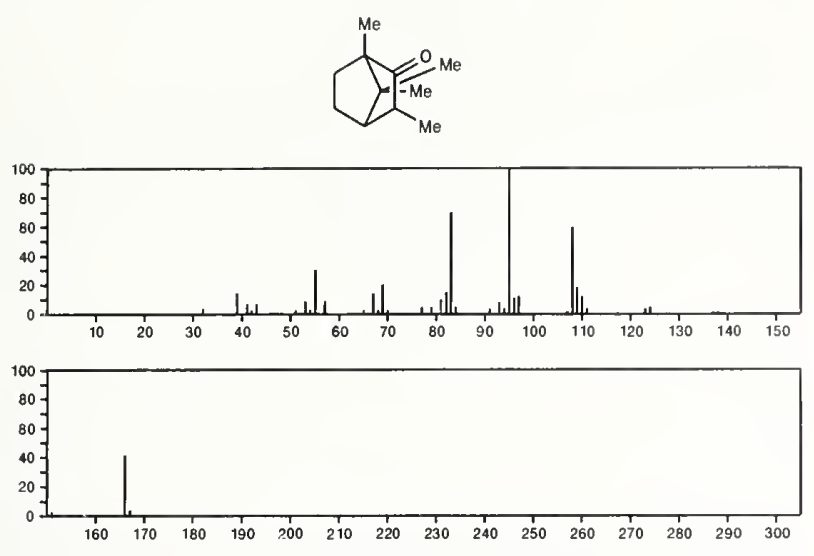

166

$\mathrm{C}_{11} \mathrm{H}_{18} \mathrm{O}$

Cyclohexanone, 2,5-dimethyl-2-(1-methylethenyl)-
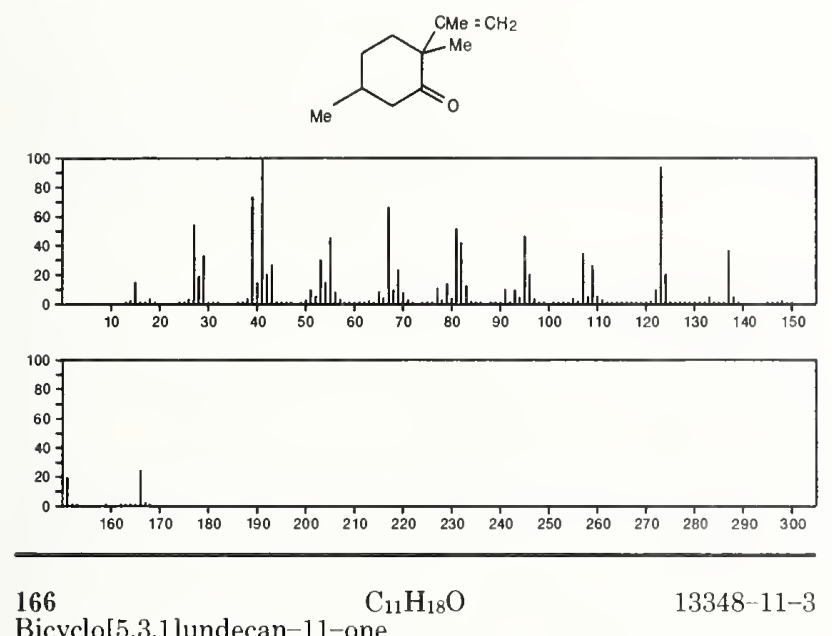

Bicyclo[5.3.1]undecan-11-one
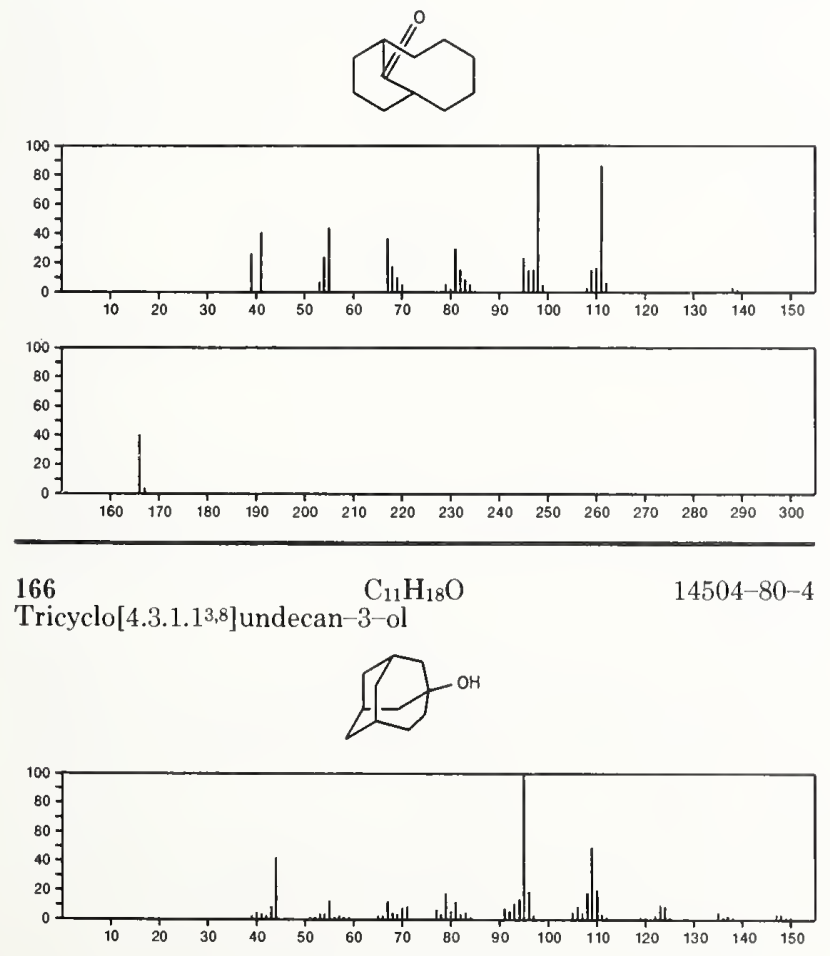

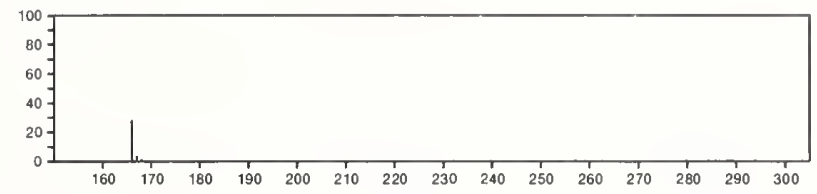

166

$\mathrm{C}_{11} \mathrm{H}_{18} \mathrm{O}$

21102-88-5

$2(1 H)$-Naphthalenone, octahydro-1-methyl-, $(1 \alpha, 4 \mathrm{a} \beta, 8 \mathrm{a} \alpha)-$
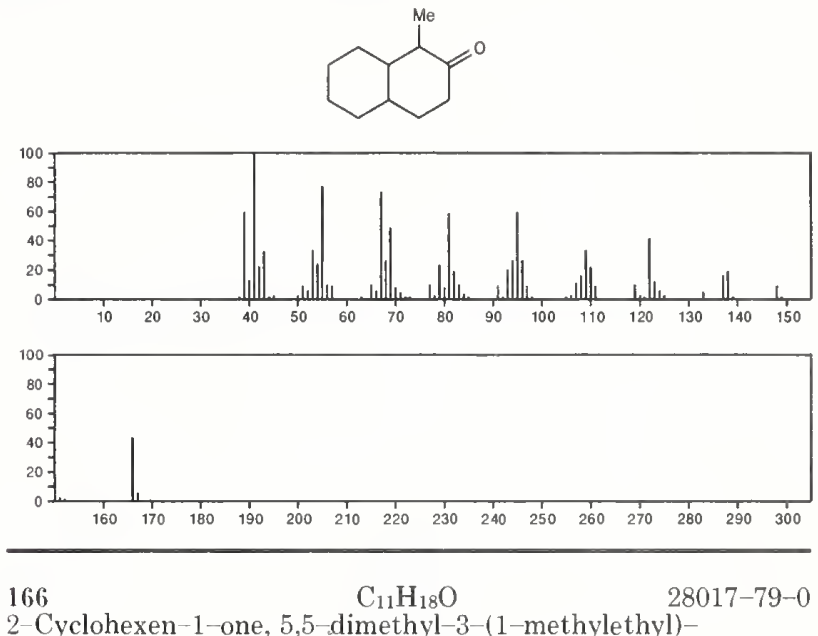

2-Cyclohexen-1-one, 5,5-dimethyl-3-(1-methylethyl)-
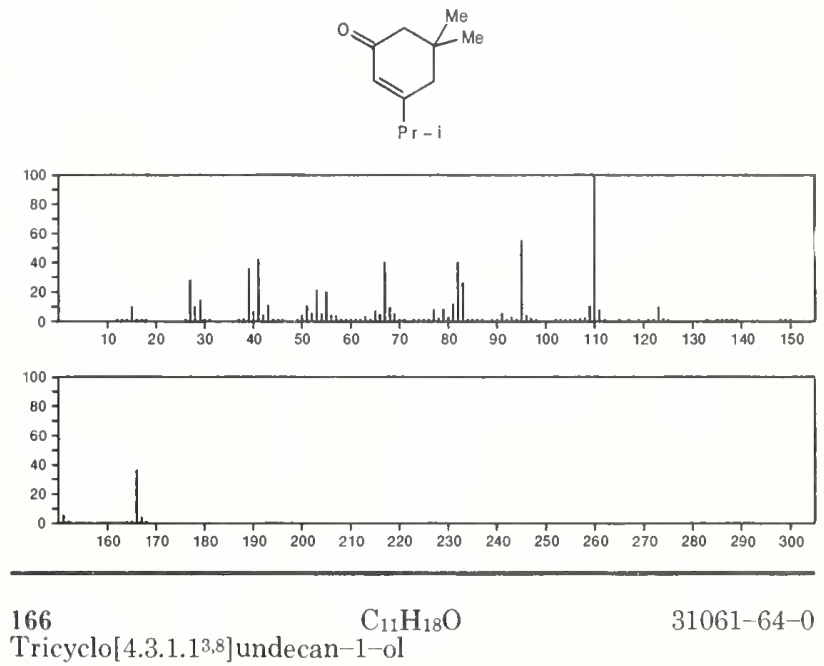

Tricyclo[4.3.1.13,8]undecan-1-ol
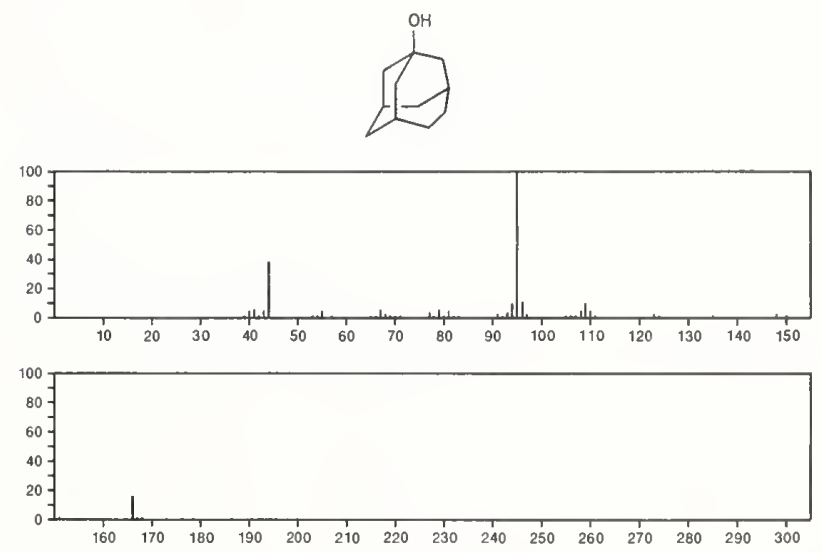
$166 \quad \mathrm{C}_{11} \mathrm{H}_{18} \mathrm{O}$

Cyclohexanone, 2,2,5,5-tetramethyl-3-methylene-

35505-97-6<smiles>C=C1CC(C)(N)CC(=O)C1(C)C</smiles>
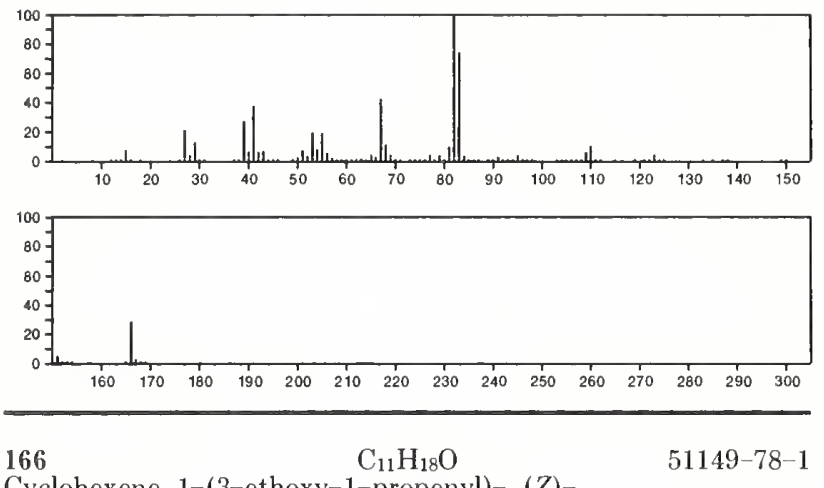

Cyclohexene, 1-(3-ethoxy-1-propenyl)-, (Z)-
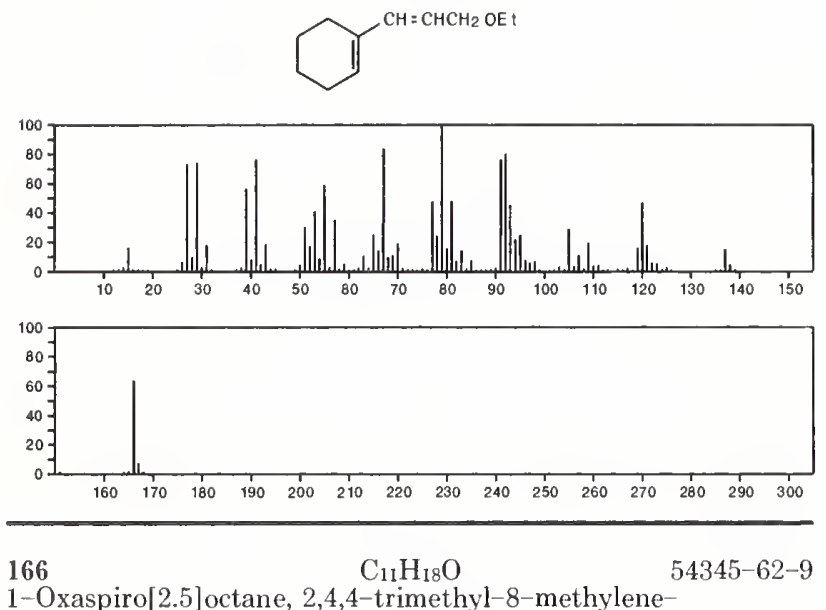

1-Oxaspiro[2.5]octane, 2,4,4-trimethyl-8-methylene-
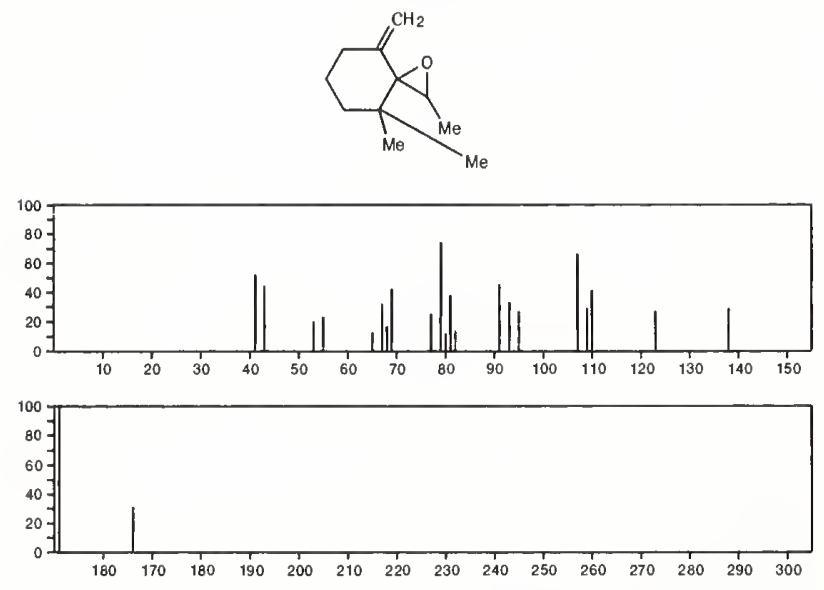

166

$\mathrm{C}_{11} \mathrm{H}_{18} \mathrm{O}$

2-Cyclohexen-1-one, 3,6-dimethyl-6-(1-methylethyl)-<smiles>CC1=CC(=O)C(C)(CP)CC1</smiles>

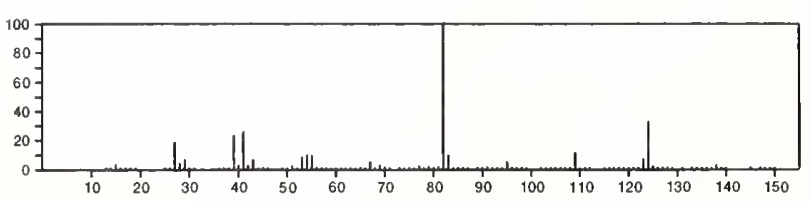

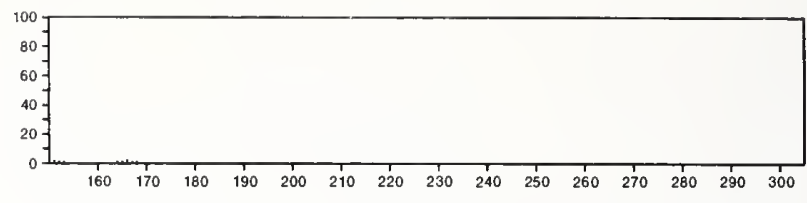

166

$\mathrm{C}_{11} \mathrm{H}_{18} \mathrm{O}$

1-Butanone, 1-bicyclo[4.1.0]hept-7-yl-

$54764-62-4$
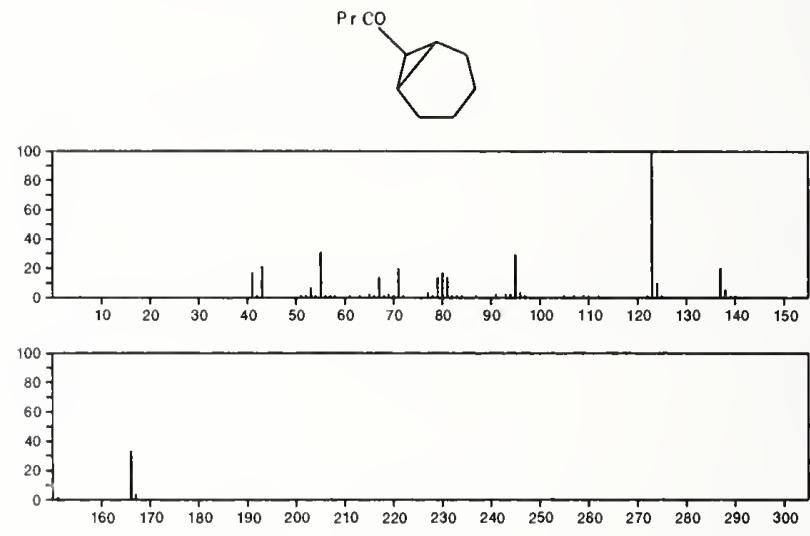

166

$\mathrm{C}_{11} \mathrm{H}_{18} \mathrm{O}$

$55332-01-9$

$2(1 H)$-Naphthalenone, octahydro-3-methyl-, $(3 \alpha, 4 \mathrm{a} \beta, 8 \mathrm{a} \alpha)$
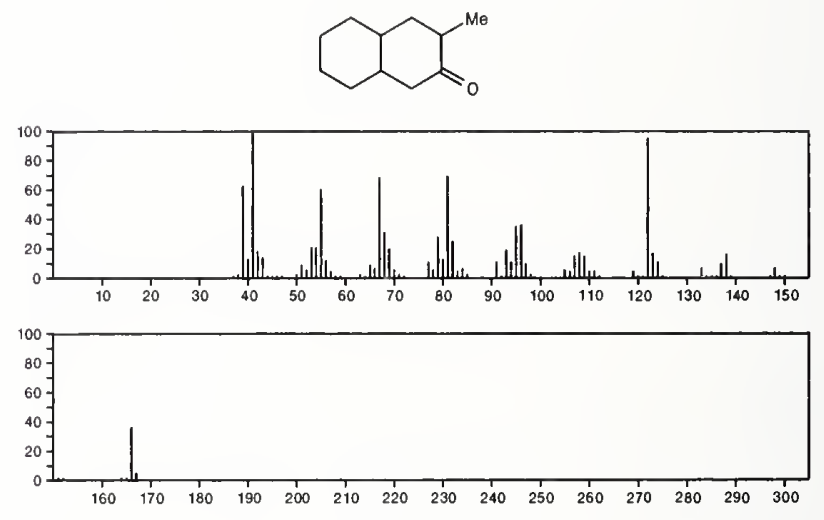

166

$\mathrm{C}_{11} \mathrm{H}_{18} \mathrm{O}$

$55702-54-0$

4-Penten-2-one, 3-cyclohexyl-
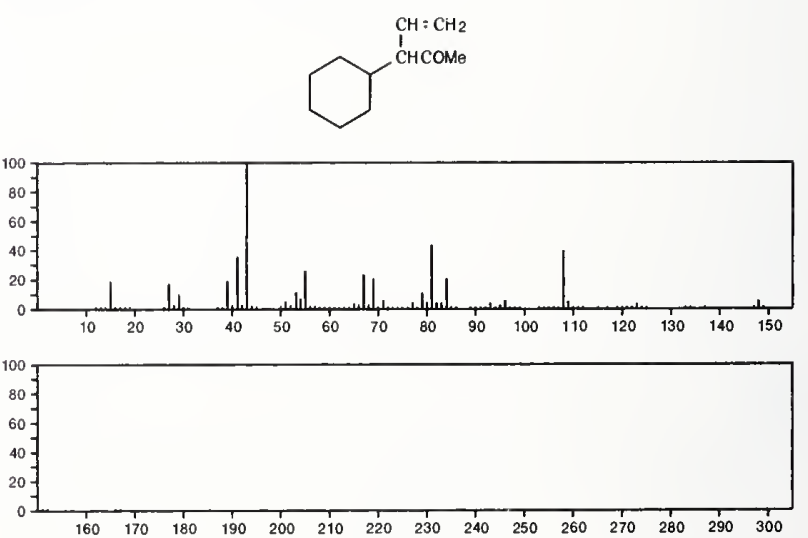
$166 \quad \mathrm{C}_{11} \mathrm{H}_{18} \mathrm{O}$

$4 H$-Cyclopentacycloocten-4-one, decahydro-
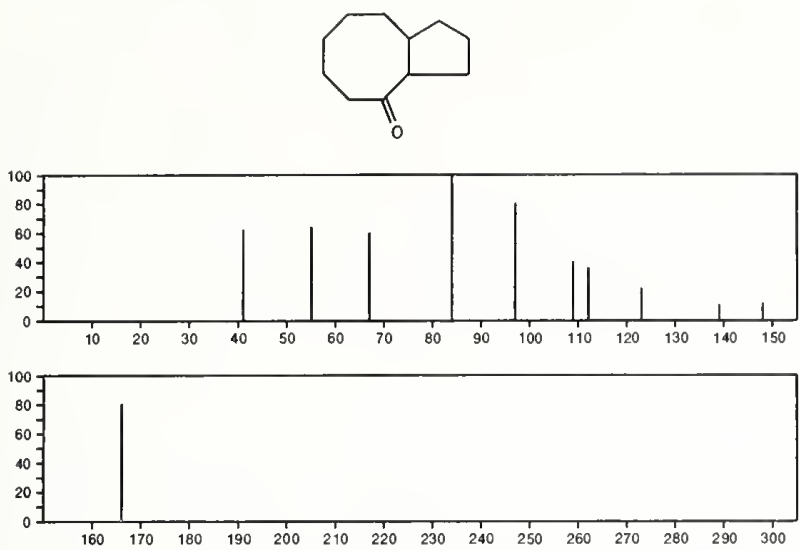

166

$\mathrm{C}_{11} \mathrm{H}_{18} \mathrm{O}$

$56362-32-4$

Ethanone, 1-(octahydro-1H-inden-1-yl)-, $(1 \alpha, 3 \mathrm{a} \alpha, 7 \mathrm{a} \beta)-$
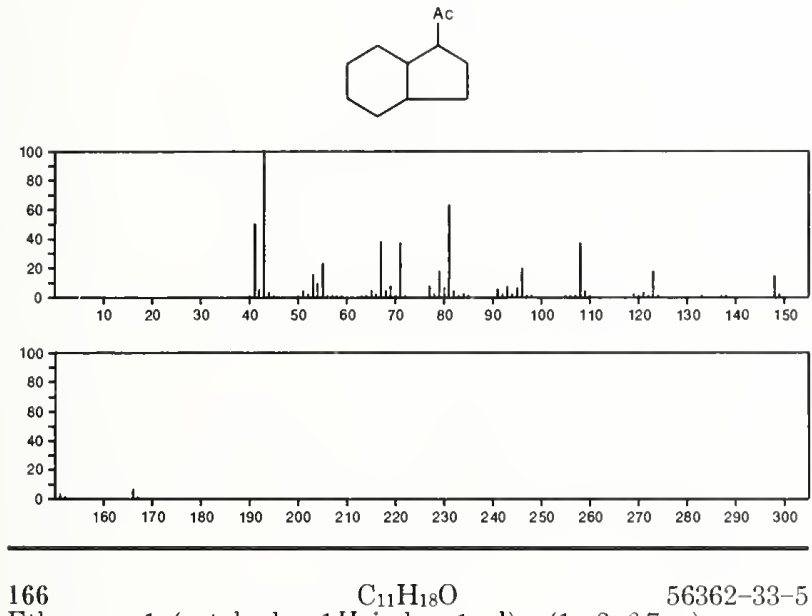

Ethanone, 1-(octahydro-1H-inden-1-yl)-, $(1 \alpha, 3 \mathrm{a} \beta, 7 \mathrm{a} \alpha)$ -
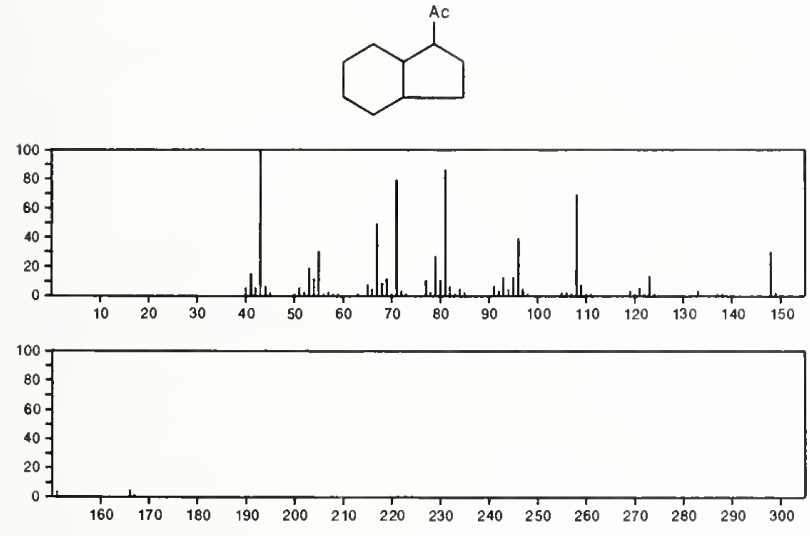

166

1,1'-Bicyclohexyl

$\mathrm{C}_{12} \mathrm{H}_{22}$

$92-51-3$
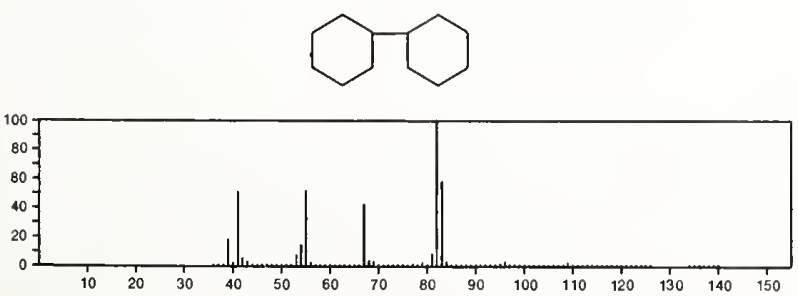

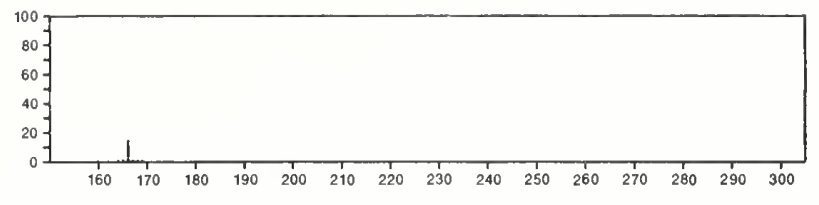

166

$\mathrm{C}_{12} \mathrm{H}_{22}$

$181-15-7$

Spiro[5.6]dodecane
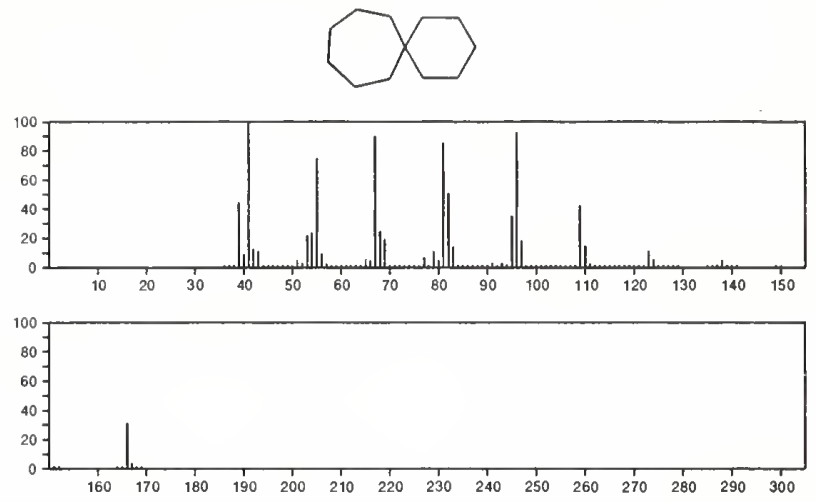

166

1-Dodecyne

$\mathrm{C}_{12} \mathrm{H}_{22}$

$765-03-7$

$\mathrm{HC} \equiv \mathrm{C}\left(\mathrm{CH}_{2}\right)_{9} \mathrm{Me}$
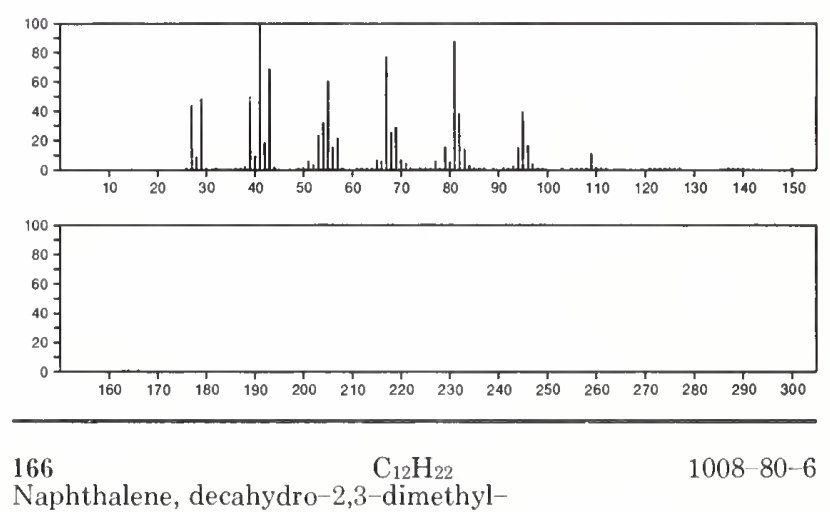

Naphthalene, decahydro-2,3-dimethyl-
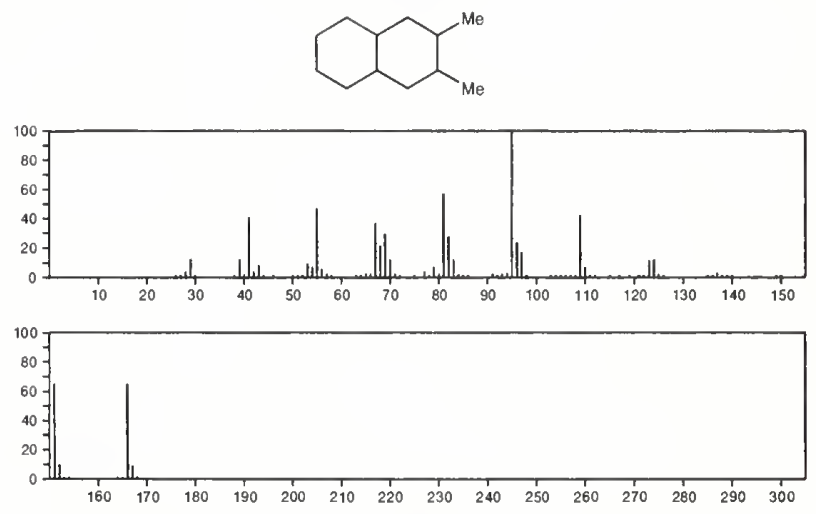

166

Cyclododecene

$\mathrm{C}_{12} \mathrm{H}_{22}$

1501-82-2
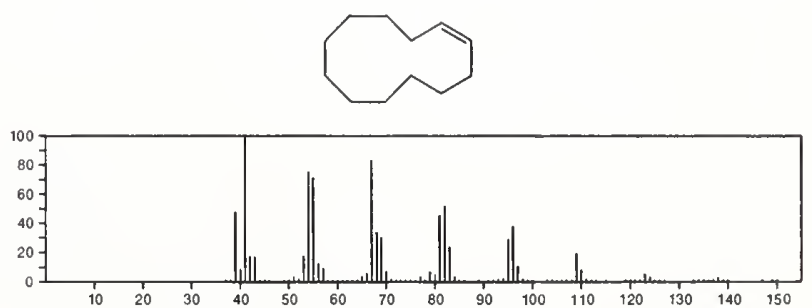


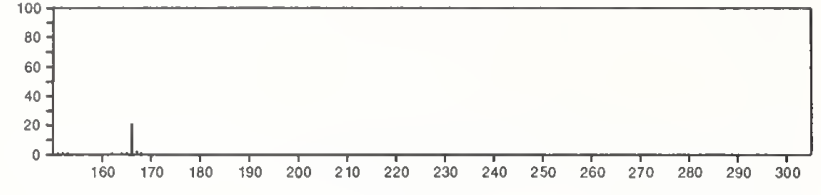

166

$\mathrm{C}_{12} \mathrm{H}_{22}$

Naphthalene, decahydro-2,6-dimethyl-

$1618-22-0$<smiles>CC1CCC2CC(N)CCC2C1</smiles>
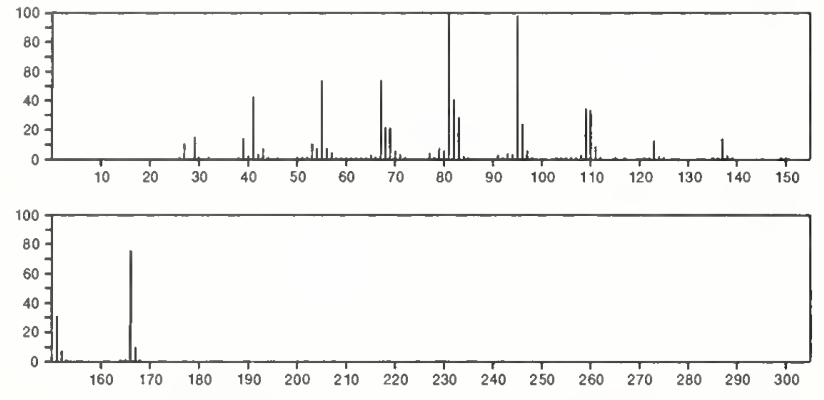

166

Naphthalene, decahydro-1,6-dimethyl-

$1750-51-2$
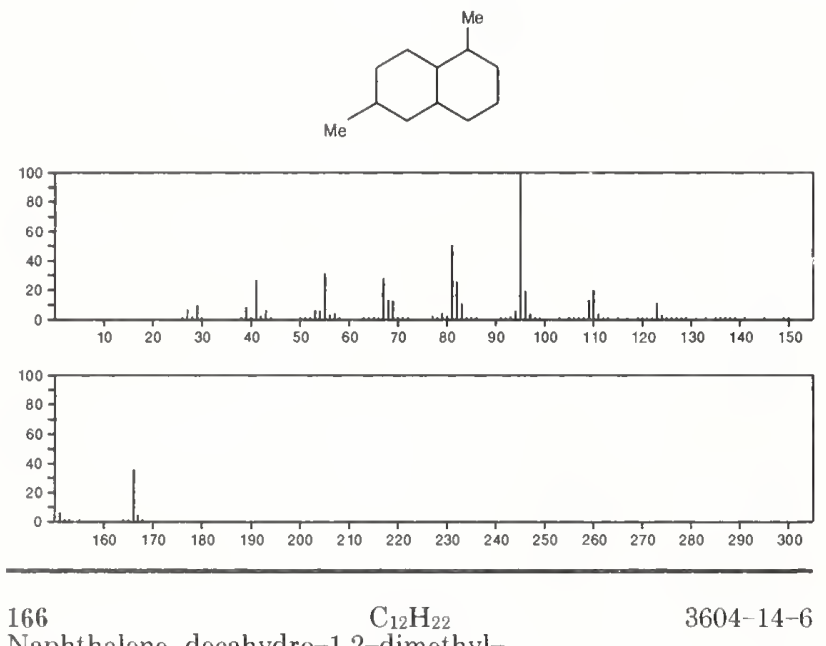

Naphthalene, decahydro-1,2-dimethyl
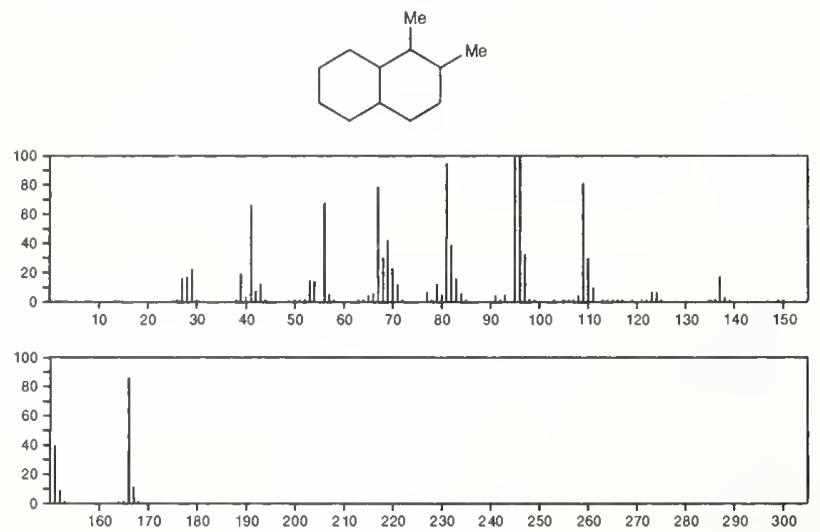

166

$\mathrm{C}_{12} \mathrm{H}_{22}$

$4413-21-2$

Cyclopentane, 1,1'-ethylidenebis-
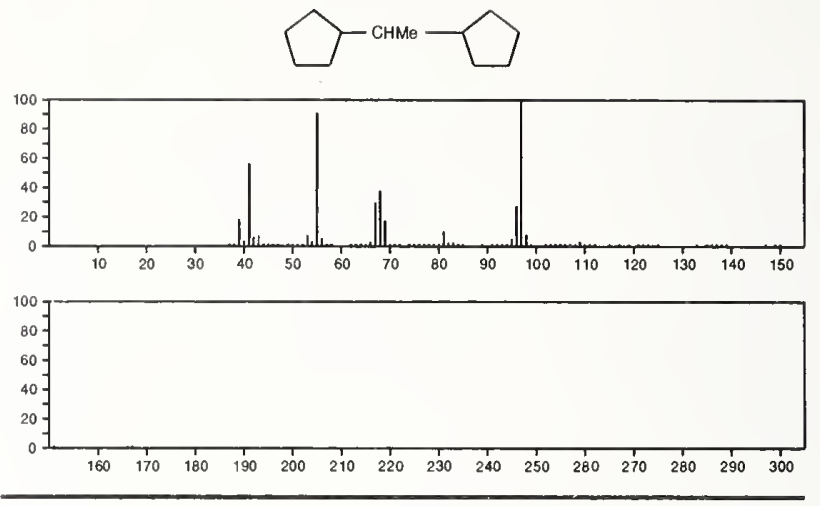

166

$\mathrm{C}_{12} \mathrm{H}_{22}$

Cyclohexane, (cyclopentylmethyl)-

$4431-89-4$
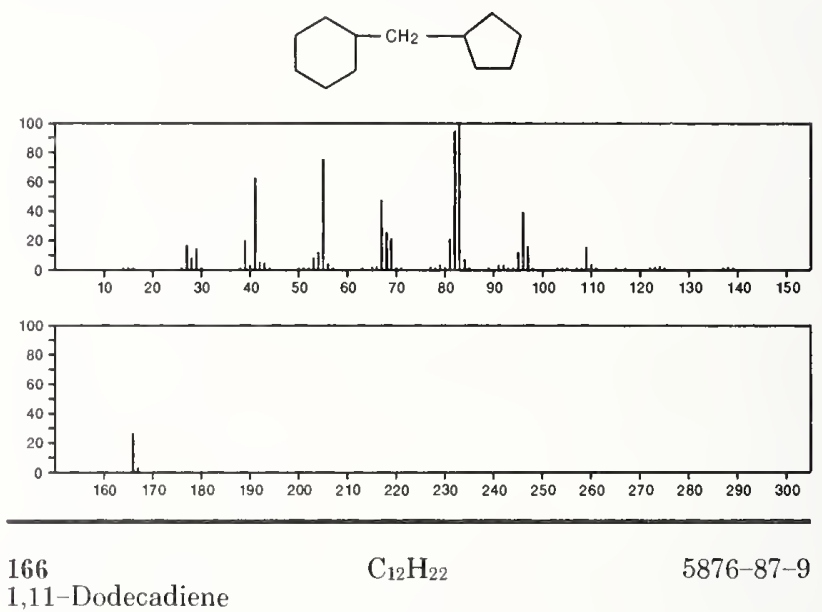

$\mathrm{H}_{2} \mathrm{C}=\mathrm{CH}\left(\mathrm{CH}_{2}\right) \& \mathrm{CH}=\mathrm{CH}_{2}$
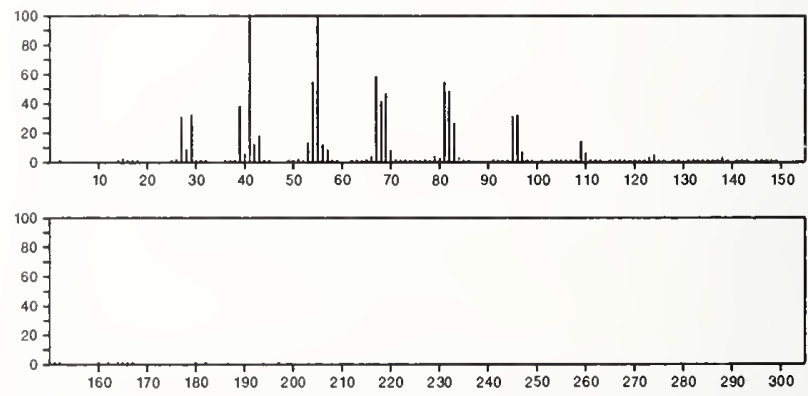

5,7-Dodecadiene, $(Z, Z)$ -

$\mathrm{C}_{12} \mathrm{H}_{22}$

6108-62-9

$\mathrm{Me}\left(\mathrm{CH}_{2}\right)_{3} \mathrm{CH}=\mathrm{CHCH}=\mathrm{CH}\left(\mathrm{CH}_{2}\right)_{3} \mathrm{Me}$
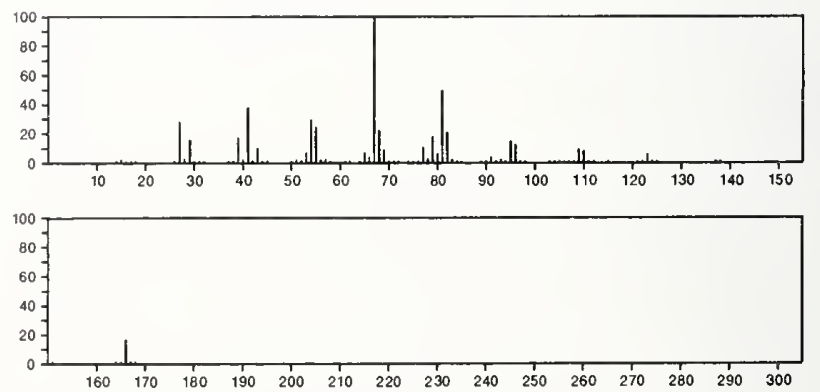
166
$3,5-$ Octadiene, 4,5-diethyl-,

21293-02-7

$E T C H=C E t C E t=C H E t$
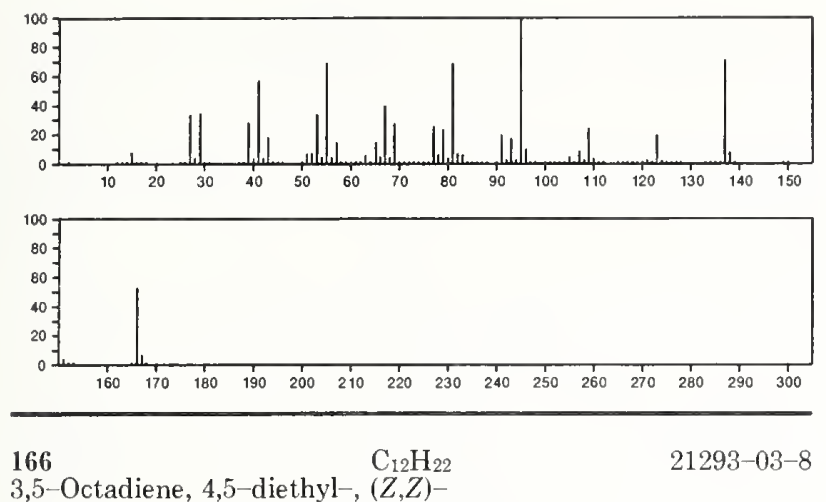

3,5-Octadiene, 4,5-diethyl-, $(Z, Z)$ -

$\mathrm{EtCH}=\mathrm{CE} \mathrm{CE} \mathrm{t}=\mathrm{CHE} \mathrm{t}$
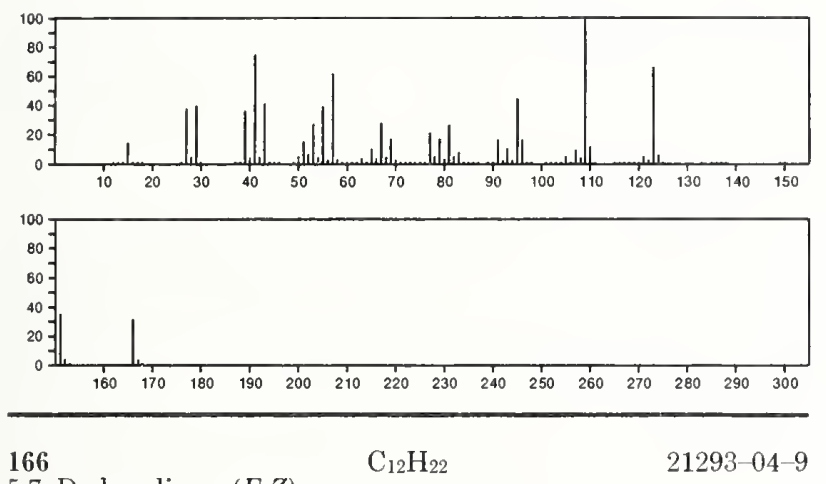

5,7-Dodecadiene, $(E, Z)-$

$\mathrm{Me}\left(\mathrm{CH}_{2}\right)_{3} \mathrm{CH}=\mathrm{CHCH}=\mathrm{CH}\left(\mathrm{CH}_{2}\right)_{3} \mathrm{Me}$
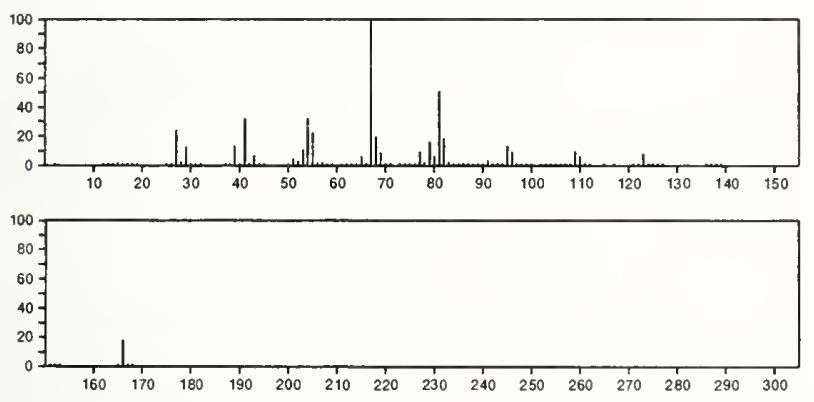

$$
166 \quad \mathrm{C}_{12} \mathrm{H}_{22}
$$

Hexane, 1-(isopropylidenecyclopropyl)-
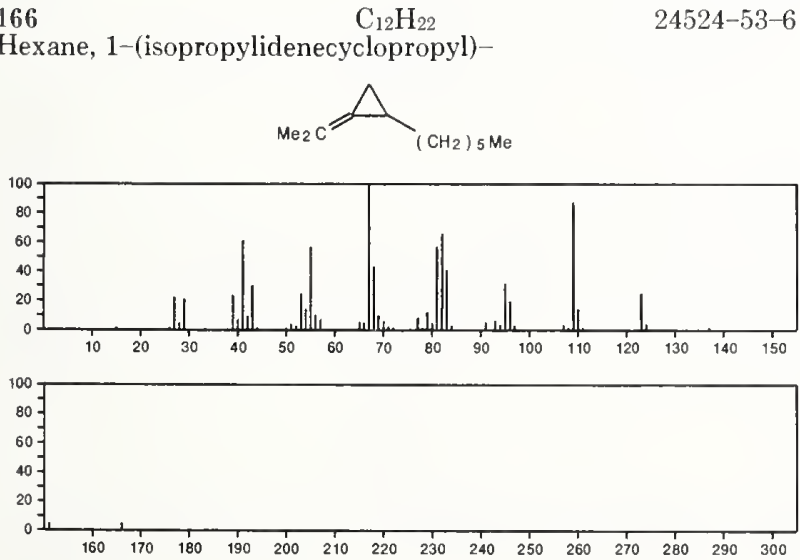

$166 \quad \mathrm{C}_{12} \mathrm{H}_{22}$

Bicyclo[4.1.0]heptane, 7-pentyl-

41977-45-1
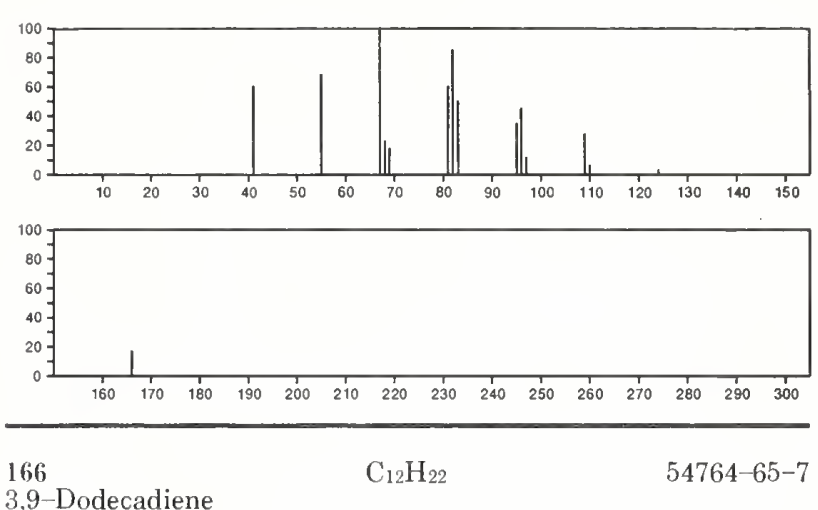

3,9-Dodecadiene

$\mathrm{EtCH}=\mathrm{CH}\left(\mathrm{CH}_{2}\right){ }_{4} \mathrm{CH}=\mathrm{CHEt}$
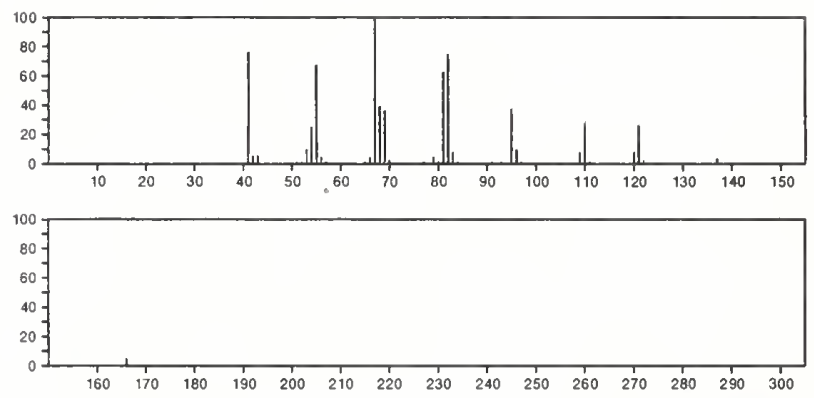

166

3,5-Decadiene, 2,2-dimethyl-, $(Z, Z)$ -

$55638-50-1$

$\mathrm{Me} 3 \mathrm{CCH}=\mathrm{CHCH}=\mathrm{CH}\left(\mathrm{CH}_{2}\right){ }_{3} \mathrm{Me}$
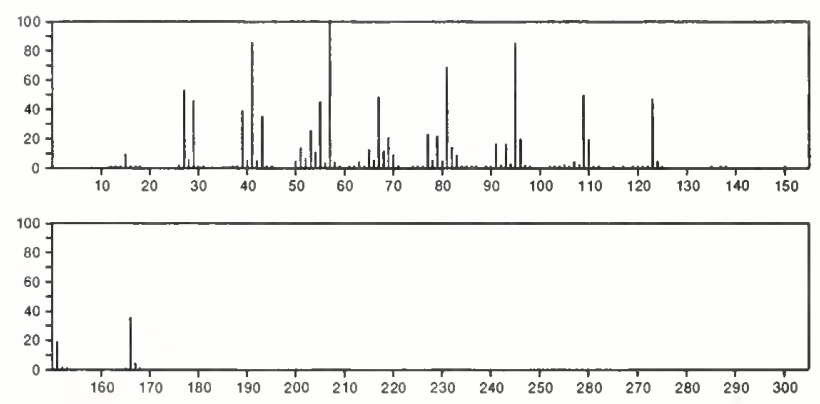

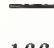

$166 \quad \mathrm{C}_{12} \mathrm{H}_{22} \quad 56324-71-1$

$1 H$-Indene, 1-ethyloctahydro-7a-methyl-, $(1 \alpha, 3 \mathrm{a} \beta, 7 \mathrm{a} \alpha)-$
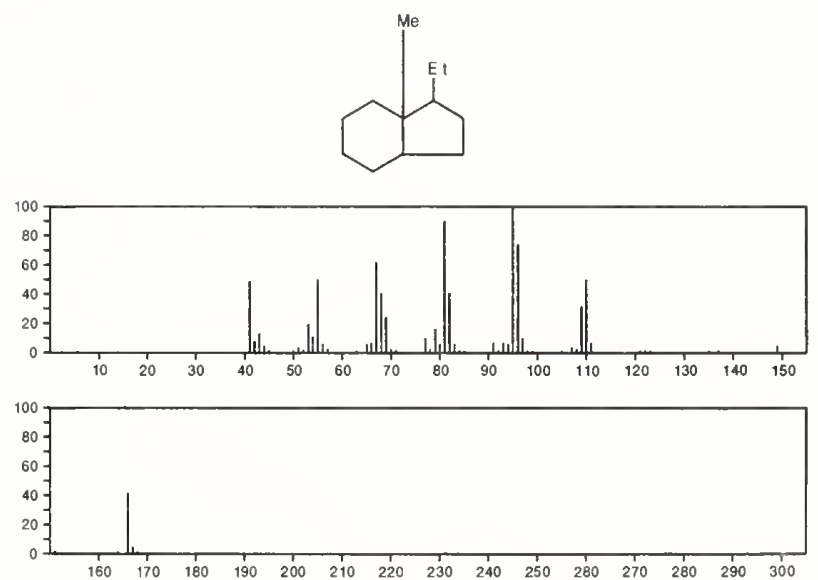
166

Cyclopropane, hexyl(1-methylethylidene)-

$56701-46-3$
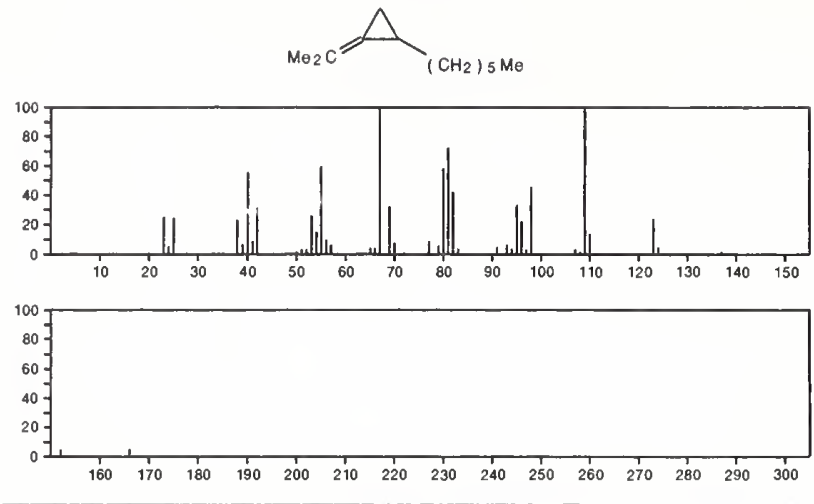

166

$9 H$-Fluorene

$\mathrm{C}_{13} \mathrm{H}_{10}$

86-73-7
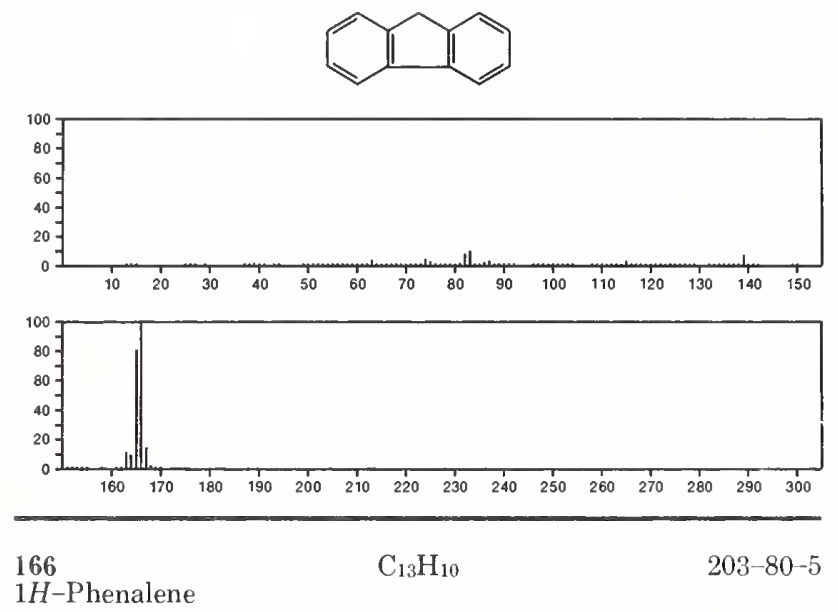

$H$-Phenalene
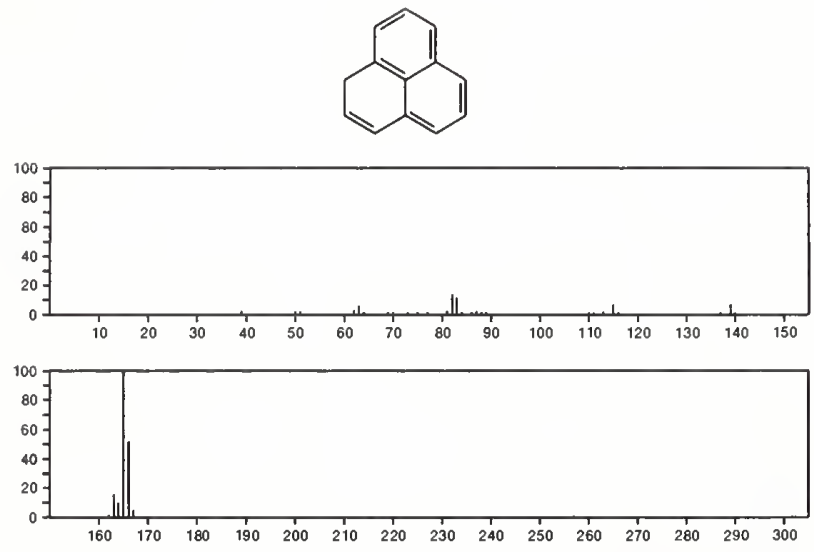

167

$\mathrm{C}_{4} \mathrm{H}_{10} \mathrm{NO}_{2} \mathrm{PS}$

$7114-53-6$

1,3,2-Dioxaphospholan-2-amine, $N, N$-dimethyl-, 2-sulfide
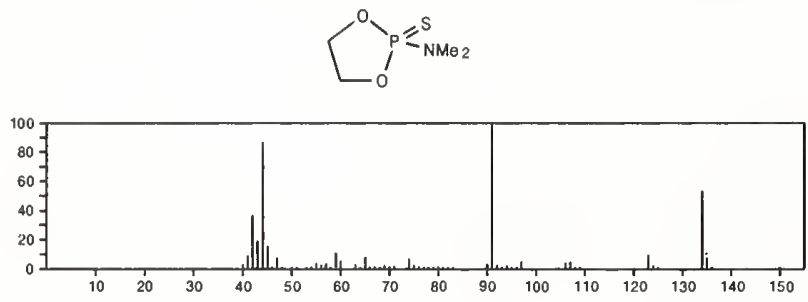

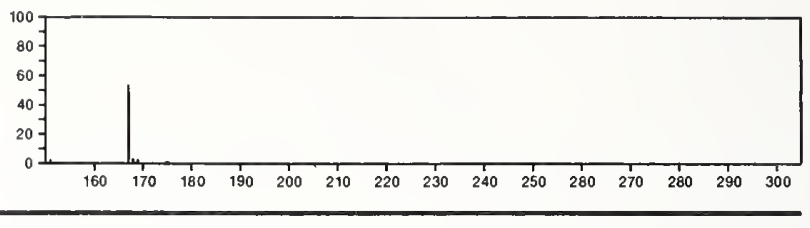

$167 \quad \mathrm{C}_{5} \mathrm{H}_{14} \mathrm{~N}_{3} \mathrm{O} . \mathrm{Cl} 123-46-6$ Ethanaminium, 2-hydrazino- $N, N, N$-trimethyl-2-oxo-, chloride
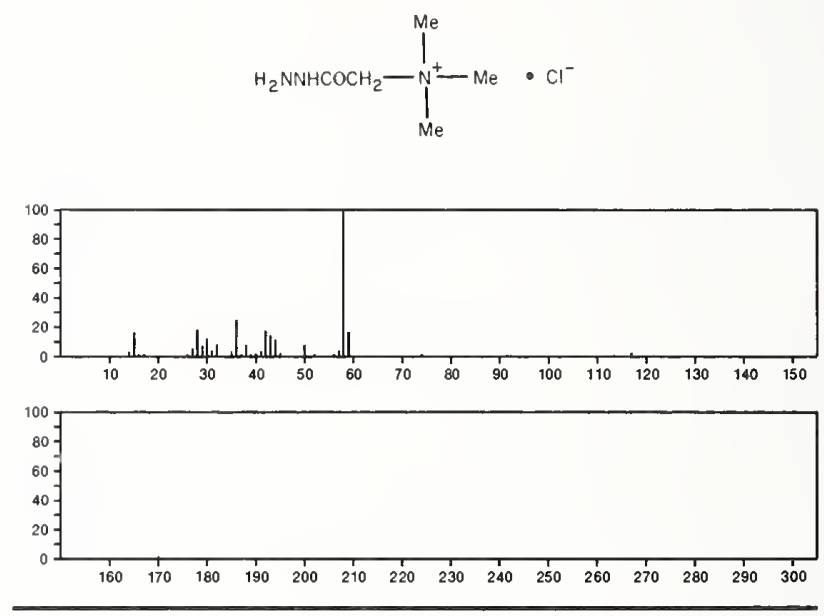

167

$\mathrm{C}_{7} \mathrm{H}_{5} \mathrm{NO}_{4}$

62-23-7

Benzoic acid, 4-nitro-
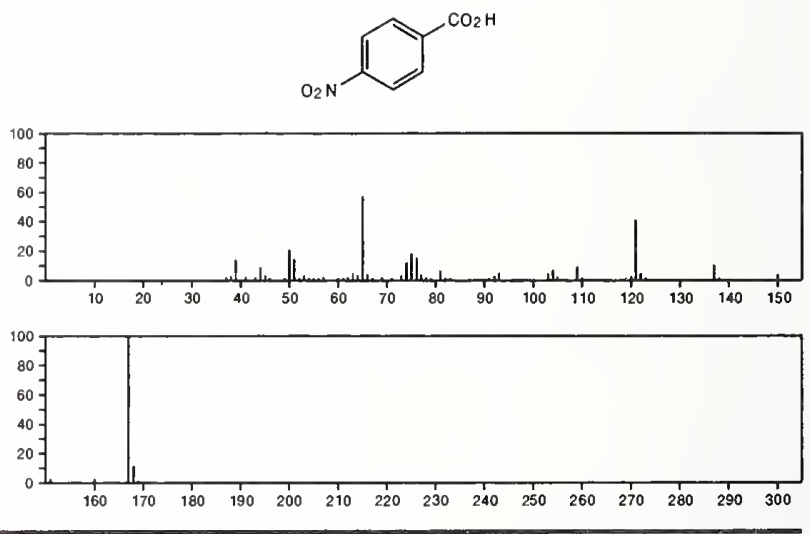

167

2,3-Pyridinedicarboxylic acid

$\mathrm{C}_{7} \mathrm{H}_{5} \mathrm{NO}_{4}$

89-00-9
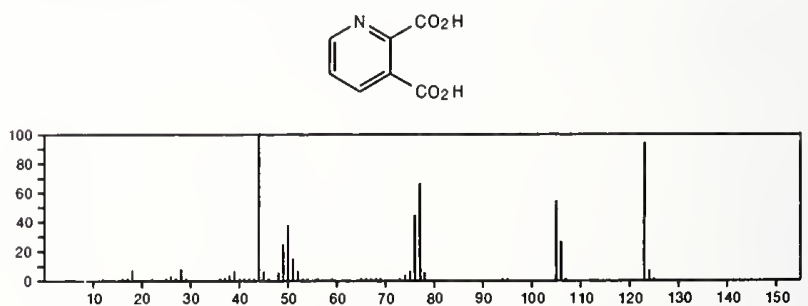
167 $\mathrm{C}_{7} \mathrm{H}_{5} \mathrm{NO}_{4}$

Benzaldehyde, 2-hydroxy-5-nitro-
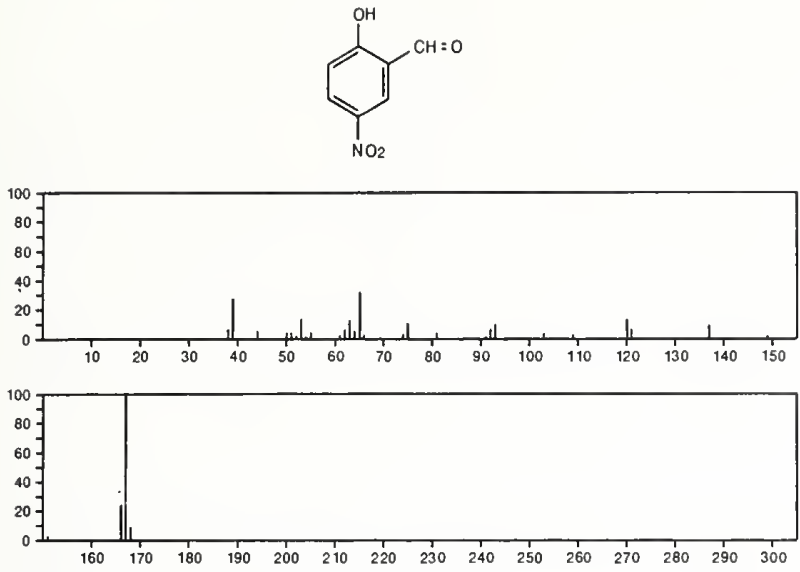

167

2,5-Pyridinedicarboxylic acid

$\mathrm{C}_{7} \mathrm{H}_{5} \mathrm{NO}_{4}$

$100-26-5$
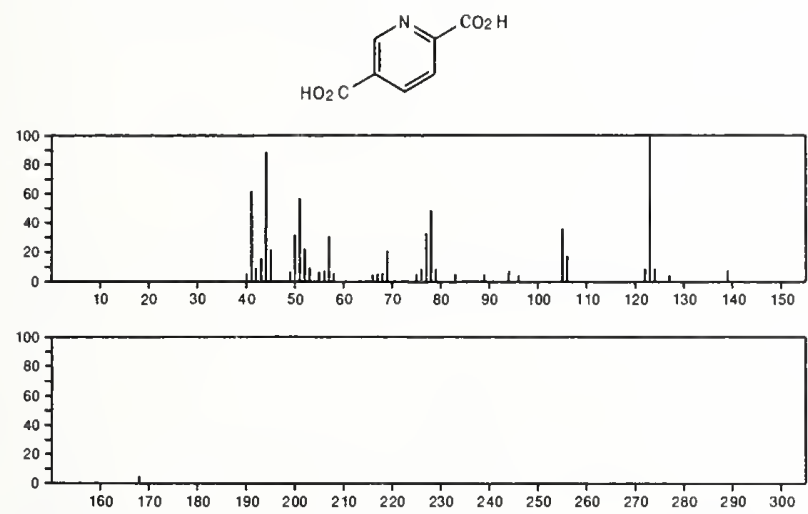

167

Benzoic acid, 3-nitro-

$$
\mathrm{C}_{7} \mathrm{H}_{5} \mathrm{NO}_{4}
$$

$121-92-6$
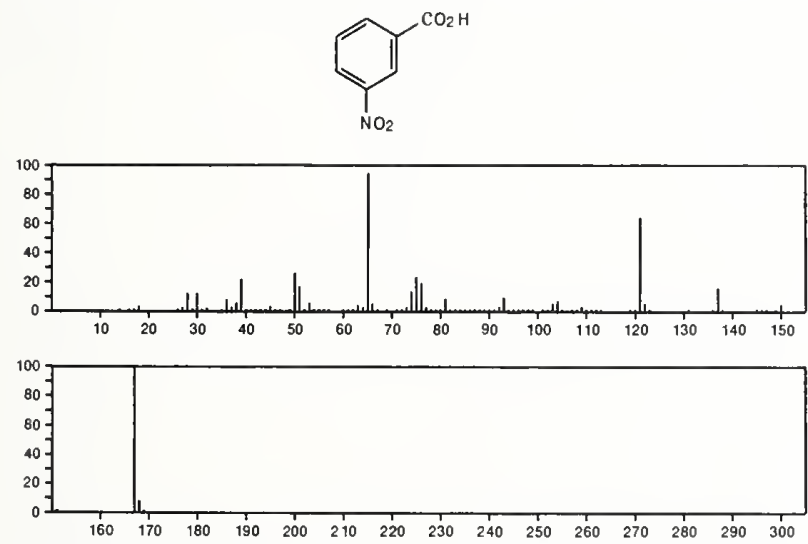

167

$\mathrm{C}_{7} \mathrm{H}_{5} \mathrm{NO}_{4}$

$552-16-9$

Benzoic acid, 2-nitro-<smiles>O=C(O)c1ccccc1[N+](=O)[O-]</smiles>

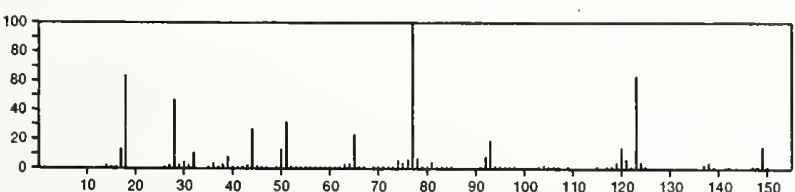

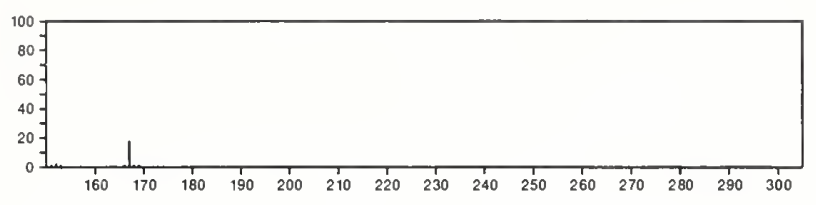

167

2(3H)-Benzothiazolethione

$\mathrm{C}_{7} \mathrm{H}_{5} \mathrm{NS}_{2}$

149-30-4
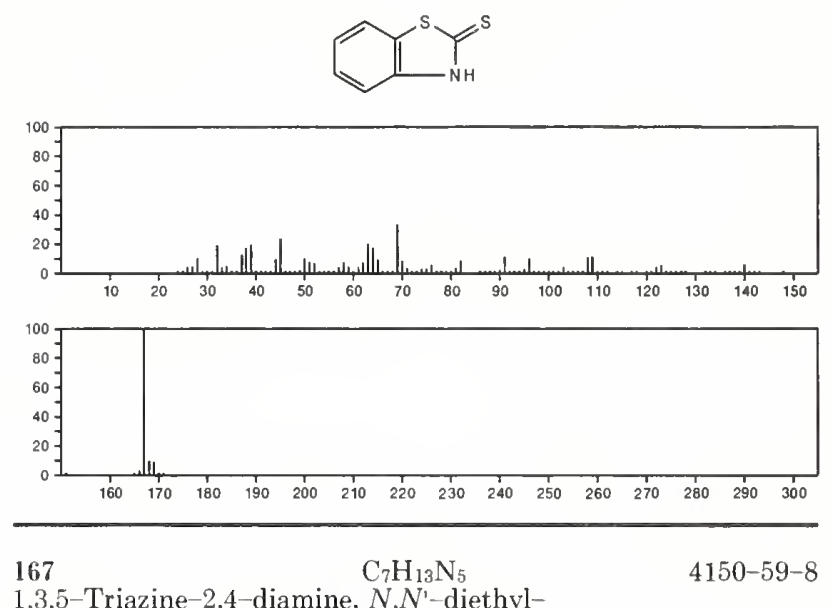

1,3,5-Triazine-2,4-diamine, $N, N^{\prime}$-diethyl-
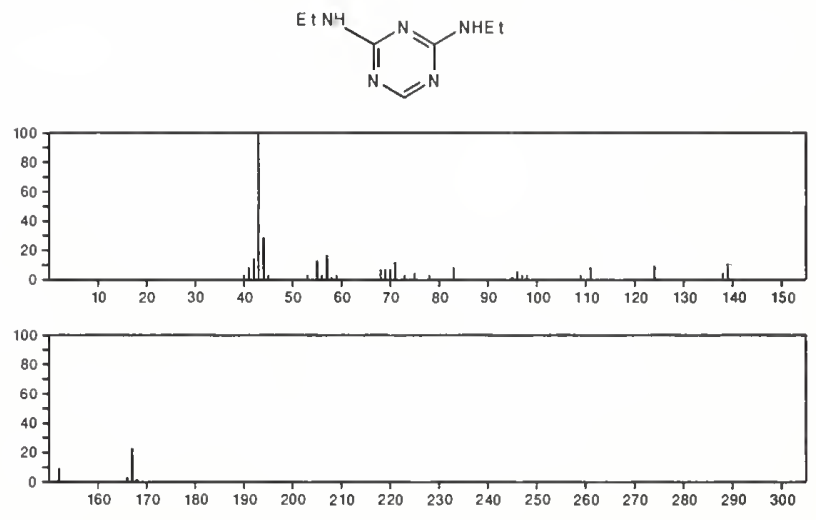

167

$\mathrm{C}_{8} \mathrm{H}_{9} \mathrm{NOS}$

13509-38-1

Carbamothioic acid, phenyl-, $S-$ methyl ester

PhNHC( O) SMe
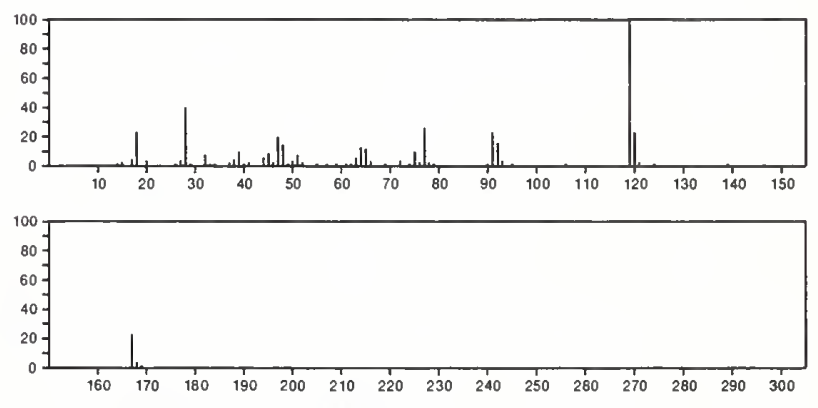

167
Carbamothioic acid, methyl-, $S$-phenyl ester

$13509-39-2$

PhSCI (O) NHMe

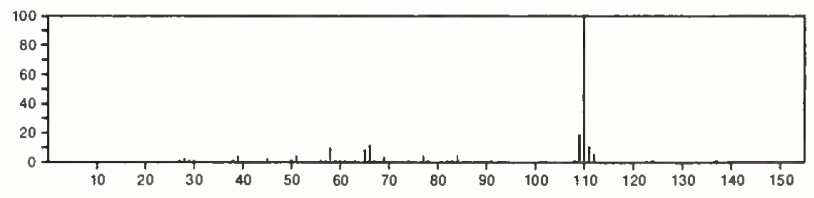




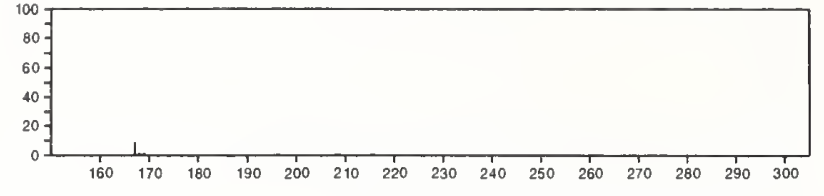

167

$\mathrm{C}_{8} \mathrm{H}_{9} \mathrm{NOS}$

Benzenamine, 2,6-dimethyl- $N$-sulfinyl-
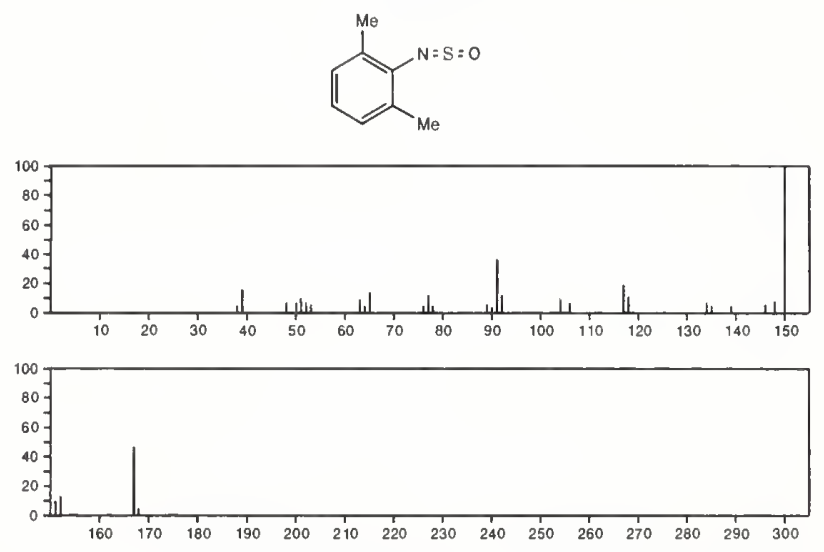

167

$\mathrm{C}_{8} \mathrm{H}_{9} \mathrm{NOS}$

$23003-43-2$

Thiazolo[3,2-a]pyridinium, 2,3-dihydro-8-hydroxy-5-methyl-. hydroxide, inner salt
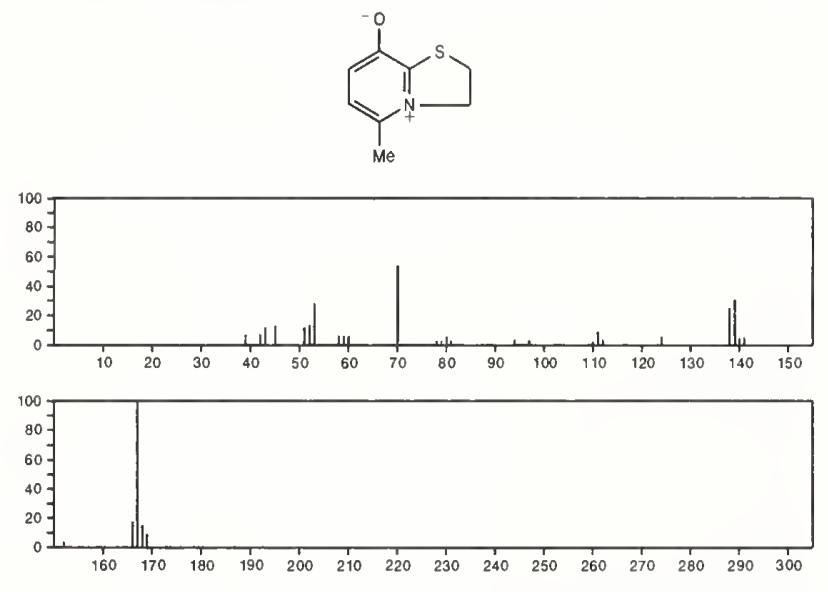

$167 \quad \mathrm{C}_{8} \mathrm{H}_{9} \mathrm{NO}_{3} \quad 66-72-8$

4-Pyridinecarboxaldehyde, 3-hydroxy-5-(hydroxymethyl)-2methyl-
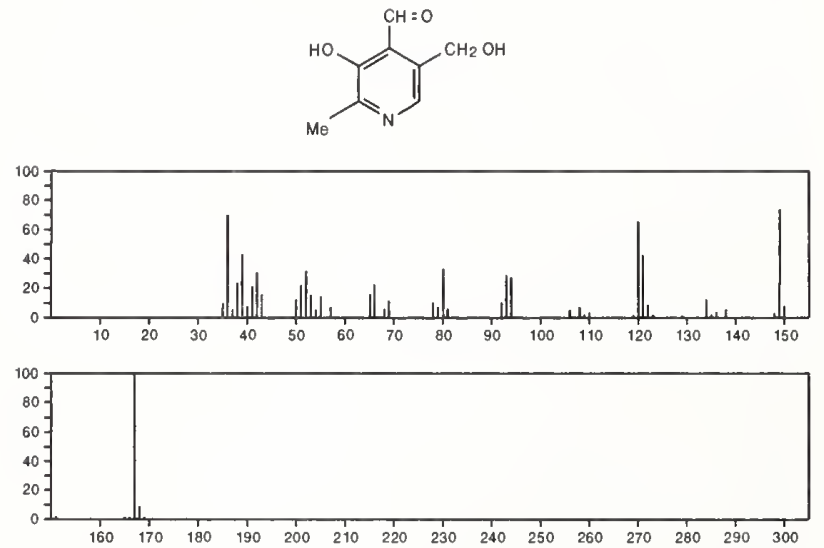

167

$\mathrm{C}_{8} \mathrm{H}_{9} \mathrm{NO}_{3}$

$5501-39-3$

2(1H)-Pyridinone, 3-acetyl-4-hydroxy-6-methyl-
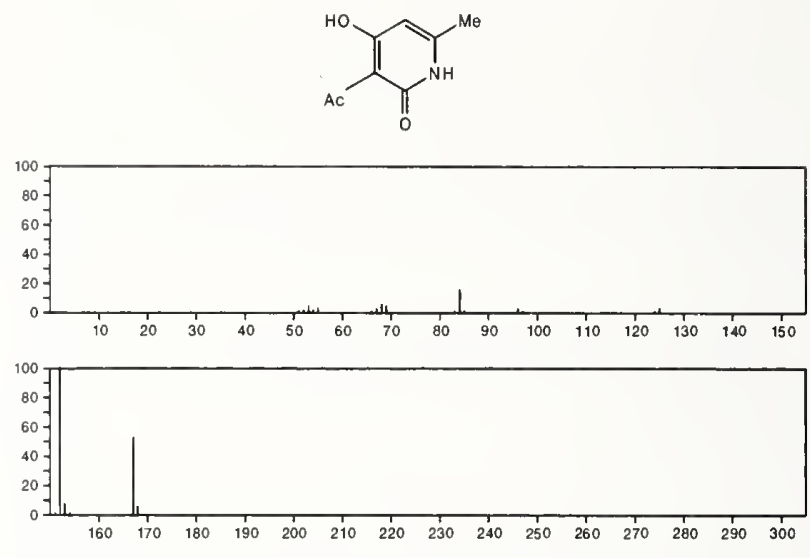

167

$\mathrm{C}_{8} \mathrm{H}_{9} \mathrm{NO}_{3}$

Glycine, $2-(m$-hydroxyphenyl $)-, \mathrm{DL}^{-}$

$7292-76-4$
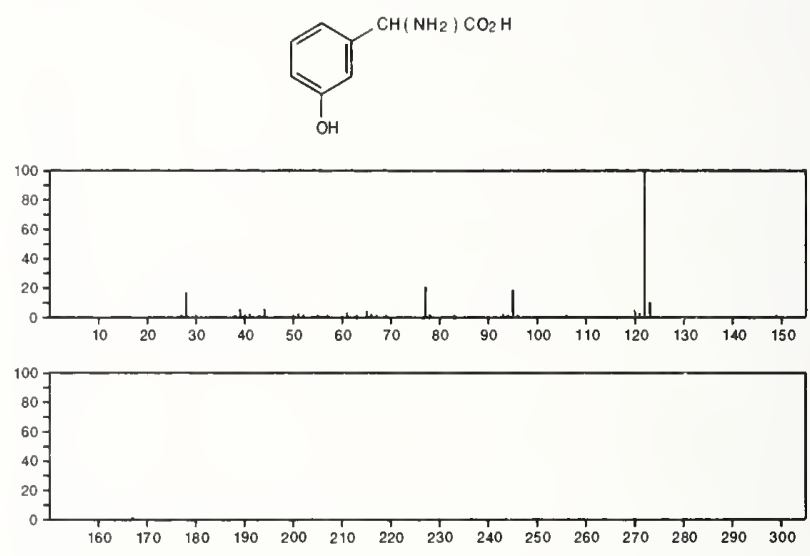

167

$\mathrm{C}_{8} \mathrm{H}_{9} \mathrm{NO}_{3}$

$13959-08-5$

2(1H)-Pyridinone, 4-(acetyloxy)-6-methyl-
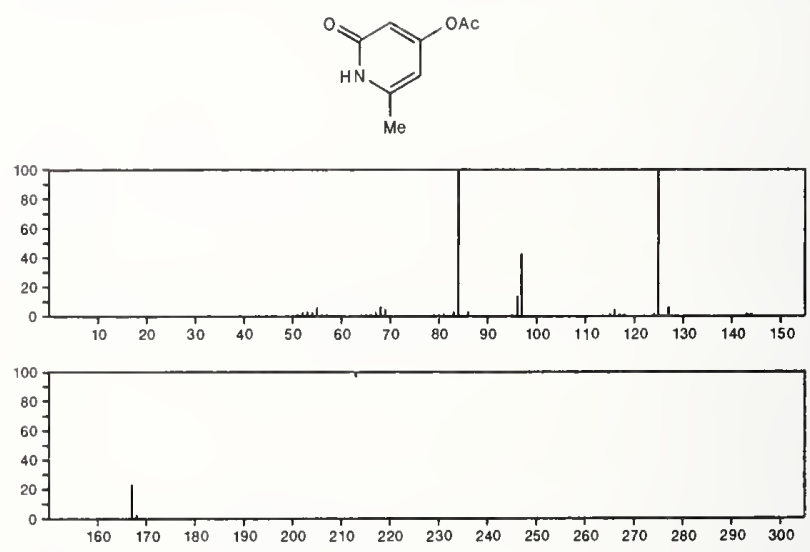

167

$\mathrm{C}_{8} \mathrm{H}_{9} \mathrm{NO}_{3}$

$52022-77-2$

Benzeneethanol, 3-nitro-
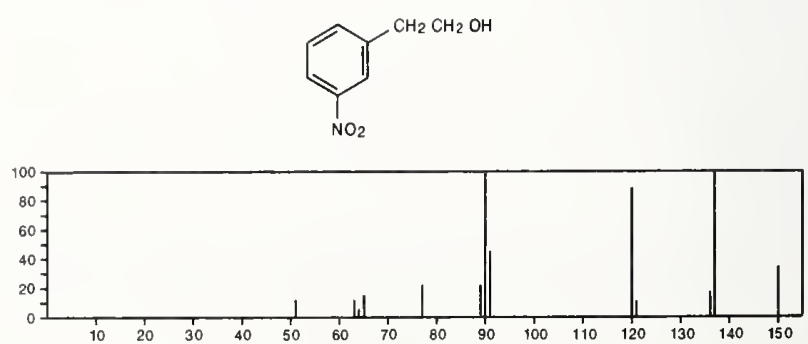


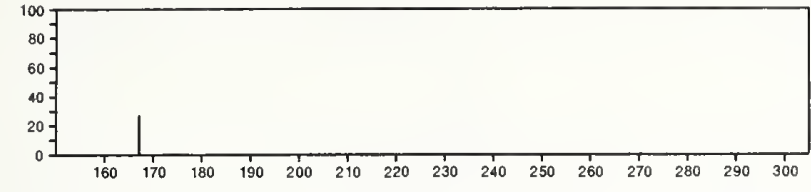

167

$\mathrm{C}_{8} \mathrm{H}_{11} \mathrm{BClN}$

$1196-44-7$

Boranamine, 1-chloro- $N, N$-dimethyl-1-phenyl-

$\mathrm{Me}_{2} \mathrm{NBCl} P \mathrm{Ph}$
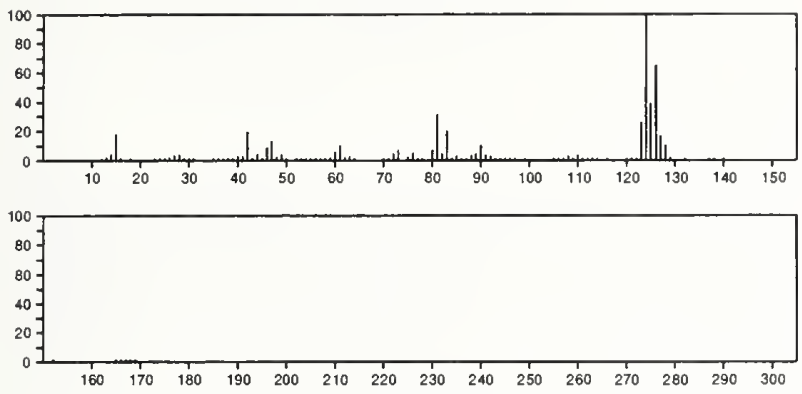

\section{7}

$\mathrm{C}_{8} \mathrm{H}_{13} \mathrm{NOSi}$

4(1H)-Pyridinone, 1-(trimethylsilyl)-
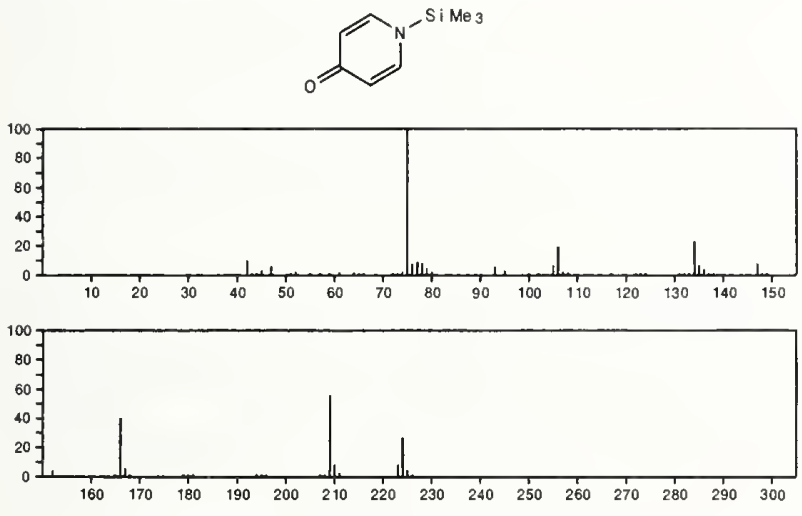

167

Azetidine, 1-chloro-2-phenyl-

$\mathrm{C}_{9} \mathrm{H}_{10} \mathrm{ClN}$

$30839-64-6$
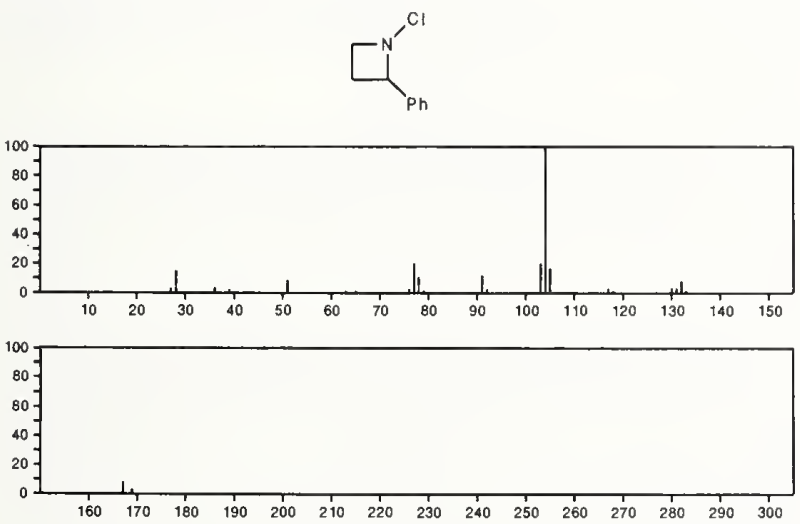

167

$\mathrm{C}_{9} \mathrm{H}_{13} \mathrm{NO}_{2}$

$77-04-3$

2,4(1H,3H)-Pyridinedione, 3,3-diethyl-
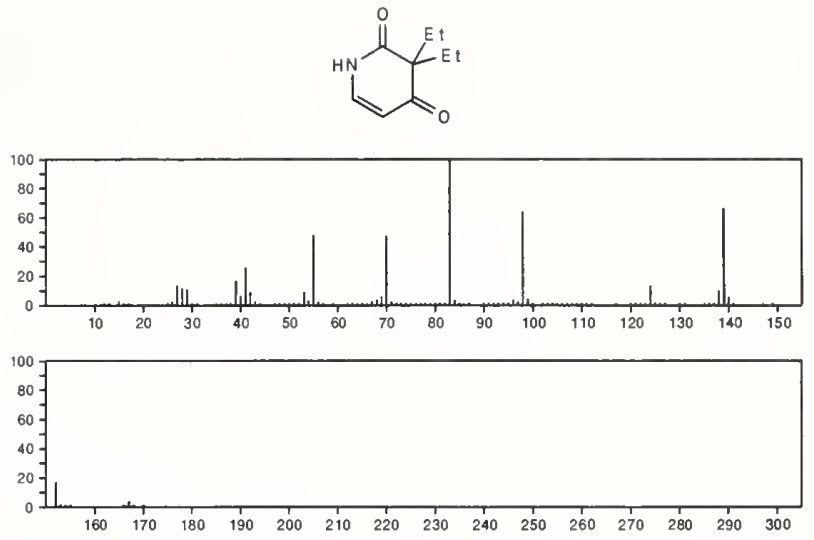

167

$\mathrm{C}_{9} \mathrm{H}_{13} \mathrm{NO}_{2}$

$94-07-5$

Benzenemethanol, 4-hydroxy- $\alpha-[($ methylamino) methyl $]-$
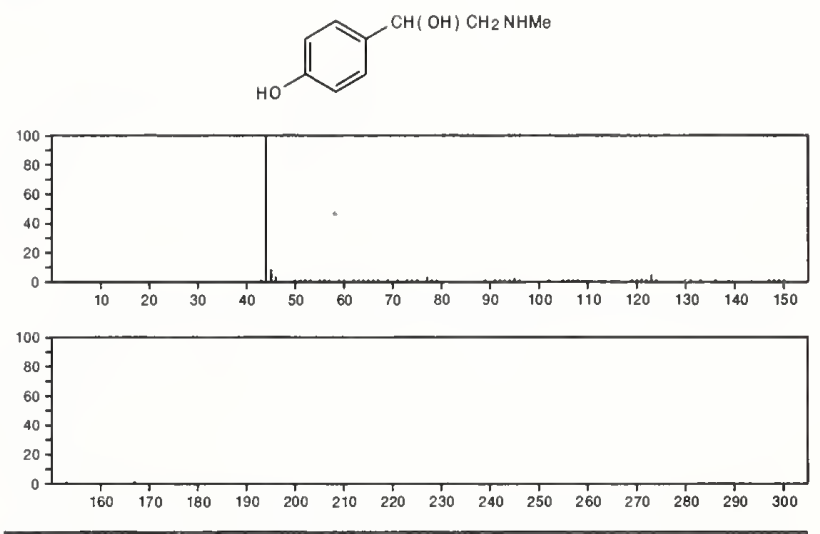

167

$\mathrm{C}_{9} \mathrm{H}_{13} \mathrm{NO}_{2}$

Cyclohexanol, 1-ethynyl-, carbamate

$126-52-3$
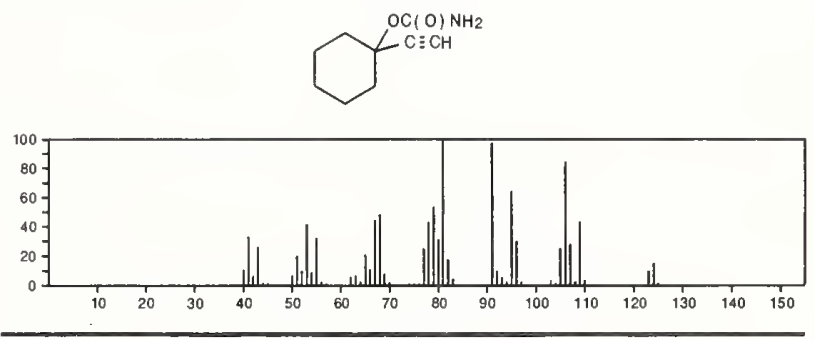

167

$\mathrm{C}_{9} \mathrm{H}_{13} \mathrm{NO}_{2}$

Phenol, 4-(2-aminoethyl)-2-methoxy-

$554-52-9$
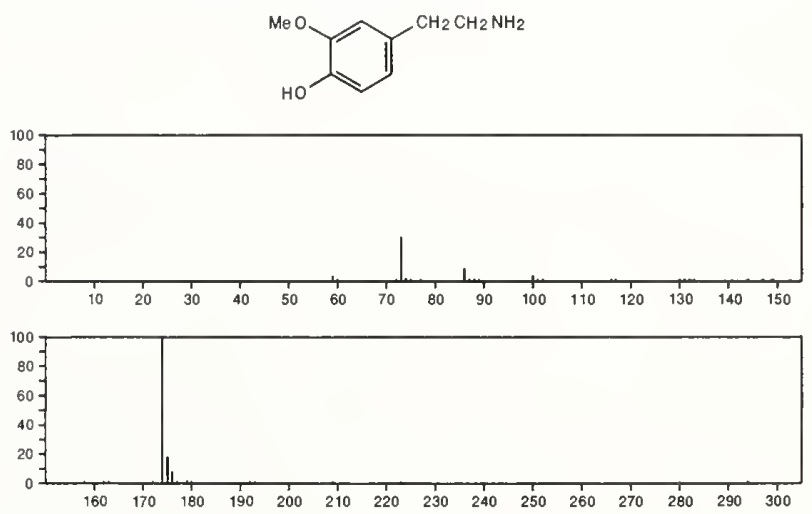


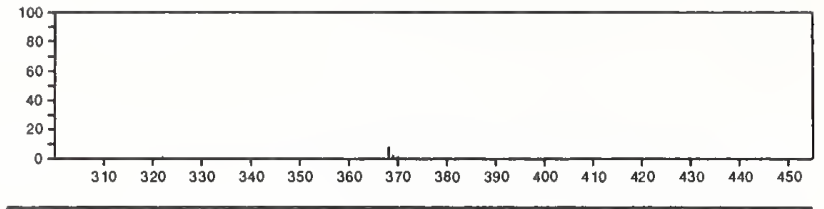

$167 \quad \mathrm{C}_{9} \mathrm{H}_{13} \mathrm{NO}_{2}$

Phenol, 5-(2-aminoethyl)-2-methoxy-

$3213-30-7$
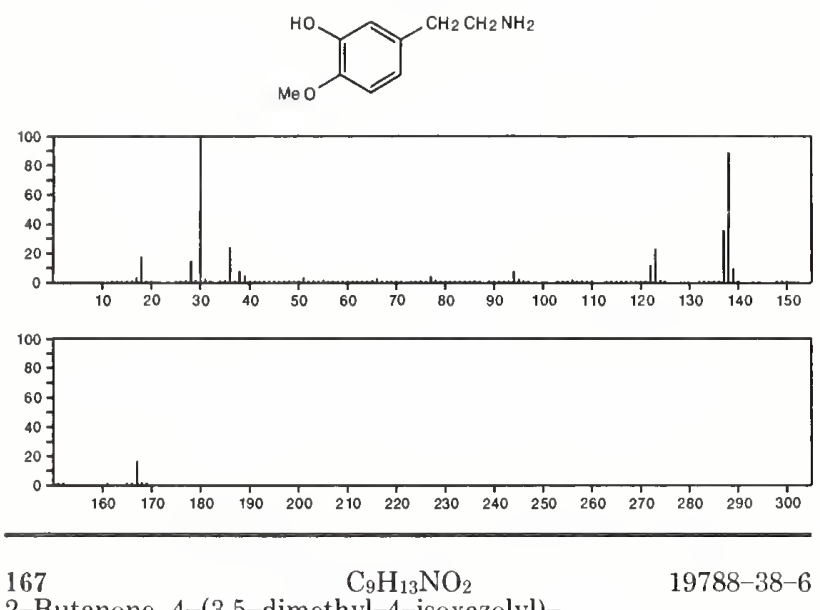

2-Butanone, 4-(3,5-dimethyl-4-isoxazolyl)-
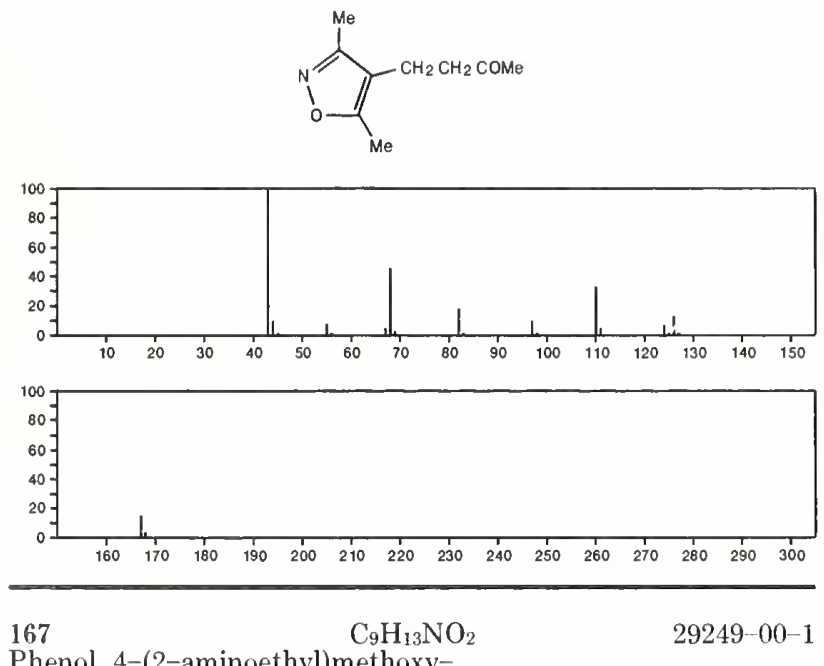

Phenol, 4-(2-aminoethyl)methoxy-
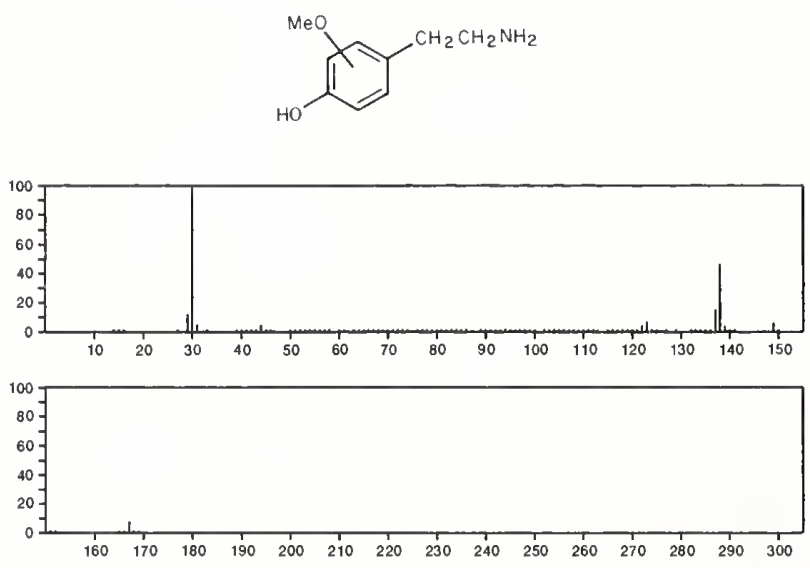

167

$\mathrm{C}_{9} \mathrm{H}_{13} \mathrm{NO}_{2}$

31539-88-5

1-Azabicyclo[2.2.2]oct-2-ene-3-carboxylic acid, methyl ester
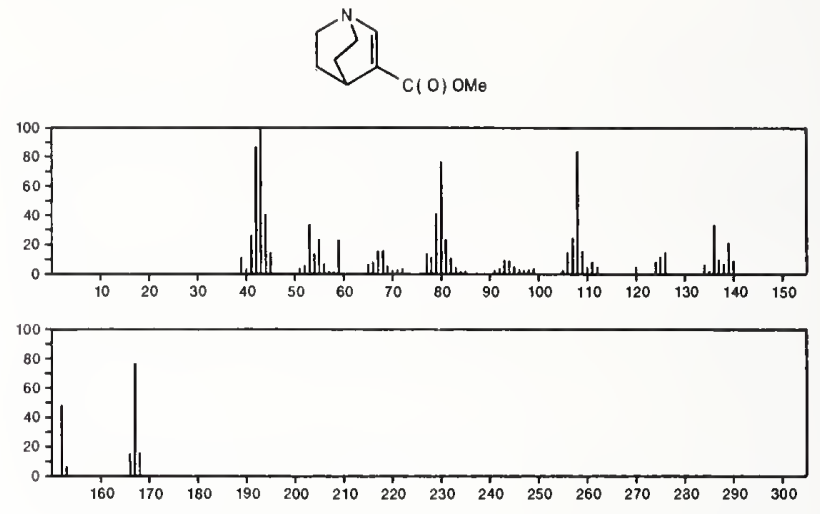

167

$\mathrm{C}_{9} \mathrm{H}_{13} \mathrm{NO}_{2}$

39998-23-7

3-Pyridineacetic acid, 1,4-dihydro-1-methyl-, methyl ester
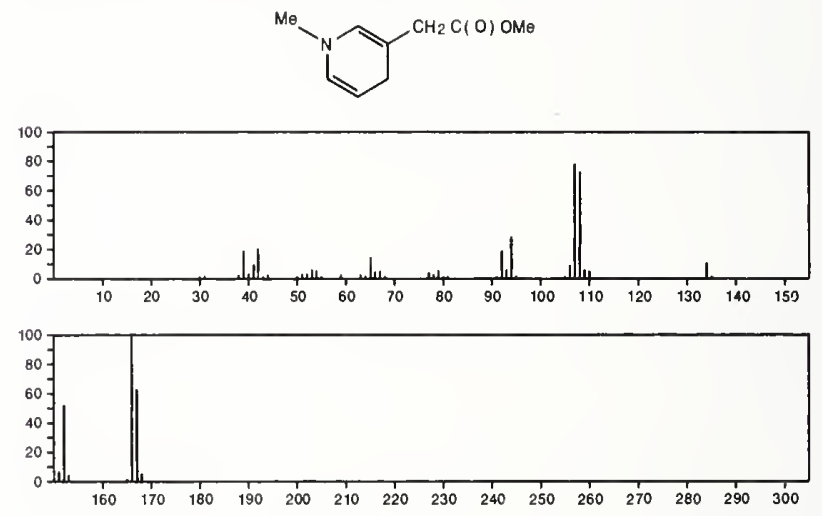

167

$\mathrm{C}_{9} \mathrm{H}_{13} \mathrm{NO}_{2}$

$50267-24-8$

2-Oxa-6-azatricyclo[3.3.1.1 ${ }^{3,7}$ ]decane-6-carboxaldehyde
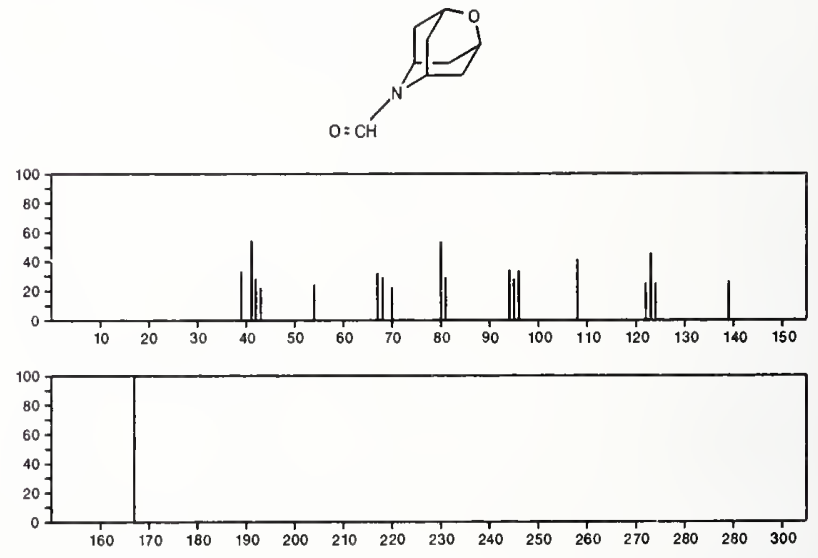

167

$\mathrm{C}_{9} \mathrm{H}_{13} \mathrm{NO}_{2}$

Phenol, 2-(2-aminoethyl)-5-methoxy-

$54410-97-8$
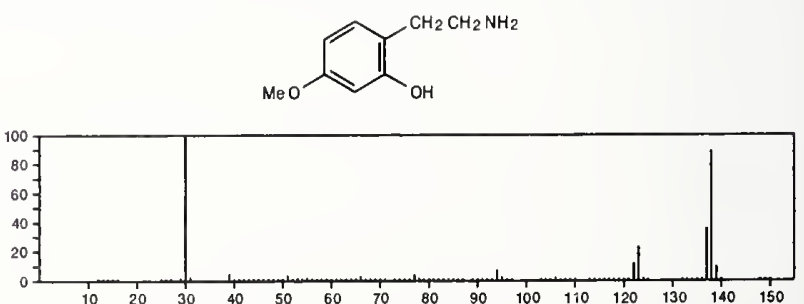


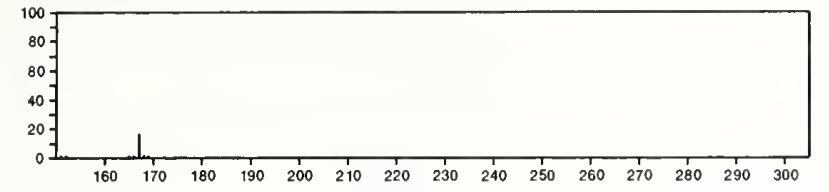

167 C $\mathrm{C}_{9} \mathrm{H}_{13} \mathrm{NS}$

$18794-26-8$

Pyridine, 4-(tert-butylthio)
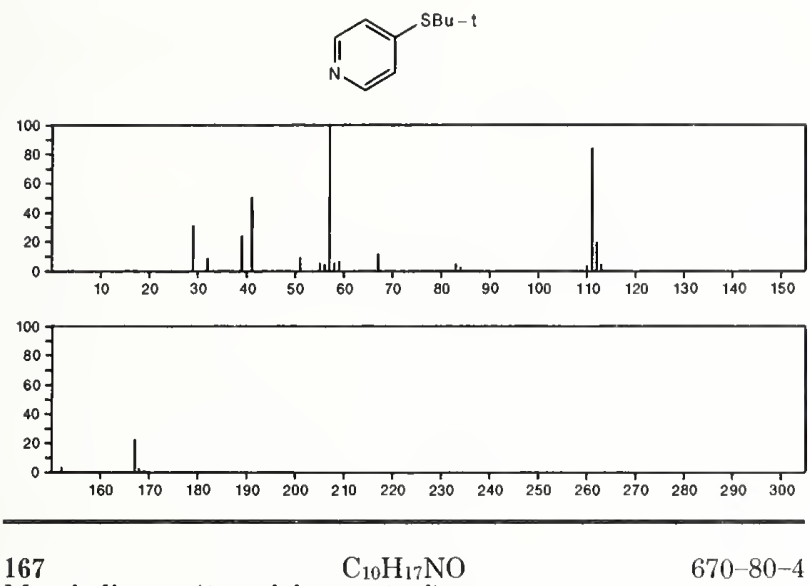

Morpholine, 4-(1-cyclohexen-1-yl)-
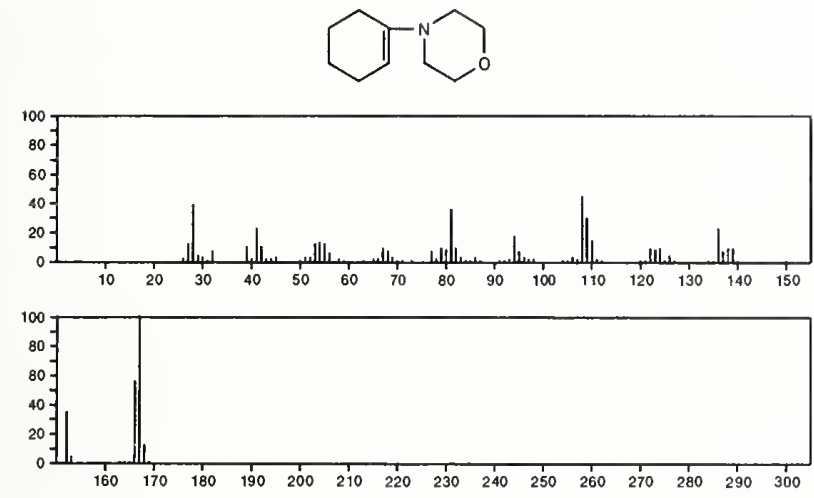

167

$\mathrm{C}_{10} \mathrm{H}_{17} \mathrm{NO}$

$4146-36-5$

8-Azabicyclo[4.3.1]decan-10-one, 8-methyl-
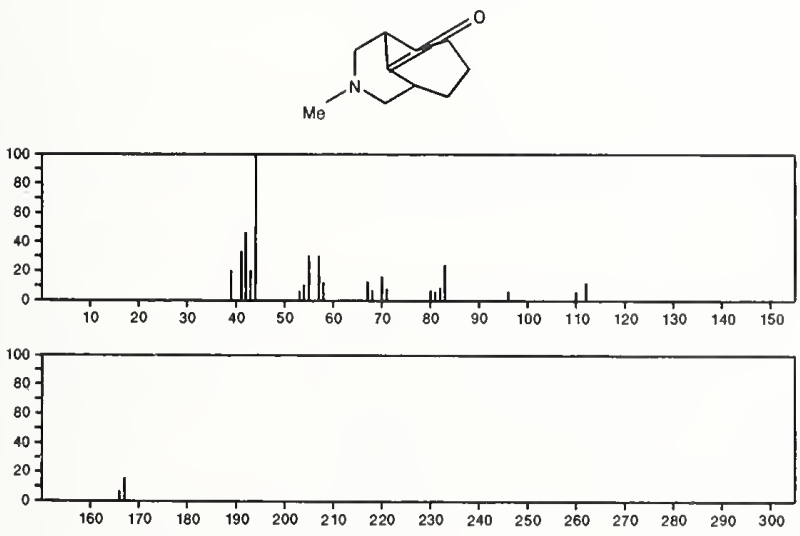

167

$\mathrm{C}_{10} \mathrm{H}_{17} \mathrm{NO}$

$4514-87-8$

Bicyclo[2.2.1]heptan-2-one, 4,7,7-trimethyl-, oxime
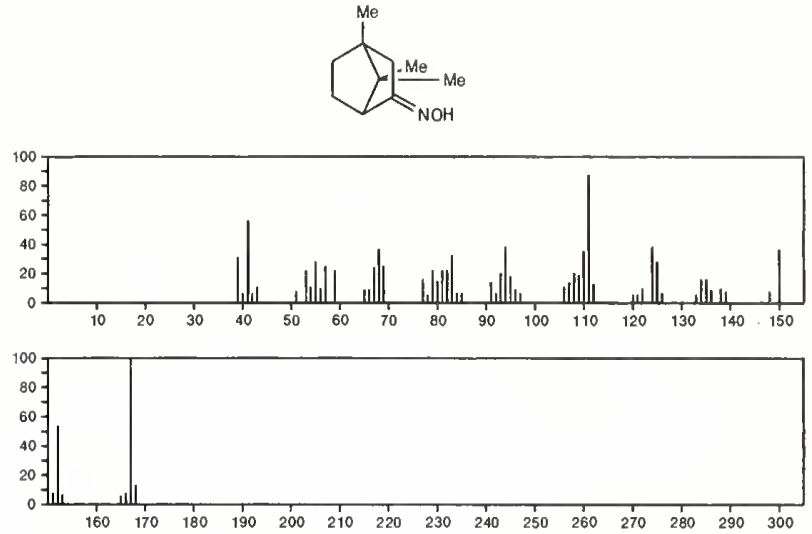

167

Bicyclo[2.2.1]heptan-2-one, 1,7,7-trimethyl-, oxime

$13559-66-5$
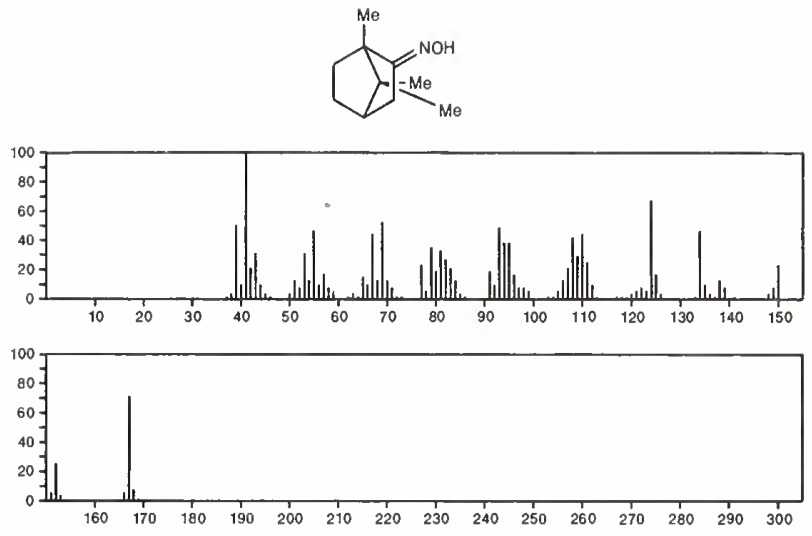

167

$\mathrm{C}_{10} \mathrm{H}_{17} \mathrm{NO}$

$55760-17-3$

Bicyclo[3.2.0]heptan-3-one, 1,4,4-trimethyl-, oxime
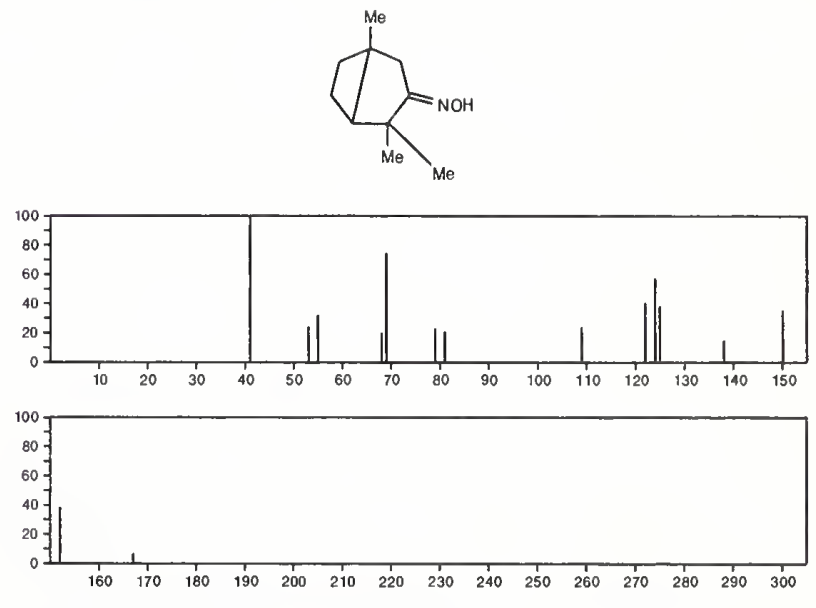

167

Bicyclo[3.3.1]nonan-3-one, 7-(aminomethyl)-

56701-31-6

$\mathrm{C}_{10} \mathrm{H}_{17} \mathrm{NO}$
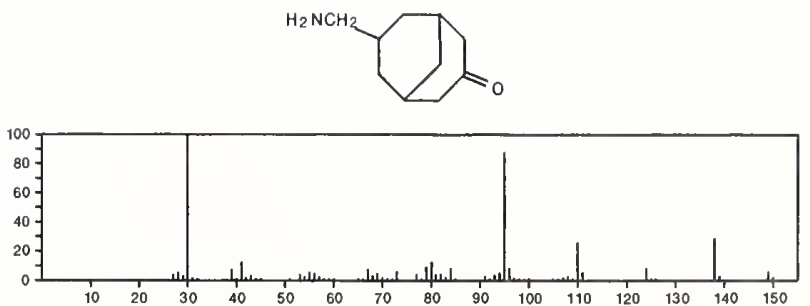

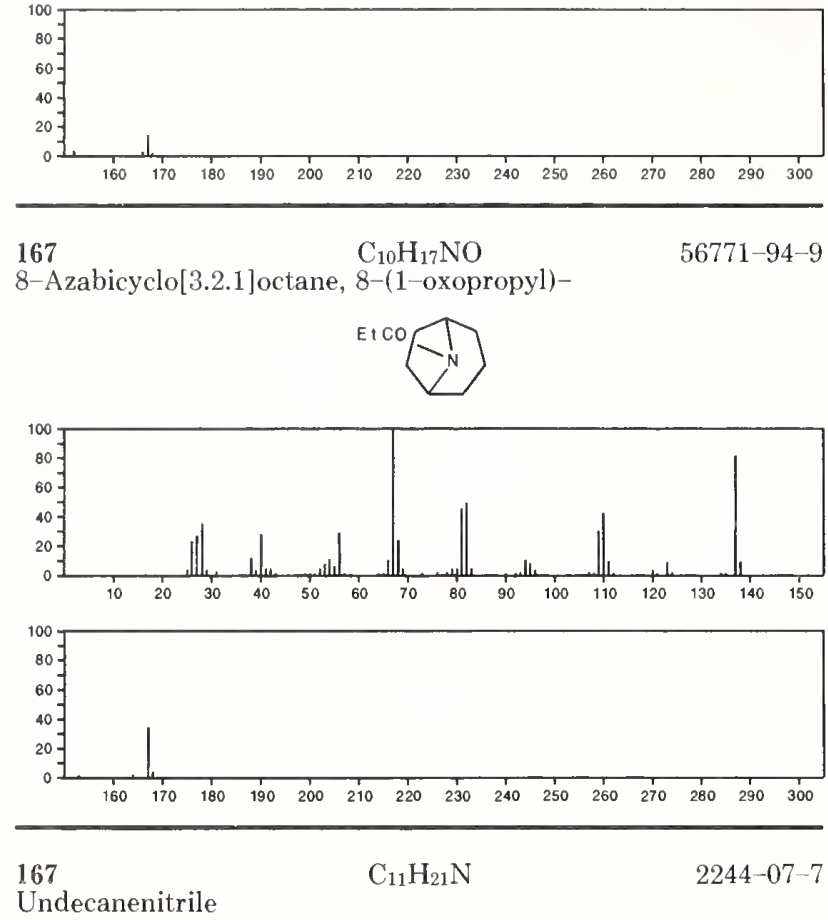

$\mathrm{NC}\left(\mathrm{CH}_{2}\right) 9 \mathrm{Me}$
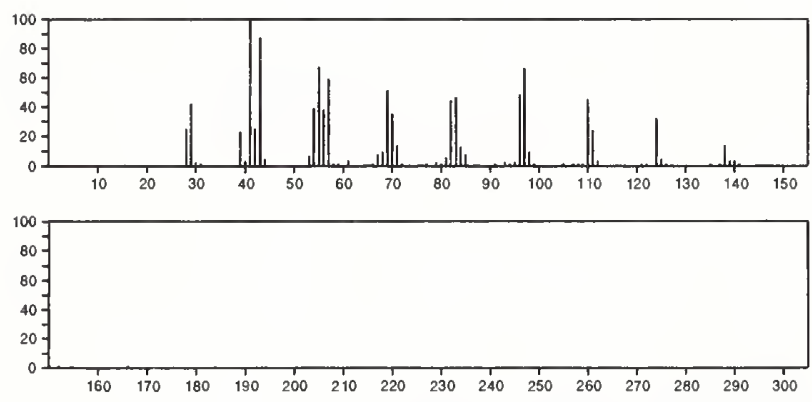

167

Bicyclo[2.2.1] heptan-2-amine, N,1,7,7-tetramethyl-
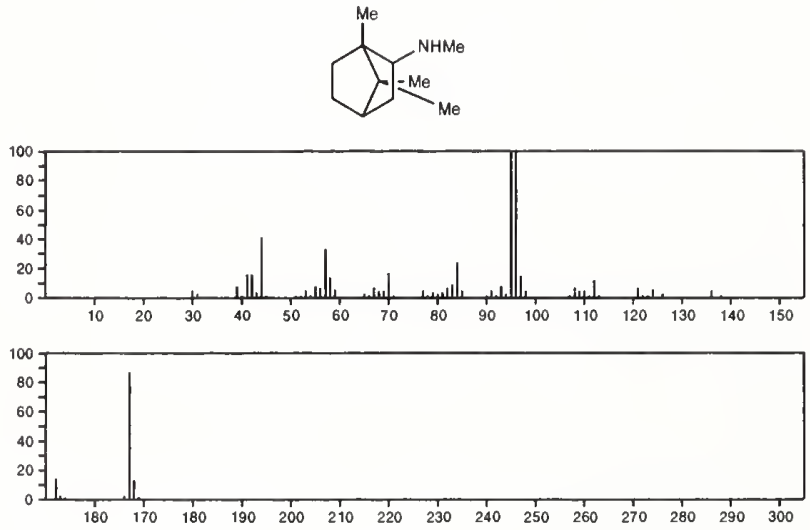

167 $\mathrm{C}_{11} \mathrm{H}_{21} \mathrm{~N}$

Quinoline, decahydro-1,7-dimethyl-
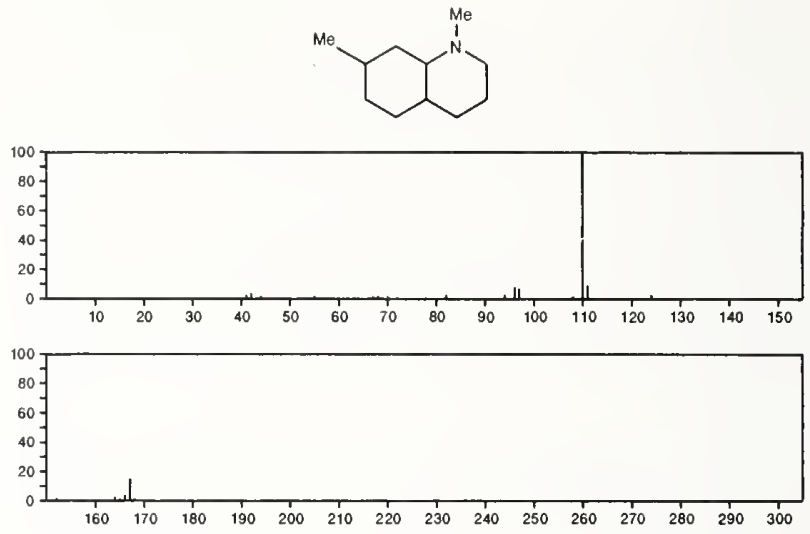

167

$\mathrm{C}_{11} \mathrm{H}_{21} \mathrm{~N}$

Bicyclo[2.2.1] heptan-2-amine, N,4,7,7-tetramethyl-

$35973-44-5$
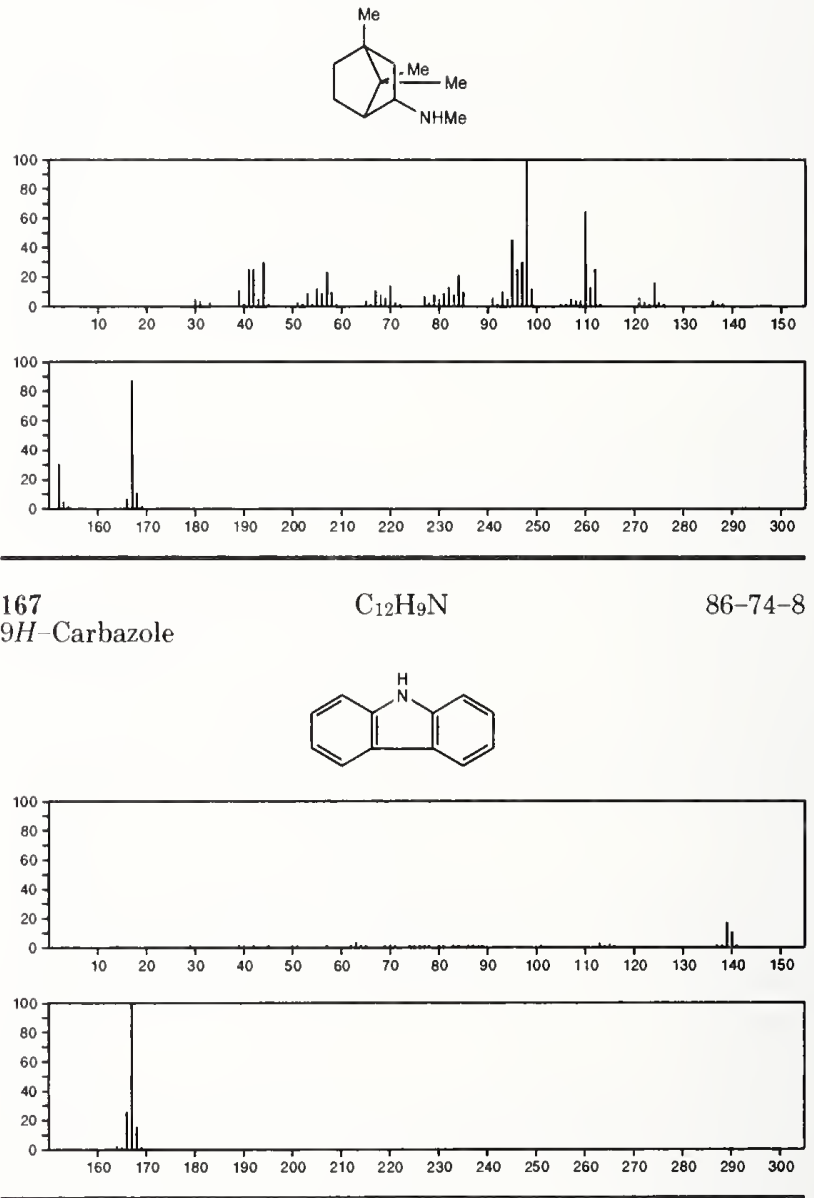

168

$\mathrm{C}_{2} \mathrm{HCl}_{3} \mathrm{~F}_{2}$

Ethane, 1,2,2-trichloro-1,1-difluoro-

354-21-2

$\mathrm{Cl}_{2} \mathrm{CHCClF}_{2}$

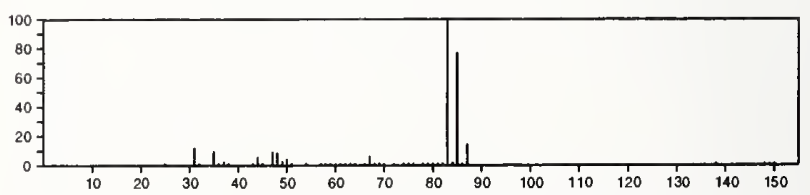




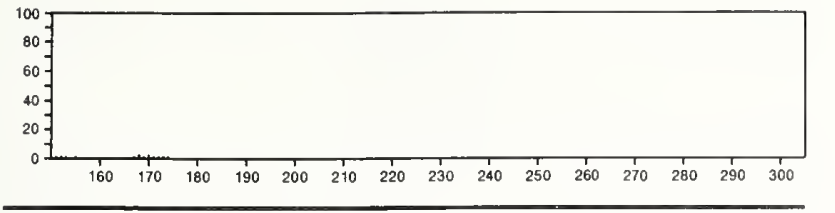

$168 \quad \mathrm{C}_{3} \mathrm{H}_{5} \mathrm{I} \quad 556-56-9$

1-Propene, 3-iodo-

I $\mathrm{CH}_{2} \mathrm{CH}: \mathrm{CH}_{2}$
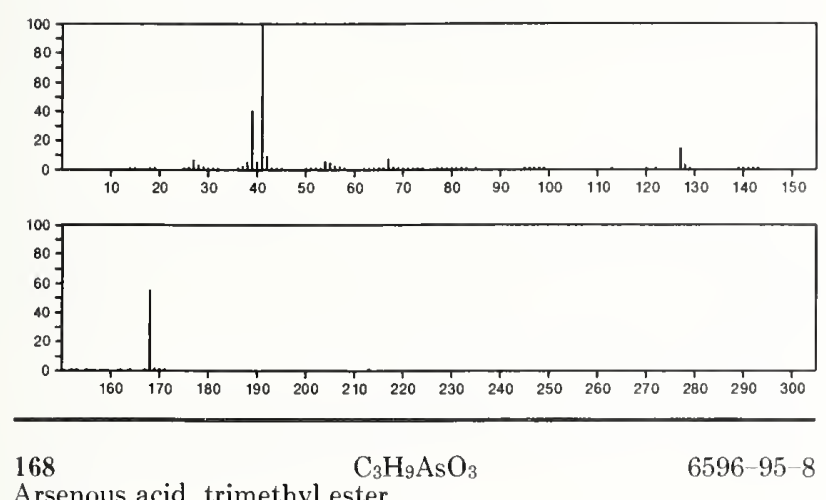

Arsenous acid, trimethyl ester
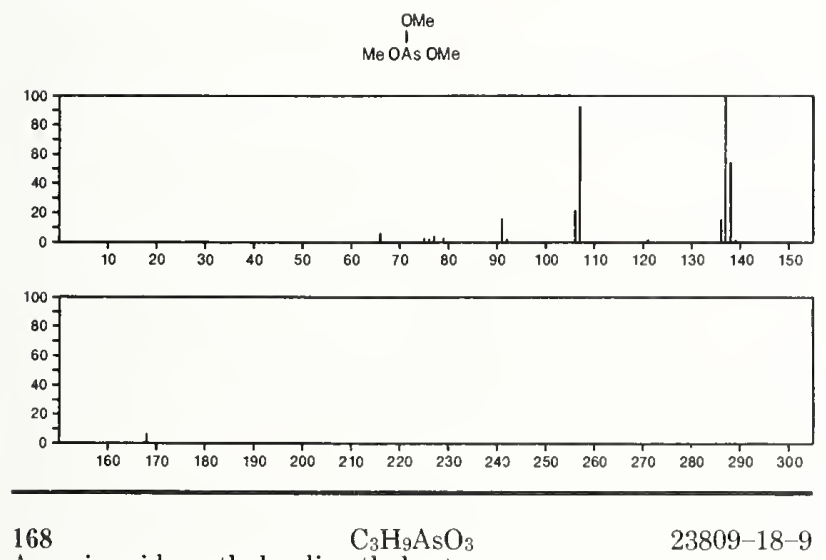

Arsonic acid, methyl-, dimethyl ester
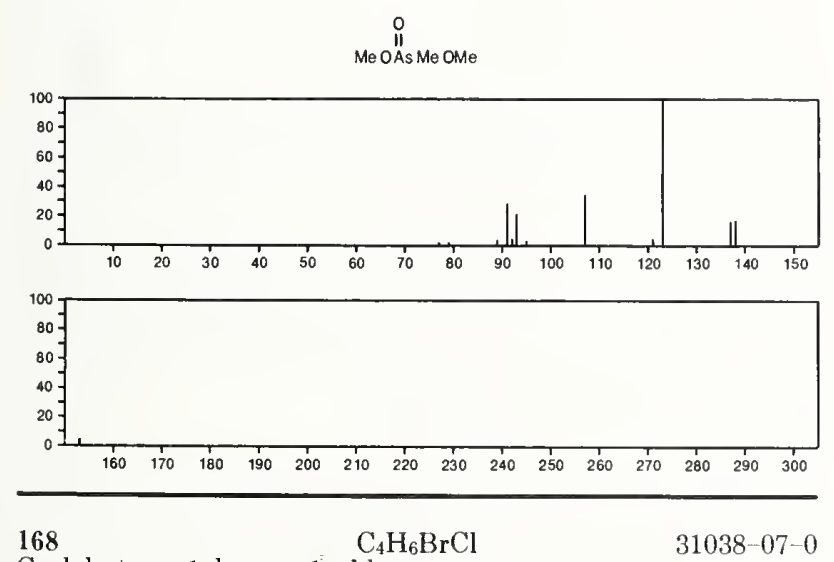

Cyclobutane, 1-bromo-1-chloro-
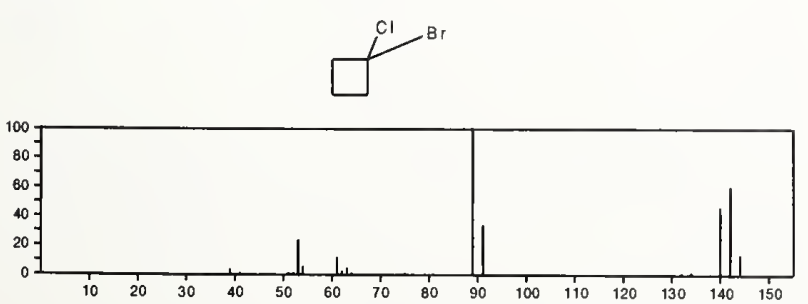

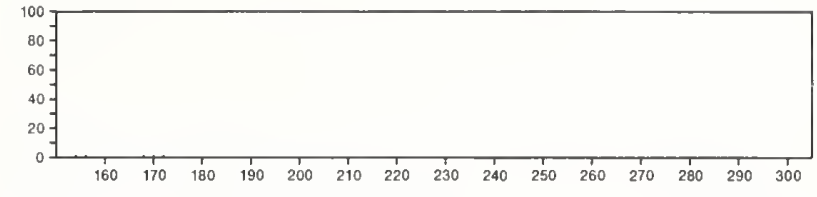

168

2-Butene, 1-bromo-2-chloro-

$\mathrm{C}_{4} \mathrm{H}_{6} \mathrm{BrCl}$

$54410-84-3$

$\mathrm{Br} \mathrm{CH}_{2} \mathrm{CCl}=\mathrm{CHMe}$
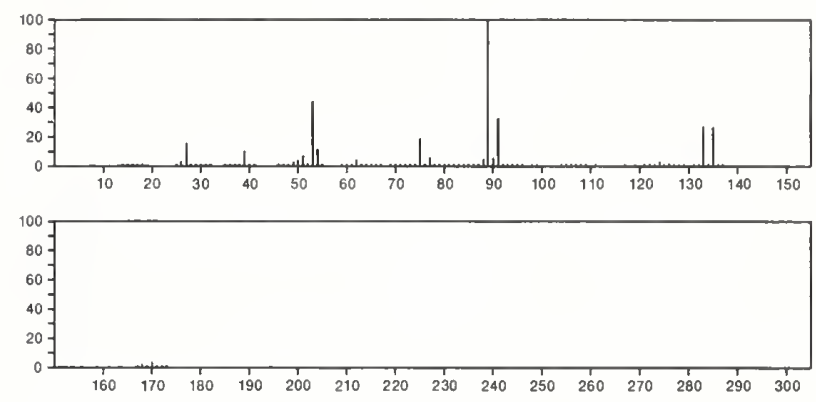

168

$\mathrm{C}_{4} \mathrm{H}_{6} \mathrm{BrCl}$

$55887-83-7$

Cyclobutane, 1-bromo-2-chloro-
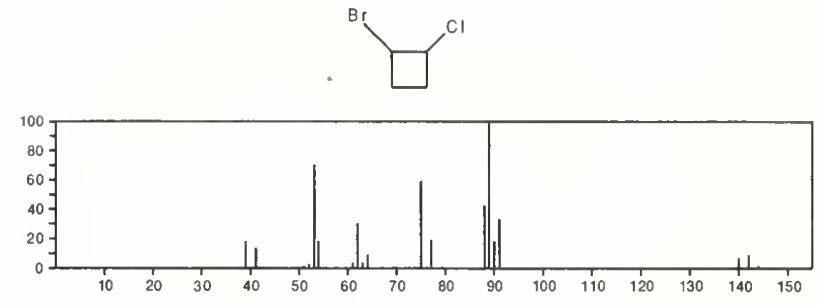

$168 \quad \mathrm{C}_{5} \mathrm{H}_{4} \mathrm{~N}_{4} \mathrm{O}_{3}$

1 H-Purine-2,6,8(3H)-trione, 7,9-dihydro-

69-93-2
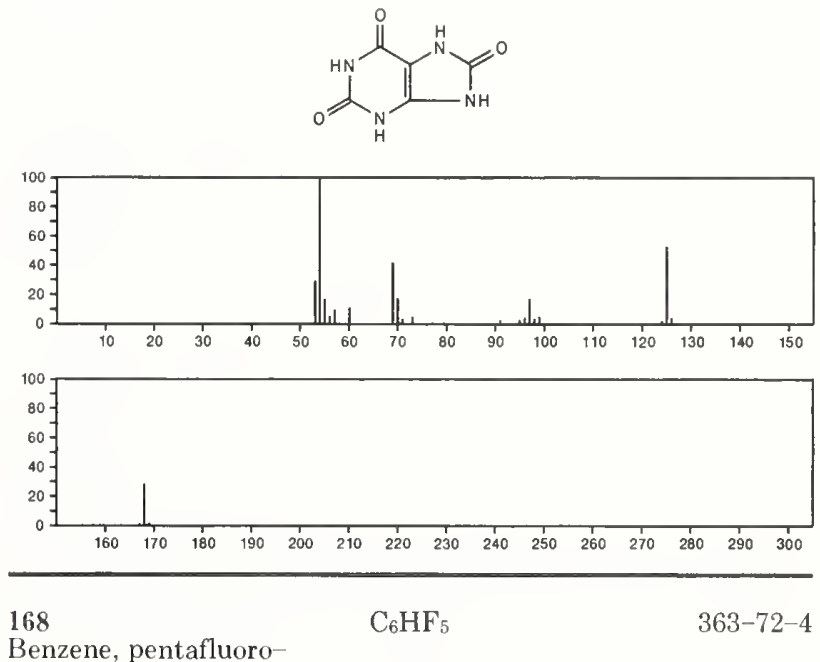

Benzene, pentafluoro
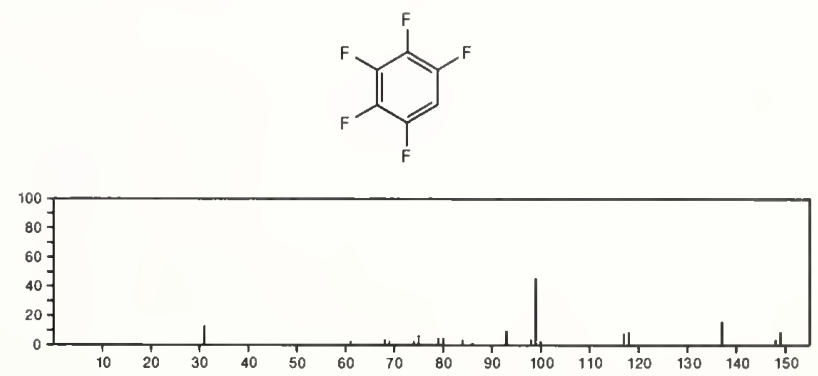

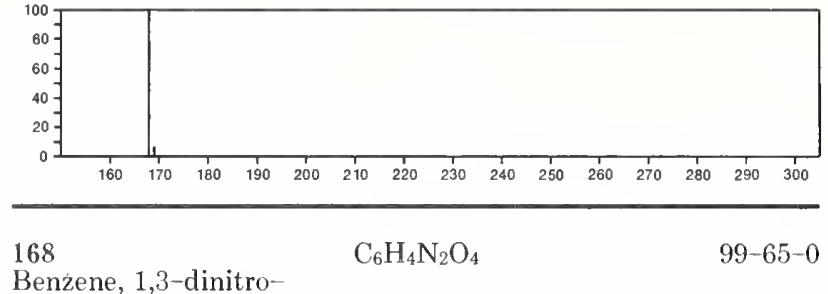

Benżene, 1,3-dinitro-
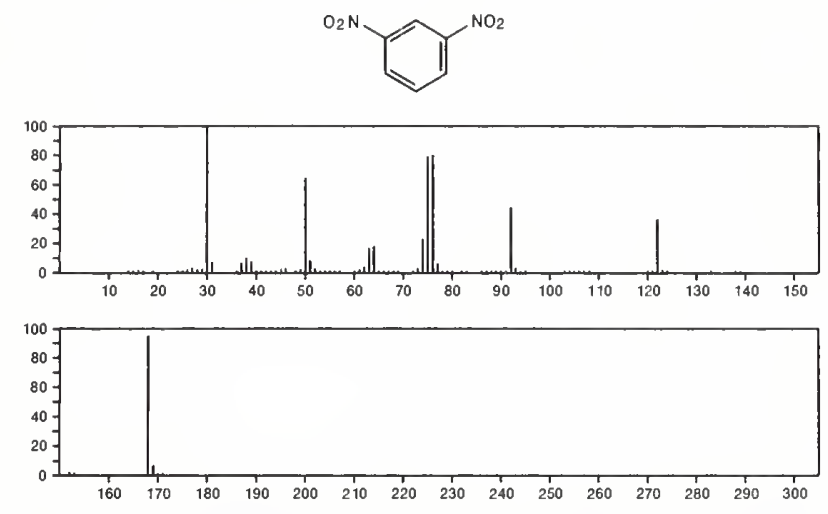

168

$\mathrm{C}_{6} \mathrm{H}_{4} \mathrm{~N}_{2} \mathrm{O}_{4}$

$100-25-4$

Benzene, 1,4-dinitro-
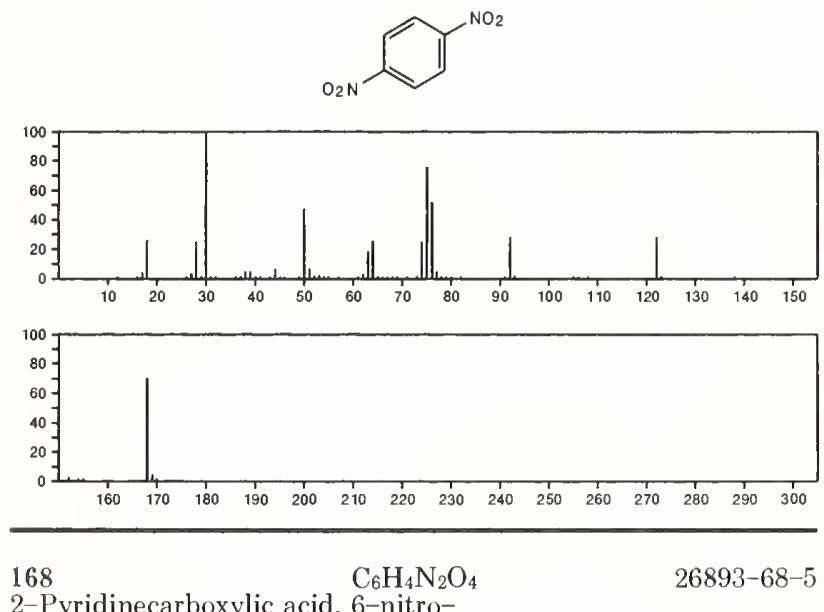

2-Pyridinecarboxylic acid, 6-nitro-
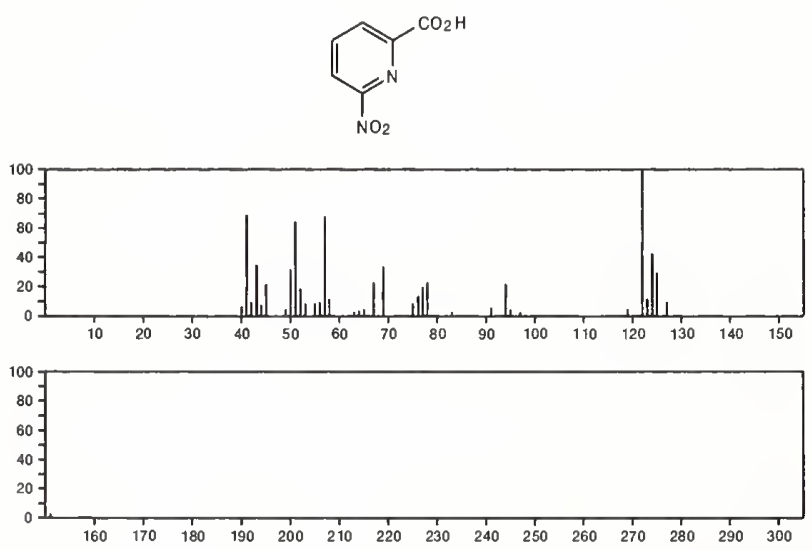

168

$\mathrm{C}_{6} \mathrm{H}_{4} \mathrm{~N}_{2} \mathrm{O}_{4}$

$30651-24-2$

2-Pyridinecarboxylic acid, 5-nitro-
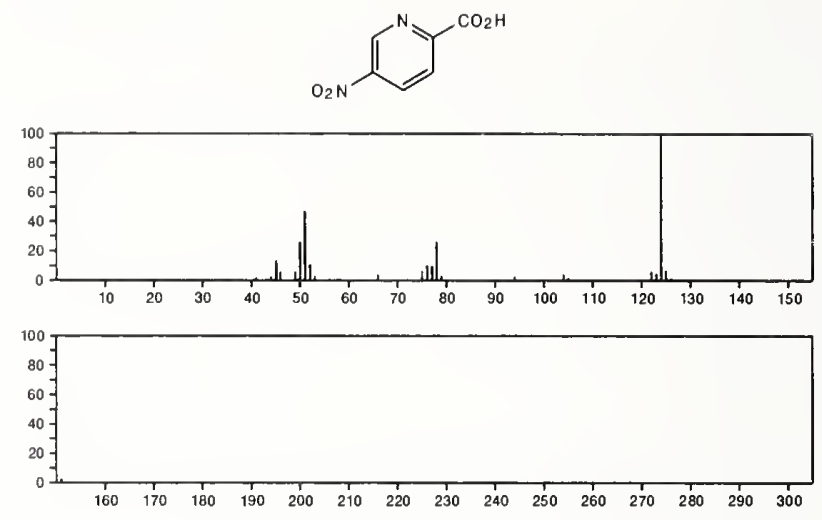

168

$\mathrm{C}_{6} \mathrm{H}_{7} \mathrm{~F}_{3} \mathrm{O}_{2}$

2,4-Hexanedione, 1,1,1-trifluoro-

$400-54-4$

$\mathrm{F}_{3} \mathrm{CCOCH}_{2} \mathrm{COE} \mathrm{t}$
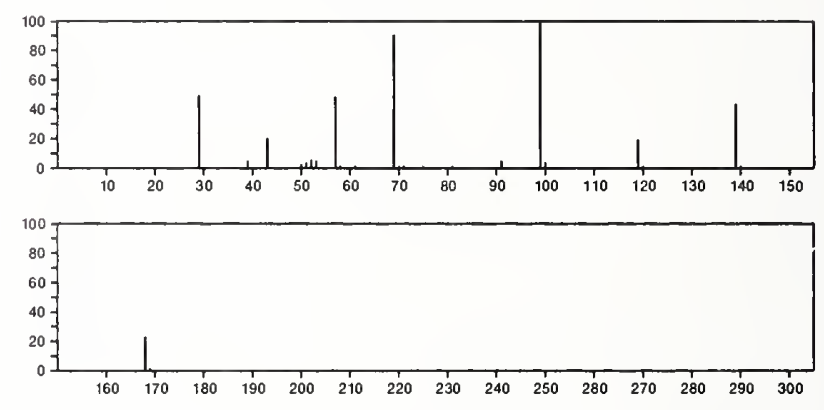

168

$\mathrm{C}_{6} \mathrm{H}_{8} \mathrm{~N}_{4} \mathrm{O}_{2}$

$35975-28-1$

Formamide, $N, N^{\prime}-2,6$-piperazinediylidenebis-
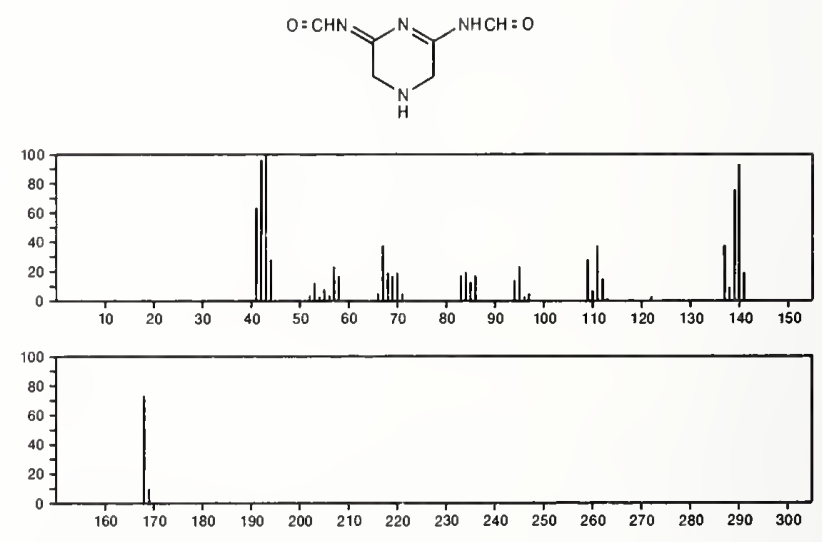

168

$\mathrm{C}_{6} \mathrm{H}_{12} \mathrm{~N}_{6}$

$s$-Tetrazine, 3,6-bis(dimethylamino)-

$877-77-0$<smiles>CNc1nnc(N)nn1</smiles>
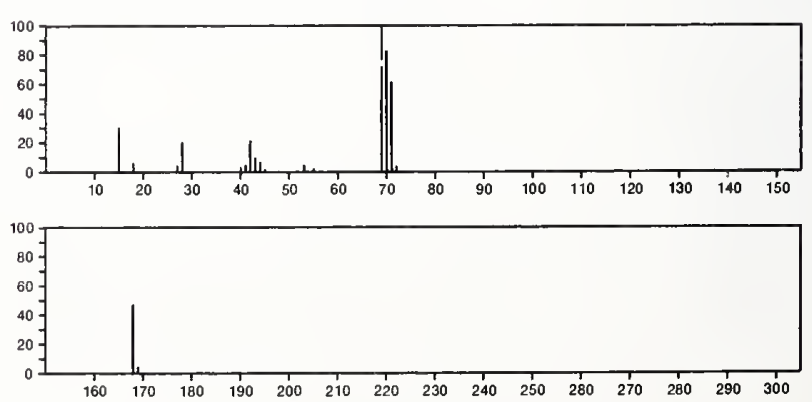
168

$\mathrm{C}_{6} \mathrm{H}_{13} \mathrm{ClO}_{3}$

Ethanol, 2-[2-(2-chloroethoxy)ethoxy]-

$5197-62-6$

$\mathrm{HOCH}_{2} \mathrm{CH}_{2} \mathrm{OCH}_{2} \mathrm{CH}_{2} \mathrm{OCH}_{2} \mathrm{CH}_{2} \mathrm{Cl}$

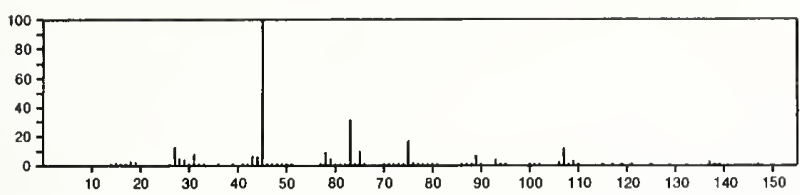

168

Boroxin, triethyl-

$\mathrm{C}_{6} \mathrm{H}_{15} \mathrm{~B}_{3} \mathrm{O}_{3}$

$3043-60-5$<smiles>CCB1OB(CC)OB(CC)O1</smiles>
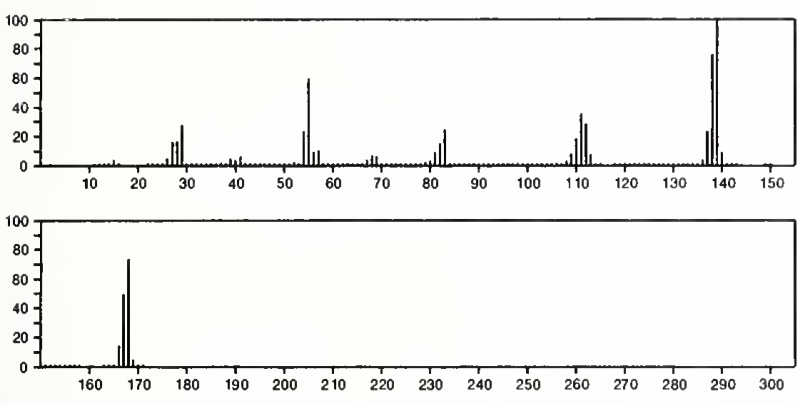

168

$\mathrm{C}_{7} \mathrm{H}_{5} \mathrm{ClN}_{2} \mathrm{O}$

61-80-3

2-Benzoxazolamine, 5-chloro-
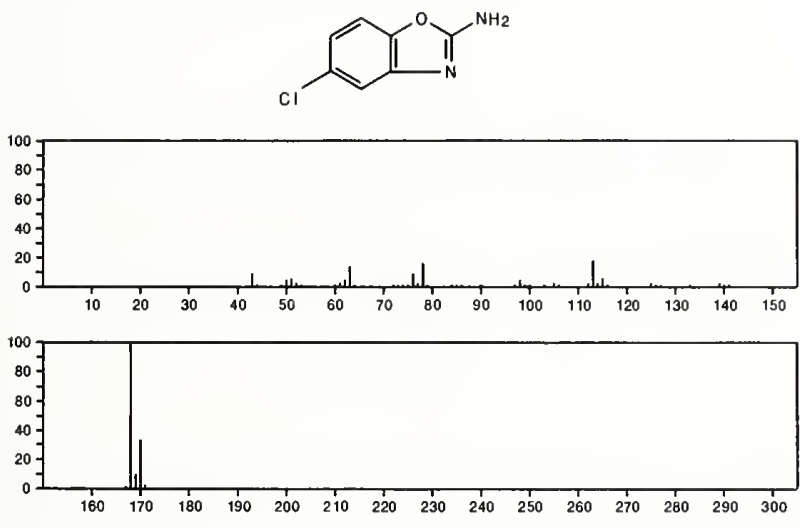

168

$\mathrm{C}_{7} \mathrm{H}_{8} \mathrm{~N}_{2} \mathrm{OS}$

24614-07-1

Thiazolo[3,2-c]pyrimidin-4-ium, 2,3-dihydro-8-hydroxy-5-methyl-, hydroxide, inner salt
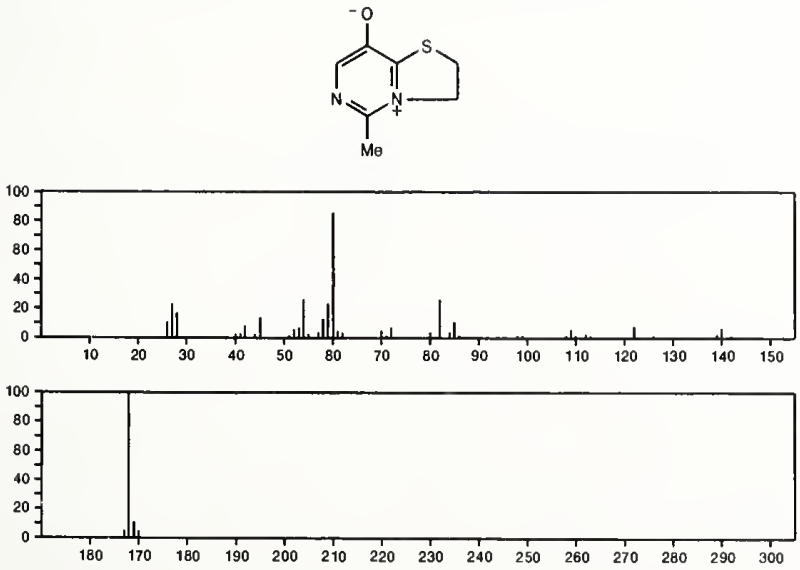

168

Heptane, 1,1-dichloro-

$\mathrm{C}_{7} \mathrm{H}_{44} \mathrm{Cl}_{2}$

$821-25-0$

$\mathrm{Cl}{ }_{2} \mathrm{CH}\left(\mathrm{CH}_{2}\right) 5 \mathrm{Me}$
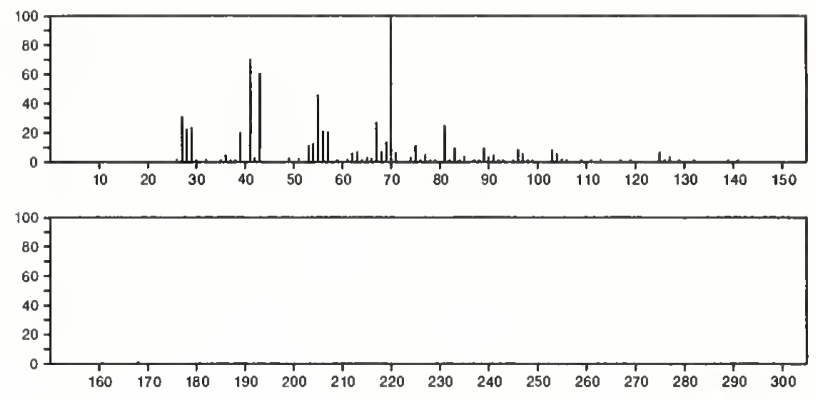

168

Hexane, 1,1-dichloro-3-methyl-

$16703-32-5$

$\mathrm{PrCHMeCH} \mathrm{CHCl}_{2}$
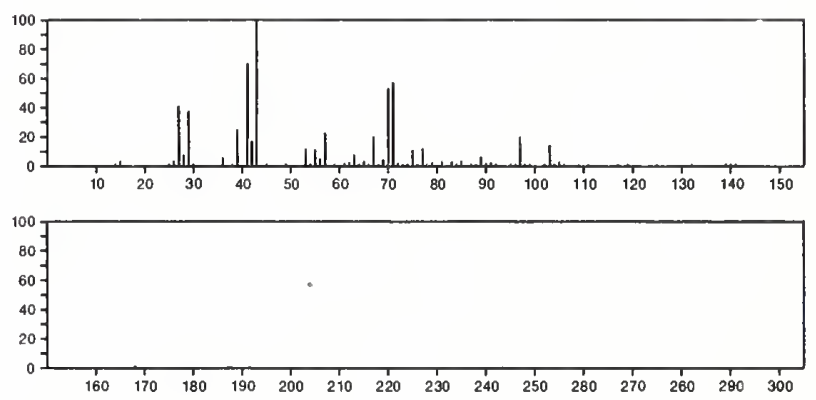

$168 \quad \mathrm{C}_{8} \mathrm{H}_{5} \mathrm{ClS}$

Benzo $[b]$ thiophene, 3-chloro-
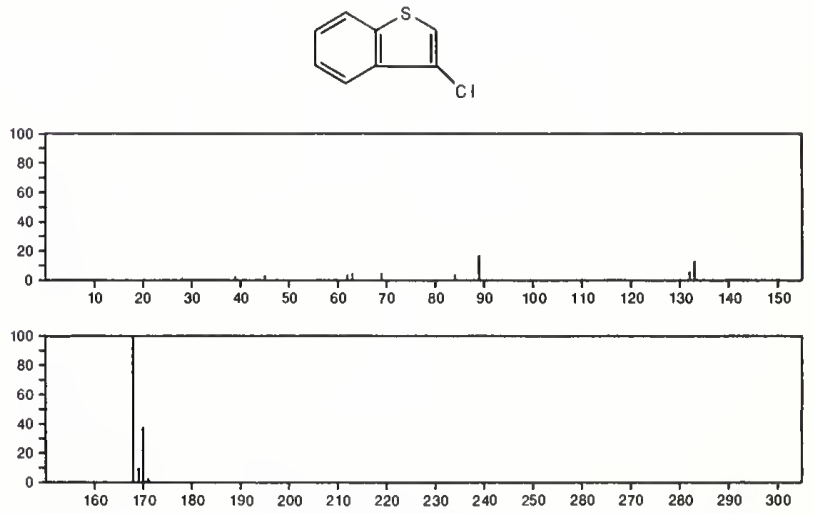

168
Acetic acid, (phenylthio)

$\mathrm{C}_{8} \mathrm{H}_{8} \mathrm{O}_{2} \mathrm{~S}$

$103-04-8$

$\mathrm{HO}_{2} \mathrm{CCH}_{2} \mathrm{SPh}$
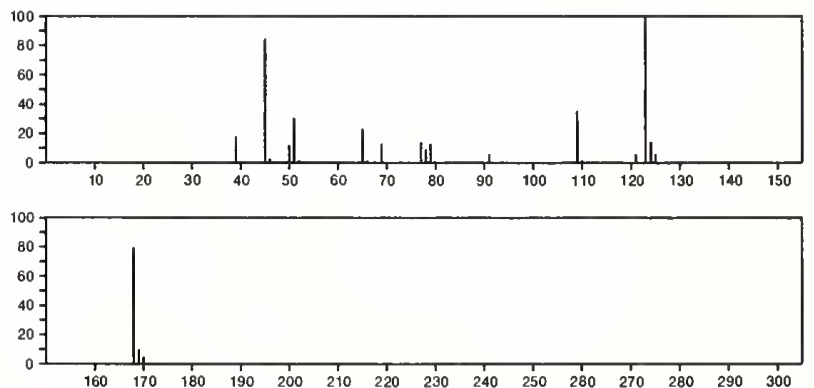
168

$\mathrm{C}_{8} \mathrm{H}_{8} \mathrm{O}_{2} \mathrm{~S}$

$1007-37-0$

Carbonic acid, thio-, $\mathrm{O}^{- \text {methyl } O} \mathrm{O}$-phenyl ester

PhOC(S) OMe
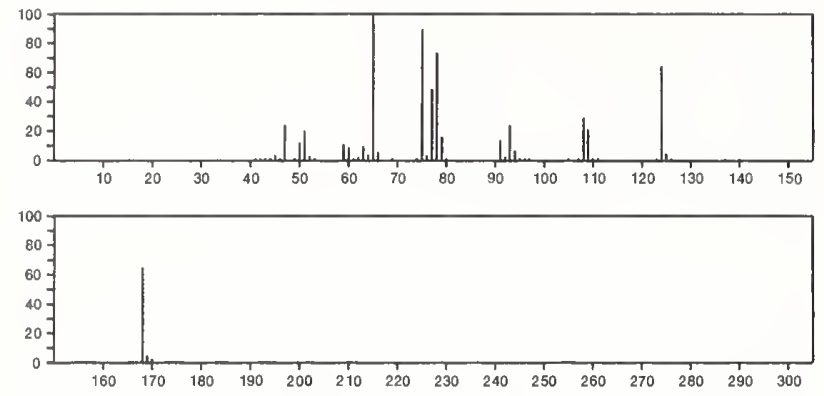

168

$\mathrm{C}_{8} \mathrm{H}_{8} \mathrm{O}_{2} \mathrm{~S}$

$3186-52-5$

Carbonothioic acid, $O$-methyl $S$-phenyl ester

$\mathrm{PhSC}(\mathrm{O}) \mathrm{OMe}$
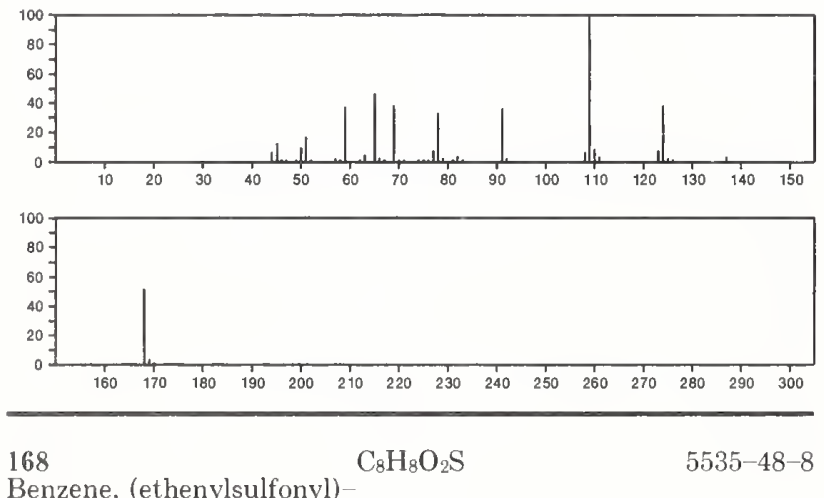

Benzene, (ethenylsulfonyl)

$\mathrm{H}_{2} \mathrm{C}=\mathrm{CHSO}_{2} \mathrm{Ph}$
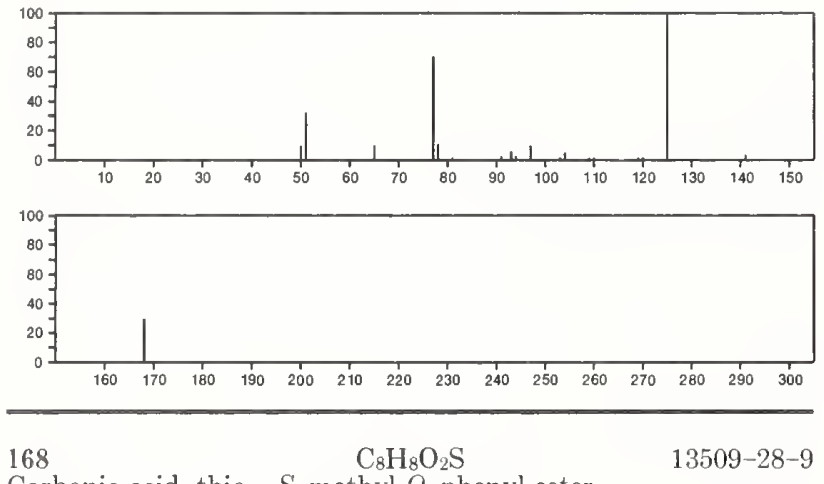

Carbonic acid, thio-, $S$-methyl $O$-phenyl ester

PhOC (O) SMe
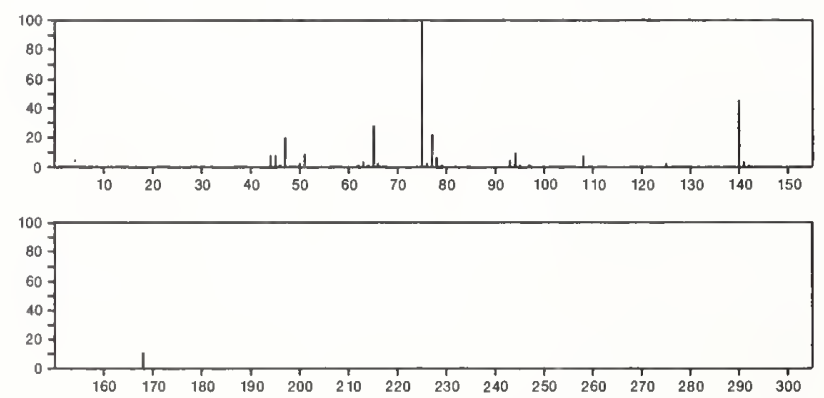

168

$\mathrm{C}_{8} \mathrm{H}_{8} \mathrm{O}_{4}$

$102-32-9$

Benzeneacetic acid, 3,4-dihydroxy-
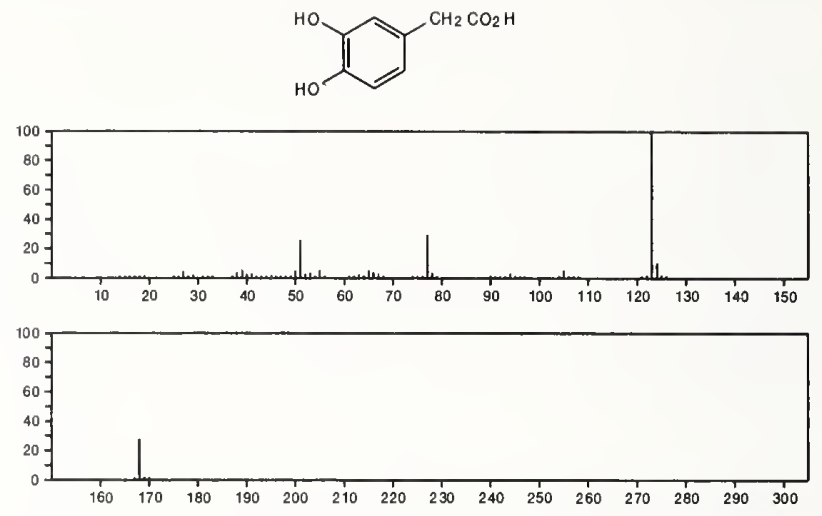

168

$\mathrm{C}_{8} \mathrm{H}_{8} \mathrm{O}_{4}$

Benzoic acid, 4-hydroxy-3-methoxy--

$121-34-6$
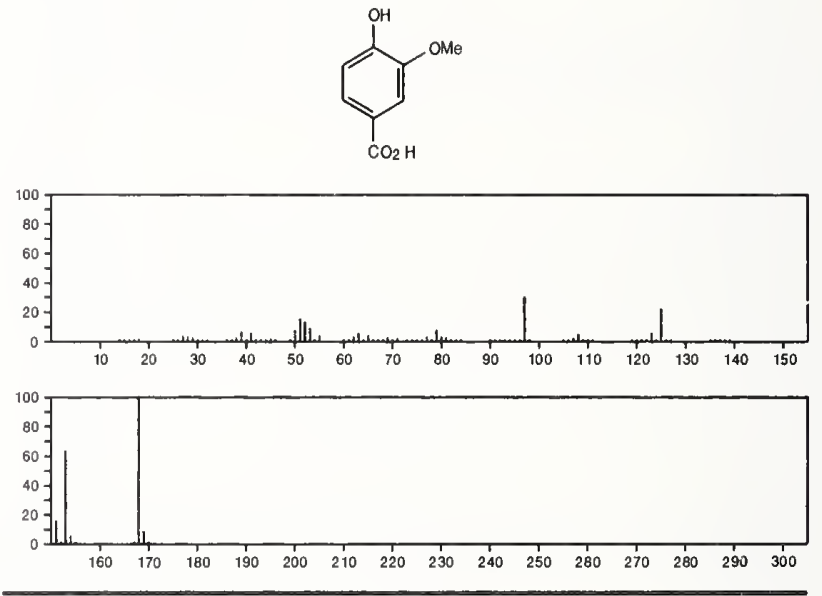

168

$\mathrm{C}_{8} \mathrm{H}_{8} \mathrm{O}_{4}$

Benzeneacetic acid, 2,5-dihydroxy-

$451-13-8$
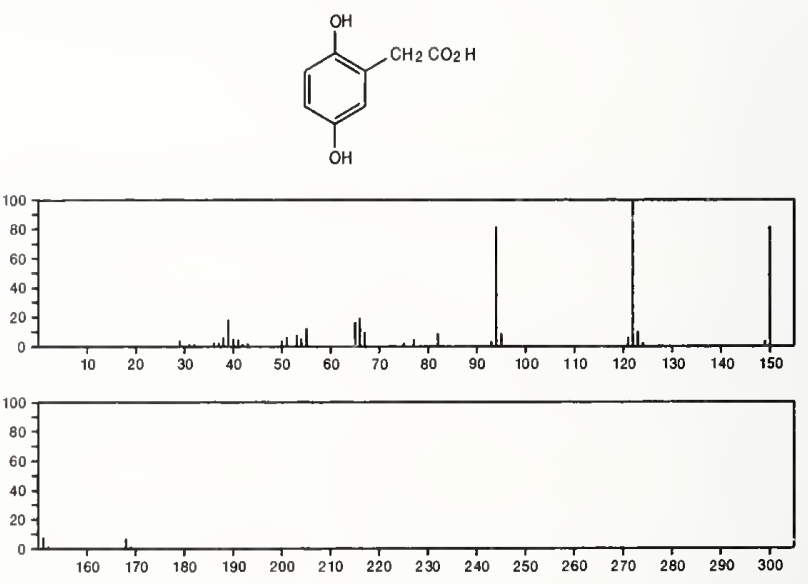
168

Benzoic acid, 2,4-dihydroxy-6-methyl-
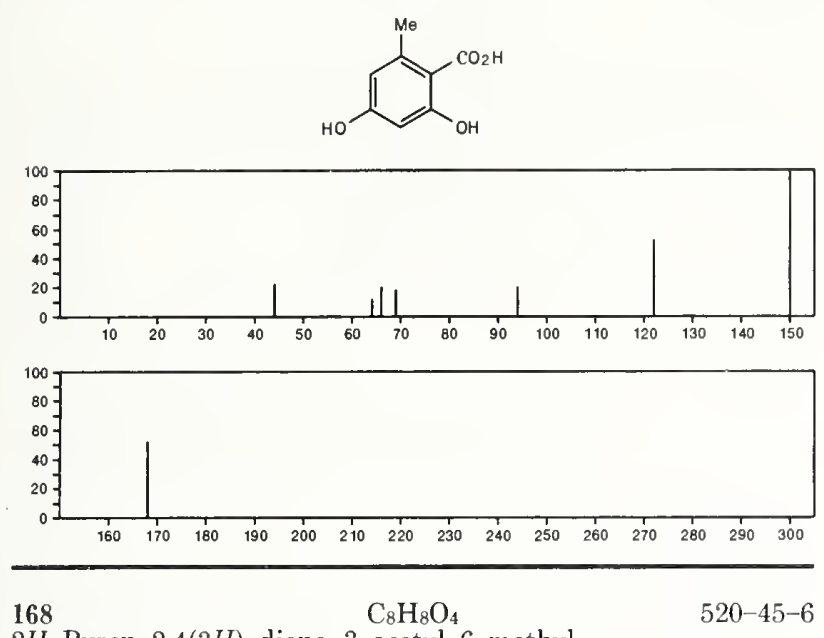

2H-Pyran-2,4(3H)-dione, 3-acetyl-6-methyl-
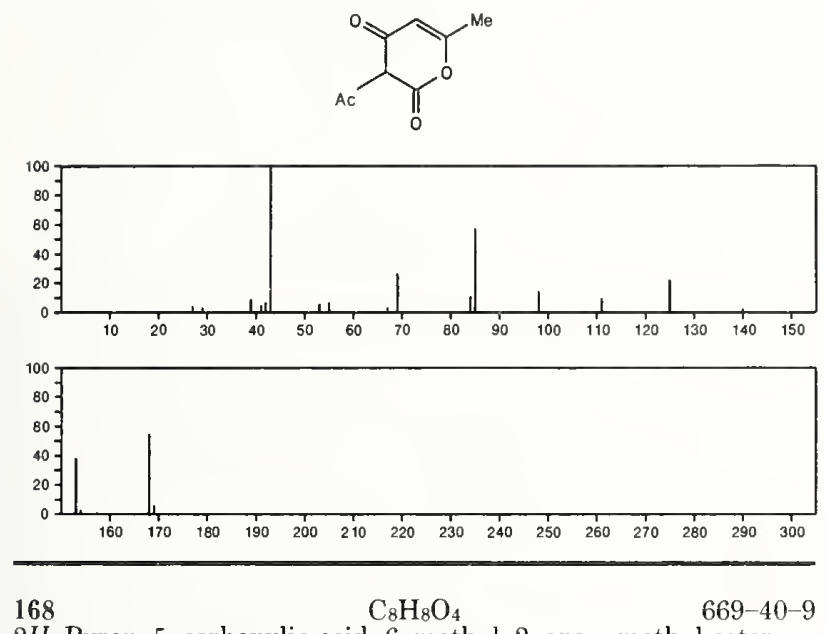

2H-Pyran-5-carboxylic acid, 6-methyl-2-oxo-, methyl ester
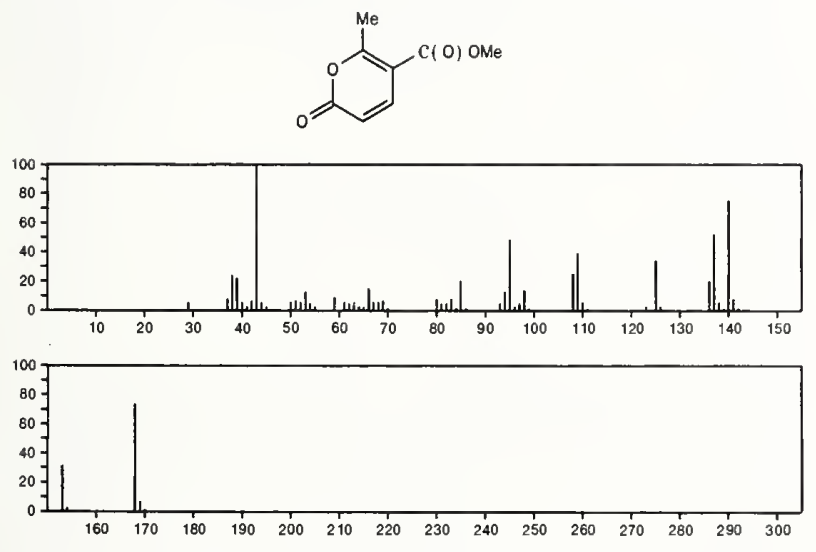

168

$\mathrm{C}_{8} \mathrm{H}_{8} \mathrm{O}_{4}$

Benzeneacetic acid, $\alpha, 4$-dihydroxy-
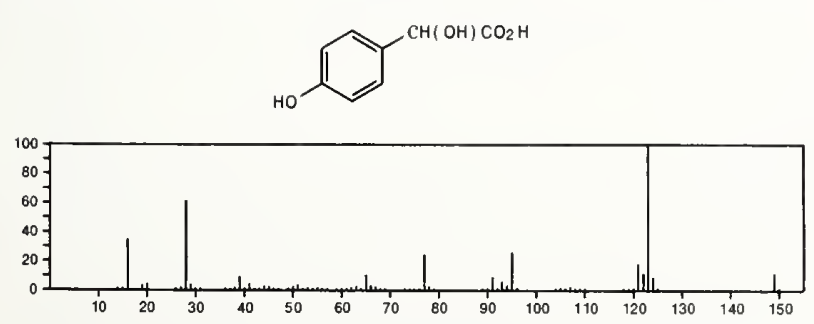

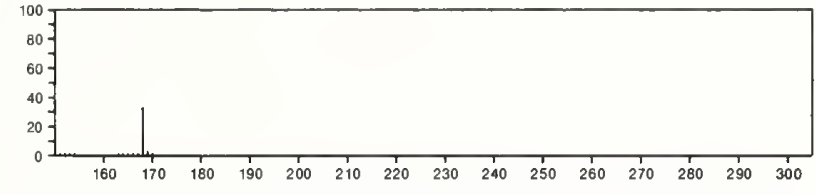

168

$\mathrm{C}_{8} \mathrm{H}_{8} \mathrm{O}_{4}$

$2150-43-8$

Benzoic acid, 3,4-dihydroxy-, methyl ester
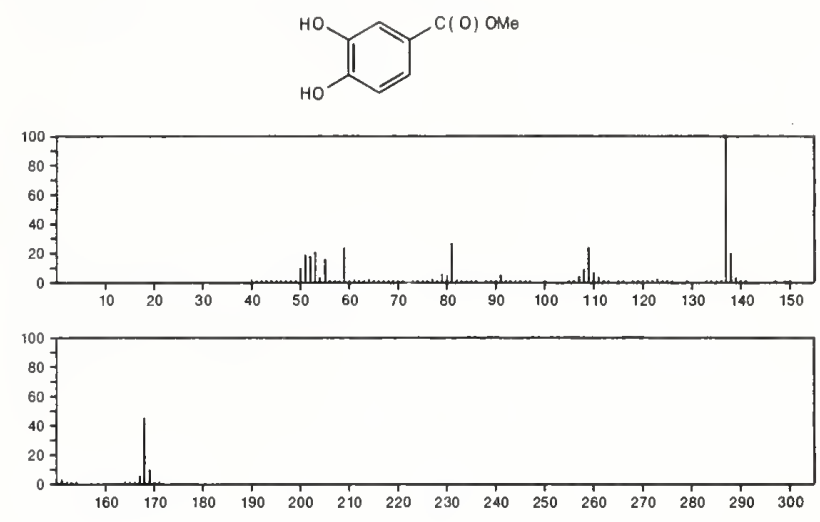

168

$\mathrm{C}_{8} \mathrm{H}_{8} \mathrm{O}_{4}$

$2150-45-0$

Benzoic acid, 2,6-dihydroxy-, methyl ester
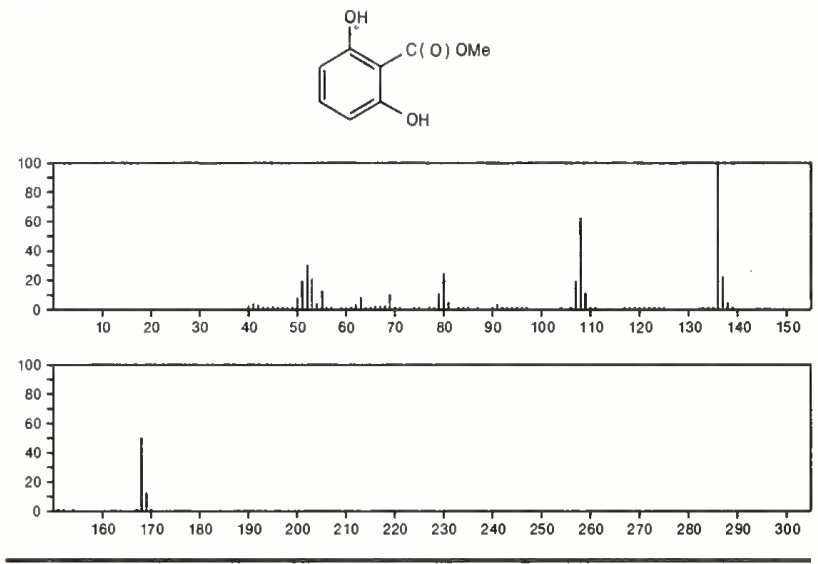

168

$\mathrm{C}_{8} \mathrm{H}_{8} \mathrm{O}_{4}$

$2150-46-1$

Benzoic acid, 2,5-dihydroxy-, methyl ester
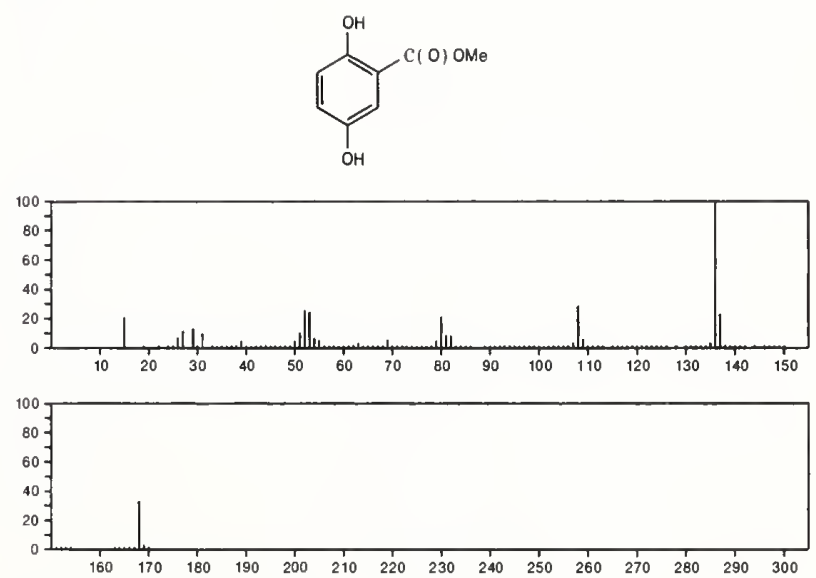
168

$\mathrm{C}_{8} \mathrm{H}_{8} \mathrm{O}_{4}$

Benzoic acid, 2,4-dihydroxy-, methyl ester

$2150-47-2$
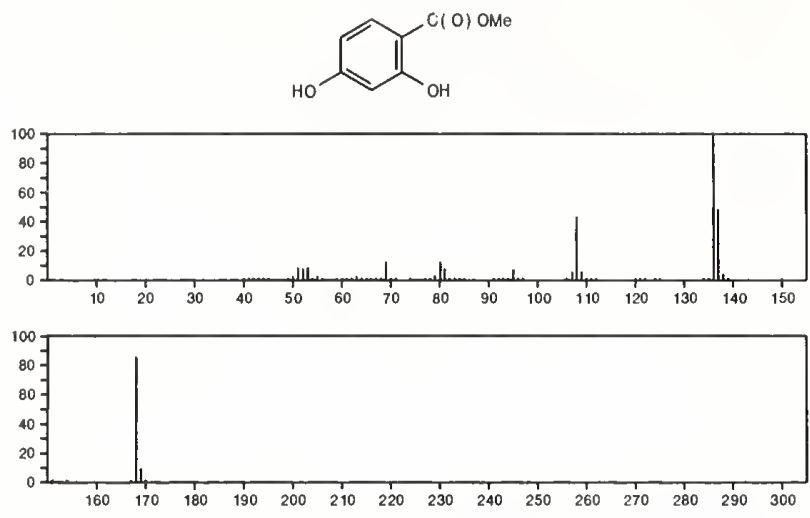

168

$\mathrm{C}_{8} \mathrm{H}_{8} \mathrm{O}_{4}$

Benzoic acid, 2,3-dihydroxy-, methyl ester
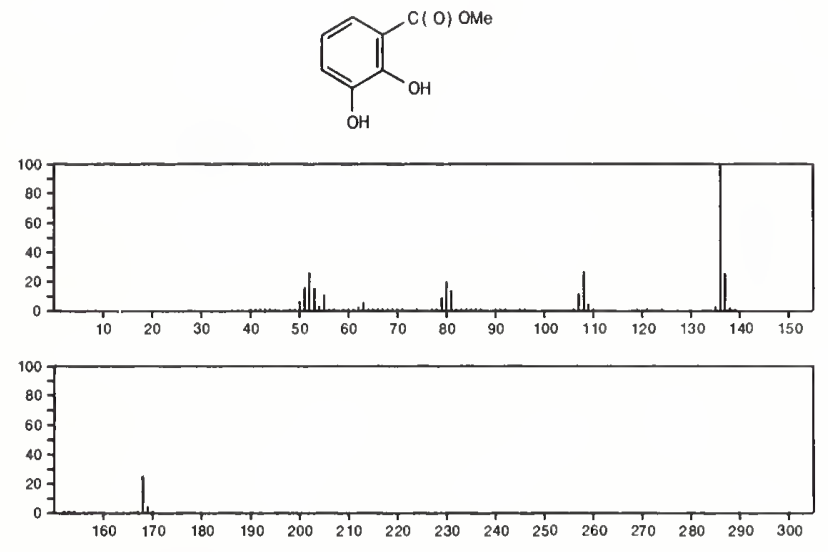

$168 \quad \mathrm{C}_{8} \mathrm{H}_{8} \mathrm{O}_{4} \quad 2654-72-0$ 2,5-Cyclohexadiene-1,4-dione, 2,5-dihydroxy-3,6-dimethyl-
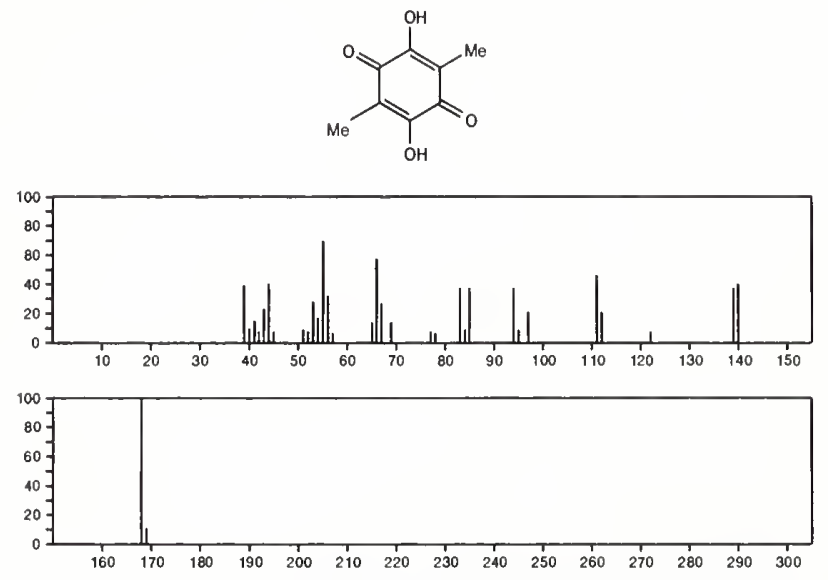

$168 \quad \mathrm{C}_{8} \mathrm{H}_{8} \mathrm{O}_{4}$

Benzeneacetic acid, $\alpha, 3$-dihydroxy-

$17119-15-2$
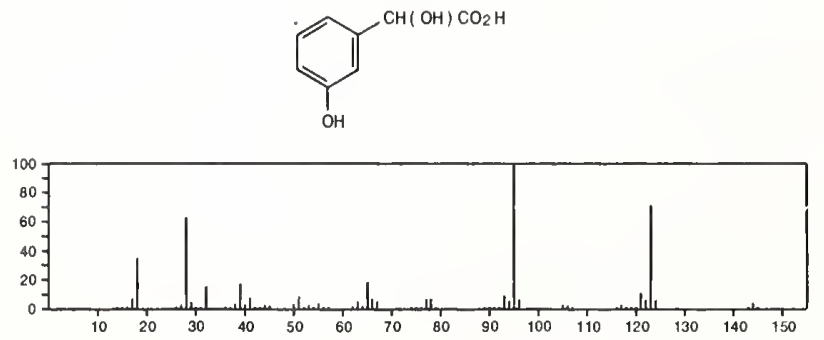

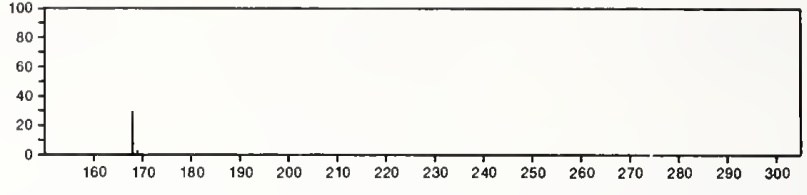

168 $\mathrm{C}_{8} \mathrm{H}_{8} \mathrm{~S}_{2}$

2168-78-7

Benzenecarbodithioic acid, methyl ester

$\mathrm{MeSC}(\mathrm{S}) \mathrm{Ph}$
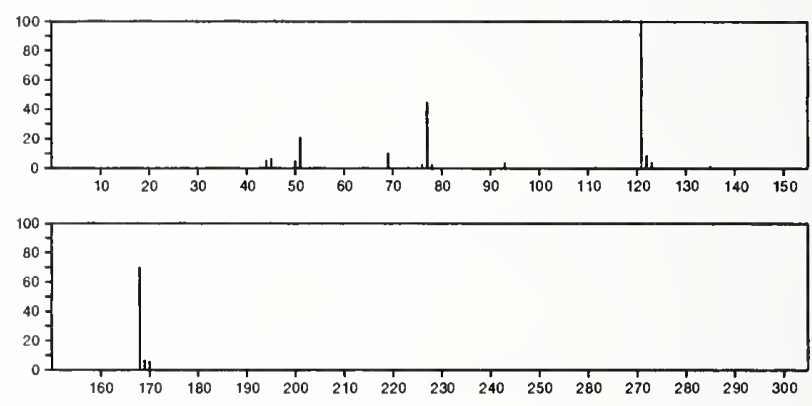

168

$\mathrm{C}_{8} \mathrm{H}_{12} \mathrm{~N}_{2} \mathrm{O}_{2}$

7454-99-1

Uracil, 6-methyl-3-propyl-
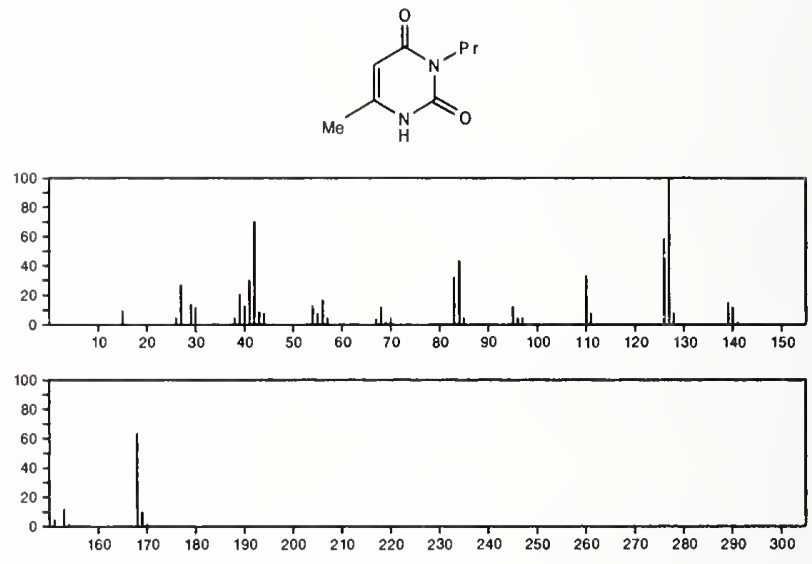

168

$\mathrm{C}_{8} \mathrm{H}_{12} \mathrm{~N}_{2} \mathrm{O}_{2}$

20600-69-5

Sydnone, 3-cyclohexyl-
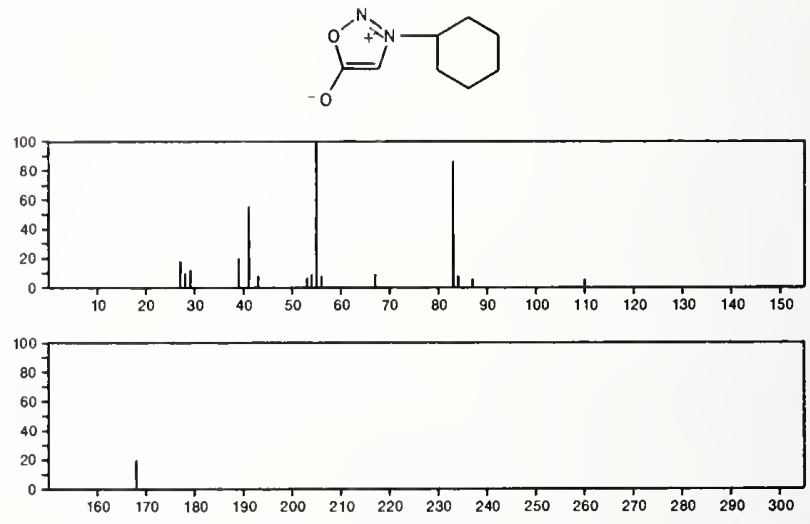
168

$\mathrm{C}_{8} \mathrm{H}_{12} \mathrm{~N}_{2} \mathrm{O}_{2}$

24614-11-7

$4(3 H)$-Pyrimidinone, 5-ethoxy-2,3-dimethyl<smiles>CCOc1cnc(C)n(C)c1=O</smiles>
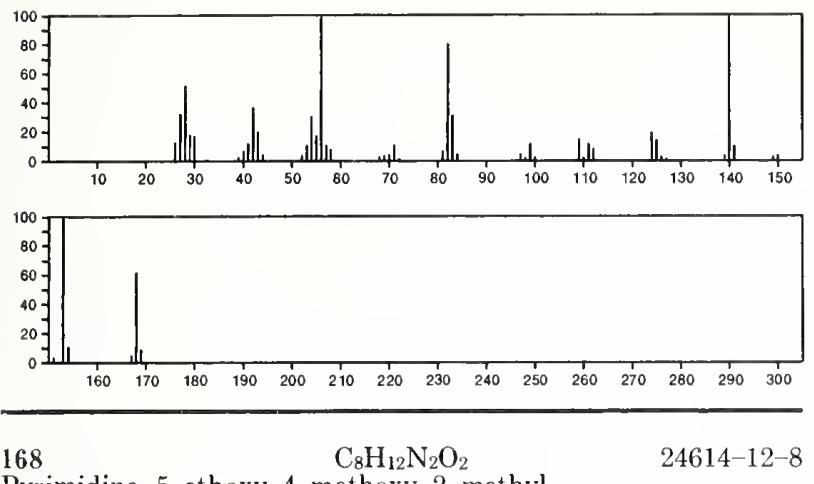

Pyrimidine, 5-ethoxy-4-methoxy-2-methyl-
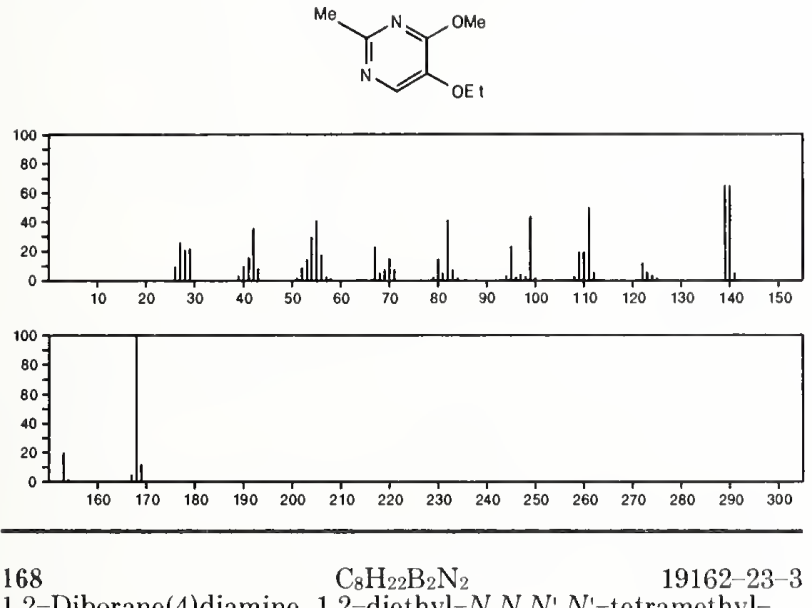

1,2-Diborane(4)diamine, 1,2-diethyl- $N, N, N^{\prime}, N^{\prime}$-tetramethyl-

$\mathrm{Me} 2 \mathrm{NBE}$ ? BE $\left\{\mathrm{NM}{ }_{2}\right.$
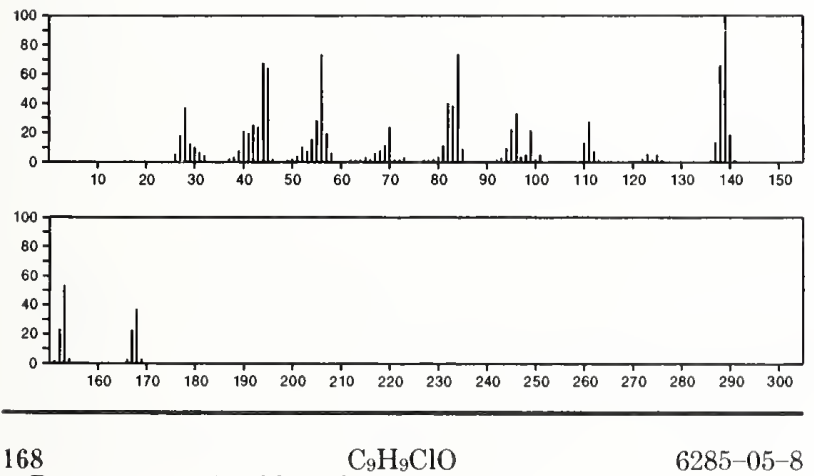

1-Propanone, 1-(4-chlorophenyl)-
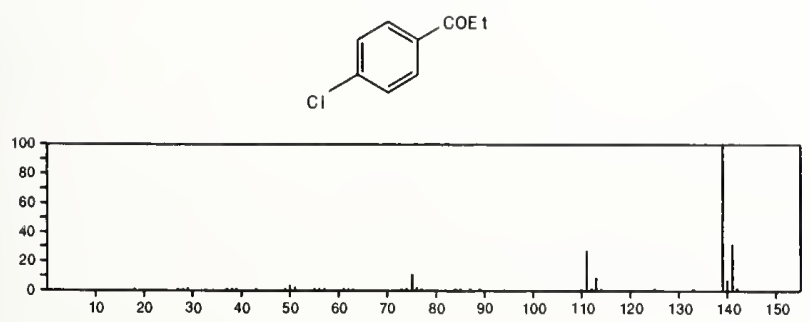

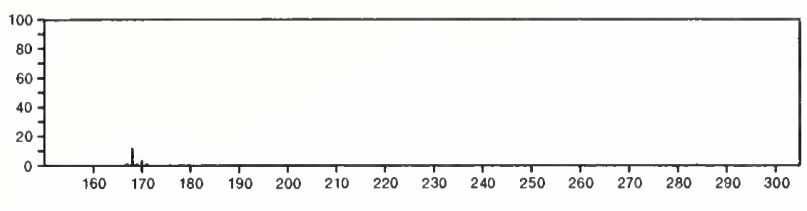

168

$\mathrm{C}_{9} \mathrm{H}_{9} \mathrm{ClO}$

$37074-39-8$

Ethanone, 1-(4-chloro-3-methylphenyl)-<smiles>Cc1ccc(Cl)c([N+](=O)[O-])c1</smiles>
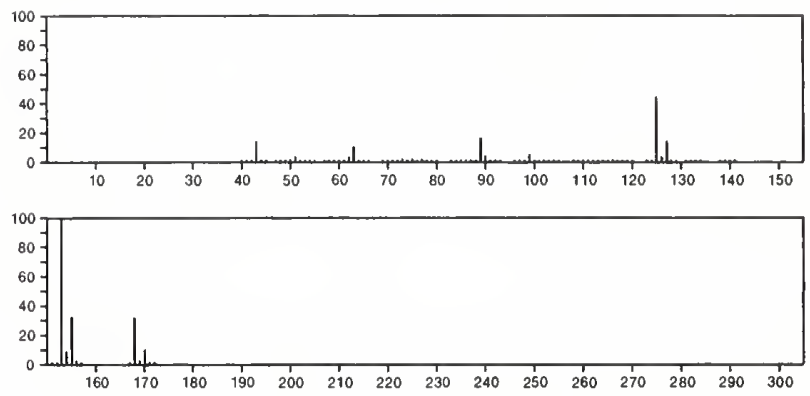

168

$\mathrm{C}_{9} \mathrm{H}_{9} \mathrm{ClO}$

Benzene, [(2-chloro-2-propenyl)oxy]-

53299-53-9

$\mathrm{PhOCH}_{2} \mathrm{CCl}=\mathrm{CH}_{2}$
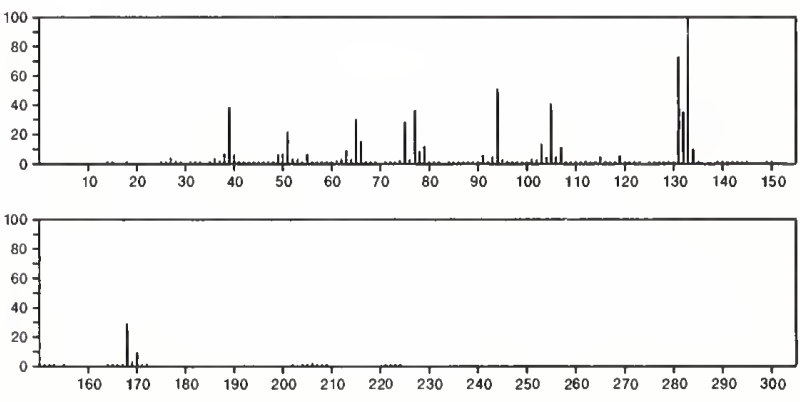

168

$\mathrm{C}_{9} \mathrm{H}_{9} \mathrm{ClO}$

Benzene, [(3-chloro-2-propenyl)oxy]-

$54410-95-6$

$\mathrm{Cl} \mathrm{CH}=\mathrm{CHCH}_{2} \mathrm{OPh}$
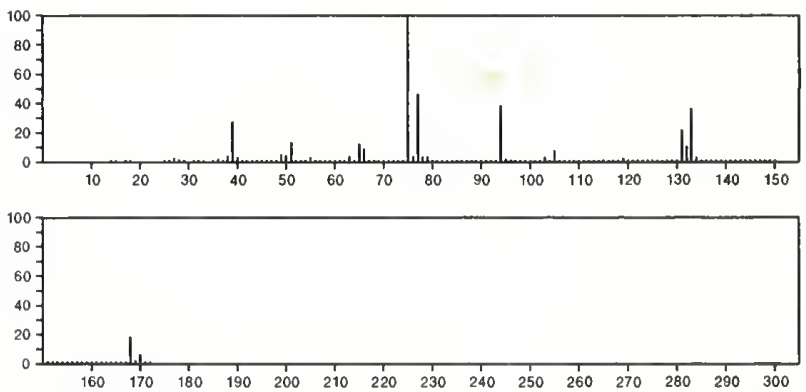

168

$\mathrm{C}_{9} \mathrm{H}_{9} \mathrm{ClO}$

Benzofuran, 5-chloro-2,3-dihydro-2-methyl-

$54410-96-7$
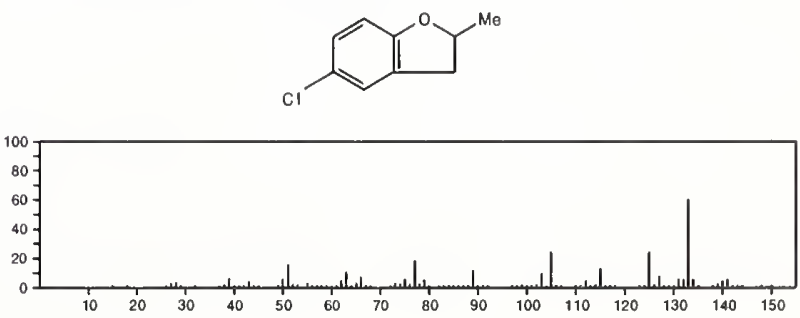


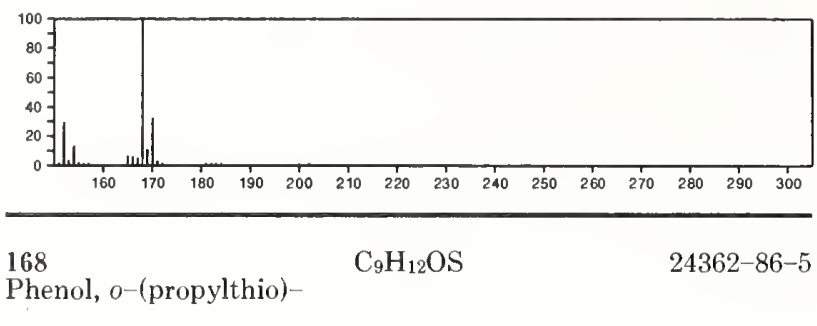

168

1,2-Propanediol, 3-phenoxy-

$\mathrm{C}_{9} \mathrm{H}_{12} \mathrm{O}_{3}$
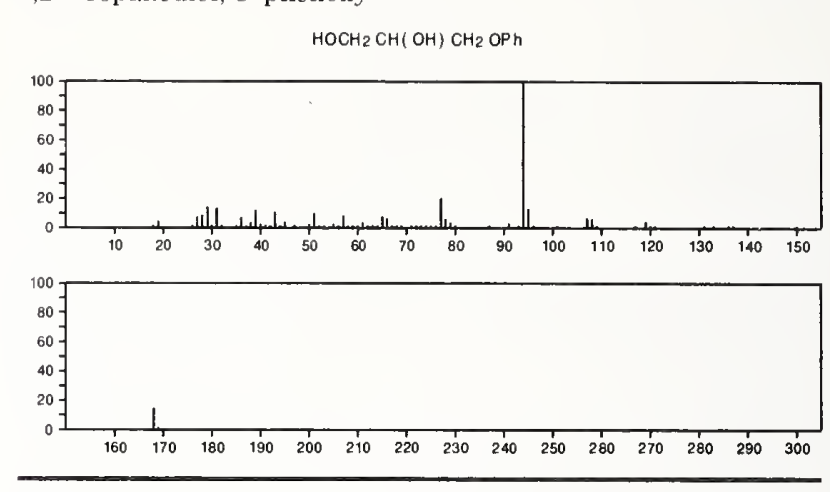

168

$\mathrm{C}_{9} \mathrm{H}_{12} \mathrm{O}_{3}$

583-33-5

2-Furancarboxylic acid, butyl ester

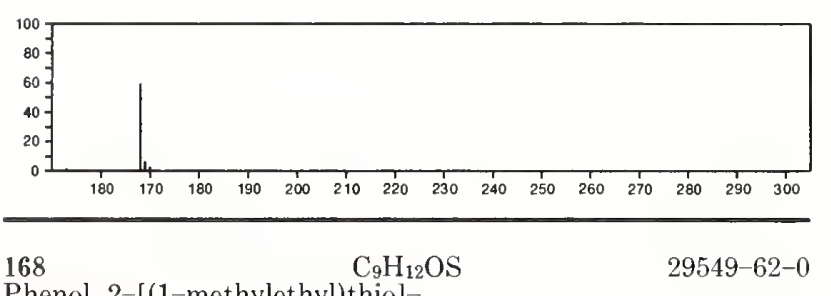

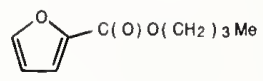
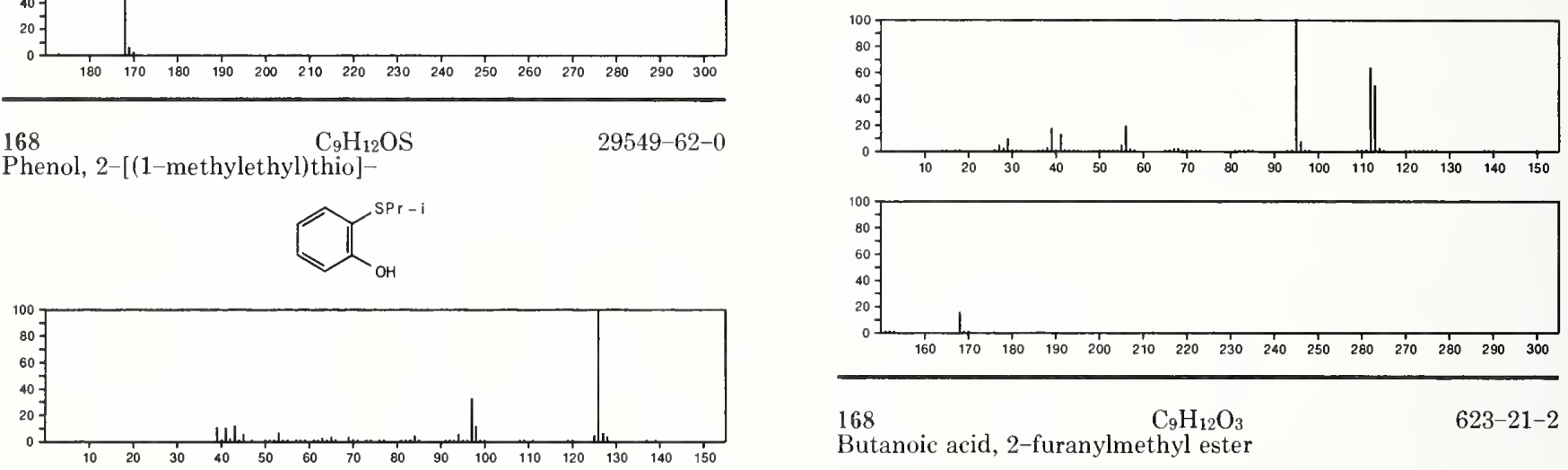

168

$\mathrm{C}_{9} \mathrm{H}_{12} \mathrm{O}_{3}$

Butanoic acid, 2-furanylmethyl ester

623-21-2

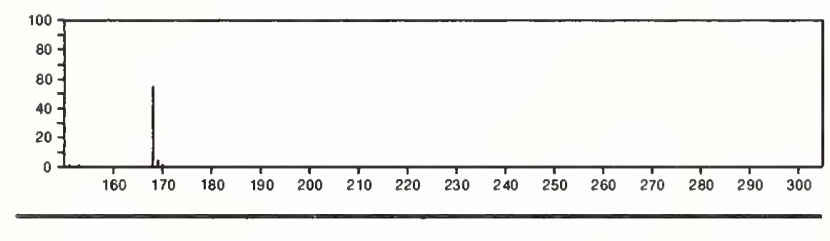

$168 \quad \mathrm{C}_{9} \mathrm{H}_{12} \mathrm{O}_{3}$

93-03-8

Benzenemethanol, 3,4-dimethoxy-
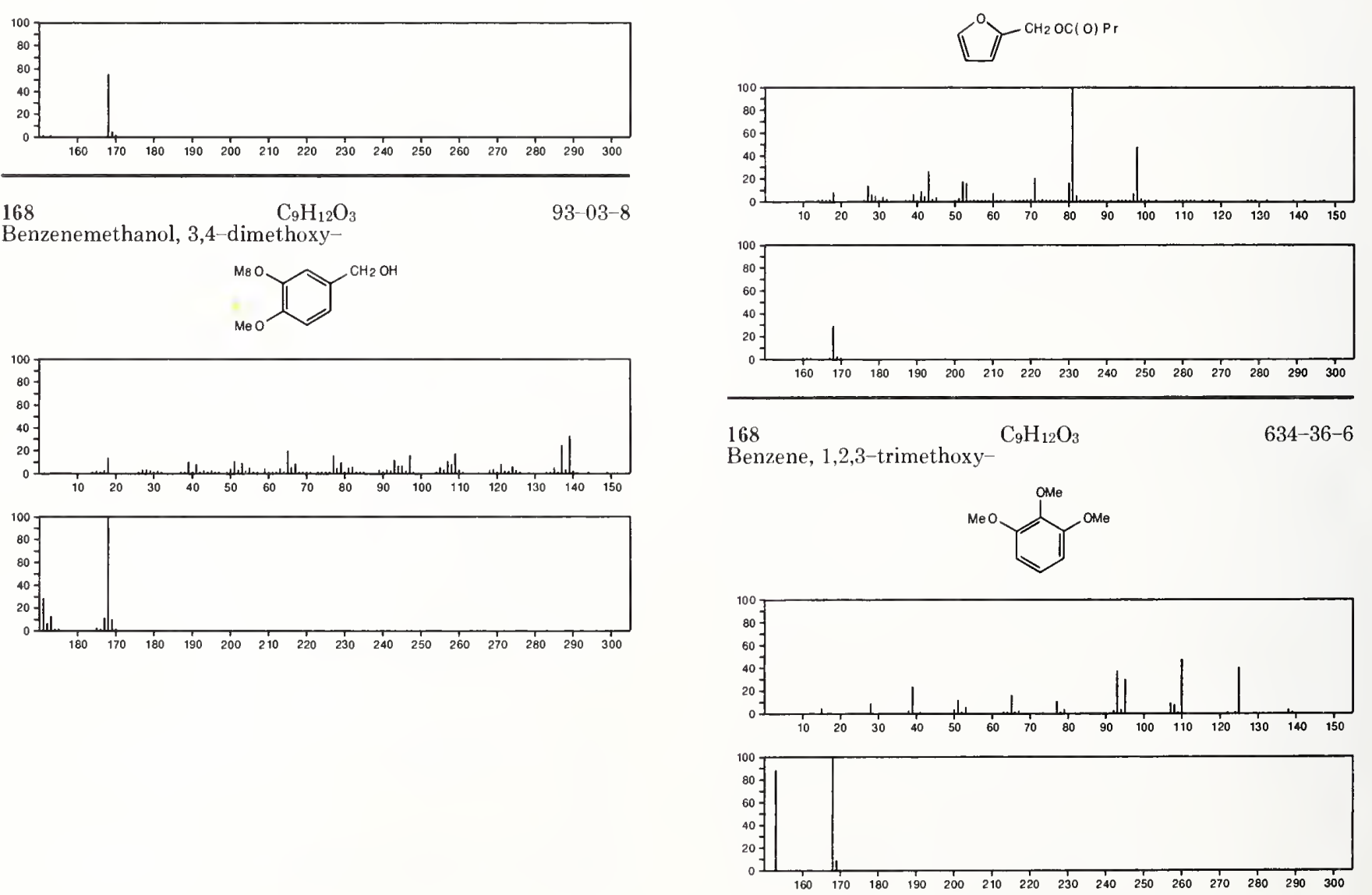
$168 \quad \mathrm{C}_{9} \mathrm{H}_{12} \mathrm{O}_{3}$

Benzeneethanol, 4-hydroxy-3-methoxy-
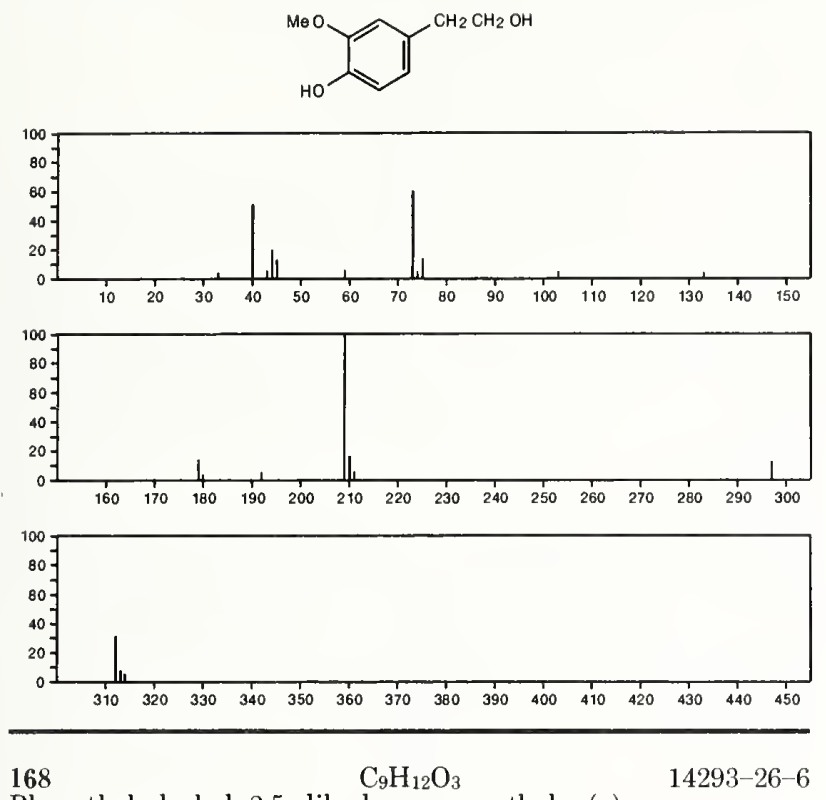

Phenethyl alcohol, 2,5-dihydroxy- $\alpha$-methyl-, (-)-
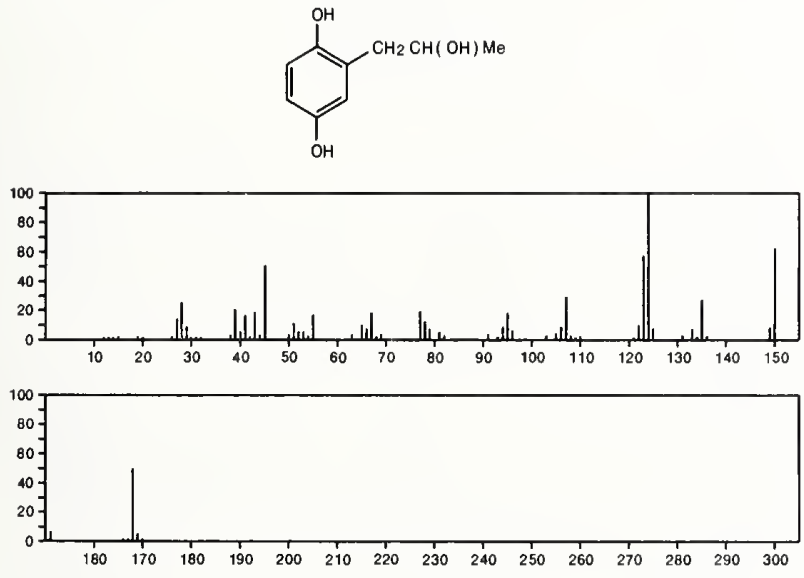

168

3-Butene-1,2-diol, 1-(2-furanyl)-2-methyl-

$18927-20-3$
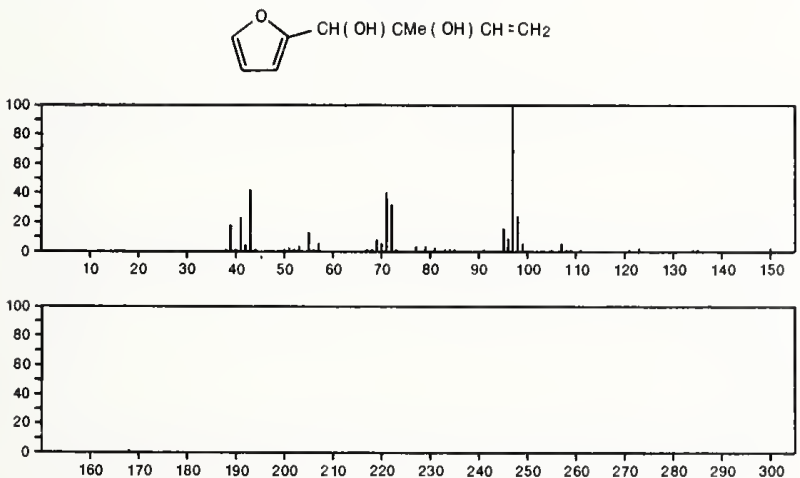

$168 \quad \mathrm{C}_{9} \mathrm{H}_{12} \mathrm{O}_{3}$

3-Butene-1,2-diol, 1-(2-furanyl)-3-methyl-

$21141-71-9$

C $\mathrm{CH}(\mathrm{OH}) \mathrm{CH}(\mathrm{OH}) \mathrm{CMe}_{\mathrm{C}}=\mathrm{CH}_{2}$
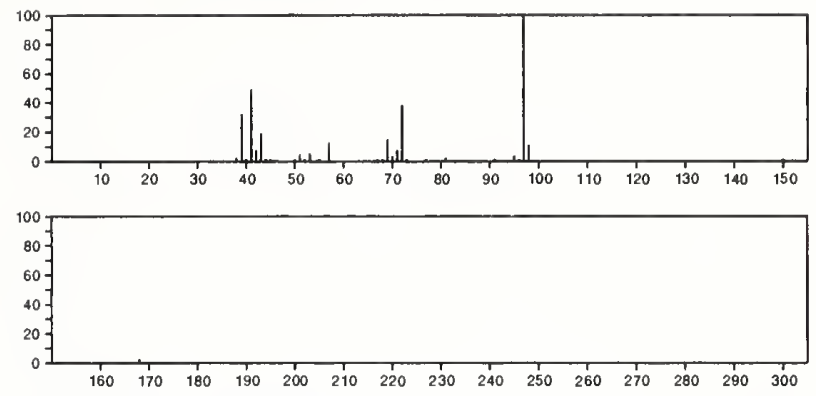

168

1,2,4-Cyclopentanetrione, 3-butyl-

$46005-09-8$
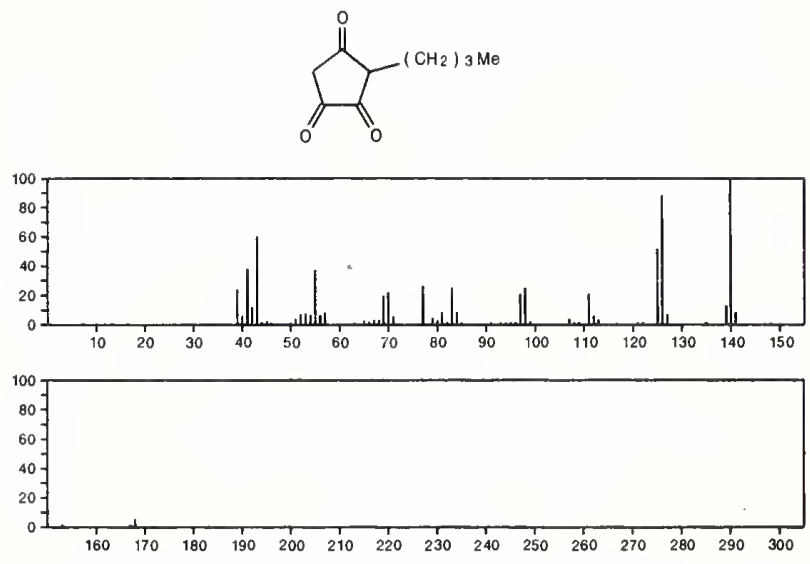

168

$\mathrm{C}_{9} \mathrm{H}_{12} \mathrm{O}_{3}$

$55956-42-8$

Cyclohexanecarboxylic acid, 3-methylene-2-0xo-, methyl ester
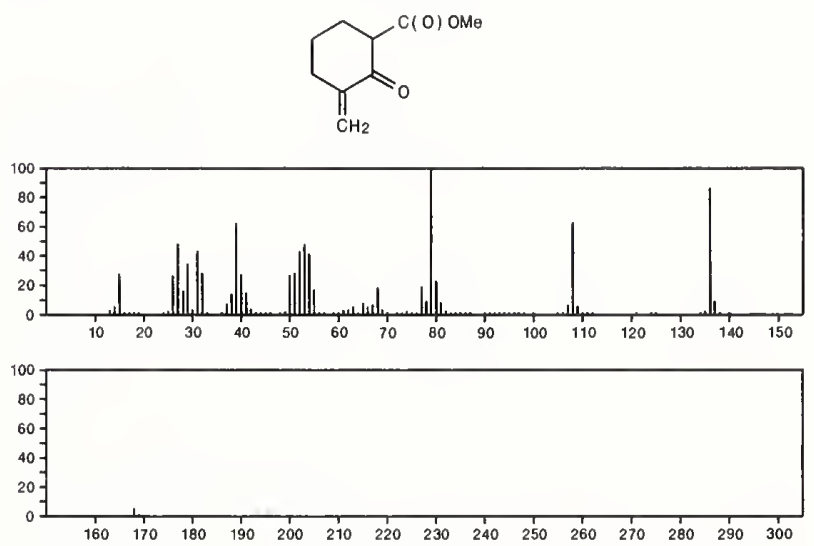

$\begin{array}{lllllllllllll}1 & 1_{1} & 1 & 1 & 1 & 1 & 1 & 1 & 1 & 1 & 1 & 1 & 1\end{array}$

168

$\mathrm{C}_{9} \mathrm{H}_{16} \mathrm{~N}_{2} \mathrm{O}$

16620-84-1

Pyrido[1,2-d][1,4]diazepin-2(3H)-one, octahydro-
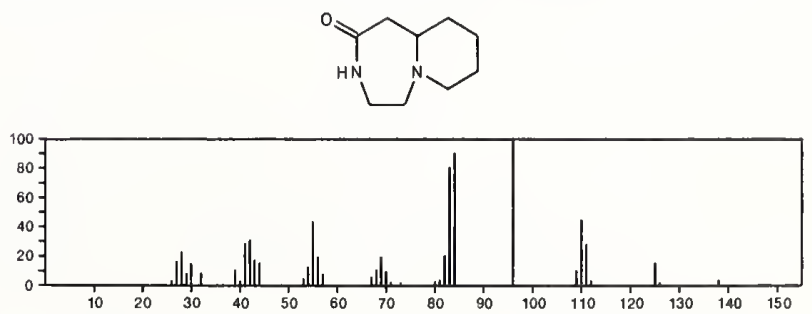


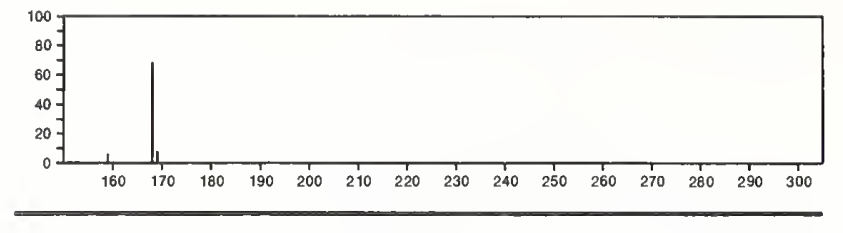

$168 \quad \mathrm{C}_{9} \mathrm{H}_{16} \mathrm{~N}_{2} \mathrm{O} \quad 54411-09-5$ $1 H$-Pyrazole-1-carboxaldehyde, 4-ethyl-4,5-dihydro-5-propyl-
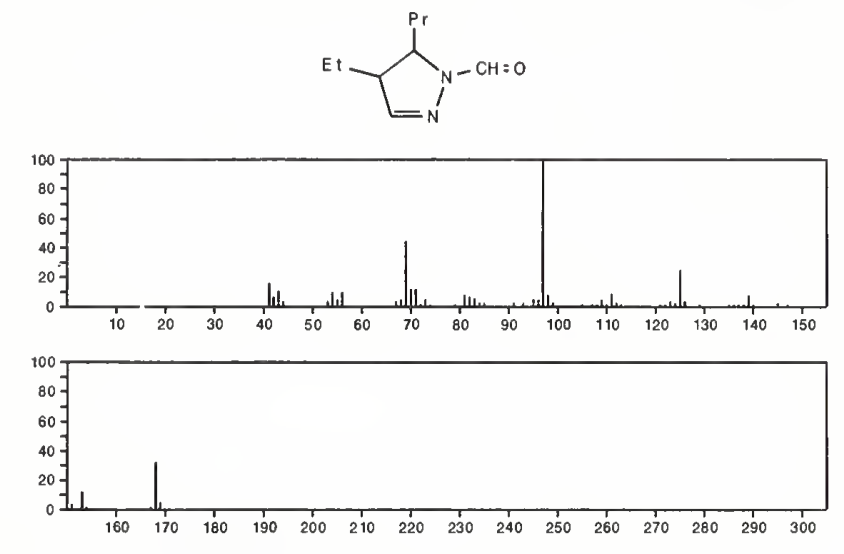

168

$\mathrm{C}_{10} \mathrm{H}_{13} \mathrm{Cl}$

Benzene, 2-chloro-1-methyl-4-(1-methylethyl)-

$4395-79-3$
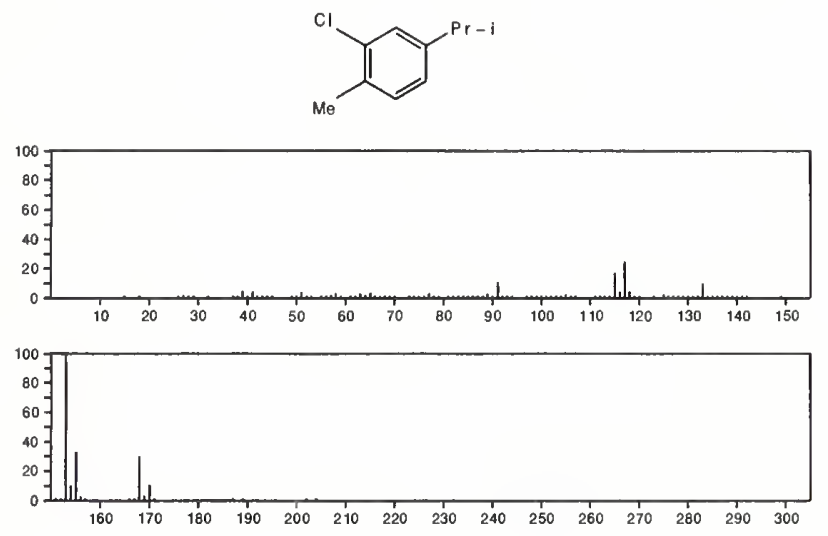

168

Benzene, sec-butylchloro

$\mathrm{C}_{10} \mathrm{H}_{13} \mathrm{Cl}$

$26937-23-5$
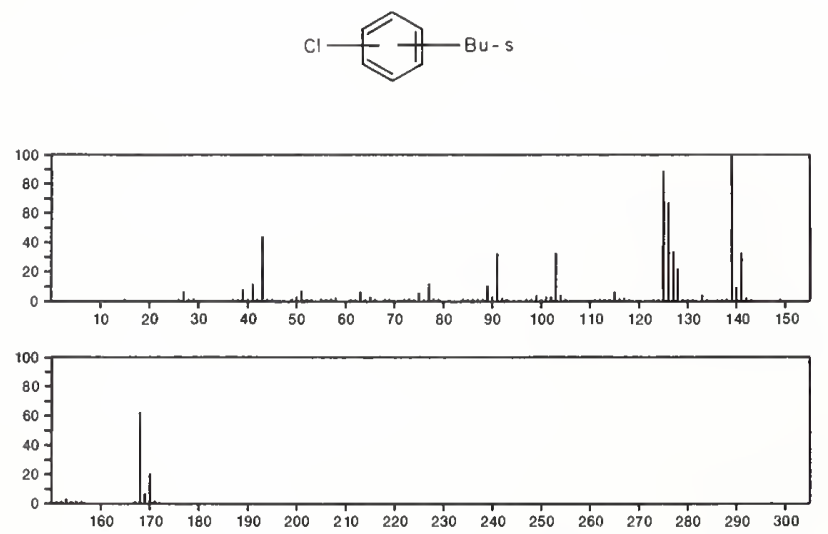

168

Benzene, chloro(1,1-dimethylethyl)-
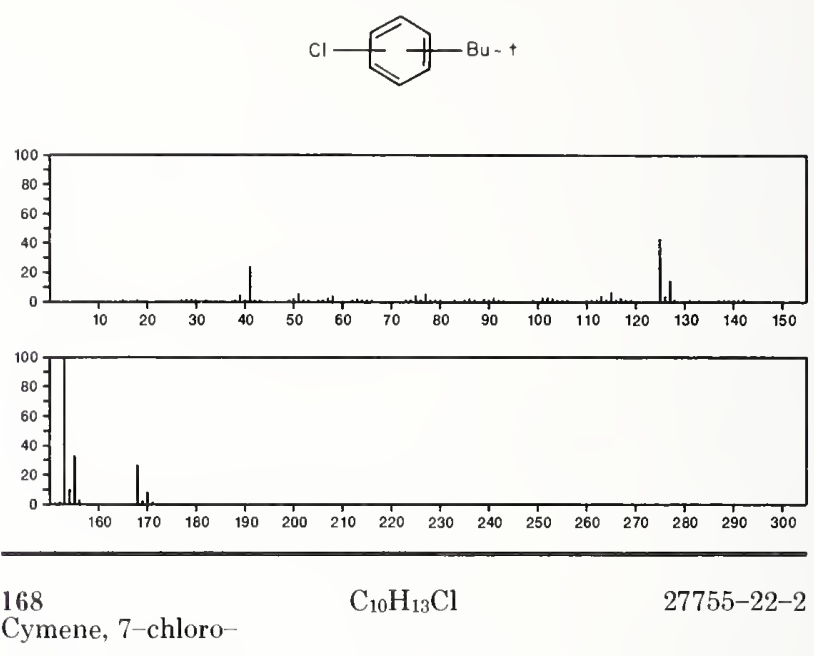

168
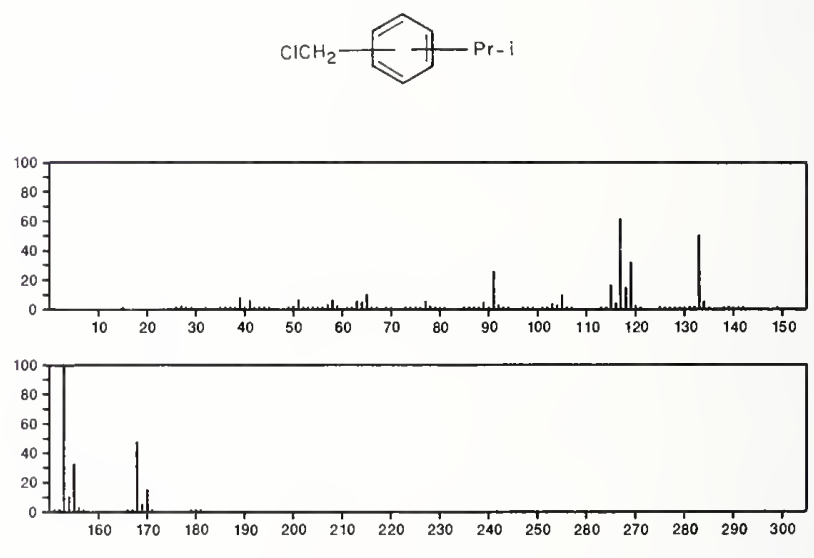

168

$\mathrm{C}_{10} \mathrm{H}_{13} \mathrm{Cl}$

Benzene, chloro-1-methyl-4-(1-methylethyl)-

54411-19-7
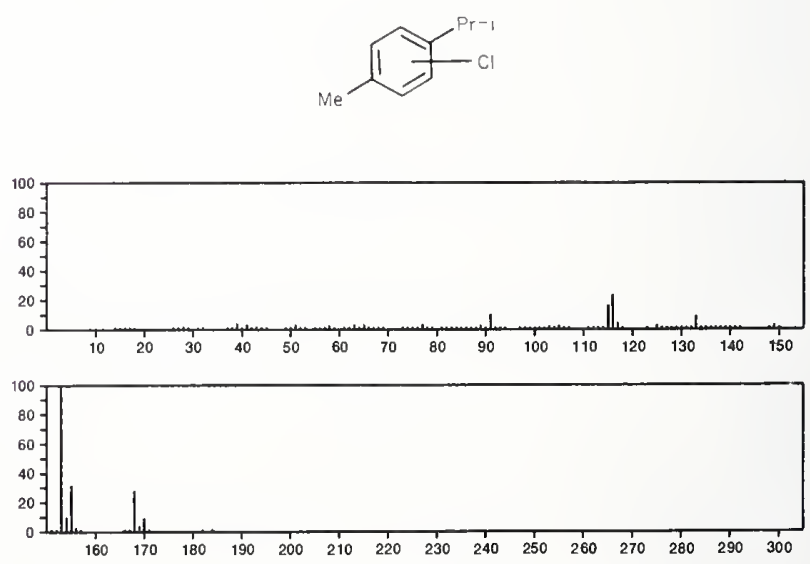
168 $\mathrm{C}_{10} \mathrm{H}_{13} \mathrm{Cl}$

Benzene, (1-chloroethyl)dimethyl-
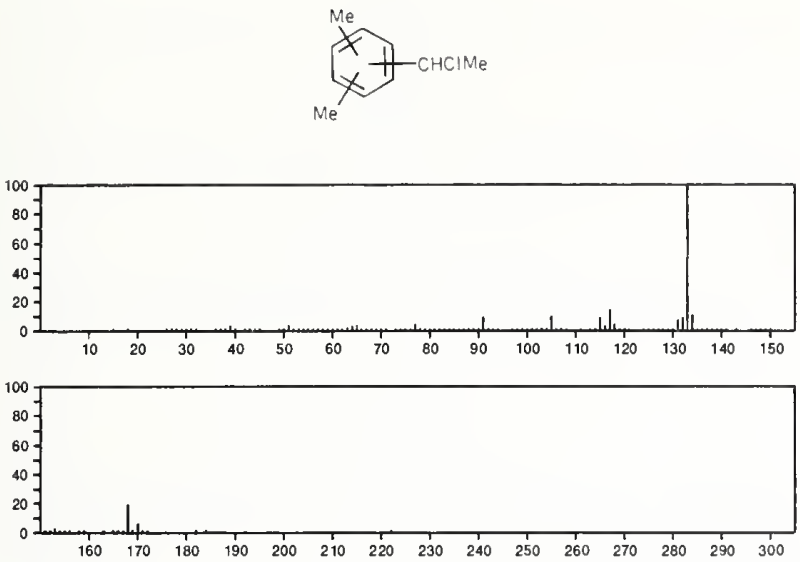

168

$\mathrm{C}_{10} \mathrm{H}_{13} \mathrm{Cl}$

Benzene, diethyl-, monochloro deriv.
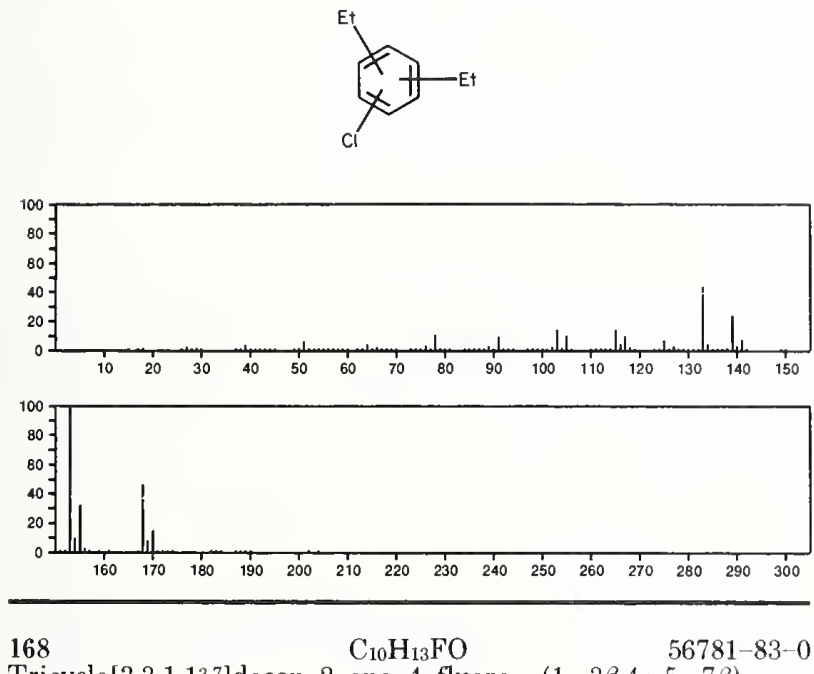

Tricyclo[3.3.1.13,7]decan-2-one, 4-fluoro-, $(1 \alpha, 3 \beta, 4 \alpha, 5 \alpha, 7 \beta)$
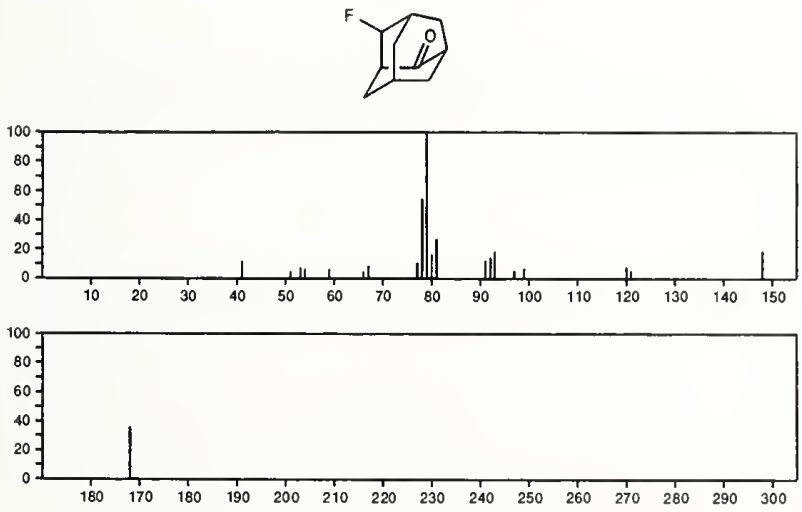

$168 \quad \mathrm{C}_{10} \mathrm{H}_{13} \mathrm{FO} \quad 56781-84-1$

Tricyclo[3.3.1.1 $\left.1^{3,7}\right]$ decan-2-one, 4-fluoro-, $(1 \alpha, 3 \beta, 4 \beta, 5 \alpha, 7 \beta)$ -<smiles>OC1CCC2CC1C=C2F</smiles>
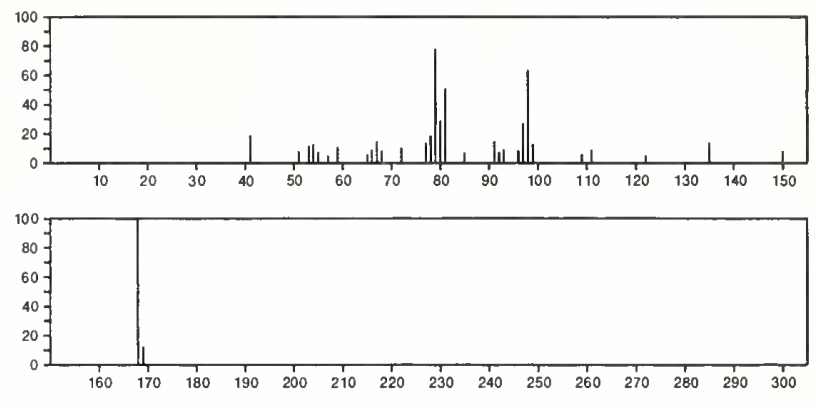

168

2-Nonynoic acid, methyl ester

$111-80-8$

$\mathrm{Me}\left(\mathrm{CH}_{2}\right){ }_{5} \mathrm{C} \equiv \mathrm{CC}(\mathrm{O}) \mathrm{OMe}$
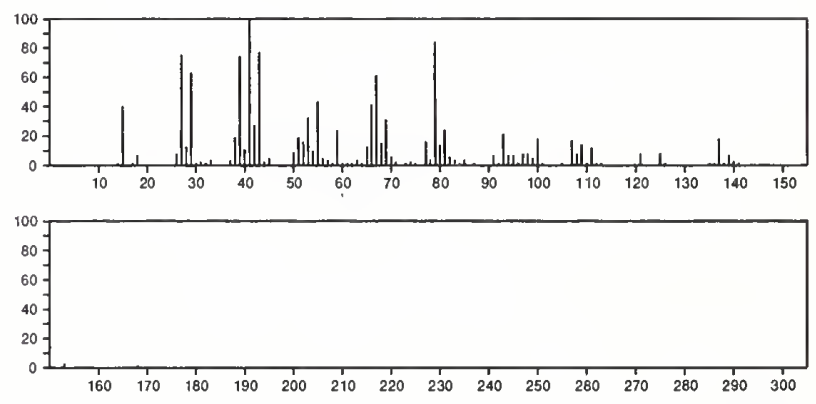

168

$\mathrm{C}_{10} \mathrm{H}_{16} \mathrm{O}_{2}$

$512-85-6$

2,3-Dioxabicyclo[2.2.2] oct-5-ene, 1-methyl-4-(1-methylethyl)-
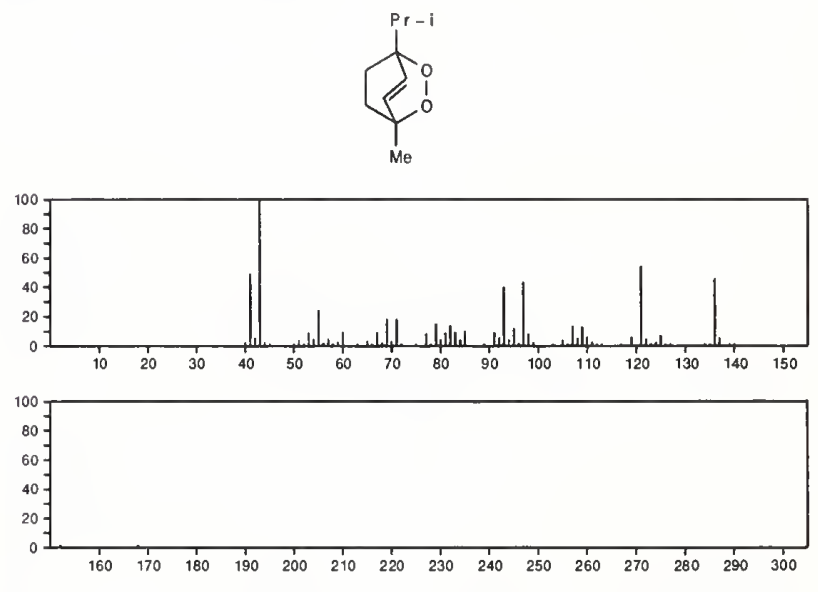

168

$\mathrm{C}_{10} \mathrm{H}_{16} \mathrm{O}_{2}$

$702-67-0$

Bicyclo[2.2.2 ]octane-1-carboxylic acid, 4-methyl-
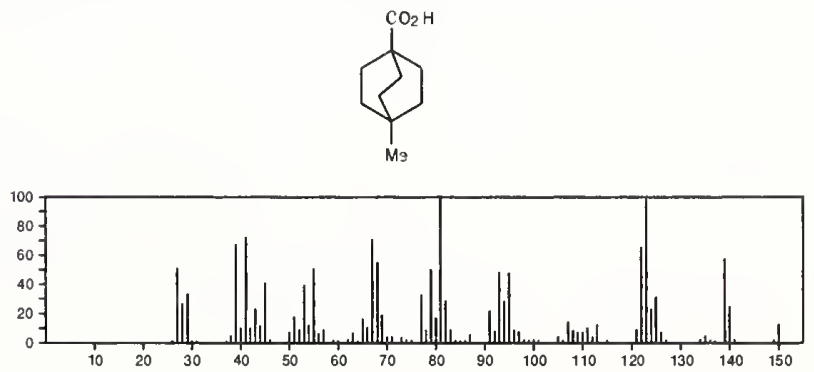


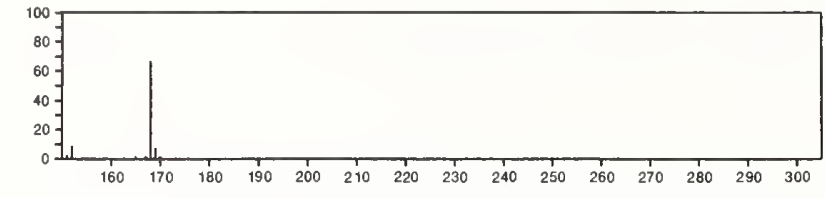

$168 \quad \mathrm{C}_{10} \mathrm{H}_{16} \mathrm{O}_{2} \quad 705-16-8$ Cyclopropanecarboxylic acid, 2,2-dimethyl-3-(2-methyl-1propenyl)-, trans $^{-}( \pm)-$
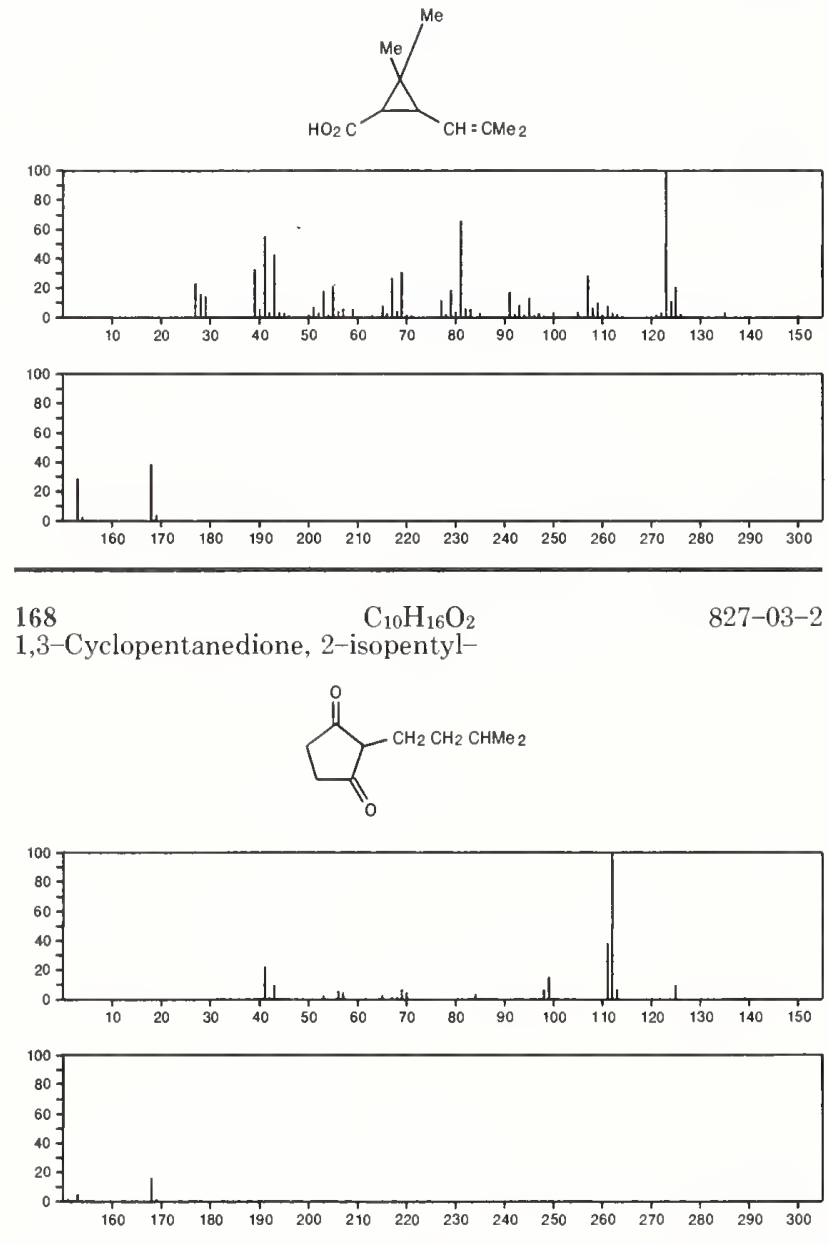

$168 \quad \mathrm{C}_{10} \mathrm{H}_{16} \mathrm{O}_{2}$

1,3-Cyclopentanedione, 4-isopentyl-
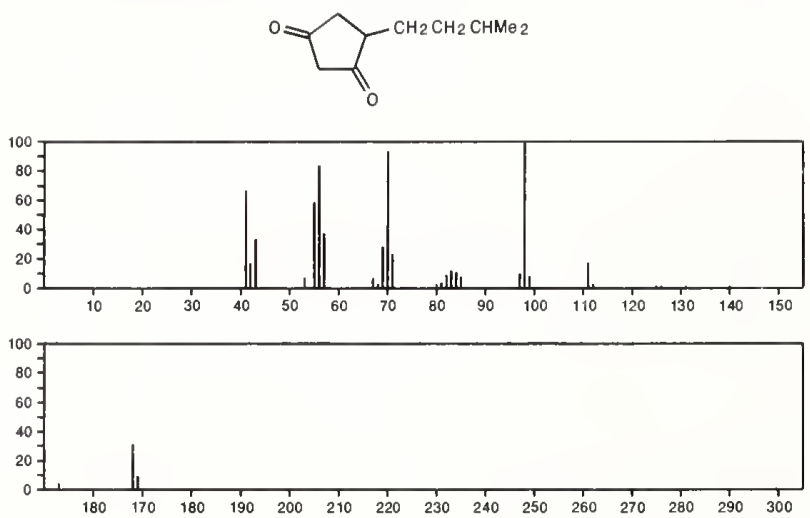

168

$\mathrm{C}_{10} \mathrm{H}_{16} \mathrm{O}_{2}$

$3907-11-7$

Bicyclo[2.2.2]octanone, 4-methoxy-1-methyl-
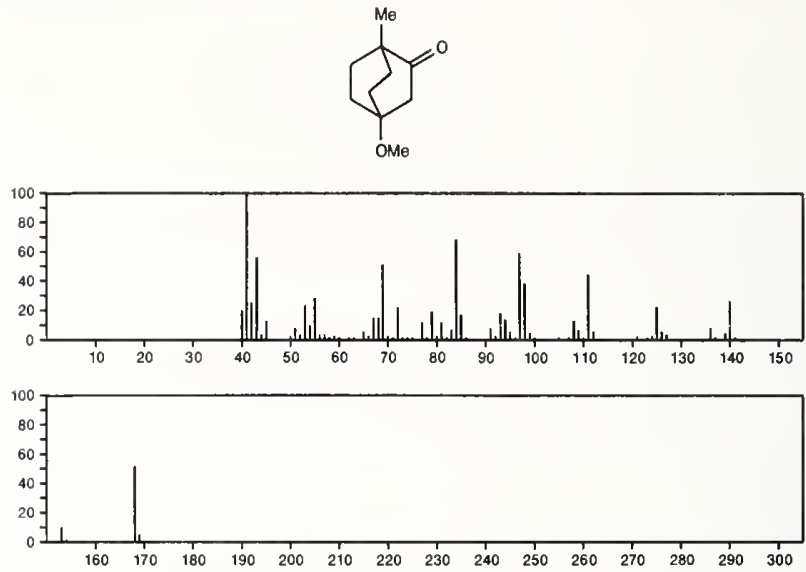

168

8-Nonynoic acid, methyl ester

$\mathrm{C}_{10} \mathrm{H}_{16} \mathrm{O}_{2}$

$7003-48-7$

$\mathrm{HC} \equiv \mathrm{C}\left(\mathrm{CH}_{2}\right)_{6} \mathrm{C}(\mathrm{O}$ ) $\mathrm{OMe}$
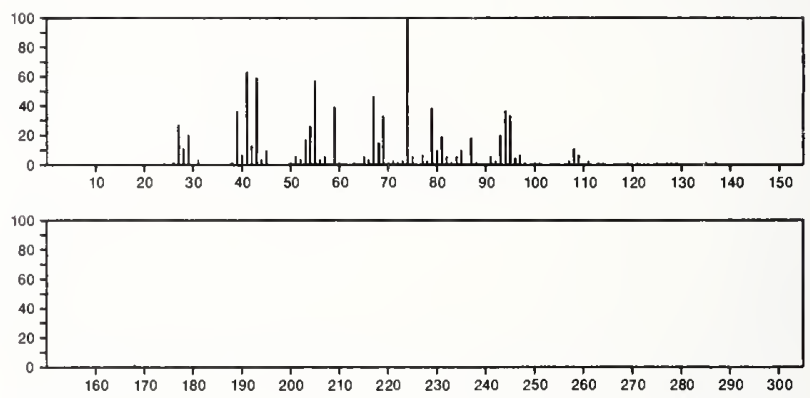

$168 \quad \mathrm{C}_{10} \mathrm{H}_{16} \mathrm{O}_{2} \quad 10453-89-1$

Cyclopropanecarboxylic acid, 2,2-dimethyl-3-(2-methyl-1propenyl)
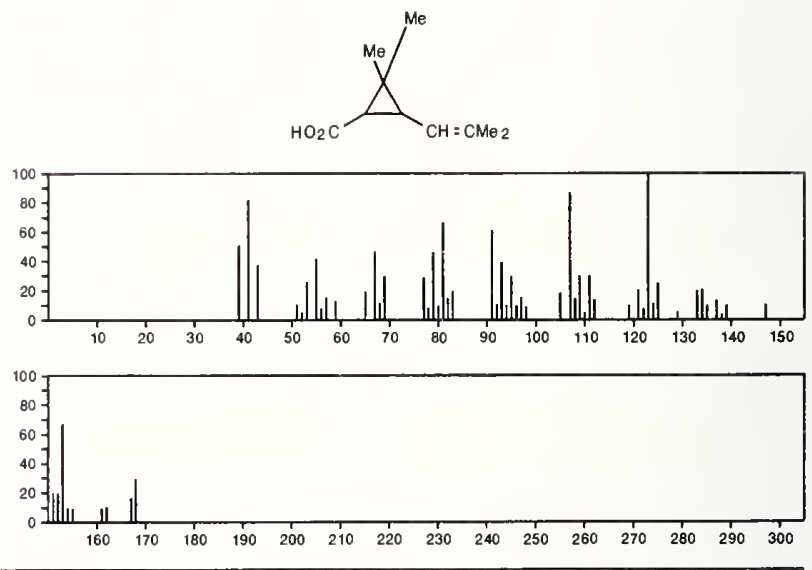

168

$\mathrm{C}_{10} \mathrm{H}_{16} \mathrm{O}_{2}$

$13080-28-9$

1-Oxaspiro[2.5]octan-4-one, 2,2,6-trimethyl-, trans-
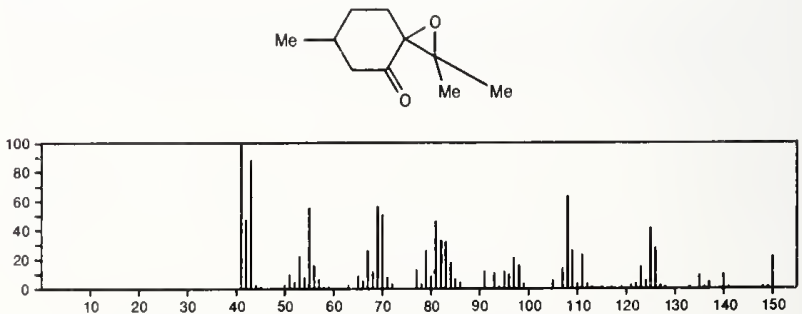


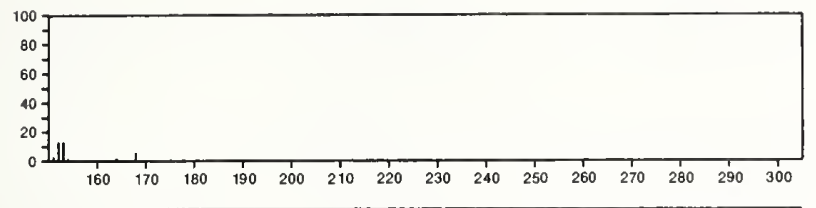

$168 \quad \mathrm{C}_{10} \mathrm{H}_{16} \mathrm{O}_{2}$ 13080-29-0 1-Oxaspiro[2.5]octan-4-one, 2,2,6-trimethyl-, cis-
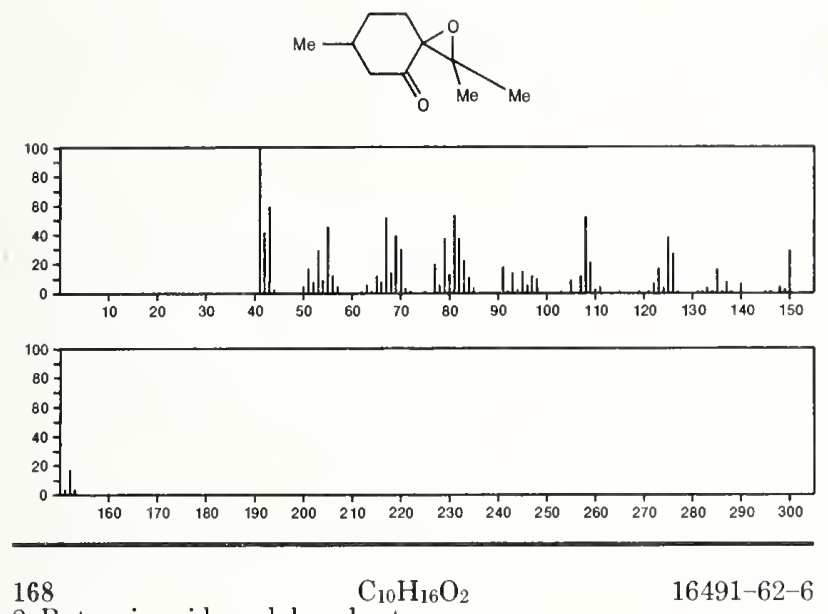

2-Butenoic acid, cyclohexyl ester
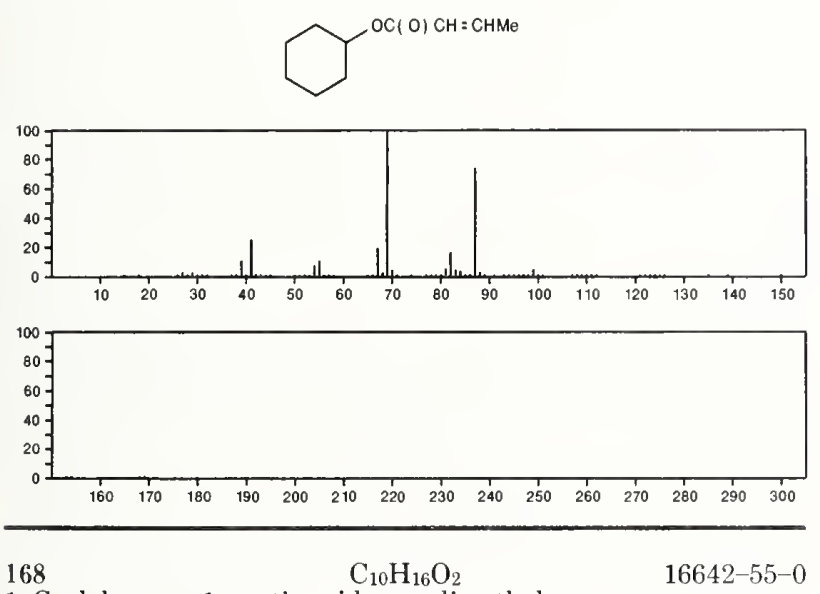

1-Cyclohexene-1-acetic acid, $\alpha, \alpha$-dimethyl-
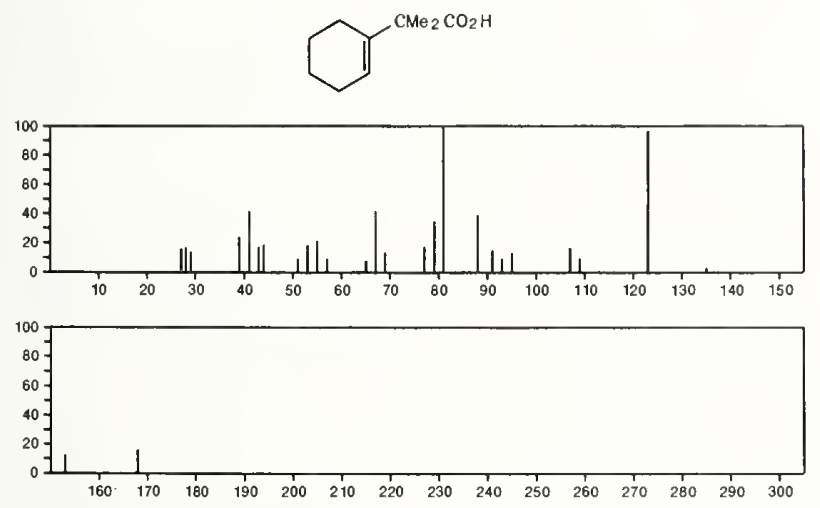

$168 \quad \mathrm{C}_{10} \mathrm{H}_{16} \mathrm{O}_{2} \quad 17672-96-7$ Cyclopenta[c]pyran-1(3H)-one, hexahydro-4,7-dimethyl-, $(4 \alpha, 4 \mathrm{a} \alpha, 7 \alpha, 7 \mathrm{a} \alpha)$
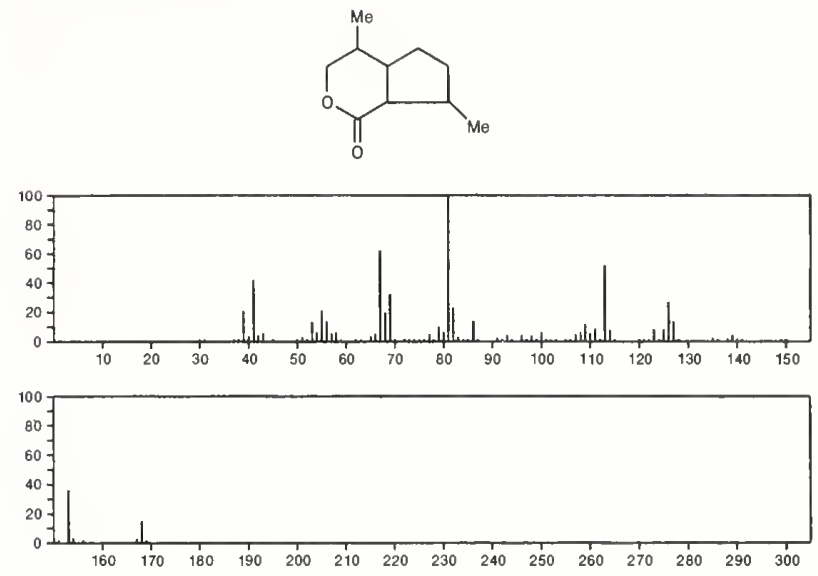

168

$\mathrm{C}_{10} \mathrm{H}_{16} \mathrm{O}_{2}$

19931-20-5

Bicyclo[1.1.0]butane-1-carboxylic acid, 2,2,4,4-tetramethyl-, methyl ester
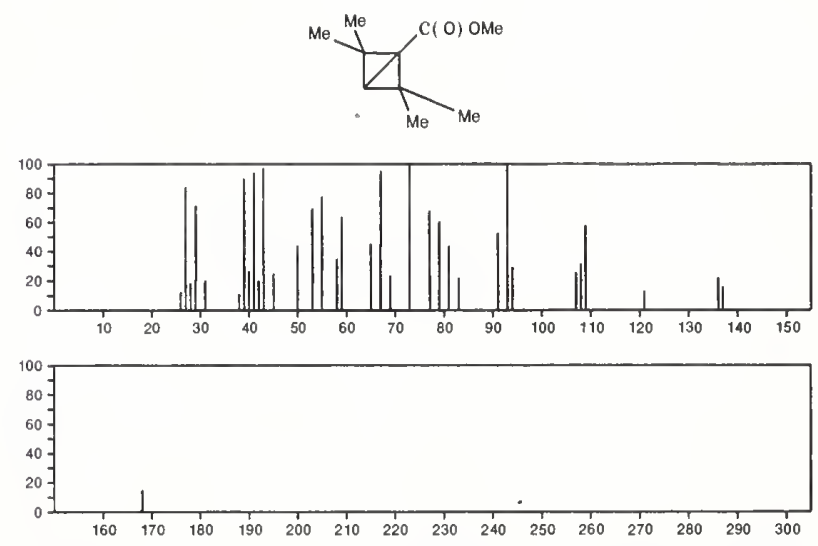

168

$\mathrm{C}_{10} \mathrm{H}_{16} \mathrm{O}_{2}$

20731-15-1

4-Nonynoic acid, methyl ester

$\mathrm{Me}\left(\mathrm{CH}_{2}\right)_{3} \mathrm{C} \equiv \mathrm{CCH}_{2} \mathrm{CH}_{2} \mathrm{Cl}(\mathrm{O}) \mathrm{OMe}$
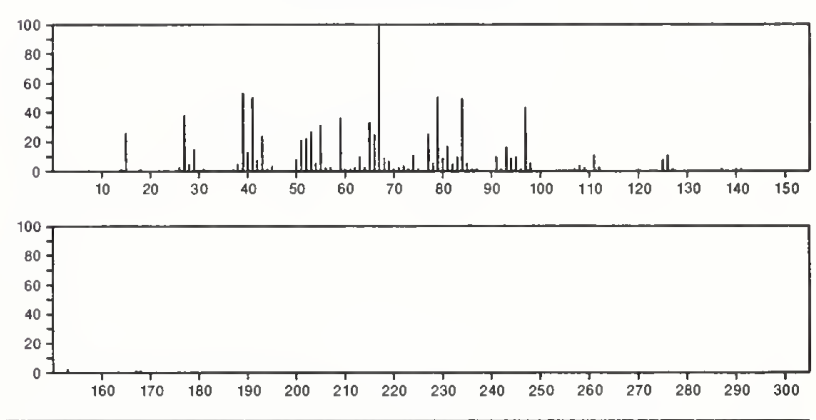

168

6-Nonynoic acid, methyl ester

$\mathrm{C}_{10} \mathrm{H}_{16} \mathrm{O}_{2}$

20731-17-3

$\mathrm{E}+\mathrm{C} \equiv \mathrm{C}\left(\mathrm{CH}_{2}\right)_{4} \mathrm{C}(\mathrm{O}) \mathrm{OMe}$

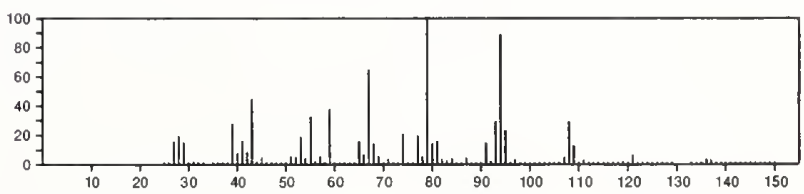




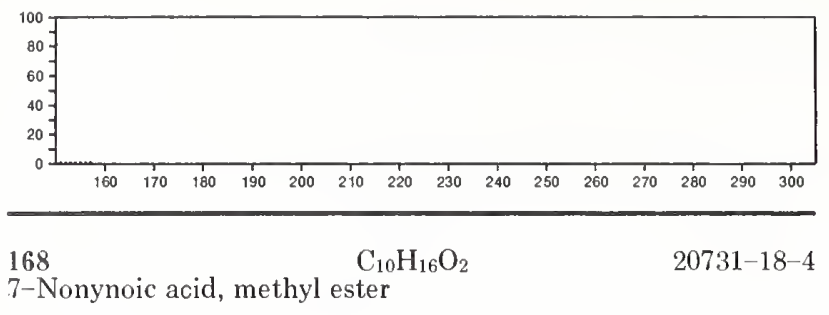

$\mathrm{MeOC}(\mathrm{O})\left(\mathrm{CH}_{2}\right){ }_{5} \mathrm{C} \equiv \mathrm{CMe}$
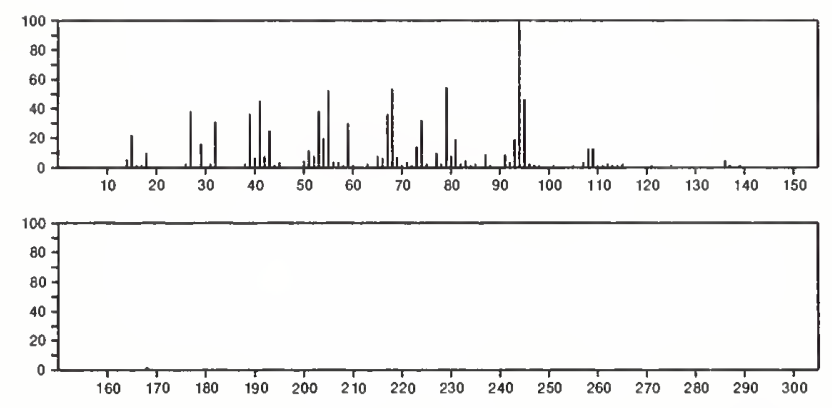

168

1(2H)-Naphthalenone, octahydro-4-hydroxy-, trans-
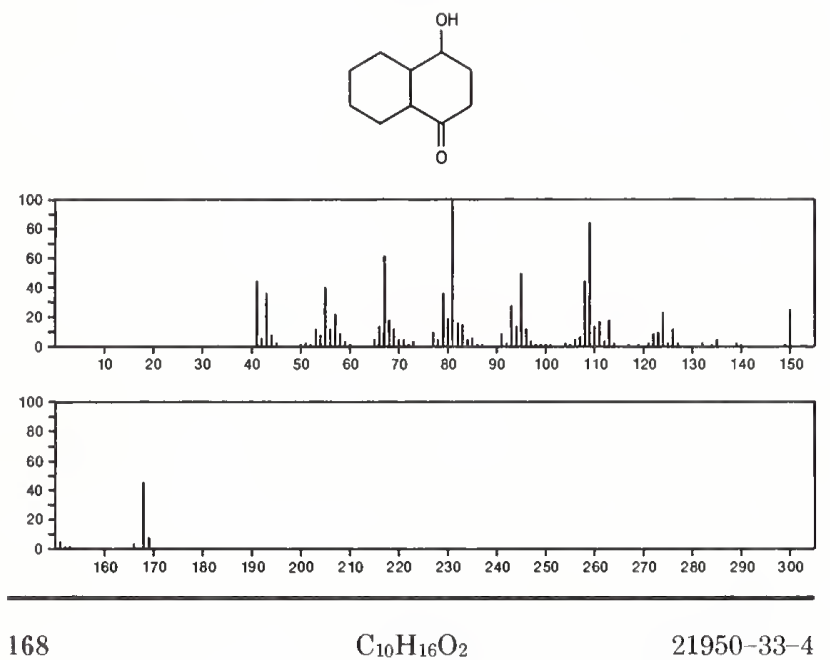

Cyclopenta[c]pyran-1(3H)-one, hexahydro-4,7-dimethyl-
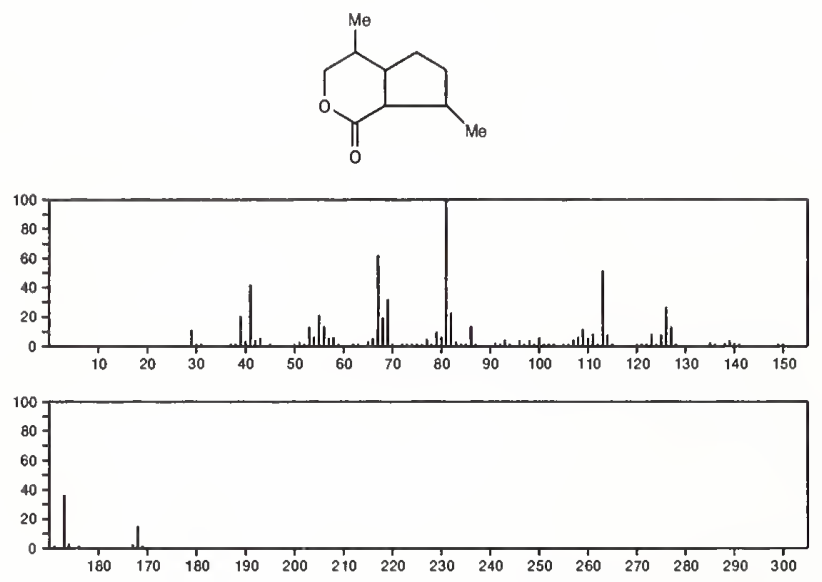

168

$\mathrm{C}_{10} \mathrm{H}_{16} \mathrm{O}_{2}$

2-Cyclopenten-1-one, 2-butyl-3-methoxy-
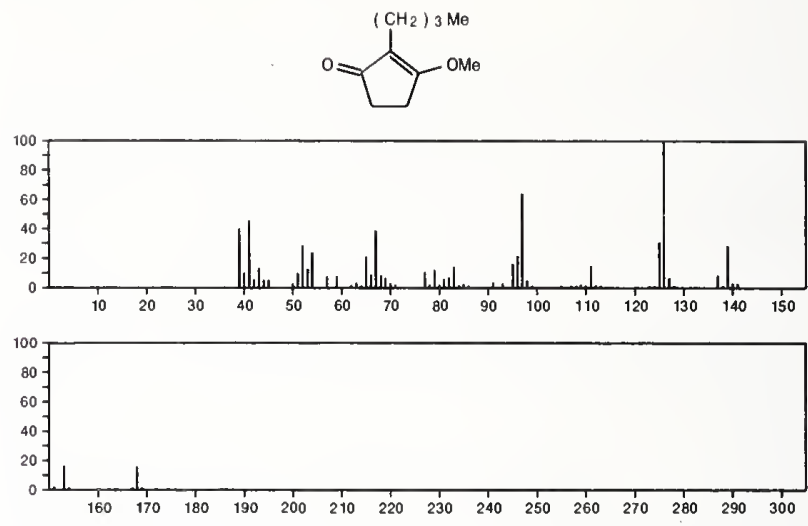

168

$\mathrm{C}_{10} \mathrm{H}_{16} \mathrm{O}_{2}$

$33383-56-1$

Cyclopropanecarboxylic acid, 2,2-dimethyl-3 (1-propenyl)-, methyl ester, $[1 \alpha, 3 \beta(Z)]$
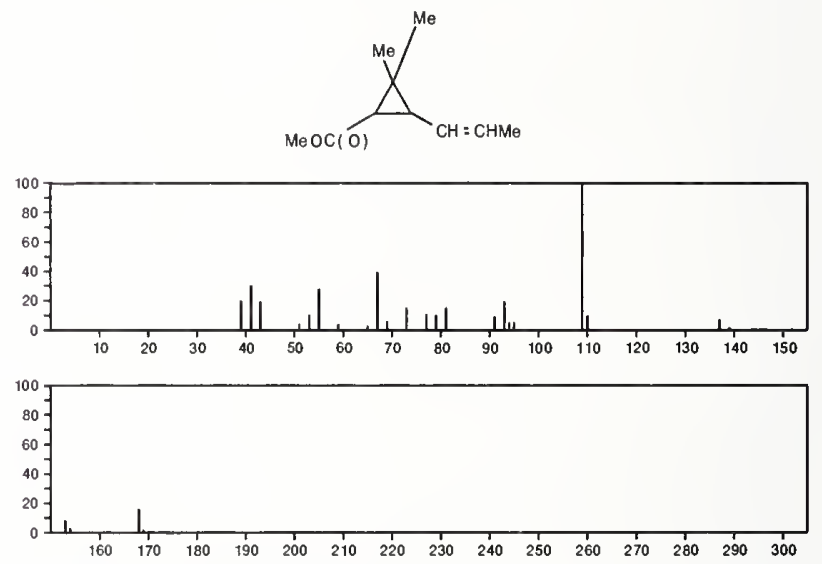

168

$\mathrm{C}_{10} \mathrm{H}_{16} \mathrm{O}_{2}$

2,6-Nonadienoic acid, methyl ester, $(E, Z)$ -

$41654-18-6$

$\mathrm{MeOC}(\mathrm{O}) \mathrm{CH}: \mathrm{CHCH}_{2} \mathrm{CH}_{2} \mathrm{CH}=\mathrm{CHE}$ t
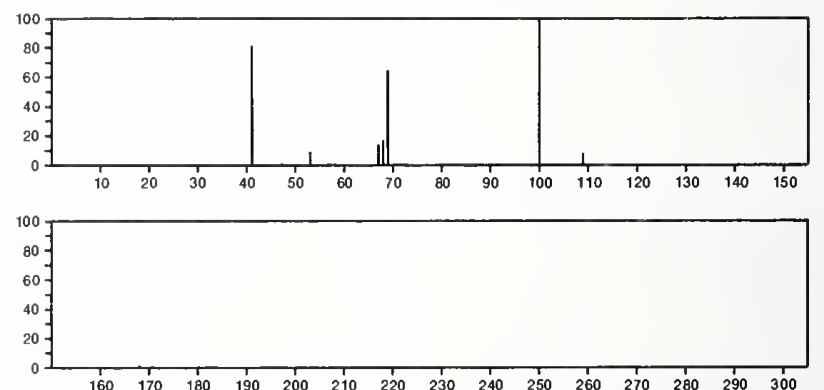
$168 \quad \mathrm{C}_{10} \mathrm{H}_{16} \mathrm{O}_{2} \quad 42569-58-4$ 4,8-Dioxatricyclo[5.1.0.03,5]octane, 1-methyl-5-(1-methylethyl)-, $(1 \alpha, 3 \alpha, 5 \alpha, 7 \alpha)-$<smiles>CC12CC3OC3(CC3OC31)C2</smiles>
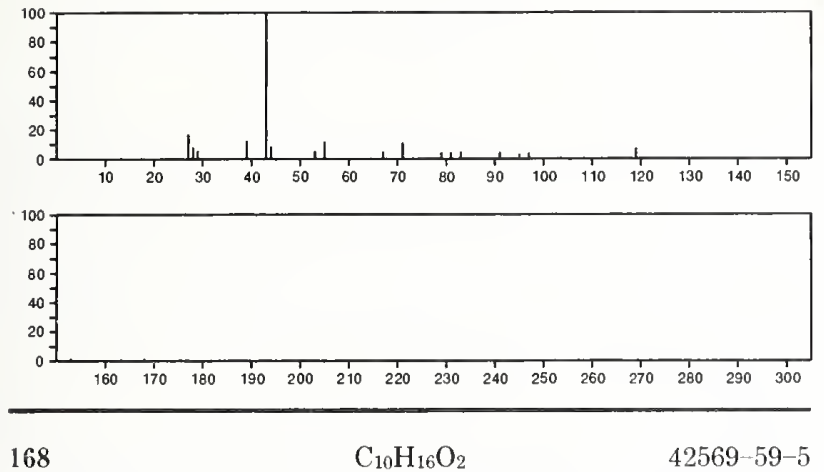

4,8-Dioxatricyclo[5.1.0.03,5]octane, 1-methyl-5-(1-methylethyl)-, $(1 \alpha, 3 \beta, 5 \beta, 7 \alpha)-$
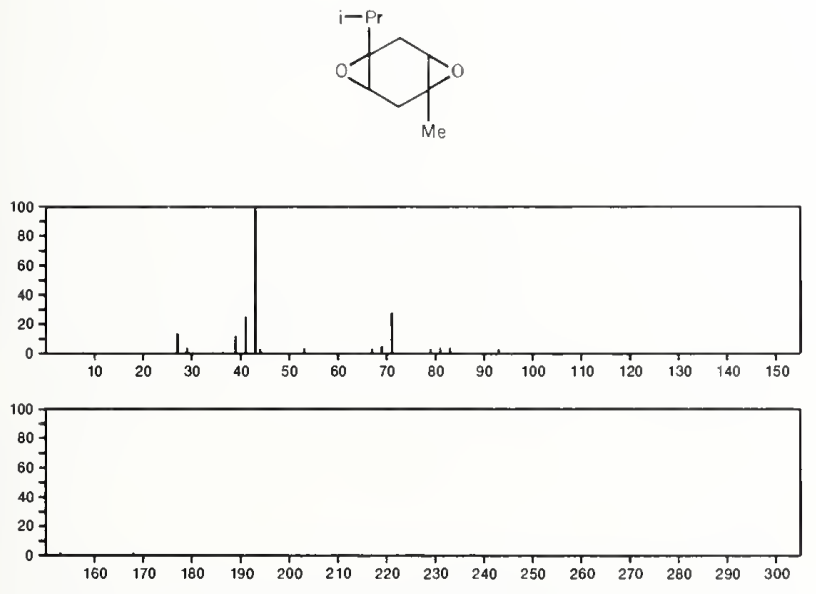

168

$\mathrm{C}_{10} \mathrm{H}_{16} \mathrm{O}_{2}$

$53690-89-4$

2-Cyclopenten-1-one, 5-butyl-3-methoxy-
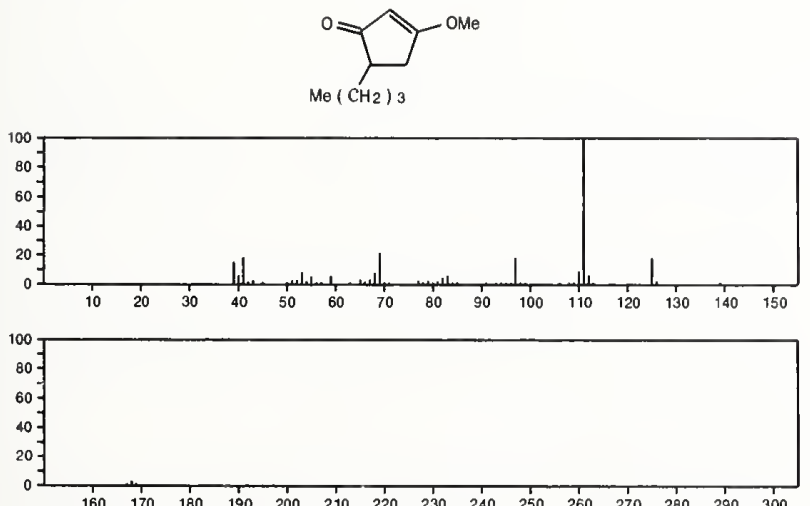

168

$\mathrm{C}_{10} \mathrm{H}_{16} \mathrm{O}_{2}$

2-Cyclopenten 1-one, 4-butyl-3-methoxy-

$53690-92-9$
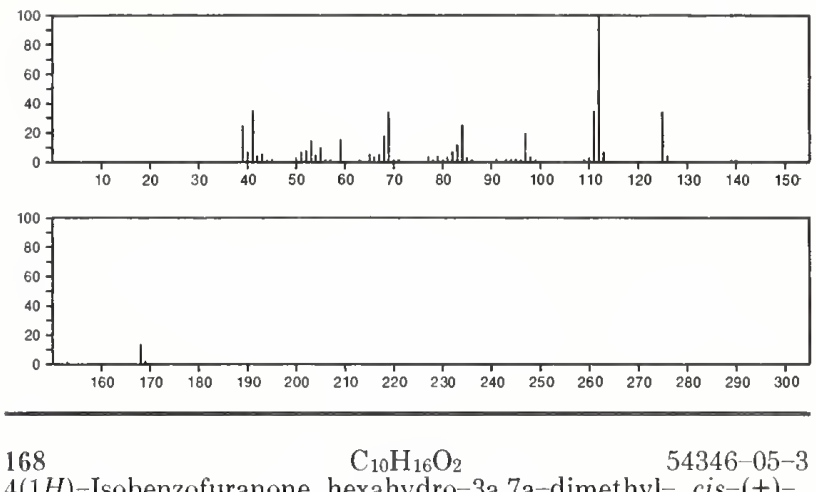

$4(1 H)$-Isobenzofuranone, hexahydro-3a,7a-dimethyl-, cis-( \pm - -
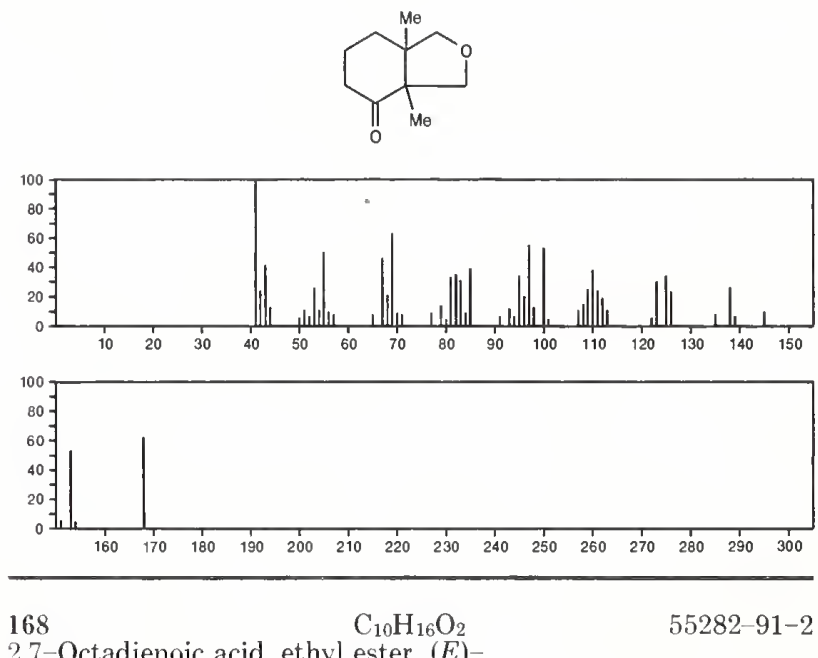

$55282-91-2$

2,7-Octadienoic acid, ethyl ester, $(E)$

$\mathrm{H}_{2} \mathrm{C}=\mathrm{CH}\left(\mathrm{CH}_{2}\right)_{3} \mathrm{CH}=\mathrm{CHC}(\mathrm{O}) \mathrm{OE} \mathrm{t}$
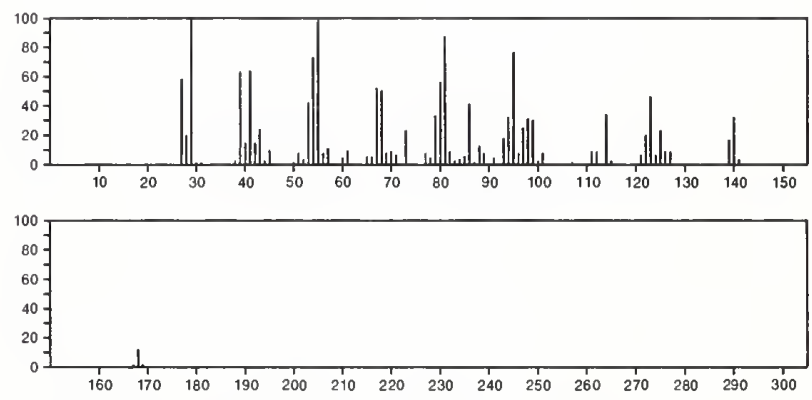

168

$\mathrm{C}_{10} \mathrm{H}_{16} \mathrm{O}_{2}$

$55283-12-0$

2,6-Octadienoic acid, 3-methyl-, methyl ester, $(E, Z)$ -

$\mathrm{Me} \mathrm{CH}: \mathrm{CHCH}_{2} \mathrm{CH}_{2} \mathrm{CMe}=\mathrm{CHC}(\mathrm{O}) \mathrm{OMe}$
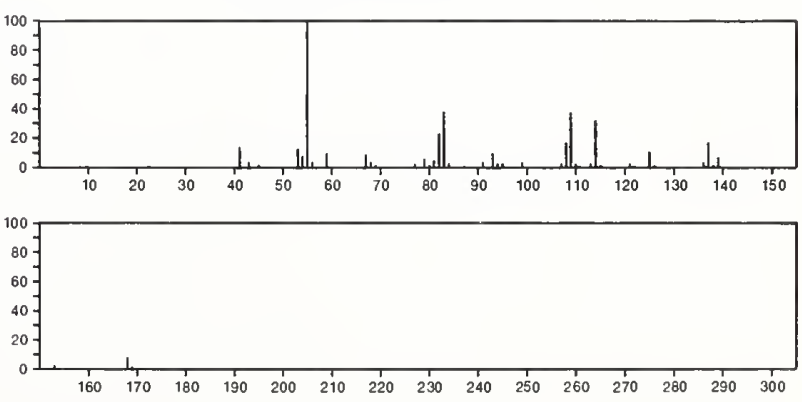
168

$\mathrm{C}_{10} \mathrm{H}_{16} \mathrm{O}_{2}$

$55283-13-1$

2,6-Octadienoic acid, 3-methyl-, methyl ester, $(E, E)-$

$\mathrm{Me} \mathrm{CH}=\mathrm{CHCH}_{2} \mathrm{CH}_{2} \mathrm{CMe}=\mathrm{CHC}(0) \mathrm{OMe}$
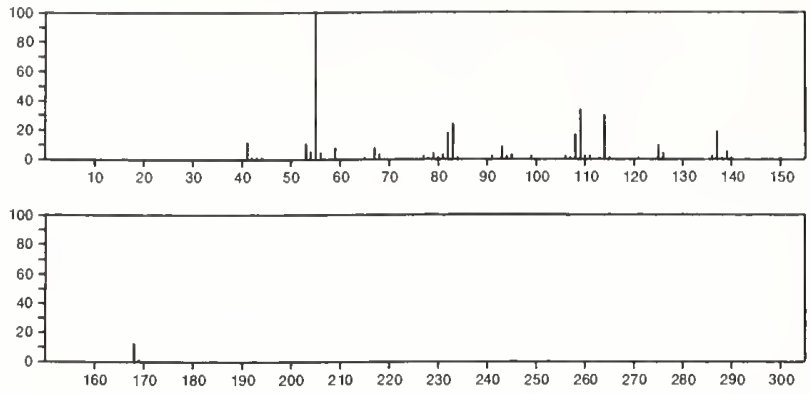

$168 \quad \mathrm{C}_{10} \mathrm{H}_{16} \mathrm{O}_{2} \quad 55760-16-2$

Cyclobutaneacetic acid, 1-methyl-2-(1-methylethenyl)-
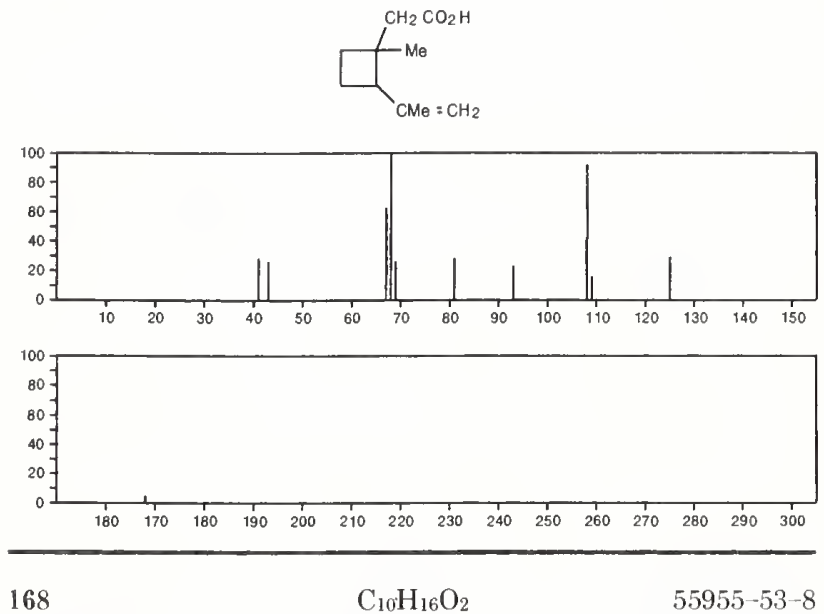

2-Cyclohexen-1-one, 4-hydroxy-3-methyl-6-(1-methylethyl)-, trans-
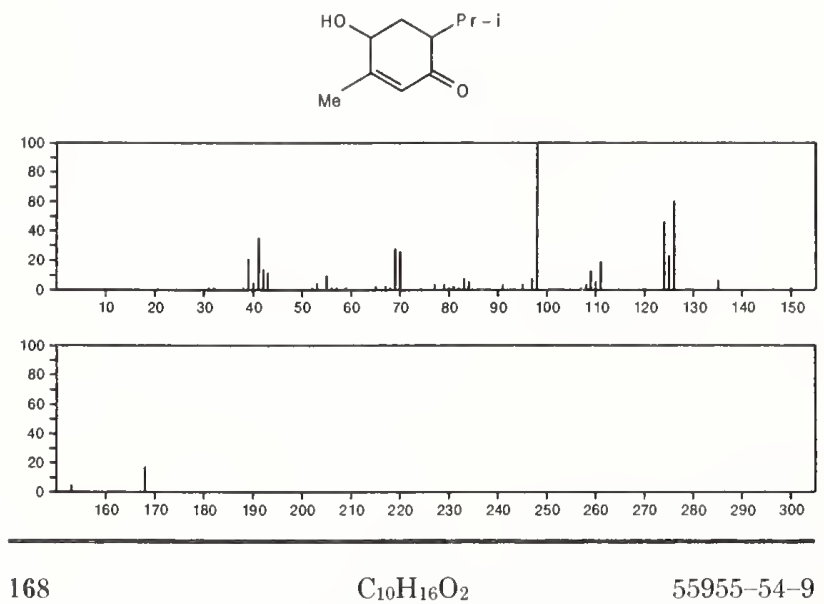

2-Cyclohexen-1-one, 3-(hydroxymethyl)-6-(1-methylethyl)-
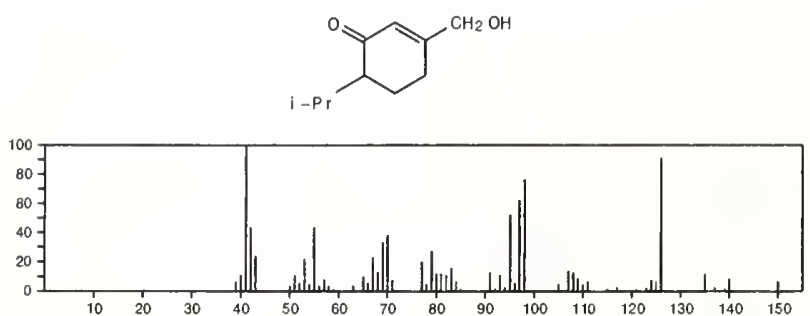

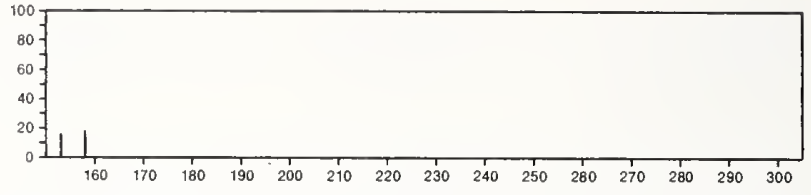

168

$\mathrm{C}_{10} \mathrm{H}_{16} \mathrm{O}_{2}$

1,3-Cyclopentanedione, 2-ethyl-4-propyl-

$57157-04-7$
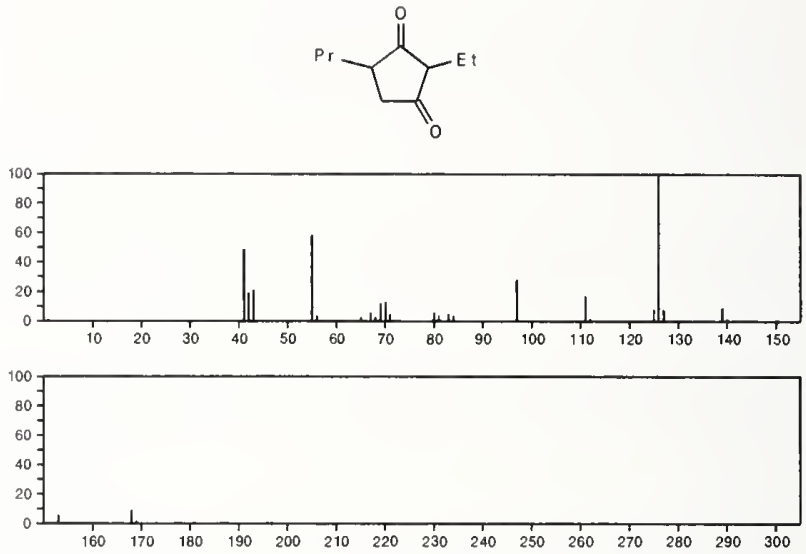

168

$\mathrm{C}_{10} \mathrm{H}_{16} \mathrm{~S}$

875-06-9

Bicyclo[2.2.1]heptane-2-thione, 1,3,3-trimethyl-
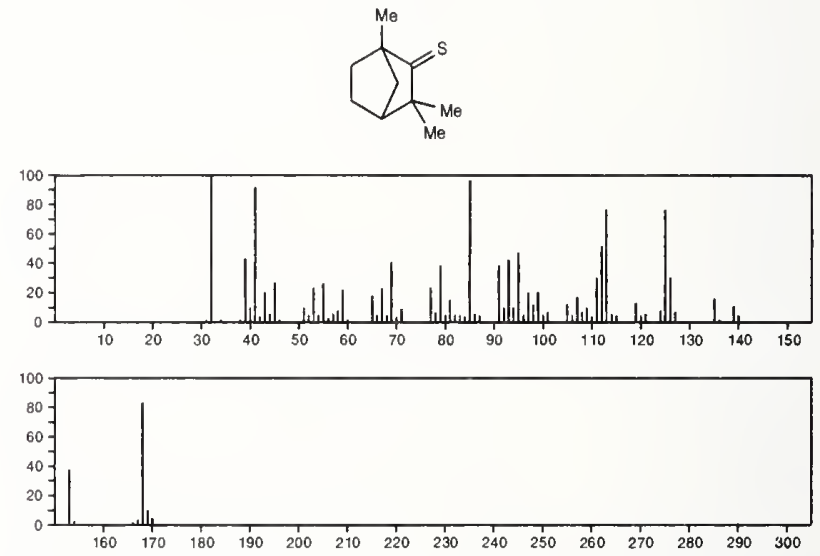

168

$\mathrm{C}_{10} \mathrm{H}_{16} \mathrm{~S}$

Bicyclo[2.2.1] heptane-2-thione, 1,7,7-trimethyl-

7519-74-6
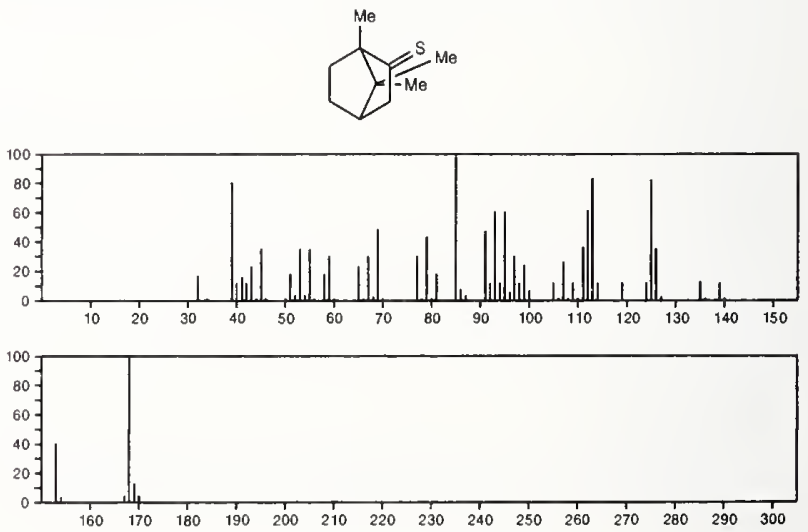
168

Thiophene, 2-hexyl-

$\mathrm{C}_{10} \mathrm{H}_{16} \mathrm{~S}$

18794-77-9

(C) $\left(\mathrm{CH}_{2}\right) 5 \mathrm{Me}$
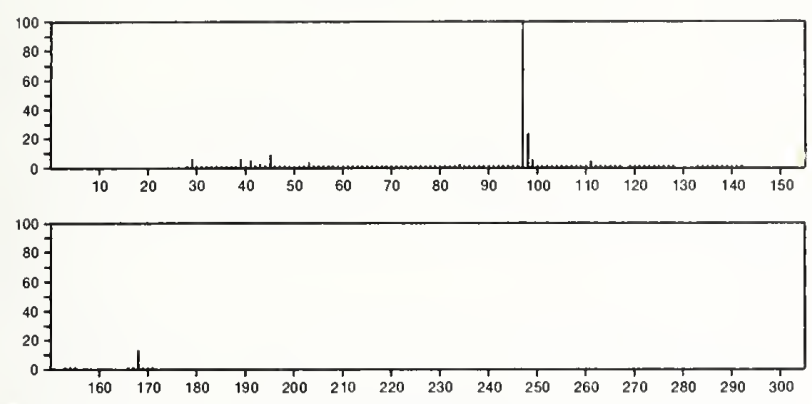

168

Thiophene, 2,5-dipropyl-

$\mathrm{C}_{10} \mathrm{H}_{16} \mathrm{~S}$

$54411-07-3$
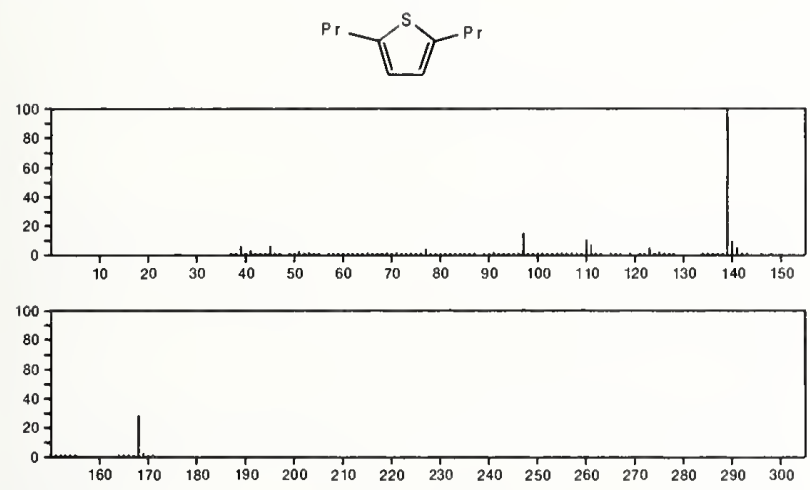

168

4,7-Ethanobenzo[c]thiophene, octahydro-, cis $^{-}$

54411-18-6
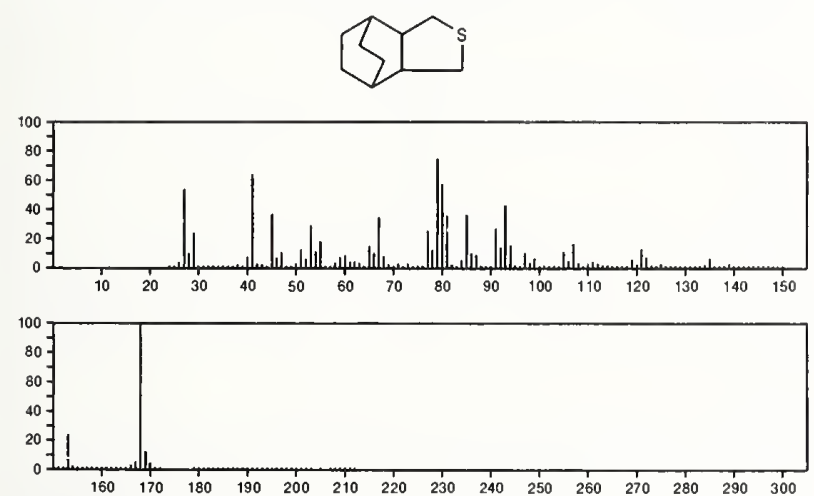

168

$\mathrm{C}_{10} \mathrm{H}_{20} \mathrm{~N}_{2}$

$28075-23-2$

$1 H$-Azepin-1-amine, hexahydro-N-(1-methyl-2-propenyl)-
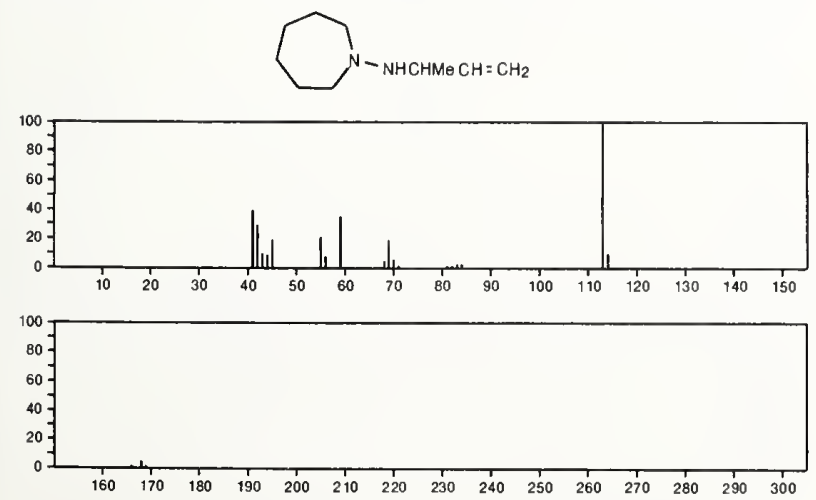

168

9H-Pyrido[3,4-b]indole

$\mathrm{C}_{11} \mathrm{H}_{8} \mathrm{~N}_{2}$

$244-63-3$
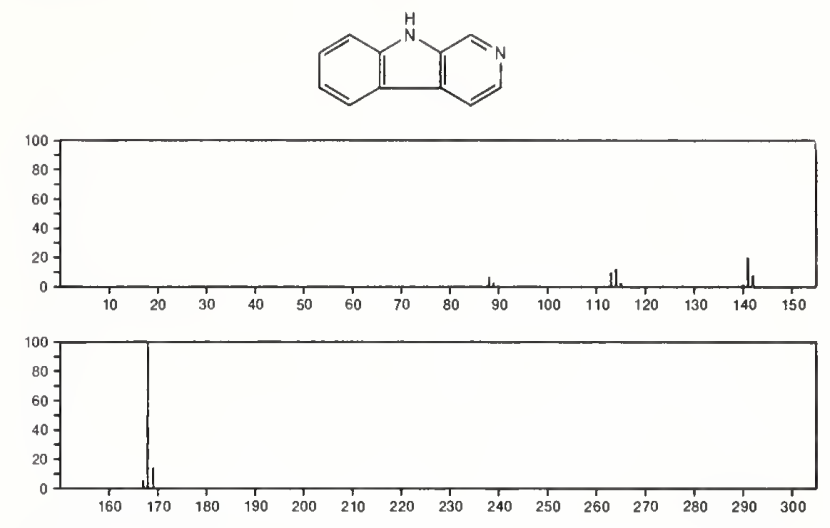

$\mathrm{C}_{11} \mathrm{H}_{20} \mathrm{O}$
2,6 -Octadiene, 1-methoxy-3,7-dimethyl-, $(E)-$

$2565-82-4$

$\mathrm{Me}_{2} \mathrm{C}=\mathrm{CHCH}_{2} \mathrm{CH}_{2} \mathrm{CMe}_{e}=\mathrm{CHCH}_{2} \mathrm{OMe}_{\theta}$
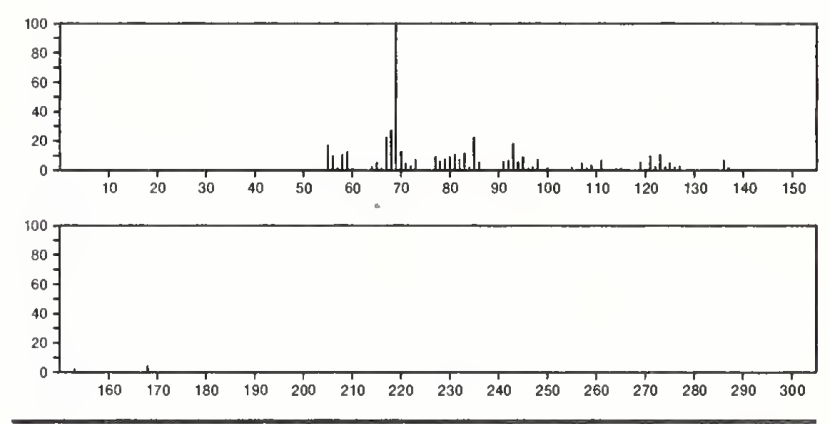

168

$\mathrm{C}_{11} \mathrm{H}_{20} \mathrm{O}$

$3664-64-0$

7-Nonen-2-one, 4,8-dimethyl-

$\mathrm{Me}_{2} \mathrm{C}=\mathrm{CHCH}_{2} \mathrm{CH}_{2} \mathrm{CHMeCH}_{2} \mathrm{COMe}$
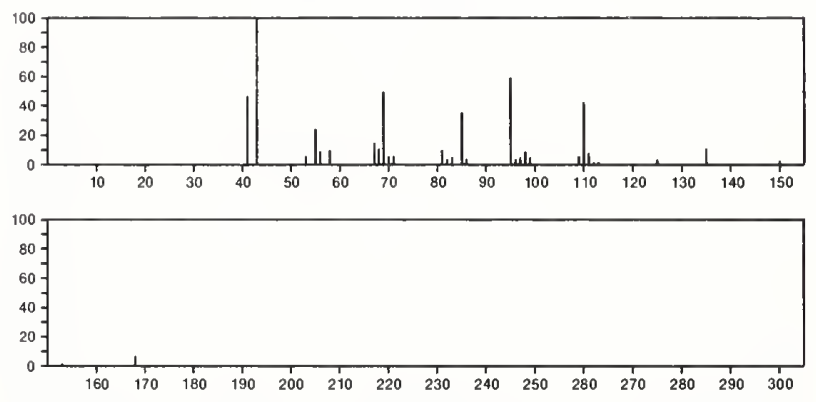

168

$\mathrm{C}_{11} \mathrm{H}_{20} \mathrm{O}$

$20144-44-9$

Cyclohexanone, 2-isopropyl-2,5-dimethyl-
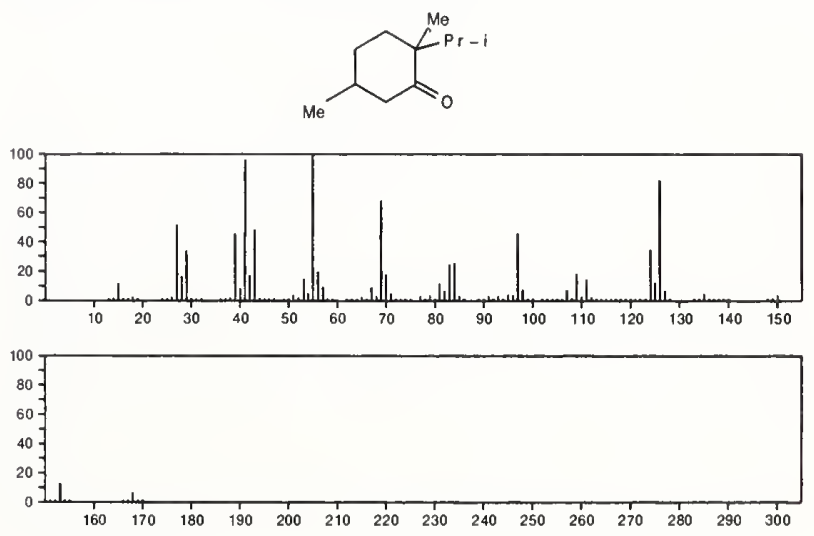
168

$\mathrm{C}_{11} \mathrm{H}_{20} \mathrm{O}$

Naphthalene, decahydro-1-methoxy-
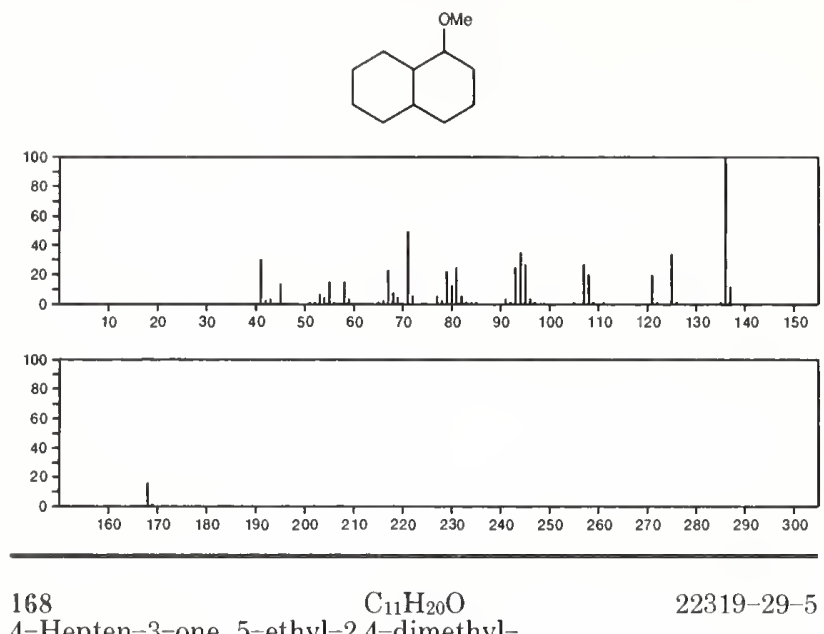

4-Hepten-3-one, 5-ethyl-2,4-dimethyl-

$\mathrm{Me}_{2} \mathrm{CHCOCMe}_{\mathrm{C}}=\mathrm{CE} \mathrm{t}_{2}$
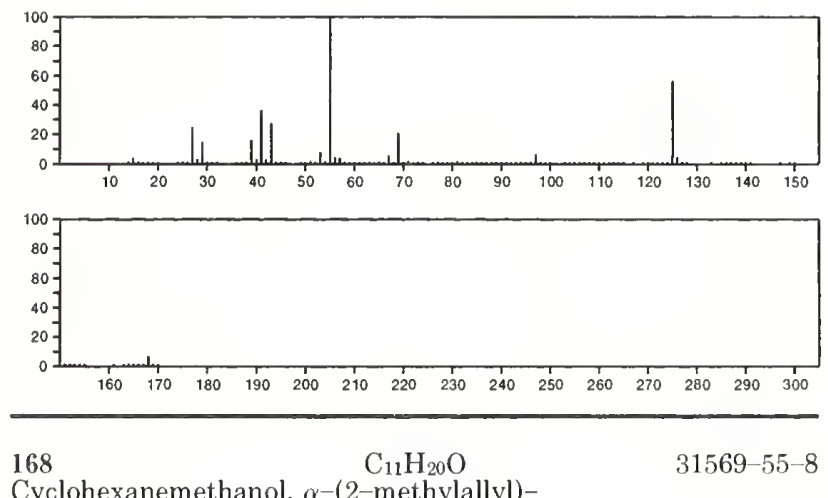

Cyclohexanemethanol, $\alpha-(2-$ methylallyl)-
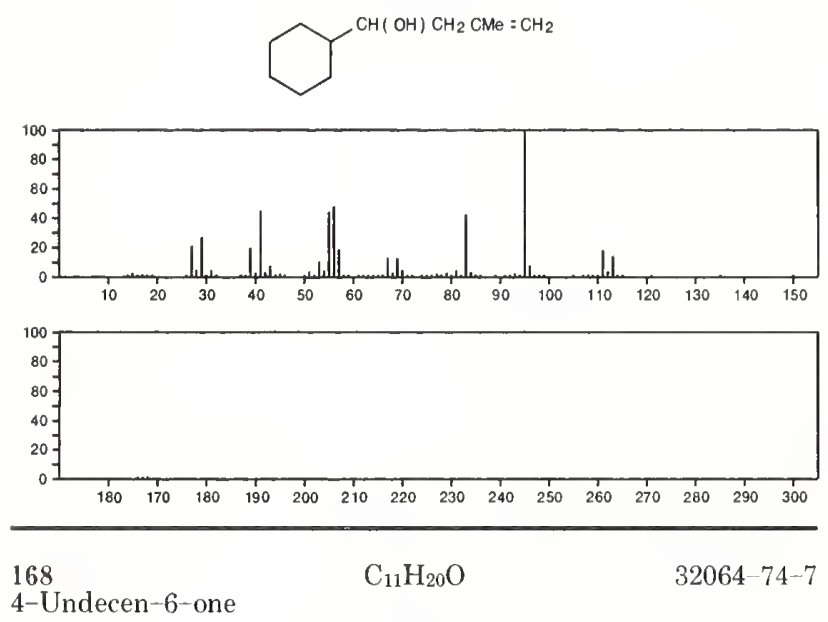

$\mathrm{PrCH}=\mathrm{CHCO}\left(\mathrm{CH}_{2}\right) 4 \mathrm{Me}$
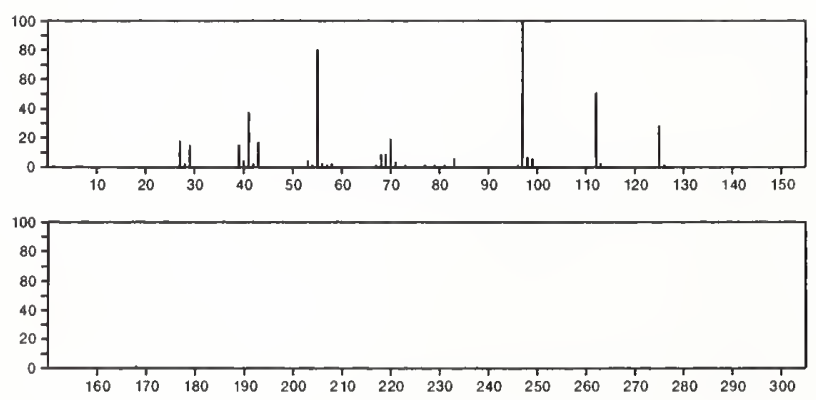

168 3-Decen-5-one, 2-methyl-

$\mathrm{C}_{11} \mathrm{H}_{20} \mathrm{O}$

$32064-75-8$

$\mathrm{Me} 2 \mathrm{CHCH}=\mathrm{CHCO}\left(\mathrm{CH}_{2}\right)_{4} \mathrm{Me}$
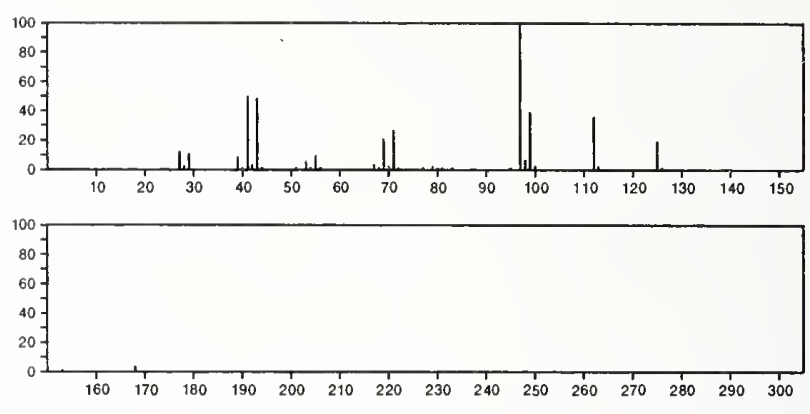

168

$\mathrm{C}_{11} \mathrm{H}_{20} \mathrm{O}$

$40648-24-6$

Cyclohexene, 1-(1,1-dimethylethoxy)-3-methyl-
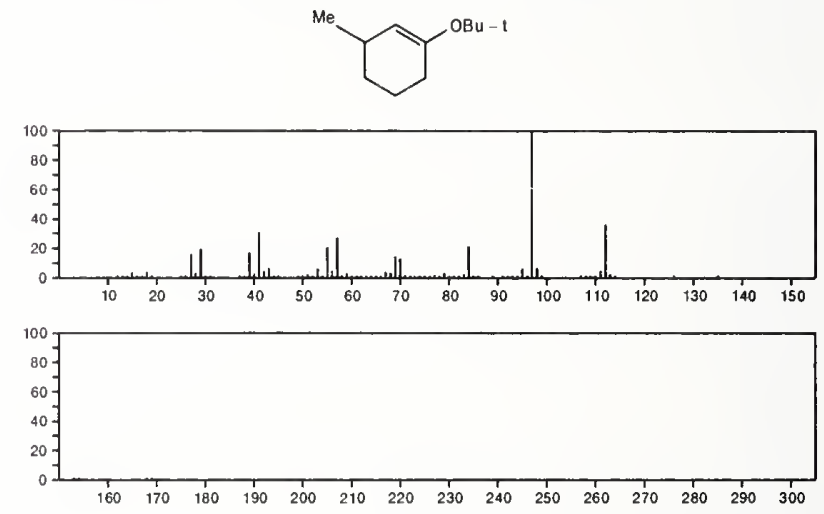

$168 \quad \mathrm{C}_{11} \mathrm{H}_{20} \mathrm{O}$

Cyclohexene, 1-(1,1-dimethylethoxy)-6-methyl-

$40648-25-7$
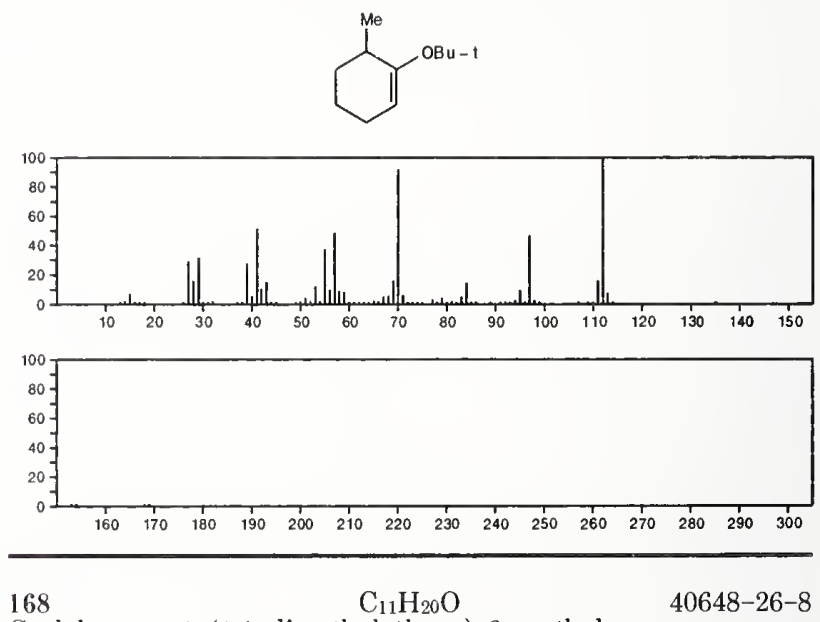

Cyclohexene, 1-(1,1-dimethylethoxy)-2-methyl-
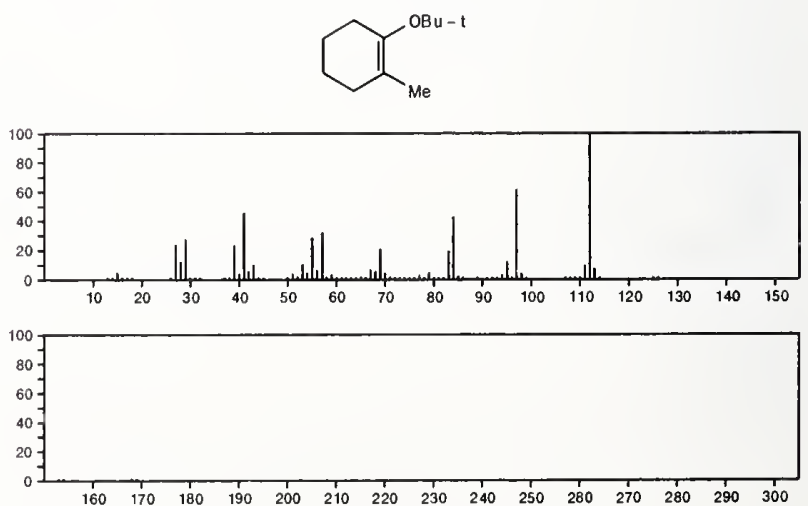
168

$\mathrm{C}_{11} \mathrm{H}_{20} \mathrm{O}$

Cycloheptene, 1-(1,1-dimethylethoxy)-

$49565-07-3$
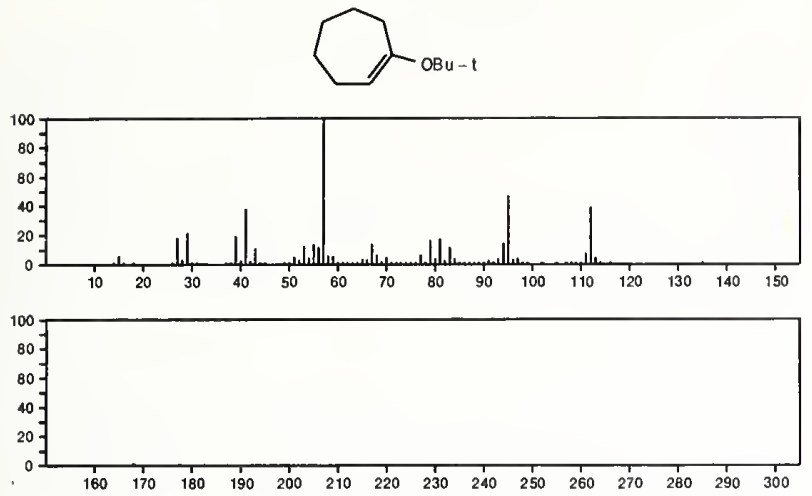

\section{$168 \quad \mathrm{C}_{11} \mathrm{H}_{20} \mathrm{O}$}

1-Cyclohexene-1-methanol, $\alpha, 2,6,6$-tetramethyl-
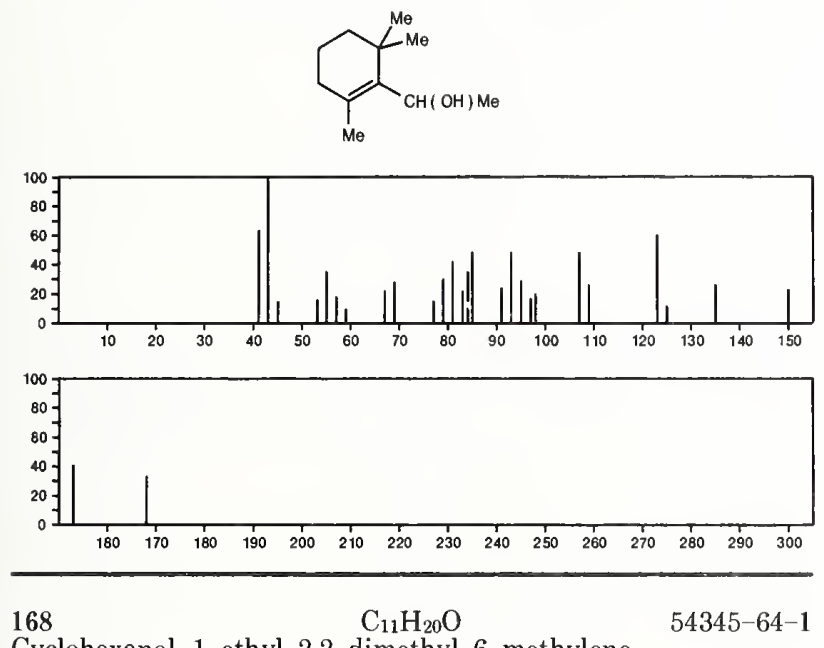

Cyclohexanol, 1-ethyl-2,2-dimethyl-6-methylene-
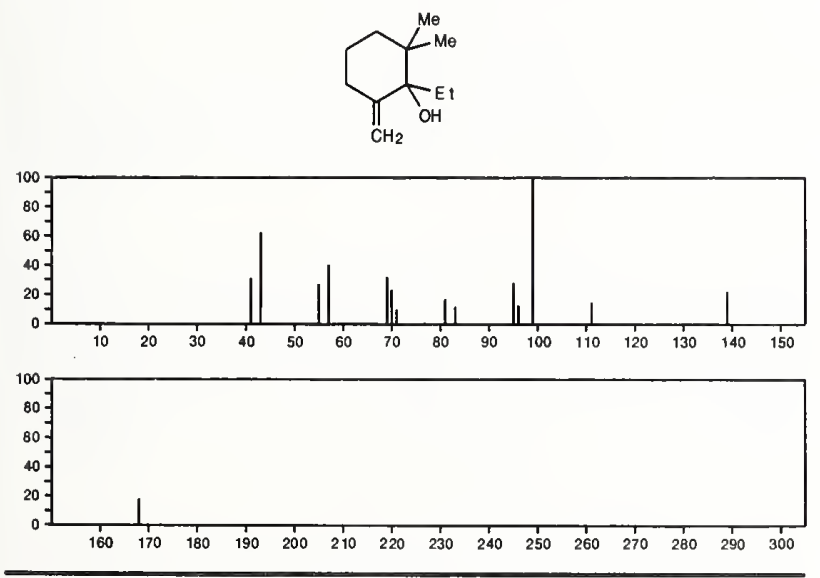

168

$$
\mathrm{C}_{11} \mathrm{H}_{20} \mathrm{O}
$$

54411-03-9

3-Decen-2-one, 3-methyl-

$\mathrm{Me} C O \mathrm{CM}_{\theta}=\mathrm{CH}\left(\mathrm{CH}_{2}\right) 5 \mathrm{Me}$

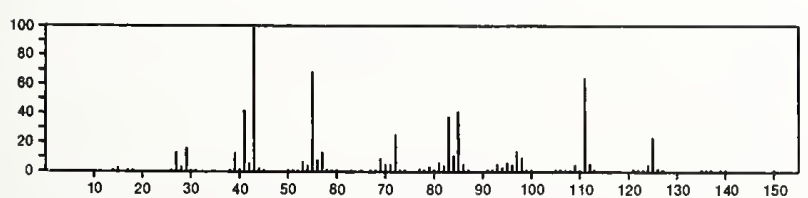

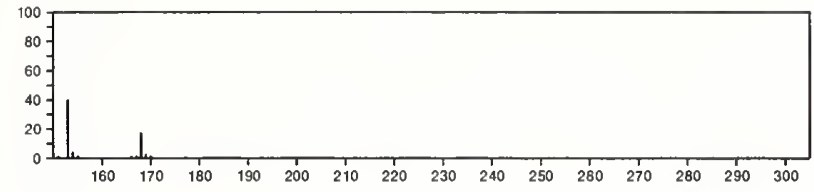

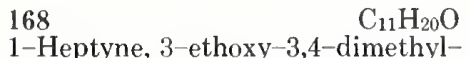

$54411-04-0$

$H C \equiv C C M e(O E t) C H P r M e$
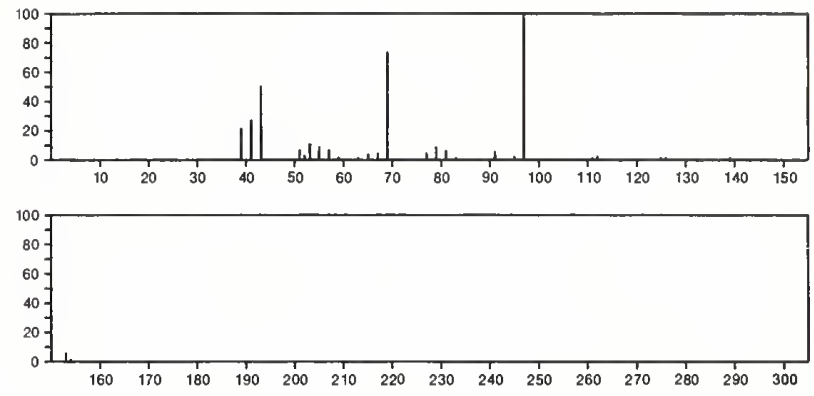

168

$\mathrm{C}_{11} \mathrm{H}_{20} \mathrm{O}$

$54965-85-4$

Cyclohexene, 3-(2,2-dimethylpropoxy)-
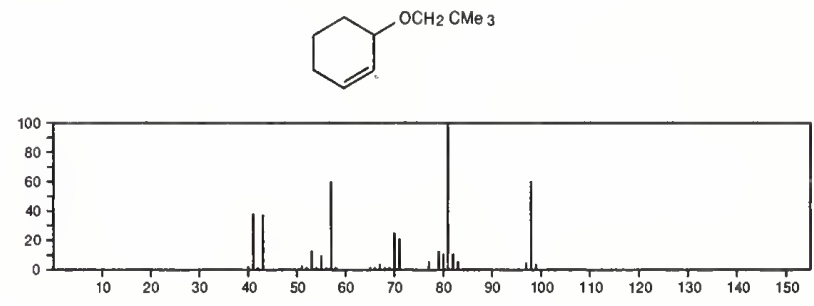

$168 \quad \mathrm{C}_{11} \mathrm{H}_{20} \mathrm{O}$

Cyclohexanone, 2-ethyl-2-propyl-

$55283-56-2$
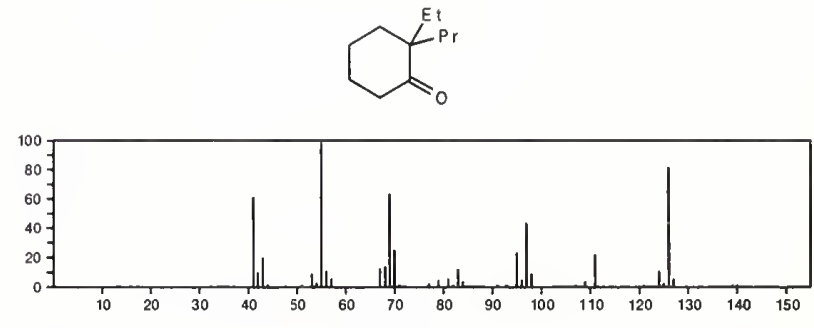

168

$\mathrm{C}_{11} \mathrm{H}_{20} \mathrm{O}$

$55702-30-2$

Cyclohexane, (3-ethoxy-1-propenyl)-, (Z)-
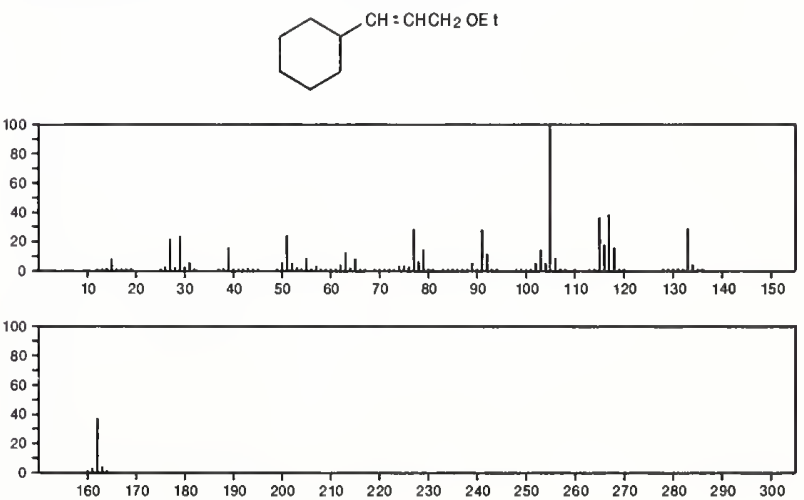
168

5-Undecen-4-one

$\mathrm{C}_{11} \mathrm{H}_{20} \mathrm{O}$

$\mathrm{Me}\left(\mathrm{CH}_{2}\right){ }_{4} \mathrm{CH}=\mathrm{CHCOP}$
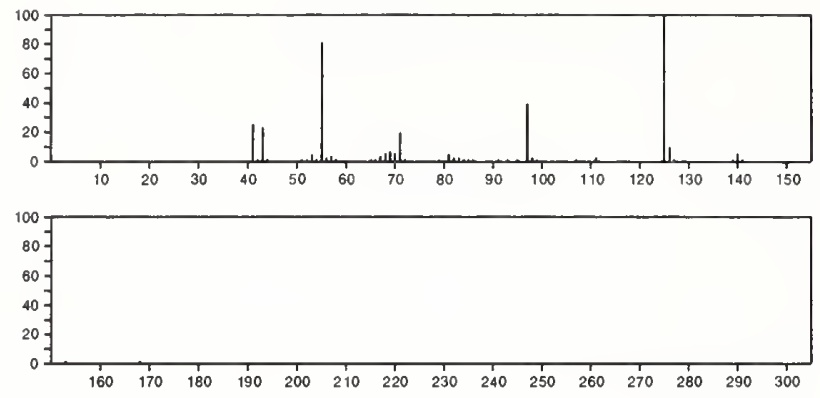

$168 \quad \mathrm{C}_{11} \mathrm{H}_{20} \mathrm{O} \quad 56312-56-2$

3-Nonen-2-one, 3-ethyl-

$\mathrm{Me}\left(\mathrm{CH}_{2}\right){ }_{4} \mathrm{CH}=\mathrm{CE}+\mathrm{COMe}$
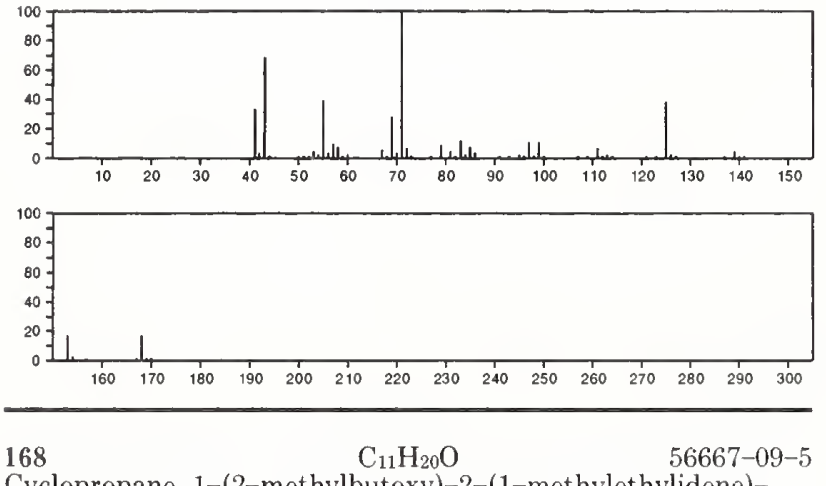

Cyclopropane, 1-(2-methylbutoxy)-2-(1-methylethylidene)-
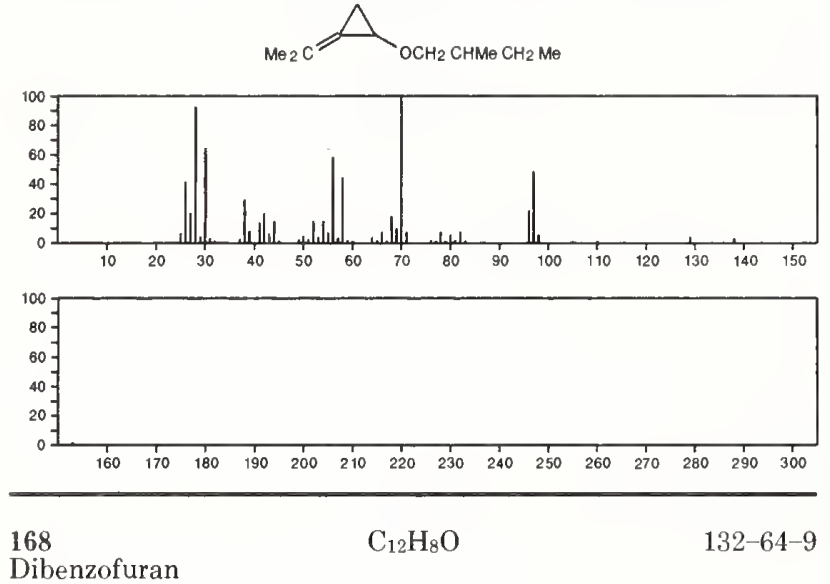

Dibenzofuran
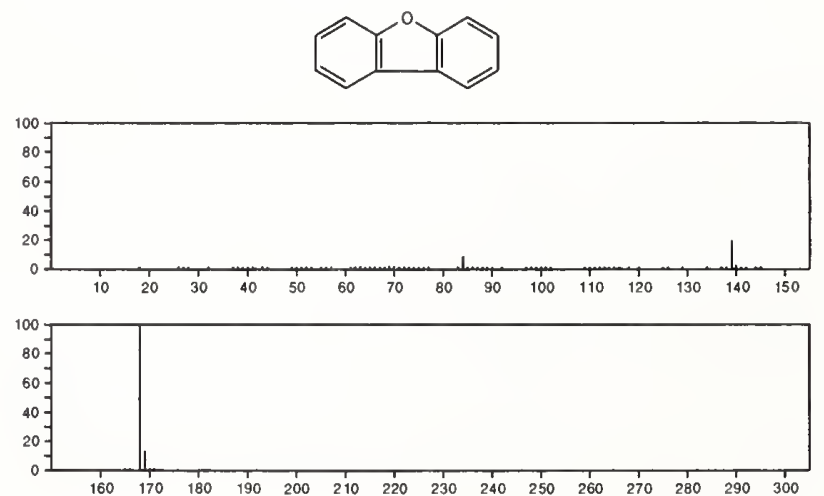

$\underset{2,4-\text { Hexadiyn-1-one, 1-phenyl-- }}{\mathrm{C}_{12} \mathrm{H}_{8} \mathrm{O}}$

$495-74-9$

$\mathrm{PhCOC} \equiv \mathrm{CC} \equiv \mathrm{CM}$
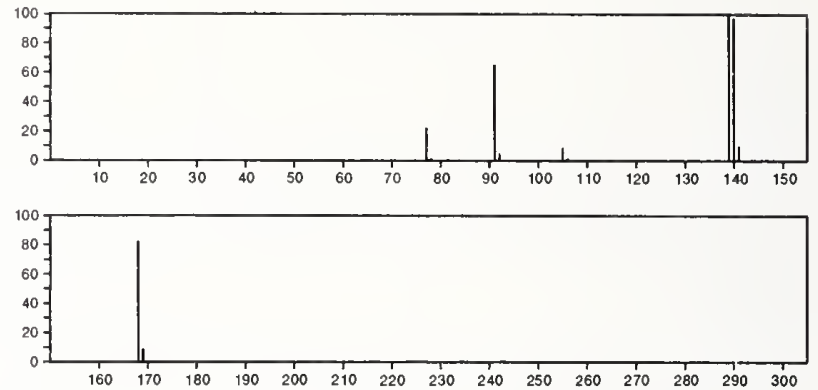

168

1-Dodecene

$\mathrm{C}_{12} \mathrm{H}_{24}$

$112-41-4$

$\mathrm{H}_{2} \mathrm{C}=\mathrm{CH}\left(\mathrm{CH}_{2}\right){ }_{9} \mathrm{Me}$
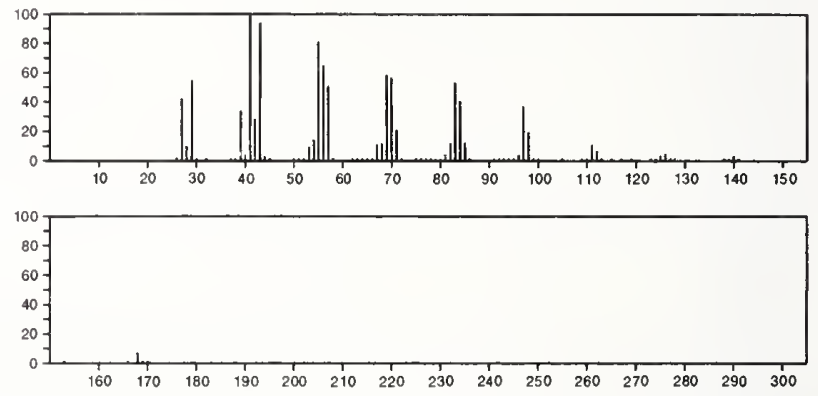

168

Cyclododecane

$\mathrm{C}_{12} \mathrm{H}_{24}$

$294-62-2$
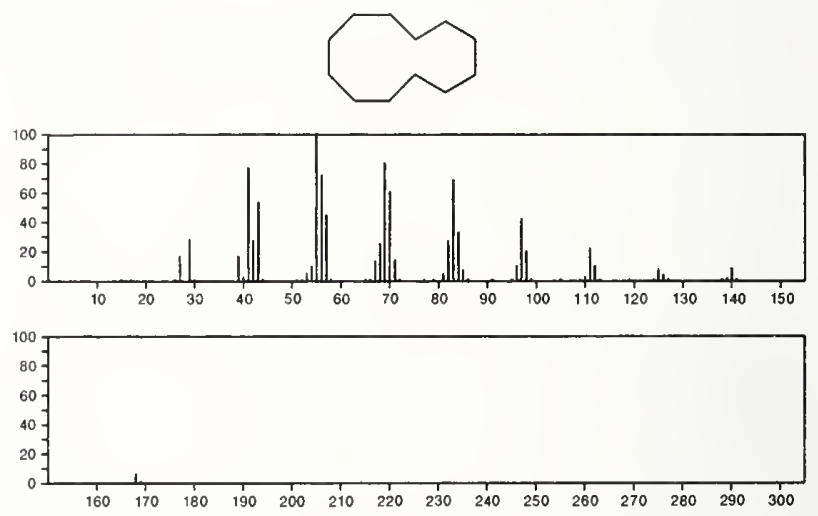

$168 \quad \mathrm{C}_{12} \mathrm{H}_{24}$

1-Heptene, 2-isobutyl-6-methyl-

$7323-15-1$

\section{$\mathrm{Me}_{2} \mathrm{CH}\left(\mathrm{CH}_{2}\right)_{3} \stackrel{\mathrm{CH}}{\mathrm{C} C \mathrm{CH}_{2}} \mathrm{CHM}_{2}$}
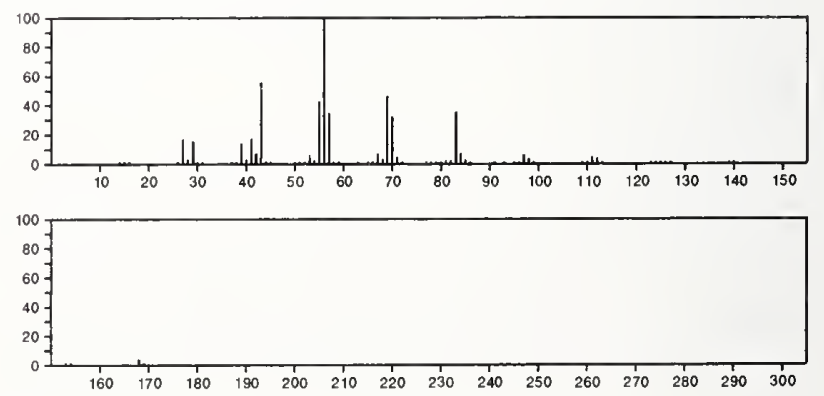
168

$\mathrm{C}_{12} \mathrm{H}_{24}$

17799-46-1

$\mathrm{CH}_{2}$

$\mathrm{Me}\left(\mathrm{CH}_{2}\right)_{4} \stackrel{\mathrm{Cl}}{\mathrm{C}}\left(\mathrm{CH}_{2}\right)_{4} \mathrm{Me}$
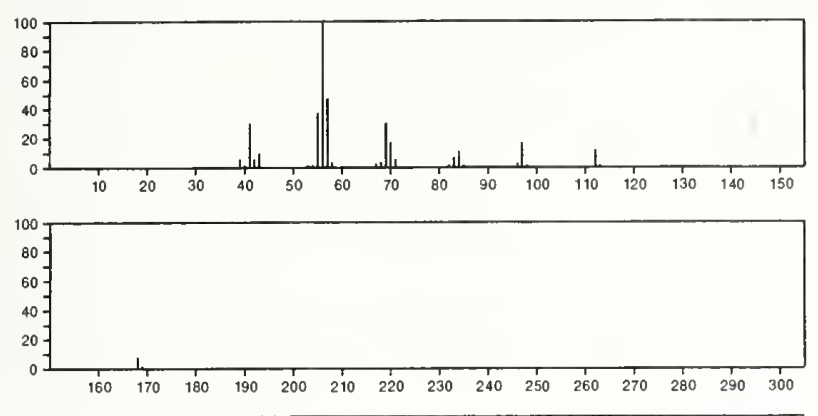

$168 \quad \mathrm{C}_{12} \mathrm{H}_{24}$

1-Hexene, 2-isopentyl-5-methyl-

$33717-92-9$

\section{$\mathrm{CH}_{2}$}

$\mathrm{Me}_{2} \mathrm{CHCH}_{2} \mathrm{CH}_{2} \mathrm{CCH}_{2} \mathrm{CH}_{2} \mathrm{CHM}_{2}$
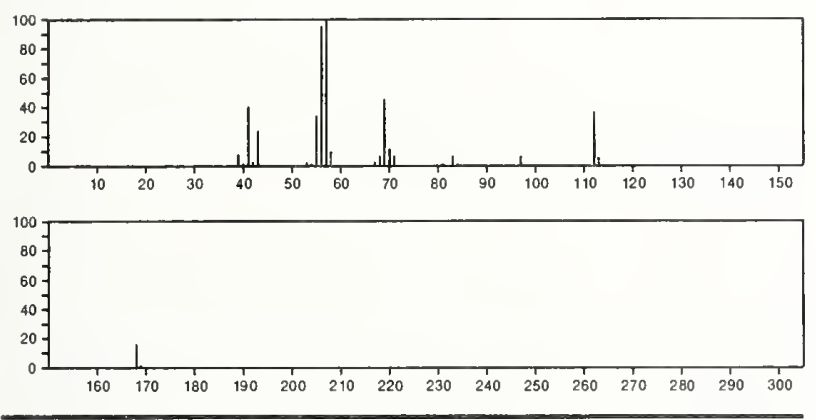

168

1-Nonene, 4,6,8-trimethyl-

$\mathrm{C}_{12} \mathrm{H}_{24}$

$54410-98-9$

$\mathrm{H}_{2} \mathrm{C}: \mathrm{CHCH}_{2} \mathrm{CHMeCH}_{2} \mathrm{CHMeCH}_{2} \mathrm{CHMe}_{2}$
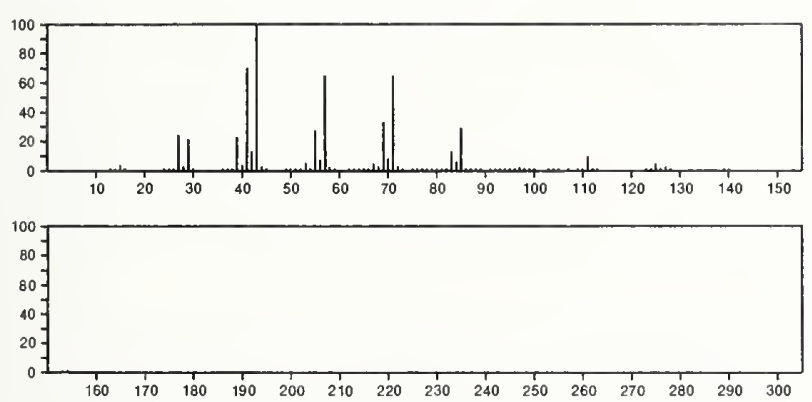

\section{8}

Cyclohexane, 1-butyl-3-ethyl-

54410-99-0
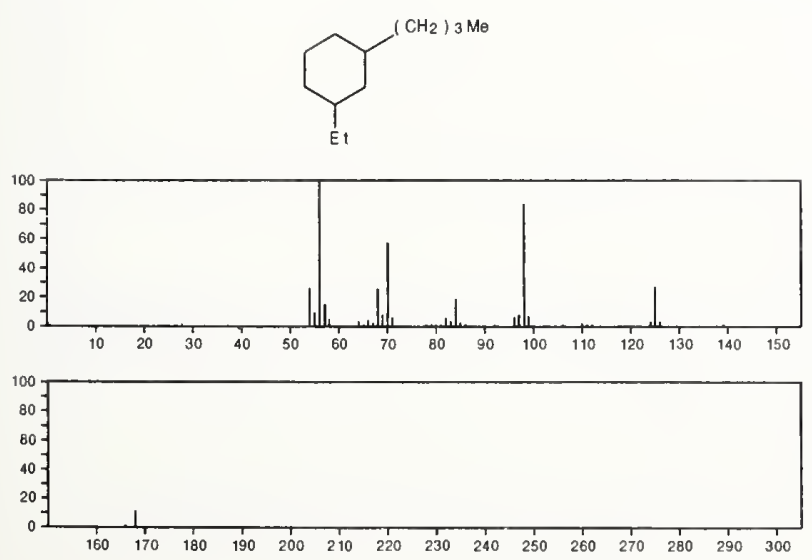

$168 \quad \mathrm{C}_{12} \mathrm{H}_{24}$

Cyclohexane, 1-methyl-4-(1-methylbutyl)-

$54411-00-6$
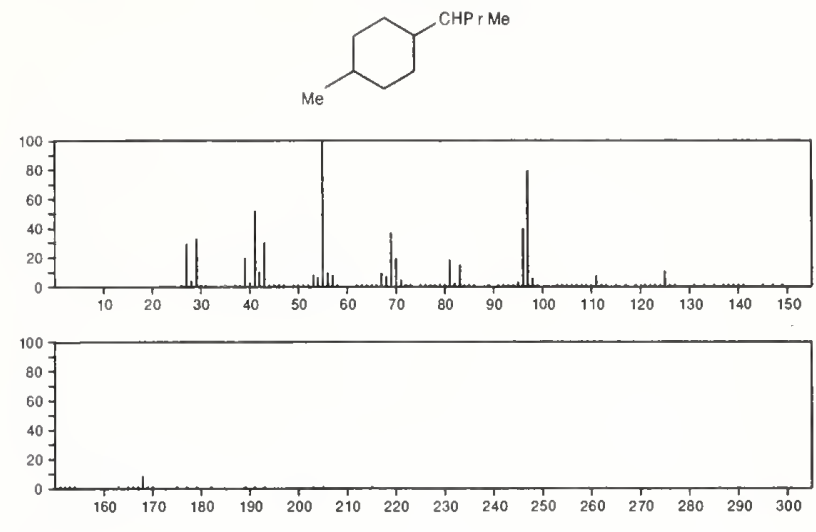

168

Cyclohexane, 1-methyl-2-pentyl-

54411-01-7
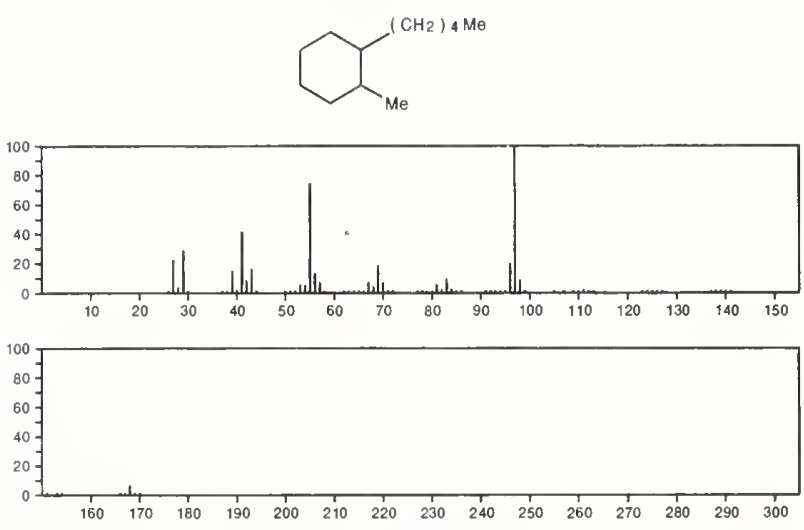

168

$\mathrm{C}_{12} \mathrm{H}_{24}$

Cyclohexane, 1-methyl-3-pentyl-

54411-02-8
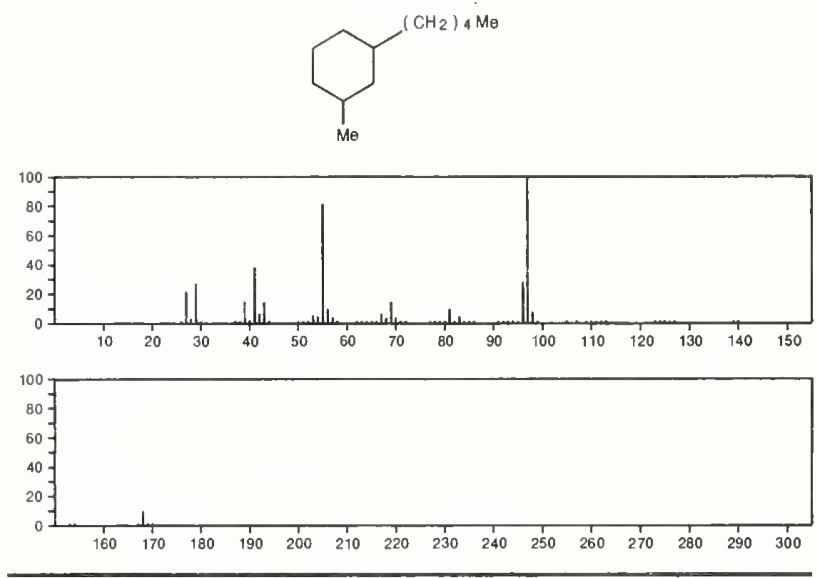

168

$\mathrm{C}_{12} \mathrm{H}_{24}$

$54411-17-5$

Cyclohexane, 1,4-dimethyl-2-(2-methylpropyl)-, (1 $\alpha, 2 \beta, 5 \alpha)-$
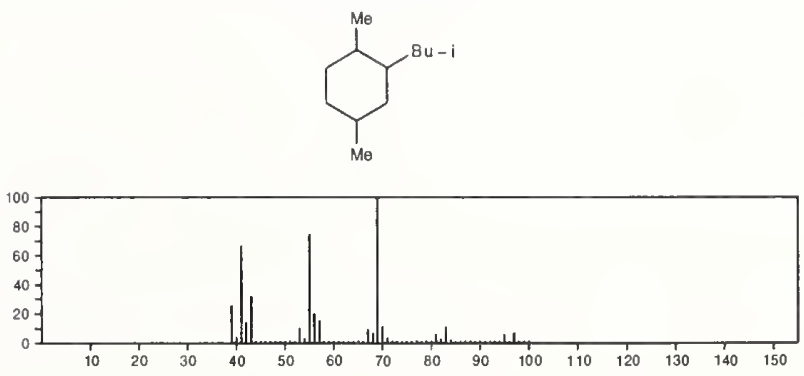
168
Benzene, 1,1'-methylenebis--

$\mathrm{CH}_{2} \mathrm{Ph}_{2}$
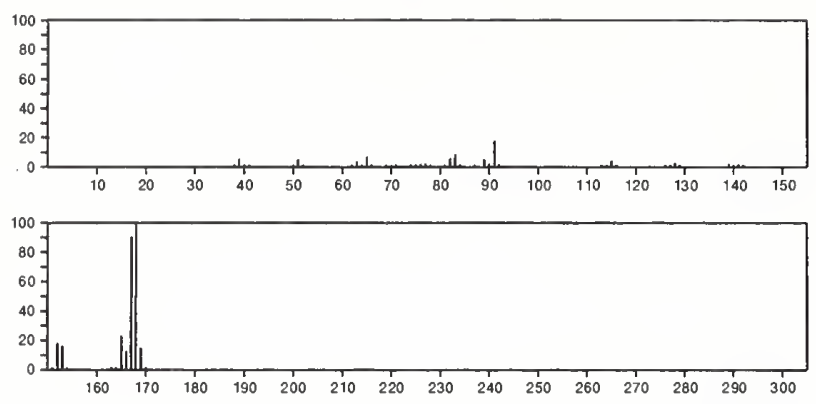

168

1,1'-Biphenyl, 2-methyl-

$$
\mathrm{C}_{13} \mathrm{H}_{12}
$$

$643-58-3$
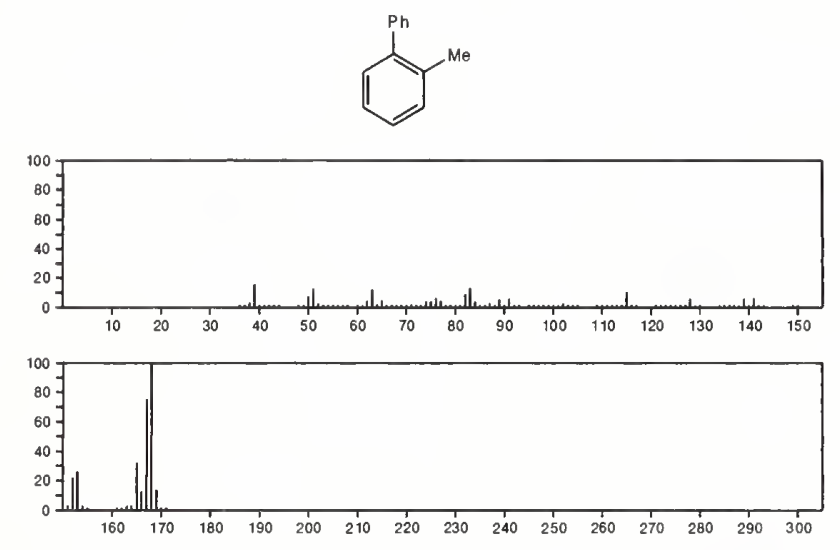

$168 \quad \mathrm{C}_{13} \mathrm{H}_{12}$

1,1'-Biphenyl, 3-methyl-
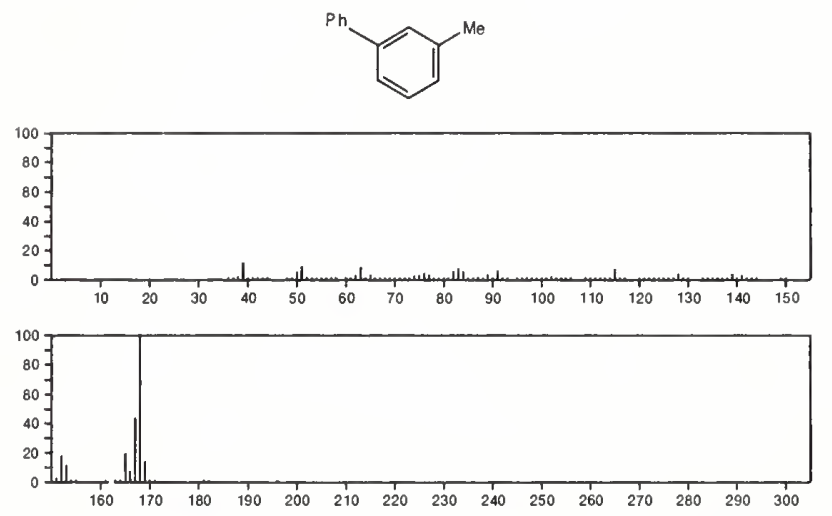

$$
168
$$

168
Naphthalene, 1-(2-propenyl)-

\section{$\mathrm{C}_{13} \mathrm{H}_{12}$}
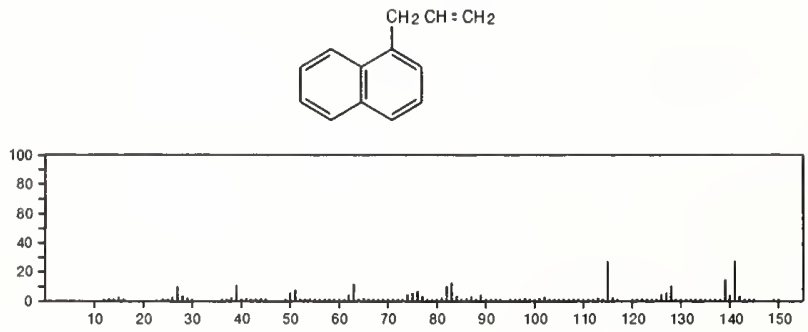

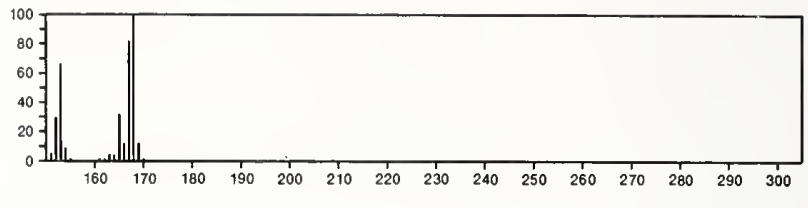

168

$\mathrm{Cl}_{4} \mathrm{Si}$

$10026-04-7$

Silane, tetrachloro-

$\mathrm{SiCl}_{4}$
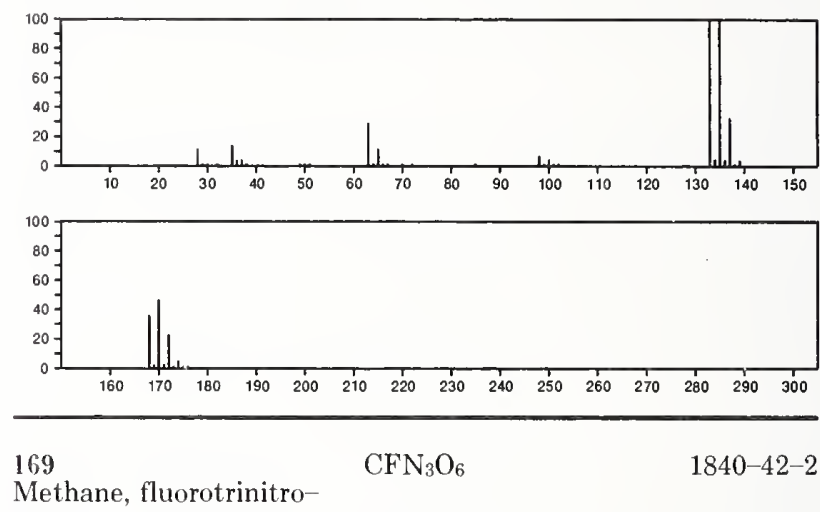

Methane, fluorotrinitro-

$\mathrm{FC}\left(\mathrm{NO}_{2}\right)_{3}$

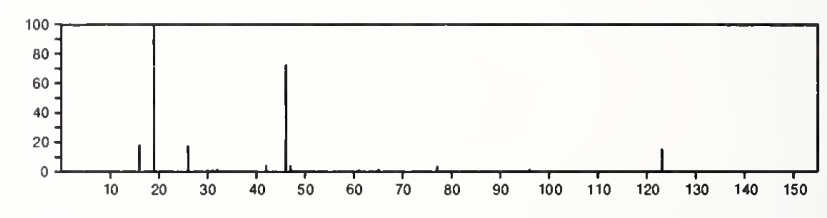

169

$\mathrm{C}_{4} \mathrm{H}_{12} \mathrm{NO}_{2} \mathrm{PS}$

Phosphoramidothioic acid, $O, O$-diethyl ester

$17321-48-1$

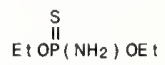
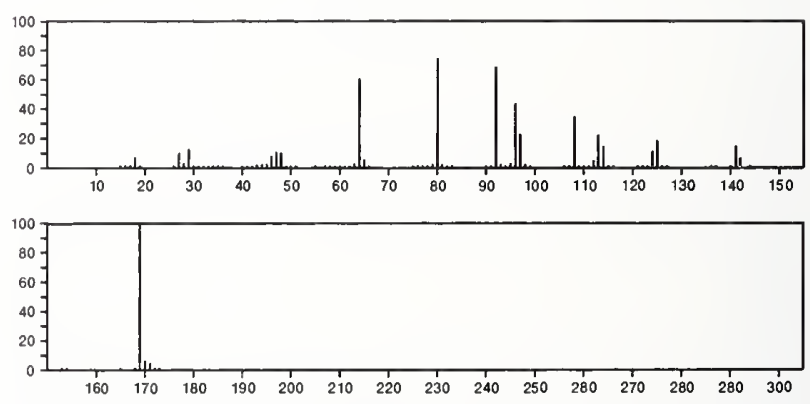

169

Pyridine, pentafluoro-

$\mathrm{C}_{5} \mathrm{~F}_{5} \mathrm{~N}$

$700-16-3$
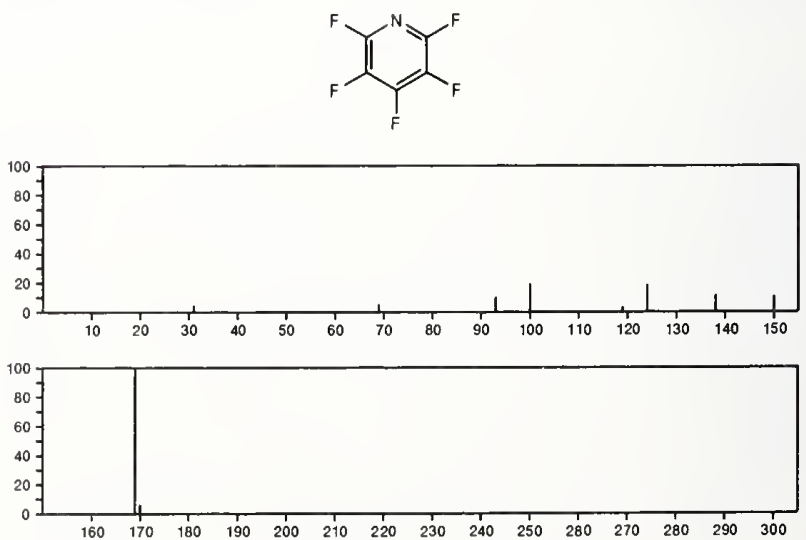
169

$\mathrm{C}_{6} \mathrm{H}_{10} \mathrm{~F}_{3} \mathrm{NO}$

Acetamide, $\mathrm{N}$-butyl-2,2,2-trifluoro-

$\mathrm{F}_{3} \mathrm{CCONH}\left(\mathrm{CH}_{2}\right)_{3} \mathrm{Me}$
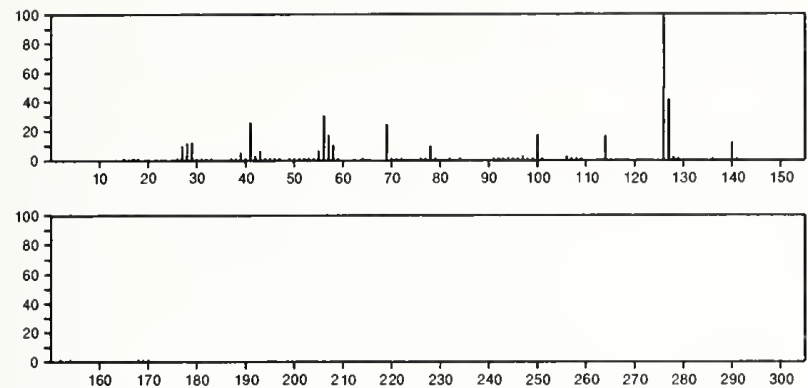

169

Acetamide, $N$-sec-butyl-2,2,2-trifluoro-

$1815-81-2$

$s-\mathrm{BuNHCOCF} 3$
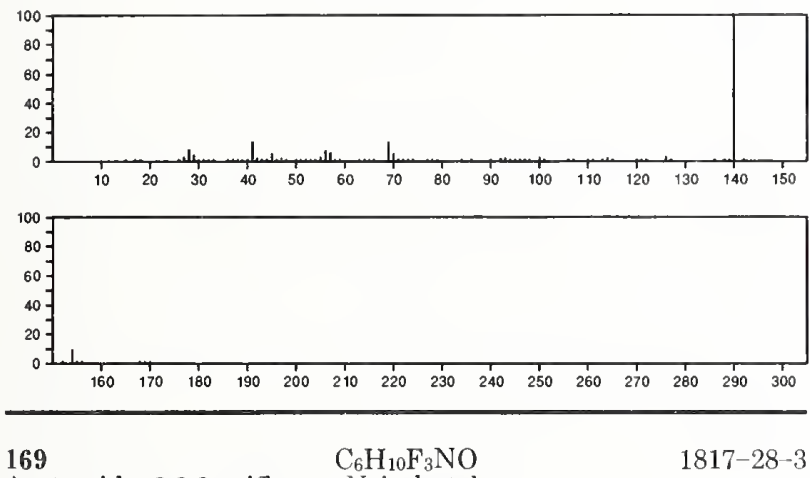

Acetamide, 2,2,2-trifluoro- $N$-isobutyl-

$1817-28-3$

$\mathrm{i}-\mathrm{BuNHCOCF} 3$
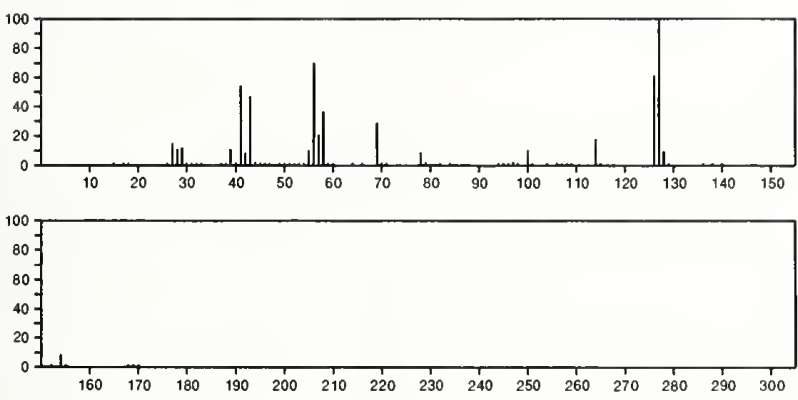

169

$\mathrm{C}_{6} \mathrm{H}_{10} \mathrm{~F}_{3} \mathrm{NO}$

1960-29-8

Acetamide, $N$-tert-butyl-2,2,2-trifluoro-

$\mathrm{t}-\mathrm{BuNHCOCF}$
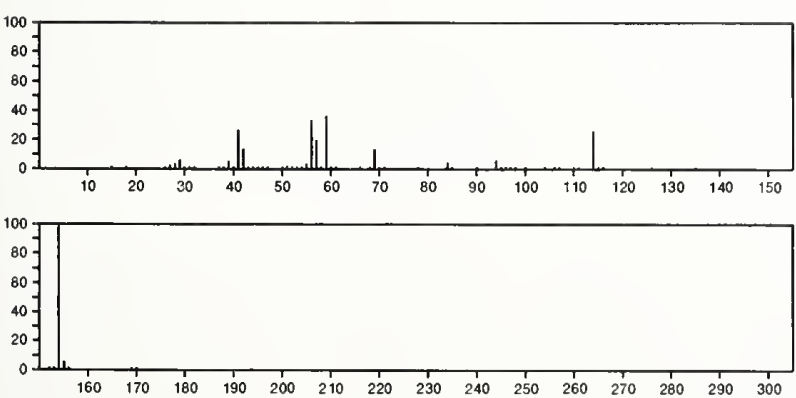

169

$\mathrm{C}_{6} \mathrm{H}_{11} \mathrm{~N}_{5} \mathrm{O}$

$19988-24-0$

1,3,5-Triazin-2(1H)-one, 4-amino-6-[(1-methylethyl)amino $]$<smiles>CCNc1nc(=O)nc(N)[nH]1</smiles>
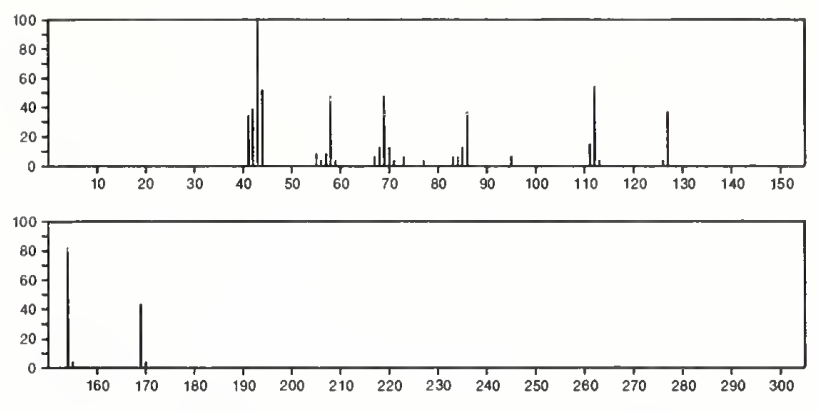

169 - $\mathrm{C}_{6} \mathrm{H}_{11} \mathrm{~N}_{5} \mathrm{O}$

$30360-56-6$

1,3,5-Triazine-2,4-diamine, $N$-ethyl-6-methoxy-
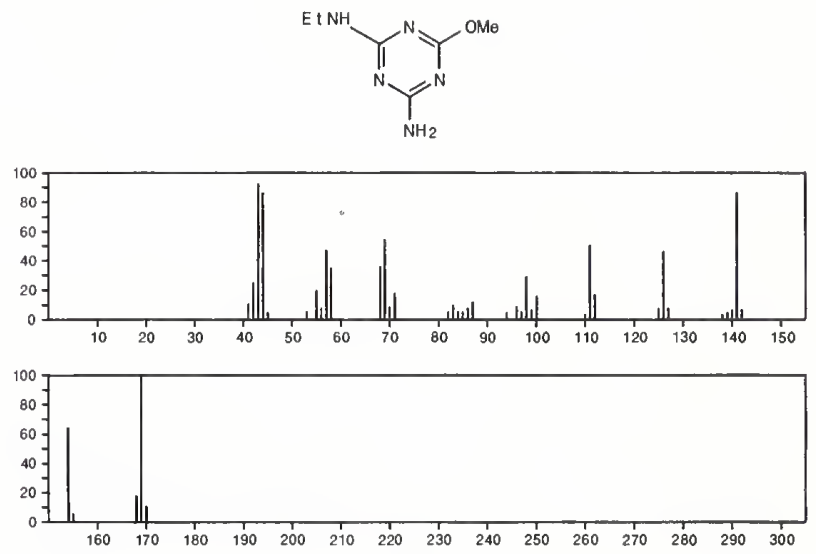

169

2(3H)-Benzoxazolone, 5-chloro-

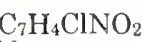

95-25-0
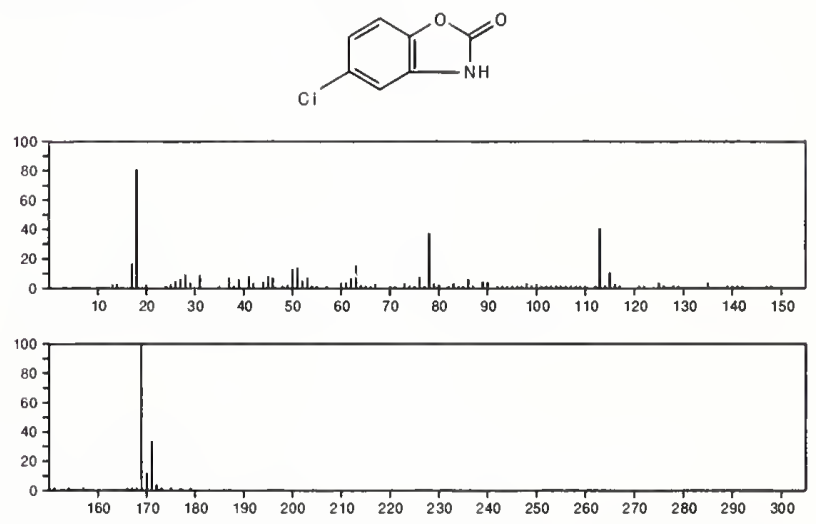

169

$\mathrm{C}_{7} \mathrm{H}_{4} \mathrm{ClNS}$

7716-66-7

1,2-Benzisothiazole, 3-chloro-
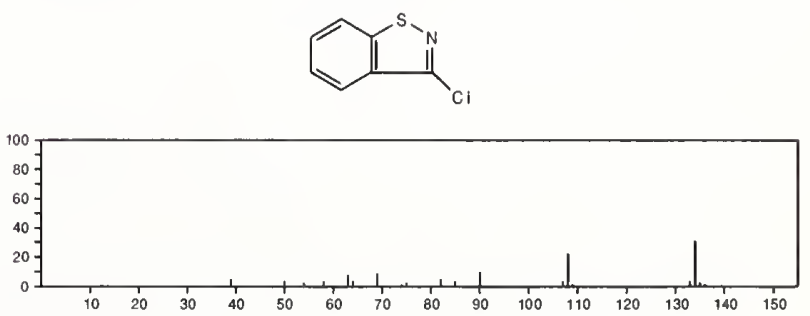


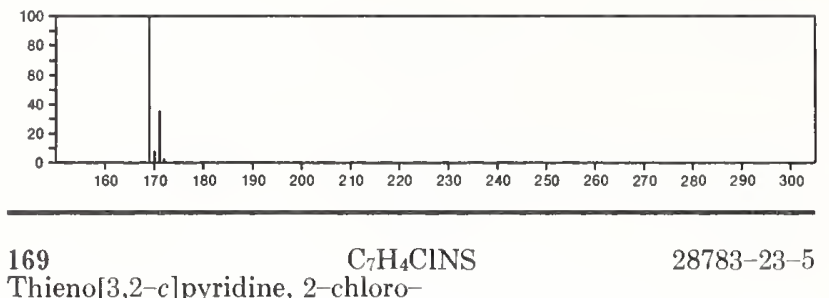

Thieno[3,2-c]pyridine, 2-chloro-
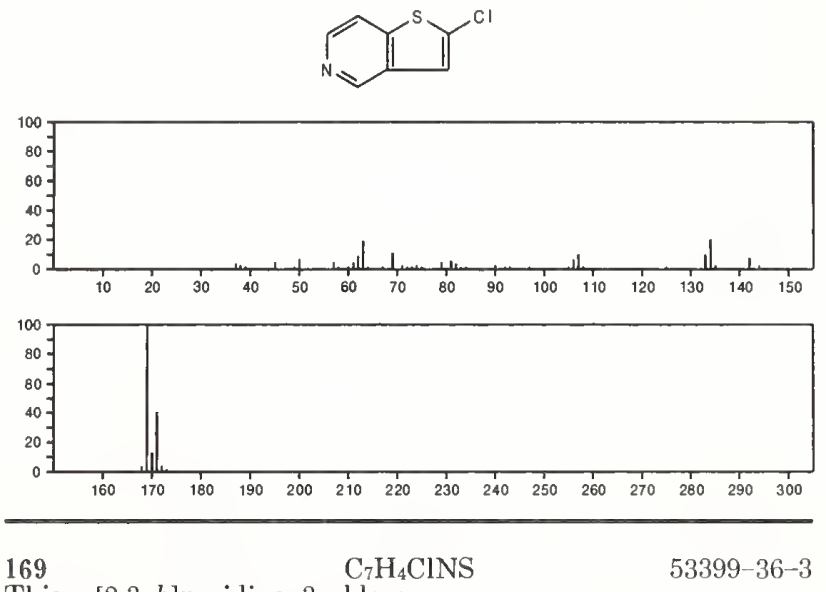

Thieno[2,3-b]pyridine, 3-chloro-
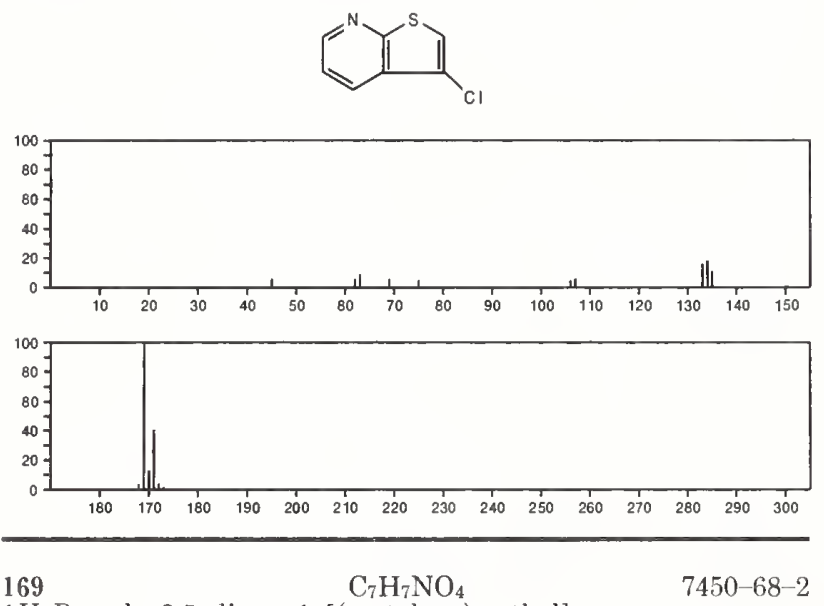

1 H-Pyrrole-2,5-dione, 1-[(acetyloxy)methyl $]-$
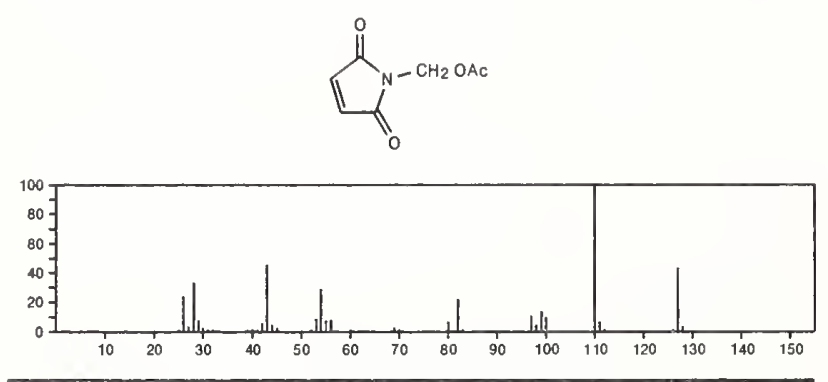

$169 \quad \mathrm{C}_{7} \mathrm{H}_{11} \mathrm{~N}_{3} \mathrm{O}_{2} \quad 332-80-9$

L-Histidine, 1-methyl-
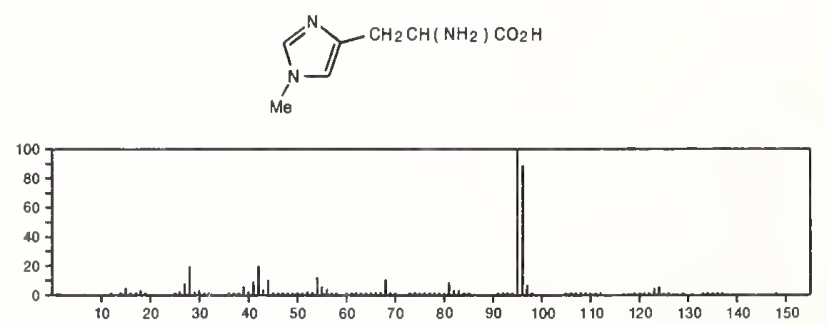

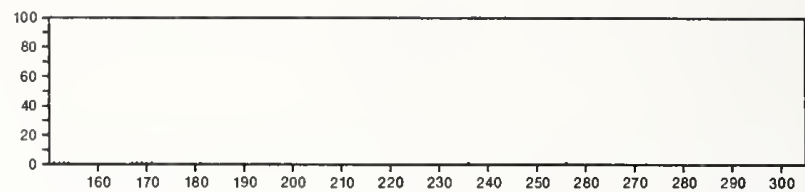

169

L-Histidine, 3-methyl-

$\mathrm{C}_{7} \mathrm{H}_{11} \mathrm{~N}_{3} \mathrm{O}_{2}$

$368-16-1$
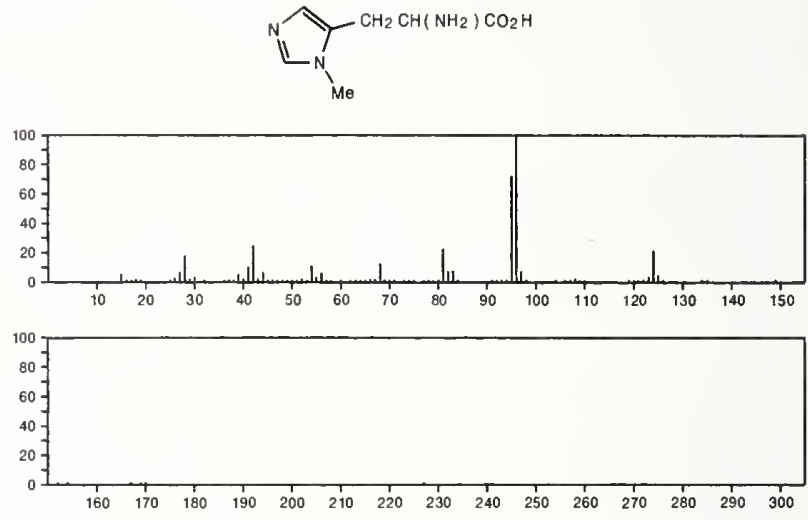

169
$1,2,4-$ Triazabicyclo[2.2.2] octan-3-one, 2-acetyl-

$29924-76-3$
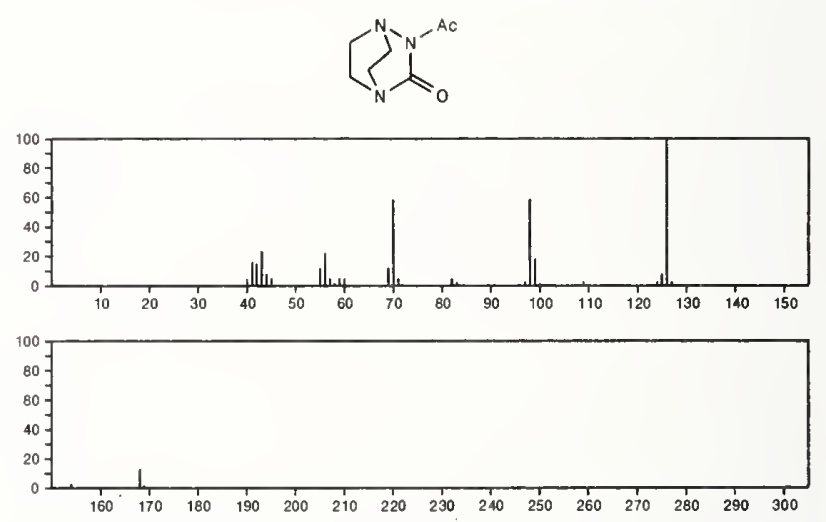

169

$\mathrm{C}_{7} \mathrm{H}_{11} \mathrm{~N}_{3} \mathrm{~S}$

$54410-87-6$

4-Pyrimidinamine, 2-(ethylthio)-5-methyl-
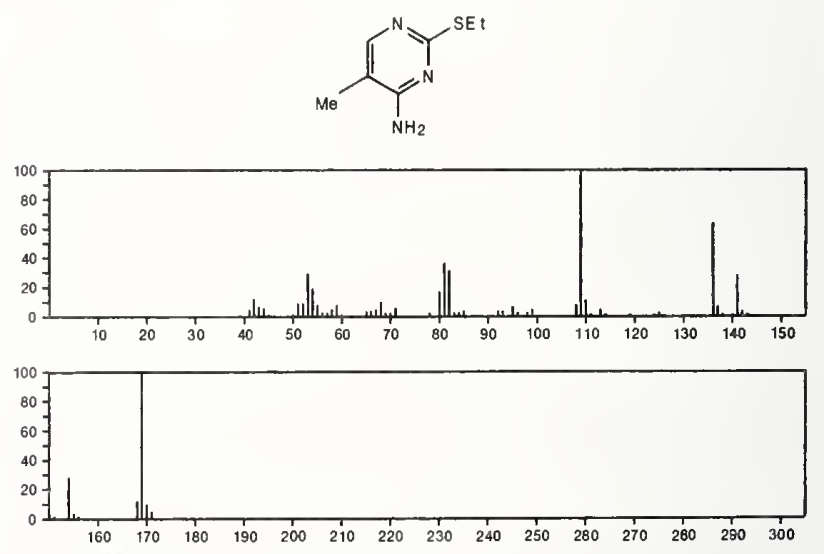
169

$\mathrm{C}_{7} \mathrm{H}_{11} \mathrm{~N}_{3} \mathrm{~S}$

4-Pyrimidinamine, 2-(propylthio)-
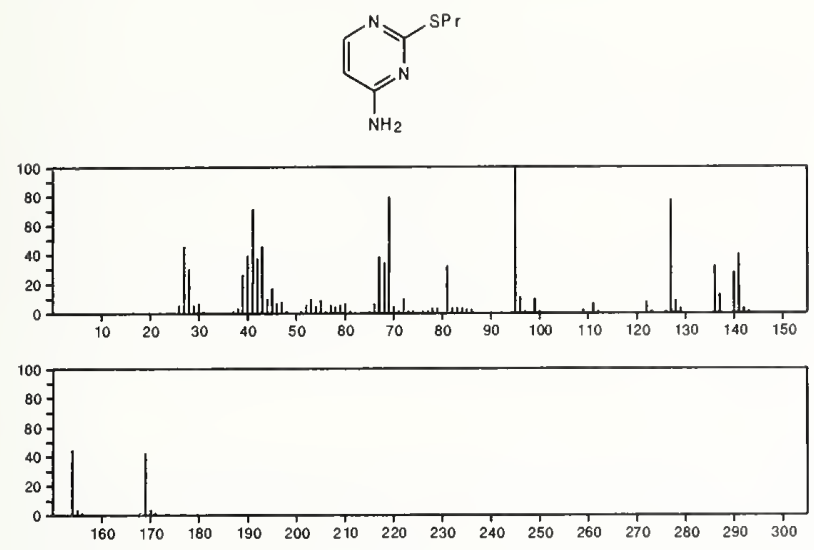

169
Benzene, (difluoroisocyanatomethyl)

$\mathrm{PhCF}_{2}$ ( NCO)
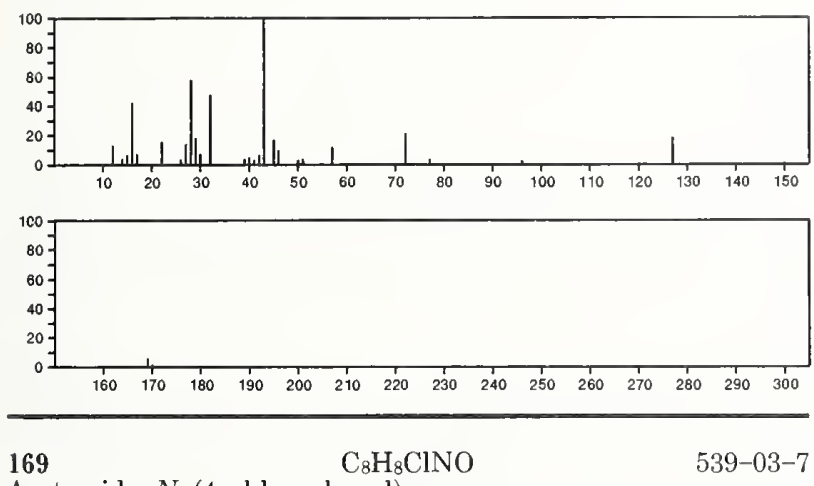

$539-03-7$

Acetamide, $N$-(4-chlorophenyl)-
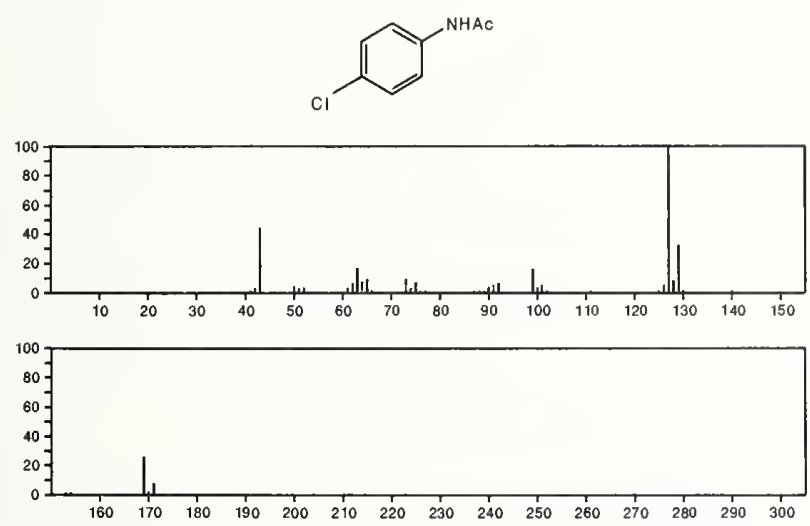

169

Benzaldehyde, $m$-chloro-, $O$-methyloxime
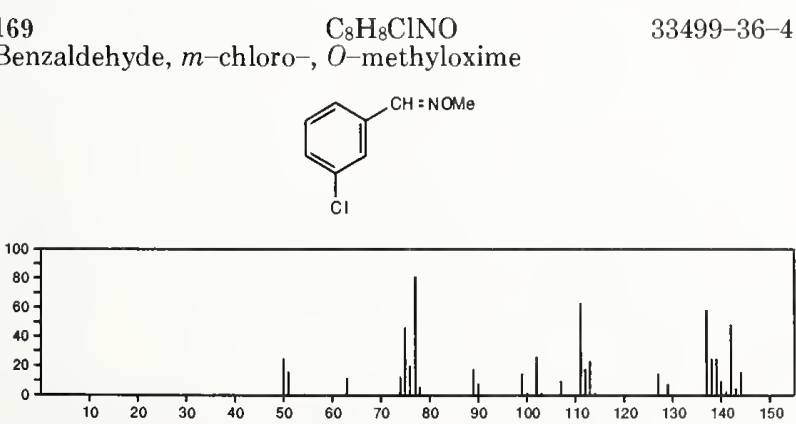

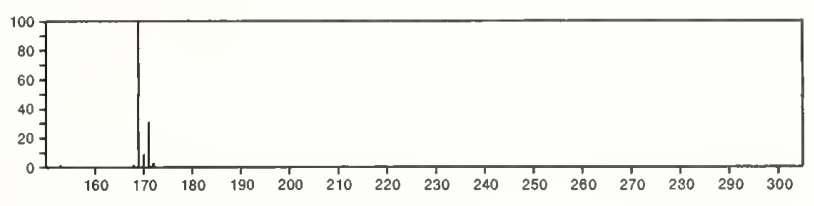

169

$\mathrm{C}_{8} \mathrm{H}_{8} \mathrm{ClNO}$

Benzaldehyde, 4-chloro--, O-methyloxime

$33499-37-5$
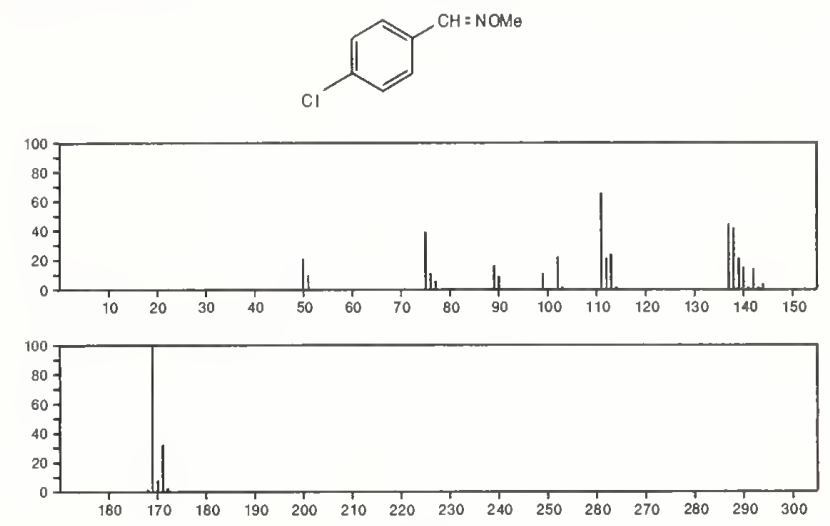

169

$\mathrm{C}_{8} \mathrm{H}_{8} \mathrm{ClNO}$

$33513-35-8$

Benzaldehyde, $\mathrm{o}^{-}$chloro- $^{-} \mathrm{O}^{-}$-methyloxime
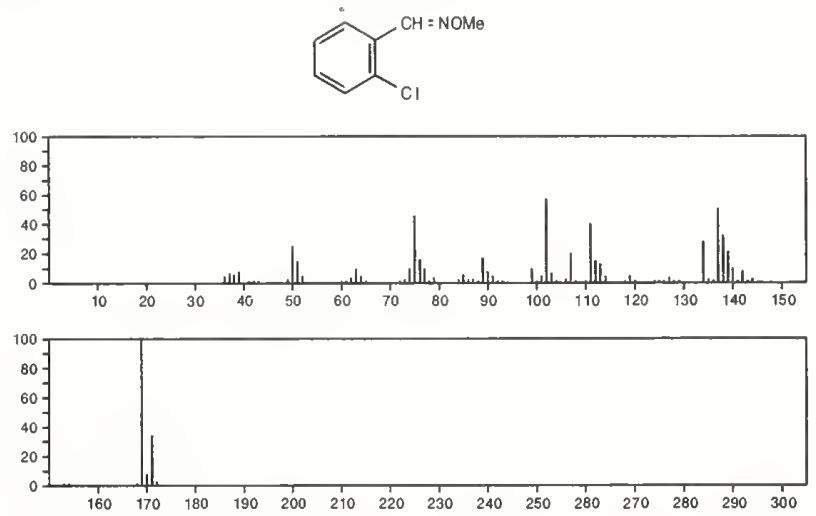

169

$\mathrm{C}_{8} \mathrm{H}_{11} \mathrm{NOS}$

3-Pyridinol, 2-(ethylthio)-6-methyl-

23003-26-1
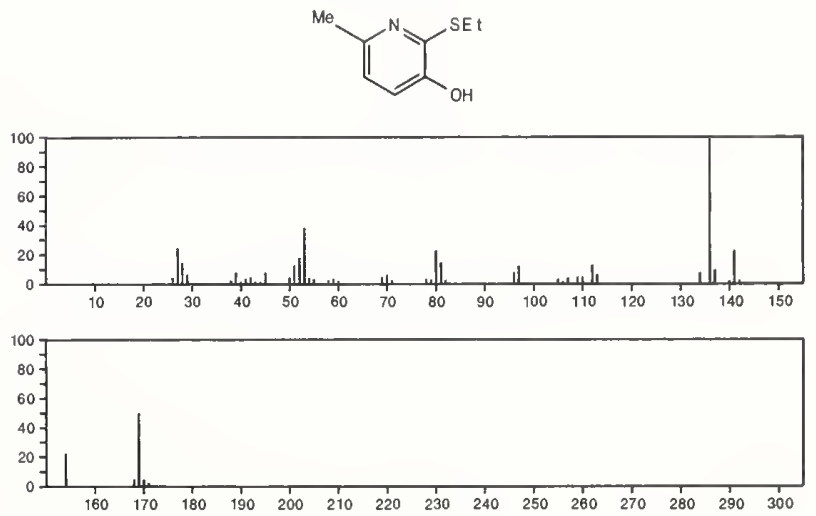
$\mathrm{C}_{8} \mathrm{H}_{11} \mathrm{NOS}$

24207-15-6

2(1H)-Pyridinethione, 1-ethyl-3-hydroxy-6-methyl
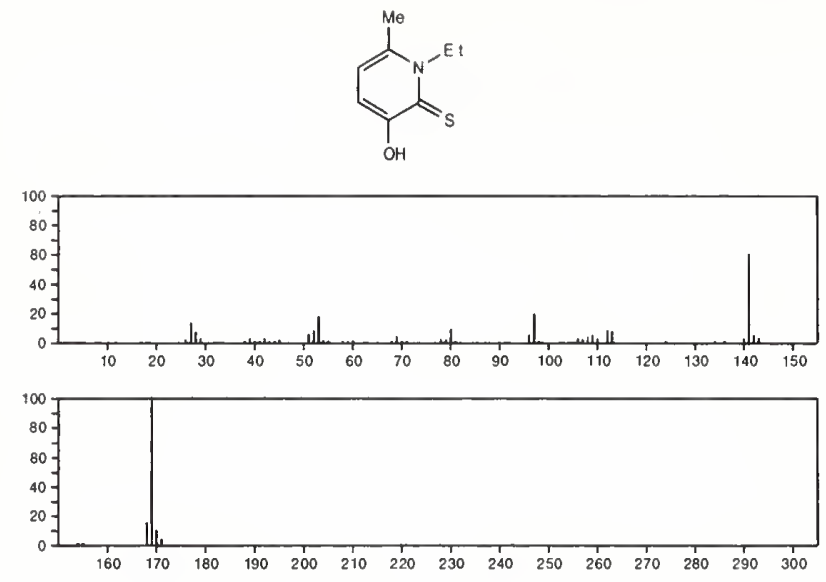

169

$\mathrm{C}_{8} \mathrm{H}_{11} \mathrm{NOS}$

$40585-12-4$

2(1H)-Pyridinethione, 3-ethoxy-6-methyl-
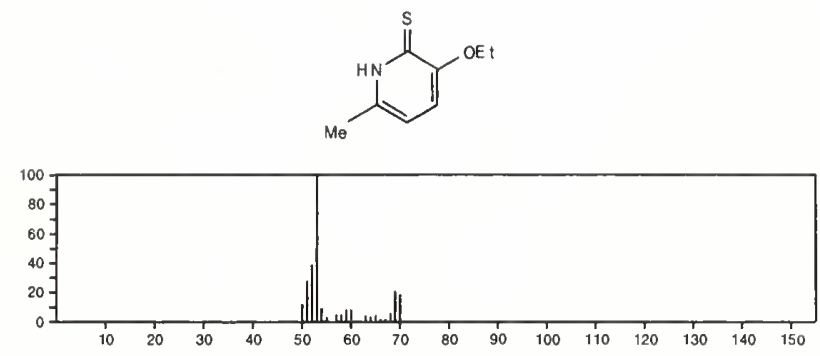

169

$\mathrm{C}_{8} \mathrm{H}_{11} \mathrm{NOS}$

$55956-24-6$

Ethanol, 2-[(methyl-2-thienylmethylene)amino]-
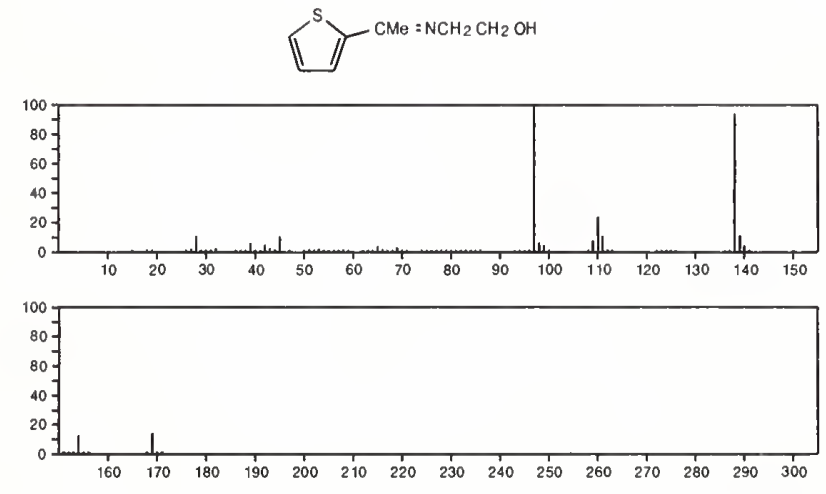

169

$\mathrm{C}_{8} \mathrm{H}_{11} \mathrm{NO}_{3}$

$51-41-2$

1,2-Benzenediol, 4-(2-amino-1-hydroxyethyl)-, $(R)$ -
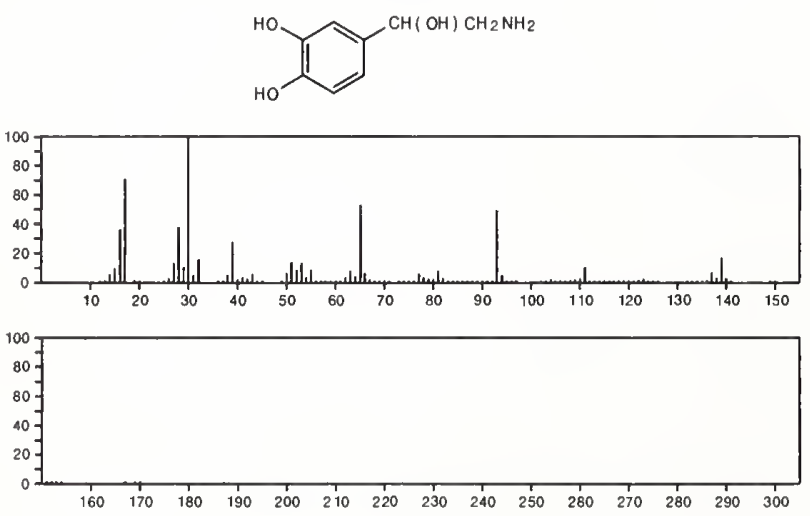

$169 \quad \mathrm{C}_{8} \mathrm{H}_{11} \mathrm{NO}_{3}$

149-95-1

1,2-Benzenediol, 4-(2-amino-1-hydroxyethyl)-, (S)-
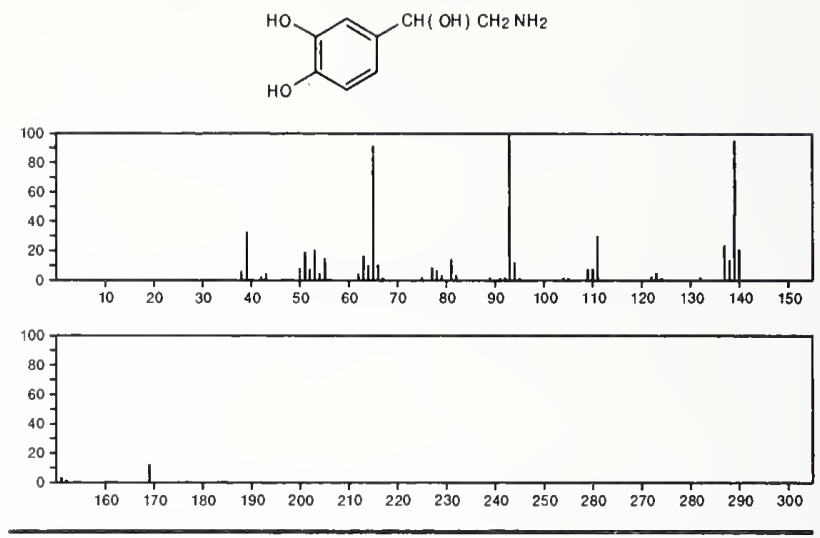

169

$\mathrm{C}_{8} \mathrm{H}_{15} \mathrm{~N}_{3} \mathrm{O}$

Hydrazinecarboxamide, 2-(2-methylcyclohexylidene)-

$4549-20-6$
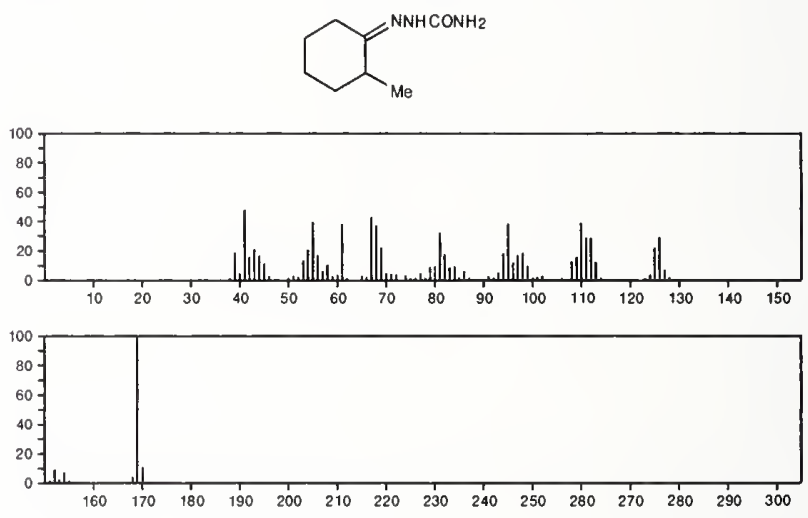

$169 \quad \mathrm{C}_{8} \mathrm{H}_{15} \mathrm{~N}_{3} \mathrm{O}$

Cyclohexanone, 4-methyl-, semicarbazone

$5439-97-4$
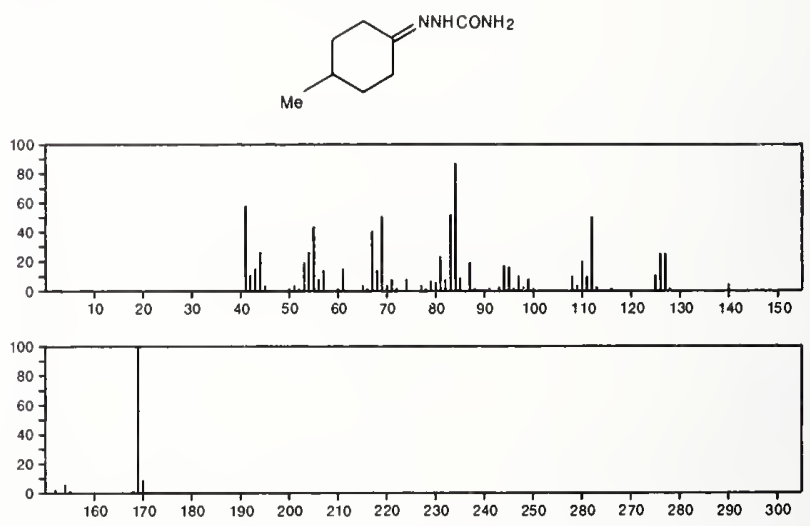

169

$\mathrm{C}_{8} \mathrm{H}_{15} \mathrm{~N}_{3} \mathrm{O}$

$54410-86-5$

Hydrazinecarboxamide, 2-(3-methylcyclohexylidene)-
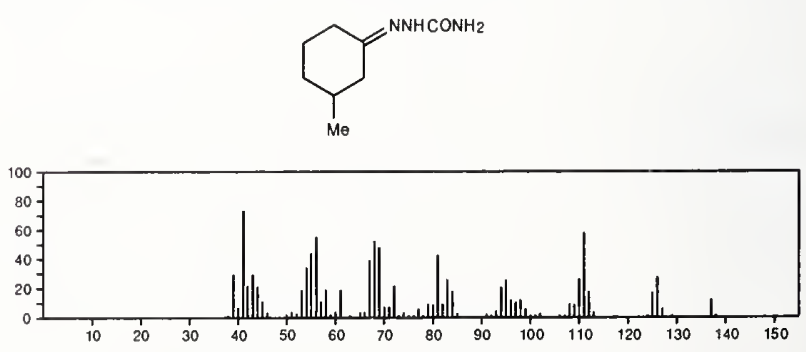


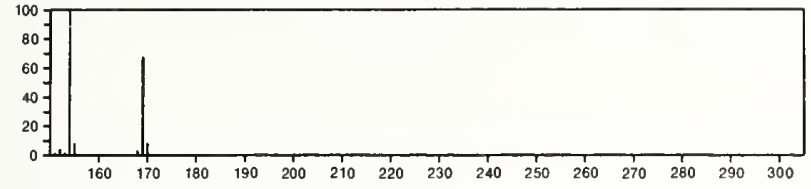

169

$\mathrm{C}_{9} \mathrm{H}_{15} \mathrm{NO}_{2}$

3-Penten-2-one, 4-(4-morpholinyl)-
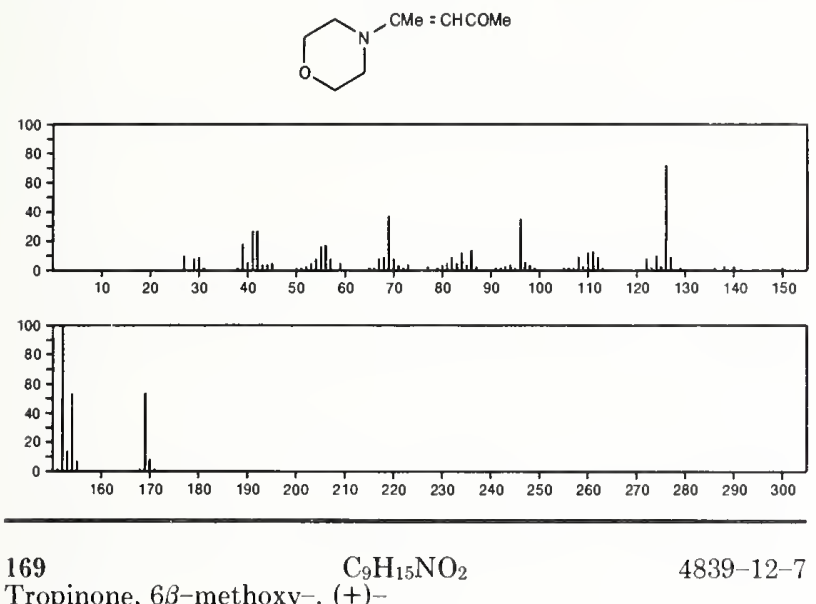

Tropinone, $6 \beta$-methoxy-, (+)
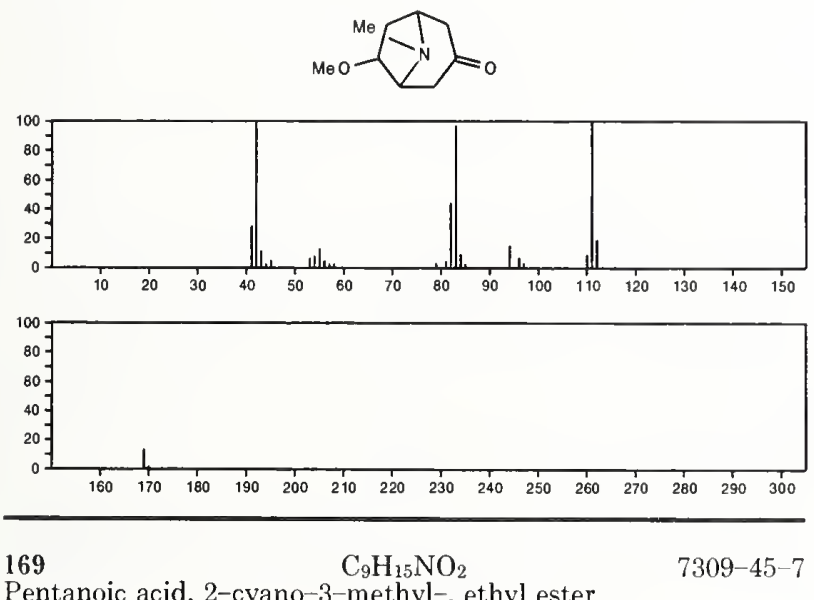

Pentanoic acid, 2-cyano-3-methyl-, ethyl ester

$\mathrm{E}+\mathrm{OC}(\mathrm{O}) \mathrm{CH}(\mathrm{CN}) \mathrm{CHMeCH}_{2} \mathrm{Me}$
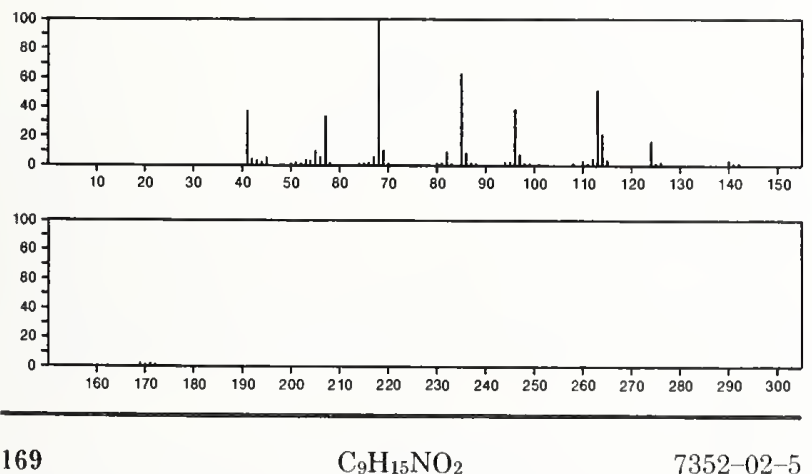

Valeric acid, 2-cyano-4-methyl-, ethyl ester

$\mathrm{E}$ ( OC (O) $\mathrm{CH}$ ( $\mathrm{CN}$ ) $\mathrm{CH}_{2} \mathrm{CHMe}_{2}$

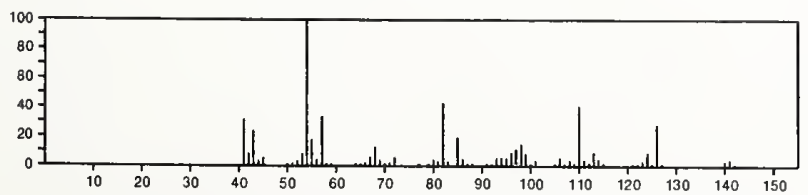

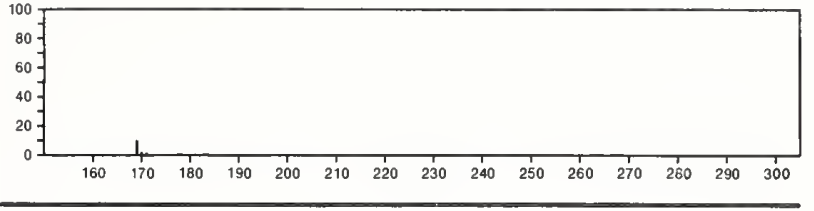

169

$\mathrm{C}_{9} \mathrm{H}_{15} \mathrm{NO}_{2}$

Hexanoic acid, 2-cyano--, ethyl ester

7391-39-1

$\mathrm{E}\left(\mathrm{OC}(\mathrm{O}) \mathrm{CH}(\mathrm{CN})\left(\mathrm{CH}_{2}\right)_{3} \mathrm{Me}\right.$
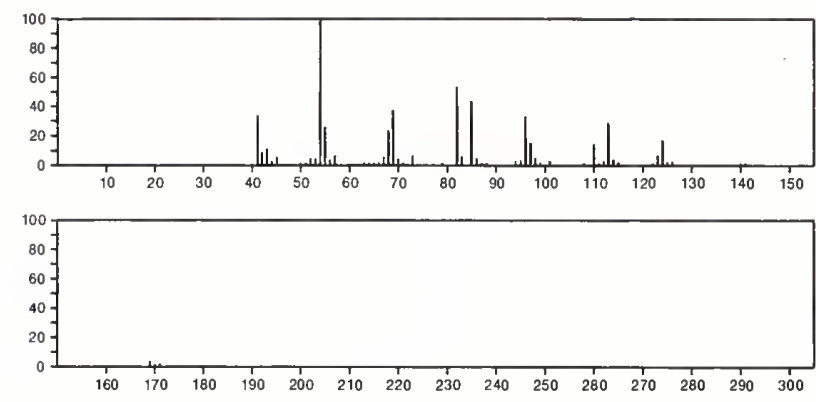

169

$\mathrm{C}_{9} \mathrm{H}_{15} \mathrm{NO}_{2}$

$54410-85-4$

2,5-Pyrrolidinedione, 1,3-diethyl-3-methyl-
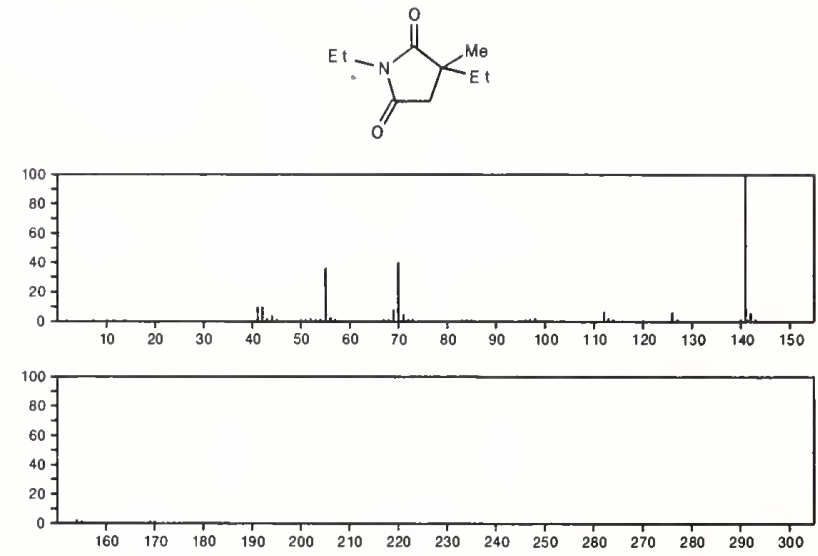

169

$\mathrm{C}_{9} \mathrm{H}_{15} \mathrm{NS}$

Thiazole, 5-ethyl-2-methyl-4-propyl-

$4276-67-9$
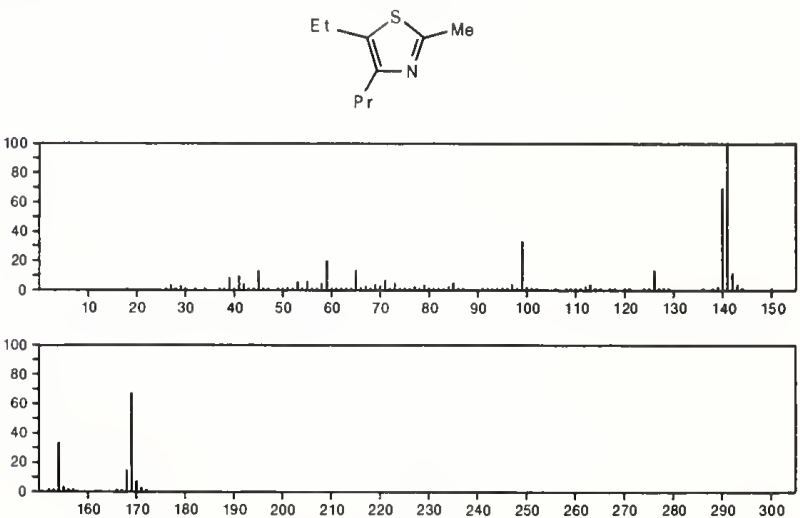
169

Thiazole, 2,5-dipropyl-

$\mathrm{C}_{9} \mathrm{H}_{15} \mathrm{NS}$

41981-73-1
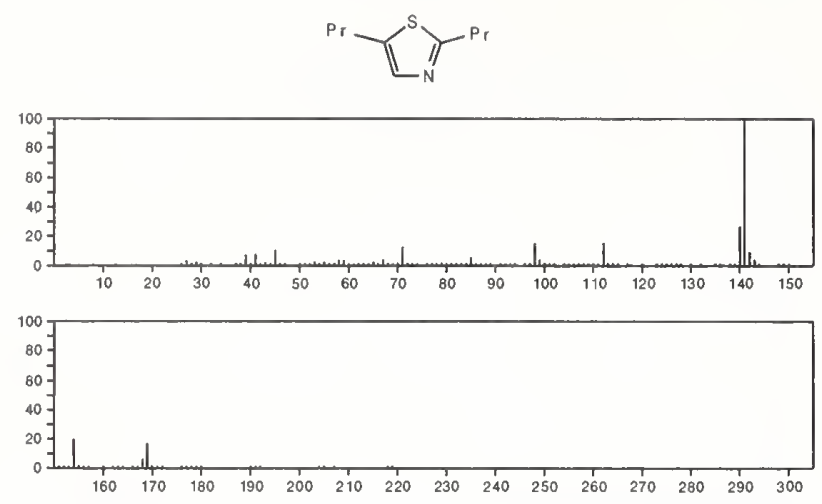

\section{9}

Thiazole, 2,4-dipropyl-

$\mathrm{C}_{9} \mathrm{H}_{15} \mathrm{NS}$

$41981-74-2$
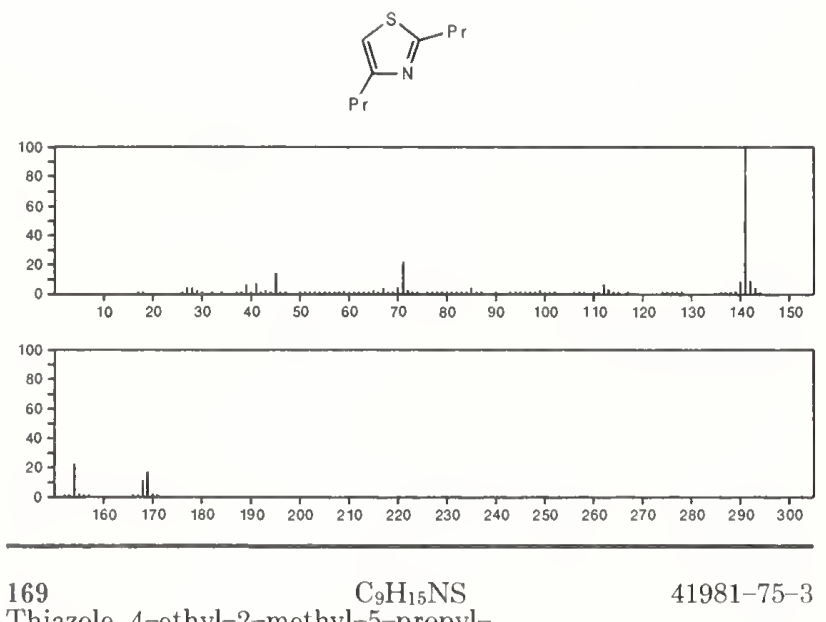

Thiazole, 4-ethyl-2-methyl-5-propyl-
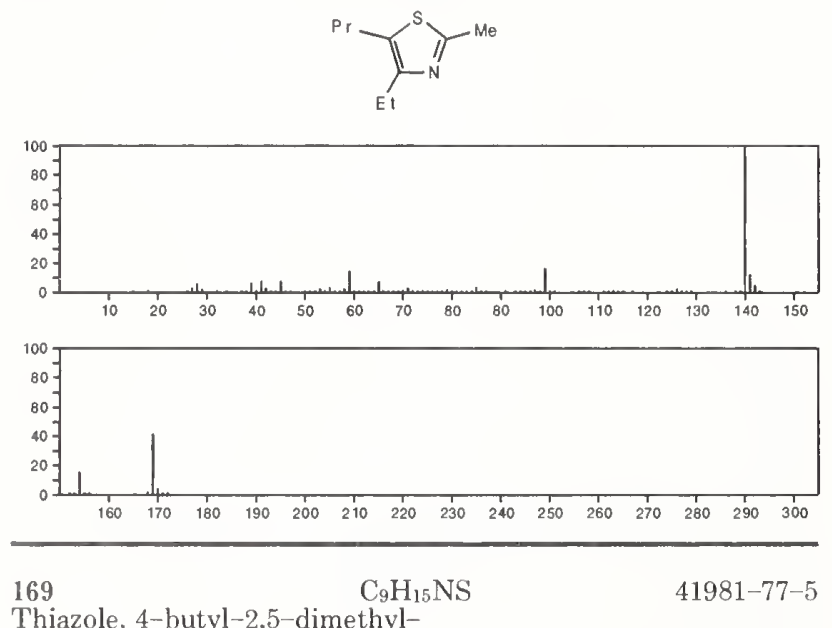

Thiazole, 4-butyl-2,5-dimethyl-
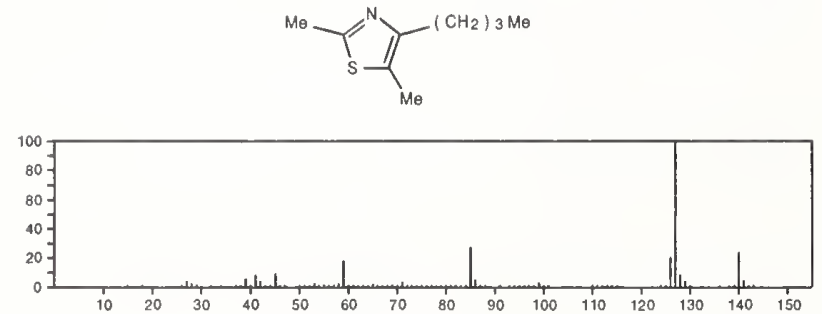

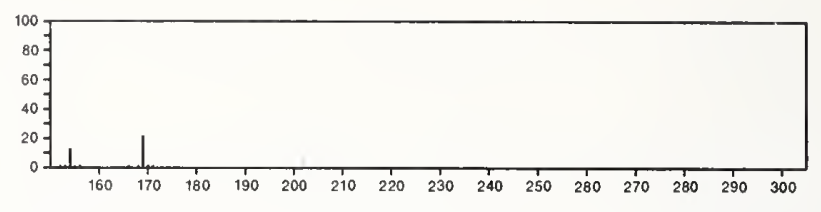

169

$\mathrm{C}_{9} \mathrm{H}_{15} \mathrm{NS}$

Thiazole, 5-ethyl-4-methyl-2-propyl-

$41981-78-6$
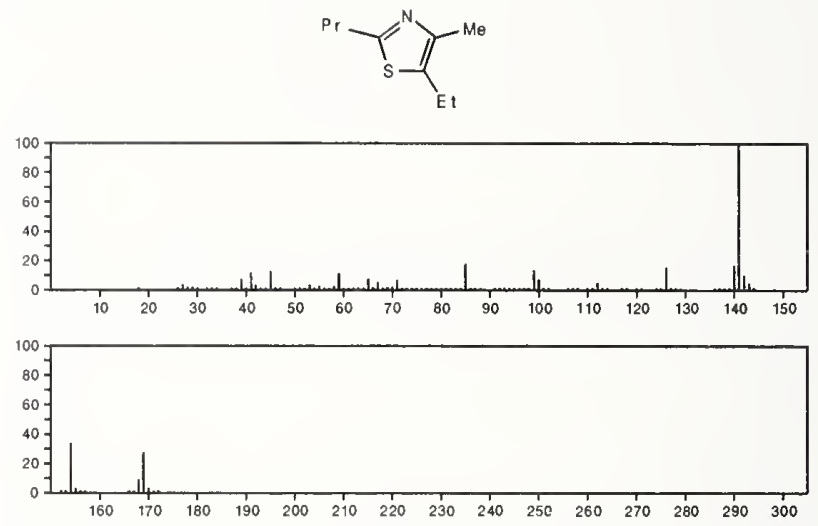

169

$\mathrm{C}_{9} \mathrm{H}_{15} \mathrm{NS}$

Thiazole, 5-butyl-2-ethyl-
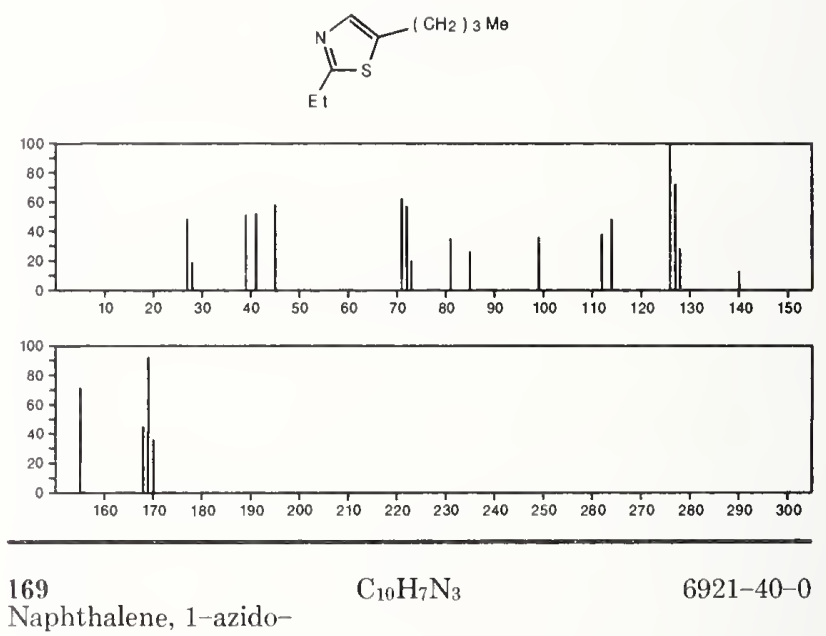

Naphthalene, 1-azido-
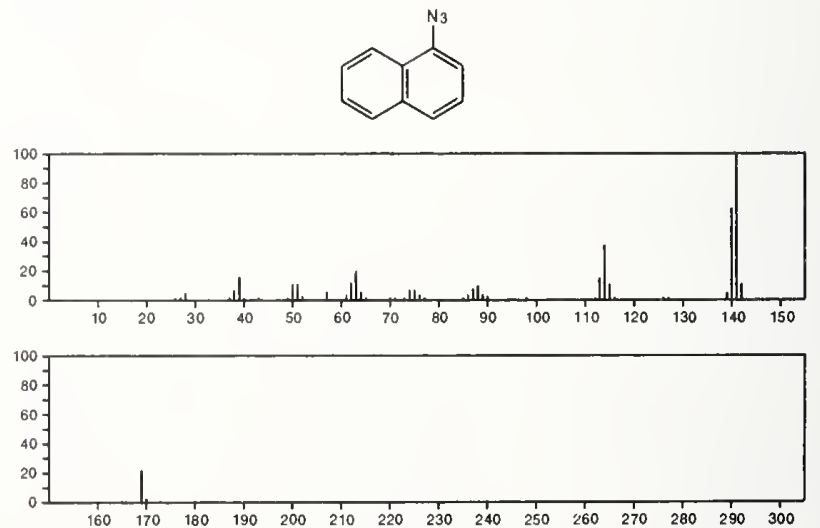
169 $\mathrm{C}_{10} \mathrm{H}_{7} \mathrm{~N}_{3}$

$17966-00-6$

$1 H$-Dipyrido $\left[2,3-b: 3^{\prime}, 2^{\prime}-d\right]$ pyrrole
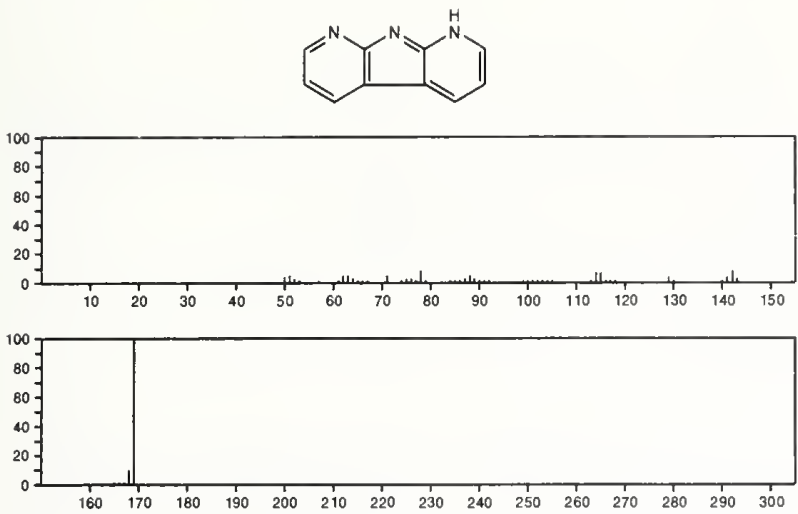

169

Acetamide, $N$-cyclohexyl- $\mathrm{N}$-ethyl-

$1128-34-3$
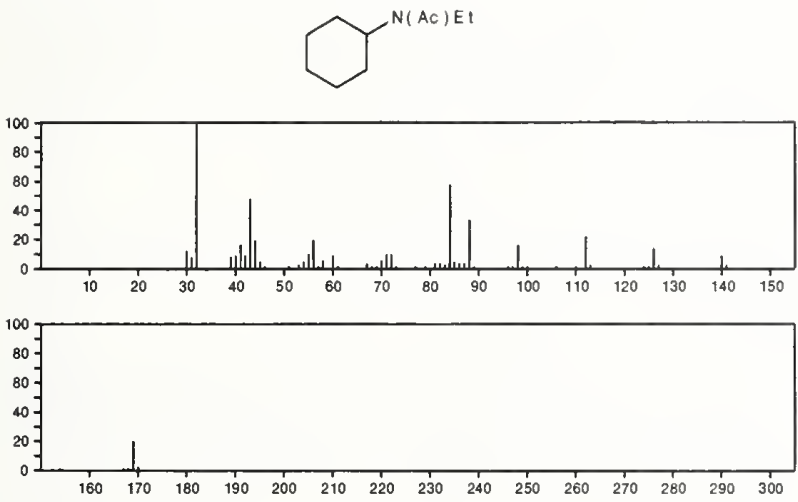

169 $\mathrm{C}_{10} \mathrm{H}_{19} \mathrm{NO}$

$1199-87-7$

Butanamide, $N$-cyclohexyl-
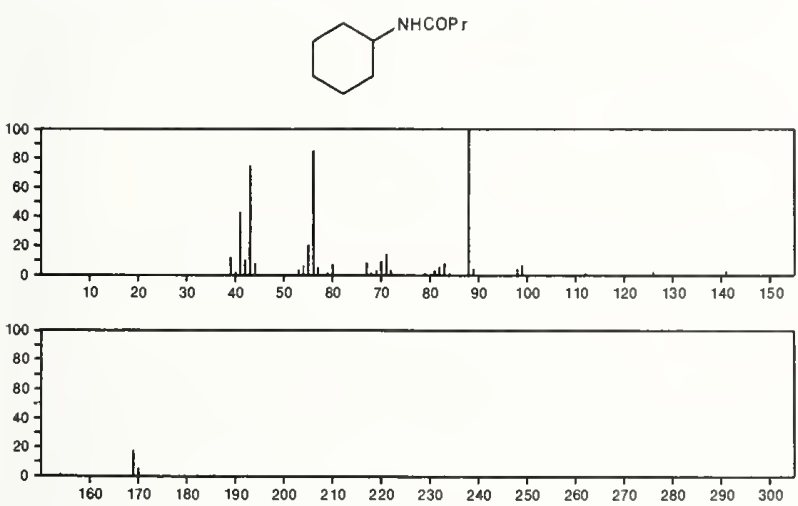

169

$\mathrm{C}_{10} \mathrm{H}_{19} \mathrm{NO}$

$1925-44-6$

Bicyclo[2.2.1]heptan-2-ol, 3-amino-1,7,7-trimethyl-, (endo,endo)-
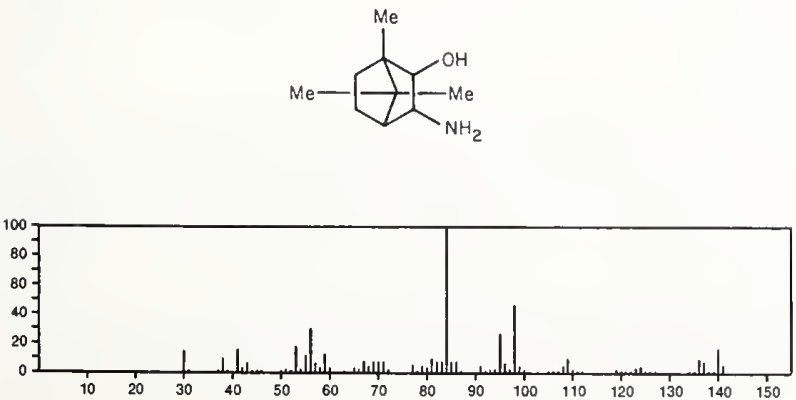
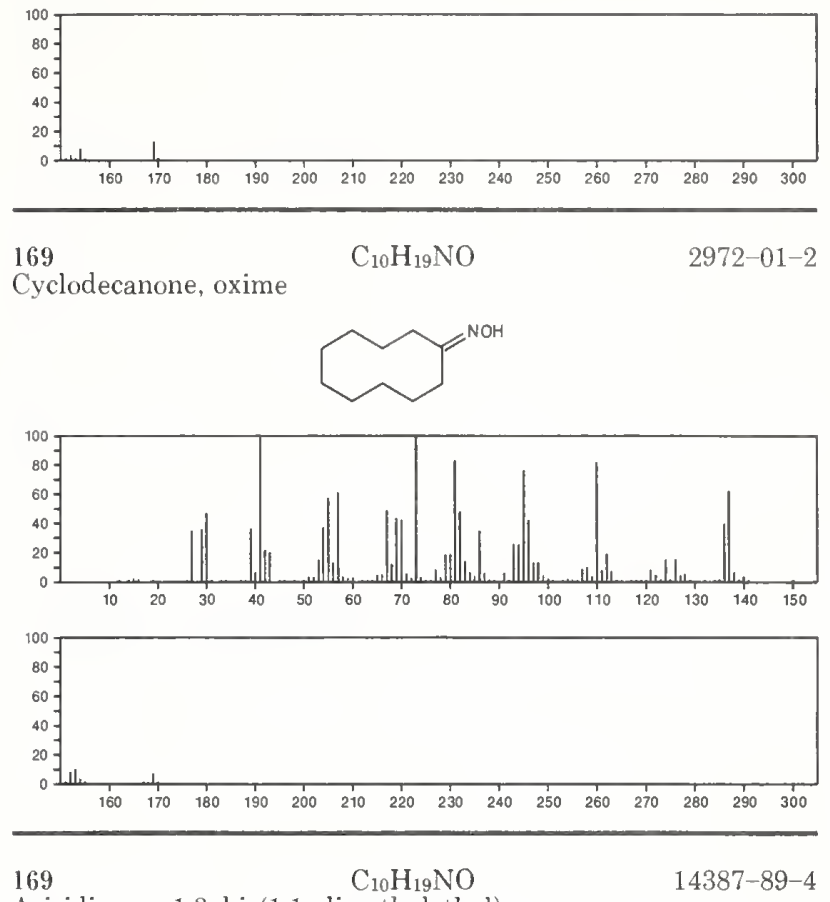

Aziridinone, 1,3-bis(1,1-dimethylethyl)-
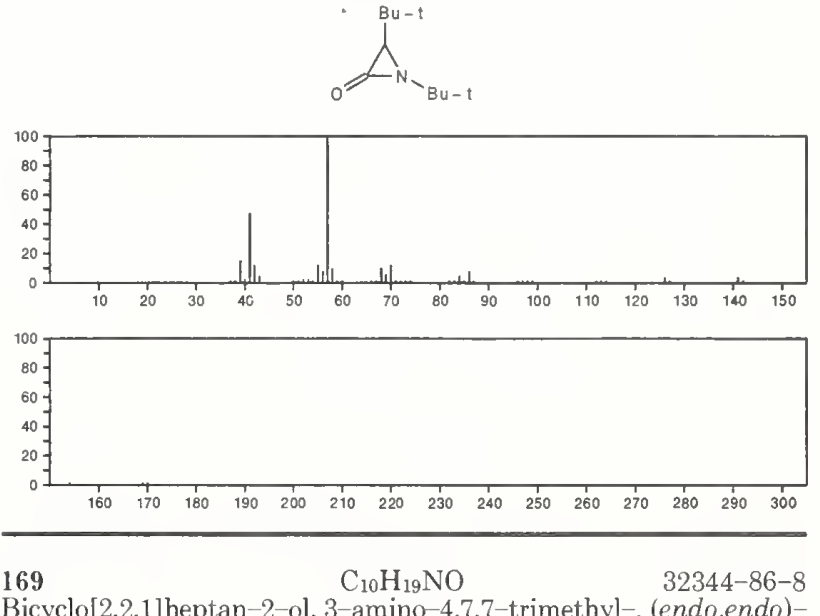

Bicyclo[2.2.1] heptan-2-ol, 3-amino-4,7,7-trimethyl-, (endo,endo)-
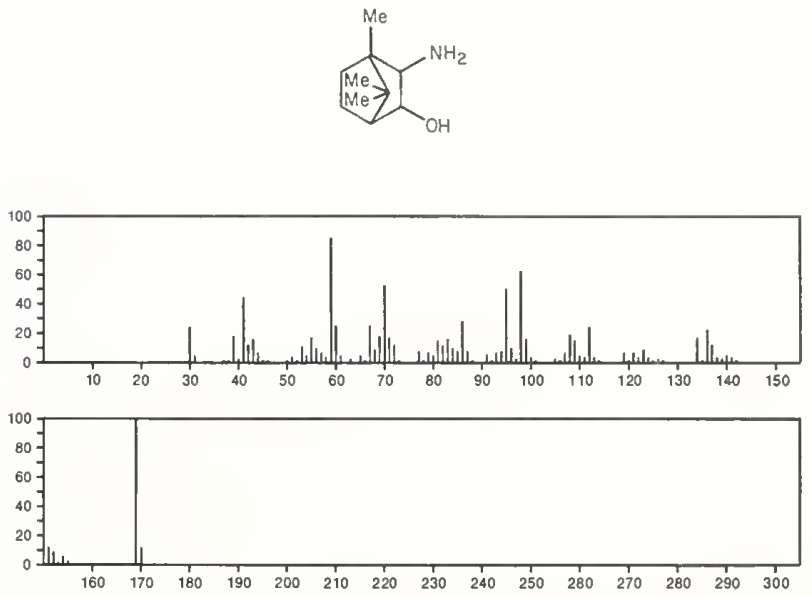
169

$\mathrm{C}_{10} \mathrm{H}_{19} \mathrm{NO}$

Morpholine, 4-[1-(1-methylethyl)-1-propenyl]-

$55103-87-2$
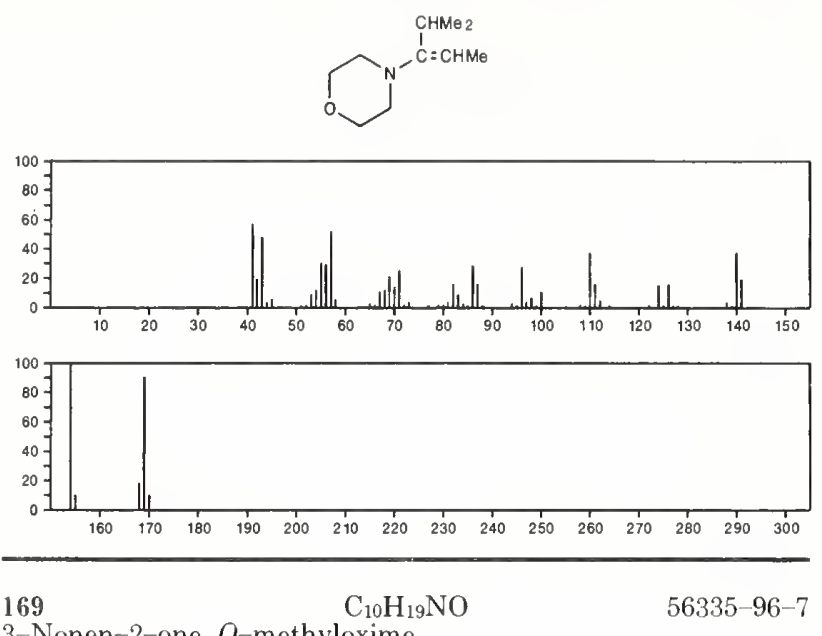

3-Nonen-2-one, $\mathrm{O}$-methyloxime

$\mathrm{Me}\left(\mathrm{CH}_{2}\right){ }_{4} \mathrm{CH}=\mathrm{CHCMe}=\mathrm{NOMe}$
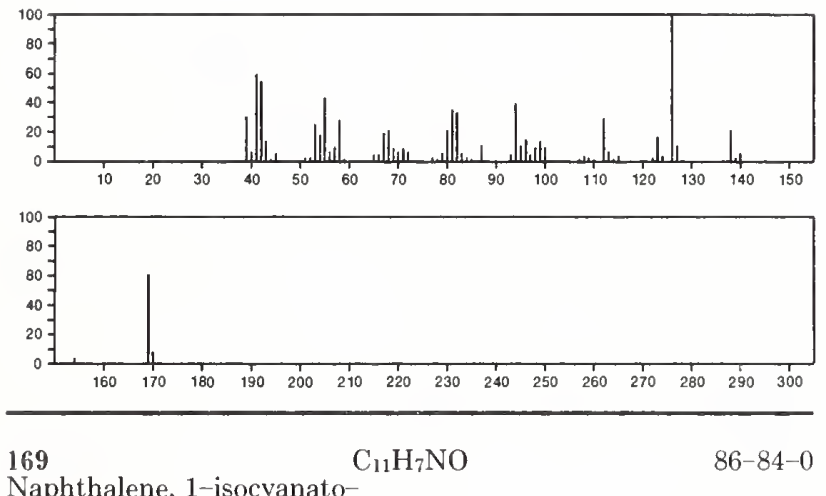

Naphthalene, 1-isocyanato-
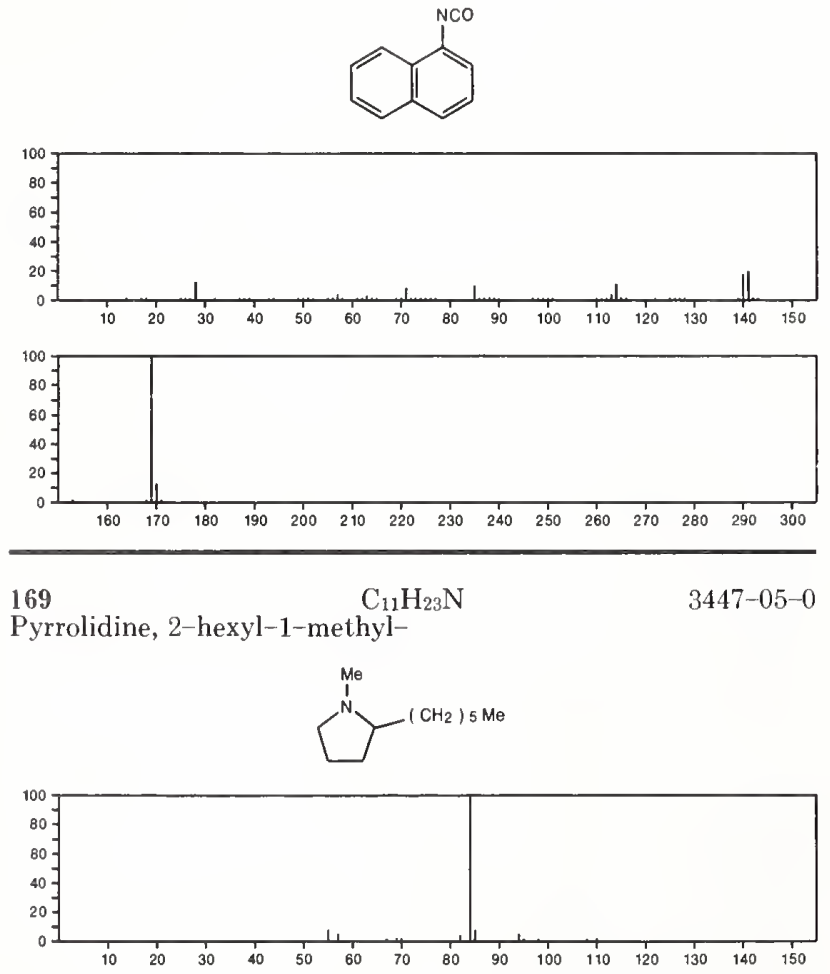

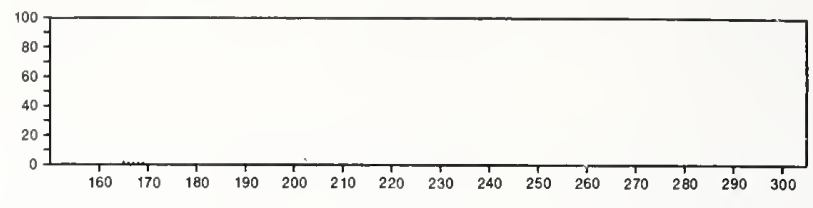

169

$\mathrm{C}_{11} \mathrm{H}_{23} \mathrm{~N}$

Butylamine, $N$-(1-propylbutylidene)-

$10599-80-1$

$\mathrm{Me}\left(\mathrm{CH}_{2}\right)_{3} \mathrm{~N}=\mathrm{CPr}_{2}$
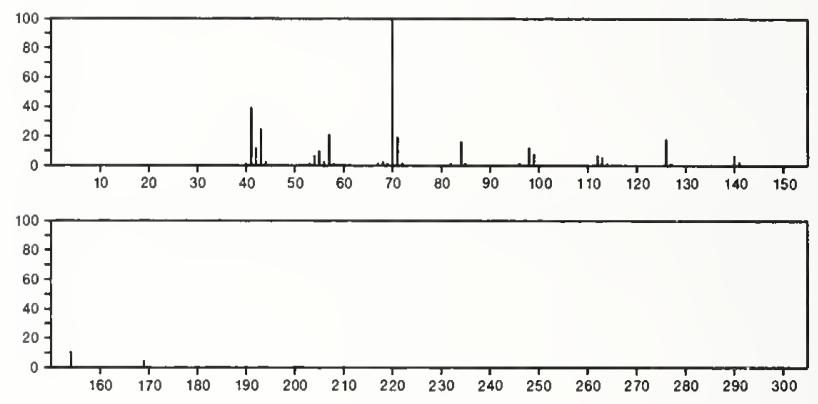

169

$\mathrm{C}_{11} \mathrm{H}_{23} \mathrm{~N}$

Ethylamine, $N$-(1-butylpentylidene)-

$10599-82-3$

$\left(\mathrm{CH}_{2}\right)_{3} \mathrm{Me}$

$\mathrm{Me}\left(\mathrm{CH}_{2}\right)_{3} \mathrm{C}=\mathrm{NE}$ t
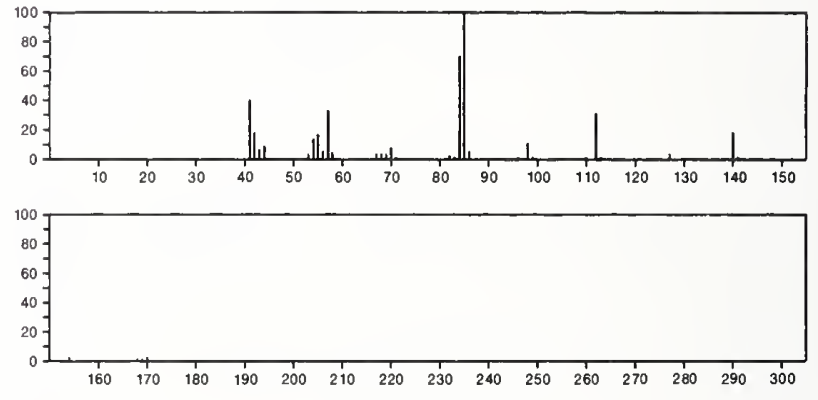

169

$\mathrm{C}_{11} \mathrm{H}_{23} \mathrm{~N}$

$18641-76-4$

Methylamine, $N$-(1-butylhexylidene)-

$\left(\mathrm{CH}_{2}\right)_{4} \mathrm{Me}$

$\mathrm{Me}\left(\mathrm{CH}_{2}\right)_{3} \mathrm{C}=\mathrm{NMe}$

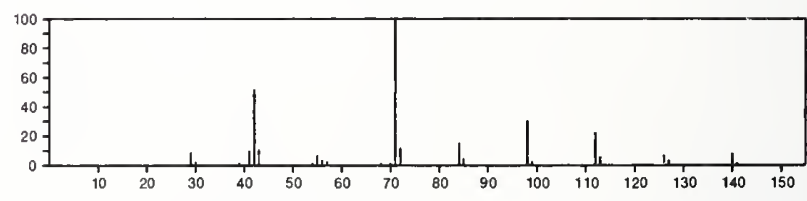

169

[1,1'-Biphenyl]-2-amine

$\mathrm{C}_{12} \mathrm{H}_{11} \mathrm{~N}$

$90-41-5$
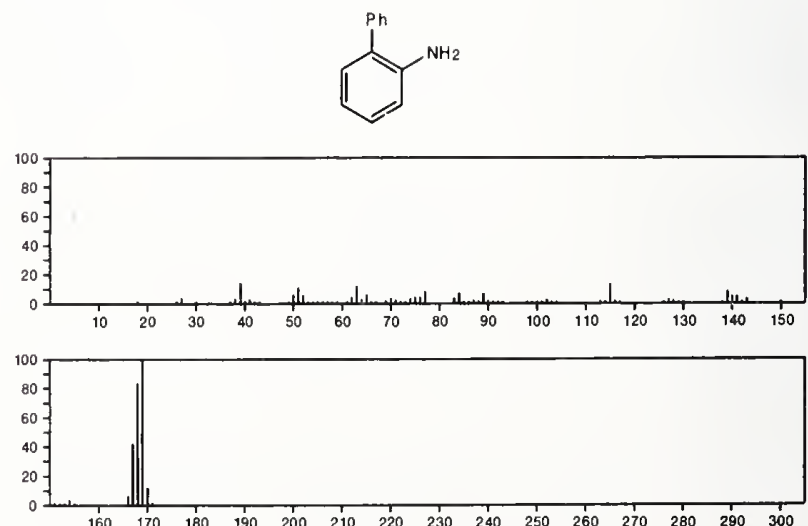
169

$\mathrm{C}_{12} \mathrm{H}_{11} \mathrm{~N}$

$92-67-1$

[1,1'-Biphenyl]-4-amine
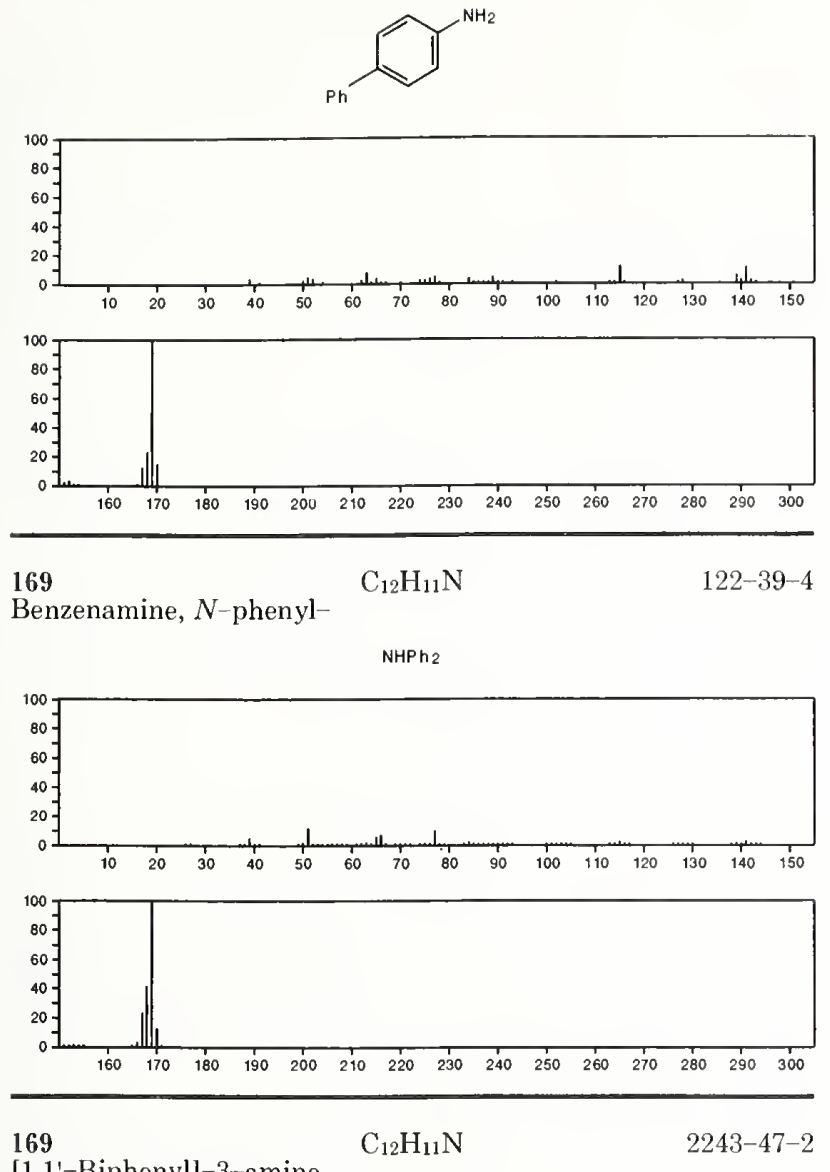

[1,1'-Biphenyl]-3-amine
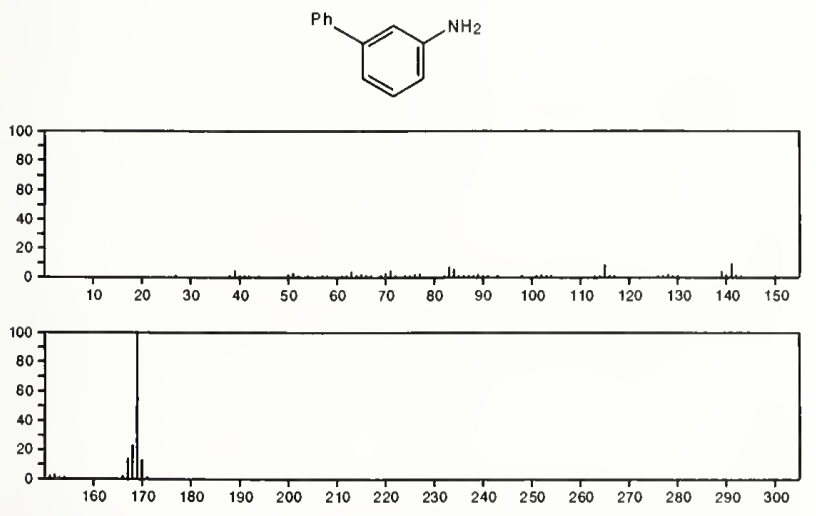

170

$\mathrm{C}_{2} \mathrm{Cl}_{2} \mathrm{~F}_{4}$

$76-14-2$

Ethane, 1,2-dichloro-1,1,2,2-tetrafluoro-

$\mathrm{F}_{2} \mathrm{CCICCIF}_{2}$
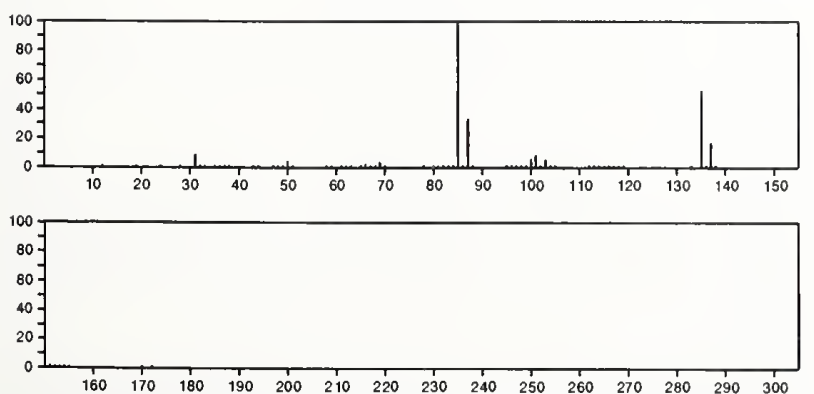

$170 \quad \mathrm{C}_{2} \mathrm{Cl}_{2} \mathrm{~F}_{4}$

Ethane, 1,1-dichloro-1,2,2,2-tetrafluoro

$374-07-2$
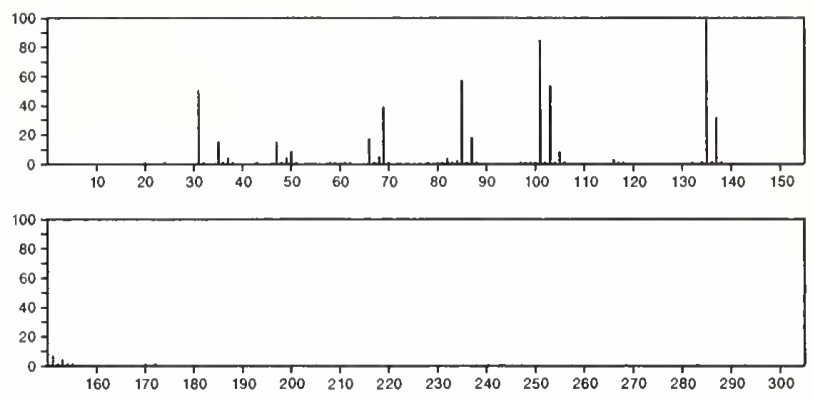

170
Methane, thiobis[trifluoro-$\mathrm{F}_{3} \mathrm{CSCF}_{3}$
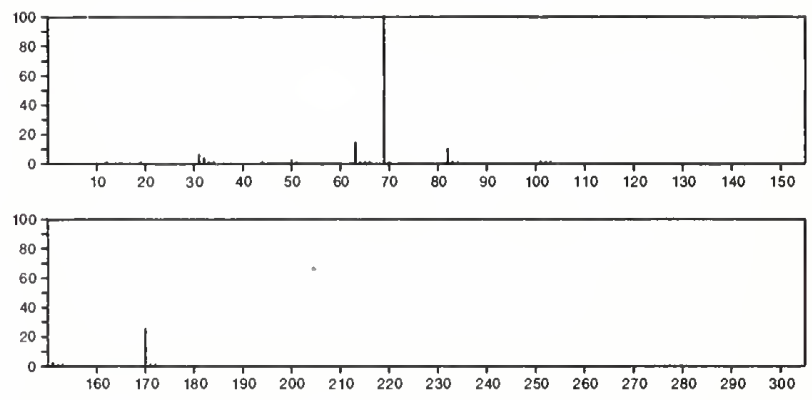

170 1,2,4,6-Tetrathiepane

$\mathrm{C}_{3} \mathrm{H}_{6} \mathrm{~S}_{4}$

$292-45-5$
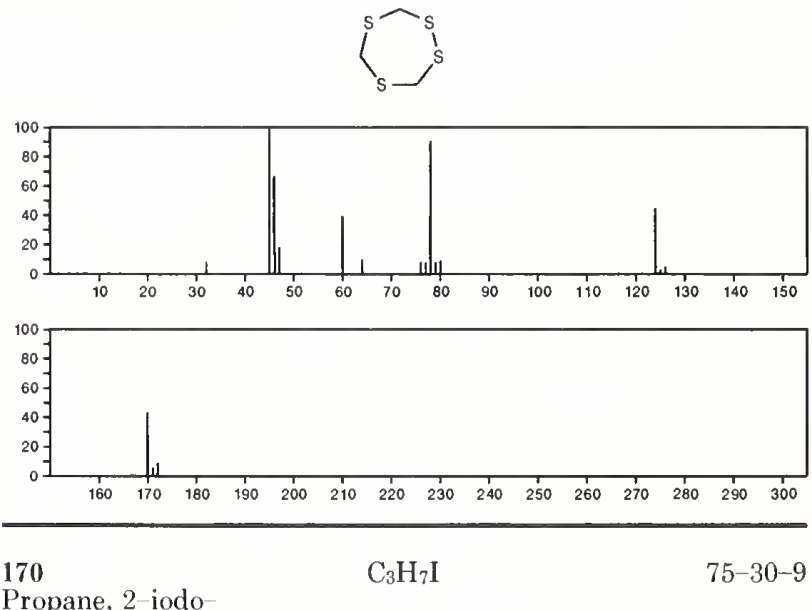

Propane, 2-iodo-

$\mathrm{i}-\mathrm{Pr} \mathrm{I}$
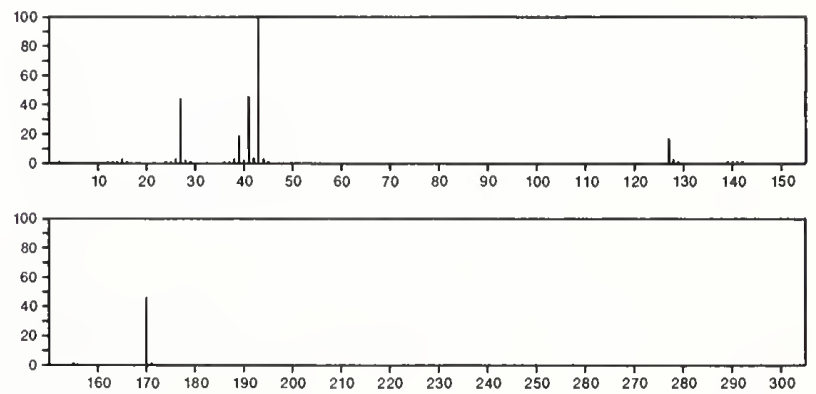
170

Propane, 1-iodo-

$\mathrm{C}_{3} \mathrm{H}_{7} \mathrm{I}$

$107-08-4$

$\operatorname{Pr} 1$
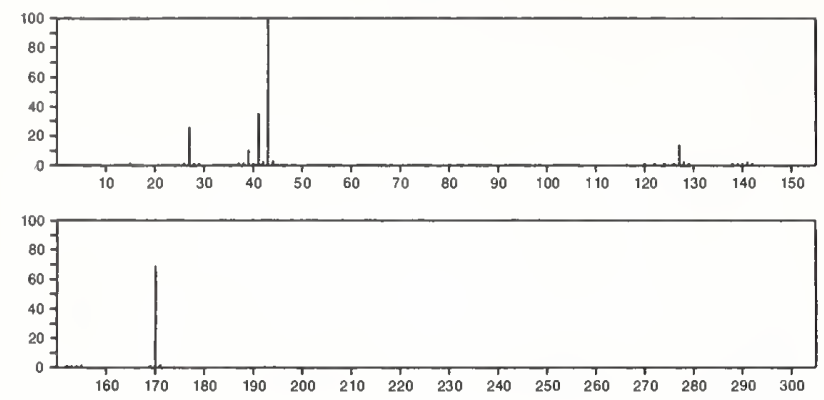

170

Propane, iodo-

$\mathrm{C}_{3} \mathrm{H}_{7} \mathrm{I}$

$26914-02-3$

$\mathrm{E}+\mathrm{Me}+\mathrm{I}$
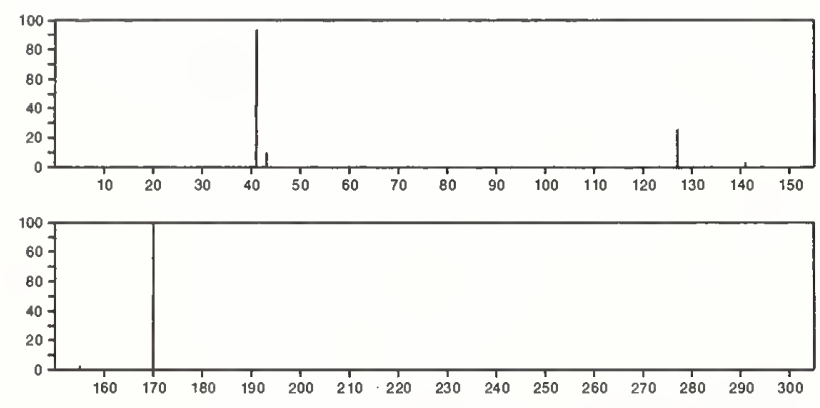

${ }_{2,30-\text { Trioxabicyclo[2.1.0]pentane }}^{\mathrm{C}_{4} \mathrm{H}_{4} \mathrm{Cl}_{2} \mathrm{O}_{3}}$

$56247-52-0$

2,3,5-Trioxabicyclo[2.1.0]pentane, 1,4-bis(chloromethyl)-
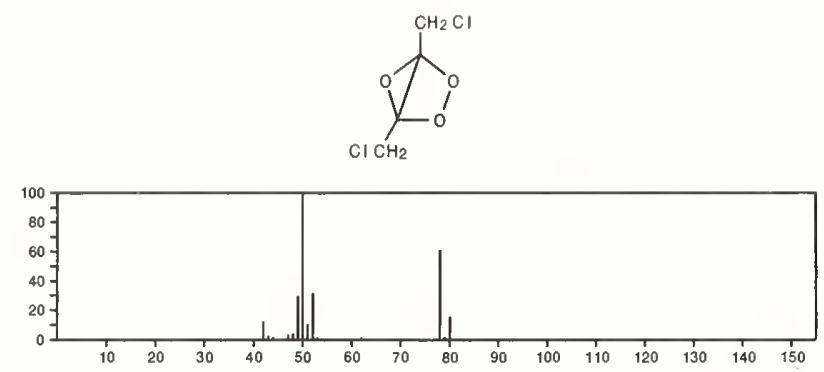

170

$\mathrm{C}_{4} \mathrm{H}_{12} \mathrm{FN}_{2} \mathrm{O}_{2} \mathrm{P}$

22692-27-9

Phosphorodiamidous fluoride, $N, N^{\prime}$-dimethoxy- $N, N^{\prime}$-dimethyl-

Me ONME PF NME OMe
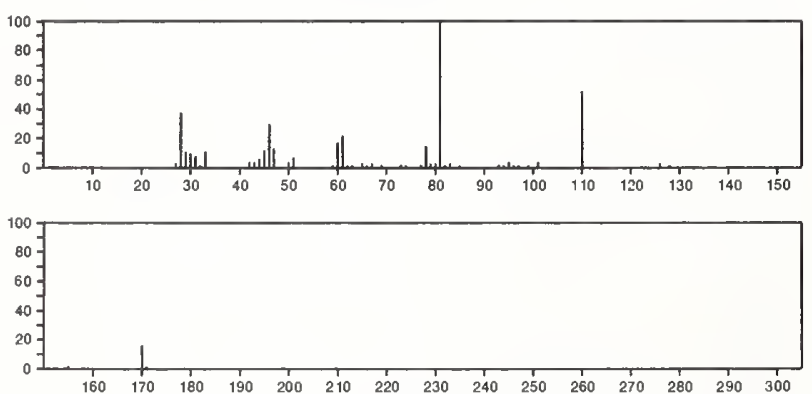

170

$\mathrm{C}_{4} \mathrm{H}_{12} \mathrm{FN}_{2} \mathrm{PS}$

$36267-53-5$

Phosphonofluoridothioic hydrazide, $P$-ethyl-2,2-dimethyl-

$S=P F(E t)$ NHNME2
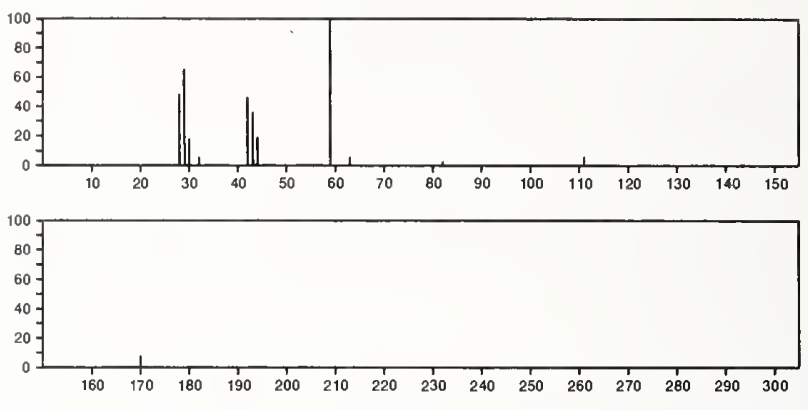

170

$\mathrm{C}_{4} \mathrm{NiO}_{4}$

Nickel carbonyl $\left(\mathrm{Ni}(\mathrm{CO})_{4}\right),(T-4)-$

$13463-39-3$
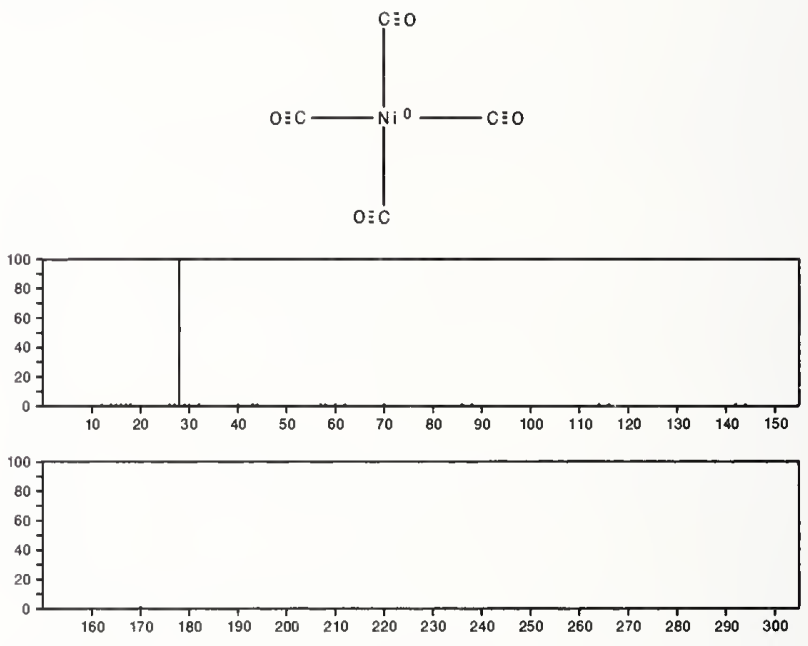

$170 \quad \mathrm{C}_{5} \mathrm{H}_{8} \mathrm{Cl}_{2} \mathrm{O}_{2}$

1-Propanol, 2,3-dichloro-, acetate

$589-96-8$

$\mathrm{ACOCH}_{2} \mathrm{CHCl} \mathrm{CH}_{2} \mathrm{Cl}$
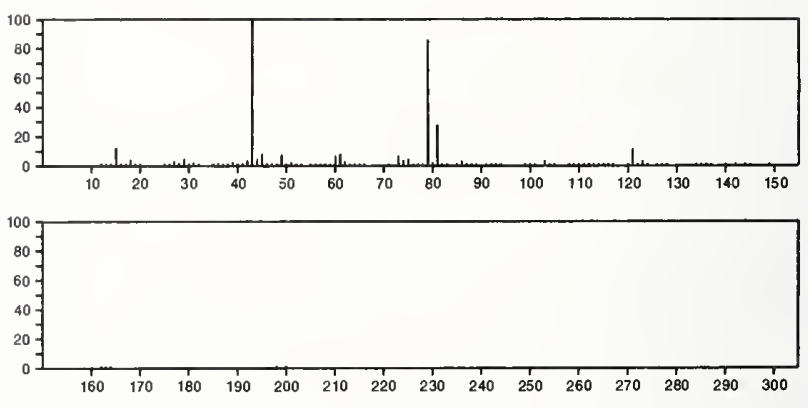

170

$\mathrm{C}_{5} \mathrm{H}_{8} \mathrm{Cl}_{2} \mathrm{O}_{2}$

$18545-44-3$

Butyric acid, 2,2-dichloro-, methyl ester

$\mathrm{MeOC}(\mathrm{O}) \mathrm{CCl}_{2} \mathrm{Et}$
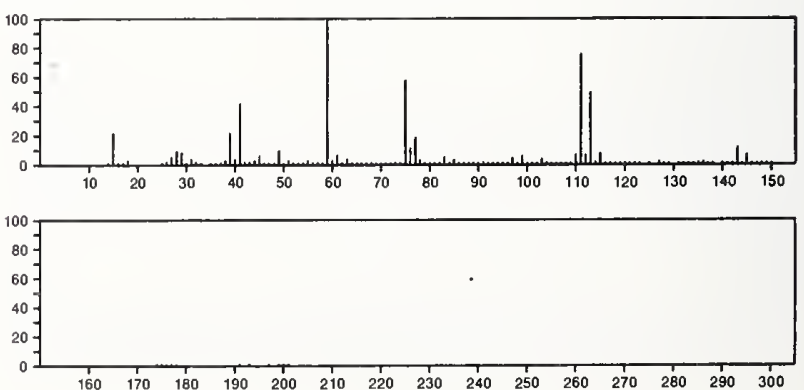
170

$\mathrm{C}_{5} \mathrm{H}_{8} \mathrm{Cl}_{2} \mathrm{O}_{2}$

$54460-97-8$

Butanoic acid, 2,3-dichloro-, methyl ester

$\mathrm{MeCHCl} \mathrm{CHCl} \mathrm{C(O)} \mathrm{OMe}$

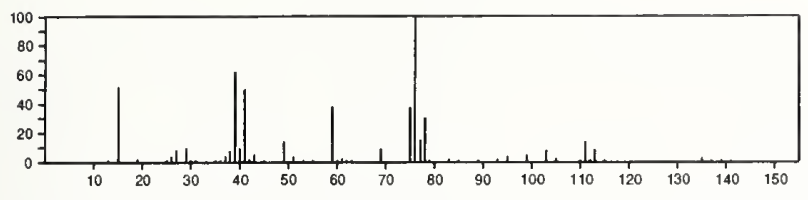

$170 \quad \mathrm{C}_{5} \mathrm{H}_{8} \mathrm{Cl}_{2} \mathrm{O}_{2}$

Carbonochloridic acid, 1-(chloromethyl)propyl ester

$54460-98-9$

$\mathrm{ClC}(\mathrm{O}) \mathrm{OCHE}: \mathrm{CH}_{2} \mathrm{Cl}$

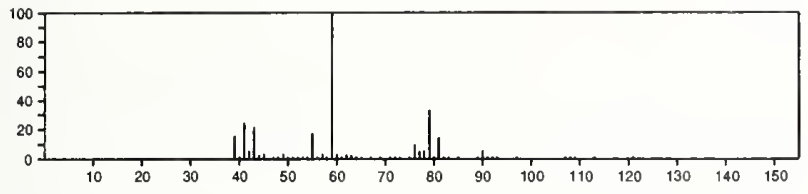

170

$\mathrm{C}_{6} \mathrm{H}_{2} \mathrm{O}_{6}$

$118-76-3$

5-Cyclohexene-1,2,3,4-tetrone, 5,6-dihydroxy-
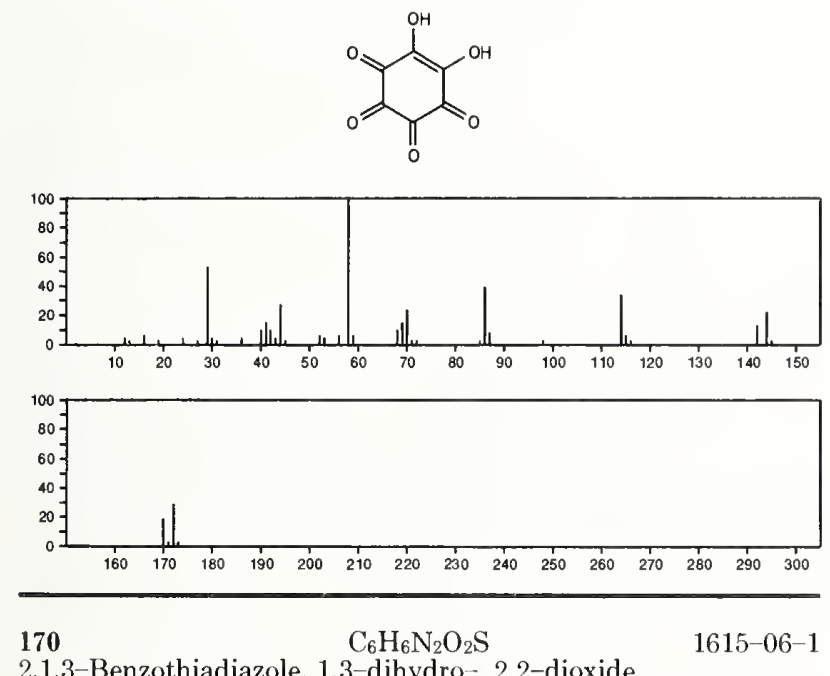

2,1,3-Benzothiadiazole, 1,3-dihydro-, 2,2-dioxide
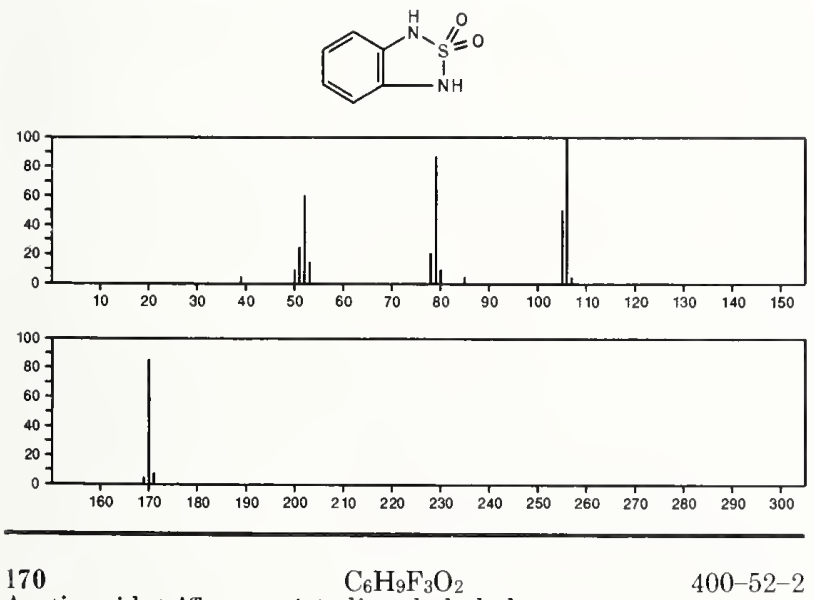

Acetic acid, trifluoro-, 1,1-dimethylethyl ester

$1-\mathrm{BuOC}(\mathrm{O}) \mathrm{CF}_{3}$

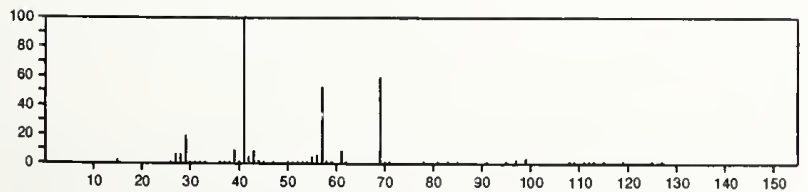

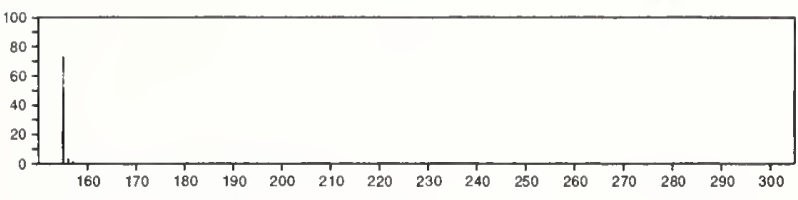

170

$\mathrm{C}_{6} \mathrm{H}_{10} \mathrm{~N}_{4} \mathrm{O}_{2}$

$35975-36-1$

1(2H)-Pyrazineacetamide, 5-amino-3,6-dihydro-3-oxo-
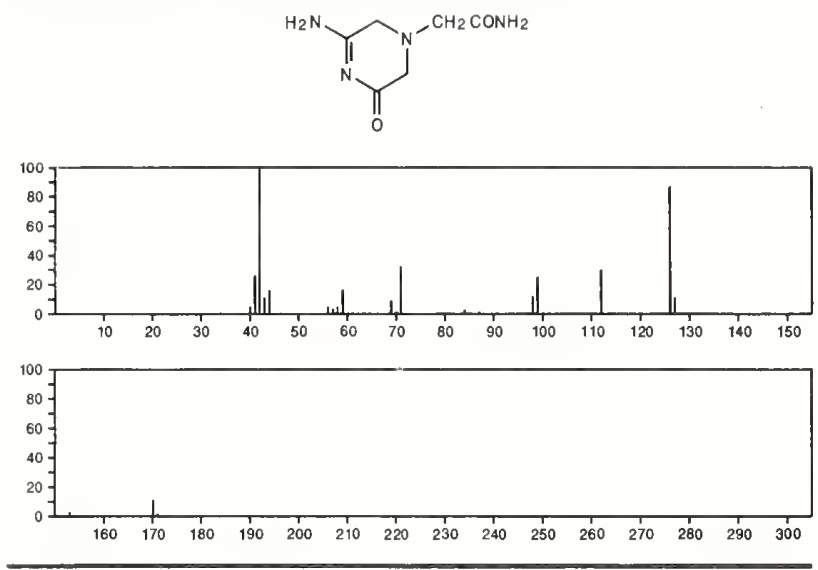

170

$\mathrm{C}_{6} \mathrm{H}_{12} \mathrm{Cl}_{2} \mathrm{O}$

$108-60-1$

Propane, 2,2'-oxybis[1-chloro-

$\mathrm{Cl} \mathrm{CH}_{2} \mathrm{CHMe} \mathrm{OCHMe} \mathrm{CH} \mathrm{Cl}_{2}$
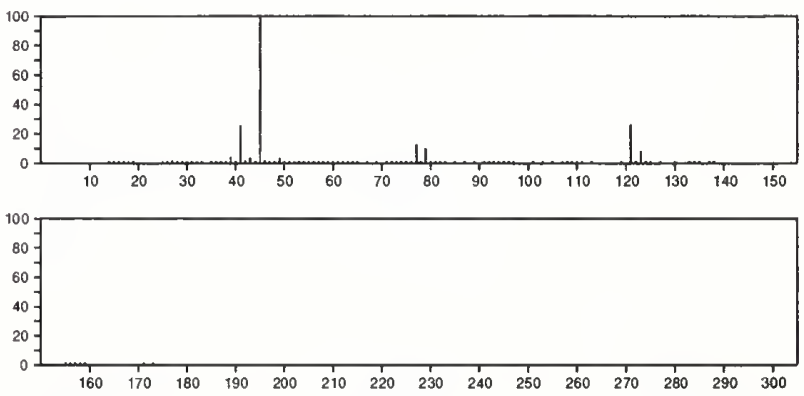

170

Propane, 1,1'-oxybis[3-chloro-

$\mathrm{C}_{6} \mathrm{H}_{12} \mathrm{Cl}_{2} \mathrm{O}$

$629-36-7$

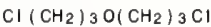
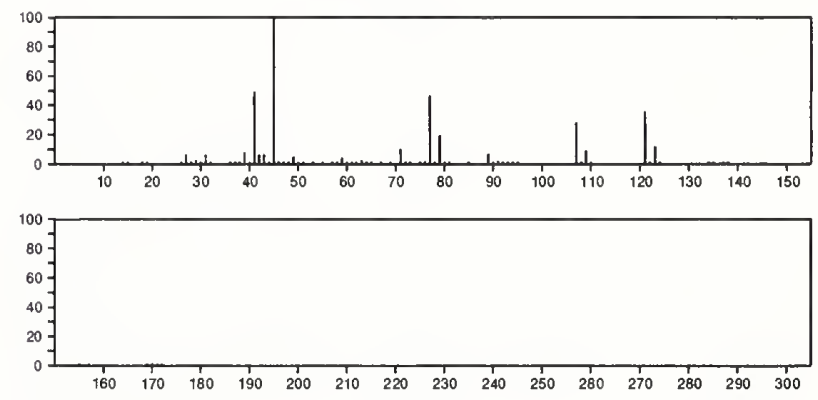

170

Propane, 2,2'-oxybis [2-chloro-

$\mathrm{C}_{6} \mathrm{H}_{2} \mathrm{Cl}_{2} \mathrm{O}$

$39638-32-9$

$\mathrm{Me}_{2} \mathrm{CCl} \mathrm{OCCIMe} 2$

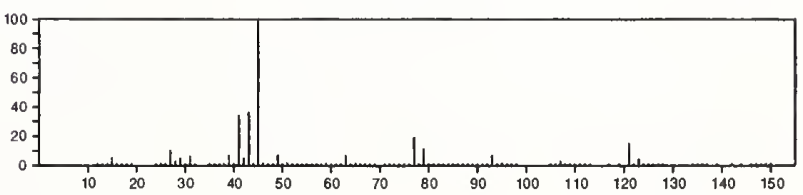


170

Propane, 1,1'-oxybis [2-chloro-

$\mathrm{MeCHCl} \mathrm{CH} 2 \mathrm{OCH}_{2} \mathrm{CHCl}_{\mathrm{MO}}$
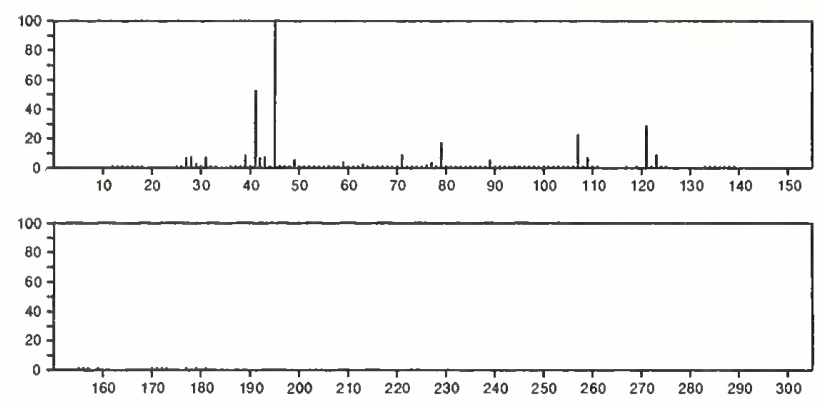

$170 \quad \mathrm{C}_{7} \mathrm{H}_{6} \mathrm{O}_{5}$

3,4-Furandicarboxylic acid, 2-methyl-
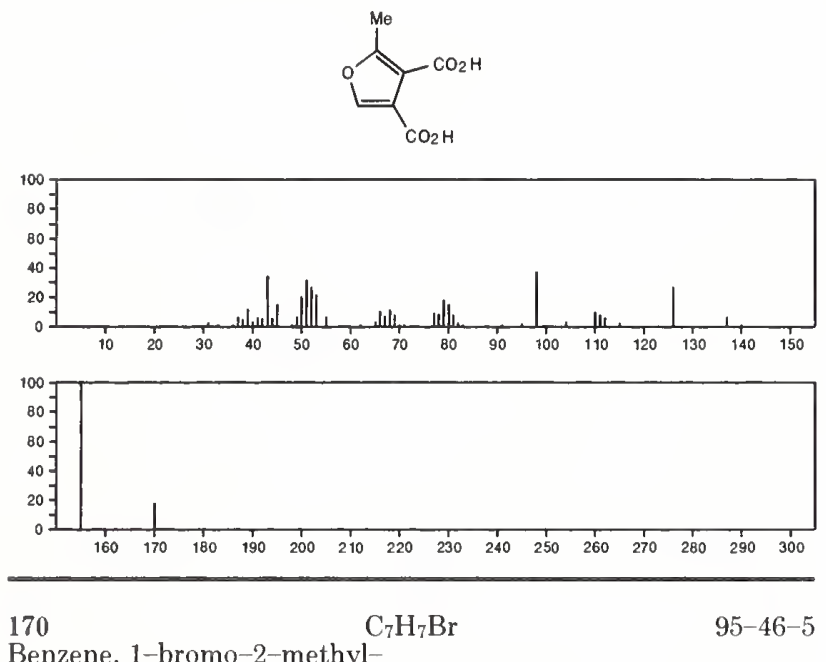

Benzene, 1-bromo-2-methyl-
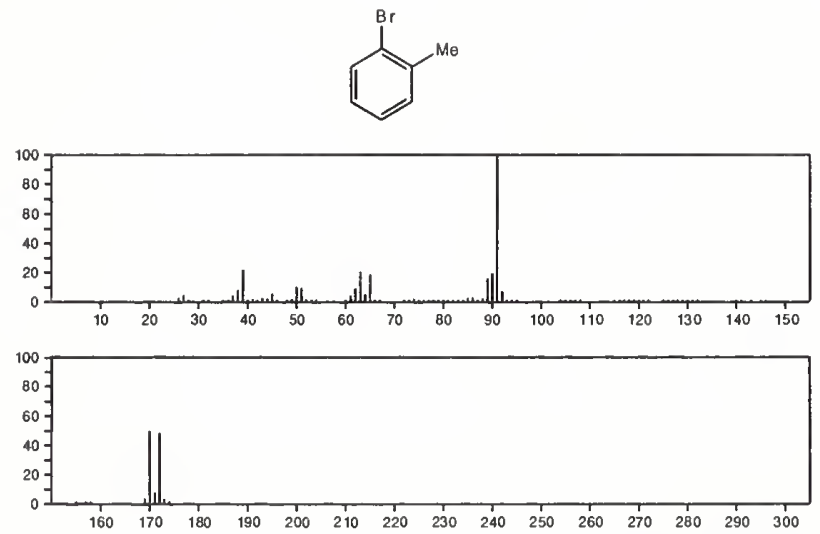

170

Benzene, (bromomethyl)-

$\mathrm{C}_{7} \mathrm{H}_{7} \mathrm{Br}$

$\mathrm{BrCH}_{2} \mathrm{Ph}$
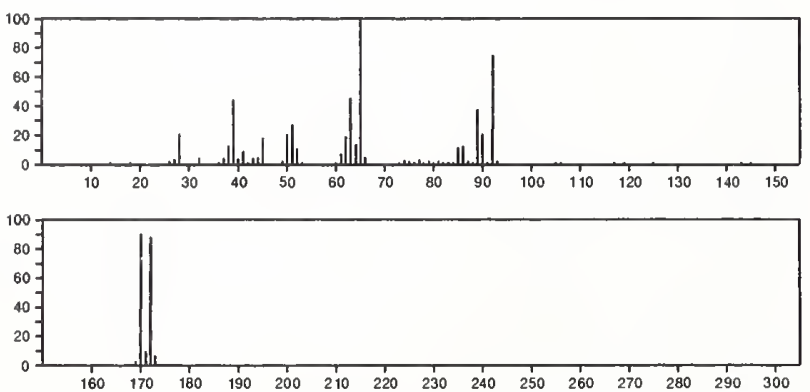

170

$\mathrm{C}_{7} \mathrm{H}_{7} \mathrm{Br}$

106-38-7

Benzene, 1-bromo-4-methyl-
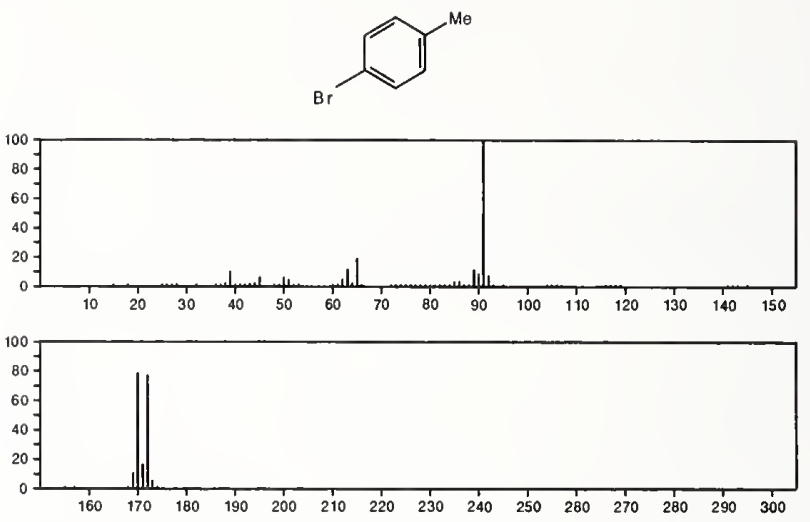

170

$\mathrm{C}_{7} \mathrm{H}_{7} \mathrm{Br}$

Benzene, 1-bromo-3-methyl-

$591-17-3$
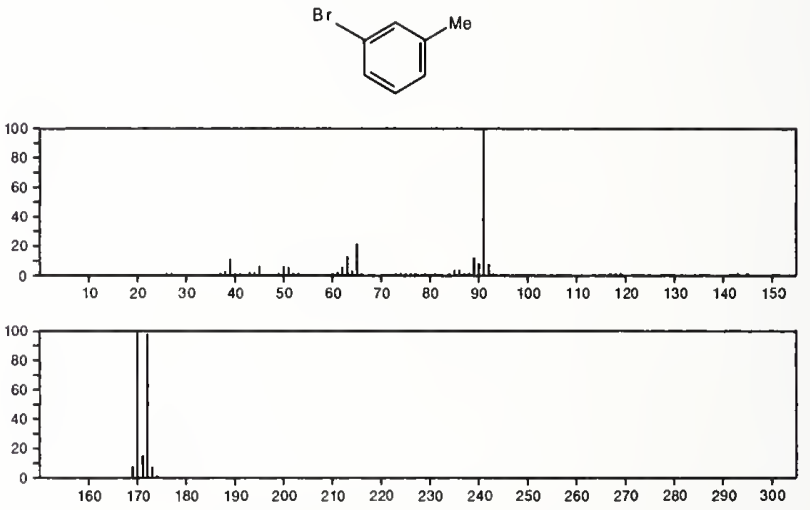

170

$\mathrm{C}_{7} \mathrm{H}_{10} \mathrm{~N}_{2} \mathrm{OS}$

13480-95-0

4(1H)-Pyrimidinone, 2-(ethylthio)-5-methyl-
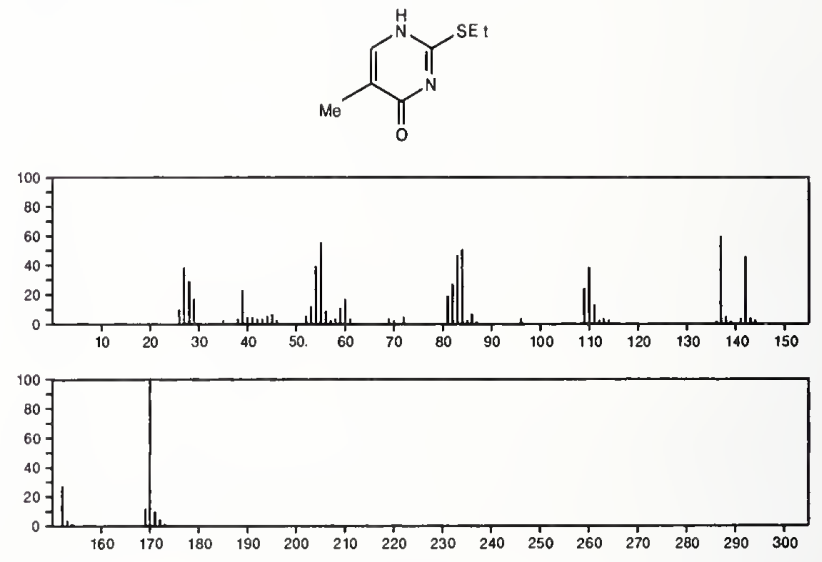

170

$\mathrm{C}_{7} \mathrm{H}_{10} \mathrm{~N}_{2} \mathrm{OS}$

$24611-13-0$

$4(1 H)$-Pyrimidinethione, 5-ethoxy-2-methyl-
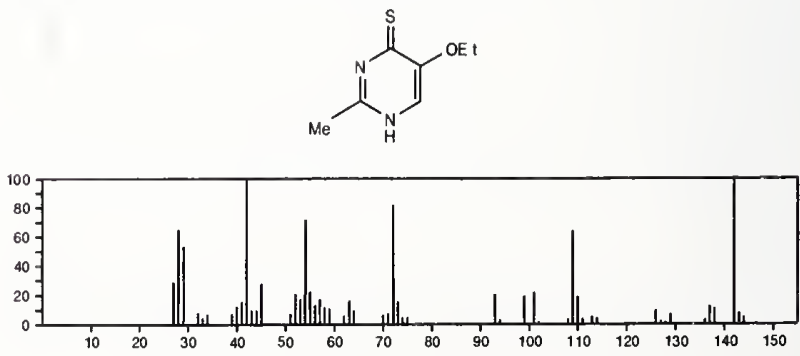


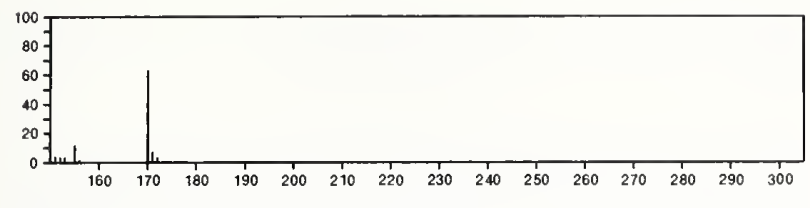

170

$\mathrm{C}_{7} \mathrm{H}_{10} \mathrm{~N}_{2} \mathrm{OS}$

$54460-95-6$

$4(1 H)$-Pyrimidinone, 2 -(propylthio)-
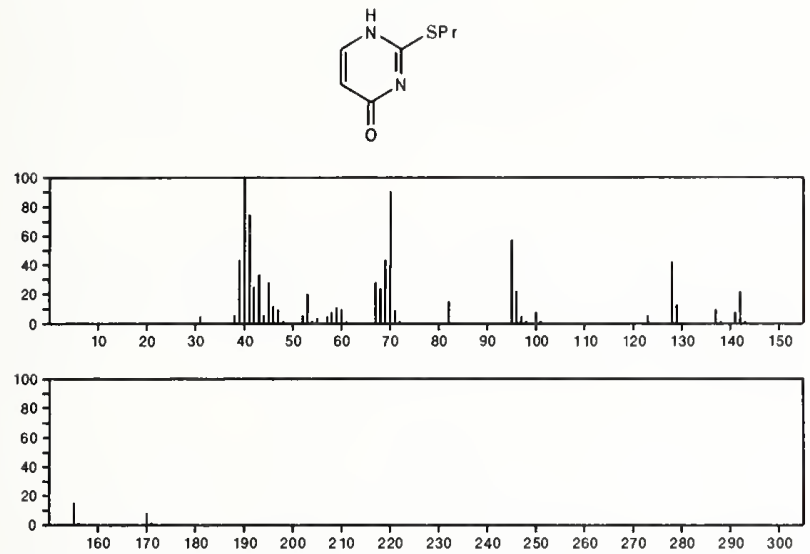

$170 \quad \mathrm{C}_{7} \mathrm{H}_{10} \mathrm{~N}_{2} \mathrm{O}_{3} \quad 55557-02-3$

3-Pyridinecarboxylic acid, 1,2,5,6-tetrahydro-1-nitroso-, methyl ester
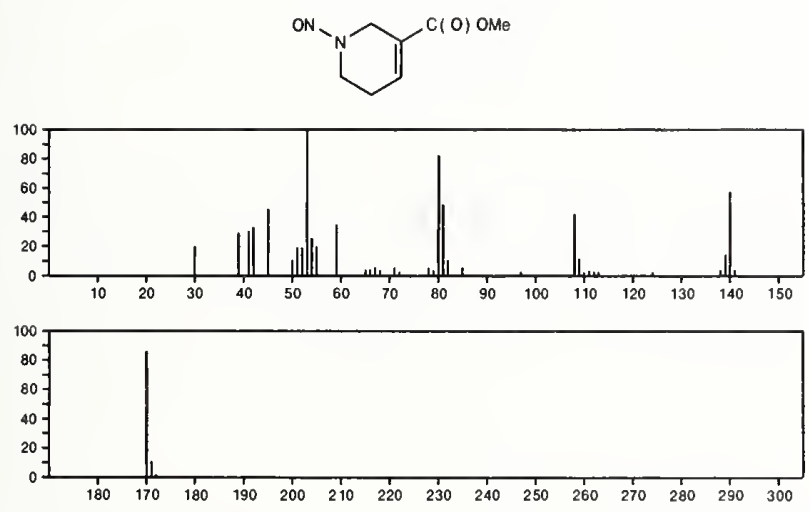

170

$\mathrm{C}_{8} \mathrm{H}_{7} \mathrm{ClO}_{2}$

Benzoic acid, 2-chloro--, methyl ester

610-96-8
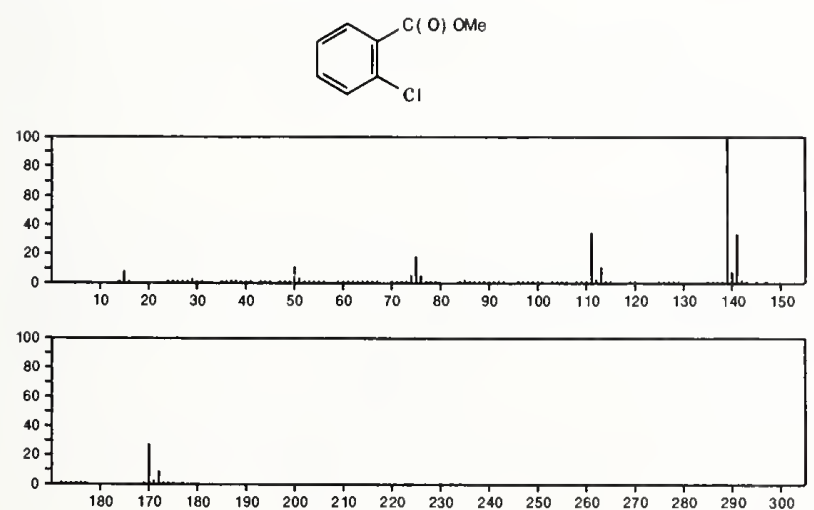

170

Acetyl chloride, phenoxy-

$\mathrm{C}_{8} \mathrm{H}_{7} \mathrm{ClO}_{2}$

$701-99-5$

$\mathrm{PhOCH}+\mathrm{COCl}$
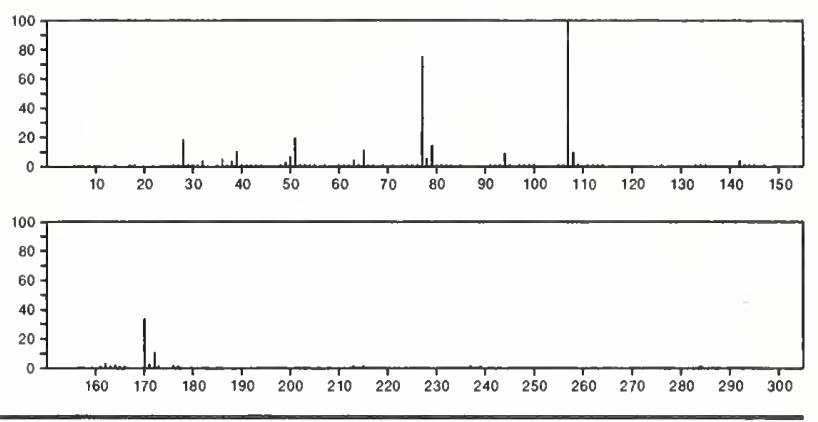

170

$\mathrm{C}_{8} \mathrm{H}_{7} \mathrm{ClO}_{2}$

Acetic acid, 4-chlorophenyl ester

$876-27-7$
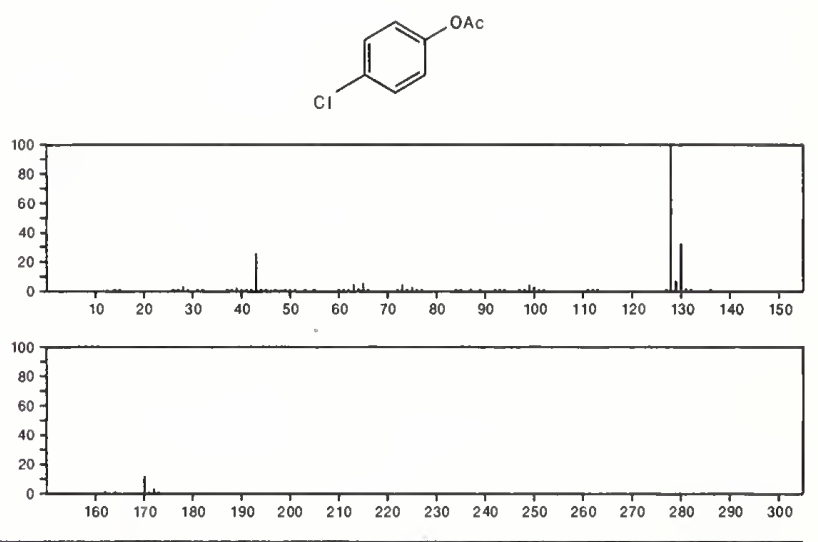

170

$\mathrm{C}_{8} \mathrm{H}_{7} \mathrm{ClO}_{2}$

Benzoic acid, 4-chloro--, methyl ester

1126-46-1
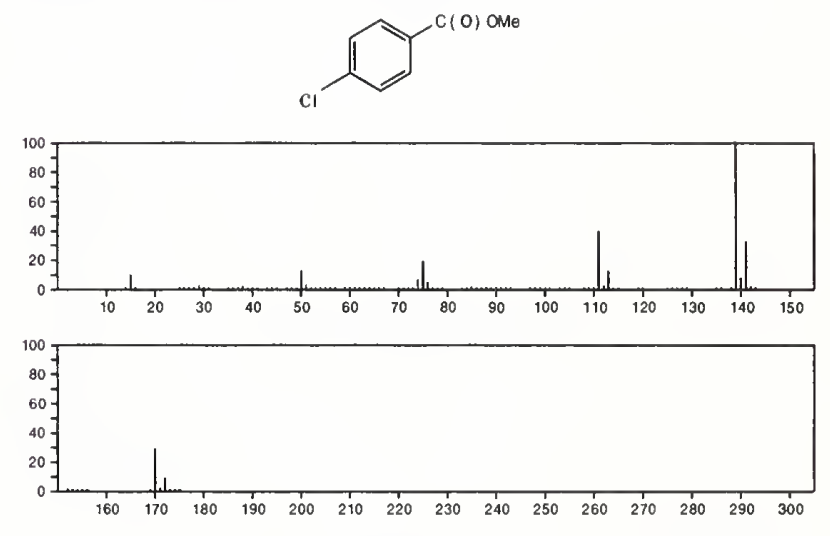

170

$\mathrm{C}_{8} \mathrm{H}_{7} \mathrm{ClO}_{2}$

1450-74-4

Ethanone, 1-(5-chloro-2-hydroxyphenyl)-
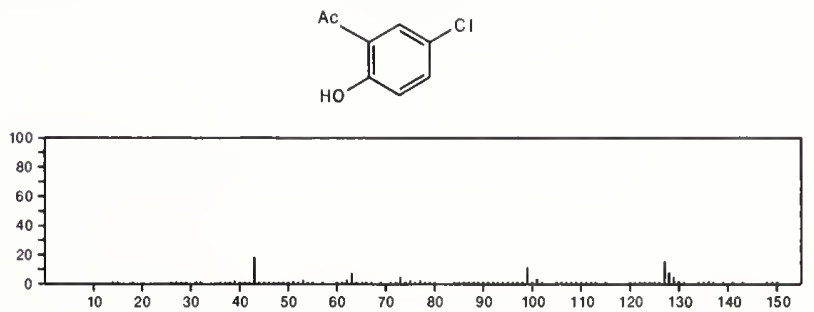

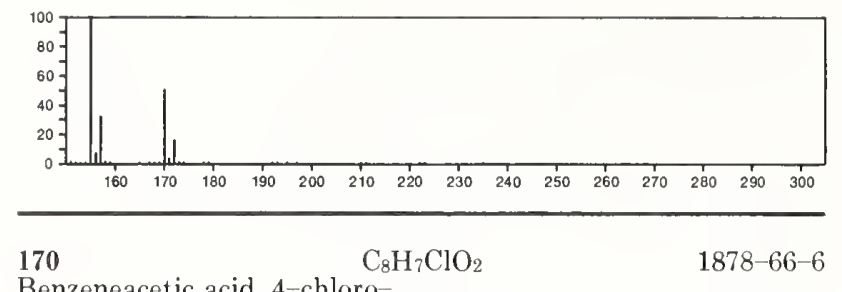

Benzeneacetic acid, $4-$ chloro-
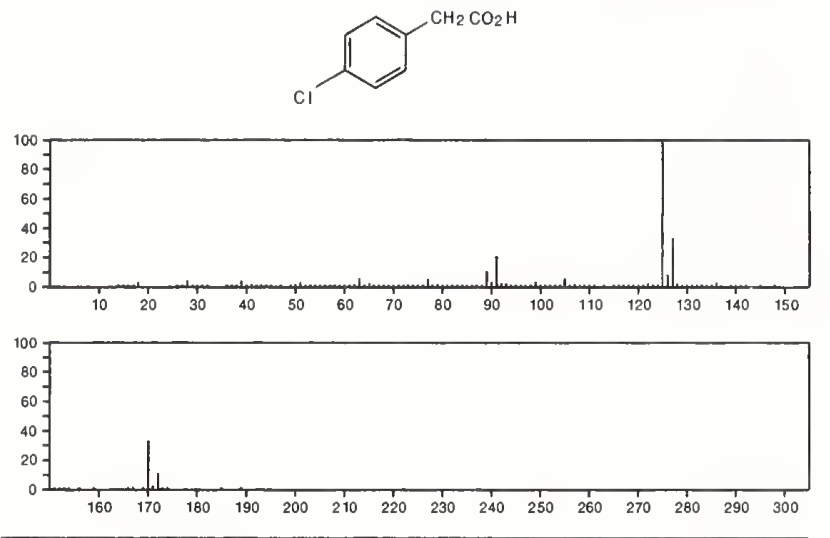

$170 \quad \mathrm{C}_{8} \mathrm{H}_{7} \mathrm{ClO}_{2} \quad 2444-36-2$

Benzeneacetic acid, 2-chloro-
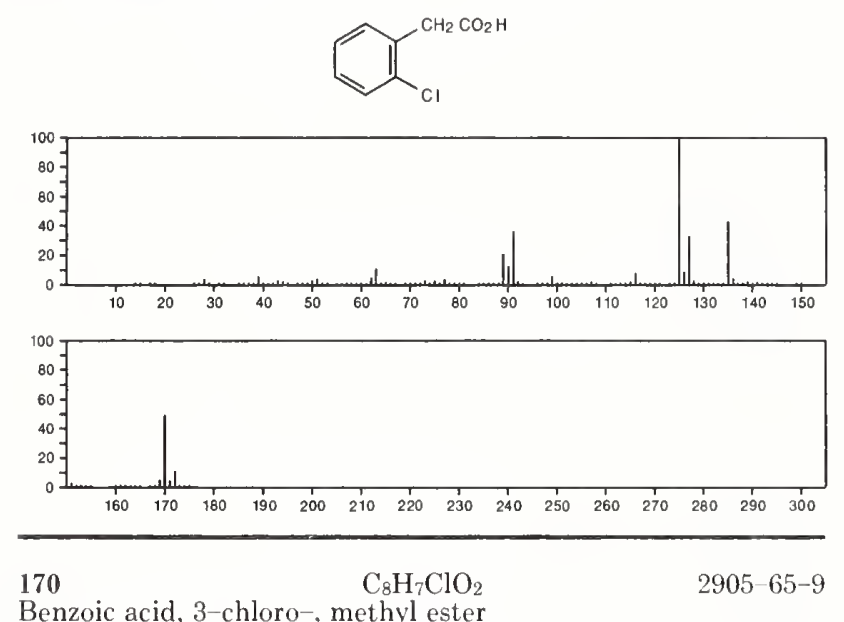

Benzoic acid, 3-chloro-, methyl ester
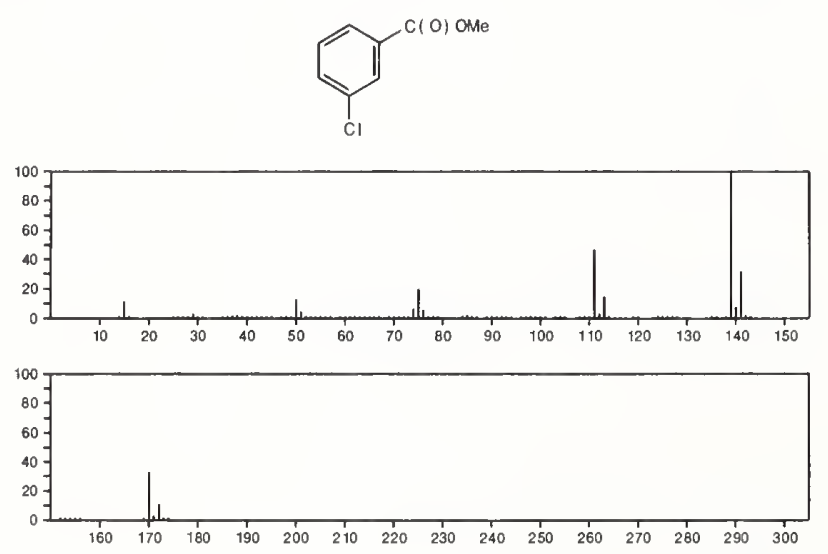

170

$\mathrm{C}_{8} \mathrm{H}_{7} \mathrm{ClO}_{2}$

Benzaldehyde, 5-(chloromethyl)-2-hydroxy-
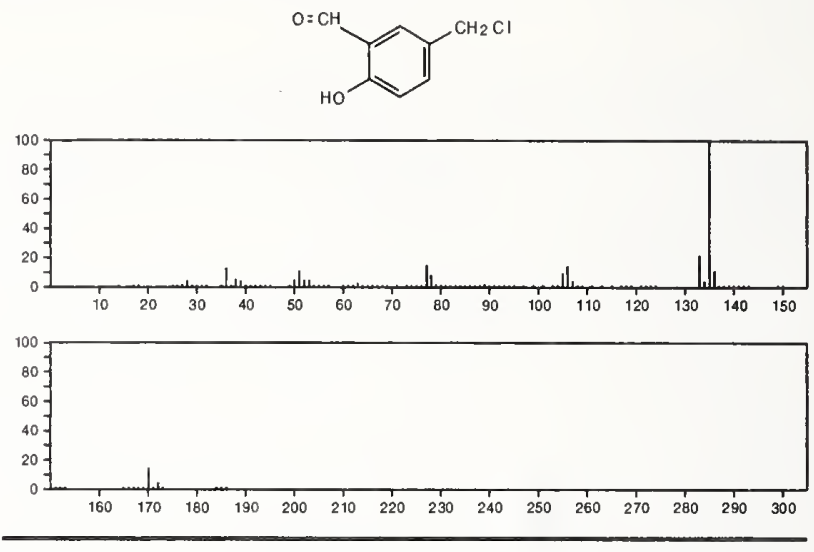

170

$\mathrm{C}_{8} \mathrm{H}_{7} \mathrm{FO}_{3}$

Carbonic acid, $p$-fluorophenyl methyl ester

$1847-98-9$
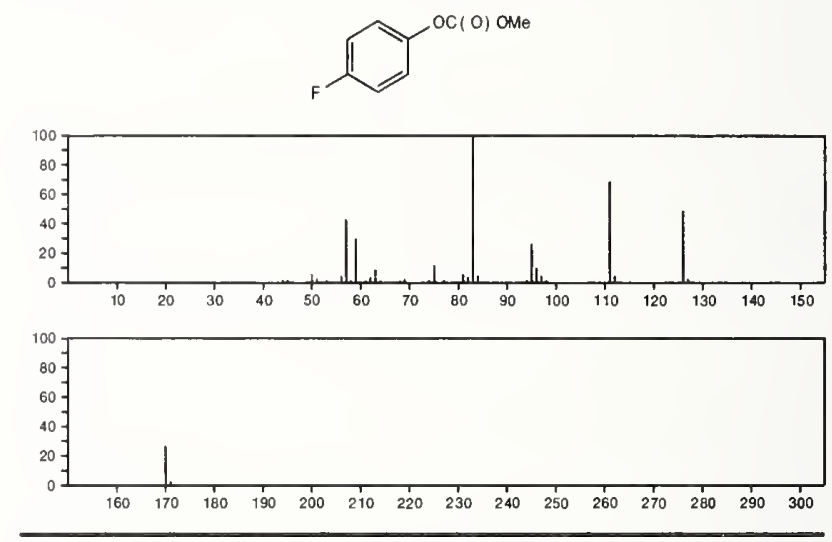

170

$\mathrm{C}_{8} \mathrm{H}_{7} \mathrm{FO}_{3}$

$1847-99-0$

Carbonic acid, $m$-fluorophenyl methyl ester
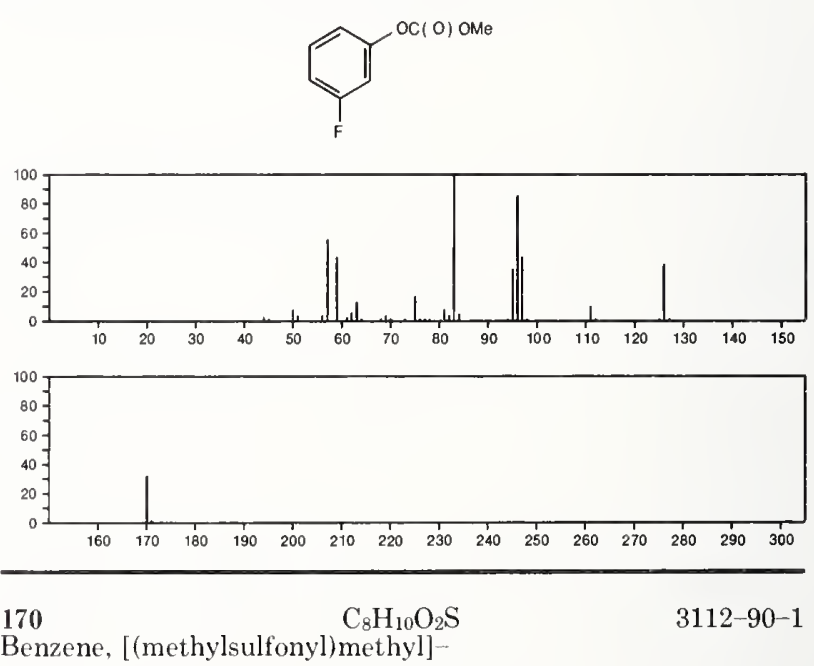

Benzene, [(methylsulfonyl)methyl] -

$\mathrm{MeSO} \mathrm{SH}_{2} \mathrm{Ph}$

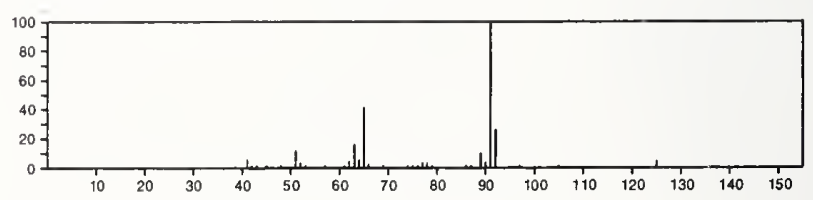



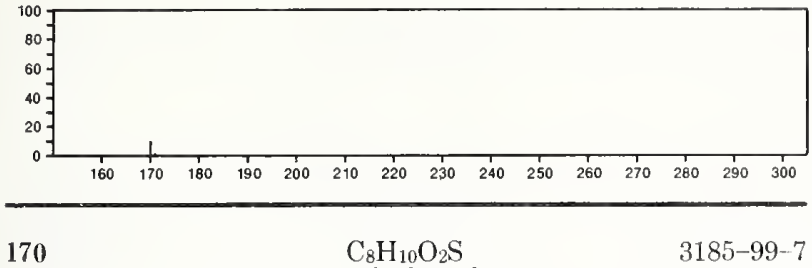

Benzene, 1-methyl-4-(methylsulfonyl)
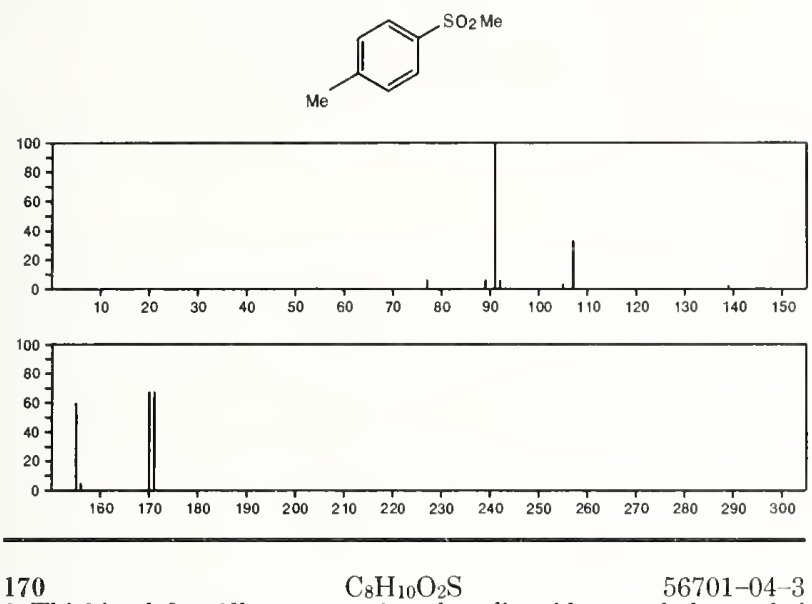

2-Thiabicyclo[3.1.0]hex-3-ene-6-carboxylic acid, 3-methyl-, methyl ester
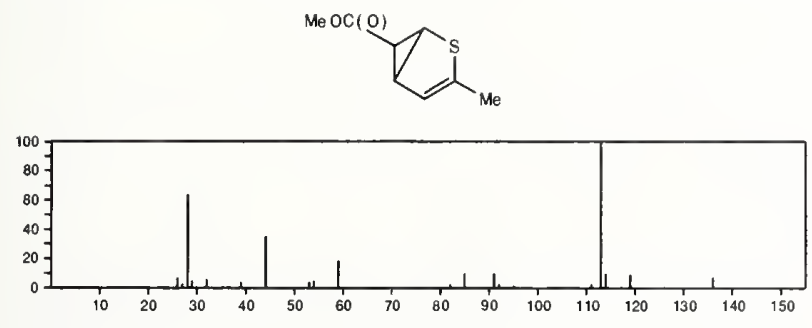

170

1-Cyclohexene-1,2-dicarboxylic acid

$635-08-5$
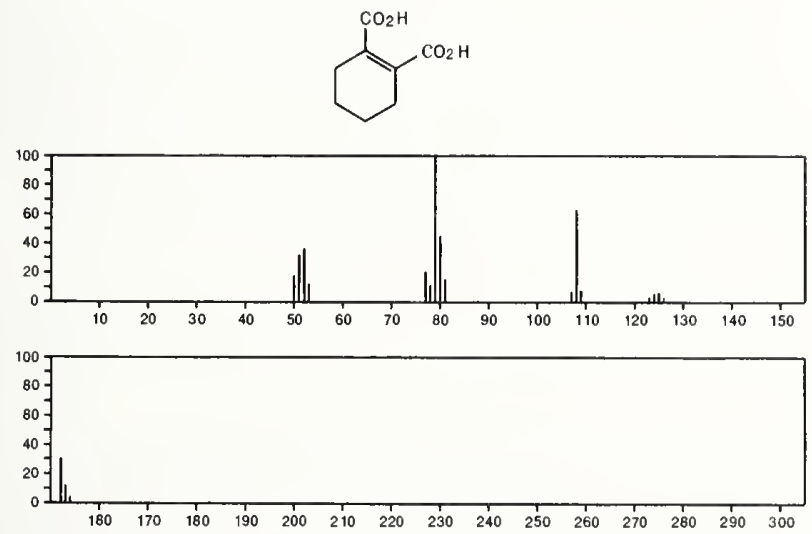

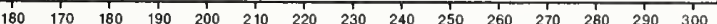

170

$\mathrm{C}_{8} \mathrm{H}_{10} \mathrm{O}_{4}$

$2305-26-2$

4-Cyclohexene-1,2-dicarboxylic acid, cis-<smiles>O=C(O)C1CC=CCC1C(=O)O</smiles>

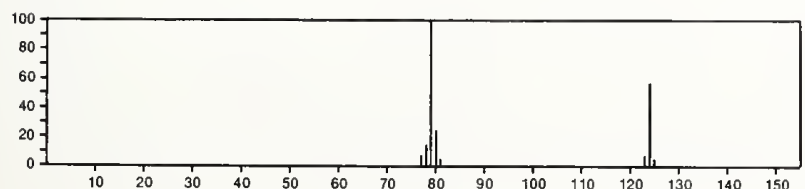

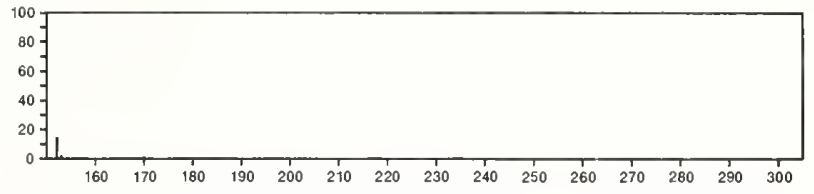

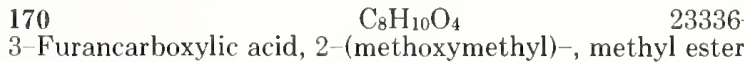

$23336-82-5$
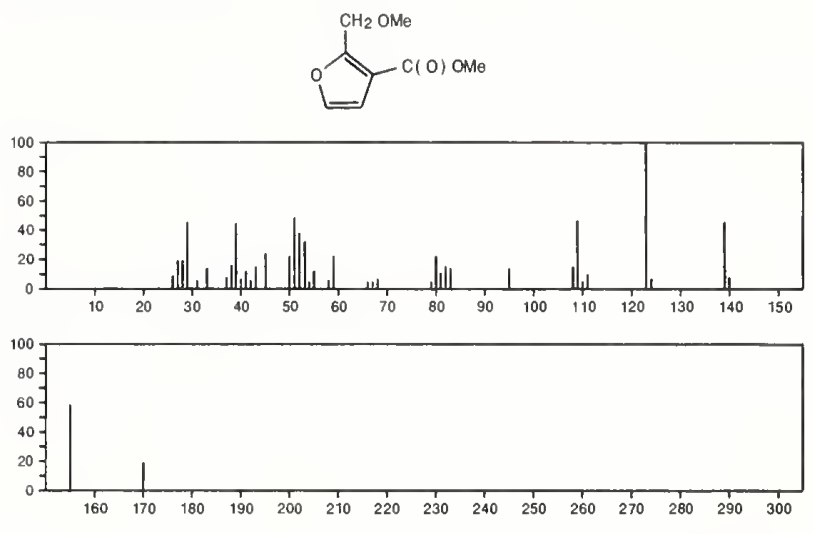

$170 \quad \mathrm{C}_{8} \mathrm{H}_{10} \mathrm{O}_{4}$

28822-73-3

1,2-Benzenediol, 4-(1,2-dihydroxyethyl)-, ( \pm )
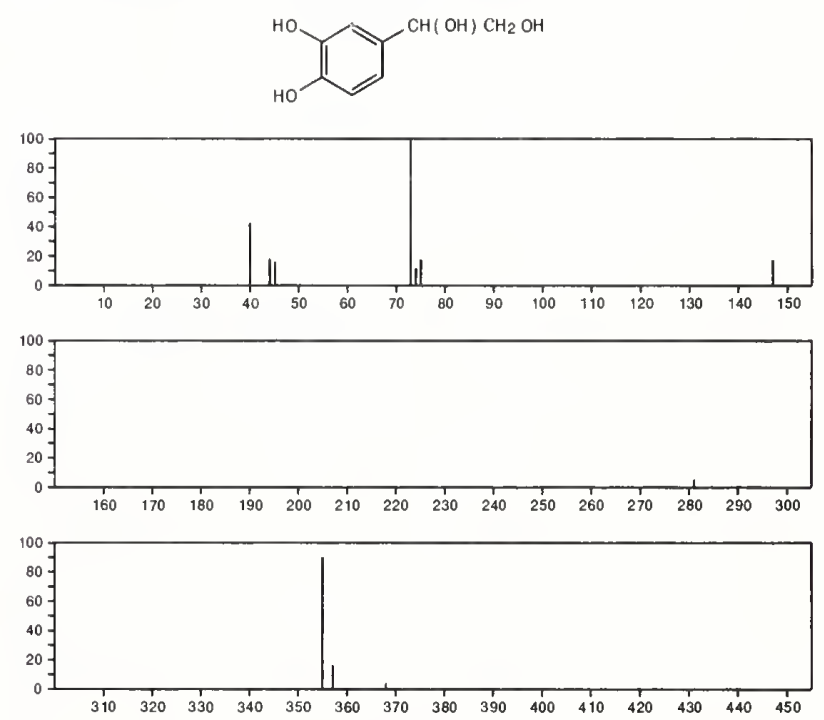

170

$\mathrm{C}_{8} \mathrm{H}_{10} \mathrm{O}_{4}$

$38765-78-5$

2-Cyclohexene-1,2-dicarboxylic acid
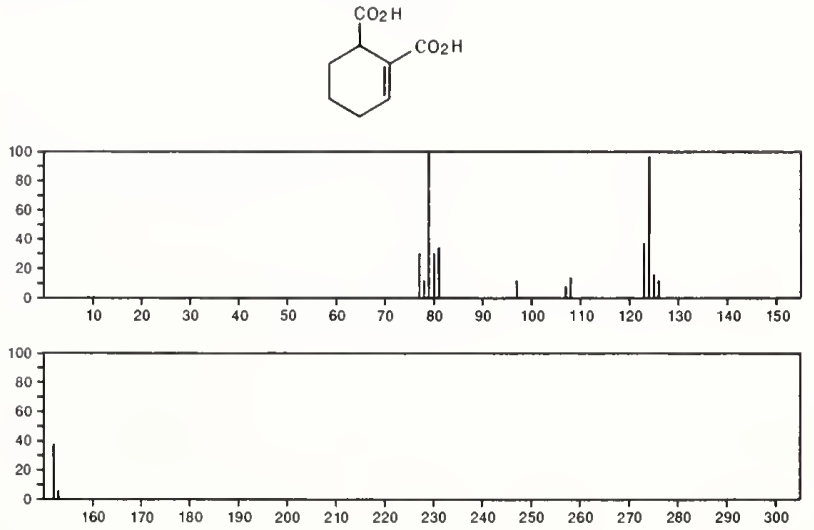
170 1,5-Cyclohexadiene-1-carboxylic acid, 3,4-dihydroxy-, methyl ester, trans-
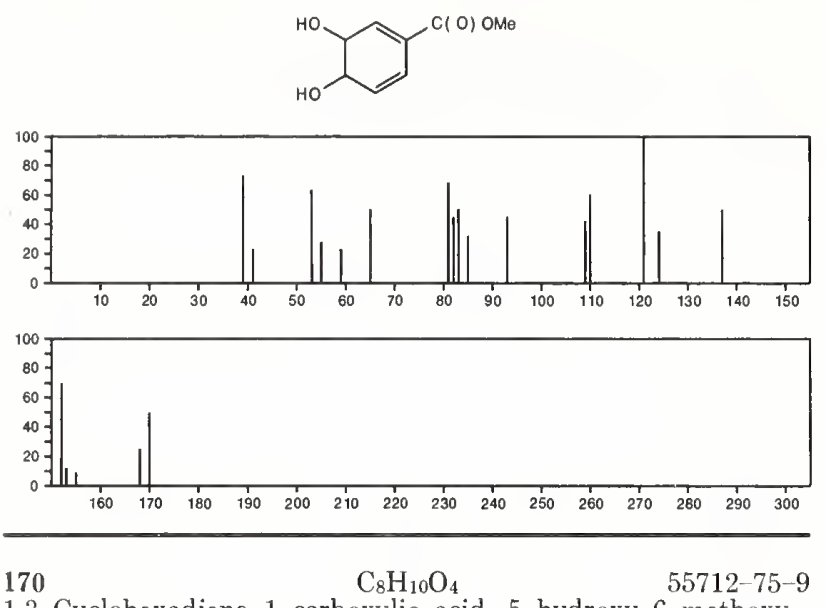

1,3-Cyclohexadiene-1-carboxylic acid, 5-hydroxy-6-methoxy-, trans-
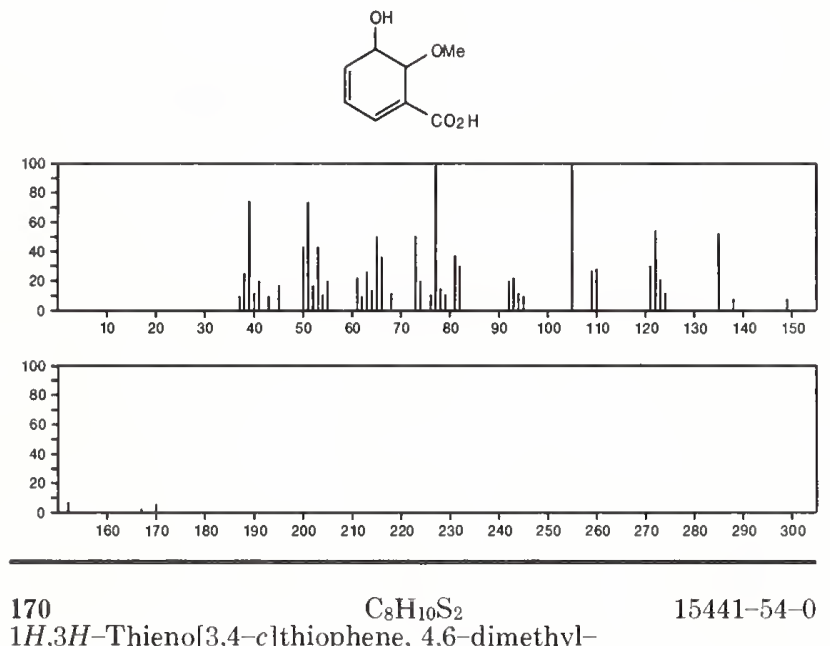

$1 H, 3 H$-Thieno[3,4-c] thiophene, 4,6-dimethyl-
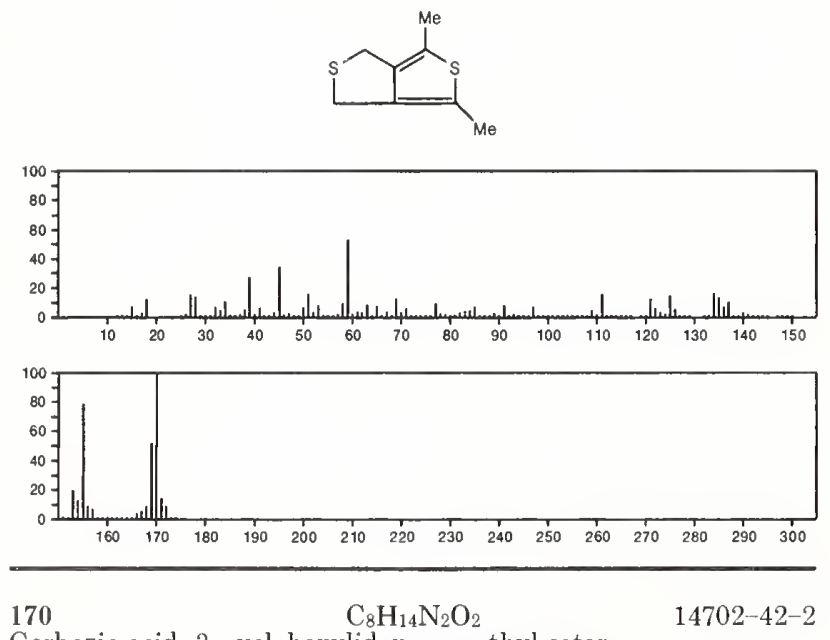

Carbazic acid, 3-cyclohexylidene-, methyl ester
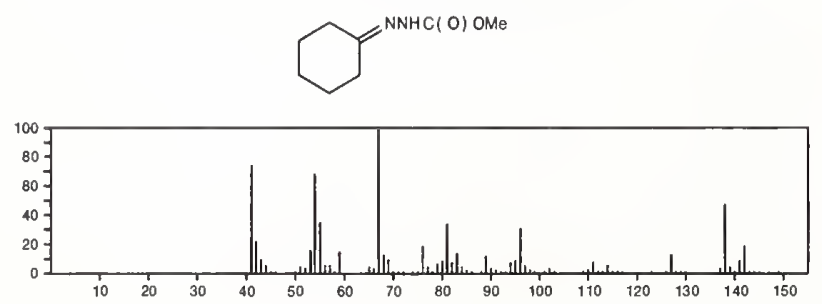

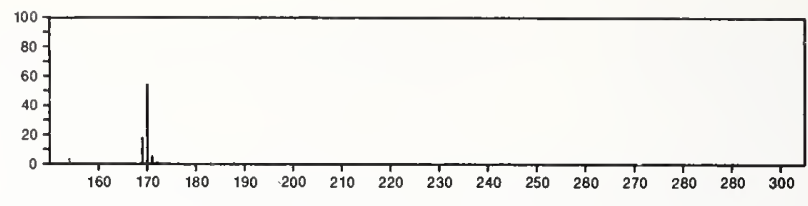

170

Sydnone, 3-(3,3-dimethylbutyl)-

$\mathrm{C}_{8} \mathrm{H}_{14} \mathrm{~N}_{2} \mathrm{O}_{2}$

$26537-49-5$
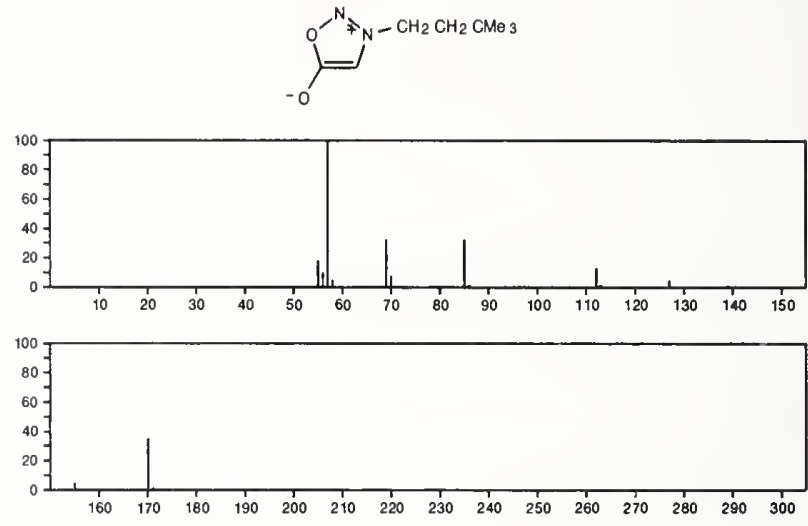

$170 \quad \mathrm{C}_{8} \mathrm{H}_{14} \mathrm{~N}_{2} \mathrm{O}_{2}$

$27886-67-5$

2,4-Imidazolidinedione, 5-methyl-5-(2-methylpropyl)-
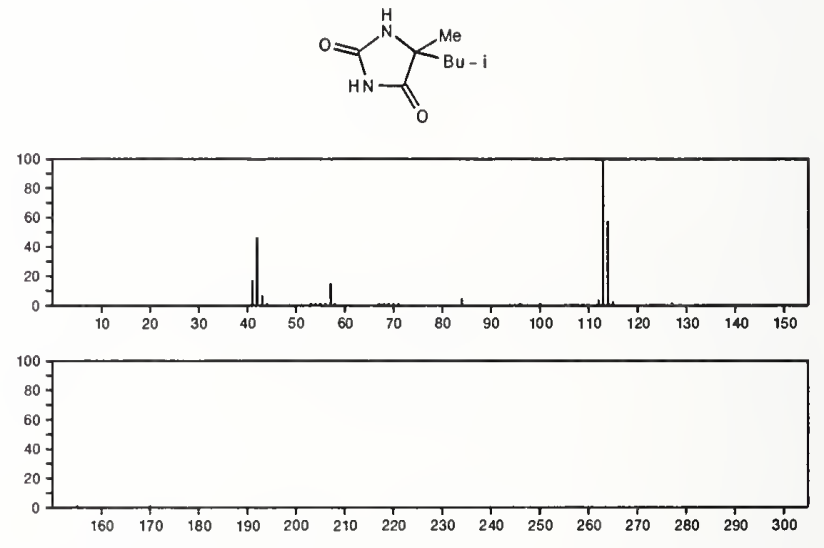

170

$\mathrm{C}_{8} \mathrm{H}_{14} \mathrm{~N}_{2} \mathrm{O}_{2}$

29924-68-3

1,4-Diazabicyclo[2.2.2]octane-2-carboxylic acid, methyl ester
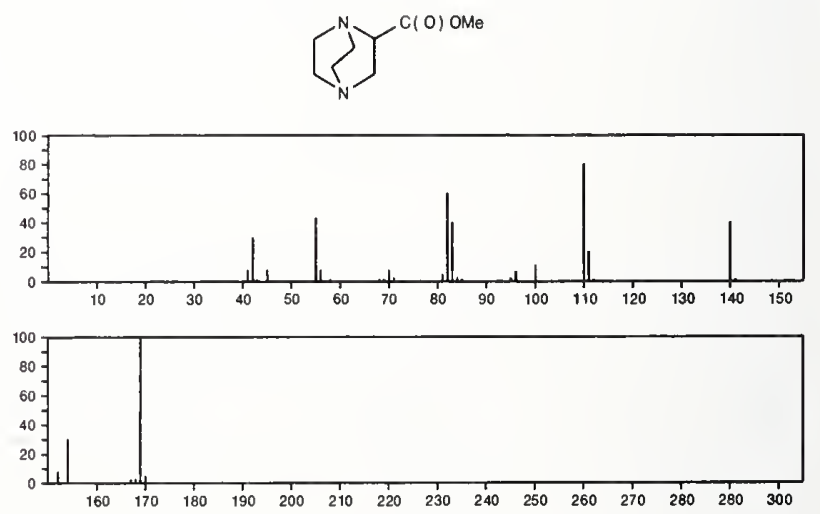
170

$\mathrm{C}_{8} \mathrm{H}_{14} \mathrm{~N}_{2} \mathrm{O}_{2}$

49582-44-7

2-Propenoic acid, 3-(1-aziridinyl)-3-(dimethylamino)-, methyl ester
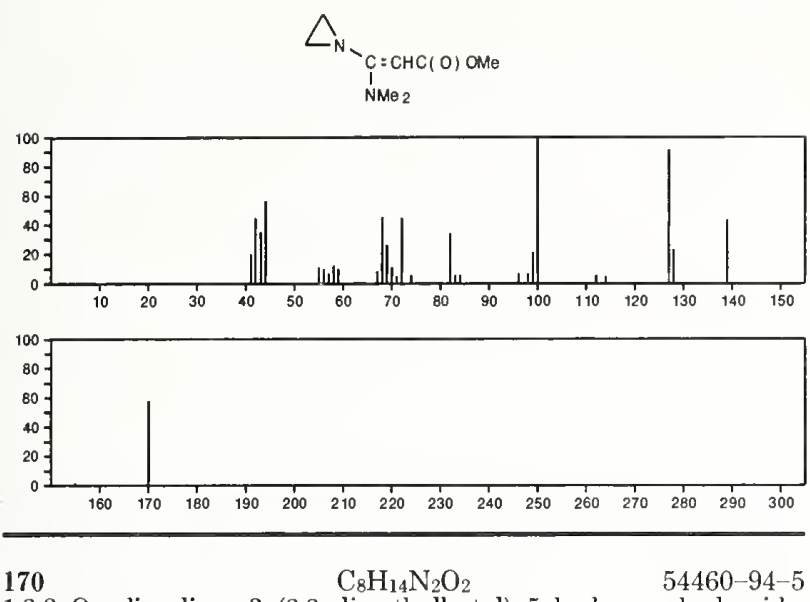

1,2,3-Oxadiazolium, 3-(2,2-dimethylbutyl)-5-hydroxy-, hydroxide, inner salt
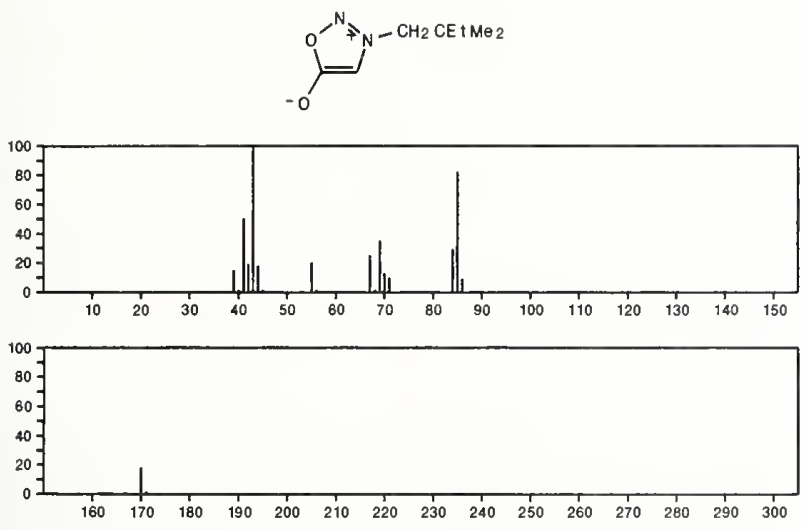

170

$\mathrm{C}_{8} \mathrm{H}_{14} \mathrm{~N}_{2} \mathrm{O}_{2}$

55401-89-3

Hydrazinecarboxylic acid, cyclopentylidene-, ethyl ester
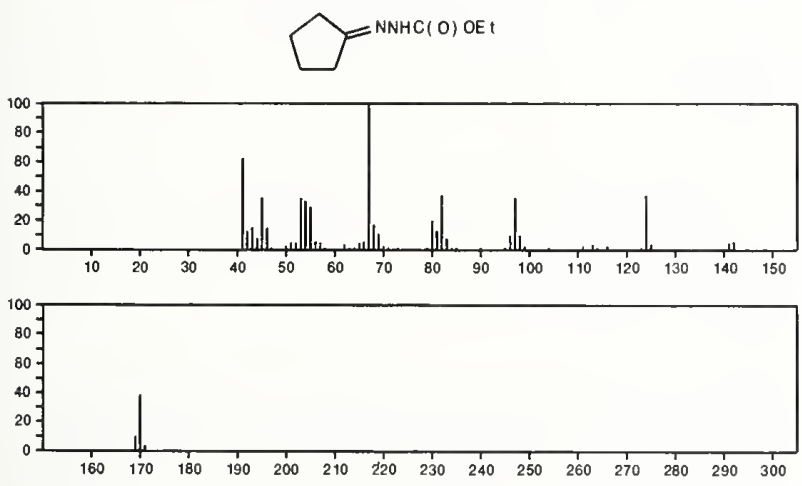

170

$\mathrm{C}_{8} \mathrm{H}_{15} \mathrm{BO}_{3}$

24372-02-9

Lactic acid, 2-methyl-, monoanhydride with 1-butaneboronic acid, cyclic ester
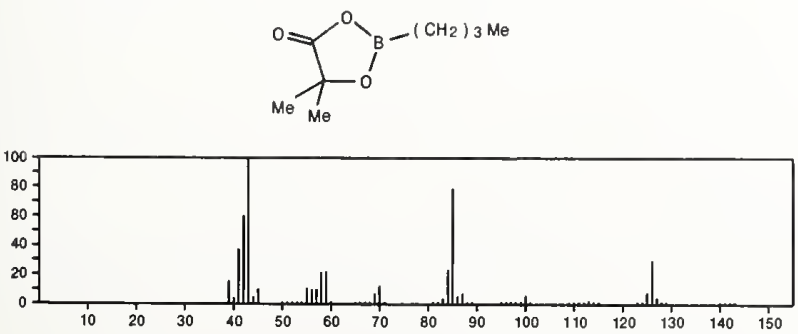

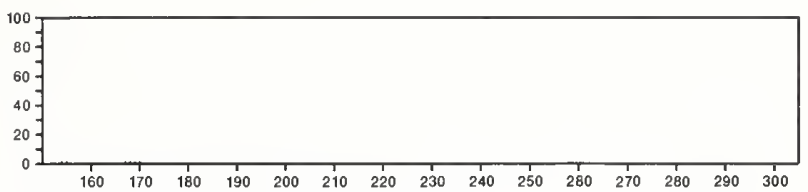

170

$\mathrm{C}_{8} \mathrm{H}_{15} \mathrm{BO}_{3}$

$31767-20-1$

Butyric acid, 3-hydroxy-, monoanhydride with 1-butaneboronic acid, cyclic ester

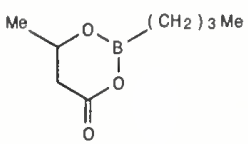
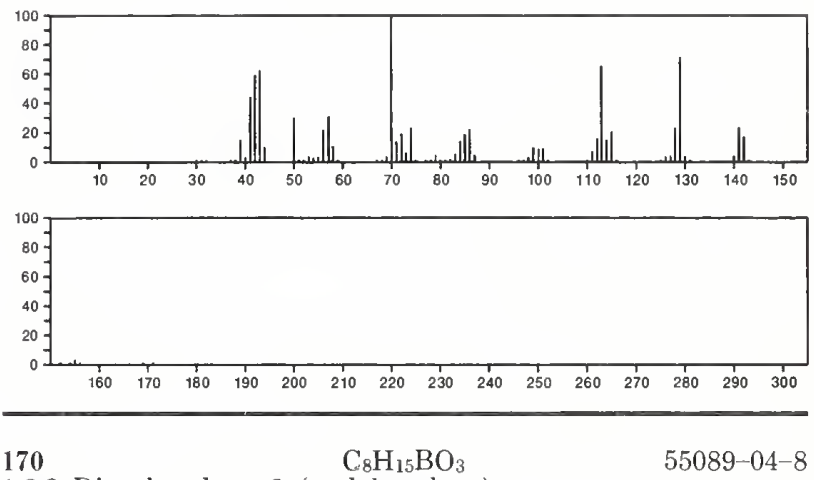

1,3,2-Dioxaborolane, 2-(cyclohexyloxy)-

$55089-04-8$
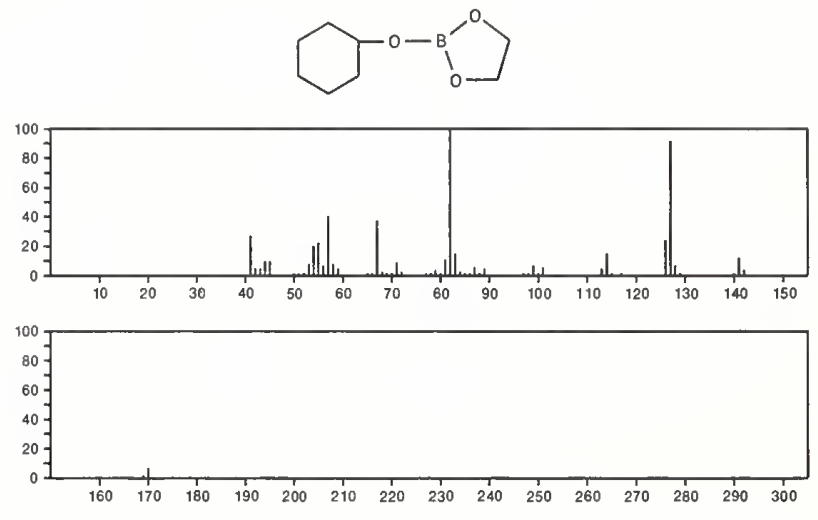

170

$1,3,6,9 \mathrm{~b}-$ Tetraazaphenalene

$\mathrm{C}_{9} \mathrm{H}_{6} \mathrm{~N}_{4}$

$37159-99-2$
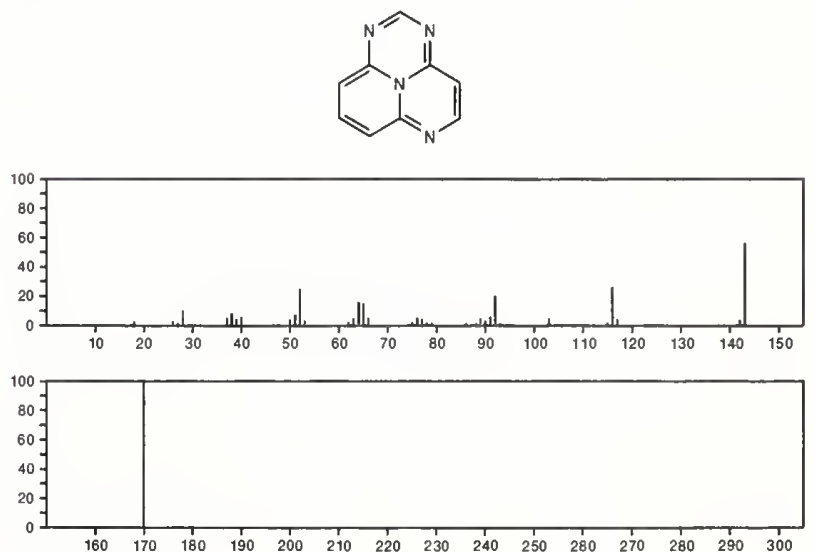
170

Phenetole, $\beta$-chloro-o-methyl-

$\mathrm{C}_{9} \mathrm{H}_{11} \mathrm{ClO}$
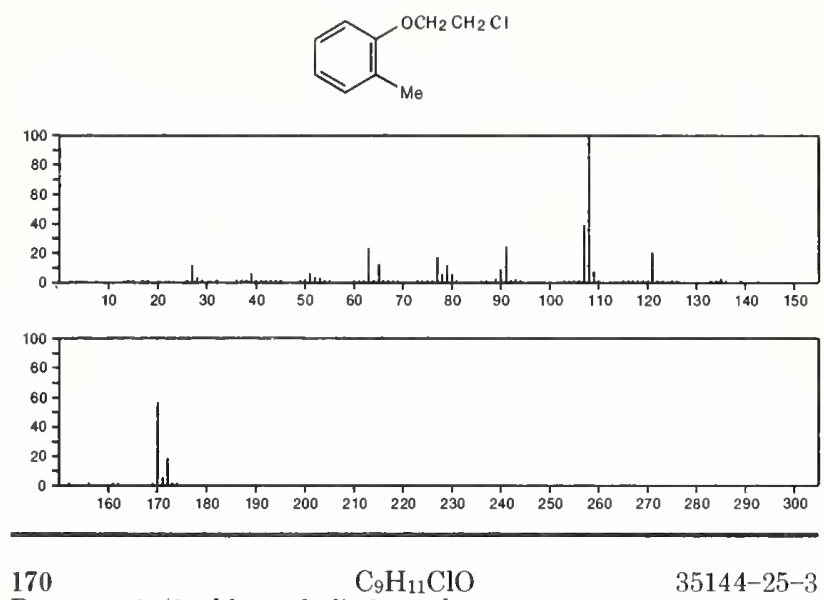

Benzene, 1-(2-chloroethyl)-2-methoxy-

$35144-25-3$
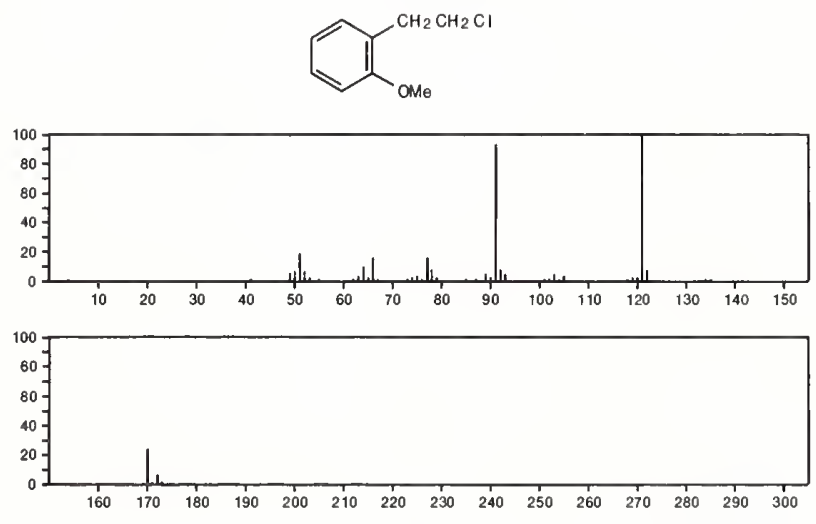

$170 \quad \mathrm{C}_{9} \mathrm{H}_{11} \mathrm{ClO}$

Phenol, 4-chloro-2-(1-methylethyl)-
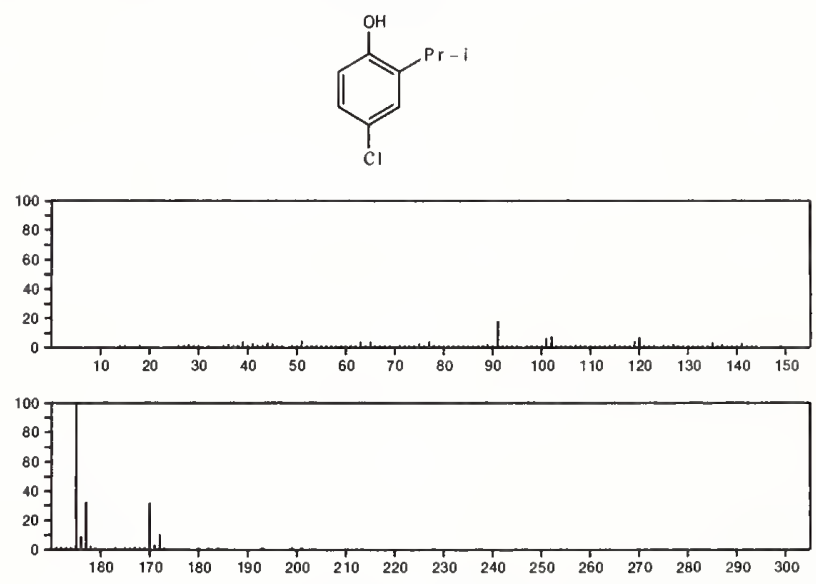

170

$\mathrm{C}_{9} \mathrm{H}_{14} \mathrm{O}_{3}$

4-Pentenoic acid, 2-acetyl-, ethyl ester

$610-89-9$

$\mathrm{E}: \mathrm{OC}(\mathrm{O}) \stackrel{!}{\mathrm{C}} \mathrm{HCH}_{2} \mathrm{CH}: \mathrm{CH}_{2}$

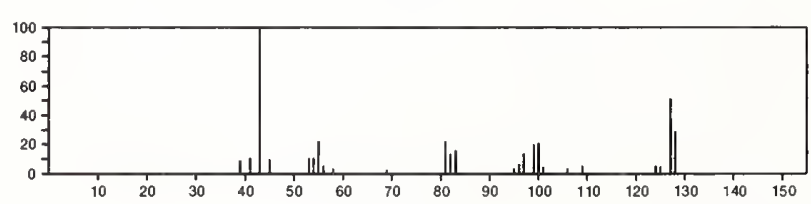

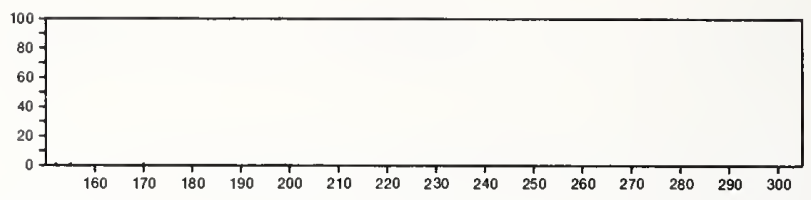

170
Cyclopentanepropanoic acid, $2-\mathrm{C}_{9} \mathrm{H}_{14} \mathrm{O}_{3}$
, methyl ester

10407-36-0
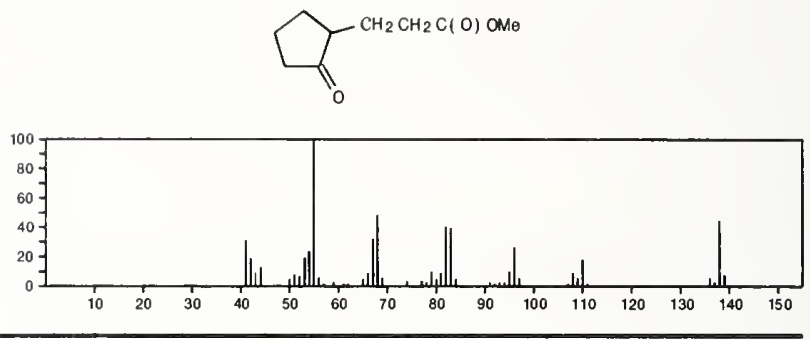

170

$\mathrm{C}_{9} \mathrm{H}_{14} \mathrm{O}_{3}$

1,2-Butanediol, 1-(2-furyl)-2-methyl-

$18927-21-4$
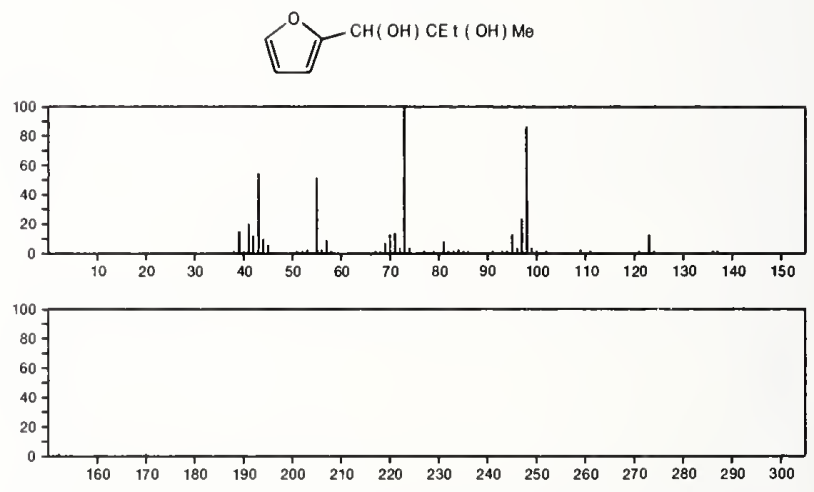

170

$\mathrm{C}_{9} \mathrm{H}_{14} \mathrm{O}_{3}$

$20962-71-4$

4-Pentenoic acid, 2-acetyl-4-methyl-, methyl ester

$\mathrm{COMe}$

$\mathrm{MeOC}(\mathrm{O}) \stackrel{\mathrm{C}}{\mathrm{C}} \mathrm{HCH}_{2} \mathrm{CM}_{e}=\mathrm{CH}_{2}$
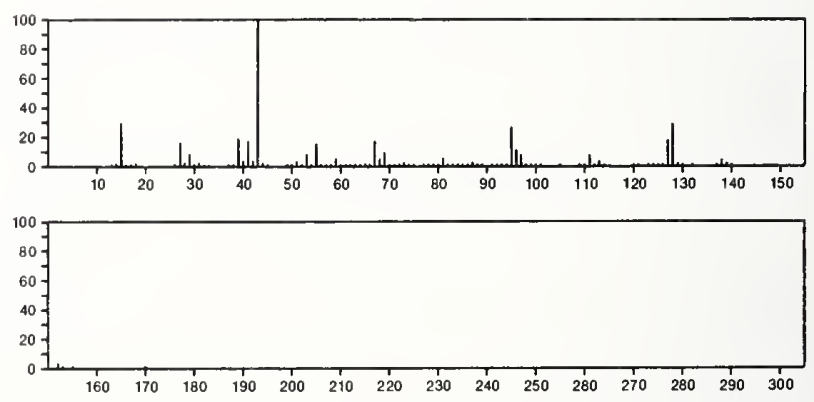

170

$\mathrm{C}_{9} \mathrm{H}_{14} \mathrm{O}_{3}$

24588-61-2

2H-Pyran-2-carboxylic acid, 3,6-dihydro-4,5-dimethyl-, methyl ester
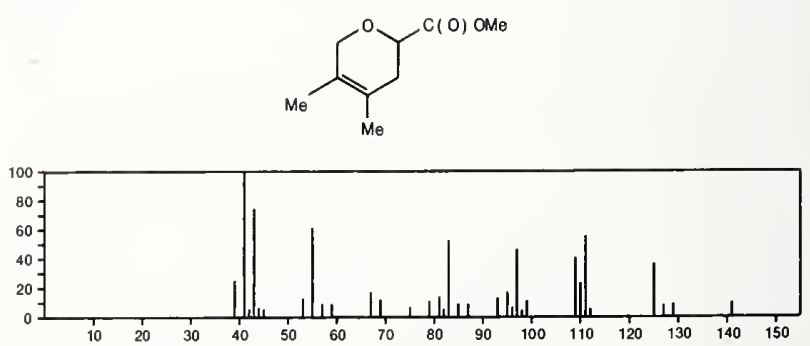


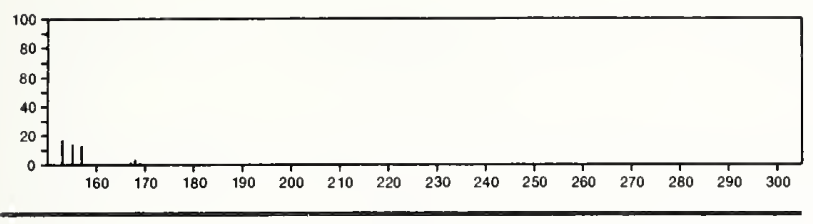

170

$\mathrm{C}_{9} \mathrm{H}_{14} \mathrm{O}_{3}$

$38653-27-9$

2-Propanol, 1-[(1-methyl-2-propynyl)oxy]-, acetate

$\mathrm{HC} \equiv \mathrm{CCHM}_{\mathrm{O}} \mathrm{OCH}_{2} \mathrm{CHM}_{\Theta} \mathrm{OAC}$
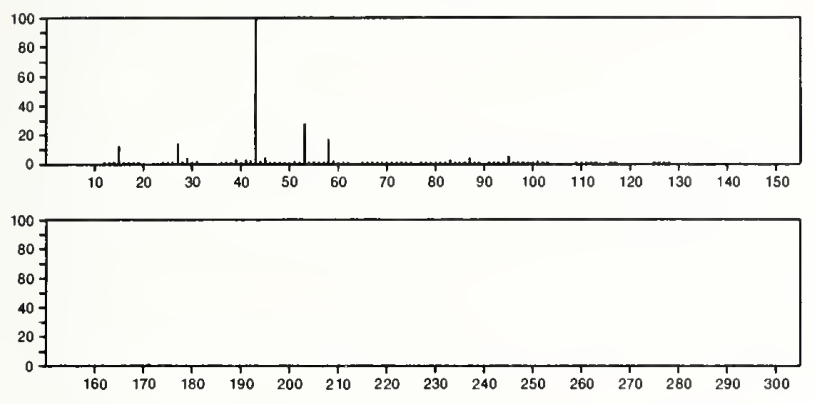

$170 \quad \mathrm{C}_{9} \mathrm{H}_{14} \mathrm{O}_{3} \quad 38858-64-9$ 2H-Pyran-4-carboxylic acid, 3,4-dihydro-5-methyl-, ethyl ester
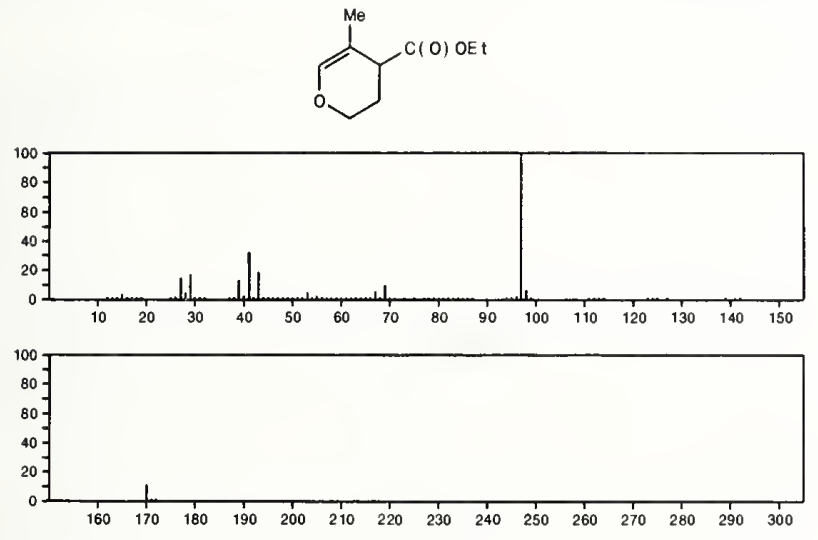

$170 \quad \mathrm{C}_{9} \mathrm{H}_{14} \mathrm{O}_{3} \quad 38858-66-1$

4-Oxepincarboxylic acid, 2,3,6,7-tetrahydro-, ethyl ester
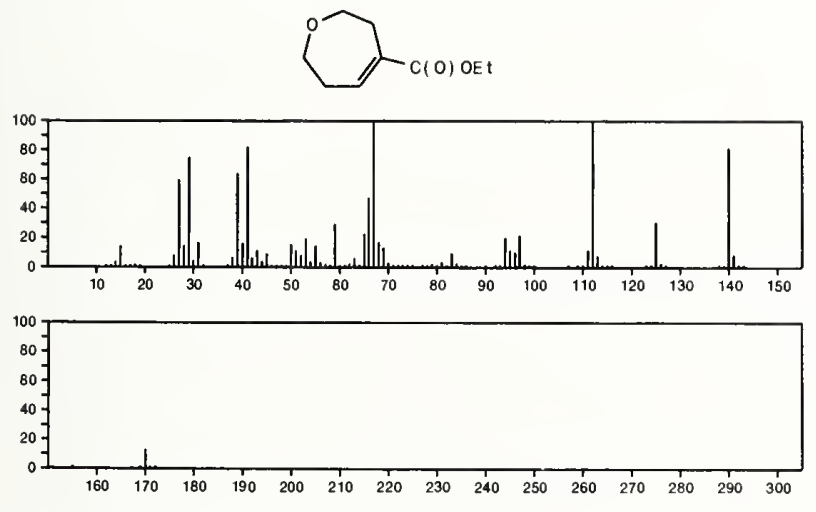

170

3-Pentyn-2-one, 5,5-diethoxy-

55402-04-5

(EtO) ${ }_{2} \mathrm{CHC} \equiv$ CCOME

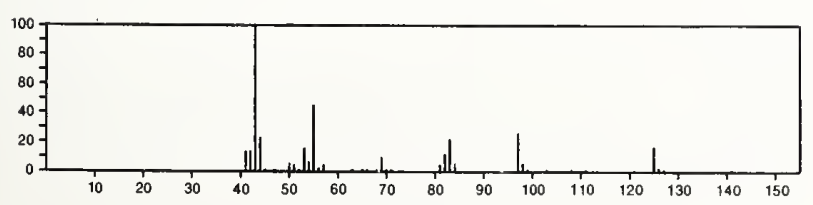

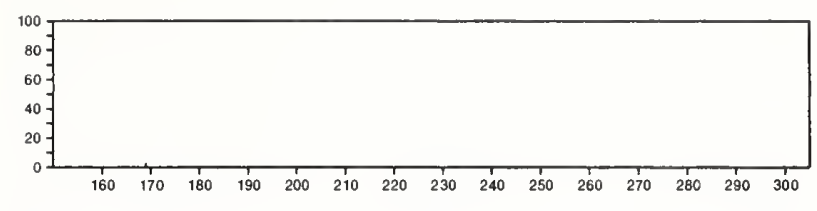

170

$\mathrm{C}_{9} \mathrm{H}_{14} \mathrm{O}_{3}$

$56666-76-3$

2,5-Furandione, 3-(1,1-dimethylpropyl)dihydro-
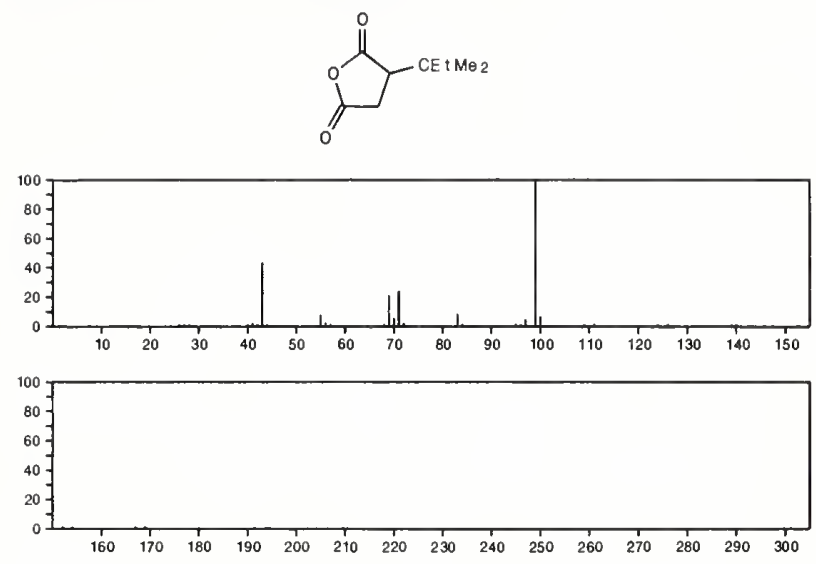

170

$\mathrm{C}_{9} \mathrm{H}_{16} \mathrm{NO}_{2}$

2896-70-0

1-Piperidinyloxy, 2,2,6,6-tetramethyl-4-oxo-
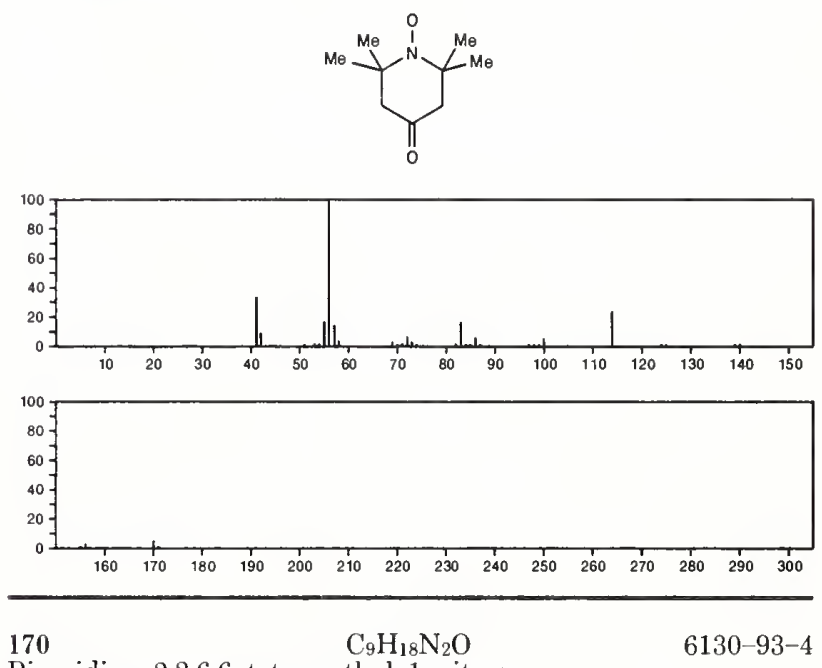

Piperidine, 2,2,6,6-tetramethyl-1-nitroso-
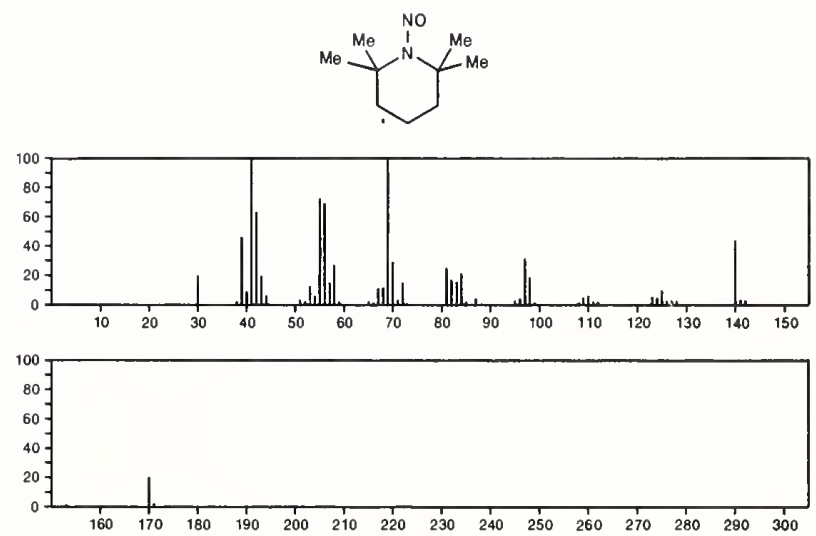
170 Diaziridinone, bis(1,1-dimethylethyl)-
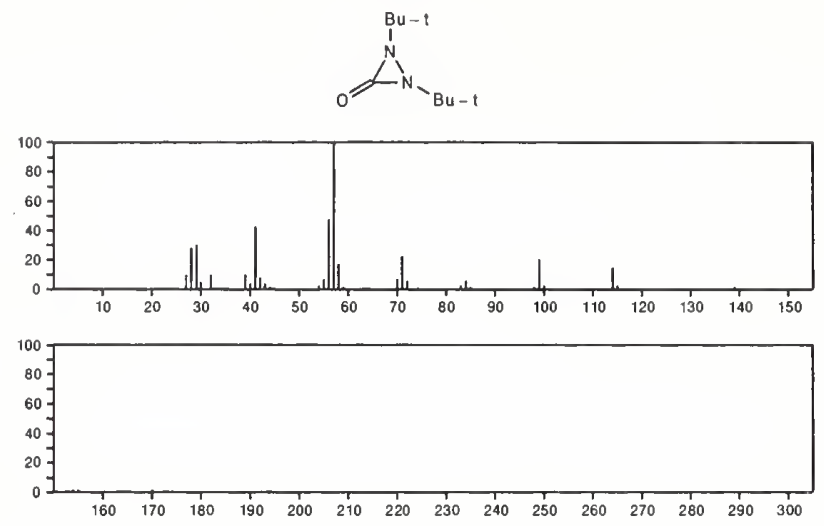

170

$\mathrm{C}_{9} \mathrm{H}_{18} \mathrm{~N}_{2} \mathrm{O}$

$49582-55-0$

3-Buten-2-one, 4-(dimethylamino)-4-[(1-methylethyl)amino $]-$

Me ${ }_{2} \mathrm{NC}\left(\mathrm{NHPr}_{\mathrm{r}}-1\right)=\mathrm{CHCOMe}$
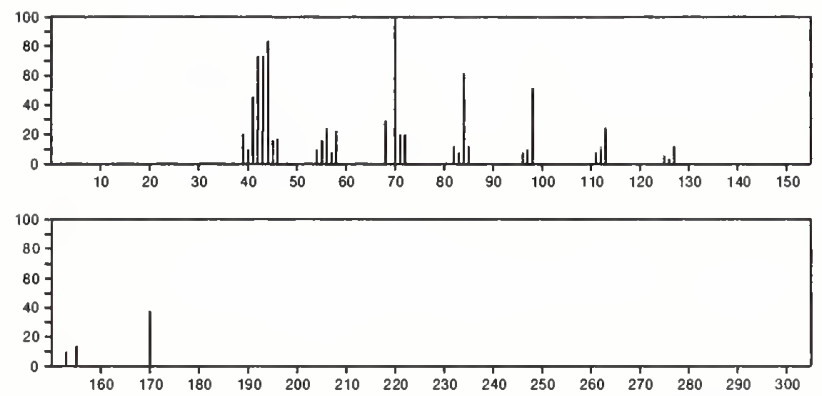

170

$\mathrm{C}_{9} \mathrm{H}_{18} \mathrm{~N}_{2} \mathrm{O}$

$49582-61-8$

2-Propenal, 2-(diethylamino)-3-(dimethylamino)-

$\mathrm{Me} 2 \mathrm{NCH}=\mathrm{C}(\mathrm{CHO}) \mathrm{NE} t_{2}$
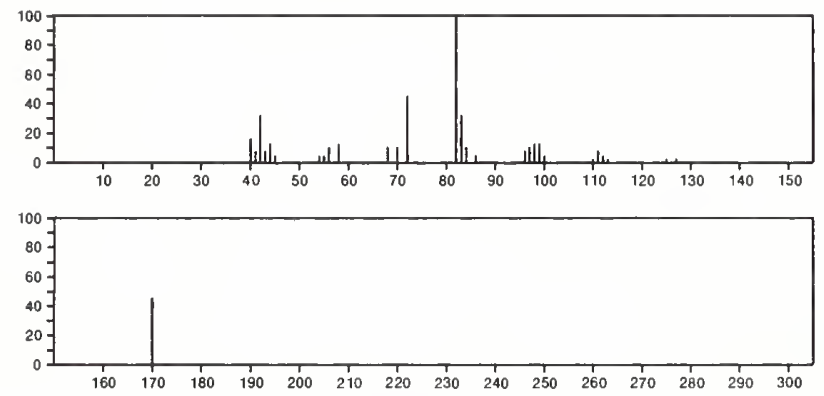

170

$\mathrm{C}_{9} \mathrm{H}_{18} \mathrm{~N}_{2} \mathrm{O}$

$49582-65-2$

3-Buten-2-one, 4-(dimethylamino)-3-[(1-methylethyl)amino $]-$

$\mathrm{Me}_{2} \mathrm{NCH}=\mathrm{C}(\mathrm{NHPr}-\mathrm{i})$ COMe
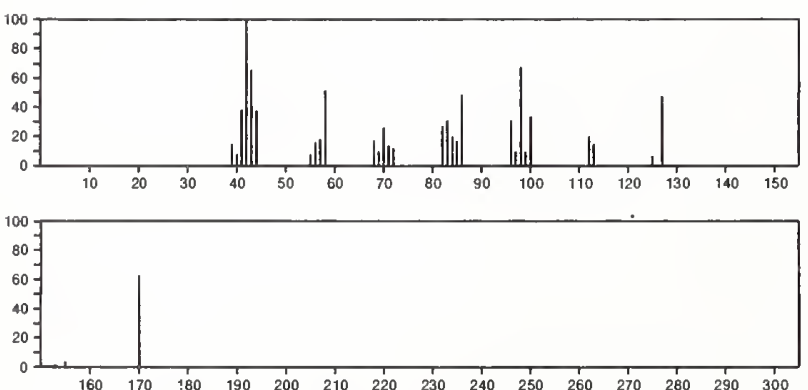

170

$\mathrm{C}_{9} \mathrm{H}_{18} \mathrm{OSi}$

$6651-36-1$

Silane, (1-cyclohexen-1-yloxy)trimethyl-
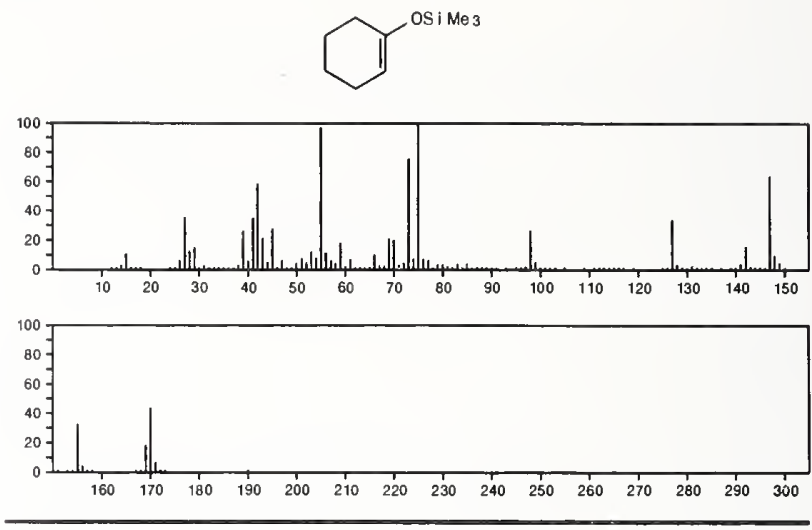

170

$\mathrm{C}_{9} \mathrm{H}_{18} \mathrm{OS}$

$54725-71-2$

Silane, (2-cyclohexen-1-yloxy)trimethyl-
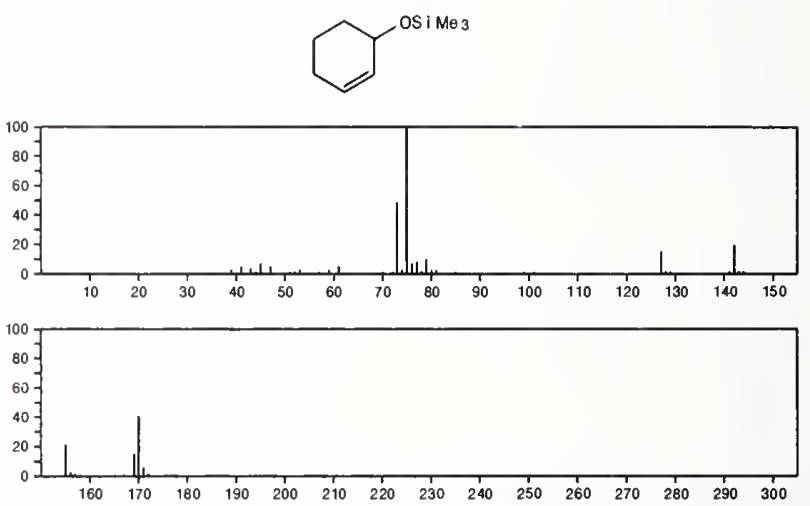

170

$\mathrm{C}_{10} \mathrm{H}_{6} \mathrm{~N}_{2} \mathrm{O}$

$6969-11-5$

1-Isoquinolinecarbonitrile, 2-oxide
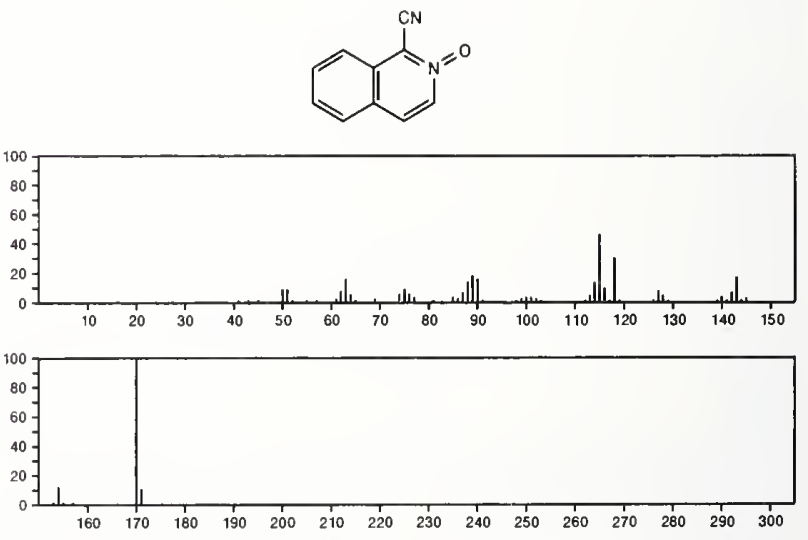

170

$\mathrm{C}_{10} \mathrm{H}_{6} \mathrm{~N}_{2} \mathrm{O}$

3,1-Benzoxazepine-2-carbonitrile

$18457-80-2$
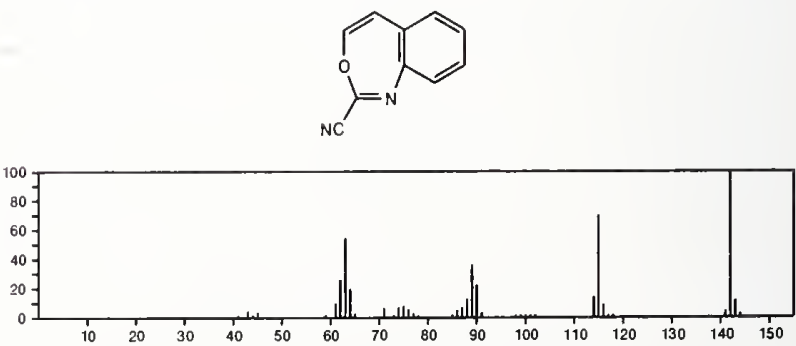


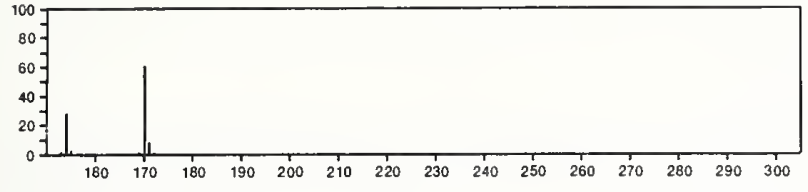

170

$\mathrm{C}_{10} \mathrm{H}_{18} \mathrm{O}_{2}$

$111-79-5$

2-Nonenoic acid, methyl ester

$\mathrm{Me}\left(\mathrm{CH}_{2}\right)_{5} \mathrm{CH}=\mathrm{CHC}(\mathrm{O}) \mathrm{OMe}$
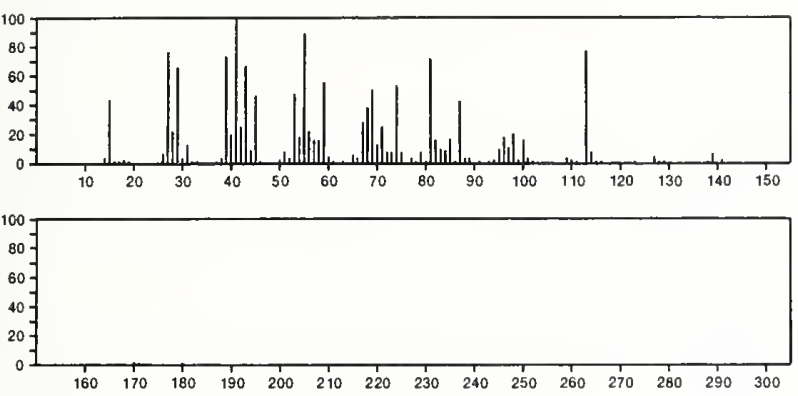

$170 \quad \mathrm{C}_{10} \mathrm{H}_{18} \mathrm{O}_{2} \quad 512-77-6$

Cyclopentanecarboxylic acid, 1-methyl-3-(1-methylethyl)-, cis-
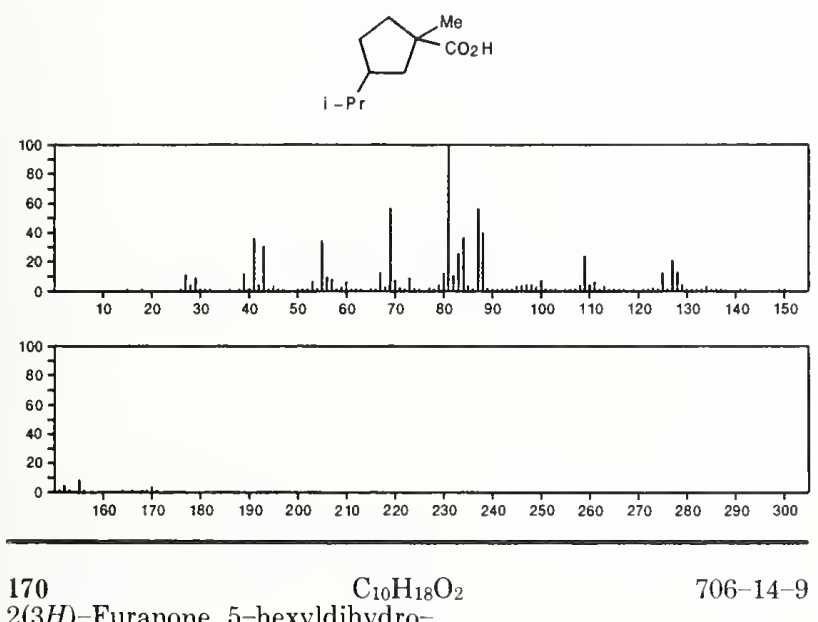

2(3H)-Furanone, 5-hexyldihydro-
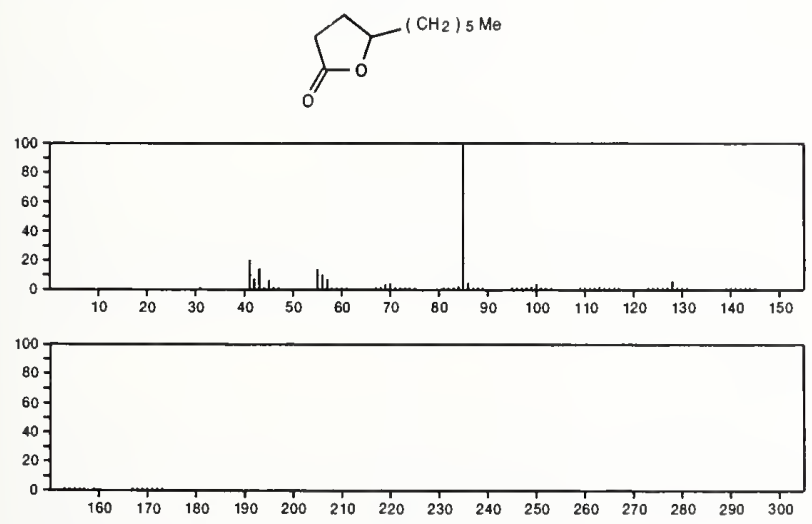

$170 \quad \mathrm{C}_{10} \mathrm{H}_{18} \mathrm{O}_{2}$

1,4-Naphthalenediol, decahydro-, $(1 \alpha, 4 \alpha, 4 \mathrm{a} \alpha, 8 \mathrm{a} \alpha)$

$1127-51-1$<smiles>OC1CCC(O)C2CCCCC12</smiles>
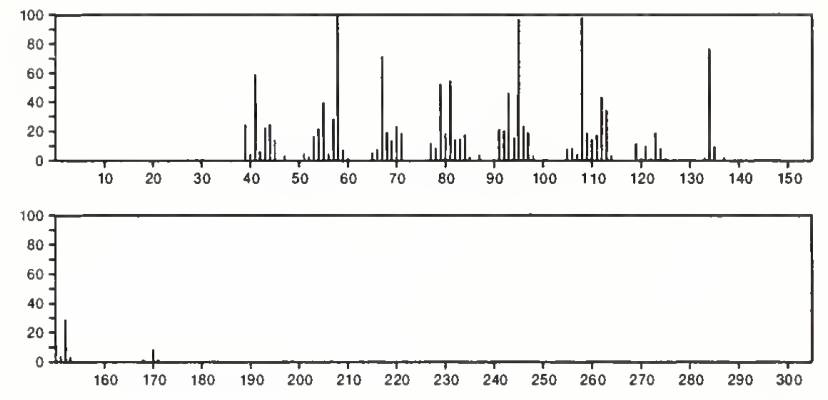

170

$\mathrm{C}_{10} \mathrm{H}_{18} \mathrm{O}_{2}$

$1127-52-2$

1,4-Naphthalenediol, decahydro-, $(1 \alpha, 4 \alpha, 4 \mathrm{a} \alpha, 8 \mathrm{a} \beta)_{-}^{-}$<smiles>OC1CCC(O)C2CCCCC12</smiles>
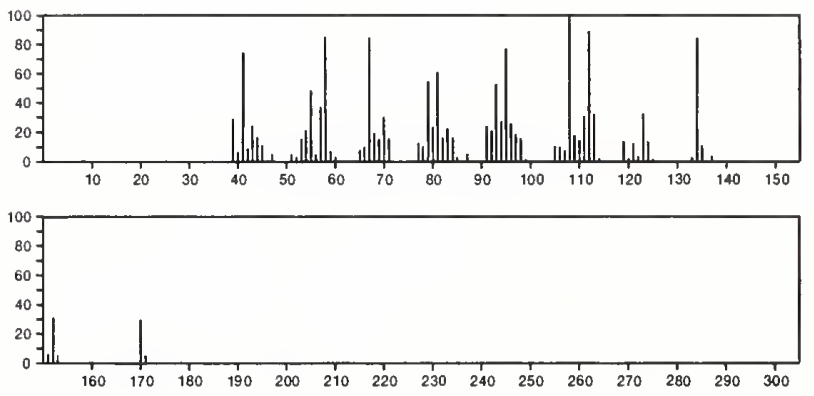

\section{0}

$1127-53-3$

1,4-Naphthalenediol, decahydro-, $(1 \alpha, 4 \beta, 4 \mathrm{a} \beta, 8 \mathrm{a} \alpha)-$
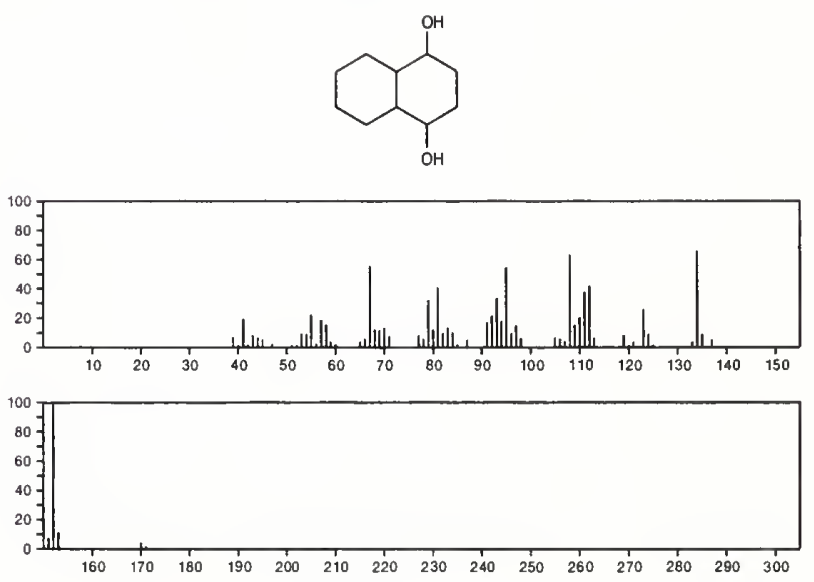
170 $\mathrm{C}_{10} \mathrm{H}_{18} \mathrm{O}_{2}$

$1127-54-4$

1,4-Naphthalenediol, decahydro-, $(1 \alpha, 4 \beta, 4 \mathrm{a} \alpha, 8 \mathrm{a} \alpha)-$<smiles>OC1CCCC2CCCCC12</smiles>
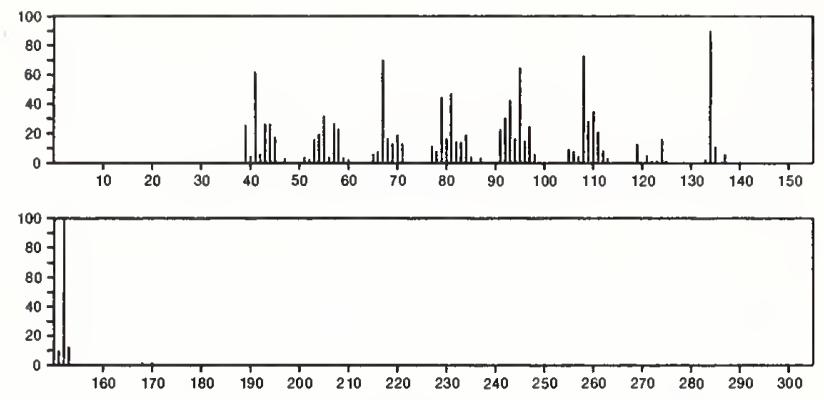

170

$\mathrm{C}_{10} \mathrm{H}_{18} \mathrm{O}_{2}$

$1127-55-5$

$1,4-$ Naphthalenediol, decahydro-,$(1 \alpha, 4 \beta, 4 \mathrm{a} \alpha, 8 \mathrm{a} \beta)-$<smiles>OC1CCCC2CCCCC12</smiles>
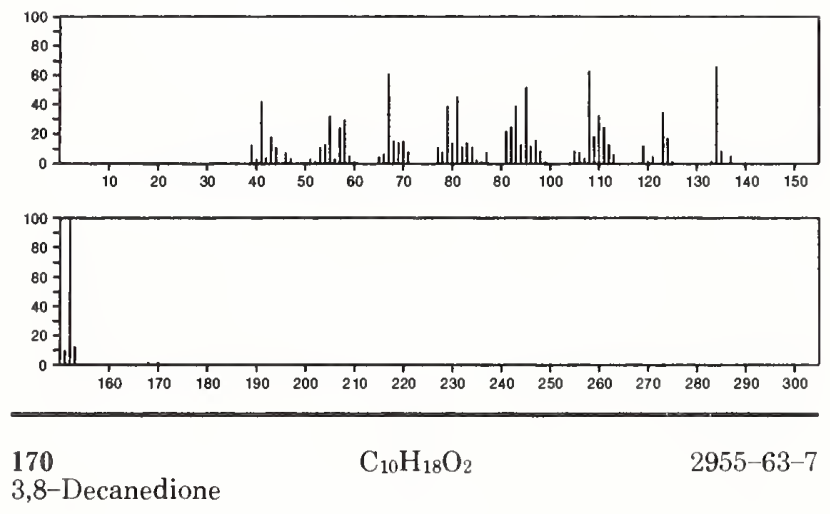

$\mathrm{Et} \mathrm{CO}\left(\mathrm{CH}_{2}\right)_{4} \mathrm{COEt}$
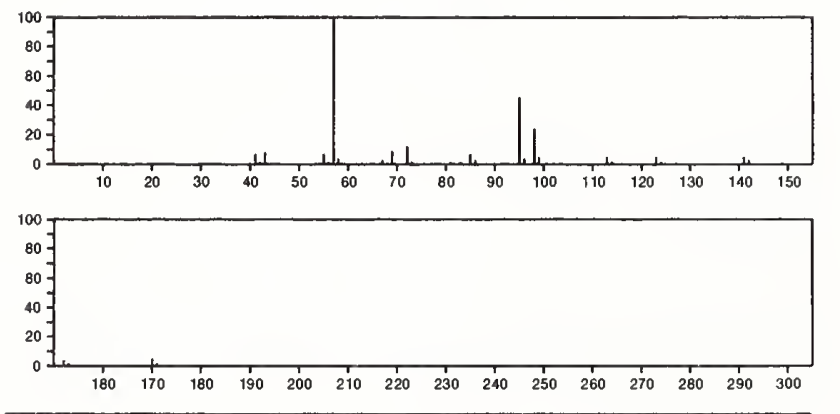

$170 \quad \mathrm{C}_{10} \mathrm{H}_{18} \mathrm{O}_{2} \quad 3618-40-4$

Octanoic acid, 2-methylene--, methyl ester

$\operatorname{MeOC}(0) \stackrel{\stackrel{\mathrm{CH}}{\mathrm{C}}\left(\mathrm{CH}_{2}\right) 5 \mathrm{Me}}{\mathrm{Cu}}$

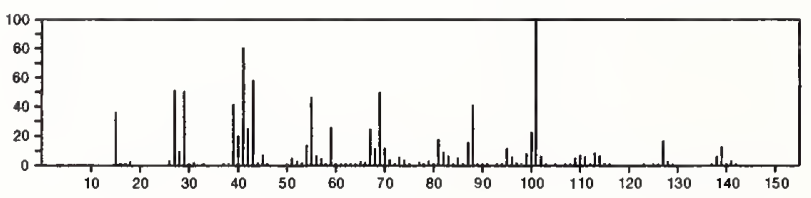

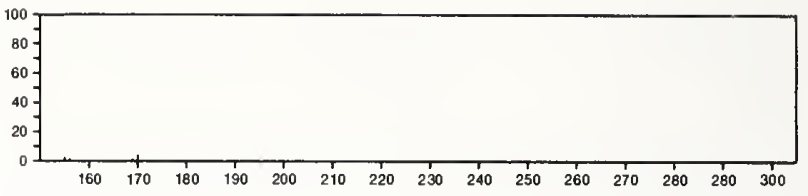

$170 \quad \mathrm{C}_{10} \mathrm{H}_{18} \mathrm{O}_{2}$

3,4-Hexanedione, 2,2,5,5-tetramethyl-

$4388-88-9$

$\mathrm{Me}_{3} \mathrm{CCOCOCM}_{3}$
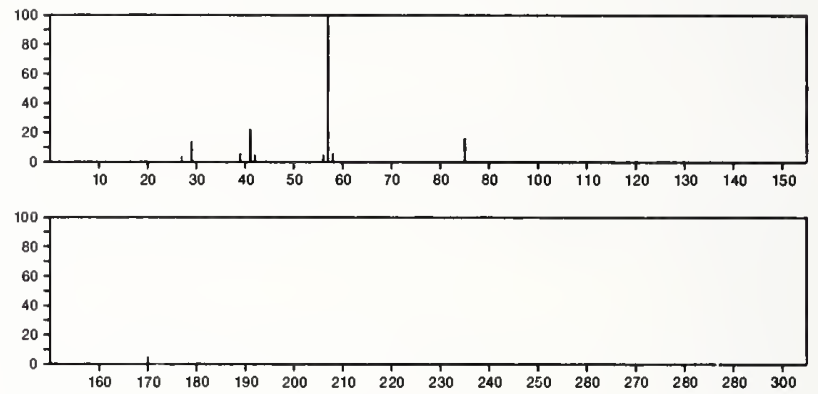

170

Cyclohexanebutanoic acid

$\mathrm{C}_{10} \mathrm{H}_{18} \mathrm{O}_{2}$

4441-63-8
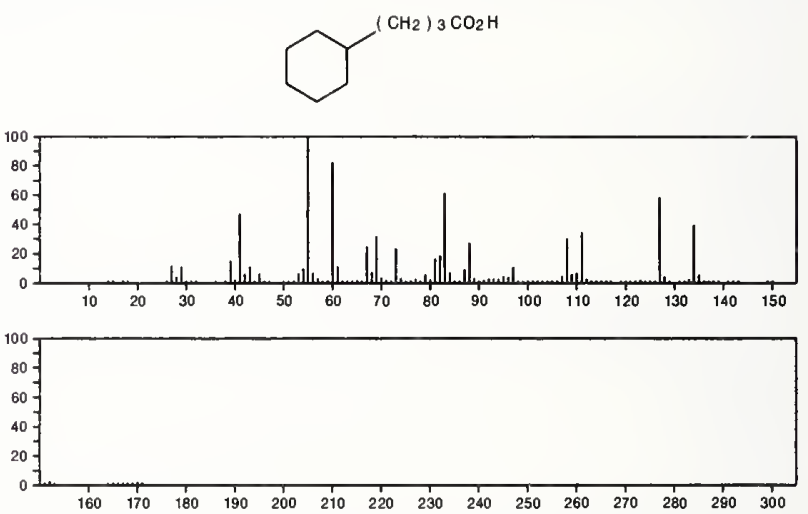

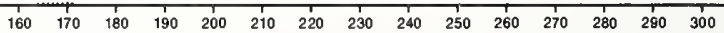

170

$\mathrm{C}_{10} \mathrm{H}_{18} \mathrm{O}_{2}$

$5989-33-3$

2-Furanmethanol, 5-ethenyltetrahydro- $\alpha, \alpha, 5$-trimethyl-, cis-
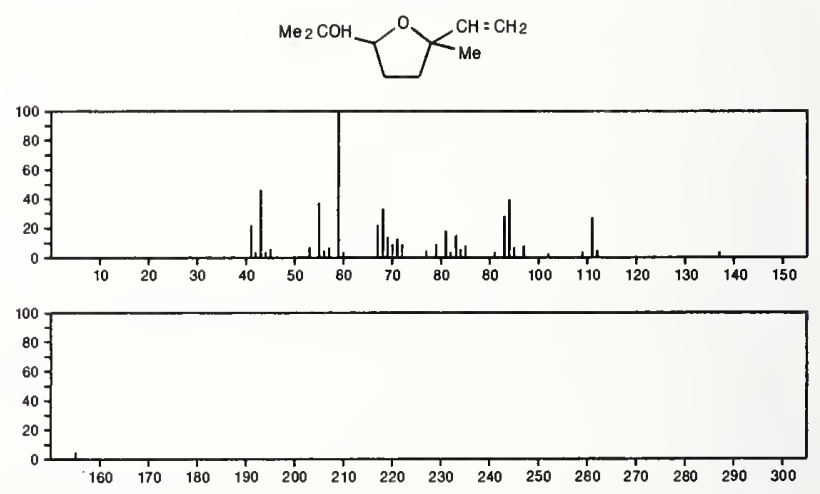

170

$\mathrm{C}_{10} \mathrm{H}_{18} \mathrm{O}_{2}$

$7560-66-9$

3-Cyclohexene-1-carboxaldehyde, 4-methyl-, dimethyl acetal
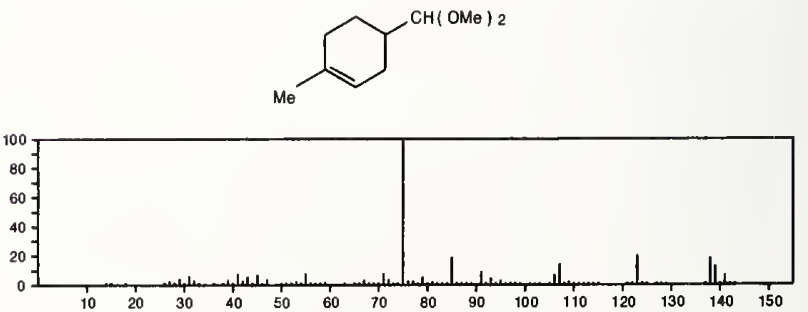


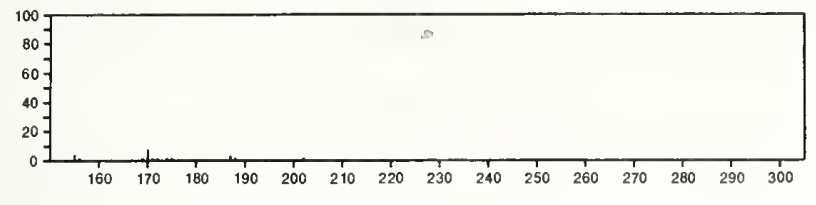

170

2,4-Pentanedione, 3-isopentyl-

$$
\mathrm{C}_{10} \mathrm{H}_{18} \mathrm{O}_{2}
$$

10225-31-7

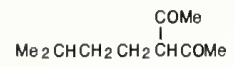
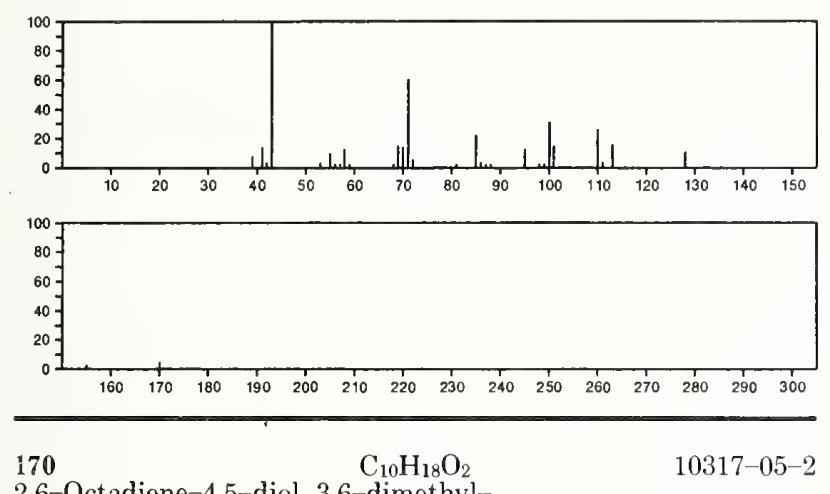

2,6-Octadiene-4,5-diol, 3,6-dimethyl-

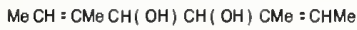
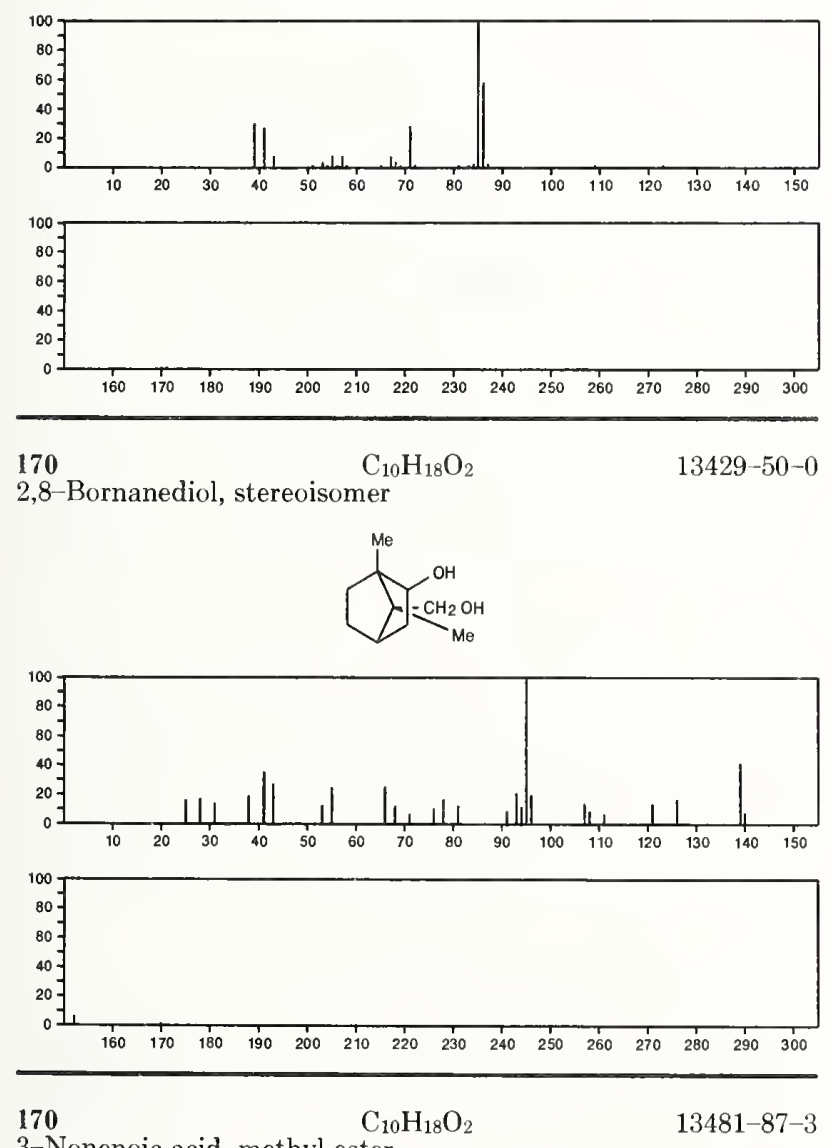

3-Nonenoic acid, methyl ester

$\mathrm{MeOC}_{0} \mathrm{O} \mathrm{CH}_{2} \mathrm{CH}=\mathrm{CH}\left(\mathrm{CH}_{2}\right)_{4} \mathrm{Me}$

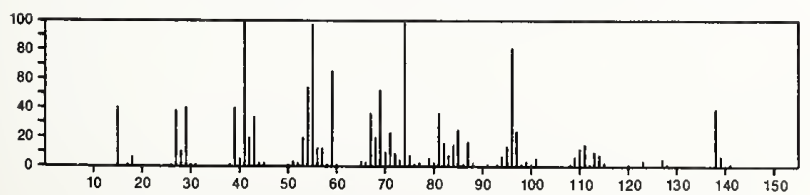

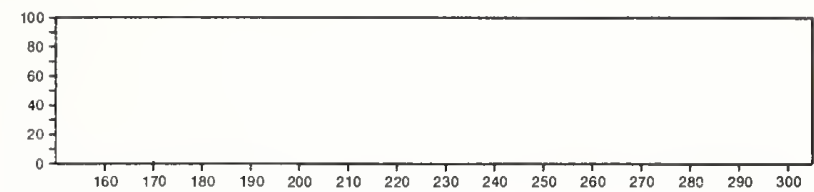

170

2,3-Bornanediol, endo-2,exo-3-

$\mathrm{C}_{10} \mathrm{H}_{18} \mathrm{O}_{2}$

$13837-85-9$
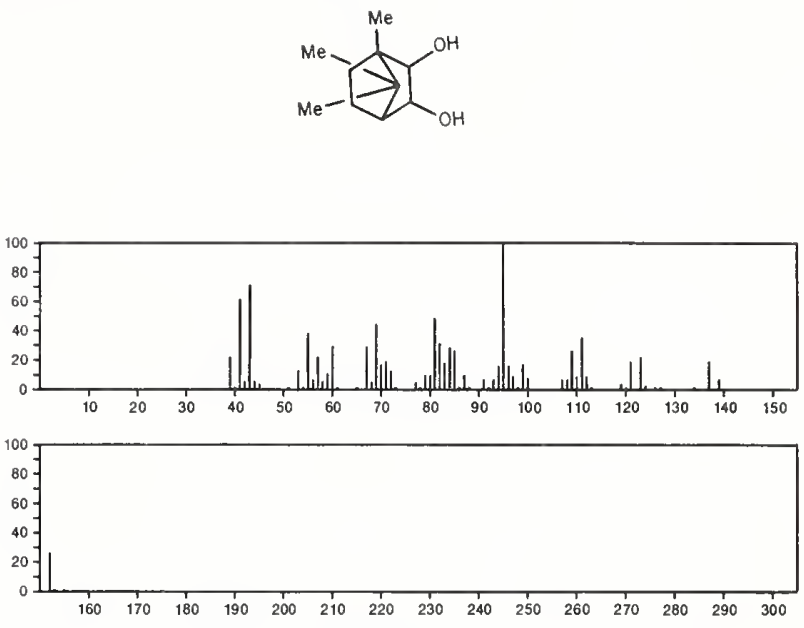

170

$\mathrm{C}_{10} \mathrm{H}_{18} \mathrm{O}_{2}$

$14049-11-7$

2H-Pyran-3-ol, 6-ethenyltetrahydro-2,2,6-trimethyl-
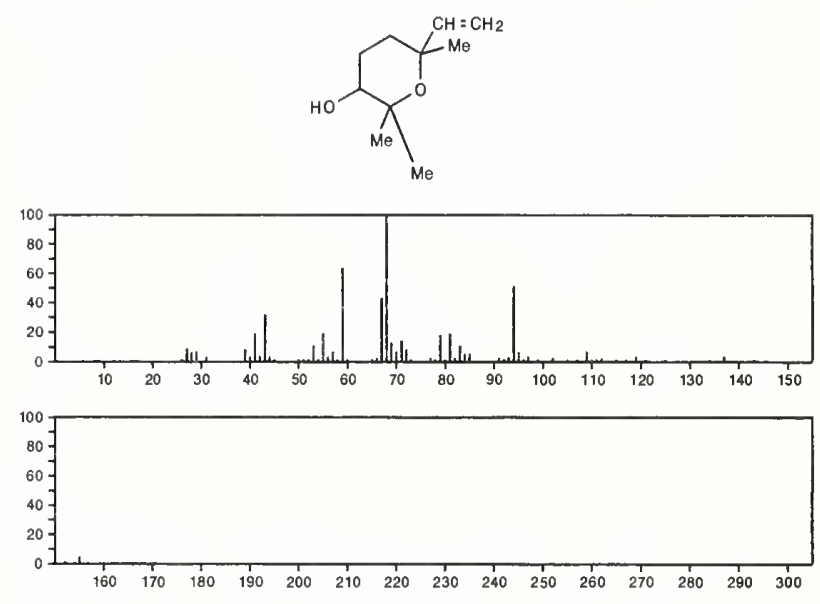

170

Cyclohexanol, 2-methyl-, propionate, trans-

$15287-79-3$
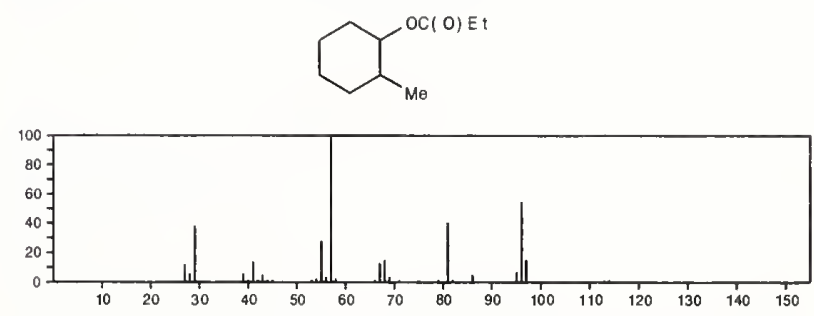

$170 \quad \mathrm{C}_{10} \mathrm{H}_{18} \mathrm{O}_{2}$

2-Pentenoic acid, 3,4,4-trimethyl-, ethyl ester, $(E)$ -

$16812-82-1$

$E$ t OC $(\mathrm{O}) \mathrm{CH}=\mathrm{CMe}_{\mathrm{CM}} 3$

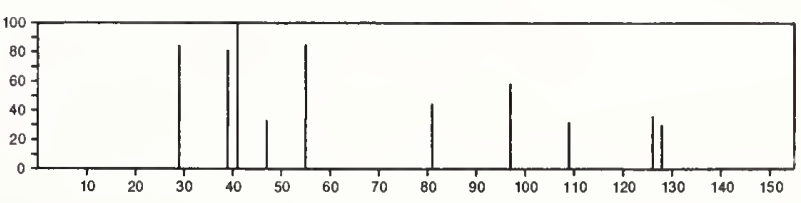




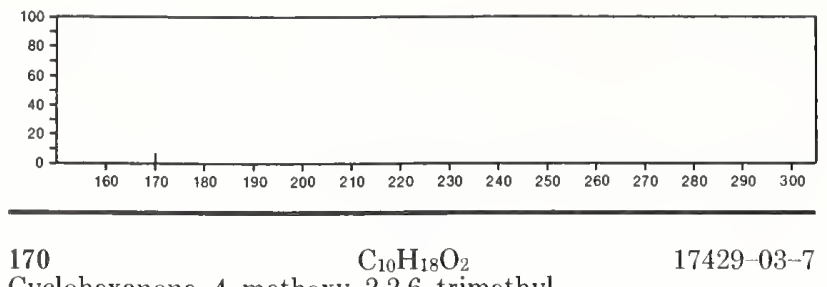

170 4-Nonenoic acid, methyl ester

$\mathrm{C}_{10} \mathrm{H}_{18} \mathrm{O}$

20731-19-5

$\mathrm{Me}\left(\mathrm{CH}_{2}\right)_{3} \mathrm{CH}=\mathrm{CHCH}_{2} \mathrm{CH}_{2} \mathrm{C}(\mathrm{O}) \mathrm{OM}_{0}$
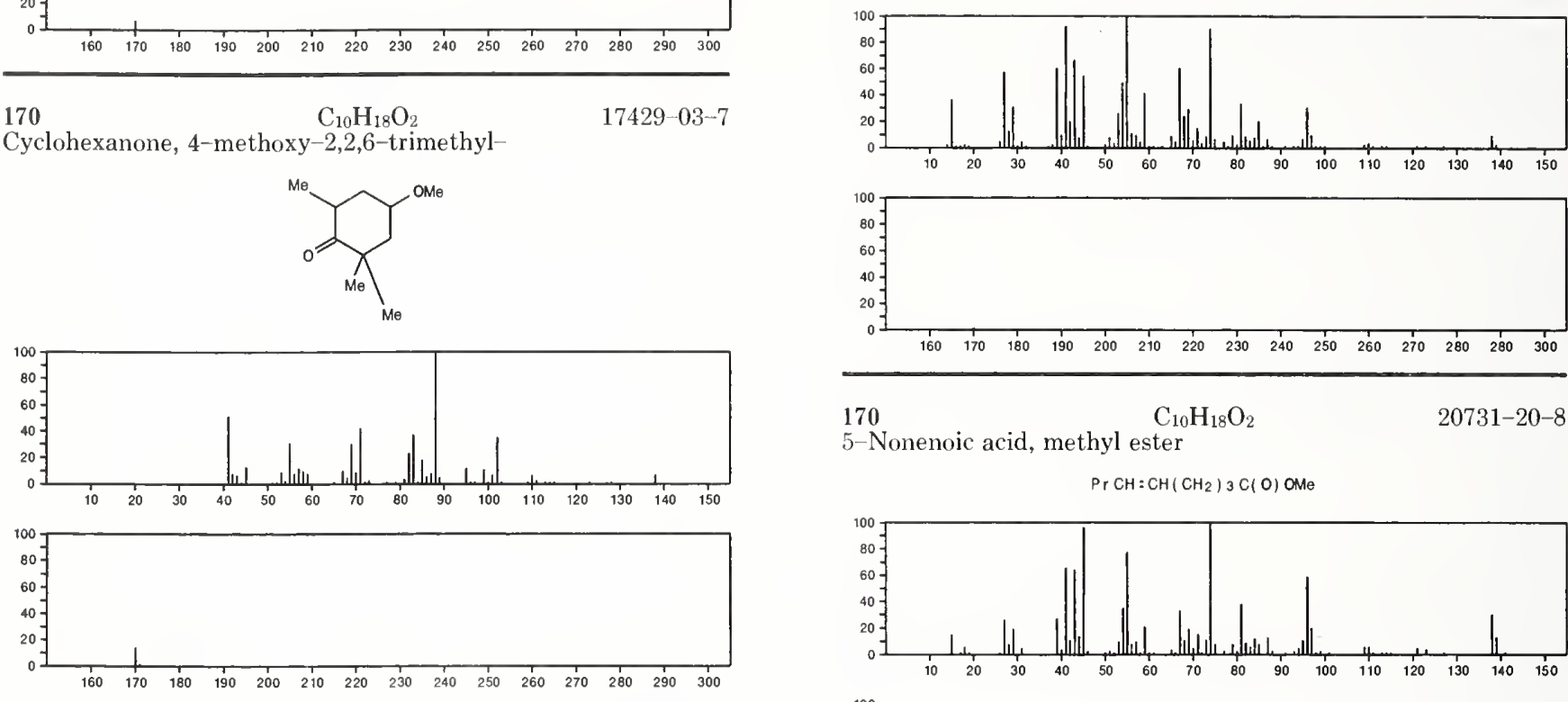

$170 \quad \mathrm{C}_{10} \mathrm{H}_{18} \mathrm{O}_{2} \quad 17429-06-0$ Cyclohexanone, 4-hydroxy-3,3,5,5-tetramethyl-
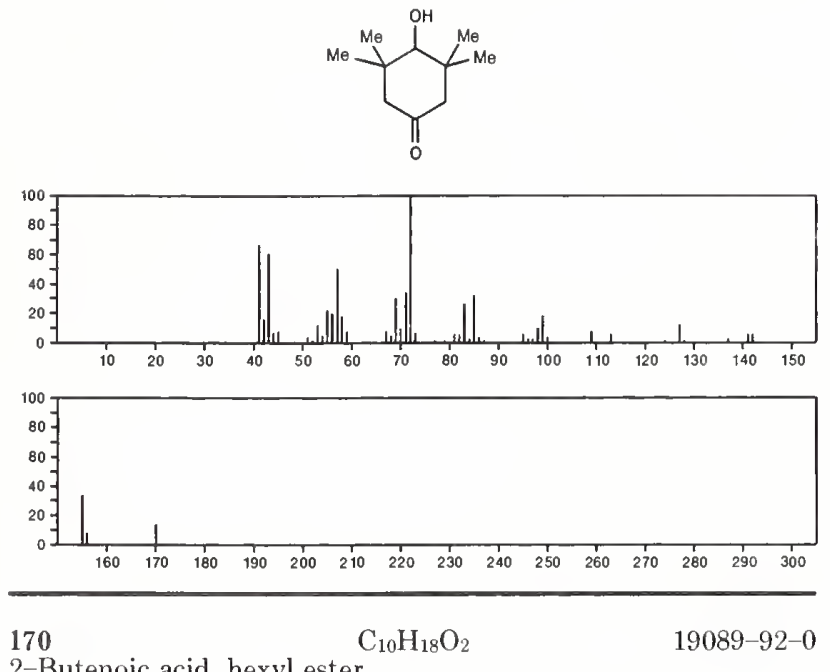

2-Butenoic acid, hexyl ester

$\mathrm{Me}\left(\mathrm{CH}_{2}\right) 5 \mathrm{OC}(\mathrm{O}) \mathrm{CH}=\mathrm{CHMe}$
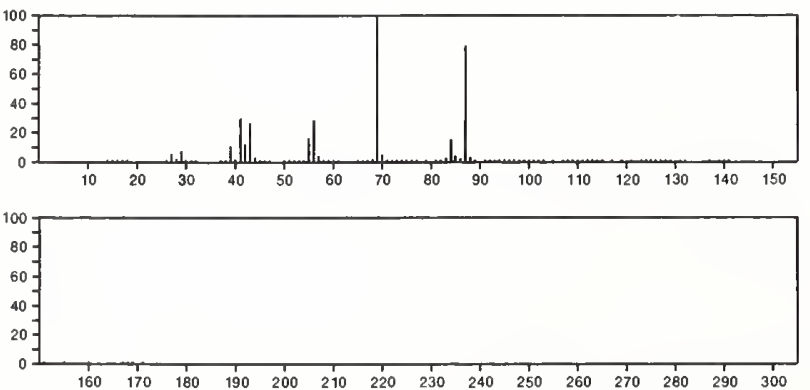

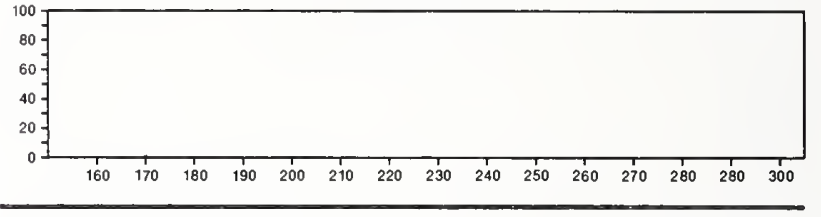

170

5-Nonenoic acid, methyl ester

$\mathrm{C}_{10} \mathrm{H}_{18} \mathrm{O}_{2}$

20731-20-8

$\mathrm{PrCH}=\mathrm{CH}\left(\mathrm{CH}_{2}\right) 3 \mathrm{C}(\mathrm{O}) \mathrm{OM}$
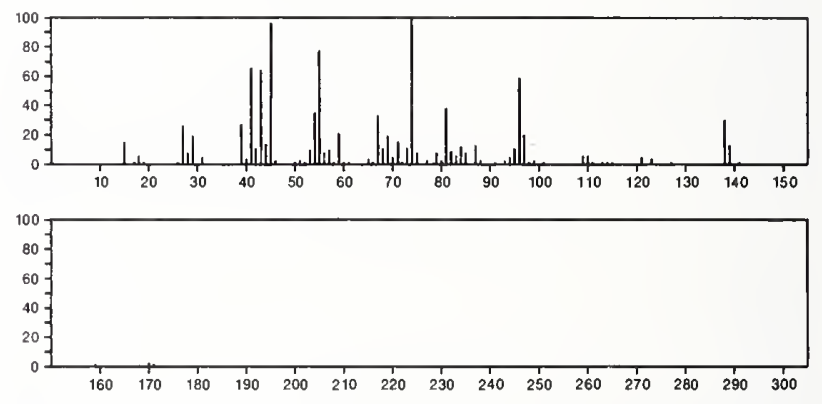

170

6-Nonenoic acid, methyl ester

$$
\mathrm{C}_{10} \mathrm{H}_{18} \mathrm{O}_{2}
$$

20731-21-9

$\mathrm{EtCH}=\mathrm{CH}\left(\mathrm{CH}_{2}\right\}_{4} \mathrm{C}(\mathrm{O}) \mathrm{OM}$
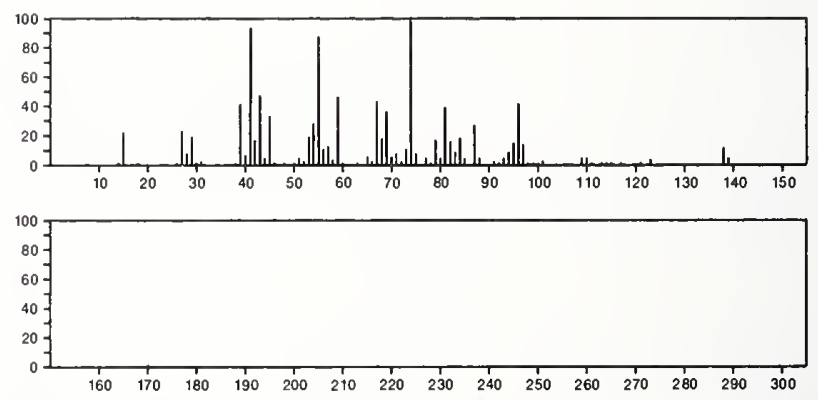

170

7-Nonenoic acid, methyl ester

$\mathrm{C}_{10} \mathrm{H}_{18} \mathrm{O}_{2}$

20731-22-0

$\mathrm{MeOC}(\mathrm{O})\left(\mathrm{CH}_{2}\right) 5 \mathrm{CH}=\mathrm{CHMe}$
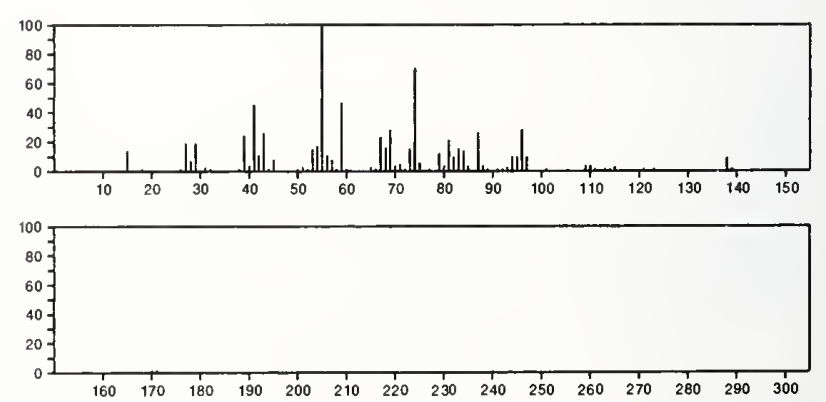
$170 \quad \mathrm{C}_{10} \mathrm{H}_{18} \mathrm{O}_{2}$

8-Nonenoic acid, methyl ester

$\mathrm{H}_{2} \mathrm{C}=\mathrm{CH}\left(\mathrm{CH}_{2}\right) 6 \mathrm{C}(\mathrm{O}) \mathrm{OMe}$
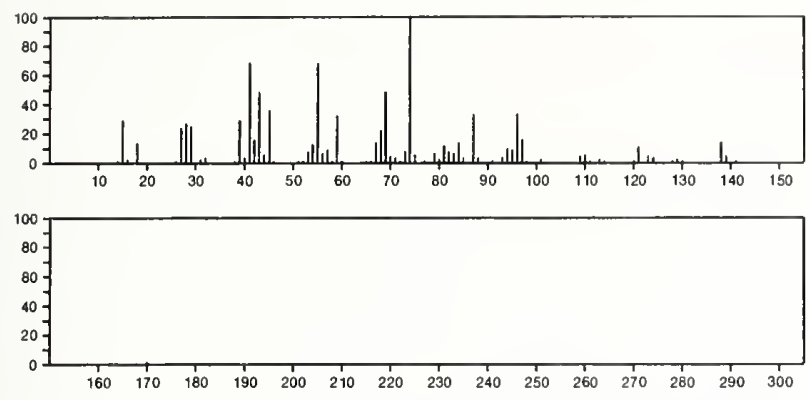

170

$\mathrm{C}_{10} \mathrm{H}_{18} \mathrm{O}_{2}$

2,3-Naphthalenediol, decahydro-, $(2 \alpha, 3 \beta, 4 \mathbf{a} \alpha, 8 \mathbf{a} \beta)-$
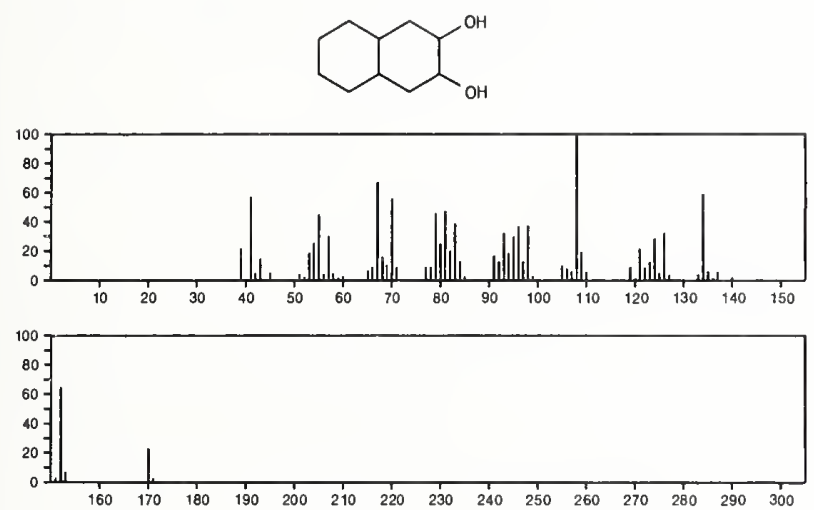

170

2-Octen-2-ol, acetate

$\mathrm{C}_{10} \mathrm{H}_{18} \mathrm{O}_{2}$

26735-85-3

$A C O C M_{\theta}=\mathrm{CH}\left(\mathrm{CH}_{2}\right) 4 \mathrm{Me}$
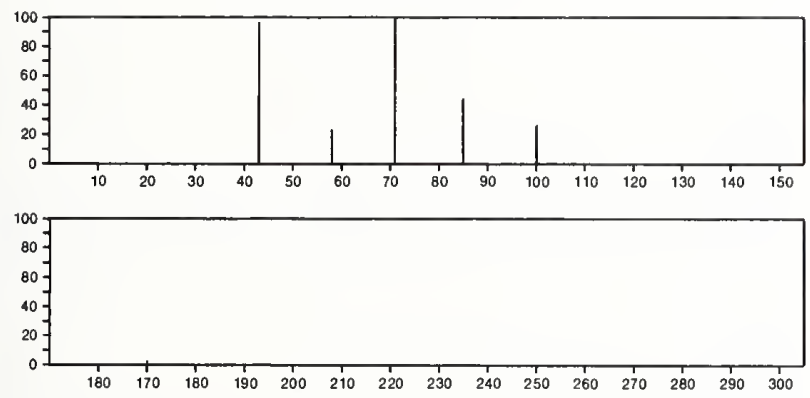

170

4a,8a-Naphthalenediol, octahydro-, cis- $^{-}$<smiles>OC12CCCCC1(O)CCCC2</smiles>
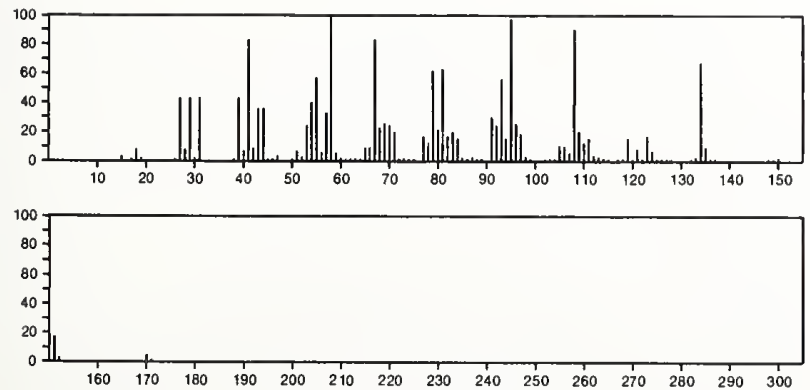

$170 \quad \mathrm{C}_{10} \mathrm{H}_{18} \mathrm{O}_{2}$

35194-38-8
$\mathrm{H}=\mathrm{CH}\left(\mathrm{CH}_{2}\right)=\mathrm{C}(\mathrm{O}) \mathrm{OE}$
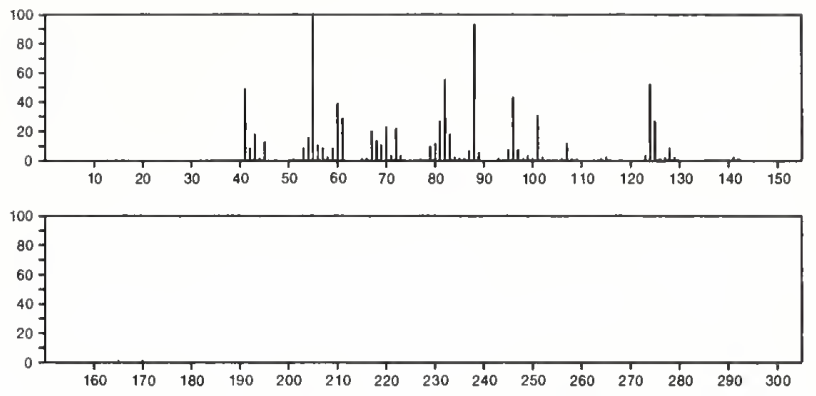

170

$\mathrm{C}_{10} \mathrm{H}_{18} \mathrm{O}_{2}$

Pentanoic acid, 4,4-dimethyl-3-methylene-, ethyl ester

Etoc(0) $\mathrm{CH}_{2} \stackrel{\mathrm{CH}}{\mathrm{CH}} \mathrm{CM}_{3}$
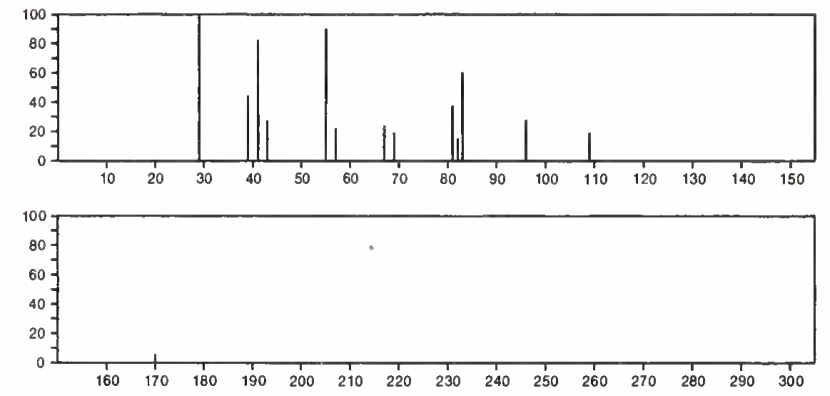

170

$\mathrm{C}_{10} \mathrm{H}_{18} \mathrm{O}_{2}$

$38226-15-2$

Bicyclo[2.2.1]heptane-2,3-diol, 1,7,7-trimethyl-, (endo,endo)-
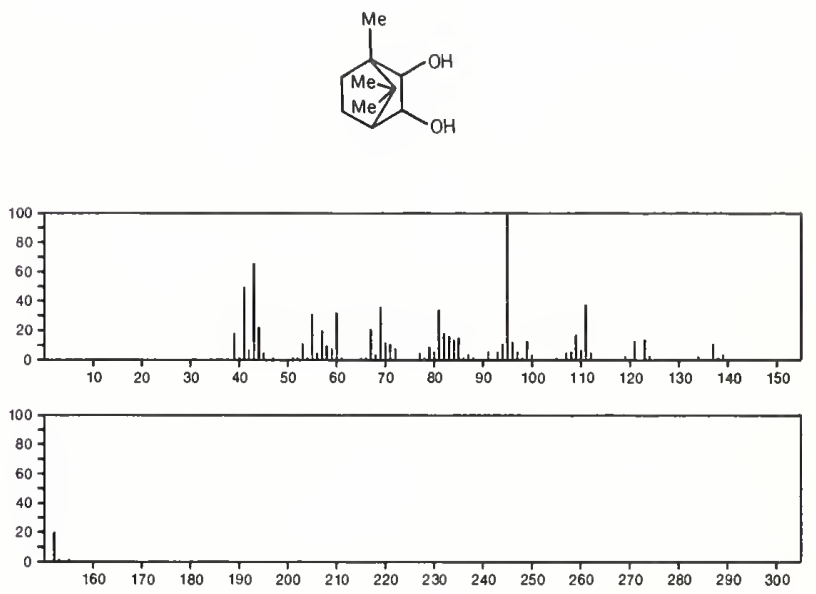

$170 \quad \mathrm{C}_{10} \mathrm{H}_{18} \mathrm{O}_{2} \quad 40730-61-8$ 1,6-Dioxaspiro[4.5]decane, 9,9-dimethyl-
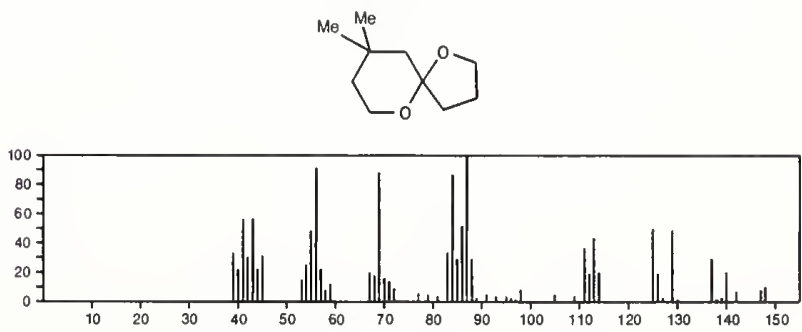


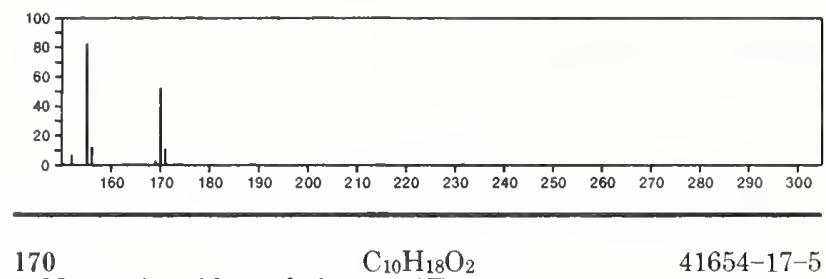

6-Nonenoic acid, methyl ester, $(Z)$ -

$\mathrm{E}+\mathrm{CH}=\mathrm{CH}\left(\mathrm{CH}_{2}\right)+\mathrm{C}(\mathrm{O}) \mathrm{OM}$
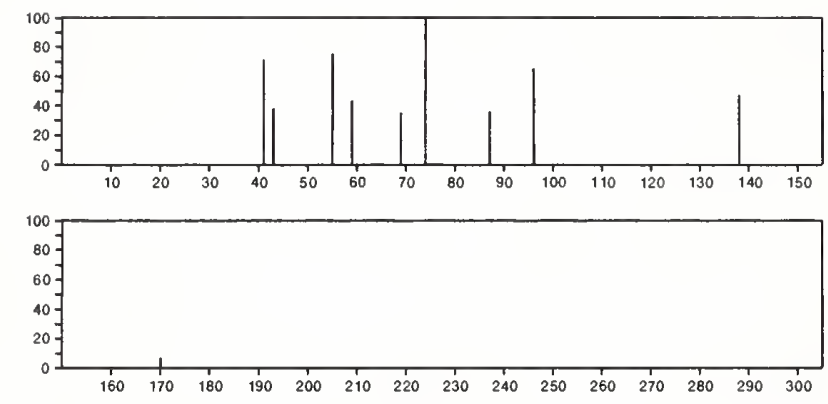

$170 \quad \mathrm{C}_{10} \mathrm{H}_{18} \mathrm{O}_{2}$

2,3-Naphthalenediol, decahydro-', $(2 \alpha, 3 \beta, 4 \mathrm{a} \alpha, 8 \mathrm{a} \alpha)$
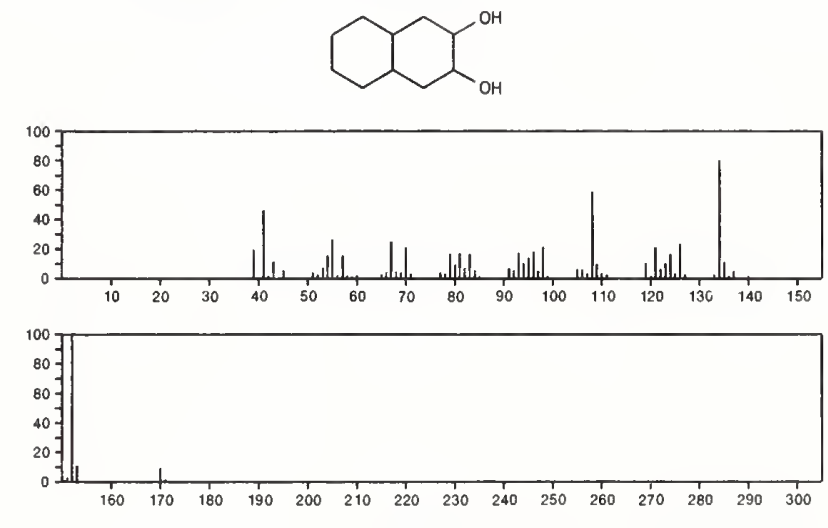

170

$\mathrm{C}_{10} \mathrm{H}_{18} \mathrm{O}_{2}$

2-Propanone, 1-cyclopentyl-3-ethoxy-

$51149-71-4$
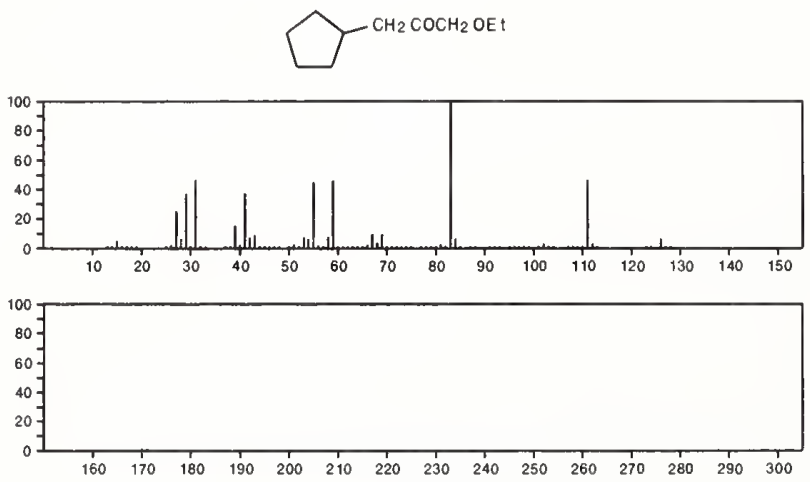

170

$\mathrm{C}_{10} \mathrm{H}_{18} \mathrm{O}_{2}$

$54382-58-0$ 4-Isobenzofuranol, octahydro-3a,7a-dimethyl-, $(3 \mathrm{a} \alpha, 4 \beta, 7 \mathrm{a} \alpha)-( \pm)-$
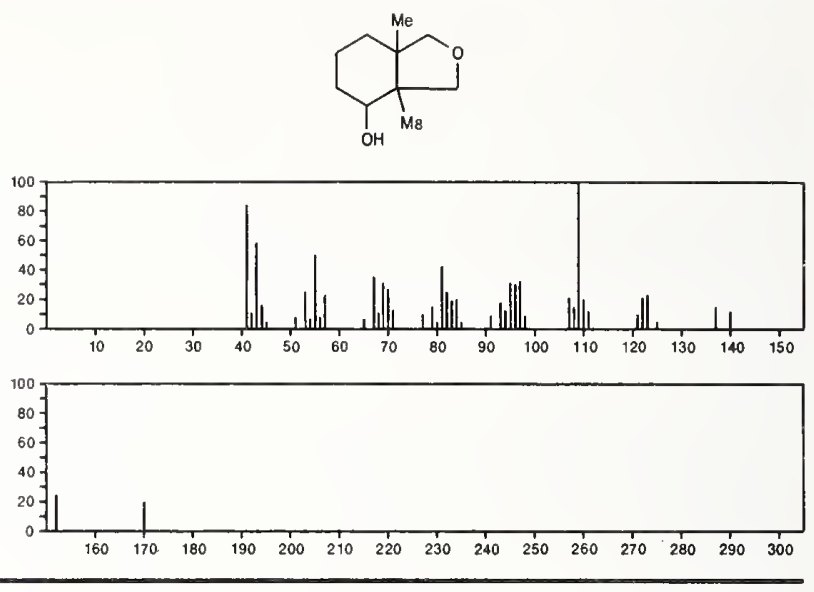

170

$\mathrm{C}_{10} \mathrm{H}_{18} \mathrm{O}_{2}$

$54410-94-5$

Butanoic acid, 3-methyl-, 3-methyl-3-butenyl ester

$\mathrm{H}_{2} \mathrm{C}=\mathrm{CMeCH}_{2} \mathrm{CH}_{2} \mathrm{OC}(\mathrm{O}) \mathrm{CH}_{2} \mathrm{CHMB}_{2}$

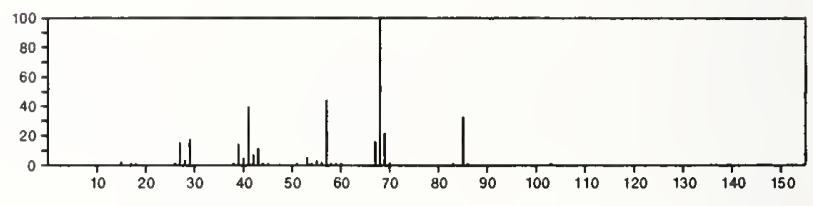

170

$\mathrm{C}_{10} \mathrm{H}_{18} \mathrm{O}_{2}$

$56614-57-4$

Bicyclo[2.2.1] heptane-2,3-diol, 1,7,7-trimethyl-, (exo,exo)-
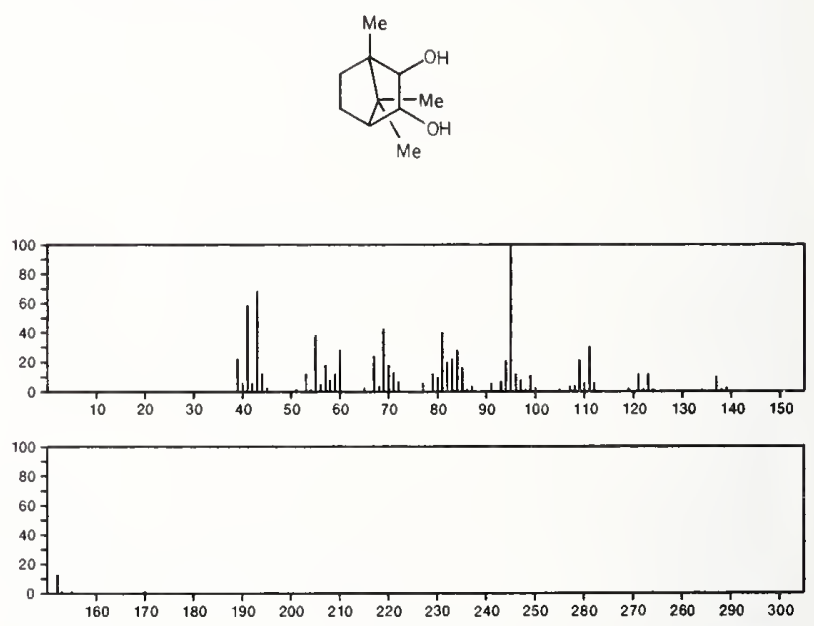

170

$\mathrm{C}_{10} \mathrm{H}_{18} \mathrm{O}_{2}$

$56614-58-5$

Bicyclo[2.2.1]heptane-2,3-diol, 1,7,7-trimethyl-, (2-exo,3-endo)-
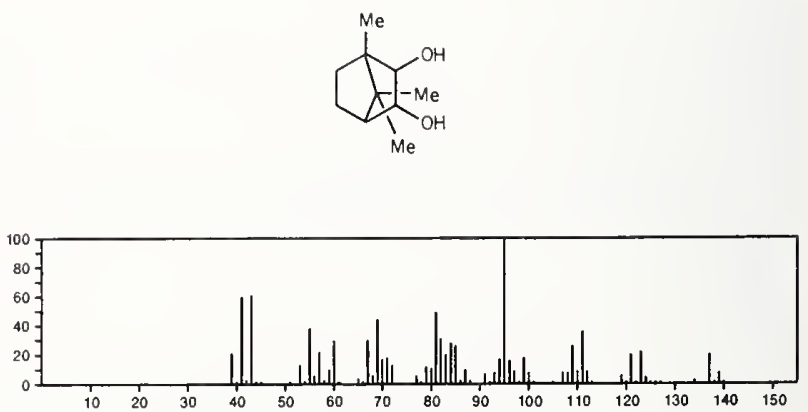


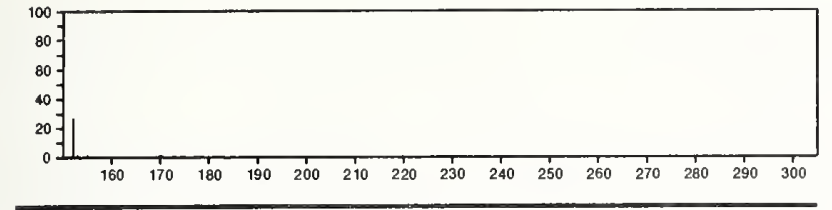

$170 \quad \mathrm{C}_{10} \mathrm{H}_{18} \mathrm{O}_{2}$

57289-63-1 4a,8a-Naphthalenediol, octahydro-, trans-
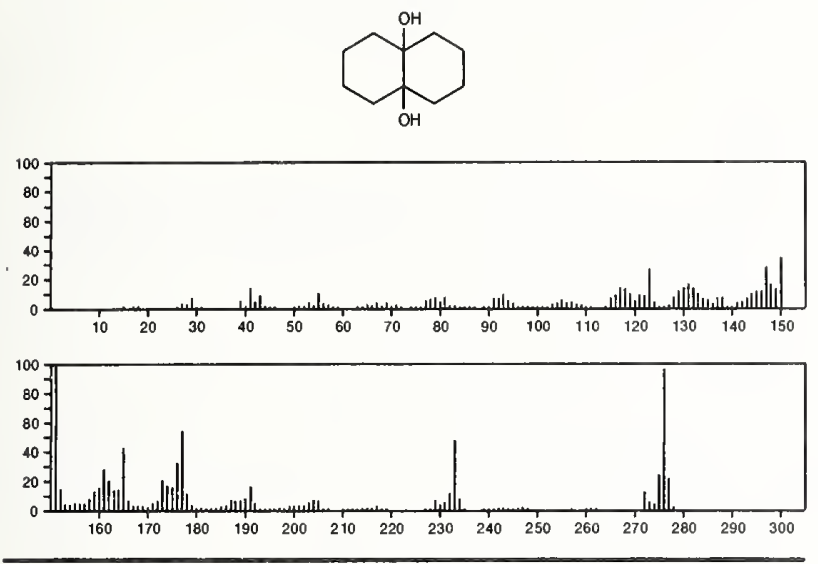

$170 \quad \mathrm{C}_{10} \mathrm{H}_{18} \mathrm{O}_{2}$

2,3-Naphthalenediol, decahydro-
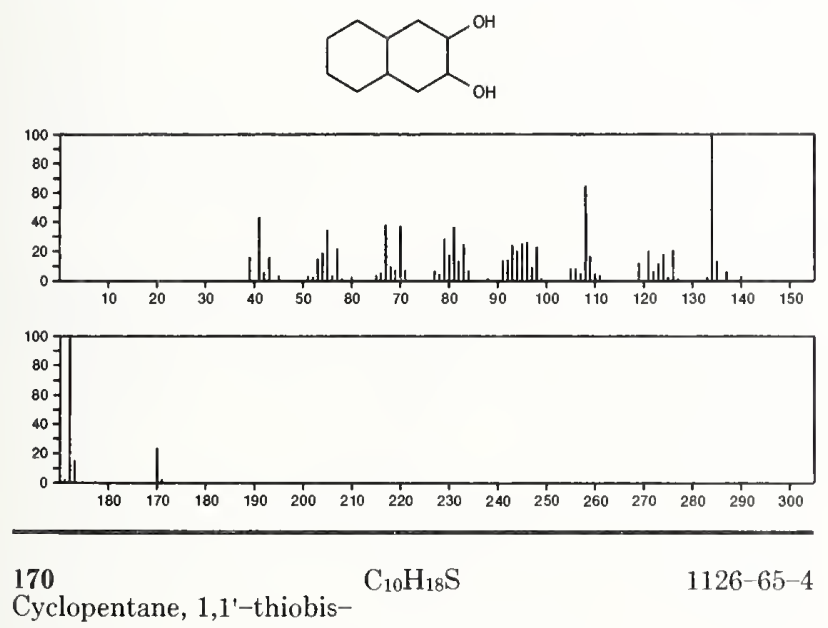

Cyclopentane, 1,1'-thiobis-
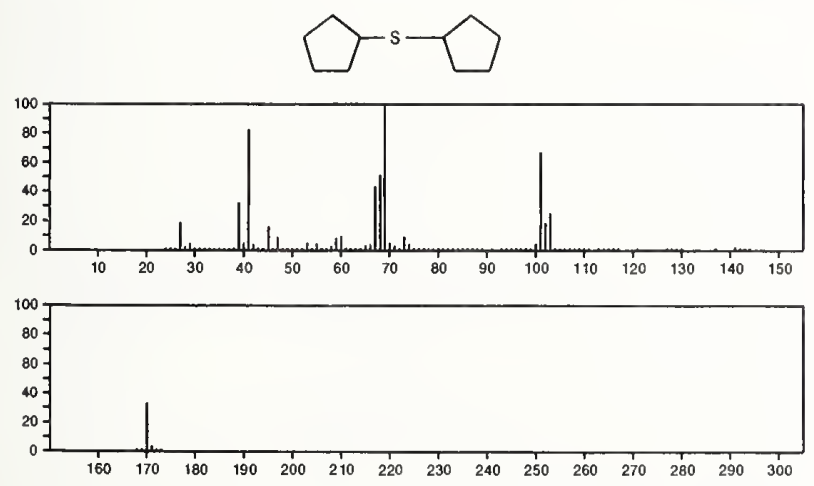

170

$\mathrm{C}_{10} \mathrm{H}_{18} \mathrm{~S}$

$54461-02-8$

Bicyclo[2.2.2]octane, 1-methyl-4-(methylthio)
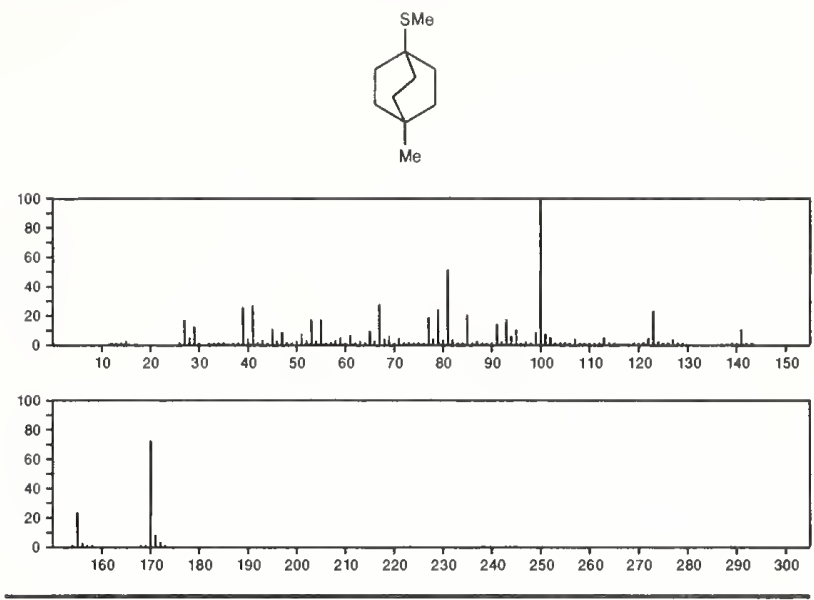

170

$\mathrm{C}_{10} \mathrm{H}_{22} \mathrm{~N}_{2}$

$54410-91-2$

Piperazine, 2,3-dimethyl-5-(2-methylpropyl)-
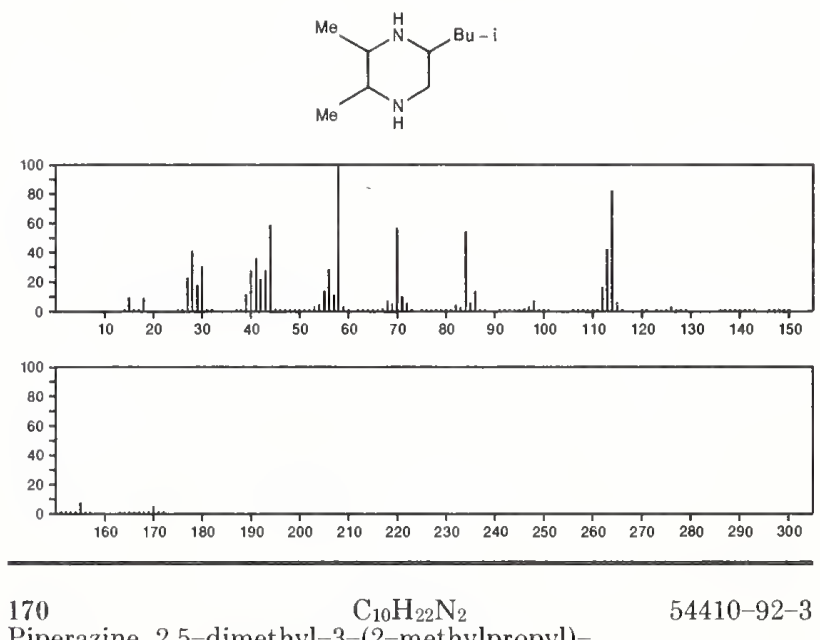

Piperazine, 2,5-dimethyl-3-(2-methylpropyl)-
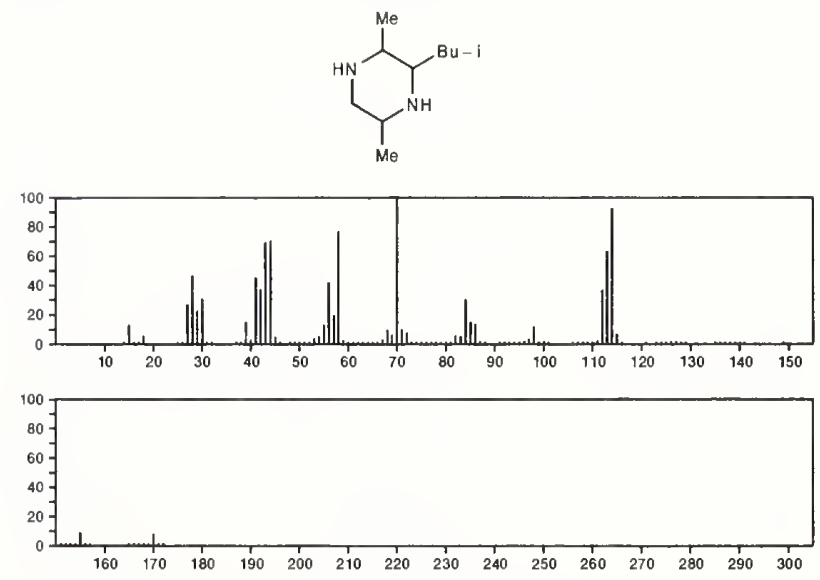
170 Piperazine, 3-butyl-2,5-dimethyl-

$\mathrm{C}_{10} \mathrm{H}_{22} \mathrm{~N}_{2}$<smiles>CCCC1NC(C)CNC1C</smiles>
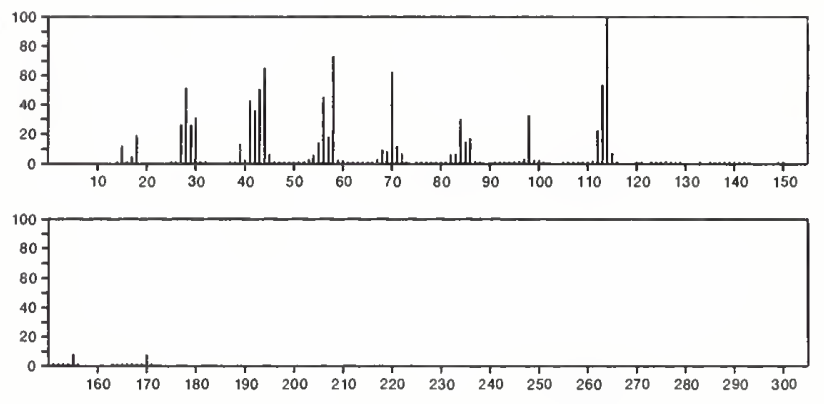

$170 \quad \mathrm{C}_{11} \mathrm{H}_{10} \mathrm{~N}_{2} \quad 24046-22-8$

Pyrrole, 1-(benzylideneamino)-

$$
\underbrace{-N=C H P h}
$$
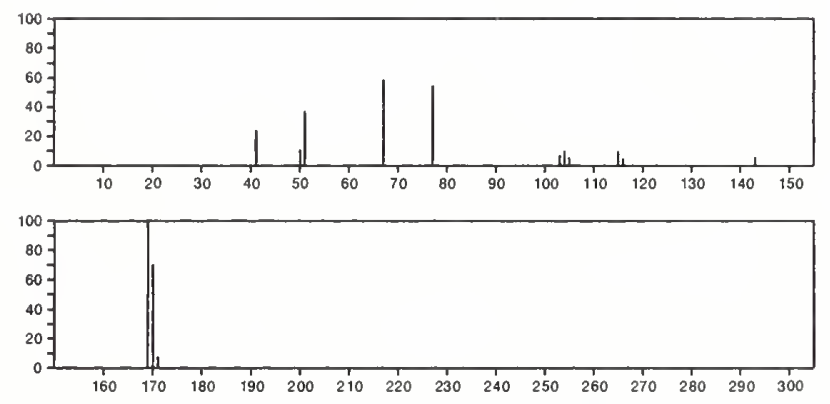

$170 \quad \mathrm{C}_{11} \mathrm{H}_{10} \mathrm{~N}_{2}$

Pyridinium, 1-anilino-, hydroxide, inner salt
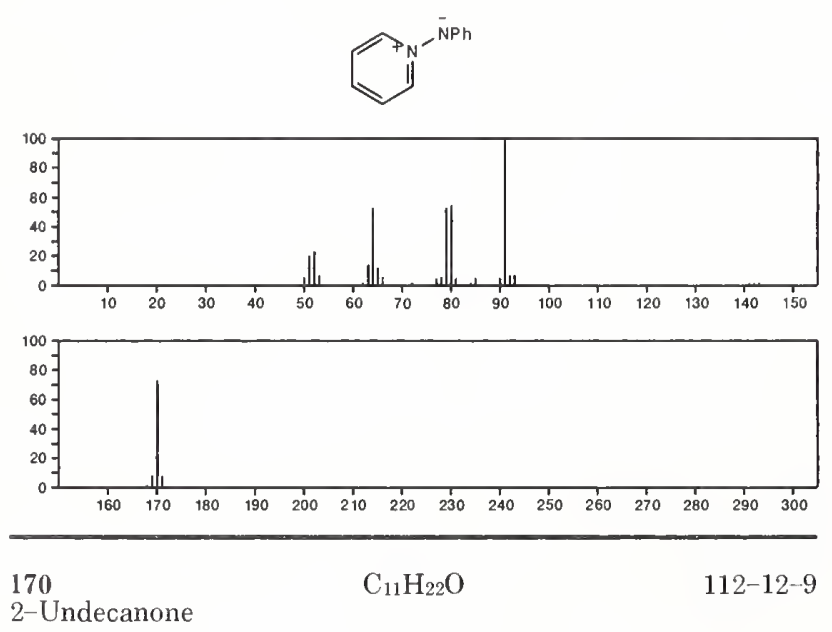

$\mathrm{Me}\left(\mathrm{CH}_{2}\right)_{8} \mathrm{COMe}$

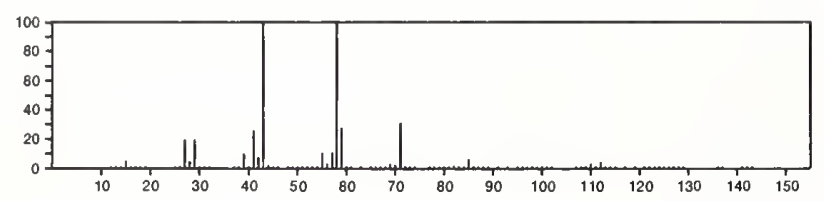

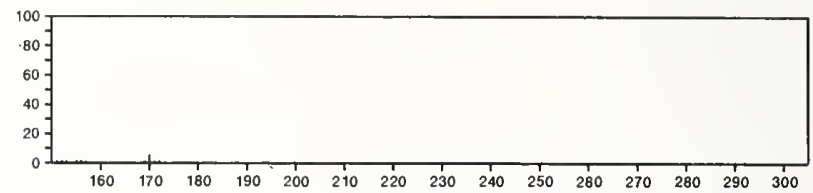

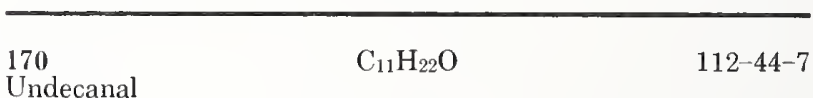

Undecanal

$\mathrm{OCH}\left(\mathrm{CH}_{2}\right) 9 \mathrm{Me}$
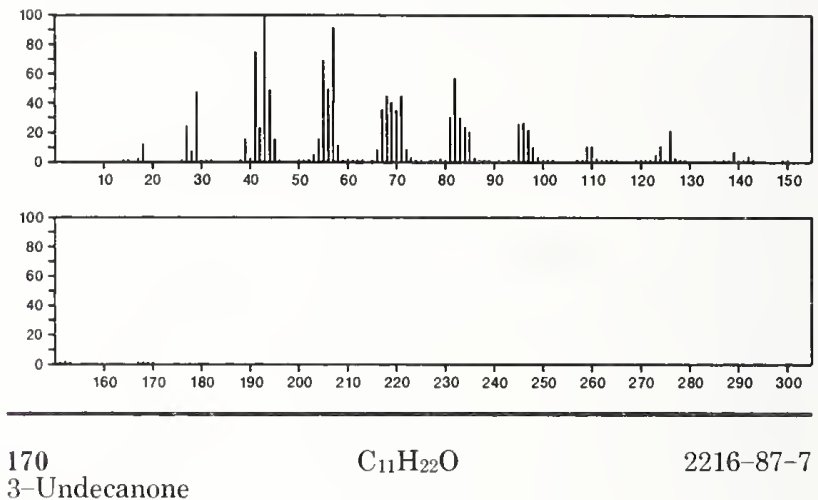

$\mathrm{Me}\left(\mathrm{CH}_{2}\right)>\mathrm{COE} \mathrm{t}$
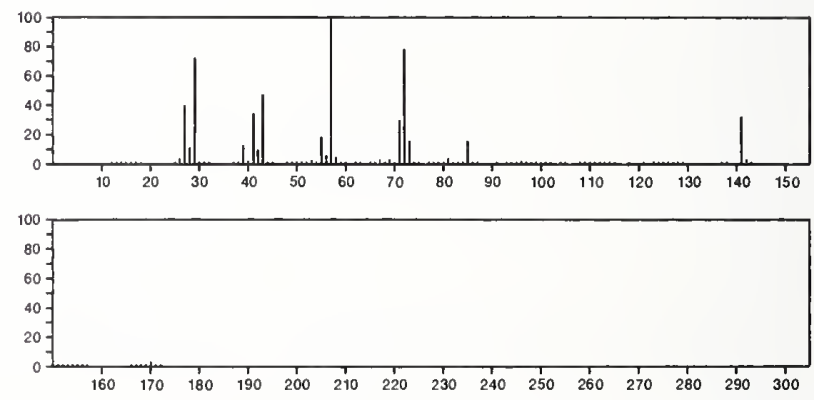

170

$\mathrm{Me}_{2} \mathrm{CH}\left(\mathrm{CH}_{2}\right)_{4} \mathrm{COPr}$
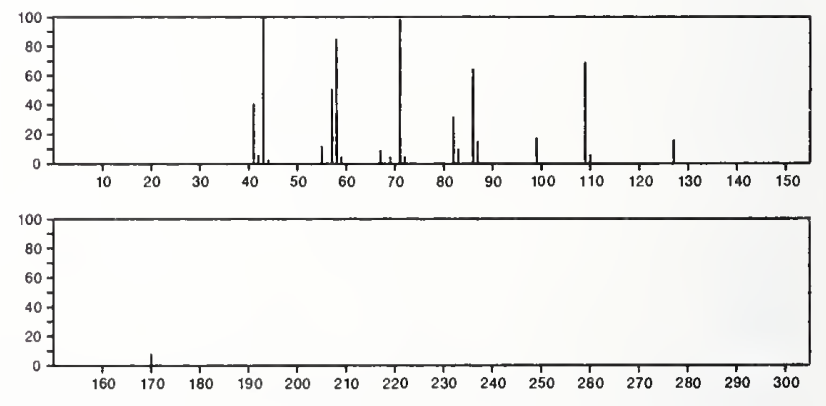

170

5-Undecanone

$\mathrm{C}_{11} \mathrm{H}_{22} \mathrm{O}$

33083-83-9

$\mathrm{Me}\left(\mathrm{CH}_{2}\right){ }_{5} \mathrm{CO}\left(\mathrm{CH}_{2}\right){ }_{3} \mathrm{Me}$
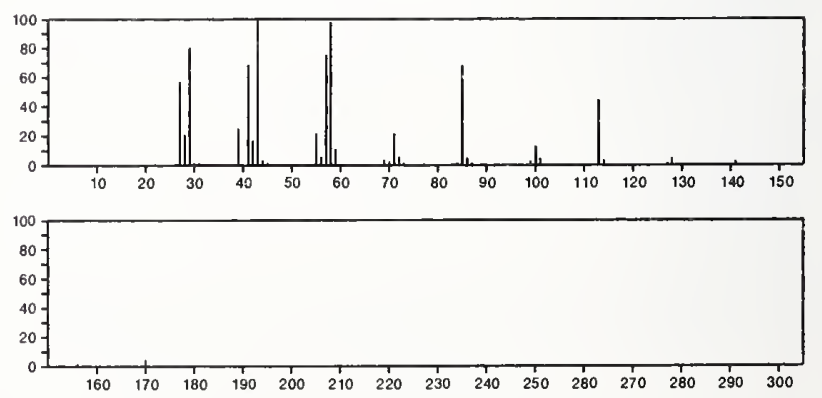

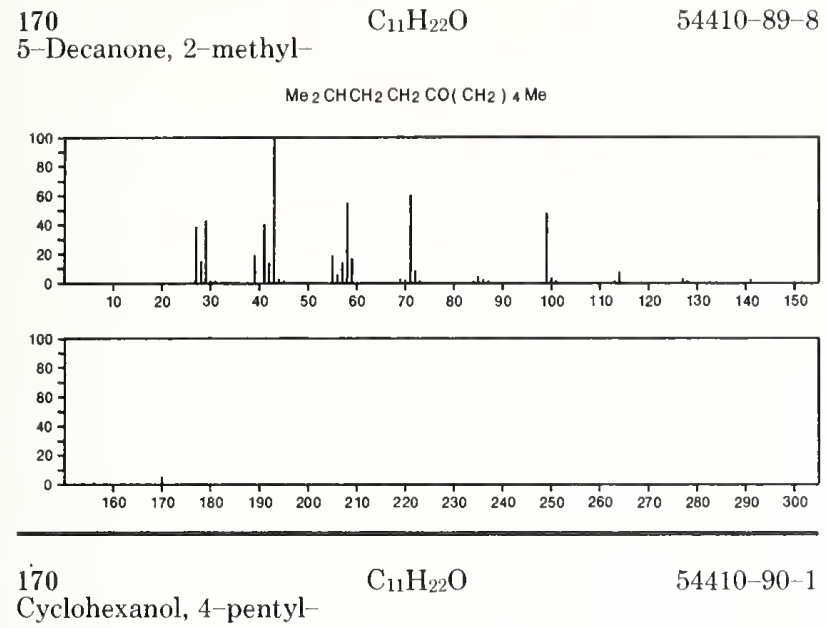

Cyclohexanol, 4-pentyl-
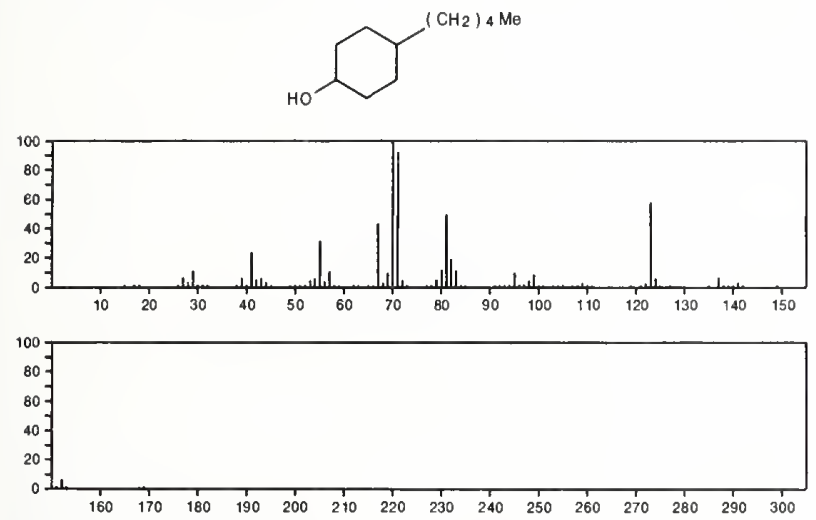

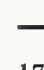

170

Heptane, 1-(2-butenyloxy)- ${ }^{\mathrm{C}_{11} \mathrm{H}_{22} \mathrm{O}}$

$56052-77-8$

$\mathrm{Me}\left(\mathrm{CH}_{2}\right){ }_{6} \mathrm{OCH}_{2} \mathrm{CH}=\mathrm{CHM}$

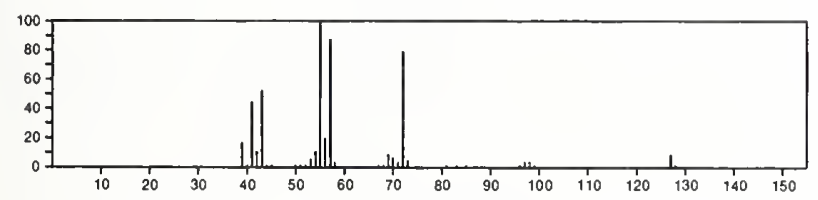

$$
20
$$

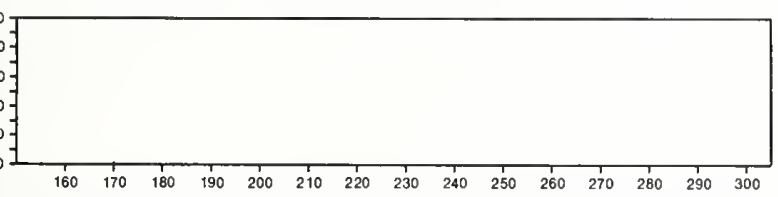

170

Heptane, 1-(1-butenyloxy)-, $(Z)^{-}$

$56052-79-0$

$\mathrm{Et} \mathrm{CH}=\mathrm{CHO}\left(\mathrm{CH}_{2}\right) 6 \mathrm{Me}$
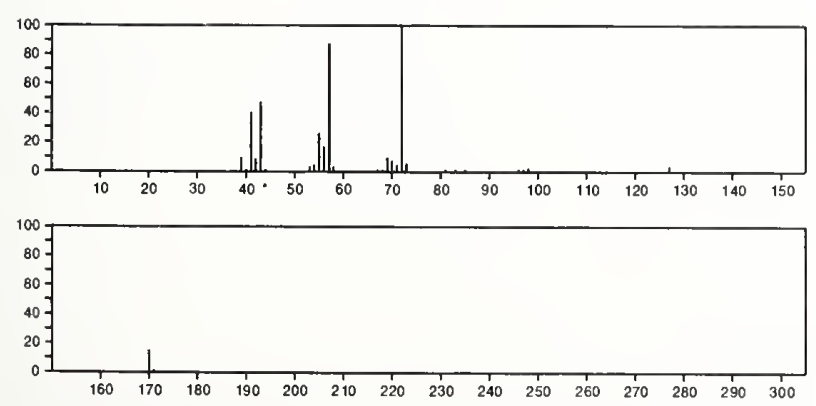

$170 \quad \mathrm{C}_{11} \mathrm{H}_{22} \mathrm{O}$

Heptane, 1-(1-butenyloxy)-, $(E)-$

$56052-80-3$

$\mathrm{Et} \mathrm{CH}_{\mathrm{t}}=\mathrm{CHO}\left(\mathrm{CH}_{2}\right){ }_{8} \mathrm{Me}$
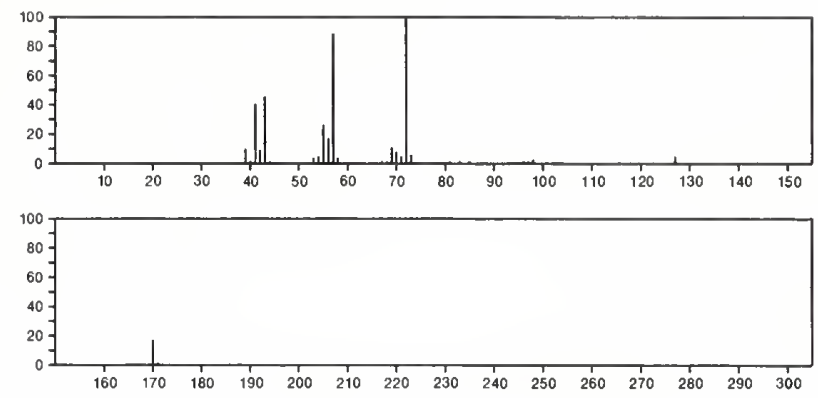

$170 \quad \mathrm{C}_{11} \mathrm{H}_{22} \mathrm{O}$

$56052-82-5$

2-Hexene, 1-(pentyloxy)-, (E)

$\mathrm{Me}\left(\mathrm{CH}_{2}\right)_{4} \mathrm{OCH}_{2} \mathrm{CH}=\mathrm{CHP}$ ?
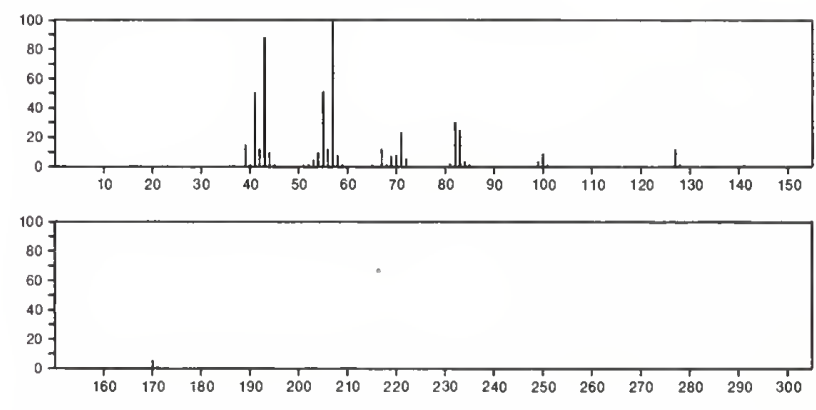

170

$\mathrm{C}_{12} \mathrm{H}_{10} \mathrm{O}$

90-43-7

[1,1'-Biphenyl]-2-ol
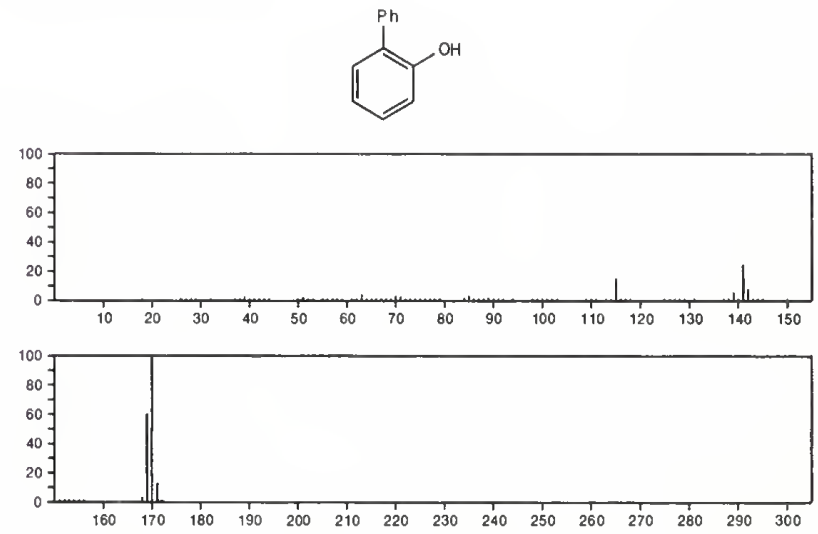

170

[1,1'-Biphenyl $]-4-o l$

$\mathrm{C}_{12} \mathrm{H}_{10} \mathrm{O}$

$92-69-3$
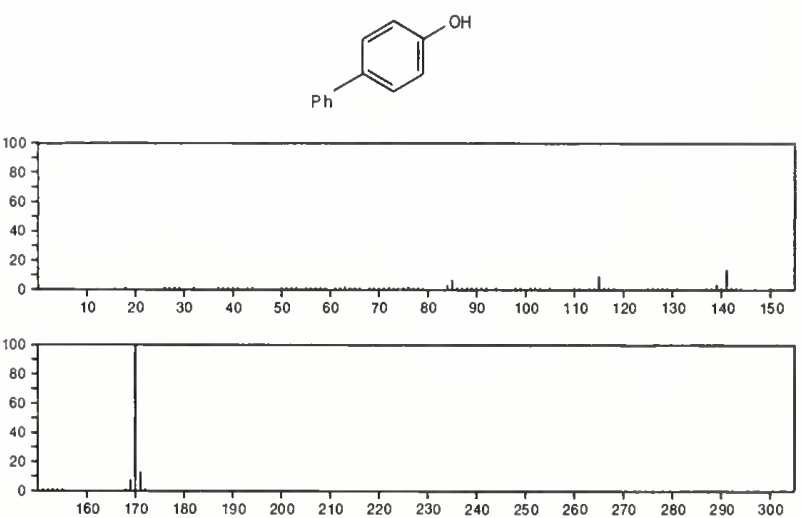
170

Ethanone, 1-(2-naphthalenyl)-

93-08-3
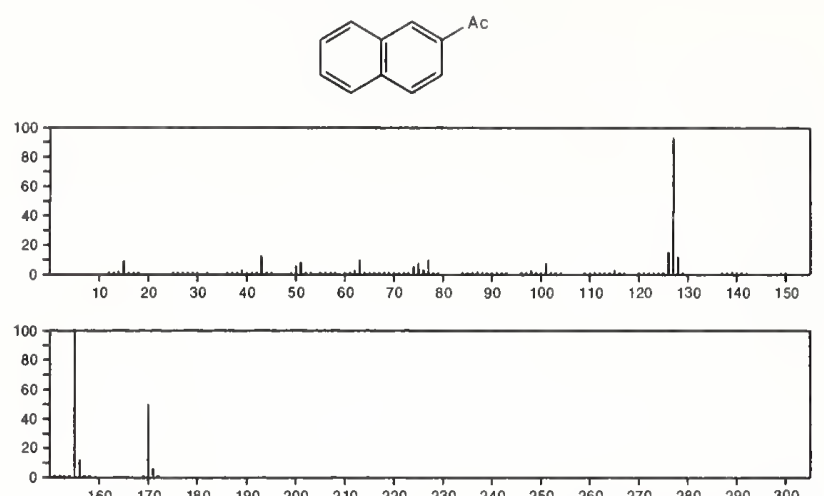

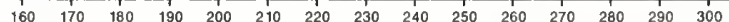

170

$\mathrm{C}_{12} \mathrm{H}_{10} \mathrm{O}$

$101-84-8$

Benzene, 1,1'-oxybis-

$\mathrm{OPh}_{2}$
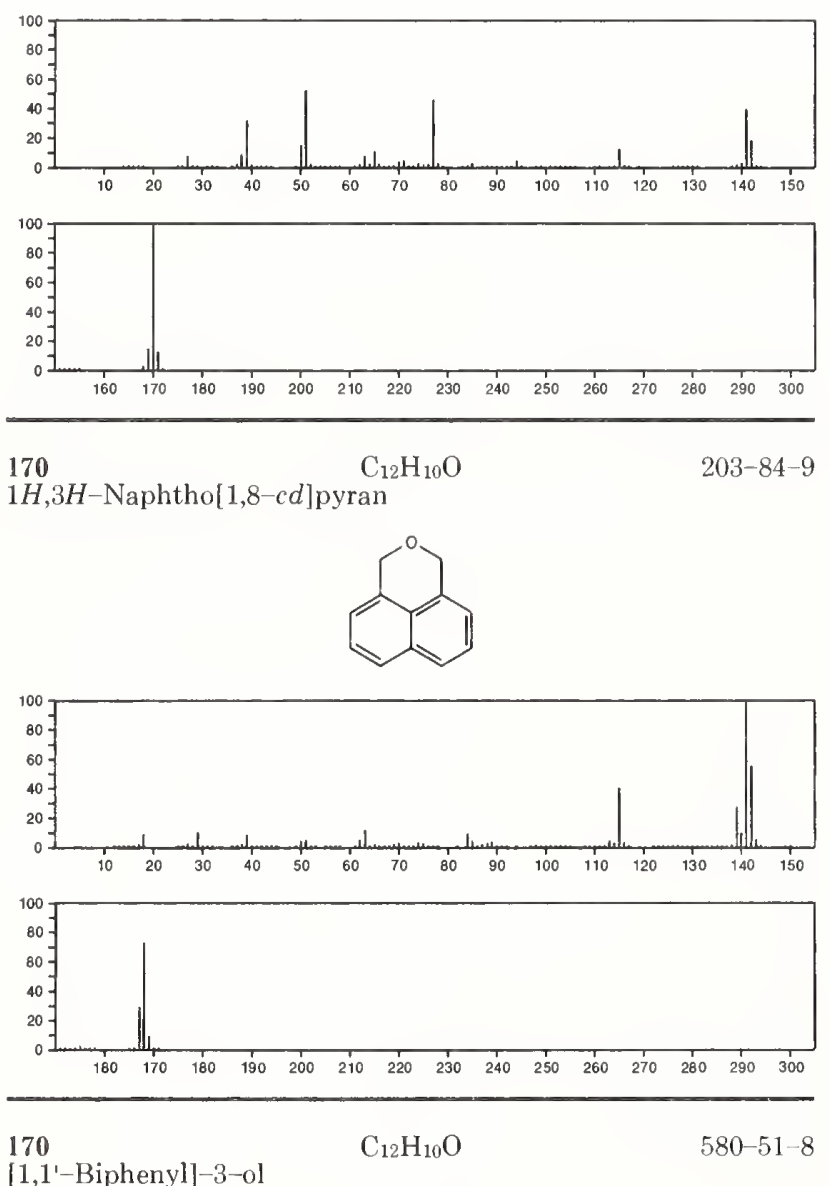

[1,1'-Biphenyl]-3-ol
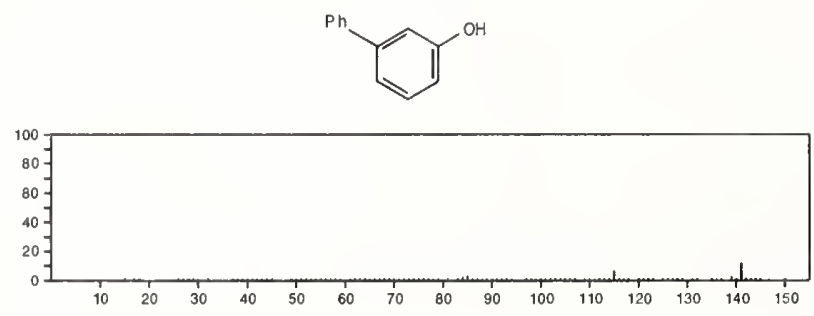

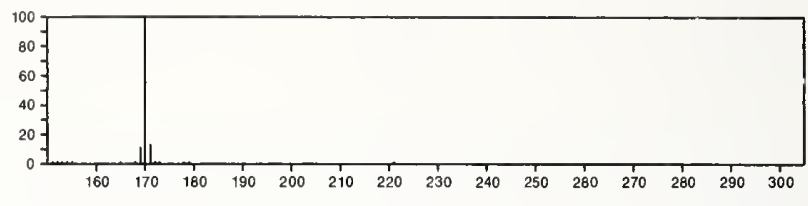

170

Ethanone, 1-(1-naphthalenyl)-

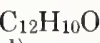

941-98-0
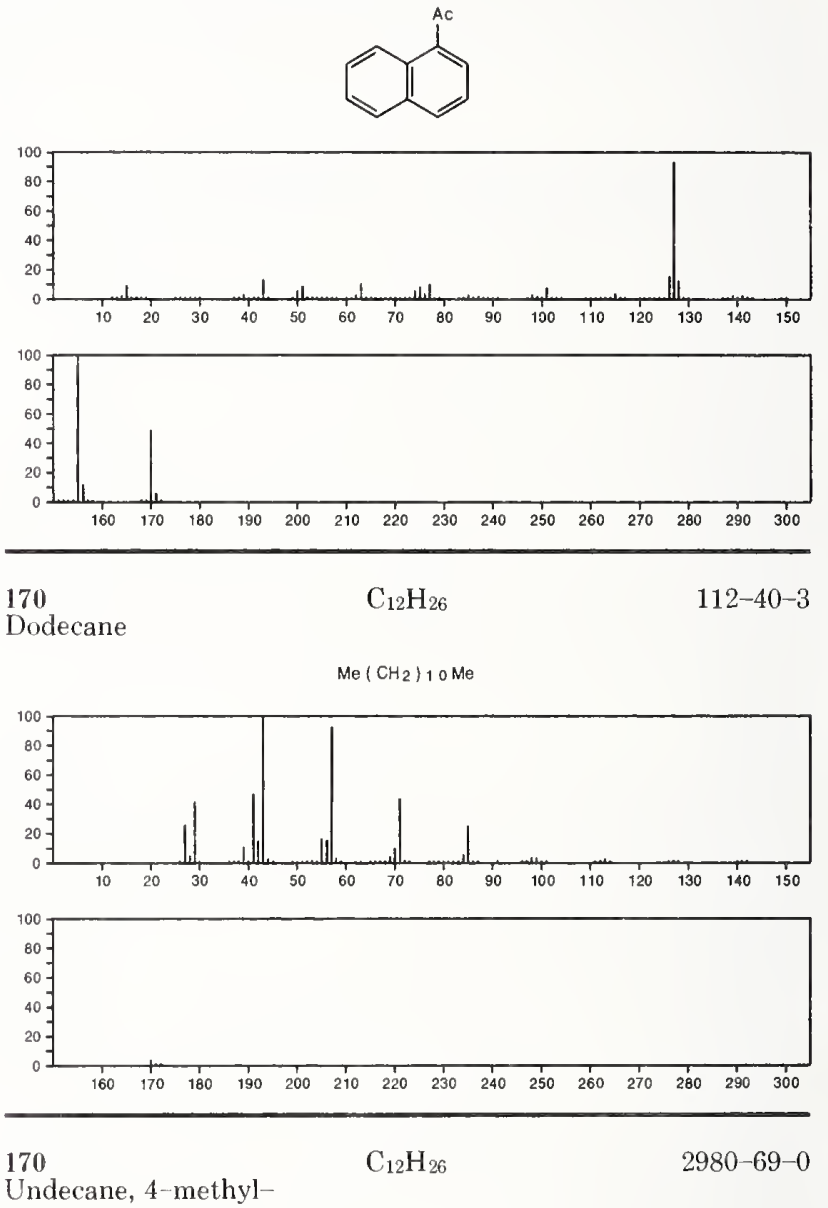

Undecane, 4-methyl

$\operatorname{PrCHMe}\left(\mathrm{CH}_{2}\right)_{6 \mathrm{Me}}$
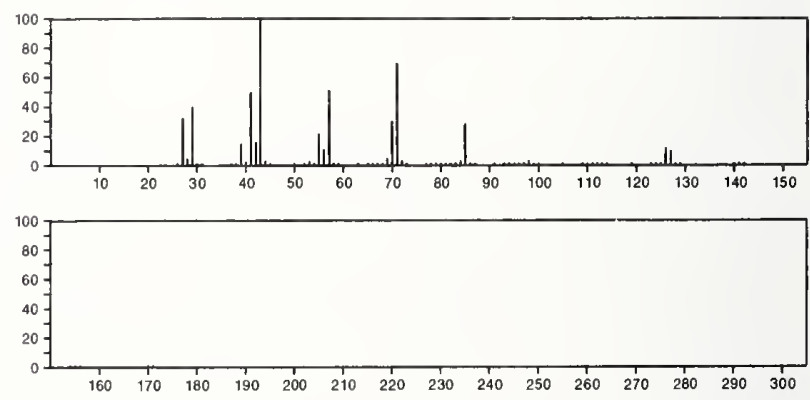

170

Undecane, 2-methyl-

$\mathrm{C}_{12} \mathrm{H}_{26}$

7045-71-8

$\mathrm{Me}_{2} \mathrm{CH}\left(\mathrm{CH}_{2}\right)_{8} \mathrm{Me}$

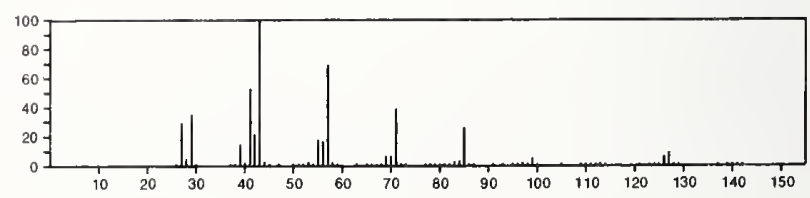




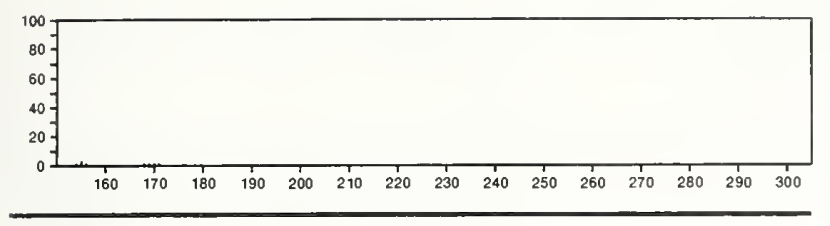

170 $\mathrm{C}_{12} \mathrm{H}_{26}$

13475-82-6

Heptane, 2,2,4,6,6-pentamethyl-

$\mathrm{Me}_{3} \mathrm{CCH}_{2} \mathrm{CHMe} \mathrm{CH}_{2} \mathrm{CMle}_{3}$
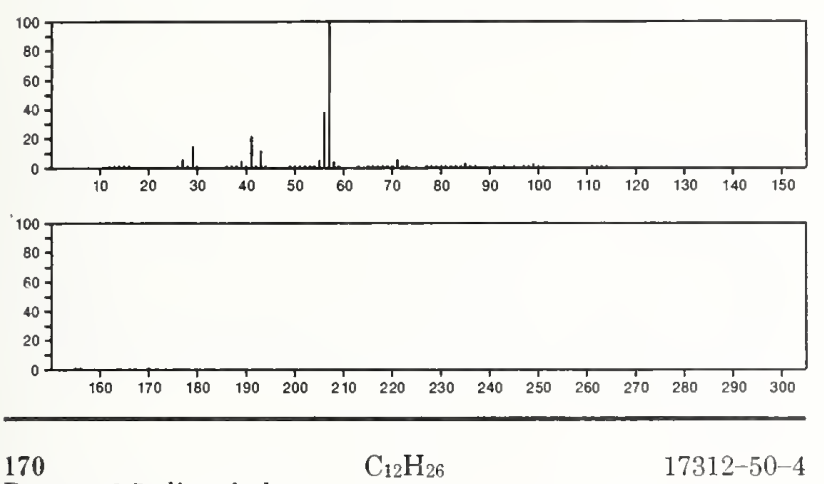

Decane, 2,5-dimethyl-

$\mathrm{Me}_{2} \mathrm{CHCH}_{2} \mathrm{CH}_{2} \mathrm{CHMe}\left(\mathrm{CH}_{2}\right)_{4} \mathrm{Me}$
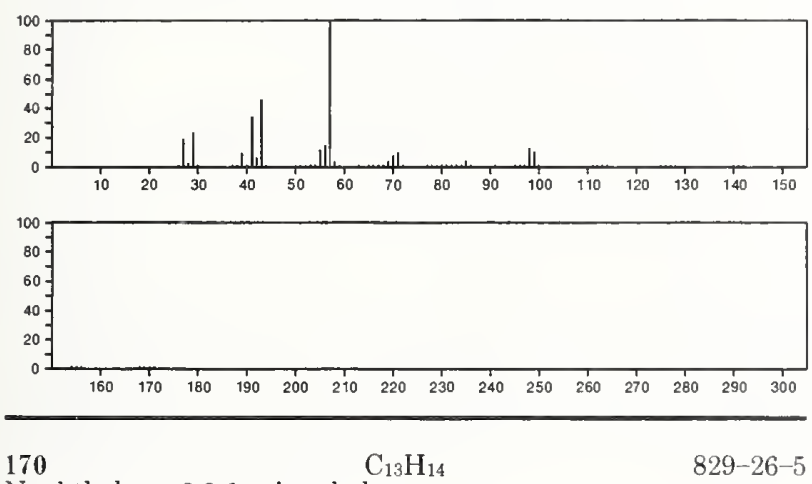

Naphthalene, 2,3,6-trimethyl-
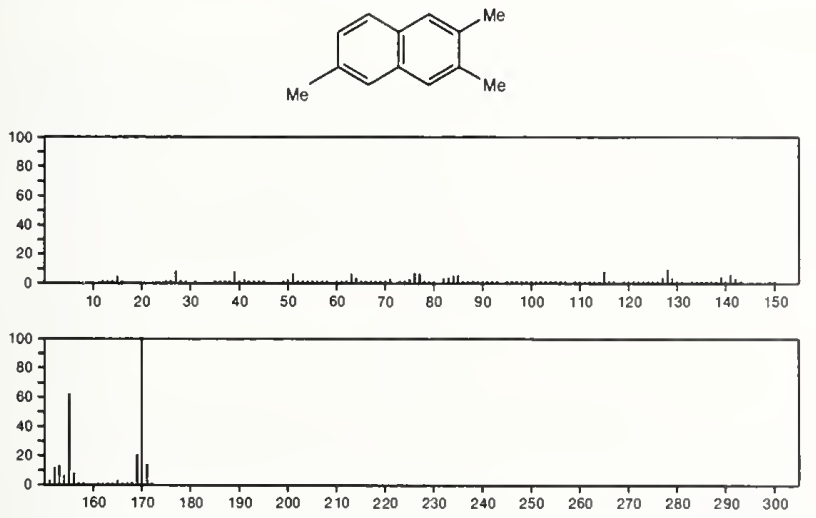

170

$2027-17-0$

Naphthalene, 2-(1-methylethyl)-
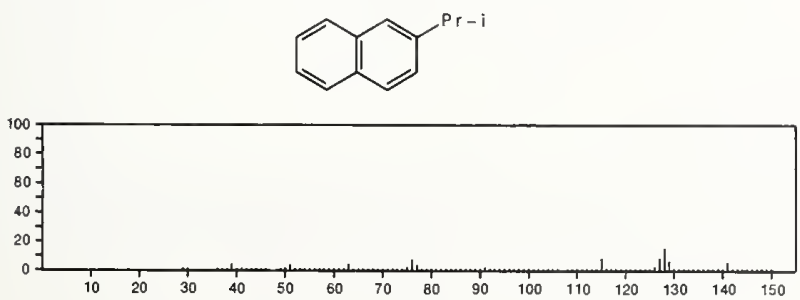

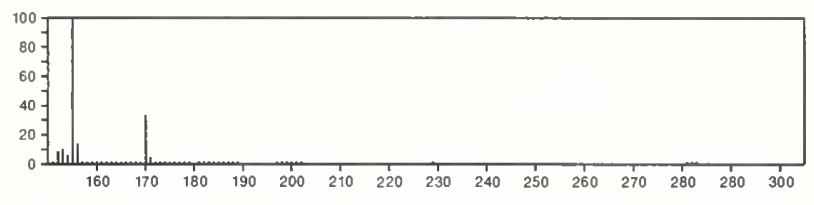

170 $\mathrm{C}_{13} \mathrm{H}_{14}$

2245-38-7

Naphthalene, 1,6,7-trimethyl
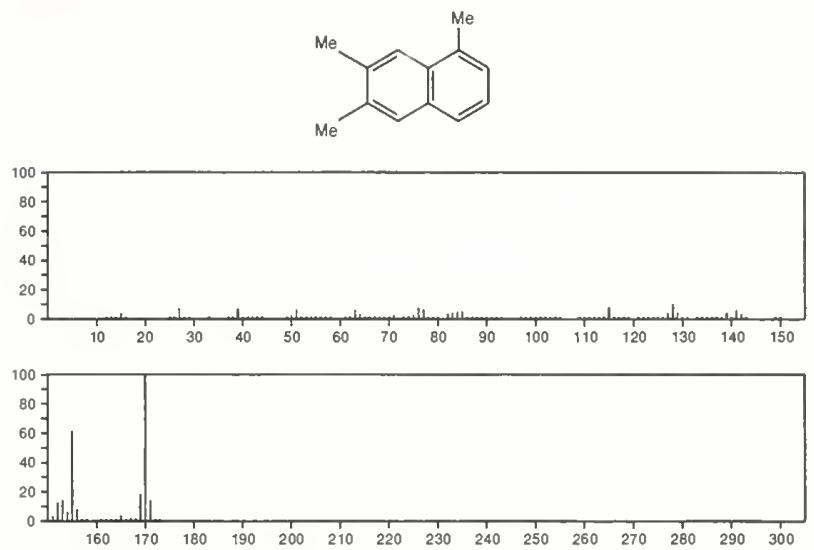

170

Naphthalene, 1,3,6-trimethyl-

$\mathrm{C}_{13} \mathrm{H}_{14}$

3031-08-1
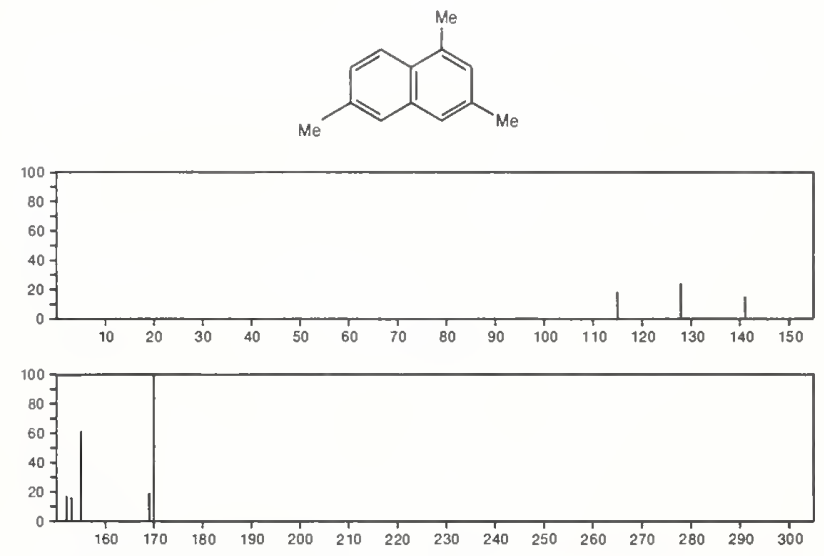

170
Naphthalene, (1-methylethyl)- $\mathrm{C}_{13} \mathrm{H}_{14}$

29253-36-9

$\mathrm{C}_{13} \mathrm{H}_{1}$
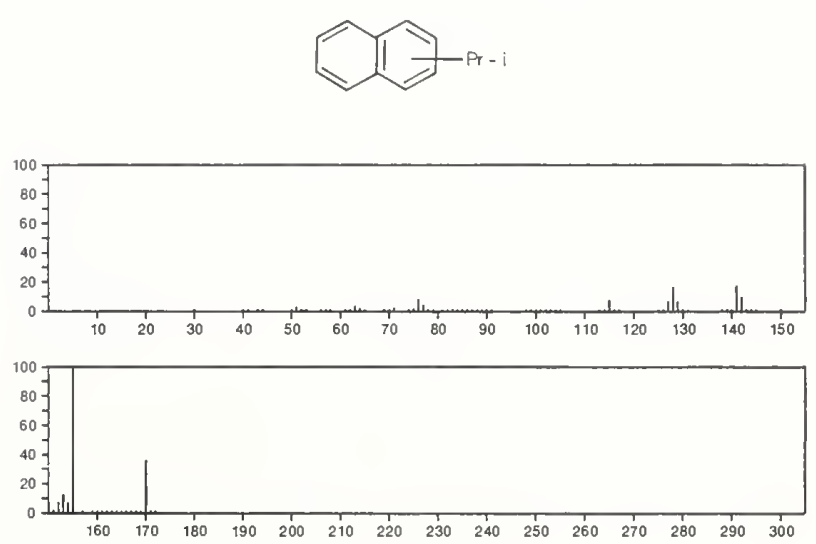
171

$\mathrm{C}_{5} \mathrm{H}_{2} \mathrm{ClN}_{3} \mathrm{~S}$

Thiazolo[5,4-d]pyrimidine, 5-chloro-
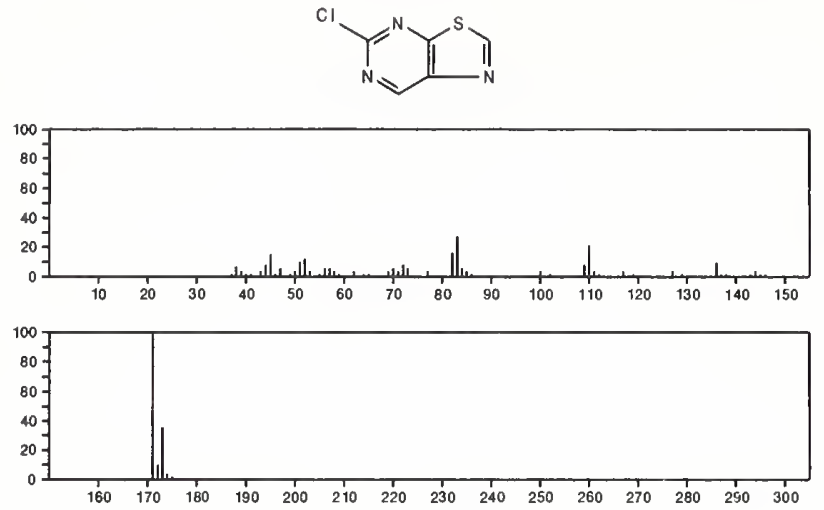

$171 \quad \mathrm{C}_{5} \mathrm{H}_{2} \mathrm{ClN}_{3} \mathrm{~S}$

Thiazolo[5,4-d]pyrimidine, 7-chloro-
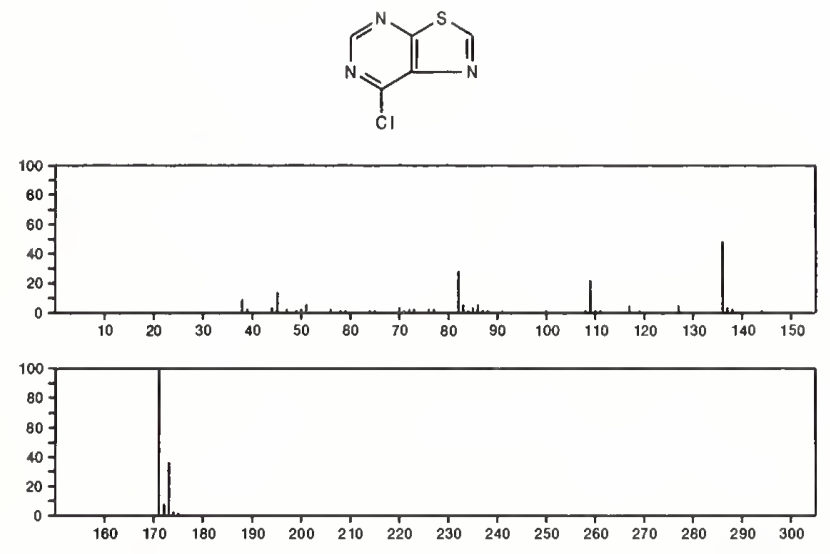

171

$\mathrm{C}_{6} \mathrm{H}_{5} \mathrm{NO}_{5}$

668-43-9

Sorbic acid, 3,5-dihydroxy-2-nitro-, $\delta$-lactone
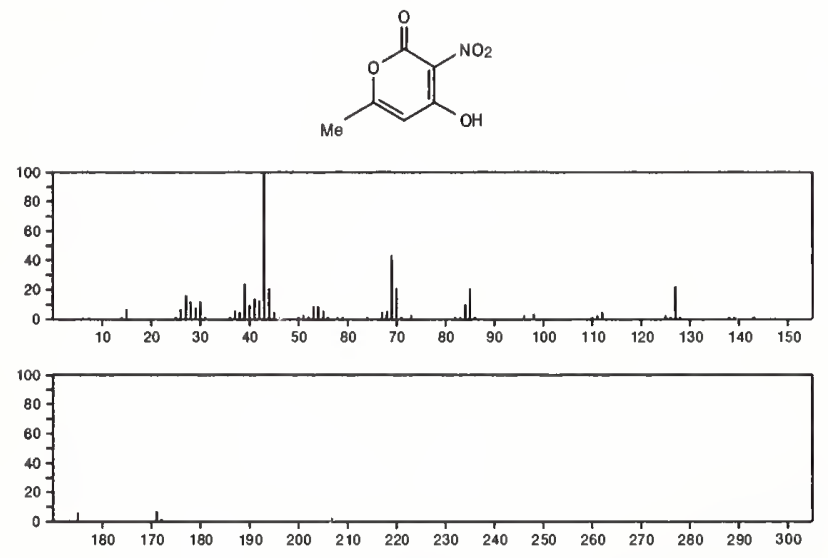

171

Pyridine, 2-(bromomethyl)-

$\mathrm{C}_{6} \mathrm{H}_{6} \mathrm{BrN}$

$55401-97-3$
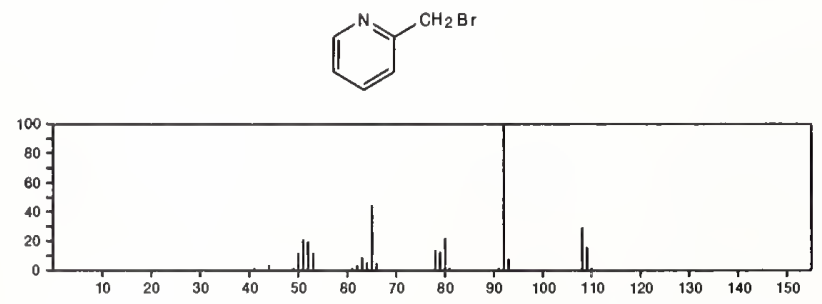

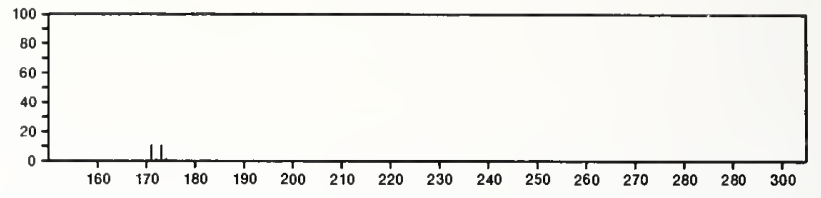

171

$\mathrm{C}_{6} \mathrm{H}_{9} \mathrm{~N}_{3} \mathrm{O}_{3}$

$827-16-7$

1,3,5-Triazine-2,4,6(1H,3H,5H)-trione, 1,3,5-trimethyl-
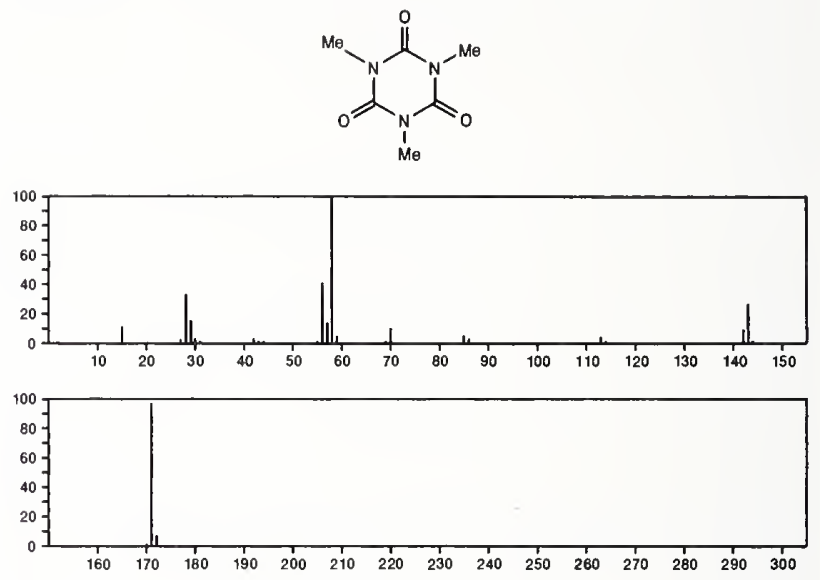

171

1,3,5-Triazine, 2,4,6-trimethoxy-

$\mathrm{C}_{6} \mathrm{H}_{9} \mathrm{~N}_{3} \mathrm{O}_{3}$

877-89-4
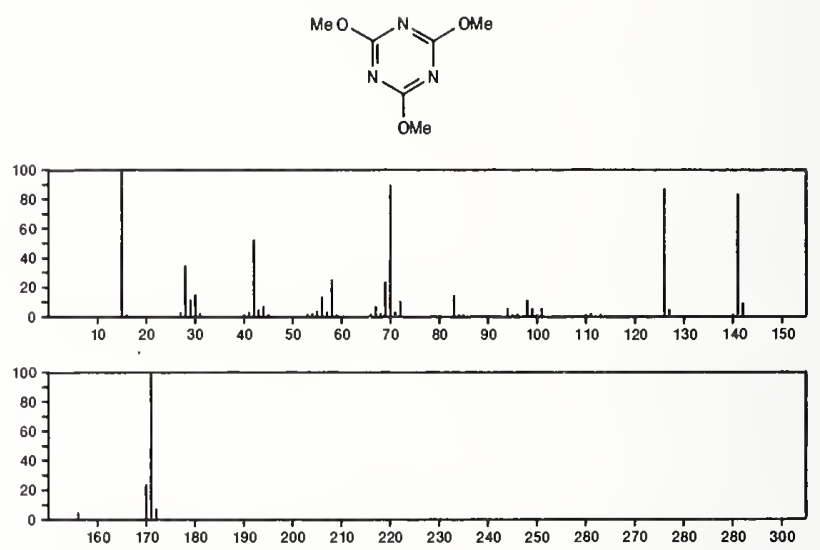

171

$\mathrm{C}_{6} \mathrm{H}_{9} \mathrm{~N}_{3} \mathrm{O}_{3}$

$20379-33-3$

Ribopyranoside, methyl 2,3-anhydro-4-azid $0^{-4-\operatorname{deoxy}}-\boldsymbol{}^{-},{ }^{-} \mathrm{L}^{-}$
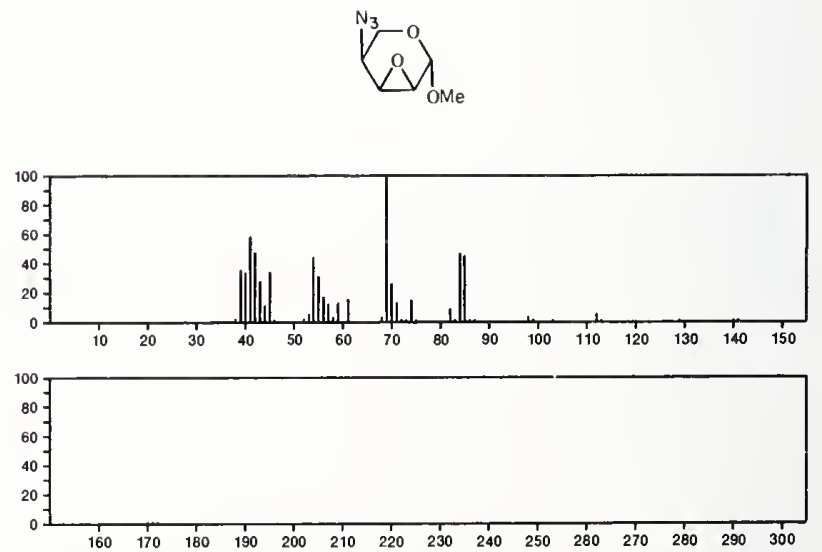
171

Benzonitrile, 2,6-dichloro-

$\mathrm{C}_{7} \mathrm{H}_{3} \mathrm{Cl}_{2} \mathrm{~N}$
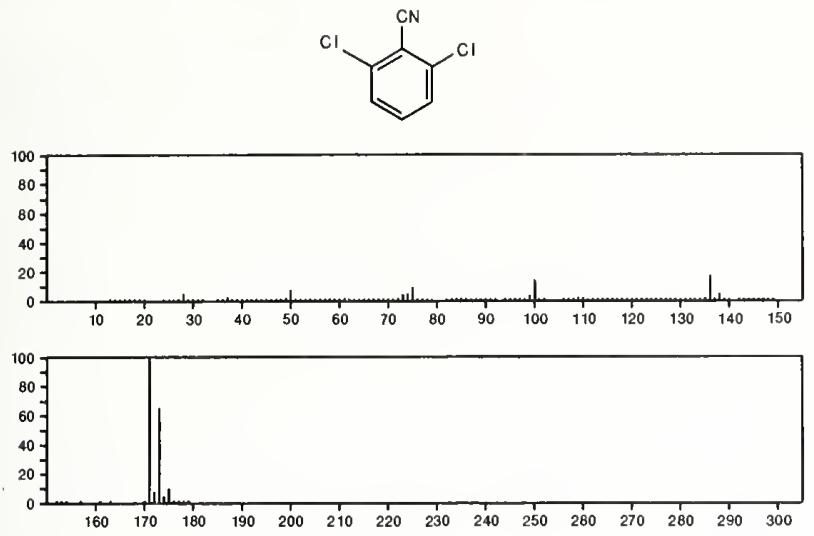

\section{1}

Benzene, 1-chloro-2-methyl-3-nitro-

83-42-1
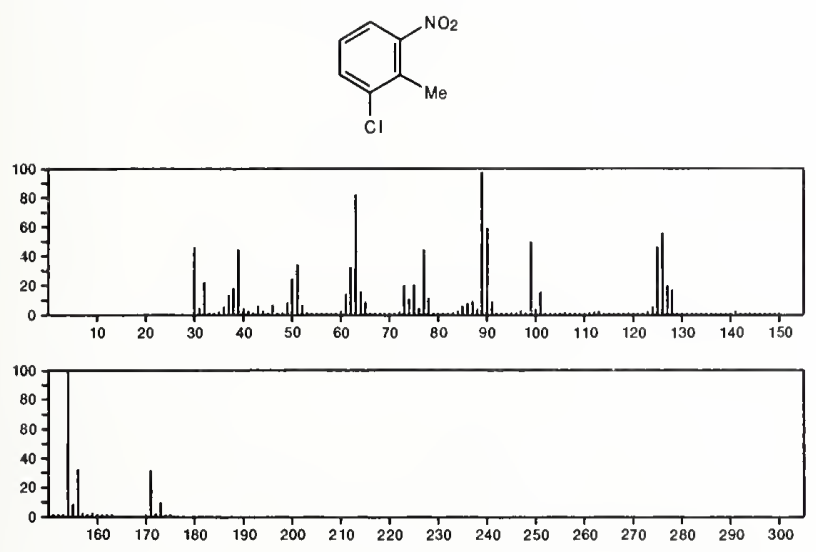

\section{7}

Methanethioamide, $\mathrm{N}$-(2-chlorophenyl)
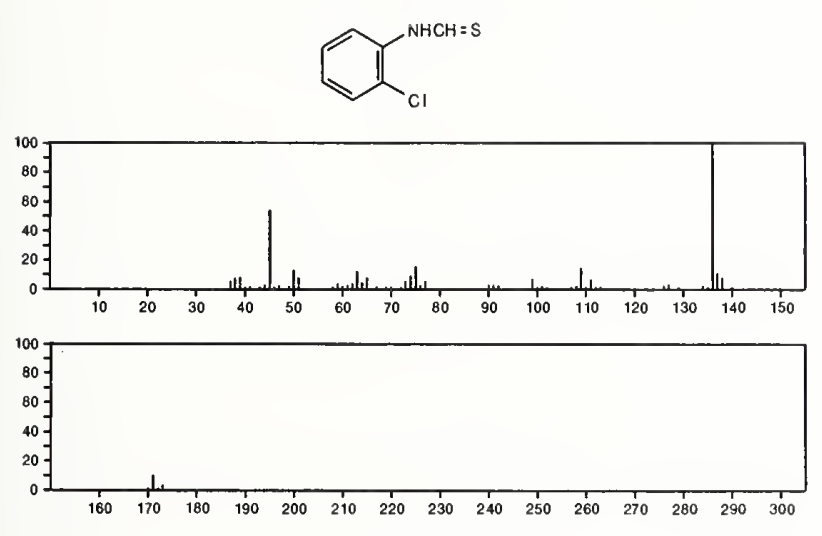

171

Benzenesulfonamide, ${ }_{4-} \mathrm{C}_{7} \mathrm{H}_{9} \mathrm{NO}_{2} \mathrm{~S}$

$70-55-3$
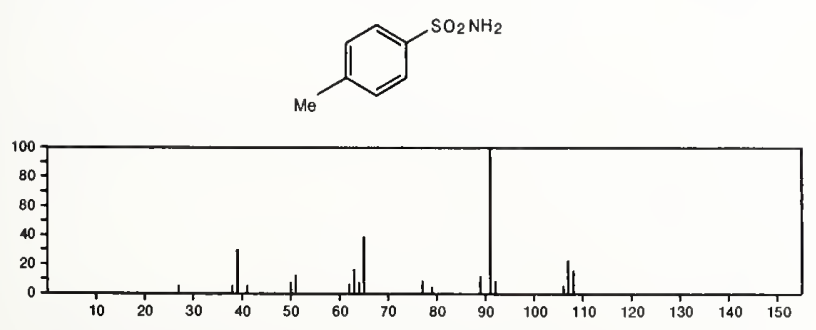

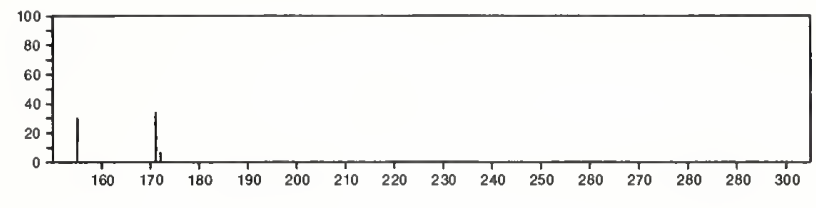

171

$\mathrm{C}_{7} \mathrm{H}_{9} \mathrm{NO}_{2} \mathrm{~S}$

88-19-7
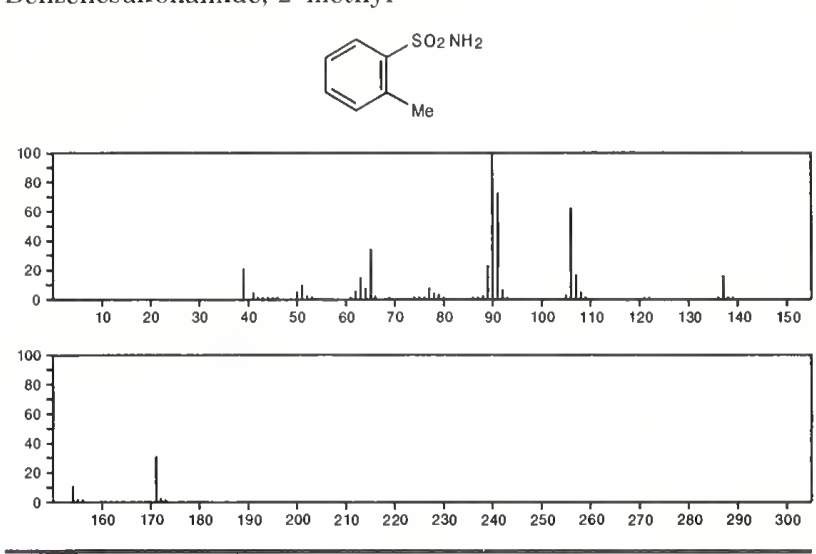

171

Proline, 1-acetyl-5-oxo-

$\mathrm{C}_{7} \mathrm{H}_{9} \mathrm{NO}_{4}$

56805-18-6
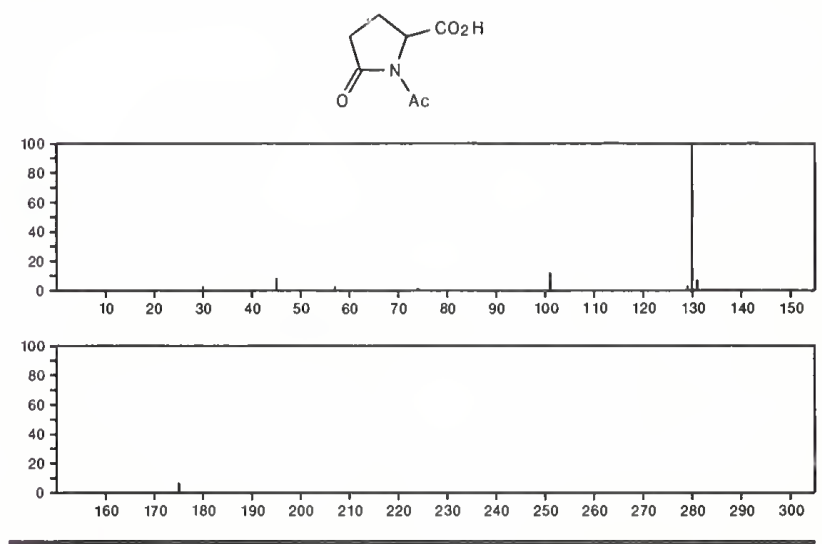

171

$\mathrm{C}_{7} \mathrm{H}_{13} \mathrm{~N}_{3} \mathrm{~S}$

$5351-77-9$

Hydrazinecarbothioamide, 2-cyclohexylidene-
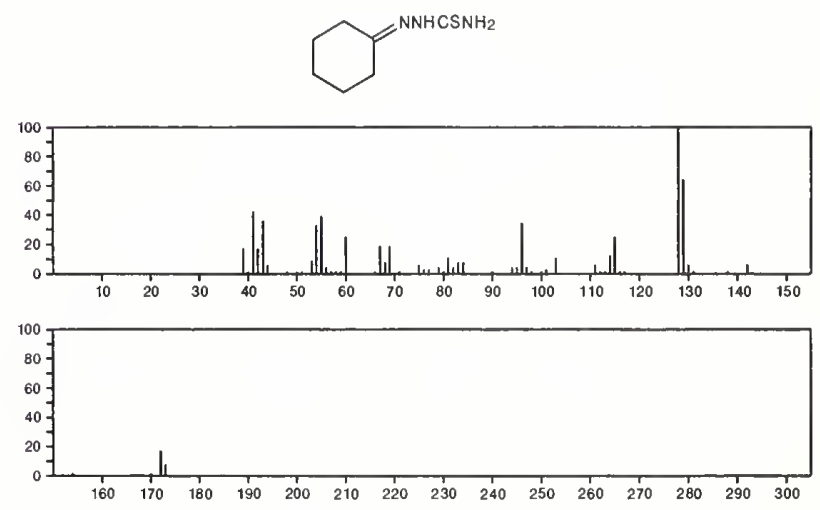
171 8-Azabicyclo[3.2.1]octan-3-one, 6,7-dihydroxy-8-methyl-, $($ exo,exo)-
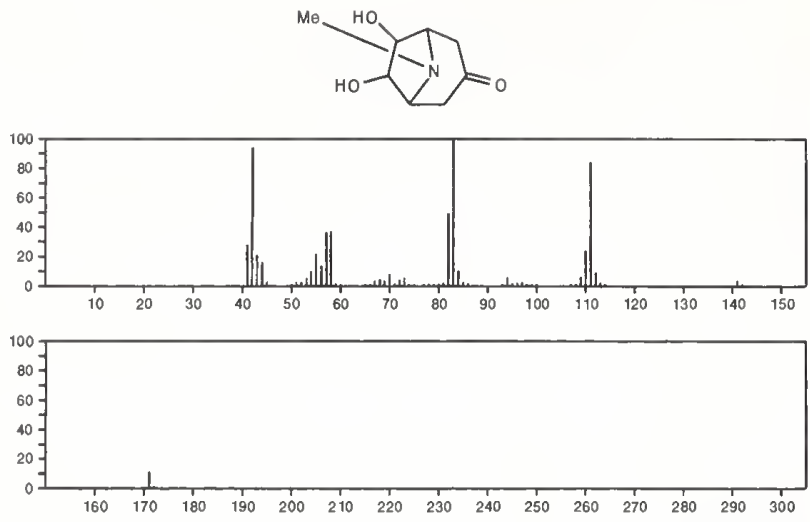

171

L-Proline, 1-acetyl-, methyl ester

$$
\mathrm{C}_{8} \mathrm{H}_{13} \mathrm{NO}_{3}
$$

$27460-51-1$
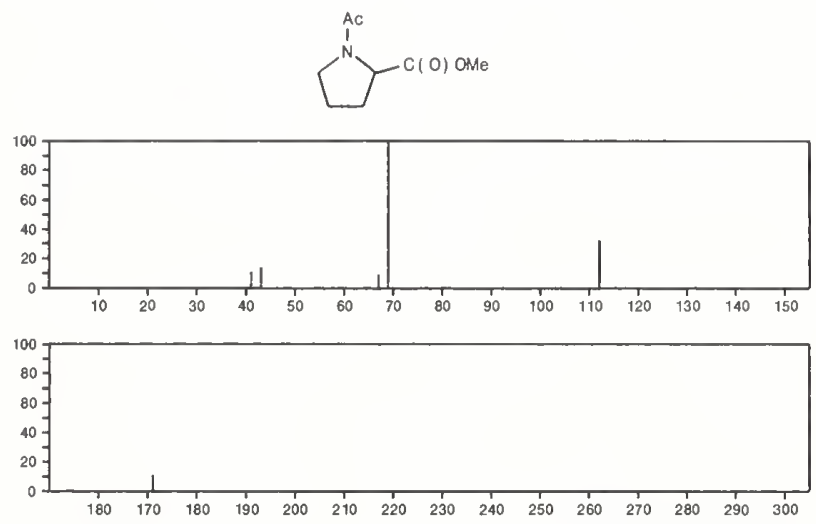

171

8-Azabicyclo[3.2.1]octan-3-one, 6,7-dihydroxy-8-methyl-
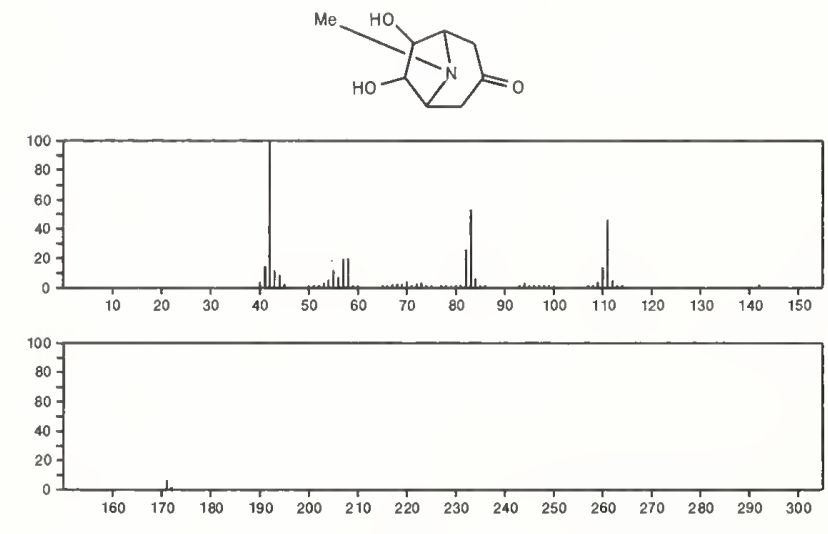

$171 \quad \mathrm{C}_{8} \mathrm{H}_{13} \mathrm{NO}_{3} \quad 55649-53-1$ Glycine, $N$-(2-methyl-1-oxo-2-butenyl)-, methyl ester, $(E)-$

$\mathrm{Me} C \mathrm{CH}=\mathrm{CMe}_{\mathrm{CONHCH}} \mathrm{C}(\mathrm{O}) \mathrm{OMe}$

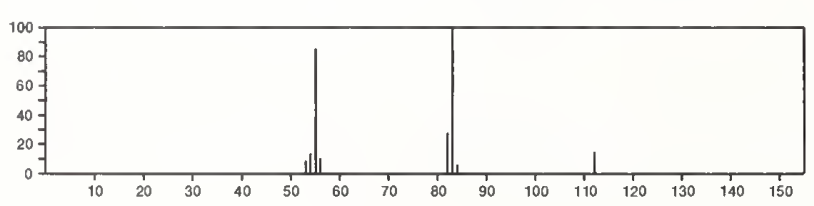

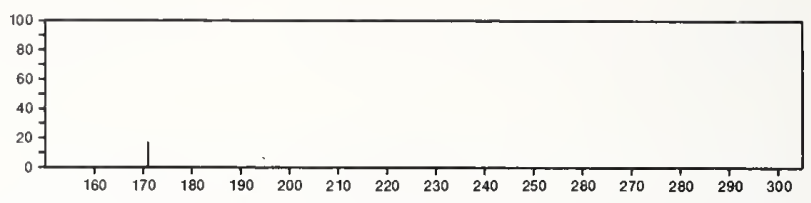

171

$\mathrm{C}_{8} \mathrm{H}_{13} \mathrm{NO}_{3}$

$56009-34-8$

Glycine, $N$-(3-methyl-1-oxo-2-butenyl)-, methyl ester

$\mathrm{MeOC}(0) \mathrm{CH}_{2} \mathrm{NHCOCH}=\mathrm{CMe}_{2}$
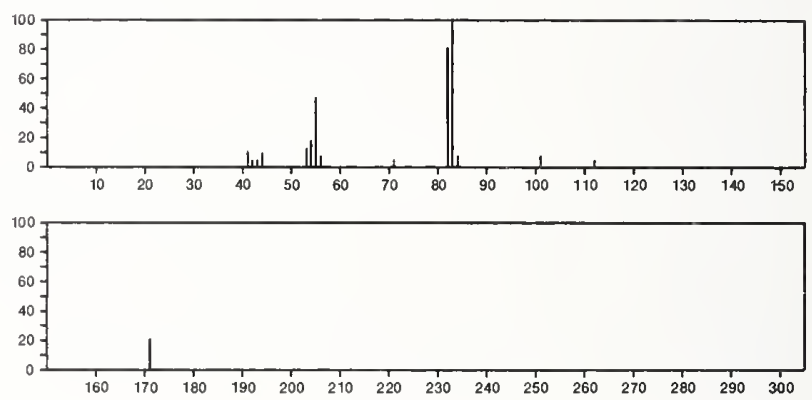

171

$\mathrm{C}_{8} \mathrm{H}_{13} \mathrm{NO}_{3}$

$56145-23-4$

2-Pyrrolidinecarboxylic acid, 1,2-dimethyl-5-oxo-, methyl ester
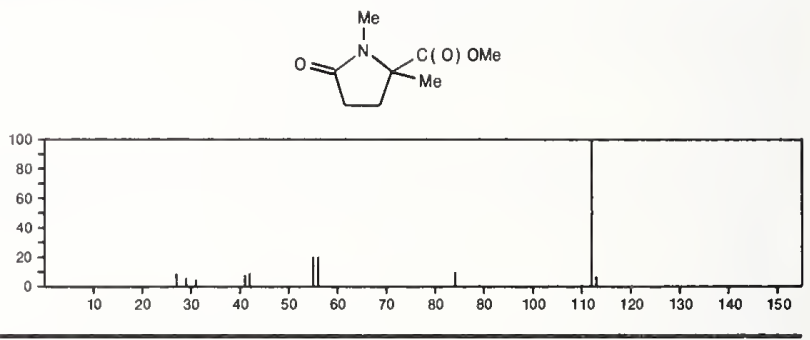

171

$\mathrm{C}_{8} \mathrm{H}_{17} \mathrm{NOSi}$

2-Piperidinone, 1-(trimethylsilyl)-

3553-93-3
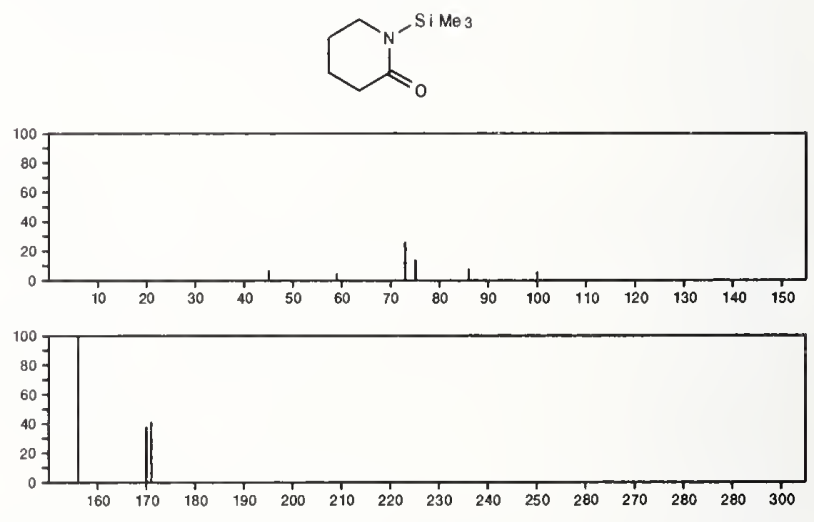

171

4-Heptanone, semicarbazone

$\mathrm{C}_{8} \mathrm{H}_{17} \mathrm{~N}_{3} \mathrm{O}$

3622-68-2

$\mathrm{Pr}_{2} \mathrm{C}=\mathrm{NNHCONH}_{2}$
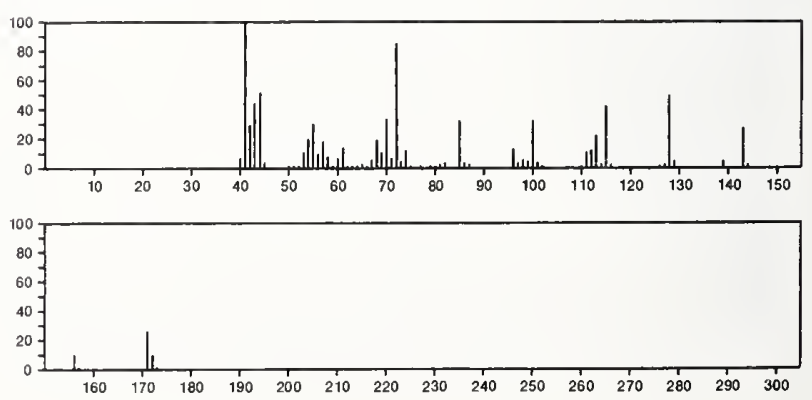
171

$\mathrm{C}_{8} \mathrm{H}_{17} \mathrm{~N}_{3} \mathrm{O}$

Valeraldehyde, 2,2-dimethyl-, semicarbazone

$16519-71-4$ $\mathrm{H}_{2} \mathrm{NCONHN}=\mathrm{CHCP} \mathrm{M}$ Me
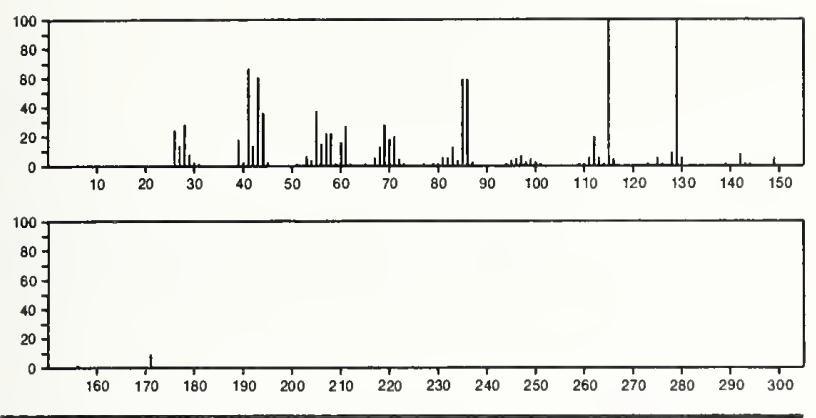

171

$\mathrm{C}_{9} \mathrm{H}_{5} \mathrm{~N}_{3} \mathrm{O}$

2-Quinoxalinecarbonitrile, 1-oxide

$18457-81-3$
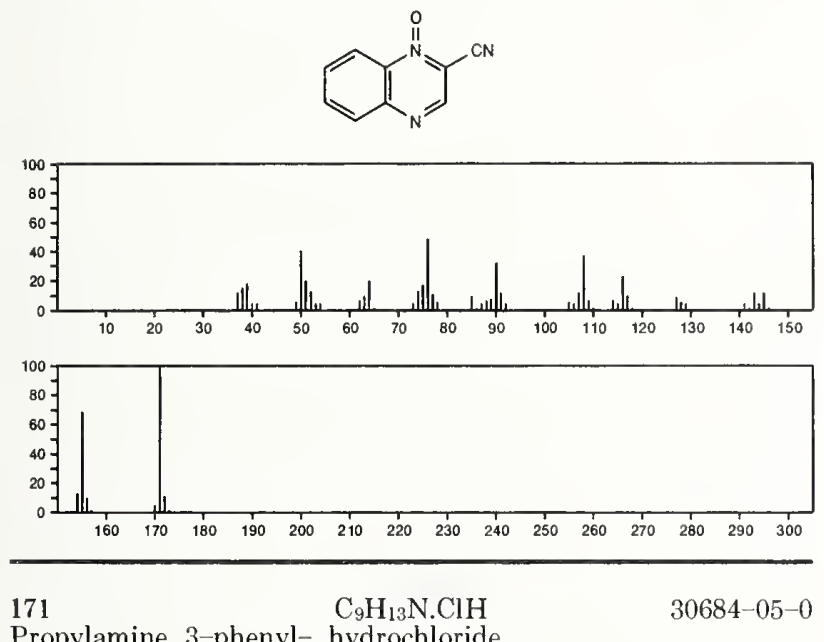

Propylamine, 3-phenyl-, hydrochloride

$\mathrm{Ph}\left(\mathrm{CH}_{2}\right)_{3} \mathrm{NH}_{2} \cdot \mathrm{HCl}$

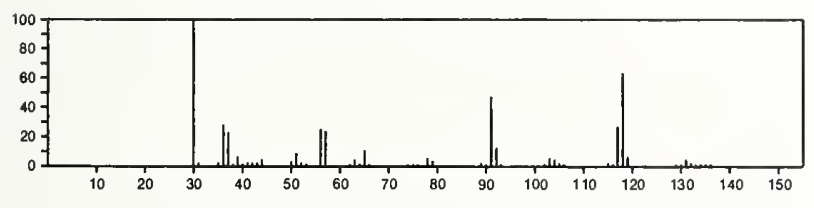

$171 \quad \mathrm{C}_{9} \mathrm{H}_{17} \mathrm{NO}_{2}$

Cyclooctanecarboxylic acid, 1 -amino-

$28248-38-6$
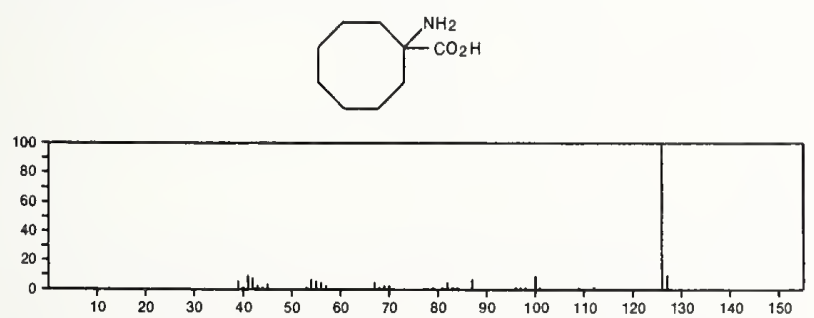

171

$\mathrm{C}_{9} \mathrm{H}_{17} \mathrm{NO}_{2}$

39077-13-9

6-Azabicyclo[3.2.1]octan-8-ol, 5-methoxy-6-methyl-, syn-
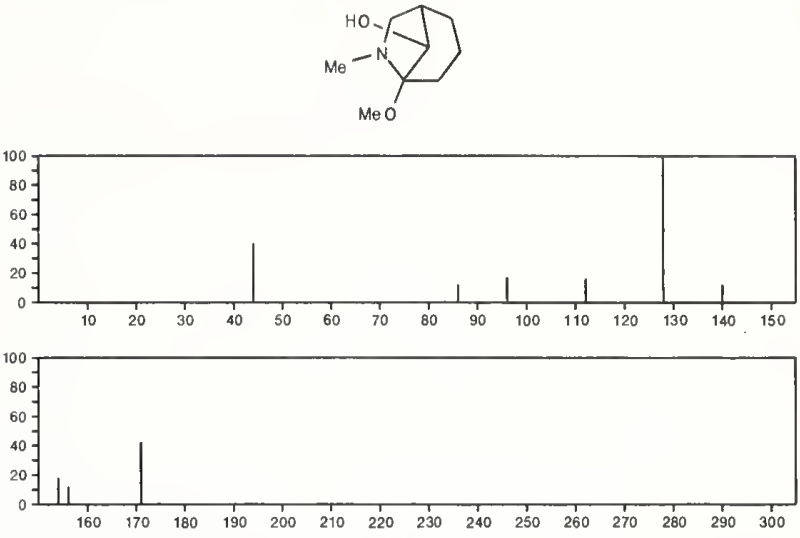

171

$\mathrm{C}_{9} \mathrm{H}_{17} \mathrm{NO}_{2}$

49656-39-5

9-Azabicyclo[4.2.1]nonane-2,5-diol, 9-methyl-, (endo,endo)-
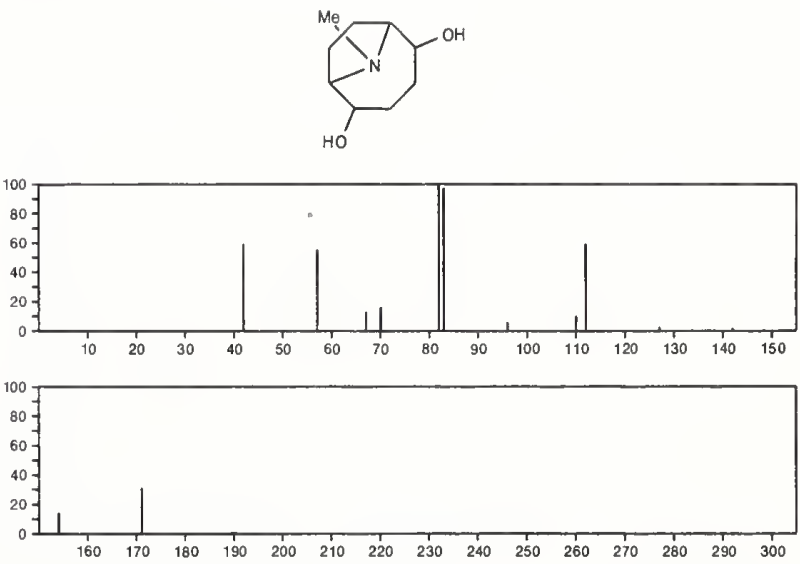

171

$\mathrm{C}_{9} \mathrm{H}_{17} \mathrm{NO}_{2}$

$49656-40-8$

9-Azabicyclo[3.3.1]nonane-2,6-diol, 9-methyl-, (endo,endo)-
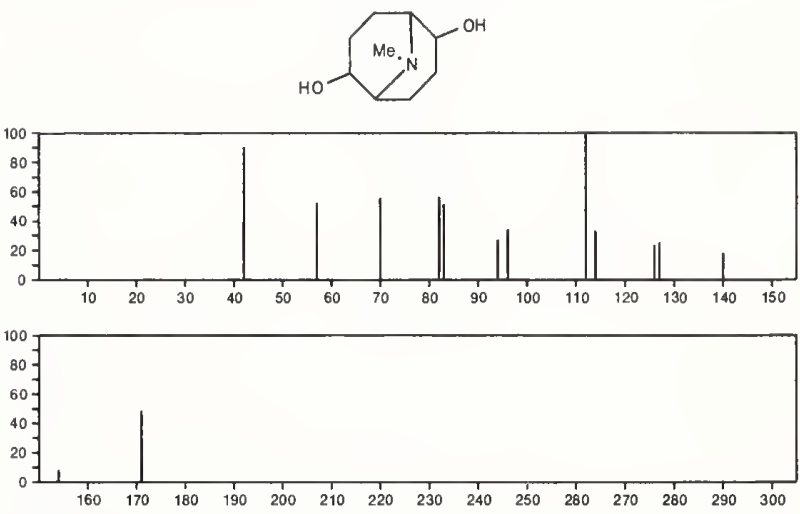

171

$\mathrm{C}_{9} \mathrm{H}_{17} \mathrm{NO}_{2}$

$54725-47-2$

8-Azabicyclo[3.2.1]octan-3-ol, 6-methoxy-8-methyl-
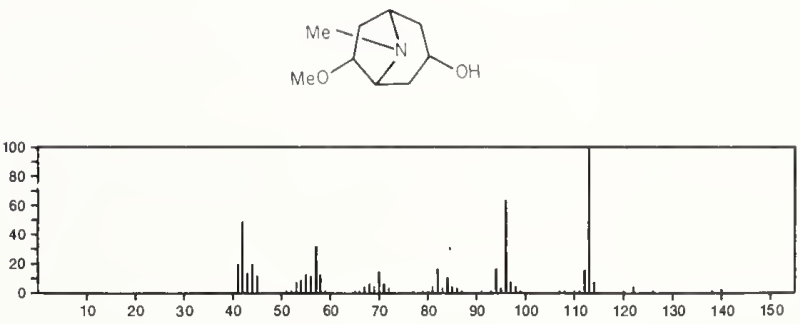


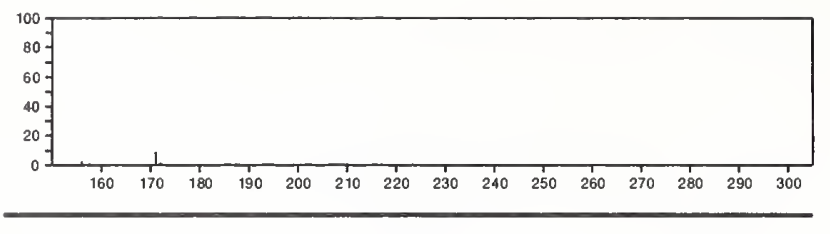

$171 \quad \mathrm{C}_{9} \mathrm{H}_{17} \mathrm{NO}_{2} \quad 56051-37-7$ 8-Azabicyclo[3.2.1]octan-3-ol, 6-methoxy-8-methyl-, (3endo,6-exo)-
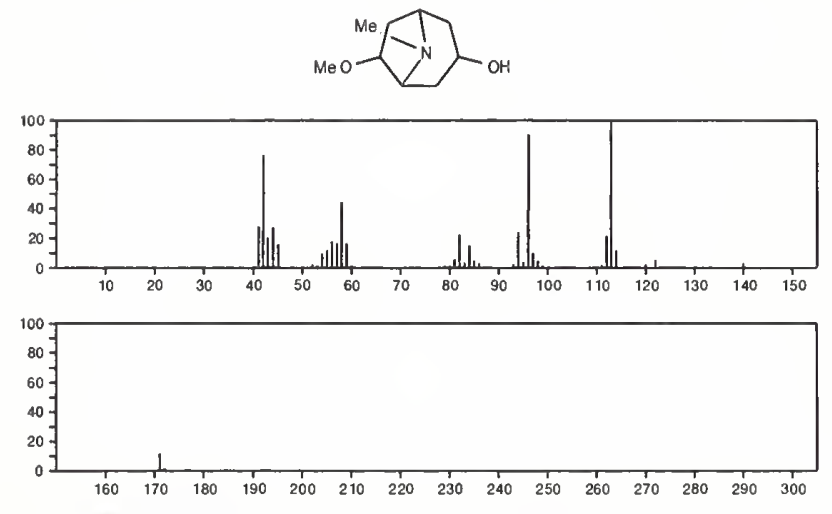

171

1,3,5-Triazine, 1,3,5-triethylhexahydro-
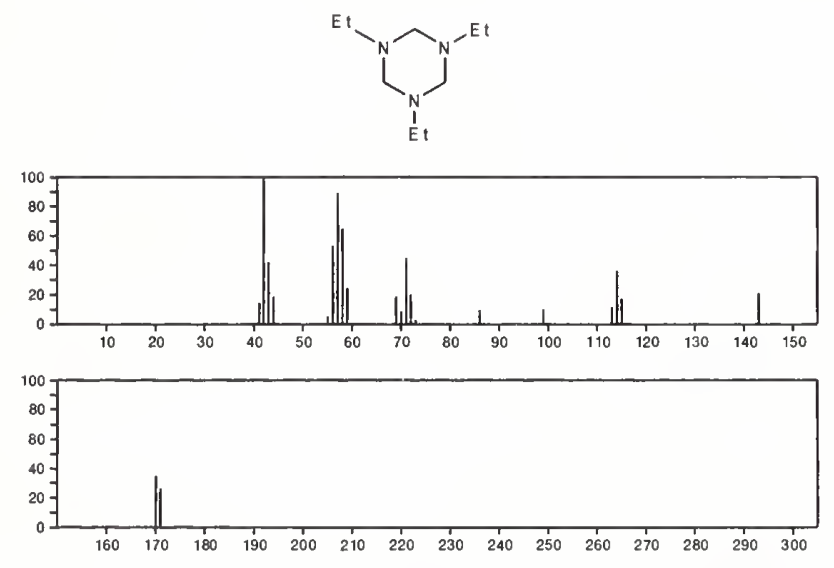

$171 \quad \mathrm{C}_{10} \mathrm{H}_{9} \mathrm{~N}_{3}$

Pyrimidine, 5-amino-4-phenyl-

$3435-23-2$
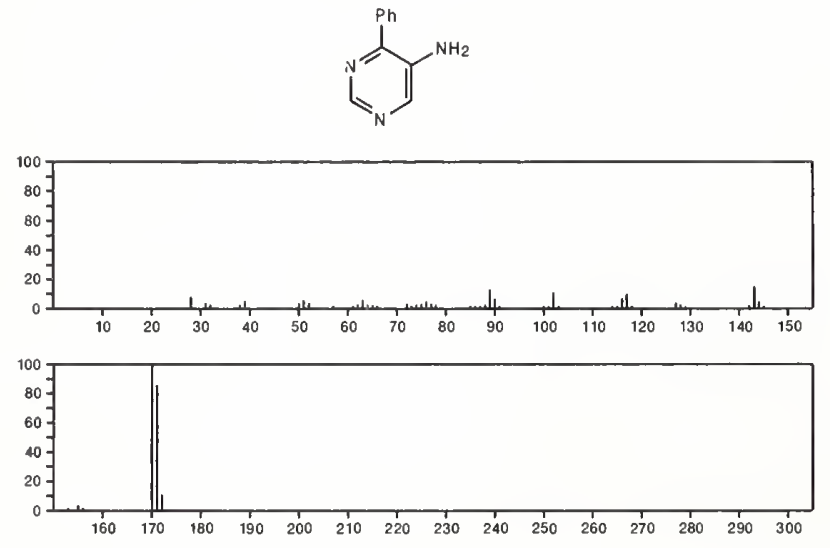

171

Pyrazinamine, 5-phenyl-

$\mathrm{C}_{10} \mathrm{H}_{9} \mathrm{~N}_{3}$

$13535-13-2$
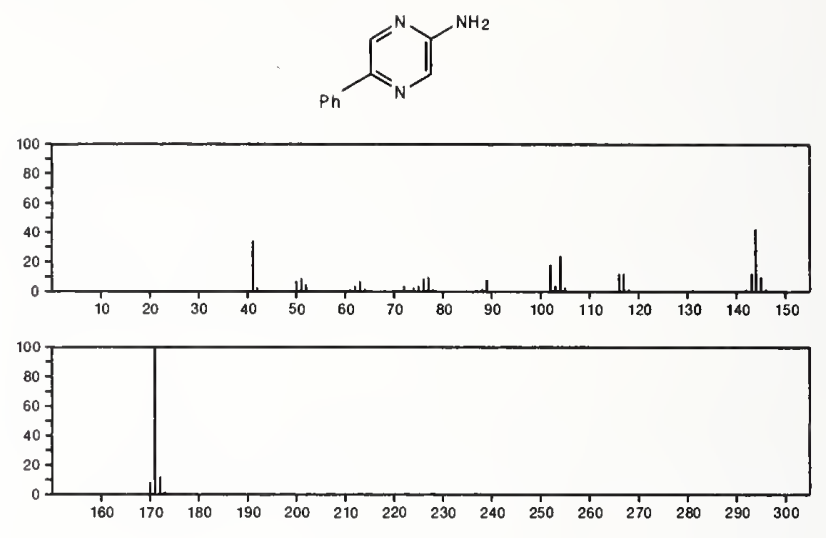

171

Acetamide, $N, N$-dibutyl-

$\mathrm{C}_{10} \mathrm{H}_{21} \mathrm{NO}$

$1563-90-2$

$\mathrm{Me}\left(\mathrm{CH}_{2}\right)_{3} \mathrm{~N}(\mathrm{AC})\left(\mathrm{CH}_{2}\right)_{3} \mathrm{Me}$
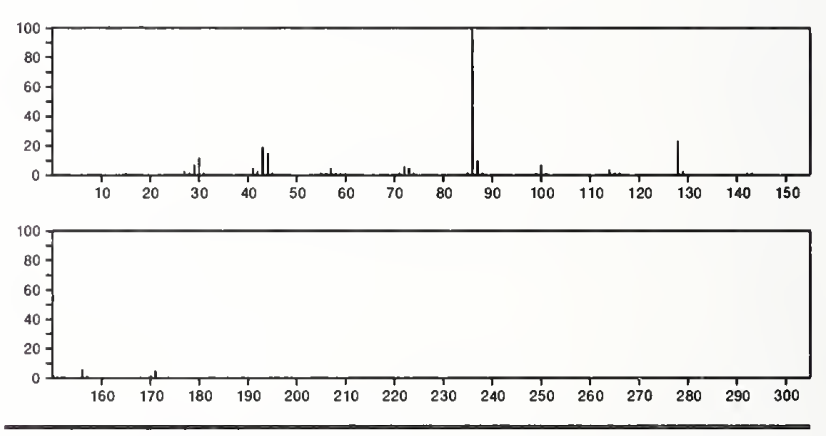

171

Hexanamide, $N, N$-diethyl-

$\mathrm{C}_{10} \mathrm{H}_{21} \mathrm{NO}$

$6282-97-9$

$\mathrm{Me}\left(\mathrm{CH}_{2}\right){ }_{4} \mathrm{CONE} / 2$
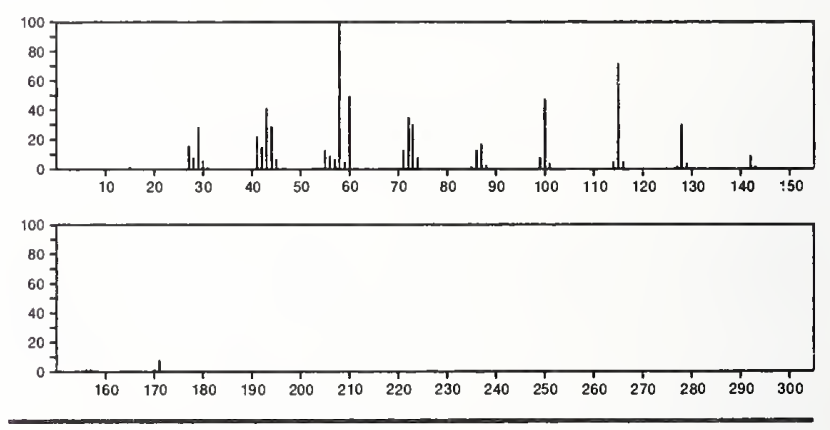

171

$\mathrm{C}_{10} \mathrm{H}_{21} \mathrm{NO}$

$10264-17-2$

Butanamide, $N$-hexyl-

$\operatorname{PrCONH}\left(\mathrm{CH}_{2}\right){ }_{5} \mathrm{Me}$
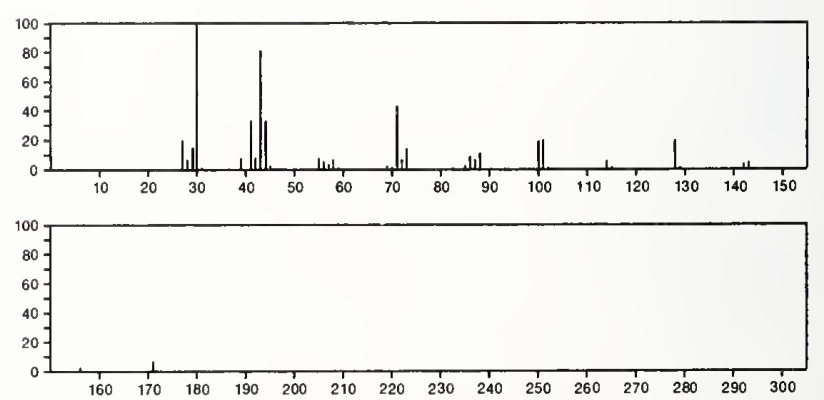
171

$\mathrm{C}_{10} \mathrm{H}_{21} \mathrm{NO}$

Hexanamide, 4-ethyl-5,5-dimethyl-

$\mathrm{H}_{2} \mathrm{NCOCH}_{2} \mathrm{CH}_{2} \mathrm{CHE}+\mathrm{CMe}_{3}$
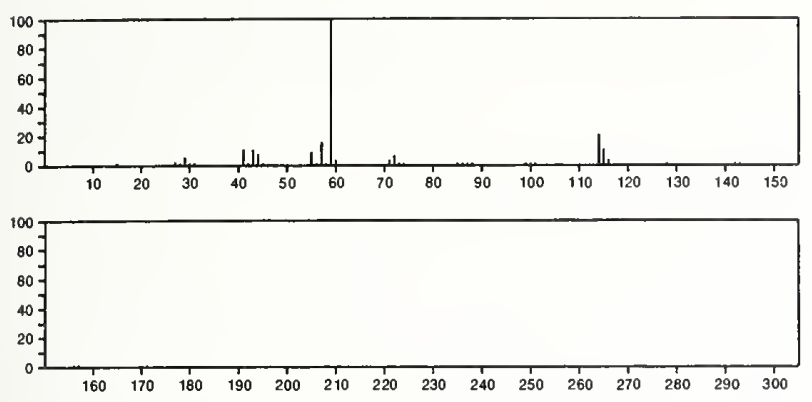

$171 \quad \mathrm{C}_{10} \mathrm{H}_{21} \mathrm{NO}$

Heptanamide, 4-ethyl-5-methyl-

54789-40-1

$\mathrm{H}_{2} \mathrm{NCOCH}_{2} \mathrm{CH}_{2} \mathrm{CHE}$ t $\mathrm{CHM}_{\theta} \mathrm{CH}_{2} \mathrm{Me}$
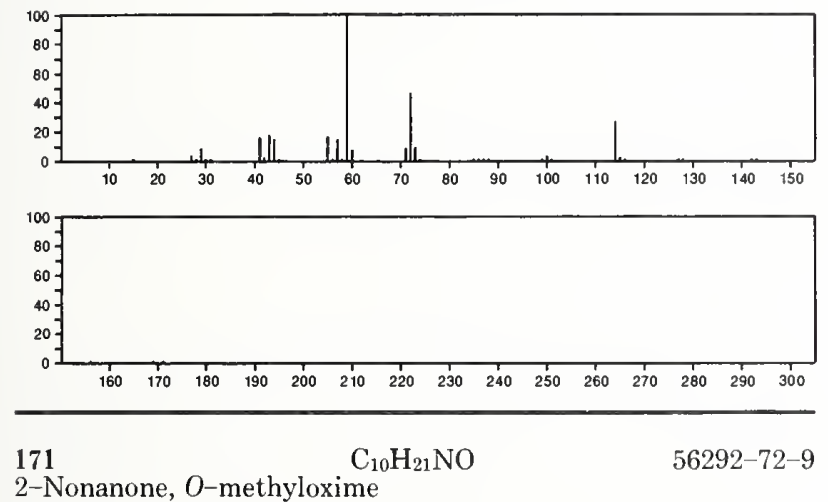

2-Nonanone, $\mathrm{O}$-methyloxime

$\mathrm{MeON}=\mathrm{CMe}\left(\mathrm{CH}_{2}\right)_{6} \mathrm{Me}$
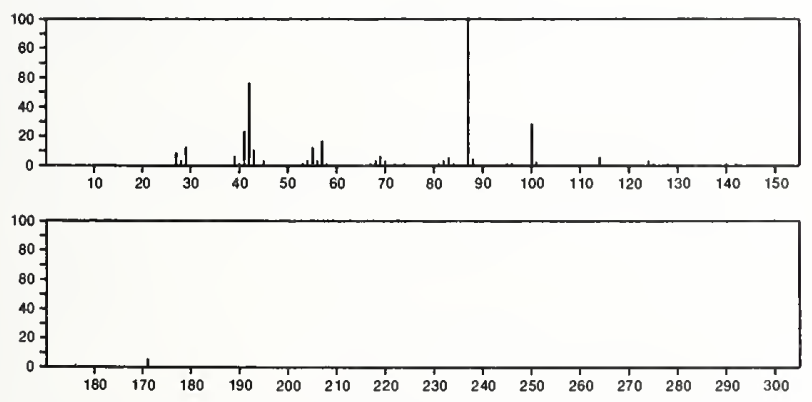

171

5-Nonanone, $\mathrm{O}$-methyloxime

$\mathrm{C}_{10} \mathrm{H}_{21} \mathrm{NO}$

56292-94-5

$\left(\mathrm{CH}_{2}\right)_{3} \mathrm{Me}$

$\mathrm{MeON}=\mathrm{C}\left(\mathrm{CH}_{2}\right)_{3} \mathrm{Me}_{\theta}$
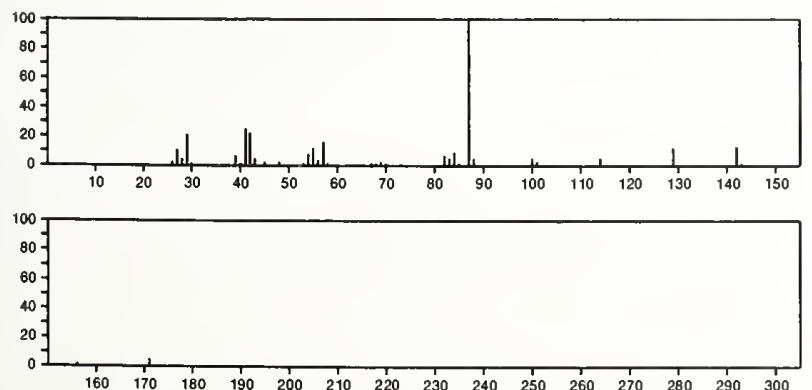

171

3-Pyridinol, 2-phenyl

$\mathrm{C}_{11} \mathrm{H}_{9} \mathrm{NO}$
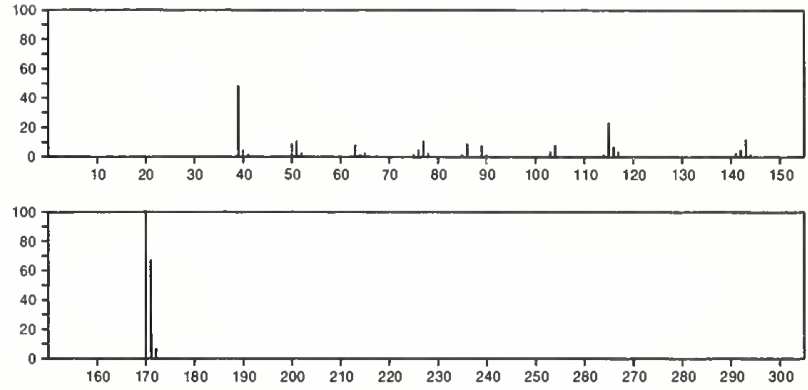

171

2(1H)-Pyridinone, 1-phenyl-

$\mathrm{C}_{11} \mathrm{H}_{9} \mathrm{NO}$

$13131-02-7$
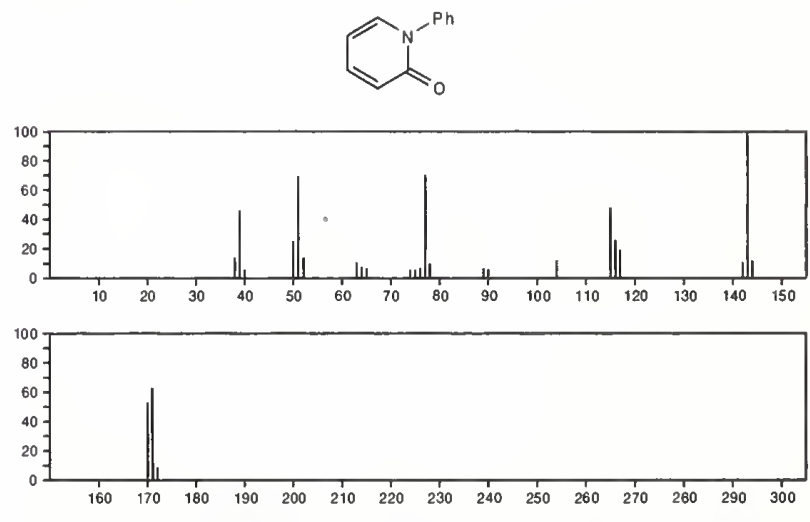

$171 \quad \mathrm{C}_{11} \mathrm{H}_{9} \mathrm{NO} \quad 19006-81-6$ 2(1H)-Pyridinone, 4-phenyl
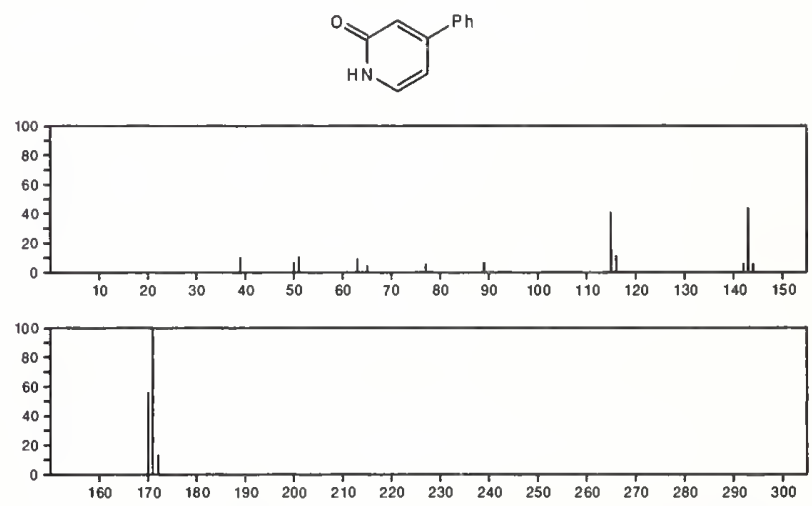

171

2(1H)-Pyridinone, 6-phenyl

$\mathrm{C}_{11} \mathrm{H}_{9} \mathrm{NO}$

$19006-82-7$
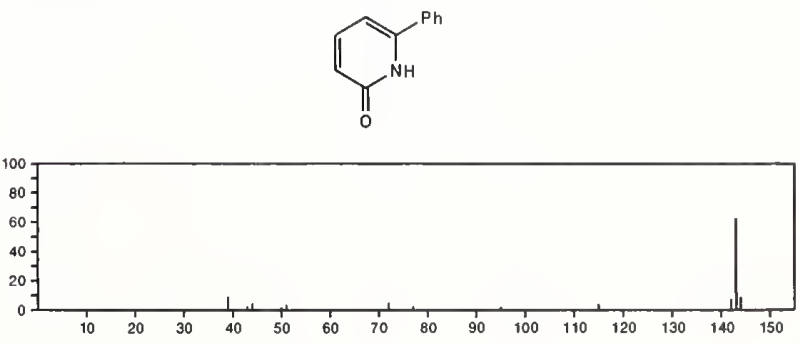


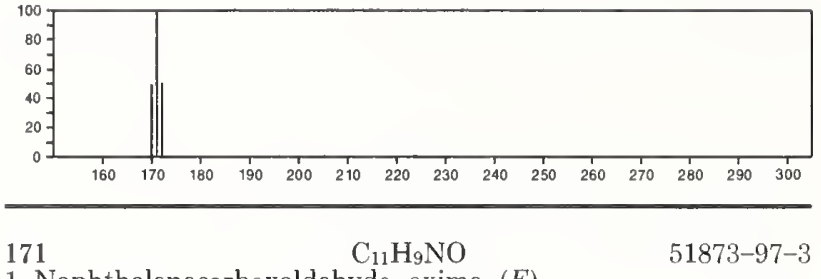

1-Naphthalenecarboxaldehyde, oxime, $(E)$
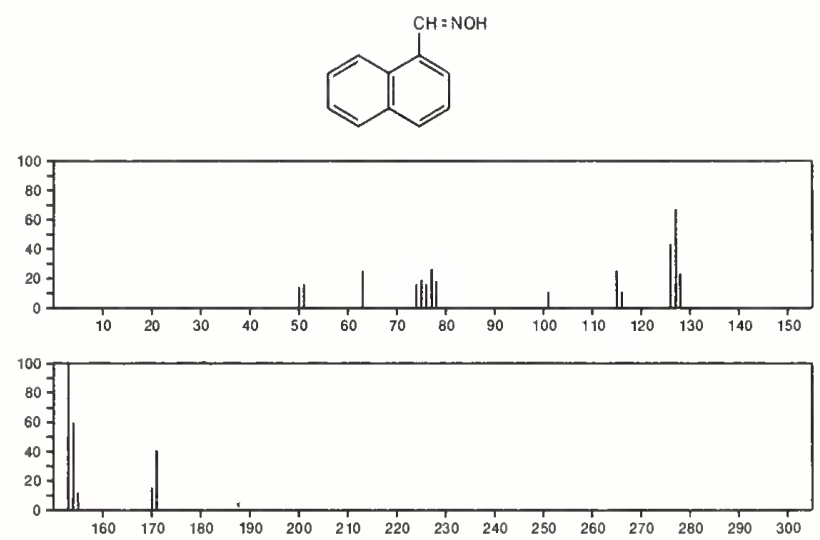

$171 \quad \mathrm{C}_{11} \mathrm{H}_{9} \mathrm{NO}$

$51873-98-4$

2-Naphthalenecarboxaldehyde, oxime, $(E)$ -
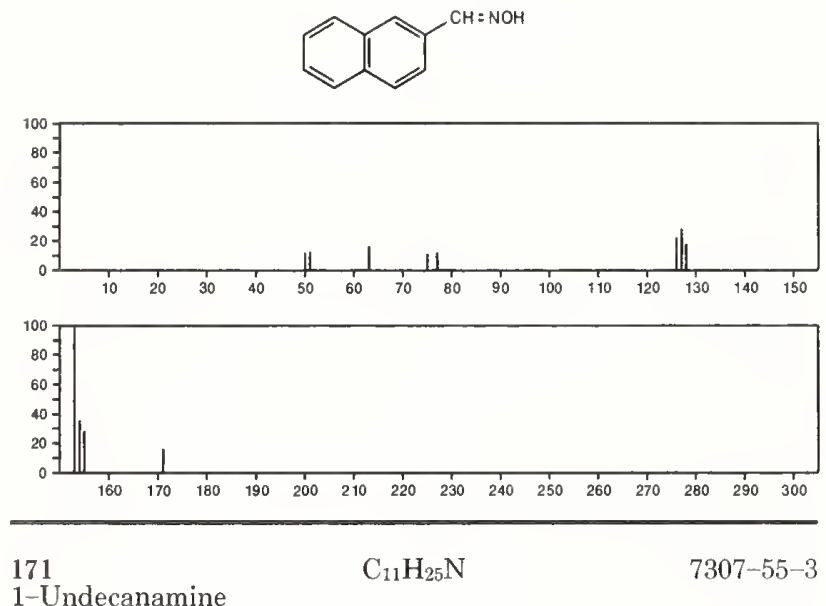

1-Undecanamine

$\mathrm{Me}\left(\mathrm{CH}_{2}\right) 10 \mathrm{NH}_{2}$
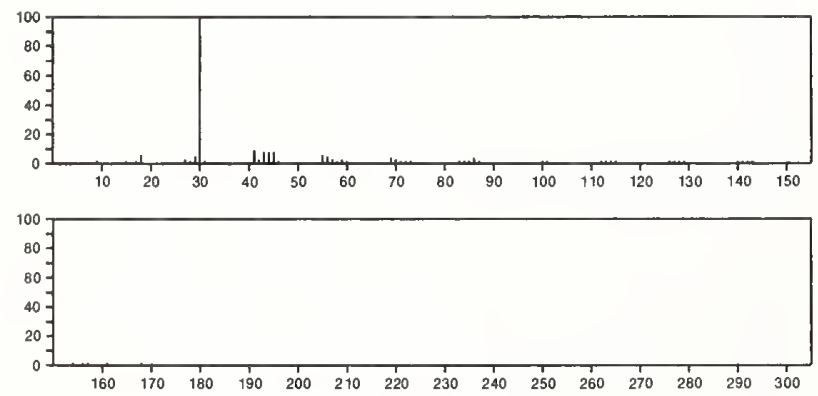

$171 \quad \mathrm{C}_{11} \mathrm{H}_{25} \mathrm{~N}$

$41495-45-8$

1-Hexanamine, $N$-pentyl-

$\mathrm{Me}\left(\mathrm{CH}_{2}\right) 5 \mathrm{NH}_{(}\left(\mathrm{CH}_{2}\right){ }_{4} \mathrm{Me}$

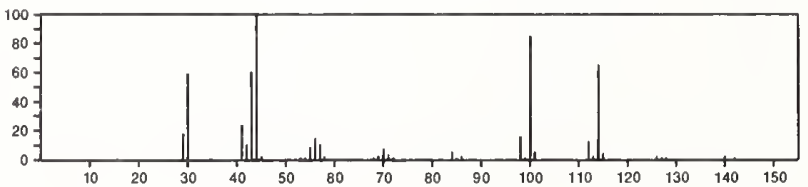

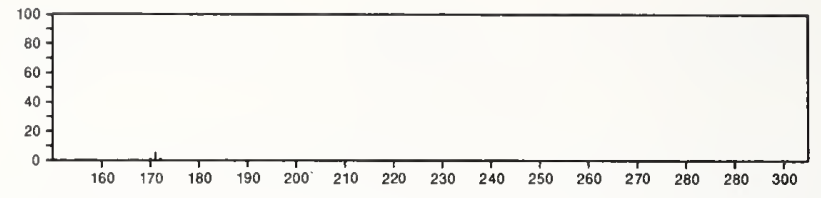

$171 \quad \mathrm{C}_{12} \mathrm{H}_{13} \mathrm{~N}$

942-01-8

1H-Carbazole, 2,3,4,9-tetrahydro-
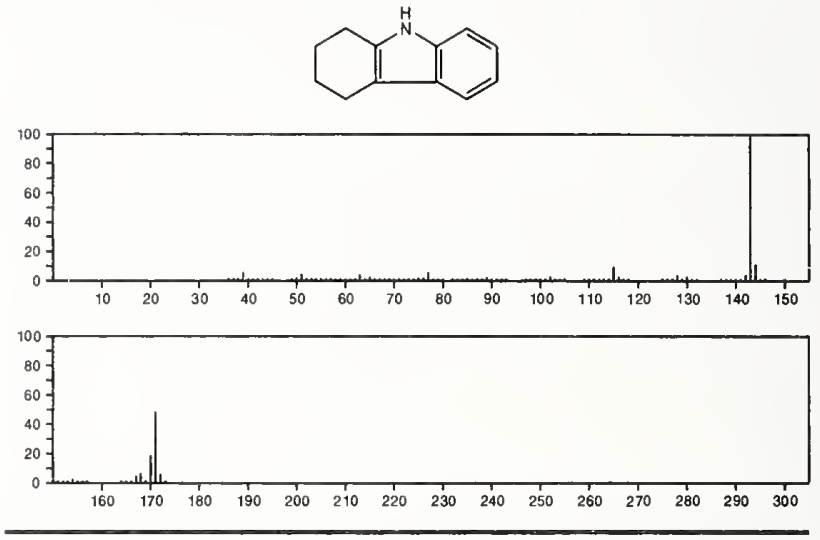

171

$\mathrm{C}_{12} \mathrm{H}_{13} \mathrm{~N}$

1613-32-7

Quinoline, 2-propyl-
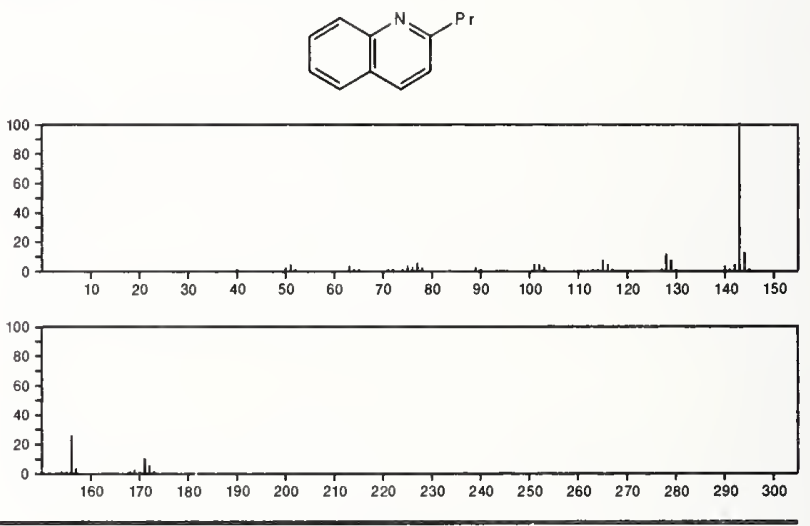

171

$\mathrm{C}_{12} \mathrm{H}_{13} \mathrm{~N}$

$2437-72-1$

Quinoline, 2,3,4-trimethyl-
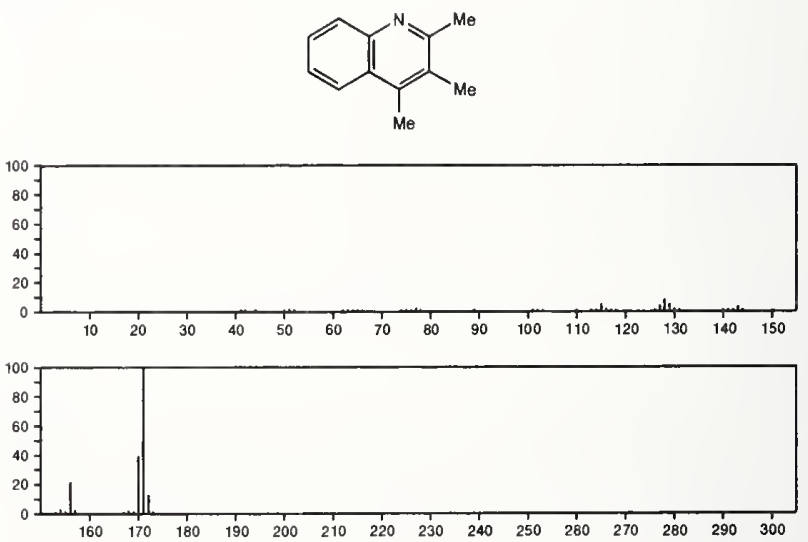
171

Isoquinoline, 1-propyl-

$\mathrm{C}_{12} \mathrm{H}_{13} \mathrm{~N}$

$7661-37-2$
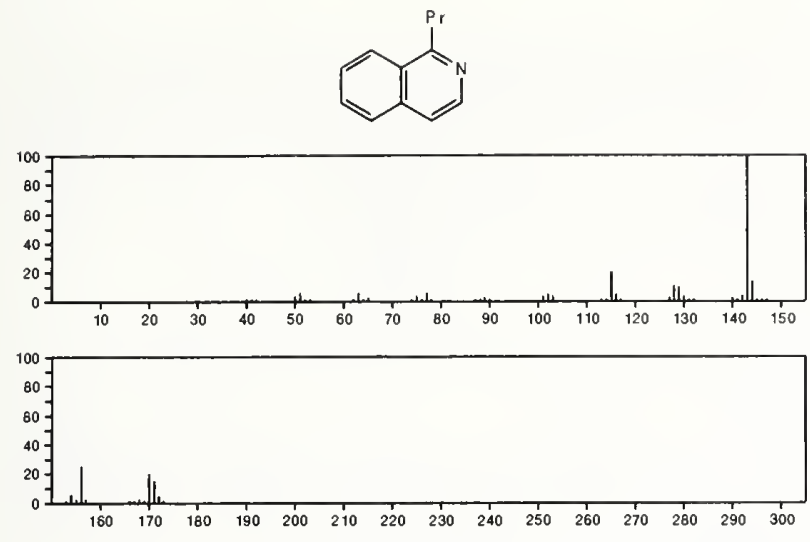

\begin{tabular}{ll}
\hline 171 & $\mathrm{C}_{12} \mathrm{H}_{13} \mathrm{~N}$
\end{tabular}

Quinoline, 8-propyl-
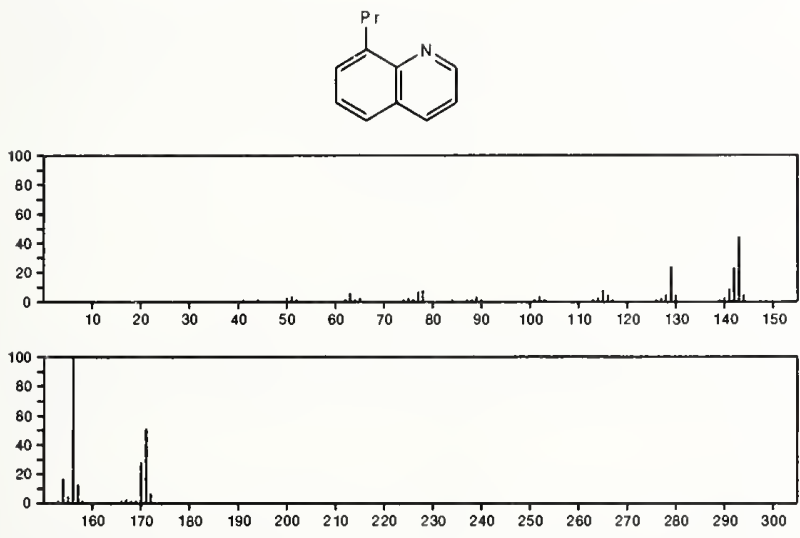

171

Quinoline, 6-propyl-

$\mathrm{C}_{12} \mathrm{H}_{13} \mathrm{~N}$

7661-58 7
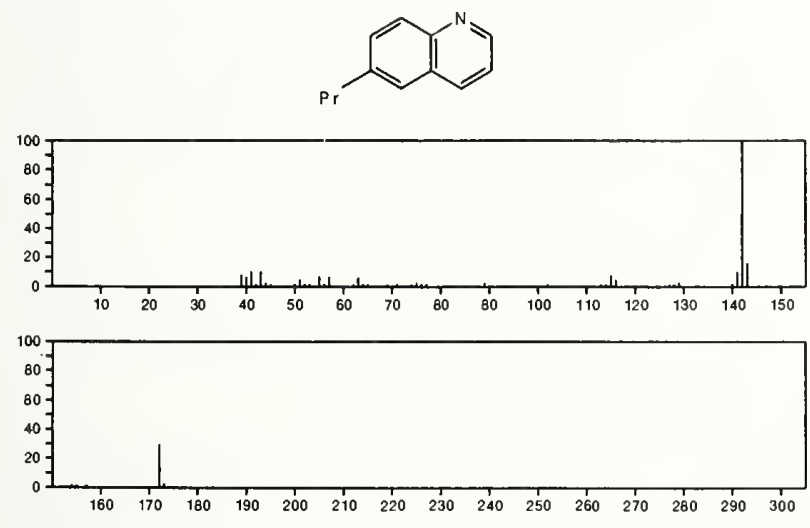

171

Quinoline, 7-propyl-

$\mathrm{C}_{12} \mathrm{H}_{13} \mathrm{~N}$

7661-59-8
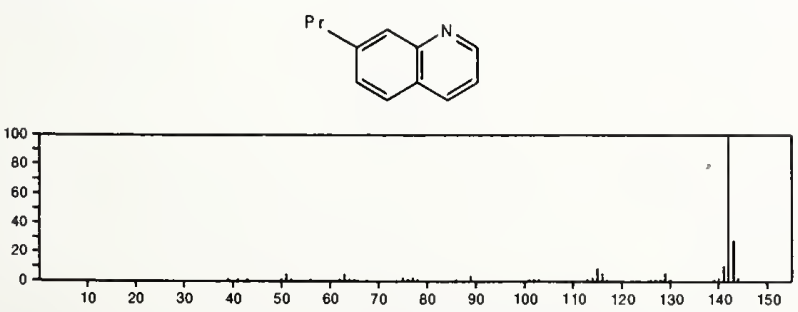

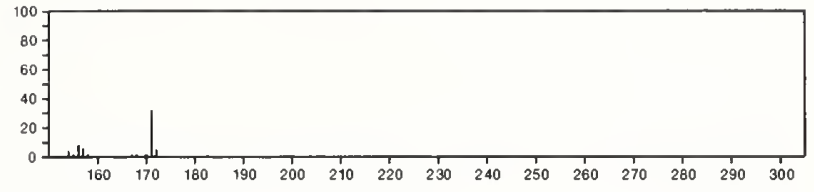

171

Lepidine, 2-ethyl-

$\mathrm{C}_{12} \mathrm{H}_{13} \mathrm{~N}$

33357-44-7<smiles>CCc1cc([N+](=O)[O-])c2ccccc2n1</smiles>
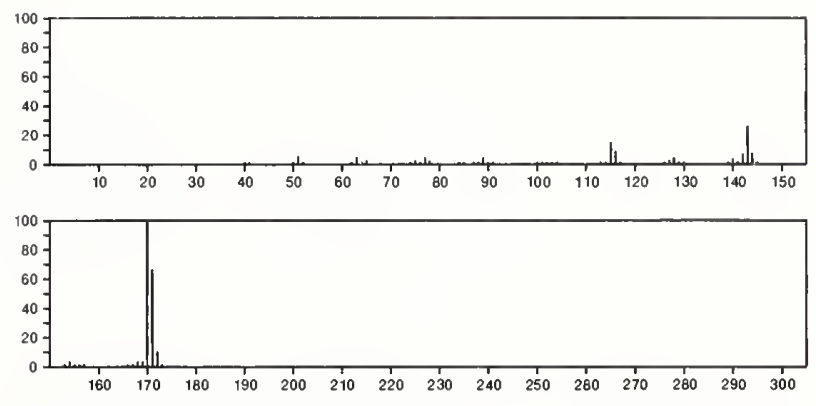

172

Methane, dibromo-

$\mathrm{CH}_{2} \mathrm{Br} 2$

74-95-3

$\mathrm{CH}_{2} \mathrm{Br}_{2}$
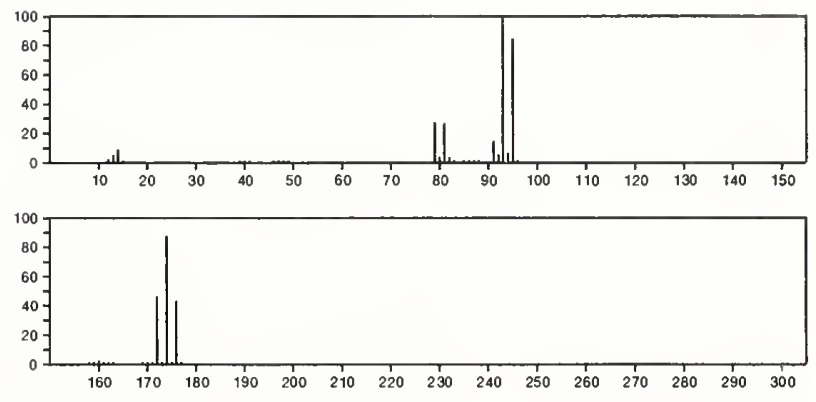

172

$\mathrm{CH}_{5} \mathrm{ISi}$

7570-22-1

Silane, (iodomethyl)-

$\mathrm{I} \mathrm{CH}_{2} \mathrm{SiH}_{3}$
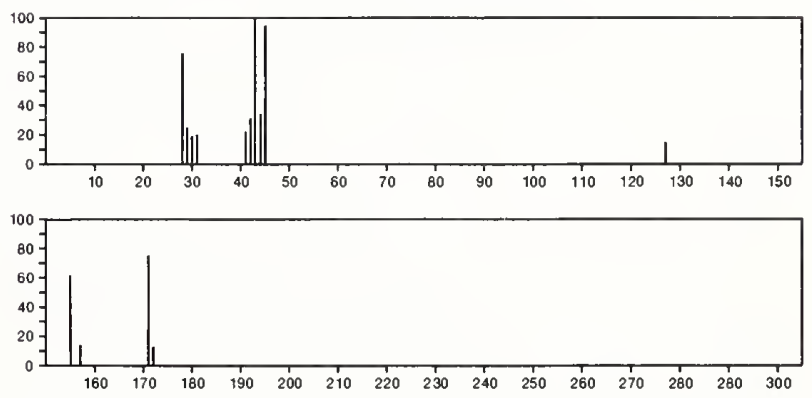

172

$\mathrm{C}_{3} \mathrm{BrF}_{3}$

29777-44-4

Cyclopropene, 1-bromo-2,3,3-trifluoro-
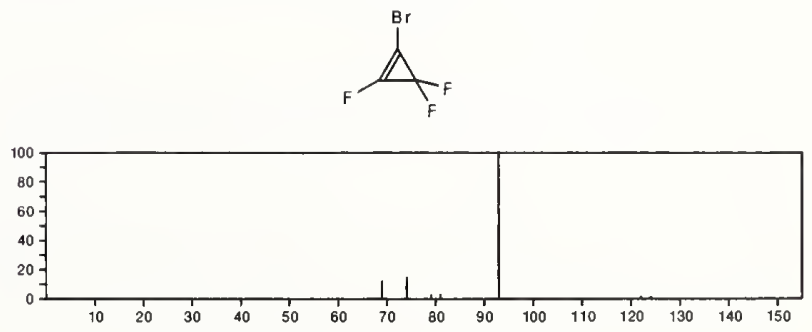


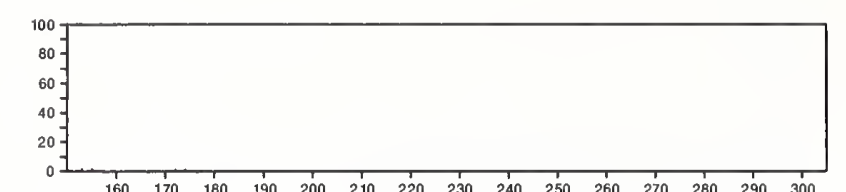

$\begin{array}{lllllllllllllll}160 & 170 & 180 & 190 & 200 & 210 & 220 & 230 & 240 & 250 & 260 & 270 & 280 & 290 & 300\end{array}$

$172 \quad \mathrm{C}_{3} \mathrm{H}_{3} \mathrm{BrClF}$

Cyclopropane, 1-bromo-1-chloro-2-fluoro-

24071-59-8
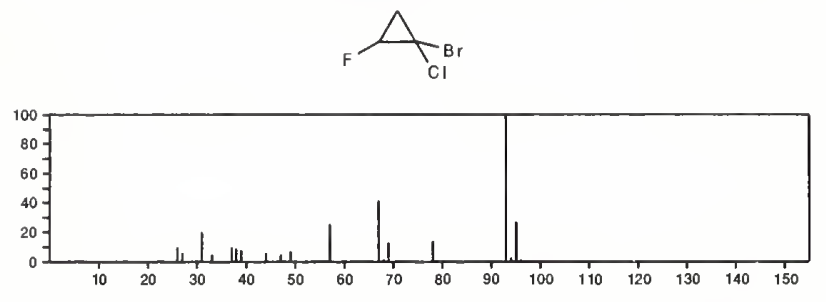

172

Phosphorodithioic acid, $O, O, S$-trimethyl ester

$2953-29-9$
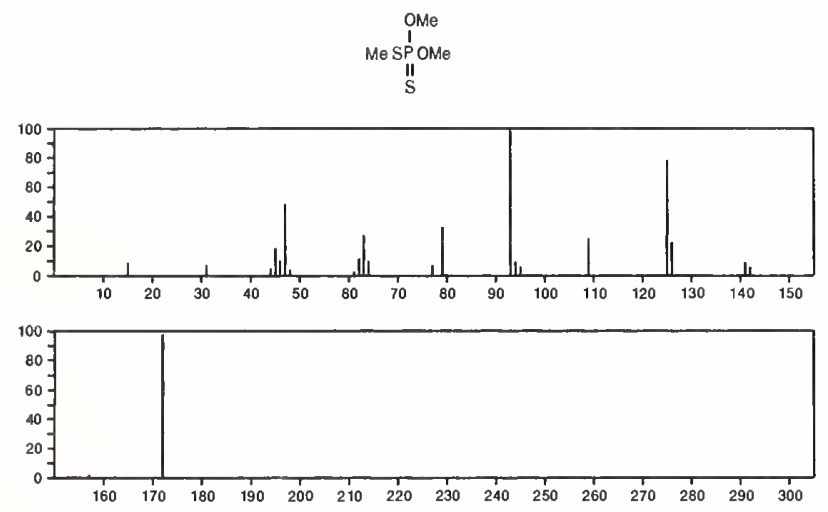

172

Phosphorodithioic acid, $O, S, S$-trimethyl ester

$22608-53-3$
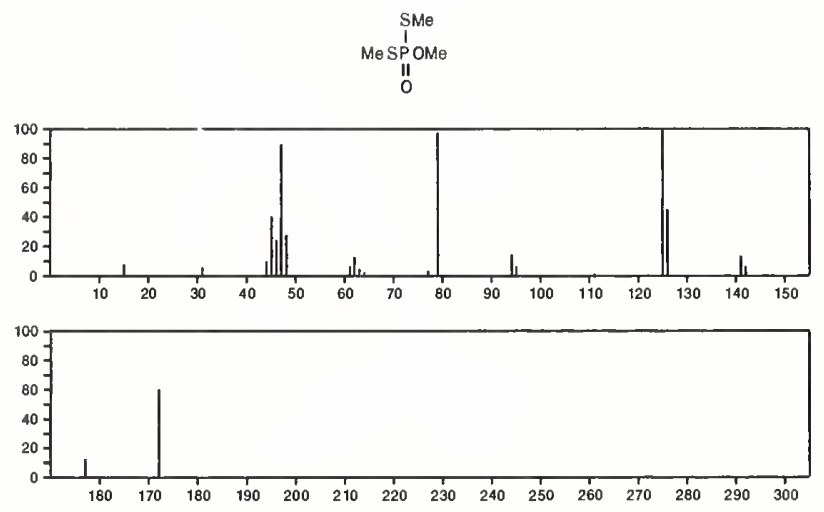

172

$\mathrm{C}_{4} \mathrm{HCoO}_{4}$

$16842-03-8$

Cobalt, tetracarbonylhydro-
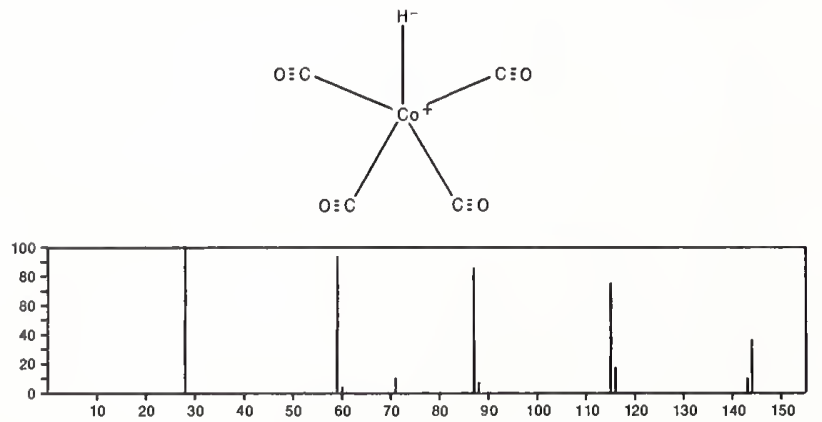

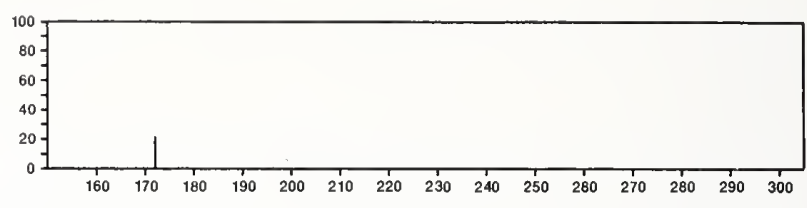

172

$\mathrm{C}_{4} \mathrm{H}_{10} \mathrm{ClO}_{3} \mathrm{P}$

Phosphorochloridic acid, diethyl ester

$814-49-3$

II
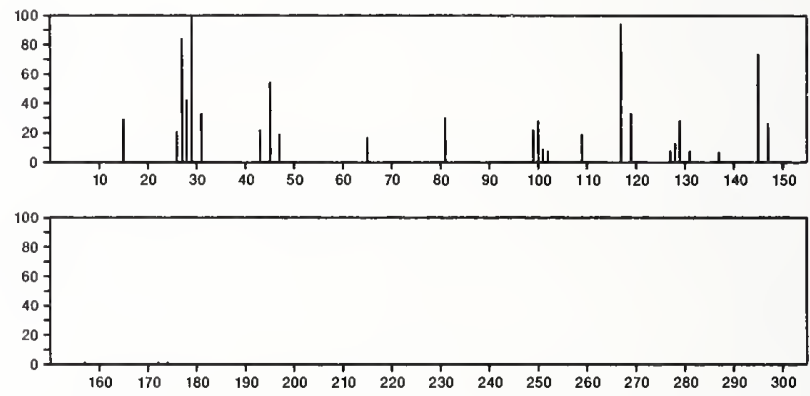

172

1-Pentene, 1,1,5-trichloro-

$\mathrm{C}_{5} \mathrm{H}_{7} \mathrm{Cl}_{3}$

$2677-33-0$

$\mathrm{Cl}\left(\mathrm{CH}_{2}\right)_{3} \mathrm{CH}=\mathrm{CCl}_{2}$
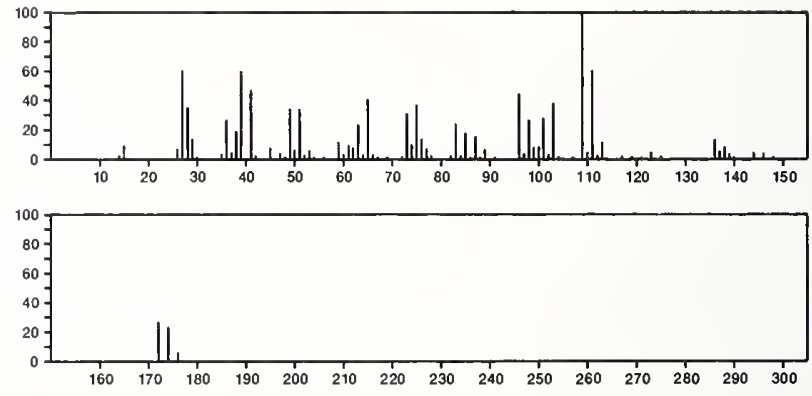

172

$\mathrm{C}_{5} \mathrm{H}_{10} \mathrm{Cl}_{2} \mathrm{O}_{2}$

Ethane, 1,1'-[methylenebis(oxy)]bis[2-chloro-

111-91-1

$\mathrm{Cl} \mathrm{CH}_{2} \mathrm{CH}_{2} \mathrm{OCH}_{2} \mathrm{OCH}_{2} \mathrm{CH}_{2} \mathrm{Cl}$
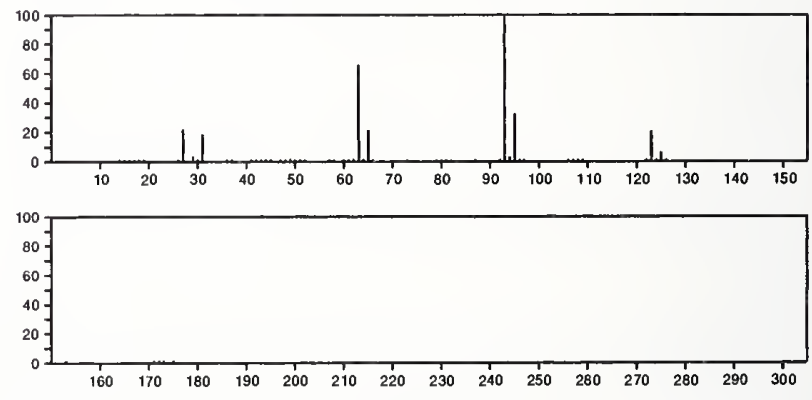

172

$\mathrm{C}_{6} \mathrm{H}_{4} \mathrm{O}_{6}$

319-89-1

2,5-Cyclohexadiene-1,4-dione, 2,3,5,6-tetrahydroxy-
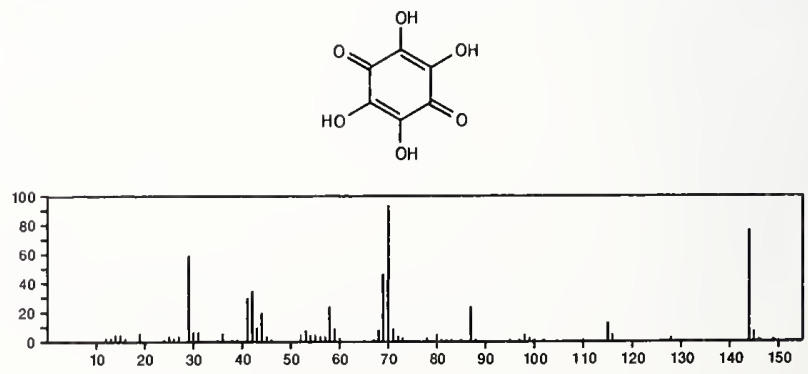

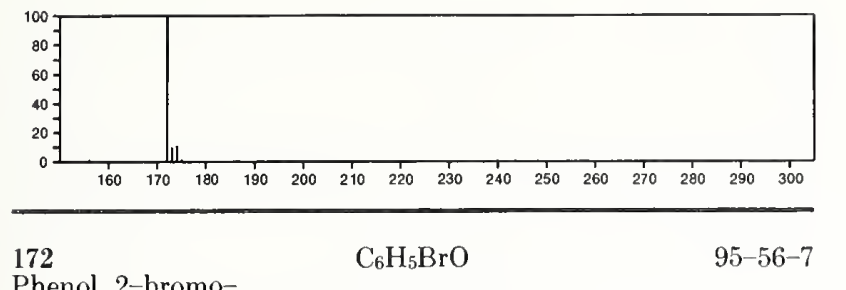

Phenol, 2-bromo-
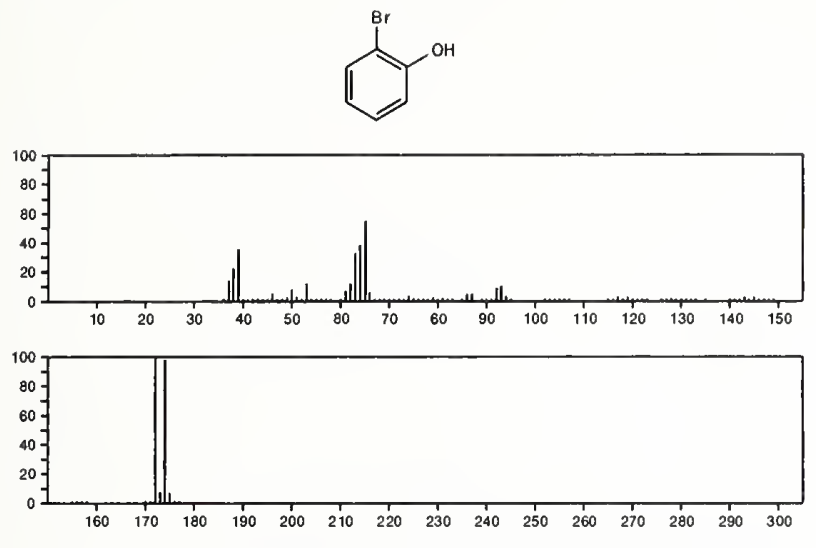

$172 \quad \mathrm{C}_{6} \mathrm{H}_{5} \mathrm{BrO} \quad 106-41-2$

Phenol, 4-bromo-
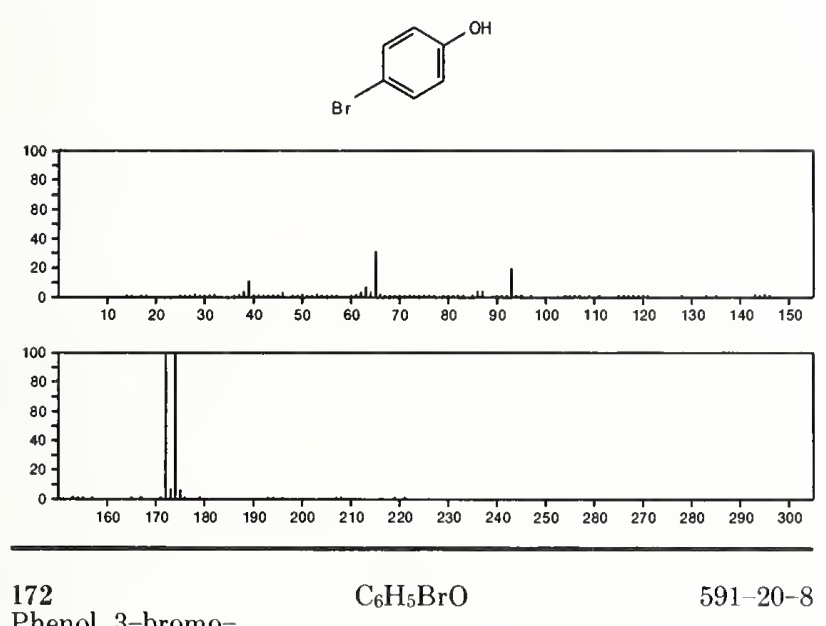

Phenol, 3-bromo-
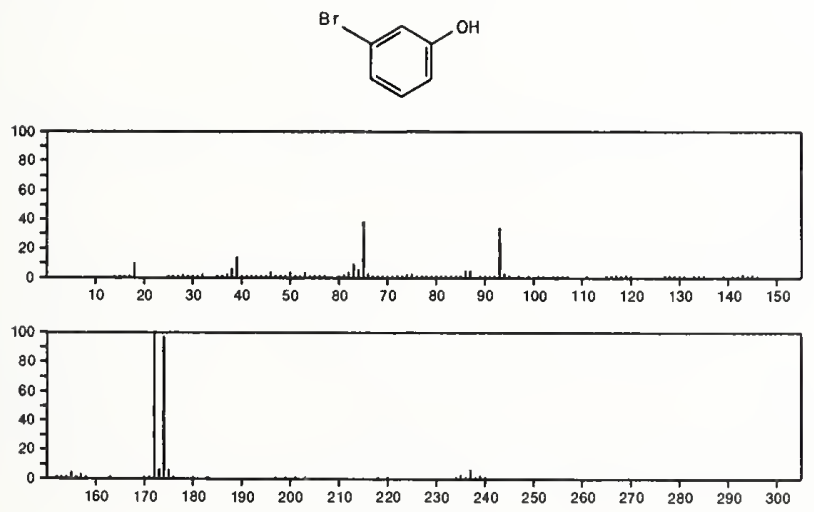

172

Benzenamine, 4-chloro-2-nitro-
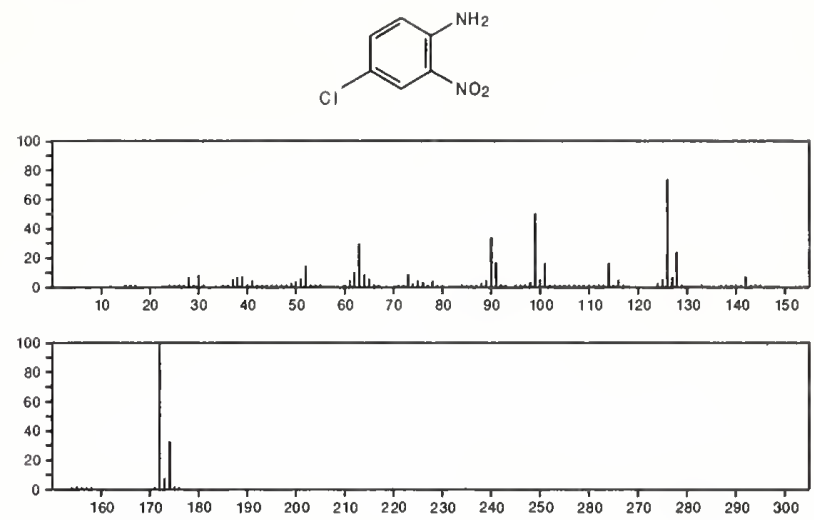

172

Benzenesulfonamide, 4-amino-

$\mathrm{C}_{6} \mathrm{H}_{8} \mathrm{~N}_{2} \mathrm{O}_{2} \mathrm{~S}$

$63-74-1$
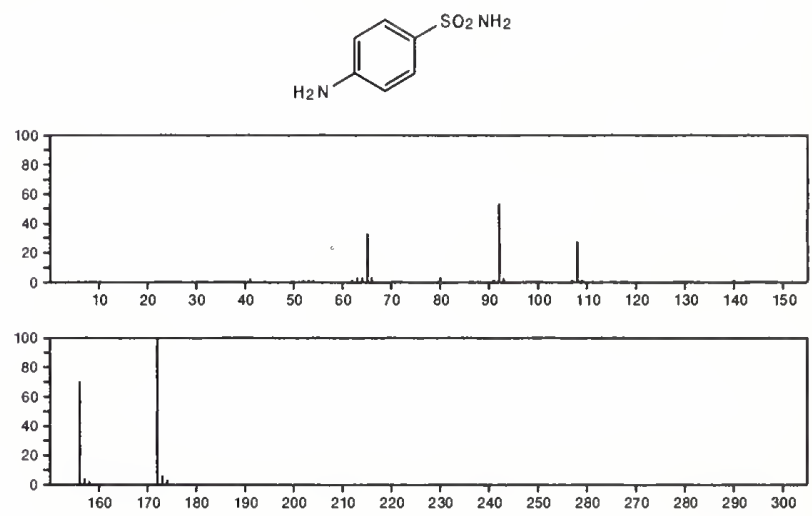

172

$\mathrm{C}_{6} \mathrm{H}_{8} \mathrm{~N}_{2} \mathrm{O}_{2} \mathrm{~S}$

$80-17-1$

Benzenesulfonic acid, hydrazide

$\mathrm{H}_{2} \mathrm{NNHSO}_{2} \mathrm{Ph}$

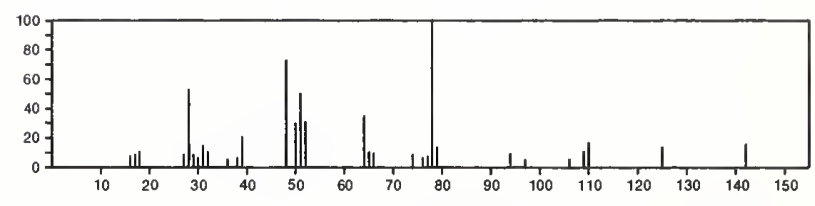

172

$\mathrm{C}_{6} \mathrm{H}_{8} \mathrm{~N}_{2} \mathrm{O}_{2} \mathrm{~S}$

$29682-53-9$

1,2,3-Thiadiazole-4-carboxylic acid, 5-methyl-, ethyl ester
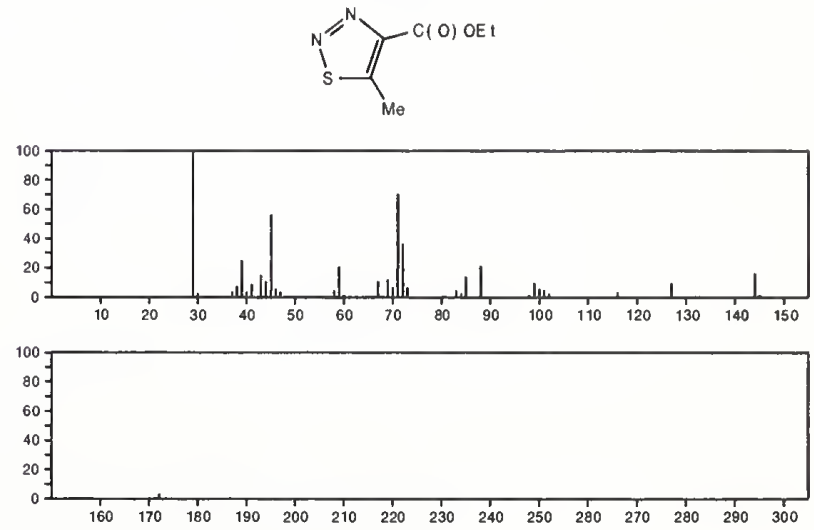
172

$\mathrm{C}_{6} \mathrm{H}_{12} \mathrm{~N}_{4} \mathrm{O}_{2}$

Piperazine, 2,6-dimethyl-1,4-dinitroso-<smiles>CC1CN([O-])C[C@@H](O)N1O</smiles>
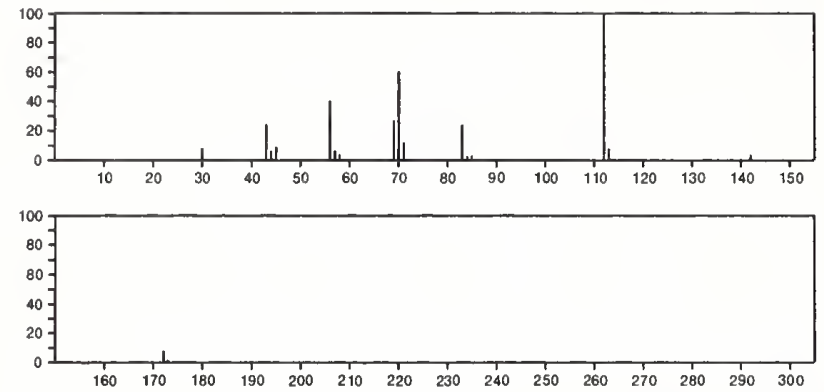

172

Piperazine, 2,5-dimethyl-1,4-dinitroso-

$55556-88-2$<smiles>CC1CN([O-])[C@H](C)CN1O</smiles>
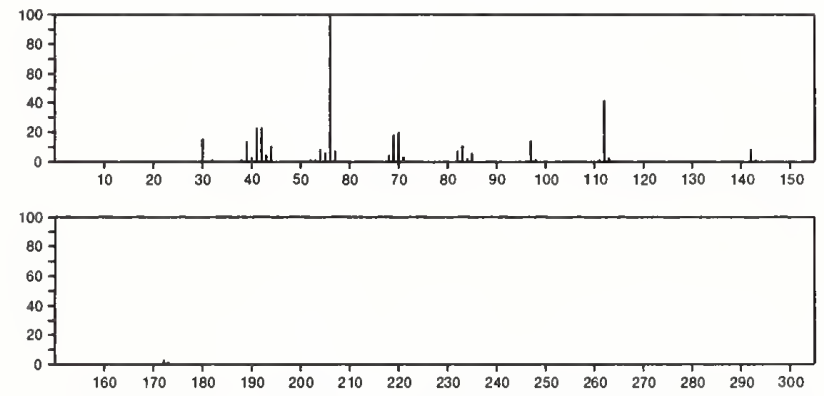

$172 \quad \mathrm{C}_{6} \mathrm{H}_{12} \mathrm{~N}_{4} \mathrm{O}_{2}$

1,5-Diazocine, octahydro-1,5-dinitroso-

$55556-89-3$
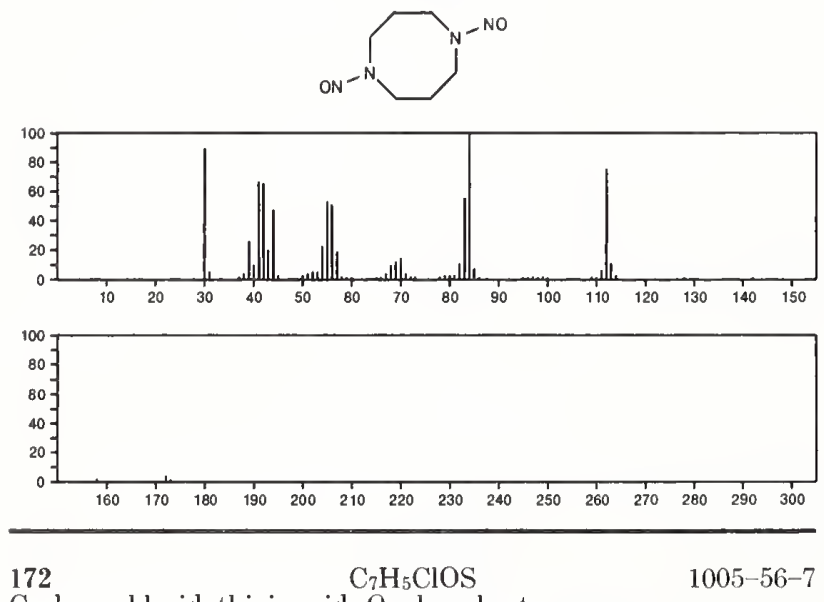

$\mathrm{C}_{7} \mathrm{H}_{5} \mathrm{ClOS}$

$1005-56-7$

Carbonochloridothioic acid, $O$-phenyl ester

$\mathrm{CIC}$ (S) OPh

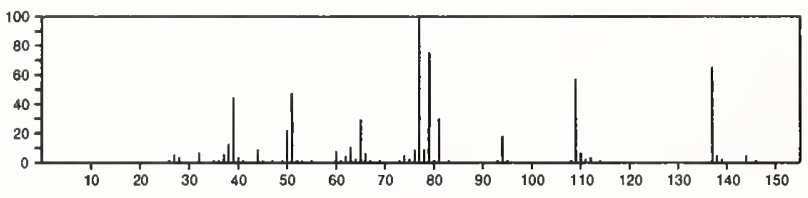

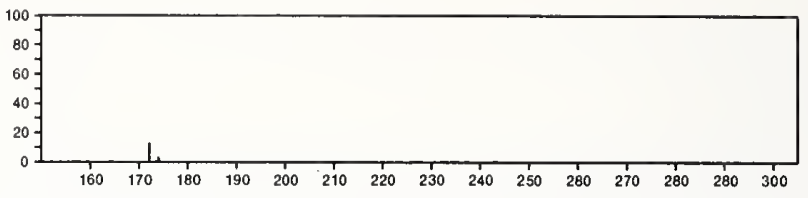

172

$\mathrm{C}_{7} \mathrm{H}_{5} \mathrm{ClOS}$

13464-19-2

Carbonochloridothioic acid, $S$-phenyl ester

$\mathrm{CIClO} \mathrm{SPh}$
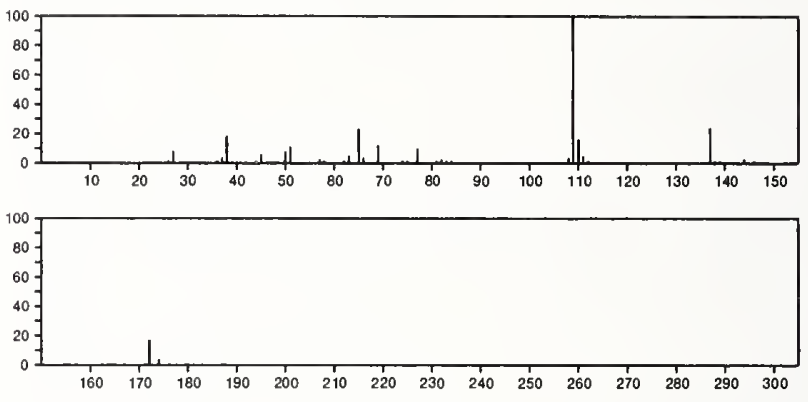

172

$\mathrm{C}_{7} \mathrm{H}_{8} \mathrm{OS}_{2}$

1005-55-6

2-Propanone, 1-(5-methyl-3H-1,2-dithiol-3-ylidene)-
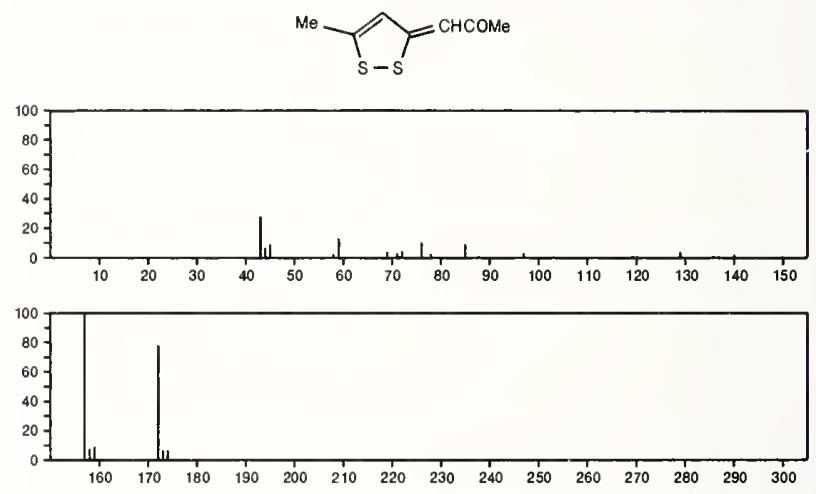

17

$\mathrm{C}_{7} \mathrm{H}_{8} \mathrm{OS}{ }_{2}$

2-Furancarbodithioic acid, ethyl ester

20849-29-0

$\pi^{\mathrm{O}(S) S E t}$
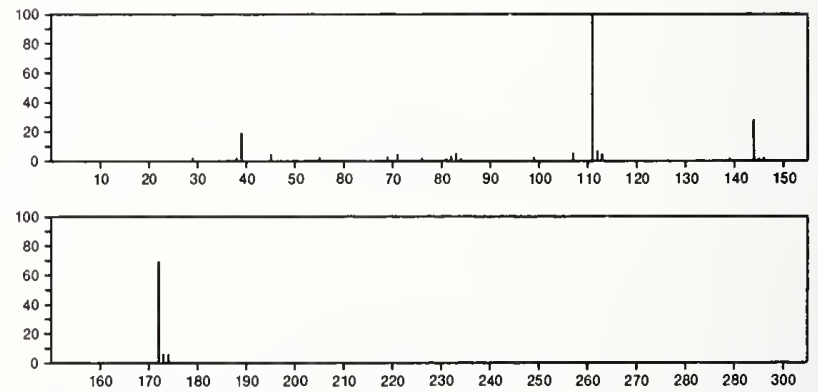

172

$\mathrm{C}_{7} \mathrm{H}_{8} \mathrm{O}_{3} \mathrm{~S}$

Benzenesulfonic acid, 4-methyl-

104-15-4
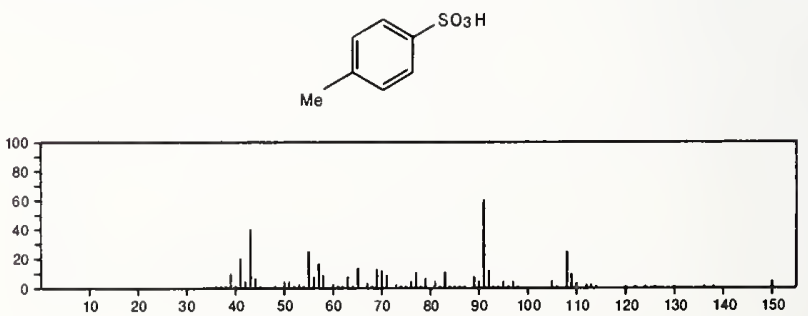


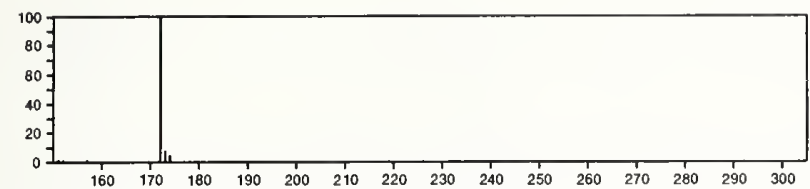

172

$\mathrm{C}_{7} \mathrm{H}_{8} \mathrm{O}_{3} \mathrm{~S}$

$2158-88-5$

2-Thiophenecarboxylic acid, 3-hydroxy-, ethyl ester
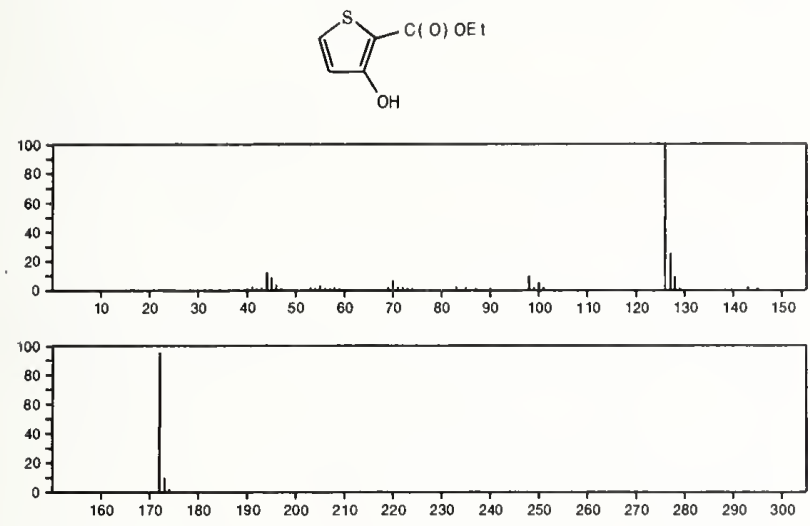

172

$\mathrm{C}_{7} \mathrm{H}_{8} \mathrm{O}_{3} \mathrm{~S}$

$7210-60-8$

2-Thiophenecarboxylic acid, 5-hydroxy-, ethyl ester
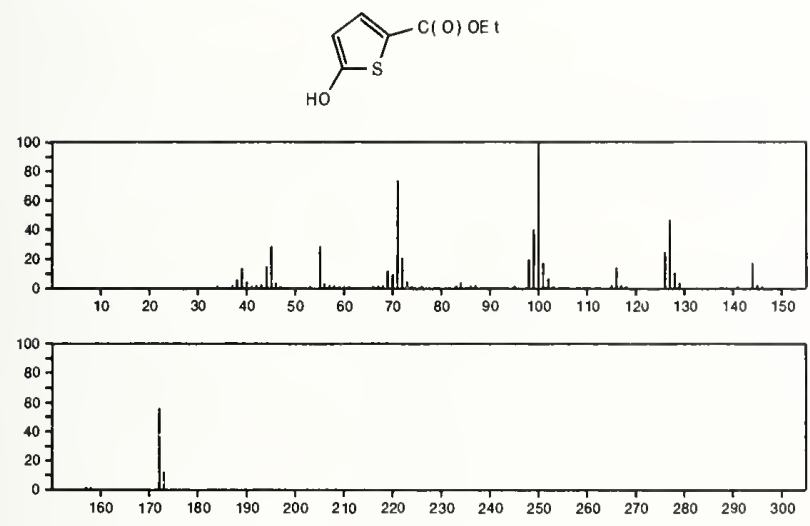

172

$\mathrm{C}_{7} \mathrm{H}_{8} \mathrm{O}_{3} \mathrm{~S}$

27489-33-4

Phenol, $o^{-}$(methylsulfonyl)-
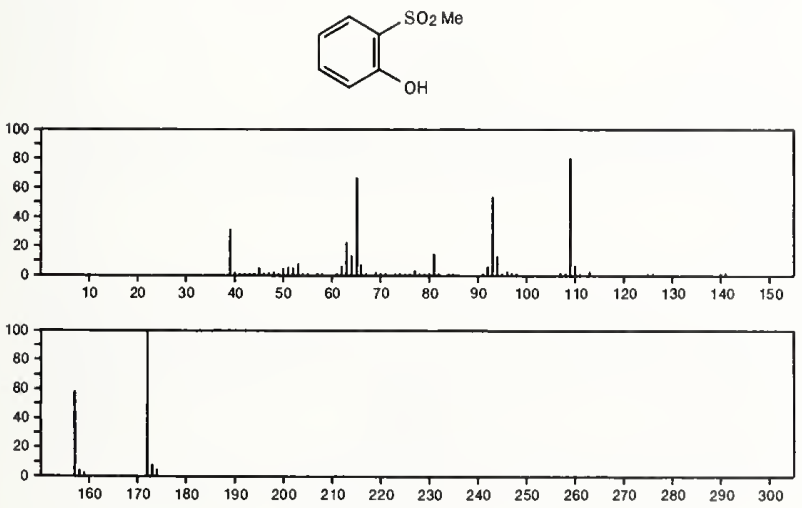

172

$\mathrm{C}_{7} \mathrm{H}_{9} \mathrm{ClN}_{2} \mathrm{O}$

20551-33-1

4(3H)-Pyrimidinone, 5-chloro-2-ethyl-6-methyl-<smiles>CCc1nc(=O)c(Cl)c(C)[nH]1</smiles>
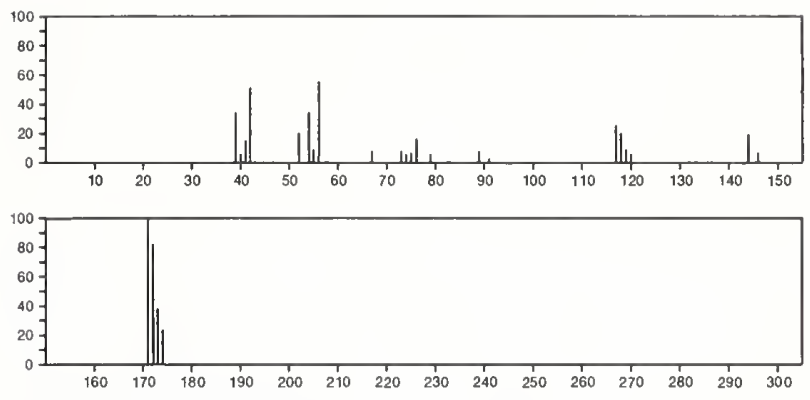

172

$\mathrm{C}_{7} \mathrm{H}_{9} \mathrm{ClN}_{2} \mathrm{O}$

Pyrimidine, 4-chloro-5-ethoxy-2-methyl-

24611-12-9<smiles>CCOc1cnc(N)nc1Cl</smiles>

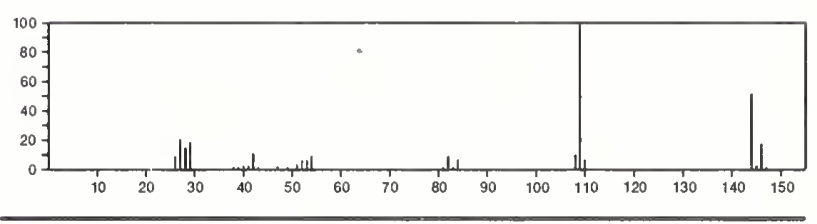

172

$\mathrm{C}_{7} \mathrm{H}_{12} \mathrm{~N}_{2} \mathrm{OS}$

56805-19-7

4-Imidazolidinone, 5-(2-methylpropyl)-2-thioxo-
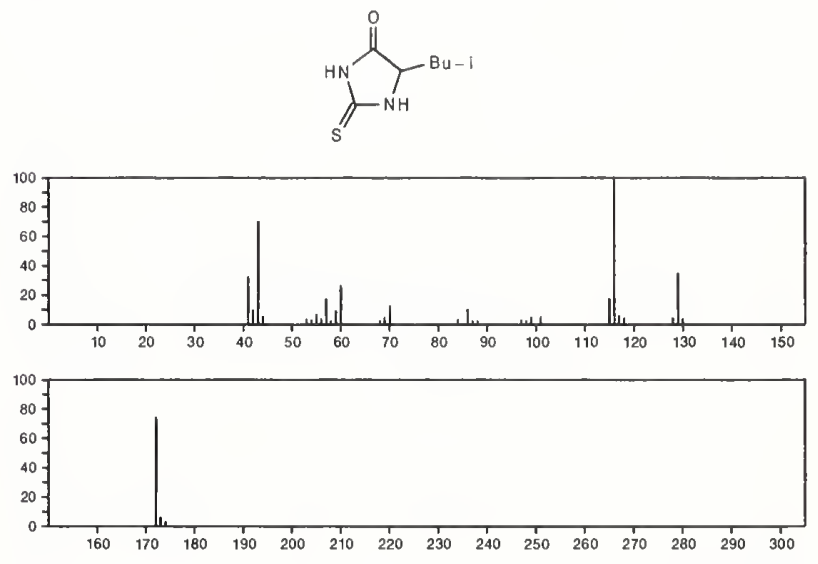

172

$\mathrm{C}_{7} \mathrm{H}_{12} \mathrm{~N}_{2} \mathrm{OS}$

$56830-83-2$

4-Imidazolidinone, 5-(1-methylpropyl)-2-thioxo-
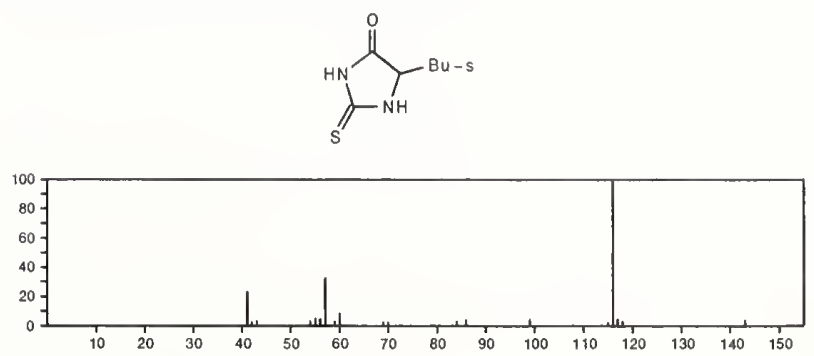


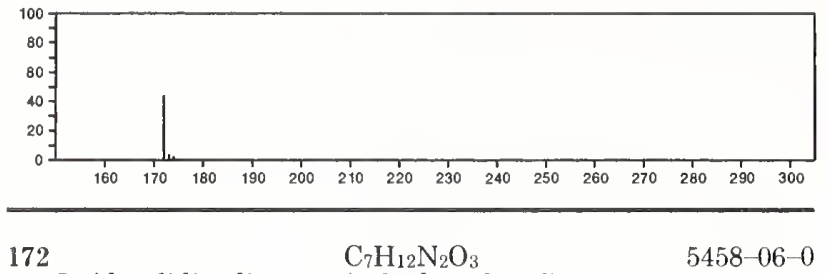

2,4-Imidazolidinedione, 5-(4-hydroxybutyl)
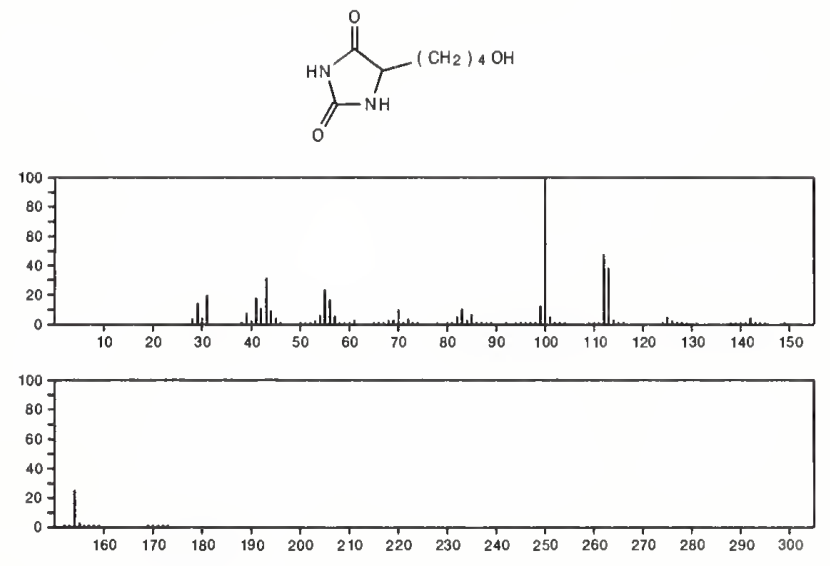

172

$\mathrm{C}_{7} \mathrm{H}_{12} \mathrm{~N}_{2} \mathrm{O}_{3}$

29071-93-0

2,4-Imidazolidinedione, 3-(2-hydroxyethyl)-5,5-dimethyl-
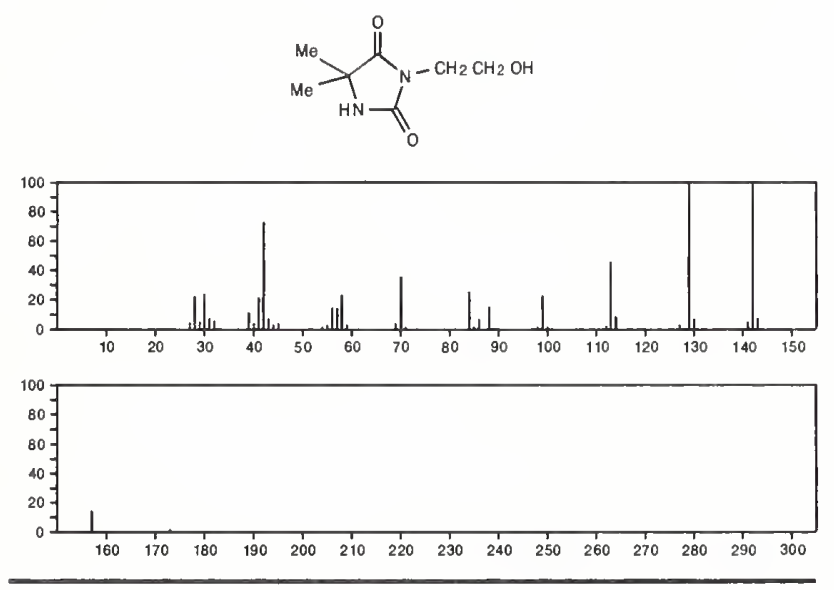

$172 \quad \mathrm{C}_{7} \mathrm{H}_{14} \mathrm{Ge} \quad 4514-07-2$

4-Germaspiro[3.4]octane
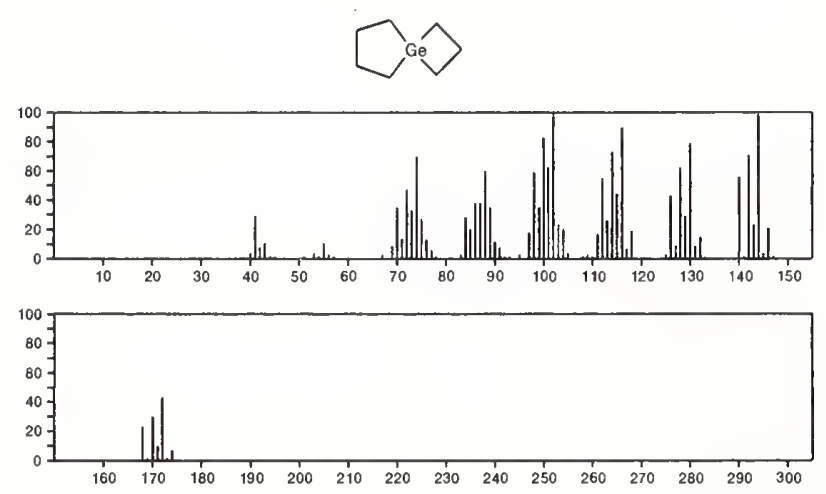

172

$1123-84-8$

Benzene, 1,4-dichoro-2-ethenyl-
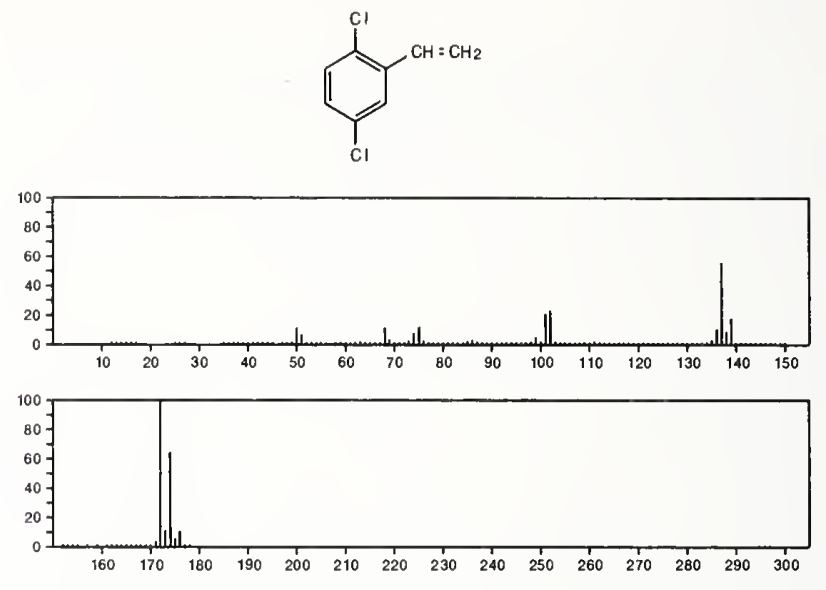

172

$\mathrm{C}_{8} \mathrm{H}_{9} \mathrm{ClO}_{2}$

Ethanol, 2-(4-chlorophenoxy)-
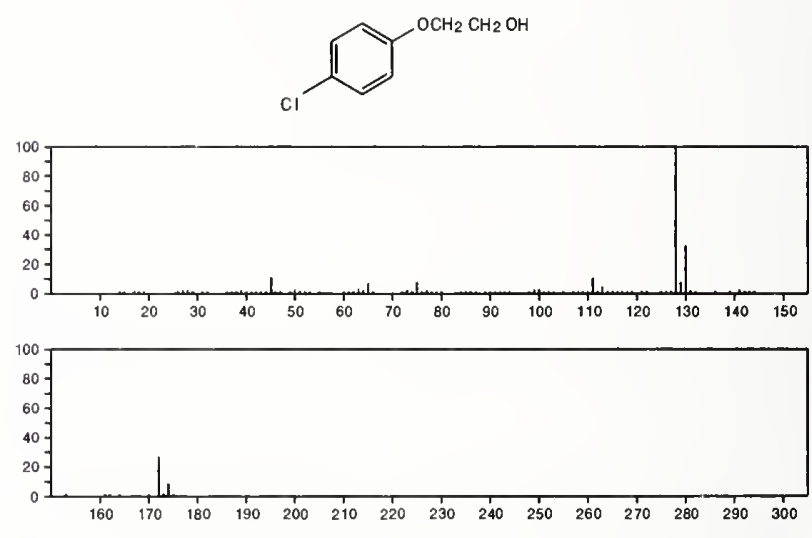

172

$\mathrm{C}_{8} \mathrm{H}_{12} \mathrm{O}_{2} \mathrm{~S}$

1-Oxa-4-thiaspiro[4.5]decan-6-one

33266-05-6
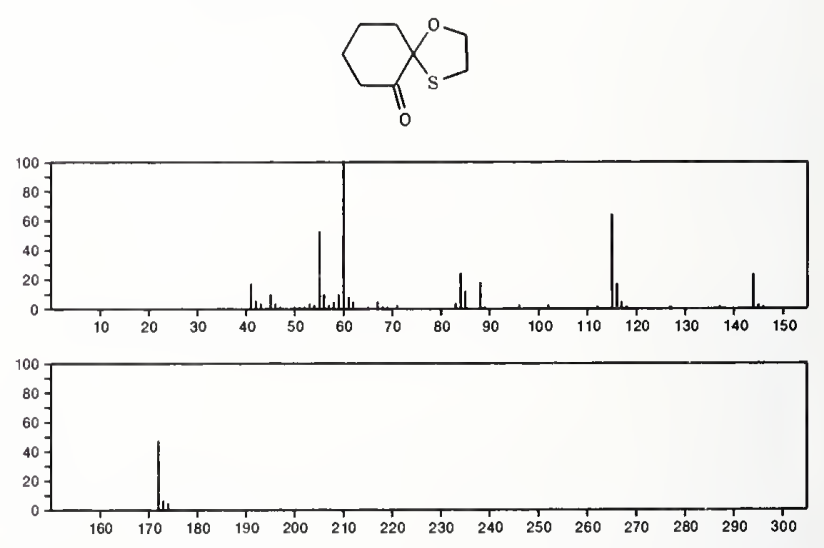

172

1,2-Cyclohexanedicarboxylic acid, cis-

$610-09-3$
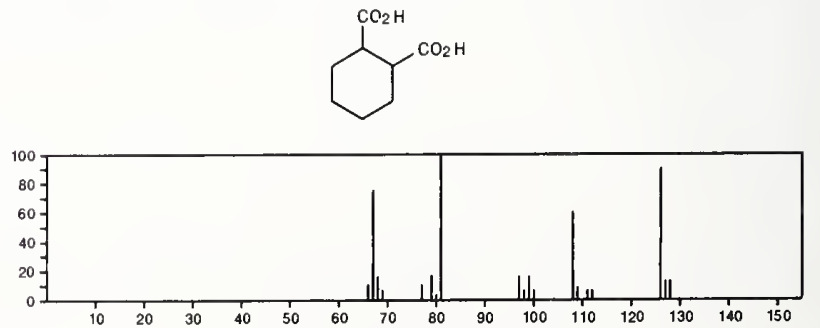

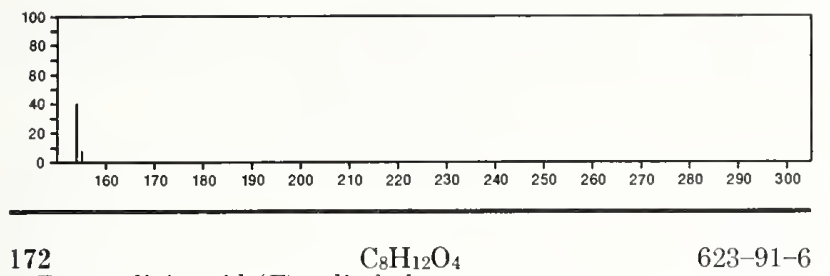

2-Butenedioic acid $(E)$-, diethyl ester

$\mathrm{EtOC}(\mathrm{O}) \mathrm{CH}=\mathrm{CHC}(\mathrm{O}) \mathrm{OE}$ :
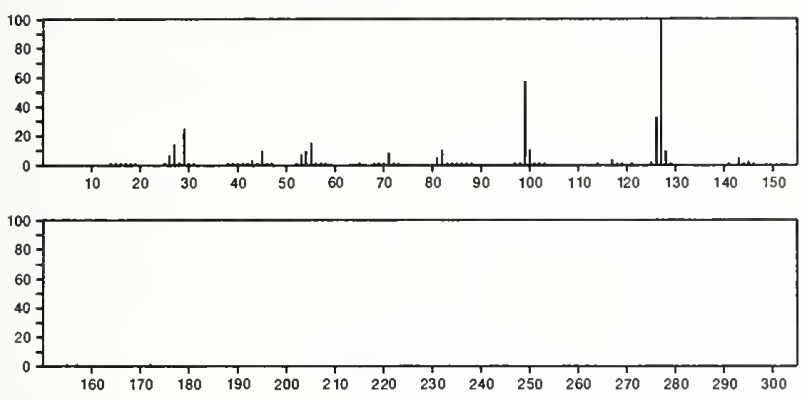

172

$$
\mathrm{C}_{8} \mathrm{H}_{12} \mathrm{O}_{4}
$$

$925-21-3$

2-Butenedioic acid (Z)-, monobutyl ester

$\mathrm{HO}_{2} \mathrm{CCH}=\mathrm{CHC}(\mathrm{O}) \mathrm{O}\left(\mathrm{CH}_{2}\right)_{3} \mathrm{Me}$
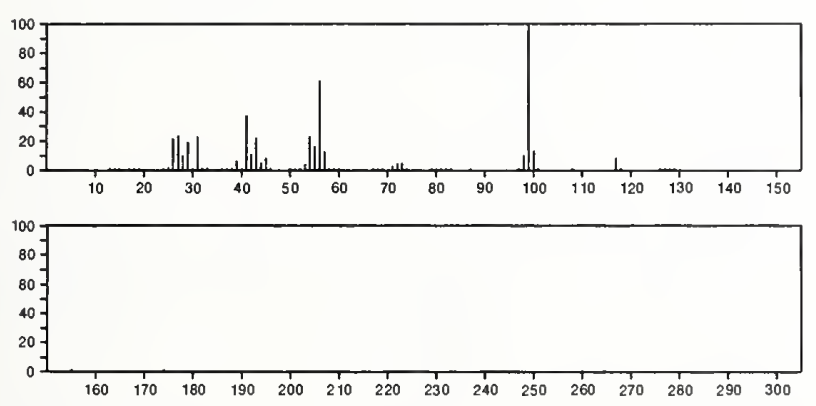

$172 \quad \mathrm{C}_{8} \mathrm{H}_{12} \mathrm{O}_{4} \quad 2305-32-0$

1,2-Cyclohexanedicarboxylic acid, trans-
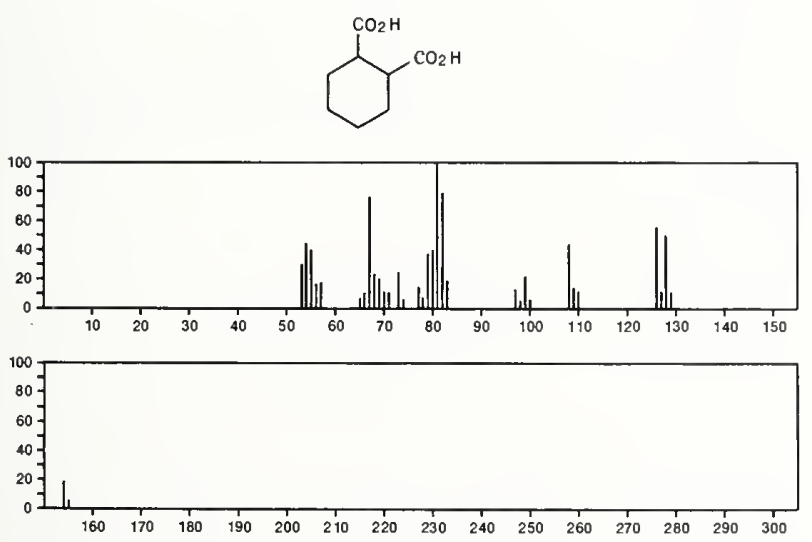

172

$\mathrm{C}_{8} \mathrm{H}_{12} \mathrm{O}_{4}$

1,2-Cyclobutanedicarboxylic acid, dimethyl ester, cis-
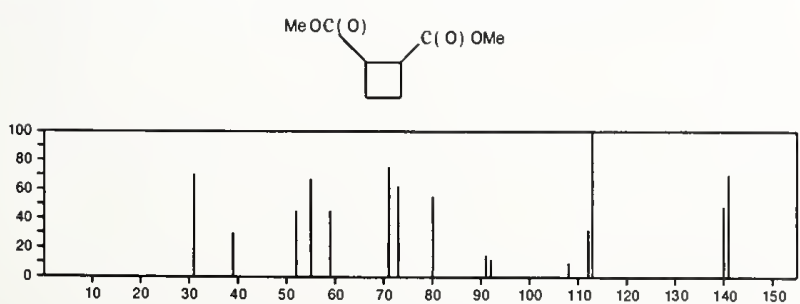
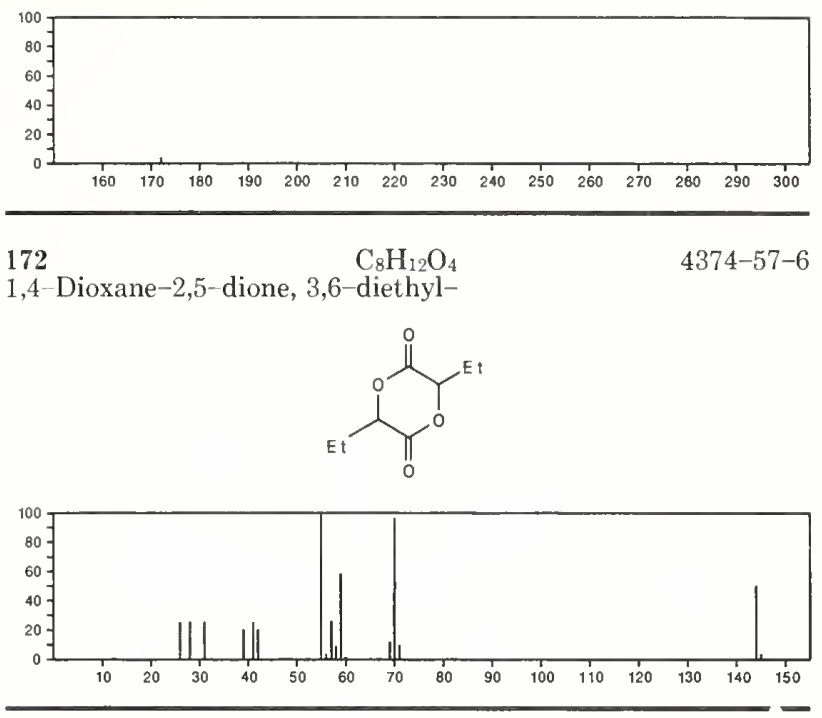

172

$\mathrm{C}_{8} \mathrm{H}_{12} \mathrm{O}_{4}$

$4625-13-2$

Ribofuranose, 1,5-anhydro-2,3-O-isopropylidene-, D-
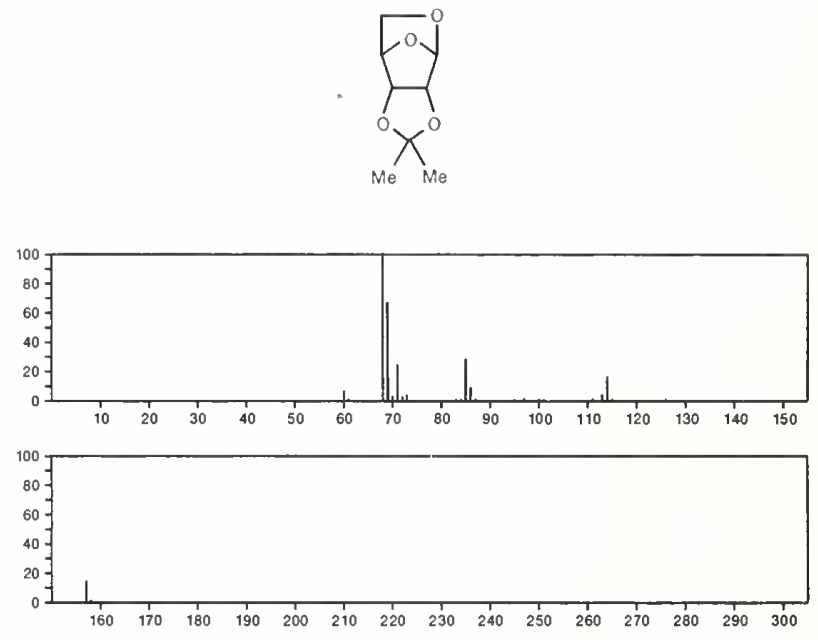

172

$\mathrm{C}_{8} \mathrm{H}_{12} \mathrm{O}_{4}$

1,4-Dioxane-2,5-dione, 3,3,6,6-tetramethyl-

$6713-72-0$<smiles>CC1(C)OC(=O)C(C)([N+](=O)[O-])OC1=O</smiles>

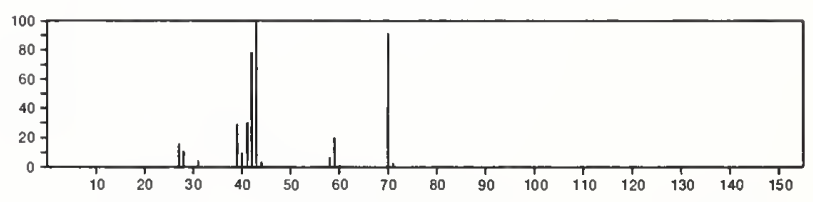

$172 \quad \mathrm{C}_{8} \mathrm{H}_{12} \mathrm{O}_{4}$

$7371-67-7$

1,2-Cyclobutanedicarboxylic acid, dimethyl ester, trans-
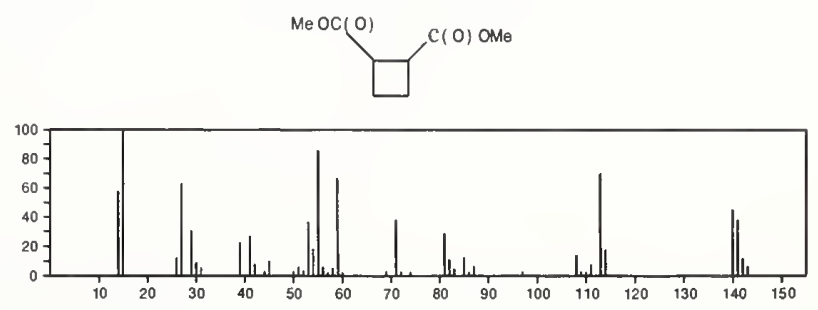


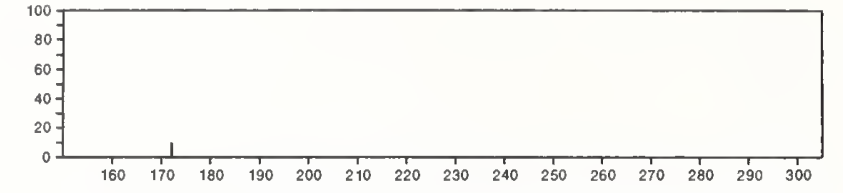

172

2-Propene-1,1-diol, 2-methyl-, diacetate

$$
\mathrm{C}_{8} \mathrm{H}_{12} \mathrm{O}_{4}
$$

OAC

$\mathrm{ACOCHCMO}=\mathrm{CH}_{2}$
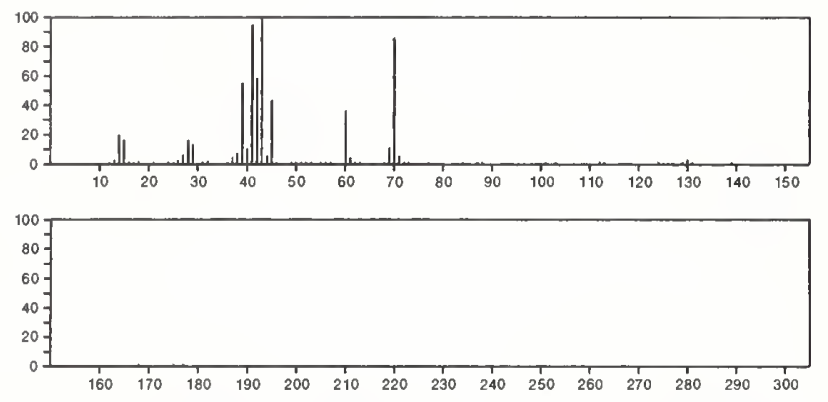

$172 \quad \mathrm{C}_{8} \mathrm{H}_{12} \mathrm{O}_{4} \quad 22870-43-5$ 2H-Pyran-2-carboxylic acid, 3,6-dihydro-6-methoxy-, methyl ester
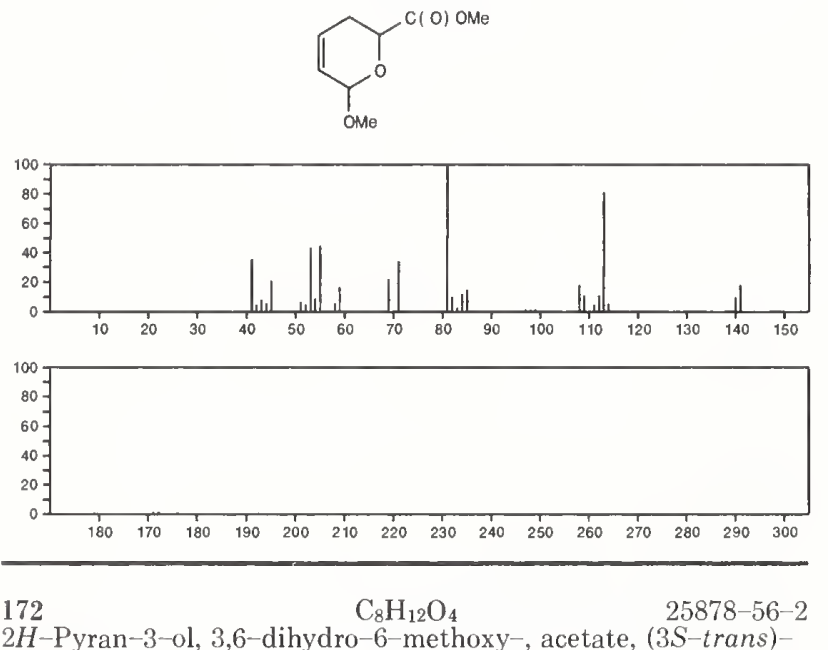

2H-Pyran-3-ol, 3,6-dihydro-6-methoxy-, acetate, (3S-trans)-
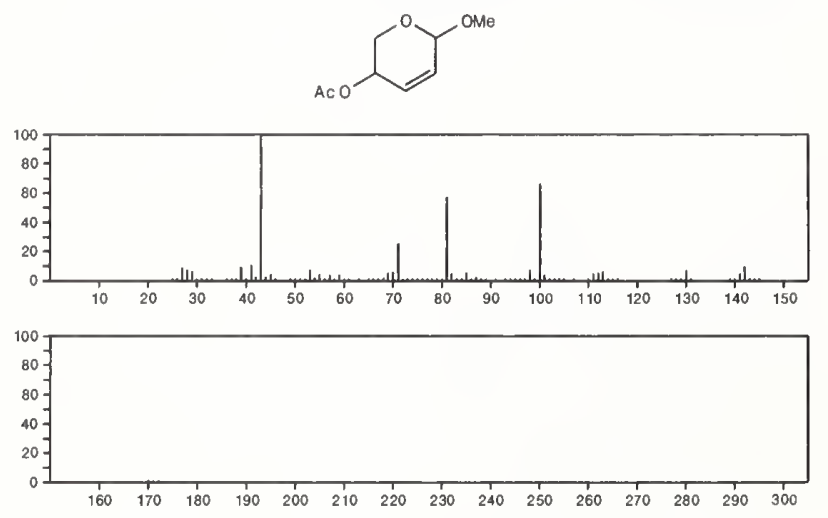

172

$\mathrm{C}_{8} \mathrm{H}_{12} \mathrm{O}_{4}$

26532-19-4

2H-Pyran-3-ol, 3,6-dihydro-6-methoxy-, acetate, (3R-cis)-
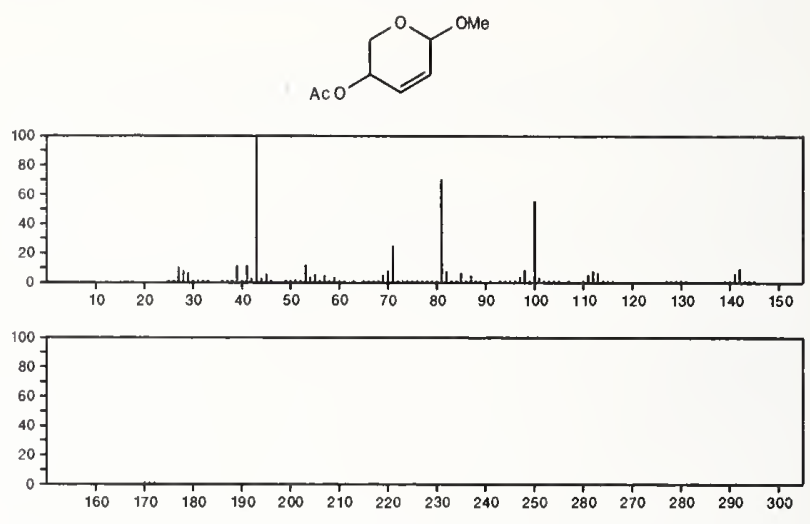

172

$\mathrm{C}_{8} \mathrm{H}_{12} \mathrm{O}_{4}$

$40637-56-7$

Propanedioic acid, 2-propenyl-, dimethyl ester

$\mathrm{C}(\mathrm{O}) \mathrm{OMe}$

$\mathrm{MeOC}(\mathrm{O}) \stackrel{\mathrm{CHCH}}{\mathrm{C}} \mathrm{CH}=\mathrm{CH}_{2}$
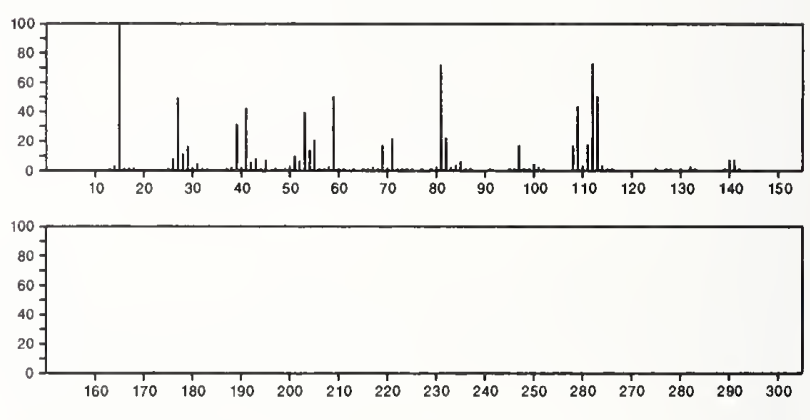

172

1-Butene-1,4-diol, diacetate

$\mathrm{C}_{8} \mathrm{H}_{12} \mathrm{O}_{4}$

$54484-67-2$

$\mathrm{AcOCH}=\mathrm{CHCH}_{2} \mathrm{CH}_{2} \mathrm{OAC}$

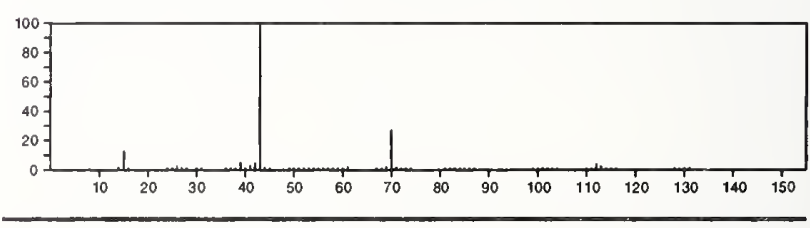

172

$\mathrm{C}_{8} \mathrm{H}_{12} \mathrm{~S}_{2}$

3988-71-4

Thiophene, 2-(butylthio)-
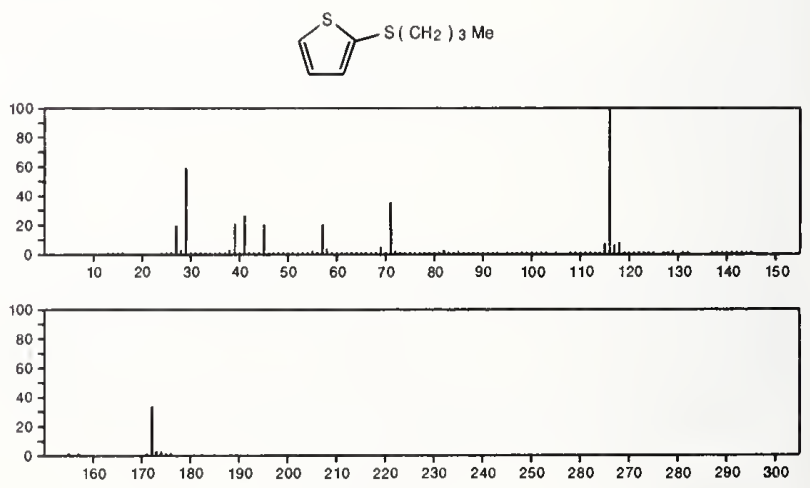
$172 \quad \mathrm{C}_{8} \mathrm{H}_{12} \mathrm{~S}_{2} \quad 40697-97-0$ Thiophene, 3-(dihydro-3(2H)-thienylidene)tetrahydro-
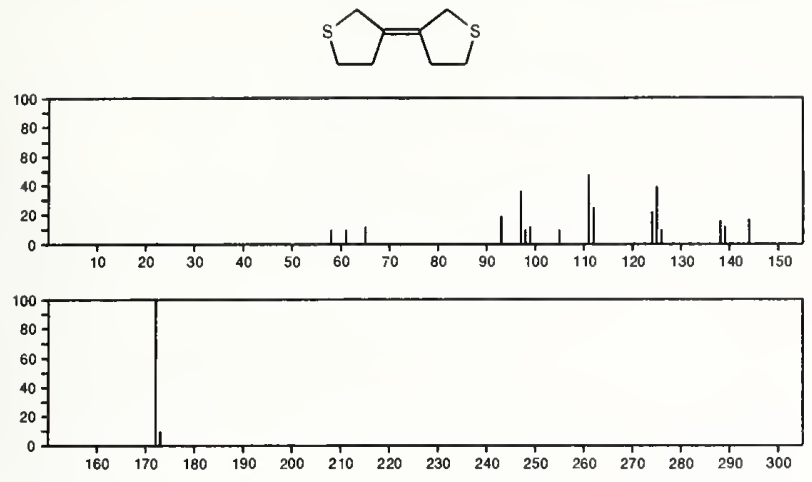

172

Carbazic acid, 3-pentylidene--, ethyl ester

$\mathrm{Me}\left(\mathrm{CH}_{2}\right)_{3} \mathrm{CH}=\mathrm{NNHC}(\mathrm{O}) \mathrm{OEt}$
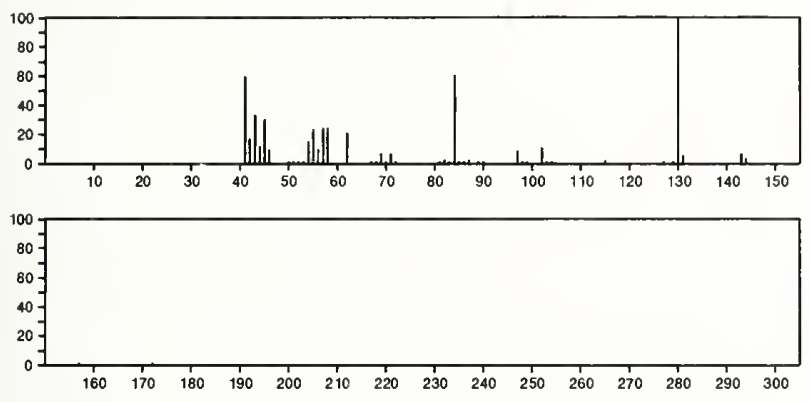

172

$\mathrm{C}_{8} \mathrm{H}_{16} \mathrm{~N}_{2} \mathrm{O}_{2}$

26394-95-6

2-Propenoic acid, 3,3-bis(dimethylamino)-, methyl ester

\section{NMe 2}

$\mathrm{Me} \mathrm{OC}(0) \mathrm{CH}=\mathrm{CNME} 2$
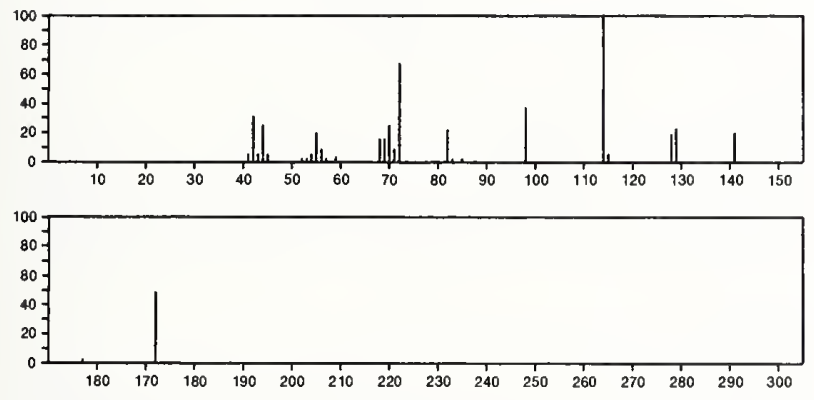

172

4-Pentenoic acid, trimethylsilyl ester

$M e S_{3} \mathrm{OC}(\mathrm{O}) \mathrm{CH}_{2} \mathrm{CH}_{2} \mathrm{CH}=\mathrm{CH}_{2}$
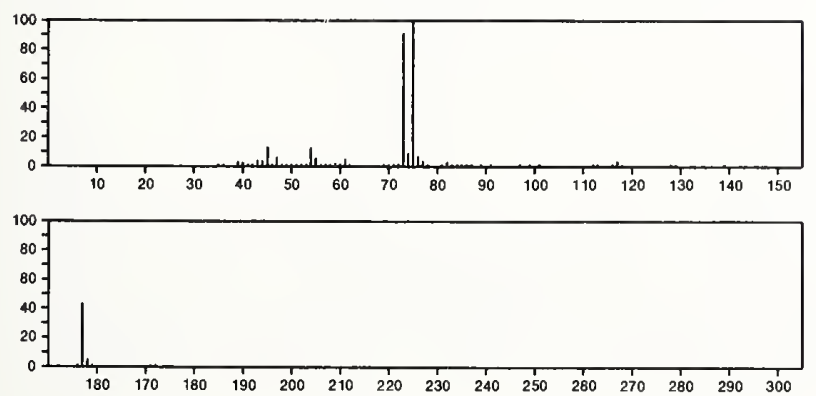

172

$\mathrm{C}_{8} \mathrm{H}_{16} \mathrm{O}_{2} \mathrm{Si}$

$25436-25-3$
$\mathrm{Me}{ }_{3} \mathrm{Si} \mathrm{OC}(\mathrm{O}) \mathrm{CH}=\mathrm{CMe}_{2}$
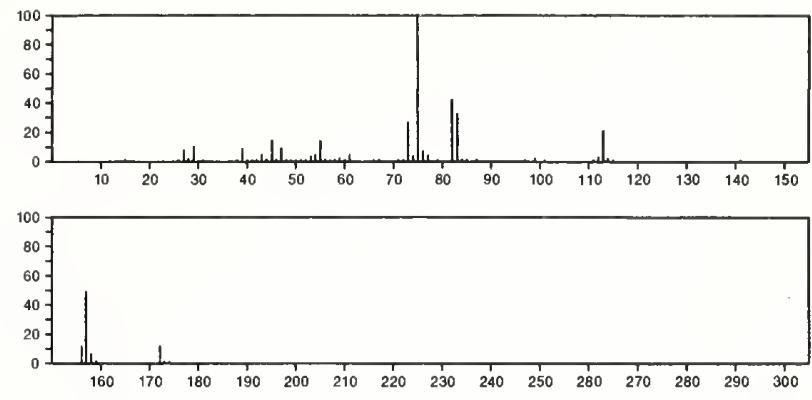

172

$\mathrm{C}_{8} \mathrm{H}_{17} \mathrm{BO}_{3}$

1,3,2-Dioxaborinane, 2-(pentyloxy)-

$55162-68-0$

$\left[\begin{array}{c}\mathrm{C}_{\mathrm{B}} \\ 1 \\ 0\end{array}\right.$
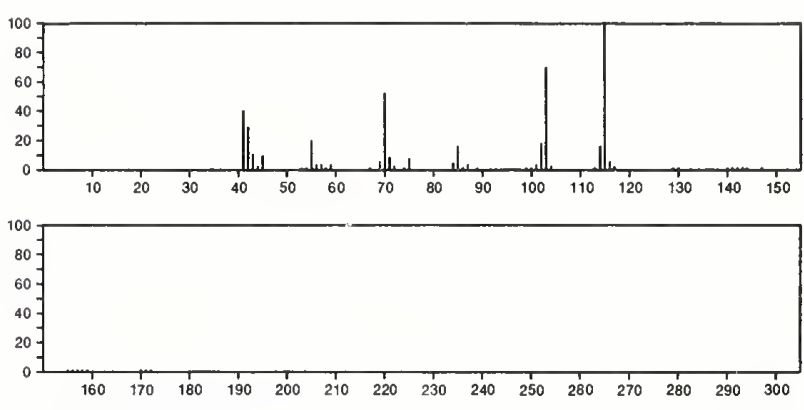

172

1,3,2-Dioxaborinane, 2-(1-methylbutoxy)-

$55162-69-1$

$\mathrm{C}_{8} \mathrm{H}_{17} \mathrm{BO}_{3}$

$\left[\begin{array}{c}0 \\ 1 \\ 1\end{array}\right.$
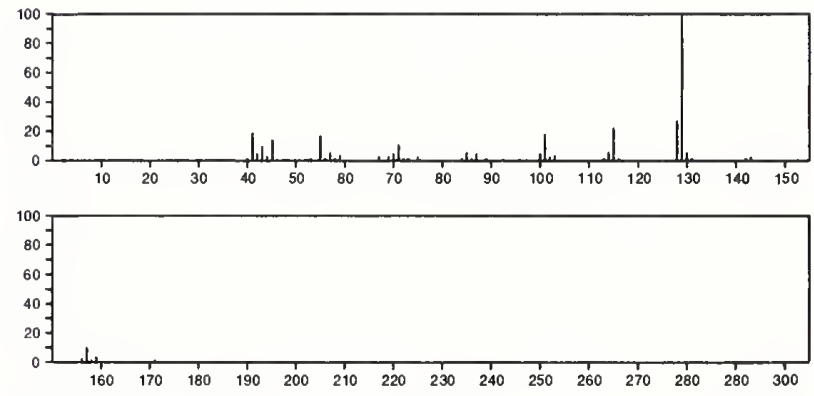

172

$\mathrm{C}_{9} \mathrm{H}_{4} \mathrm{~N}_{2} \mathrm{O}_{2}$

$1807-49-4$

$1 H$-Indene-1,3(2H)-dione, 2-diazo-
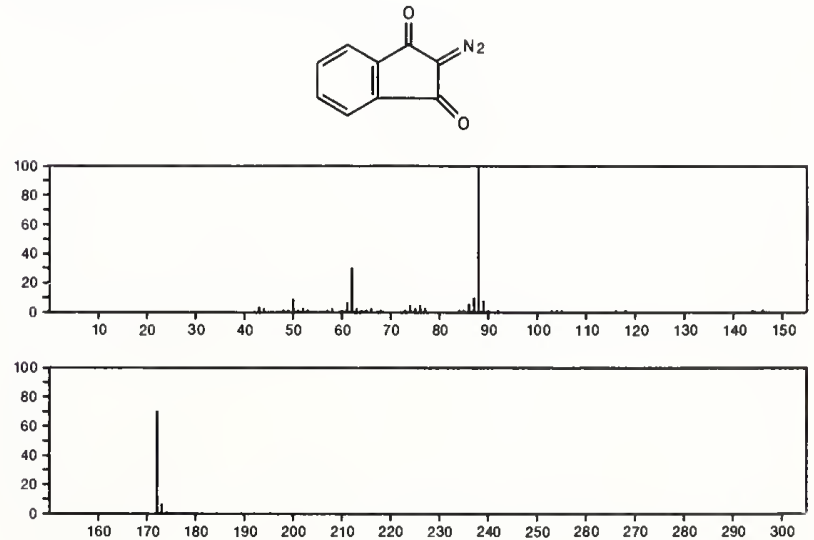
172

$\mathrm{C}_{9} \mathrm{H}_{16} \mathrm{OS}$

$57156-88-4$

1-Oxa-4-thiaspiro[4.4 ]nonane, 6,9-dimethyl-
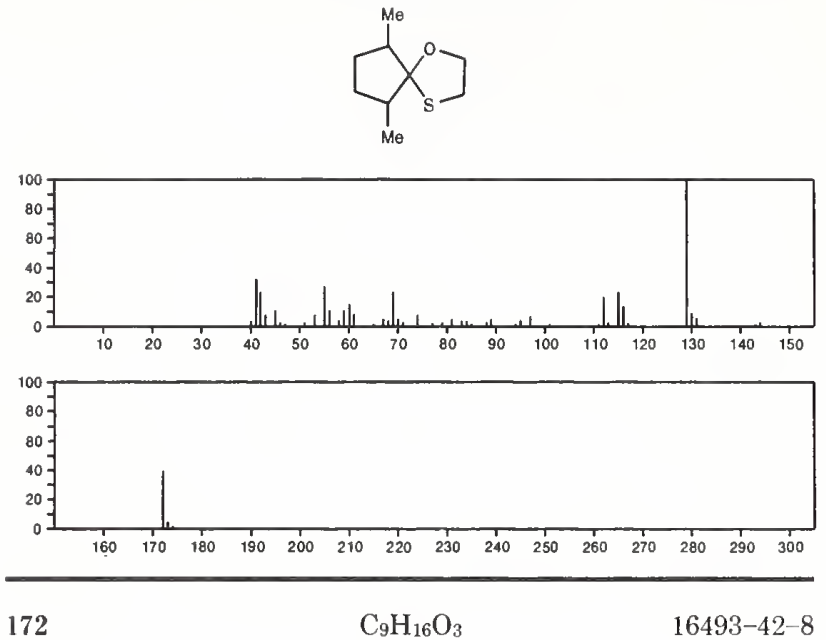

Octanoic acid, 7-oxo-, methyl ester
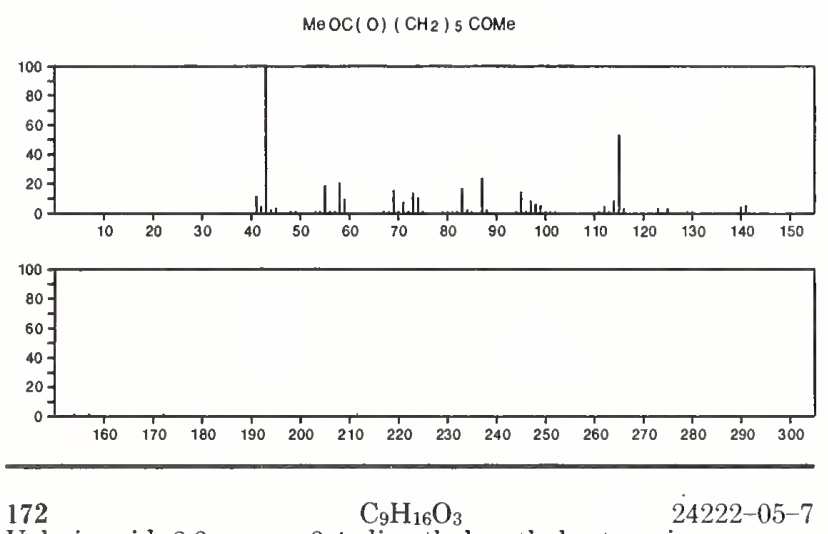

Valeric acid, 2,3-epoxy-3,4-dimethyl-, ethyl ester, cis-
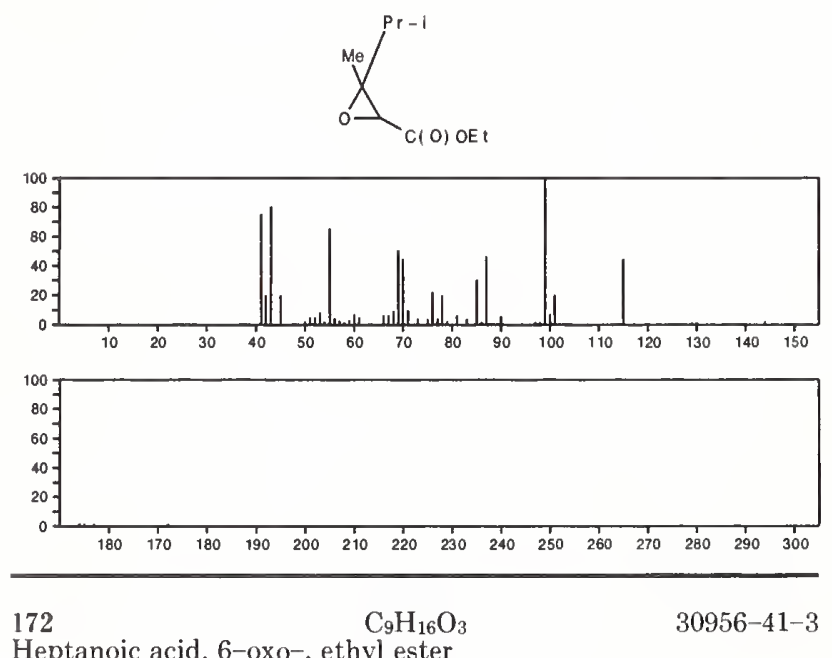

Heptanoic acid, 6-oxo-, ethyl ester

$\mathrm{Me} \mathrm{CO}\left(\mathrm{CH}_{2}\right){ }_{4} \mathrm{C}(\mathrm{O}) \mathrm{OE}$ t
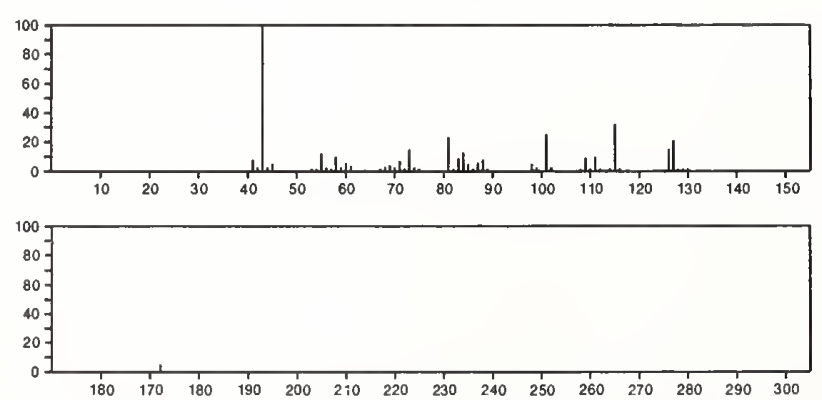

172

$\mathrm{C}_{9} \mathrm{H}_{16} \mathrm{O}_{3}$

$51756-09-3$

Pentanoic acid, 2-acetyl-4-methyl-, methyl ester

COMe

$\mathrm{MeOC}(0) \mathrm{CHCH}_{2} \mathrm{CHM}_{2}$
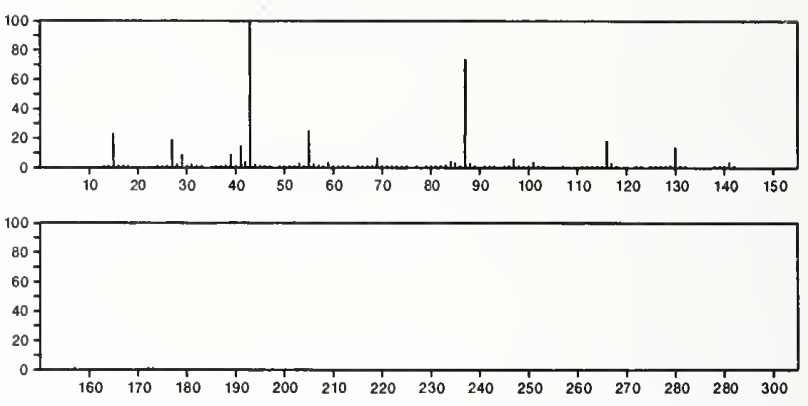

172

$\mathrm{C}_{9} \mathrm{H}_{16} \mathrm{O}_{3}$

$55162-84-0$

4-Pentenoic acid, 5- ethoxy-, ethyl ester, $(E)$ -

$\mathrm{E}$ (OC) (O) $\mathrm{CH}_{2} \mathrm{CH}_{2} \mathrm{CH}=\mathrm{CHOE} \mathrm{t}$
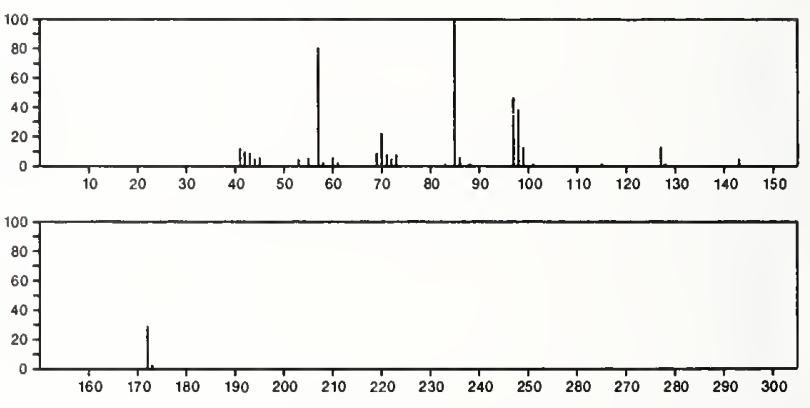

172

$\mathrm{C}_{9} \mathrm{H}_{16} \mathrm{O}_{3}$

$56292-99-0$

1,4-Dioxaspiro[4.5]decane, 8-methoxy-
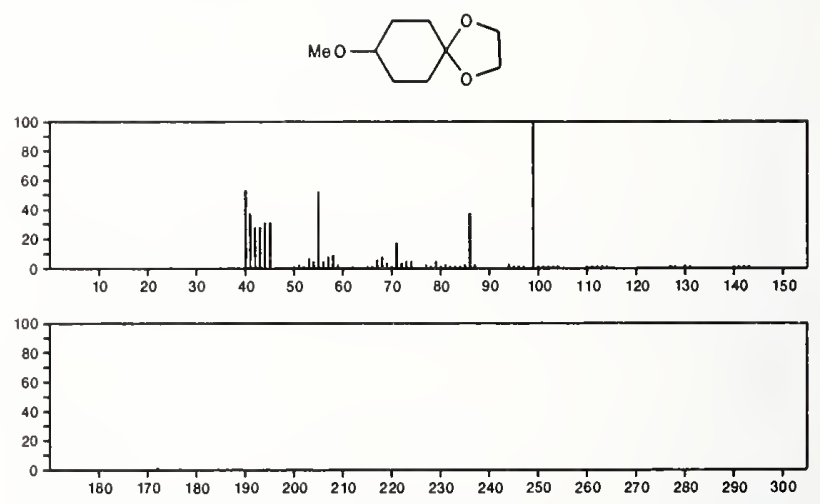

172

$\mathrm{C}_{9} \mathrm{H}_{18} \mathrm{NO}_{2}$

$2226-96-2$

1-Piperidinyloxy, 4-hydroxy-2,2,6,6-tetramethyl-
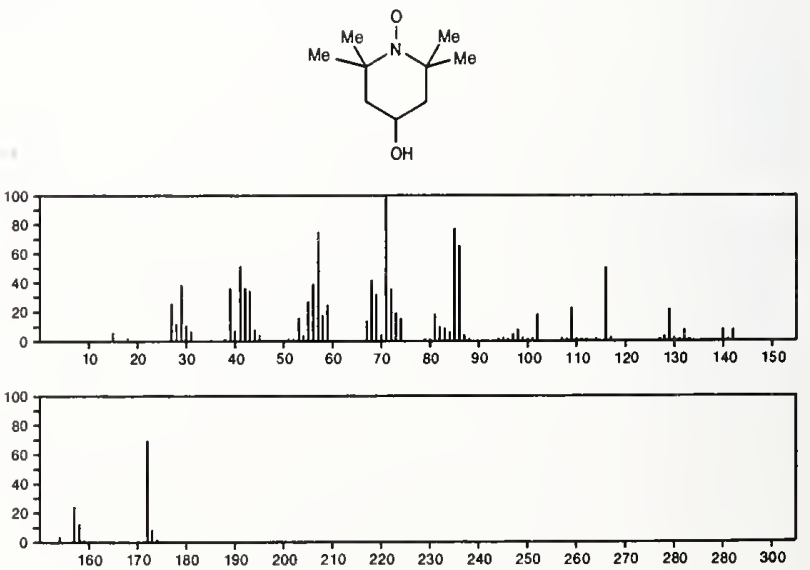
172

$\mathrm{C}_{9} \mathrm{H}_{18} \mathrm{NO}_{2}$

27298-75-5

1-Pyrrolidinyloxy, 3-(hydroxymethyl)-2,2,5,5-tetramethyl
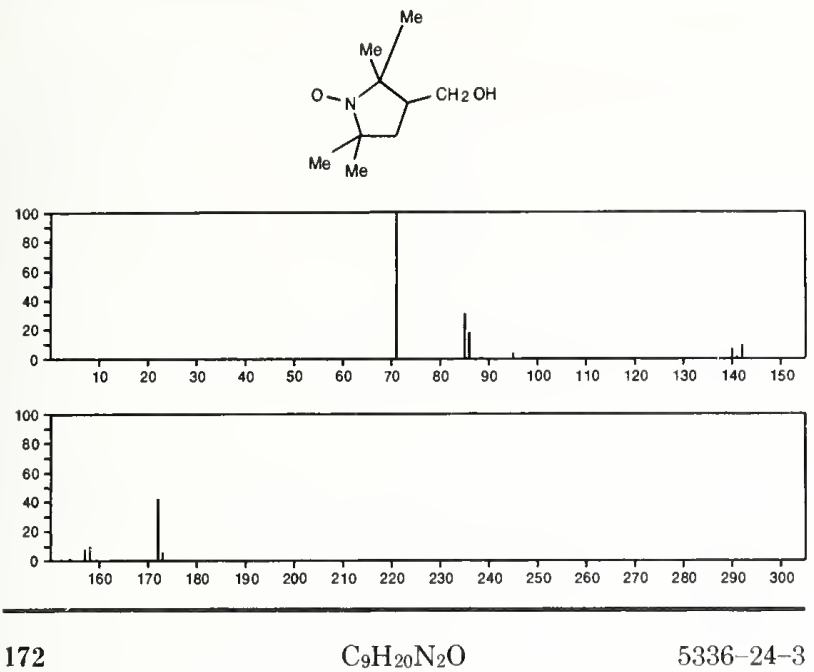

Urea, $N, N^{\prime}$-bis(1,1-dimethylethyl)-

t-BuNHCONHBu-t
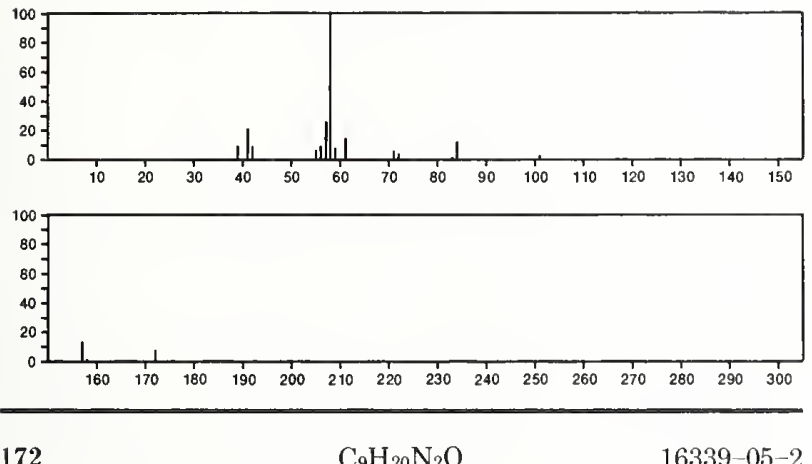

172

$\mathrm{C}_{9} \mathrm{H}_{20} \mathrm{~N}_{2} \mathrm{O}$

$16339-05-2$

1-Pentanamine, $N$-butyl- $N$-nitroso

$\mathrm{Me}\left(\mathrm{CH}_{2}\right)_{4} \mathrm{~N}(\mathrm{NO})\left(\mathrm{CH}_{2}\right)_{3} \mathrm{Me}$
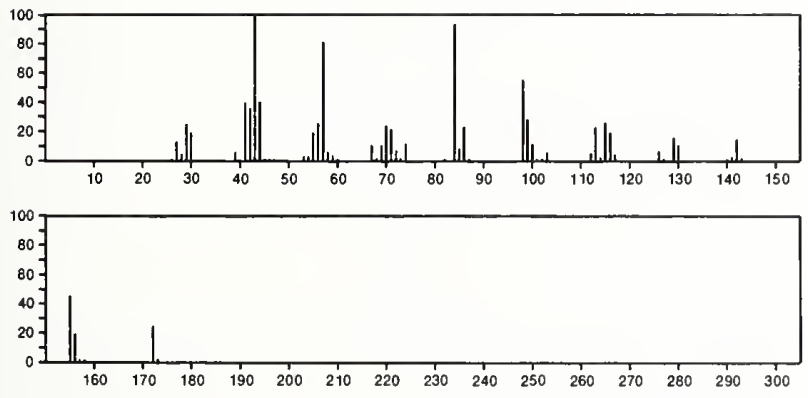

172

$\mathrm{C}_{9} \mathrm{H}_{20} \mathrm{~N}_{2} \mathrm{O}$

Pentylamine, $N$-sec-butyl- $N$-nitroso-

S-BUN(NO) $\left(\mathrm{CH}_{2}\right)_{4} \mathrm{Me}$
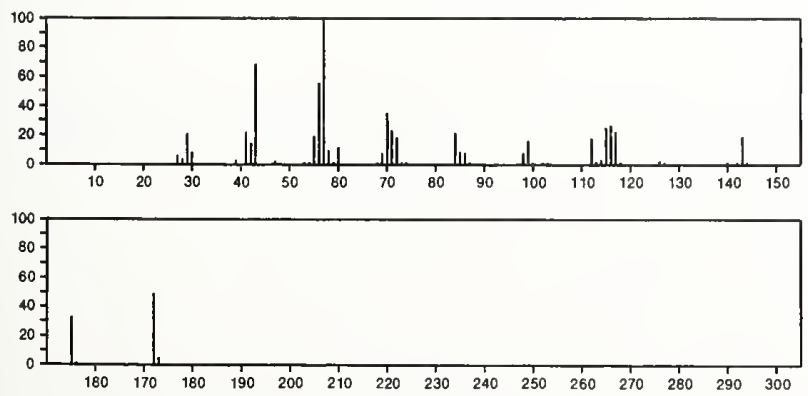

172

$\mathrm{C}_{9} \mathrm{H}_{20} \mathrm{~N}_{2} \mathrm{O}$

$34423-54-6$

Octylamine, $N$-methyl- $N$-nitroso-

$\mathrm{MeN}(\mathrm{NO})\left(\mathrm{CH}_{2}\right)>\mathrm{Me}$
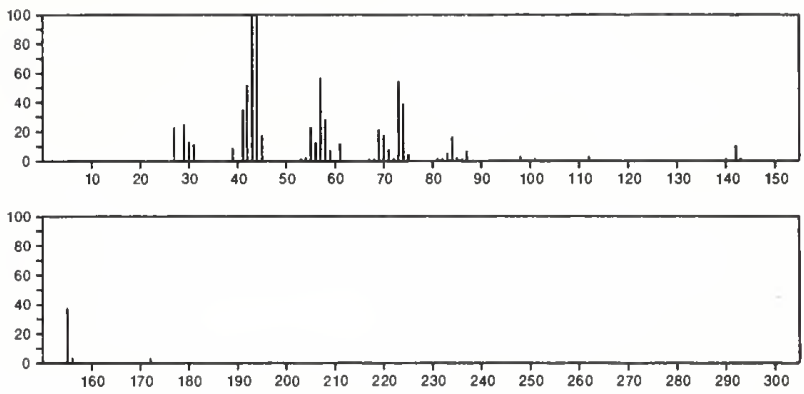

172

$\mathrm{C}_{9} \mathrm{H}_{20} \mathrm{OSi}$

Silane, (cyclohexyloxy) trimethyl-

13871-89-1
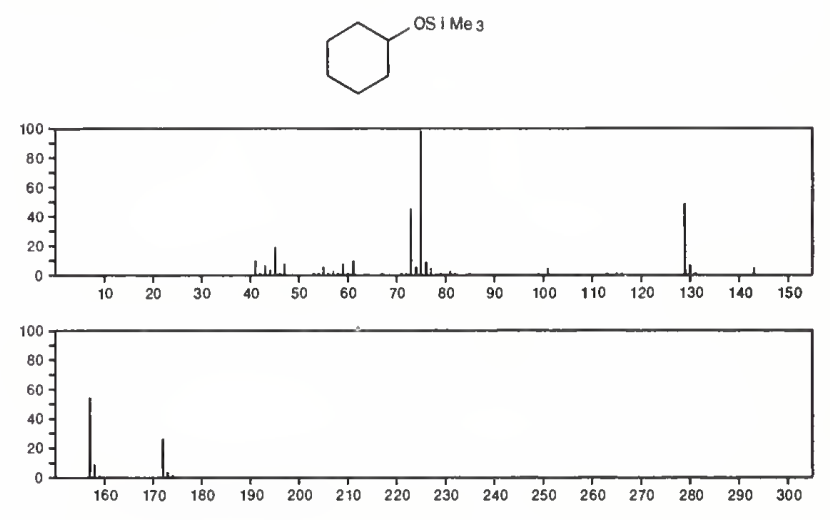

172

$\mathrm{C}_{9} \mathrm{H}_{20} \mathrm{OSi}$

$20584-41-2$

Cyclohexanol, 2-(trimethylsilyl)-, trans-
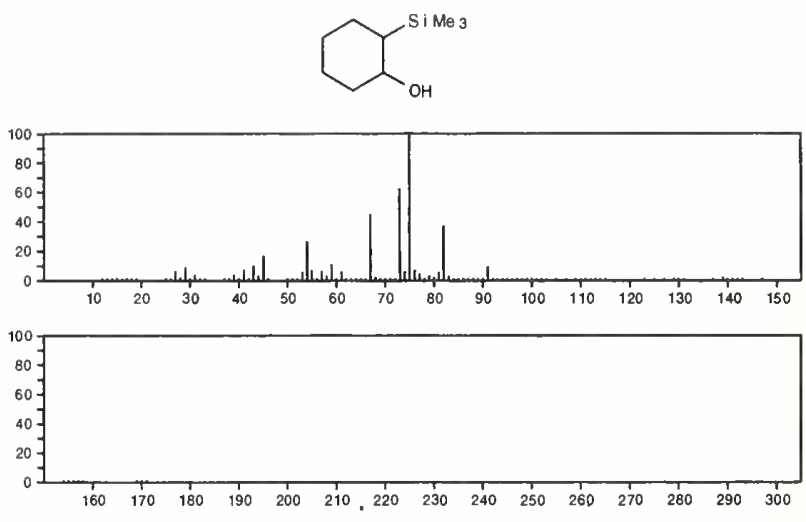

172

$\mathrm{C}_{9} \mathrm{H}_{20} \mathrm{OSi}$

Cyclohexanol, 2-(trimethylsilyl)-, cis-

20584-43-4
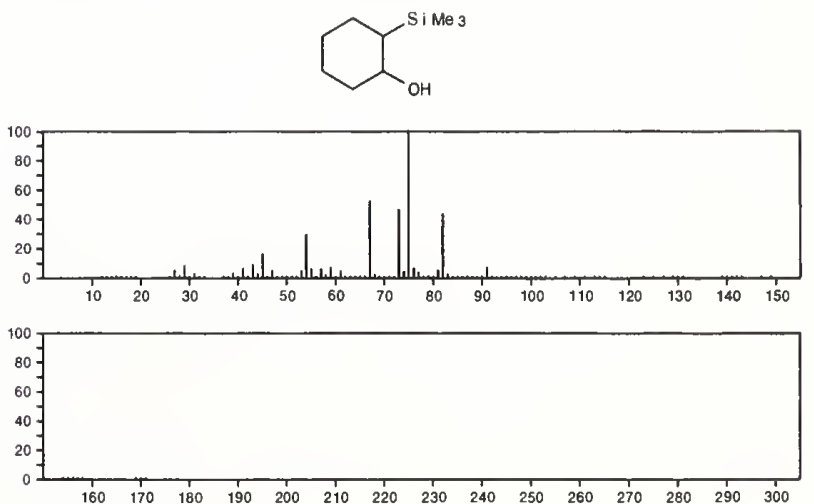

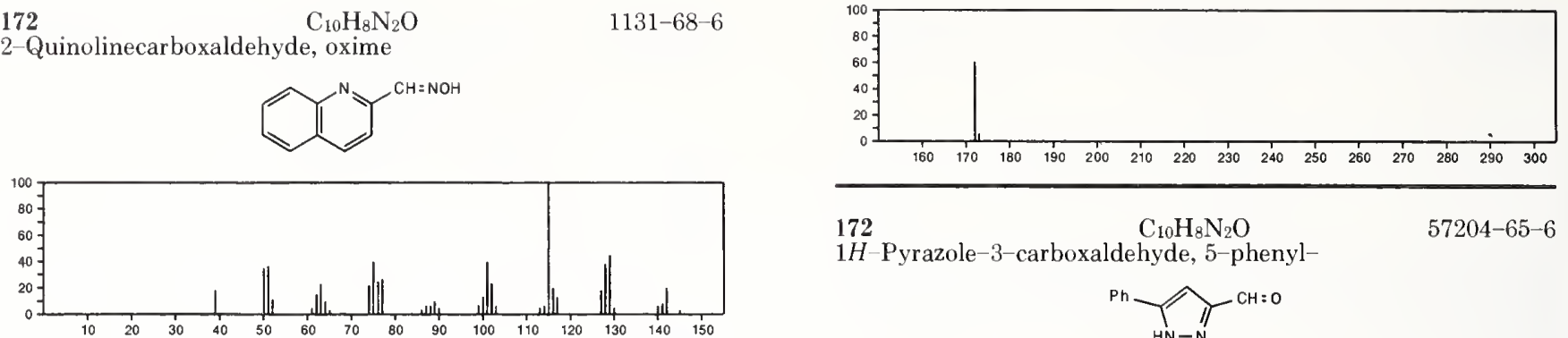

172

$\mathrm{C}_{10} \mathrm{H}_{8} \mathrm{~N}_{2} \mathrm{O}$

$57204-65-6$

1H-Pyrazole-3-carboxaldehyde, 5-phenyl-
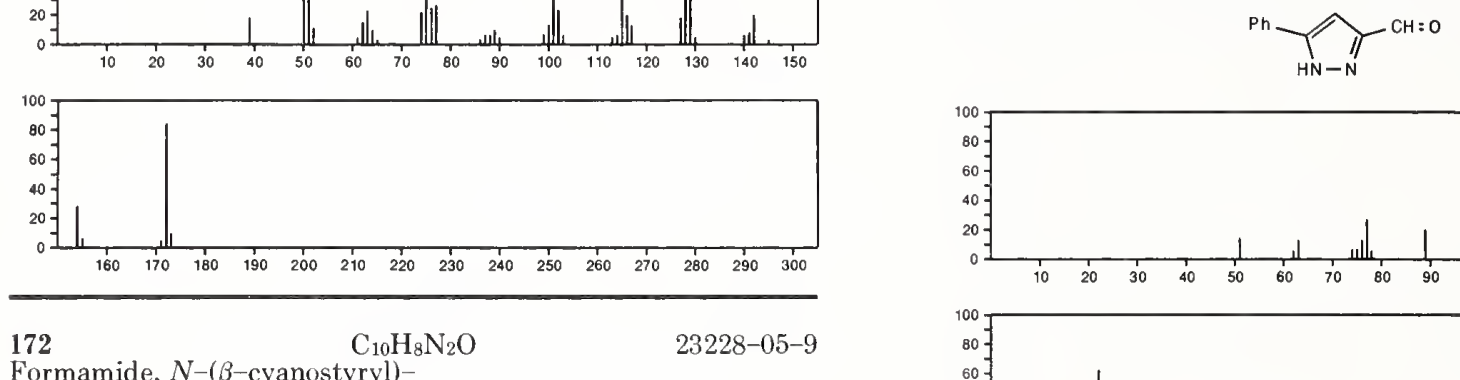

Formamide, $N$-( $\beta$-cyanostyryl)-

$\mathrm{NCCPh}=\mathrm{CHNHCH}=0$
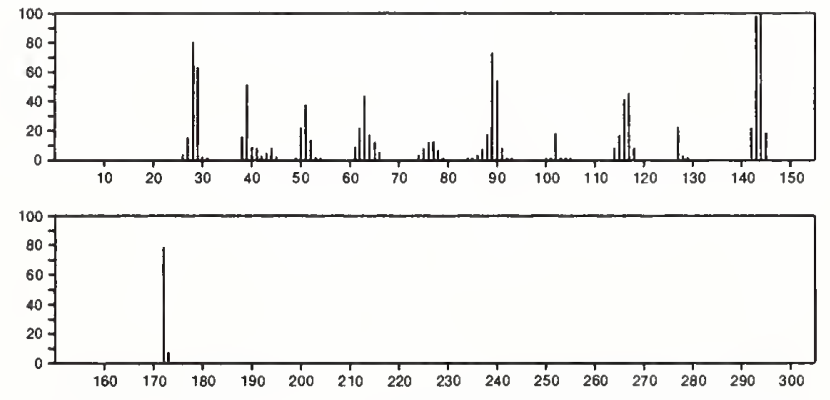

$172 \quad \mathrm{C}_{10} \mathrm{H}_{8} \mathrm{~N}_{2} \mathrm{O}$

$54789-38-7$

1H-Inden-1-one, 2-diazo-2,3-dihydro-3-methyl
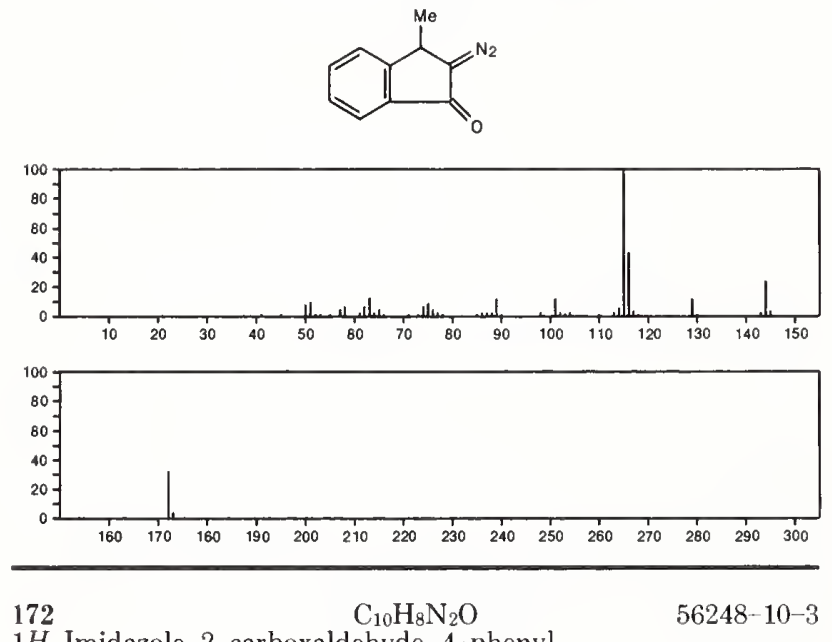

$1 H$-Imidazole-2-carboxaldehyde, 4 -phenyl
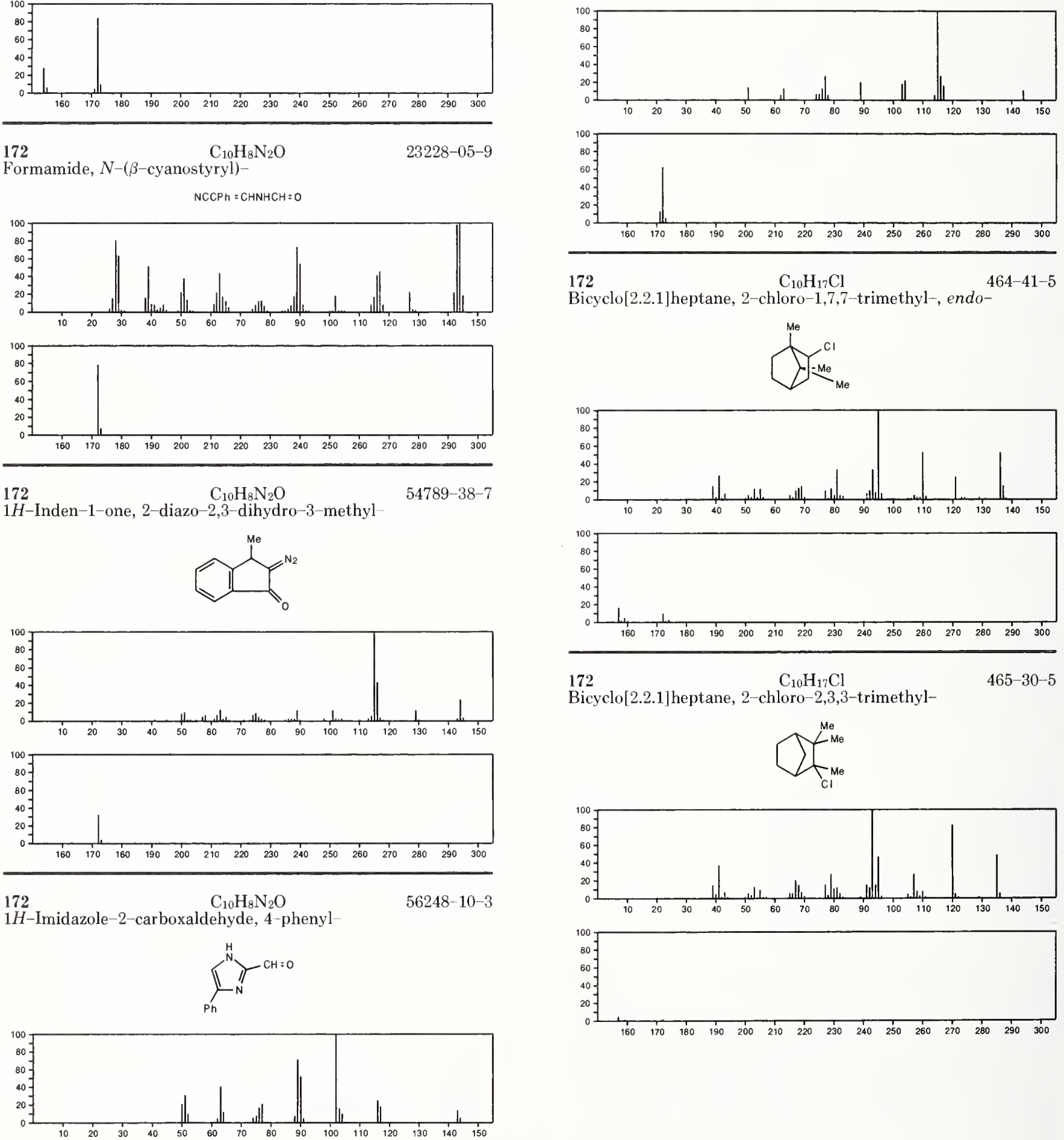

172

$\mathrm{C}_{10} \mathrm{H}_{17} \mathrm{Cl}$

Bicyclo[2.2.1] heptane, 2-chloro-1,7,7-trimethyl-, endo-
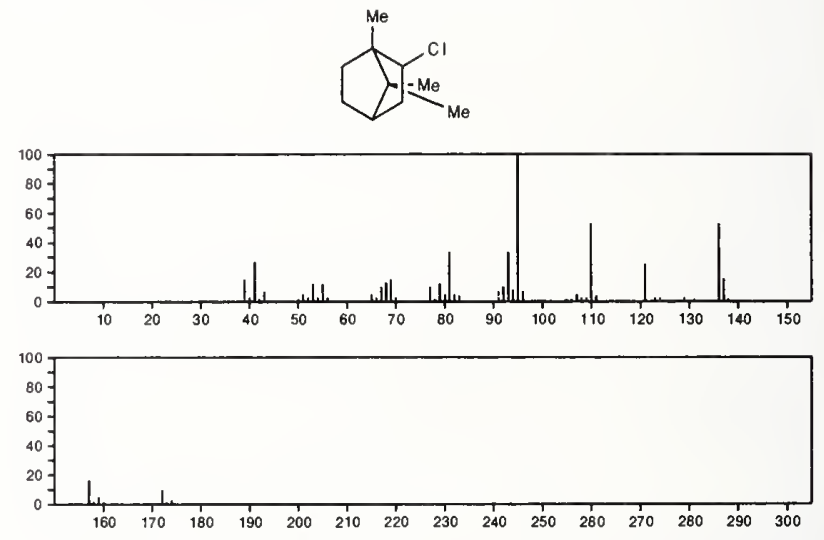

172

$\mathrm{C}_{10} \mathrm{H}_{17} \mathrm{Cl}$

Bicyclo[2.2.1] heptane, 2-chloro-2,3,3-trimethyl-

$465-30-5$
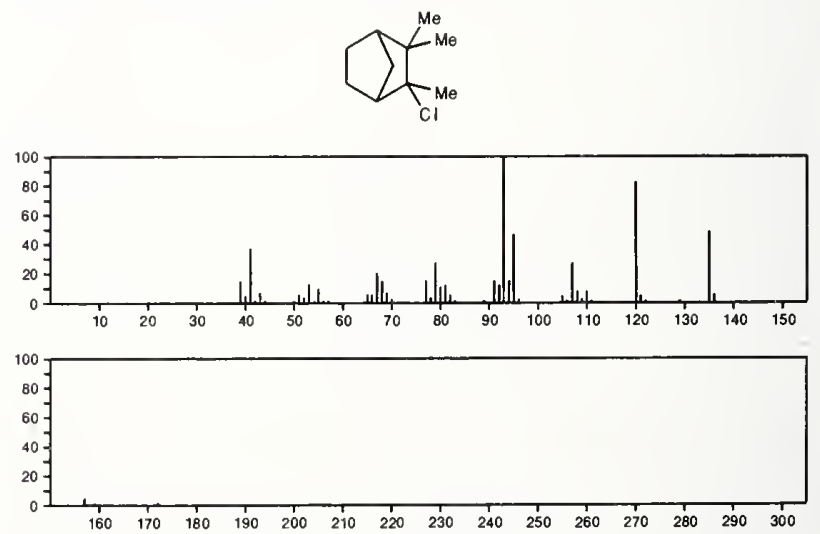
$172 \quad \mathrm{C}_{10} \mathrm{H}_{17} \mathrm{Cl} \quad 559-45-5$

Bicyclo[2.2.1]heptane, 2-chloro-1,7,7-trimethyl-, exo-
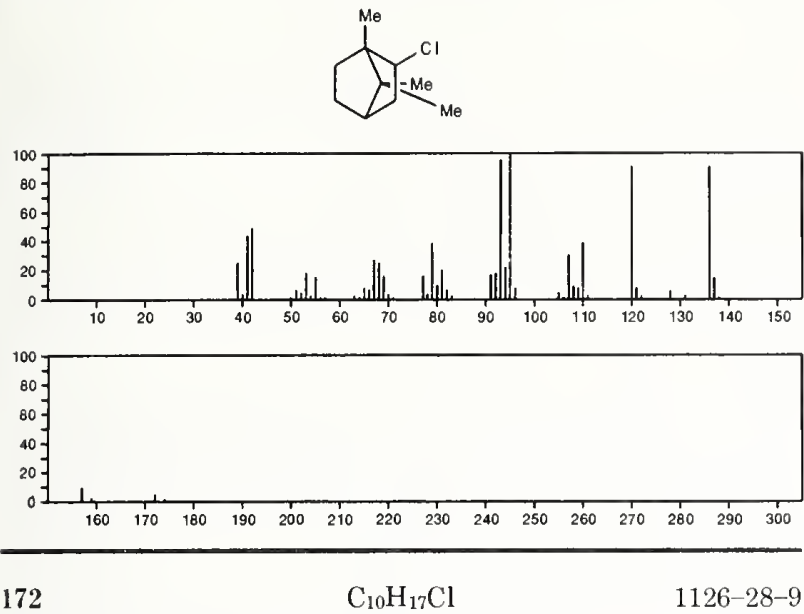

Norbornane, 2-chloro-1,5,5-trimethyl-, exo-
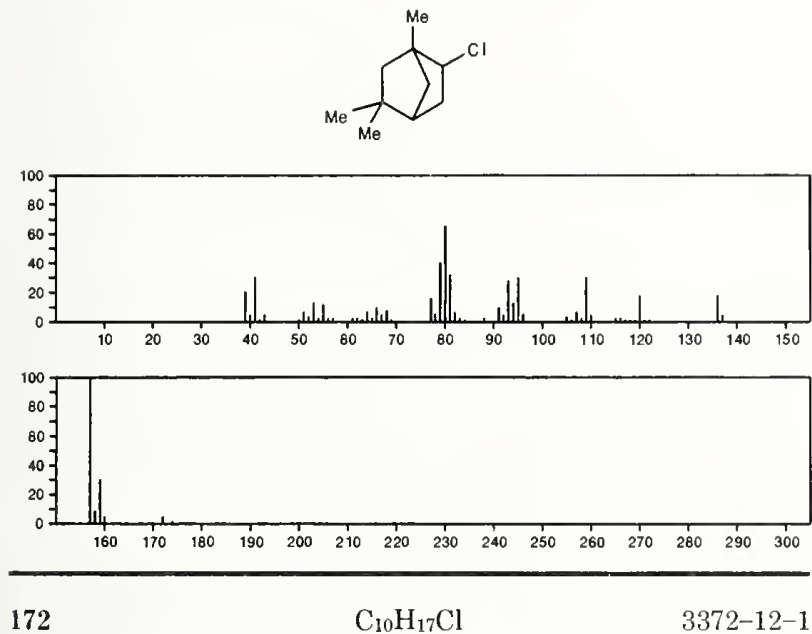

Bicyclo[2.2.1] heptane, 2-chloro-1,3,3-trimethyl-, endo-
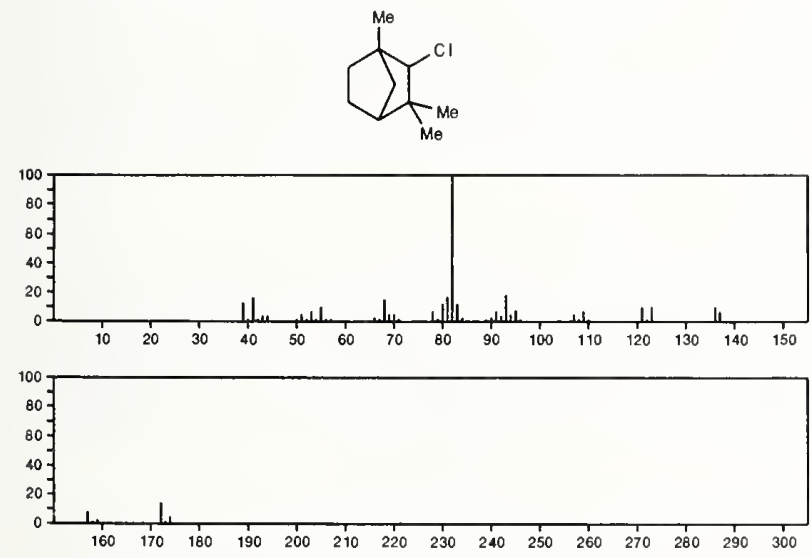

172

$\mathrm{C}_{10} \mathrm{H}_{17} \mathrm{Cl}$

22768-99-6

Norbornane, 2-chloro-2,5,5-trimethyl-, exo-<smiles>CC1(C)CC2CC1CC2(C)Cl</smiles>

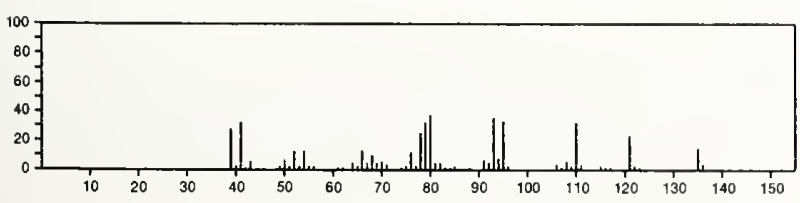

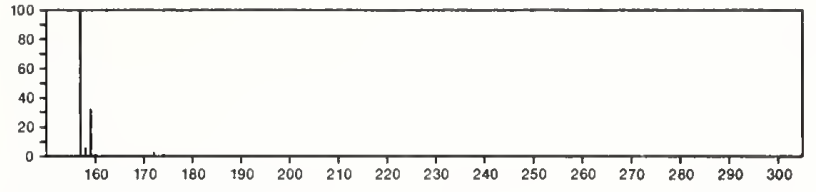

172

$\mathrm{C}_{10} \mathrm{H}_{17} \mathrm{Cl}$

$22852-22-8$

Bicyclo[2.2.1] heptane, 2-chloro-2,7,7-trimethyl-, exo-
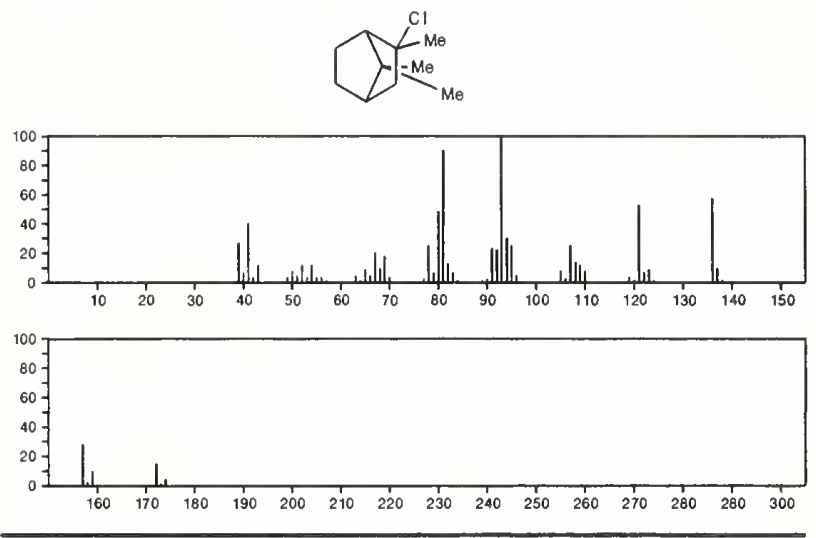

$172 \quad \mathrm{C}_{10} \mathrm{H}_{20} \mathrm{O}_{2}$

Acetic acid, 2-ethylhexyl ester

103-09-3

$\mathrm{ACOCH} \mathrm{OHE}_{2} \mathrm{CH}\left(\mathrm{CH}_{2}\right) 3 \mathrm{Me}$

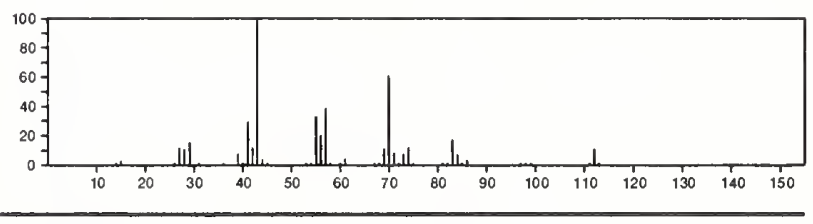

172

$\mathrm{C}_{10} \mathrm{H}_{20} \mathrm{O}_{2}$

Octanal, 7-hydroxy-3,7-dimethyl-

$107-75-5$

$\mathrm{Me}_{2} \mathrm{COH}\left(\mathrm{CH}_{2}\right)_{3} \mathrm{CHMe} \mathrm{CH}_{2} \mathrm{CHO}$
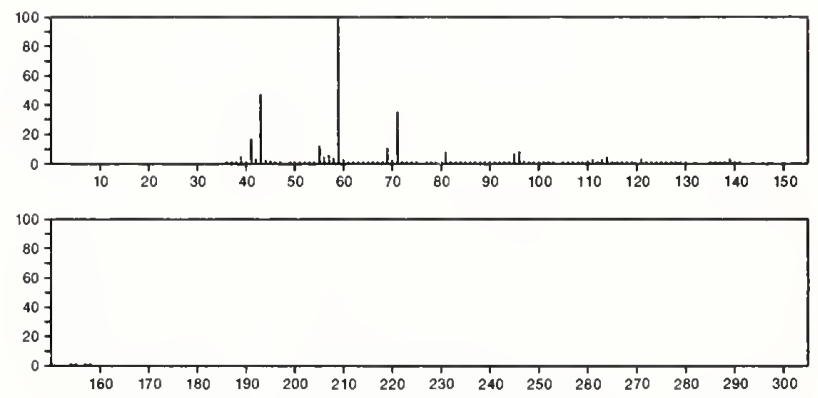

172

Acetic acid, octyl ester

$\mathrm{C}_{10} \mathrm{H}_{20} \mathrm{O}_{2}$

112-14-1

$\mathrm{Me}\left(\mathrm{CH}_{2}\right)_{7} \mathrm{OAC}$

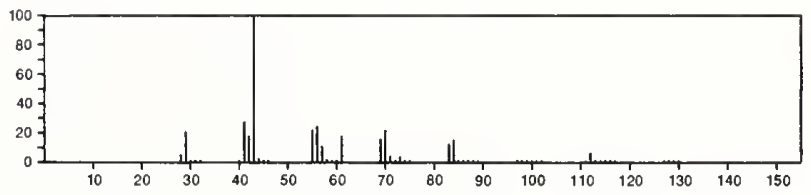


172

$\mathrm{C}_{10} \mathrm{H}_{20} \mathrm{O}_{2}$

$334-48-5$

$\mathrm{HO}_{2} \mathrm{C}\left(\mathrm{CH}_{2}\right) \& \mathrm{Me}$
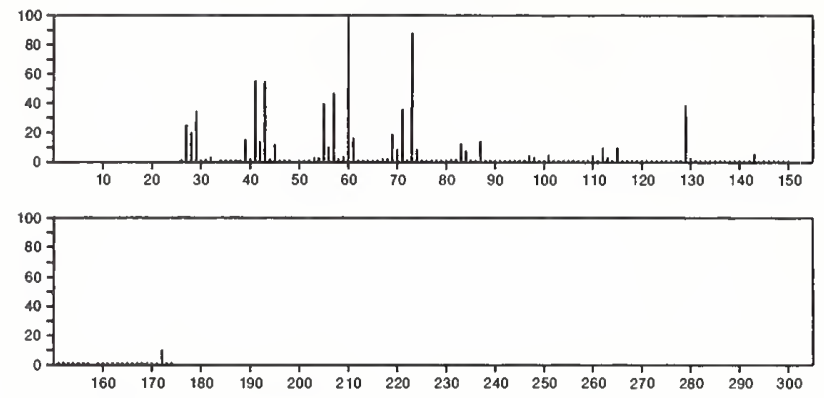

172

$\mathrm{C}_{10} \mathrm{H}_{20} \mathrm{O}_{2}$

Heptanoic acid, 2-ethyl-, methyl ester

$\mathrm{MeOC}(\mathrm{O}) \mathrm{CHE}+\left(\mathrm{CH}_{2}\right) 4 \mathrm{Me}$
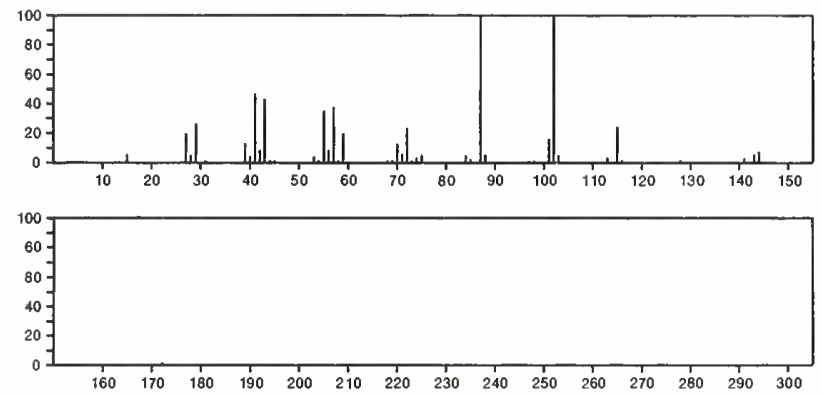

172

Nonanoic acid, methyl ester

$\mathrm{C}_{10} \mathrm{H}_{20} \mathrm{O}_{2}$

$\mathrm{Me}\left(\mathrm{CH}_{2}\right)>\mathrm{C}(\mathrm{O}) \mathrm{OMe}$
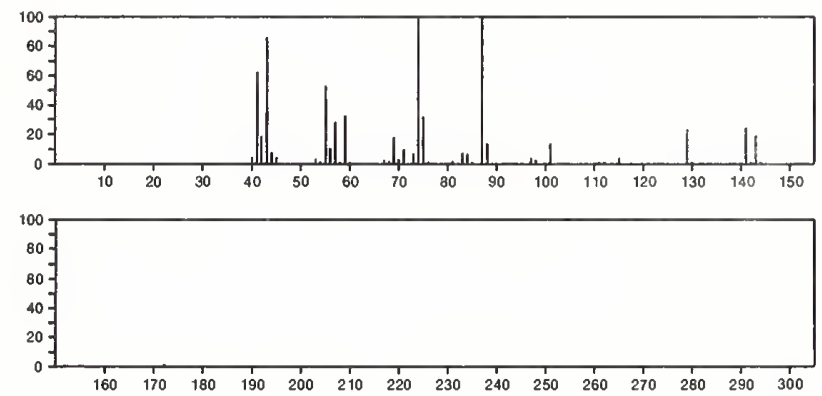

172

Pentanoic acid, pentyl ester

$\mathrm{C}_{10} \mathrm{H}_{20} \mathrm{O}_{2}$

$2173-56-0$

$\mathrm{Me}\left(\mathrm{CH}_{2}\right)_{3} \mathrm{C}(\mathrm{O}) \mathrm{O}\left(\mathrm{CH}_{2}\right)_{4} \mathrm{Me}$

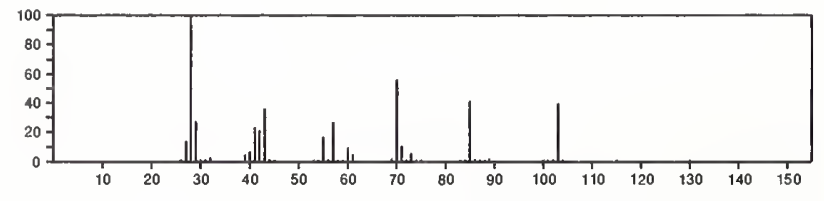

172

$\mathrm{C}_{10} \mathrm{H}_{20} \mathrm{O}_{2}$

Octanoic acid, 2-methyl-, methyl ester

$2177-86-8$

$\mathrm{MeOC}(\mathrm{O}) \mathrm{CHMe}\left(\mathrm{CH}_{2}\right) 5 \mathrm{M}$

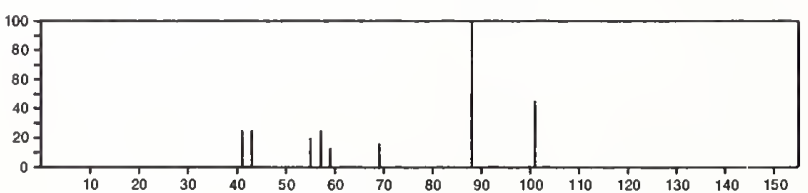

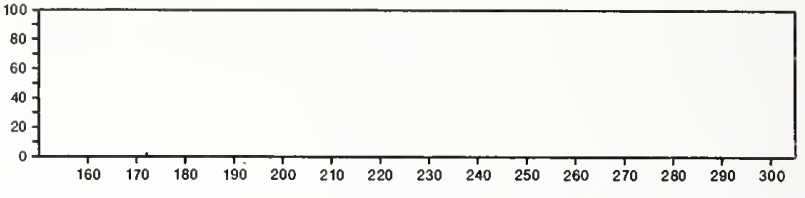

172

Propanoic acid, heptyl ester

$\mathrm{C}_{10} \mathrm{H}_{20} \mathrm{O}_{2}$

$2216-81-1$

$\mathrm{Me}\left(\mathrm{CH}_{2}\right){ }_{6} \mathrm{OC}(\mathrm{O}) \mathrm{E}$

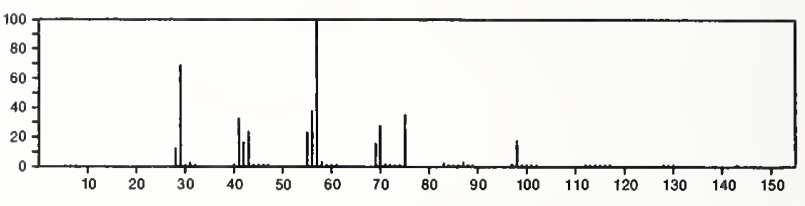

172

$\mathrm{C}_{10} \mathrm{H}_{20} \mathrm{O}_{2}$

$2639-63-6$

Butanoic acid, hexyl ester

$\operatorname{PrC}(\mathrm{O}) \mathrm{O}\left(\mathrm{CH}_{2}\right) 5 \mathrm{Me}$
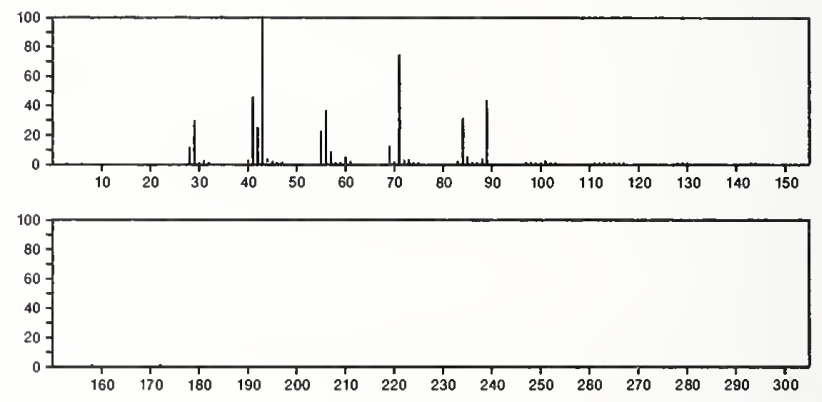

172

$\mathrm{C}_{10} \mathrm{H}_{20} \mathrm{O}_{2}$

29887-72-7

Cyclohexane, 1,4-diethoxy-, trans-
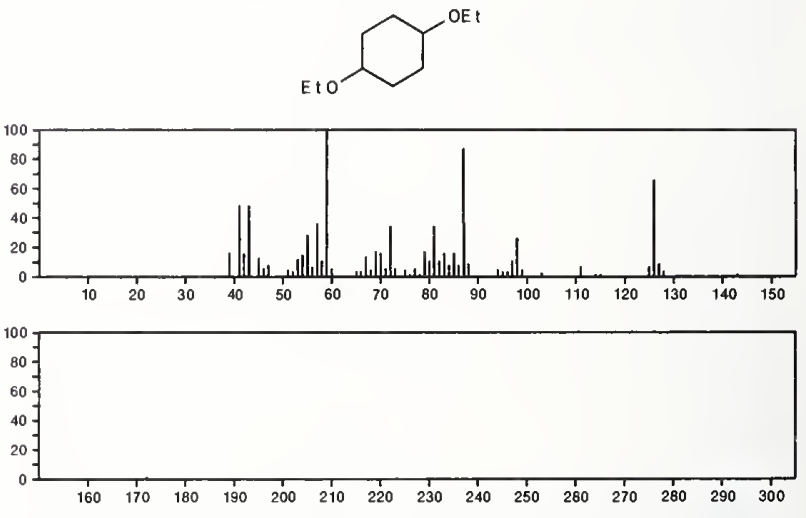

172

$\mathrm{C}_{10} \mathrm{H}_{20} \mathrm{O}_{2}$

$30363-87-2$

Cyclohexane, 1,4-diethoxy--, cis-
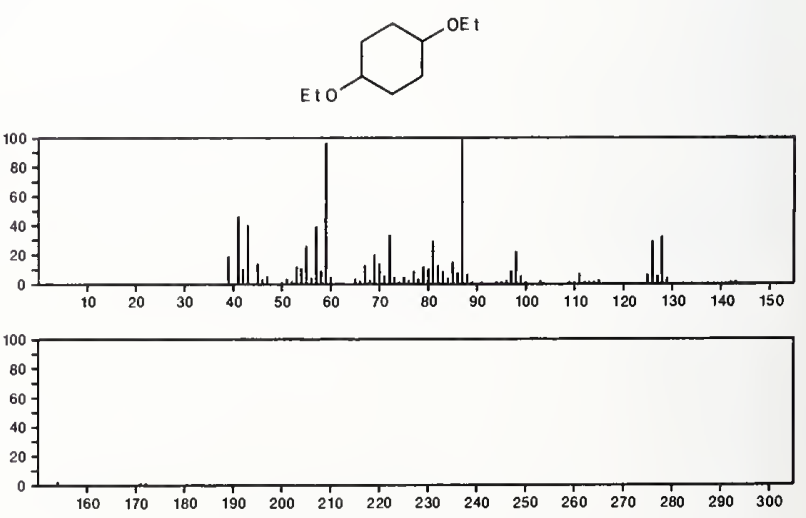
172 Heptanoic acid, 2,6-dimethyl-, methyl ester

$\mathrm{Me}_{2} \mathrm{CH}\left(\mathrm{CH}_{2}\right)_{3} \mathrm{CHM}_{e} \mathrm{C}(0)$ OMe
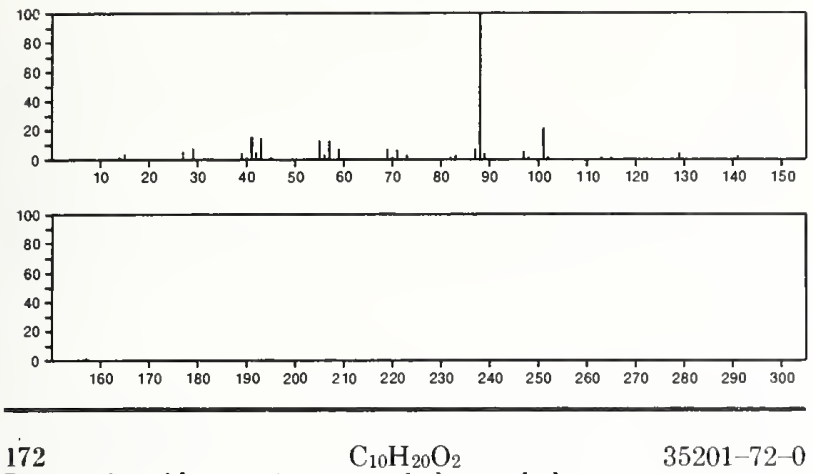

Pentanoic acid, 2,2,4,4-tetramethyl-, methyl ester

$\mathrm{MeOC}(\mathrm{O}) \mathrm{CMe}_{2} \mathrm{CH}_{2} \mathrm{CMe}_{3}$
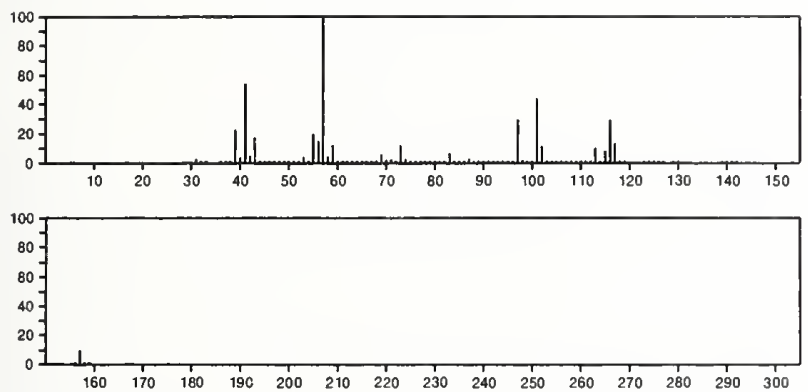

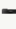

172

$\mathrm{C}_{10} \mathrm{H}_{20} \mathrm{O}$
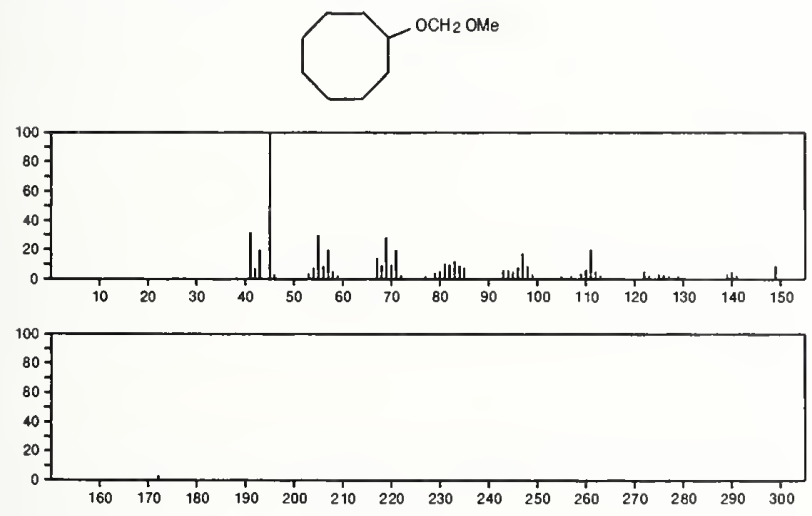

$172 \quad \mathrm{C}_{10} \mathrm{H}_{20} \mathrm{O}_{2} \quad 54461-01-7$ Butanoic acid, 3,3-dimethyl-2-(1-methylethyl)-, methyl ester

CHMe 2

$\mathrm{MeOC}(\mathrm{O}) \mathrm{CHCM}_{3}$
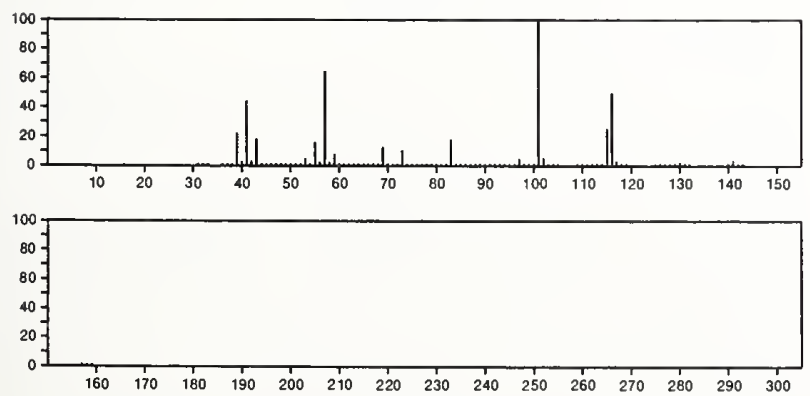

172

Acetic acid, sec-octyl ester

$\mathrm{C}_{10} \mathrm{H}_{20} \mathrm{O}_{2}$

$54515-77-4$

( $\mathrm{SEC}-\mathrm{C}_{8} \mathrm{H}_{1} 7$ ) OAC
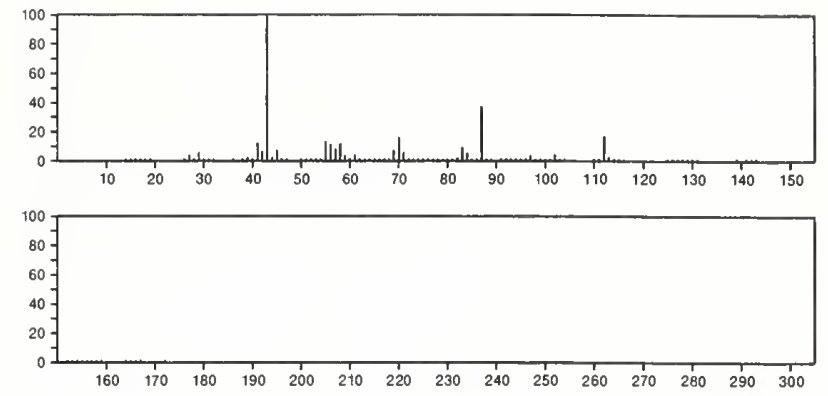

$\begin{aligned} & 172 \\ & 4-\text { Nonanone, 9-methoxy- }\end{aligned} \mathrm{C}_{10} \mathrm{H}_{20} \mathrm{O}_{2} \quad 54699-40-0$

$\operatorname{PrCO}\left(\mathrm{CH}_{2}\right) 5 \mathrm{OMe}$
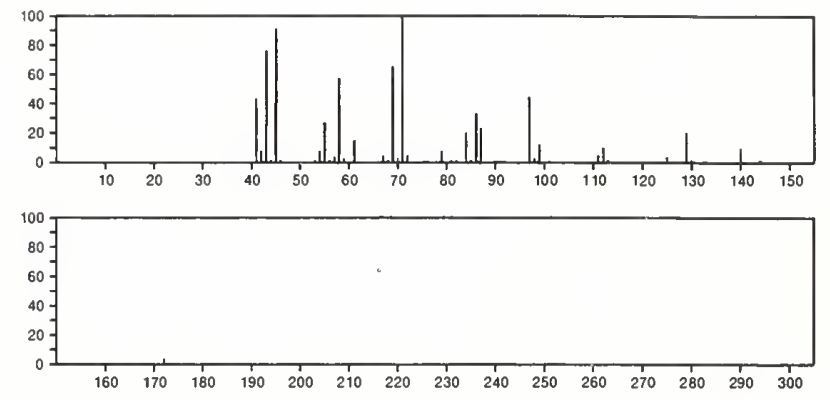

172

Pentanoic acid, 2-methylbutyl ester

$55590-83-5$

$\mathrm{MeCH}_{2} \mathrm{CHMe} \mathrm{CH}_{2} \mathrm{OC}(\mathrm{O})$ ( $\mathrm{CH}_{2}$ ) 3 Me
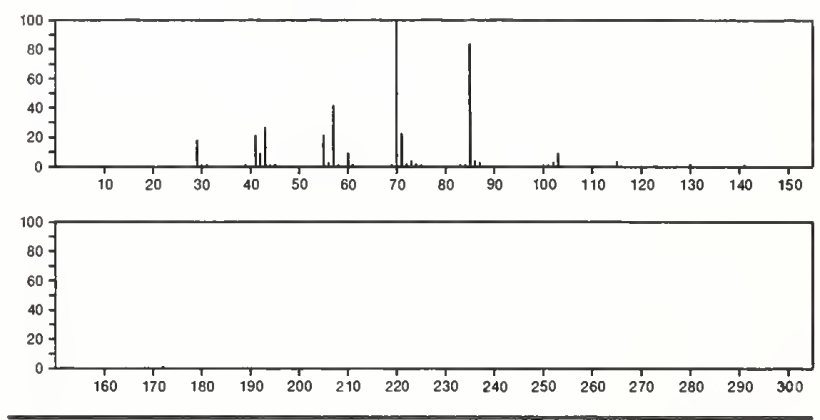

${ }_{1,2-\text { Cyclohexanediol, }}^{172-\text { diethyl- }} \stackrel{\mathrm{C}_{10} \mathrm{H}_{20} \mathrm{O}_{2}}{1,2-}$

56363-86-1
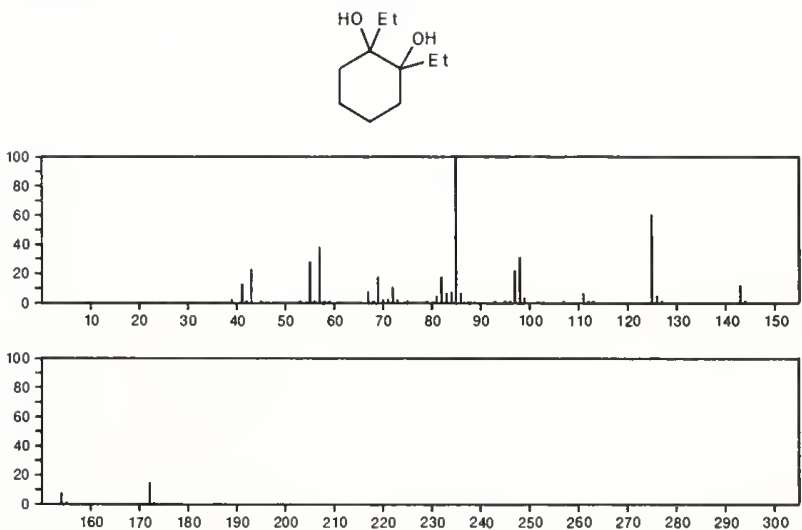
172

$\mathrm{C}_{10} \mathrm{H}_{20} \mathrm{O}_{2}$

Pentanoic acid, 2-methyl-, l-methylpropyl ester

$57983-17-2$

$s-B U O C(O)$ CHP r Me
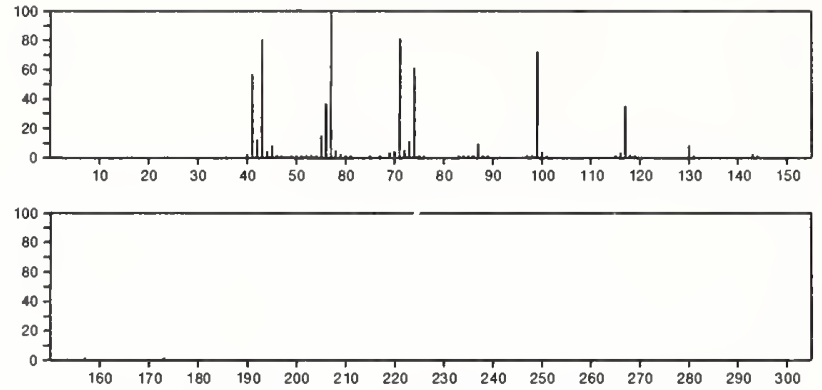

172 Sulfide, cyclopentyl pentyl $\mathrm{C}_{10} \mathrm{H}_{20} \mathrm{~S}$

$7133-20-2$

$\left.\bigcirc-\mathrm{CH}_{2}\right){ }_{4 \mathrm{Me}}$
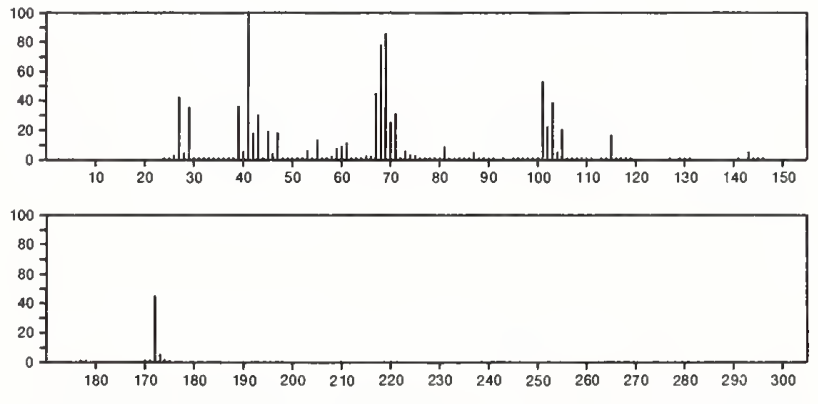

$172 \quad \mathrm{C}_{10} \mathrm{H}_{20} \mathrm{~S} \quad 7133-22-4$

Sulfide, sec-butyl cyclohexyl
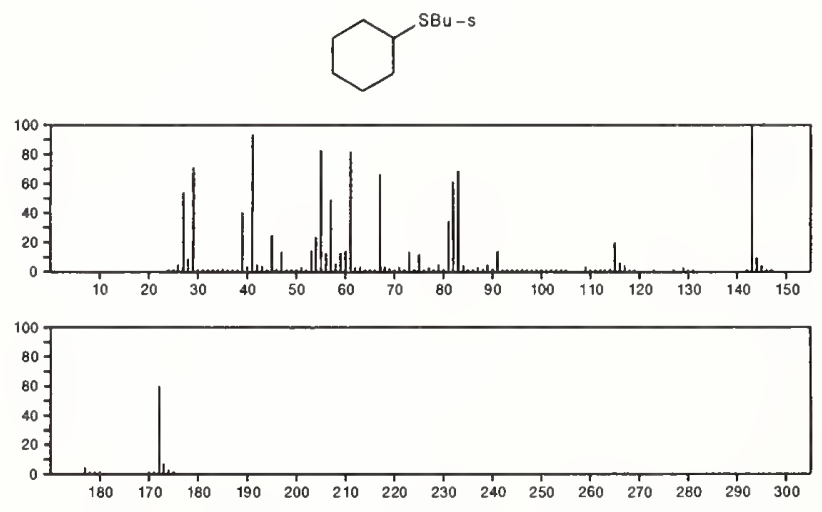

$172 \quad \mathrm{C}_{10} \mathrm{H}_{20} \mathrm{~S}$

Sulfide, tert-butyl cyclohexyl

$7133-23-5$
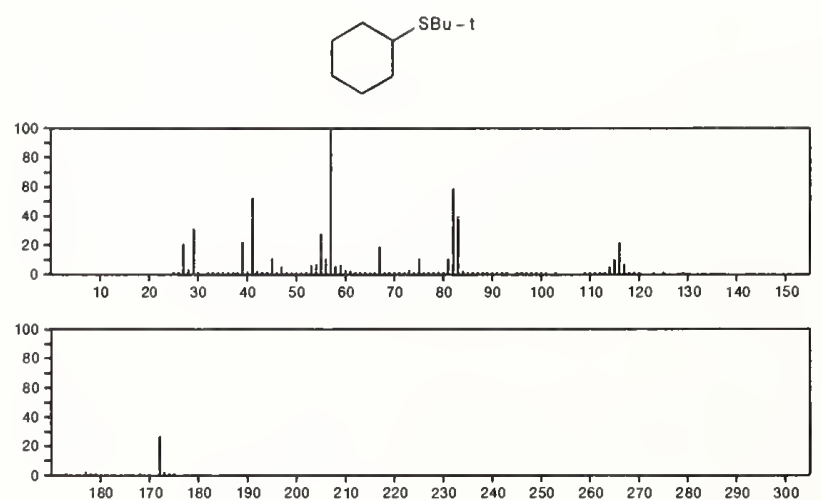

172

Cyclohexane, (butylthio)-

$\mathrm{C}_{10} \mathrm{H}_{20} \mathrm{~S}$

$7133-40-6$
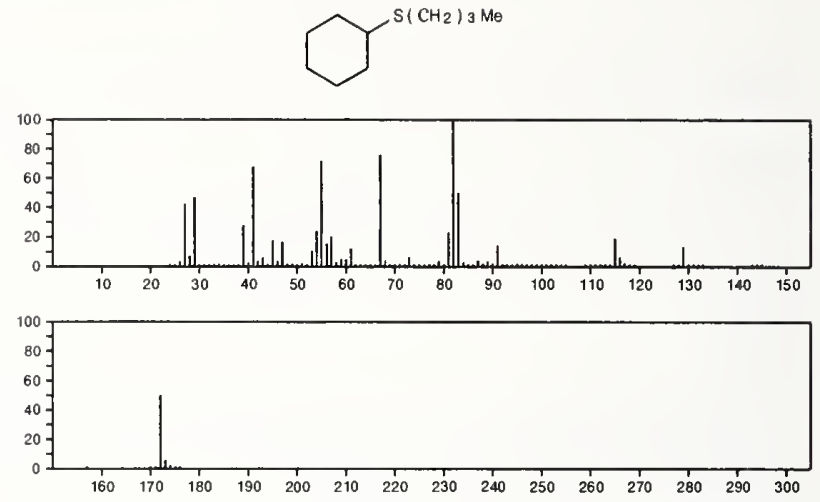

172

Octane, 1-(ethenylthio)

$\mathrm{C}_{10} \mathrm{H}_{20} \mathrm{~S}$

$42779-08-8$

$\mathrm{Me}\left(\mathrm{CH}_{2}\right) 7 \mathrm{SCH}=\mathrm{CH}_{2}$
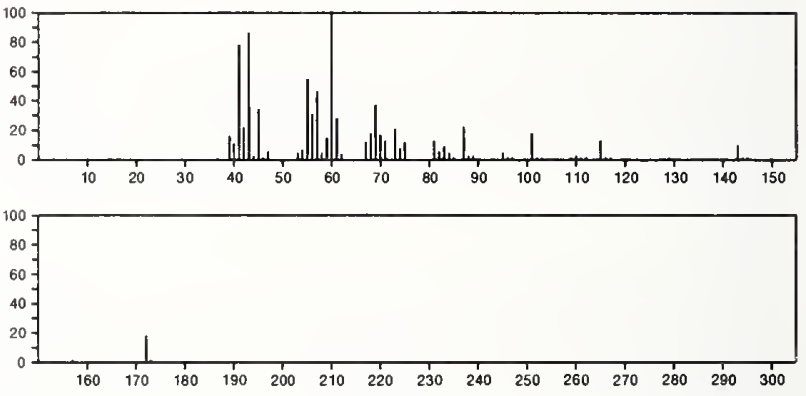

$172 \quad \mathrm{C}_{10} \mathrm{H}_{24} \mathrm{~N}_{2} \quad 54966-00-6$ 1,2 -Ethanediamine, $N, N^{\prime}$-dimethyl-N,N'-bis(1-methylethyl)-

$\operatorname{MeN}(\mathrm{Pr}-\mathrm{i}) \mathrm{CH}_{2} \mathrm{CH}_{2} \mathrm{~N}(\mathrm{Pr}-\mathrm{i}) \mathrm{Me}$
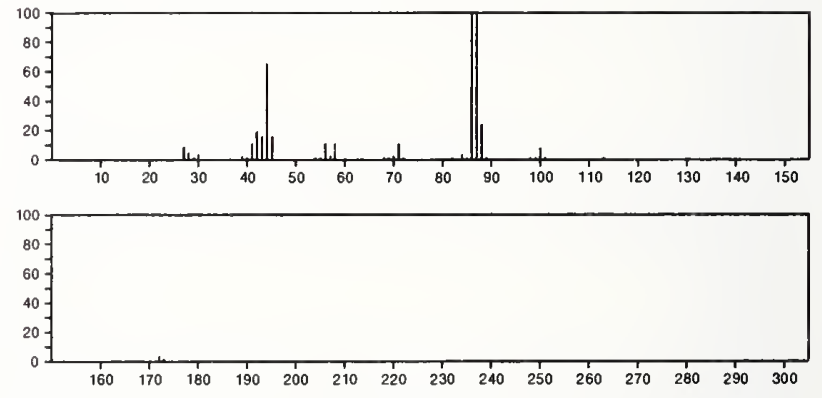

$172 \quad \mathrm{C}_{11} \mathrm{H}_{8} \mathrm{O}_{2}$

1,4-Naphthalenedione, 2-methyl-

$58-27-5$
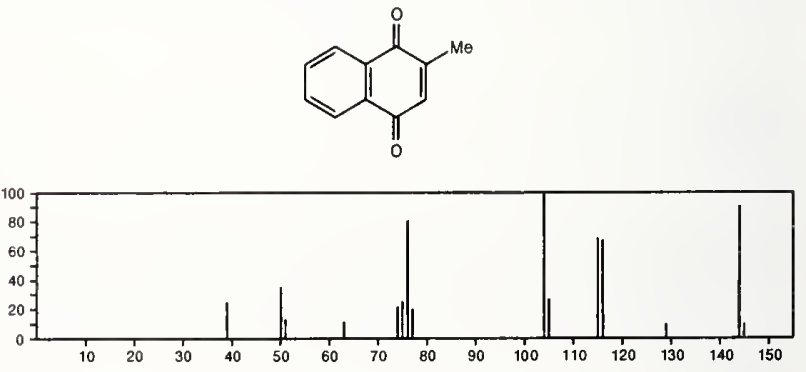
$\begin{aligned} & 172 \\ & 1-\text { Naphthalenecarboxylic acid } \\ & \mathrm{C}_{11} \mathrm{H}_{8} \mathrm{O}_{2}\end{aligned} 86-55-5$
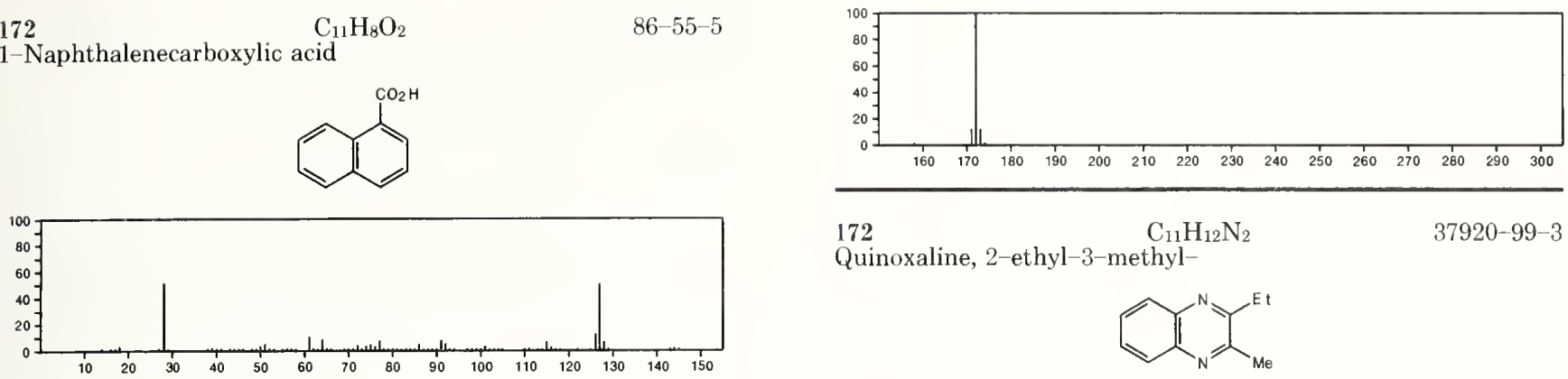

172

Quinoxaline, 2-ethyl-3-methyl-

$\mathrm{C}_{11} \mathrm{H}_{12} \mathrm{~N}_{2}$

37920-99-3
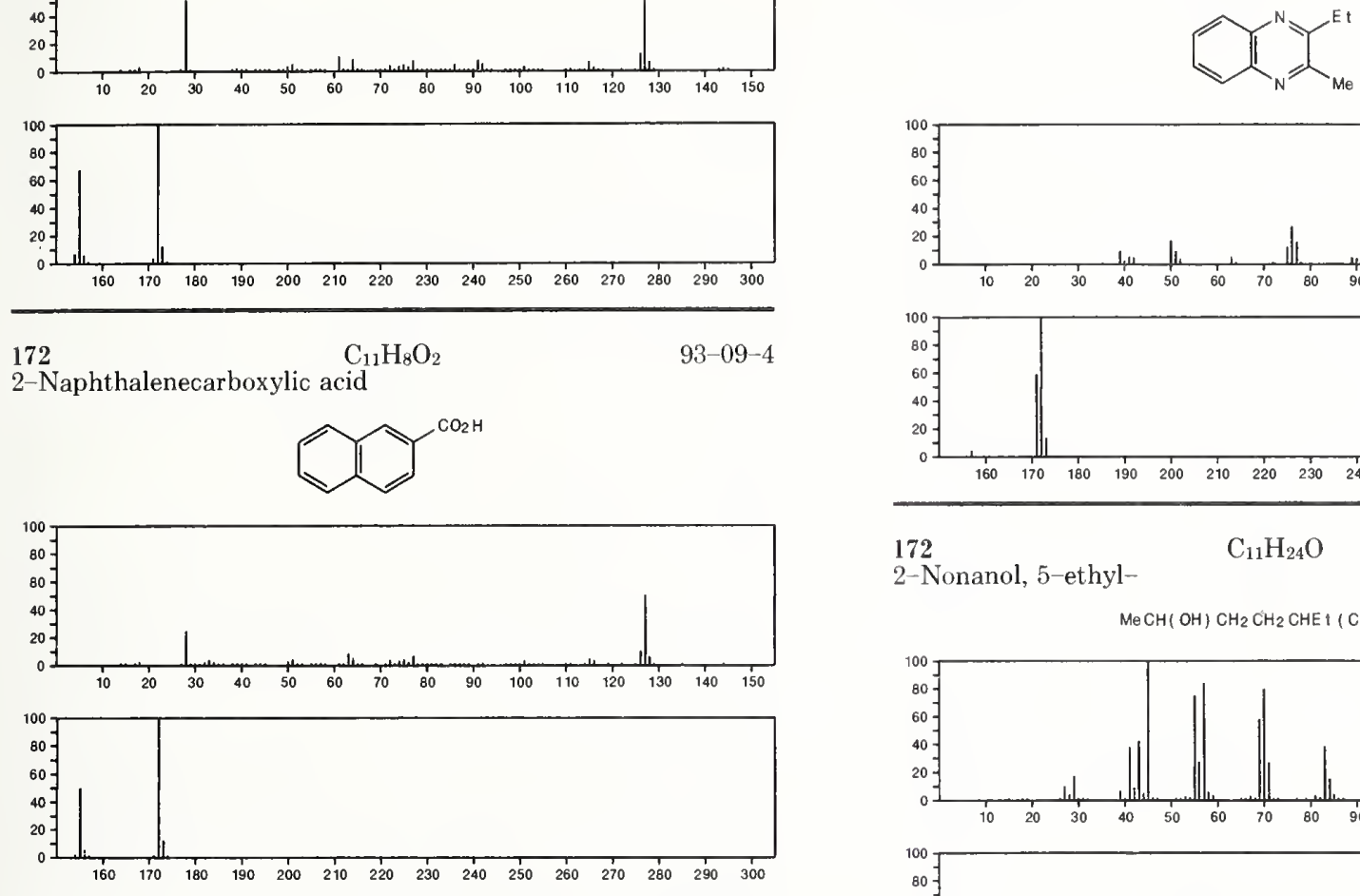

$172 \quad \mathrm{C}_{11} \mathrm{H}_{12} \mathrm{~N}_{2}$

$14757-44-9$

1,8-Naphthyridine, 2,4,7-trimethyl-
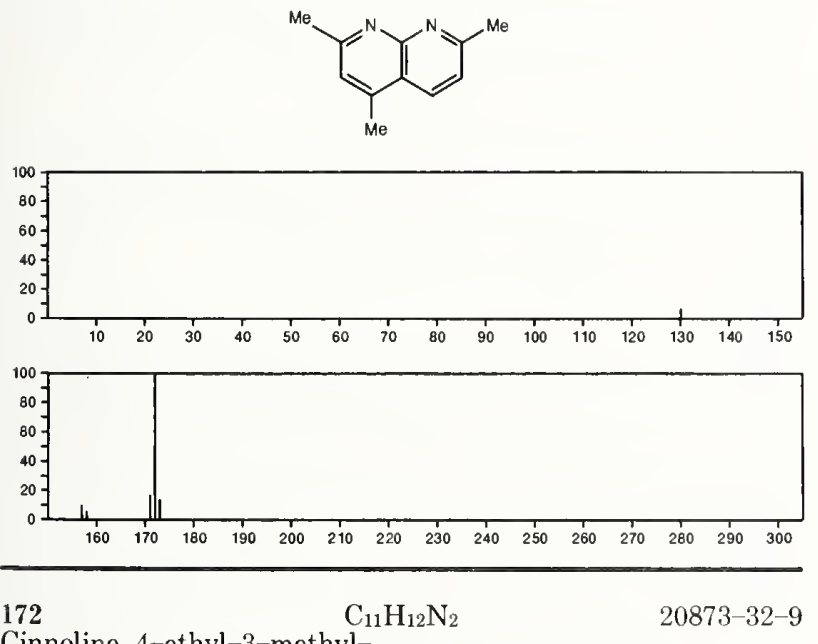

Cinnoline, 4-ethyl-3-methyl-
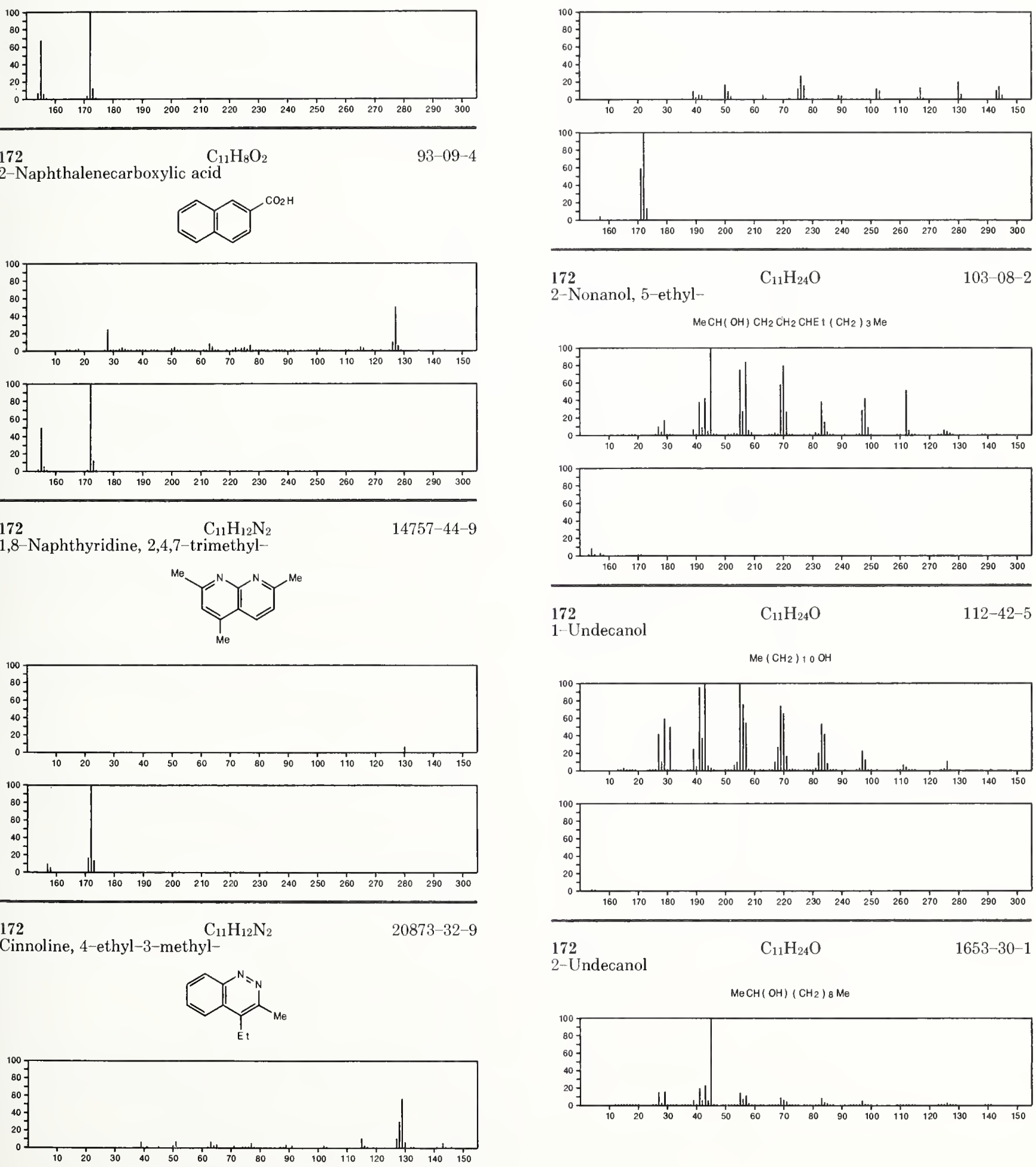

2-Nonanol, 5-ethyl-

$\mathrm{MeCH}(\mathrm{OH}) \mathrm{CH}_{2} \mathrm{CH}_{2} \mathrm{CHE} 1\left(\mathrm{CH}_{2}\right)_{3} \mathrm{Me}$
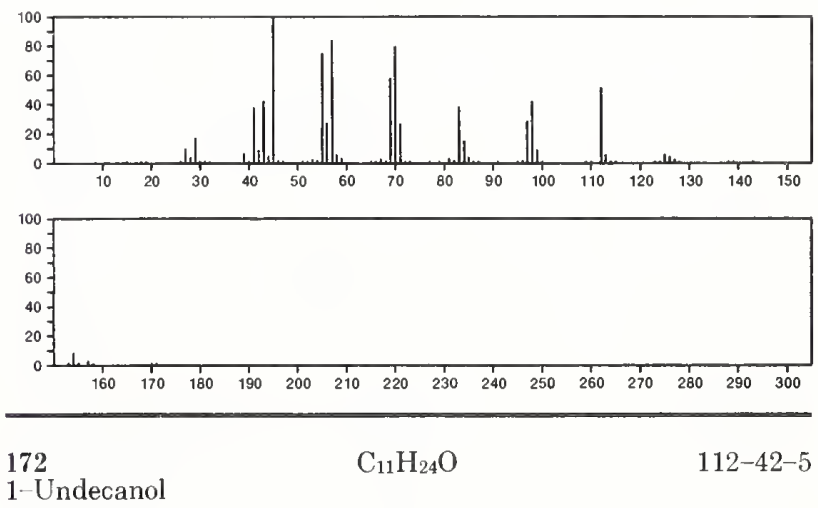

1-Undecanol

$\mathrm{Me}\left(\mathrm{CH}_{2}\right){ }_{10} \mathrm{OH}$
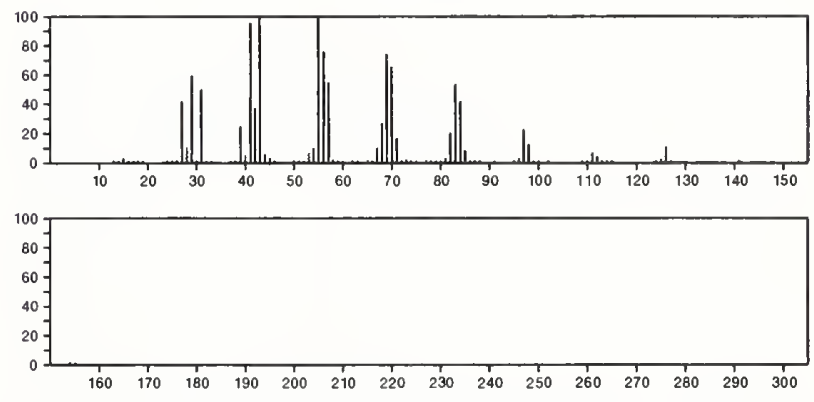

172

2-Undecanol

$\mathrm{C}_{11} \mathrm{H}_{24} \mathrm{O}$

1653-30-1

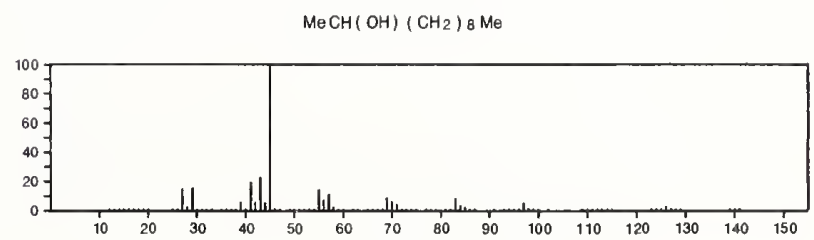




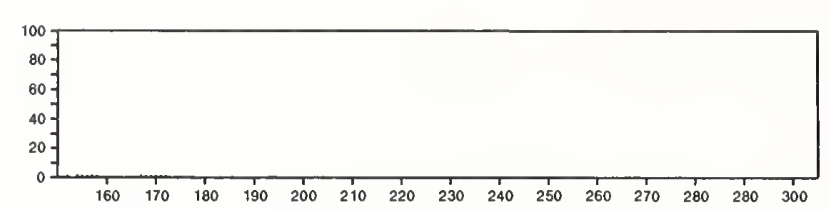

$\begin{array}{lllllllllllllll}160 & 170 & 180 & 190 & 200 & 210 & 220 & 230 & 240 & 250 & 260 & 270 & 280 & 280 & 300\end{array}$

172

6-Undecanol

$\mathrm{C}_{11} \mathrm{H}_{24} \mathrm{O}$

$23708-56-7$

$\mathrm{Me}\left(\mathrm{CH}_{2}\right){ }_{4} \mathrm{CH}(\mathrm{OH})\left(\mathrm{CH}_{2}\right)_{4} \mathrm{Me}$
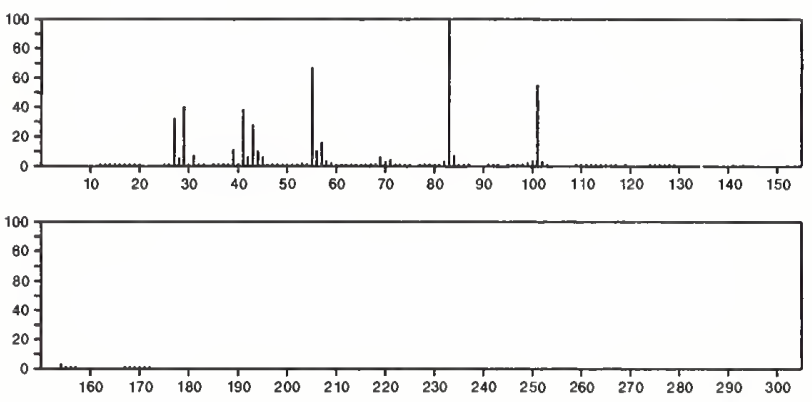

172

$\mathrm{C}_{11} \mathrm{H}_{24} \mathrm{O}$

$32357-83-8$

Ether, hexyl pentyl

$\mathrm{Me}\left(\mathrm{CH}_{2}\right) 5 \mathrm{O}\left(\mathrm{CH}_{2}\right){ }_{4} \mathrm{Me}$

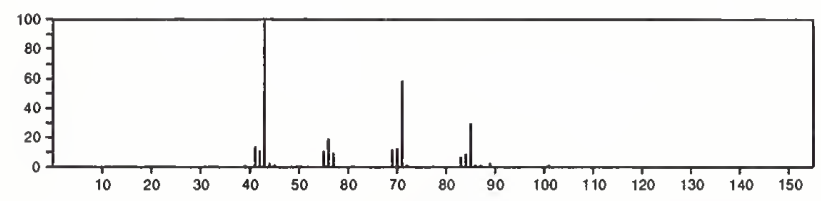

172

$\mathrm{C}_{11} \mathrm{H}_{24} \mathrm{O}$

4-Heptanol, 4-ethyl-2,6-dimethyl-

$\mathrm{Me}_{2} \mathrm{CHCH}_{2} \mathrm{CE}+(\mathrm{OH}) \mathrm{CH}_{2} \mathrm{CHM}_{2}$
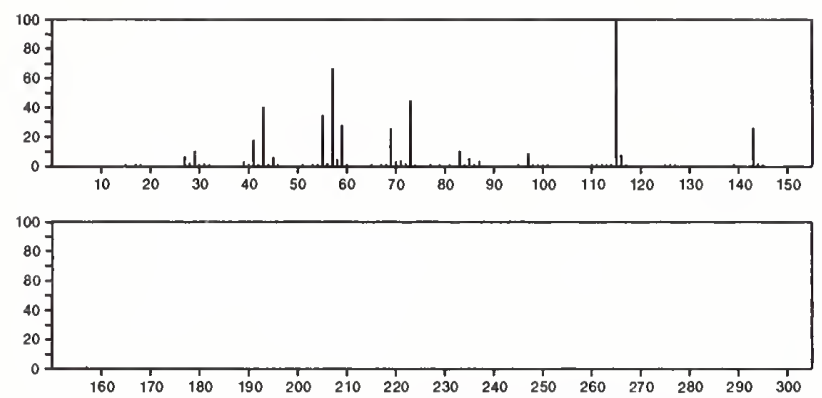

172

1-Hexanol, 2-ethyl-2-propyl-

$\mathrm{C}_{11} \mathrm{H}_{24} \mathrm{O}$

$\mathrm{Me}\left(\mathrm{CH}_{2}\right)_{3} \mathrm{CPrE}_{1} \mathrm{CH}_{2} \mathrm{OH}$
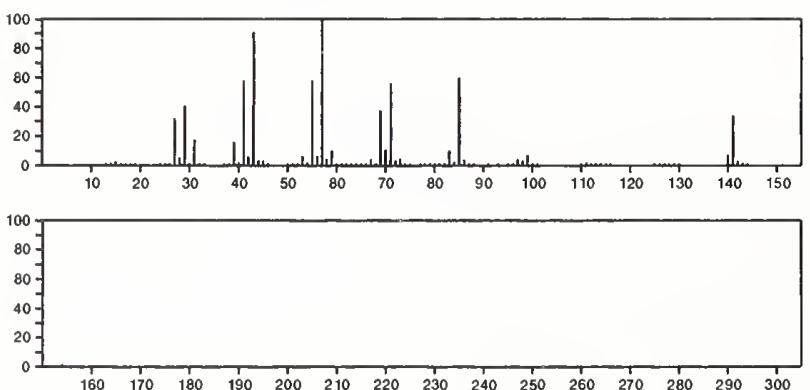

172

Decane, 3-methoxy-

$\mathrm{C}_{11} \mathrm{H}_{24} \mathrm{O}$

55955-64-1

$\mathrm{EtCH}(\mathrm{OMe})\left(\mathrm{CH}_{2}\right) \& \mathrm{Me}$
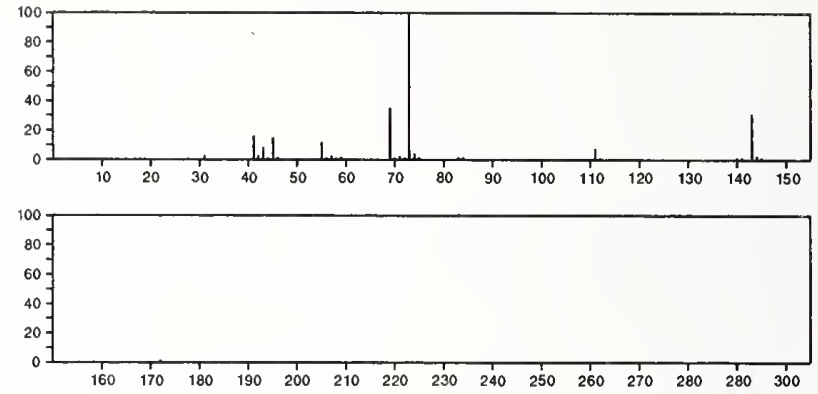

172

1,1'-Biphenyl, 4-fluoro-

$\mathrm{C}_{12} \mathrm{H}_{9} \mathrm{~F}$

$324-74-3$
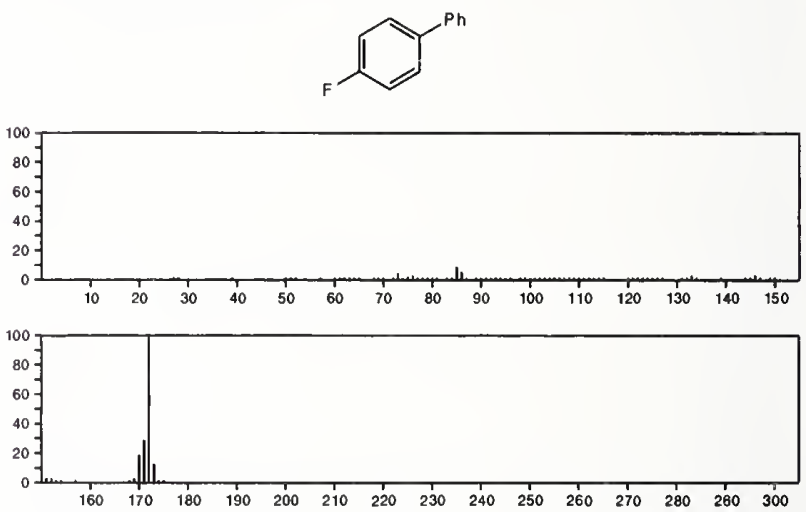

172

Naphthalene, 2-ethoxy-

$\mathrm{C}_{12} \mathrm{H}_{12} \mathrm{O}$

$93-18-5$
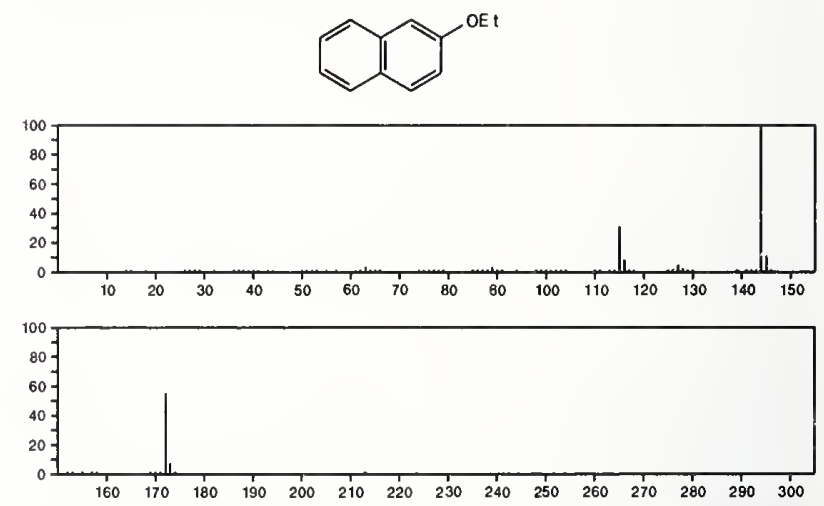

172

$\mathrm{C}_{12} \mathrm{H}_{12} \mathrm{O}$

$5328-01-8$

Naphthalene, 1-ethoxy-
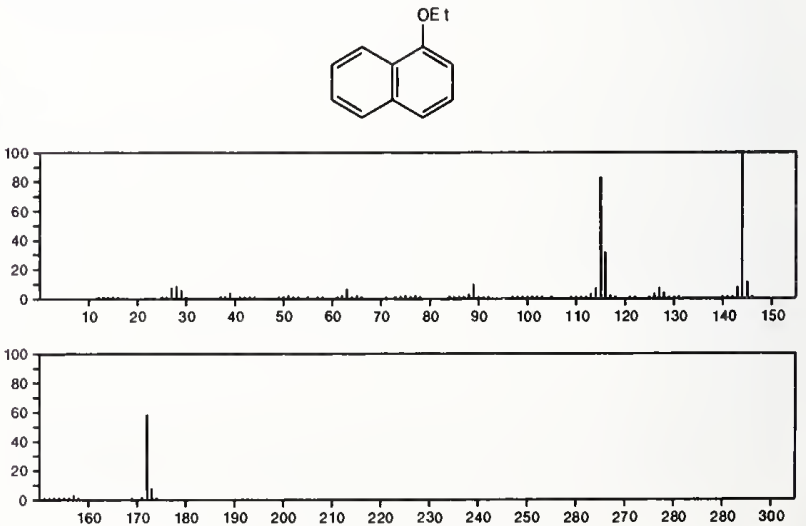
$172 \quad \mathrm{C}_{12} \mathrm{H}_{12} \mathrm{O}$

1,4-Ethanonaphthalen-2(1H)-one, 3,4-dihydro-

$13153-76-9$
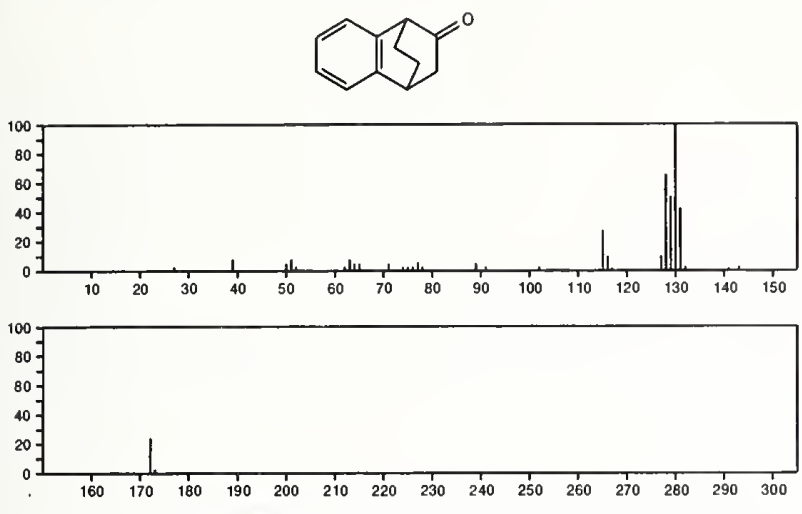

172

$\mathrm{C}_{12} \mathrm{H}_{12} \mathrm{O}$

$23911-58-2$

Benzofuran, 3-methyl-2-(1-methylethenyl)-
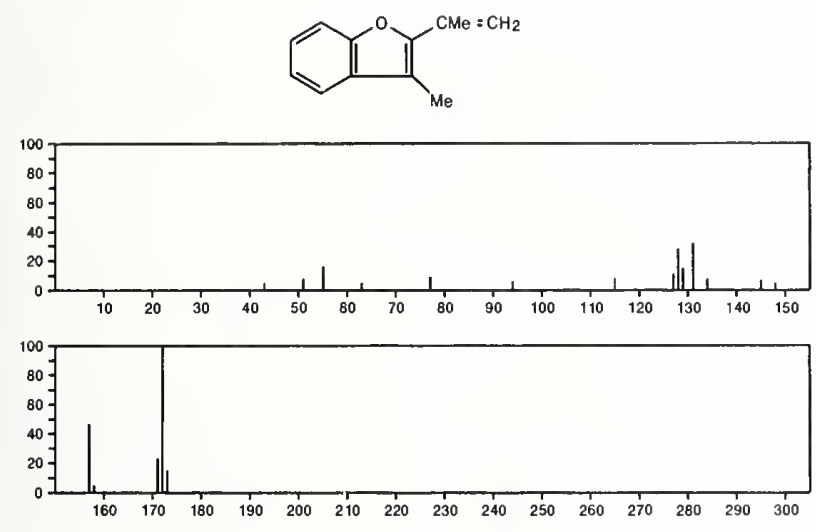

172

$$
\mathrm{C}_{12} \mathrm{H}_{12} \mathrm{O}
$$

$31706-76-0$

1-Naphthol, 5,7-dimethyl-
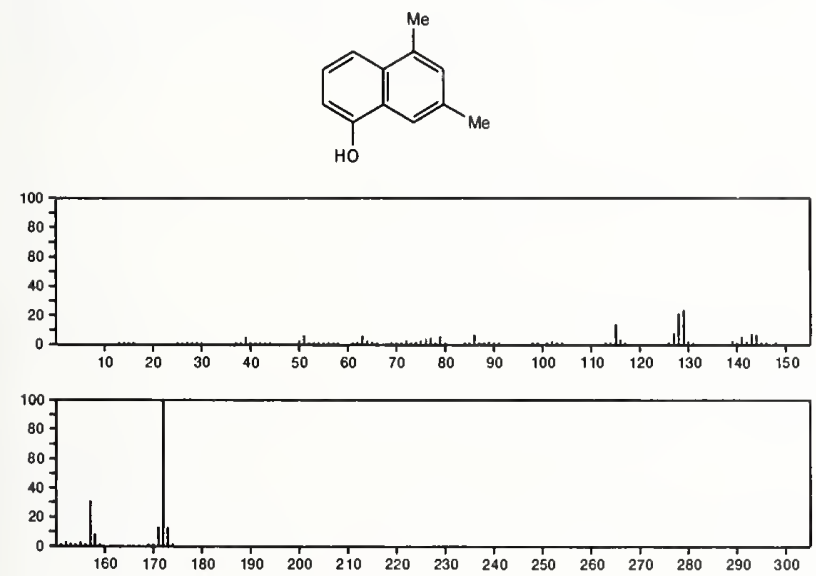

172

1-Naphthol, 6,7-dimethyl-

$$
\mathrm{C}_{12} \mathrm{H}_{12} \mathrm{O}
$$

$31776-14-4$
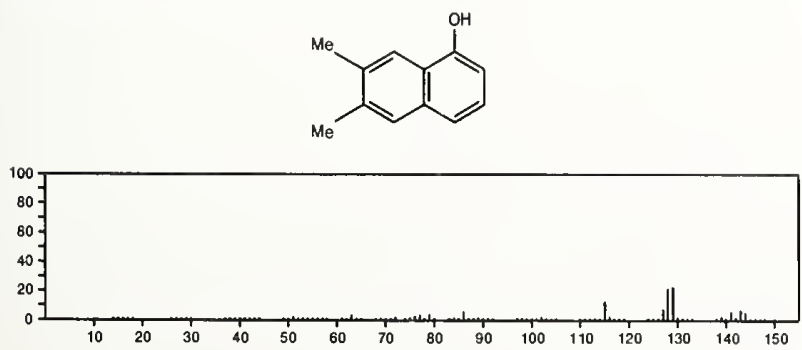

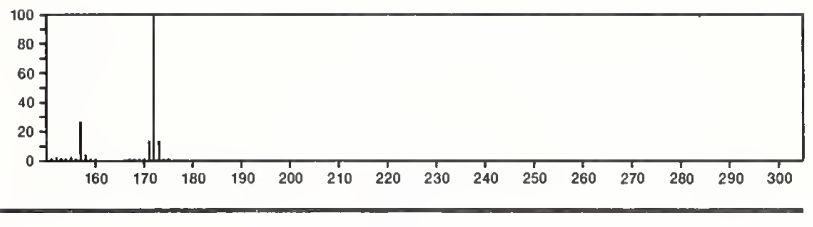

172

$\mathrm{C}_{12} \mathrm{H}_{12} \mathrm{O}$

$54461-07-3$

2,7-Ethanonaphth $[2,3-b]$ oxirene, 1a,2,7,7a-tetrahydro-, $(1 \mathrm{a} \alpha,=$ $2 \beta, 7 \beta, 7 \mathrm{a} \alpha)-$
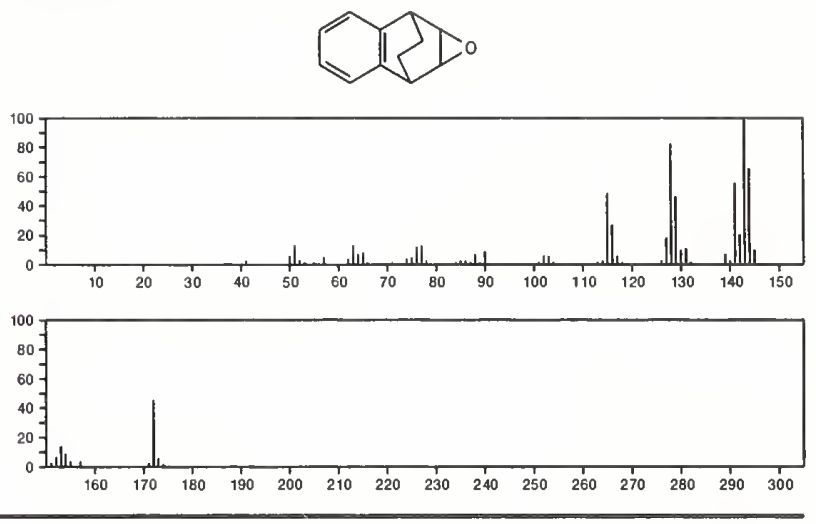

172

$\mathrm{C}_{12} \mathrm{H}_{12} \mathrm{O}$

$54515-76-3$

2,7-Ethanonaphth[2,3-b]oxirene, 1a,2,7,7a-tetrahydro-, $(1 \mathrm{a} \alpha,=$ $2 \alpha, 7 \alpha, 7 \mathrm{a} \alpha)$
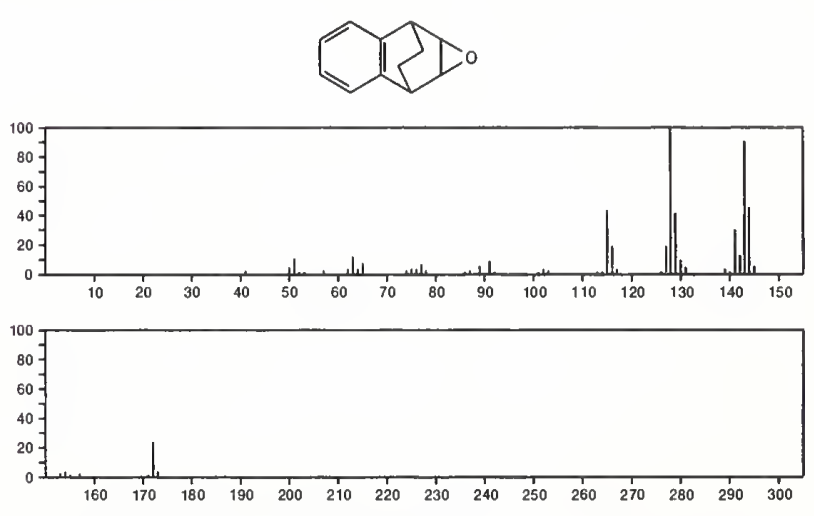

172

$\mathrm{C}_{12} \mathrm{H}_{12} \mathrm{O}$

$56701-48-5$

Cyclobut [c]indene-1-carboxaldehyde, 1,2,2a,3-tetrahydro-
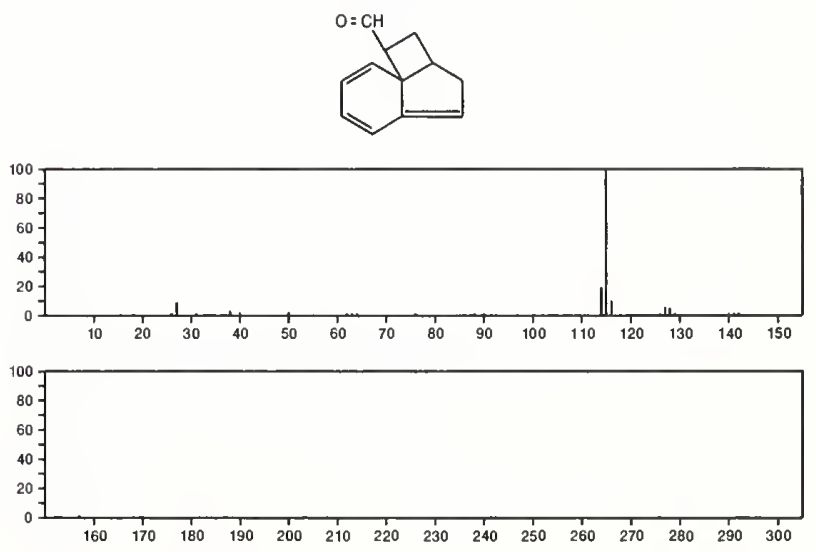
172 $\mathrm{C}_{13} \mathrm{H}_{16}$

Naphthalene, 1,2-dihydro-1,5,8-trimethyl-
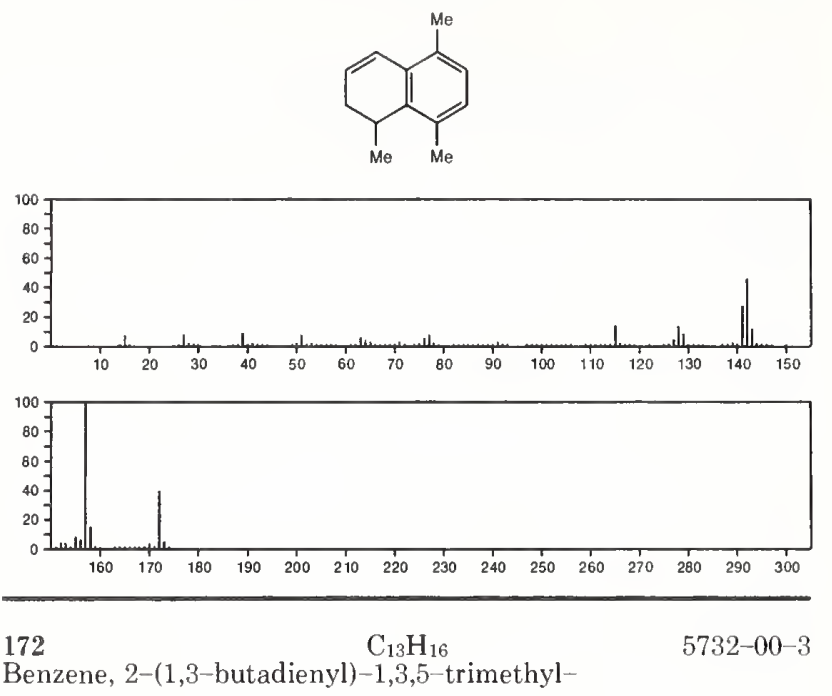

Benzene, 2-(1,3-butadienyl)-1,3,5-trimethyl-
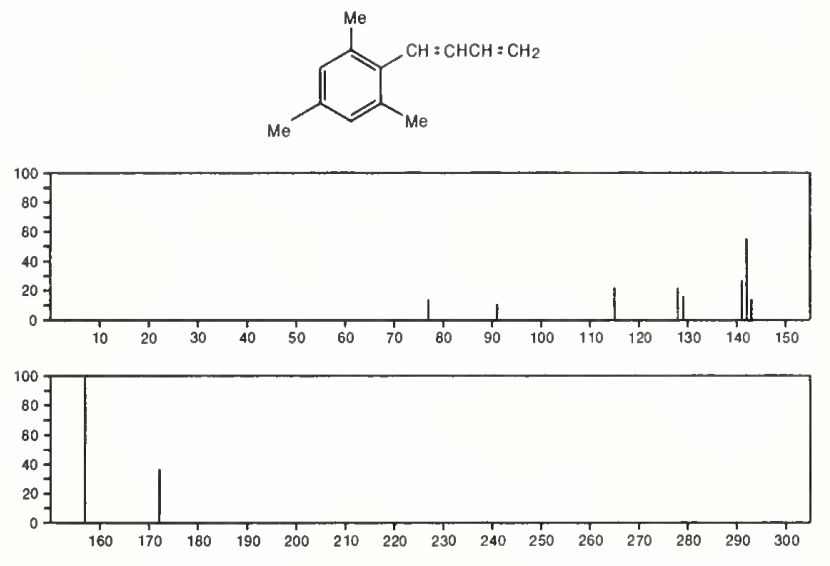

172

$\mathrm{C}_{13} \mathrm{H}_{16}$

$24578-287$

Benzene, 1-methyl-4-[(1-methylethylidene)cyclopropyl]-
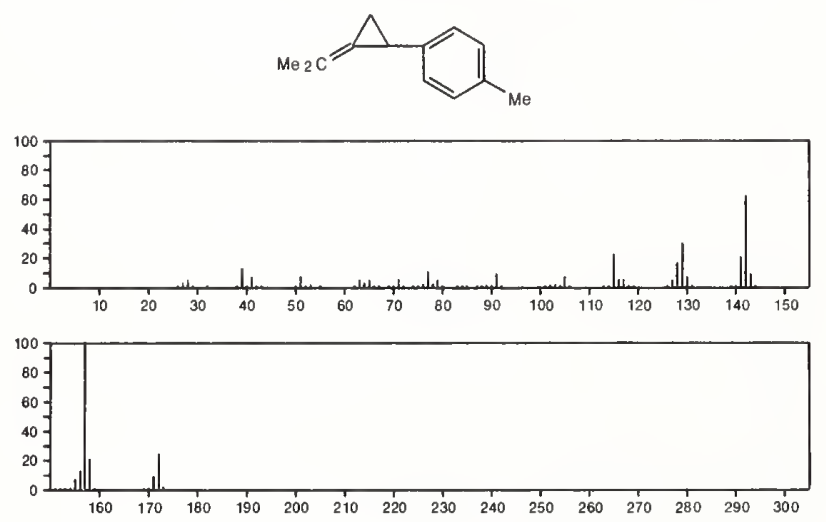

172

$\mathrm{C}_{13} \mathrm{H}_{16}$

$30316-18-8$

Naphthalene, 1,2-dihydro-3,5,8-trimethyl-
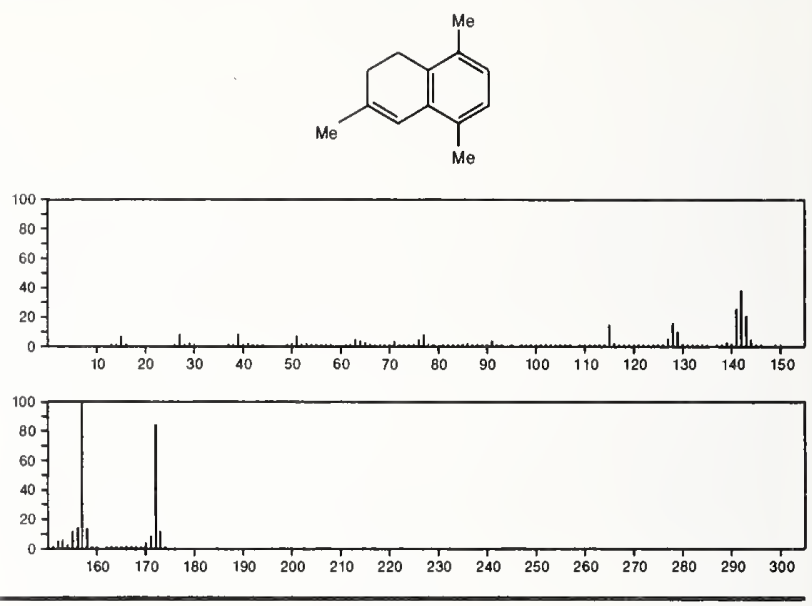

172

$\mathrm{C}_{13} \mathrm{H}_{16}$

$30316-19-9$

Naphthalene, 1,4-dihydro-2,5,8-trimethyl-
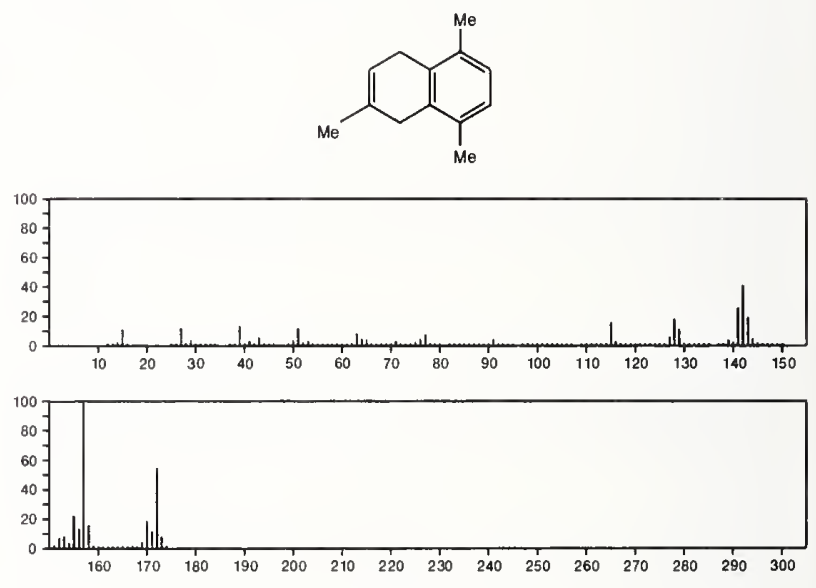

172

$\mathrm{C}_{13} \mathrm{H}_{16}$

$30316-23-5$

Naphthalene, 1,2-dihydro-2,5,8-trimethyl-
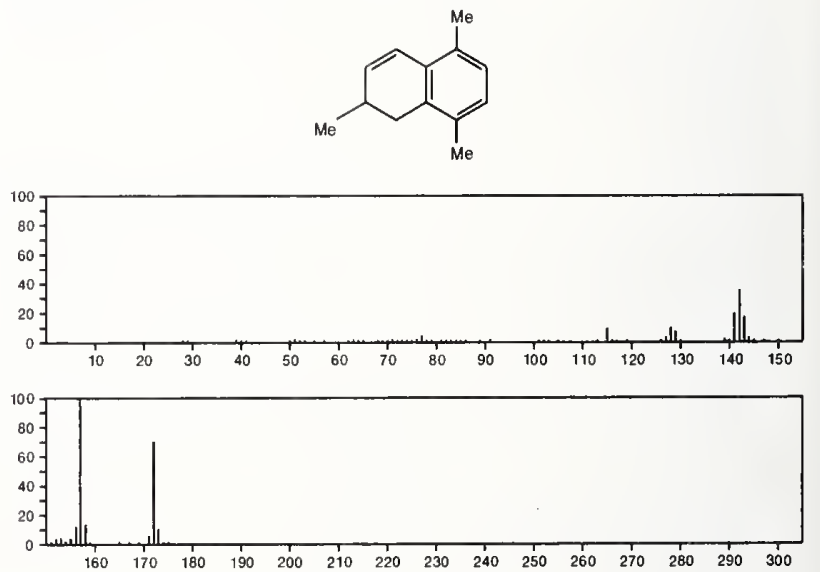
$172 \quad \mathrm{C}_{13} \mathrm{H}_{1}$

Naphthalene, 1,2-dihydro-2,5,7-trimethyl-
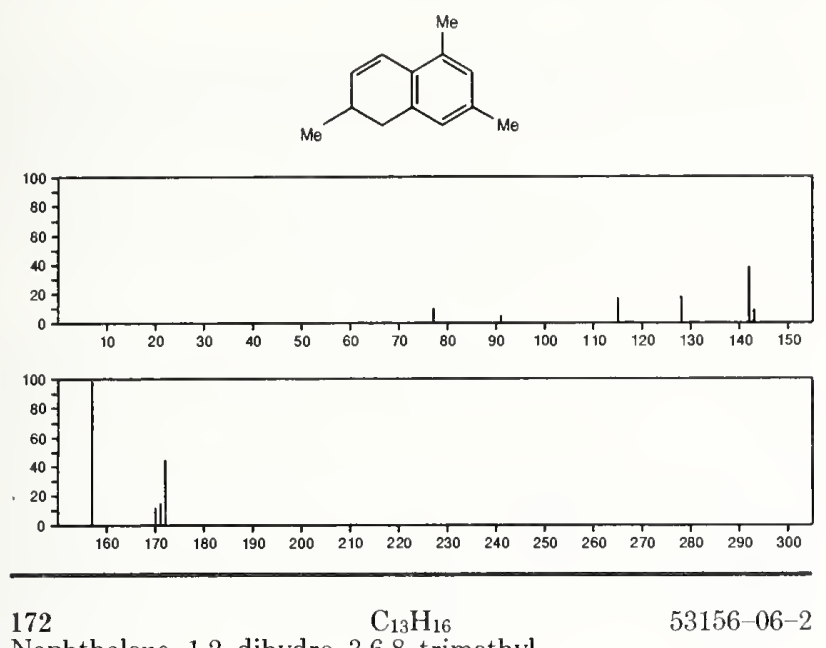

Naphthalene, 1,2-dihydro-3,6,8-trimethyl-
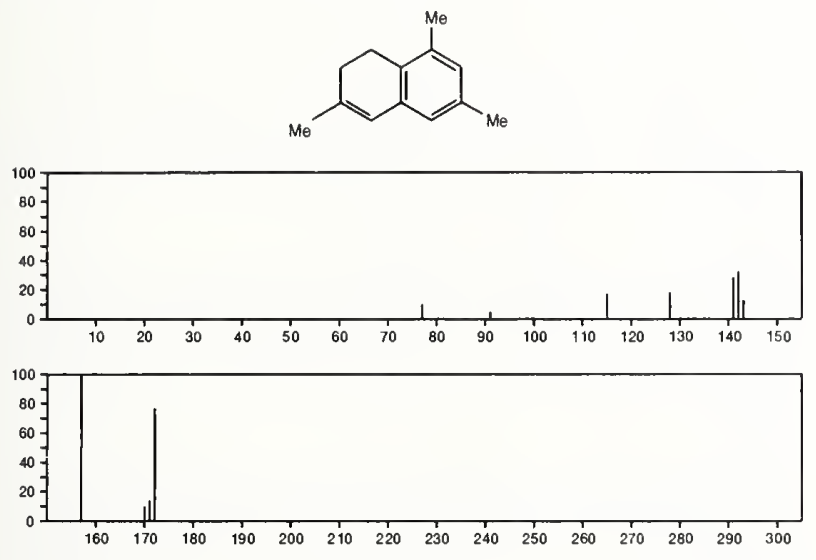

172

$\mathrm{C}_{13} \mathrm{H}_{16}$

$53156-11-9$

Naphthalene, 1,2-dihydro-4,5,7-trimethyl-
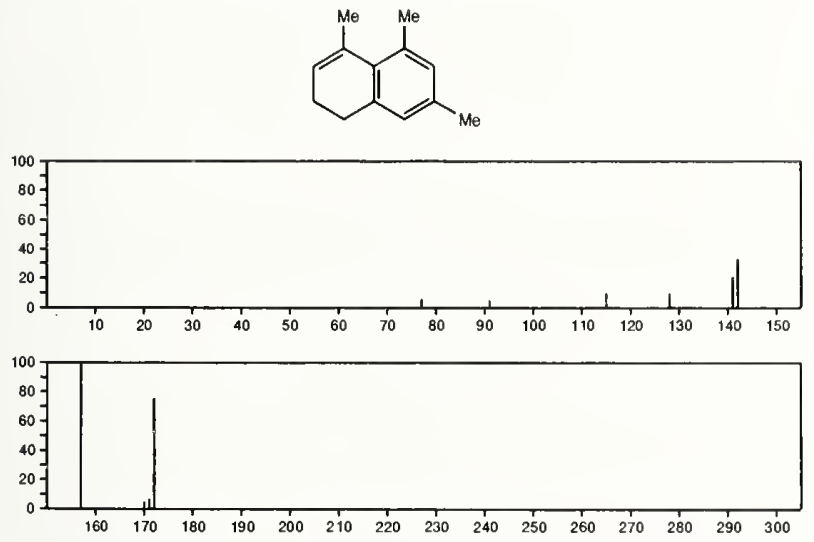

$172 \quad \mathrm{C}_{13} \mathrm{H}_{16}$

Naphthalene, 1,2-dihydro-4,6,8-trimethyl-

$53156-12-0$
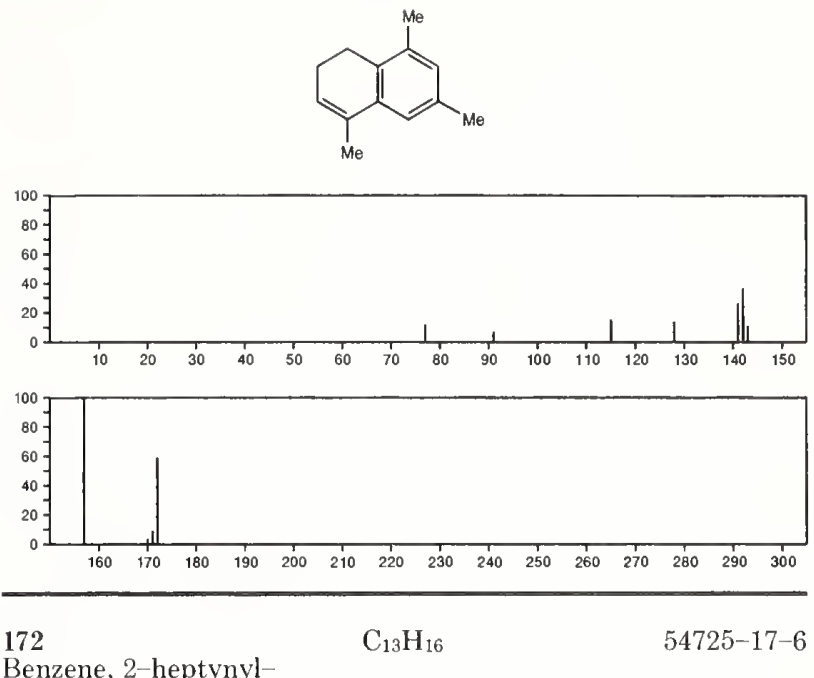

Benzene, 2-heptynyl

$\mathrm{Me}\left(\mathrm{CH}_{2}\right)_{3} \mathrm{C} \equiv \mathrm{CCH}_{2} \mathrm{Ph}$
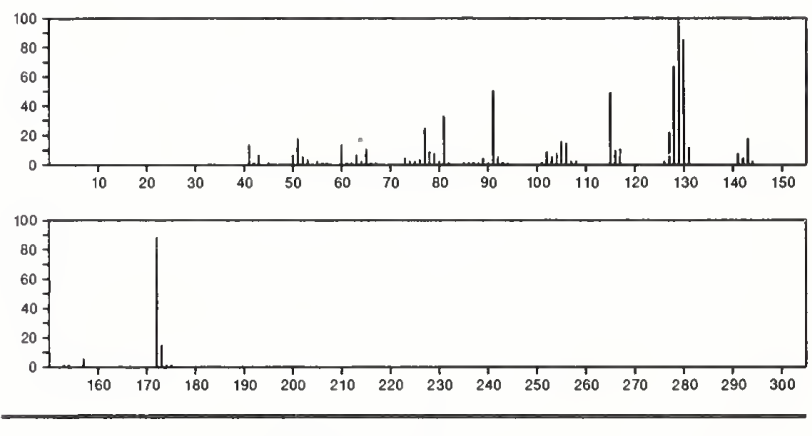

172

$\mathrm{C}_{13} \mathrm{H}_{16}$

$55682-80-9$

Naphthalene, 1,2-dihydro-1,4,6-trimethyl-<smiles></smiles>
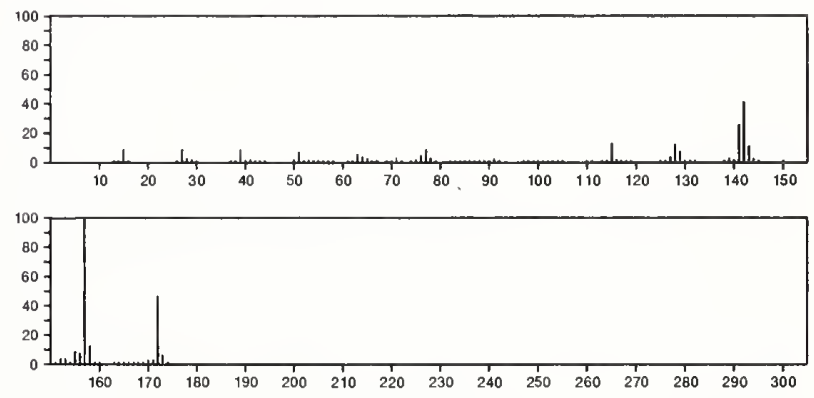

172

$\mathrm{C}_{13} \mathrm{H}_{16}$

$56293-02-8$

Benzene, 6-heptynyl-

$\mathrm{HC} \equiv \mathrm{C}\left(\mathrm{CH}_{2}\right)_{5} \mathrm{Ph}$

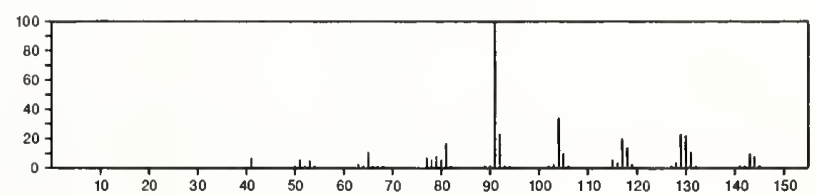




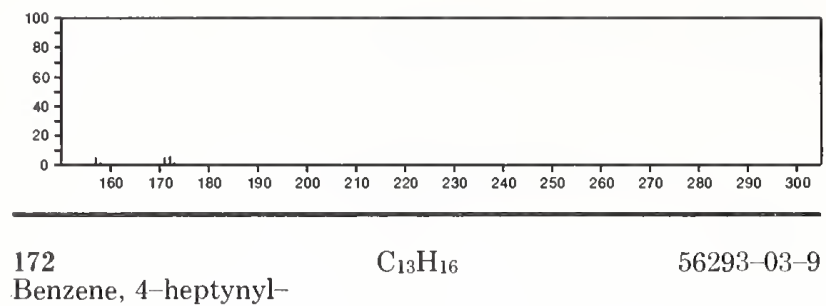

$\mathrm{Ph}\left(\mathrm{CH}_{2}\right)_{3} \mathrm{C} \equiv \mathrm{CEt}$
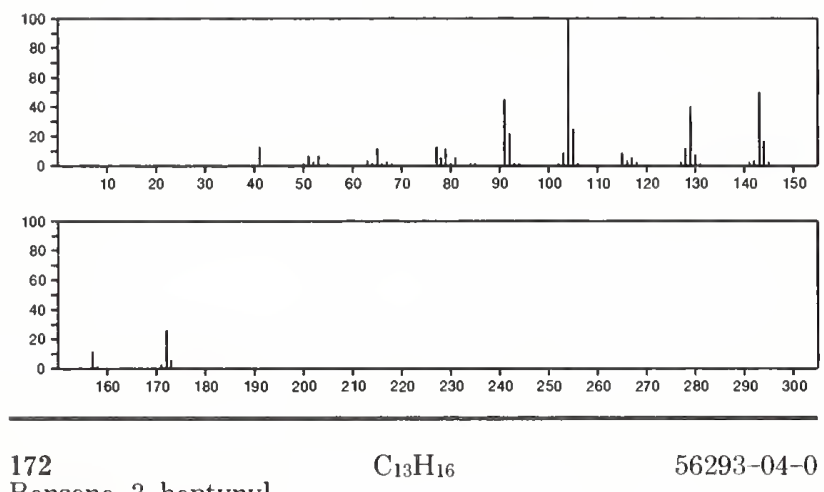

Benzene, 3-heptynyl-

$\operatorname{PrC} \equiv \mathrm{CCH}_{2} \mathrm{CH}_{2} \mathrm{Ph}$
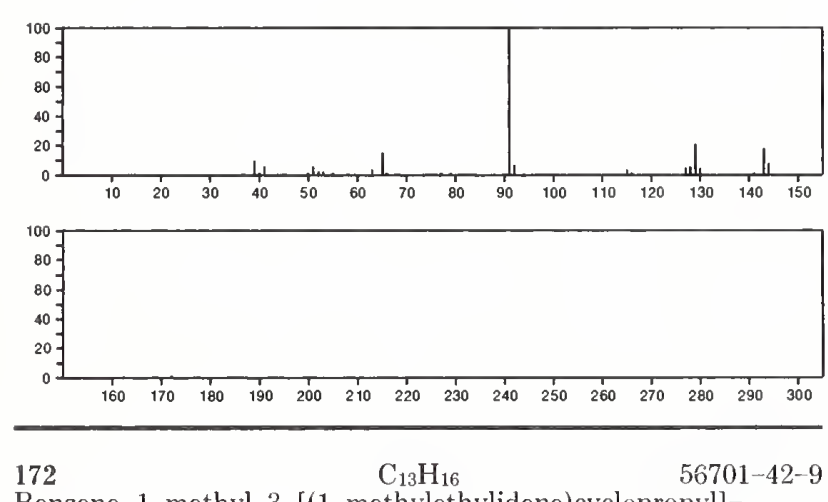

Benzene, 1-methyl-3-[(1-methylethylidene)cyclopropyl]-
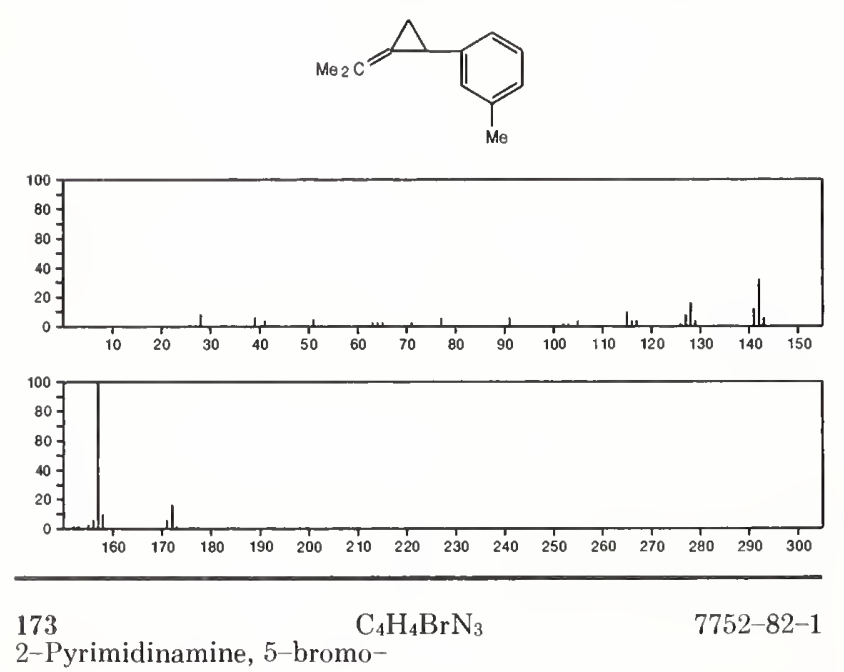

2-Pyrimidinamine, 5-bromo-
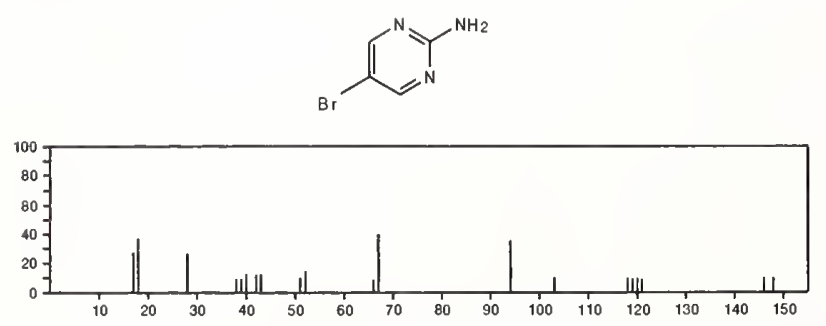

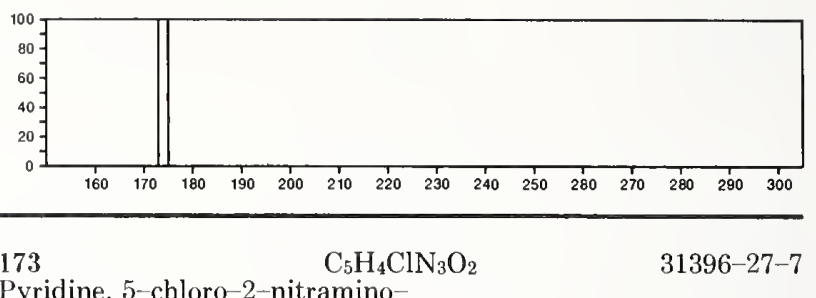

Pyridine, 5-chloro-2-nitramino-

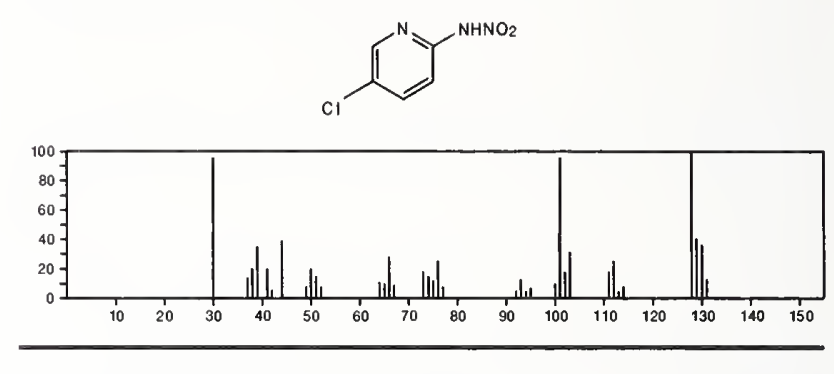

173

$\mathrm{C}_{5} \mathrm{H}_{8} \mathrm{ClN}_{5}$

$1007-28-9$

1,3,5-Triazine-2,4-diamine, 6 - chloro- $N$-ethyl-
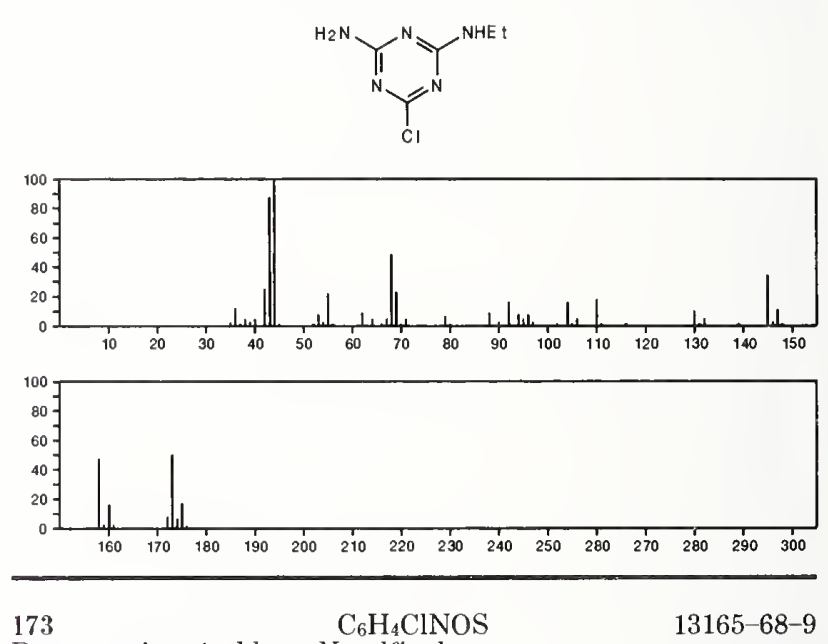

$13165-68-9$

Benzenamine, 4-chloro-N-sulfinyl-
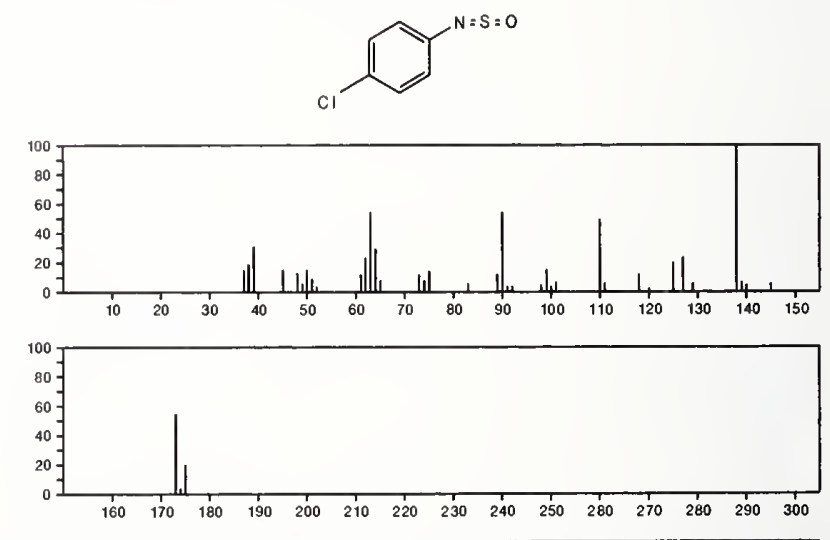

$173 \quad \mathrm{C}_{6} \mathrm{H}_{4} \mathrm{CINOS}$

Benzenamine, 3 -chloro- $N$-sulfinyl-

$15851-82-8$
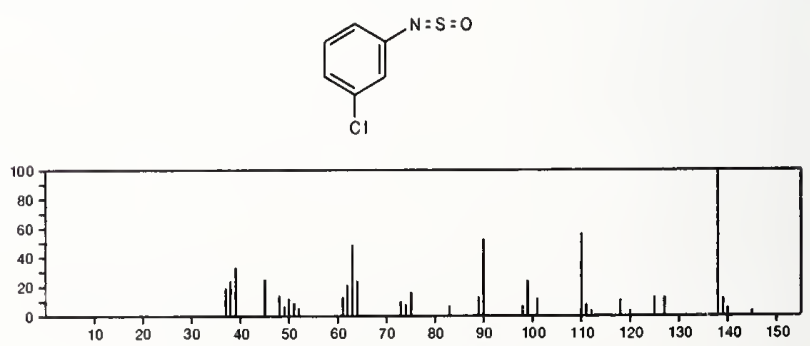


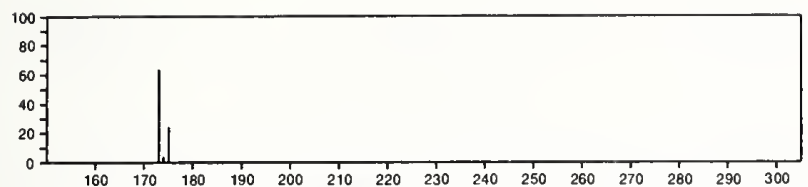

173

$\mathrm{C}_{6} \mathrm{H}_{7} \mathrm{NO}_{3} \mathrm{~S}$

$56196-66-8$

Acetic acid, (4-oxo-2-thiazolidinylidene)-, methyl ester
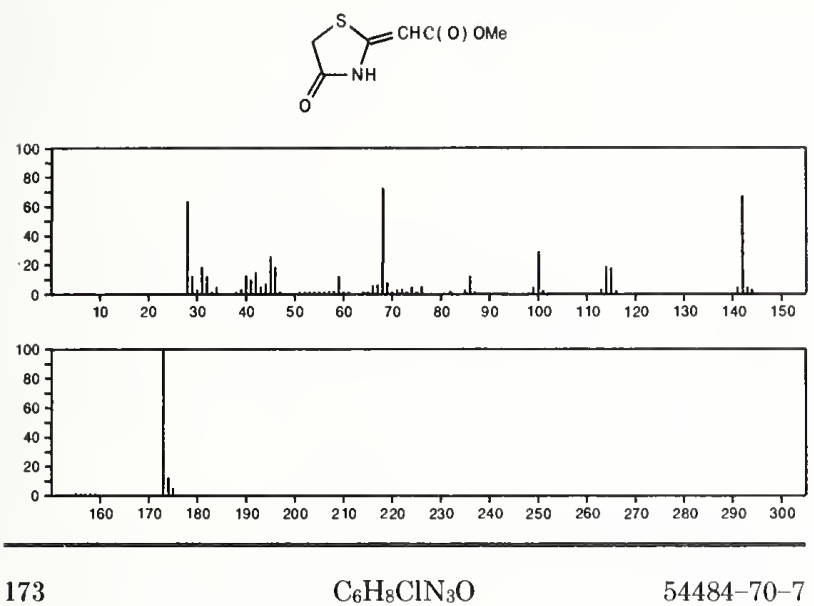

5-Pyrimidinamine, 2-chloro-4-ethoxy-
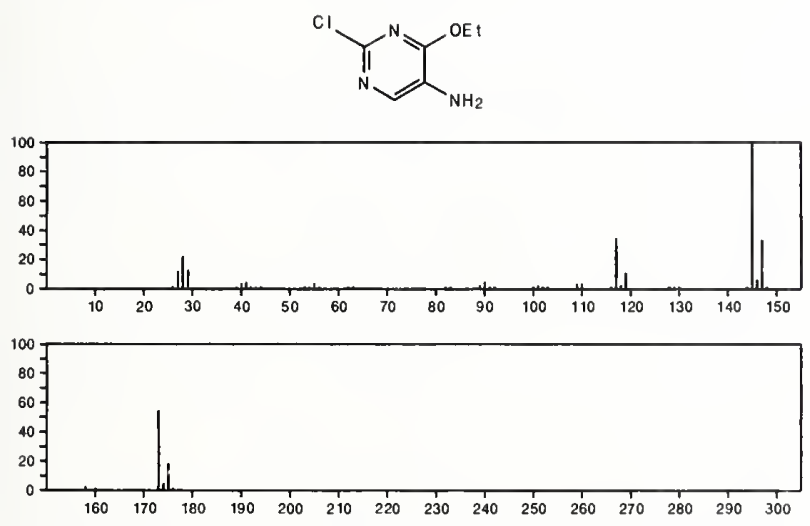

173

$\mathrm{C}_{7} \mathrm{H}_{11} \mathrm{NO}_{2} \mathrm{~S}$

2-Propenethioamide, 3-(acetyloxy)- N,N-dimethyl-, $(Z)-$

$\mathrm{ACOCH}=\mathrm{CHCSNME} 2$
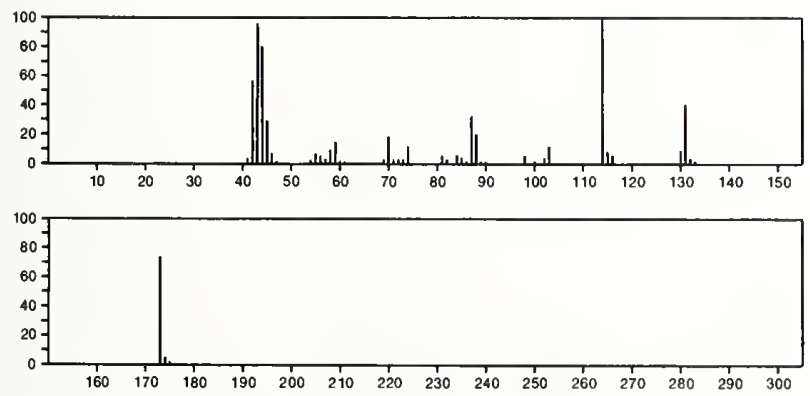

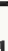

$173 \quad \mathrm{C}_{7} \mathrm{H}_{11} \mathrm{NO}_{2} \mathrm{~S} \quad 52118-16-8$ 2-Propenethioamide, $3-$ (acetyloxy) $-N, N$-dimethyl-, $(E)-$

$\mathrm{ACOCH}=\mathrm{CHCSNME} 2$

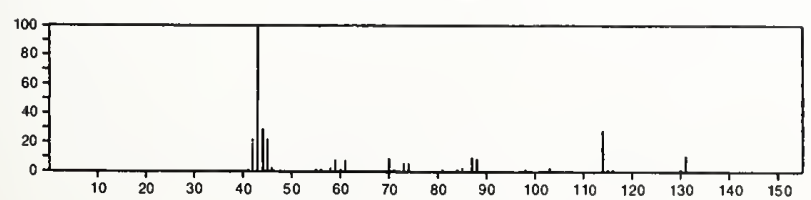

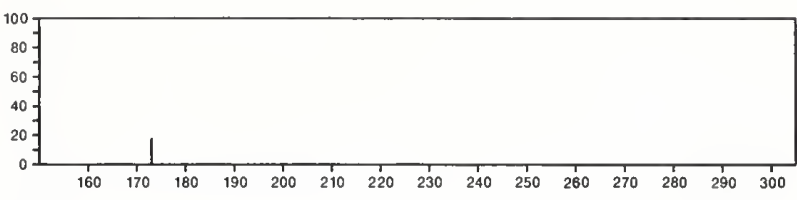

173

$\mathrm{C}_{7} \mathrm{H}_{11} \mathrm{NO}_{4}$

L-Proline, 1-acetyl-4-hydroxy-, trans

$33996-33-7$<smiles>O=C(O)C1CC(O)CN1C(=O)O</smiles>
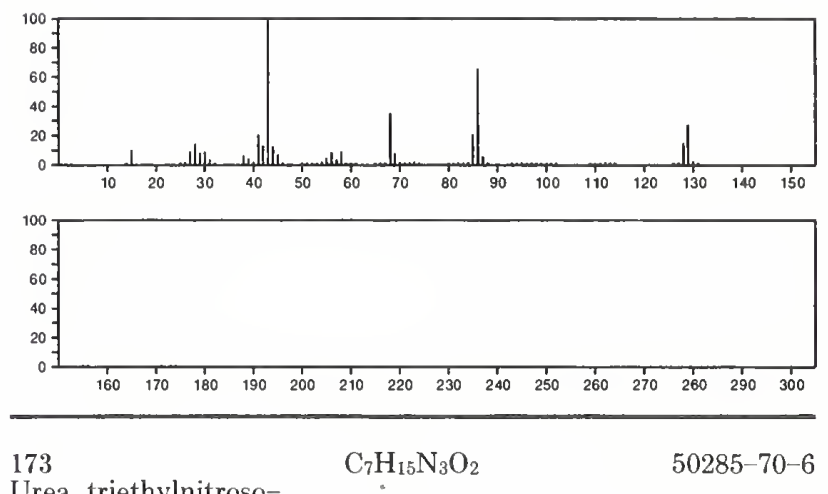

Urea, triethylnitroso-

Et 2 NCON(NO)Et
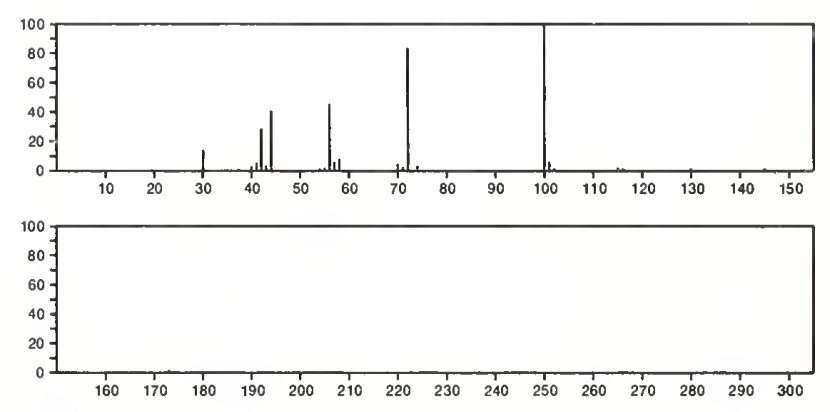

173

DL-Leucine, $N$-acetyl-

$\mathrm{C}_{8} \mathrm{H}_{15} \mathrm{NO}_{3}$

$99-15-0$

$\mathrm{Me}_{2} \mathrm{CHCH}_{2} \mathrm{CH}\left(\mathrm{CO}_{2} \mathrm{H}\right) \mathrm{NHAC}$
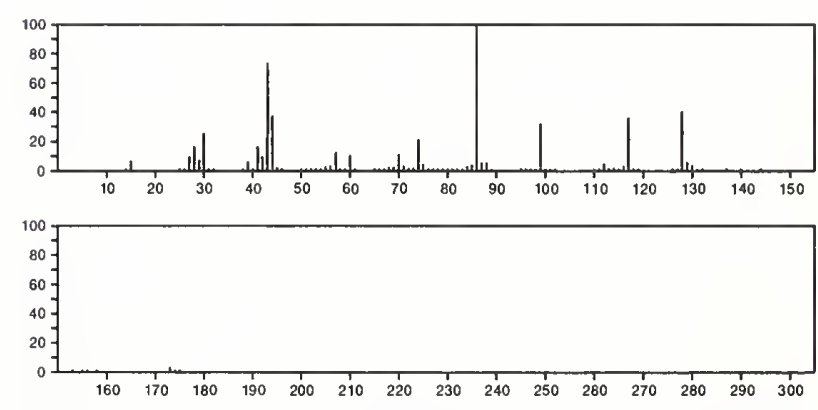

173

$\mathrm{L}$-Isoleucine, $\mathrm{N}$-acetyl-

$\mathrm{C}_{8} \mathrm{H}_{15} \mathrm{NO}_{3}$

$3077-46-1$

$\mathrm{MeCH} 2 \mathrm{CHMe} C \mathrm{CH}\left(\mathrm{CO}_{2} \mathrm{H}\right) \mathrm{NHAC}$

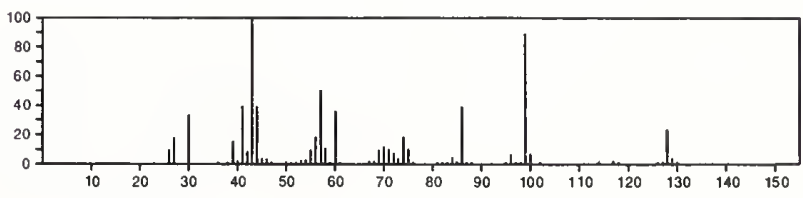




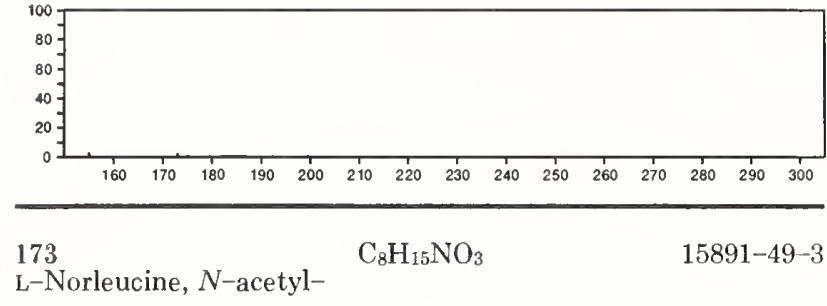

$\mathrm{ACNHCH}\left(\mathrm{CO}_{2} \mathrm{H}\right)\left(\mathrm{CH}_{2}\right)_{3} \mathrm{Me}$
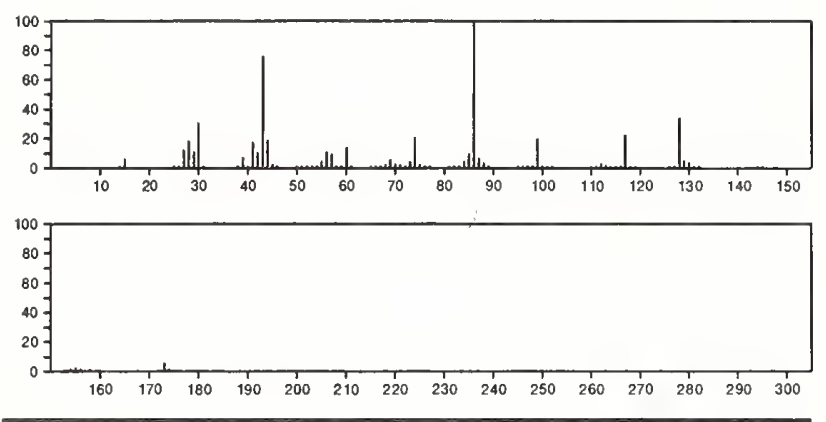

173

$\mathrm{C}_{8} \mathrm{H}_{15} \mathrm{NO}_{3}$

$16067-01-9$

2-Octanone, 1-nitro-

$\mathrm{Me}\left(\mathrm{CH}_{2}\right)_{5} \mathrm{COCH}_{2} \mathrm{NO}_{2}$

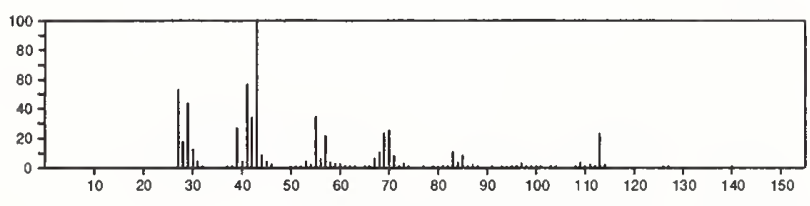

173

$\mathrm{C}_{8} \mathrm{H}_{15} \mathrm{NO}_{3}$

Isoleucine, $N$-acetyl-, $\mathrm{DL}^{-}$

$\mathrm{MeCH} 2 \mathrm{CHMeCH}\left(\mathrm{CO}_{2} \mathrm{H}\right)$ NHAC
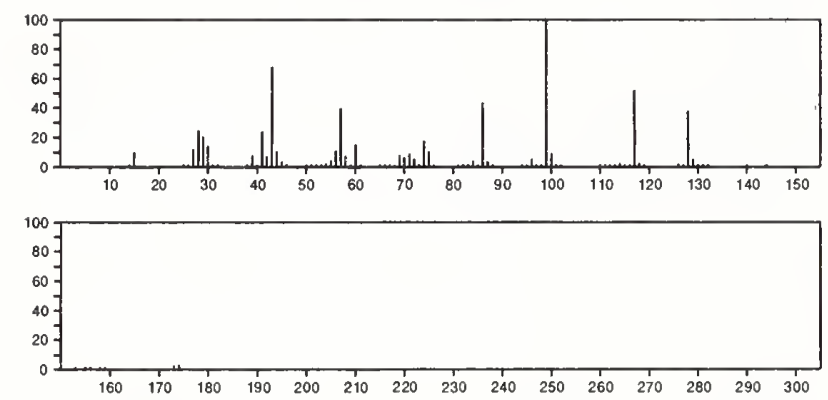

$173 \quad \mathrm{C}_{8} \mathrm{H}_{15} \mathrm{NO}_{3}$

DL-Valine, $N$-acetyl-, methyl ester

CHMe 2

MeOC(O) CHNHAC
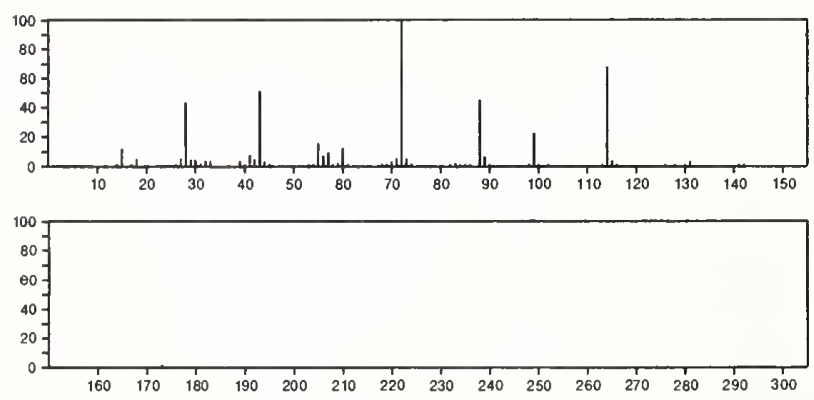

173

D-Alloisoleucine, $N$-acetyl-

$\mathrm{C}_{8} \mathrm{H}_{15} \mathrm{NO}_{3}$

$54831-20-8$

$\mathrm{Me} \mathrm{CH}_{2} \mathrm{CHM} \mathrm{CH}_{\theta}\left(\mathrm{CG}_{2} \mathrm{H}\right) \mathrm{NHAC}$
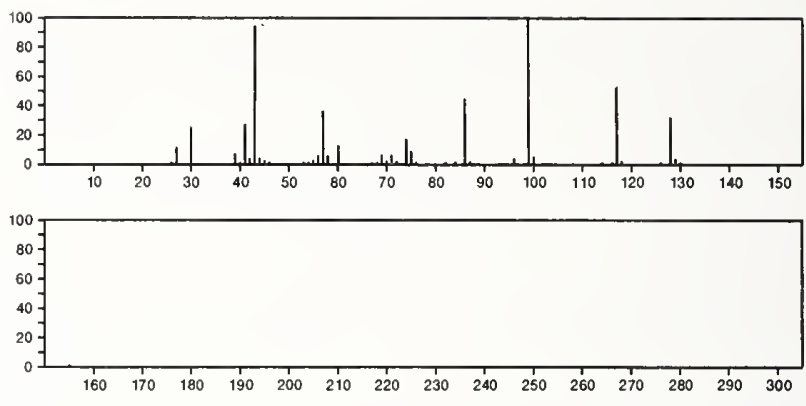

173

$\mathrm{C}_{8} \mathrm{H}_{15} \mathrm{NO}_{3}$

Glycine, $N$-(3-methyl-1-oxobutyl $)-$, methyl ester

$56009-37-1$

$\mathrm{MeOC}(\mathrm{O}) \mathrm{CH}_{2} \mathrm{NHCOCH}_{2} \mathrm{CHM}_{2}$
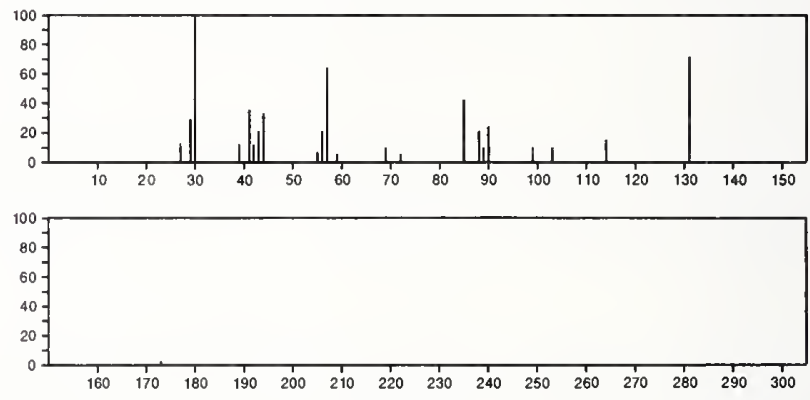

$173 \quad \mathrm{C}_{9} \mathrm{H}_{7} \mathrm{~N}_{3} \mathrm{O}$

$s$-Triazole-3-carboxaldehyde, 5-phenyl-

$26899-64-9$
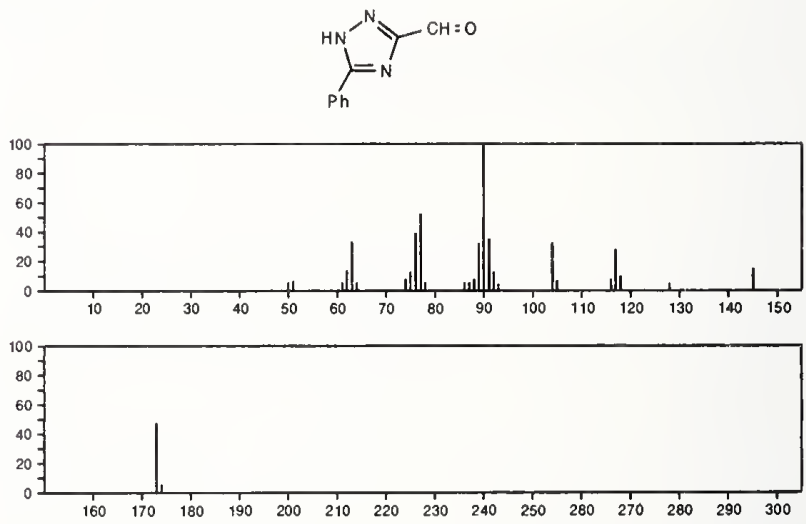

$173 \quad \mathrm{C}_{9} \mathrm{H}_{19} \mathrm{NO}_{2}$

L-Alanine, $N-(1-$ methylethyl $)-, 1-$ methylethyl ester

$56805-00-6$

$\mathrm{i}-\mathrm{PrOC}(\mathrm{O}) \mathrm{CH}\left(\mathrm{NHPr}_{-} \mathrm{i}\right) \mathrm{Me}$
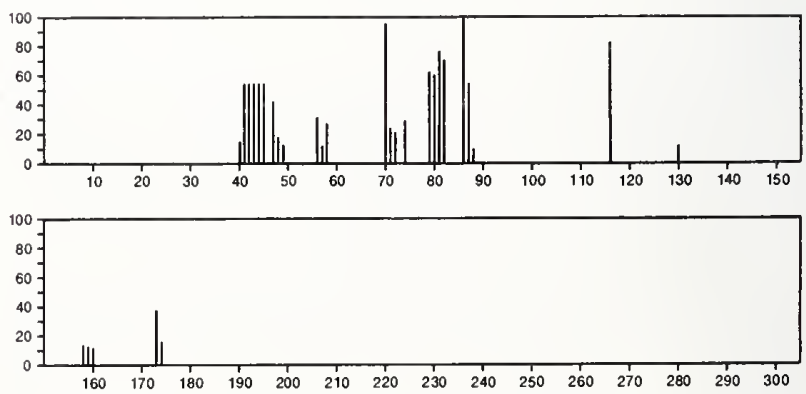
173

$\mathrm{C}_{10} \mathrm{H}_{7} \mathrm{NO}_{2}$

$86-57-7$

Naphthalene, 1-nitro-
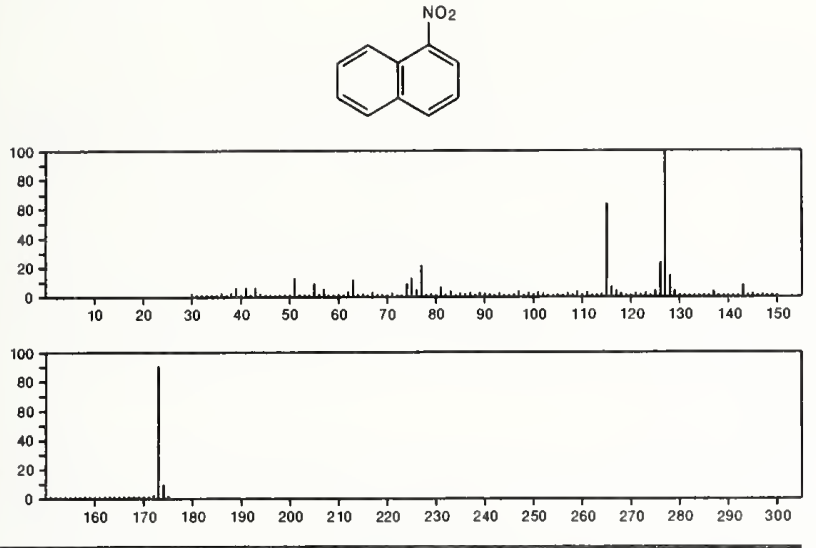

173

2-Quinolinecarboxylic acid

$\mathrm{C}_{10} \mathrm{H}_{7} \mathrm{NO}_{2}$

$93-10-7$
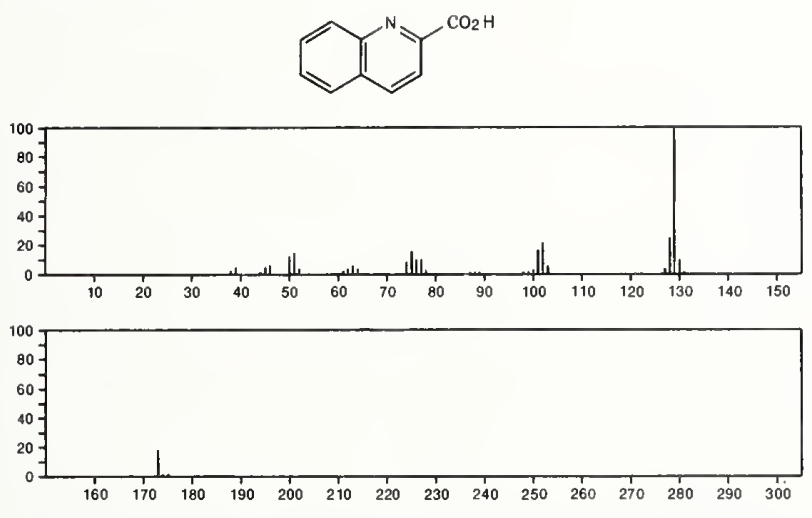

173
$1 H$-Pyrrole-2,5-dione,
1-phenyl-
$\mathrm{C}_{10} \mathrm{H}_{7} \mathrm{NO}_{2}$

$941-69-5$
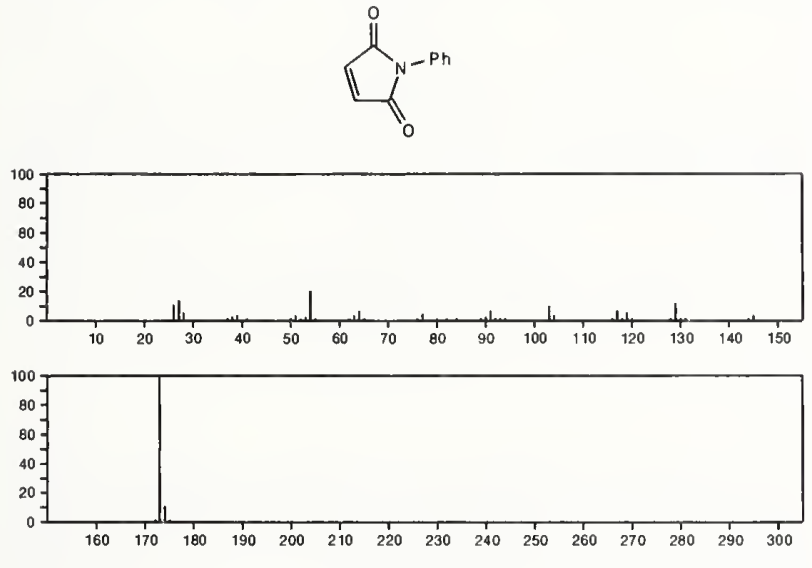

$173 \quad \mathrm{C}_{10} \mathrm{H}_{7} \mathrm{NO}_{2}$

2-Quinolinecarboxaldehyde, 8-hydroxy-

$14510-06-6$
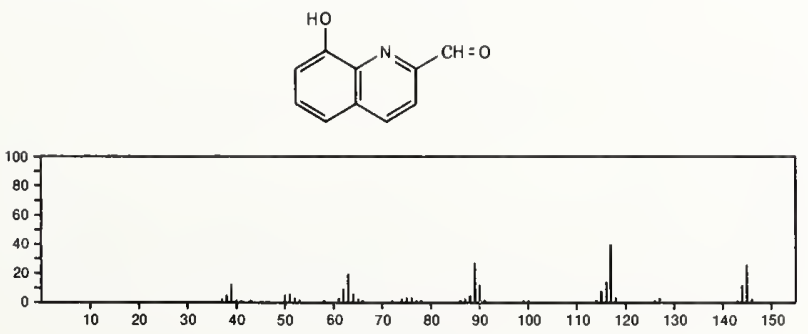

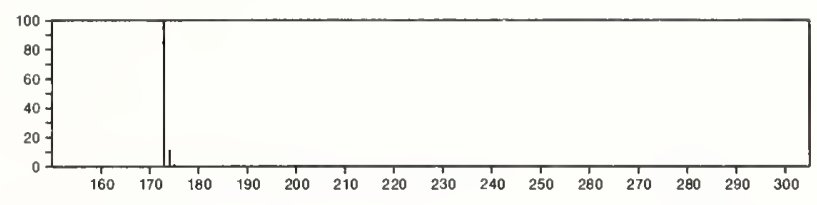

173

$\mathrm{C}_{10} \mathrm{H}_{7} \mathrm{NO}_{2}$

2(5H)-Furanone, 5-(phenylimino)-
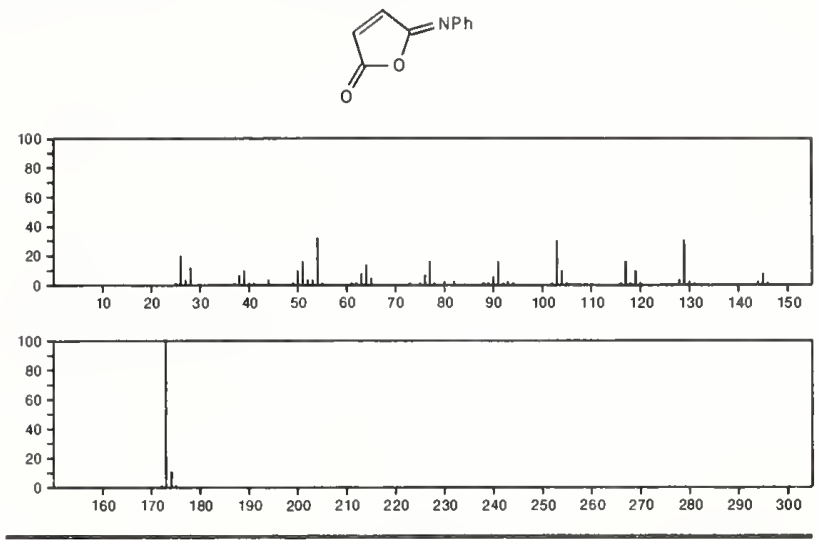

173

$\mathrm{C}_{10} \mathrm{H}_{23} \mathrm{NO}$

29812-79-1

Hydroxylamine, $\mathrm{O}$-decyl-

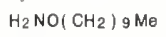
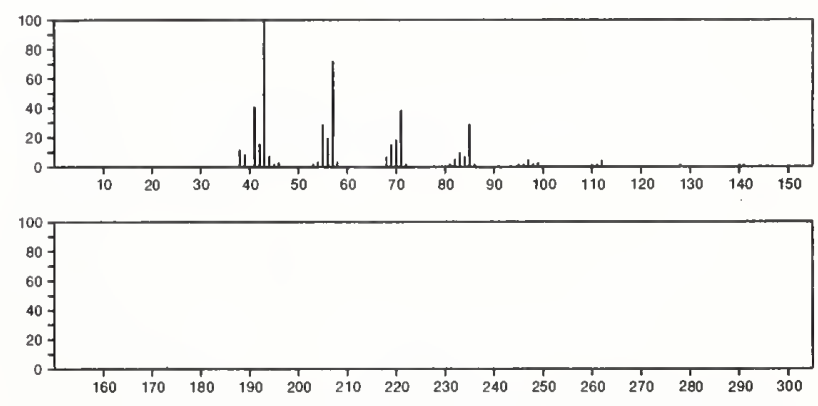

173

Isoxazole, 3-ethyl-5-phenyl-

$\mathrm{C}_{11} \mathrm{H}_{11} \mathrm{NO}$

$4211-90-9$
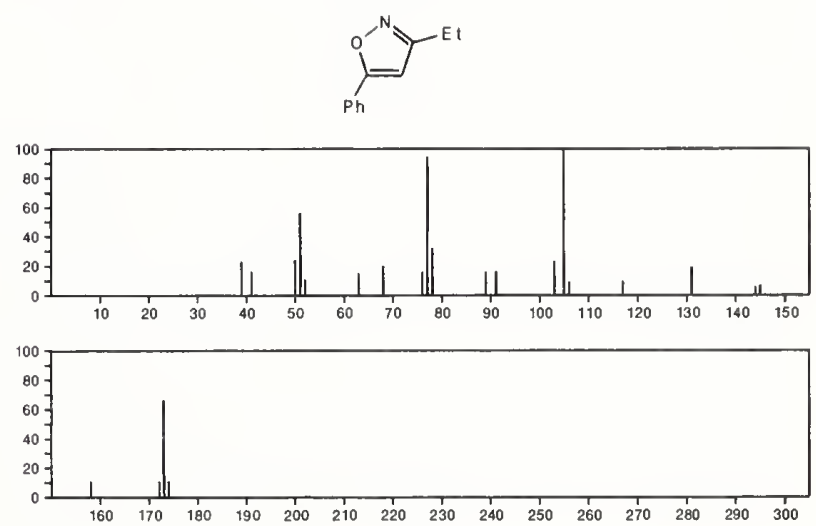
173

$\mathrm{C}_{11} \mathrm{H}_{11} \mathrm{NO}$

Quinoline, 2,3-dimethyl-, 1-oxide

$14300-11-9$
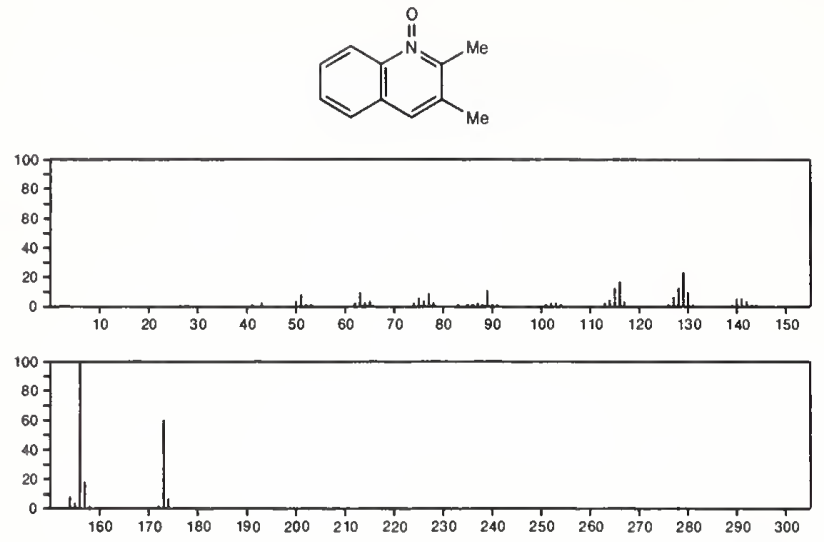

173

$\mathrm{C}_{11} \mathrm{H}_{11} \mathrm{NO}$

$14300-12-0$
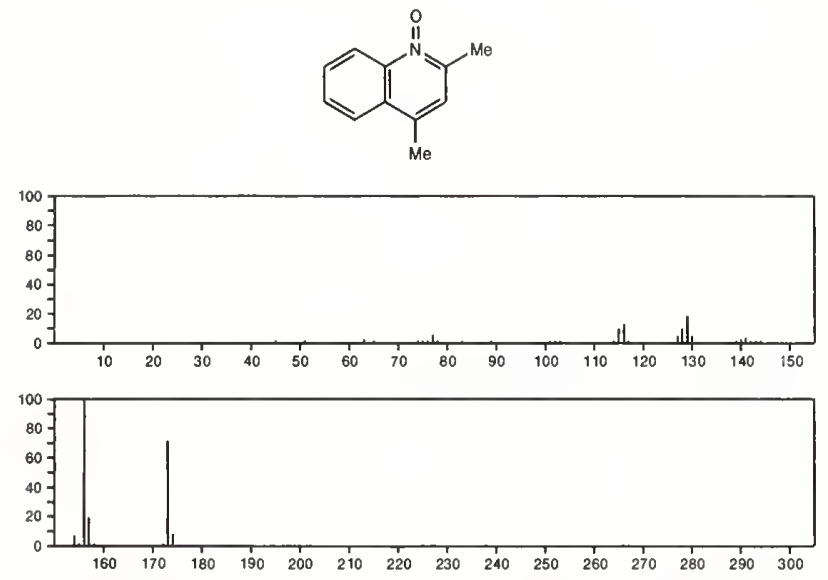

173

$\mathrm{C}_{11} \mathrm{H}_{11} \mathrm{NO}$

$17336-90-2$

methyl-
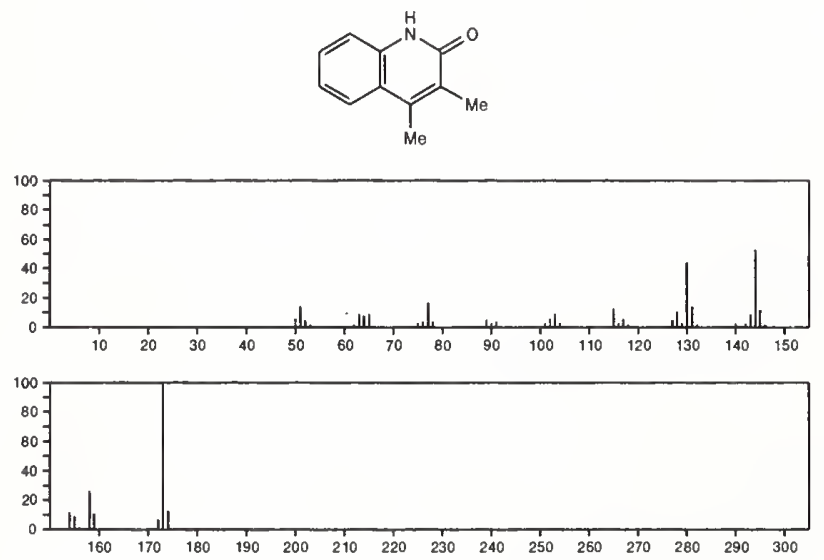

173

Oxazole, 5-ethyl-4-phenyl-

$\mathrm{C}_{11} \mathrm{H}_{11} \mathrm{NO}$

$20662-91-3$
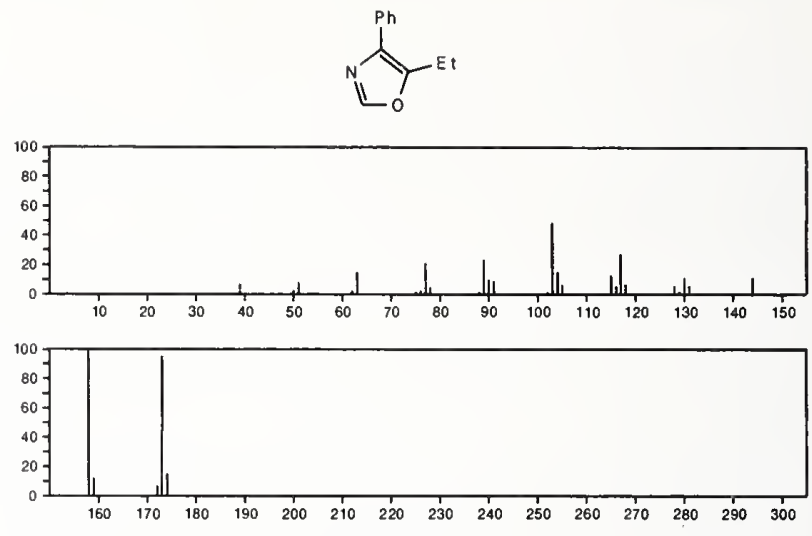

173

$\mathrm{C}_{11} \mathrm{H}_{11} \mathrm{NO}$

Oxazole, 2,5-dimethyl-4-phenyl-

$20662-92-4$<smiles>Cc1nc(-c2ccccc2)c(C)o1</smiles>
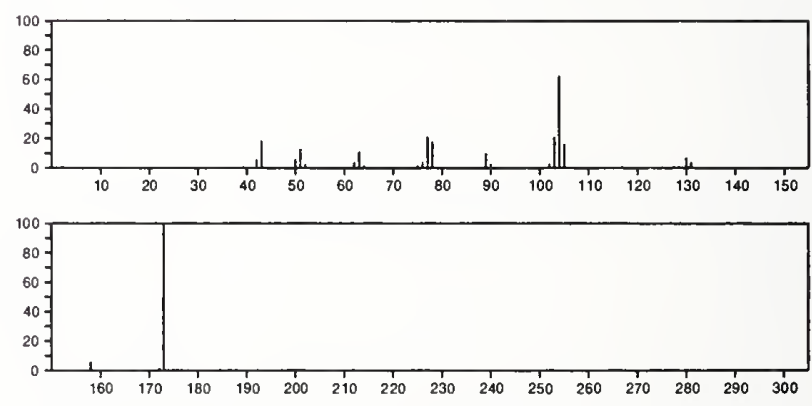

173

$\mathrm{C}_{11} \mathrm{H}_{11} \mathrm{NO}$

24562-79-6

2H-1,4-Ethanoquinolin-3(4H)-one
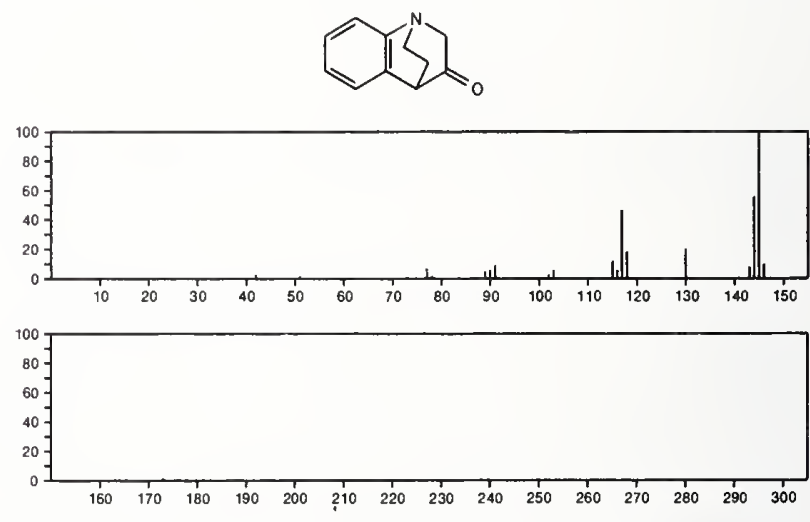

173

$\mathrm{C}_{11} \mathrm{H}_{11} \mathrm{NO}$

Ketone, methyl 5-methyl-3-indolizinyl

$31108-61-9$
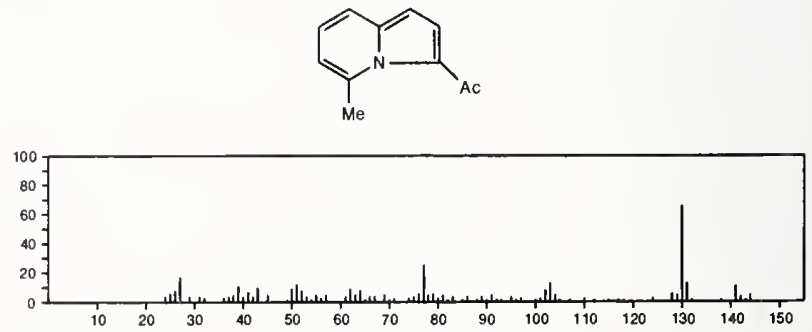


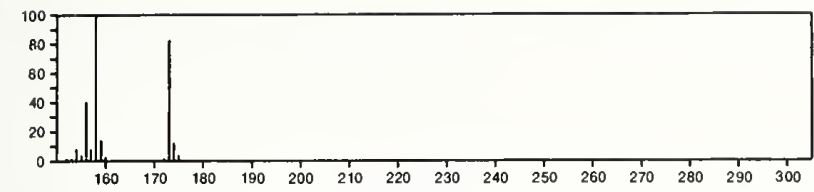

$\begin{array}{lllllllllllllll}160 & 170 & 180 & 190 & 200 & 210 & 220 & 230 & 240 & 250 & 260 & 270 & 280 & 290 & 300\end{array}$

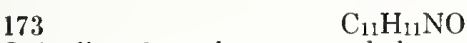

$41037-26-7$

Quinoline, 6-methoxy-4-methyl-
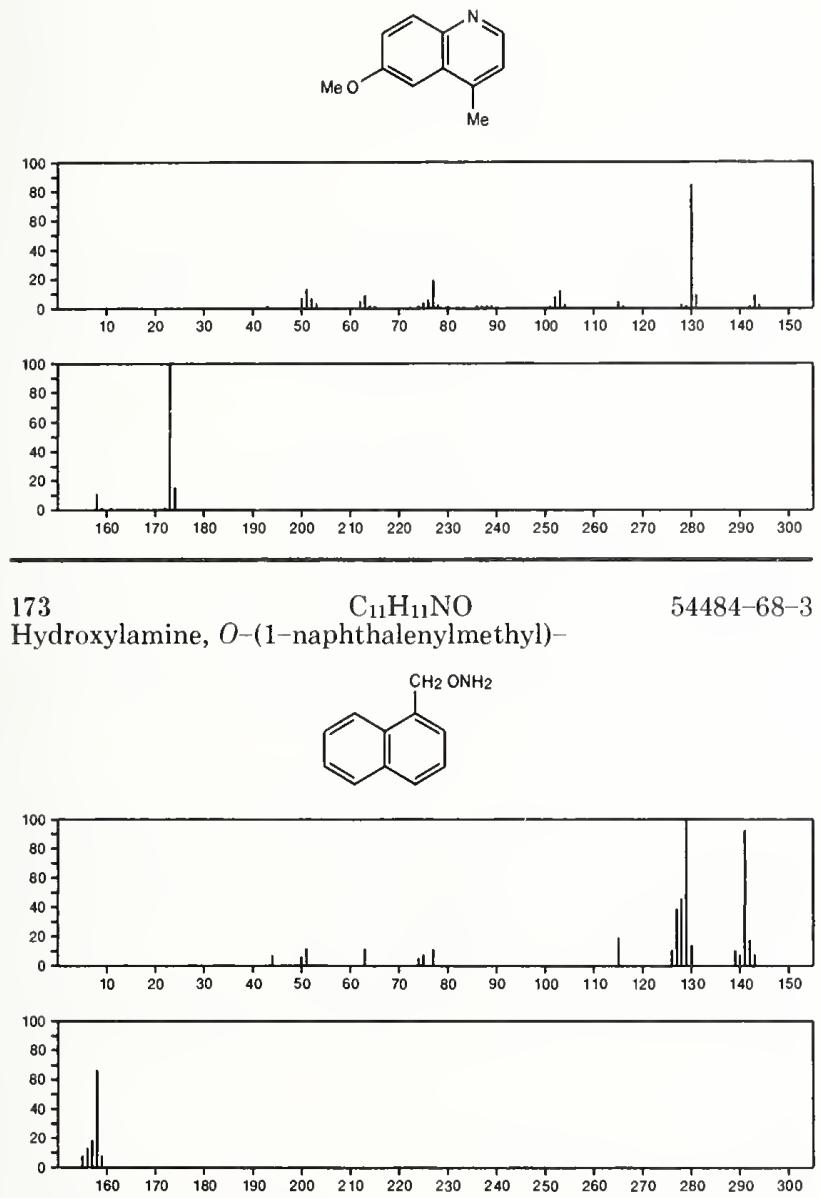

$\begin{array}{lllllllllllllll}160 & 170 & 180 & 190 & 200 & 210 & 220 & 230 & 240 & 250 & 260 & 270 & 280 & 290 & 300\end{array}$

$173 \quad \mathrm{C}_{11} \mathrm{H}_{11} \mathrm{NO}$

Hydroxylamine, $\mathrm{O}$-(2-naphthalenylmethyl)-

$54484-69-4$
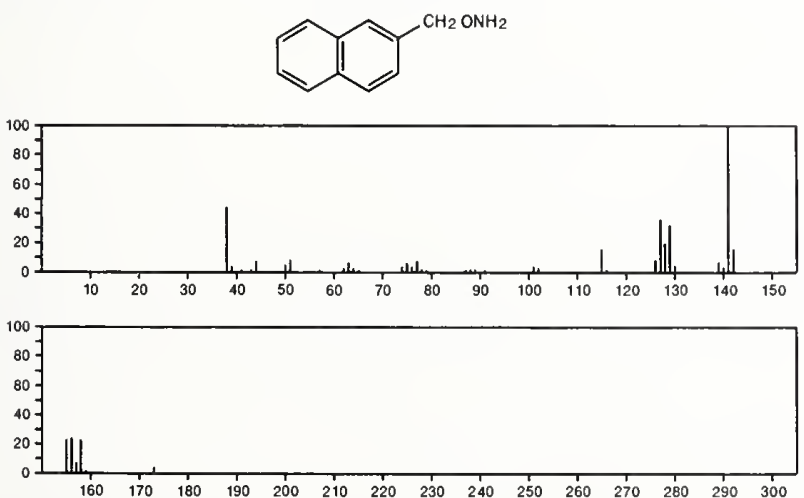

173

$\mathrm{C}_{11} \mathrm{H}_{11} \mathrm{NO}$

$56909-00-3$

5-Azatricyclo[7.2.0.01,4] undeca-2,5,7,10-tetraene, 6-methoxy-
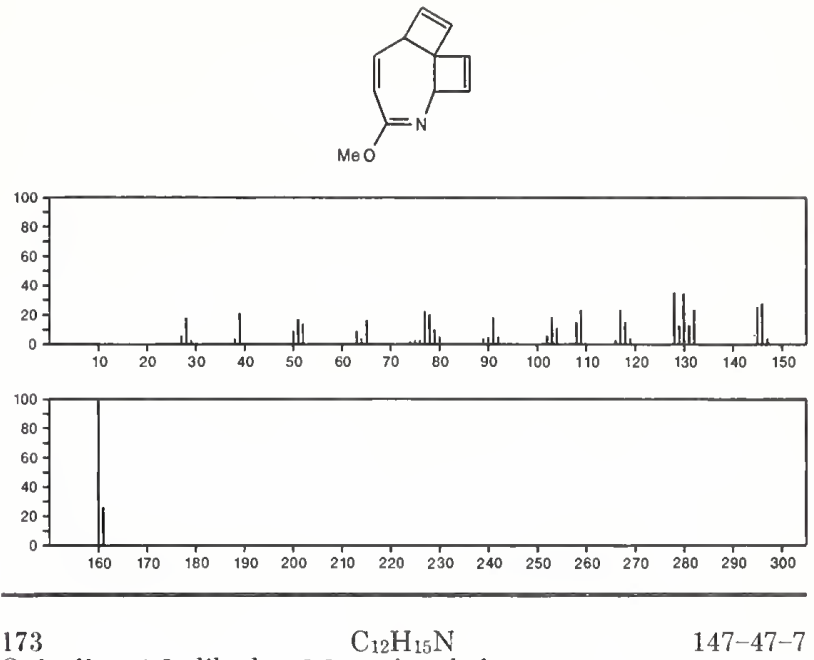

Quinoline, 1,2-dihydro-2,2,4-trimethyl-

$147-47-7$<smiles></smiles>
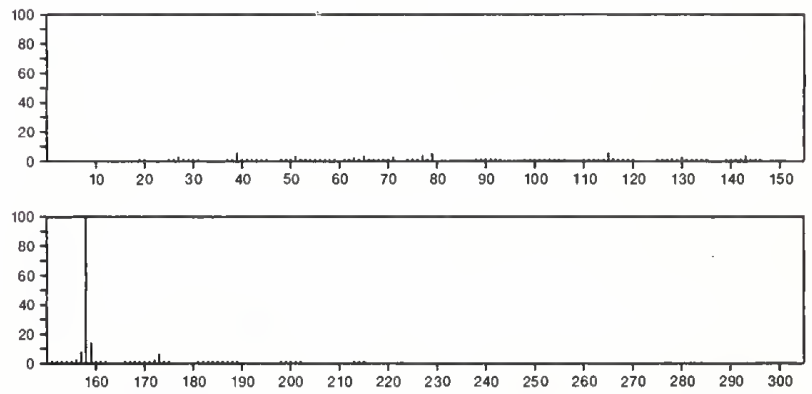

173

3H-Indole, 3-ethyl-2,3-dimethyl-

$1798-39-6$
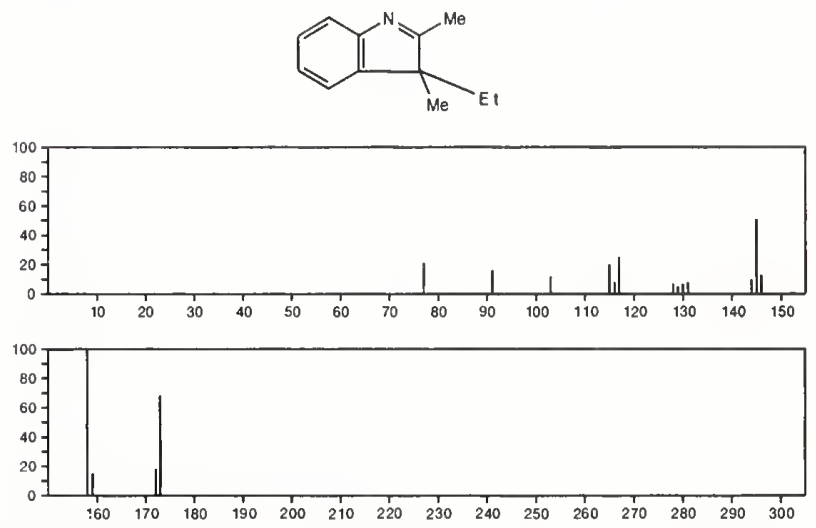

173

$\mathrm{C}_{12} \mathrm{H}_{15} \mathrm{~N}$

$3 H$-Indole, 2-ethyl-3,3-dimethyl-

$18781-53-8$<smiles>CCC1=Nc2ccccc2C1(C)[N+]#N</smiles>

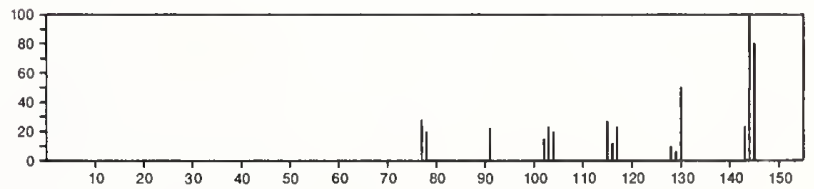




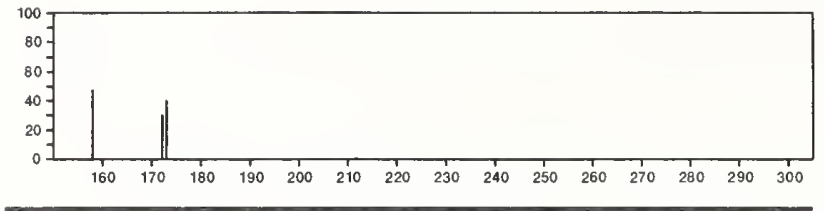

$173 \quad \mathrm{C}_{12} \mathrm{H}_{15} \mathrm{~N} \quad 23853-53-4$ Aziridine, 1-(1,2,3,4-tetrahydro-2-naphthyl)-
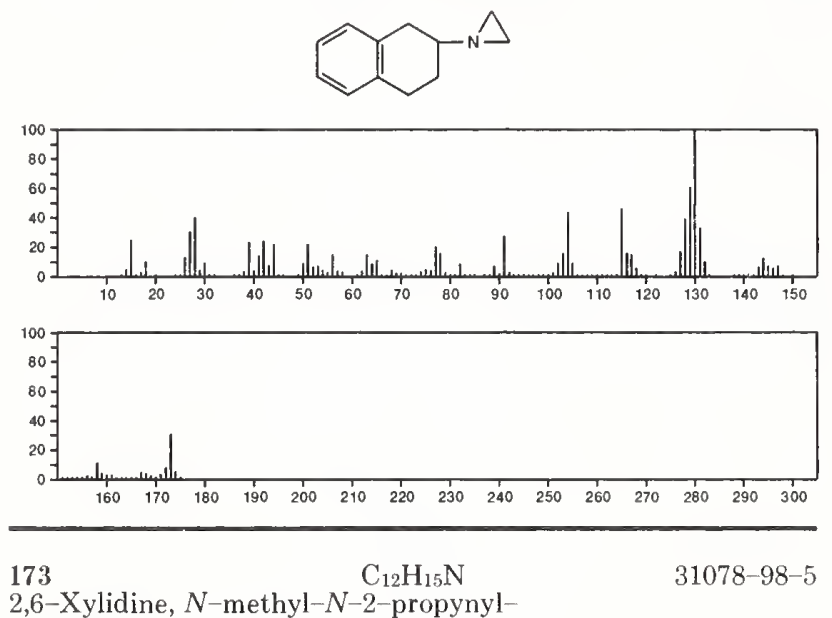

2,6-Xylidine, $N$-methyl- $N-2-$ propynyl-
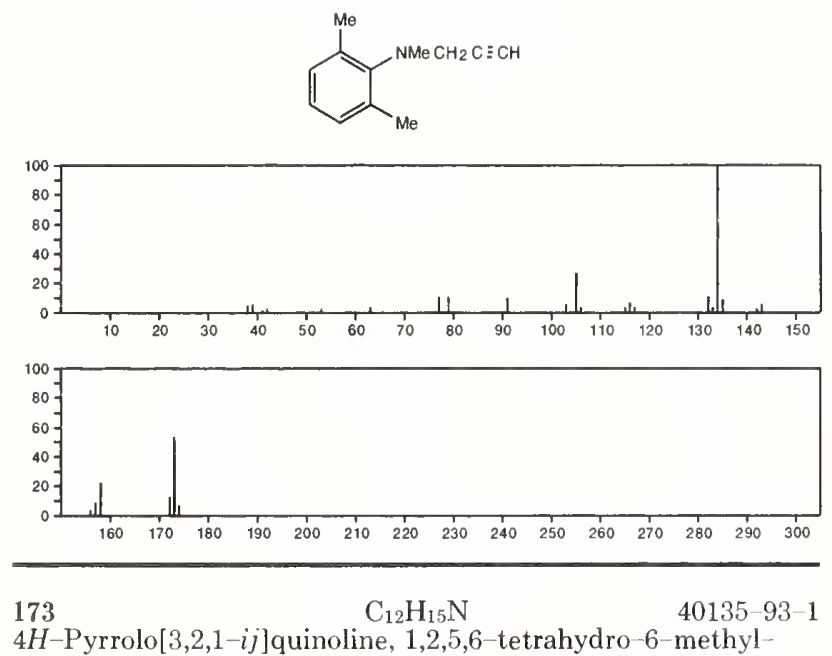

4H-Pyrrolo[3,2,1-ij]quinoline, 1,2,5,6-tetrahydro-6-methyl-
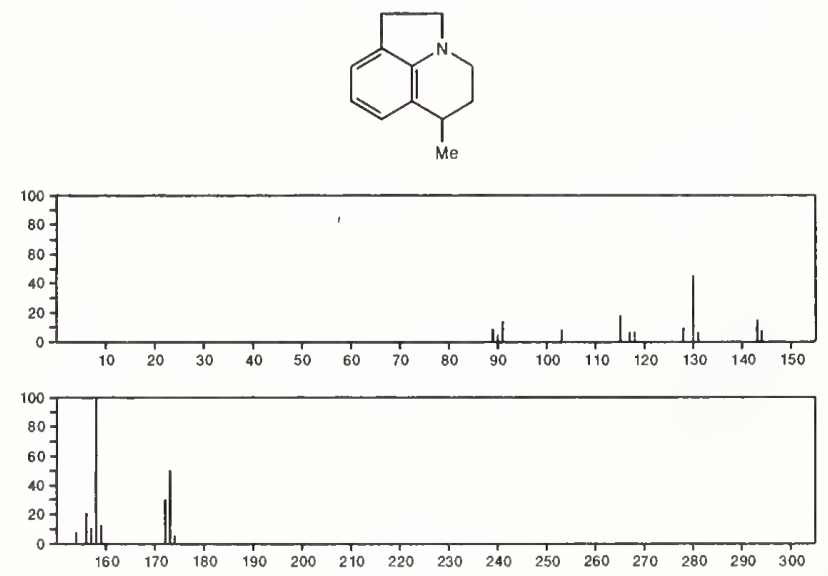

173

$\mathrm{C}_{12} \mathrm{H}_{15} \mathrm{~N}$

40135-99-7

4H-Pyrrolo[3,2,1-ij]quinoline, 1,2,5,6-tetrahydro-4-methyl-
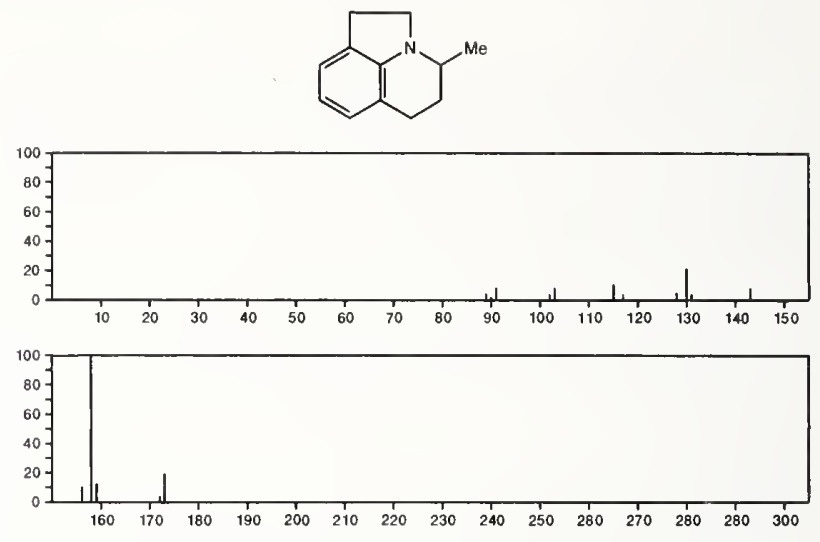

174

2-Propenoic acid, 2,3,3-trichloro-

$\mathrm{C}_{3} \mathrm{HCl}_{3} \mathrm{O}_{2}$

$\mathrm{Cl}_{2} \mathrm{C}=\mathrm{CCICO} \mathrm{CO}_{2} \mathrm{H}$
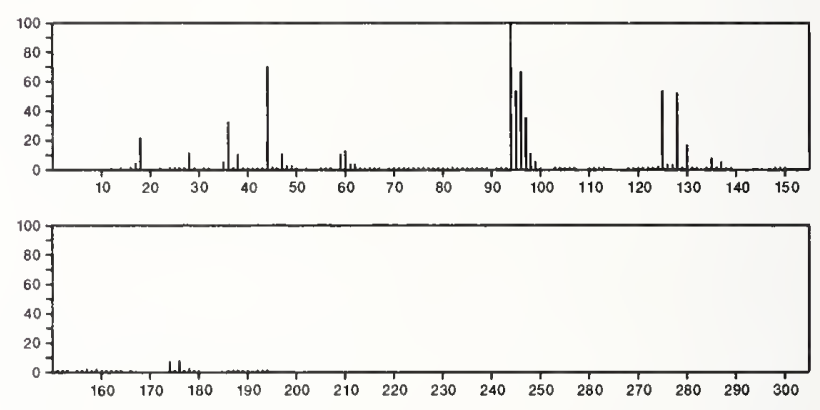

174

$\mathrm{C}_{3} \mathrm{H}_{9} \mathrm{Cl}_{2} \mathrm{~N}_{2} \mathrm{P}$

22692-21-3

Phosphorodichloridous hydrazide, trimethyl-

Me $2 \mathrm{NNMePCl}_{2}$

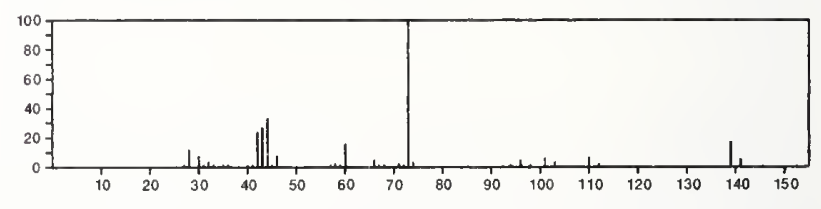

174

4(1H)-Pyrimidinone, 5-bromo-

19808-30-1
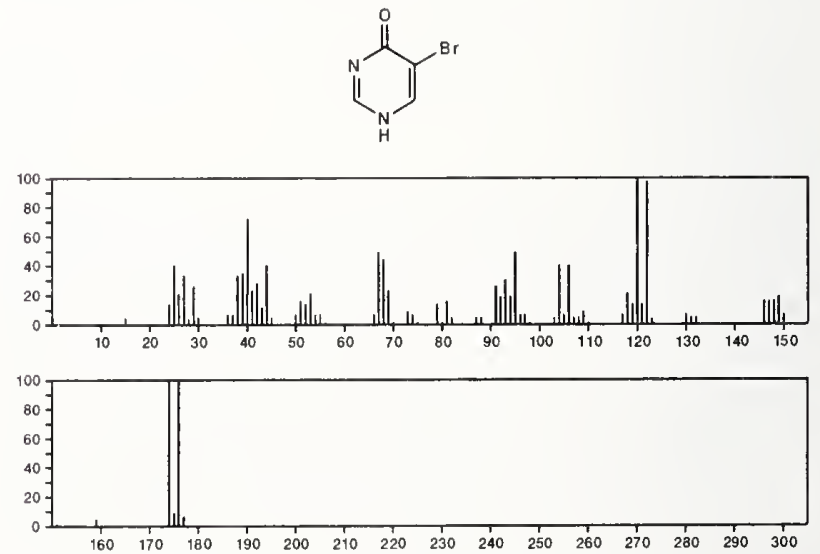
174

$\mathrm{C}_{4} \mathrm{H}_{5} \mathrm{Cl}_{3} \mathrm{O}$

Oxirane, (2,2,2-trichloroethyl)-
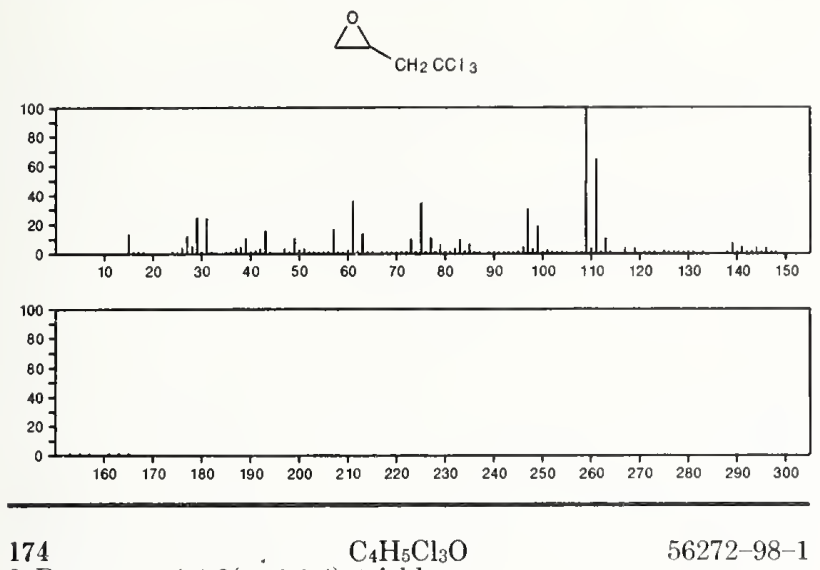

2-Butanone, 1,1,3(or 1,1,4)-trichloro-

$\mathrm{Cl}_{2} \mathrm{CHCOE} \uparrow+\mathrm{Cl}$
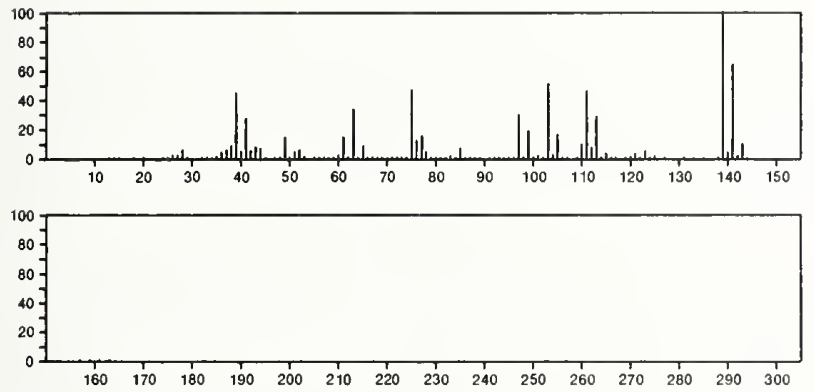

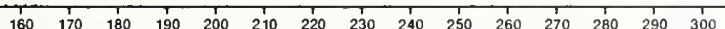

174

$\mathrm{C}_{5} \mathrm{H}_{3} \mathrm{BrO}_{2}$

2-Furancarboxaldehyde, 5-bromo-
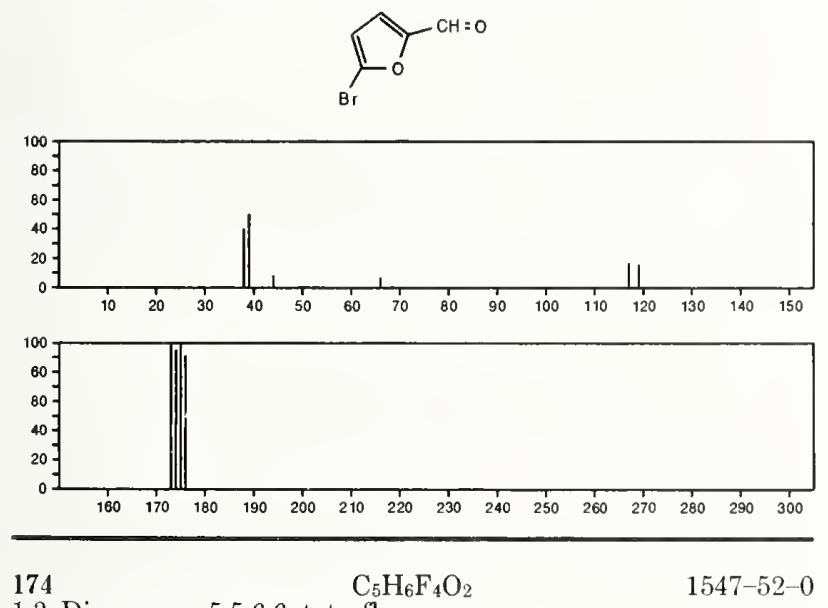

1,3-Dioxepane, 5,5,6,6-tetrafluoro-
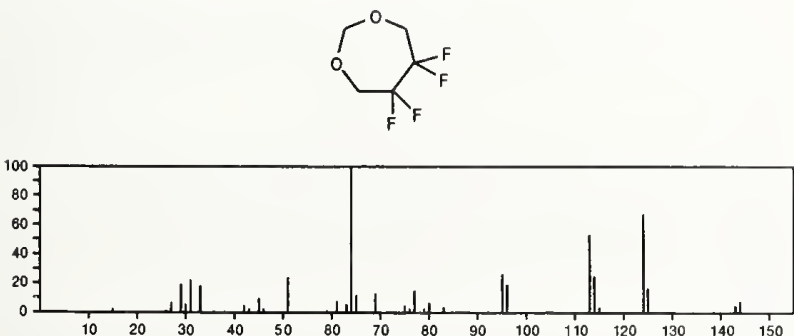

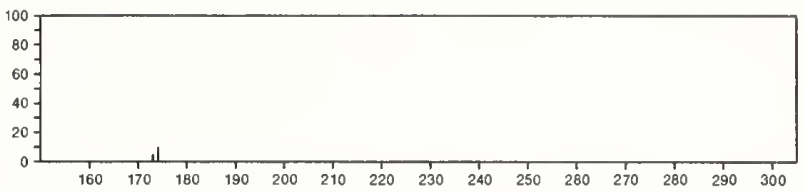

174

$\mathrm{C}_{6} \mathrm{H}_{4} \mathrm{BrF}$

$460-00-4$
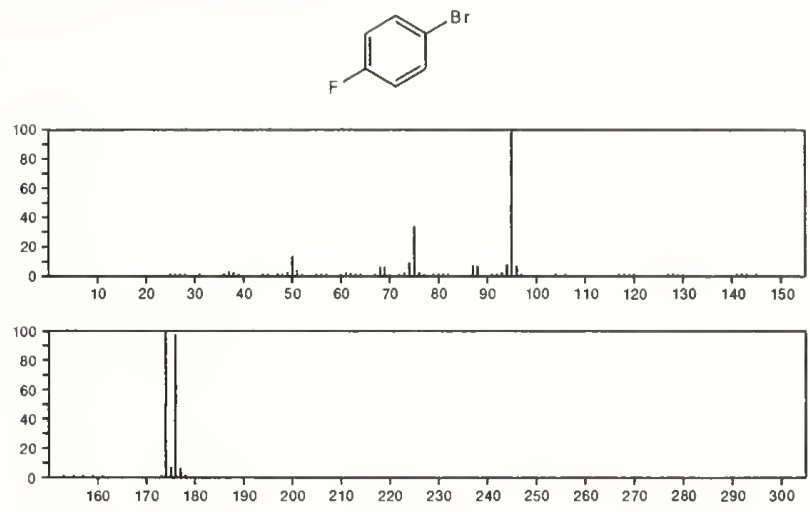

174

Benzene, 1-bromo-2-fluoro-

$\mathrm{C}_{6} \mathrm{H}_{4} \mathrm{BrF}$

$1072-85-1$
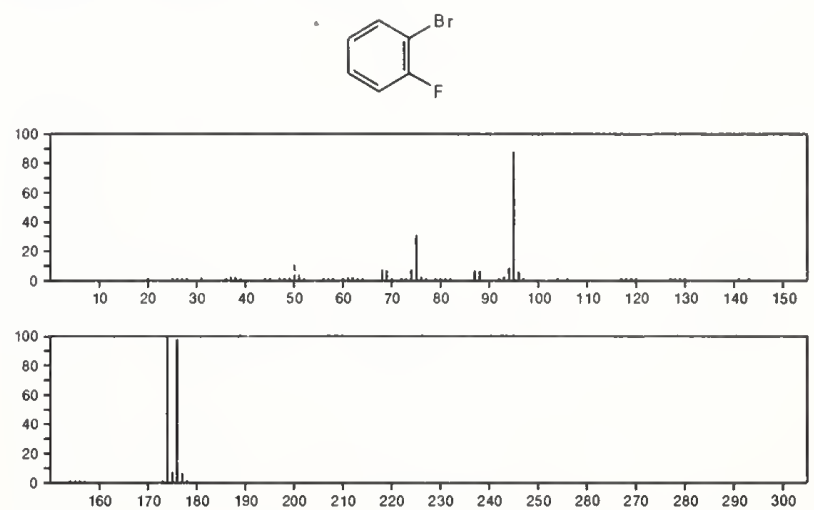

174

Benzene, 1-bromo-3-fluoro-

$$
\mathrm{C}_{6} \mathrm{H}_{4} \mathrm{BrF}
$$

1073-06-9
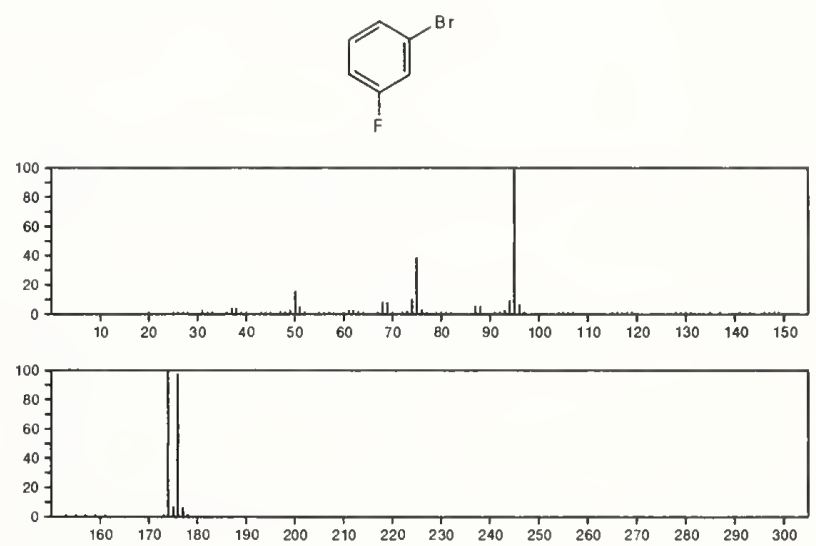
174

1,3,5-Trisilacyclohexane, 1,1,3-trimethyl-
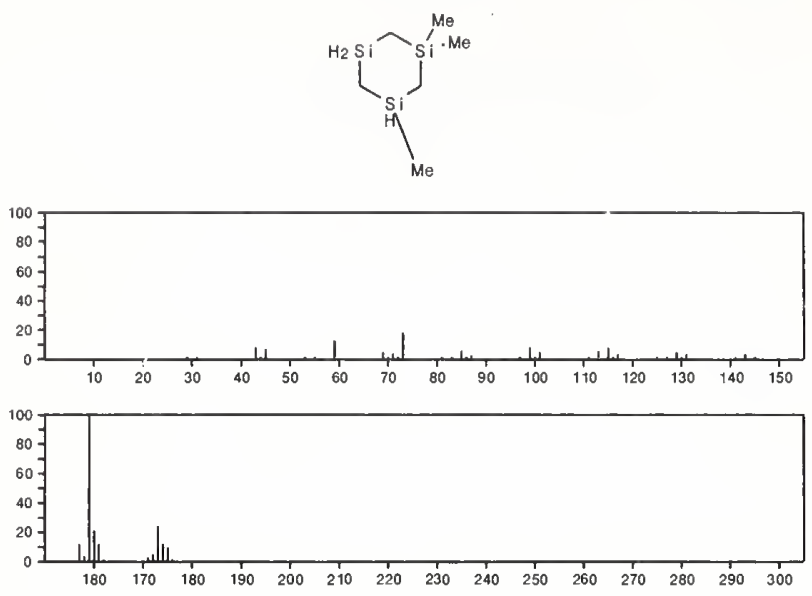

174

Benzoyl chloride, 4-chloro-

\section{$\mathrm{C}_{7} \mathrm{H}_{4} \mathrm{Cl}_{2} \mathrm{O}$}

$122-01-0$
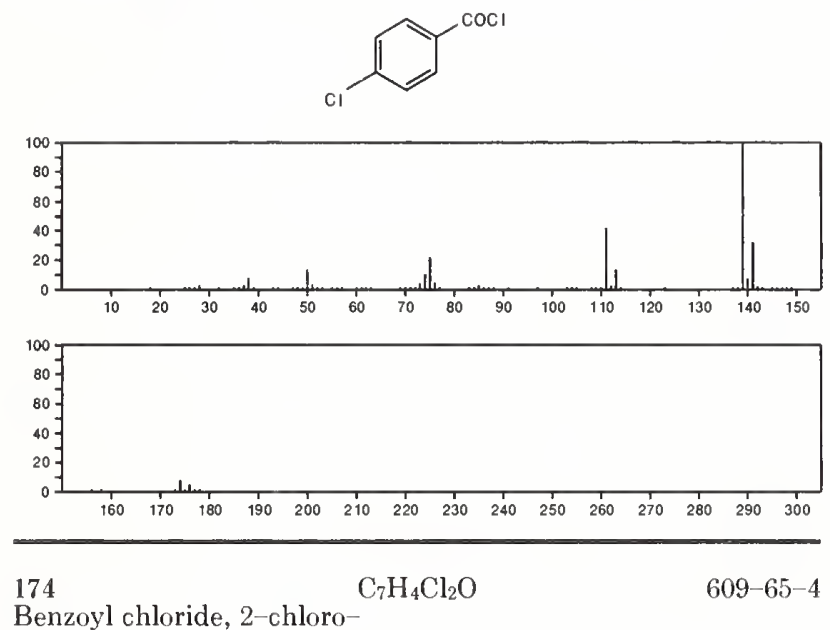

Benzoyl chloride, 2-chloro-
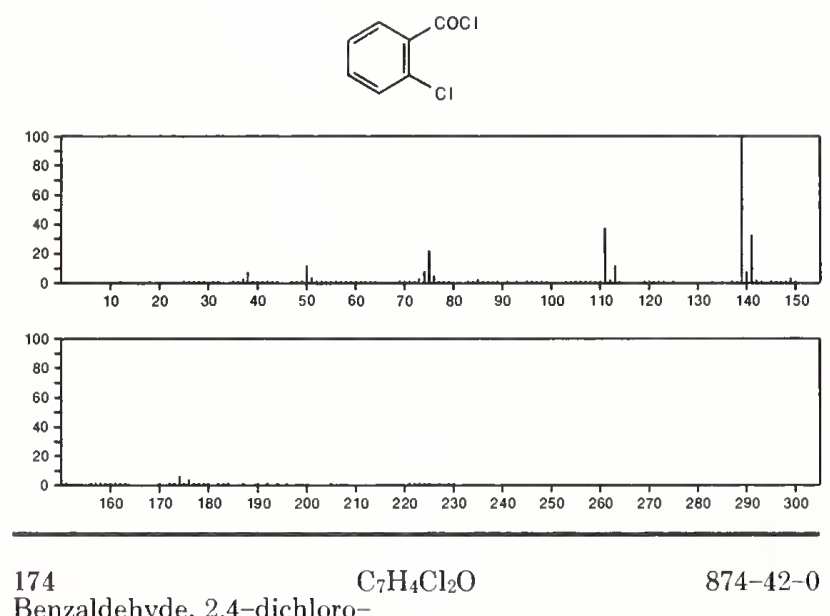

Benzaldehyde, 2,4-dichloro-
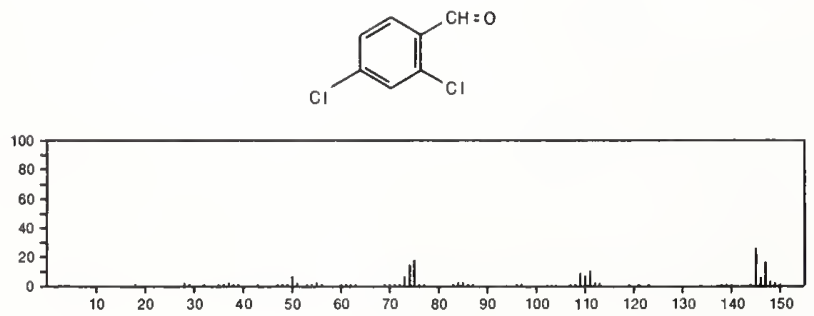

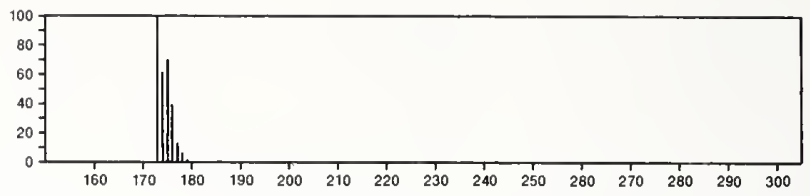

174

Benzaldehyde, 3,4-dichloro-

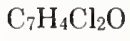

$6287-38-3$
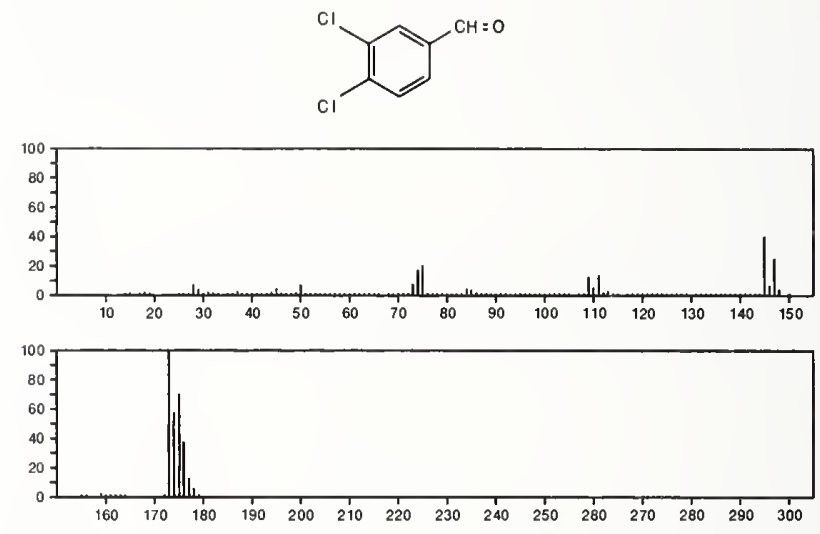

$174 \quad \mathrm{C}_{7} \mathrm{H}_{7} \mathrm{ClO}_{3}$

1,4-Benzenediol, 2-chloro-6-(hydroxymethyl)

$32744-80-2$
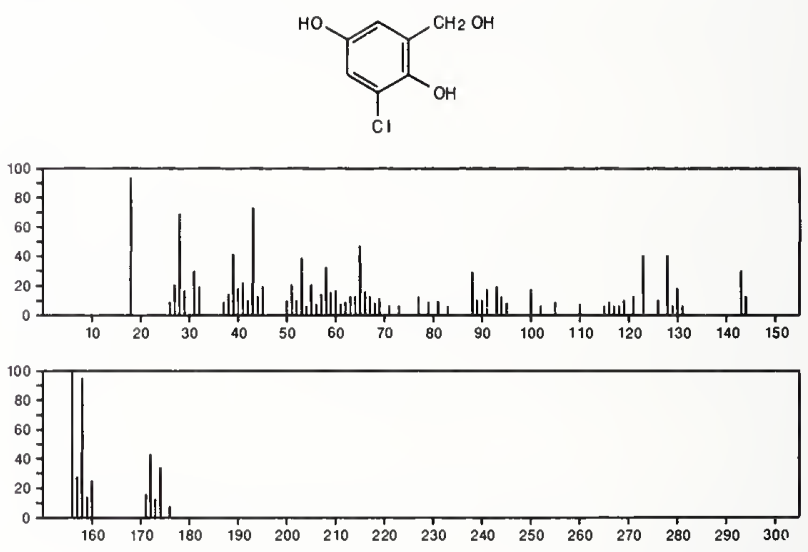

174

$\mathrm{C}_{7} \mathrm{H}_{10} \mathrm{~N}_{2} \mathrm{O} . \mathrm{ClH}$

$19501-58-7$

Hydrazine, (4-methoxyphenyl)-, monohydrochloride
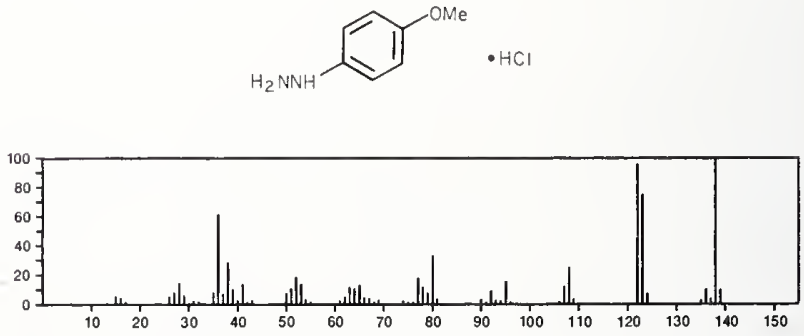

174

$\mathrm{C}_{7} \mathrm{H}_{10} \mathrm{O}_{5}$

$13192-04-6$

Pentanedioic acid, ${ }^{-}{ }^{-} \mathrm{xO}^{-}$, dimethyl ester

$\mathrm{MeOC}(\mathrm{O}) \mathrm{COCH}_{2} \mathrm{CH}_{2} \mathrm{C}(\mathrm{O}) \mathrm{OMe}$

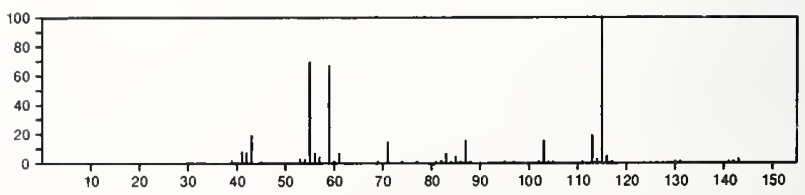


174 $\mathrm{C}_{7} \mathrm{H}_{10} \mathrm{O}_{5}$

$26579-97-5$

2-Butenedioic acid, 2-methoxy-, dimethyl ester

$\mathrm{MeOC}(\mathrm{O}) \mathrm{CH}=\mathrm{C}(\mathrm{OMe}) \mathrm{C}(\mathrm{O}) \mathrm{OMe}$
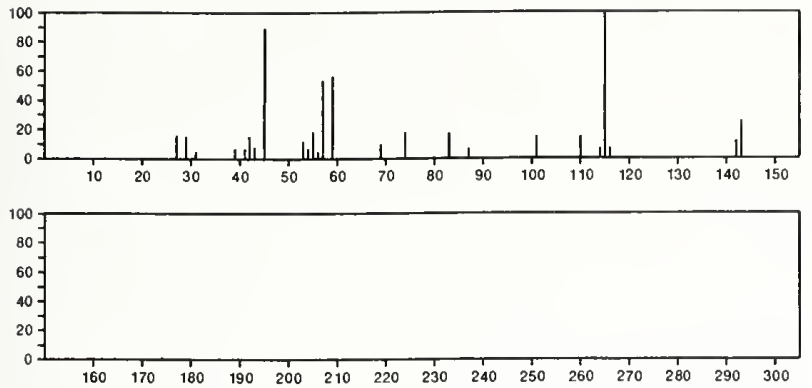

\section{4}

Cycloheptene, 1-bromo-

$\mathrm{C}_{7} \mathrm{H}_{11} \mathrm{Br}$

$18317-64-1$
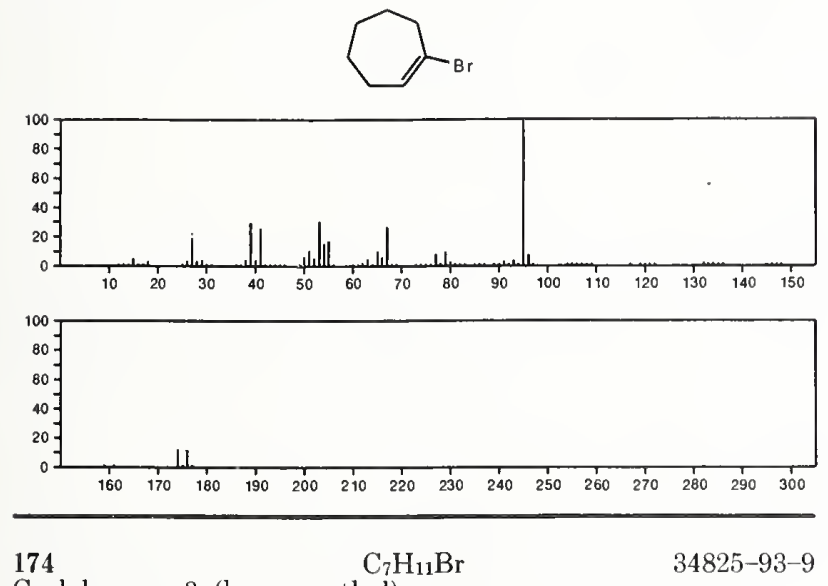

Cyclohexene, 3-(bromomethyl)-
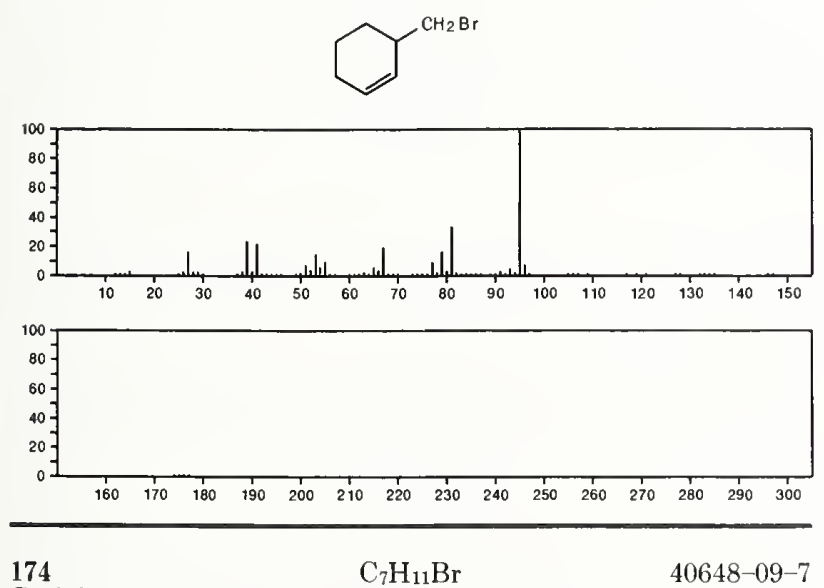

40648-09-7

Cyclohexene, 1-bromo-6-methyl-
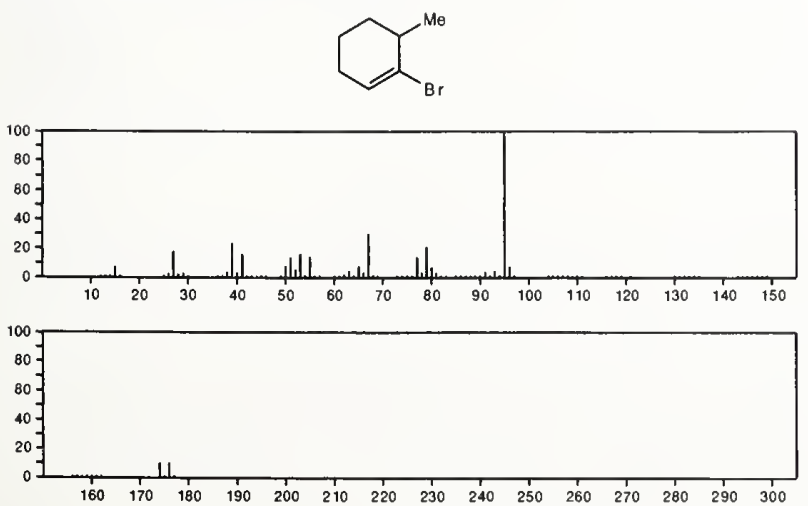

174

Cycloheptene, 5-bromo-

$\mathrm{C}_{7} \mathrm{H}_{11} \mathrm{Br}$

$54484-64-9$
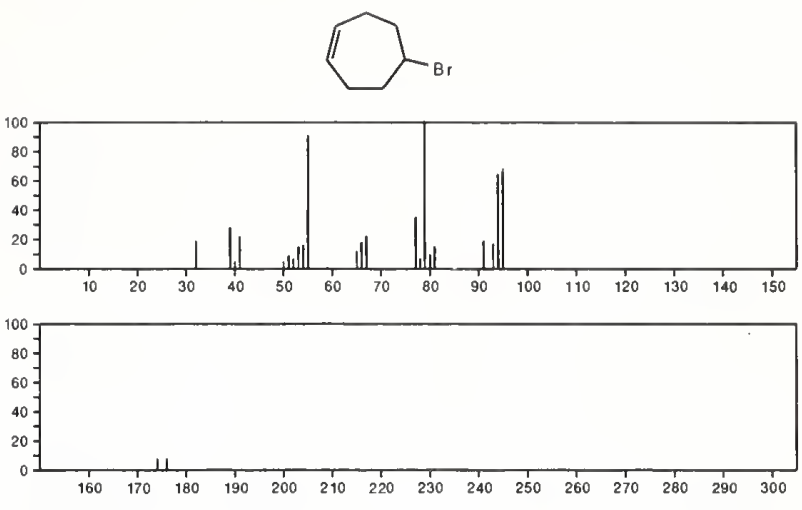

174

$\mathrm{C}_{7} \mathrm{H}_{16} \mathrm{Ge}$

$4554-78-3$

Germacyclopentane, 1-propyl-
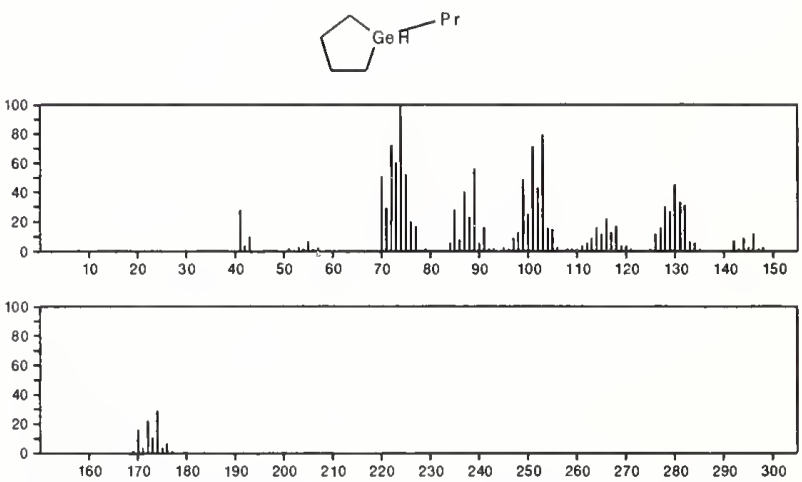

174

$\mathrm{C}_{8} \mathrm{H}_{6} \mathrm{~N}_{4} \mathrm{O}$

$42786-73-2$

1H-1,2,4-Triazole-3-carboxaldehyde, 5-(4-pyridinyl)-
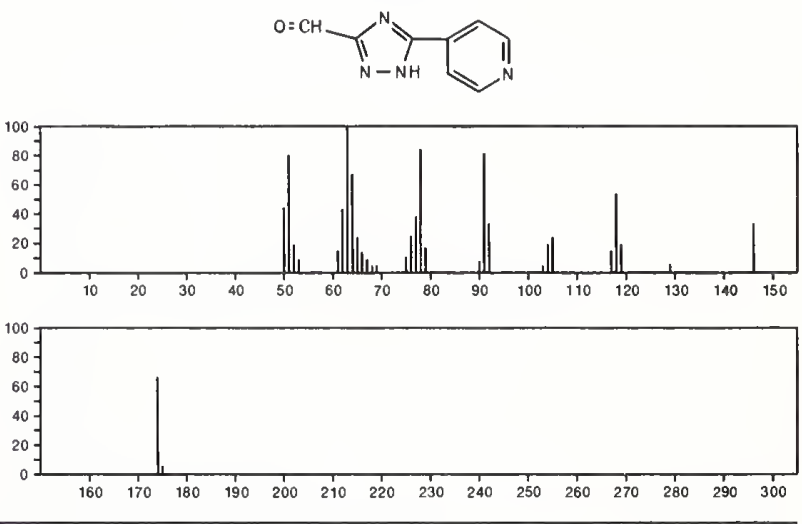

174

$\mathrm{C}_{8} \mathrm{H}_{8} \mathrm{Cl}_{2}$

626-16-4

Benzene, 1,3-bis(chloromethyl)-
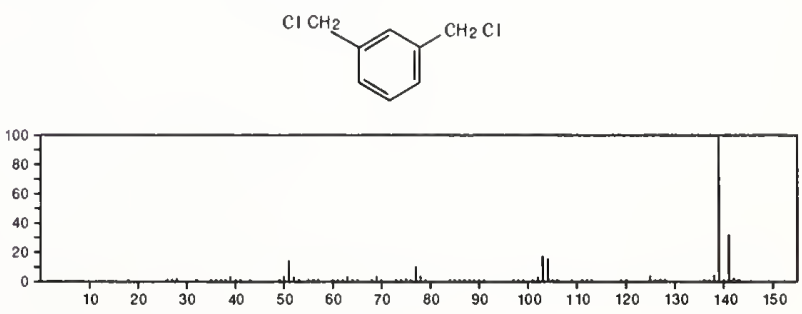

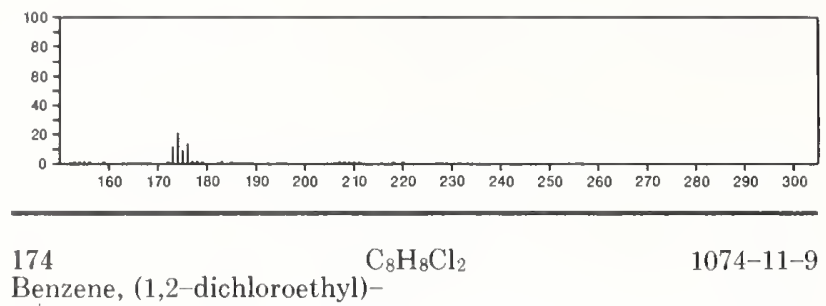

Benzene, (1,2-dichloroethyl)-

$\mathrm{Cl} \mathrm{CH}_{2} \mathrm{CHClPh}$
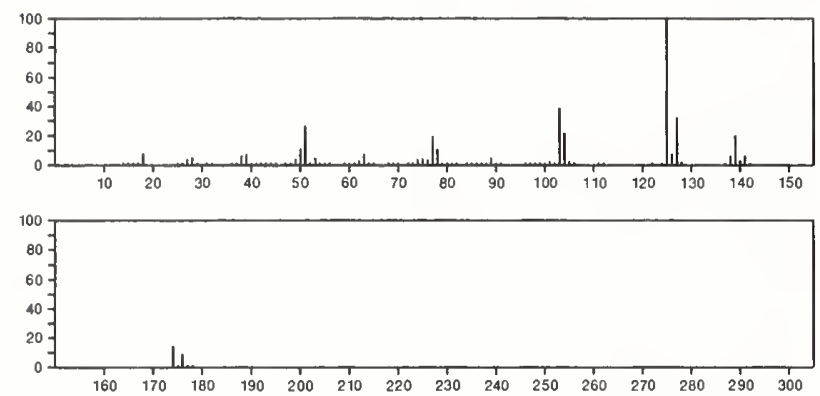

174

$\mathrm{C}_{8} \mathrm{H}_{8} \mathrm{Cl}_{2}$

Benzene, 1,4-dichloro-2,5-dimethyl-
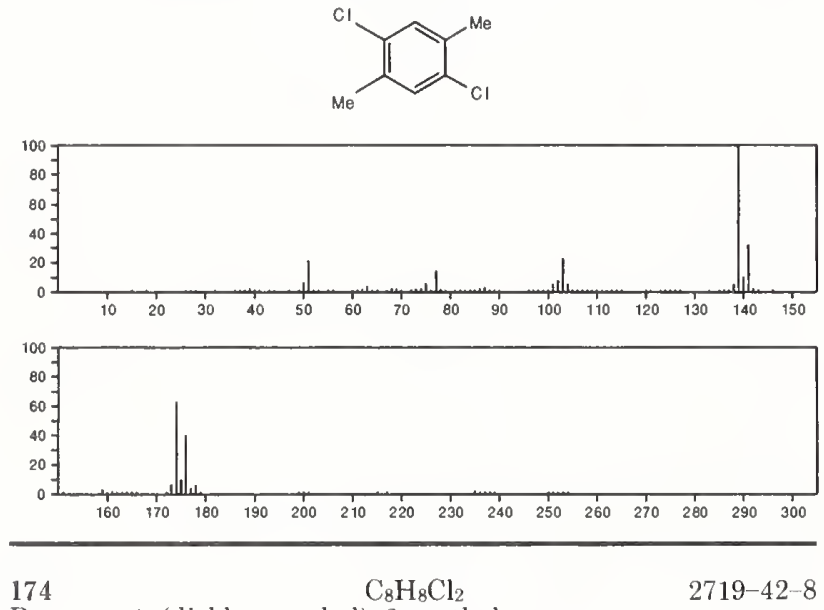

Benzene, 1-(dichloromethyl)-3-methyl

$2719-42-8$
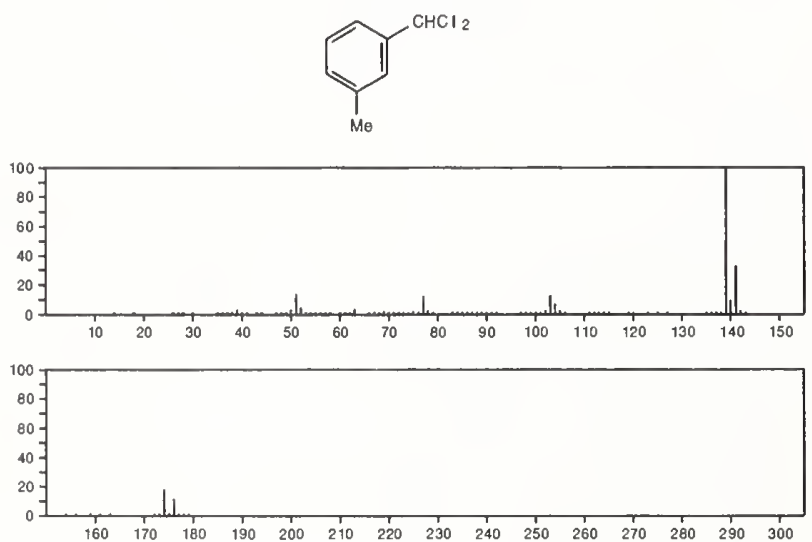

174

$\mathrm{C}_{8} \mathrm{H}_{8} \mathrm{Cl}_{2}$

Benzene, 1,2-dichloro-4-ethyl
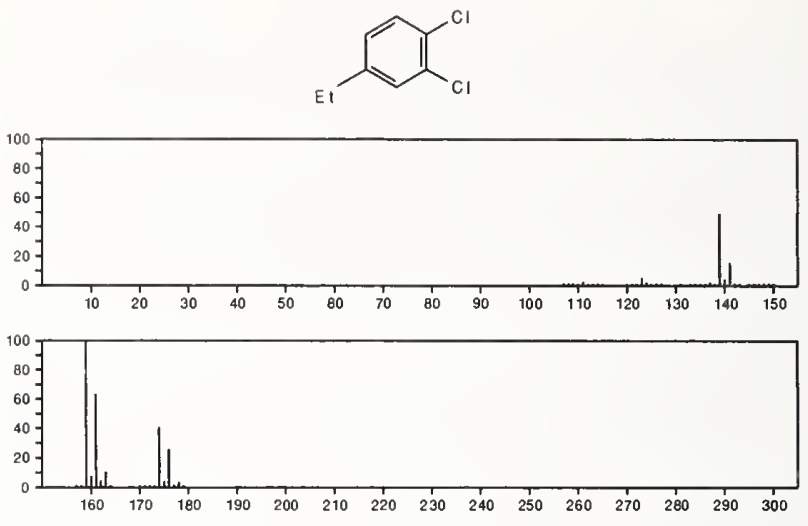

174

$\mathrm{C}_{8} \mathrm{H}_{8} \mathrm{Cl}_{2}$

Benzene, 1-chloro-2-(1-chloroethyl)-

20001-64-3
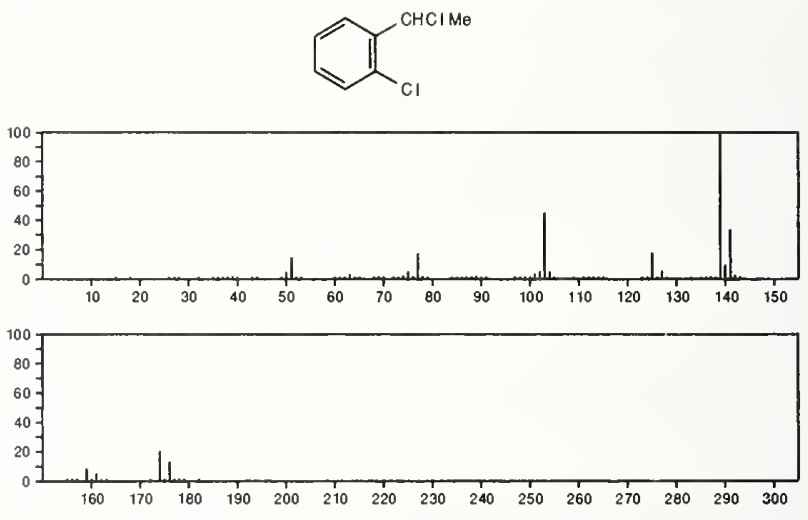

174

$\mathrm{C}_{8} \mathrm{H}_{8} \mathrm{Cl}_{2}$

23063-36-7

Benzene, 1-(dichloromethyl)-4-methyl-
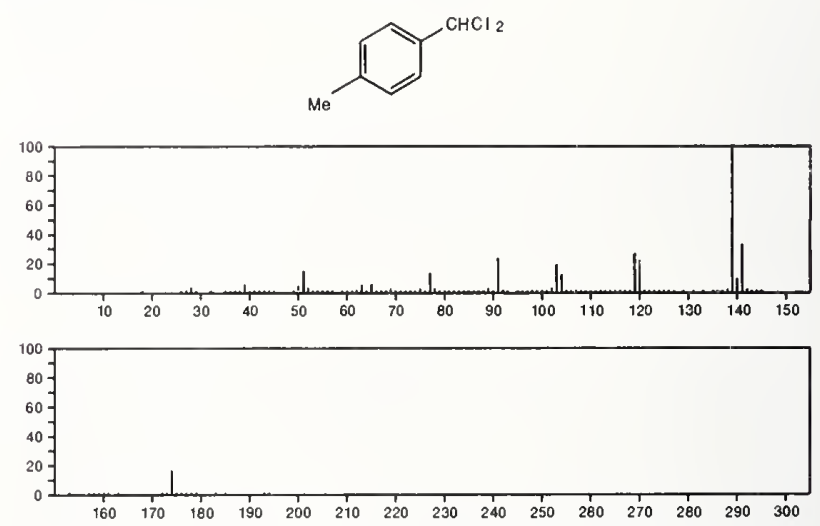

174

$\mathrm{C}_{8} \mathrm{H}_{8} \mathrm{Cl}_{2}$

Benzene, 1,3-dichloro-2-ethyl-

$33407-02-2$
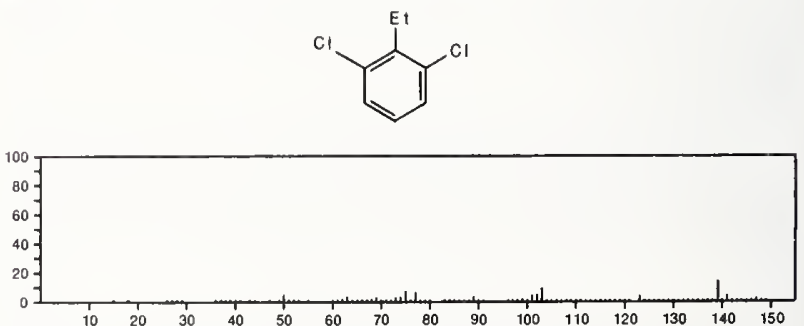

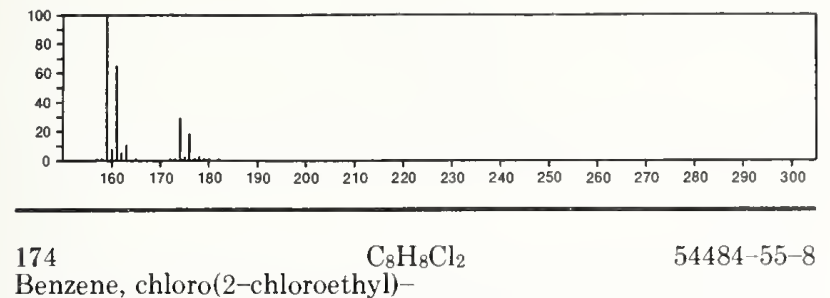

Benzene, chloro(2-chloroethyl)-
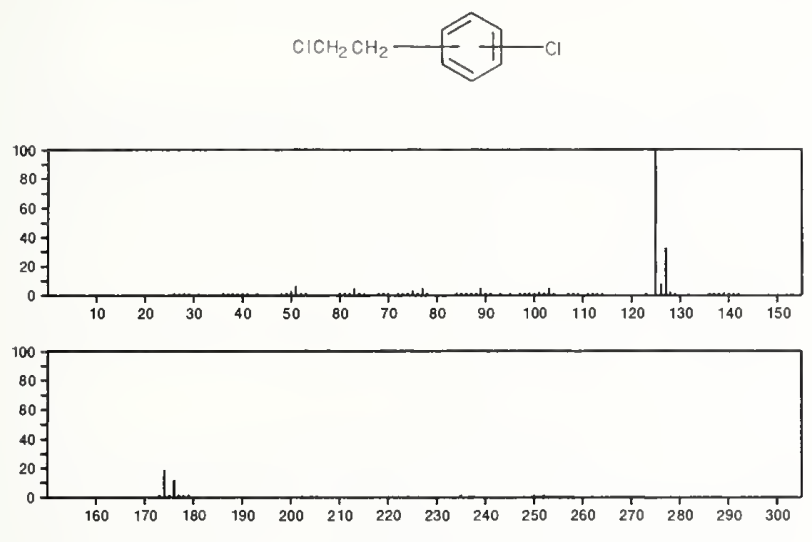

$174 \quad \mathrm{C}_{8} \mathrm{H}_{8} \mathrm{Cl}_{2}$

Benzene, 1,2-dichloro-3-ethyl-
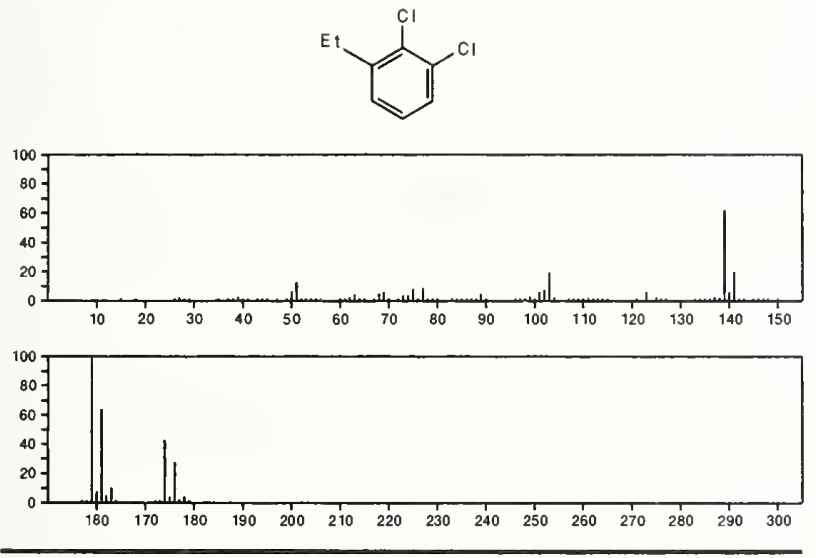

174

$\mathrm{C}_{8} \mathrm{H}_{8} \mathrm{Cl}_{2}$

$54484-62-7$

Benzene, 2,4-dichloro-1-ethyl-
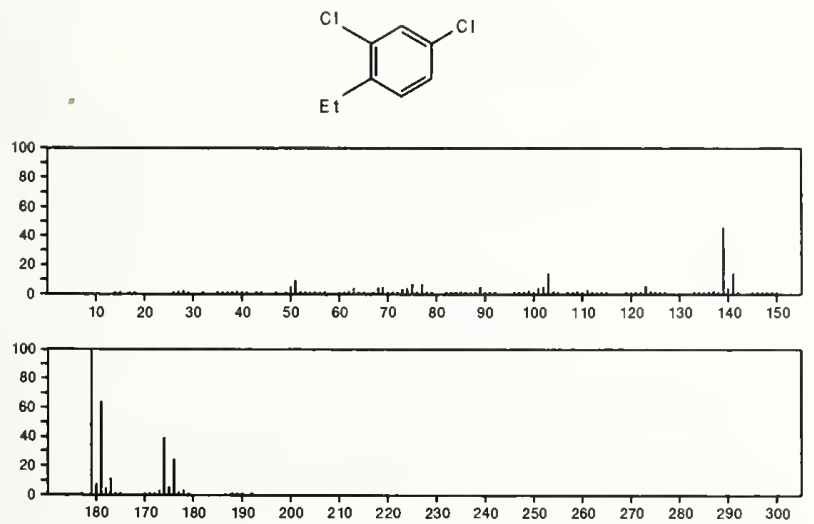

174

Benzene, 1,4-dichloro-2-ethyl-

$54484-63-8$
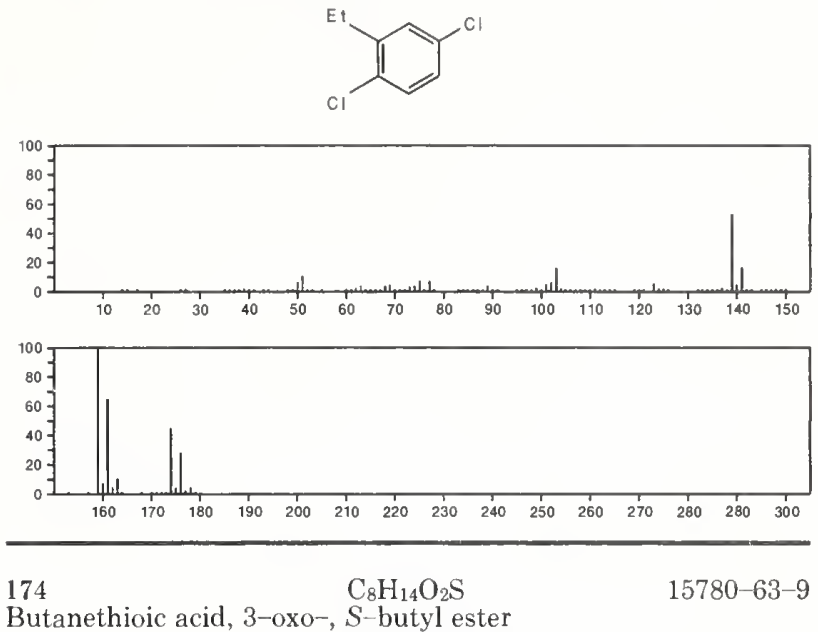

Butanethioic acid, 3-oxo-, $S$-butyl ester

$\mathrm{Me}\left\{\mathrm{CH}_{2}\right)_{3} \mathrm{SC}(\mathrm{O}) \mathrm{CH}_{2} \mathrm{COM}_{\theta}$
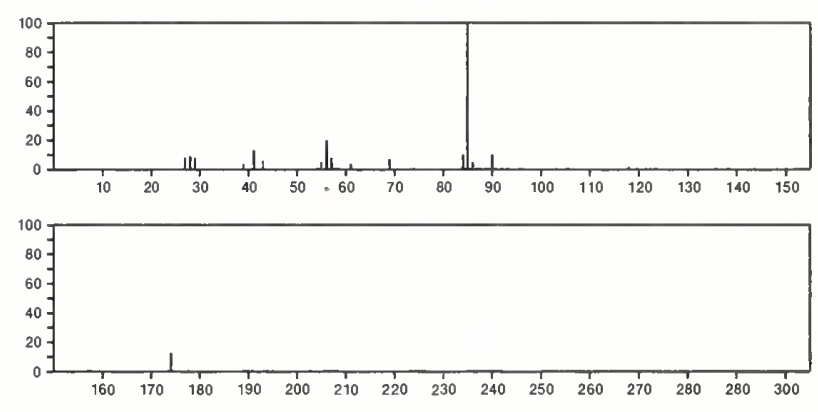

$174 \quad \mathrm{C}_{8} \mathrm{H}_{14} \mathrm{O}_{2} \mathrm{~S}$

Acetic acid, mercapto-, cyclohexyl ester

$16849-98-2$
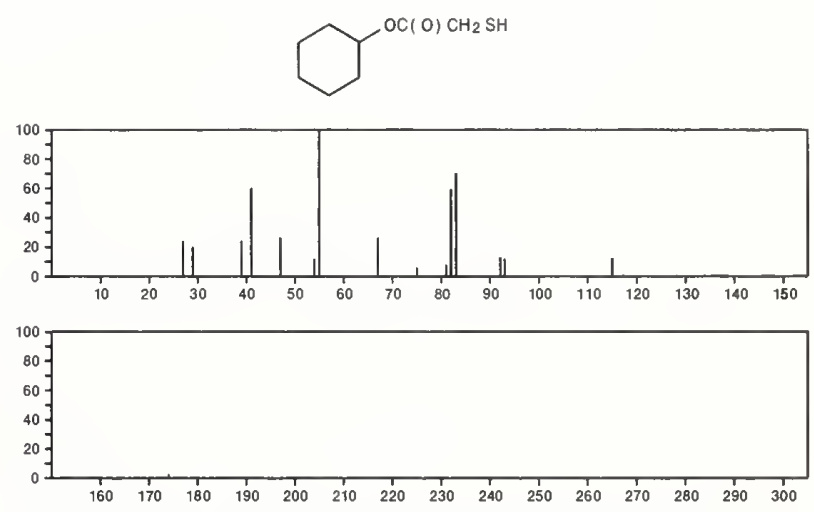

174

$\mathrm{C}_{8} \mathrm{H}_{14} \mathrm{O}_{2} \mathrm{~S}$

$23246-24-4$

Propionic acid, 3-(allylthio)-, ethyl ester

$\mathrm{Et} O \mathrm{O}$ (O) $\mathrm{CH}_{2} \mathrm{CH}_{2} \mathrm{SCH}_{2} \mathrm{CH}=\mathrm{CH}_{2}$
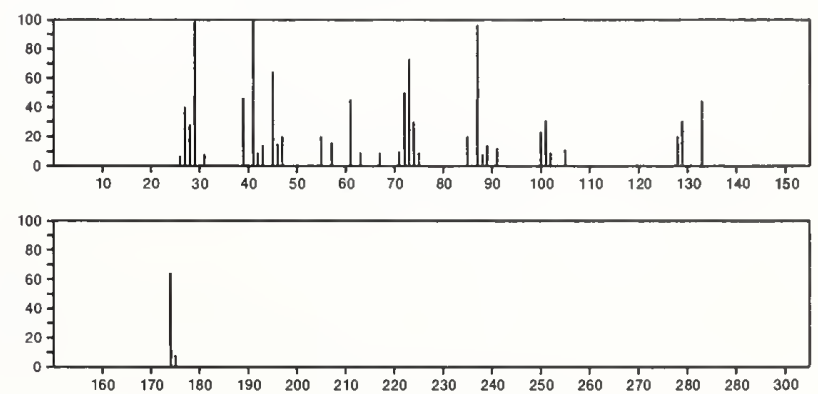
174

$\mathrm{C}_{8} \mathrm{H}_{14} \mathrm{O}_{2} \mathrm{~S}$

2-Propenoic acid, 3-[(1,1-dimethylethyl)thio]-, methyl ester

$1-\mathrm{BuSCH}=\mathrm{CHC}(\mathrm{O}) \mathrm{OMe}$
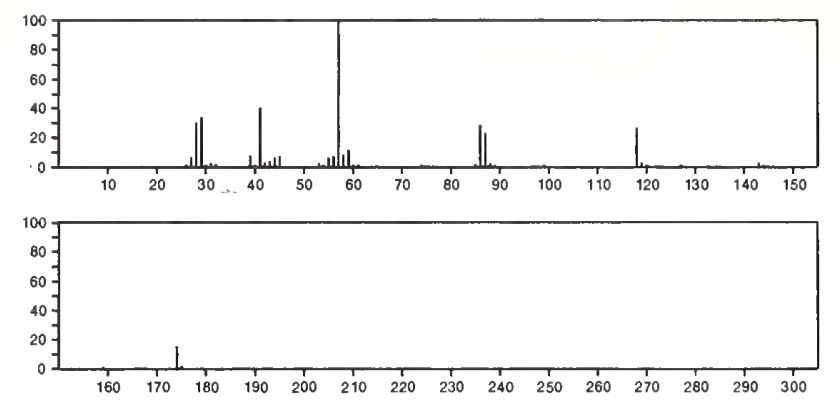

$174 \quad \mathrm{C}_{8} \mathrm{H}_{14} \mathrm{O}_{2} \mathrm{~S} \quad 54725-51-8$ 8-Thiabicyclo[3.2.1]octan-3-ol, 6-methoxy-
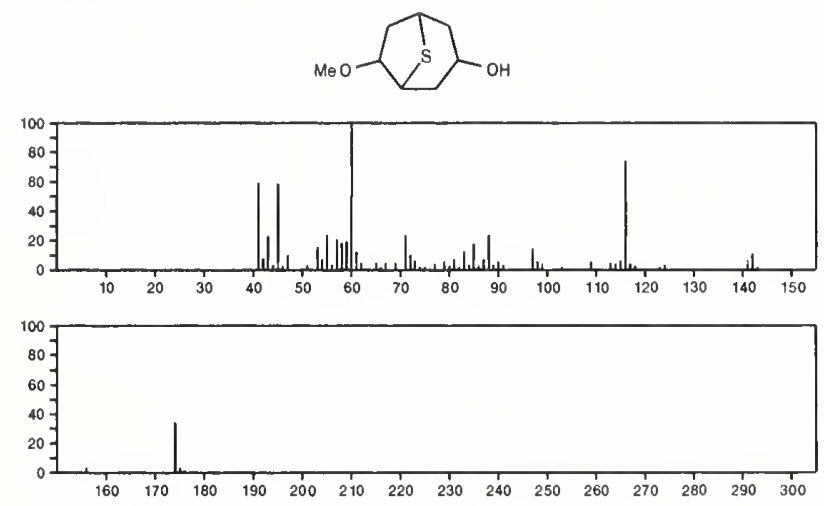

174

$\mathrm{C}_{8} \mathrm{H}_{14} \mathrm{O}_{2} \mathrm{~S}$

$56323-65-0$

8-Thiabicyclo[3.2.1]octan-3-ol, 6-methoxy-, (3-endo,6-exo)-
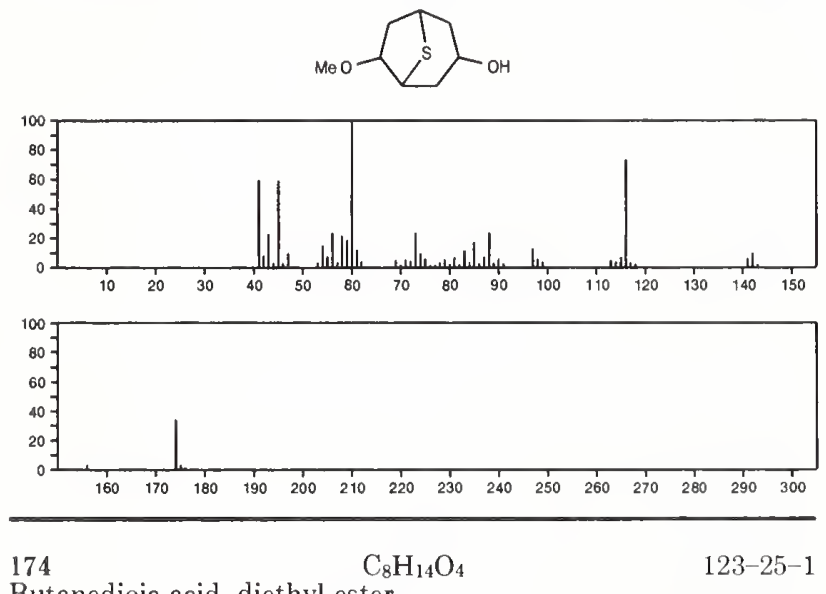

Butanedioic acid, diethyl ester

$\mathrm{E} 1 \mathrm{OC}(\mathrm{O}) \mathrm{CH}_{2} \mathrm{CH}_{2} \mathrm{C}(\mathrm{O}) \mathrm{OE}$ t
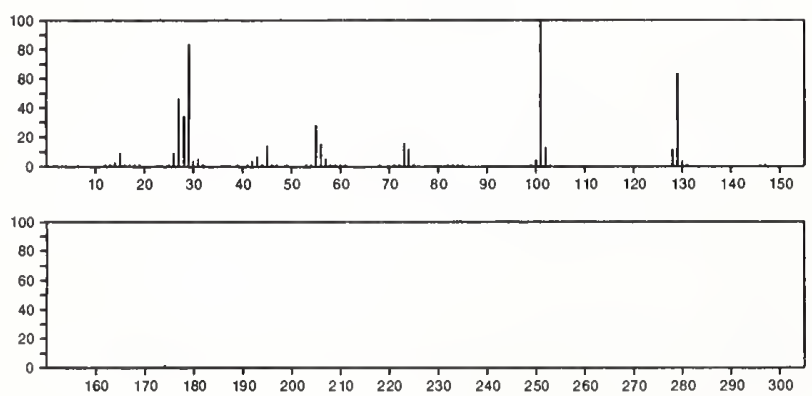

174

1,2-Ethanediol, dipropanoate

$\mathrm{C}_{8} \mathrm{H}_{14} \mathrm{O}_{4}$

$123-80-8$

$\mathrm{EtC}(\mathrm{O}) \mathrm{OCH}_{2} \mathrm{CH}_{2} \mathrm{OC}(\mathrm{O}) \mathrm{E}$ ?
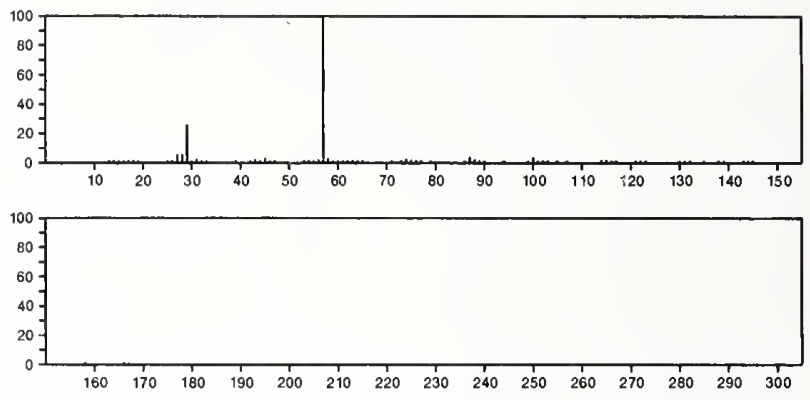

174

Octanedioic acid

$\mathrm{C}_{8} \mathrm{H}_{14} \mathrm{O}_{4}$

$505-48-6$

$\mathrm{HO}_{2} \mathrm{C}\left(\mathrm{CH}_{2}\right)_{6} \mathrm{CO}_{2} \mathrm{H}$

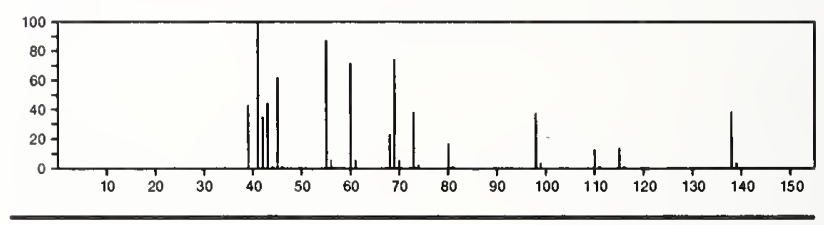

174

$\mathrm{C}_{8} \mathrm{H}_{14} \mathrm{O}_{4}$

609-08-5

Propanedioic acid, methyl-, diethyl ester

ETOC (O) CHMeC(O) OE t
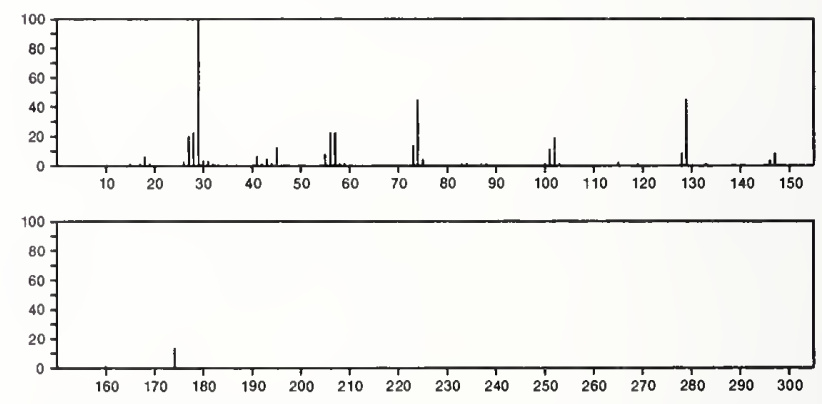

174

$\mathrm{C}_{8} \mathrm{H}_{14} \mathrm{O}_{4}$

627-93-0

Hexanedioic acid, dimethyl ester

$\mathrm{MeOC}(\mathrm{O})\left(\mathrm{CH}_{2}\right)_{4} \mathrm{C}(\mathrm{O}) \mathrm{OM}_{\theta}$

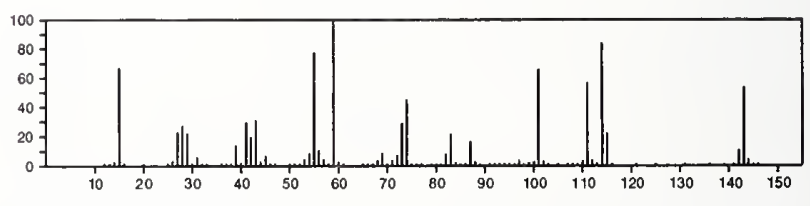

$174 \quad \mathrm{C}_{8} \mathrm{H}_{14} \mathrm{O}_{4}$

$628-67-1$

1,4-Butanediol, diacetate

$\mathrm{ACO}\left(\mathrm{CH}_{2}\right){ }_{4} \mathrm{OAC}$

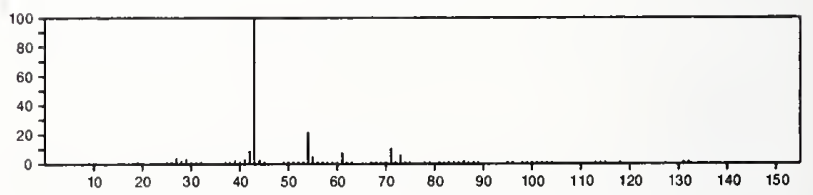


174

$\mathrm{C}_{8} \mathrm{H}_{14} \mathrm{O}_{4}$

1,3-Butanediol, diacetate

$\mathrm{ACOCHMe} \mathrm{CH}_{2} \mathrm{CH}_{2} \mathrm{OAC}$
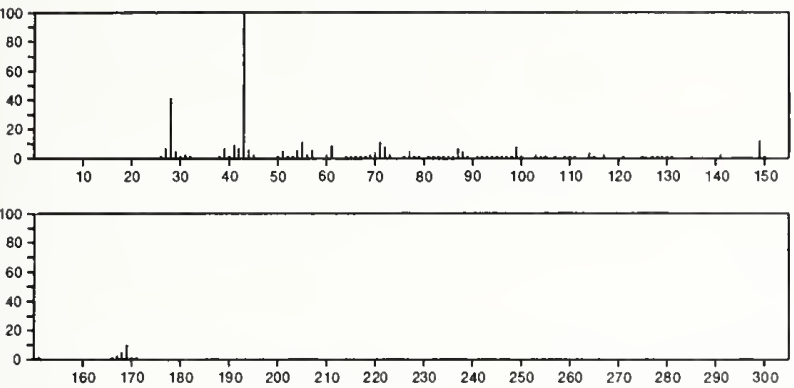

$174 \mathrm{C}_{8} \mathrm{H}_{14} \mathrm{O}_{4} \quad 14035-94-0$

Pentanedioic acid, 2-methyl-, dimethyl ester

$\mathrm{MeOC}(\mathrm{O}) \mathrm{CHMeCH}_{2} \mathrm{CH}_{2} \mathrm{C}(\mathrm{O}) \mathrm{OMe}$

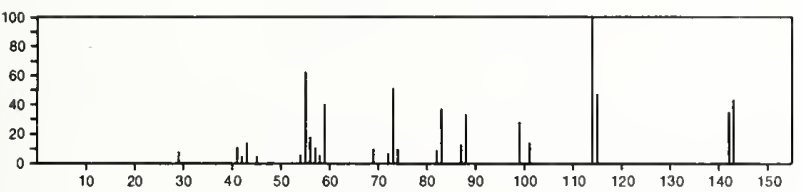

174

$\mathrm{C}_{8} \mathrm{H}_{14} \mathrm{O}_{4}$

$14035-96-2$

Propanedioic acid, propyl-, dimethyl ester

$\mathrm{MeOC}(\mathrm{O}) \mathrm{CHPr} \mathrm{C}(\mathrm{O}) \mathrm{OMe}$
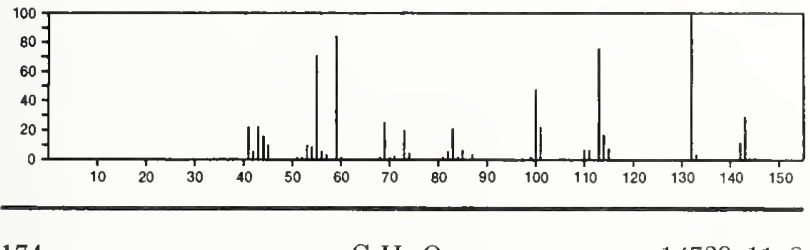

$174 \quad \mathrm{C}_{8} \mathrm{H}_{14} \mathrm{O}_{4}$

$14739-11-8$

1,3-Dioxolane-4-methanol, 2,2-dimethyl-, acetate
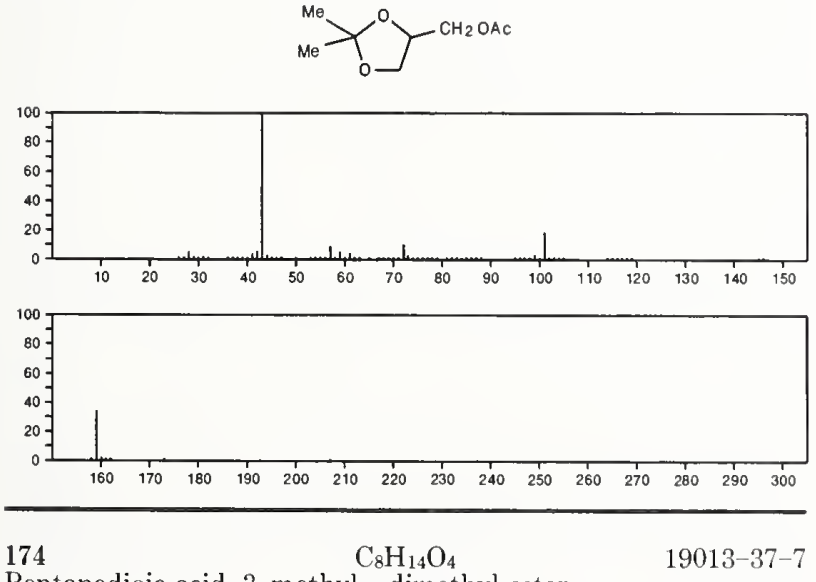

Pentanedioic acid, 3-methyl-, dimethyl ester

$\mathrm{MeOC}(0) \mathrm{CH}_{2} \mathrm{CHMeCH}_{2} \mathrm{C}(0) \mathrm{OMe}$

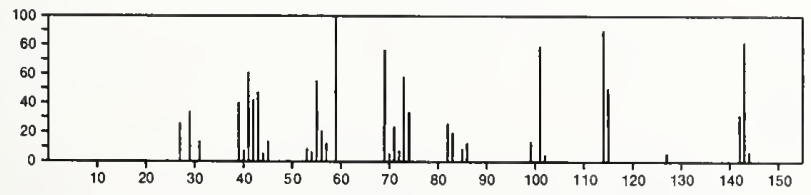

174

$\mathrm{C}_{8} \mathrm{H}_{14} \mathrm{O}_{4}$

$35351-33-8$

1,3-Dioxolane-2-propanoic acid, 2-methyl-, methyl ester

$\sum_{0}^{0}<_{\mathrm{Me}}^{\mathrm{CH}_{2} \mathrm{CH}_{2} \mathrm{C}(\mathrm{O}) \mathrm{OMe}}$
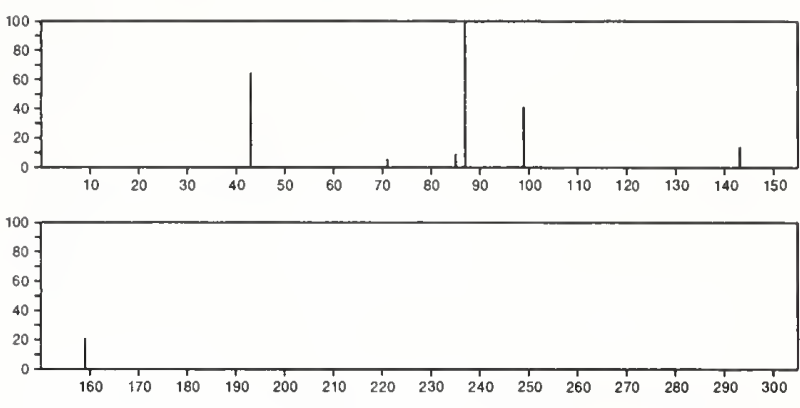

$174 \quad \mathrm{C}_{8} \mathrm{H}_{14} \mathrm{O}_{4}$

$49827-44-3$

Butanedioic acid, 2,2-dimethyl-, dimethyl ester

$\mathrm{MeOC}(0) \mathrm{CH}_{2} \mathrm{CMe}_{2} \mathrm{C}(0) \mathrm{OMe}$

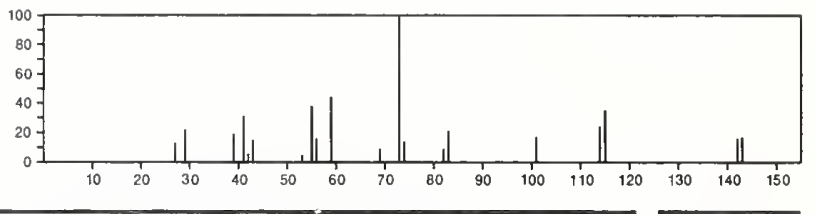

174

$\mathrm{C}_{8} \mathrm{H}_{14} \mathrm{O}_{4}$

$51122-91-9$

Propanedioic acid, (1-methylethyl)--, dimethyl ester

CHMe 2

$\mathrm{MeOC}(0) \mathrm{CHC}(\mathrm{O}) \mathrm{OM}$
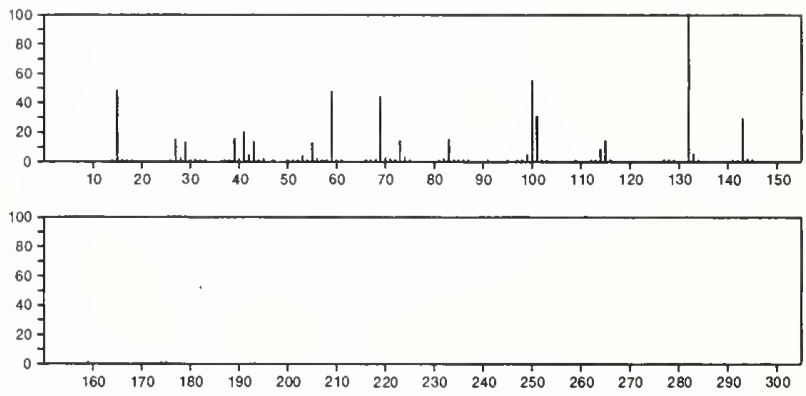

174

$\mathrm{C}_{8} \mathrm{H}_{14} \mathrm{O}_{4}$

$56196-33-9$

2H-Pyran-2-methanol, 6-ethoxy-3,6-dihydro-3-hydroxy-<smiles>CCOC1C=CC(O)C(CO)O1</smiles>

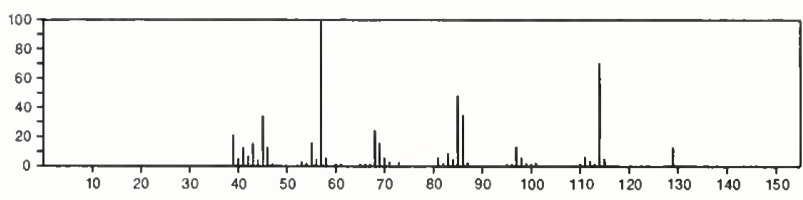

174

L-Lysine, $N^{6}, N^{6}$-dimethyl-

$\mathrm{C}_{8} \mathrm{H}_{18} \mathrm{~N}_{2} \mathrm{O}_{2}$

$2259-86-1$

$\mathrm{HO}_{2} \mathrm{CCH}\left(\mathrm{NH}_{2}\right)\left(\mathrm{CH}_{2}\right)_{4} \mathrm{NMe}_{2}$

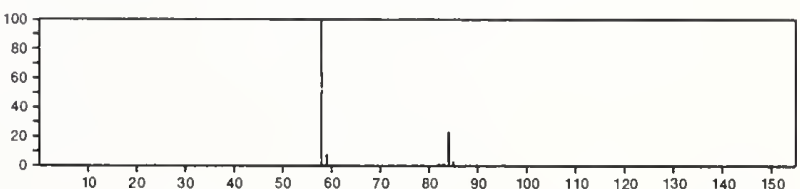



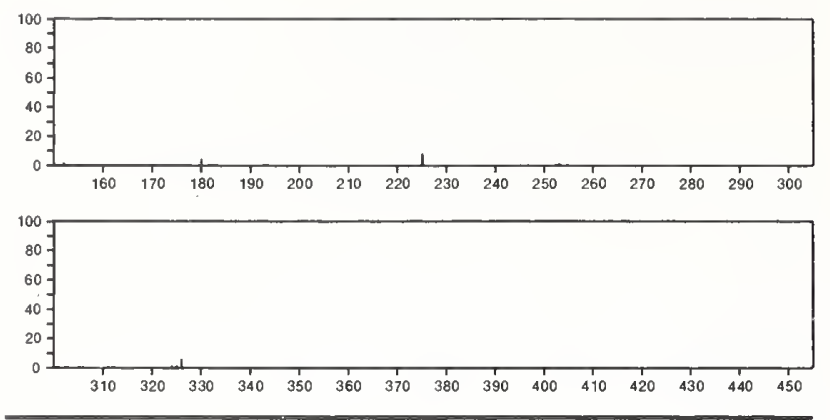

174

L-Lysine, ethyl ester

$\mathrm{C}_{8} \mathrm{H}_{18} \mathrm{~N}_{2} \mathrm{O}_{2}$

$4117-33-3$

Et OC $(0) \mathrm{CH}\left(\mathrm{NH}_{2}\right)\left(\mathrm{CH}_{2}\right)_{4} \mathrm{NH}_{2}$
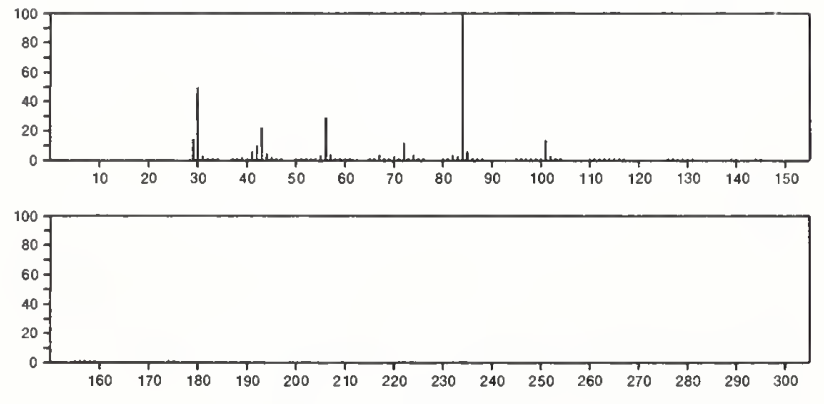

\section{4}

1-Butanamine, $N$-butyl- $N$-nitro

\section{$\mathrm{C}_{8} \mathrm{H}_{18} \mathrm{~N}_{2} \mathrm{O}_{2}$}

$4164-31-2$

$\mathrm{Me}\left(\mathrm{CH}_{2}\right)_{3} \mathrm{~N}\left(\mathrm{NO}_{2}\right)\left(\mathrm{CH}_{2}\right) 3 \mathrm{Me}$
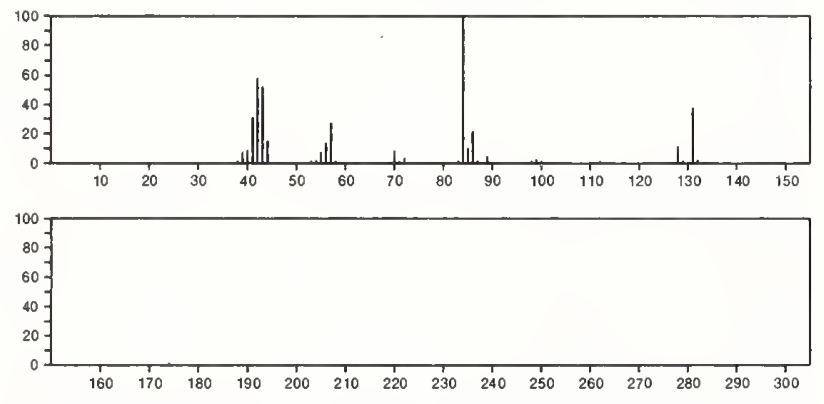

$174 \quad \mathrm{C}_{8} \mathrm{H}_{18} \mathrm{~N}_{2} \mathrm{O}_{2}$

1-Propanamine, 2-methyl-N-(2-methylpropyl) $-N$-nitro-

$-\mathrm{Bu} 2 \mathrm{NNO}_{2}$
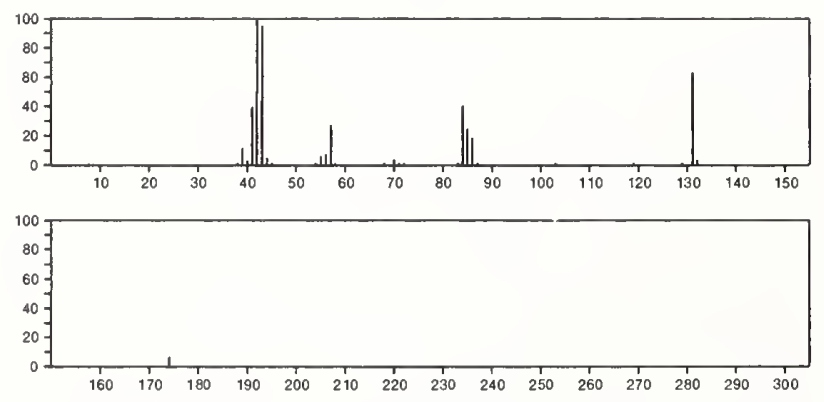

174

$\mathrm{C}_{8} \mathrm{H}_{18} \mathrm{O}_{2} \mathrm{Si}$

$18388-42-6$

Propanoic acid, 2-methyl-3-(trimethylsilyl)-, methyl ester

$\mathrm{MeOC}(\mathrm{O}) \mathrm{CHMeCH}_{2} \mathrm{SiMe}_{3}$

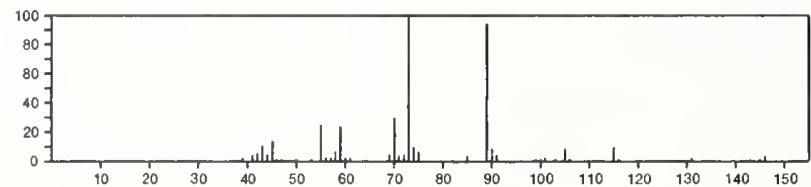

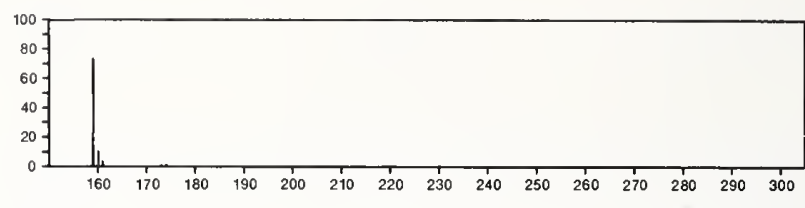

174

$\mathrm{C}_{8} \mathrm{H}_{18} \mathrm{O}_{2} \mathrm{Si}$

26429-16-3

Valeric acid, trimethylsilyl ester

$\mathrm{Me} 3 \mathrm{SiOC}(\mathrm{O})\left(\mathrm{CH}_{2}\right)_{3} \mathrm{Me}$
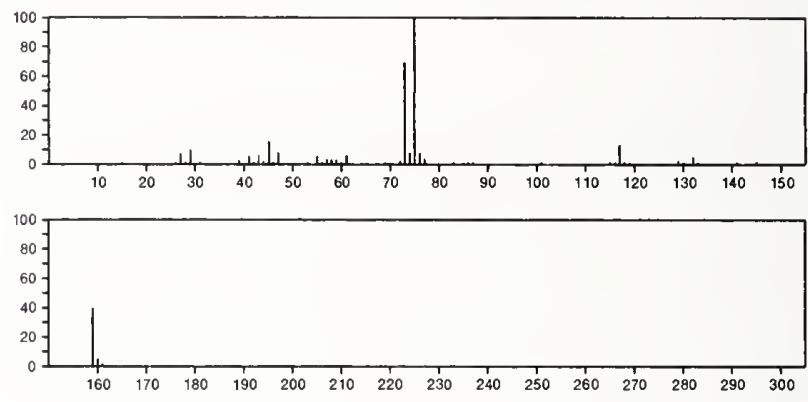

174

$\mathrm{C}_{8} \mathrm{H}_{18} \mathrm{O}_{2} \mathrm{Si}$

$55557-13-6$

Butanoic acid, 3-methyl-, trimethylsilyl ester

$\mathrm{Me} 3 \mathrm{Si} \mathrm{OC}(\mathrm{O}) \mathrm{CH}_{2} \mathrm{CHMe}_{2}$
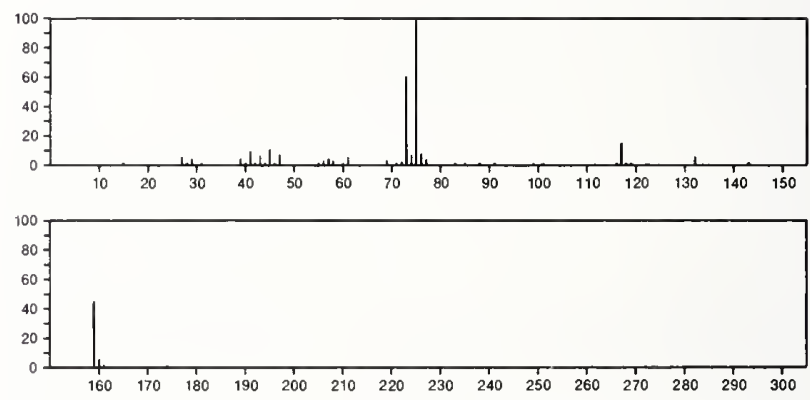

174

$\mathrm{C}_{8} \mathrm{H}_{18} \mathrm{O}_{2} \mathrm{Si}$

$55557-14-7$

Butanoic acid, 2-methyl-, trimethylsilyl ester

$\mathrm{MeCH}_{2} \mathrm{CHMe} \mathrm{C}(\mathrm{O}) \mathrm{OSIMe}_{3}$
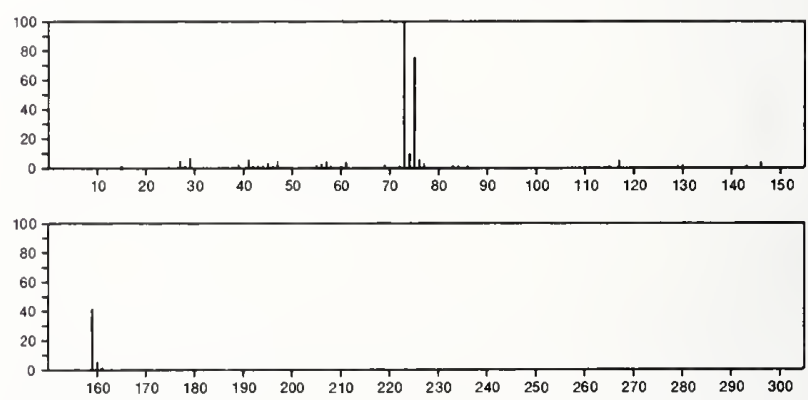

174

$\mathrm{C}_{8} \mathrm{H}_{22} \mathrm{Si}_{2}$

Silane, 1,2-ethanediylbis[trimethyl

$6231-76-1$

$\mathrm{Me}_{3} \mathrm{Si} \mathrm{CH}_{2} \mathrm{CH}_{2} \mathrm{SiMe}_{3}$
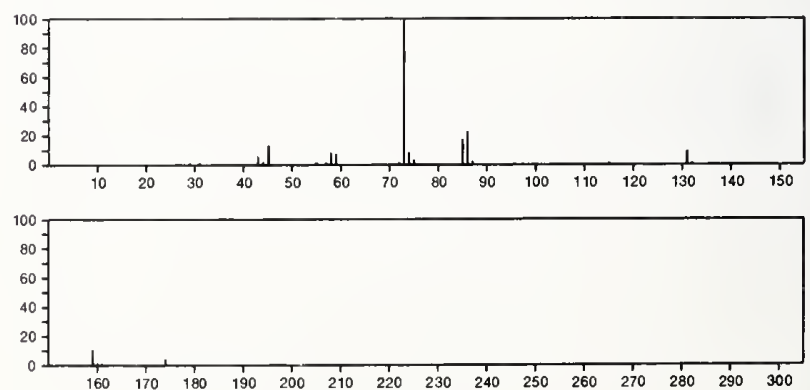
174

$\mathrm{C}_{8} \mathrm{H}_{22} \mathrm{Si}_{2}$

Silane, ethylidenebis[trimethy]-

$\mathrm{Me}_{3} \mathrm{Si} \mathrm{CHMSOM}_{3}$
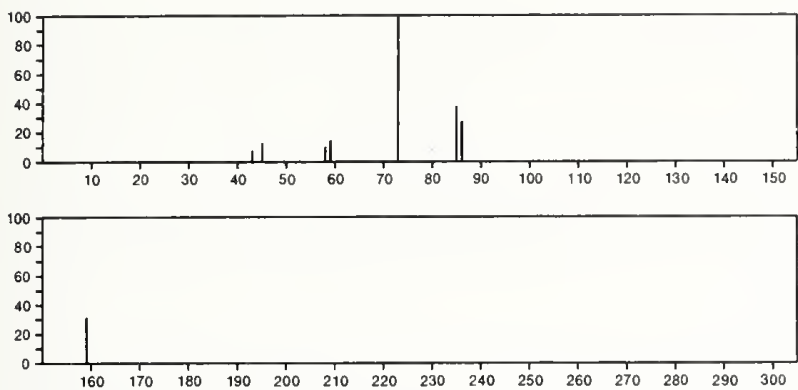

174

Quinoline, 5-nitro-

$\mathrm{C}_{9} \mathrm{H}_{6} \mathrm{~N}_{2} \mathrm{O}_{2}$

$607-34-1$
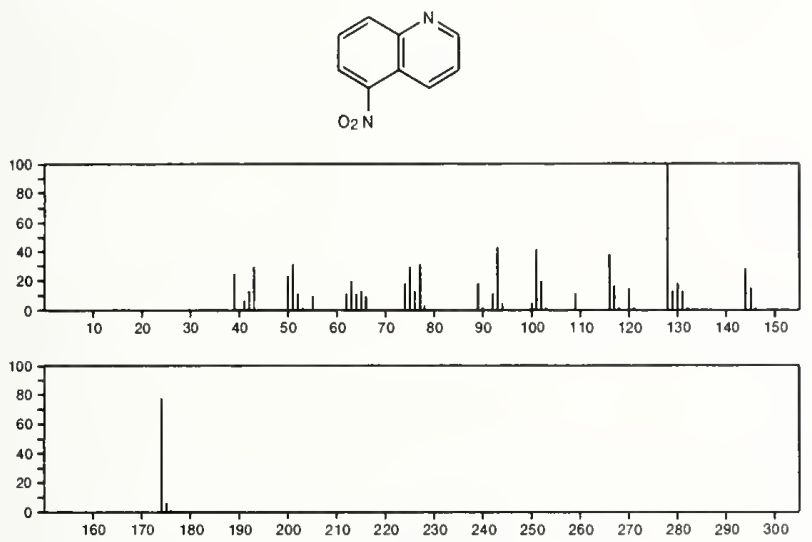

174

$\begin{array}{lllllllllllllll}160 & 170 & 180 & 190 & 200 & 210 & 220 & 230 & 240 & 250 & 260 & 270 & 280 & 1 & 1 \\ 1 & 1 & 1 & 1 & 1 & 1\end{array}$ Quinoline, 8-nitro-

$\mathrm{C}_{9} \mathrm{H}_{6} \mathrm{~N}_{2} \mathrm{O}_{2}$

$607-35-2$
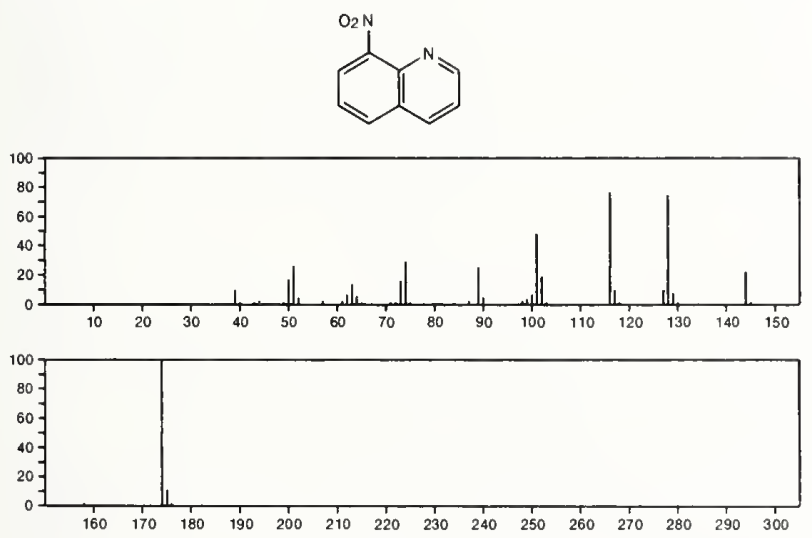

174

Quinoline, 7-nitro-

$\mathrm{C}_{9} \mathrm{H}_{6} \mathrm{~N}_{2} \mathrm{O}_{2}$

613-51-4
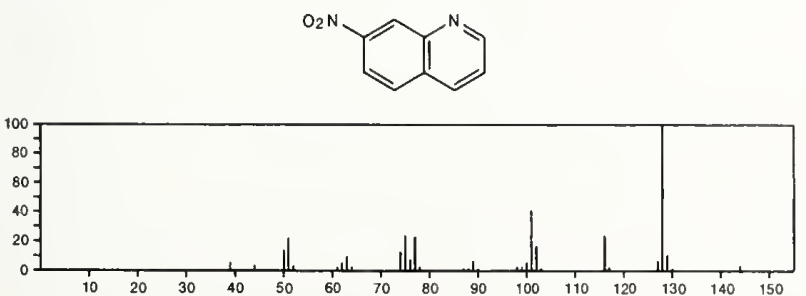

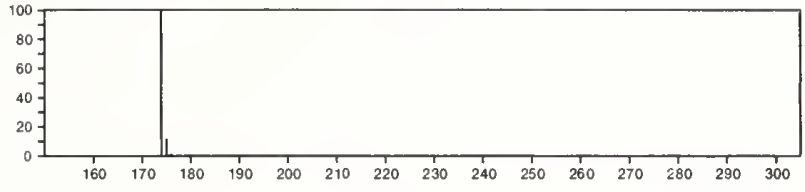

$\mathrm{C}_{9} \mathrm{H}_{6} \mathrm{~N}_{2} \mathrm{O}_{2}$

174

Benzene, 1,3-diisocyanatomethyl-

$26471-62-5$<smiles>O=[N+]([O-])c1ccc([N+](=O)[O-])c([N+](=O)[O-])c1</smiles>
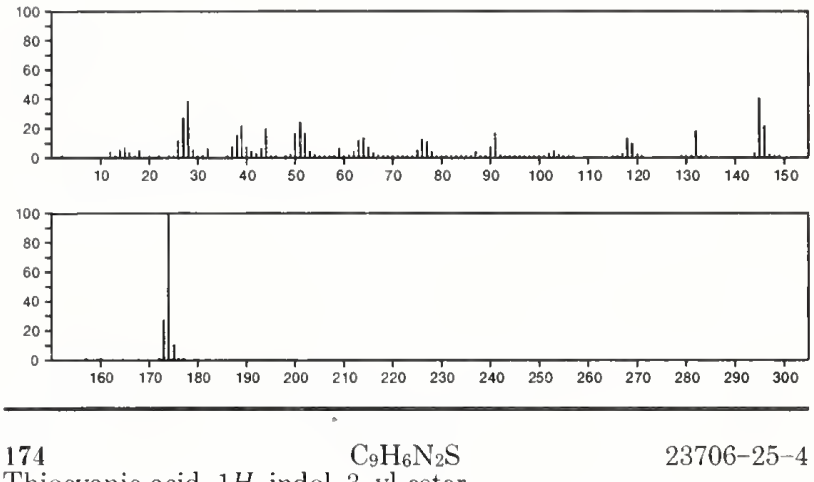

Thiocyanic acid, $1 \mathrm{H}$-indol-3-yl ester
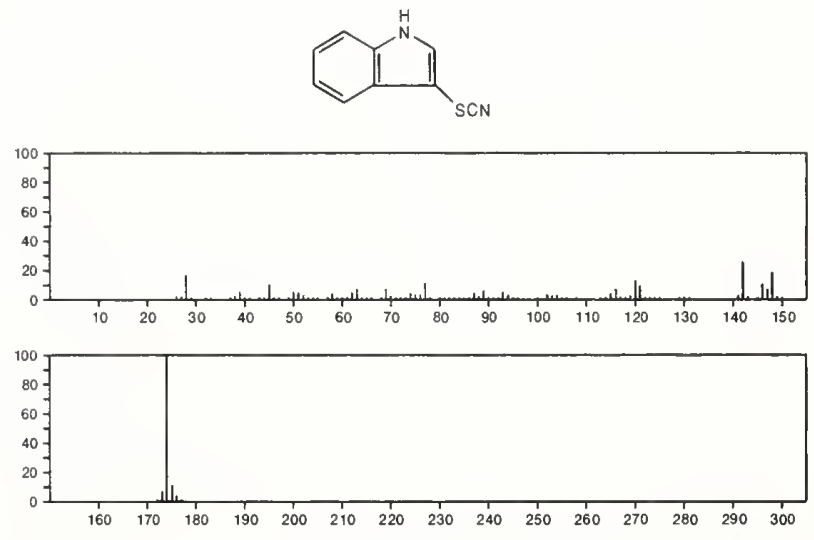

$174 \quad \mathrm{C}_{9} \mathrm{H}_{10} \mathrm{~N}_{4}$

1H-1,2,3-Triazole, 1-anilino-4-methyl-

$14757-63-2$<smiles>Cc1cn(NP)nn1</smiles>
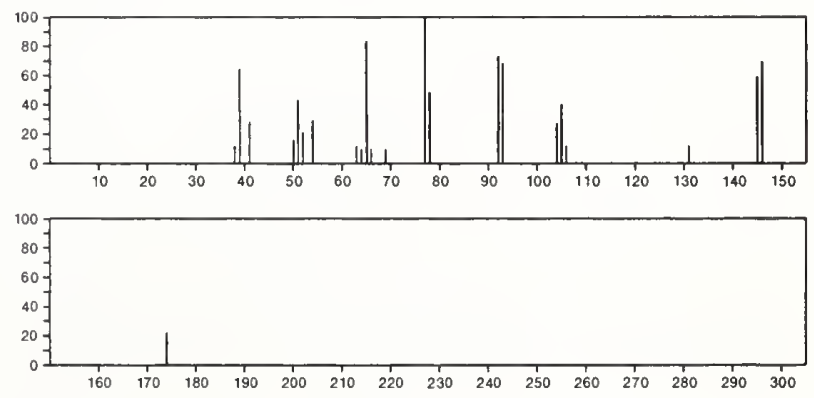
174

2H-Pyran, 2-(tert-butylthio)tetrahydro-

$1927-53-3$
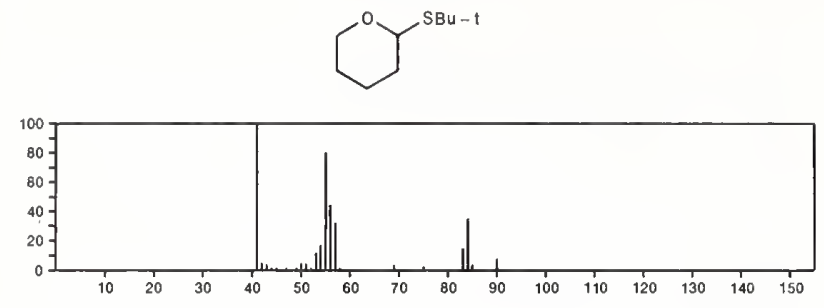

$174 \quad \mathrm{C}_{9} \mathrm{H}_{18} \mathrm{OS}$

Butyric acid, thio-, $S$-pentyl ester

$\operatorname{PrC}(0) S\left(\mathrm{CH}_{2}\right) 4 \mathrm{Me}$
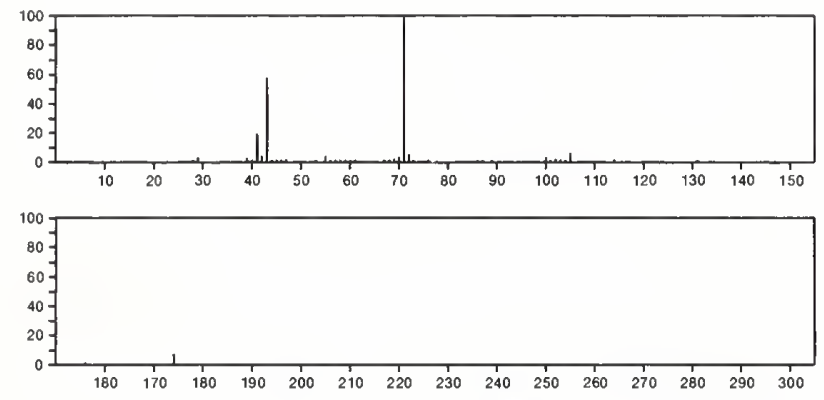

$174 \quad \mathrm{C}_{9} \mathrm{H}_{18} \mathrm{OS}$

Hexanethioic acid, $S$-propyl ester

$\mathrm{Me}\left(\mathrm{CH}_{2}\right)_{4} \mathrm{C}(\mathrm{O}) \mathrm{SPr}$
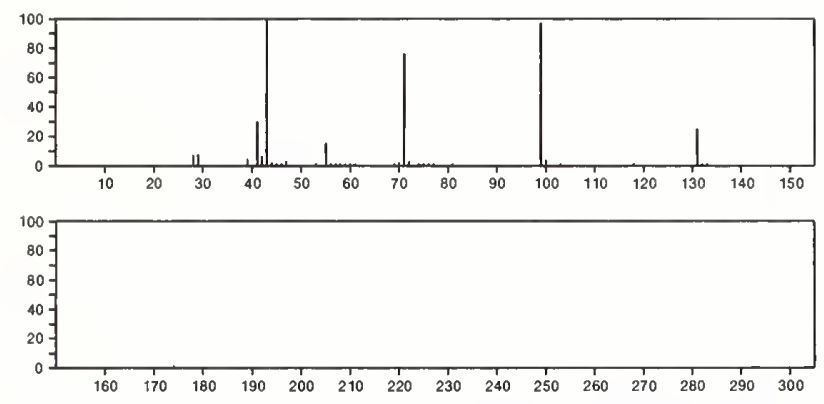

$174 \quad \mathrm{C}_{9} \mathrm{H}_{18} \mathrm{OS}$

Octanethioic acid, $S$-methyl ester

2432-83-9

$\mathrm{Me}\left(\mathrm{CH}_{2}\right)_{6} \mathrm{C}(\mathrm{O}) \mathrm{SM}$
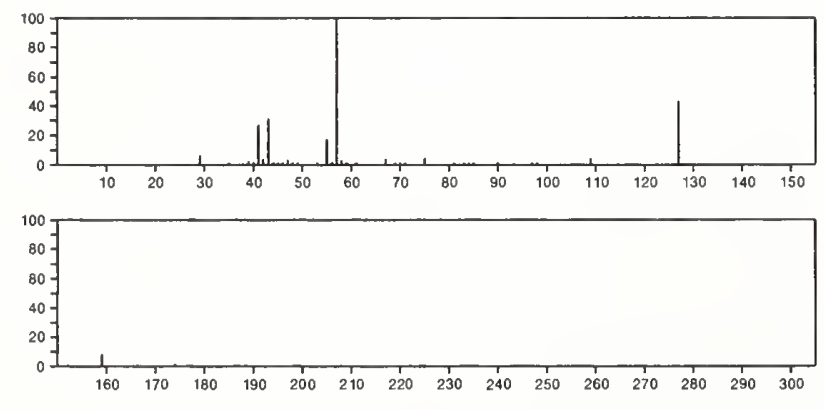

174

$\mathrm{C}_{9} \mathrm{H}_{18} \mathrm{OS}$

Butanethioic acid, 3-methyl-, $S$-(1-methylpropyl) ester

$\mathrm{s}-\mathrm{BuSC}(\mathrm{O}) \mathrm{CH}_{2} \mathrm{CHMe}_{2}$

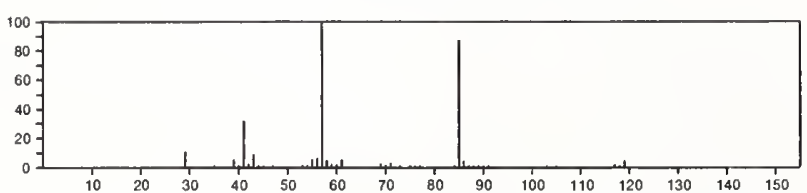

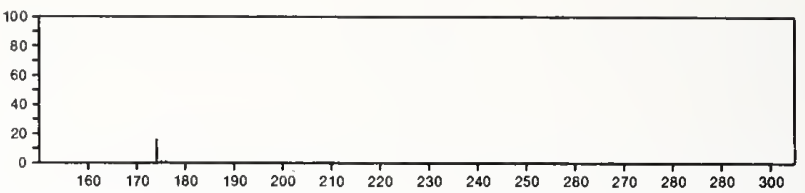

174

$\mathrm{C}_{9} \mathrm{H}_{18} \mathrm{OS}$

Valeric acid, thio-, $S$-sec-butyl ester

$2450-11-5$

s-BuSC $(0)\left(\mathrm{CH}_{2}\right) 3 \mathrm{Me}$
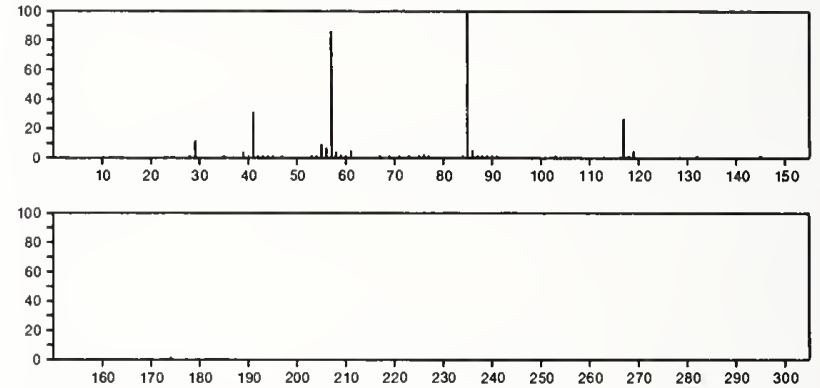

174

$\mathrm{C}_{9} \mathrm{H}_{18} \mathrm{OS}$

2H-Pyran, 2-(butylthio)tetrahydro-

$16315-52-9$
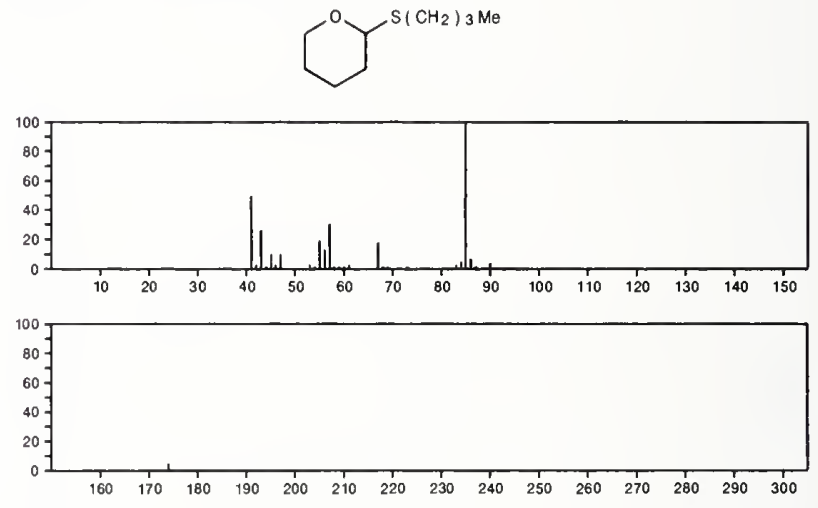

$174 \quad \mathrm{C}_{9} \mathrm{H}_{18} \mathrm{OS}$

24699-60-3

1,3-Oxathiane, 2-(1,1-dimethylethyl)-2-methyl-
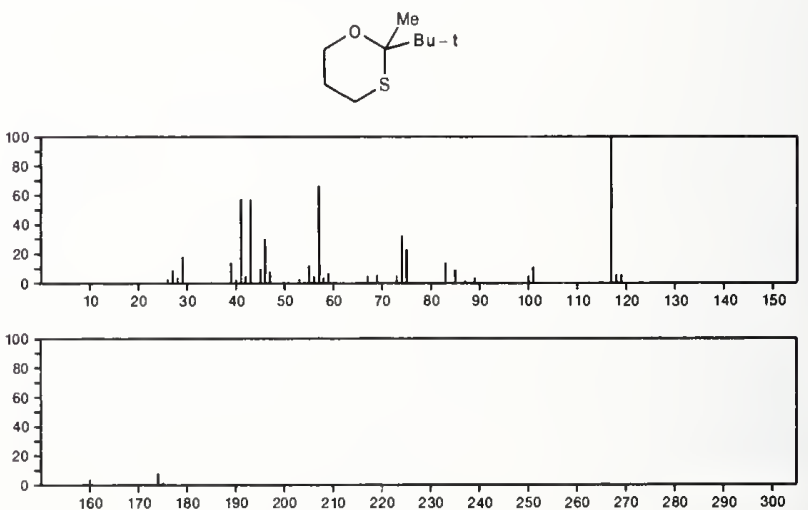
174

1,3-Oxathiane, 2-isopropyl-2,6-dimethyl-
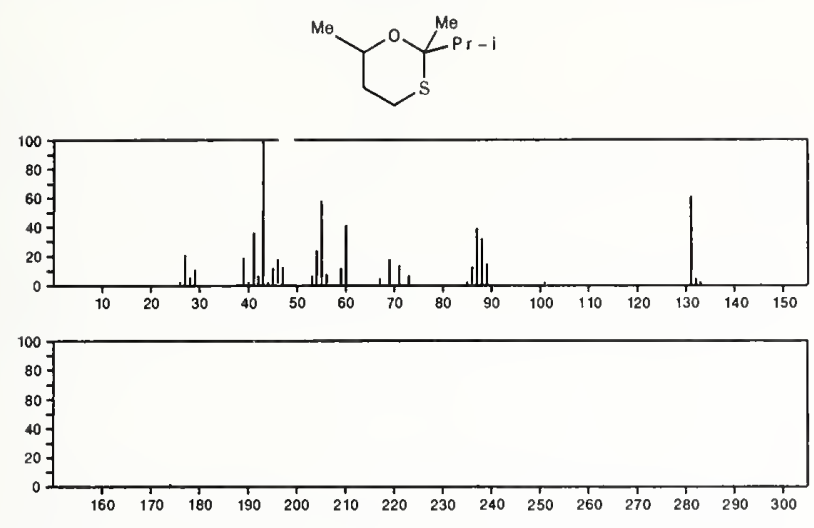

174 $\mathrm{C}_{9} \mathrm{H}_{18} \mathrm{O}_{3}$

Carbonic acid, bis(2-methylpropyl) ester

$\mathrm{i}-8 \mathrm{u} 0 \mathrm{C}(0) 08 \mathrm{0}-\mathrm{i}$
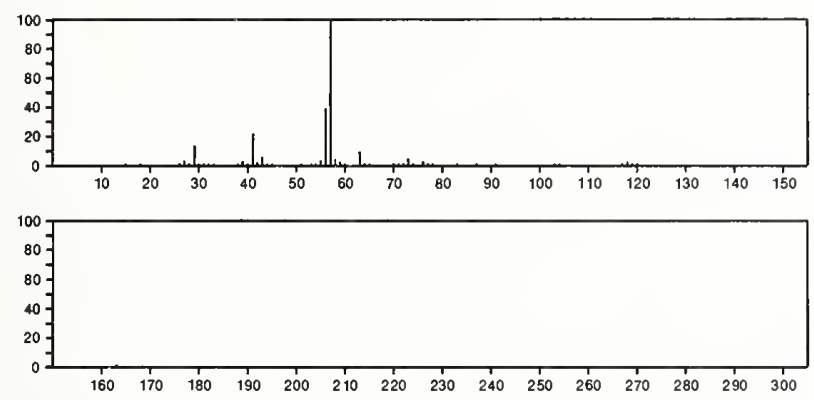

174

Carbonic acid, dibutyl ester

$\mathrm{C}_{9} \mathrm{H}_{18} \mathrm{O}_{3}$

$542-52-9$

Me ( $\left.\mathrm{CH}_{2}\right)_{3} \mathrm{OC}(\mathrm{O}) \mathrm{O}\left(\mathrm{CH}_{2}\right){ }_{3} \mathrm{Me}$
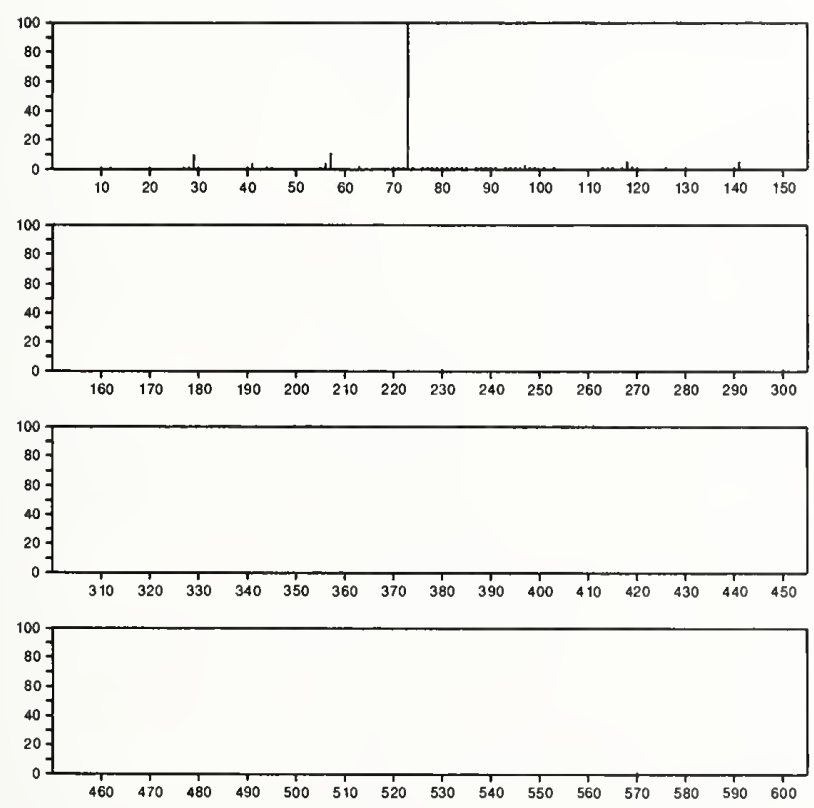

174

Carbonic acid, bis(1-methylpropyl) ester

623-63-2

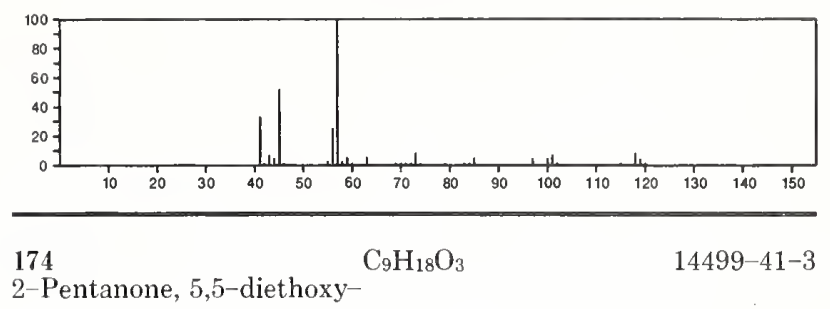

(EtO) ${ }_{2} \mathrm{CHCH}_{2} \mathrm{CH}_{2} \mathrm{COMO}_{\mathrm{N}}$

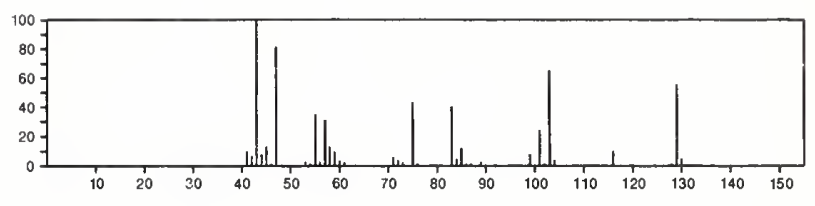

174

$\mathrm{C}_{9} \mathrm{H}_{18} \mathrm{O}_{3}$

Butyric acid, 4-butoxy-, methyl ester

29006-06-2

$\mathrm{Me}\left(\mathrm{CH}_{2}\right)_{3} \mathrm{O}\left(\mathrm{CH}_{2}\right)_{3} \mathrm{C}(\mathrm{O}) \mathrm{OMe}$

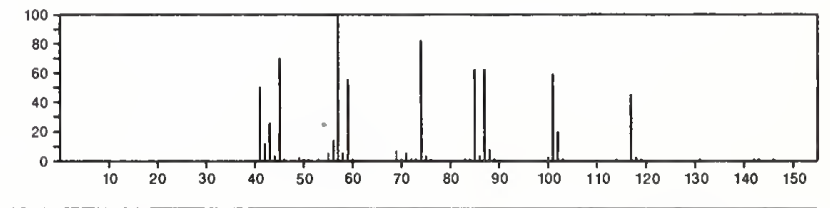

174

$\mathrm{C}_{9} \mathrm{H}_{18} \mathrm{O}_{3}$

$29887-73-8$

Cyclohexane, 1,2,3-trimethoxy-, stereoisomer
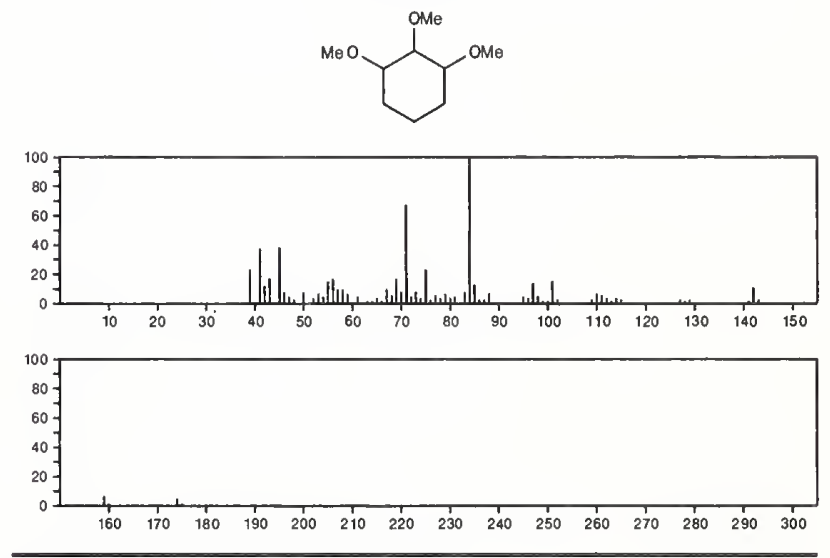

174

$\mathrm{C}_{9} \mathrm{H}_{18} \mathrm{O}_{3}$

29887-74-9

Cyclohexane, 1,2,4-trimethoxy-, stereoisomer<smiles>COC1CCC(OC)C(OC)C1</smiles>
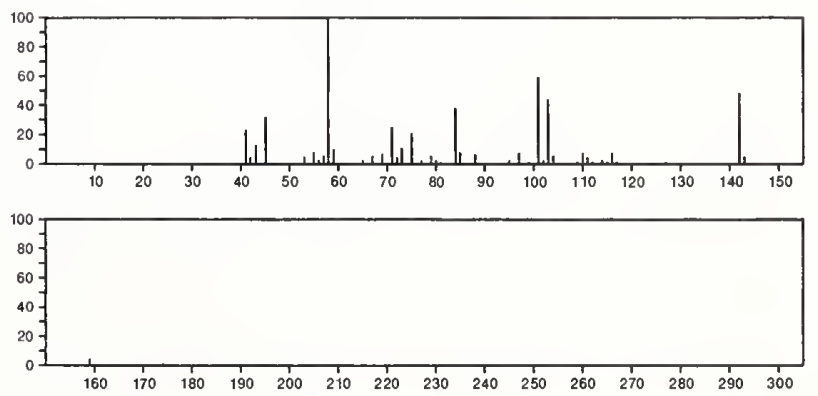
174

$\mathrm{C}_{9} \mathrm{H}_{18} \mathrm{O}_{3}$

Cyclohexane, 1,3,5-trimethoxy-, $(1 \alpha, 3 \alpha, 5 \beta)$ -<smiles>COC1CC(OC)CC(OC)C1</smiles>
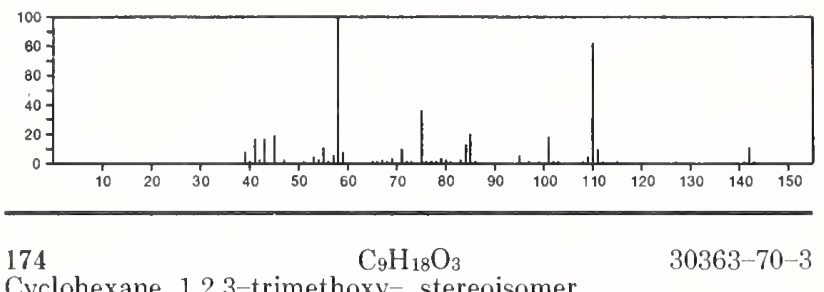

Cyclohexane, 1,2,3-trimethoxy-, stereoisomer
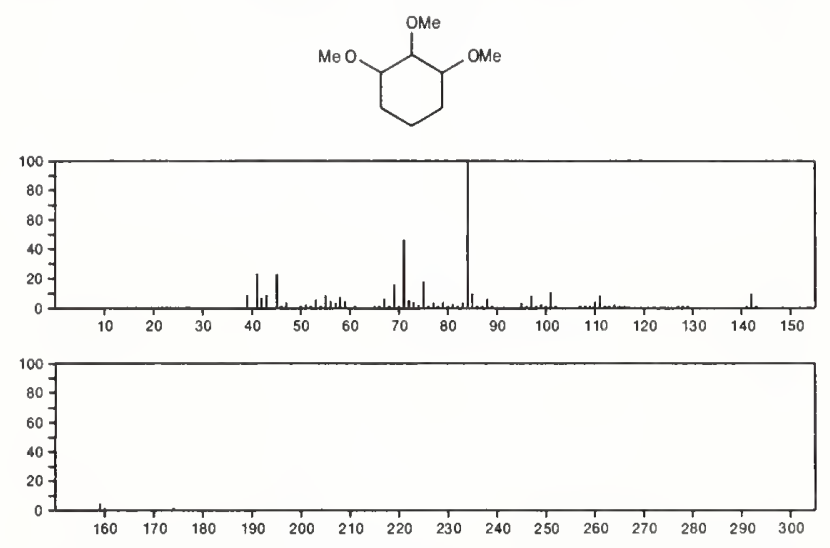

174

$\mathrm{C}_{9} \mathrm{H}_{18} \mathrm{O}_{3}$

$30363-72-5$

Cyclohexane, 1,2,4-trimethoxy-, stereoisomer
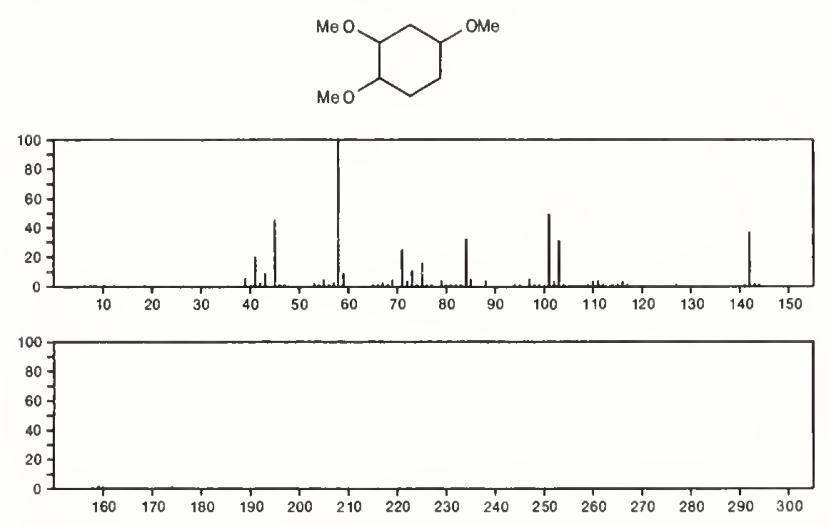

174

$\mathrm{C}_{9} \mathrm{H}_{18} \mathrm{O}_{3}$

Cyclohexane, 1,3,5-trimethoxy-, $(1 \alpha, 3 \alpha, 5 \alpha)-$<smiles>COC1CC(OC)CC(OC)C1</smiles>

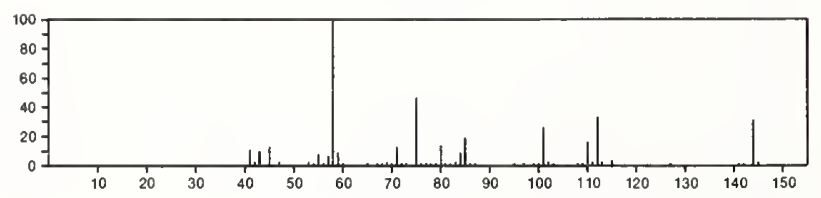

174

$\mathrm{C}_{9} \mathrm{H}_{18} \mathrm{O}_{3}$

$30377-28-7$ Cyclohexane, 1,2,3-trimethoxy-, stereoisomer
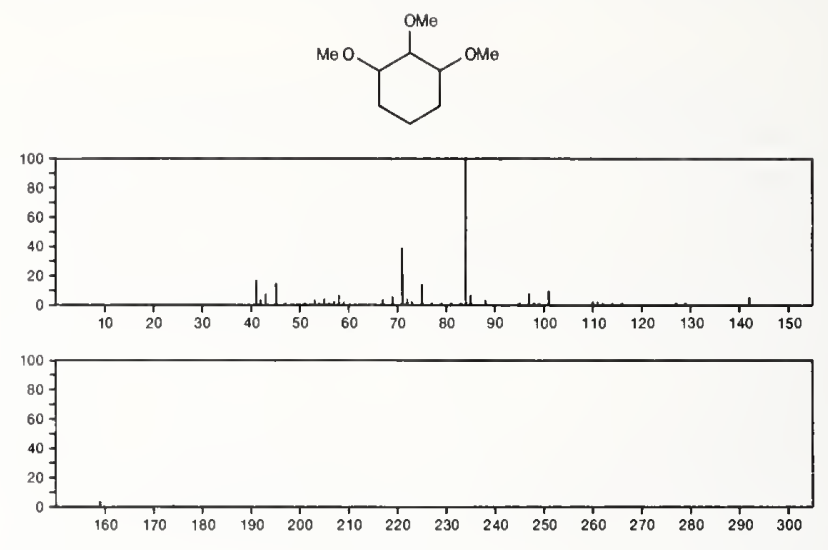

174

$\mathrm{C}_{9} \mathrm{H}_{18} \mathrm{O}_{3}$

1,3-Dioxolane-2-pentanol, 2-methyl-

$36651-23-7$
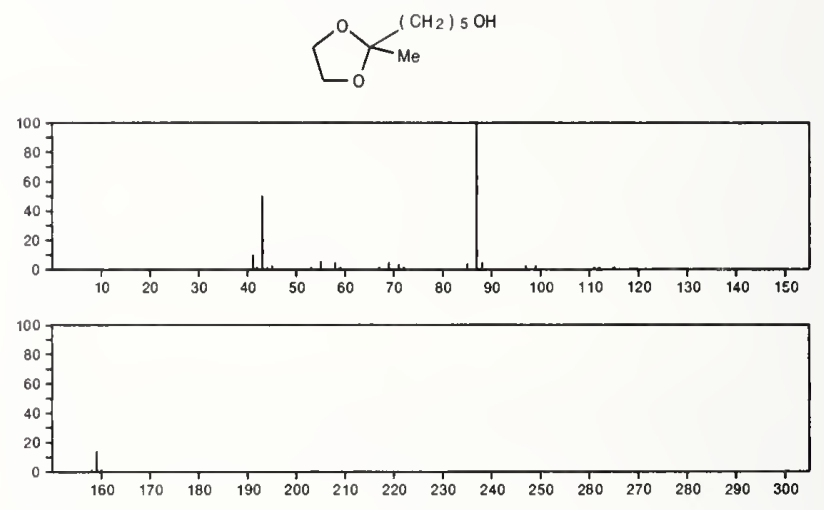

174

$\mathrm{C}_{9} \mathrm{H}_{18} \mathrm{O}_{3}$

$55956-25-7$

2-Propanol, 1-[1-methyl-2-(2-propenyloxy)ethoxy]-

$\mathrm{Me} \mathrm{CH}(\mathrm{OH}) \mathrm{CH}_{2} \mathrm{OCHMeCH} \mathrm{OCH}_{2} \mathrm{CH}=\mathrm{CH}_{2}$
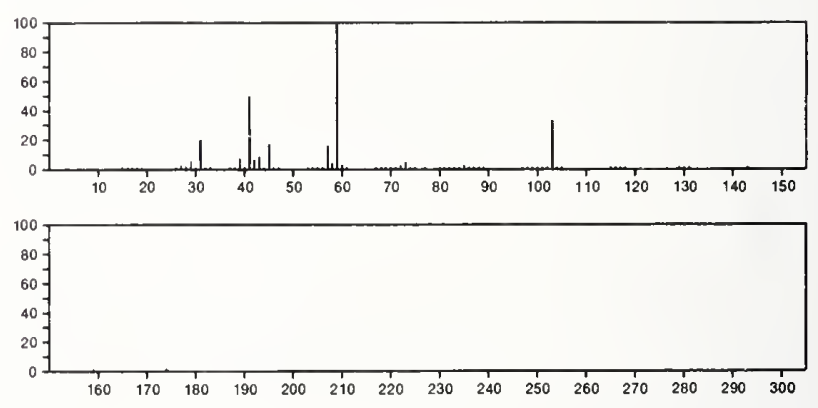

174

$\mathrm{C}_{9} \mathrm{H}_{22} \mathrm{OSi}$

Silane, trimethyl[(2-methylpentyl)oxy $]-$

$17877-22-4$

$\mathrm{Me}_{3} \mathrm{Si} \mathrm{OCH} \mathrm{CHP}_{2} \mathrm{Me}$
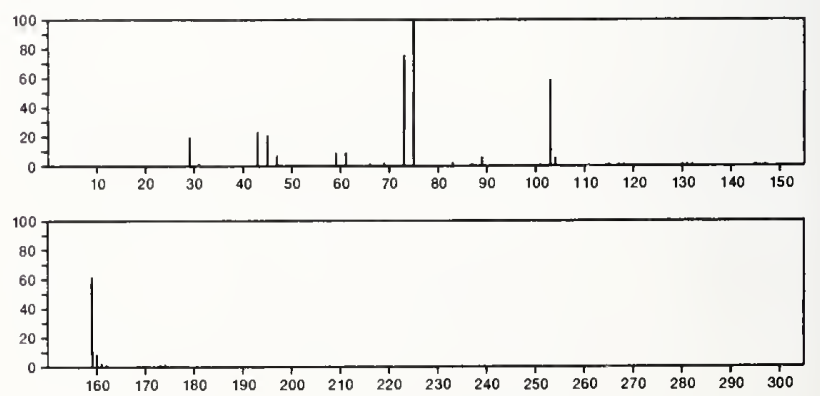
$174 \quad \mathrm{C}_{9} \mathrm{H}_{22} \mathrm{OS}$

Silane, (2-ethylbutoxy)trimethyl-

$\mathrm{Me}_{3} \mathrm{Si} \mathrm{OCH}_{2} \mathrm{CHE}_{2}$
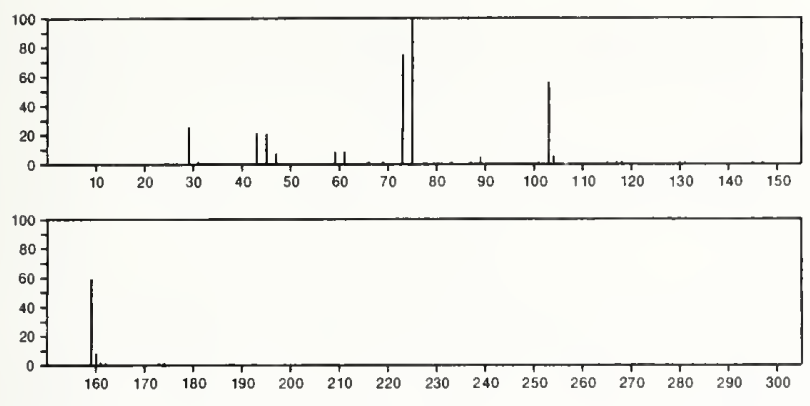

174

$\mathrm{C}_{9} \mathrm{H}_{22} \mathrm{OSi}$

$17888-62-9$

Silane, (hexyloxy)trimethyl-
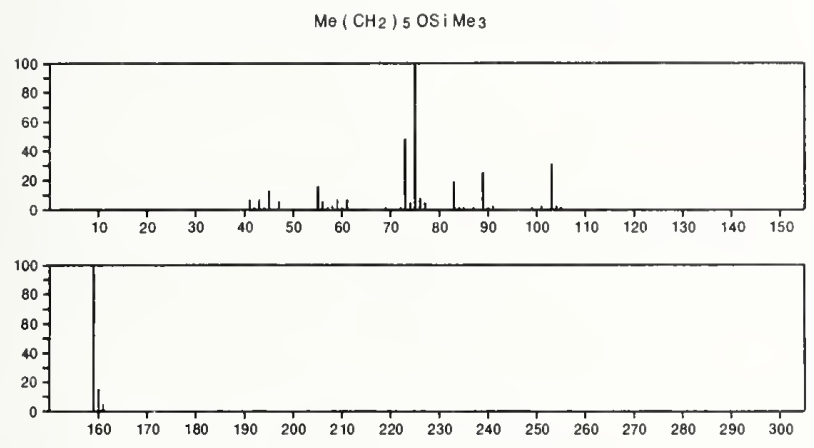

174

$\mathrm{C}_{9} \mathrm{H}_{22} \mathrm{OSi}$

$17888-63-0$

Silane, trimethyl[(1-methylpentyl)oxy]-

$\mathrm{Me} 3 \mathrm{Si} \mathrm{OCHMe}_{2}\left(\mathrm{CH}_{2}\right)_{3} \mathrm{Me}$
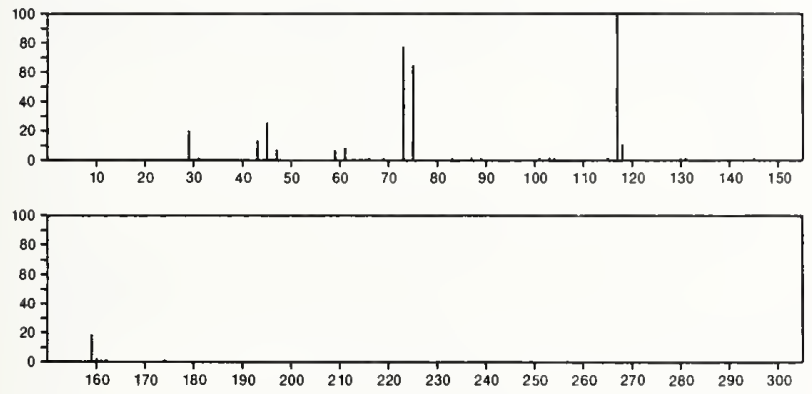

\section{4}

$\mathrm{C}_{9} \mathrm{H}_{22} \mathrm{OSi}$

Silane, trimethyl[(3-methylpentyl)oxy]-

17888-64-1

$\mathrm{Me}_{3} \mathrm{Si} \mathrm{OCH}_{2} \mathrm{CH}_{2} \mathrm{CHMeCH}_{2} \mathrm{Me}$
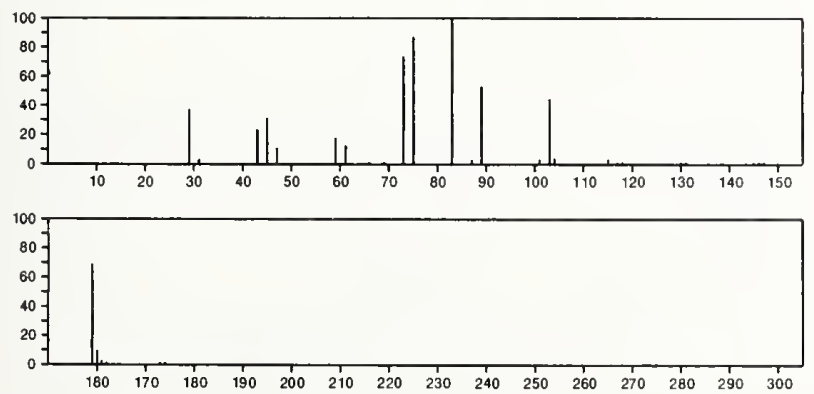

174

1,4-Naphthalenedione, 2-hydroxy

$83-72-7$
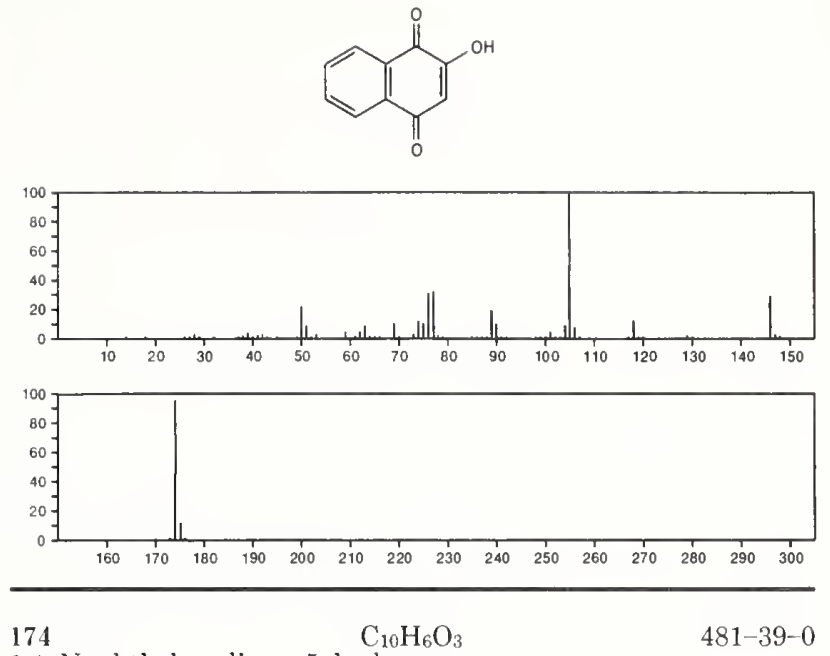

1.4-Naphthalenedione, 5-hydroxy-
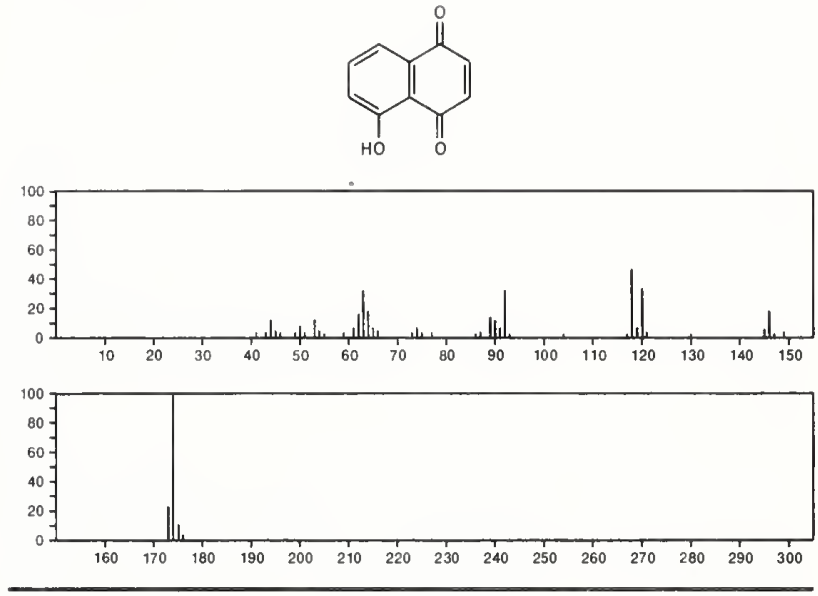

$174 \quad \mathrm{C}_{10} \mathrm{H}_{6} \mathrm{O}_{3}$

$607-20-5$

1,2-Naphthalenedione, 6 -hydroxy-
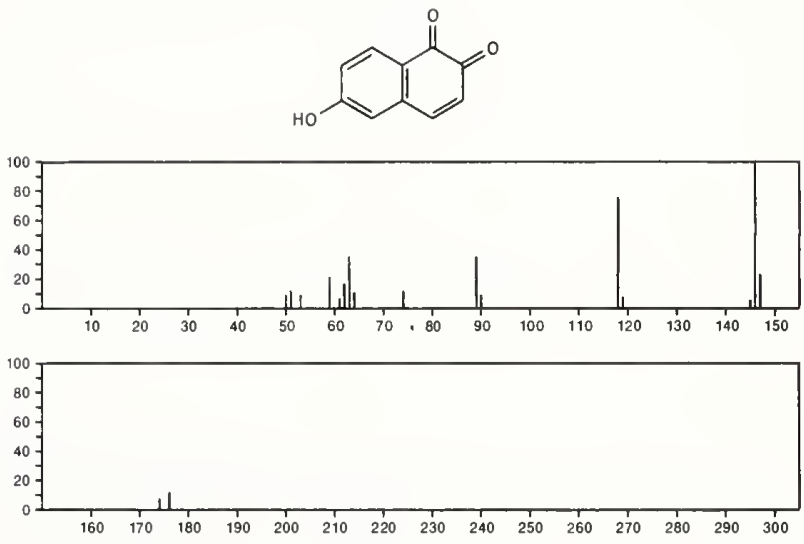
$\mathrm{C}_{10} \mathrm{H}_{10} \mathrm{~N}_{2} \mathrm{O}$

89-25-8

3H-Pyrazol-3-one, 2,4-dihydro-5-methyl-2-phenyl-<smiles>CC1=NN(P)C(=O)C1</smiles>
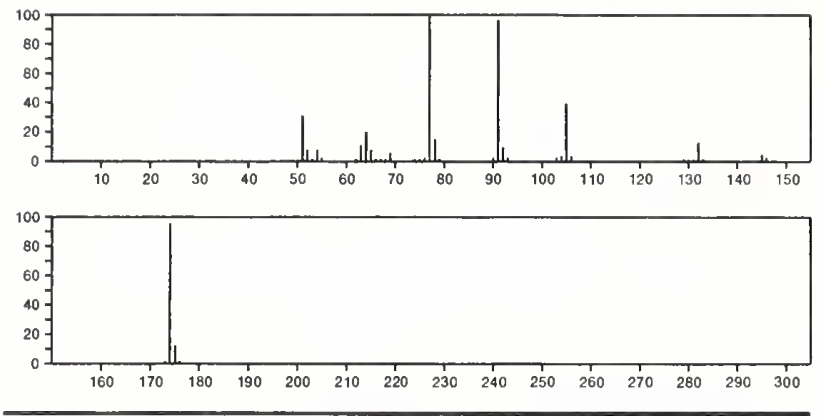

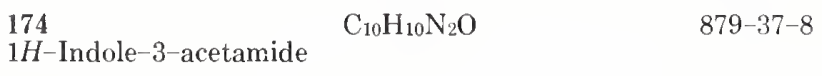
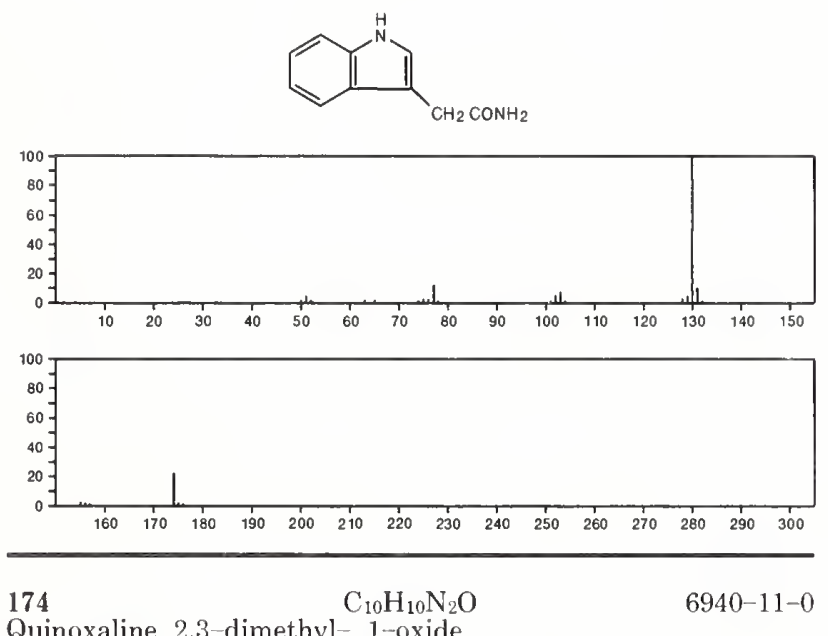

Quinoxaline, 2,3-dimethyl-, 1 - oxide
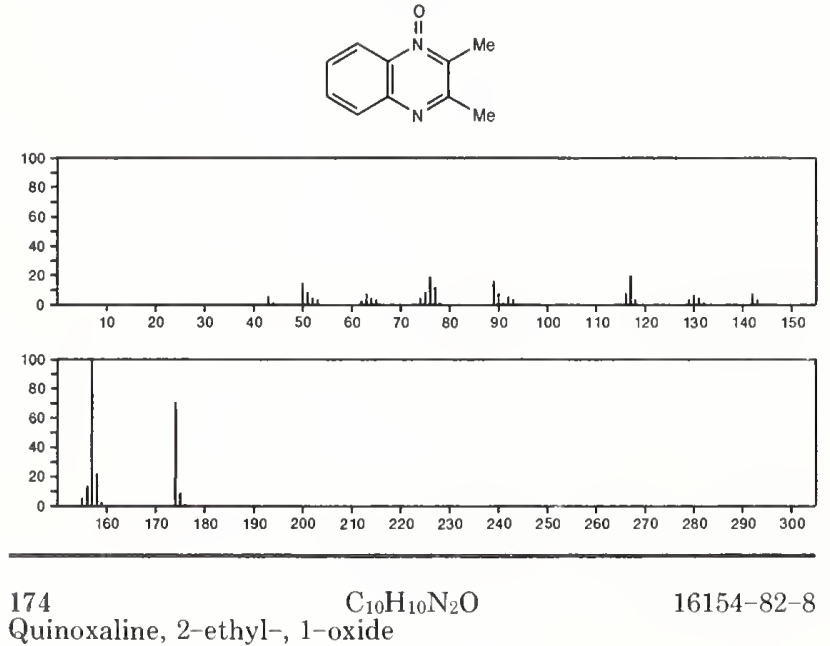

Quinoxaline, 2-ethyl-, 1-oxide
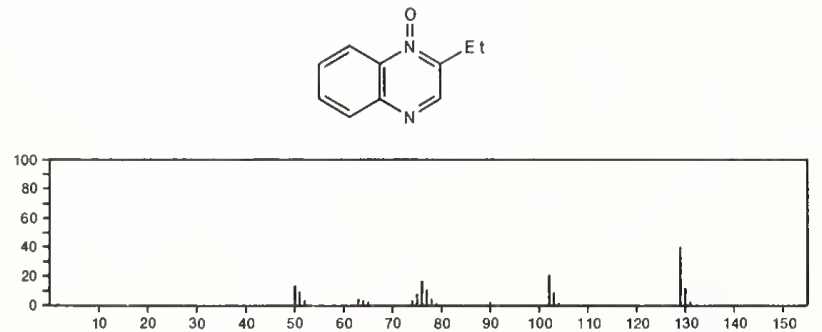

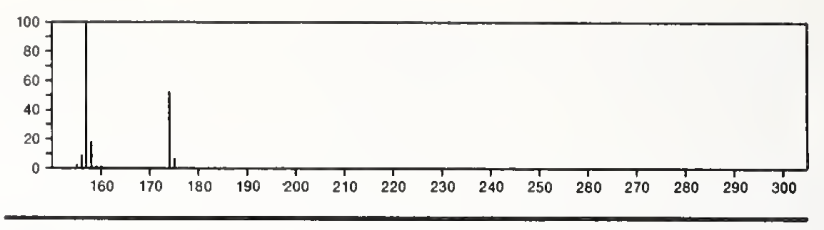

174

Quinoxaline, 2-ethyl-, 4-oxide

$16154-83-9$
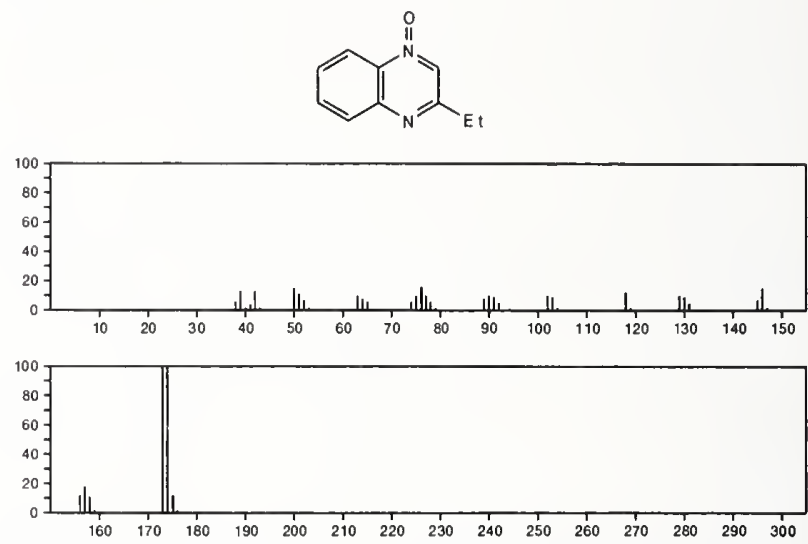

174

8-Quinolinol, 2-(aminomethyl)-

$\mathrm{C}_{10} \mathrm{H}_{10} \mathrm{~N}_{2} \mathrm{O}$

$17018-81-4$
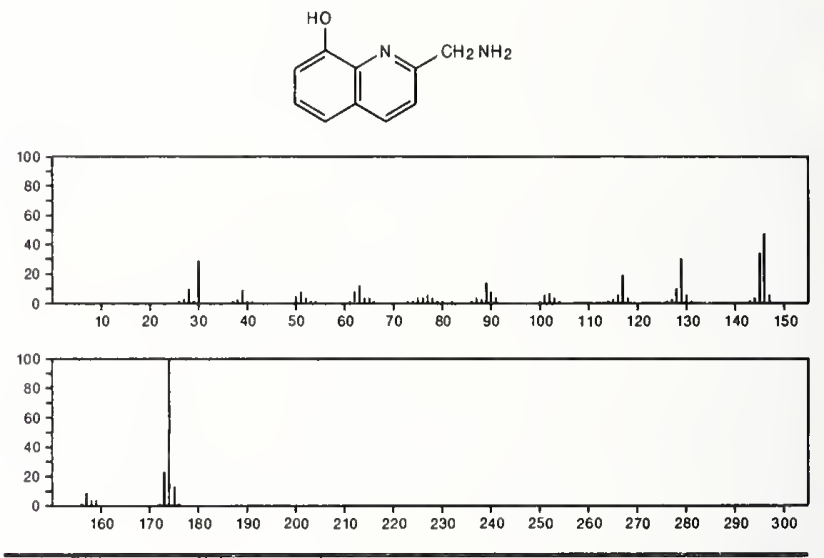

174

$\mathrm{C}_{10} \mathrm{H}_{10} \mathrm{~N}_{2} \mathrm{O}$

$17408-29-6$

Ethanone, 1-(2-methylpyrazolo[1,5-a]pyridin-3-yl)-
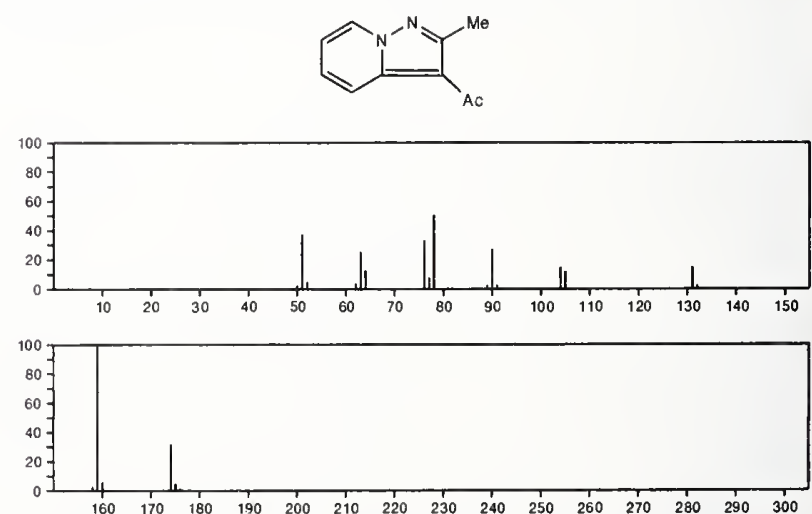
$174 \quad \mathrm{C}_{10} \mathrm{H}_{10} \mathrm{~N}_{2} \mathrm{O}$

$2 H$-Pyrido[1,2-a]pyrimidin-2-one, 4,8-dimethyl-
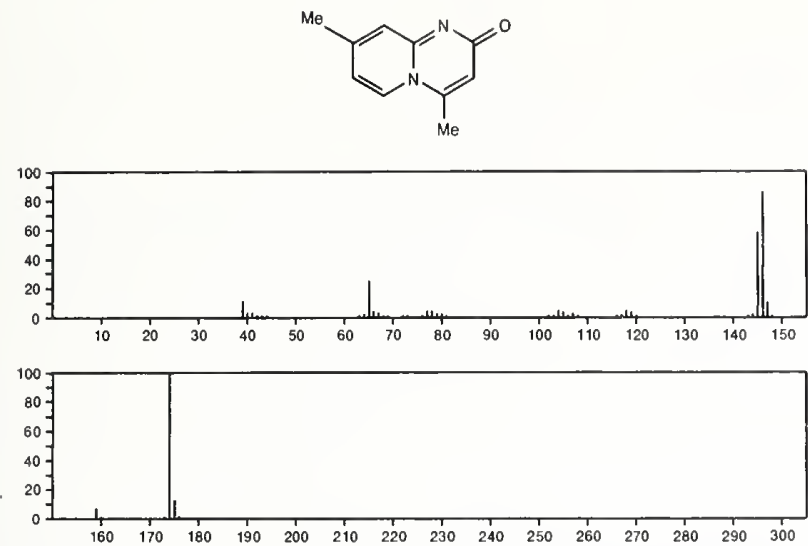

\section{4}

6-Indolizinecarboxamide, $\mathrm{C}_{10} \mathrm{H}_{10} \mathrm{~N}_{2} \mathrm{O}$

$22380-20-7$
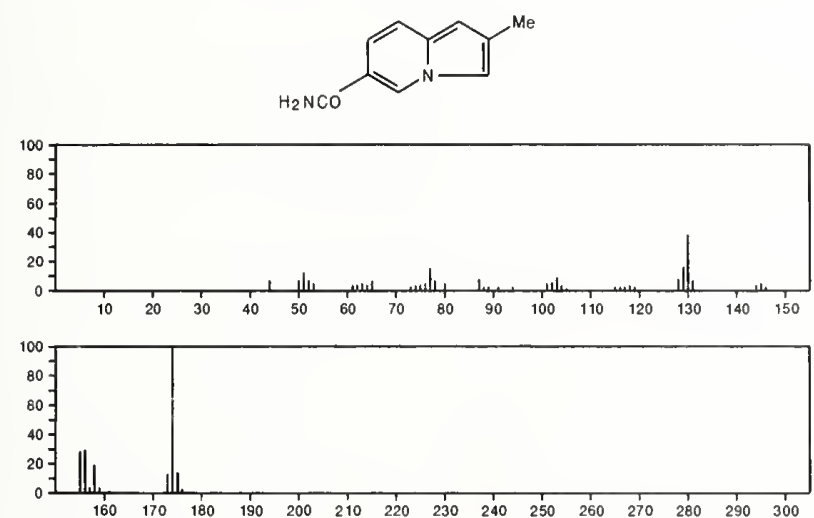

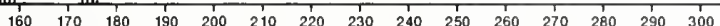

\section{4}

Isoxazole, 5-amino-3-p-tolyl-
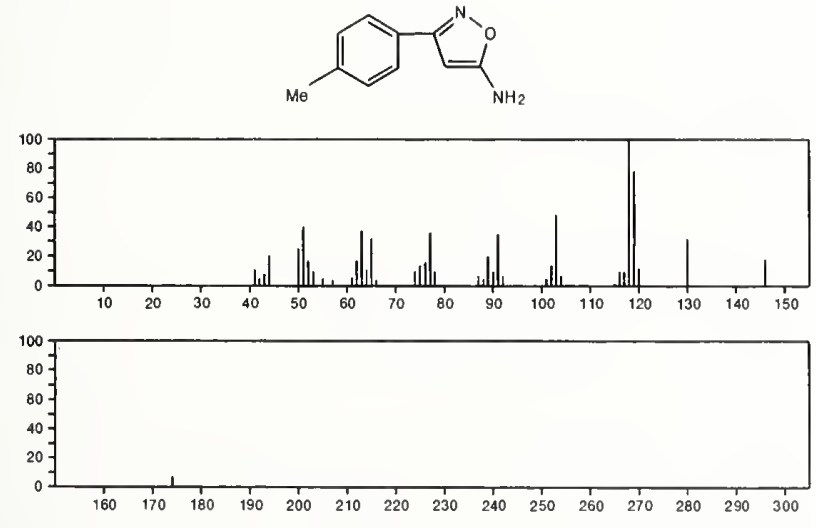

$174 \quad \mathrm{C}_{10} \mathrm{H}_{10} \mathrm{~N}_{2} \mathrm{O}$

$2 \mathrm{H}$-Azirine-2-carboxamide, $3-p$-tolyl-
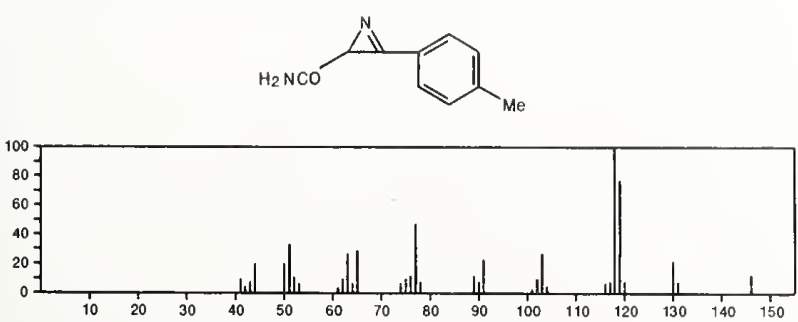

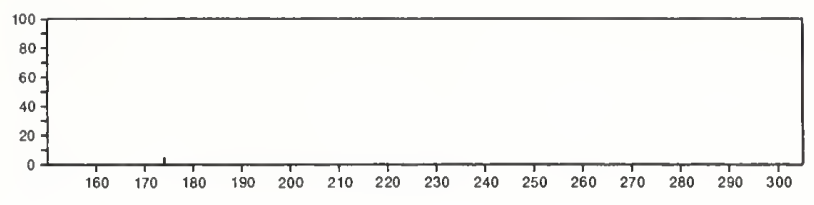

174

$\mathrm{C}_{10} \mathrm{H}_{10} \mathrm{~N}_{2} \mathrm{O}$

$30986-10-8$

$2 H-1,4-$ Ethanocinnolin-3(4H)-one
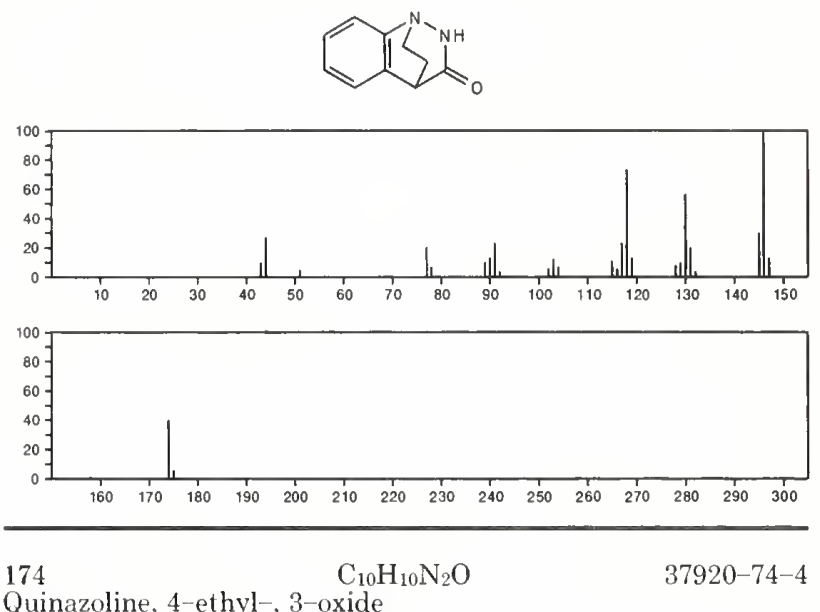

Quinazoline, 4-ethyl-, 3-oxide
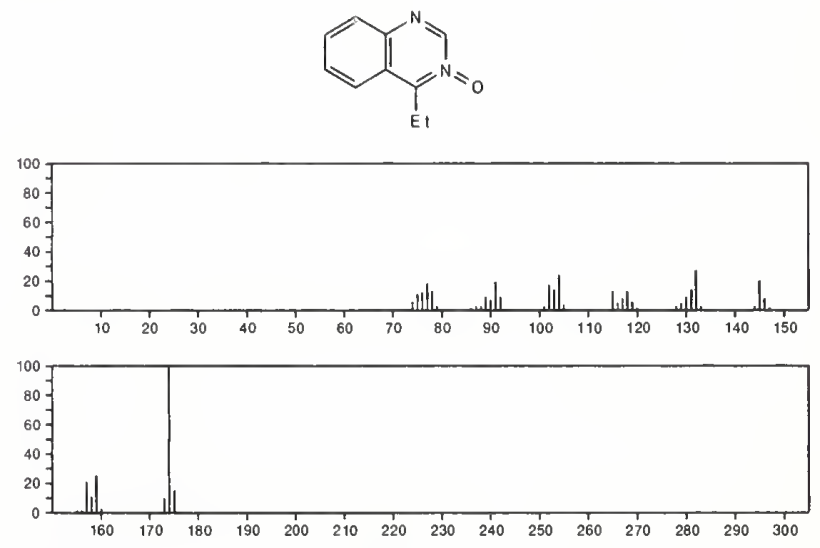

174

Quinazoline, 4-ethyl-, 1-oxide

37920-75-5<smiles></smiles>
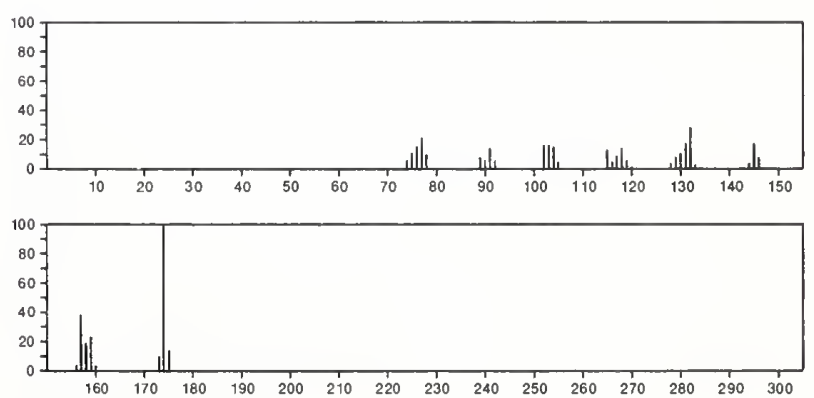
174

$\mathrm{C}_{10} \mathrm{H}_{10} \mathrm{~N}_{2} \mathrm{O}$

$41927-50-8$

3H-Pyrazol-3 one, 2,4-dihydro-2-methyl-5-phenyl-
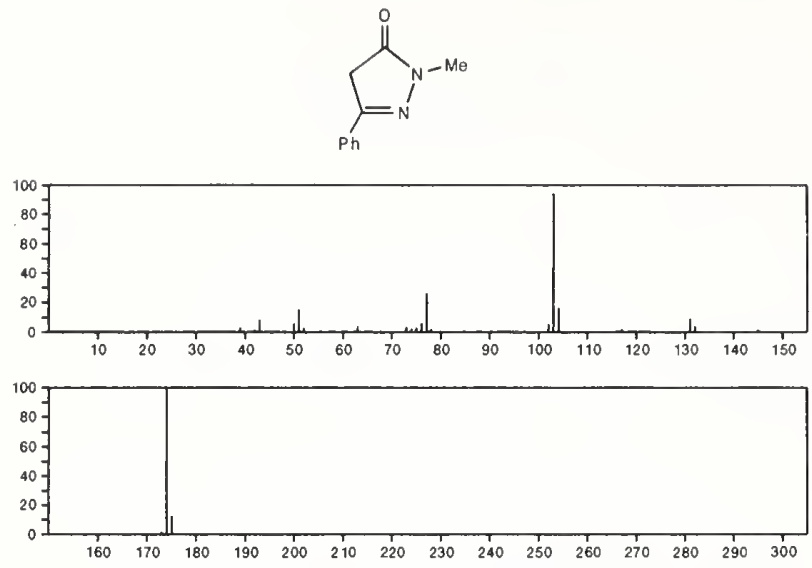

174

$\mathrm{C}_{10} \mathrm{H}_{15} \mathrm{BN}_{2}$

1H-1,3,2-Benzodiazaborole, 2-butyl-2,3-dihydro-

$31748-14-8$
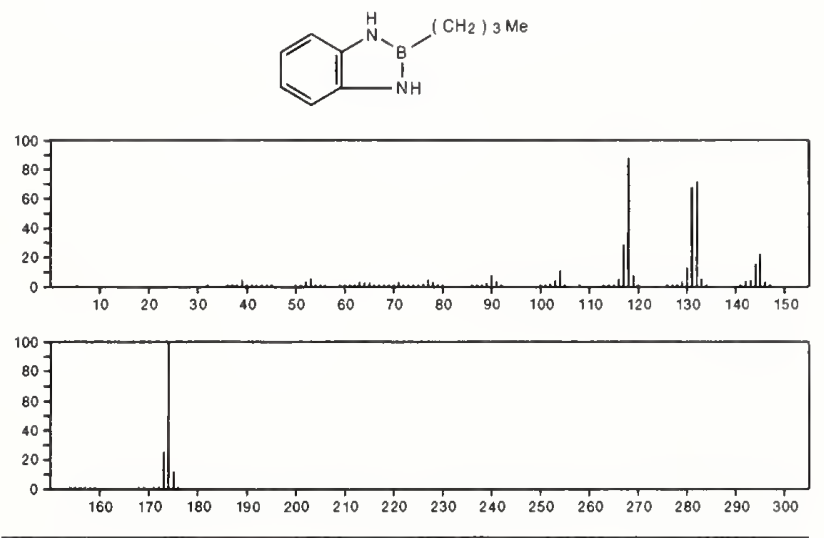

$174 \quad \mathrm{C}_{10} \mathrm{H}_{22} \mathrm{O}_{2}$

1,7-Octanediol, 3,7-dimethyl-

$\mathrm{HOCH}_{2} \mathrm{CH}_{2} \mathrm{CHMe}\left\{\mathrm{CH}_{2}\right\}_{3} \mathrm{CM} \mathrm{CM}_{2} \mathrm{OH}$
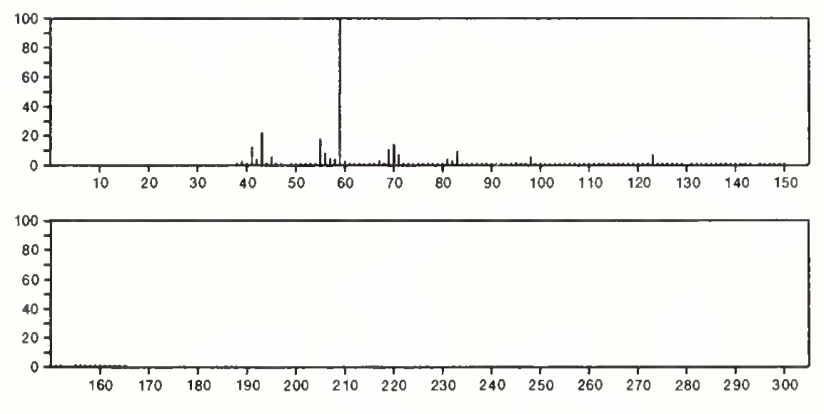

174

Butane, 1, 1'-[ethylidenebis(oxy)]bis-

$871-22-7$

$\mathrm{Me}\left(\mathrm{CH}_{2}\right)_{3} \mathrm{OCHMeO}\left(\mathrm{CH}_{2}\right)_{3} \mathrm{Me}$
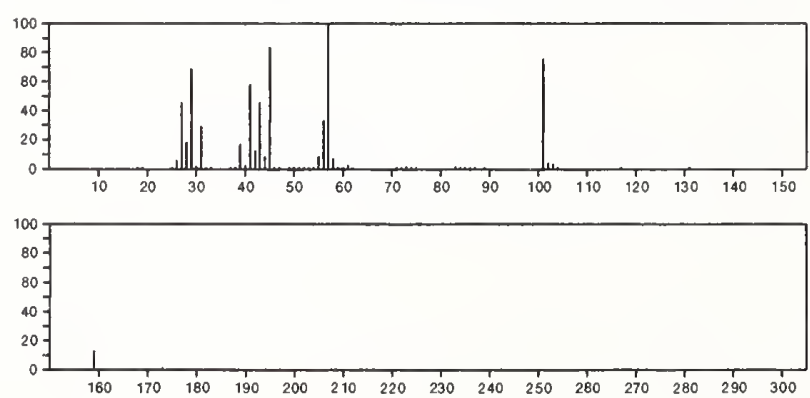

174

1-Butanol, 4-(hexyloxy)-

$\mathrm{C}_{10} \mathrm{H}_{22} \mathrm{O}_{2}$

$4541-13-3$

$\mathrm{Me}\left(\mathrm{CH}_{2}\right) 5 \mathrm{O}\left(\mathrm{CH}_{2}\right){ }_{4} \mathrm{OH}$

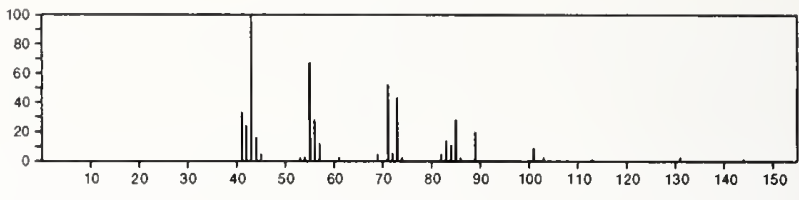

174
Acetaldehyde, di-sec-butyl acetal

$5314-41-0$

$\mathrm{MeCH}(\mathrm{OBu}-\mathrm{s})_{2}$
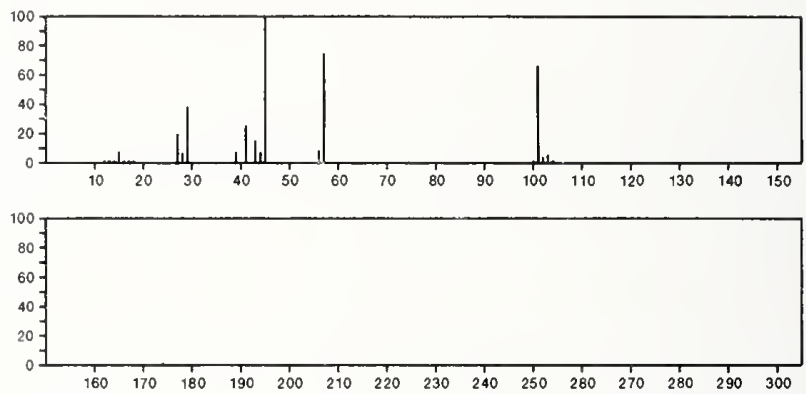

174

$\mathrm{C}_{10} \mathrm{H}_{22} \mathrm{O}_{2}$

$5669-09-0$

Propane, 1,1'-[ethylidenebis(oxy)]bis[2-methyl-

$\mathrm{MeCH}(\mathrm{OBu}-i)_{2}$
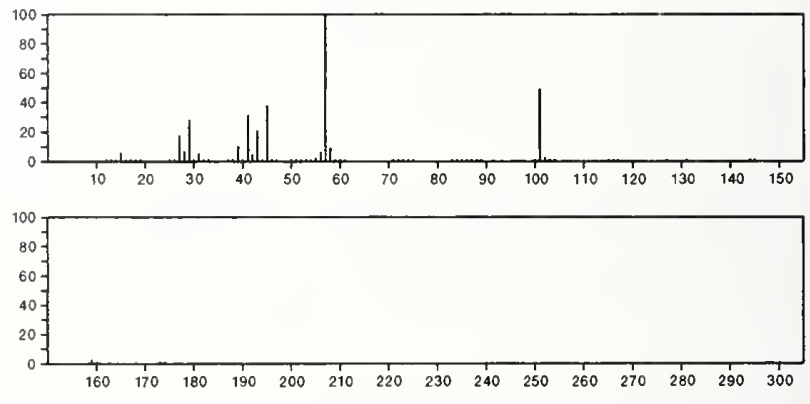

174

Ethanol, 2-(octyloxy)-

$\mathrm{C}_{10} \mathrm{H}_{22} \mathrm{O}_{2}$

$10020-43-6$

$\mathrm{HOCH}_{2} \mathrm{CH}_{2} \mathrm{O}\left(\mathrm{CH}_{2}\right) 7 \mathrm{Me}$
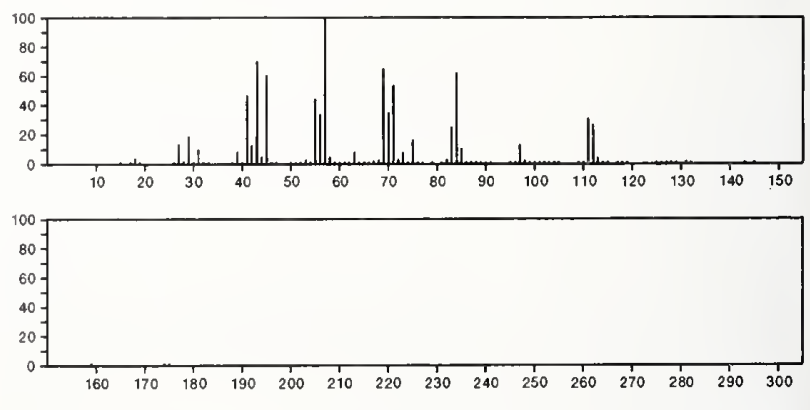

174

$\mathrm{C}_{10} \mathrm{H}_{22} \mathrm{O}_{2}$

20637-47-2

Heptane, 4-methoxy-3-(methoxymethyl)-

$\mathrm{PrCH}(\mathrm{OMe}) \mathrm{CHE}_{t} \mathrm{CH}_{2} \mathrm{OMe}_{\mathrm{M}}$

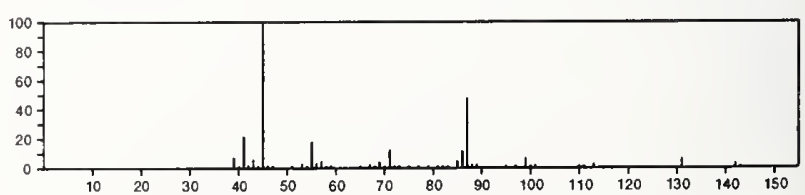



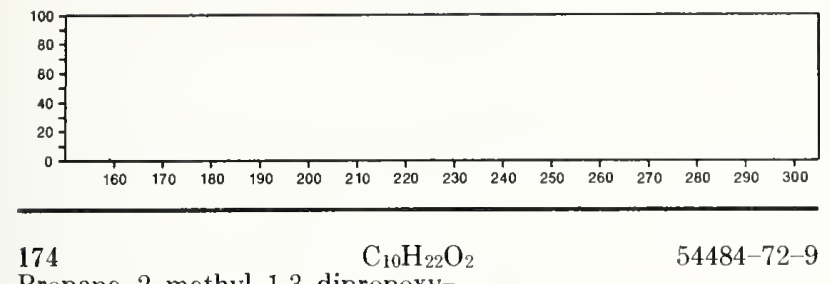

Propane, 2-methyl-1,3-dipropoxy-

$\mathrm{Pr} \mathrm{OCH} \mathrm{CHM}_{2} \mathrm{CH}_{2} \mathrm{OP}_{\mathrm{P}}$
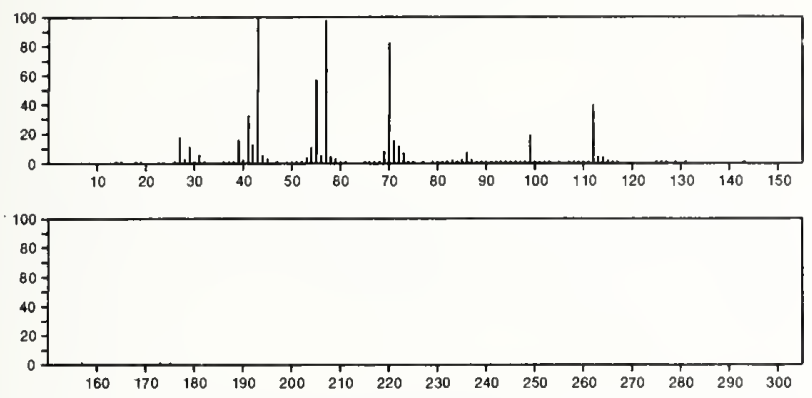

$174 \quad \mathrm{C}_{10} \mathrm{H}_{22} \mathrm{O}_{2}$

$54725-73-4$

1,8-Nonanediol, 8-methyl-

$\mathrm{MB} 2 \mathrm{COH}\left(\mathrm{CH}_{2}\right)>\mathrm{OH}$
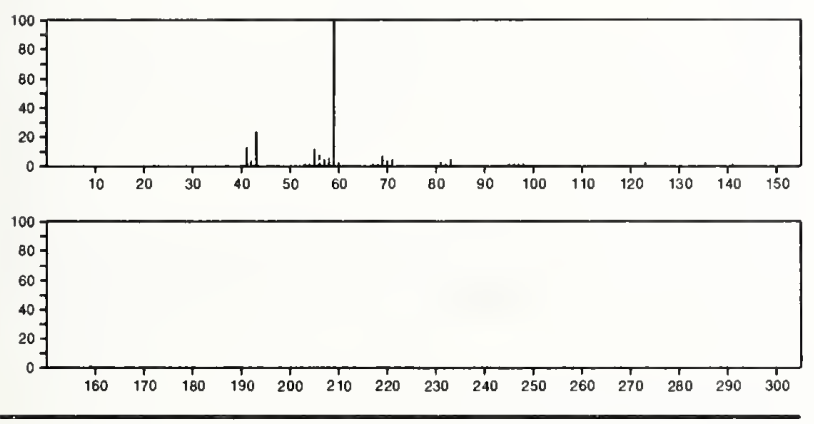

174

1-Decanethiol

$\mathrm{C}_{10} \mathrm{H}_{22} \mathrm{~S}$

$143-10-2$

$\mathrm{Me}\left(\mathrm{CH}_{2}\right)_{9} \mathrm{SH}$
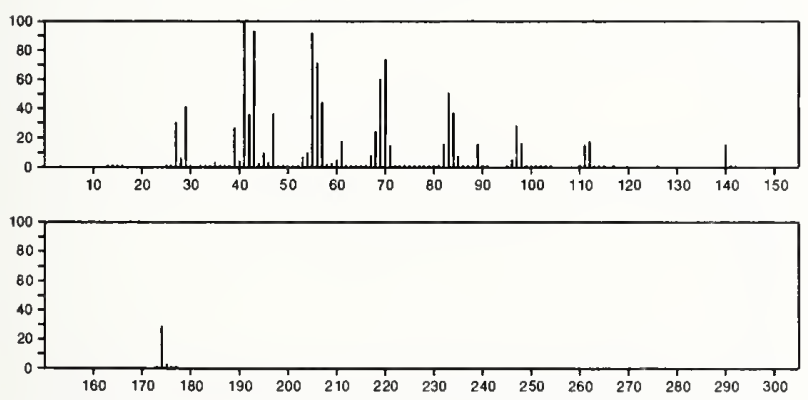$$
17
$$

Butane, 1,1'-thiobis [3-methyl-

544-02-5

$\mathrm{Me}_{2} \mathrm{CHCH}_{2} \mathrm{CH}_{2} \mathrm{SCH}_{2} \mathrm{CH}_{2} \mathrm{CHM}_{2}$

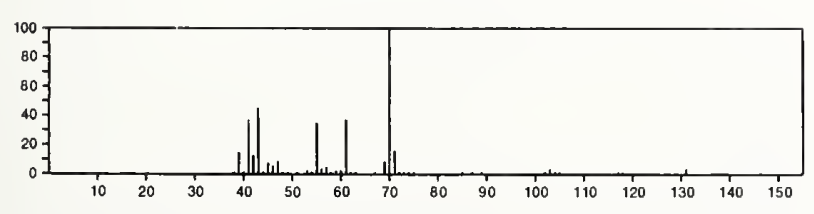

100
80
80
40
20

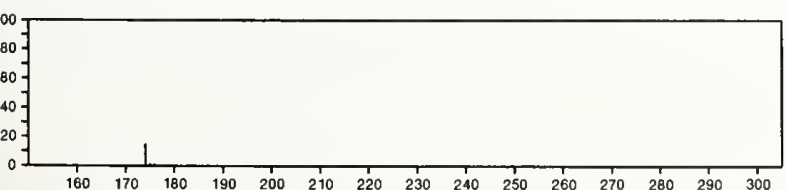

174

Pentane, 1,1'-thiobis-

$\mathrm{C}_{10} \mathrm{H}_{22} \mathrm{~S}$

$872-10-6$

$\mathrm{Me}\left(\mathrm{CH}_{2}\right)_{4} \mathrm{~S}\left(\mathrm{CH}_{2}\right)_{4} \mathrm{Me}$
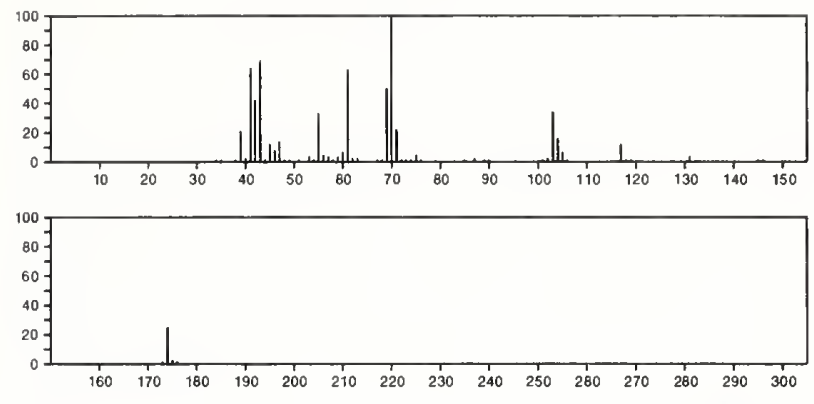

174

Pentane, 1-[(3-methylbutyl)thio]-

$7352-01-4$

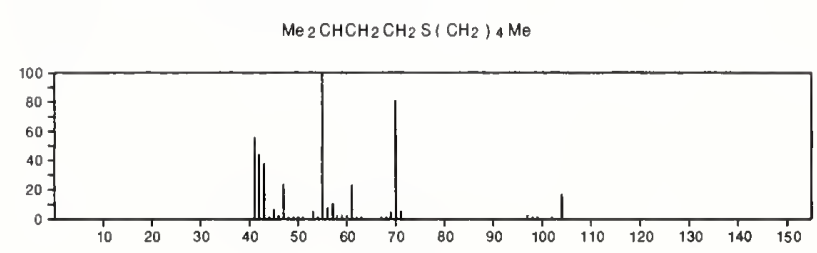

174

$\mathrm{C}_{10} \mathrm{H}_{22} \mathrm{~S}$

$56009-26-8$

3-Decanethiol

$\mathrm{E} \uparrow \mathrm{CH}(\mathrm{SH})\left(\mathrm{CH}_{2}\right)_{6} \mathrm{Me}$
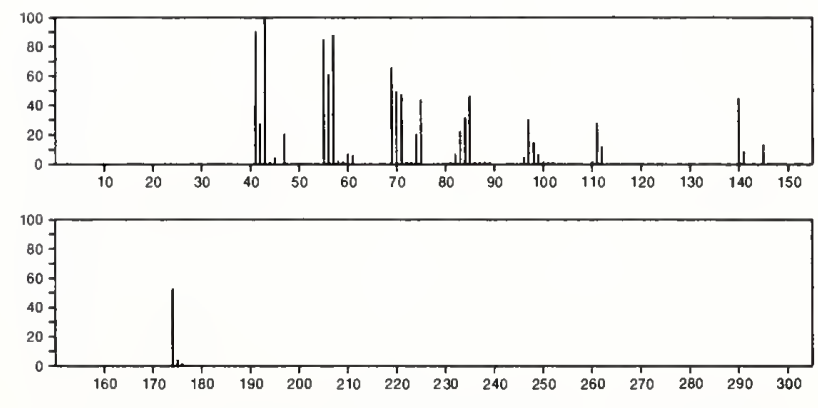

174

2-Naphthalenol, 3-methoxy-

$\mathrm{C}_{11} \mathrm{H}_{10} \mathrm{O}_{2}$

$18515-11-2$
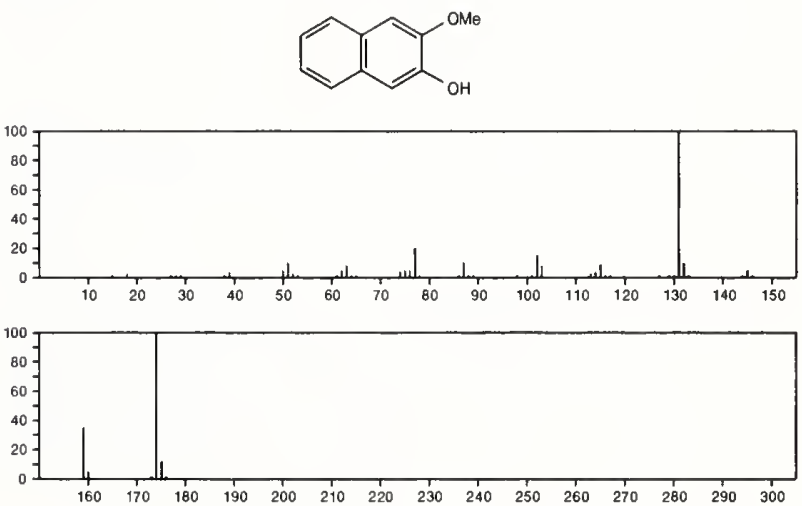
174

$1 \mathrm{H}$-Indene $1, \mathrm{C}_{11} \mathrm{H}_{10} \mathrm{O}_{2}$

3,3-dimethyl

20651-88-1
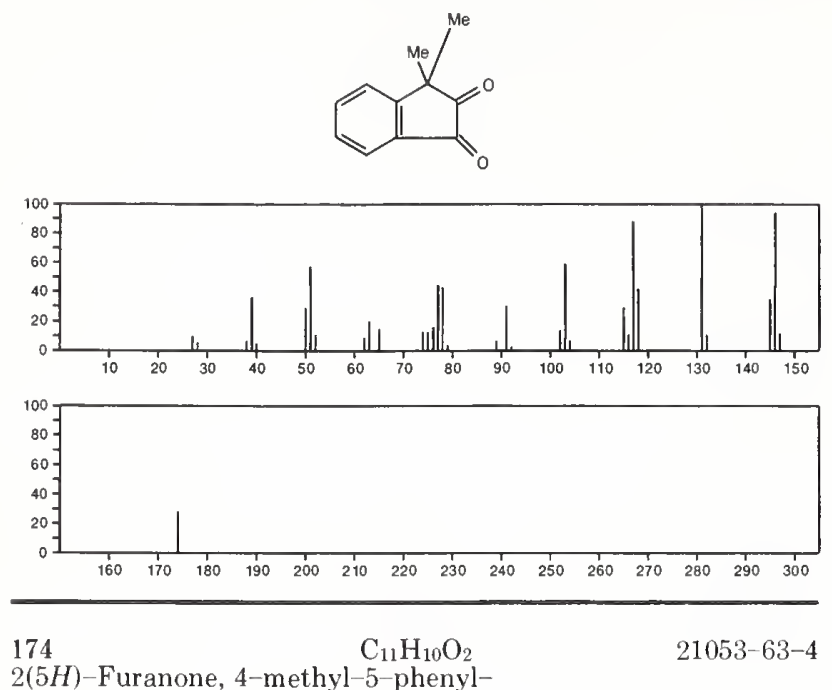

2(5H)-Furanone, 4-methyl-5-phenyl-
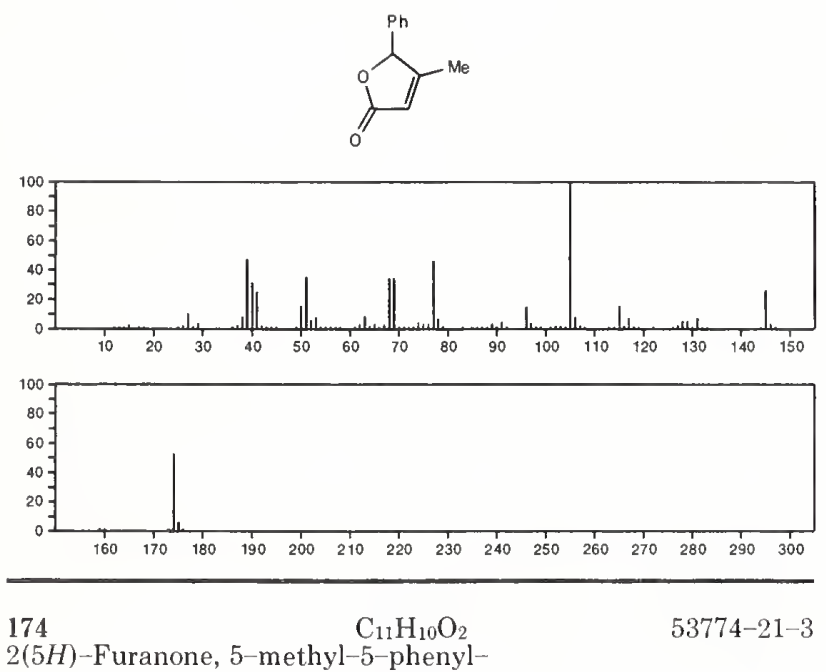

2(5H)-Furanone, 5-methyl-5-phenyl-
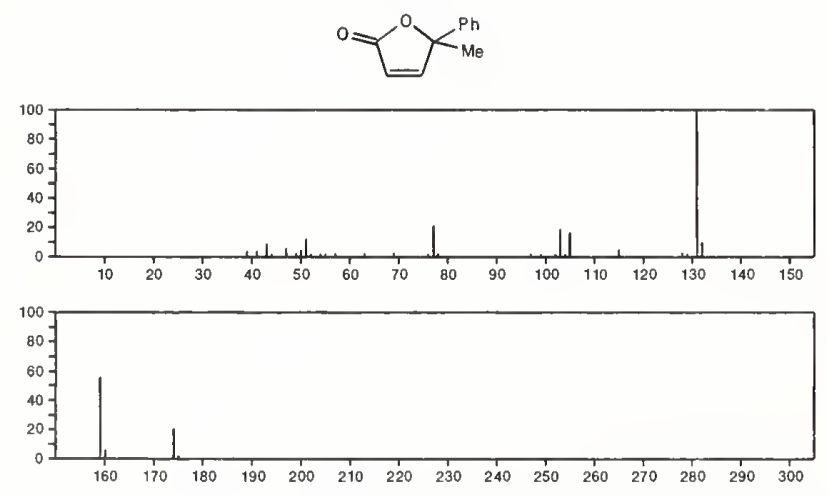

174

$\mathrm{C}_{11} \mathrm{H}_{10} \mathrm{O}_{2}$

2-Oxatricyclo[5.5.0.04,10]dodeca-5,8,11-trien-3-one

$56909-26-3$
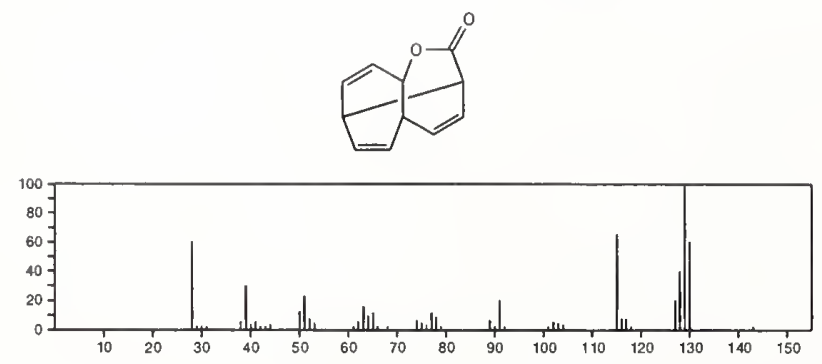

174

Thiophene, 2-(phenylmethyl)-

$\mathrm{C}_{11} \mathrm{H}_{10 \mathrm{~S}}$

$13132-15-5$
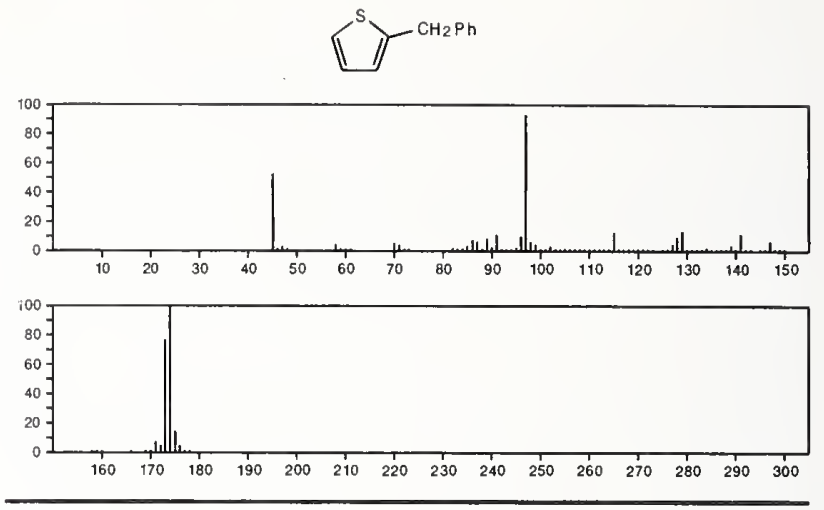

174

$\mathrm{C}_{11} \mathrm{H}_{14} \mathrm{~N}_{2}$

$87-52-5$

$1 H$-Indole-3-methanamine, $N, N$-dimethyl-
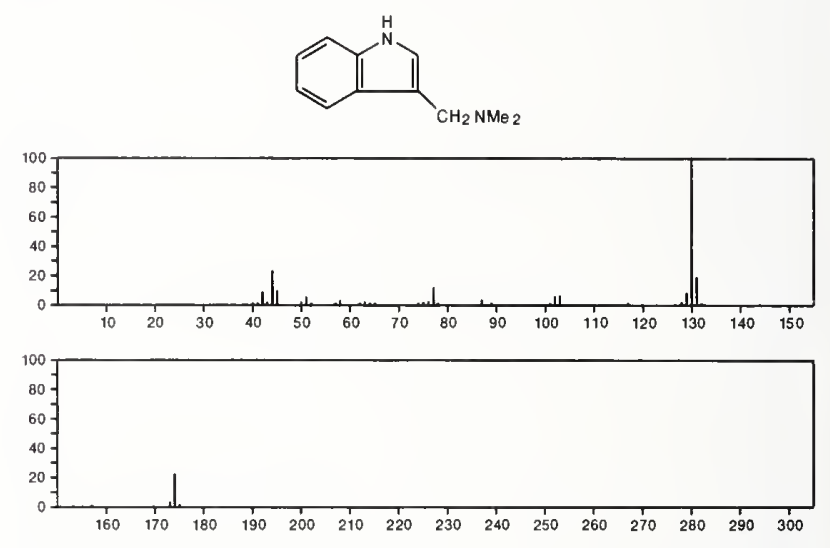

174
$1 \mathrm{H}$-Benzimidazole, 2-butyl-
$\mathrm{C}_{11} \mathrm{H}_{14} \mathrm{~N}_{2}$

$5851-44-5$
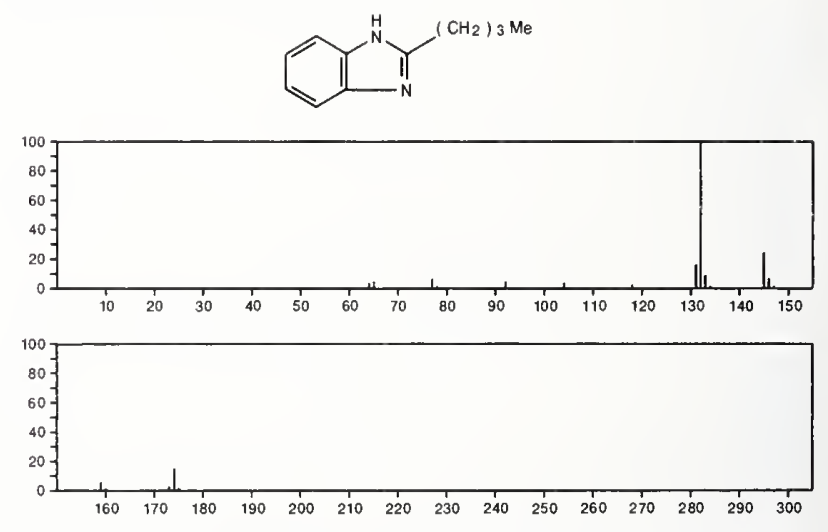

174

$\mathrm{C}_{11} \mathrm{H}_{14} \mathrm{~N}_{2}$

$1 \mathrm{H}$-Benzimidazole, 2-(2-methylpropyl)-

5851-45-6
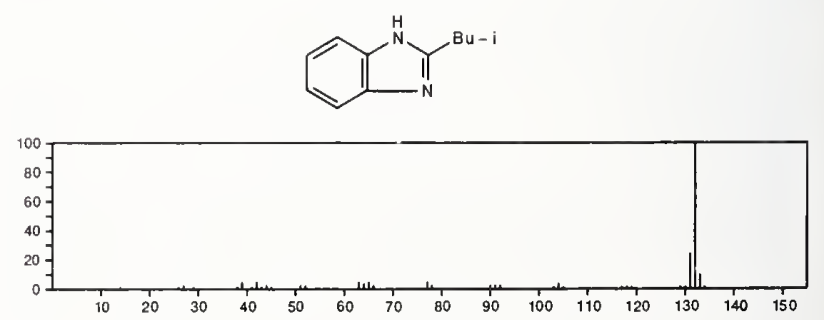

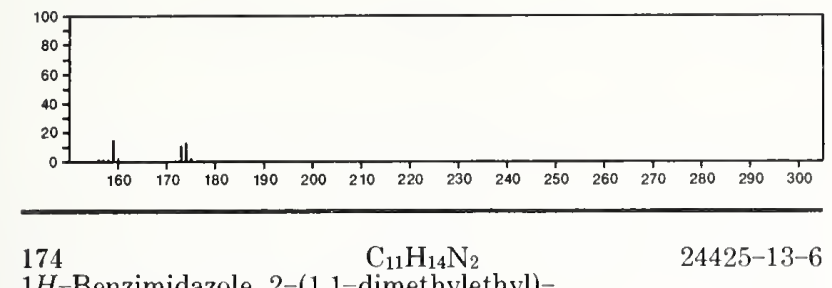

1 H-Benzimidazole, 2-(1,1-dimethylethyl)-
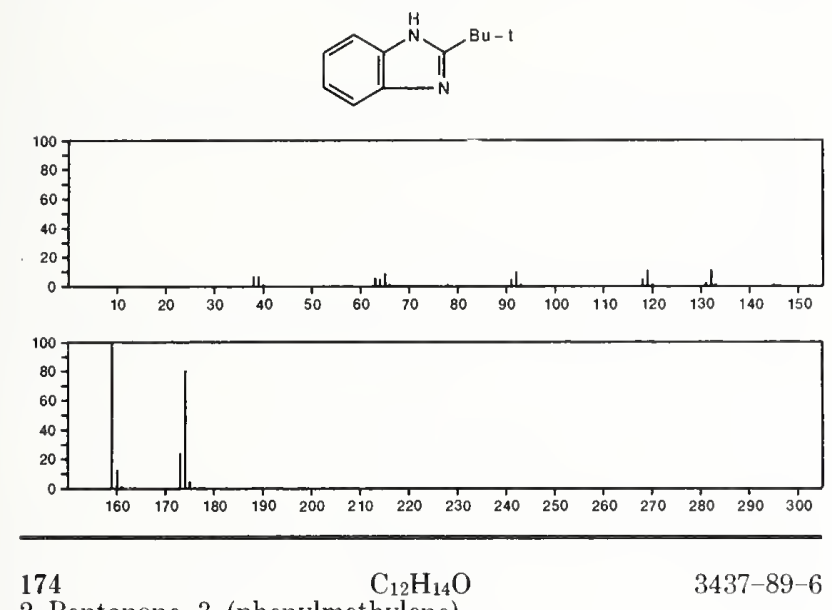

2-Pentanone, 3-(phenylmethylene)-
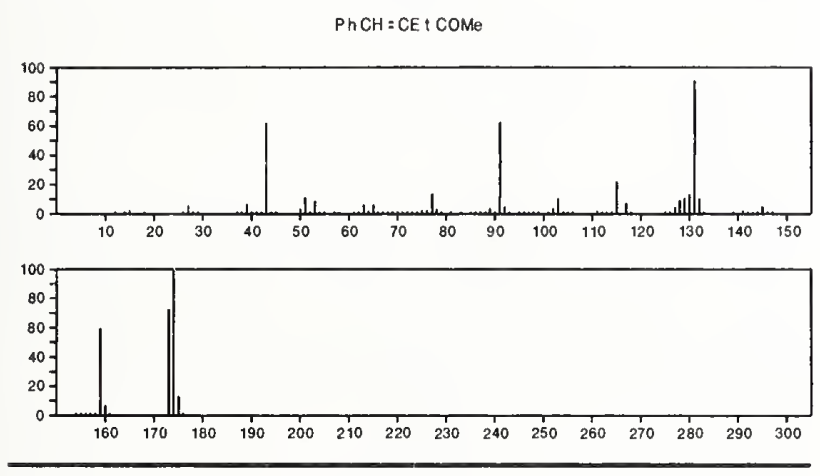

$174 \quad \mathrm{C}_{12} \mathrm{H}_{14} \mathrm{O} \quad 5037-63-8$

1(2H)-Naphthalenone, 3,4-dihydro-5,8-dimethyl-
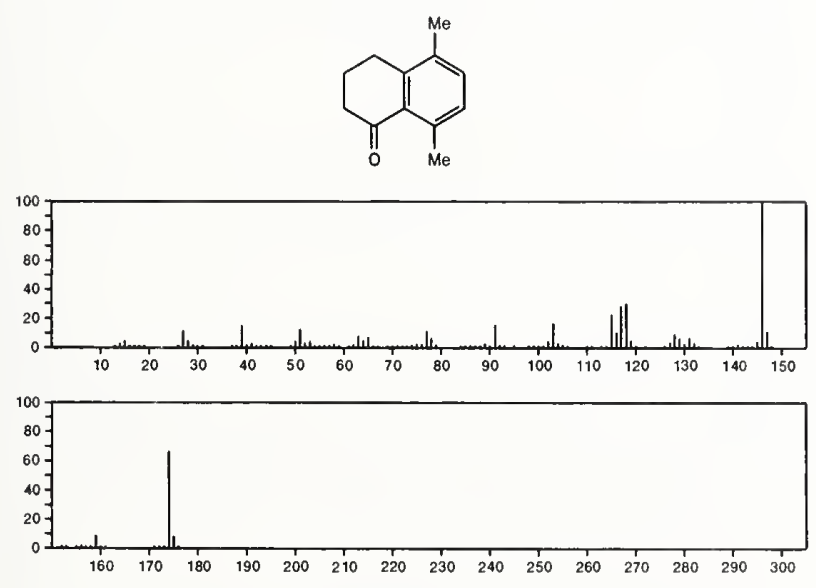

174

$\mathrm{C}_{12} \mathrm{H}_{14} \mathrm{O}$

13153-77-0

1,4-Ethanonaphthalen-2-ol, 1,2,3,4-tetrahydro--, exo-
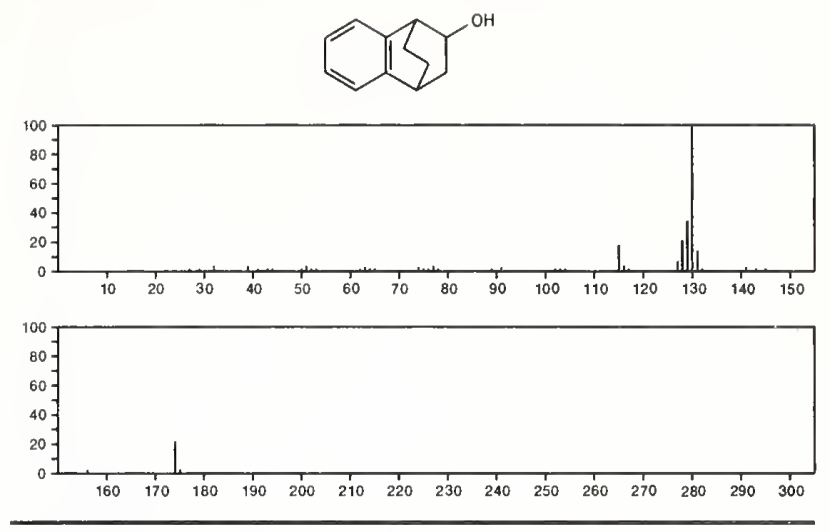

174

$\mathrm{C}_{12} \mathrm{H}_{14} \mathrm{O}$

13153-78-1

1,4-Ethanonaphthalen-2-ol, 1,2,3,4-tetrahydro-, $(1 \alpha, 2 \beta, 4 \alpha)-$
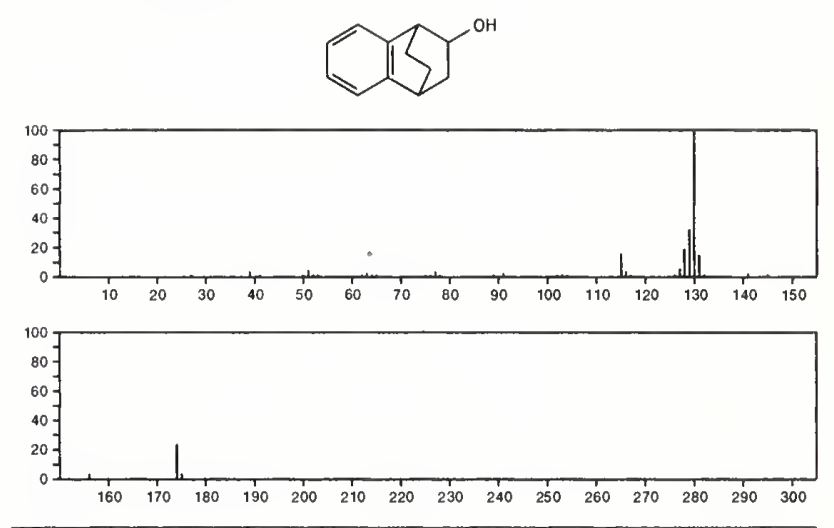

$174 \quad \mathrm{C}_{12} \mathrm{H}_{14} \mathrm{O} \quad 13621-25-5$

1(2H)-Naphthalenone, 3,4-dihydro-5,7-dimethyl-
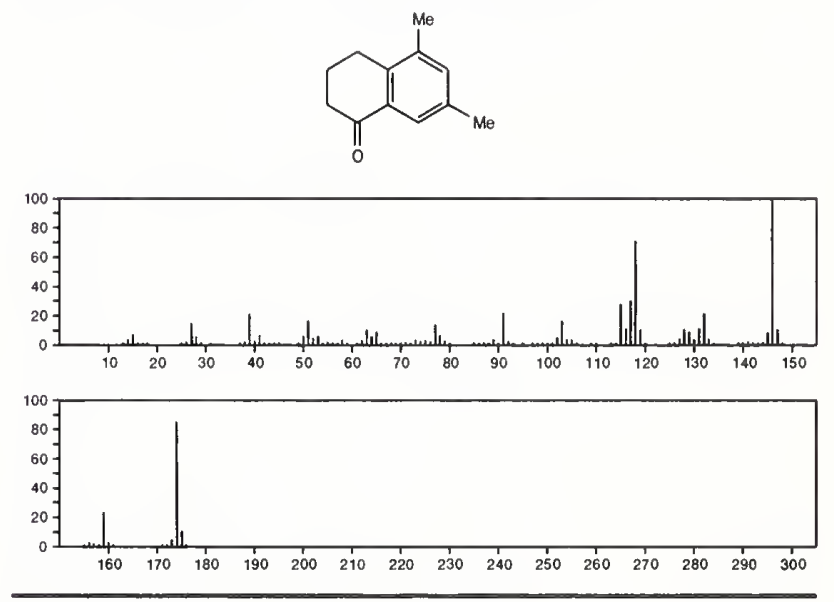

174

$\mathrm{C}_{12} \mathrm{H}_{14} \mathrm{O}$

15561-15-6

Crotonophenone, 2',5'-dimethyl-<smiles>CCOC(=O)c1cc([N+](=O)[O-])ccc1C</smiles>

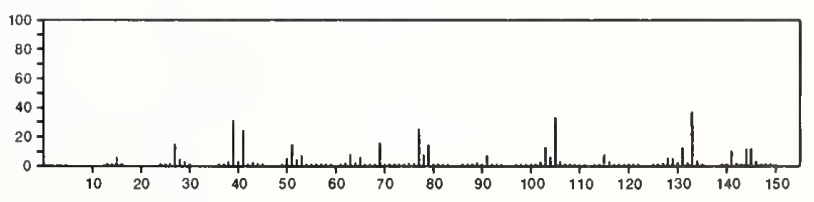




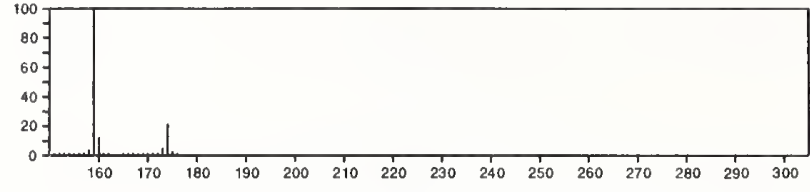

$174 \quad \mathrm{C}_{12} \mathrm{H}_{14} \mathrm{O}$

Acrylophenone, 2,2',5'-trimethyl-
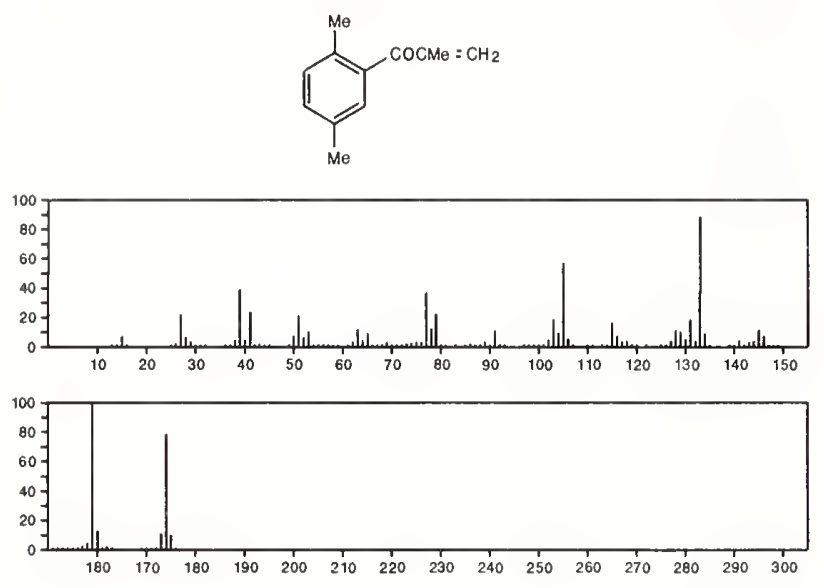

$174 \quad \mathrm{C}_{12} \mathrm{H}_{14} \mathrm{O}$

1(2H)-Naphthalenone, 3,4-dihydro-6,7-dimethyl-

$19550-57-3$
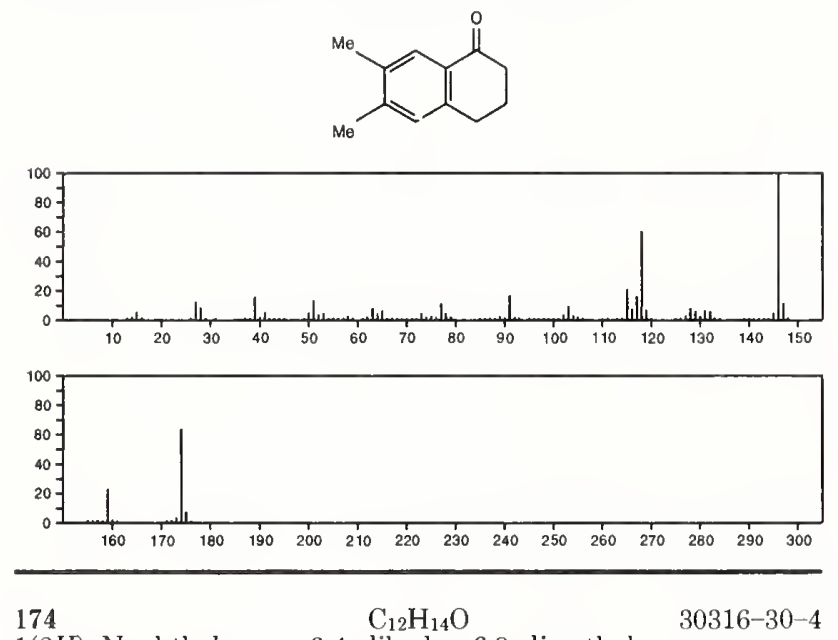

1(2H)-Naphthalenone, 3,4-dihydro-6,8-dimethyl
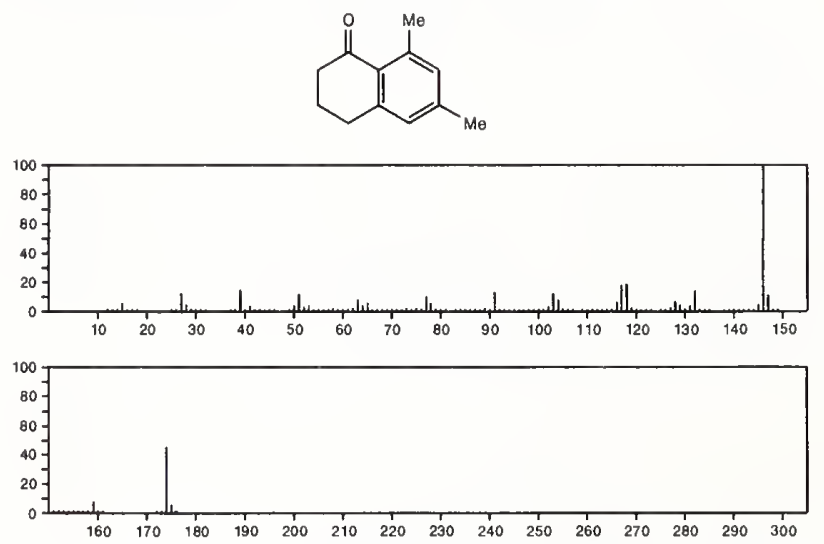

174

$\mathrm{C}_{12} \mathrm{H}_{14} \mathrm{O}$

$32281-65-5$

1(2Hi)-Naphthalenone, 3,4-dihydro-5,6-dimethyl-
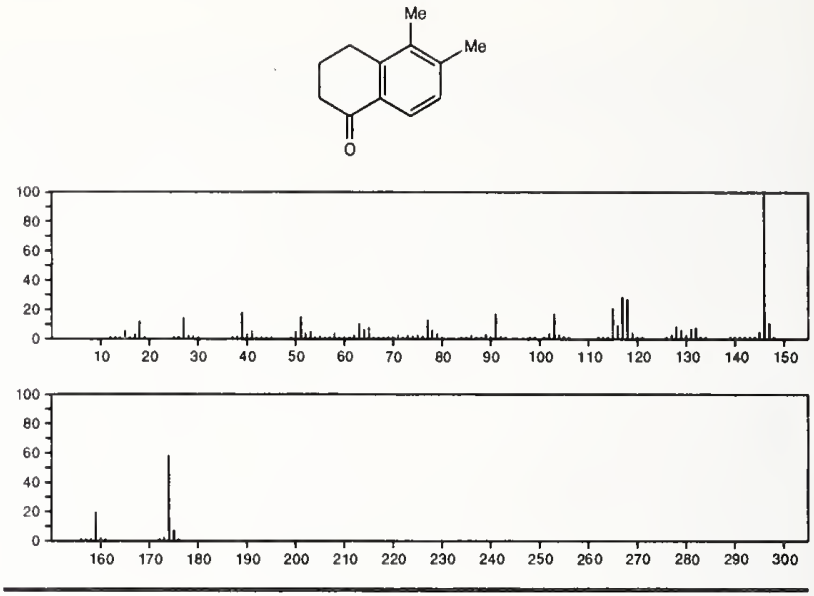

174

3-Hexen-2-one, 6-phenyl-

$\mathrm{C}_{12} \mathrm{H}_{14} \mathrm{O}$

$33046-41-2$

$\mathrm{PhCH}_{2} \mathrm{CH}_{2} \mathrm{CH}=\mathrm{CHCOM}$
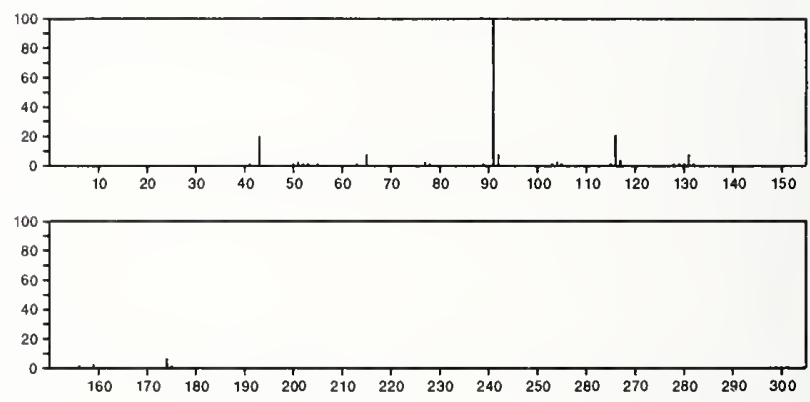

174

$\mathrm{C}_{12} \mathrm{H}_{14} \mathrm{O}$

$35322-84-0$

1H-Inden-1-one, 2,3-dihydro-3,4,7-trimethyl-
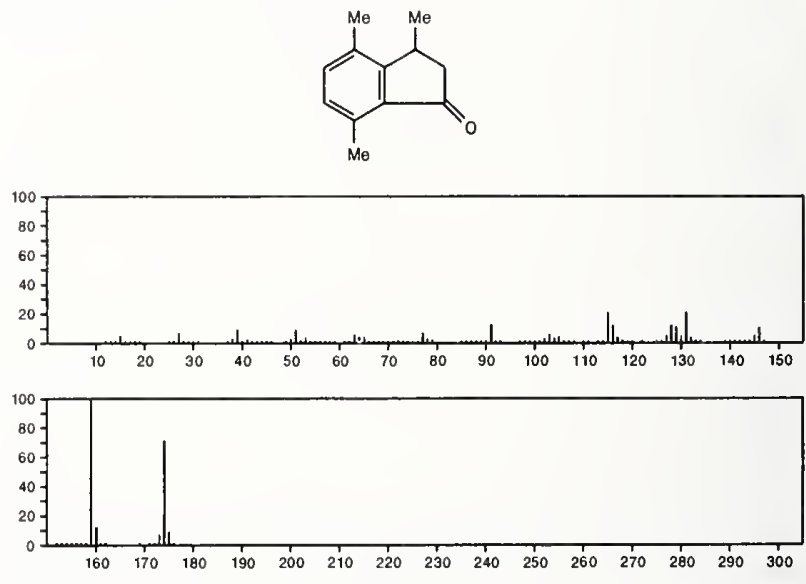

174

$\mathrm{C}_{12} \mathrm{H}_{14} \mathrm{O}$

36051-81-7

$1 H, 3 H$-Naphtho[ $1,8-c d]$ pyran, 3a,4,5,6-tetrahydro-
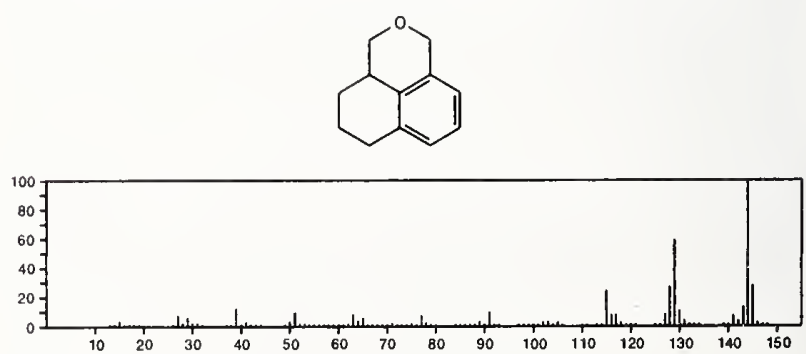


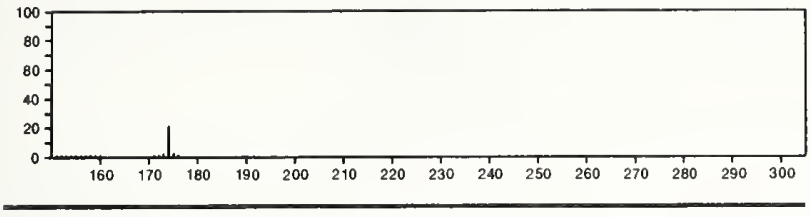

174

$\mathrm{C}_{12} \mathrm{H}_{14} \mathrm{O}$

$39877-86-6$

Benzene, 1-(1-cyclopenten-1-yl)-2-methoxy-
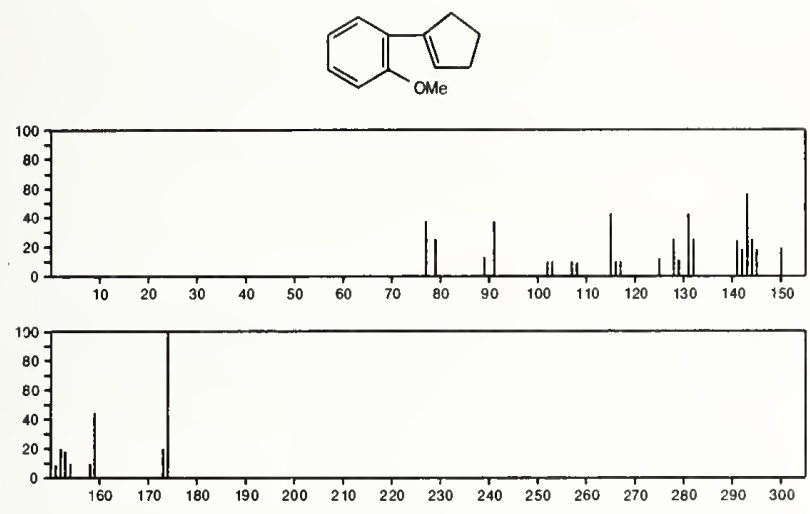

174

1(2H)-Naphthalenone, 5-ethyl-3,4-dihydro-

$51015-31-7$
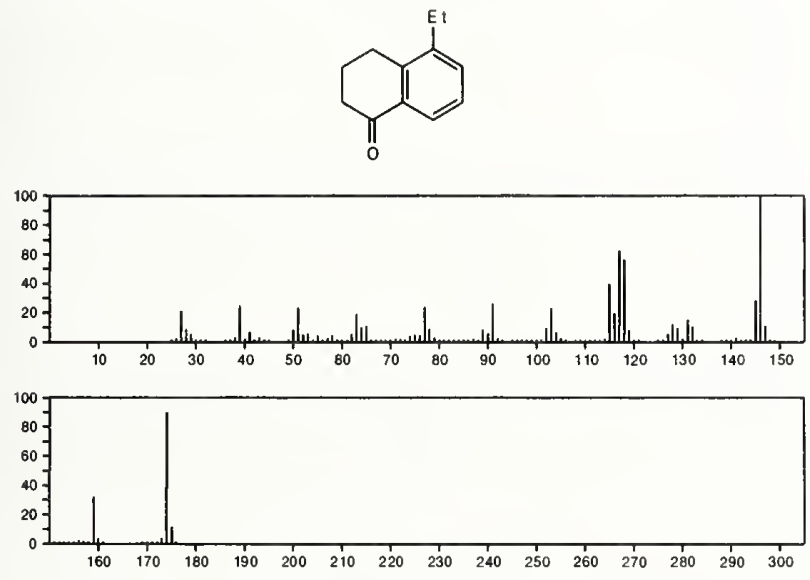

174

$\mathrm{C}_{12} \mathrm{H}_{14} \mathrm{O}$

$51015-33-9$

1(2H)-Naphthalenone, 8-ethyl-3,4-dihydro-
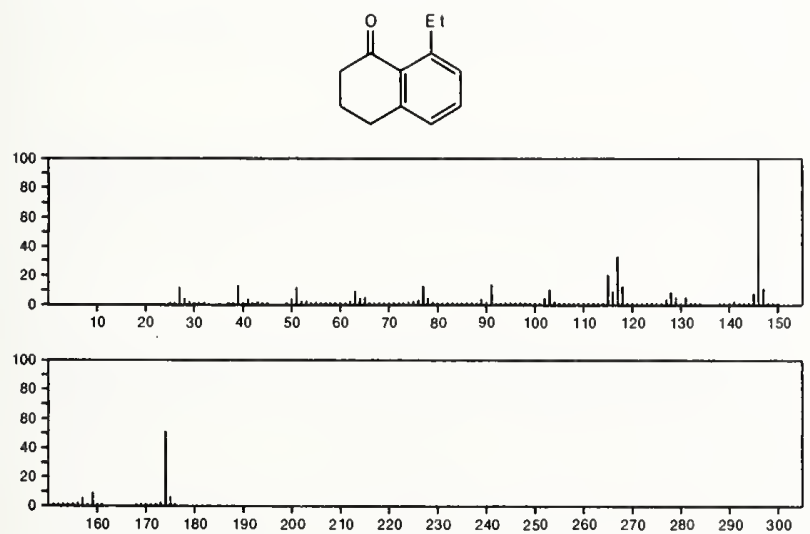

174

$\mathrm{C}_{12} \mathrm{H}_{14} \mathrm{O}$

1H-Inden-1-one, 2,3-dihydro-3,3,6-trimethyl-

$54484-71-8$
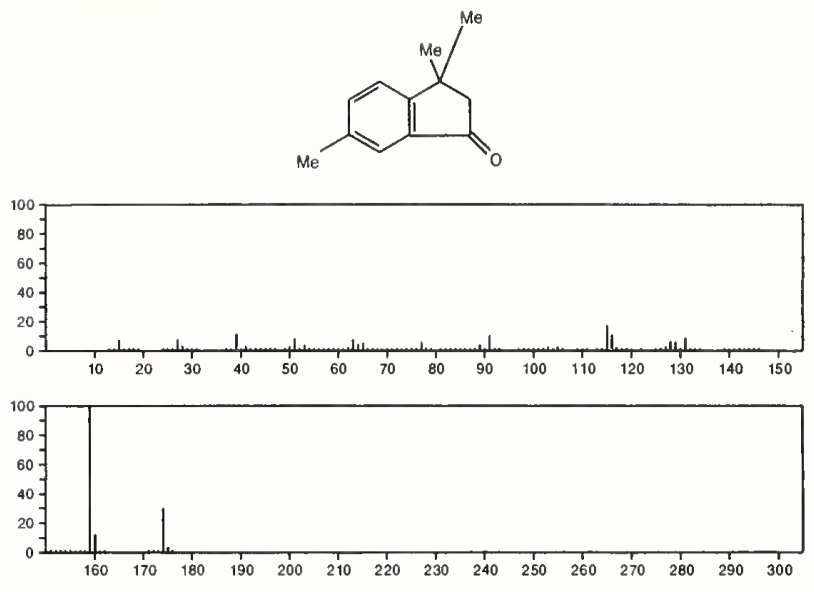

\begin{tabular}{ll}
\hline 174 & $\mathrm{C}_{12} \mathrm{H}_{14} \mathrm{O}$ \\
2-Hexenal, 6-phenyl-, $(E)-$
\end{tabular}

$\mathrm{Ph}\left(\mathrm{CH}_{2}\right)_{3} \mathrm{CH}=\mathrm{CHCHO}$
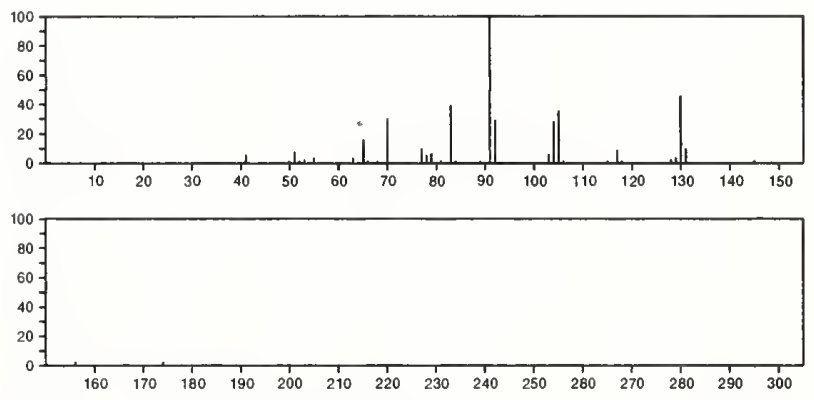

174

$\mathrm{C}_{13} \mathrm{H}_{18}$

$475-03-6$

Naphthalene, 1,2,3,4-tetrahydro-1,1,6-trimethyl-
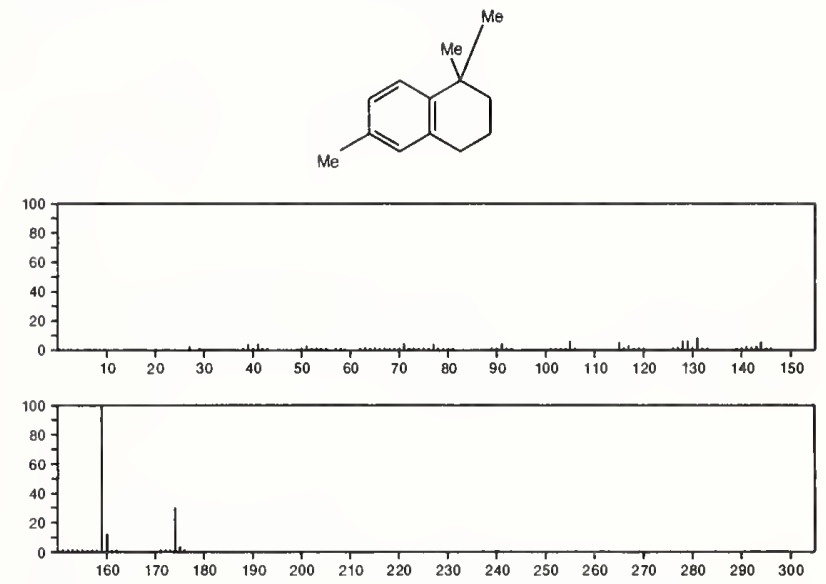

174

Benzene, 1-heptenyl-

$\mathrm{C}_{13} \mathrm{H}_{18}$

829-99-2

$\mathrm{PhCH}=\mathrm{CH}\left(\mathrm{CH}_{2}\right) 4 \mathrm{Me}$

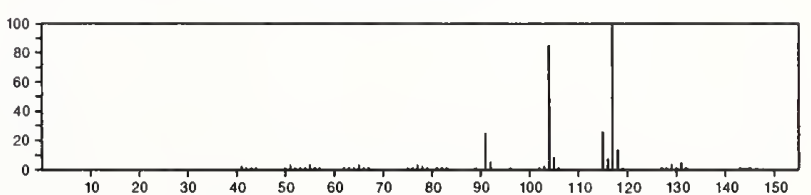




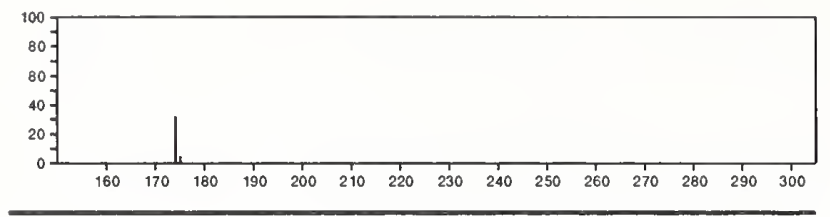

$174 \quad \mathrm{C}_{13} \mathrm{H}_{18} \quad 941-60-6$
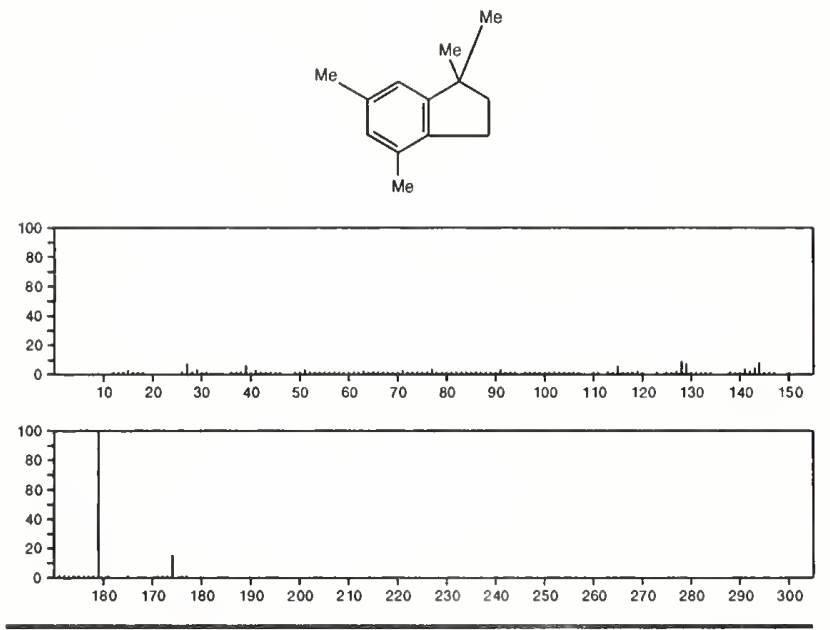

$174 \quad \mathrm{C}_{13} \mathrm{H}_{18} \quad 1078-04-2$ $1 H$-Indene, 2,3-dihydro-1,1,4,7-tetramethyl-
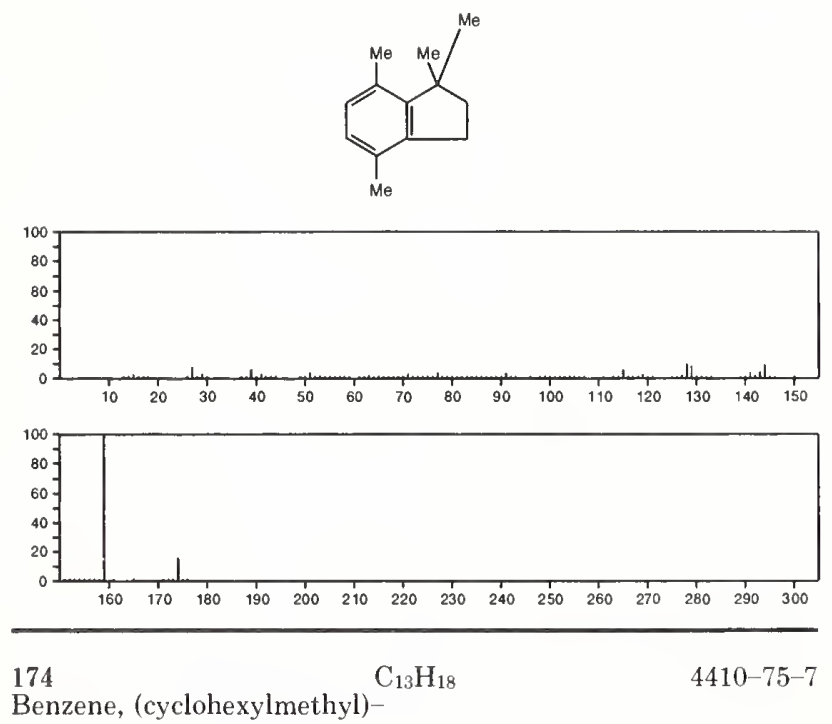

Benzene, (cyclohexylmethyl)
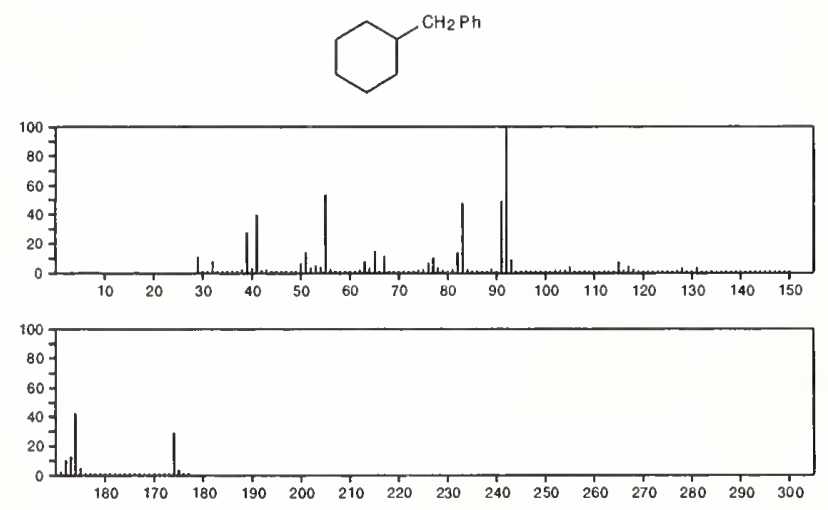

174

$\mathrm{C}_{13} \mathrm{H}_{18}$

$4575-46-6$

Benzene, 1-cyclohexyl-3-methyl-
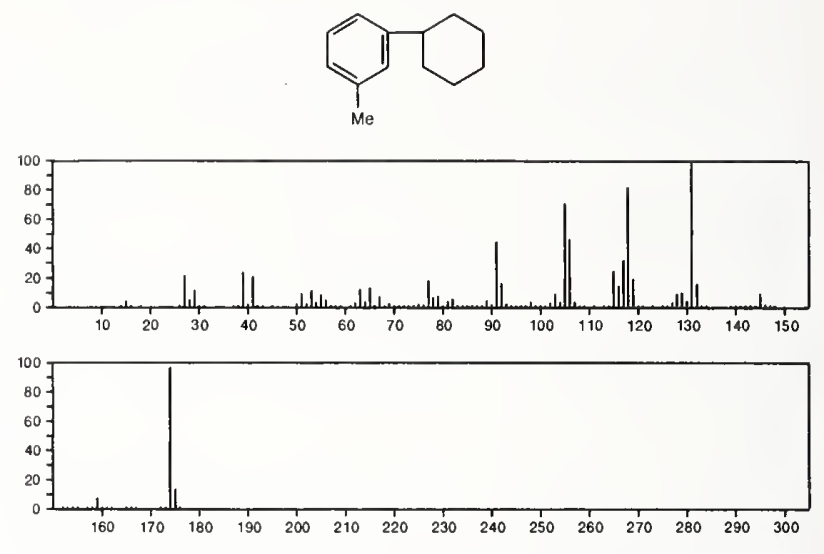

$174 \quad \mathrm{C}_{13} \mathrm{H}_{18} \quad$ 16204-57-2 $1 H$-Indene, 2,3-dihydro-1,1,4,5-tetramethyl-
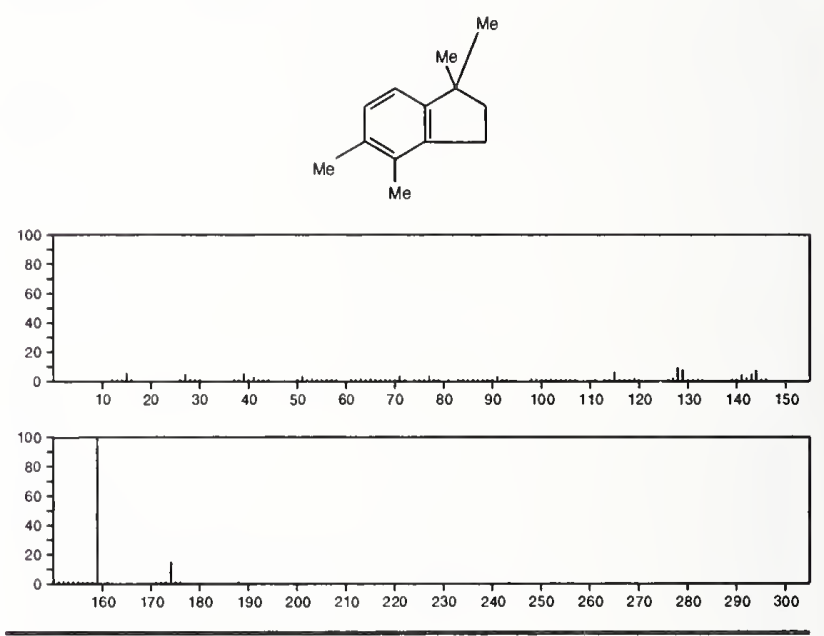

174

$\mathrm{C}_{13} \mathrm{H}_{18}$

16204-58-3

Indan, 1,1,6,7-tetramethyl-
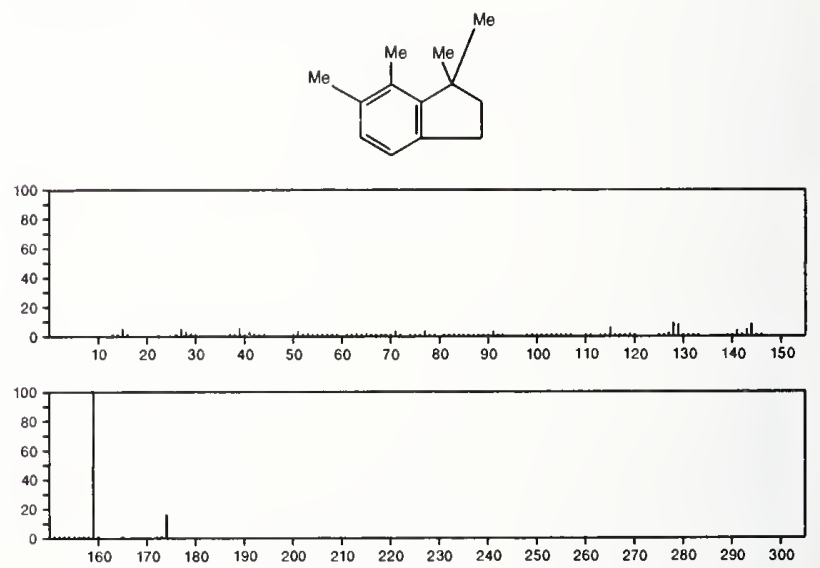
174

$\mathrm{C}_{13} \mathrm{H}_{18}$

21693-51-6

Naphthalene, 1,2,3,4-tetrahydro-1,5,8-trimethyl-
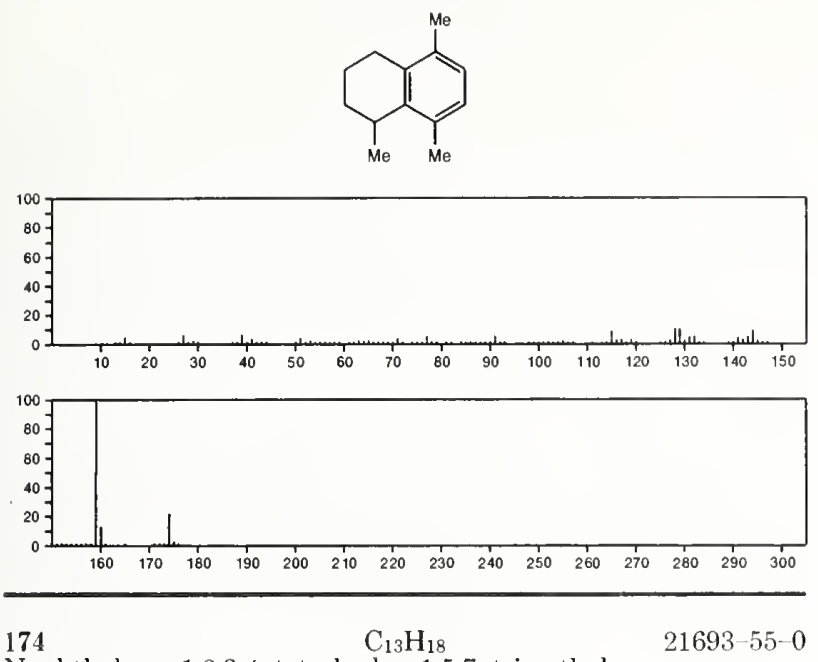

Naphthalene, 1,2,3,4-tetrahydro-1,5,7-trimethyl-
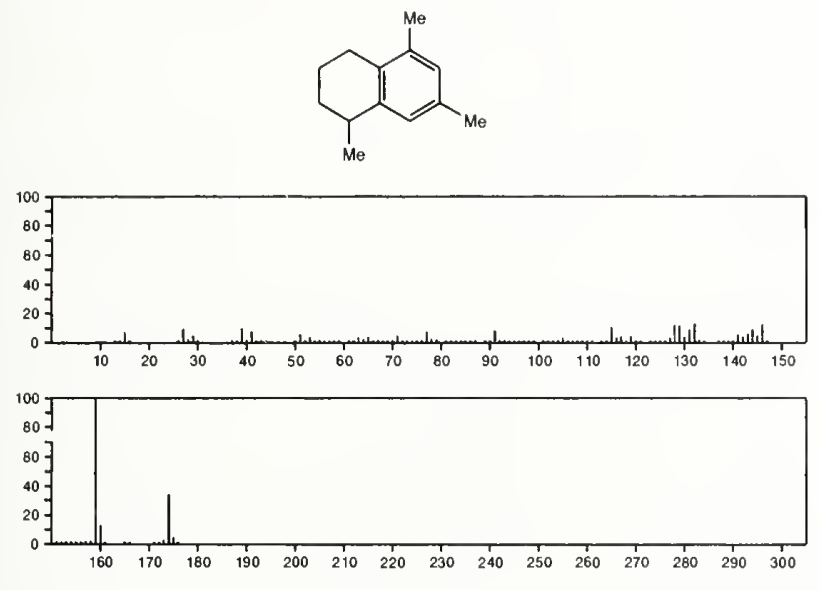

$174 \quad \mathrm{C}_{13} \mathrm{H}_{18} \quad 22824-32-4$ Naphthalene, 1,2,3,4-tetrahydro-1,4,6-trimethyl-
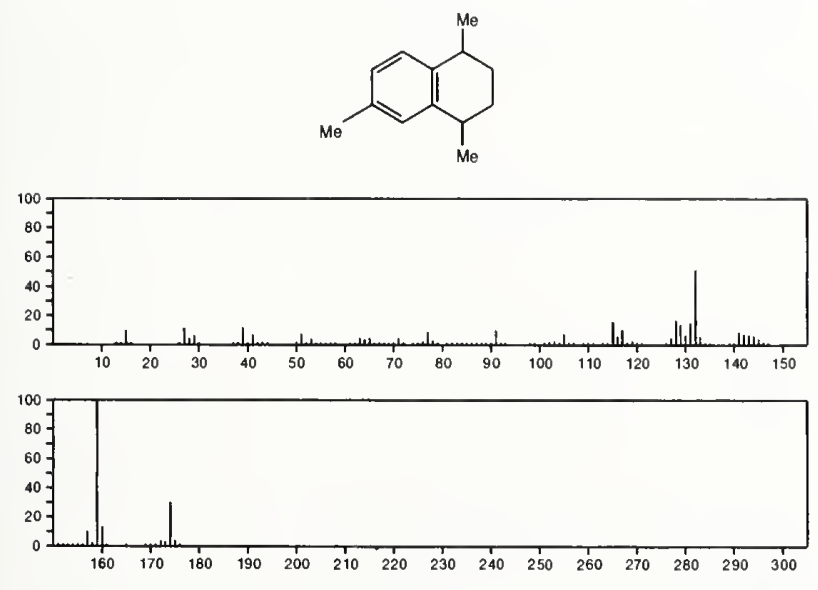

174

Benzene, 2-heptenyl-

$\mathrm{C}_{13} \mathrm{H}_{18}$

$26447-63-2$

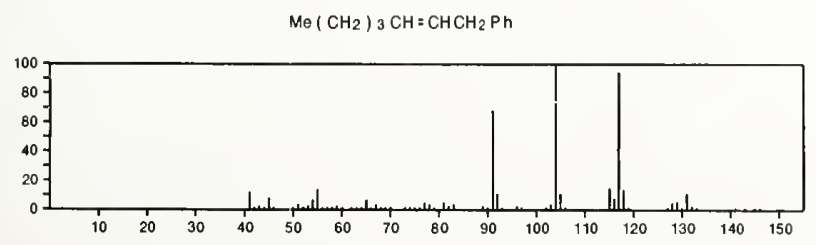

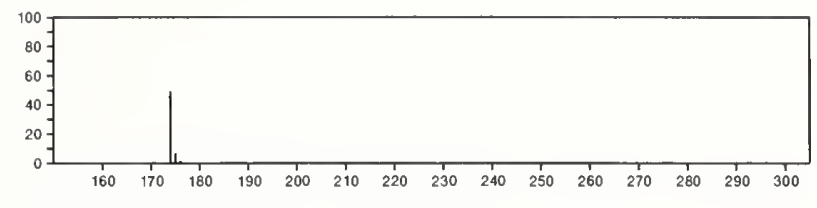

174

Benzene, 3-heptenyl-

$\mathrm{C}_{13} \mathrm{H}_{18}$

26447-64-3

$\mathrm{PrCH}=\mathrm{CHCH}_{2} \mathrm{CH}_{2} \mathrm{Ph}$
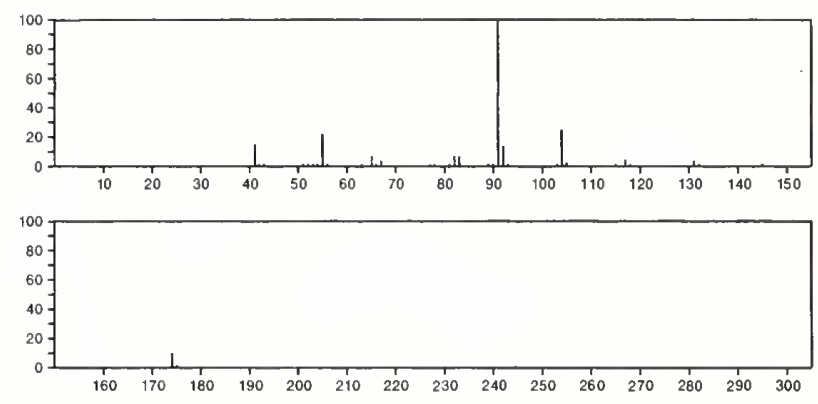

174

3-Heptene, 7-phenyl-

$\mathrm{C}_{13} \mathrm{H}_{18}$

26447-65-4

$\mathrm{Ph}\left(\mathrm{CH}_{2}\right){ }_{3} \mathrm{CH}=\mathrm{CHEt}$
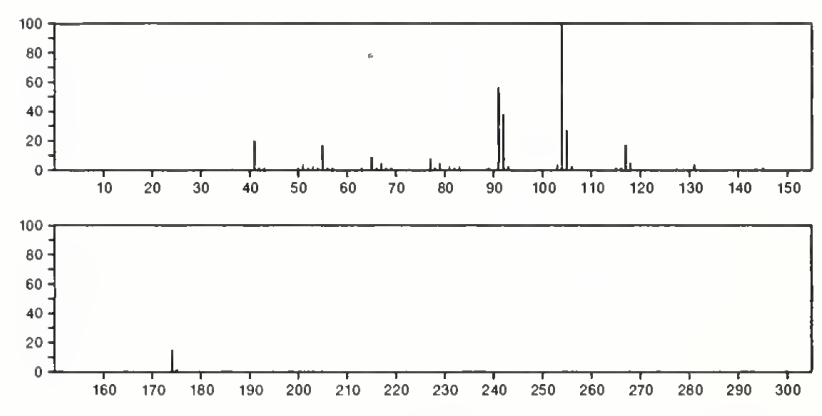

174

Benzene, 5-heptenyl-

$\mathrm{C}_{13} \mathrm{H}_{18}$

26447-66-5

$\mathrm{Ph}\left(\mathrm{CH}_{2}\right)_{4} \mathrm{CH}=\mathrm{CHM}$
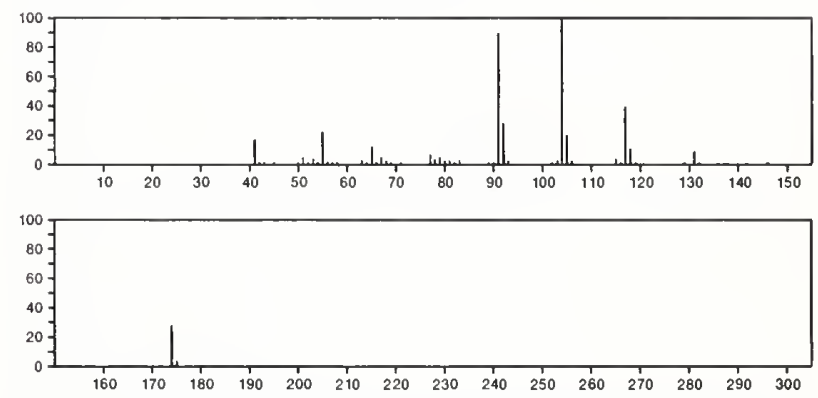

174

$\mathrm{C}_{13} \mathrm{H}_{18}$

Naphthalene, 1,2,3,4-tetrahydro-2,5,8-trimethyl-

30316-17-7<smiles>Cc1ccc([N+](=O)[O-])c2c1CC[C@H](C)C2</smiles>

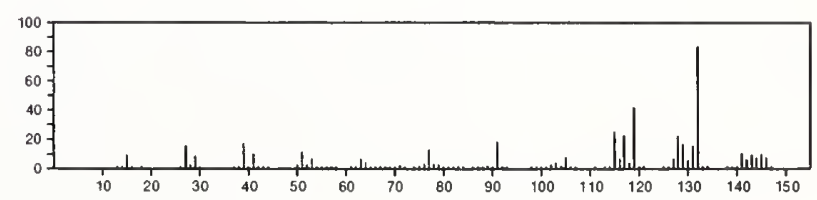




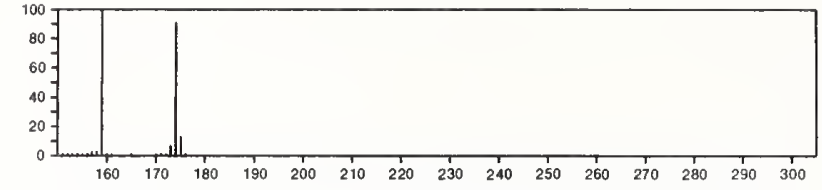

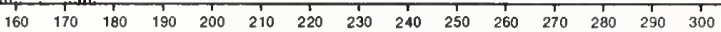

$174 \quad \mathrm{C}_{13} \mathrm{H}_{18} \quad 30316-36-0$

Naphthalene, 1,2,3,4-tetrahydro-1,6,8-trimethyl-
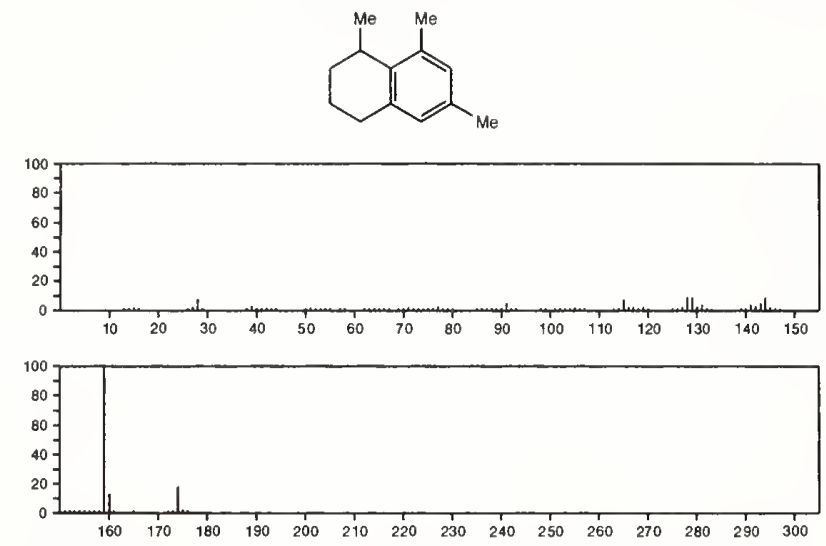

174

Benzene, 2-heptenyl-, $(Z)$ -

$$
\mathrm{C}_{13} \mathrm{H}_{18}
$$

$54725-18-7$

$\mathrm{Me}\left(\mathrm{CH}_{2}\right)_{3} \mathrm{CH}: \mathrm{CHCH}_{2} \mathrm{Ph}$
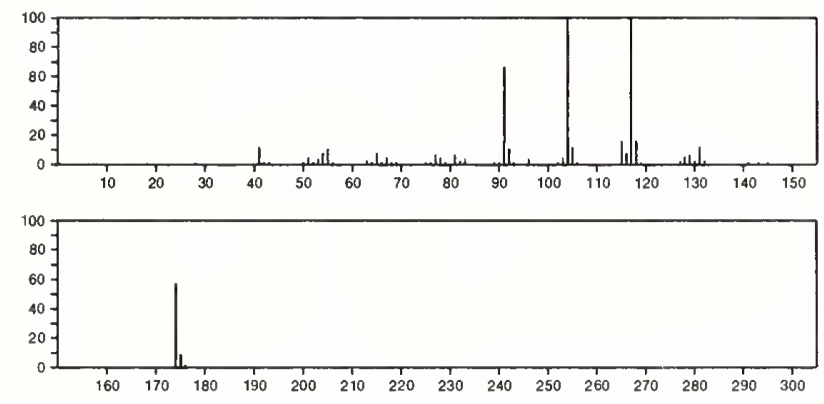

175

$\mathrm{C}_{5} \mathrm{H}_{9} \mathrm{~N}_{3} \mathrm{~S}_{2}$

1,3,4-Thiadiazol-2-amine, 5-[(1-methylethyl)thio]-

$30062-47-6$
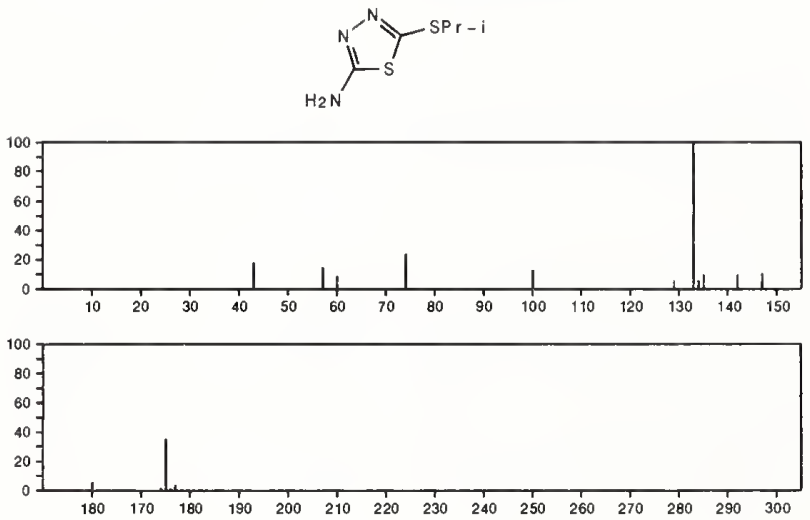

175

$\mathrm{C}_{5} \mathrm{H}_{9} \mathrm{~N}_{3} \mathrm{~S}_{2}$

1,3,4-Thiadiazol-2-amine, 5 -(propylthio)-

$30062-49-8$<smiles>Nc1nnc(Br)s1</smiles>
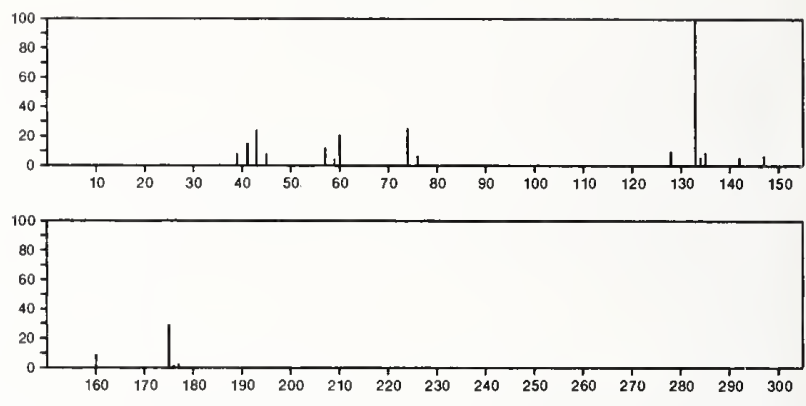

175

DL-Aspartic acid, $N$-acetyl

$\mathrm{C}_{6} \mathrm{H}_{9} \mathrm{NO}_{5}$

2545-40-6

$\mathrm{HO}_{2} \mathrm{CCH}_{2} \mathrm{CH}\left(\mathrm{CO}_{2} \mathrm{H}\right) \mathrm{NHAC}$
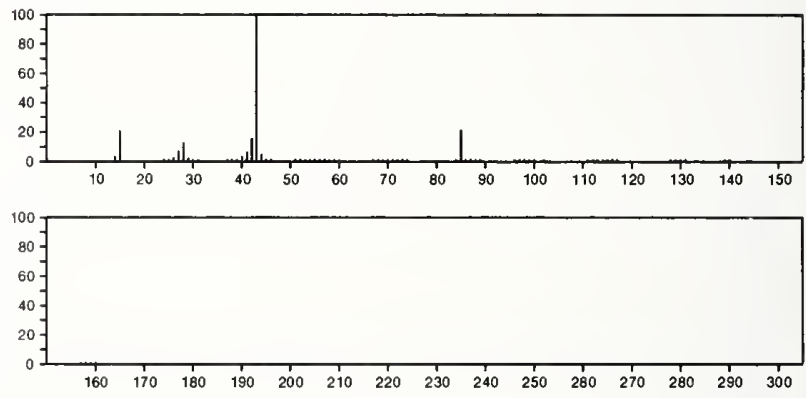

175

$\mathrm{C}_{6} \mathrm{H}_{9} \mathrm{NO}_{5}$

27160-23-2

Malonic acid, formamido-, dimethyl ester

$$
\text { C( } 0 \text { ) OMe }
$$

$\mathrm{MeOC}(0) \mathrm{CHNHCH}=\mathrm{O}$

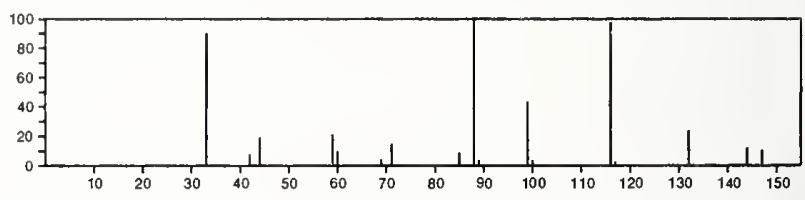

\section{$175 \quad \mathrm{C}_{6} \mathrm{H}_{9} \mathrm{NO}_{5}$}

Propanedioic acid, (methoxyimino)-, dimethyl ester

$55590-76-6$
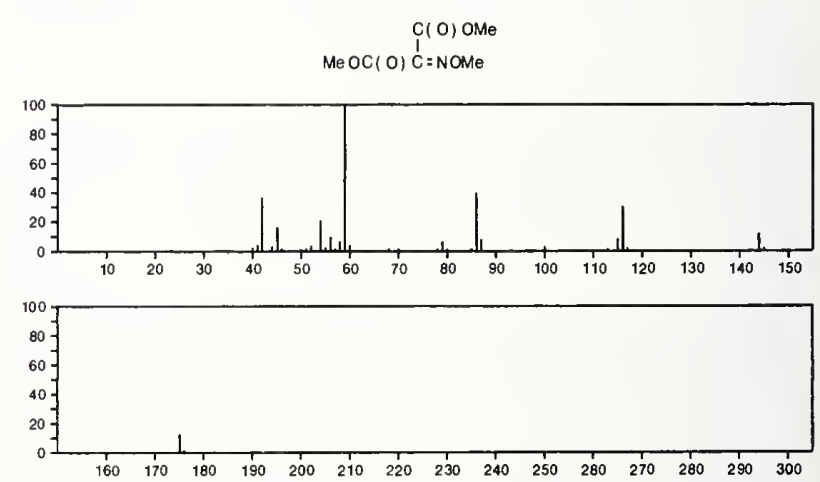
175 Acetic acid, (methoxyimino)-, trimethylsilyl ester

Me $3 \mathrm{SiOC}(\mathrm{O}) \mathrm{CH}$ : NOMe
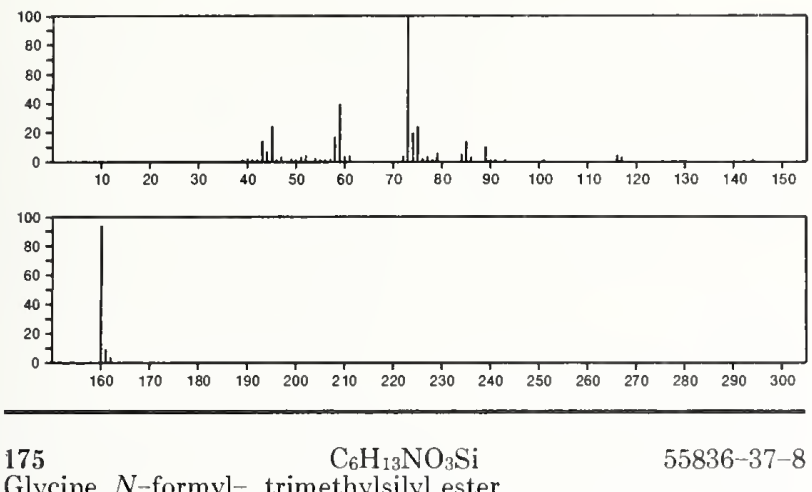

Glycine, $N$-formyl-, trimethylsilyl ester

$\mathrm{Me}_{3} \mathrm{Si} \mathrm{OC}(0) \mathrm{CH}_{2} \mathrm{NHCH}=\mathrm{O}$
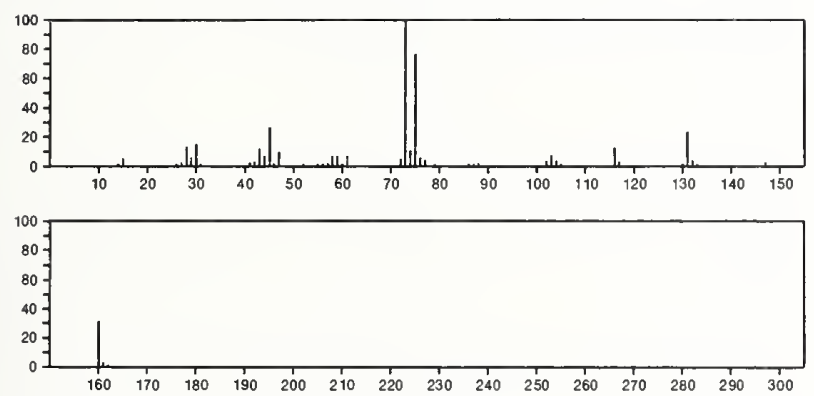

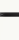

175

2,4-Pentanedione, 3-(1-aminoethylidene)-1-chloro-

$54484-57-0$ $\mathrm{C}\left(\mathrm{NH}_{2}\right) \mathrm{Me}$

$\mathrm{Cl} \mathrm{CH} 2$ COCCOMe
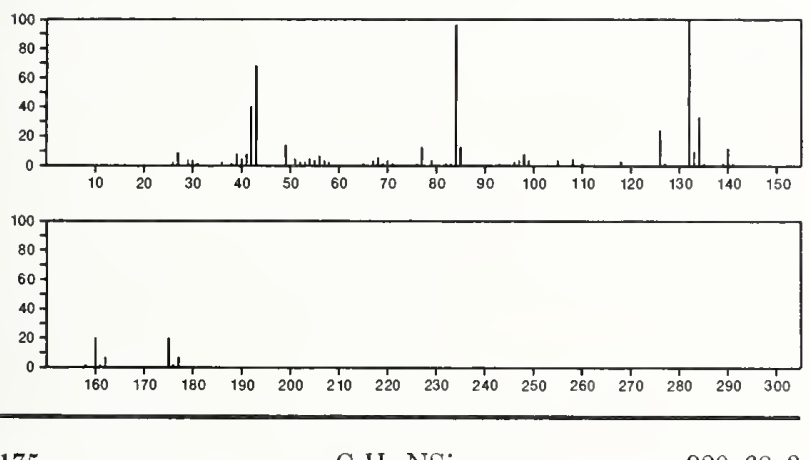

175

$\mathrm{C}_{7} \mathrm{H}_{21} \mathrm{NS}_{2}$

$920-68-3$

Silanamine, $N, 1,1,1-$ tetramethyl-N-(trimethylsilyl)-

MezsinMeSiMe 3
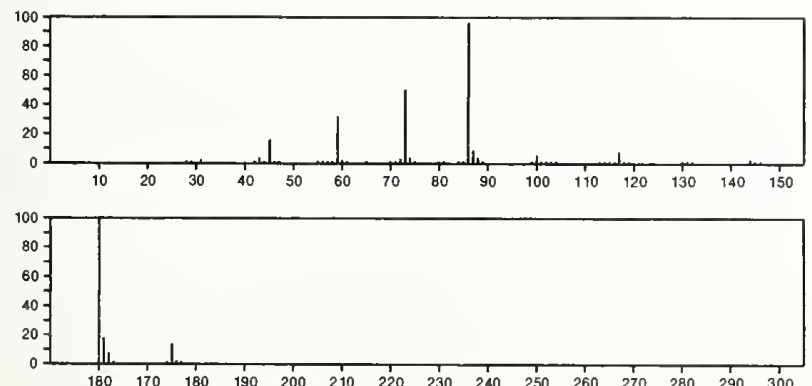

$175 \quad \mathrm{C}_{8} \mathrm{H}_{17} \mathrm{NOS}$

Carbamic acid, dimethylthio-, $O$-neopentyl ester

21299-37-6

$\mathrm{Me} 2 \mathrm{NC}(\mathrm{S}) \mathrm{OCH}_{2} \mathrm{CM}_{3}$
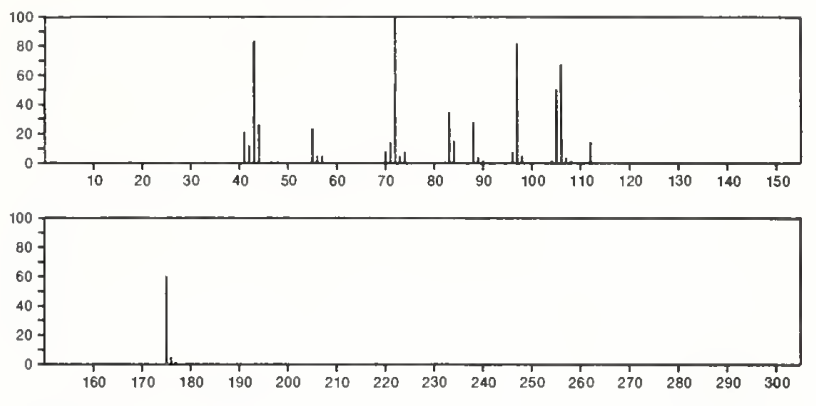

$175 \quad \mathrm{C}_{8} \mathrm{H}_{17} \mathrm{NO}_{3} \quad 629-39-0$

Nitric acid, octyl ester

$\mathrm{Me}\left(\mathrm{CH}_{2}\right)_{7} \mathrm{ONO}_{2}$

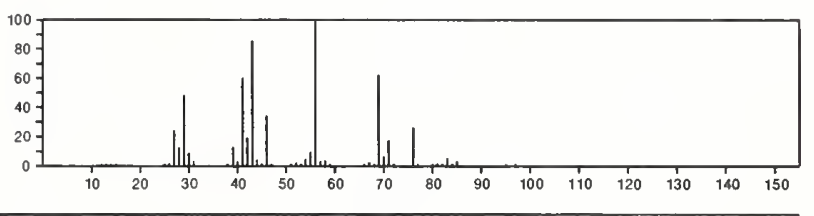

175

$\mathrm{C}_{9} \mathrm{H}_{9} \mathrm{~N}_{3} \mathrm{O}$

$22378-51-4$

Pyrido[3,4-d]pyrimidin-4(3H)-one, 6,8-dimethyl-
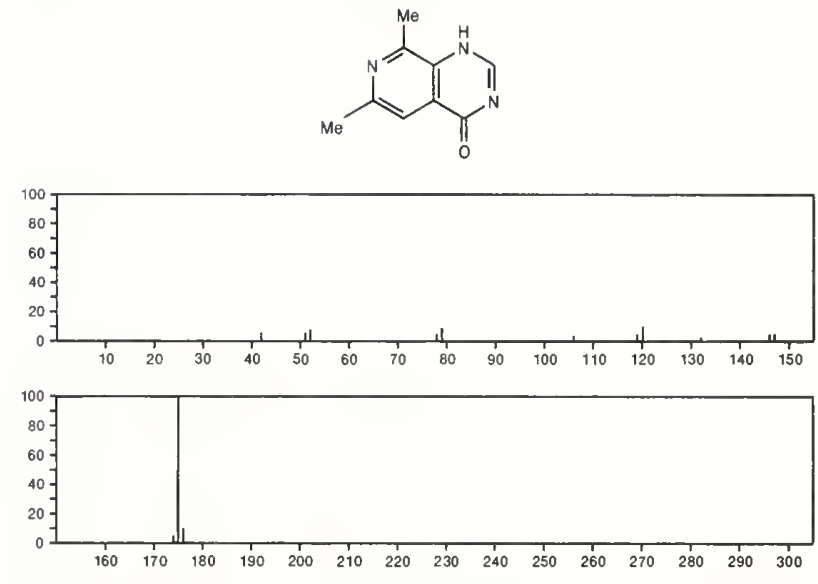

175

$\mathrm{C}_{9} \mathrm{H}_{9} \mathrm{~N}_{3} \mathrm{O}$

$22863-24-7$

3H-1,2,4-Triazol-3-one, 2,4-dihydro-5-methyl-2-phenyl-
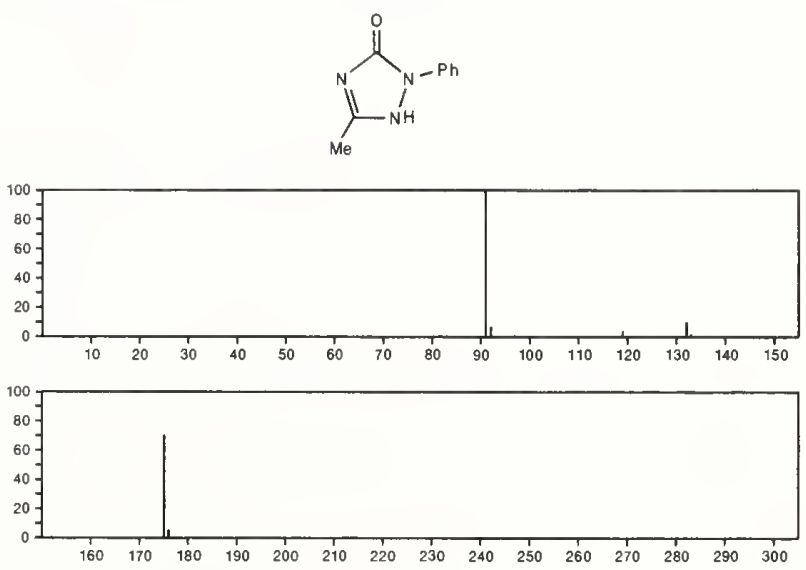
175

$\mathrm{C}_{9} \mathrm{H}_{9} \mathrm{~N}_{3} \mathrm{O}$

$28718-27-6$

1H-1,2,4-Triazolium, 3-hydroxy-4-methyl-1-phenyl-, hydroxide, inner salt
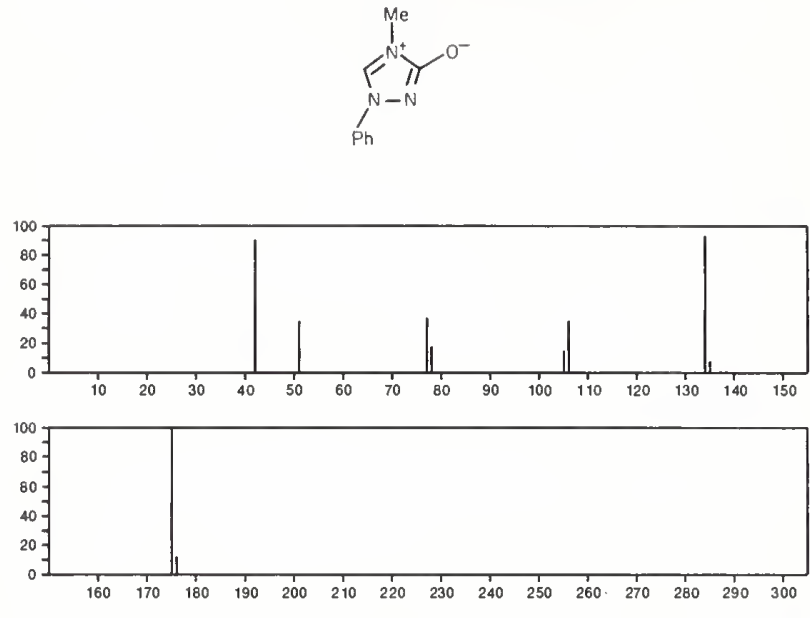

$175 \quad \mathrm{C}_{9} \mathrm{H}_{9} \mathrm{~N}_{3} \mathrm{O}$

$41536-79-2$

3(2H)-Isoquinolinone, 1-amino-, oxime
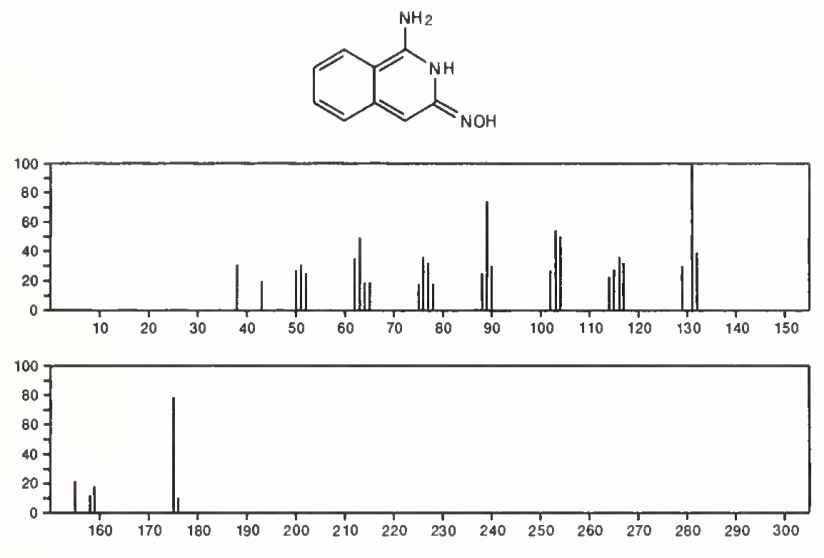

175

$\mathrm{C}_{10} \mathrm{H}_{9} \mathrm{NO}_{2}$

$87-51-4$

$1 H$-Indole-3-acetic acid
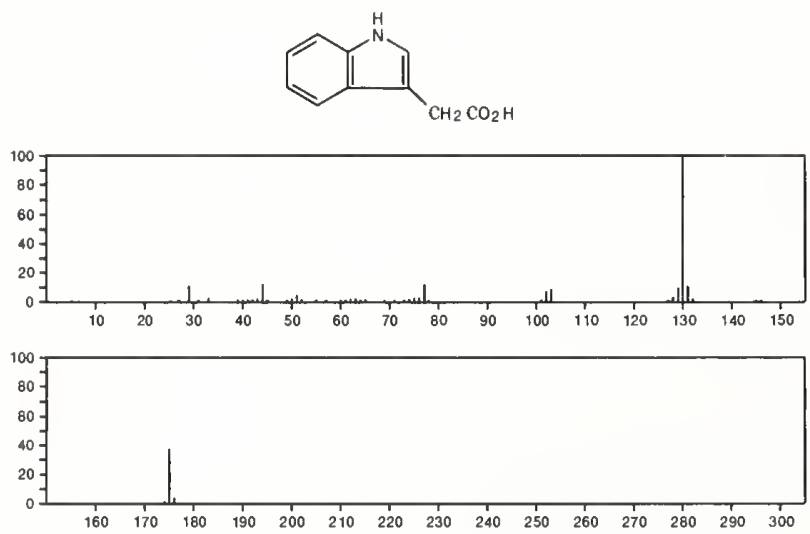

175

$\mathrm{C}_{10} \mathrm{H}_{9} \mathrm{NO}_{2}$

942-24-5

$1 H$-Indole-3-carboxylic acid, methyl ester
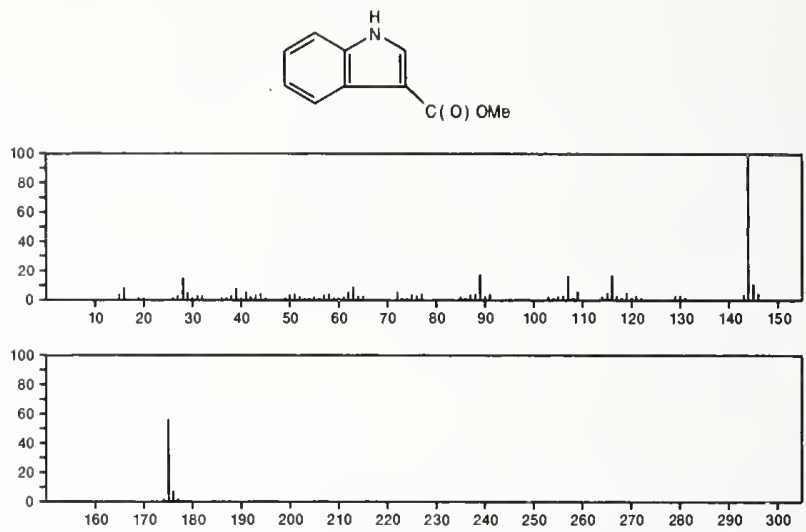

175

H-Indole-3-acetaldehyde

$1892-21-3$
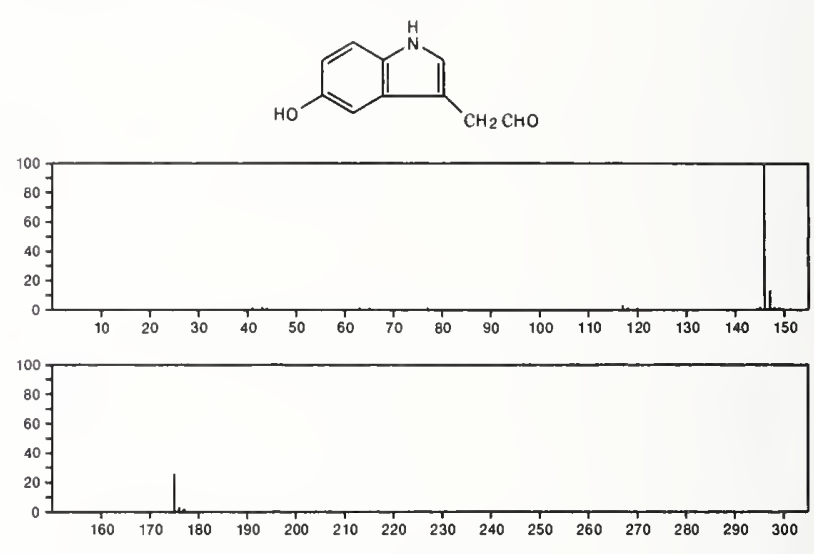

175

$\mathrm{C}_{10} \mathrm{H}_{9} \mathrm{NO}_{2}$

$1 H$-Isoindole-1,3(2H)-dione, $N$-ethyl-

$5022-29-7$
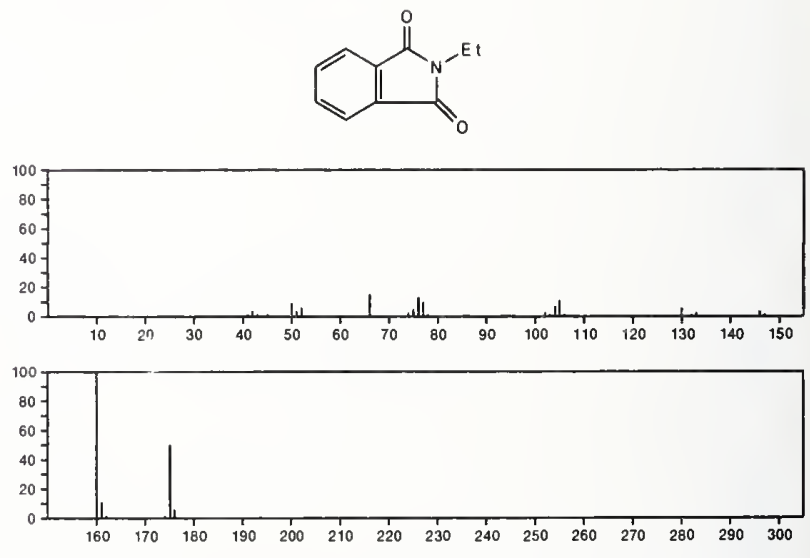

175

Quinoline, 6-methoxy-, 1-oxide

6563-13-9
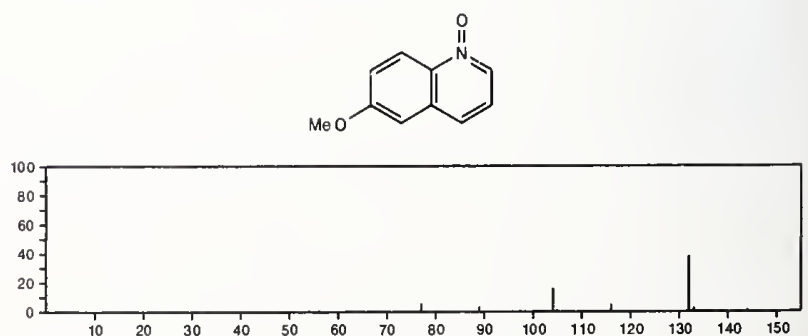


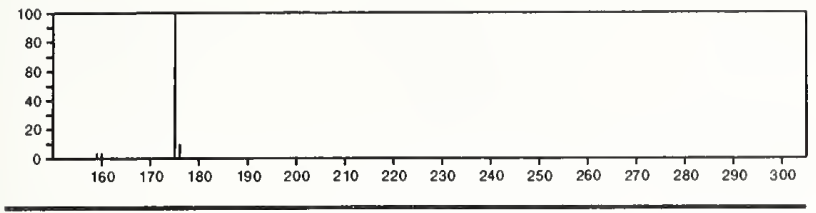

$175 \quad \mathrm{C}_{10} \mathrm{H}_{9} \mathrm{NO}_{2} \quad 16511-38-9$ 1H-1-Benzazepine-2,5-dione, 3,4-dihydro-
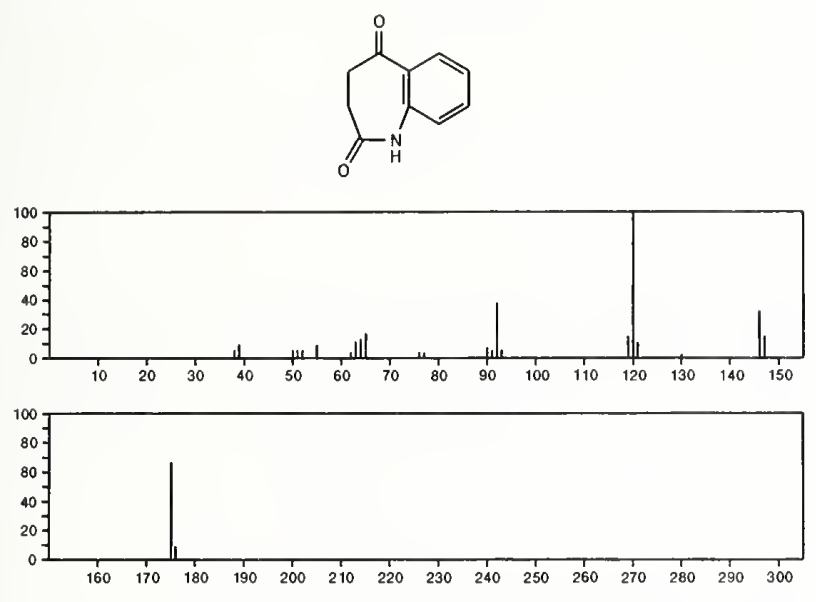

$175 \quad \mathrm{C}_{10} \mathrm{H}_{9} \mathrm{NO}_{2} \quad 16959-62-9$

2-Indolizinecarboxylic acid, methyl ester
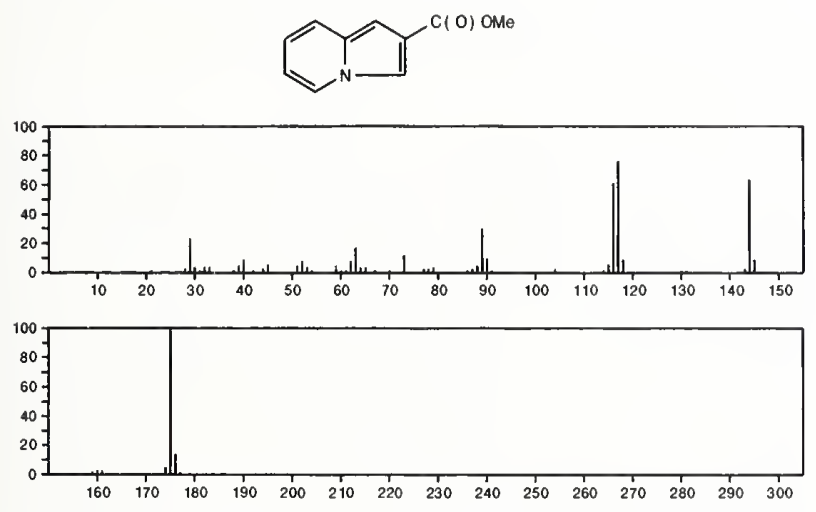

175

$\mathrm{C}_{10} \mathrm{H}_{9} \mathrm{NO}_{2}$

$17018-82-5$
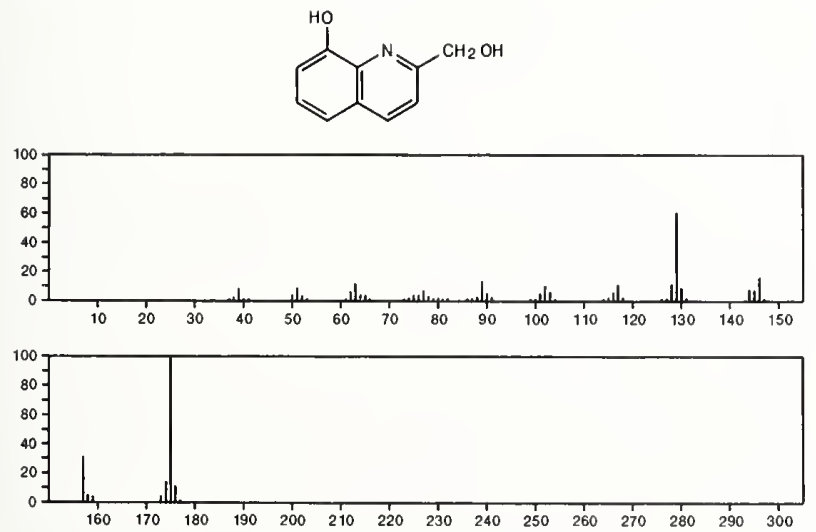

175

$\mathrm{C}_{10} \mathrm{H}_{9} \mathrm{NO}_{2}$

$21201-47-8$

Carbostyril, 1-hydroxy-4-methyl
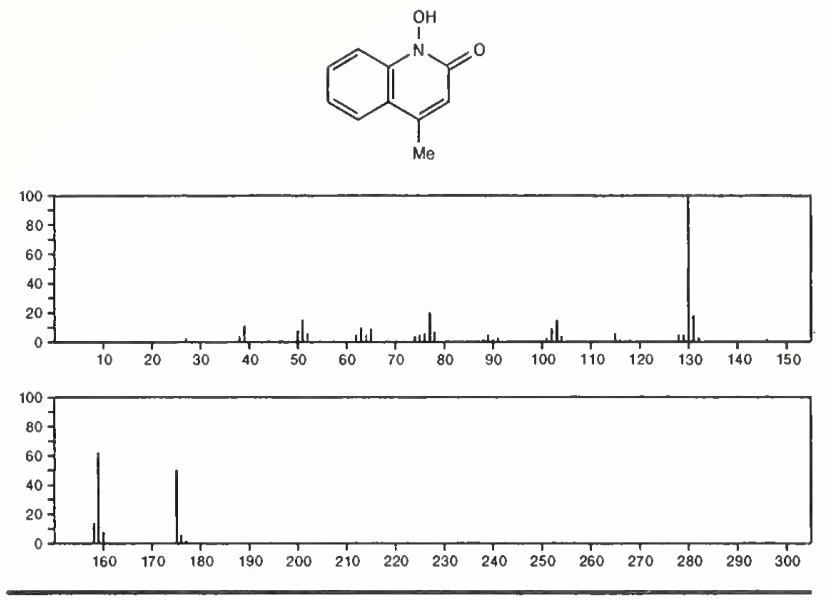

175

$\mathrm{C}_{10} \mathrm{H}_{9} \mathrm{NO}_{2}$

21905-78-2

2H-Indol-2-one, 1-acetyl-1,3-dihydro-
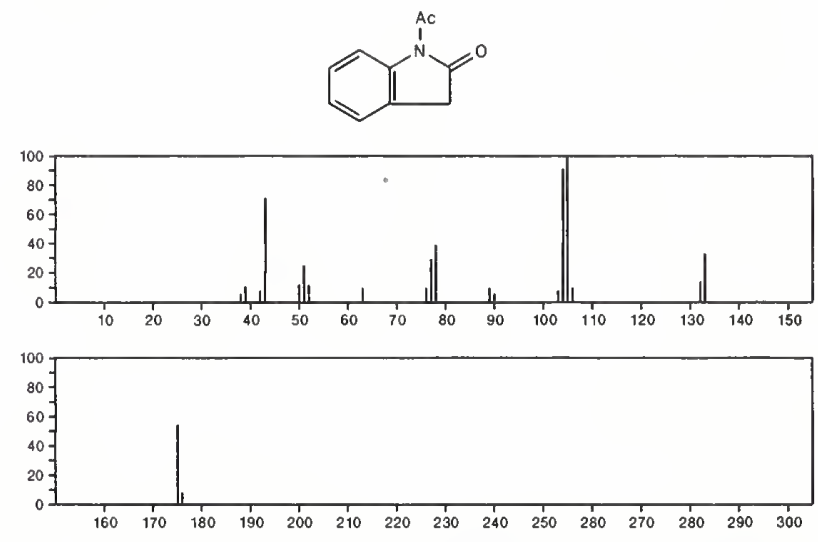

175

$\mathrm{C}_{10} \mathrm{H}_{9} \mathrm{NO}_{2}$

5(2H)-Oxazolone, 4-(phenylmethyl)-

$49656-77-1$
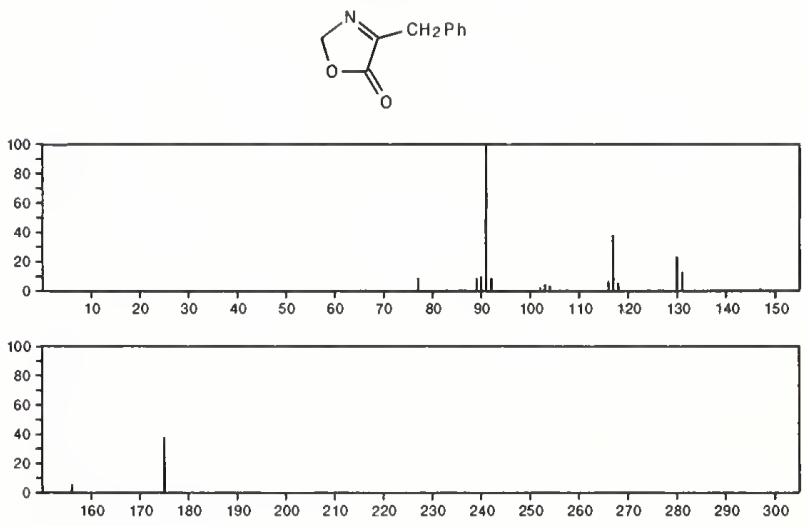
175

$\mathrm{C}_{10} \mathrm{H}_{9} \mathrm{NO}_{2}$

4(1H)-Quinolinone, 3-hydroxy-1-methyl-
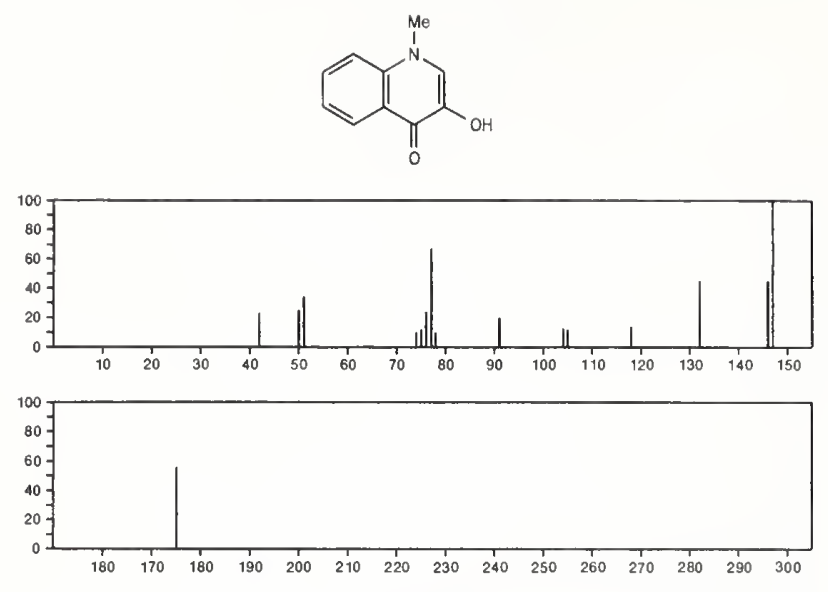

$175 \quad \mathrm{C}_{10} \mathrm{H}_{9} \mathrm{NS}$

Isothiazole, 3-methyl-5-phenyl-
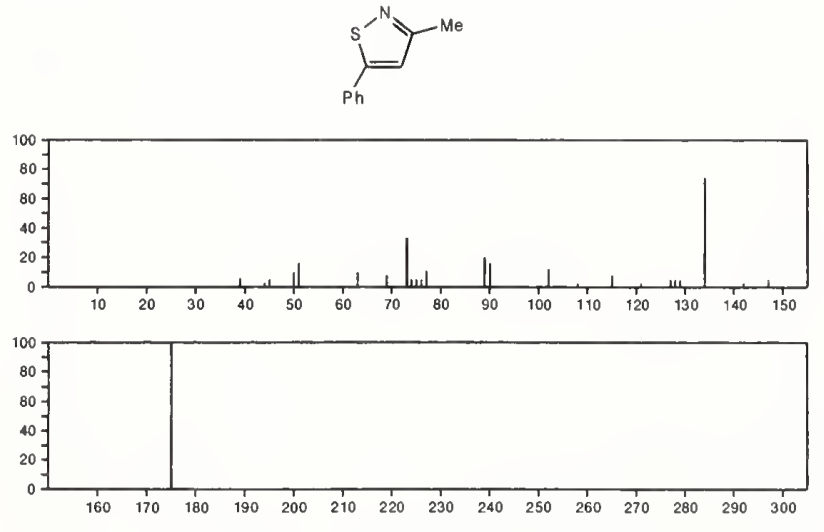

$175 \quad \mathrm{C}_{10} \mathrm{H}_{13} \mathrm{~N}_{3} \quad 49629-06-3$

$6 H$-[1,2,4]Triazolo[1,5-a]indole, 4a, 5, 7,8,8a,9-hexahydro-9methylene-
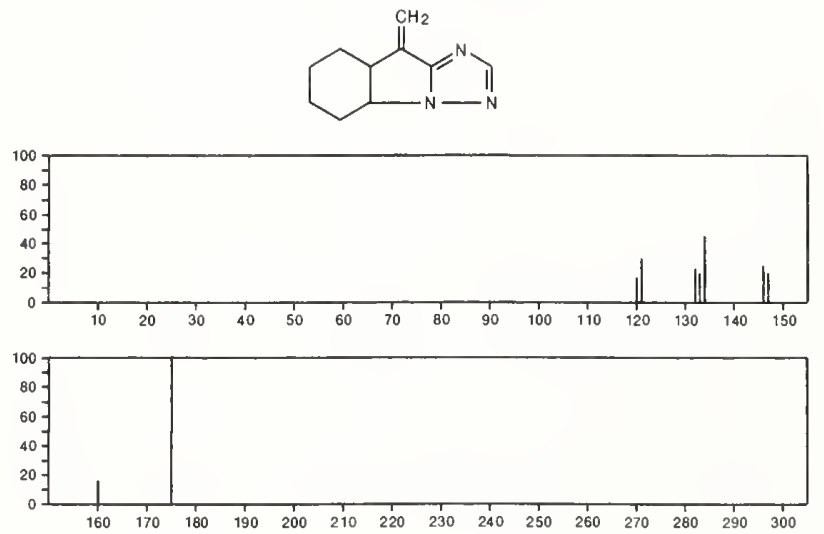

175

$\mathrm{C}_{10} \mathrm{H}_{13} \mathrm{~N}_{3}$

$49629-08-5$ $5 H$-Pyrrolo[1,2-b] $[1,2,4]$ triazole, 6,7-dihydro-6-methyl-7methylene-6-(1-methylethenyl)
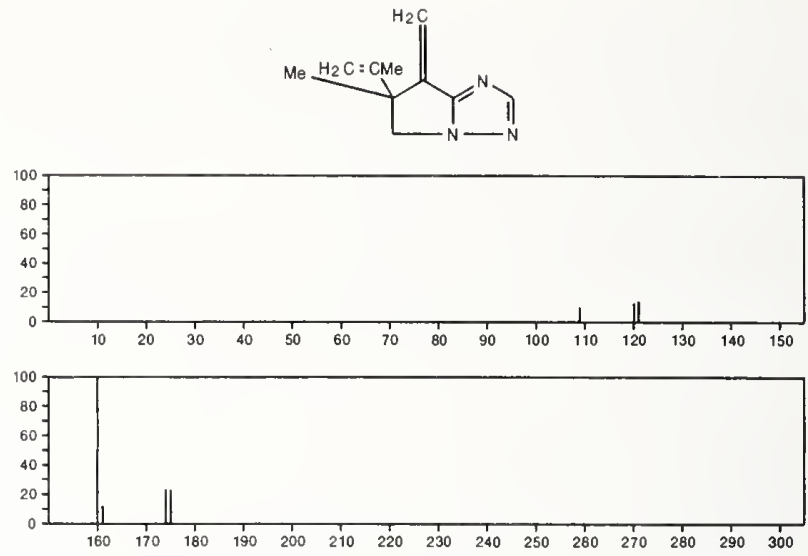

175

$\mathrm{C}_{10} \mathrm{H}_{13} \mathrm{~N}_{3}$

49629-10-9

$5 H$-[1,2,4]Triazolo[1,5-a]azepine, 8,9-dihydro-6,7-dimethyl-9methylene-
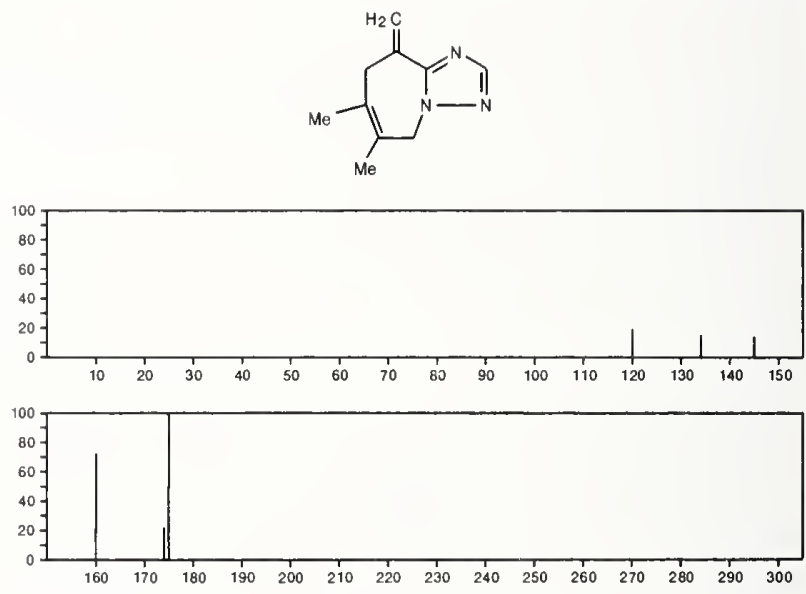

175

$\mathrm{C}_{10} \mathrm{H}_{13} \mathrm{~N}_{3}$

$50873-04-6$

6H-1,2,4-Triazolo[4,3-a]indole, 4a,5,7,8,8a,9-hexahydro-9methylene-
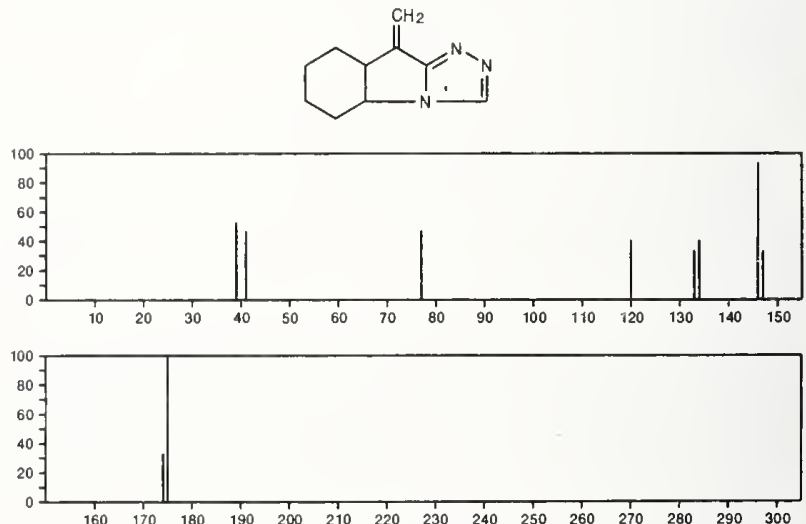
175

1,3,2-Oxazaborolidine, 2,4-dimethyl-5-phenyl-<smiles>CB1N[C@@H](C)C([18OH])O1</smiles>
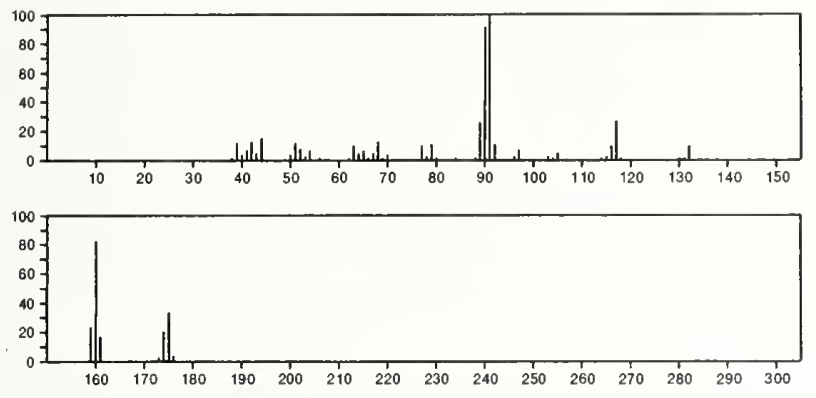

175

$\mathrm{C}_{10} \mathrm{H}_{14} \mathrm{BNO}$

31748-13-7

1,3,2-Benzoxazaborole, 2-butyl-2,3-dihydro-
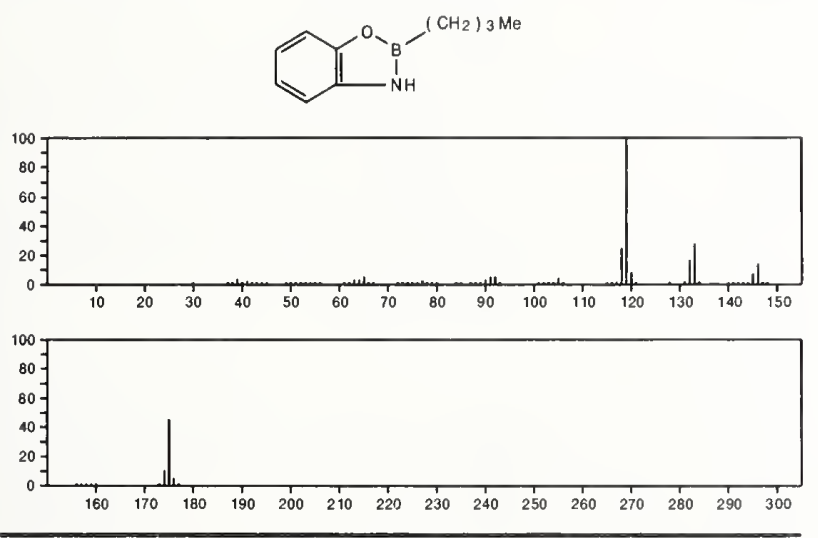

175

2-Pyrrolidinone, 1-(4-methylphenyl)-
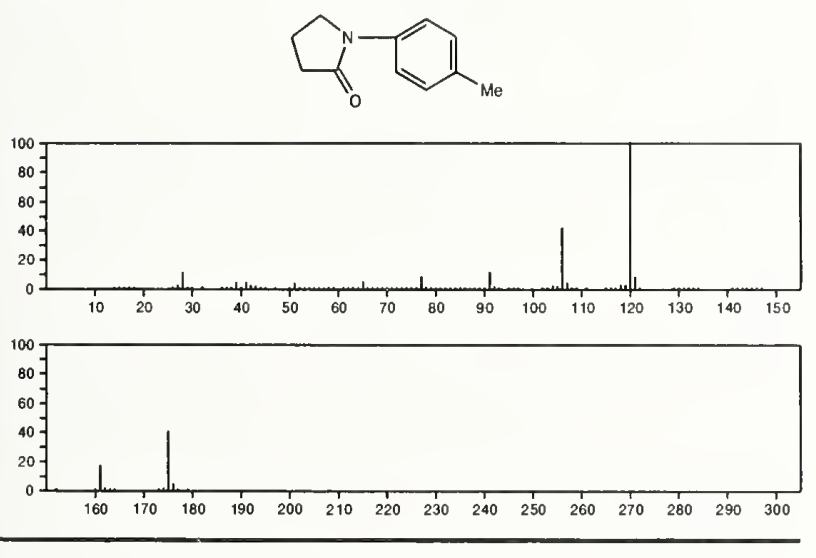

175

$\mathrm{C}_{11} \mathrm{H}_{13} \mathrm{NO}$

$14091-93-1$

2-Buten-1-one, 3-(methylamino)-1-phenyl

MeC(NHM) $=$ CHCOPh

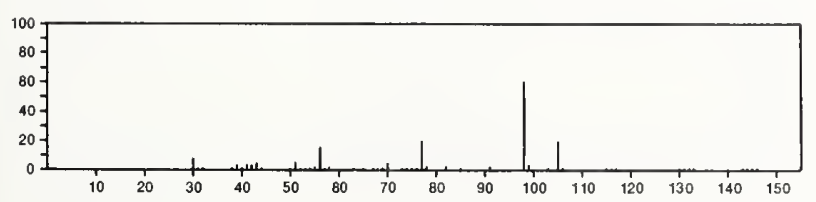

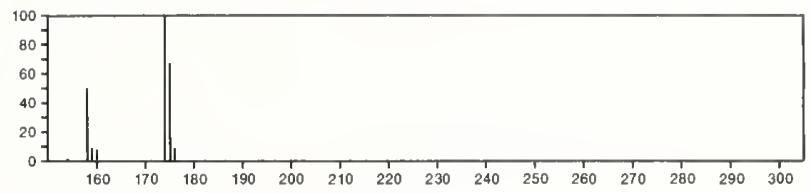

$175 \quad \mathrm{C}_{11} \mathrm{H}_{13} \mathrm{NO} 20205-45-2$ 7-Azabicyclo[4.2.2]deca-2,4,7,9-tetraene, 8-methoxy-10-methyl-
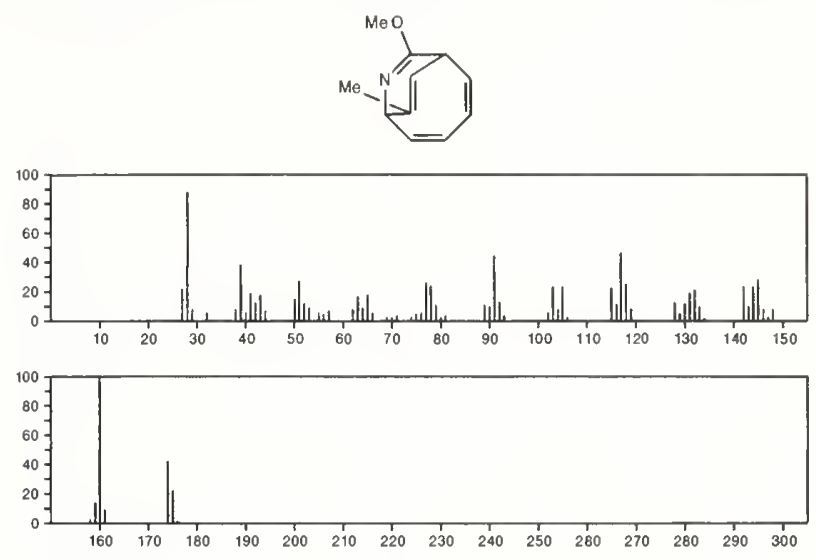

175

$\mathrm{C}_{11} \mathrm{H}_{13} \mathrm{NO}$

3H-Indole, 3-methoxy-2,3-dimethyl-

$37914-61-7$
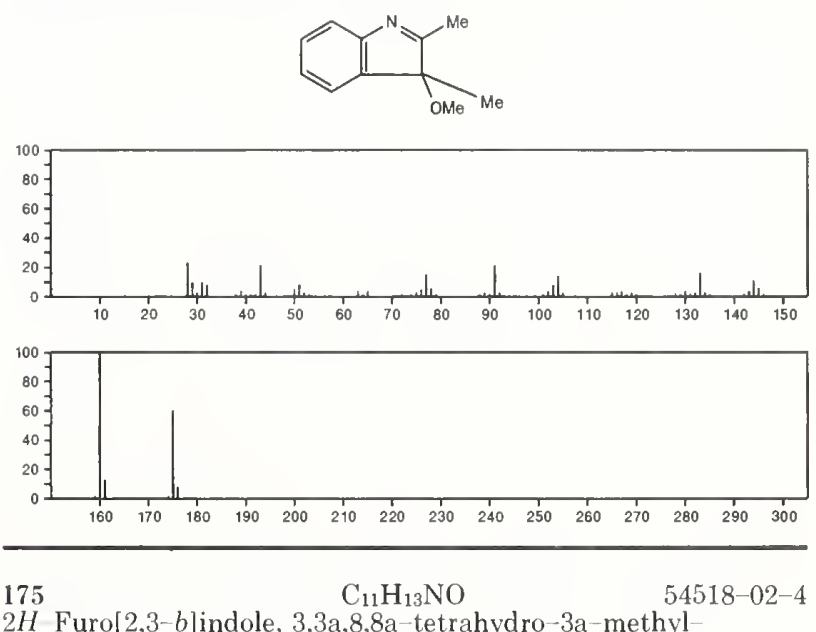

$2 H$ Furo[2,3-b]indole, 3,3a,8,8a-tetrahydro-3a-methyl-
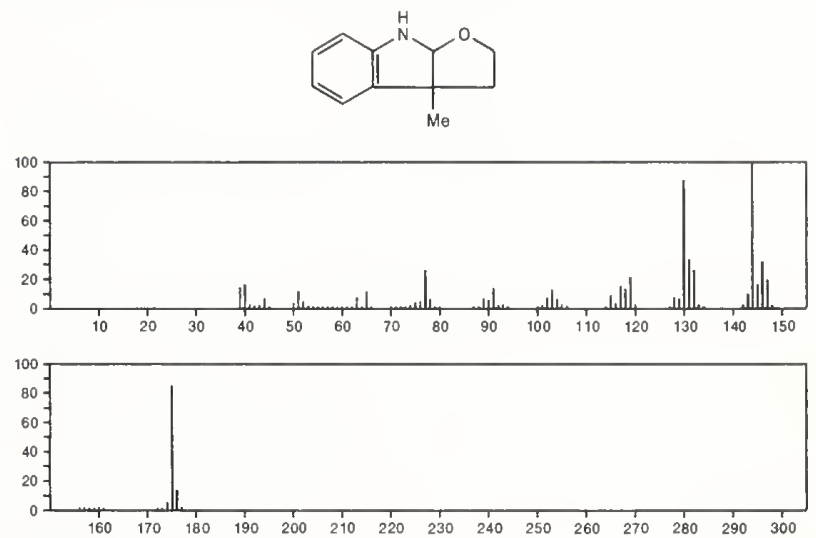
175

$\mathrm{C}_{11} \mathrm{H}_{13} \mathrm{NO}$

$56298-85-2$

2H-Furo[2,3-b]indole, 3,3a,8,8a-tetrahydro-3-methyl-
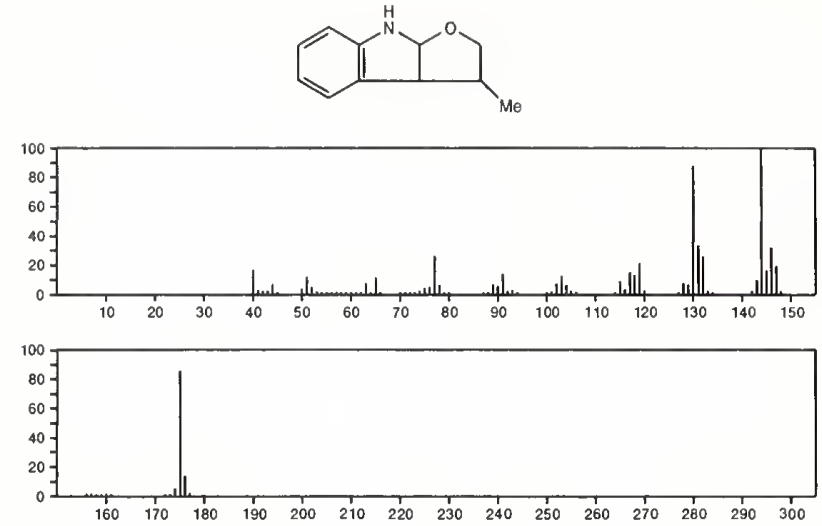

175

$\begin{array}{lllllllllllllll}160 & 170 & 180 & 190 & 200 & 210 & 220 & 230 & 240 & 250 & 260 & 270 & 280 & 290 & 300\end{array}$

Boranamine, $N, N$-dimethyl-1-phenyl-1-propyl-

$\mathrm{Me}{ }_{2} \mathrm{NBPrPh}$
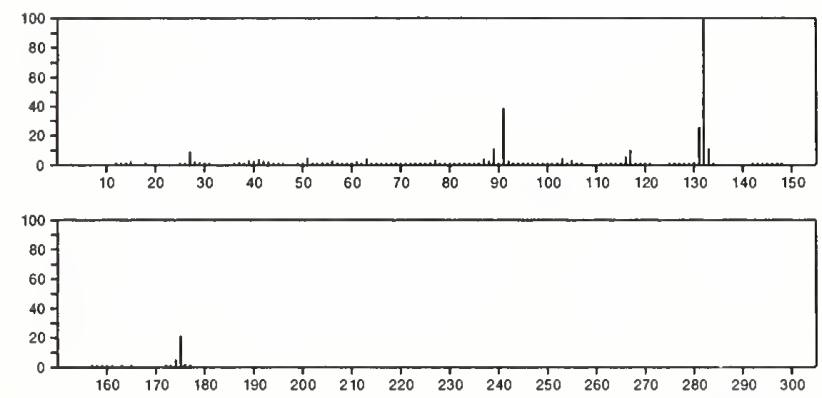

175

$\begin{array}{lllllllllllllll}160 & 170 & 180 & 190 & 200 & 210 & 220 & 230 & 240 & 250 & 260 & 270 & 280 & 290 & 300\end{array}$

4806-81-9
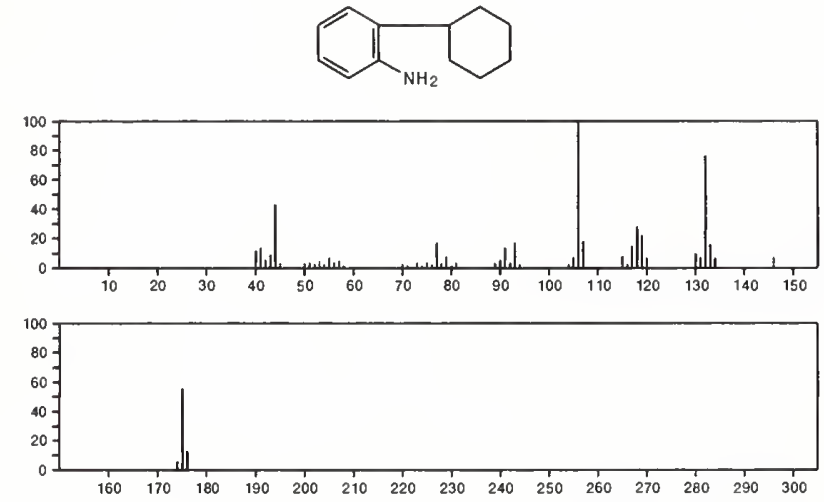

175

Benzenamine, 4-cyclohexyl-
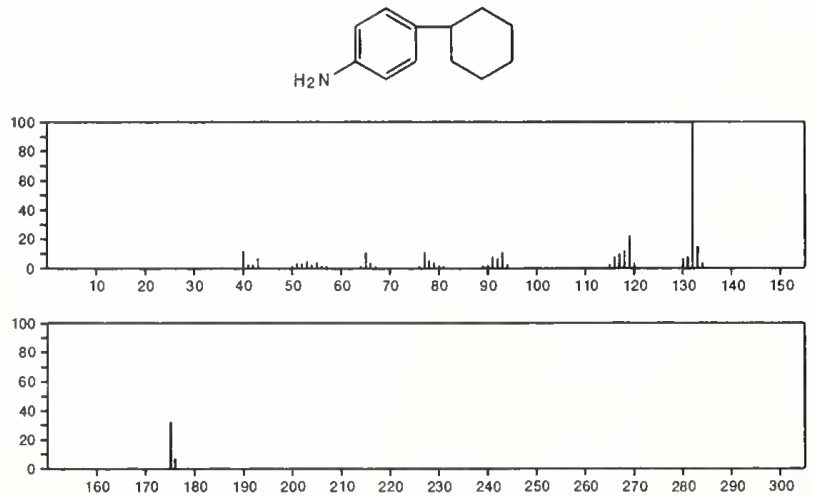

$6373-50-8$
175

Indoline, 3-ethyl-2,3-dimethyl-

$\mathrm{C}_{12} \mathrm{H}_{17} \mathrm{~N}$

$18781-59-4$
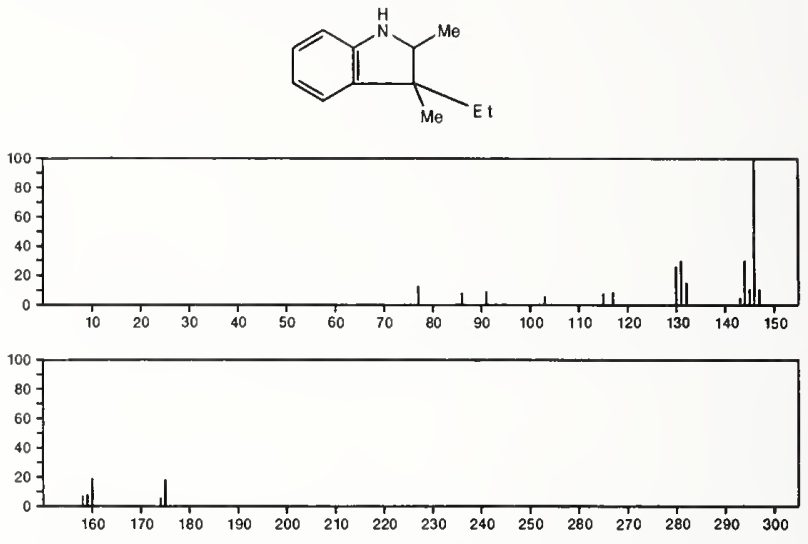

175

1-Pentanamine, $\mathrm{N}$-(phenylmethylene)-

$22710-00-5$

$\mathrm{PhCH}=\mathrm{N}\left(\mathrm{CH}_{2}\right) 4 \mathrm{Me}$
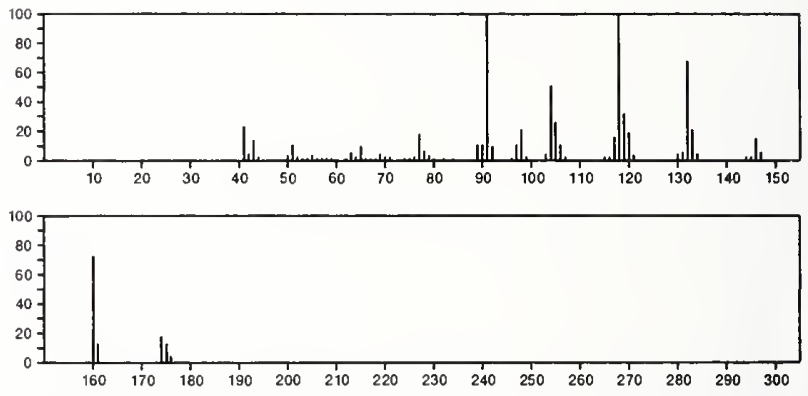

$175 \quad \mathrm{C}_{12} \mathrm{H}_{17} \mathrm{~N}$

2-Pentanamine, $N$-(phenylmethylene)-

$41122-65-0$

$\operatorname{Pr}$ CHiMe $=\mathrm{CHPh}$
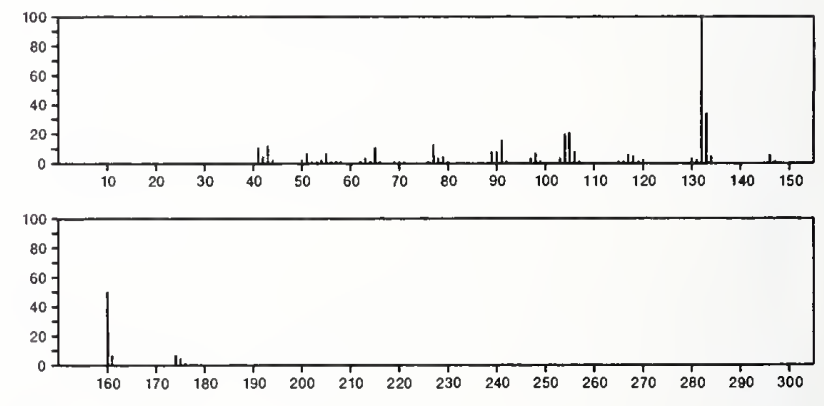

$175 \quad \mathrm{C}_{12} \mathrm{H}_{17} \mathrm{~N}$

Naphthalenamine, $N$-ethyl-1,2,3,4-tetrahydro-

$54484-56-9$
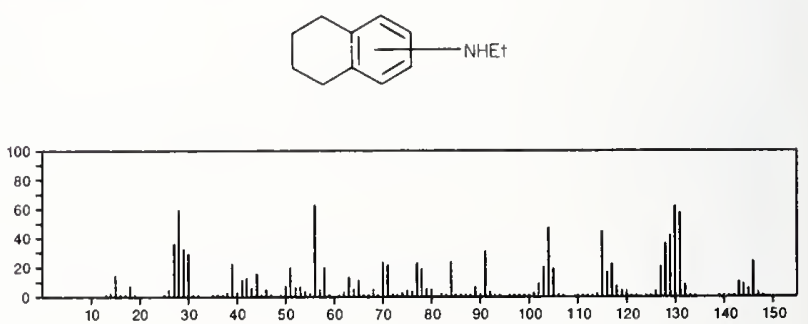


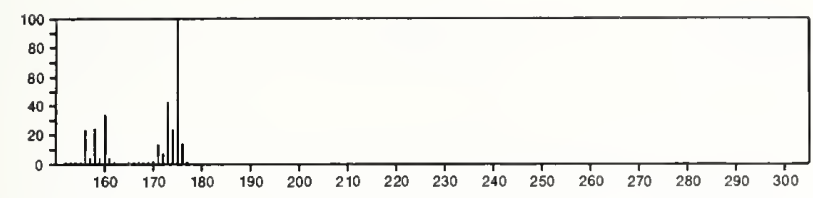

175 $\mathrm{C}_{12} \mathrm{H}_{17} \mathrm{~N}$

1H-Indole, 2-ethyl-2,3-dihydro-3,3-dimethyl
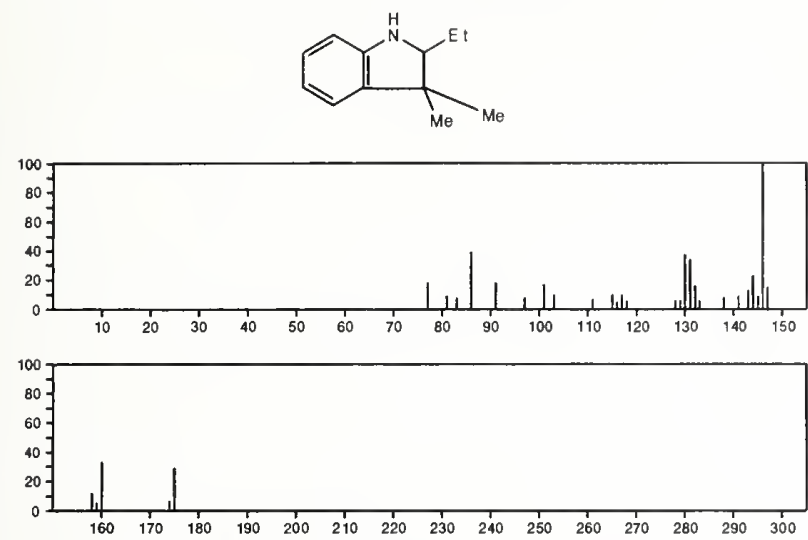

175

$\mathrm{C}_{12} \mathrm{H}_{17} \mathrm{~N}$

$55955-58-3$

$1 H$-Indole, 2,3-dihydro-1-(1-methylpropyl)-
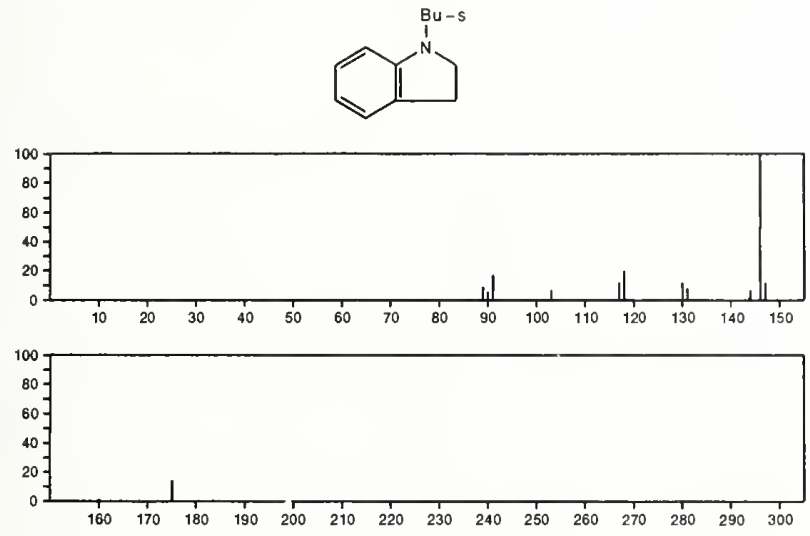

176

$\mathrm{C}_{2} \mathrm{BrClF}_{2}$

$758-24-7$

Ethene, 1-bromo-1-chloro-2,2-difluoro-

$\mathrm{F}_{2} \mathrm{C}=\mathrm{CBr} \mathrm{Cl}$
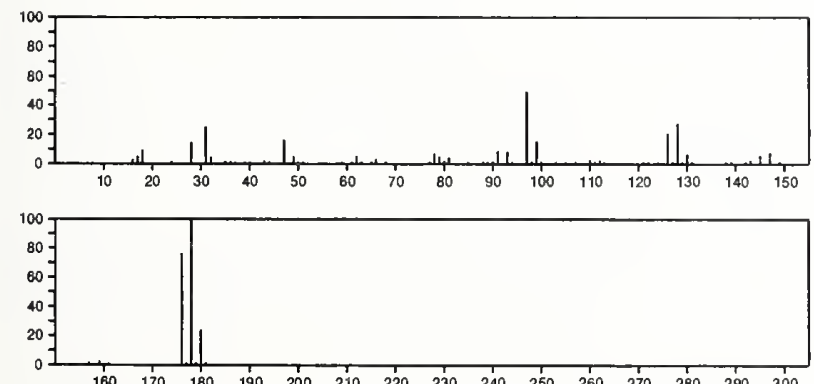

176

$\mathrm{C}_{2} \mathrm{BrClF}_{2}$

$2106-93-6$

Ethylene, 1-bromo-2-chloro-1,2-difluoro-

$\mathrm{CI} C \mathrm{~F}=\mathrm{CBr} F$

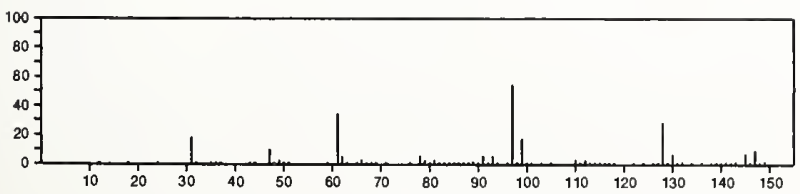

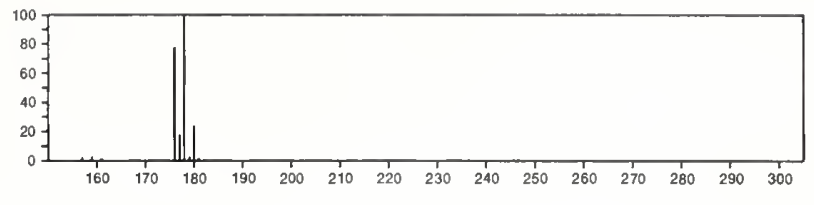

176

Ethane, 2-bromo-1,1-dichloro-

$\mathrm{C}_{2} \mathrm{H}_{3} \mathrm{BrCl}_{2}$

$683-53-4$

$\mathrm{Br} \mathrm{CH}_{2} \mathrm{CHCl}_{2}$
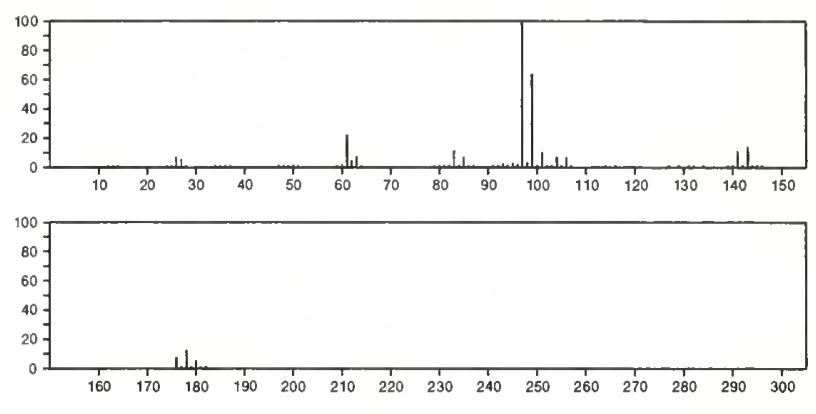

176

$\mathrm{C}_{3} \mathrm{H}_{3} \mathrm{Cl}_{3} \mathrm{O}_{2}$

Acetic acid, trichloro-, methyl ester

598-99-2

$\mathrm{MeOC}(0) \mathrm{CCl}_{3}$
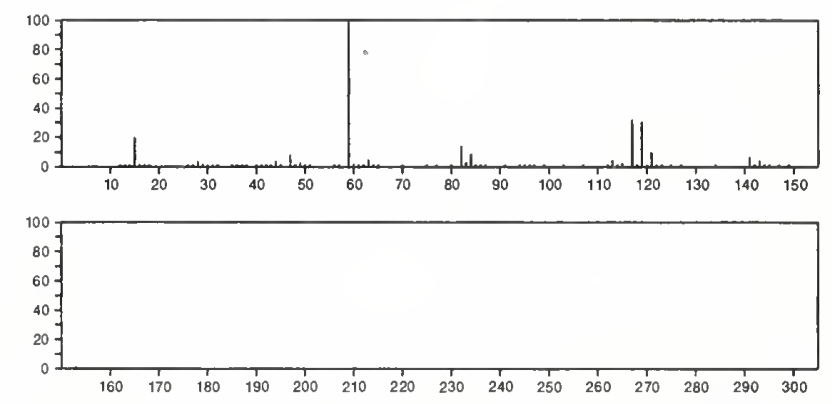

$176 \quad \mathrm{C}_{3} \mathrm{H}_{3} \mathrm{Cl}_{3} \mathrm{O}_{2}$

Propanoic acid, 2,2,3-trichloro-

$3278-46-4$

$\mathrm{ClCH}_{2} \mathrm{CCl}_{2} \mathrm{CO}_{2} \mathrm{H}$

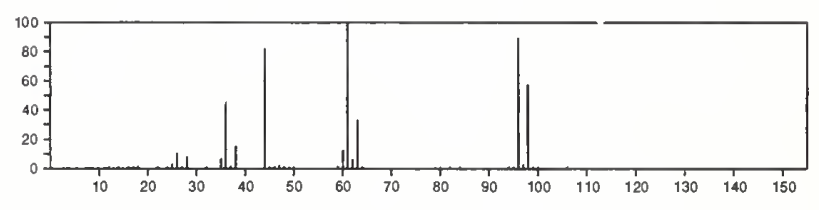

176

$\mathrm{C}_{4} \mathrm{H}_{8} \mathrm{~N}_{4} \mathrm{~S}_{2}$

$38362-24-2$

1,2,4-Thiadiazole, 5-(1-methylhydrazino)-3-(methylthio)-
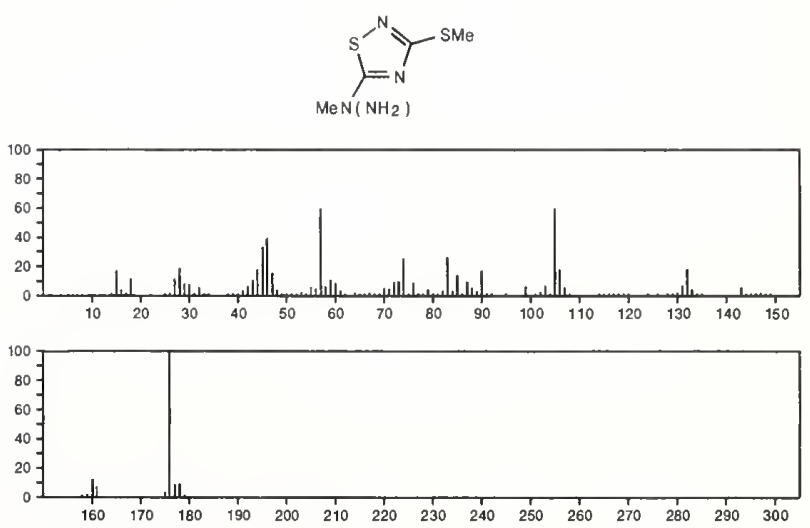
$\mathrm{C}_{5} \mathrm{H}_{5} \mathrm{BrO}_{2}$

1,3-Cyclopentanedione, 2-bromo-
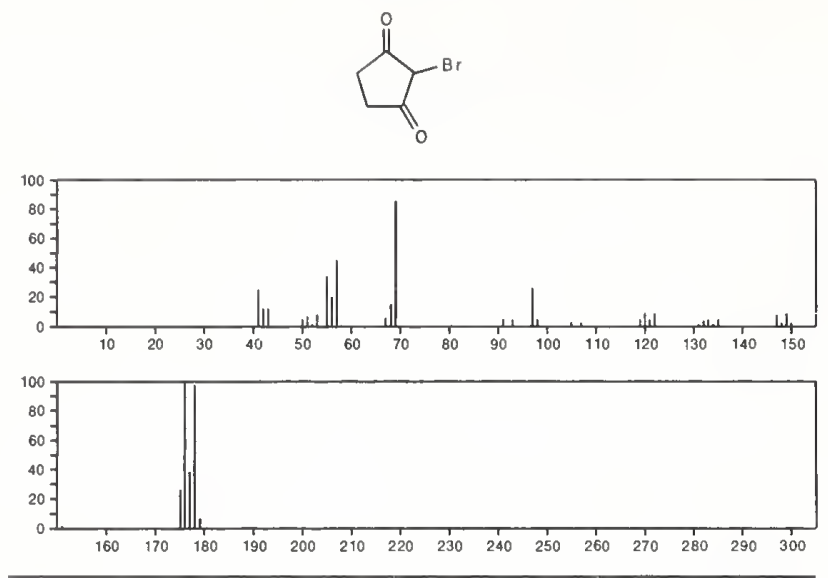

176

Benzenesulfonyl chloride

\section{$\mathrm{C}_{6} \mathrm{H}_{5} \mathrm{ClO}_{2} \mathrm{~S}$}

$\mathrm{Cl} \mathrm{SO}_{2} \mathrm{Ph}$
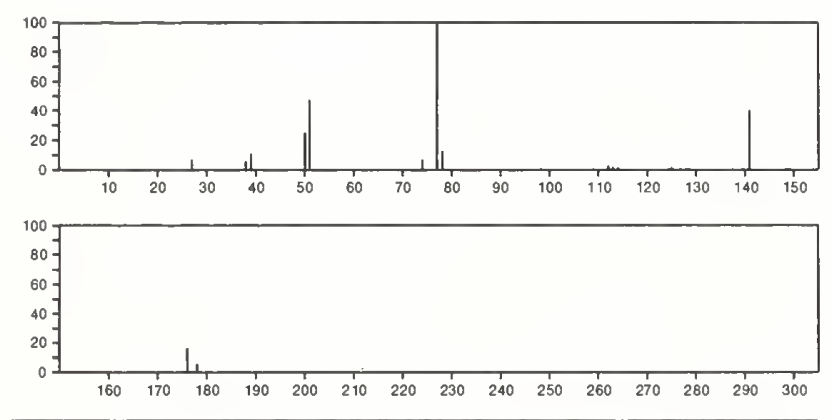

176
L-Ascorbic acid

$\mathrm{C}_{6} \mathrm{H}_{8} \mathrm{O}_{6}$

$50-81-7$
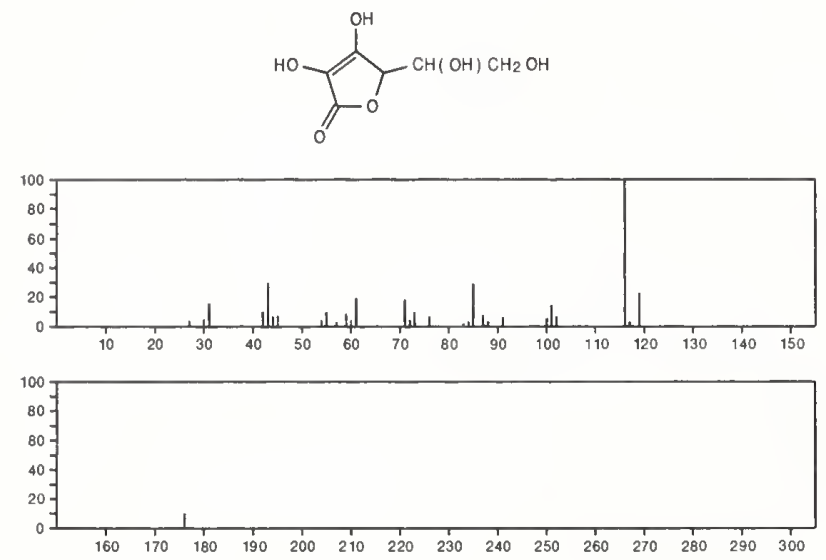

176

D-Glucuronic acid, $\gamma$-lactone

$\mathrm{C}_{6} \mathrm{H}_{8} \mathrm{O}_{6}$

$32449-92-6$
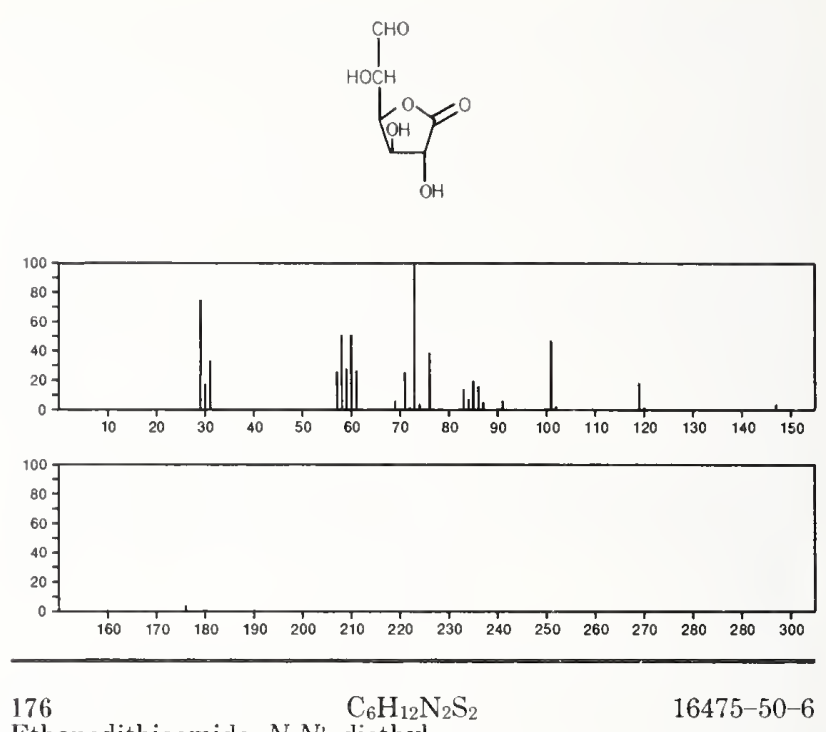

Ethanedithioamide, $N, N^{\prime}$-diethyl-

$16475-50-6$

EINHCSCSNHE:
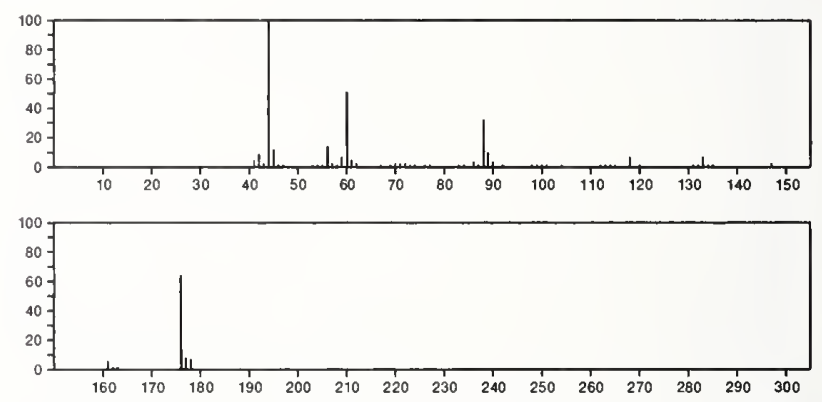

$176 \quad \mathrm{C}_{7} \mathrm{H}_{6} \mathrm{Cl}_{2} \mathrm{O}$

$553-82-2$

Benzene, 2,4-dichloro-1-methoxy-
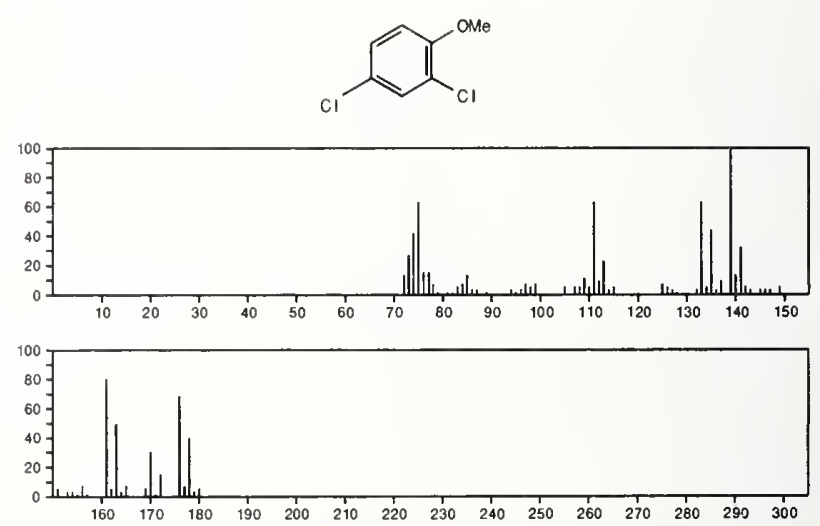
176

$\mathrm{C}_{7} \mathrm{H}_{6} \mathrm{Cl}_{2} \mathrm{O}$

$1570-65-6$

Phenol, 2,4-dichloro-6-methyl-
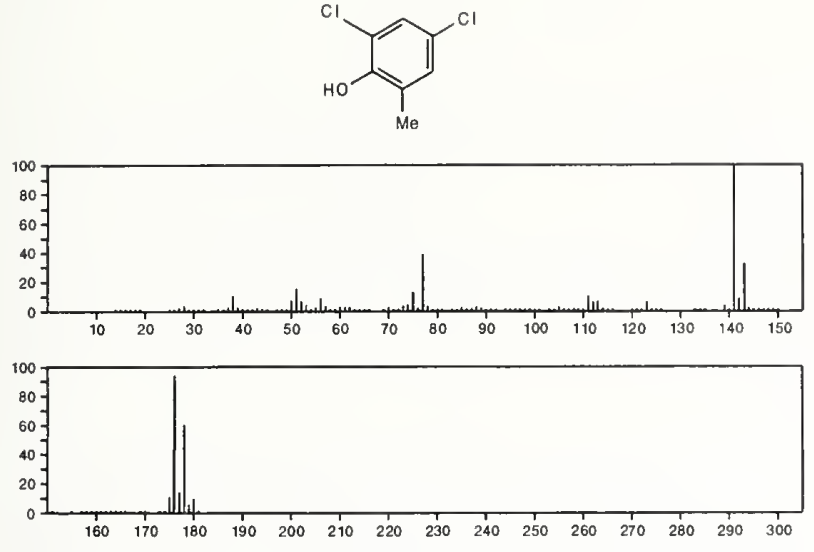

176

$\mathrm{C}_{7} \mathrm{H}_{6} \mathrm{Cl}_{2} \mathrm{O}$

Benzene, dichloromethoxy-
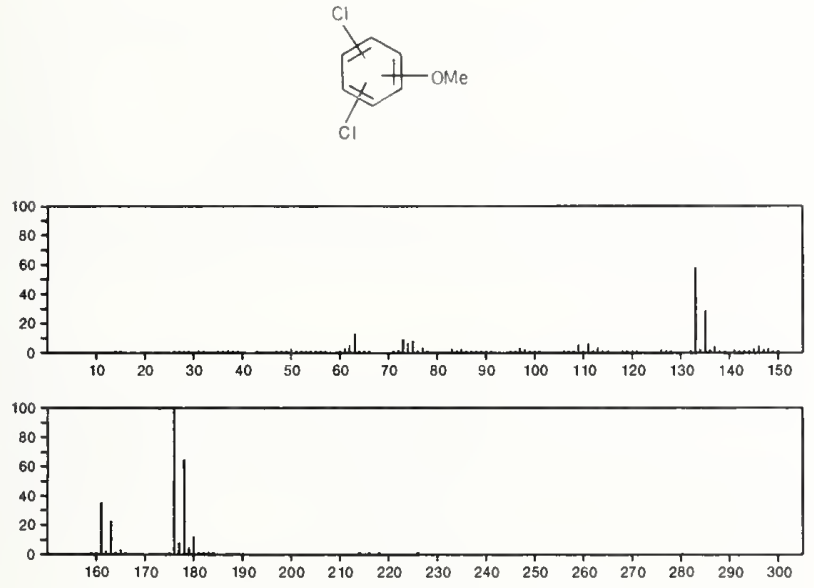

176

$\mathrm{C}_{7} \mathrm{H}_{12} \mathrm{OS}_{2}$

$20560-74-1$

Acetoacetic acid, 1,3-dithio-, $S$ - propyl ester

$\mathrm{PrSC}(\mathrm{O}) \mathrm{CH}_{2} \mathrm{CSMe}$
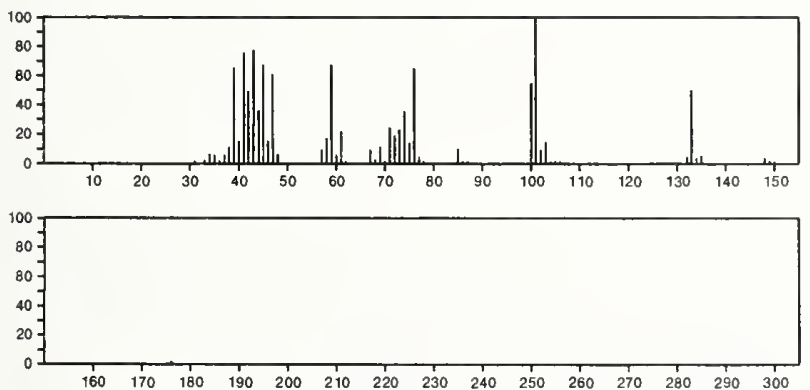

$\begin{array}{lllllllllllllll}160 & 170 & 180 & 190 & 100 & 210 & 220 & 230 & 240 & 250 & 260 & 270 & 280 & 290 & 300\end{array}$

176

1,2,3-Propanetriol, 1,2-diacetate

$\mathrm{C}_{7} \mathrm{H}_{12} \mathrm{O}_{5}$

$102-62-5$

$\mathrm{CH}_{2} \mathrm{OH}$

$\mathrm{AC} \mathrm{OCH}_{2} \mathrm{CHOAC}_{2}$

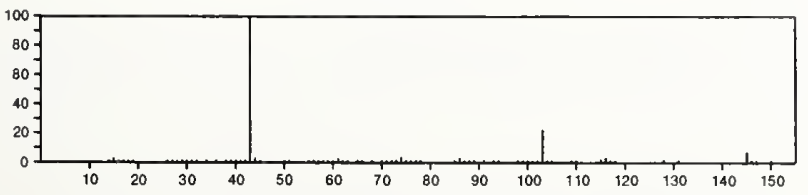

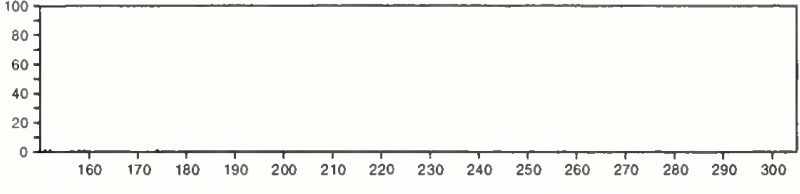

${ }_{\beta-D}^{176}$-Glucopyranoside, methyl $\stackrel{\mathrm{C}_{7} \mathrm{H}_{12} \mathrm{O}_{5}}{3,6 \text {-anhydro- }}$

$3056-46-0$<smiles>OC1C(O)C2OCC2(O)C1O</smiles>

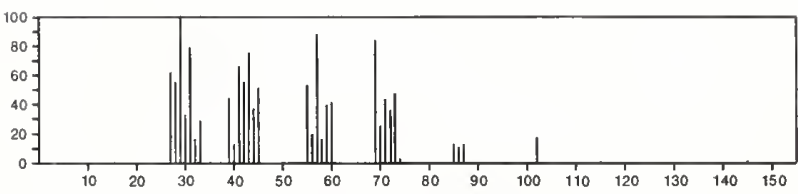

176

$\mathrm{C}_{7} \mathrm{H}_{12} \mathrm{O}_{5}$

$4148-97-4$

Butanedioic acid, methoxy-, dimethyl ester

$\mathrm{MeOC}(\mathrm{O}) \mathrm{CH}_{2} \mathrm{CH}(\mathrm{OMe}) \mathrm{C}(\mathrm{O}) \mathrm{OMN}_{0}$
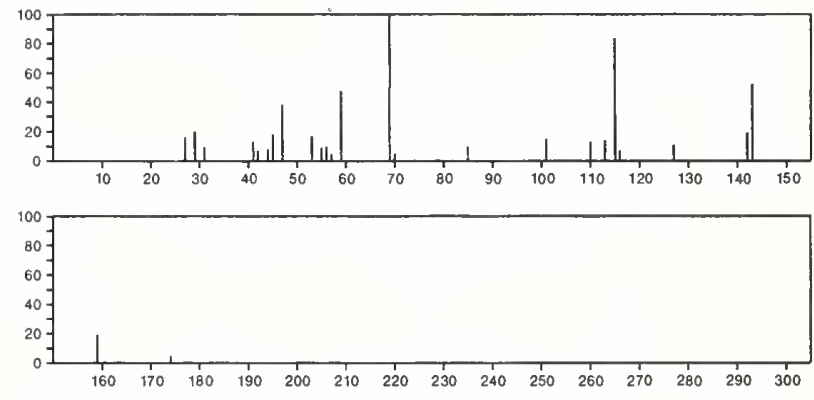

176

$\mathrm{C}_{7} \mathrm{H}_{12} \mathrm{O}_{5}$

$5540-31-8$

$\alpha-$ D-Galactopyranoside, methyl 3,6 anhydro-
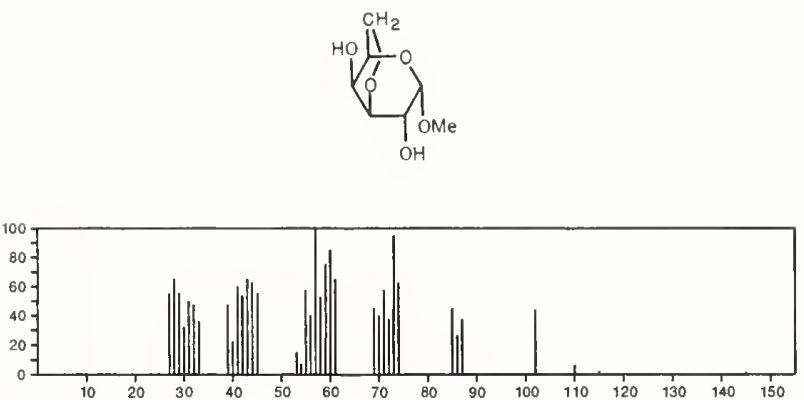
176

$\alpha-\mathrm{D}$-Glucopyranoside, methyl 3,6-anhydro-

$13407-60-8$
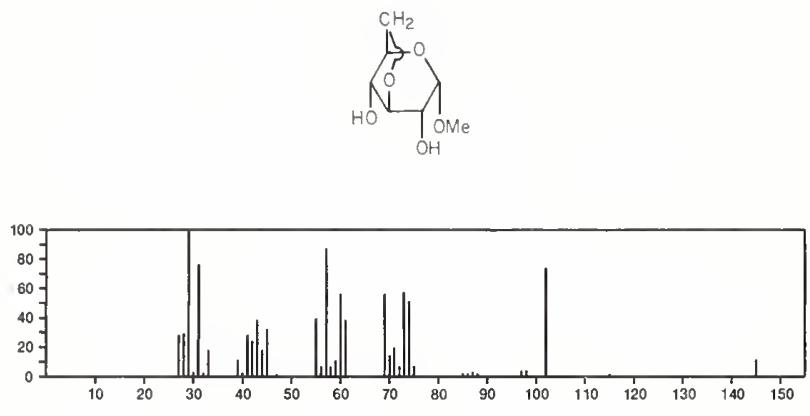

176

$\mathrm{C}_{7} \mathrm{H}_{12} \mathrm{O}_{5}$

$15814-56-9$

Mannopyranoside, methyl 3,6-anhydro-, $\alpha-\mathrm{D}^{-}$
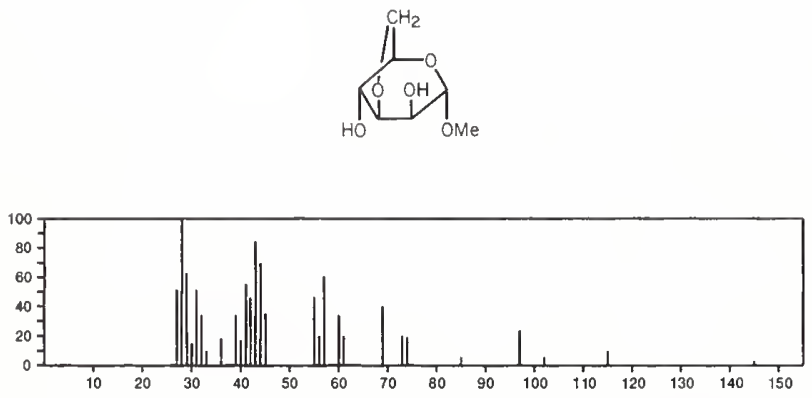

176

$\mathrm{C}_{7} \mathrm{H}_{13} \mathrm{Br}$

$2404-35-5$

Cycloheptane, bromo-
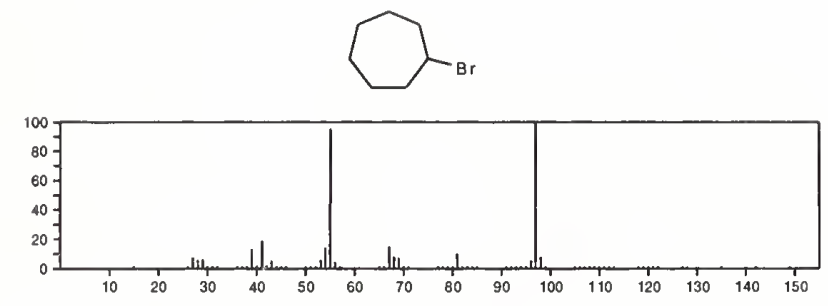

$176 \quad \mathrm{C}_{7} \mathrm{H}_{13} \mathrm{Br}$

Cyclohexane, 1-bromo-2-methyl-

6294-39-9
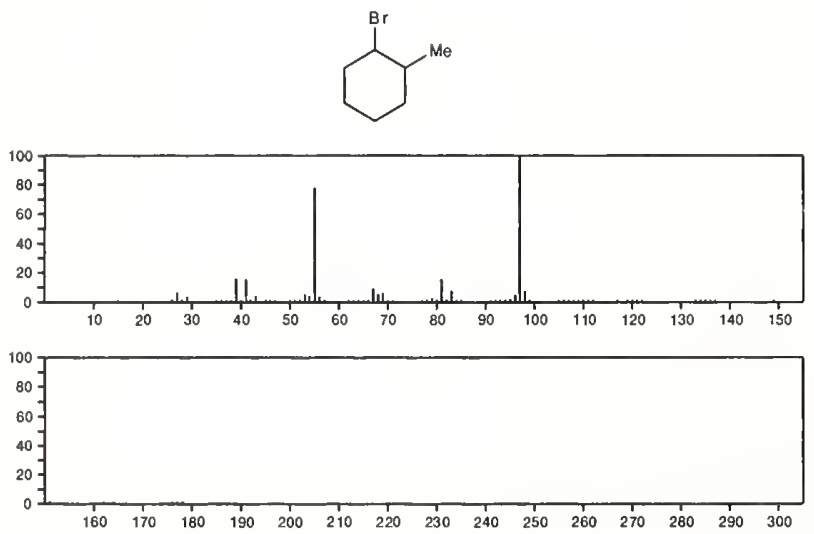

176

$\mathrm{C}_{7} \mathrm{H}_{13} \mathrm{~B}$

$6294-40-2$
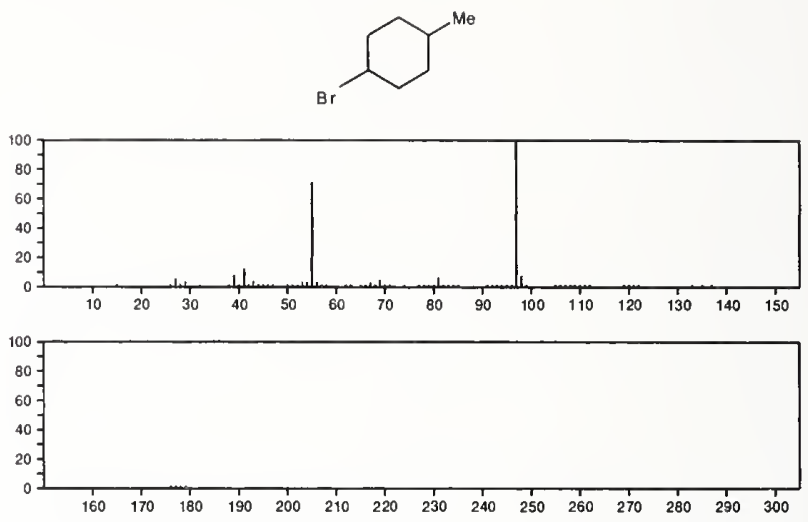

176

$\mathrm{C}_{7} \mathrm{H}_{13} \mathrm{Br}$

Cyclohexane, 1-bromo-3-methyl-

13905-48-1
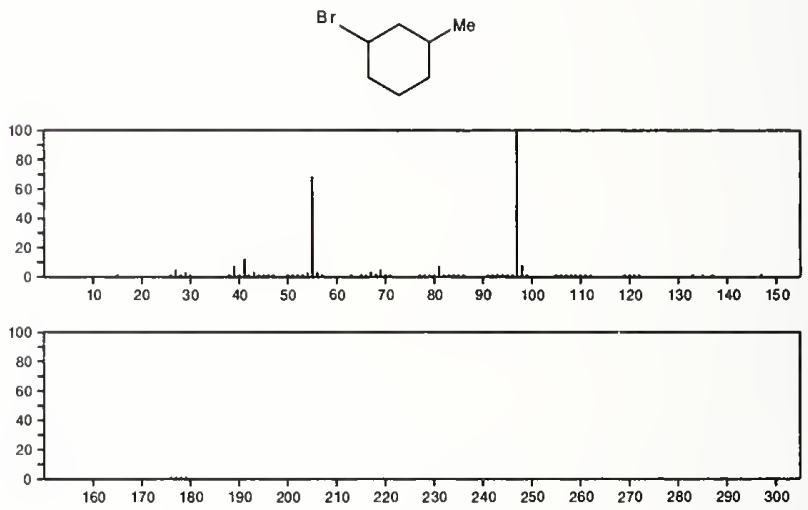

176

$\mathrm{C}_{7} \mathrm{H}_{13} \mathrm{Br}$

Cyclopropane, 1-bromo-2-butyl-, trans-

$32816-30-1$
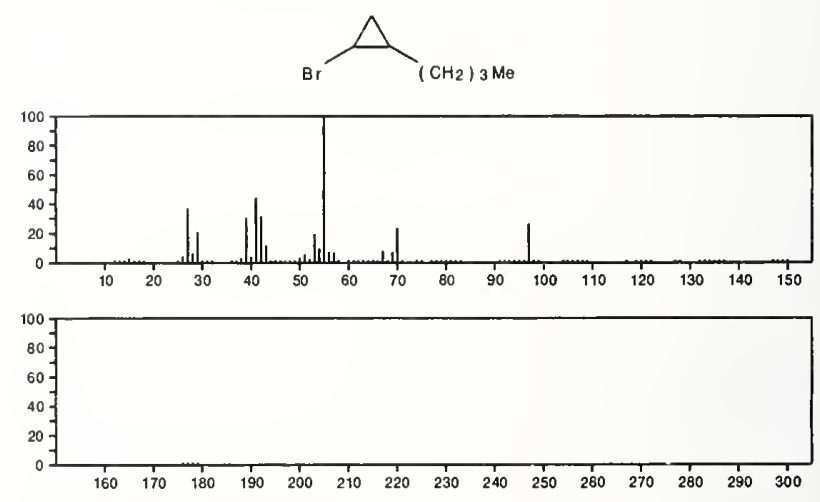

176

$\mathrm{C}_{7} \mathrm{H}_{13} \mathrm{Br}$

$55682-99-0$

Cyclopropane, 1-bromo-2-(1,1-dimethylethyl)-
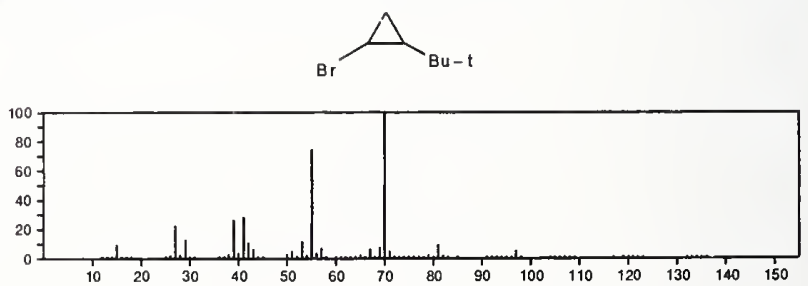


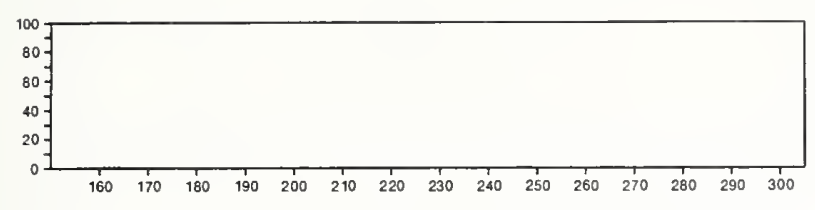

176

$\mathrm{C}_{7} \mathrm{H}_{13} \mathrm{Br}$

2-Pentene, 5-bromo-2,3-dimethyl-

$56312-52-8$

$\mathrm{Me}_{2} \mathrm{C}=\mathrm{CMe} \mathrm{CH}_{2} \mathrm{CH}_{2} \mathrm{~B}$

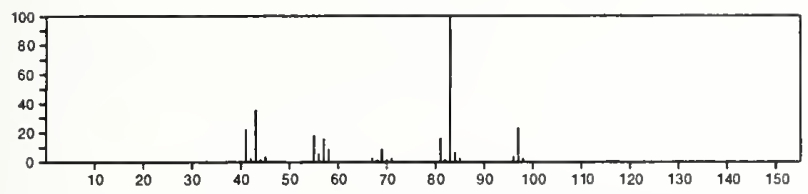

176

$\mathrm{C}_{7} \mathrm{H}_{13} \mathrm{O}_{3} \mathrm{P}$

$18644-16-1$

2,6,7-Trioxa-1-phosphabicyclo[2.2.2]octane, 4-propyl-
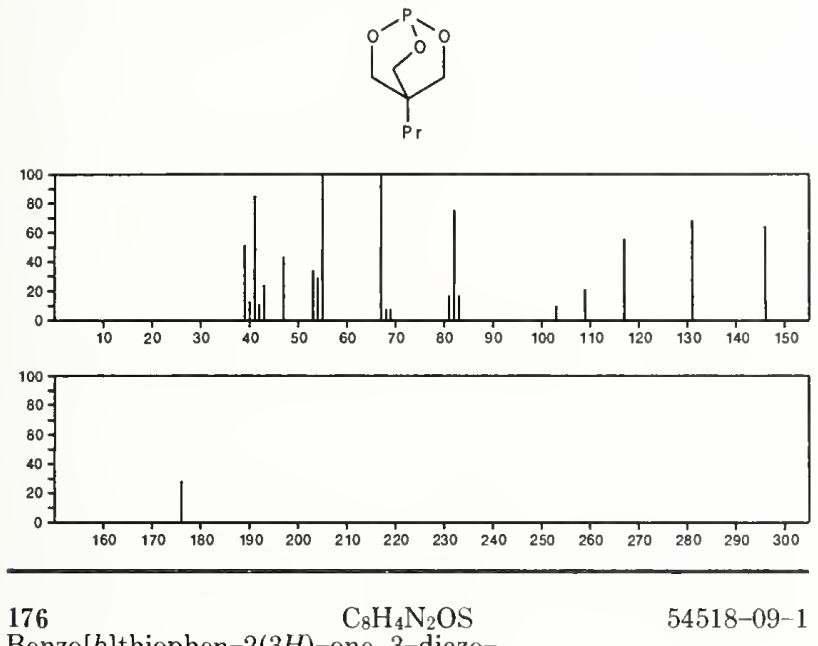

Benzo $[b]$ thiophen-2(3H)-one, 3-diazo-
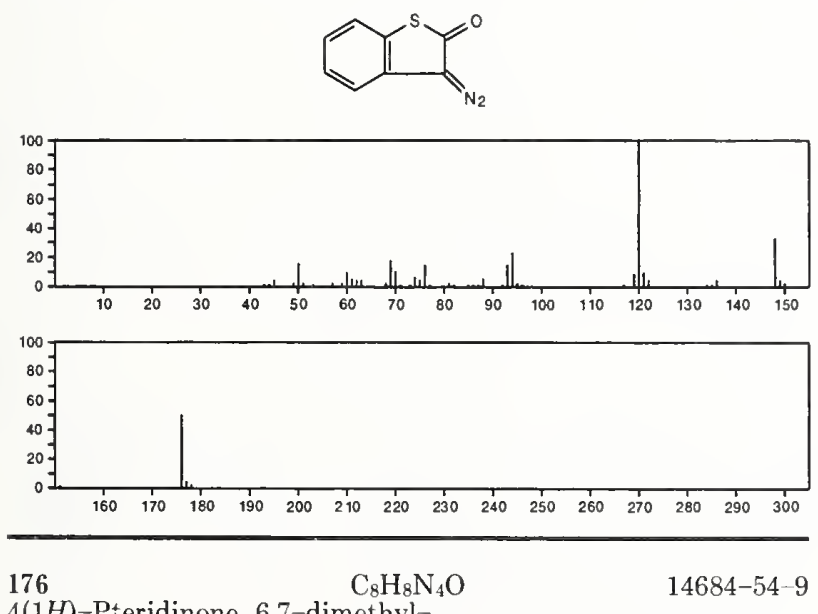

4(1H)-Pteridinone, 6,7-dimethyl-<smiles>Cc1nc2[nH]cnc(=O)c2nc1C</smiles>

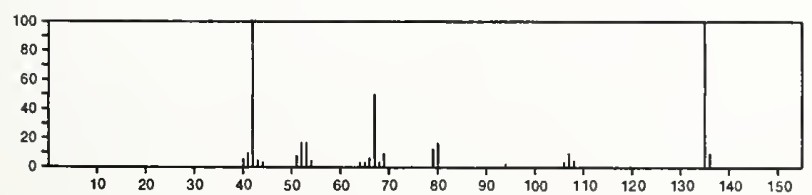

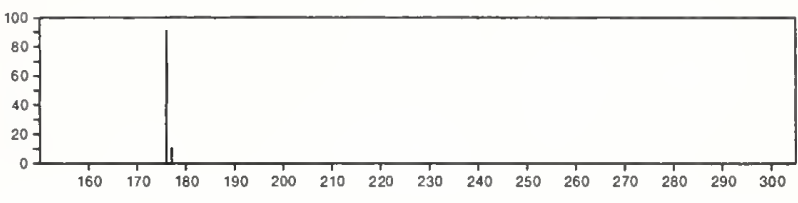

176 $\mathrm{C}_{8} \mathrm{H}_{8} \mathrm{~N}_{4} \mathrm{O}$

$34244-77-4$ $4(3 H)$-Pteridinone, 2,6-dimethyl-<smiles></smiles>
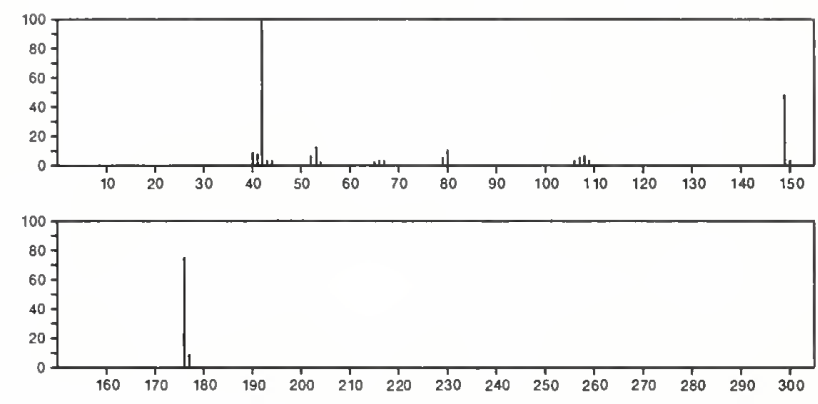

176

4(3H)-Pteridinone, 2,7-dimethyl-

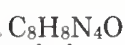

$34244-79-6$
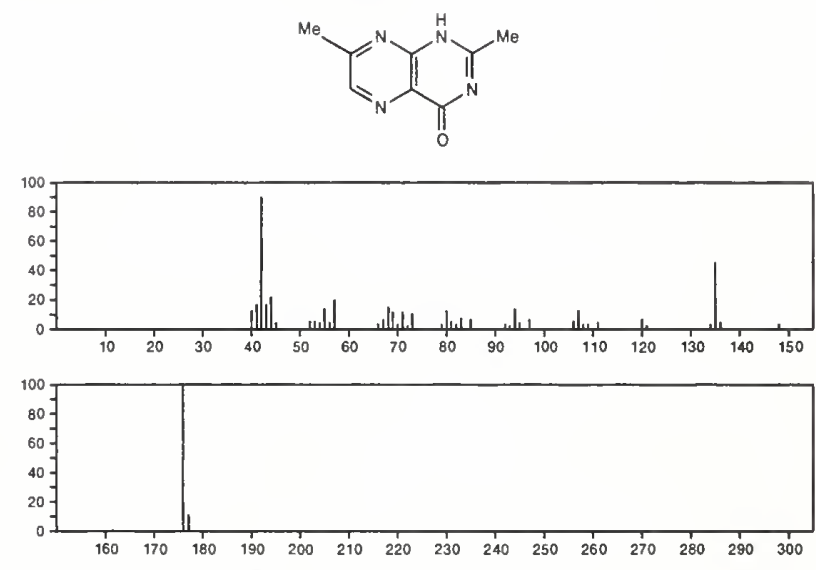

176

$\mathrm{C}_{8} \mathrm{H}_{10} \mathrm{Cl}_{2}$

$13547-06-3$

Cyclohexene, 1-chloro-4-(1-chloroethenyl)-
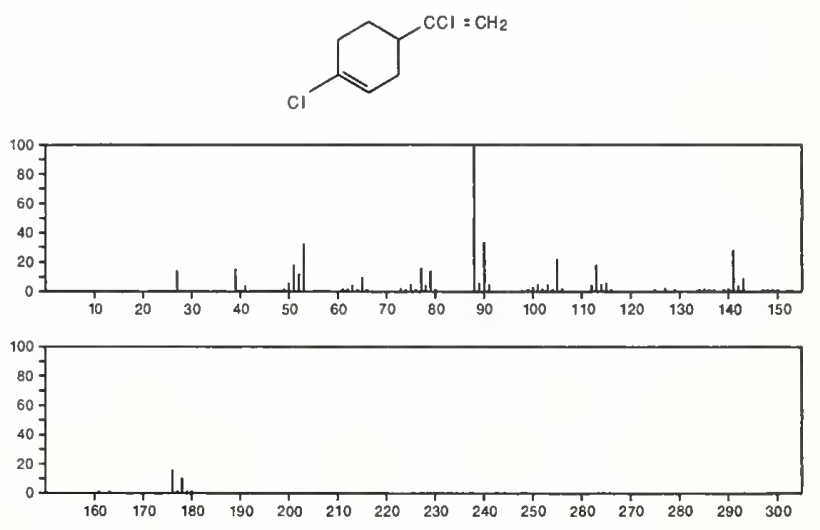
176

$\mathrm{C}_{8} \mathrm{H}_{10} \mathrm{Cl}_{2}$

Cyclohexene, 1-chloro-5-(1-chloroethenyl)

$13547-07-4$<smiles>CC(C)(Cl)C1CCC=C(Cl)C1</smiles>
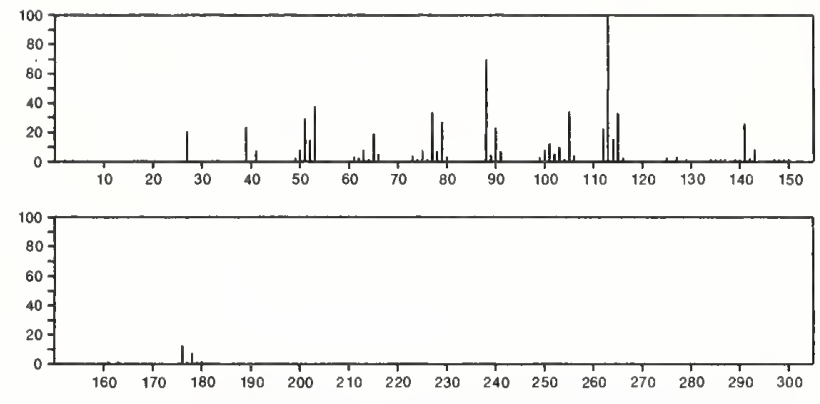

$176 \quad \mathrm{C}_{8} \mathrm{H}_{10} \mathrm{Cl}_{2}$

$29480-42-0$

1,5-Cyclooctadiene, 1,6-dichloro-
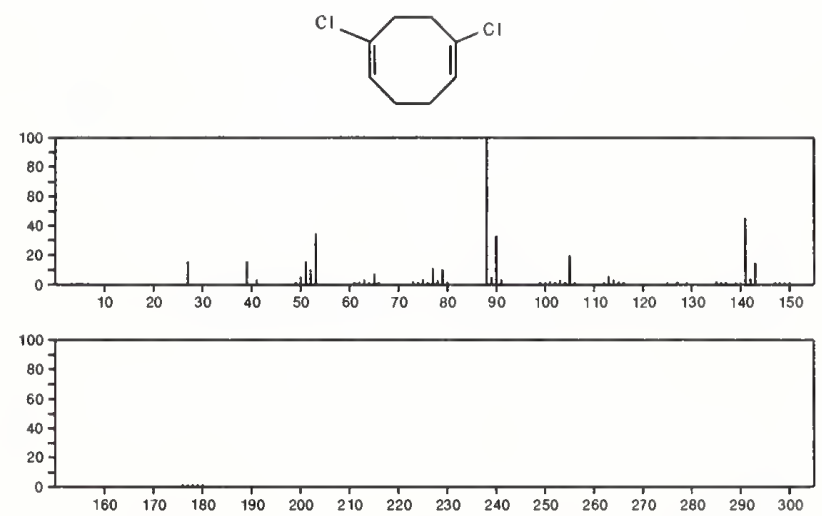

$176 \quad \mathrm{C}_{8} \mathrm{H}_{13} \mathrm{ClO}_{2}$

1,4-Dioxaspiro[4.5]decane, 8-chloro-

$55724-03-3$
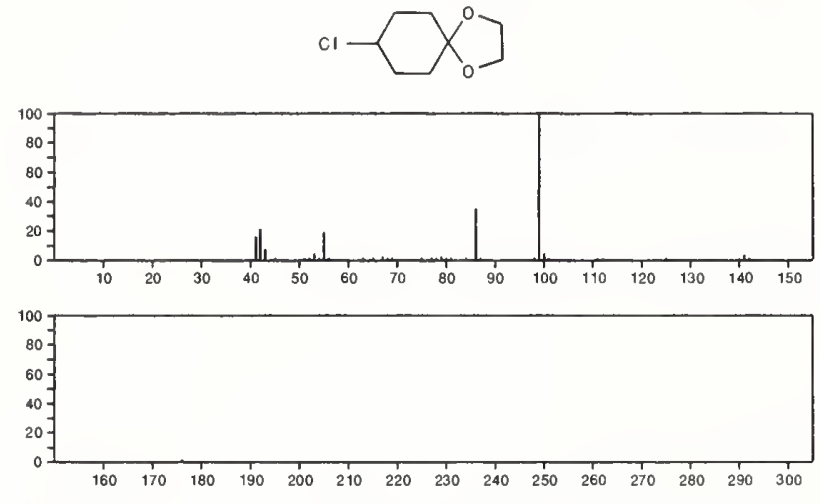

176

$\mathrm{C}_{8} \mathrm{H}_{16} \mathrm{O}_{2} \mathrm{~S}$

$23246-22-2$

Propionic acid, 3-(butylthio)-, methyl ester

$\mathrm{MeOC}(\mathrm{O}) \mathrm{CH}_{2} \mathrm{CH}_{2} \mathrm{~S}\left(\mathrm{CH}_{2}\right)_{3} \mathrm{Me}$
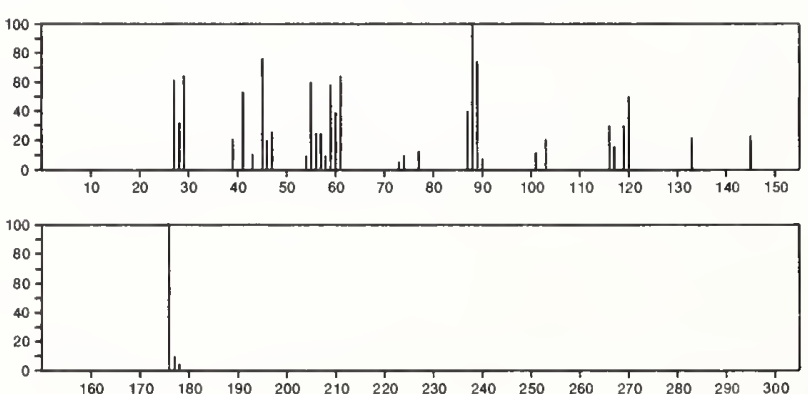

$176 \quad \mathrm{C}_{8} \mathrm{H}_{16} \mathrm{O}_{4}$

Ethanol, 2-(2-ethoxyethoxy)-, acetate

$112-15-2$

AC $\mathrm{OCH}_{2} \mathrm{CH}_{2} \mathrm{OCH}_{2} \mathrm{CH}_{2} \mathrm{OE}$ ?

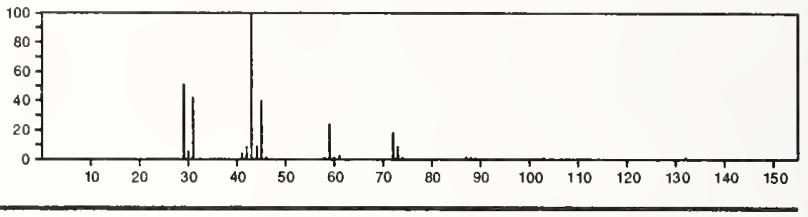

176

$\mathrm{C}_{8} \mathrm{H}_{16} \mathrm{O}_{4}$

$25252-24-8$

Succinaldehydic acid, 2-methyl-, methyl ester, 4-(dimethyl acetal) $\mathrm{MeOC}(\mathrm{O}) \mathrm{CHMe} \mathrm{CH}_{2} \mathrm{CH}(\mathrm{OMe})_{2}$

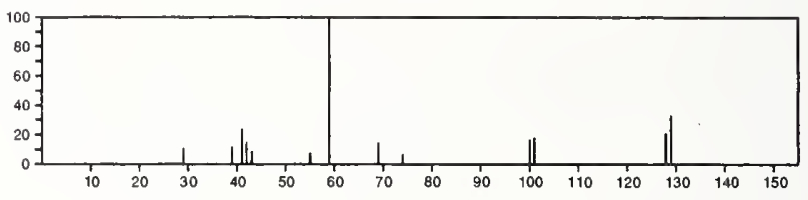

176

$\mathrm{C}_{8} \mathrm{H}_{20} \mathrm{O}_{2} \mathrm{Si}$

Silane, (4-methoxybutoxy)trimethyl-

16654-44-7

$\mathrm{Me}_{3} \mathrm{SiO}\left(\mathrm{CH}_{2}\right)_{4} \mathrm{OM}_{0}$
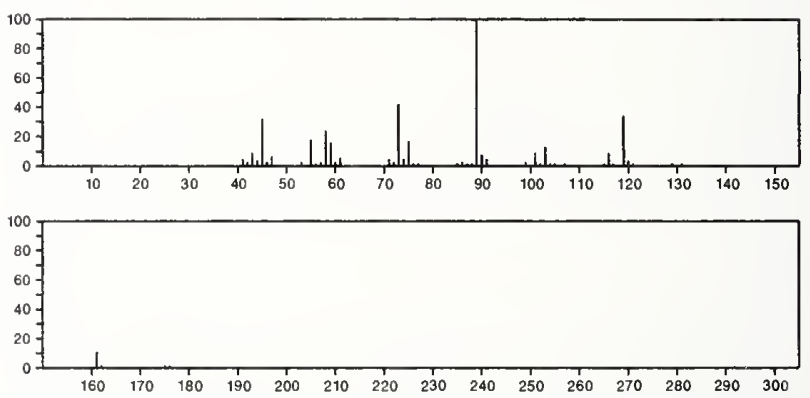

176

$\mathrm{C}_{8} \mathrm{H}_{20} \mathrm{O}_{2} \mathrm{Si}$

$54550-18-4$

Silane, trimethyl[2-(1-methylethoxy)ethoxy]-

$\mathrm{i}-\mathrm{PrOCH} \mathrm{CH}_{2} \mathrm{OSIMe} 3$
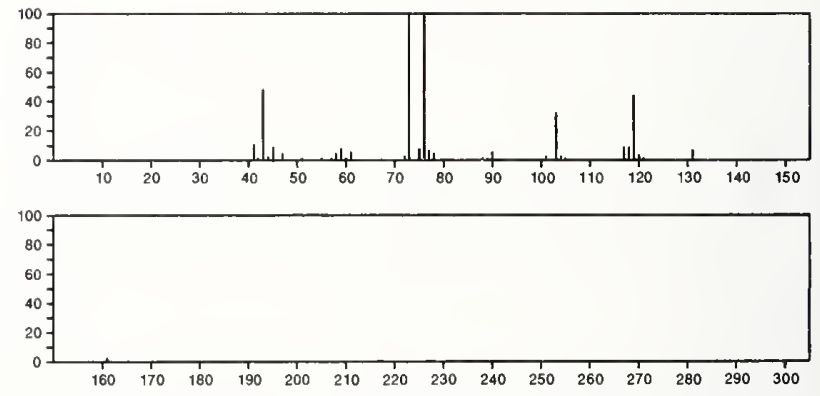

176

$\mathrm{C}_{9} \mathrm{H}_{8} \mathrm{~N}_{2} \mathrm{O}_{2}$

$89-24-7$

2,4-Imidazolidinedione, 5-phenyl
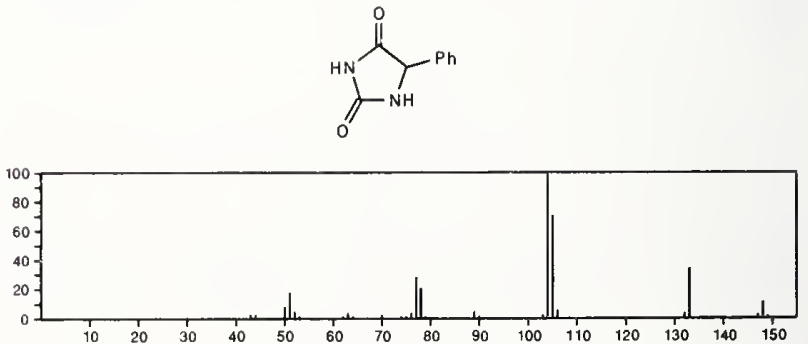


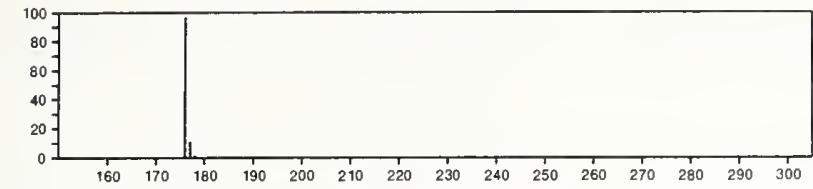

176

$\mathrm{C}_{9} \mathrm{H}_{8} \mathrm{~N}_{2} \mathrm{O}_{2}$

2152-34-3

4(5H)-Oxazolone, 2-amino-5-phenyl-

$\int_{0}^{\mathrm{Ph}} \prod^{\mathrm{NH}}$
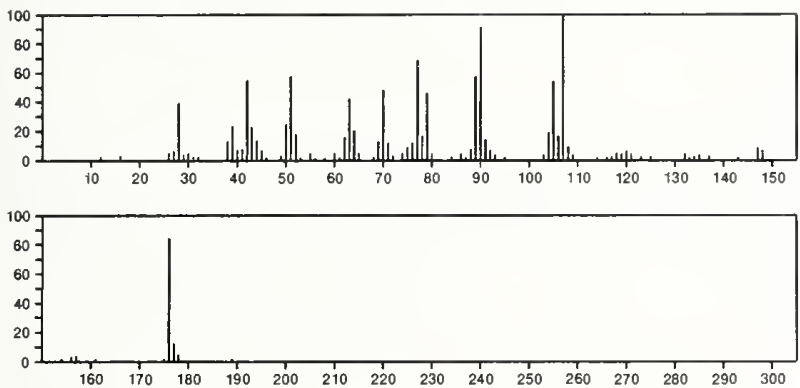

$176 \quad \mathrm{C}_{9} \mathrm{H}_{8} \mathrm{~N}_{2} \mathrm{O}_{2}$

$3483-16-7$

Sydnone, 4-methyl-3-phenyl-
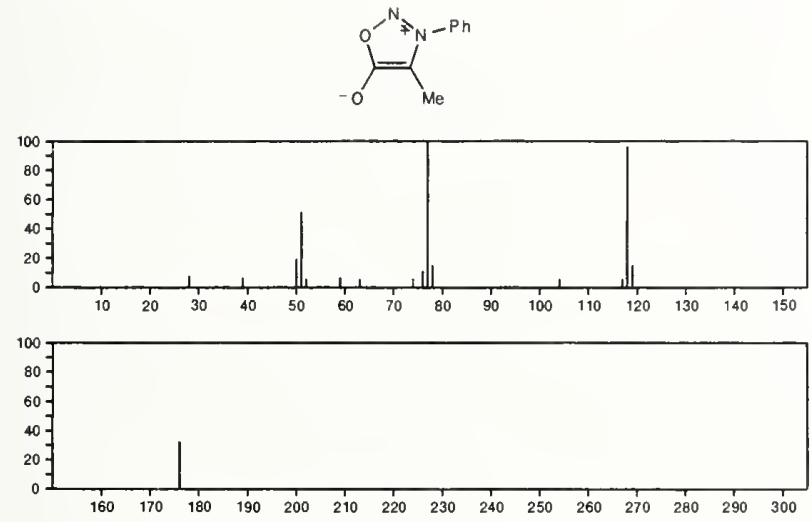

176

$\mathrm{C}_{9} \mathrm{H}_{8} \mathrm{~N}_{2} \mathrm{O}_{2}$

3483-18-9

Sydnone, 3-(2-methylphenyl)-
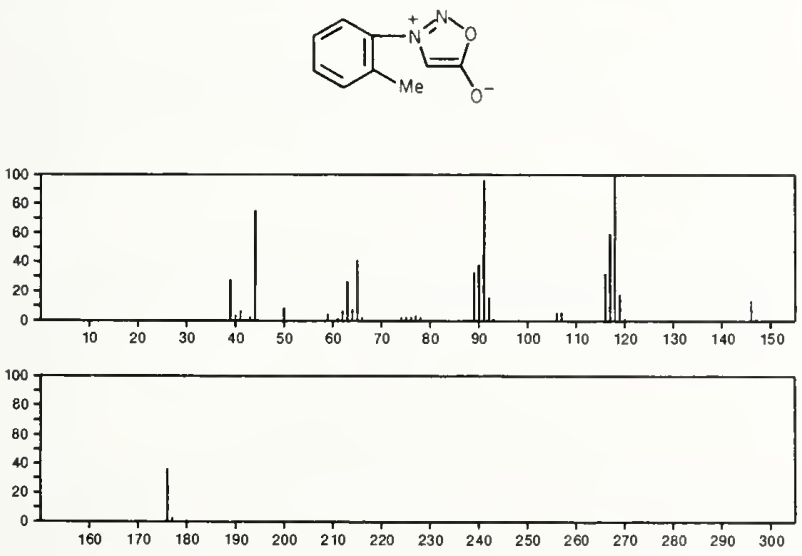

176

$\mathrm{C}_{9} \mathrm{H}_{8} \mathrm{~N}_{2} \mathrm{O}_{2}$

5004-33-1

Cinnoline, 4-methyl-, 1,2-dioxide
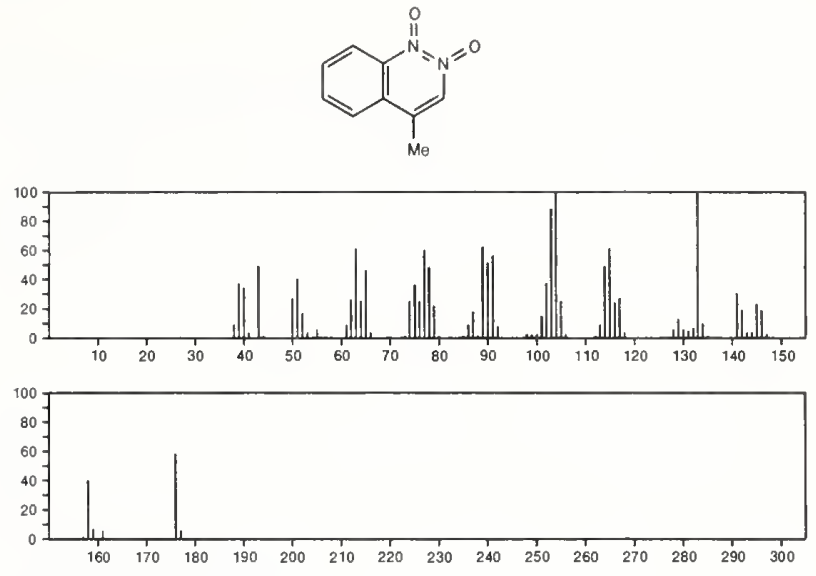

176

$\mathrm{C}_{9} \mathrm{H}_{8} \mathrm{~N}_{2} \mathrm{O}_{2}$

Carbostyril, 3-amino-1-hydroxy-

$16551-96-5$
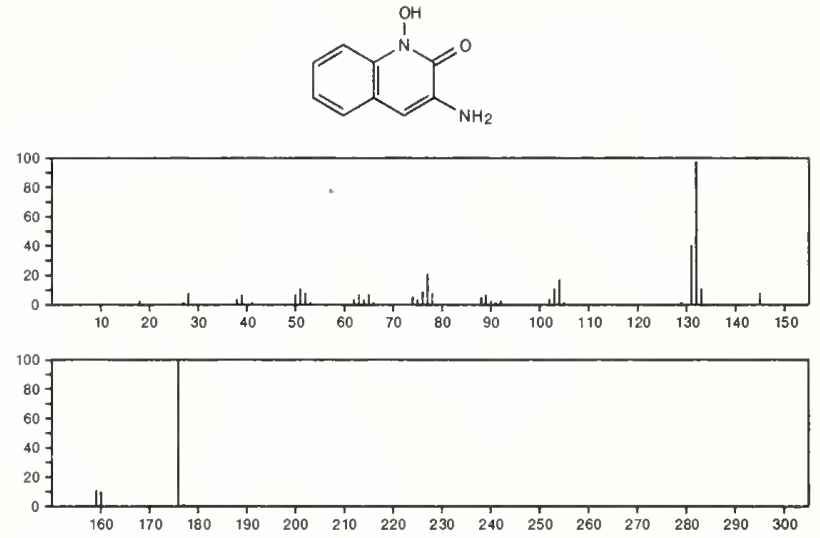

176
Sydnone, 3-(phenylmethyl)

$\mathrm{C}_{9} \mathrm{H}_{8} \mathrm{~N}_{2} \mathrm{O}_{2}$

$16844-42-1$
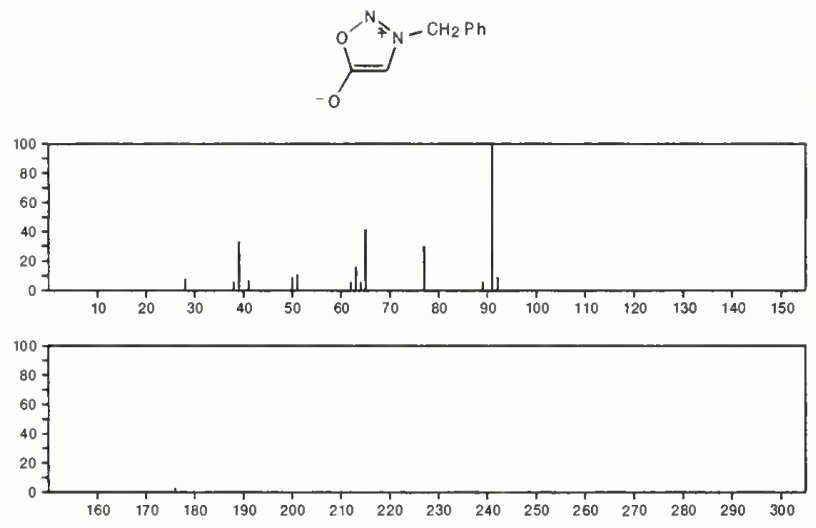

176

Quinoxaline, 2-methoxy-, 4-oxide

18916-46-6

$\mathrm{C}_{9} \mathrm{H}_{8} \mathrm{~N}_{2} \mathrm{O}_{2}$
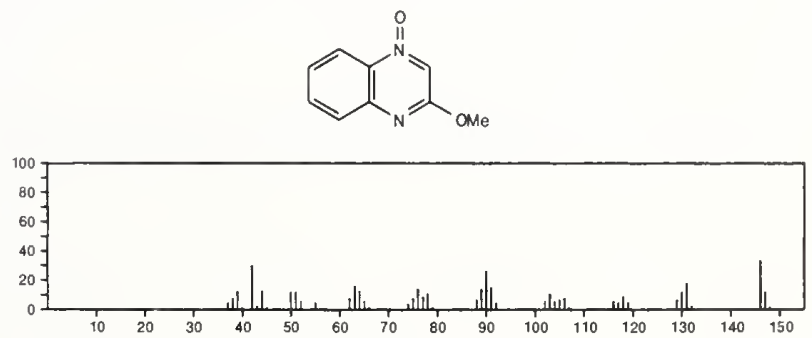


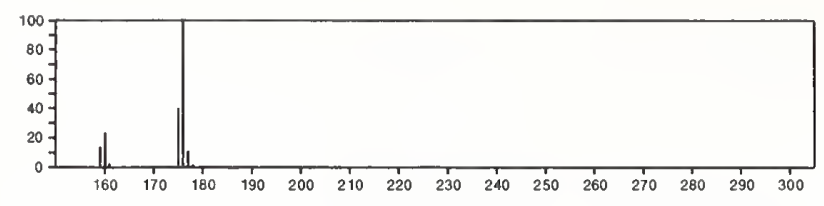

176

$\mathrm{C}_{9} \mathrm{H}_{8} \mathrm{~N}_{2} \mathrm{O}_{2}$

1,3,4-Oxadiazolium, 5-hydroxy-2-methyl-3-phenyl inner salt
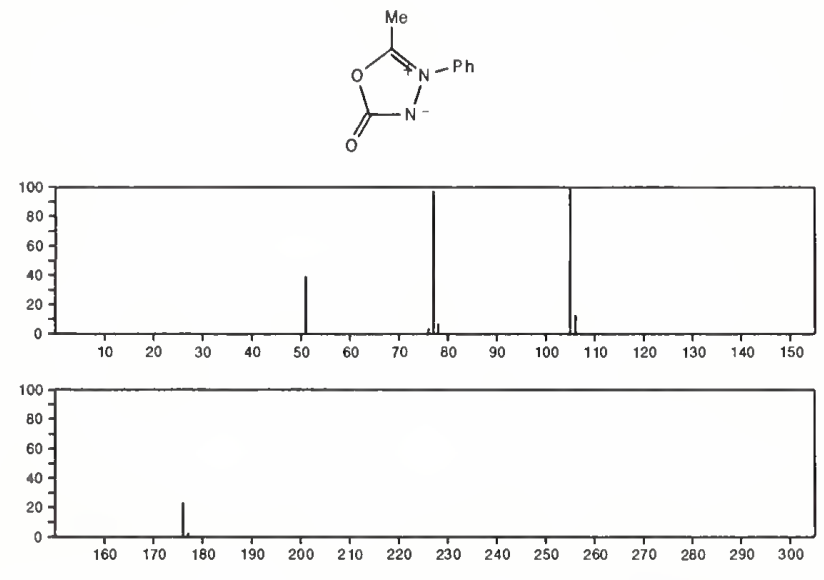

$176 \quad \mathrm{C}_{9} \mathrm{H}_{8} \mathrm{~N}_{2} \mathrm{O}_{2}$

$28740-63-8$

1,3,4-Oxadiazol-2(3H)-one, 5-methyl-3-phenyl
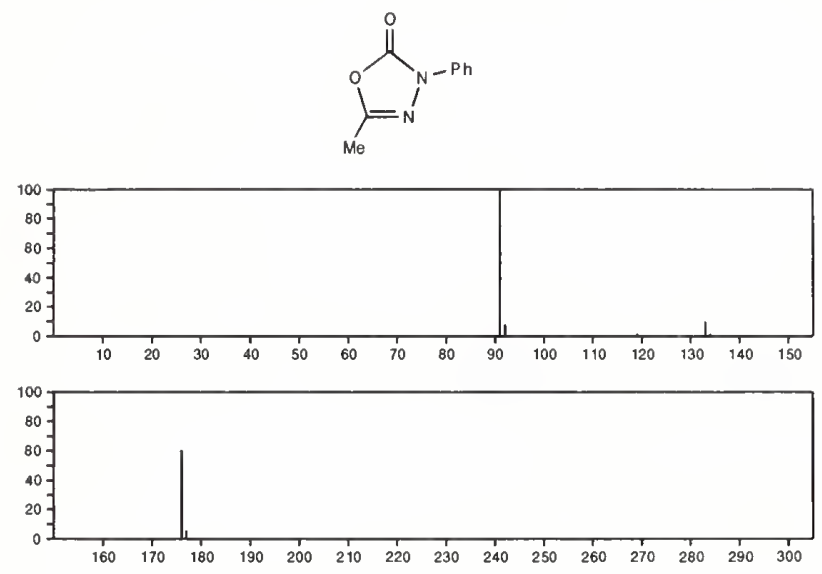

176

$\mathrm{C}_{9} \mathrm{H}_{8} \mathrm{~N}_{2} \mathrm{O}$

4-Quinazolinol, 2-methyl-, 3-oxide

$54518-07 \cdot 9$
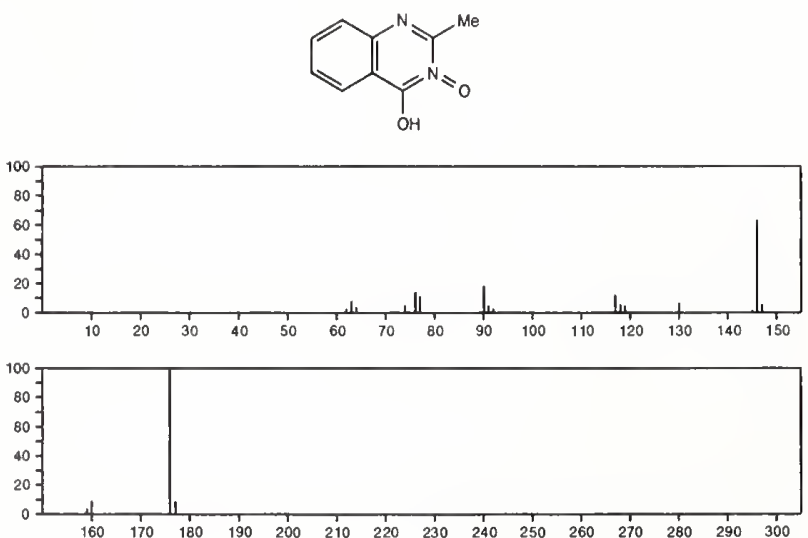

176

$\mathrm{C}_{9} \mathrm{H}_{8} \mathrm{~N}_{2} \mathrm{~S}$

4H-Pyrido[1,2- $a]$ pyrimidine-4-thione, 2 -methyl

$50993-74-3$
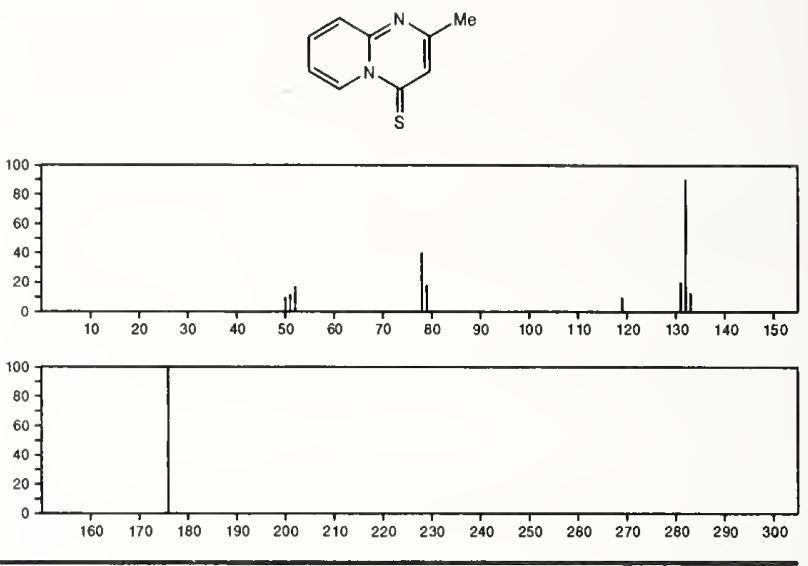

176

$\mathrm{C}_{9} \mathrm{H}_{9} \mathrm{BO}_{3}$

$54518-06-8$

1,3,2-Dioxaborolan-4-one, 2-methyl-5-phenyl-
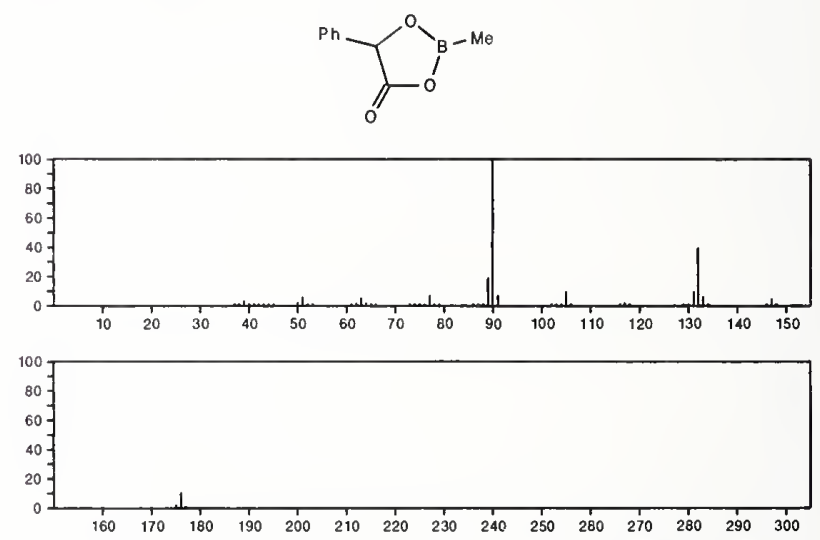

$\mathrm{C}_{9} \mathrm{H}_{12} \mathrm{~N}_{4}$

$19848-81-8$

$s$-Triazolo[4,3-a]pyrazine, 3-ethyl-5,8-dimethyl-
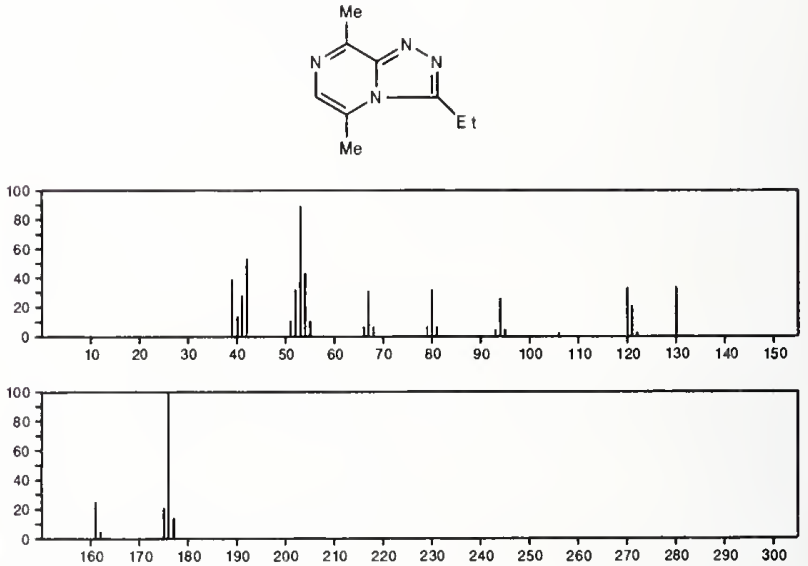
$176 \quad \mathrm{C}_{9} \mathrm{H}_{12} \mathrm{~N}_{4} \quad 54518-05-7$

$[1,2,4]$ Triazolo[1,5-a]pyrazine, 2-ethyl-5,8-dimethyl-
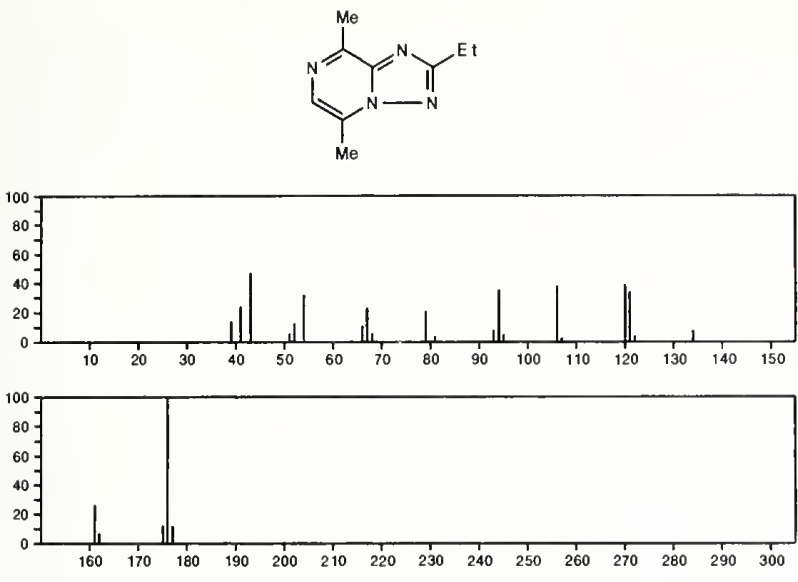

176

$\mathrm{C}_{9} \mathrm{H}_{20} \mathrm{O}_{3}$

$115-80-0$

Propane, 1,1,1-triethoxy-

$E+C(O E t) 3$

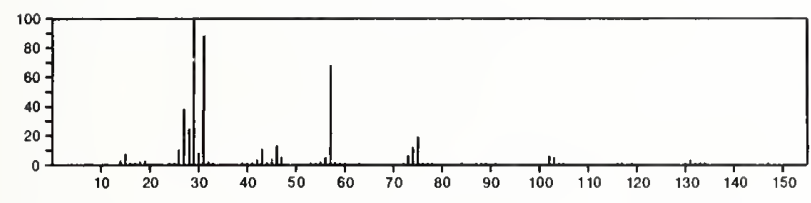

176

$\mathrm{C}_{9} \mathrm{H}_{20} \mathrm{O}_{3}$

20637-29-0

Hexane, 1,2,3-trimethoxy-

$\mathrm{Pr} \mathrm{CH}(\mathrm{OMe}) \mathrm{CH}(\mathrm{OMe}) \mathrm{CH}_{2} \mathrm{OMe}$
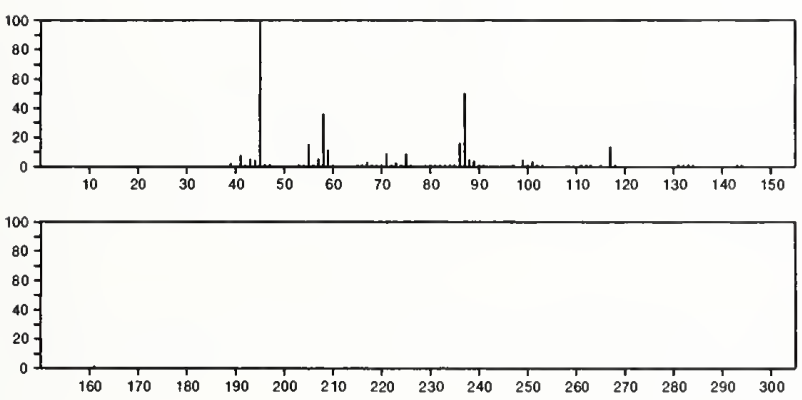

176

$\mathrm{C}_{9} \mathrm{H}_{20} \mathrm{O}_{3}$

$54518-03-5$

1-Propanol, 3-[3-(1-methylethoxy)propoxy]-

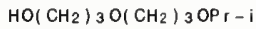

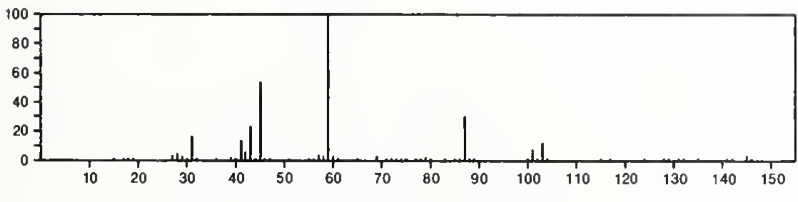

176

$\mathrm{C}_{9} \mathrm{H}_{20} \mathrm{O}_{3}$

$54518-04-6$

Methanol, dibutoxy-

$\mathrm{Me}\left(\mathrm{CH}_{2}\right)_{3} \mathrm{OCH}(\mathrm{OH}) \mathrm{O}\left(\mathrm{CH}_{2}\right)_{3} \mathrm{Me}$

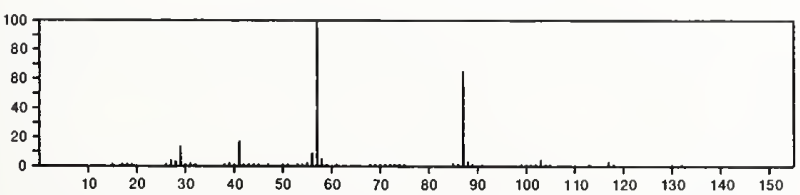

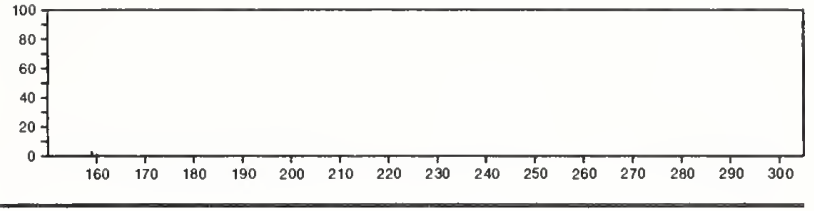

176

$\mathrm{C}_{10} \mathrm{H}_{8} \mathrm{O}_{3}$

90-33-5

2H-1-Benzopyran-2-one, 7-hydroxy-4-methyl-
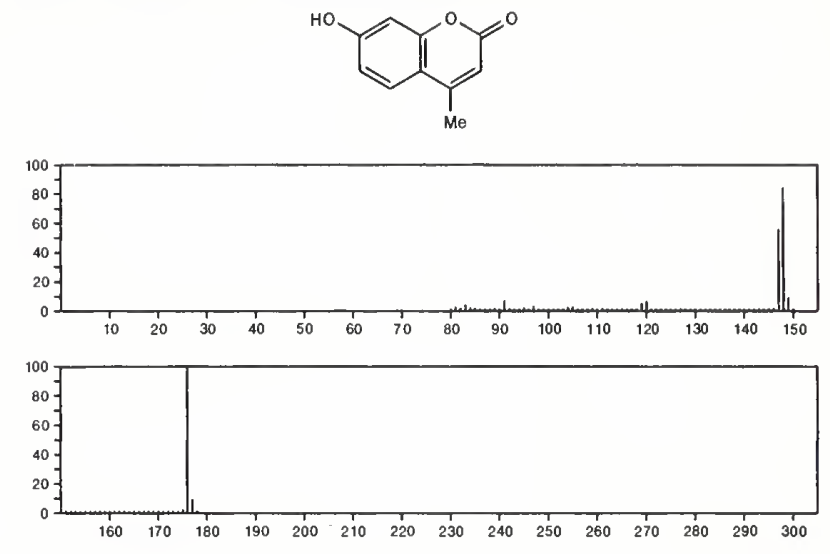

$176 \quad \mathrm{C}_{10} \mathrm{H}_{8} \mathrm{O}_{3}$

1,3-Isobenzofurandione, 4,7-dimethyl-

$5463-50-3$
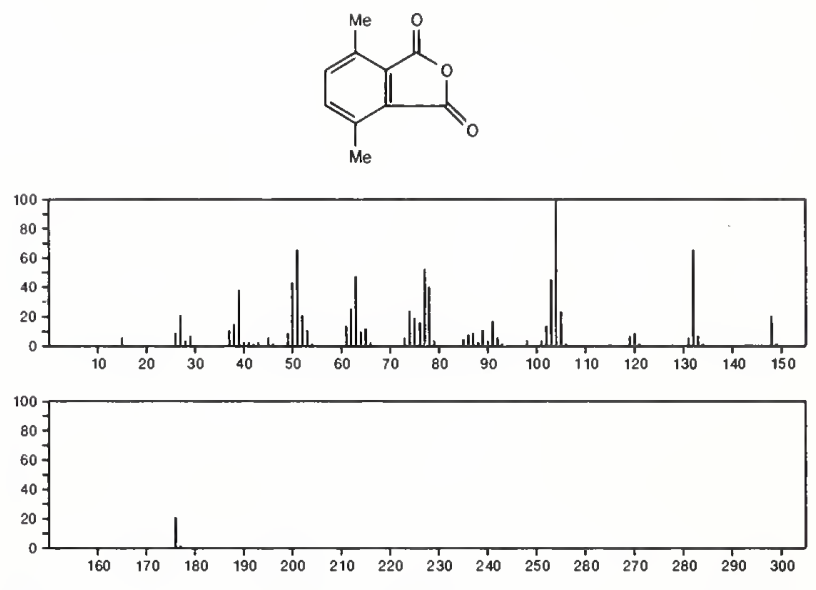

176

$\mathrm{C}_{10} \mathrm{H}_{8} \mathrm{O}_{3}$

$22105-12-0$

4H-1-Benzopyran-4-one, 6-hydroxy-2-methyl-
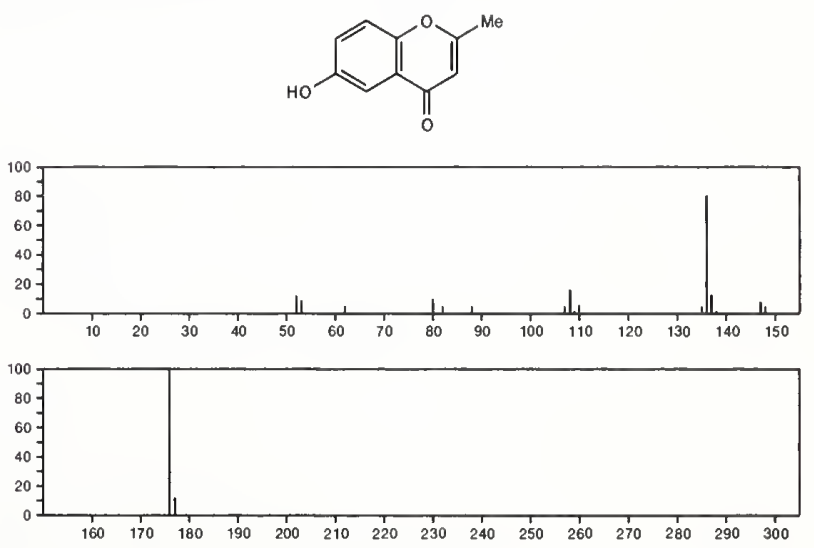
176

$\mathrm{C}_{10} \mathrm{H}_{8} \mathrm{O}_{3}$

2-Furancarboxaldehyde, 5-(2-furanylmethyl)-<smiles>O=Cc1ccc(Cc2ccco2)o1</smiles>
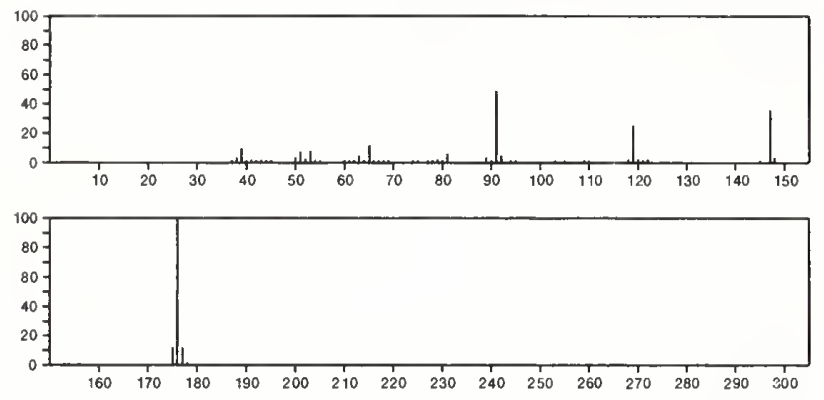

$176 \quad \mathrm{C}_{10} \mathrm{H}_{8} \mathrm{O}_{3} \quad 40800-89-3$

3-Benzofurancarboxaldehyde, 2-methoxy
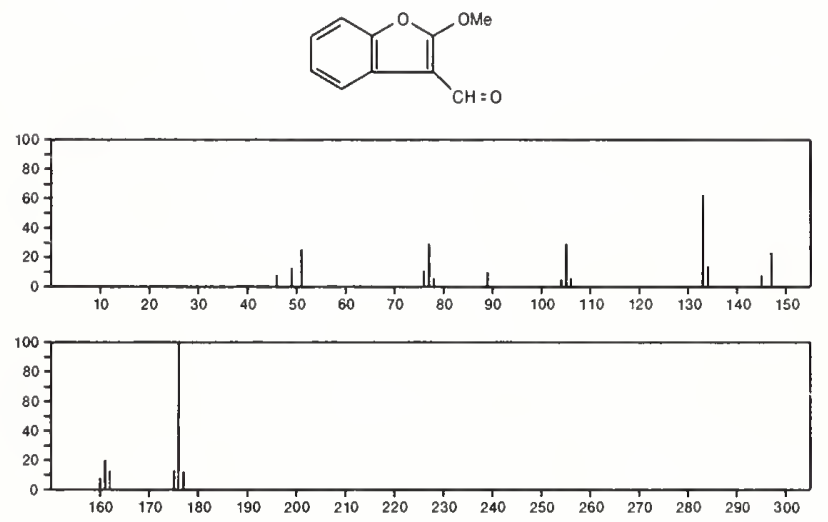

176

$\mathrm{C}_{10} \mathrm{H}_{8} \mathrm{O}_{3}$

$40800-90-6$

2(3H)-Benzofuranone, 3-(methoxymethylene)-
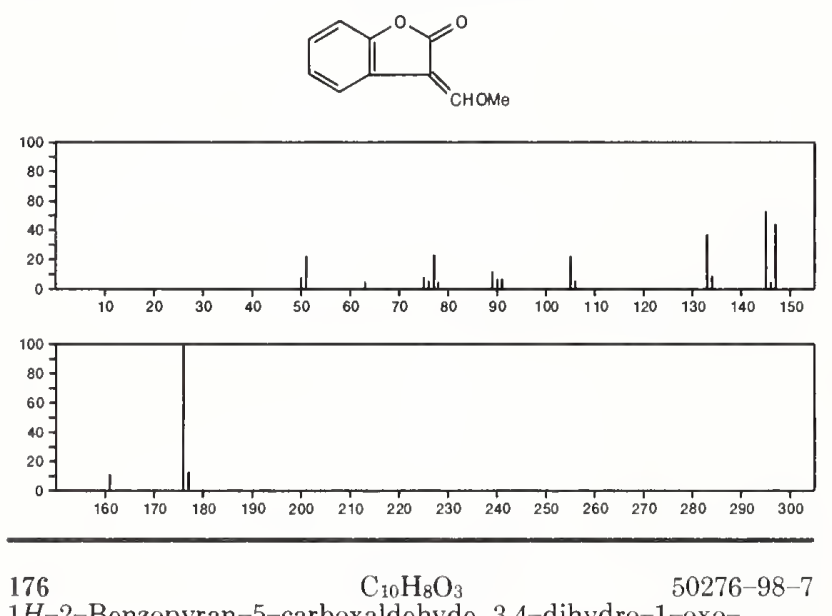

1H-2-Benzopyran-5-carboxaldehyde, 3,4-dihydro-1-oxo-
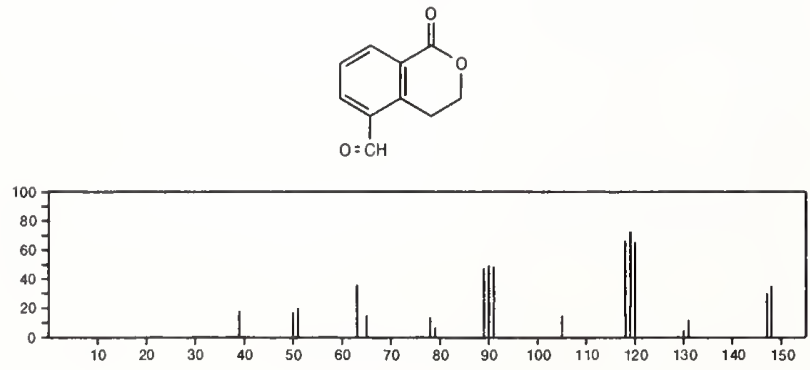

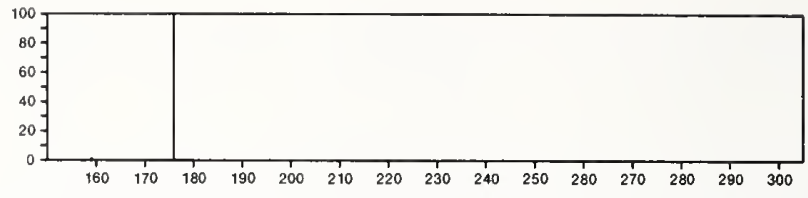

176

1H-Indol-5-ol, 3-(2-aminoethyl)-

$50-67-9$
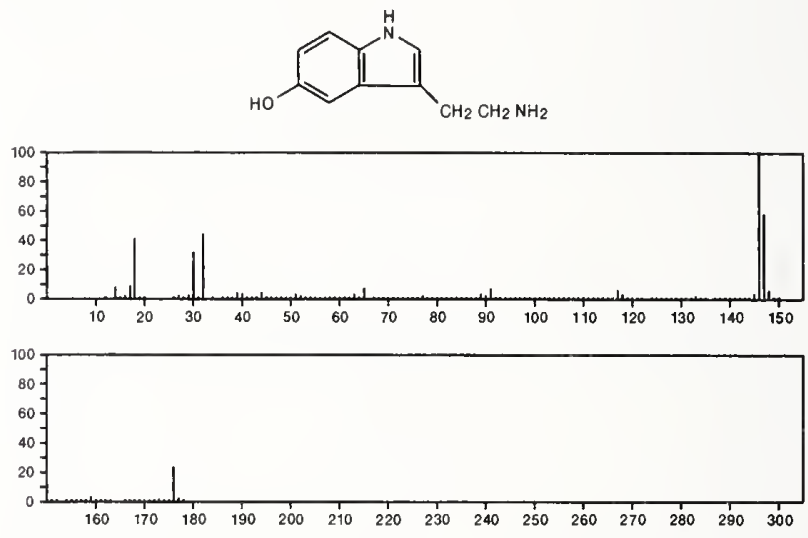

176

$\mathrm{C}_{10} \mathrm{H}_{12} \mathrm{~N}_{2} \mathrm{O}$

$486-56-6$

2-Pyrrolidinone, 1-methyl-5-(3-pyridinyl)-, (S)-
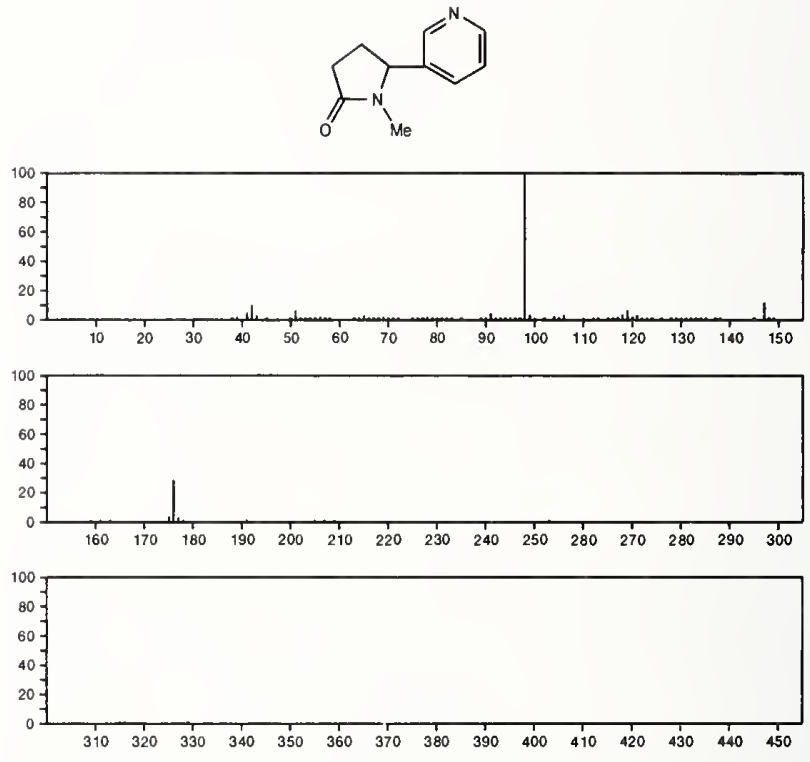

176

$\mathrm{C}_{10} \mathrm{H}_{12} \mathrm{~N}_{2} \mathrm{O}$

1-Aziridinecarboxamide, $N$-(4-methylphenyl)-

829-65-2
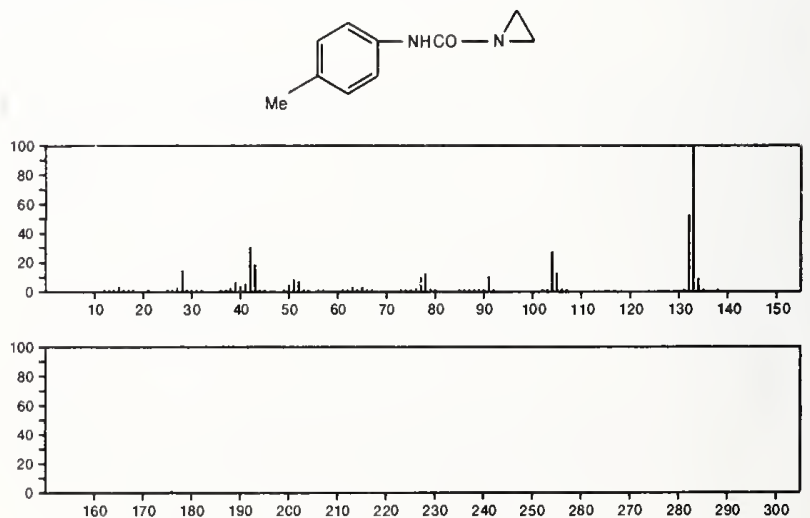
$176 \quad \mathrm{C}_{10} \mathrm{H}_{12} \mathrm{~N}_{2} \mathrm{O}$

$1 H$-Imidazole, 4,5-dihydro-2-(4-methoxyphenyl)
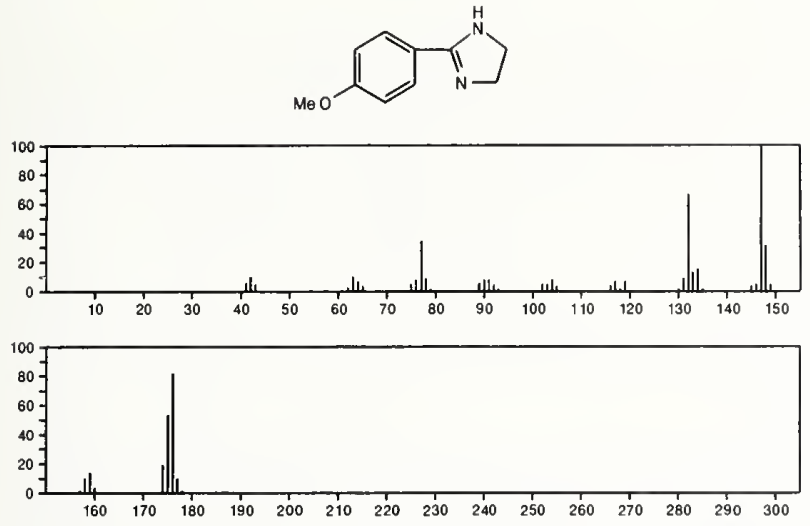

176

$\mathrm{C}_{10} \mathrm{H}_{12} \mathrm{~N}_{2} \mathrm{O}$

Benzimidazole, 2-isopropyl-, 3-oxide
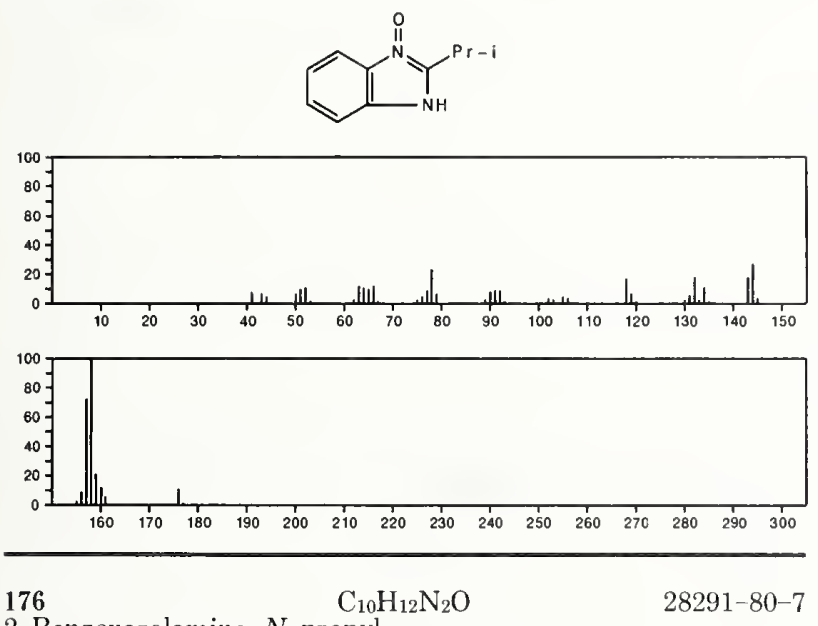

2-Benzoxazolamine, $N$-propyl-
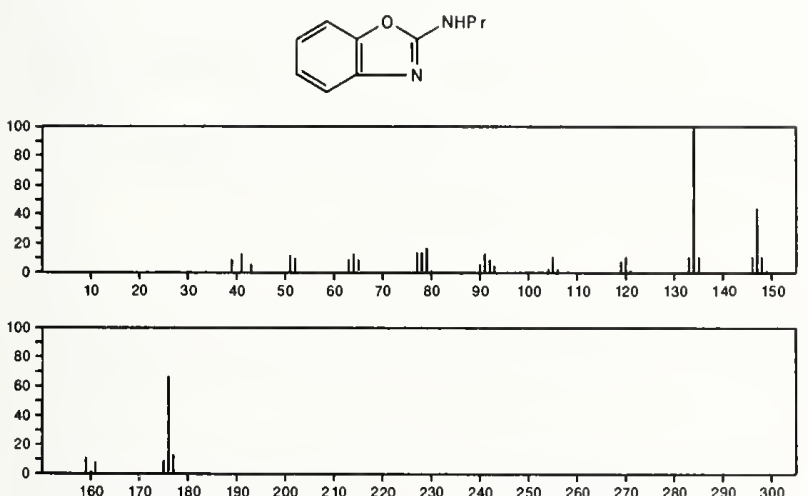

$\begin{array}{lllllllllllllll}160 & 170 & 180 & 190 & 200 & 210 & 220 & 230 & 240 & 250 & 260 & 270 & 280 & 290 & 300\end{array}$

176 $\mathrm{C}_{10} \mathrm{H}_{12} \mathrm{~N}_{2} \mathrm{O}$

$28455-42-7$

Benzoxazole, 2-(isopropylamino)
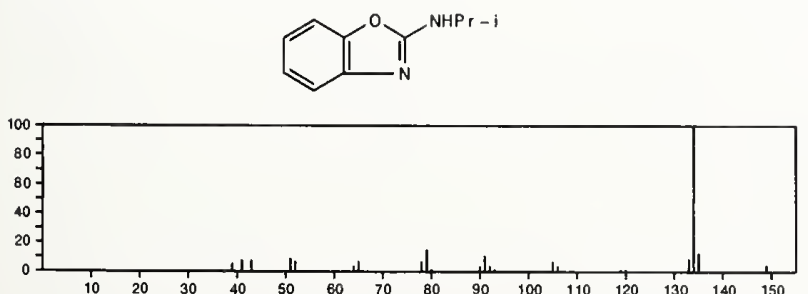

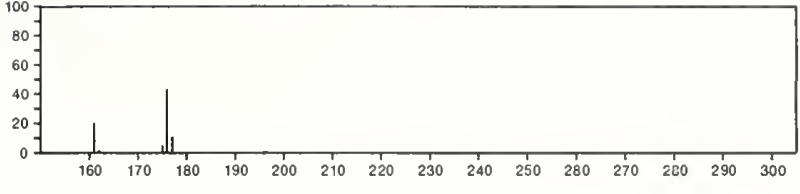

176
$1,5-$ Benzodiazocin-6(1H) - one, $2,3,4,5$-tetrahydro-

$51111-02-5$
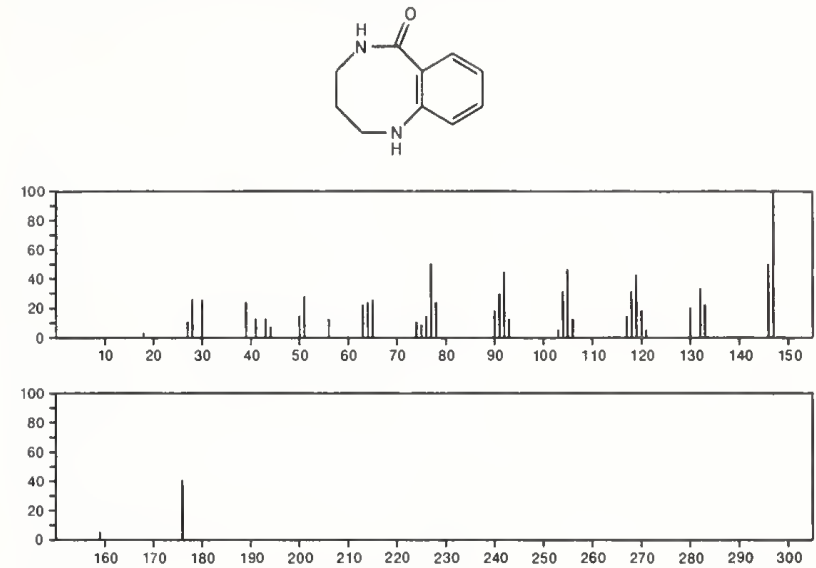

176

Decane, 3-chloro-

$\mathrm{C}_{10} \mathrm{H}_{21} \mathrm{Cl}$

$1002-11-5$

$\mathrm{E}+\mathrm{CHCl}\left(\mathrm{CH}_{2}\right) 6 \mathrm{Me}$

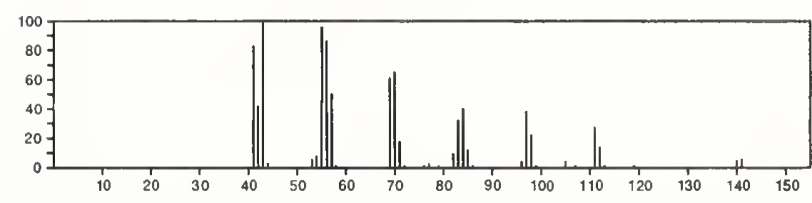

176

$\mathrm{C}_{10} \mathrm{H}_{21} \mathrm{Cl}$

1002-69-3

Decane, 1-chloro-

$\mathrm{Me}\left(\mathrm{CH}_{2}\right){ }_{9} \mathrm{Cl}$
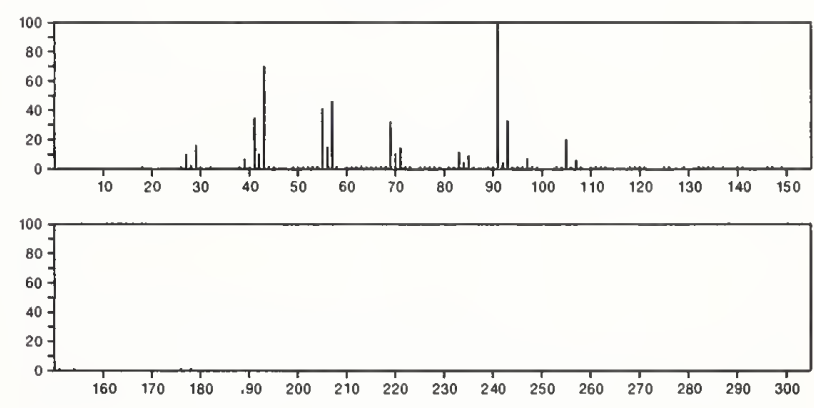

176

$\mathrm{C}_{11} \mathrm{H}_{9} \mathrm{Cl}$

86-52-2

Naphthalene, 1-(chloromethyl)
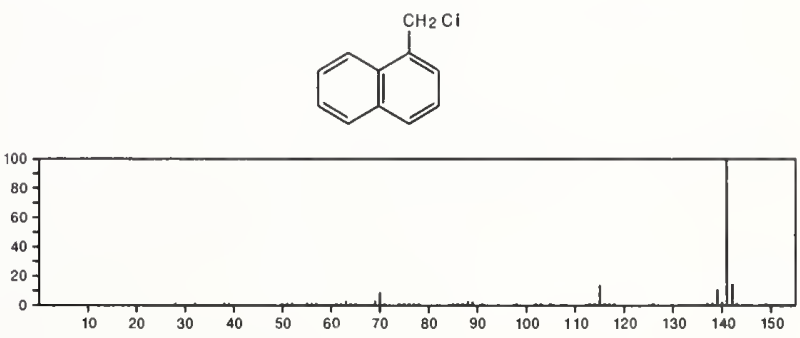


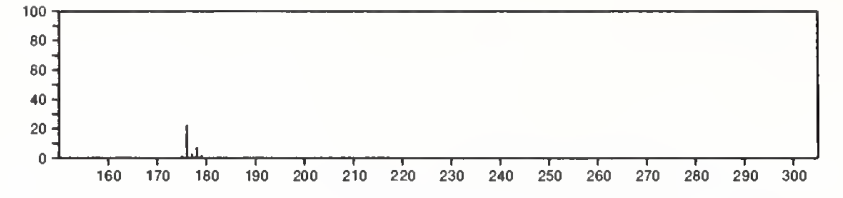

$176 \quad \mathrm{C}_{11} \mathrm{H}_{12} \mathrm{O}_{2} \quad 103-36-6$ 2-Propenoic acid, 3-phenyl-, ethyl ester

$\mathrm{E} \mathrm{OOC}(\mathrm{O}) \mathrm{CH}=\mathrm{CHPh}$
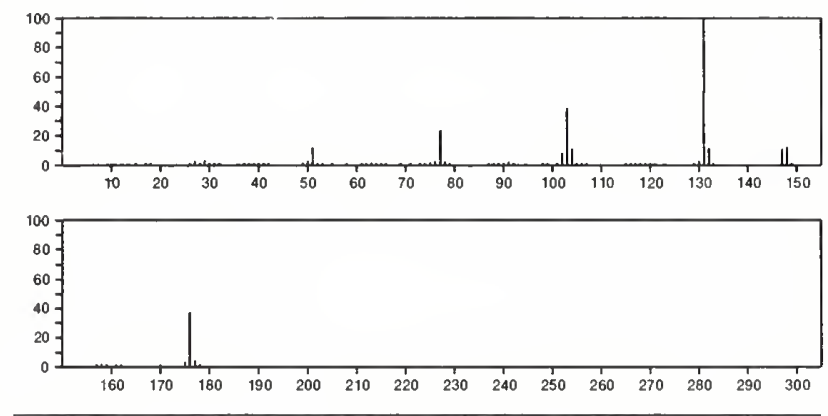

176

$\mathrm{C}_{11} \mathrm{H}_{12} \mathrm{O}_{2}$

2-Propen-1-ol, 3-phenyl-, acetate

$\mathrm{ACOCH} 2 \mathrm{CH}=\mathrm{CHPh}$
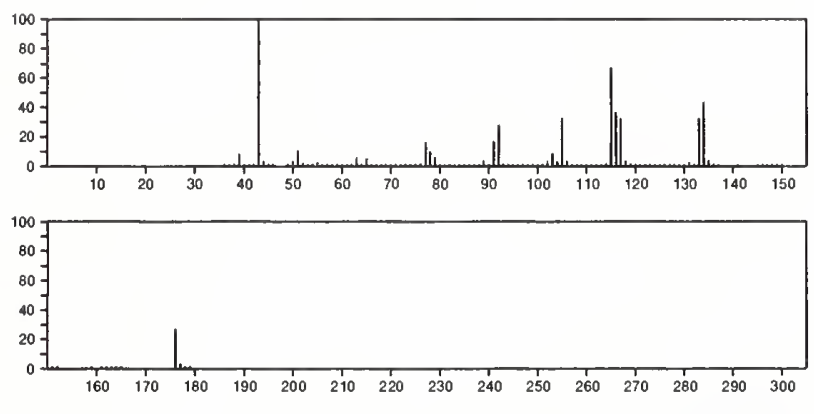

$176 \quad \mathrm{C}_{11} \mathrm{H}_{12} \mathrm{O}_{2} \quad 1078-19-9$

1(2H)-Naphthalenone, 3,4-dihydro-6-methoxy-
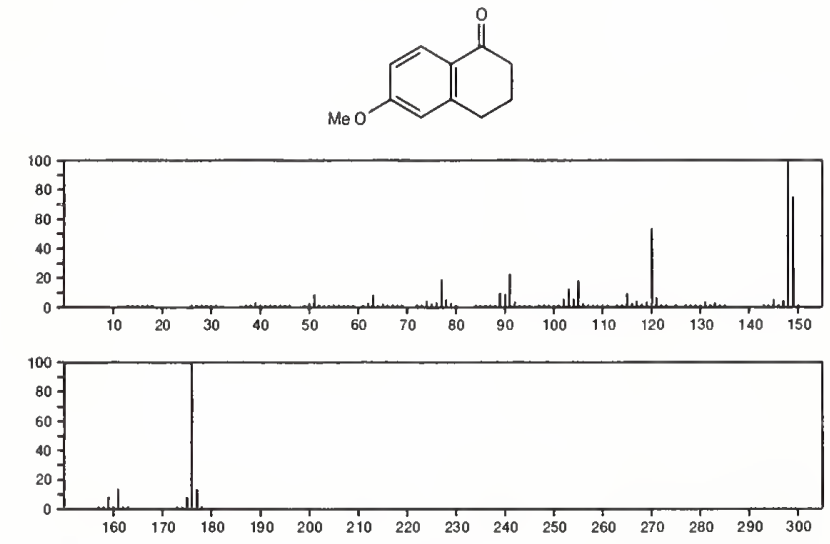

176

$\mathrm{C}_{11} \mathrm{H}_{12} \mathrm{O}_{2}$

Benzeneacetic acid, 2-propenyl ester

$1797-74-6$

$\mathrm{PhCH} 2 \mathrm{C}(\mathrm{O}) \mathrm{OCH}_{2} \mathrm{CH}=\mathrm{CH}_{2}$

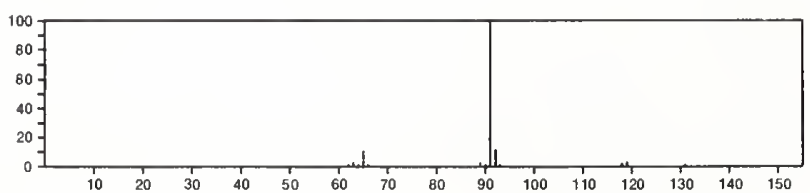

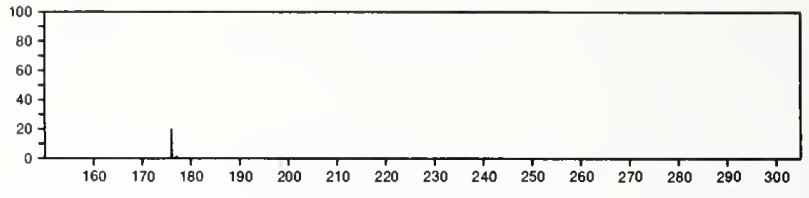

$176 \quad \mathrm{C}_{11} \mathrm{H}_{12} \mathrm{O}_{2}$

Benzenepropanoic acid, $\alpha$-methylene-, methyl ester

3070-71-1 $\mathrm{CH}_{2}$ $\mathrm{MeOC}(\mathrm{O}) \stackrel{\mathrm{C}}{\mathrm{C}} \mathrm{CH}_{2} \mathrm{Ph}$
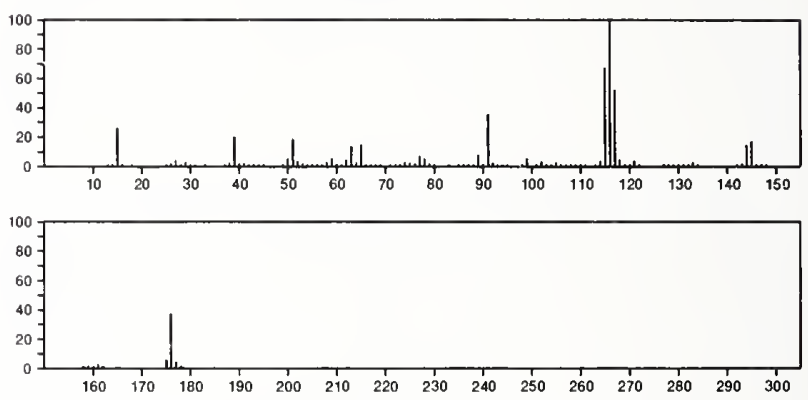

176

$\mathrm{C}_{11} \mathrm{H}_{12} \mathrm{O}_{2}$

Phenol, 2-(2-propenyl)-, acetate

4125-54-6
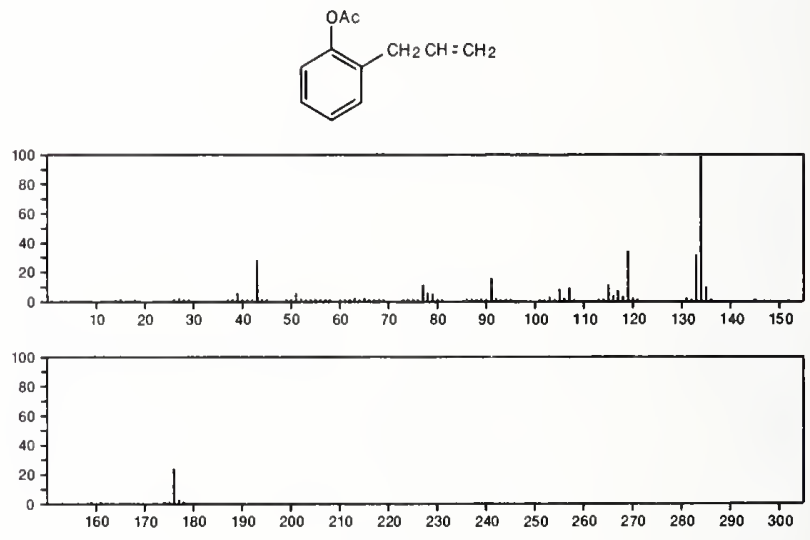

176

$\mathrm{C}_{11} \mathrm{H}_{12} \mathrm{O}_{2}$

1-Naphthalenecarboxylic acid, 5,6,7,8-tetrahydro-

4242-18-6
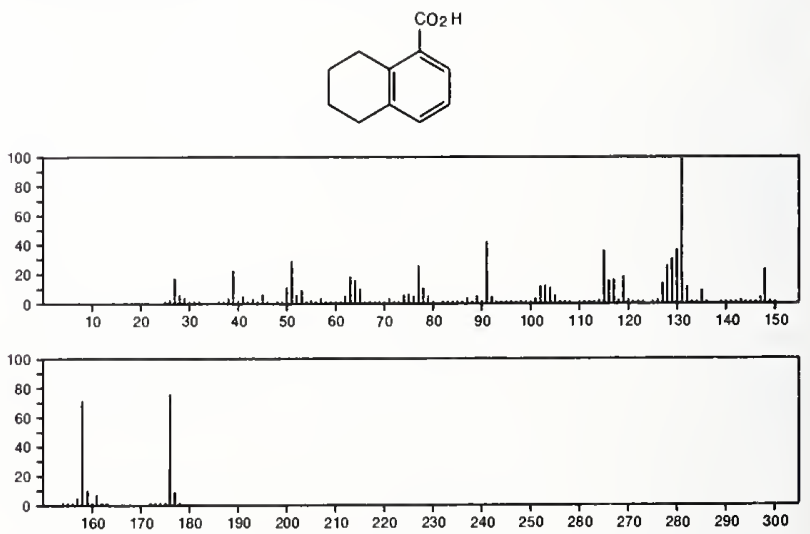
176 $\mathrm{C}_{11} \mathrm{H}_{12} \mathrm{O}_{2}$ 2-Buten-1-one, 1-(2-hydroxy-5-methylphenyl)-
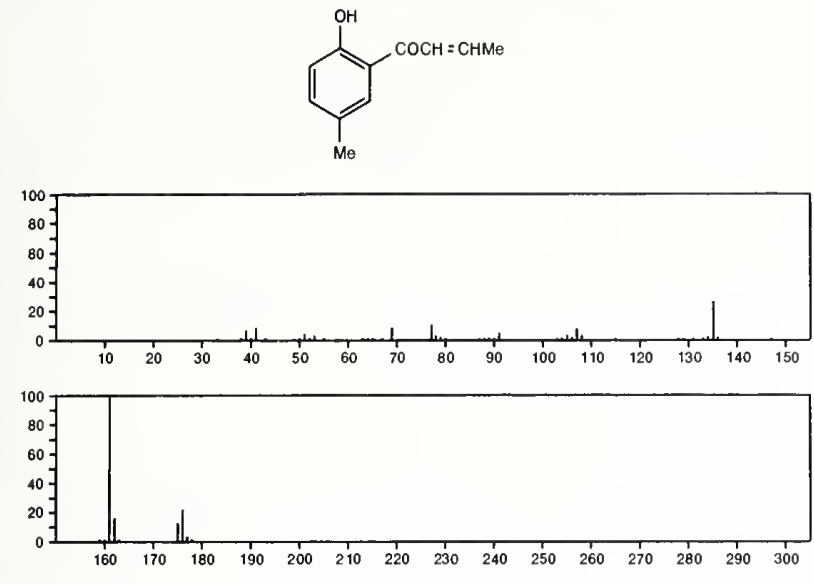

176

2,4-Pentanedione, 3-phenyl-

$\mathrm{C}_{11} \mathrm{H}_{12} \mathrm{O}_{2}$

$5910-25-8$

Me COCHPh COMe
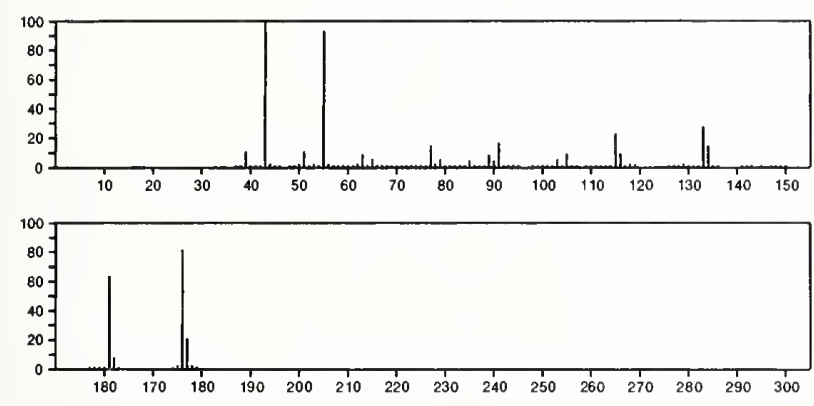

176

1,3-Butanedione, 2-methyl-1-phenyl-

$6668-24-2$

$\mathrm{PhCOCHMECOMO}$
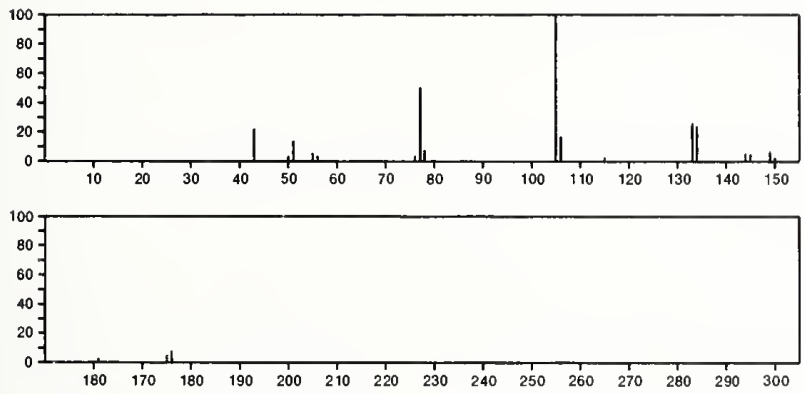

176

$\mathrm{C}_{11} \mathrm{H}_{12} \mathrm{O}_{2}$

2(3H)-Furanone, dihydro-5-methyl-5-phenyl-
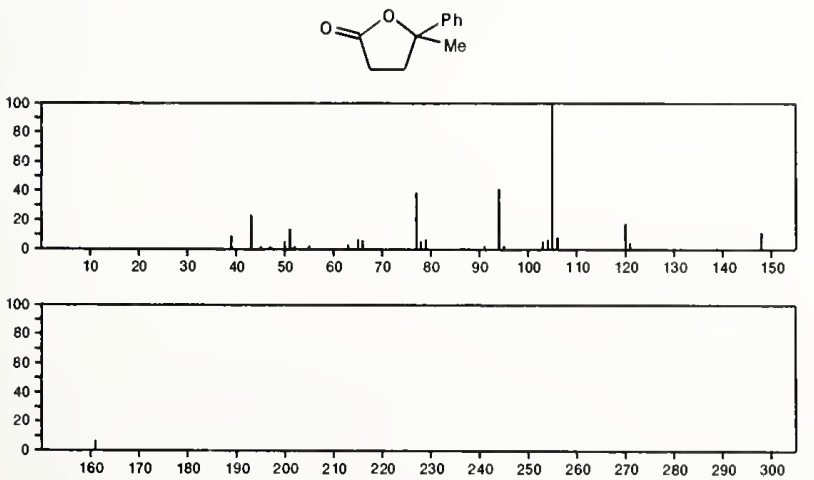

176

$\mathrm{C}_{11} \mathrm{H}_{12} \mathrm{O}_{2}$

Benzofuran, 5-methoxy-6,7-dimethyl-

$35355-35-2$
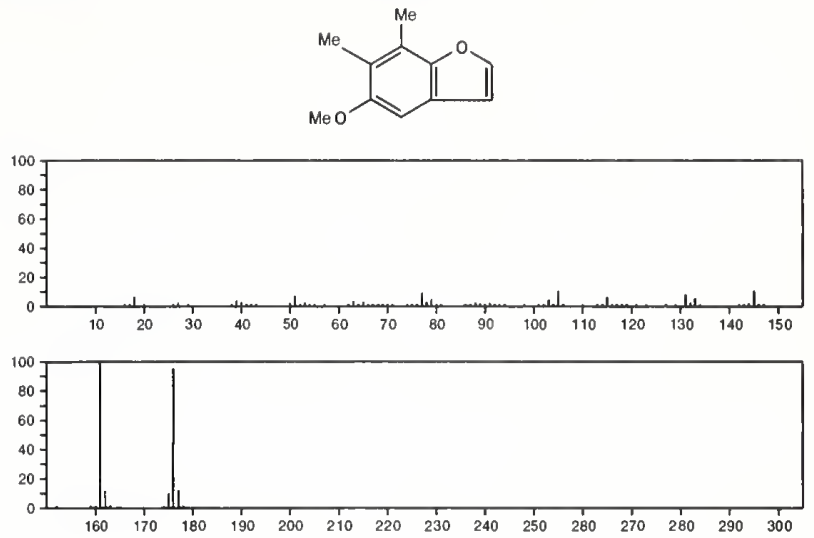

176

3-Pentenoic acid, 4-phenyl-

$\mathrm{C}_{11} \mathrm{H}_{12} \mathrm{O}_{2}$

53774-19-9

$\mathrm{HO}_{2} \mathrm{CCH}_{2} \mathrm{CH}=\mathrm{CMePh}$
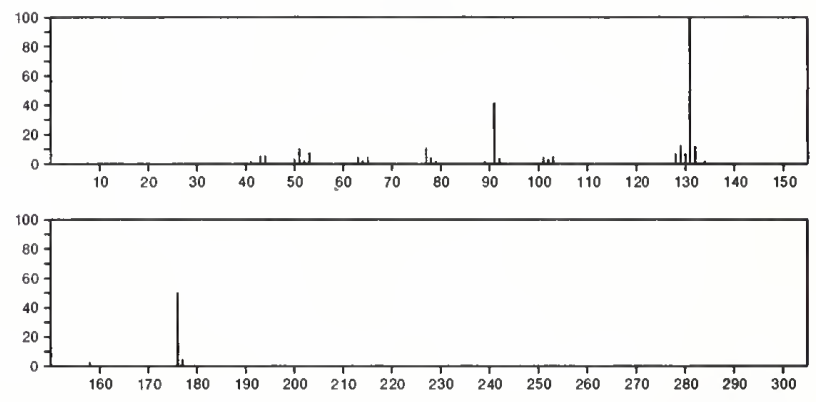

176

$\mathrm{C}_{11} \mathrm{H}_{12} \mathrm{O}_{2}$

2-Pentenoic acid, 5-phenyl-, $(E)$ -

$55320-96-2$

$\mathrm{HO}_{2} \mathrm{CCH}=\mathrm{CHCH}_{2} \mathrm{CH}_{2} \mathrm{Ph}$
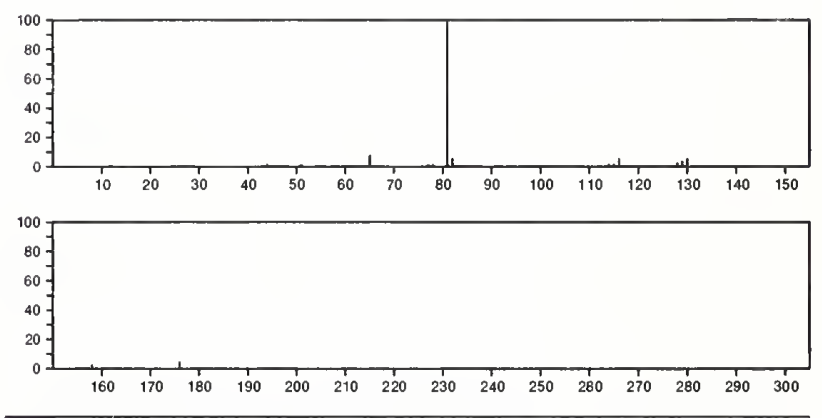

176

Benzo[b]thiophene, 2-propyl-

$\mathrm{C}_{11} \mathrm{H}_{12} \mathrm{~S}$

$16587-32-9$
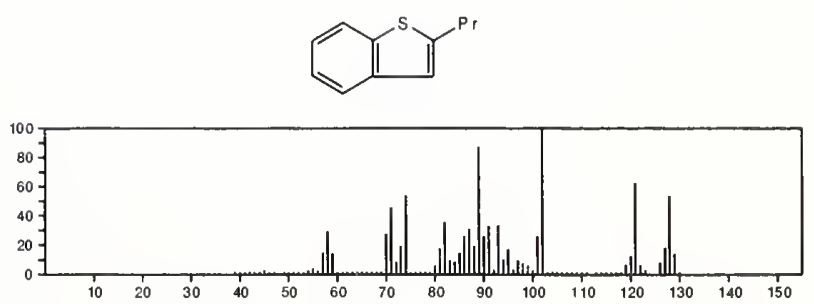
176 $\mathrm{C}_{11} \mathrm{H}_{12} \mathrm{~S}$

Benzo[b]thiophene, 2-ethyl-7-methyl-

$16587-43-2$
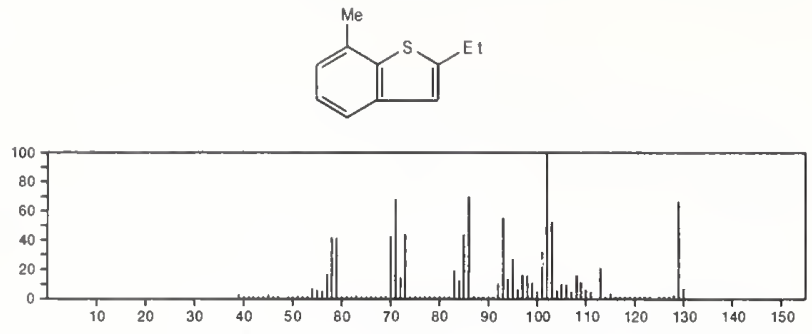

176

Benzo[b]thiophene, 7-ethyl-2-methyl
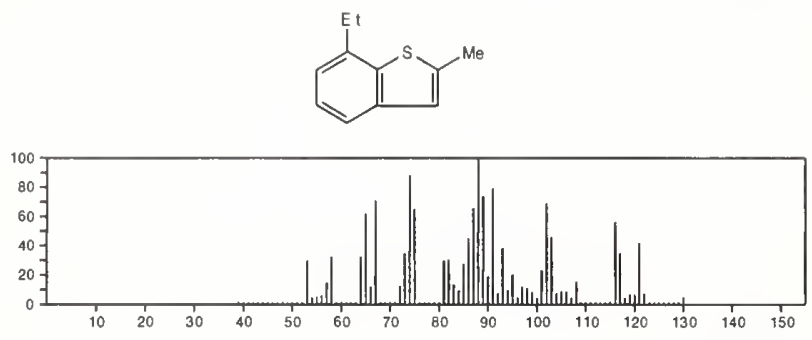

176

Benzo[b]thiophene, 2-ethyl-5-methyl
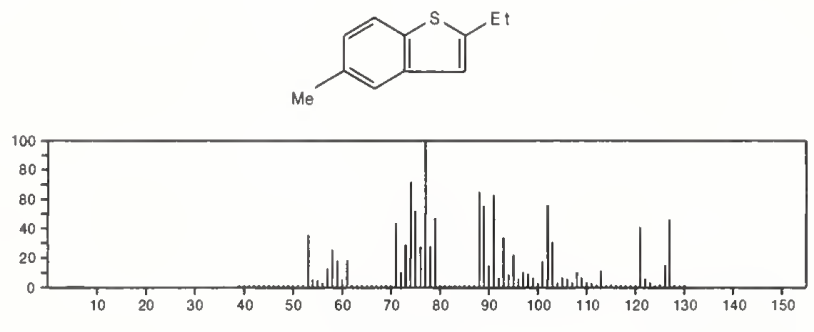

$176 \quad \mathrm{C}_{11} \mathrm{H}_{12} \mathrm{~S}$

Benzo[b]thiophene, 2,5,7-trimethyl-
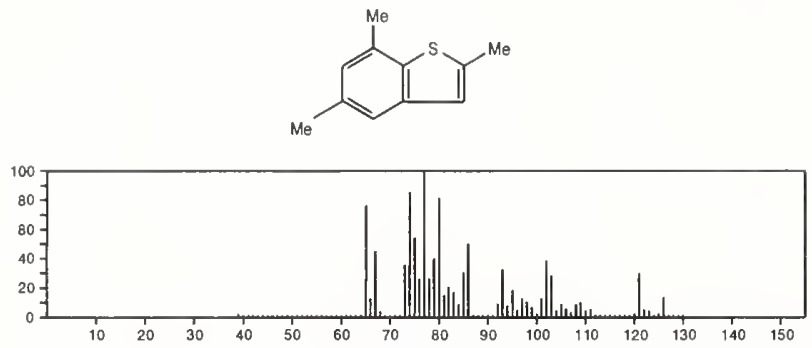

176

1,1-Cyclopropanedicarbonitrile, 2-methyl-2-pentyl-

$16738-90-2$
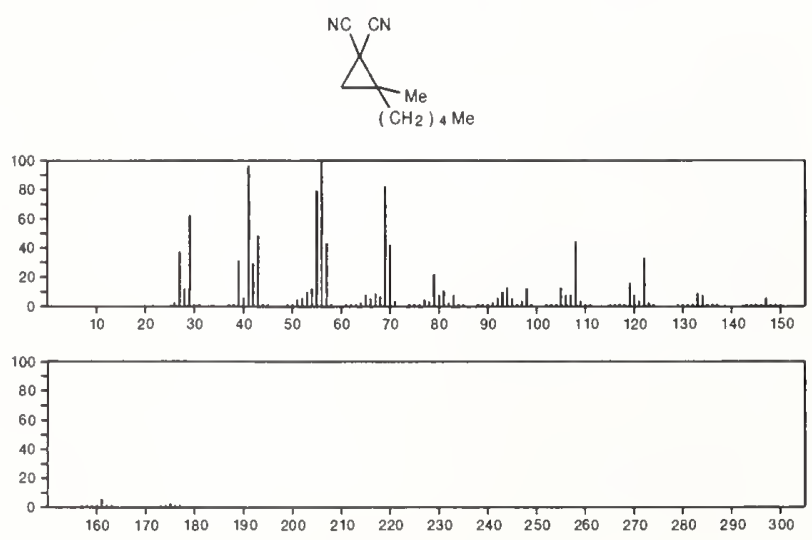

176 Pyridine, 2-(1-methyl-2-pyridinyl)--
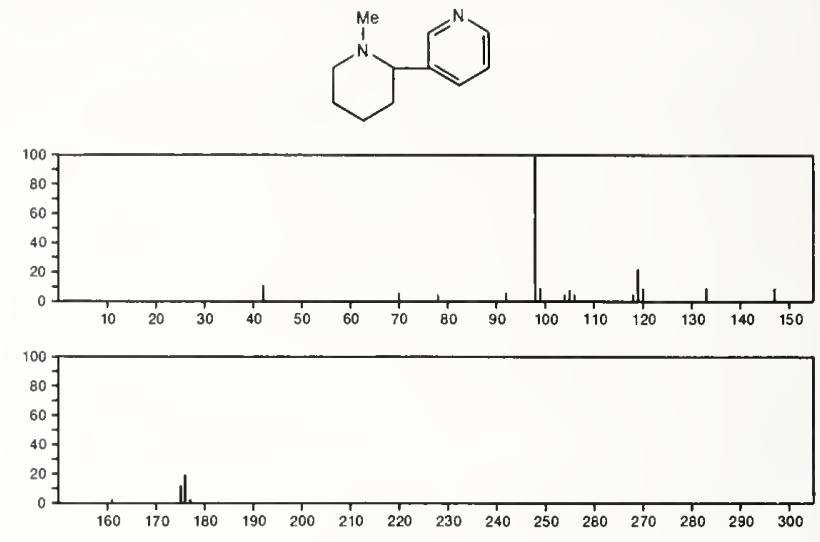

176

$\mathrm{C}_{11} \mathrm{H}_{16} \mathrm{~N}_{2}$

Imidazolidine, 1,3-dimethyl-2-phenyl-

$23229-37-0$
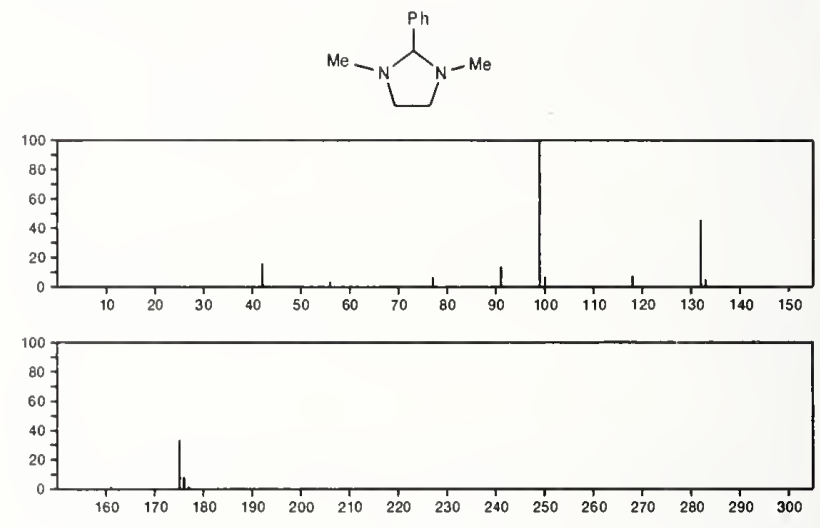

176

$\mathrm{C}_{11} \mathrm{H}_{16} \mathrm{~N}_{2}$

Pyridine, 3-(1-methyl-2-piperidinyl)-, (S)-

$24380-92-5$
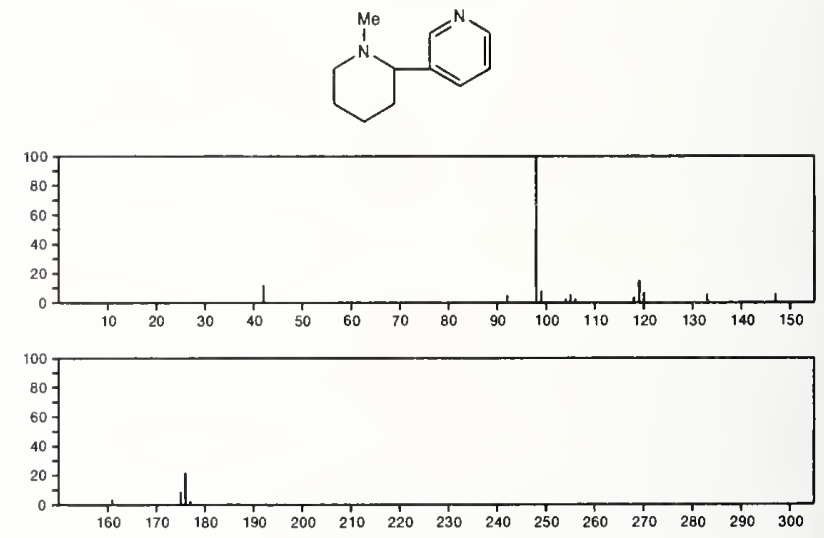

176

$\mathrm{C}_{12} \mathrm{H}_{16} \mathrm{O}$

$119-42-6$

Phenol, 2-cyclohexyl-
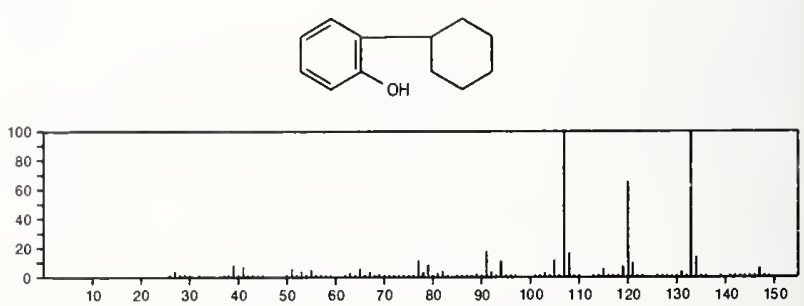


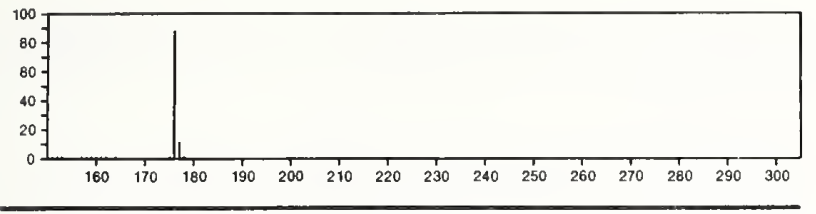

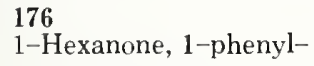

$\mathrm{C}_{12} \mathrm{H}_{16} \mathrm{O}$

$\mathrm{Me}\left(\mathrm{CH}_{2}\right)_{4} \mathrm{COPh}$
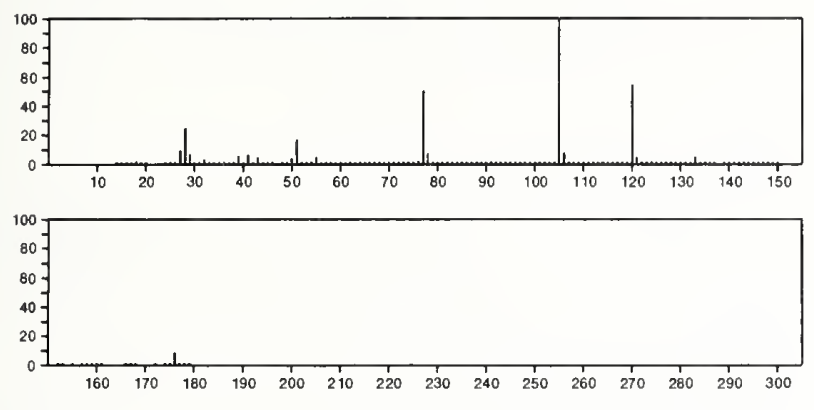

176

$\mathrm{C}_{12} \mathrm{H}_{16} \mathrm{O}$

$943-27-1$

Ethanone, 1-[4-(1,1-dimethylethyl)phenyl]-
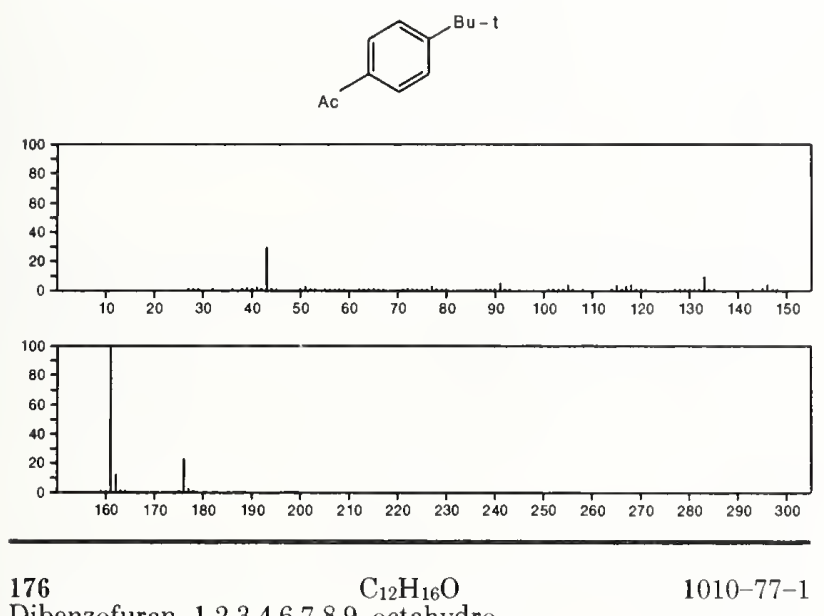

Dibenzofuran, 1,2,3,4,6,7,8,9- octahydro-
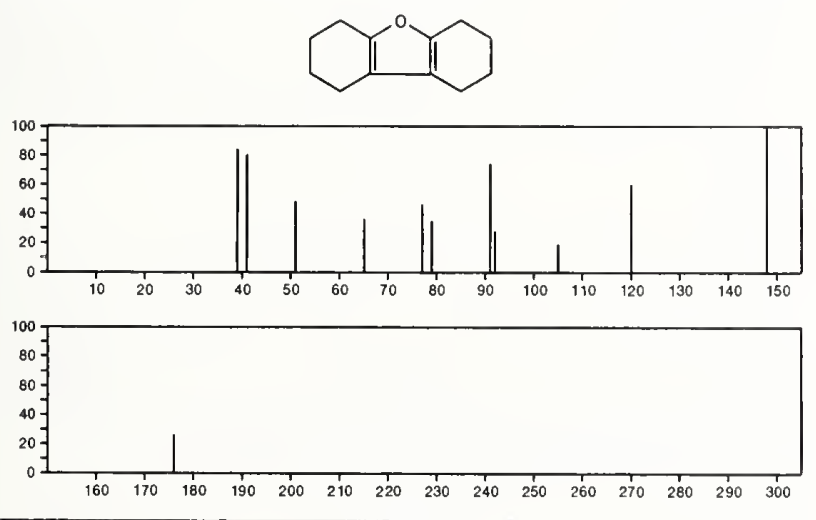

176

Phenol, 4-cyclohexyl-

$\mathrm{C}_{12} \mathrm{H}_{16} \mathrm{O}$

$1131-60-8$
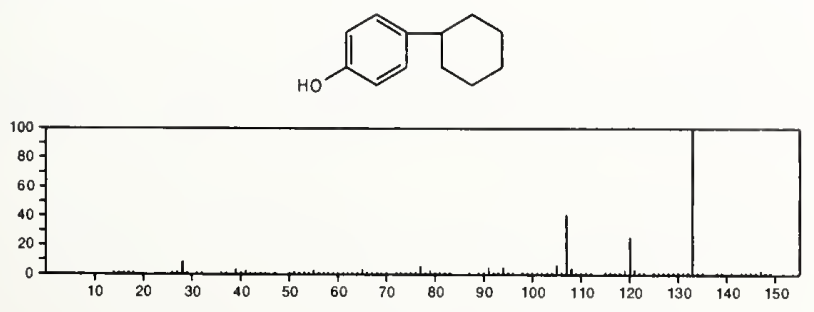

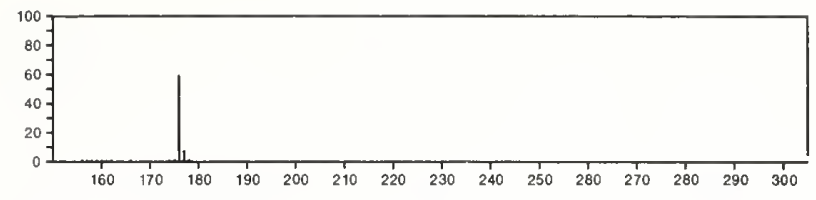

\begin{tabular}{lll}
\hline 176 & $\mathrm{C}_{12} \mathrm{H}_{16} \mathrm{O}$ & $1444-64-0$
\end{tabular}
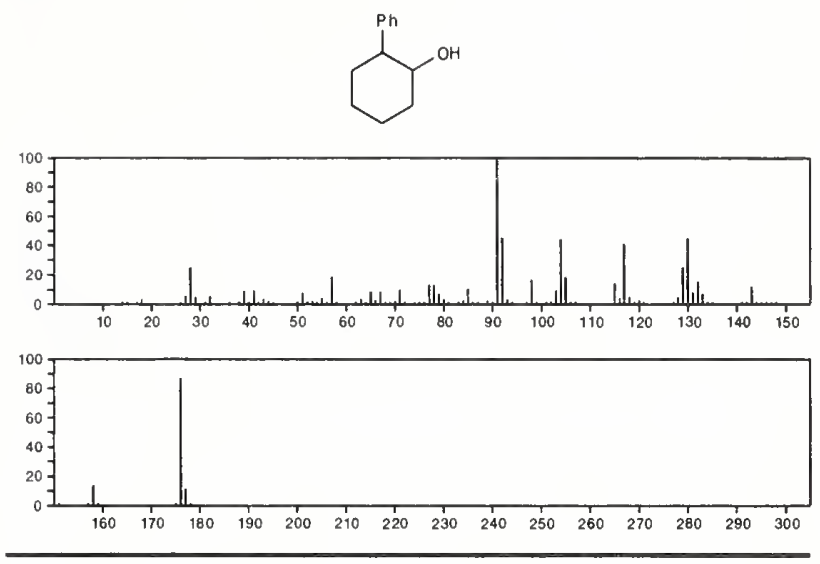

176

$\mathrm{C}_{12} \mathrm{H}_{16} \mathrm{O}$

$1943-95-9$

Phenol, 3 -cyclohexyl-
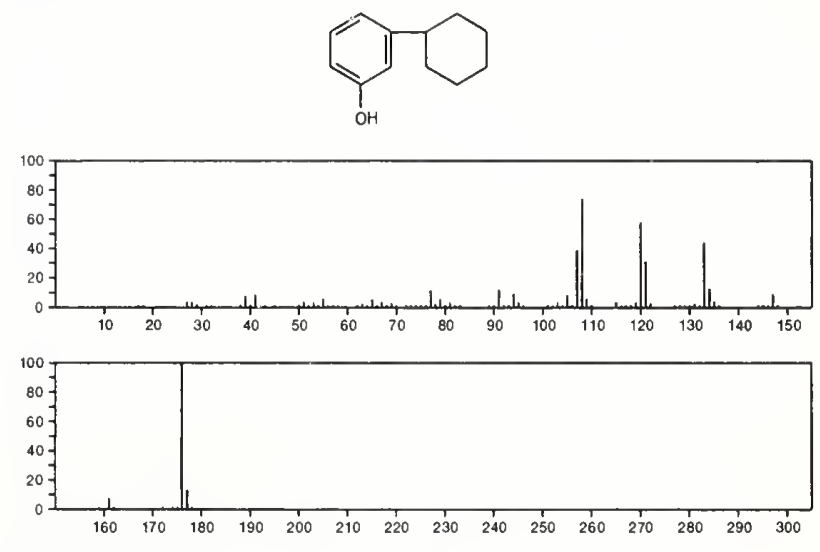

176

Benzene, (cyclohexyloxy)-

$\mathrm{C}_{12} \mathrm{H}_{16} \mathrm{O}$

2206-38-4
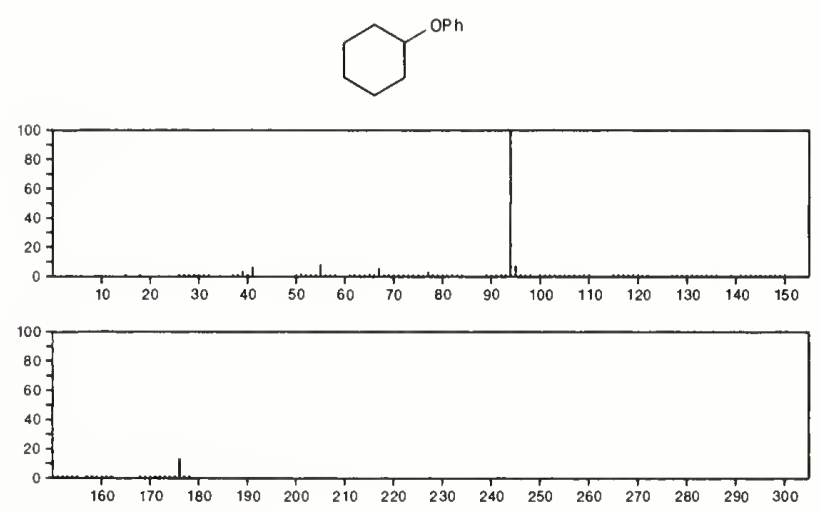
176

Cyclohexanol, 4-phenyl-

$\mathrm{C}_{12} \mathrm{H}_{16} \mathrm{O}$

$5437-46-7$
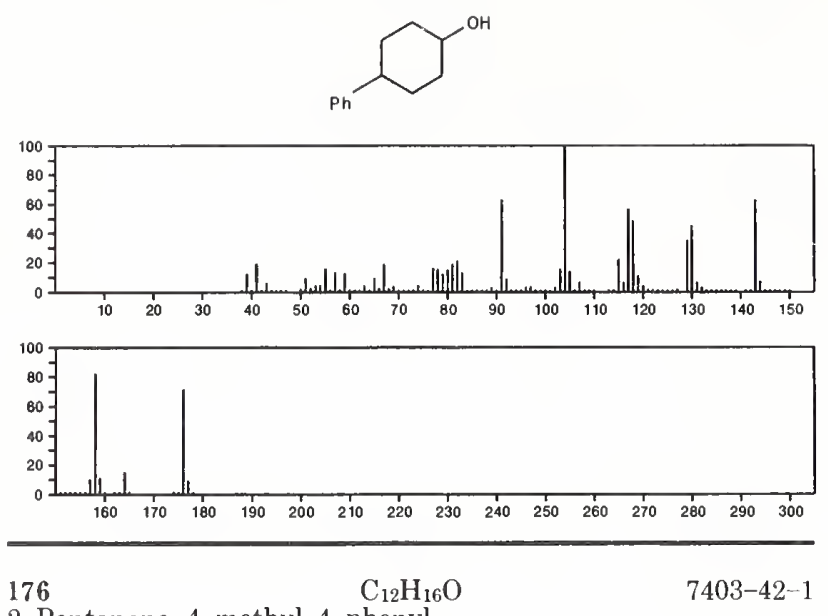

2-Pentanone, 4-methyl-4-phenyl-

$\mathrm{MeCOCH}_{2} \mathrm{CMe}_{2} \mathrm{Ph}$
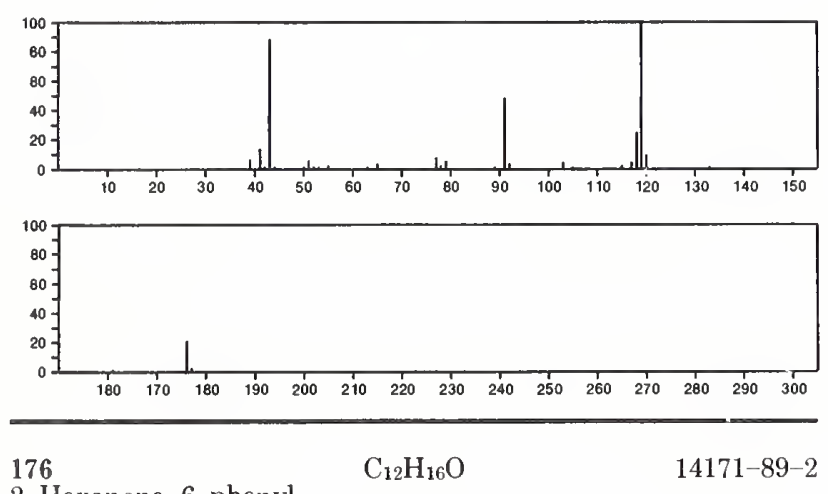

2-Hexanone, 6-phenyl-

$\mathrm{MeCO}\left(\mathrm{CH}_{2}\right)_{4} \mathrm{Ph}$
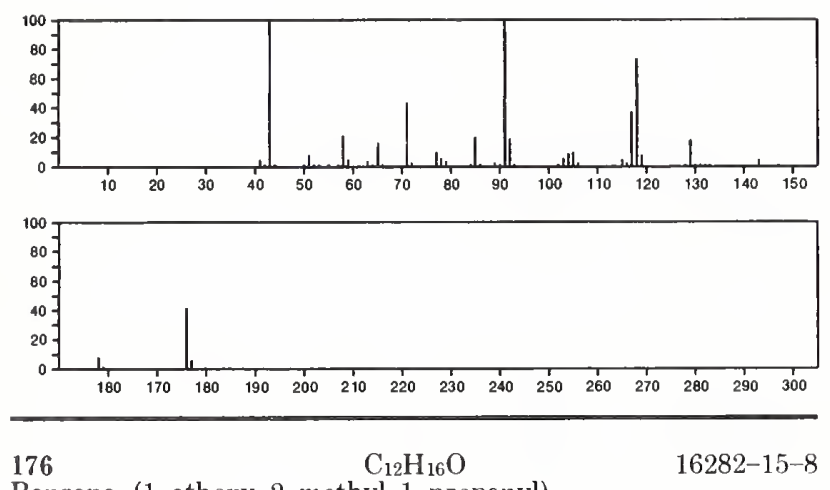

Benzene, (1-ethoxy-2-methyl-1-propenyl)-

$\mathrm{Me} 2 \mathrm{C}=\mathrm{C}(\mathrm{OEt}) \mathrm{Ph}$
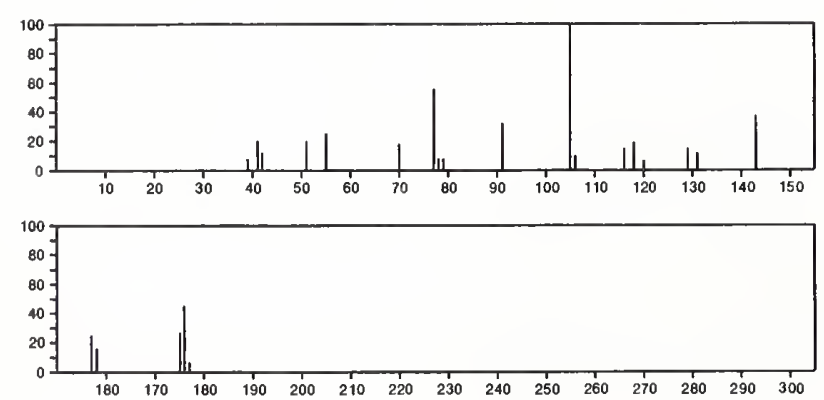

176

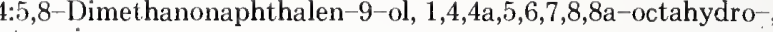
stereoisomer
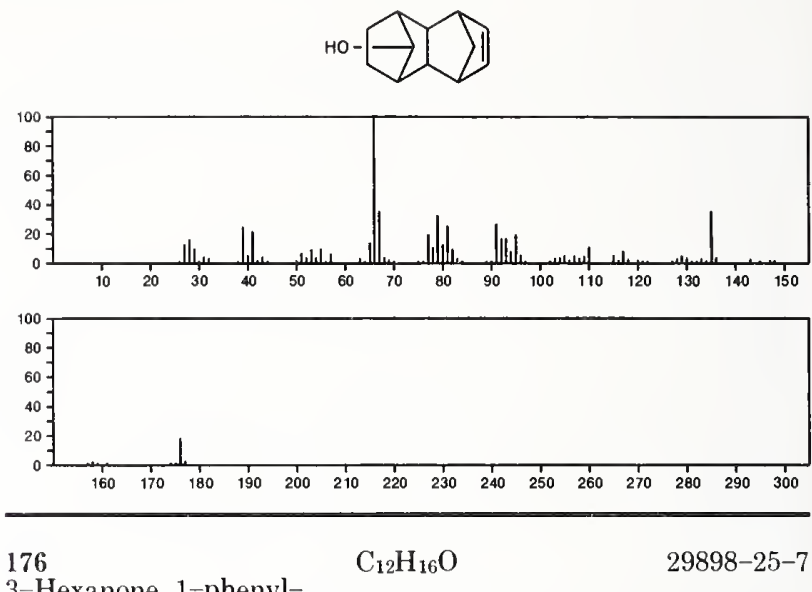

3-Hexanone, 1-phenyl-

$\mathrm{PhCH}_{2} \mathrm{CH}_{2} \mathrm{COPr}$
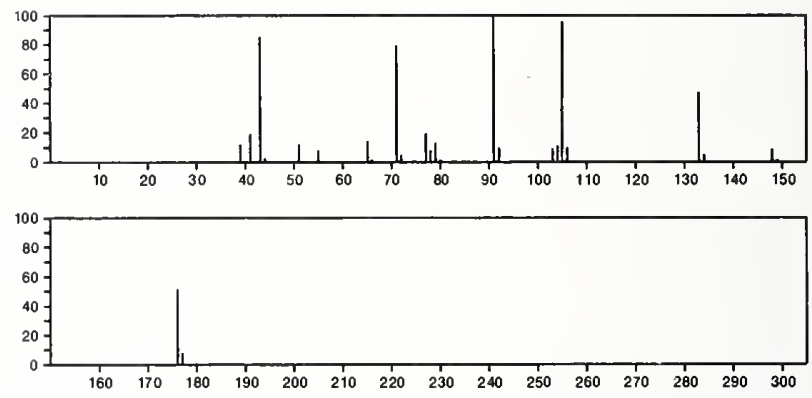

$\begin{array}{lllllllllllllll}160 & 170 & 180 & 190 & 200 & 210 & 220 & 230 & 240 & 250 & 260 & 270 & 280 & 290 & 300\end{array}$

$176 \quad \mathrm{C}_{12} \mathrm{H}_{16} \mathrm{O} \quad 36052-28-5$ 1-Naphthalenemethanol, 1,2,3,4-tetrahydro-8-methyl-
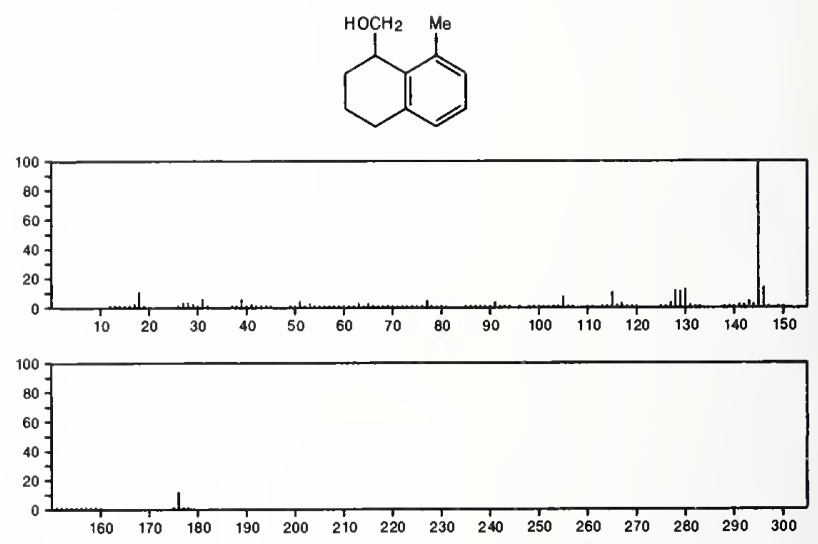

176

1,4.5,8-Dimethanonaphthal $(1 \alpha, 2 \alpha, 4 \alpha, 4 \mathrm{a} \alpha, 5 \alpha, 8 \alpha, 8 \mathrm{a} \alpha)-$
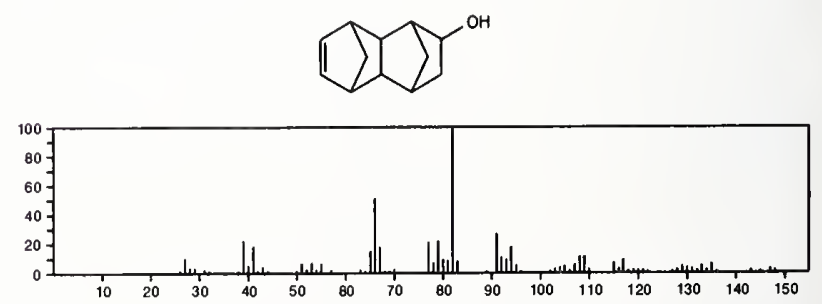


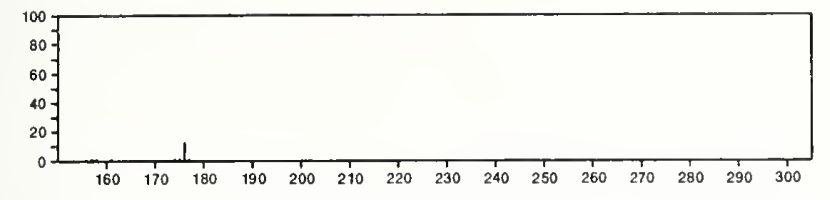

176

2-Cyclopenten-1-one, methylethenyl)-
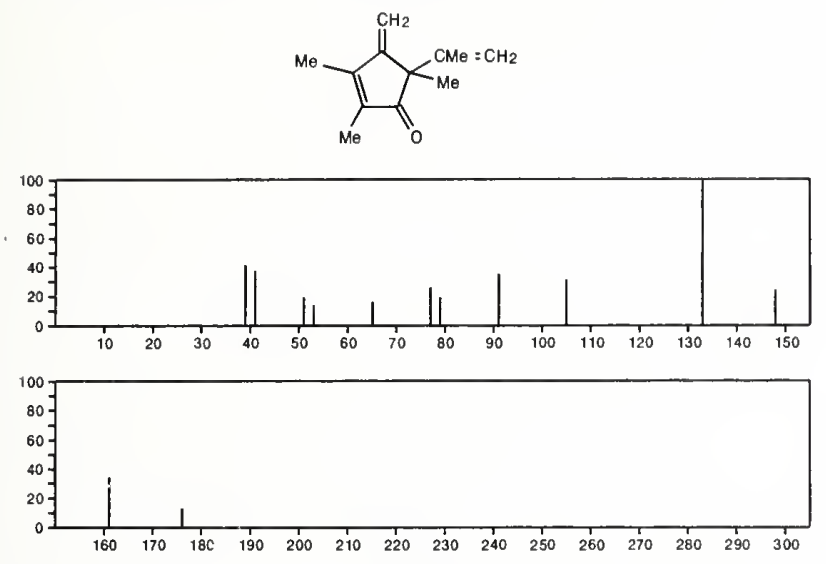

176

$\mathrm{C}_{12} \mathrm{H}_{16} \mathrm{O}$

Benzene, (3-propoxy-1-propenyl)-

$\mathrm{PrOCH}_{2} \mathrm{CH}=\mathrm{CHPh}$
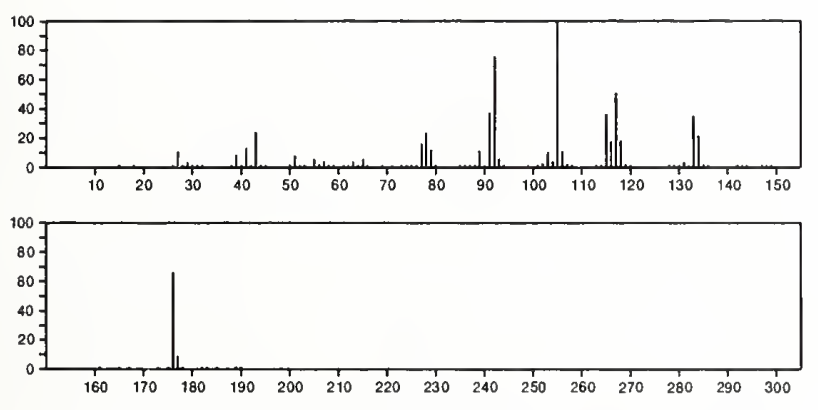

$176 \quad \mathrm{C}_{12} \mathrm{H}_{16} \mathrm{O} \quad 55103-77-0$

2(1H)-Naphthalenone, 4a,5,8,8a-tetrahydro-4,4a-dimethyl-, trans-
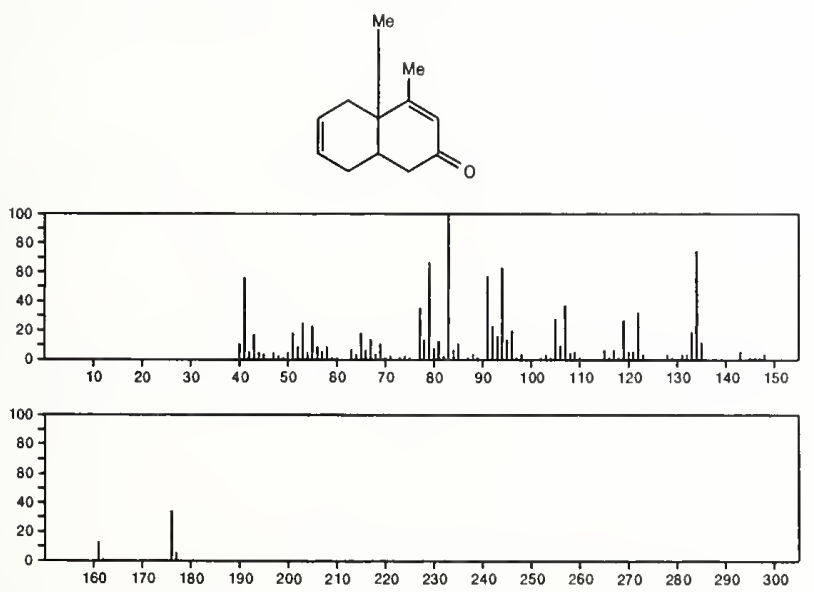

176

$\mathrm{C}_{12} \mathrm{H}_{16} \mathrm{O}$

$55591-09-8$

1H-Indene-4-methanol, 2,3-dihydro-1,1-dimethyl-
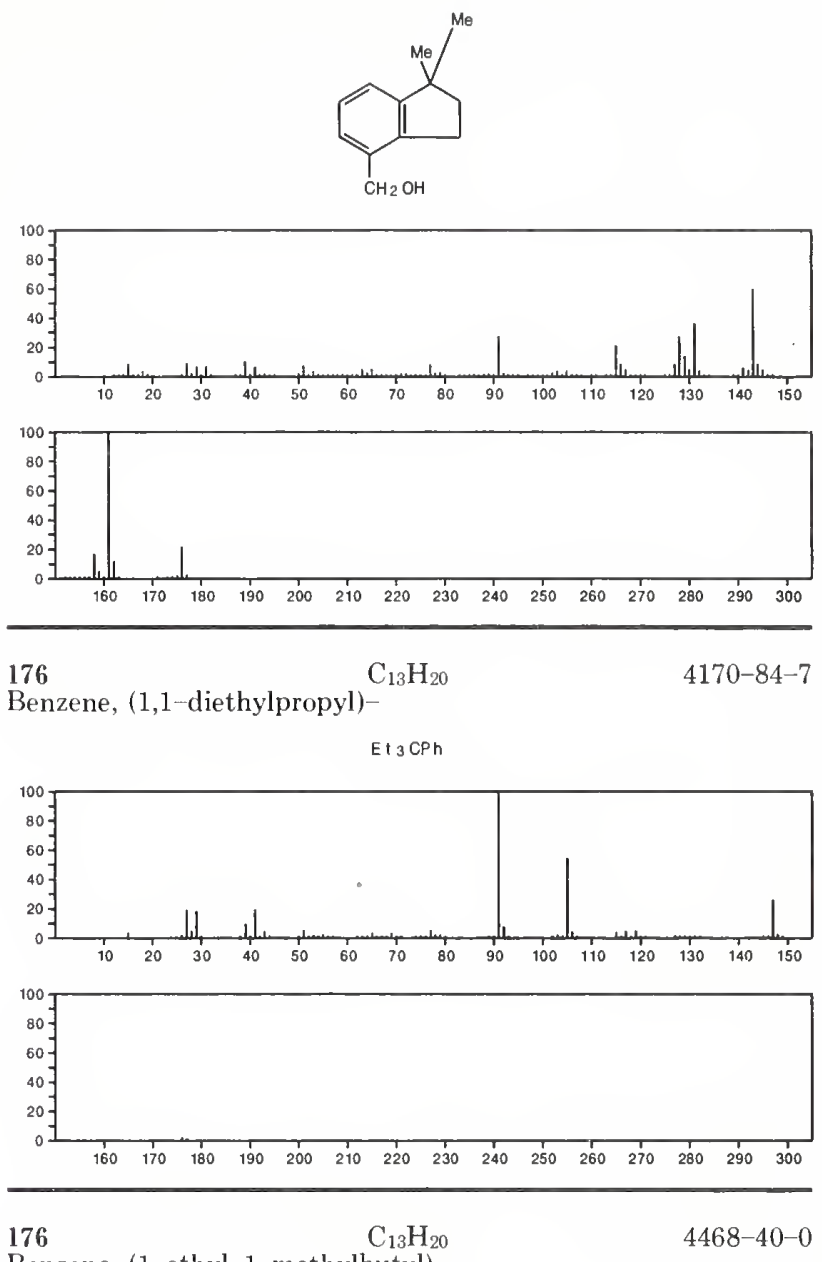

Benzene, (1-ethyl-1-methylbutyl)-

CPhEtE:Pr
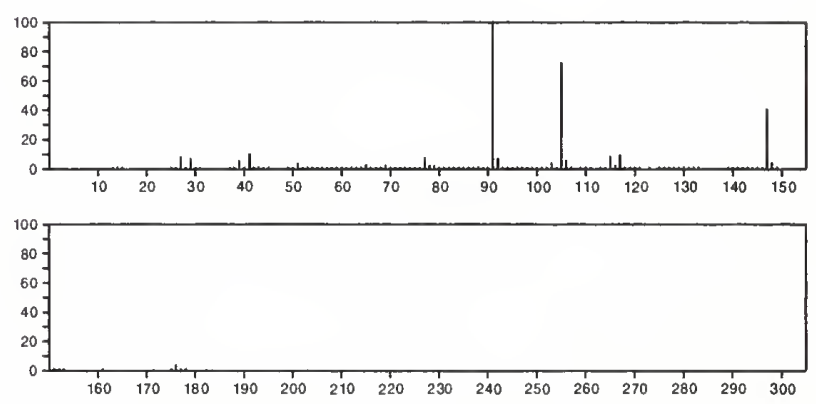

176

$\mathrm{C}_{13} \mathrm{H}_{20}$

$6630-01-9$

Benzene, 1-(1,1-dimethylethyl)-3-ethyl-5-methyl-
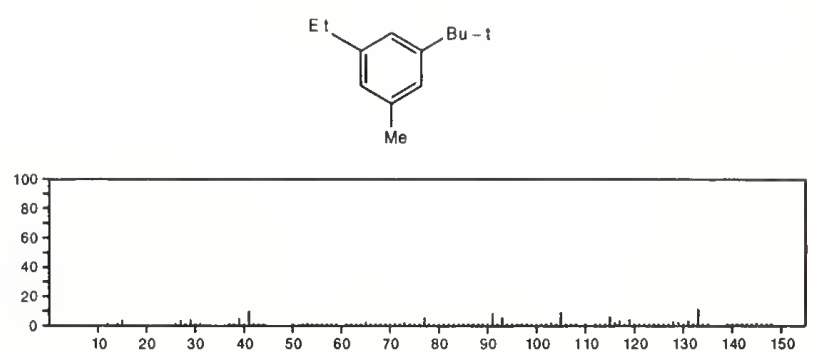


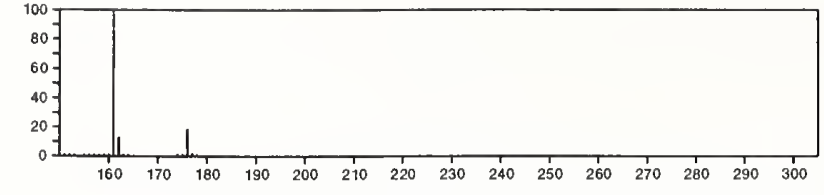

176

$\mathrm{C}_{13} \mathrm{H}_{20}$

Benzene, [2-methyl-1-(1-methylethyl)propyl]-

$21777-84-4$

$\mathrm{Me} 2 \mathrm{CHCHPh} \mathrm{CHM}_{2}$
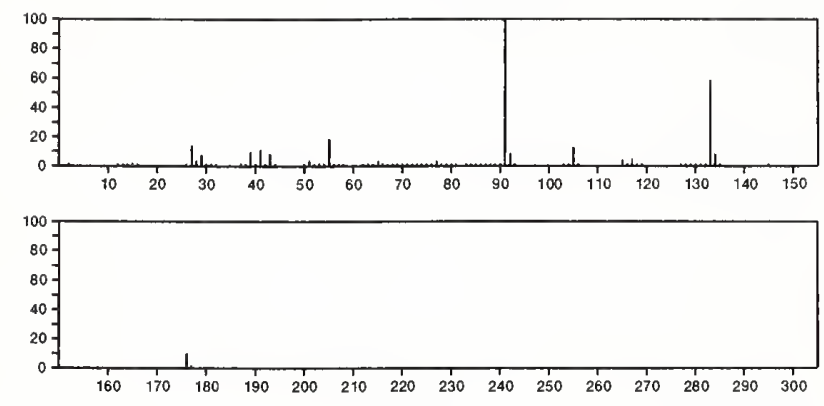

176

$\mathrm{C}_{13} \mathrm{H}_{20}$

$54518-00-2$

Benzene, (2,4-dimethylpentyl)

$\mathrm{PhCH}_{2} \mathrm{CHMeCH}_{2} \mathrm{CHMe}_{2}$
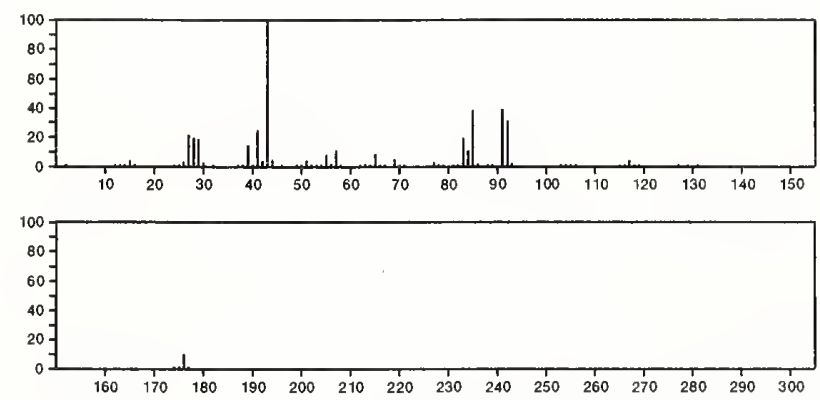

176

3,5-Dodecadiyne, 2-methyl-

$\mathrm{C}_{13} \mathrm{H}_{20}$

$55638-52-3$

$\mathrm{Me}\left(\mathrm{CH}_{2}\right){ }_{5} \mathrm{C} \equiv \mathrm{CC} \equiv \mathrm{CCHMe}_{2}$
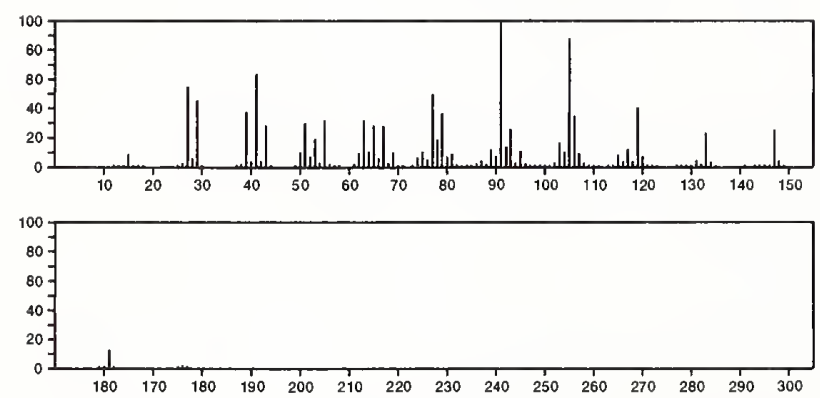

176

$\mathrm{C}_{13} \mathrm{H}_{20}$

Cyclohexene, 6-(1,3-butadienyl)-1,5,5-trimethyl-

$56248-15-8$
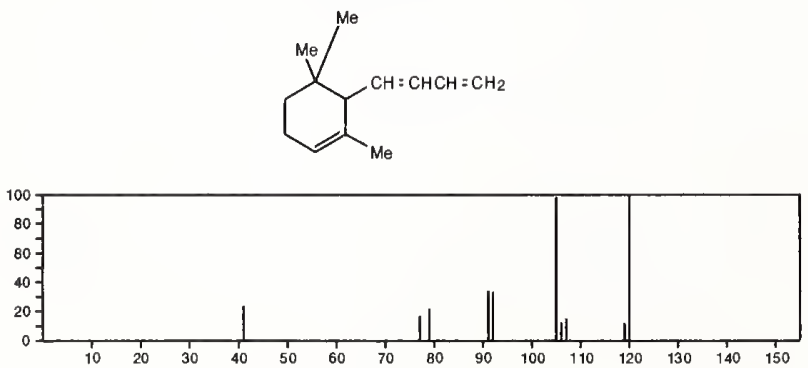

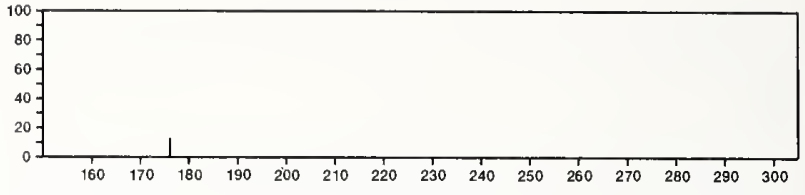

$176 \quad \mathrm{C}_{14} \mathrm{H}_{8}$

$5236-46-4$

1,3,7,11-Cyclotetradecatetraene-5,9,13-triyne
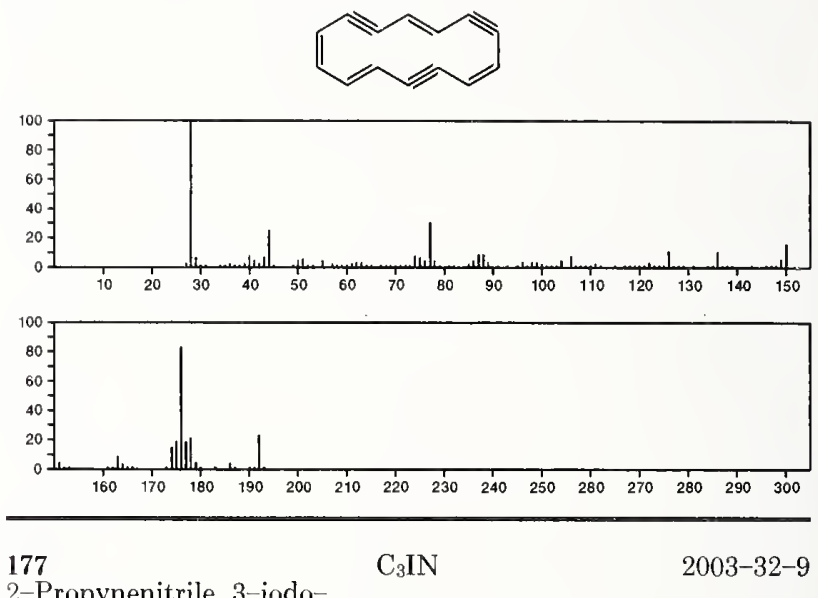

2003-32-9

2-Propynenitrile, 3-iodo-

$I C \equiv C C N$
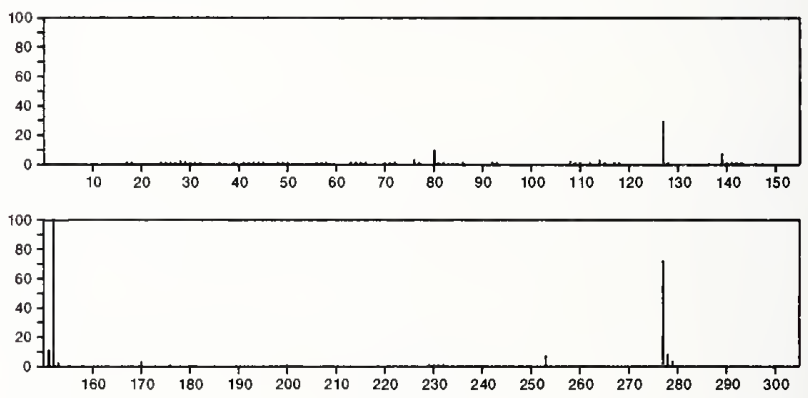

177

Isothiazole, 5-bromo-3-methyl-

$\mathrm{C}_{4} \mathrm{H}_{4} \mathrm{BrNS}$

20493-60-1
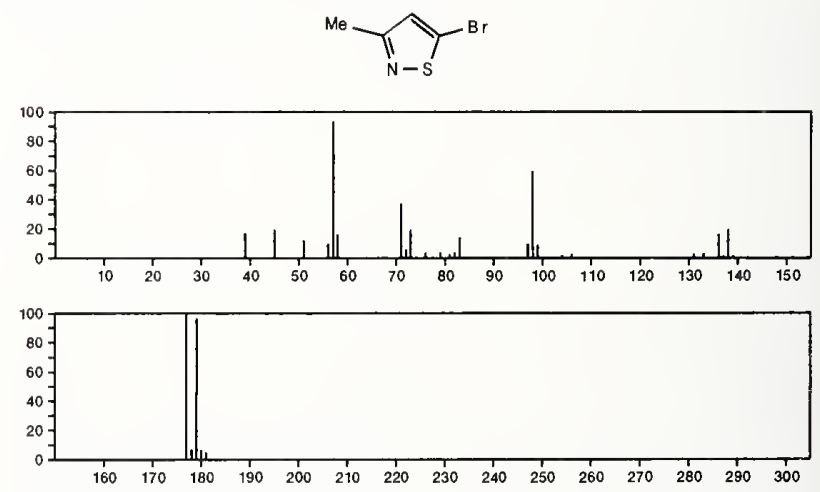

177

$\mathrm{C}_{5} \mathrm{H}_{7} \mathrm{NS}_{3}$

56248-20-5

Thiazole, 2,5-bis(methylthio)-
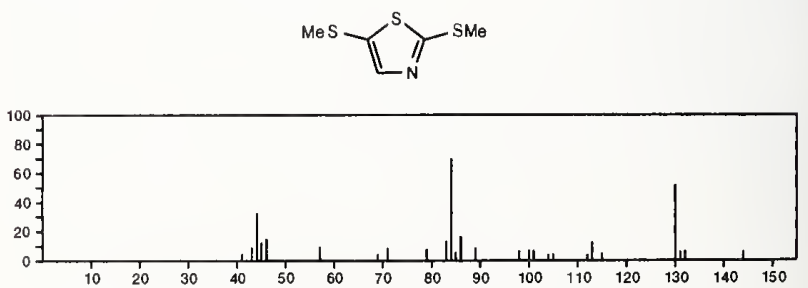


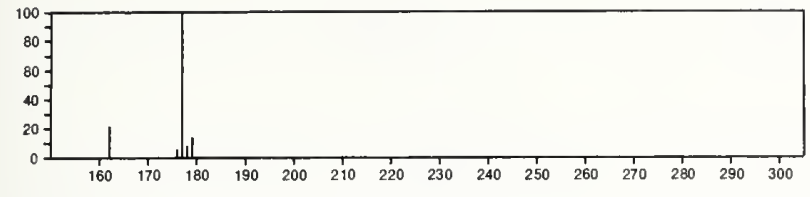

177

$\mathrm{C}_{6} \mathrm{H}_{6} \mathrm{~F}_{3} \mathrm{~N}_{3}$

$5734-63-4$

2-Pyrimidinamine, 4-methyl-6-(trifluoromethyl)-
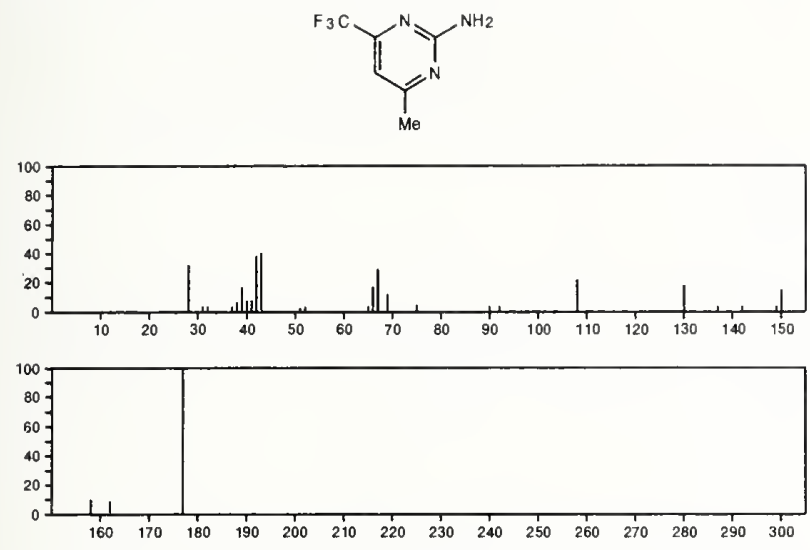

177

$\mathrm{C}_{6} \mathrm{H}_{6} \mathrm{~F}_{3} \mathrm{~N}_{3}$

$54518-10-4$

4-Pyrimidinamine, 2-methyl-6-(trifluoromethyl)-
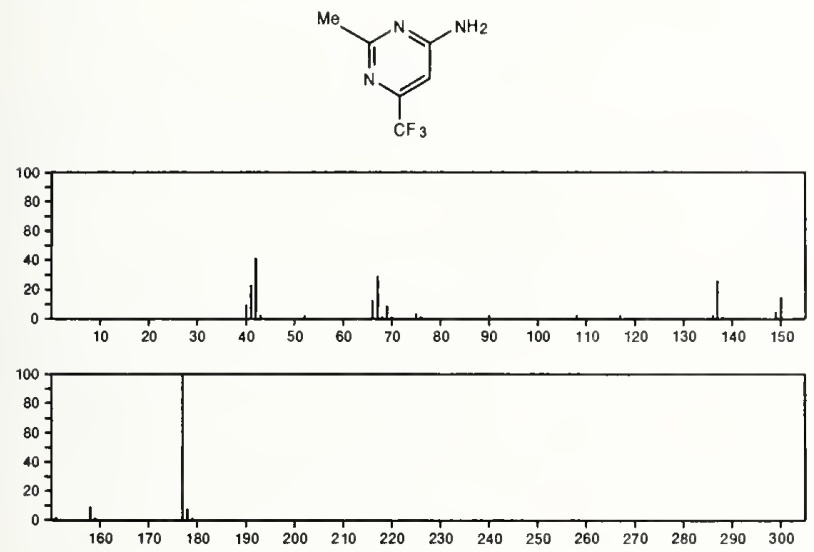

177

$\mathrm{C}_{6} \mathrm{H}_{11} \mathrm{NOS}_{2}$

$56909-10-5$

2-Oxazolidinethione, 5-[2-(methylthio)ethyl]-

$\overbrace{S}^{\mathrm{CH}_{2} \mathrm{CH}_{2} \mathrm{SMe}}$

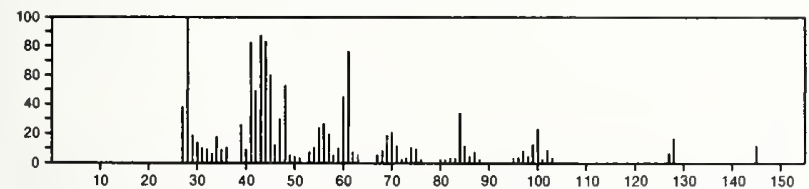

177

$\mathrm{C}_{7} \mathrm{H}_{7} \mathrm{~N}_{5} \mathrm{O}$

4(1H)-Pteridinone, 2-amino-6-methyl-<smiles>Cc1cnc2[nH]c(N)nc(=O)c2n1</smiles>
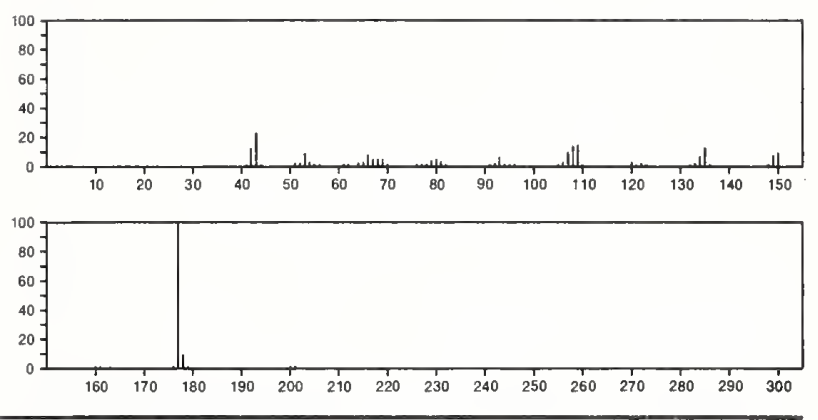

177

$\mathrm{C}_{7} \mathrm{H}_{7} \mathrm{~N}_{5} \mathrm{O}$

4(1H)-Pteridinone, 2-amino-7-methyl-

$13040-58-9$
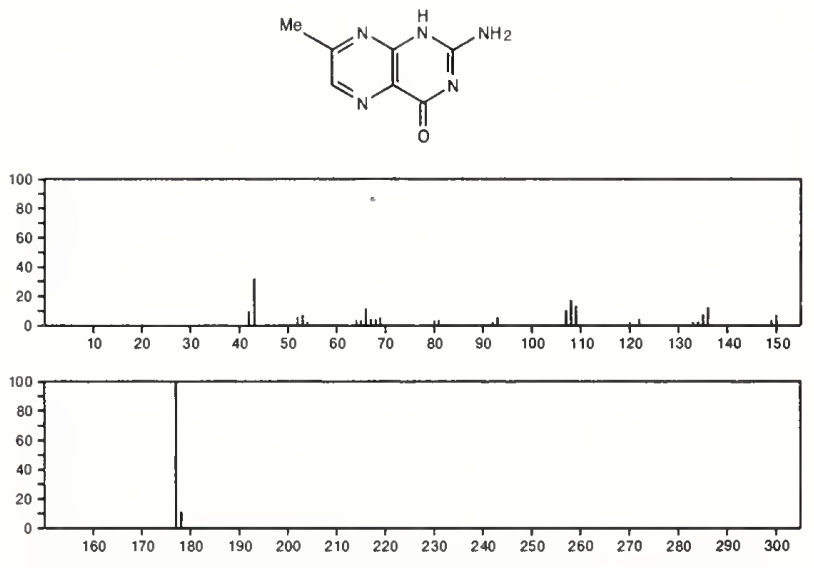

177

L-Methionine, ethyl ester

$\mathrm{C}_{7} \mathrm{H}_{15} \mathrm{NO}_{2} \mathrm{~S}$

3082-77--7

$\mathrm{MeSCH} \mathrm{CH}_{2} \mathrm{CH}\left(\mathrm{NH}_{2}\right) \mathrm{C}(\mathrm{O}) \mathrm{OE}$
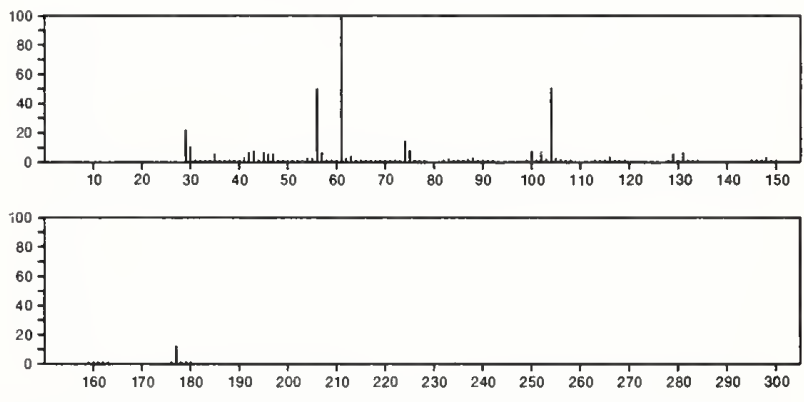

177

$\mathrm{C}_{7} \mathrm{H}_{15} \mathrm{NS}_{2}$

Carbamodithioic acid, diethyl-, ethyl ester

4740-11-8

EtSCIS) NEt 2

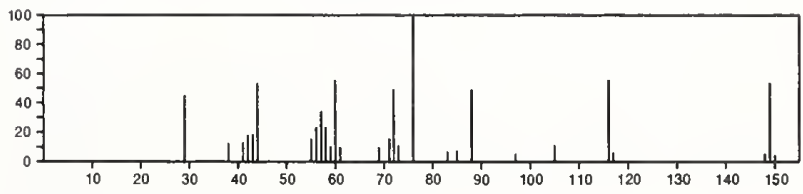




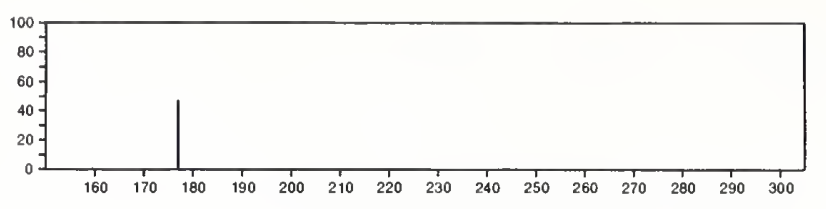

177

$\mathrm{C}_{8} \mathrm{H}_{7} \mathrm{~N}_{3} \mathrm{O}_{2}$

Pyrido[3,2-d]pyrimidine-2,4(1H,3H)-dione, 6-methyl-<smiles>Nc1ccc2[nH]c(=O)[nH]c(=O)c2n1</smiles>
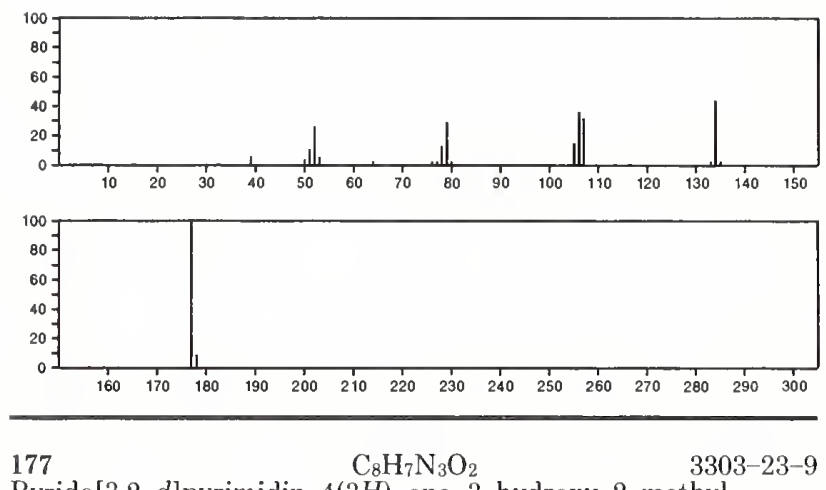

Pyrido[3,2-d]pyrimidin-4(3H)-one, 3-hydroxy-2-methyl-
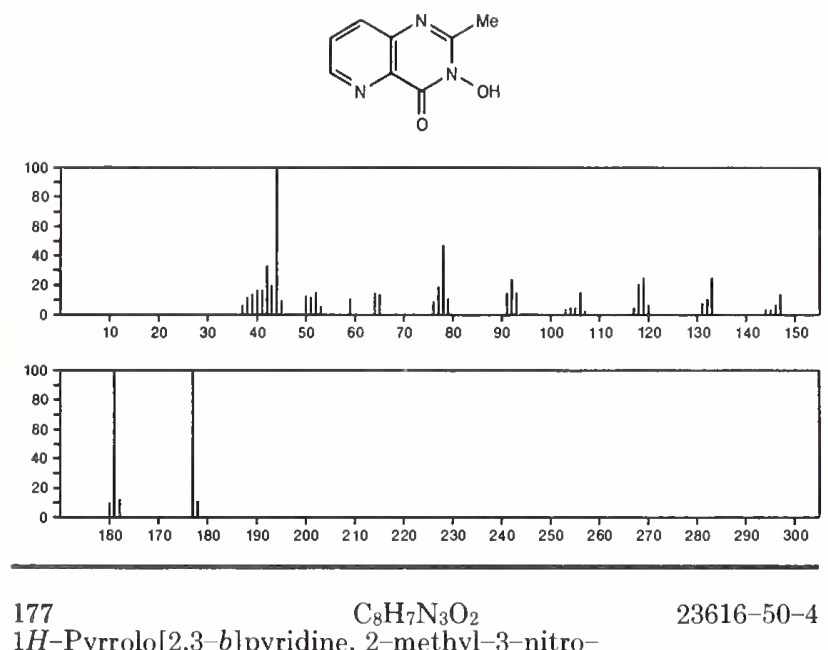

$1 \mathrm{H}$-Pyrrolo[2,3-b]pyridine, 2-methyl-3-nitro-
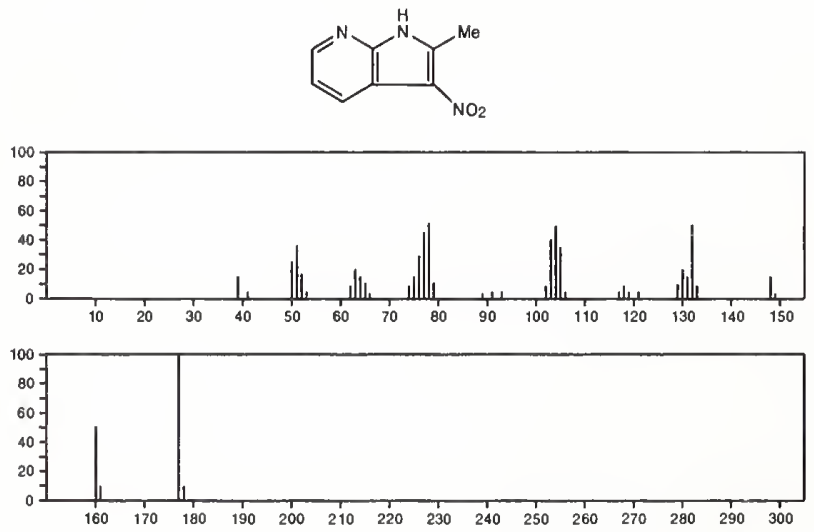

177

$\mathrm{C}_{8} \mathrm{H}_{7} \mathrm{~N}_{3} \mathrm{O}_{2}$

1,2,3 Benzotriazin-4(3H)-one, 3-(hydroxymethyl)-

$24310-40-5$
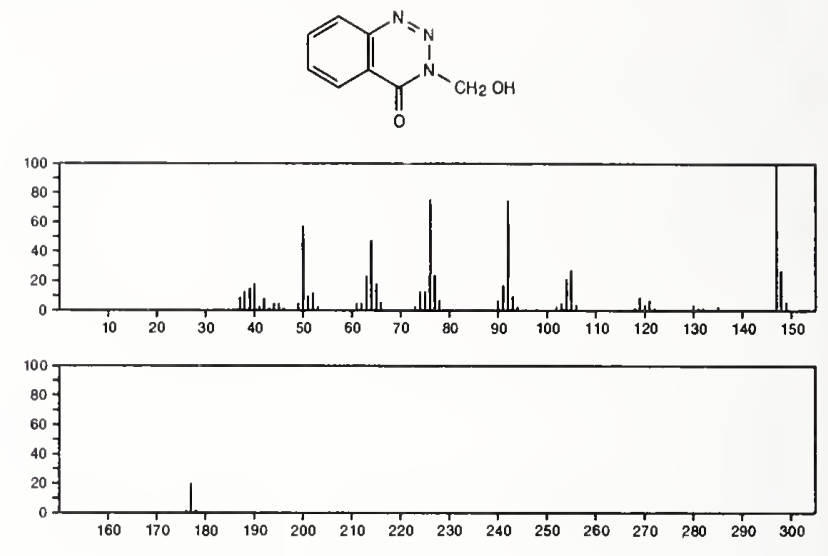

$177 \quad \mathrm{C}_{8} \mathrm{H}_{7} \mathrm{~N}_{3} \mathrm{O}_{2}$

$26120-43-4$

1H-Indazole, 1-methyl-4-nitro-
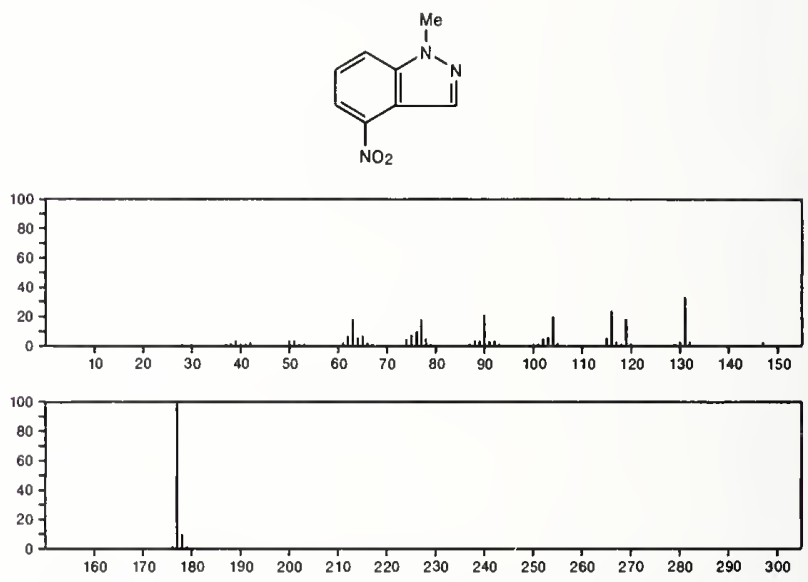

177

2H-Indazole, 2-methyl-4-nitro-
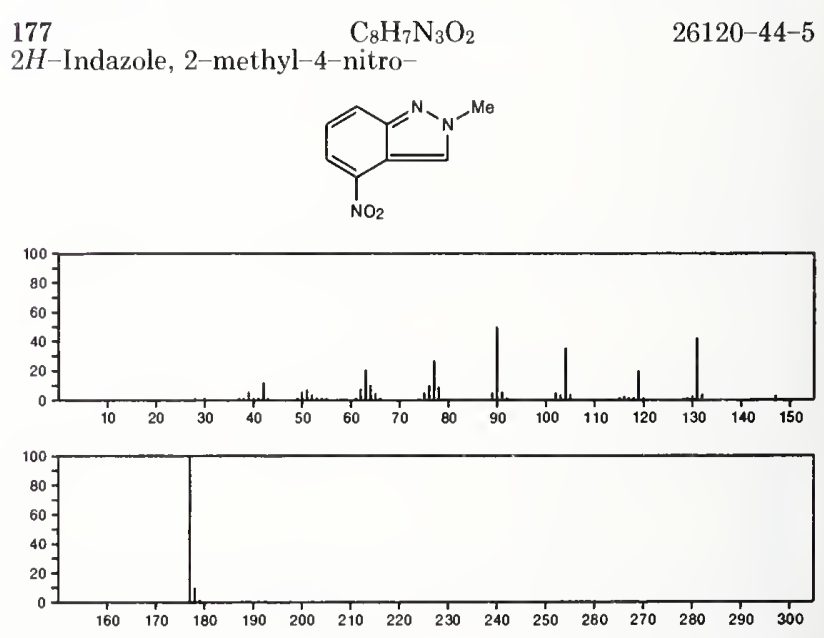

$177 \quad \mathrm{C}_{8} \mathrm{H}_{7} \mathrm{~N}_{3} \mathrm{~S}$

1,2,4-'Thiadiazol-5-amine, 3-phenyl-

$17467-15-1$
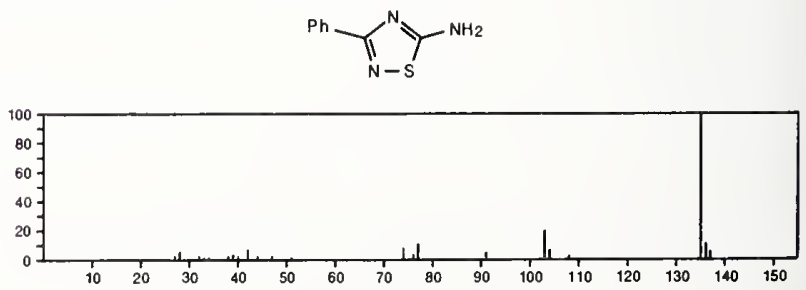


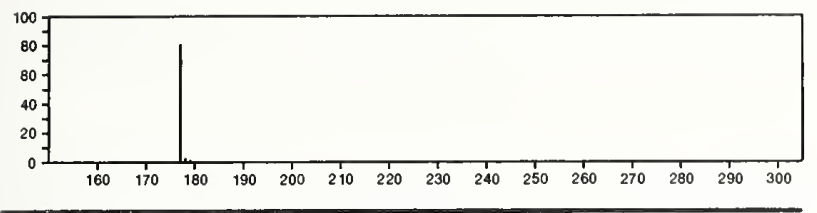

$177 \quad \mathrm{C}_{8} \mathrm{H}_{7} \mathrm{~N}_{3} \mathrm{~S}$

20970-15-4

Pyrido[2,3-d]pyridazine, 5-(methylthio)-
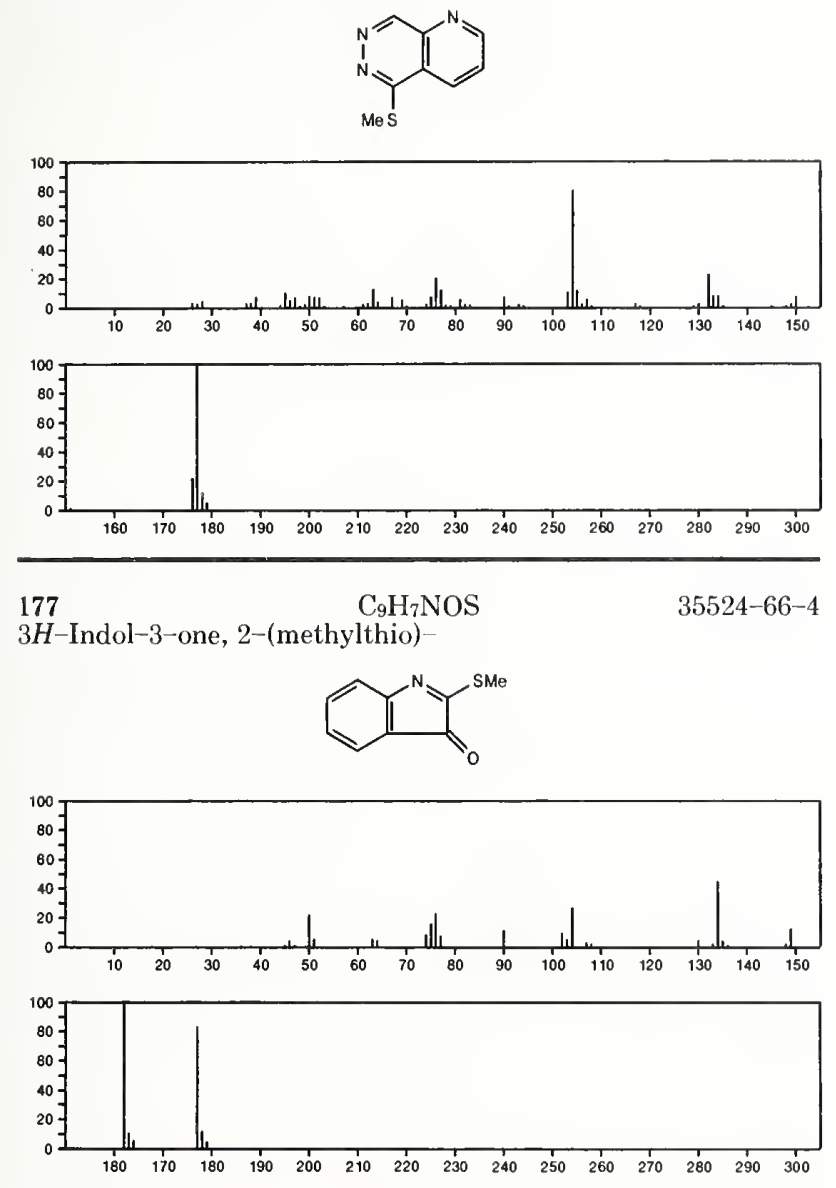

$177 \quad \mathrm{C}_{9} \mathrm{H}_{7} \mathrm{NO}_{3} \quad 17175-18-7$ Carbonic acid, methyl ester, ester with $p$-hydroxybenzonitrile
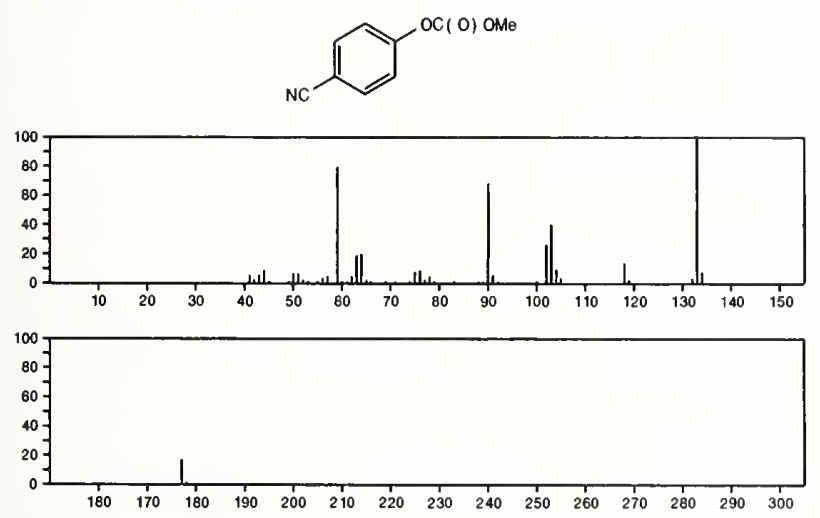

177

$\mathrm{C}_{9} \mathrm{H}_{7} \mathrm{NO}_{3}$

$17175-19-8$

Carbonic acid, methyl ester, ester with $m$-hydroxybenzonitrile
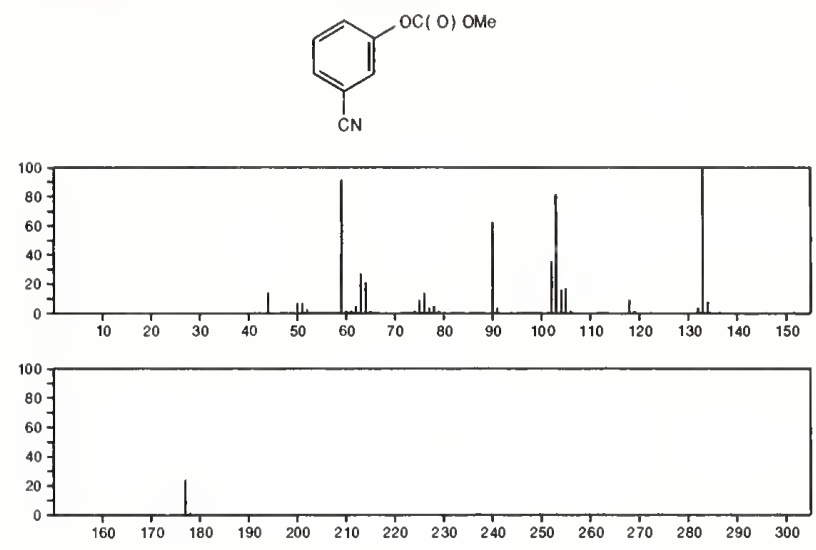

177

Carbostyril, 1,4-dihydroxy-

$\mathrm{C}_{9} \mathrm{H}_{7} \mathrm{NO}_{3}$

21201-44-5<smiles>O=c1cc(O)c2ccccc2n1O</smiles>
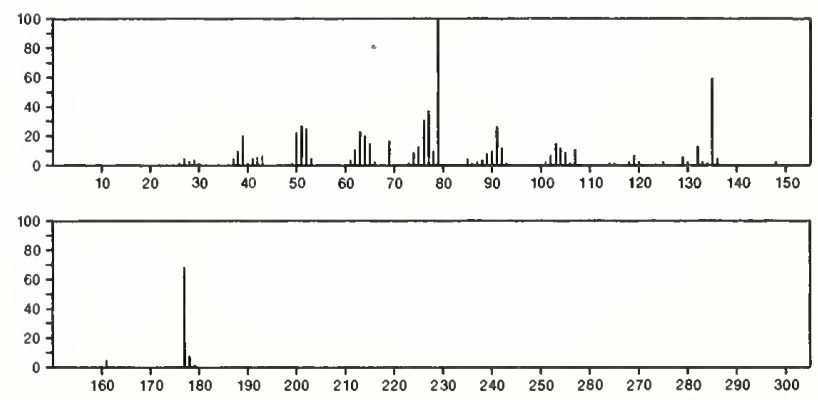

177

$\mathrm{C}_{9} \mathrm{H}_{11} \mathrm{~N}_{3} \mathrm{O}$

$2492-30-0$

Hydrazinecarboxamide, 2-(1-phenylethylidene)-

$\mathrm{PhCMe}=\mathrm{NNHCONH}_{2}$
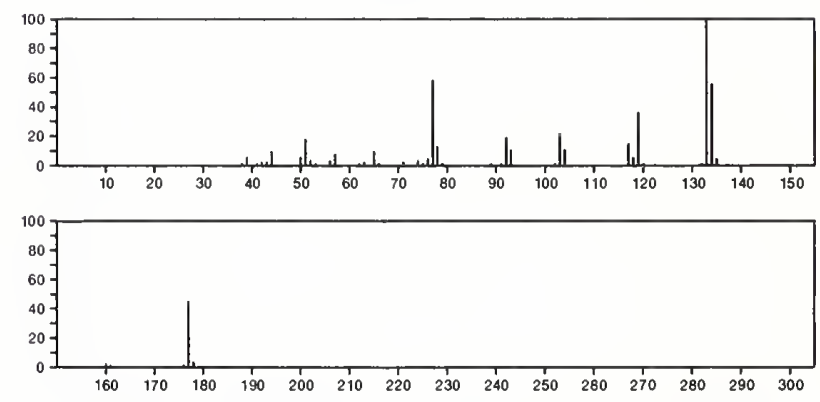

177

$1 \mathrm{H}$-Indole-3-ethanol, 5-hydroxy-

$154-02-9$
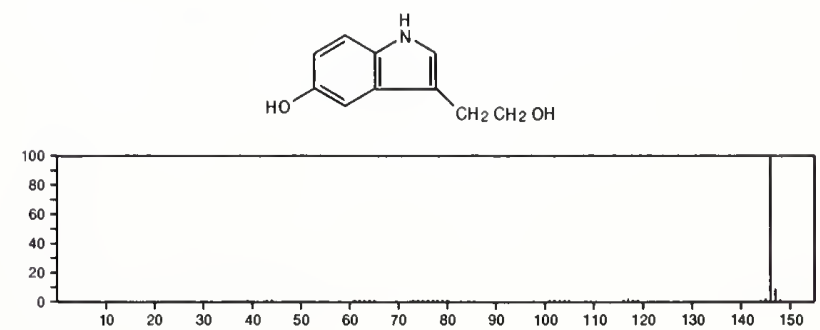

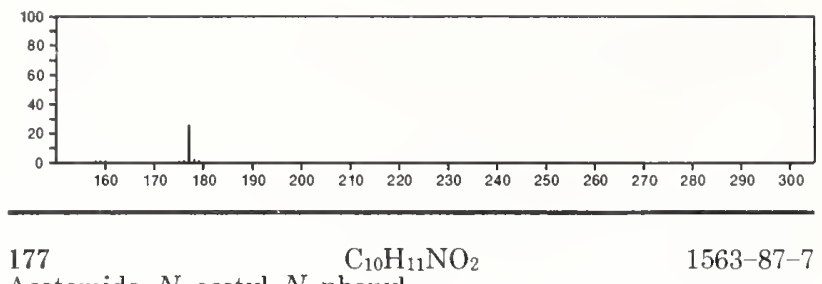

Acetamide, $N$-acetyl- $N$-phenyl-

$\operatorname{PhN}(A C) 2$
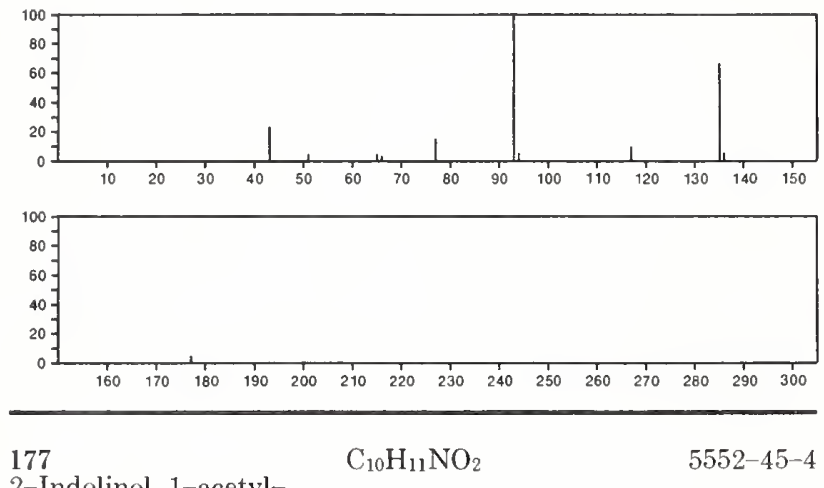

2-Indolinol, 1-acetyl-
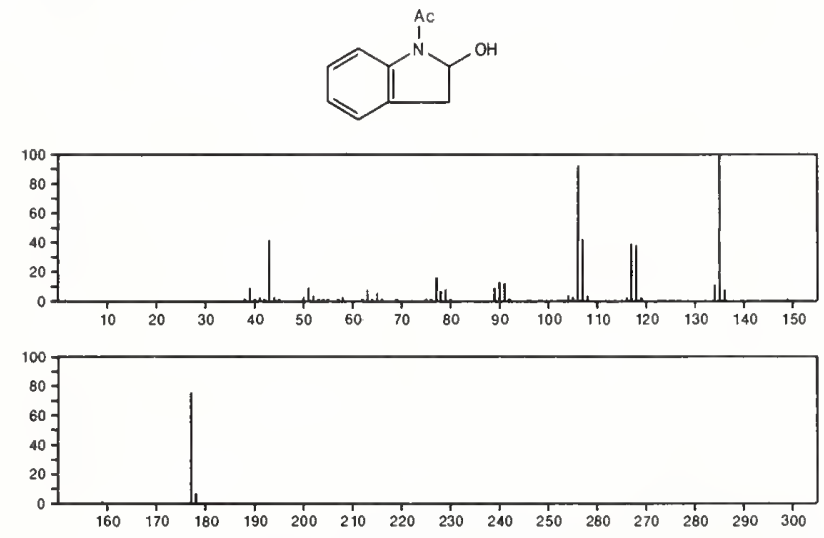

$177 \quad \mathrm{C}_{10} \mathrm{H}_{11} \mathrm{NO}_{2} \quad 13303-69-0$

1-Indolinecarboxaldehyde, 2-hydroxy-5-methyl-
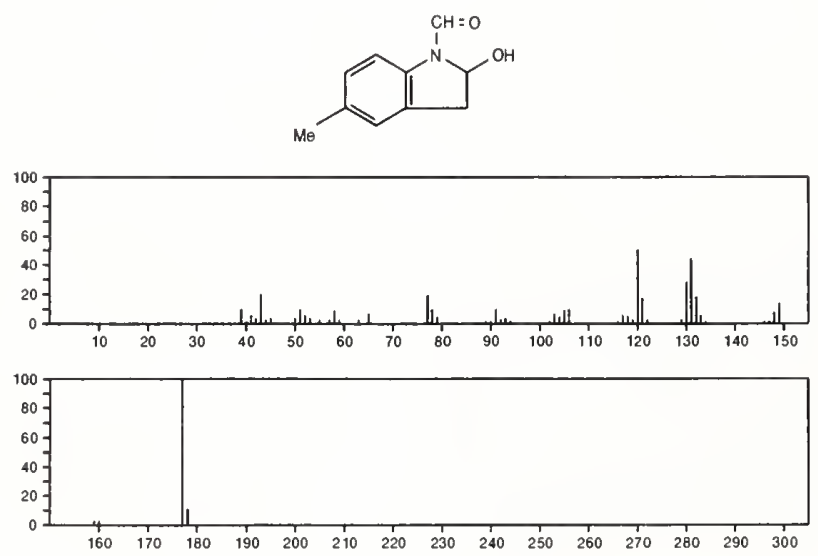

177 Naphthalene, 1,2,3,4-tetrahydro-6-nitro-

$19353-86-7$
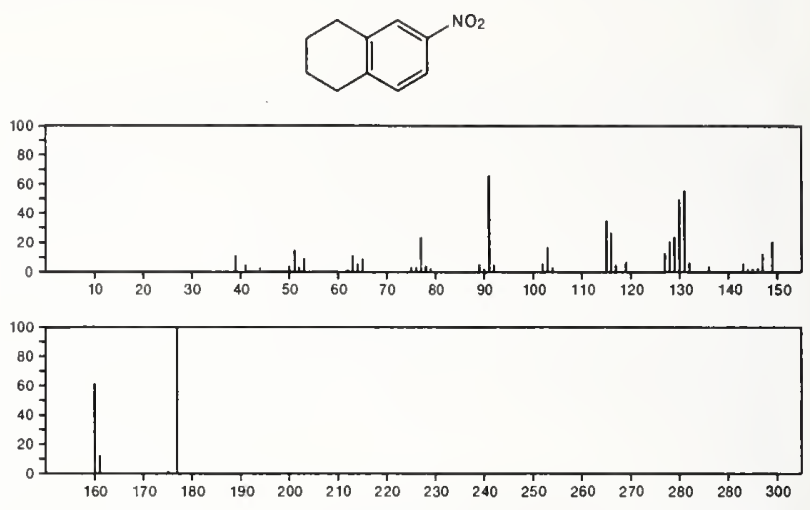

177

$\mathrm{C}_{10} \mathrm{H}_{11} \mathrm{NO}_{2}$

$19901-85-0$

2-Oxazolidinone, 5-methyl-4-phenyl-, trans-
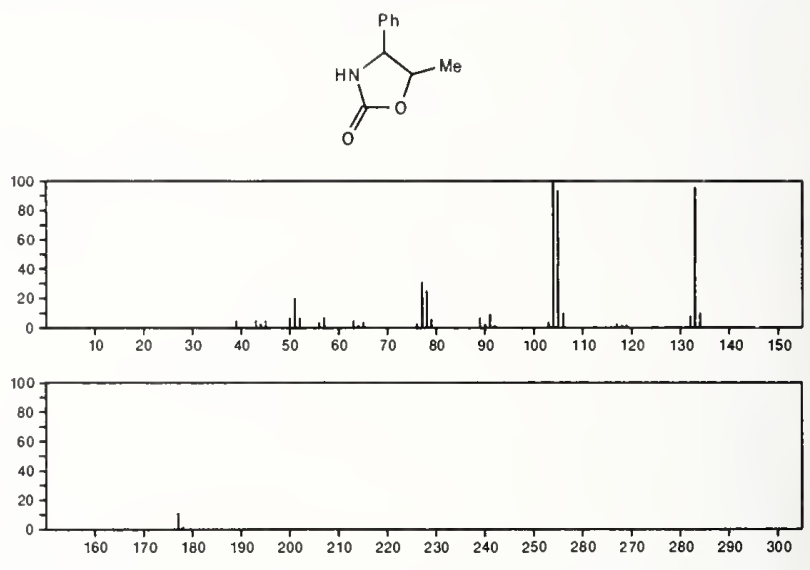

177

$\mathrm{C}_{10} \mathrm{H}_{11} \mathrm{NO}_{2}$

$19901-86-1$

2-Oxazolidinone, 5-methyl-4-phenyl-, cis-
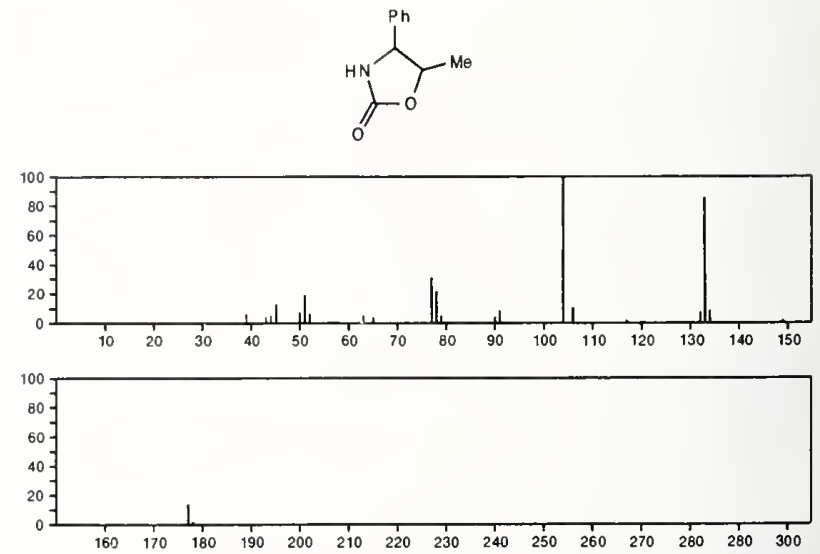

$177 \quad \mathrm{C}_{10} \mathrm{H}_{11} \mathrm{NO}_{2}$

1 -Indolinecarboxaldehyde, 2-hydroxy-7-methyl-

22614-65-9
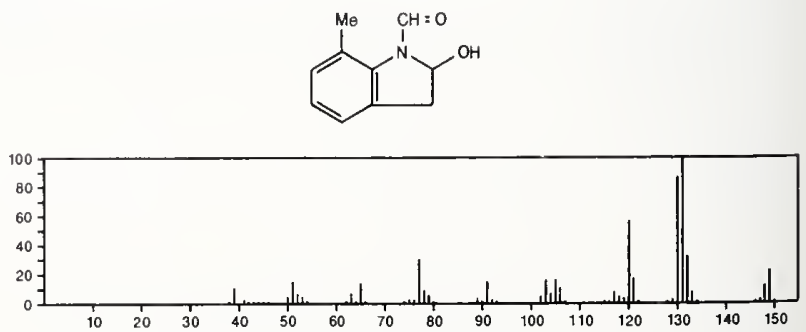
177

EPA/NIH MASS SPECTRAL DATA BASE

859

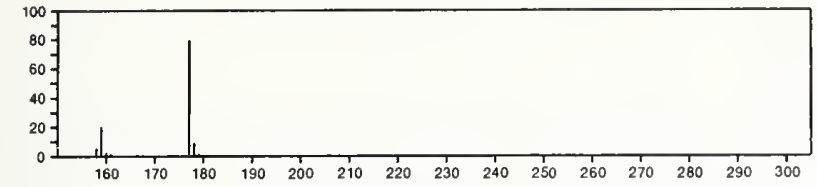

177

$\mathrm{C}_{10} \mathrm{H}_{11} \mathrm{NO}_{2}$

$28044-22-6$

2-Oxazolidinone, 4-methyl-5-phenyl-, cis-
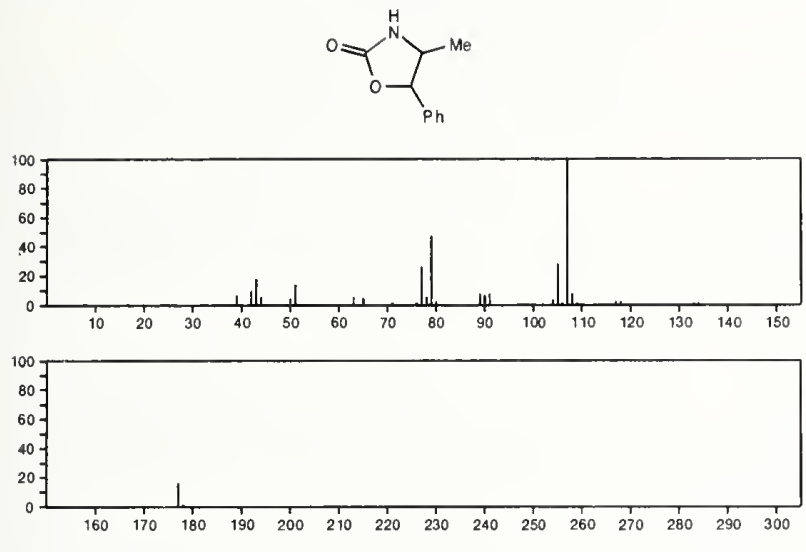

$177 \quad \mathrm{C}_{10} \mathrm{H}_{11} \mathrm{NO}_{2} \quad 29809-14-1$

Naphthalene, 1,2,3,4-tetrahydro-5-nitro-
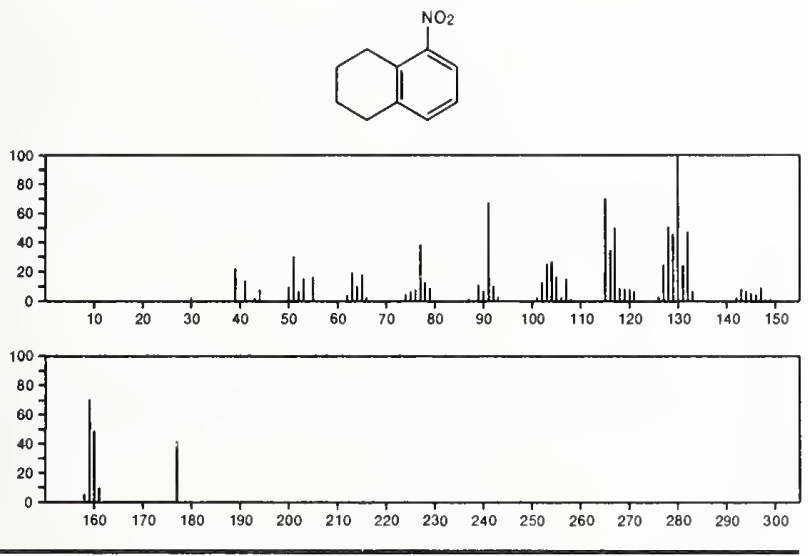

$177 \quad \mathrm{C}_{10} \mathrm{H}_{11} \mathrm{NO}_{2} \quad 50838-16-9$

2-Propenoic acid, 3-(di-2-propynylamino)-, methyl ester

$\mathrm{MeOC}(\mathrm{O}) \mathrm{CH}=\stackrel{\mathrm{CHNCH}}{\mathrm{CH}_{2} \mathrm{C} \equiv \mathrm{CH}}$
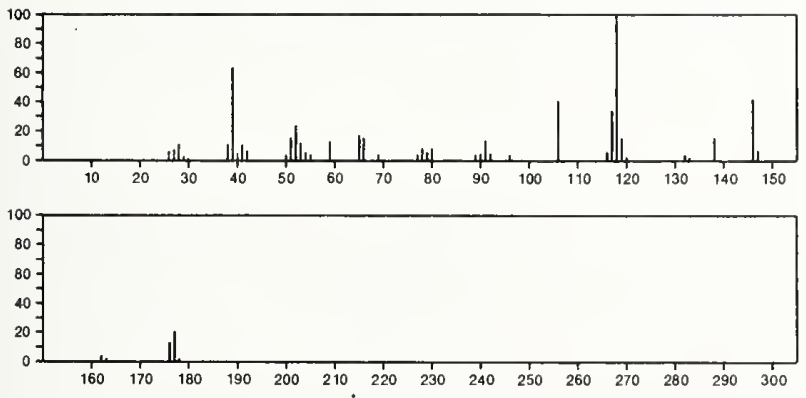

$177 \quad \mathrm{C}_{10} \mathrm{H}_{11} \mathrm{NO}_{2}$

$2 H$-1,6-Benzoxazocin-5(6H)-one, 3,4-dihydro-

$51110-93-1$
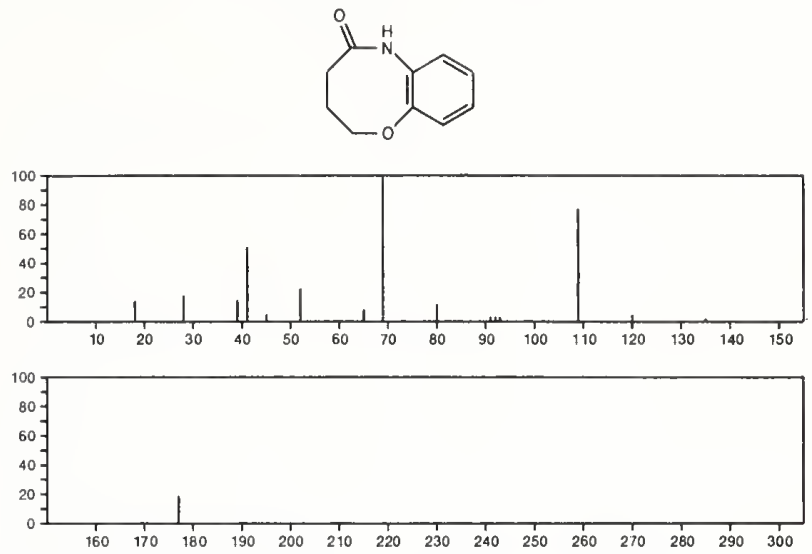

$177 \quad \mathrm{C}_{10} \mathrm{H}_{11} \mathrm{NO}_{2} \quad 51110-99-7$

6H-1,5-Benzoxazocin-6-one, 2,3,4,5-tetrahydro-
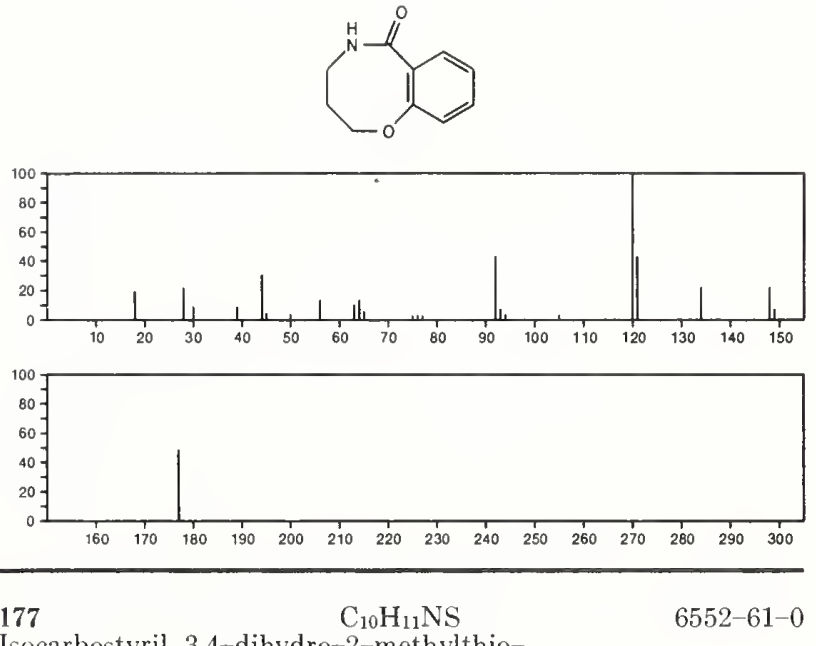

Isocarbostyril, 3,4-dihydro-2-methylthio
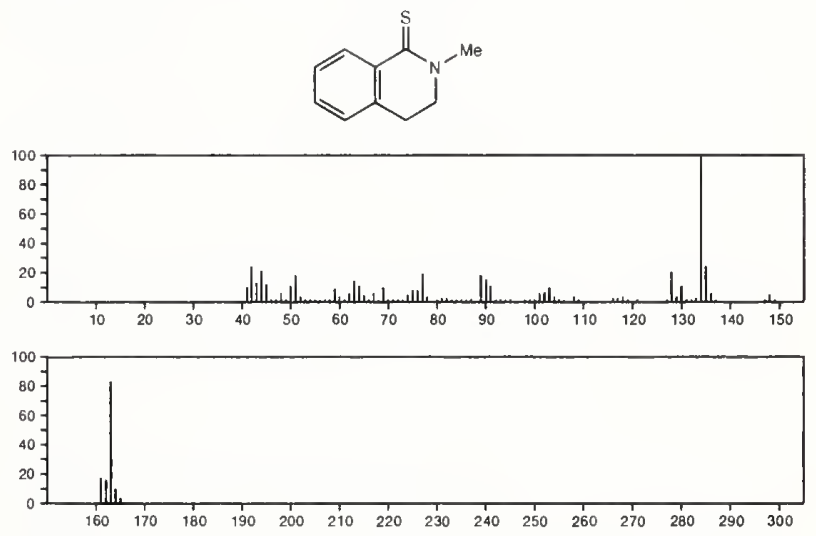

\begin{tabular}{lll}
\hline $\mathrm{C}_{11} \mathrm{H}_{15} \mathrm{NO}$ & $120-21-8$
\end{tabular}

Benzaldehyde, 4-(diethylamino)-
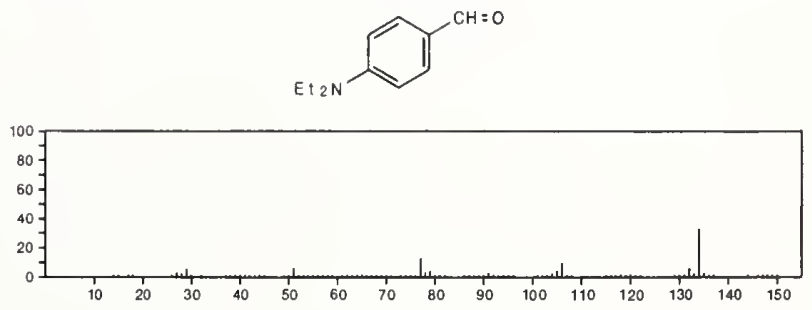


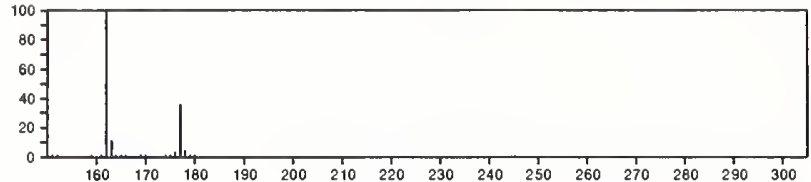

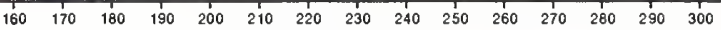

177

$\mathrm{C}_{11} \mathrm{H}_{15} \mathrm{NO}$

Morpholine, 3-methyl-2-phenyl-
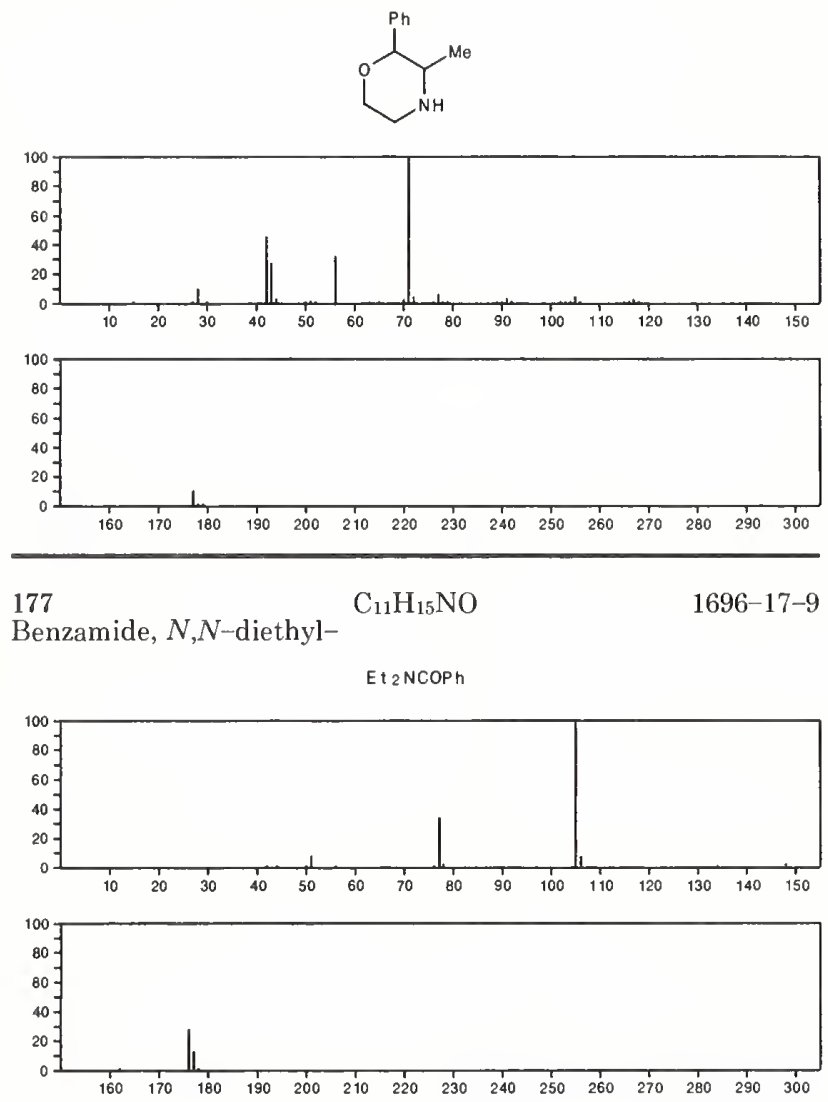

177

Benzamide, $N$-butyl-

$$
\mathrm{C}_{11} \mathrm{H}_{15} \mathrm{NO}
$$

$2782-40-3$

$\mathrm{PhCONH}\left(\mathrm{CH}_{2}\right) 3 \mathrm{Me}$
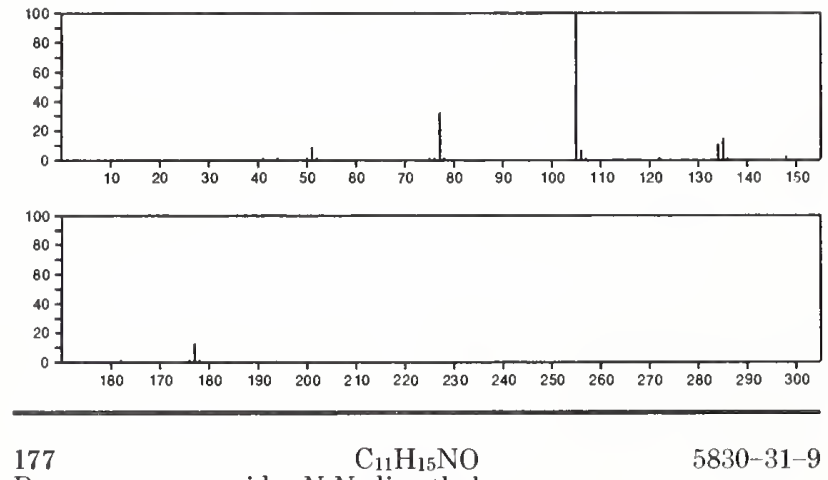

Benzenepropanamide, $N, N$-dimethyl-

$\mathrm{PhCH}_{2} \mathrm{CH}_{2} \mathrm{CONMe} 2$

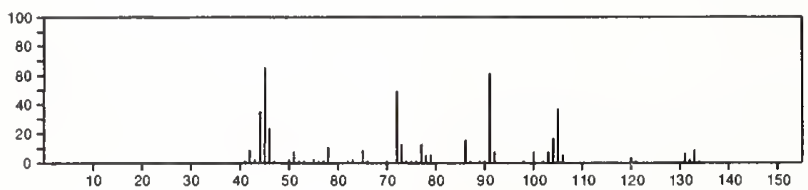

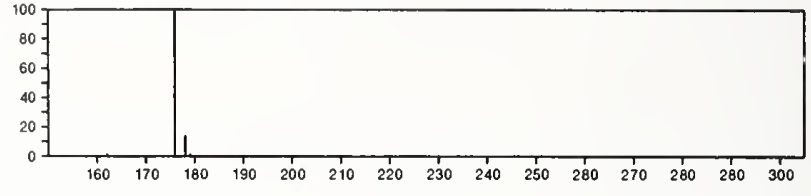

177

$\mathrm{C}_{11} \mathrm{H}_{15} \mathrm{NO}$

Propanamide, 2,2-dimethyl- $N$-phenyl-

$6625-74-7$

Me 3 CCONHPh
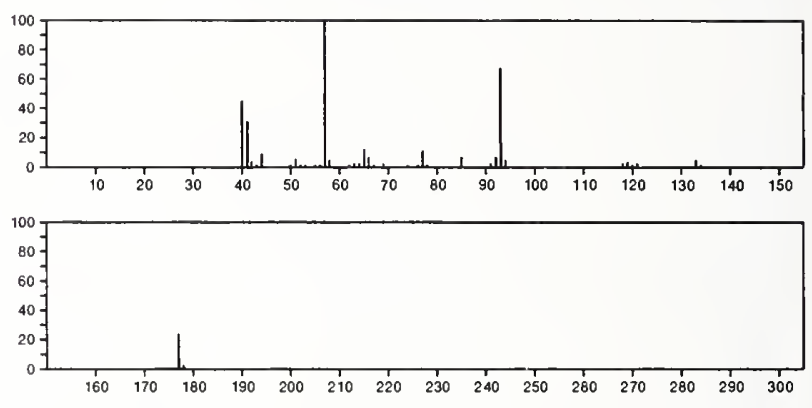

177

$\mathrm{C}_{11} \mathrm{H}_{15} \mathrm{NO}$

5-Hexen-3-yn-2-one, 6-(1-piperidinyl)-

29971-61-7
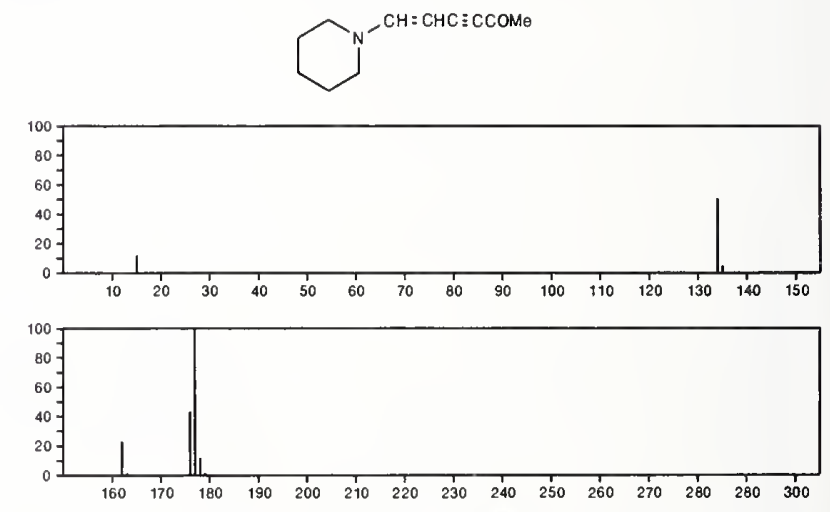

177

Acetamide, $N$-(3-phenylpropyl)-

$$
\mathrm{C}_{11} \mathrm{H}_{15} \mathrm{NO}
$$

$34059-10-4$

$\mathrm{Ph}\left(\mathrm{CH}_{2}\right)$ 3 NHAC
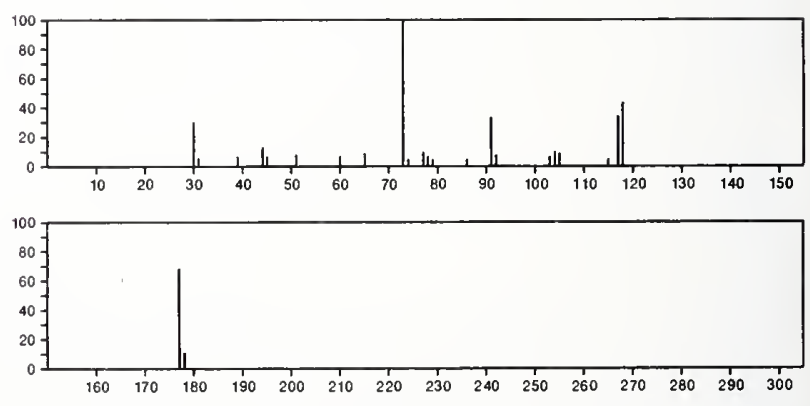

177

$$
\mathrm{C}_{11} \mathrm{H}_{15} \mathrm{NO}
$$

Acetamide, $N$-ethyl- $N$-(phenylmethyl)-

34597-04-1

$\mathrm{E}: \mathrm{N}(\mathrm{AC}) \mathrm{CH}_{2} \mathrm{Ph}$

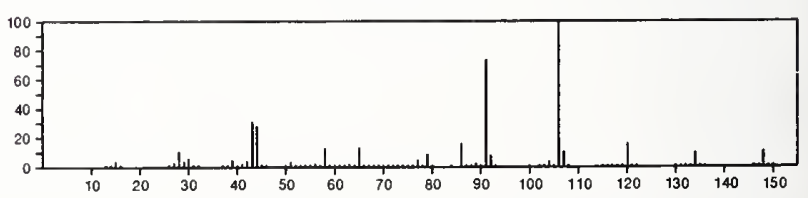




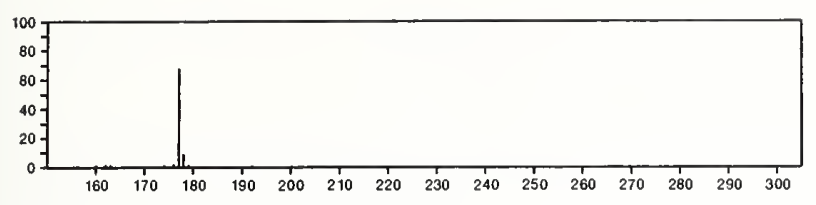

177

$\mathrm{C}_{11} \mathrm{H}_{15} \mathrm{NO}$

1-Hexanone, 1-(2-pyridinyl)-
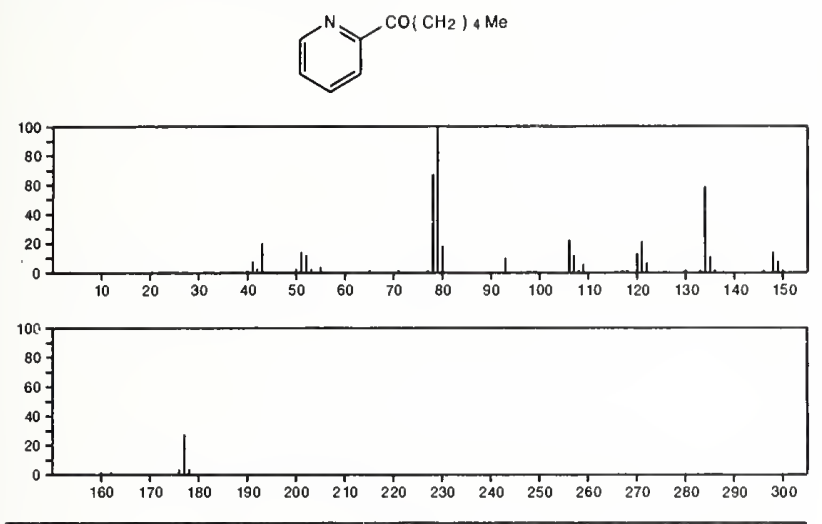

$177 \quad \mathrm{C}_{11} \mathrm{H}_{15} \mathrm{NO} \quad 42540-70-5$ Benzenamine, $N$-[1-(methoxymethyl)cyclopropyl] -
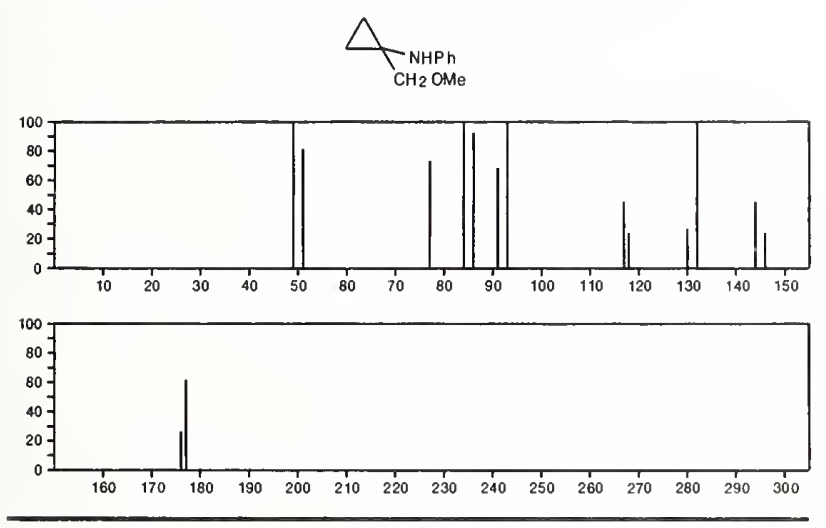

177

Acetamide, $N$-methyl $-N-(2-$ phenylethyl)-

50893-11-3

$\mathrm{MeN}(\mathrm{AC}) \mathrm{CH}_{2} \mathrm{CH}_{2} \mathrm{Ph}$
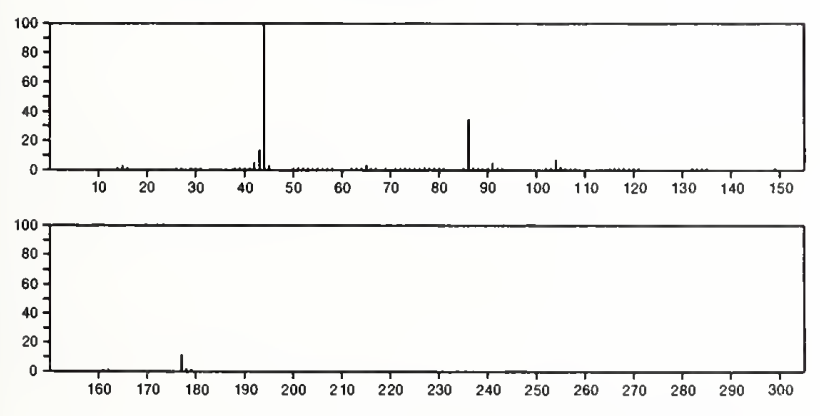

$$
177
$$

Benzenehexanamine

$\mathrm{C}_{12} \mathrm{H}_{19} \mathrm{~N}$

$17734-20-2$

$\mathrm{Ph}\left(\mathrm{CH}_{2}\right) 6 \mathrm{NH}_{2}$

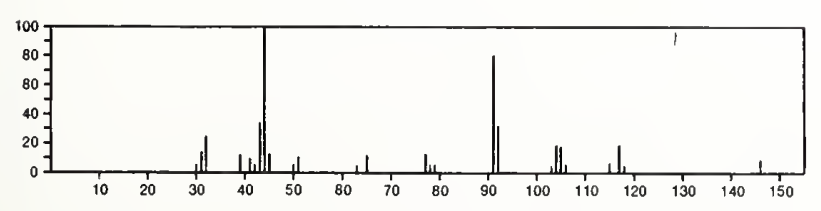

177

$\mathrm{C}_{12} \mathrm{H}_{19} \mathrm{~N}$

$49826-47-3$

Pyrrolidine, 1-bicyclo[3.2.1]oct-2-en-3-yl-
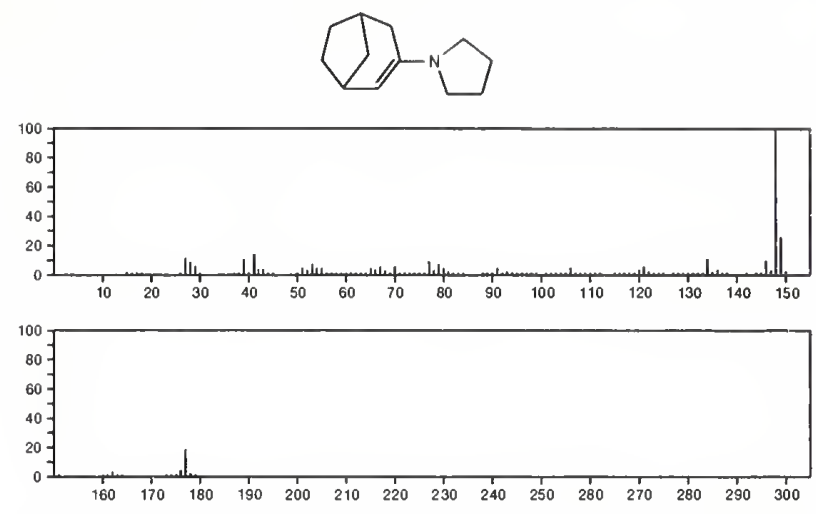

177

$\mathrm{C}_{12} \mathrm{H}_{19} \mathrm{~N}$

Benzenamine, $N$-(2,2-dimethylpropyl)- $N$-methyl

$53927-61-0$

$\mathrm{PhNMe} \mathrm{CH}_{2} \mathrm{CMe}_{3}$
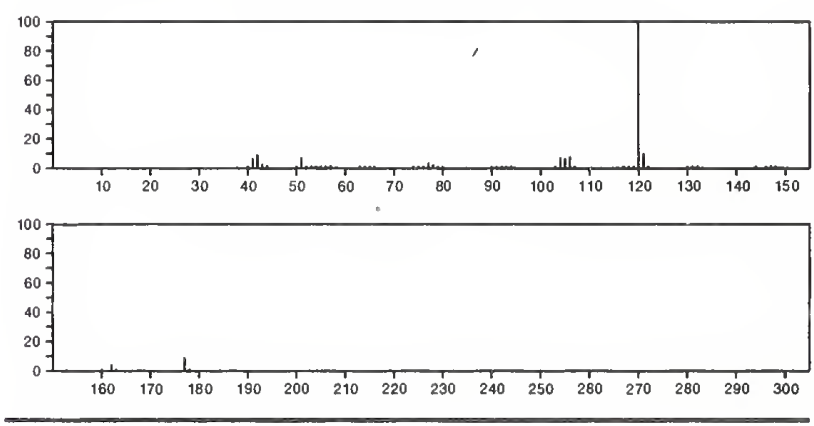

177

$\mathrm{C}_{12} \mathrm{H}_{19} \mathrm{~N}$

54518-13-7

Pyridine, 2-(1-propylbutyl)-
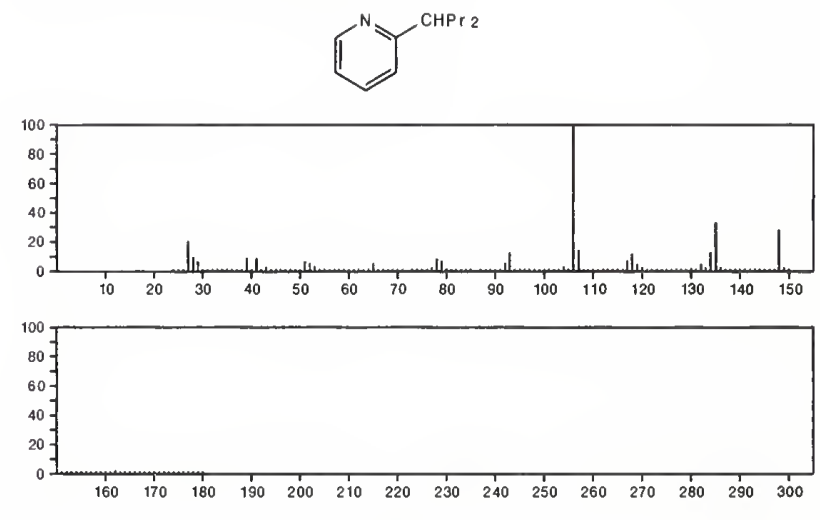

178

1-Propene, 1,2,3,3-tetrachloro-

$\mathrm{C}_{3} \mathrm{H}_{2} \mathrm{Cl}_{4}$

20589-85-9

$\mathrm{Cl} \mathrm{CH}=\mathrm{CCl} \mathrm{CHCl}_{2}$
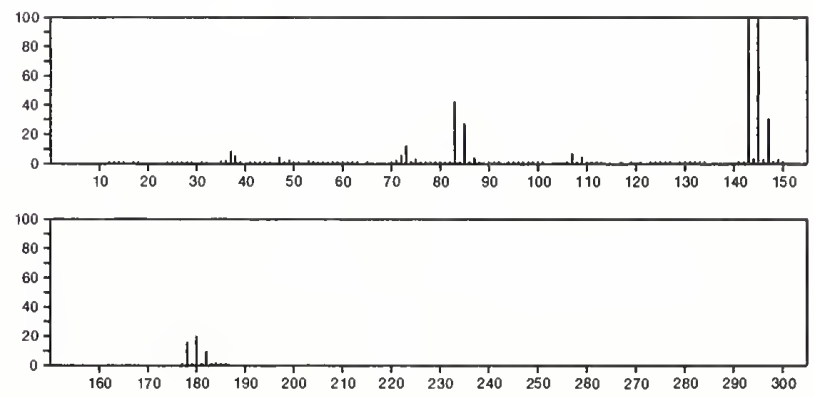
178

$\mathrm{C}_{4} \mathrm{ClF}_{5}$

1,3-Butadiene, 1-chloropentafluoro-

$392-44-9$

$\mathrm{F}_{2} \mathrm{C}=\mathrm{CF} \mathrm{CF}=\mathrm{CCI} F$
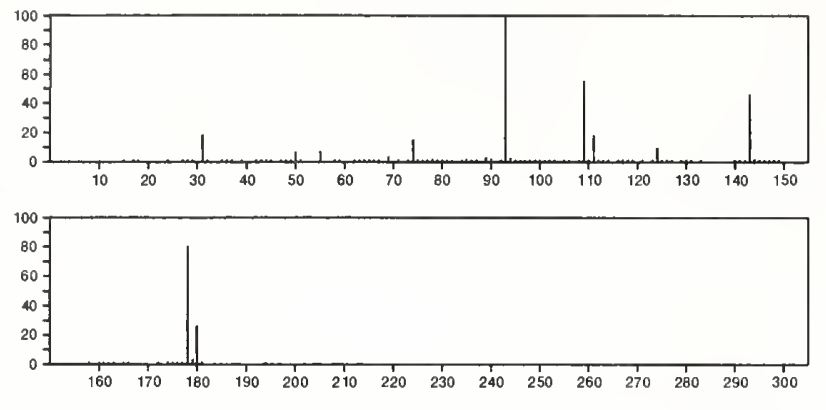

$178 \quad \mathrm{C}_{4} \mathrm{H}_{12} \mathrm{~N}_{2} \cdot \mathrm{C}_{2} \mathrm{H}_{2} \mathrm{O}_{4}$

Hydrazine, butyl-, oxalate (1:1)

$\mathrm{Me}\left(\mathrm{CH}_{2}\right)_{3} \mathrm{NHNH}_{2} \cdot \mathrm{HO}_{2} \mathrm{CCO}_{2} \mathrm{H}$

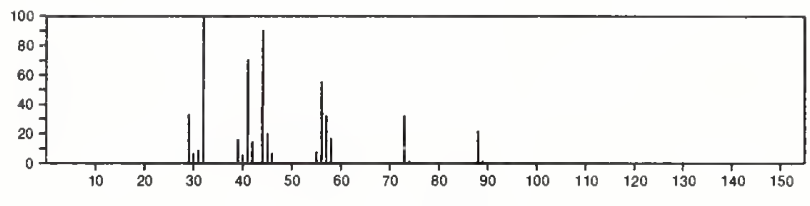

178

Hydrazine, tert-butyl-, oxalate (1:1)

$\mathrm{H}_{2} \mathrm{NNHBU}-+\cdot \mathrm{HO}_{2} \mathrm{CCO}_{2} \mathrm{H}$

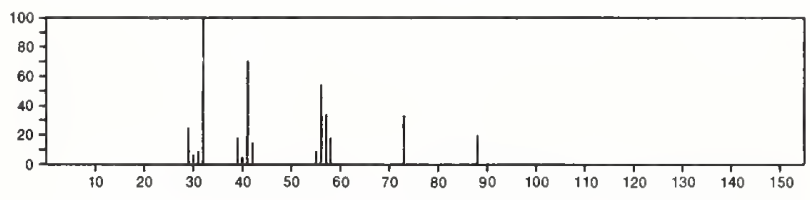

178

$\mathrm{C}_{5} \mathrm{H}_{6} \mathrm{SSe}$

Thiophene, 2-(methylseleno)-
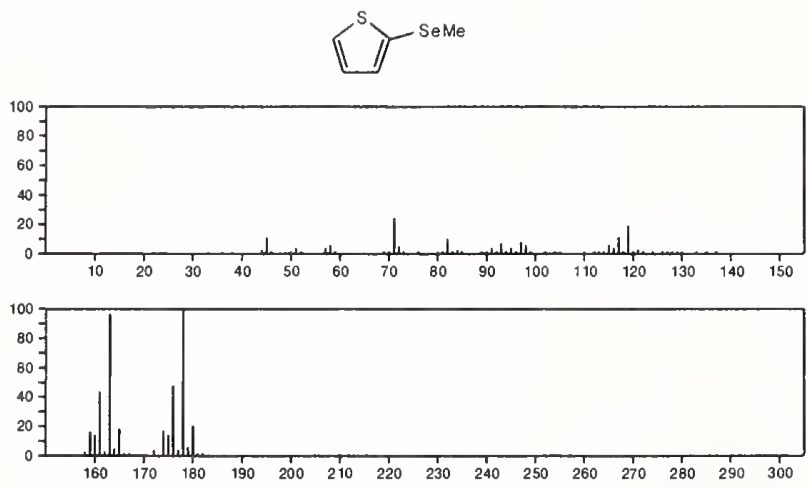

178

Thiophene, 3-(methylseleno)-

$\mathrm{C}_{5} \mathrm{H}_{6} \mathrm{SSe}$

31053-53-9
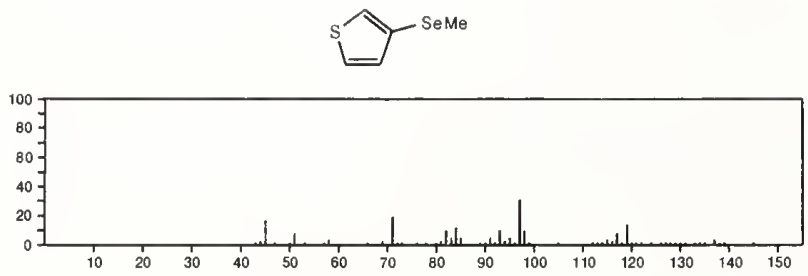

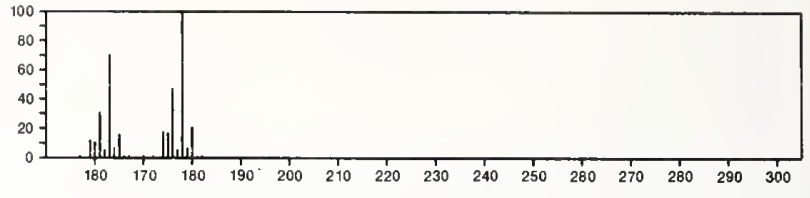

178

Selenophene, 2-(methylthio)-

$\mathrm{C}_{5} \mathrm{H}_{6} \mathrm{SSe}$

$31053-54-0$
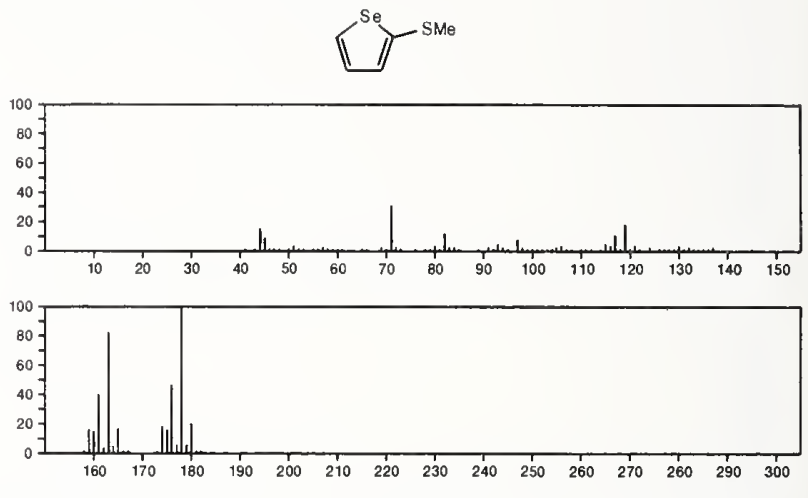

178

1,3,2-Dioxarsenane, 2-ethyl-

$\mathrm{C}_{5} \mathrm{H}_{11} \mathrm{AsO}_{2}$

42541-31-1
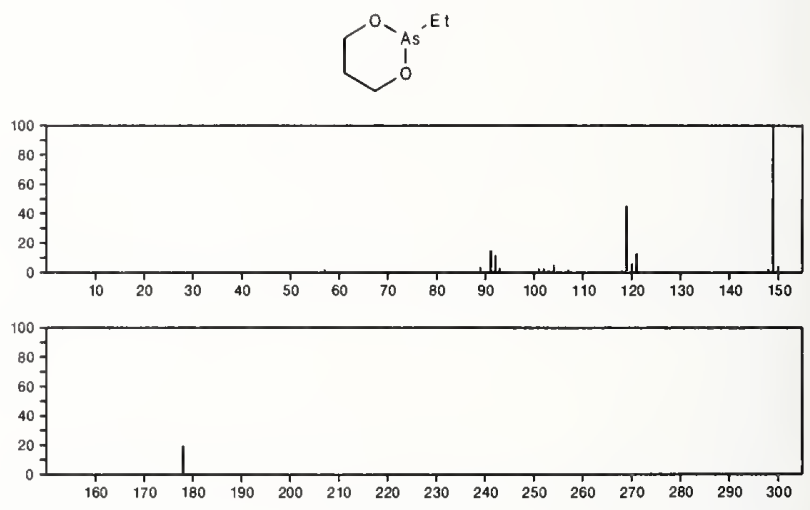

178 $\mathrm{C}_{6} \mathrm{H}_{5} \mathrm{Cl}_{2} \mathrm{P}$

Phosphonous dichloride, phenyl-

$644-97-3$

$\mathrm{Cl}_{2} \mathrm{PPh}$
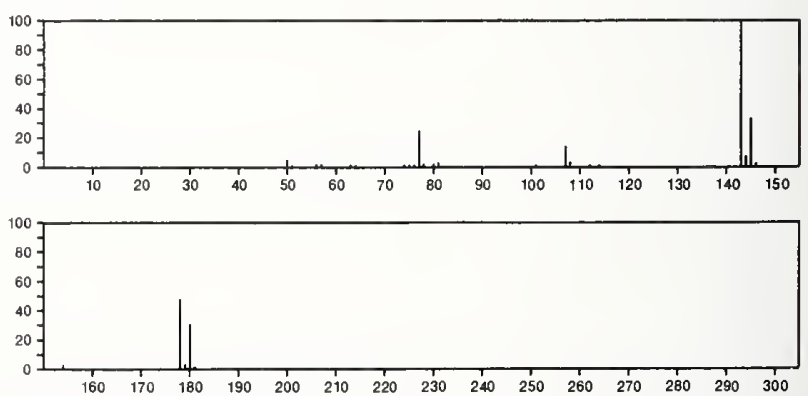
$178 \quad \mathrm{C}_{6} \mathrm{H}_{5} \mathrm{~F}_{3} \mathrm{~N}_{2} \mathrm{O}$

4-Pyrimidinol, 6 methyl-2-(trifluoromethyl)
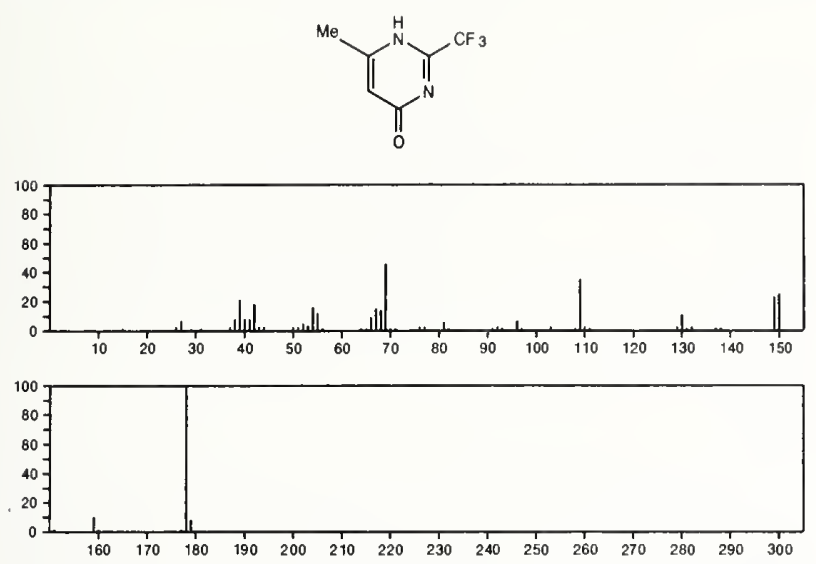

$$
-
$$

178

4-Pyrimidinol, 2-methyl-6-(trifluoromethyl)-
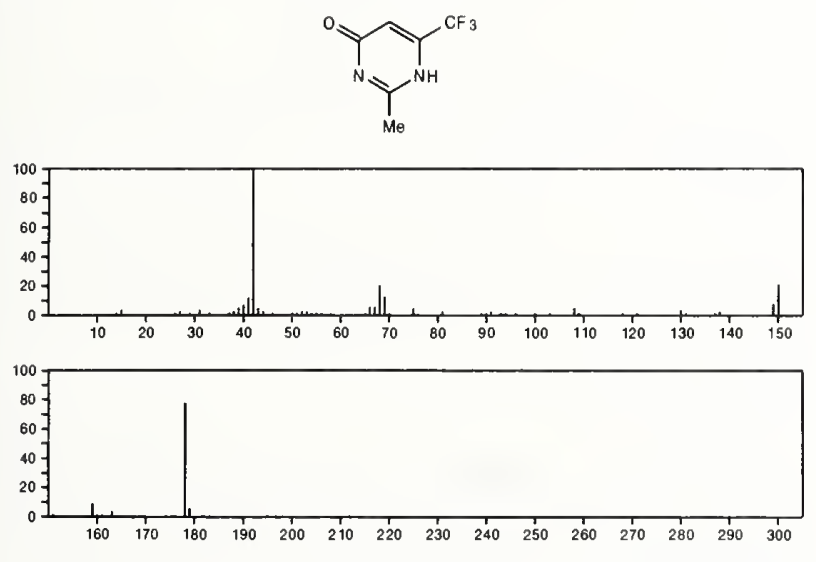

178

$\mathrm{C}_{6} \mathrm{H}_{7} \mathrm{ClN}_{2} \mathrm{ClH}$

1073-70-7

Hydrazine, (4-chlorophenyl)-, monohydrochloride
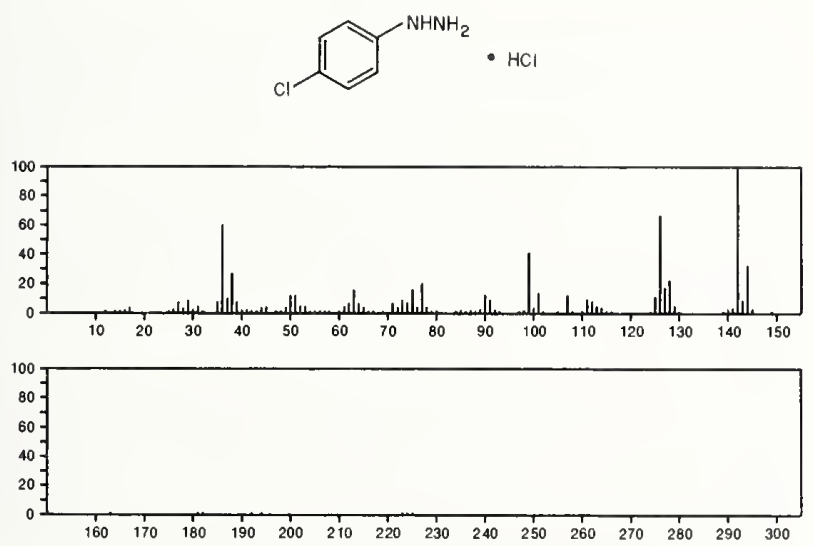

178

Hydrazine, (3-chlorophenyl)-, monohydrochloride

$2312-23-4$
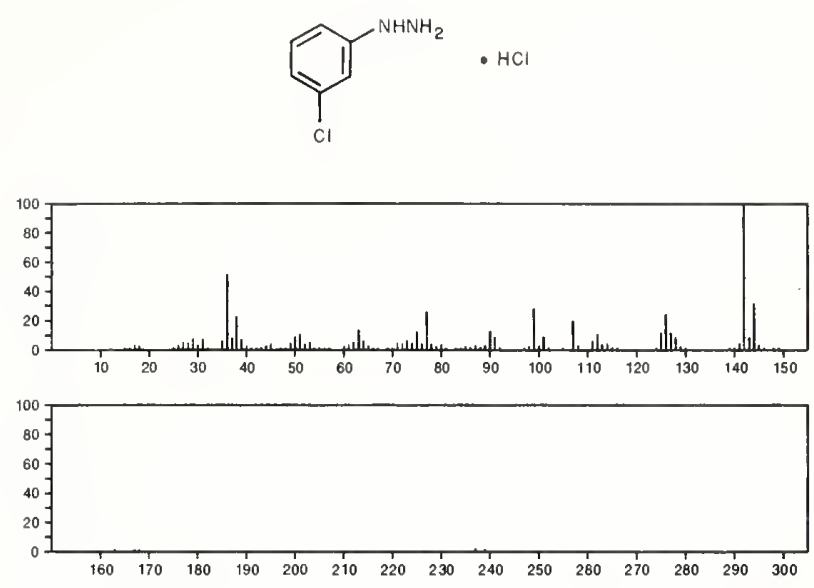

178

$\mathrm{C}_{6} \mathrm{H}_{10} \mathrm{O}_{2} \mathrm{~S}_{2}$

1,2-Dithiolane-3-propanoic acid

$13125-44-5$
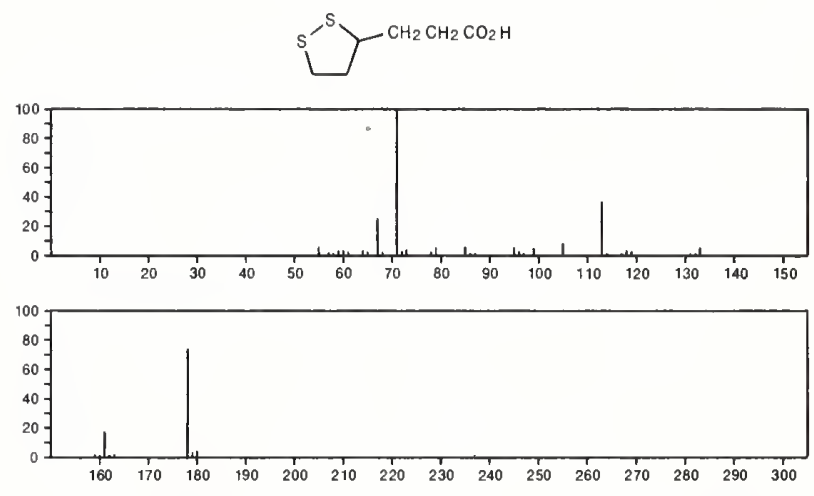

178

$\mathrm{C}_{6} \mathrm{H}_{10} \mathrm{O}_{6}$

608-68-4

Butanedioic acid, 2,3-dihydroxy- $\left[R-\left(R^{*}, R^{*}\right)\right]-$, dimethyl ester

$\mathrm{MeOC}(\mathrm{O}) \mathrm{CH}(\mathrm{OH}) \mathrm{CH}(\mathrm{OH}) \mathrm{C}(\mathrm{O}) \mathrm{OMe}$

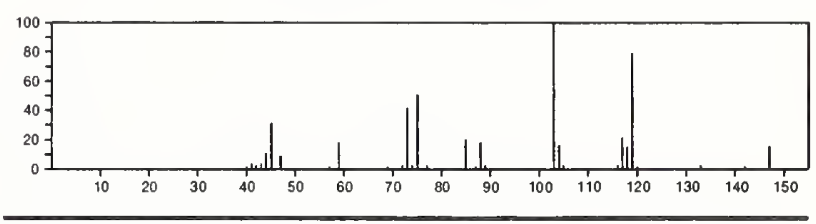

178

$\mathrm{C}_{6} \mathrm{H}_{10} \mathrm{~S}_{3}$

$2050-87-5$

Trisulfide, di-2-propenyl

$\mathrm{H}_{2} \mathrm{C}=\mathrm{CHCH}_{2} \mathrm{SSSCH}_{2} \mathrm{CH} \equiv \mathrm{CH}_{2}$
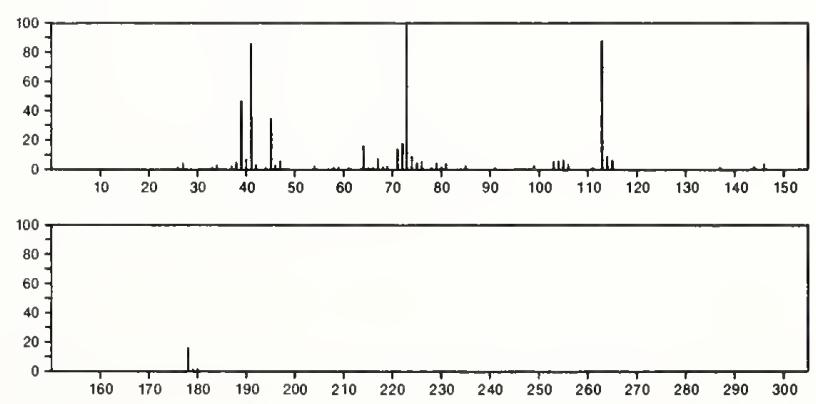
$\mathrm{C}_{6} \mathrm{H}_{11} \mathrm{BrO}$

Cyclohexanol, 2-bromo-, trans-
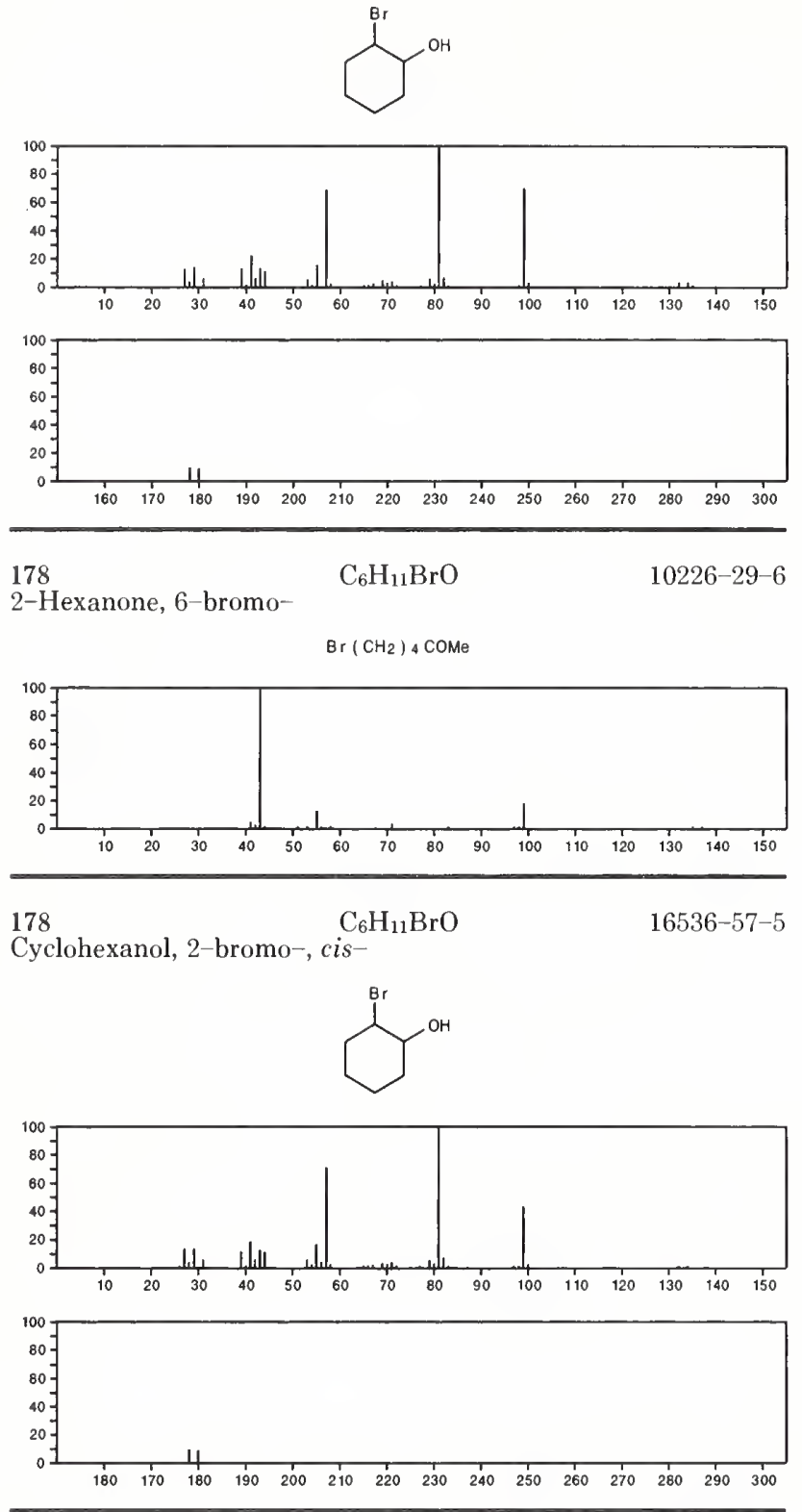

$178 \quad \mathrm{C}_{6} \mathrm{H}_{11} \mathrm{BrO}$

Cyclopentane, 1-bromo-2-methoxy-, trans ${ }^{-}$

$51422-76-5$
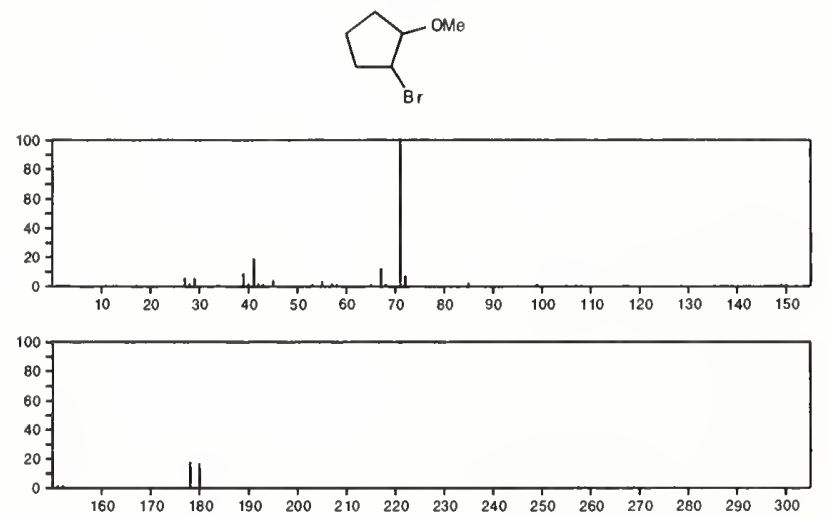

178

1475-11-7

Cyclopentane, 1-bromo-2-methoxy-, cis-
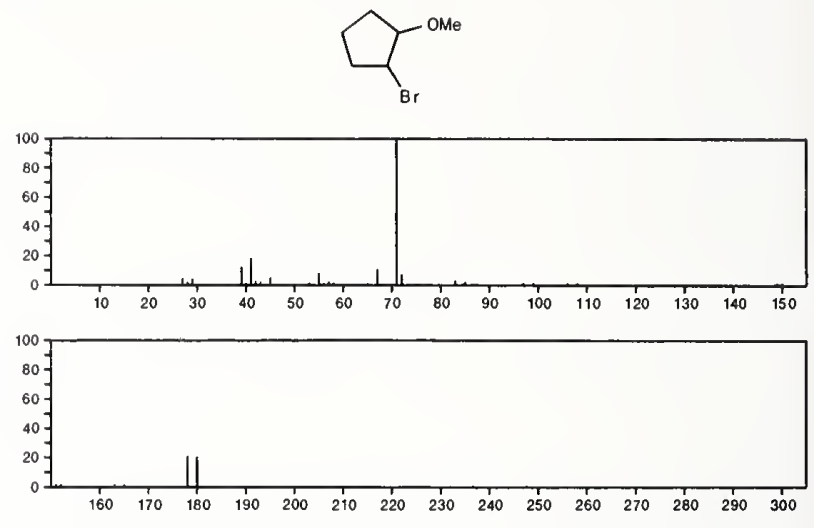

178

$\mathrm{C}_{7} \mathrm{H}_{6} \mathrm{~N}_{4} \mathrm{O}_{2}$

6726-55-2

Pyrazolo[5,1-c]-as-triazine-3-carboxylic acid, 4-methyl-
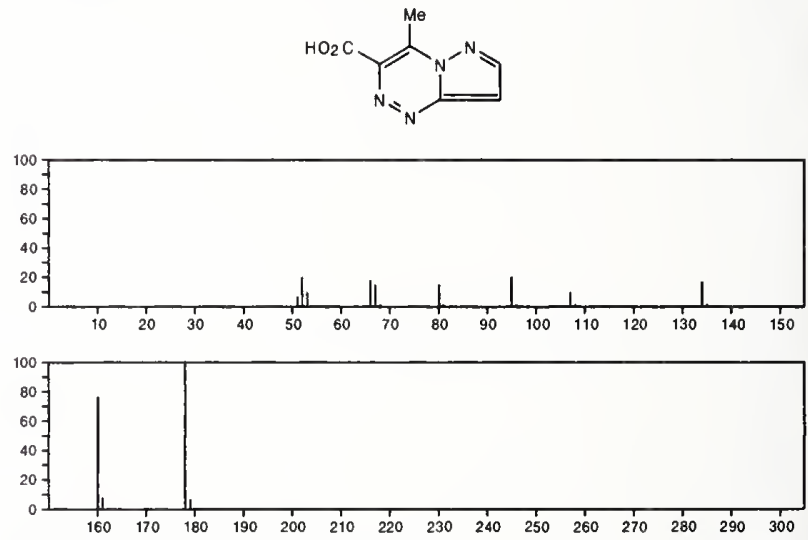

178

$\mathrm{C}_{7} \mathrm{H}_{6} \mathrm{~N}_{4} \mathrm{O}_{2}$

1H-Benzotriazole, 1-methyl-7-nitro-

$14209-07-5$
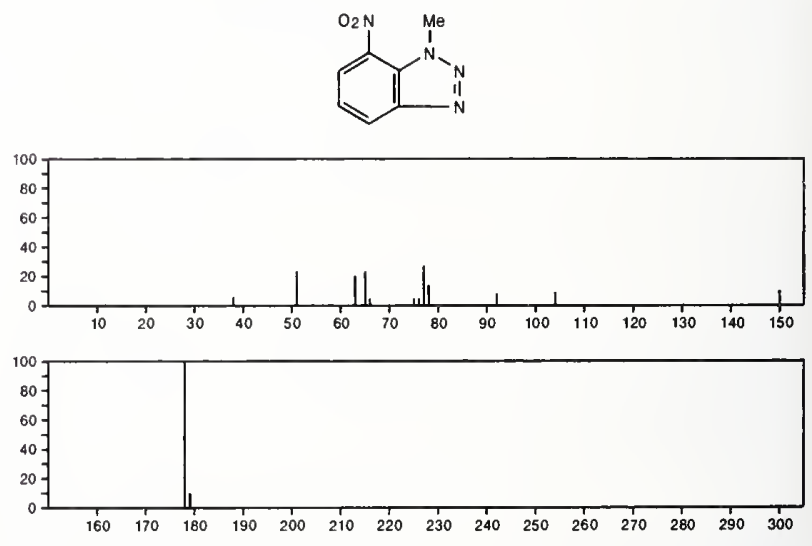

178

$\mathrm{C}_{7} \mathrm{H}_{6} \mathrm{~N}_{4} \mathrm{O}_{2}$

$18106-58-6$

$4(3 H)$-Pteridinone, 3-hydroxy-2-methyl-
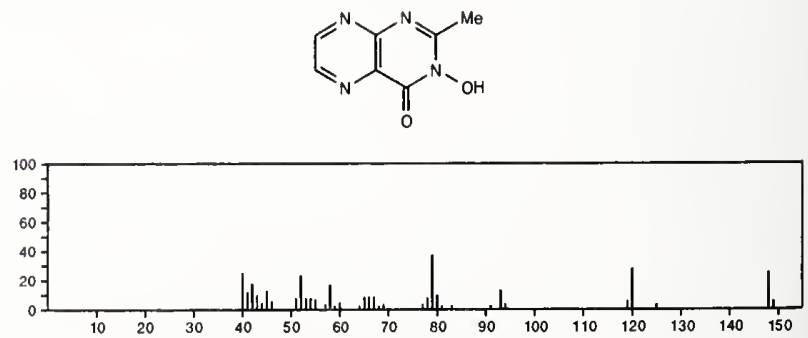
178

EPA/NIH MASS SPECTRAL DATA BASE

865

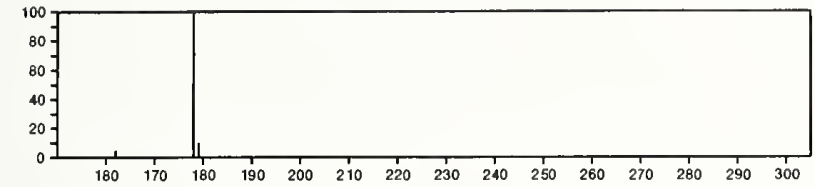

\begin{tabular}{lc}
\hline 178 & $\mathrm{C}_{7} \mathrm{H}_{6} \mathrm{~N}_{4} \mathrm{O}_{2}$ \\
$4(3 H)$-Pteridinone, 3 -hydroxy-6-methyl- & $18106-59-7$
\end{tabular}
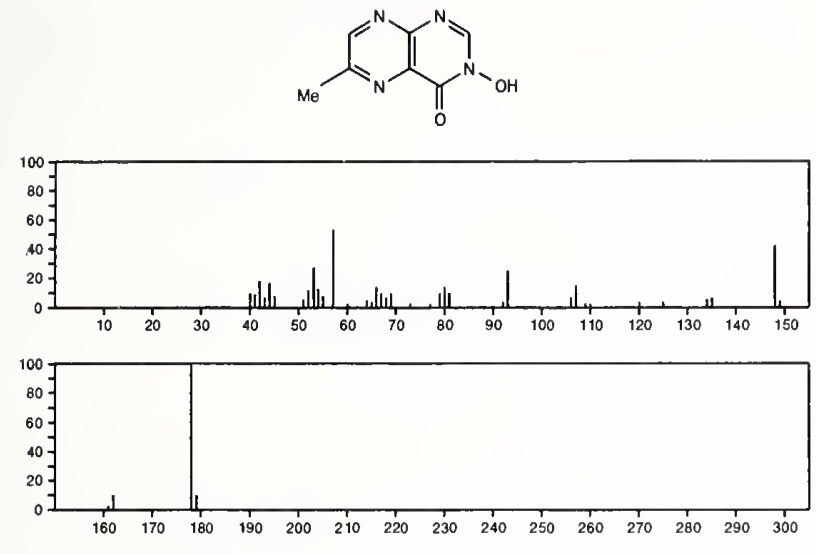

178

$\mathrm{C}_{7} \mathrm{H}_{6} \mathrm{~N}_{4} \mathrm{O}_{2}$

$18106-60-0$

4(3H)-Pteridinone, 3-hydroxy-7-methyl-
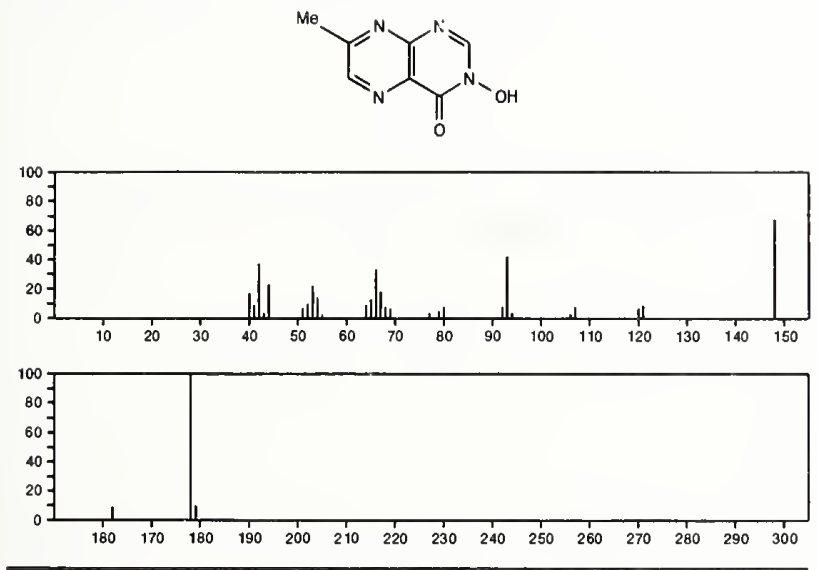

$178 \quad \mathrm{C}_{7} \mathrm{H}_{6} \mathrm{~N}_{4} \mathrm{O}_{2} \quad 20615-75-2$

Benzene, 1-azido-4-methyl-2-nitro-
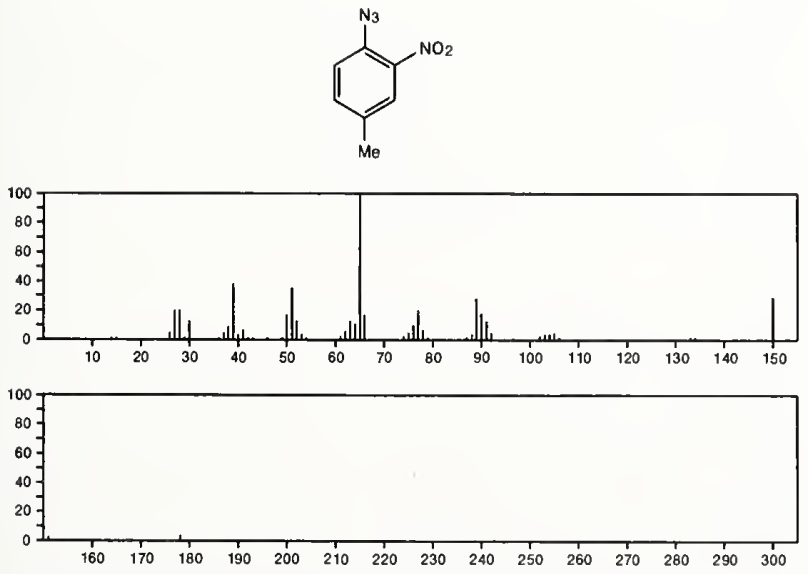

178 -Benzotriazole, 1-methyl-5-nitro-
$\mathrm{C}_{7} \mathrm{H}_{6} \mathrm{~N}_{4} \mathrm{O}_{2}$

$25877-34-3$
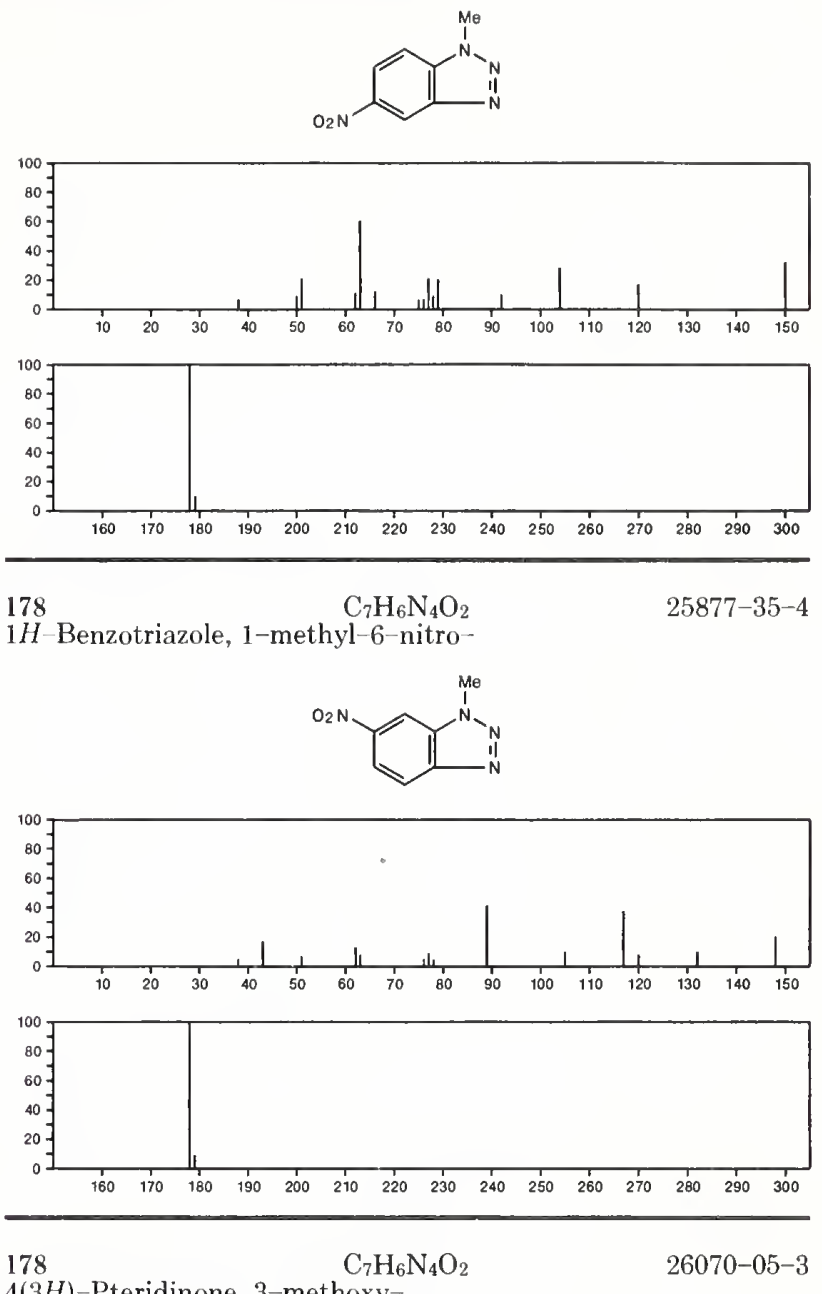

4(3H)-Pteridinone, 3-methoxy-
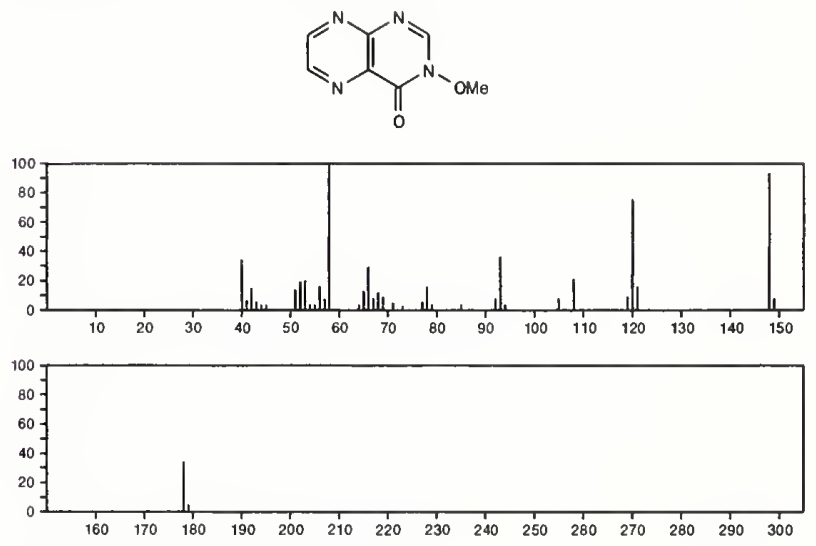
$178 \quad \mathrm{C}_{7} \mathrm{H}_{6} \mathrm{~N}_{4} \mathrm{O}_{2}$

1 H-Benzotriazole, 1-methyl-4-nitro-
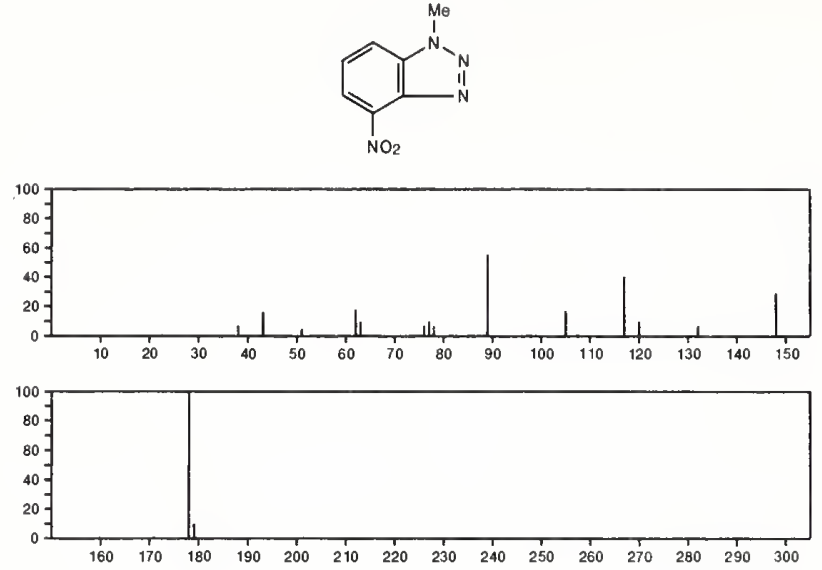

178

$\mathrm{C}_{7} \mathrm{H}_{6} \mathrm{~N}_{4} \mathrm{O}_{2}$

40515-18-2

Benzene, 4-azido-1-methyl-2-nitro-
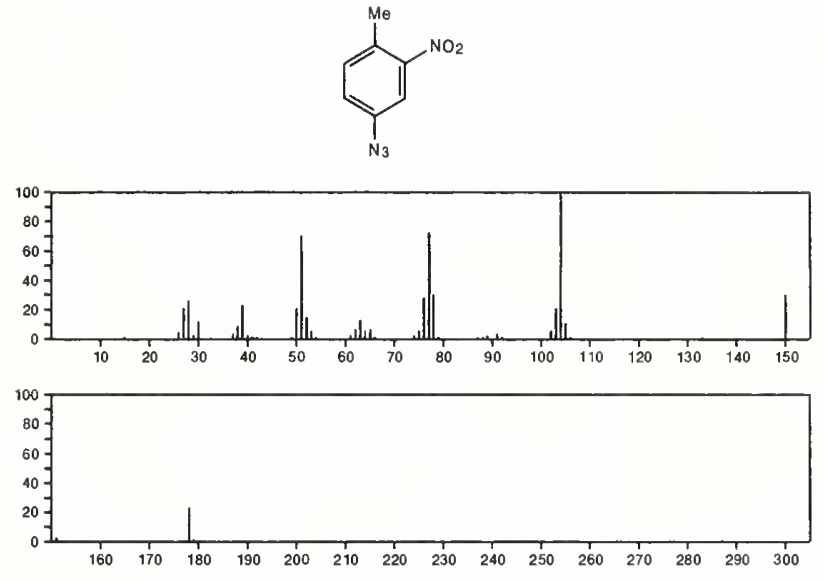

178

$\mathrm{C}_{7} \mathrm{H}_{6} \mathrm{~N}_{4} \mathrm{O}_{2}$

Benzene, 2-azido-1-methyl-4-nitro-

$40515-19-3$
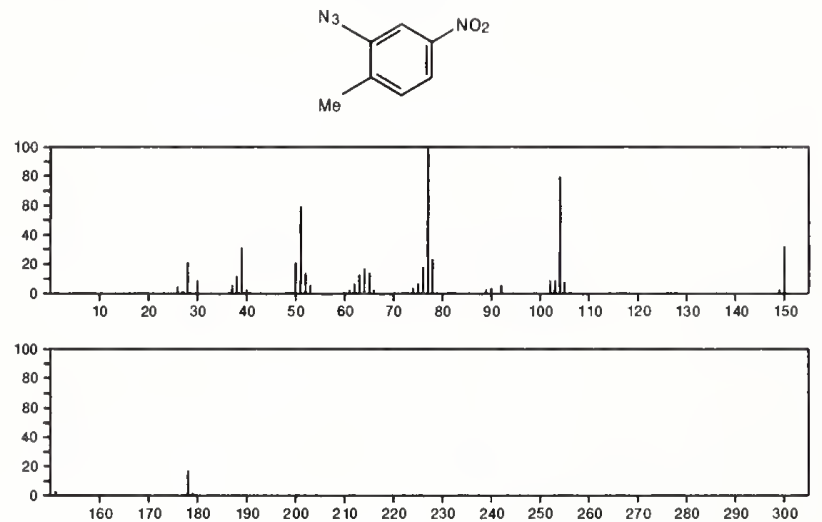

178

$\mathrm{C}_{7} \mathrm{H}_{7} \cdot \mathrm{BF}_{4}$

$27081-10-3$

Cycloheptatrienylium, tetrafluoroborate(1-)
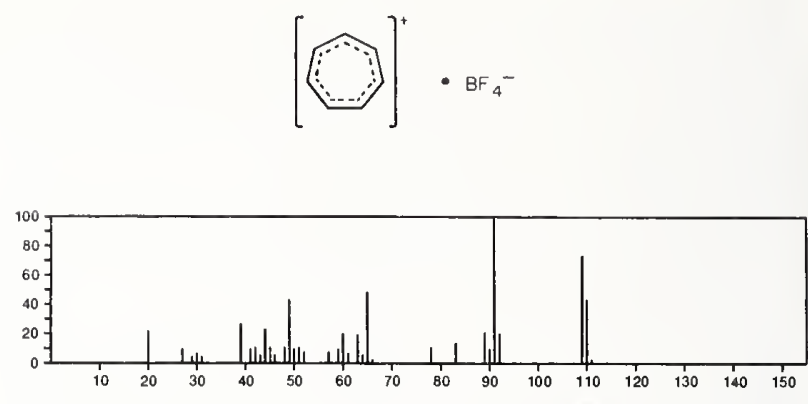

178

$\mathrm{C}_{7} \mathrm{H}_{10} \mathrm{~N}_{6}$

50473-86-4

Imidazo $[5,1-f][1,2,4]$ triazine-2,7-diamine, 4,5-dimethyl-
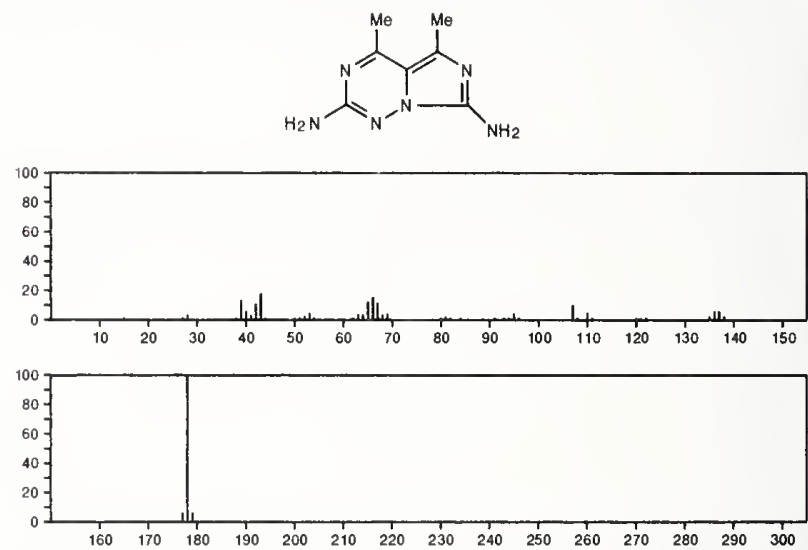

178
Carbonic acid, dithio-, $S, S$-dipropyl
$\mathrm{C}_{7} \mathrm{H}_{14} \mathrm{OS}_{2}$

PrSC(0) SPr
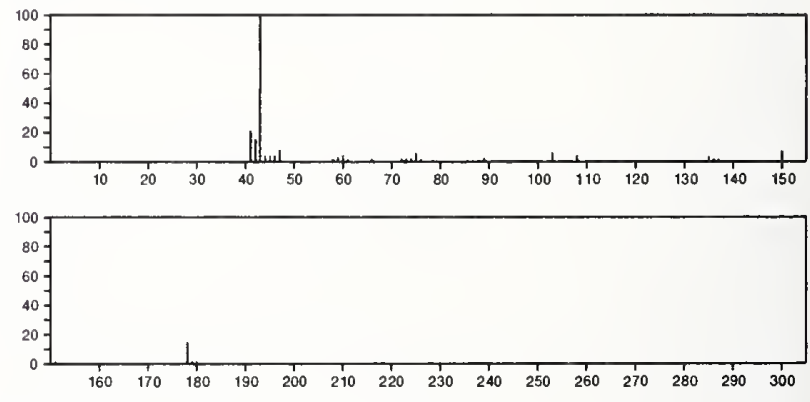

178

Carbonic acid, dithio-, $S, S$-diisopropyl ester

$16118-33-5$

$\mathrm{C}_{7} \mathrm{H}_{14} \mathrm{OS}$

$i-\operatorname{PrSC}(0) S P r-i$
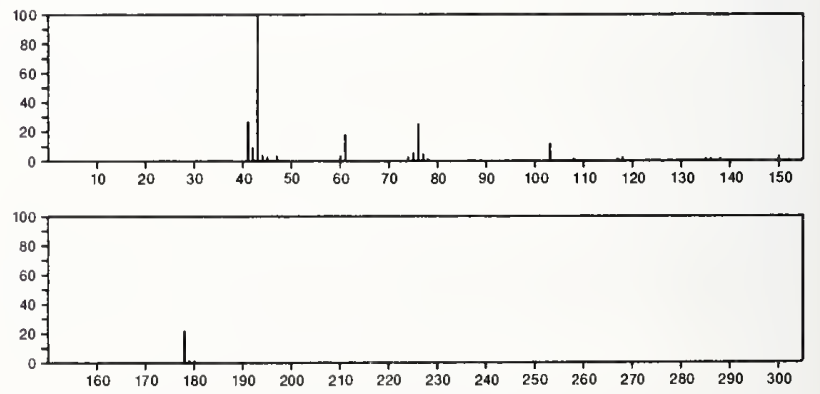
$178 \quad \mathrm{C}_{7} \mathrm{H}_{14} \mathrm{OS}_{2}$

Carbonodithioic acid, $O, S$-bis(1-methylethyl) ester

$i-\operatorname{PrOC}(S) S P r-i$
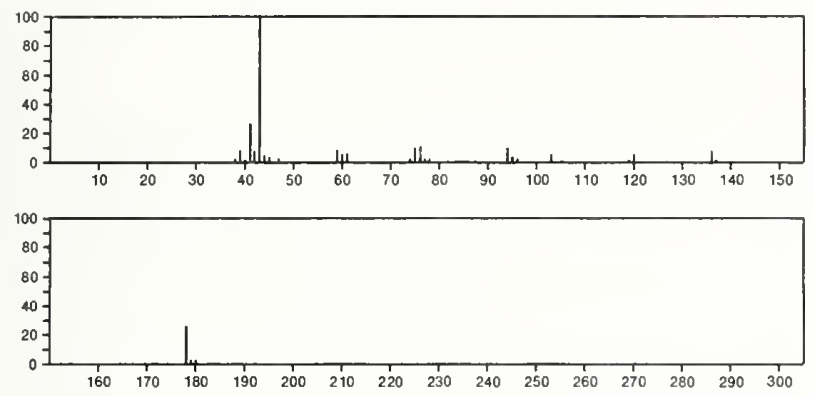

178

$178 \quad \mathrm{C}_{7} \mathrm{H}_{14} \mathrm{O}_{5}$

$626-84-6$

Ethanol, 2-methoxy-, carbonate

$\mathrm{MeOCH} 2 \mathrm{CH}_{2} \mathrm{OC}(\mathrm{O}) \mathrm{OCH}_{2} \mathrm{CH}_{2} \mathrm{OMe}$

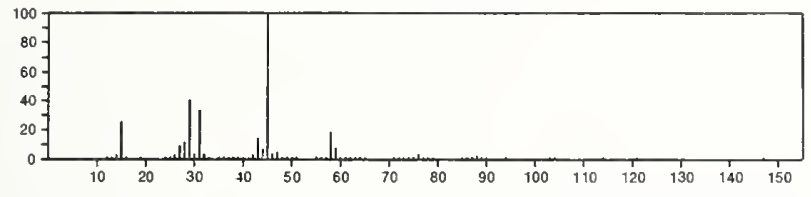

178

$\mathrm{C}_{7} \mathrm{H}_{14} \mathrm{O}_{5}$

$14687-15-1$

$\alpha-\mathrm{L}$-Galactopyranoside, methyl $6-$ deoxy-
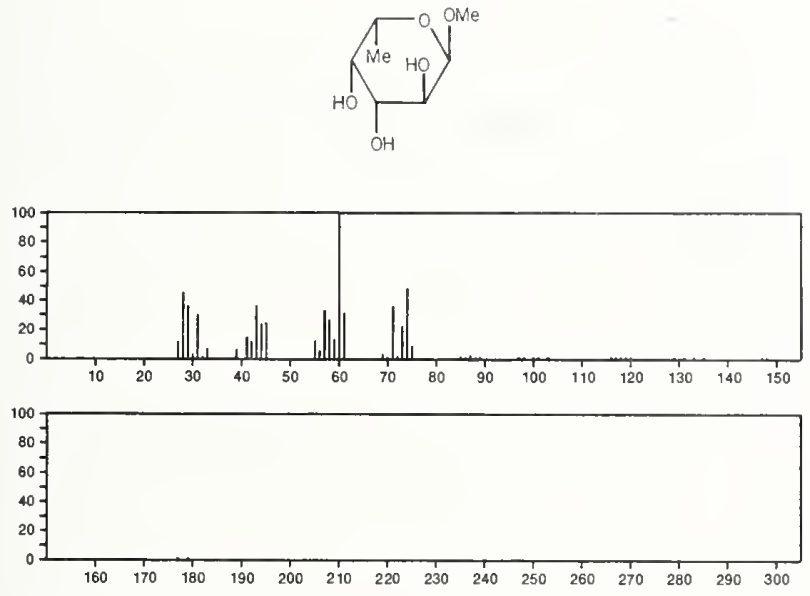

\section{8}

L-Glucose, 6-deoxy-3-O-methyl-

$18546-09-3$

$\mathrm{MeCH}(\mathrm{OH}) \mathrm{CH}(\mathrm{OH}) \mathrm{CH}(\mathrm{OMe}) \mathrm{CH}(\mathrm{OH}) \mathrm{CHO}$

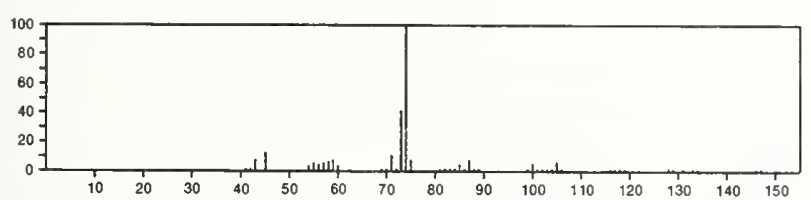

100
8
8
40

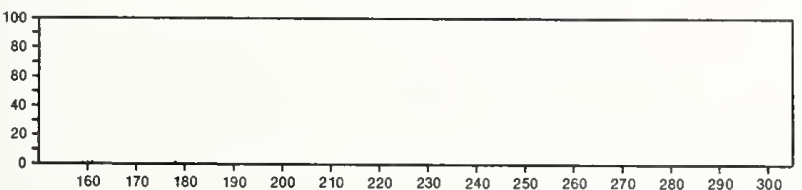

$178 \quad \mathrm{C}_{7} \mathrm{H}_{14} \mathrm{O}_{5}$ $\alpha-\mathrm{D}$-Xylofuranoside, methyl 2-O-methyl-

$32469-86-6$
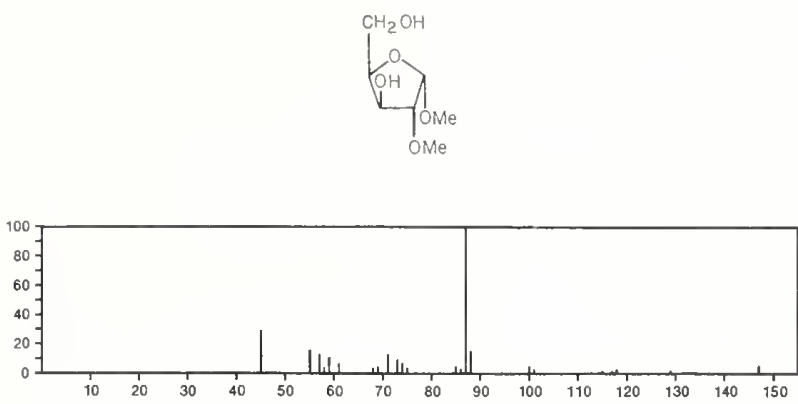

178

$\mathrm{C}_{7} \mathrm{H}_{14} \mathrm{O}_{5}$

$34338-86-8$

$\alpha-\mathrm{D}-\mathrm{X} y$ lofuranoside, methyl $3-O-$ methyl-
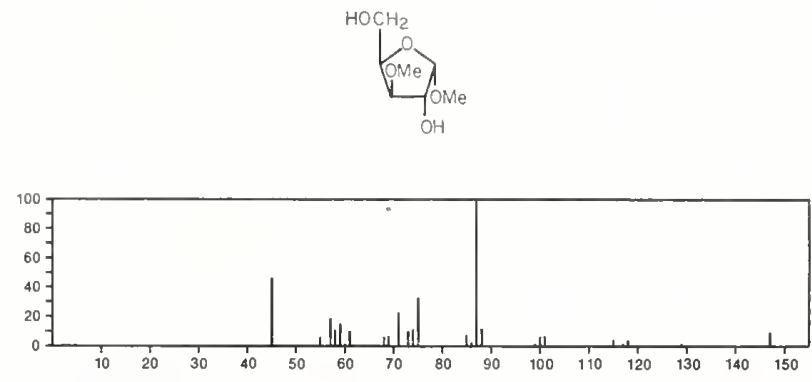

178

$\mathrm{C}_{7} \mathrm{H}_{14} \mathrm{O}_{5}$

$35007-57-9$

$\alpha-\mathrm{D}-\mathrm{X}$ ylofuranoside, methyl 5-O-methyl-
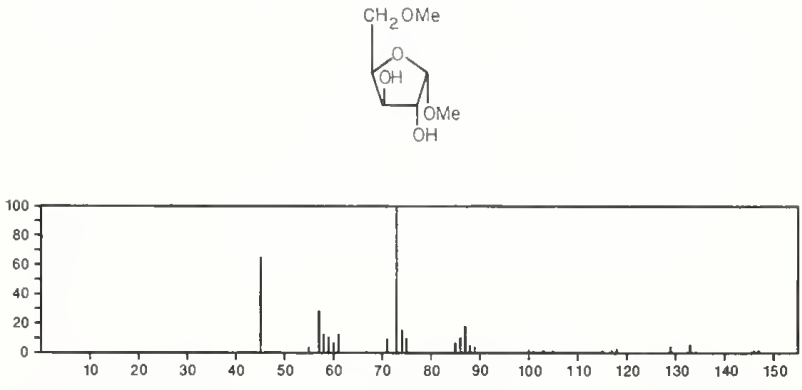

178

$\mathrm{C}_{7} \mathrm{H}_{15} \mathrm{Br}$

629-04-9

Heptane, 1-bromo-

$\mathrm{Br}\left(\mathrm{CH}_{2}\right)_{6} \mathrm{Me}$
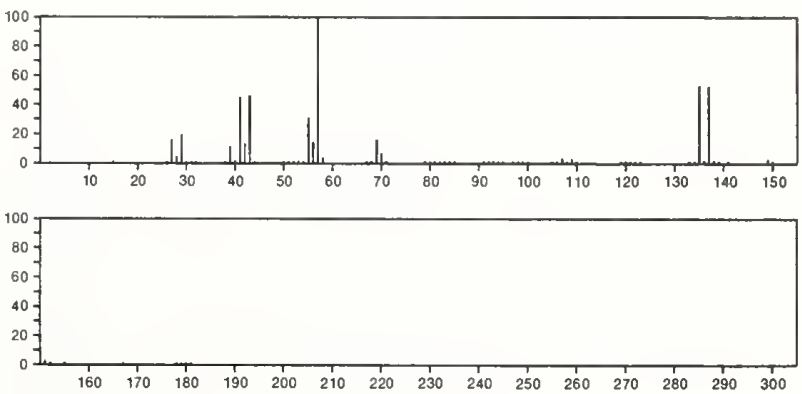
178

Heptane, 3-bromo-

$\mathrm{C}_{7} \mathrm{H}_{15} \mathrm{Br}$

$\mathrm{E} t \mathrm{CHBr}\left(\mathrm{CH}_{2}\right)_{3} \mathrm{Me}$
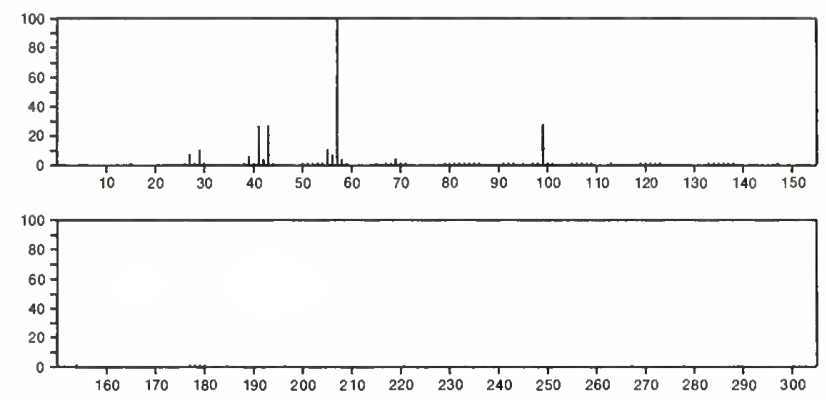

178

Pentane, 1-bromo-3,4-dimethyl-

$\mathrm{Me}_{2} \mathrm{CHCHM}_{2} \mathrm{CH}_{2} \mathrm{CH}_{2} \mathrm{Br}$
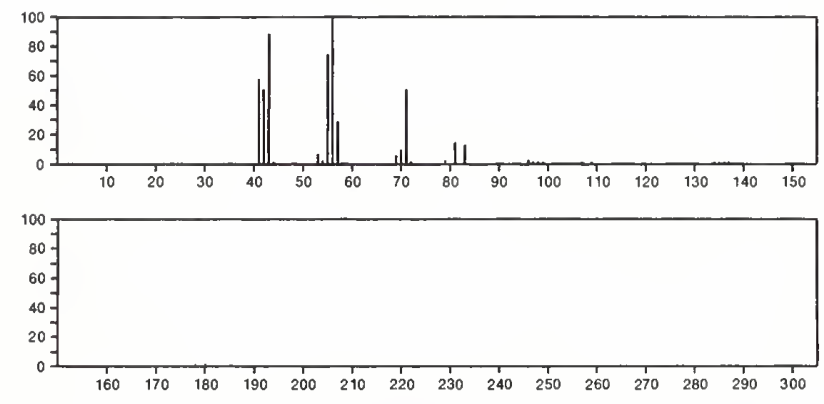

178

1,2,3-Oxadiazolium, 5-mercapto-3-phenyl-, hydroxide, inner salt
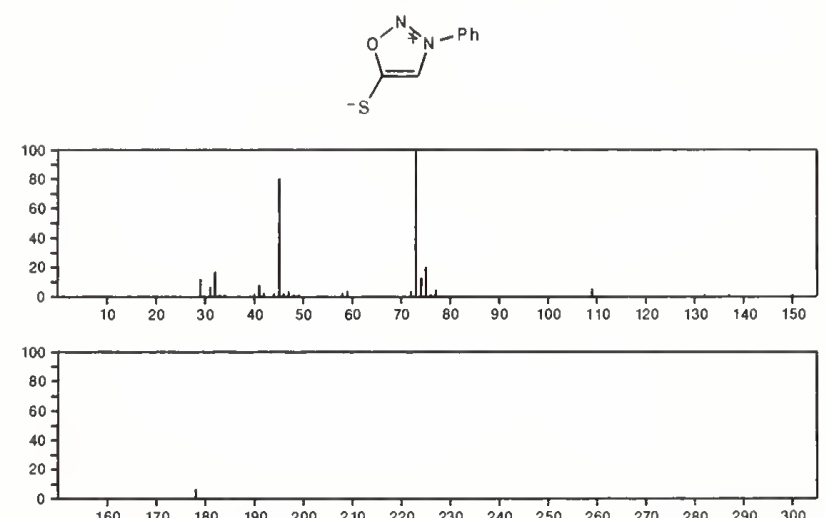

$178 \quad \mathrm{C}_{8} \mathrm{H}_{12} \mathrm{Cl}_{2}$

Bicyclo[2.2.2]octane, 1,4-dichloro-

1123-39-3
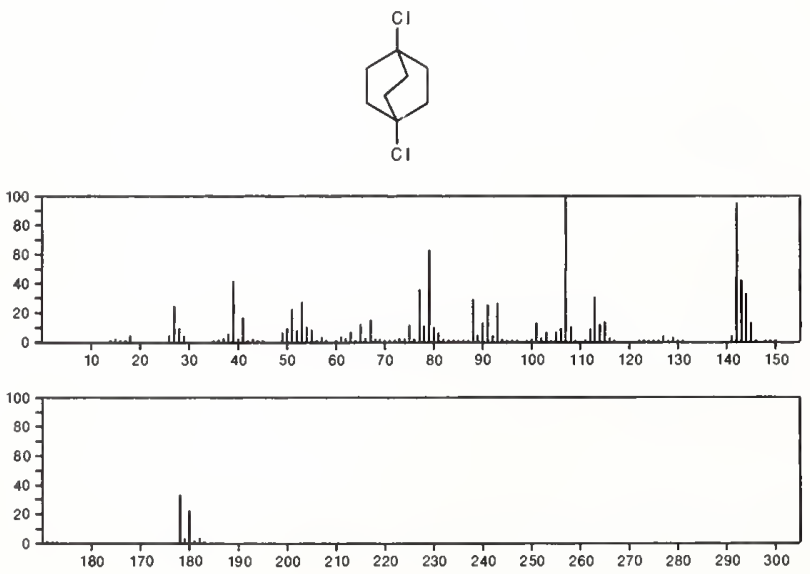

178 3,5- Octadiene, 1,8-dichloro-

$\mathrm{C}_{8} \mathrm{H}_{12} \mathrm{Cl}_{2}$

$55682-96-7$

$\mathrm{Cl} \mathrm{CH}_{2} \mathrm{CH}_{2} \mathrm{CH}=\mathrm{CHCH}=\mathrm{CHCH}_{2} \mathrm{CH}_{2} \mathrm{Cl}$
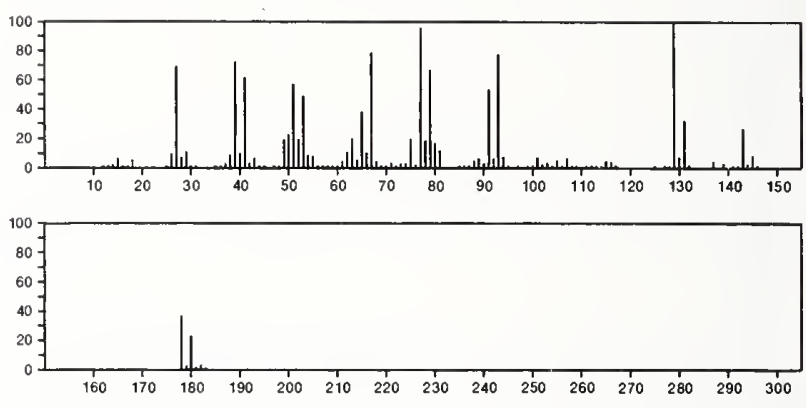

178

Bicyclo[3.2.1] octane, 2,2-dichloro-

$55956-44-0$
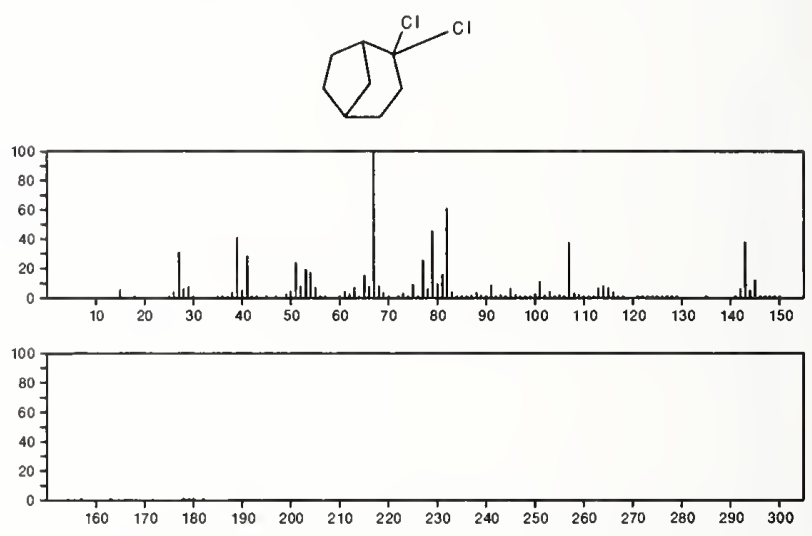

178

$\mathrm{C}_{8} \mathrm{H}_{18} \mathrm{O}_{2} \mathrm{~S}$

598-04-9

Butane, 1,1'-sulfonylbis-

$\mathrm{Me}\left(\mathrm{CH}_{2}\right)_{3} \mathrm{SO}_{2}\left(\mathrm{CH}_{2}\right)_{3} \mathrm{Me}$
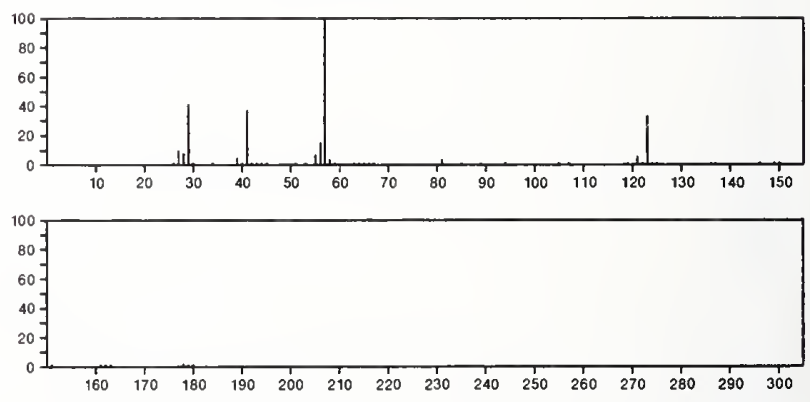

178

$\mathrm{C}_{8} \mathrm{H}_{18} \mathrm{O}_{2} \mathrm{~S}$

Propane, 1,1'-sulfonylbis[2-methyl-

10495-45-1

$\mathrm{i}-\mathrm{BuSO}_{2} \mathrm{Bu}-\mathrm{i}$
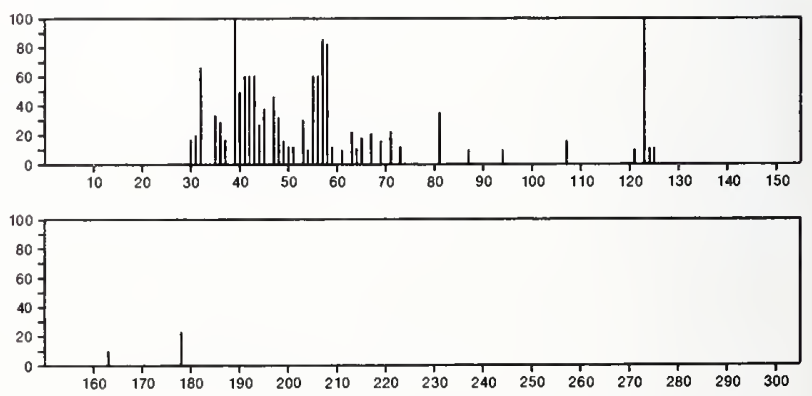
178

2,5,8,11-Tetraoxadodecane

$\mathrm{C}_{8} \mathrm{H}_{18} \mathrm{O}_{4}$

$\mathrm{MeOCH}_{2} \mathrm{CH}_{2} \mathrm{OCH}_{2} \mathrm{CH}_{2} \mathrm{OCH}_{2} \mathrm{CH}_{2} \mathrm{OMe}$

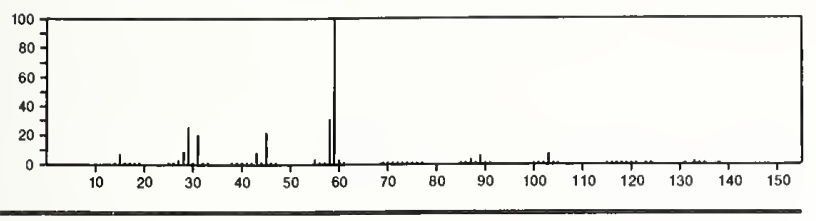

178

$\mathrm{C}_{8} \mathrm{H}_{18} \mathrm{O}_{4}$

$112-50-5$

Ethanol, 2-[2-(2-ethoxyethoxy)ethoxy $]-$

$\mathrm{Et} \mathrm{OCH}_{2} \mathrm{CH}_{2} \mathrm{OCH}_{2} \mathrm{CH}_{2} \mathrm{OCH}_{2} \mathrm{CH}_{2} \mathrm{OH}$

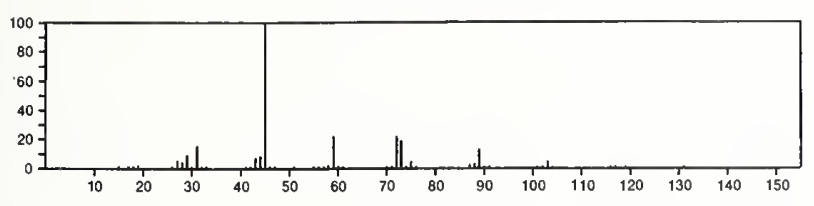

178

$\mathrm{C}_{8} \mathrm{H}_{18} \mathrm{~S}_{2}$

Disulfide, bis(1,1-dimethylethyl)

$t-B u S S B u-t$
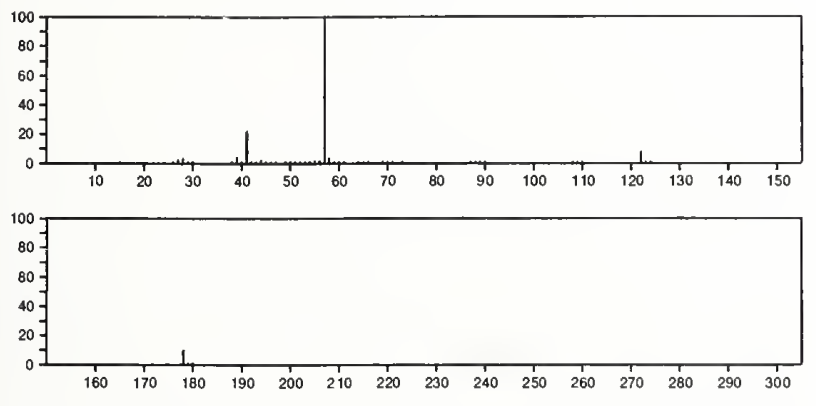

178

Disulfide, dibutyl

$\mathrm{C}_{8} \mathrm{H}_{18} \mathrm{~S}_{2}$

$629-45-8$

$\mathrm{Me}\left(\mathrm{CH}_{2}\right)_{3} \mathrm{SS}\left(\mathrm{CH}_{2}\right)_{3} \mathrm{Me}$

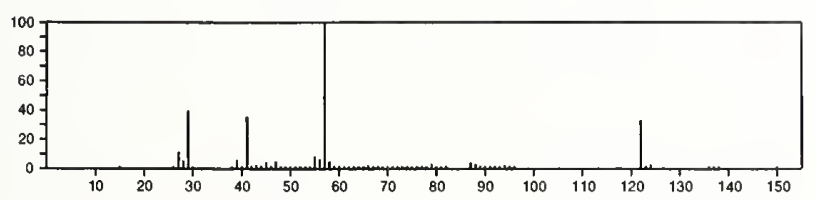

$$
\begin{array}{r}
100 \\
80 \\
60 \\
40 \\
20 \\
0
\end{array}
$$

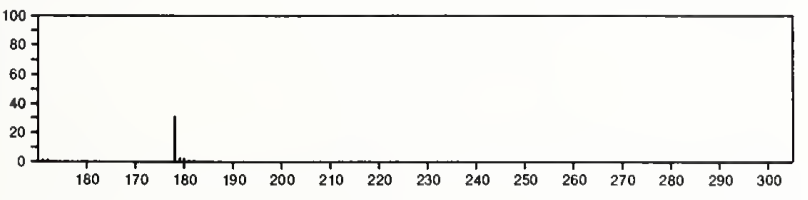

178

Disulfide, bis(2-methylpropyl)

$1518-72-5$

i-BuSSBu-i

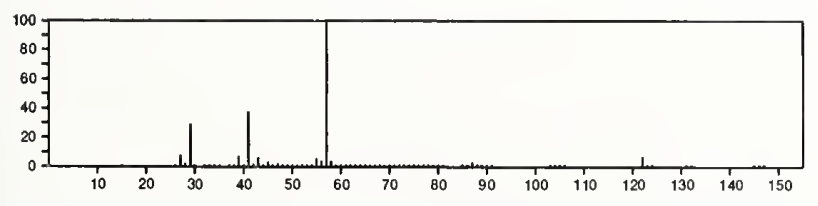

100
80
80
40
20

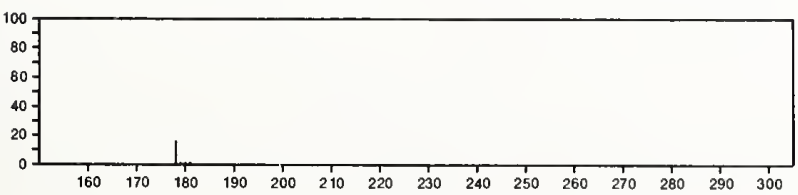

178

$\mathrm{C}_{8} \mathrm{H}_{18} \mathrm{~S}_{2}$

$5865-15-6$

Ethane, 1,2-bis(isopropylthio)-

$i-\operatorname{PrSCH} \mathrm{CH}_{2} \mathrm{SPr}_{-1}$
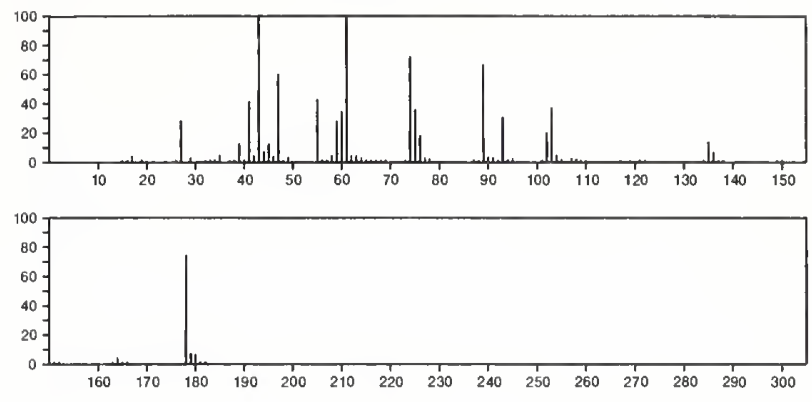

178

Disulfide, bis(1-methylpropyl)

$\mathrm{C}_{8} \mathrm{H}_{18} \mathrm{~S}_{2}$

5943-30-6

$s-B u S S B u-s$
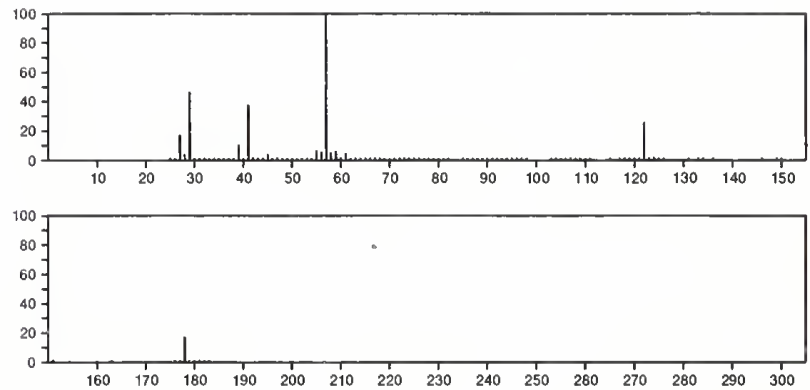

178

Butane, 1,4-bis(ethylthio)-

$\mathrm{C}_{8} \mathrm{H}_{18} \mathrm{~S}_{2}$

$54576-32-8$

$\mathrm{EtS}\left(\mathrm{CH}_{2}\right){ }_{4} \mathrm{SEt}$
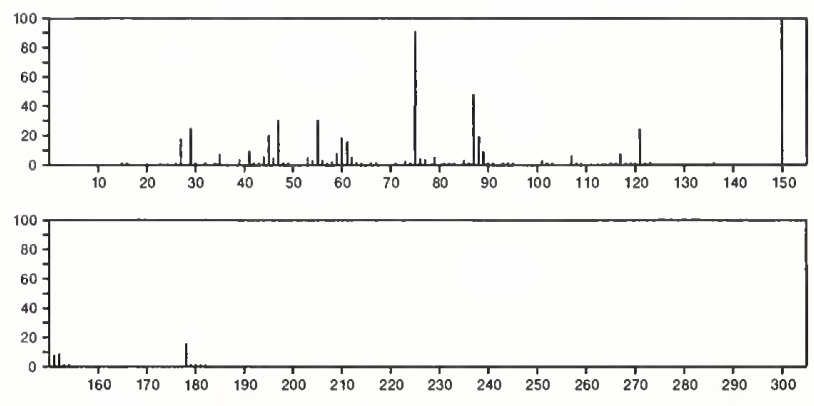

178

8 Quinolinamine, 6-chloro-

$\mathrm{C}_{9} \mathrm{H}_{7} \mathrm{ClN}_{2}$

5470-75-7
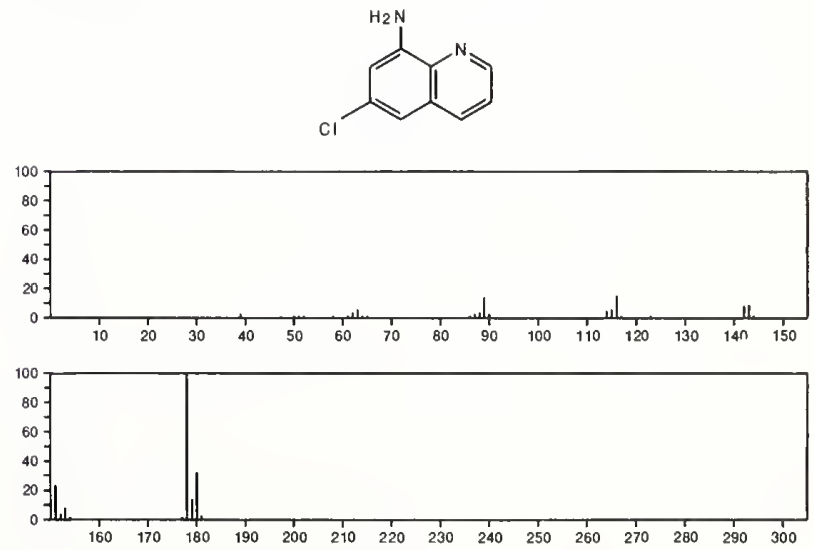
178

$\mathrm{C}_{9} \mathrm{H}_{10} \mathrm{~N}_{2} \mathrm{O}_{2}$

$63-98-9$

Benzeneacetamide, $N$-(aminocarbonyl)

$\mathrm{H}_{2} \mathrm{NCONHCOCH}_{2} \mathrm{Ph}$
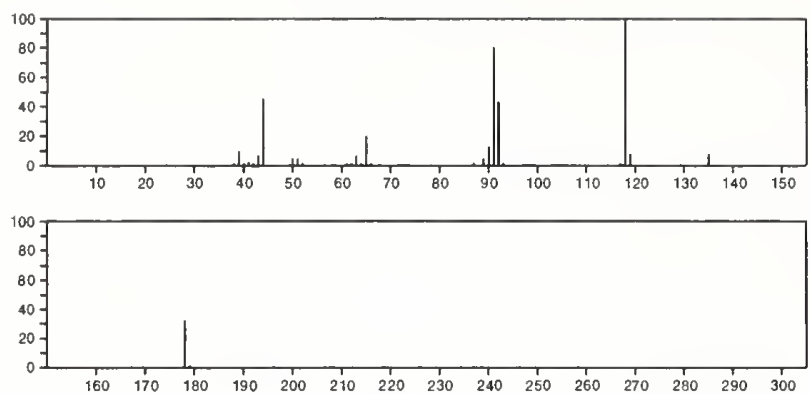

178

Benzimidazole, 2-ethoxy-, 3-oxide

$\mathrm{C}_{9} \mathrm{H}_{10} \mathrm{~N}_{2} \mathrm{O}_{2}$

$16007-57-1$
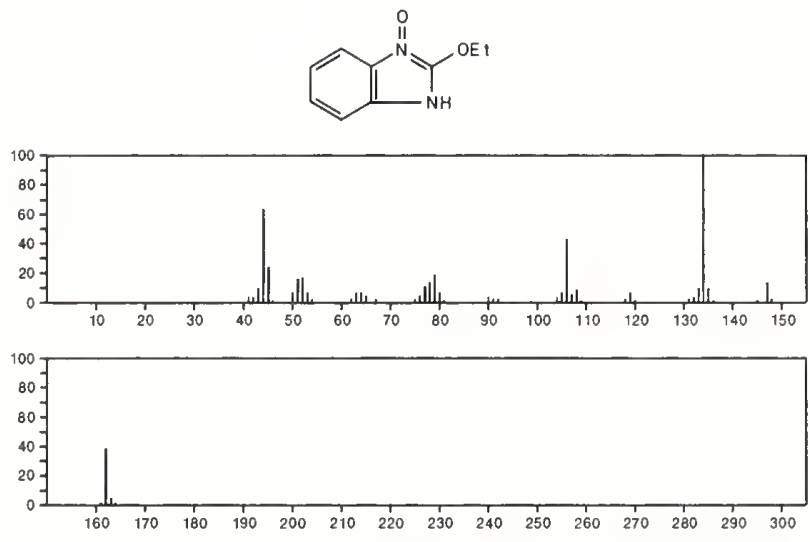

$178 \quad \mathrm{C}_{9} \mathrm{H}_{10} \mathrm{~N}_{2} \mathrm{O}_{2}$

Isoxazole, 5,5'-(1,3-propanediyl $)$ bis-

$37704-51-1$
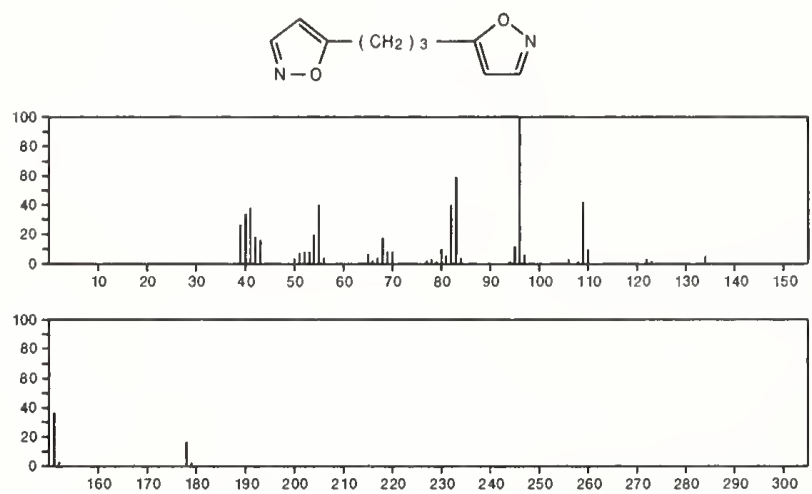

178

$\mathrm{C}_{9} \mathrm{H}_{10} \mathrm{~N}_{2} \mathrm{O}_{2}$

$51460-33-4$

Ethanone, 1,1'-(3-amino-2,4-pyridinediyl)bis-
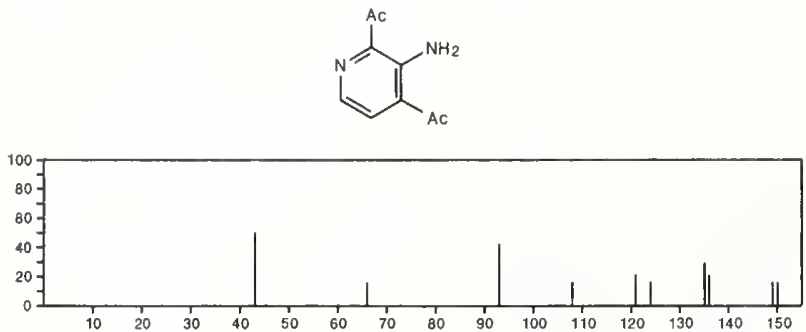

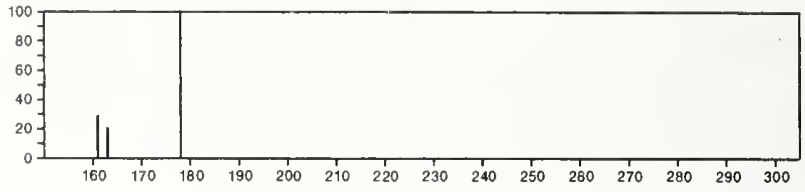

178

2-Thiazolamine, 4,5-dihydro- $N$-phenyl-

$1009-70-7$
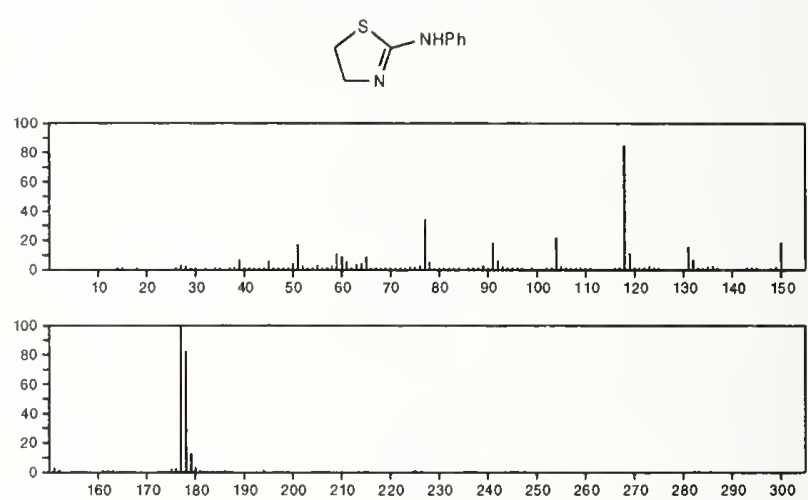

178

2 -Benzothiazolamine, $N$-ethyl

$\mathrm{C}_{9} \mathrm{H}_{10} \mathrm{~N}_{2} \mathrm{~S}$

28291-69-2
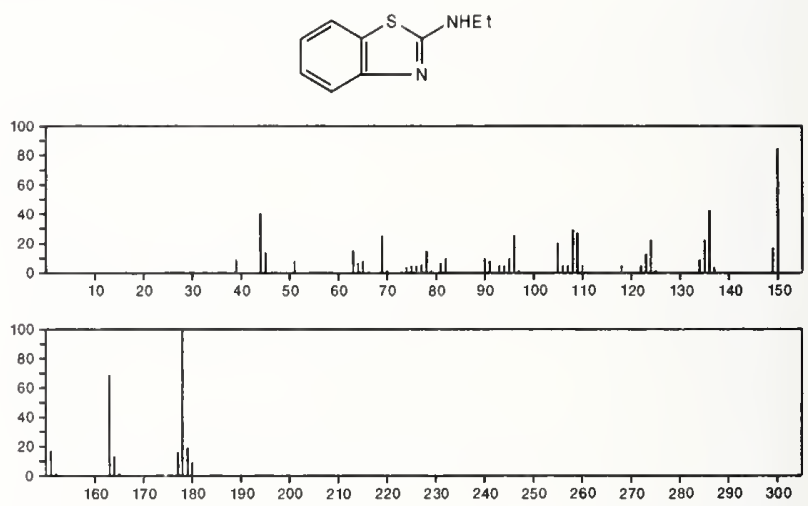

178

$\mathrm{C}_{9} \mathrm{H}_{11} \mathrm{Co}$

$1271-08-5$

Cobalt, $\pi$-cyclopentadienyl( $1-$ methylene $-\pi$-allyl $)-$
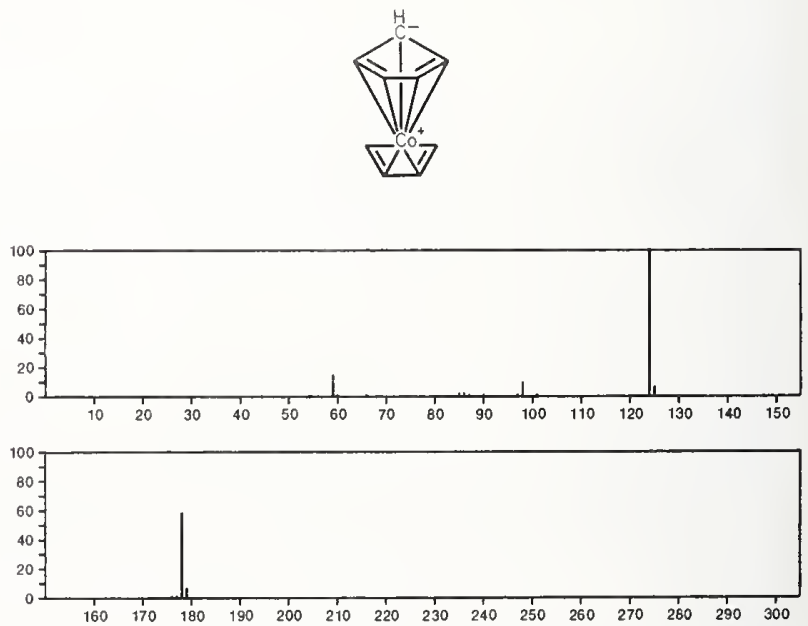
178

1,3-Disilaindan, 1,3-dimethyl-

$\mathrm{C}_{9} \mathrm{H}_{14} \mathrm{Si}_{2}$
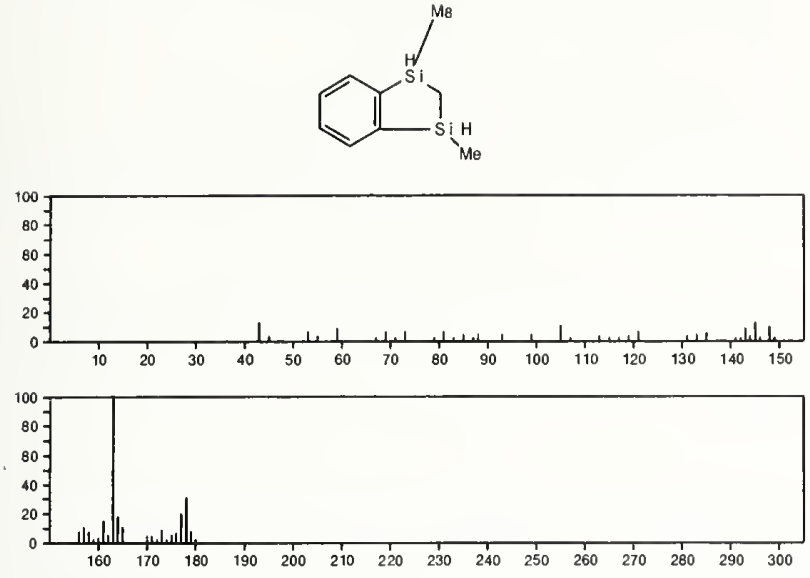

178

4H-1-Benzothiopyran-4-one, 2,3-dihydro-3-methyl-
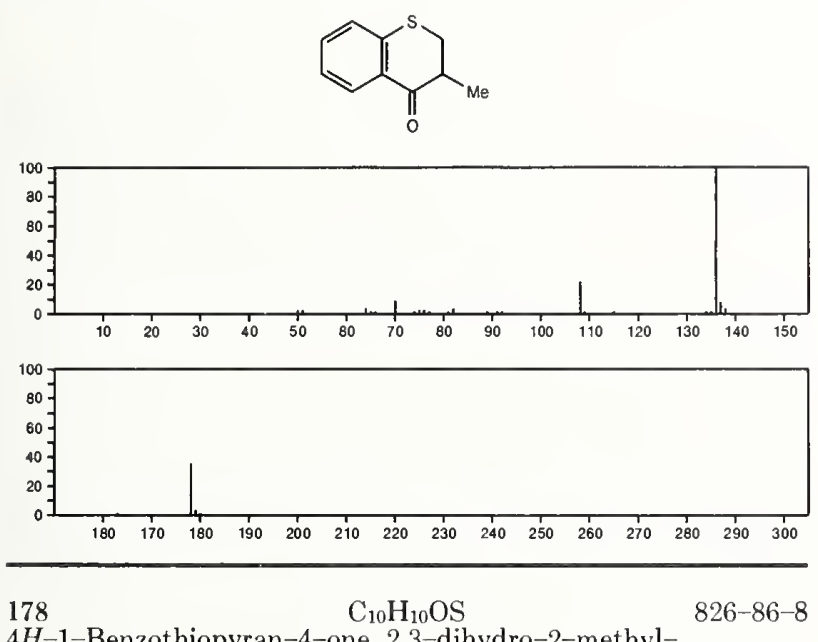

4H-1-Benzothiopyran-4-one, 2,3-dihydro-2-methyl-
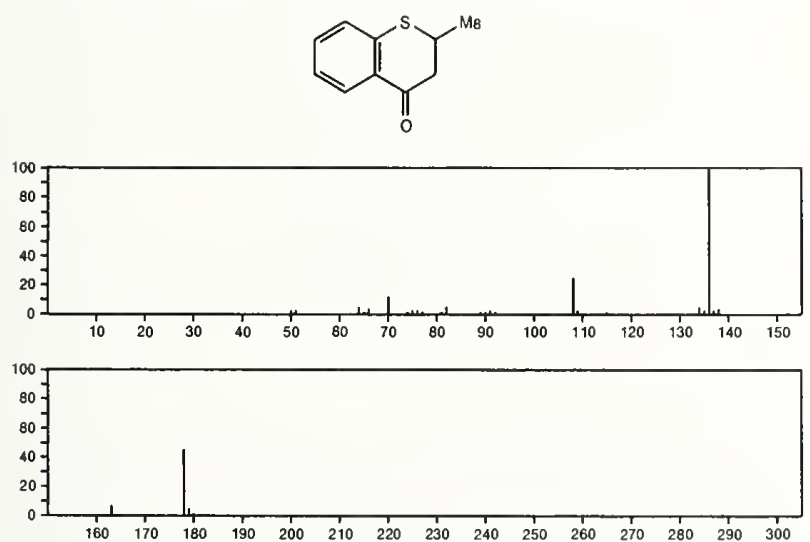

178

$\mathrm{C}_{10} \mathrm{H}_{10} \mathrm{OS}$

4H-1 Benzothiopyran-4-one, 2,3-dihydro-8-methyl

29373-02-2
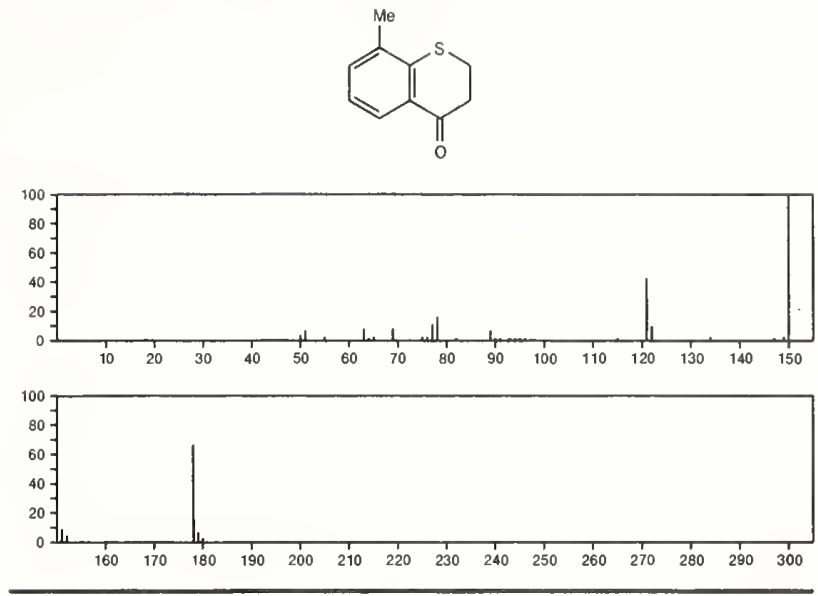

178

$\mathrm{C}_{10} \mathrm{H}_{10} \mathrm{O}_{3}$

$614-27-7$

Benzenepropanoic acid, $\beta$-oxo-, methyl ester

$\mathrm{MeOC}$ ( O) $\mathrm{CH}_{2} \mathrm{COPh}$
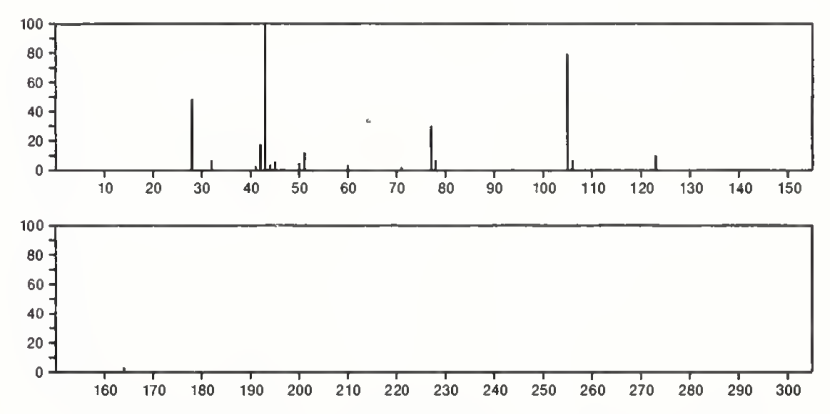

$\mathrm{C}_{10} \mathrm{H}_{10} \mathrm{O}_{3}$
Benzeneacetic acid, $\alpha-$ oxo- $^{-}$, ethyl ester

$1603-79-8$

$\mathrm{PhCOC}(\mathrm{O}) \mathrm{OEt}$
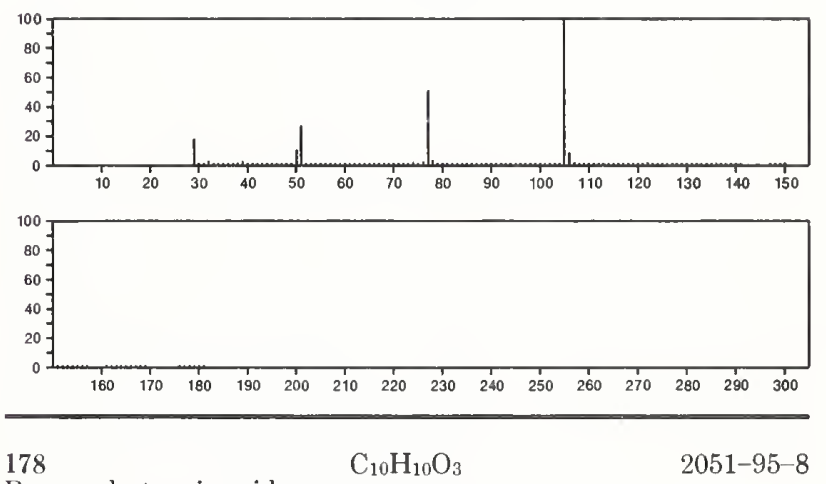

Benzenebutanoic acid, $\gamma-\mathrm{oxo}^{-}$

$\mathrm{PhCOCH}_{2} \mathrm{CH}_{2} \mathrm{CO}_{2} \mathrm{H}$
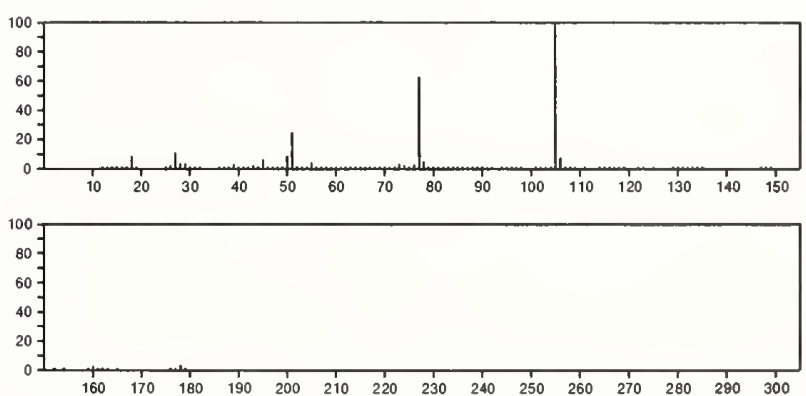
178 $\mathrm{C}_{10} \mathrm{H}_{10} \mathrm{O}_{3}$

Ethanone, 2-(acetyloxy)-1-phenyl-

$\mathrm{PhCOCH} 2 \mathrm{OAC}$
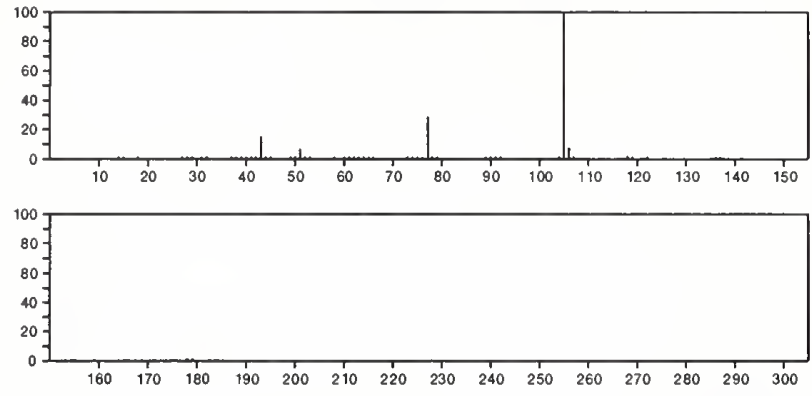

$178 \quad \mathrm{C}_{10} \mathrm{H}_{10} \mathrm{O}_{3}$

2-Propenoic acid, 3-(4-hydroxyphenyl)-, methyl ester

3943-97-3
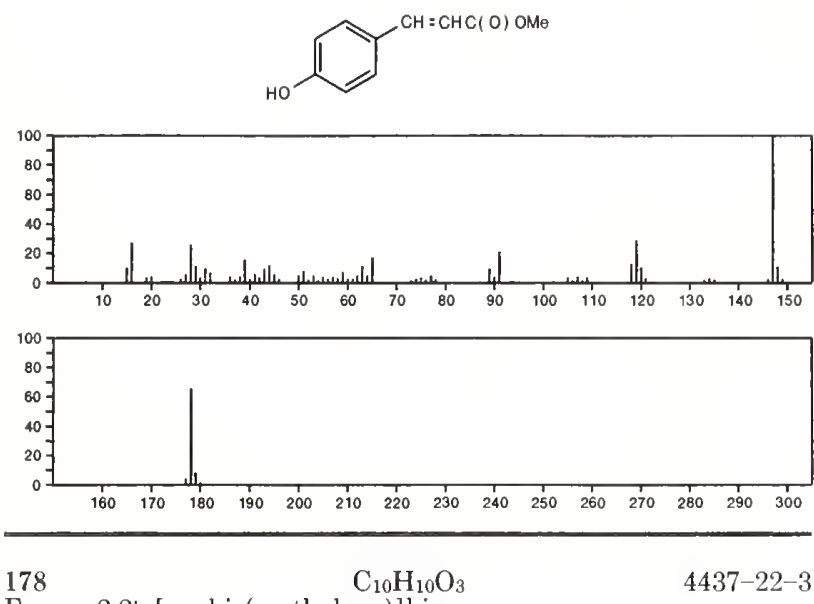

Furan, 2,2'-[oxybis(methylene)]bis-
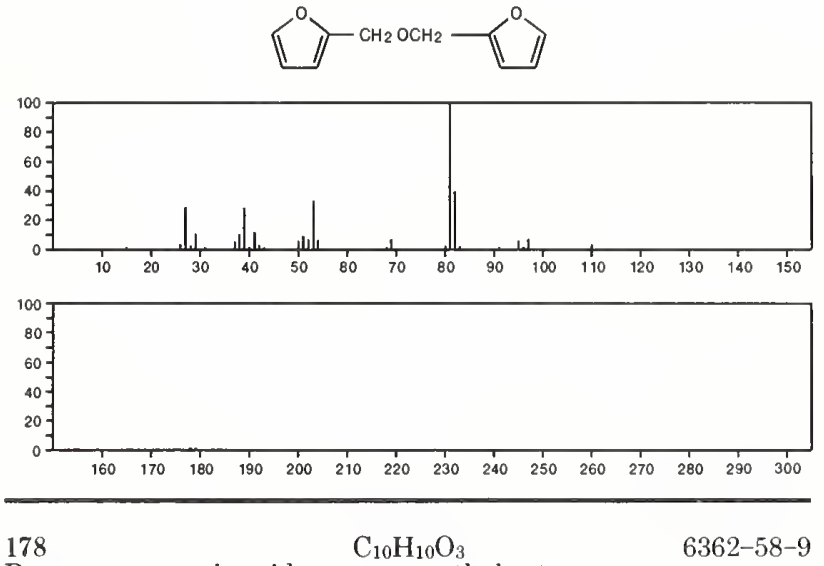

Benzenepropanoic acid, $\alpha-$ oxo- $^{-}$, methyl ester

$\mathrm{MeOC}(\mathrm{O}) \mathrm{COCH}_{2} \mathrm{Ph}$
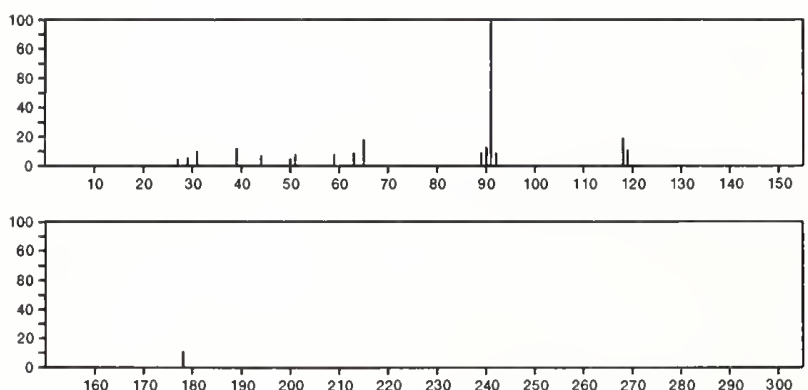

178

$\mathrm{C}_{10} \mathrm{H}_{10} \mathrm{O}_{3}$

$16824-02-5$

1(3H)-Isobenzofuranone, 3-ethoxy-
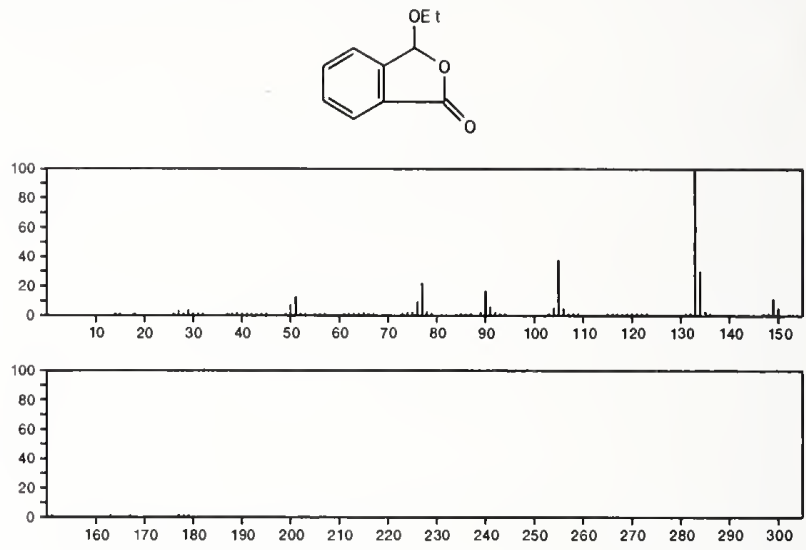

178

$\mathrm{C}_{10} \mathrm{H}_{10} \mathrm{O}_{3}$

17397-85-2

1H-2-Benzopyran-1-one, 3,4-dihydro-8-hydroxy-3-methyl-
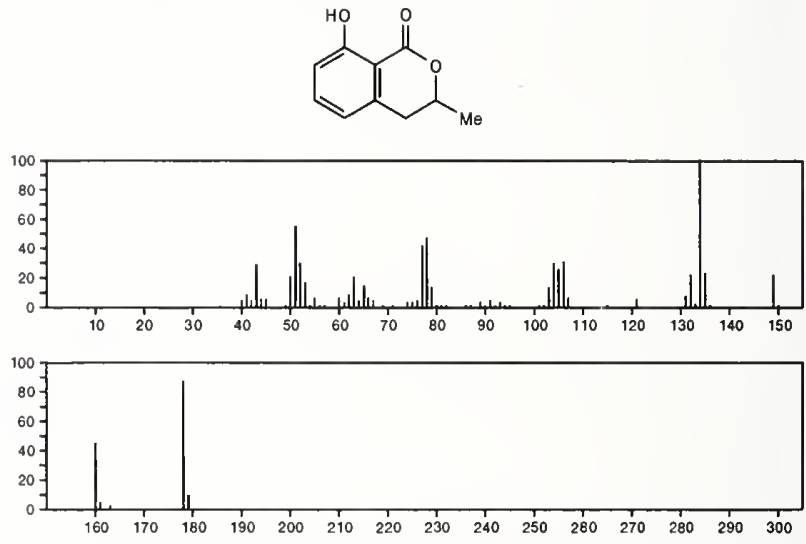

178

$\mathrm{C}_{10} \mathrm{H}_{10} \mathrm{O}_{3}$

2-Furanmethanol, 5-(2-furanylmethyl)-

29953-17-1
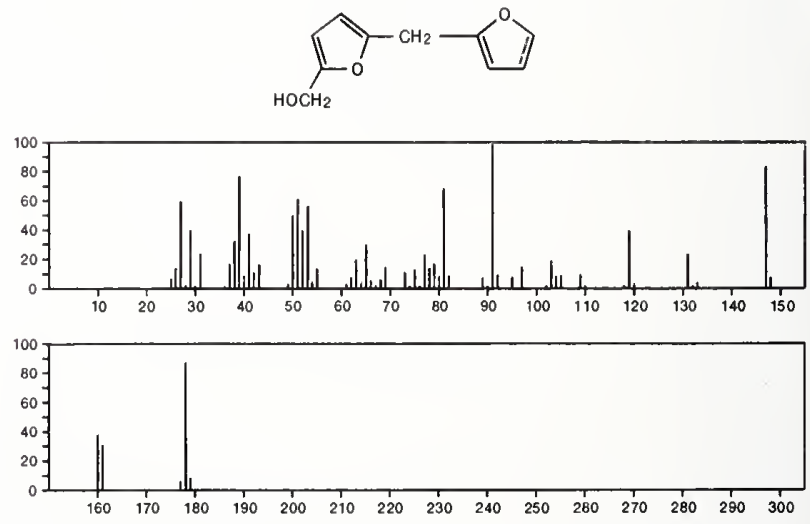

178

$\mathrm{C}_{10} \mathrm{H}_{10} \mathrm{O}_{3}$

2(5H)-Furanone, 5-(2-furanylmethyl)-5-methyl-

$31969-27-4$
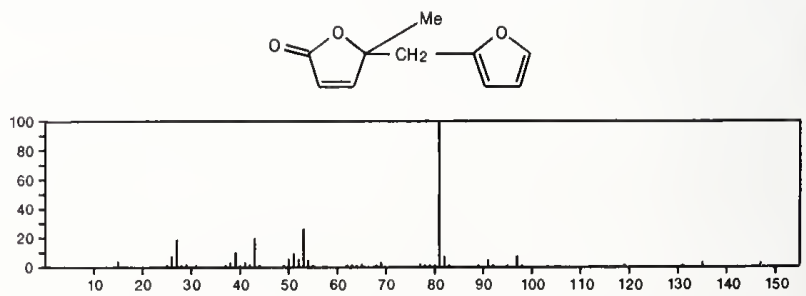


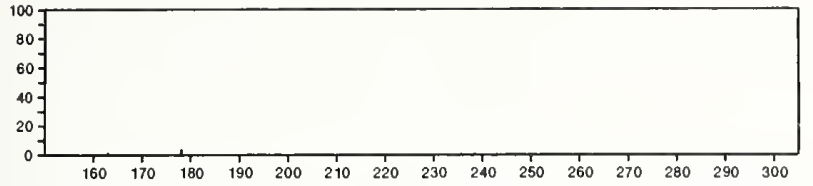

$\overline{178} \mathrm{C}_{10} \mathrm{H}_{10} \mathrm{O}_{3} \quad 54549-74-5$

Benzaldehyde, 4-[(acetyloxy)methyl]
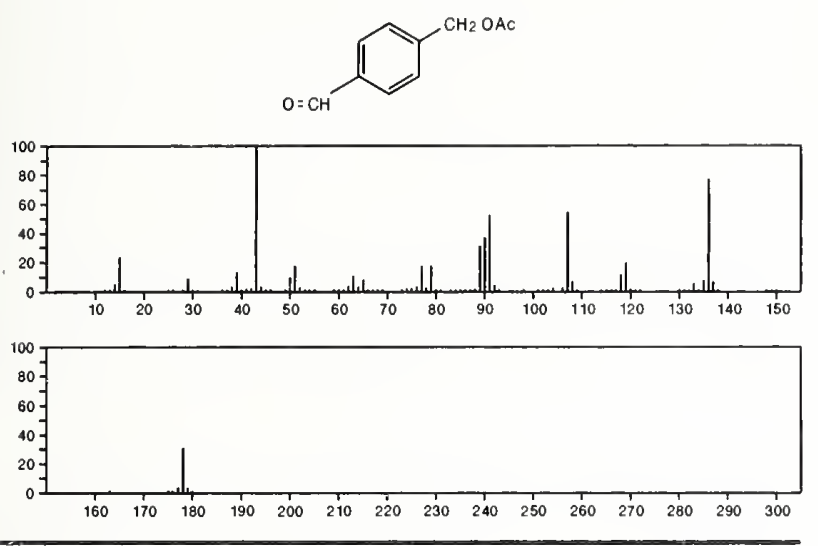

$178 \quad \mathrm{C}_{10} \mathrm{H}_{10} \mathrm{O}_{3} \quad 54549-75-6$

1(2H)-Naphthalenone, 3,4-dihydro-6,7-dihydroxy-
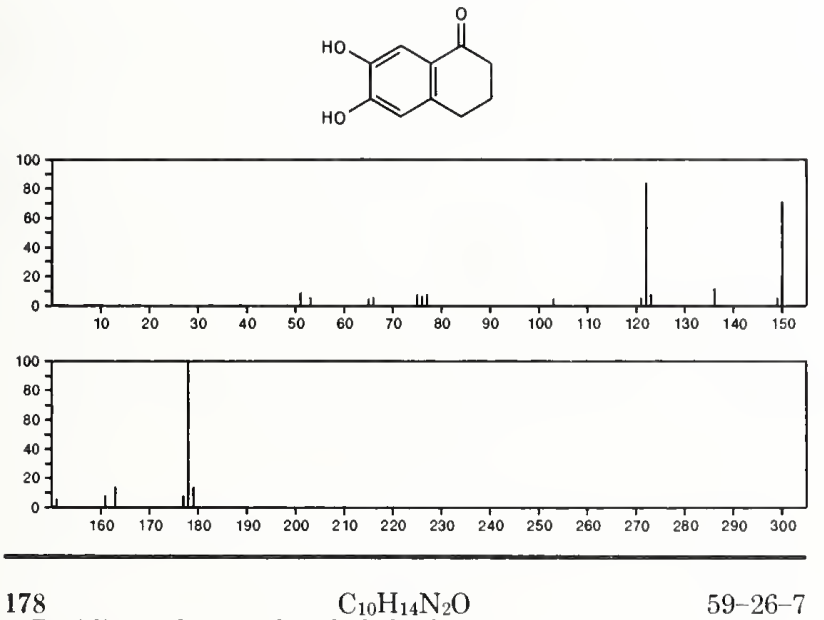

3-Pyridinecarboxamide, $N, N$-diethyl-
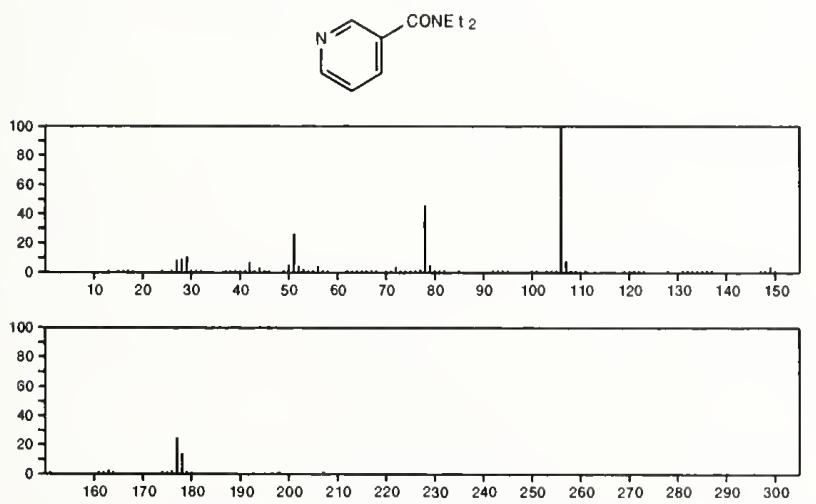

178

$\mathrm{C}_{10} \mathrm{H}_{14} \mathrm{~N}_{2} \mathrm{O}$

491-26-9

Pyridine, 3-(1-methyl-2-pyrrolidinyl)-, $N$-oxide, (2S)
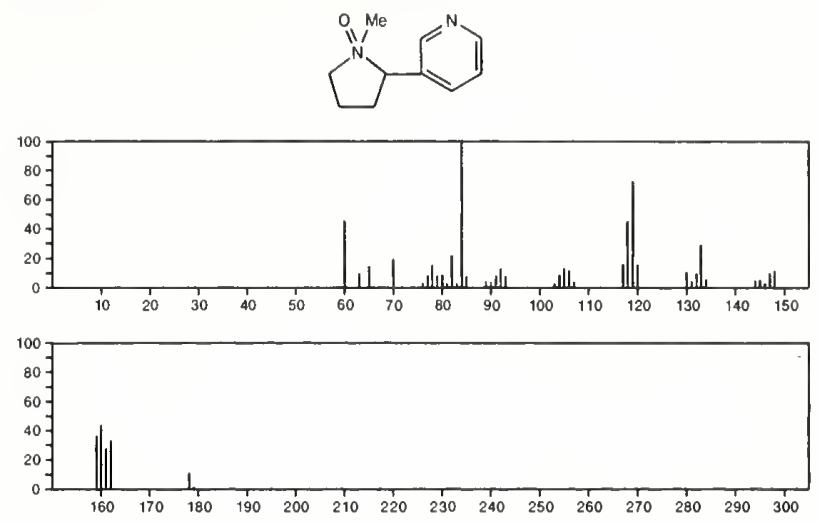

178

$\mathrm{C}_{10} \mathrm{H}_{14} \mathrm{~N}_{2} \mathrm{O}$

1202-42-2

Methanimidamide, $N^{\prime}$-(3-methoxyphenyl)-N,N-dimethyl-
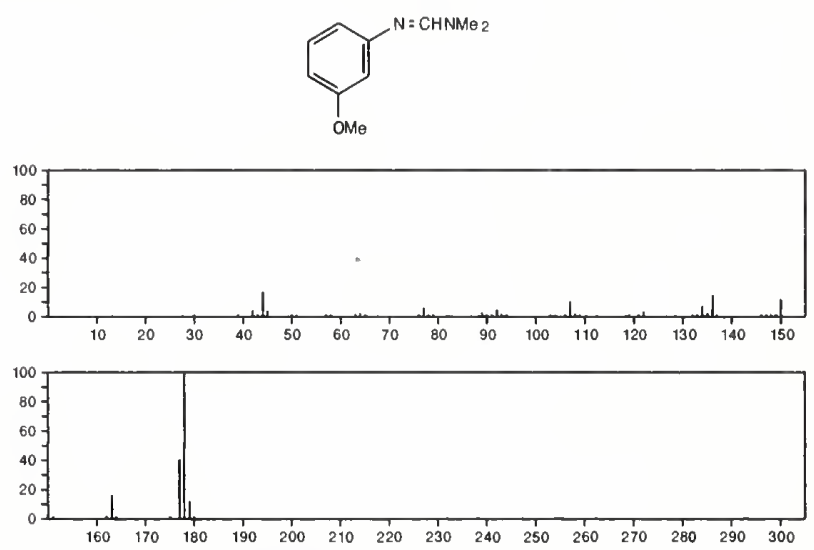

178

$\mathrm{C}_{10} \mathrm{H}_{14} \mathrm{~N}_{2} \mathrm{O}$

$1202-62-6$

Methanimidamide, $N^{\prime}$-(4-methoxyphenyl)-N,N-dimethyl-
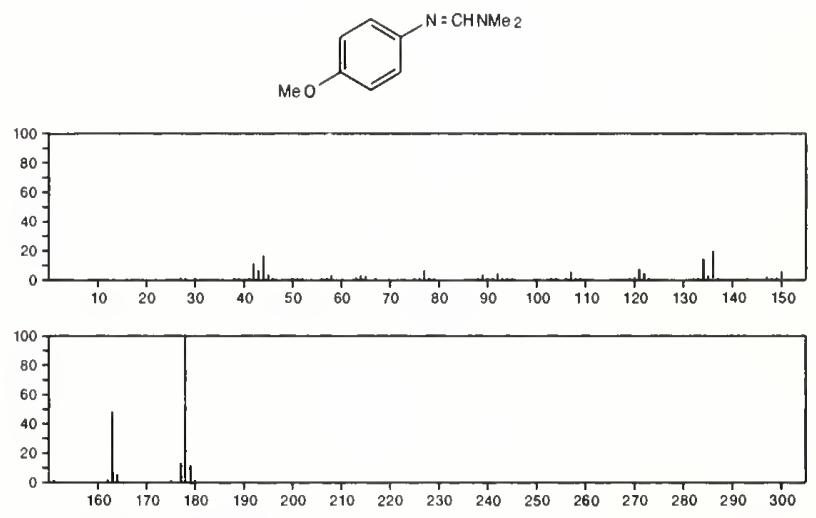

$178 \quad \mathrm{C}_{10} \mathrm{H}_{14} \mathrm{~N}_{2} \mathrm{O} \quad 2820-55-5$

Pyridine, 3-(1-methyl-2-pyrrolidinyl)-, 1-oxide, $(S)$ -
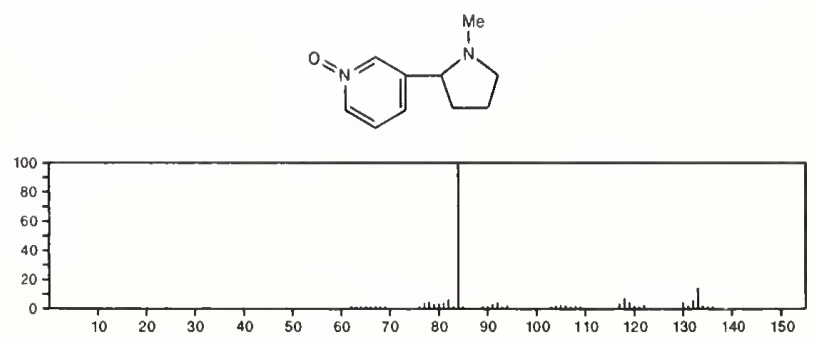

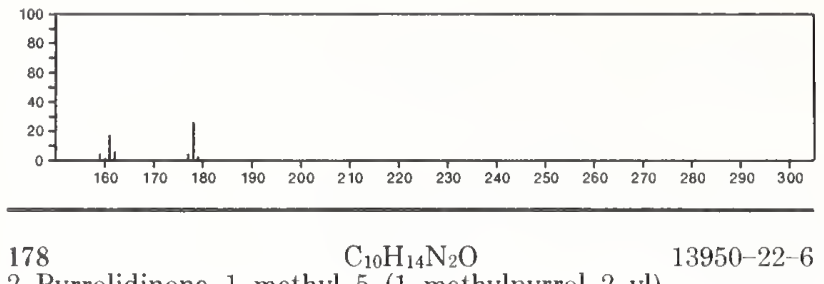

2-Pyrrolidinone, 1-methyl-5-(1-methylpyrrol-2-yl)-
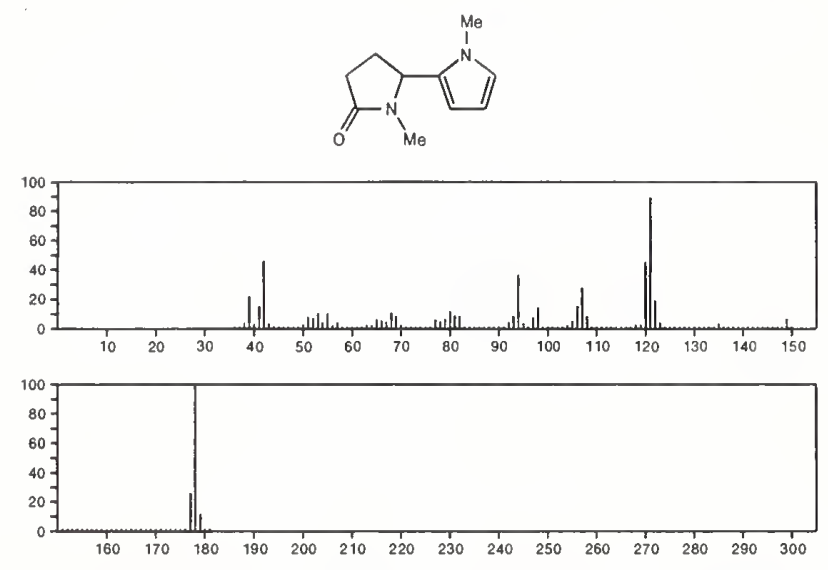

178

$\mathrm{C}_{10} \mathrm{H}_{14} \mathrm{~N}_{2} \mathrm{O}$

2-Pyrrolidinone, 1-methyl-5-(1-methylpyrrol-3-yl)-
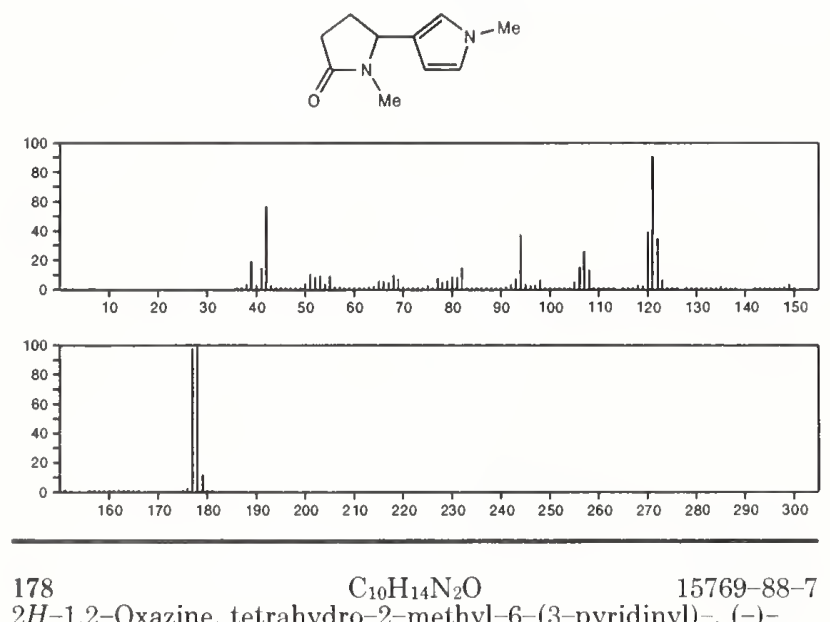

$2 \mathrm{H}-1,2-\mathrm{Oxazine}$, tetrahydro-2-methyl-6-(3-pyridinyl)-, (-)-
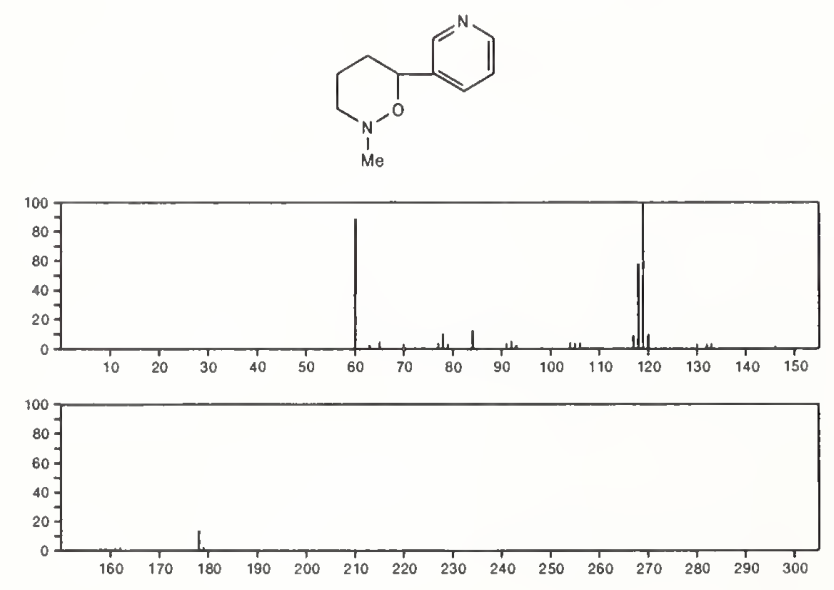

178

$\mathrm{C}_{10} \mathrm{H}_{14} \mathrm{~N}_{2} \mathrm{O}$

Benzaldehyde, 4-(dimethylamino)-, $\mathrm{O}$-methyloxime

$19293-74-4$
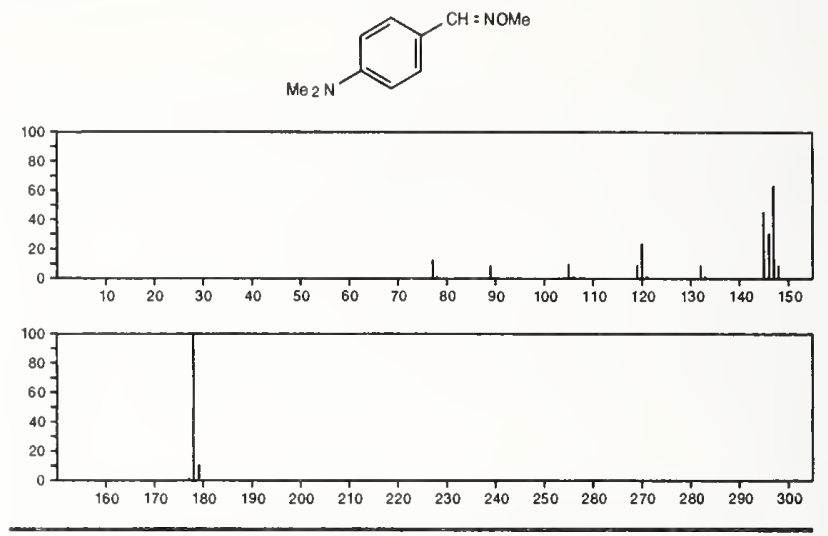

178

$\mathrm{C}_{10} \mathrm{H}_{14} \mathrm{~N}_{2} \mathrm{O}$

54966-09-5

1-Piperidinecarboxaldehyde, 2-(1H-pyrrol-2-yl)-
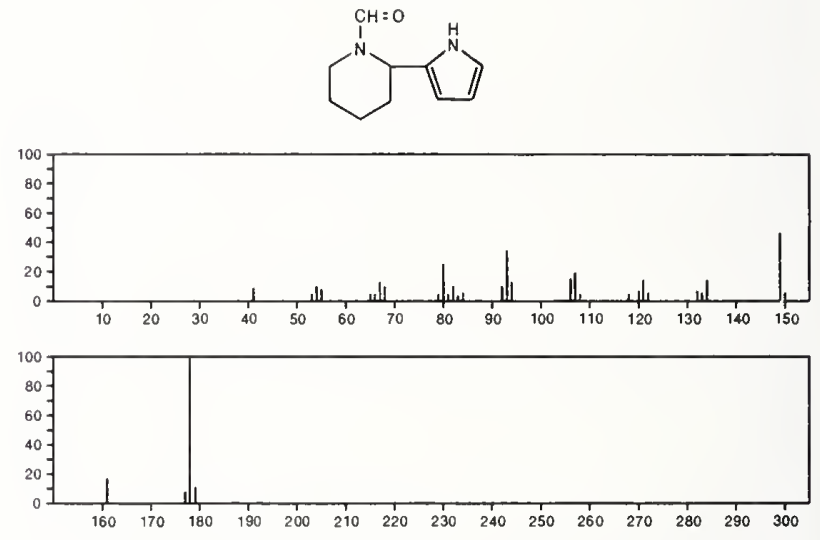

178

$\mathrm{C}_{11} \mathrm{H}_{14} \mathrm{O}_{2}$

Benzene, 1,2-dimethoxy-4-(2-propenyl)-

$93-15-2$
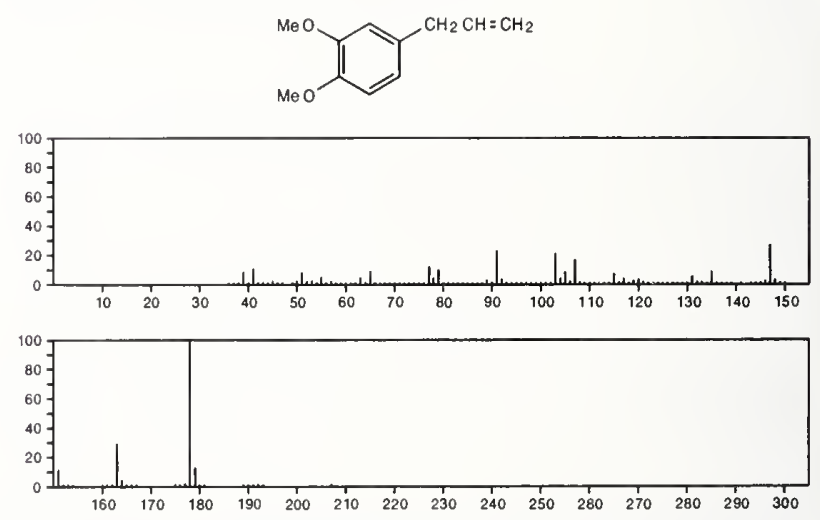

178

$\mathrm{C}_{11} \mathrm{H}_{14} \mathrm{O}_{2}$

$93-16-3$

Benzene, 1,2-dimethoxy-4-(1-propenyl)-
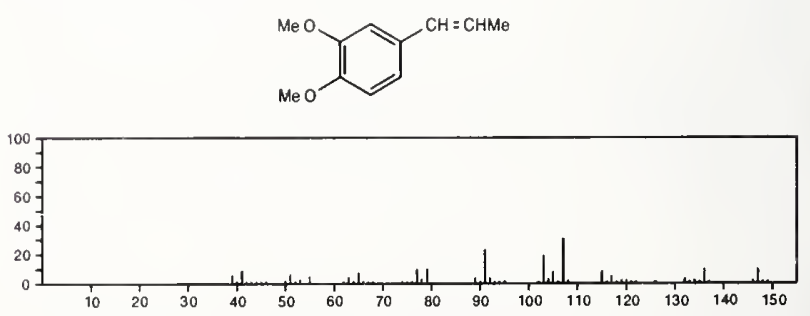


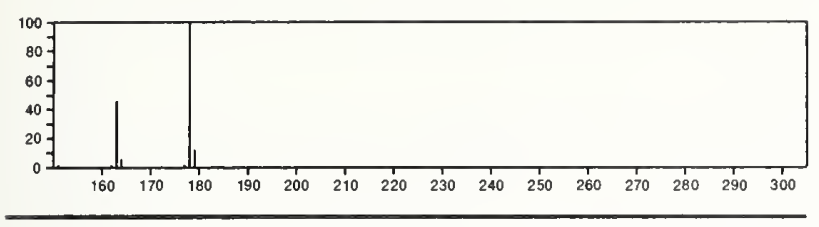

178

$\mathrm{C}_{11} \mathrm{H}_{14} \mathrm{O}_{2}$

Benzoic acid, 4-(1,1-dimethylethyl)-

98-73-7
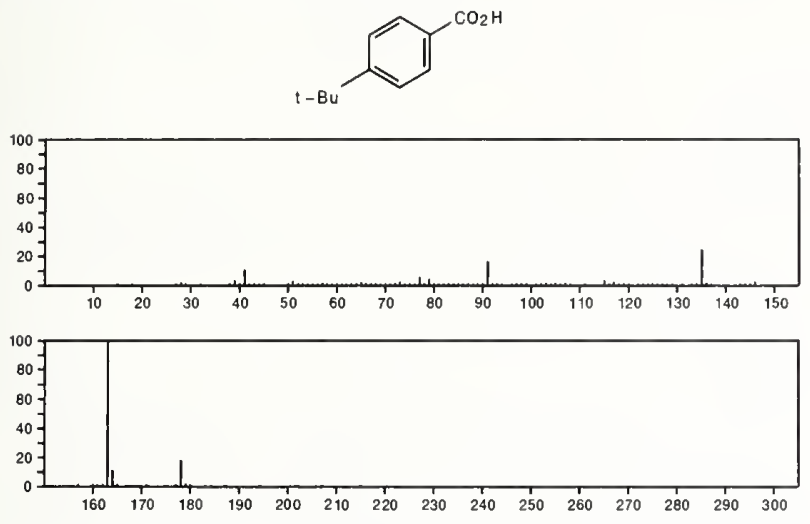

178

$\mathrm{C}_{11} \mathrm{H}_{14} \mathrm{O}_{2}$

$103-37-7$

Butanoic acid, phenylmethyl ester

$\mathrm{PhCH}_{2} \mathrm{OC}(\mathrm{O}) \mathrm{Pr}$
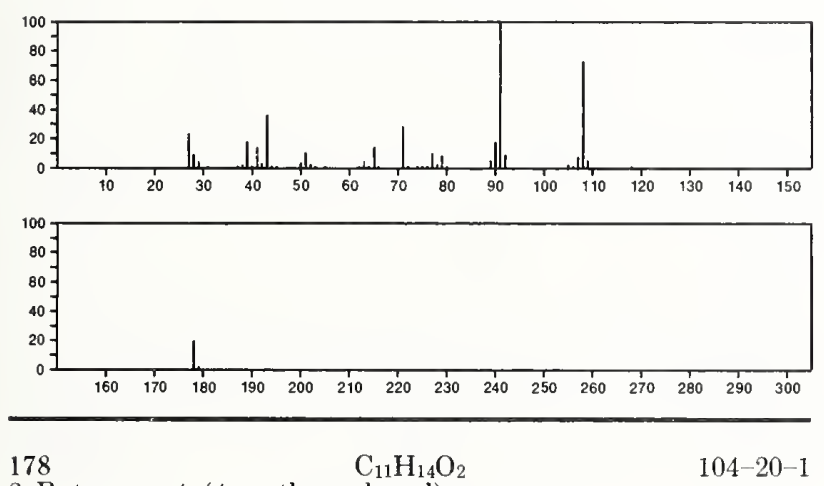

2-Butanone, 4-(4-methoxyphenyl)-
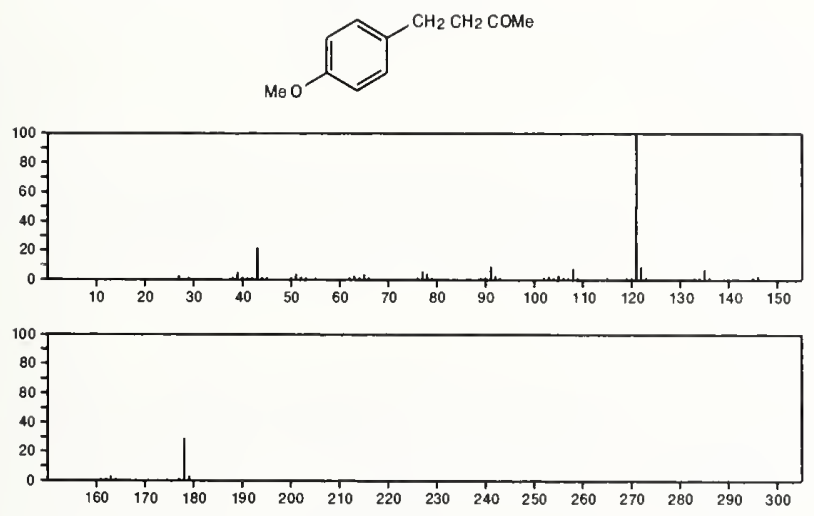

178

$\mathrm{C}_{11} \mathrm{H}_{14} \mathrm{O}_{2}$

Benzoic acid, 2-methylpropyl ester

$i-B u O C(0) P h$

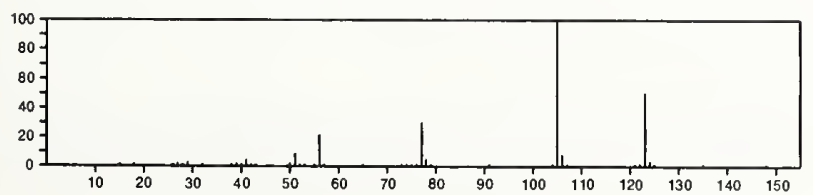

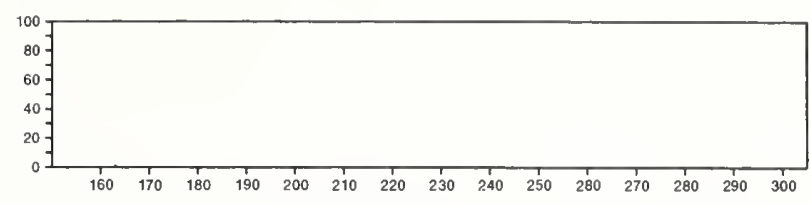

178

Benzenepropanol, acetate

$\mathrm{C}_{11} \mathrm{H}_{14} \mathrm{O}_{2}$

$122-72-5$

$\mathrm{ACO}\left(\mathrm{CH}_{2}\right)_{3} \mathrm{Ph}$
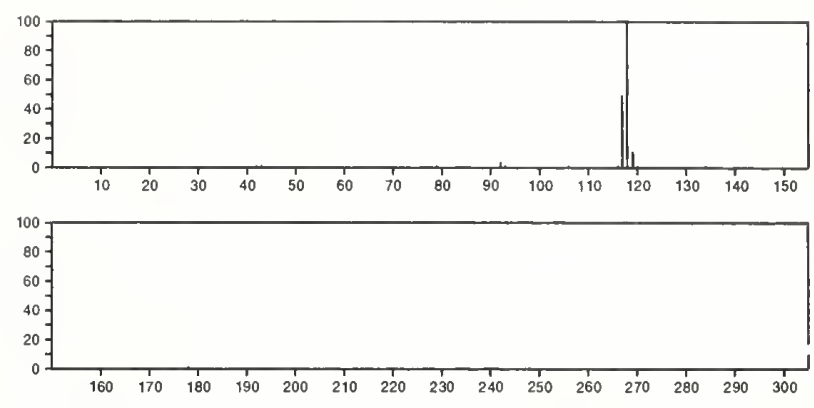

178

Benzoic acid, butyl ester

$\mathrm{C}_{11} \mathrm{H}_{14} \mathrm{O}_{2}$

$136-60-7$

$\mathrm{PhC}(\mathrm{O}) \mathrm{O}\left(\mathrm{CH}_{2}\right)_{3} \mathrm{Me}$
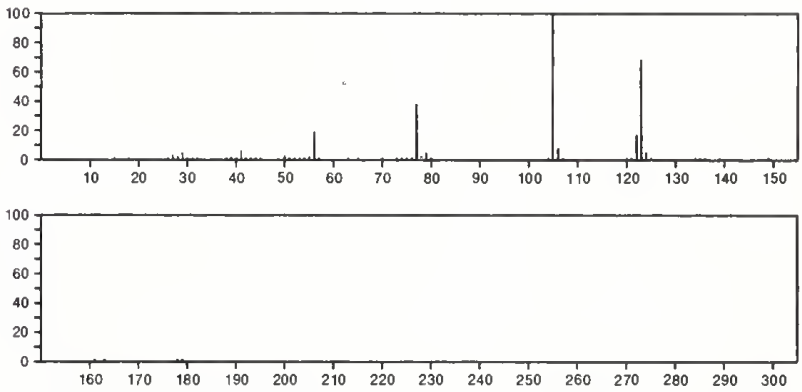

178

$\mathrm{C}_{11} \mathrm{H}_{14} \mathrm{O}_{2}$

$487-67-2$

2-Cyclopenten-1-one, 4-hydroxy-3-methyl-2-(2,4-pentadienyl)-, $(Z)-(+)$
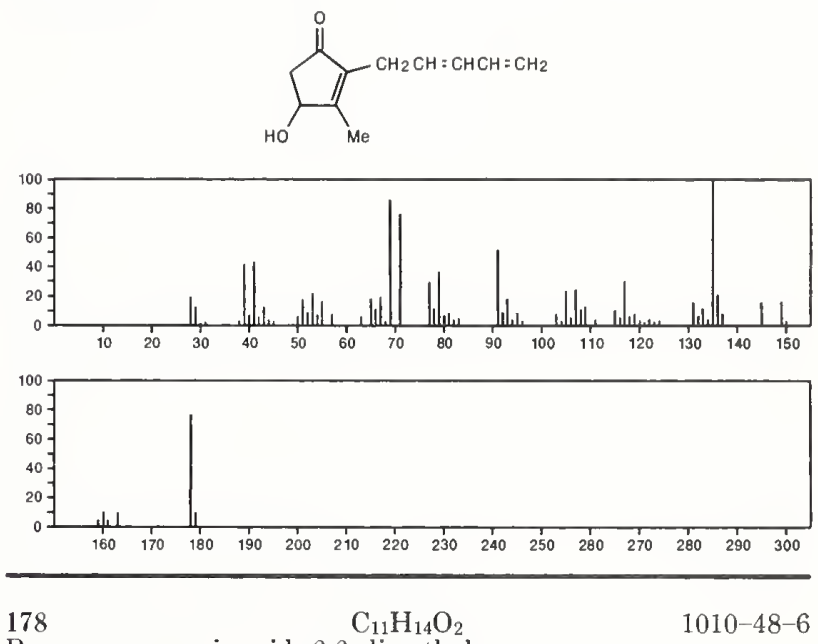

Benzenepropanoic acid, $\beta, \beta$-dimethyl-

$1010-48-6$

$\mathrm{HO}_{2} \mathrm{CCH}_{2} \mathrm{CMe}_{2} \mathrm{Ph}$

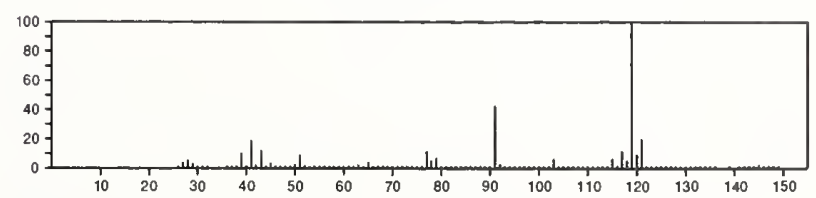



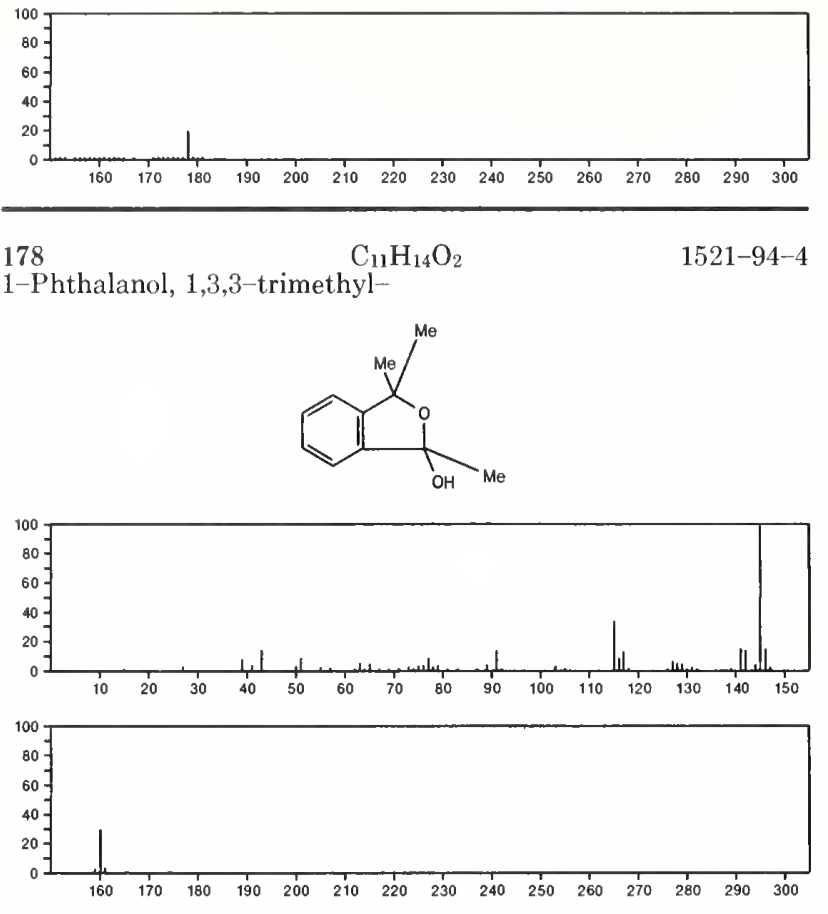

$178 \quad \mathrm{C}_{11} \mathrm{H}_{14} \mathrm{O}_{2}$

Benzenebutanoic acid, methyl ester

$2046-17-5$

$\mathrm{Ph}\left(\mathrm{CH}_{2}\right)_{3} \mathrm{C}(\mathrm{O}) \mathrm{OMe}$
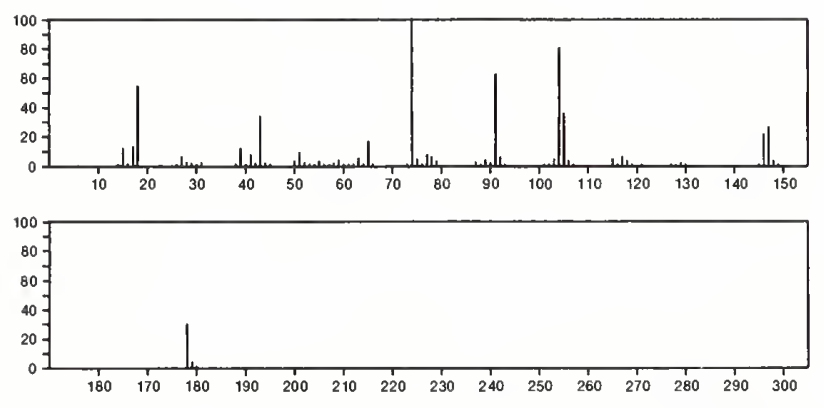

178

Benzeneacetic acid, $\alpha$-ethyl-, methyl ester

$2294-71-5$

Me OC( 0 ) CHE tPh
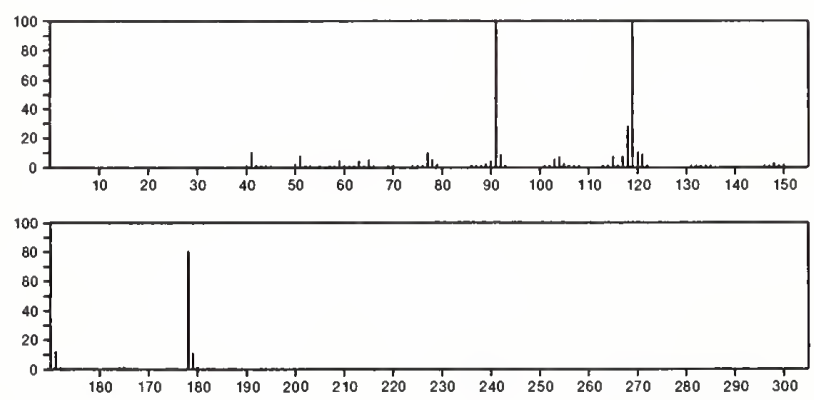

178

$\mathrm{C}_{11} \mathrm{H}_{14} \mathrm{O}_{2}$

4362-18-9

1,3-Dioxolane, 2-methyl-2-(phenylmethyl)-
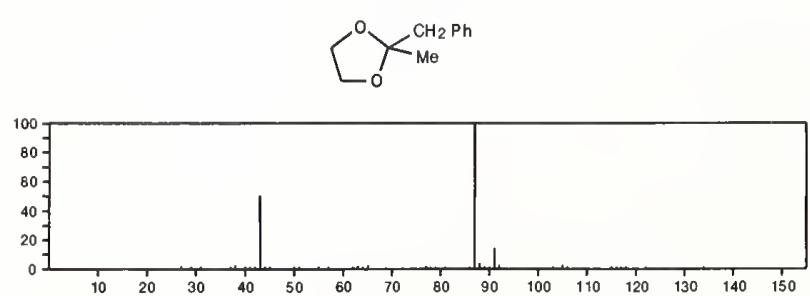

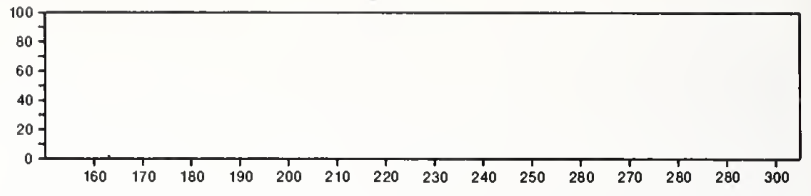

178

$\mathrm{C}_{11} \mathrm{H}_{14} \mathrm{O}_{2}$

4920-92-7

Propanoic acid, 2,2-dimethyl-, phenyl ester

$\mathrm{Me} 3 \mathrm{CC}(0) \mathrm{OPh}$
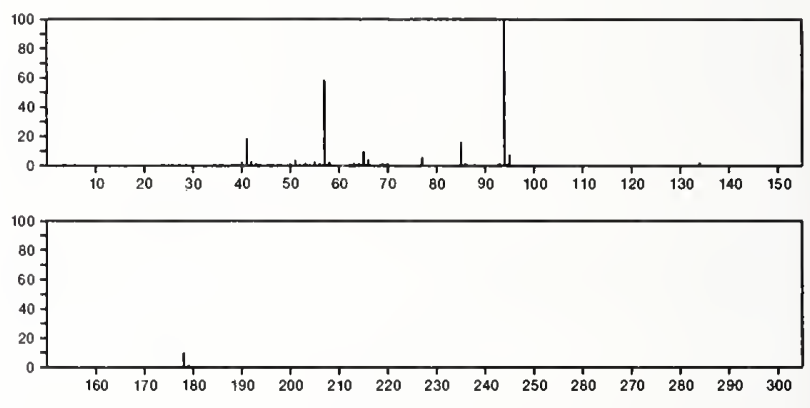

178

$\mathrm{C}_{11} \mathrm{H}_{14} \mathrm{O}_{2}$

$2 \mathrm{H}$-1,7-Benzodioxonin, 3,4,5,6-tetrahydro-

$7124-99-4$
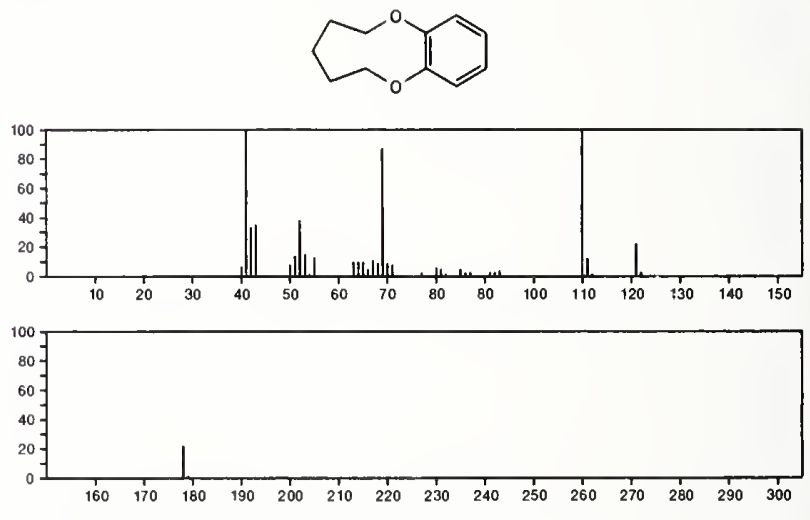

178

$\mathrm{C}_{11} \mathrm{H}_{14} \mathrm{O}_{2}$

Benzenebutanoic acid, $\beta$-methyl-

7315-68-6

$\mathrm{PhCH}_{2} \mathrm{CHMeCH}_{2} \mathrm{CO}_{2} \mathrm{H}$
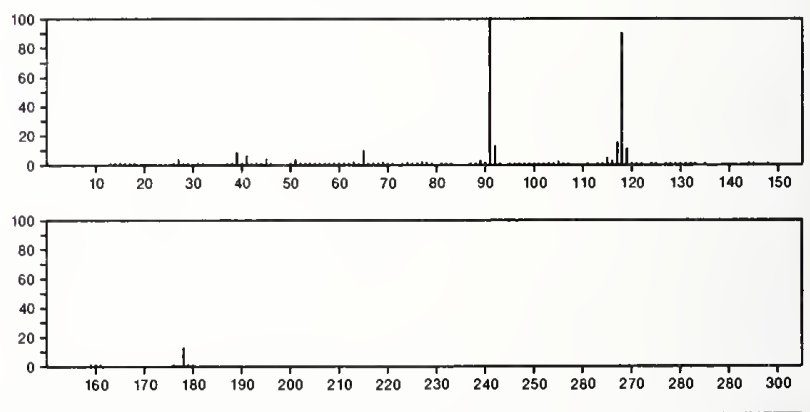

178

$\mathrm{C}_{11} \mathrm{H}_{14} \mathrm{O}_{2}$

Phenol, 2-(3-hydroxy-3-methyl-1-butenyl)-, (Z)-

$17235-14-2$
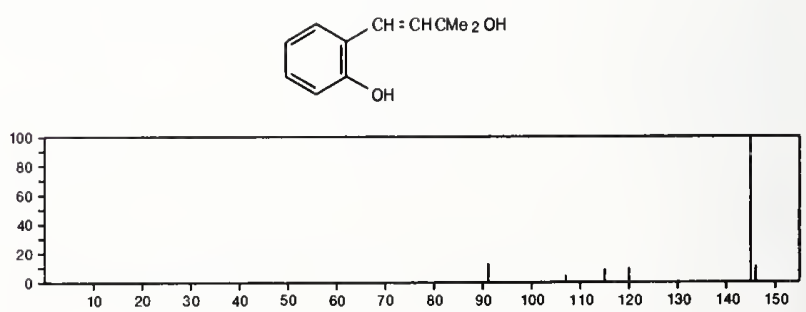


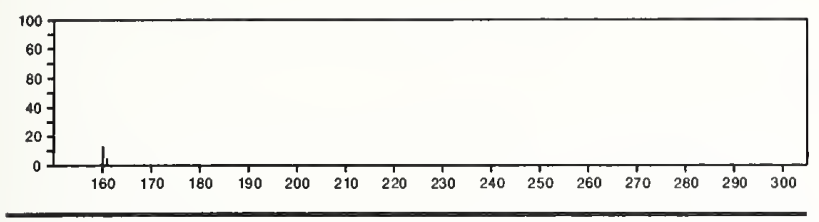

$178 \quad \mathrm{C}_{11} \mathrm{H}_{14} \mathrm{O}_{2} \quad 19731-91-0$

Benzenepropanoic acid, $\alpha, \beta$-dimethyl-

$\mathrm{HO}_{2} \mathrm{CCHMe} \mathrm{CHMePh}$
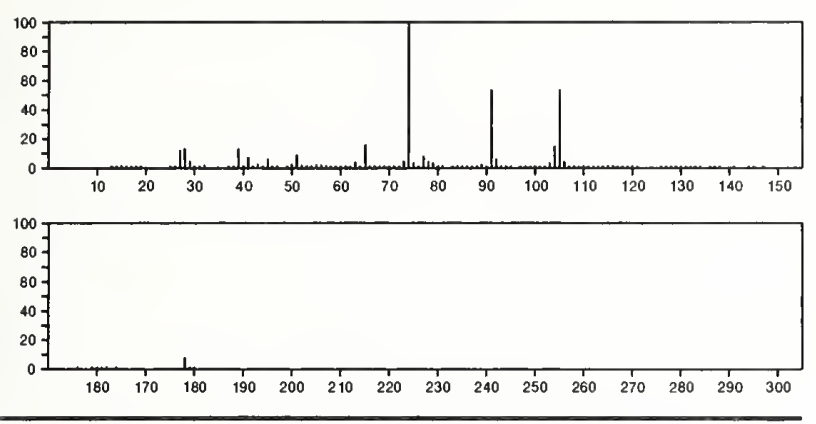

178

Pentanoic acid, phenyl ester

$$
\mathrm{C}_{11} \mathrm{H}_{14} \mathrm{O}_{2}
$$

20115-23-5

$\mathrm{PhOC}(\mathrm{O})\left(\mathrm{CH}_{2}\right)_{3} \mathrm{Me}$
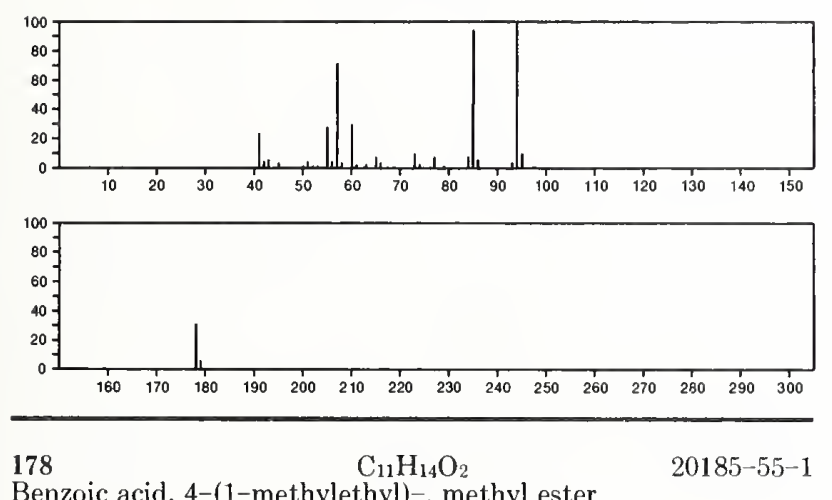

Benzoic acid, 4-(1-methylethyl)-, methyl ester
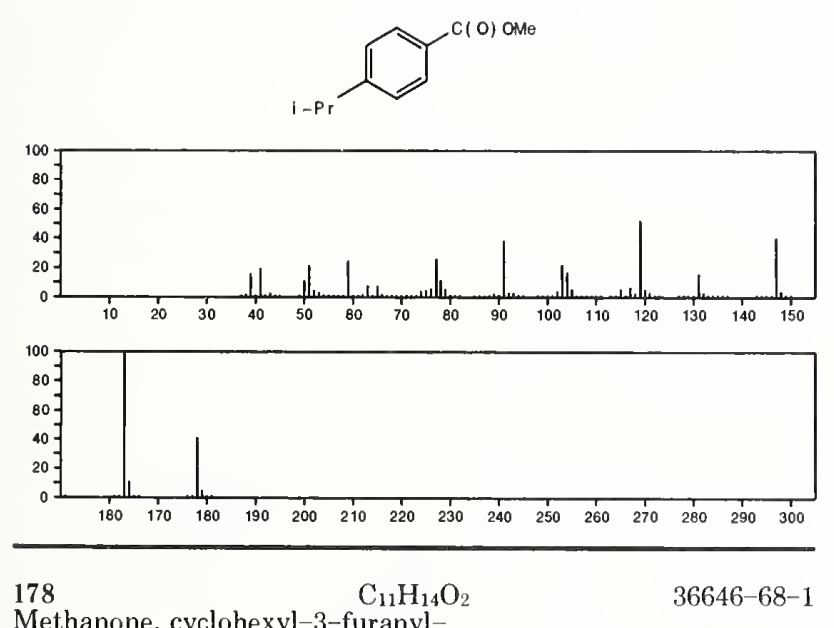

Methanone, cyclohexyl-3-furanyl--
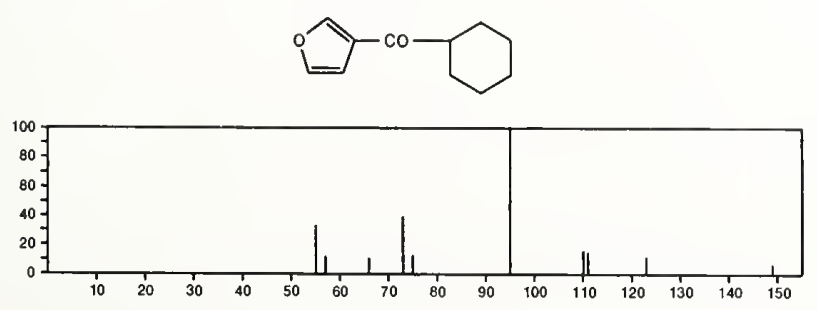

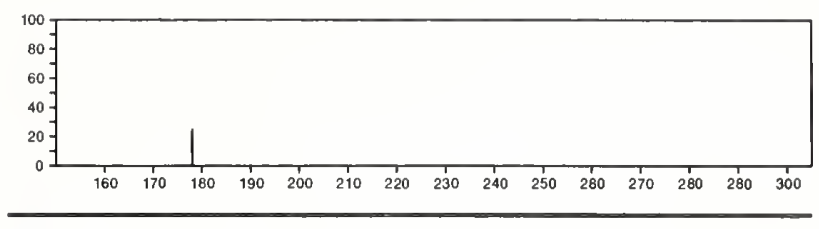

178

$\mathrm{C}_{11} \mathrm{H}_{14} \mathrm{O}_{2}$

$40924-58-1$

2H-Pyran, 2-(2,5-hexadiynyloxy)tetrahydro-
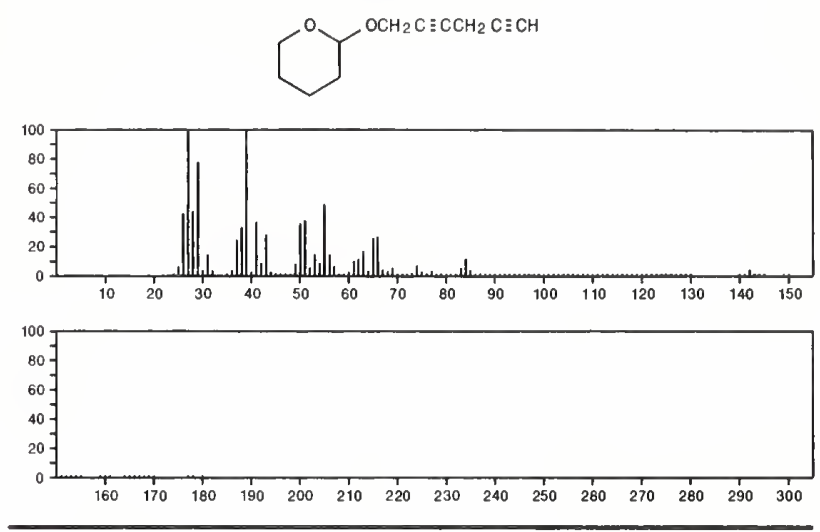

$\mathrm{C}_{11} \mathrm{H}_{14} \mathrm{O}_{2}$
$1,2-$ Naphthalenediol,
$1,2,3,4$-tetrahyd

$51086-38-5$

1,2-Naphthalenediol, 1,2,3,4-tetrahydro-4-methyl-<smiles>CC1CC(O)C(O)c2ccccc21</smiles>
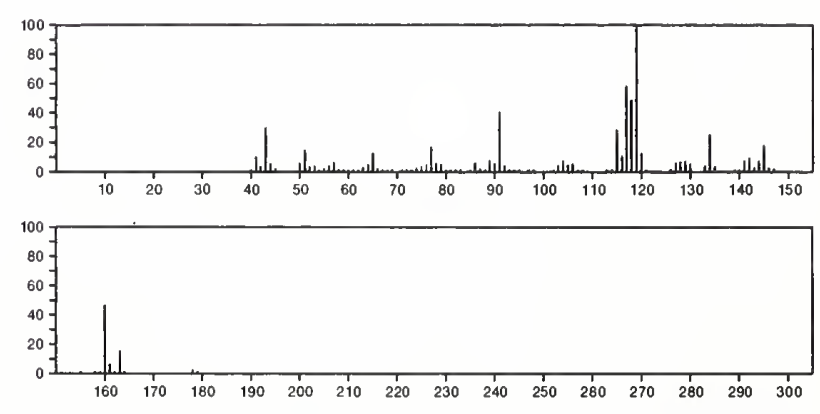

178

2-Propanone, 1-ethoxy-3-phenyl-

$51149-73-6$

$\mathrm{E}+\mathrm{OCH}_{2} \mathrm{COCH}_{2} \mathrm{Ph}$
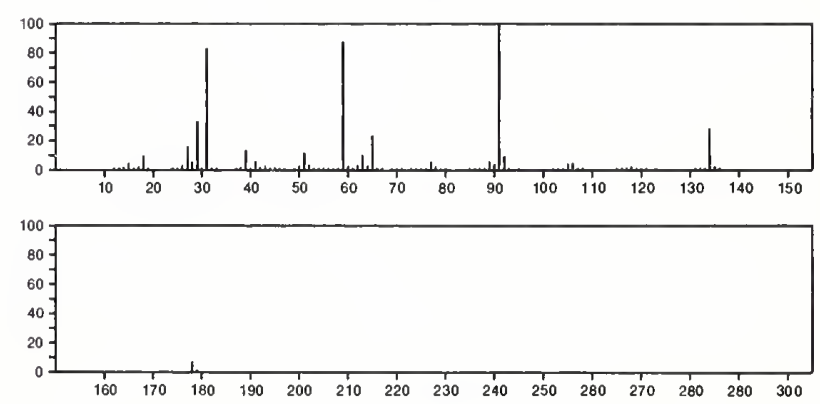
178 $\mathrm{C}_{11} \mathrm{H}_{14} \mathrm{O}_{2}$

Benzoic acid, 2,4,5-trimethyl-, methyl ester
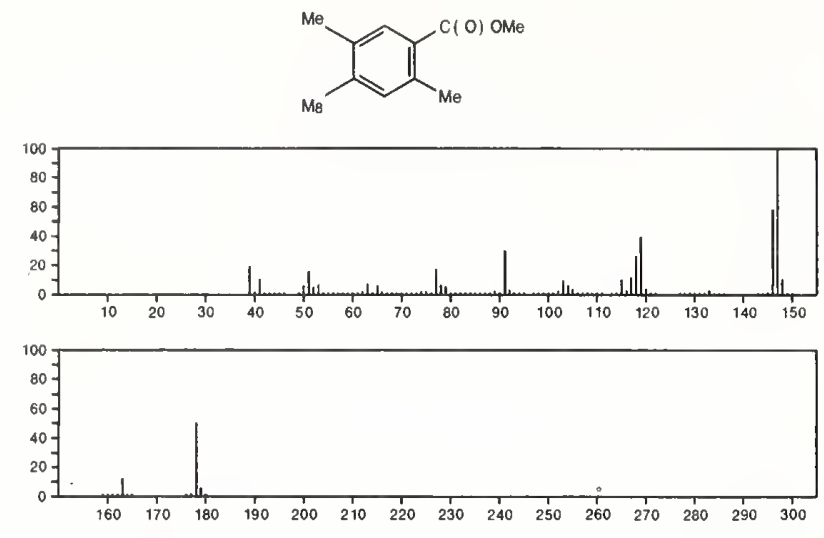

178

Propanoic acid, 4-ethylphenyl ester
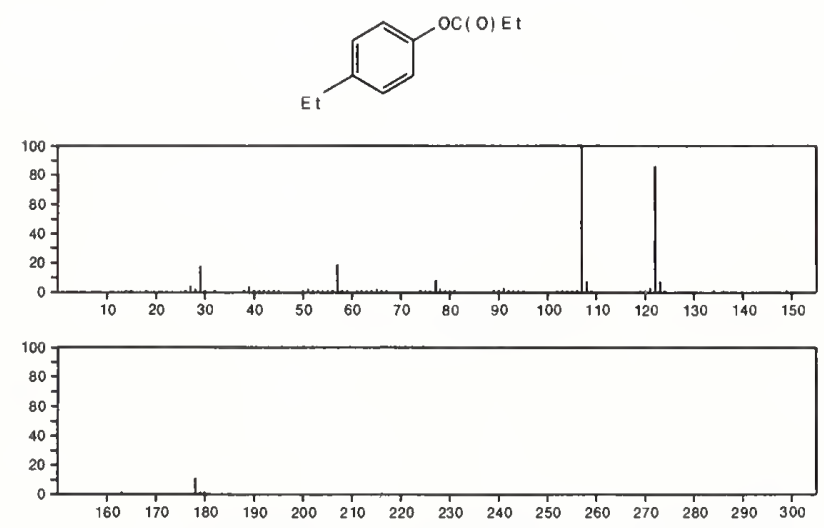

178

$$
\mathrm{C}_{11} \mathrm{H}_{14} \mathrm{O}_{2}
$$

$54549-72-3$

Ethanone, 1-[4-(1-hydroxy-1-methylethyl)phenyl]--
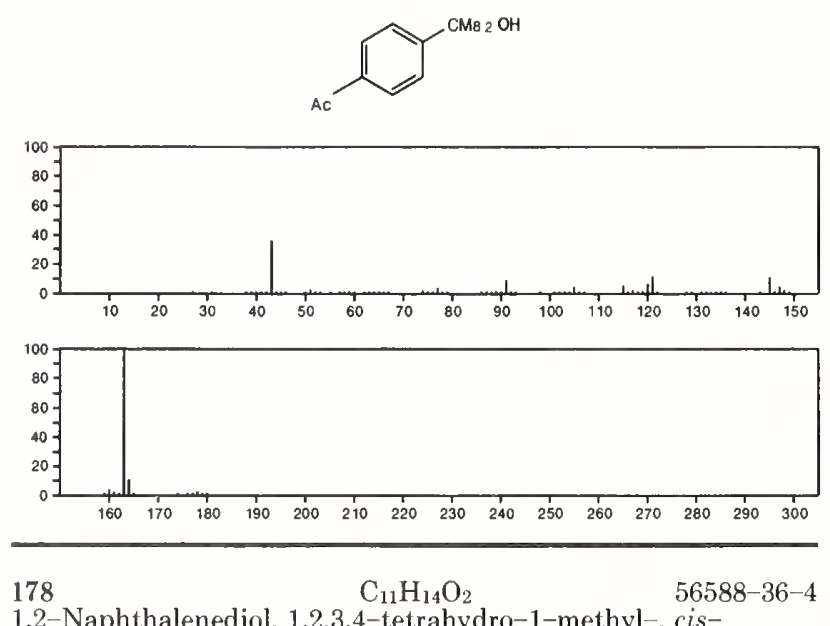

1,2-Naphthalenediol, 1,2,3,4-tetrahydro-1-methyl-, cis-
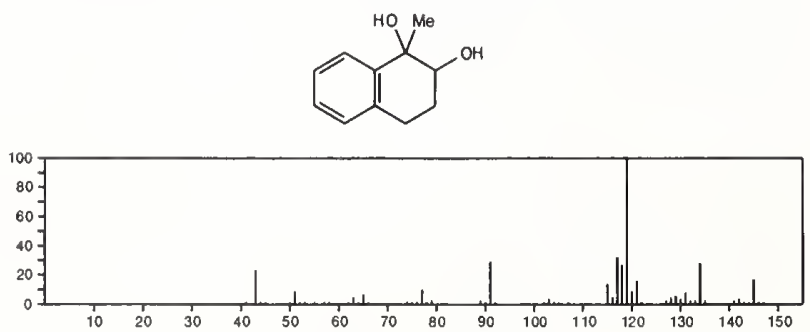

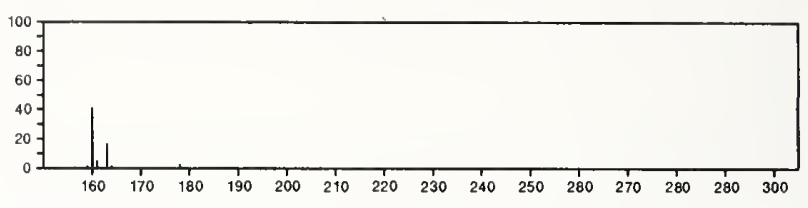

178

$\mathrm{C}_{11} \mathrm{H}_{14} \mathrm{~S}$

Benzene, [(3-methyl-2-butenyl)thio]-

$10276-04-7$

$\mathrm{PhSCH}_{2} \mathrm{CH}=\mathrm{CMB}_{2}$
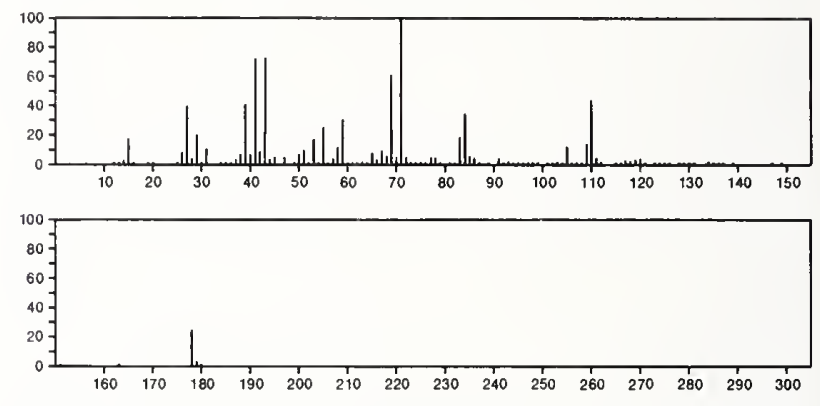

178

$\mathrm{C}_{11} \mathrm{H}_{14} \mathrm{~S}$

$54549-73-4$

2H-1-Benzothiopyran, 2-ethyl-3,4-dihydro-
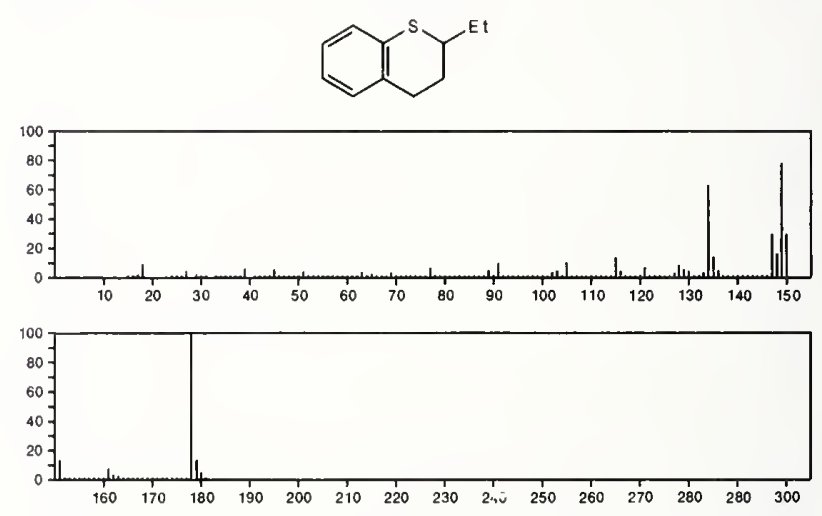

178

$\mathrm{C}_{11} \mathrm{H}_{18} \mathrm{~N}_{2}$

Pyrazine, 2,5-dimethyl-3-(3-methylbutyl)-

18433-98-2
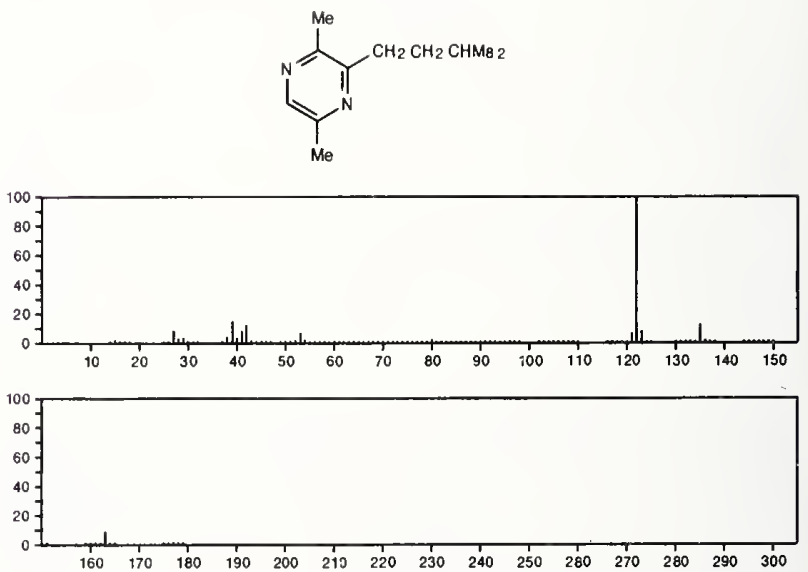
$178 \quad \mathrm{C}_{11} \mathrm{H}_{18} \mathrm{~N}_{2}$

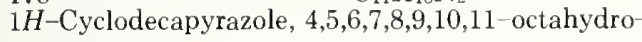

$34176^{-71-1}$
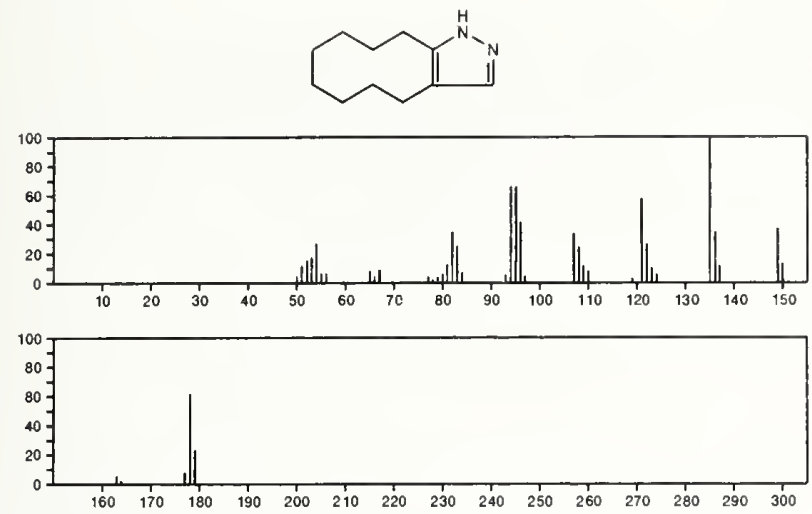

178

$\mathrm{C}_{11} \mathrm{H}_{18} \mathrm{~N}_{2}$

Hexanenitrile, 3-(1-pyrrolidinylmethylene)-

$54518-12-6$

$\overbrace{N}-\mathrm{CH}=\mathrm{CPr}_{\mathrm{CH}} \mathrm{CN}$
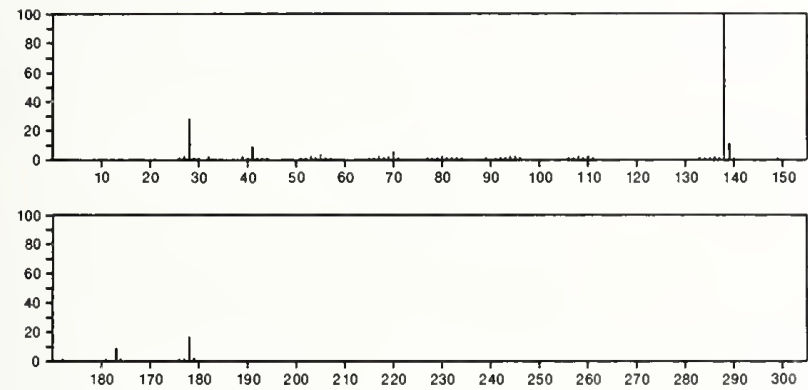

178

$\mathrm{C}_{12} \mathrm{H}_{18} \mathrm{O}$

$1011-12-7$

Cyclohexanone, 2-cyclohexylidene-
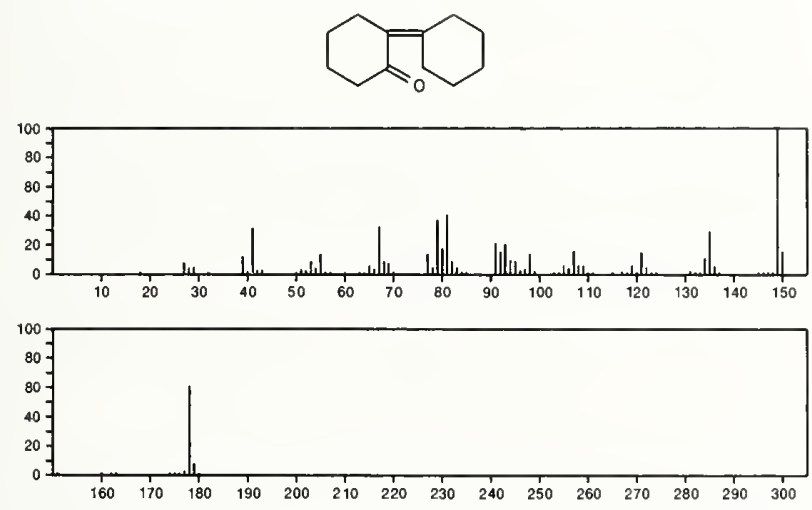

178

$\mathrm{C}_{12} \mathrm{H}_{18} \mathrm{O}$

$1132-66-7$

Benzene, (hexyloxy)-

$\mathrm{Me}\left\{\mathrm{CH}_{2}\right) 5 \mathrm{OPh}$
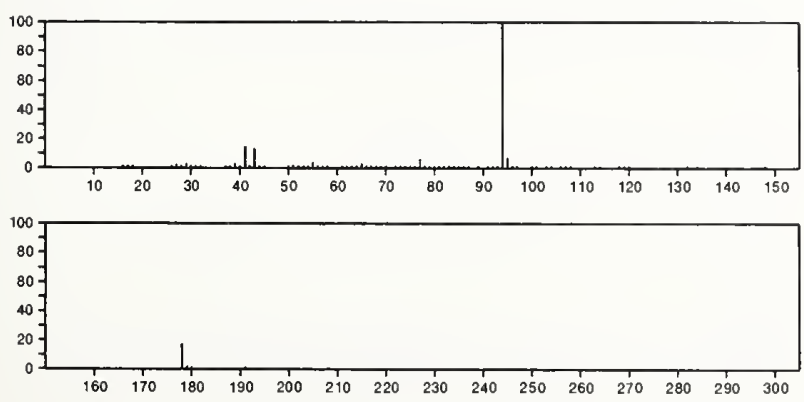

178

Phenol, 2,6-bis(1-methylethyl)-

$\mathrm{C}_{12} \mathrm{H}_{18} \mathrm{O}$

$2078-54-8$
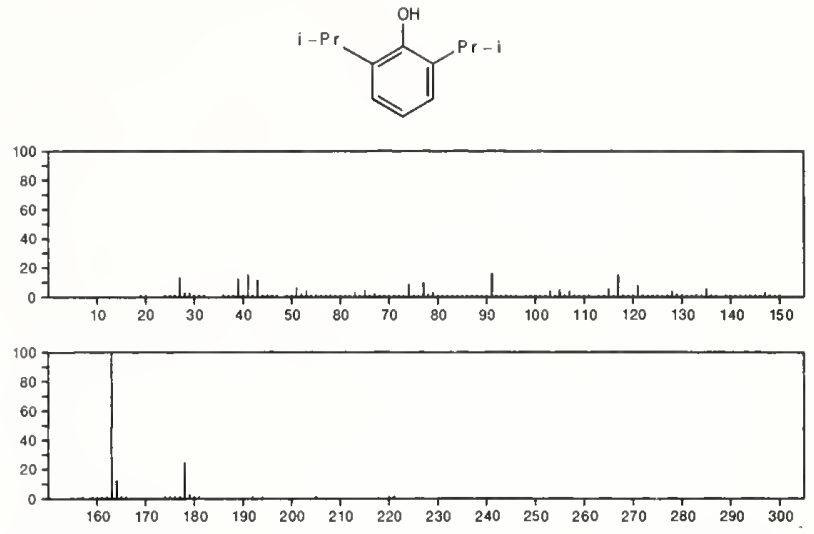

178

$\mathrm{C}_{12} \mathrm{H}_{18} \mathrm{O}$

2934-05-6

Phenol, 2,4-bis(1-methylethyl)-
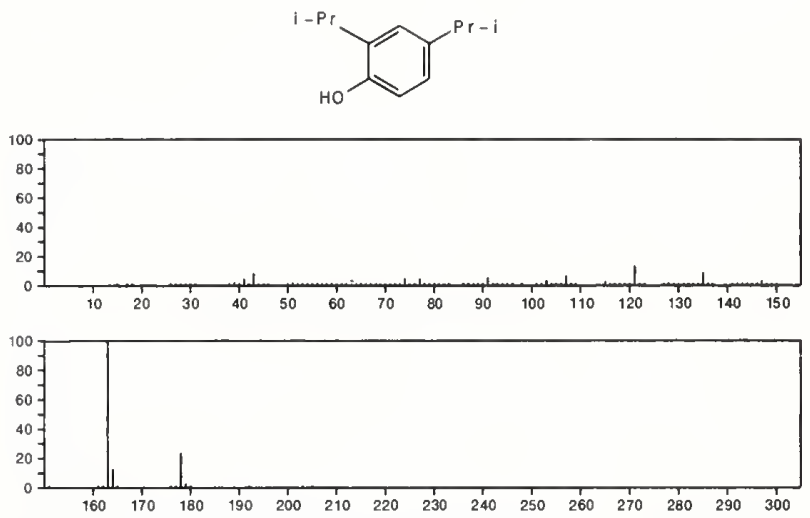

$178 \quad \mathrm{C}_{12} \mathrm{H}_{18} \mathrm{O} \quad 13485-66-0$ 2(1H)-Naphthalenone, 4a,5,6,7,8,8a-hexahydro-4a,8a-dimethyl-, cis-
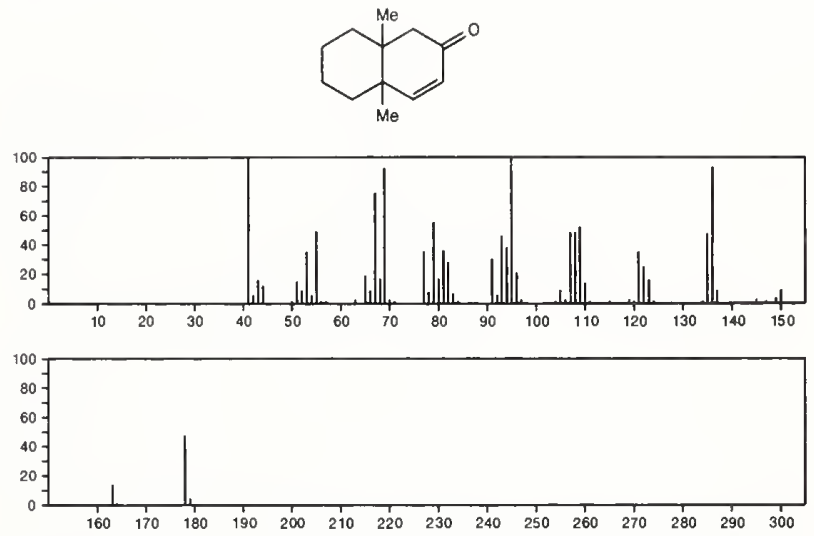

178

Ether, 3-phenylpropyl propyl

$14289-73-7$

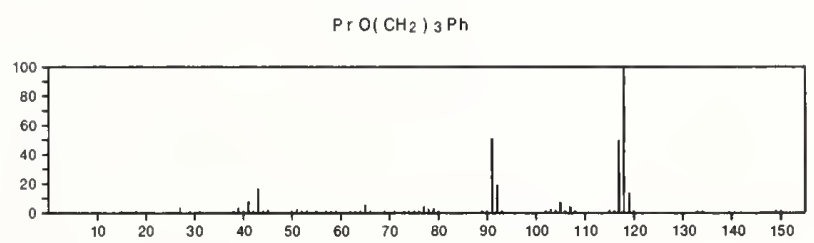




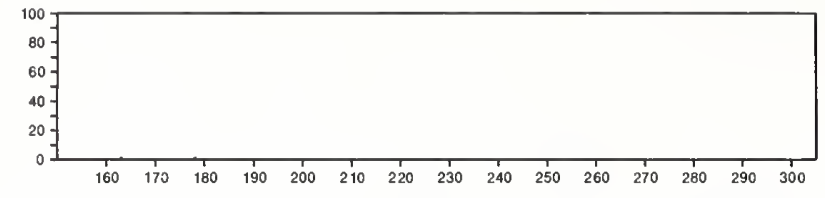

$178 \quad \mathrm{C}_{12} \mathrm{H}_{18} \mathrm{O}$

$17269-94-2$

Benzene, 1-(1,1-dimethylethyl)-4-ethoxy-
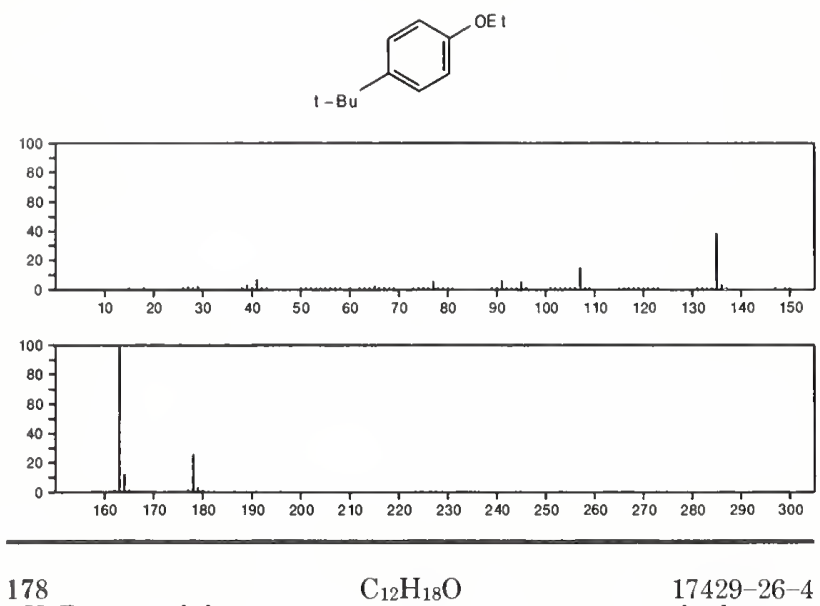

$2 \mathrm{H}$-Benzocyclohepten-2-one, $1,4 \mathrm{a}, 5,6,7,8,9,9 \mathrm{a}$-octahydro-4amethyl-, trans-
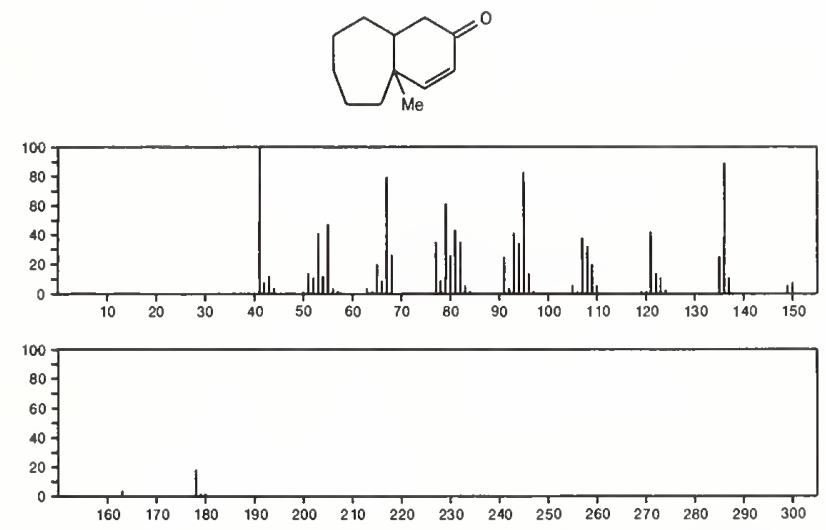

178

$\mathrm{C}_{12} \mathrm{H}_{18} \mathrm{O}$

$18346-78-6$

Bicyclo[3.3.1]nonan-2-one, 9-isopropylidene-
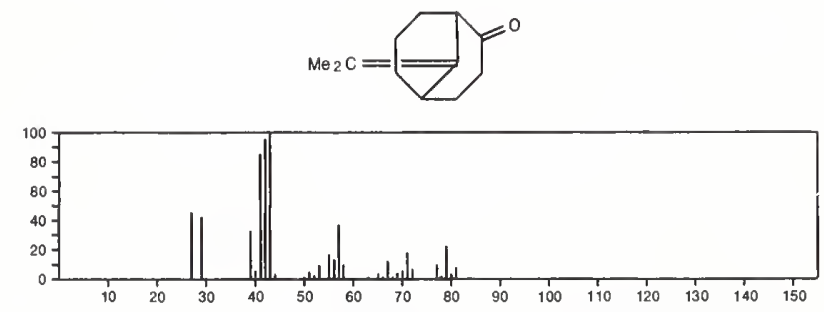

178

$\mathrm{C}_{12} \mathrm{H}_{18} \mathrm{O}$

$20056-56-8$

Anisole, o-pentyl-
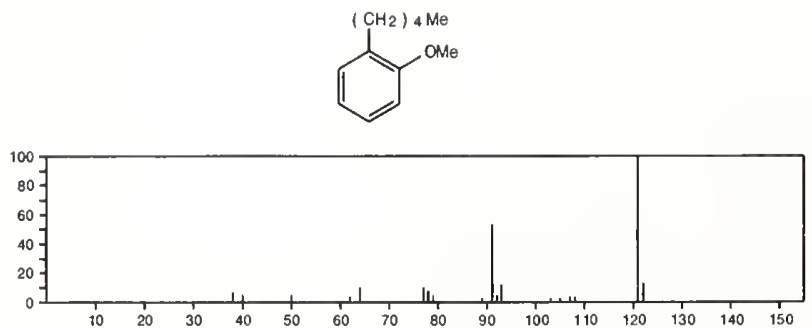

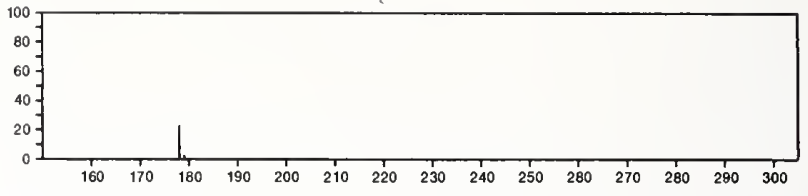

$\mathrm{C}_{12} \mathrm{H}_{18} \mathrm{O}$

$20056-57-9$

Benzene, 1-methoxy-3-pentyl
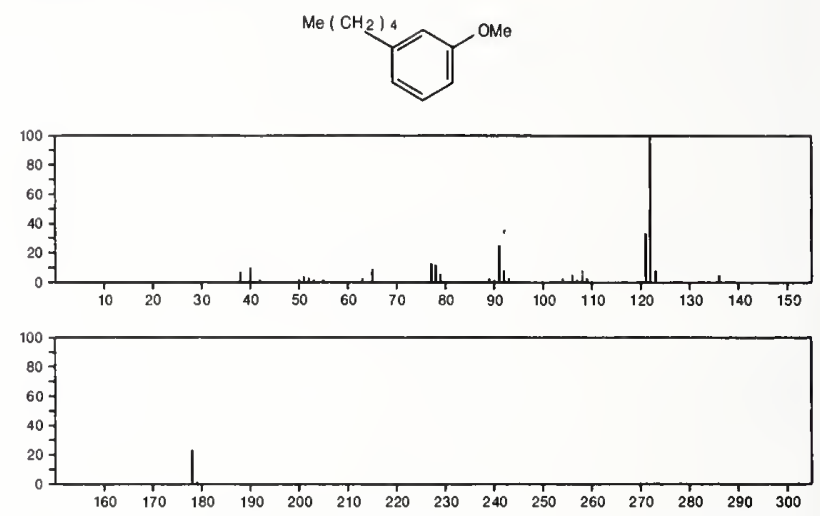

$178 \quad \mathrm{C}_{12} \mathrm{H}_{18} \mathrm{O}$

20056-58-0

Benzene, 1-methoxy-4-pentyl-
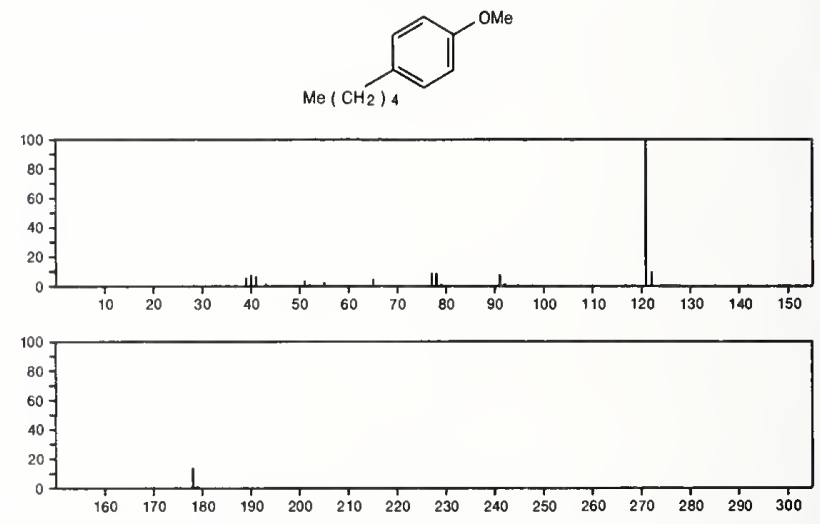

178

$\mathrm{C}_{12} \mathrm{H}_{18} \mathrm{O}$

Ether, $\alpha, \alpha$-dimethylbenzyl propyl

$24142-77-6$

$\mathrm{PhCMe}_{2}(\mathrm{OPr})$
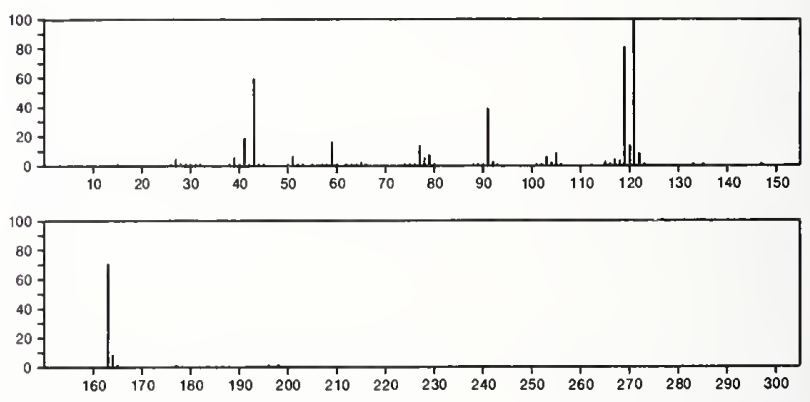

178

$\mathrm{C}_{12} \mathrm{H}_{18} \mathrm{O}$

Ether, $\alpha, \alpha$-dimethylbenzyl isopropyl

$\mathrm{PhCMe}_{2}\left(\mathrm{OPr}_{-1}\right)$

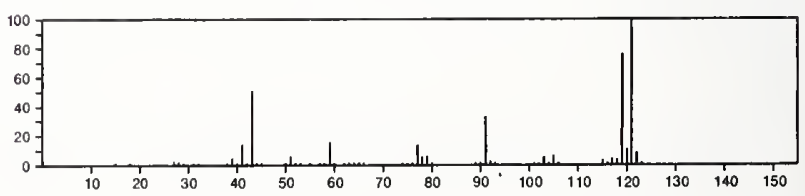




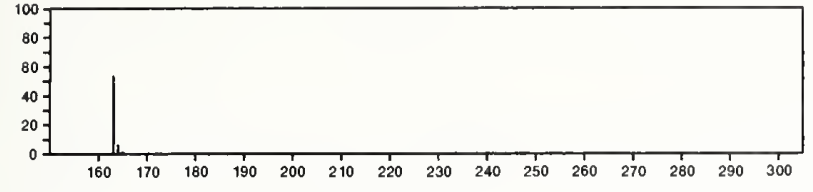

178

$\mathrm{C}_{12} \mathrm{H}_{18} \mathrm{O}$

$29460-68-2$

2-Cyclohexene-1-acrolein, 2,6,6-trimethyl-
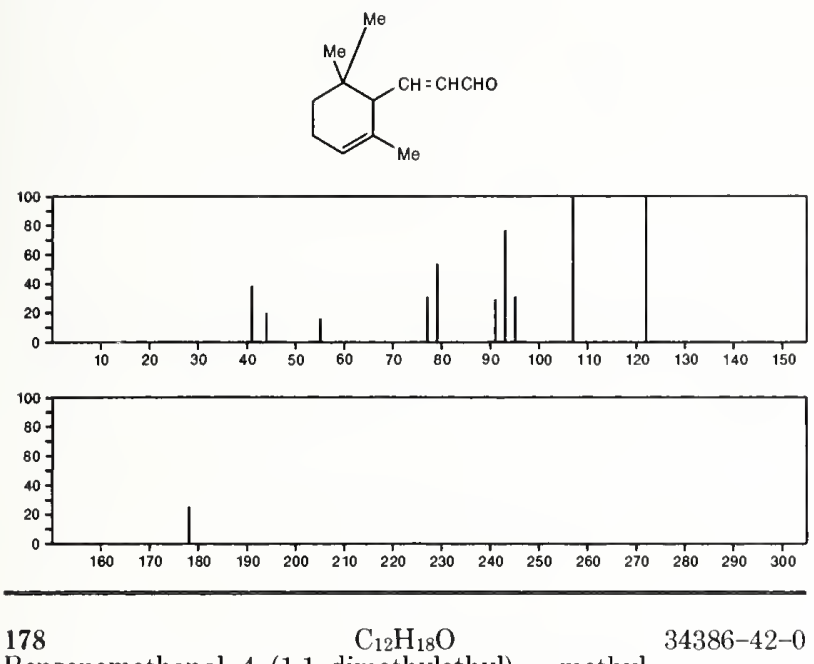

Benzenemethanol, 4-(1,1-dimethylethyl)- $\alpha$-methyl-
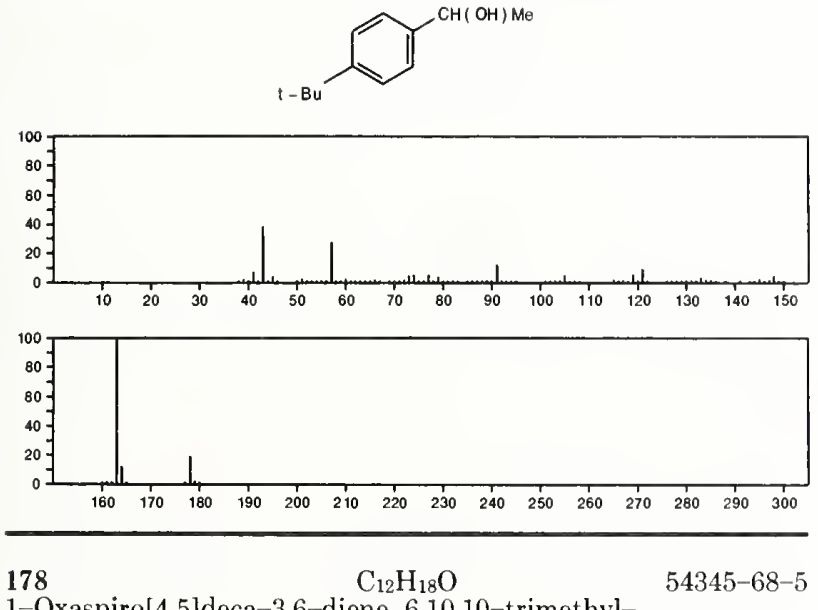

1-Oxaspiro[4.5]deca-3,6-diene, 6,10,10-trimethyl-
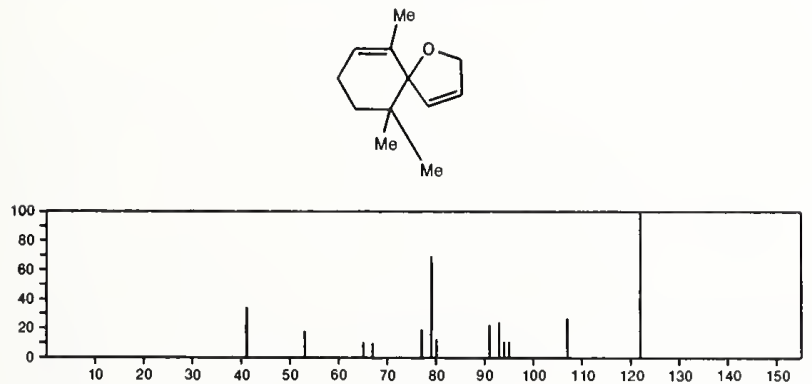

178

$\mathrm{C}_{12} \mathrm{H}_{18} \mathrm{O}$

$54345-69-6$

1-Oxaspiro[4.5] dec-3-ene, 6,6-dimethyl-10-methylene-
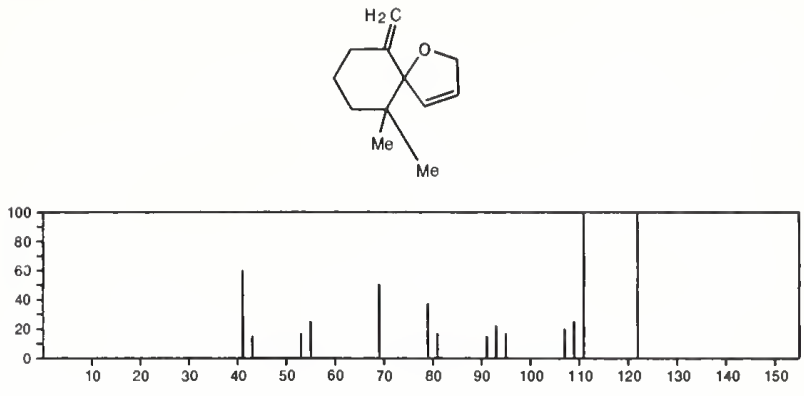

178

$\mathrm{C}_{12} \mathrm{H}_{18} \mathrm{O}$

$54518-11-5$

Benzeneethanol, $\alpha$-methyl-3-(1-methylethyl)-
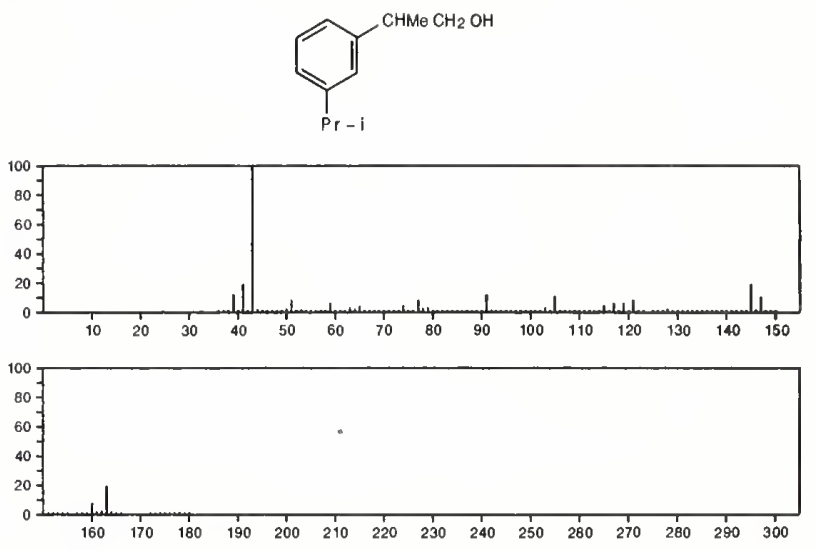

178

$\mathrm{C}_{12} \mathrm{H}_{18} \mathrm{O}$

$54518-14-8$

Benzeneethanol, ar,ar-diethyl-
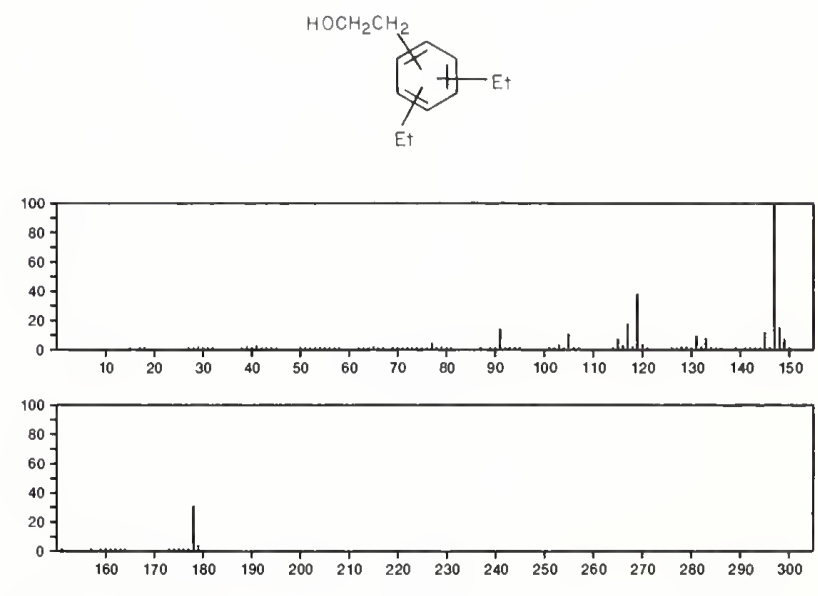

178

$\mathrm{C}_{12} \mathrm{H}_{18} \mathrm{O}$

55103-71-4

$2 H$-Benzocyclohepten-2-one, $3,4,4 \mathrm{a}, 5,6,7,8,9$-octahydro-4a-methyl-, (S) -
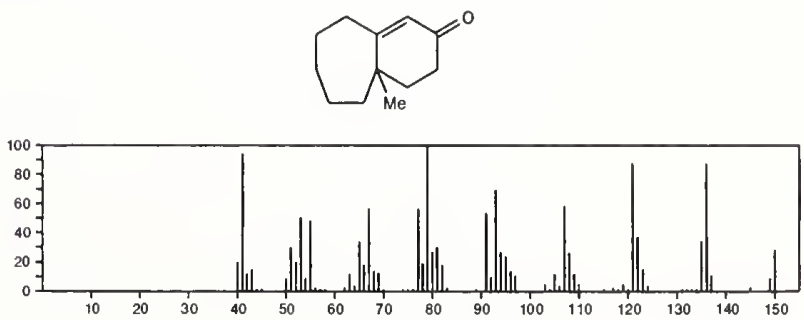

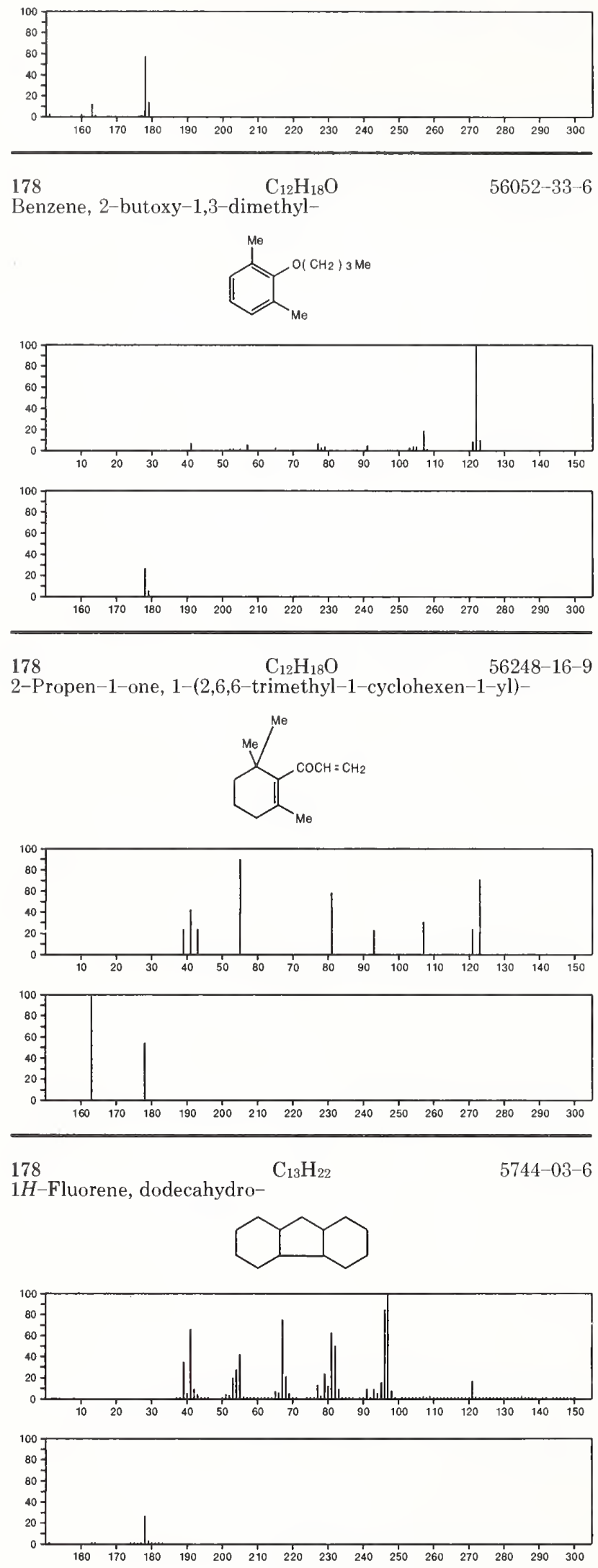

178

$\mathrm{C}_{13} \mathrm{H}_{22}$

$50746-55-9$ Bicyclo[3.1.1]heptane, 2,6,6-trimethyl-3-(2-propenyl)-, $(1 \alpha,=$ $2 \beta, 3 \alpha, 5 \alpha)-$
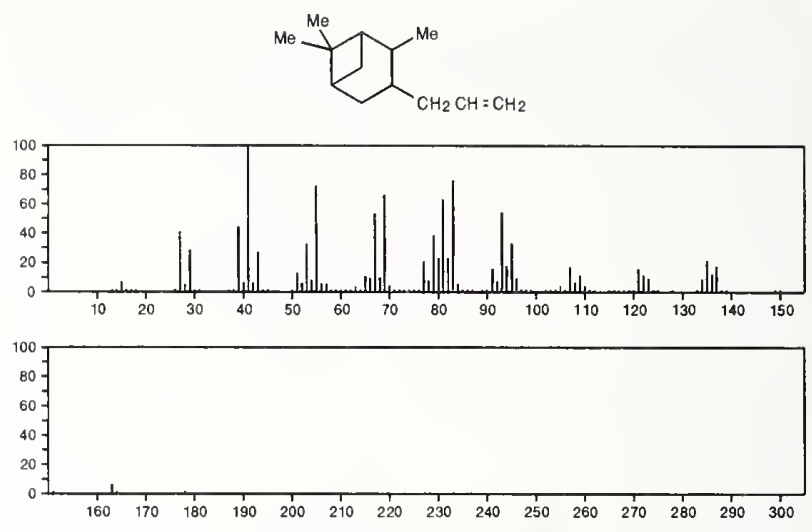

178

$\mathrm{C}_{13} \mathrm{H}_{22}$

$55103-62-3$

Benzocyclooctene, 1,4,4a,5,6,7,8,9,10,10a-decahydro-4a-methyl-, trans-
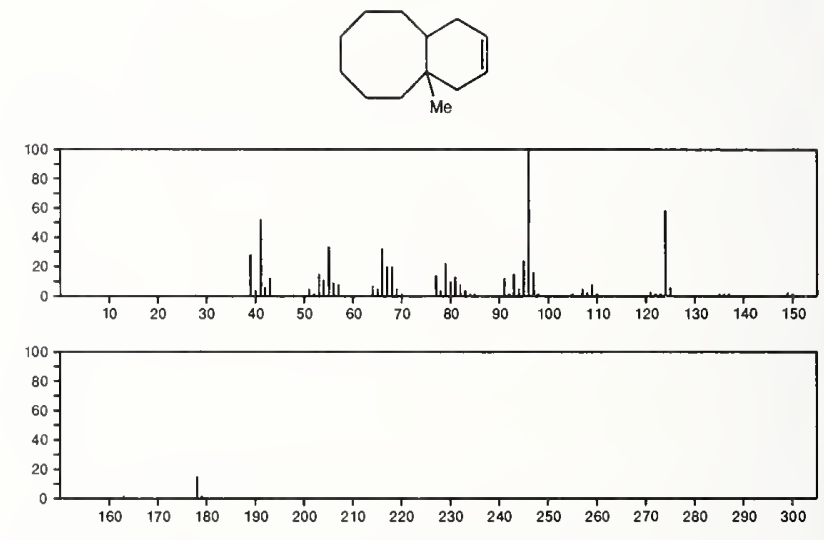

178

Phenanthrene

$\mathrm{C}_{14} \mathrm{H}_{10}$

$85-01-8$
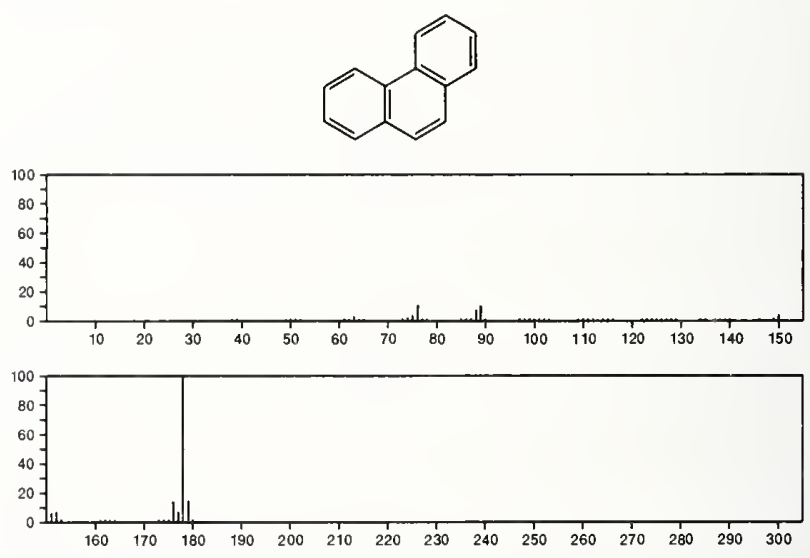

178

$\mathrm{C}_{14} \mathrm{H}_{10}$

120-12-7

Anthracene
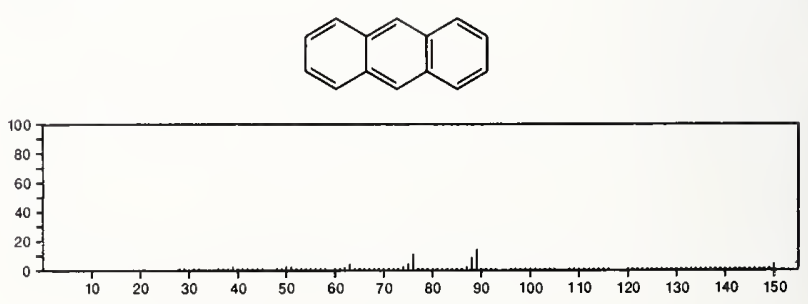

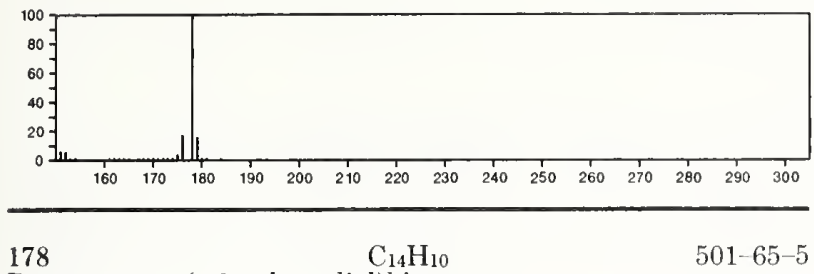

Benzene, 1,1'-(1,2-ethynediyl)bis-

$\mathrm{PhC} \equiv \mathrm{CPh}$
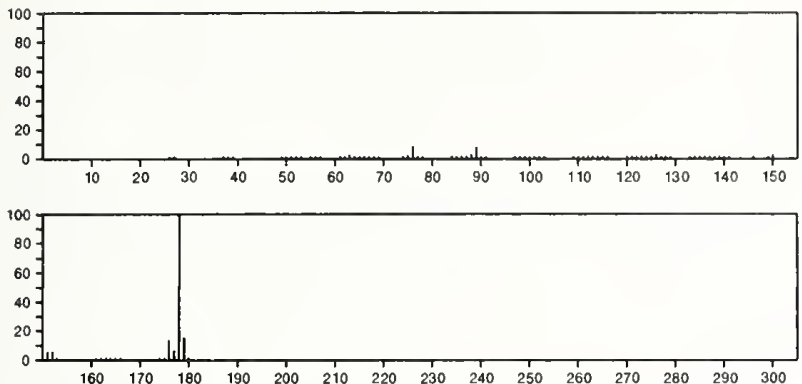

179

$\mathrm{C}_{4} \mathrm{H}_{6} \mathrm{NO}_{5} \mathrm{P}$

$3048-73-5$

2,6,7-Trioxa-1-phosphabicyclo[2.2.2]octane, 4-nitro-
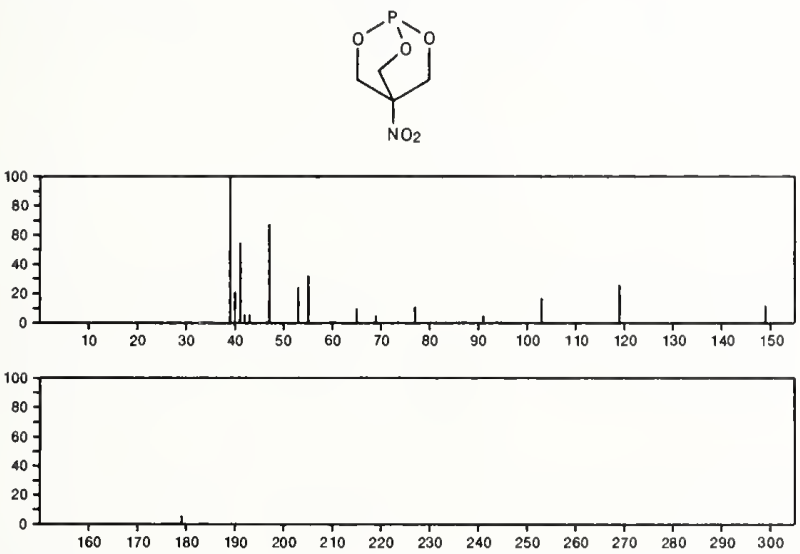

$179 \quad \mathrm{C}_{6} \mathrm{H}_{5} \mathrm{~N}_{5} \mathrm{O}_{2}$

4,6-Pteridinedione, 2-amino-1,5-dihydro-

$119-44-8$<smiles>Nc1nc(=O)c2[nH]c(=O)cnc2[nH]1</smiles>
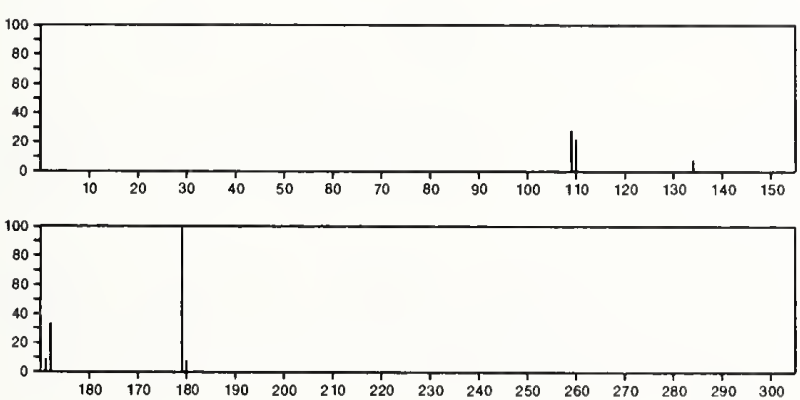

179

$\mathrm{C}_{6} \mathrm{H}_{5} \mathrm{~N}_{5} \mathrm{O}_{2}$

$529-69-1$

$4,7(1 \mathrm{H}, 8 \mathrm{H})$-Pteridinedione, 2-amino-
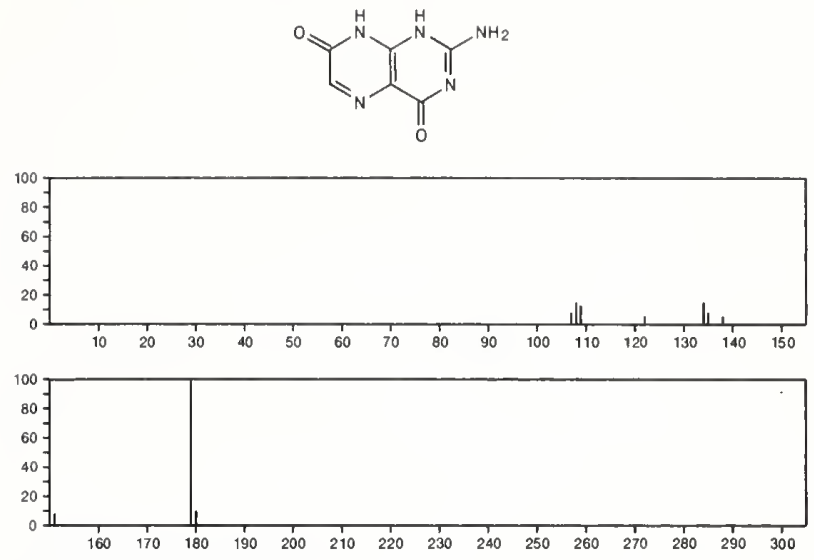

$179 \quad \mathrm{C}_{6} \mathrm{H}_{18} \mathrm{~N}_{3} \mathrm{OP}$

$680-31-9$

Phosphoric triamide, hexamethyl-

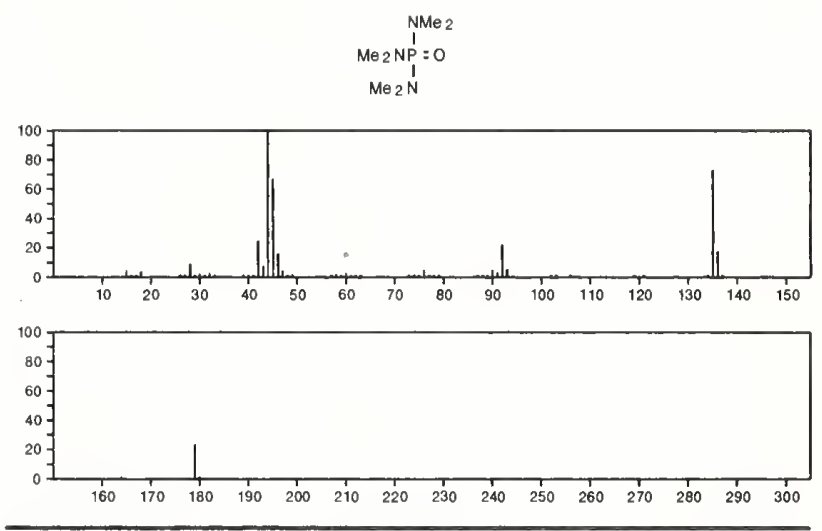

III.

$\mathrm{C}_{7} \mathrm{H}_{5} \mathrm{~N}_{3} \mathrm{O}_{3}$

$53975-72-7$

1,2,4-Triazolo[4,3-a]pyridine-8-carboxylic acid, 2,3-dihydro-3-oxo-
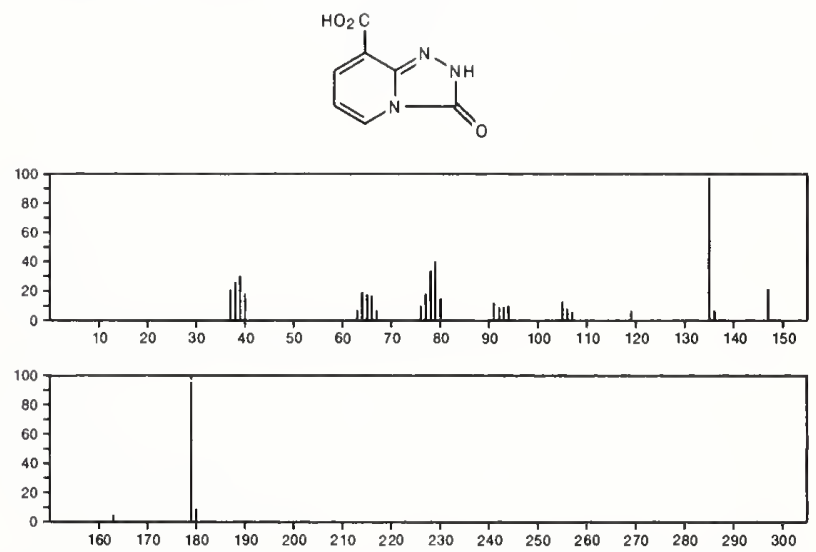

179

$\mathrm{C}_{7} \mathrm{H}_{9} \mathrm{~N}_{5} \mathrm{O}$

6H-Purin-6-one, 2-(dimethylamino)-1,7-dihydro-

$1445-15-4$<smiles>CNc1nc(=O)c2[nH]cnc2[nH]1</smiles>

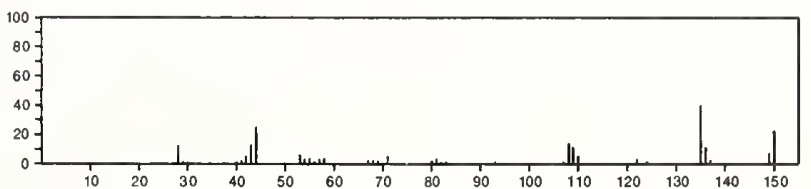



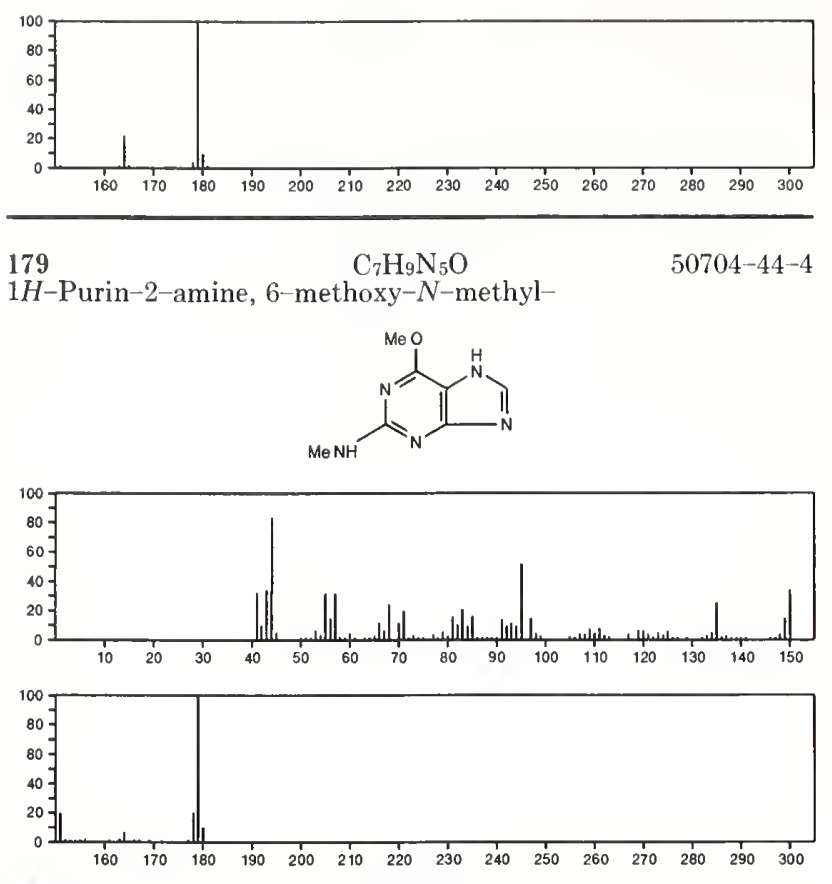

$179 \quad \mathrm{C}_{8} \mathrm{H}_{5} \mathrm{NO}_{2} \mathrm{~S}$

1,2-Benzisothiazole-3-carboxylic acid
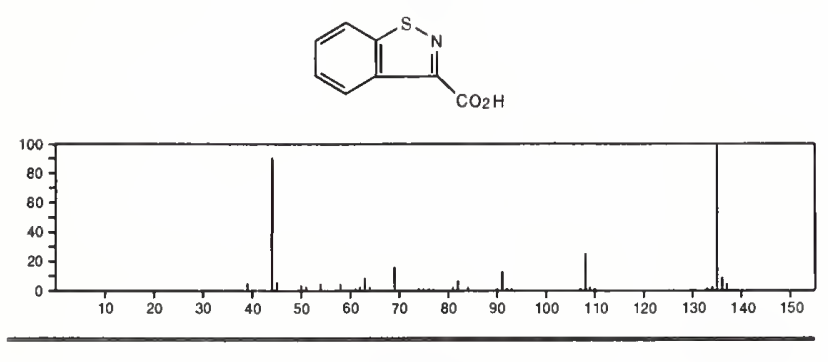

179

$\mathrm{C}_{8} \mathrm{H}_{9} \mathrm{~N}_{3} \mathrm{~S}$

$1627-73-2$

Hydrazinecarbothioamide, 2-(phenylmethylene)-

$\mathrm{H}_{2} \mathrm{NCSNHN}=\mathrm{CHPh}$
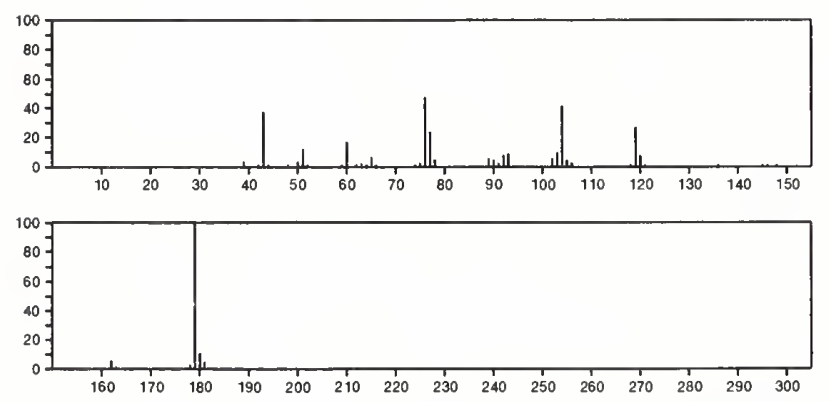

179

2,3,5,6-Pyridinetetracarbonitrile

$\mathrm{C}_{9} \mathrm{HN}_{5}$

17638-20-9<smiles>Cc1cc(N)c(N)nc1N</smiles>

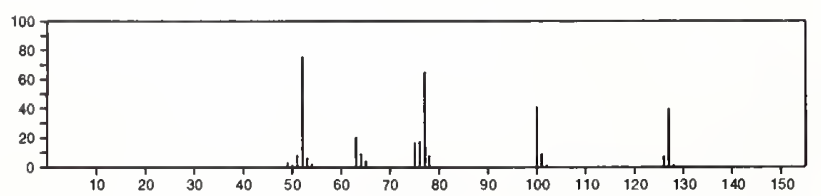

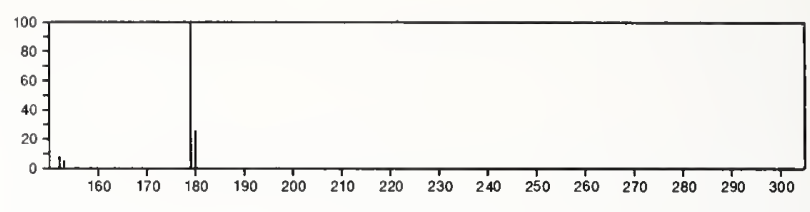

179

Isoxazole, 5-chloro-3-phenyl-

$\mathrm{C}_{9} \mathrm{H}_{6} \mathrm{ClNO}$

3356-89-6
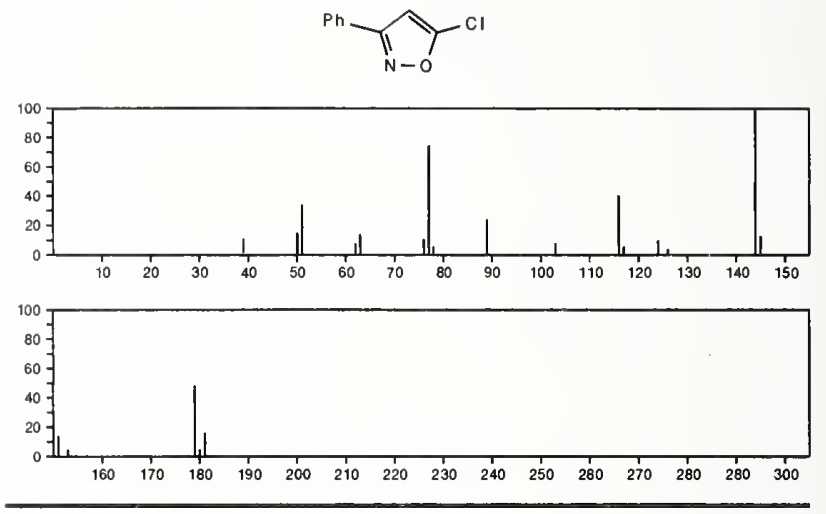

179

$\mathrm{C}_{9} \mathrm{H}_{9} \mathrm{NOS}$

30276-97-2

Thiazolo[3,2-a]pyridinium, 8-hydroxy-2,5-dimethyl-, hydroxide, inner salt
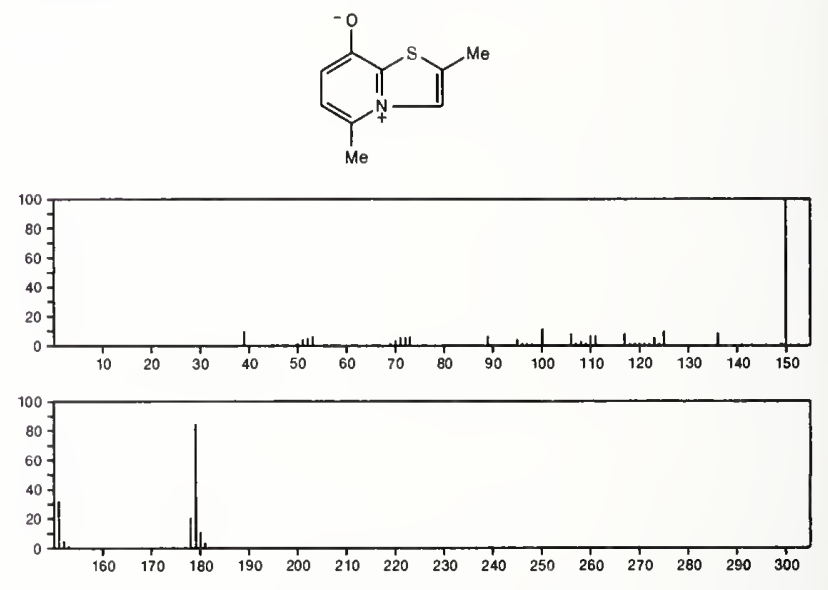

$179 \quad \mathrm{C}_{9} \mathrm{H}_{9} \mathrm{NOS} \quad 30277-00-0$ Thiazolo[3,2-a]pyridinium, 8 -hydroxy-3,5-dimethyl-, hydroxide,
inner salt
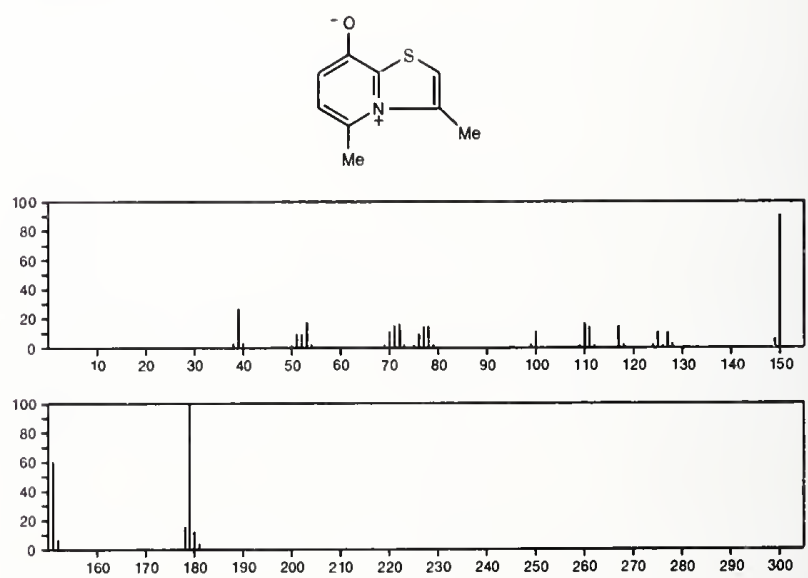
179

$\mathrm{C}_{9} \mathrm{H}_{9} \mathrm{NOS}$

1,2-Benzisothiazole, 3-ethoxy-
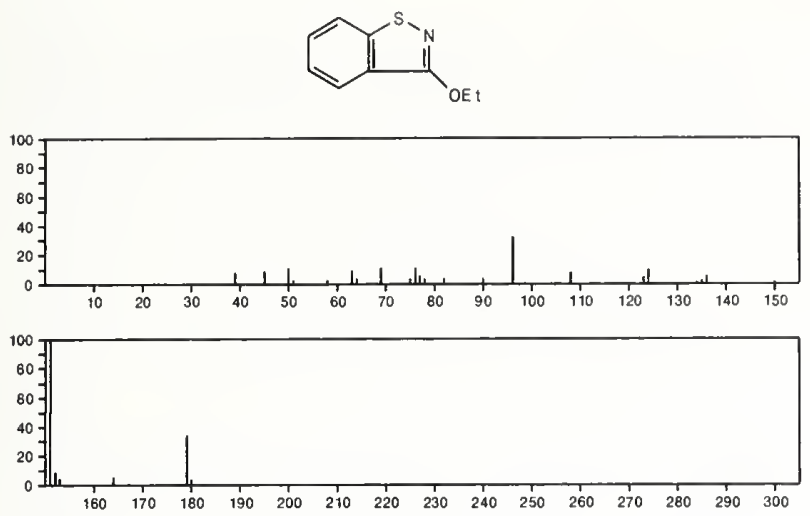

179

Glycine, $N$-benzoyl-

$\mathrm{C}_{9} \mathrm{H}_{9} \mathrm{NO}_{3}$

495-69-2

PhCONHCH $\mathrm{CO}_{2} \mathrm{H}$
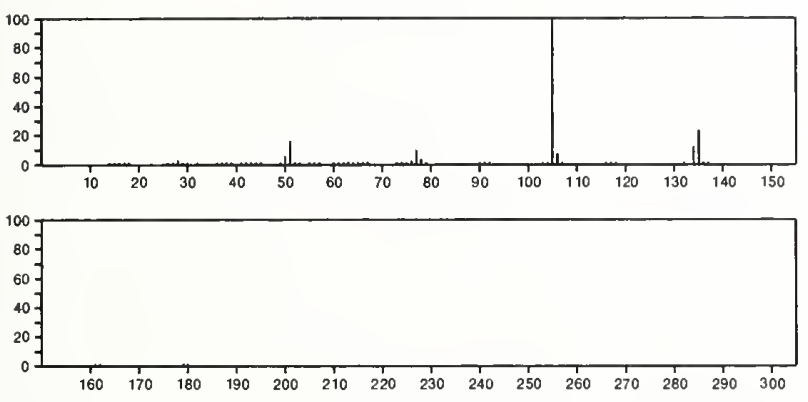

179

$\mathrm{C}_{9} \mathrm{H}_{9} \mathrm{NO}_{3}$

$556-08-1$

Benzoic acid, 4-(acetylamino)-
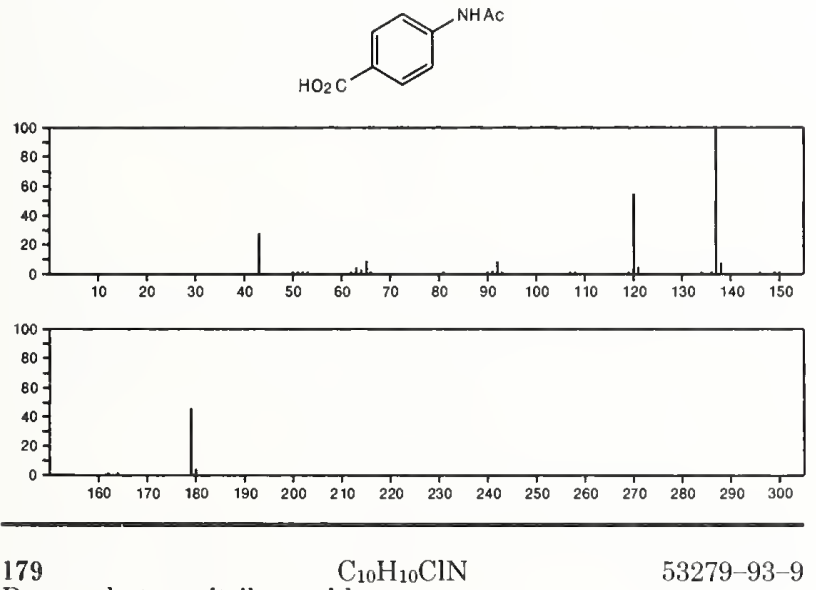

Benzenebutanenitrile, $\alpha$-chloro-

$\mathrm{NCCHCl} \mathrm{CH} \mathrm{CH}_{2} \mathrm{Ph}$
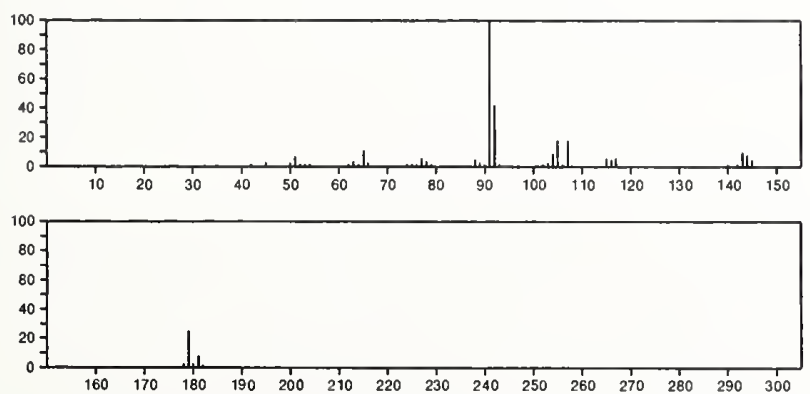

179 Acetamide, $N$-(4-ethoxyphenyl)-

$\mathrm{C}_{10} \mathrm{H}_{13} \mathrm{NO}_{2}$

$62-44-2$
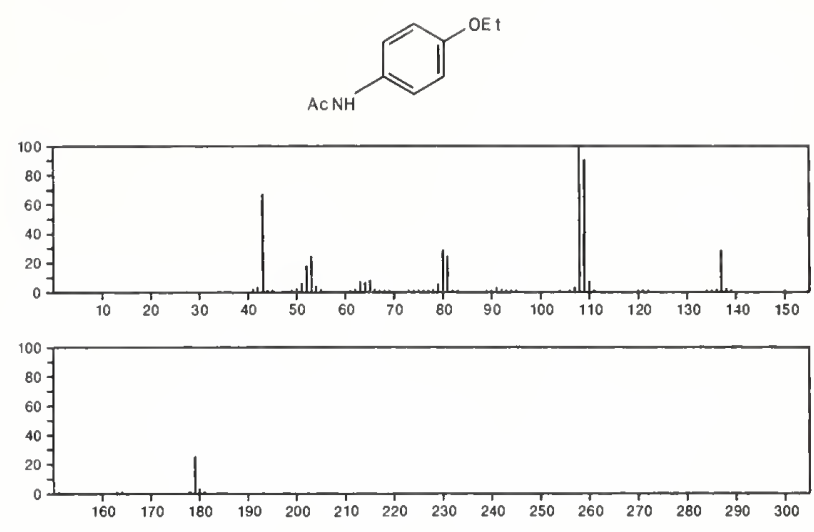

179

$\mathrm{C}_{10} \mathrm{H}_{13} \mathrm{NO}_{2}$

$122-42-9$

Carbamic acid, phenyl-, 1-methylethyl ester

$\mathrm{PhNHC}(0) \mathrm{OPr}_{-}-\mathrm{I}$
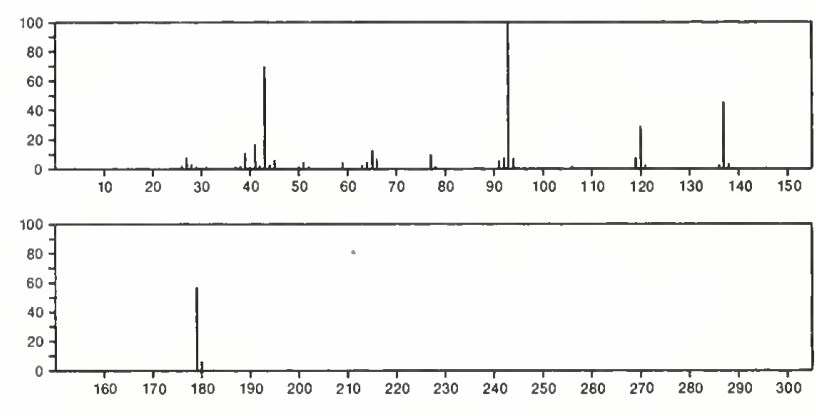

$179 \quad \mathrm{C}_{10} \mathrm{H}_{13} \mathrm{NO}_{2}$

$2577-90-4$

L-Phenylalanine, methyl ester

$\mathrm{MeOC}(0) \mathrm{CH}\left(\mathrm{NH}_{2}\right) \mathrm{CH}_{2} \mathrm{Ph}$
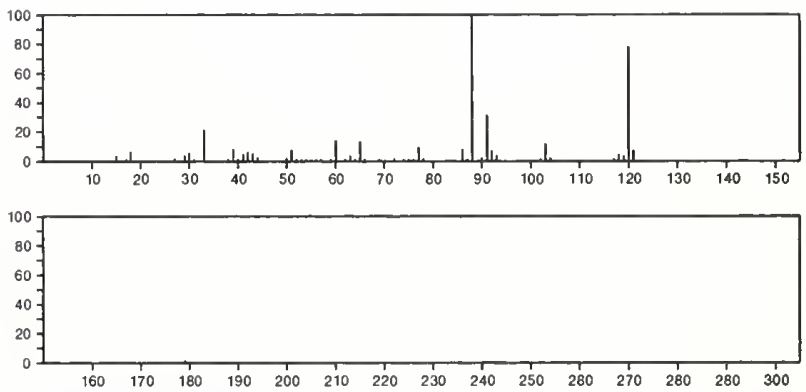

179

$\mathrm{C}_{10} \mathrm{H}_{13} \mathrm{NO}_{2}$

$5532-90-1$

Carbamic acid, phenyl-, propyl ester

$\mathrm{PhNHC}(\mathrm{O}) \mathrm{OPr}$
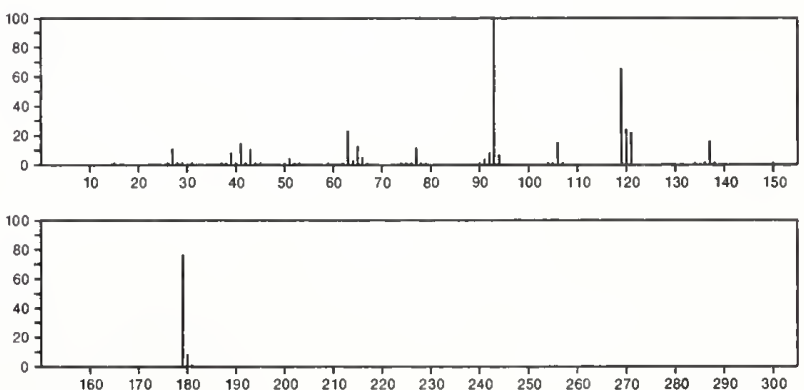
179

$\mathrm{C}_{10} \mathrm{H}_{13} \mathrm{NO}_{2}$

Benzoic arid, 2-(dimethylamino)-, methyl ester

$10072-05-6$<smiles>Nc1ccccc1Cl</smiles>
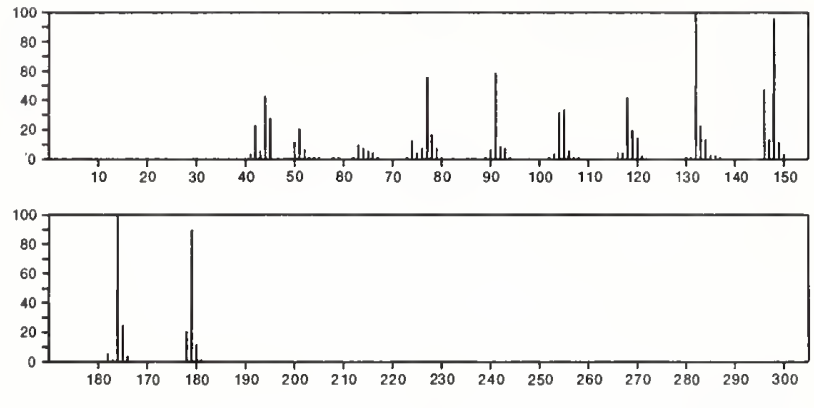

$179 \quad \mathrm{C}_{10} \mathrm{H}_{13} \mathrm{NO}_{2} \quad 10315-42-1$

$1 H$-Azepine-2,5-dione, 4-isopropyl-7-methyl-
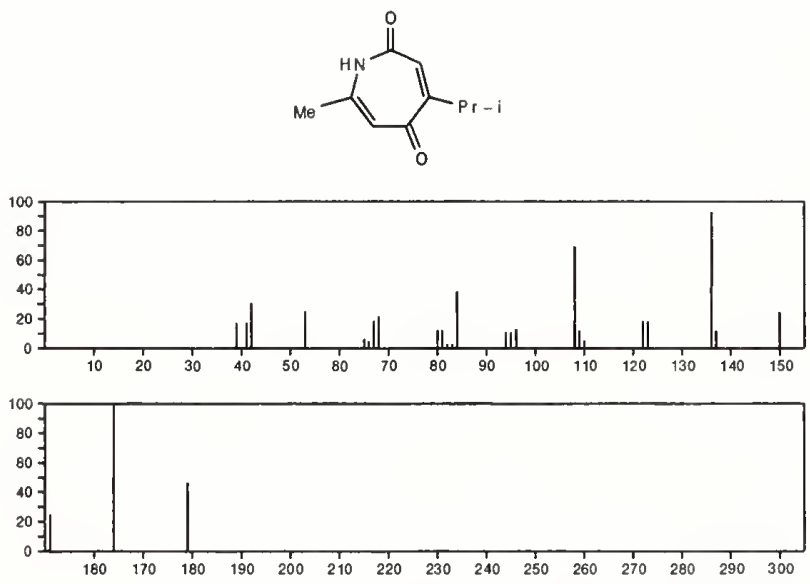

$179 \quad \mathrm{C}_{10} \mathrm{H}_{13} \mathrm{NO}_{2}$

$18189-02-1$

Anthranilic acid, isopropyl ester
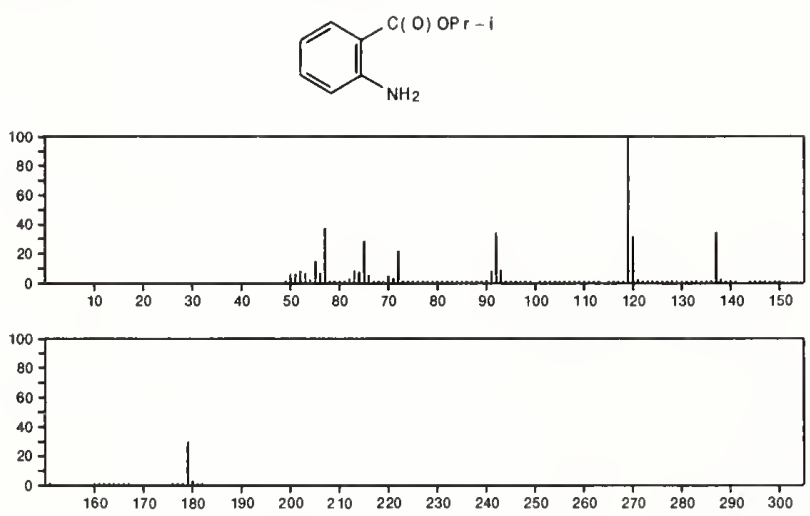

179

$\mathrm{C}_{10} \mathrm{H}_{13} \mathrm{NO}_{2}$

Carbamic acid, (2,6-dimethylphenyl)-, methyl ester

20642-93-7
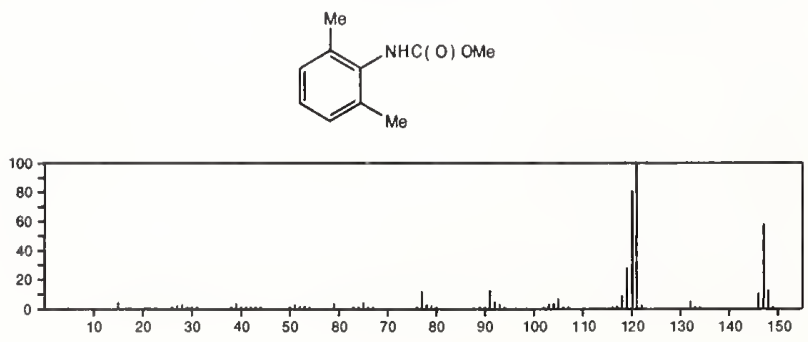

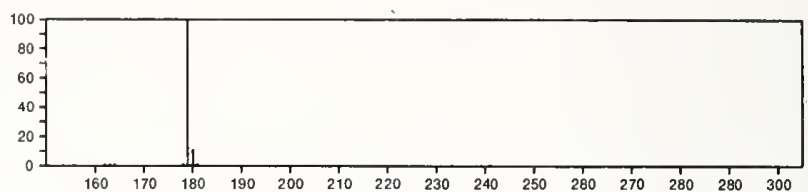

179

$\mathrm{C}_{10} \mathrm{H}_{13} \mathrm{NO}_{2}$

$20646-44-0$

1H-Azepine-1-carboxylic acid, 4,5-dimethyl-, methyl ester
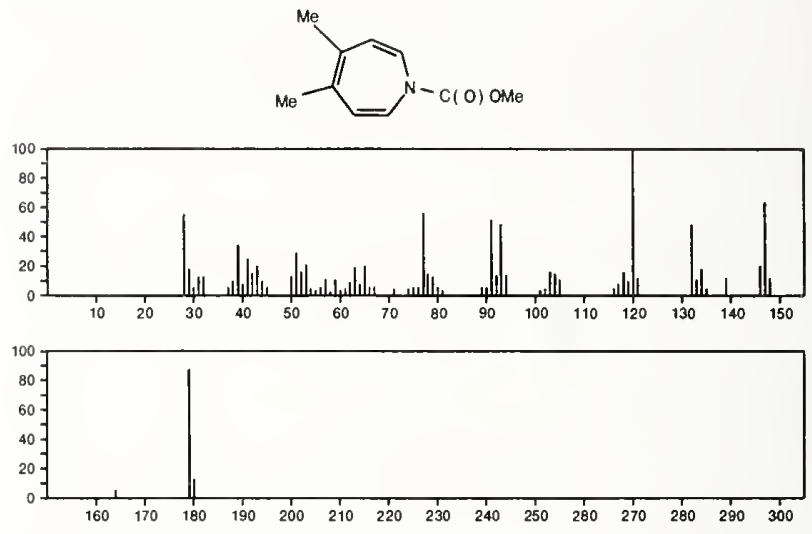

$179 \quad \mathrm{C}_{10} \mathrm{H}_{13} \mathrm{NO}_{2} \quad 21864-63-1$

Benzenaminium, 2-carboxy- $N, N, N$-trimethyl-, hydroxide, inner salt
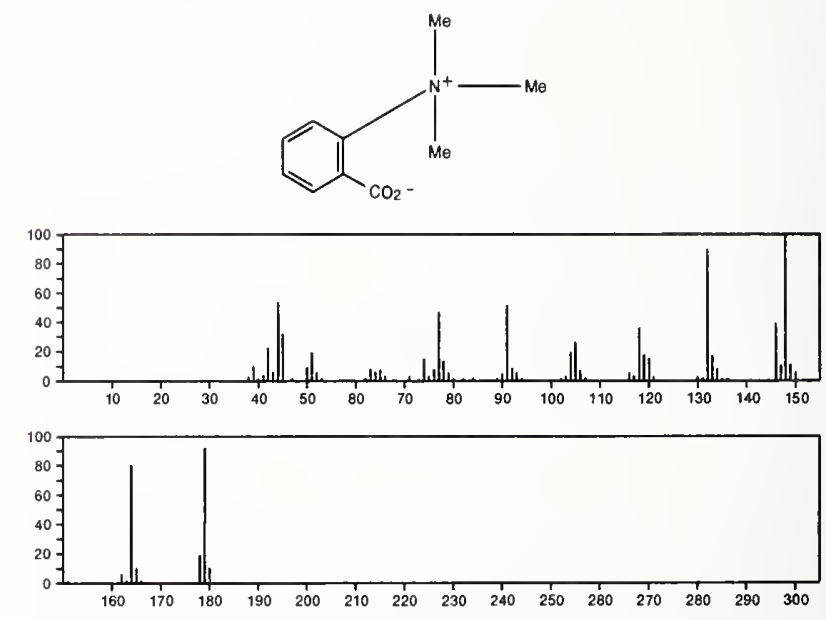

179

$\mathrm{C}_{10} \mathrm{H}_{13} \mathrm{NO}_{2}$

$27740-96-1$

6,7-Isoquinolinediol, 1,2,3,4-tetrahydro-1-methyl-, $(S)$ -
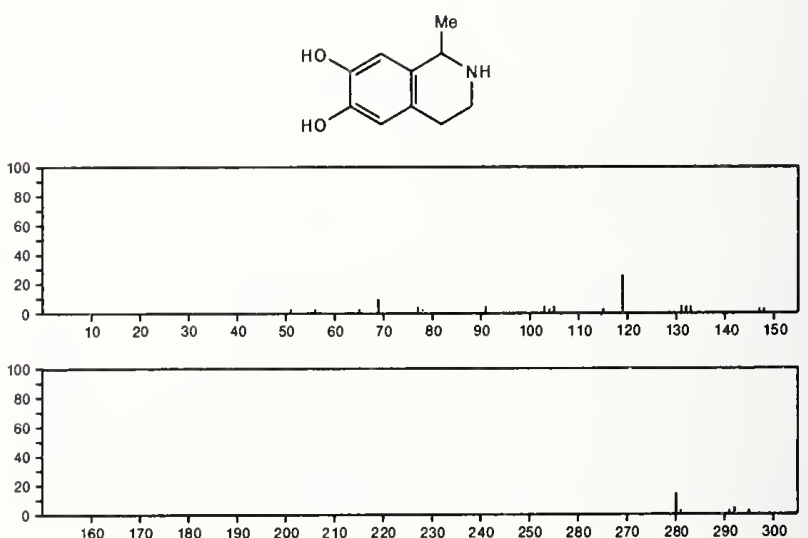

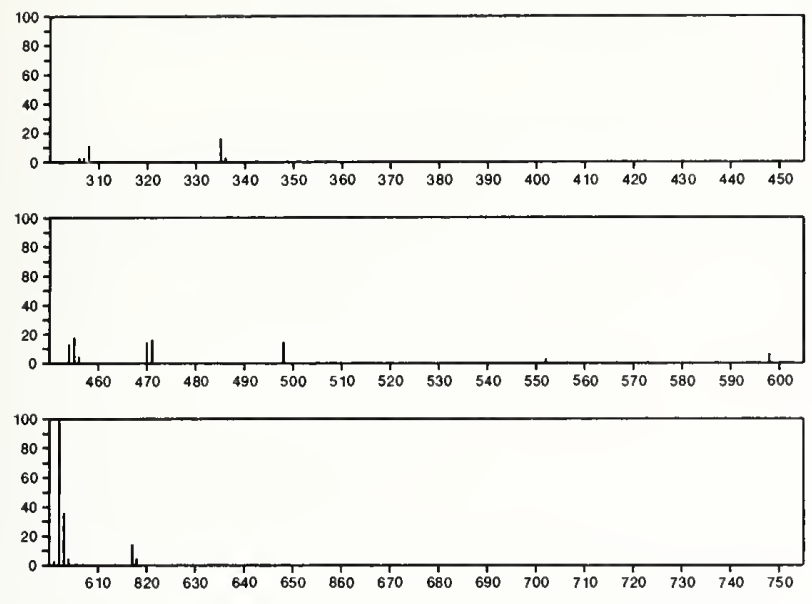

$179 \quad \mathrm{C}_{10} \mathrm{H}_{13} \mathrm{NO}_{2}$

4-Cyclohexene-1,2-dicarboximide, $N$-ethyl-, cis-

28915-98-2
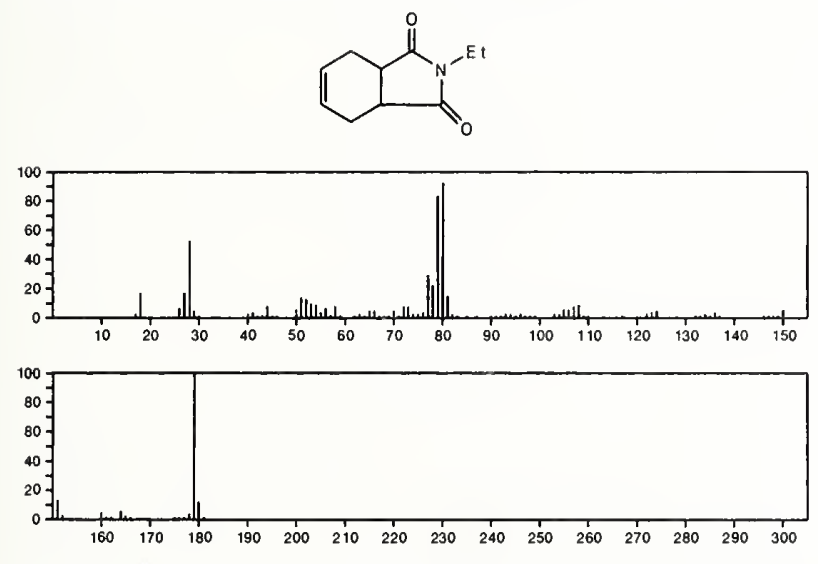

179

$\mathrm{C}_{10} \mathrm{H}_{13} \mathrm{NO}_{2}$

$33046-28-5$

Benzenaminium, 4-carboxy- $N, N, N$-trimethyl-, hydroxide, inner salt
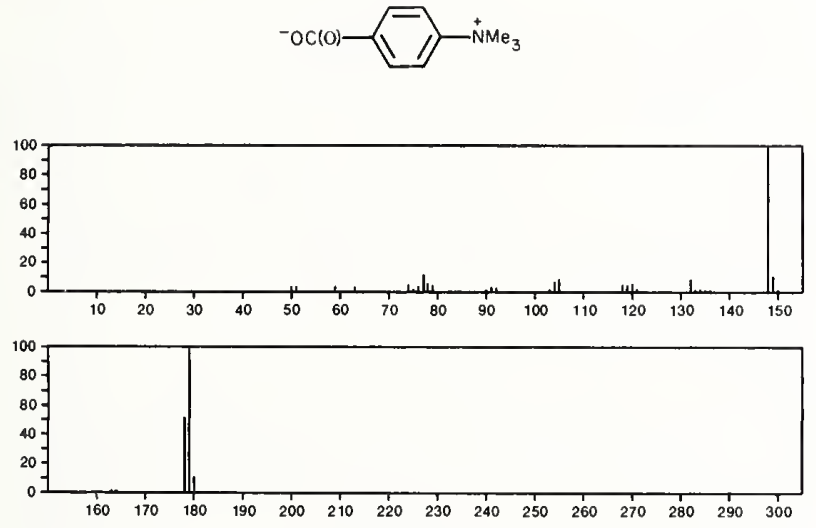

$179 \quad \mathrm{C}_{10} \mathrm{H}_{13} \mathrm{NO}_{2} \quad 33192-03-9$ Benzenaminium, 3-carboxy- $N, N, N$-trimethyl-, hydroxide, inner salt
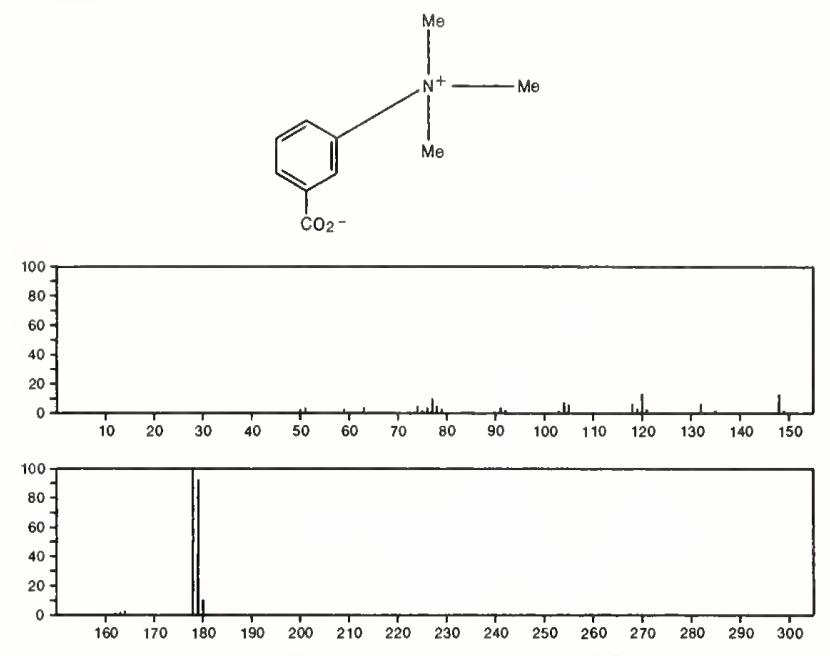

179

$\mathrm{C}_{10} \mathrm{H}_{13} \mathrm{NO}_{2}$

$35103-34-5$

Acetamide, $\mathrm{N}-[(4-$ methoxyphenyl)methyl $]-$<smiles>CCc1ccc(OC)cc1</smiles>
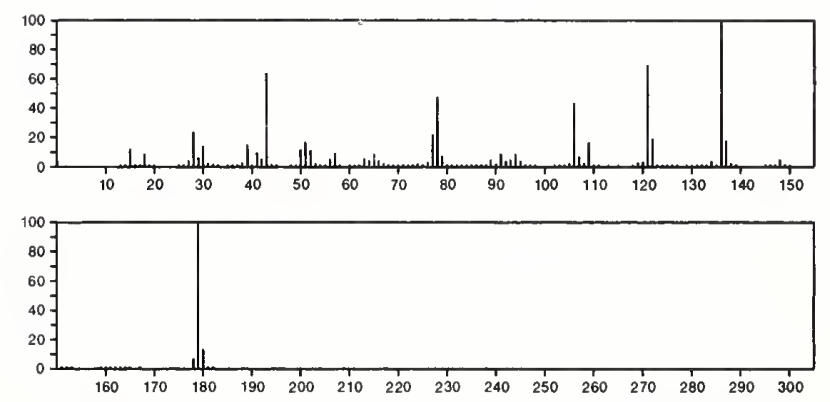

179

$\mathrm{C}_{10} \mathrm{H}_{13} \mathrm{NO}_{2}$

$43021-97-2$

2-Propanone, 1-(2-methoxyphenyl)-, oxime
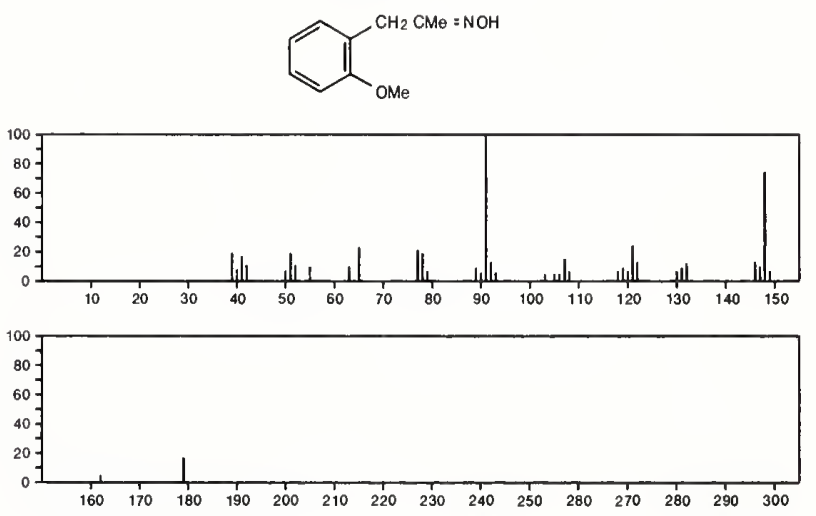
179 $\mathrm{C}_{10} \mathrm{H}_{13} \mathrm{NO}_{2}$

2-Propanone, 1-(4-methoxyphenyl)-, oxime

$52271-41-7$
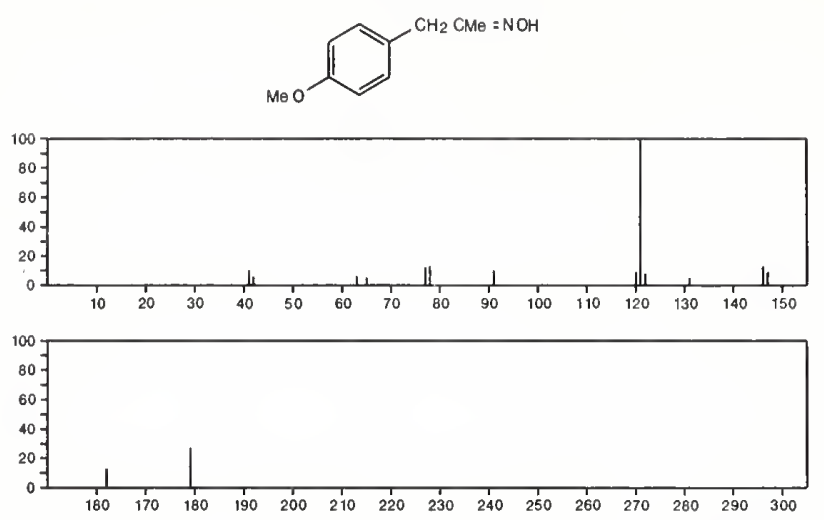

179

$\mathrm{C}_{10} \mathrm{H}_{13} \mathrm{NO}_{2}$

1H-Indol-2-ol, 2,3-dihydro-5-methoxy-1-methyl

$56588-19-3$
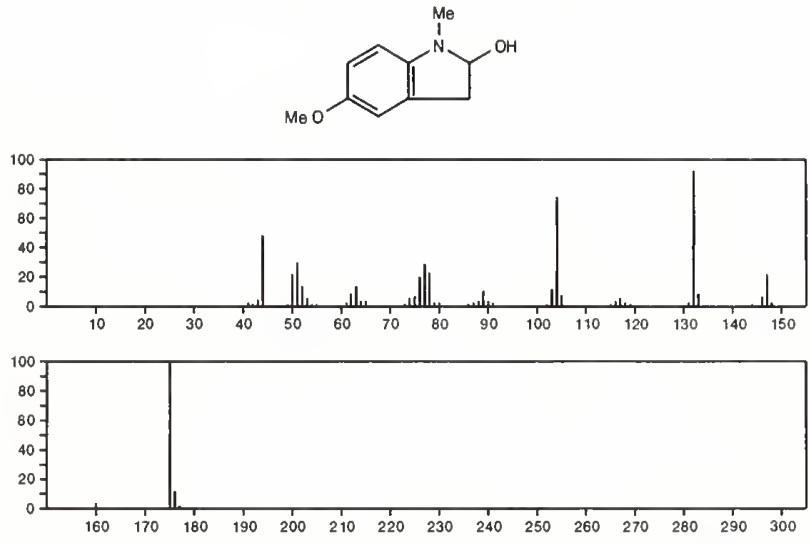

179

$\mathrm{C}_{10} \mathrm{H}_{13} \mathrm{NO}_{2}$

$56701-07-6$

2-Azabicyclo[3.2.0]hepta-3,6-diene-2-carboxylic acid, 1,3-dimethyl-, methyl ester
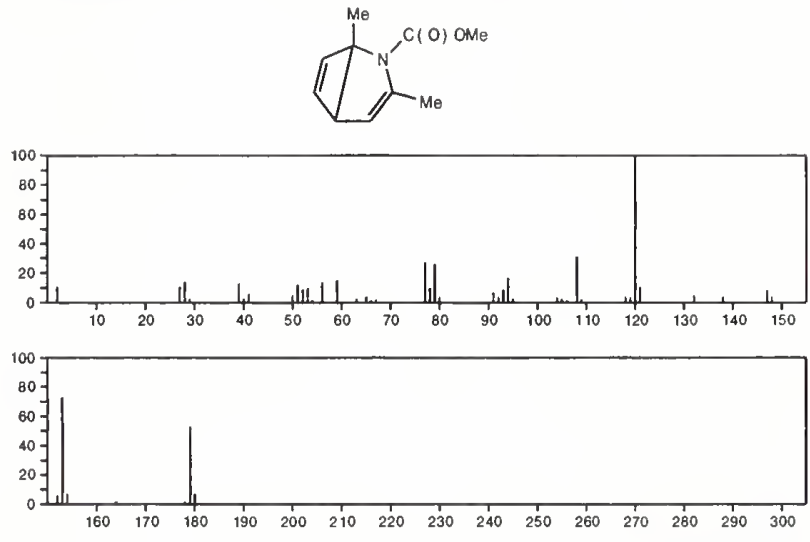

$179 \quad \mathrm{C}_{10} \mathrm{H}_{13} \mathrm{NO}_{2} \quad 56728-08-6$

Tricyclo[3.3.1.13,7]decane-2,6-dione, 4-amino-
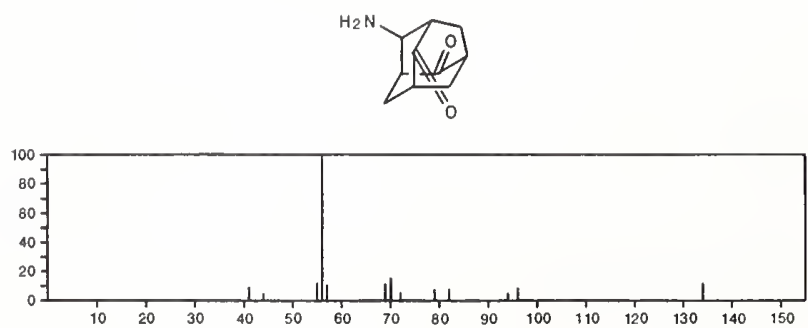

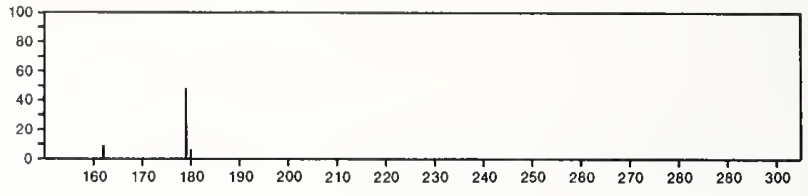

179

$\mathrm{C}_{10} \mathrm{H}_{17} \mathrm{NSi}$

$14856-79-2$

Silanamine, 1,1,1-trimethyl- $N$-(phenylmethyl)-

$\mathrm{Me}_{3} \mathrm{Si} \mathrm{NHCH}_{2} \mathrm{Ph}$
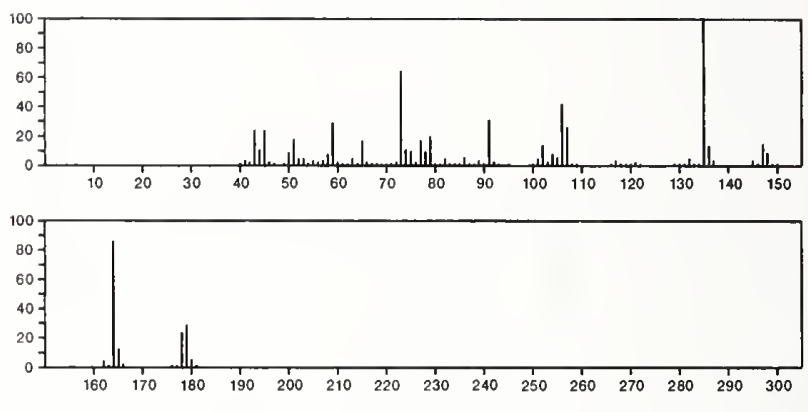

179

$\mathrm{C}_{10} \mathrm{H}_{17} \mathrm{NSi}$

Pyridine, 2-[2-(trimethylsilyl)ethyl $]-$

$17890-16-3$
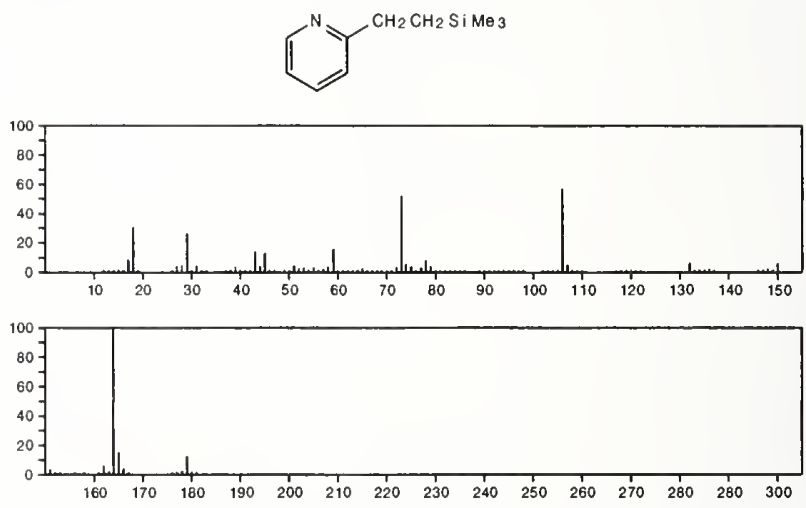

179

$\mathrm{C}_{11} \mathrm{H}_{17} \mathrm{NO}$

$6721-66-0$

Benzeneethanamine, $\beta$-methoxy- $N, N$-dimethyl-

$\mathrm{PhCH}$ ( OMe) $\mathrm{CH}_{2} \mathrm{NMe}_{2}$
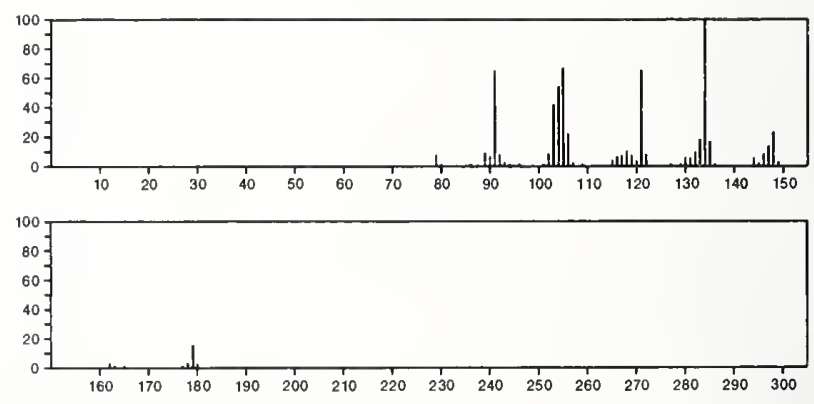

179

$\mathrm{C}_{11} \mathrm{H}_{17} \mathrm{NO}$

Ethanamine, 2-(2,6-dimethylphenoxy)-N-methyl-

$14573-22-9$
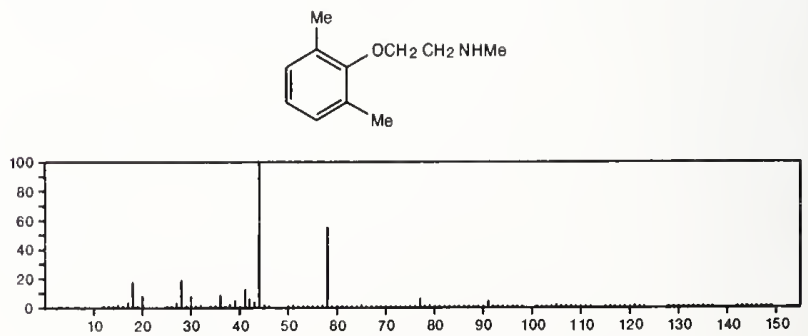


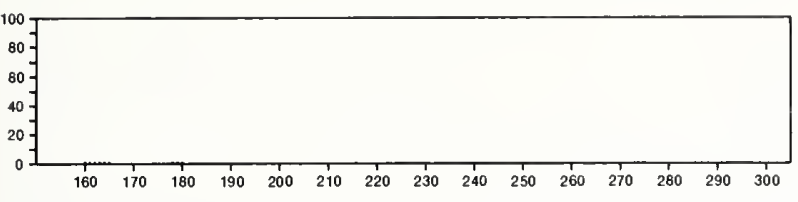

179

$\mathrm{C}_{11} \mathrm{H}_{17} \mathrm{NO}$

19059-89-3

Phenol, 2-amino-6-(1,1-dimethylethyl)-4-methyl-
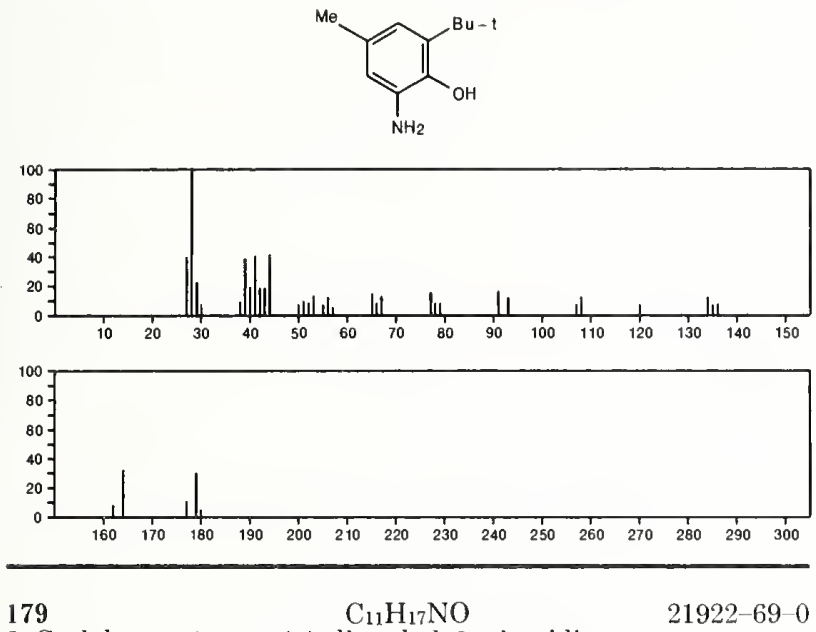

2-Cyclobuten-1-one, 4,4-dimethyl-3-piperidino-
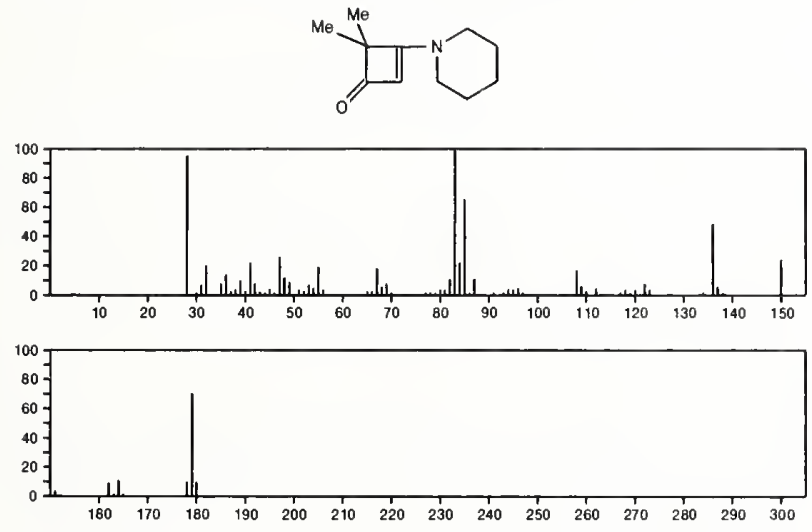

179

$\mathrm{C}_{11} \mathrm{H}_{17} \mathrm{NO}$

$27058-12-4$

Ethanamine, $N, N$-dimethyl-2-(phenylmethoxy)-

$\mathrm{Me}_{2} \mathrm{NCH}_{2} \mathrm{CH}_{2} \mathrm{OCH}_{2} \mathrm{Ph}$
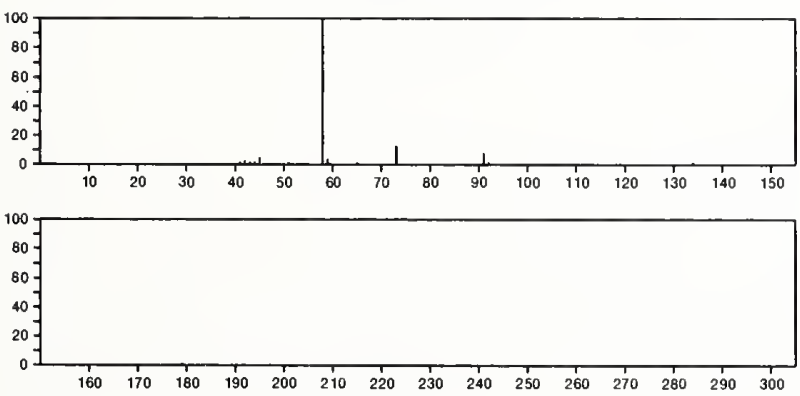

179 $\mathrm{C}_{11} \mathrm{H}_{17} \mathrm{NO}$

$55955-99-2$

Phenol, 2-[(dimethylamino)methyl]-4-ethyl-
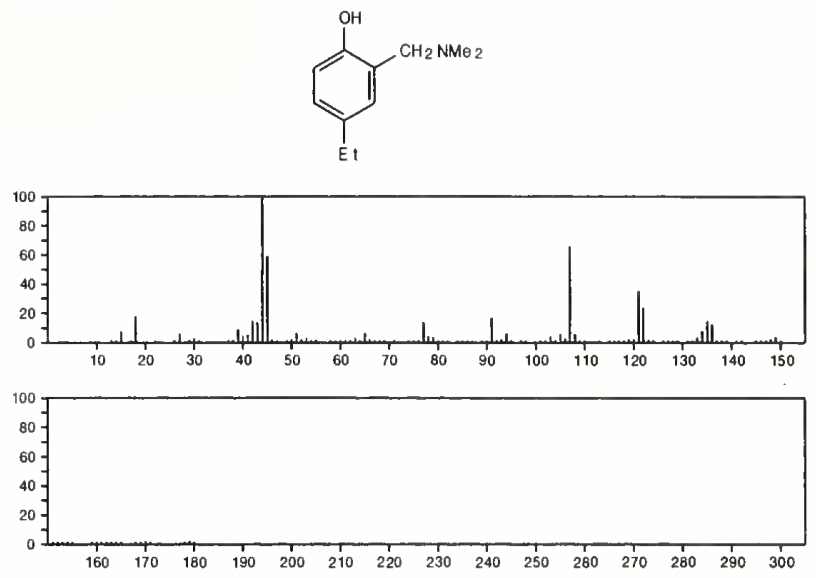

179

$\mathrm{C}_{11} \mathrm{H}_{17} \mathrm{NO}$

$57397-12-3$

2-Cyclohexen-1-one, 2-methyl-5-(1-methylethenyl)-, Omethyloxime, $(+)-$
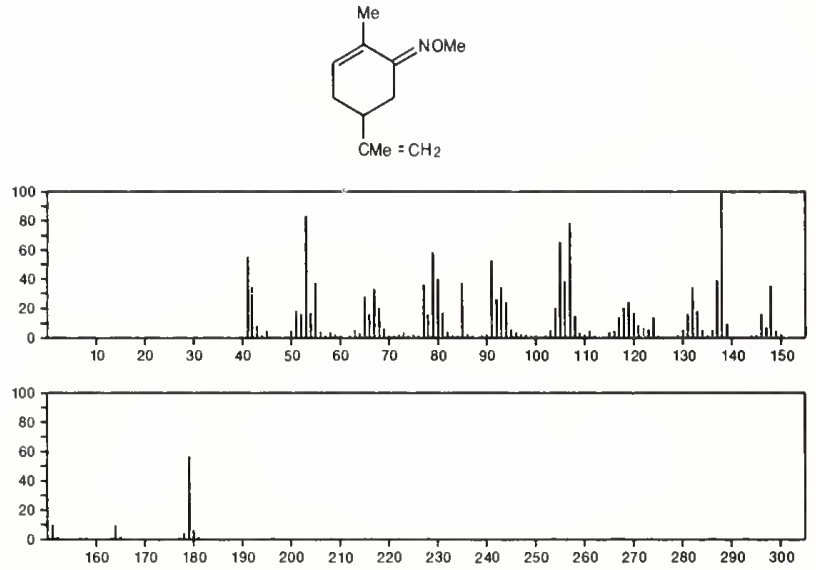

$179 \quad \mathrm{C}_{12} \mathrm{H}_{21} \mathrm{~N} \quad 23430-63-9$

1H-Azepine, 1-(1-cyclohexen-1-yl)hexahydro-
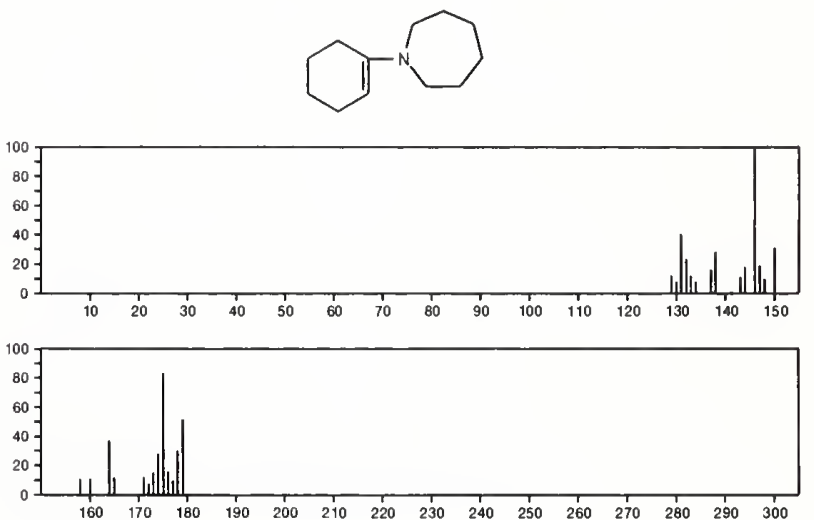
890

EPA/NIH MASS SPECTRAL DATA BASE

179

179

$\mathrm{C}_{12} \mathrm{H}_{21} \mathrm{~N}$

Pyrrolidine, 1-(6-ethyl-1-cyclohexen-1-yl)-

26974-21-0
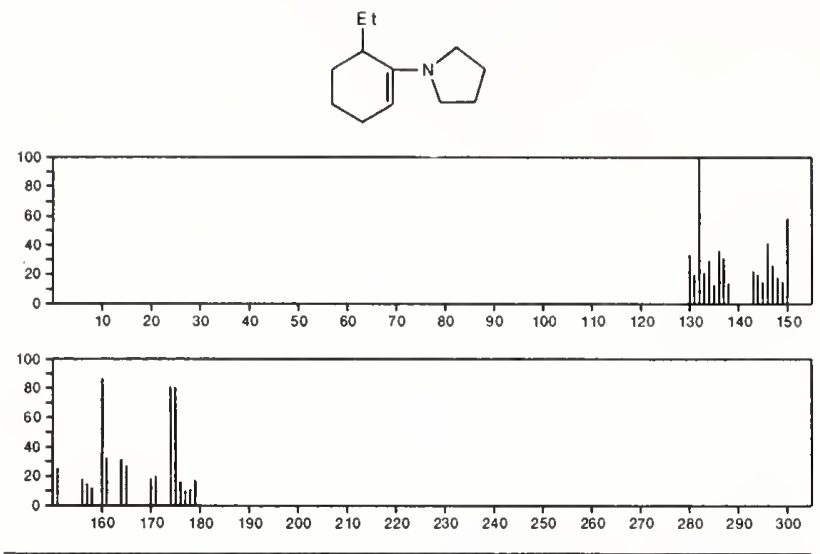

179

$\mathrm{C}_{13} \mathrm{H}_{9} \mathrm{~N}$

$229-87-8$

Phenanthridine
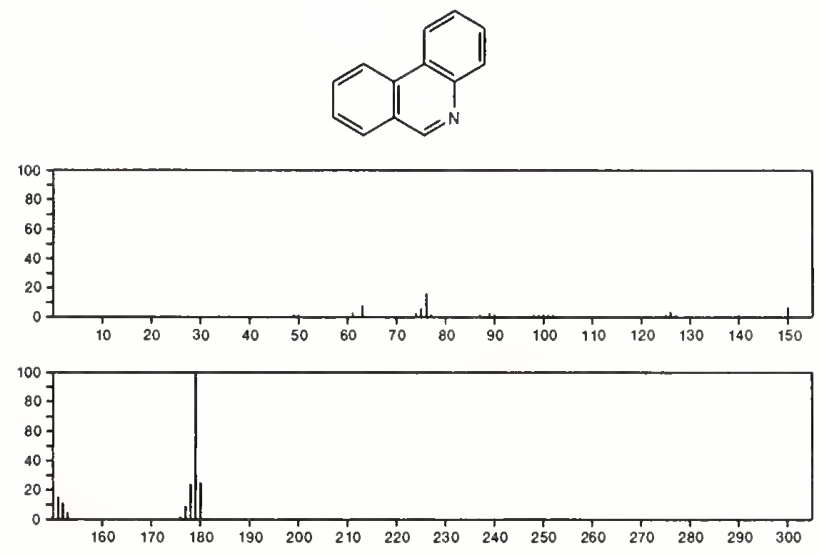

179

$\mathrm{C}_{13} \mathrm{H}_{9} \mathrm{~N}$

Benzo[h]quinoline
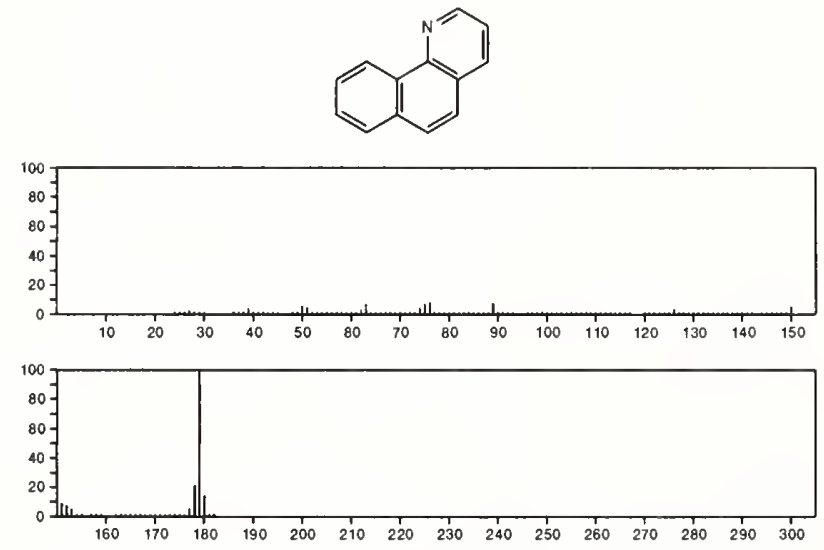

179

$260-94-6$

Acridine

$\mathrm{C}_{13} \mathrm{H}_{9} \mathrm{~N}$
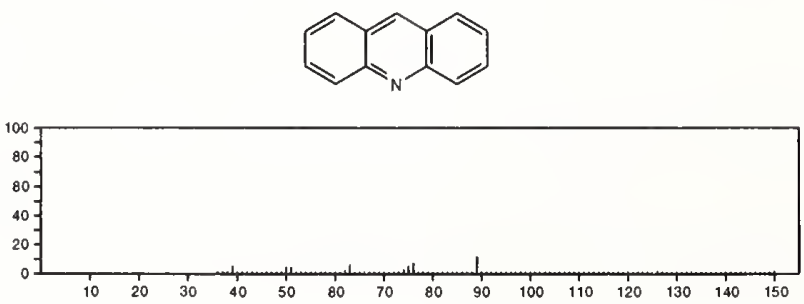
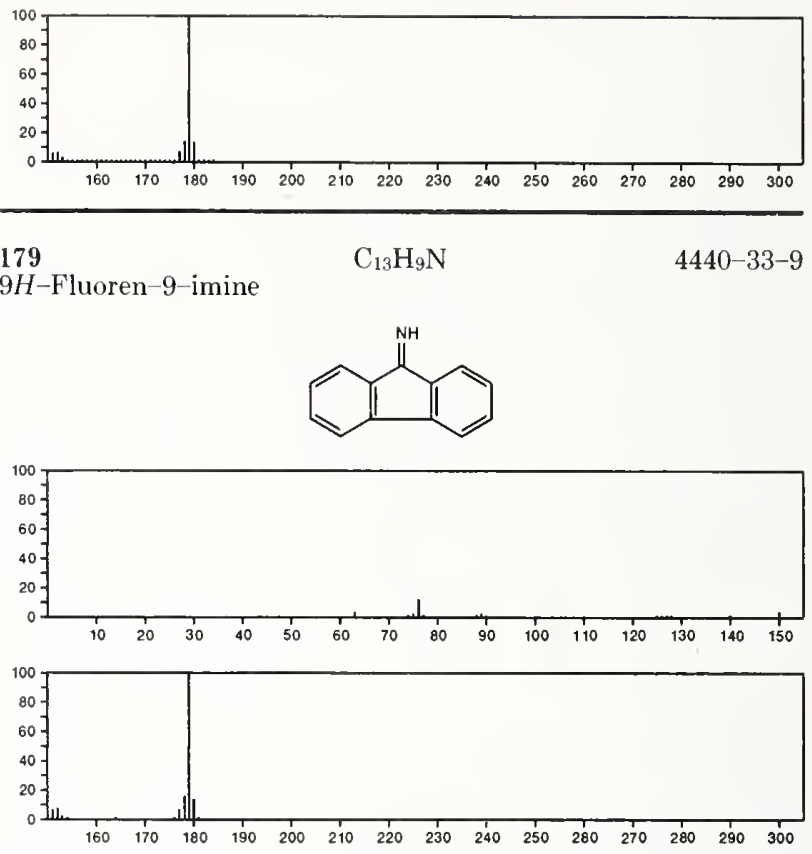

179

13141-42-9

Pyridine, 2-(phenylethynyl)-
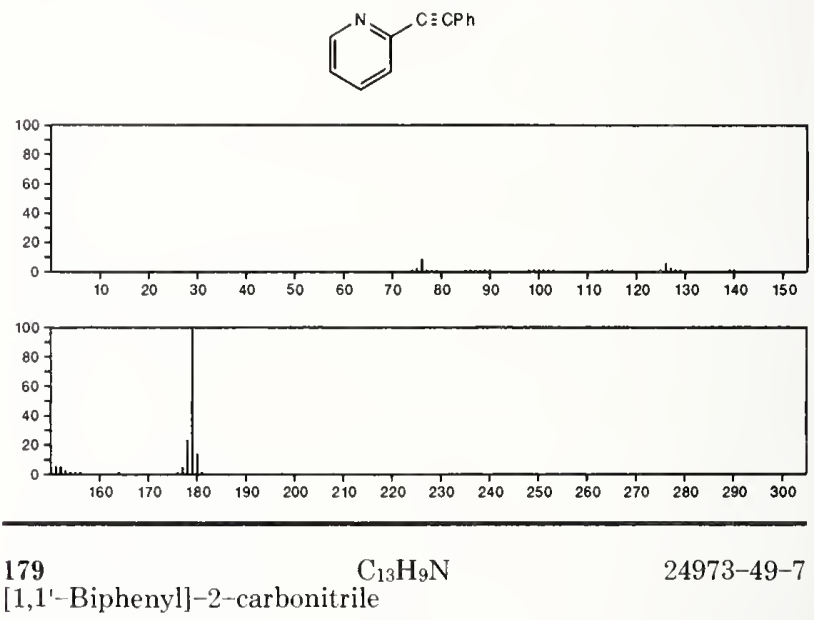<smiles>N#Cc1ccccc1-c1ccccc1</smiles>
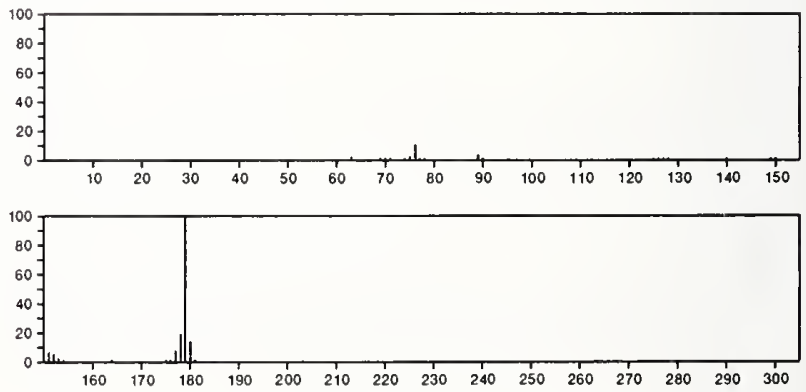
180

Methane, bromodichlorofluoro-

$\mathrm{CBrCl}_{2} \mathrm{~F}$

$\mathrm{BrCCl}_{2}(\mathrm{~F})$
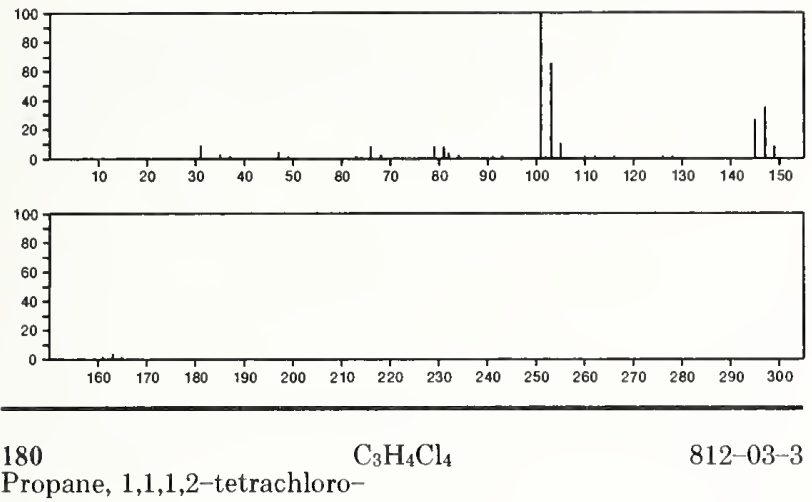

Propane, 1,1,1,2-tetrachloro-

$\mathrm{MeCHCl} \mathrm{CCl} 3$
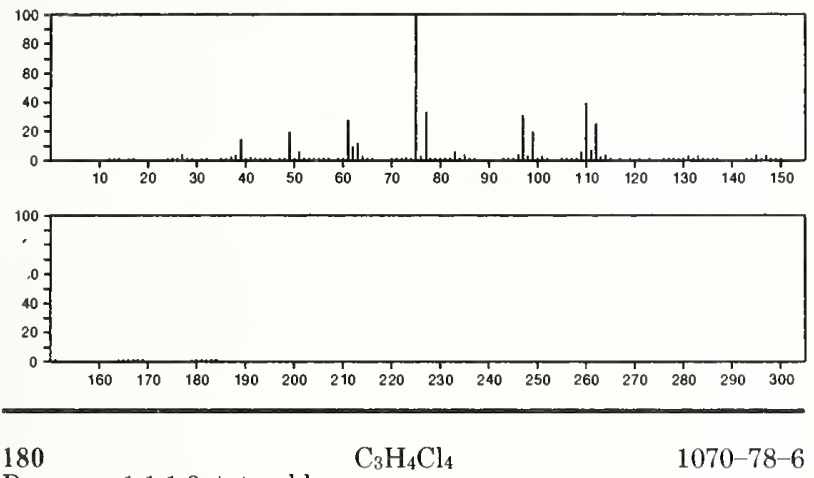

Propane, 1,1,1,3-tetrachloro-

$\mathrm{ClCH}_{2} \mathrm{CH}_{2} \mathrm{CCl}_{3}$
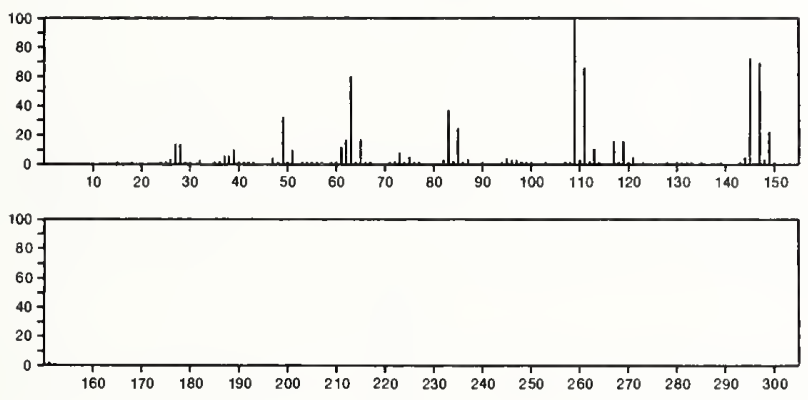

180

Propane, 1,2,2,3-tetrachloro-

$13116-53-5$
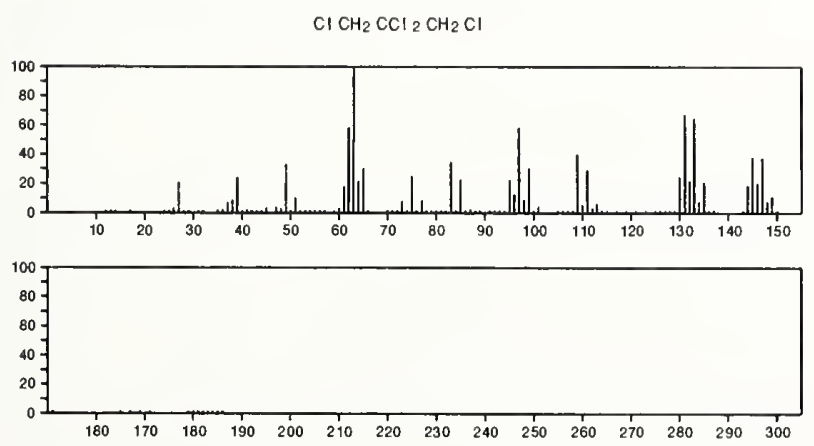

180

Propane, 1,1,2,2-tetrachloro-

$\mathrm{C}_{3} \mathrm{H}_{4} \mathrm{Cl}_{4}$

$13116-60-4$

$\mathrm{Cl}_{2} \mathrm{CHCCl}_{2} \mathrm{Me}$
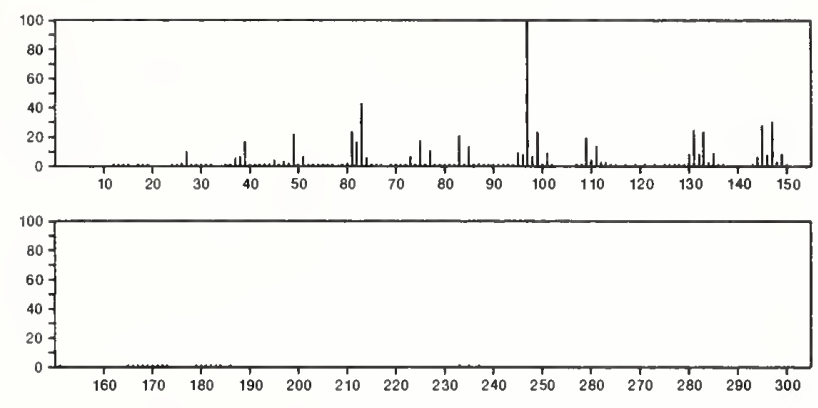

180

Propane, 1,1,2,3-tetrachloro-

$\mathrm{C}_{3} \mathrm{H}_{4} \mathrm{Cl}_{4}$

$18495-30-2$

$\mathrm{Cl} \mathrm{CH}_{2} \mathrm{CHCl} \mathrm{CHCl}$
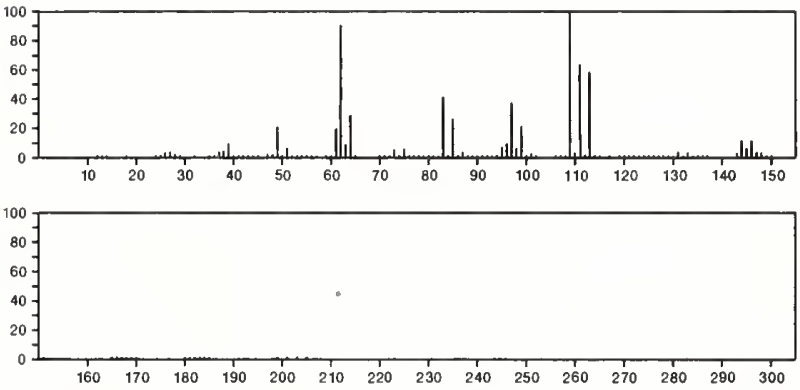

180 -Butanediol, dinitrate $\mathrm{C}_{4} \mathrm{H}_{8} \mathrm{~N}_{2} \mathrm{O}_{6}$

$\left.\mathrm{O}_{2} \mathrm{NO}_{\left(\mathrm{CH}_{2}\right)}\right)_{4} \mathrm{ONO}_{2}$

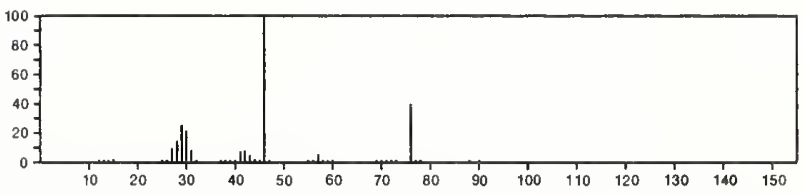

180

2,3-Butanediol, dinitrate

$\mathrm{C}_{4} \mathrm{H}_{8} \mathrm{~N}_{2} \mathrm{O}_{6}$

$6423-45-6$

$\mathrm{O}_{2} \mathrm{NOCHMe} C H M e \mathrm{ONO}_{2}$
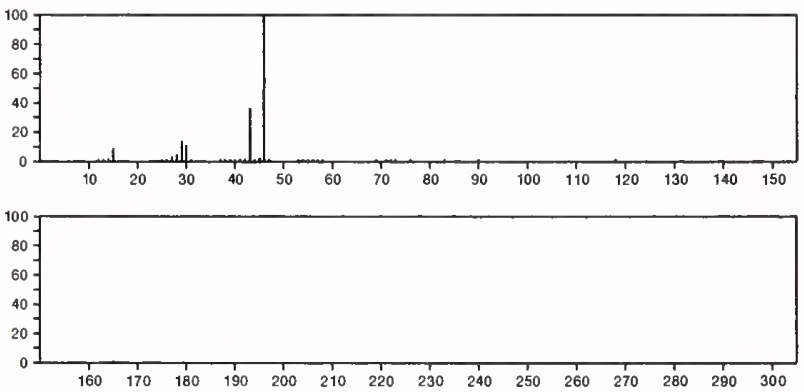

180

Stamnane, tetramethyl-

$\mathrm{C}_{4} \mathrm{H}_{12} \mathrm{Sn}$

$594-27-4$

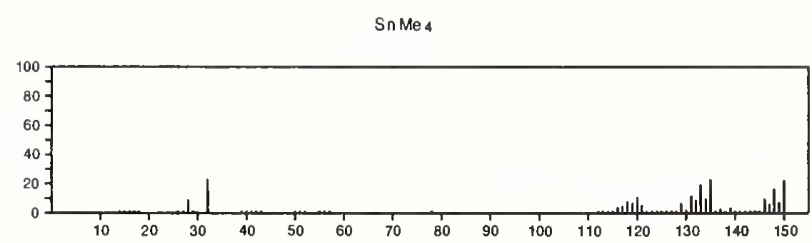




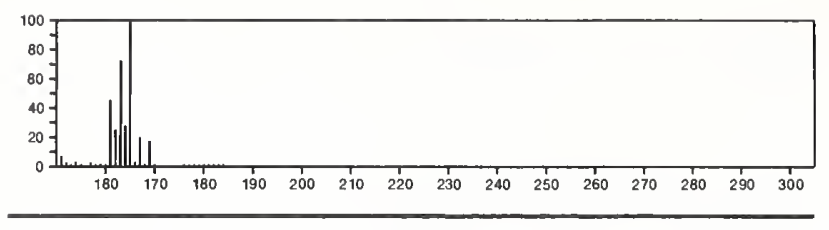

$180 \quad \mathrm{C}_{5} \mathrm{H}_{3} \mathrm{~F}_{3} \mathrm{~N}_{2} \mathrm{O}_{2}$

2,4(1H,3H)-Pyrimidinedione, 6-(trifluoromethyl)-

$672-45-7$<smiles>CC(Cl)(Cl)c1cc(=O)[nH]c(=O)[nH]1</smiles>
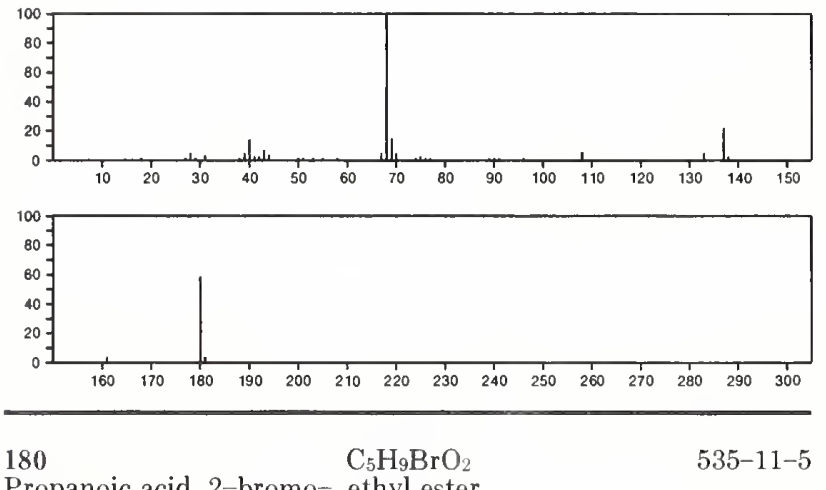

Propanoic acid, 2-bromo-, ethyl ester

EtOC(O) CHBrMe
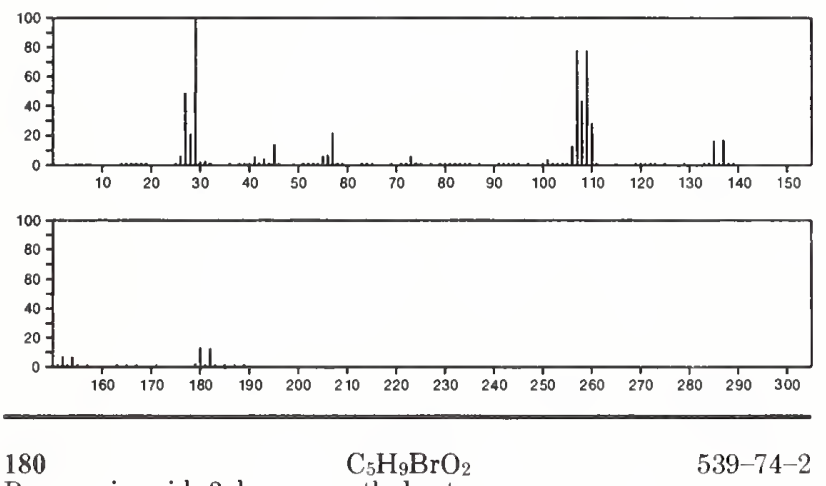

Propanoic acid, 3-bromo-, ethyl ester

$\mathrm{Br} \mathrm{CH}_{2} \mathrm{CH}_{2} \mathrm{C}(\mathrm{O}) \mathrm{OE}$
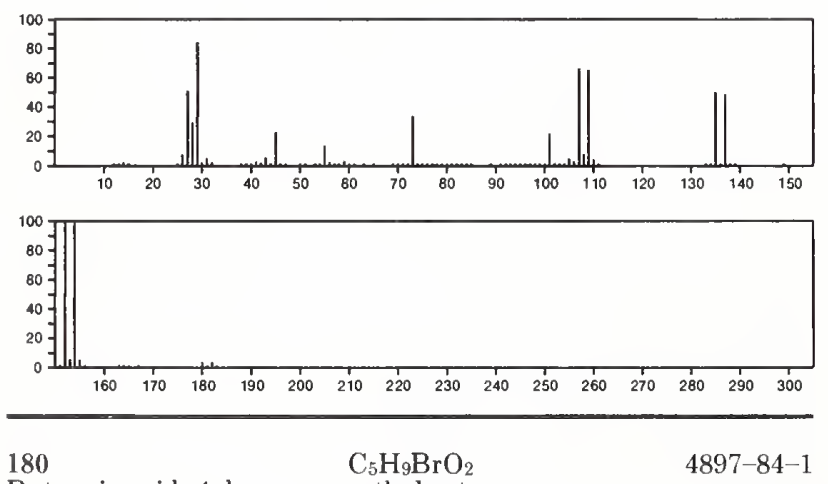

Butanoic acid, 4-bromo-, methyl ester

$\mathrm{Br}\left(\mathrm{CH}_{2}\right)_{3} \mathrm{C}(\mathrm{O}) \mathrm{OMe}_{0}$

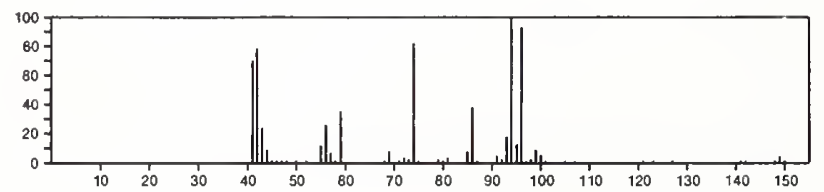

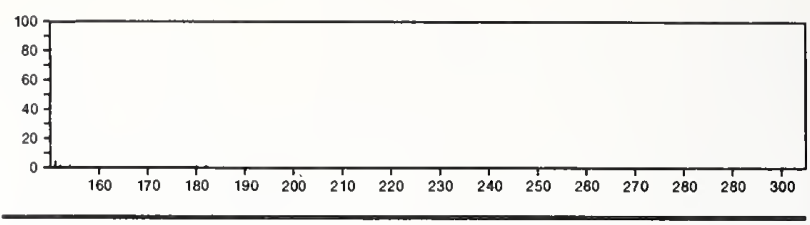

180

2-Propanol, 1-bromo-, acetate

$10299-39-5$
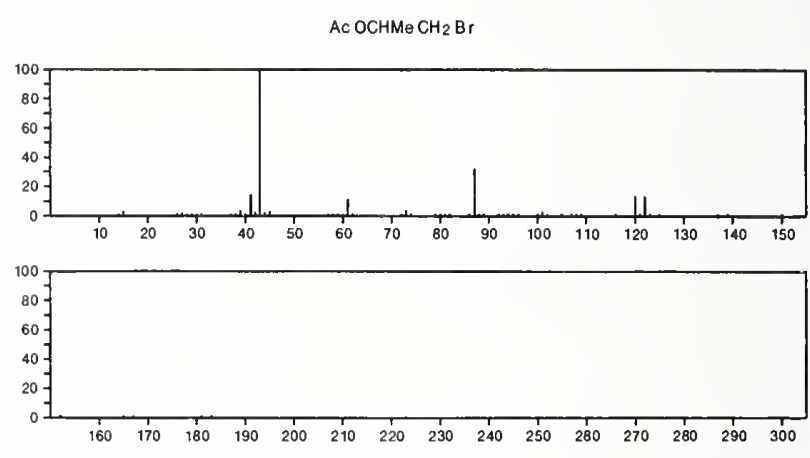

180

$\mathrm{C}_{5} \mathrm{H}_{9} \mathrm{BrO}_{2}$

$35878-05-8$

1,3-Dioxane, 5-bromo-2-methyl-,trans-
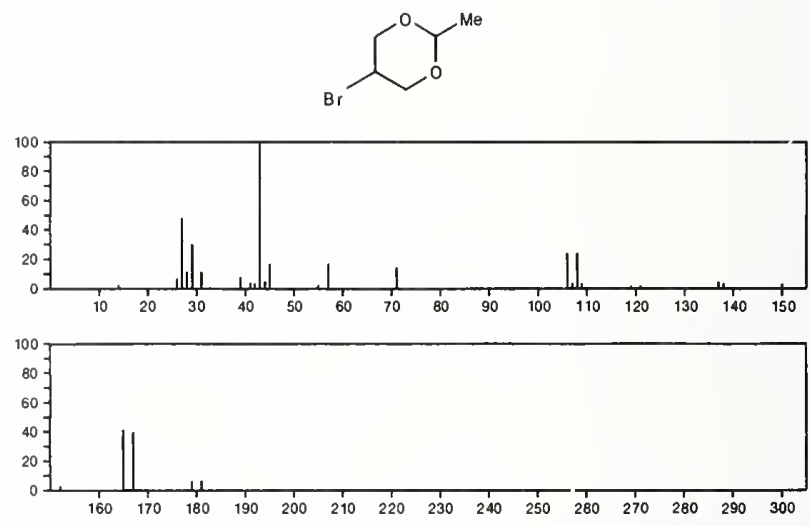

180
Selenourea, tetramethyl-

$5943-53-3$

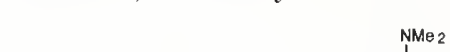

$$
\begin{aligned}
& \mathrm{NMe} 2 \\
& \mathrm{M} \operatorname{No}_{2} \mathrm{NC}=\mathrm{Se}
\end{aligned}
$$
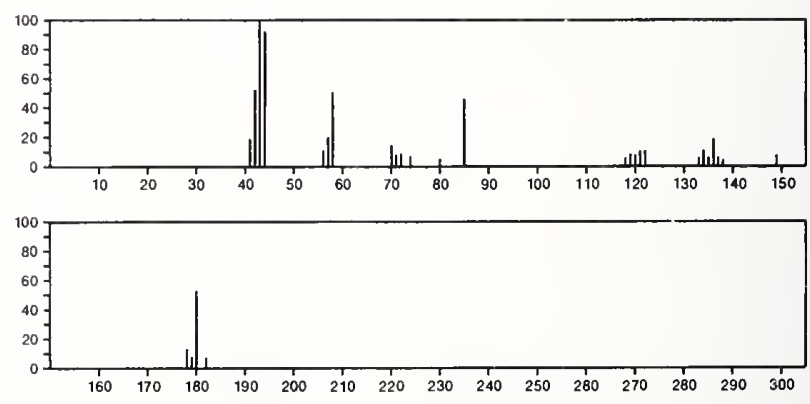

180

$\mathrm{C}_{5} \mathrm{H}_{13} \mathrm{AsO}_{2}$

Arsonous acid, methyl-, diethyl ester

40515-06-8

ETOAsMe OE I

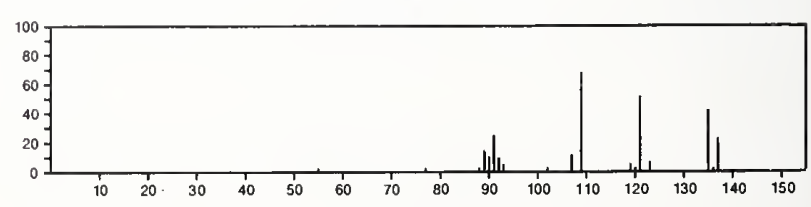


180

EPA/NIH MASS SPECTRAL DATA BASE

893

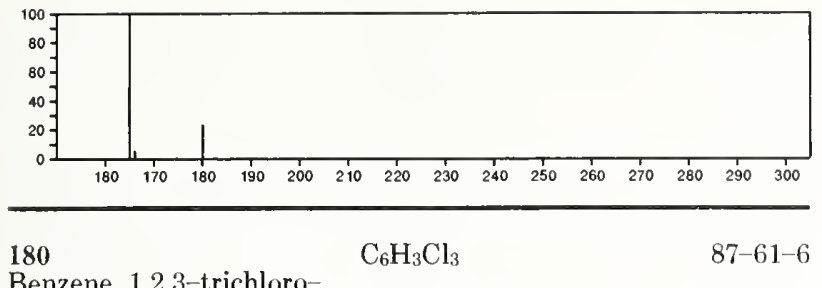

Benzene, 1,2,3-trichloro-
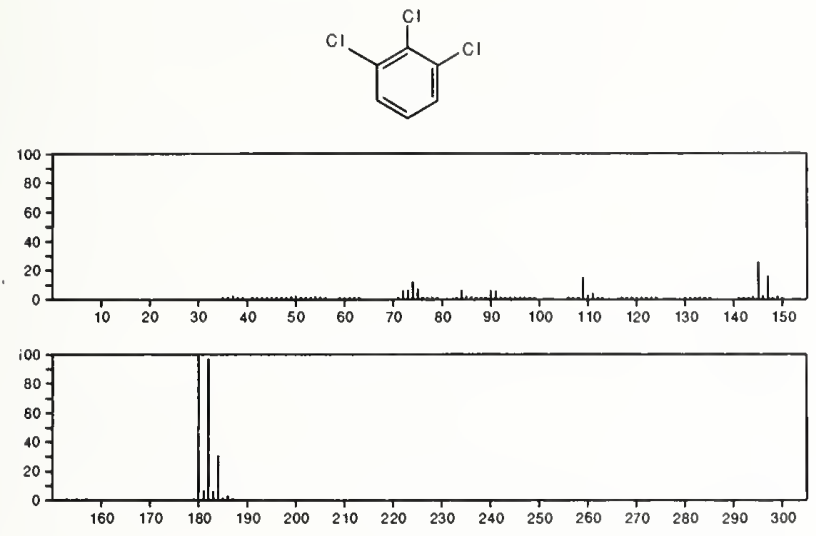

$180 \quad \mathrm{C}_{6} \mathrm{H}_{3} \mathrm{Cl}_{3} \quad 108-70-3$

Benzene, 1,3,5-trichloro-
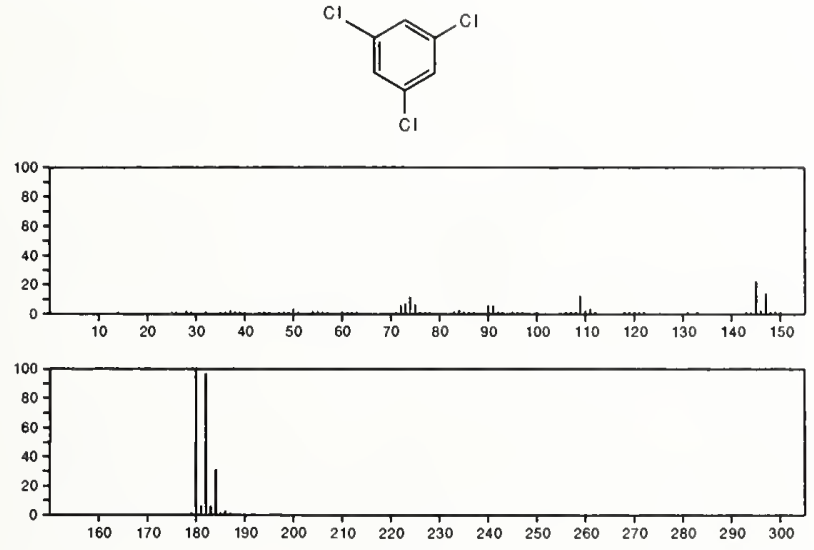

180

Benzene, 1,2,4-trichloro-

$$
\mathrm{C}_{6} \mathrm{H}_{3} \mathrm{Cl}_{3} \quad 120-82-1
$$
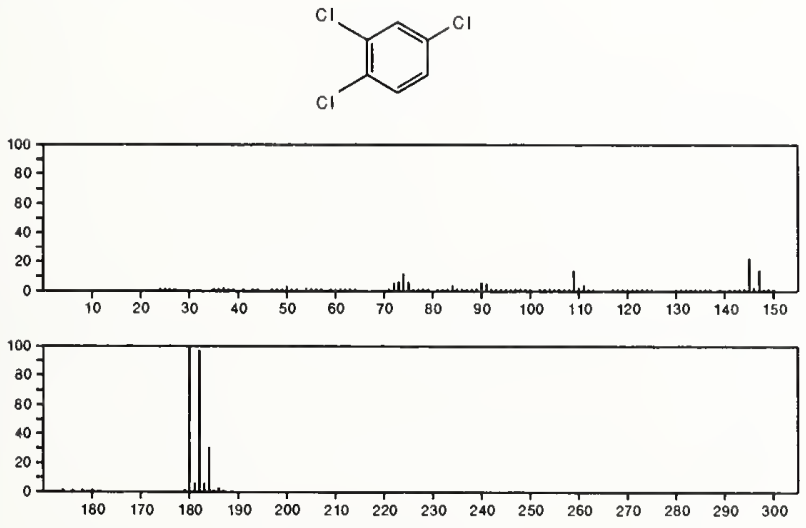

$180 \quad \mathrm{C}_{6} \mathrm{H}_{4} \mathrm{~F}_{4} \mathrm{~N}_{2}$

1,3-Benzenediamine, 2,4,5,6-tetrafluoro-

1198-63-6
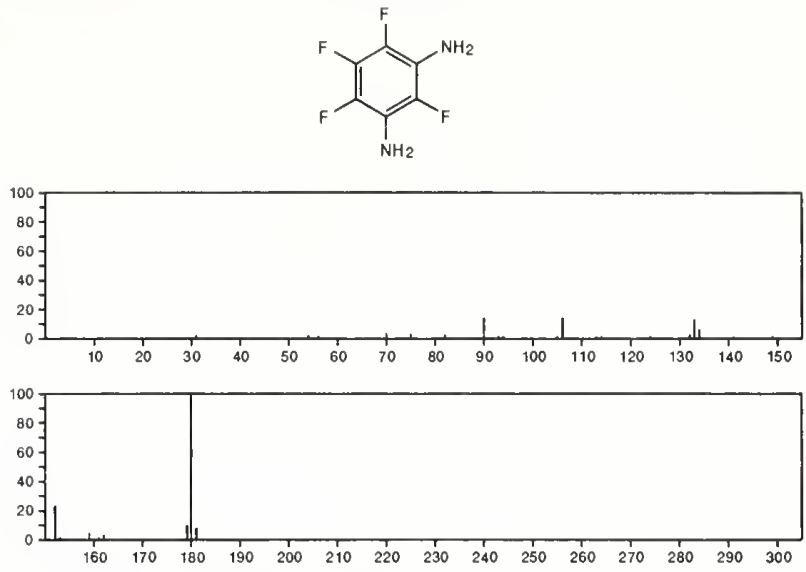

180

$\mathrm{C}_{6} \mathrm{H}_{4} \mathrm{~F}_{4} \mathrm{~N}_{2}$

$1198-64-7$

1,4-Benzenediamine, 2,3,5,6-tetrafluoro-
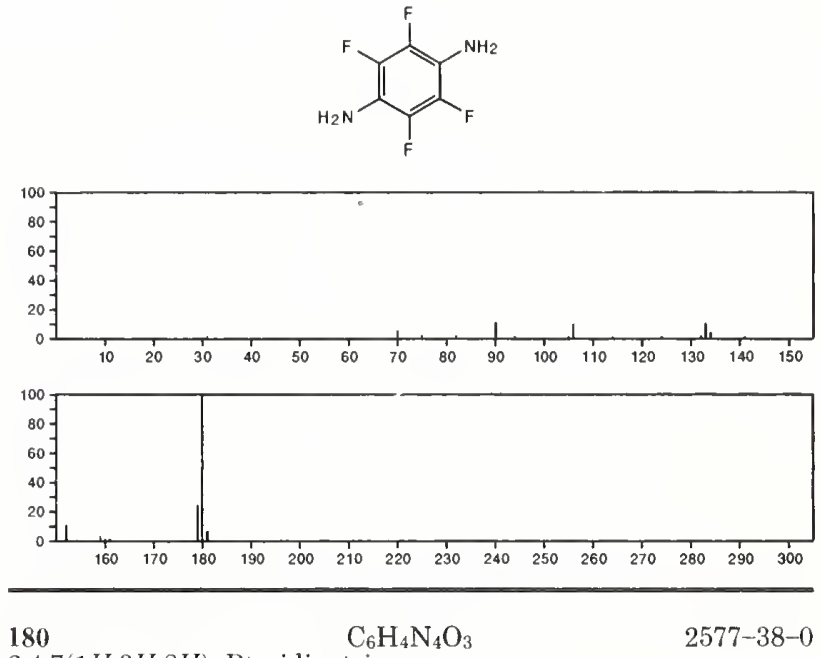

2,4,7(1H,3H,8H)-Pteridinetrione
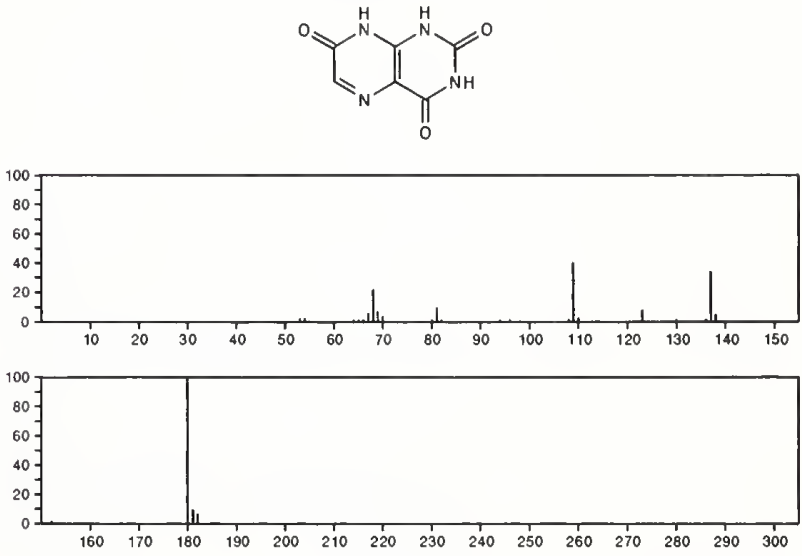
180

1H-1,2,4-Triazole, 3-(5-nitro-2-furanyl)
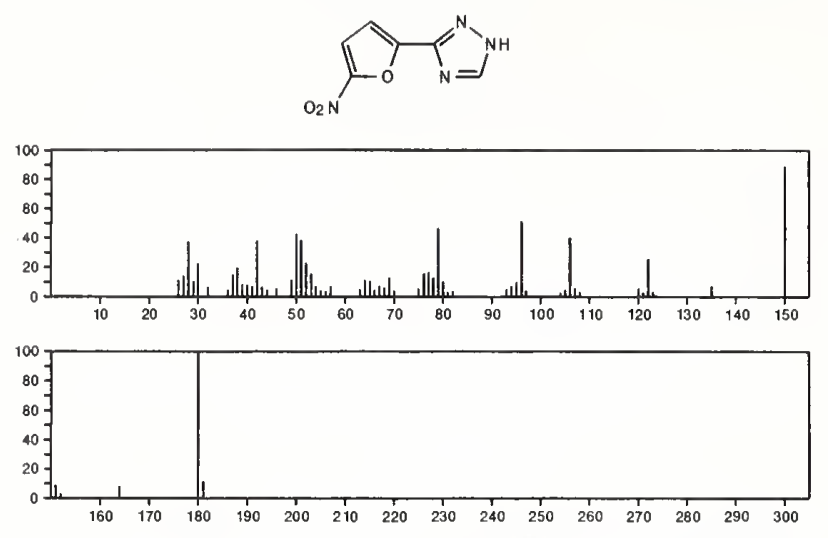

180

1,2-Cyclopentanedione, dichloromethyl-
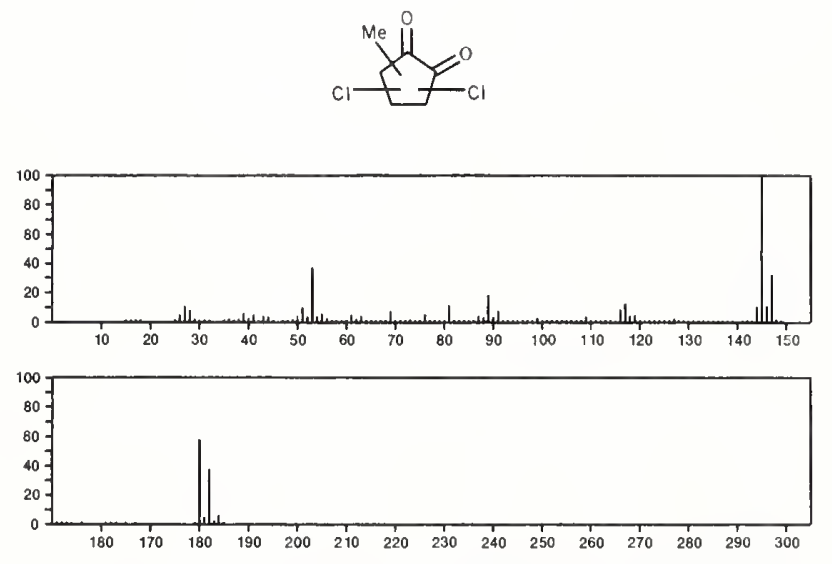

$180 \quad \mathrm{C}_{6} \mathrm{H}_{10} \mathrm{BrF}$

Cyclohexane, 1-bromo-2-fluoro-, trans-

$17170-96-6$
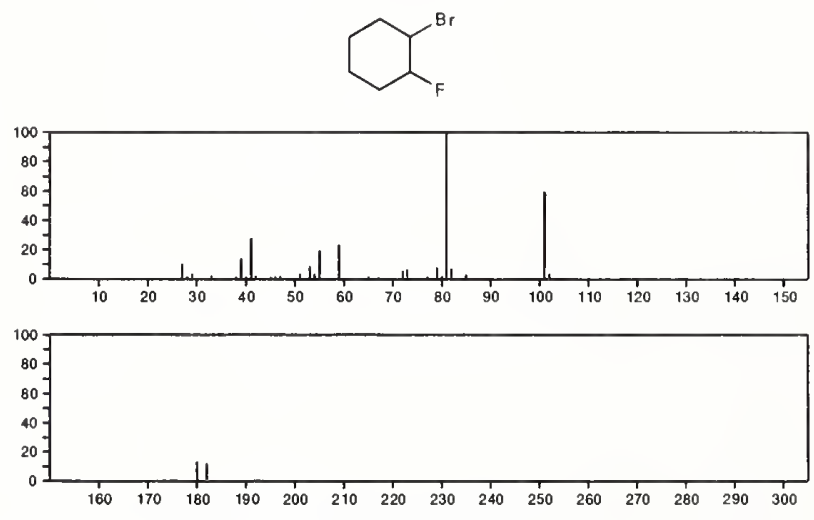

$180 \quad \mathrm{C}_{6} \mathrm{H}_{10} \mathrm{BrF}$

Cyclohexane, 1-bromo-2-fluoro-, cis- $^{-}$
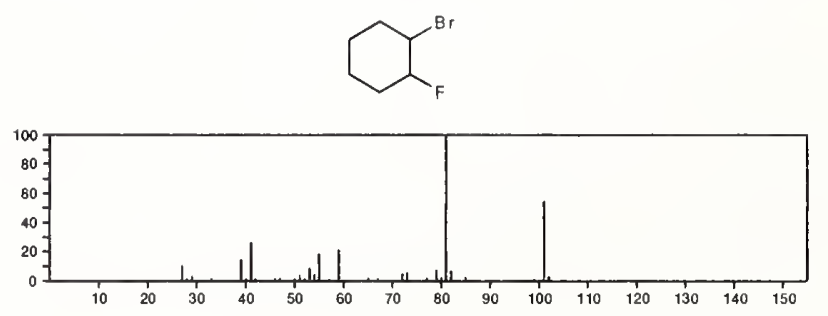

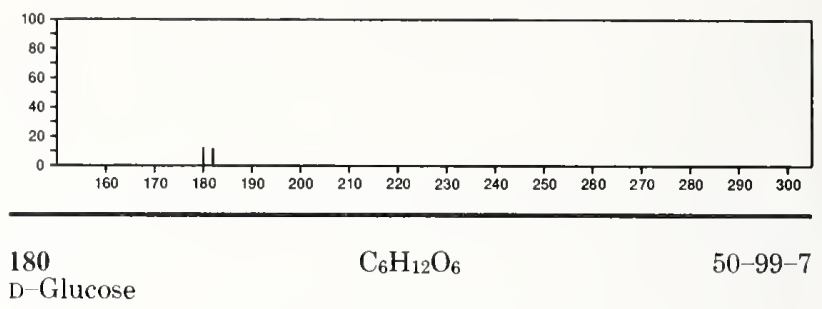

D-Glucose

$\mathrm{HOCH}_{2} \mathrm{CH}(\mathrm{OH}) \mathrm{CH}(\mathrm{OH}) \mathrm{CH}(\mathrm{OH}) \mathrm{CH}(\mathrm{OH}) \mathrm{CHO}$
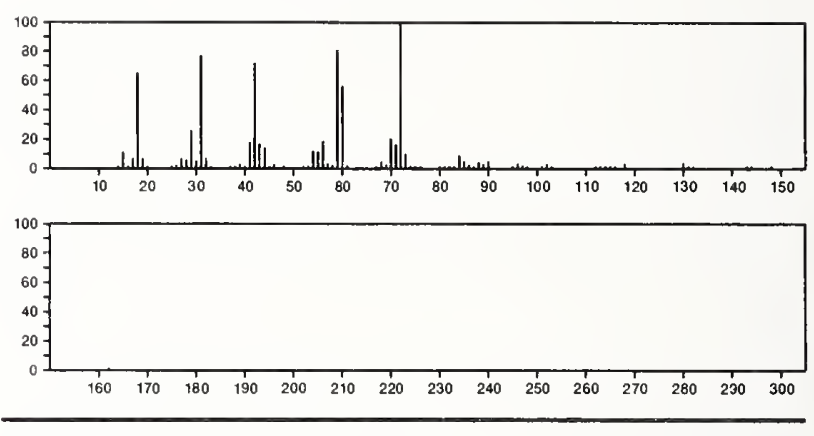

180

myo-Inositol

$\mathrm{C}_{6} \mathrm{H}_{12} \mathrm{O}_{6}$

87-89-8
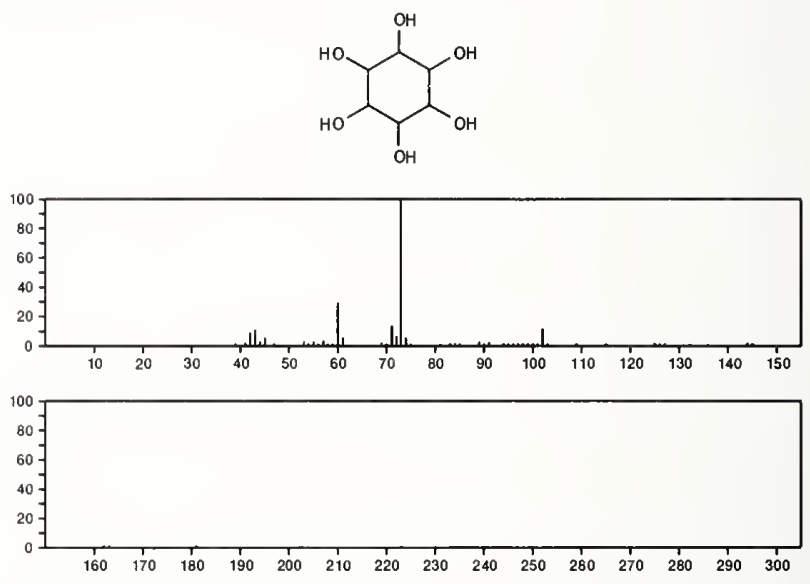

180

$\mathrm{C}_{6} \mathrm{H}_{12} \mathrm{O}_{6}$

$488-54-0$

neo-Inositol
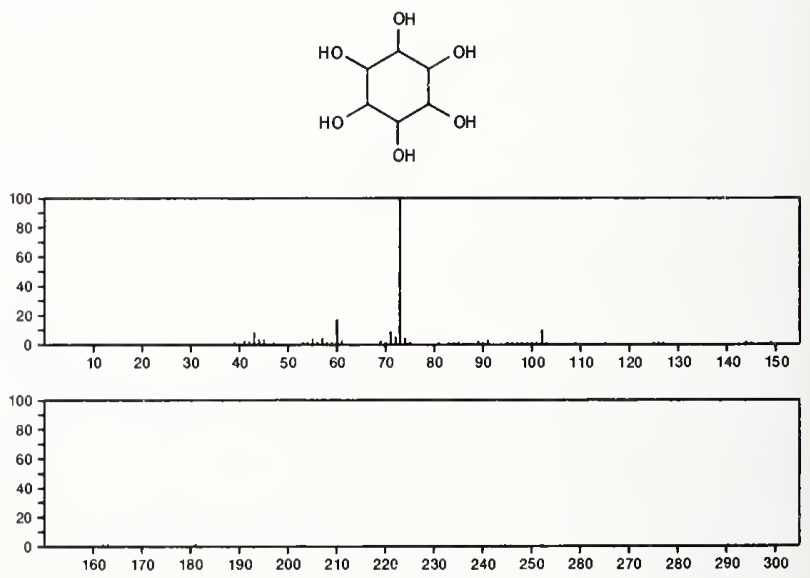
180

EPA/NIH MASS SPECTRAL DATA BASE

895

180

$\mathrm{C}_{6} \mathrm{H}_{12} \mathrm{O}_{6}$
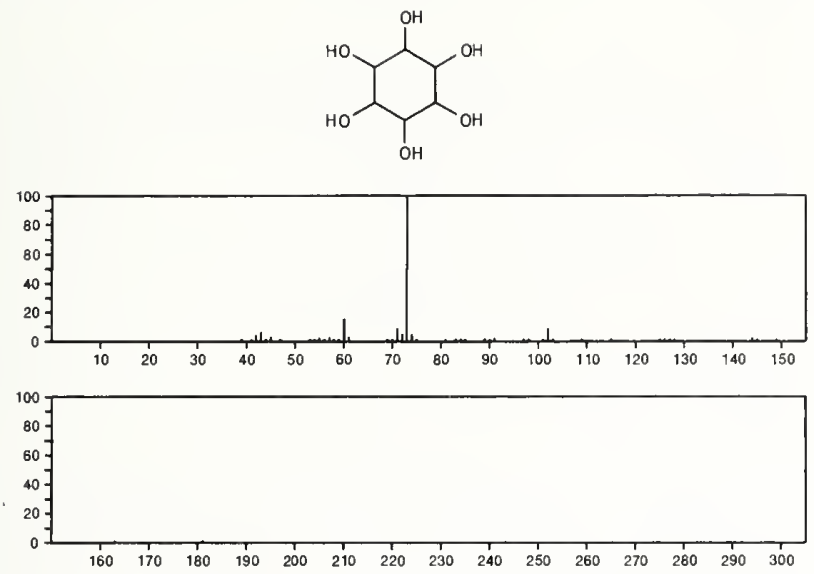

\begin{tabular}{lll}
\hline 180 & $\mathrm{C}_{6} \mathrm{H}_{12} \mathrm{O}_{6}$ & $488-58-4$
\end{tabular}

epi-Inositol
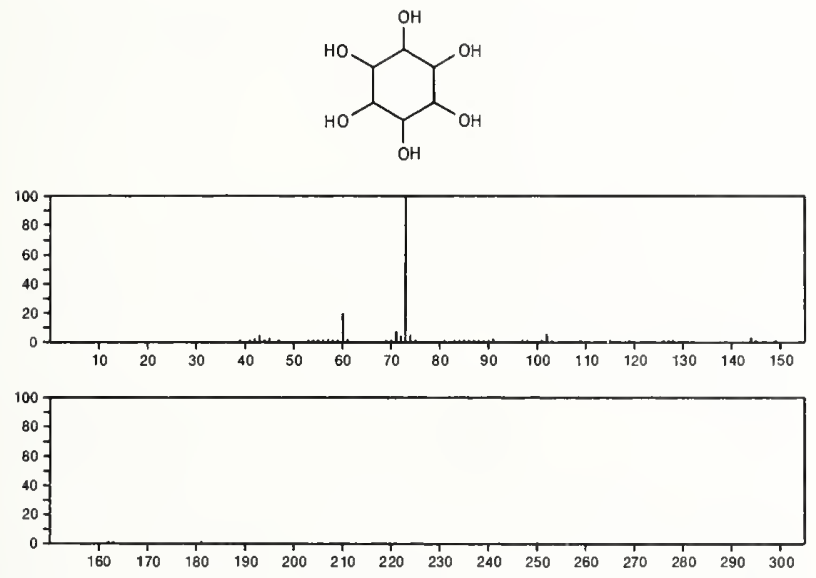

$180 \quad \mathrm{C}_{6} \mathrm{H}_{12} \mathrm{O}_{6} \quad 488-59-5$

scyllo-Inositol
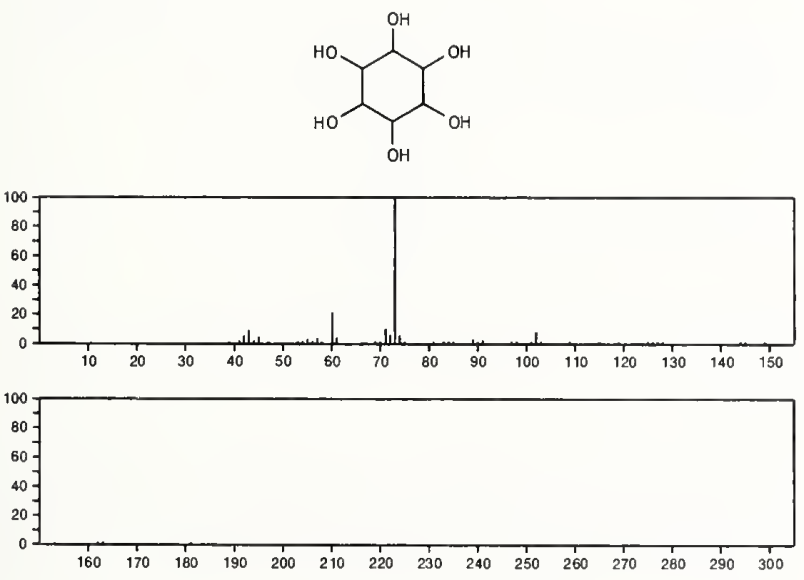

$180 \quad \mathrm{C}_{6} \mathrm{H}_{12} \mathrm{O}_{6}$

$576-63-6$<smiles>OC1C(O)C(O)C(O)C(O)C1O</smiles>
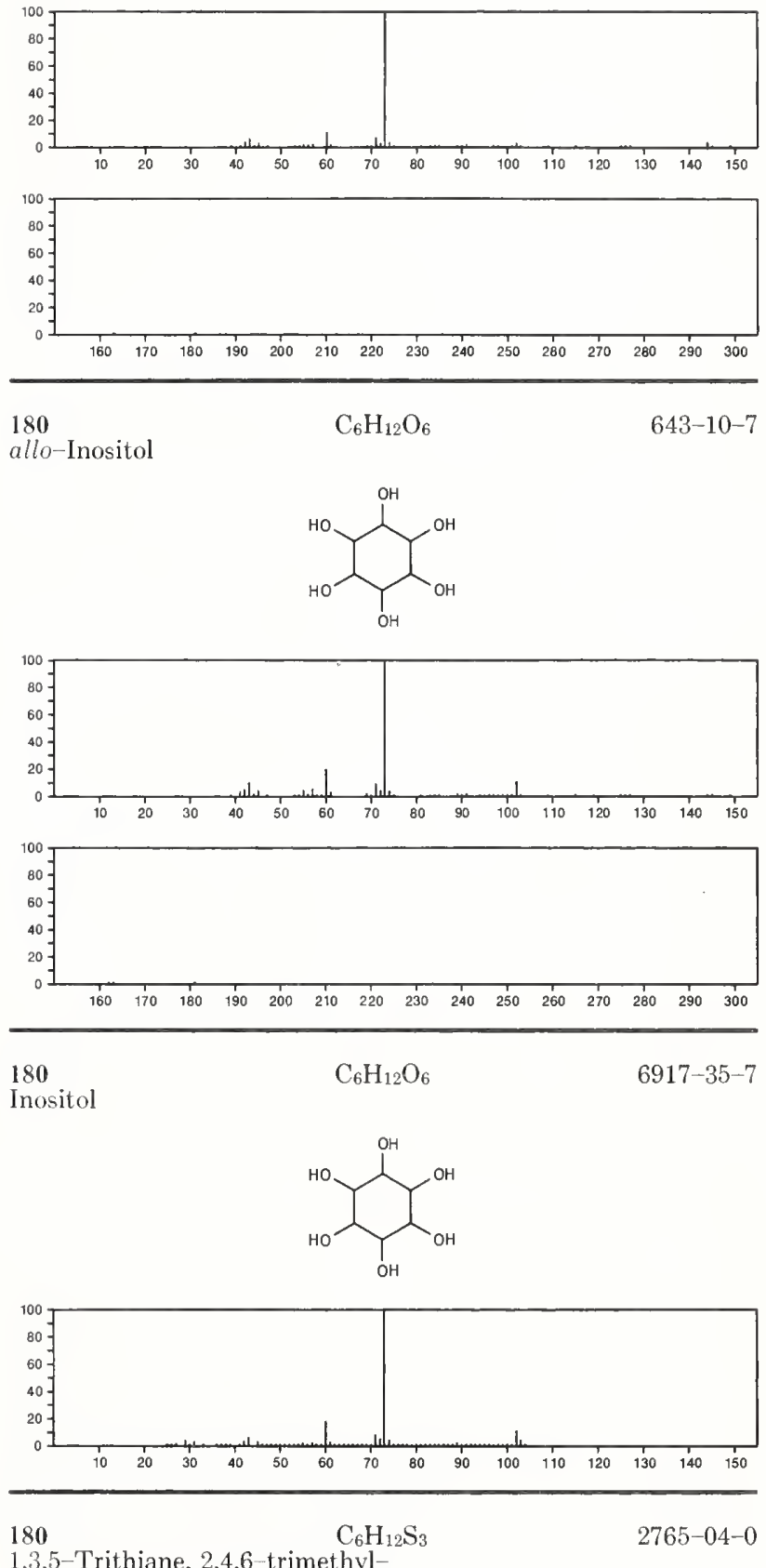

1,3,5-Trithiane, 2,4,6-trimethyl-
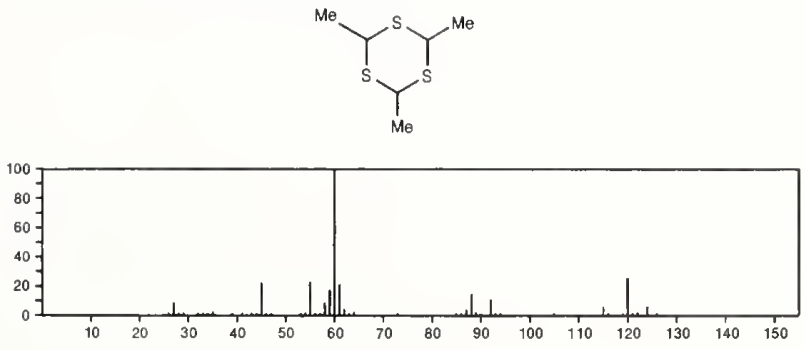

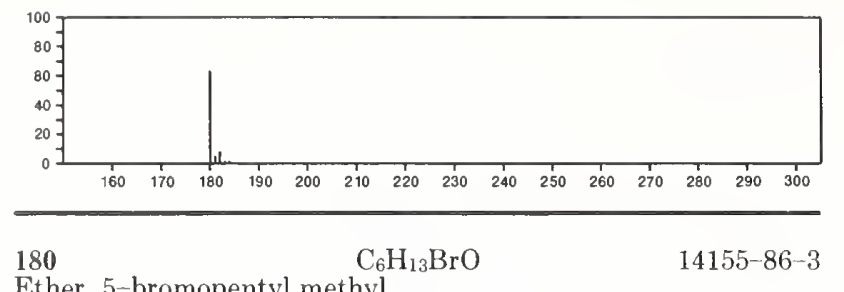

Ether, 5-bromopentyl methyl

$\mathrm{MeO}\left(\mathrm{CH}_{2}\right) 5 \mathrm{Br}$

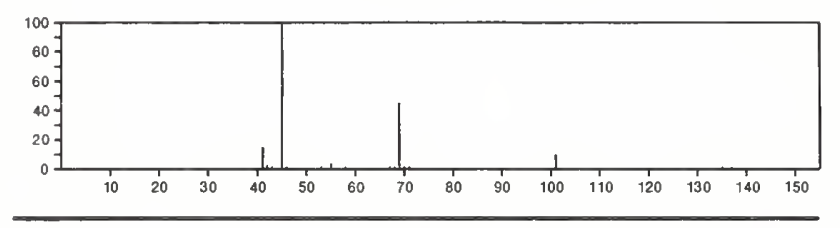

180

$\mathrm{C}_{6} \mathrm{H}_{13} \mathrm{O}_{4} \mathrm{P}$

1005-96-5

1,3,2-Dioxaphosphorinane, 2-methoxy-5,5-dimethyl-, 2-oxide
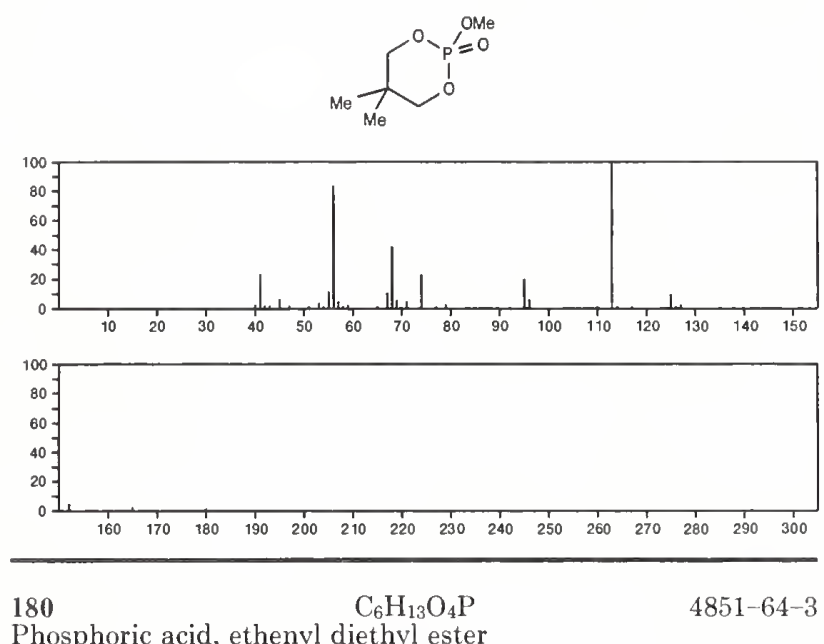

Phosphoric acid, ethenyl diethyl ester

$$
\mathrm{H}_{2} \mathrm{C}=\mathrm{CH} \mathrm{CP}_{\text {II }}^{\mathrm{OEE} \mathrm{t}}
$$
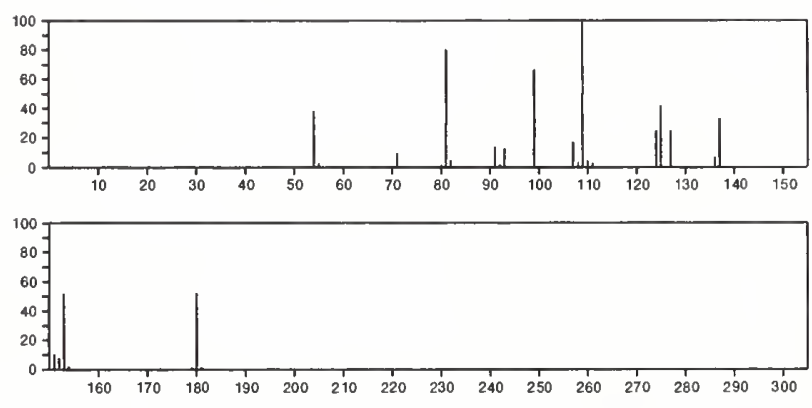

$180 \quad \mathrm{C}_{6} \mathrm{H}_{13} \mathrm{O}_{4} \mathrm{P} \quad 14477-80-6$

Phosphoric acid, dimethyl 1-methylpropenyl ester
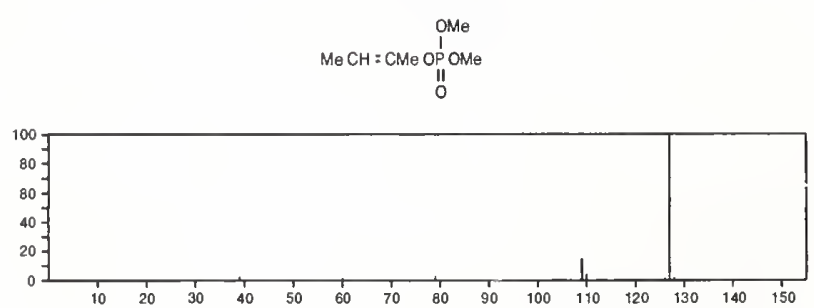

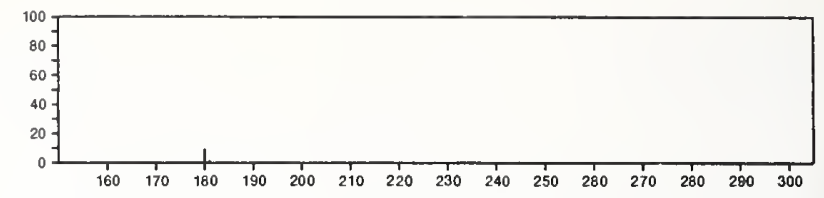

180

Thieno[3,2-c]pyridine, $\mathrm{C}_{7} \mathrm{H}_{4} \mathrm{~N}_{2} \mathrm{O}_{2} \mathrm{~S}$

$28783-05-3$
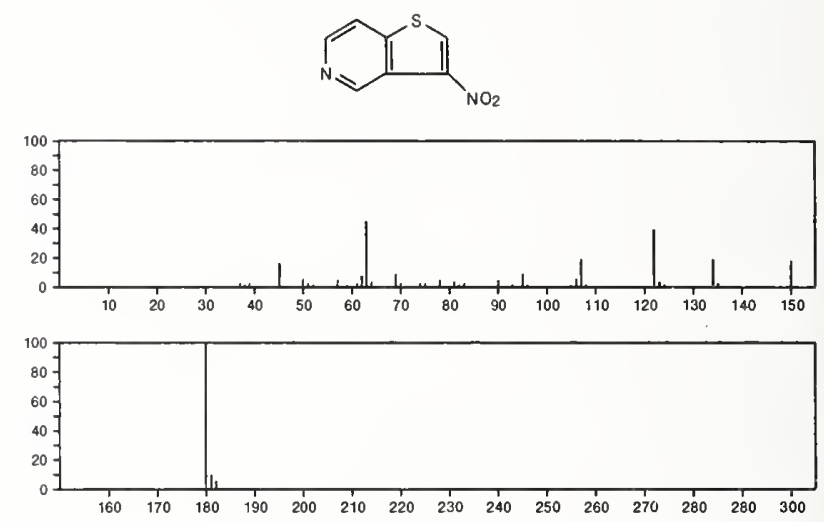

180

$\mathrm{C}_{7} \mathrm{H}_{4} \mathrm{~N}_{2} \mathrm{O}_{2} \mathrm{~S}$

$28783-28-0$

Thieno[2,3-c]pyridine, 3-nitro-
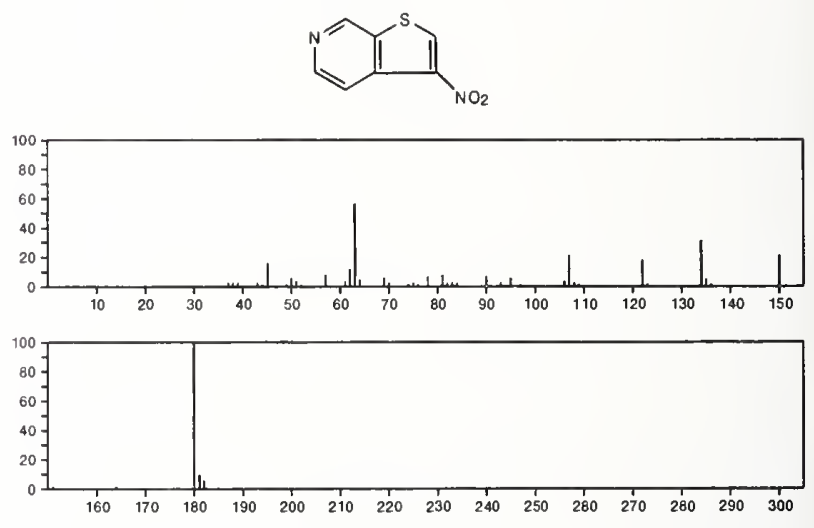

$180 \quad \mathrm{C}_{7} \mathrm{H}_{5} \mathrm{CoO}_{2} \quad 12078-25-0$

Cobalt, dicarbonyl $\left(\eta^{5-2,4-c y c l o p e n t a d i e n-1-y l)-}\right.$
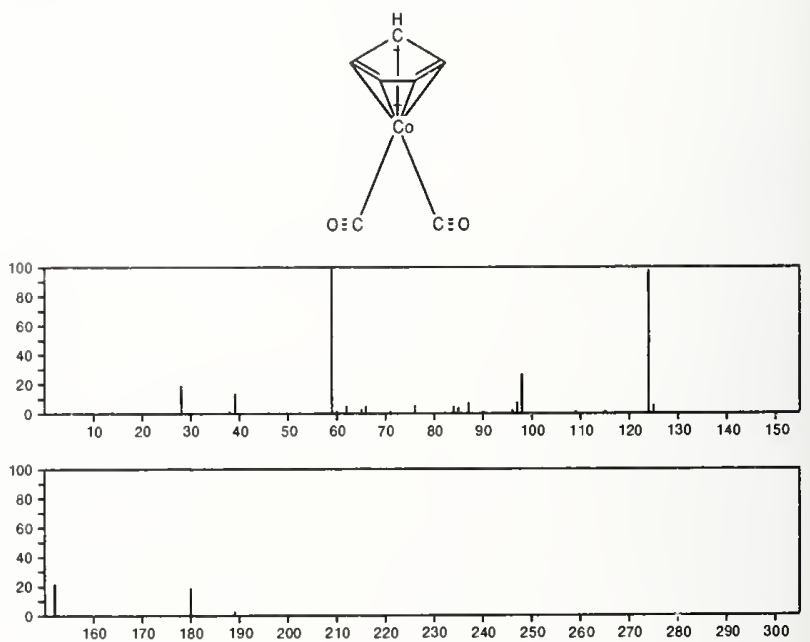
180

1,3-Butanedione, 1-cyclopropyl-4,4,4-trifluoro-

$30923-69-4$
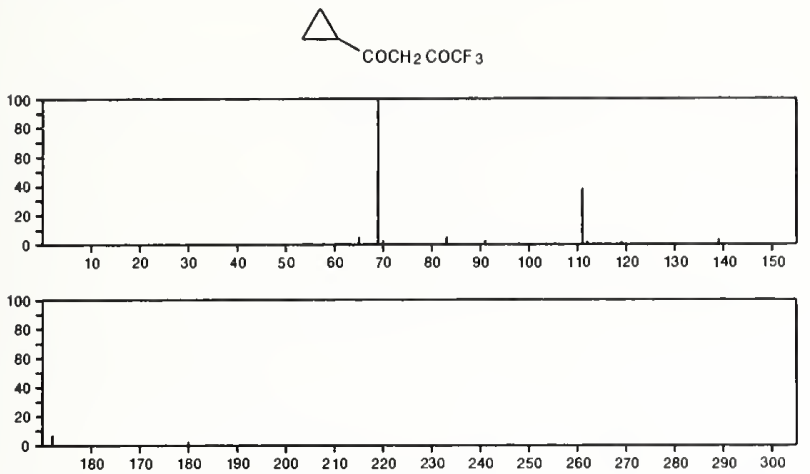

$\begin{array}{lllllllllllllll}180 & 170 & 180 & 190 & 200 & 210 & 220 & 230 & 240 & 250 & 260 & 270 & 280 & 290 & 300\end{array}$

180

$\mathrm{C}_{7} \mathrm{H}_{8} \mathrm{~N}_{4} \mathrm{O}_{2}$

$58-55-9$

1H-Purine-2,6-dione, 3,7-dihydro-1,3-dimethyl-
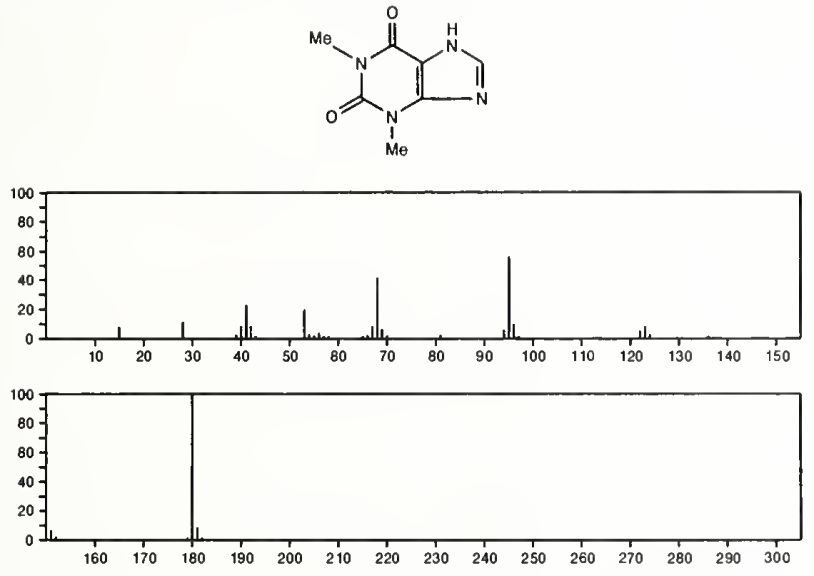

$\stackrel{180}{{ }_{1} H \text {-Purine-2,6-dione, }} \stackrel{\mathrm{C}_{7} \mathrm{H}_{8} \mathrm{~N}_{4} \mathrm{O}_{2}}{3,7 \text {-dihydro-3,7-dimethyl- }}$
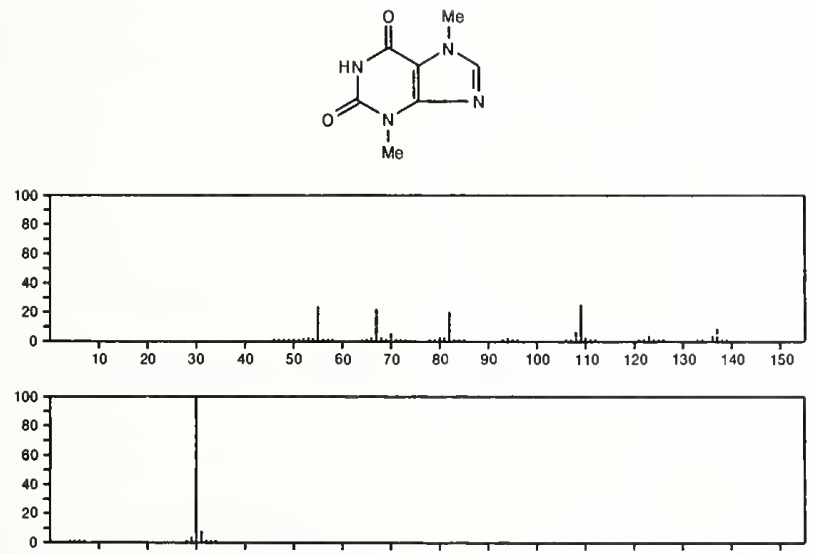

$\begin{array}{llllllllllllll}160 & 170 & 180 & 190 & 200 & 210 & 220 & 230 & 240 & 250 & 160 & 270 & 180 & 1\end{array}$

180

$1008-01-1$

$\mathrm{C}_{7} \mathrm{H}_{8} \mathrm{~N}_{4} \mathrm{~S}$
methylthio)

Nes

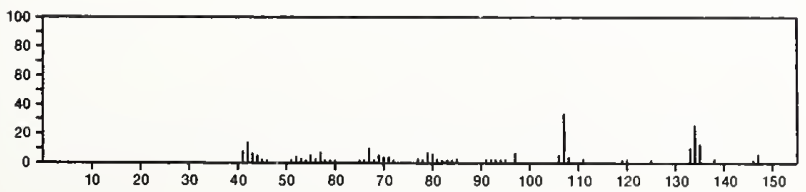

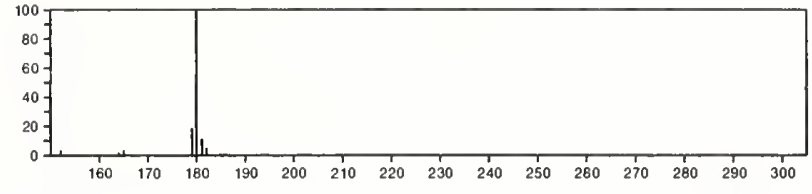

$1008-47-5$

180
$1 \mathrm{H}$-Purine, 2-methyl-6-(methylthio)<smiles>Cc1nc(N)c2[nH]cnc2n1</smiles>
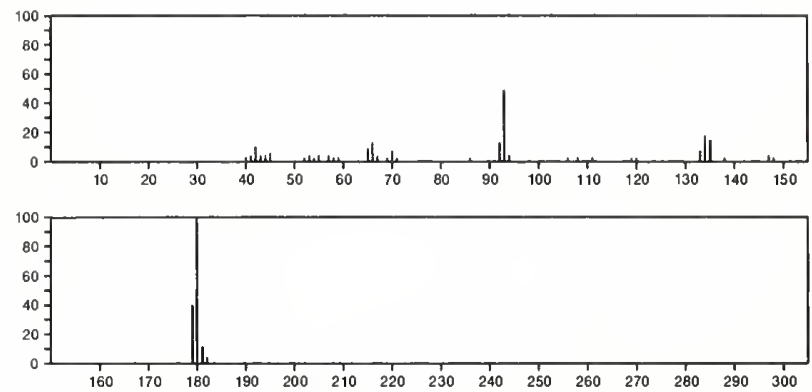

180

$\mathrm{C}_{7} \mathrm{H}_{8} \mathrm{~N}_{4} \mathrm{~S}$

1H-Purine, 8-methyl-6-(methylthio)

1008-51-1<smiles>CSc1ncnc2nc([N+](=O)[O-])[nH]c12</smiles>
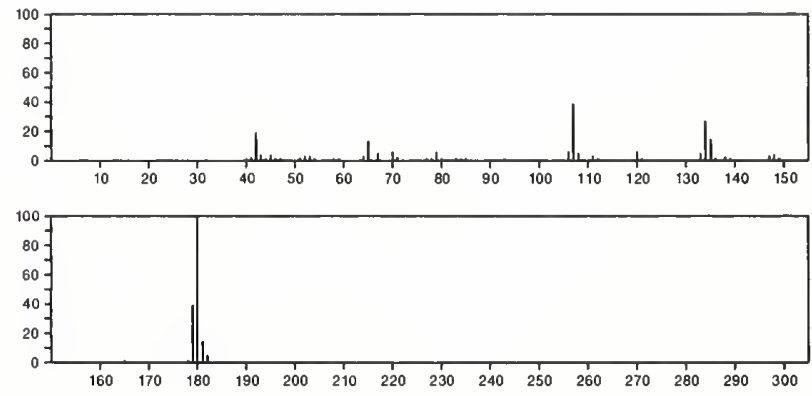

180

9H-Purine, 9-methyl-6-(methylthio)-

$1127-75-9$
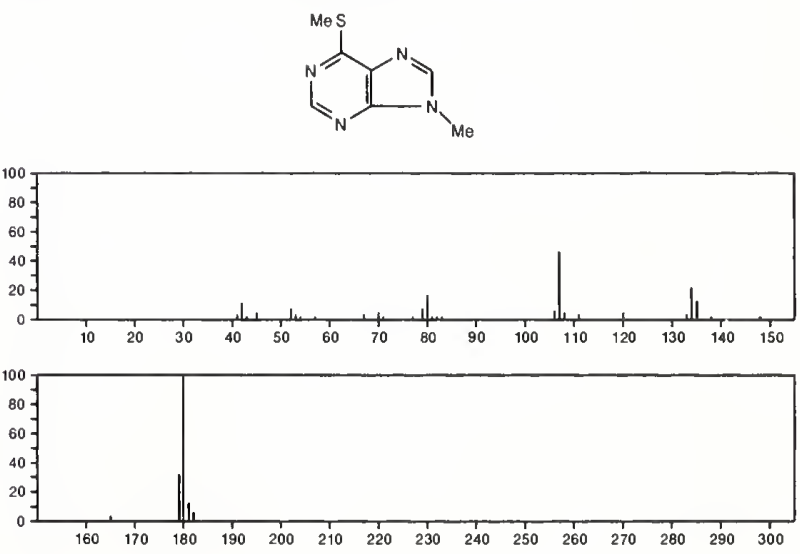
180

7H-Purinium, 6-mercapto-7,9-dimethyl-, hydroxide, inner salt
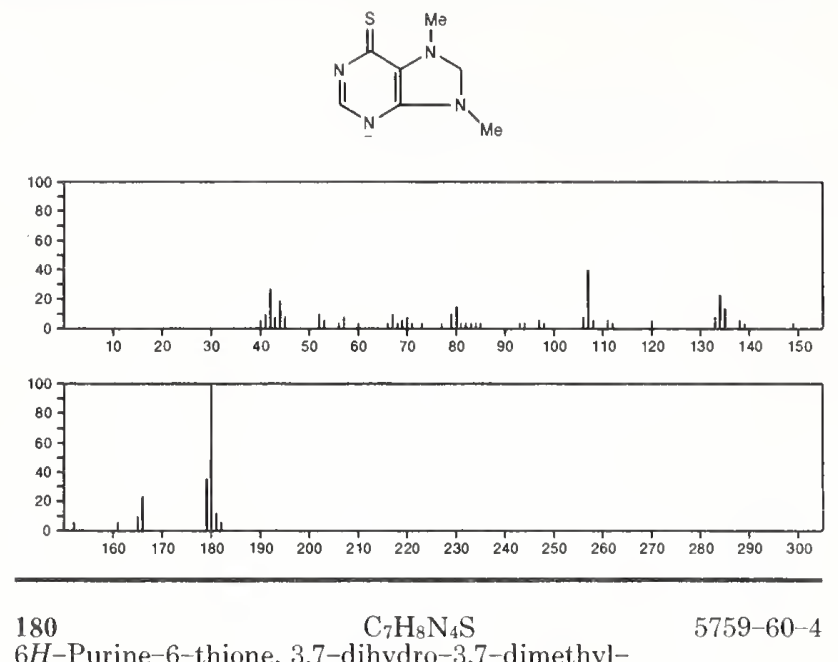

6H-Purine-6-thione, 3,7-dihydro-3,7-dimethyl-
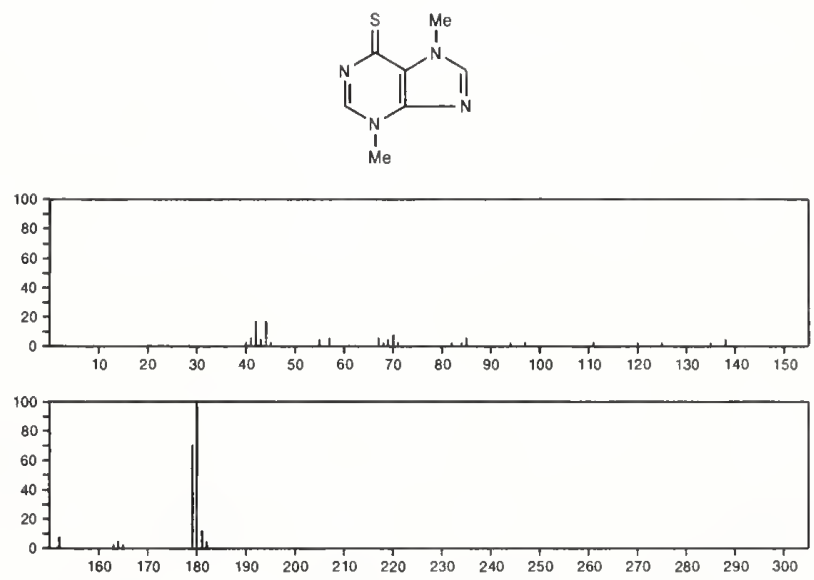

180

$\mathrm{C}_{7} \mathrm{H}_{8} \mathrm{~N}_{4} \mathrm{~S}$

$19835-21-3$

Thiazolo[5,4-d]pyrimidine, 5-(ethylamino)-
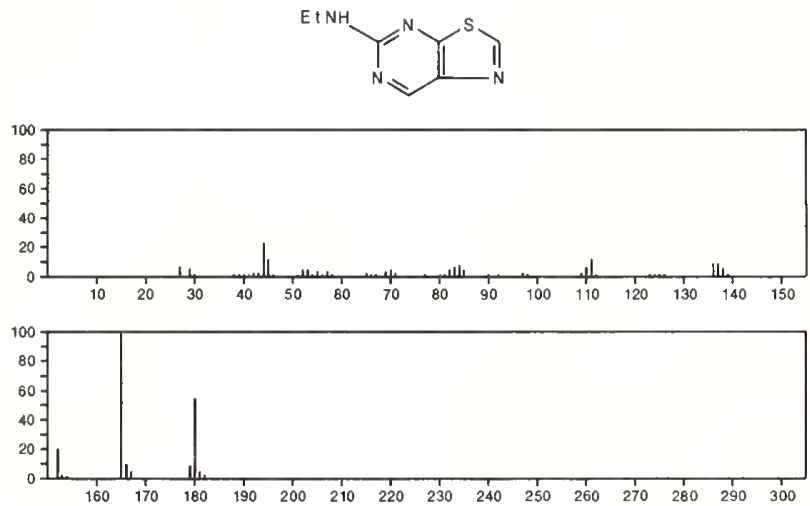

180

$\mathrm{C}_{7} \mathrm{H}_{8} \mathrm{~N}_{4} \mathrm{~S}$

$s$-Triazolo[4,3-a]pyrazine-3-thiol, 5,8-dimethyl-

19854-99-0
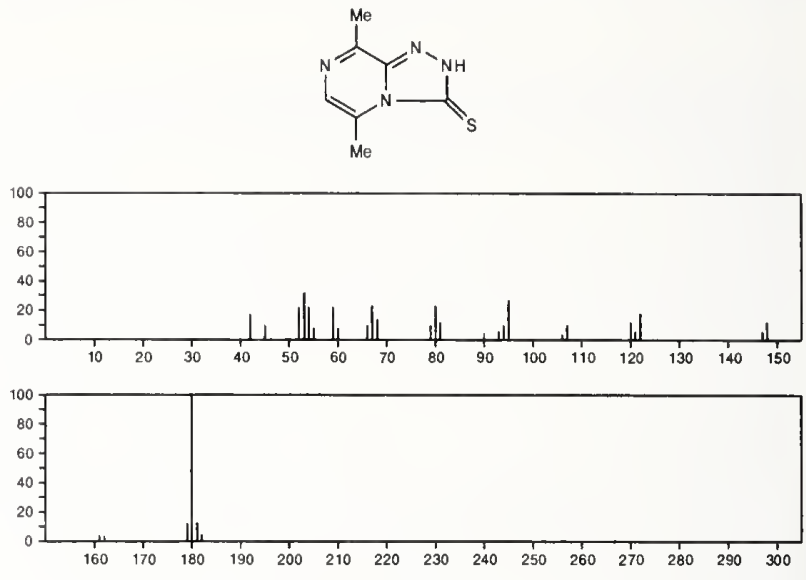

180

$\mathrm{C}_{8} \mathrm{H}_{5} \mathrm{Br}$

$932-87-6$

Benzene, (bromoethynyl)-

$\mathrm{Br} \mathrm{C} \equiv \mathrm{CPh}$
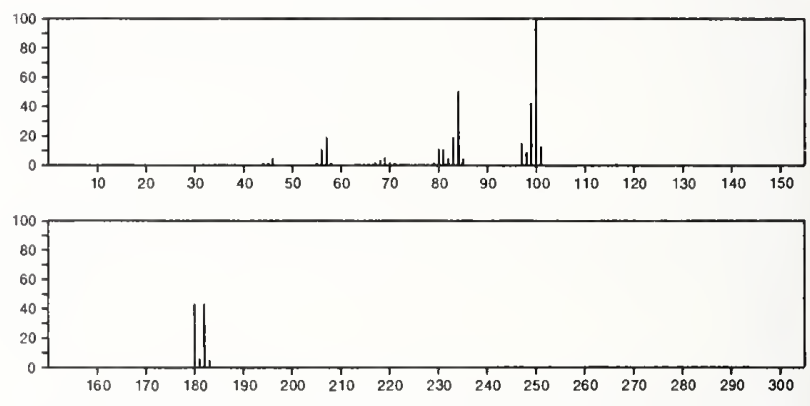

180

$\mathrm{C}_{8} \mathrm{H}_{5} \mathrm{FN}_{2} \mathrm{O}_{2}$

$5352-95-4$

Sydnone, 3-(p-fluorophenyl)
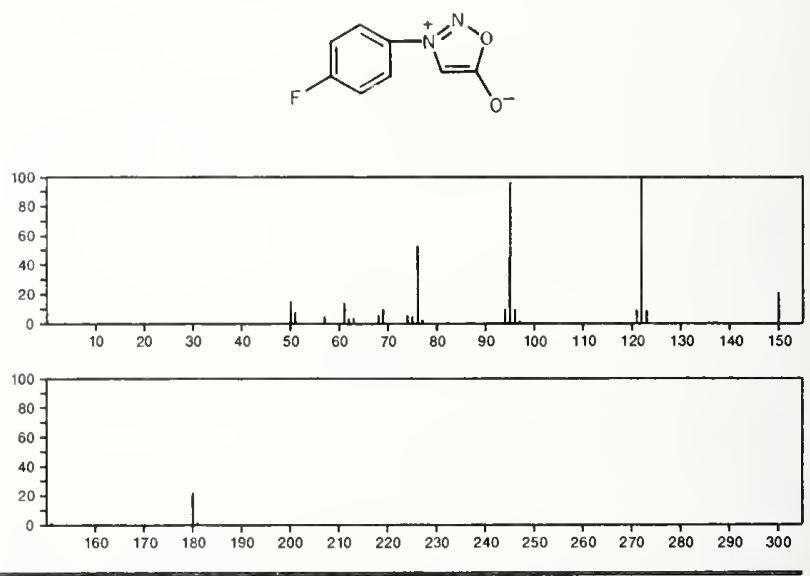

180

$\mathrm{C}_{8} \mathrm{H}_{8} \mathrm{~N}_{2} \mathrm{O}_{3}$

104-04-1

Acetamide, $N$-(4-nitrophenyl)-
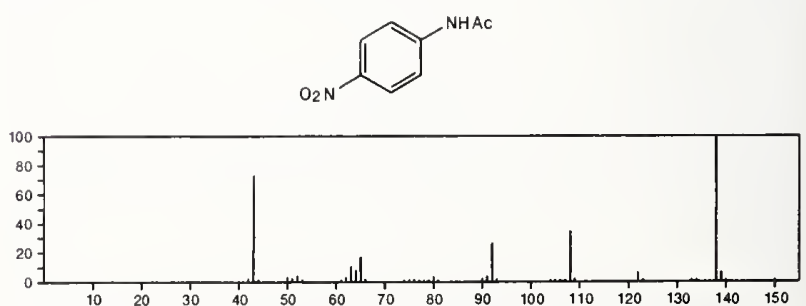


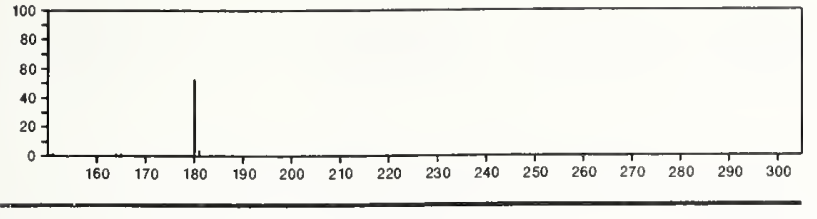

$180 \quad \mathrm{C}_{8} \mathrm{H}_{8} \mathrm{~N}_{2} \mathrm{O}_{3}$

$122-28-1$

Acetamide, $N$-(3-nitrophenyl)-
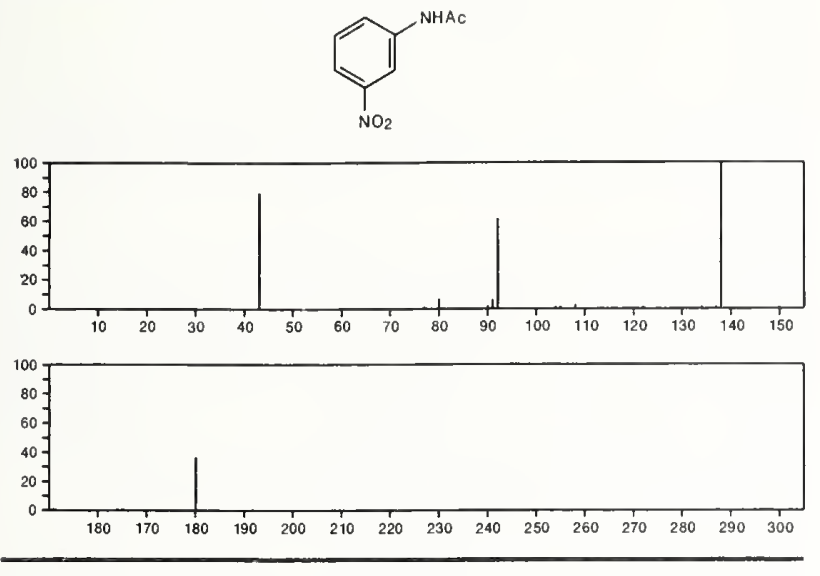

180

\section{$\mathrm{C}_{8} \mathrm{H}_{8} \mathrm{~N}_{2} \mathrm{O}$}

$552-32-9$

Acetamide, $\mathrm{N}-(2-$ nitrophenyl)-
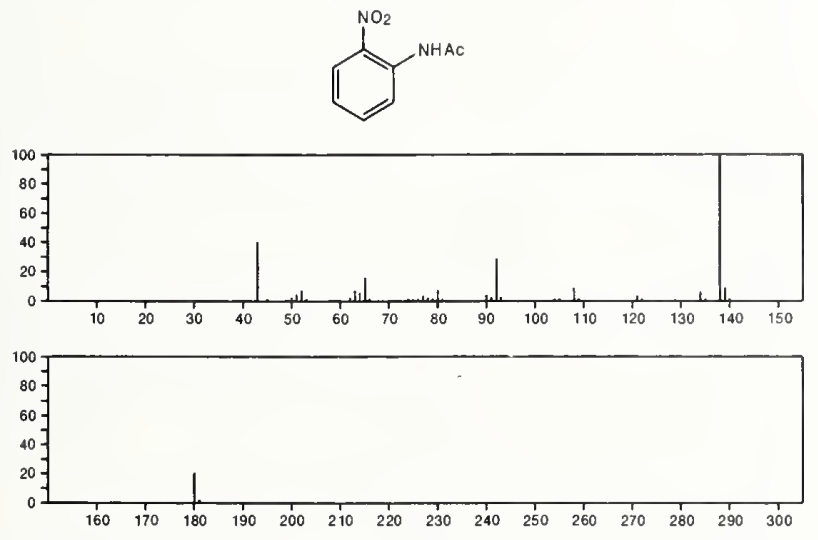

180

$\mathrm{C}_{8} \mathrm{H}_{8} \mathrm{~N}_{2} \mathrm{O}_{3}$

$583-08-4$

Glycine, $N$-(3-pyridinylcarbonyl)-
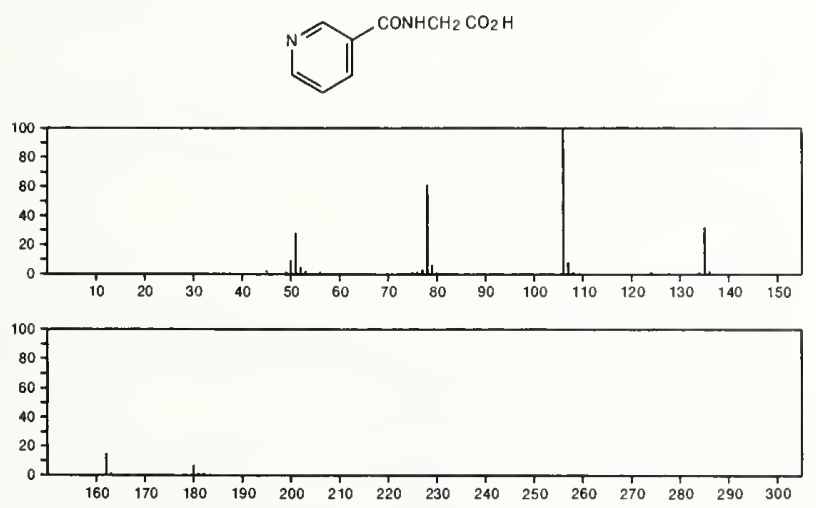

180

$\mathrm{C}_{8} \mathrm{H}_{8} \mathrm{~N}_{2} \mathrm{O}_{3}$

Acetamide, 2-nitro-N-phenyl-

$10151-95-8$

$\mathrm{PhNHCOCH} \mathrm{NO}_{2}$
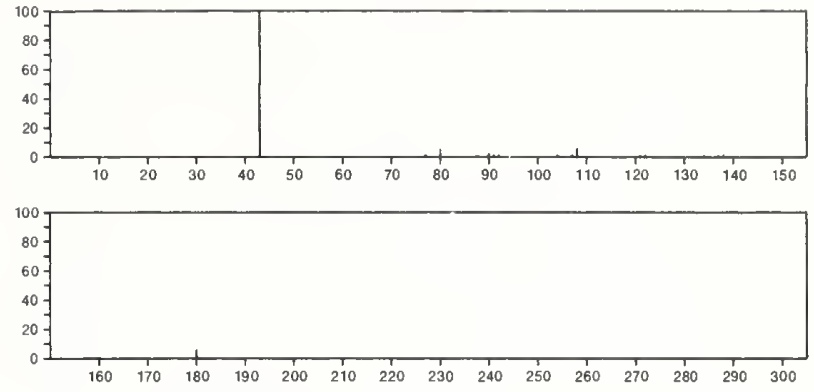

180

$\mathrm{C}_{8} \mathrm{H}_{8} \mathrm{~N}_{2} \mathrm{O}_{3}$

Ethanone, 1-(4-nitrophenyl)-, oxime

$10342-64-0$
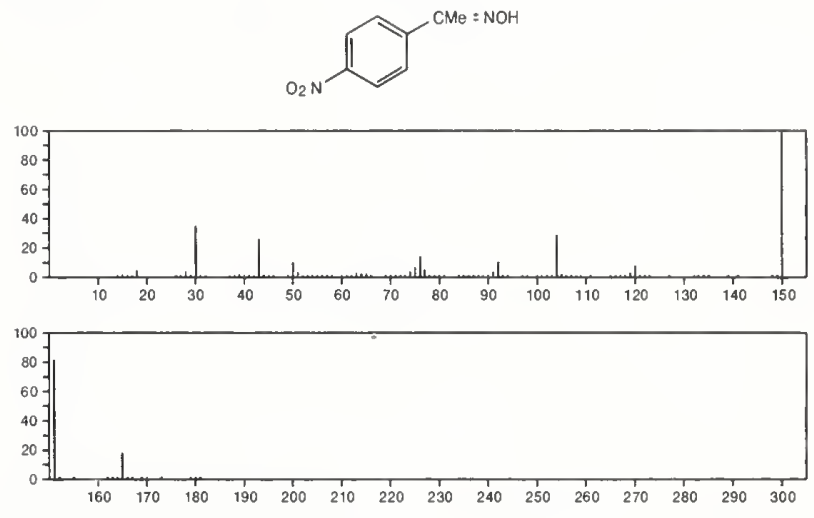

180

$\mathrm{C}_{8} \mathrm{H}_{8} \mathrm{~N}_{2} \mathrm{O}_{3}$

$26893-72-1$

2-Pyridinecarboxylic acid, 6-(acetylamino)
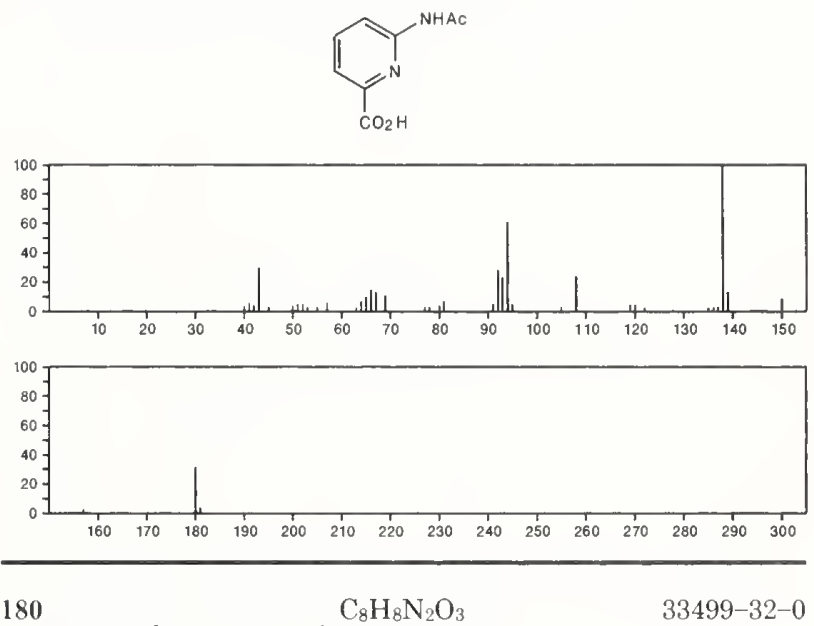

Benzaldehyde, 4-nitro--, $\mathrm{O}$-methyloxime

$33499-32-0$
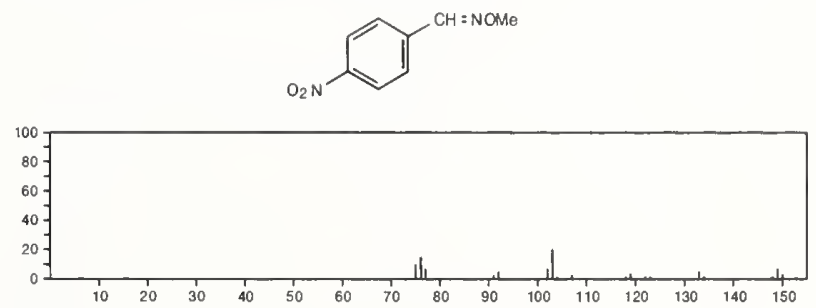


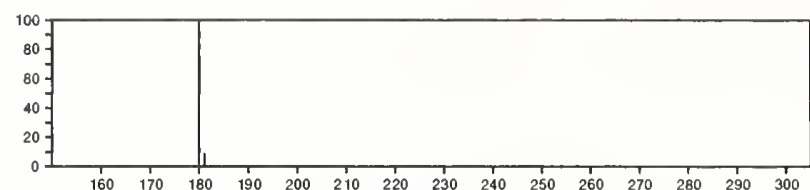

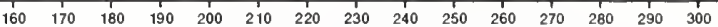

180

$\mathrm{C}_{8} \mathrm{H}_{8} \mathrm{~N}_{2} \mathrm{O}_{3}$

$33499-33-1$

Benzaldehyde, $m$-nitro-, $O$-methyloxime
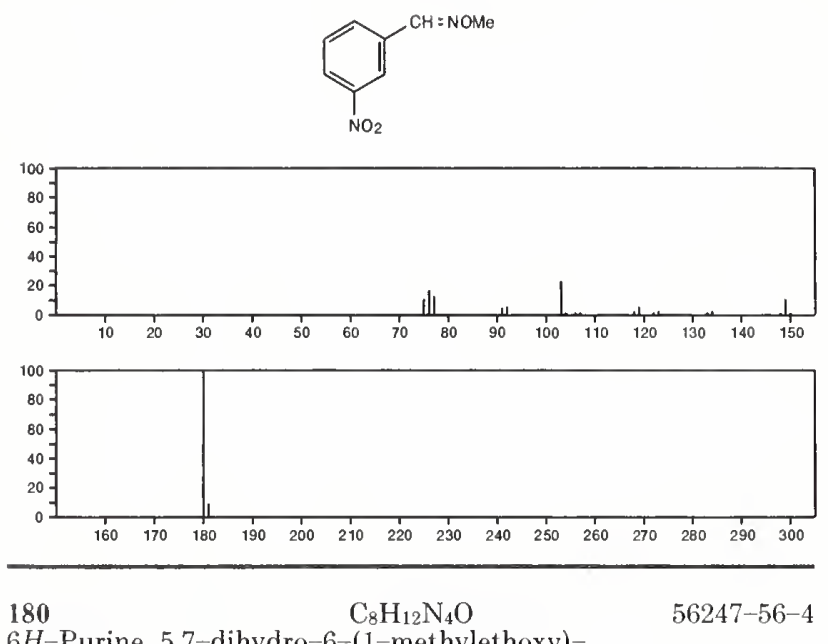

6H-Purine, 5,7-dihydro-6-(1-methylethoxy)-
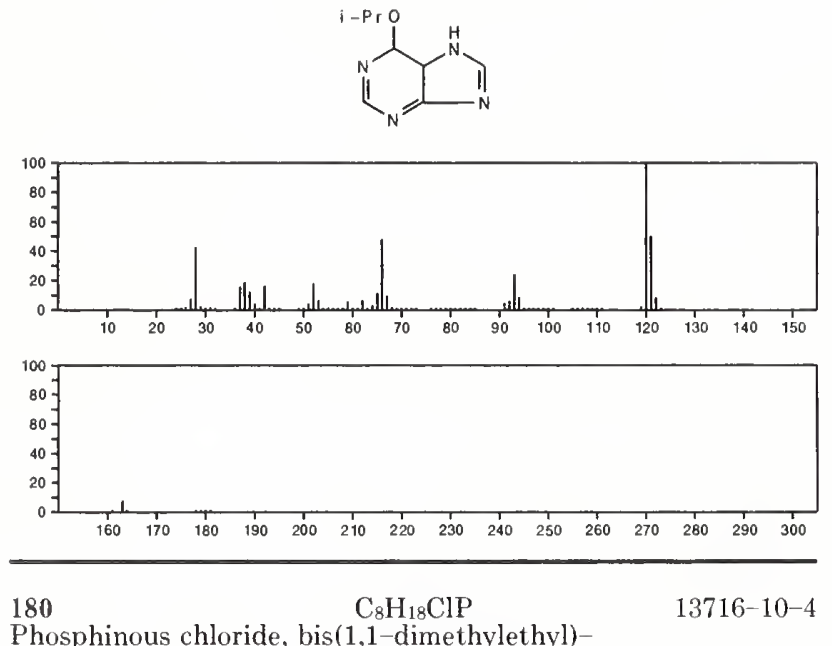

Phosphinous chloride, bis(1,1-dimethylethyl)-

$\mathrm{CIP}(\mathrm{Bu}-\mathrm{t})_{2}$
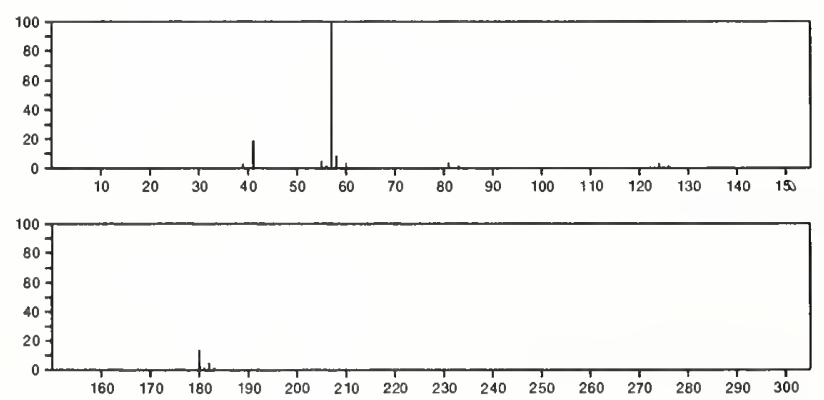

180

$\mathrm{C}_{9} \mathrm{H}_{8} \mathrm{O}_{2} \mathrm{~S}$

4H-1-Benzothiopyran-4-one, 2,3-dihydro-, 1-oxide
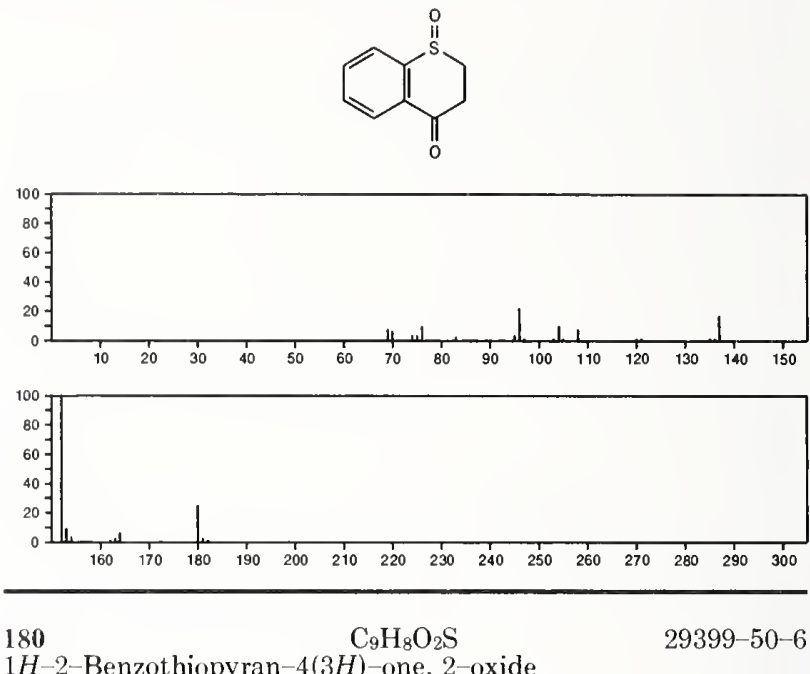

$1 H-2-$ Benzothiopyran-4(3H)-one, 2 -oxide
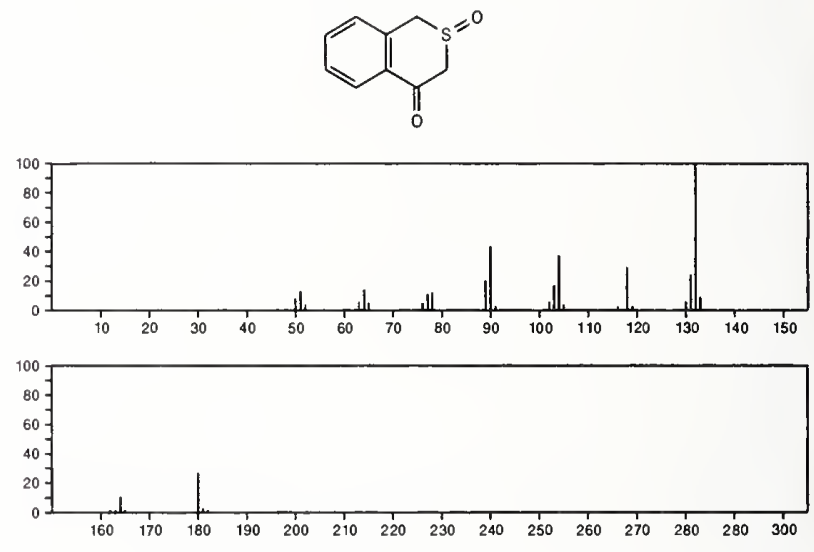

180

Benzoic acid, 2-(acetyloxy)

$\mathrm{C}_{9} \mathrm{H}_{8} \mathrm{O}_{4}$

$50-78-2$
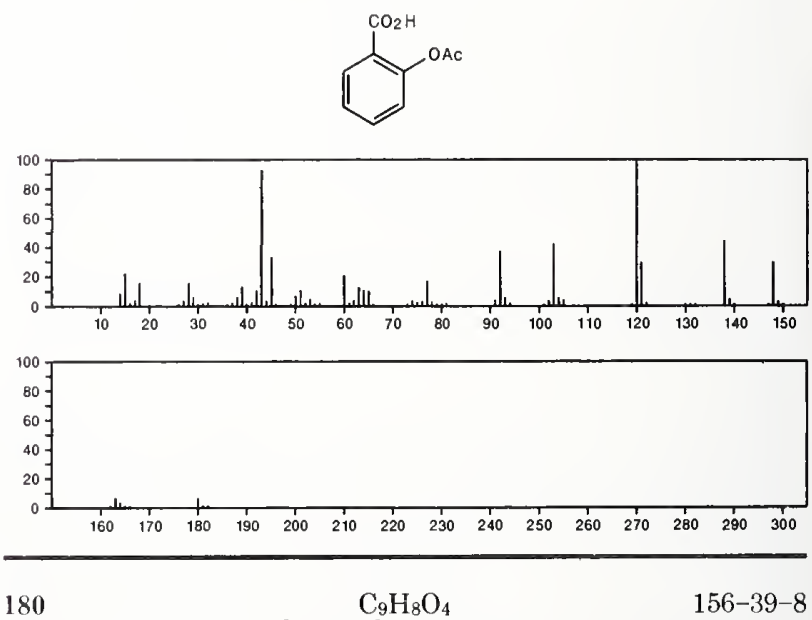

Benzenepropanoic acid, 4-hydroxy- $\alpha-\mathrm{oxo}^{-}$
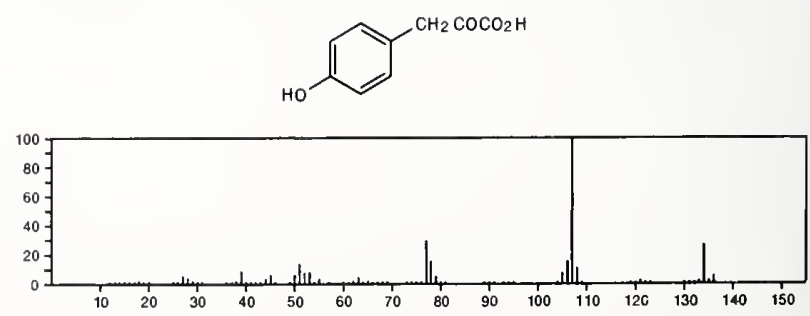

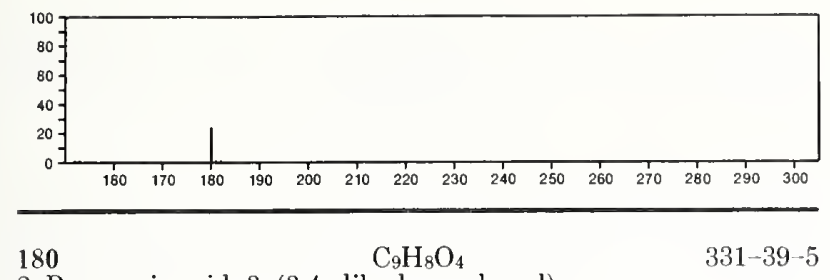

2-Propenoic acid, 3-(3,4-dihydroxyphenyl)-
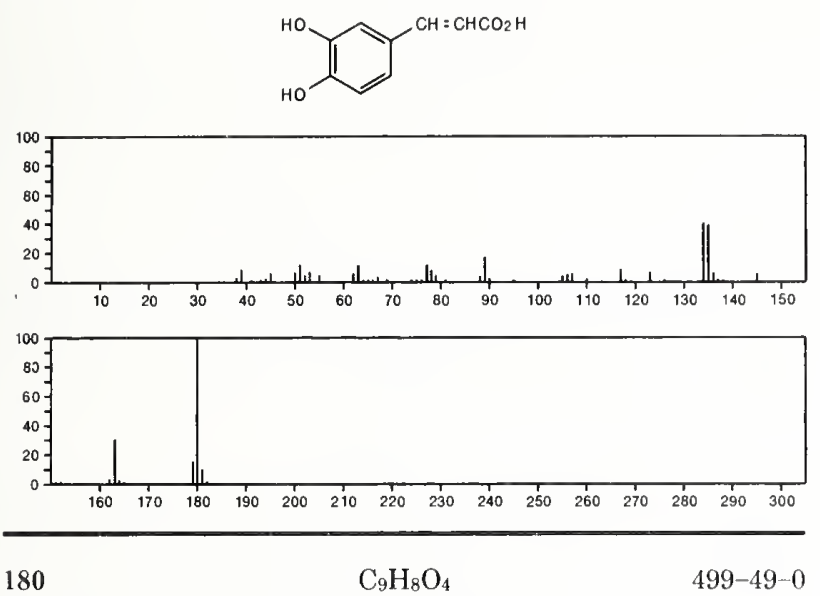

1,3-Benzenedicarboxylic acid, 5-methyl-

$499-49-0$
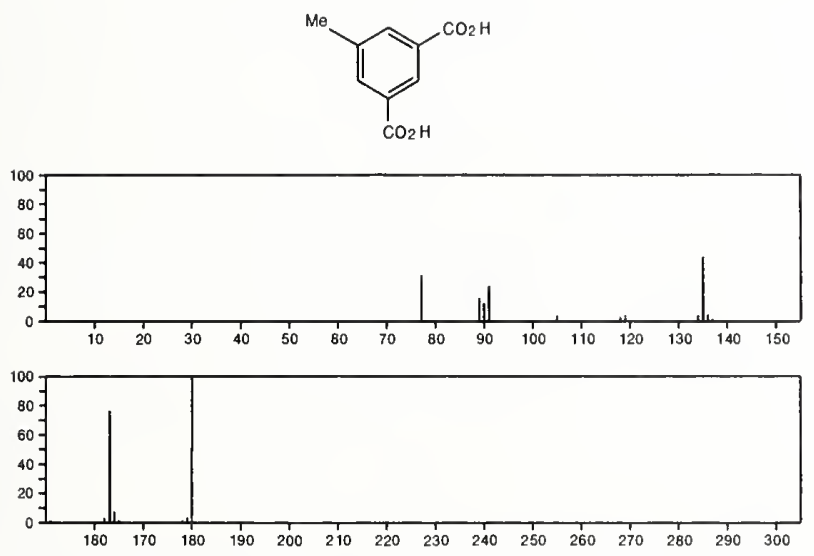

180

$\mathrm{C}_{9} \mathrm{H}_{8} \mathrm{O}_{4}$

$1877-71-0$

1,3-Benzenedicarboxylic acid, monomethyl ester
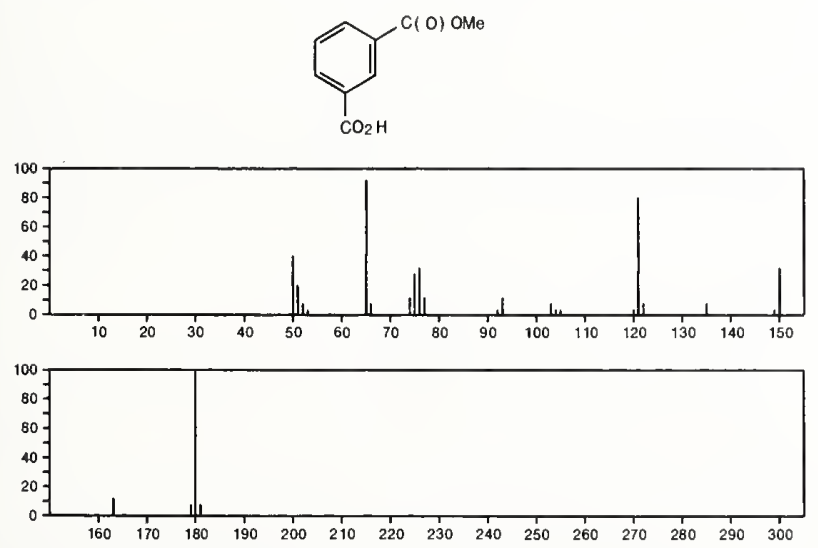

180

1,3-Benzenedicarboxylic acid, 4-methyl-
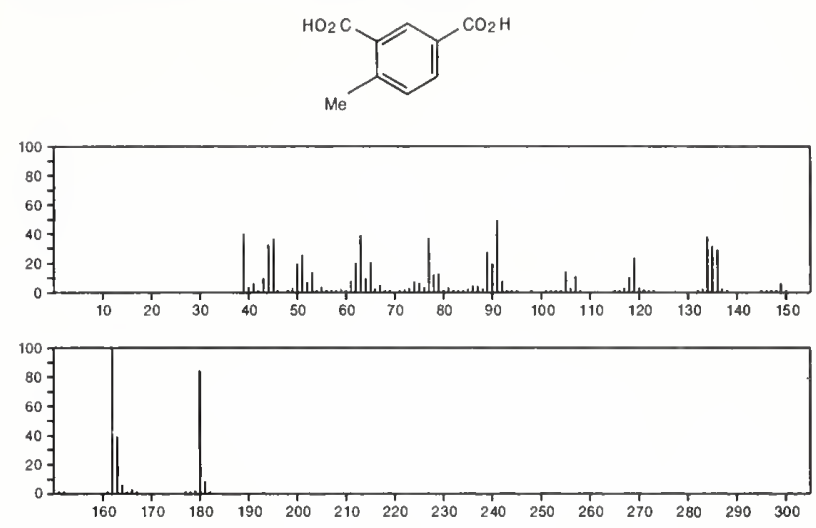

180

1,2-Benzenedicarboxylic acid, 4-methyl-

$4316-23-8$
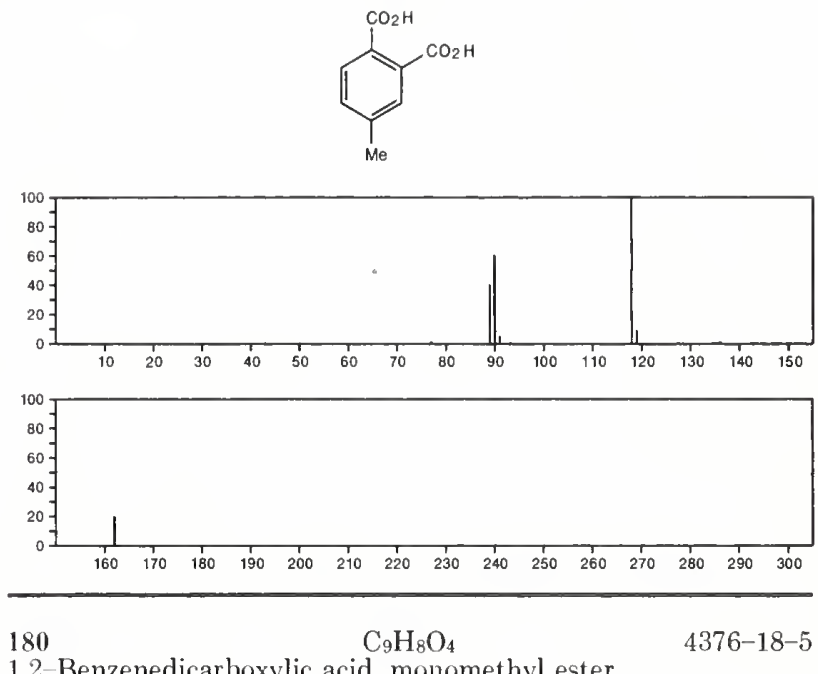

1,2-Benzenedicarboxylic acid, monomethyl ester
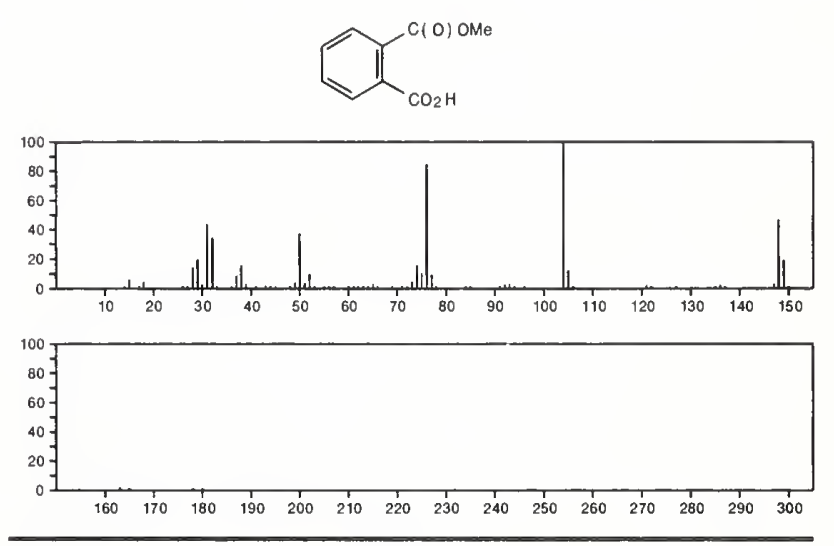

180

$\mathrm{C}_{9} \mathrm{H}_{8} \mathrm{O}_{4}$

$5156-01-4$

1,4-Benzenedicarboxylic acid, 2-methyl-<smiles>O=C(O)c1ccc(C(=O)O)c([N+](=O)[O-])c1</smiles>

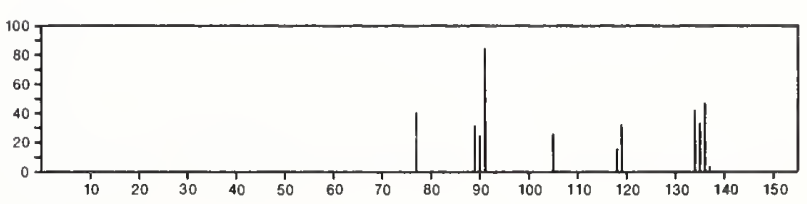




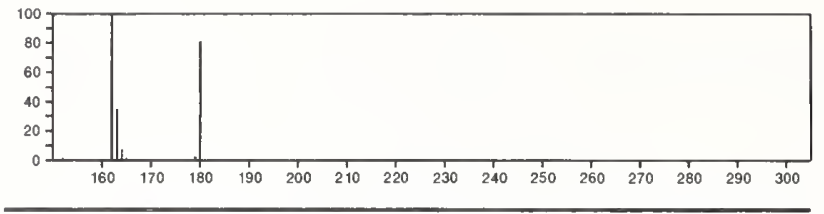

$180 \quad \mathrm{C}_{9} \mathrm{H}_{8} \mathrm{O}_{4} \quad 10209-57-1$ 1,3-Benzenedicarboxaldehyde, 2,4-dihydroxy-6-methyl-
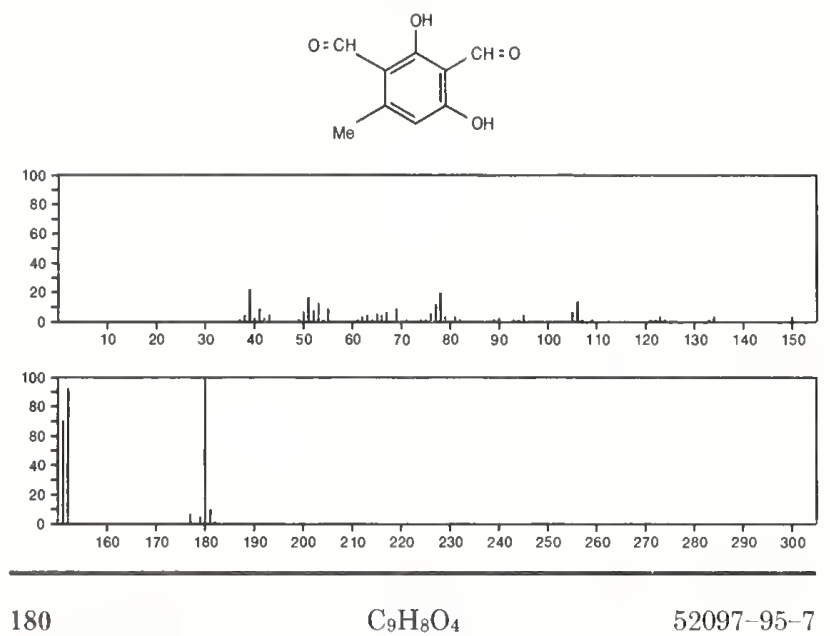

Spiro[3.3] hepta-1,5-diene-2,6-dicarboxylic acid, ( \pm )-
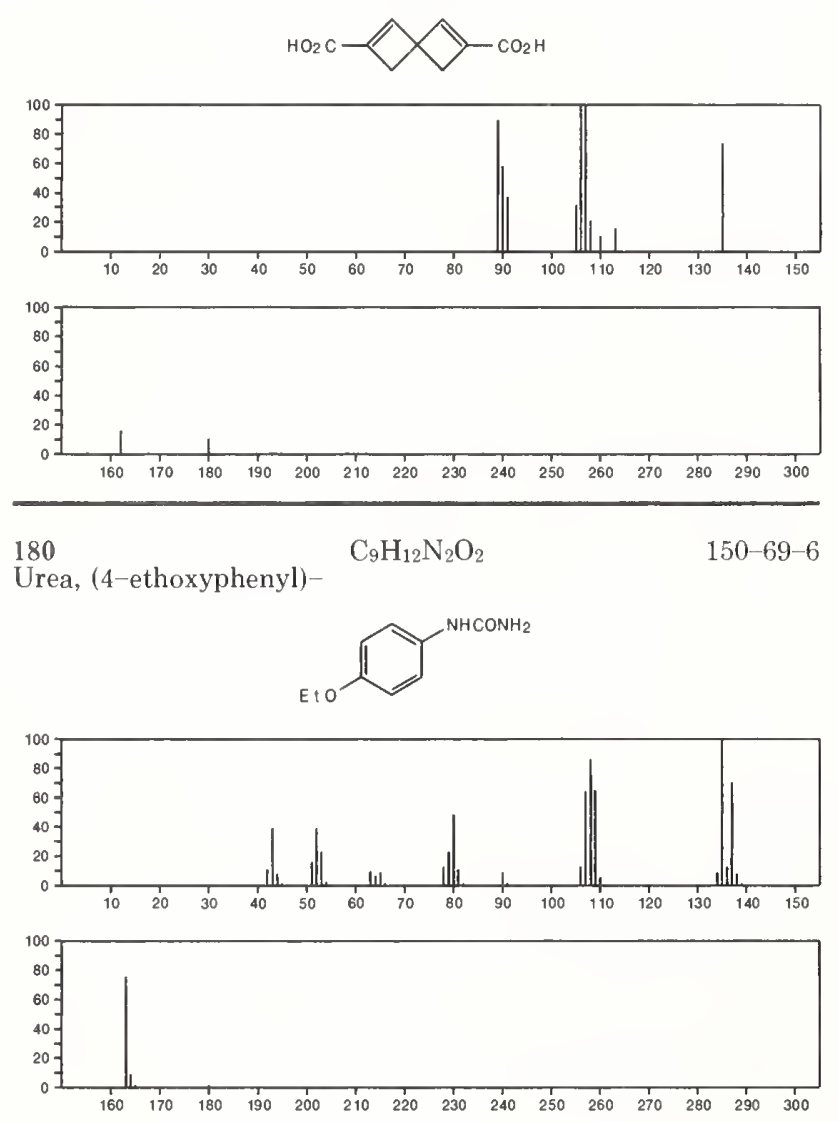

180

$\mathrm{C}_{9} \mathrm{H}_{12} \mathrm{~N}_{2} \mathrm{O}_{2}$

$1521-60-4$

Benzenamine, 2,4,6-trimethyl-3-nitro-
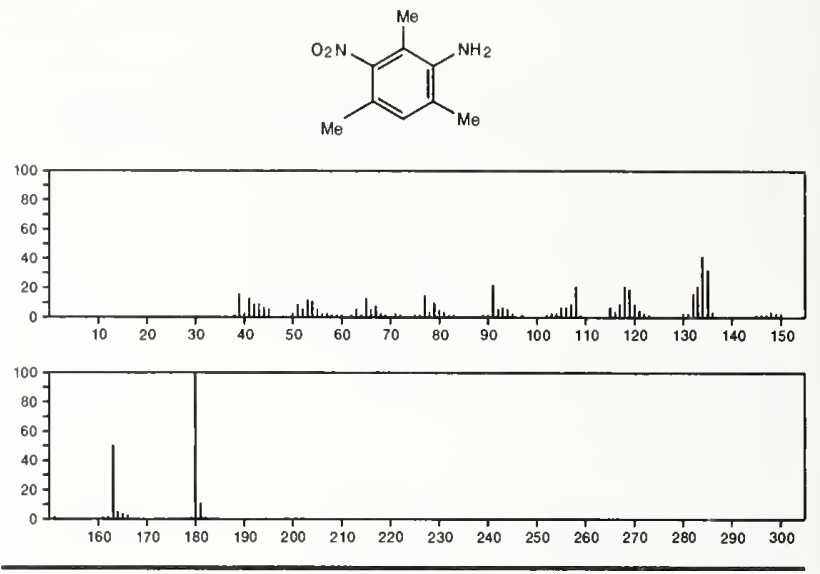

180

$\mathrm{C}_{9} \mathrm{H}_{12} \mathrm{~N}_{2} \mathrm{~S}$

Thiourea, $N, N$-dimethyl- $N^{\prime}$-phenyl-

$705-62-4$

Me2NCSNHPh
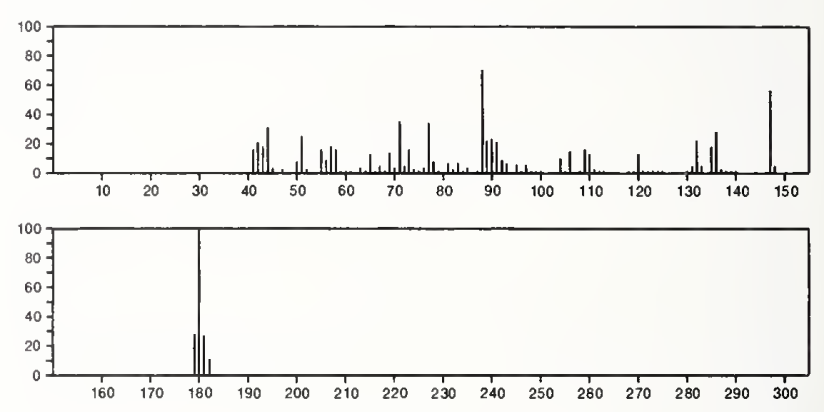

180

$\mathrm{C}_{9} \mathrm{H}_{12} \mathrm{~N}_{2} \mathrm{~S}$

Thiourea, $N$-ethyl-N'-phenyl-

$2741-06-2$

PhNHCSNHE t
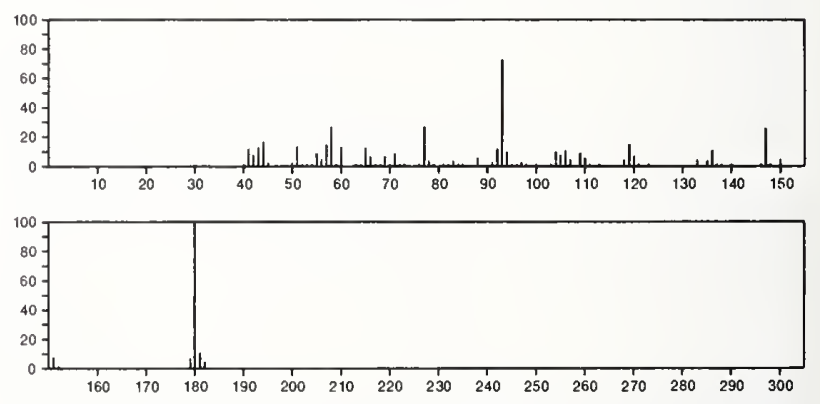

180

$\mathrm{C}_{10} \mathrm{H}_{9} \mathrm{ClO}$

3-Buten-2-one, 4-(4-chlorophenyl)-

$3160-40-5$
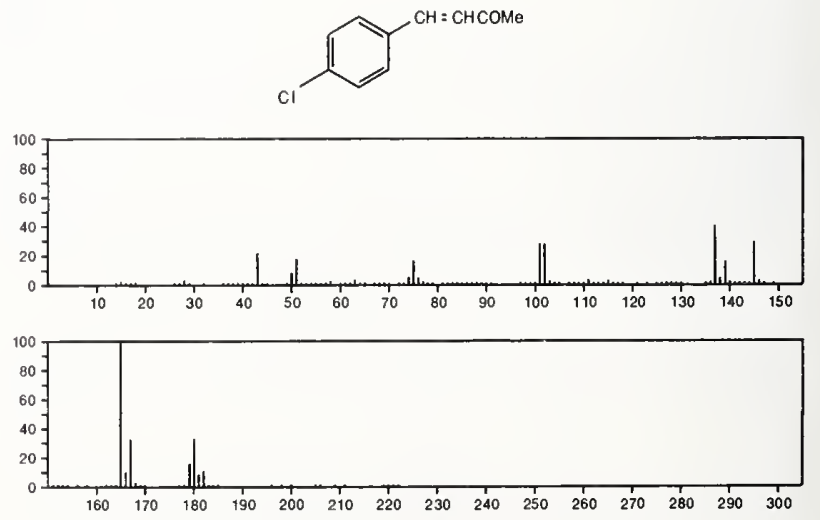
180

Sulfoxide, methyl $\beta$-methylstyryl

$\mathrm{MeS}(\mathrm{O}) \mathrm{CH}=\mathrm{CMePh}$
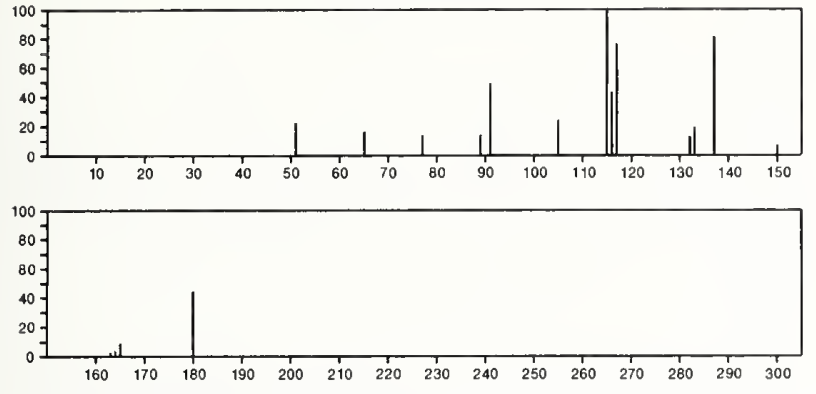

180

$\mathrm{C}_{10} \mathrm{H}_{12} \mathrm{OS}$

$24378-01-6$

Benzene, [2-(methylsulfinyl)-1-propenyl $]$ -

$\mathrm{PhCH}=\mathrm{CMeS}(\mathrm{O}) \mathrm{Me}$
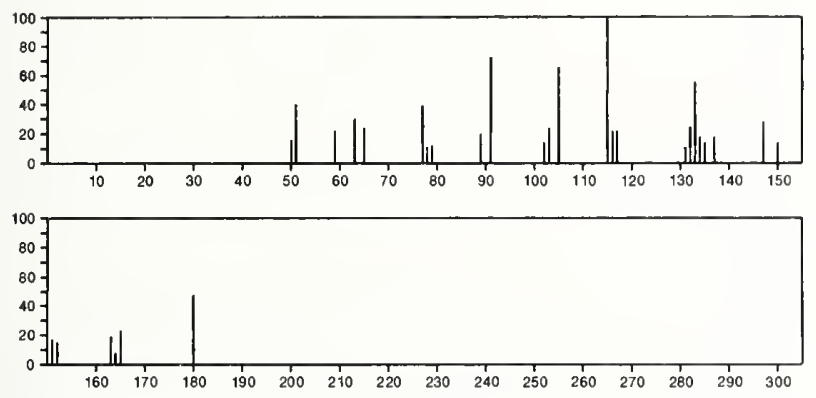

180

$$
\mathrm{C}_{10} \mathrm{H}_{12} \mathrm{OS}
$$

Benzenecarbothioic acid, 4-methyl-, $O$-ethyl ester
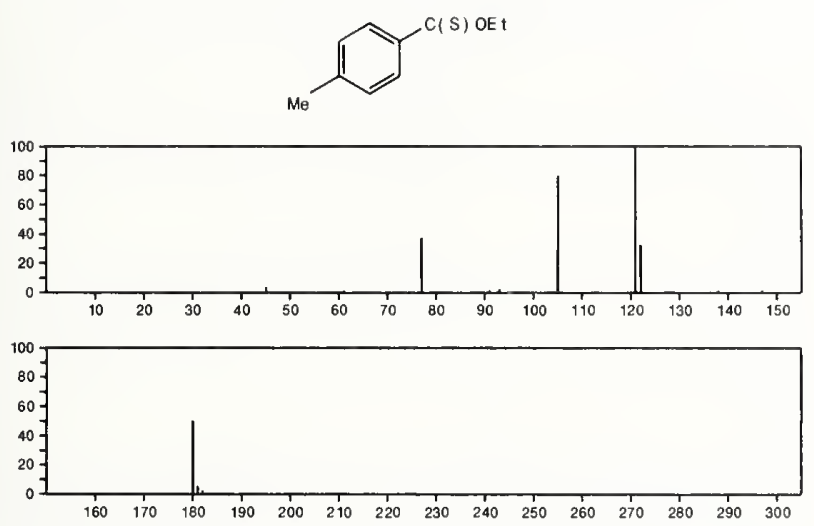

$180 \quad \mathrm{C}_{10} \mathrm{H}_{12} \mathrm{OS}$

$m$-Toluic acid, thio-, $O$-ethyl ester
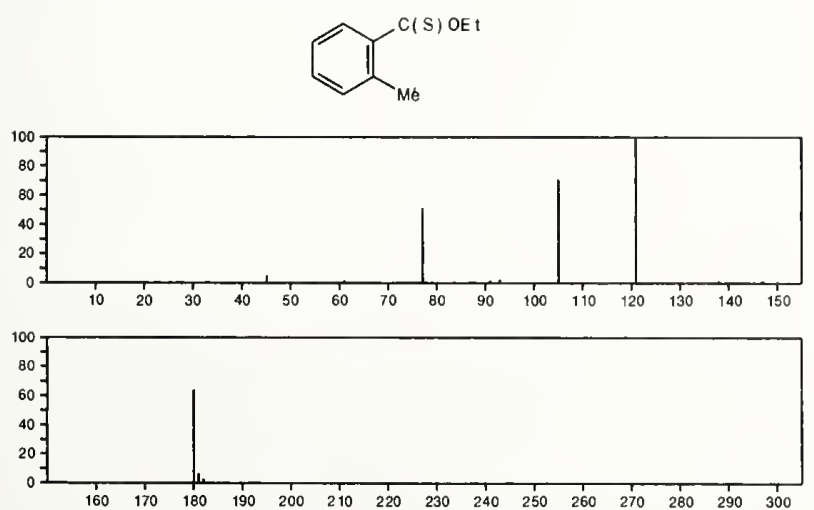

$180 \quad \mathrm{C}_{10} \mathrm{H}_{12} \mathrm{OS}$

Benzenecarbothioic acid, 4-methyl-, S-ethyl ester

$28145-60-0$
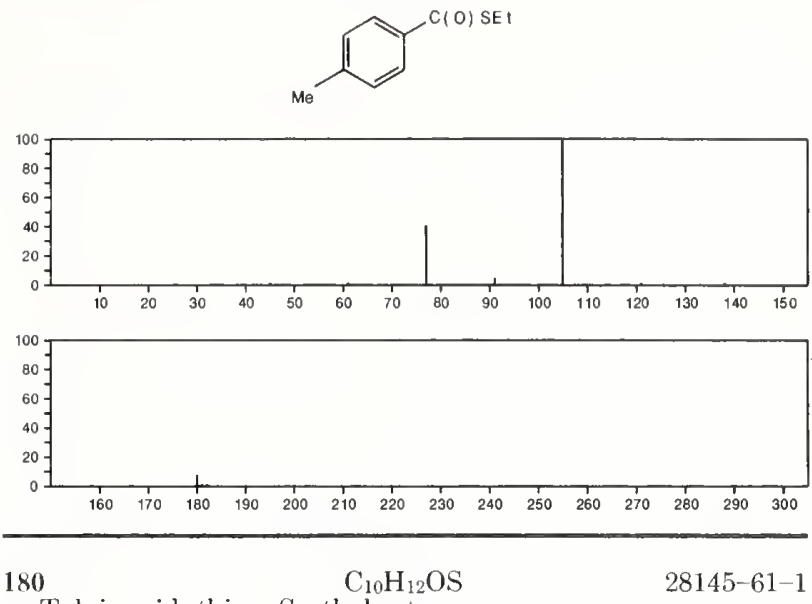

$m$-Toluic acid, thio-, S-ethyl ester
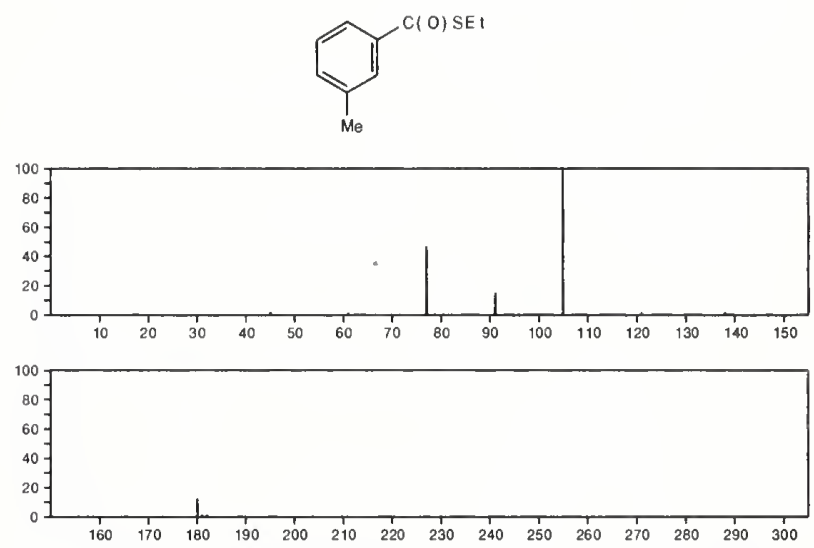

180

29549-68-6

Phenol, o-(2-butenylthio)-
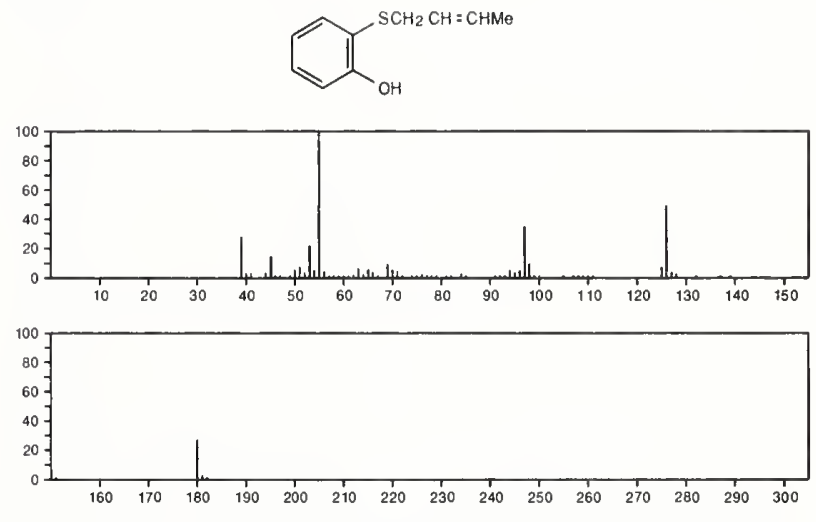

180

$\mathrm{C}_{10} \mathrm{H}_{12} \mathrm{O}_{3}$

Benzoic acid, 4-hydroxy-, propyl ester

$94-13-3$
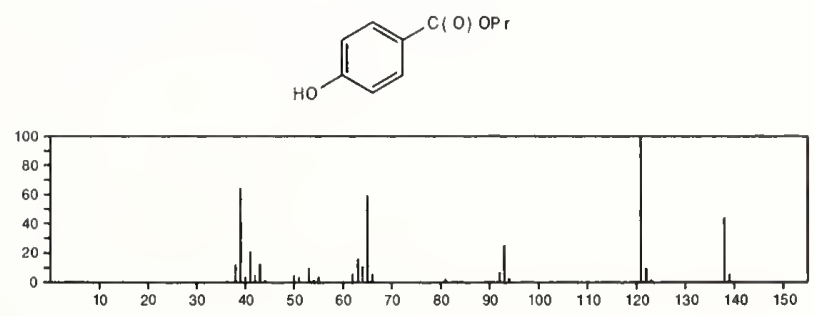


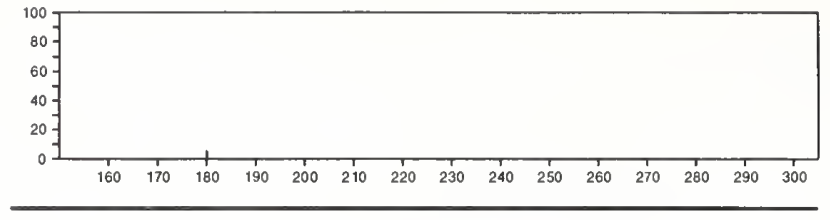

$180 \quad \mathrm{C}_{10} \mathrm{H}_{12} \mathrm{O}_{3} \quad 94-30-4$

Benzoic acid, 4-methoxy-, ethyl ester
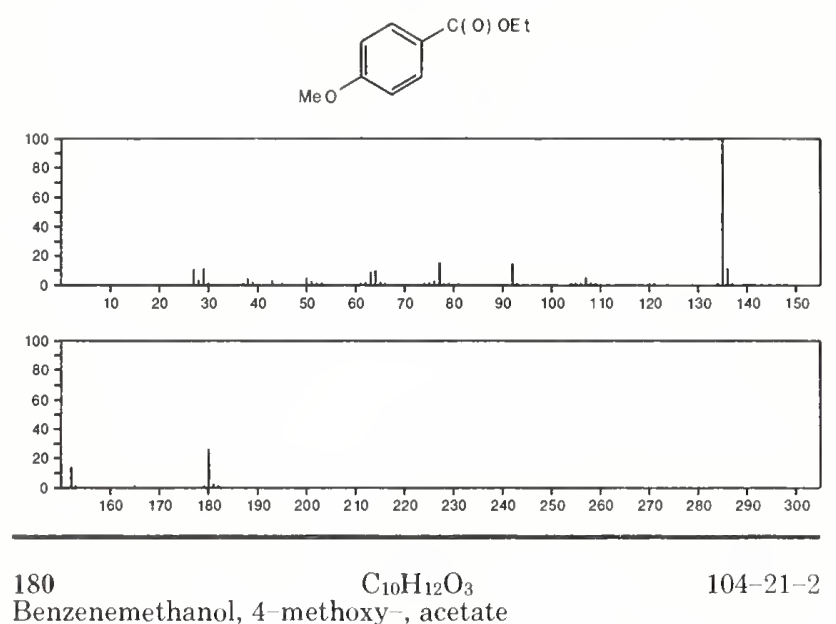

Benzenemethanol, 4-methoxy-, acetate
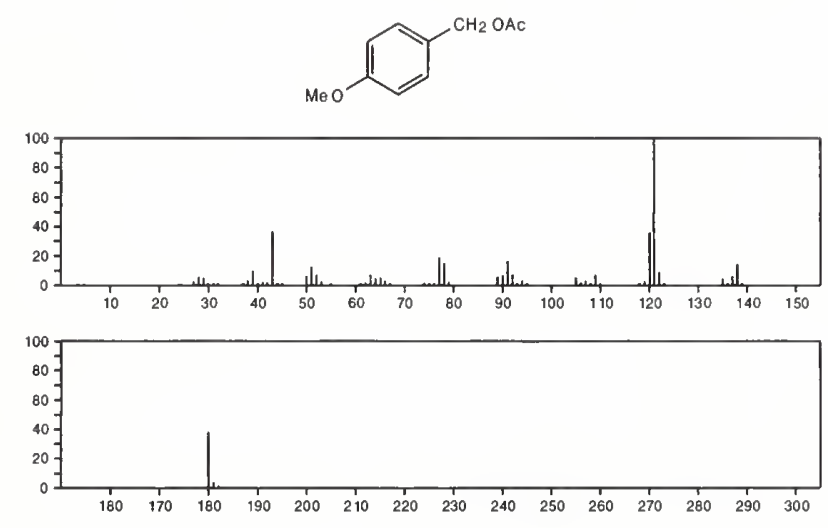

180

$\mathrm{C}_{10} \mathrm{H}_{12} \mathrm{O}_{3}$

Phenol, 4-(3-hydroxy-1-propenyl)-2-methoxy-

$458-35-5$
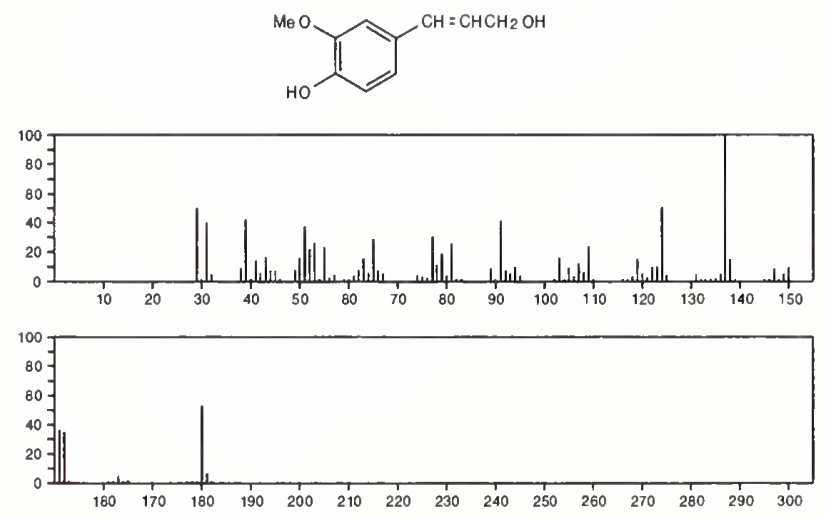

180

Benzeneacetic acid, $\alpha$-hydroxy-, ethyl ester

$774-40-3$

$\mathrm{E} t \mathrm{OC}(\mathrm{O}) \mathrm{CH}(\mathrm{OH}) \mathrm{Ph}$
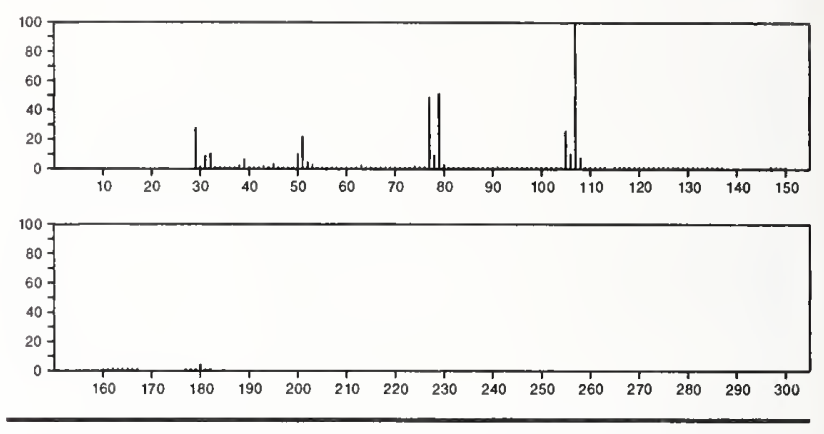

180

$\mathrm{C}_{10} \mathrm{H}_{12} \mathrm{O}_{3}$

$943-57-7$

Carbonic acid, 1-methylethyl phenyl ester

$\mathrm{PhOC}(\mathrm{O}) \mathrm{OPr}-1$
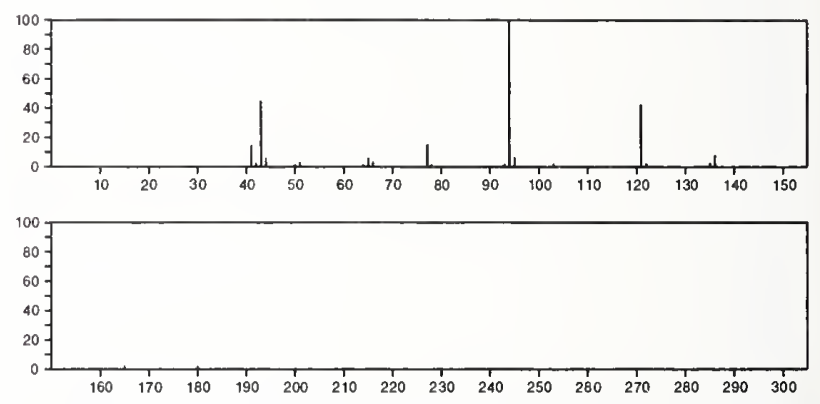

180

$\mathrm{C}_{10} \mathrm{H}_{12} \mathrm{O}_{3}$

Ethanone, 1-(3,4-dimethoxyphenyl)-

$1131-62-0$
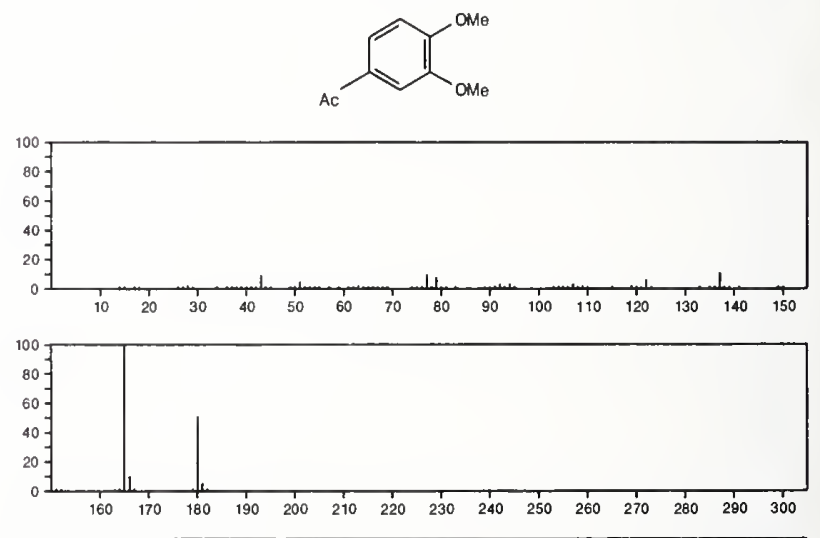

180

$\mathrm{C}_{10} \mathrm{H}_{12} \mathrm{O}_{3}$

$1331-83-5$

Benzenemethanol, ar-methoxy-, acetate
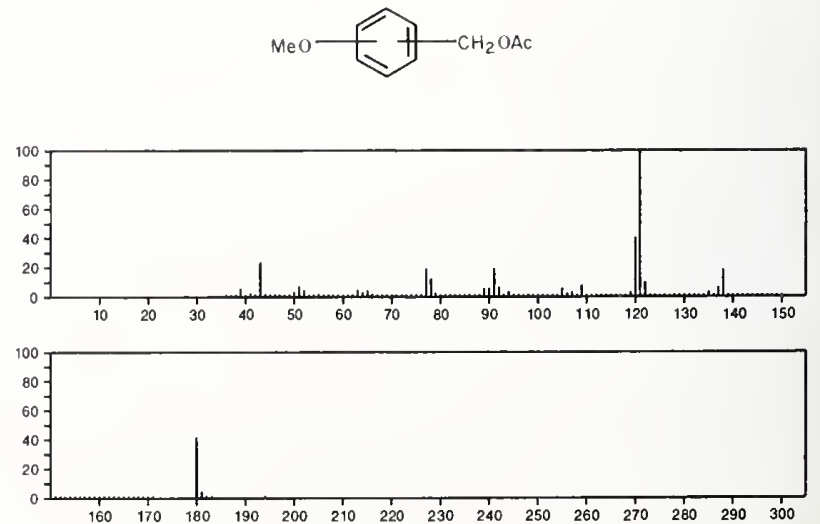
180

1,3-Dioxolane, 2-(4-methoxyphenyl)
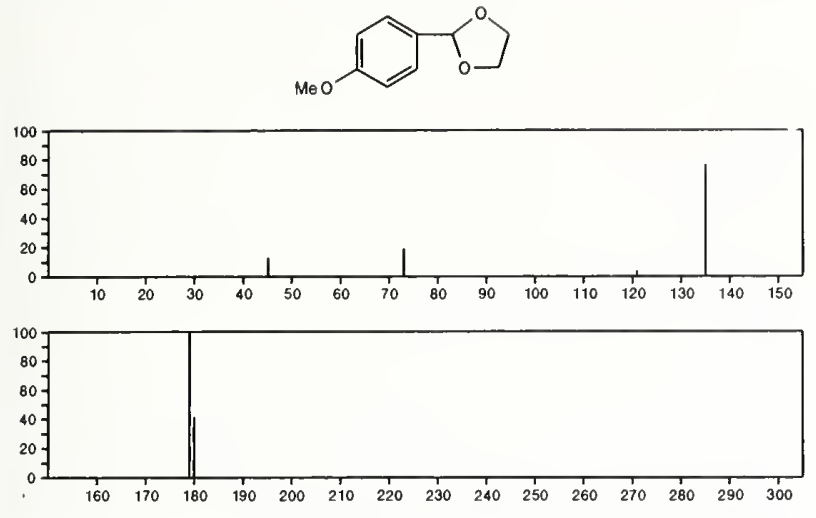

$180 \quad \mathrm{C}_{10} \mathrm{H}_{12} \mathrm{O}_{3}$

$2503-46-0$

2-Propanone, 1-(4-hydroxy-3-methoxyphenyl)-
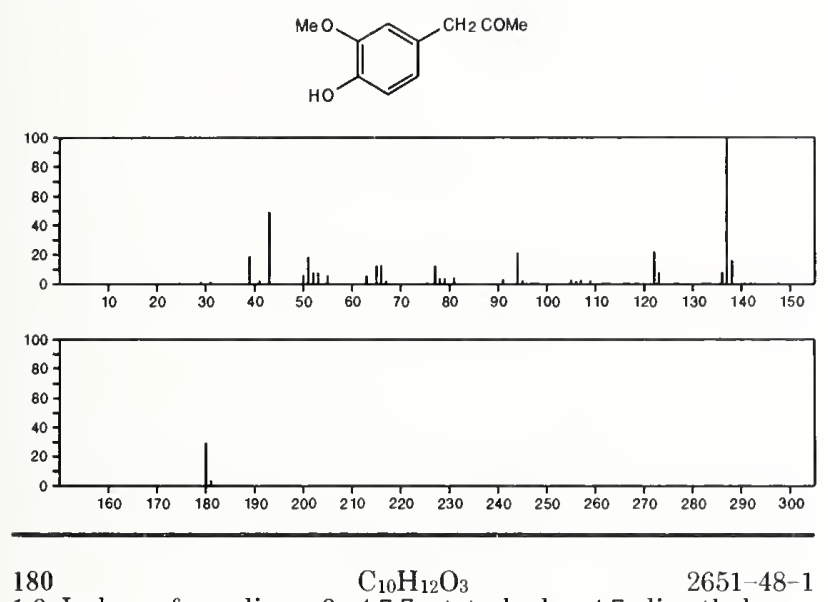

1,3-Isobenzofurandione, 3a,4,7,7a-tetrahydro-4,7-dimethyl
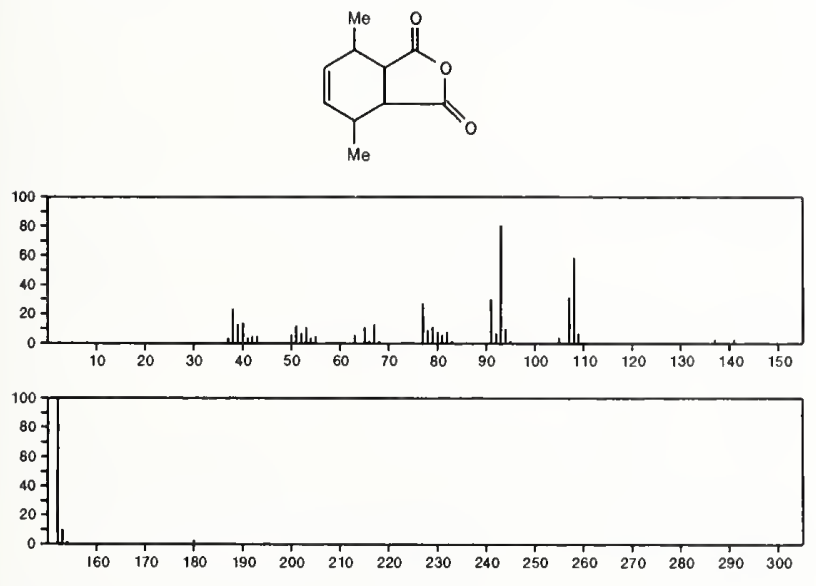

$$
180
$$

$180 \quad \mathrm{C}_{10} \mathrm{H}_{12} \mathrm{O}_{3} \quad 4223-84-1$

Ethanone, 1-(2-hydroxy-5-methoxy-4-methylphenyl)-
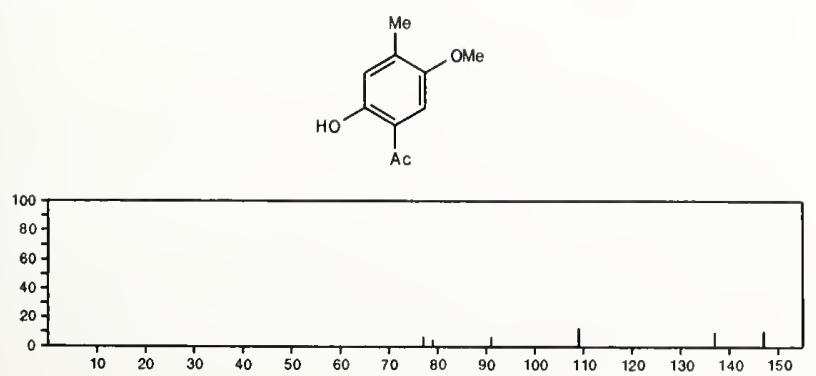

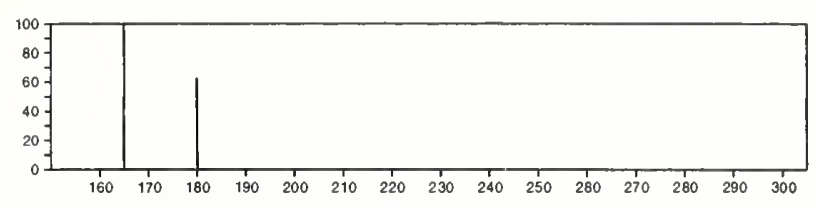

180

$\mathrm{C}_{10} \mathrm{H}_{12} \mathrm{O}_{3}$

$5438-24-4$

1,3-Isobenzofurandione, 3a,4,7,7a-tetrahydro-5,6-dimethyl-<smiles>CC1=C(C)CC2C(=O)OC(=O)C2C1</smiles>
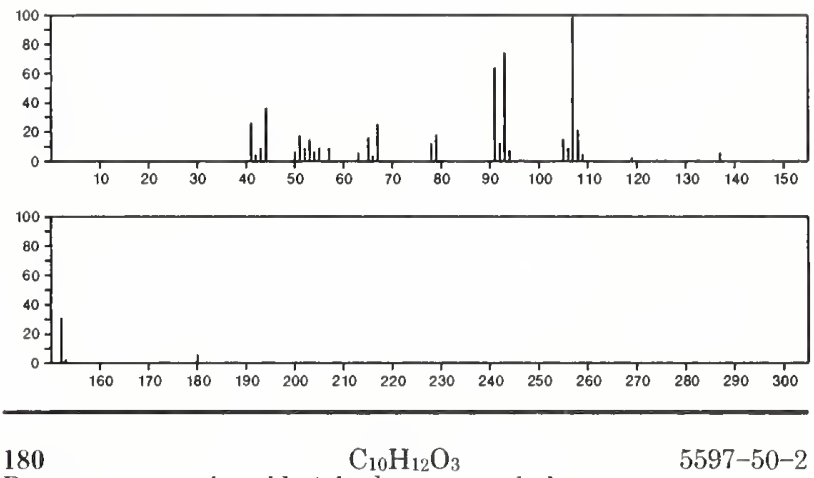

Benzenepropanoic acid, 4-hydroxy-, methyl ester
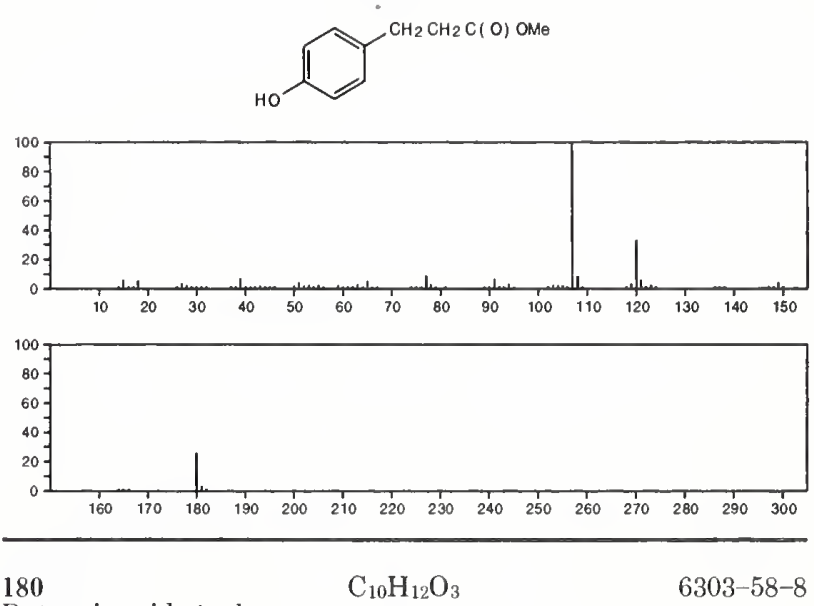

Butanoic acid, 4-phenoxy-

$\mathrm{HO}_{2} \mathrm{C}\left(\mathrm{CH}_{2}\right)_{3} \mathrm{OPh}$
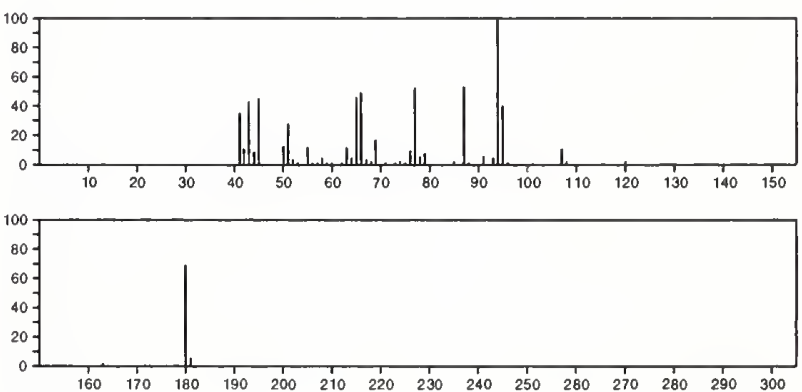
180

$\mathrm{C}_{10} \mathrm{H}_{12} \mathrm{O}_{3}$

Benzaldehyde, 2,4-dimethoxy-6-methyl
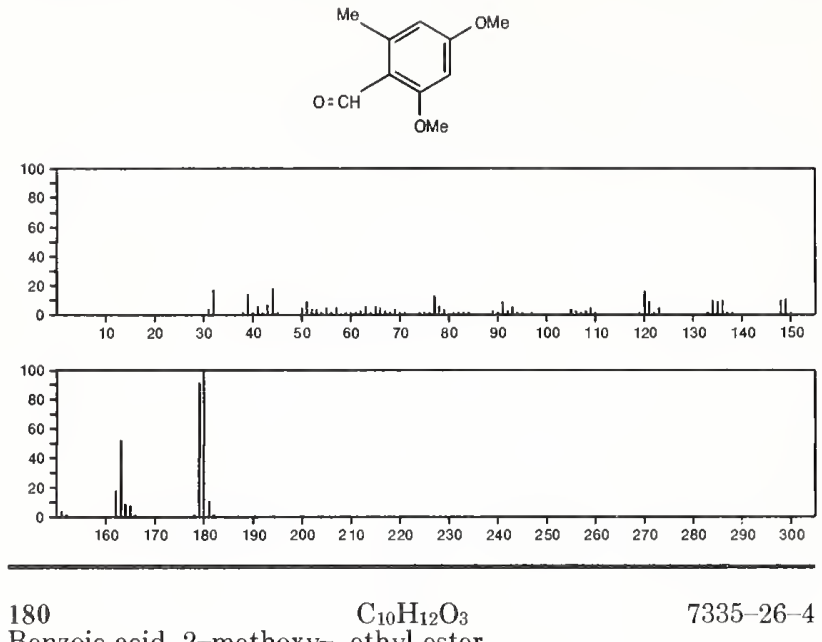

Benzoic acid, 2-methoxy-, ethyl ester
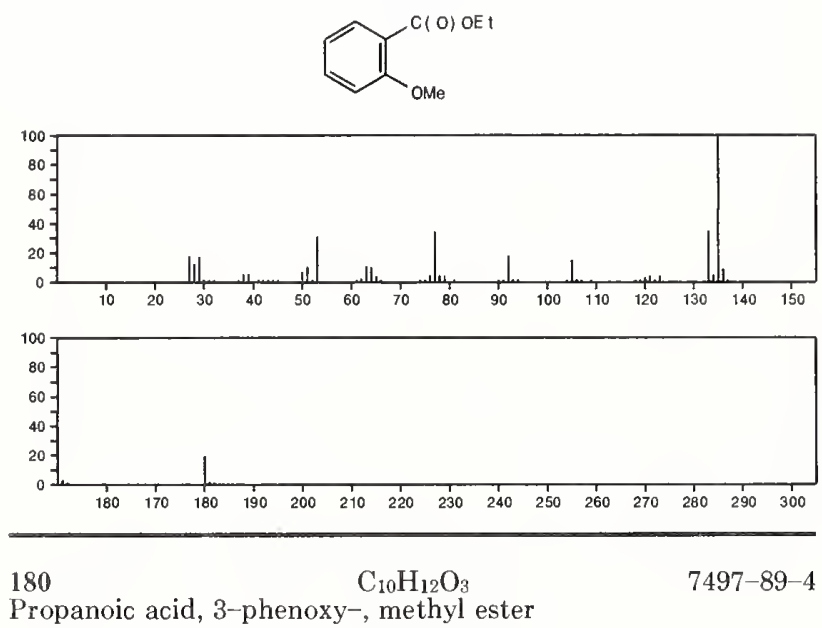

$\mathrm{PhOCH} 2 \mathrm{CH}_{2} \mathrm{C}(\mathrm{O}) \mathrm{OMe}$
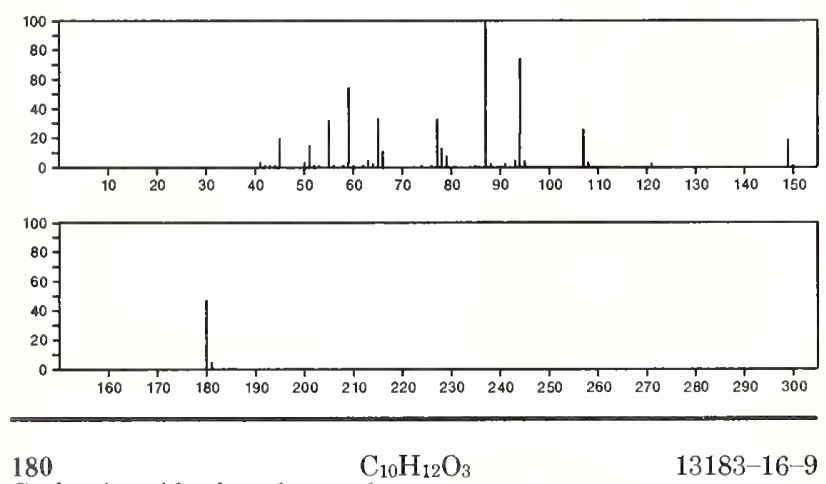

Carbonic acid, phenyl propyl ester

$13183-16-9$

PhOC (O) OPt
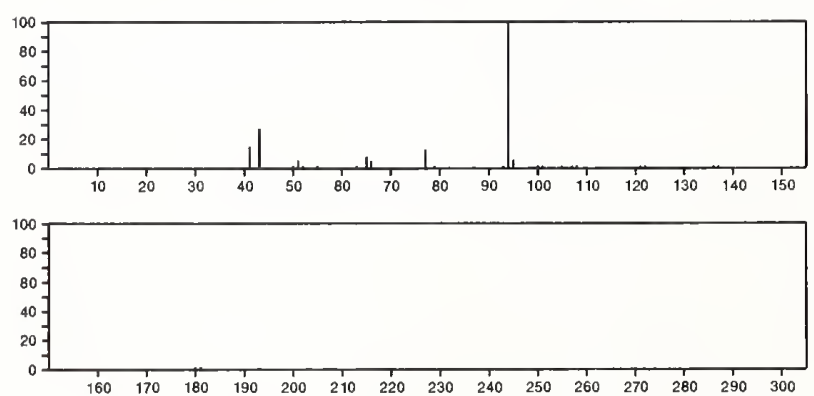

180

$\mathrm{C}_{10} \mathrm{H}_{12} \mathrm{O}_{3}$

13674-16-3

Benzenepropanoic acid, $\alpha$-hydroxy-, methyl ester

$\mathrm{MeOC}(\mathrm{O}) \mathrm{CH}(\mathrm{OH}) \mathrm{CH}_{2} \mathrm{Ph}$
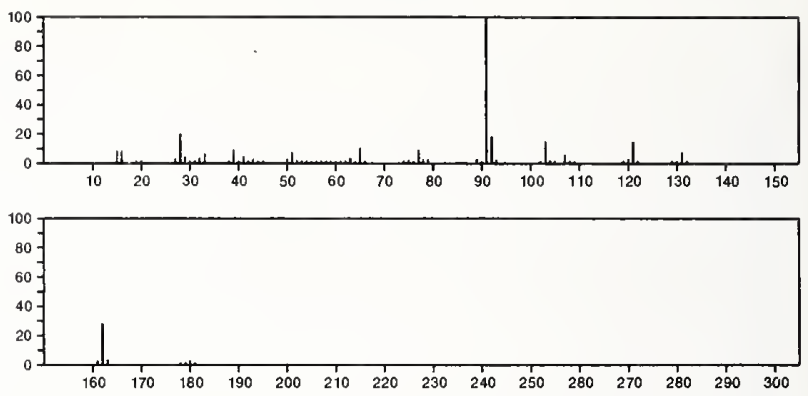

180

$\mathrm{C}_{10} \mathrm{H}_{12} \mathrm{O}_{3}$

$17138-28-2$

Benzeneacetic acid, 4-hydroxy-, ethyl ester
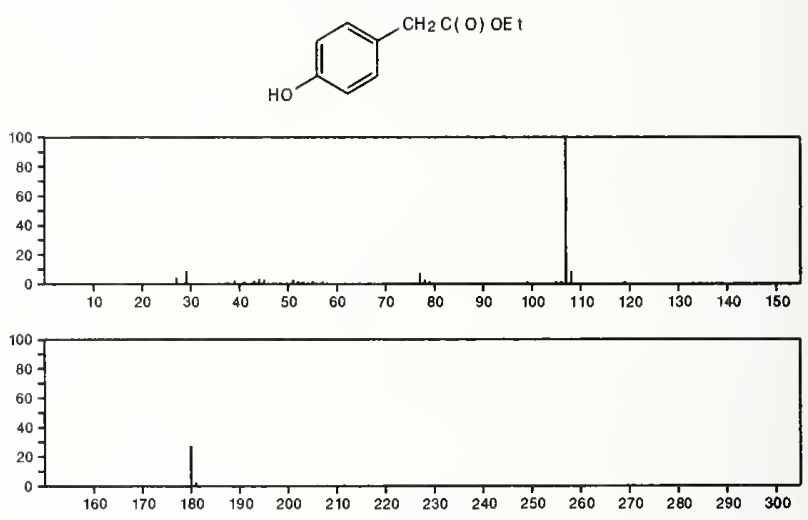

180

$\mathrm{C}_{10} \mathrm{H}_{12} \mathrm{O}_{3}$

$18927-05-4$

Benzeneacetic acid, 3-methoxy-, methyl ester
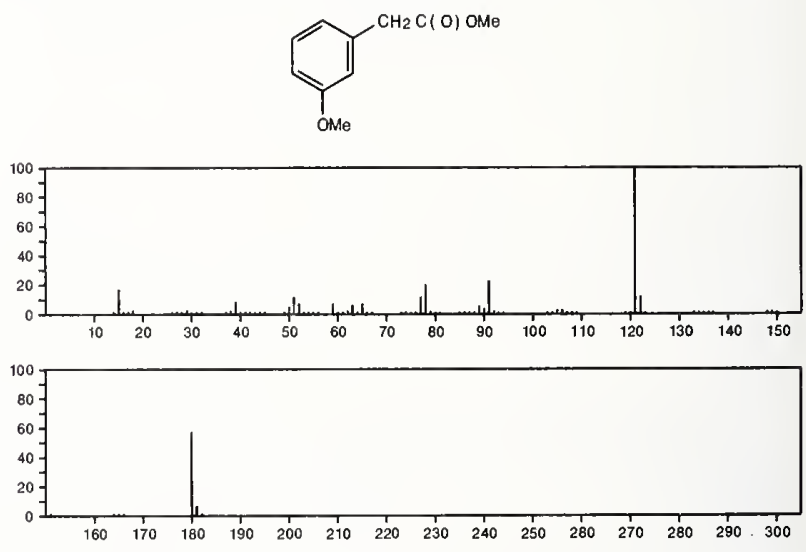

$180 \quad \mathrm{C}_{10} \mathrm{H}_{12} \mathrm{O}_{3}$

Mandelic acid, $\alpha$-methyl-, methyl ester

20731-95-7

$\mathrm{MeOC}(\mathrm{O}) \mathrm{CMe}(\mathrm{OH}) \mathrm{Ph}$
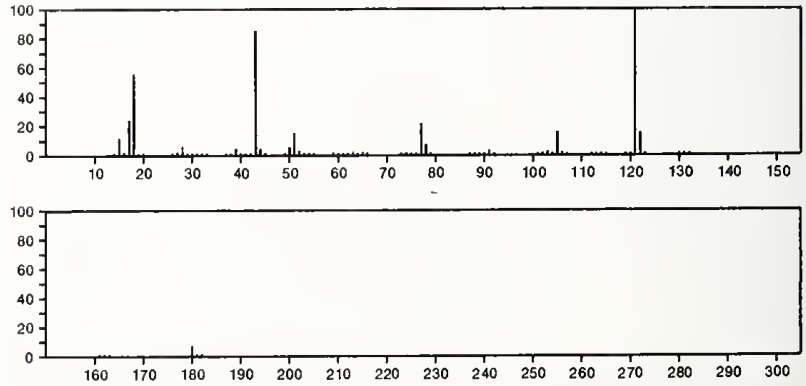
180 $\mathrm{C}_{10} \mathrm{H}_{12} \mathrm{O}_{3}$

Acetic acid, ( $m$-hydroxyphenyl)-, ethyl ester

$22446-38-4$
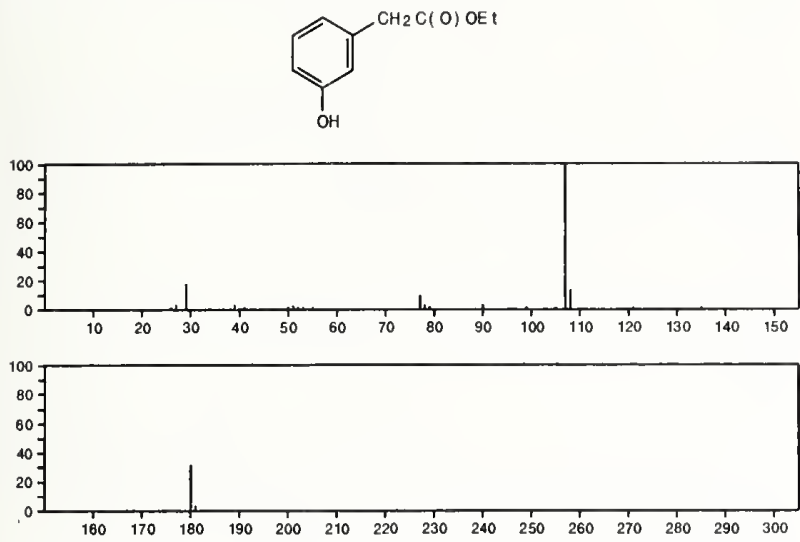

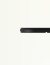

180

$\mathrm{C}_{10} \mathrm{H}_{12} \mathrm{O}_{3}$

$23786-14-3$

Benzeneacetic acid, 4-methoxy-, methyl ester
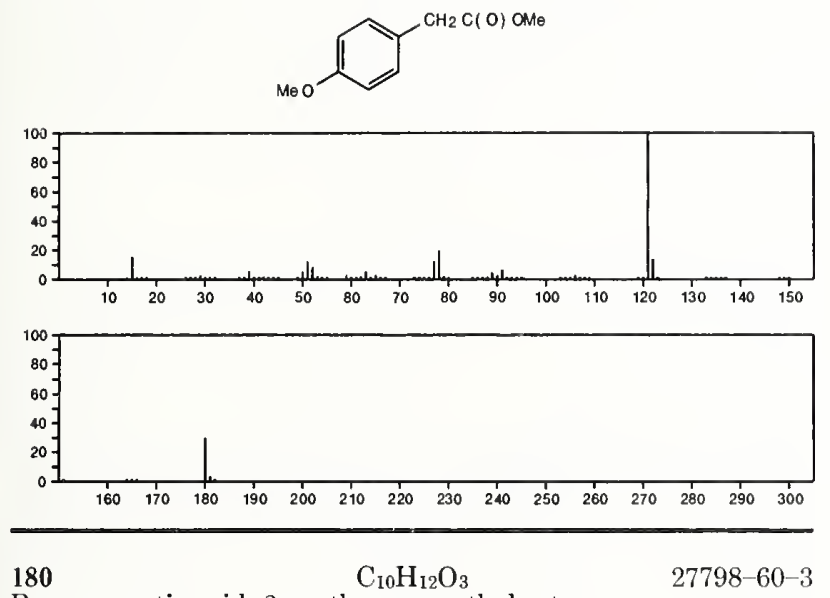

Benzeneacetic acid, 2-methoxy-, methyl ester
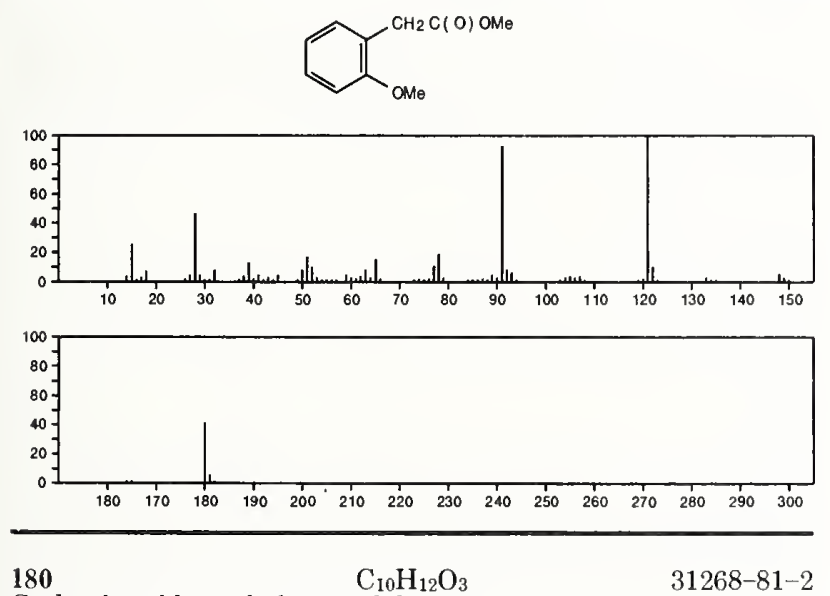

$31268-81-2$

Carbonic acid, methyl 3,4-xylyl ester
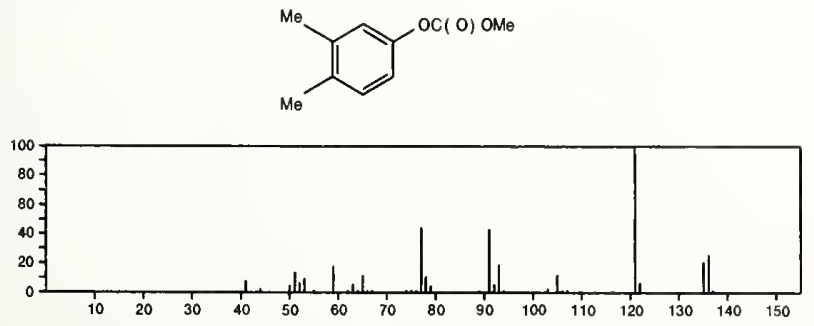
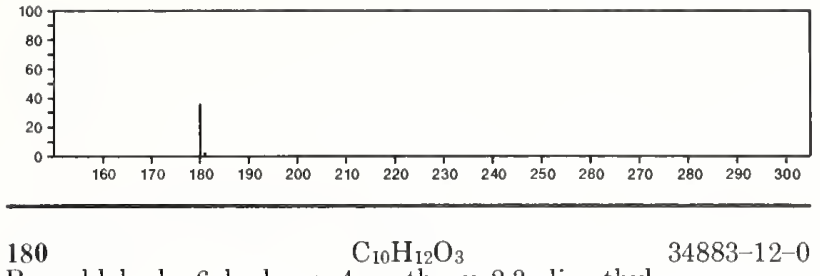

Benzaldehyde, 6-hydroxy-4-methoxy-2,3-dimethyl-
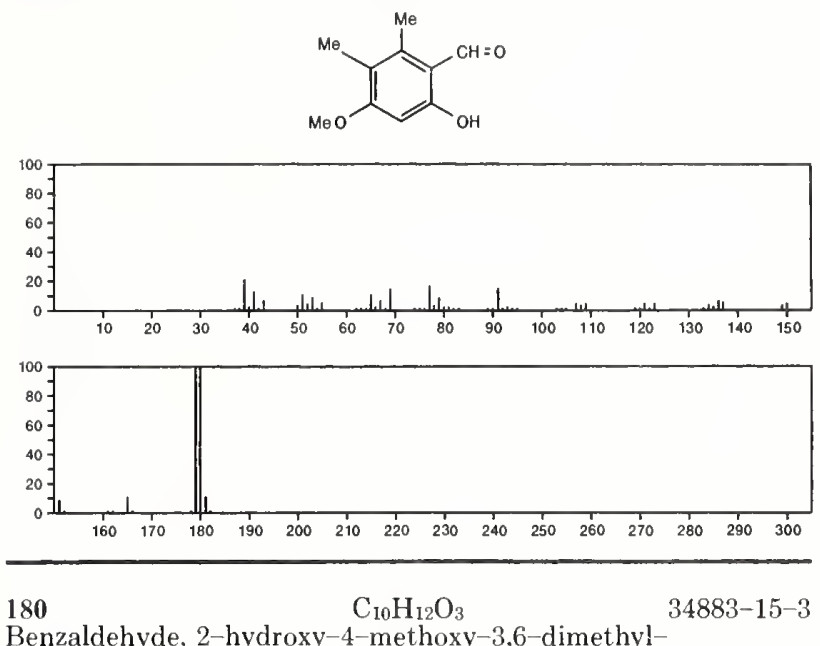

Benzaldehyde, 2-hydroxy-4-methoxy-3,6-dimethy!-
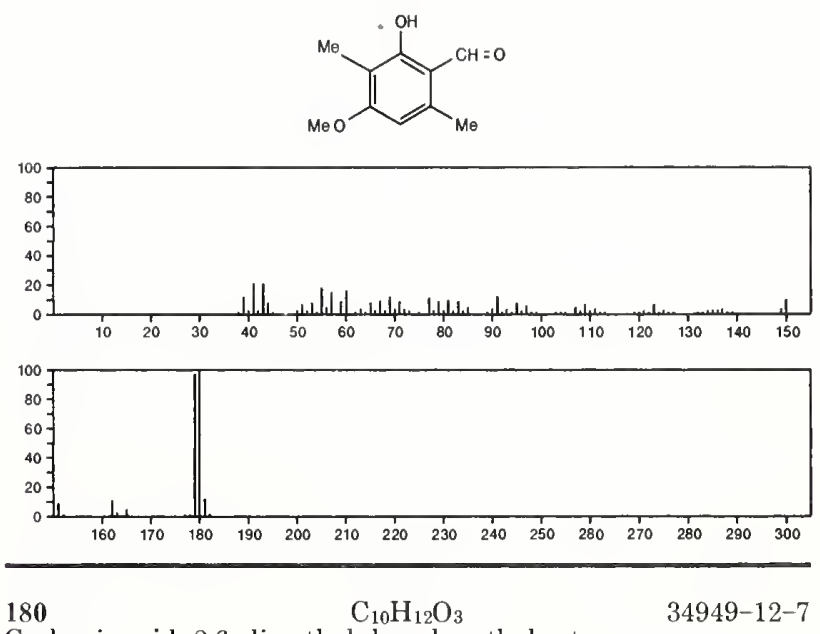

$34949-12-7$

Carbonic acid, 2,6-dimethylphenyl methyl ester
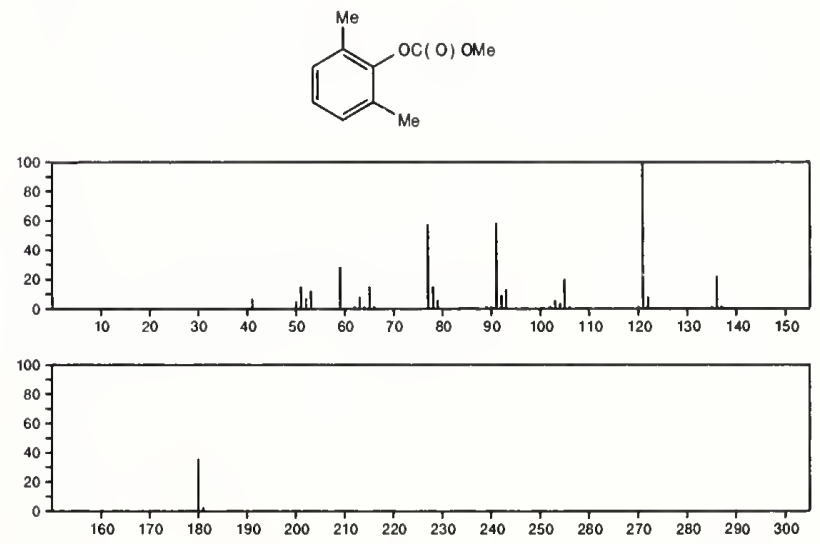
180

$\mathrm{C}_{10} \mathrm{H}_{12} \mathrm{O}_{3}$

$35942-12-2$

4H-1-Benzopyran-4-one, 5,6,7,8-tetrahydro-3-hydroxy-2-methyl-<smiles>Cc1oc2c(c(=O)c1O)CCCC2</smiles>
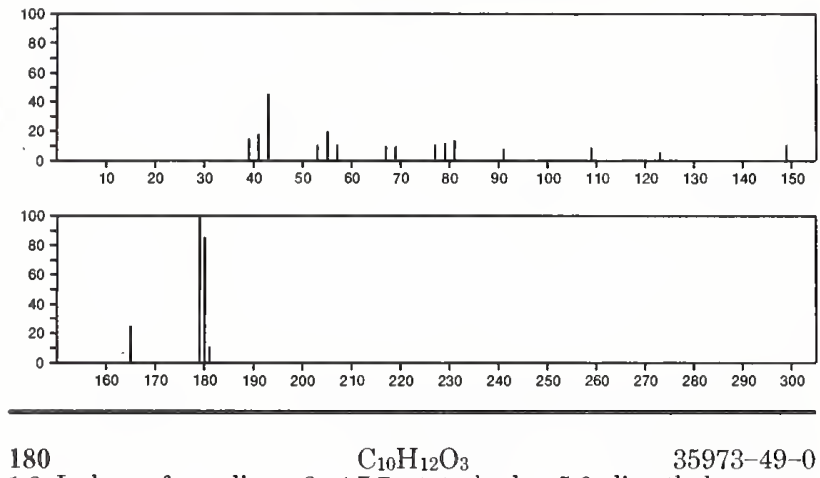

1,3-Isobenzofurandione, 3a,4,7,7a-tetrahydro-5,6-dimethyl-, trans-
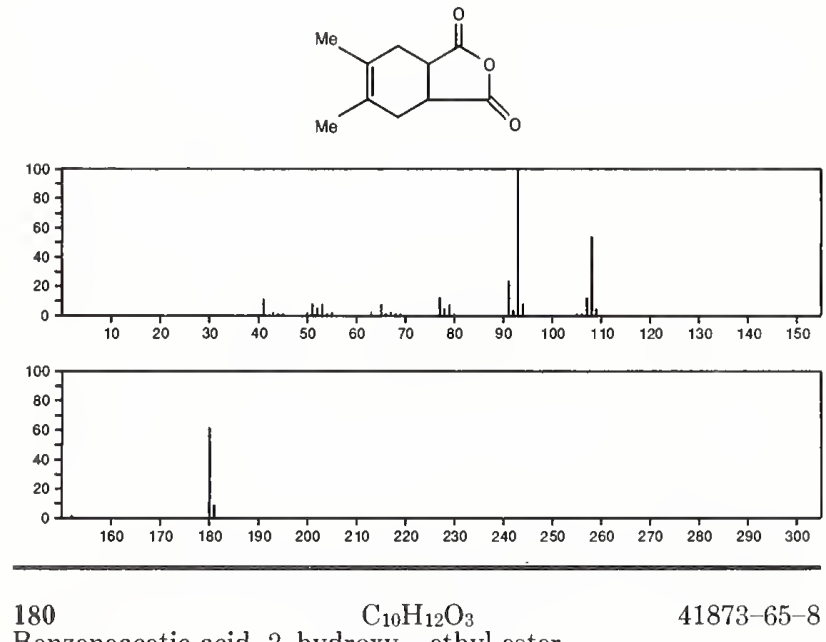

Benzeneacetic acid, 2-hydroxy-, ethyl ester
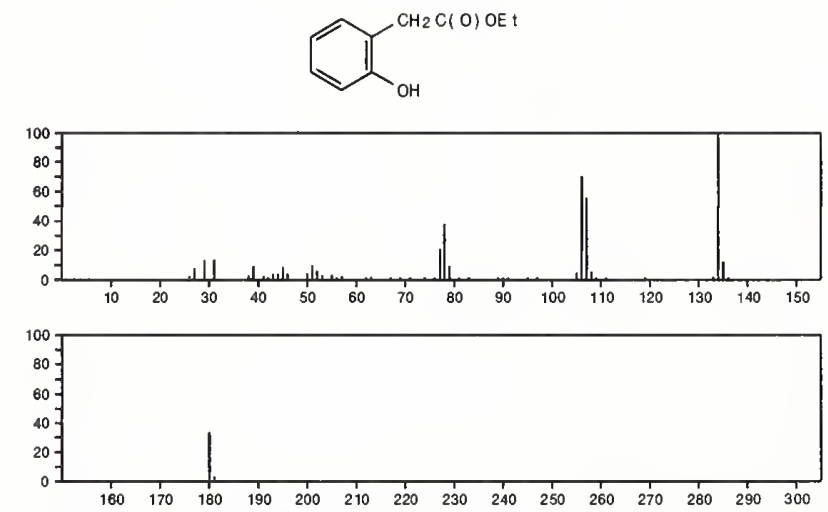

180

Ethanol, 1-methoxy-, benzoate

$$
\mathrm{C}_{10} \mathrm{H}_{12} \mathrm{O}_{3}
$$

$51835-44-0$

$\mathrm{MeCH}(\mathrm{OMe}) \mathrm{OC}(\mathrm{O}) \mathrm{Ph}$

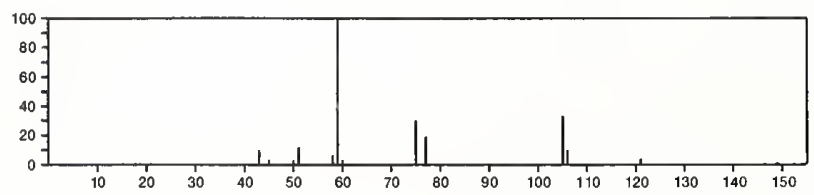

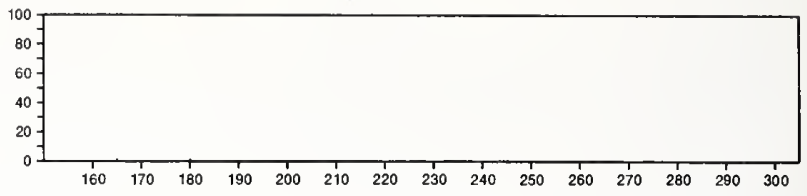

180

$\mathrm{C}_{10} \mathrm{H}_{12} \mathrm{O}_{3}$

$51835-45-1$

Benzenemethanol, $\alpha$-methoxy-, acetate

$\mathrm{ACOCH}$ ( OMe ) Ph
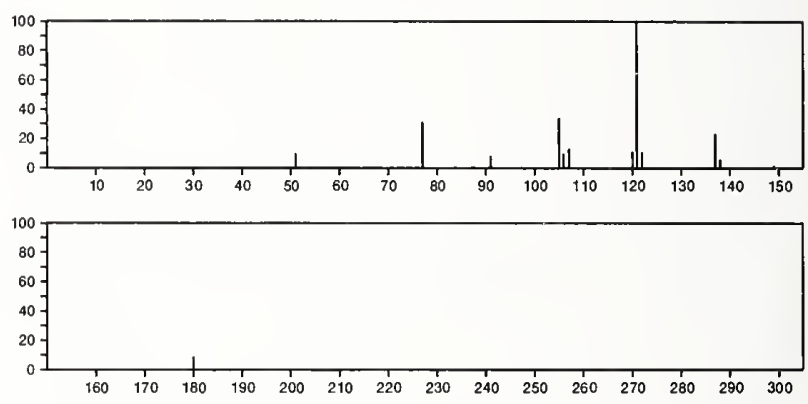

180

$\mathrm{C}_{10} \mathrm{H}_{12} \mathrm{O}_{3}$

$54576-43-1$

1,3-Isobenzofurandione, 4,5,6,7-tetrahydro-4,7-dimethyl-
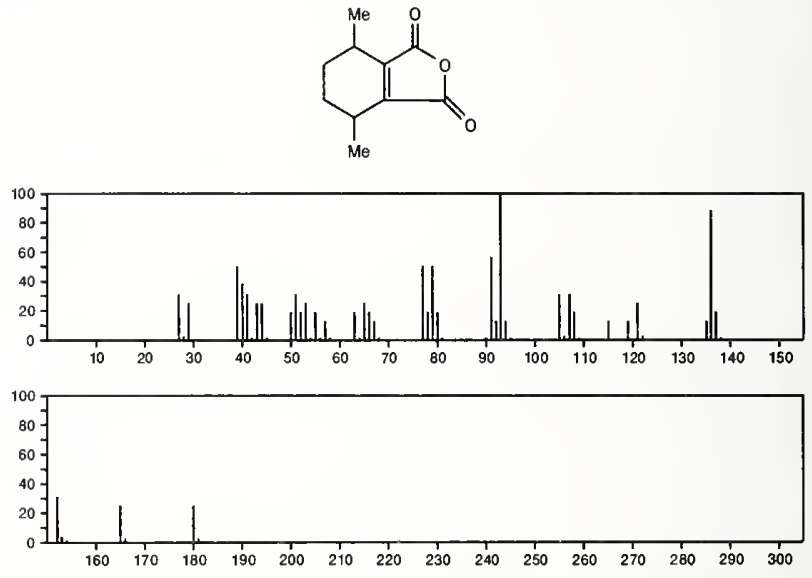

180

$\mathrm{C}_{10} \mathrm{H}_{12} \mathrm{O}_{3}$

$54644-27-8$

1,2,4-Cyclopentanetrione, 3-(2-pentenyl)-
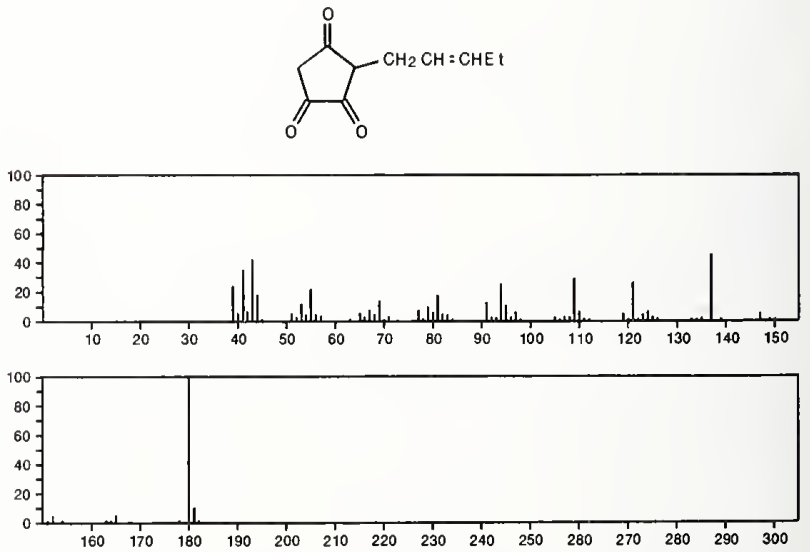
180

Carbonic acid, 2,3-dimethylphenyl methyl ester
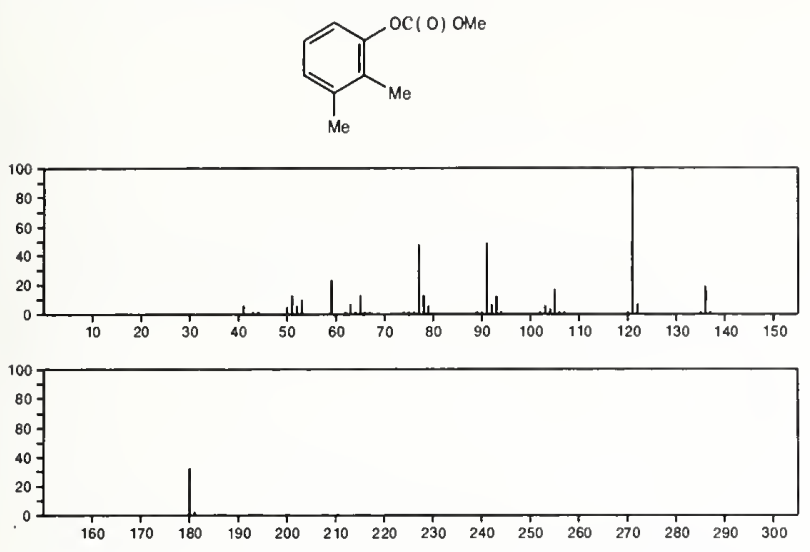

180

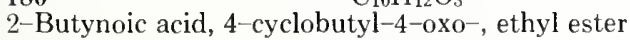

$54966-51-7$
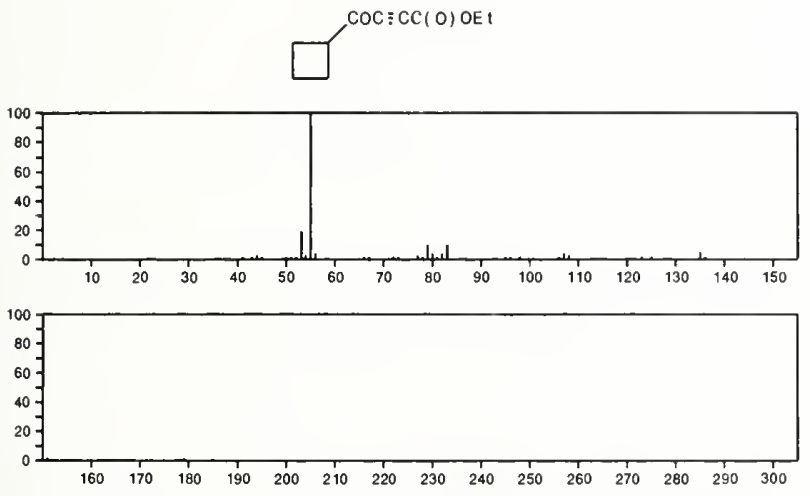

180

$\mathrm{C}_{10} \mathrm{H}_{12} \mathrm{O}_{3}$

$55836-64-1$

Benzoic acid, 2-ethyl-6-hydroxy-, methyl ester
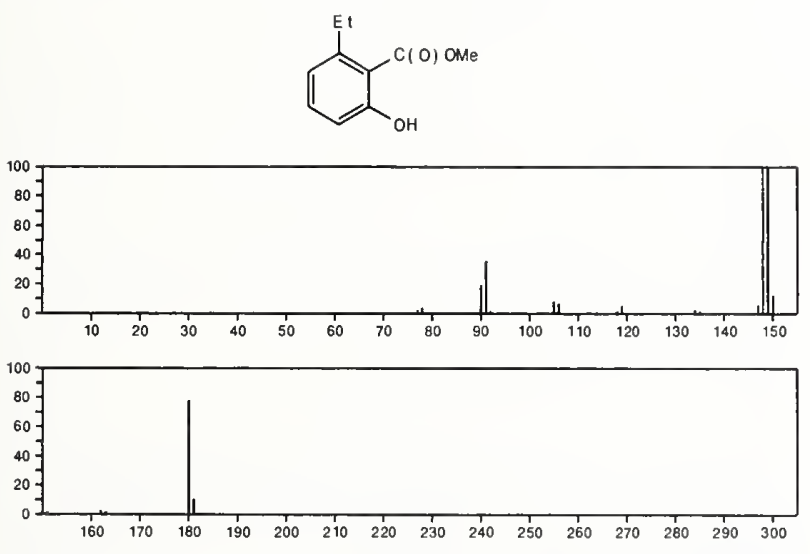

$180 \quad \mathrm{C}_{10} \mathrm{H}_{12} \mathrm{O}_{3} \quad 56143-21-6$

Benzeneacetic acid, $\alpha$-methoxy-, methyl ester, $( \pm)-$

$\mathrm{MeOC}(\mathrm{O}) \mathrm{CH}(\mathrm{OMe}) \mathrm{Ph}$

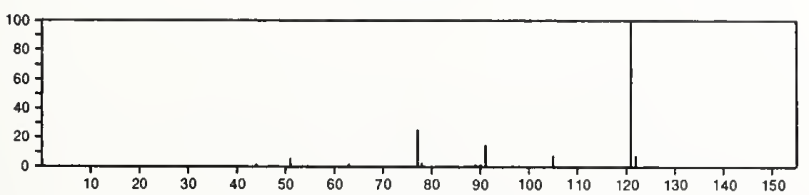

$180 \quad \mathrm{C}_{10} \mathrm{H}_{12} \mathrm{O}_{3}$

Tricyclo[3.3.1.13,7]decane-2,6-dione, 4-hydroxy-

$56781-80-7$
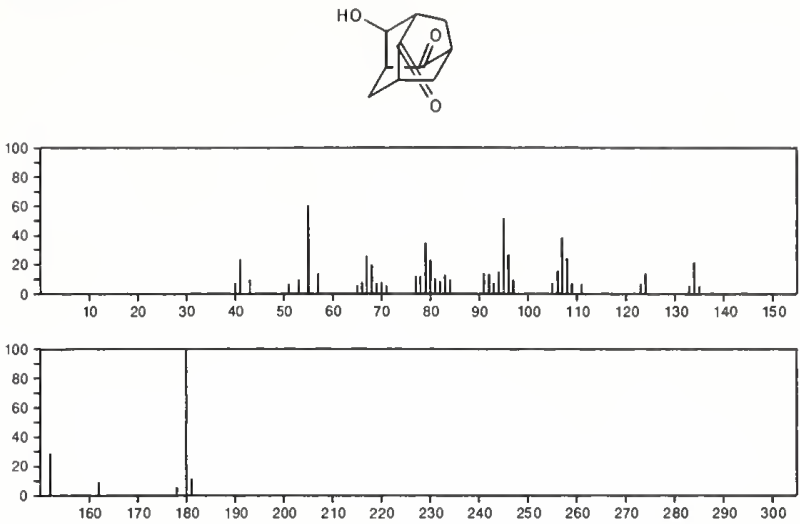

180

$\mathrm{C}_{10} \mathrm{H}_{16} \mathrm{~N}_{2} \mathrm{O}$

$52196-11-9$

1-Piperidinecarboxaldehyde, 2-(3,4-dihydro- $2 H$-pyrrol-5-yl)-
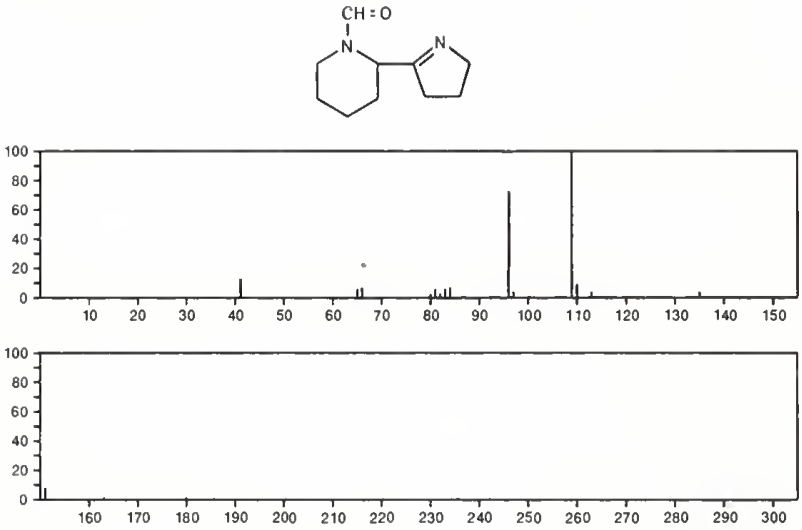

180

$\mathrm{C}_{10} \mathrm{H}_{16} \mathrm{OSi}$

Silane, (4-methoxyphenyl)trimethyl-

877-68-9
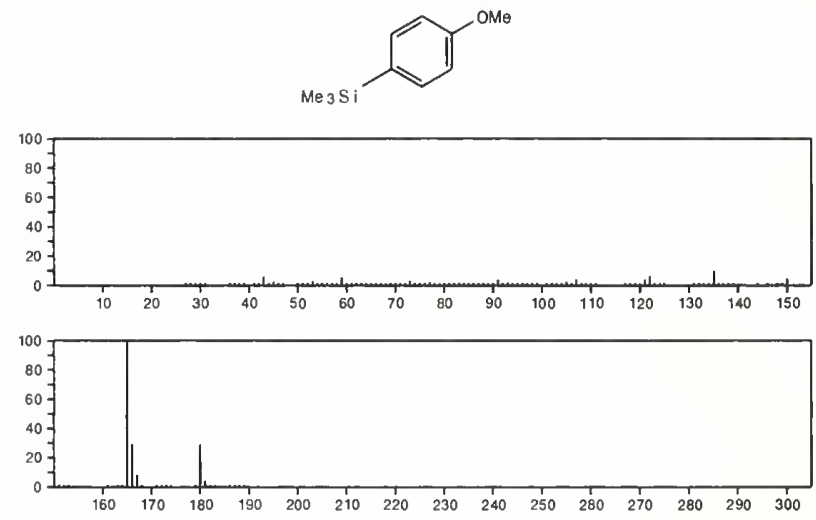

180

$\mathrm{C}_{10} \mathrm{H}_{16} \mathrm{OSi}$

Silane, trimethyl(2-methylphenoxy)-

1009-02-5
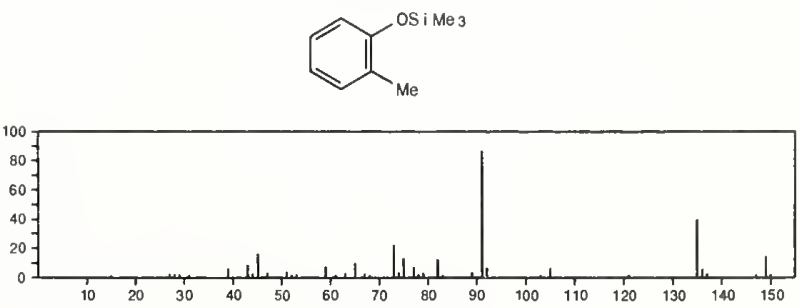


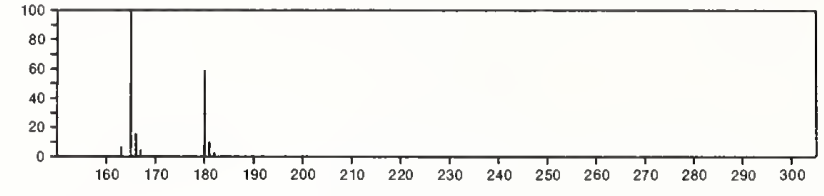

180

$\mathrm{C}_{10} \mathrm{H}_{16} \mathrm{OSi}$

Silane, trimethyl(phenylmethoxy)

$\mathrm{Me}_{3} \mathrm{Si} \mathrm{OCH}_{2} \mathrm{Ph}$
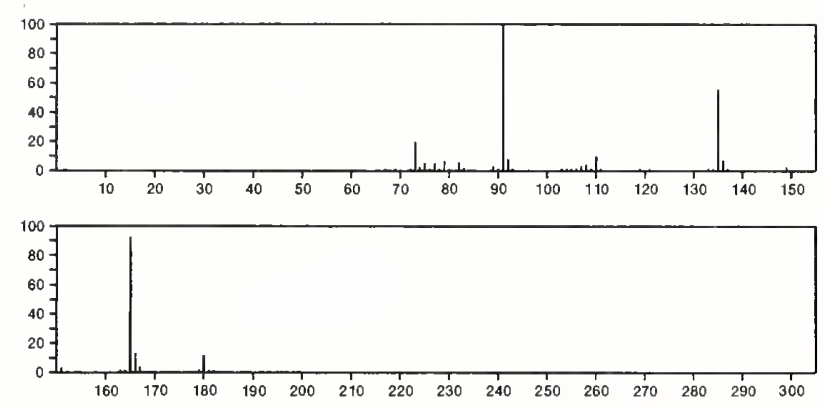

180

$\mathrm{C}_{10} \mathrm{H}_{16} \mathrm{OSi}$

Silane, trimethyl(3-methylphenoxy)-
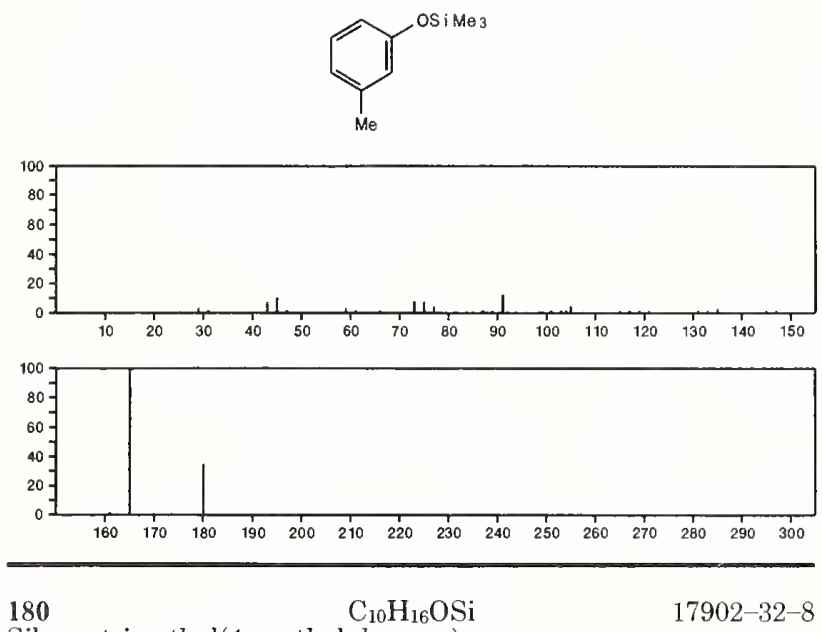

$17902-32-8$

Silane, trimethyl(4-methylphenoxy)-
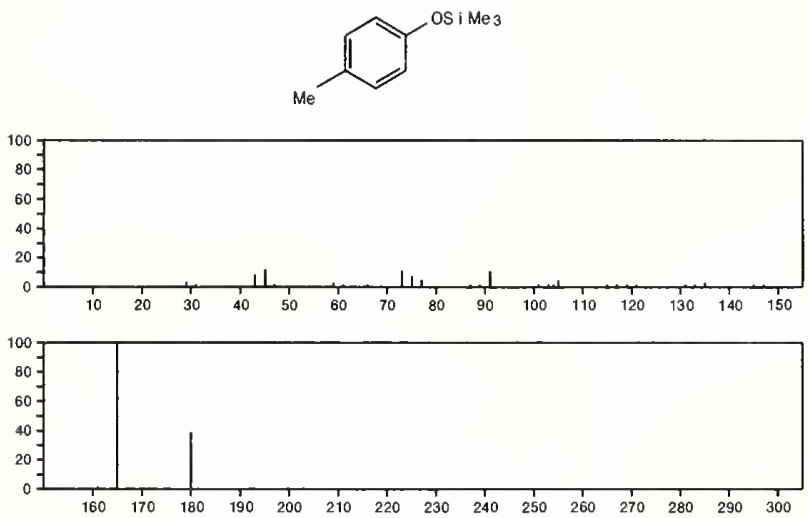

180 $\mathrm{C}_{10} \mathrm{H}_{17} \mathrm{BO}_{2}$

26600-82-8

1-Butaneboronic acid, cyclic 1-cyclohexen-1,2-ylene ester
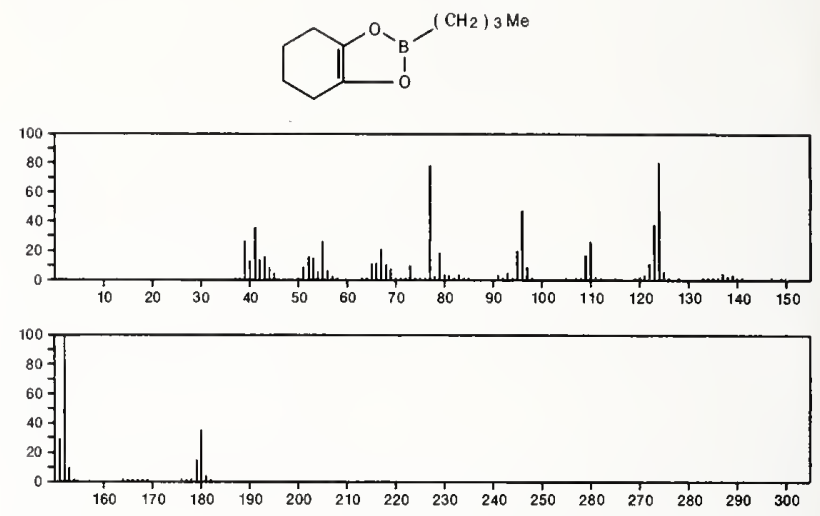

180

$\mathrm{C}_{11} \mathrm{H}_{16} \mathrm{O}_{2}$

$1202-10-4$

4H-Pyran-4-one, 2,6-diethyl-3,5-dimethyl-
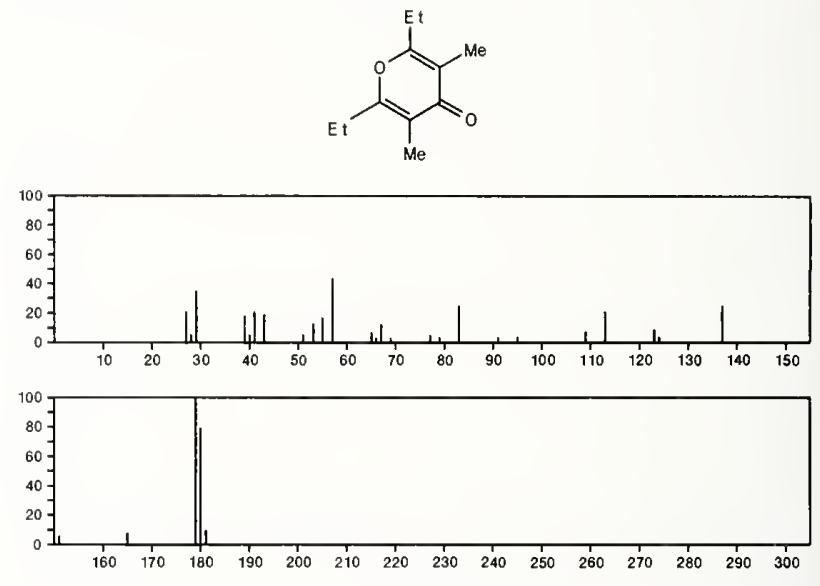

180

$$
\mathrm{C}_{11} \mathrm{H}_{16} \mathrm{O}_{2}
$$

4541-14-4

1-Butanol, 4-(phenylmethoxy)-

$\mathrm{PhCH}_{2} \mathrm{O}\left(\mathrm{CH}_{2}\right)_{4} \mathrm{OH}$
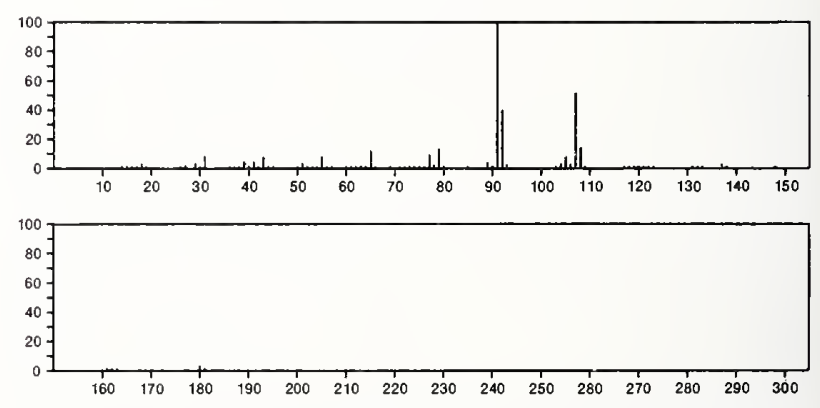

180

2-Butanol, 4-(benzyloxy)

$$
\mathrm{C}_{11} \mathrm{H}_{16} \mathrm{O}_{2}
$$

4799-69-3

$\mathrm{MeCH}(\mathrm{OH}) \mathrm{CH}_{2} \mathrm{CH}_{2} \mathrm{OCH}_{2} \mathrm{Ph}$
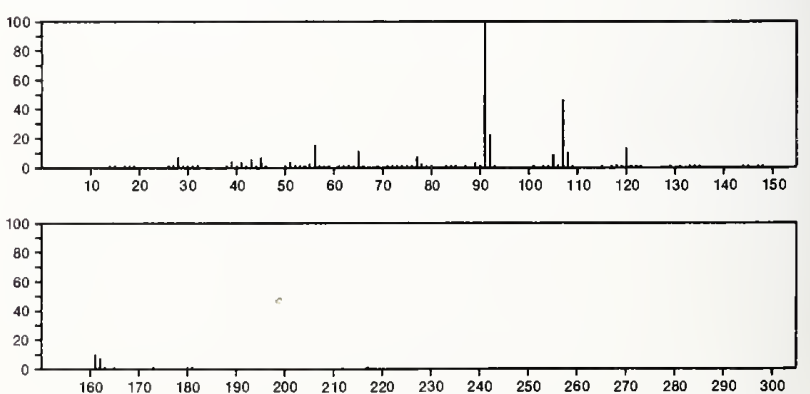
180 $\mathrm{C}_{11} \mathrm{H}_{16} \mathrm{O}_{2}$

$5107-69-7$

Methane, sec-butoxyphenoxy-

$\mathrm{PhOCH}_{2} \mathrm{OBu}-\mathrm{s}$
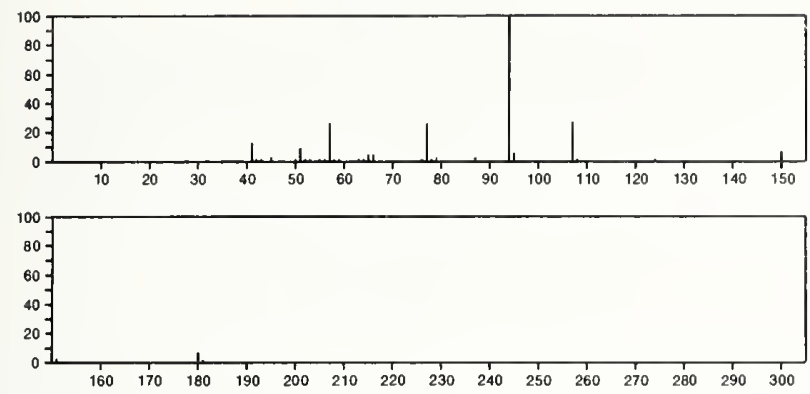

$\begin{array}{lllllllllllllll}160 & 170 & 180 & 190 & 200 & 210 & 220 & 230 & 240 & 250 & 260 & 270 & 280 & 290 & 300\end{array}$

180

$\mathrm{C}_{11} \mathrm{H}_{16} \mathrm{O}_{2}$

$14869-00-2$

2-Butanol, 1-(phenylmethoxy)-

$\mathrm{PhCH}_{2} \mathrm{OCH}_{2} \mathrm{CH}(\mathrm{OH}) \mathrm{Et}$
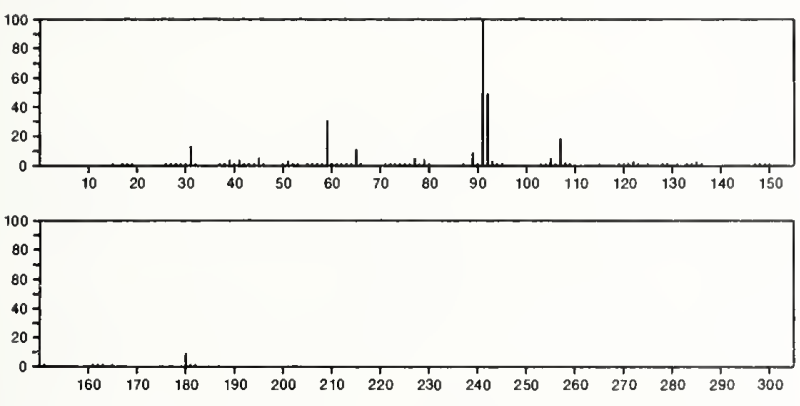

180

$\mathrm{C}_{11} \mathrm{H}_{16} \mathrm{O}_{2}$

$15356-74-8$

2(4H)-Benzofuranone, 5,6,7,7a-tetrahydro-4,4,7a- trimethyl
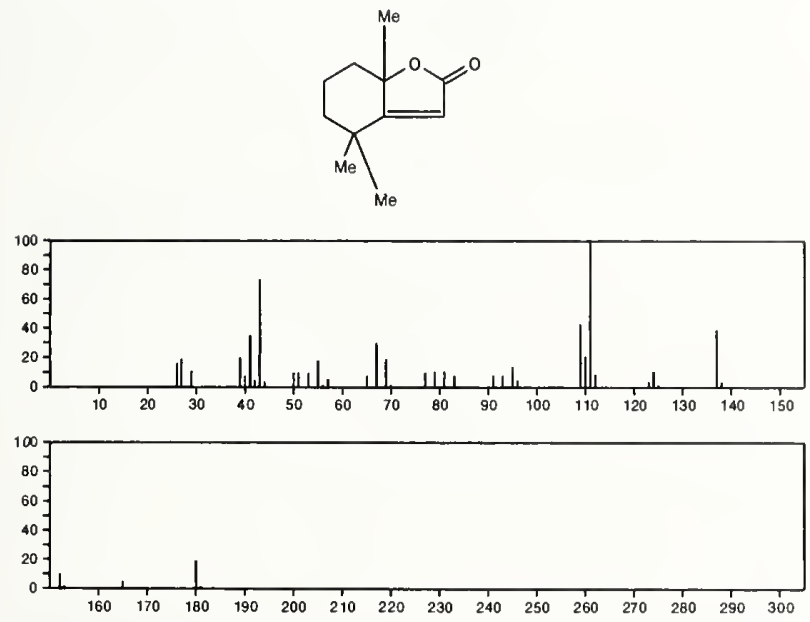

180

$\mathrm{C}_{11} \mathrm{H}_{16} \mathrm{O}_{2}$

16778-26-0

2(3H)-Benzofuranone, 3a,4,5,6-tetrahydro-3a,6,6-trimethyl-
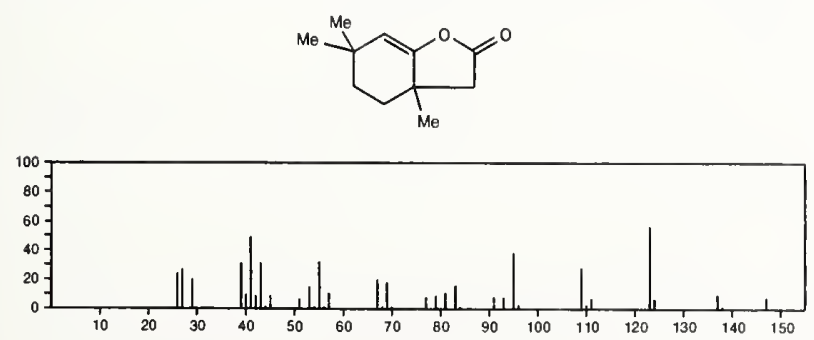

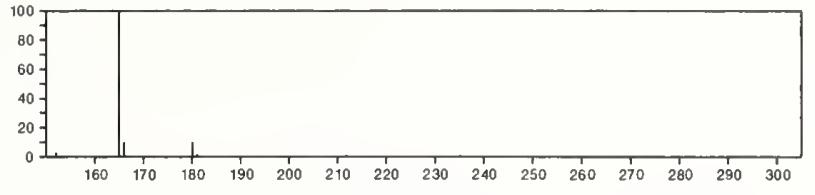

$\mathrm{C}_{11} \mathrm{H}_{16} \mathrm{O}_{2}$

17092-92-1

180

2(4H)-Benzofuranone, 5,6,7,7a-tetrahydro-4,4,7a-trimethyl-, $(S)$ -
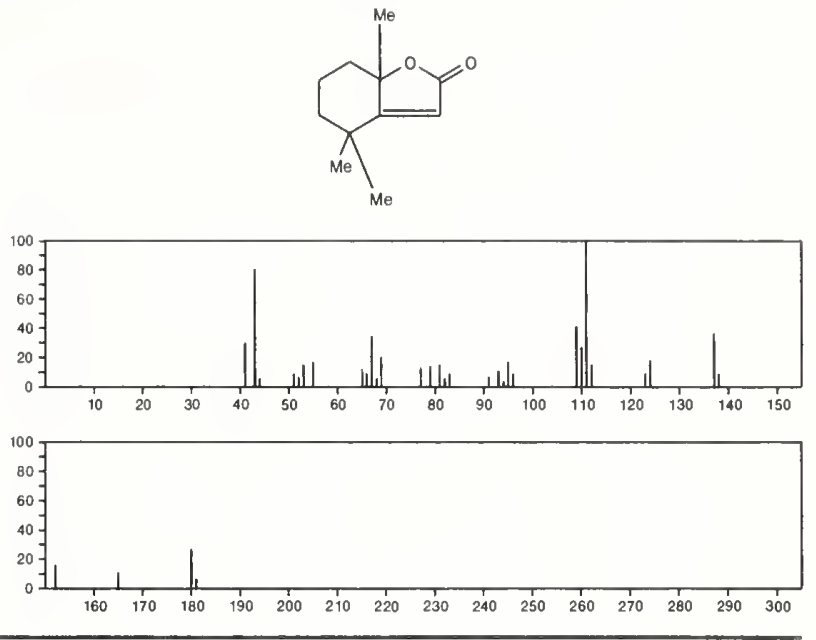

180

$\mathrm{C}_{11} \mathrm{H}_{16} \mathrm{O}_{2}$

$22054-39-3$

2-Cyclopenten-1-one, 4-hydroxy-3-methyl-2-(2-pentenyl)-
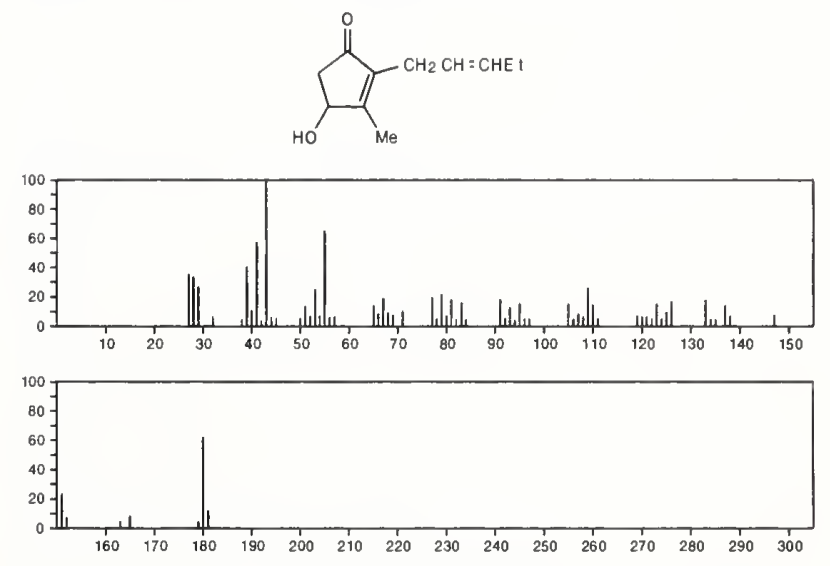

180

$\mathrm{C}_{11} \mathrm{H}_{16} \mathrm{O}_{2}$

Phenol, (1,1-dimethylethyl)-4-methoxy-

25013-16-5
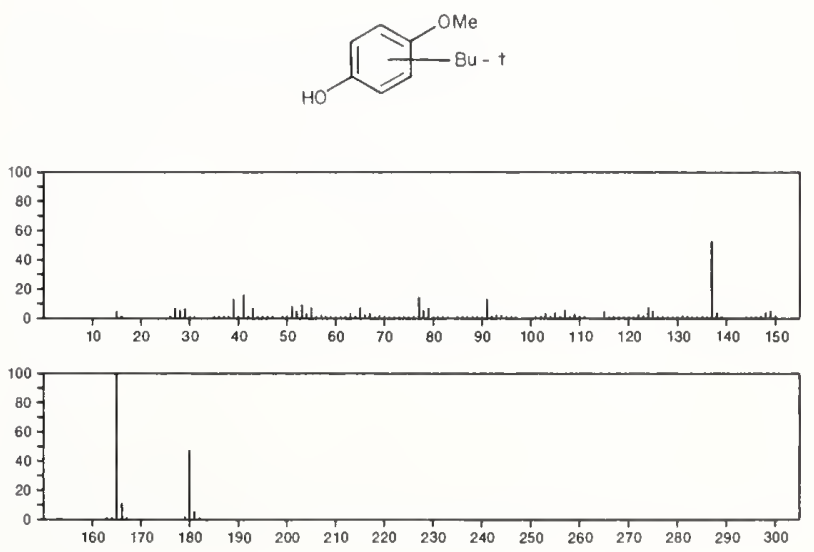
180 3-Furanmethanol, $\alpha$-cyclohexyl-

$\mathrm{C}_{11} \mathrm{H}_{16} \mathrm{O}$

$36646-66-9$
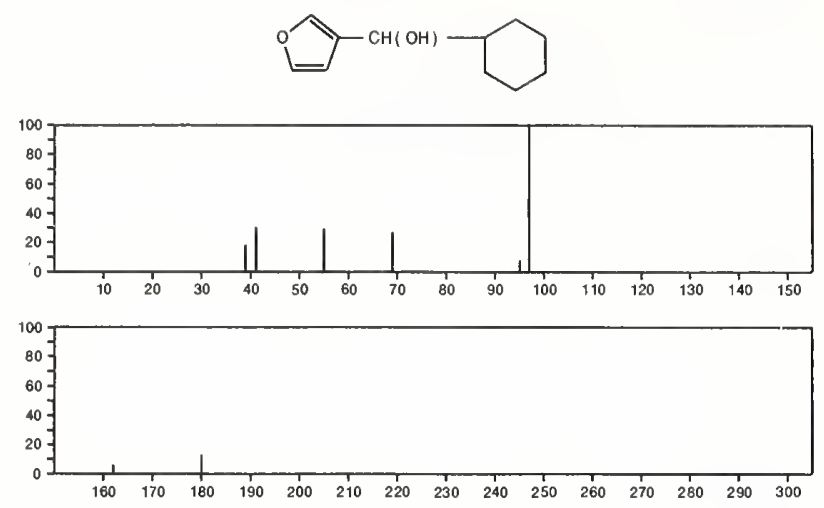

41398-33-8

180

$\mathrm{C}_{11} \mathrm{H}_{16} \mathrm{O}_{2}$

$, 5 \alpha, 7 \beta)-$
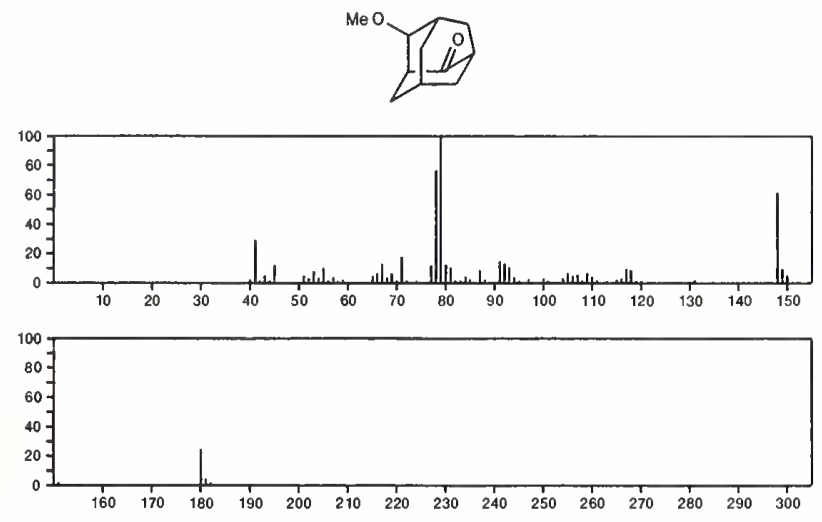

180

$\mathrm{C}_{11} \mathrm{H}_{16} \mathrm{O}_{2}$

49833-95-6

1-Propen-2-ol, 3-cyclohexylidene-, acetate
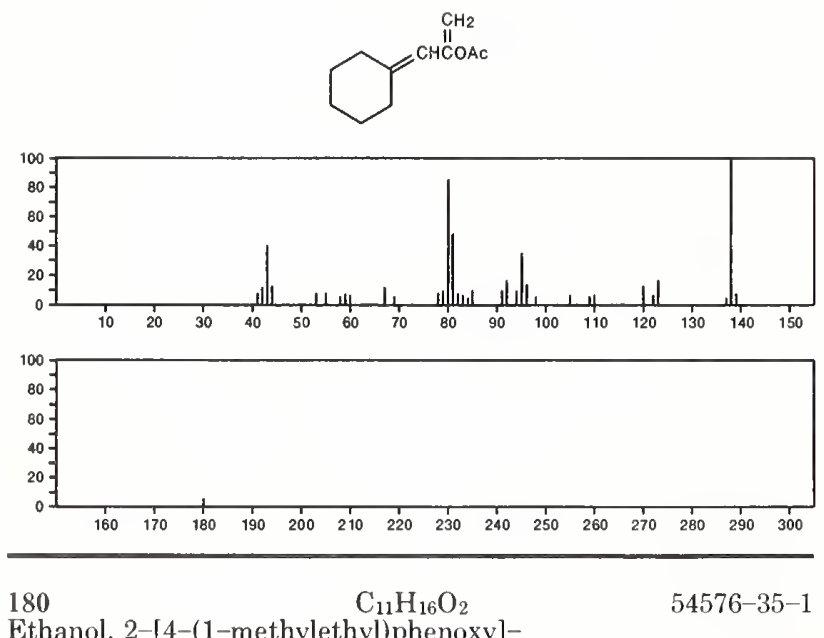

Ethanol, 2-[4-(1-methylethyl)phenoxy]-
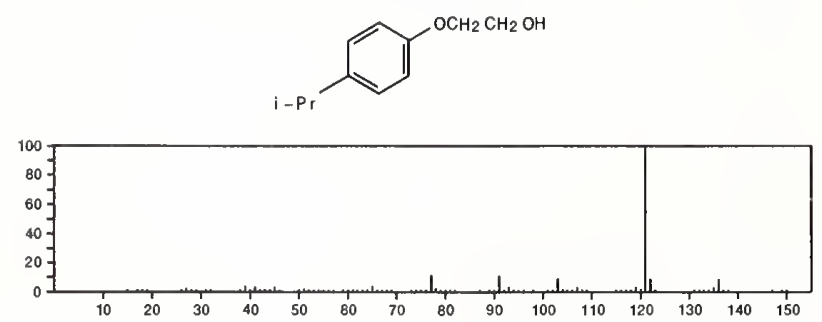

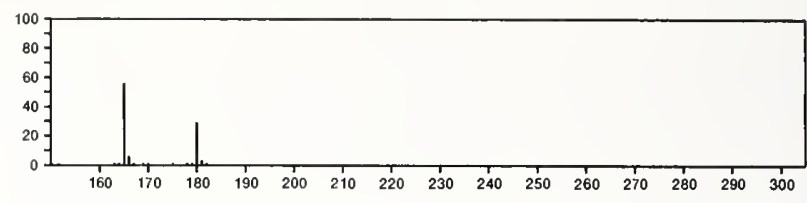

180

$\mathrm{C}_{11} \mathrm{H}_{16} \mathrm{O}_{2}$

$56781-91-0$

Tricyclo[3.3.1.13,7]decan-2-one, 4-(hydroxymethyl)-, $(1 \alpha, 3 \beta,=$ $4 \beta, 5 \alpha, 7 \beta)$
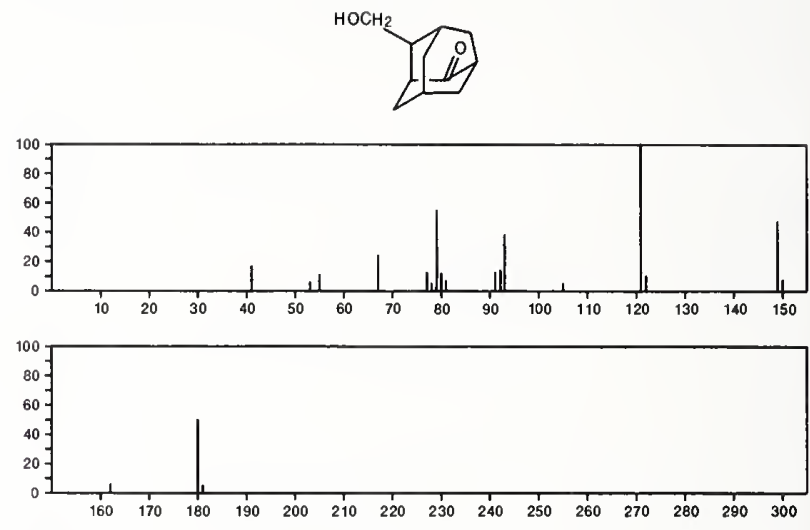

180

$\mathrm{C}_{11} \mathrm{H}_{16} \mathrm{~S}$

Benzene, [(2,2-dimethylpropyl)thio]-

$7210-80-2$

$\mathrm{Me}_{3} \mathrm{CCH}_{2} \mathrm{SPh}$
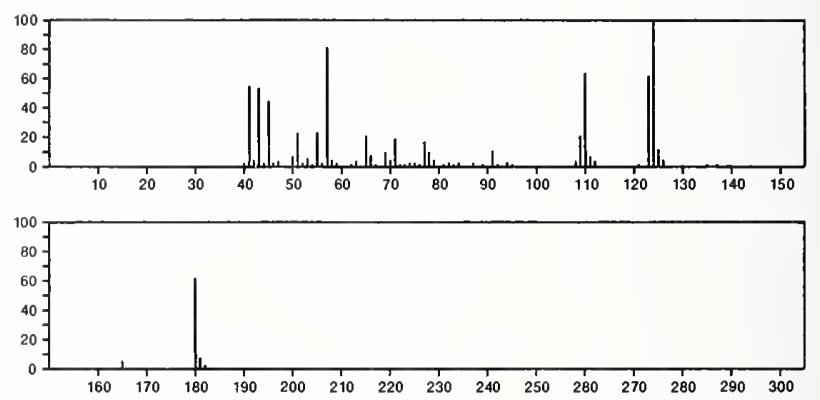

180

$\mathrm{C}_{11} \mathrm{H}_{16} \mathrm{~S}$

$7439-10-3$

Benzene, 1-[(1,1-dimethylethyl)thio]-4-methyl-
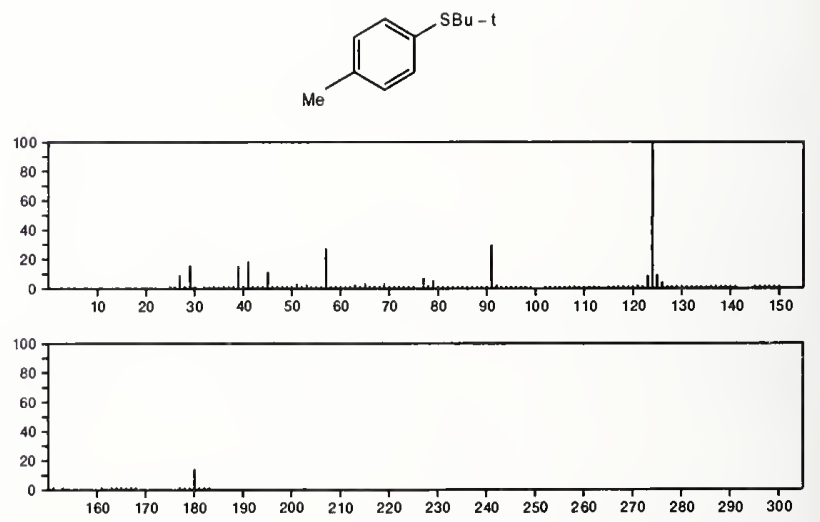
180

Sulfide, butyl $o$-tolyl

$$
\mathrm{C}_{11} \mathrm{H}_{16} \mathrm{~S}
$$

$15560-99-3$
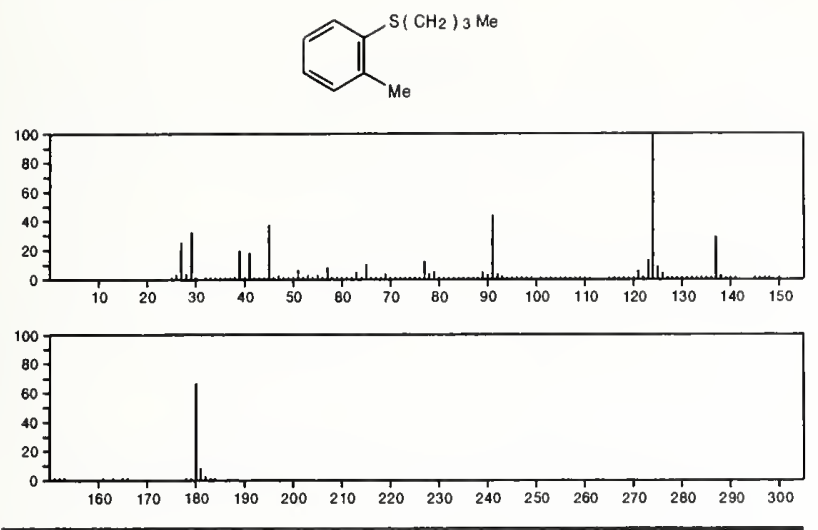

$180 \quad \mathrm{C}_{11} \mathrm{H}_{16} \mathrm{~S} \quad 15561-00-9$

Sulfide, isobutyl $o$-tolyl
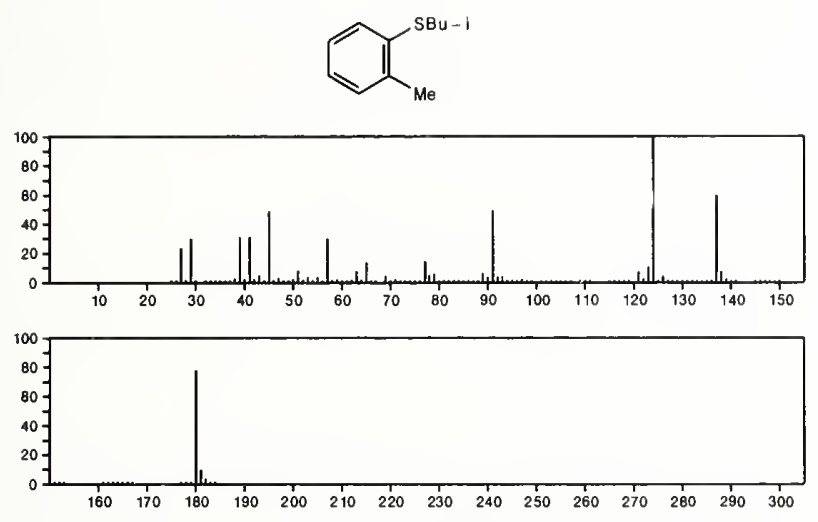

180

$\mathrm{C}_{11} \mathrm{H}_{16} \mathrm{~S}$

Benzene, 1-(butylthio)-4-methyl-

21784-96-3
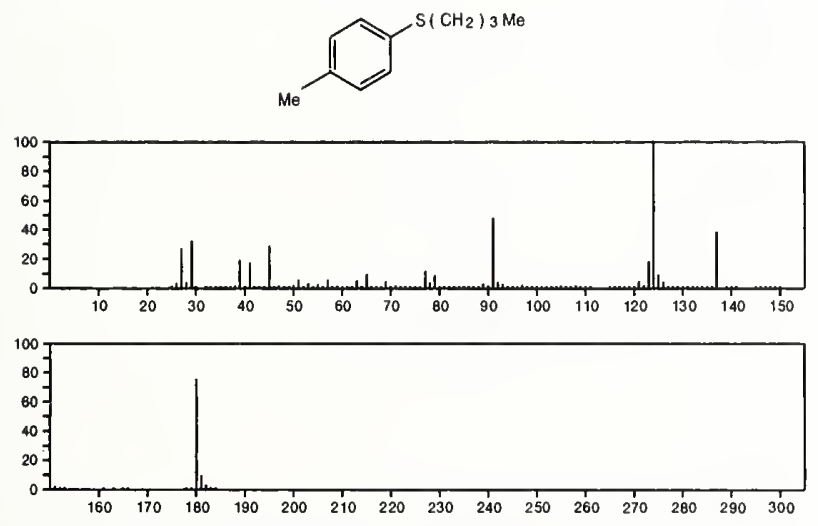

180

$\mathrm{C}_{11} \mathrm{H}_{16} \mathrm{~S}$

$34786-26-0$

Benzene, 1-[(1,1-dimethylethyl)thio]-3-methyl-
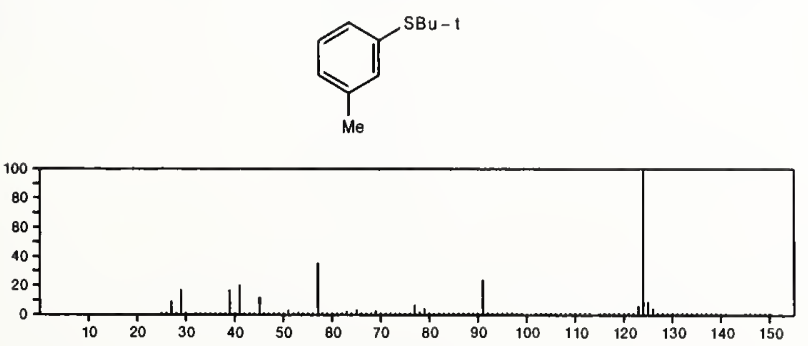
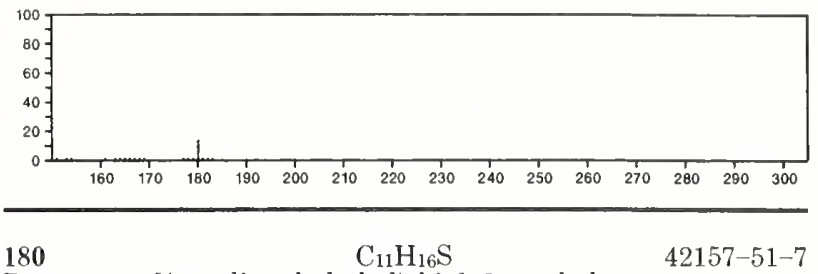

Benzene, 1-[(1,1-dimethylethyl)thio]-2-methy]-
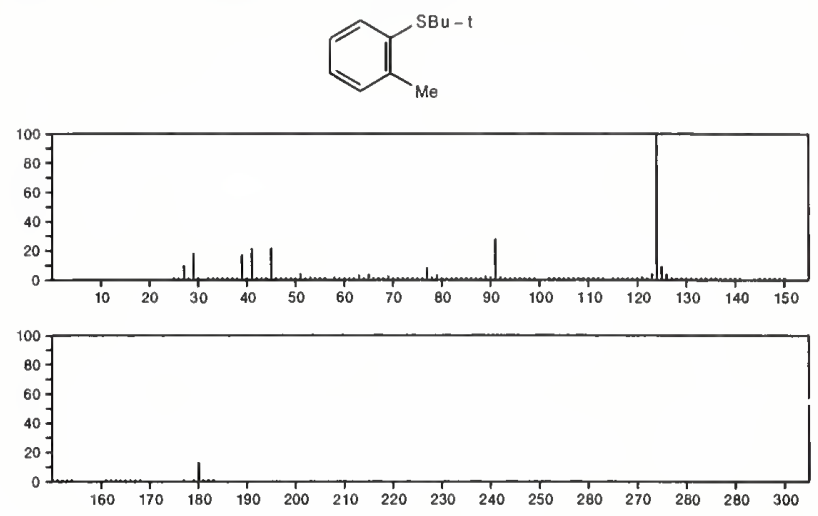

180

$\mathrm{C}_{11} \mathrm{H}_{16} \mathrm{~S}$

$54576-36-2$

Benzene, 1-methyl-3-[(2-methylpropyl)thio]-<smiles>[N+]=[N+]([Hg])c1cccc([131I]I)c1</smiles>
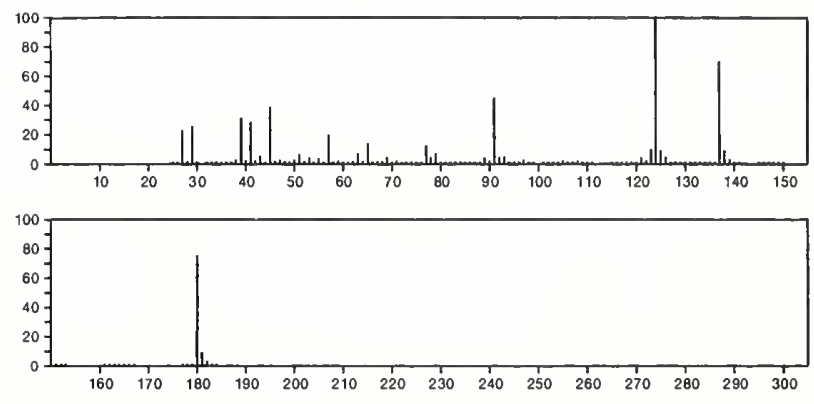

180

$\mathrm{C}_{11} \mathrm{H}_{16} \mathrm{~S}$

Benzene, 1-methyl-4-[(2-methylpropyl)thio]-

$54576-37-3$
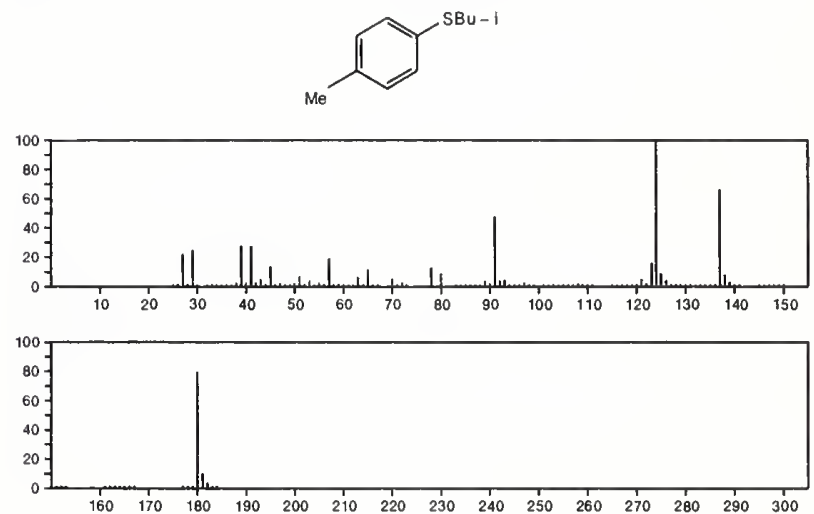
180

$\mathrm{C}_{11} \mathrm{H}_{16} \mathrm{~S}$

Benzene, 1-methyl-2-[(1-methylpropy])thio]-

$54576-38-4$<smiles>Cc1ccccc1Br</smiles>
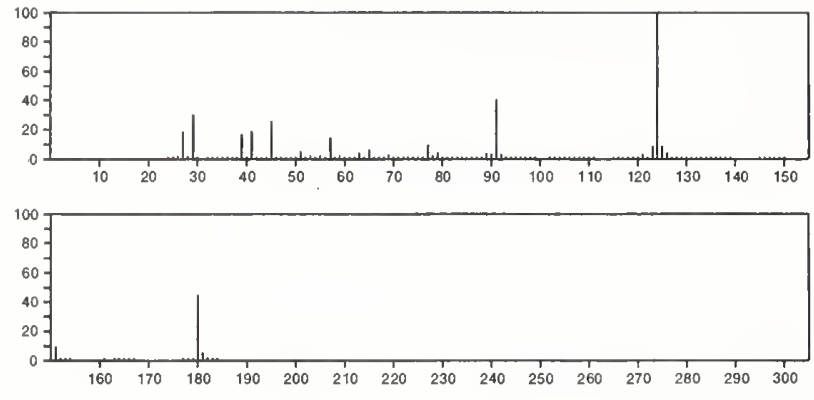

180

$\mathrm{C}_{11} \mathrm{H}_{16} \mathrm{~S}$

$54576-39-5$

Benzene, 1-methyl-3-[(1-methylpropyl)thio]-
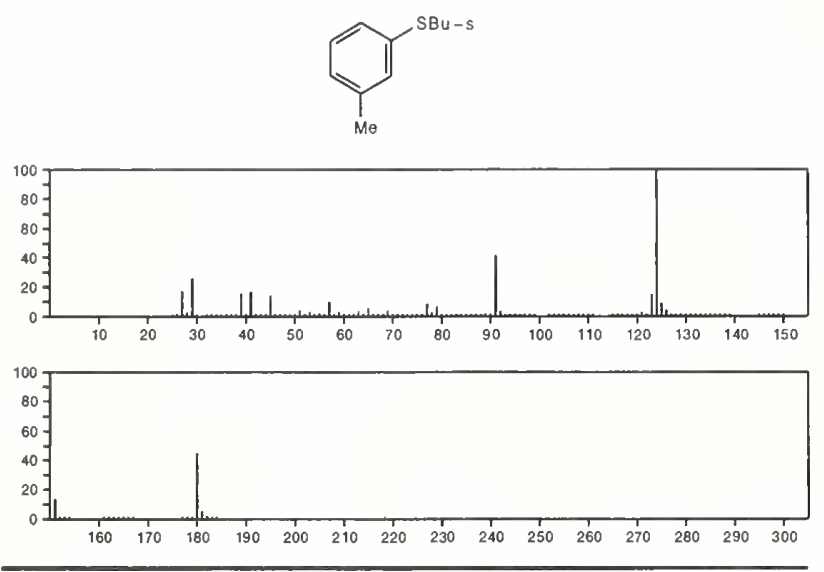

180

$\mathrm{C}_{11} \mathrm{H}_{16} \mathrm{~S}$

$54576-40-8$

Benzene, 1-methyl-4-[(1-methylpropyl)thio]-
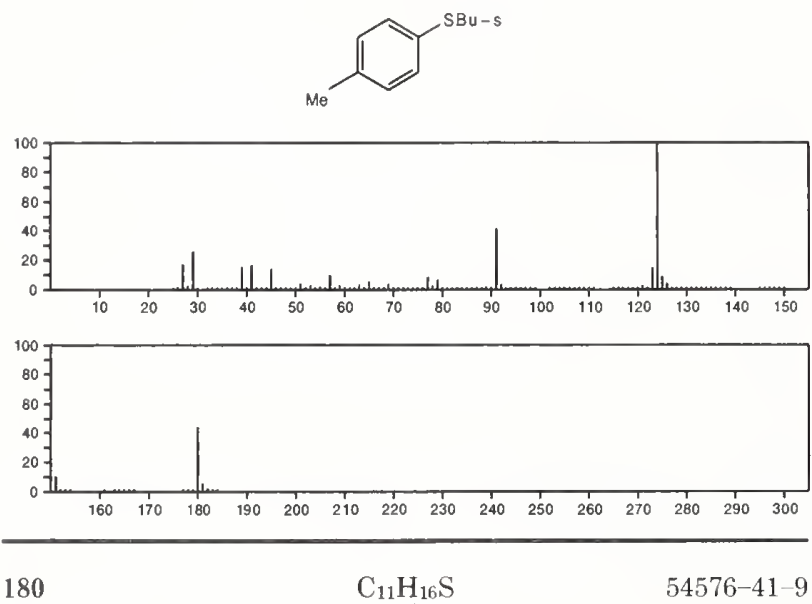

Benzene, 1-(butylthio)-3-methyl-

$54576-41-9$
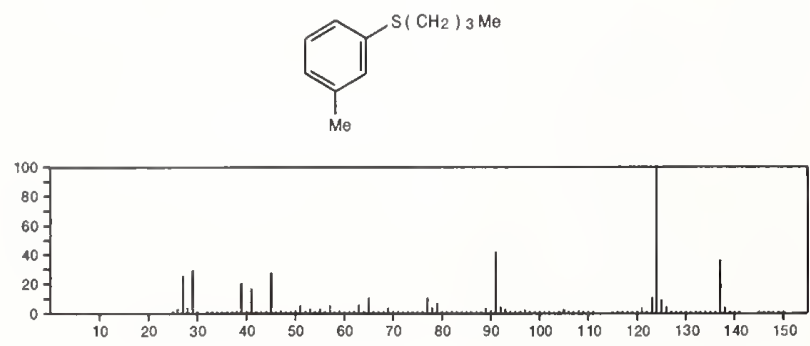

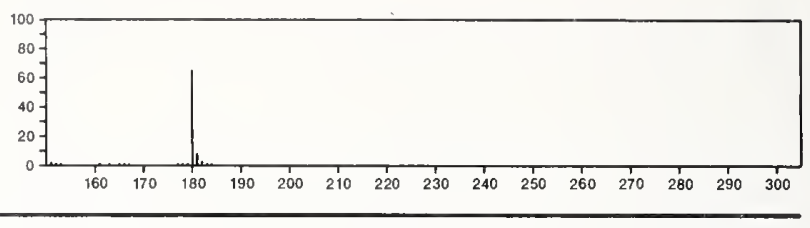

180 $\mathrm{C}_{11} \mathrm{H}_{16} \mathrm{~S}$

$54576-42-0$

Benzene, [2-[(1-methylethyl)thio]ethyl]-

$\mathrm{PhCH}_{2} \mathrm{CH}_{2} \mathrm{SPr}-\mathrm{i}$
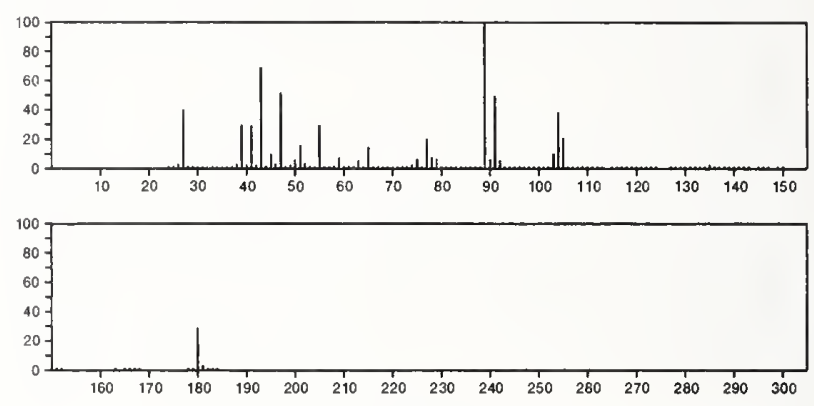

180

$\mathrm{C}_{12} \mathrm{H}_{8} \mathrm{~N}_{2}$

230-17-1

Benzo[c]cinnoline
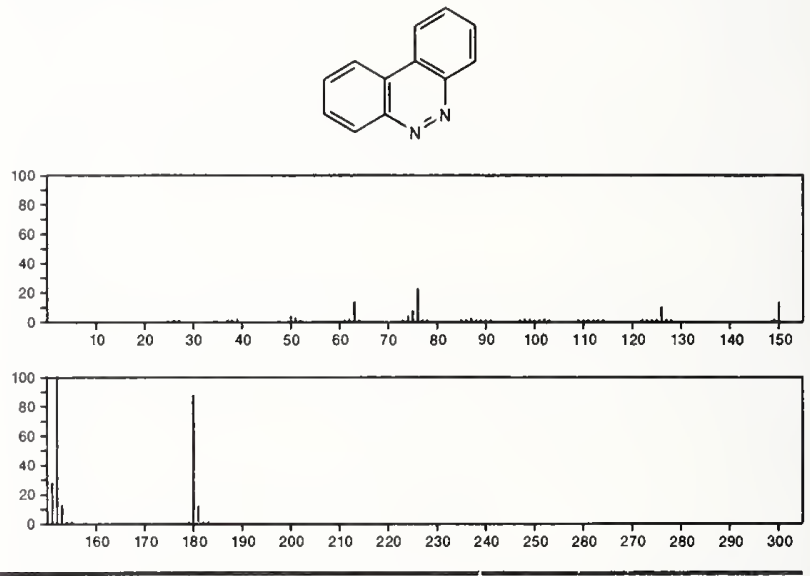

180

$\mathrm{C}_{12} \mathrm{H}_{8} \mathrm{~N}_{2}$

Pyridine, 3,3 '-(1,2-ethynediyl) bis

50559-45-0
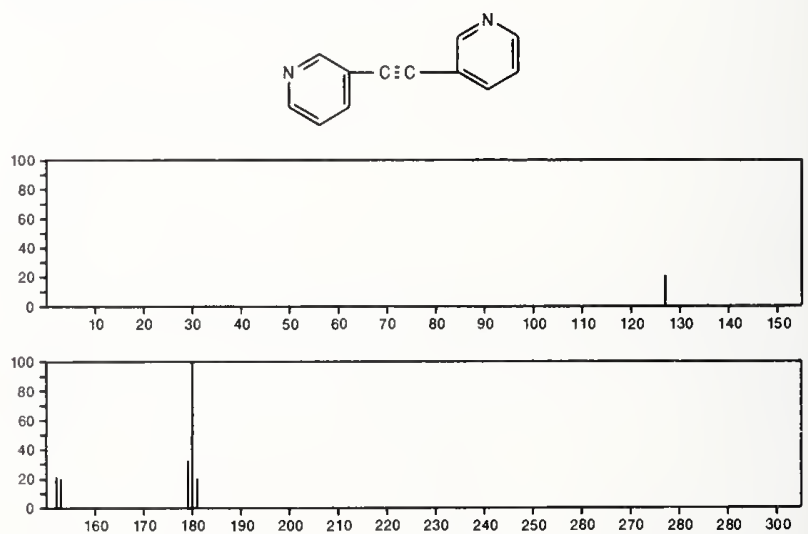
180

[1,1'-Bicyclohexyl]-2-one

$\mathrm{C}_{12} \mathrm{H}_{20} \mathrm{O}$

$90-42-6$
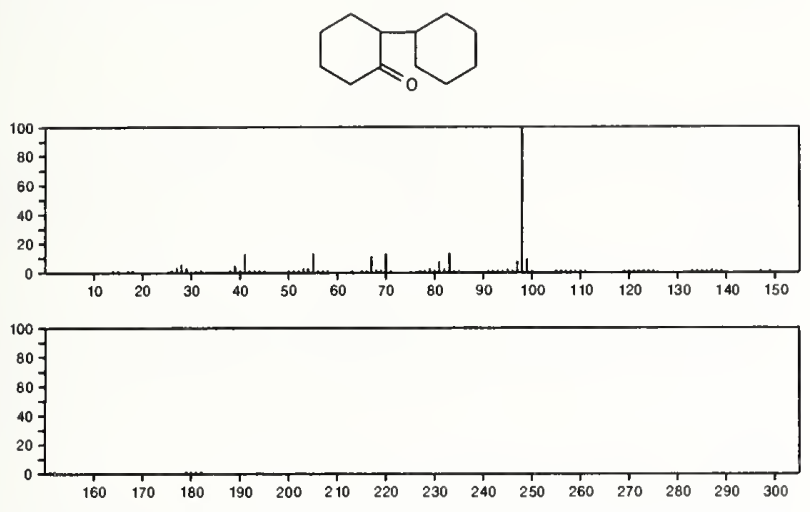

\section{0}

[1,1'-Bicyclohexyl]-4-one

$\mathrm{C}_{12} \mathrm{H}_{20} \mathrm{O}$

$92-68-2$
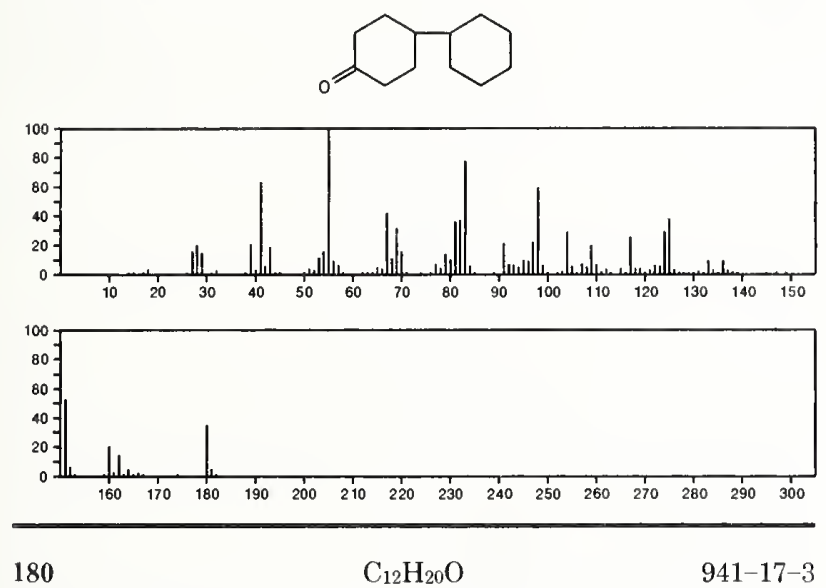

2(1H)-Naphthalenone, octahydro-8,8a-dimethyl-, $(4 \mathrm{a} \alpha, 8 \beta, 8 \mathrm{a} \beta)-$
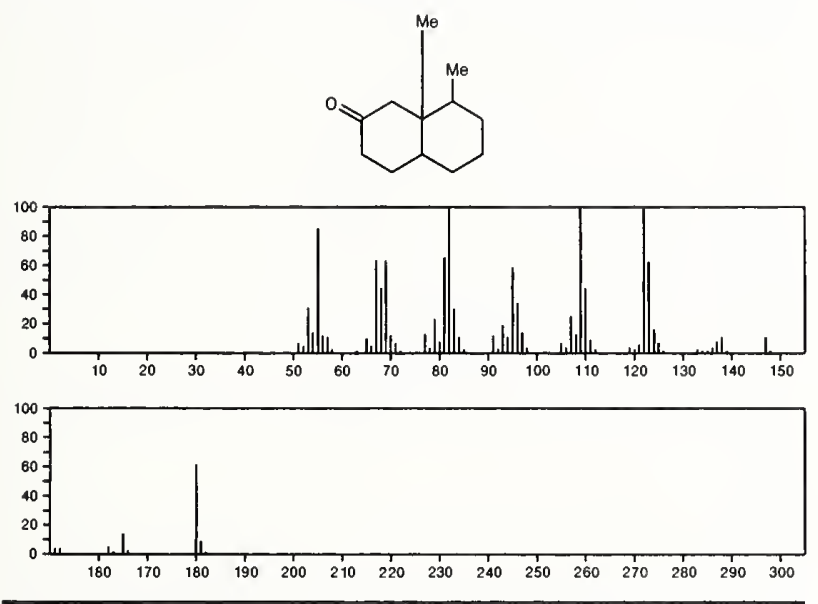

180

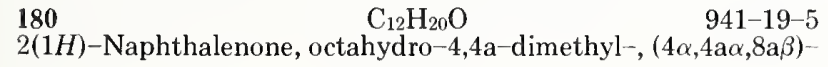
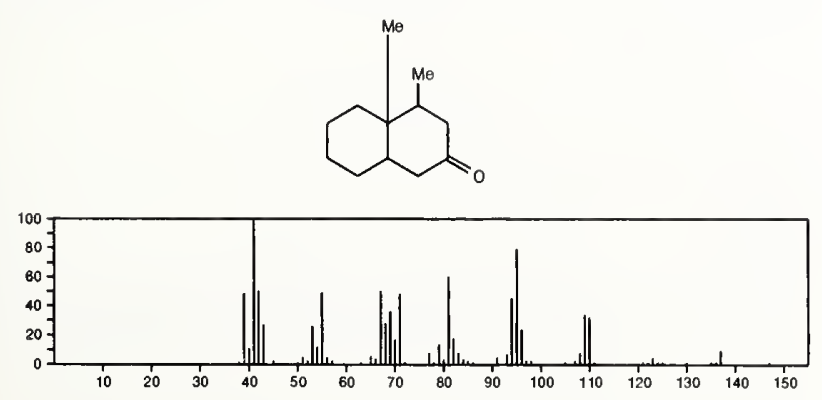
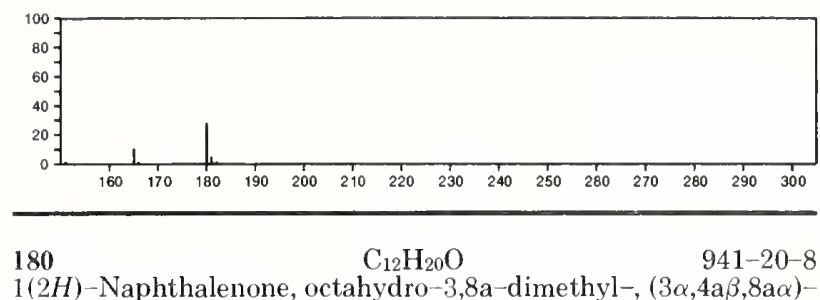

1(2H)-Naphthalenone, octahydro-3,8a-dimethyl-, $(3 \alpha, 4 \mathrm{a} \beta, 8 \mathrm{a} \alpha)$ -
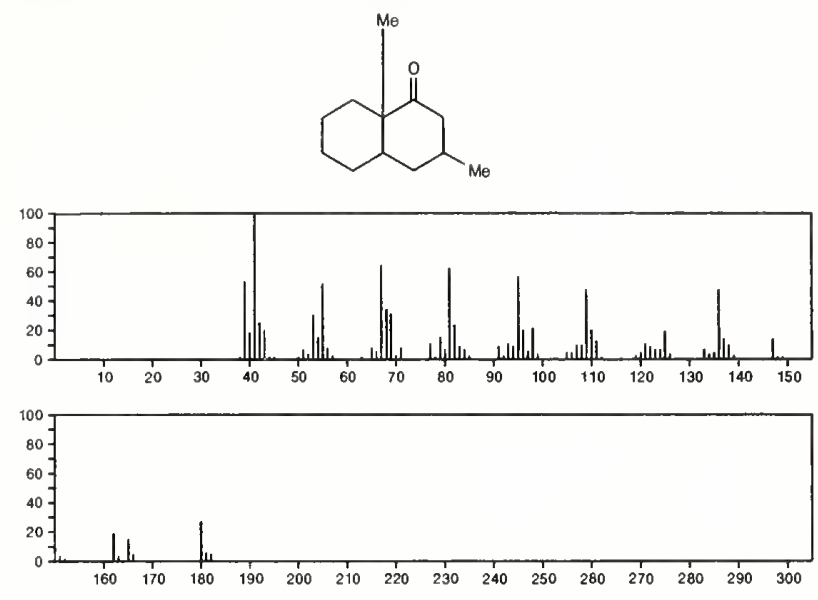

180

$\mathrm{C}_{12} \mathrm{H}_{20} \mathrm{O}$

Furan, 2,5-bis(1,1-dimethylethyl)-

$4789-40-6$
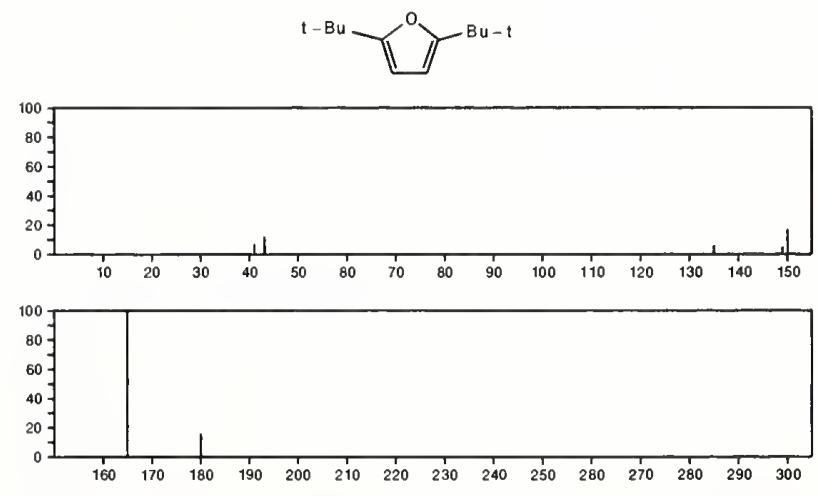

$180 \quad \mathrm{C}_{12} \mathrm{H}_{20} \mathrm{O} \quad 4808-01-9$

2-Propen-1-ol, 3-(2,6,6-trimethyl-1-cyclohexen-1-yl)-
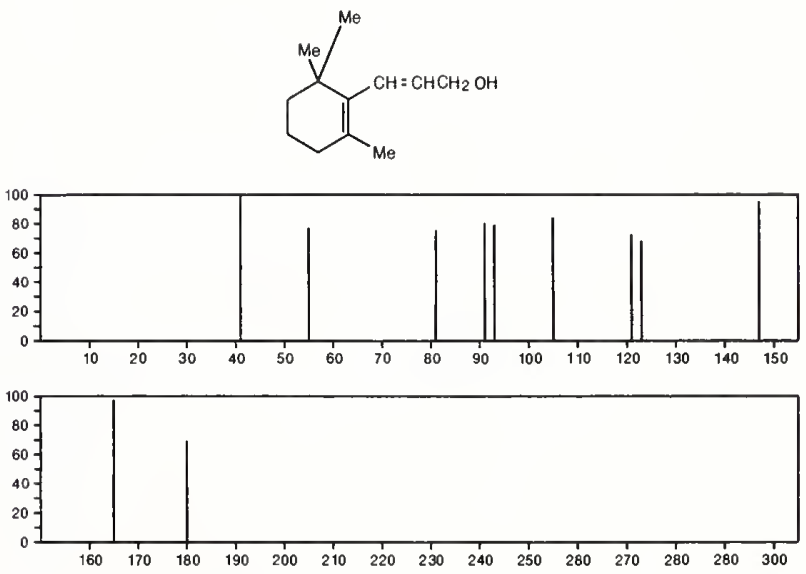
180

$\mathrm{C}_{12} \mathrm{H}_{20} \mathrm{O}$

$16510-55-7$

Ethanone, 1-(octahydro-7a-methyl-1H-inden-1-yl)-, $(1 \alpha, 3 \mathbf{a} \beta, 7 \mathbf{a} \alpha)$ -
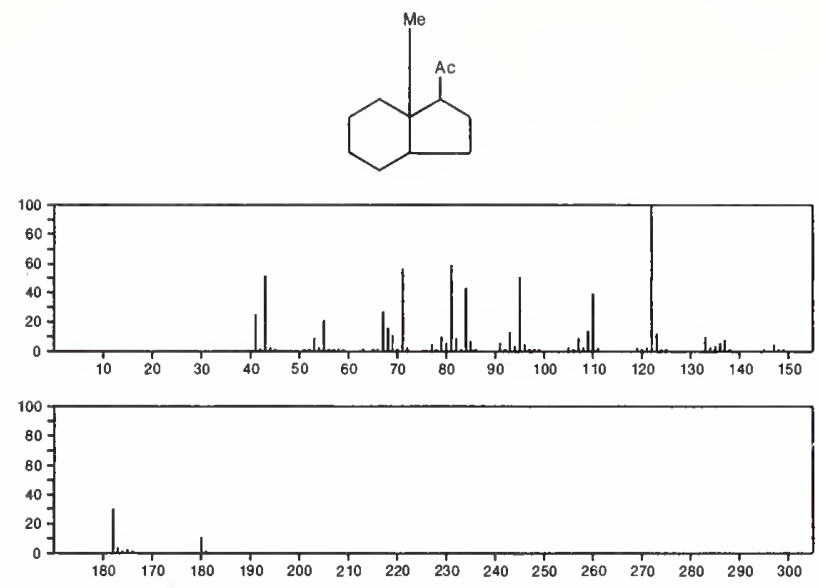

180

$\mathrm{C}_{12} \mathrm{H}_{20} \mathrm{O}$

$16510-56-8$

Cyclobut $[c]$ inden-2-ol, decahydro-2-methyl-
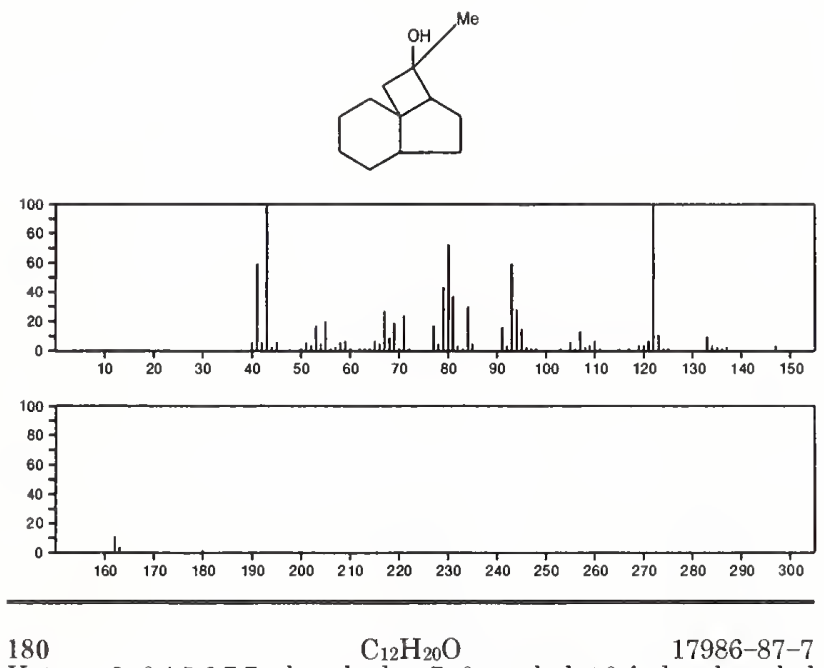

Ketone, $3 \mathrm{a} \beta, 4,5,6,7,7 \mathrm{a}$-hexahydro-7a $\beta$-methyl- $1 \beta$-indanyl methyl
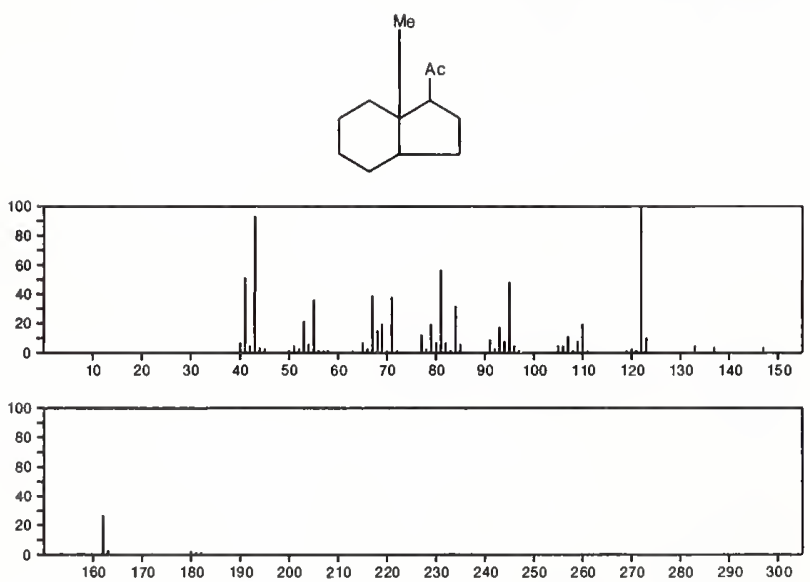

180

$\mathrm{C}_{12} \mathrm{H}_{20} \mathrm{O}$

17986-96-8 Ethanone, 1-(octahydro-7a-methyl-1 $H$-inden-1-yl)-, $(1 \alpha, 3 \mathrm{a} \alpha, 7 \mathrm{a} \beta)-$
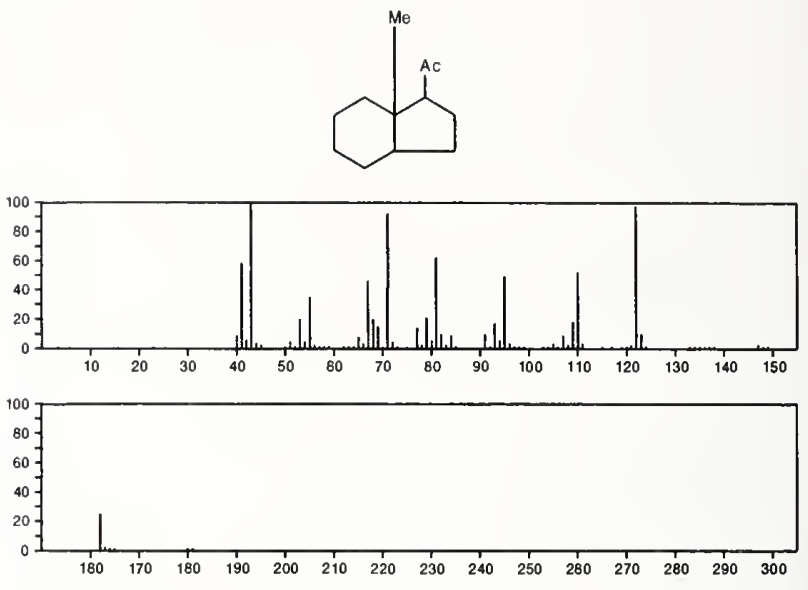

180

$\mathrm{C}_{12} \mathrm{H}_{20} \mathrm{O}$

17986-97-9

Ketone, $3 \mathrm{a} \beta, 4,5,6,7,7 \mathrm{a}$-hexahydro-7a $\beta$-methyl- $1 \alpha$-indanyl methyl
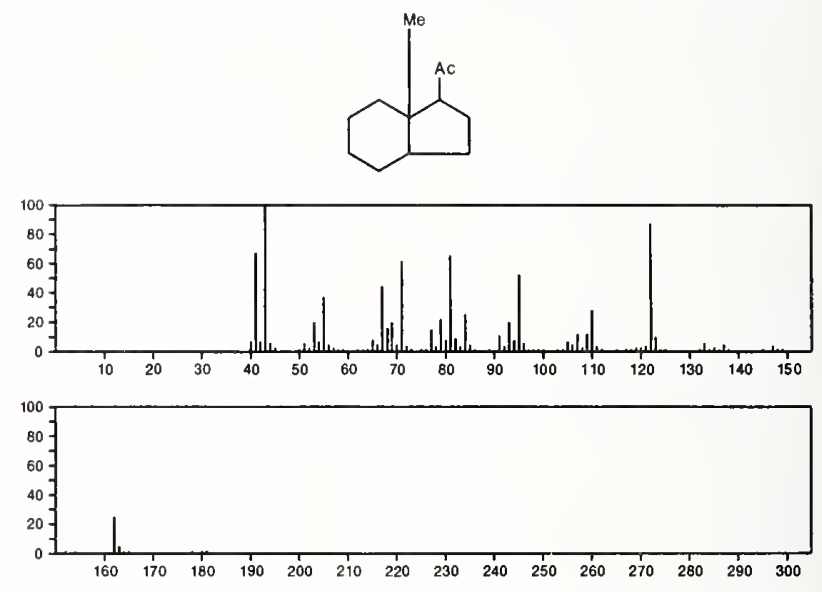

180

4,5-Octadien-3-one, 2,2,7,7-tetramethyl-

$19377-97-0$

$\mathrm{Me} 3 \mathrm{CCH}: \mathrm{C}: \mathrm{CHCOCMe}_{3}$
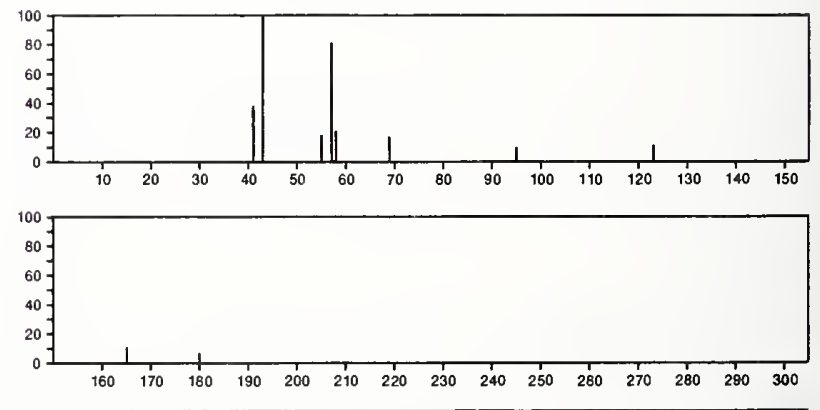

$180 \quad \mathrm{C}_{12} \mathrm{H}_{20} \mathrm{O} \quad 19576-21-7$

1-Propanone, 1-[2-(1,1-dimethylethyl)-2-cyclopropen-1-yl]2,2 -dimethyl-
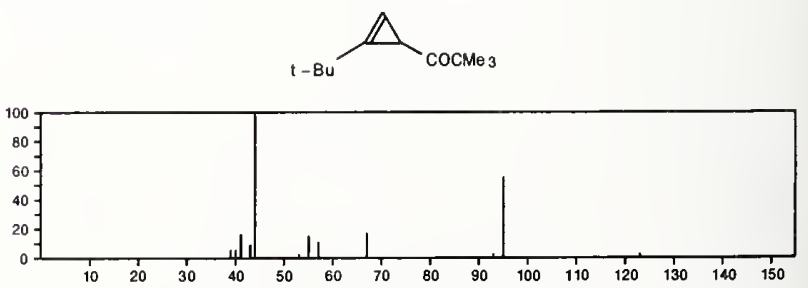


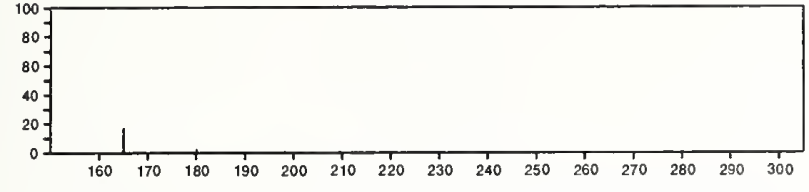

$180 \quad \mathrm{C}_{12} \mathrm{H}_{20} \mathrm{O}$

$21898-92-0$

Tricyclo[4.3.1.13,8]undecane, 3 -methoxy-
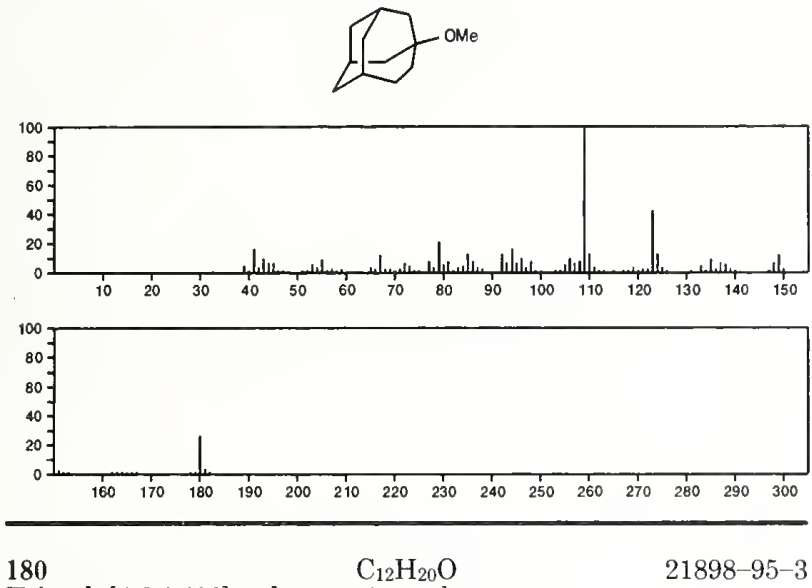

Tricyclo[4.3.1.13,8]undecane, 1-methoxy-
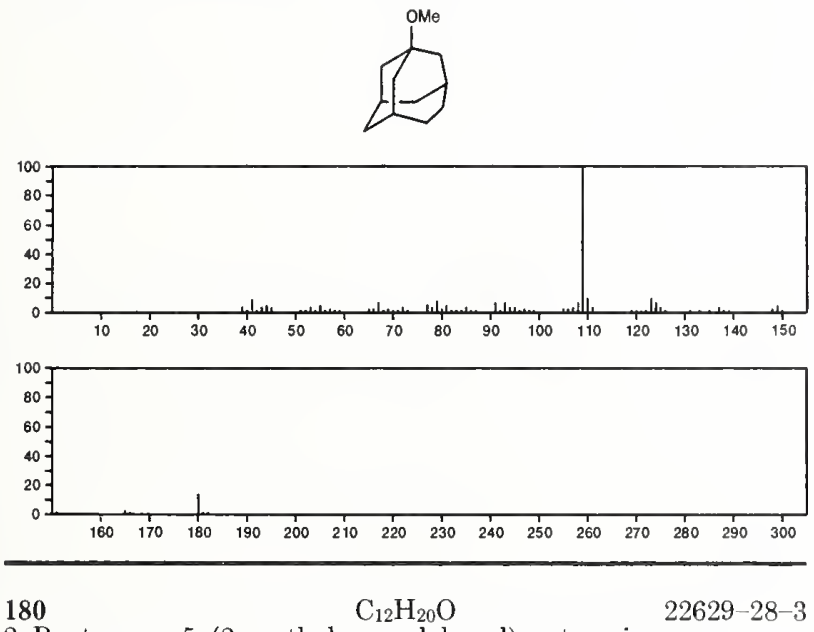

2-Pentanone, 5-(2-methylenecyclohexyl)-, stereoisomer
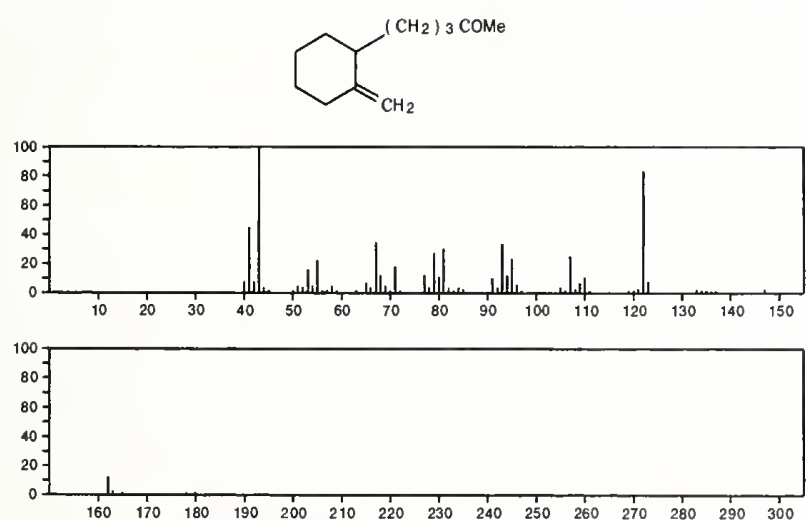

180 $\mathrm{C}_{12} \mathrm{H}_{20} \mathrm{O}$

22738-31-4

2(1H)-Naphthalenone, octahydro-1,4a-dimethyl--, $(1 \alpha, 4 \mathrm{a} \beta, 8 \mathrm{a} \alpha)-$<smiles>CC1C(=O)CCC2(C)CCCCC12</smiles>
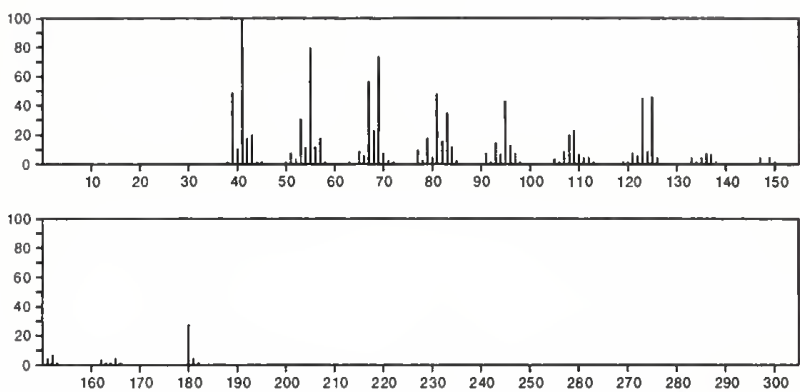

180

$\mathrm{C}_{12} \mathrm{H}_{20} \mathrm{O}$

5-Octyn-4-one, 2,2,7,7-tetramethyl-

$28884-89-1$

$\mathrm{Me}_{3} \mathrm{CC} \equiv \mathrm{CCOCH}_{2} \mathrm{CMe}_{3}$
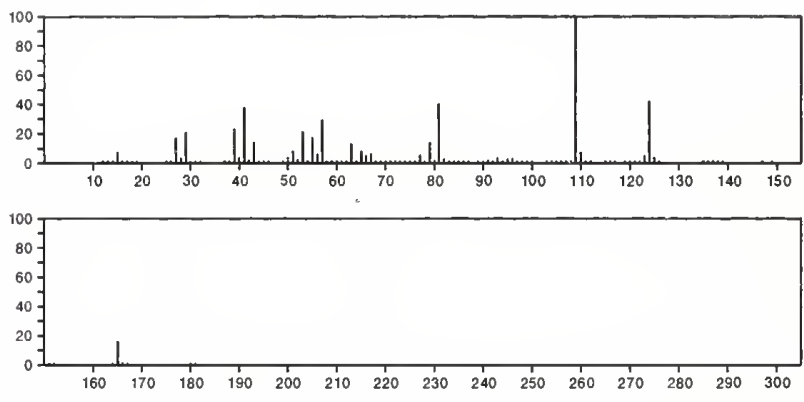

180

$\mathrm{C}_{12} \mathrm{H}_{20} \mathrm{O}$

29460-67-1

2-Propen-1-ol, 3-(2,6,6-trimethyl-2-cyclohexen-1-yl)-
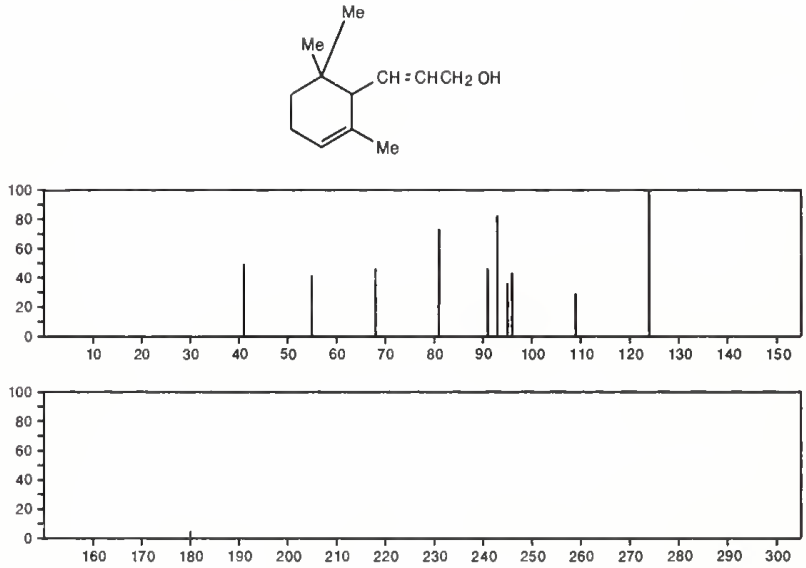

180

$\mathrm{C}_{12} \mathrm{H}_{20} \mathrm{O}$

$37609-41-9$

Bicyclo[3.2.1]oct-2-ene, 3-(1,1-dimethylethoxy)-
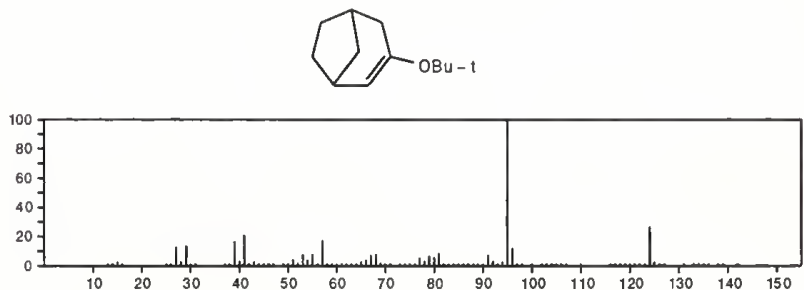


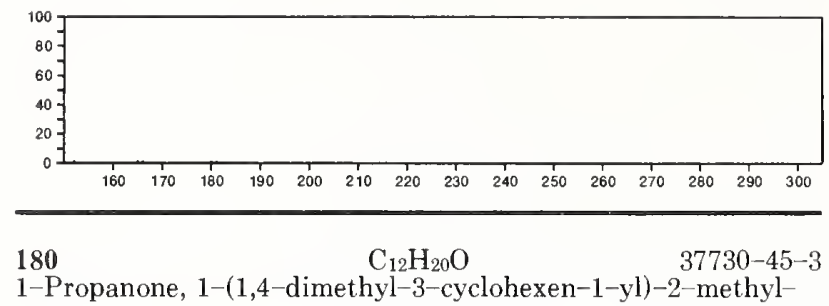

1-Propanone, 1-(1,4-dimethyl-3-cyclohexen-1-yl)-2-methyl-
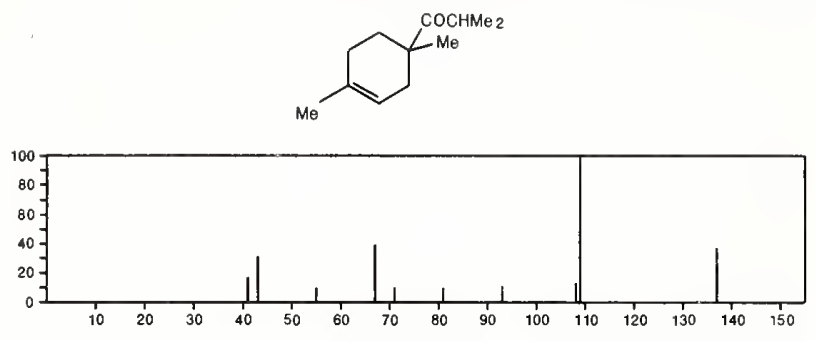

$180 \quad \mathrm{C}_{12} \mathrm{H}_{20} \mathrm{O} \quad 38366-85-7$

Cyclohexanone, 3-ethylidene-2,2,5,5-tetramethyl-
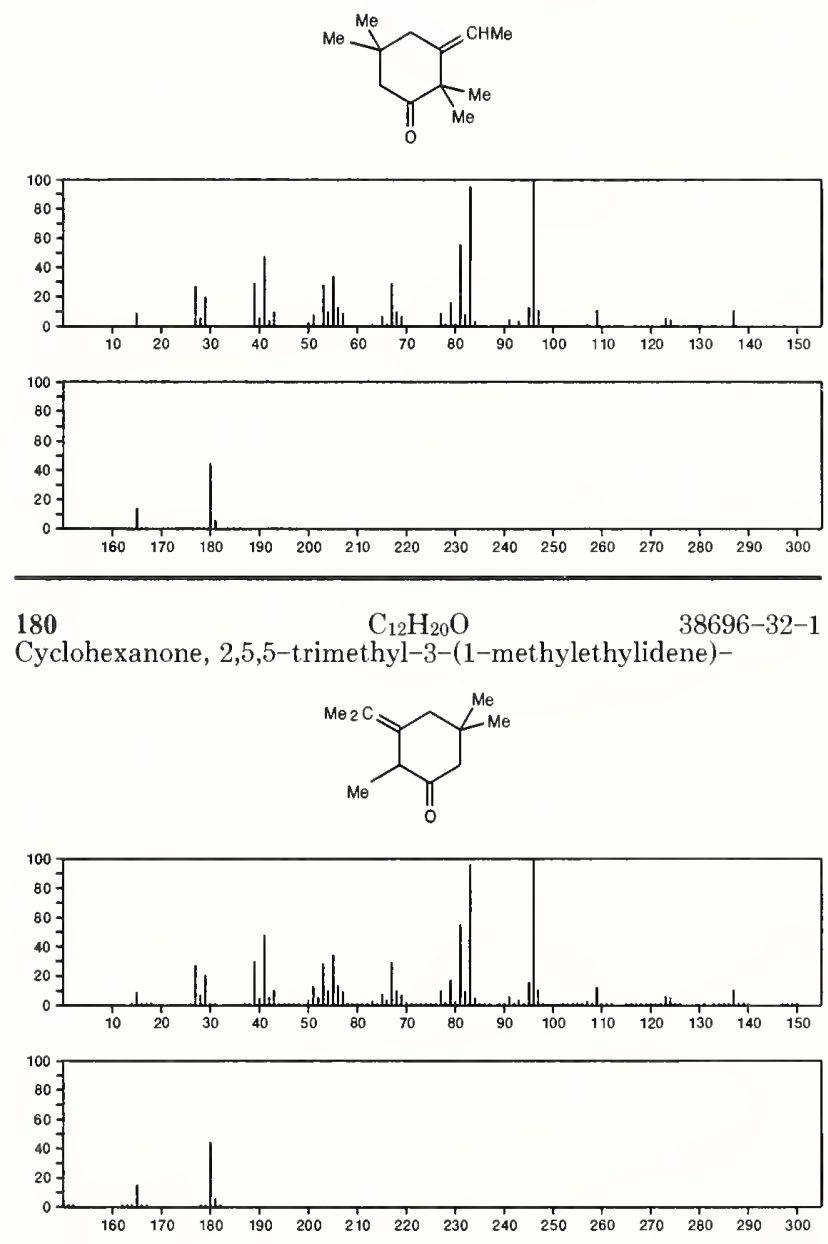

180

$\mathrm{C}_{12} \mathrm{H}_{20} \mathrm{O}$

Bicyclo[3.2.1]oct-2-ene, 4-(1,1-dimethylethoxy)-

$49826-51-9$
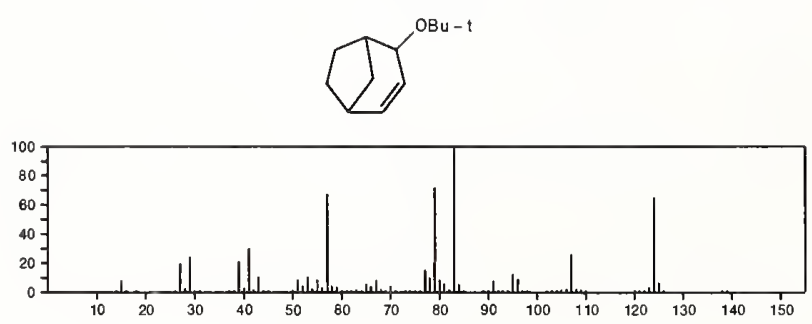
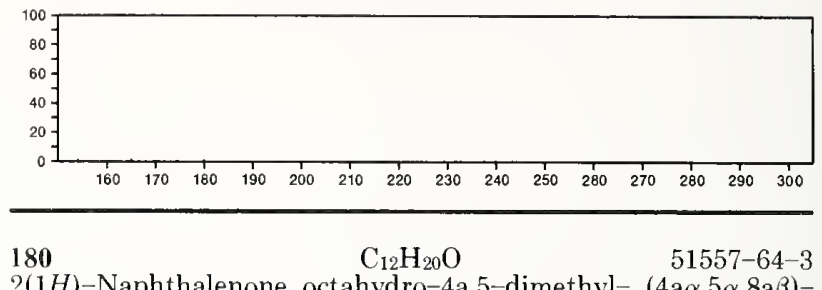

2(1H)-Naphthalenone, octahydro-4a,5-dimethyl-, $(4 \mathrm{a} \alpha, 5 \alpha, 8 \mathrm{a} \beta)-$
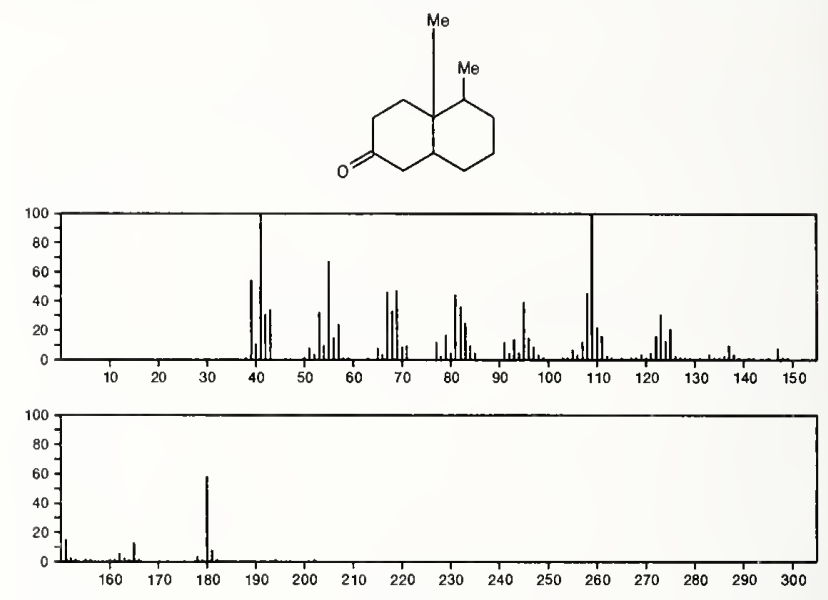

180

$\mathrm{C}_{12} \mathrm{H}_{20} \mathrm{O}$

$51768-87-7$

1-Cyclohexene-1-methanol, $\alpha$-ethenyl-2,6,6-trimethyl-
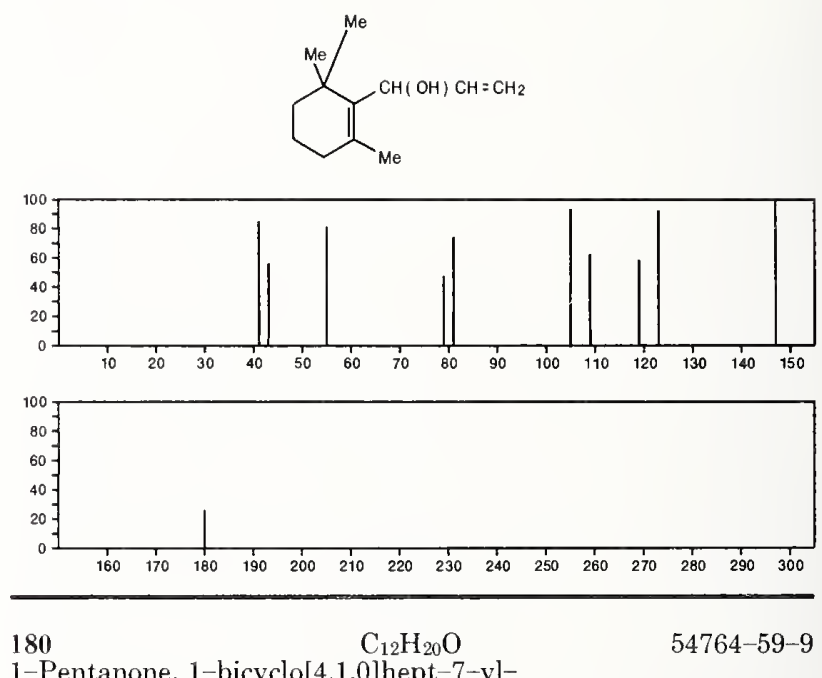

1-Pentanone, 1-bicyclo[4.1.0]hept-7-yl-

$\mathrm{Me}\left(\mathrm{CH}_{2}\right)_{3} \mathrm{CO}$
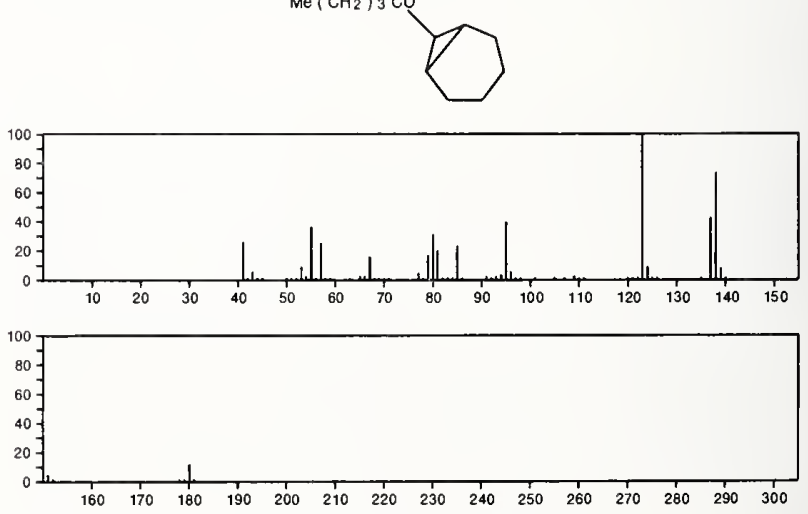
180

$\mathrm{C}_{12} \mathrm{H}_{20} \mathrm{O}$

$55103-64-5$

$2 \mathrm{H}$-Benzocyclohepten-2-one, decahydro-4a-methyl-, trans-
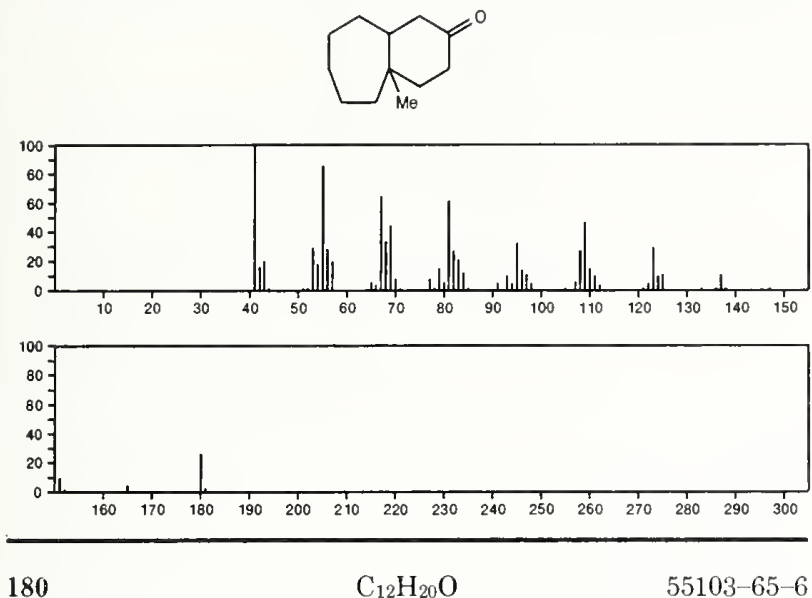

$2 H_{-C y c l o p e n t a c y c l o o c t e n}-2-{ }_{12 n e}$, decahydro-3a-methyl-, trans-
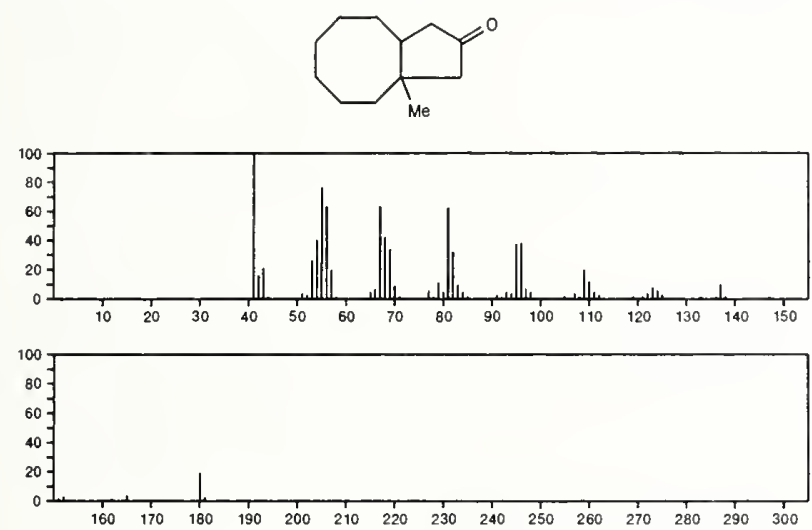

$180 \quad \mathrm{C}_{12} \mathrm{H}_{20} \mathrm{O} \quad 55103-67-8$ $2 H$-Benzocyclohepten-2-one, decahydro-9a-methyl-, trans-
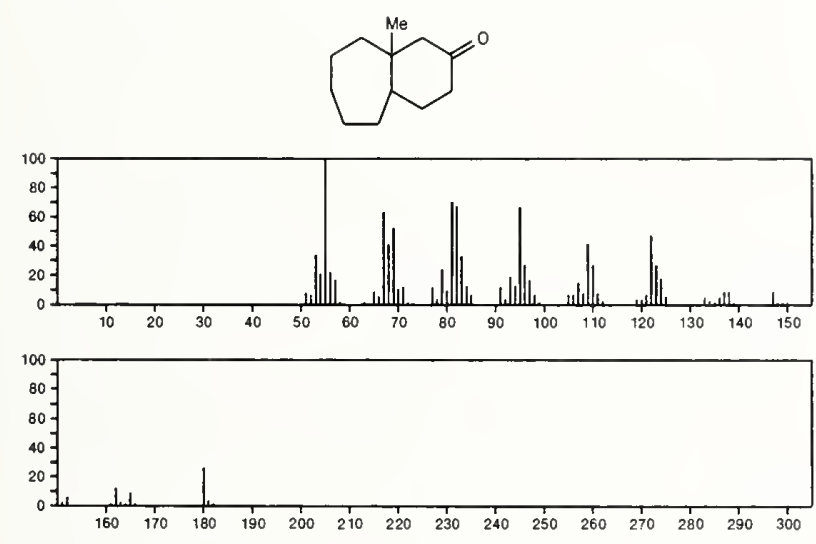

180

$\mathrm{C}_{12} \mathrm{H}_{20} \mathrm{O}$

$55976-08-4$

Naphth $[1,2-b]$ oxirene, decahydro-1a,7-dimethyl-
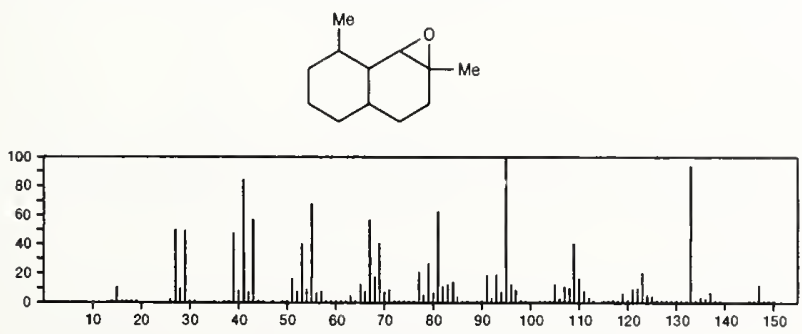

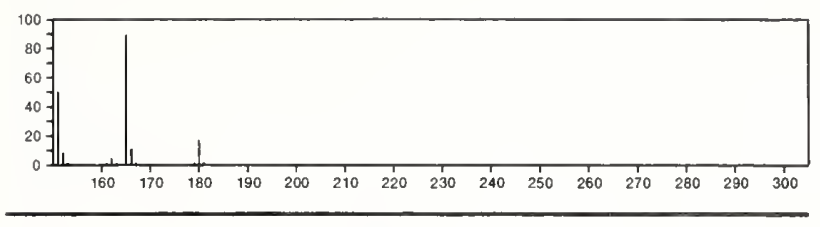

180 $\mathrm{C}_{12} \mathrm{H}_{20} \mathrm{O}$

$56298-45-4$

Cyclohexanol, 4-ethenyl-4-methyl-3-(1-methylethenyl)-, $(1 \alpha=$ $3 \alpha, 4 \beta)-$
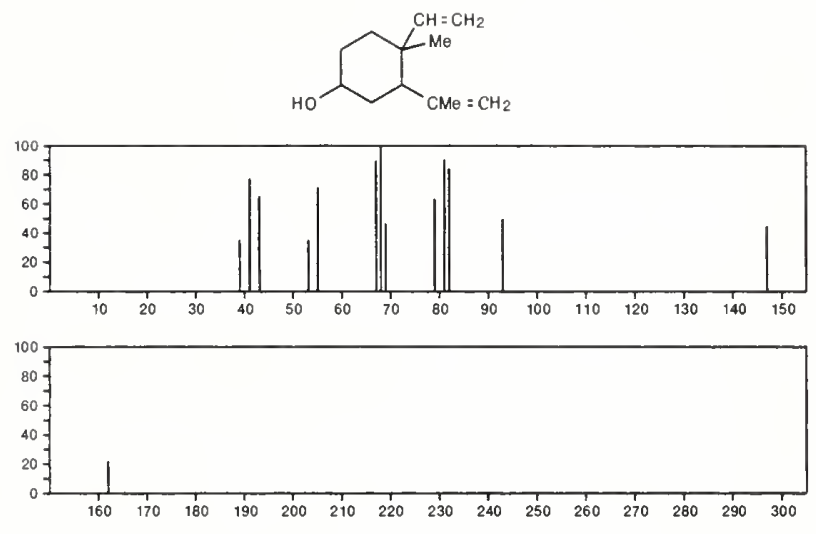

$180 \quad \mathrm{C}_{12} \mathrm{H}_{20} \mathrm{O} \quad 56298-46-5$ Cyclohexanol, 4-ethenyl-4-methyl-3-(1-methylethenyl)-, (1 $\alpha$, = $3 \beta, 4 \alpha)$
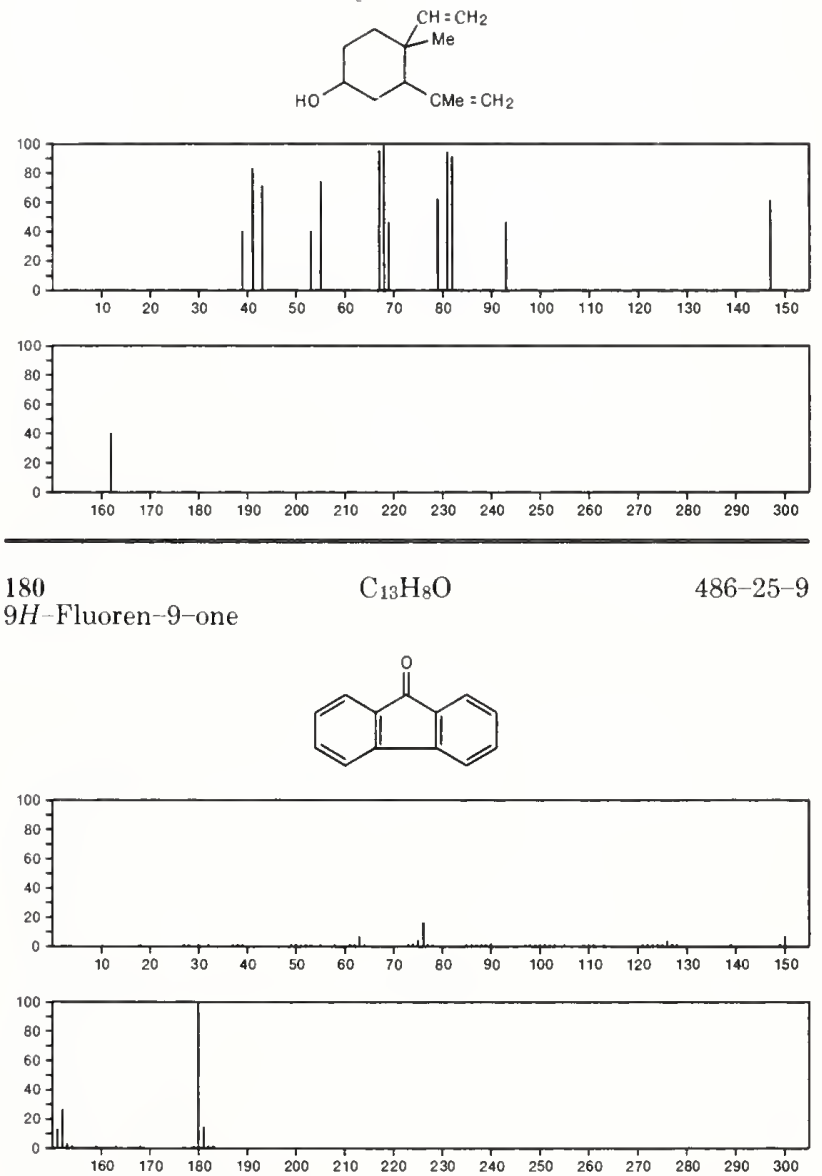
180

Cyclohexane, 1,1'-methylenebis-
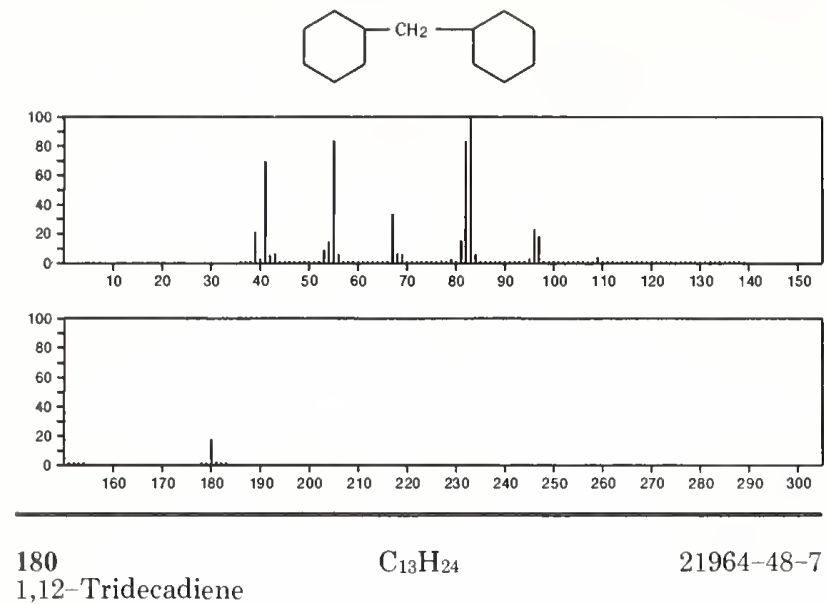

$\mathrm{H}_{2} \mathrm{C}: \mathrm{CH}\left(\mathrm{CH}_{2}\right) 9 \mathrm{CH}: \mathrm{CH}_{2}$
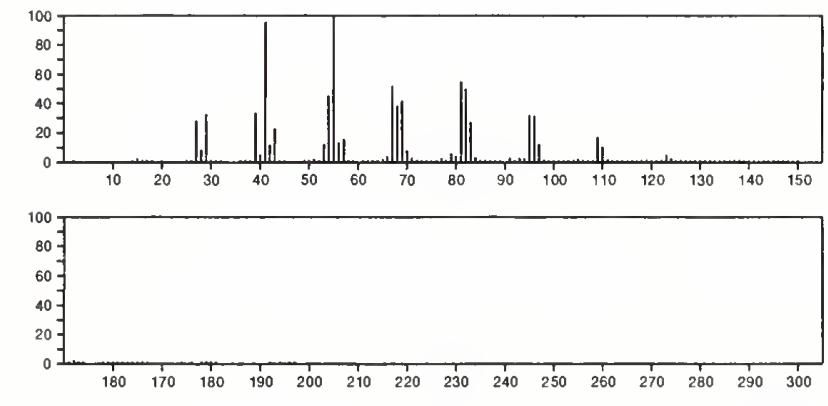

$180 \quad \mathrm{C}_{13} \mathrm{H}_{24}$

Bicyclo[4.1.0]heptane, 3-methyl-7-pentyl-
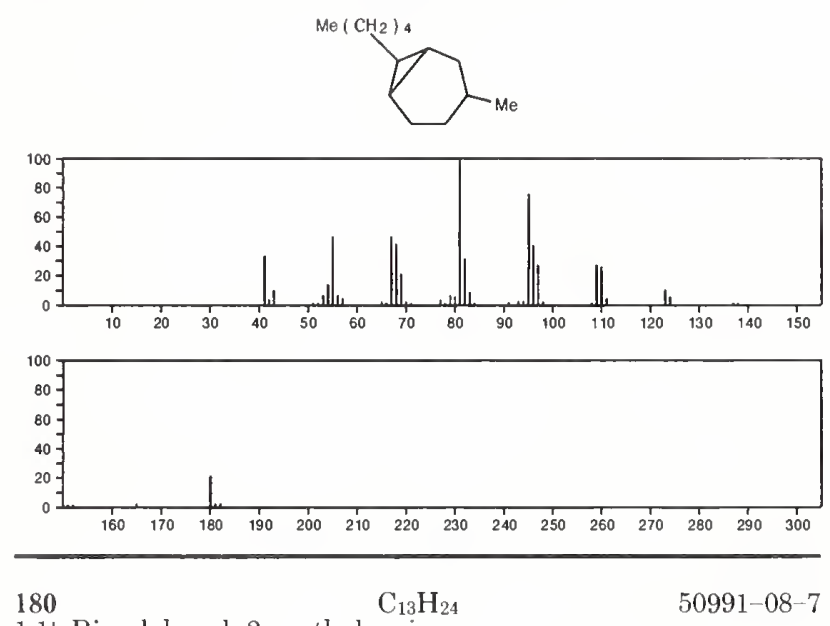

1,1'-Bicyclohexyl, 2-methyl-, cis-
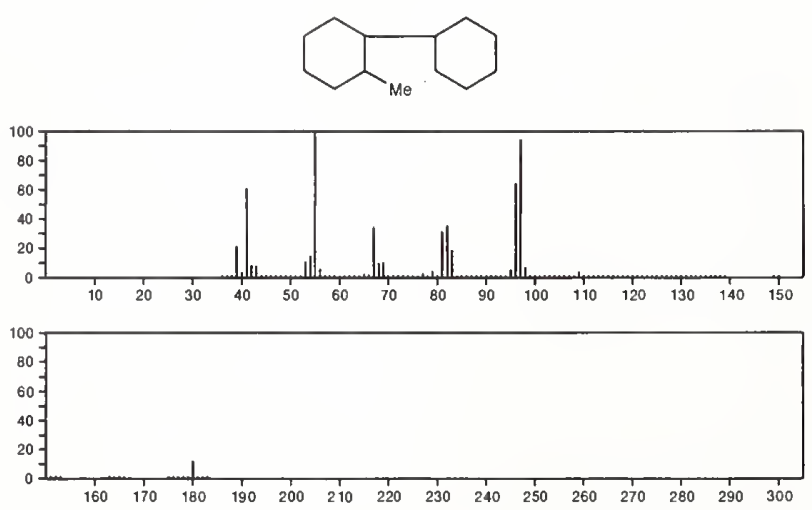

$180 \quad \mathrm{C}_{13} \mathrm{H}_{24}$

$50991-09-8$

1,1'-Bicyclohexyl, 2-methyl-, trans-
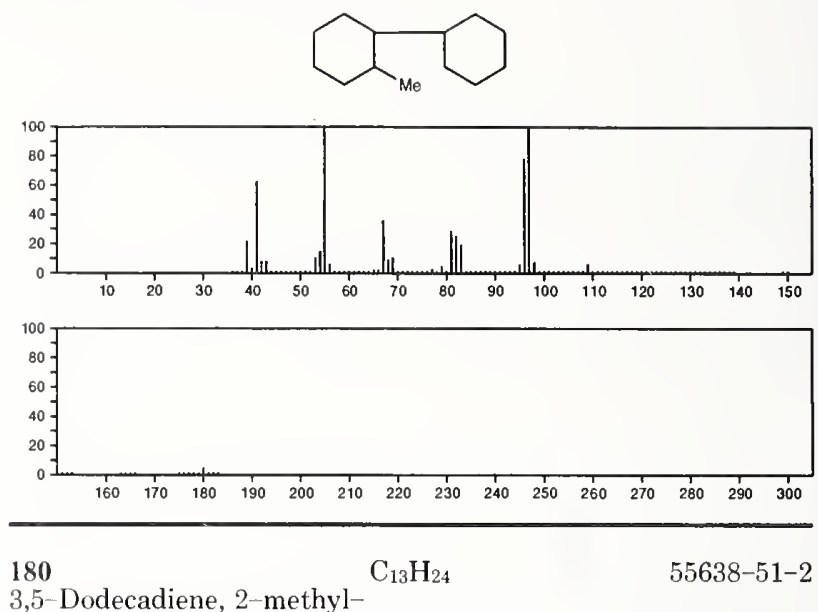

3,5-Dodecadiene, 2-methyl-

$\mathrm{Me}\left(\mathrm{CH}_{2}\right){ }_{5} \mathrm{CH}: \mathrm{CHCH}: \mathrm{CHCHME} 2$
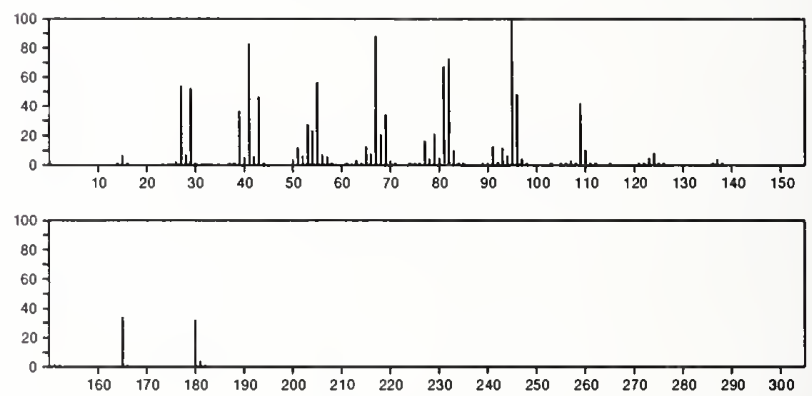

180

$\mathrm{C}_{13} \mathrm{H}_{24}$

Bicyclo[4.1.0]heptane, 2-methyl-7-pentyl-

$55937-92-3$
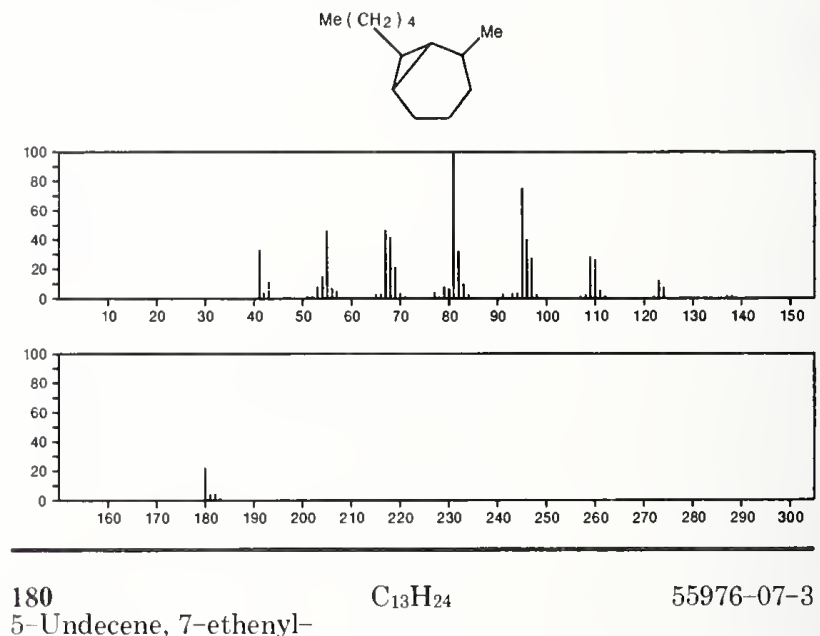

$\mathrm{CH}: \mathrm{CH}_{2}$

$\mathrm{Me}\left(\mathrm{CH}_{2}\right)_{3} \mathrm{CH}=\mathrm{CHCH}\left(\mathrm{CH}_{2}\right)_{3} \mathrm{Me}$
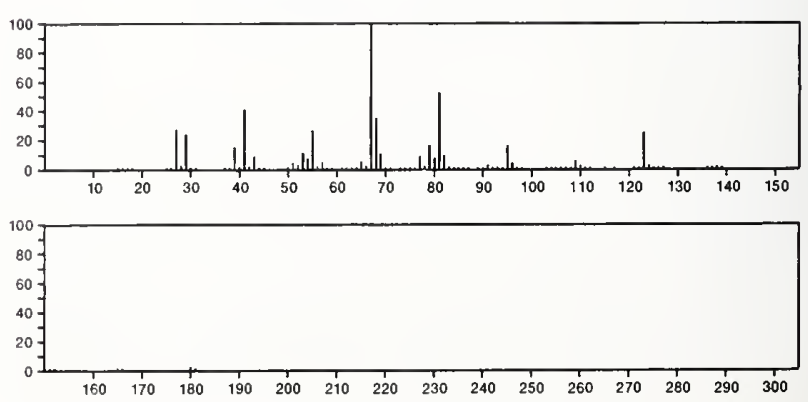
180 $\mathrm{C}_{14} \mathrm{H}_{12}$

$103-30-0$

Benzene, 1,1'-(1,2-ethenediyl) bis-, $(E)$

$\mathrm{PhCH}=\mathrm{CHPh}$
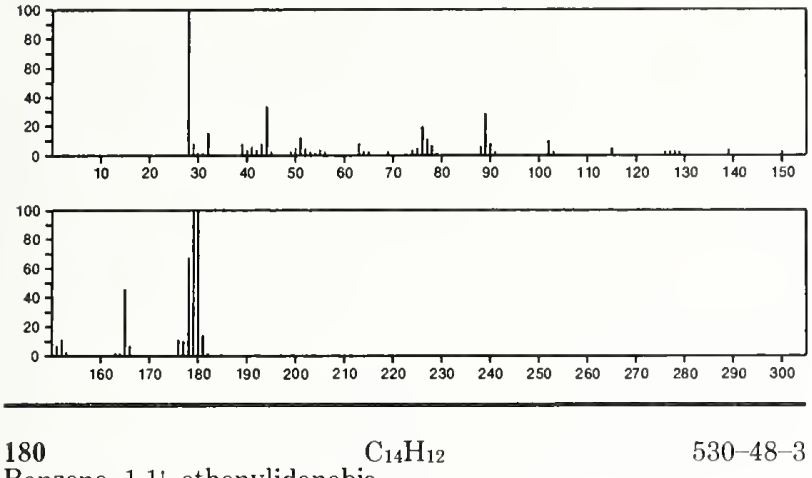

Benzene, 1,1'-ethenylidenebis--

$\mathrm{Ph}_{2} \mathrm{C}=\mathrm{CH}_{2}$
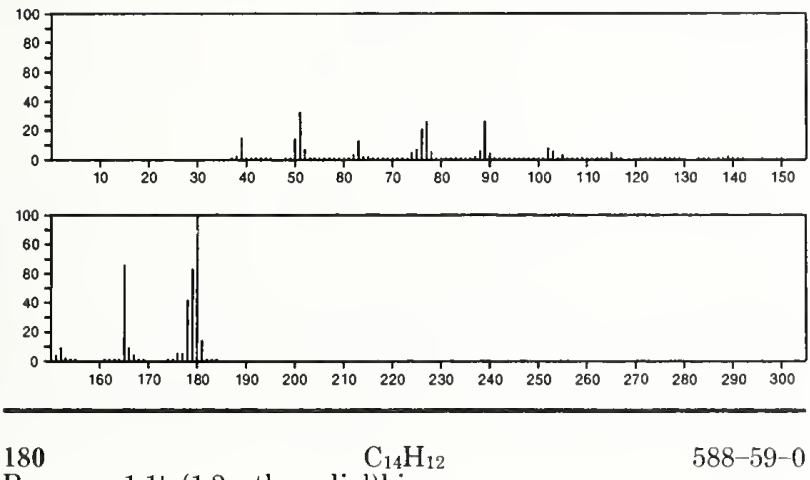

$588-59-0$

Benzene, 1,1'-(1,2-ethenediyl) bis-

$\mathrm{PhCH}=\mathrm{CHPh}$
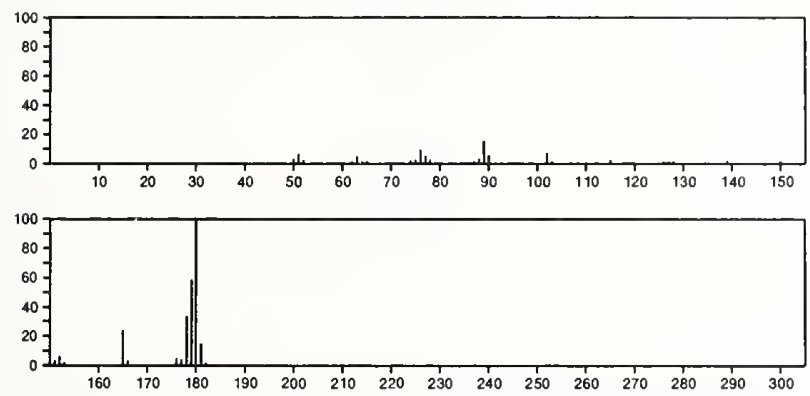

180

$\mathrm{C}_{14} \mathrm{H}_{12}$

Benzene, 1,1'-(1,2-ethenediyl)bis-, $(Z)$

$645-49-8$

$\mathrm{PhCH}=\mathrm{CHPh}$
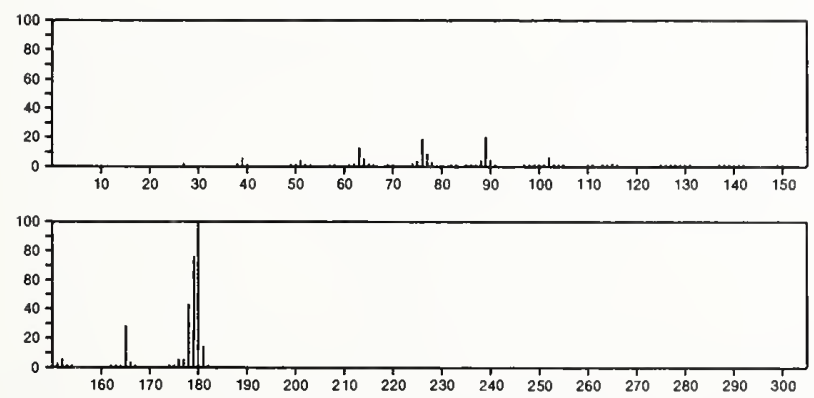

180

$\mathrm{C}_{14} \mathrm{H}_{12}$

$776-35-2$

Phenanthrene, 9,10-dihydro-
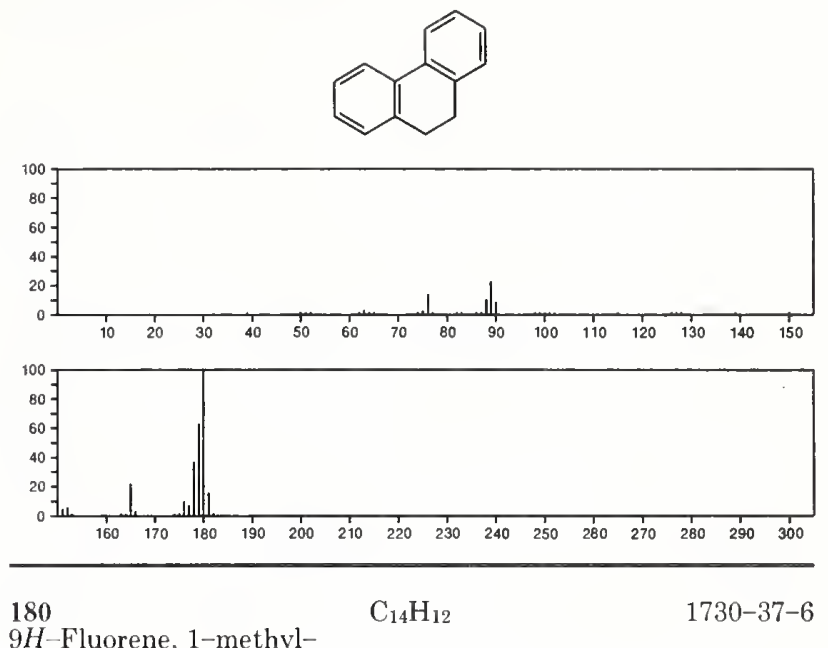

9H-Fluorene, 1-methyl-
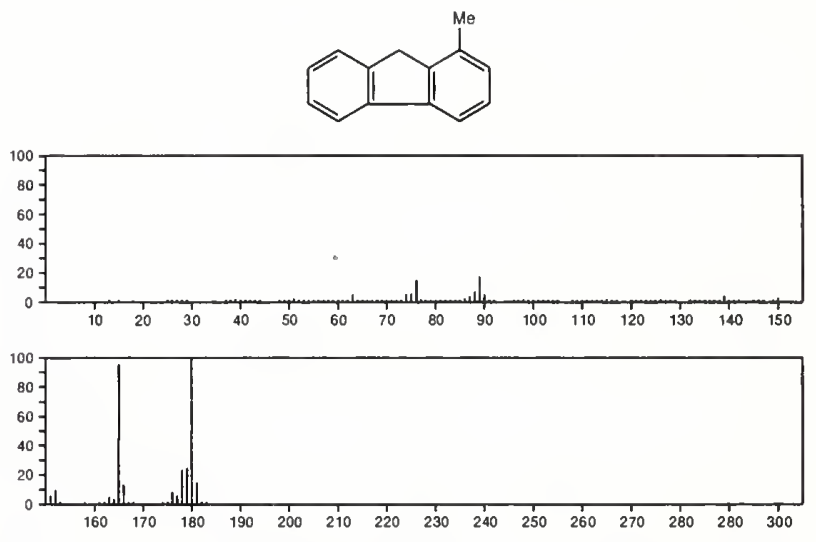

180

$\mathrm{C}_{14} \mathrm{H}_{12}$

$2523-37-7$

9H-Fluorene, 9-methyl-
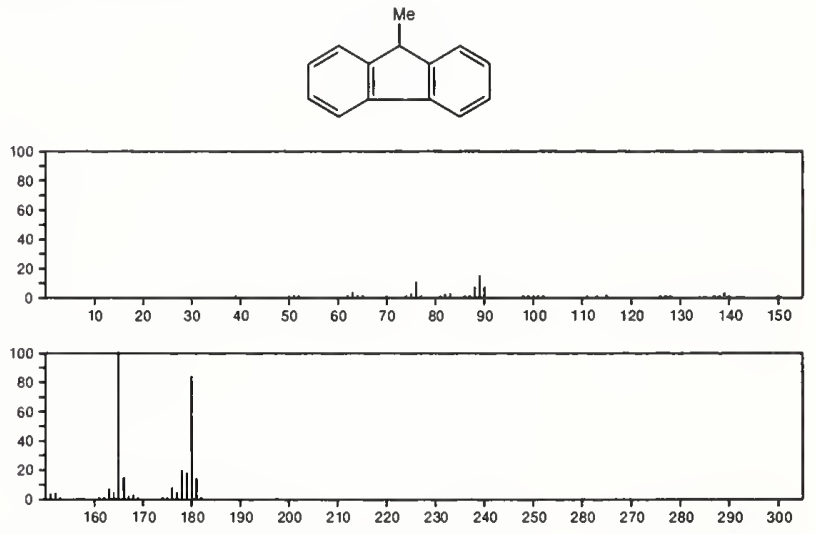

181

$\mathrm{C}_{2} \mathrm{~F}_{5} \mathrm{NOS}$

24433-65-6

Imidosulfurous difluoride, (trifluoroacetyl)-

$\mathrm{F}_{2} \mathrm{~S}=\mathrm{NCOCF}_{3}$

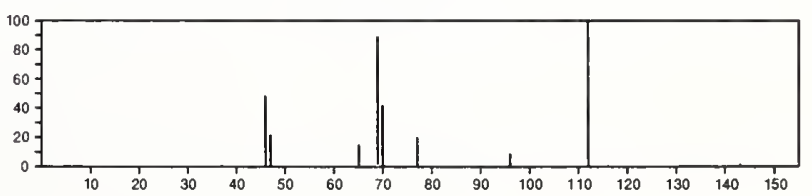




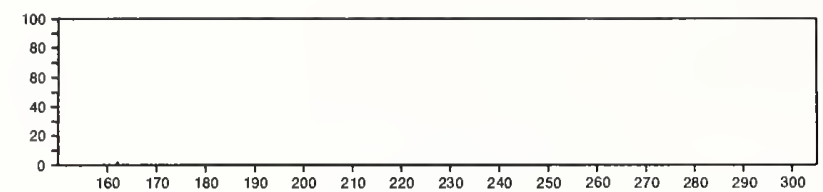

181

$\mathrm{C}_{6} \mathrm{H}_{16} \mathrm{NO}_{3} \mathrm{P}$

$6415-20-9$

Phosphoramidic acid, bis(1-methylethyl) ester

$\stackrel{O}{i}-\mathrm{PrOP}\left(\mathrm{NH}_{2}\right) \mathrm{OPr}_{-i}$
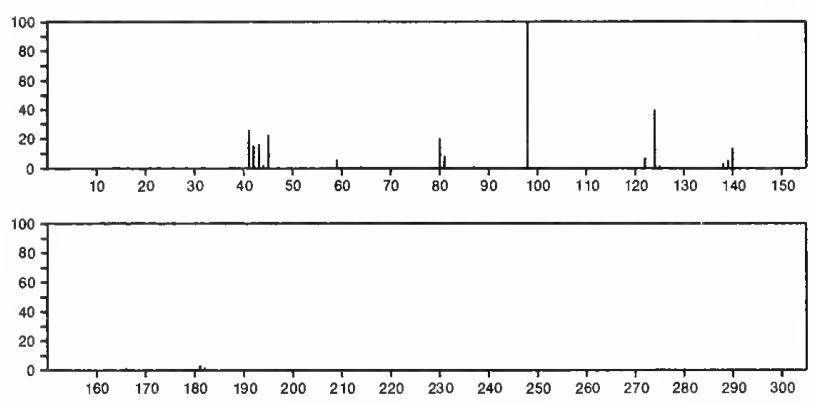

$181 \quad \mathrm{C}_{6} \mathrm{H}_{16} \mathrm{NO}_{3} \mathrm{P}$

$17123-09-0$

Phosphoramidic acid, dipropyl ester

$\stackrel{\mathrm{II}}{\mathrm{PrOP}\left(\mathrm{NH}_{2}\right) \mathrm{OPr}}$
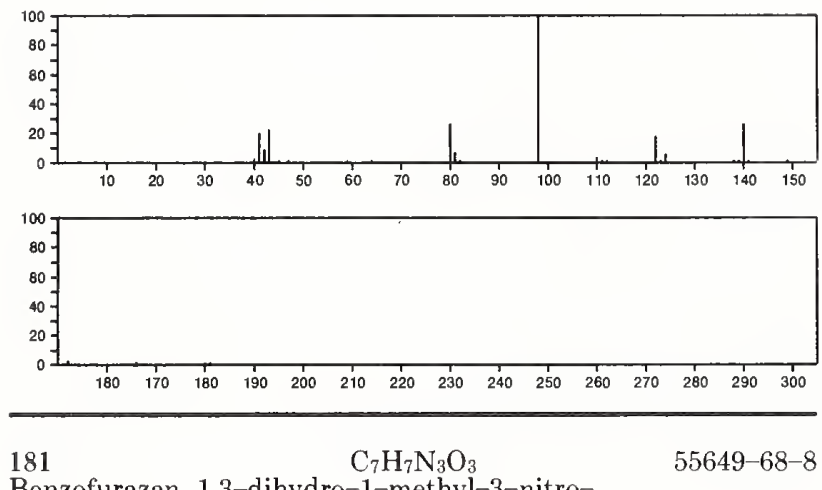

Benzofurazan, 1,3-dihydro-1-methyl-3-nitro-
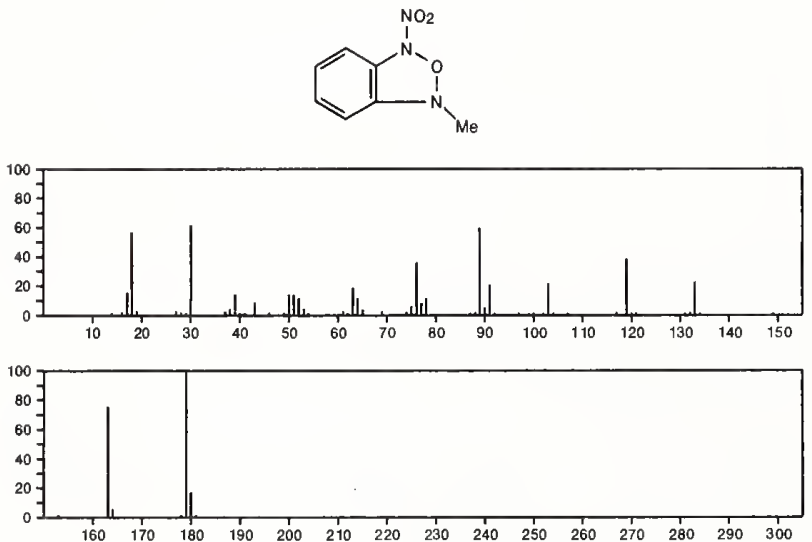

181

$\mathrm{C}_{8} \mathrm{H}_{7} \mathrm{NO}_{2} \mathrm{~S}$

2H-1,4-Benzothiazin-3(4H)-one, 4-hydroxy-

21069-05-6<smiles>O=C1CSc2ccccc2N1O</smiles>
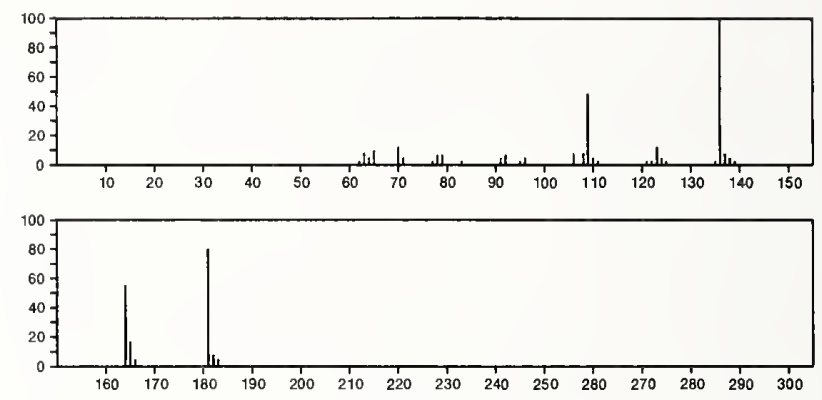

181

$\mathrm{C}_{8} \mathrm{H}_{7} \mathrm{NO}_{4}$

Benzoic acid, 4-nitro-, methyl ester

$619-50-1$
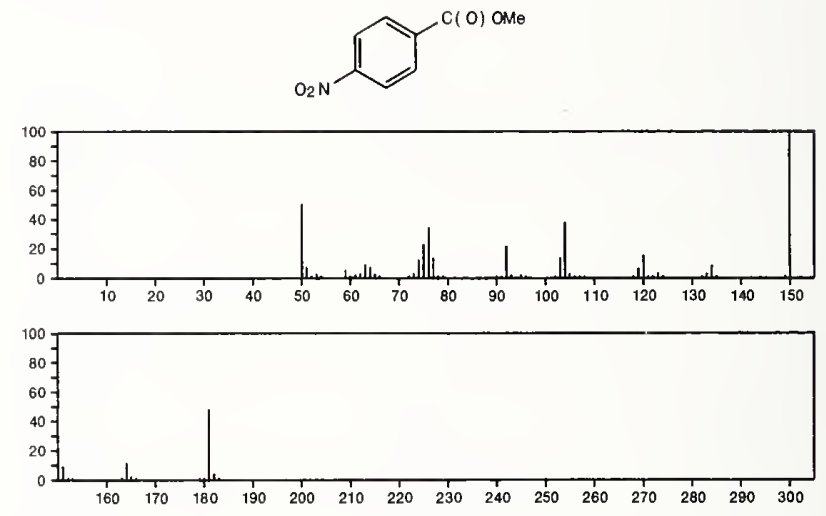

181

$\mathrm{C}_{8} \mathrm{H}_{7} \mathrm{NS}_{2}$

$615-22-5$

Benzothiazole, 2-(methylthio)-
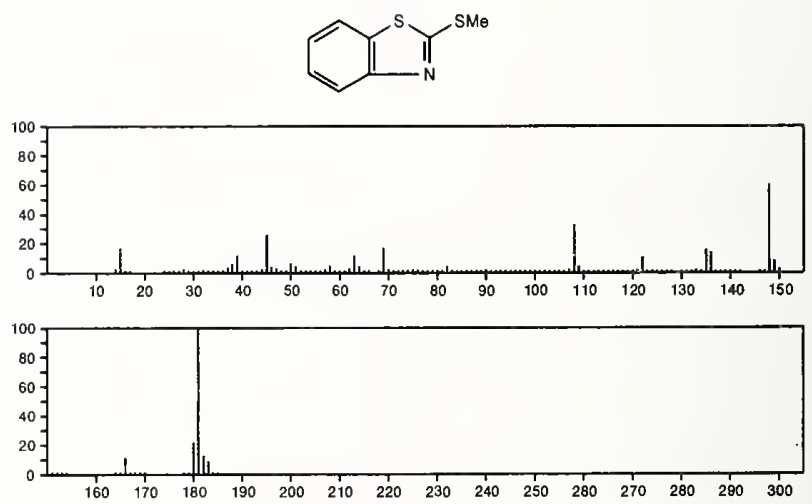

181

$\mathrm{C}_{8} \mathrm{H}_{15} \mathrm{~N}_{5}$

$s$-Triazine, 2,4-bis(ethylamino)-6-methyl-

1973-07-5
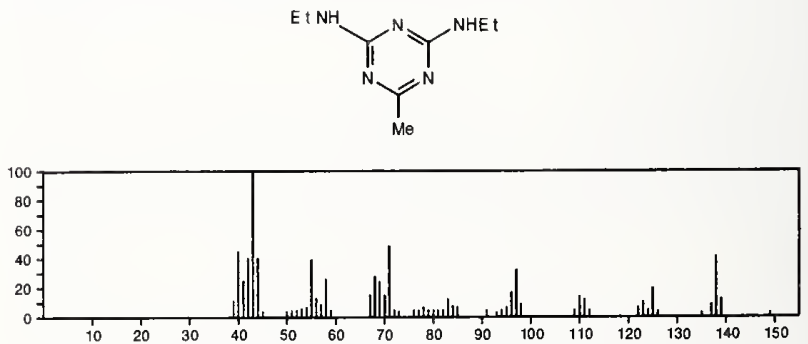


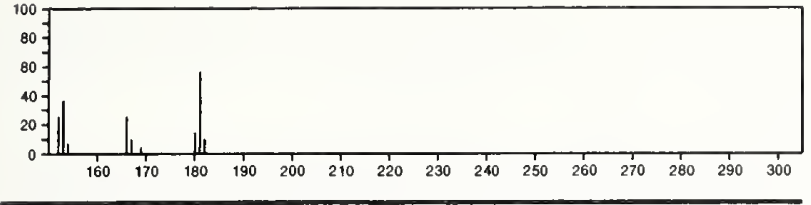

181

$\mathrm{C}_{9} \mathrm{H}_{11} \mathrm{NOS}$

$7304-68-9$

Carbamothioic acid, dimethyl--, $S$-phenyl ester

$\mathrm{Me}_{2} \mathrm{NC}(\mathrm{O}) \mathrm{SPh}$
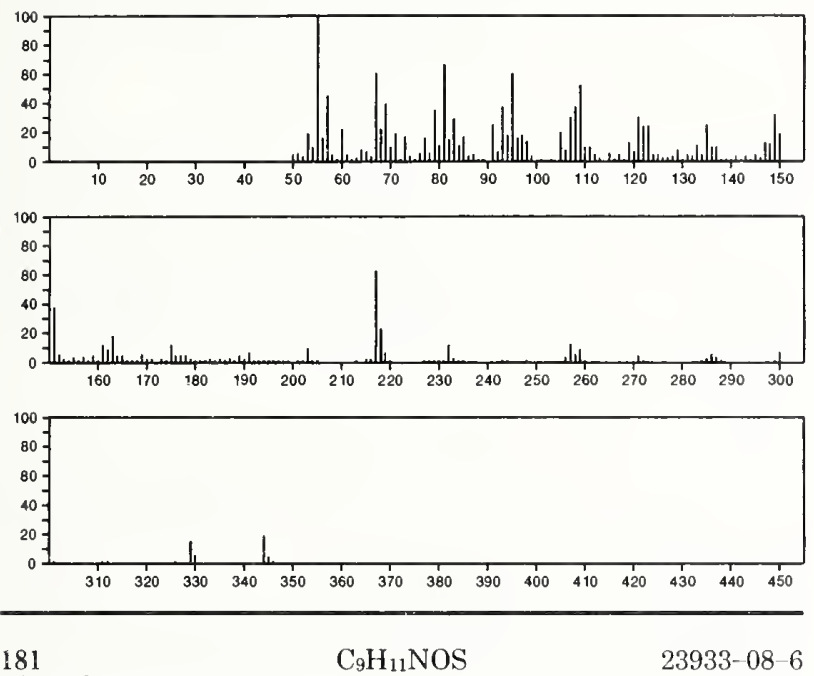

Thiazolo[3,2-a]pyridinium, 2,3-dihydro-8-hydroxy-2,5-dimethyl-, hydroxide, inner salt
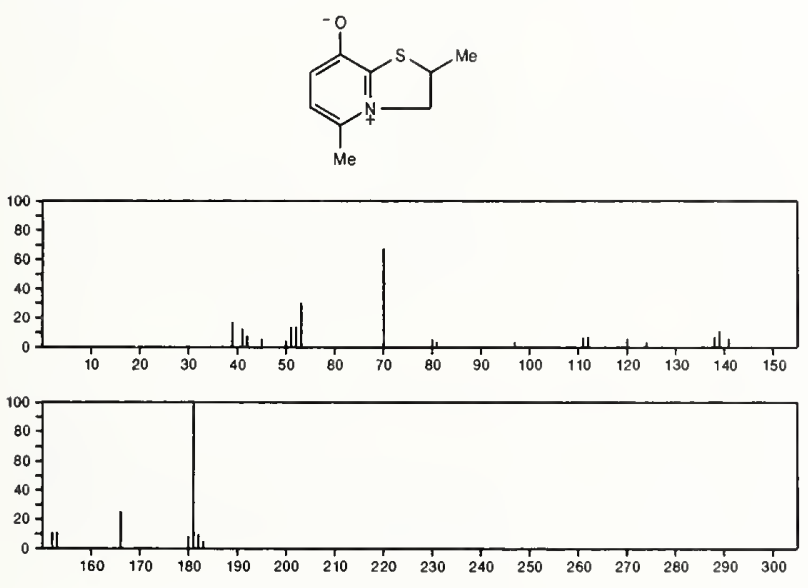

181

$\mathrm{C}_{9} \mathrm{H}_{11} \mathrm{NOS}$

55649-96-2

Sulfonium, (benzoylamino)dimethyl-, hydroxide, inner salt

Mer $\stackrel{+}{S}-\bar{N}$ COPh
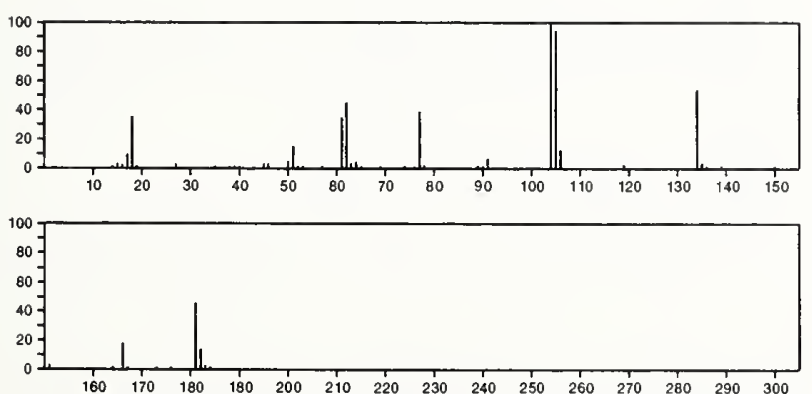

181

L-Tyrosine

$\mathrm{C}_{9} \mathrm{H}_{11} \mathrm{NO}_{3}$

60-18-4<smiles>O=C(O)CCCc1ccc(O)cc1</smiles>
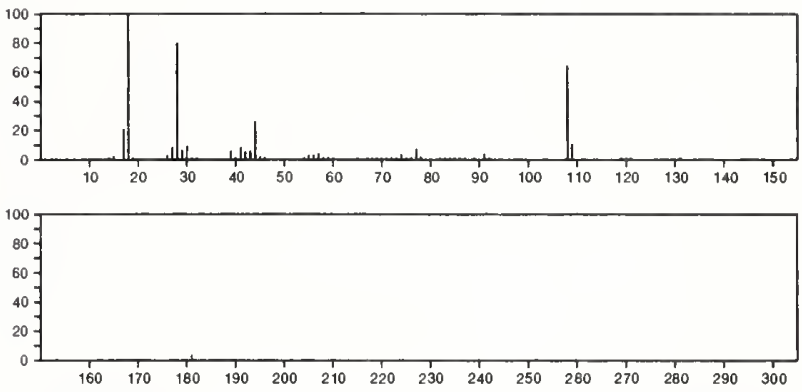

181

1,2-Ethanediol, 1-phenyl-, 2-carbamate

$94-35-9$

$\mathrm{PhCH}(\mathrm{OH}) \mathrm{CH}_{2} \mathrm{OC}(\mathrm{O}) \mathrm{NH}_{2}$

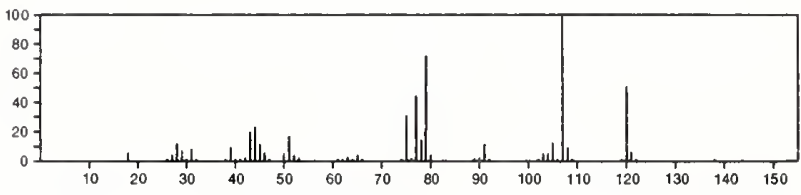

181

$\mathrm{C}_{9} \mathrm{H}_{11} \mathrm{NO}_{3}$

$1719-21-7$

Phenol, 2,4,6-trimethyl-3-nitro-<smiles>Cc1cc([N+](=O)[O-])c(O)c([N+](=O)[O-])c1[N+](=O)[O-]</smiles>
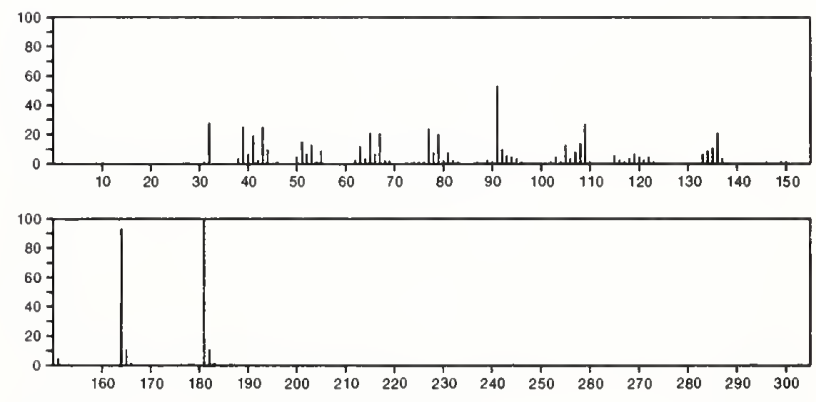

181

$\mathrm{C}_{9} \mathrm{H}_{11} \mathrm{NO}_{3}$

$7135-82-2$

2(1H)-Pyridinone, 4-hydroxy-6-methyl-3-(1-oxopropyl)-<smiles>CCOC(=O)c1c(O)cc(C)[nH]c1=O</smiles>
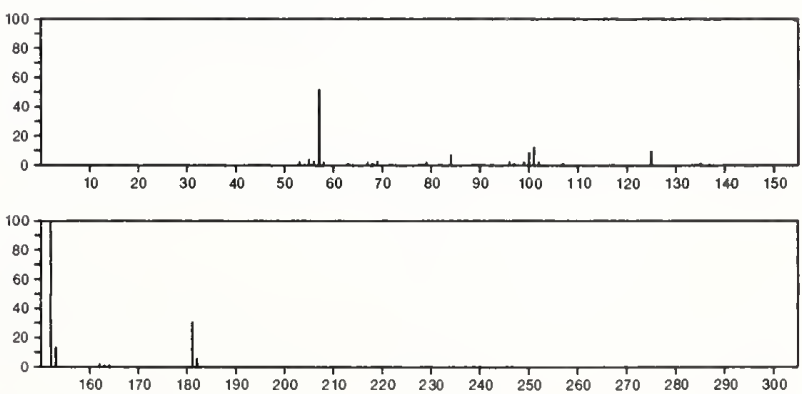
181

$\mathrm{C}_{9} \mathrm{H}_{11} \mathrm{NO}_{3}$

$7202-55-3$

2(1H)-Pyridone, 3-acetyl-4-hydroxy-1,6-dimethyl-
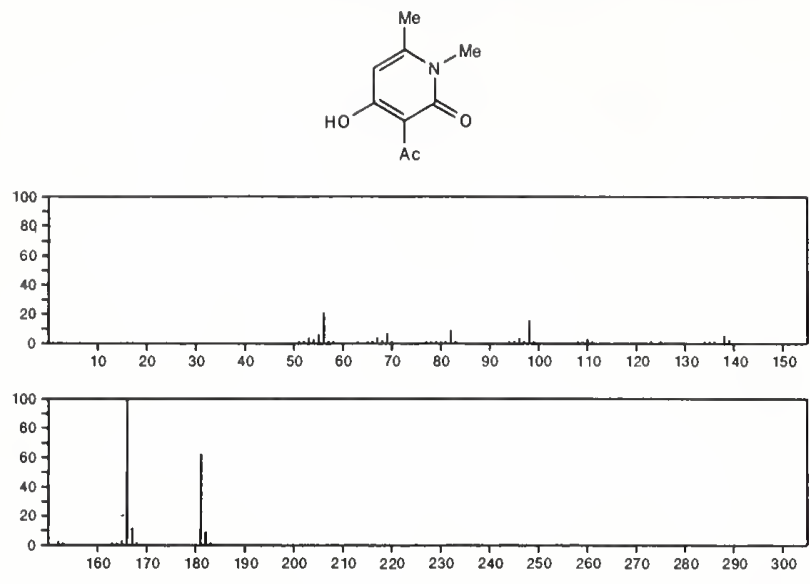

181

$\mathrm{C}_{9} \mathrm{H}_{11} \mathrm{NO}_{3}$

$7211-75-8$

2(1H)-Pyridone, 4-hydroxy-1,6-dimethyl-, acetate (ester)
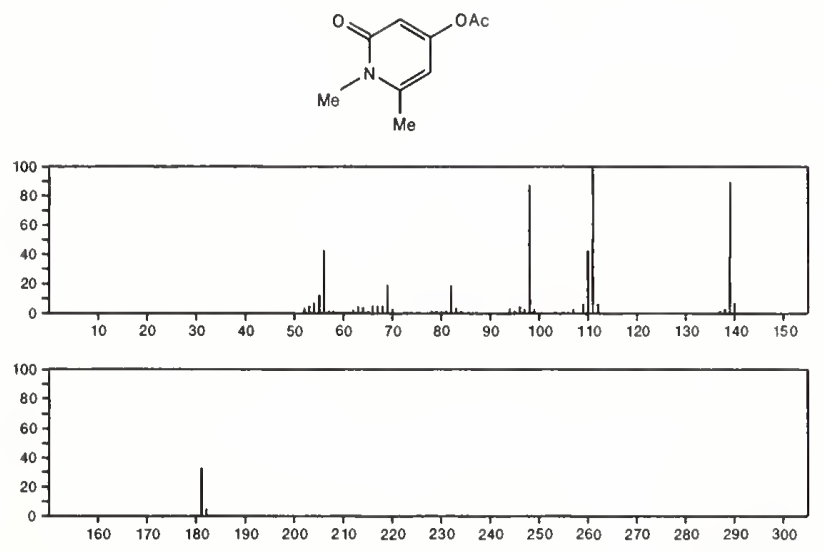

181

$\mathrm{C}_{9} \mathrm{H}_{11} \mathrm{NO}_{3}$

$29121-49-1$

Acetamide, 2-(4-hydroxy-3-methoxyphenyl)
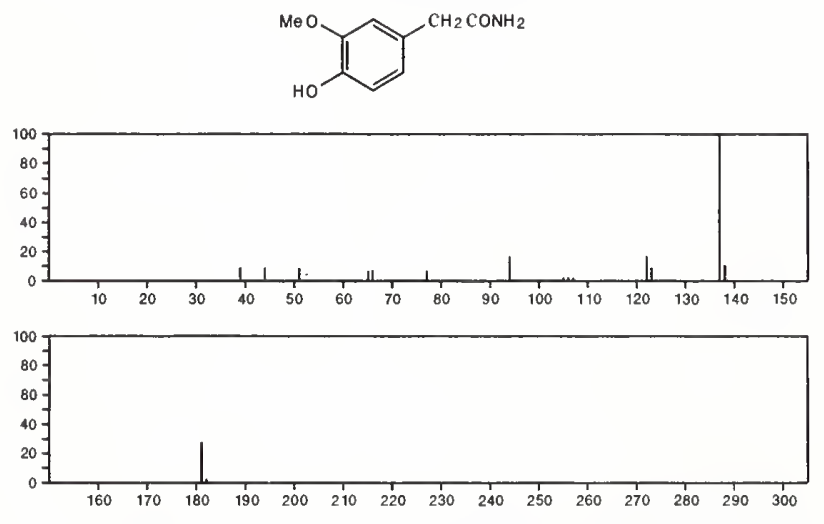

$181 \quad \mathrm{C}_{9} \mathrm{H}_{11} \mathrm{NO}_{3} \quad 30569-18-7$

Pyrrole-2-carboxaldehyde, 5-(hydroxymethyl)-1-methyl-, acetate (ester)
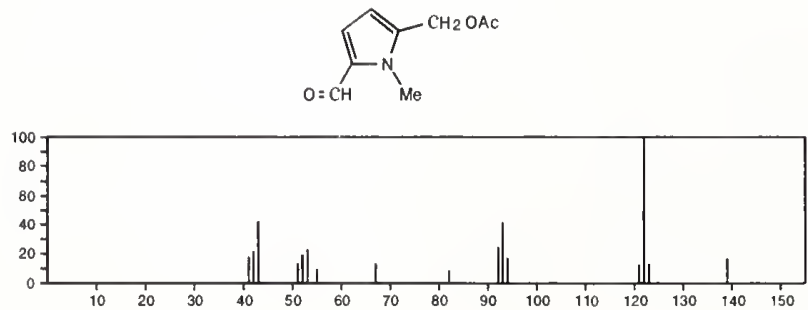

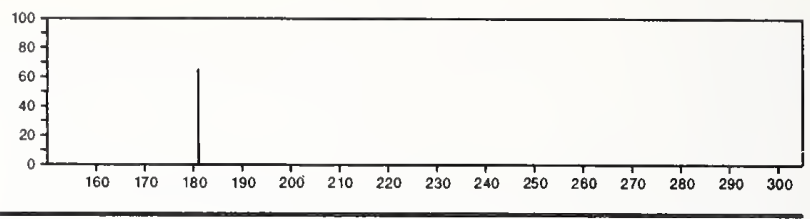

181

$\mathrm{C}_{9} \mathrm{H}_{11} \mathrm{NO}_{3}$

$50267-15-7$

3,8-Dioxa-11-azatetracyclo[4.4.1.02,4.07,9] undecane-11-carbox= aldehyde, $(1 \alpha, 2 \beta, 4 \beta, 6 \alpha, 7 \beta, 9 \beta)$
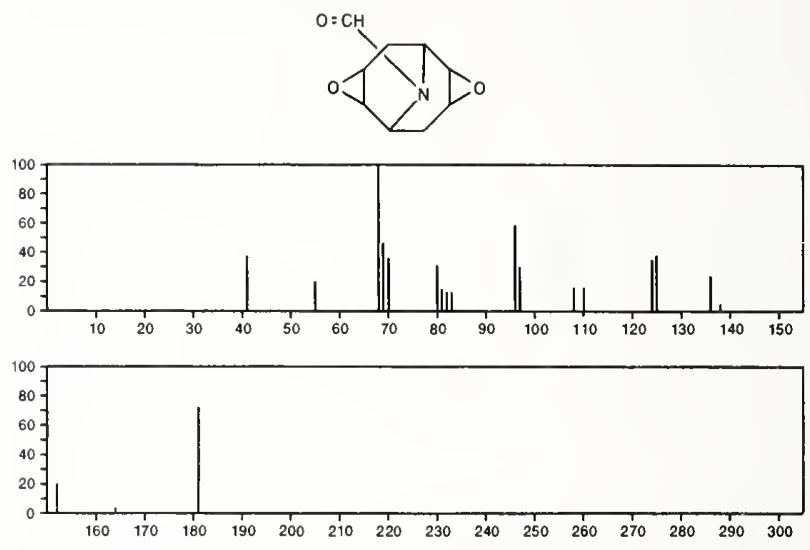

181

$\mathrm{C}_{9} \mathrm{H}_{11} \mathrm{NO}_{3}$

$51422-77-6$

Carbamic acid, (3-methoxyphenyl)-, methyl ester
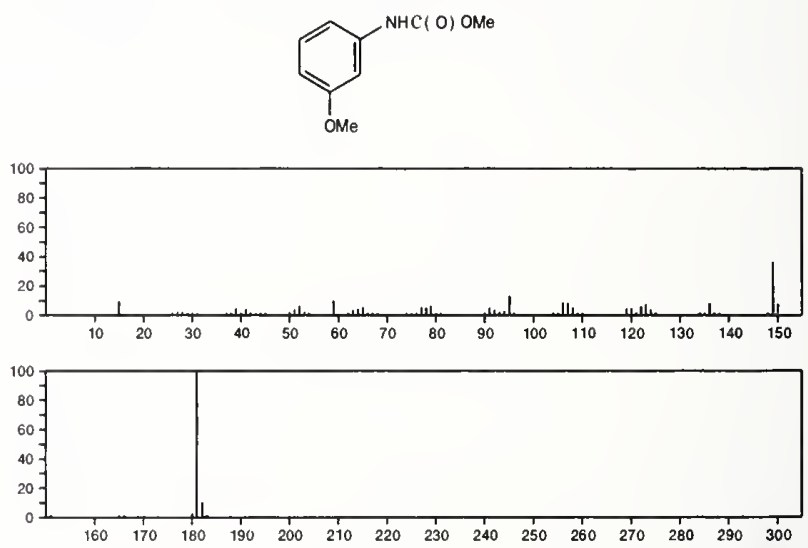

181

$\mathrm{C}_{9} \mathrm{H}_{13} \mathrm{BClN}$

Boranamine, 1-chloro-1-ethyl- $N$-methyl- $N$-phenyl-

$55702-64-2$

EtBCINMEPh
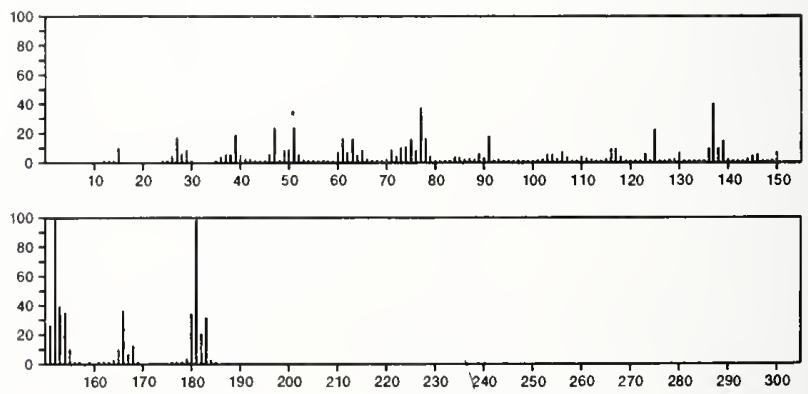
181

$\mathrm{C}_{10} \mathrm{H}_{12} \mathrm{ClN}$

42540-69-2

Benzenamine, $N-[1-($ chloromethyl $)$ cyclopropyl $]-$
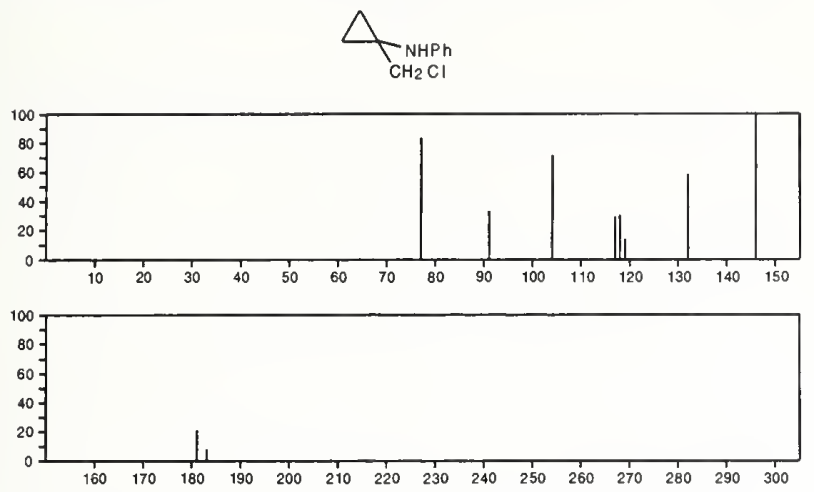

$\begin{array}{lllllllllllllll}160 & 170 & 180 & 190 & 200 & 210 & 220 & 230 & 240 & 250 & 260 & 270 & 280 & 290 & 300\end{array}$

181

$\mathrm{C}_{10} \mathrm{H}_{15} \mathrm{NO}_{2}$

$120-20-7$

Benzeneethanamine, 3,4-dimethoxy-
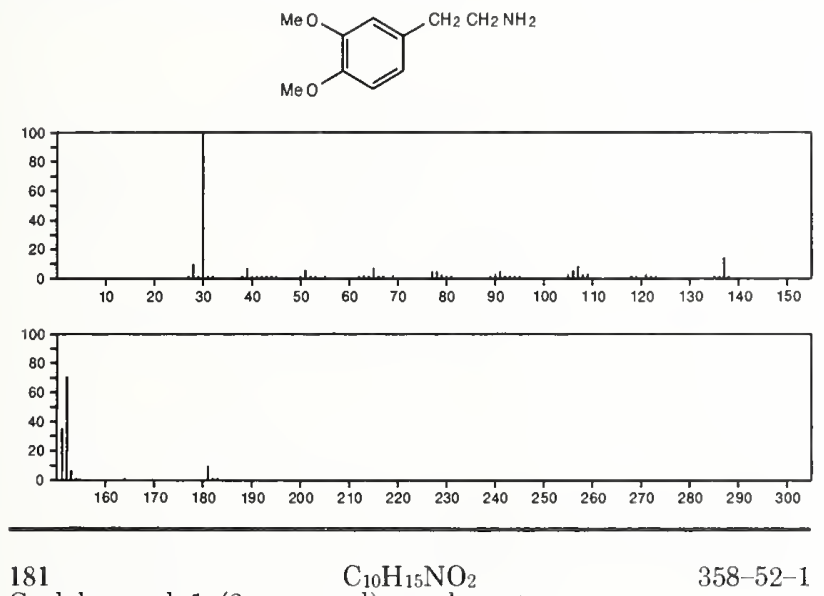

Cyclohexanol, 1-(2-propynyl)-, carbamate
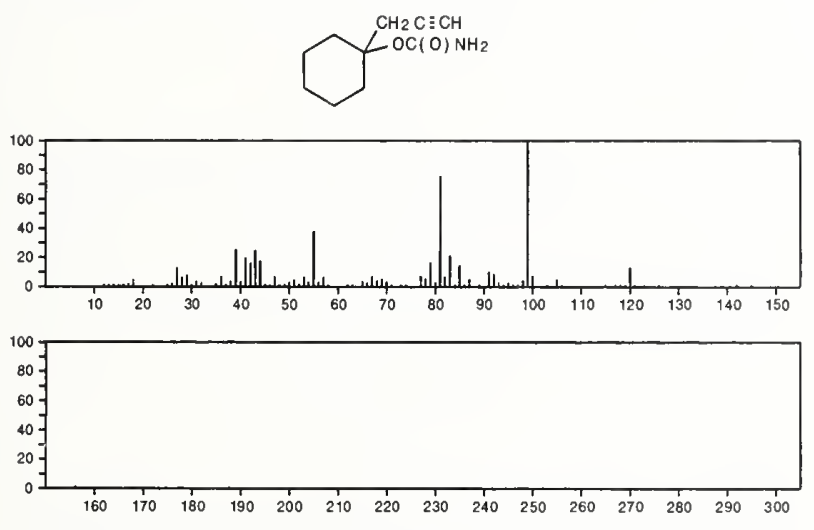

181

$\mathrm{C}_{10} \mathrm{H}_{15} \mathrm{NO}_{2}$

3693-69-4

2-Azabicyclo[2.2.2] oct-5-ene-2-carboxylic acid, ethyl ester
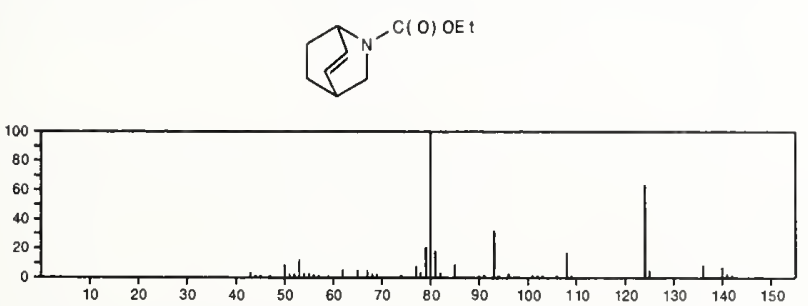
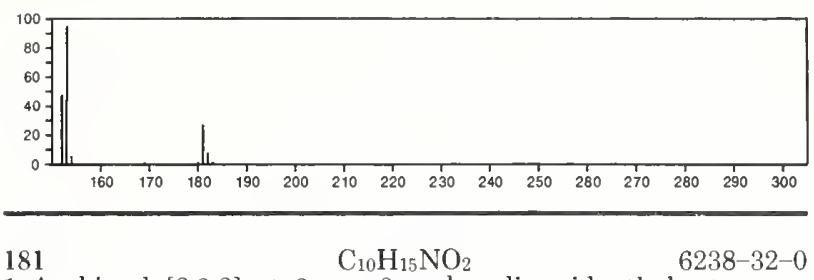

1-Azabicyclo[2.2.2]oct-2-ene-3-carboxylic acid, ethyl ester
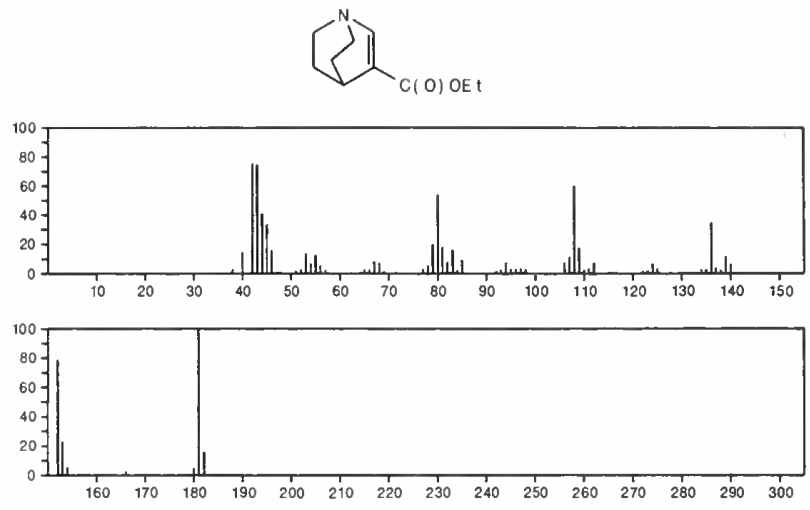

181

$\mathrm{C}_{10} \mathrm{H}_{15} \mathrm{NO}_{2}$

2,4-Pyridinediol, 3-butyl-6-methyl-

$6967-70-0$<smiles>CCCCCCc1c(O)cc(C)[nH]c1=O</smiles>
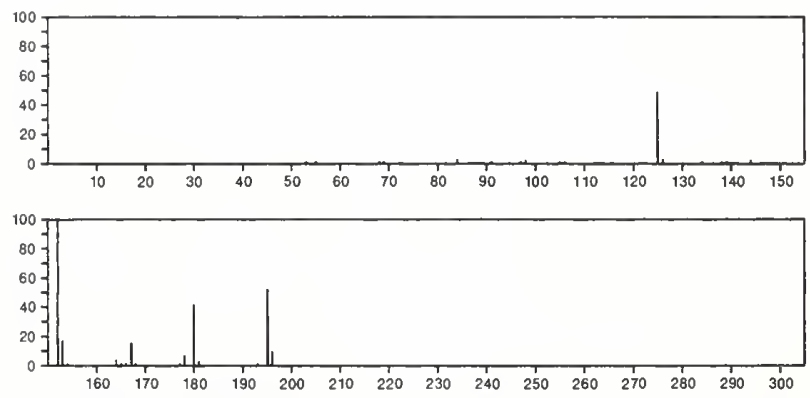

181

$\mathrm{C}_{10} \mathrm{H}_{15} \mathrm{NO}_{2}$

Phenol, 2-[(dimethylamino)methyl $]-4-$ methoxy-

$23562-77-8$<smiles>COCCNCc1cc(OC)ccc1O</smiles>
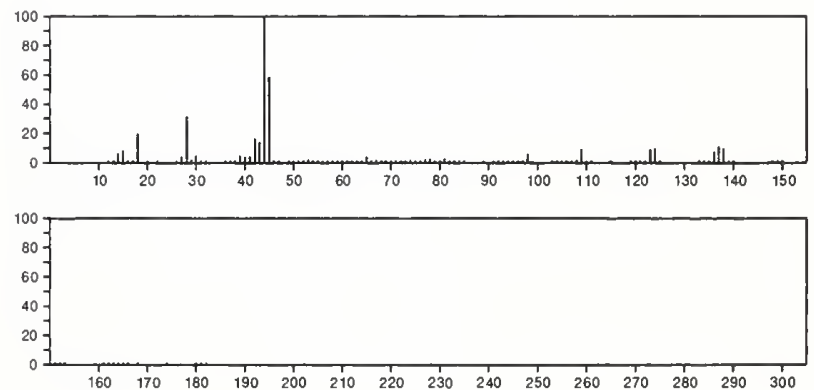
181

$\mathrm{C}_{10} \mathrm{H}_{15} \mathrm{NO}_{2}$

54774-92-4

Morpholine, 4-[(3,4-dihydro-2H-pyran-2-ylidene) methyl]-
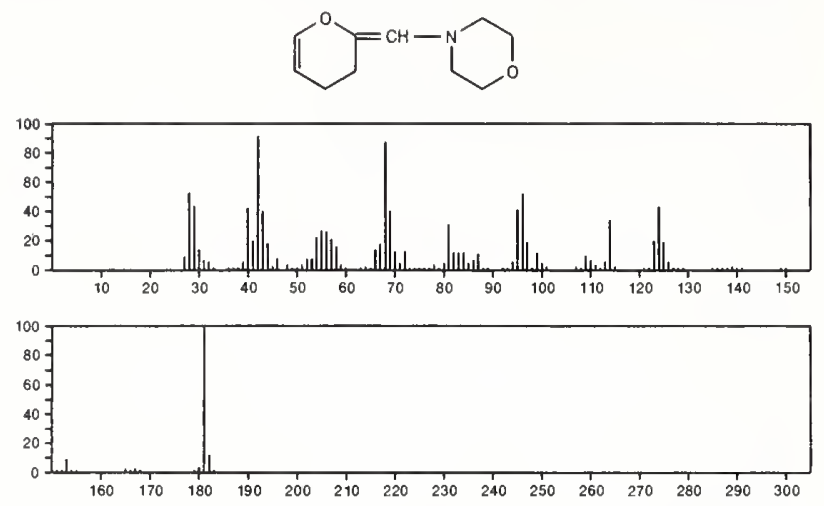

$181 \quad \mathrm{C}_{10} \mathrm{H}_{15} \mathrm{NS}$

Pyridine, 4-[(tert-butylthio) methyl]-
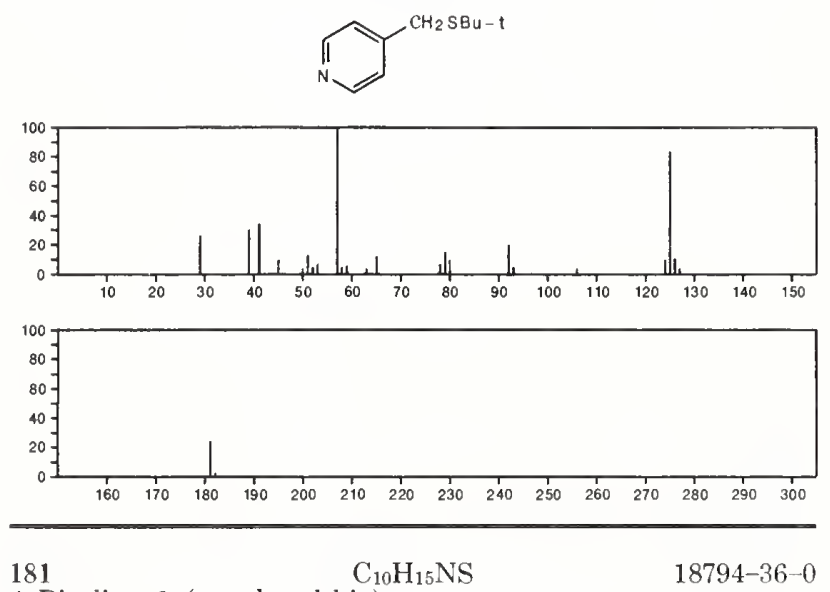

$18794-36 \sim 0$

4-Picoline, 2-(tert-butylthio)-
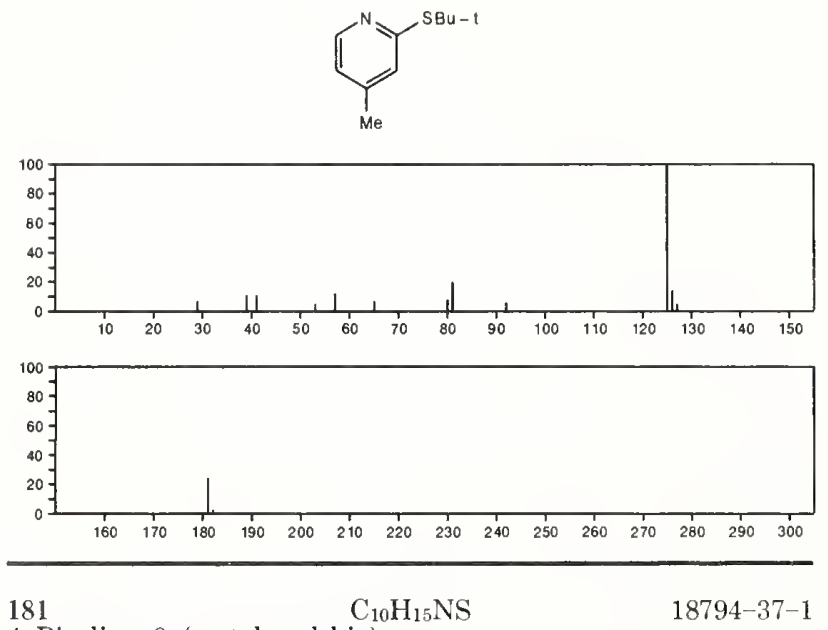

4-Picoline, 3-(tert-butylthio)-
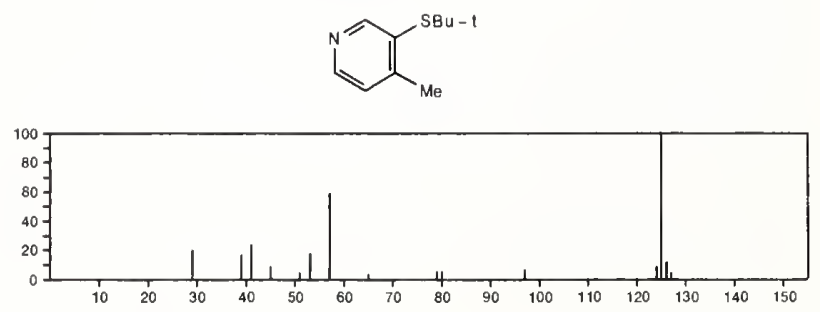

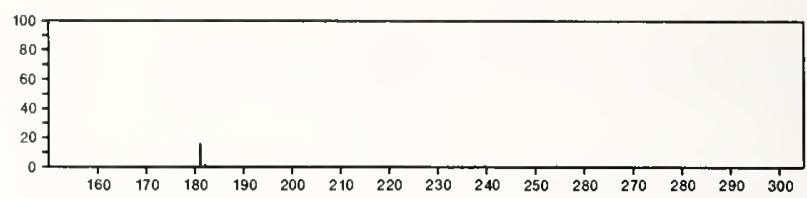

181

2-Picoline, 6-(tert-butylthio)-

$\mathrm{C}_{10} \mathrm{H}_{15 \mathrm{NS}}$

$18794-43-9$
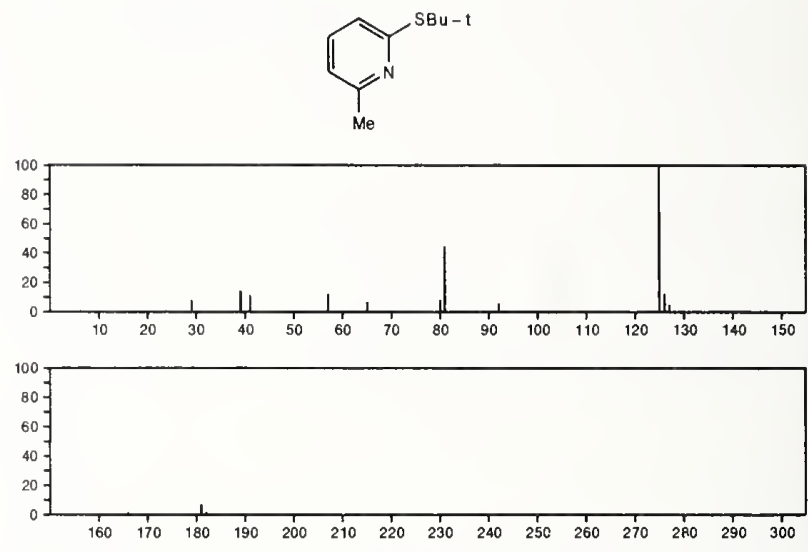

181

$\mathrm{C}_{10} \mathrm{H}_{15} \mathrm{NS}$

18794-44-0

2-Picoline, 5-(tert-butylthio)-
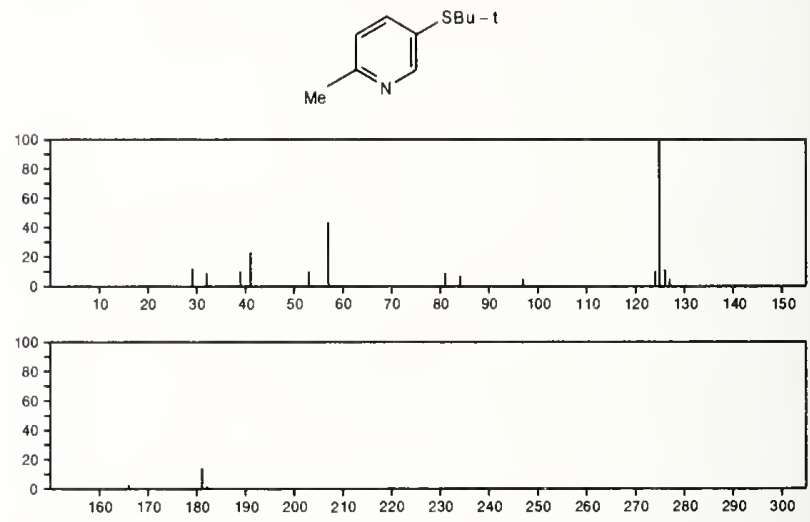

181

$\mathrm{C}_{10} \mathrm{H}_{15} \mathrm{NS}$

Pyridine, 2-[(tert-butylthio)methyl]-

$18794-45-1$
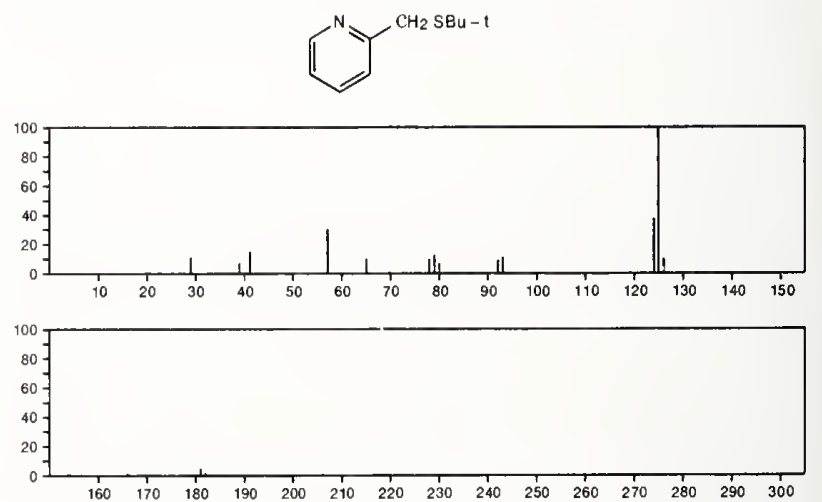
181

$\mathrm{C}_{10} \mathrm{H}_{15} \mathrm{NS}$

$18794-46-2$

3-Picoline, 6-(tert-butylthio)-
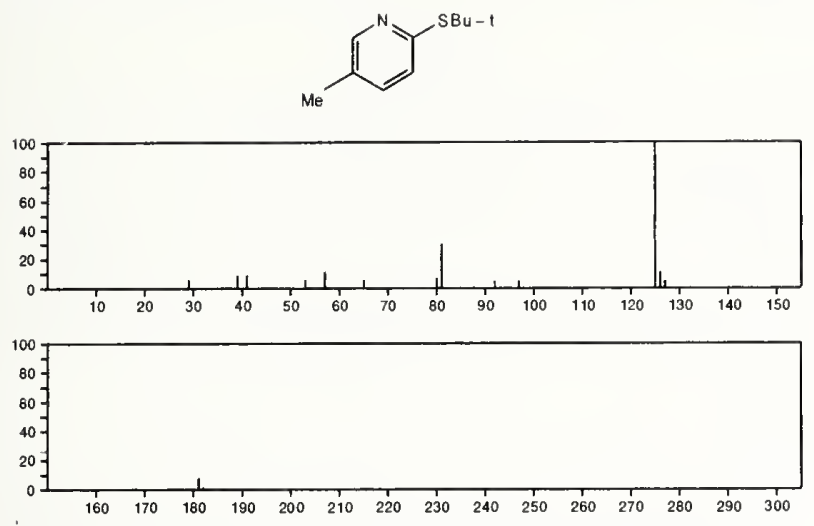

181

3-Picoline, 5-(tert-butylthio)-

$\mathrm{C}_{10} \mathrm{H}_{15} \mathrm{NS}$

$18794-47-3$
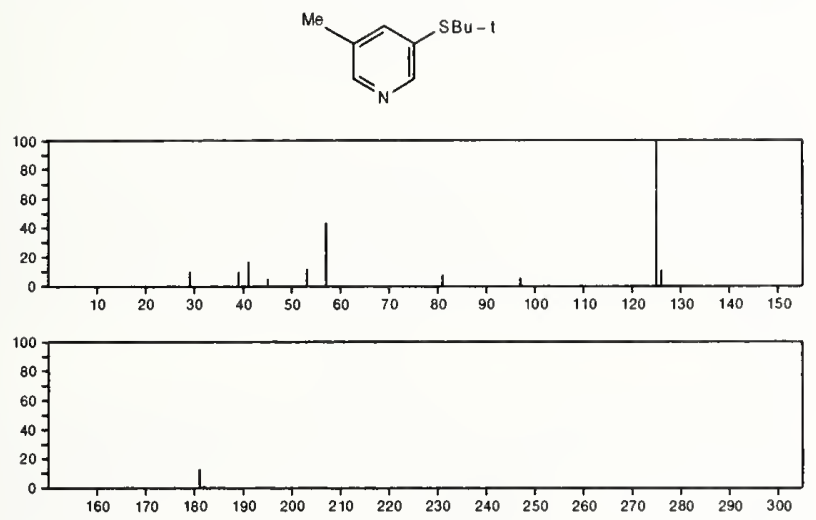

181

3-Picoline, 2-(tert-butylthio)-

\section{$\mathrm{C}_{10} \mathrm{H}_{15} \mathrm{NS}$}

18833-87-9
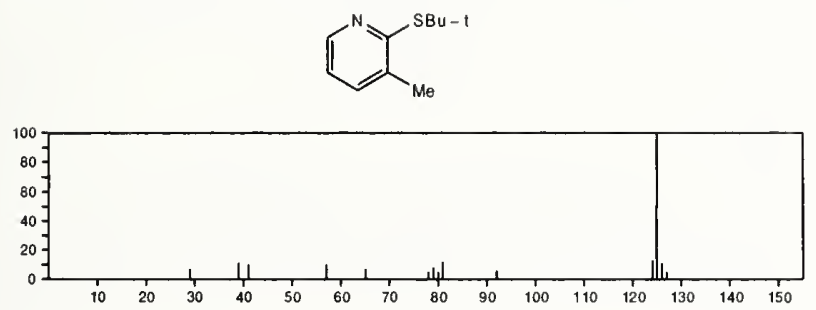

$$
\begin{array}{r}
100 \\
80 \\
60 \\
40 \\
20 \\
\hline
\end{array}
$$

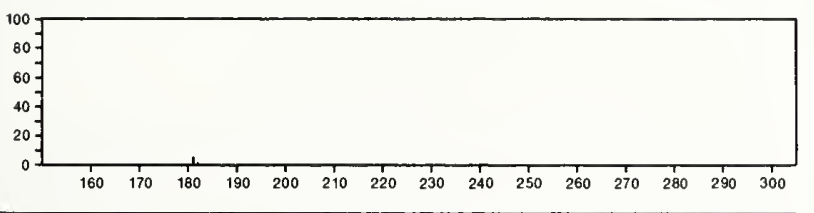

181

\section{$\mathrm{C}_{11} \mathrm{H}_{19} \mathrm{NO}$}

$1130-36-5$

Acetamide, $N$-(4-methylbicyclo[2.2.2]oct-1-yl)-
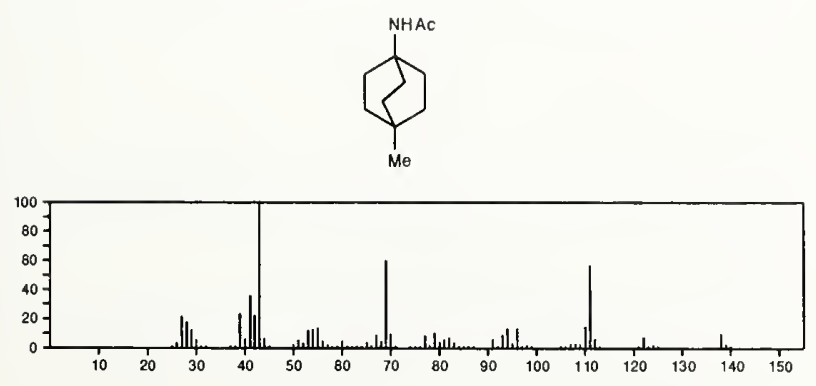
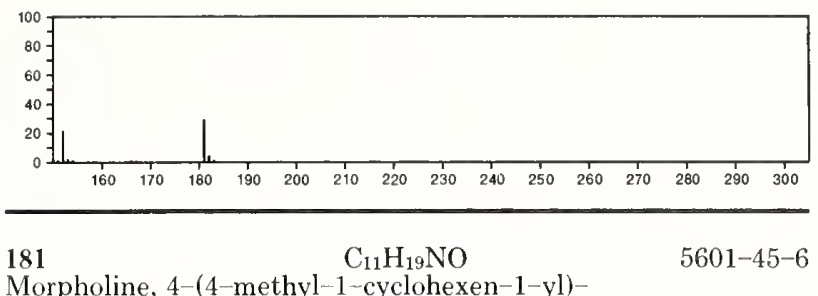

Morpholine, 4-(4-methyl-1-cyclohexen-1-yl)-
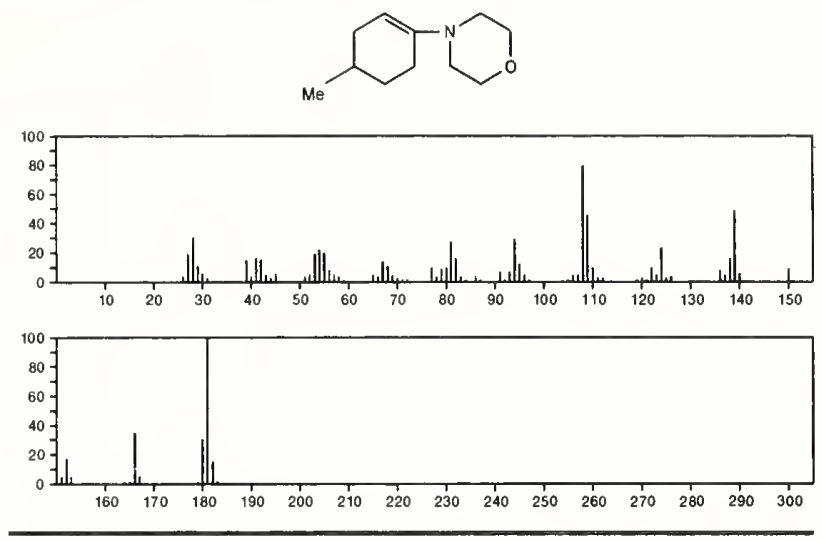

181

$\mathrm{C}_{11} \mathrm{H}_{19} \mathrm{NO}$

13606-83-2

1-Penten-3-one, 4-methyl-1-piperidino-

$\mathrm{N}^{-} \mathrm{CH}=\mathrm{CHCOCHMO} 2$
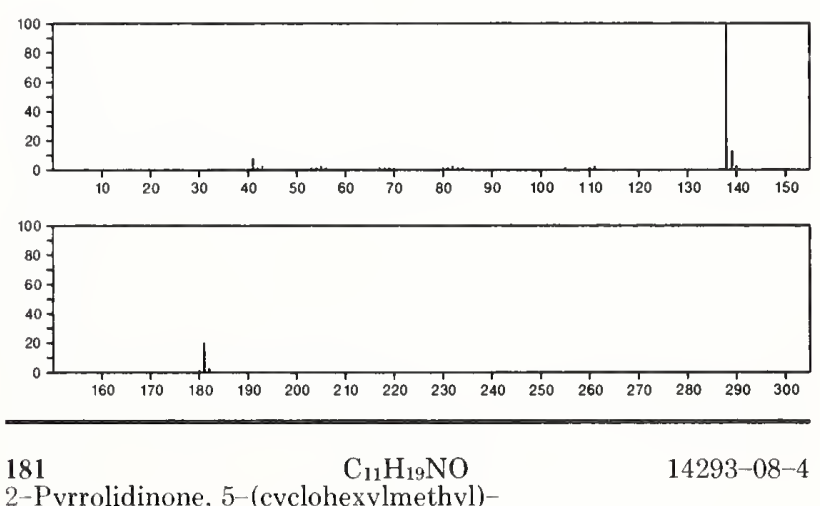

2-Pyrrolidinone, 5-(cyclohexylmethyl)-
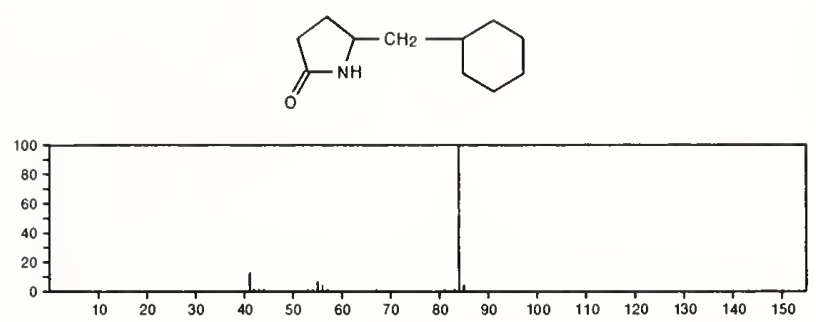
181

$\mathrm{C}_{11} \mathrm{H}_{19} \mathrm{NO}$

$32134-53-5$

2-Norbornanone, 1,3,7,7-tetramethyl-, oxime
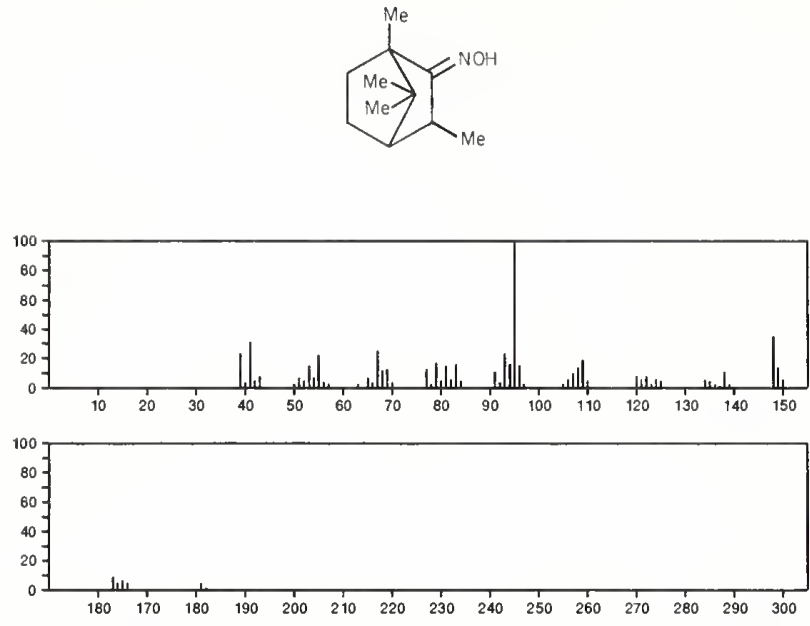

181

Ethanone, 1-[3-methyl-2-(1-pyrrolidinyl)cyclobutyl]-
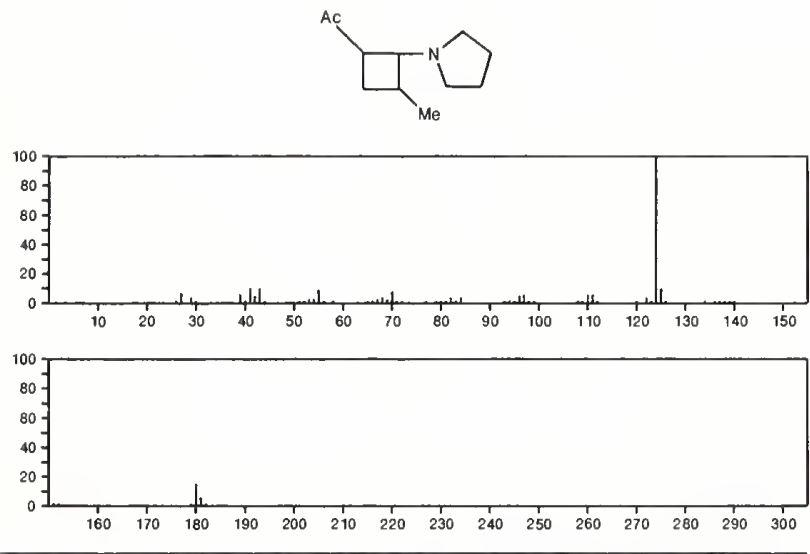

$181 \quad \mathrm{C}_{12} \mathrm{H}_{23} \mathrm{~N}$

$101-83-7$

Cyclohexanamine, $N$-cyclohexyl
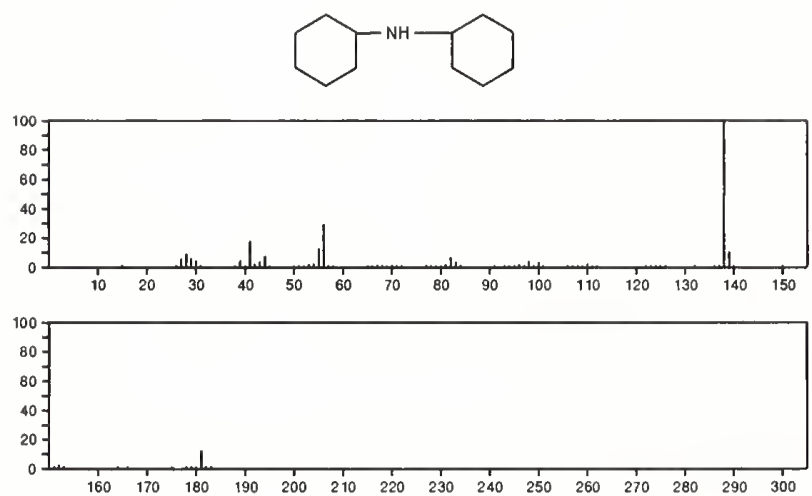

181

$\mathrm{C}_{12} \mathrm{H}_{23} \mathrm{~N}$

$3570-07-8$

Bicyclo[2.2.1]heptan-2-amine, $N, N, 2,3,3$-pentamethyl-
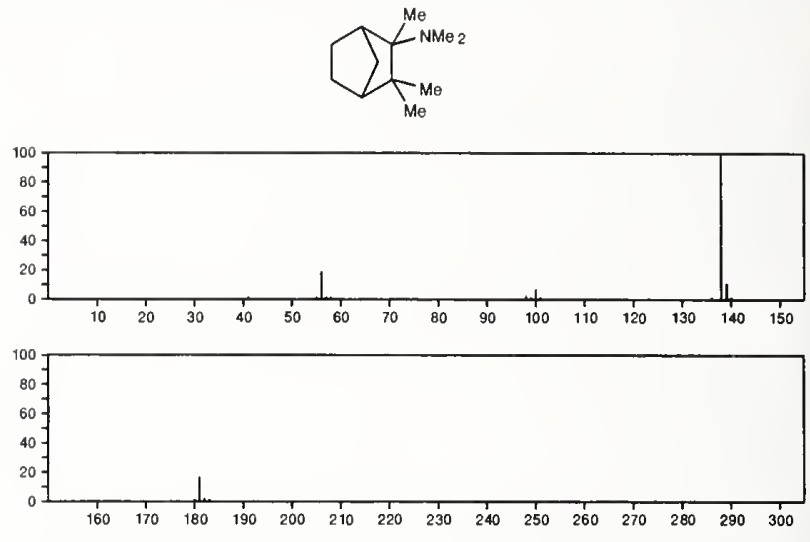

181

2,6-Octadien-1-amine, $N, N, 3,7$-tetramethyl-

$3710-93-8$

$\mathrm{Me}_{2} \mathrm{C}: \mathrm{CHCH}_{2} \mathrm{CH}_{2} \mathrm{CMe}_{\mathrm{C}}=\mathrm{CHCH}_{2} \mathrm{NMe}_{2}$
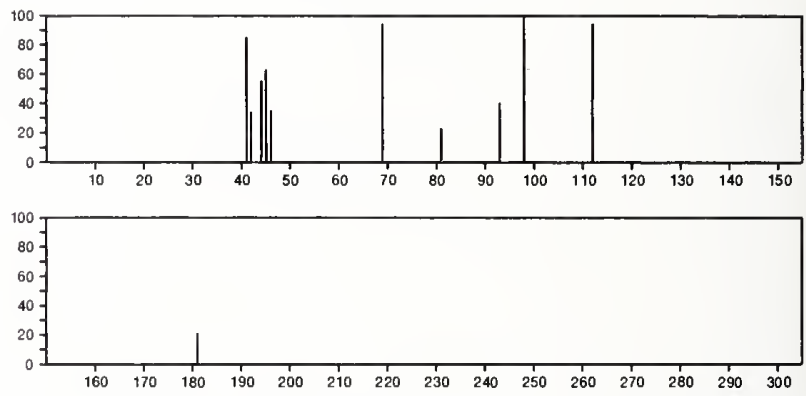

181

$\mathrm{C}_{12} \mathrm{H}_{23} \mathrm{~N}$

2-Bornanamine, $N, N$-dimethyl-, endo-

$14727-50-5$
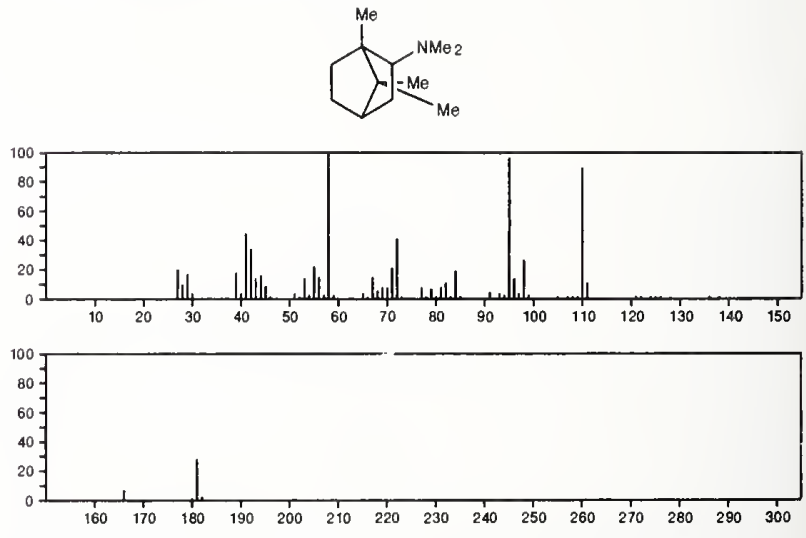

181

$\mathrm{C}_{12} \mathrm{H}_{23} \mathrm{~N}$

17943-83-8

Cyclopentanemethylamine, 2-isopropylidene- $N, N, 5-$ trimethyl-, $(1 R, 5 R)-(-)$
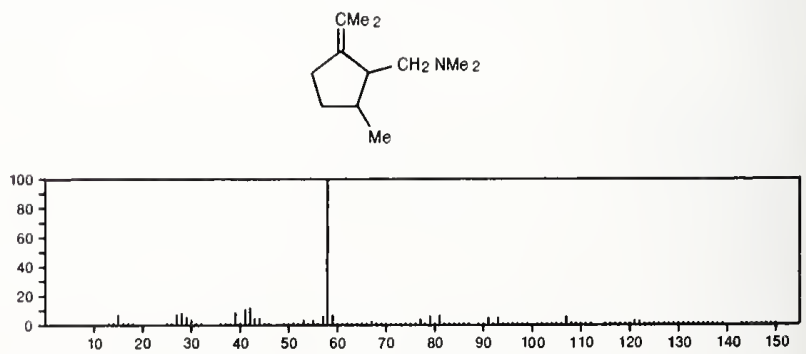
181

EPA/NIH MASS SPECTRAL DATA BASE

929

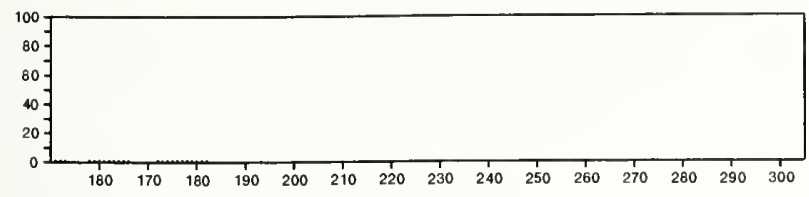

181 $\mathrm{C}_{12} \mathrm{H}_{23} \mathrm{~N} \quad 17943-85-0$ Cyclopentanemethylamine, 2-isopropylidene- $N, N, 5$-trimethyl-, $(1 S, 5 R)-(+)-$
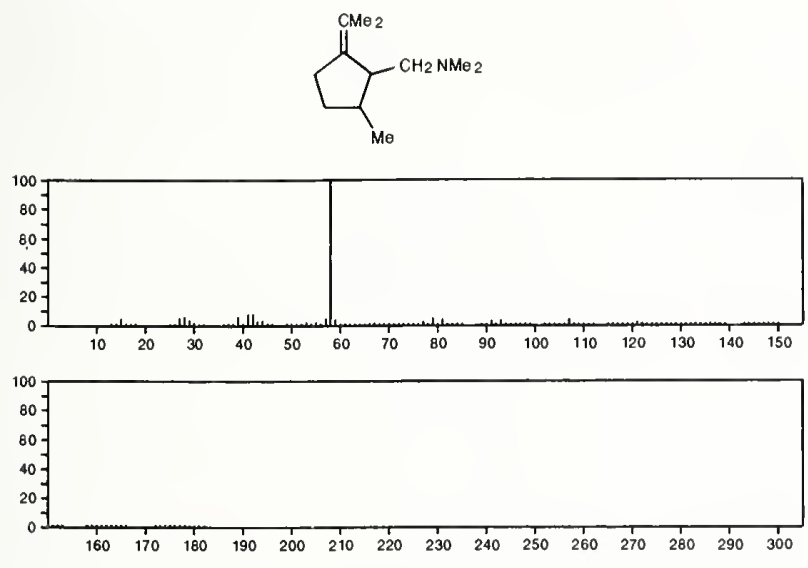

$181 \quad \mathrm{C}_{12} \mathrm{H}_{23} \mathrm{~N} \quad 35973-45-6$ Bicyclo[2.2.1] heptan-2-amine, $N, N, 4,7,7$-pentamethyl-
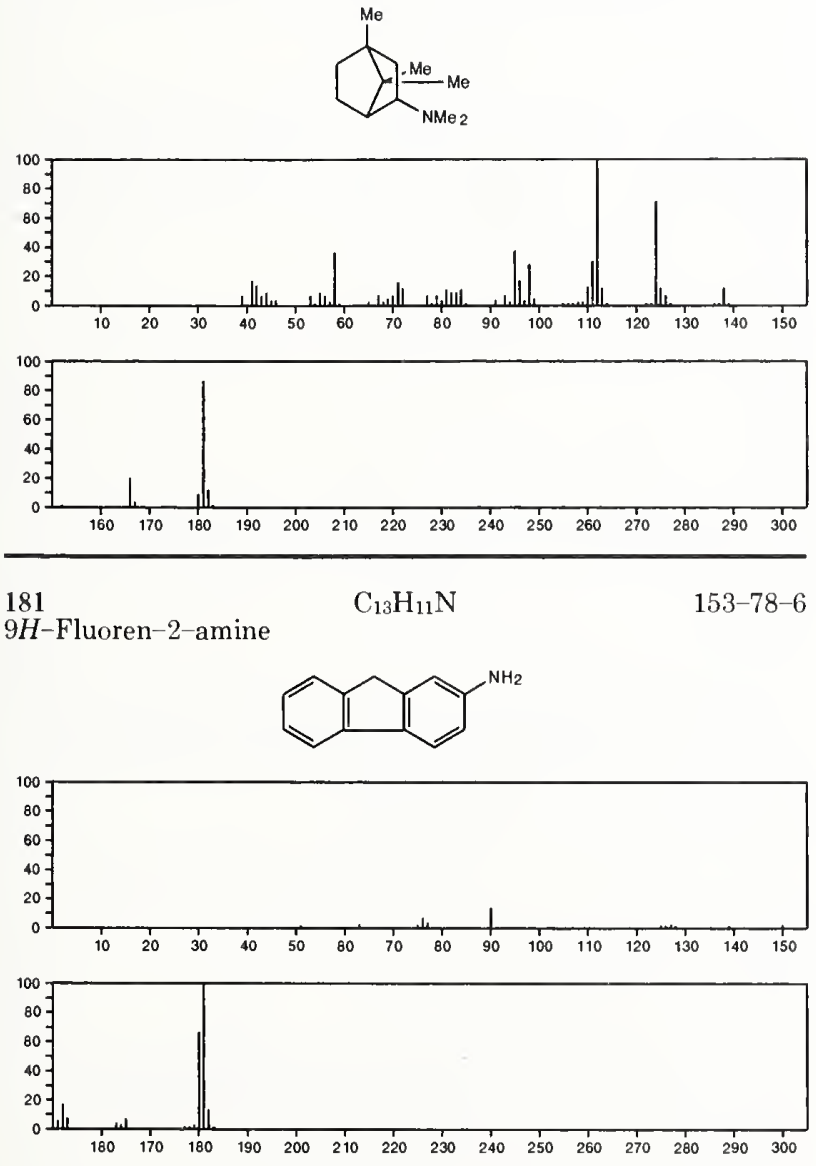

181

$\mathrm{C}_{13} \mathrm{H}_{11} \mathrm{~N}$

Benzenamine, $N$-(phenylmethylene)-

$538-51-2$

$\mathrm{PhN}=\mathrm{CHPh}$
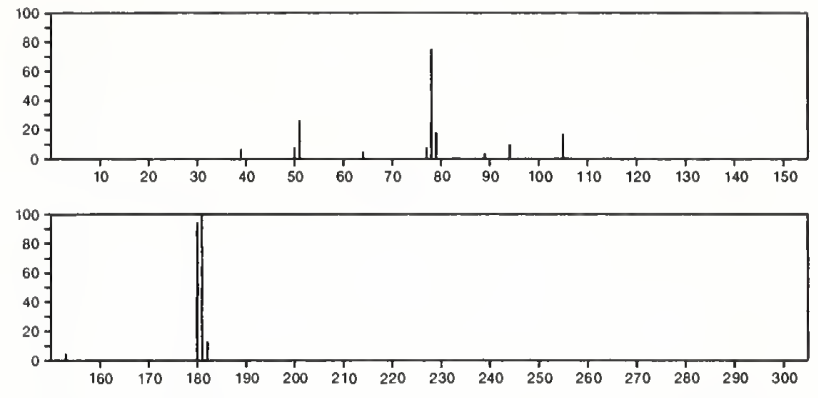

9H-Carbazole, 9-methyl-

$\mathrm{C}_{13} \mathrm{H}_{11} \mathrm{~N}$

$1484-12-4$
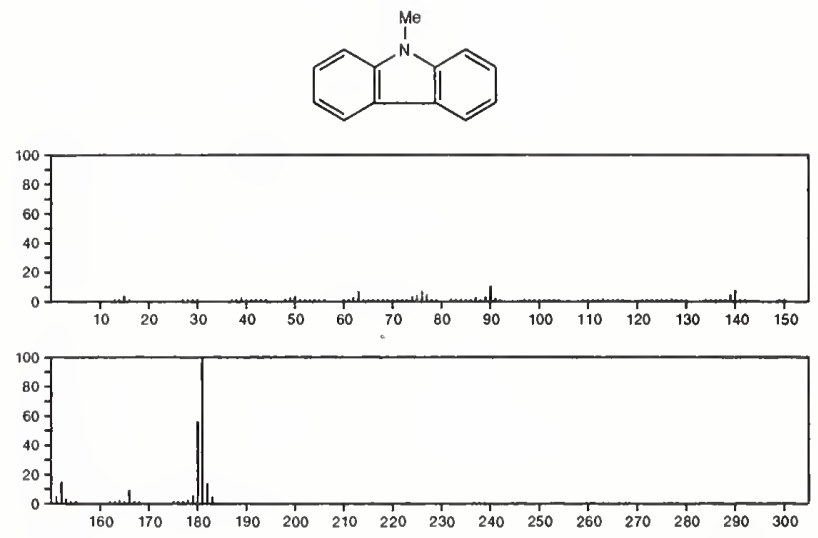

\begin{tabular}{ll}
\hline 181 -Carbazole, 2-methyl- & $\mathrm{C}_{13} \mathrm{H}_{11} \mathrm{~N}$ \\
$9652-91-3$
\end{tabular}
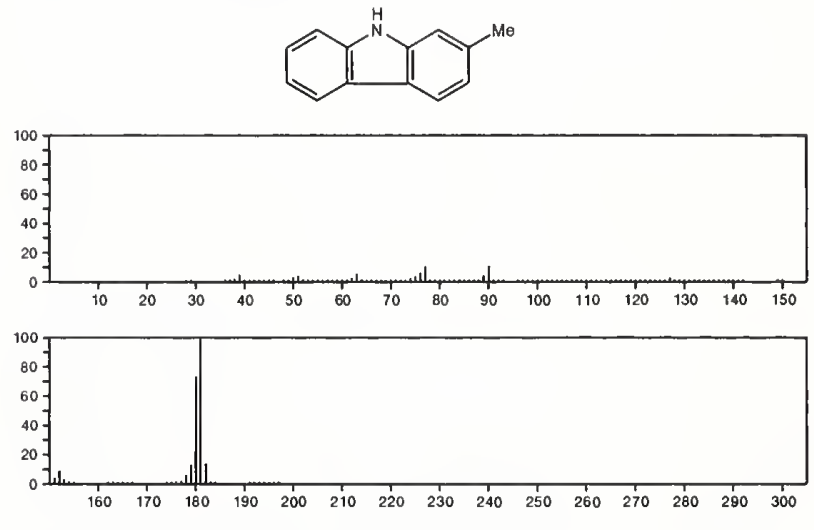

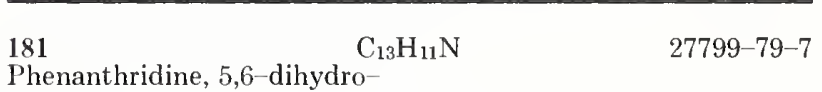
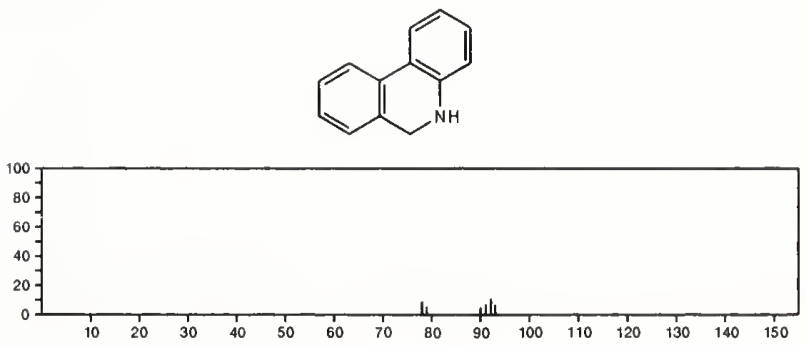

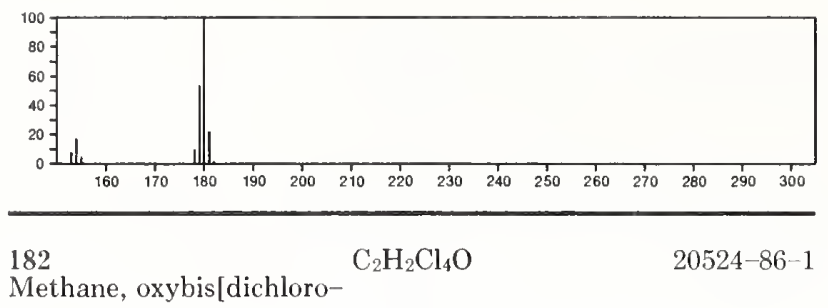

$\mathrm{Cl}_{2} \mathrm{CHOCHCl}_{2}$

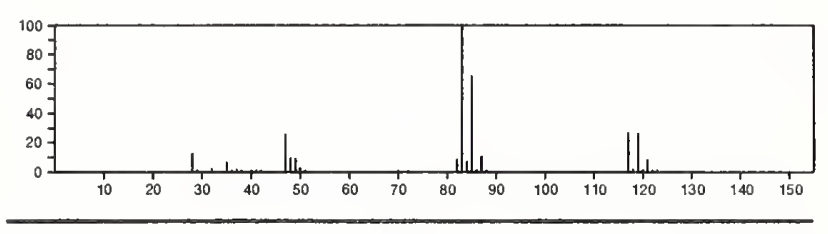

182

Digermane, ethyl-

$\mathrm{C}_{2} \mathrm{H}_{10} \mathrm{Ge}_{2}$

$20549-65-9$

$\mathrm{E} t \mathrm{GeH}_{2} \mathrm{GeH}_{3}$
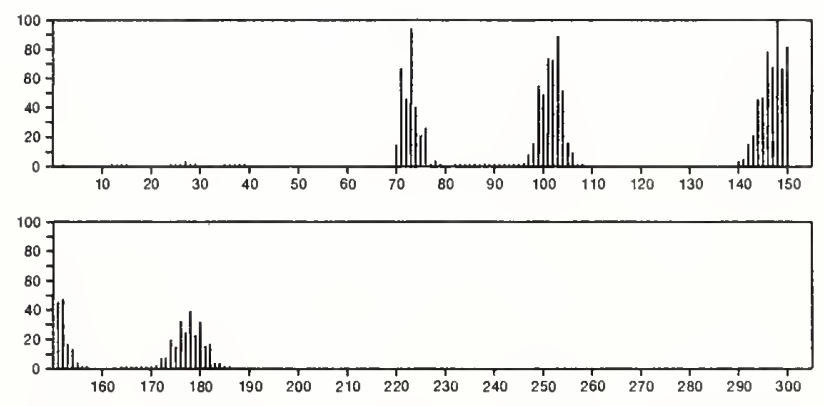

182

$\mathrm{C}_{3} \mathrm{Cl}_{2} \mathrm{~F}_{4}$

$431-53-8$

Propene, 1,2-dichlorotetrafluoro-

$\mathrm{F}_{3} \mathrm{CCCl}=\mathrm{CCIF}$
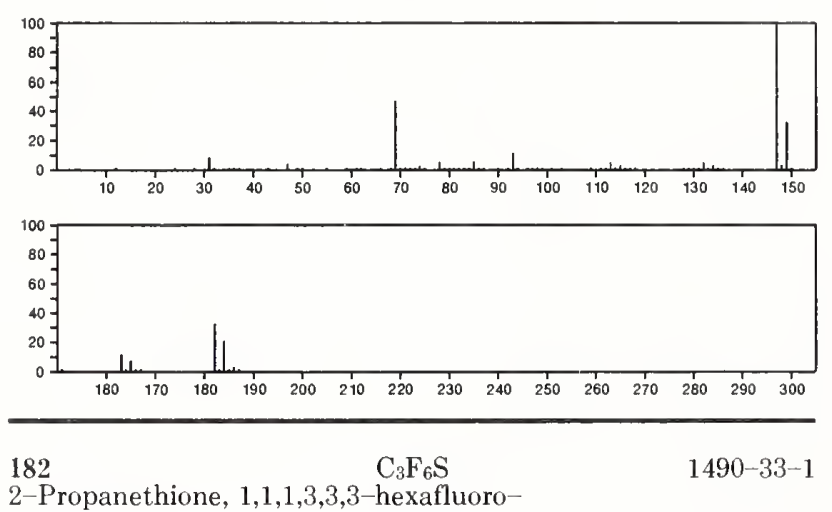

$\mathrm{F}_{3} \mathrm{CCSCF}_{3}$
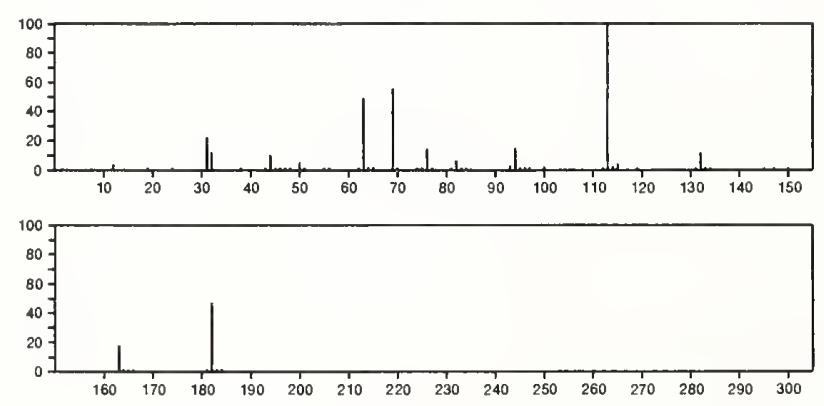

182

$\mathrm{C}_{3} \mathrm{~F}_{6} \mathrm{~S}$

$24345-51-5$

Thietane, hexafluoro-
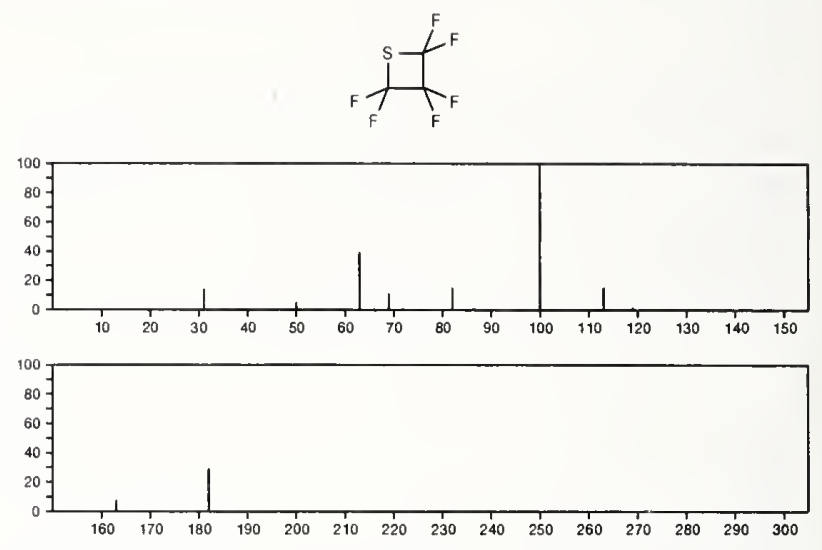

182

$\mathrm{C}_{3} \mathrm{H}_{3} \mathrm{Cl}_{2} \mathrm{~F}_{3} \mathrm{O}$

Ethane, 2-chloro-1-(chloromethoxy)-1,1,2-trifluoro-

$428-92-2$

$\mathrm{FCHCl} \mathrm{CF} 2 \mathrm{OCH}_{2} \mathrm{Cl}$
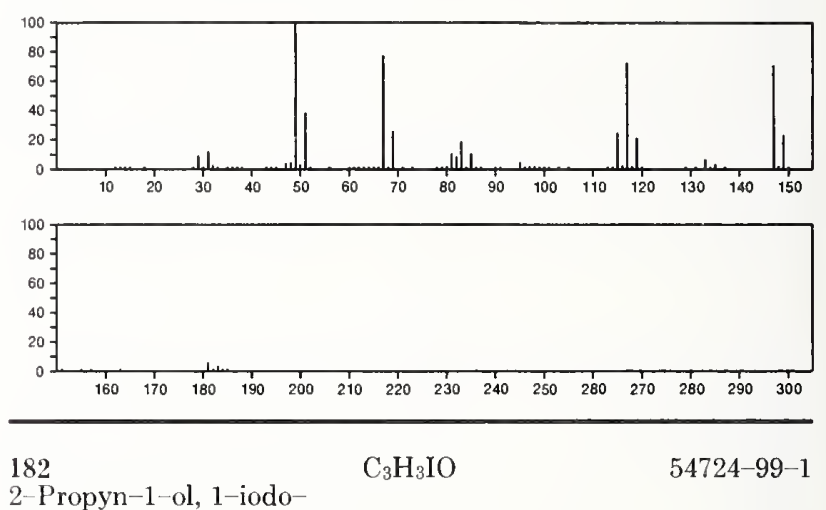

2-Propyn-1 ol, 1-iodo-

( $\mathrm{HO}) \mathrm{CHIC} \equiv \mathrm{CH}$
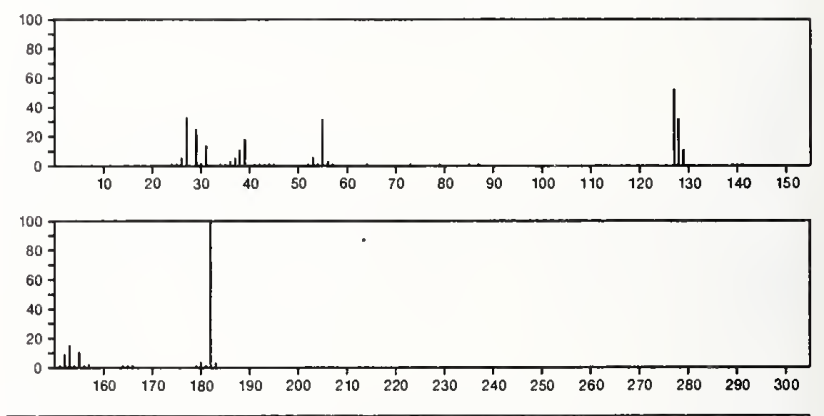

182

$\mathrm{C}_{3} \mathrm{H}_{6} \mathrm{~N}_{2} \mathrm{O}_{7}$

1,2,3-Propanetriol, 1,3-dinitrate

$623-87-0$

$\mathrm{O}_{2} \mathrm{NOCH}_{2} \mathrm{CH}(\mathrm{OH}) \mathrm{CH}_{2} \mathrm{ONO}_{2}$

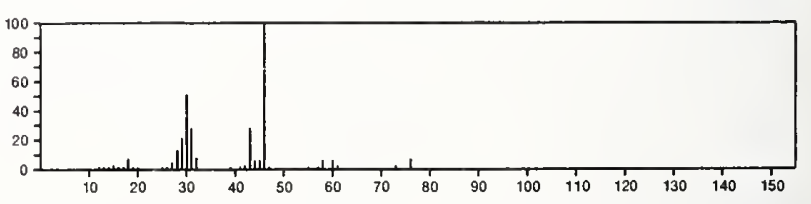


$182 \quad \mathrm{C}_{4} \mathrm{H}_{10} \mathrm{~N}_{2} \mathrm{O}_{2} \mathrm{~S}_{2}$

Urea, 1-ethyl-3-(methylsulfonyl)-2-thio-

6171-08-0

$\mathrm{MeSO}_{2}$ NHCSNHE
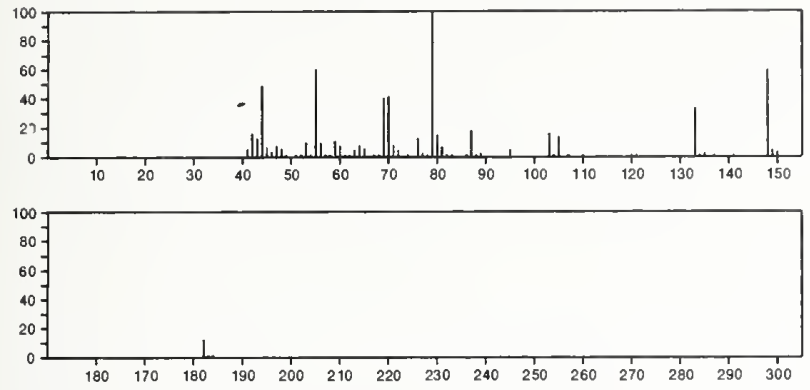

$182 \quad \mathrm{C}_{5} \mathrm{H}_{8} \mathrm{BrCl}$

Cyclopentane, 1-bromo-2-chloro-, trans-
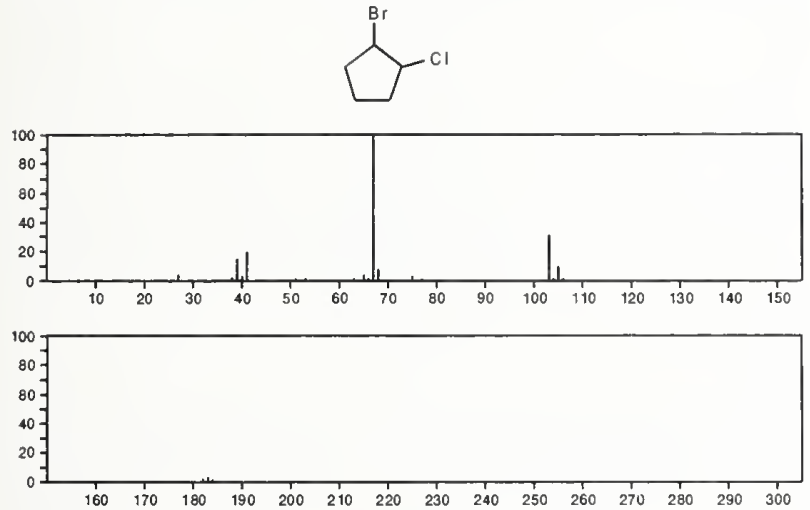

182

$\mathrm{C}_{5} \mathrm{H}_{8} \mathrm{BrCl}$

$37722-39-7$

Cyclopentane, 1-bromo-2-chloro-, cis-
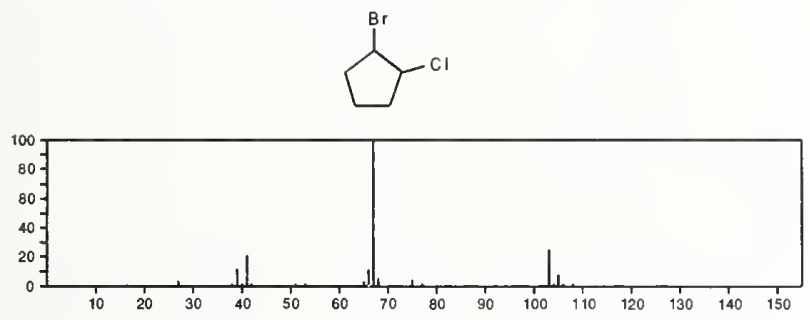

${ }^{100}$

18

$1-\mathrm{P}$

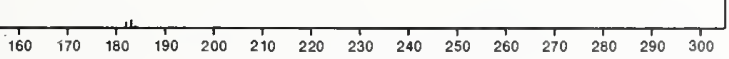

$\mathrm{C}_{5} \mathrm{H}_{8} \mathrm{BrCl}$

55683-03-9

$\mathrm{ClCBr}=\mathrm{CHPr}$

$$
\begin{aligned}
& 100 \\
& 80 \\
& 20 \\
& 20 \\
& 0
\end{aligned}
$$

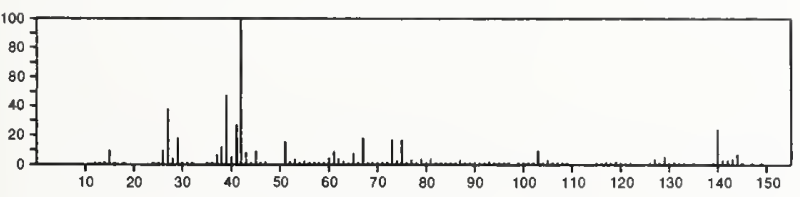

100
80
60
40
20
0

14376-82-0
182

$\mathrm{C}_{6} \mathrm{H}_{2} \mathrm{~F}_{4} \mathrm{O}_{2}$

1,4-Benzenediol, 2,3,5,6-tetrafluoro-

$771-63-1$
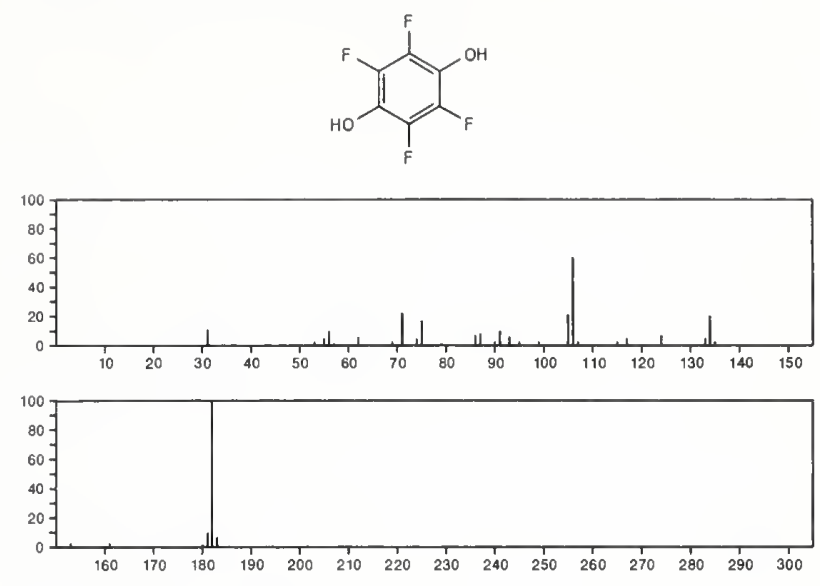

182

$\mathrm{C}_{6} \mathrm{H}_{2} \mathrm{~F}_{4} \mathrm{O}_{2}$

1,3-Benzenediol, 2,4,5,6-tetrafluoro-

$16840-25-8$<smiles>Oc1c(F)c(O)c(F)c(F)c1F</smiles>
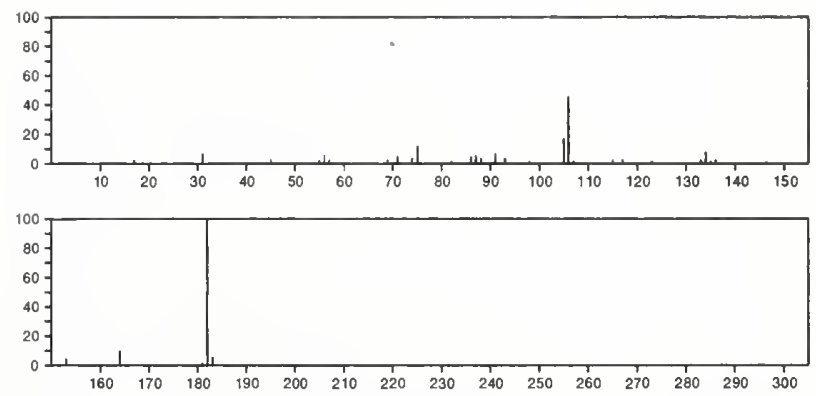

182

$\mathrm{C}_{6} \mathrm{H}_{6} \mathrm{~N}_{4} \mathrm{OS}$

28139-02-8

Xanthine, 3-methyl-2-thio-
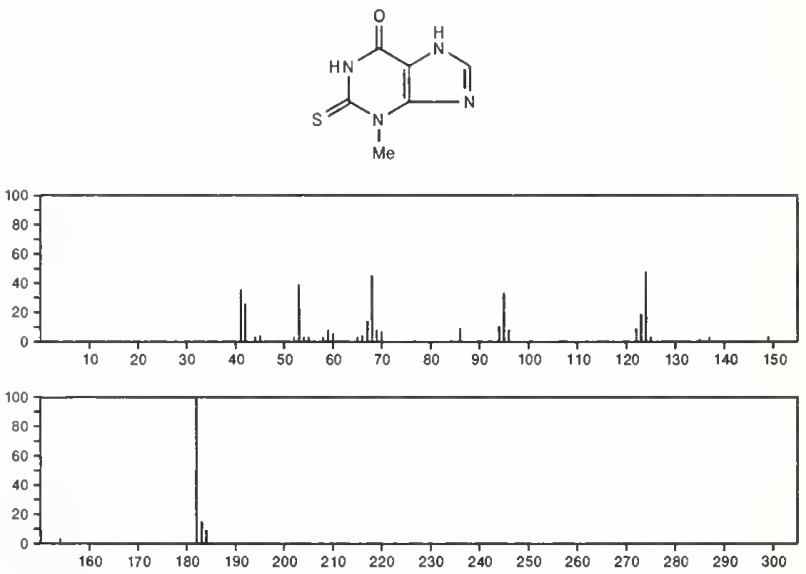
182

$\mathrm{C}_{6} \mathrm{H}_{6} \mathrm{~N}_{4} \mathrm{O}_{3}$

$33070-47-2$

$[1,2,5]$ Oxadiazolo $[3,4$ - d] pyrimidine-5,7(4H,6H)-dione, 4,6-dimethyl-
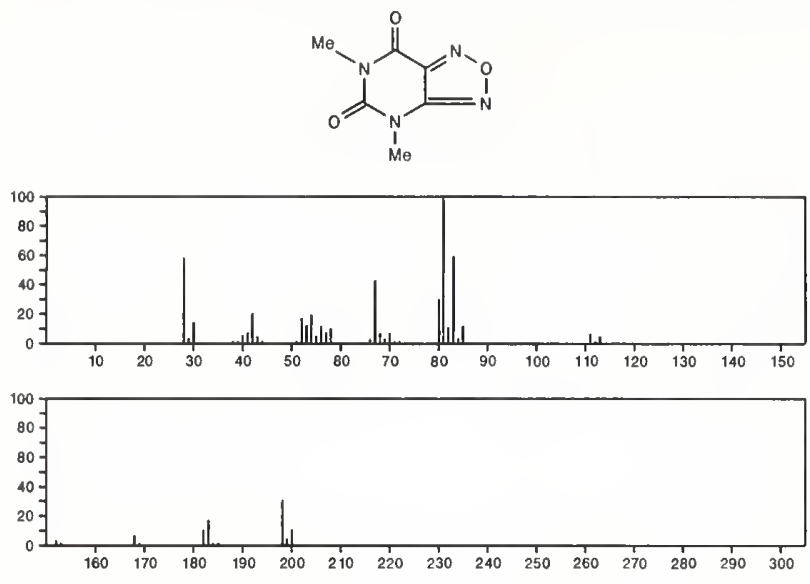

182

$\mathrm{C}_{6} \mathrm{H}_{11} \mathrm{ClN}_{2} . \mathrm{ClH}$

$40645-62-3$

Propanimidamide, $N$-(1-chloro-1-propenyl)-, monohydrochloride

$\mathrm{MeCH}=\mathrm{CCINHCE}+=\mathrm{NH} \quad \cdot \mathrm{HC}$

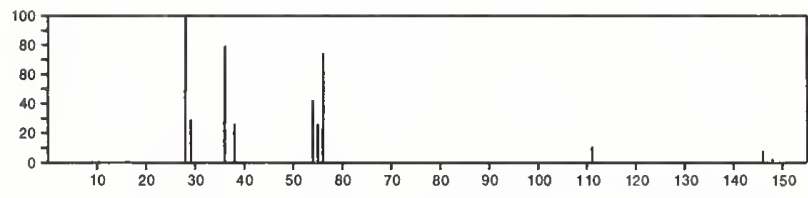

$182 \quad \mathrm{C}_{6} \mathrm{H}_{14} \mathrm{O}_{2} \mathrm{~S}_{2}$

Ethanol, 2,2-[1,2-ethanediylbis(thio)]bis-

$5244-34-8$

$\mathrm{HOCH}_{2} \mathrm{CH}_{2} \mathrm{SCH}_{2} \mathrm{CH}_{2} \mathrm{SCH}_{2} \mathrm{CH}_{2} \mathrm{OH}$
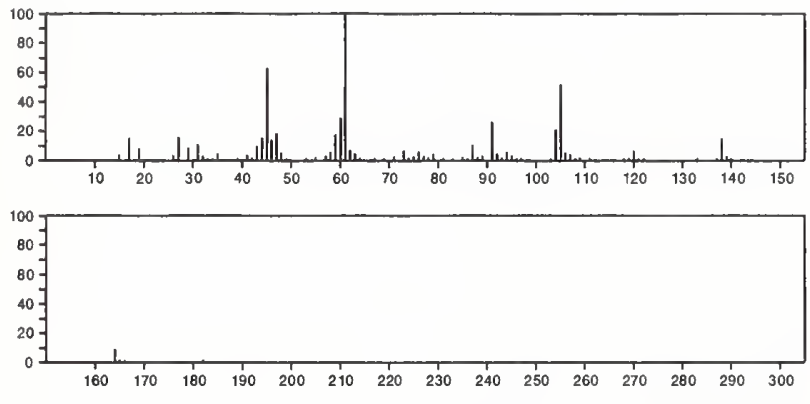

182

Trisulfide, dipropyl

$\mathrm{C}_{6} \mathrm{H}_{14} \mathrm{~S}_{3}$

$6028-61-1$

PrSSSPr
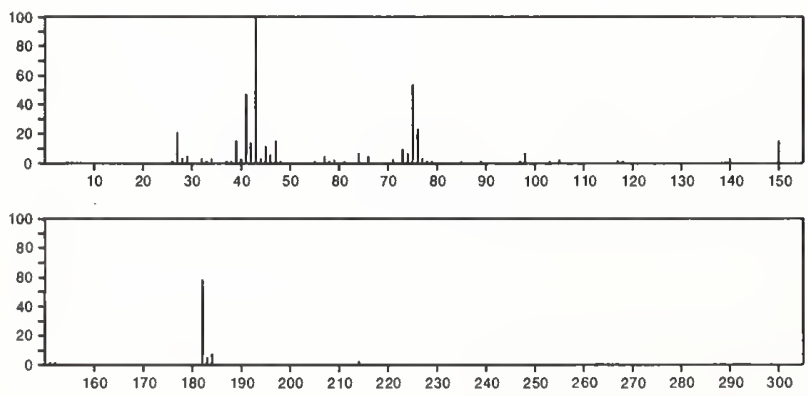

182

$\mathrm{C}_{6} \mathrm{H}_{14} \mathrm{~S}_{3}$

$54724-98-0$

$\mathrm{E} \mathrm{tS}_{2} \mathrm{CHSMe}_{\mathrm{O}}$
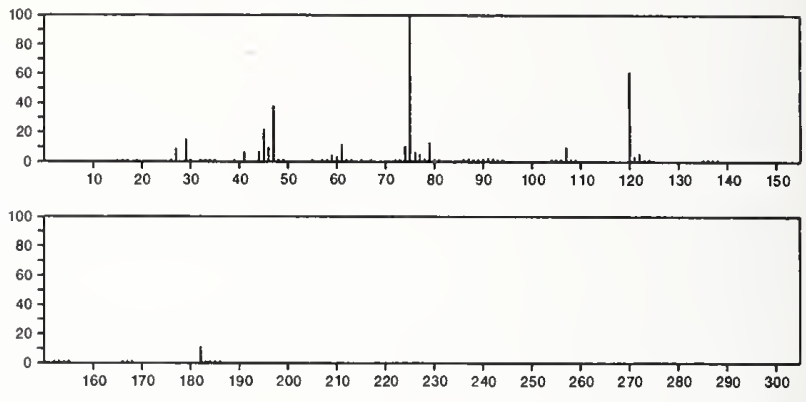

182

$\mathrm{C}_{6} \mathrm{H}_{15} \mathrm{O}_{2} \mathrm{PS}$

13088-83-0

Phosphonothioic acid, methyl-, $O$-ethyl $S$-propyl ester

$\stackrel{\text { III }}{\text { PrSPME OE } t}$
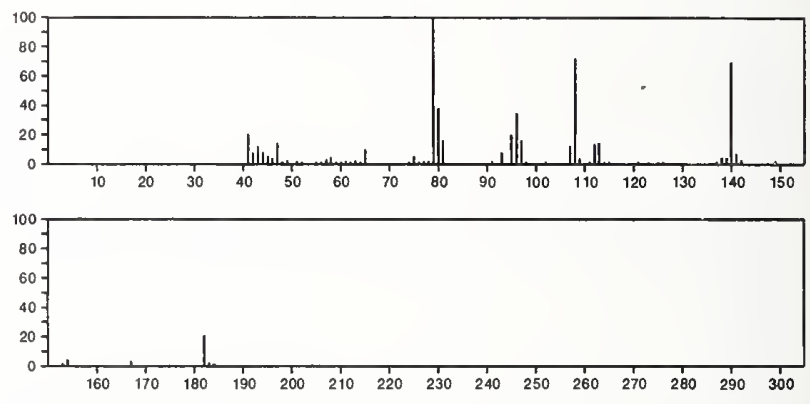

182

Benzonitrile, 2-chloro-6-nitro-

6575-07-1
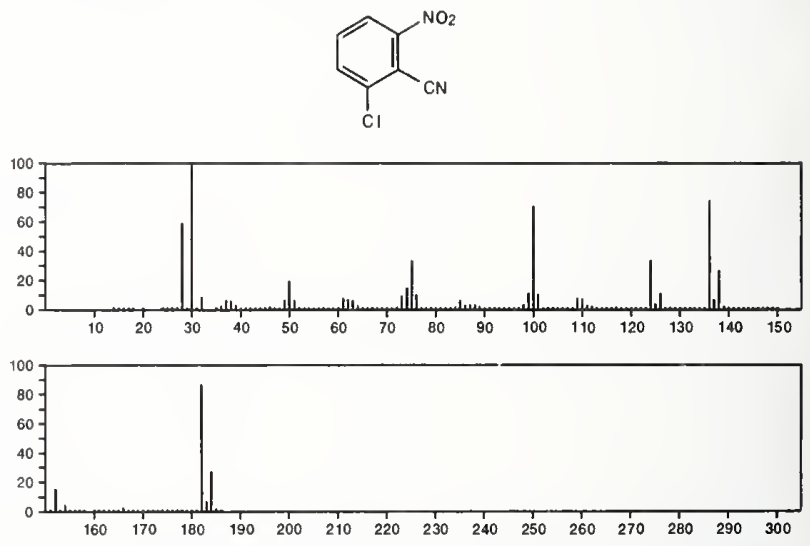

182

$\mathrm{C}_{7} \mathrm{H}_{3} \mathrm{~F}_{5}$

$771-56-2$

Benzene, pentafluoromethyl-
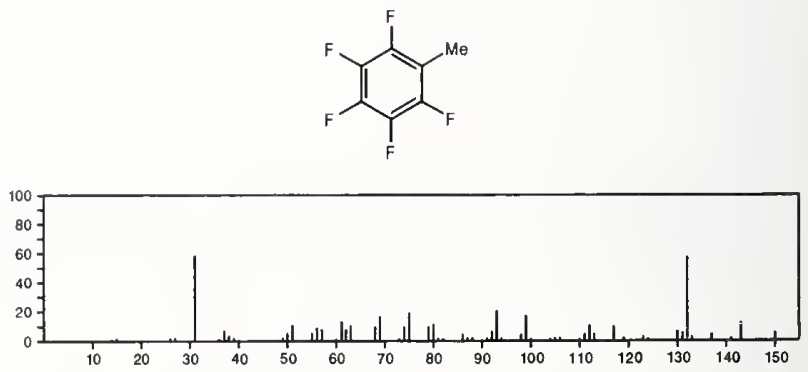


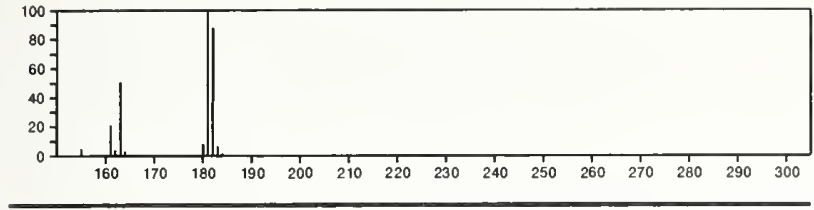

182

$\mathrm{C}_{7} \mathrm{H}_{6} \mathrm{~N}_{2} \mathrm{O}_{4}$

121-14-2

Benzene, 1-methyl-2,4-dinitro-
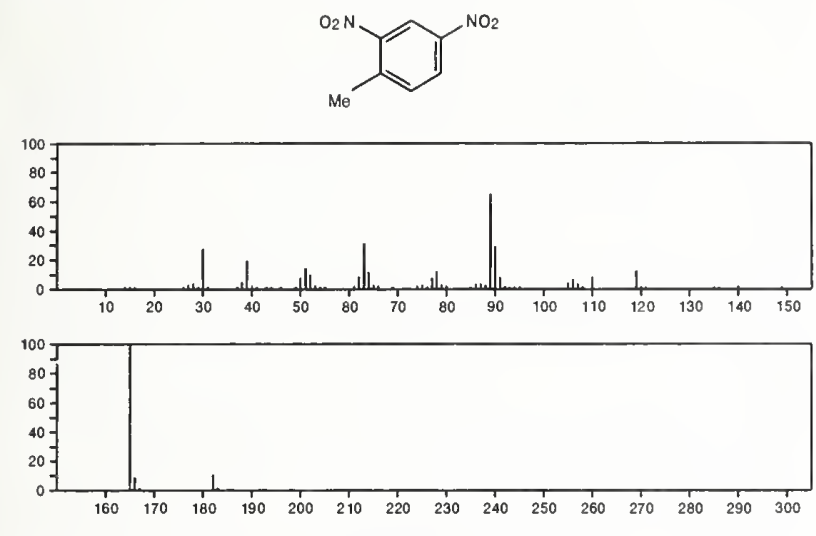

182

$\mathrm{C}_{7} \mathrm{H}_{6} \mathrm{~N}_{2} \mathrm{O}_{4}$

Benzene, 1-methyl-2,3-dinitro-
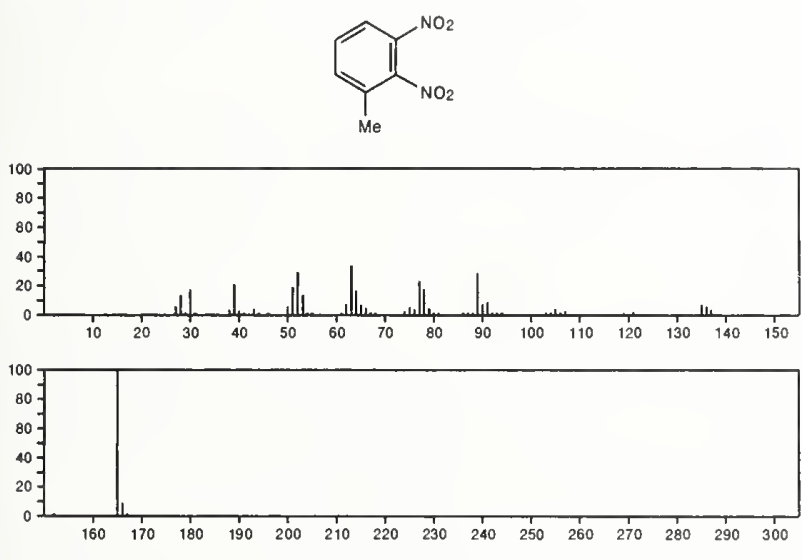

182

$\mathrm{C}_{7} \mathrm{H}_{6} \mathrm{~N}_{2} \mathrm{O}_{4}$

$606-20-2$

Benzene, 2-methyl-1,3-dinitro-
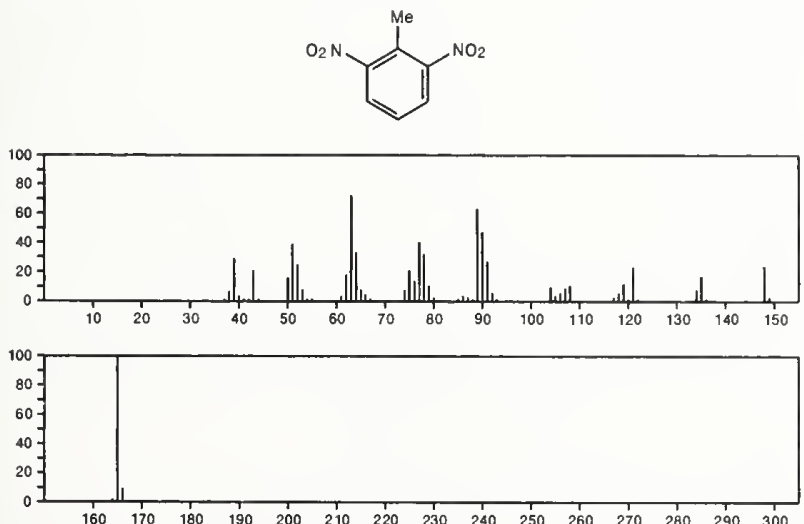

182

$\mathrm{C}_{7} \mathrm{H}_{6} \mathrm{~N}_{2} \mathrm{O}_{4}$

610-39-9

Benzene, 4-methyl-1,2-dinitro-
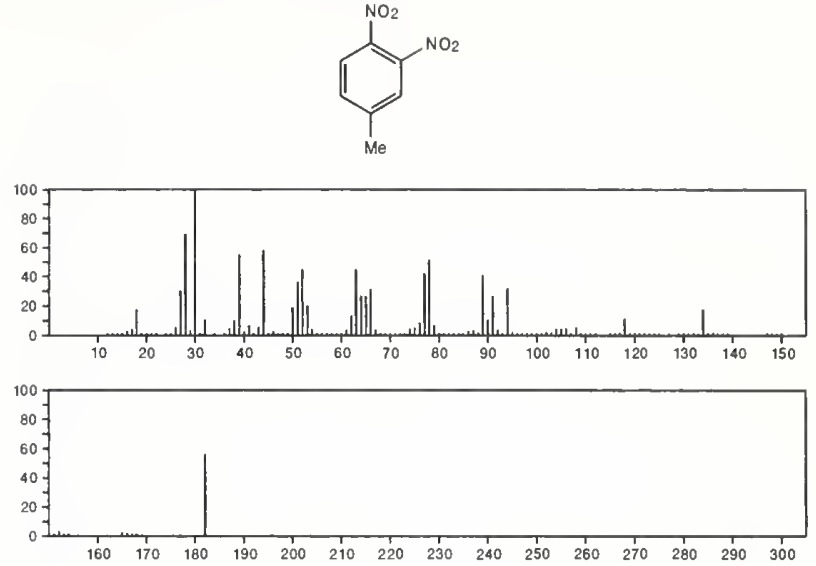

182

Benzene, 1-methyl-3,5-dinitro-

618-85-9<smiles>Cc1cc([N+](=O)[O-])cc([N+](=O)[O-])c1</smiles>
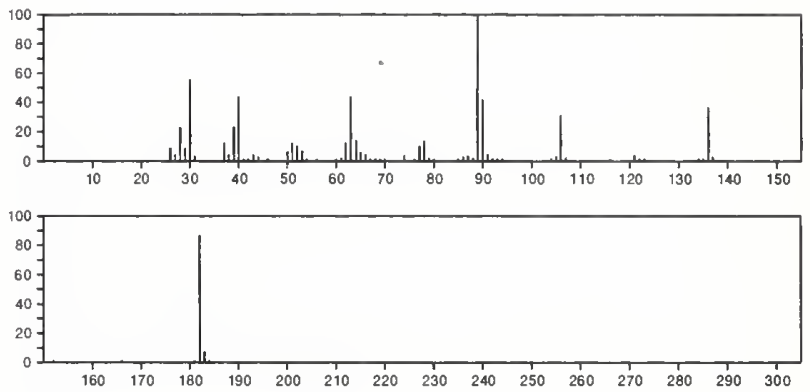

$182 \quad \mathrm{C}_{7} \mathrm{H}_{6} \mathrm{~N}_{2} \mathrm{O}_{4}$

$619-15-8$

Benzene, 2-methyl-1,4-dinitro-
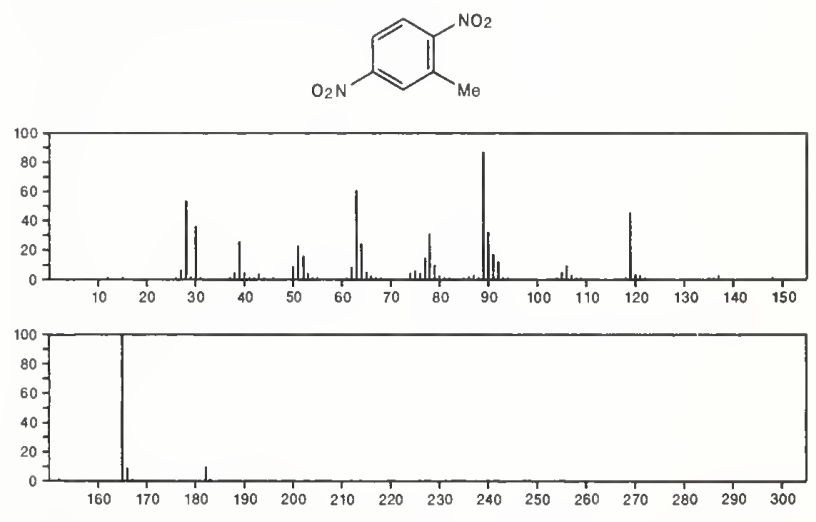

182

$\mathrm{C}_{7} \mathrm{H}_{9} \mathrm{~F}_{3} \mathrm{O}_{2}$

30984-28-2

2,4-Hexanedione, 1,1,1-trifluoro-5-methyl-

$\mathrm{F}_{3} \mathrm{CCOCH}_{2} \mathrm{COCHMe}_{2}$

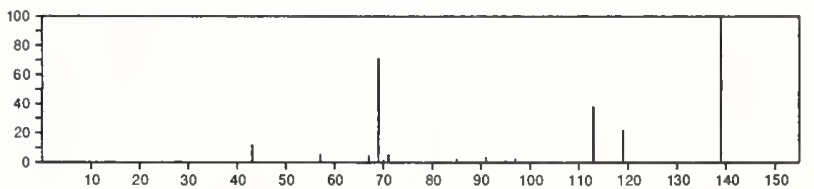




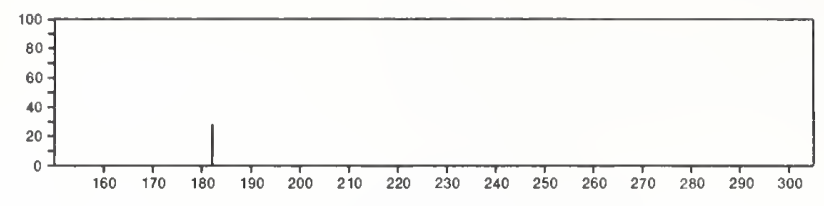

$182 \quad \mathrm{C}_{7} \mathrm{H}_{9} \mathrm{~F}_{3} \mathrm{O}_{2}$

2,4-Heptanedione, 1,1,1-trifluoro-

$\mathrm{F}_{3} \mathrm{CCOCH}_{2} \mathrm{COPr}$
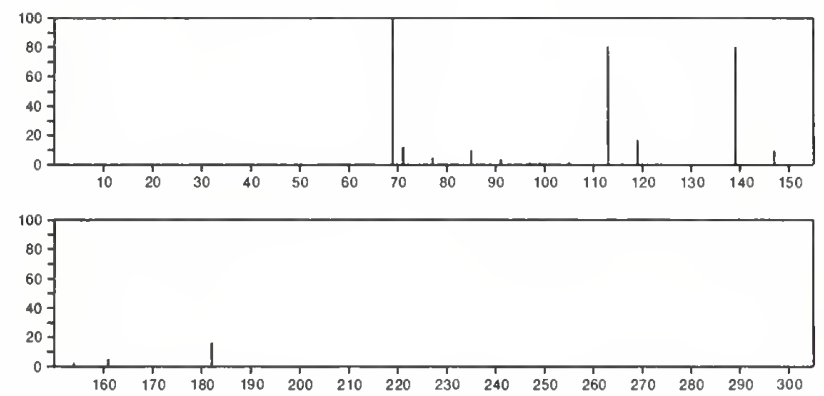

182

3H-Purine, 6,7-dihydro-3-methyl-6-(methylthio)-

$37527-51-8$
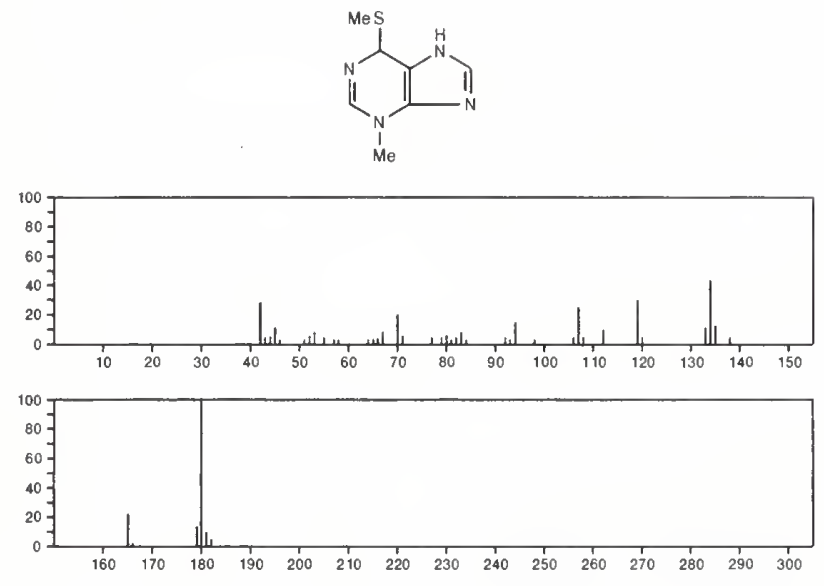

182

$$
\mathrm{C}_{7} \mathrm{H}_{12} \mathrm{Cl}_{2} \mathrm{O}
$$

40624-07-5

4-Heptanone, 1,7-dichloro-

$\mathrm{Cl}\left(\mathrm{CH}_{2}\right)_{3} \mathrm{CO}\left(\mathrm{CH}_{2}\right)_{3} \mathrm{Cl}$
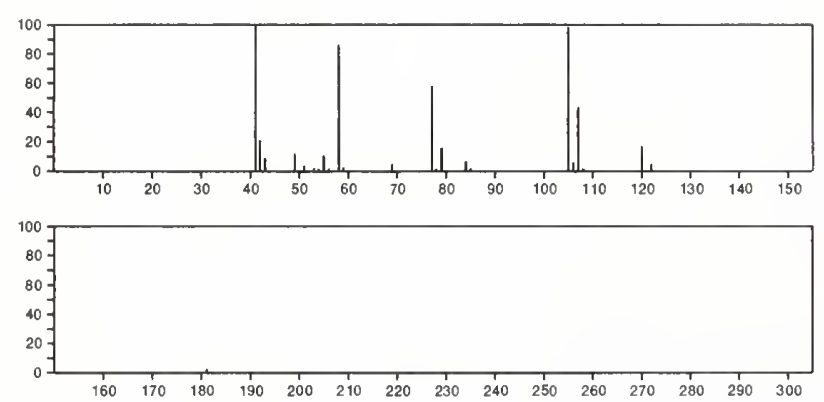

182

1,3,5-Triazine-2,4,6-triamine, $N, N^{\prime}$-diethyl-

$5606-16-6$
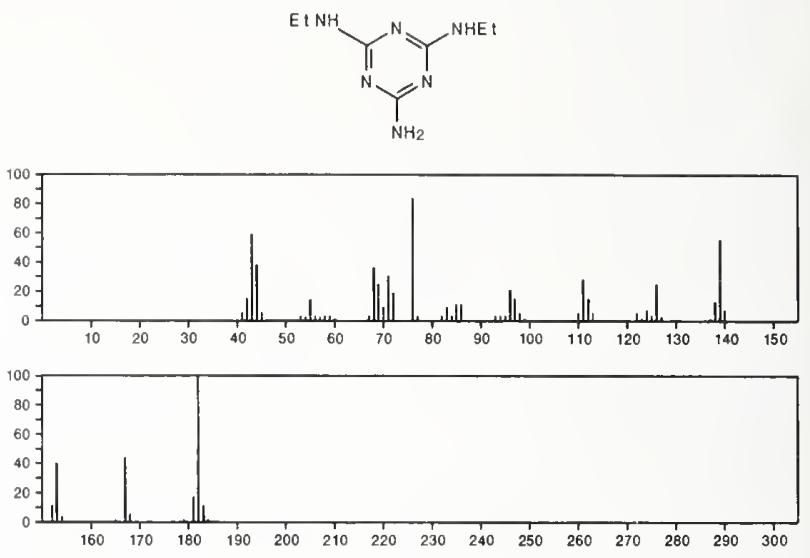

182

$\mathrm{C}_{8} \mathrm{H}_{6} \mathrm{O}_{5}$

$52183-73-0$

Bisoxireno[e,g]isobenzofuran-3,5-dione, hexahydro-, $(1 \mathrm{a} \alpha, 1 \mathrm{~b} \beta,=$ $2 \mathrm{a} \beta, 2 \mathrm{~b} \beta, 5 \mathrm{a} \alpha, 5 \mathrm{~b} \alpha)$
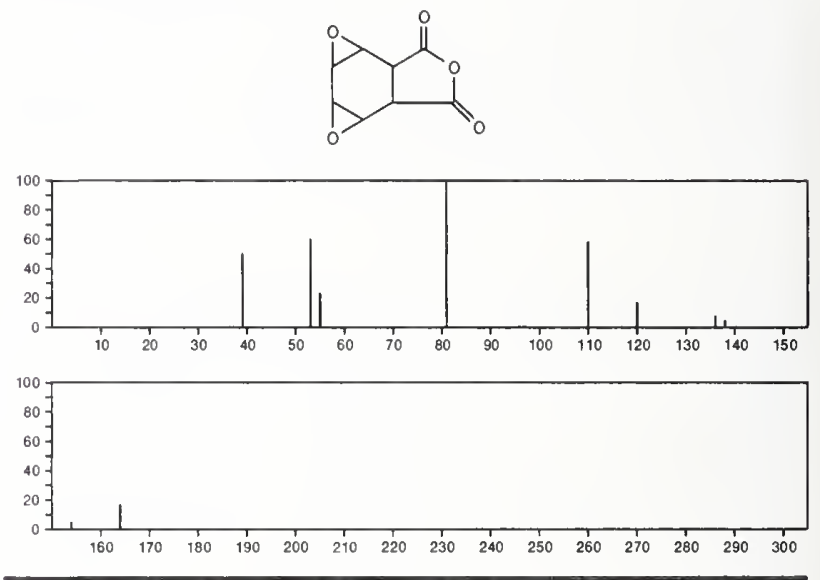

182

$\mathrm{C}_{8} \mathrm{H}_{6} \mathrm{Se}$

272-30-0

Benzo[b]selenophene
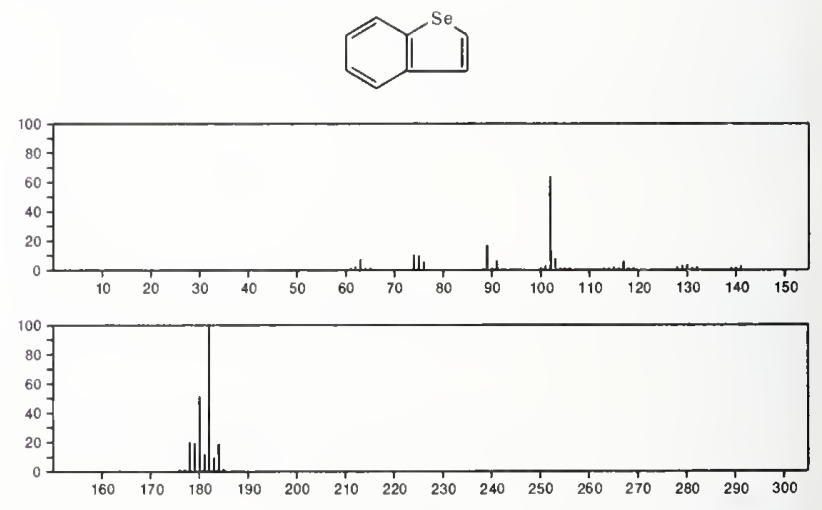

182

$\mathrm{C}_{8} \mathrm{H}_{7} \mathrm{Br}$

$103-64-0$

Benzene, (2-bromoethenyl)

$\mathrm{BrCH}=\mathrm{CHPh}$

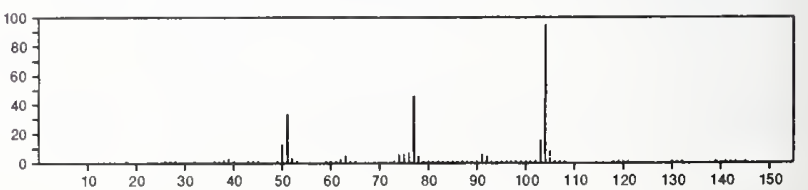




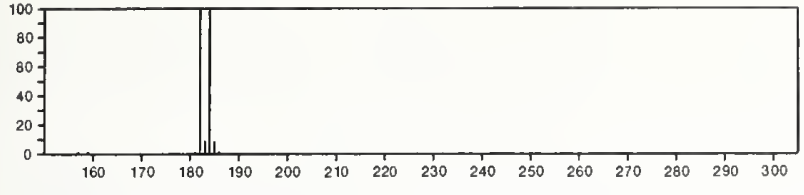

182

$\mathrm{C}_{8} \mathrm{H}_{10} \mathrm{~N}_{2} \mathrm{OS}$

Carbazic acid, 3-phenylthio--, $O$-methyl ester

20184-98-9

MeOC(S) NHNHPh
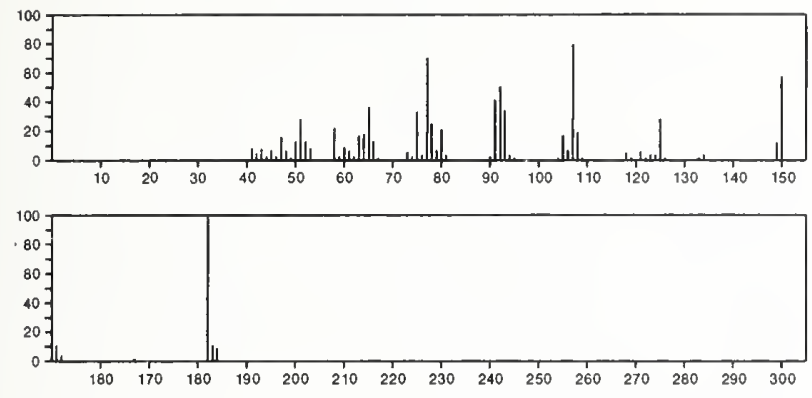

182

Acetic acid, [(phenylmethyl)thio]-

$\mathrm{PhCH}_{2} \mathrm{SCH}_{2} \mathrm{CO}_{2} \mathrm{H}$
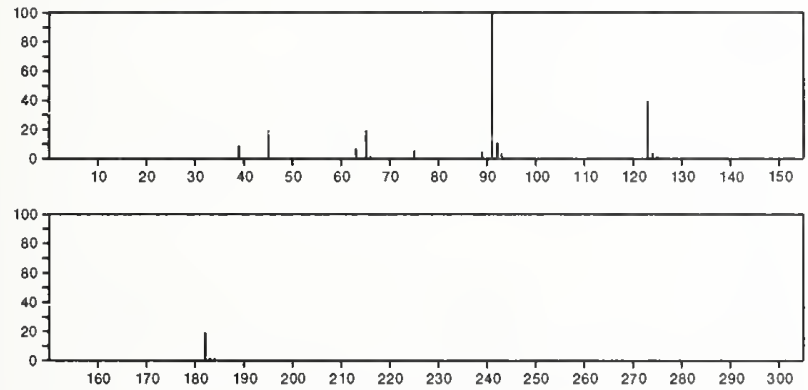

182

Benzene, [2-(methylsulfonyl)ethenyl]

$\mathrm{C}_{9} \mathrm{H}_{10} \mathrm{O}_{2} \mathrm{~S}$

$\mathrm{PhCH}: \mathrm{CHSO}_{2} \mathrm{Me}$
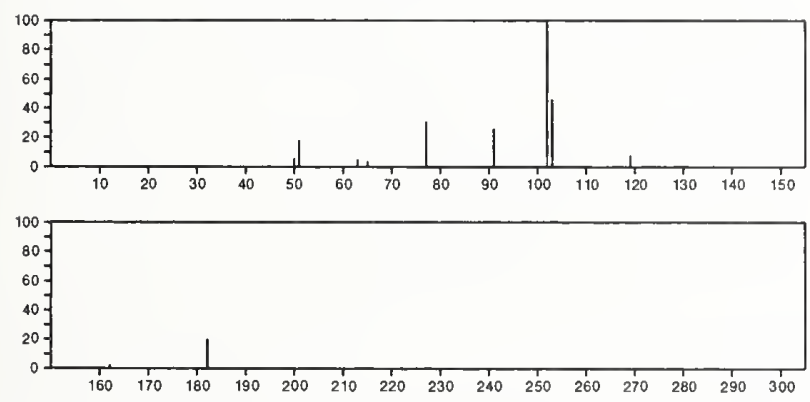

182

$\mathrm{C}_{9} \mathrm{H}_{10} \mathrm{O}_{2} \mathrm{~S}$

$5535-52-4$

Benzene, 1-(ethenylsulfonyl)-4-methyl-
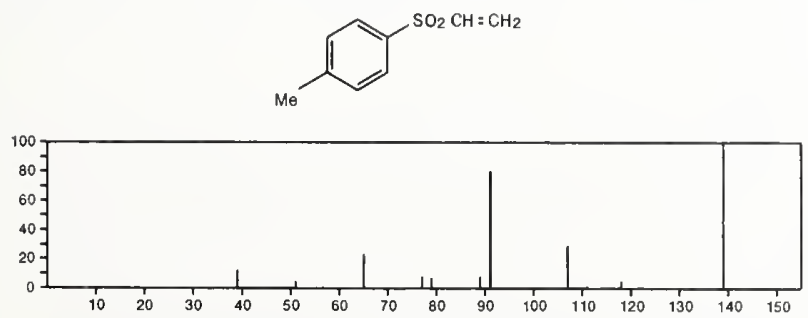

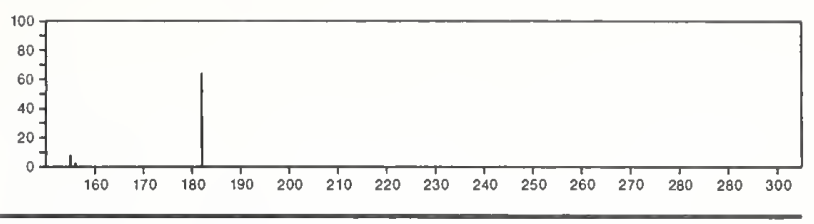

182

$\mathrm{C}_{9} \mathrm{H}_{10} \mathrm{O}_{2} \mathrm{~S}$

Benzenecarbothioic acid, 4-methoxy-, $\mathrm{O}$-methyl ester

$5925-50-8$
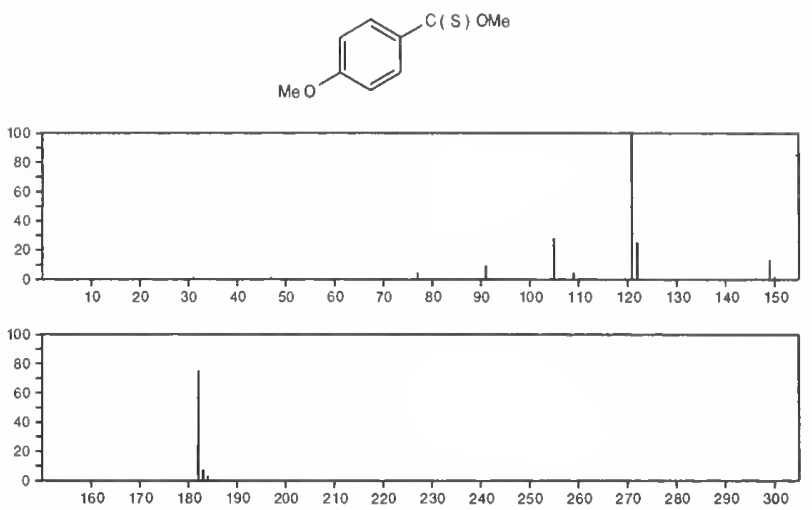

182

$\mathrm{C}_{9} \mathrm{H}_{10} \mathrm{O}_{2} \mathrm{~S}$

$5925-72-4$

Benzenecarbothioic acid, 4-methoxy-, $S$-methyl ester
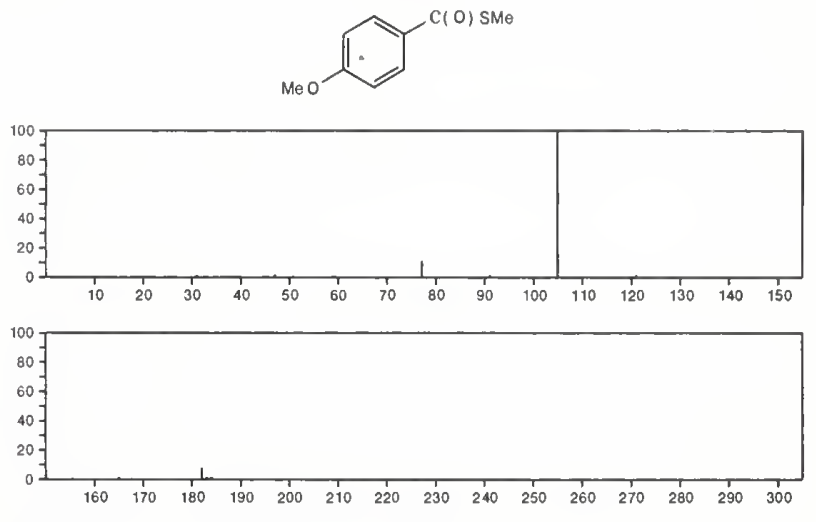

182

Benzoic acid, 3,4-dimethoxy-

$\mathrm{C}_{9} \mathrm{H}_{10} \mathrm{O}_{4}$

$93-07-2$
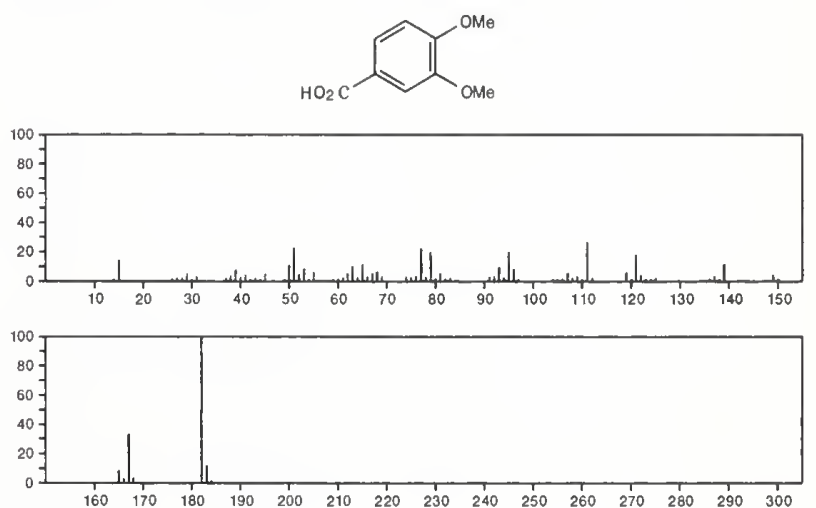
182

$\mathrm{C}_{9} \mathrm{H}_{10} \mathrm{O}_{4}$

Benzaldehyde, 4-hydroxy-3,5-dimethoxy-<smiles>COc1cc(C=O)cc(OC)c1O</smiles>
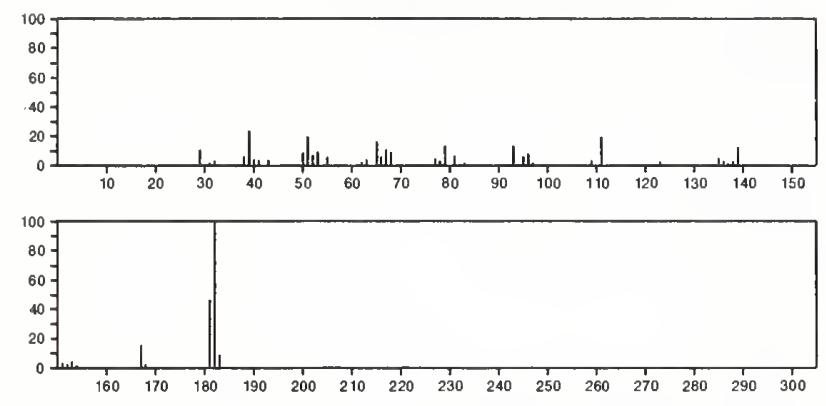

182

$\mathrm{C}_{9} \mathrm{H}_{10} \mathrm{O}_{4}$

306-08-1

Benzeneacetic acid, 4-hydroxy-3-methoxy-
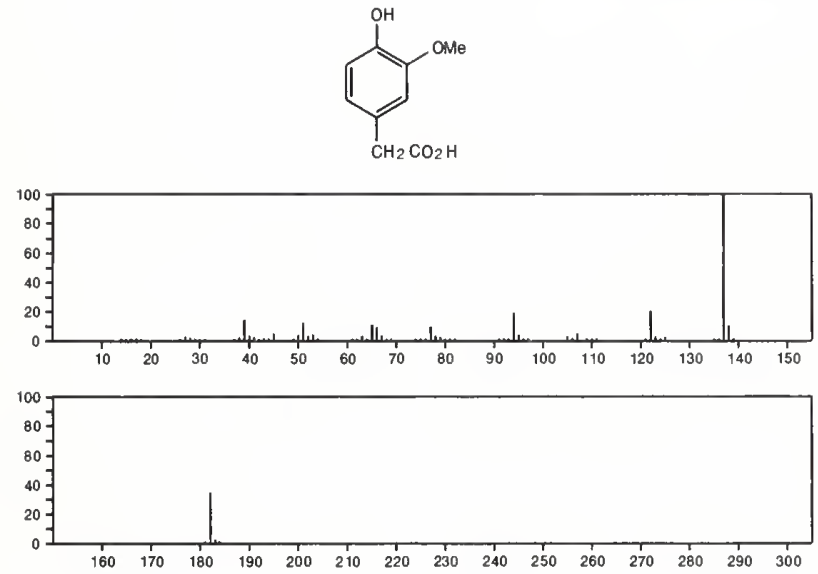

182

$\mathrm{C}_{9} \mathrm{H}_{10} \mathrm{O}_{4}$

Benzenepropanoic acid, $\alpha, 4$-dihydroxy-
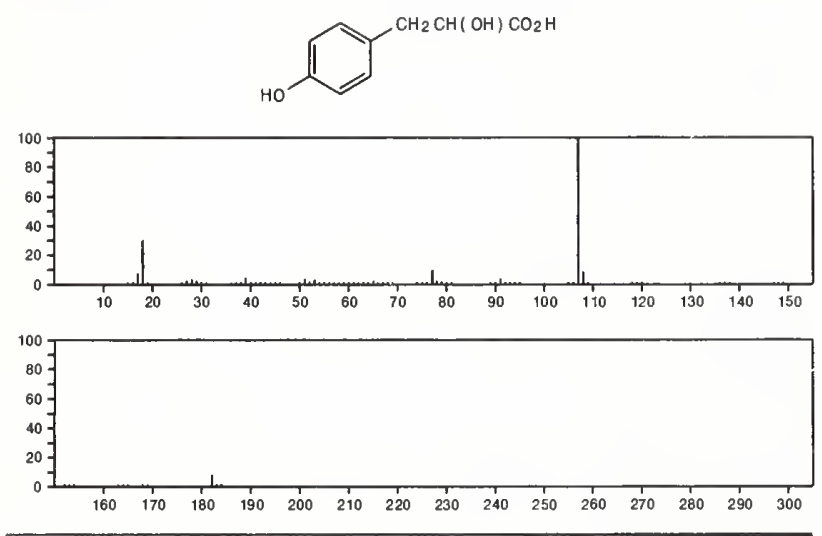

182

$\mathrm{C}_{9} \mathrm{H}_{10} \mathrm{O}_{4}$

$570-10-5$

Benzoic acid, 2-hydroxy-4-methoxy-6-methyl-<smiles>COc1cc(O)c(C(=O)O)c([N+](=O)[O-])c1</smiles>

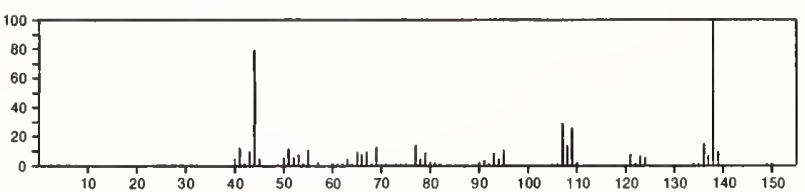

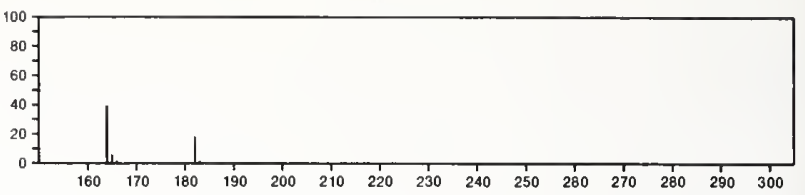

182

$\mathrm{C}_{9} \mathrm{H}_{10} \mathrm{O}_{4}$

$605-94-7$

2,5-Cyclohexadiene-1,4-dione, 2,3-dimethoxy-5-methyl-
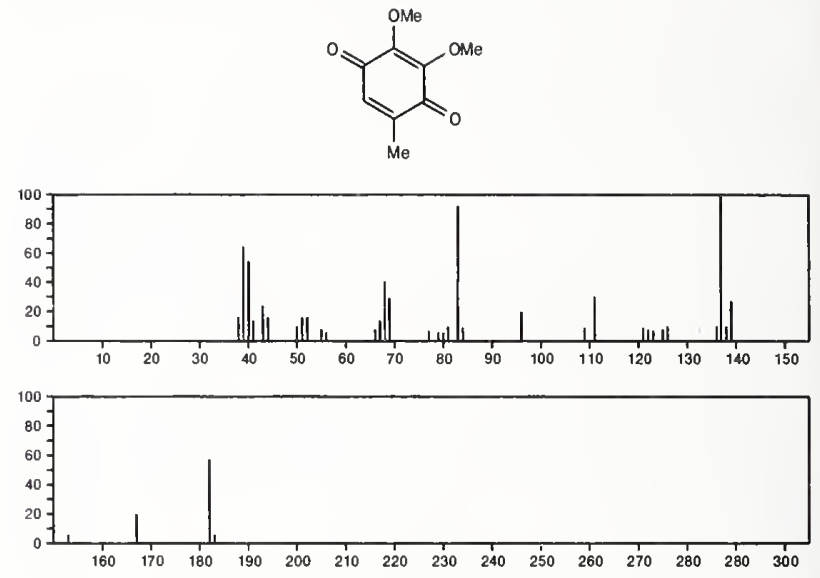

182

$\mathrm{C}_{9} \mathrm{H}_{10} \mathrm{O}_{4}$

Benzenepropanoic acid, 3,4-dihydroxy-

$1078-61-1$
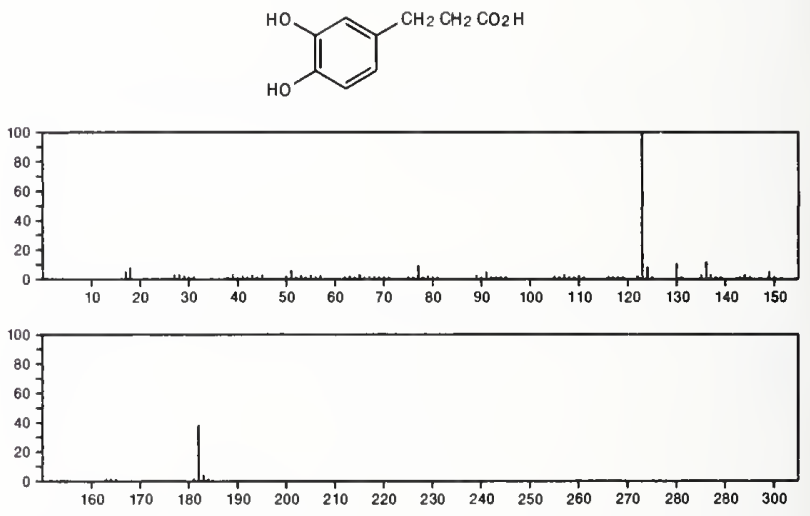

182

$\mathrm{C}_{9} \mathrm{H}_{10} \mathrm{O}_{4}$

$3187-58-4$

Benzoic acid, 2,4-dihydroxy-6-methyl-, methyl ester
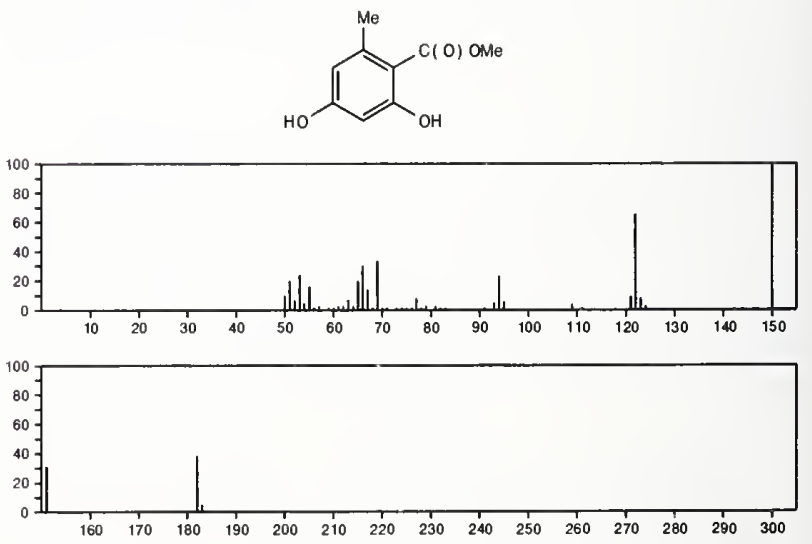
182

$\mathrm{C}_{9} \mathrm{H}_{10} \mathrm{O}_{4}$

$3943-74-6$

Benzoic acid, 4-hydroxy-3-methoxy-, methyl ester
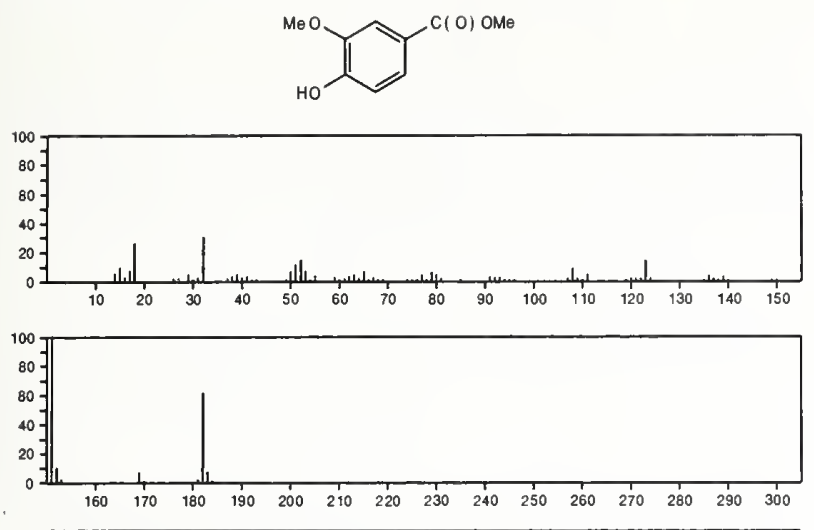

182

$\mathrm{C}_{9} \mathrm{H}_{10} \mathrm{O}_{4}$

$7507-89-3$

Ethanone, 1-(2,6-dihydroxy-4-methoxyphenyl)-
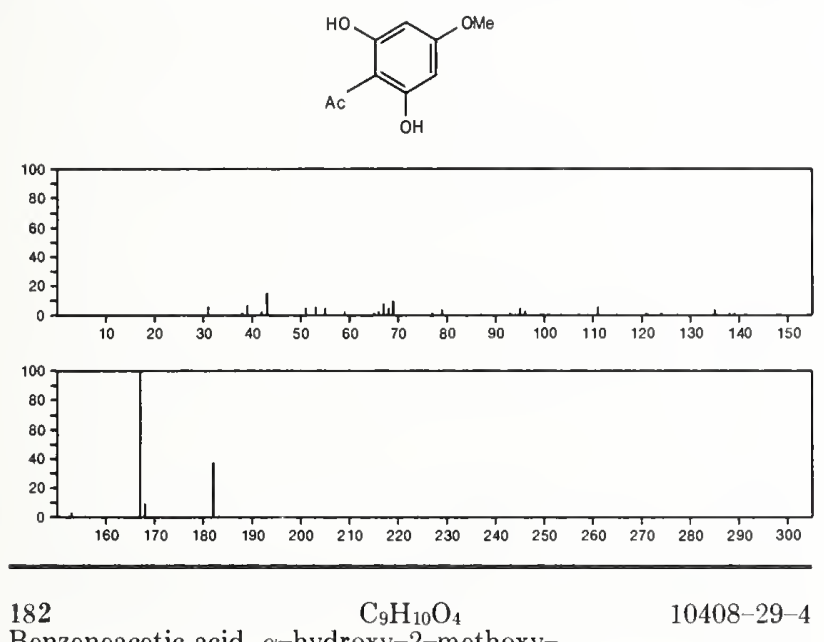

Benzeneacetic acid, $\alpha$-hydroxy-2-methoxy-
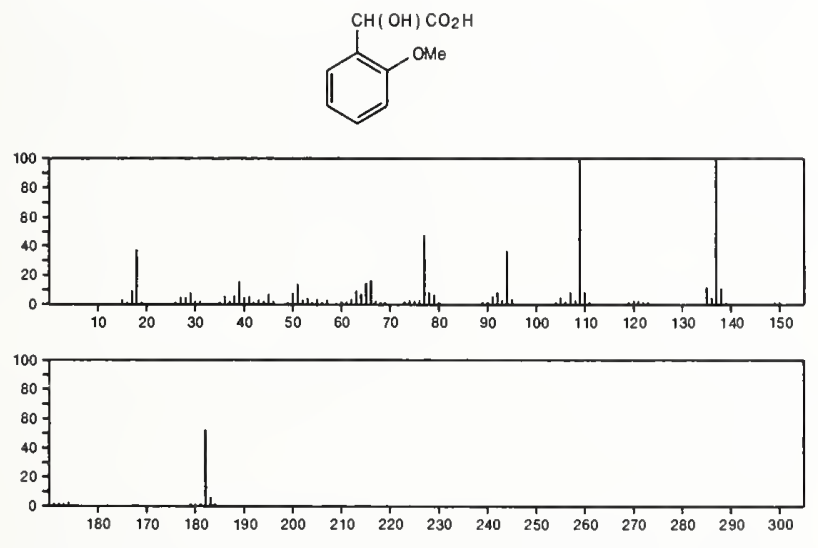

182

$\mathrm{C}_{9} \mathrm{H}_{10} \mathrm{O}_{4}$

$10502-44-0$

Benzeneacetic acid, $\alpha$-hydroxy $-4-$ methoxy-
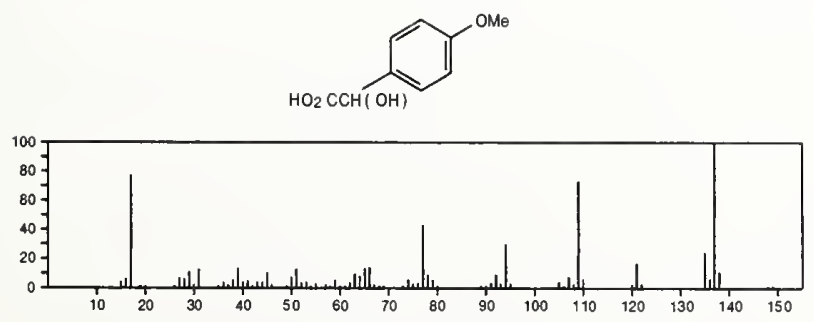

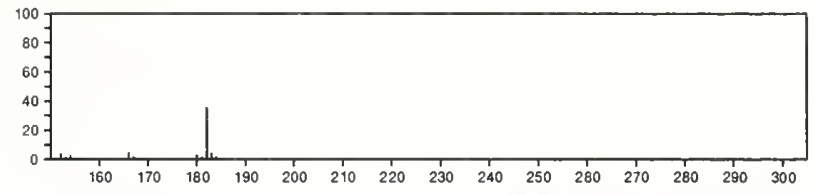

182

$\mathrm{C}_{9} \mathrm{H}_{10} \mathrm{O}_{4}$

$21150-12-9$

Benzeneacetic acid, $\alpha$-hydroxy-3-methoxy-
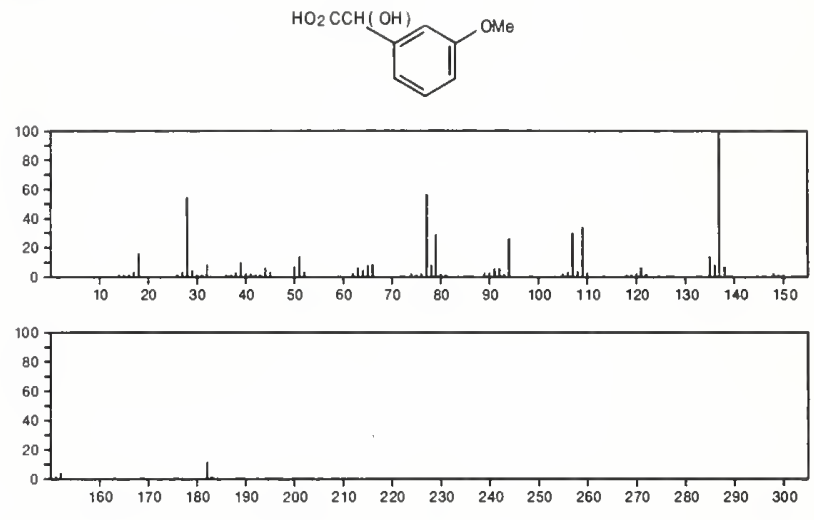

182

$\mathrm{C}_{9} \mathrm{H}_{10} \mathrm{O}_{4}$

$22159-41-7$

Carbonic acid, 4-methoxyphenyl methyl ester
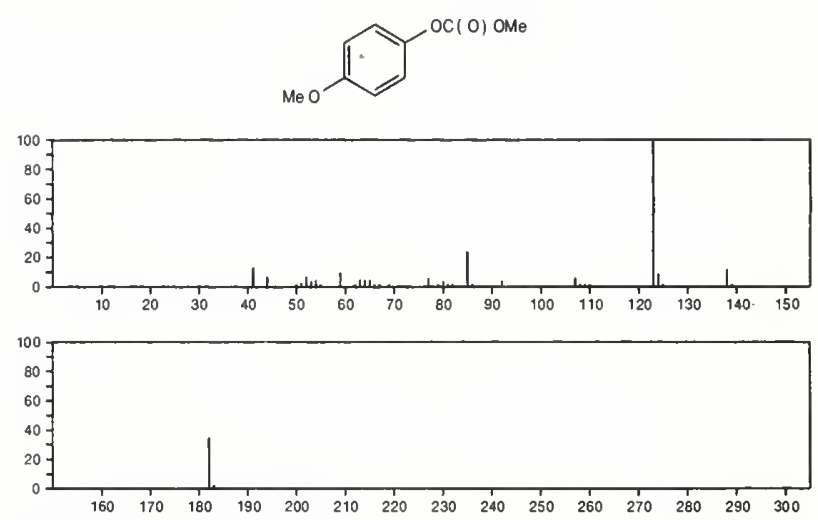

182

$\mathrm{C}_{9} \mathrm{H}_{10} \mathrm{O}_{4}$

$54644-49-4$

Carbonic acid, 3-methoxyphenyl methyl ester
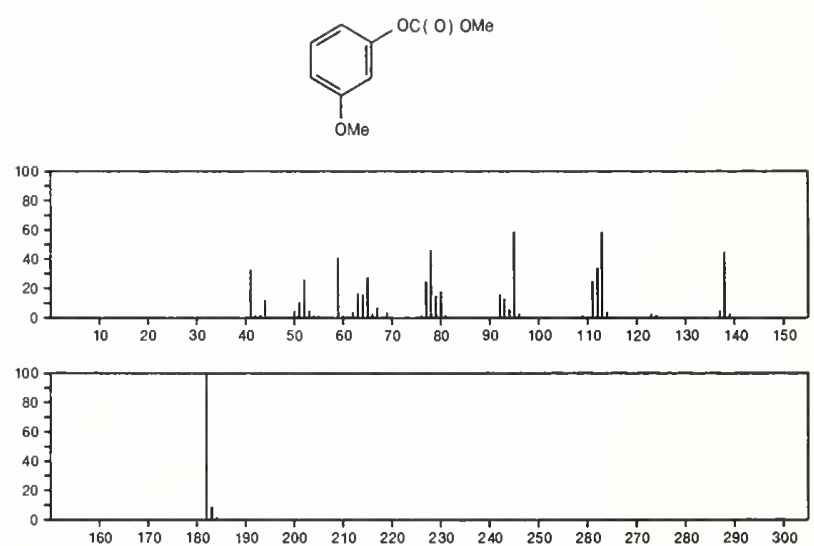
182

$\mathrm{C}_{9} \mathrm{H}_{10} \mathrm{O}_{4}$

57174-14-8

1,2,4-Cyclopentanetrione, 3-methyl-5-(1-oxopropyl)-
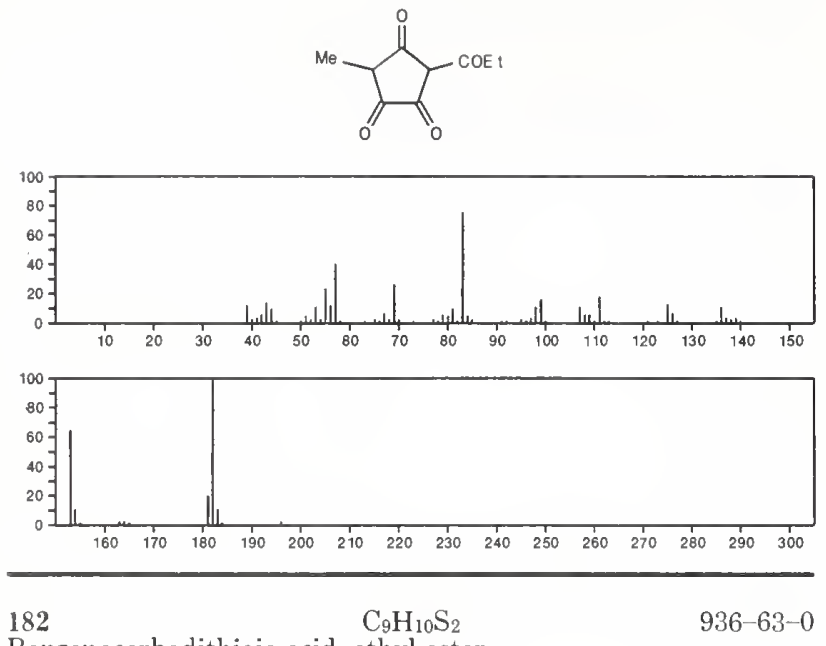

Benzenecarbodithioic acid, ethyl ester

$E t S C(S) P h$
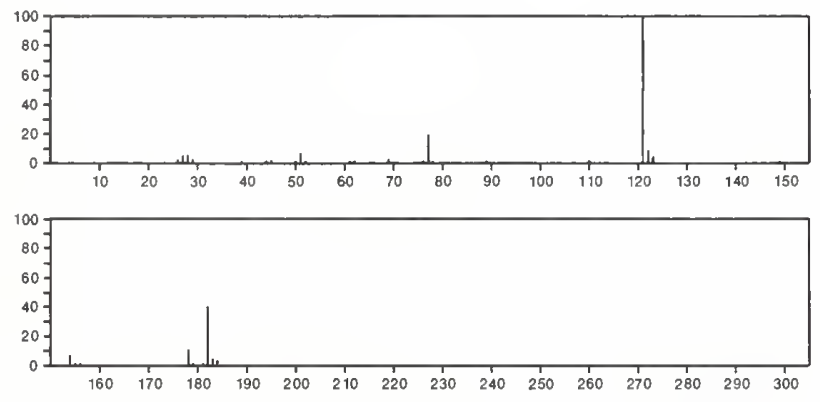

$182 \quad \mathrm{C}_{9} \mathrm{H}_{10} \mathrm{~S}_{2}$

1,3-Dithiolane, 2-phenyl-
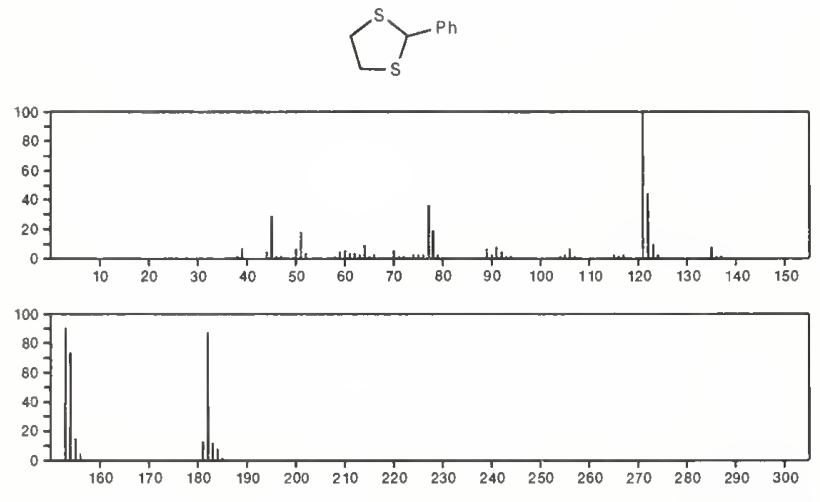

182

$\mathrm{C}_{9} \mathrm{H}_{11} \mathrm{ClN}_{2}$

Methanimidamide, $N^{\prime}$-(4-chlorophenyl)- $N, N$-dimethyl-
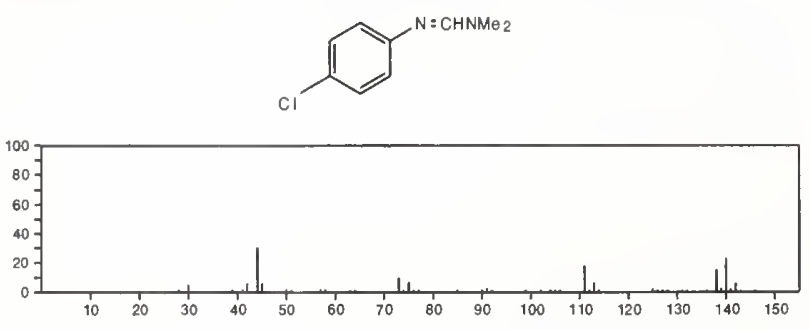

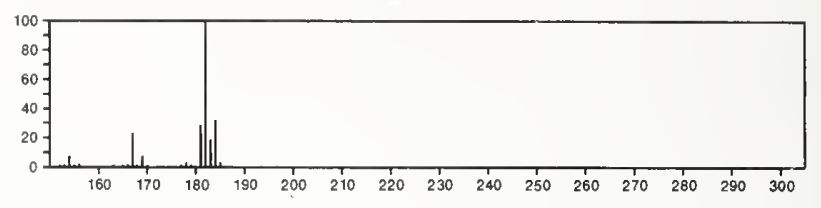

182

$\mathrm{C}_{9} \mathrm{H}_{11} \mathrm{ClN}_{2}$

$2103-49-3$

Methanimidamide, $N^{\prime}$-(2-chlorophenyl)- $N, N$-dimethyl-
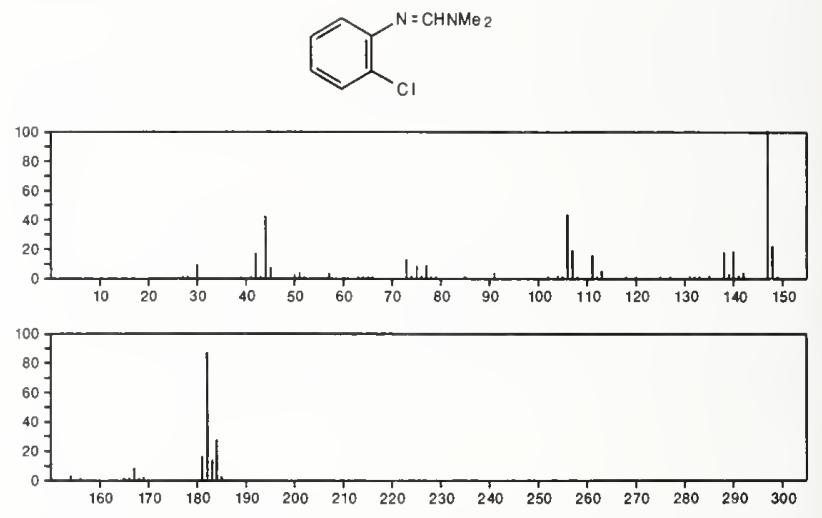

182

$\mathrm{C}_{9} \mathrm{H}_{11} \mathrm{ClN}_{2}$

$2103-50-6$

Methanimidamide, $N^{\prime}$-(3-chlorophenyl)- $N, N$-dimethyl-
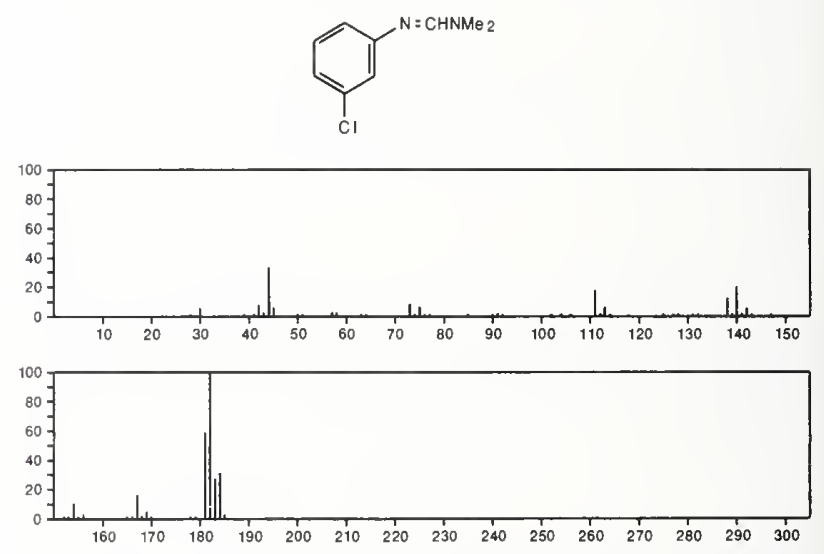

182

$\mathrm{C}_{9} \mathrm{H}_{14} \mathrm{~N}_{2} \mathrm{O}_{2}$

$707-09-5$

1,3-Diazaspiro[4.5]decane-2,4-dione, 3-methyl-
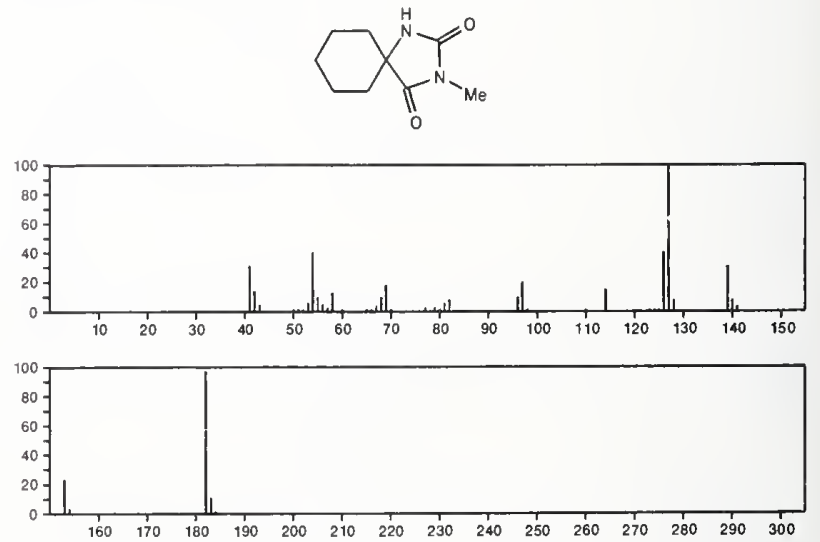
$182 \quad \mathrm{C}_{9} \mathrm{H}_{14} \mathrm{~N}_{2} \mathrm{O}_{2} \quad 878-46-6$

1,3-Diazaspiro[4.5]decane-2,4-dione, 1-methyl-
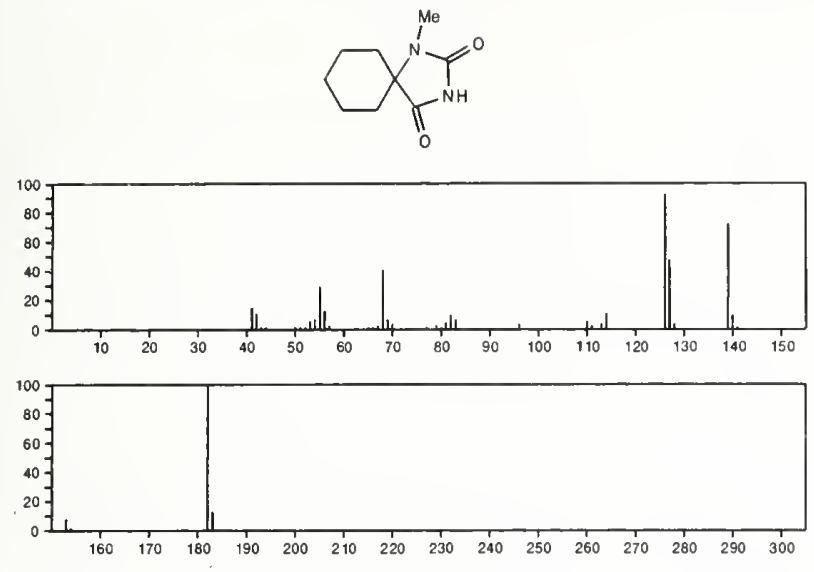

182

$\mathrm{C}_{9} \mathrm{H}_{14} \mathrm{~N}_{2} \mathrm{O}_{2}$

$1010-89-5$

Uracil, 1-butyl-6-methyl-
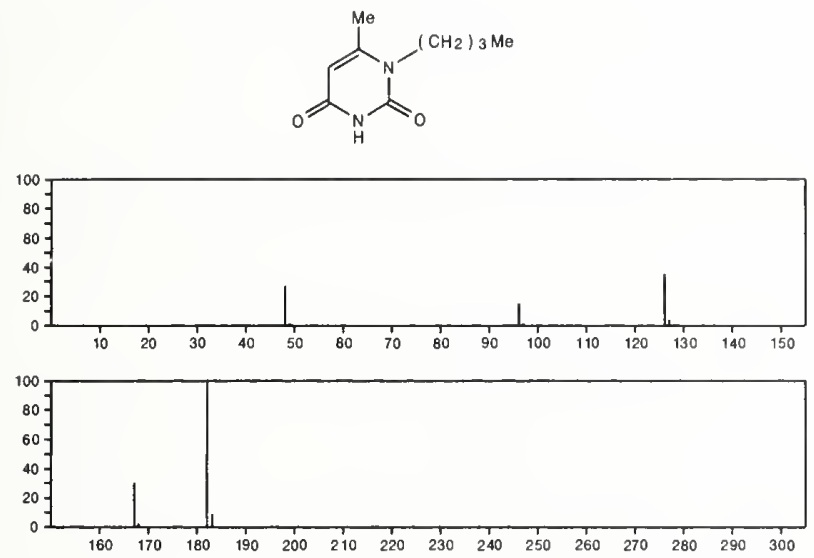

182

2,4(1H,3H)-Pyrimidinedione, 3-butyl-6-methyl-
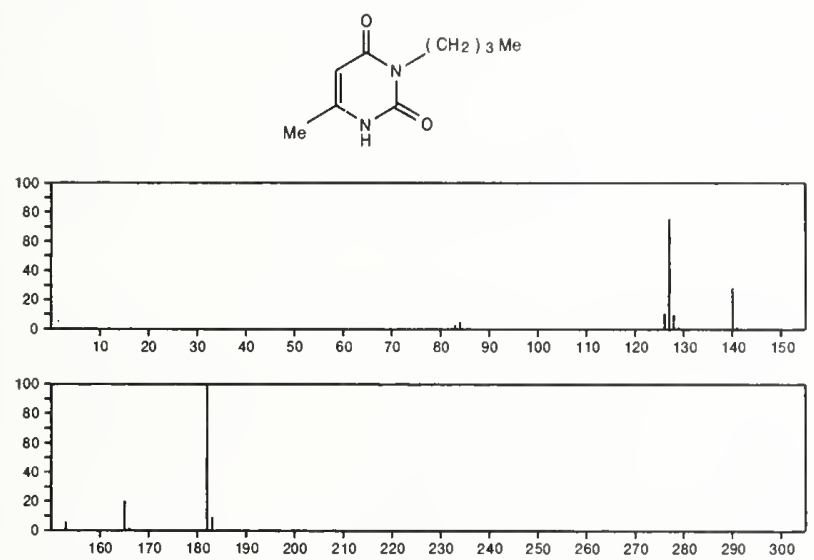

182

-Butanone, 1-(4-chlorophenyl)-

$4981-63-9$<smiles>COc1ccc(Cl)cc1</smiles>
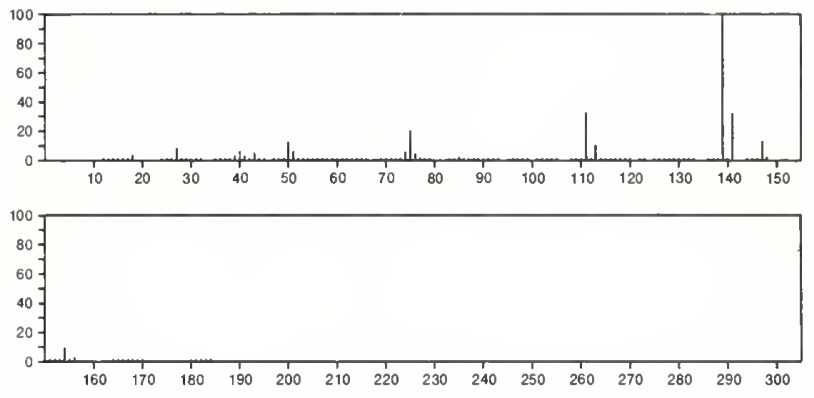

182

$\mathrm{C}_{10} \mathrm{H}_{11} \mathrm{ClO}$

$54644-21-2$

Benzene, 1-[(3-chloro-2-propenyl)oxy]-2-methyl-
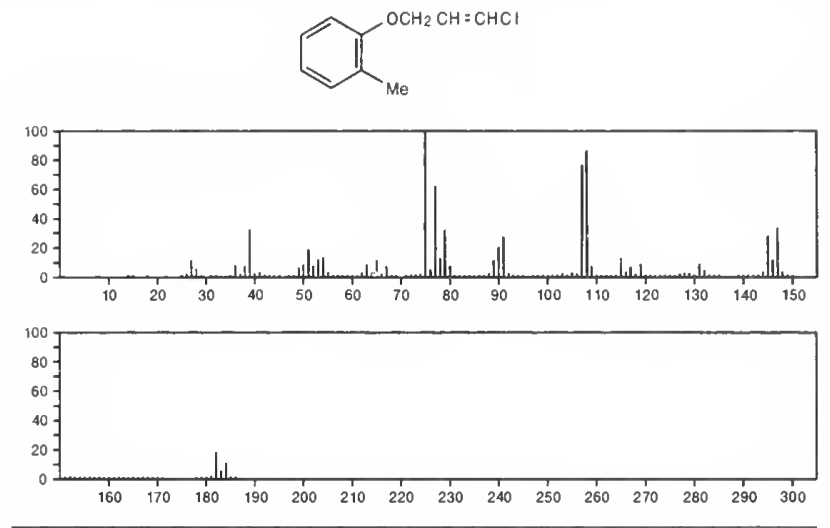

182

$\mathrm{C}_{10} \mathrm{H}_{11} \mathrm{ClO}$

$54644-22-3$

Benzene, 1-[(3-chloro-2-propenyl)oxy]-3-methyl-
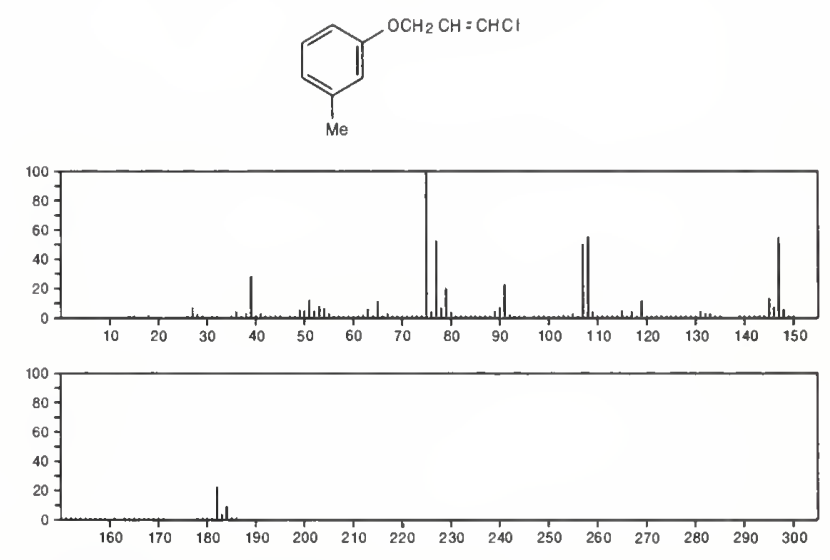

182

$\mathrm{C}_{10} \mathrm{H}_{11} \mathrm{ClO}$

$54644-23-4$

Benzene, 1-(3-chloro-2-propenyl)-4-methoxy-
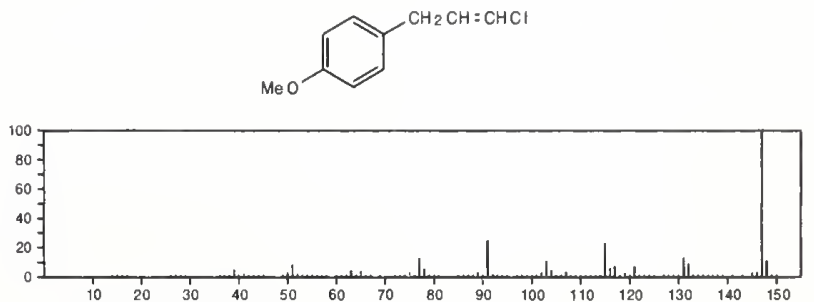


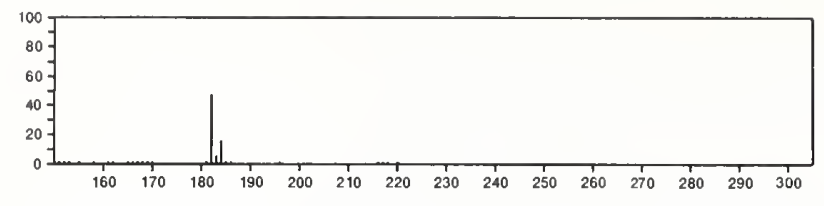

182

$\mathrm{C}_{10} \mathrm{H}_{11} \mathrm{ClO}$

1-Propanone, 1-(3-chlorophenyl)-2-methyl-
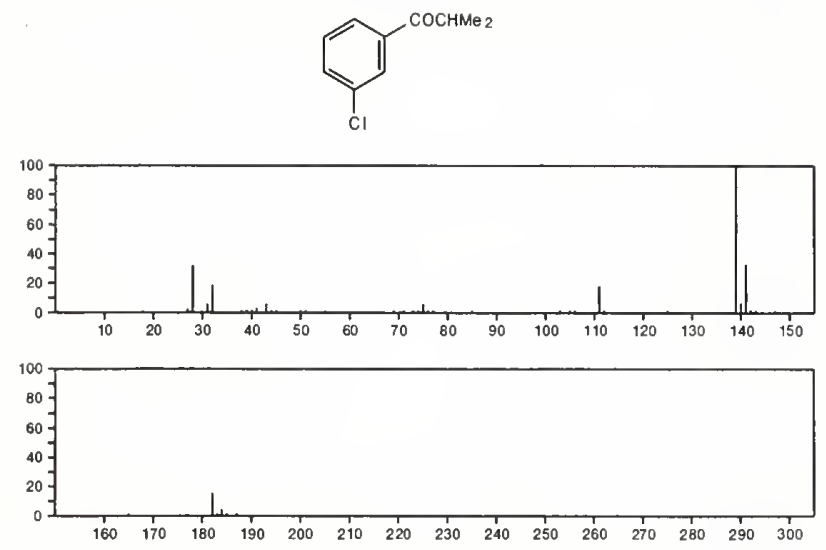

$182 \quad \mathrm{C}_{10} \mathrm{H}_{11} \mathrm{FO}_{2}$

2,6-Adamantanedione, 4-fluoro-
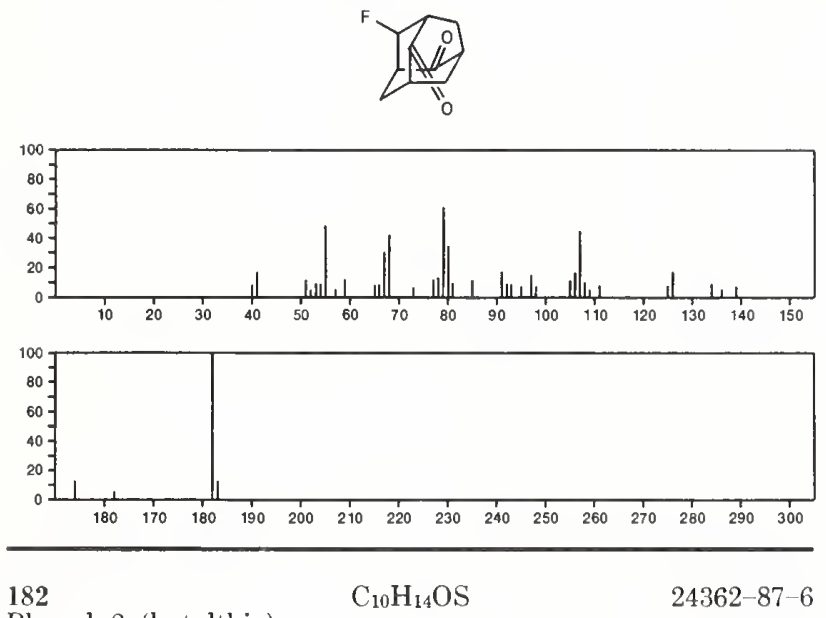

Phenol, 2-(butylthio)-
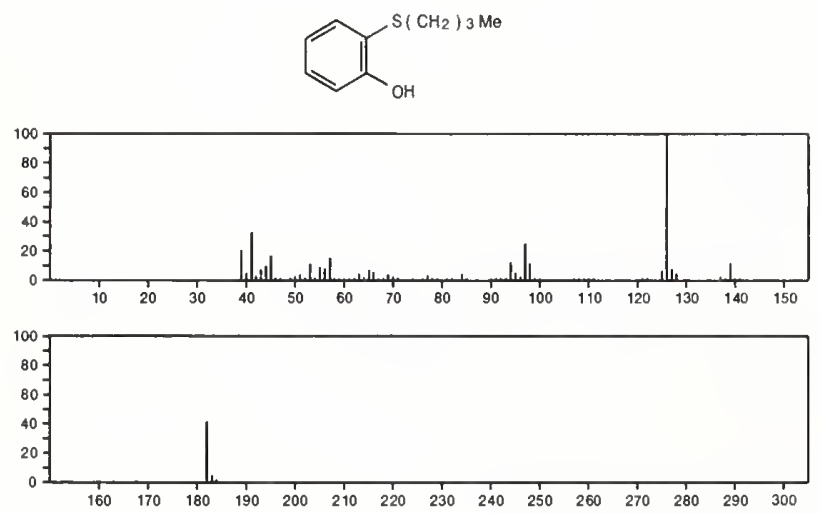

182

Phenol, o-(tert-butylthio)-

$\mathrm{C}_{10} \mathrm{H}_{14} \mathrm{OS}$

24362-88-7
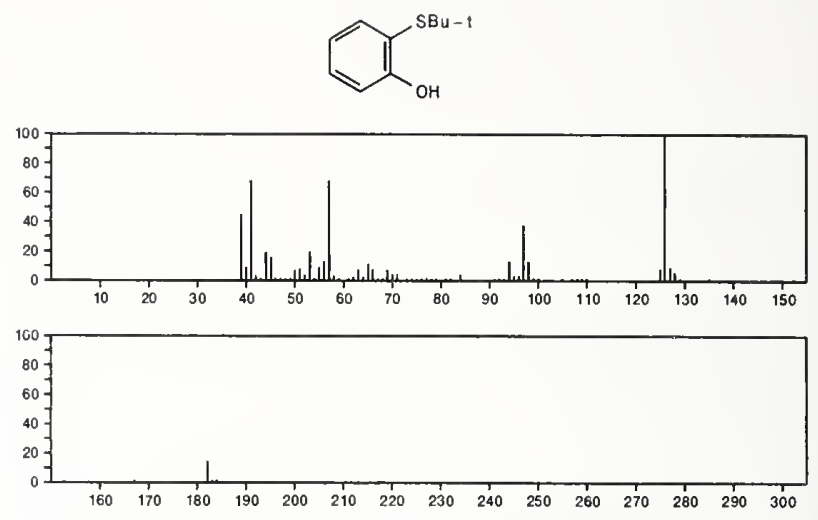

182
$1-$ Hexanone, $1-(2-$ thienyl $)-$

(I) $\mathrm{CO}\left(\mathrm{CH}_{2}\right)_{4} \mathrm{Me}$
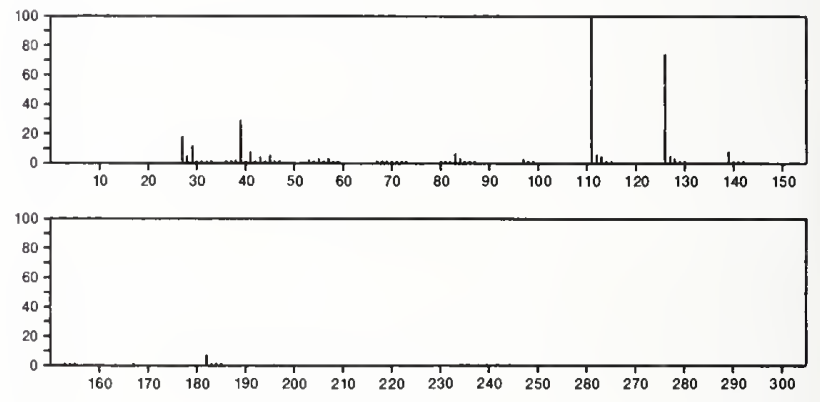

182

$\mathrm{C}_{10} \mathrm{H}_{14} \mathrm{OS}$

Phenol, 2-[(1-methylpropyl)thio]-

29549-64-2
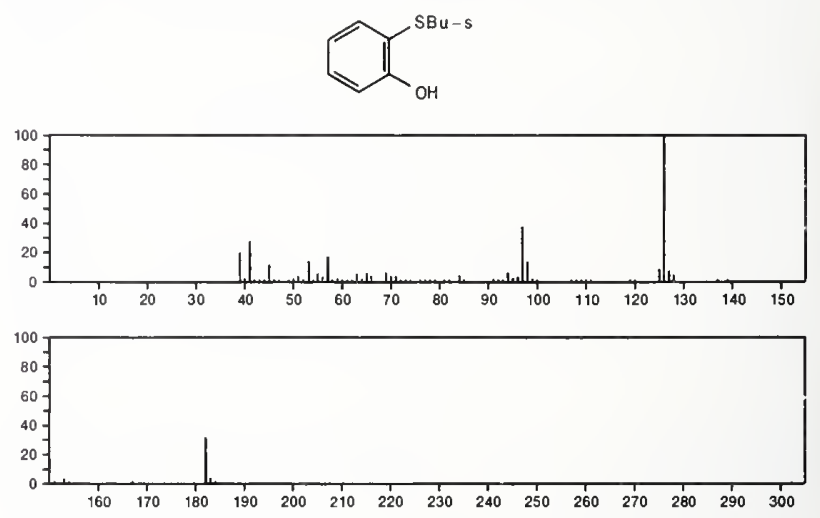

182

$\mathrm{C}_{10} \mathrm{H}_{14} \mathrm{OS}$

Phenol, 2-[(2-methylpropyl)thio]-

29549-65-3
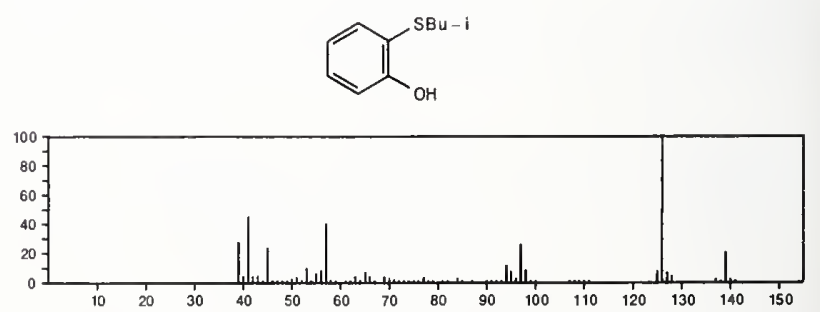

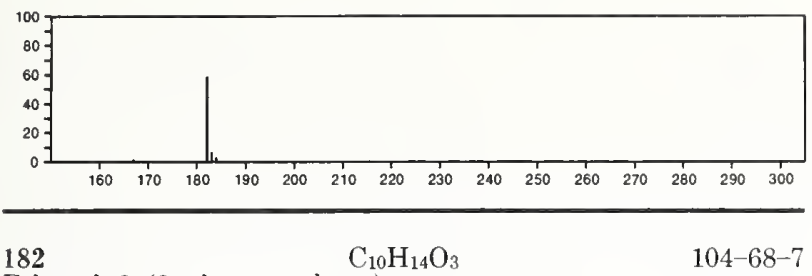

Ethanol, 2-(2-phenoxyethoxy)-

$\mathrm{HOCH}_{2} \mathrm{CH}_{2} \mathrm{OCH}_{2} \mathrm{CH}_{2} \mathrm{OPh}$
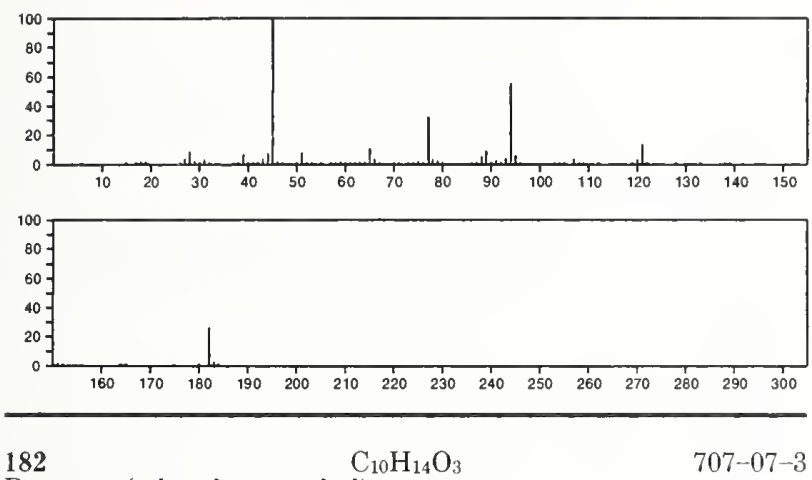

Benzene, (trimethoxymethyl)-

$$
\mathrm{C}_{10} \mathrm{H}_{14} \mathrm{O}_{3}
$$

$707-07-3$

$\mathrm{PhC}(\mathrm{OMe})_{3}$
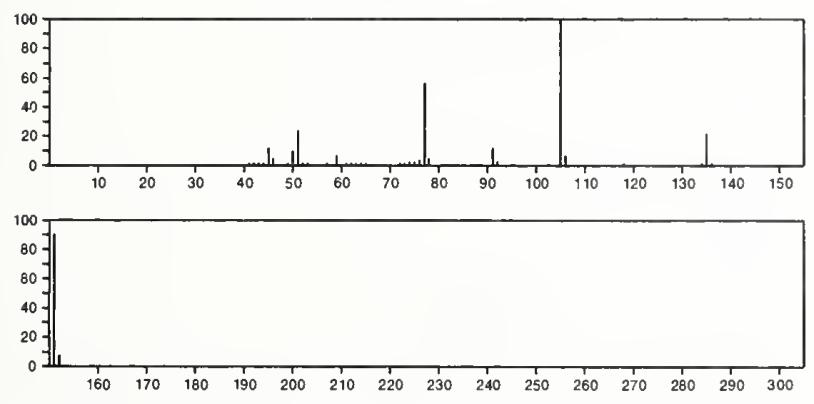

\section{2}

$\mathrm{C}_{10} \mathrm{H}_{14} \mathrm{O}_{3}$

3-Butene-1,2-diol, 1-(2-furyl)-2,3-dimethyl-

$19757-51-8$
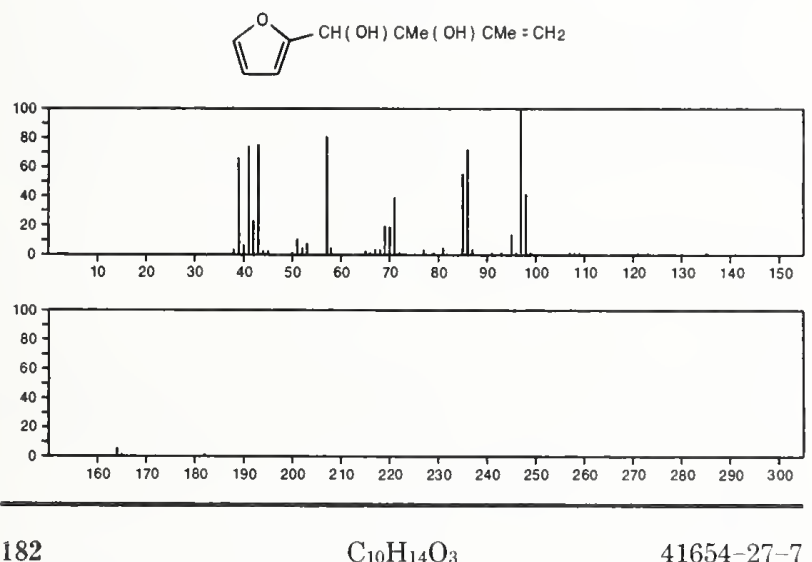

182

$\mathrm{C}_{10} \mathrm{H}_{14} \mathrm{O}_{3}$

$41654-27-7$

2-Cyclohexene-1,4-dione, 2-methoxy-3,5,5-trimethyl-
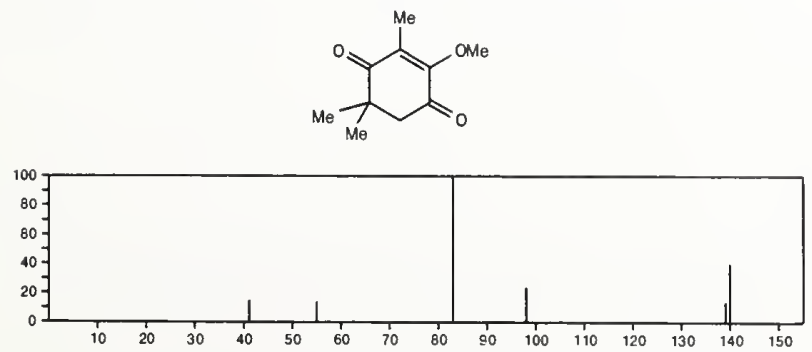

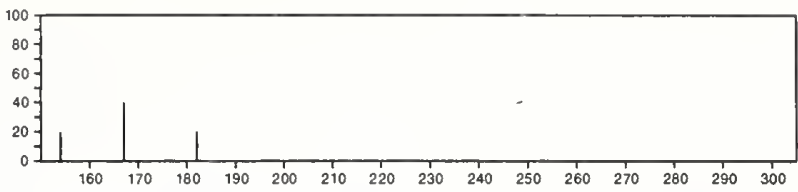

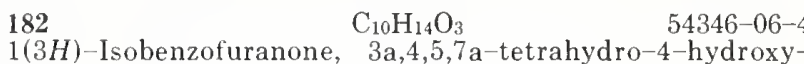

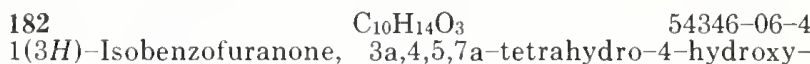

$3 \mathrm{a}, 7 \mathrm{a}$-dimethyl-, $(3 \mathrm{a} \alpha, 4 \beta, 7 \mathrm{a} \alpha)-( \pm)-$
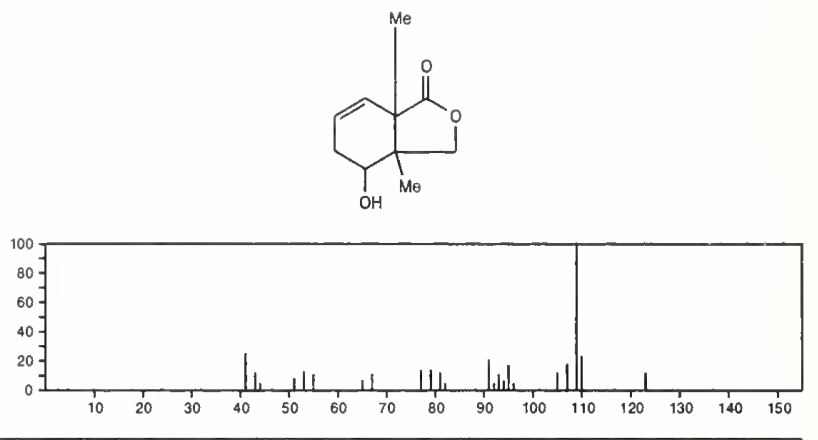

$182 \quad \mathrm{C}_{10} \mathrm{H}_{14} \mathrm{O}_{3} \quad 54644-18-7$

1,3-Isobenzofurandione, hexahydro-4,7-dimethyl-
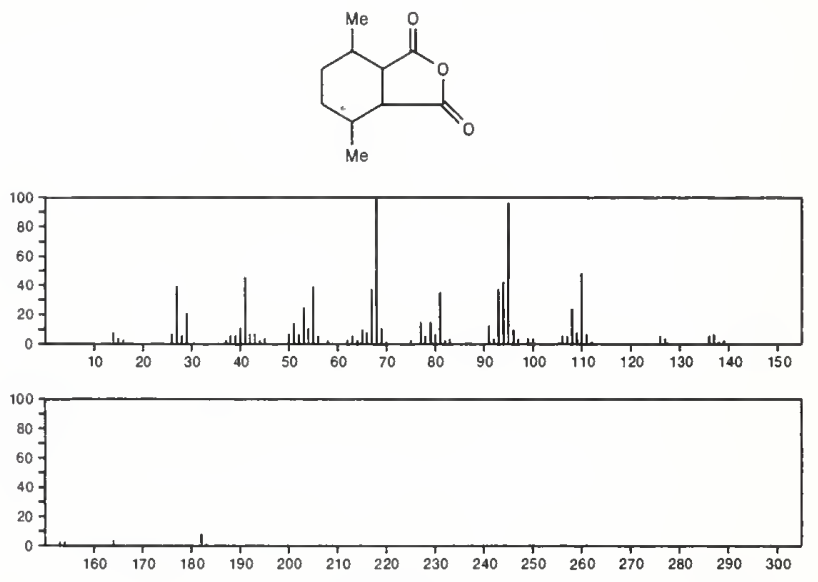

182

$\mathrm{C}_{10} \mathrm{H}_{14} \mathrm{O}_{3}$

$54644-19-8$

1,2,4-Cyclopentanetrione, 3-(1-methylbutyl)-
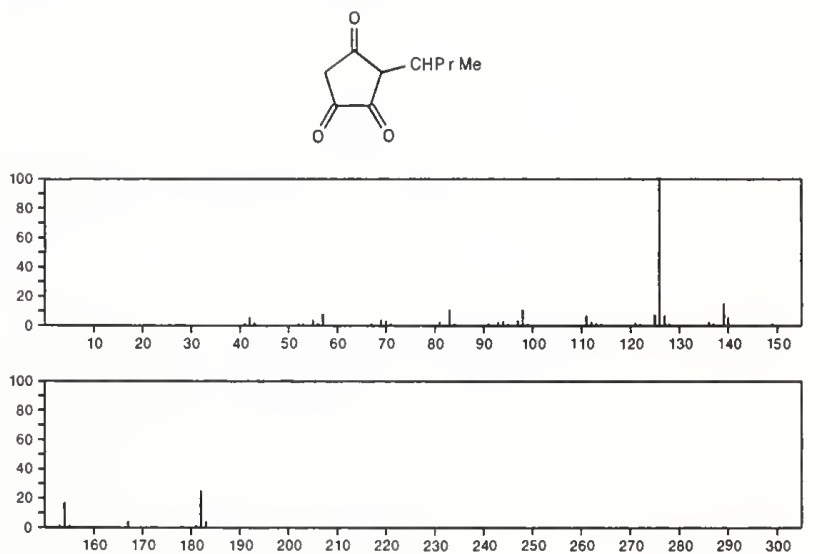
182

Bicyclo[2.2.2]octan-2-one, 4-(acetyloxy)
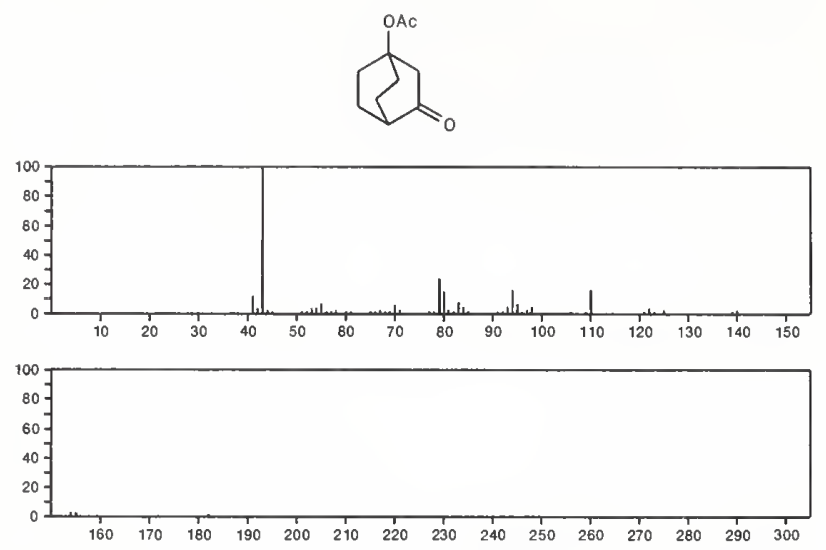

182

$57156-89-5$

1,3-Cyclopentanedione, 4-hydroxy-5-(3-methyl-1-butenyl)-
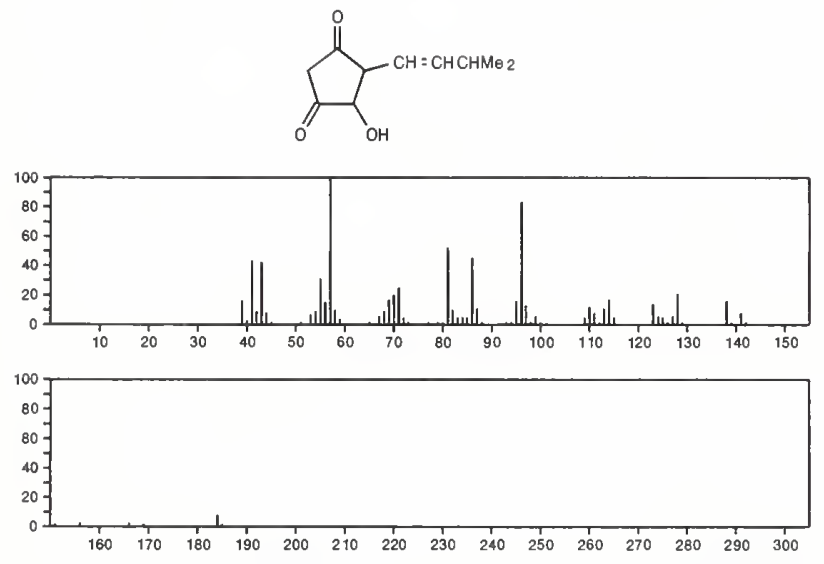

$182 \quad \mathrm{C}_{10} \mathrm{H}_{18} \mathrm{~N}_{2} \mathrm{O} \quad 4074-30-0$

3-Azabicyclo[3.2.1]octane, 1,8,8-trimethyl-3-nitroso--
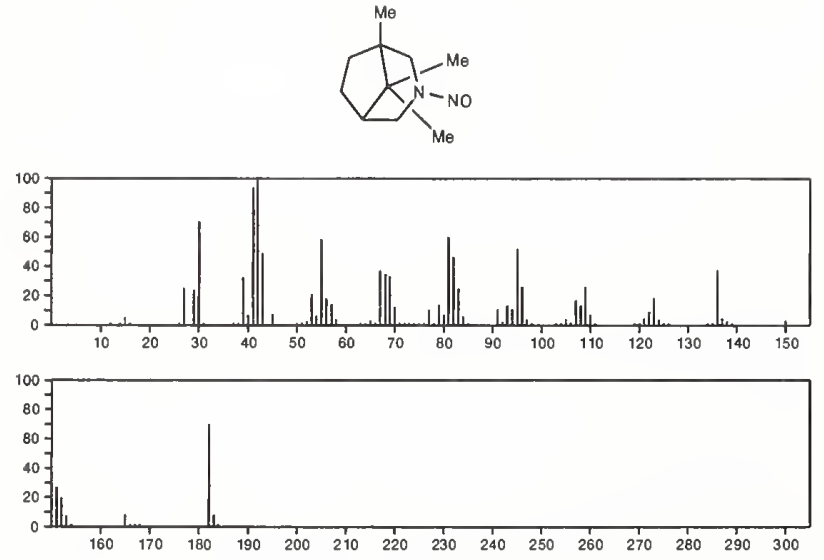

182

$\mathrm{C}_{10} \mathrm{H}_{18} \mathrm{~N}_{2} \mathrm{O}$

Isoxazole, 5-amino-3-butyl-4-propyl-

$28884-14-2$
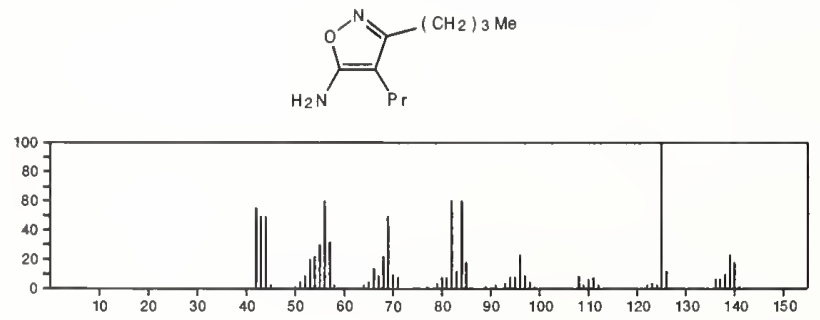

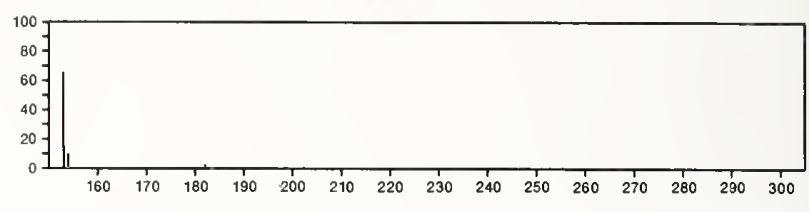

182

$\mathrm{C}_{10} \mathrm{H}_{18} \mathrm{~N}_{2} \mathrm{O}$

2-Quinuclidinone, 6,6,8,8-tetramethyl-

$29924-75-2$
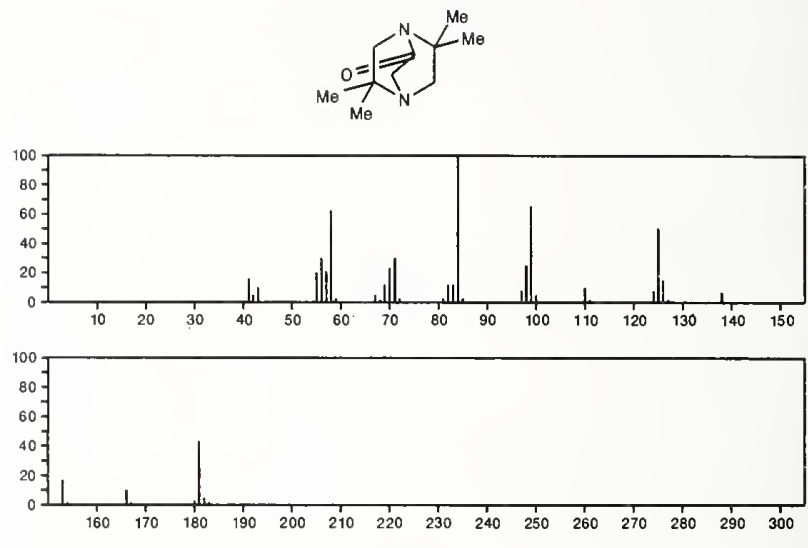

$182 \quad \mathrm{C}_{10} \mathrm{H}_{18} \mathrm{~N}_{2} \mathrm{O}$

2-Propenal, 3-(dimethylamino)-3-(1-piperidinyl)-

49582-39-0
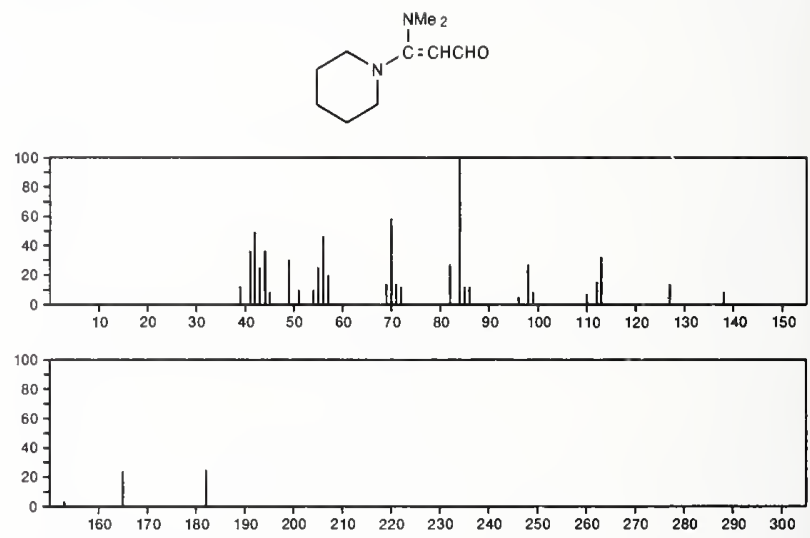

182

$\mathrm{C}_{11} \mathrm{H}_{15} \mathrm{Cl}$

Benzene, (3-chloro-3-methylbutyl)-

4830-95-9

$\mathrm{Me}_{2} \mathrm{CCl} \mathrm{CH}_{2} \mathrm{CH}_{2} \mathrm{Ph}$
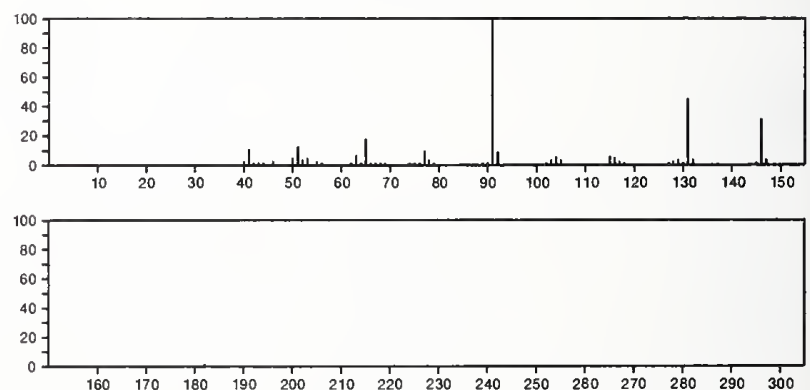
182 $\mathrm{C}_{11} \mathrm{H}_{15} \mathrm{Cl}$

Benzene, chloro(1-methylbutyl)-

$54657-99-7$
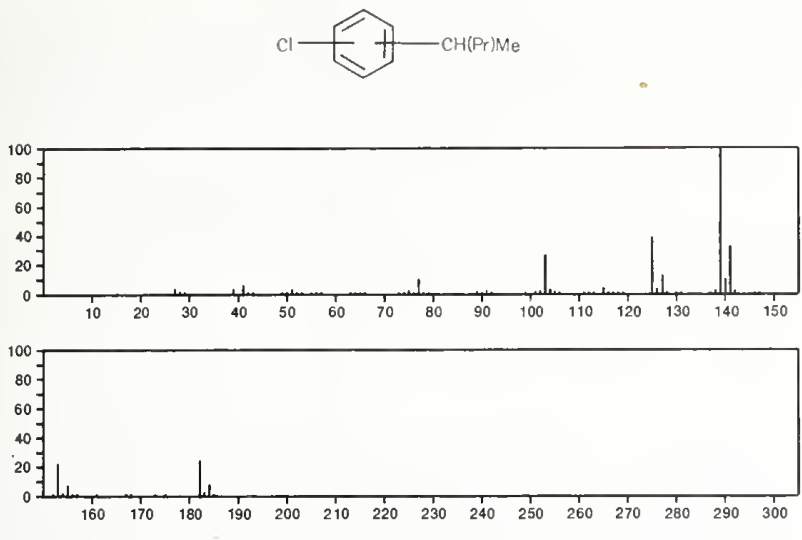

182

Benzene, chlorodiethylmethyl-

$\mathrm{C}_{11} \mathrm{H}_{15} \mathrm{Cl}$

$54658-00-3$
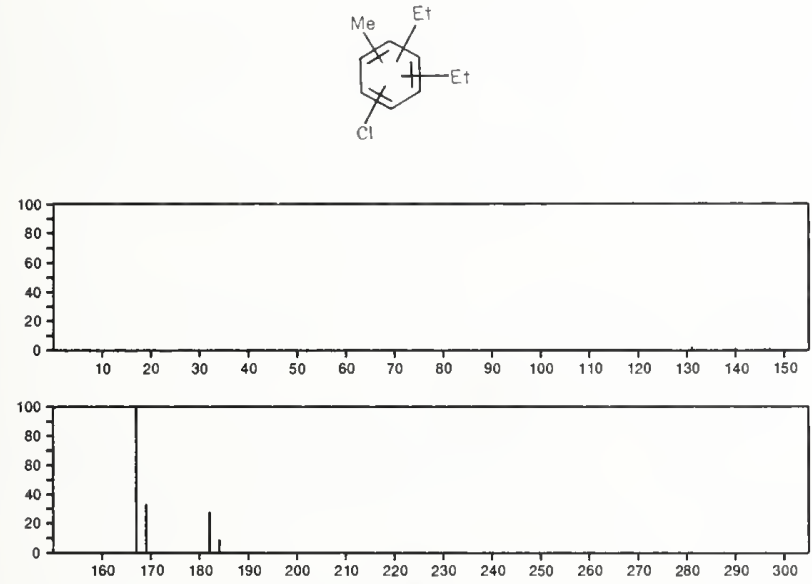

182

$\mathrm{C}_{11} \mathrm{H}_{18} \mathrm{O}_{2}$

$105-86-2$

2,6-Octadien-1-ol, 3,7-dimethyl-, formate, $(E)$ -

$\mathrm{O}=\mathrm{CHOCH}_{2} \mathrm{CH}=\mathrm{CM}_{\mathrm{CH}} \mathrm{CH}_{2} \mathrm{CH}_{2} \mathrm{CH}=\mathrm{CMe} 2$

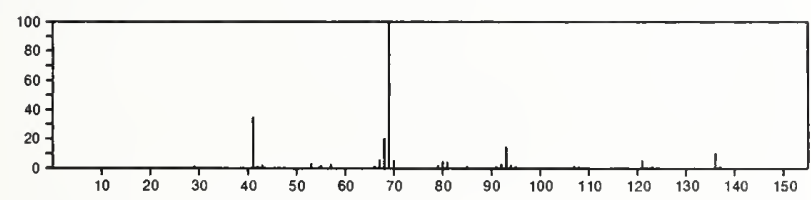

182

$\mathrm{C}_{11} \mathrm{H}_{18} \mathrm{O}_{2}$

2,6-Octadienoic acid, 3,7-dimethyl-, methyl ester, $(E)$ -

$\mathrm{MeOC}(\mathrm{O}) \mathrm{CH}=\mathrm{CMeCH}_{2} \mathrm{CH}_{2} \mathrm{CH}=\mathrm{CMe} 2$
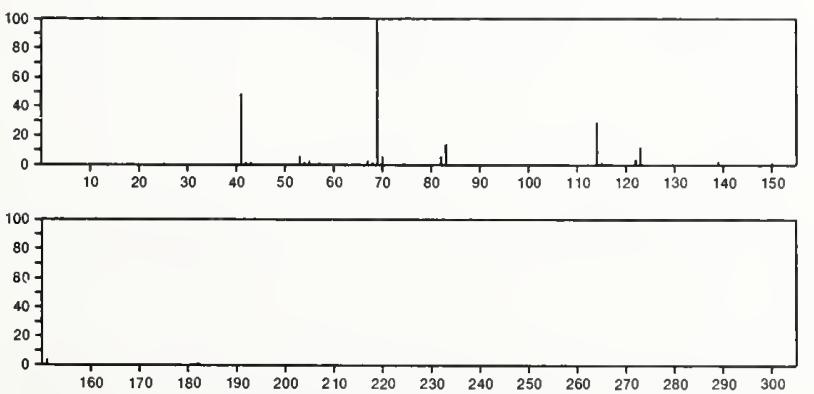

$82 \quad \mathrm{C}_{11} \mathrm{H}_{18} \mathrm{O}$

2,6-Octadienoic acid, 3,7-dimethyl-, methyl ester, $(Z)$

$862-61-9$

Me OC $(0) \mathrm{CH}_{2}=\mathrm{CM}_{0} \mathrm{CH}_{2} \mathrm{CH}_{2} \mathrm{CH}=\mathrm{CMe}_{2}$
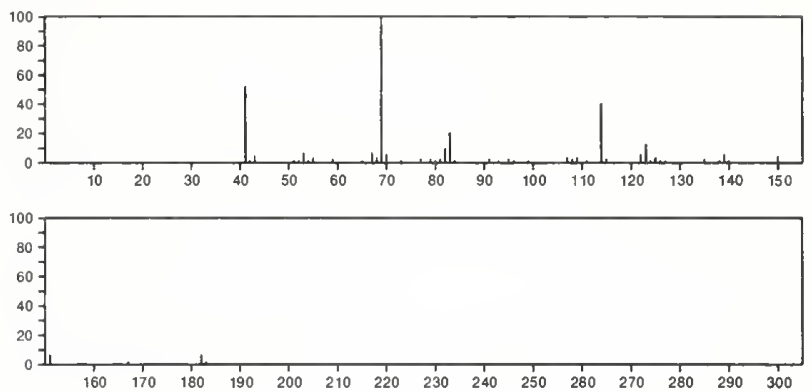

182

$\mathrm{C}_{11} \mathrm{H}_{18} \mathrm{O}_{2}$

$1919-64-8$

1,3-Cyclohexanedione, 5,5-dimethyl-2-propyl-
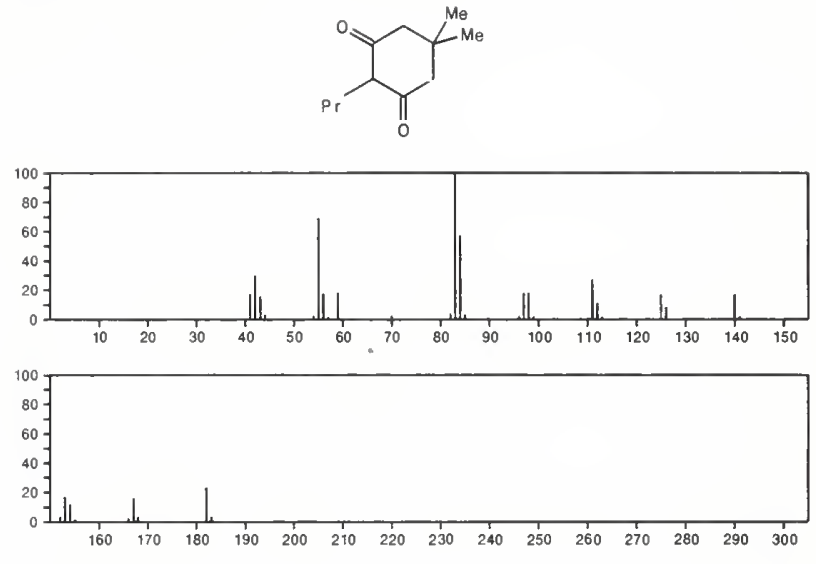

$182 \quad \mathrm{C}_{11} \mathrm{H}_{18} \mathrm{O}_{2}$

2349-14-6

2,6-Octadienoic acid, 3,7-dimethyl-, methyl ester

$\mathrm{MeOC}(\mathrm{O}) \mathrm{CH}=\mathrm{CMeCH}_{2} \mathrm{CH}_{2} \mathrm{CH}=\mathrm{CMe} 2$
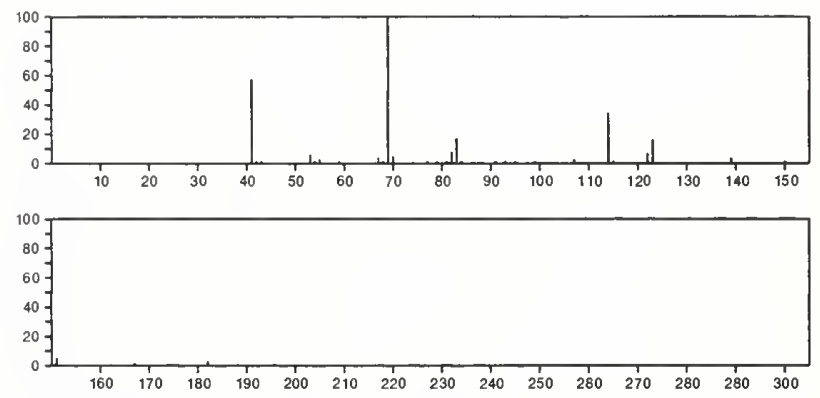

182

$\mathrm{C}_{11} \mathrm{H}_{18} \mathrm{O}_{2}$

4707-07-7

2(1H)-Naphthalenone, octahydro-8a-hydroxy-4a-methyl-, cis-
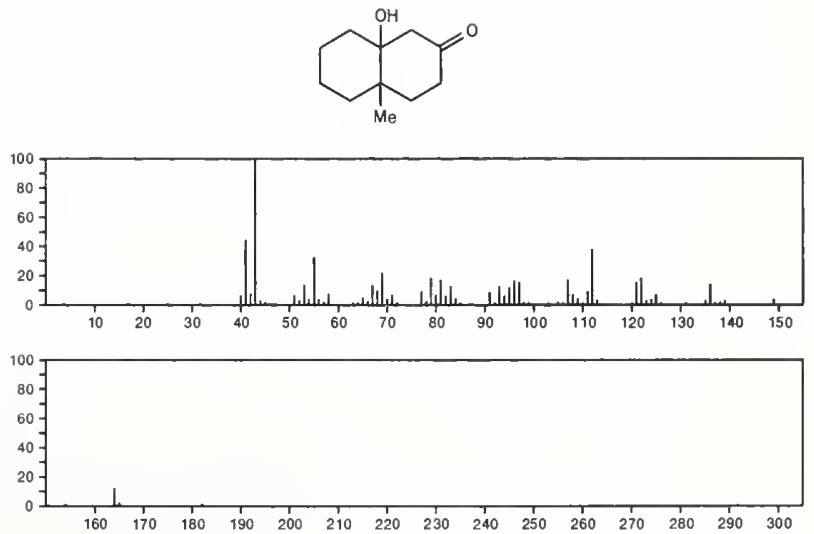
182

$\mathrm{C}_{11} \mathrm{H}_{18} \mathrm{O}_{2}$

Cyclopropanecarboxylic acid 2 2 dimethyl-3=(2propenyl)-, methyl ester
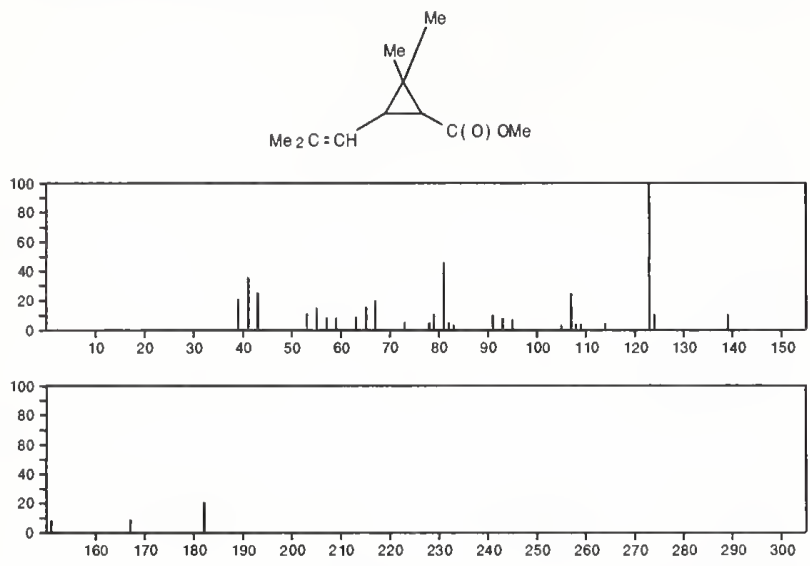

182

1-Cycloheptene-1-acetic acid, $\alpha, \alpha$-dimethyl-
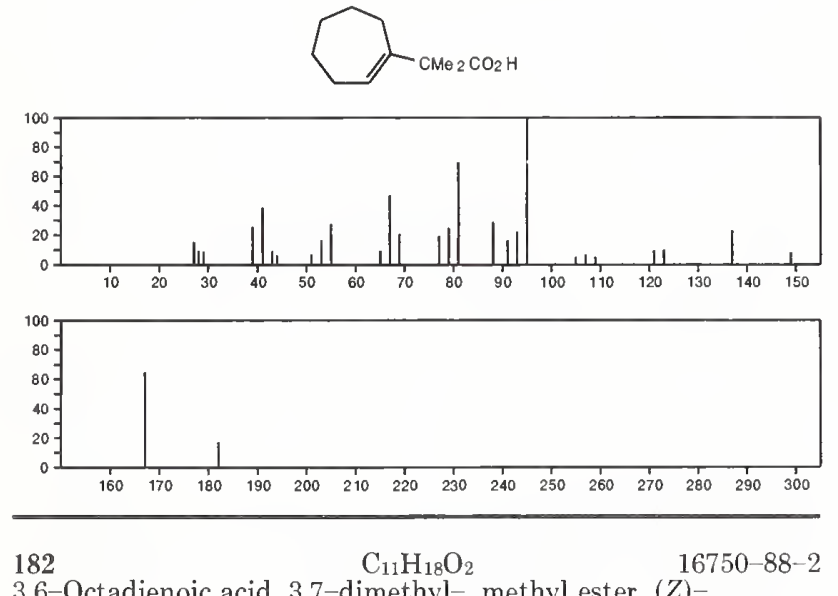

3,6-Octadienoic acid, 3,7-dimethyl-, methyl ester, $(Z)-$

$\mathrm{MeOC}$ (0) $\mathrm{CH}_{2} \mathrm{CM}_{\theta}=\mathrm{CHCH}_{2} \mathrm{CH}=\mathrm{CMe}_{2}$
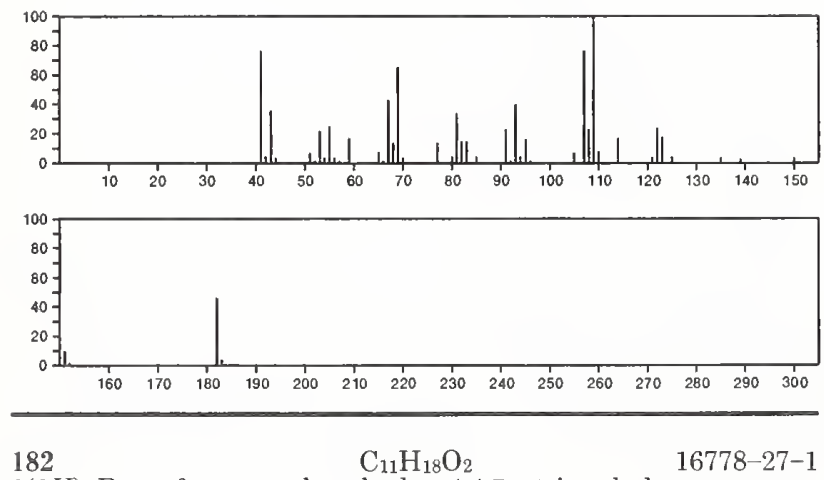

2(3H)-Benzofuranone, hexahydro-4,4,7a-trimethyl-
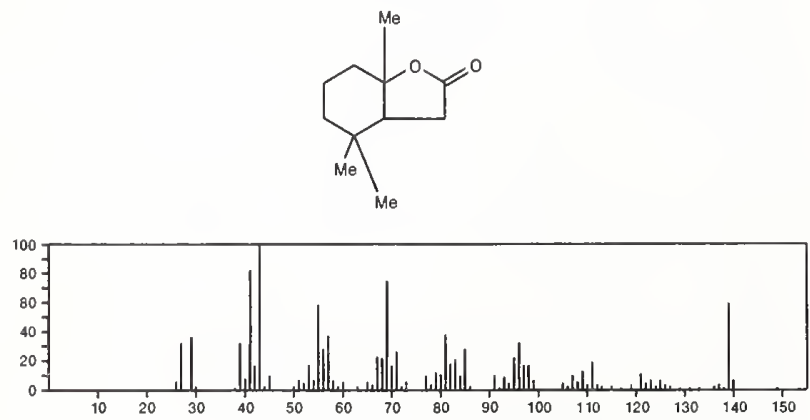
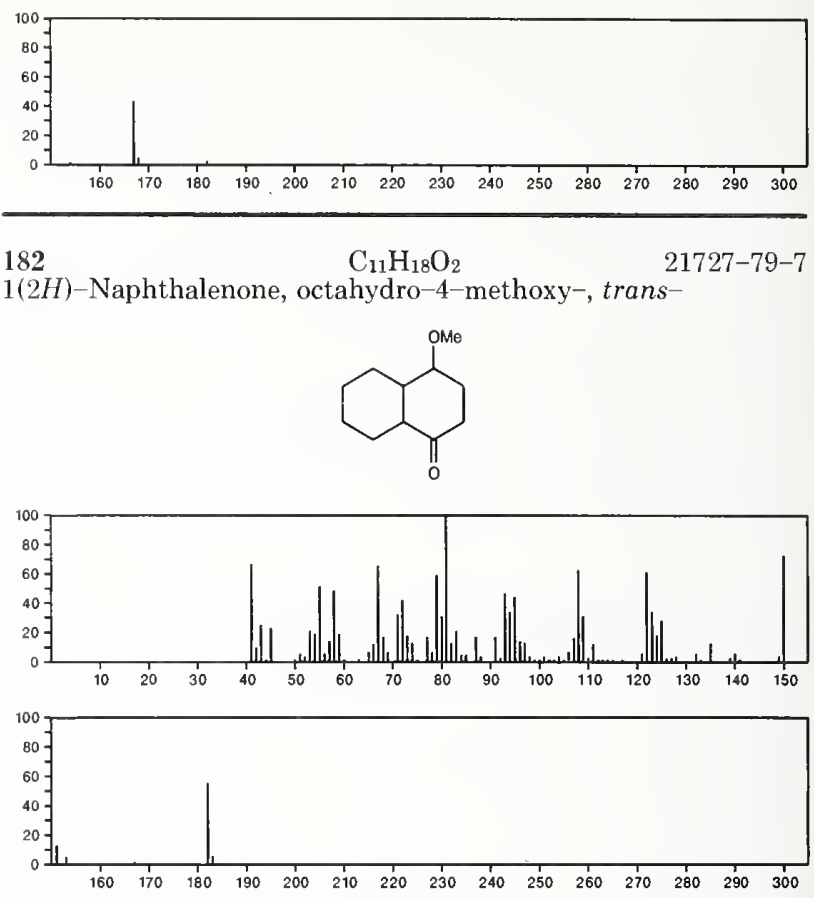

182

$\mathrm{C}_{11} \mathrm{H}_{18} \mathrm{O}_{2}$

$36334-87-9$

1,3-Dioxolane, 2,2-dimethyl-4,5-bis(1-methylethenyl)-
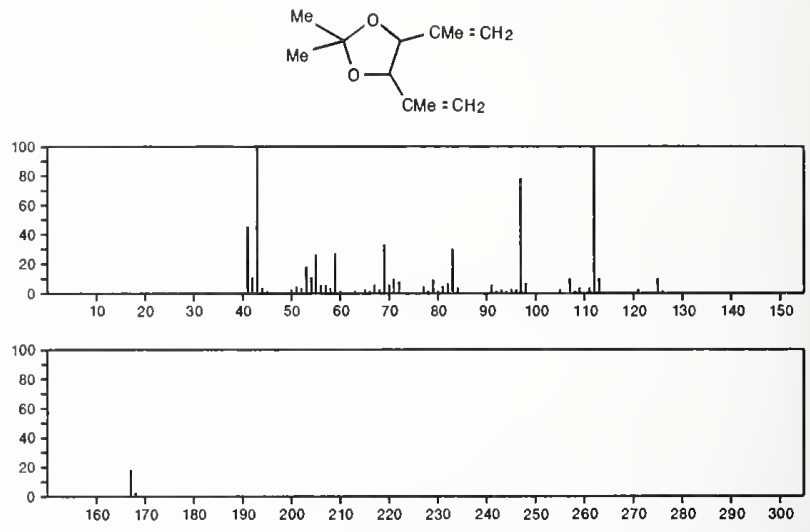

182

$\mathrm{C}_{11} \mathrm{H}_{18} \mathrm{O}_{2}$

1,3-Dioxolane, 2,2-dimethyl-4,5-di-1-propenyl-

$36334-88-0$
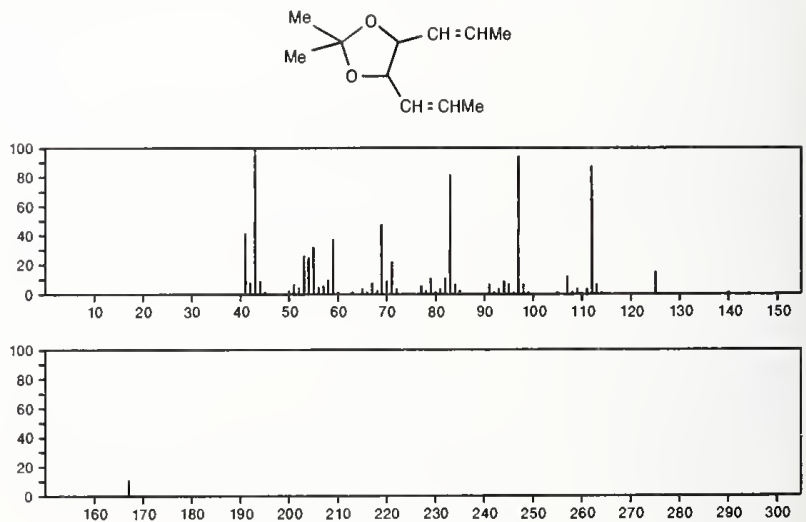
$182 \quad \mathrm{C}_{11} \mathrm{H}_{18} \mathrm{O}_{2}$

2-Propanone, 1-(1-cyclohexen-1-yl)-3-ethoxy-

$51149-72-5$
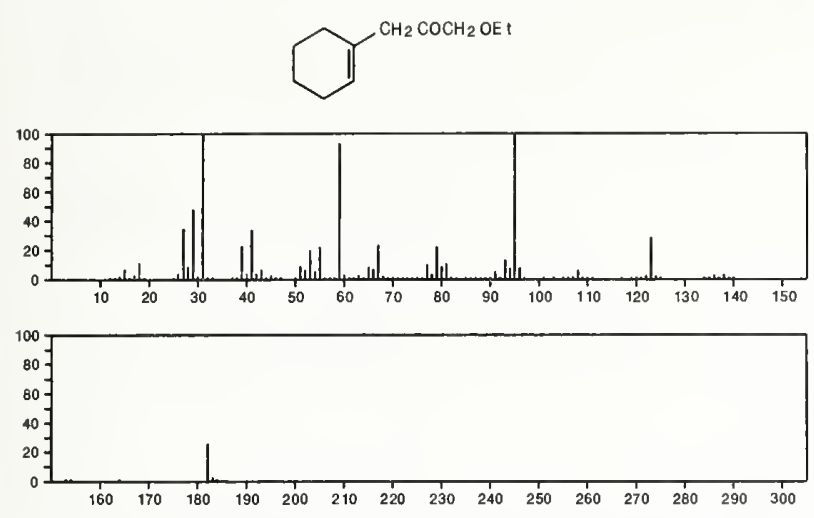

$182 \quad \mathrm{C}_{11} \mathrm{H}_{18} \mathrm{O}_{2} \quad 53690-81-6$

2-Cyclohexen-1-one, 6-butyl-3-methoxy-
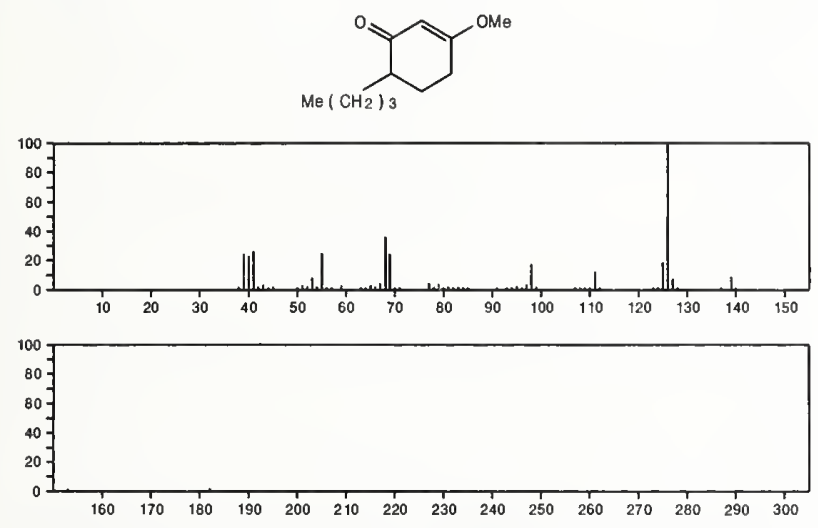

$182 \quad \mathrm{C}_{11} \mathrm{H}_{18} \mathrm{O}_{2} \quad 53690-84-9$

2-Cyclohexen-1-one, 4-butyl-3-methoxy-
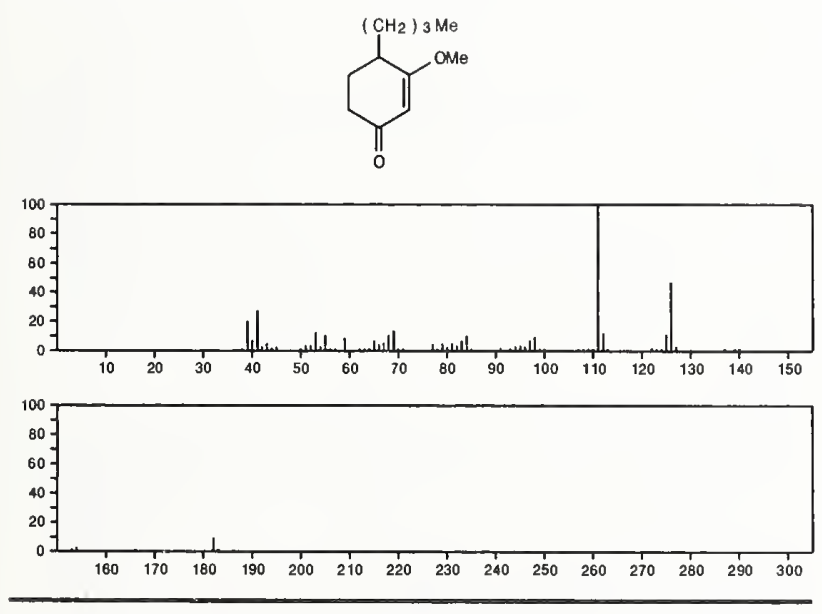

182

2-Cyclohexen-1-one, 2-butyl-3-methoxy-

$53690-86-1$
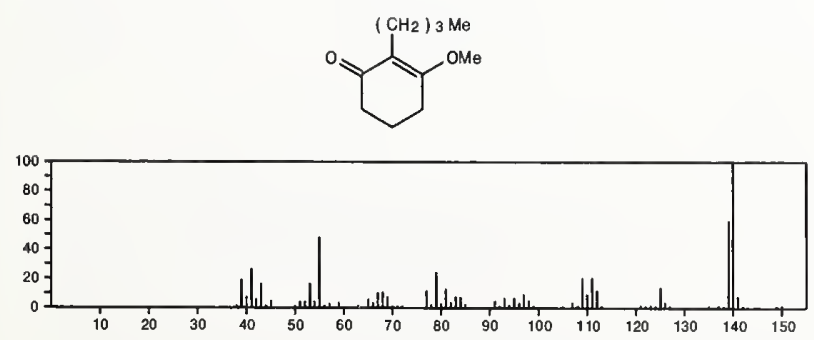

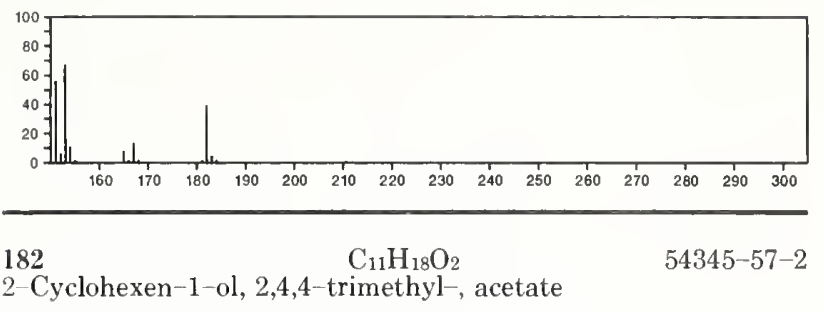

OAC

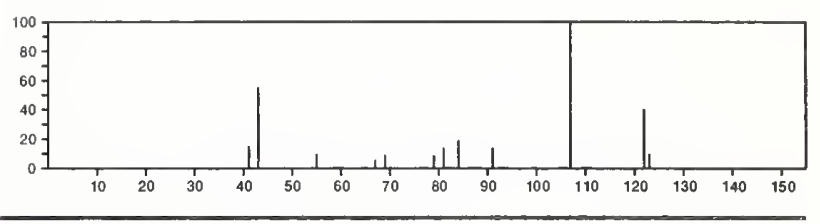

182

$\mathrm{C}_{11} \mathrm{H}_{18} \mathrm{O}_{2}$

54345-58-3

2-Cyclohexen-1-ol, 2,6,6-trimethyl-, acetate
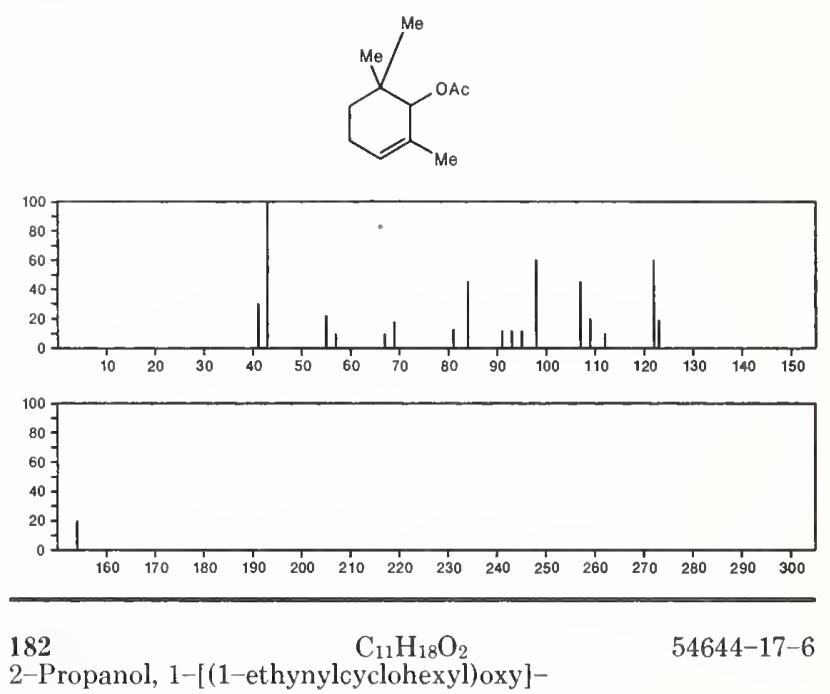

2-Propanol, 1-[(1-ethynylcyclohexyl)oxy]-
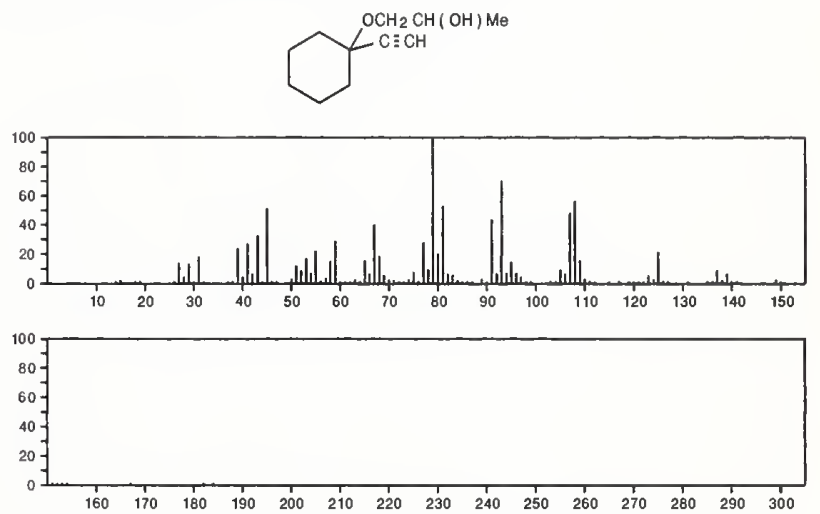
182

$$
\mathrm{C}_{11} \mathrm{H}_{18} \mathrm{O}_{2}
$$

$54644-24-5$

1-Pentalenecarboxylic acid, octahydro-3-methyl-, methyl ester
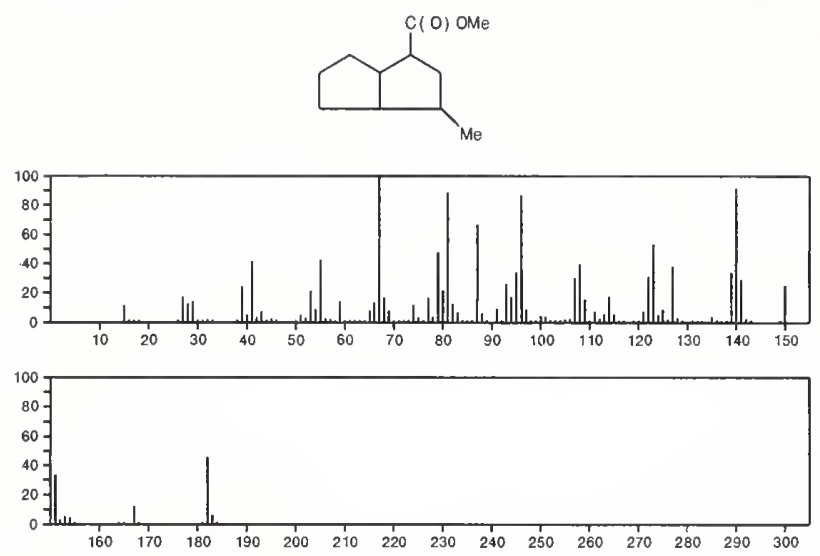

182

Bicyclo[2.2.2] octan-1-ol, 4-methyl-, acetate
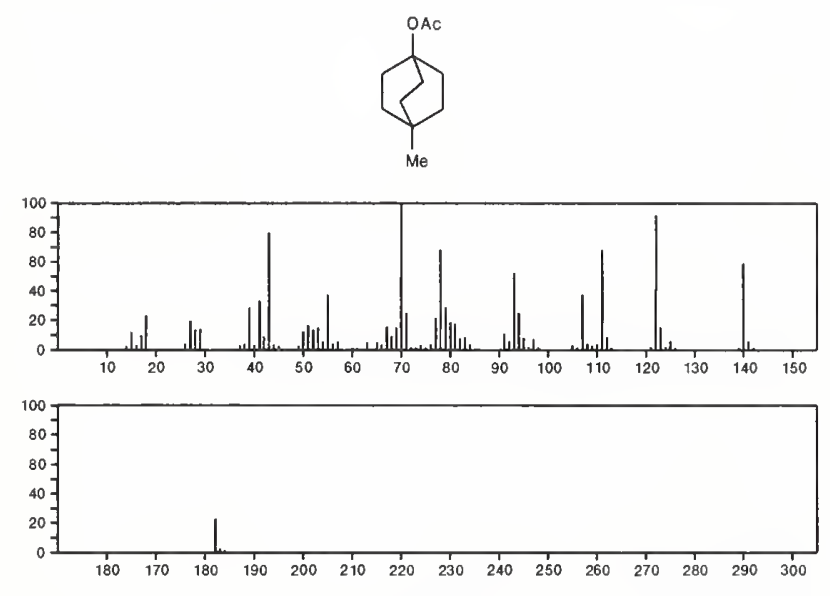

$182 \quad \mathrm{C}_{11} \mathrm{H}_{18} \mathrm{O}_{2} \quad 54764-60-2$

Bicyclo[4.1.0]heptane-7-carboxylic acid, 3-methyl-, ethyl ester
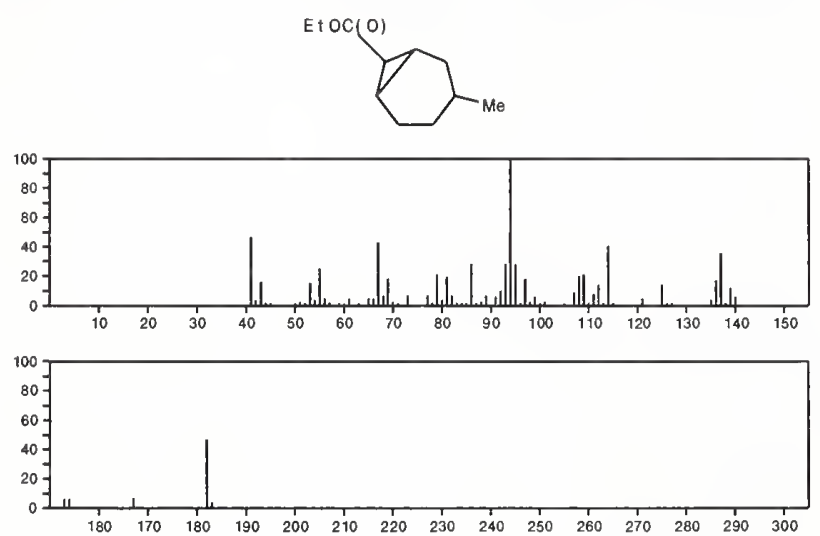

$\mathrm{C}_{11} \mathrm{H}_{18} \mathrm{O}_{2}$
$1,3-\mathrm{Cyclopentanedione,}$
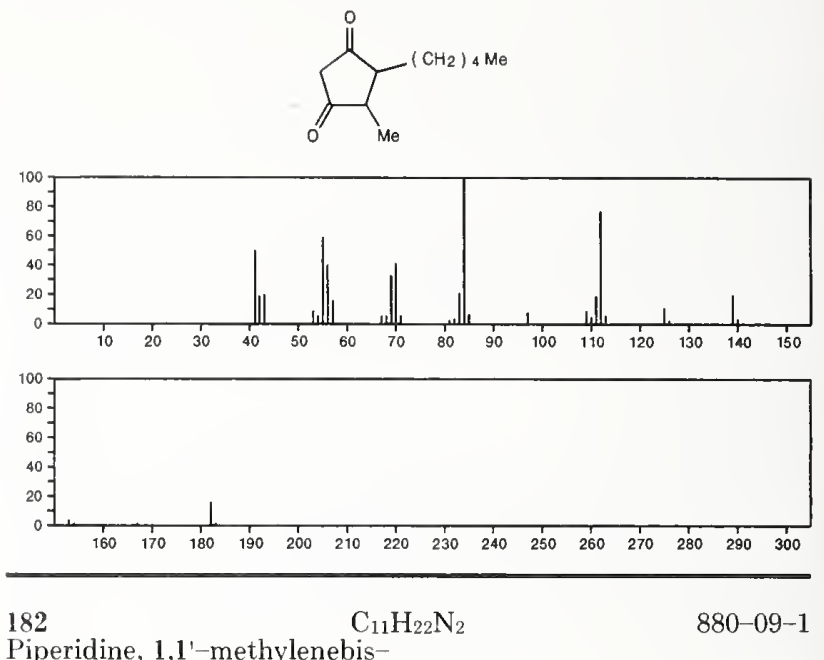

Piperidine, 1,1'-methylenebis-
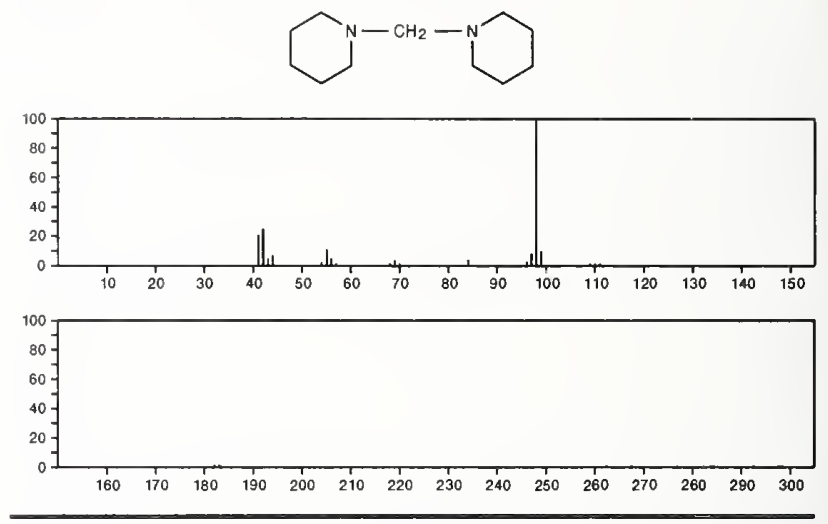

182

$\mathrm{C}_{12} \mathrm{H}_{10} \mathrm{~N}_{2}$

$103-33-3$

Diazene, diphenyl-

$P h N=N P h$
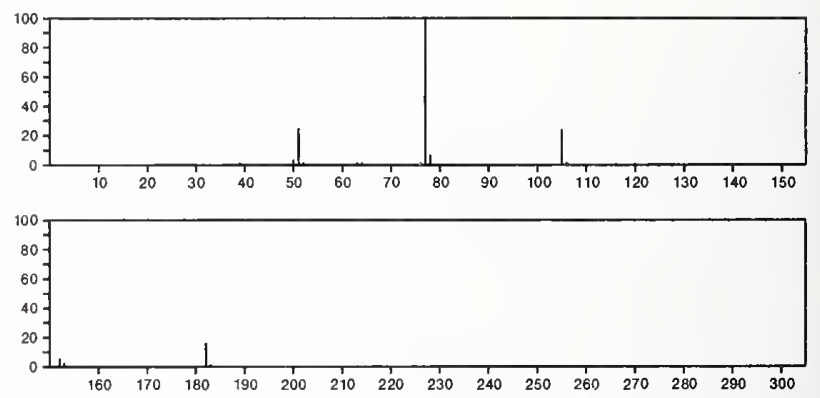

182

${ }_{12} \mathrm{C}_{12} \mathrm{H}_{10} \mathrm{~N}$

$486-84-0$
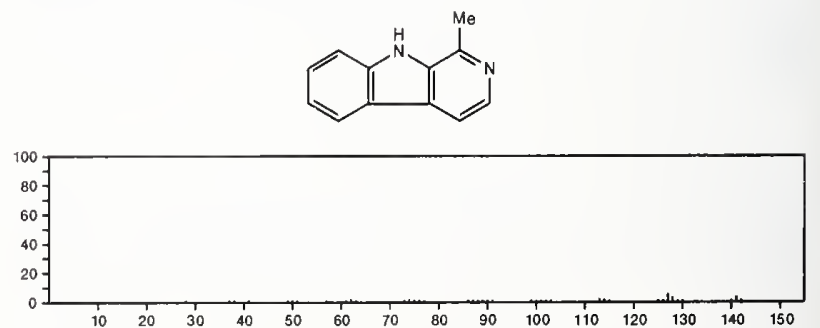


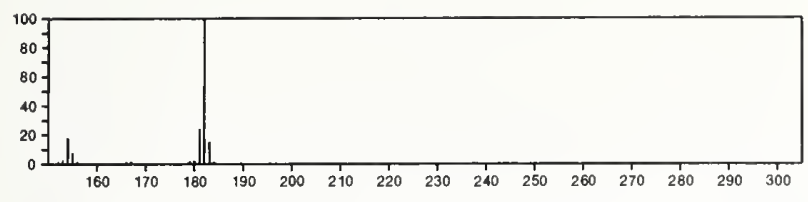

182 $\mathrm{C}_{12} \mathrm{H}_{10} \mathrm{~N}_{2}$

Pyridine, 4,4'-(1,2-ethenediyl) bis-
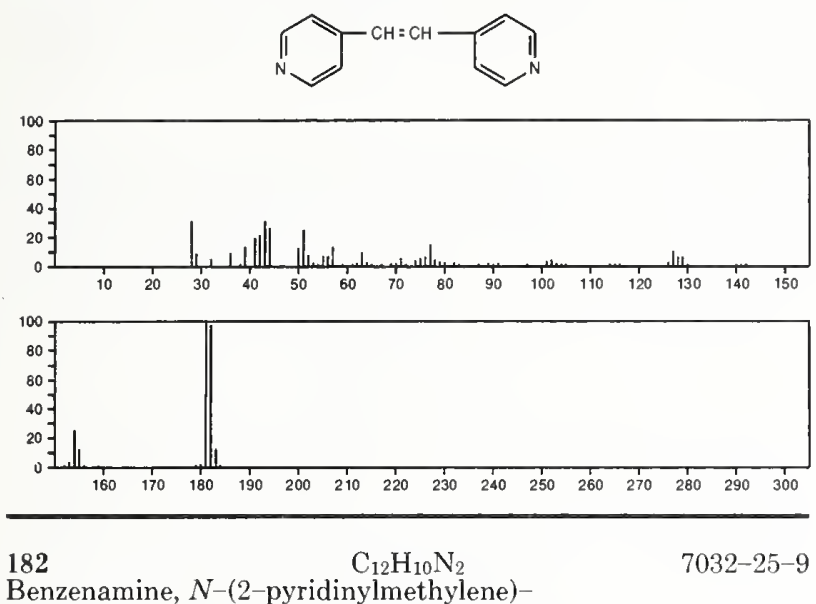

Benzenamine, $N$-(2-pyridinylmethylene $)$
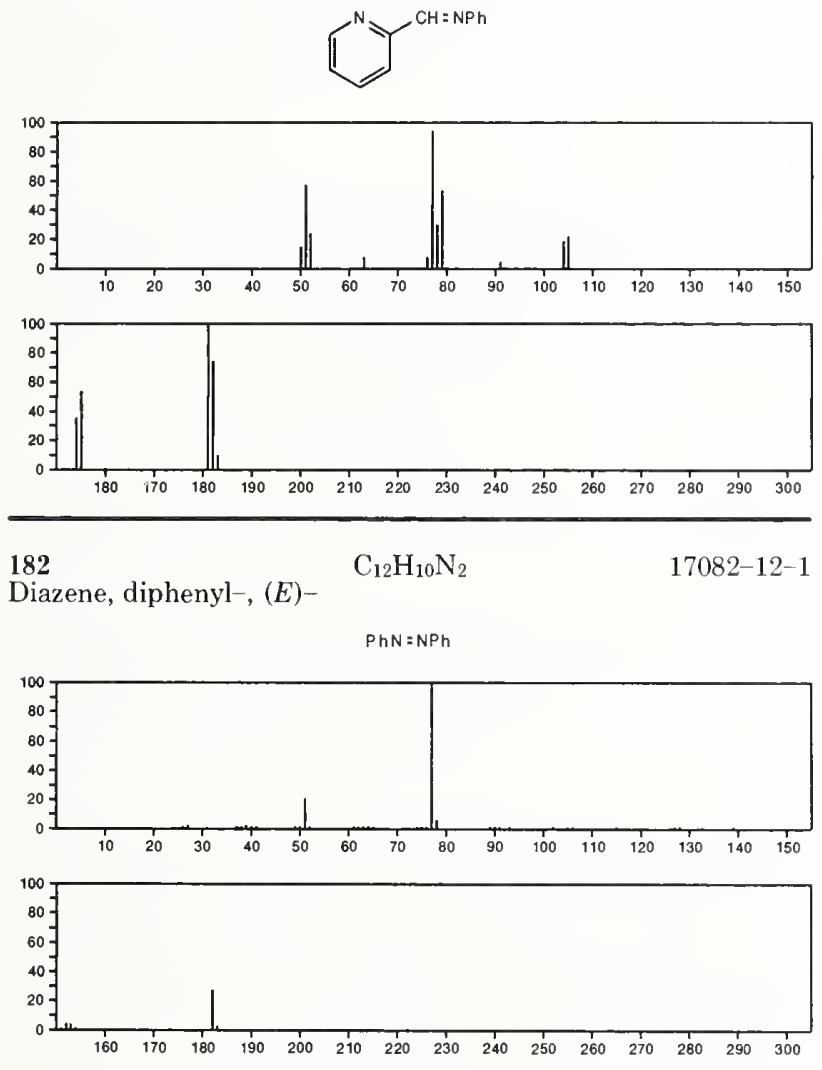

$182 \quad \mathrm{C}_{12} \mathrm{H}_{10} \mathrm{~N}_{2}$

27768-46-3

Benzenamine, $N$-(4-pyridinylmethylene)-
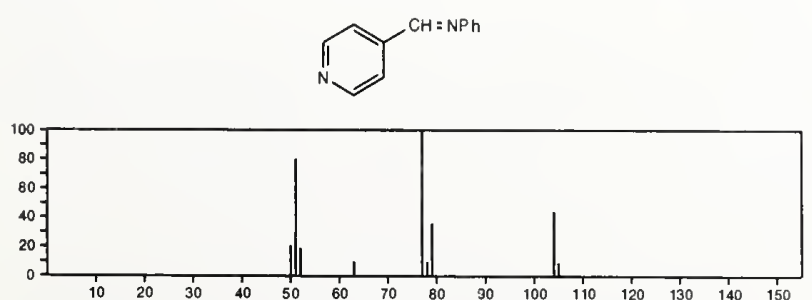

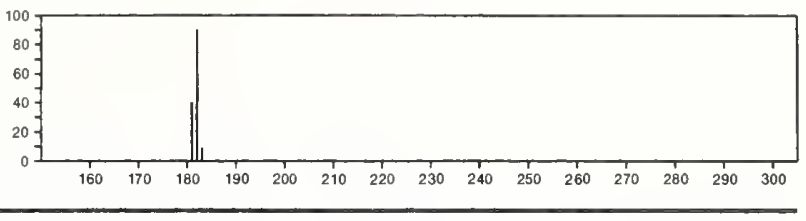

182 $\mathrm{C}_{12} \mathrm{H}_{10} \mathrm{~N}_{2}$

29722-97-2

Benzenamine, $N$-(3-pyridinylmethylene)-<smiles>N=Cc1cccnc1</smiles>
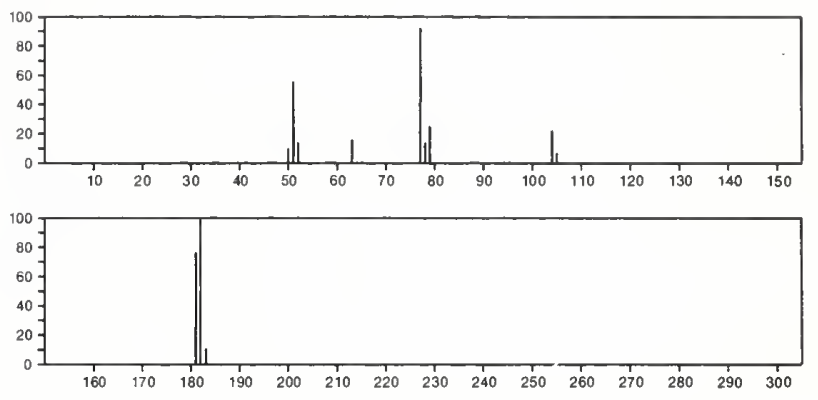

$182 \quad \mathrm{C}_{12} \mathrm{H}_{22} \mathrm{O}$

286-99-7

13-Oxabicyclo[10.1.0]tridecane
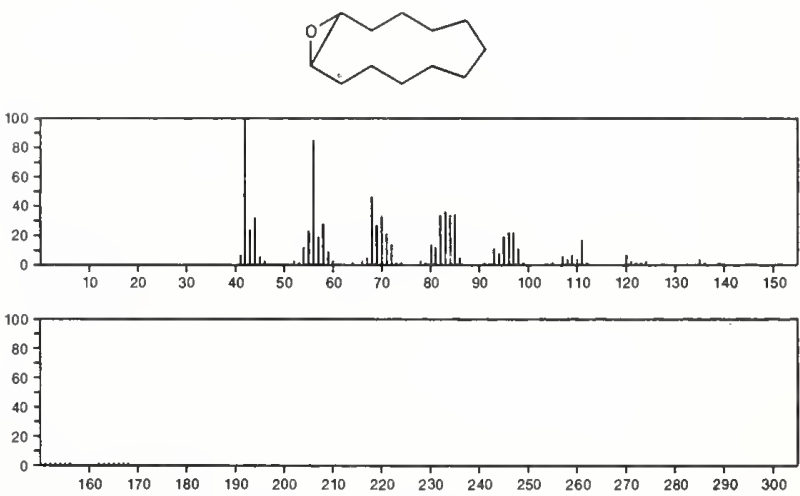

182

Cyclododecanone

$\mathrm{C}_{12} \mathrm{H}_{22} \mathrm{O}$

830-13-7
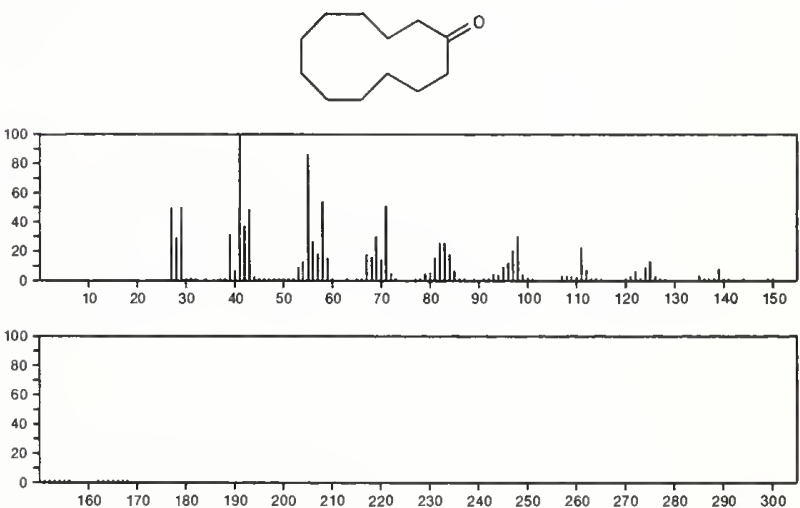
182

[1,1'-Bicyclohexyl]-4-ol

$\mathrm{C}_{12} \mathrm{H}_{22} \mathrm{O}$
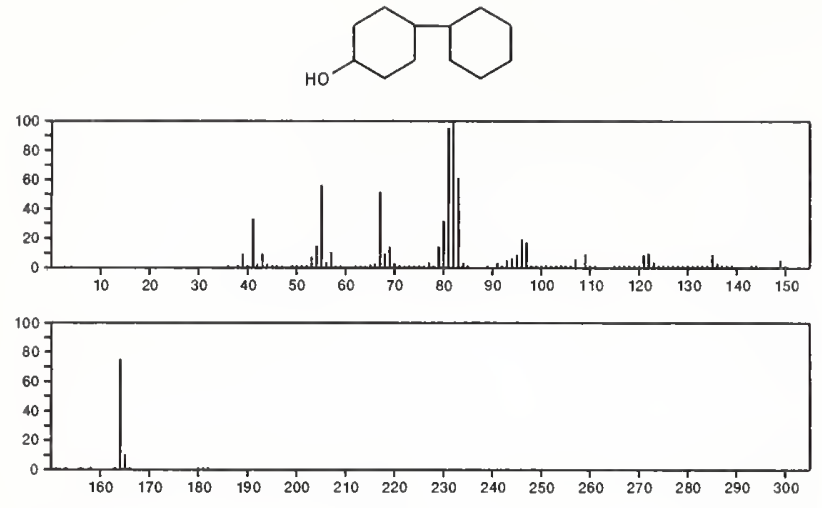

$\begin{aligned} & 182 \\ & \text { Cyclohexane, 1,1'-oxybis-- }\end{aligned} \mathrm{C}_{12} \mathrm{H}_{22} \mathrm{O} \quad 4645-15-2$
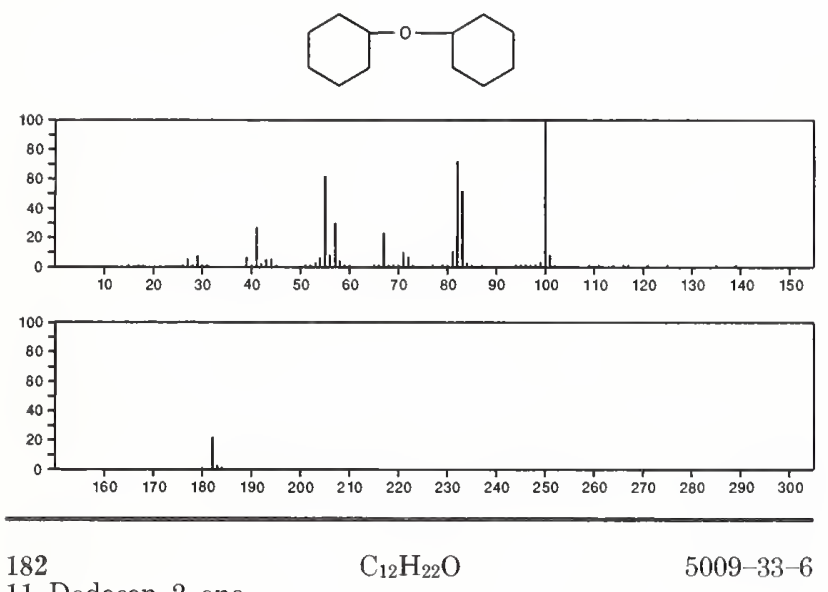

11-Dodecen-2-one

$\mathrm{Me} \mathrm{CO}\left(\mathrm{CH}_{2}\right){ }_{8} \mathrm{CH}=\mathrm{CH}_{2}$
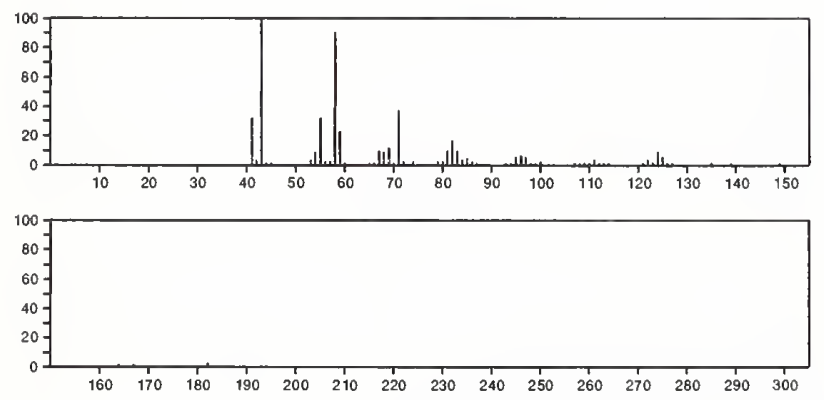

182

[1,1'-Bicyclohexyl]-2-ol

$\mathrm{C}_{12} \mathrm{H}_{22} \mathrm{O}$

6531-86-8<smiles>OC1CCCCC1C1CCCCC1</smiles>
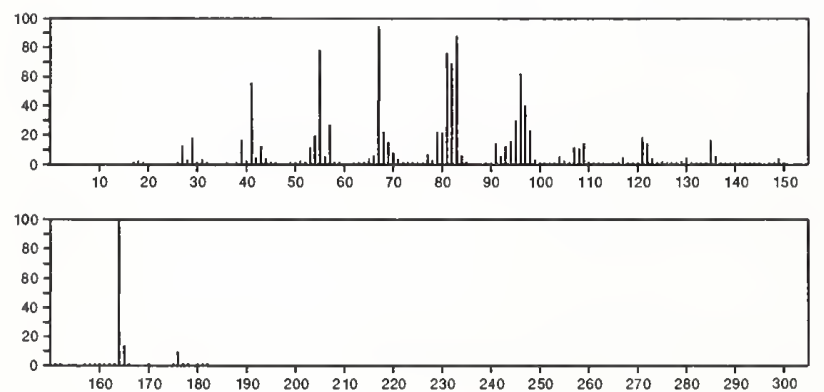

182

2-Octenal, 2-butyl

$\mathrm{C}_{12} \mathrm{H}_{22} \mathrm{O}$

13019-16-4 $\mathrm{Me}\left(\mathrm{CH}_{2}\right)_{4} \mathrm{CH}=\mathrm{C}(\mathrm{CHO})\left(\mathrm{CH}_{2}\right)_{3} \mathrm{Me}$
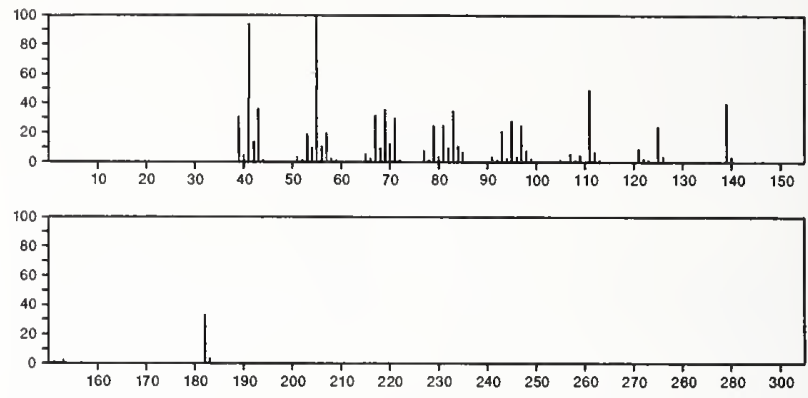

182

[1,1'-Bicyclohexyl]-3-ol

$\mathrm{C}_{12} \mathrm{H}_{22} \mathrm{O}$

20653-41-2
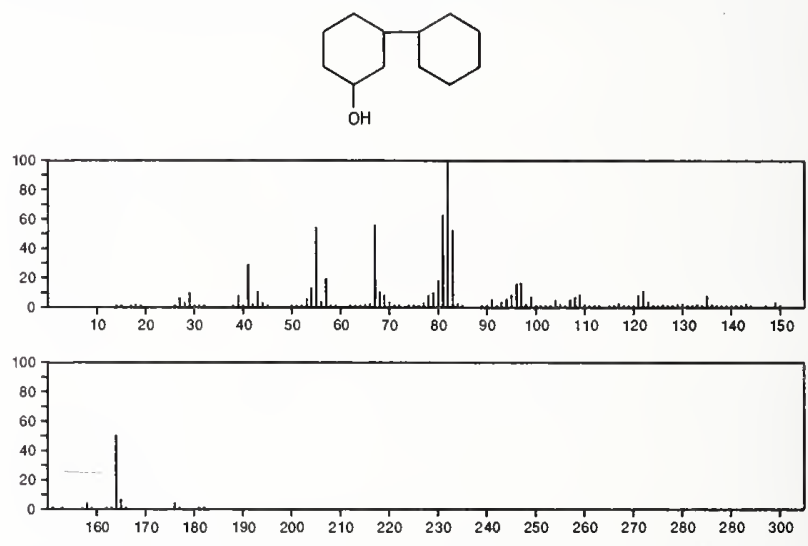

182

$\mathrm{C}_{12} \mathrm{H}_{22} \mathrm{O}$

$21727-85-5$

Naphthalene, 1-ethoxydecahydro-, trans-
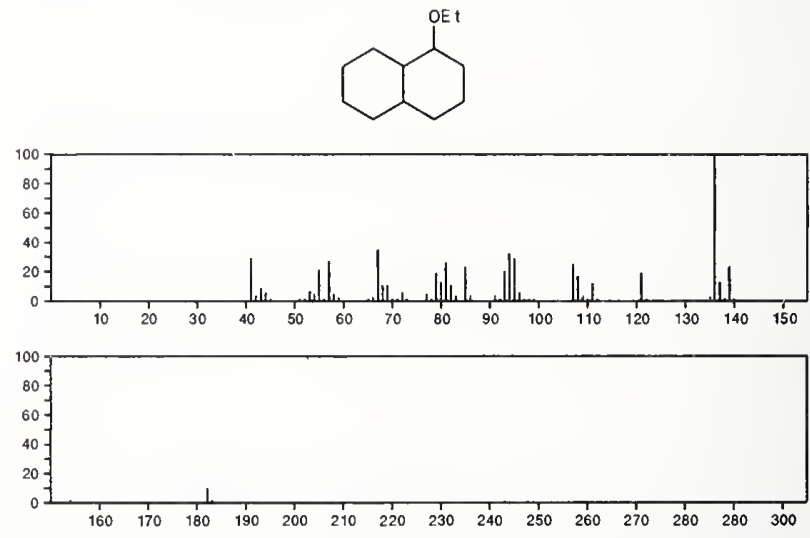

182

3-Octen-2-one, 3-butyl-

$\mathrm{C}_{12} \mathrm{H}_{22} \mathrm{O}$

32064-71-4

COMe

$\mathrm{Me}\left(\mathrm{CH}_{2}\right)_{3} \mathrm{CH}=\stackrel{\mathrm{C}}{\mathrm{C}}\left(\mathrm{CH}_{2}\right)_{3} \mathrm{Me}$
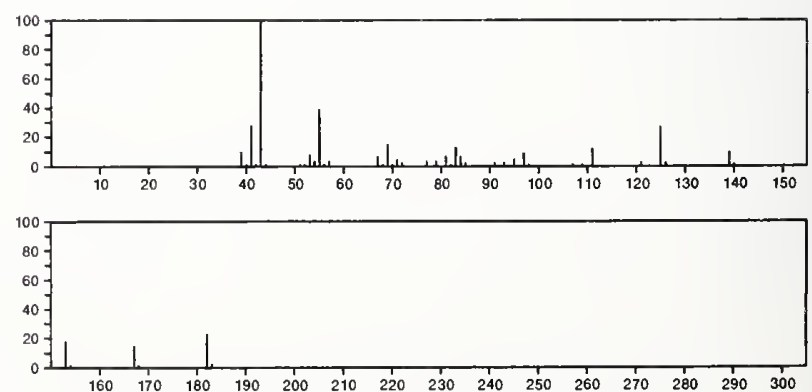
182

$\mathrm{C}_{12} \mathrm{H}_{22} \mathrm{O}$

32064-76-9

7-Dodecen-6-one

$\mathrm{Me}\left(\mathrm{CH}_{2}\right){ }_{4} \mathrm{COCH}: \mathrm{CH}\left(\mathrm{CH}_{2}\right) 3 \mathrm{Me}$
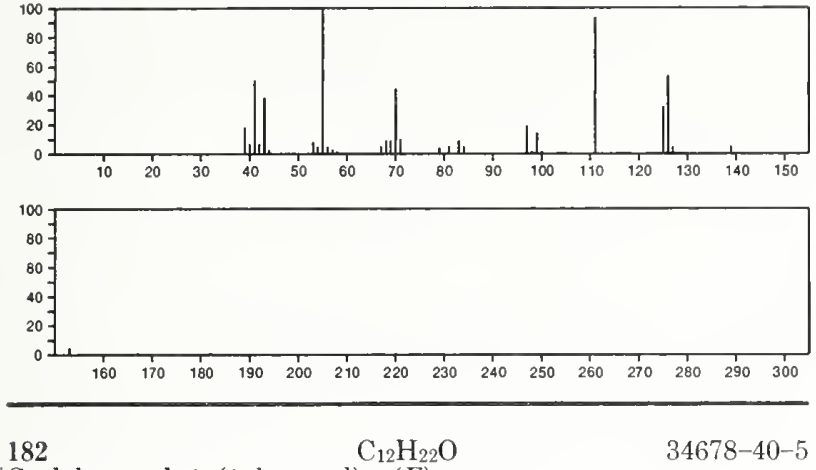

Cyclohexanol, 1-(1-hexenyl)-, $(E)-$
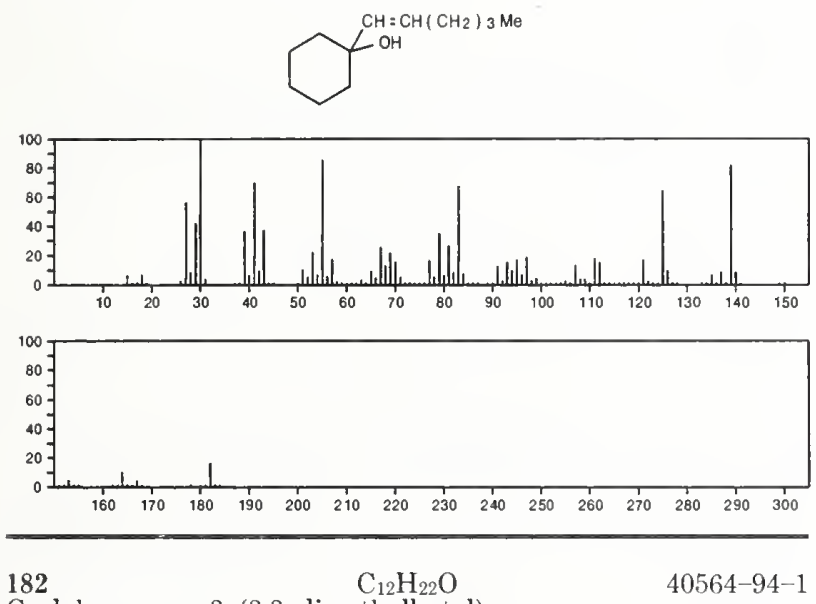

Cyclohexanone, 3-(3,3-dimethylbutyl)-
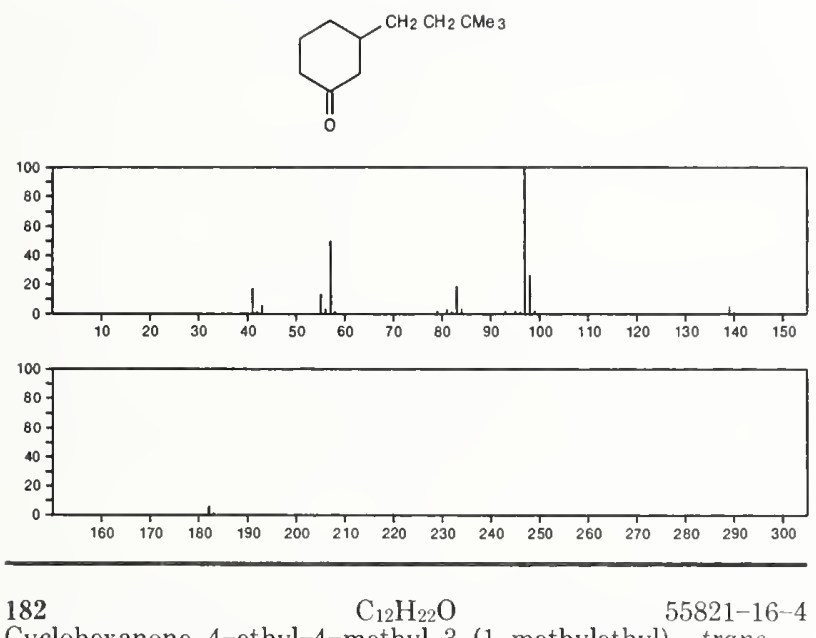

Cyclohexanone, 4-ethyl-4-methyl-3-(1-methylethyl)-, trans-<smiles>CCC1([Al])CCC(=O)CC1PI</smiles>

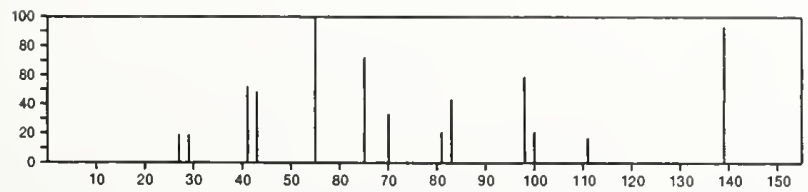

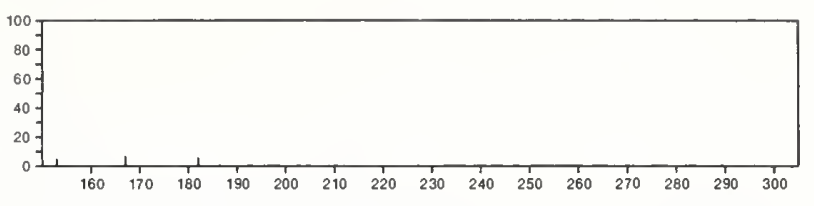

182

$\mathrm{C}_{12} \mathrm{H}_{22} \mathrm{O}$

$56272-08-3$

Cyclohexanol, 4-ethyl-4-methyl-3-(1-methylethenyl)-, $(1 \alpha, 3 \alpha, 4 \beta)$
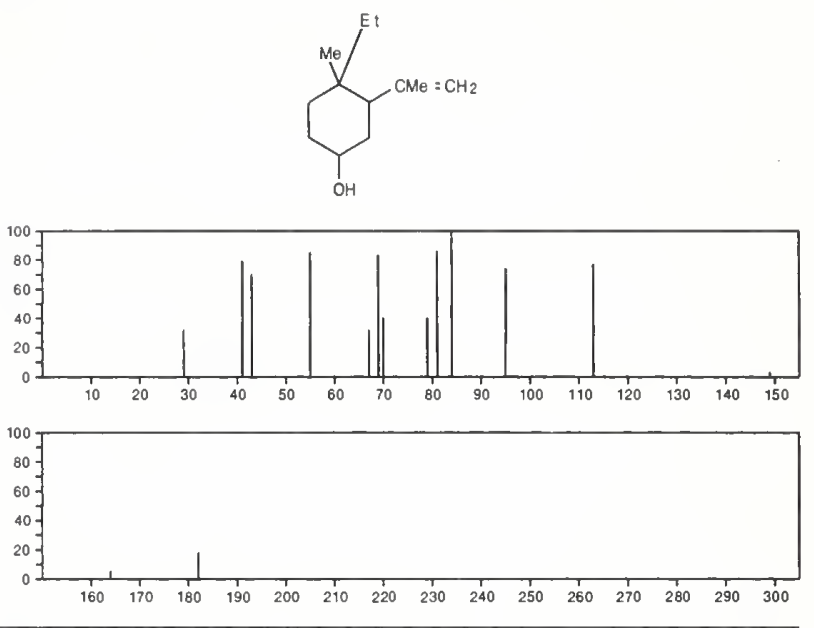

182

$\mathrm{C}_{12} \mathrm{H}_{22} \mathrm{O}$

56272-09-4

Cyclohexanol, 4-ethyl-4-methyl-3-(1-methylethenyl)-, $(1 \alpha, 3 \beta, 4 \alpha)-$
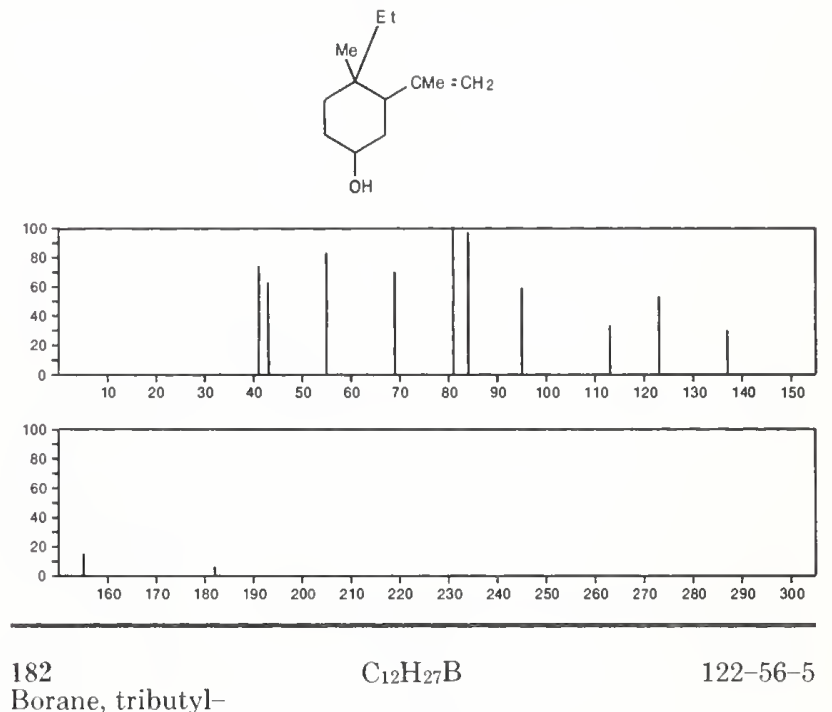

Borane, tributyl-

$\left(\mathrm{CH}_{2}\right)_{3} \mathrm{Me}$

$\mathrm{Me}\left(\mathrm{CH}_{2}\right)_{3} \mathrm{~B}\left(\mathrm{CH}_{2}\right)_{3} \mathrm{Me}$
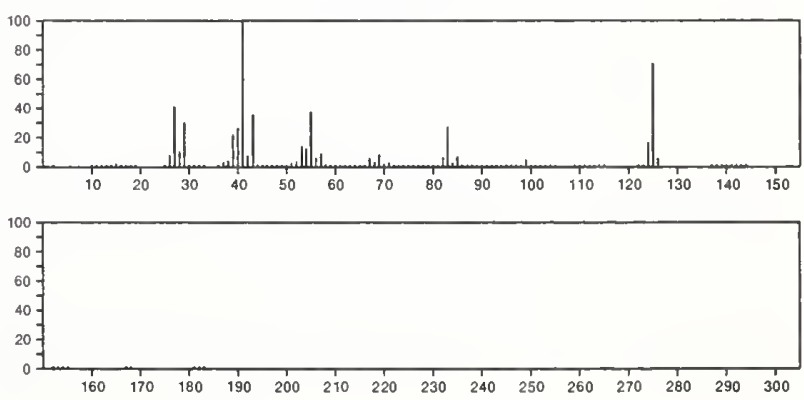
182

$9 H$-Xanthene

$\mathrm{C}_{13} \mathrm{H}_{10} \mathrm{O}$
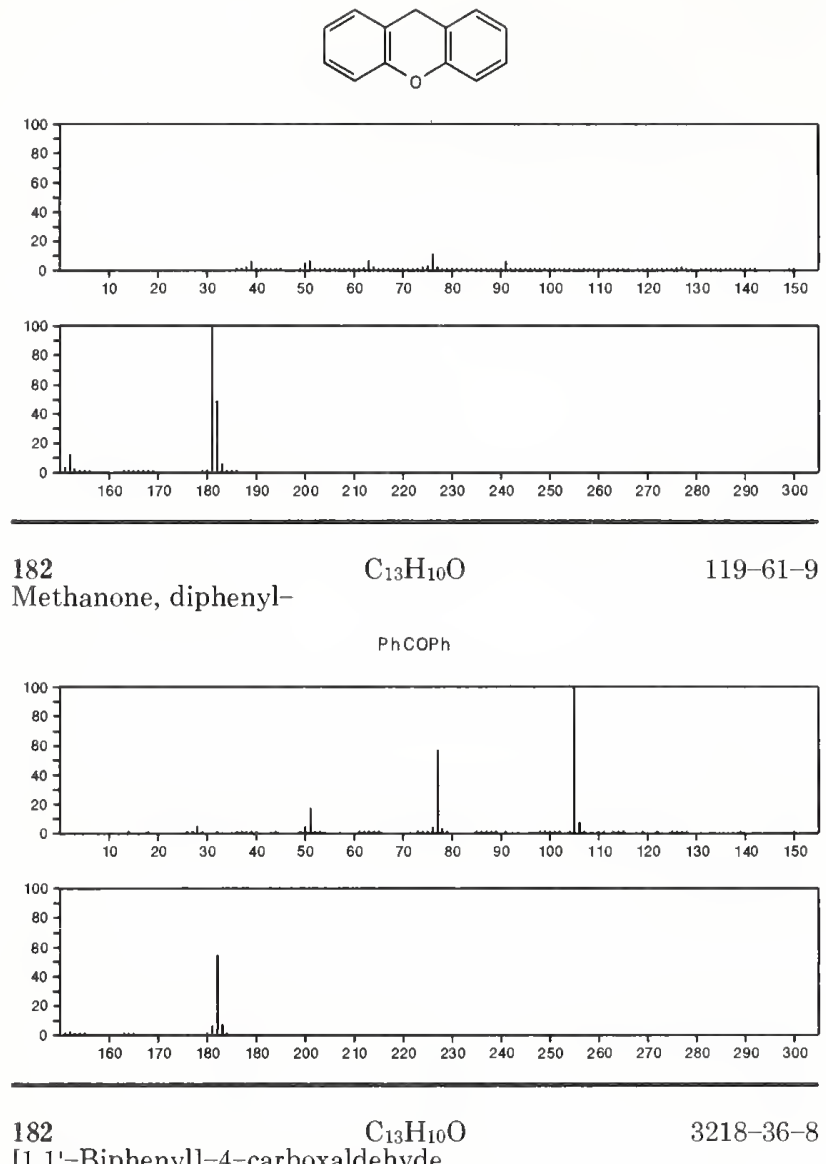

[1,1'-Biphenyl]-4-carboxaldehyde
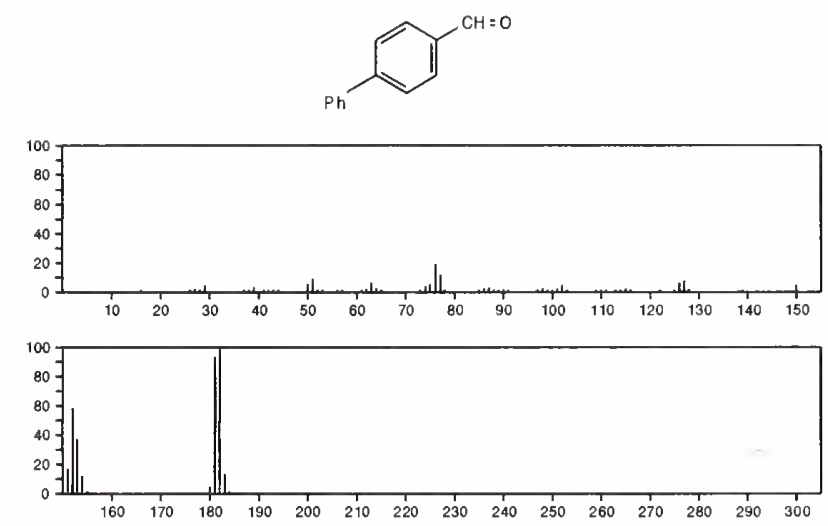

182

$\mathrm{C}_{13} \mathrm{H}_{10} \mathrm{O}$

$7320-53-8$

Dibenzofuran, 4-methyl-
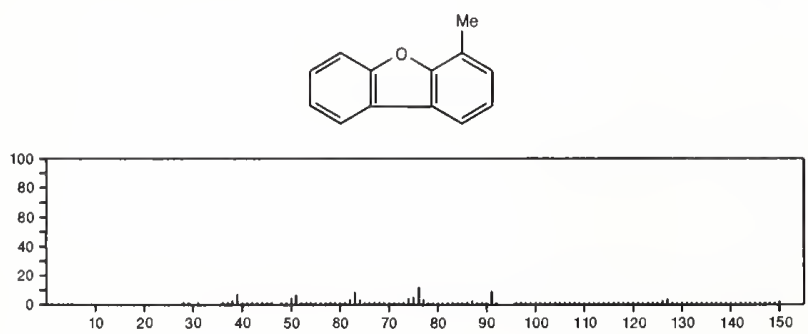

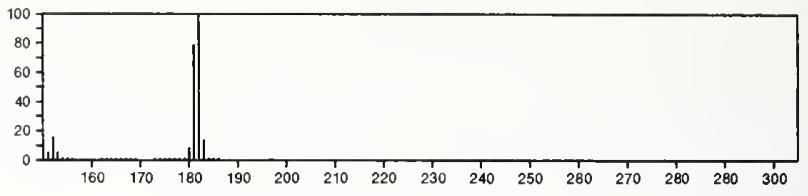

182

1-Tridecene

$\mathrm{C}_{13} \mathrm{H}_{26}$

2437-56-1

$\mathrm{H}_{2} \mathrm{C}=\mathrm{CH}\left(\mathrm{CH}_{2}\right) 10 \mathrm{Me}$
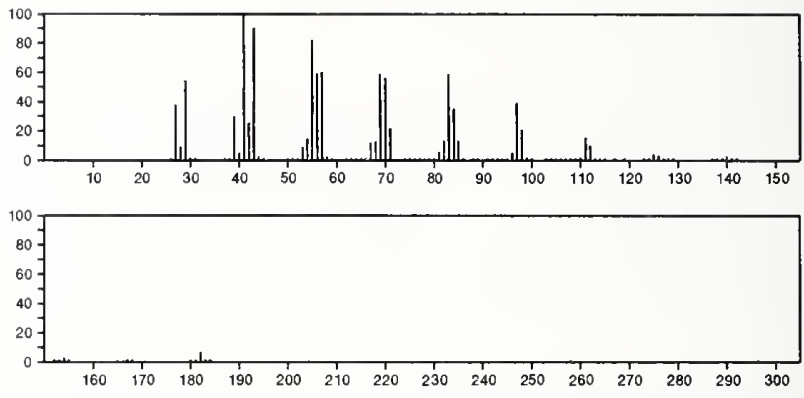

\begin{tabular}{lll}
\hline 182 & $\mathrm{C}_{13} \mathrm{H}_{26}$ & $7367-38-6$
\end{tabular}

4-Nonese

$\mathrm{Me}\left(\mathrm{CH}_{2}\right)_{3} \mathrm{C}=\mathrm{CHPr}$
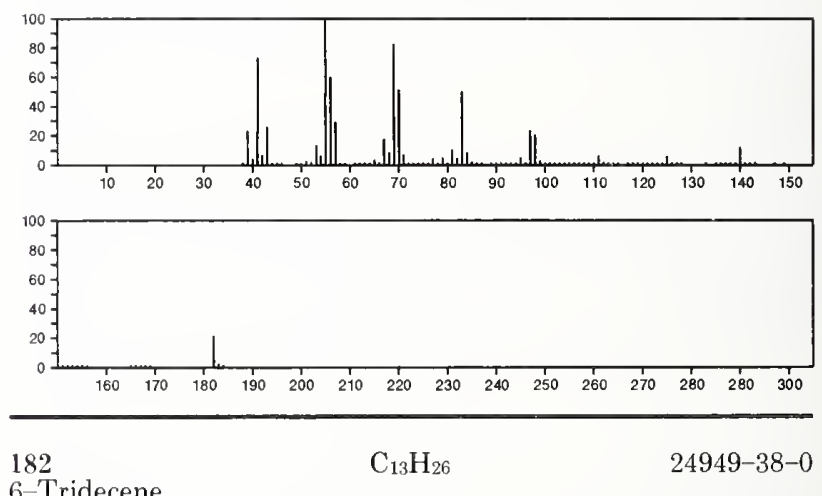

6-Tridecene

$\mathrm{Me}\left(\mathrm{CH}_{2}\right)_{4} \mathrm{CH}=\mathrm{CH}\left(\mathrm{CH}_{2}\right){ }_{5} \mathrm{Me}$
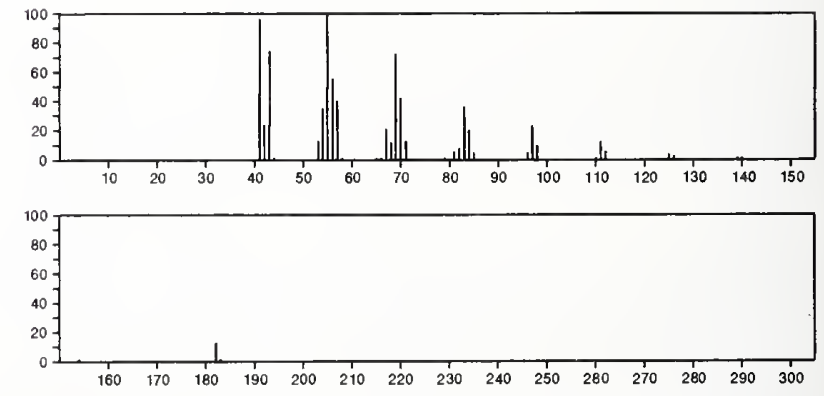

182

$\mathrm{C}_{13} \mathrm{H}_{26}$

Cyclohexane, 2-butyl-1,1,3-trimethyl-

54676-39-0
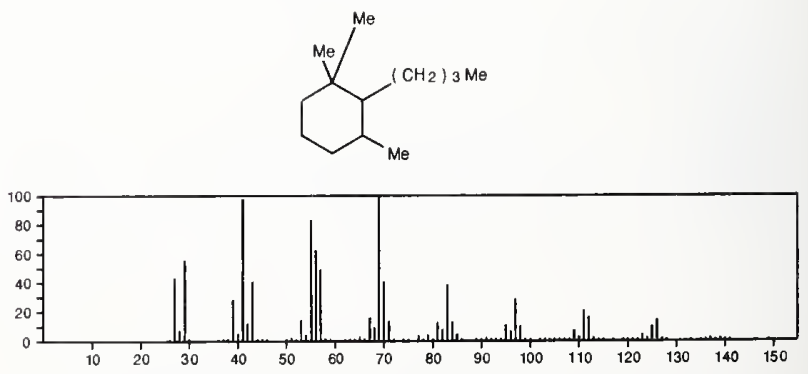
182

EPA/NIH MASS SPECTRAL DATA BASE

951
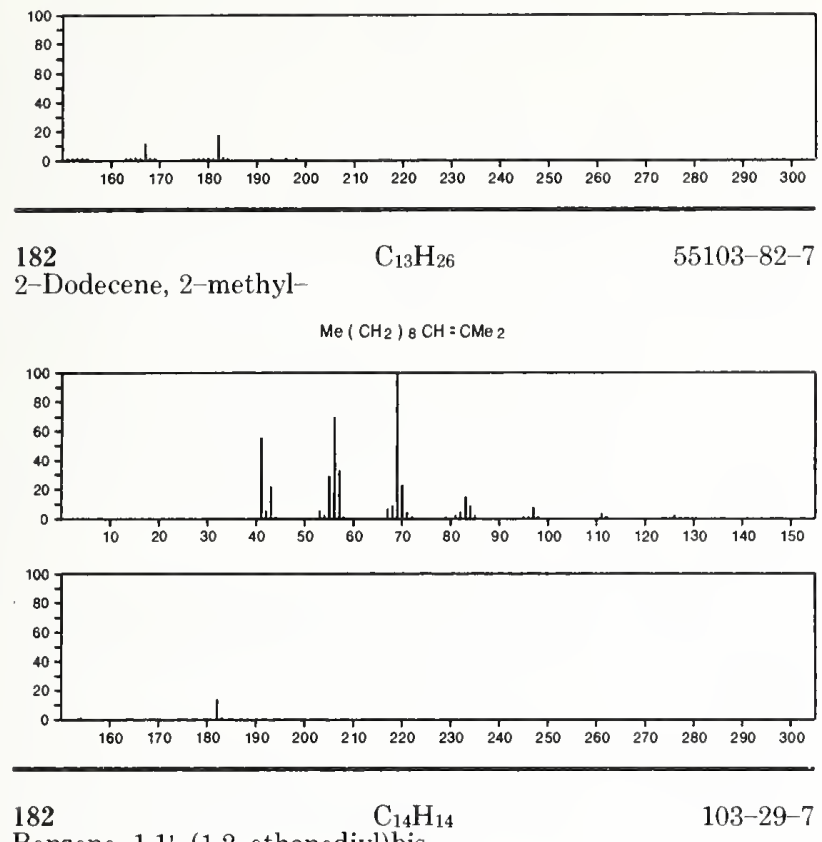

Benzene, 1,1'-(1,2-ethanediyl) bis-

$\mathrm{PhCH}_{2} \mathrm{CH}_{2} \mathrm{Ph}$
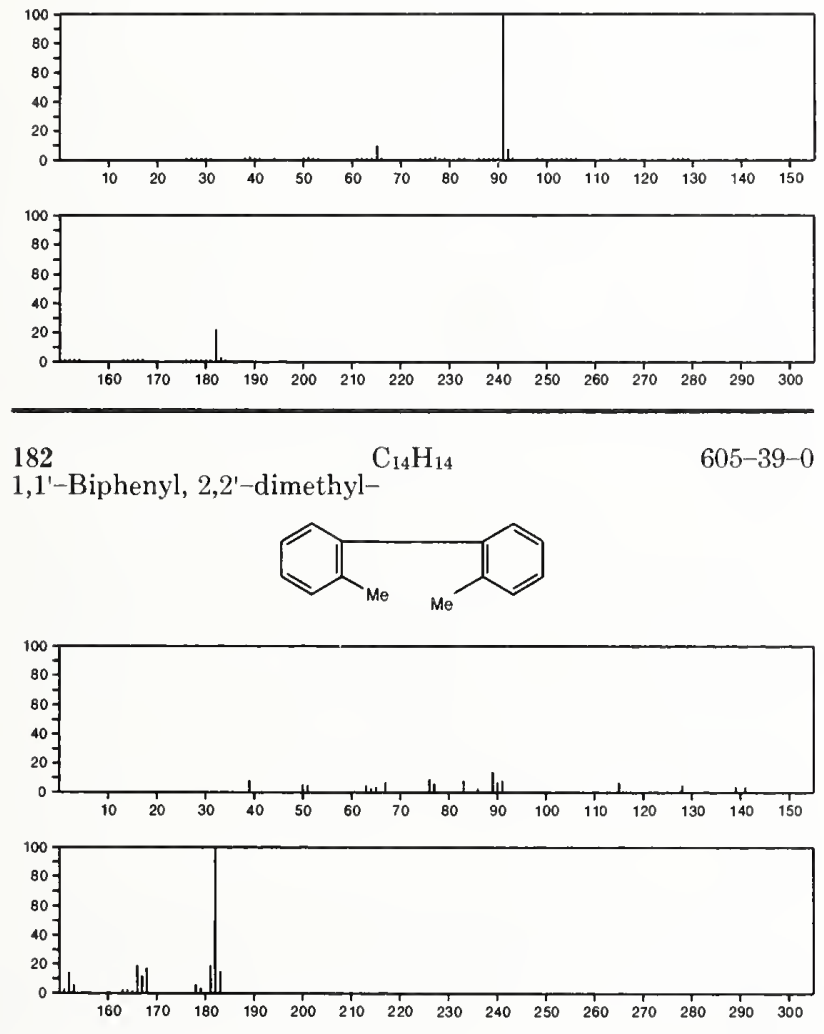

182
Benzene, 1,1'-ethylidenebis-

$\mathrm{Ph}_{2} \mathrm{CHMe}$

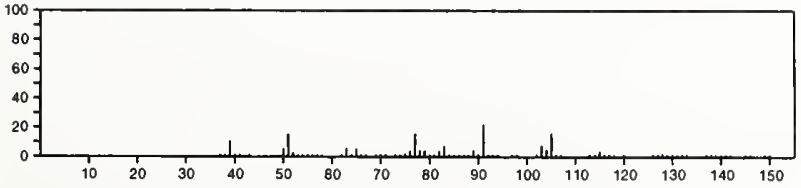

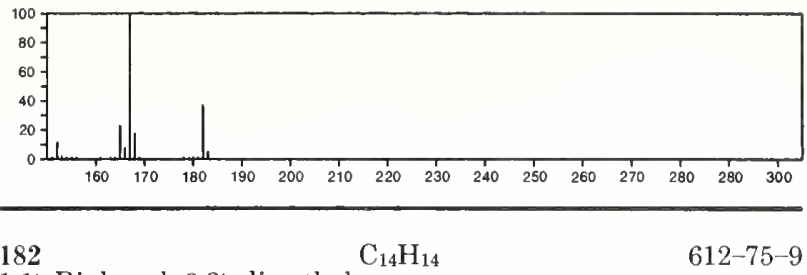

1,1'-Biphenyl, 3,3'-dimethyl-
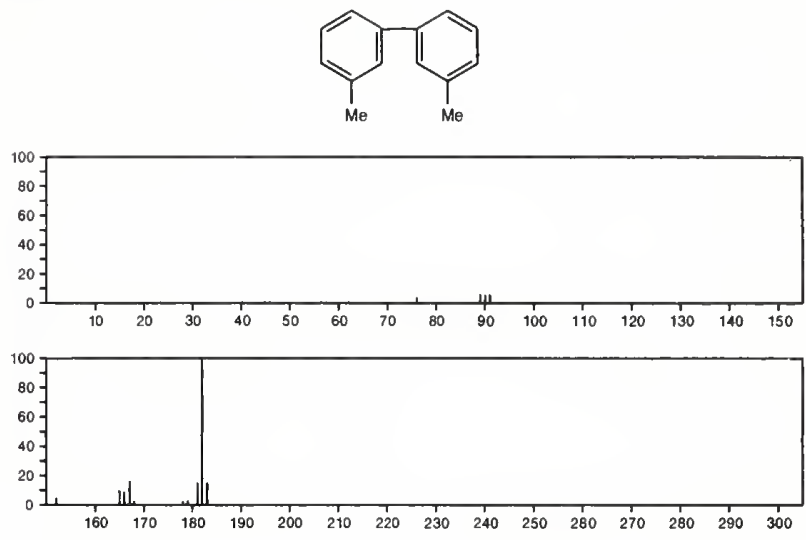

182
$1,1^{\prime}$-Biphenyl, 4,4'-dimethyl- $\mathrm{C}_{14} \mathrm{H}_{14}$
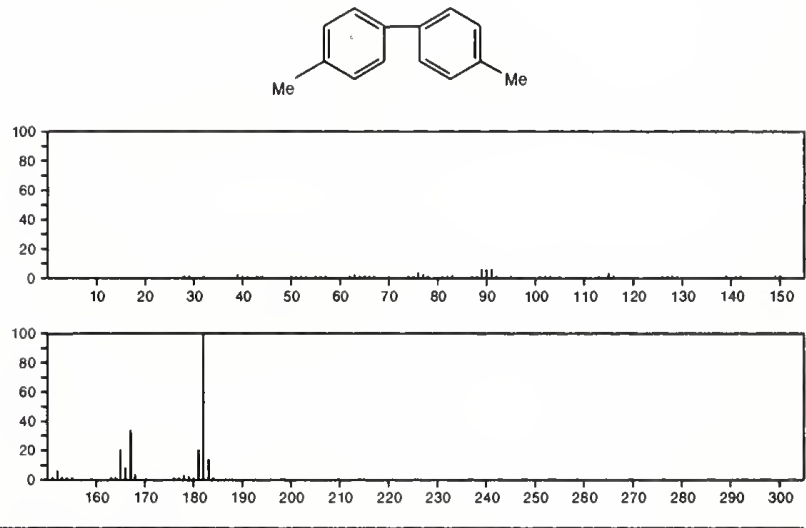

$182 \underset{814}{\mathrm{C}_{14} \mathrm{H}_{14}}$
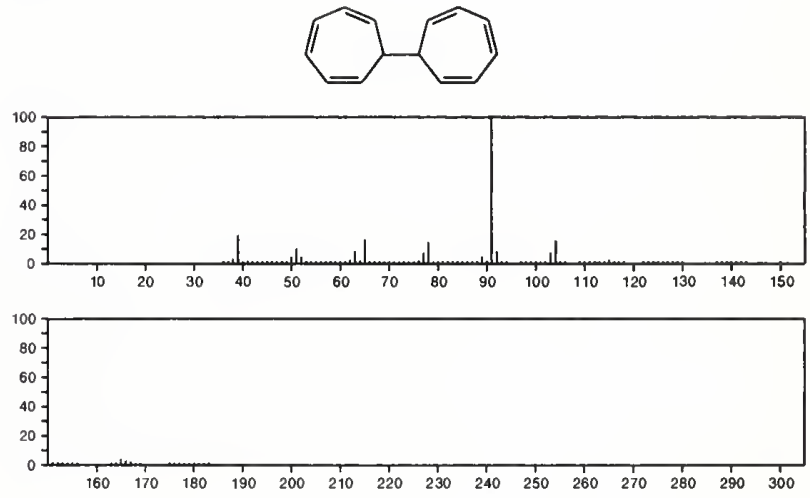
182

1,1'-Biphenyl, 2-ethyl-

$\mathrm{C}_{14} \mathrm{H}_{14}$

$1812-51-7$
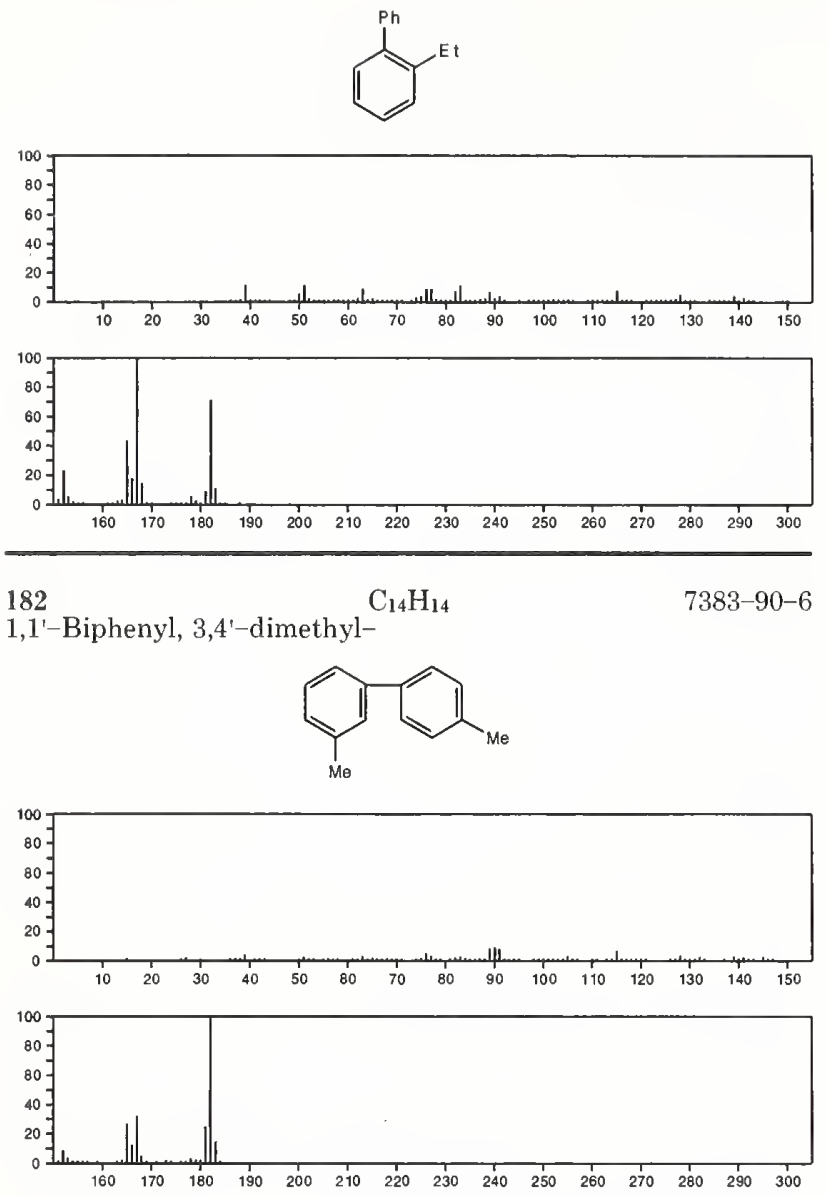

182

$\mathrm{C}_{14} \mathrm{H}_{14}$

$22245-13-2$

Bi-1,3,5-cycloheptatrien-1-yl
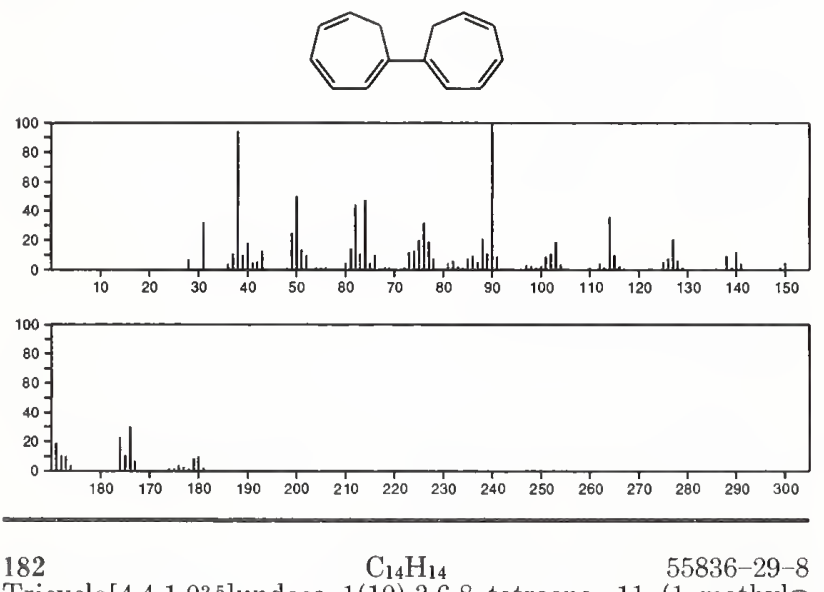

Tricyclo[4.4.1.02,5] undeca-1(10),3,6,8-tetraene, 11-(1-methyl= ethylidene) -
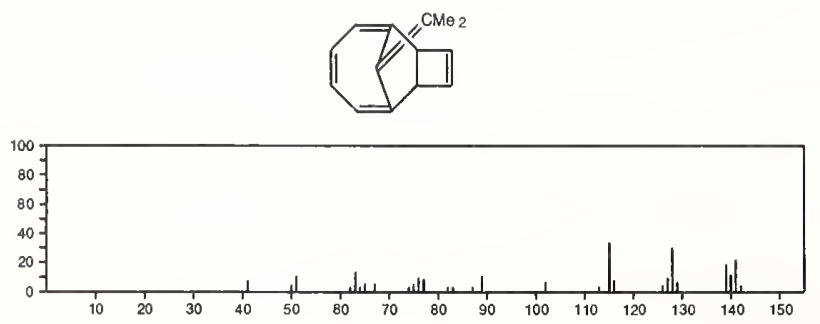

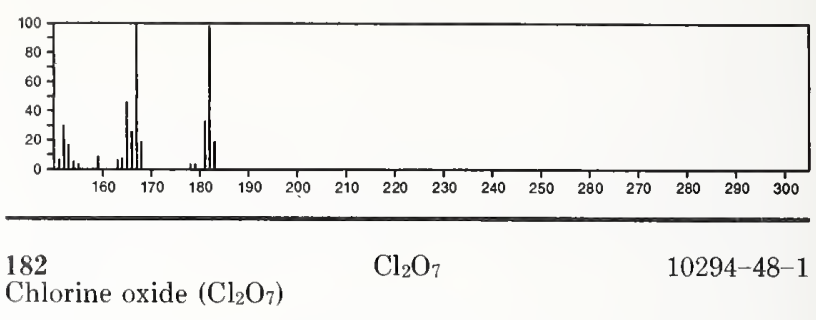

STRUCTURE UNDEFINED
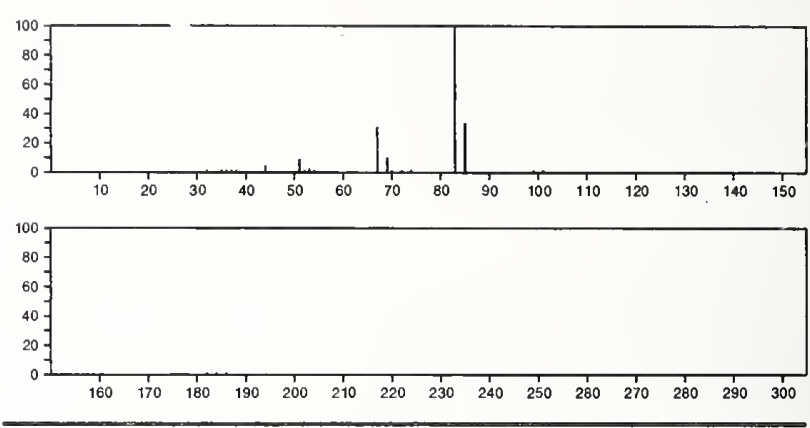

183

1,3,5-Triazine, 2,4,6-trichloro-

$108-77-0$
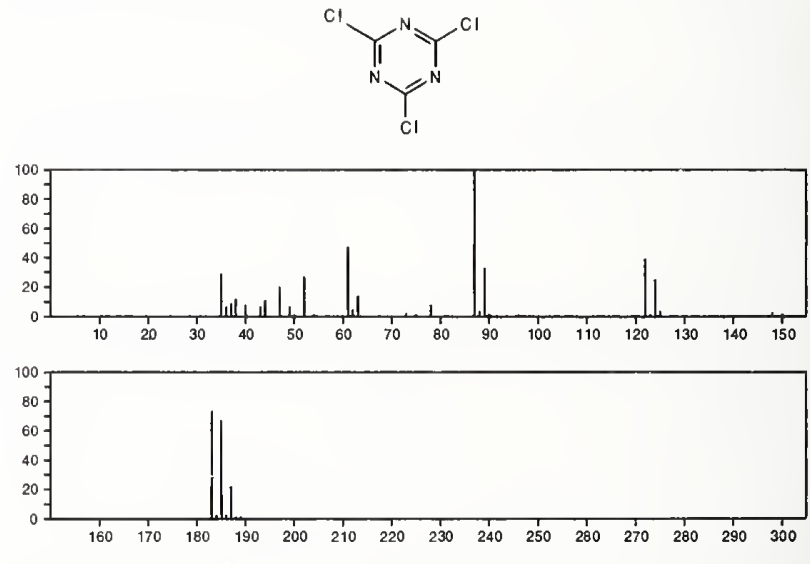

183

$\mathrm{C}_{4} \mathrm{H}_{9} \mathrm{NSSe}$

$21347-33-1$

Carbamoselenothioic acid, dimethyl-, $S$-methyl ester

$\mathrm{Me}_{2} \mathrm{NC}(\mathrm{SMe})=\mathrm{Se}$
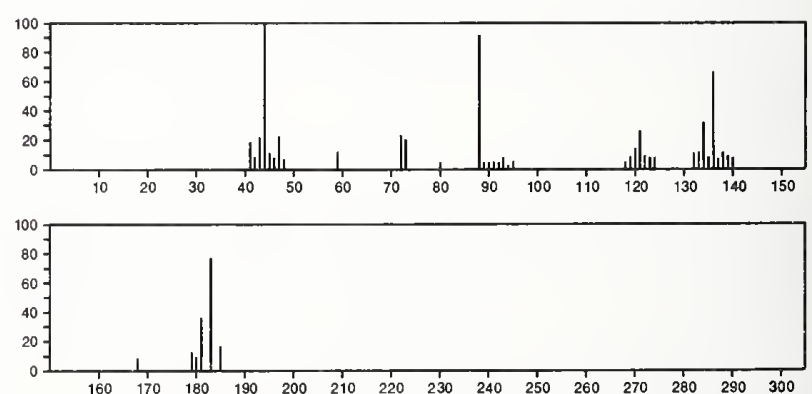
183

EPA/NIH MASS SPECTRAL DATA BASE

953

183

$\mathrm{C}_{6} \mathrm{H}_{2} \mathrm{~F}_{5} \mathrm{~N}$

Benzenamine, 2,3,4,5,6-pentafluoro-
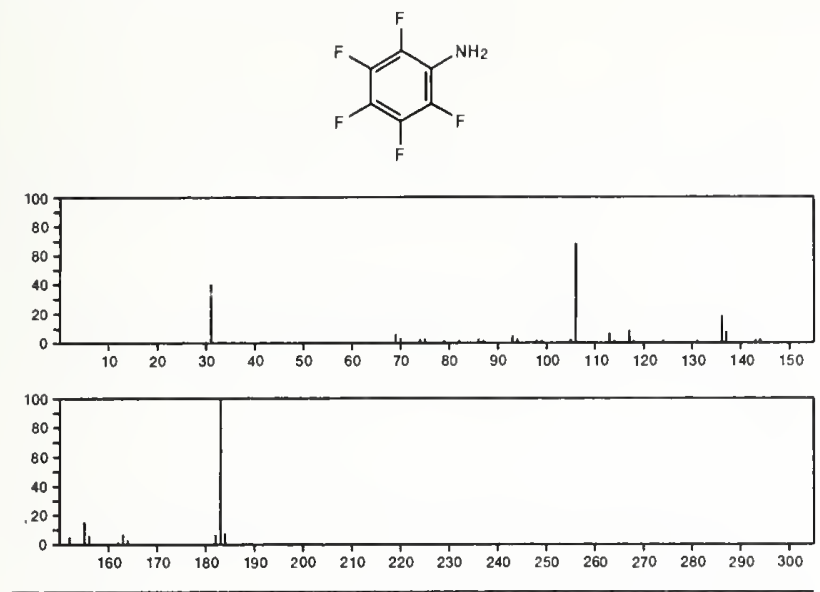

$\begin{array}{ll}183 & \mathrm{C}_{6} \mathrm{H}_{5} \mathrm{~N}_{3} \mathrm{O}_{2} \mathrm{~S} \\ \text { Benzenesulfonyl azide } & \end{array}$

$\mathrm{N}_{3} \mathrm{SO}_{2} \mathrm{Ph}$
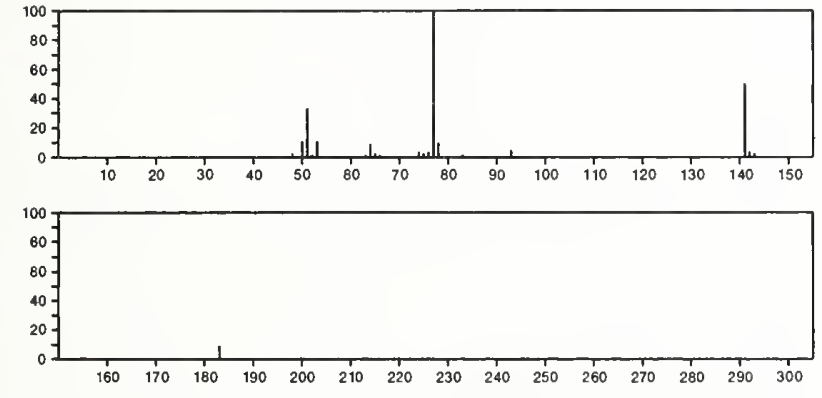

$183 \quad \mathrm{C}_{6} \mathrm{H}_{5} \mathrm{~N}_{3} \mathrm{O}_{4} \quad 97-02-9$

Benzenamine, 2,4-dinitro-
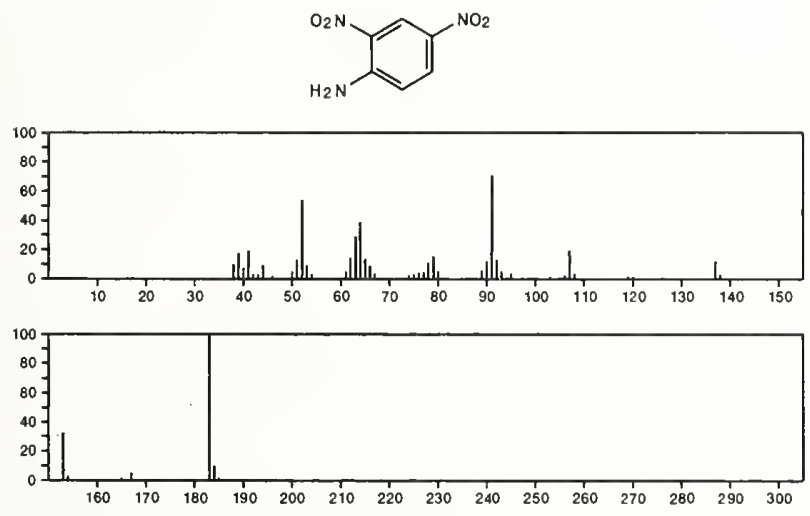

183
Benzenamine, 2,6-dinitro--
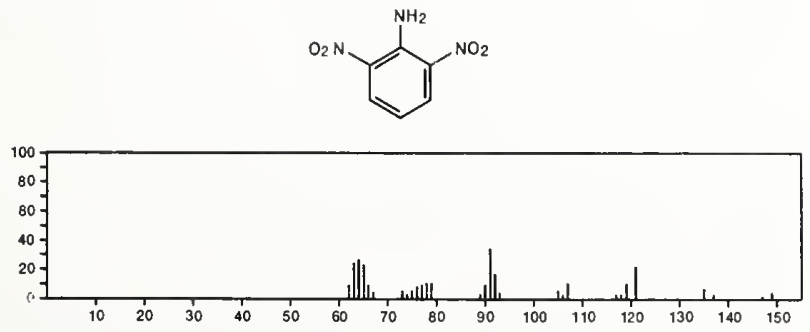
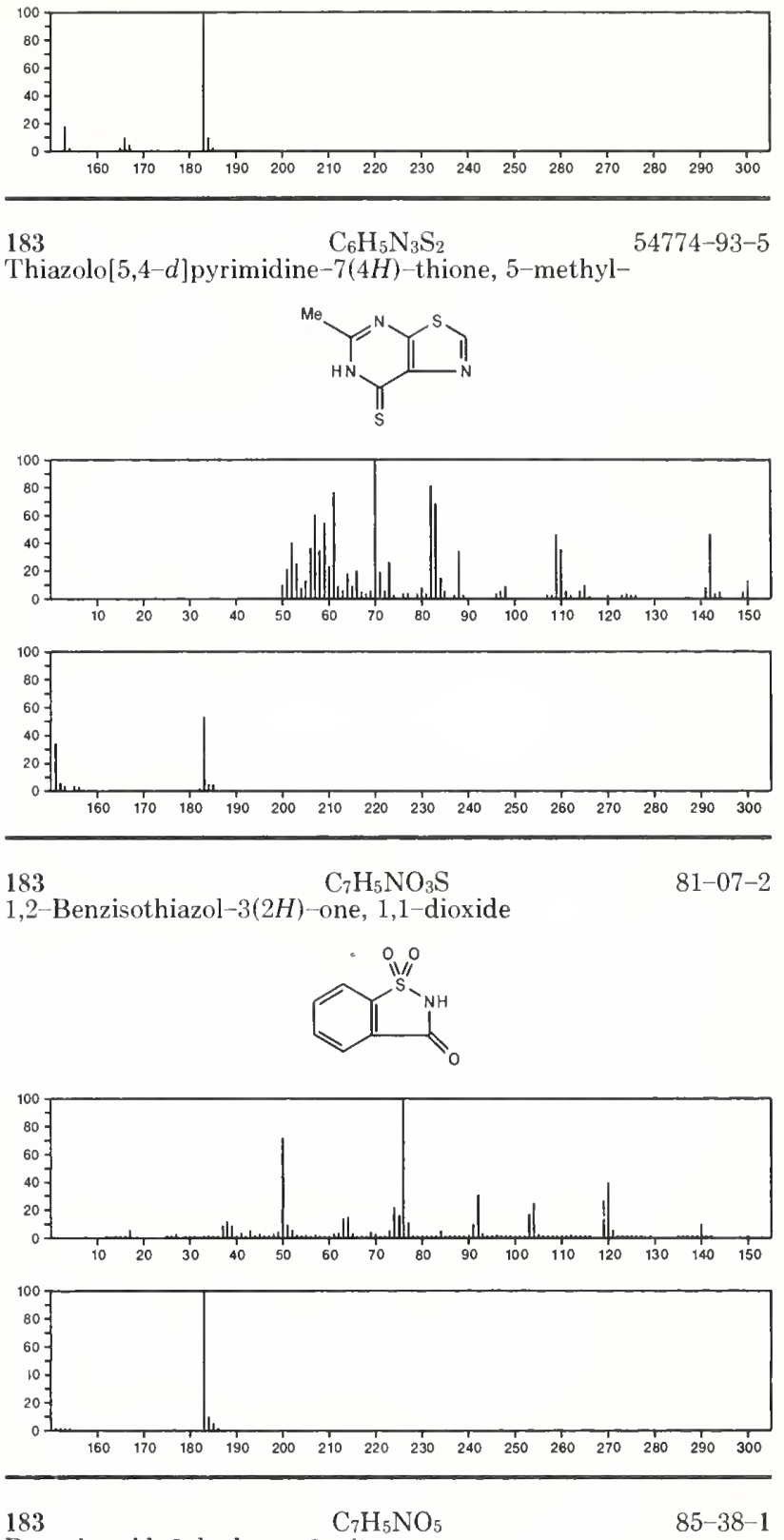

Benzoic acid, 2-hydroxy-3-nitro-
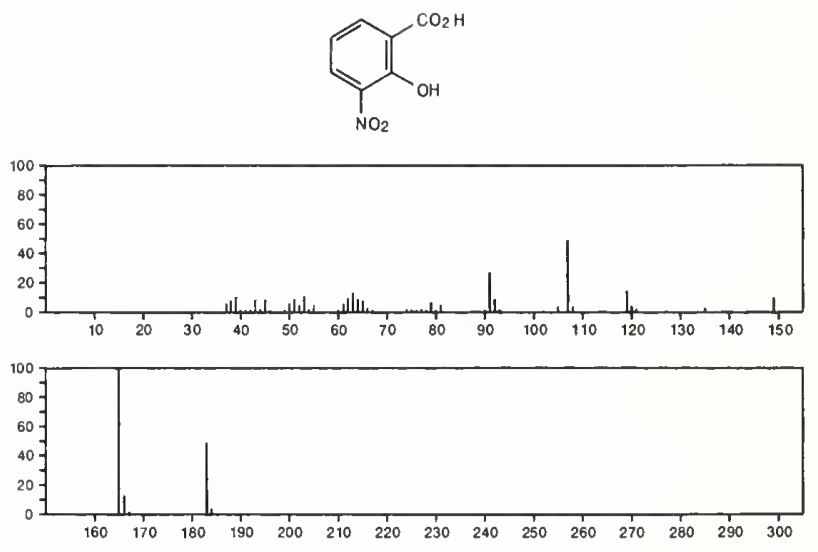
183

1,2-Benzisoselenazole

$\mathrm{C}_{7} \mathrm{H}_{5} \mathrm{NSe}$

$272-31-1$
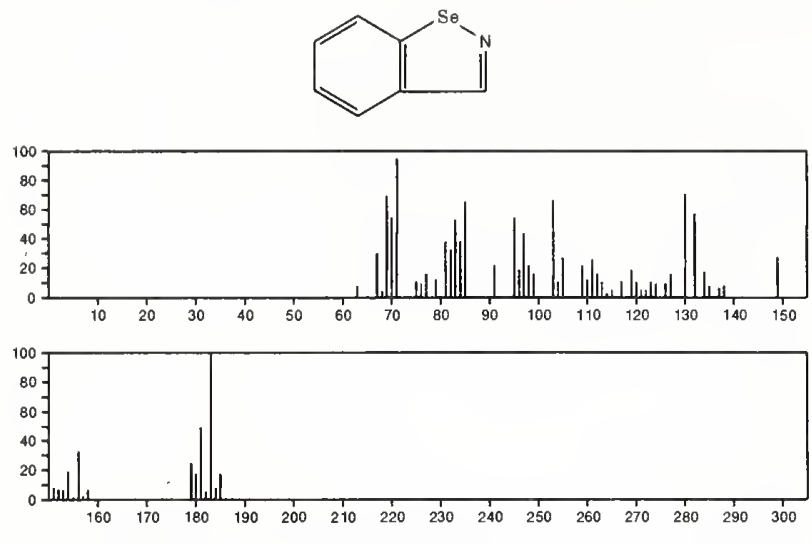

183

$\mathrm{C}_{7} \mathrm{H}_{5} \mathrm{NSe}$

273-91-6

Benzoselenazole
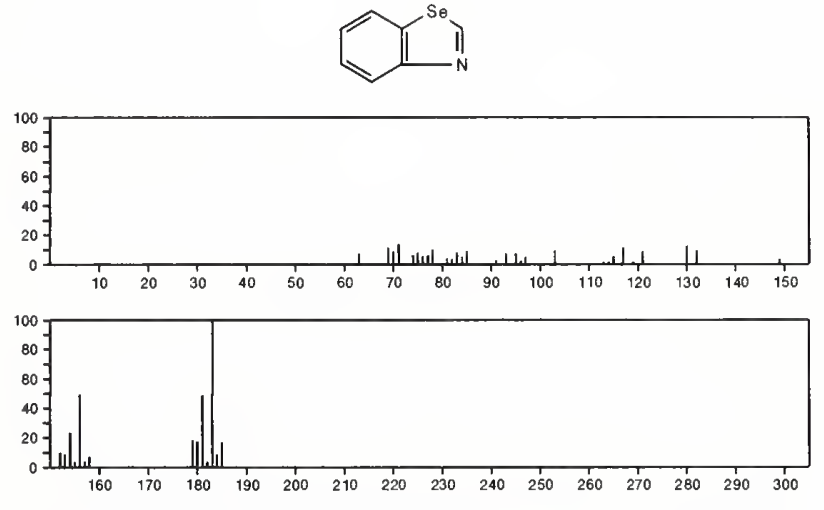

$183 \quad \mathrm{C}_{7} \mathrm{H}_{12} \mathrm{~F}_{3} \mathrm{NO}$

Acetamide, 2,2,2-trifluoro- $N$-pentyl-

$\mathrm{F}_{3} \mathrm{CCONH}\left(\mathrm{CH}_{2}\right)_{4} \mathrm{Me}$
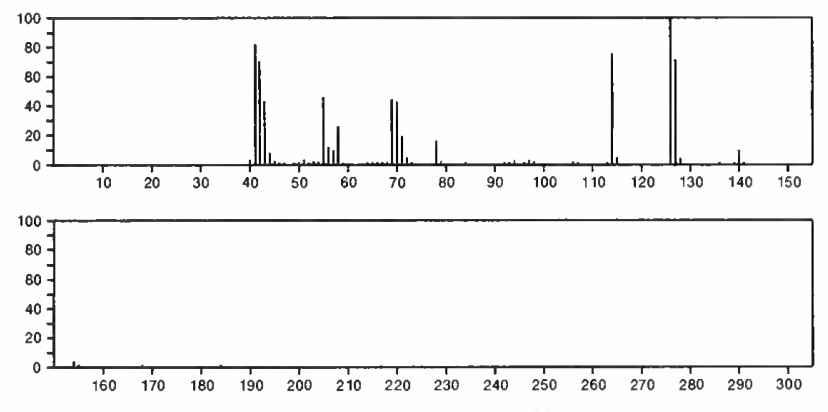

$183 \quad \mathrm{C}_{7} \mathrm{H}_{12} \mathrm{~F}_{3} \mathrm{NO}$

Acetamide, 2,2,2-trifluoro- $N$-isopentyl-

$14719-24-5$

$\mathrm{Me}_{2} \mathrm{CHCH}_{2} \mathrm{CH}_{2} \mathrm{NHCOCF}_{3}$
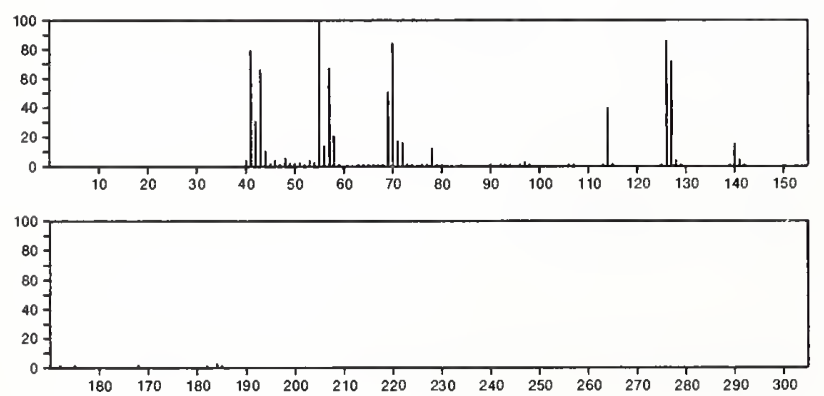

183

$\mathrm{C}_{7} \mathrm{H}_{13} \mathrm{~N}_{5} \mathrm{O}$

1,3,5-Triazin-2(1H)-one, 4,6-bis(ethylamino)-
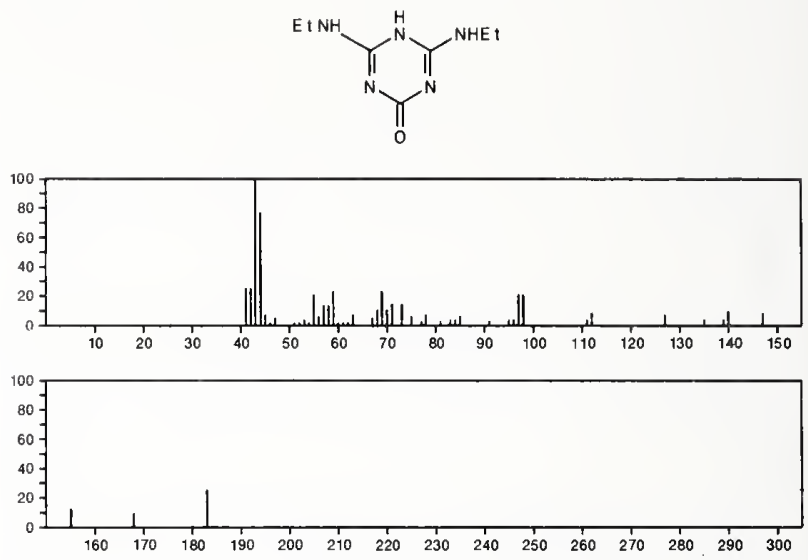

183

$\mathrm{C}_{8} \mathrm{H}_{6} \mathrm{CINS}$

$1006-99-1$

Benzothiazole, 5-chloro-2-methyl-
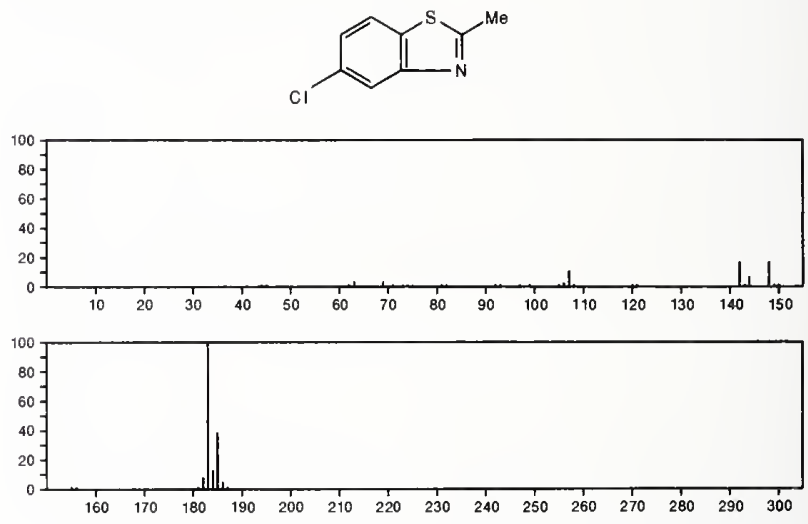

183

$\mathrm{C}_{8} \mathrm{H}_{9} \mathrm{NO}_{2} \mathrm{~S}$

$30221-74-0$

2-Propanone, 1-[(3-hydroxy-2-pyridinyl)thio]-
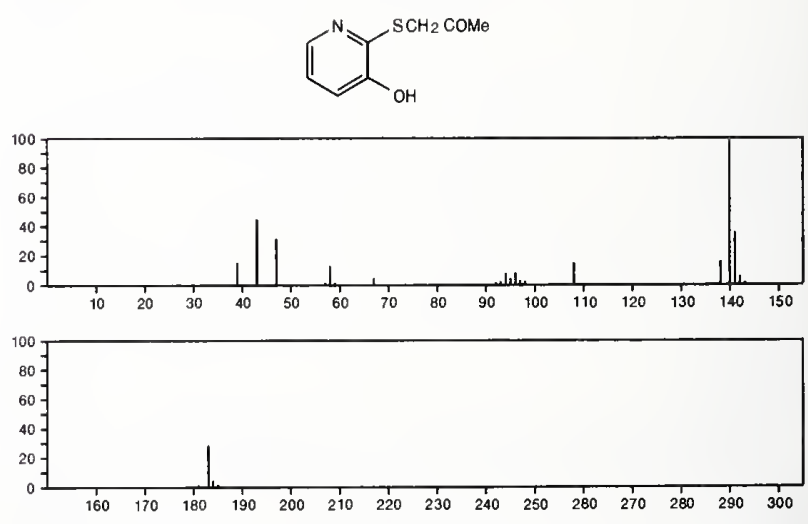

$183 \quad \mathrm{C}_{8} \mathrm{H}_{9} \mathrm{NO}_{2} \mathrm{~S}$

$42715-30-0$

3-Pyridinol, 2-(methylthio)-, acetate (ester)
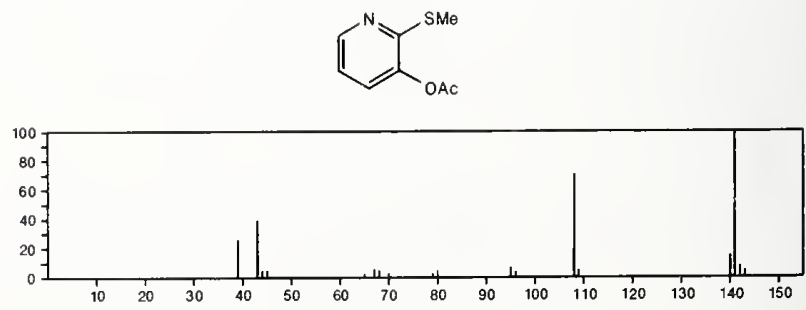


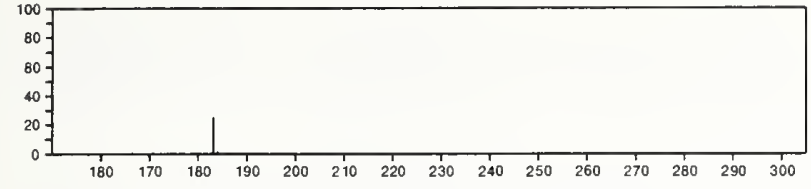

183

$\mathrm{C}_{8} \mathrm{H}_{9} \mathrm{NO}_{4}$

$13290-00-1$

Glycine, $N$-(2-furanylcarbonyl)-, methyl ester

${ }^{0} \mathrm{CONHCH}_{2} \mathrm{C}(0) \mathrm{OMe}$
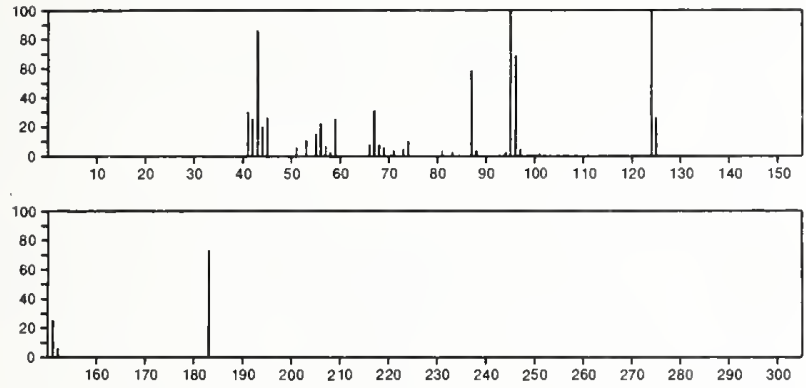

183

$\mathrm{C}_{8} \mathrm{H}_{9} \mathrm{NO}_{4}$

$56145-22-3$

Glycine, $N$-(3-furanylcarbonyl)-, methyl ester

CONHCH $2 \mathrm{Cl}(0) \mathrm{OMe}^{-}$
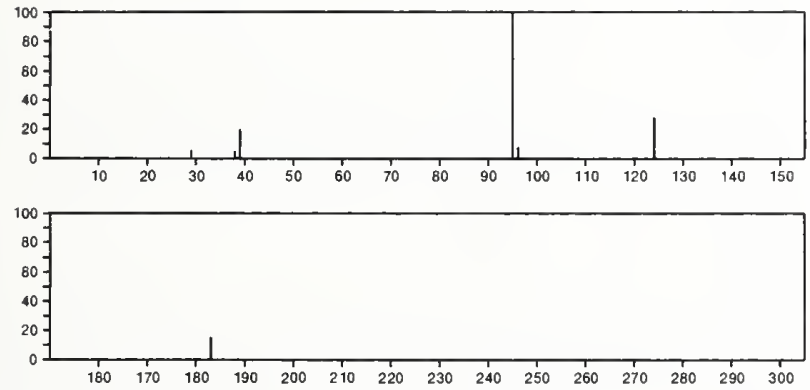

183

$\mathrm{C}_{8} \mathrm{H}_{9} \mathrm{NS}_{2}$

Carbamodithioic acid, phenyl-, methyl ester

$701-73-5$

PhNHC( S) SME

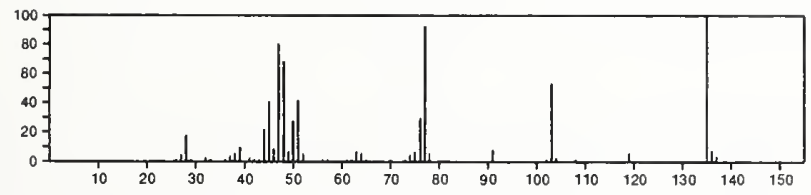

183

4-Pyrimidinamine, 2-(butylthio)

$54774-88-8$
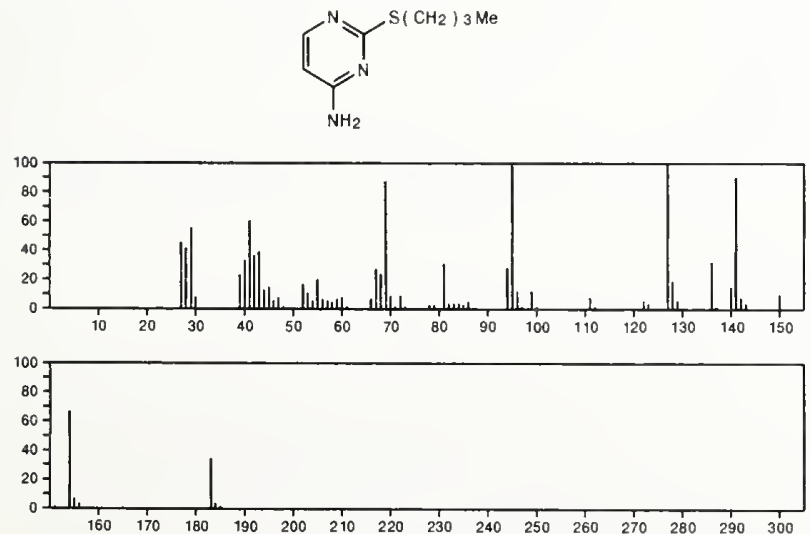

183

$\mathrm{C}_{9} \mathrm{H}_{7} \mathrm{~F}_{2} \mathrm{NO}$

$55682-93-4$

Benzene, 1-(difluoroisocyanatomethyl)-4-methyl-
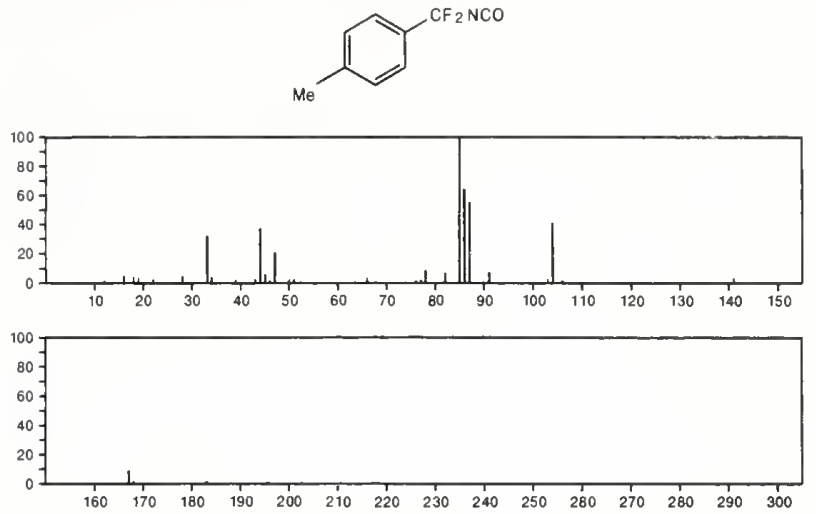

183

$\mathrm{C}_{9} \mathrm{H}_{7} \mathrm{~F}_{2} \mathrm{NO}$

$55682-94-5$

Benzene, 1-(difluoroisocyanatomethyl)-3-methyl-
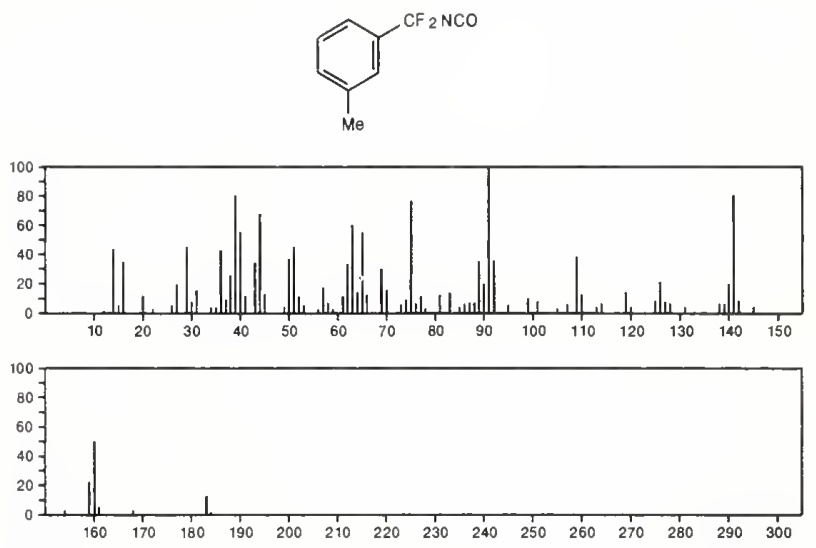

183

$\mathrm{C}_{9} \mathrm{H}_{10} \mathrm{ClNO}$

Benzamide, 2-chloro- $N, N$-dimethyl-

$6526-67-6$
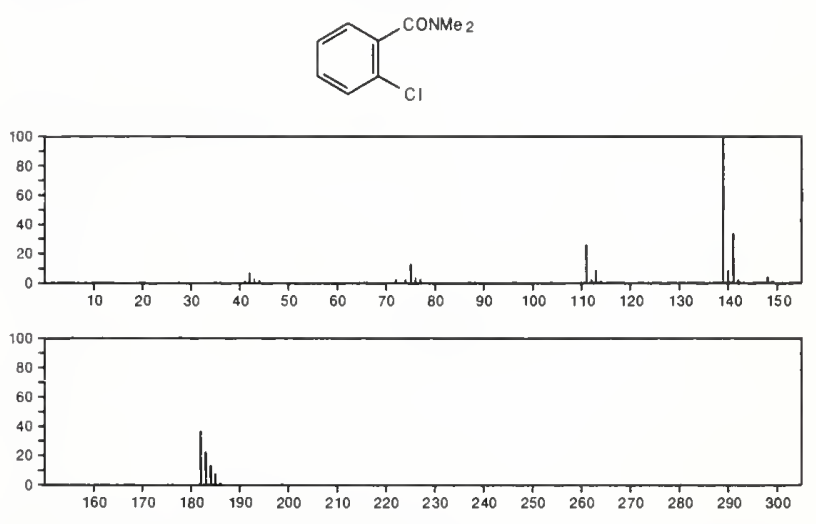

183

$\mathrm{C}_{9} \mathrm{H}_{13} \mathrm{NOS}$

$37989-61-0$

Pyridine, 3-ethoxy-6-methyl-2-(methylthio)-
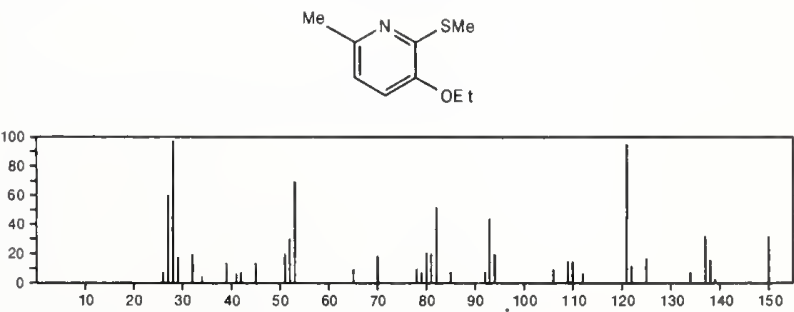


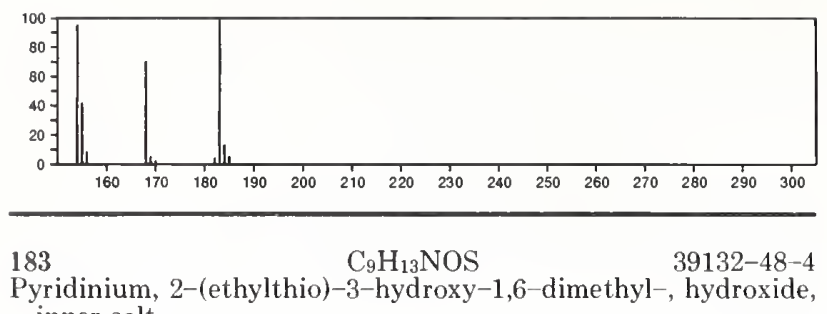

inner salt
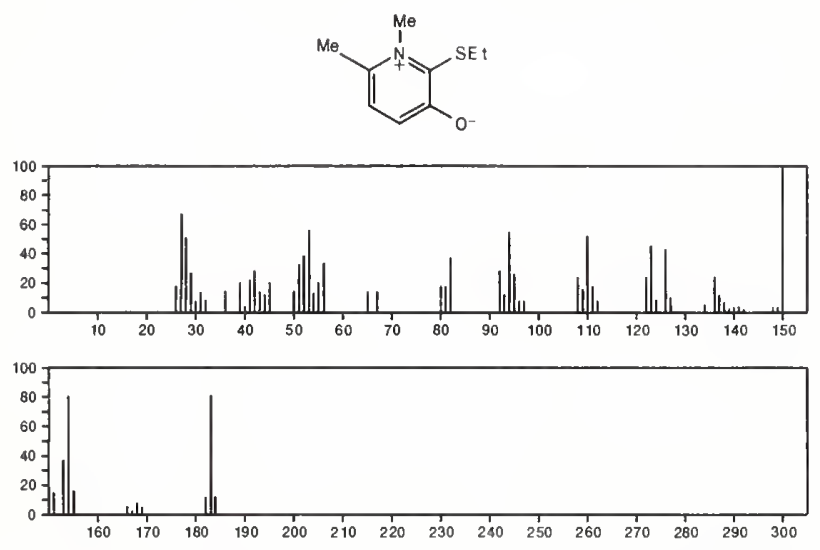

183

$\mathrm{C}_{9} \mathrm{H}_{13} \mathrm{NO}_{3}$

$51-43-4$

1,2-Benzenediol, 4-[1-hydroxy-2-(methylamino)ethyl]-, $(R)$ -
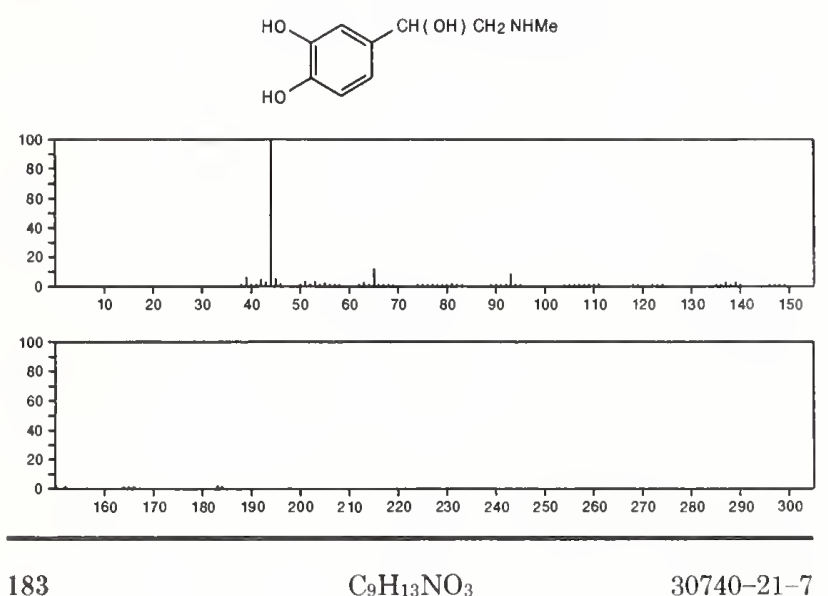

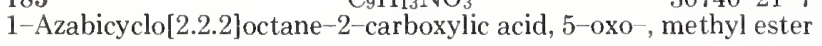
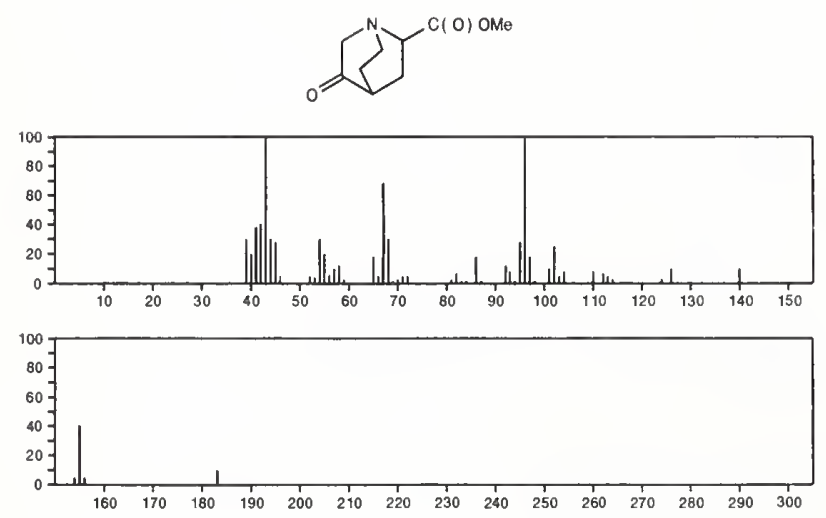

183

$\mathrm{C}_{9} \mathrm{H}_{15} \mathrm{~N}_{2} \mathrm{O}_{2}$

$3229-73-0$

1H-Pyrrol-1-yloxy, 3-(aminocarbonyl)-2,5-dihydro-2,2,5,5tetramethyl
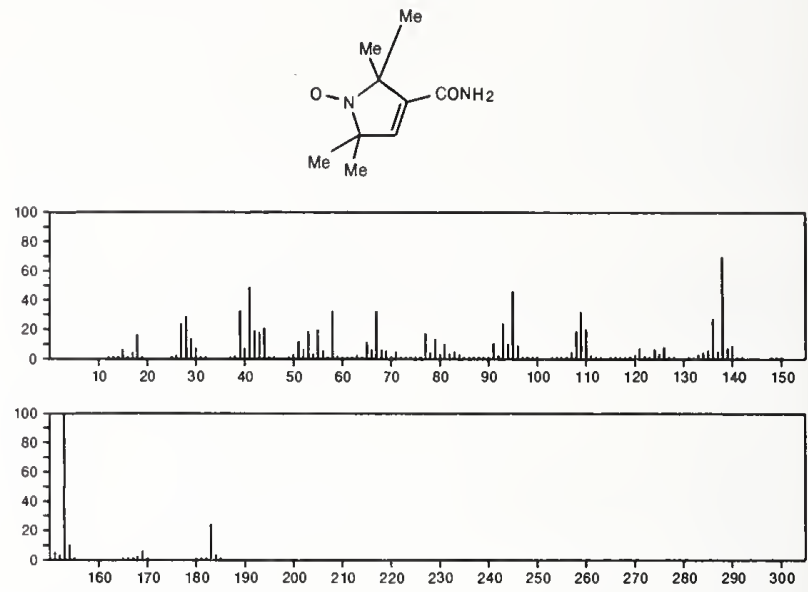

183

$\mathrm{C}_{9} \mathrm{H}_{17} \mathrm{~N}_{3} \mathrm{O}$

$57174-11-5$

Hydrazinecarboxamide, 2-(2,6-dimethylcyclohexylidene)-
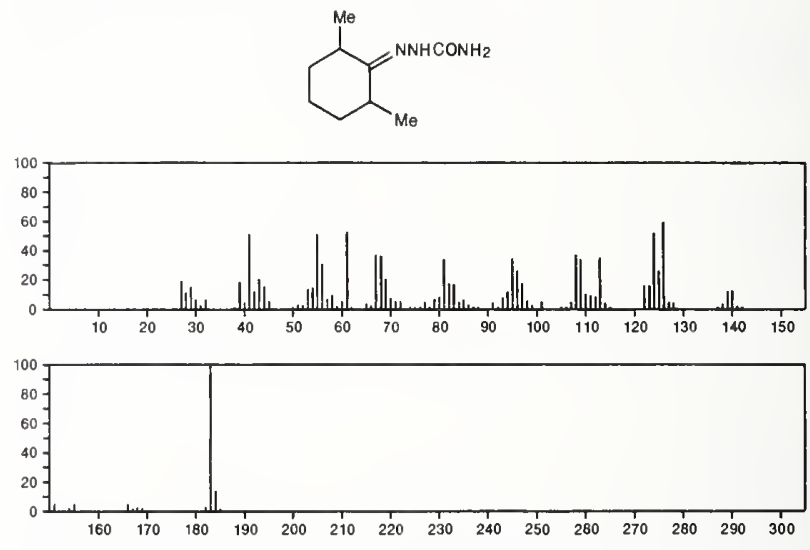

$\mathrm{C}_{10} \mathrm{H}_{17} \mathrm{NO}_{2}$

$125-64-4$

2,4-Piperidinedione, 3,3-diethyl-5-methyl-
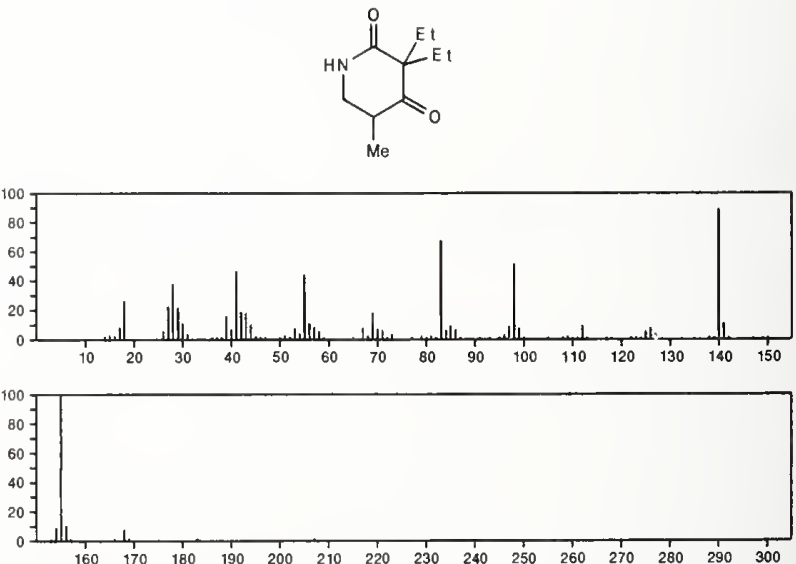
$183 \quad \mathrm{C}_{10} \mathrm{H}_{17} \mathrm{NO}_{2} \quad 22766-68-3$

1-Azabicyclo[2.2.2]octane-4-carboxylic acid, ethyl ester
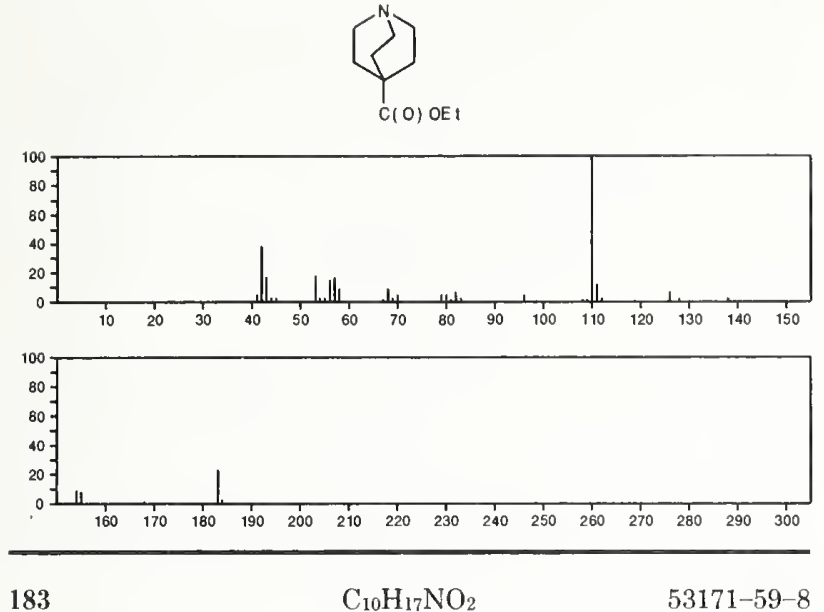

Bicyclo[3.2.0]heptan-3-one, 2-hydroxy-1,4,4-trimethyl-, oxime
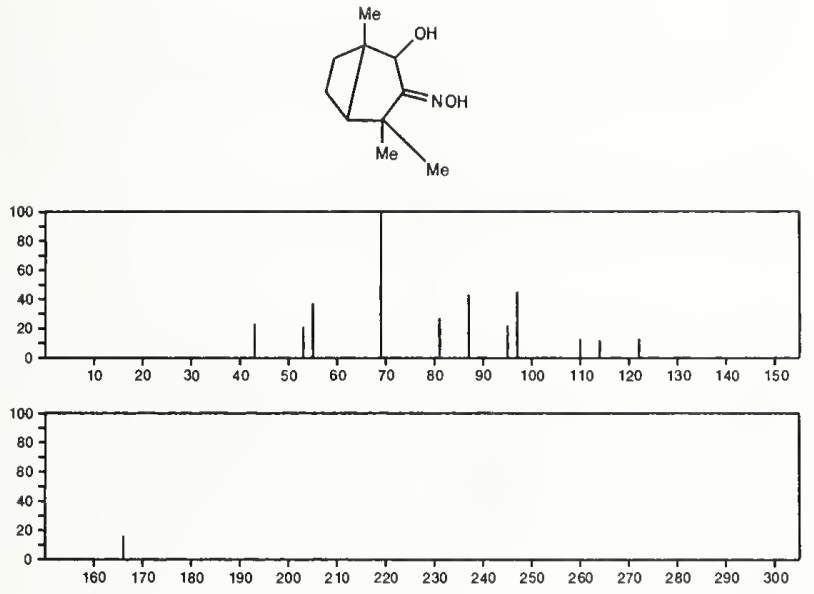

183

$\mathrm{C}_{10} \mathrm{H}_{17} \mathrm{NS}$

$52414-86-5$

Thiazole, 2-butyl-5-propyl-
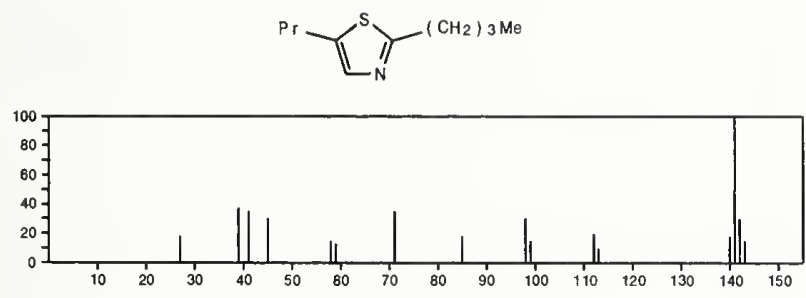

$$
\begin{array}{r}
100 \\
80 \\
60 \\
40 \\
20 \\
0
\end{array}
$$

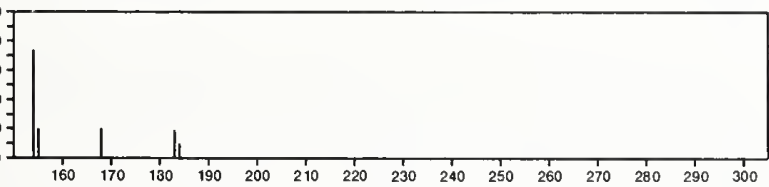

183

$\mathrm{C}_{10} \mathrm{H}_{17} \mathrm{NS}$

Thiazole, 2-butyl-4-ethyl-5-methyl-

$52414-88-7$
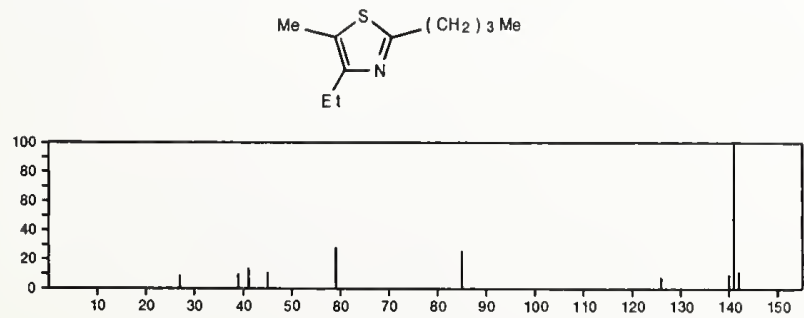

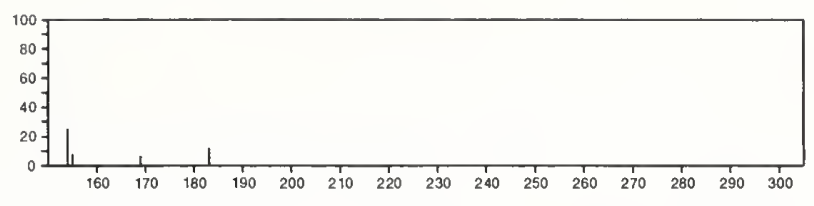

183

$$
\mathrm{C}_{11} \mathrm{H}_{21} \mathrm{NO}
$$

$1925-46-8$

2-Bornanol, 3-(methylamino)-, endo,endo
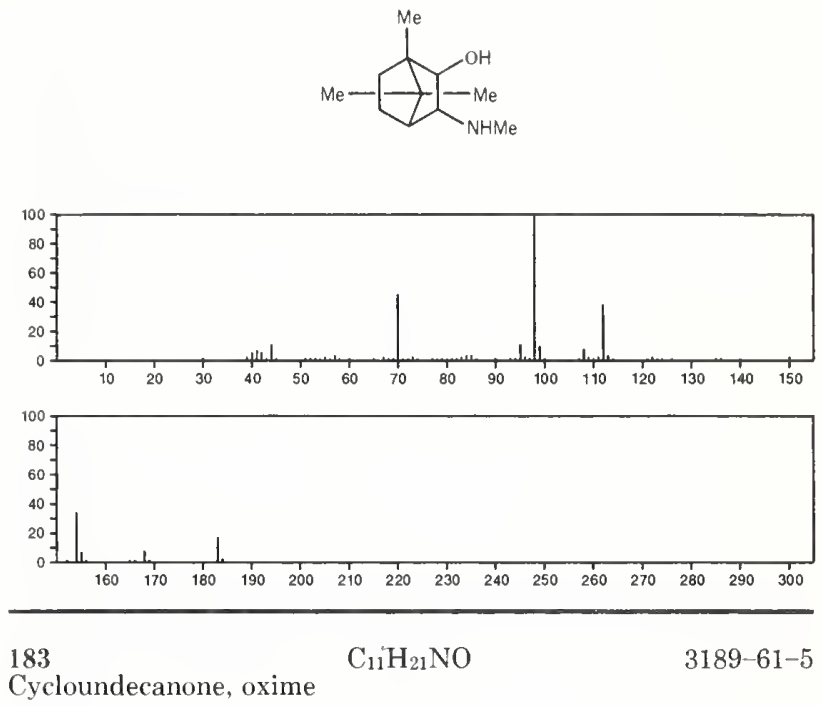

Cycloundecanone, oxime
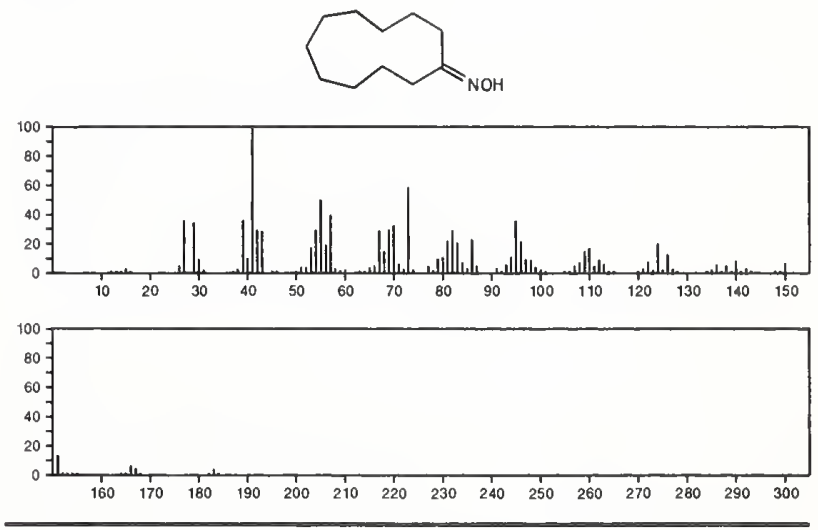

183

$\mathrm{C}_{11} \mathrm{H}_{21} \mathrm{NO}$

$32232-17-0$

3-Bornanol, 2-(methylamino)-, endo,endo-
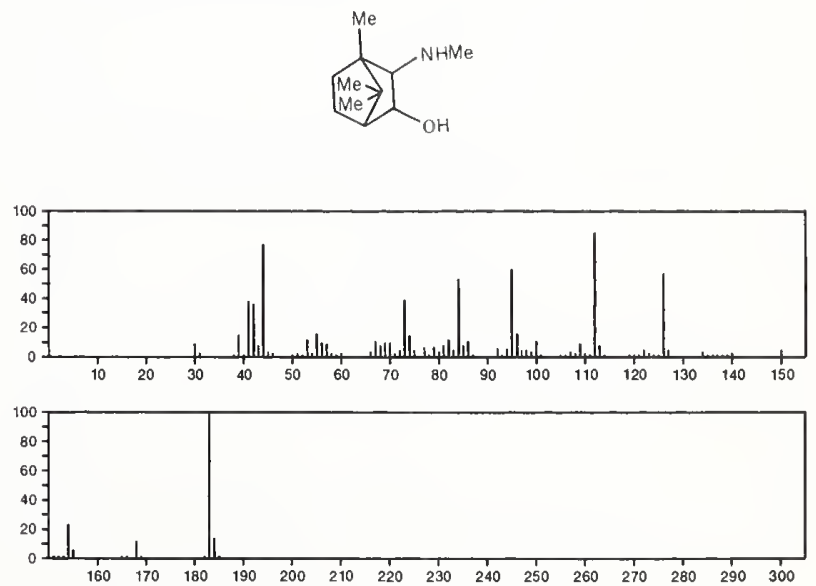
183 $\mathrm{C}_{11} \mathrm{H}_{21} \mathrm{NO}$

39209-06-8

3-Decen-2-one, $O$-methyloxime

$\mathrm{Me}\left(\mathrm{CH}_{2}\right){ }_{5} \mathrm{CH}=\mathrm{CHCMe}=\mathrm{NOMe}$
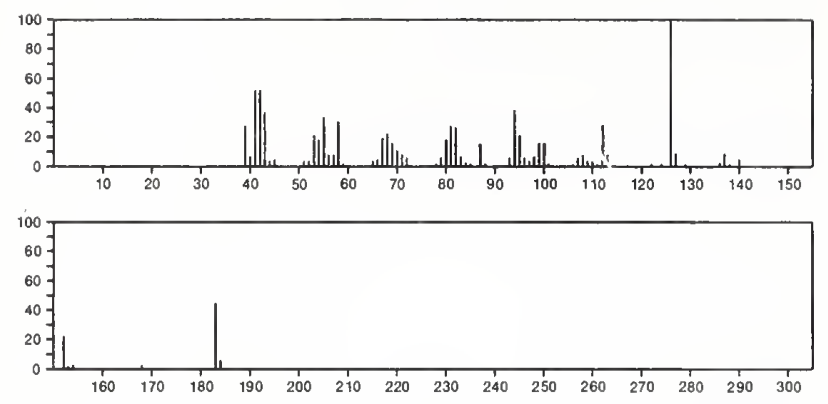

183

$\mathrm{C}_{11} \mathrm{H}_{21} \mathrm{NO}$

Morpholine, 4-(3-methylcyclohexyl)-<smiles>CC1CCCC(N2CCOCC2)C1</smiles>
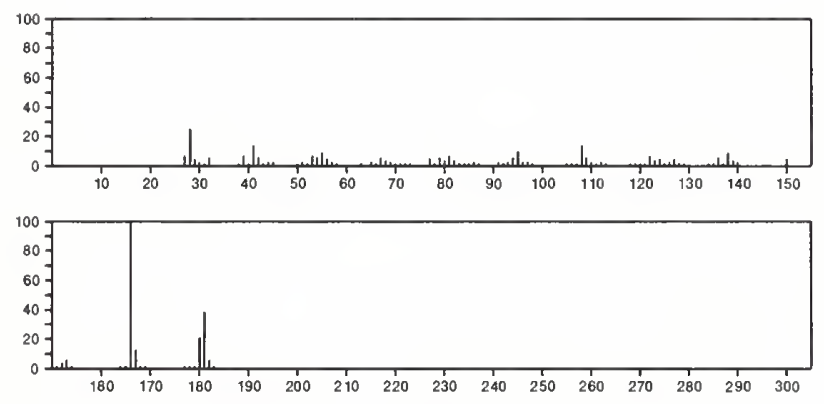

$183 \quad \mathrm{C}_{11} \mathrm{H}_{21} \mathrm{NO} \quad 57396-81-3$

Cyclohexanone, 5-methyl-2-(1-methylethyl)-, O-methyloxime, (2S-trans)-
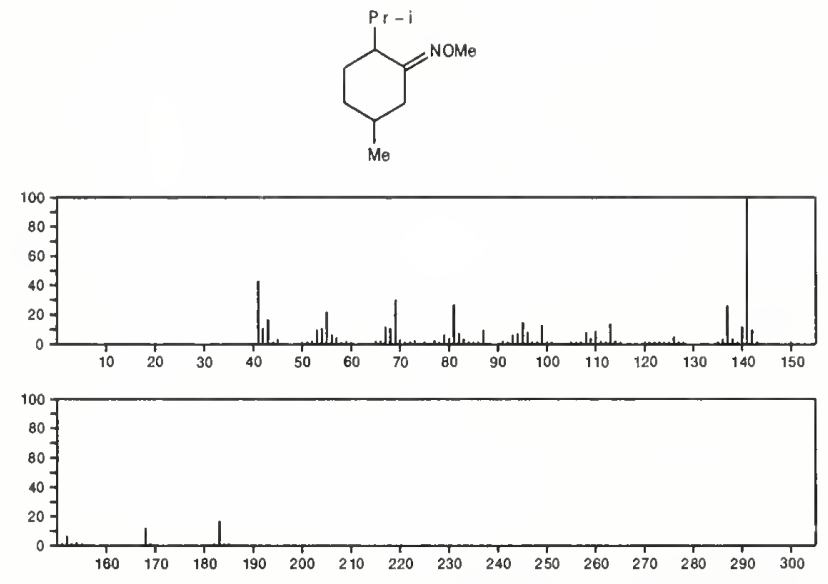

183

$\mathrm{C}_{12} \mathrm{H}_{9} \mathrm{NO}$

Methanone, phenyl-2-pyridinyl-
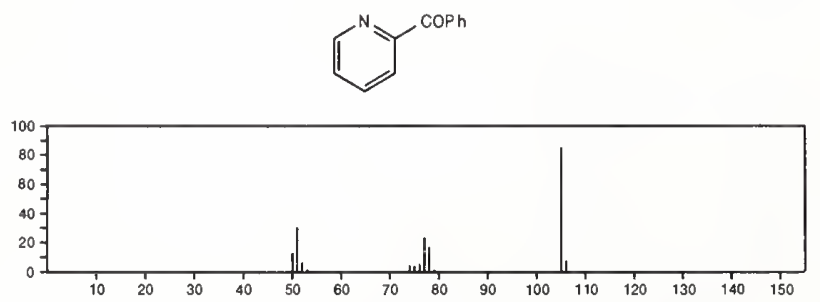
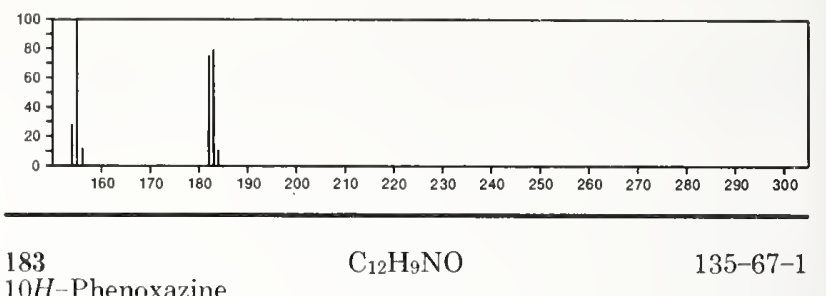

$10 H$-Phenoxazine<smiles>c1ccc2c(c1)Nc1ccccc1O2</smiles>
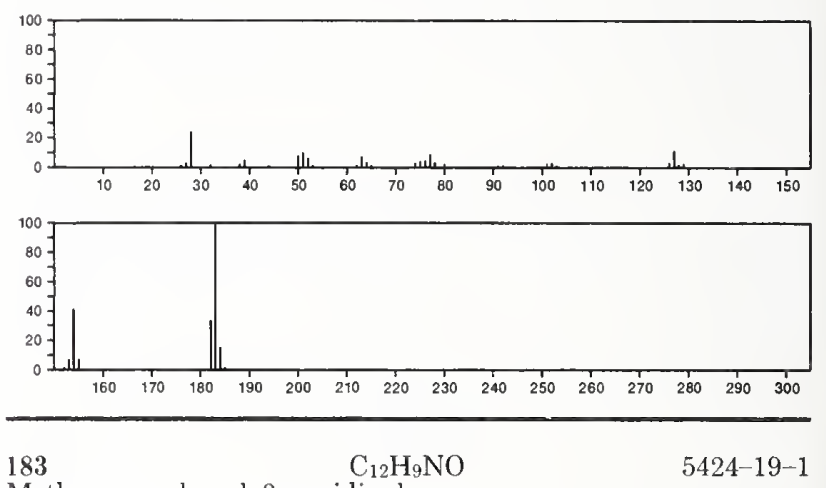

$5424-19-1$ Methanone, phenyl-3-pyridinyl-
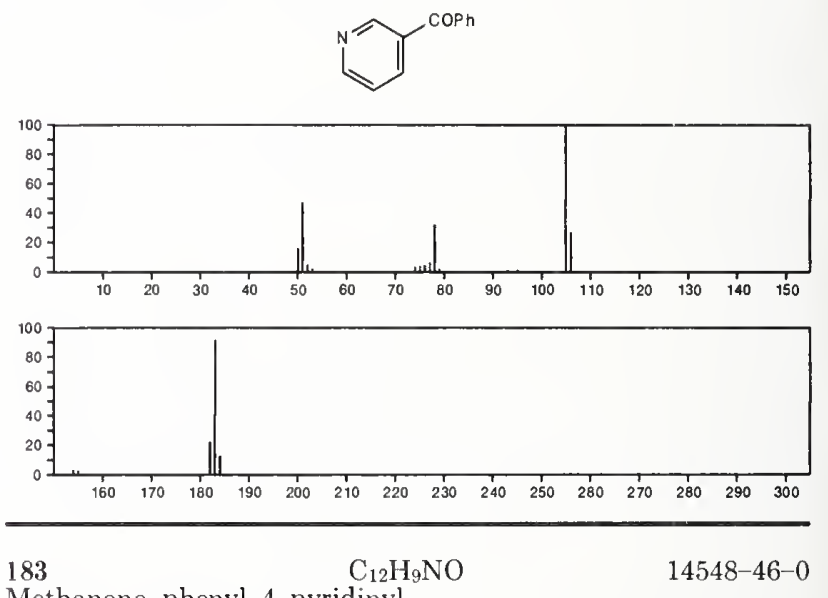

14548-46-0

Methanone, phenyl-4-pyridinyl-
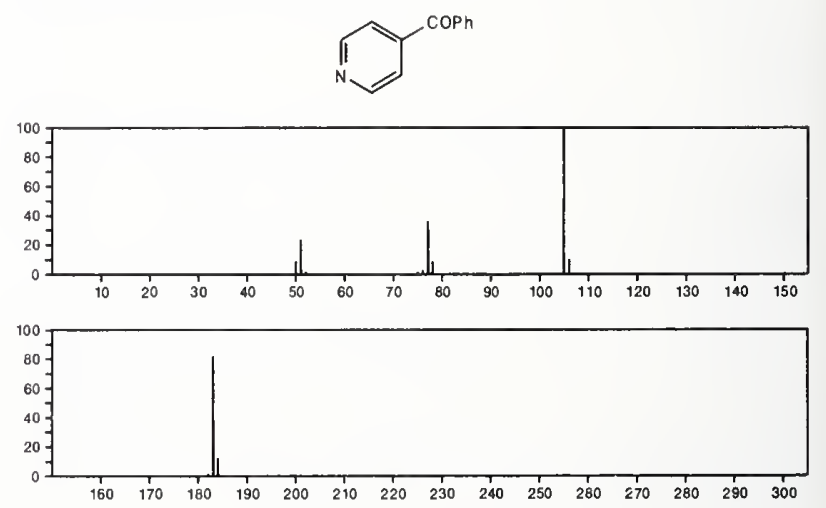
183

$\mathrm{C}_{13} \mathrm{H}_{13} \mathrm{~N}$

$552-82-9$

Benzenamine, $N$-methyl- $N$-phenyl

$\mathrm{Ph}_{2} \mathrm{NMe}$
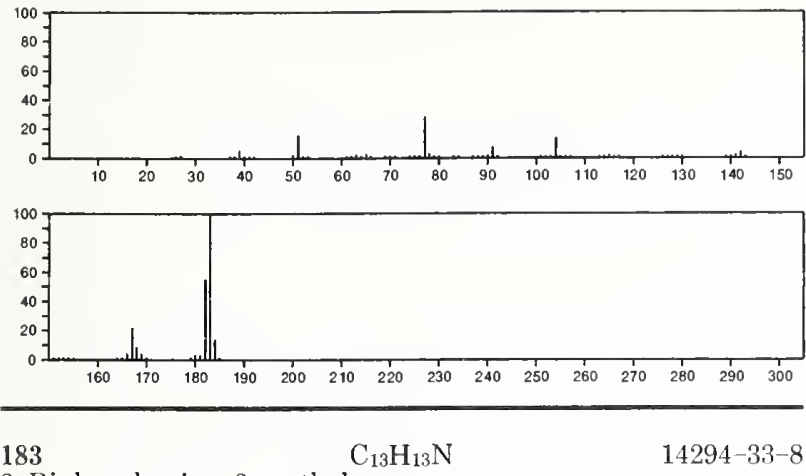

$14294-33-8$

2-Biphenylamine, 3-methyl-
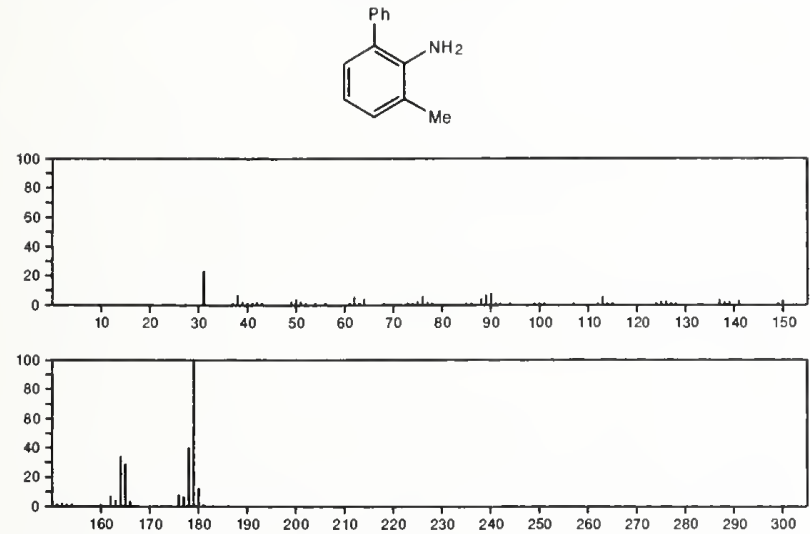

183

Benzenamine, ar-(phenylmethyl)-
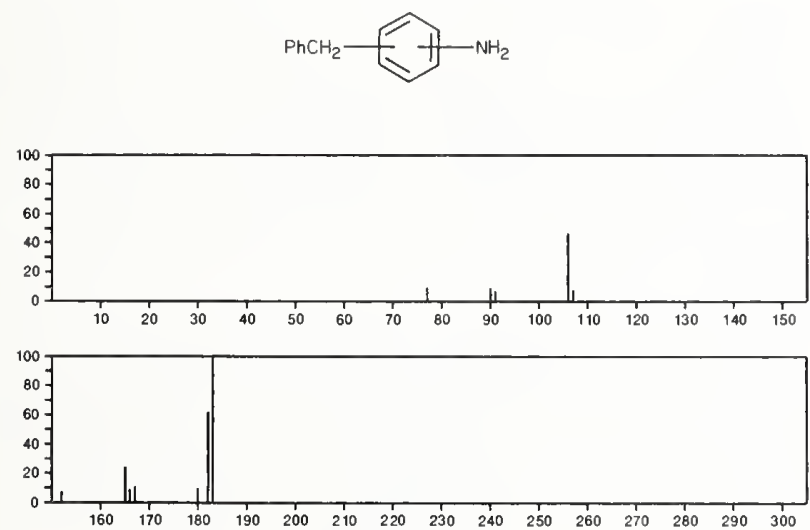

184

$\mathrm{C}_{2} \mathrm{H}_{2} \mathrm{Br}_{2}$

540-49-8

Ethene, 1,2-dibromo-

$\mathrm{Br} \mathrm{CH}=\mathrm{CHBr}$

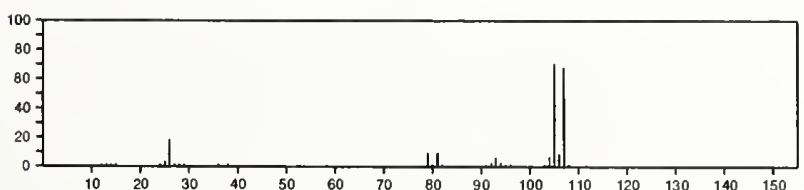

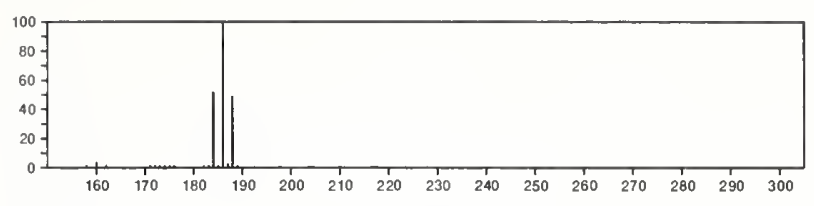

184

$\mathrm{C}_{3} \mathrm{H}_{2} \mathrm{ClF}_{5} \mathrm{O}$

$13838-16-9$

Ethane, 2-chloro-1-(difluoromethoxy)-1,1,2-trifluoro-

$\mathrm{F}_{2} \mathrm{CHOCF}_{2} \mathrm{CHCIF}$

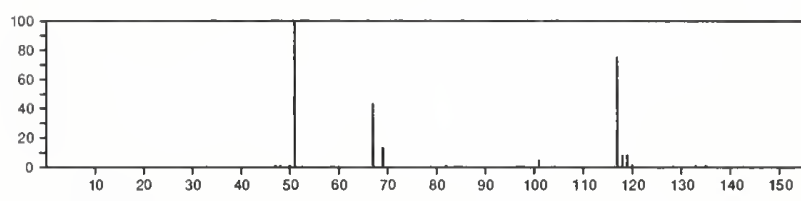

184

$\mathrm{C}_{3} \mathrm{H}_{9} \mathrm{AsO}_{4}$

Arsenic acid $\left(\mathrm{H}_{3} \mathrm{AsO}_{4}\right)$, trimethyl ester

$13006-30-9$
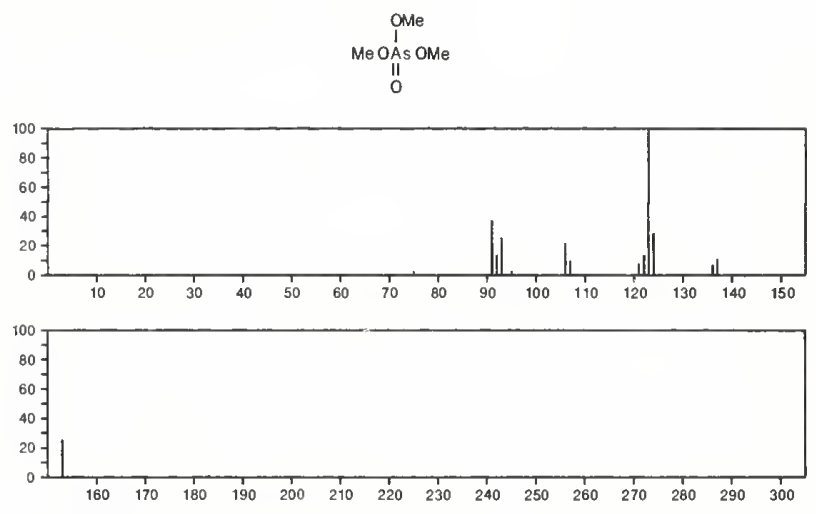

184

$184 \quad \mathrm{C}_{4} \mathrm{H}_{9} \mathrm{I}$

$513-38-2$

i-Bu
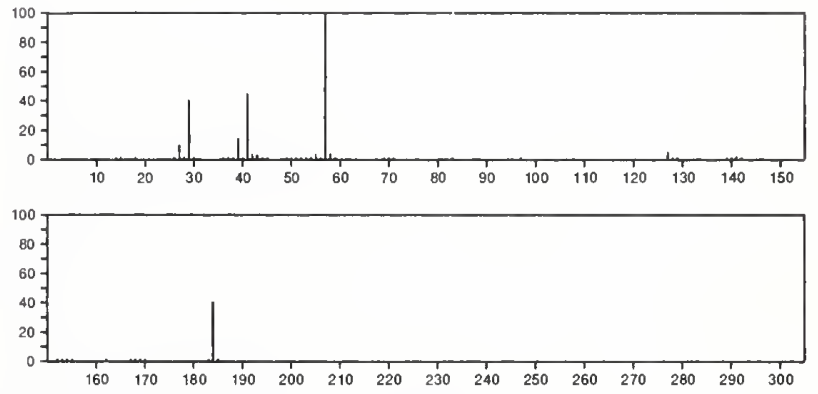

184

Butane, 2-iodo-

$\mathrm{C}_{4} \mathrm{H}_{9} \mathrm{I}$

$513-48-4$

$s-B u I$
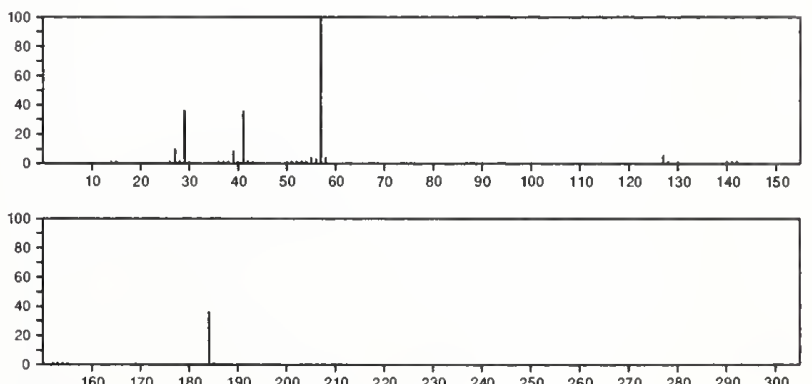
184

Butane, 1-iodo-

$\mathrm{C}_{4} \mathrm{H}_{9} \mathrm{I}$

$542-69-8$

$\mathrm{Me}\left(\mathrm{CH}_{2}\right)_{3} \mathrm{I}$
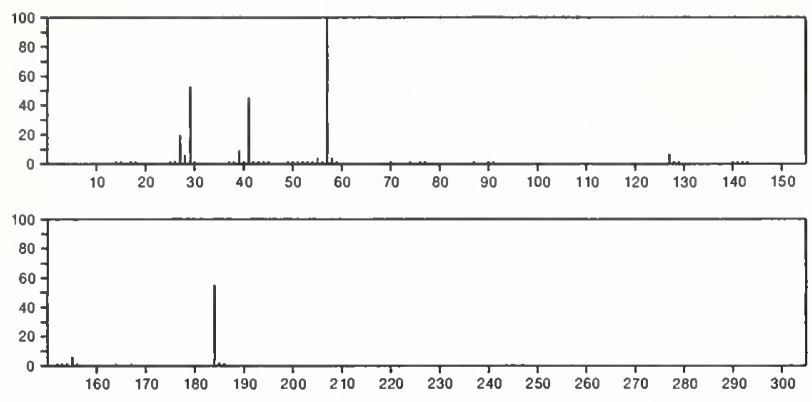

184

Propane, 2-iodo-2-methyl-

$\mathrm{C}_{4} \mathrm{H}_{9} \mathrm{I}$

t-Bul
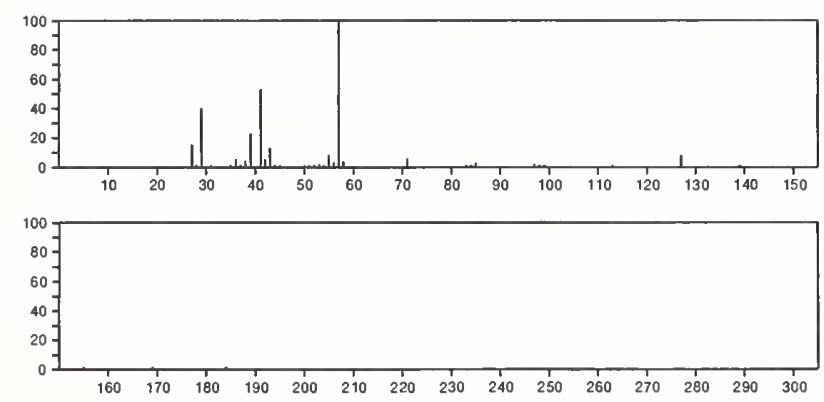

184

Phenol, pentafluoro-

$\mathrm{C}_{6} \mathrm{HF}_{5} \mathrm{O}$

$771-61-9$
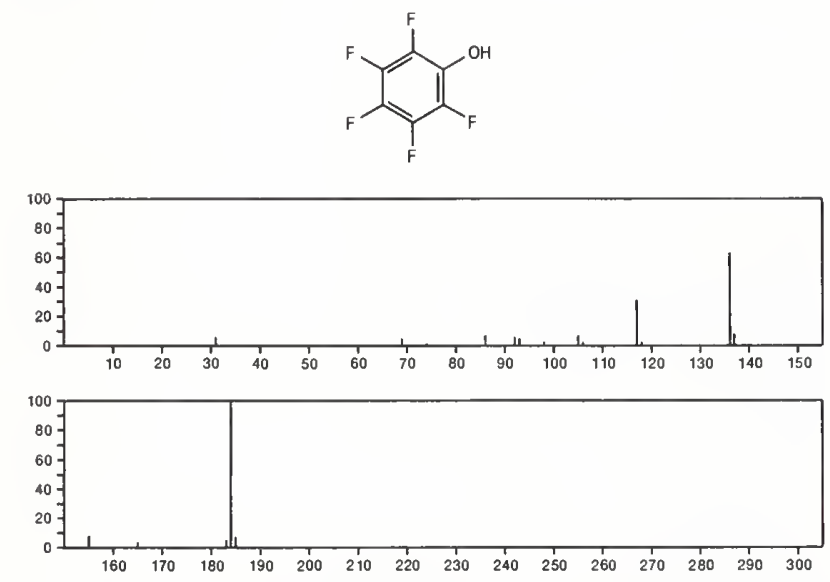

$184 \quad \mathrm{C}_{6} \mathrm{H}_{10} \mathrm{Cl}_{2} \mathrm{O}_{2} \quad 54587-48-3$

Propanoic acid, 2,2-dichloro-, 1-methylethyl ester

$\mathrm{i}-\mathrm{PrOC}(\mathrm{O}) \mathrm{CCl}_{2} \mathrm{Me}$
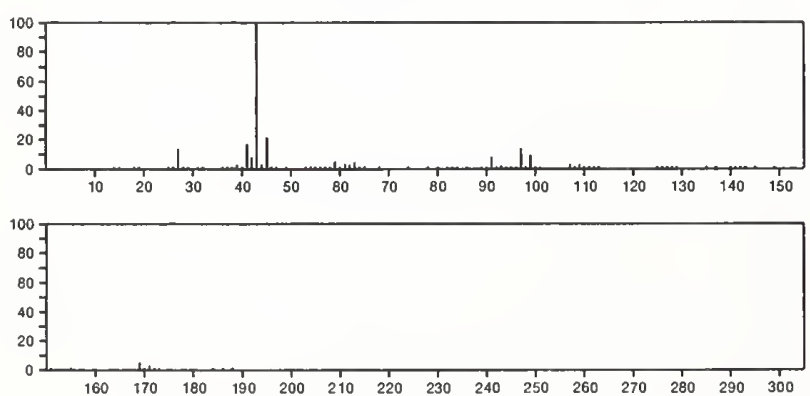

184

Propanoic acid, 2,3-dichloro-, 1-methylethyl ester

$54774-99-1$
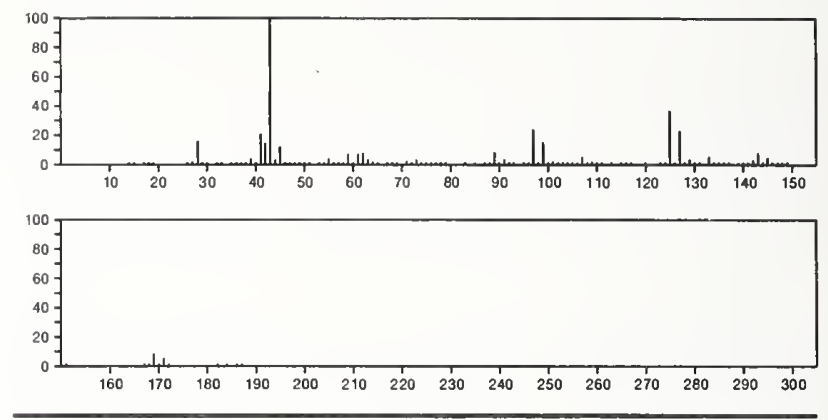

$\mathrm{C}_{7} \mathrm{H}_{8} \mathrm{~N}_{2} \mathrm{O}_{2} \mathrm{~S}$
$1 \mathrm{H}-2,1,3-$ Benzothiadiazine, $3,4-$ dihydro

$33853-77-9$

1H-2,1,3-Benzothiadiazine, 3,4-dihydro-, 2,2-dioxide
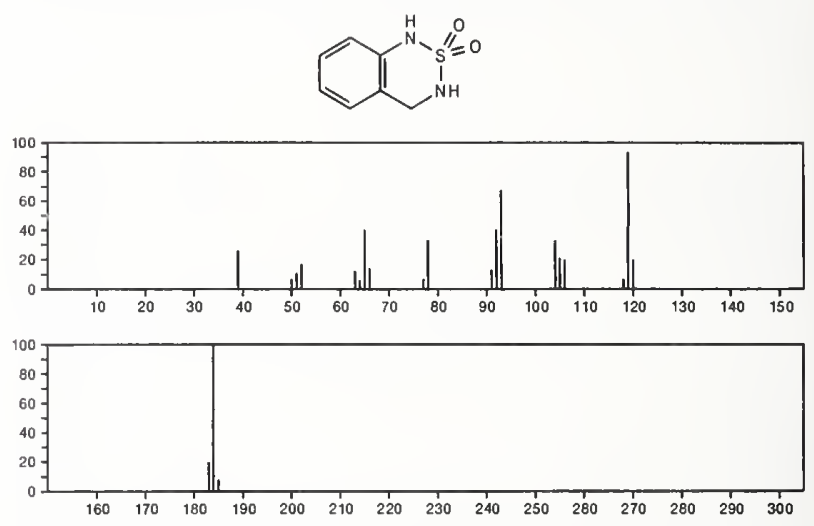

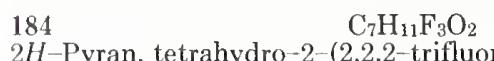

$16408-83-6$

2H-Pyran, tetrahydro-2-(2,2,2-trifluoroethoxy)-
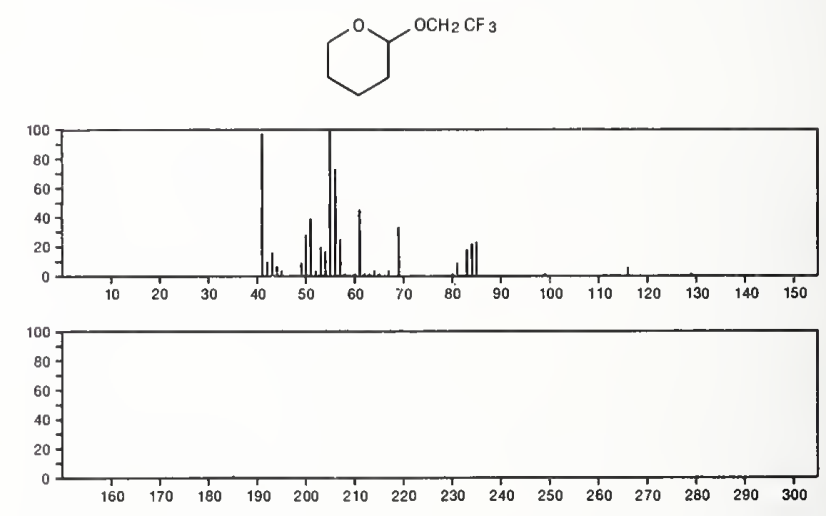

$184 \quad \mathrm{C}_{8} \mathrm{H}_{8} \mathrm{OS}_{2} \quad 6047-46-7$

Carbonic acid, dithio-, $O^{-}$methyl $S^{-}$-phenyl ester

PhSC(S) OMe
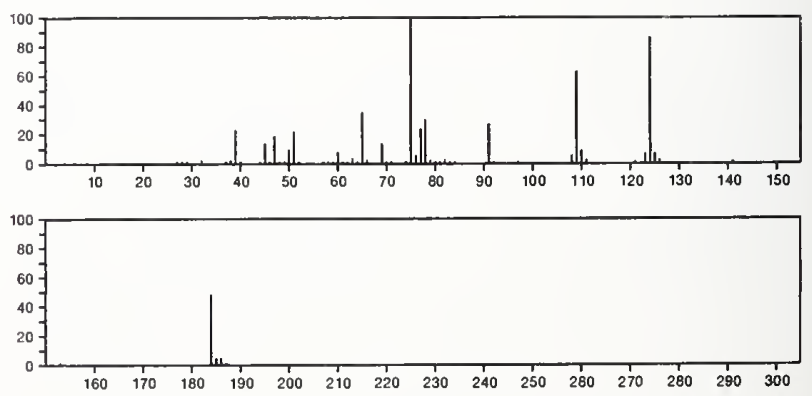
$184 \quad \mathrm{C}_{8} \mathrm{H}_{8} \mathrm{OS}_{2}$

Carbonic acid, dithio-, $S$-methyl $S$-phenyl ester

13509-29-0

PhSC(0) SMe
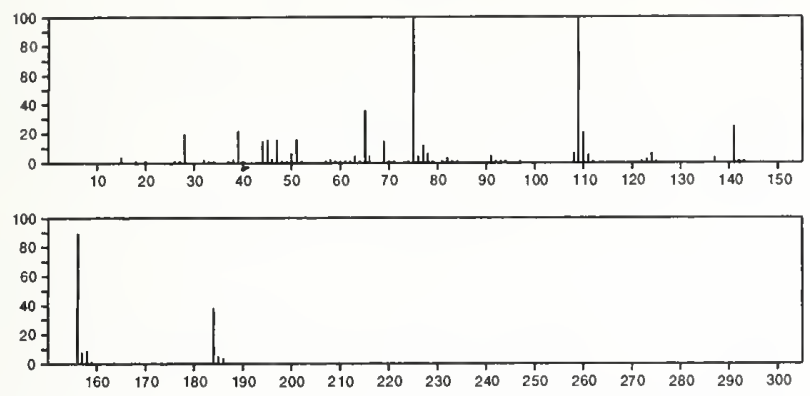

184

$\mathrm{C}_{8} \mathrm{H}_{8} \mathrm{OS}_{2}$

$13509-30-3$

Carbonodithioic acid, $S$-methyl $O$-phenyl ester

PhOC(S) SMe
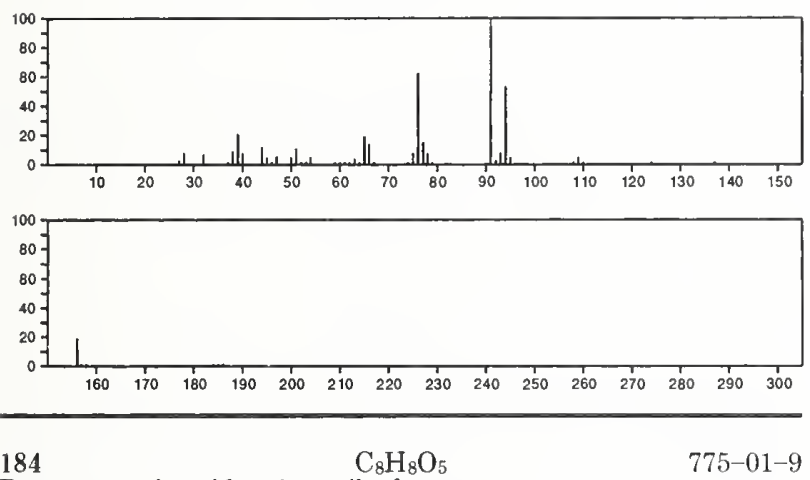

Benzeneacetic acid, $\alpha, 3,4$-trihydroxy-
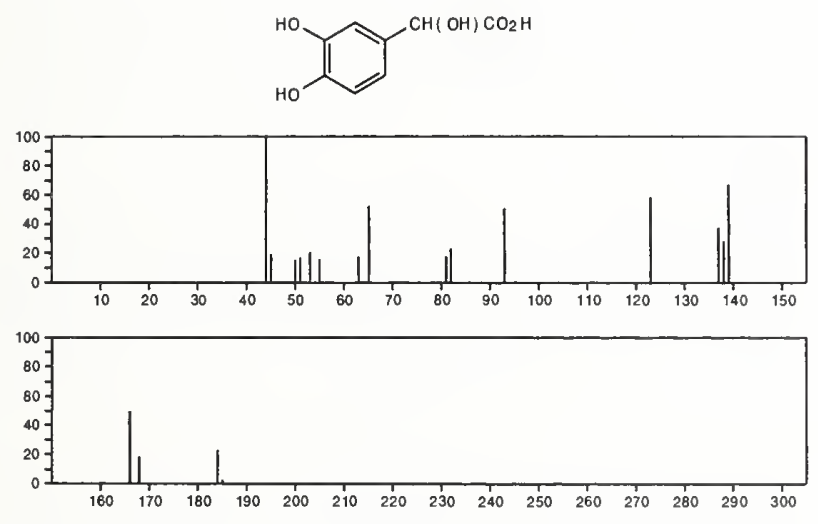

184

2,4-Furandicarboxylic acid, dimethyl ester

$1710-13-0$
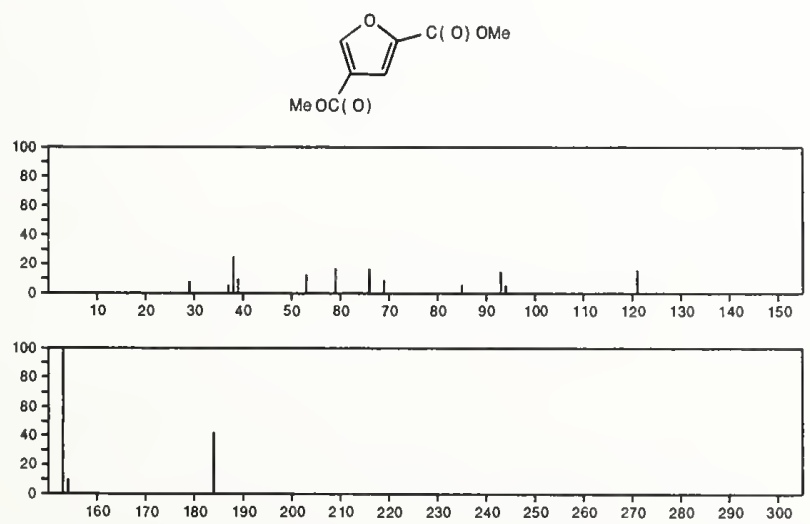

$184 \quad \mathrm{C}_{8} \mathrm{H}_{8} \mathrm{O}_{5}$

2,5-Furandicarboxylic acid, dimethyl ester

4282-32-0
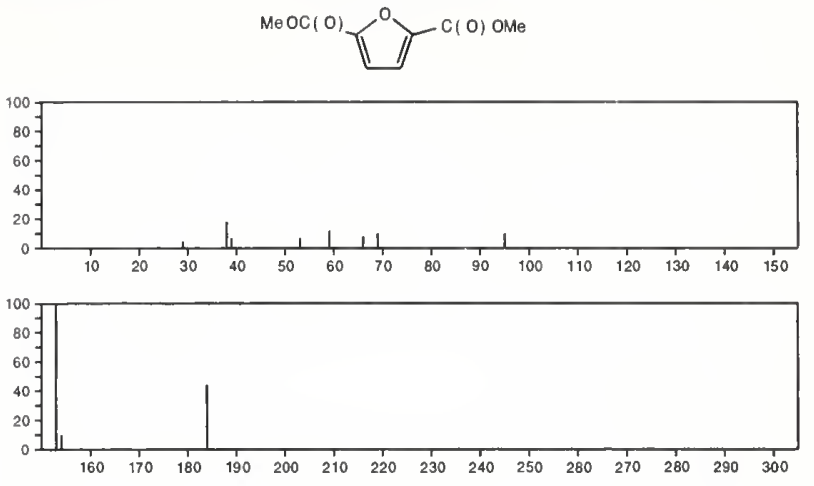

184

$\mathrm{C}_{8} \mathrm{H}_{9} \mathrm{Br}$

Benzene, 1-(bromomethyl)-2-methyl-

89-92-9
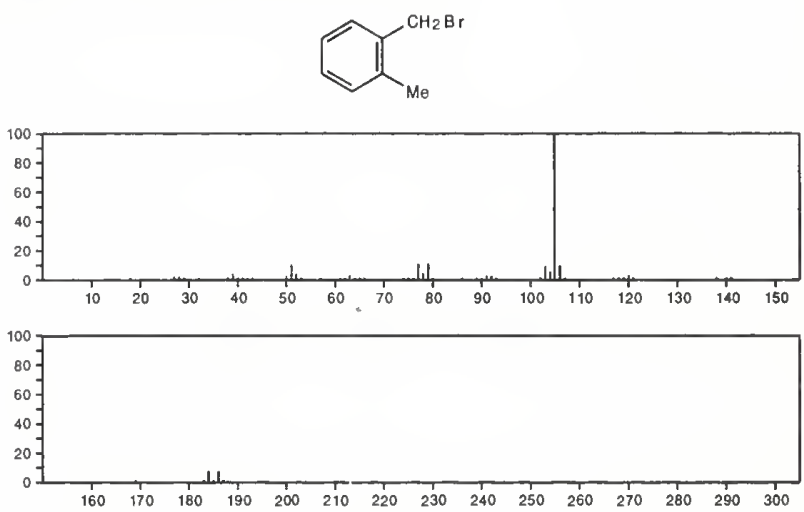

184

Benzene, (2-bromoethyl)-

$\mathrm{C}_{8} \mathrm{H}_{9} \mathrm{Br}$

$103-63-9$

$\mathrm{Br} \mathrm{CH}_{2} \mathrm{CH}_{2} \mathrm{Ph}$
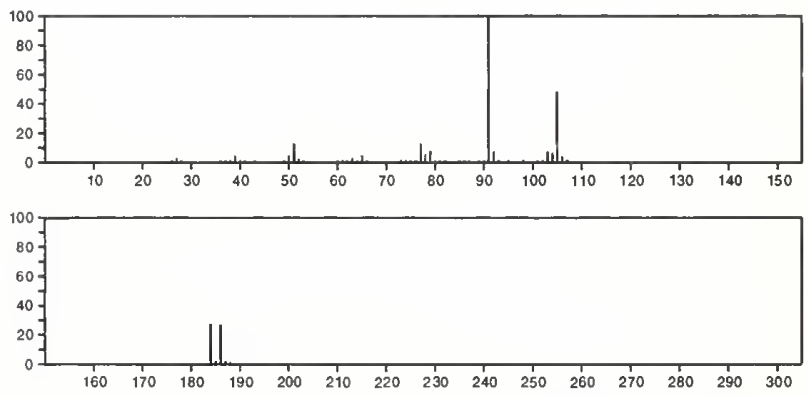

184

$\mathrm{C}_{8} \mathrm{H}_{9} \mathrm{Br}$

$104-81-4$

Benzene, 1-(bromomethyl)-4-methyl-
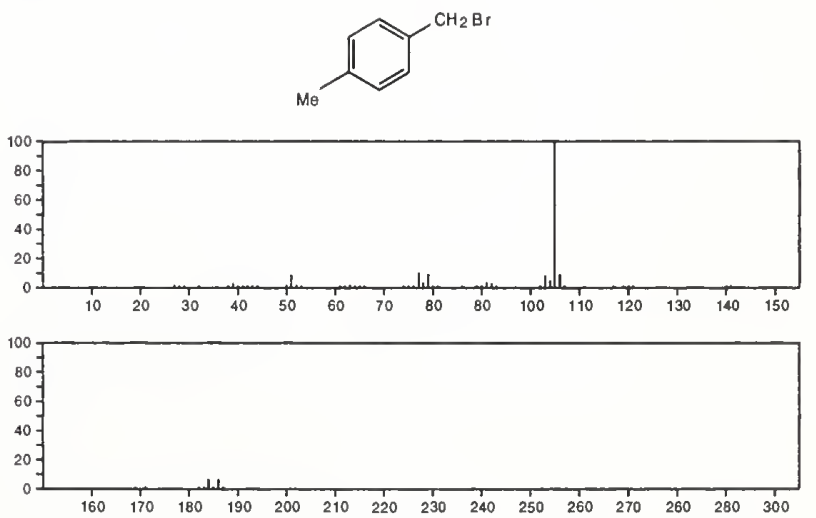
184

$\mathrm{C}_{8} \mathrm{H}_{9} \mathrm{Br}$

Benzene, 2-bromo-1,4-dimethyl
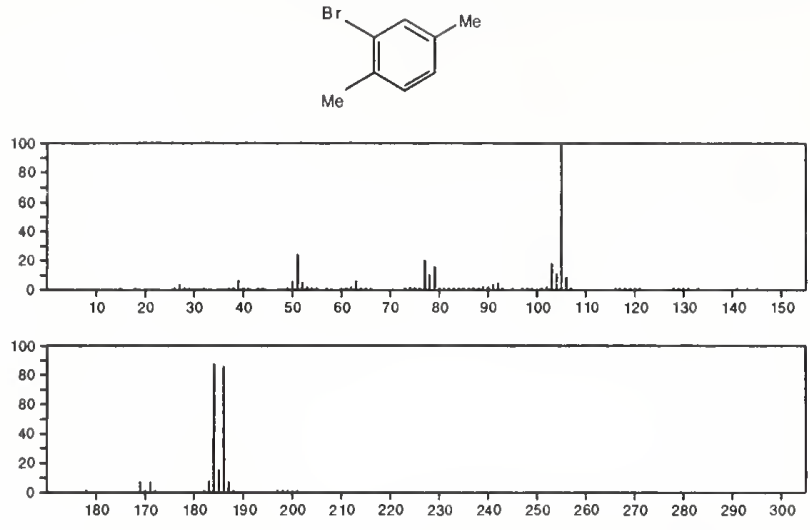

$184 \quad \mathrm{C}_{8} \mathrm{H}_{9} \mathrm{Br} \quad 583-70-0$ Benzene, 1-bromo-2,4-dimethyl-
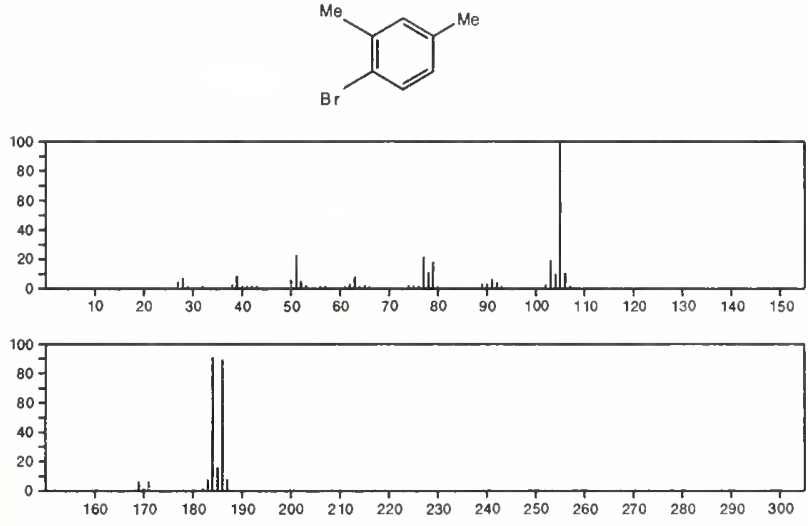

$184 \quad \mathrm{C}_{8} \mathrm{H}_{9} \mathrm{Br}$

Benzene, 4-bromo-1,2-dimethyl-
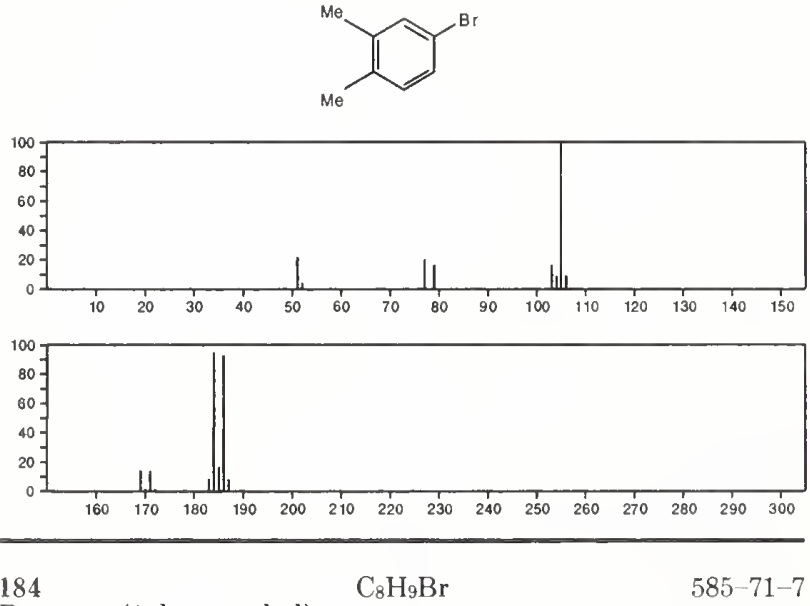

Benzene, (1-bromoethyl)-

$\operatorname{PhCHBr}(\mathrm{Ph})$

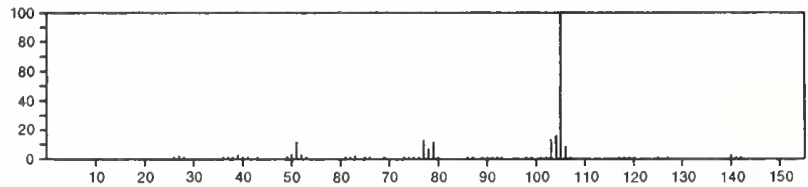

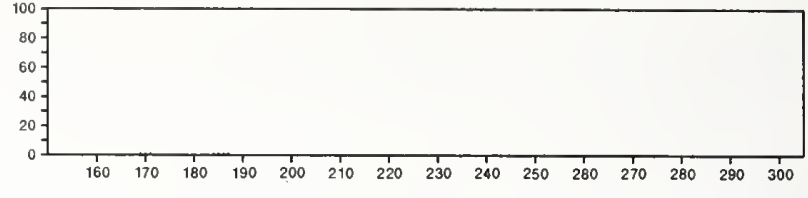

184

$\mathrm{C}_{8} \mathrm{H}+\mathrm{Br}$

Benzene, 1-(bromomethyl)-3-methyl-

$620-13-3$
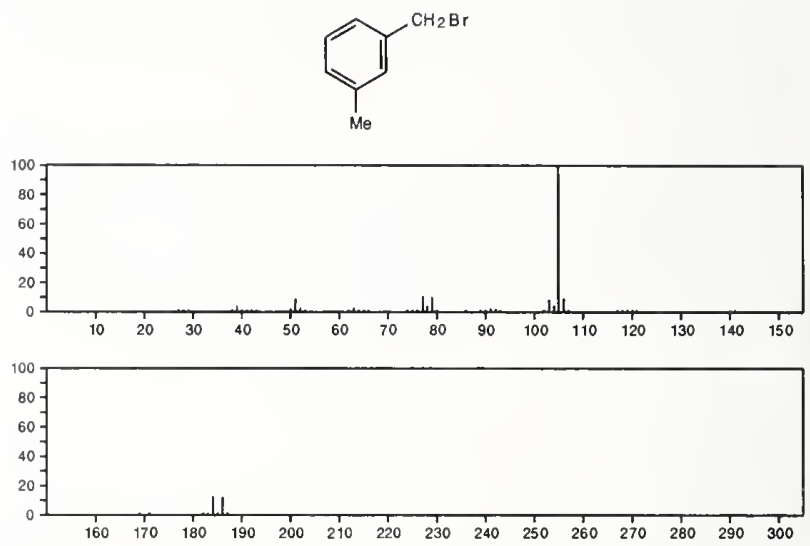

184

Benzene, 1-bromo-4-ethyl-

$\mathrm{C}_{8} \mathrm{H}_{9} \mathrm{Br}$

$1585-07-5$
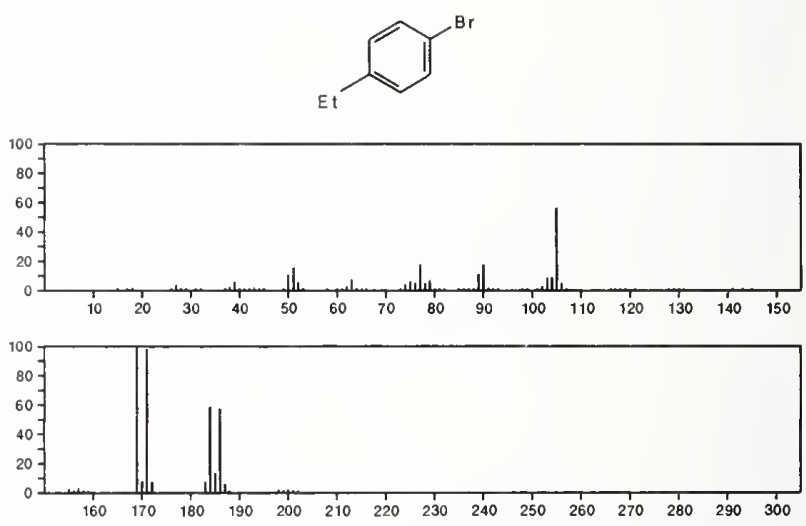

184

$\mathrm{C}_{8} \mathrm{H}_{9} \mathrm{Br}$

1973-22-4

Benzene, 1-bromo-2-ethyl-
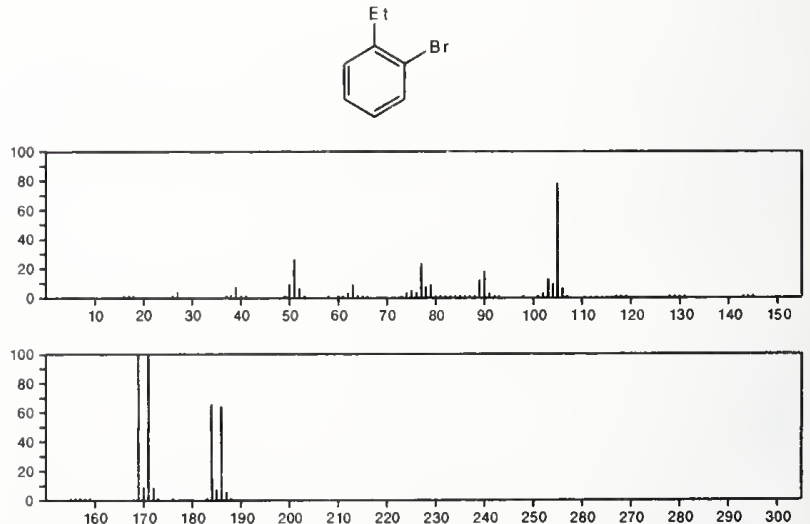
184

$\mathrm{C}_{8} \mathrm{H}_{9} \mathrm{Br}$

Xylene, bromo-
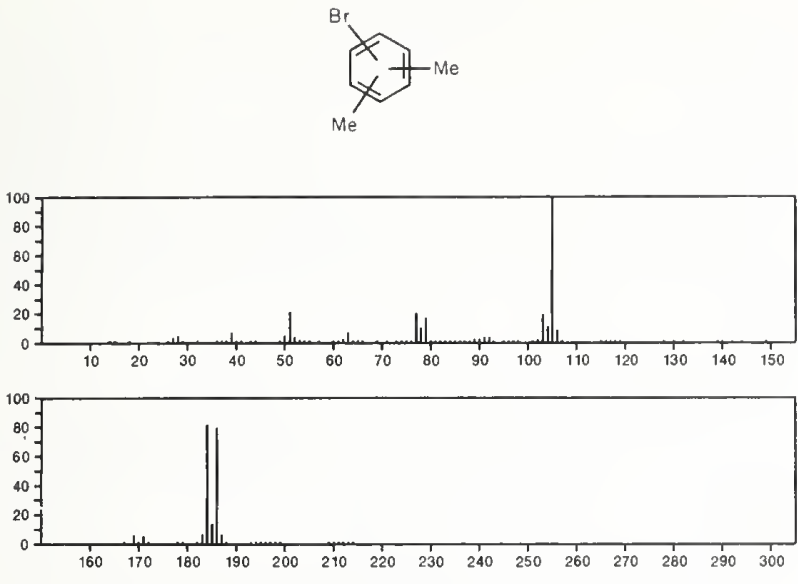

184

$\mathrm{C}_{8} \mathrm{H}_{9} \mathrm{Br}$

$31620-80-1$

Benzene, bromoethyl-
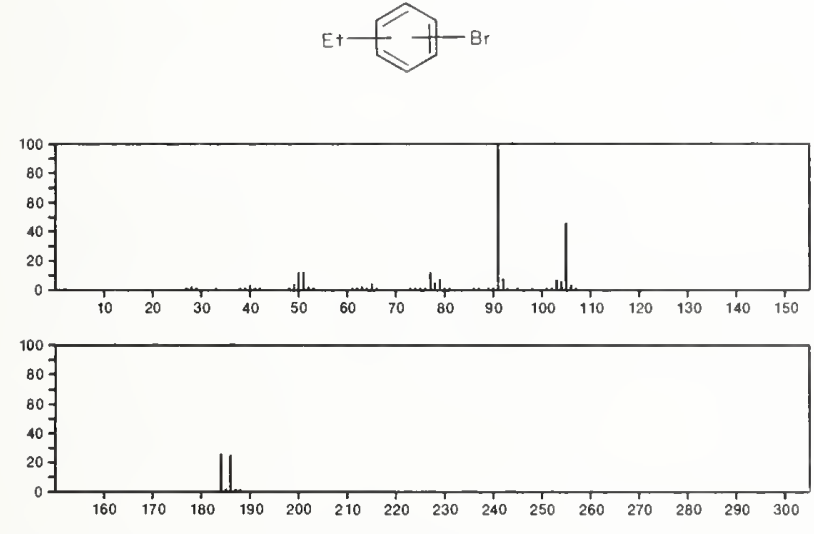

184

$\mathrm{C}_{8} \mathrm{H}_{9} \mathrm{ClN}_{2} \mathrm{O}$

Urea, $N$-(4-chlorophenyl)- $N^{\prime}$-methyl-
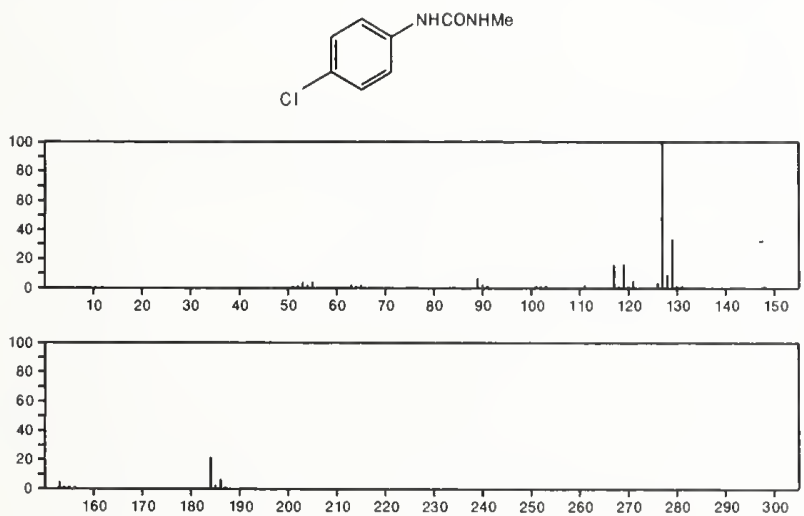

$184 \quad \mathrm{C}_{8} \mathrm{H}_{9} \mathrm{ClN}_{2} \mathrm{O}$

Urea, 1-(p-chlorophenyl)-1-methyl-

$22517-43-7$
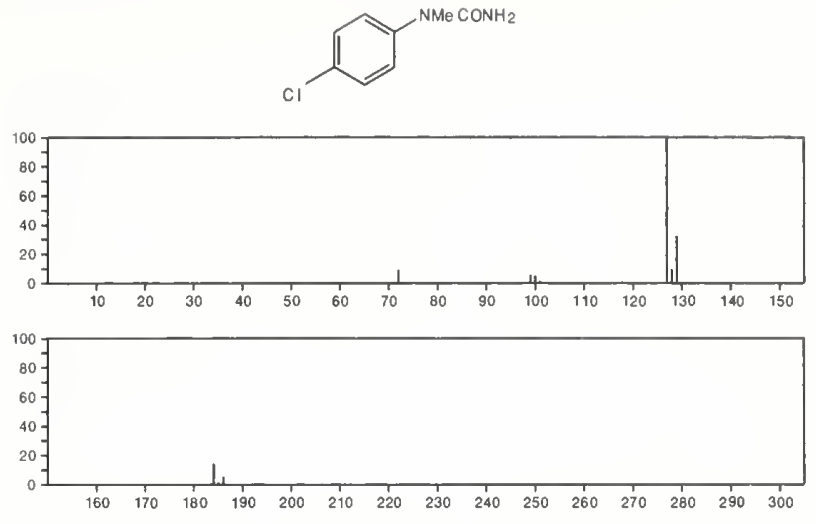

$184 \quad \mathrm{C}_{8} \mathrm{H}_{12} \mathrm{~N}_{2} \mathrm{OS} \quad 35231-62-0$

Pyrimidine, 5-ethoxy-2-methyl-4-(methylthio)-
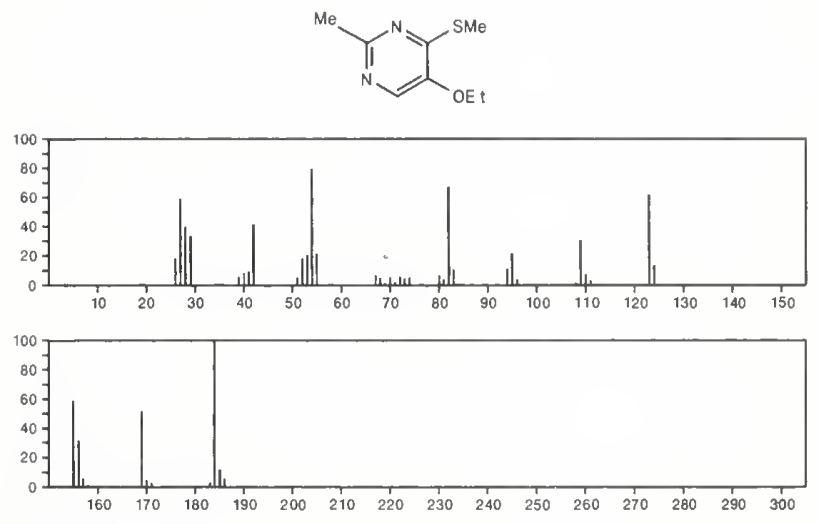

$184 \quad \mathrm{C}_{8} \mathrm{H}_{12} \mathrm{~N}_{2} \mathrm{OS}$

4(1H)-Pyrimidinone, 2-(butylthio)-

54774-97-9

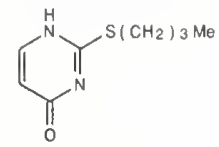
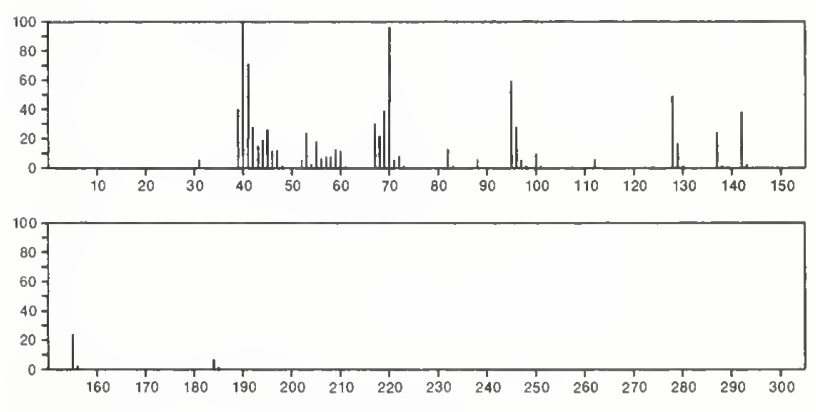

184

$\mathrm{C}_{8} \mathrm{H}_{12} \mathrm{~N}_{2} \mathrm{OS}$

54774-98-0

4(1H)-Pyrimidinone, 5-methyl-2-(propylthio)-<smiles>Nc1c[nH]c(Br)nc1=O</smiles>

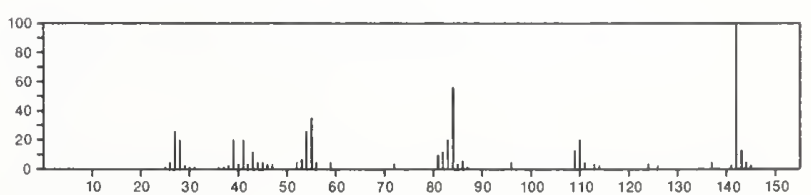




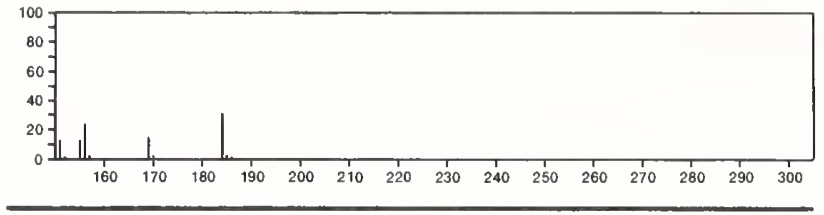

$184 \quad \mathrm{C}_{8} \mathrm{H}_{12} \mathrm{~N}_{2} \mathrm{O}_{3}$

$57-44-3$

2,4,6(1H,3H,5H)-Pyrimidinetrione, 5,5-diethyl-
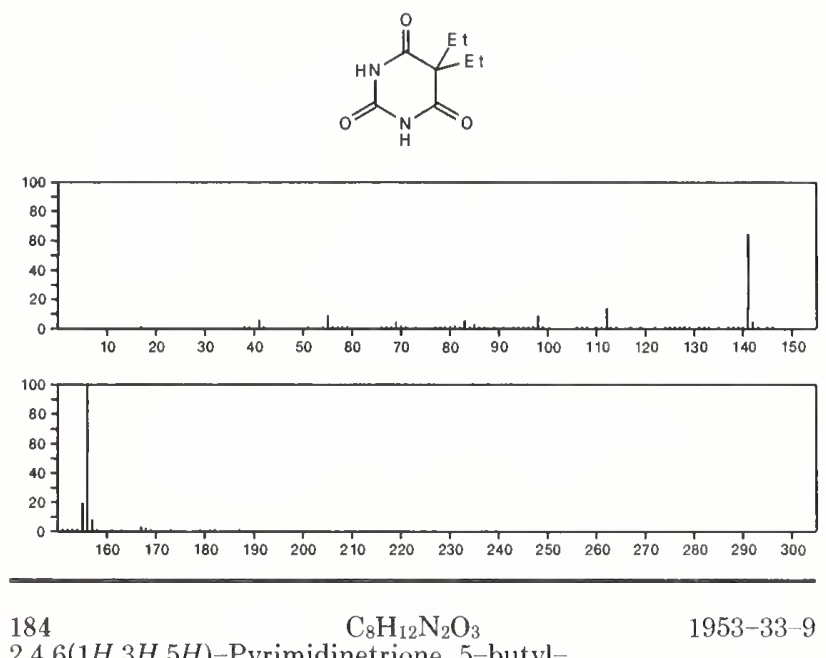

2,4,6(1H,3H,5H)-Pyrimidinetrione, 5 -butyl-
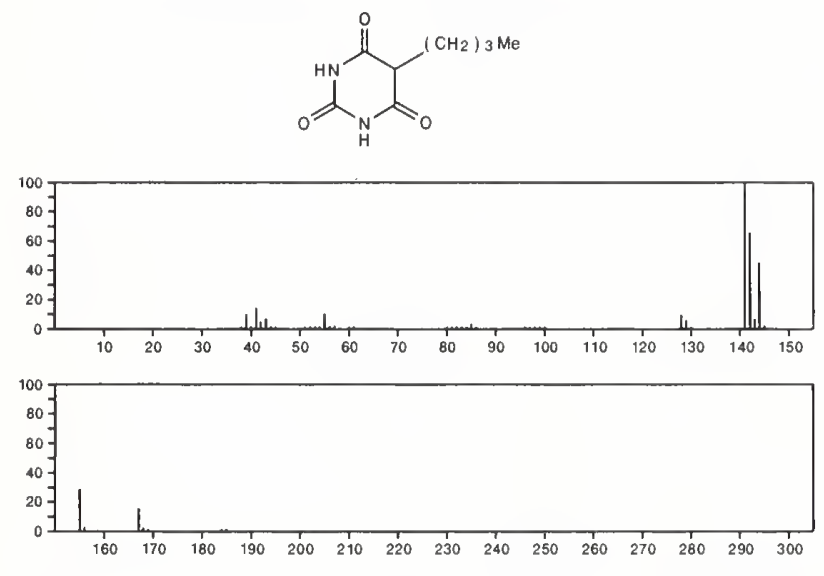

184

$\mathrm{C}_{8} \mathrm{H}_{12} \mathrm{~N}_{2} \mathrm{O}_{3}$

$7391-61-9$

2,4,6(1H,3H,5H)-Pyrimidinetrione, 5-ethyl-1,3-dimethyl-<smiles>CCC1C(=O)N(C)C(=O)N(C)C1=O</smiles>
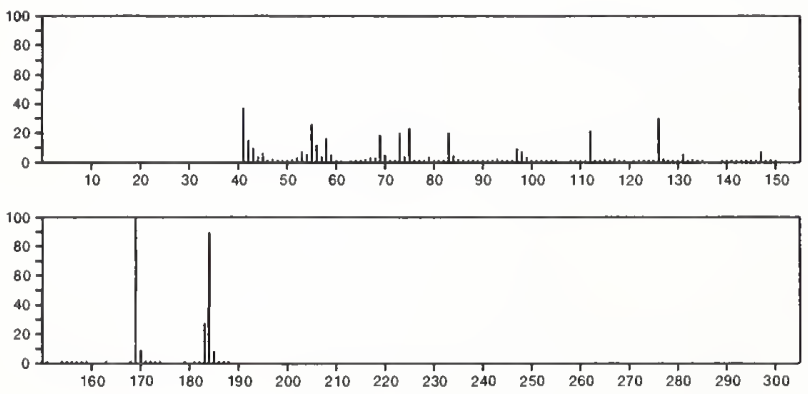

184 $\mathrm{C}_{8} \mathrm{H}_{12} \mathrm{O}_{3} \mathrm{Si}$

2-Furancarboxylic acid, trimethylsilyl ester
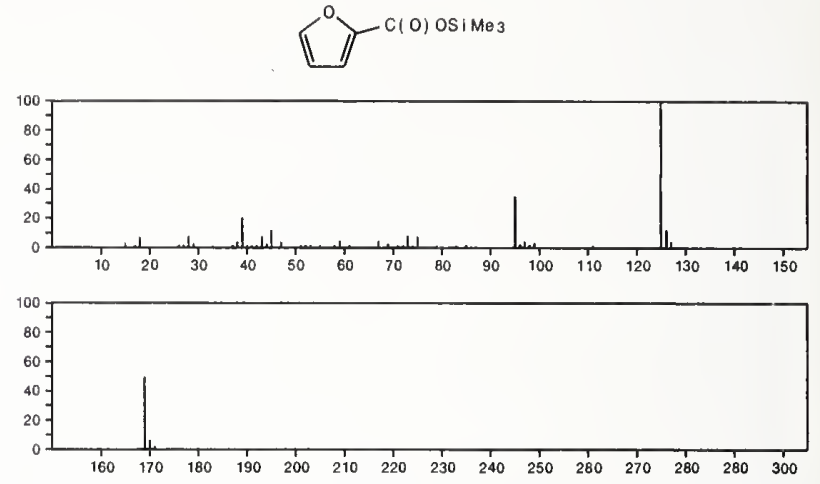

184

2-Octanol, 1,1,1-trifluoro-

$\mathrm{C}_{8} \mathrm{H}_{15} \mathrm{~F}_{3} \mathrm{O}$

$453-43-0$

$\mathrm{Me}\left(\mathrm{CH}_{2}\right){ }_{5} \mathrm{CH}(\mathrm{OH}) \mathrm{CF}_{3}$
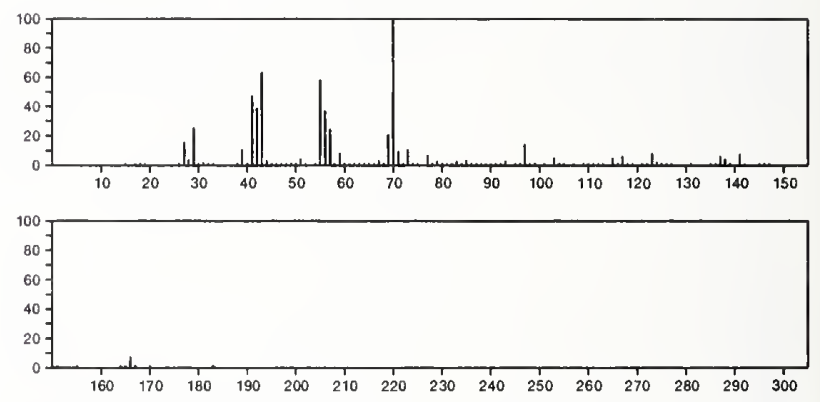

184

$\mathrm{C}_{9} \mathrm{H}_{9} \mathrm{ClO}_{2}$

Acetic acid, chloro-, phenylmethyl ester

$140-18-1$

$\mathrm{Cl} \mathrm{CH}_{2} \mathrm{C}(\mathrm{O}) \mathrm{OCH}_{2} \mathrm{Ph}$
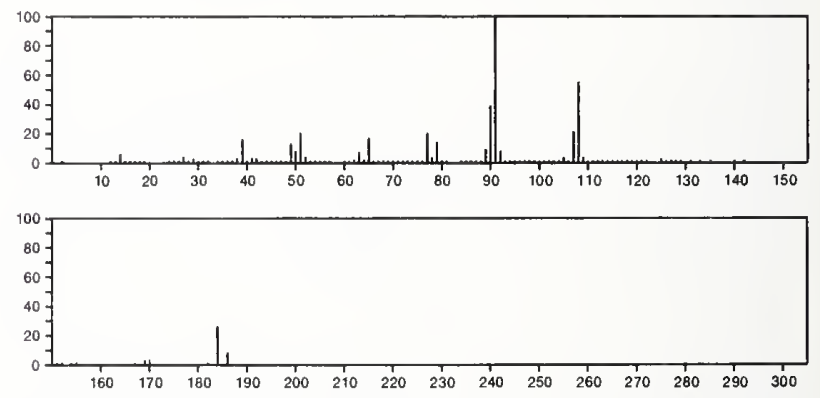

184

$\mathrm{C}_{9} \mathrm{H}_{9} \mathrm{ClO}_{2}$

Benzoic acid, 3-chloro-, ethyl ester

$1128-76-3$
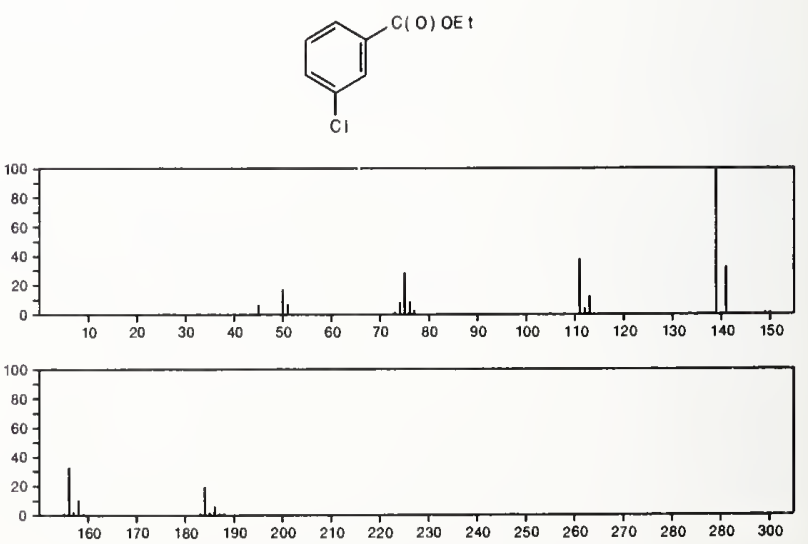
184

$\mathrm{C}_{9} \mathrm{H}_{9} \mathrm{ClO}_{2}$

1,3-Dioxolane, 2-(4-chlorophenyl)
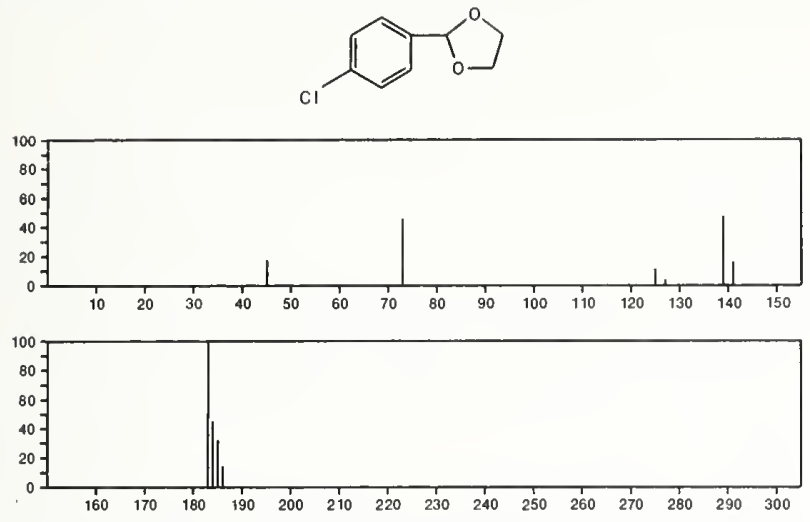

$184 \quad \mathrm{C}_{9} \mathrm{H}_{9} \mathrm{ClO}_{2} \quad 6341-98-6$

Phenol, 2-chloro-6-methyl-, acetate
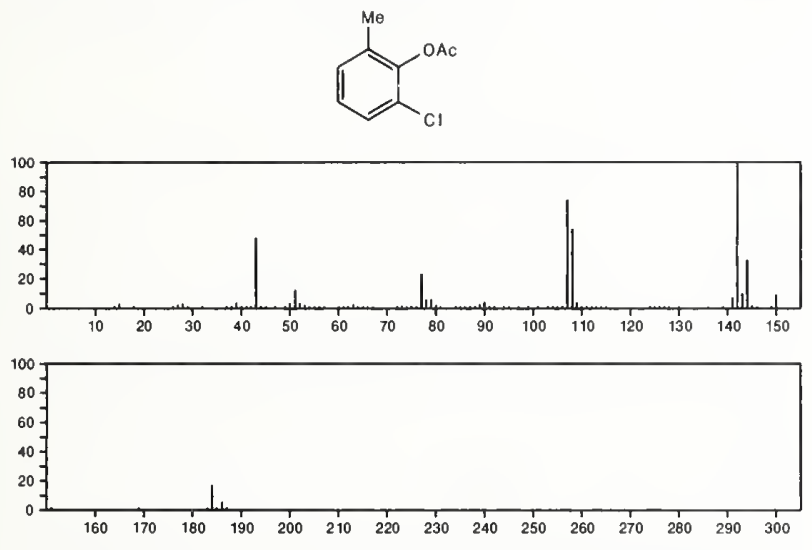

184

$\mathrm{C}_{9} \mathrm{H}_{9} \mathrm{ClO}_{2}$

$34040-64-7$

Benzoic acid, 4-(chloromethyl)-, methyl ester
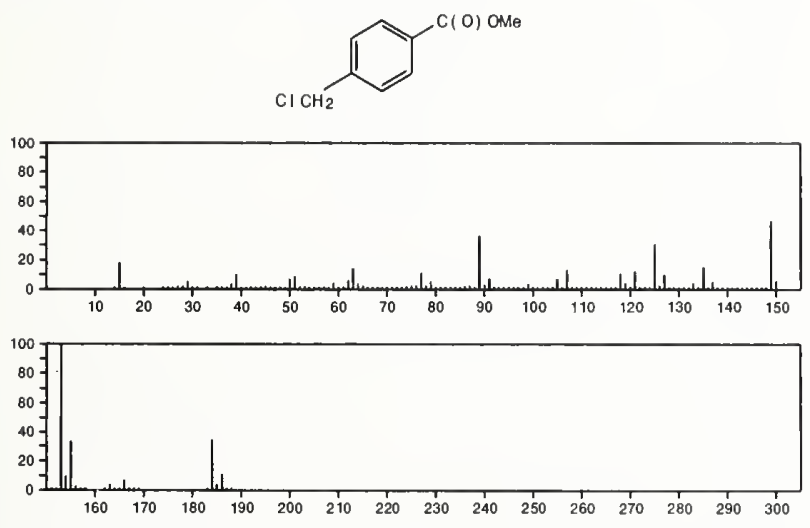

184

$\mathrm{C}_{9} \mathrm{H}_{9} \mathrm{ClO}_{2}$

$37612-52-5$

Ethanone, 1-(3-chloro-4-methoxyphenyl)-
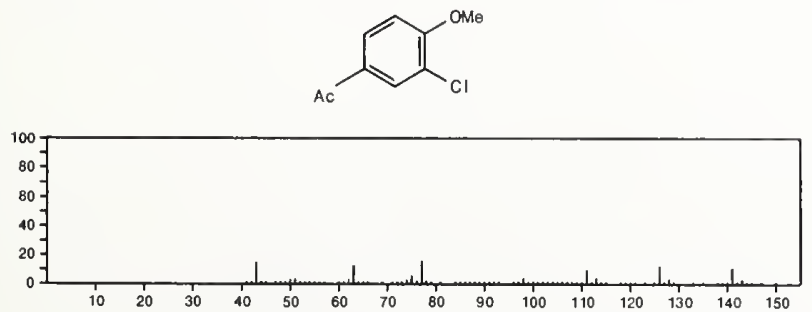

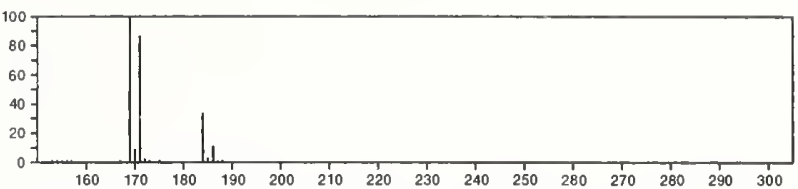

184 $_{9} \mathrm{H}_{12} \mathrm{O}_{2} \mathrm{~S}$
9-Thiabicyclo[6.2.0]deca-1(8),6-diene, 9,9-dioxide

$20452-34-0$<smiles>O=S1(=O)CC2=CC=CCCCCC2C1</smiles>
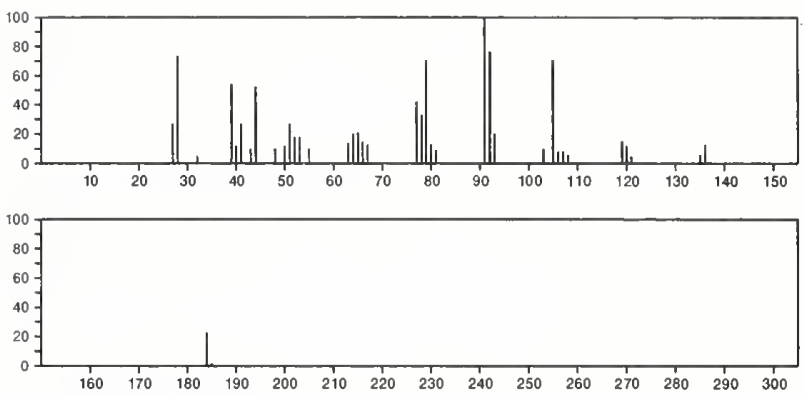

184

$\mathrm{C}_{9} \mathrm{H}_{12} \mathrm{O}_{2} \mathrm{~S}$

$56666-52-5$

2-Thiabicyclo[3.1.0]hex-3-ene-6-carboxylic acid, 1,3-dimethyl-, methyl ester
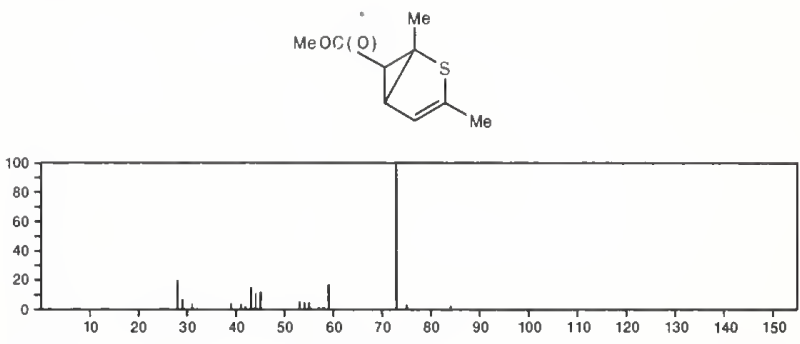

184

$\mathrm{C}_{9} \mathrm{H}_{12} \mathrm{O}_{4}$

$35339-97-0$

3-Furancarboxylic acid, 2-(methoxymethyl)-5-methyl-, methyl ester
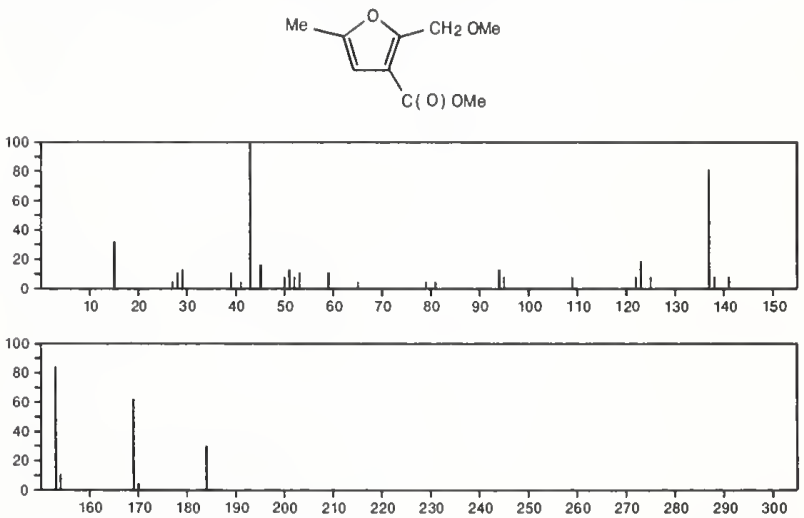

3-Furancarboxylic acid, 2-(ethoxymethyl)-5-methyl-

$35339-99-2$
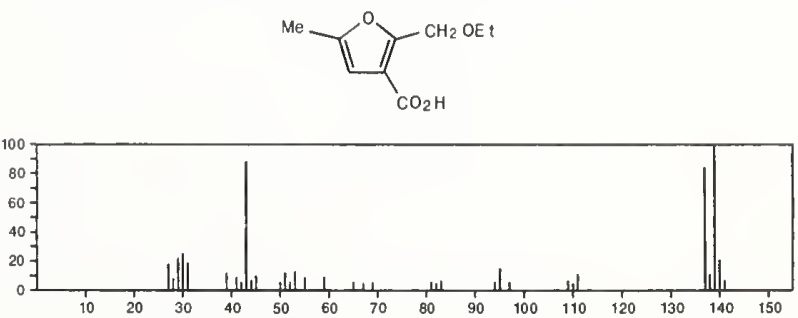


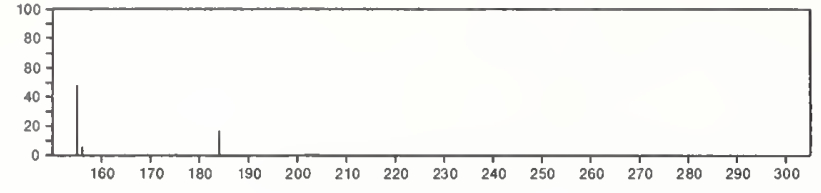

184

$\mathrm{C}_{9} \mathrm{H}_{12} \mathrm{O}_{4}$

$35340-00-2$

3-Furancarboxylic acid, 5-(methoxymethyl)-2-methyl-, methyl ester<smiles>COCc1cc(C(C)=O)c([18O])o1</smiles>
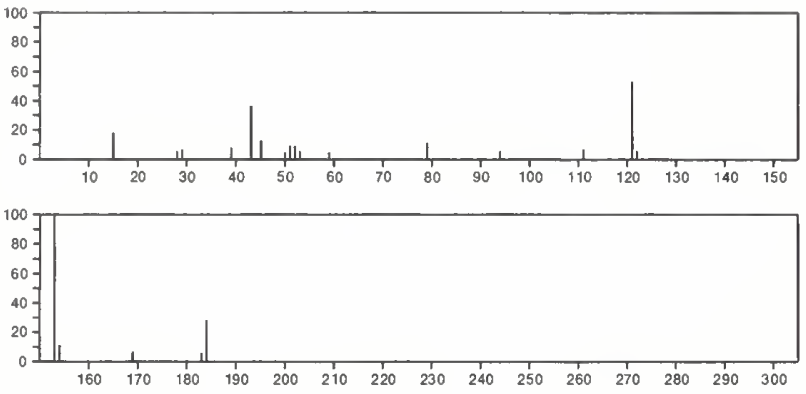

$184 \quad \mathrm{C}_{9} \mathrm{H}_{12} \mathrm{O}_{4} \quad 35340-01-3$ 3-Furancarboxylic acid, 5-(ethoxymethyl)-2-methyl--
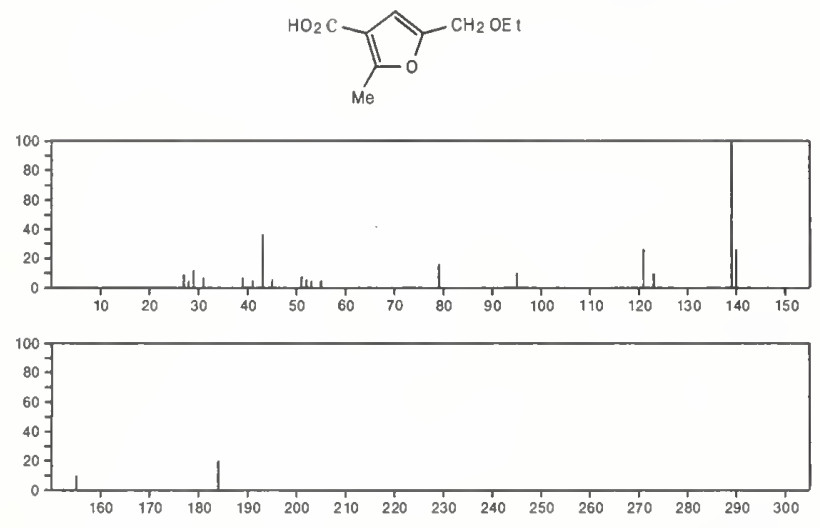

184

$\mathrm{C}_{9} \mathrm{H}_{12} \mathrm{~S}_{2}$

$54774-96-8$

Thiophene, 2-(cyclopentylthio)-
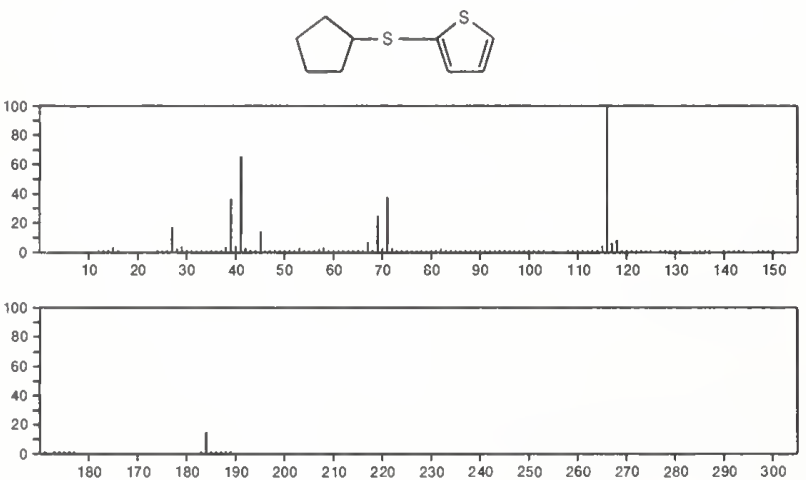

184

$\mathrm{C}_{9} \mathrm{H}_{16} \mathrm{~N}_{2} \mathrm{O}_{2}$

$640-01-7$

4-Piperidinone, 2,2,6,6-tetramethyl-1-nitroso-
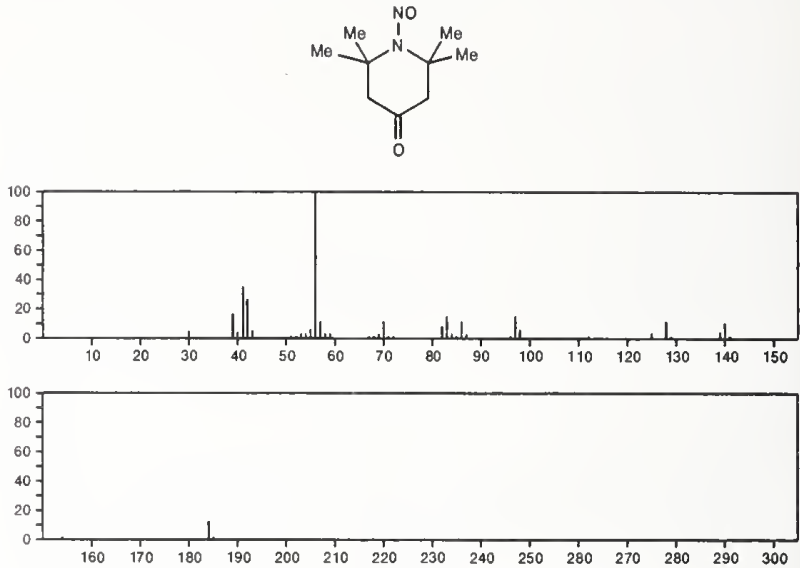

184

$\mathrm{C}_{9} \mathrm{H}_{17} \mathrm{BO}_{3}$

$55162-66-8$

1,3,2-Dioxaborolane, 2-[(2-methylcyclohexyl)oxy]
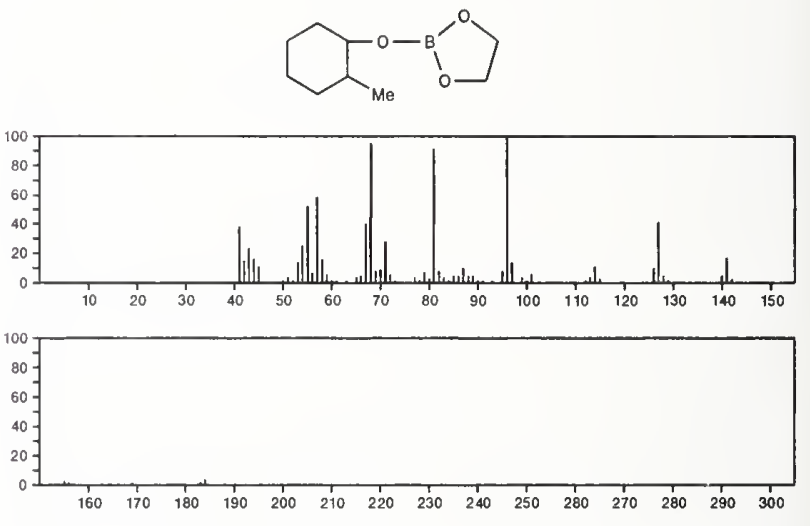

184

$\mathrm{C}_{10} \mathrm{H}_{8} \mathrm{~N}_{4}$

$1,3,6,9 \mathrm{~b}$-Tetraazaphenalene, 2-methyl-

$37550-68-8$
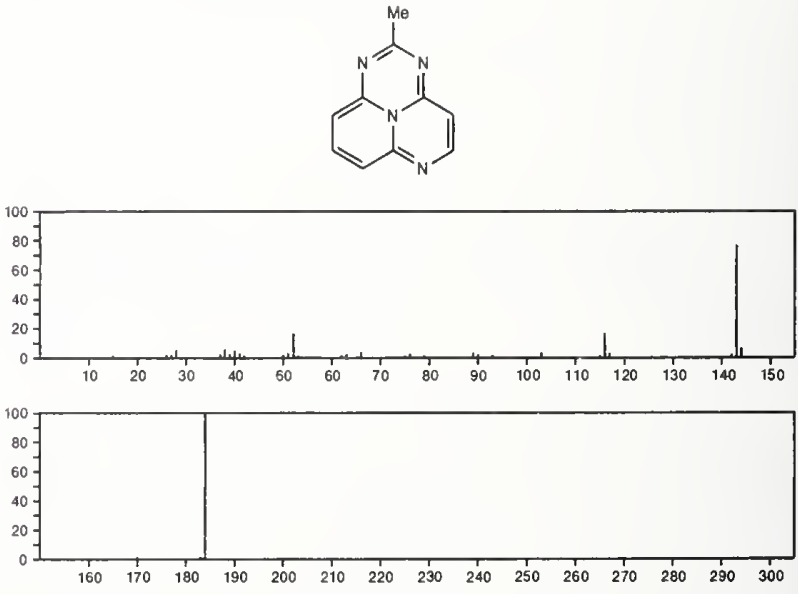
184 $\mathrm{C}_{10} \mathrm{H}_{13} \mathrm{ClO}$

Phenol, 4-chloro-5-methyl-2-(1-methylethyl)
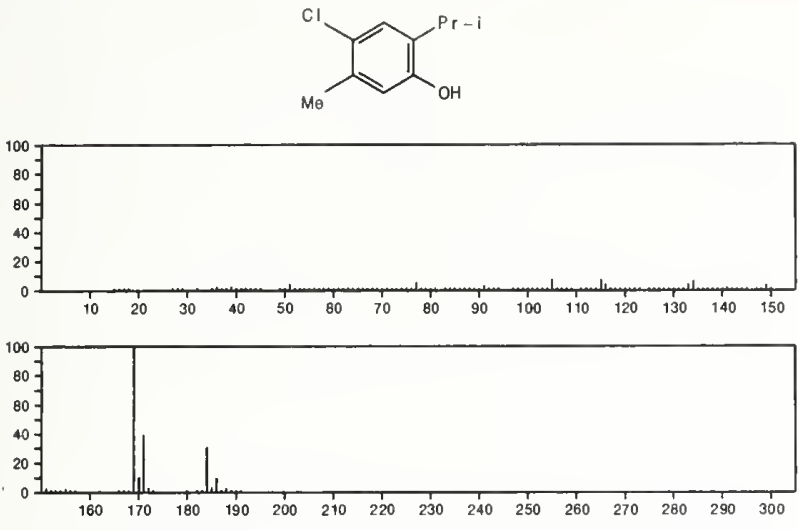

184

$\mathrm{C}_{10} \mathrm{H}_{13} \mathrm{ClO}$

Phenol, 2-chloro-4-(1,1-dimethylethyl)-
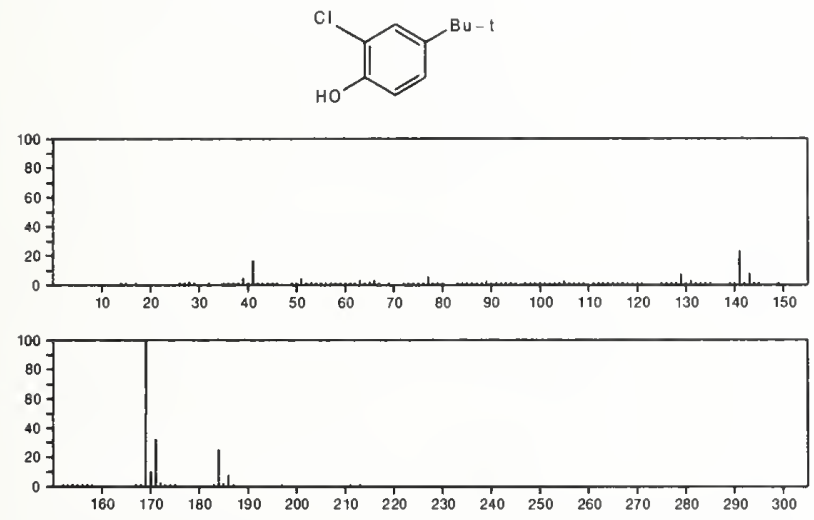

184

$\mathrm{C}_{10} \mathrm{H}_{13} \mathrm{ClO}$

Phenol, 2-chloro-6-(1,1-dimethylethyl)-
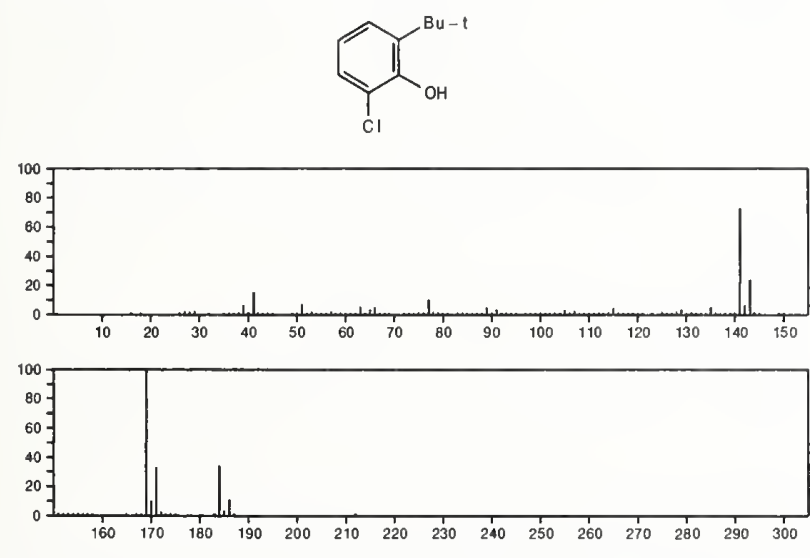

184

$\mathrm{C}_{10} \mathrm{H}_{13} \mathrm{ClO}$

$19301-54-3$

Tricyclo[3.3.1.1 $\left.1^{3,7}\right]$ decanone, 4 -chloro-, $(1 \alpha, 3 \beta, 4 \beta, 5 \alpha, 7 \beta)-$
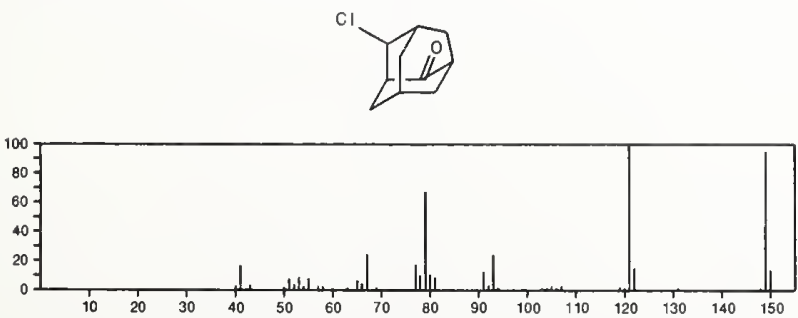

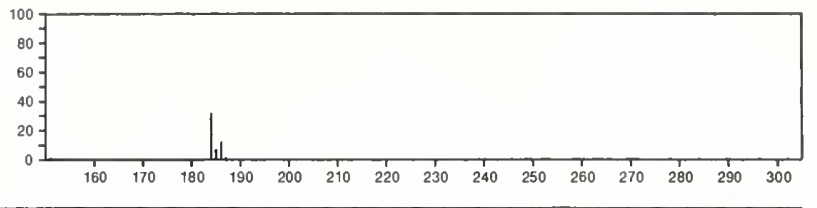

$184 \quad \mathrm{C}_{10} \mathrm{H}_{13} \mathrm{ClO}$ 19543-61-4

Tricyclo[3.3.1.13,7]decanone, 4 -chloro-, $[1 S-(1 \alpha, 3 \beta, 4 \alpha, 5 \alpha, 7 \beta)]-$
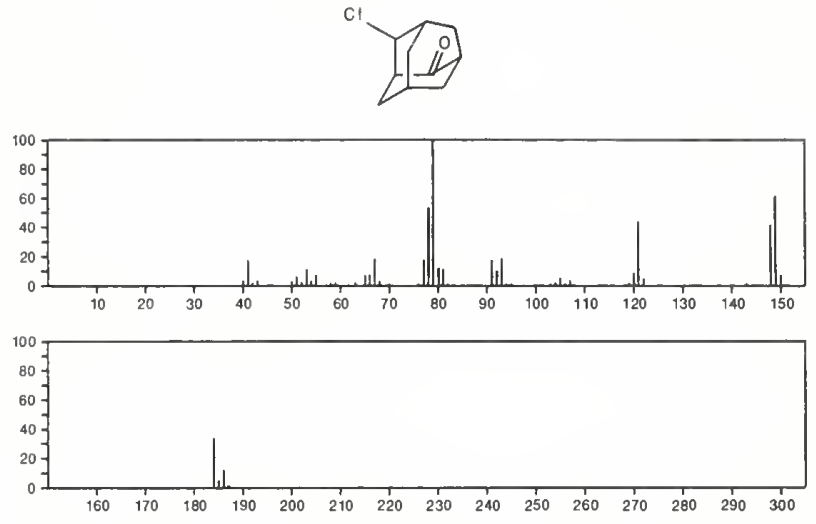

184

$\mathrm{C}_{10} \mathrm{H}_{13} \mathrm{ClO}$

Benzene, (1-chloro-3-methoxypropyl)-

$55955-55-0$

$\mathrm{PhCHCl} \mathrm{CH} \mathrm{CH}_{2} \mathrm{OMe}$
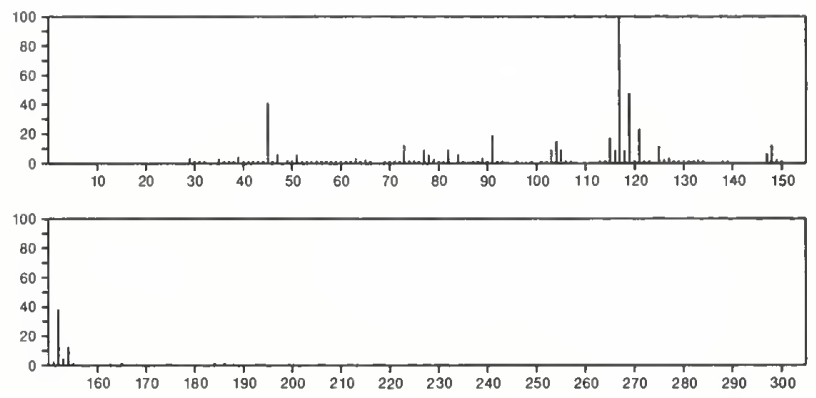

184

$\mathrm{C}_{10} \mathrm{H}_{16} \mathrm{O}_{3}$

$14128-60-0$

Cyclopentanepropionic acid, $\alpha$-methyl-2-oxo-, methyl ester
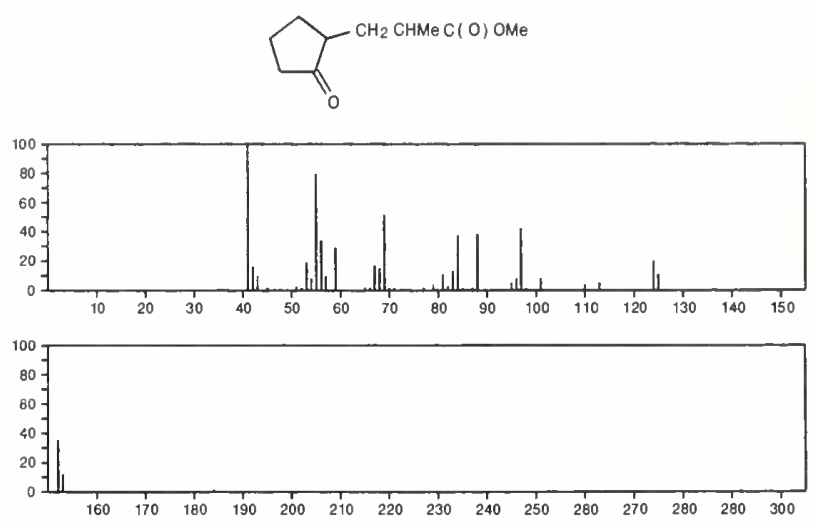

184

1-Propene, $3,3^{\prime}, 3^{\prime \prime}-[$ methylidynetris(oxy)] tris-

$16754-50-0$

$$
\mathrm{C}_{10} \mathrm{H}_{16} \mathrm{O}_{3}
$$

$\mathrm{OCH}_{2} \mathrm{CH}=\mathrm{CH}_{2}$

$\mathrm{H}_{2} \mathrm{C}=\mathrm{CHCH}_{2} \mathrm{OCHOCH}_{2} \mathrm{CH}=\mathrm{CH}_{2}$

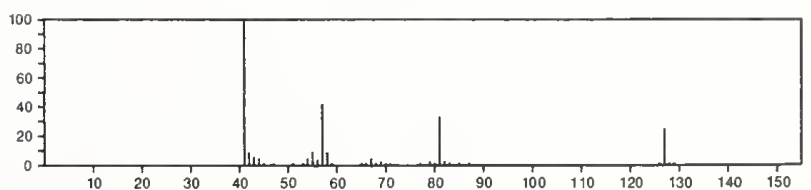




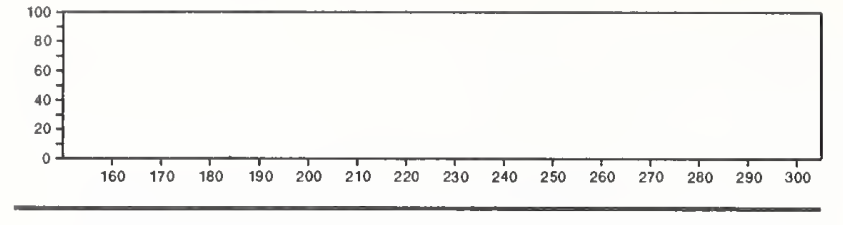

$184 \quad \mathrm{C}_{10} \mathrm{H}_{16} \mathrm{O}_{3}$

1,2-Butanediol, 1-(2-furyl)-2,3-dimethyl-

$18927-22-5$

${ }^{\circ} \mathrm{CH}(\mathrm{OH}) \mathrm{CMe}(\mathrm{OH}) \mathrm{CHM}_{2}$
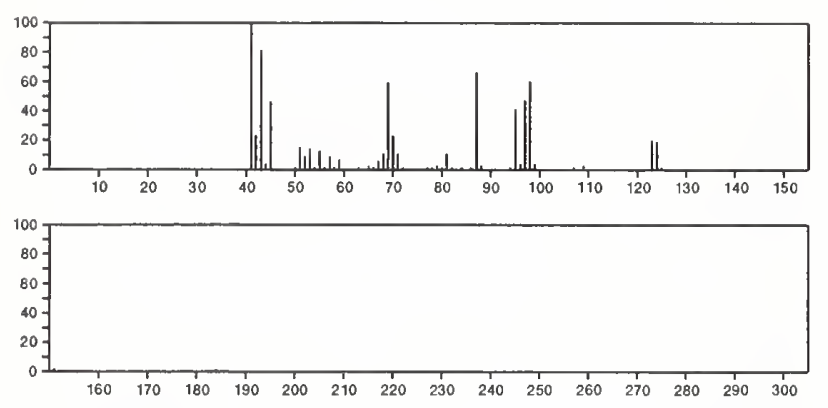

$184 \quad \mathrm{C}_{10} \mathrm{H}_{16} \mathrm{O}_{3} \quad 36903-65-8$ 1,3-Cyclopentanedione, 4-hydroxy-5-(3-methylbutyl)-
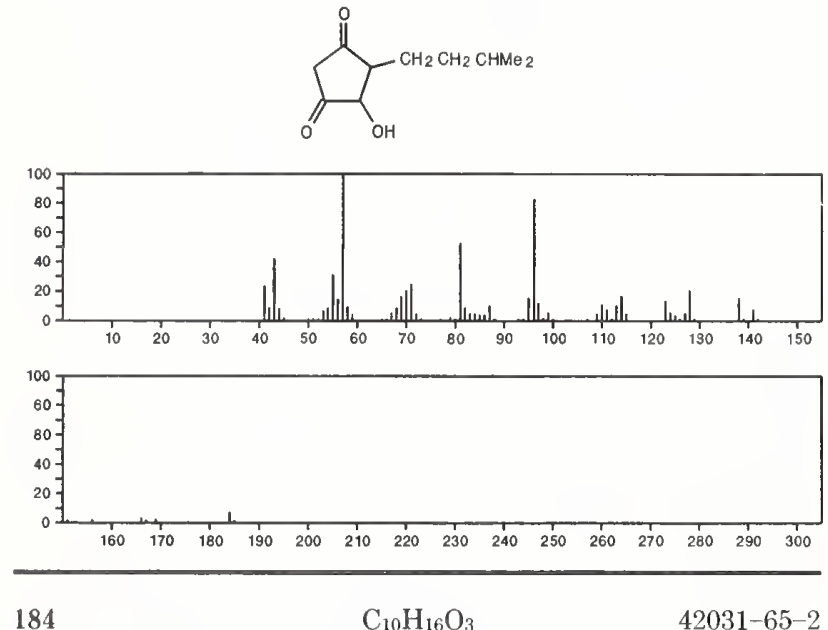

4,5-Oxepanedione, 3,3,6,6-tetramethyl-

$42031-65-2$
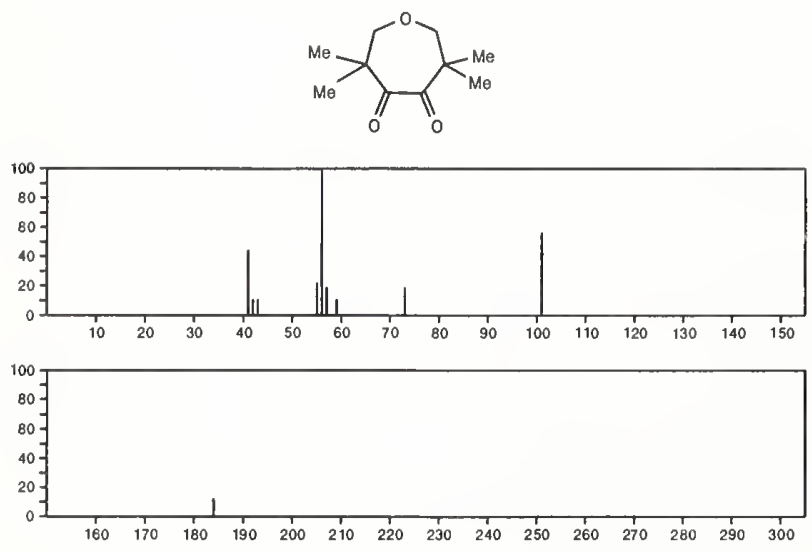

184

Bicyclo[2.2.2]octane-1,4-diol, monoacetate

$54774-94-6$
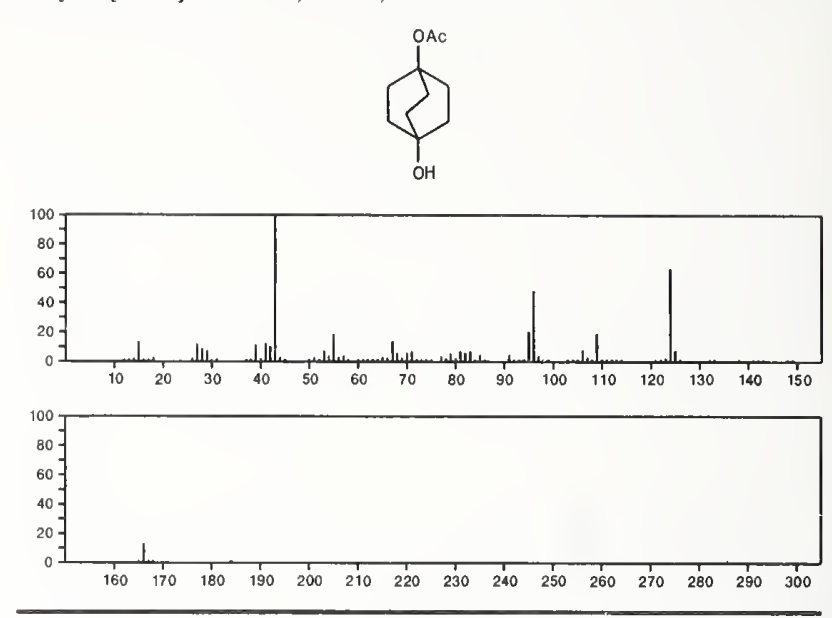

184

$\mathrm{C}_{10} \mathrm{H}_{16} \mathrm{O}_{3}$

1,3-Cyclopentanedione, 4-hydroxy-2-pentyl-

$54774-95-7$
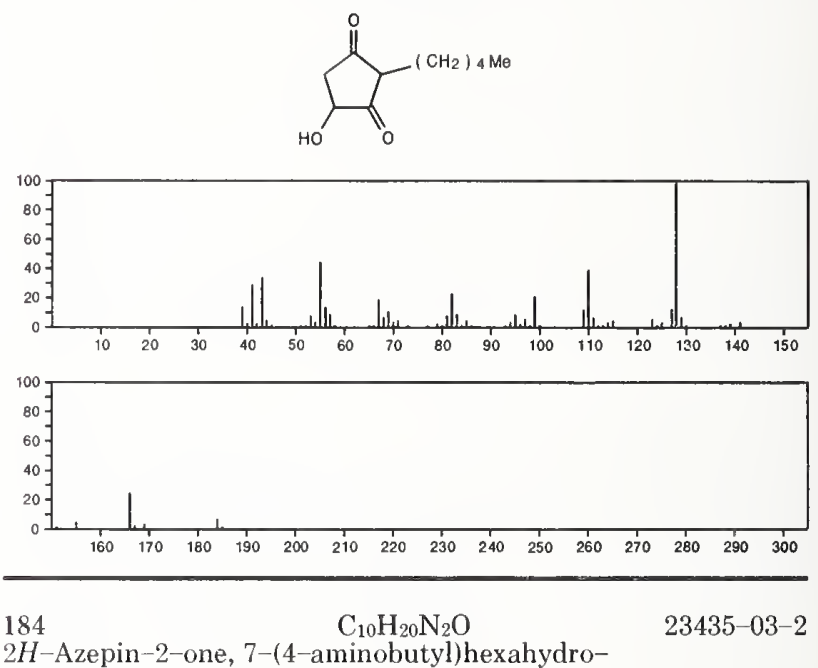

2H-Azepin-2-one, 7-(4-aminobutyl)hexahydro-
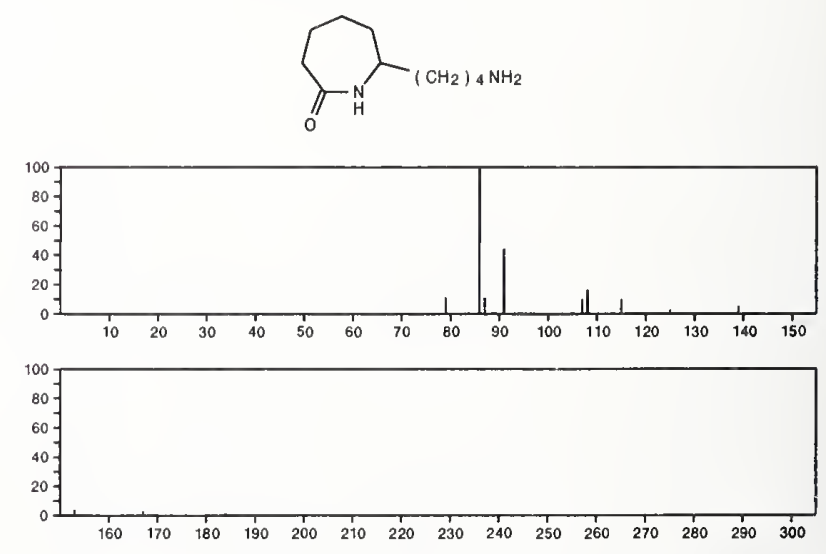

184

$\mathrm{C}_{10} \mathrm{H}_{20} \mathrm{~N}_{2} \mathrm{O}$

3-Buten-2-one, 4-(diethylamino)-4-(dimethylamino)-

$49582-49-2$

Me COCH : $\begin{gathered}\text { Nine } 2 \\ \text { CNEt } 2\end{gathered}$

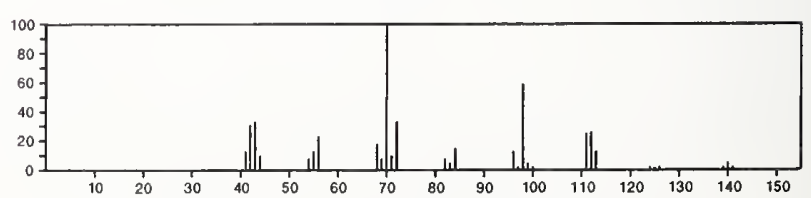




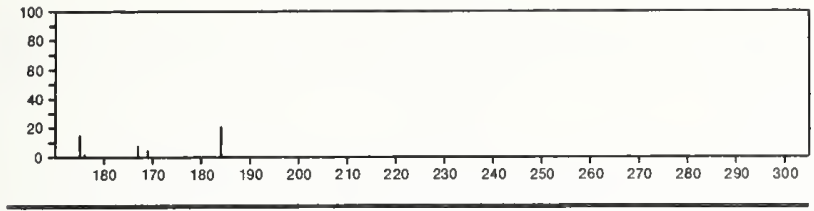

184

$\mathrm{C}_{10} \mathrm{H}_{20} \mathrm{~N}_{2} \mathrm{O}$

$55975-99-0$

Propanal, 2-(cyclohexylamino)-2-methyl-, oxime
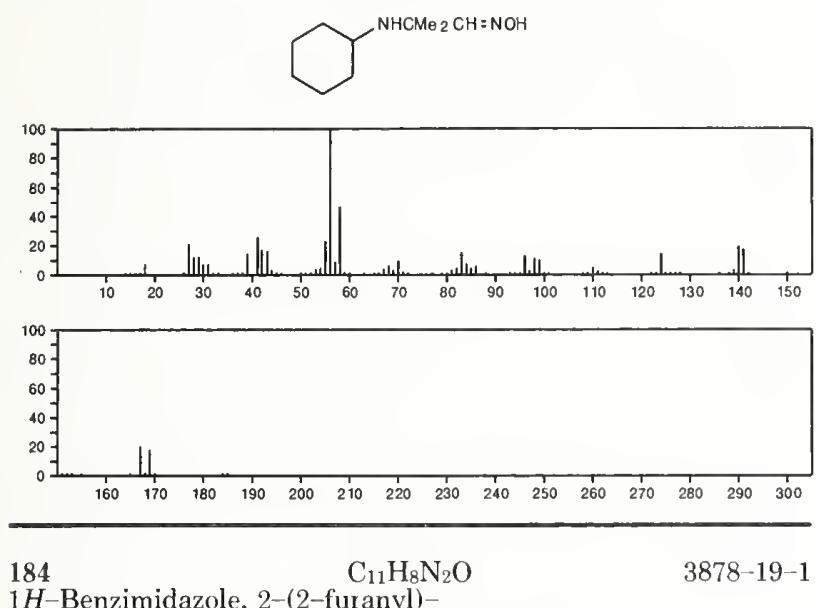

$1 H$-Benzimidazole, 2-(2-furanyl)-
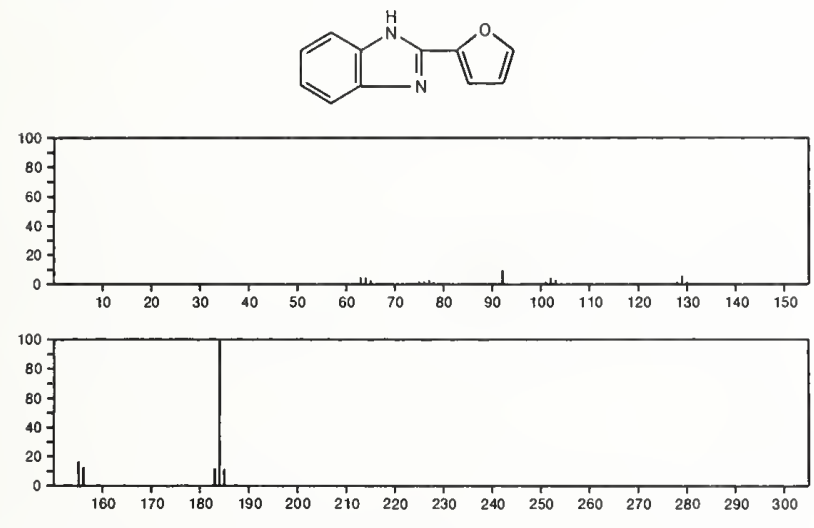

184
$4(3 H)$-Quinazolinone,
$\mathrm{C}_{11} \mathrm{H}_{8} \mathrm{~N}_{2} \mathrm{O}$
$3-(2-$ propynyl $)-$
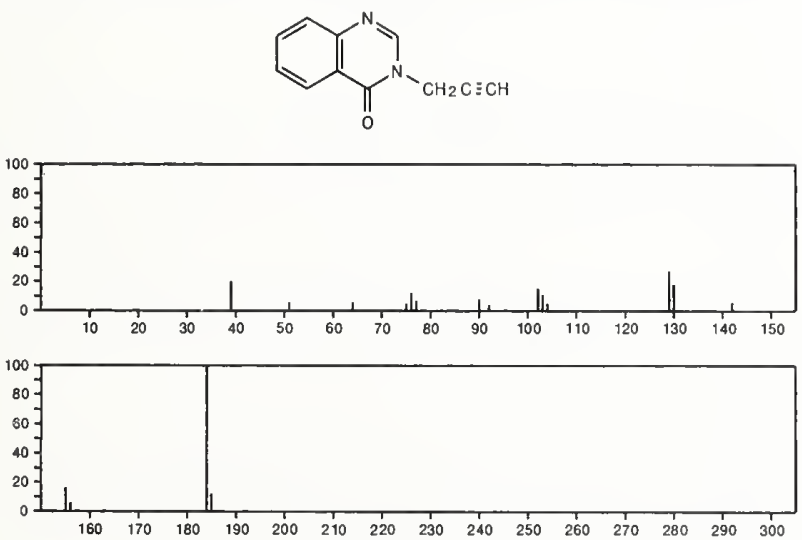

184

$\mathrm{C}_{11} \mathrm{H}_{8} \mathrm{~N}_{2} \mathrm{O}$

$19062-85-2$<smiles>CC1=Cc2ccccc2N=C(C#N)O1</smiles>
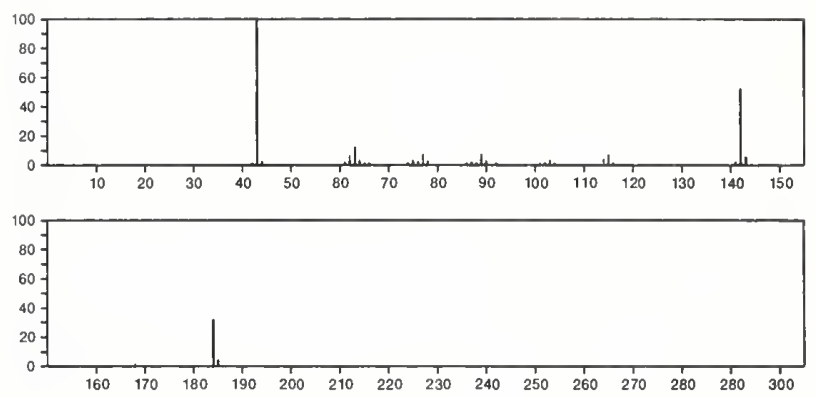

184

$\mathrm{C}_{11} \mathrm{H}_{8} \mathrm{~N}_{2} \mathrm{O}$

$19062-86-3$

3,1-Benzoxazepine-2-carbonitrile, 5-methyl-
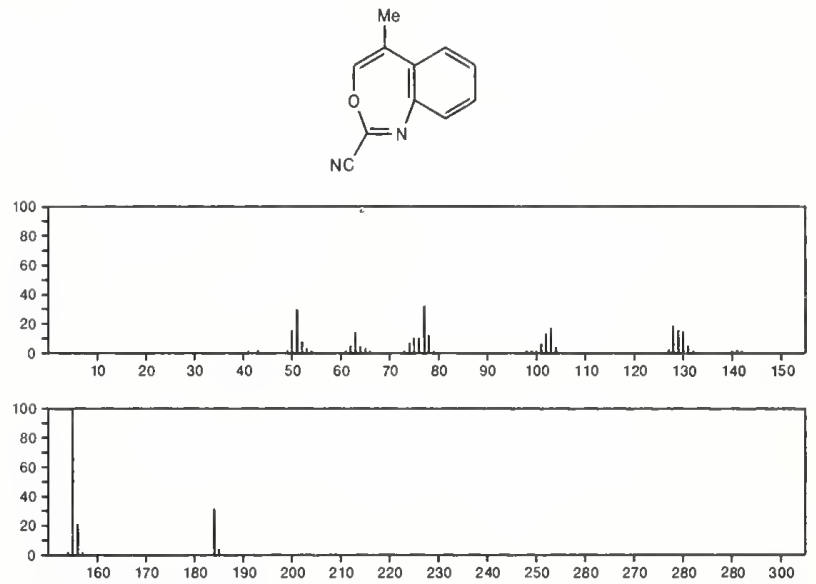

184

$\mathrm{C}_{11} \mathrm{H}_{8} \mathrm{~N}_{2} \mathrm{O}$

$19062-87-4$

3,1-Benzoxazepine-2-carbonitrile, 7-methyl-
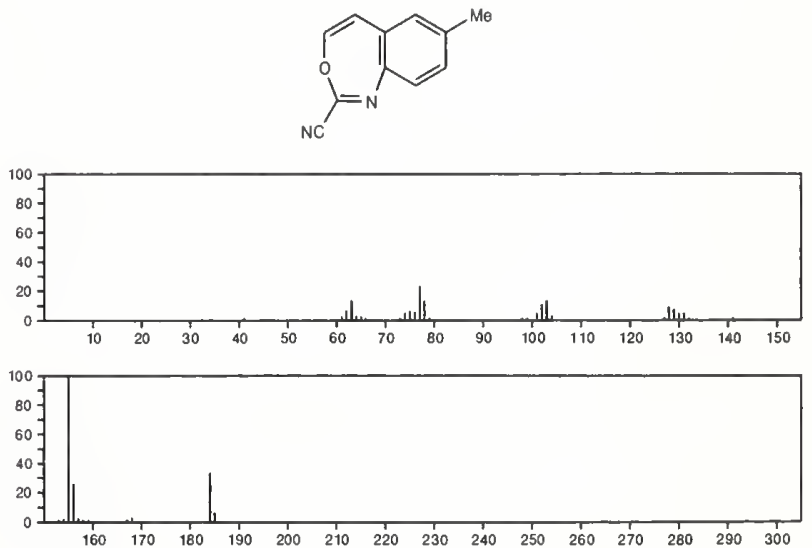
184

$\mathrm{C}_{11} \mathrm{H}_{8} \mathrm{~N}_{2} \mathrm{O}$

4(3H)-Quinazolinone, 3-propadienyl-
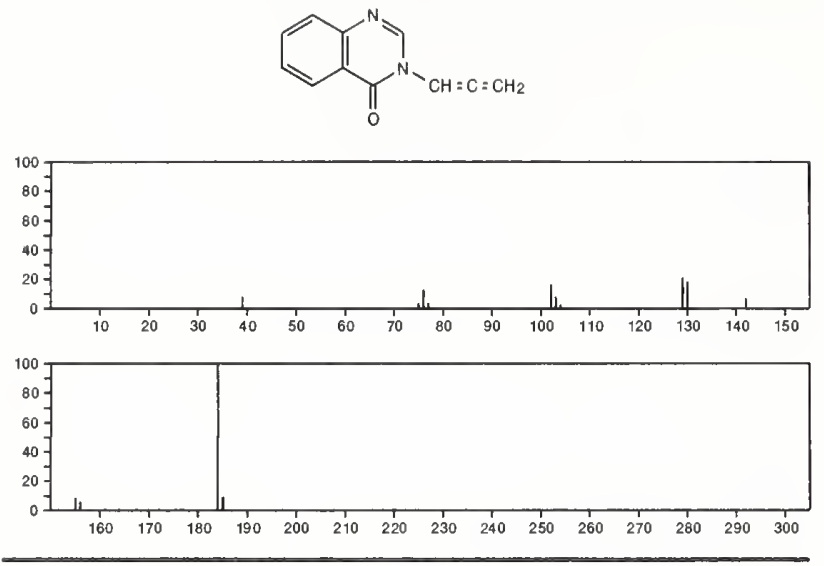

184

$\mathrm{C}_{11} \mathrm{H}_{17} \mathrm{Cl}$

Tricyclo[4.3.1.13,8]undecane, 1-chloro-

$27011-46-7$
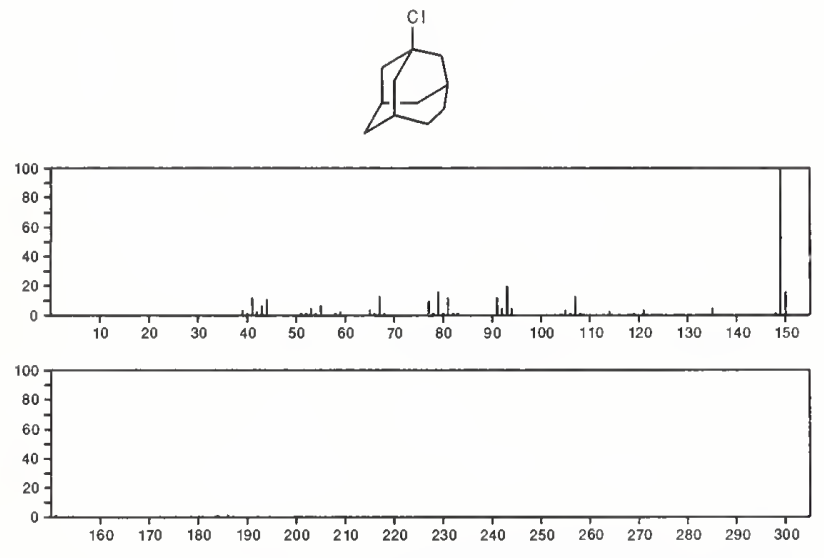

$184 \quad \mathrm{C}_{11} \mathrm{H}_{17} \mathrm{Cl}$

Tricyclo[4.3.1.13,8]undecane, 3-chloro-
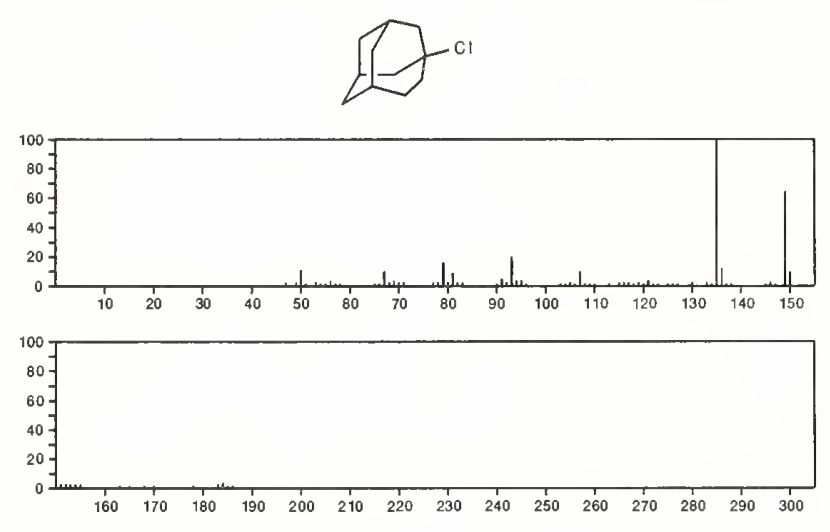

$184 \quad \mathrm{C}_{11} \mathrm{H}_{20} \mathrm{O}_{2} \quad 104-67-6$

2(3H)-Furanone, 5-heptyldihydro-

$\int_{0}^{\left(\mathrm{CH}_{2}\right) 6 \mathrm{Me}}$

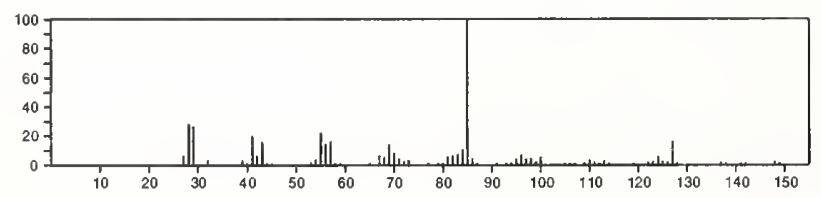

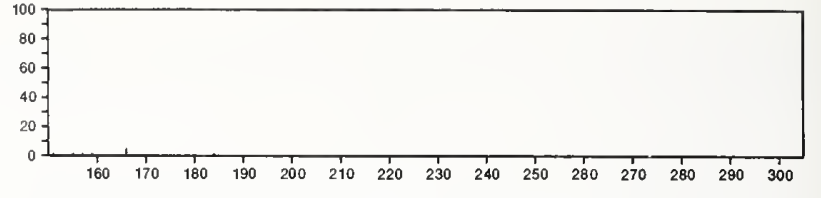

184

1,5-Dioxaspiro[5.5] undecane, 3,3-dimethyl-

707-29-9
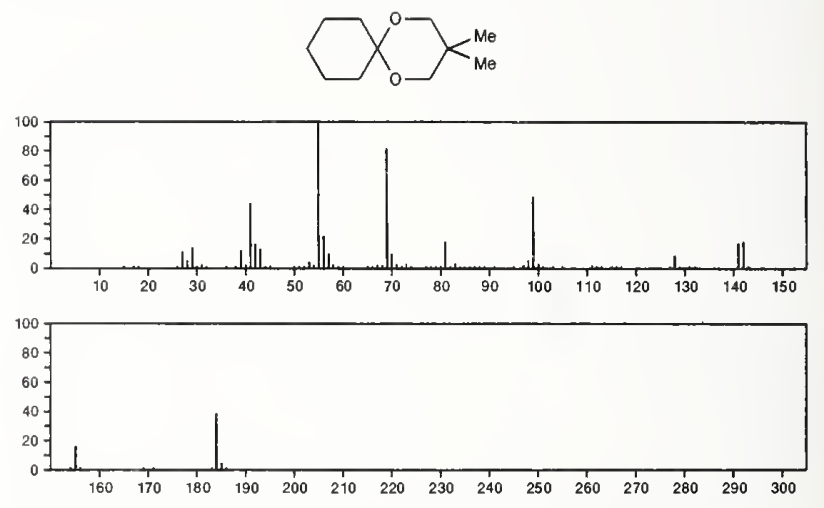

184

$\mathrm{C}_{11} \mathrm{H}_{20} \mathrm{O}_{2}$

2H-Pyran-2-one, 6-hexyltetrahydro-

$710-04-3$
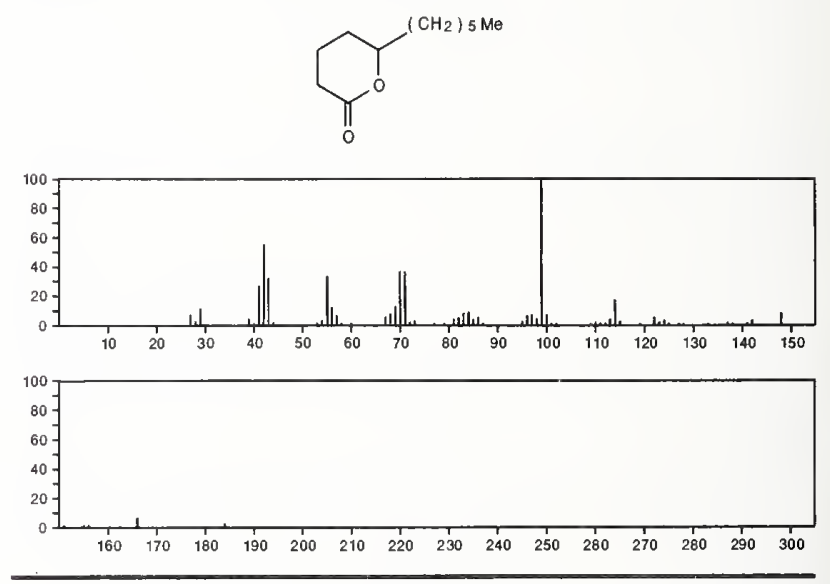

184

$\mathrm{C}_{11} \mathrm{H}_{20} \mathrm{O}_{2}$

943-28-2

Cyclohexanecarboxylic acid, 4-(1,1-dimethylethyl)-, cis-
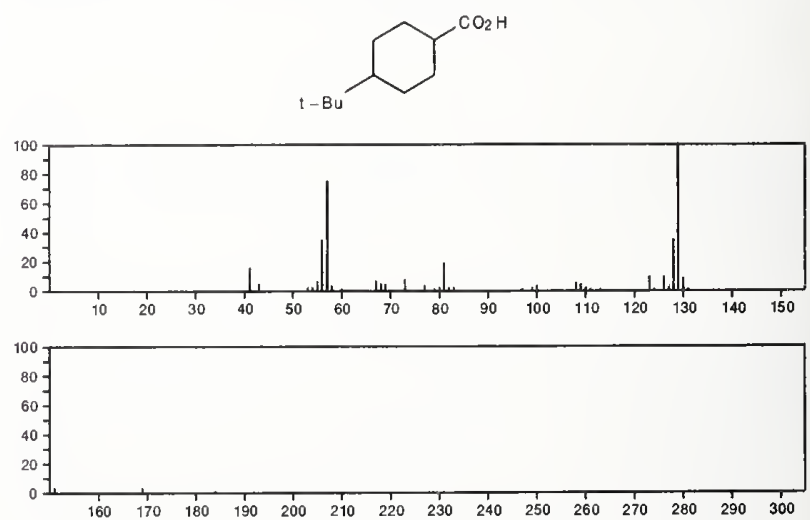
$184 \quad \mathrm{C}_{11} \mathrm{H}_{20} \mathrm{O}_{2} \quad 943-29-3$

Cyclohexanecarboxylic acid, 4-(1,1-dimethylethyl)-, trans-
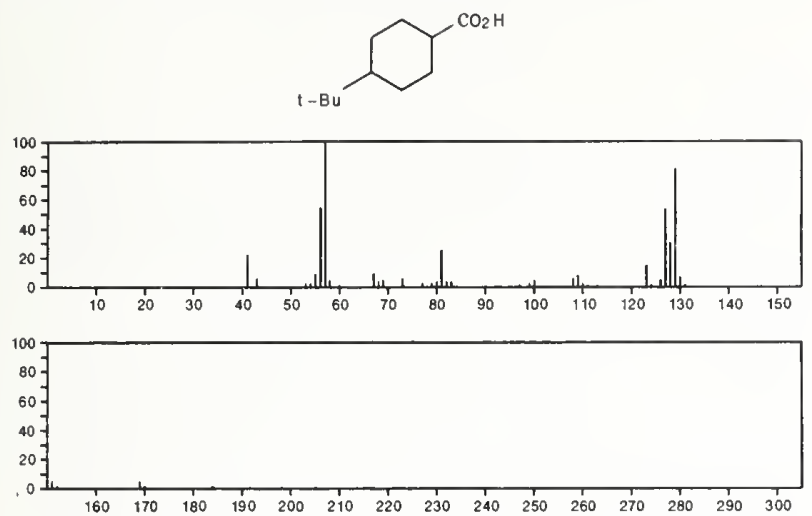

$$
-
$$

184

4-Decenoic $\mathrm{C}_{11} \mathrm{H}_{20} \mathrm{O}_{2}$

$1191-02-2$

$\mathrm{MBOC}(\mathrm{O}) \mathrm{CH}_{2} \mathrm{CH}_{2} \mathrm{CH}=\mathrm{CH}\left(\mathrm{CH}_{2}\right)_{4} \mathrm{Me}$
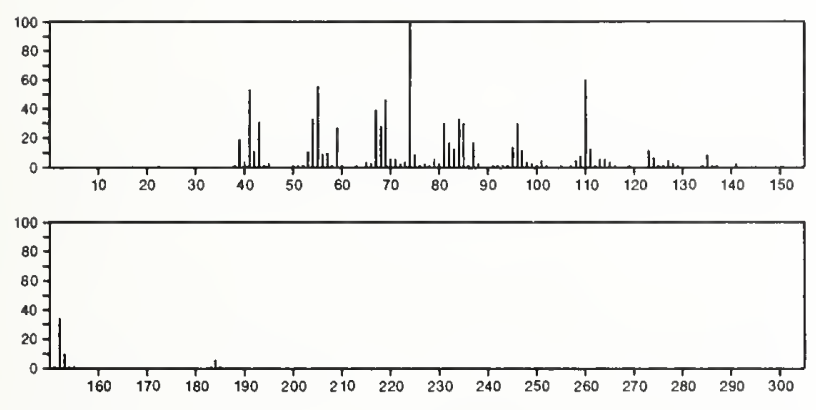

$184 \quad \mathrm{C}_{11} \mathrm{H}_{20} \mathrm{O}_{2}$

2-Decenoic acid, methyl ester

2482-39-5

$\mathrm{Me}\left(\mathrm{CH}_{2}\right)_{6} \mathrm{CH}=\mathrm{CHC}(\mathrm{O}) \mathrm{OMe}$
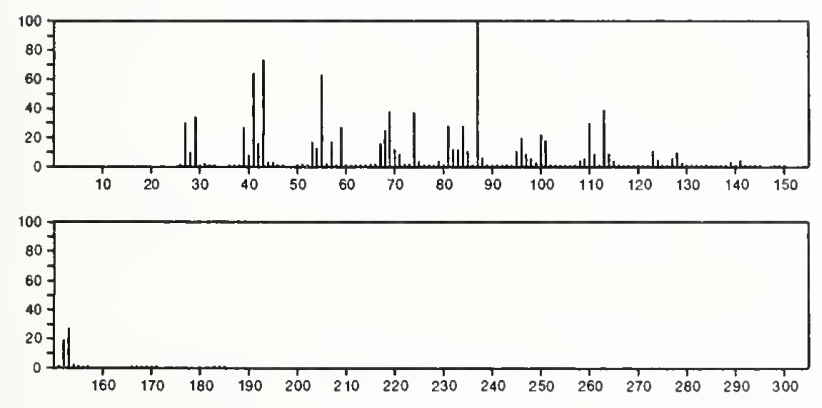

$184 \quad \mathrm{C}_{11} \mathrm{H}_{20} \mathrm{O}_{2} \quad 2499-59-4$

2-Propenoic acid, octyl ester

$\mathrm{H}_{2} \mathrm{C}=\mathrm{CHC}(\mathrm{O}) \mathrm{O}\left(\mathrm{CH}_{2}\right)>\mathrm{Me}$

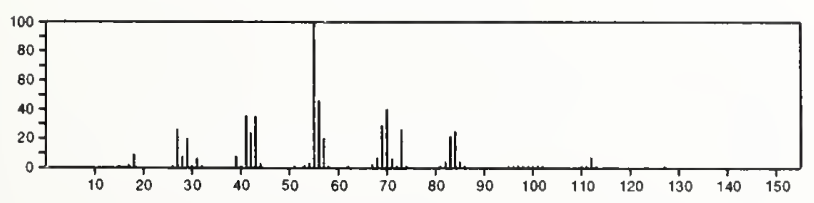

184 $\mathrm{C}_{11} \mathrm{H}_{20} \mathrm{O}_{2}$
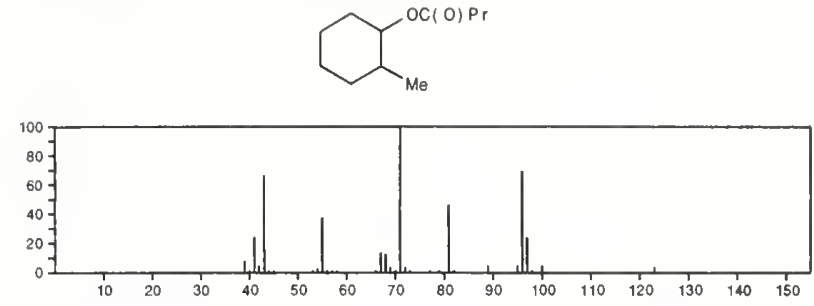

184

Cyclohexanecarboxylic acid, 1-(1,1-dimethylethyl)-

$27334-43-6$
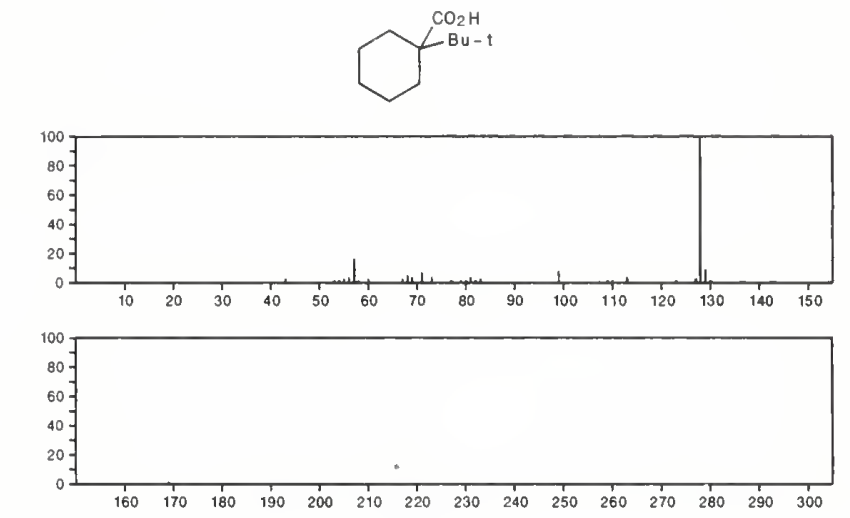

$184 \quad \mathrm{C}_{11} \mathrm{H}_{20} \mathrm{O}_{2} \quad 27392-15-0$ Cyclohexanecarboxylic acid, 2-(1,1-dimethylethyl)-, cis-
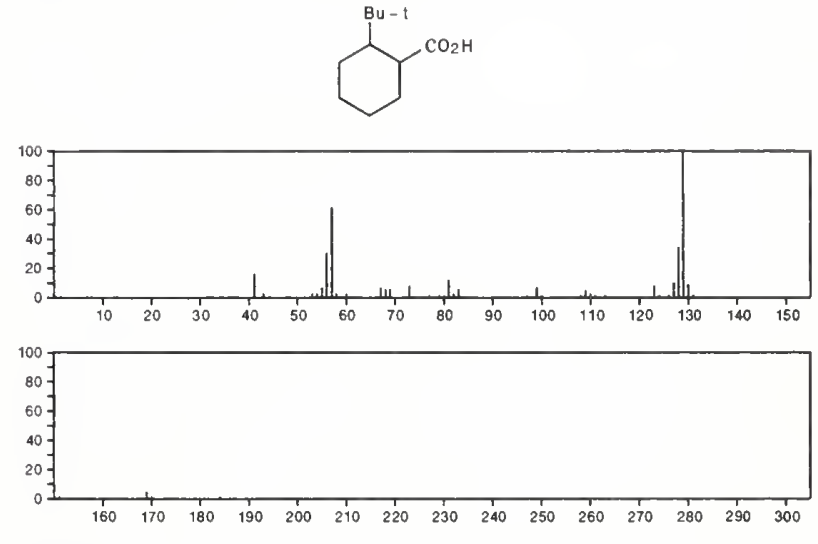

$184 \quad \mathrm{C}_{11} \mathrm{H}_{20} \mathrm{O}_{2} \quad 27392-16-1$

Cyclohexanecarboxylic acid, 2-(1,1-dimethylethyl)-, trans-
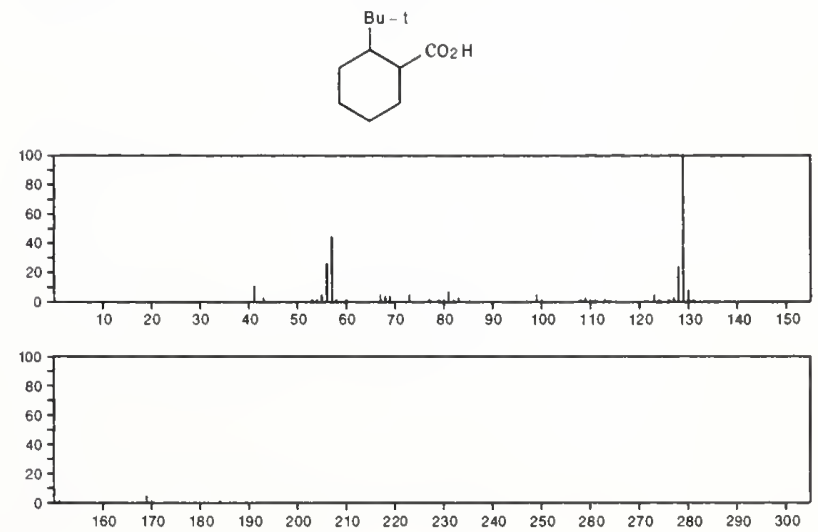
184

$\mathrm{C}_{11} \mathrm{H}_{20} \mathrm{O}_{2}$

Cyclohexanecarboxylic acid, 3-(1,1-dimethylethyl)-, cis
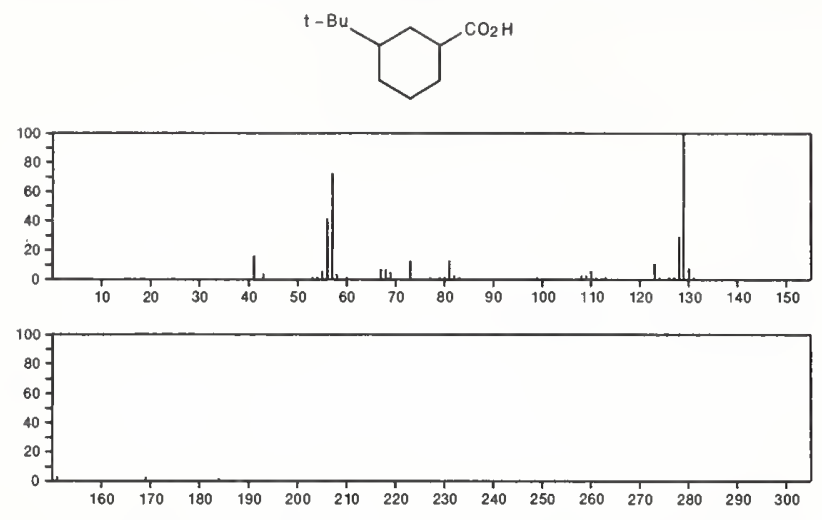

$184 \quad \mathrm{C}_{11} \mathrm{H}_{20} \mathrm{O}_{2} \quad 27392-18-3$ Cyclohexanedicarboxylic acid, 3-(1,1-dimethylethyl)-, trans-
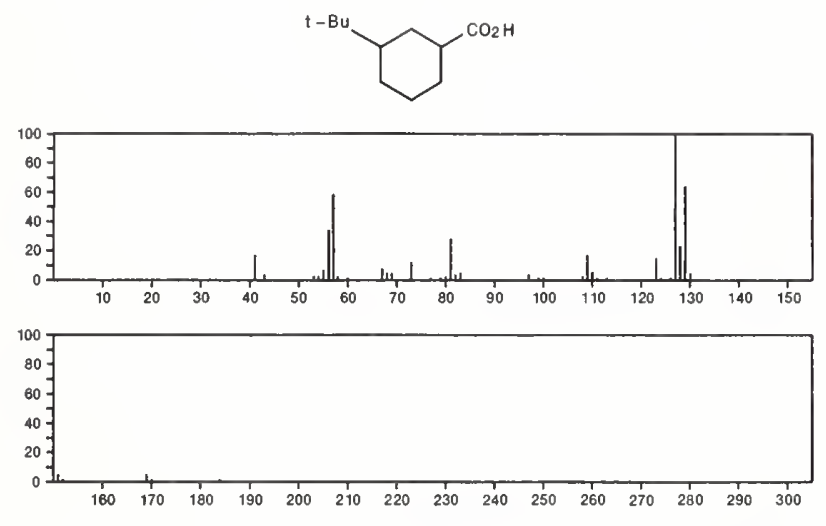

$184 \quad \mathrm{C}_{11} \mathrm{H}_{20} \mathrm{O}_{2} \quad 35194-39-9$ 8-Nonenoic acid, ethyl ester

$\mathrm{H}_{2} \mathrm{C}=\mathrm{CH}\left(\mathrm{CH}_{2}\right) \& \mathrm{C}(\mathrm{O}) \mathrm{OE}$
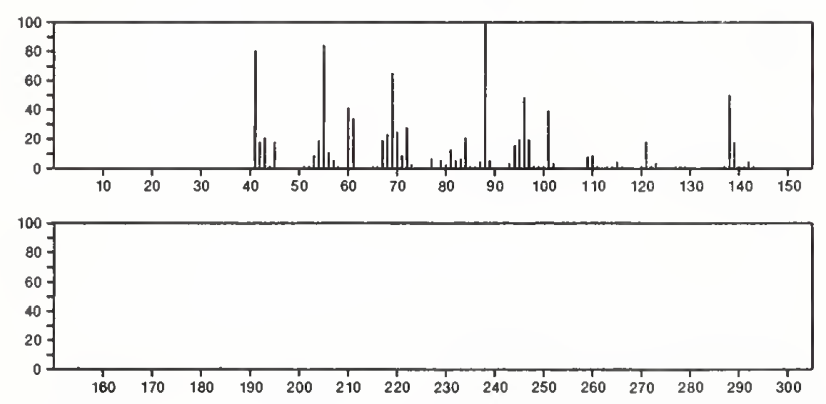

184

$\mathrm{C}_{11} \mathrm{H}_{20} \mathrm{O}$

54714-35-1

Butanoic acid, 2-methylcyclohexyl ester, cis-
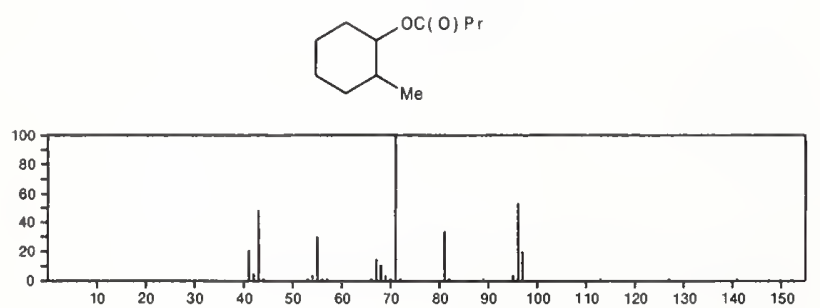

184 2-Propenoic acid, 6-methylheptyl ester

$\mathrm{Me}_{2} \mathrm{CH}\left(\mathrm{CH}_{2}\right){ }_{5} \mathrm{OC}(\mathrm{O}) \mathrm{CH}=\mathrm{CH}_{2}$
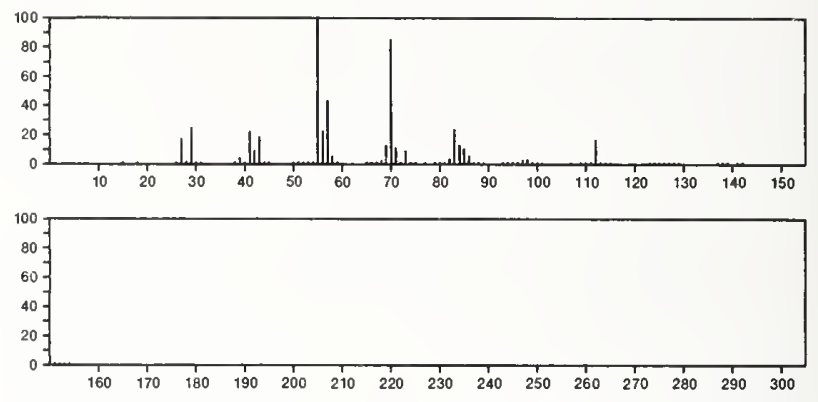

184 $\mathrm{C}_{11} \mathrm{H}_{20 \mathrm{~S}}$

$7133-21-3$

Sulfide, cyclohexyl cyclopentyl
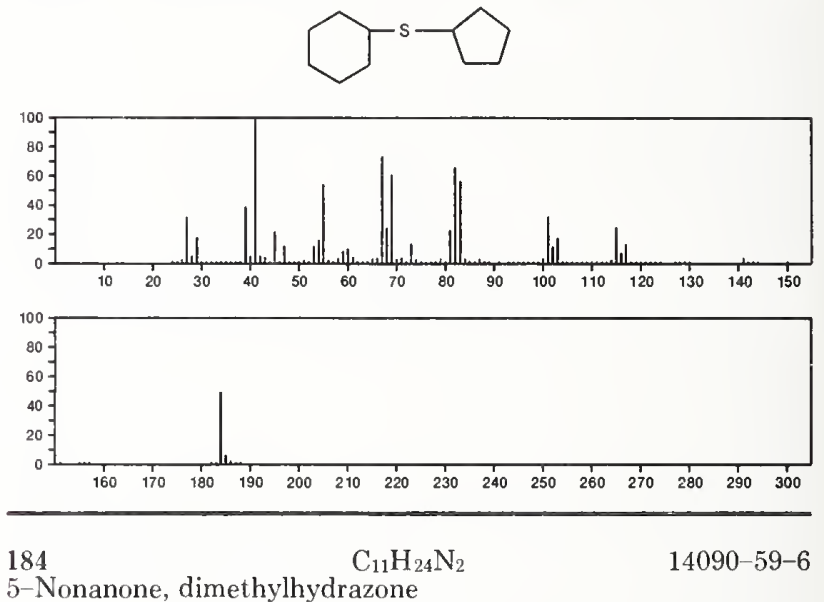

5 -Nonanone, dimethylhydrazone

$\mathrm{Me}\left(\mathrm{CH}_{2}\right)_{3} \mathrm{CI}\left(\mathrm{CH}_{2}\right)_{3} \mathrm{Me}$
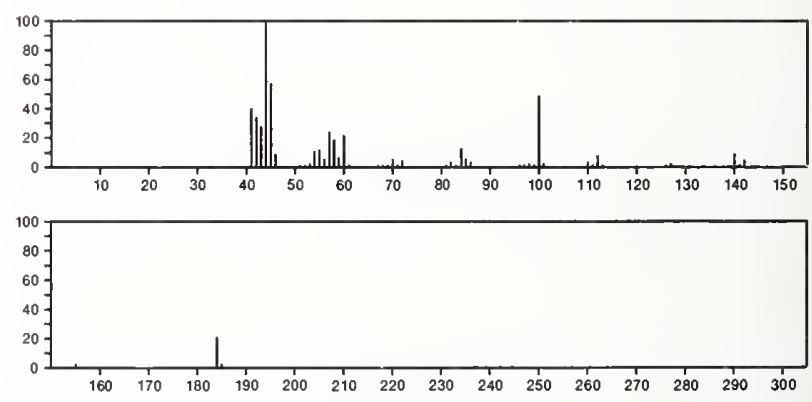

184

Dibenzo $[b, e][1,4]$ dioxin

$$
\mathrm{C}_{12} \mathrm{H}_{8} \mathrm{O}_{2}
$$

262-12-4
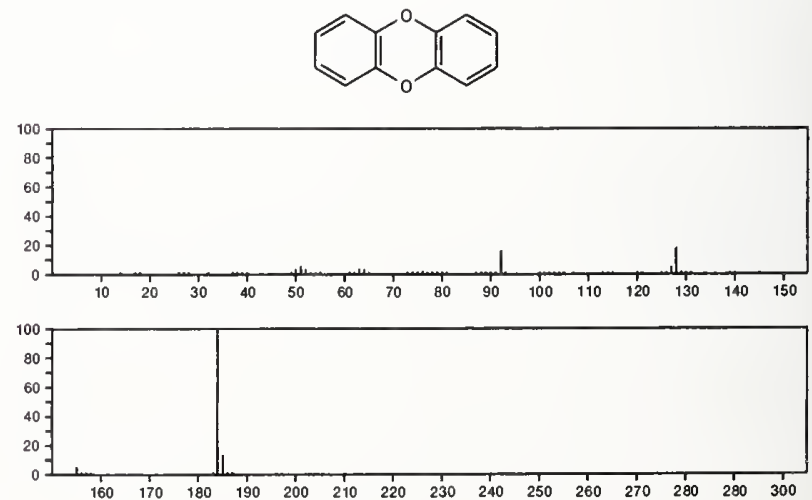
184

$\mathrm{C}_{12} \mathrm{H}_{8} \mathrm{O}_{2}$

2,5-Cyclohexadiene-1,4-dione, 2-phenyl-
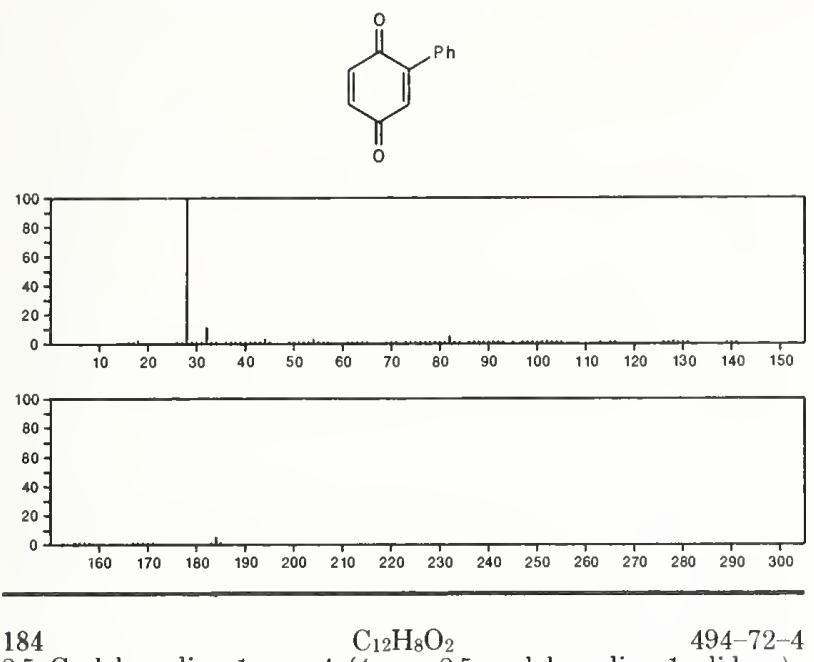

2,5-Cyclohexadien-1-one, 4-(4-oxo-2,5-cyclohexadien-1-ylidene)-
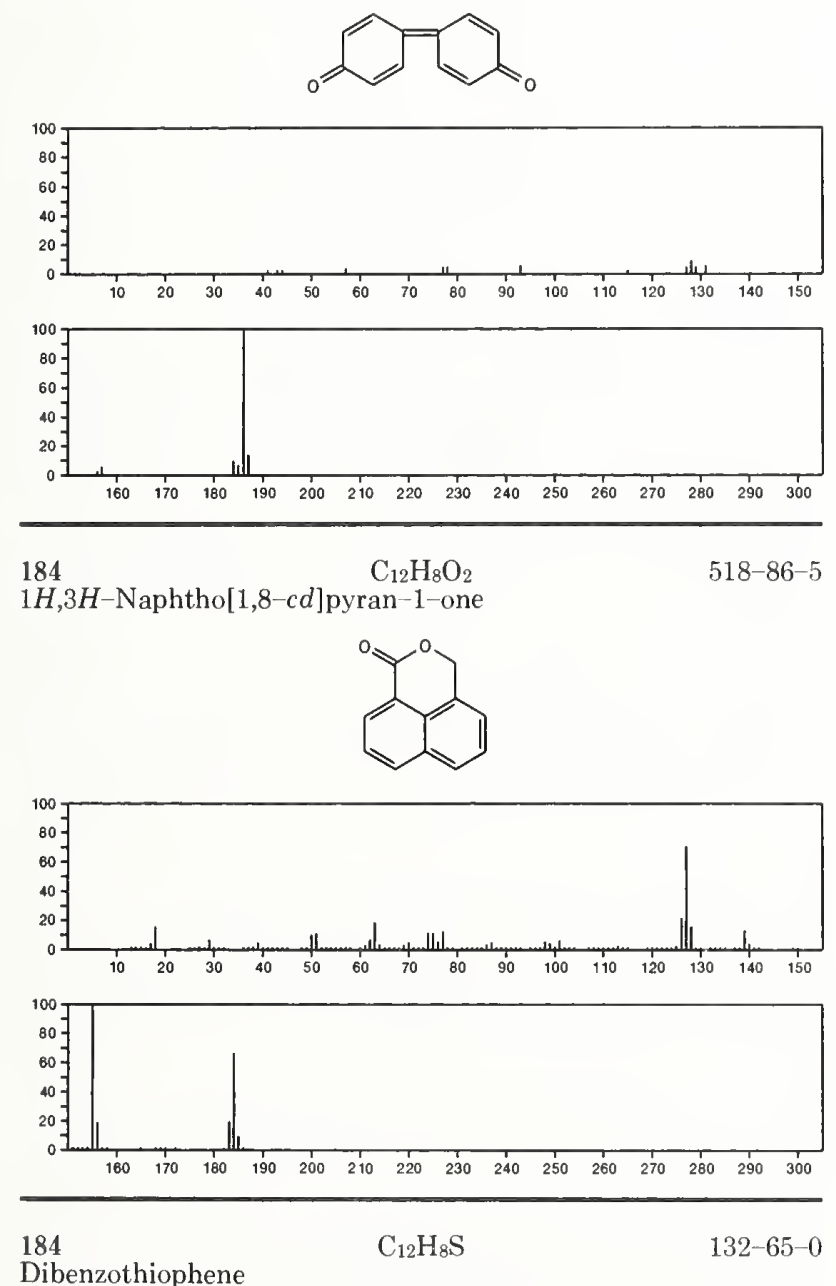

Dibenzothiophene
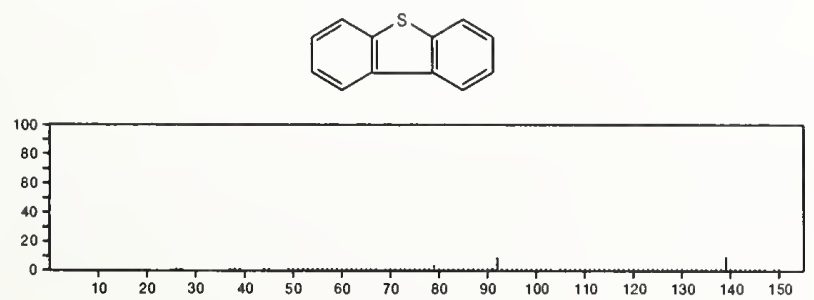
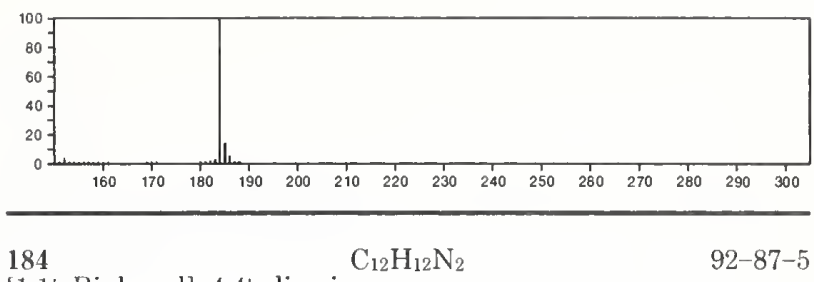

[1,1'-Biphenyl $]-4,4^{\prime}$-diamine
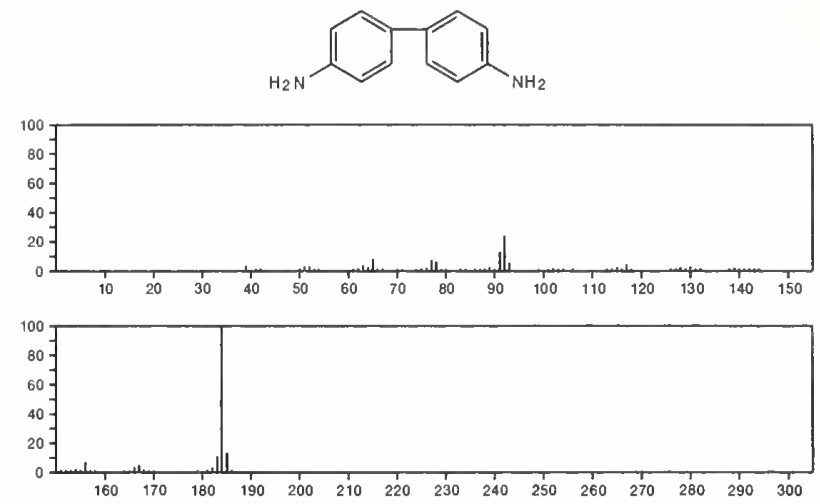

184

Hydrazine, 1,1-diphenyl-

$\mathrm{C}_{12} \mathrm{H}_{12} \mathrm{~N}_{2}$

$530-50-7$
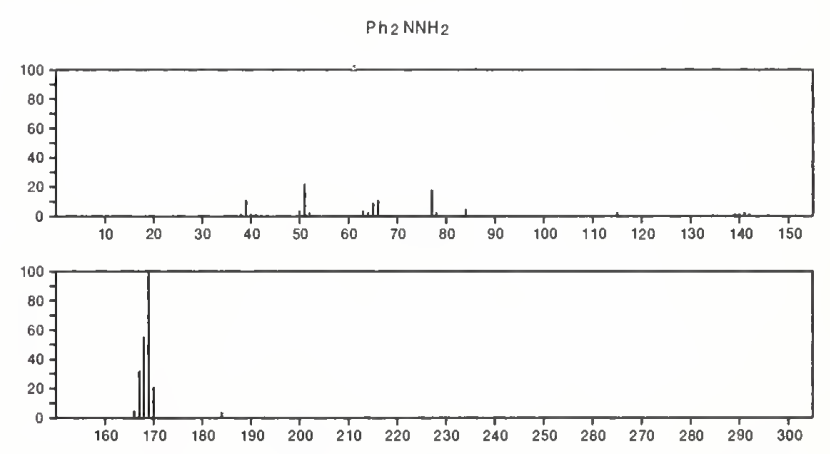

184

$\mathrm{C}_{12} \mathrm{H}_{12} \mathrm{~N}_{2}$

$10183-74-1$

$4 H$-Pyrrolo[1,2-b]pyrazole, 5,6-dihydro-3-phenyl-
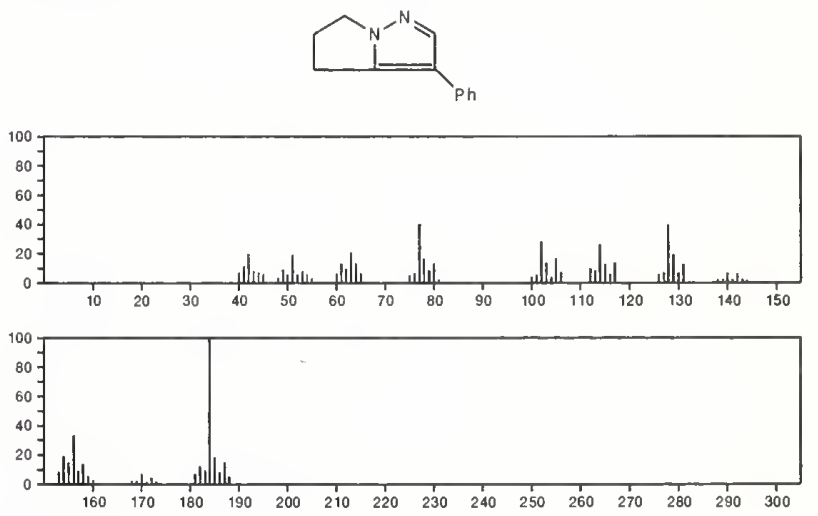

184

$\mathrm{C}_{12} \mathrm{H}_{12} \mathrm{~N}_{2}$

Pyrrole, 1-[( $\alpha$-methylbenzylidene $)$ amino]-

$24046-23-9$

$\mathrm{N}^{-\mathrm{N}=\mathrm{CM} \mathrm{MPh}}$

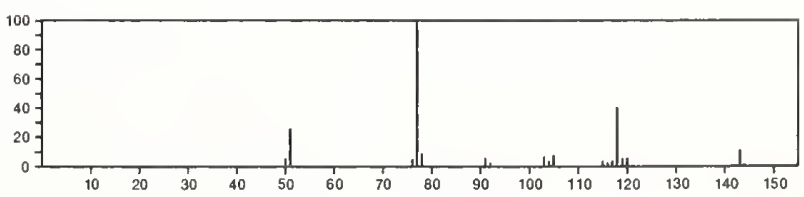


974

EPA/NIH MASS SPECTRAL DATA BASE

184

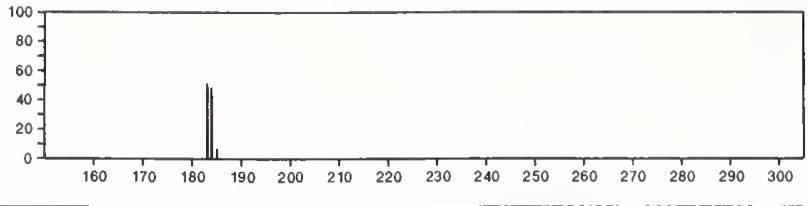

184

Pyridinium, 1-o-toluidino-, hydroxide, inner salt
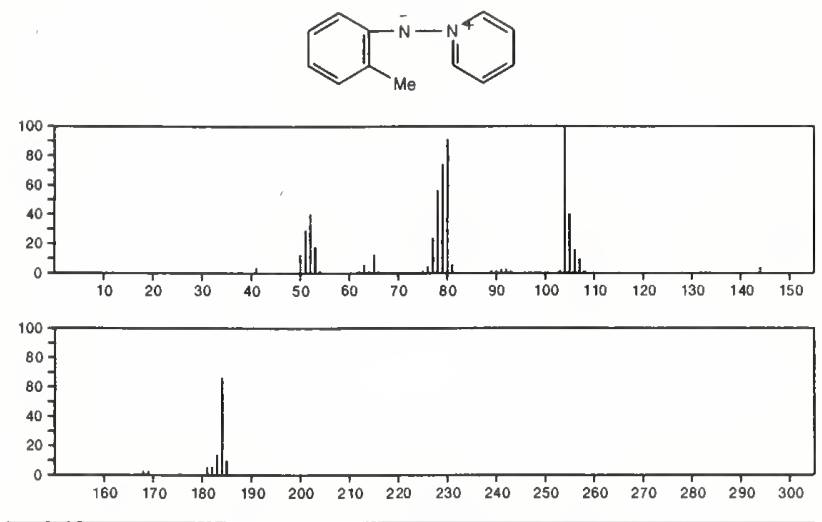

184

$\mathrm{C}_{12} \mathrm{H}_{12} \mathrm{~N}_{2}$

$31378-89-9$

184
3-Picolinium, 1-anilino-, hydroxide, inner salt
$\mathrm{C}_{12} \mathrm{H}_{12} \mathrm{~N}_{2}$

$31382-88-4$
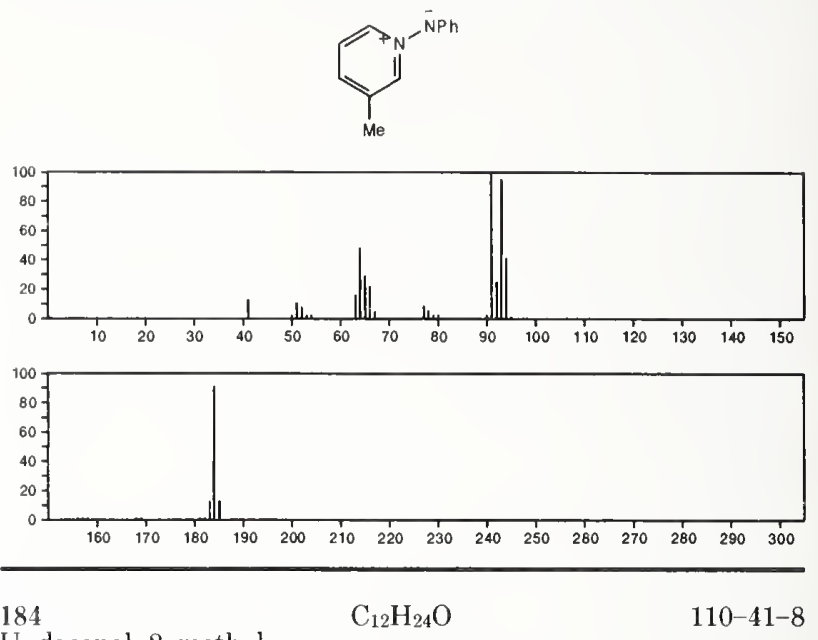

Undecanal, 2-methylOCHCHMe $\left(\mathrm{CH}_{2}\right)_{8} \mathrm{Me}$
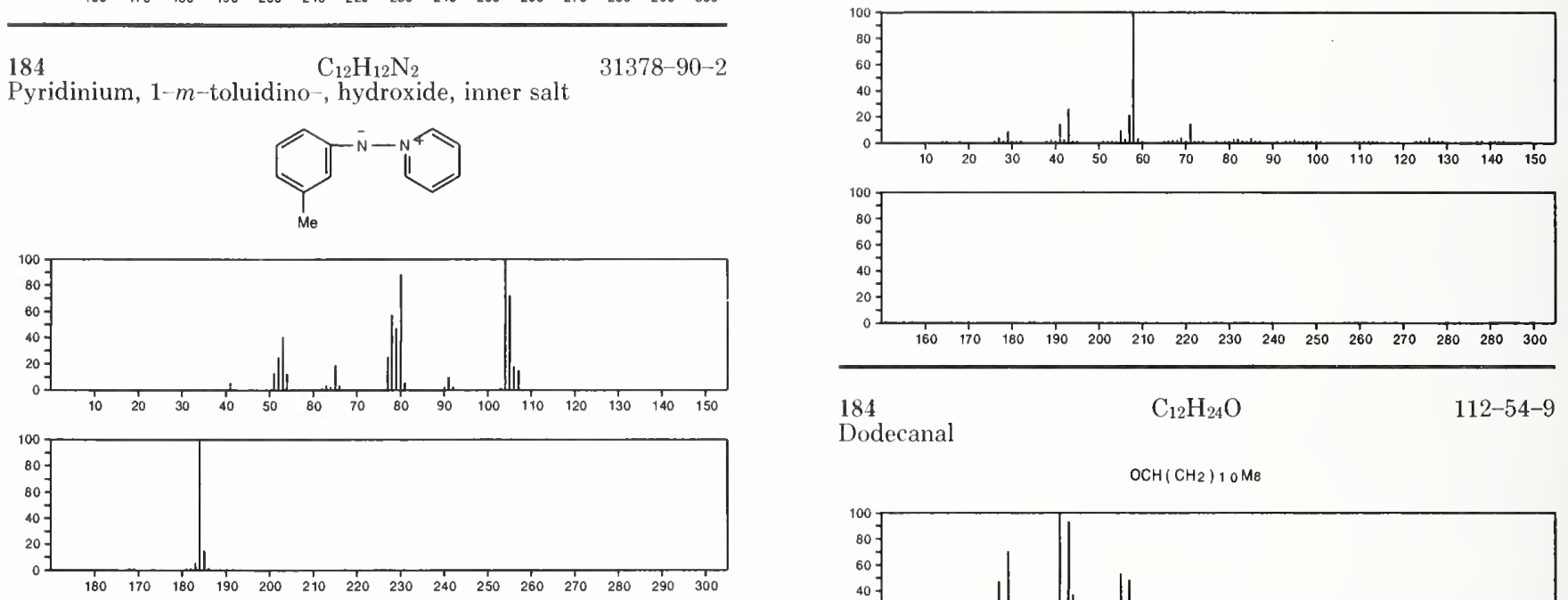

184

$\mathrm{C}_{12} \mathrm{H}_{12} \mathrm{~N}_{2}$

$31378-92-4$

Pyridinium, 1-p-toluidino-, hydroxide, inner salt
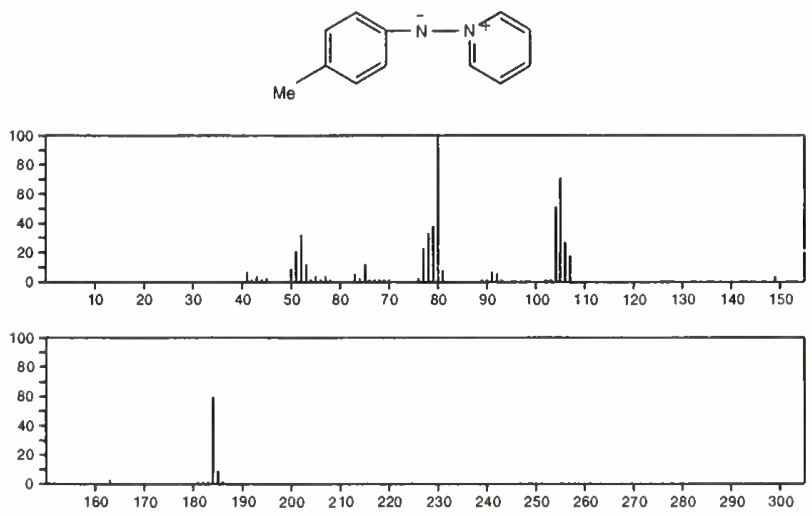

Dodecanal

$\mathrm{OCH}\left(\mathrm{CH}_{2}\right){ }_{10 \mathrm{MB}}$
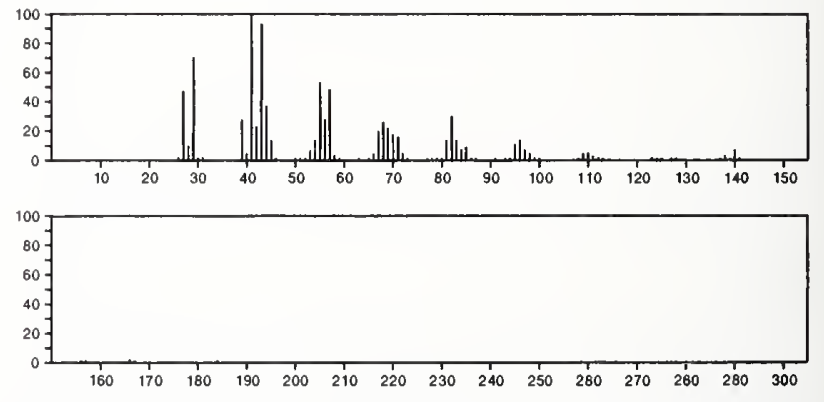

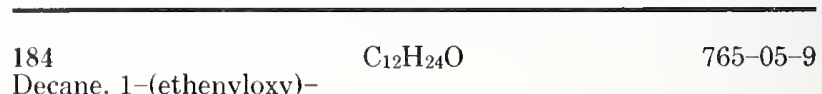

Decane, 1-(ethenyloxy)-
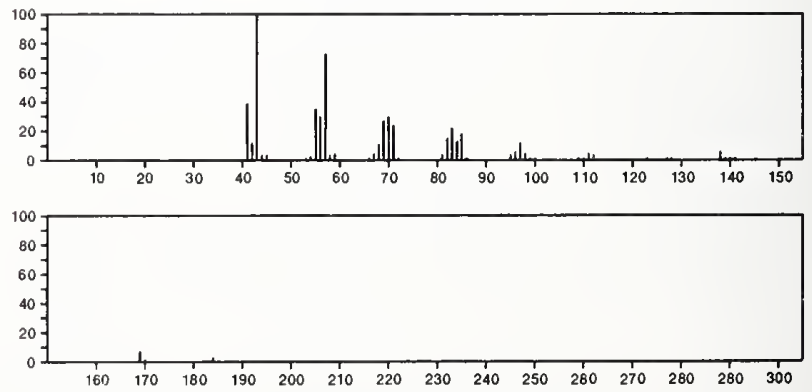

$\mathrm{Me}\left(\mathrm{CH}_{2}\right){ }_{9} \mathrm{OCH}=\mathrm{CH}_{2}$ 
184

3-Dodecanone

$\mathrm{C}_{12} \mathrm{H}_{24} \mathrm{O}$

$\mathrm{Me}\left(\mathrm{CH}_{2}\right){ }_{8} \mathrm{COE}$
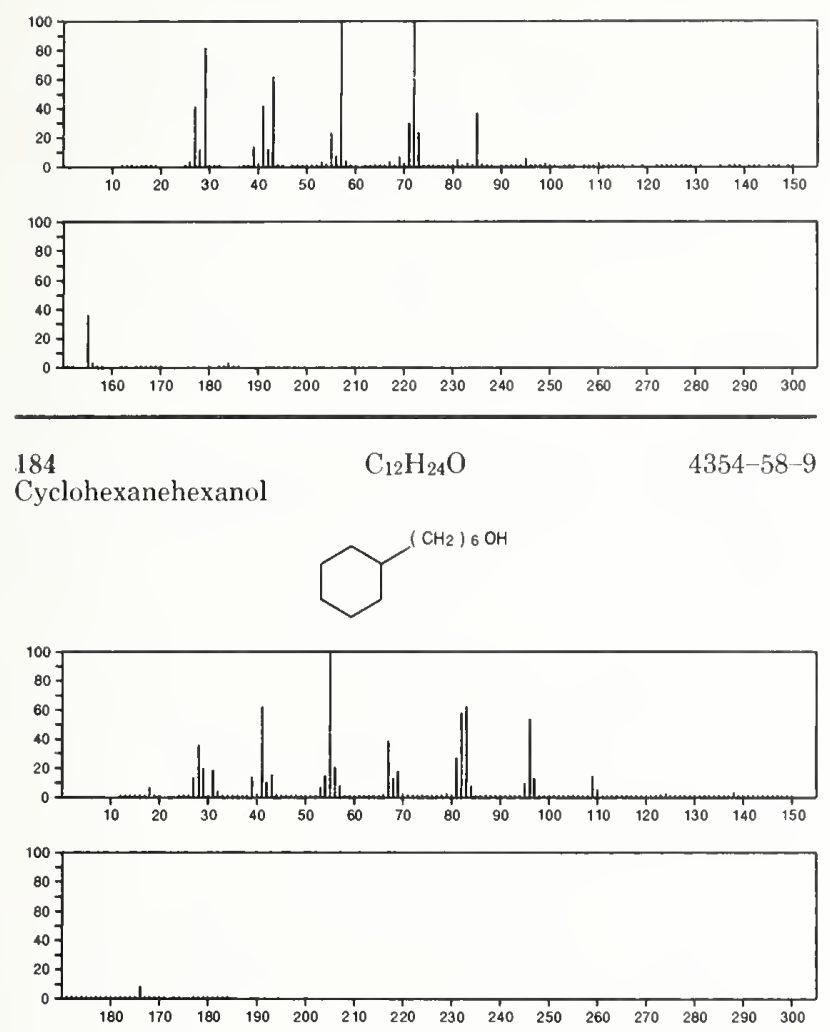

184

6-Dodecanone

$\mathrm{C}_{12} \mathrm{H}_{24} \mathrm{O}$

$\mathrm{Me}\left(\mathrm{CH}_{2}\right){ }_{5} \mathrm{CO}_{\left(\mathrm{CH}_{2}\right)}{ }_{4} \mathrm{Me}$
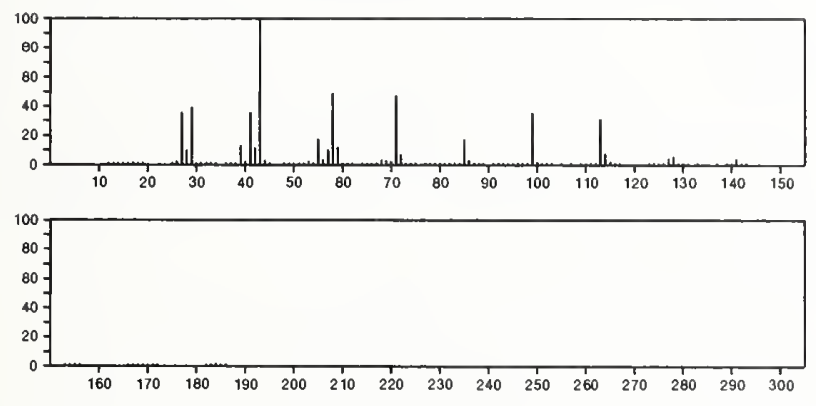

184

4-Dodecanone

$\mathrm{C}_{12} \mathrm{H}_{24} \mathrm{O}$

$6137-26-4$

$\mathrm{Me}\left(\mathrm{CH}_{2}\right)>\mathrm{COPr}$
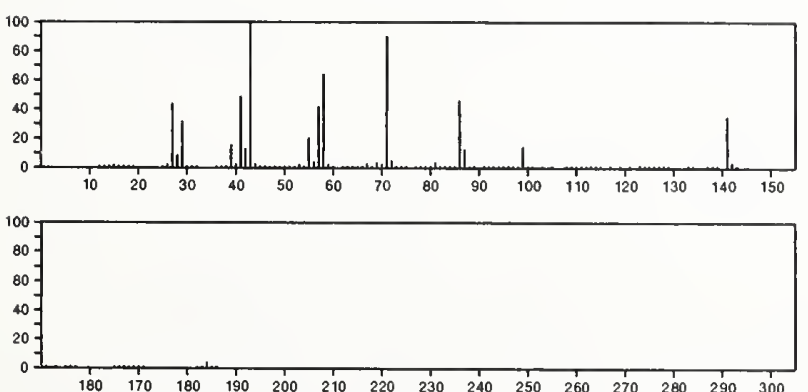

184

2-Dodecanone

$\mathrm{C}_{22} \mathrm{H}_{24} \mathrm{O}$

$6175-49-1$
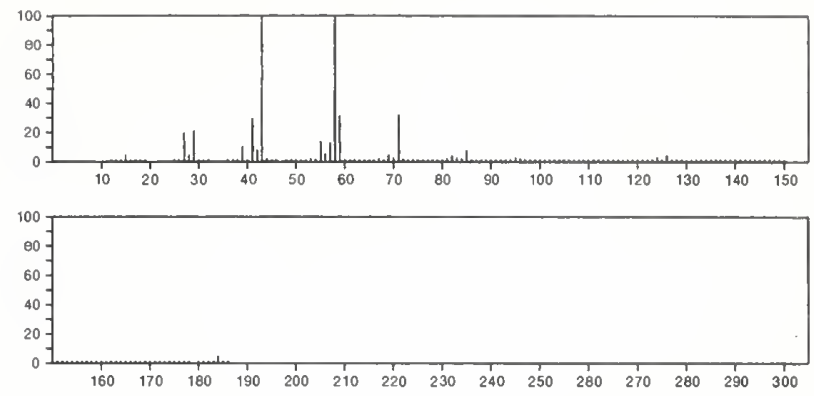

184

$\mathrm{C}_{12} \mathrm{H}_{24} \mathrm{O}$

19780-10-0

5-Dodecanone

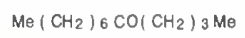
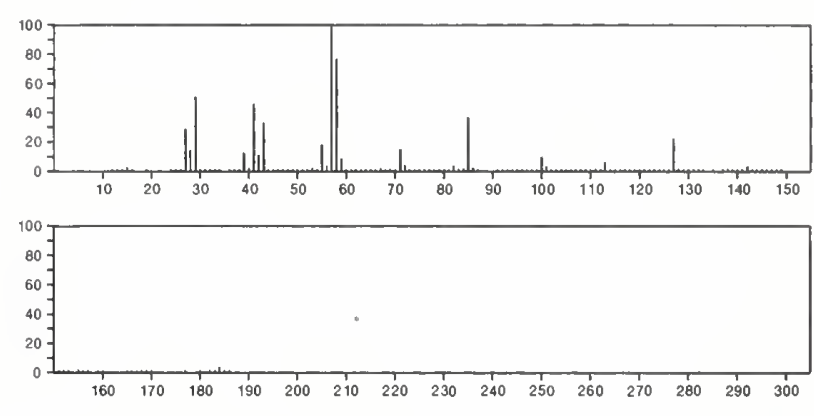

184

4-Undecanone, 10-methyl-

$\mathrm{C}_{12} \mathrm{H}_{24} \mathrm{O}$

29379-12-2

$\mathrm{Me}_{2} \mathrm{CH}\left(\mathrm{CH}_{2}\right){ }_{5} \mathrm{COP}$
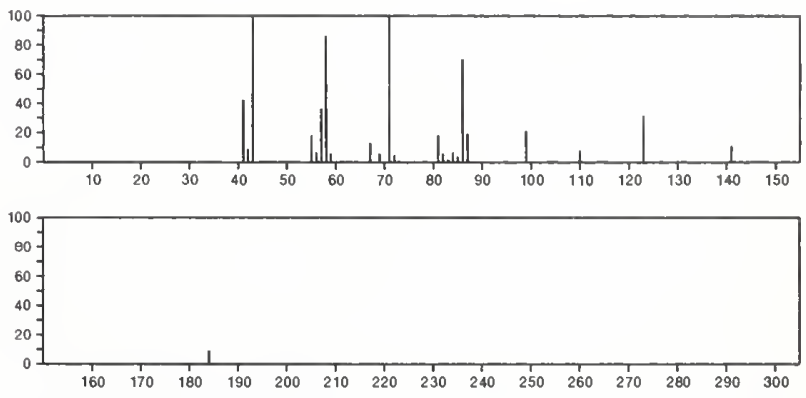

184

$\mathrm{C}_{12} \mathrm{H}_{24} \mathrm{O}$

$32383-56-5$

Cyclohexanol, 4-tert-butyl-1,2-dimethyl-, stereoisomer<smiles>[N+]=[N+]([O-])C1CC(Br)CCC1(O)O</smiles>
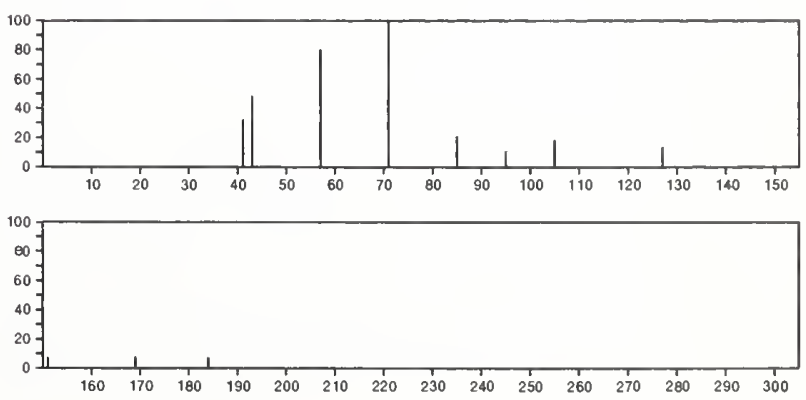
$184 \quad \mathrm{C}_{12} \mathrm{H}_{24} \mathrm{O}$

Cyclohexanol, 3-(3,3-dimethylbutyl)-
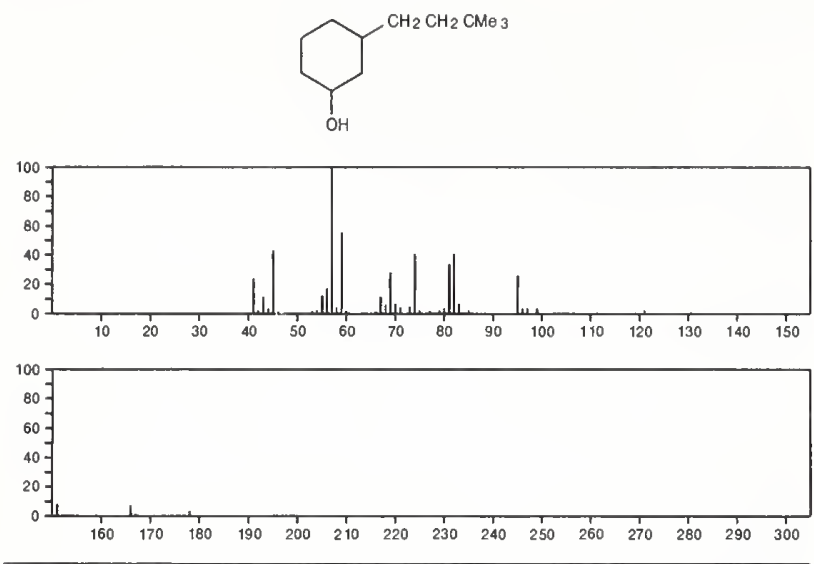

184

5-Undecanone, 2-methyl-
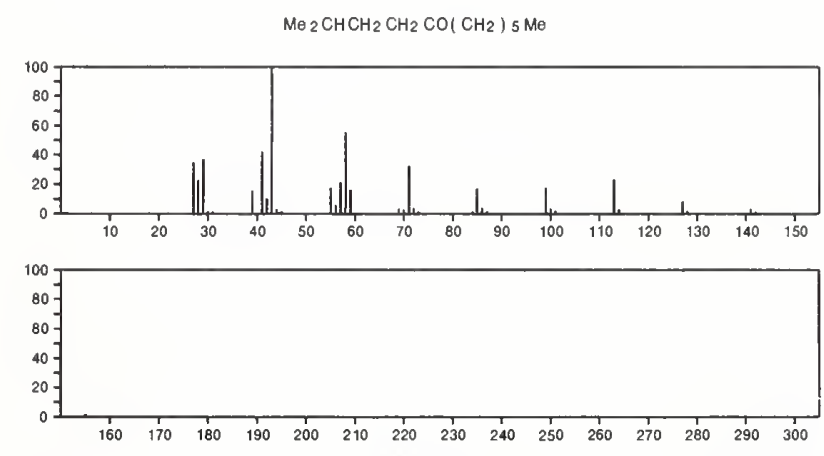

$184 \quad \mathrm{C}_{12} \mathrm{H}_{24} \mathrm{O} \quad 55869-52-8$

Cyclohexanol, 4-ethyl-4-methyl-3-(1-methylethyl)-, $(1 \alpha, 3 \alpha, 4 \beta)-$
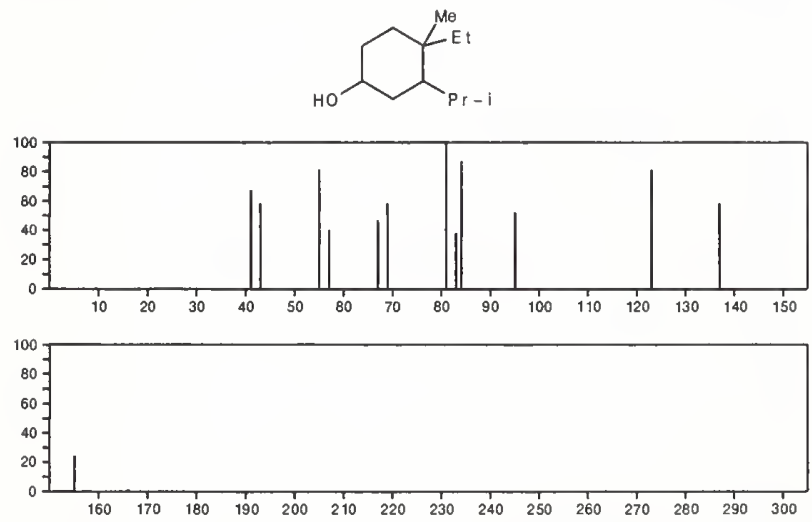

$184 \quad \mathrm{C}_{12} \mathrm{H}_{24} \mathrm{O} \quad 55869-53-9$

Cyclohexanol, 4-ethyl-4-methyl-3-(1-methylethyl)-, $(1 \alpha, 3 \beta, 4 \alpha)-$<smiles>CPC1CC(O)CCC1(C)C</smiles>

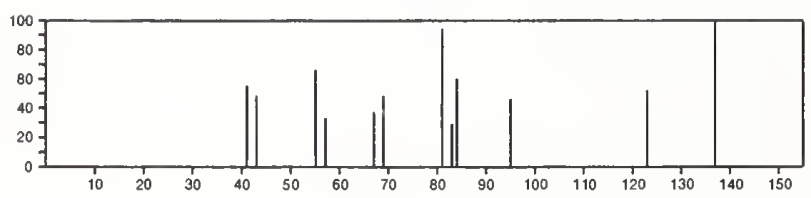

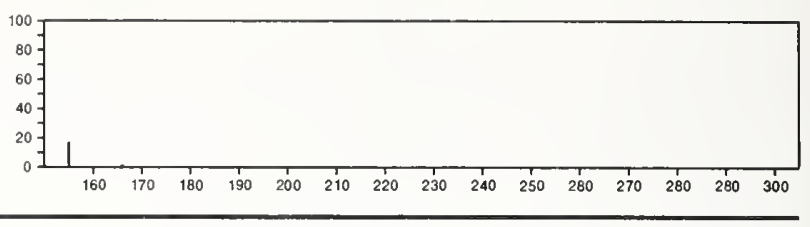

184 $\mathrm{C}_{13} \mathrm{H}_{12} \mathrm{O}$

86-26-0

1,1'-Biphenyl, 2-methoxy-
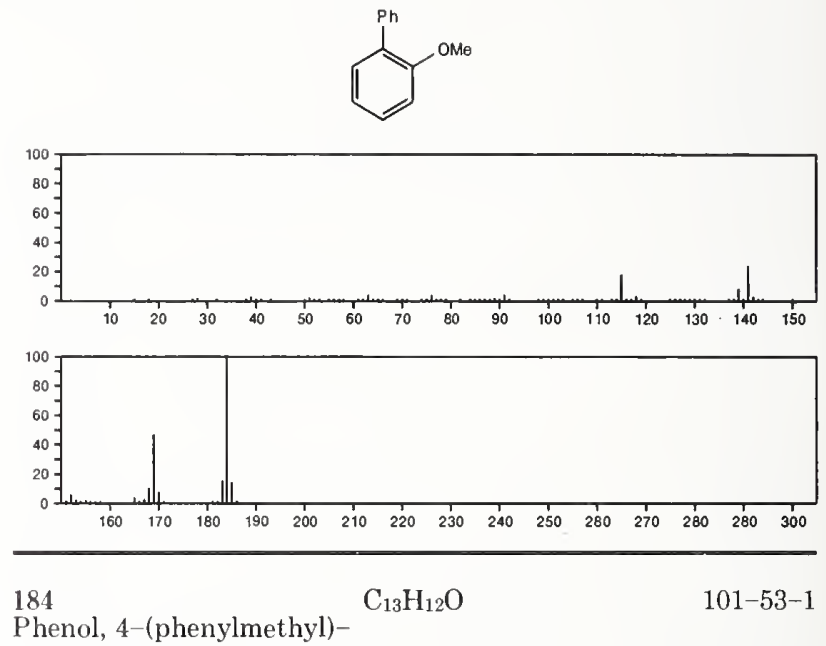

Phenol, 4-(phenylmethyl)-
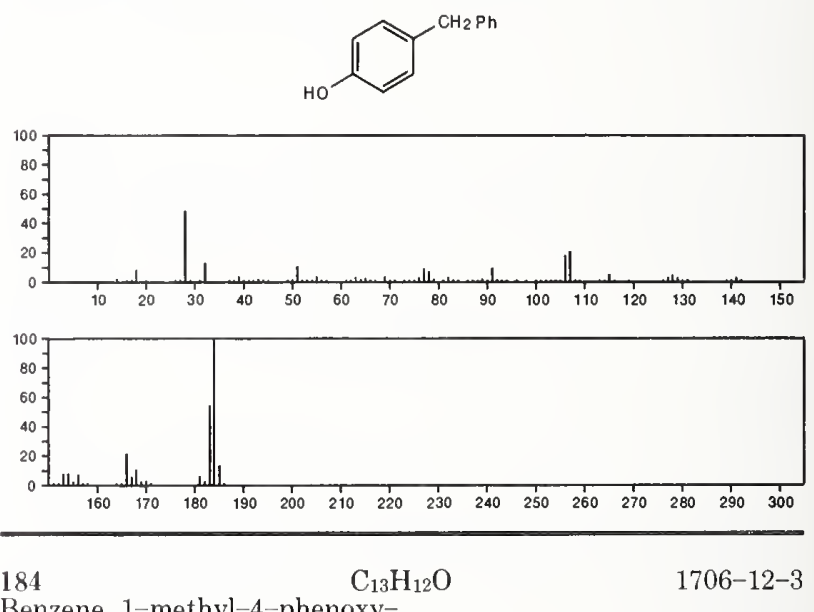

Benzene, 1-methyl-4-phenoxy-
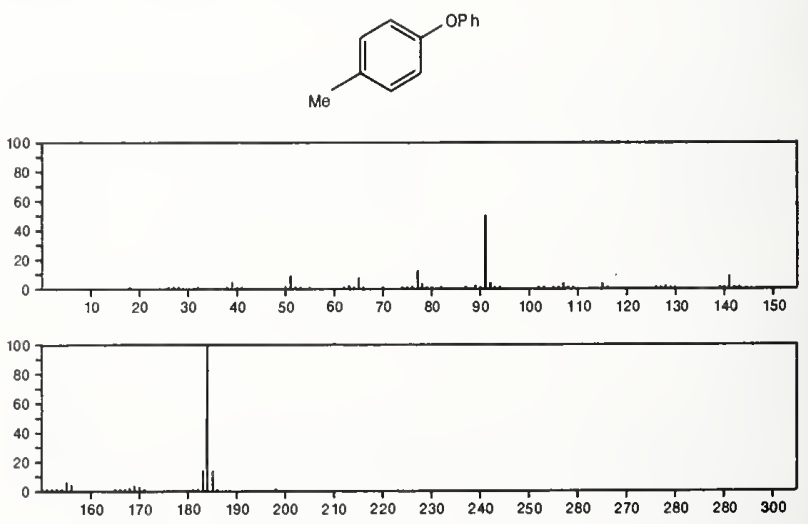
184

$\mathrm{C}_{13} \mathrm{H}_{12} \mathrm{O}$

3586-14-9

Benzene, 1-methyl-3-phenoxy-<smiles>O=[N+]c1cccc(O)c1</smiles>
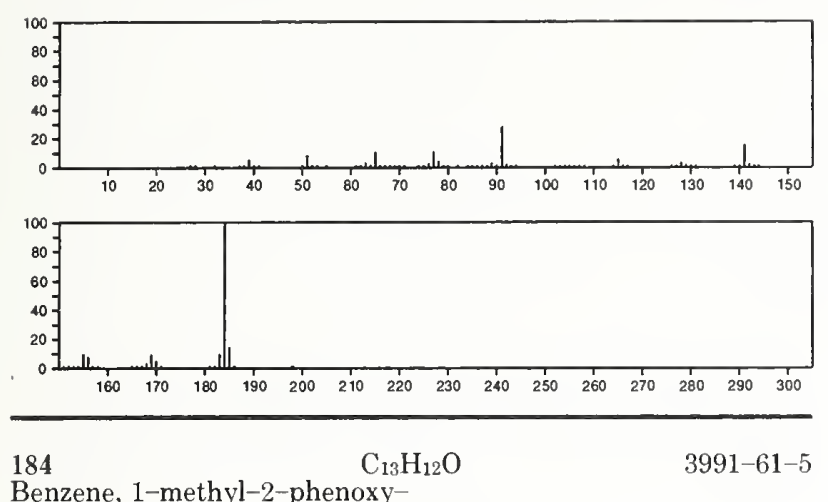

Benzene, 1-methyl-2-phenoxy-
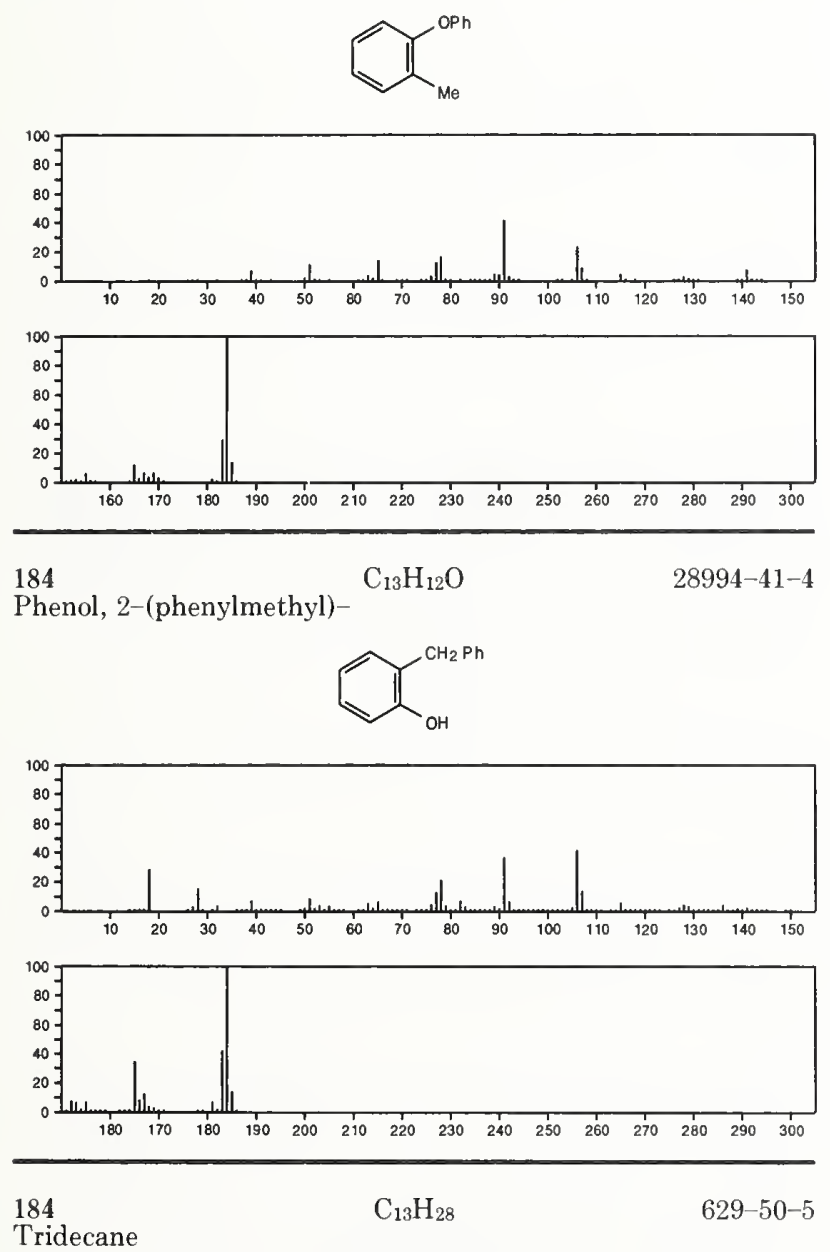

Tridecane

$\mathrm{Me}\left(\mathrm{CH}_{2}\right) 11 \mathrm{Me}$

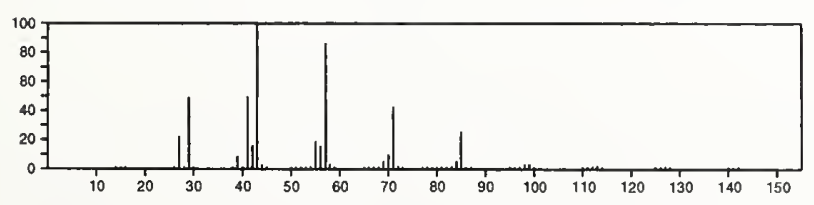

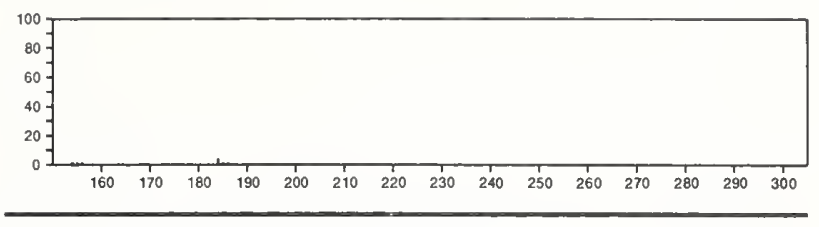

184

Dodecane, 2-methyl-

$$
\mathrm{C}_{13} \mathrm{H}_{28}
$$

$1560-97-0$

$\mathrm{Me} 2 \mathrm{CH}\left(\mathrm{CH}_{2}\right){ }_{9} \mathrm{Me}$
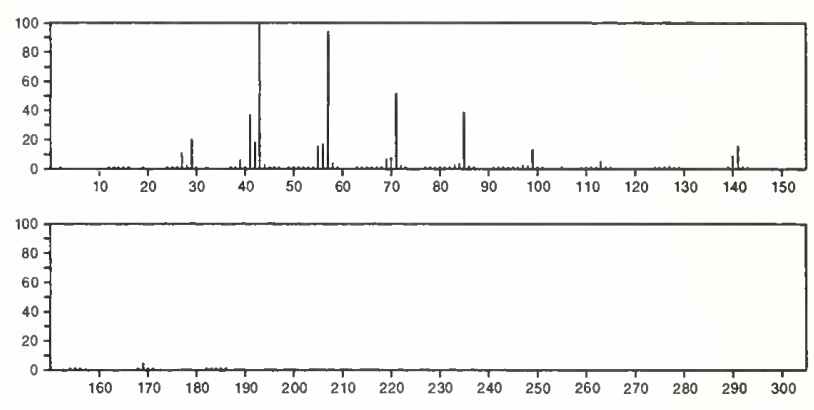

$184 \quad \mathrm{C}_{13} \mathrm{H}_{28} \quad 17301-22-3$

Undecane, 2,5-dimethyl-

$\mathrm{Me}_{2} \mathrm{CHCH}_{2} \mathrm{CH}_{2} \mathrm{CHMe}\left(\mathrm{CH}_{2}\right){ }_{5} \mathrm{Me}$
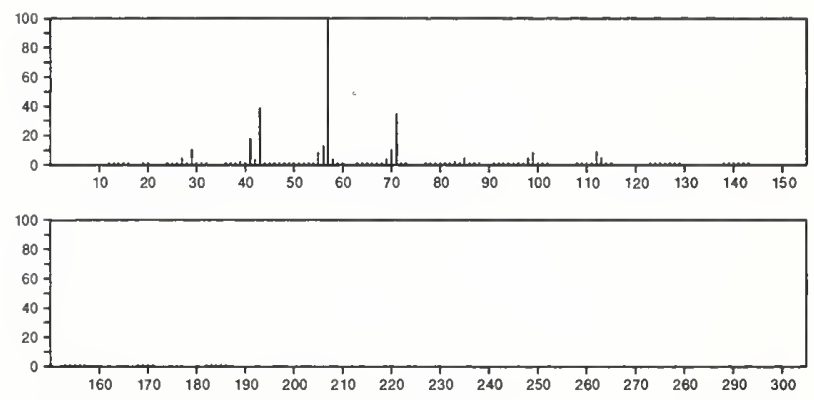

184

Undecane, 2,6-dimethyl-

$\mathrm{C}_{13} \mathrm{H}_{28}$

$17301-23-4$

$\mathrm{Me}_{2} \mathrm{CH}\left(\mathrm{CH}_{2}\right)_{3} \mathrm{CHMe}\left(\mathrm{CH}_{2}\right)_{4} \mathrm{Me}$
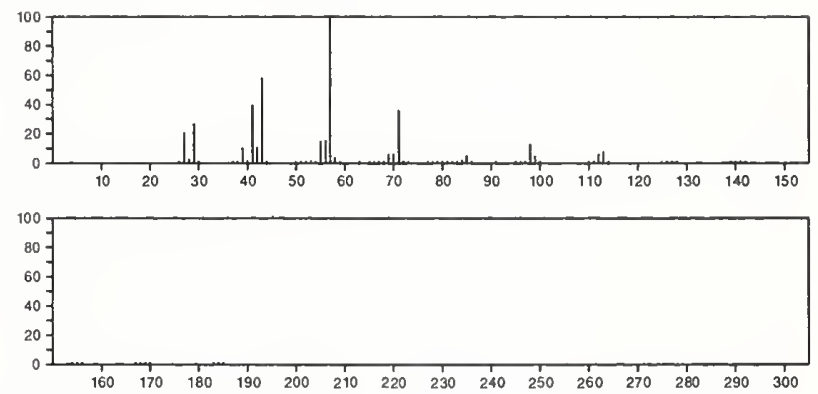

184

Undecane, 4,8-dimethyl-

$\mathrm{C}_{13} \mathrm{H}_{28}$

$17301-33-6$

$\operatorname{PrCHMe}\left(\mathrm{CH}_{2}\right)_{3} \mathrm{CHP}$ rMe
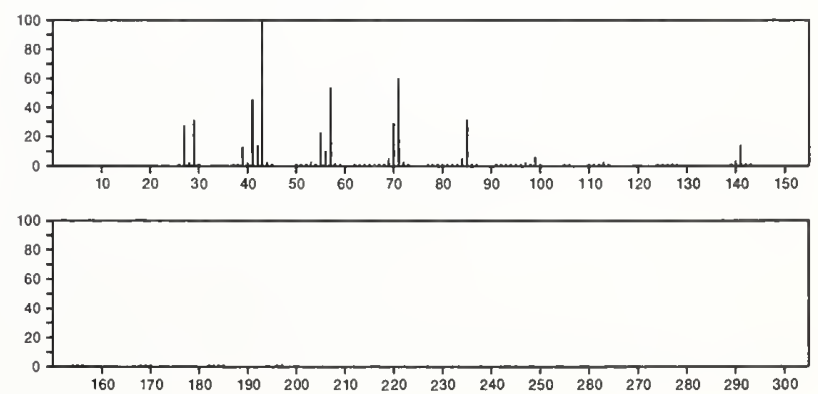
978

EPA/NIH MASS SPECTRAL DATA BASE

184

184

Nonane, 5-butyl-

$\mathrm{C}_{13} \mathrm{H}_{28}$

$17312-63-9$

$$
\begin{gathered}
\left(\mathrm{CH}_{2}\right)_{3} \mathrm{Me} \\
\mathrm{Me}\left(\mathrm{CH}_{2}\right){ }_{3} \mathrm{CH}\left(\mathrm{CH}_{2}\right)_{3} \mathrm{Me}
\end{gathered}
$$
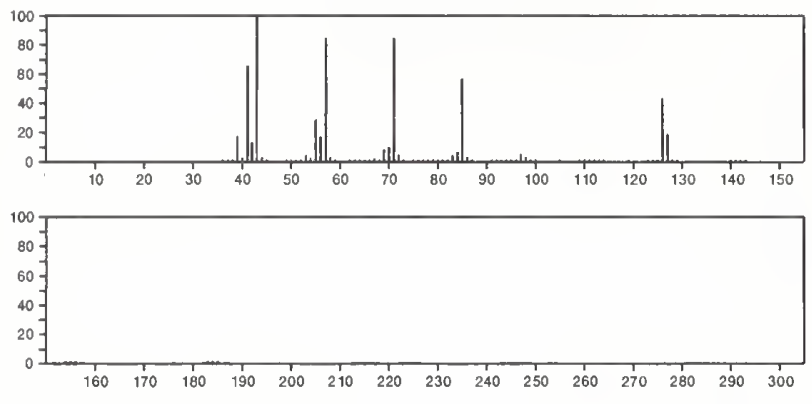

184
Decane, 5-ethyl-5-methyl--

$\mathrm{Me}\left(\mathrm{CH}_{2}\right)_{4} \mathrm{CE} t \mathrm{Me}\left(\mathrm{CH}_{2}\right)_{3} \mathrm{Me}$
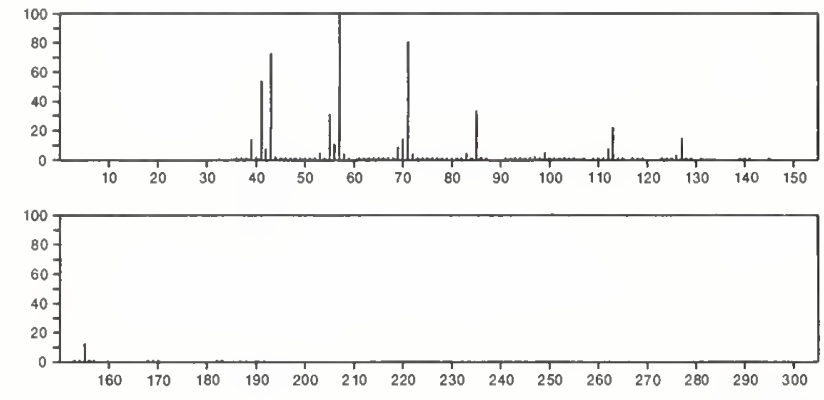

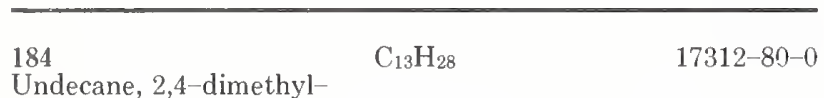

Undecane, 2,4-dimethyl-

$\mathrm{Me}\left(\mathrm{CH}_{2}\right)_{6} \mathrm{CHMe} \mathrm{CH}_{2} \mathrm{CHMe}_{2}$
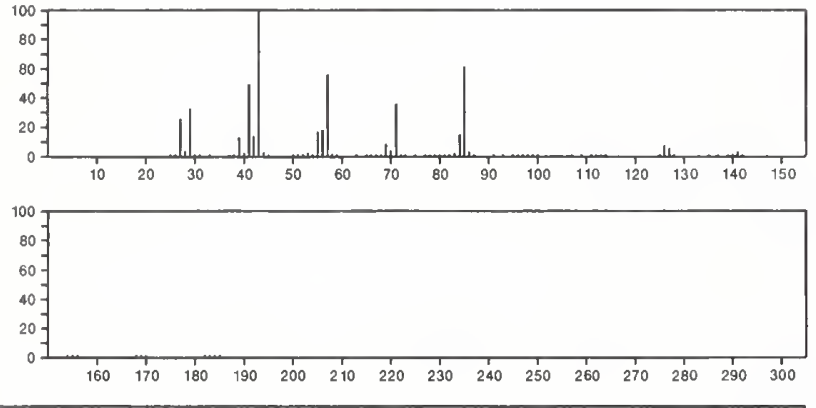

184

$\mathrm{C}_{14} \mathrm{H}_{16}$

$490-65-3$

Naphthalene, 1-methyl-7-(1-methylethyl)-
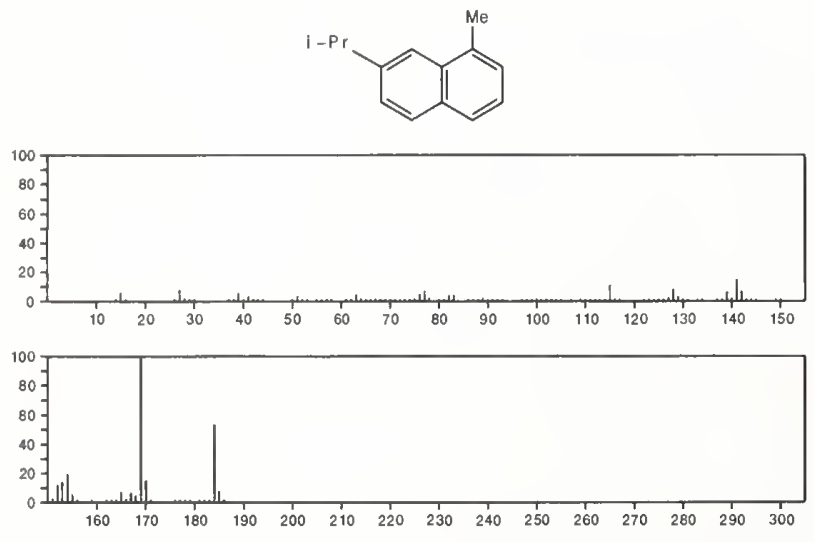

184 thalene, 2-butyl- $\quad \mathrm{C}_{14} \mathrm{H}_{16}$

1134-62-9
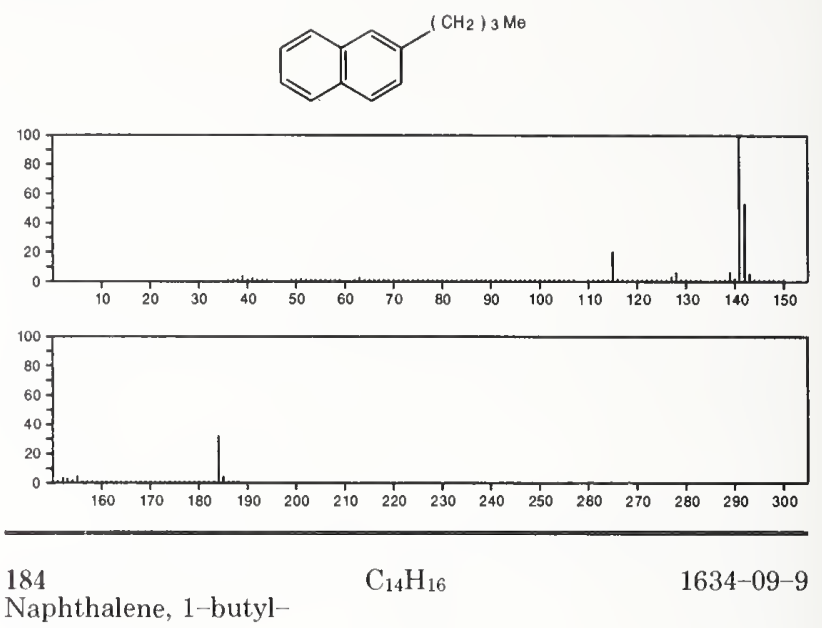

Naphthalene, 1-butyl-
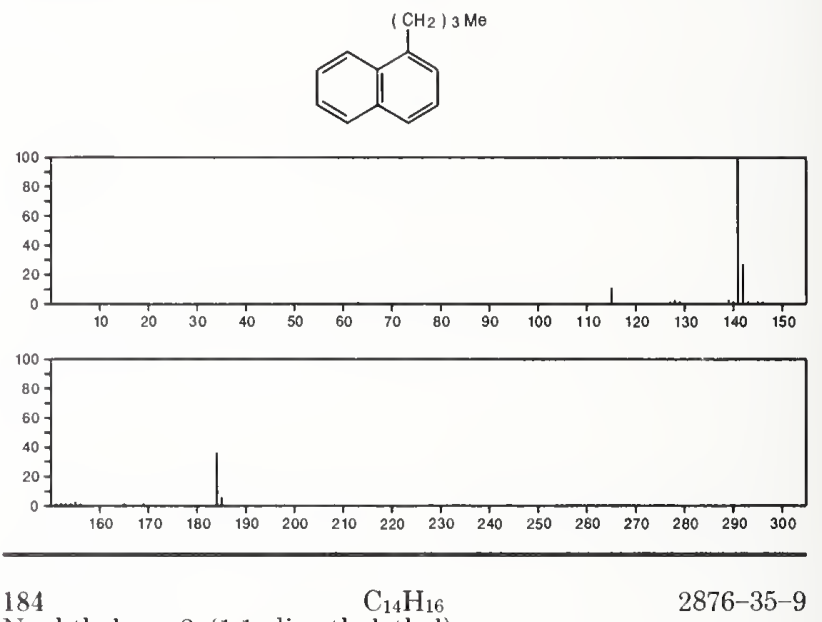

Naphthalene, 2-(1,1-dimethylethyl)-
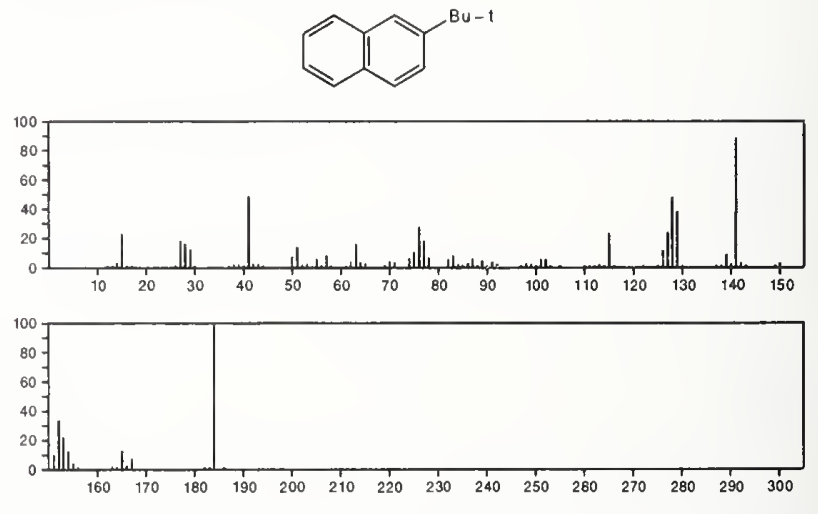

184

$\mathrm{C}_{14} \mathrm{H}_{16}$

16727-91-6

Naphthalene, 1-(2-methylpropyl)-
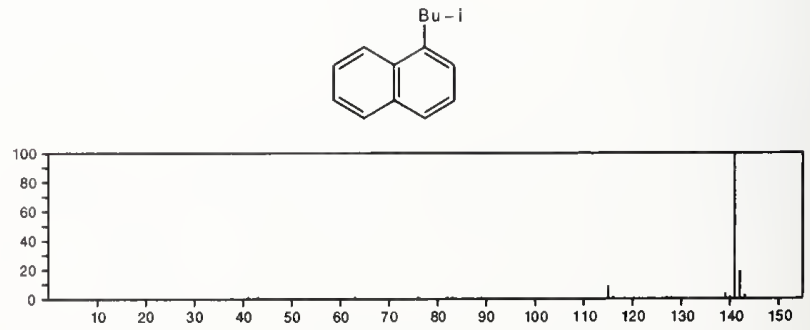

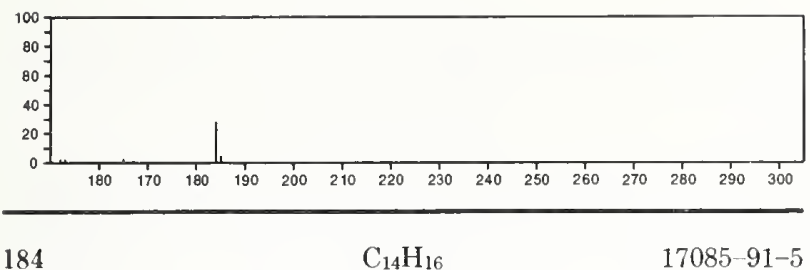

Naphthalene, 1-(1,1-dimethylethyl)-
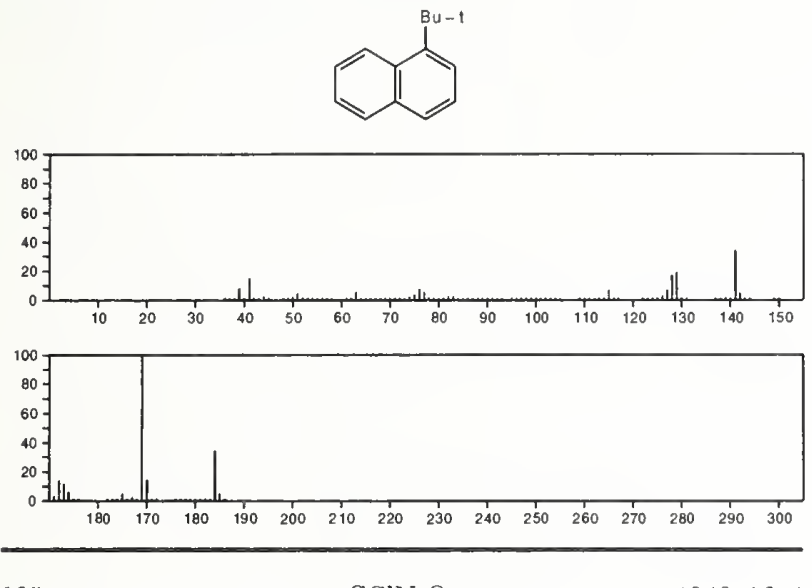

185

$\mathrm{CClN}_{3} \mathrm{O}_{6}$

$\mathrm{ClC}\left(\mathrm{NO}_{2}\right)_{3}$

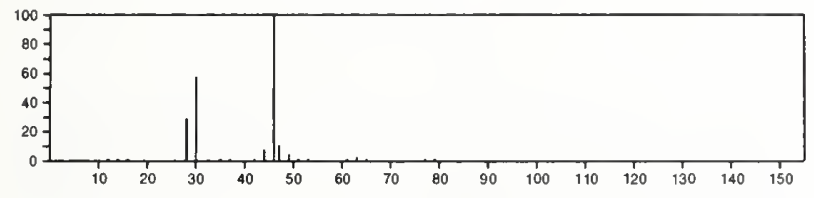

185

$\mathrm{C}_{5} \mathrm{ClF}_{4} \mathrm{~N}$

Pyridine, 2-chloro-3,4,5,6-tetrafluoro-

$54774-81-1$
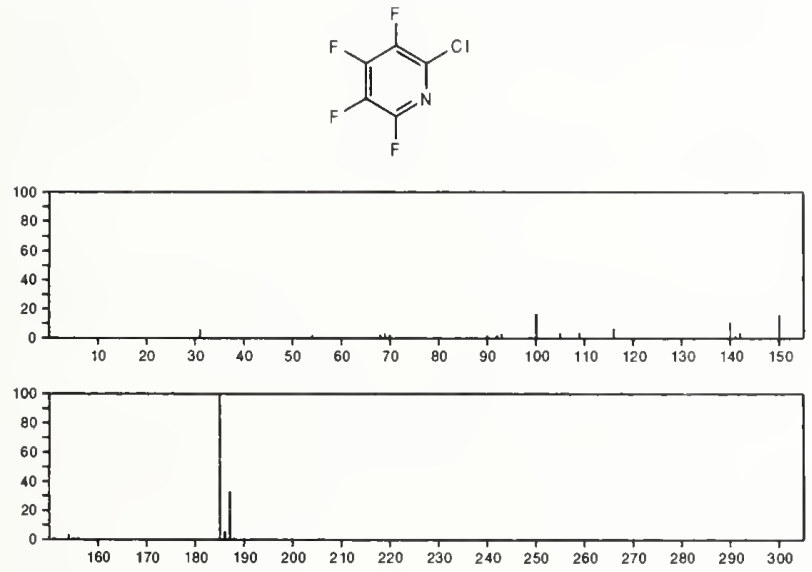

185

$\mathrm{C}_{5} \mathrm{H}_{12} \mathrm{NO}_{2} \mathrm{~S} . \mathrm{Cl}$

$29548-68-3$

Sulfonium, [(ethoxycarbonyl)amino]dimethyl-, chloride

$\mathrm{Me}_{2} \stackrel{+}{\mathrm{S} N H C l O} \mathrm{OE}+\quad \cdot \mathrm{Cl}^{-}$

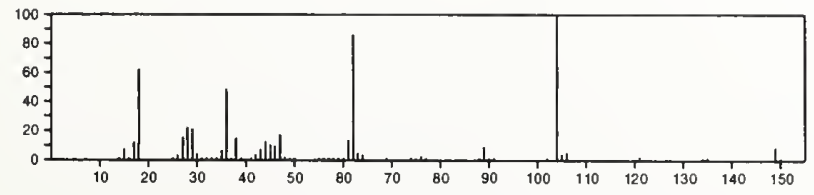

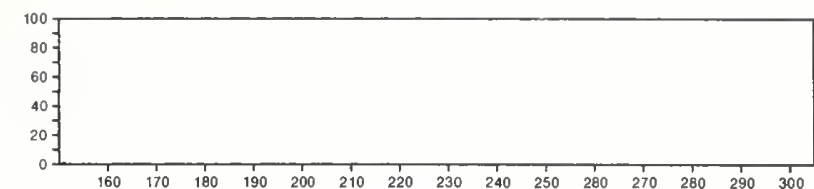

Thiazolo[5,4-d]pyrimidine, 7-chloro-5-methyl-

$13316-09-1$
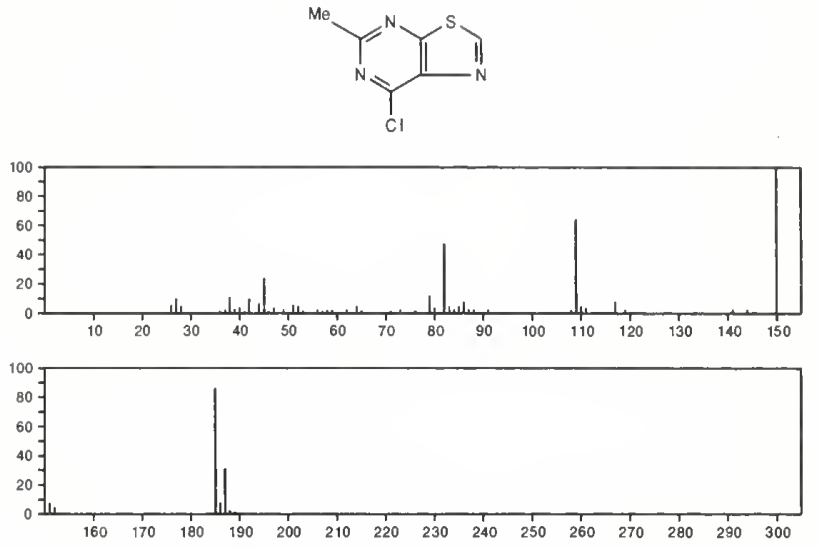

185

$\mathrm{C}_{7} \mathrm{H}_{7} \mathrm{NO}_{5}$

$54774-80-0$

2H-Pyran-2-one, 4-methoxy-6-methyl-3-nitro-
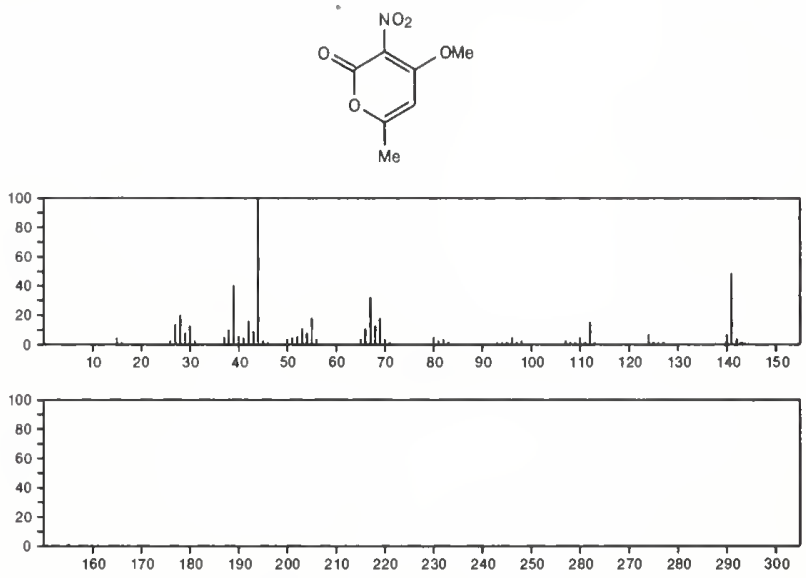

185

$\mathrm{C}_{8} \mathrm{H}_{8} \mathrm{ClNO}_{2}$

$940-36-3$

Carbamic acid, (4-chlorophenyl)-, methyl ester
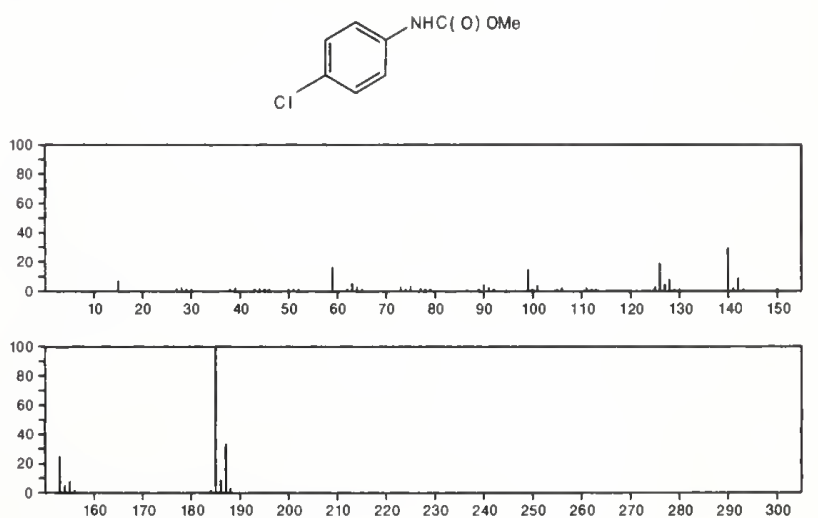
185

$\mathrm{C}_{8} \mathrm{H}_{8} \mathrm{CINO}_{2}$

Benzoic acid, 2-amino-5-chloro-, methyl ester

$5202-89-1$<smiles>CC(=O)c1cc(Cl)ccc1N</smiles>
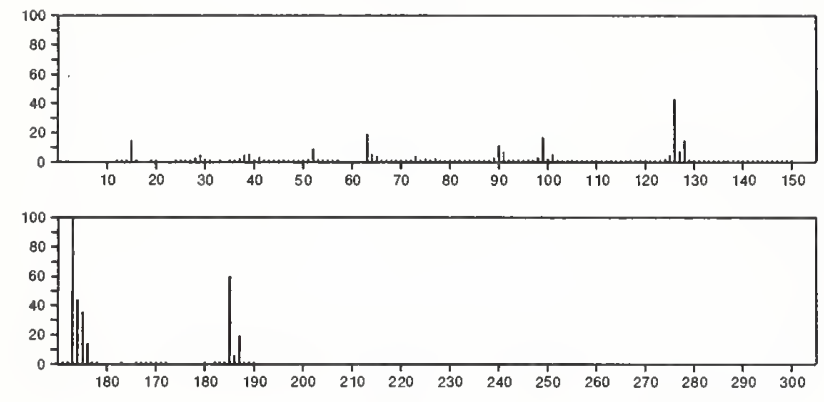

$185 \quad \mathrm{C}_{8} \mathrm{H}_{8} \mathrm{ClNO}_{2}$

$\begin{array}{lllllllllllllll}180 & 170 & 180 & 190 & 200 & 210 & 220 & 230 & 240 & 250 & 260 & 270 & 280 & 290 & 300\end{array}$

20668-13-7

Carbamic acid, (2-chlorophenyl)-, methyl ester
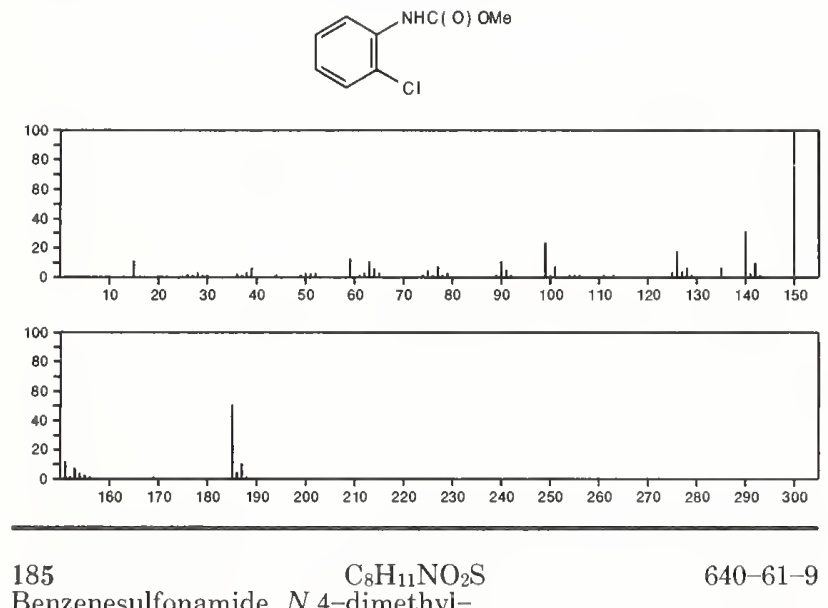

Benzenesulfonamide, $N$,4-dimethyl-
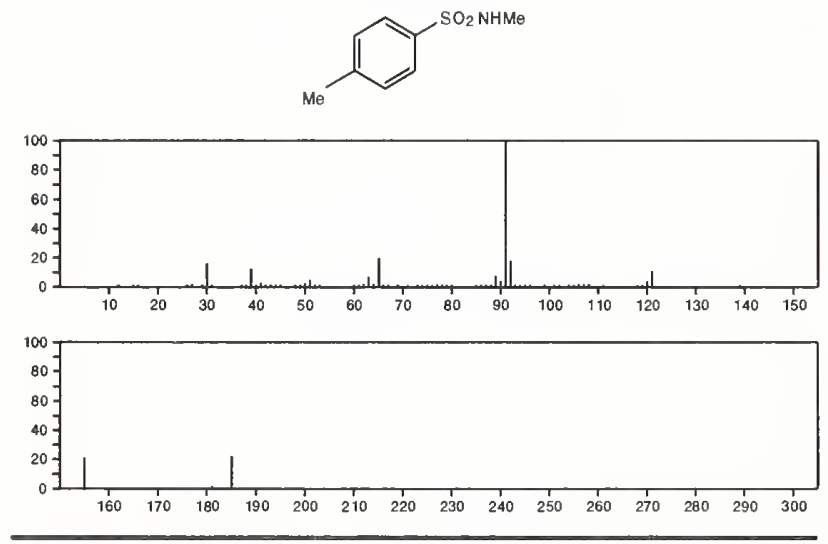

185

3,4-Xylenesulfonamide

$\mathrm{C}_{8} \mathrm{H}_{11} \mathrm{NO}_{2} \mathrm{~S}$

$6326-18-7$
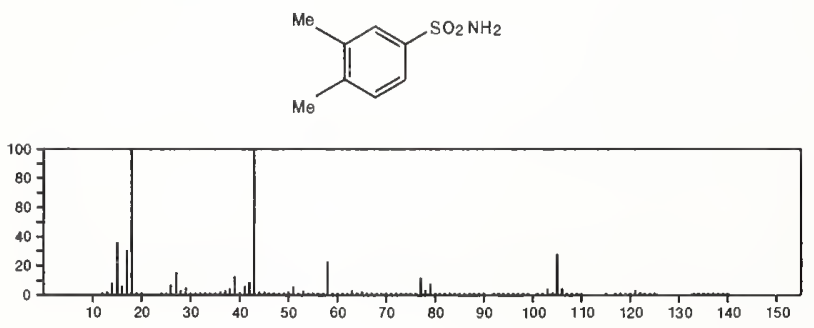

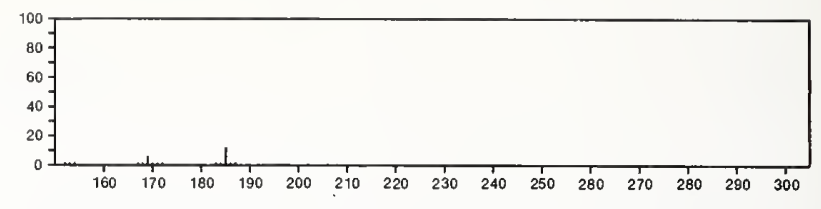

185

$\mathrm{C}_{8} \mathrm{H}_{11} \mathrm{NO}_{2} \mathrm{~S}$

Benzenesulfonamide, $N, N$-dimethyl-

$14417-01-7$

$\mathrm{Me}_{2} \mathrm{NSO}_{2} \mathrm{Ph}$
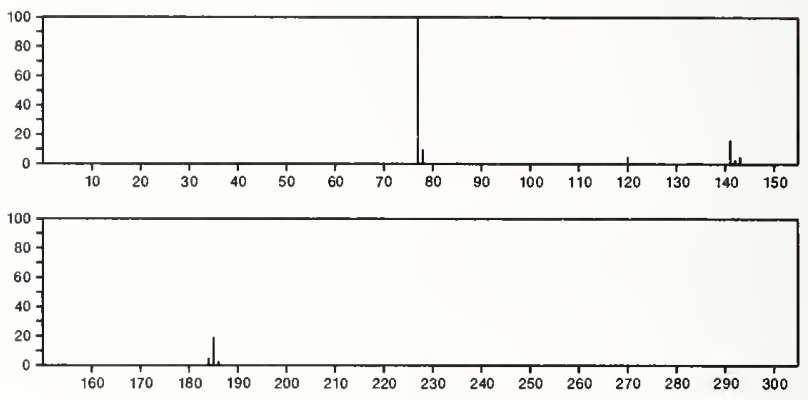

185

$\mathrm{C}_{8} \mathrm{H}_{11} \mathrm{NO}_{2} \mathrm{~S}$

3-Pyridinol, 2-[(2-hydroxyethyl)thio]-6-methyl-

23003-28-3
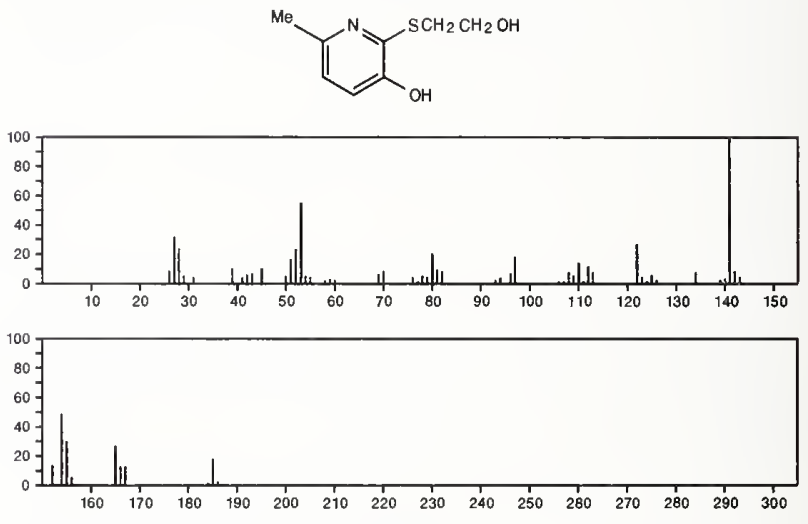

185

$\mathrm{C}_{8} \mathrm{H}_{15} \mathrm{~N}_{3} \mathrm{~S}$

$22397-22-4$

Cyclohexanone, 4-methyl-, thiosemicarbazone
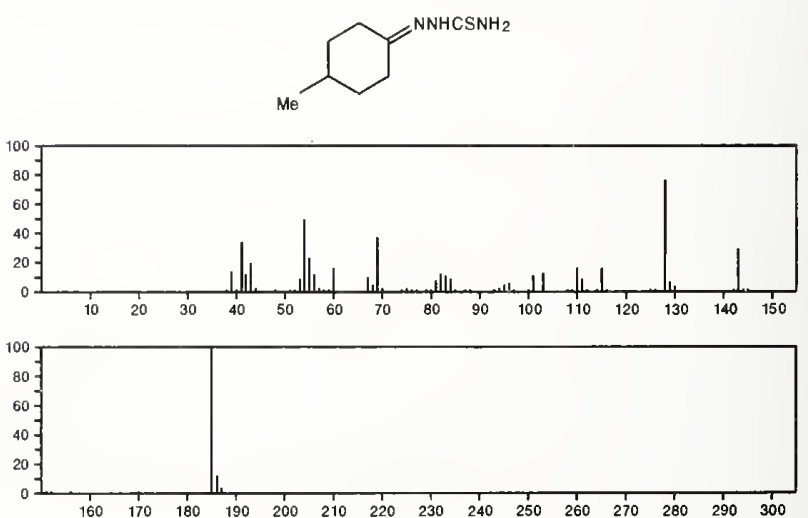
185

$\mathrm{C}_{8} \mathrm{H}_{15} \mathrm{~N}_{3} \mathrm{~S}$

$56324-61-9$

Hydrazinecarbothioamide, 2-(2-methylcyclohexylidene)-
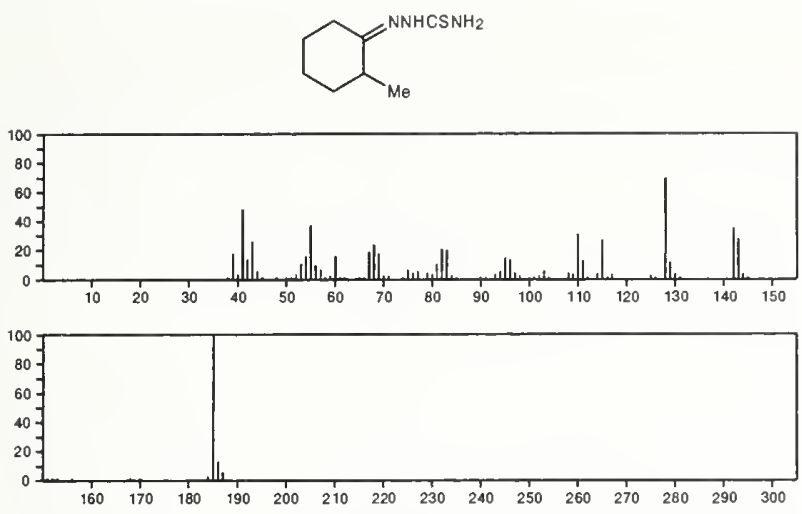

\section{5}

$\mathrm{C}_{8} \mathrm{H}_{16} \mathrm{BNO}_{3}$

$31970-40-8$

1,3,2-Oxazaborolane-4-carboxylic acid, 2-butyl-, methyl ester, L-
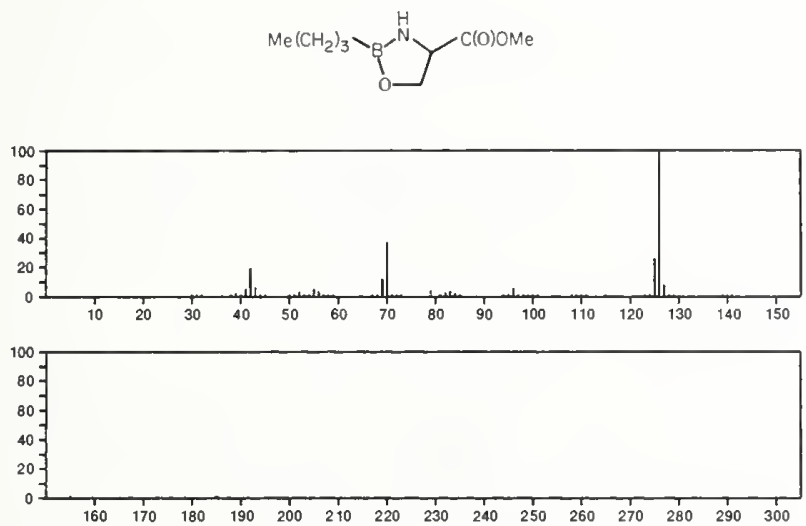

185

$\mathrm{C}_{9} \mathrm{H}_{15} \mathrm{NO}_{3}$

481-37-8

8-Azabicyclo[3.2.1 boctane-2-carboxylic acid, 3-hydroxy-8-methyl-, $[1 R-(\text { exo,exo })]^{-}$
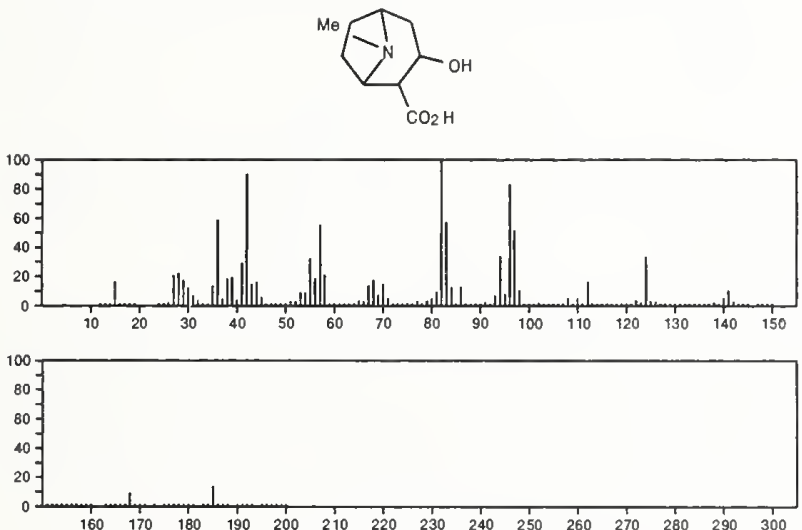

185

(3. Azabicyclo[3.2.1]octane-2-carboxylic acid, 3-hydroxy-8-methyl-, $[1 R-(2-\text { endo,3-exo })]^{-}$
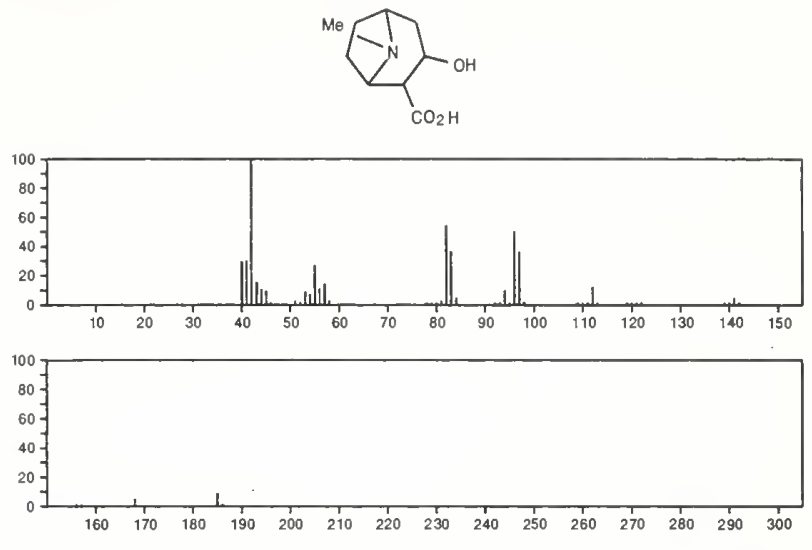

185

$\mathrm{C}_{9} \mathrm{H}_{15} \mathrm{NO}_{3}$

$33927-64-9$

1-Pyrrolidineacetic acid, 2-methyl-5-oxo-, ethyl ester
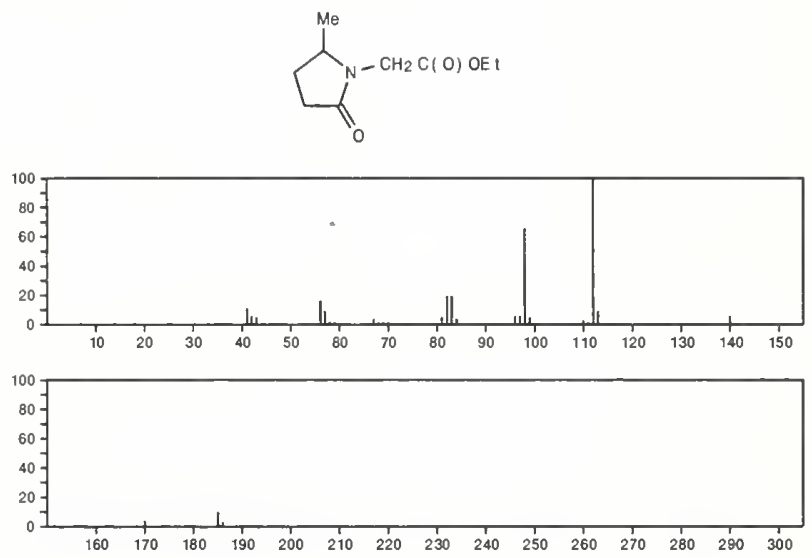

185

$2-0 \times a-6-a z a t r i c y c l o[3.3 .1$. 3.1.13,7]decane-4,8-diol, 6-methyl-, $(1 \alpha,=$ $3 \beta, 4 \alpha, 5 \beta, 7 \beta, 8 \beta)-$
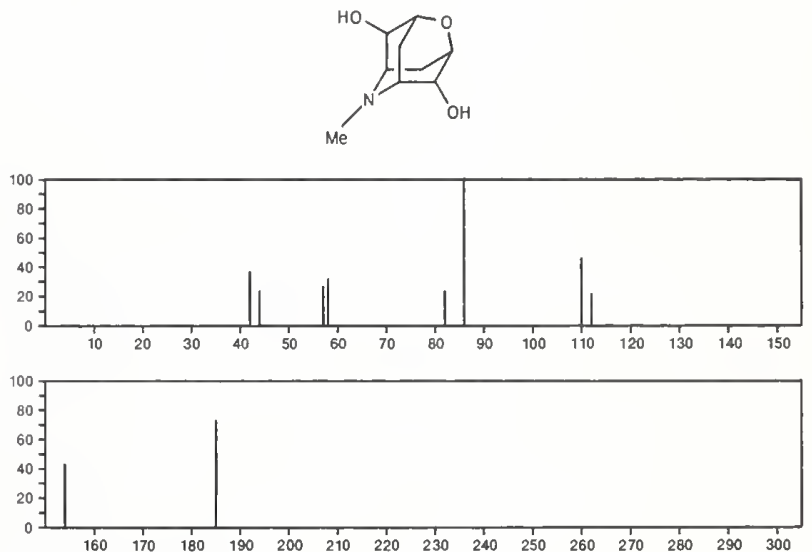
185 8-Azabicyclo[3.2.1] octane-2-carboxylic acid, 3-hydroxy-8-methyl-, (exo,exo)-
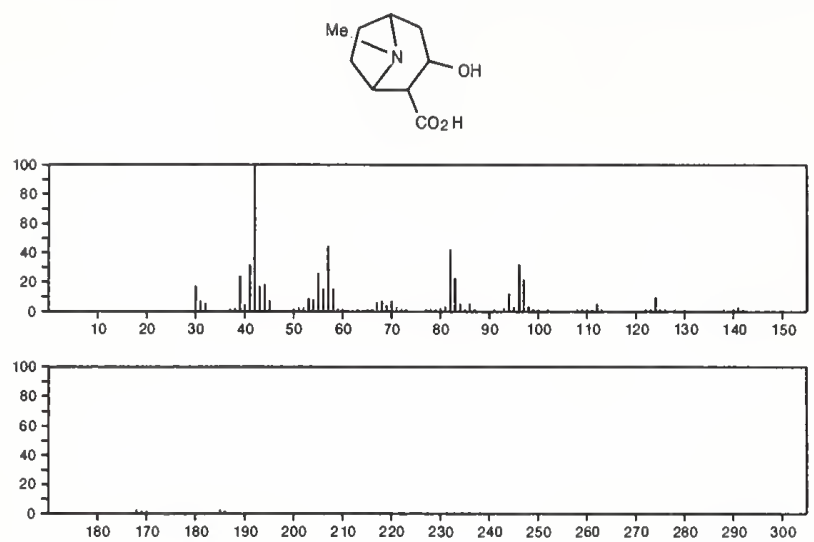

185

$\mathrm{C}_{9} \mathrm{H}_{15} \mathrm{NO}_{3}$

$54808-88-7$

8-Azabicyclo[3.2.1] octane-2-carboxylic acid, 3-hydroxy-8-methyl-, (2-endo,3-exo)
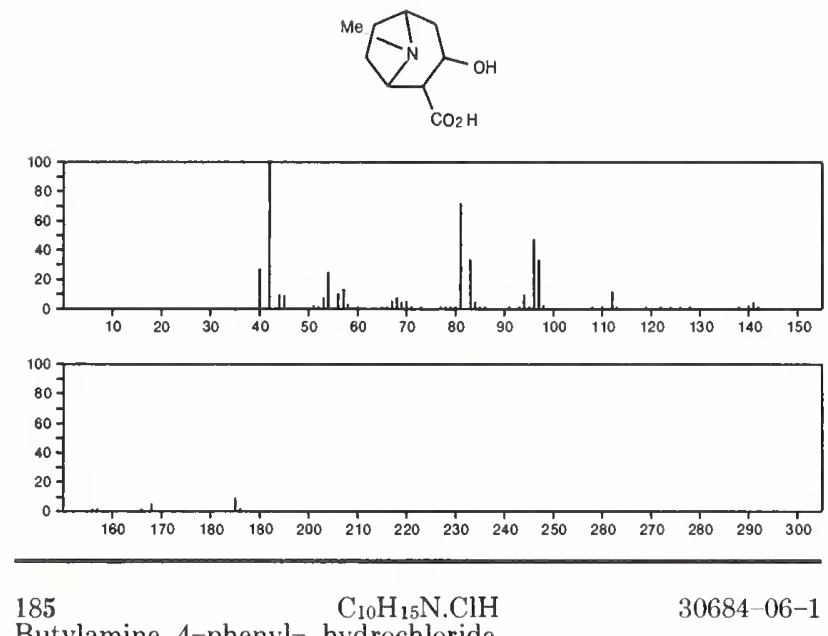

Butylamine, 4-phenyl-, hydrochloride

$\mathrm{Ph}\left(\mathrm{CH}_{2}\right)_{4} \mathrm{NH}_{2}$ - $\mathrm{HCl}$

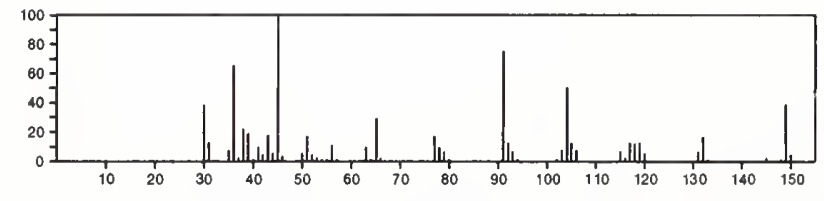

$185 \quad \begin{aligned} & \mathrm{C}_{10} \mathrm{H}_{15} \mathrm{~N} . \mathrm{ClH} \\ & \text { Benzenepropanamine, } N \text {-methyl-, hydrochloride }\end{aligned} \quad 30684-07-2$

$\mathrm{MeNH}\left(\mathrm{CH}_{2}\right)_{3} \mathrm{Ph} \cdot \mathrm{HCl}$

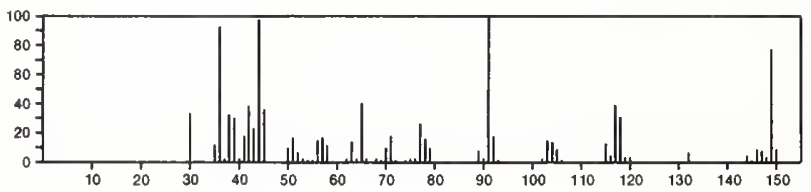

185

Hexanoic acid, 2-(1-aminoethylidene)-, ethyl ester

$3168-91-0$
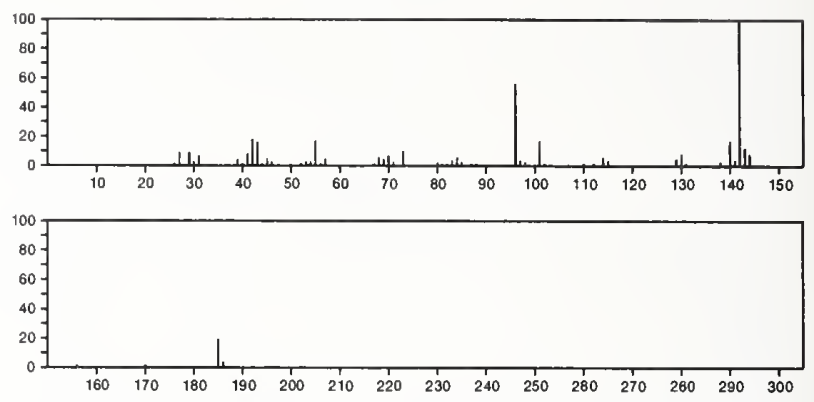

185

$\mathrm{C}_{10} \mathrm{H}_{19} \mathrm{NO}_{2}$

$23435-00-9$

Azacycloundecan-2-one, 7-hydroxy-
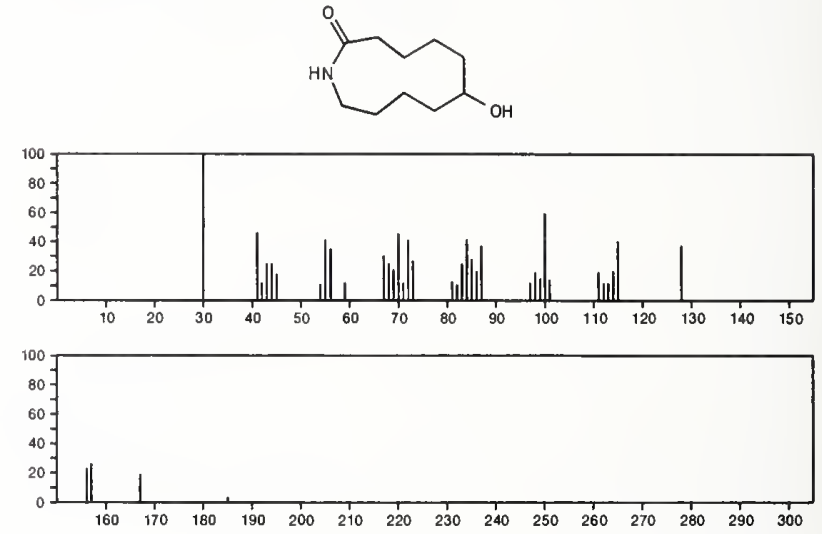

185

$\mathrm{C}_{10} \mathrm{H}_{19} \mathrm{NO}_{2}$

54751-92-7

3-Piperidinol, 1-acetyl-6-propyl-, (3R-trans)-<smiles>CCCC1CCC(O)CN1C</smiles>
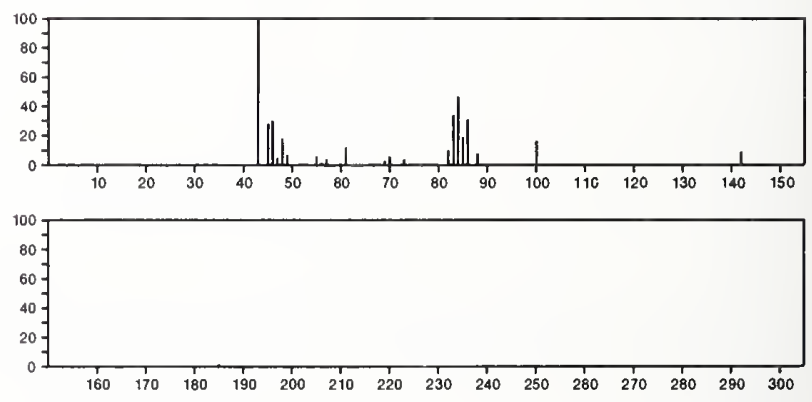

185

$\mathrm{C}_{10} \mathrm{H}_{19} \mathrm{NO}_{2}$

55669-84-6

1-Aziridineacetic acid, 2-methyl-3-(1-methylethyl)-, ethyl ester, trans
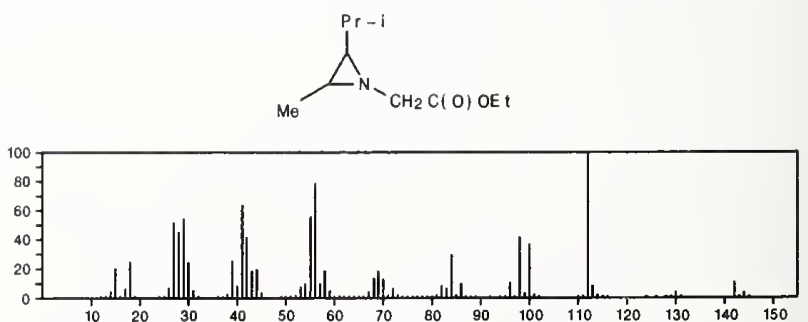


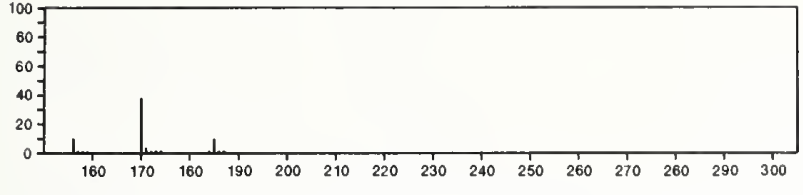

185

Naphthalene, 1-isothiocyanato-

\section{$\mathrm{C}_{11} \mathrm{H}_{7} \mathrm{NS}$}

$551-06-4$
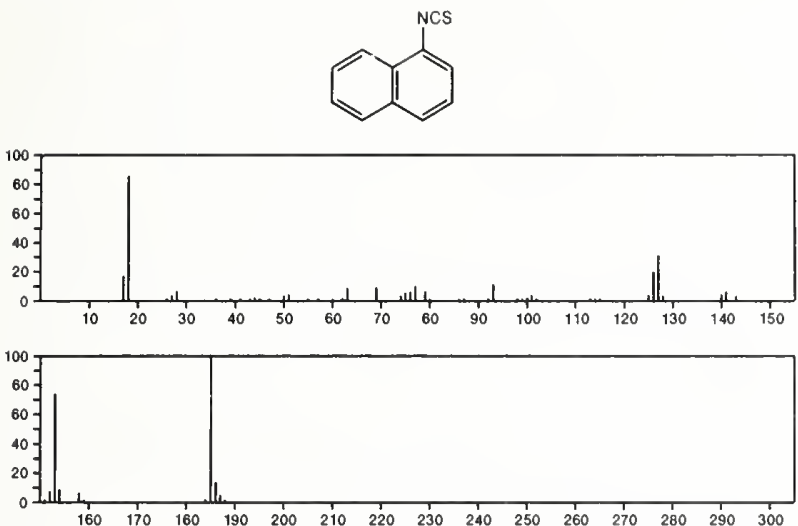

$\begin{array}{lllllllllllllll}160 & 170 & 160 & 190 & 200 & 210 & 220 & 230 & 240 & 250 & 260 & 270 & 280 & 290 & 300\end{array}$

185

$\mathrm{C}_{11} \mathrm{H}_{11} \mathrm{~N}_{3}$

$16728-92-0$

Acetonitrile, 2,2'-[(phenylmethyl)imino $]$ bis-

$\mathrm{CH}_{2} \mathrm{Ph}$

$\mathrm{NCCH}_{2} \stackrel{1}{\mathrm{~N}} \mathrm{CH}_{2} \mathrm{CN}$
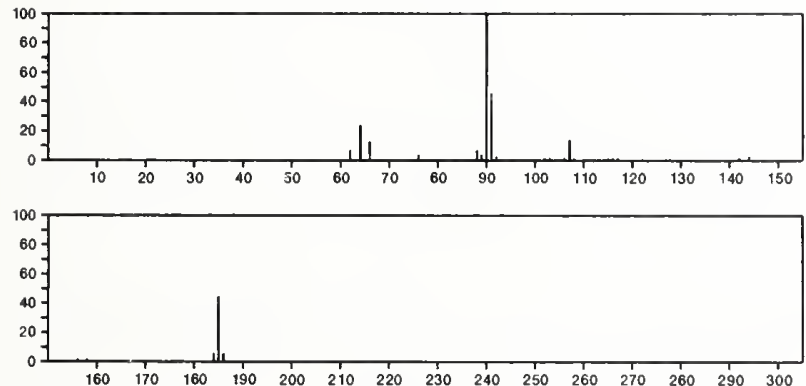

\section{5}

Valeramide, $N$-hexyl-

$\mathrm{C}_{11} \mathrm{H}_{23} \mathrm{NO}$

$10264-25-2$

$\mathrm{Me}\left(\mathrm{CH}_{2}\right)_{5} \mathrm{NHCO}\left(\mathrm{CH}_{2}\right)_{3} \mathrm{Me}$
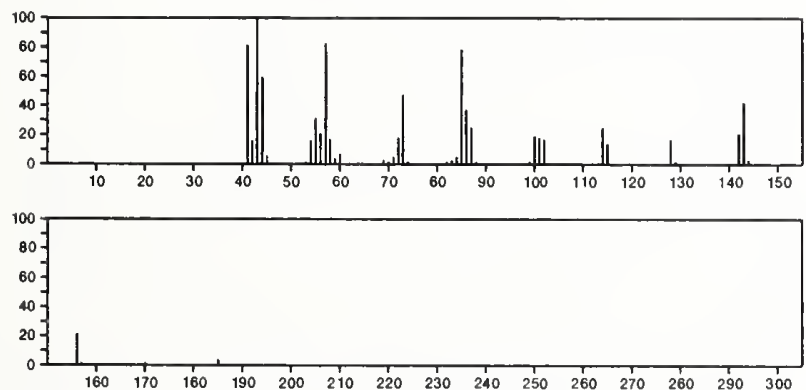

$\begin{array}{lllllllllllllll}160 & 170 & 160 & 190 & 200 & 210 & 220 & 230 & 240 & 250 & 260 & 270 & 160 & 290 & 1 \\ 1 & 1 & 1\end{array}$

185

Decanal, $O$-methyloxime

$\mathrm{C}_{11} \mathrm{H}_{23} \mathrm{NO}$

$35473-94-0$

$\mathrm{Me} O \mathrm{ON}=\mathrm{CH}\left(\mathrm{CH}_{2}\right){ }_{8} \mathrm{Me}$

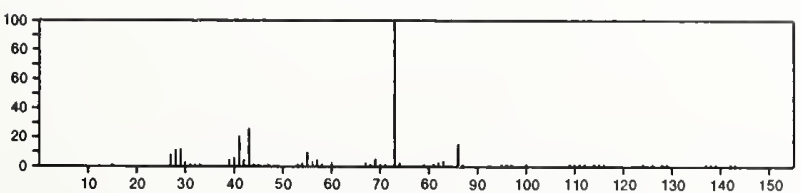

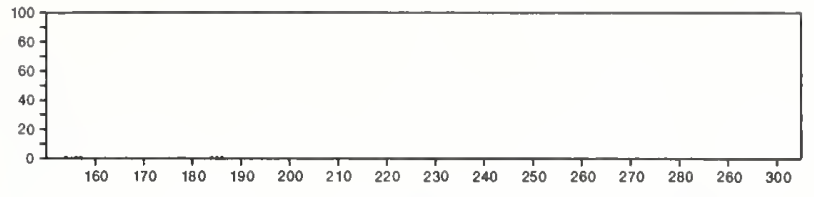

185

$36382-61-3$

2-Decanone, $\mathrm{O}$-methyloxime

$\mathrm{Me}\left(\mathrm{CH}_{2}\right)>\mathrm{CMe}=\mathrm{NOM}$
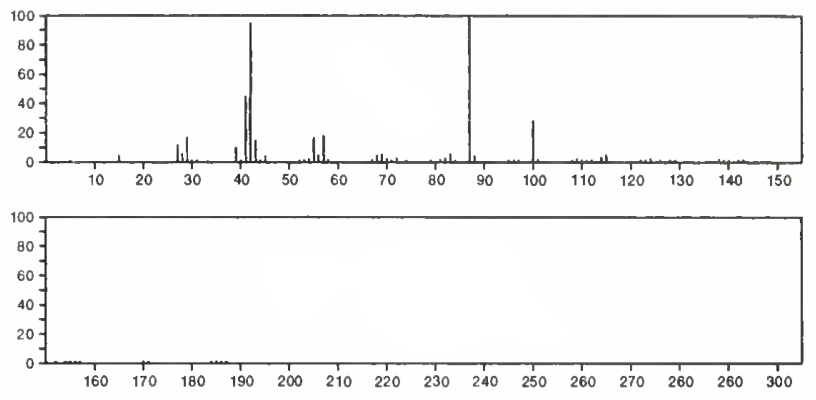

$85 \quad \mathrm{C}_{11} \mathrm{H}_{23} \mathrm{NO} \quad 50837-73-5$

Propanamide, 2,2-dimethyl- $N, N$-bis(1-methylethyl)-

$(\mathrm{i}-\mathrm{Pr}) 2 \mathrm{NCOCM}_{3}$
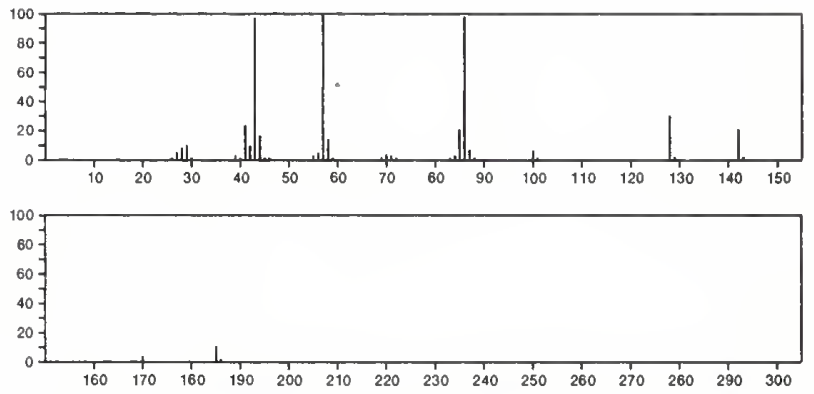

$185 \quad \mathrm{C}_{12} \mathrm{H}_{11} \mathrm{NO}$

1-Naphthalenecarboxamide, $N$-methyl-

$3400-33-7$<smiles>CC(=O)c1cccc2ccccc12</smiles>
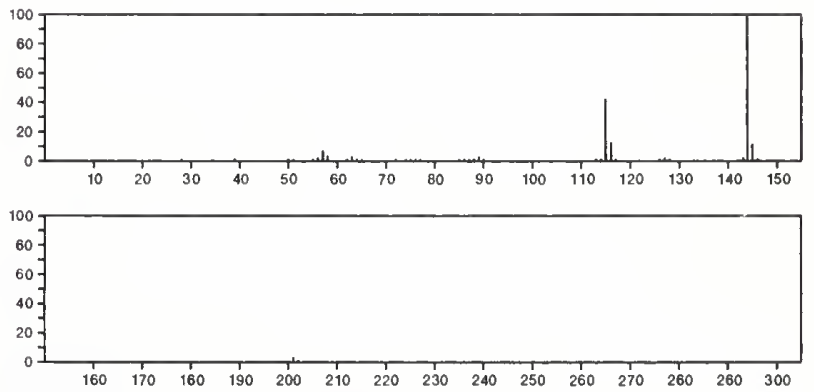

185

$\mathrm{C}_{12} \mathrm{H}_{11} \mathrm{NO}$

2(1H)-Pyridinone, 1-(2-methylphenyl)-

$54774-86-6$
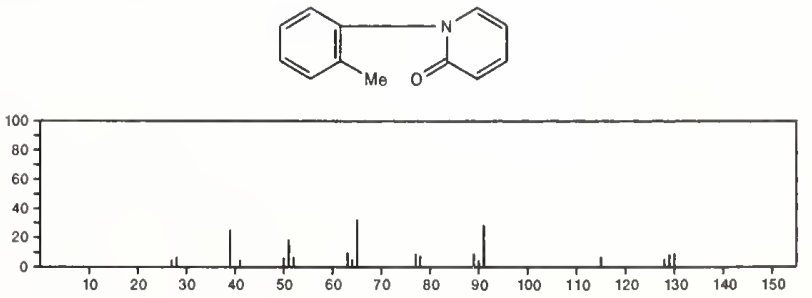


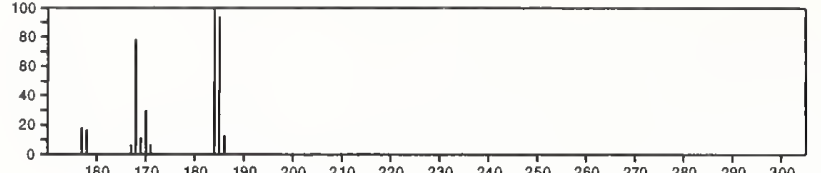

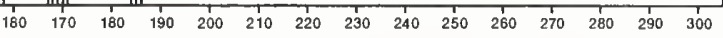

185 1-Butanamine, $N, N$-dibutyl-

$\mathrm{C}_{12} \mathrm{H}_{27} \mathrm{~N}$

$102-82-9$

$\left(\mathrm{CH}_{2}\right)_{3} \mathrm{Me}$

$\mathrm{Me}\left(\mathrm{CH}_{2}\right)_{3} \mathrm{~N}\left(\mathrm{CH}_{2}\right)_{3} \mathrm{Me}$
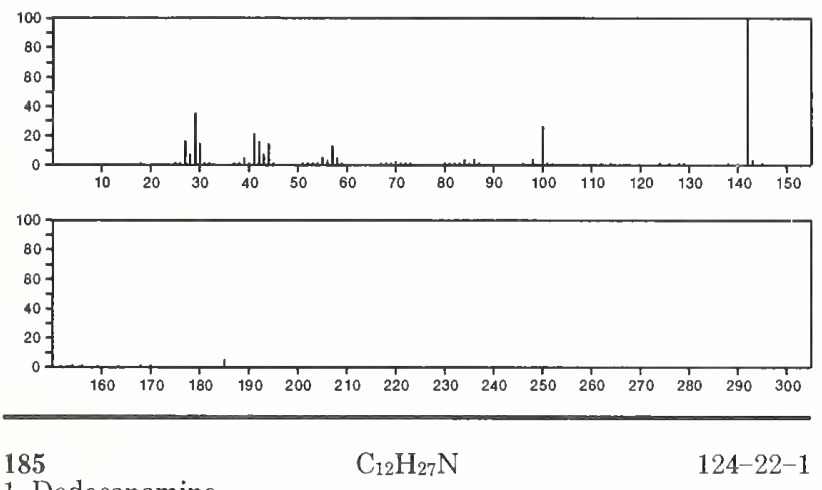

1-Dodecanamine

$\mathrm{Me}\left(\mathrm{CH}_{2}\right) 11 \mathrm{NH}_{2}$
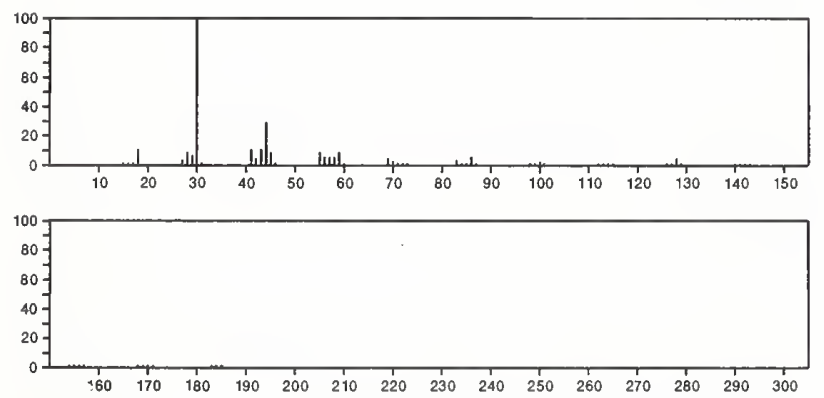

185

1-Hexanamine, $N$-hexyl-

$\mathrm{Me}\left(\mathrm{CH}_{2}\right) 5 \mathrm{NH}\left(\mathrm{CH}_{2}\right) 5 \mathrm{Me}$
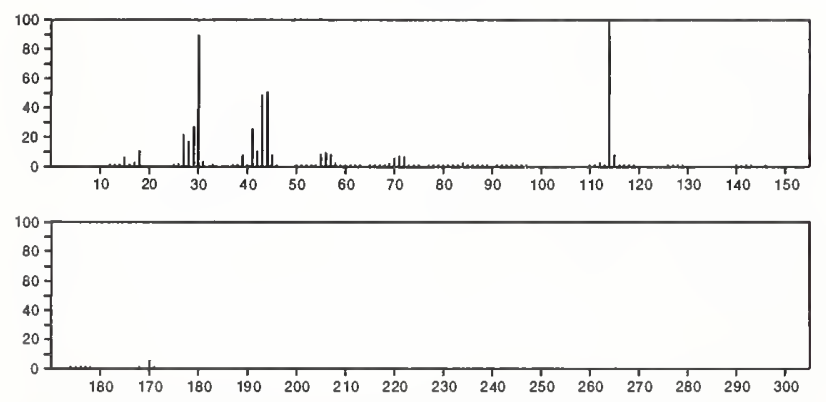

$185 \quad \mathrm{C}_{12} \mathrm{H}_{27} \mathrm{~N}$

1-Butanamine, 2-ethyl-N-(2-ethylbutyl)-

$54774-85-5$

$\mathrm{E} t_{2} \mathrm{CHCH}_{2} \mathrm{NHCH}_{2} \mathrm{CHE}$ $_{2}$

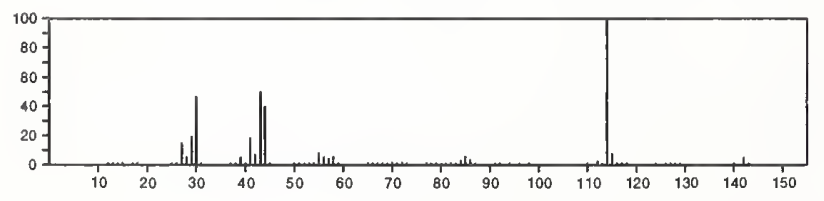

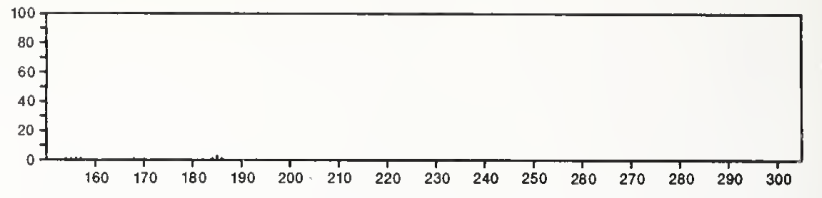

$185 \quad \mathrm{C}_{12} \mathrm{H}_{27} \mathrm{~N} \quad 54775-00-7$ 1-Pentanamine, 4-methyl-N-(4-methylpentyl)-

$\mathrm{Me} 2 \mathrm{CH}\left(\mathrm{CH}_{2}\right)_{3} \mathrm{NH}\left(\mathrm{CH}_{2}\right)_{3} \mathrm{CHMe} 2$
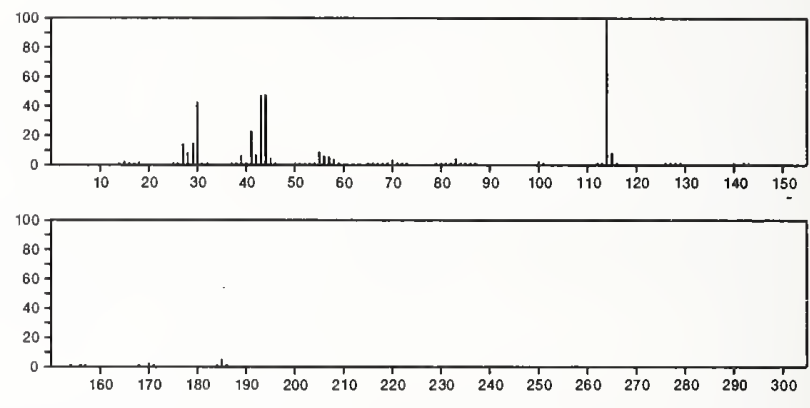

185

Quinoline, 2-(2-methylpropyl)

$\mathrm{C}_{13} \mathrm{H}_{15} \mathrm{~N}$

$93-19-6$
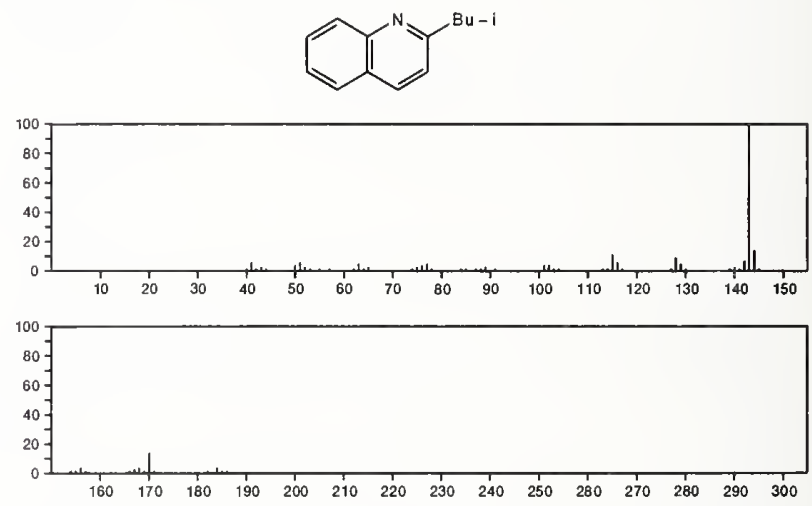

185

Quinoline, 6-butyl-

$\mathrm{C}_{13} \mathrm{H}_{15} \mathrm{~N}$

7634-74-4
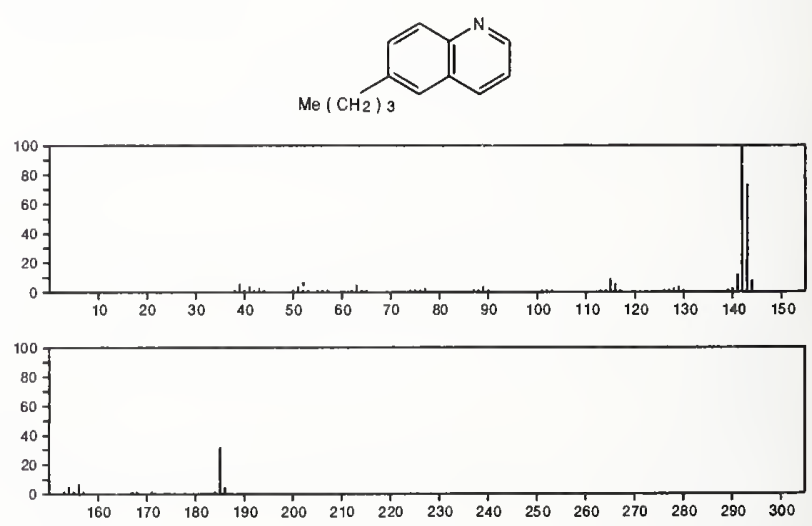
185

Isoquinoline, 1-butyl-

$\mathrm{C}_{13} \mathrm{H}_{15} \mathrm{~N}$

7661-38-3
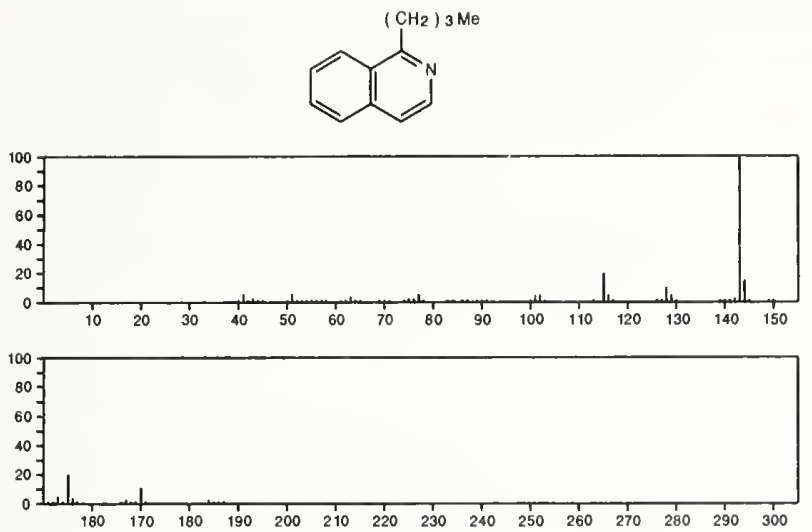

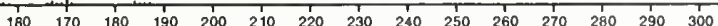

185

Quinoline, 2-butyl-

$\mathrm{C}_{13} \mathrm{H}_{15} \mathrm{~N}$

$7661-39-4$
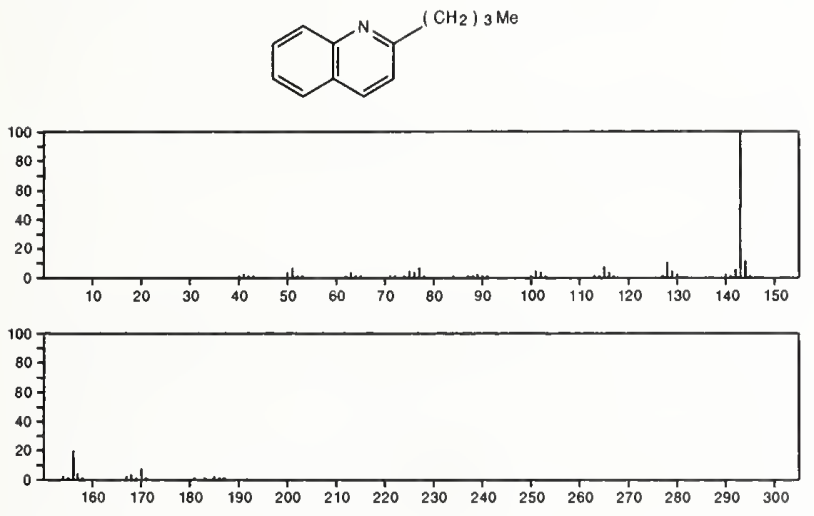

\begin{tabular}{ll}
\hline 185 & $\mathrm{C}_{13} \mathrm{H}_{15} \mathrm{~N}$ \\
$7661-40-7$
\end{tabular}

Isoquinoline, 1-isobutyl-
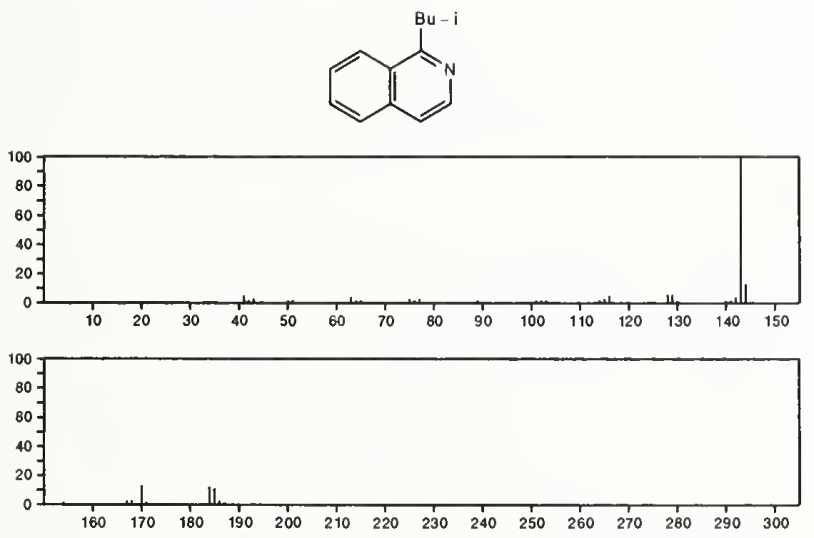

$185 \quad \mathrm{C}_{13} \mathrm{H}_{15} \mathrm{~N} \quad 7661-42-9$

Isoquinoline, 3-butyl-
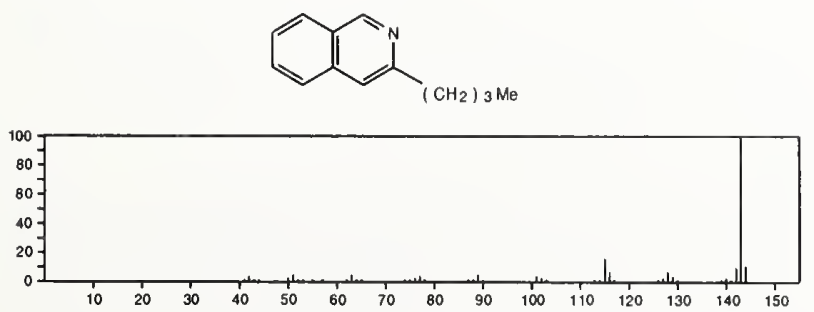

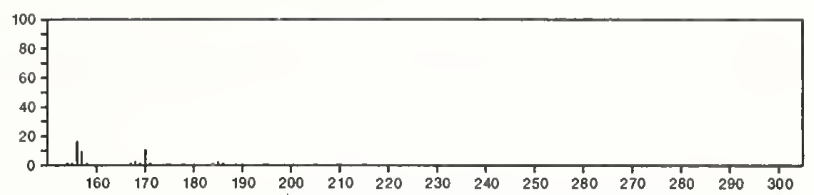

185

Quinoline, 4-isobutyl-

$$
\mathrm{C}_{13} \mathrm{H}_{15} \mathrm{~N}
$$

$7661-51-0$<smiles>Brc1ccnc2ccccc12</smiles>
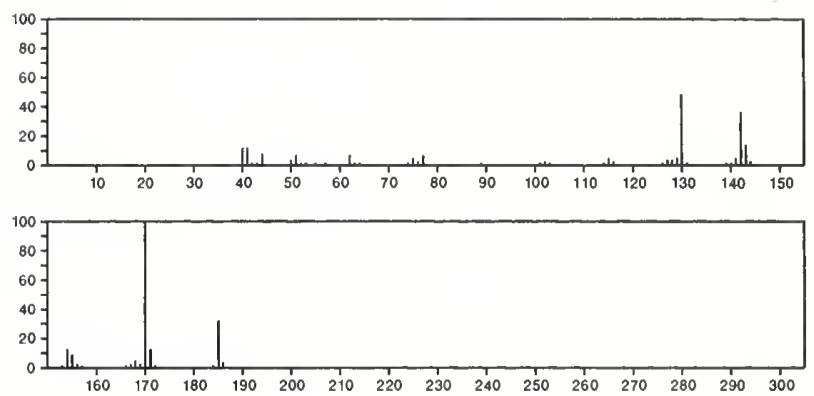

185

Quinoline, 7-butyl-

$$
\mathrm{C}_{13} \mathrm{H}_{15} \mathrm{~N}
$$

$7661-52-1$
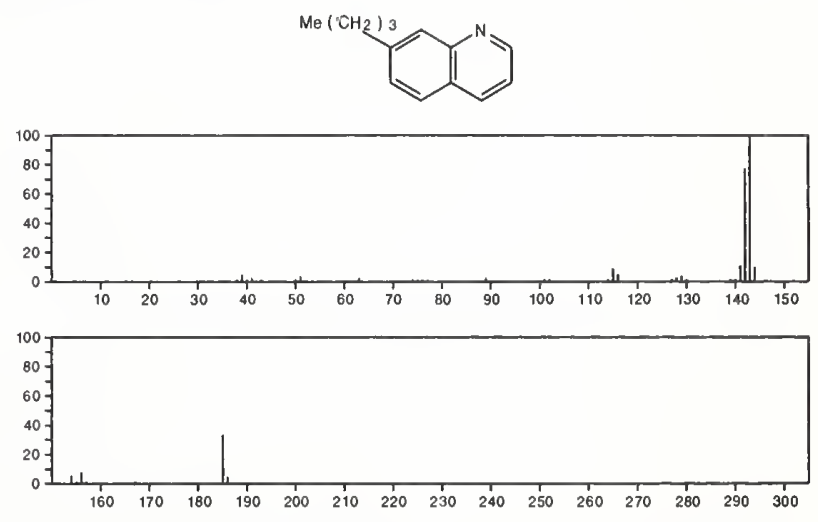

185

$\mathrm{C}_{13} \mathrm{H}_{15} \mathrm{~N}$

$18781-72-1$

$1 H$-Carbazole, 2,3,4,4a-tetrahydro-4a-methyl-
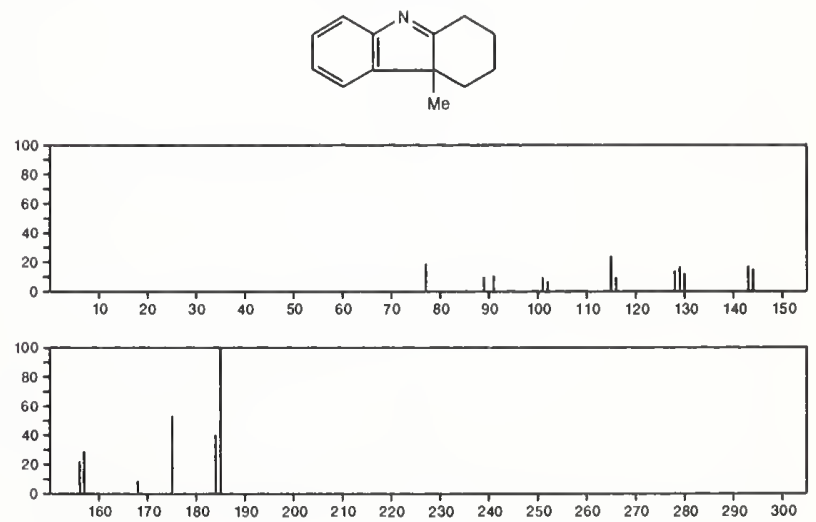
185 $\mathrm{C}_{13} \mathrm{H}_{15} \mathrm{~N}$

Spiro[cyclopentane-1,3'-[3H]indole], 2'-methyl
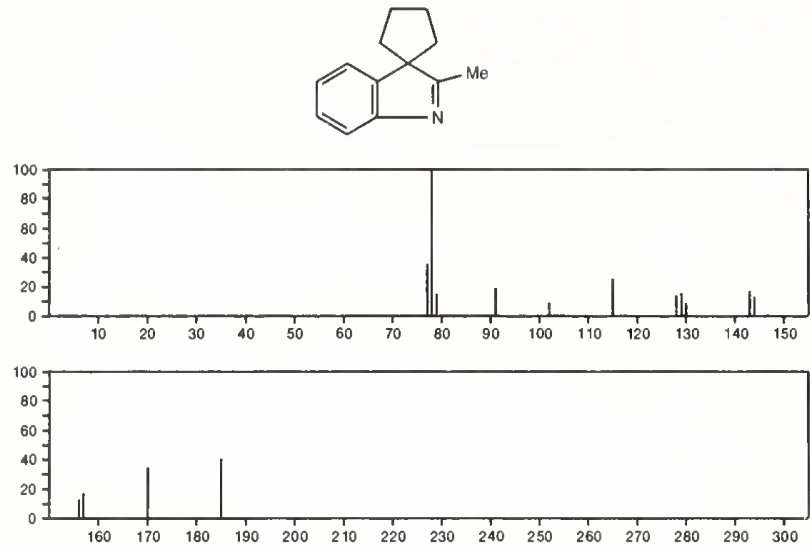

186

$\mathrm{C}_{2} \mathrm{Cl}_{3} \mathrm{~F}_{3}$

Ethane, 1,1,2-trichloro-1,2,2-trifluoro-

$76-13-1$

$\mathrm{F}_{2} \mathrm{CClCCl}_{2} \mathrm{~F}$
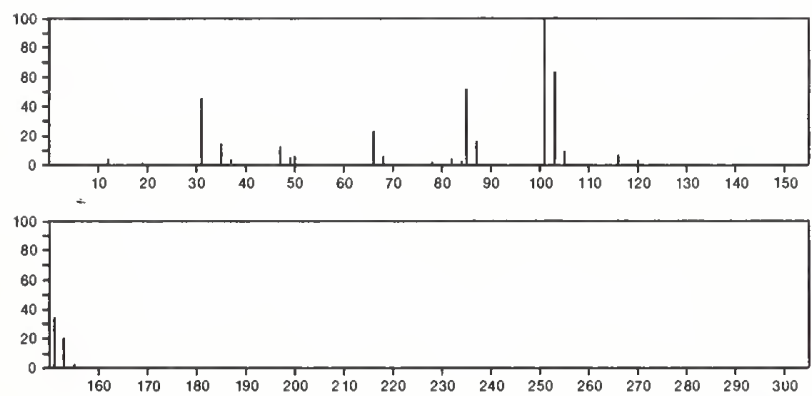

186

$\mathrm{C}_{2} \mathrm{Cl}_{3} \mathrm{~F}_{3}$

Ethane, 1,1,1-trichloro-2,2,2-trifluoro-

$354-58-5$

$\mathrm{F}_{3} \mathrm{CCCl}_{3}$
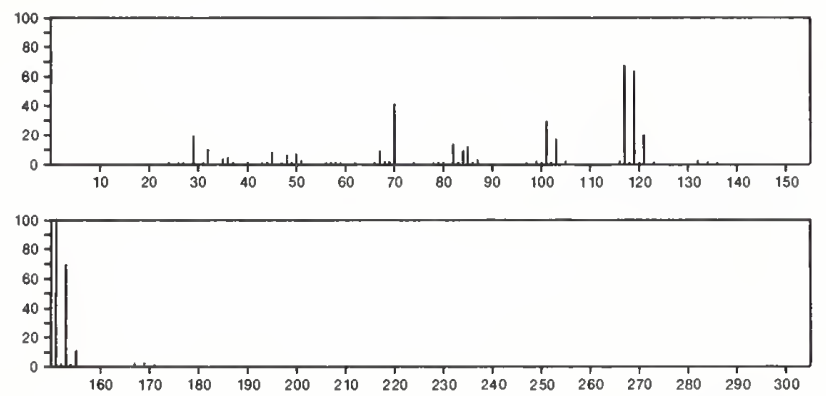

186

Trioxide, bis(trifluoromethyl)

$$
\mathrm{C}_{2} \mathrm{~F}_{6} \mathrm{O}_{3}
$$

$1718-18-9$

$\mathrm{F}_{3} \mathrm{COOOCF}_{3}$
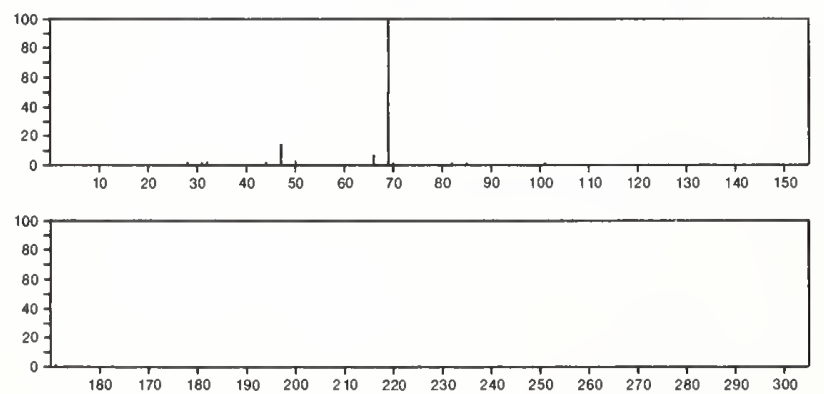

186

Acetic acid, iodo

$\mathrm{C}_{2} \mathrm{H}_{3} \mathrm{IO}_{2}$

$64-69-7$
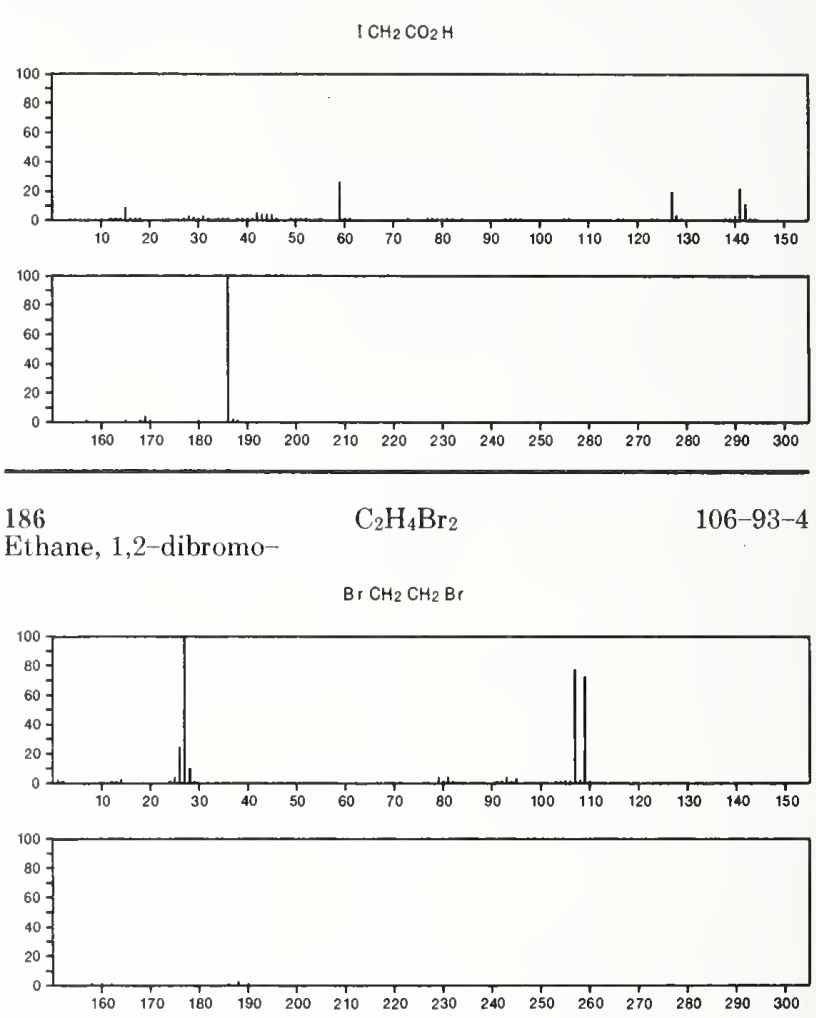

186

$\mathrm{C}_{2} \mathrm{H}_{4} \mathrm{Br} 2$

$557-91-5$

Ethane, 1,1-dibromo-

$\mathrm{Br}_{2}$ CHMe
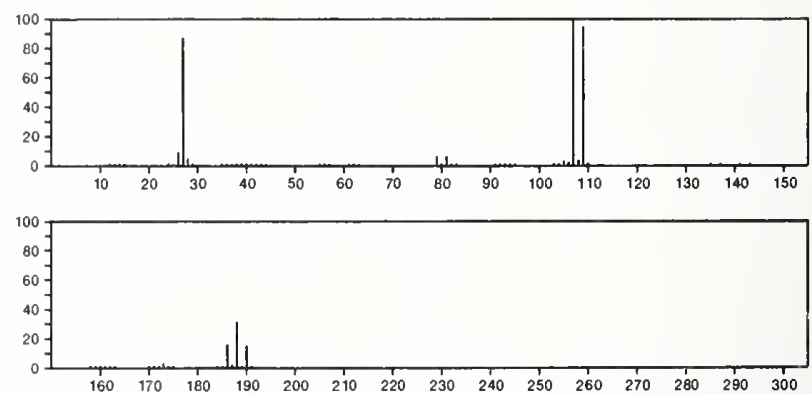

186

$\mathrm{C}_{4} \mathrm{H}_{8} \mathrm{ClO}_{4} \mathrm{P}$

$17027-41-7$

Phosphoric acid, 2-chloroethenyl dimethyl ester
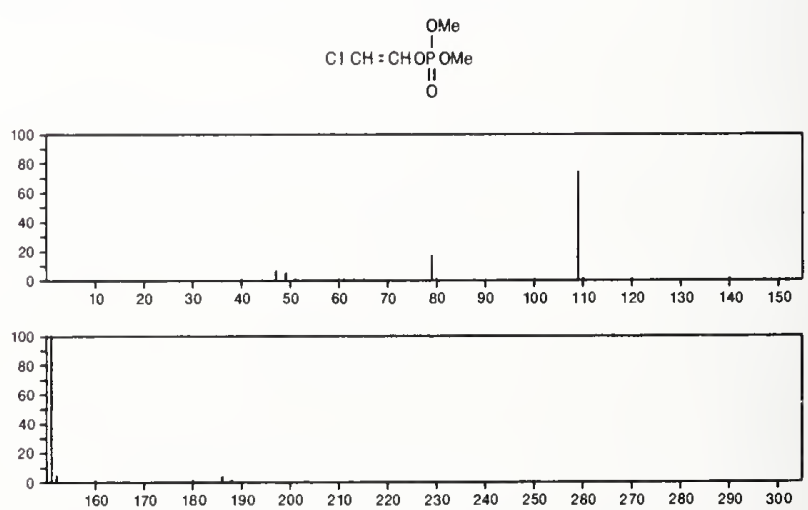
186

Tellurophene, tetrahydro

$\mathrm{C}_{4} \mathrm{H}_{8} \mathrm{Te}$

$3465-99-4$
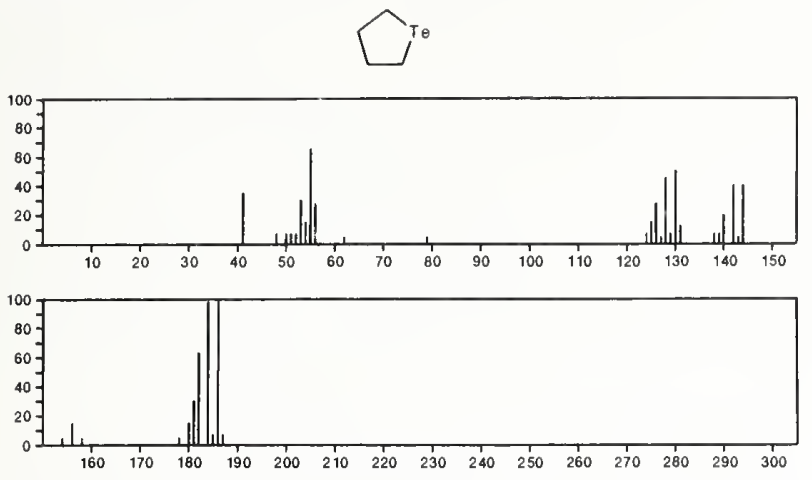

186

$\mathrm{C}_{4} \mathrm{H}_{12} \mathrm{ClN}_{2} \mathrm{O}_{2} \mathrm{P}$

22753-44-2

Phosphorodiamidous chloride, $N, N^{\prime}$-dimethoxy- $N, N^{\prime}$-dimethyl-

Me ONMe PCI NMe OMe
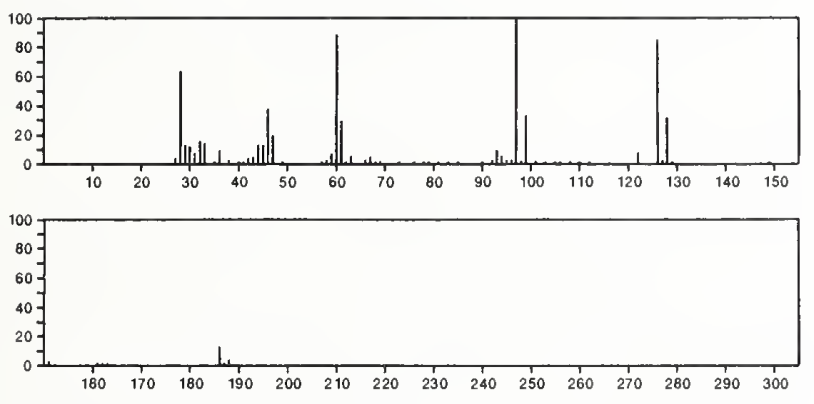

186

$\mathrm{C}_{4} \mathrm{H}_{12} \mathrm{ClN}_{2} \mathrm{PS}$

$3732-81-8$

Phosphorodiamidothioic chloride, tetramethyl-

$$
\text { NME } 2
$$

$\mathrm{Me}_{2} \mathrm{NPCl}=\mathrm{S}$
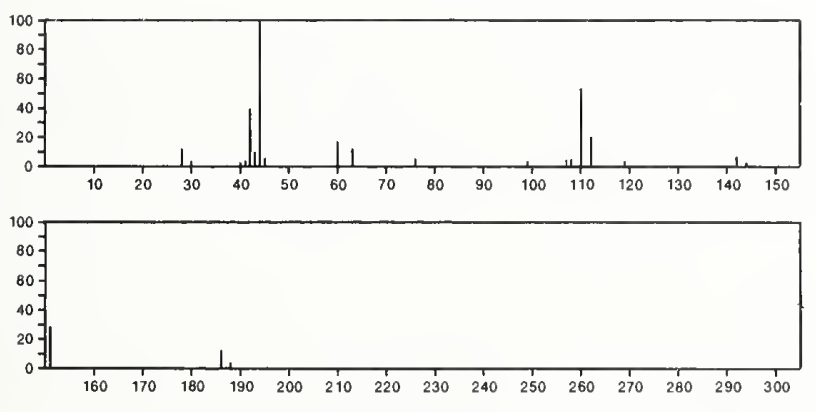

$186 \quad \mathrm{C}_{5} \mathrm{H}_{12} \mathrm{ClO}_{3} \mathrm{P} \quad 3167-63-3$

Phosphonic acid, (chloromethyl)-, diethyl ester

$$
\begin{gathered}
\text { OEt } \\
\text { I } \\
\mathrm{CI} \mathrm{CH}_{2} \text { POE } \mathrm{I} \\
0 \\
0
\end{gathered}
$$
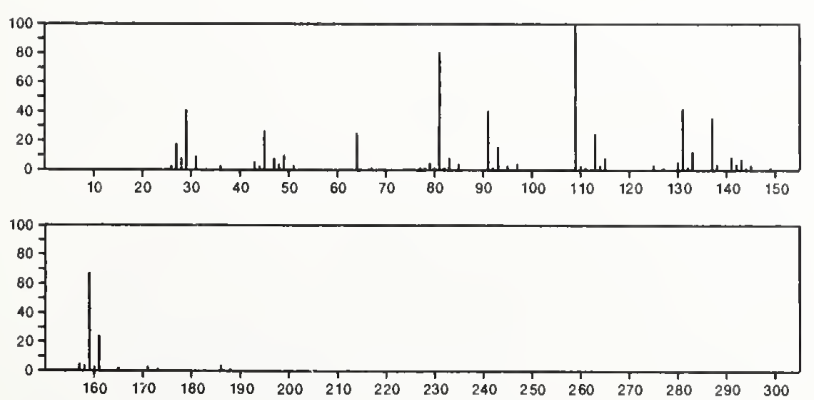

186

Benzene, hexafluoro

$\mathrm{C}_{6} \mathrm{~F}_{6}$

$392-56-3$
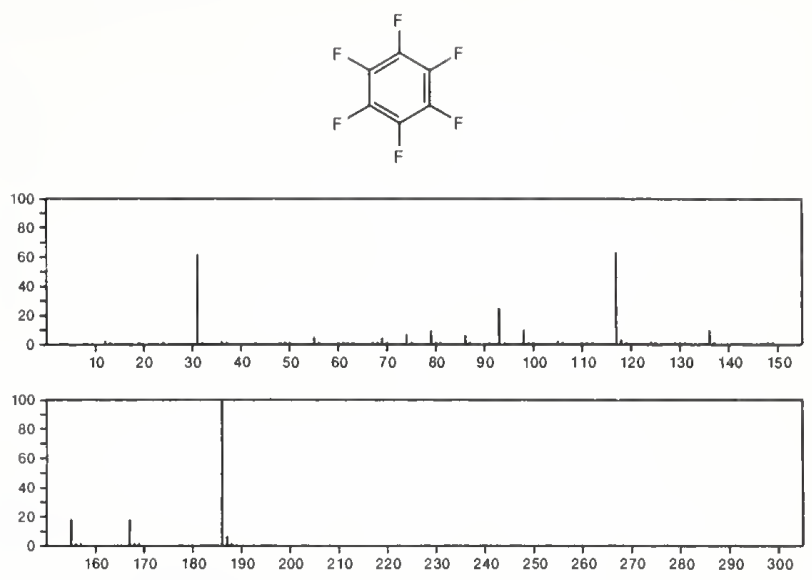

186

Benzene, 1-fluoro-2,4-dinitro-

$\mathrm{C}_{6} \mathrm{H}_{3} \mathrm{FN}_{2} \mathrm{O}_{4}$

70-34-8
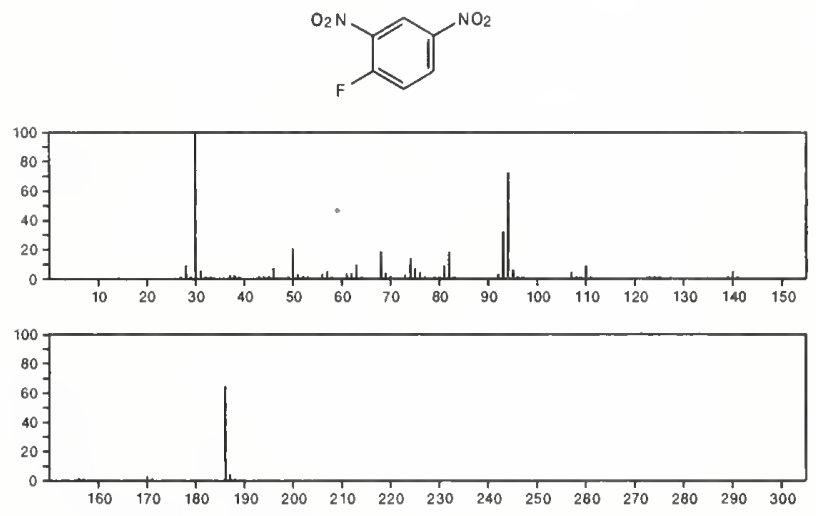

186

$\mathrm{C}_{6} \mathrm{H}_{6} \mathrm{~N}_{2} \mathrm{O}_{3} \mathrm{~S}$

16238-33-8

4H-1,3-Thiazine-6-carboxylic acid, 2-amino-4-oxo-, methyl ester<smiles>COC(=O)c1cc(=O)nc(N)s1</smiles>
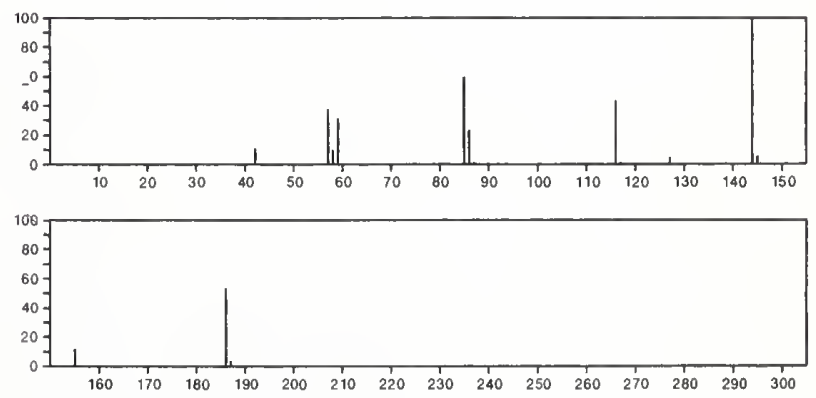

$186 \quad \mathrm{C}_{6} \mathrm{H}_{10} \mathrm{~N}_{4} \mathrm{OS} \quad 56247-55-3$

1,2,4-Thiadiazole-5-carbohydrazonic acid, 3-methyl-, ethyl ester

$$
\prod_{N-S}^{N e} C(O E 1)=N_{N}^{N} H_{2}
$$

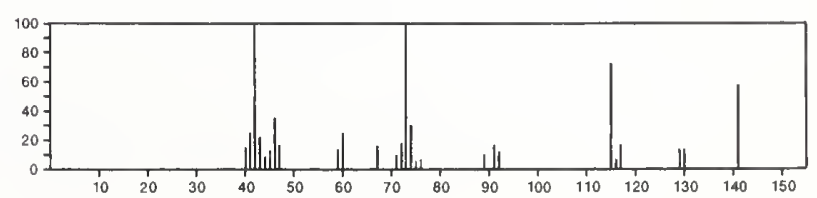




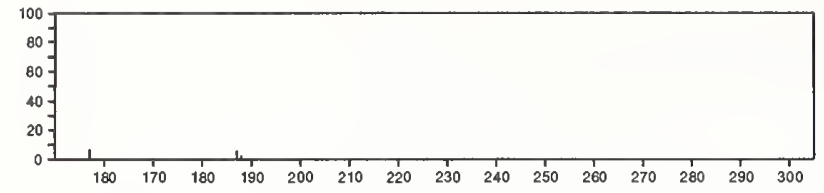

$186 \quad \mathrm{C}_{6} \mathrm{H}_{10} \mathrm{~N}_{4} \mathrm{O}_{3} \quad 35975-26-9$

2,6-Piperazinedione, 4-acetyl-, 2,6-dioxime
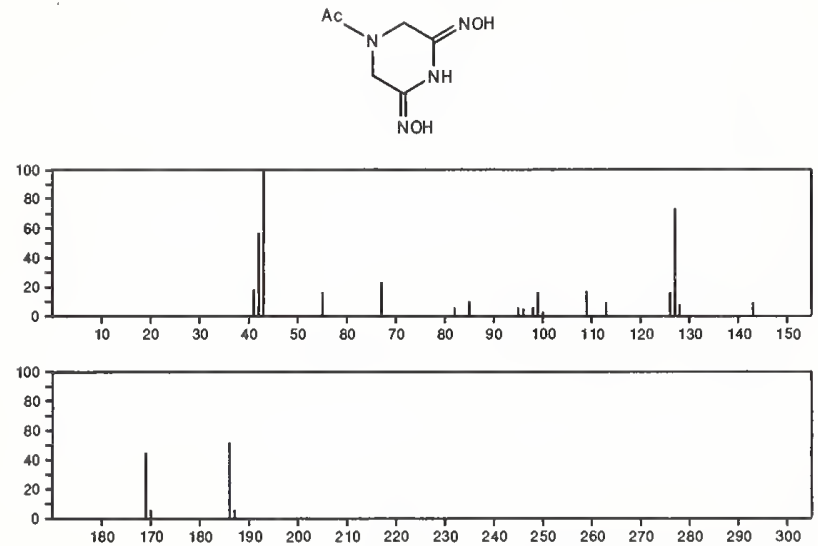

186

$\mathrm{C}_{6} \mathrm{H}_{12} \mathrm{Cl}_{2} \mathrm{O}_{2}$

Ethane, 1,2-bis(2-chloroethoxy)-

$112-26-5$

$\mathrm{CI} \mathrm{CH}_{2} \mathrm{CH}_{2} \mathrm{OCH}_{2} \mathrm{CH}_{2} \mathrm{OCH}_{2} \mathrm{CH}_{2} \mathrm{Cl}$

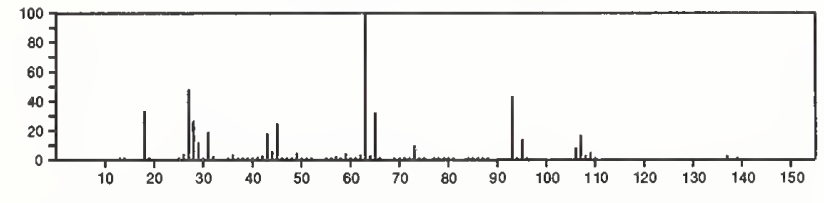

186

$\mathrm{C}_{7} \mathrm{H}_{7} \mathrm{BrO}$

$578-57-4$

Benzene, 1-bromo-2-methoxy-<smiles>COc1ccccc1Br</smiles>
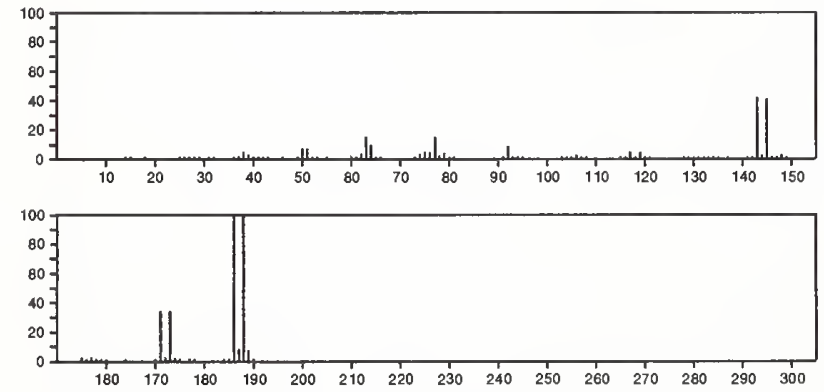

$186 \quad \mathrm{C}_{7} \mathrm{H}_{10} \mathrm{~N}_{2} \mathrm{O}_{2} \mathrm{~S}$

Benzenesulfonic acid, 4-methyl-, hydrazide

$1576-35-8$
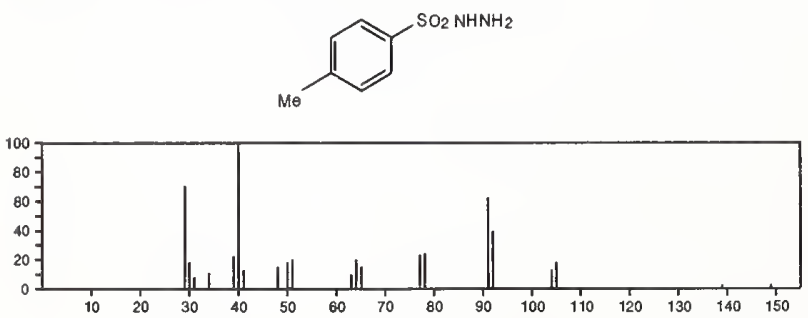

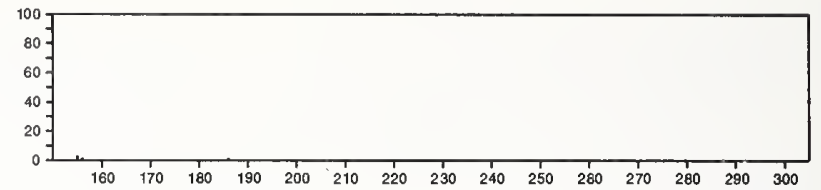

186

$\mathrm{C}_{7} \mathrm{H}_{18} \mathrm{~N}_{2} \mathrm{Si}_{2}$

Silanamine, $N, N^{\prime}$-methanetetraylbis[1,1,1-trimethyl-

$1000-70-0$

Me3SiN $=\mathrm{C}=\mathrm{NSIMe3}$
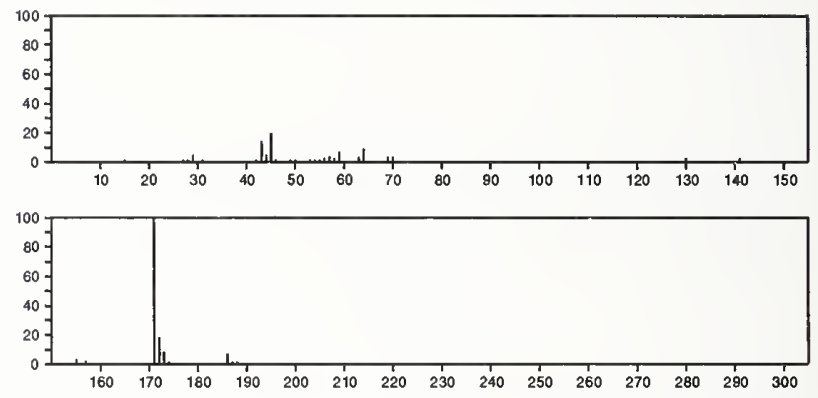

186

$\mathrm{C}_{8} \mathrm{H}_{7} \mathrm{ClOS}$

$5925-49-5$

Benzenecarbothioic acid, 4-chloro-, $O$-methyl ester
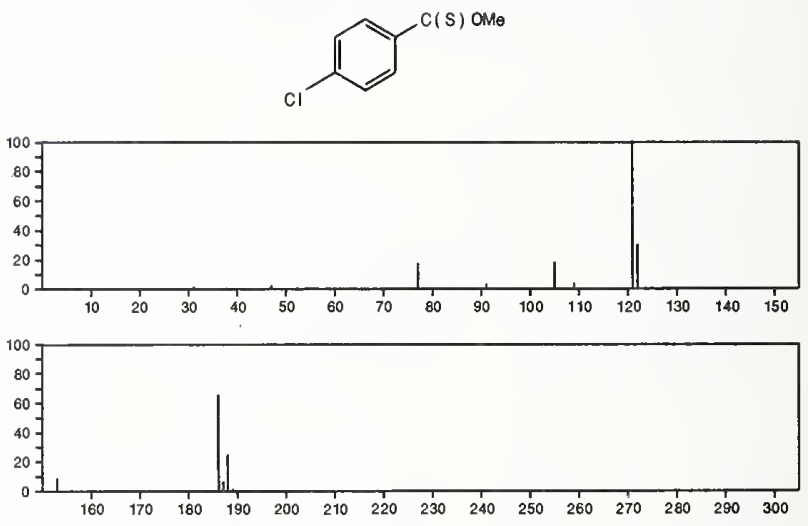

186

$\mathrm{C}_{8} \mathrm{H}_{7} \mathrm{ClOS}$

Benzenecarbothioic acid, 4-chloro-, $S$-methyl ester

$5925-67-7$
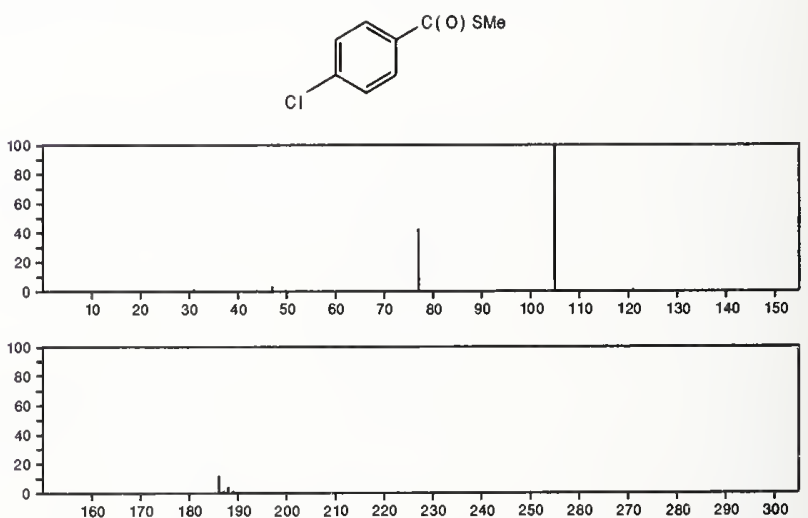
NBS-114A (REV. 11.77 )

\begin{tabular}{|c|c|c|c|}
\hline $\begin{array}{l}\text { U.S. DEPT. OF COMM. } \\
\text { BIBLIOGRAPHIC DATA } \\
\text { SHEET }\end{array}$ & $\begin{array}{l}\text { 1. PUBLICATION OR REPORT NO. } \\
\text { NSRDS-NBS 63, Vol. } 1\end{array}$ & $\begin{array}{l}\text { 2. Gov't Accession } \\
\text { No. }\end{array}$ & 3. Recipient's Accession No. \\
\hline \multirow{2}{*}{\multicolumn{3}{|c|}{$\begin{array}{l}\text { 4. TITLE AND SUBTITLE } \\
\text { EPA/NIH Mass Spectral Data Base } \\
\text { Volume 1, Molecular Weights } 30-186\end{array}$}} & $\begin{array}{l}\text { 5. Publication Date } \\
\text { December } 1978\end{array}$ \\
\hline & & & 6. Performing Organization Code \\
\hline 7. AUTHOR(S) S. R. H & ler and G. W. A. Milne & & 8. Performing Organ. Report No. \\
\hline \multicolumn{3}{|c|}{$\begin{array}{l}\text { 9. PERFORMING ORGANIZATION NAME AND ADDRESS } \\
\qquad \begin{array}{l}\text { NATIONAL BUREAU OF STANDARDS } \\
\text { DEPARTMENT OF COMMERCE } \\
\text { WASHINGTON, D.C. } 20234\end{array}\end{array}$} & 10. Project/Task/Work Unit No. \\
\hline \multirow{2}{*}{\multicolumn{3}{|c|}{$\begin{array}{l}\text { 12. Sponsoring Organization Name and Complete Address (Street, City, State, ZIP) } \\
\text { Environmental Protection Agency, Washington, DC } 20460 \\
\text { and } \\
\text { National Institutes of Health, Bethesda, MD } 20014\end{array}$}} & $\begin{array}{l}\text { 13. Type of Report \& Period } \\
\text { Covered } \\
\text { N/A }\end{array}$ \\
\hline & & & 14. Sponsoring Agency Code \\
\hline
\end{tabular}

15. SUPPLEMENTARY NOTES

Library of Congress Catalog Card Number: 78-606175

16. ABSTRACT (A 200-word or less factual summary of most significant information. If document includes a significant bibliography or literature survey, mention it here.)

This publication presents a collection of 25,556 verified mass spectra of individual substances compiled from the EPA/NIH mass spectral file. The spectra are given in bar graph format over the full mass range. Each spectrum is accompanied by a Chemical Abstracts Index substance name, molecular formula, molecular weight, structural formula, and Chemical Abstracts Service Registry Number.

17. KEY WORDS (six to twelve entries; alphabetical order; capitalize only the first letter of the first key word unless a proper name; separated by semicolons)

Analytical data; mass spectra; organic substances; verified spectra.

\begin{tabular}{|c|c|c|}
\hline $\begin{array}{l}\text { 18. AVAILABILITY Unlimited } \\
\square \text { For Official Distribution. Do Not Release to NTIS }\end{array}$ & $\begin{array}{l}\text { 19. SECURITY CLASS } \\
\text { (THIS REPURT) } \\
\text { UNCL ASSIFIED }\end{array}$ & $\begin{array}{l}\text { 21. NO. OF PAGES } \\
1001\end{array}$ \\
\hline
\end{tabular}




\section{Where can you find all the reference data you need? \\ ta}

\section{Right in the}

Journal of Physical and Chemical Reference Data!

Now in its sixth year, this valuable publication has proved that it fills the important gaps for you in the literature of the physical sciences.

Published by the American Institute of Physics and the American Chemical Society for the National Bureau of Standards, this quarterly gives you quantitative numerical data, with recommended values and uncertainty limits chosen by experts in the field.

Critical commentary on methods of measurement and sources of error, as well as full references to the original literature, is an integral part of each of your four issues a year.

Can you afford to be without this prime source of reliable data on physical and chemical properties? To start receiving your copies, just fill in the order form and drop into the mail. If you do use a pur chase order, please attach the printed form as this will help us to expedite your order. Send for complete list of reprints!
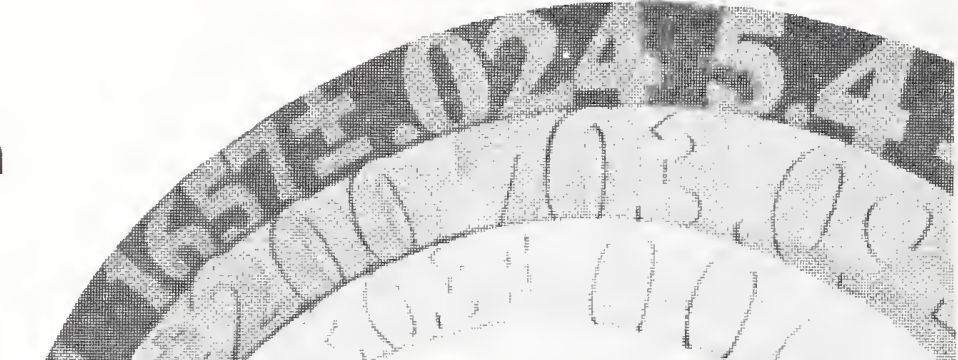

(1)




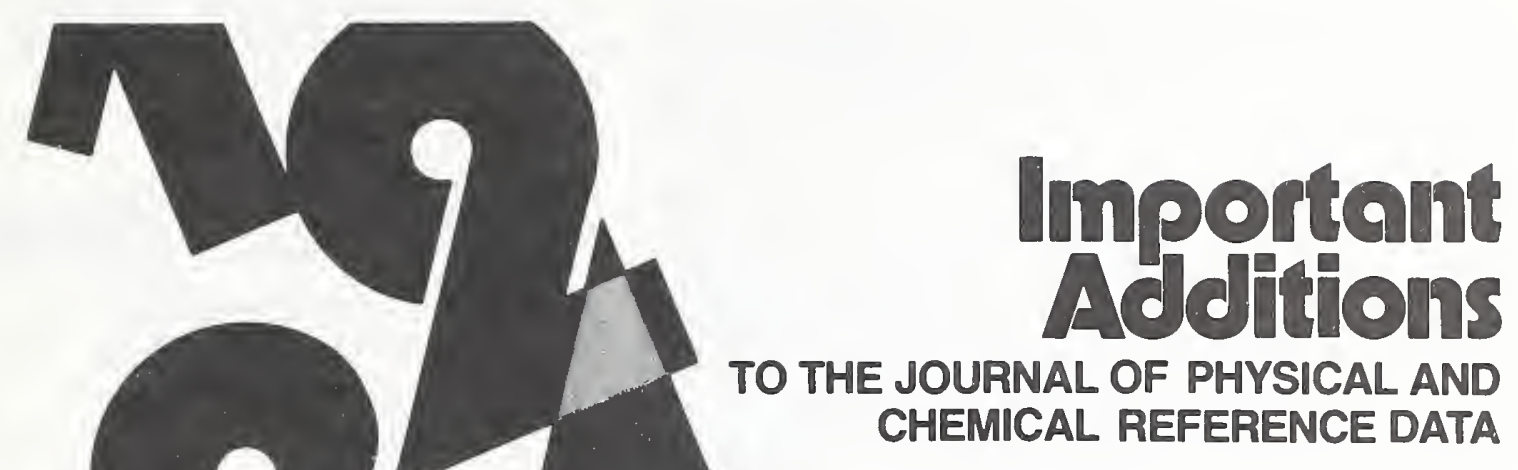

Three comprehensive reference volumes, each, as the Journal itself, published by the American Institute of Physics and the American Chemical Society for the National Bureau of Standards... your triple assurance of their accuracy, immediacy, and usefulness.

Supplement No. 1 to Vol. 2

"PHYSICAL AND THERMODYNAMIC PROPERTIES OF ALIPHATIC ALCOHOLS" by R. C. Wilhoit and B. J. Zwolinski, Thermodynamics Research Center, Deparfment ot Chemistry. Texas A \& M University

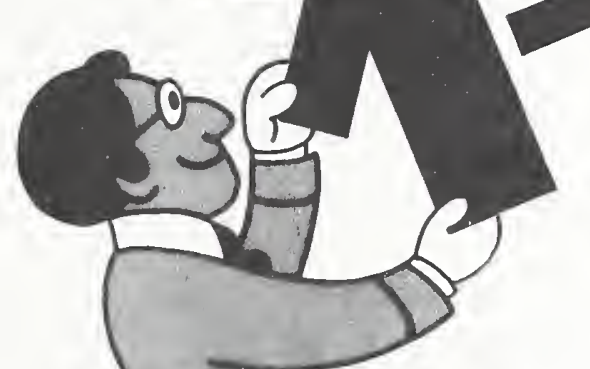
Represents the most exhaustive review and critical analysis of selected physical and thermodynamic properties of aliphatic alcohols that has been published in the world literature of chemistry.

\section{Supplement No. 1 to $\mathrm{Vol} .3$ \\ “THERMAL CONDUCTIVITY OF THE ELEMENTS: A COMPREHENSIVE REVIEW'"}

by C. Y. Ho. R. W. Powell, and P. E. Liley, Thermophysical Properties Research Center, Purdue University, West Lafayette, Indiana

This comprehensive review of the world's thermal conductivity data presents recommended or estimated values for all 105 elements.

Business Operations-Books and Journals Dept. American Chemical Society

1155 16th Street, N.W.

Washington, D.C. 20036

Please send copies of at $\$$

A. "PHYSICAL AND THERMOdYNAMIC PROPERTIES OF ALIPHATIC ALCOHOLS." (First supplement to Vol. 2 of the Journal of Physical and Chemical Reference Data.) Hard Cover: $\$ 33.00$. Soft Cover: $\$ 30.00$.

B. "THERMAL CONDUCTIVITY OF THE ELEMENTS. A COMPREHENSIVE REVIEW." (First supplement to Vol 3 of the Journal of Physical and Chemical Reference Data.) Hard Cover $\$ 60.00$. Sott Cover: $\$ 55.00$.

C. "ENERGETICS OF GASEOUS IONS." (First supplement to Vol. 6 of the Journal of Physical and Chemical Reference Data.) Hard Cover: $\$ 70.00$ Sott Cover: $\$ 65.00$

$\square$ I am enclosing a check

$\square$ I am enclosing a money order

Name

Address

City

State

Zip Code

Title

Employer

Mlease add $\$ 1.50$ extra for foreign posiage and handling.
Supplement No. 1 to $\mathrm{Vol} .6$

ENERGETICS OF GASEOUS IONS

by H. M. Rosenstock, K. Draxl, B. Steiner, and J. T. Herron, National Bureau of Standards

Provides a comprehensive body of critically evaluated information on ionization potentials, appearance potentials, electron affinities and heats of formation of gaseous positive and negative ions. It is a complete revision and extension of the earlier reference work, "Ionization Potentials, Appearance Potentials and Heats for Formation of Gaseous Positive Ions," NSRDS-NBS 26. 


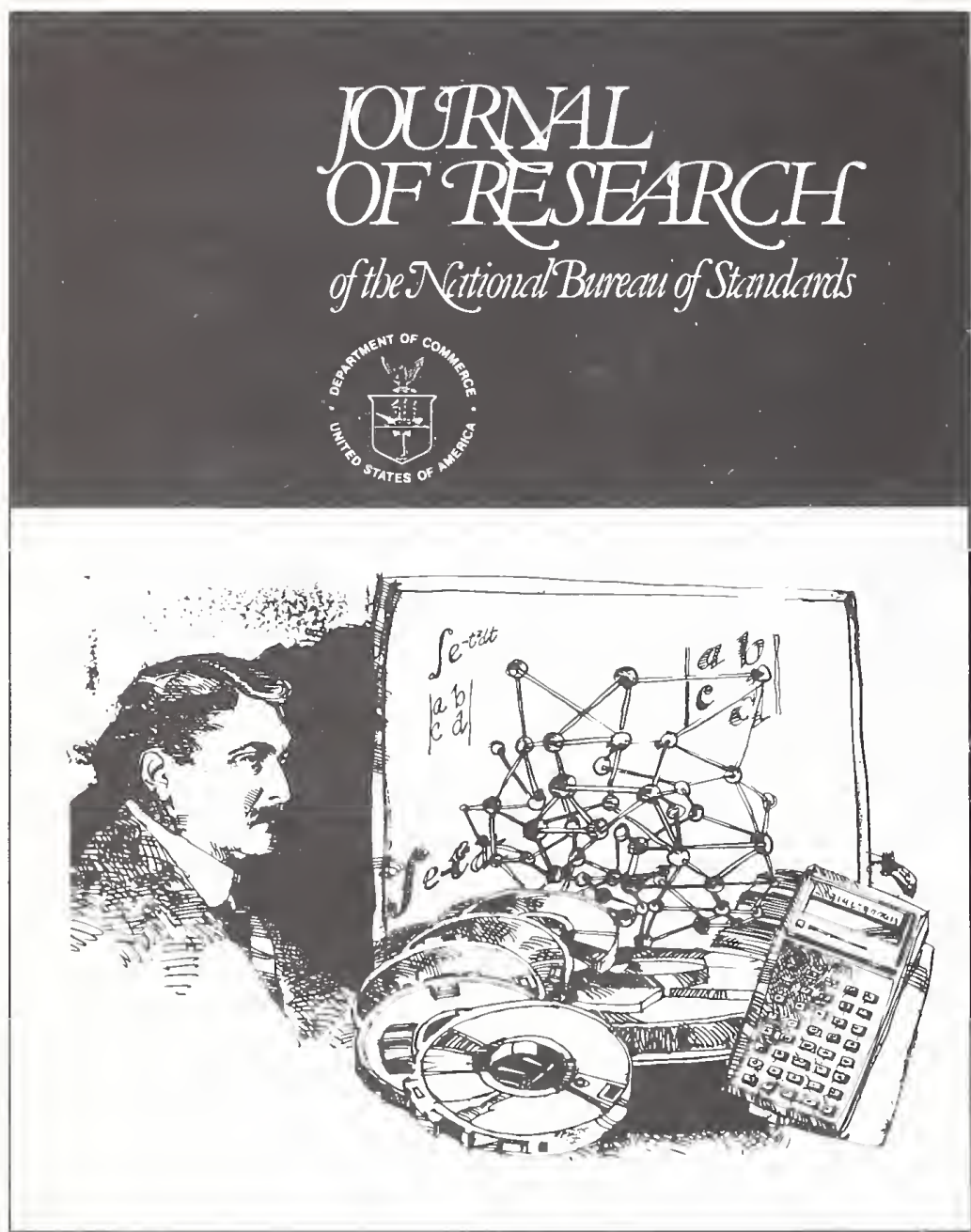

For a review copy, write Journal of Research, National Bureau of Standards, U.S. DEPARTMENT OF COMMERCE Washington, D.C. 20234

\section{Subseribe now - the new Tational Burean of Standards Journal}

The expanded Journal of Research of the National Bureau of Standards reports NBS research and development in those disciplines of the physical and engineering sciences in which the Bureau is active. These include physics, chemistry, engineering, mathematics, and computer sciences. Papers cover a broad range of subjects, with major emphasis on measurement methodology, and the basic technology underlying standardization. Also included from time to time are survey articles on topics closely related to the Bureau's technical and scientific programs. As a special service to subscribers each issue contains complete citations to all recent NBS publications in NBS and nonNBS media. Issued six times a year. Annual subscription: domestic $\$ 17.00$; foreign $\$ 21.25$. Single copy, $\$ 3.00$ domestic; $\$ 3.75$ foreign.

- Note: The Journal was formerly published in two sections: Section A "Physics and Chemistry" and Section B "Mathematical Sciences."

NBS Board of Editors

Churchill Eisenhart,

Executive Editor (Mathematics)

John W. Cooper (Physics)

Donald D. Wagman (Chemistry)

Andrew J. Fowell (Engineering)

Joseph 0. Harrison (Computer Science)

Stephen J. Smith (Boulder Labs.)
Subscription Order Form

Enter my subscription to NBS Journal of Research

at $\$ 17.00$. Add $\$ 4.25$ for foreign mailing. No additional postage is required for mailing within the United States or its possessions.

(SJR-File Code 2Q)

Send Subscription to:

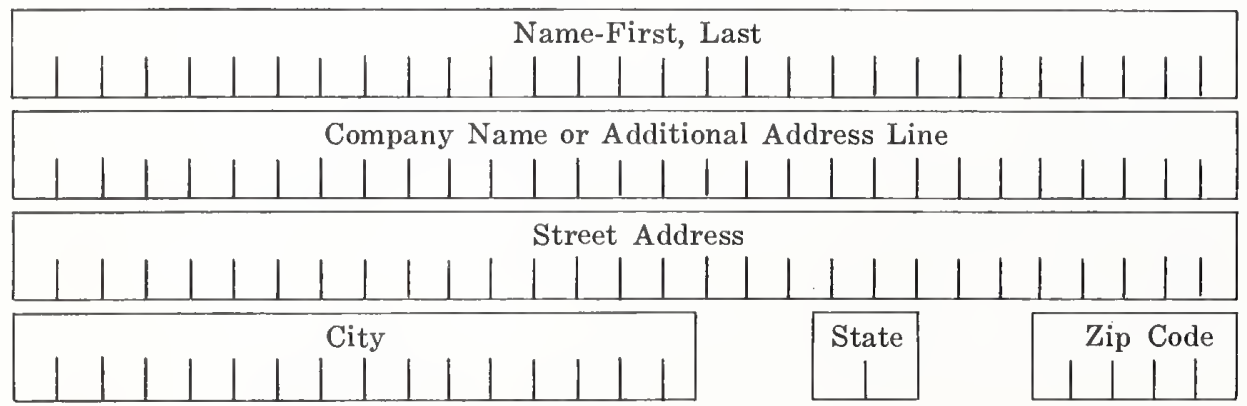

Remittance Enclosed (Make checks payable to Superintendent of Documents)

Charge to my Deposit Account No.
MAIL ORDER FORM TO: Superintendent of Documents Government Printing Office Washington, D.C. 20402 


\section{Announcement of New Publications in}

National Standard Reference Data Serieo

Superintendent of Documents, Government Printing Office,

Washington, D.C. 20402

Dear Sir:

Please add my name to the announcement list of new publications to be issued in the series: National Standard Reference Data Series-National Bureau of Standards.

Name

Company

Address

City

State

Zip Code

(Notification Key N-519) 


